

$$
\text { Dr. G dy the f. Af rumors }
$$

$$
\begin{gathered}
\text { Pirksoille, lino." } \\
\text { Jaw. 1,1415. }
\end{gathered}
$$

UNIVERSITY OF CALIFORNIA

CALIFORNIA COLLEGE OF MEDICINE

I.PRRARY

.1111871971

IRVINE. CALIFORNIA 92664 

, 
How to prepare bones for museums:

clear k...n the bors by the scalpel all the soft time. then pert into. coli rater to bail writ as week of that

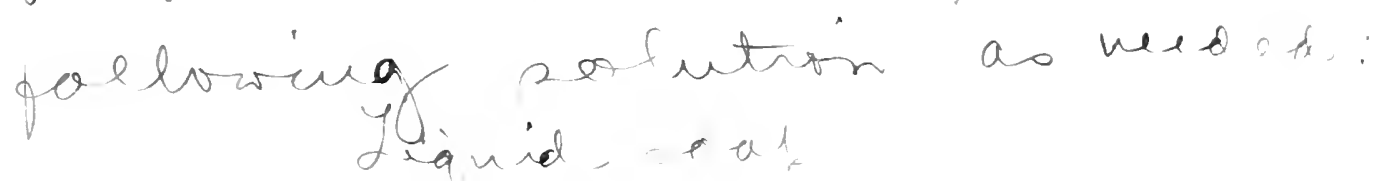
ratio go gals. Cumbria 10 g ts

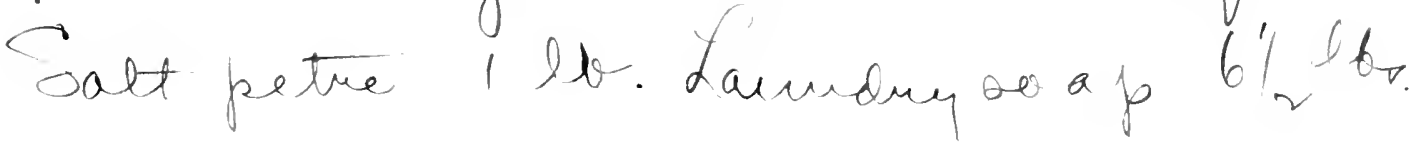

If the chad carnot be got and of the bones by the' meted, a napotia batt nara be neasasary. Hare the punter add to on win talk a lat form of ararat mir mach. blow which pase pigs for hot rater or ottar. Jav a close fitting cover made so that IRe unpota wile, nil evaporate. Oceasionalety remove refuses that collects in the nafta from the Hashing op the bones. Ot may reprice for tan ho to for 
to get all the zease ant of fones.

After thos dipfing in Jevell woter will give them ar extra whitemes but be careful in ito appliciation for is un eat up the bones.

yerce rate

brater I gallon

(Y) loride of line $1 l b$

yra thing ooda 2 lleo.

Iten warnis rith a

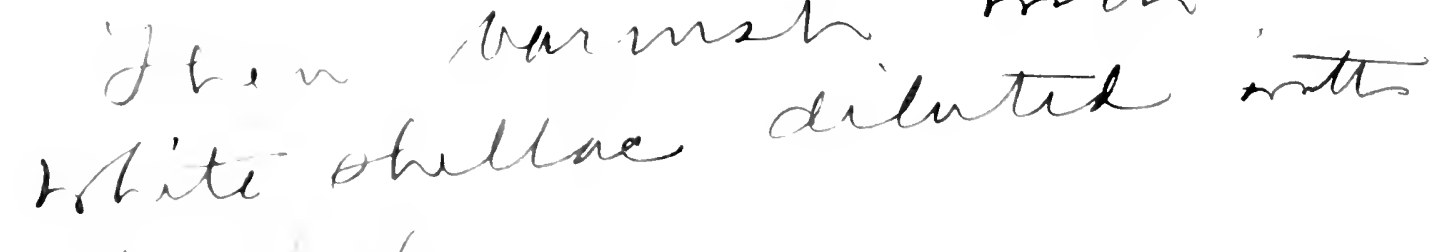
ateo hot.

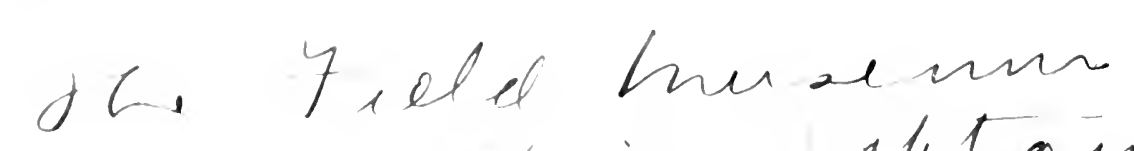
meltad tereggo abtainid.

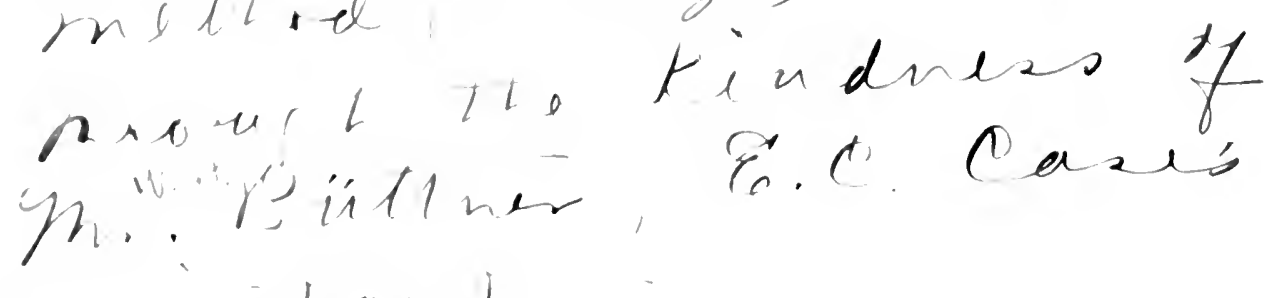




\section{IIORRIS'S \\ TREATISE ON ANATOMY}

FIFTH EDITION 


\section{CONTRIBLTORS TO FIFTH EDITION}

('HARLES R BARDEEN, University of Wisconsin.

EIIOT R ('IARK, Jolns Hopkins University.

IRVING H.ARDESTY, Tulane University of Louisiana.

(". M. J.ACLSON, University of Minnesuta.

F. W. JONES, London School of Medi(ine for Women.

ABRAMT. KERR, comell University.
J. PLAYFAIR MCMURRICH, University of Toronto.

JOHN MORLEY, Manchester University.

H. D. SENIOR, University and Bellevue Hospital Medical College., N. Y.

R. J. TERRY, Washington University, St. Louis.

PETER THOMPSON, University of Birmingham.

DAVID WATERSTON, King's College, London.

For arrangement of subjects and authors see page $v$.

TIIIS WORK IS ALSO PUBLISHED IN FIVE PARTS AS FOLLOWS:

P.HRT I. Morphogenesis. Ostcology. Articulations. Index. \$1.50.

PAR'T II. Murcles. Blood-Vascular System. Lymphatic System. Index. $\$ 2.50$

P.JI'T III. Norous Systom. Special Sense Organs. Index. $\$ 2.00$.

'AR'T JV. I Igentive System. Respiratory System. Skin, Mammary and Ductless (ilands. Irogenital System. Index. $\$ 1.50$.

PAR' V. C'liniral and 'Topographical Anatomy. Index. \$1.50. 


\section{MORRIS'S}

\section{HUMAN ANATOMY}

A COMPLETE SYSTEMATIC' TREATISE BY ENGLISH AND AMERICAN AU'THORS

EDITED BY

C. M. JACKSON, M.S., M. D.

PROFESSOR AND DIRECTOR OF THE DEPARTMENT OF ANATOMY.

DNTERSITY OF MINNESOTA

ELEVEN HUNDRED AND EIGHTY TWO ILLUSTRATIONS

THREE HUNDRED AND FIFTY EIGHT PRINTED IN COLOLRS

FIFTH EDITION, REIISED AND LARGELY REWRITTEX 
Copyright, 1914, by P. Blakiston's Son \& Co. 


\section{ARRAIGEIENT OF STB.JE'TS' ANI AI'THORS}

The names of the more recent of those who wrote or revised articles for previous editions have been retained in the following list in order that due credit should be given them for the work done and for their share in the great suceess which Morris's "Anatomy" has achieved.

MORPHOGENESIS. Revised and largely rewritten for the fifth edition by C. M. JACkson, M.S., M.D., Professor of Anatomy in the University of Mimnesota. Originally written by J. Playfair McMurrich, A.M., Ph.D., Professor of Anatomy, University of Toronto.

OSTEOLOGY. Revised for the third, fourth and fifth editions by Peter Thompson, M.D., Professor of Anatomy, University of Birmingham; Member of Anatomical Society of Great Britain. This article was originally written by Sir John Bland Sutton, F.R.C.S.

ARTICULATIONS. Rerised for the fifth edition by Frederic Wood Jones, D.Sc., M.B., B.S. (Lond.), M.R.C.S., L.R.C.P., Head of the Department of Anatomy and Lecturer in the London School of Medicine for Women. Originally written by Sir Henry Morris, A.M., M.B.

MUSCLES. Rewritten and revised for the fourth and fifth editions by Charles R. Bardeen, A.B., M.D., Professor of Anatomy in the University of Wisconsin; Member Association of American Anatomists; Member of Editorial Board of "American Journal of Anatomy."

BLOOD-VASCULAR SYSTEM. Revised and in part rewritten by HAROLD D. Senior, M.B., F.R.C.S., Professor of Anatomy, University and Bellerue Hospital Medical College. The section on Blood-vessels was formerly revised by Florence R. Sabin, B.S., M.D., Associate Professor of Anatomy, Johns Hopkins University.

LYMPHATIC SYSTEM. Revised and partly rewritten for the fifth edition by Eliot R. Clark, A.B., M.D., Assoeiate in Anatomy, Johns Hopkins Iniversity. Revised for previous edition by Florence R. Sabin, B.S., M.D.

NERVOUS SYSTEM. Revised and largely rewritten for the fourth and fifth editions by Irving Hardesty, A.B., Ph.D., Professor of Anatomy, Tulane University, Louisiana; Member Association of American Anatomists.

SPECIAL SENSE ORGANS. Revised for the fifth orlition by DAvil Waterston, M.A., M.I)., F.R.('S., Professor of Anatomy in the University of London. In the earlier edition, the Ear, Nose, Tongue were revised by Abram T. Kerr, B.S., M.D.

DIGESTIVE SYSTEM. Rerised and largely rewritten for the fifth ectition by C. M. JACkson, M.S., M.D., Professor of Anatomy, Lniversity of Minnesota. Revised for the fourth edition by G. Carl Huber, M.I). 
RESPIRATORY SYSTEM. Revised for the fourth and fifth editions by P. J. Terry, A.B., M.D., Professor of Anatomy, Washington University, St. Louis: Member Association of American Anatomists.

UROGENITAL SYSTEM. Revised for the fourth and fifth editions by J. Playfar McMurrich, A.M., Ph.D., Professor of Anatomy, University of Toronto; Member Association of American Anatomists.

THE SKIN AND MAMMARY GLAND; THE DUCTLESS GLANDS. By Abray T. Kerr, B.S., M.D., Professor of Anatomy, Cornell University; Member Association of American Anatomists, etc. The article on the Ductless (ilands was originally written by G. Carl Huber, M.D.

CLINICAL AND TOPOGRAPHICAL ANATOMY. By John Morley, Cir.M., F.R.C.s., Honorary Surgeon, Ancoats Hospital, Manchester, and Lecturer in Clinical Anatomy, Nanchester University. Originally written by II. H. A. Jacobson, F.R.C.S. 


\section{EDITOR'S PREFACE TO THE FIFTH EITTON}

One criticism upon most of the current text-books of human anatomy is that they are too extensive for the beginner. Much precious time is wasted by him in floundering through a mass of details which obseure the fundamental facts. And yet it is important to have these details conveniently accessible for both present and future reference. To meet this difficulty, the attempt is made in this edition to discriminate systematically in the use of sizes of type. The larger type is used for the more fundamental facts, which should be mastered first, and the smaller type for details. While it has been found difficult to apply this principle uniformly through the various sections, it is hoped that the plan, even though but imperfectly realized, will prove useful to the beginner.

In the illustrations of the bones, as heretofore, the origins of muscles are indicated by red lines, the insertions by blue lines, and the attachments of ligaments by dotted black lines.

While the authors of the present edition are for the most part the same as in the previous edition, a few changes have been made as noted under the preceding section, "Arrangement of Subjects and Authors." Owing to the retirement of the distinguished originator and former editor of this work, Sir Henry Morris, and of Professor McMurrich as co-editor, the responsibility for the general supervision of the fifth revision has fallen to the present editor.

Each author is alone responsible for the subject-matter of the article following his name. Care has been exercised on the part of the editor, however, to make the whole uniform, complete and systematic.

As to nomenclature, the Anglicised form of the BNA has been continued, excepting those cases where the Latin form is adopted into English (e. g., most of the muscles), and rare cases where the BNA term seems undesirable. As a rule, the Anglicised form where first used is followed by the BNA Latin term in brackets, except where the two are practically identical. For convenience of reference, some of the commoner synonyms of the old nomenclature are also added in parenthesis.

The previous edition of Morris's Anatomy was the first general text-book of anatomy in English to adopt the BNA. During the past few years the merit of this system of nomenclature has become so widely recognized that it is now very generally accepted among the English-speaking nations. Lack of space forbids the enumeration here of the many advantages of this system, not the least of which is the reduction of some 30,000 anatomical terms (including synonyms) to 5000 . The comparatively few defects of the BNA will doubtless be remedied by revision (preferably through the International Anatomical Congress). For a full discussion of the BNA system, with complete list of the Latin terms and English equivalents, the reader is referred to the excellent work on the BNA by Professor L. F. Barker, of Johns Hopkins University.

In addition to the bibliographical references scattered throughout the text, a brief list is given at the close of each section. These brief lists of carefully sclected references are intended merely as a guide to put the student "on track" of the original literature. 
In addition to a thorough revision of the various sections, there has also been a rearrangement of a part of the subject matter in the present edition. The Teeth have been transferred from the seetion on Osteology to the Digestive System. The Tongue and Nose are transferred to the Digestive System and Respiratory System, respectively, excepting those portions forming the organs of Taste and Smell, which have been retained in the section on Special Sense Organs. The Pelvie Outlet has been discontinued as a separate section, the subject matter being divided between Musculature and Clinical and Topographical Anatomy. The Duetless Glands have been included in the section with the Skin and Mammary Crlands.

Due credit has been given throughout the book wherever illustrations have been taken, or modified, from other works. Special acknowledgment should be made of our indebtedness to the works of Toldt, Rauber-Kopsch, Poirier and Charpy, Henle and Spalteholz.

The number of figures in the present edition has been increased about one hundred and sixty and in addition many of the older figures have been improved or replaced. For the generosity of the publishers in this connection, and for the hearty coöperation of the contributors in the revision of the various sections, the editor desires to express his deep indebtedness. Valuable assistance has been rendered by Mr. Walter F. Camp in the reading of proof and preparation of the index.

Minneapolis.

C. M. JACKsON. 


\section{(ONTENTS}

INTRODUCTION

BY C. M. JACKsON, M.S., M.D.

SECTION I

\section{MORPHOGEVESIS}

BY C. M. JACKson, M.S., M.D.

Segmentation of the Ovum Embryonic Disc and Derivatives Metamerism.

Branchiomerism
PAGE

9 Viscera and Limbs.

PIG F

10 Prenatal Growth.

15 Variability

16 References
18

22

\section{SECTION II}

OSTEOLOGY

By Peter Thompson, M.D.

The Skeleton

I. The Axial Skeleton

A. The Vertebral Column

The Cervical Vertebra

The Thoracic Vertebræ

The Lumbar Vertebræ.

The Sacrum.

The Coccygeal Vertebra.....

The Vertebral Column as a

Whole.

B. Bones of the Skull . . . . . . . . . .

The Occipital. ............ 5

The Parietal................ 57

The Frontal. . . . . . . . . . 59

The Sphenoid........... 62

The Sphenoidal Conchæ.... 67

The Epipteric and Wormian Bones.

The Temporal Bone

The Tympanum

The Osseous Labyrintl

The Ethmoid

The Inferior Nasal Concha

The Lacrimal Bone.

The Vomer.

The Nasal Bones

The Maxilla or Upper Jam

The Palate Bone

The Zygomatic or Malar Bone

The Mandible or Lower Jaw.

The Hyoid Bone...........

The Skull as a Whole........

The Orbits.
The Nasal Fossæ............ 110

The Interior of the skull. . . 112

The Morphology of the Skull. 117

The Skull at Birth. ...... $\quad 120$

C. The Thorax........... 126

The Ribs. 126

The Sternum. . . . . . . . 132

The Thorax as a Whole...... 138

II. The Appendicular skeleton ..... 139

A. Bones of the Upper Extremity. 139

The Clavicle ........... 139

The Scapula ............... 141

The Humerus 146

The Radius............... 152

The Ulna.............. 155

The Carpus............. 159

The Metacarpals ........ 164

The Phalanges........... 167

B. Bones of the Lower Extremity 169

The Coxal Bone............ 169

The Pelvis.

The Femur or Thigh Bone. 17s

The Patella..... 184

The Tibia 18.5

The Fibula 189

The Tarsus 191

The Metatarsus $\quad 200$

$\begin{array}{ll}\text { The Phalanges. } & 20.3\end{array}$

The Bones of the Foot $\quad 205$

Homology of the Bones of the Extremities.............. 206

References............. 209 


\section{SECTION III}

\section{THE ARTICLLATIONS}

By F. H. Jones, D. Sc, M. B., M. R. C. S., L. R. C. P.

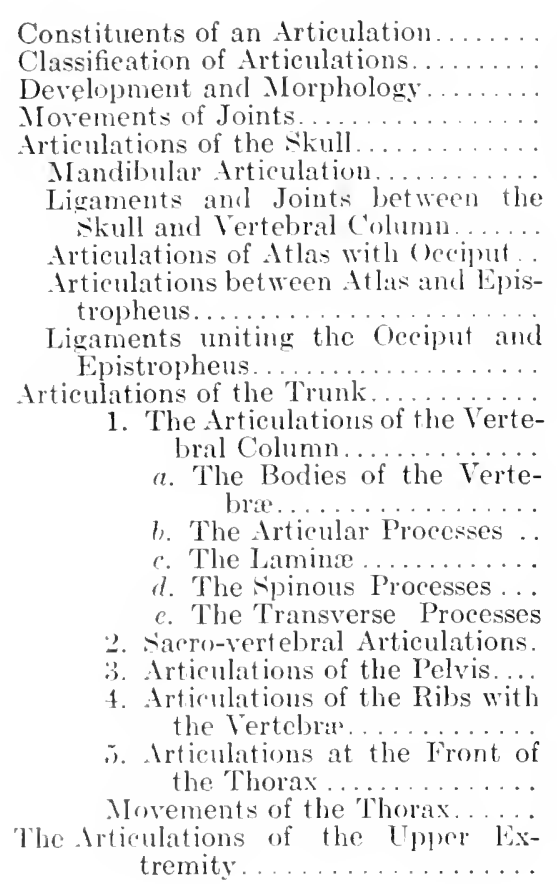

PAGE

211

212

213

214

215

215

218

218

220

223

224

225

\section{5}

228

229

229

231

232

234

244

247

248
1. Sterno-costo-clavicular Articu-

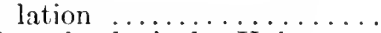

2. Scapulo-clavicular Union ....

3. Shoulder-joint. . . . . . . . 253

4. Elbow-joint............ 258

5. Union of Radius with Ulna. 261

6. Radio-carpal Articulation... 265

7. Carpal Joints............ 268

8. Carpo-metacarpal Joints.... 272

9. Intermetacarpal Articulations. 273

10. Metacarpo-phalangeal Joints. 274

11. Interphalangeal Articulations. 276

The Articulations of the Lower Limb . . . $\quad 276$

1. Hip-joint............. 276

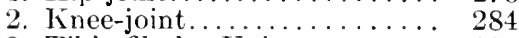

3. Tibio-fibular Union......... 295

4. Ankle-joint............. 297

5. Tarsal Joints............ 301

a. The Talo-calcancal Union.. 301

b. Articulations of Anterior Part of Tarsus....... 303

$c$. Medio-tarsal or Transverse Tarsal Joints...... 305

6. Tarso-metatarsal Articulations 307

7. Intermetatarsal Articulations. 309

8. Metatarso-phalangeal Articulations.............. 310

9. Interphalangeal Joints..... 310

Rioferences................... 311

SECTION IV

THE MUSCULATURE

Br C. R.. Bardenen, A.B., M.D.

Ciencral Renuarks on Mluseles. . . . . . 313

Muscle lascice............... 313

Ciross Strurture.............. 311

liner Structure of Whiscles....... 315

Trendons..................... 317

Synovial limrse............. 318

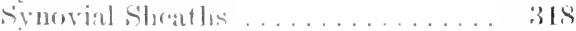

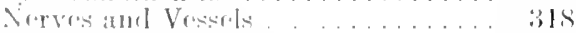

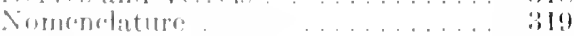

Variation . . . . . . . . $8: 0$

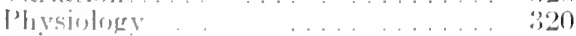

1. Muserulathere of the Howl and Arek

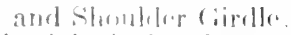

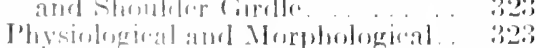

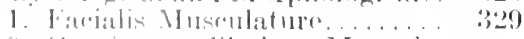

2. (ranow-mandilublar MInsmula$1111 \%$

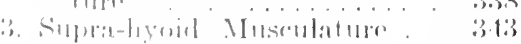

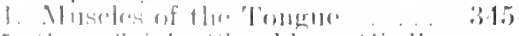

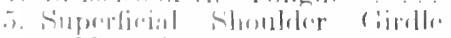

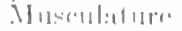

6. Infritlyourl Musclas.... .

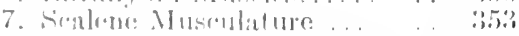

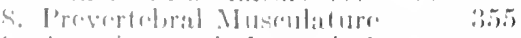

9. Antretor and Iattrat Intro-

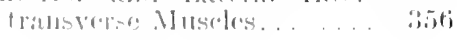

10. Decp Musculature of the Shoulder Girdle..........

II. Musculature of the Upper Limb. . 360 A. Musculature of the Slioulder.. 363

B. Pectoral Muscles and Axillary Fascia................ 370

C. Musculature of the Arm..... 374

1. Dorsal or Wxtensor Group. . 377

2. Ventral or Flexor (iroup... 379

D. Musculature of the Forearm

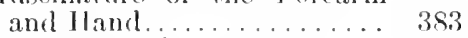

1. Dorsal-Radial I)ivision.... 387 a. Simperfieial Layer...... 387 b. Drep Tayer........... 392

2. Ulno-Volar Division...... 395 a. First layer. . . . . . . 395

b. Serond Iayer. . . . . . . 399

c. Third Layer. . . . . . . . 401

d. Fourth Layer........ 402

3. Musculature of the IIand... 403

III. Sirinal Musculature........... 410

1. Superficial Lateral ioorsal Systrin............... 414

B. Deep lateral Dorsal Muscles. 417

( Superficial Medial Dorsal System.............. 417 
D. Deep Medial Dorsal System PAGE $E$. Suboccipital MIuscles........ 419

IV. Thoracic-abdominal Musculature. 422

A. Ventral Division........... 430

B. Lateral Division............. 431

1. Serratus Group.......... 431

2. External Oblique Group.... 432

3. Internal Oblique Group.... 433

4. Transverse Group........ 434

C. Lumbar Muscle............. 436

D. Diaphragm.............. 436

V. Musculature of the Pelvic Outlet. 439

A. Muscles of the Pelvic Diaphragm, Coceyx and Anus.

$B$. Muscles of the Urogenital Diaphragm.............

C. External Genital Muscles.... .

VI. Musculature of the Lower Limb. .

A. Musculature of the Hip.......

1. Ilio-femoral Musculature... a. Anterior Group........

\section{8}

449

450

452

454

454

455 b. Posterior Group

2. Ischio-pubo-fenoral Iisculature of the Hip........ $40.0^{\circ}$

B. Musculature of the Thigh .... 464

1. Anterior (iroup......... 4tis

2. Merlial (Adeluctor) Gromp. 471

3. Posterior (H a $111 \mathrm{~s}$ t $\mathrm{ring}$

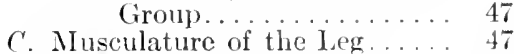

1. Muscles of the Front of the Leg.

2. Lateral Museulature of the Leg....................

3. Musculature of the Back of the Leg.

1. Muscle of the Dursum of the Foot........... 492

2. Muscles of the sole...... $49:$

Muscles Grouped According to Function 500

References.................... 506

\section{SECTION V}

\section{BLOOD-VASCULAR STSTEM}

By Harold D. Senior, M.B., M.D.

4. The Heart and Pericardium........ 50s

1. The Heart.............. 508

Exterior of the Heart....... 509

Atrial Portion........... 511

Atrio-Ventricular Valves...... 515

Ventricular Portion.......... 516

Semilunar Valves.............. 517

Architecture of the Heart.... 518

Vessels and Nerves........... 519

2. The Pericardium .......... 522

3. Surface Relations ............. 523

4. Morphogenesis ................ 523

B. The Arteries and Veins.......... 5.527

1. Pulmonary Arteries and Veins... 528

2. The Systemic Arteries ........ 529

The Aorta............... 529

Innominate Artery........... 532

Branches .............. 532

Common Carotid Arteries..... 533

External Carotid Artery . . . . 536

Branches .............. 536

Internal Carotid Artery...... 549

Branches.............. . 552

Subclavian Artery.......... 550

Branches ............... 558

Axillary Artery. . . . . . . . . . . . 569

Branches............... 570

Brachial Artery........... 573

Branches............ 57.5

Ulnar Artery............. 576

Branches............. 577

Superficial Volar Arch. . . . . . . 582

Branches............. 582

Radial Artery ............. 5. 58

Branches.............. 58.

Deep Volar Arch . . . . . . . . . . . 586

Branches.............. 586

Descending or Thoracic Aorta. 586

Visceral Branches........... 588

Parietal Branches... . . . . . . . 58s

Abdominal Aorta.............. 590

Parietal Branches... . . . . . . . 592

Visceral Branches............ 593

Terminal Branches. . . . . . . . . . 603

Middle Sacral Artery....... 603
Common Iliac Arteries..... 60.3

Hypogastric Artery. . . . . . . 605

Parietal Branches ....... 600

Visceral Branches..... . . . 6009

External Iliac Artery... . . . 611

Branches............6614

Femoral Artery.......... 616

Branches..........6.618

Popliteal Artery. . . . . . . . 621

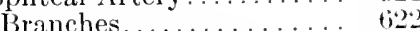

Posterior Tibial Artery.... 6.24

Branches............ $\quad 0,26$

Lateral Plantar Artery..... $6: 27$

Branches............ 602

Nedial Plantar Artery..... $\quad$ i2

Branches............ 629

Anterior 'Tibial Artery....

Branches............... (ii3)

Dorsalis Pedis Arter . . . . ti. (ii)"

Branches ....tii3?

Morphogenesis and Variations of the Arteries.

a. Arteries of the Heal and Trunk.

b. Arteries of the Frine (b....

3 The Systemic Veins titt

Teins Emptring into the Tenat

Cava Superior ............. (itl

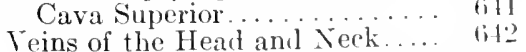

Superficial Veins of the Ilead and Neck

Deep Teins of the llearl amel Neck.

Veins of the Thorax.

Superficial Teins of the Thorax.

Deep Veins of the Thorax...

Veins of the Tpper Extremity.

Superficial Teins of Tpper Extremity. .

Deep Veins of Upper Extremity

Teins Emptying into the Tena Cava Inferior

Portal Tein and its Tributaries.

Common Iliae Teins........

Hypogastric Tein.......... (i3):

ii.3)

(i $1:)$

(it)

titi:

(iit)

(i6:)

607

gitio

670

672

675

679

679 
External Iliac Vein..........

Superficial Veins of Abdominal

IVall...................

Veins of the Lower Extremity.

Superfi ial Veins of Lower Extremity. .

Deep Veins of Lower Extremity

Morphogenesis and Variations of

the Teins. .....................

PGE
683
653
653
684
656
690 a. Vena Cava Superior and Tributaries............

b. Vena Cava Inferior and Tributaries............. 693

c. Portal System............. 694

The Fotal Circulation.......... 695

References............... 696

\title{
SECTION VI
}

\section{THE LYMPHATIC SYSTEM}

By Eliot R. Clark, A.B., M.D.

I. General Anatomy of the Lymphatic

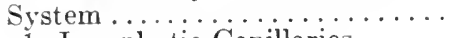

1. Lymphatic Capillaries...... 697

2. Lymphatic Vessels......... 702

3. Lymphoid Organs.......... 704

4. Development of the Lymphatic System..........

II. Special Anatomy of the Lymphatic System.................... Hy the Head and

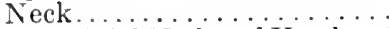

1. Superficial Nodes of Head and

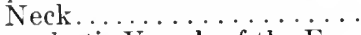

2. Lymphatic Vessels of the Face

3. Deep Lymphatic Nodes of the IIead and Neck.........

4. Deep Lymphatic Vessels of the Head and Neck ......

B. Lymphatics of the Upper Extremity.

1. Lymphatic Nodes of the Upper Extremity..............

2. Lymphatic Vessels of the Upper Extremity...........

C. Lymphaties of the Thorax.....

1. Superficial Lymphatic Vessels of the Thorax...........

2. Lymphatic Nodes of the Thorax...............
3. Deep Lymphatics of the Tho$D$. Lymphatics of Abdomen and

$E$. Lymphatics of the Lower Ex-

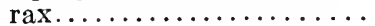
Thoracic Duct.............. Right Collecting Ducts...... Deep Lymphatic Vessels..... Pelvis.............. 730

1. Lymphatic Nodes of the Abdomen and Pelvis.........

2 . Lymphatic Vessels of the $\mathrm{A} \dot{\mathrm{b}}$ dominal Walls...........

3. Visceral Lymphatic Vessels of the Abdomen and Pelvis... Lymphatics of Alimentary

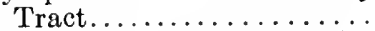
Lymphatics of Excretory Organs............... 737

Lymphatics of Reproductive Organs............. 742 tremity............. 746

728

728

1. Lymphatic Nodes of the

2. Lymphatic Vessels of the Lower Extremity.........

References.............. Lower Extremity......... 746

\section{8} 750

\section{SECTIUN VII}

\section{THE NERIOUS SYSTEM}

\author{
By Irving IAmDesty, A.B., PH.D.
}

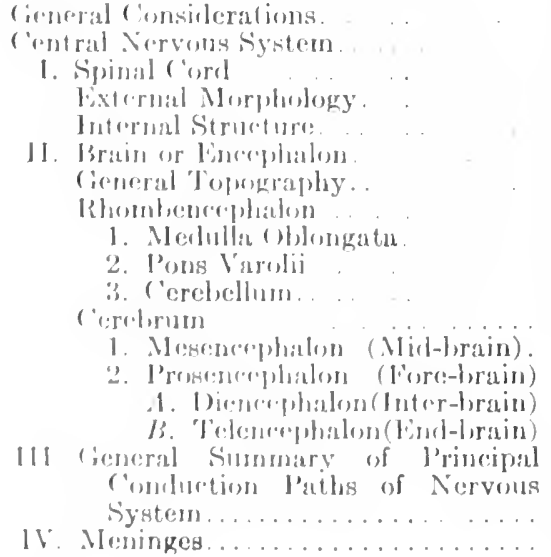

'The Peripheral Nervous System....... 924

I. Cranial Nerves. . . . . . . . . . . . . 927

Olfactory Nerves............... 929

Optic Nerves.... . . . . . . . . . . . 930

Oculo-motor Nerves........... 931

Trochlear Nerves. . . . . . . . . . . . 933

Abducens Nerves. ... . . . . . . . . . 934

Trigeminal Nerves............. 934

Masticator Nerves. . . . . . . . . . . 942

Facial Nerves. ...... 943

Glosso-palatine Nerves . . . . . . . . . 946

Vestibular Nerves.............. 949

Cochlear Nerves............... 950

(i)osso-pharyngeal Nerves........ 951

II ypoglossal Nerves. . . . . . . . 952

Viurus Nerves. 954

Siniual Aecessory Nerves. . . . . . . 958

Gangliated Cephalie l'lexus ...... 959

II. Sininal Nerves................. 964

A. Posterior Primary Divisions... 970 
1. Cervical Nerves. PAgk

2. Thoracic Nerves $\quad 971$

3. Lumbar Nerves. $\quad 973$

4. Sacral Nerves..... .... 973

B. Anterior Primary Divisions.... 973

1. Cervical Nerves... . . . . . . 974 Cervical Plexus. . . . . . . . . . 974 Brachial Plexus..... . . . 980

2. Thoracic Nerves. . . . . . . . 994

3. Lumbar Nerves. . . . . . . . 996 Lumbo-sacral Plexus . . . $\quad 996$ Lumbar Plexus......... . . 998 Lumbo-sacral Trunk. . . . . 1005

4. Sacral Nerves. . . _ . . . . 1006 Sacral Plexus... _ . . . 1006 Pudendal Plexus. _.... 1016 Coccygeal Plexus. . . . . . 1018

III. Distribution of the Cutaneous Branches................ 1018 Cutaneous Areas of Scalp......... 1018 Cutaneous Areas of Face....... 1018
Cutaneous Areas of Neck PAch

Cutaneous Areas of Trunk 1020

Cutaneous Areas of Limlss 1020

The Sympathetic System... . . 1026

Sympathetic Trunks.... 1032

Cephalic and Cervical Portions of the Sympathetic Trunk........... 1033

1. Superior Cervical Ganglion..... 1035

2. Middle Cervical Ganglion...... 1036

3. Inferior Cervical Ganglion...... 1036 Thoracic Portion of Sympathetic

Trunk.................... 1037

Lumbar Portion of Sympathetic

Trunk...................... 1039

Sacral Portion of Sympathetic Trunk. 1040

Great Prevertebral Plexuses......... 1040

1. Cardiac Plexus.............. 1041

2. Coeliac Plexus .... 1043

3. Hypogastric Plexus . . . . . . . . . 1045

References................... 1047

\section{SECTION VIII}

\section{SPECIAL SENSE ORGANS}

By David Waterston, M.A., M.D., F.R.C.S.

\begin{tabular}{|c|c|}
\hline \multicolumn{2}{|c|}{ General Considerations. . . . . . . 1049} \\
\hline I. Olfactory Organ .... & 1049 \\
\hline II. Organ of Taste. & 1051 \\
\hline III. The Eye.. & 1051 \\
\hline il surface Vien & \\
\hline of Eyeball & 55 \\
\hline Cavit & \\
\hline ngement & \\
\hline Optic Nerve & 1073 \\
\hline $\begin{array}{c}\text { 3lood-vessels and Nerves } \\
\text { Orbit...................... }\end{array}$ & \\
\hline
\end{tabular}

\section{SECTION IX}

\section{THE DIGESTIVE SYSTEM}

BY. (: M. JAChSON, M.S., M.I).

The Mouth. .

The Lips and Cheeks.

The Palate.

The Tongue.

The Salivary Glands

The Teeth.......

The Pharynx...

The OEsophagus.

The Abdomen. .

The Peritoneum.
1100

1102

1104

1106

1113

1117

1128

$113 \mathrm{~S}$

1142

1145
Eyelids.

Lacrimal Apparatus.

Development of the Eye

The Ear...

External Ear.

Middle Ear.

Internal Ear . $\ldots \ldots . .1092$

References.
1076

1079

1080

1082

1082

$109 \mathrm{~s}$

\section{SECTION $\mathrm{X}$}

\section{THE RESPIRATORY SYSTEM}

By R. J. Terry, A.B., M.D.

The Nose.

The Larynx.

Cartilages of Larynx.

Joints and Membrane

Muscles of Larynx..

Cavity of Larynx and Mucosa.
The Stomach

The small Intestine

Duodenum.

The Junum and Ileum

arge Intestine.

The Bile Passages.

The Pancreas.

References.
1151

1161

1161

1165

1170

1180

1186

1192

1197
The Trachea and Bronchi. 1225

The Lungs. . . . . . . . . . 1228

$\begin{array}{ll}\text { The Thoracic Cavity. } & 1235 \\ & 1236\end{array}$

$\begin{array}{ll}\text { The Pleuræ. . . . . . . . . . } & 1236 \\ \text { Mediastinal Septim . . . } & 1239\end{array}$

References........... 1240 


\section{SECTION XI}

\section{LPOGETITAL SYSTEM}

By J. Puayfair Momurricit, A.M., Ph.D.

\begin{tabular}{|c|c|}
\hline & \\
\hline & \\
\hline The kilneys. & 12 \\
\hline The Creters. & 12 \\
\hline The Crinaty Blamiler. & 1 \\
\hline he Wale Reprodnetive Organs. & \\
\hline Tlie Trestes and Their Appendages... & \\
\hline The sicotum. . & \\
\hline The Testes and Epididymis..... & \\
\hline The ] Juctus Deferentes and seminal & \\
\hline Vexirles...... & \\
\hline The spermatic Cord. & \\
\hline The l'enis... & \\
\hline The Male Li & \\
\hline
\end{tabular}

The Prostate ........... PAGE

The Bulbo-urethral Glands . . . . . . . 1265

The Female Reproduetive Organs. . . . 1265

The Ovaries.................... 1268

The Tubæ Uterinæ............... 1269

The Uterus. . . . . . . . . . . . . . 1271

The Vagina................. 1274

Female Exterual Genitalia and Urethra..................... 1276 Development of the Reproduetive Or-

gans................... 1278

References.................... 1280

\section{SECTION XII}

\section{THE SKIN, WAMMARY AND DUCTLESS GLANDS}

By Abram T. Kerr, B.S., M.D.

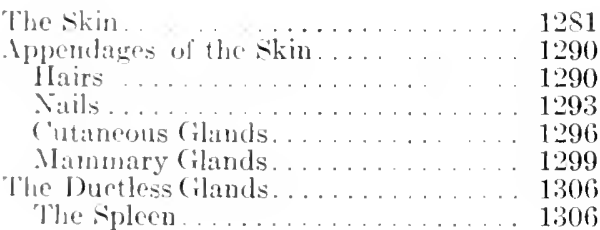

The Thyreoid Gland............. 1312

Parathyreoid Glands. . . . . . . . . . 1318

Thymus ................. 1319

Suprarenal Glands............ 1323

Glomus Carotieum. . . . . . . . . . . 1327

Aortic Paraganglia............. 1329

Glomus Coecygeum............ 1329

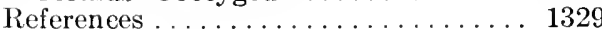

\section{SECTION XIII}

\section{('INICAL ANI) TOPOGRAPHICAL ANATOMY}

By JuIN MORLeY, Ch.M., F.R.C.S.

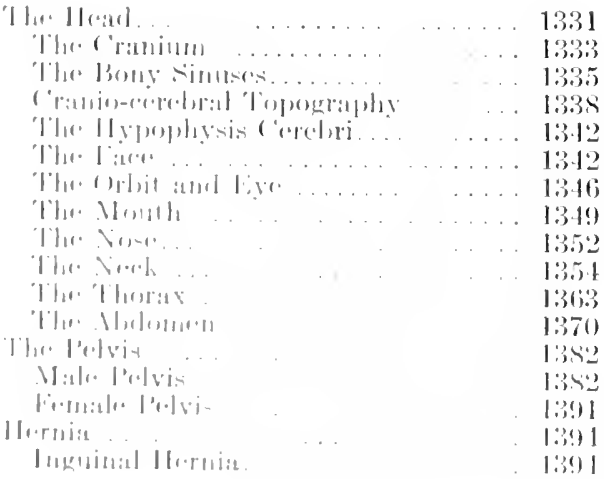

Femoral Hernia.............. 1398

Umbilieal Hernia. . . . . . . . . . . . . . 1402

The Back.................. 1403

The Tpper Extremity.............. 1409

The shoulder and Arun. . . . . . . . 1409

The Ellow................... 1417

T'he Forearm.................. 1419

The Wrist and i Iand .............. 1424

The Lower Extremity. . . . . . . . . . . . . . 1434

The llip and Thigh........... 1434

'The kinee ...................... 1444

Popliteal space............... 1451

The Ler.

The Ankle. . . . . . . . . . . . . 1459

The foot..................... 1464

Arehes of the Foot........... 1468 


\section{INTRODUCTION}

BY C. M. JACKSON, M.S., M.D.

PROFESSOR OF ANATOMY, UNIVERSITY OF MINNESOTA.

$A^{x}$ NATOMY, as the term is usually employed, denotes the study of the structure of the human body. Properly, however, it has a much wider significance, including within its scope not man alone, but all animal forms, and, indeed, plant forms as well; so that, when its application is limited to man, it should be qualified by the adjective human. Human Anatomy, then, is the study of the structure of the human body, and stands in contrast to, or rather in correlation with, Human Physiology, which treats of the functions of the human body, the two sciences, Anatomy and Physiology, including the complete study of man's organization and functional activities.

In the early history of the sciences these terms sufficed for all practical needs, but as knowledge grew, specialization of necessity resulted and new terms were from time to time introduced to designate special lines of anatomical inquiry. With the improvement of the microscope a new field of anatomy was opened up and the science of Histology came into existence, assuming control orer that portion of Anatomy which dealt with the minuter details of structure. So, too, the study of the development of the various organs gradually assumed the dignity of a more or less independent study known as Embryology, and the study of the structural changes due to disease was included in the science of Pathology; so that the term Anatomy is sometimes limited to the study of the macroscopic structure of normal adult organisms.

It is clear, however, that the lines of separation between Anatomy, Histology: Embryology, and Pathology are entirely arbitrary. Microscopic anatomy necessarily grades off into macroscopic anatomy; the development of an organism is a progressive process and the later embryonic or fœtal stages shade gradually into the adult; and structural anomalies lead insensibly from the normal to the pathological domains. Furthermore it is found that in its individual development the organism passes through stages corresponding to those of its ancestry in evolution; in other words, Ontogeny repeats Phylogeny. A comprehensive study of Anatomy must therefore include more or less of the other sciences, and since an appreciation of the significance of structural details can only be obtained by combining the studies of Anatomy, including Histology and Embryology. and since, further, much light may be thrown on the significance of embryological stages by comparative studies, Anatomy, Embryology, and Comparative Anatomy form a triumvirate of sciences by which the structure of an organism, the significance of that structure, and the laws which determine it are elucidated. For this combination it is convenient to have a single term, and that which is used is Morphology, a word meaning literally the science of form.

In morphological comparisons, the term homology denotes similarity of structure, due to a common origin in the evolution of organs or parts; while analogy denotes merely physiological correspondence in function. Thus the arm of man and the wing of a bird are homologous, but not analogous, structures; on the other haud, the wing of a bird and the wing of an insect are analgous, but not homologous. Serial homology refers to corresponding parts in successive segments of the body.

Nomenclature.-Formerly there was much confusion in the anatomical nomenclature, due to the multiplicity of names and the lack of uniformity in using them. Various names were applied to the same organs and great diversity of usage prevailed, not only between various countries, but also even among authors of the same country. Recently, however, a great improvement has been made by the general adoption of an international system of anatomical nomen- 
clature. This system was first adopted by the German Anatomical Society at a meeting in Basel, in 1895, and is hence called the Basel Nomina Anatomica, or briefly, the BNA. The BNA provides each term in Latin form, which is especially desirable for international usage. Each nation, however, is expected to translate the terms into its own language, wherever it is deemed preferable for everyday usage. Thus in the present work the Anglicised form of the BNA is generally used. Where not identical, however, the Latin form is added once for each term in a place convenient for reference, and is designated by enclosure in brackets [ ]. Where necessary the older terms have also been added as synonyms.

The Commission by whom the BNA was prepared included eminent anatomists representing various European nations. The work of the Commission was very thorough and careful, and extended through a period of six years. Among the guiding principles in the difficult task of selecting the most suitable terms were the following: (1) Each part should have one name only. (2) The names should be as short and simple as possible. (3) Related structures should have similar names. (4) Adjectives should be in opposing pairs. A few exceptions were found necessary, however.

On account of its obvious merits, the BNA system has been generally adopted throughout the civilised world, and the results are very satisfactory. Comparatively few new terms have been thereby introduced, over 4000 of the 4500 names in the BNA corresponding almost exactly to older terms already in use by the English-speaking nations. Certain minor defects in the system have been criticised; but these are outweighed by the advantages of this uniform system.

Abbreviations.-Certain frequently used words in the BNA are abbreviated as follows: a., arteria (plural, aa., arteriæ); b., bursa; g., ganglion; gl., glandula; lig., ligamentum (plural, ligg., ligamenta); m., museulus (plural, mm., museuli); n., nervus (plural, nn., nervi); oss., ossis (or ossium); proc., processus; r., ramus (plural, rr., rami); v., vena (plural, vv., venæ).

Terms of position and direction. - The exact meaning of certain fundamental terms used in anatomical description must be clearly understood and kept in mind. In defining these terms, it is supposed that the human body is in an upright position, with arms at the sides and palms to the front.

The three fundamental planes of the body are the sagittal, the transverse and the frontal. The vertical plane through the longitudinal axis of the trunk, dividing the body into right and left halves, is the median or mid-sagittal plane; and any plane parallel to this is a sagiltal plane. Any vertical plane at right angles to a sagittal plane, and dividing the body into front and rear portions is a frontal (or coronal) plane. A plane across the body at right angles to sagittal and coronal planes is a transverse or horizontal plane.

Terms pertaining to the front of the body are anterior or ventral; to the rear, posterior or dorsal; upper is designated as superior or cranial; and lower as inferior or caudal.

The term medial means nearer the mid-sagittal plane, and lateral, further from that plane. These terms should be earefully distinguished from internal (inner) and external (outer), which were formerly synonymous with them. Internal, as now used (BNA), means deeper, i. e., nearer the central axis of the body or part; while exlemal refers to struetures more superfieial in position. Proximal, in descriting a limb, refers to position nearer the trunk; while distal refers to a more peripheral position.

"Arlverbial forms are also employed, e. g., anteriorly or ventrally (forward, before); posterinrly or dorsally (backward, behind); superiorly or cranially (upward, above); and inferiorly or caurlally (downwarl, below).

It shrild also be noted that the terms ventral, dorsil, cranial and eaudal are independent of thr. brily posture, and therefore apply ecpually wel! to corresponding surfaces of vertebrates in general with horizontal borly axis. (In this aceount these terms are preferable, and will doubtless ultimately supplant the terms anterior, posterior, superior and inferior.

The discrimintion in the use of several similar terms of the BNA should also receive attention. Thus medinns (nediun) refers to the median plane. Medialis (medial) means nearer tha merlitn planc and is opposed to literal, as above stated. Medius (mirldle) is used to designatr. at pustion hetweon anterior and posterior, or letween internal and external. Between modialis and laterislis, however, the torm intermedius is used. Finally, transiersalis means transverofo fo lhe losdy axis; trunswersus, transverse to an organ or part; and transversarius, pertaining (6) somm other simature which is transverse.

Parts of the body.-'I'he: mimary divisions of the human body (fig. 1) are the hearl, nork, trunk and extromities. The head [eaput] includes cranium and face

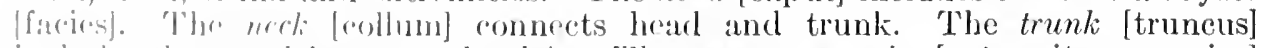
includes thorar, abdomen, and pelvis. The npper extremily [extremitas superior] inclurles arm [hrachinm], forearm [antibrachium], and hand [manus]. The 
lower extremity [extremitas inferior] includes thigh [femur], leg [crus], and foot [pes].

Each of the parts mentioned has further subdivisions, as indicated in fig. 1. The cranium includes: crown [vertex]; back of the head [occiput]; frontal region. [sinciput], including forehead [frons]; temples [tempora]; ears [aures], including auricles [auriculæ].

Fig. 1.-Parts of the Human Body. A, Posterior view. B, Anterior view:

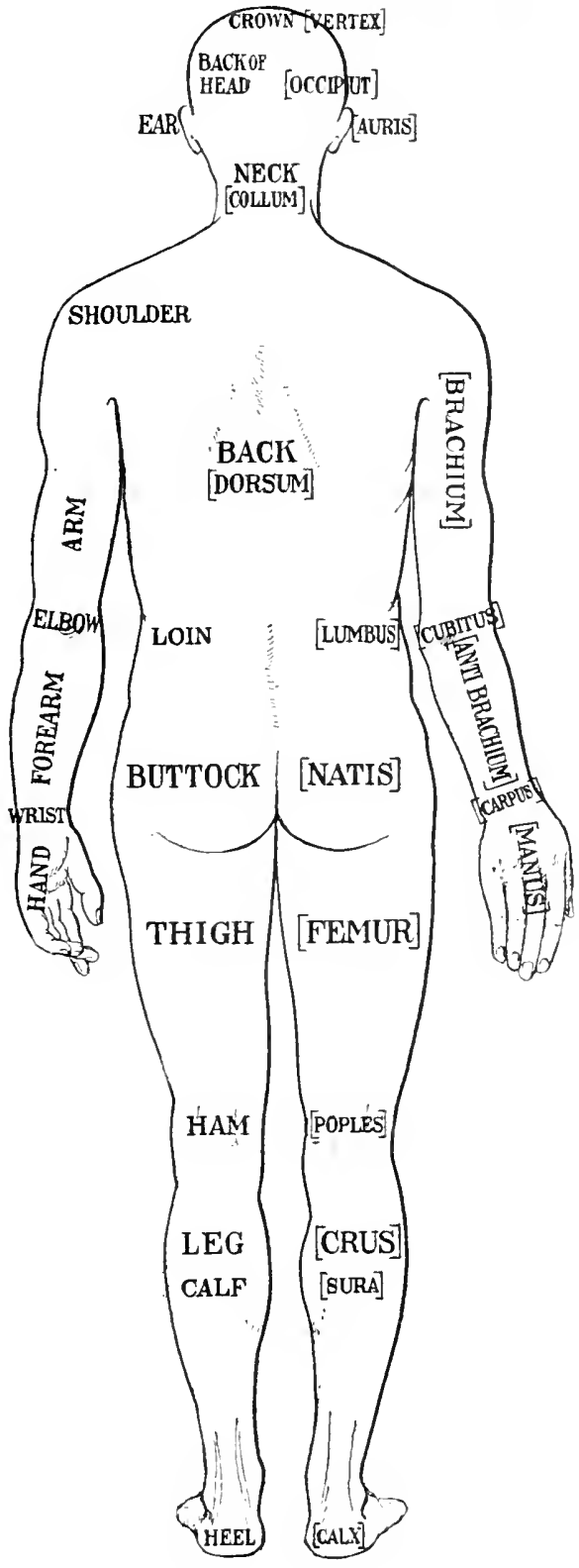

A

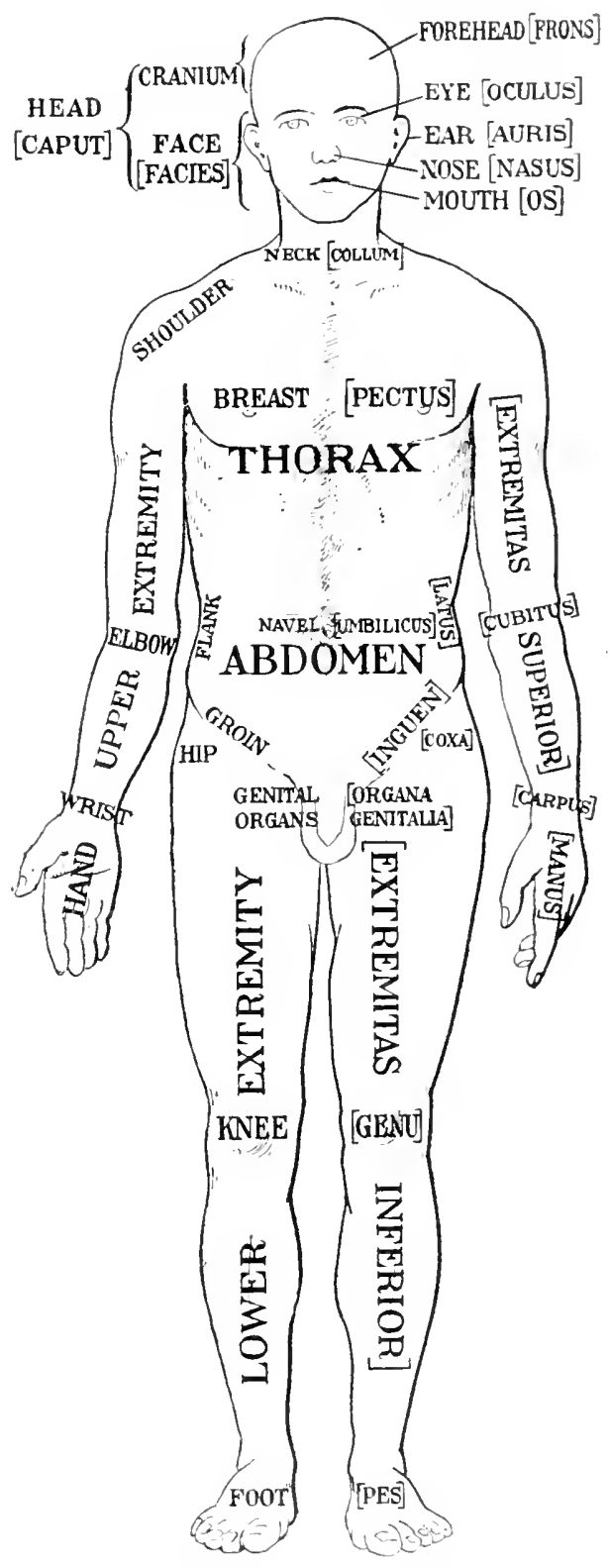

$B$

The face includes the regions of the eye [oculus], nose [nasus], and mouth [os], the subdivisions of which will be given later under the appropriate sections.

The thorax includes: breast [pectus]; mammary gland [mamma]; and thoracic cavity [cavum thoracis]. The back [dorsum] includes the vertebral column [columna vertebralis]. The abdomen includes: navel [umbilicus]; flank [latus]: groin [inguen]; loin [lumbus]; and the abdominul cavity [cavum abdominis]. The pelvis includes: pelvic cavity [cavum pelvis]; genital organs [organa genitalia], 
buttocks [nates], separated by a cleft [crena ani] at the anus. The hip [coxa] connects the pelvis with the lower extremity.

In the lower extremity, the thigh is joined to the leg by the knee [genu]. The foot includes: heel [calx]; sole [planta]; instep [tarsus]; metatursus; and five toes [digiti I-V], including the great toe [hallux] and little toe [digitus minimus].

The upper extremity is joined to the thorax by the shoulder. The arm is joined to the forearm at the elbow [cubitus]. The hand includes: wrist [carpus];

Fig. 2.-Section of the Epidernis of a Finger, from a Human Embryo of 10.2 cm.

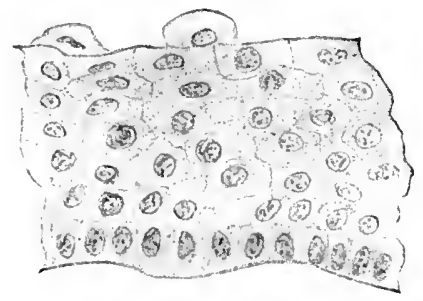

metacarpus, with palm [vola or palma] and back [dorsum manus]. The five fingers [digiti I-V] include: thumb [pollex], index finger [index]; middle finger [digitus medius]; ring finger [digitus annularis] and little finger [digitus minimus].

Organ-systems.-Each of the various parts of the body above outlined is composed of various organs, and the groups of related organs make up organsystems.

The various organ-systems are treated as special branches of descriptive anatomy. The study of the bones is called osteology; of the ligaments and joints,

Fig. 3.-Diagrait of a Trpical Cell. (Szymonowicz.)

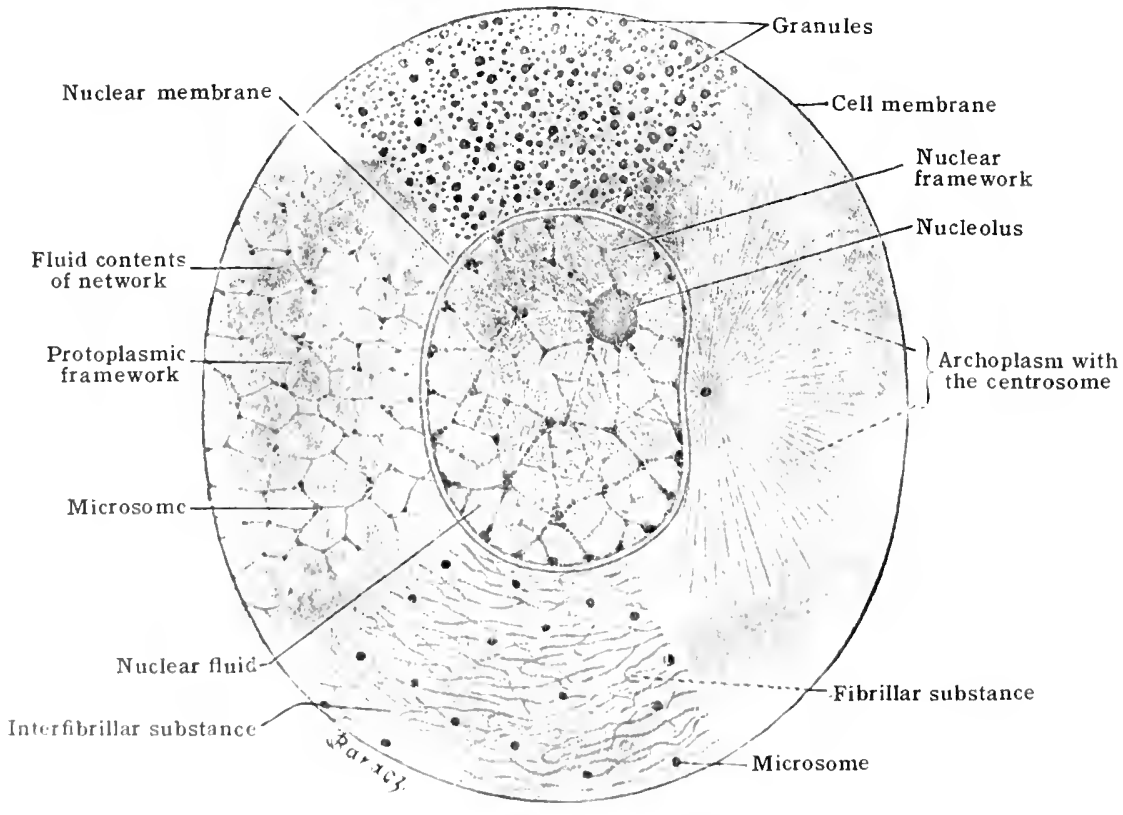

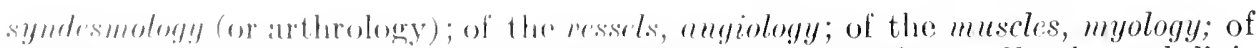

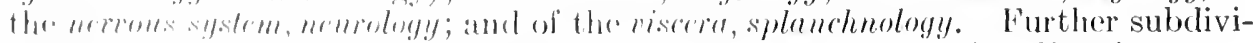
sions arre alse mate. The viscrat, for example, include the digestive tract,

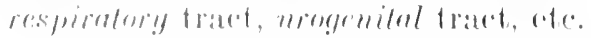

Tissues and cells. 'The: bouly, as almwe stated, has varioms parts, each of which may be

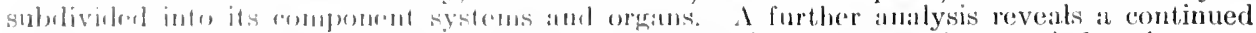

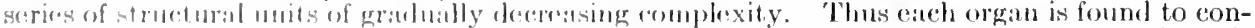
sist of a montwrof tissurs (opithelial, conuretive, muscular or nervous). Finally, each tissue is

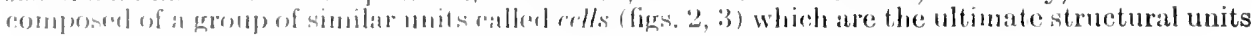


of the body. The body may therefore be regarded as composed of myriads of cell mint - orginized into units of gradually increasing complexity, very much as a social community is comproced of individuals organized into trades, municipalities, etc.

Most of the individual tissues can be reconnized by their gross appearance. In fitct. the principal tissues were first demonstrated by Bichat through skiful rlisecetion, Inaceration, ele. and without the aid of the microscope. The cellular structure of the tissues was later dincorered by Schwann in 1839 .

Each cell (fig. 3 ) is composed of a material called protoplasm, a viscid substance variable in appearance and exceedingly complex in chemical composition. It rearlily breaks down into sim. pler chemical compounds, whereby energy (chicfly in the form of heat and mechanical energy) is liberated. It has also the power of absorbing nutritive naterial to build up and roplace what was lost. Its decomposition results from stimuli of various kinds, and hence it is saill to lie irritable. The mechanical energy which it liberates is manifested by its contractility, cevprally in the muscle cells. It excretes the waste prorlucts produced by its decomposition. Finch ceil has the power, under favourable conditions, of reproducing it se lf by division. Protoplasm presents, in short, all the forms of activity manifested by the borly as a whole; and, indeed, the activities of the body are the sum of the activities of its constituent cells.

In the protoplasm of each cell is a specially differentiated portion, the nuclens (fig. 3). T'lie nucleus plays an important part in regulating the activities of the cytoplasm, the gencral protoplasm of the cell body. The nucleus differs from the cytoplasm both structurally anct chemically, and contains a very important substance, chromatin, which during cell wivision is ageregated into a definite number of masses called chromosomes. The cytoplasm of artively growing cells also contains the archoplasm and centrosome, structures of importance in the process uf cell division. Further details concerning the cells and tissues may be found in the text-books of cytology and histology.

In earlier days Human Anatomy was almost entirely a descriptive science, but little attention being paid to the significance of structure, except in so far as it could be correlaterl with physiological phenomena as they were at the time understool. In recent vears attention has been largely paid to the morphology of the hmman body and much valuable information as to the meaning of the structure and relations of the various organs has resulted. Fince the form and structure of the body are the final result of a series of complicated developmental changes, the science of Embryology has greatly contributed to our present knowledge of human Morphology; and, accordingly, a brief sketch of some of the more important phases of morphogenesis will form a fitting introduction to the study of the adult.

References.-General: For looking up the literature upon any anatomial topic, the best guide is the "Jahresbericht ueber die Fortschritte der Anatomie und Entwicklungsgeschichte," which contains classified titles and brief abstracts of the more important papers in gross anatomy, histology and embryology. Other useful aids are the "Zentralblatt fuer normale Anatomie," the "Index Medicus" and the catalogue of the Surgeon Genera 's Library of the War Dep't. (Washington, D. C.). The latter two contain titles only, but cover the whole field of medicine. The "Concilium Bibliographicum" also provides a convenient card-index system of references for the biological sciences, including Anatomy.

For nomenclature: His, Arehiv f. Anat., 1895 (BNA system); Barker, Anittomical Nomenclature. Cells and tissues: Wilson, The ('ell; Hertwig. Zello und Gewebe (also English transh.): Sehatefer, Microscopie Anatomy (in (zuain": Anatomy, 11th er.); Heidenhain, Plasma und Zelle. 



\title{
SECTION I MORPHOGENESIS
}

Revised for the Fifth Edition

\author{
By C. M. JACKSON, M.S., M.D. \\ PROFESSOR OF ANATOMY IN THE UNIVERSTTY OF MINNESOTA
}

$\mathrm{C}^{\mathrm{n}}$

HANGE is a fundamental characteristic of all living things. The human body during its life cycle accordingly passes through various phases of form and structure. In the earliest embryonic phases of development the changes are very rapid, decreasing in rapidity during the later fœetal stages, but continuing at a diminishing rate throughout infancy, childhood and youth up to the adult. Following the acme of maturity, changes continue which lead gradually to senescence and final death of the body.

This cycle of change in the body depends upon similar changes in its various component organs, each having its own characteristic life cycle. In a few of the organs this cycle is very short, as in some of the organs of the embryo (e. g., mesonephros). Other organs persist only during childhood (e. g., thymus); while the majority continue, with varying degrees of change, throughout postnatal life. The final death of the body is due to the breakdown of some of the essential organs.

A further analysis reveals the fact that the characteristic life cycles of the organs depend ultimately upon similar changes in their constituent tissues and cells. Every cell has a definite life cycle, an early period characterised by rapid and vigourous changes, later periods of differentiation and maturity, followed by stages of degeneration and death. This cycle of cell changes has been designated by Minot as cytomor phosis.

Growth.-Associated with the process of cell differentiation (cytomorphosis), and even more important as a factor in the morphogenesis of the body, is the process of grouth. The developmental changes in form and structure of the body are due largely to the unequal growth of its various parts. Growth, like other changes in the body and its parts, depends ultimately upon the characteristics of the constituent cells.

Fig. 4.-The Ovdi of a New-Born Cinld, with Follicle Cells. (After Mertens.)

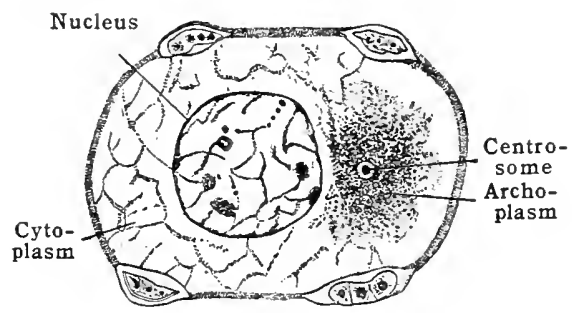

The cell changes during growth may be grouped under two heads. The first, or growth proper, involves merely the enlargement (hypertrophy) of the individual cells and intercchlular products. The second includes the multiplication (hyperplasia) of the cells, which is accomplished by mitotic division. Cell division is necessary in cell growth, for otherwise the cell would soon reach a size where its surface (for nutritive, respiratory and excretory purposes) would be inadequate for its mass. In general, however, cell division is most active in the earlier embryonic periods, during which the cells remain small. Later, cell division diminishes or ceases, and growth is due chiefly to enlargement of the cells already present. It is also during the later period, when the cells have ceased rapid division, that the process of cell differentiation and tissue formation is most marked.

The principle of the ratio of surface to mass of ten applies to the growing organs as well as to the individual cells. To maintain the necessary ratio, the surface area is increased by the formation, through localised unequal growth, of projections (e. g., villi or folds) or incuminations (e. g., glands) from surfaces. Innumerable modifications of this principle occur throughout the process of morphogenesis. 
Fig, 5.-Oycm from Orary of a Thoman Thirty Years of Age. cr, corona radiata. $n$. nucleus. $y$, volk. $p$, clear protoplasmic zone, $p s$, perivitelline space. $z p$, zona pellucida. (iIc.lurrich's Embryology, from Nagel.)

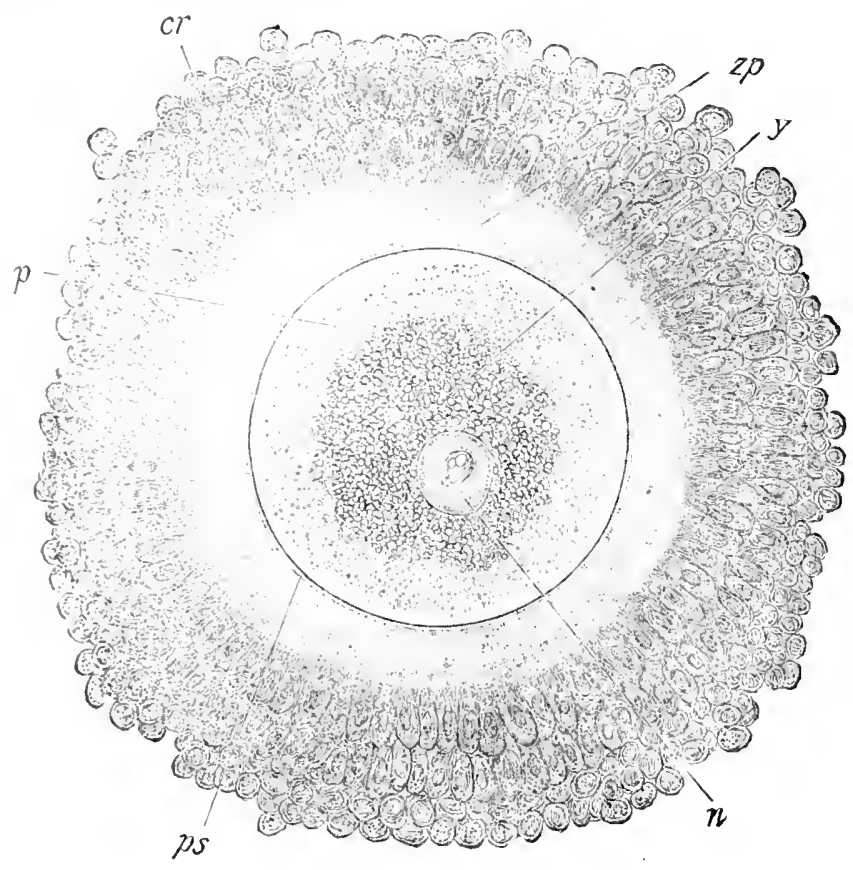

Fig. 6. - titagin of Segmextation in the Ovum of the Mouse. $x$, polar body. (McMurrich's Embryology, from sobotta.)
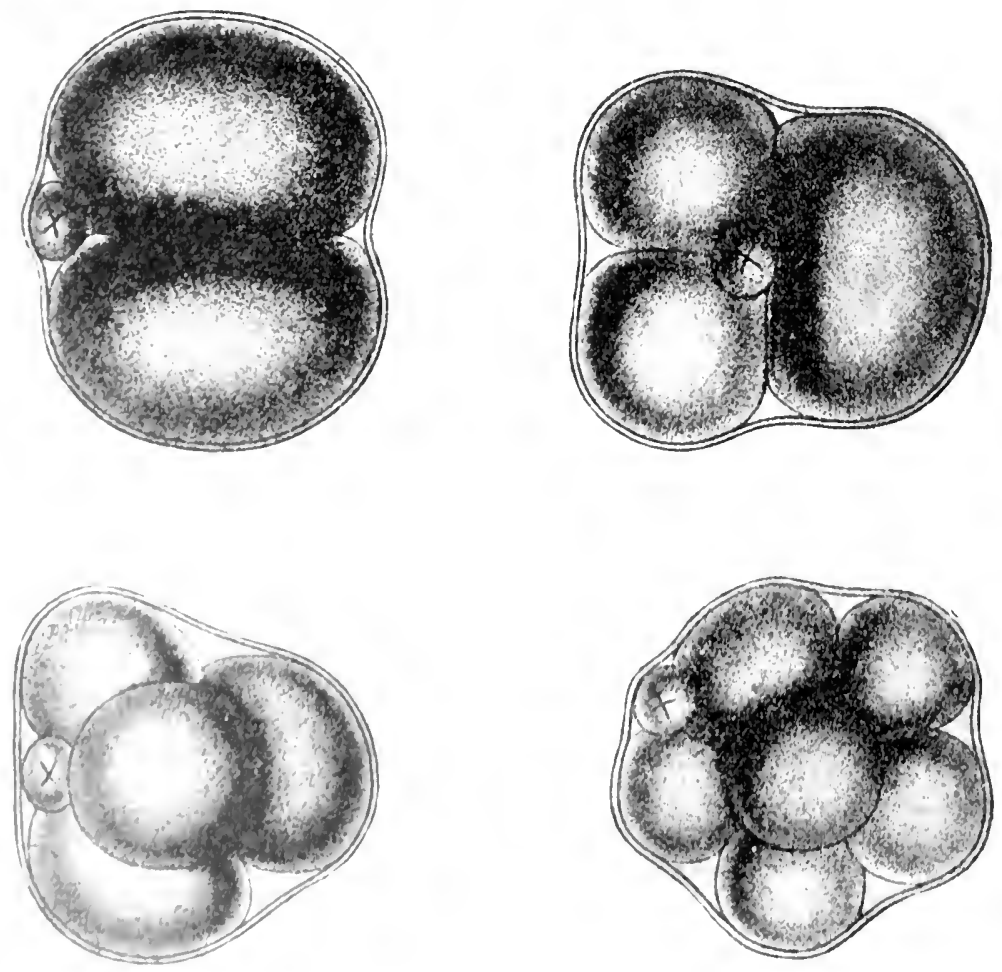
While the present work deals primarily with the adult human organiom in the stage of maturity, reference is made also to its changes according to age. Although these changes for the various systems of organs are described under the appropriate sections, it is desirable to consider first some of the more fundamental features pertaining to the body as a whole. This applies particularly to the earlier embryonic period, which includes the more general phases of morphogenesis. No attempt will be made to describe fully the process of derelopment. the details of which are to be found in text-books of embryology.

Segmentation of the ovum.-The human body, like all living organisms, arises from a single cell, the egg-cell or ovum. An early stage in the derelopment of the ovum is shown in fig. 4 , and a later stage, approaching maturity, in fig. 5 . The mature human ovum is about $0.2 \mathrm{~mm}$. in diameter. In the uterine (Fallopian) tube, the fertilised ovum undergoes segmentation, the various stages of which are represented in figs. 6 and 7 .

Fig. 7.-Diagrani of Sectiox throggh a Mammalian Orem at the Morula Stage.

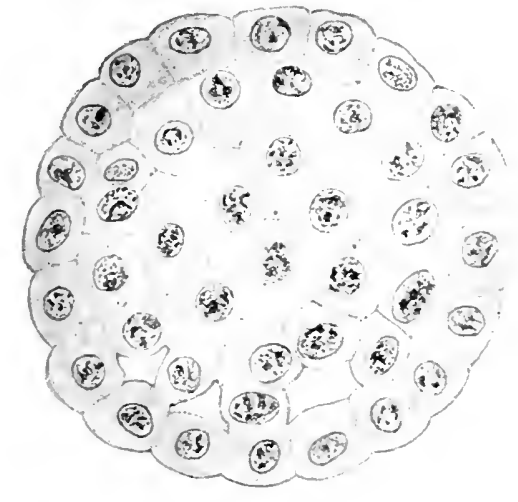

Fig. 8.-Diagray of section of A Mammalian Ovum Showing the InNer Cell Mass.

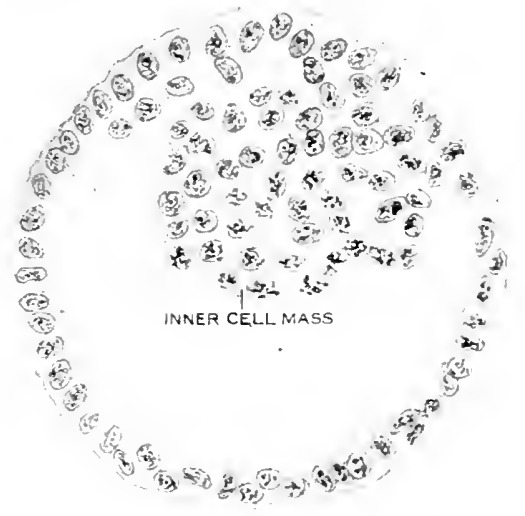

While the processes of maturation, fertilisation and segmentation liave not as yet been observed in the human ovum, the evidence of comparative anatomy makes it very probable that in all essential respects these processes are like those found in other mammals. As a result of the successive divisions of the ovum in segmentation, a spherical mass of cells, the morulu (fig. 7 ) is formed. In this mass, an excentric cavity forms (fig. S) whereby the mass is transformed into a hollow vesicle. The wall of this vesicle is probably formed throughout the greater part of its extent by a single layer of cells; but at one point of the circumference there is a group of cells termed the inner cell mass (fig. S). Probably about this time the ovum enters the uterine cavity, and through the activity of the outer layer of cells (trophoblast) becomes embedded in the uterine mucosa.

Formation of the embryonic disc and germ layers.-In the earliest human embryos which have been described, development has already proceeded berond

Fig. 9.-Diagram Showing the Relations of the Germ Layers ix ax Early Embro. Ac, amniotic cavity, lined by ectoderm. D, yolk-sac, lined by endoderm (En). Me, Me', mesoderm, $C$, extra-embryonic colom. $B$, chorion. $T$, trophoblast. (IIc)Iurrich.)

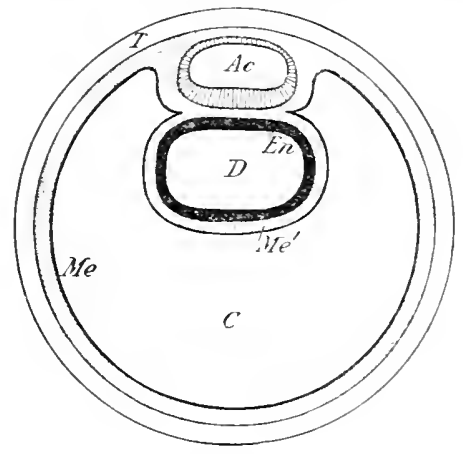

the stage represented by fig. 8 , and has reached that of fig. 9 . Within the inner cell mass, two cavities have appeared. The more superficial (ac) is the ammiotic 
cavity; the deeper (D) is the cavity of the yolk-sac; while between them is a plate of cells forming the embryonic disc. The embryonic disc (figs. 9 and 10) contains three layers of cells, - the fundamental germ layers,-ectoderm (Ec), endoderm (En), and mesoderm.

The germ layers of the embryonic disc are of prime importance in the development of the body. From the ectoderm, which lies next to the amniotic cavity and represents the upper (later outer) germ layer, are derived the epidermis and the entire nervous system. From the cndodcrm, which lies next to the yolk-sae, and represents the lower (later inner) germ layer, is derived the epithelial lining of the digestive mucosa and its derivatives. From the mesoderm, or middle germ layer, is differentiated the remainder of the body, including the skeletal and supporting tissues, vascular system, muscle and most of the urogenital organs.

The germ layers also extend beyond the embryonic disc, as shown in figs. 9 and 10 . The yolk-sac is made up of a lining of endoderm and an outer layer of mesoderm. The amnion, which

Fig. 10.-Diagam of Segtion of a Mammalian Ovum showing the Embryonic Disc, Auniotic Cavity and the Germ Layers.

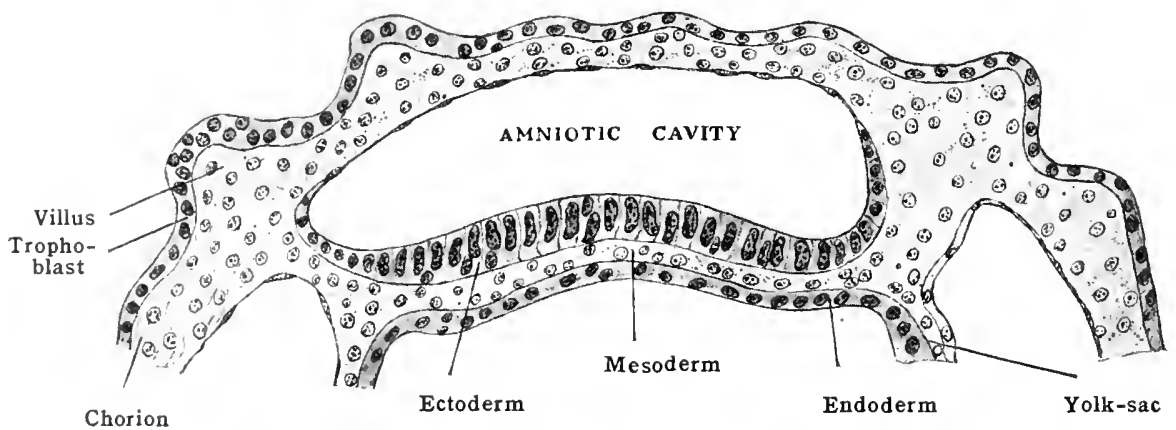

later becomes separated from the chorion, is composed of mesoderm lined by endoderm. The outer cell layers form the chorion, which likewise shows two layers, the outermost of which (trophoblast) is ectoderm, the inner,mesoderm. In fig. 10 the chorion is beginning to send out root-like projections (villi) which invade the uterine mucosa.

It is thus noteworthy that of the cells derived from the ovum relatively only a few-those of the embryonic disc-enter directly into the formation of the body. The yolk-sac, a rudimentary organ of phylogenetic significance, is later chiefly absorbed, although the proximal portion may enter slightly into the formation of the intestinal wall. The amnion is a protective membrane, while the chorion forms the fotal part of the placenta.

Development of the embryonic disc.--When first formed, the surface of the rmbryonic dise shows no trace of differentiation. A slightly later but still comparatively early stage in its development is shown in fig. 11 . It is here

Fig. 11.-Nodel Showing the Embryonic Disc from an Embryo 1.17 mm. In Length. Viewerl from above and laterally, the roof of the amniotic eavity having been removed. $n$, prinitive pit (neurenteric canal). $p g$, primitive groove. $m g$, neural groove. $b$, body-stalk. (.Me.Mrrich. from Frassi.)

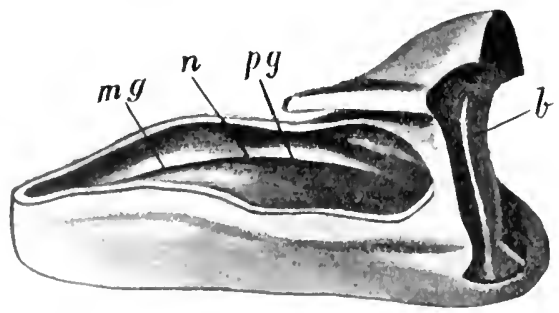

virwed from ahove, the amnion having been removed. The disc is an elliptical Hide, whese longe uxis represents the mid-line of the embryo. Near the center is a small romaded depressiom, the primilive pit. Extending back ward (toward the tail cual of the embryo) from this is a dark line, the primitive strcak, corresponding 16 a grosure, the primitien grome. Wxtending forward from the primitive pit is an imlistinet widr shallow groove, the newal groore.

1t an a:arlier stage, the prinitive streak cxtomds further forward, possibly to the anterior end

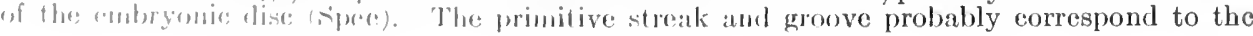


fused lips of a primitive blastopore. They represent a centre of proliferation from which the mesoderm is budded off from the ectoderm and spreads out to form the middle germ layer of the embryonic dise.

At the anterior end of the primitive streak this proliferation extends forward as a plate of cells, the so-called 'head process.' The axial portion of this process is the anlage of the notochord, the embryonic skeletal axis. It contains a canal, which opens into the primitive pit. The notochordal anlage soon fuses with the underlying endoderm, and its canal forms the transient neurenteric canal.

In the mid-line anterior to the primitive streak there appears the shallow neural groove (fig. 11), corresponding to a thickened plate of ectodermic cells, the neural plate. The neurat groove is slightly forked at its posterior extremity, in the region of the primitive node (Hensen's node), which forms the dorsal lip of the primitive pit. As development proceerls, the neural plate extends posteriorly, and the primitive pit is accordingly shifted backward, the corresponding part of the primitive groove being converted into 'head process.' The primitive streak thus becomes progressively shortened (cf. figs. 11 and 13).

Fig. 12.-Topography of the Embryonic Disc. Diagram of Relations at the Lengti OF ABOUT 1 Mm. $n g$, neural groove. $p n$, primitive node. $p p$, primitive pit. $U$, upper limb. $L$, lower limb.

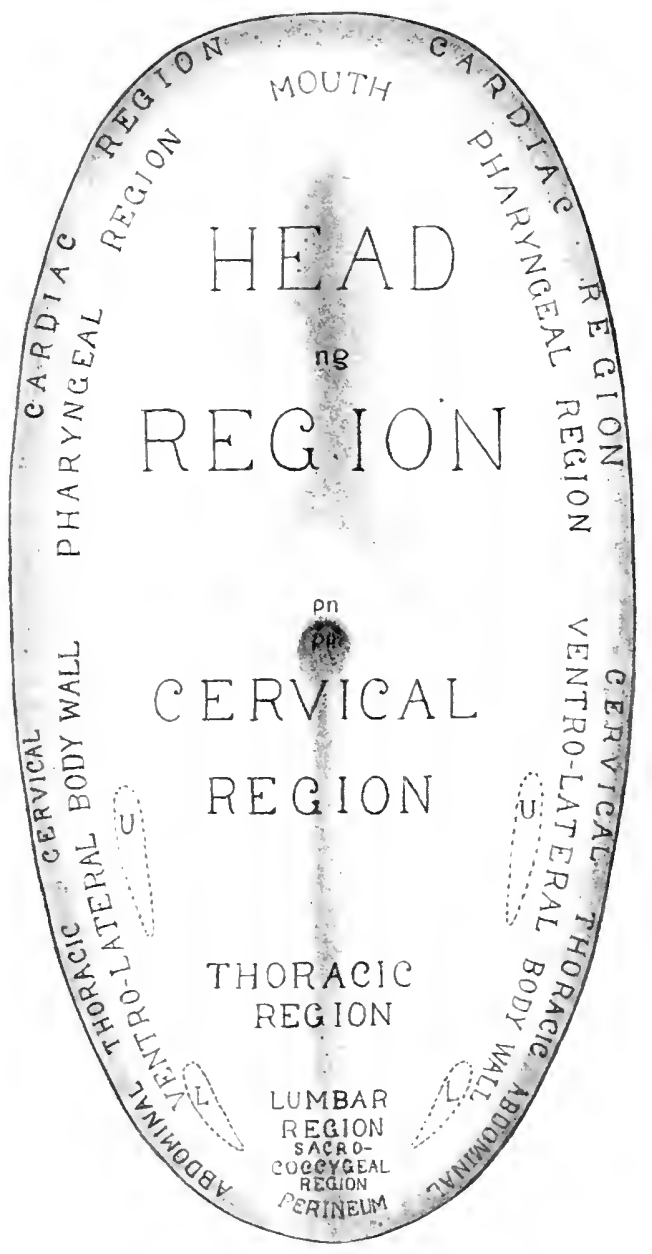

Topography of the embryonic disc.-Although only slight signs of differentiation are visible in the embryonic disc at the stage shown in fig. 11 , it is already possible to map out more or less definite areas corresponding to all the various regions of the future body, as shown in fig. 12.

Beginning anteriorly, the head region is relatively enormous in size, occupying at this time the entire portion in front of the primitive pit and forming about half of the entire disc. The cervical, thoracic, lumbar and sacro-coccygeal regions appear successively smaller, approaching the posterior end ('tail bud') of the primitive streak. It is also a striking fact that the future dorsal region of the body wall, corresponding to the central portion of the disc, along each side of the mid-line, is now larger than the ventro-lateral regions, which occupy at relatively narrow area around the periphery of the dise. 
The topography of the germinal areas in the embryonic disc shown in fig. 12 is based partly upon a study of the succeeding stages of development, and partly upon the results of experiments upon the germinal disc in lower forms, especially in the chick (Assheton, Peebles, Kopsch).

Law of developmental direction.--In the relative size of the various embryonic areas is foreshadowed what may be termed the law of direction in development. In general it is found that development (including growth and differentiation) in

Fig. 13.-Homax Embrio $1.54 \mathrm{~mm}$. long. Viewed from above, the roof of the amniotic carity having been removed. (Minot, after Graf Spee.)

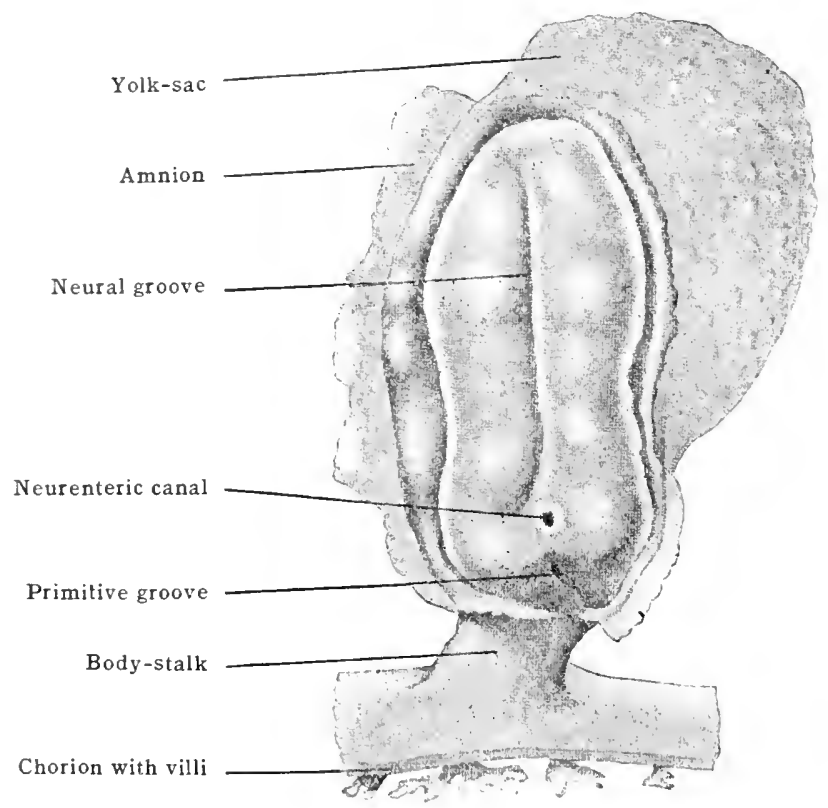

the long axis of the body appears first in the head region and progresses toward the tail region. Similarly in the transverse plane development begins in the mid-rlorsal region and progresses latero-ventrally (in the limbs, proximo-distally). The principles are of great importance in morphogenesis.

Fici. 1. - Diaghams Showlag the Constuction of the Embryo from the Yolk-Sac. $A$ and $C^{\prime}$, longitudinal sections; $B$ and $D$, corresponding ('ross-sections. (MeNurrich.)
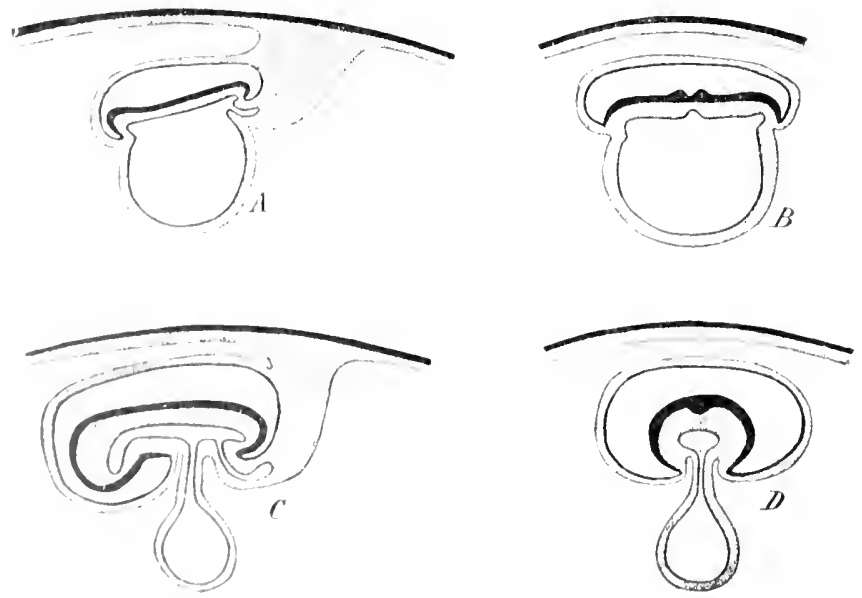

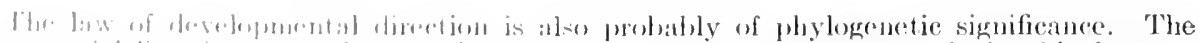

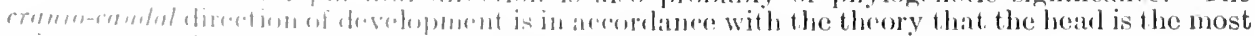

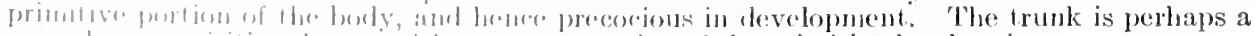

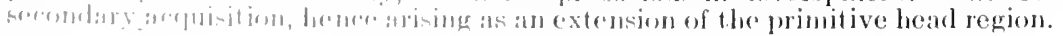


The dorso-ventral direction of development, together with the plate-like form of the enbryonic disc, has a different phylogenetic significance. Both are probably inherited from an ancestral type with a yolk-laden ovum. In such an ovım, with the meroblastic type of segmentation, the flattened embryonic disc gradually spreads from the dorsal surface in a ventral direction around the underlying yolk-mass.

Derivation of body tube from embryonic disc.-The primary result of the precocious growth in the dorsal region of the embryonic disc is the conversion of the disc into the body tube, curved ventrally in its long axis (fig. 14).

Fig. 15.-Portion of Cross Section of the Embryo shown in Fig. 13. ch, notochord. $c t$, somatic mesoderm. $d f$, splanchnic mesoderm. $g$, junction of extra-embryonic somatic and splanchnic mesoderm. ek, ectoderm. en, endoderm. me, embryonic mesoderm. $f$, neural groove, $p$, beginning of embryonic coelom (pericardial cavity). (Minot, after Graf spee.)

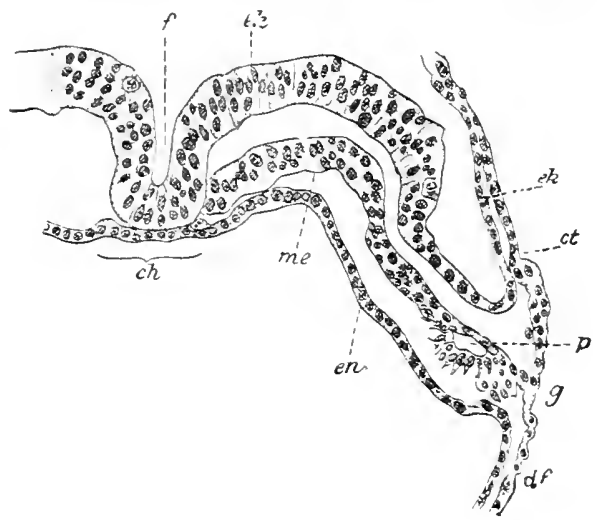

As a result of the more rapid expansion of the germ layers (especially the ectoderm) near the mid-line, the dorsal surface of the embryonic disc in general becomes convex, with a depression laterally (where growth is less rapid) forming a groove at the line of attachment of the amnion (figs. $11,12,13,14 \mathrm{~B}$ ). The unequal growth in the germ layers is clearly evident in the cross section shown in fig. 15. By a continuation of this process, the margins of the embryonic disc become still further depressed and finally folded in ventrally so as to transform the disc into a tube (fig. $14 \mathrm{D}$ ). Similarly, by a more rapid expansion of the dorsal layer of the disc in the longitudinal axis, the head and tail ends of the disc are folded and tucked in ventrally, and the primitive body tube is thus correspondingly curved in its long axis (figs. 1t $\mathrm{A}, 1+\mathrm{C}$ ).

Fig. 16.-Model of Human Embrio 1.S mim. Long. Tiewed from above, the roof of the amniotic cavity having veen removed. Near the caudal end of the neural groove, the primitive pit (opening of neurenteric canal) is visible. The primitive somites are appearing in the occipital region, the fourth corresponding to the boundary between head and neck. (Mc.Murrich, from Keibel and Elze.)

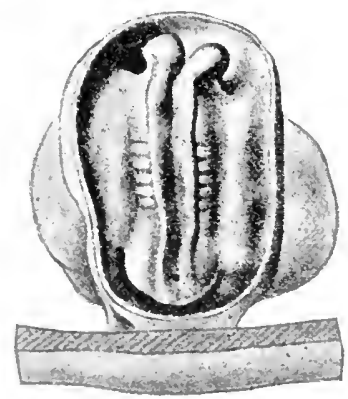

The embryonic disc is thus converted into a tube composed of an outer liyer of ectoderm. a middle layer of mesoderm and an inmer layer of endoderm. The yolk-sic now presents an expanded yolk-vesicle lined by endoderm which is still continuous through the constricted yolkstalk with the endoderm lining the primitive enteric cavity (fig. 14 C). The enteric carity (or archenteron) has a blind tubular prolongation (fore gut) into the head region, and another (hind gut) into the tail region. From the latter a slender diverticulum, the allartois, extends into the body stalk (later the umbilical cord). The allantois is an organ of phylogenetic importance, with which the urinary bladder is later connected.

Formation of the neural tube. - The principle of unequal growth applies to the formation not only of the body as a whole, but also of its constituent parts. Thus the anlage of the nervous system arises from the ectoderm as a wide groove 
whose edges (neural ridges) by local growth are folded upward so as to meet in the mid-line where they fuse, thus transforming the groove into the neural tube (figs. 11, 12, 13, 15, 16, 17, 18).

The closure begins, not at the anterior end (as might be expected from the general law of cranio-caudal development), but in the cervical region, extending forward into the brain region, and backward along the spinal cord. Thus the extreme ends (anterior and posterior neuropores) are the last to close.

The precocious and energetic growth of the neural anlage is largely responsible for the ventral flexure of the embryonic body axis, especially in the head region, where the flexures of the brain are very conspicuous (figs. 22,26 ).

With the closure of the neural tube dorsally and of the alimentary canal ventrally the human embryo assumes the typical vertebrate form. The cylindrical body wall now encloses two tubes (neural and enteric) with the longitudinal axis (notochord) between them (figs. 18, 24).

After the embryonic dise has been transformed into a tube, the body of the human embryo in cross section appears not circular but elongated dorso-ventrally. This is the typical form for vertebrates with horizontal body axis. In later foetal stages, the body becomes more rounded in cross section, and finally, with the assumption of the erect posture in postnatal life, becomes decidedly flattened dorso-ventrally (figs. 20, 21).

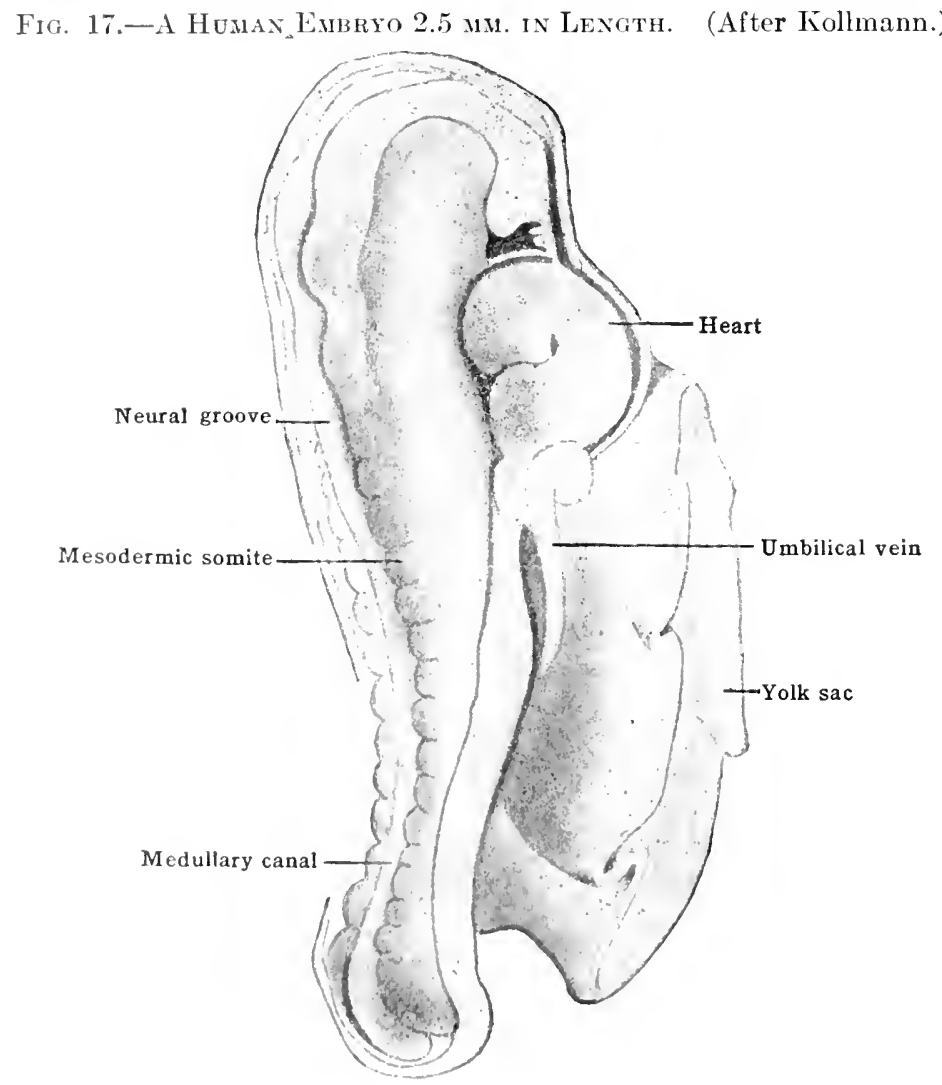

Development of the mesoderm.-The mesodermic layer on each side of the notorherd in the mubryonie dise develops in two divisions. The medial (or dorsal) divisions form it sorich of hollow segmonts, the somites (figs. 16, 17, 18).

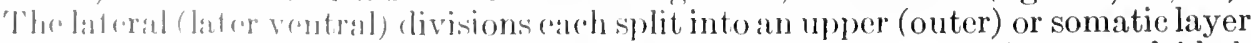
ind a lower (immer) or viseral layer. When the embryonic dise becomes folded, the forrespending somatie and viseral lavers unite ventrally and enclose between 1. hem thr" (ommmen calom or primitive body eavity (fig. 18).

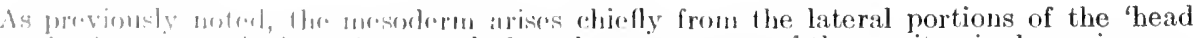

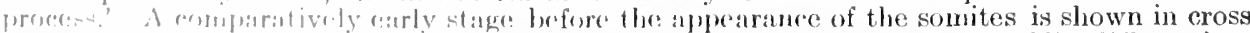

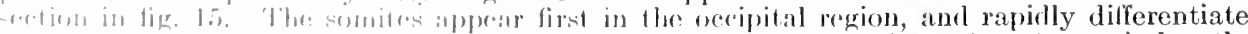

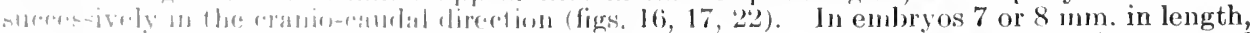

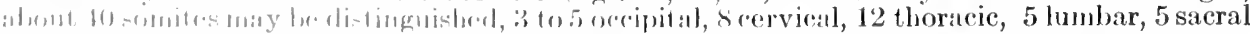

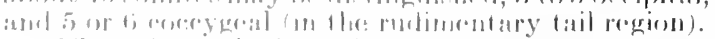

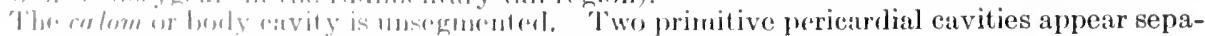


rate at first, but soon fuse and unite with the general cœlom. Later the general ccelom becomes secondarily divided into the permanent pericardial, pleural and peritoneal cavities.

The outer layer of the lateral mesodermic division forms the somatic or parietal layer of the peritoneum, etc. The inner layer forms the visceral or splanchnic layer, and develops not only the serous membrane, but also the muscular and connective tissue of the walls of the alimentary canal and its derivatives.

Development of the somites. Metamerism.-The appearance of the somites marks the beginning of metamerism, the arrangement of the body in successive

Fig. 18. -Diagran of a Cross Section of a Humax Embryo.

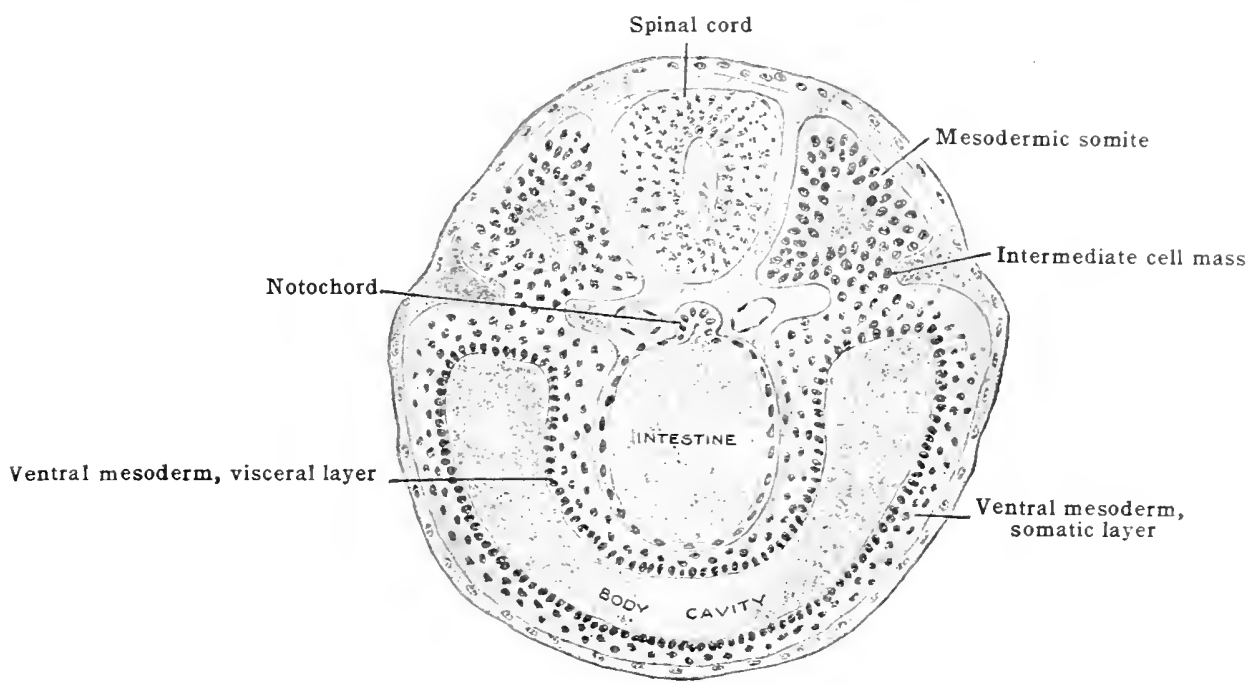

segments or metameres. Each somite develops a primitive muscle segment, myotome, and a skeletal segment, sclerotome (figs. 18, 19). Moreover, the corresponding nerves and blood-vessels likewise assume a metameric arrangement. This metamerism persists (more or less modified) in the adult neck and trunk.

The differentiation of the somites is illustrated by figs. 1s and 19. The medial wall of each somite forms the sclerotome. Its cells migrate to form the corresponding vertebra, rib, etc., as

Fig. 19.-Diagrams Illustrating the History of the Mesoderir. $M$, myotome, $d . M$, dorsal portion of myotome. $v M$, ventral portion of myotome. SC, sclerotome. gr, genital ridge. $W d$, Wolffian duct. $S m$, somatic layer of mesoderm. $\imath m$, visceral layer of mesoderm. $m r$, membrana reuniens. $I$, intestine. $N$, neural tube. (McMurrich.)
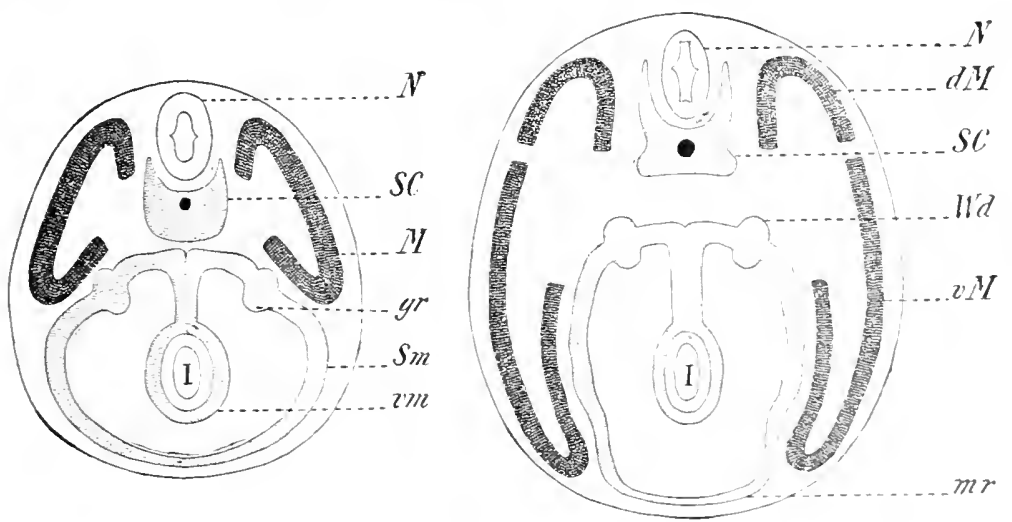

well as the mesenchyme forming the various connective tissues in this region. The remainder of the somite forms the myotome, from which the voluntary nusculature of the trunk, the neck and (in part) the head is derived. The dorsal portions of the myotomes develop the muscle in the dorsal region of the trunk, while the ventral portions extend ventralward to form the musculature of the latero-rentral body walls (figs. 19, 20, 21, 23).

At the junction of the dorsal and ventral divisions of the mesoblast is a group of cells called the intermediate cell mass. This mass becomes segmented (corresponding to the somites) and 
each segment, or nephrotome, gives rise to a portion of the mesonephros, the provisional kidney. Other cells of the mass become mesenchyme, which is converted into blood-vessels, connective tissue, etc.

As development proceeds, the metamerism of the muscles and arteries becomes more or less obscured, but that of the vertebrie and nerves is fully retained even in the adult. In the case of the muscle plates, from which all the voluntary musculature of the trunk is derived, great modifications occur. Extensive fusion of successive plates occurs, the intervening comnective tissue disappearing more or less completely; associated with this fusion there is longitudinal and tangential split ting of the somites to form individual muscles; and portions of some of the plates may wander far from their original position. But notwithstanding these complicated changes, indications of the primary metameric arrangement of the muscle plates are abundant, and even in the most extrene cases of modification the developmental history of a muscle can be determined by means of its nerve supply. For the fibres derived from each plate will usually retain, no matter what changes of independence or position they may undergo, the innervation by their originally corresponding segmental nerve; so that the occurence in the lumbar region of the body of muscle-fibres (the diaphragm) supplied by nerve-fibres from a cervical nerve is evidence that the muscle-fibres have been derived from a cervical mesodermic somite and have subsequently migrated to the position they finally occupy.

As regards the arteries, they arise primarily from a longitudinal stem, the aorta, in a strictly segmental manmer, each metamere having distributed to it two pairs of arteries and a single median one (fig. 20). One pair of arteries supplies the body wall, and these retain very distinctly their original metameric arrangement; the other pair passes to the paired viscera, such as the lungs, kidners, oraries (or testes), so many of the pairs disappearing, however, that their metameric arrangement is not very evident in the adult. The unpaired vessels supply the digestive tract and its unpared appendages, such as the liver and pancreas, and undergo great modifications, those of the lower thoracic and lumbar regions becoming reduced by fusion and degeneration to three main trunks.

Fig. 20.-Diagram of a Transverse Section through the Abdominal Region.

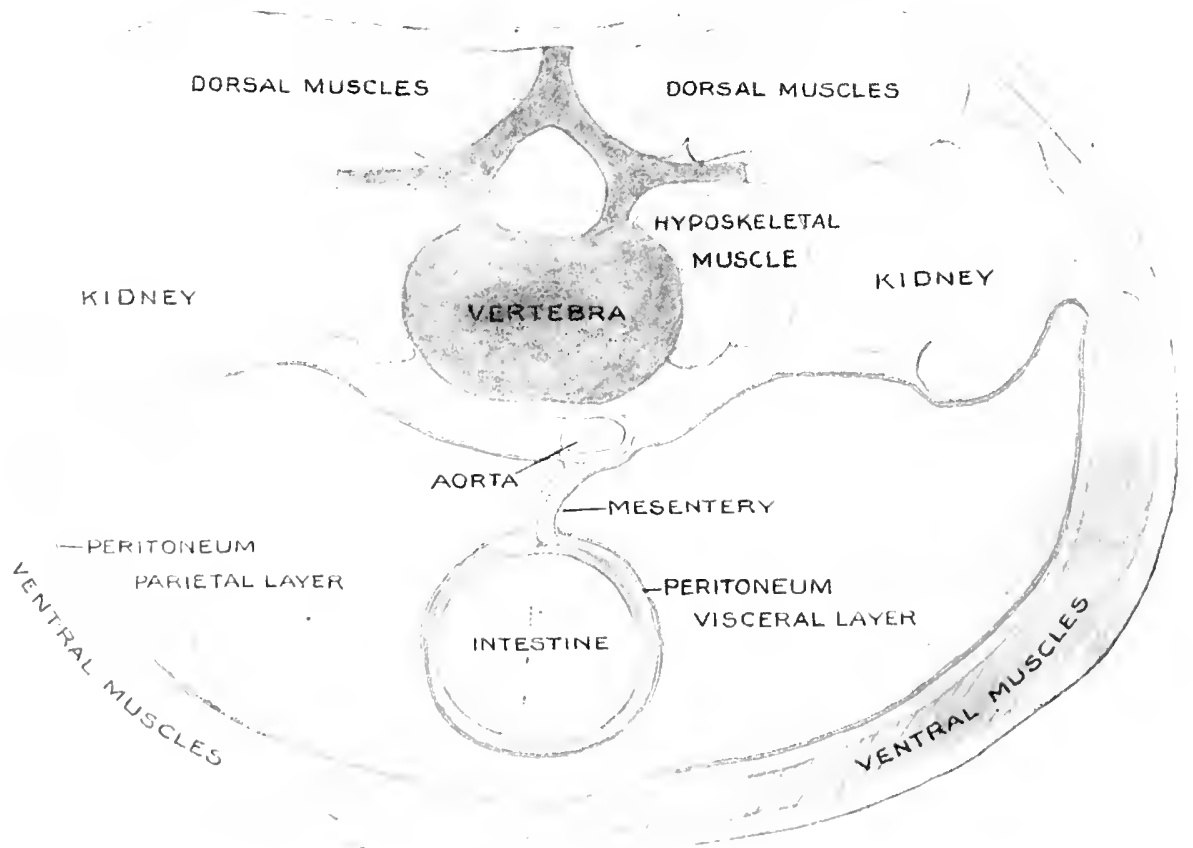

Branchiomerism. 'Thromghout the trunk and neck regions, then, a funda-

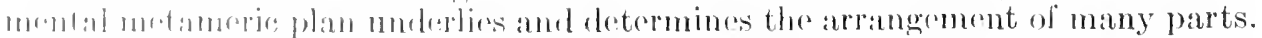

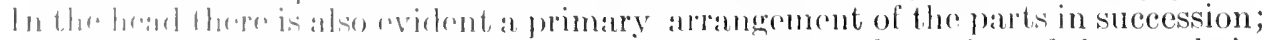
hat, this arrandermont appmats to he somewhat difforont from that of the trunk in flatt if involyes the voll rial instoal of the dorsal mosoderm and is associated with

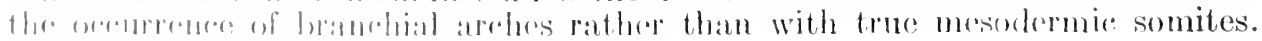

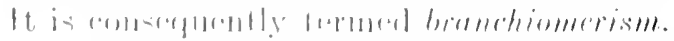

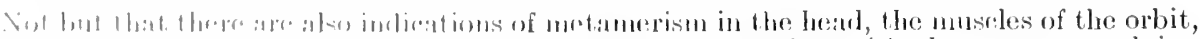

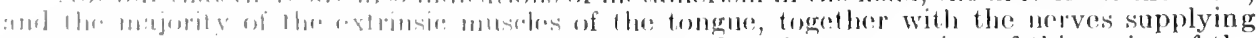

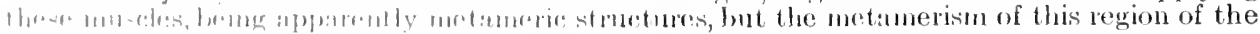

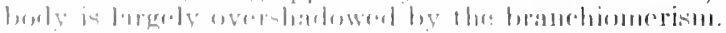

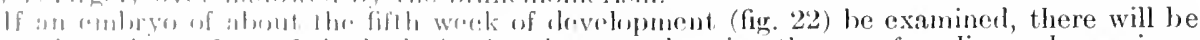

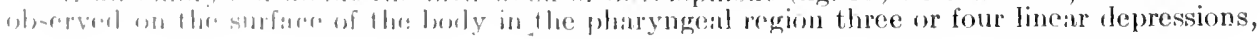


and sections will show that similar and corresponding grooves also occur upon the inner surfice of the pharyngeal wall. These are the branchial grooves, and since they are four in number (with a rudimentary fifth) in the human embryo, they mark off five branchial (ar visceral) arches, the first of which lies between the oral depression and the first branchial groove, while the fifth is situated behind the fourth groove. These branchial arches are so named becance they represent the arches which (excepting the first) support the gills (branchice) in the lower vertelrates, the grooves representing the branchial slits, even although they do not becone perforated in the human embryo.

Each branchiomere consists of an axial skeletal structure, of muscles which act on this keteton, of a nerve which supplies the muscles and the neighbouring integument and mucous membrane, and of an artery which carries blood to all these structures. The arches, however, lo not in the human embryo retain their original branchial function, but unclergo extensive modifications, becoming adapted to various functions and showing less in the arlult of their originally simple arrangement than do the metameres. Nevertheless no matter what modifications the inusculature of any arch may undergo, it will retain its original innervation alld, to a large extent, its relations to the skeletal elements of its arch; and even the arteries in their distribution show clear indications of being arranged in correspondence to the various arches.

Fig. 21.-Diagran of a Transverse Section through the Timoracic Region. (The pleura is represented in blue and the pericardium in red.)

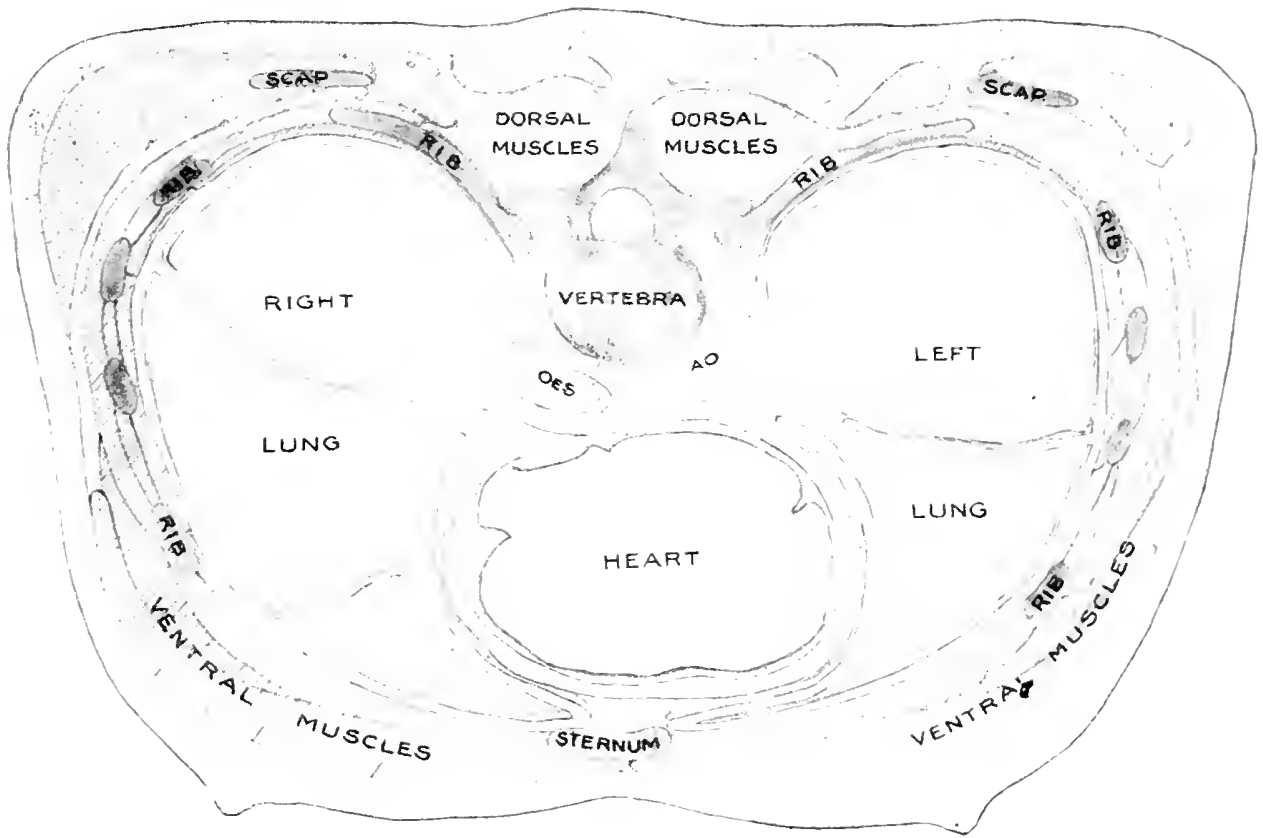

With respect to the fate of the various structures pertaining to each brumchial areh, their general arrangement in the adult body may be stated in the following table:-

Relations of the Braxrhial Arches in the Adelt
Arch
Skeleton
Muscles
Nerve

First arch...... Mandible, malleus and Masticatory, mylohoir and di- Trigeminus. incus.

Second arch.... Hyoid (lesser cornu), stylohvoid, digastric (post.), Farialis. stapes. dius.

Third $\operatorname{arch} . . \ldots$ Hyoid (greater cornu) .. Pharyngeal.............. Glosopnlaryn-

Fourth and fifth Thyreoid cartilage..... Pharyngeal and laryngeal.... Iangu<. arches.

Branchial grooves. - Of the external branchial grooses, the first lying between minulinular and hyoid arches) becomes deepened to form the externat auditory meatus, the nangins hecoming elevated to form the auricle (fig. 26). The region corresponding to the secomil. thim and

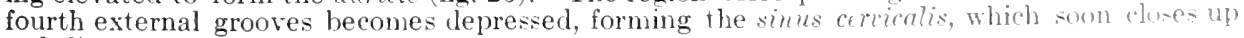
and disappears.

The internal branchial grooves or pouches communicate with the pharygeal raty and are 
lined with endoderm. The first internal groove becomes transformed into the auditory (Eustachian) tube, tym panic cavity, ete. The second internal groove persists in part as the fossa of the palatine tonsil. The third and fourth grooves are probably represented in part by the vallecula and recessus piriformis, detached portions of their lining endoderm giving rise to the thymus, parathyreoid glands, etc. The rudimentary fifth groove is said to give rise to the ultimobranchial body, a structure of uncertain significance (fig. 27).

Development of the face.-The facial region is at first relatively small. It includes the sense organs (eye, ear, nose) and mouth region. Some of the more important developmental features may be briefly mentioned. In an embryo of the sixth week (fig. 28) the wide mouth aperture is seen to be bounded below (posteriorly) by the lower (mandibular) portion of the

Fig. 22.-Humax Embryo of 4.2 ma., Showing Three Branchial Grooves.

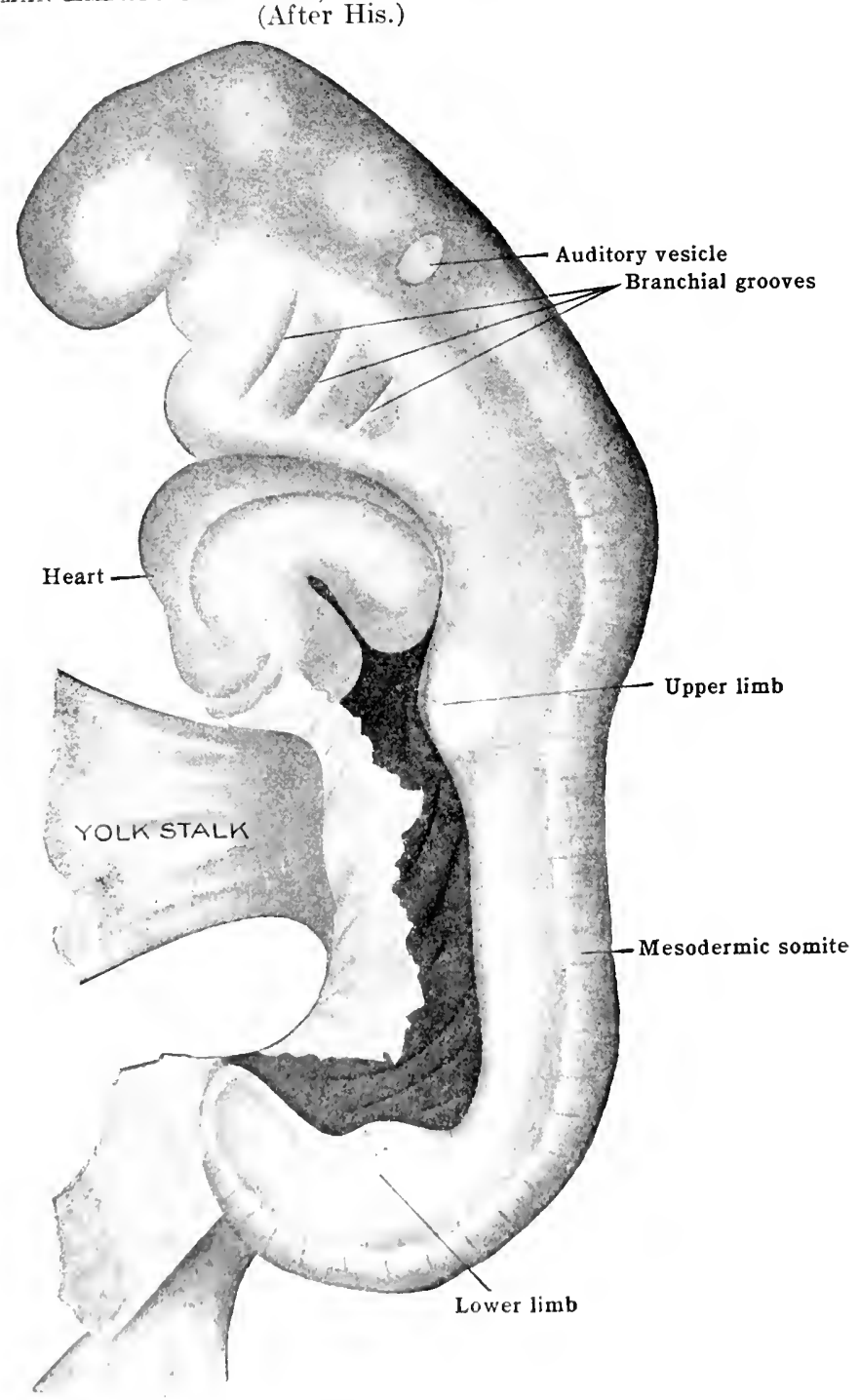

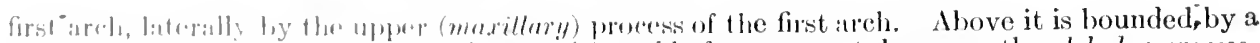

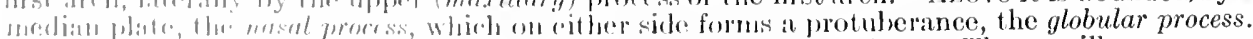

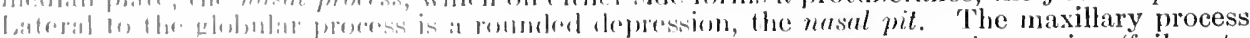
...

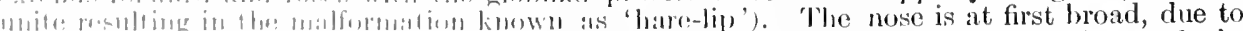

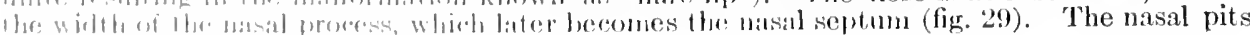

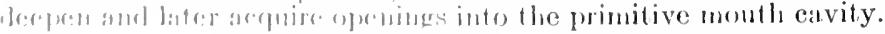

The viscera. 'l'he stmelures so far considered belong, for the most part, to the lorly wall; it monims to rousider the genepal plan of arrangement of the

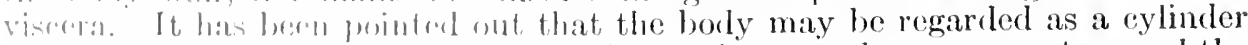

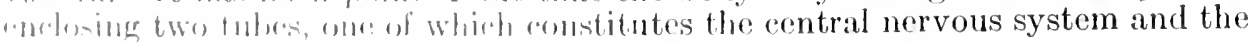


other the digestive tract. The latter may be regarded as being primarily a straight tube traversing lengthwise the body cavity enclosed by the body wall (figs. 18, 20). The layers of both the visceral and somatic plates which im-

Fig. 23.-Sagittal Section Showing the Primitive Pericardial and Cielomic Communication, Septum Transversum, Liver, etc., in a Human Embryo uf 3 m. (Aftel Kollmann, from a model by His.)

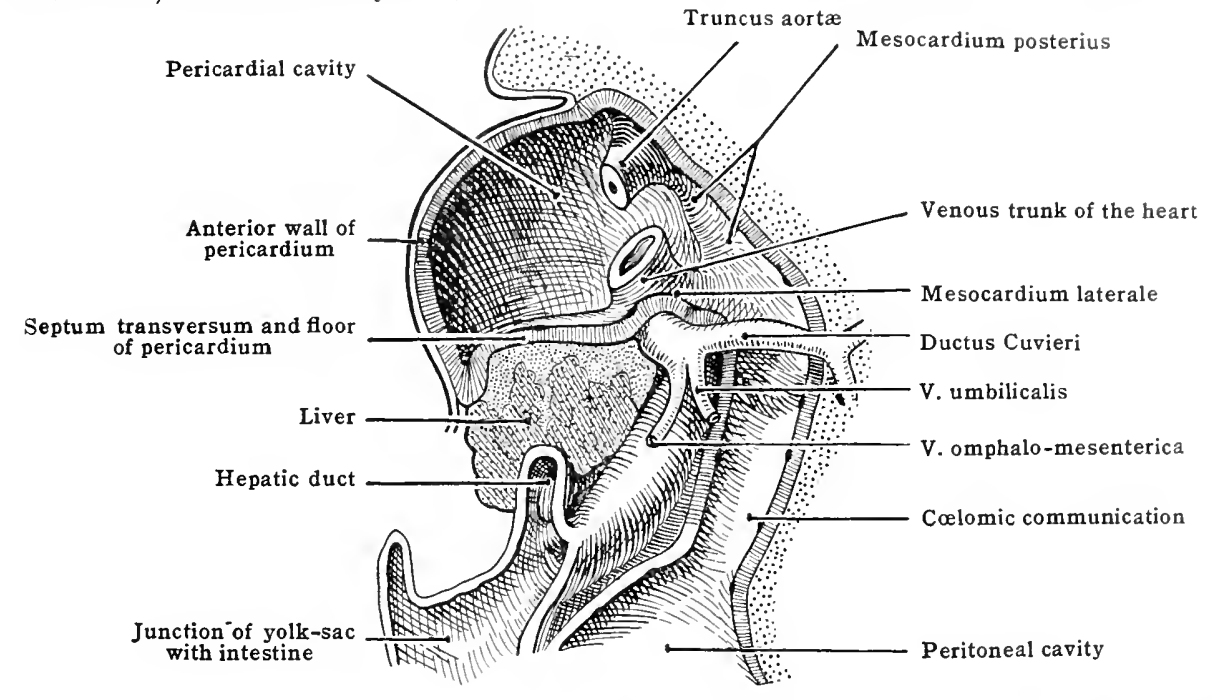

mediately enclose the body cavity become transformed into a characteristic pleuro-peritoneal membrane. Near the mid-dorsal line, a vertical double plate of peritoneum extends ventrally connecting the somatic (parictal) and visceral layers of peritoneum, and constituting what is termed the mesentery (fig. 20).

Fig. 24.-Diagram Illustrating the Recession of the |Diaphragm (Septum Traxsversum) IN THE HUMAN EMBryo. On the right are indicated the vertebral levels; on the left, the position of the septum transversum in a series of embryos from $2 \mathrm{~mm}$. (XII) to $24 \mathrm{~mm}$. (VI) in length. $p p$, pleuro-peritoneal cavity. (Mall.)

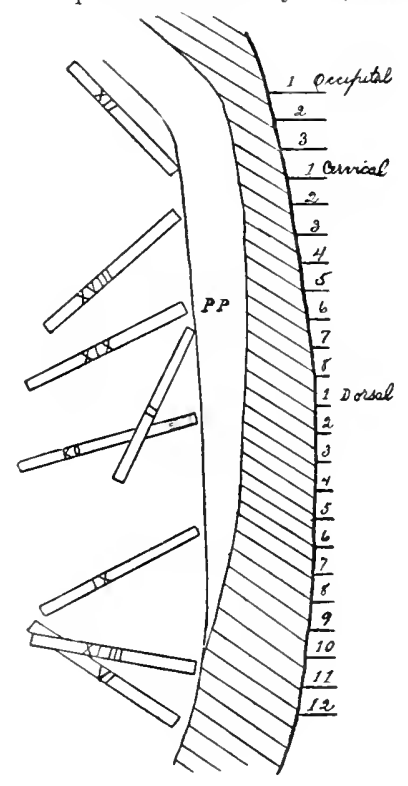

As development proceeds the digestive tract grows in length more rapiclly than the carity which contains it, and so gradually becomes thrown into numerous coils in the abrominail region, these changes leading to numerous modifications of the original arrangement of the mesentery. These will be described later on in the section on the digestive system. Several outgrowths also arise from the primitive digestive tract, to form important organs, such as the lungs, 
the liver, the parereas and the urinary bladder; and, with the exception of the bladder, each of these becomes completely invested by primitive peritoneum. In the case of the liver this original condition is practically retained, but the investment of the pancreas later becomes a partial one on account of the modifications which ensue in the mesentery. The bladder has only a portion of its surface in contact with the peritoneum, but the investment of the lungs remains complete, each lung, indeed, appropriating to itself the entire visceral layer of its half of the thorax, with the exception of a small ventral portion which forms the investment of the heart. Furthermore, the cavities which surround each of the three organs named, the two lungs and the heart, become completely separated from one another; and since each investment consists of a visceral and a pilietal layer, each of the organs is enclosed within a double-walled sac, which in the case of each lung forms its pleura, while that of the heart is known as the pericardium. The spaces which oceur within the thorax between the pleura of the two sides are known as the mediastina, which include the heart, œsophagus, ete. (fig 21).

In addition to the viscera mentioned there are some organs, such as the spleen and genitourinary organs, which are levelopments of the mesoderm, the spleen arising in the mesentery which passes to the stomach and the genito-urinary organs primarily from the intermediate cell mis.s. The morphogeny of these structures and also of the vascular system, nervous system, and sense organs will be considered later in connection with their structure.

Fig. 25.-Diagram of a Cross Section of the Enbryonic Body and Linb. (MeMurrieh, after Kollman.)

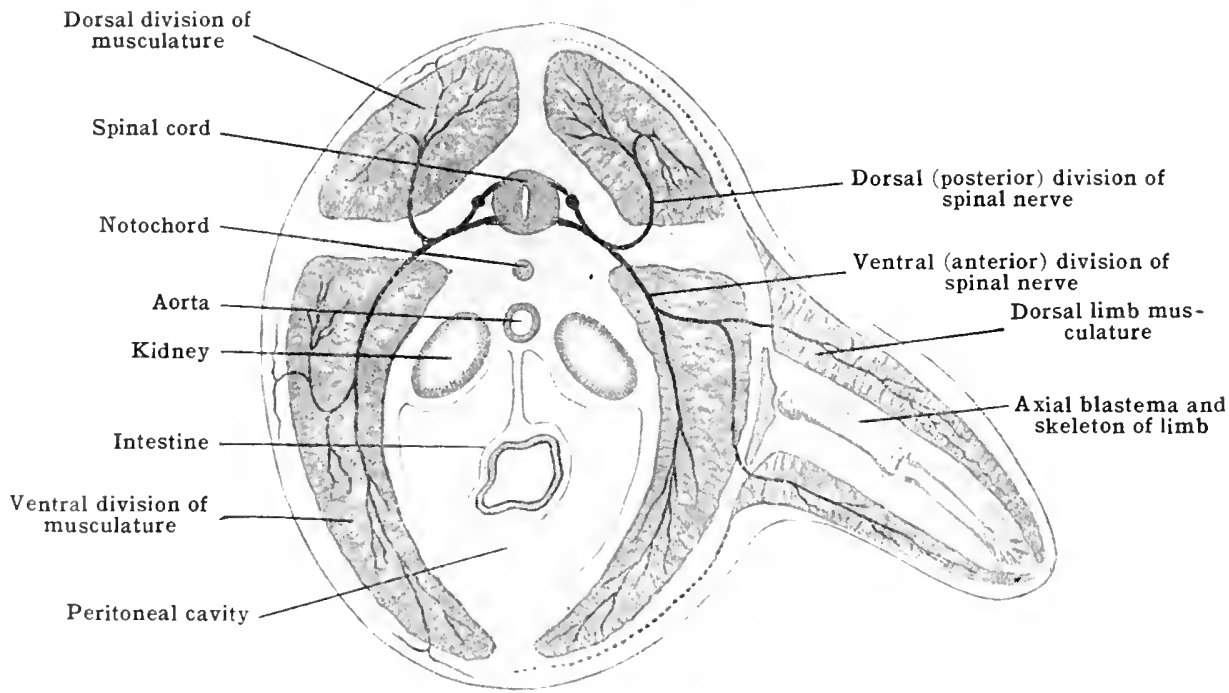

Recession of the diaphragm and heart.-In the early stages of development the heart is situated far forwarl, in what will eventually be the pharyngeal region (figs. 12, 17). Just behind (caudal to) the heart, between it and the yolksar, is a plate of connective tissue, the septum transversum, which serves for the pastage of large veins from the body wall to the heart (figs. 17, 23). This septum together with rertain accessory structures eventually gives rise to the diaphragm, which heremes a complete partition separating the thoracic and abdominal portions of the borly cavity.

The , fiaphagm and heart are therofore originally situated far above (eranial to) their final presilon ind recele in the course of development, producing an elongation of the vessels ancl neres assectated with them and foreing fownwarel such orgass as the stomach and liver (fig. 26). T'te: che factor in this clisplacenent is probably the vontral hearl flexion and the procesente grewth and axpansion of the organs in the head region. The effects of this recession arre "sperially motionabre in the nerves, these pissing to the various organs roncerned arising

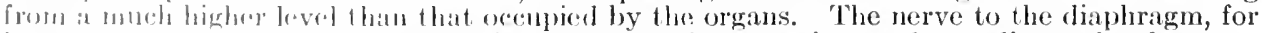
instaner, eromes from the fourth cervical segusent, these passing to the cardiae and pulmonary phexuses from the arvinal region, and those to the plexus in relation with the stomach, liver ind adjacent organs from tha thoracic region. 'The blood-vessels, however, may shift their origins from the main trmak by sumessive antstomotic roots, so that in general they keep paee with the viserera in the migralion candalward.

The limbs. Bach limb at its first appearance (fig. 22) is a fat, plate-like bntgrowth from the side of the borly, and consists of an axial mass (blastema) of Inrserlarmine tissue from which the limb skelden will develop, and, surrounding this, a layer, also of mesorlermic tissure, from which the muscles and bloot-vessels will arise. It is as yet mnoretain whether the musclo blastema is derived from the myotomes (as in lower vertobrates) or whether it dovelops from the mesenchyme. 
Fig. 26.-Lateral View of a Humax Embryo 18 min. Long, Showing the Developiext of the Extremities. M, mandibular arch.

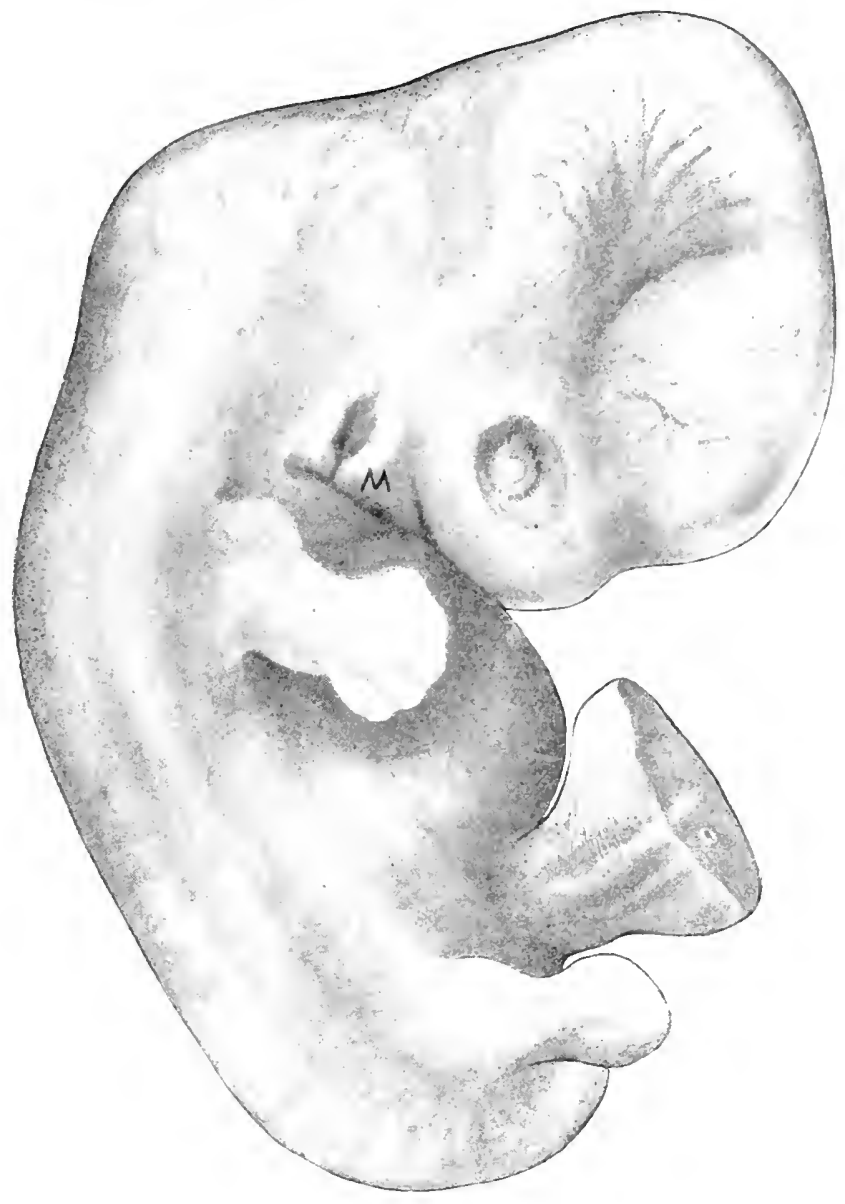

Fig. 27.-Diagram to Show the Derivatives of the Braxchin Clefts. If, IIe, Ille, IV $e$, Ve, external branchial grooves. I $i$, II $i$, III $i$, IV $i$, V $i$, internal branchial grooves. Tons., palatine tonsil. Ep III, Ep IV, epithelial bodies. Ub, ultimobranchial body. Th., thy reoid gland. D.th. gl., ductus thy reoglossus. (Modified ron Keibel and Mall.)

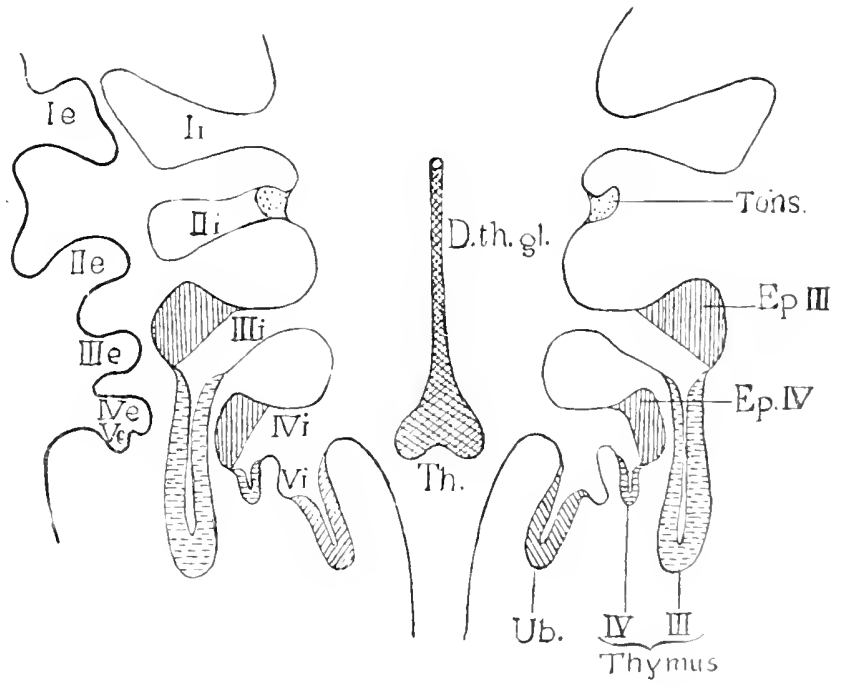


As the muscles become differentiated, nerves grow to them from a definite number of spinal segments (fig. 25).

At first each limb plate is so placed that one of its surfaces looks dorsally and the other ventrally, and one border (that corresponding to the thumb or great toe) is anterior (i. e., cranial) and the other posterior (caudal). Later, however, each limb becomes bent caudally through about ninety degrees, so that the limbs whose long axes were at first at right angles to the long axis of the body come to lie parallel to that axis. In addition there occurs a rotation of each fore-limb in such a manner that the thumb turns latero-dorsally, while in the lower limb the direction of the movement is exactly the opposite, the great toe turning ventro-medially. As a result there is an apparent reversal of the surfaces in the two limbs, the flexor muscles of the arm reaching on the surface which is directed anteriorly, while in the lower limb the corresponding muscles occupy the posterior surface. The dorsum of the foot and the great toe side correspond respectively to the back and thumb side of the hand, the tibia corresponds to the radius and the fibula to the ulna. The limb anlage soon becomes divided into three primary segments. The distal segment (hand or foot) is a flattened rounded disc, in which the digits soon appear (fig. 26). The proximal portion forms the forearm or leg and the arm or thigh. In general, the extremities follow the law of eranio-caudal and dorso-ventral (proximo-distal) development. Eig. 2SA.-FaCe of HuMAN EMbrio_of
about 8 MM. (His.)

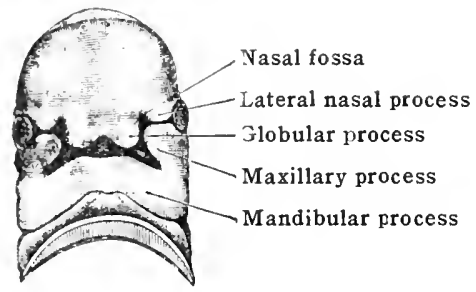

Fig. 28B.-Face of Htiman Embryo at Stage Slightly Later than 28A. (After Kallius.)

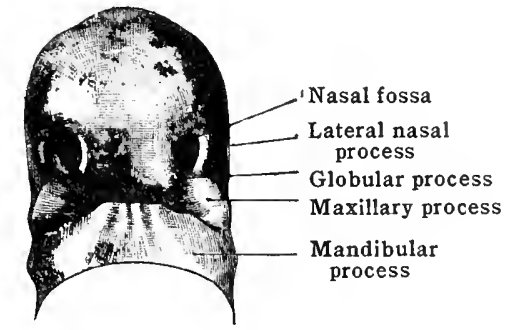

Prenatal Growth in Length and Weight

Age in

lunar

months

0

I

II

II I

IV

il

VII

VIII

* IX

\begin{abstract}
Crown-rump or sitting height
\end{abstract}

(Mall), em.
Crown-heel or standing height (Mall), cm.
Weight at end of month, grams
Ratio of increase to weight at beginning of month

$\begin{array}{lcr}\text { 0 (lianeter of ovum } & \ldots \ldots \ldots \\ \text { I } & 0.2 \mathrm{~mm} .) & \ldots \\ \text { II } & 0.25 & 0.25 \\ \text { III } & 2.5 & 3.0 \\ \text { IV } & 6.8 & 9.8 \\ \text { V } & 12.1 & 18.0 \\ \text { VI } & 16.7 & 25.0 \\ \text { VII } & 21.0 & 31.5 \\ \text { VIII } & 24.5 & 37.1 \\ \text { IX } & 28.4 & 42.5 \\ \text { I } & 31.6 & 47.0 \\ & 3.3 .6 & 50.0\end{array}$

(Ovum $=0.000004$ g. $)$

\subsection{4}

2.0

24.0

120.0

330.0

600.0

1000.0

1600.0

2400.0

3200.0

999.0
499.0
11.0
4.0
1.75
0.82
0.67
0.60
0.50
0.33

Prenatal growth. -The prenatal growth of the human body in length and weight is indirated in the joreceling titble. Aceording to Hasse, the age of the foutus may be estimated from its total longth ats follows. Before the fifth month, the sfuare of the age in (lunar) months gives the length in (antinetres. After this, the age in months multiplied by five gives the length. This gives appoximate results, except for the first month.

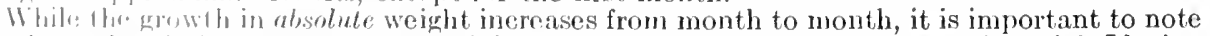
that the real (relative) growth rate rapilly rlininishes. The ovum increases in weight?during

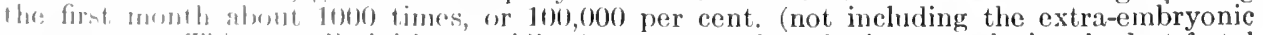

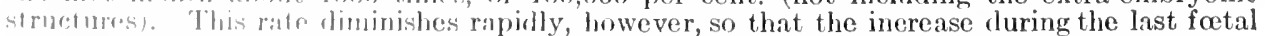
month is only alout, :3 per cent.

'lher continuation of growth in length and weight doring the postnatal period is shown in

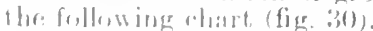

The following chart is liased upon data from Camerer (1-5 yrs.), Porter (6-17 yrs.), and

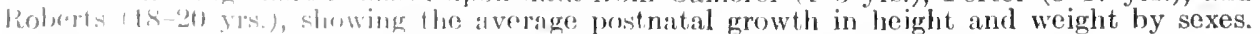

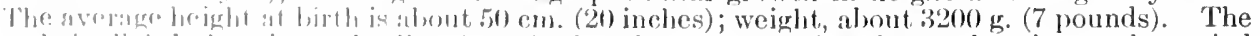
malr is slightly hravior and tallor than the female, except, furing the acceleration at the period

$271)$ (1:19: (1all). 

Fig. 29.-Face of a Human Embryo after Completion of the C'pper Jaw. (Mclfurrich
from His.)

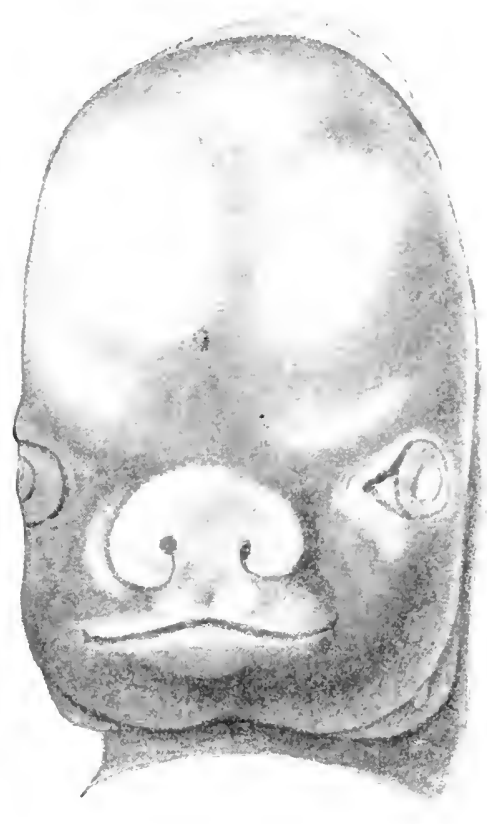

Fig. 30.-Chart Showing Average Postnatal Growth in Height and Weight.

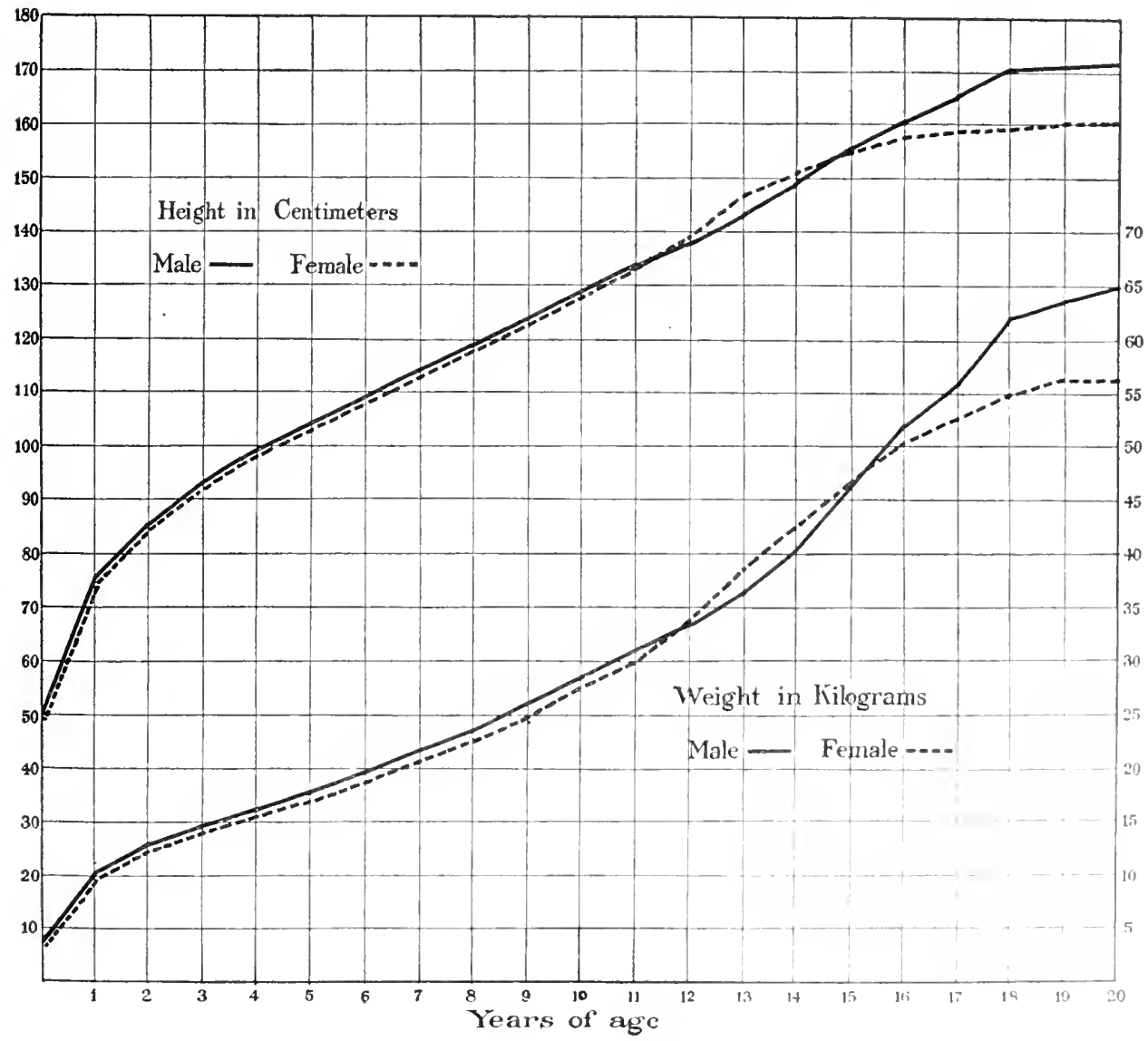


of puberty. Puberty occurs earlier in the female, so that between the ages of 12 and 15 the girls exceed the boys in average height and weight. With the exception of this period of acceleration, the (relative) growth rate in general diminishes steadily from birth, and has practically ceased at 20 years. The average height at this time is about $160 \mathrm{~cm}$. (5 ft., $3 \mathrm{in}$.) in the female, and $170 \mathrm{~cm} .(5 \mathrm{ft} ., 7$ in.) in the male; average weight, about 56 kilograms $(126 \mathrm{lbs}$.) in the female, and $65 \mathrm{kilograms}$ (146 lbs.) in the male. Under favourable conditions, grow th in height may continue slowly up to about 25 years, and in weight even longer; but in old age there is a slight decrease in both height and weight.

The following measurements (from Holt, "Diseases of Infancy and Childhood" may be taken as a normal average standard of growth during the first three vears. The weights are taken without clothing. The height is taken by placing the baby on a perfectly flat surface like a table, and having some one hold the child's knee down so that he lies out straight, then taking a tape-measure and measuring from the top of his head to the bottom of his foot, holding the tape line absolutely straight. The chest is measured by means of a tape line passed directly over the nipples around the child's body and midway between full inspiration and full expiration. The head measurement is taken directly around the circumference of the head, over the forehead and occipital bone.

\begin{tabular}{|c|c|c|c|c|c|c|}
\hline & & & $\begin{array}{l}\text { Weight, } \\
\text { pounds }\end{array}$ & $\begin{array}{l}\text { Height, } \\
\text { inches }\end{array}$ & $\begin{array}{l}\text { Chest, } \\
\text { inches }\end{array}$ & $\begin{array}{l}\text { Head, } \\
\text { inches }\end{array}$ \\
\hline \multirow{2}{*}{ Birth } & Boys &. & 7.55 & 20.6 & 13.4 & 13.9 \\
\hline & Girls & $\cdots$ & 7.16 & 20.5 & 13.0 & 13.5 \\
\hline \multirow{2}{*}{6 months. } & Boys & $\ldots \ldots \ldots$ & 16.0 & 25.4 & 16.5 & 17.0 \\
\hline & Girls & $\ldots \ldots$ & 15.5 & 25.0 & 16.1 & 16.6 \\
\hline \multirow{2}{*}{12 months... } & Boys & $\ldots \ldots \ldots \ldots$ & 20.5 & 29.0 & 18.0 & 18.0 \\
\hline & Giris & $\ldots \ldots \ldots \ldots$ & 19.8 & 29.7 & 17.4 & 17.6 \\
\hline \multirow{2}{*}{18 mouths... } & Boys & $\ldots \ldots \ldots \ldots$ & 22.8 & 30.0 & 18.5 & 18.5 \\
\hline & Girls & $\ldots \ldots \ldots \ldots$ & 22.0 & 29.7 & 18.0 & 18.0 \\
\hline & Boys & $\ldots \ldots \ldots \ldots$ & 26.5 & 32.5 & 19.0 & 18.9 \\
\hline & Givls & $\ldots \ldots \ldots \ldots$ & 25.5 & 32.5 & 18.5 & 18.6 \\
\hline \multirow{2}{*}{3 Years ..... } & Boys & $\ldots \ldots$ & 31.2 & 35.0 & 20.1 & 19.3 \\
\hline & Girls & $\ldots \ldots \ldots$ & 30.0 & 35.0 & 19.8 & 19.0 \\
\hline
\end{tabular}

Relative growth of the parts. - The growth of the body is not uniform in the various parts, and changes in proportions therefore occur during development, as

Fig. 31. - Figures Illustrating tue Chianges in Proportion During Prenatal and Postnatal Growth. (Stratz.)

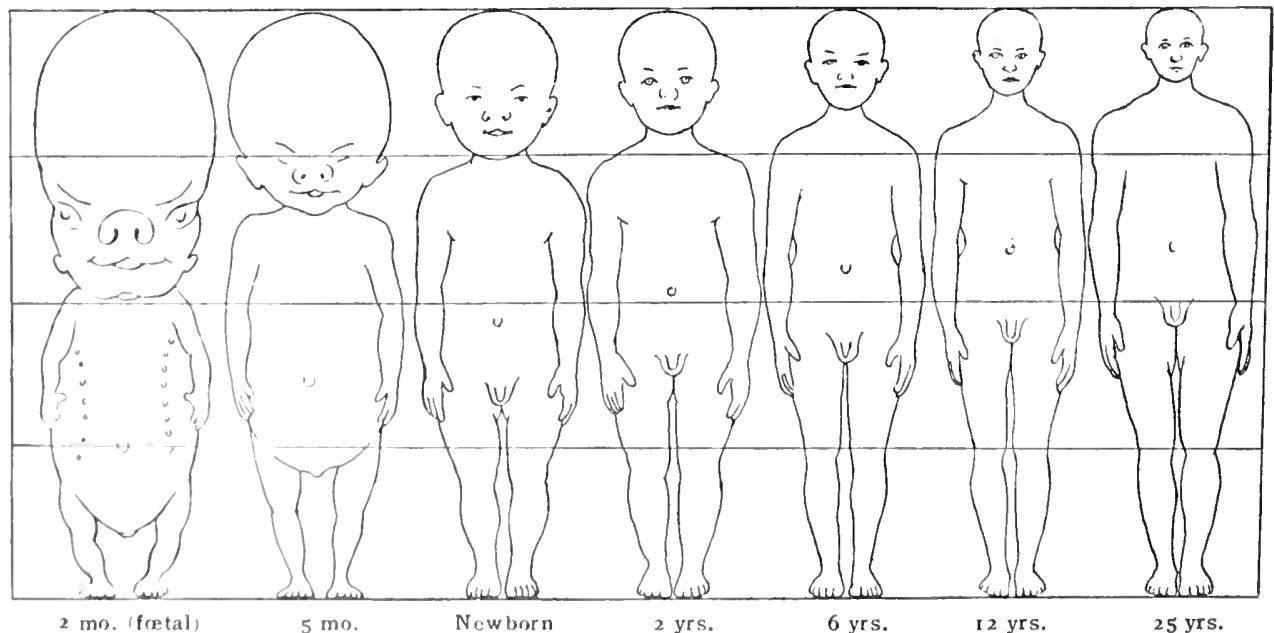

shown in fig. 31. It will be notorl that the ohanges are in aceordance with the

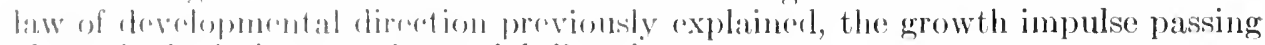
along the borly in a cranio-ramelal direction.

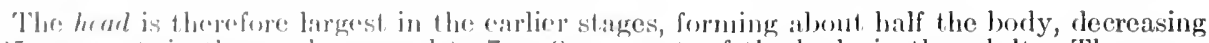

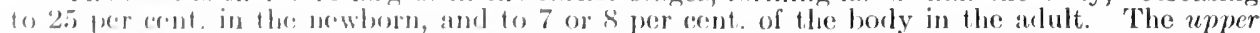

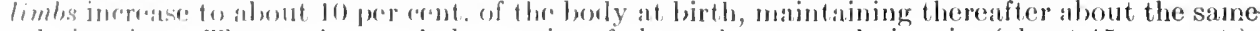
robative size. "l'he trumb as a whole rematins of about the same relative size (about 45 per cent.), 
although the thoracic portion reaches its maximum in the earlier stages, and the pelvic portion not until adult life. The lower limbs, like the pelvis, develop slowly, forming about 20 per cent. of the body at birth and reaching 35 per cent. in the adult.

Relative growth of the systems. - There is also a marked difference in the rrative growth of the various systems. Data for the shin and skeleton are somewhat scant $y$ and insatisfactory. The musculature, however, is relatively small in the embryo, increasing to about 25 per cent. of the body in the newborn, and to 40 or 45 per cent. in the adult. The visceral gromp (including brain and spinal cord), on the other hand, is relatively largest in the early embryo, decreasing from about 35 per cent. of the body to about 24 per cent. in the newborn and to about 10 per cent. in the adult.

Relative growth of the organs. - While in general, the individual organs follow the course of relative growth of the visceral group, each organ has its own characteristic course of growth. As a rule, after its appearance in the embryo, each organ increases more or less rapidly to it: maximum relative size, after which, although increasing in absolute size, jt decreases in relatiu size through subsequent prenatal and postnatal life up to the adult.

Thus the brain in the embryo of the second month forms more than 20 per cent of the body, but steadily declines to abont 13 or 14 per cent. in the newborn, and about 2 per cent. in the adult. The spinal cord and eyeballs have a sinilar course of growth. The hert declines from about 5 per cent. of the body in the embryo of the second month to about .75 per cent. in the newborn and .46 per cent. in the adult. The liver decreases from a maximum of nearly 10) per cent. in the third month to 5 per cent. in the newborn and 2.7 per cent in the adult. 'The suprarenal glands decrease from about .46 per cent. of the body in the third month to .23 per cent. in the newborn and .01 per cent. in the adult. The lungs decrease from 3.3 per cent. in the fourth month to about 2 per cent. of the body at birth and 1 per cent. (bloodless weight) in the adult. The kidneys reach a maximum of about 1 per cent. of the body toward the ent of the fotal period, decreasing to about . 46 per cent. in the adult. The thymus, thyroid, spleen and alimentary canal likewise reach their maximum slowly, being probably relatively largest about the time of birth. The ovary and testis, however, appear to be relatively largest during the prenatal period.

Variability.-It must be borne in mind that all statements concerning structure refer to the average or norm, and are always subject to variation. This is therefore a topic of importance to students of anatomy. Tariations are classified as either germinal or somatic.

Germinal variations are due to fundamental differences in the germ plasm, and are transmitted by heredity. These include many of the characters whereby one individual differs from another. Variations according to sex are included under this class. Variations inherited from more or less remote ancestors are termed atavist ic or reversional.

Somatic variations, or 'acquired characters,' are due to environmental influences, such as nutrition, temperature, shelter, disease, training, etc. While somatic variations may be very great, they do not affect the germ plasm and are not transmitted by heredity.

In many cases it is exceedingly difficult to distinguish germinal from somatic vatiations Size, for example, may be due to either or both. Moreover, somatic variations may be produced at any time after the fertilisation of the ovum. Very slight environmental changes are sometimes sufficient to produce a marked effect upon the delicately balanced mechanism of the developing embryo. Malformations and pathological conditions are thus often to be explained. As to the extent of variability, some characters are much more variable than others. Height, for example, is less variable than weight. Noreover, variability differs in the various: parts and organs. In general, the head and head organs are less variable than the remainder of the body. The skeleton and musculature appear less variable than the integunent and viscera.

Details concerning variations and methods for their measurement may be found in works on genetics and biometrical statistics.

References.-Embryology: Keibel and Mall, Human Embryology (2) rols.): Bryce, Quain's Anatomy, 11th ed., vol. 1; Minot, Laboratory Text-book of Embryology; MeMurrich, Development of the Human Body. Grouth: Minot, Age. Growth, and Death; Jackson. Amer. Jour. Anat., vol. 9; Anat. Record, vol. 3. Heredity: Davenport, Heredity and Eugenics; Walter, Cenetics. Biomelry: Davenport, Statistical Methods; Yule, Theory of Statistics. 



\section{SEC'T I O N I I \\ OSTEO LOQ ( I Y}

Revised for ine Fifth Edition

By PETER THOMPSON, M.D.,

PROFESSOR OF ANATOMY IN THE UNIVERSITY OF BIRMINGHAM; EXAMINER IN ANATOMY, THE UNIVERSITY OP CAMBRIDGE; FORMERLY EXAMINER IN ANATOMY FOR THE UNIVERSITIES OF LONDON, ABERDEEX, MAYCHESTER, DUBLIN AND FOR THE CONJOINT BOARD OF ENGLAND

\section{TIIE SKELETON}

7 HE skeleton forms the solid framework of the body, and is composed of bones, and in certain parts, of pieces of cartilage. 'The various bones and cartilages are united by means of ligaments, and are so arranged as to give the body definite shape, protect from injury the more important delicate organs, and afford attachment to the muscles by which the various movements are accomplished.

In its widest acceptance, the term skeleton includes all parts of the framework, whether internal or external, and as in many of the lower animals there are, in addition to the deeper osseous parts, hardened structures associated with the integument, it is convenient to refer to the two groups as endoskeleton and exoskeleton or dermal skeleton, respectively. All vertebrate-i. e., back-boned-animals possess an endoskeleton, and many of them a well-developed exoskeleton also, but in mammals, the highest group of vertebrates, the external skeleton, when it exists, plays a relatively subordinate part. In most of the invertebrates the endoskeleton is absent and the dermal skeleton alone is found.

In man by far the greater part of the endoskeleton is formed of bone, a tissue of definite ehemical composition, being formed mainly of a gelatine basis strongly impregnated with lime salts.

The number of bones in the skeleton varies at different ages, some, which are originally quite independent, becoming united as age advances. They are arranged in an axial set, which includes the vertebral column, the skull, the ribs, and the sternum, and an appendicular set, belonging to the limbs. The following table shows the number of bones usually distinct in middle life, excluding the auditory ossicles:-

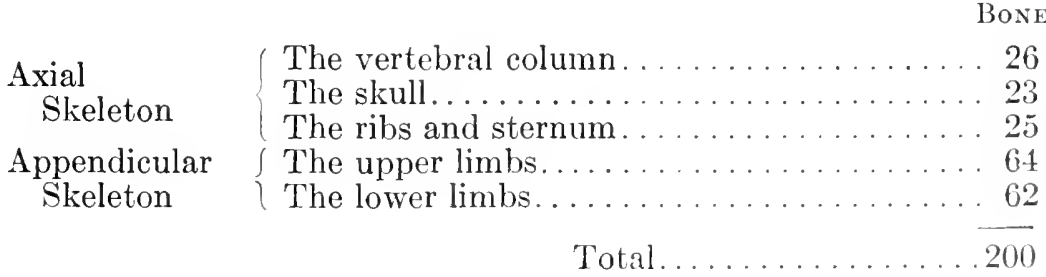

Several of the skull bones are compound, i. e., in the immature skeleton they consist of separate elements which ultimately unite to form a single bone. In order to comprehend the nature of sueh bones it is advantageous to study them in the various stages through which they pass in the process of development in the foetus and the child.

It follows, therefore, that to appreciate the morphology of the skeleton-i. e., the history of the osteological units of which it is composed-the osteogenesis or mode of development of the bones must be studied, as well as their topography or position.

Some bones arise by ossification in membrane, others in cartilage. In the embryo, many portions of the skeleton are represented by cartilage which may become infiltrated by linie salts - calcification. This earthy material is taken up and redeposited in a regular manner-ossification. Portions of the original cartilage persist at the articular ends of bones, and, in 
young bones, at the epiphysial lines, i. e., the lines of junction of the main part of a bone with the extremities or epiphyses. Long bones inerease in length at the epiphysial cartilages, and increase in thickness by ossification of the deeper layers of the investing membrane or periosteum. These processes-intraeartilaginous and intramembranous ossification-proceed concurrently in the limb-bones of a young and growing mamnal.

There is no bone in the human skeleton which, though pre-formed in eartilage, is perfected in this tissue. The ossification is completed in nembrane. On the other hand, there are numerous instances in the skull, of bones the ossifieation of which begins in, and is perfected by, the intramembranous method. Ossification in a few instances commenees in membrane, but later invades tracts of cartilage; oceasionally the process begins in the perichondrium and remains restricted to it, never invading the underlying cartilage, which gradually disappears as the result of continued pressure exerted upon it by the growing bone. The vomer and nasal bones are the best examples of this morle of development. Further details of development and ossifieation are included in the description of each bone.

The limb-bones differ in several important particulars from those of the skull. Some of the long bones have many eentres of ossification, but these have not the same significance as those of the skull. It is convenient to group the centres into two sets, primary and secondary. The primary nucleus of a long bone appears quite early in foetal life, and the main part (shaft) thus formed is called the diaphysis. In only three instances does a secondary centre appear before birth, c. g., the lower end of the femur, the head of the tibia, and occasionally the head of the humerus. Many primary ossific nuelei appear after birth, e. g., those for the carpal bones, the cuneiform and navicular bones of the foot, the coracoid process of the scapula, and for the third, fourth, and fifth pieces of the sternum.

When a bone ossifies from one nucleus only, this nueleus may appear before or after birth. Examples: the talus (astragalus) at the seventh month of fotal life, and the lesser multangular (trapezoj(l) at the eighth year. When a bone possesses one or more secondary centres, the primary nueleus, as a lule, appears early. Examples: the femur, humerus, phalanges, and the calcaneus.

Secondary centres which remain for a time distinet from the main portion of a bone are termed epiphyses. An epiphysis may arise from a single nucleus, as is the ease at the lower end of the femur, or from several, as at the upper end of the humerus. Prominenees about the ends of long bones may be capped by separate epiphyses, as illustrated at the upper end of the femur.

According to Professor F. G. Parsons, there are at least three kinds of epiphyses:-(1) Those which appear at the articular ends of long bones, which, since they transmit the weight of the borly from bone to bone, may be termed pressure epiphyses. (2) Those which appear as knob-like proecsses, where important muscles are attached to bones; and as these are coneerned with the pull of museles, they may be described as traction epiphyses. (3) The third kind ineludes those epiphyses which represent parts of the skeleton at one time of functional importance but which, having lost their function, have now become fused with neighbouring bones and only appear as separate ossifications in early life. These may be termed ataristic epiphyses and inclucle such epiphyses as the tuberosity of the isehium, the representative of the hypoischium of reptiles.

The epiphyses of bones seem to follow certain rules, thus:-

1. Those epiphyses whose centres of ossification appear last are the first to unite with the thaft. There is one exeeption, however, to this statement, viz., the upper end of the fibula, which is the last to unite with the shaft, although its centre appears two years after that for the lower encl. This mat perhaps be aceounted for by the radimentary nature of the proximal end of the fibulat in man anıl many other mammals.

2. The epiphysis towird which the mutrient artery is direeted is the first to be united with the shaft. It is also found that while the increase in length of the long bones takes place at the "piphysial cartitages, the grow th takes place more rapidly and is continued for a longer period at thre end where the spiphysis is the list to unite. It follows, therefore, that the shif ting of the investing perjostein, which results from these two lactors, leads to obliquity of the vaseular -autl by Irawing the proximal portion of the nutrient artery toward the more rapidly growing "nd. IIn'mver, when a bone has only one epiphysis, the nutrient artery will be direeted toward the axtrinity which has no epiphysis.

3 'Thar antres of ossification appear earliest in those epiphyses which bear the largest mative puportion fo the shafts of the bones to which they belong.

1. II hen atn miphysis ossifies from more than one centre, the various nuclei coalese before

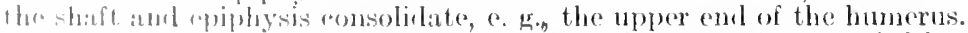

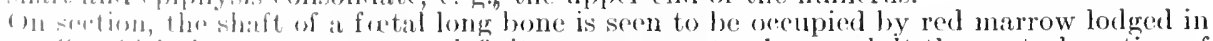

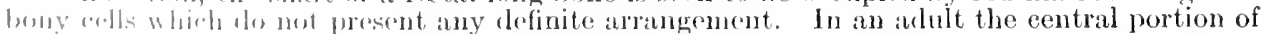
the - fat in fillad with fat or marrow hedel together by a delicate reticulum of conneetive tissue,

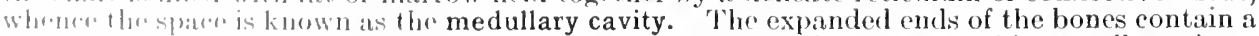

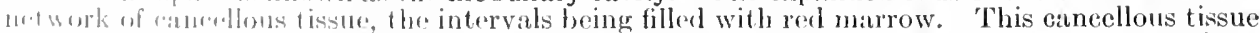
liffers from thit of the fretal homo in being arranged in a definite mamner aceording to the diree-

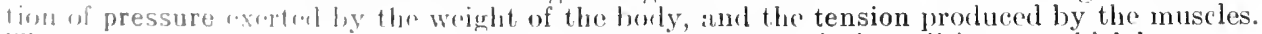

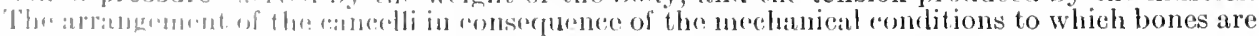

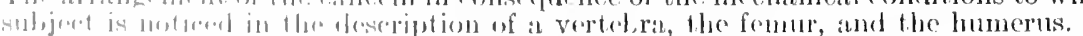

linms ar" divinilu. inte funr "lasses:-long, short, flat, and irregular. The long bones, fommel hir.lly in the limber fortal as system of levers sustaining the weight of the trunk and provid-

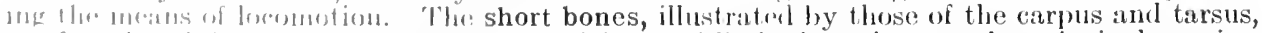

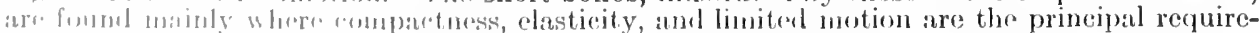

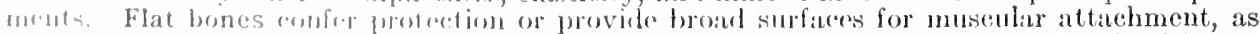
in the anc of $t_{1}$.

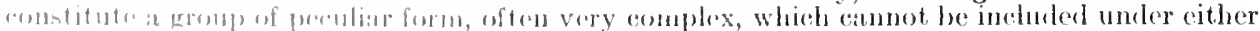

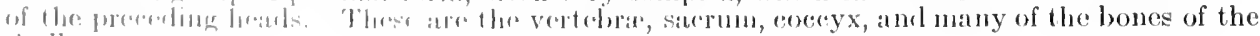
skull. 
The shafts of long bones at the time of birth are mainly cylindrical and free from ridges. The majority of the lines and ridges so conspicuous on the shafts of long bones in aclults are dun to the ossification of muscle-attachments. The more developed the muscles, the bet ter marked the ridges become.

The surfaces of bones are variously modified by environing conditions. Presure at the extremities causes enlargement, and movement renders them smooth. The two causes combined produce an articular surface. When rounded and supported upon a constricterl portion of bons, an articular surface is termed a head, sometimes a condyle; when depressefl, a glenoid fossa. Blunt, non-articular processes are called tuberosities; smaller ones, tubercles; sharp projections, spines. Slightly elevated ridges of bones are crests; when narrow and pronouncel, lines anrl

Fig. 32.- The Tibla and Fibula in section to show the Epiphyses.

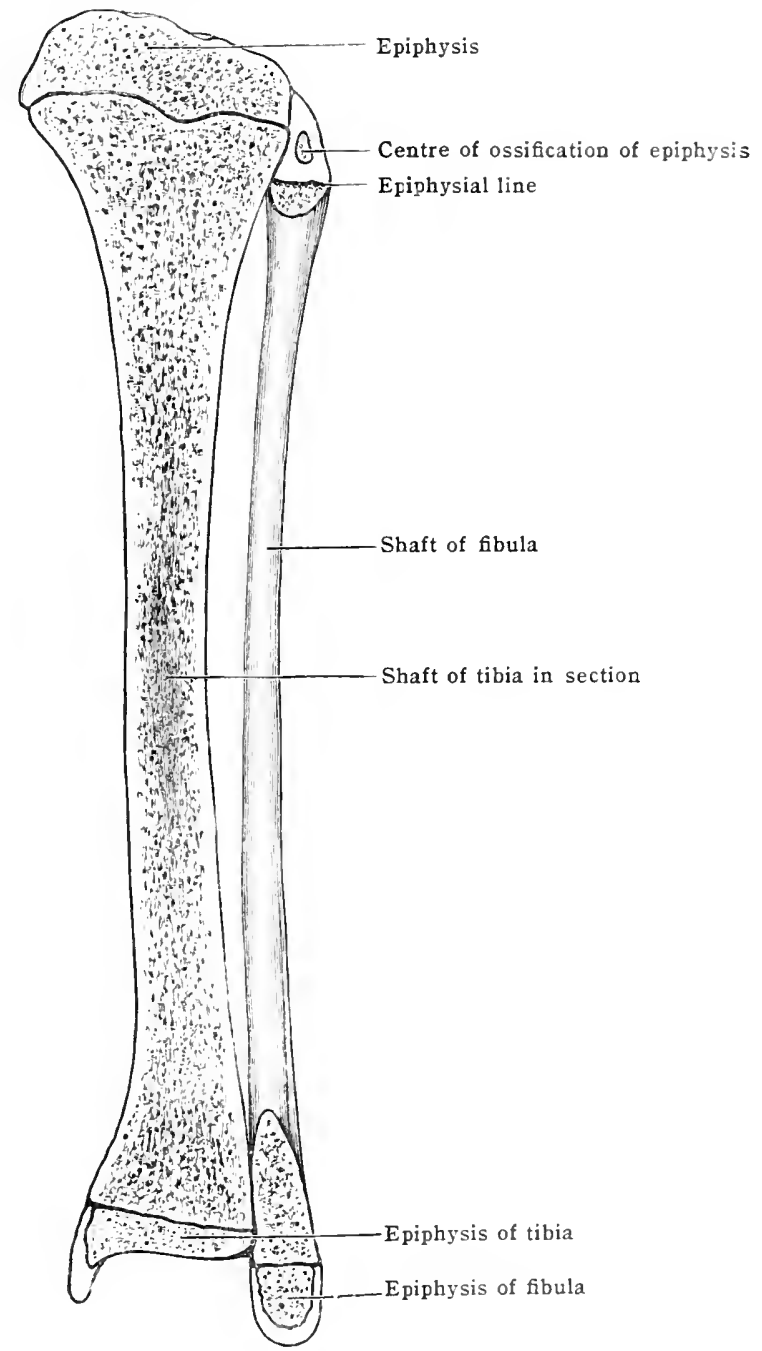

borders. A shallow depression is a fossa; when narrow and deep, a groove; a perforation is usually called a foramen.

In addition to these, other terms are employed which do not require any explanation, such as canal, notch or incisura, sulcus or furrow, and the like.

\section{THE AXIAL SKELETON}

\section{A. THE VERTEBRAL COLU $\backslash$ N}

The vertebral column [columna vertebralis] consists of a series of hones called vertebræ, closely connected by means of fibrous and elastie structures, which allow of a certain but limited amount of motion between them. In the young 
subject the vertebræ are thirty-three in number. Of these, the upper twentyfour remain separate throughout life, and are distinguished as movable or true vertebræ. The succeeding five vertebræ become consolidated in the adult to form one mass, called the sacrum, and at the terminal part of the column are four rudimentary vertebræ, which also tend to become united as age advances, to form the coccyx. The lower nine vertebra thus lose their mobility as individual bones, and are accordingly known as the fixed or false vertebræ. Of the true vertebræ, the first seven are called cervical [cervicales], the succeeding twelve thoracic [thoracales] or dorsal, and the remaining five lumbar [lumbales].

Although the vertebræ of the different regions of the column differ markedly in many respects, each vertebra is constructed on a common plan, which is more or less modified in different regions to meet special requirements. The essential characters are well seen in the vertebræ near the middle of the thoracic region, and it will be advantageous to commence the study of the vertebral structures with one selected from this region.

Description of a thoracic vertebra (figs. 33,34 ). - The vertebra consists of two essential parts - a body in front and an arch behind.

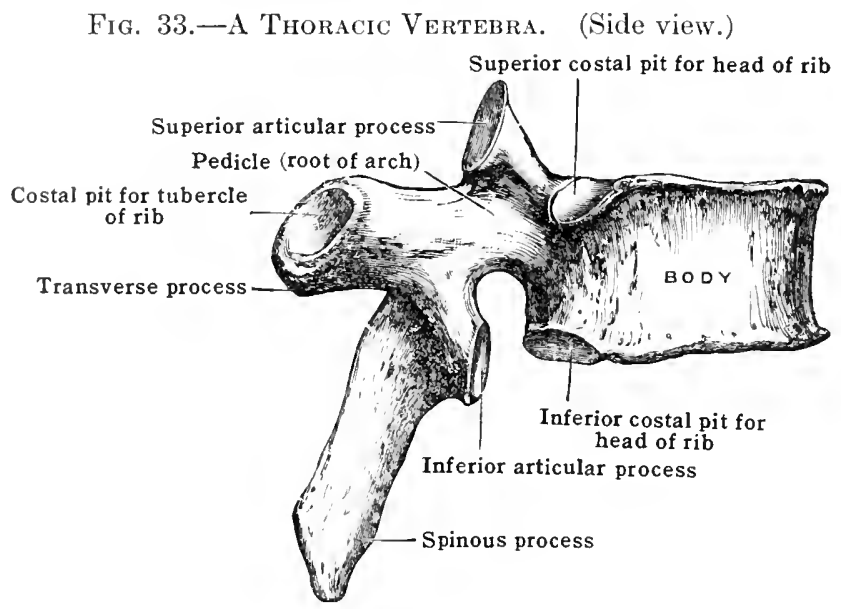

The body [corpus vertebræ] or centrum is a solid dise of bone, somewhat heart-shaped, deeper behind than in front, slightly concave on its superior and inferior surfaces, and wider transversely than antero-posteriorly. The upper and lower surfaces are rough for the intervertebral dises which are interposed between the bodies of the vertebræ, and the margins are slightly lipped. The eircumference of the body is concave from above downward in front, convex fron side to side, and perforated by numerous vascular foramina. Posteriorly it is coneave from side to side and presents one or two large foramina for the exit of veins from the cancellous tissue. On each side of the body, at the place where it joins the arch, are two costal pits (superior and inferior) [fovea costalis superior; inferior] placed at the upper and lower borders, and when two vertebra are superimposed, the arljacent costal pits form a complete artieular pit for the head of a rib. The superior and inferior costal pits were formerly designated as "demi-facets."

'The: arch [arcus vertebrae] is formed by two pedicles and two lamina, and supports seven processes - one spinous, two transverse, and four artieular. The pedicles or roots of the vertebral areh [radices arcus vertebre] are two short, constricted columns of bonc, projecting horizontally backward from the posterior surfares of the bordy. The roncivities on the upper and lower borders of each pediele, of which the lower is much the lloeper, are named vertebral notches [incisurae], and when two vertebre are in position, the notches are converted into intervertebral foramina for the transmission of the spinal nerves and blood-vessels.

'The laminze are two broad phates of bone which connect the spinous proeess with the roots (perlicles) and eomplete the arch posteriorly. The superior border and the lower part of the anterior surface of a ach lamina is rough for the insertion of the liganenta flava. 'The uppor part of the anterior' surface is smooth where it forms the posterior boundary of the vertebral canal. When artieulated, the 
laminæ in the thoracic region are imbricated or sloped, one pair over the other. somewhat like tiles on a roof.

The spinous process [processus spinosus], long and three-sided, projects backward and downward from the centre of the arch and terminates in a slight tubercle. It gives attachment by its prominent borders to the interspinous ligaments and by its free extremity to the supraspinous ligament. It serves mainly as a process for muscular attachment.

The transverse processes [processus transversus] are two in number and extend laterally from the arch at the junction of the pedicles and laminæ. They are long. thick, backwardly directed columns of bone terminating in a clubbed extremity, on each of which is a costal pit for articulation with the tuberele of a rib. The transverse processes, in addition to supporting the ribs, afford powerful leverage to muscles.

The articular processes, two superior and two inferior, project upward and downward opposite the attachments of the transverse processes. The superior are flat and bear facets or surfaces [facies articulares superiores] whicl are directed

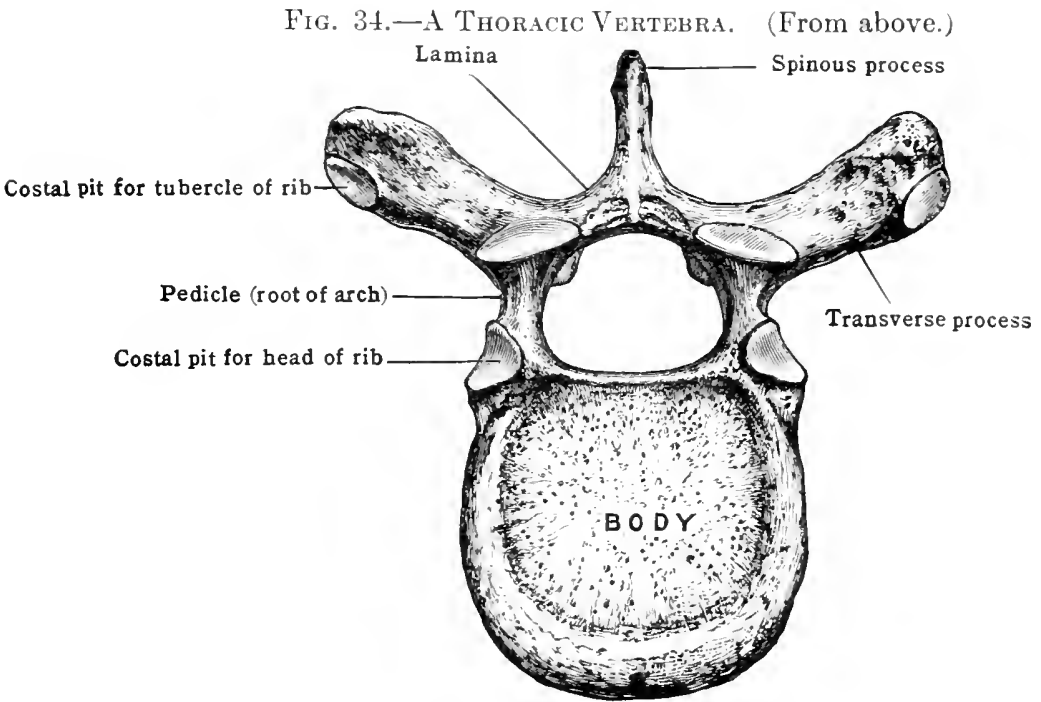

upward, backward, and laterally, and are situated a little in advanee of the inferior, the facets of which [facies articulares inferiores] are oval, concave, and directed downward, forward, and medially.

The vertebral foramen is bounded anteriorly by the body, posteriorly and on each side by the arch. It is nearly circular, and is smaller than in the cervical or the lumbar region. When the vertebræ are articulated, the series of rings constitute the spinal or vertebral canal [canalis vertebralis], in which is lodged the spinal cord.

\section{THE CERVICAL VERTEBR.}

A typical cervical vertebra (from the third to the sixth inclusive) presents the following characteristics (fig. 35):- The body is smaller than in other regions of the column and is of oval shape with the long axis transverse. 'The lateral margins of the upper surface are raised into prominent lips, so that the surface in concave from side to side; it is also sloped downward in front. The inferior surface, on the contrary, projects downward in front and is rounded off at the sides: to receive the corresponding lips of the adjacent vertebra. It is concave anternposteriorly and convex in an opposite direction.

The roots (pedicles) are directed laterally and backward and spring from the body about midway between the upper and lower border's. The superior and inferior notches are nearly equal in depth, but the inferior are usually somerthat deeper. The laminæ are long, narrow, and slender. The spinous process is short and bifid at the free extremity. 
Articular processes.-Both the superior and inferior articular processes are situated at the junction of the root with the lamina and they form the upper and lower extremities of a small column of bone. The articular surfaces are oblique and nearly flat, the superior looking backward and upward, and the inferior forward and downward.

The transverse process presents near its base a round costo-transverse foramen [foramen transversarium] for the transmission of the vertebral artery, vein, and a plexus of sympathetic nerves. Moreover, each process is deeply grooved above for a spinal nerve, and is bifid at its free cxtremity, terminating in two tuberclesanterior and posterior. The costo-transverse foramen is very characteristic of a cervical vertebra. It is bounded medially by the pedicle, posteriorly by the transverse process (which corresponds to the transverse process of a thoracic vertebra), anteriorly by the costal process (which corresponds to the rib in the thoracic region), and laterally by the costo-transverse lamella. The latter is a bar of bone joining the two processes and directed obliquely upward and forward in the upper vertebræ and horizontally in the lower. The vertebral foramen is triangular with rounded angles, and is larger than in the thoracic or lumbra rertebra.

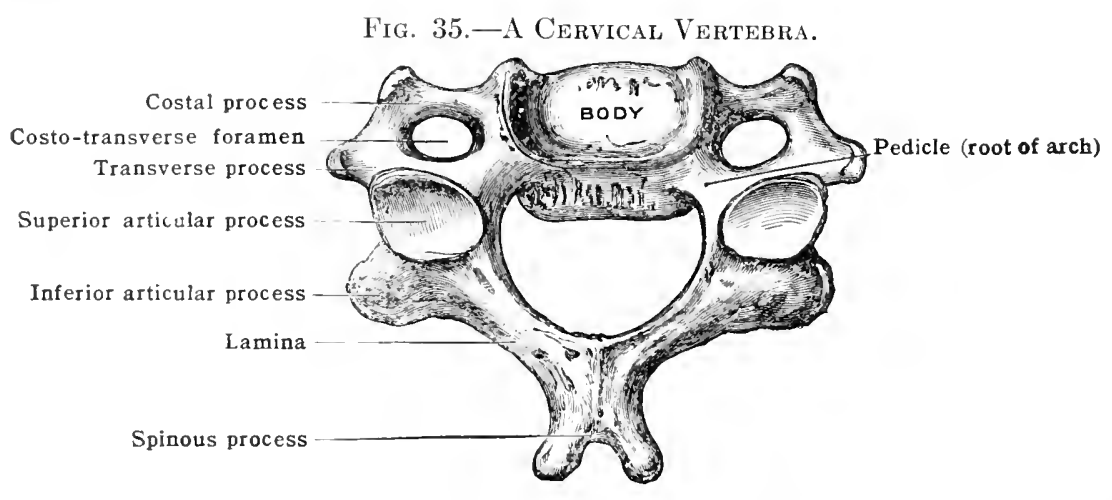

Peculiar cervical vertebræ.-The various cervical vertebra possess distinguishing features, though, with the exception of the first, second, and seventh, which are so different as to necessititle separate descriptions, these are largely confined to the direction of the costo-transverse limellit, and the size and level of the anterior and posterior tubereles. In the third the anterior tuberele is higher than the posterior and the costo-transverse lamella is oblique; in the fourth the antrior tubercle is elongated vertieally, so that its lower end is nearly on a level with the posterior, though the lamella still remains oblique. In the fifth and sixth they are nearly on the sane level, fut in the latter the anterior tuberelo is markedly developed to form the carotid tubercle.

\section{The Atras or Frist C'ervical Vertebra}

This vertobra (fig. 36) is remarkable in that it has neither body nor spinous process. It has the form of an irregular ring, and consists of two thiek portions, the lateral masses, united in front and behind by bony arches. The anterior arch joins thro latrral masses in front and constitutes about one-fifth of the entire rircumferenere of the ring. On its anterior surface it presents a tubercle for the attarhment of the longus colli musele and the anterior longitudinal ligament, and on its bostorior surface a circular facet [fovea dentis] for articulation with the ondontoiel prowess [dens] of the axis. The upper and lower horders serve for the attarhument of liganents miting the atlas to the oceipital bone and axis respertiverly.

Tho lateral masses am thick and stromg, supporting the articular processes above and below

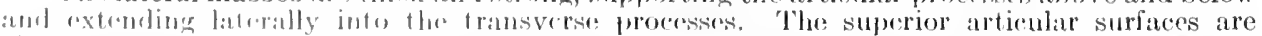

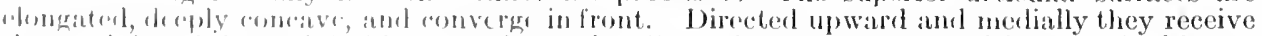
the entrlyles of ihe oreopital lume, and oreasionally cach presents two oval facets united by an isthmus. Tho inforior all ioular surfanes are circular and almost flat; they are directed downwarl anl meslially aml articulate with the axis. 'The artienlar processes, like the superior artualatr processess of tho axis, diffor from those of other vertebre in being situated in front of ther pheses of exit of thre spinal nervers.

Liefwern the mpper and lower articular surfaces on the inside of the ring are two smooth romblod tubercles, one on each side, to which the transverse higanont is attached. 'This liga- 
ment divides the interior of the ring into a smaller anterior part for the dens of the axis, and a larger posterior part, corresponding to the foramina of other vertebræ, for the spinal cord and its membranes.

The transverse processes are large and extend farther outward than those of the vertebro immediately below. They are flattened from above downward and each is perforated by a large costo-transverse foramen; the extremity is not bifid, but, on the contrary, is broist and rough for the attachment of numerous muscles. The posterior arch unites the lateral masses behind and forms about two-fif ths of the entire circumference. It presents in the iniddle line a rough elevation or tubercle representing a rudimentary spinous process. At its junction with the lateral mass on the superior surface is a deep groove, the sulcus arteriæ vertebralis, which

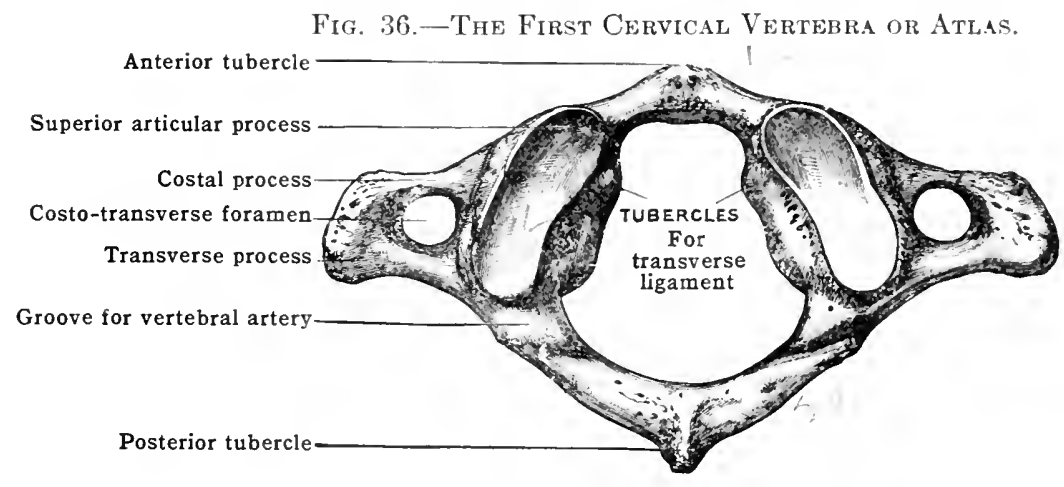

lodges the vertebral artery and the sub-occipital (first spinal) nerve. The groove corresponds to the superior notches of other vertebre and occasionally it is converted into a foramen by a bony arch-the ossified oblique ligament of the atlas. A similar but much shallower notch is present on the inferior surface of the posterior arch, and, with a corresponding notch on the axis, forms an intervertebral foramen for the exit of the second spinal nerve. The upper and lower surfaces of the arch afford attachment to ligaments uniting the atlas to the occipital bone and the axis.

The atlas gives attachment to the following muscles:-

Anterior arch.............. Longus colli.

Posterior arch........... Rectus capitis posterior minor.

Transverse ,process......... Rectus capitis anterior (minor), rectus capitis lateralis, obliquus capitis inferior, obliquus capitis superior, splenius cervicis, levator scapulæ, and intertransversarii, anterior and posterior.

Fig. 37.-The Epistropheus or Axis.

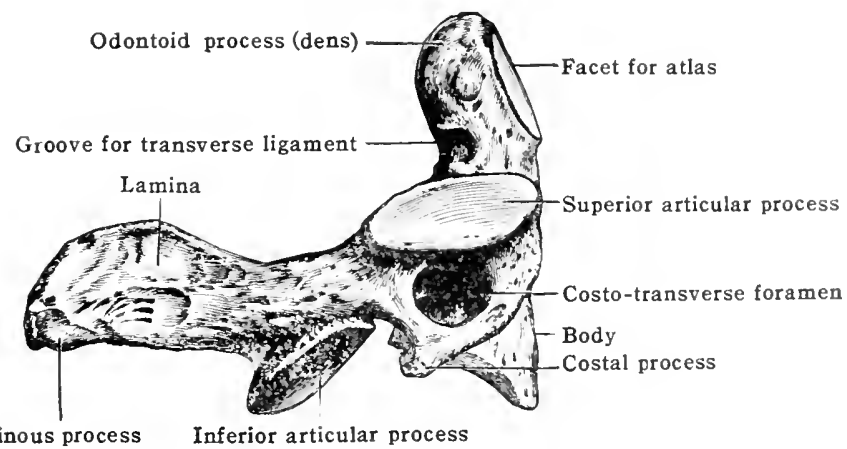

The Epistropheus (Axis)

The epistropheus (axis) (fig. 37) is the thickest and strongest of the bones of this region, and is so named from forming a pivot on which the atlas rotates, carrying the head. It is easily recognised by the rounded dens (odontoid process) which surmounts the upper surface of the body. This process, which represents the displaced body of the atlas, is large, blunt, and tooth-like, and bears on it anterior surface an oval facet for articulation with the anterior arch of the at las: posteriorly it presents a smooth groove which receives the transverse ligament. To the apex a thin narrow fibrous band (the apical dental ligament) is attacherl. and on each side of the apex is a rough surface for the attachment of the alar 
ligaments which connect it with the occipital bone. The enlarged part of the process is sometimes termed the head, and the constricted basal part the neck. The inferior surface of the body resembles that of the succeeding vertebræ and is concare from front to back and slightly convex from side to side. Its anterior surface is marked by a median ridge separating two lateral depressions for the insertion of the longus colli.

The roots (pedicles) are stout and broad; the laminæ are thick and prismatic; the spinous process is large and strong, deeply concave on its under surface, and markedly bifid; the transverse processes are small, not bifureated and not grooved. The costo-transverse foramen is directed very obliquely upward and laterally and the costal process is larger than the transverse.

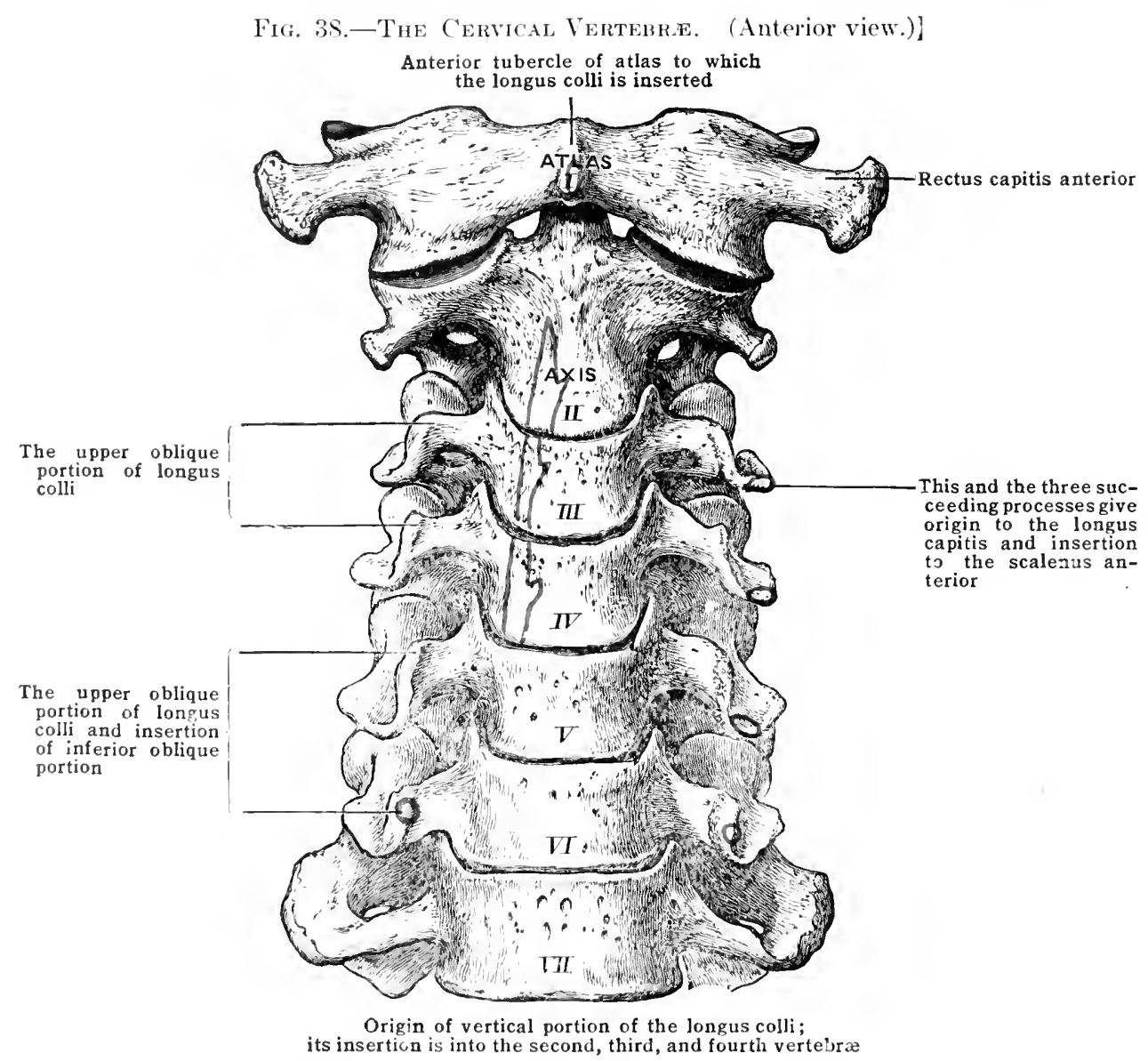

'Thr' superior articular surfaces are oval, and directed upward and laterally for articulation with the atlis. They are remarkable in being supported partly hy the borly, and partly by the perdicles, and in being situated in front of the superior notches. The inferior articular surfaces are similat in form and position to those of the sucerecling vertebra.

Thor axis gives allachument to the following muscles:-

\section{Borly:}

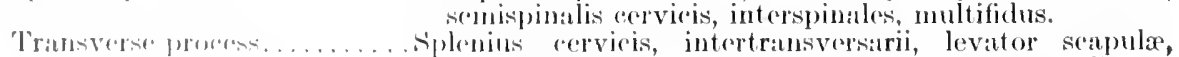
lomgissimus (transversalis) corvieis, seatemus medius.

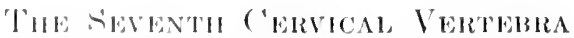

Situated at the jumetion of the cervical and thoracie regions of the vertebral colnmm, the soventh cervical vertobra (figs. 38, 39) may be deseribed as a transitional vertoblat - i. e., possessing rertain foatures characteristic of both regions.

'The spinous process is longer than that of any of the other cervical vertebre. It is mot hifurrited, but ruds in a broad tuberele projecting beneath the skin, 
whence the name vertebra prominens has been applied to this bone. The transverse process is massive; the costal element of the process is very small, but, on the other hand, the posterior or vertebral part of the process is large and becoming more like the transverse process of a thoracic vertebra.

The costo-transverse foramen is the smallest of the series and may be absent. It does not, as a rule, transmit the vertebral artery, but frequently gives pasiage to a vein. Oerasionally the costal process is segmented off and constitutes a rervical rib. The bonly sometimes bearrs on each side near the lower border at coxtal pit for the head of the first rib. When this is present, there is usually a well-developerl cerrimal rib.

Flg. 39.-The Cervelal Vertebr.e. (Posterior view.)

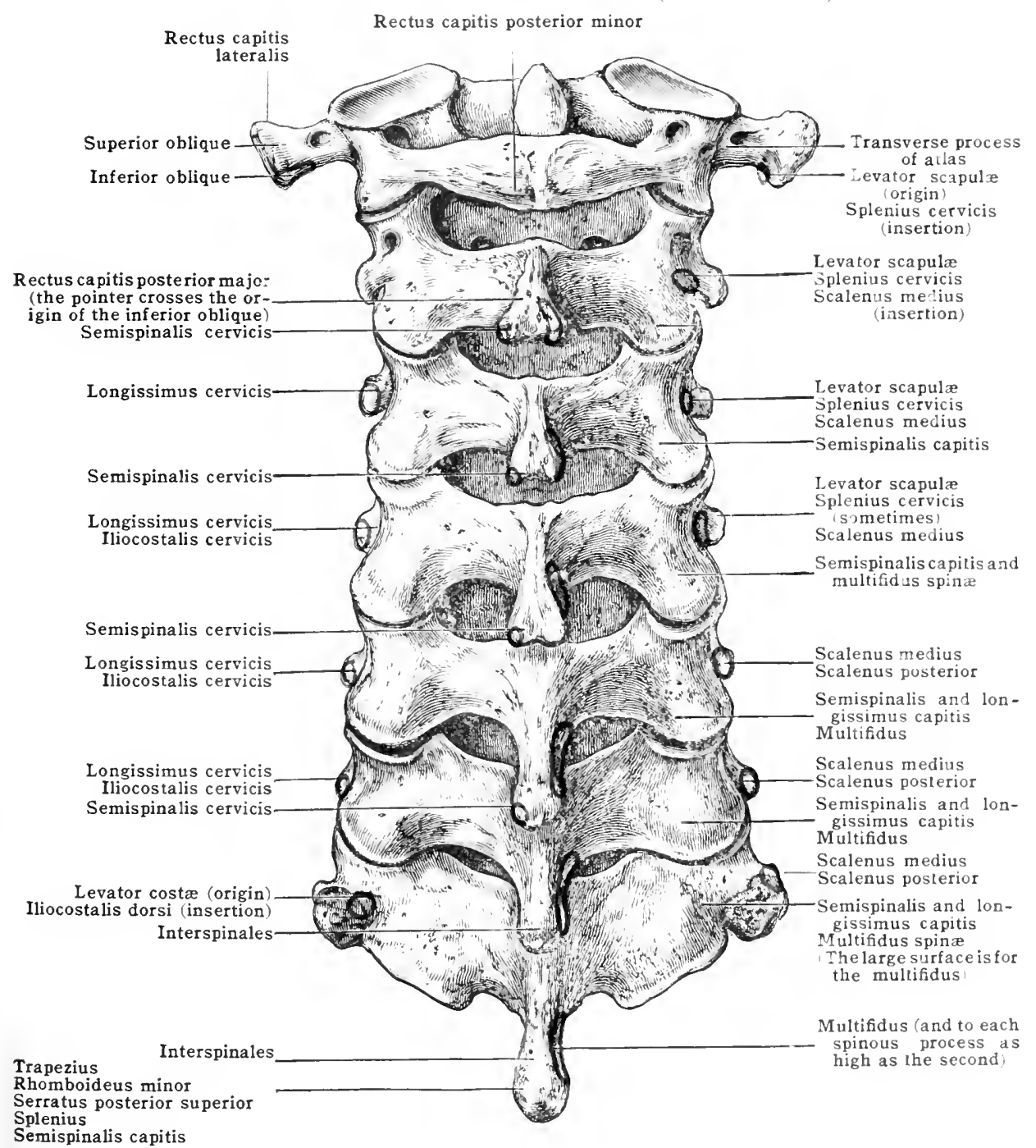

The seventh cervical vertebra gives attachment to the following muscles:-

Body.................... Longus colli.

Spinous process............ Trapezius, rhomboideus minor, serratus postoriur superior, splenius capitis, multifidus, interspinales, seruispinalis dorsi.

Transverse process.......... Intertransversarii, levator costie, scalculus persterior. iliocostalis dorsi (musculus necestorius), seralenu- medius, semispinalis eapitis (romplexus).

Articular process. .

Multifidus, longissinus capitis (trachelomastoid).

The cervical vertebra exhibit great variation in regard to the extrenitios of their spinots. processes. As a rule among Europeans, the second, third, fourth, and fifth vertellat pussus bifid spines. The sixth and seventh exhibit a tendency to bifurcate, their tips presenting two small lateral tubercles; sometimes the sixth has a bifid spine, and more lidrely the serenth pre- 
sents the same condition. Occasionally all the cervical spines, with the exception of the second, are non-bifid, and even in the axis the bifurcation is not extensive. In the lower races of men the cervical spines are relatively shorter and more stunted than in Europeans generally and, as a rule, are simple. The only cervical vertebra which presents a bifid spine in all races is the axis; even this may be non-bifid in the Negro, and occasionally in the European. (Owen, Turner, Cunningham.)

The laminæ of the lower cervical vertebræ frequently present posteriorly distinct tubercles from which fasciculi of the multifidus muscle arise. They are usually confined to the sixth and seventh vertebræ, but are fairly frequent on the fifth, and are occasionally seen on the fourth.

\section{Fig. 40.-Peculiar Thoracic Vertebre.}

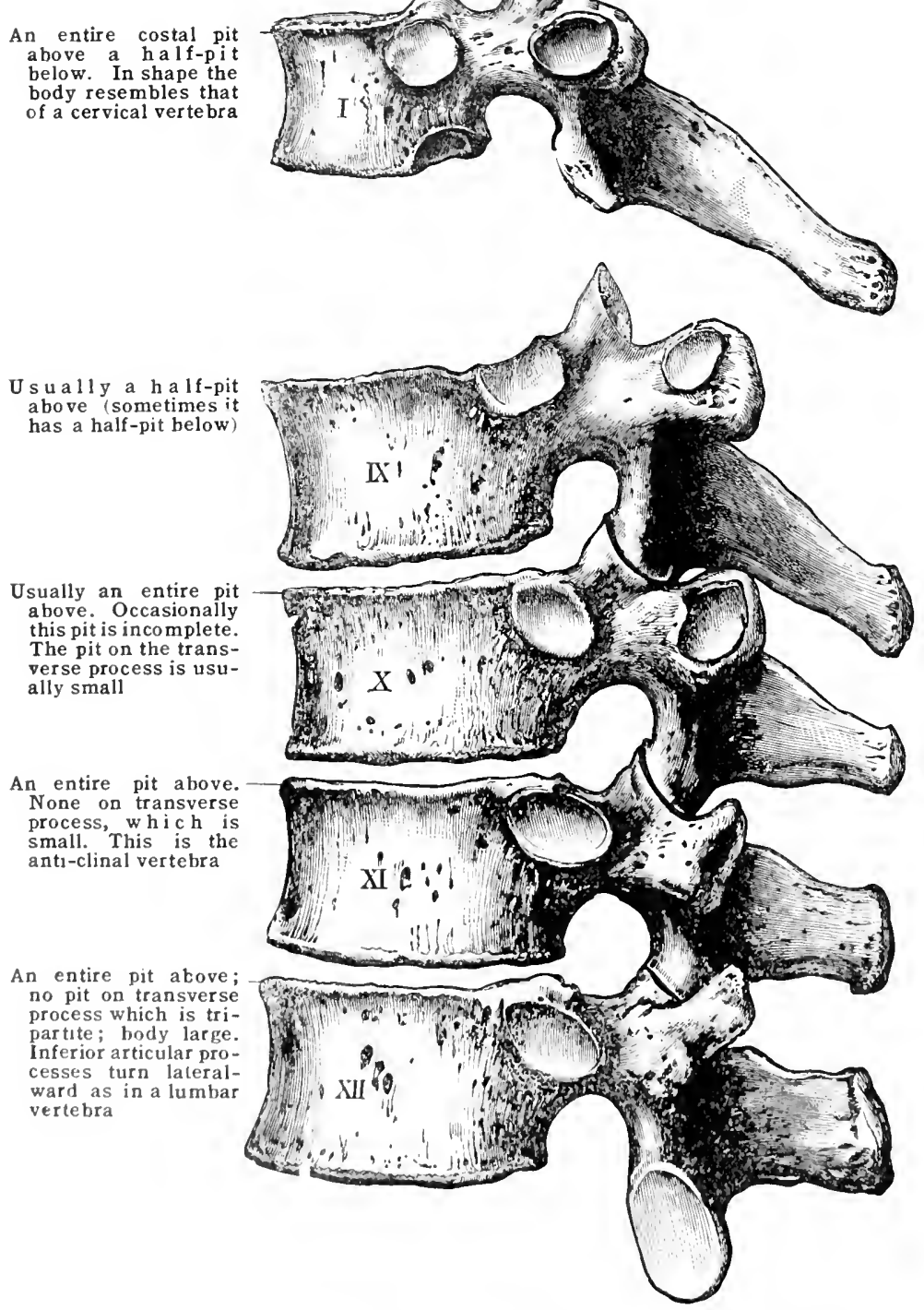

'THE: 'THORAC'IC: VERTEBRA

The general charactors of the thoracic (or dorsal) vertebræ have already been eonsidered. Thrir most distinguishing fratures are the pits on the transverse processes and sicles of the bodies for the tubercles and heads of the rib: respectively.

Peculiar thoracic vertebræ. - Several vertebræ in this series differ from the typical example. 'The exeeptional ones are--the first, ninth, tenth, eleventh, anc twelfth (fig. 40). 
The first thoracic vertebra is a transitional vertebra. The body in its general conformation approaches very closely the seventh cervical, in that the greatest diameter is transverse, its upper surface is concave from side to side, and its lateral margins bear two prominent lips. On each side is an entire pit, close to the upper border, for the head of the first rib, and a very small pit (inferior costal pit) below for the head of the second rib. The spinous process is thick, strong, almost horizontal and usually more prominent than that of the seventh cervical, an important point to remember when comnting the spines in the living subject. Occasionally the transverse process is perforated near the root.

The ninth has superior costal pits, and usually no inferior; when the inferior pits are present, this vertebra is not exceptional.

The tenth usually has an entire costal pit at its upper border, on each side, but occasionally only a superior costal pit. It has no lower pits and the pits on the transverse processes are usually small.

The eleventh has a large body resembling a lumbar vertebra. The pits are on the pedicles and they are complete and of large size. The transverse processes are short, show evidence of becoming broken up into three parts, and have no pits for the tubercles of the eleventh pair of ribs.

In many mammals, the spines of the anterior vertebra are directed backwarl, and those of the posterior directed forward, whilst in the centre of the column there is usually one spine vertical. The latter is called the anti-clinal vertebra, and indicates the point at which the thoracic begin to assume the characters of lumbar vertebræ. In man the eleventh thoracic is the anti-clinal vertebra.

The twelfth resembles in general characters the eleventh, but may be distinguished from it by the articular surfaces on the inferior articular processes being convex and turned laterally as in the lumbar vertebre. The transverse process is rudimentary and tripartite, presenting for examination three tubercles, superior, inferior, and lateral, which correspond respectively to the mammillary, accessory, and transverse processes of the lumbar vertebra. There is one complete pit on the root (pedicle) for the head of the twelfth rib.

A peculiarity, more frequent in the thoracic and lumbar than in the cervical and sacral regions of the column, is the existence of a half-vertebra. Such specimens have a wedge-shaped half-centrum, to which are attached a lamina, a transverse, superior, and inferior articular, and half a spinous process. As a rule, a half-vertebra is ankylosed to the vertebræ above and below.

\section{THE LUMBAR VERTEBRA}

The lumbar vertebræ (figs. 41,42) are distinguished by their large size and by the absence of costal articular surfaces.

The body is somewhat reniform, with the greatest diameter transverse, flat above and below, and generally slightly deeper in front than behind. The roots

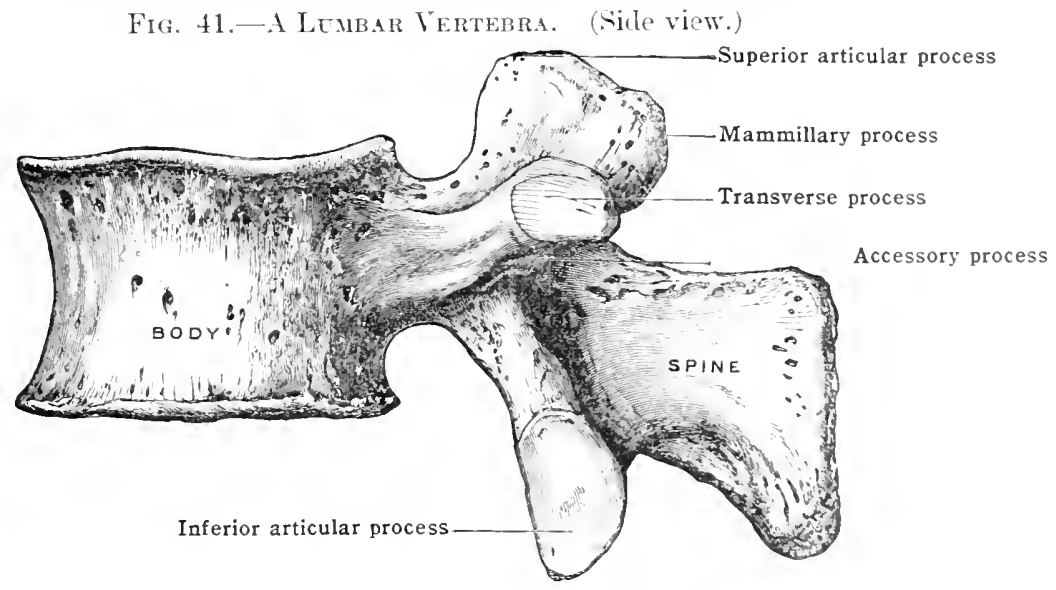

(pedicles) are strong and directed straight backward, and the lower vertebral notches are deep and large. The laminæ are shorter and thicker than those of the thoracic or cervical vertebræ, and the vertebral foramen is triangular, wider than in the thoracic, but smaller than in the cervical region. The spinous process, 
thick, broad, and somewhat quadrilateral, projects horizontally backward. It is thicker below than above and terminates in a rough posterior edge. The articular processes are thick and strong. The superior articular surface is concave and directed backward and medially; the inferior is convex and looks forward and laterally. The superior pair are more widely separated than the inferior pair and embrace the inferior articular processes of the vertebra above. The posterior margin of each superior articular process is surmounted by the mammillary process or tuhercle (metapophysis) which corresponds to the superior tubercle of the transwerse process of the last thoracic vertebra. In man the mammillary tubercles are rudimentary, but in some animals they attain large proportions, as in the kangaroo and armadillo. The transverse processes are long, slender, sonewhat spatula-shaped, compressed from before backward, and directed laterally and a little backward. They are longest in the third vertebra and diminis in the fourth, second, and fifth, in this order, to the first, in which they are shortest of all. Their extremities are in series with the lateral tubercles of the transverse processes of the twelfth thoracic vertebra and also with the ribs. With the latter the so-called transverse processes in the lumbar region are homologous, and hener they are sometimes called the costal processes. Occasionally the costal element differentiates and becomes a well-developed lumbar rib.

Fig. 42.-A Lumbar Vertebra.

(Showing the compound nature of the transverse process. Upper view.)

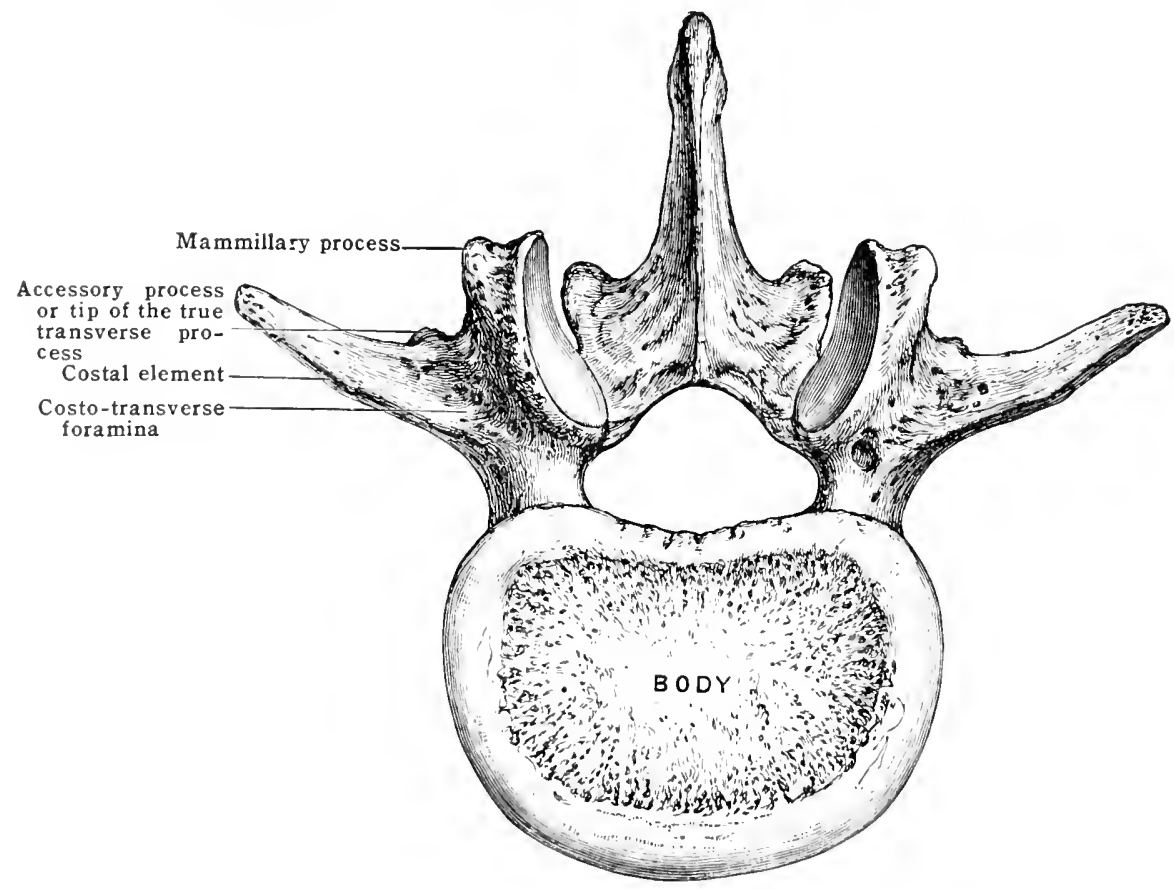

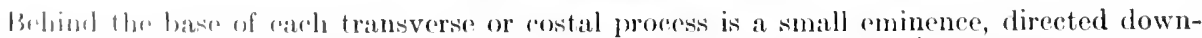
warl, whinh arrespenls whth the inferior tubercle of the lower thoracie transverse process, and witl the transverse processes of the thoracie vertebre above, amd is named the accessory process (antapphysis). "Tho acersory proress represents the tip of the partially suppressed

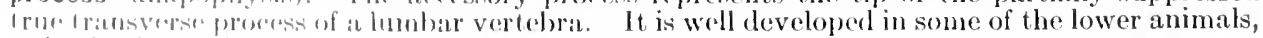
as in the rlege and rat.

Lach of the five humbar vortabra is readily recognized. The body of the first is dreper lwhind than in front; the borly of the second is equal in depth in front and lwhind; the lowlies of the third, fourth, and fifth are deeper in front than lwhind, hut the third has long transverse processes and the inferior articular promence arr not willely separaterl. The fourth has shorter transverse processes and the inforior articular processes are placed more widely apart. The fifth lumblar vortobra deviates in some of its features so widely from the other members of the sorios that surecial prominener must now be given them.

The fifth lumbar vertebra is massive, and the body is much thicker in front 
than behind in consequence of being bevelled off to form with the sacrum the sactovertebral angle. The transverse processes are short, thick, conical, and spring from the body as well as from the roots of the arch. They are very strong for the attachment of the ilio-lumbar ligaments. The spinous process is smaller than that of any of the other lumbar vertebræ; the laminæ project into the vertebral foramen on each side; and the roots are stout and flattened from above downward. The inferior articular processes are separated to such a degrce as to he wider apart than the superior, and they articulate with the first sacral vertelura.

The roots of the arch in this vertebra are liable to a remarkable deviation from the conditions found in other parts of the spine. The peculiarity consists of a complete solution in the continuity of the arch immediately behind the superior articular processes. In such sperimens the anterior part consists of the body carrying the roots, transierse and superiol articullar processes; whilst the posterior segment is composed of the lamina, spine, and inferior artirullar processes. The posterior segment of the ring of this vertebra may even consist of two piecus. There is reason to believe that this abnormality of the fifth lumbar vertebra oceurs in fire per" cent. of all subjeets examined. Sir William Turner, in his report on the human skeletons in the Challenger Reports, found seven examples among thirty skeletons examined. The rkeletons in which this occurred were:-a Malay, an Andamanese, a Chinese, two Bushmen, an Eskino, and a Negro. Turner has also seen it in the skeleton of a Sandwich Islander. A similar condition is oecasionally met with either unilaterally or bilaterally in the thoracie vertebræ.

\section{THE SACRUM}

The five sacral vertebre (figs. 43,4 ) are united in the adult to form the os sacrum, a large, curved, triangular bone, firmly wedged between the innominate bones, and completing, together with the coceyx, the posterior boundary of the

Fig. 43.-The S.cru axd Coccrx. (Anterior view.)
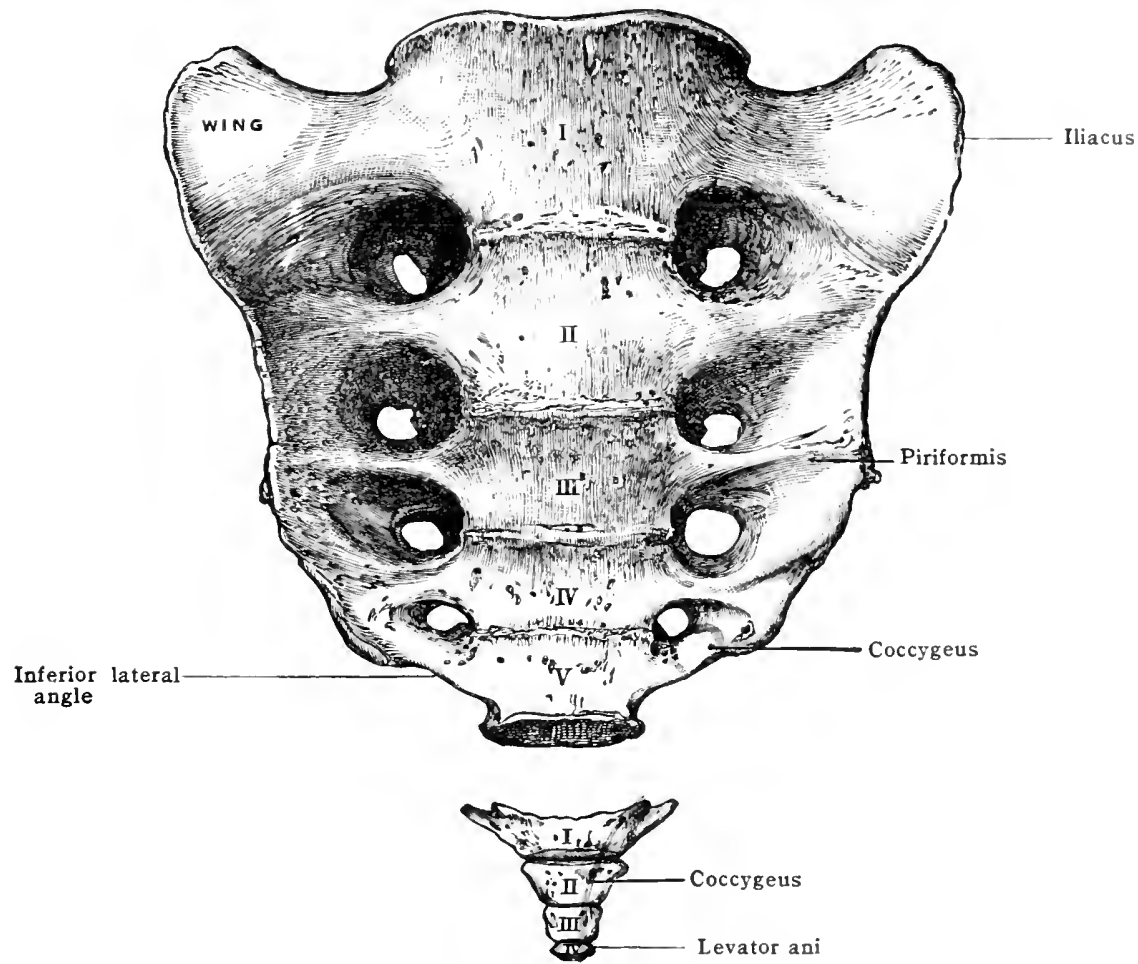

minor (or small) pelvis. Of the five vertebræ which compose the sacrum the uppermost is the largest, the succeeding ones become rapidly smaller, and the fifth is quite rudimentary. In the erect posture the sacrum lies oblicuely, being directed from above clownward and backward, and forms with the last lumbir vertebra an anterior projection known as the promontory. The sacrum presents for examination a pelvic and a clorsal surface, two lateral margins, a base, and an apex.

Surfaces.-The pelvic surface, directed downward and formart, is smooth, concave from above downward and slightly from side to side. It is crossed in the 
middle by four transverse ridges [lineæ transversæ] which represent the ossified intervertebral discs and separate the bodies of the five sacral vertebræ. Of the bodies, the first and second are nearly equal in size and are larger than the third, fourth, and fifth, which, in vertical depth, are also nearly equal to each other. At the extremities of the transverse ridges on each side are four openings, ealled the anterior sacral foramina, which correspond to the intervertebral foramina in other regions of the column, and transmit the anterior divisions of the first four sacral nerves; they are also traversed by branches of the lateral sacral arteries. The foramina are separated by wide processes, representing the costal processes of the vertebræ, which unite laterally to form the lateral portion (or mass) [pars lateralis]. The latter is grooved for the sacral nerves, and rough opposite the second, third, and fourth sacral vertebræ, for the origin of the piriformis muscle. The lateral part of the fifth sacral vertebra gives insertion to fibres of the coccygeus.

The dorsal surface is strongly convex and rough. The middle line is occupied by four eminences representing the somewhat suppressed spinous processes. Of these the first is the largest, the second and third may be confluent, and the fourth is often absent. The processes are united to form an irregular ridge or

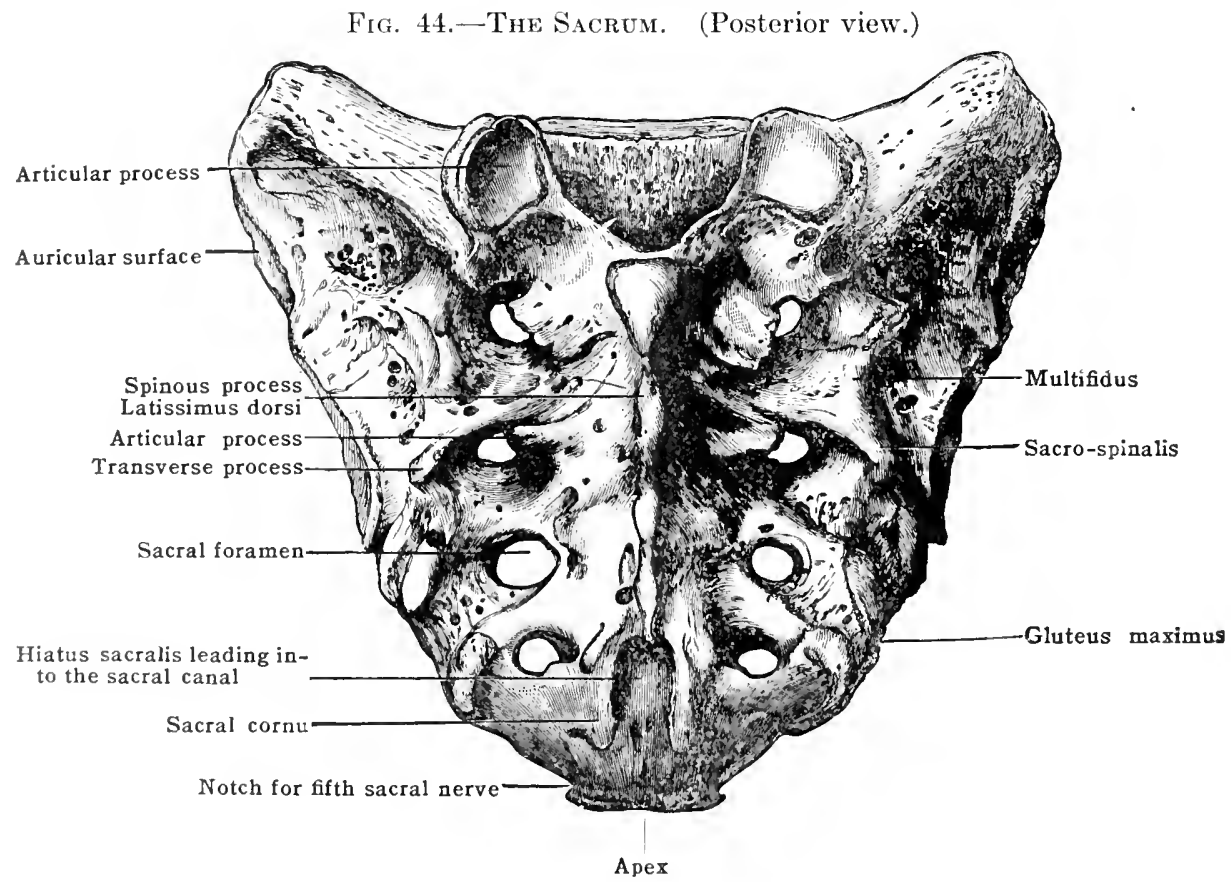

crest [erista saralis media]. The bone on each side of the spines is slightly hollowed and is formed by the mited laminæ. In the fourth sometimes, but always in the fifth, the lamina fail to meet in the middle line, leaving a gap [hiatus sacralis] at the termination of the spinal eanal, the lateral margins of which are prolonged downward as the sacral cornua. They represent the lower articular processes of the fifth sareral vertebra and give attachment to the posterior sacrococcygeal ligaments. I ateral to the lamina is a second series of small eminences which represent the articular and mammillary processes of the vertebræ above. The first pair are larer for the last lumbar vertebra, the second and third are small, and the fourth and fifth arrineonspicuous. Together they form a pair of irregular ridges [criste sacrales articulares].

Immediately lateral to the articular processes are the posterior sacral foramina, four on each sick; they are smaller than the anterior, and give exit to the posterior primary divisions of the first four sacral nerves. Lateral to the foramina on each side are five clevations representing the transverse processes. The first pair, situated at the junction of the posterior surface with the base, are large and conspicuous, and serve all for the at achment of ligaments and museles. 
Together they form on each side of the sacrum an irregular ridge [crista sacralis lateralis]. The space between the spinous and transverse processes presents a shallow concavity known as the sacral groove, continuous above with the vertebral groove of the movable part of the column, and, like it, lodging the multifudus muscle. Bridging across the groove and attarhed to the sacral spines medially, and to the lower and back part of the sacrum laterally, is the flat tendon of origin of the sacro-spinalis (erector spina). The gluteus maximus takes origin from the back of the lower two pieces of the sacrum.

The base or upper surface of the sacrum bears considerable resemblance to the upper surface of the fifth lumbar vertebra. It presents in the middle the body, of a reniform shape, posterior to which is the upper end of the sacral canal bounded by two laminæ. On each side of the canal are two articular processes bearing wellmarked mammillary tubercles. The conjoined transverse and costal processes form on each side a broad surface, the wing or ala of the sacrum, continuous with the iliac fossa of the hip bone, and giving attachment to a few fibres of the itiacus.

Fig. 45.-Left Lateral View of Sacrua and Coccrx.

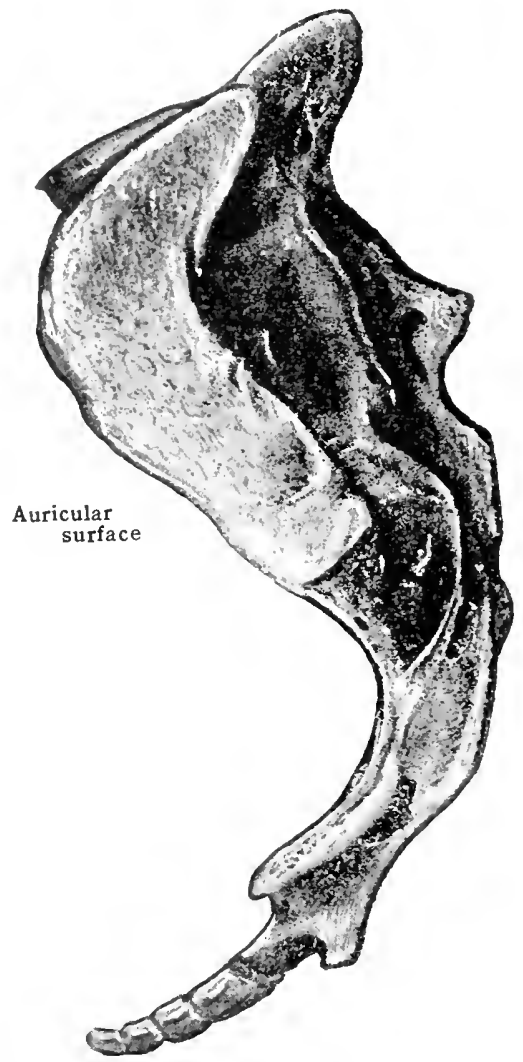

The lateral margins.--It has already been noted that the lateral portion of the sacrum is the part lateral to the foramina. It is broad and thick above. where it forms the ala, but narrowed betow. The lateral aspect of the upper part presents in front a broad irregular surface, covered in the recent state with fibro-cartilage, which articulates with the ilium and is known as the auricular surface. It is bounded posteriorly by some rough depressions for the attachment of the posterior sacro-iliac ligaments. Below the auricular surface, the laterial margin is rough for the sacro-tuberous (greater) and sacro-spinous (lesser sacrosciatic) ligaments, and terminates in the projection known as the inferior lateral angle. Immediately below the angle is a notch, converted into a foramen by the transverse process of the first coccygeal vertebra, and a ligament connecting this with the inferior lateral angle of the sacrum. Through this formen paseses the anterior branch of the fifth sacral nerve.

The apex is directed downward and forward and is formed by the inferior aspect of the body of the fifth sacral vertebra. It is transwersely oral and 
articulates by means of an intervertebral disc with the coccyx. In advanced life the apex of the sicrum becomes united to the coceyx by bone.

The sacral canal is the continuation of the spinal canal through the sacrum. Like the bone, it is curved and triangular in form at the base and flattened toward the apex. It terminates at the hiatus sacralis between the sacral cornua, where the laminie of the fourth and fifth sacral vertebræ are incomplete. The canal opens on the surface by the anterior and posterior sacral foramina and lodges the lower branches of the cauda equina, the filum terminale, and the lower extremity of the dura and arachnoid. The sub-dural and sub-arachnoid spaces extend downward within the canal as far as the body of the third sacral vertebra.

Differences in the two sexes.-The sacrum of the female is usually broader in proportion to its length, much less curved, and directed more obliquely backward than in the male. The curvature of the female sacrum belongs chiefly to the lower part of the bone, whereas in the male it is equally distributed over its whole length; but the curvature is subject to considerable variation in different skeletons.

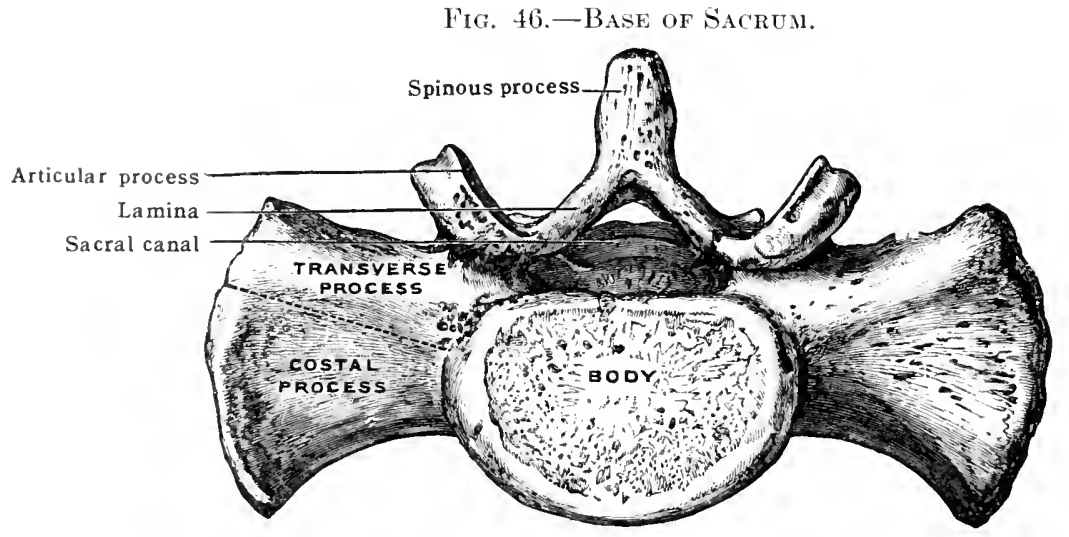

Racial differences.-The human sacrum is characterised by its great breadth in comparison with it: length, though in the lower races it is relatively longer than in the higher. The propor-

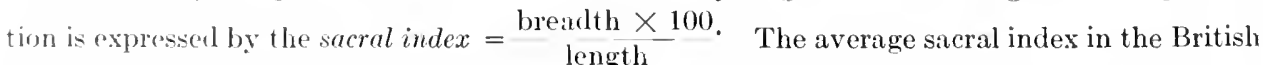
male is 112, in the female 116. Sacra in which the index is above 100 are platyhieric, as in Europeans; those unfer 100 are dolichohieric, as in most of the black races (Sir W. 'Turner).

Fig. 17.-The Coccrx. A. Posterior view; B. Anterior view.

A.

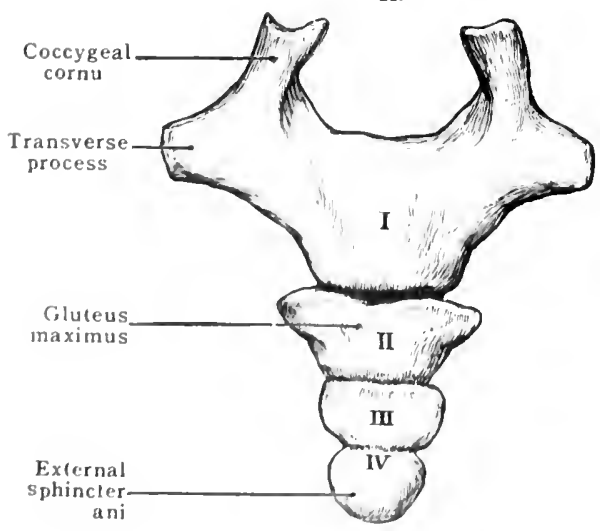

B.

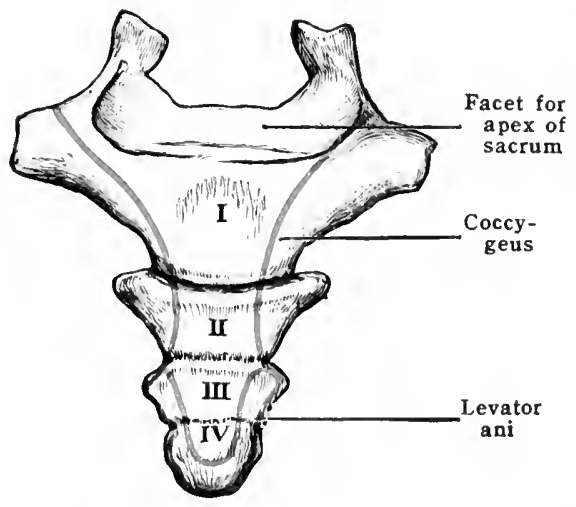

THE (') ' 'YGEAL VERTEBRA

The fome coereygeal vertobrar atre united in the ardult to form the coccyx los corergis] (fig. 17). Whilo four is the usual number of these rudimentary vertebra, oreasionally there are five, and rarcly three. In midelle life the first piece is uswally separate, and the origital divison of the remaining portion of the eoceyx 
into three parts is indieated by transverse grooves. In advanced life the pieces of the coccyx, having previously united to form one bone, may alio become joined to the sacrum.

The first piece of the roceyx is mueh broader than the others. It consists of a bonty, transverse processes, and ruliments of a neural arch. The borly presents on its upper surfarin an oval facet for articulation with the apex of the sarrum. On each sicle of the buty a transverse process projects laterally and is joined either by ligament or bone to the inferior latral angle of the sacrum, forming a foramen for the anterior division of the fifth sacral nerve. from the posterior surface of the borly two long coccygeal cornua project upward and arre connectoul to the sacral cornua by the posterior sacro-coccygeal ligaments, enclosing on each side an aur 't ur. - the last intervertebral foramen-for the exit of the fifth sarral norve. The cocryeal cormut represent the roots and superiol articular processes of the first eocreat vertebrit.

The second piece of the coccyx is much smaller than the first, and consists of a body: traces of transverse processes, anil a neural arch, in the form of slight tubercles at the silles and on the posterior aspect of the body.

The third and fourth pieces of the coccyx, smaller than the seeond piece, are mere nodule: of bone, corresponding solely to vertebral bodies.

The anterior surface of the coceyx gives attachment to the anterior sacro-coceygeal ligament and near the tip to the levator ani; it is in relation with the posterior surface of the rectum.

The posterior surface of the coceyx is convex, and the upper three pieces afford attachment to the gluteus maximus on each side, and the last piece to the rorcygeal portion of the sphincter ani externus.

The lateral margins are thin, and receive parts of the sacro-sciatic ligaments, of the coccygei muscles, and of the levatores ani.

\section{THE YERTEBRAL COLUMN AS A WHOLE}

The vertebral column (fig. 4S) is the central axis of the skeleton and is situated in the median line at the posterior aspect of the trunk. Superiorly it supports the skull; laterally it gives attachment to the ribs, through which it receives the weight of the upper limbs, and inferiorly it is supported by the hip bones, by which the weight of the trunk is transmitted to the lower limbs. Its length varies in lifferent skeletons, but on an average it measures about $70 \mathrm{~cm}$. (28 in.) in the male and about $2.5 \mathrm{~cm}$. (1 in.) less in the female. To the entire length thr cervical region contributes $12.5 \mathrm{~cm}$. (5 in.), the thoracic 27.5 ('m. (11 in.), the lumbar 17.5 ("m. (7 in.), and the sacro-coceygeal portion the remaining $12.5 \mathrm{~cm}$. (5 in.). The vertebral cohmn presents a series of curvatures, four when viewed in profile and one when viewed from the front or back. The former are directed alternately forward and backward, and are named, from the regions of the column in which they oceur, cervical, thoracic, lumbar, and sacral. The fifth curve is lateral, being in most cases ilirected toward the right sile.

The cervical, thoracie and lumbar curvatures pass imperceptibly into one another, but at the junction of the last lumbar vertebra with the saerum a well-marked angle ocours, known al: the sacro-vertebral or lumbo-sacral angle, with the result that the promontory of the sacrum overhangs the cavity of the minor (small)pelvis and forms a portion of the superior aperture of the small pelvis.

The thoracie and sacral curves have their concavities directed forward and are developed during intra-uterine life. They are in obvious relation to two great cavities of the trunk, thoracic and pelvic, and may be regarded as primary or accommodation curres, for the thoracis and pelvic viscera. The thoracic curve extends from the second to the welf th thoracie vertehrat and the sacral curve coincides with the sacrum and cocevx.

The cervical and lumbar curves have their convexities direeted forward, and are developed during the first year after birth. They are essentially curves of compensation, necessary for the maintenanee of the upright posture, and are brought about by modifications in the shape of the intervertebral discs. The cervical curve is formed about the third month, or as soon als the infant can sit upright. The great peculiarity of the curve is thit it is never consolidated. being present when the body is placed in the erect position and obliterated by bending the hoal down upon the chest. The lumbar curve is developed about the end of the first year or when the child begins to walk, but is not consolidated until adult life. (Symington.) The cervieal purv extends from the atlas to the second thoracic vertebra, and the lumbar curve from the twelfth thoracic to the promontory of the saerum.

The lateral curve is situated in the upper thoracie region, and when directed to the right is probably associated with the greater use made of the right hand. This curve, howevor, is particularly liable to modification in different occupations and in different races.

Viewed from the front, the vertebral column presents a series of pyramids lue to the successive increase and decrease in sizc of the bodies. These become broater from the axis to the first thoracic vertebra and then lecrease to the fourth thoracie. The first pyramid therefore includes all the cervical vertebre except the atlas, and has the apex rlirected upward and its base rlownward, whilst the second is inverted and formed by the first fou thoracie vertolias. The third pyramid, much the longest, is the result of the increase in size from the fout th thor:ac to the fifth lumbar vertebra, and the fourth, which is inverted, is produced by the rapral contrartion of the sacral and coceygeal vertebrie.

Viewed from behind, the spinous processes project in the middle line, and the transverste processes as two lateral rows. Of the spines, those of the axis, seventh cervical. first thoracic, and the lumbar vertebre appear most prominent. On each side is the vertebral groove, the floor of which is formed in the cervical and lumbar regions by the laminat and articular processes. 


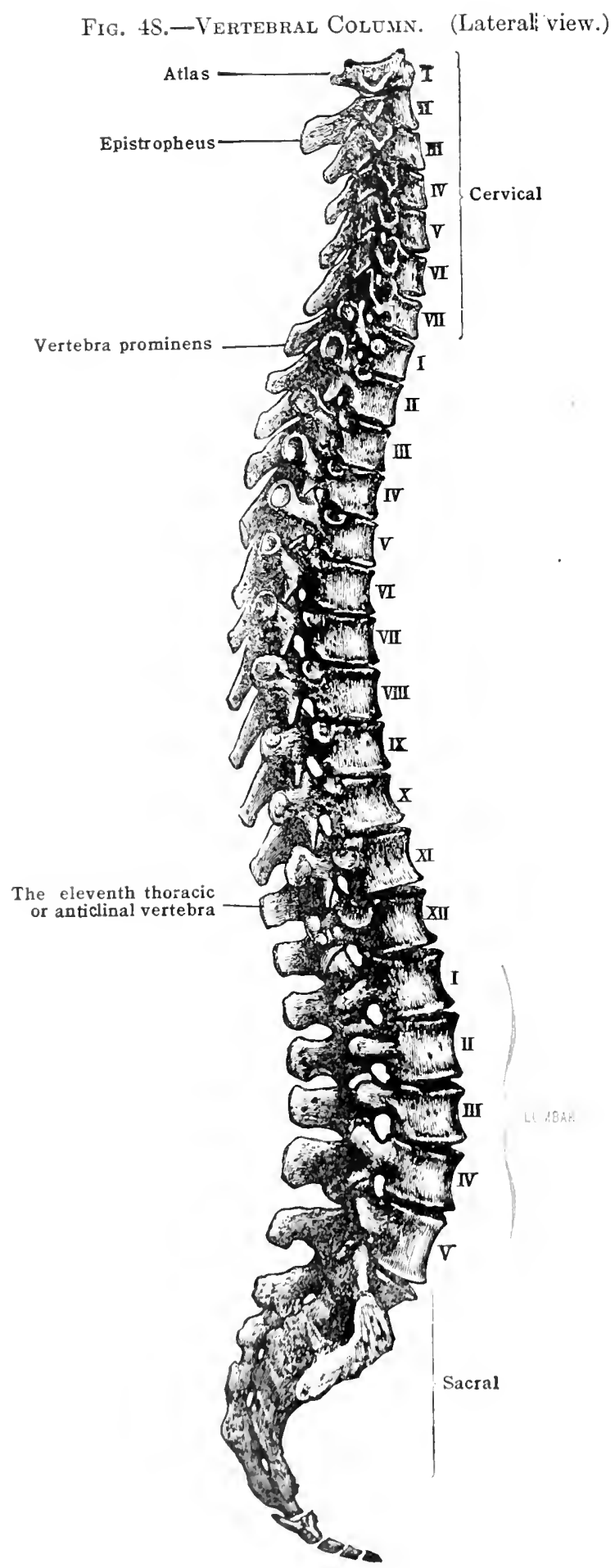


and in the thoracic region, by the laminæ and transverse processes. The transverse processes project laterally for a considerable distance in the atlas, first thoracic, and the middle of the lumbar series; they are shortest in the third cervical and the twelfth thoracic.

In the lateral view, the intervertebral foramina appear oval in shape, and are small in the cervical, larger in the thoracic, and largest in the lumbar region.

Structure of a vertebra. - The bodies of the vertebræ are largely composerl of cancellous tissue, with a thin souter covering of compact tissue. In a vertical section through the centrum

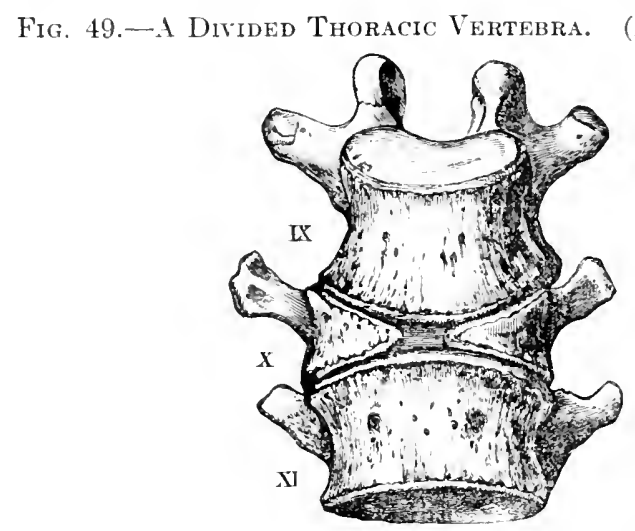

the fibres of the cancellous tissue are seen to be arranged vertically and horizontally, the vertical fibres being curved with their concavities directed toward the centre of the bone. The horizontal fibres are slightly curved parallel with the upper and lower surfaces, and have their convexities toward the centre of the bone. They are not so well defined as the vertical set. (Wagstaffe.)

Ossification.-The vertebræ in general.-The ossification of each vertebra takes place in cartilage from three primary and five secondary centres. The three primary centres

Fig. 50.-A Vertebral Centrua in Sectuon to Show the Pressure Curves.

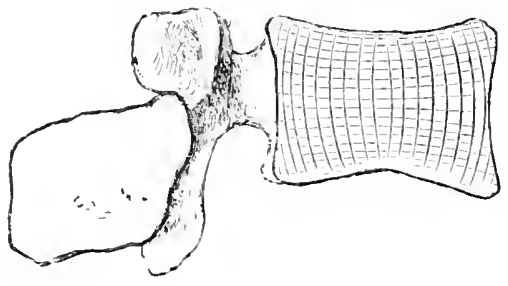

appear, one in the 'body and two in the arch, about the seventh week of intra-uterine life. In the thoracic region the nucleus for the body appears first, but in the cervical region it is preceded by the centres for the arch. The nucleus for the body soon becomes bilobed, and this condition is sometimes so pronounced as to give rise to the appearance of two distinct nuclei. Indeed, the nucleus is very rarely double and the two parts of the body may remain separate throughout life (fig. 49). The bilateral character of the nucleus is further emphasised by the occasional formation of half-vertebre. The lateral centres are deposited near the bases of the

Fig. 51.-A Vertebra at Birth.

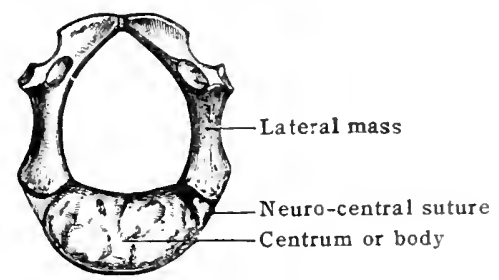

superior articular processes and give rise to the roots, laminæ, articular, and the greater parts of the transverse and spinous processes.

At birth a typical vertebra consists of three osseous pieces-a body and two lateral masses, which constitute the arch, the parts being joined together by hyaline cartilage. The line of union of the lateral portion with the body is known as the neuro-central suture, and is not actually obliterated for several years after birth. In the thoracic region the central ossification does not pass beyond the point with which the head of the rib articulates, and leaves a portion of the body. on each side formed from the lateral ossification. A thoracic vertebra at the fifth year shows 
that the pits for the heads of the ribs are situated behind the neuro-central suture, which is direeted obliquely backward and medially. The lamina unite during the first year after birth; and by the gradual extension of ossification into the various processes, the vertebra have attained almost their full size by the time of puberty. Subsequently the seeondary rentres appear in the cartilaginous extremities of the spinous and transverse processes, and in the carti-

Fig. 52.-Cervical Vertebra shoming the Epiphysal Plate on the Upper surface of THE BODY.

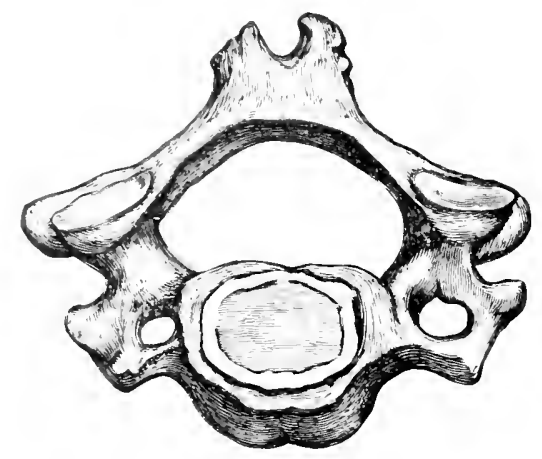

lage on the upper and lower surfaces of the bodies, forming in each vertebra two annular plates, thickest at the cireumference and gradually thinning towarl the central defieieney. The epiphyses appear from the fifteenth to the twentieth year and join with the vertebra by the twenty-fifth year.

Fig. 53.-Lumbar Vertebra at the Eighteenth Year with Secondary Centres.

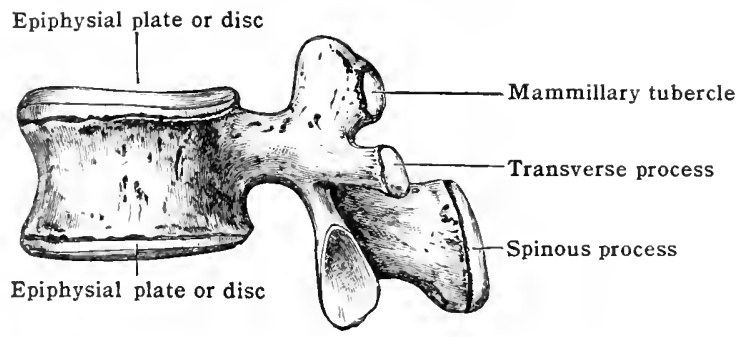

In several vertebrat the molle of ossification differs from the aecount given above-in some rase consiclerably - aml necessitates separate consideration.

Atlas. - The litteral portions and posterior arch are formel from two centres of ossifieation, which correcond to the lateral contres of other vertebre and appear about the seventh week.

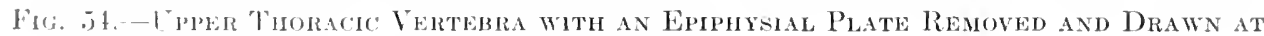
THE SIDE.

The plate show the characteristir defieiency in the centre. (Natural size.)
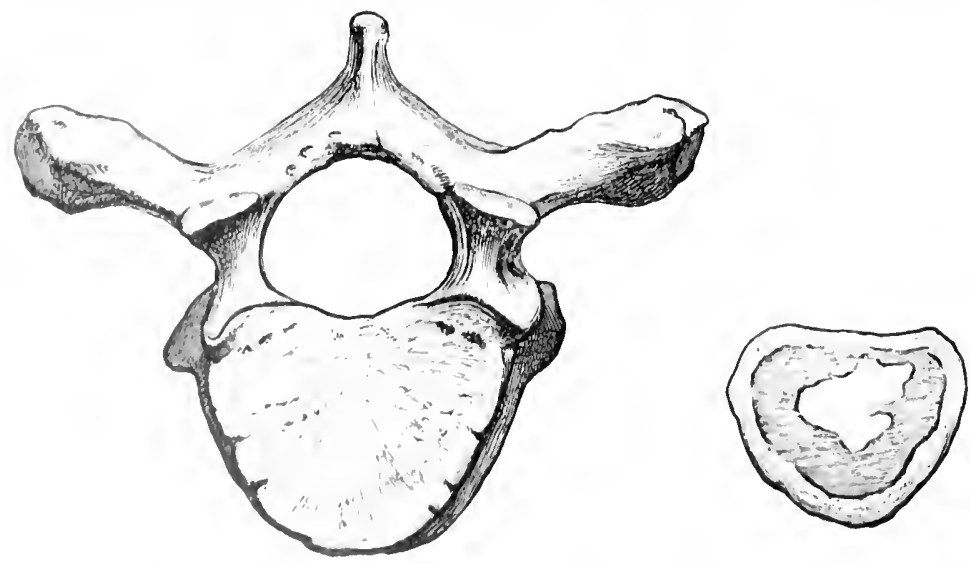

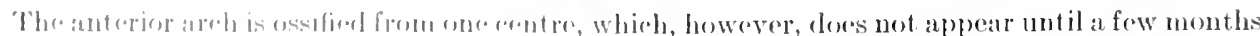
after lirth. Inion of the latromb parts ocours posteriofly in the third year, being sometimes

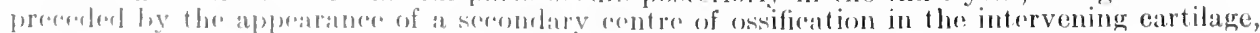
and the nuim of the latroral parts with the anterior areh oreurs about the sixth year. 
Epistropheus. - The arch, and the processes associated with it, are formed from two lateral centres which appear, like those in the other vertebre, about the serenth week. The rommun piece of cartilage which preeedes the body and dens is ossified from four (or five) centen, no (or two) for the body of the axis, in the fourth month, two, laterally disposed, for the rlens, il

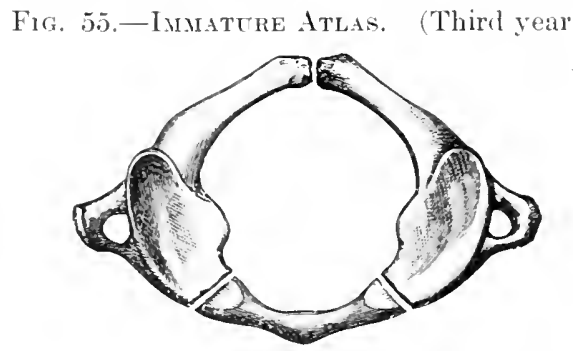

few weeks later, and one, for the apex of the tens, in the second year. The two eollaterul wnters for the main part of the dens soon coalesce, so that at birth the axis eonsists of four orsoum piecus: - two lateral portions which constitute the arch, the body, and the dens, surmounted by at piece of cartilage. During the third or fourth year the dens joins with the body, the line of

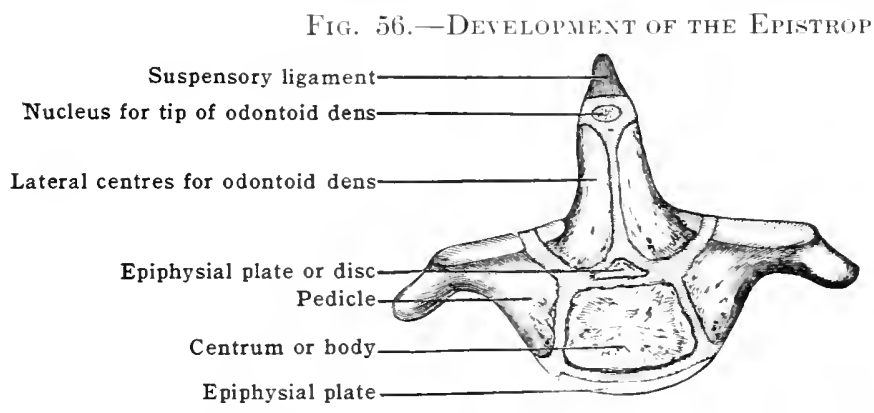

union being indicated even in adranced life by a small disc of cartilage, and the arch unites in front and behind about the same time or a little later. The apical nucleus of the lens, which represents an epiphysis, joins the main part about the twelfth year and in the sevent centh year

Fig. 57.-The Epistrophets at Focr lears of Age, shomixg tile size axd Extext of THE Dexis. (Natural size.)

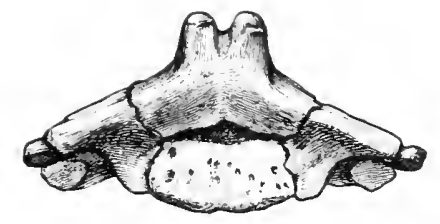

an epiphysial plate appears for the lower surface of the boly. There are also rudimentr. adjoining the cartilaginous dise, of the upper epiphysial plate of the body.

Cervical vertebræ. - In the cervieal vertehre the lateral centres form a larger share of the body than in the vertebrie of other regions, and the neuro-central suture runs almost in as sin-

Fig. 58.-The Epistropheto (From ax Adult) ax sagittal siectiox.

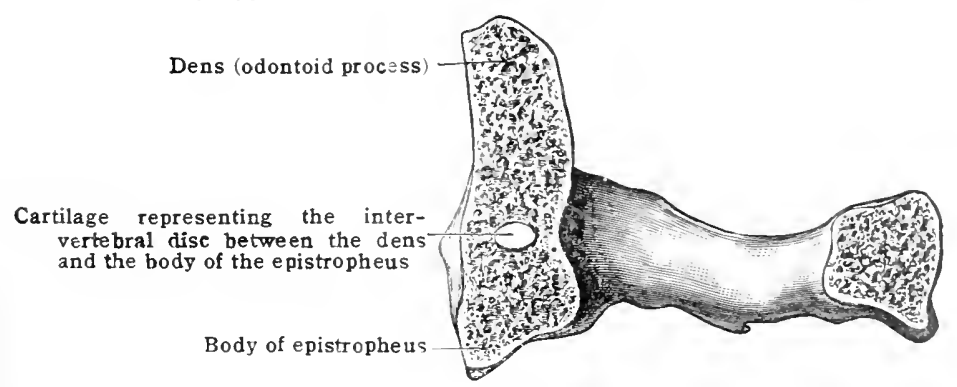

ittal direction. The sixth, seventh, and eren the fifth have additional centres which alpucar before birth for the anterior or costal divisions of the transverse processes. In the other crevical vertebræ the costal processes are ossified by extension of the lateral muclei. 'The (4)-tal processes of the seventh cervical sometimes remain separate, constituting cervical rihs. 
Lumbar vertebræ.- In the lumbar vertebræ the neuro-central suture is almost transverse, and to the usual number of centres of ossification, two other epiphyses for the mammillary tubercles are added, the centres appearing about puberty. The transverse process of the first lumbar vertebra is occasionally developed from an independent centre.

The fifth lumbar exhibits in some cases a special mode of ossification in the arch. Instead of two centres, there are four-one on each side for the root, transverse process, and supe-

Fiğ. 59.-An Imature Cervical Vertebra.

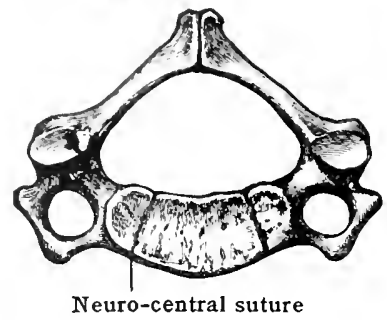

rior articular process, and another on each side for the lamina, inferior articular process, and the lateral half of the spinous process (fig. 60). There may be failure of union of roots with the laminæ or of the laminæ with one another.

Sacral vertebræ. - The sacrum ossifies from thirty-five centres, which may be classified as follows:- In eacl of the five vertebra there are three primary nuclei-one for the body and two for the arch; in each of the first three the costal element of the lateral mass on each side is

Fig. 60.- Ossification of the Fifth Lumbar Vertebra.

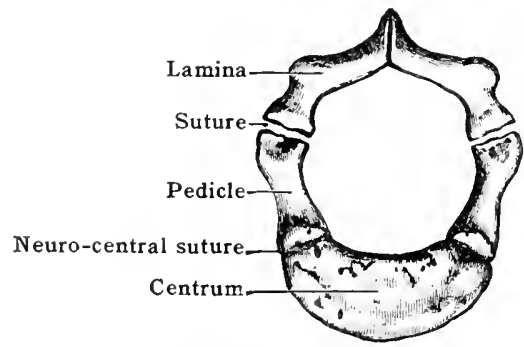

formed from a separate nucleus; associated with each body are two epiphysial plates; and on each lateral margin are two irregular epiphyses, one for the auricular surface and another for the rough elge below.

The centres for the bodies appear about the eighth or ninth week and for the vertebral arches about the sixth month. The arches join the bodies at different times in the different

Fig. 61.-Sacrum at Birti to show Centres of Ossification. (Enlarged one-third.)

Ossific centre in the body of first sacral vertebra. Beneath this are seen in succession the centres in the

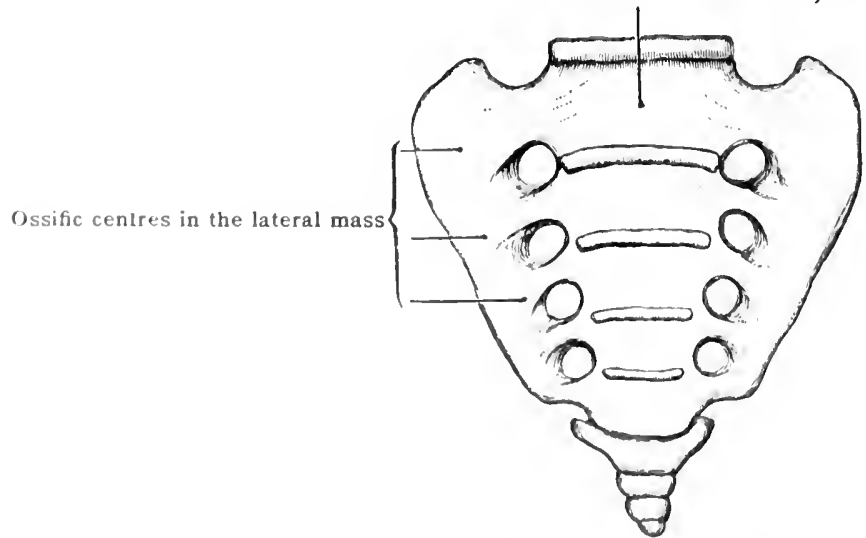

vertebra, ranging from the second year bolow, to the fifth or sixth year above, and union of the lamina takes plaee behimel some years later, from ahout the ninth to the fifteenth year.

The centres for the costal elonents appoar outsirle the anterior sacral foramina, from the fifth to the seventh month, and these mitc with the bodies somewhat later than the arches.

The centres for the epiphysial plates appear about the fifteenth year, and for the aurieular epiphyses and the edges below, from the eighteenth to the twenticth year. 
Consolidation begins soon after puberty by fusion of the costal processes, and this is followed by ossification from below upward in the intervertebral dises, resulting in the union of the adjacent bodies and the epiphysial plates, the ossific union of the first and second being completed by the twenty-fifth year or a little later. The marginal epiphyses are also united to tie

Fig. 62.-The Sacrux at Four Years of Age (B). The Figure at the Top (A) Shows the Base Drawn from Above. (Three-fourths natural size.)

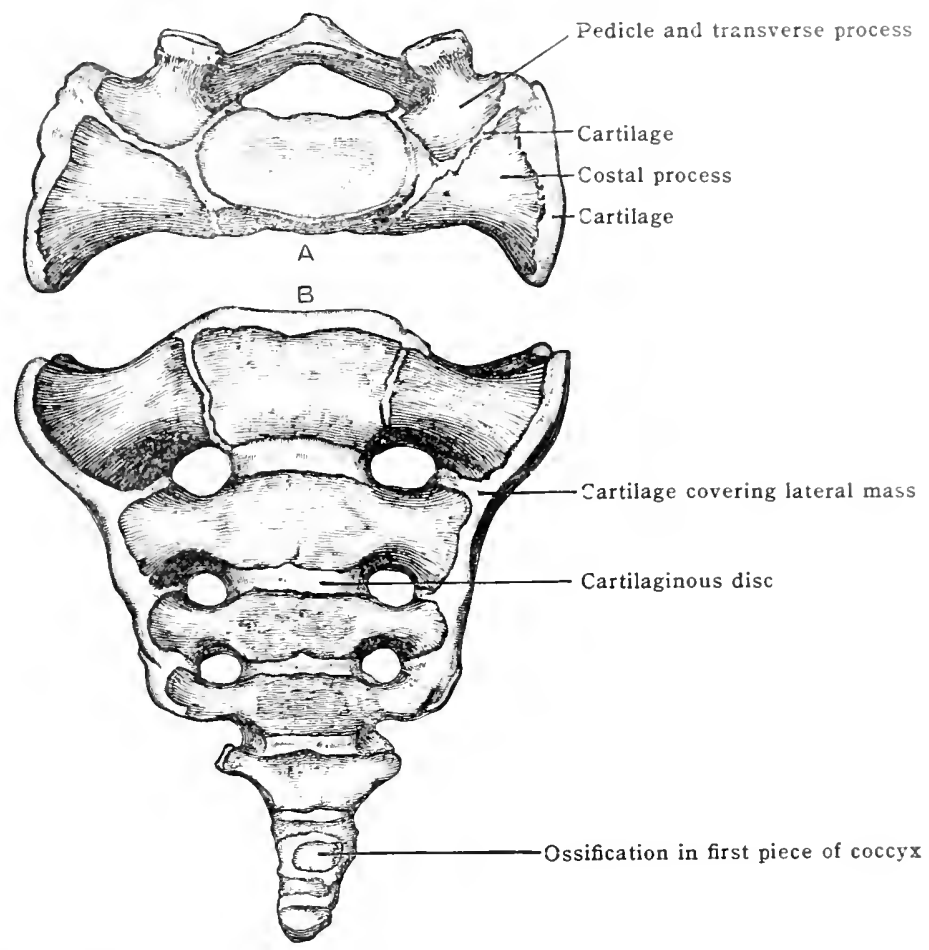

sacrum by the twenty-fifth year. Fven in advanced life intervertebral discs persist in the more central parts of the bone and can be well seen in sections.

Coccygeal vertebræ.- The coccygeal vertebre are cartilaginous at birth and each is usually ossified from a single centre, though there may be two for the first piece. Ossification begins soon after birth in the first segment, and in the second from the fifth to the tenth year.

Fig. 63.-Sacrum at about Twenty-two Years. (Tluree-fifths natural size.)

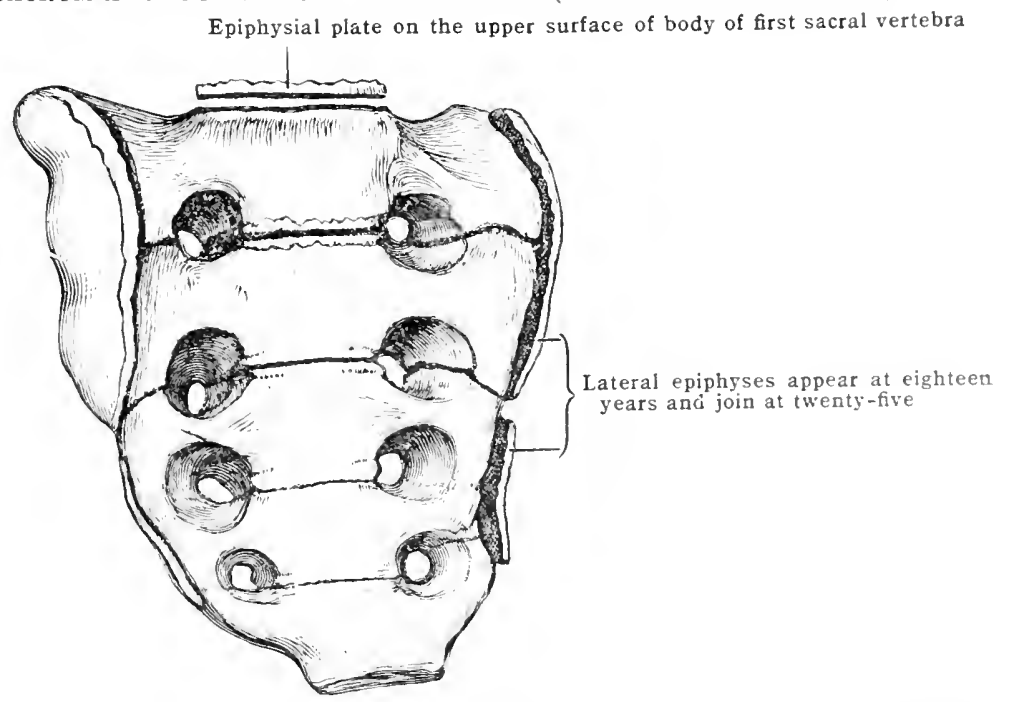

The centres for the third and fourth segments appear just before, and after, puberty repertively. As age advances the various pieces become united with each other, the three lower uniting before middle life and the upper somewhat later. In advanced life the coccy may joir with the sacrum, the union occurring earlier and more frequently in the male than in the female. 


\section{The Serial Morphology of the Vertebra}

Although at first sight many of the vertebre exhibit peculiarities, nevertheless a study of the mode by which they develop, and their variations, indicates the serial homology of the constituent parts of the vertebra in each region of the column.

The body (centrum) of the vertebra is that part which immediately surrounds the notochord. This part is present in all the vertebre of man, but the centrum of the atlas is dissociated from its arch, and ankylosed to the body of the epistropheus. The reasons for regard-

Fig, 64.-Morphology of the Transverse and Articular Processes.
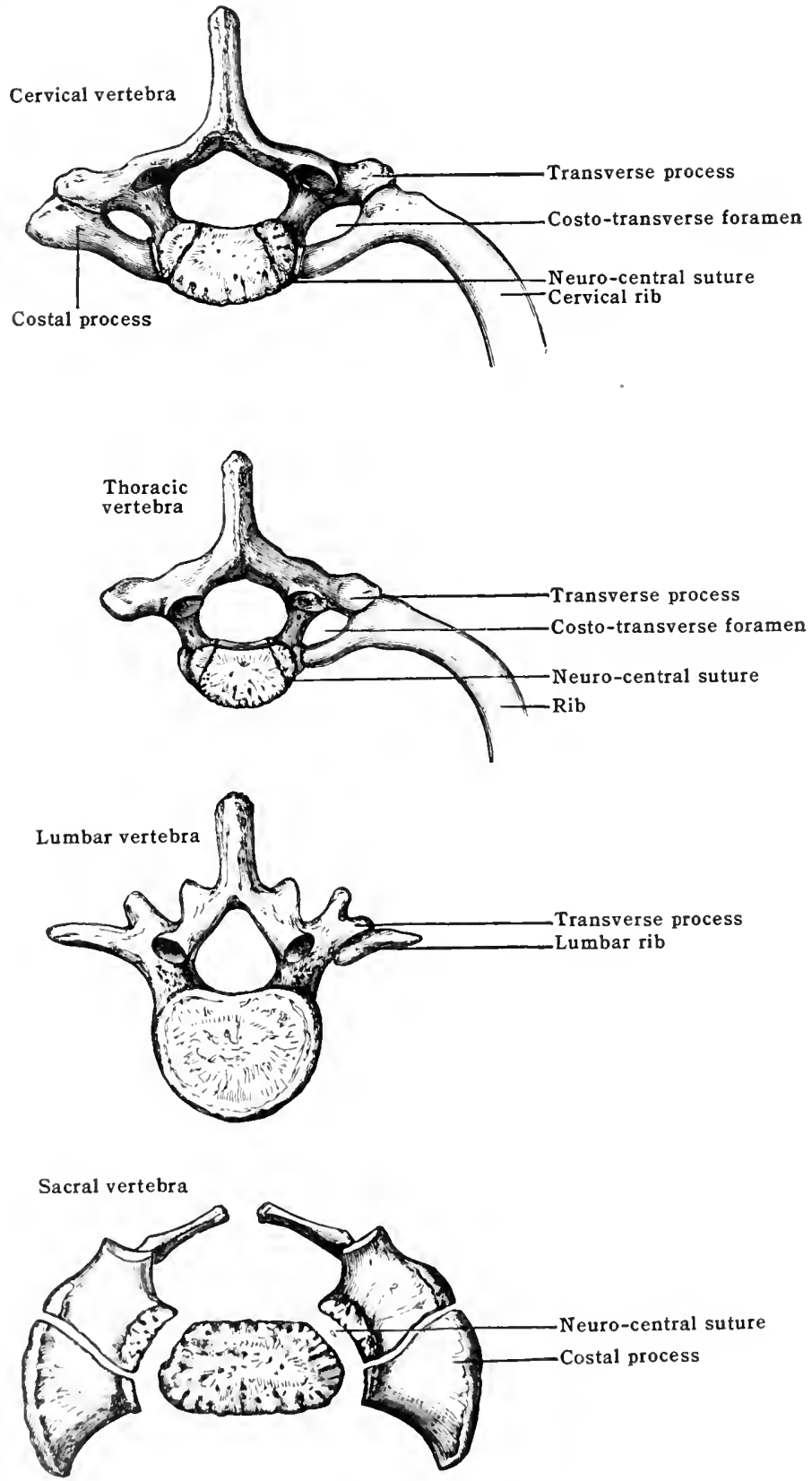

ing the rlens as thr buly of the atlas are these: In the embryo the notochord passes through it on its way to the base of the cranium. Between the dens and the body of the axis there is a swrlling of the notochord in the early embryo as in other intervertebral regions. This swelling is later indieated by a small intervertebral disc hidden in the bone, but persistent even in old agr. Horeover, the dens ossifies from primary centres, and in chelonians it remains as a separate ossiele throughout life; in Ornithorhynehus it remains distinct for a long time, and it bas becn found separate even in an adult man. Lastly, in man and many mammals, an epi- 
physial plate develops between it and the body of the axis. The anterior areh of the atlas represents a cartilaginous hypochordal bar, which is present in the early stages of development of the vertebræ, but disappears in all but the atlas in the ossification of the brody.

The arches and spinous processes are easily recognised throughout the various parts of the column in which eomplete vertebrie are present.

The articular processes or zygapophyses are of no morphologieal value, and do not require consideration here.

The transuerse processes offer more diffieulty. They oecur in the simplest form in the thoracic series. Here they articulate with the tubereles of the ribs, whence the term tubercular processes or diapophyses has been given them (the place of artieulation of the head of the rib with the vertebra is the capitular process or parapophysis), and the transverse proeess and the neck of the rib enclose an arterial foramen named the costo-transverse foramen. In the cervieal region the costal element (pleurapophysis) and the transverse process are fused together, and the conjoint process thus formed is piereed by the costo-transverse foramen. The compound nature of the proeess is indicated by the fact that the anterior or costal processes in the lower cervical vertebræ arise from alditional centres and occasionally retain their independence as cervical ribs, and in Sauropsida (birds and reptiles) these processes are represented by free ribs. In the lumbar region, the compound nature of the transverse process is further marked. The true transverse proeess is greatly suppressed, and its extremity is indicated by the accessory tubercle. Anterior to this in the adult vertebrie a group of holes represents the costo-transverse foramen, and the portion in front of this is the costal element. Occasionally it persists as an independent ossicle, the lumbar rib.

In the sacral series the costal elements are coalesced in the first three vertehra to form the greater portion of the lateral portion for articulation with the ilium, the costo-transverse foralmina being completely obseured. In rare instances the first sacral vertebra will artieulate with the ilium on one side, but remain free on the other, and under such conditions the fres process exactly resembles the elongated transverse proeess of a lumbar vertebra. The first threesaral vertebræ which develop costal processes for articulation with the ilium are termed true sicral vertebræ, while the fourth and fifth are termel psendo-sacral. A glance at fig. 64 will show the homology of the various parts of a vertebra from the cervical, thoracie, lumbar, and sacral regions.

\section{B. BONES OF THE SKULL}

The skull is the expanded upper portion of the axial skeleton and is supported on the summit of the vertebral column. It consists of the cranium, a strong bony case enclosing the brain and made up of eight bones-viz., occipital, two parietal, frontal, two temporal, sphenoid, ethmoid; and the bones of the face, surrounding the mouth and nose, and forming with the cranium the orbital cavity for the reception of the eye. The bones of the face are fourteen in number-riz., two maxilla, two zygomatic (malar), two nasal, two lacrimal, two palate, two inferior conche (turbinates), the mandible, and the comer. All the bones enumerated above, with the exception of the mandible, are united by suture and are therefore immovable. The proportion between the facial and cranial parts of the skull varies at different periods of life, being in the adult about one (facial) to two (cranial), and in the new-born infant about one to eight. A group of movable bones, comprising the hyoid, suspended from the basilar surface of the cranium. and three small bones, the incus, malleus, and stapes, situated in the middle ear or tympanic eavity, is also included in the enumeration of the bones of the skull.

According to the BNA nonenelature, the term cranium is used in a wider sense as synonymous with shull, and is subdivided into cranium cerebrale (cranium in the narrower sense) and cranium viscerale (facial skeleton). In the BNA, seven bones above listed with the facial, two inferior conchæ, two lacrimal, two nasal and the voner-are elassed with the cranium cerebrale.

\section{THE OCCIPITAL}

The occipital bone [os oceipitale] (fig. 65) is situated at the posterior and inferior part of the eranium. In general form it is flattened and trapezoid in shape, curved upon itself so that one surface is convex and directed barkwird and somewhat downward, while the other is concave and looks in the opposite direction. It is piereed in its lower and front part by a large aperture, the foramen magnum, by which the rertebral canal communieates with the carity of the cranium.

The occipital bone is divisible into four parts, basilar, squamous, and two condylar, so arranged around the foramen magnum that the basilar part lies in front, the condylar parts on either side, and the squamous part above and behind. 
Speaking generally, this division corresponds to the four separate parts of which the bone consists at the time of birth (fig. 69), known as the basi-occipital, supra-occipital, and exoccipital. In early life these parts fuse together, the lines of junction of the supra-occipital and ex-occipitals extending lateralward from the posterior margin of the foramen magnum, and those of the ex-occipitals and basi-occipital passing through the condyles near their anterior extremities. It must be noted, however, that the upper portion of the squamous part represents an additional bone, the interparietal.

The squamous part [squama occipitalis] (supra-occipital and interparietal) presents on its convex posterior surface, and midway between the superior angle and the posterior margin of the foramen magnum, a prominent tubercle known as the external occipital protuberance, from which a vertical ridge - the external occipital crest-runs downward and forward as far as the foramen. The protuberance and crest give attachment to the ligamentum nuchæ.

\section{Flg, 65.-The Occipital. (External view.)}

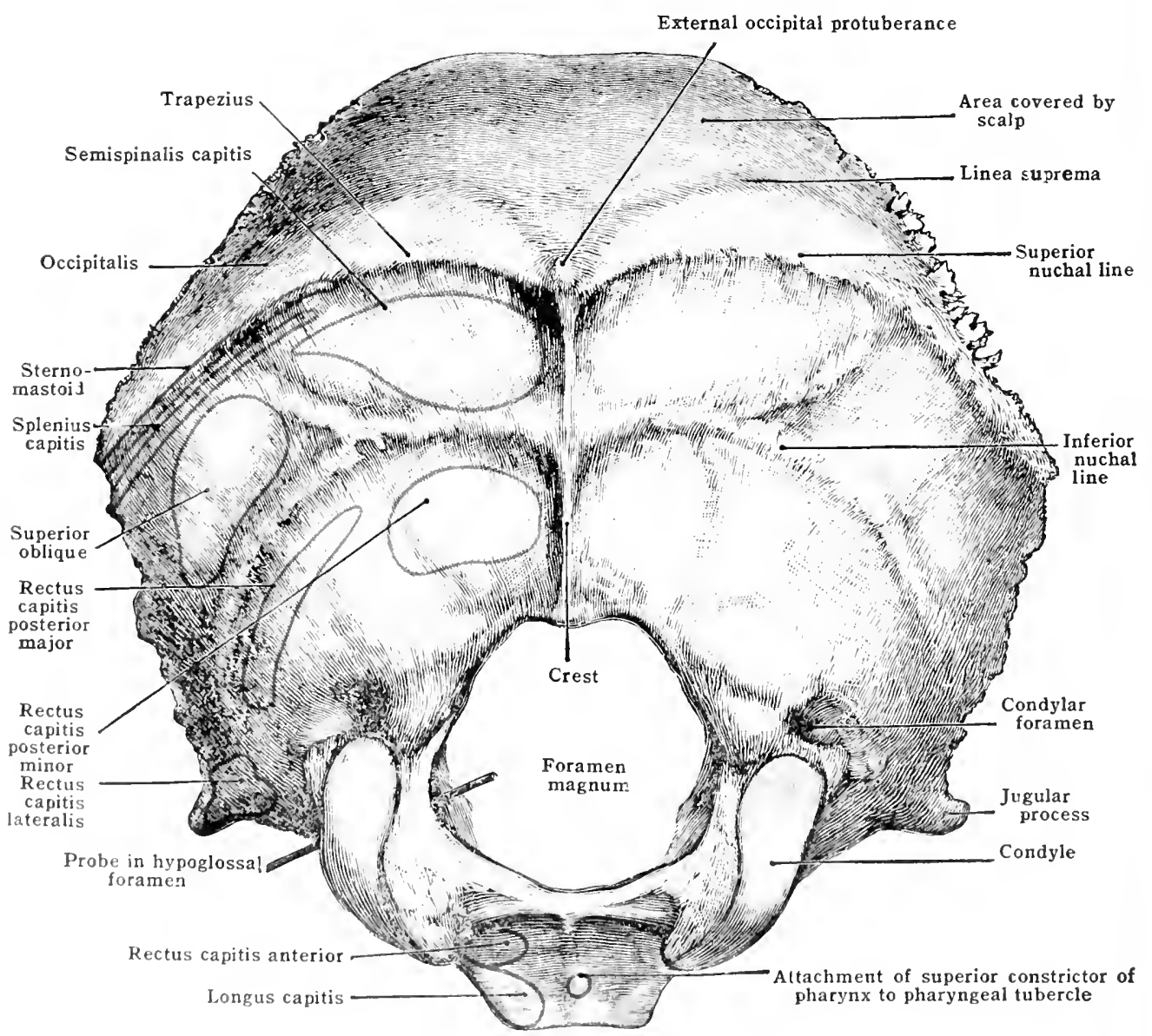

Arching littralwarel on ateh sirle from the external occipital protuberance foward the lateral angle of the bone is a semiejentar ridge, the superior nuchal

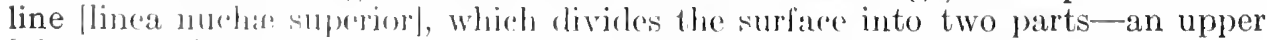
[planum oceipitalet and a lower [planum nuchale]. Above this line, a second less distinctly markol ridge the highest nuchal line |linea nuchie suprema]-is weilally seren. It is the most rurverl of the three lines on this surface and gives attachment to the "gicranial apromenosis and to a few fibres of the occipitalis musele. Jintwers the suprrior and highest enrved lines is a narrow erescentic area in which the bone is smosthere and lelester than the rest of the surface, whilst the pat of the hone alowe the lineat suppemat is convex and covered by the seal p.

The lower part of the surfase is very meven and sublivieled into an upper and a lower arra by the inferior nuchal line, which runs laterally from the middle of the orest to the jugular prowersis. 
The curved lines and the areas thus mapped out between and below then give attachment to several muscles. To the superior nuchal line are attached, medially the trapezius, and laterally the occipitalis and sterno-cleido-mastoid; the area between the superior and inferior curved lines receives the semispinalis capitis (complexus) medially, and splenius capitis and obliquus capitis superior laterally; the inferior nuchal line and the area below it afford insertion to the rectus capitis posterior minor and major.

The anterior or cerebral surface is deeply concave and marked by two grooved ridges which cross one another and divide the surface into four fossa of which the two upper, triangular in form, lodge the occipital lobes of the cerebrum, and the two lower, more quadrilateral in outline, the lobes of the cerebellum. The vertical ridge extends from the superior angle to the foramen magnum and the transverse ridge from one lateral angle to the other, the point of intersection being indicated by the internal occipital protuberance [eminentia erueiata]. The

Fig. 66.-Occipital Bone, Cerebral Surface.

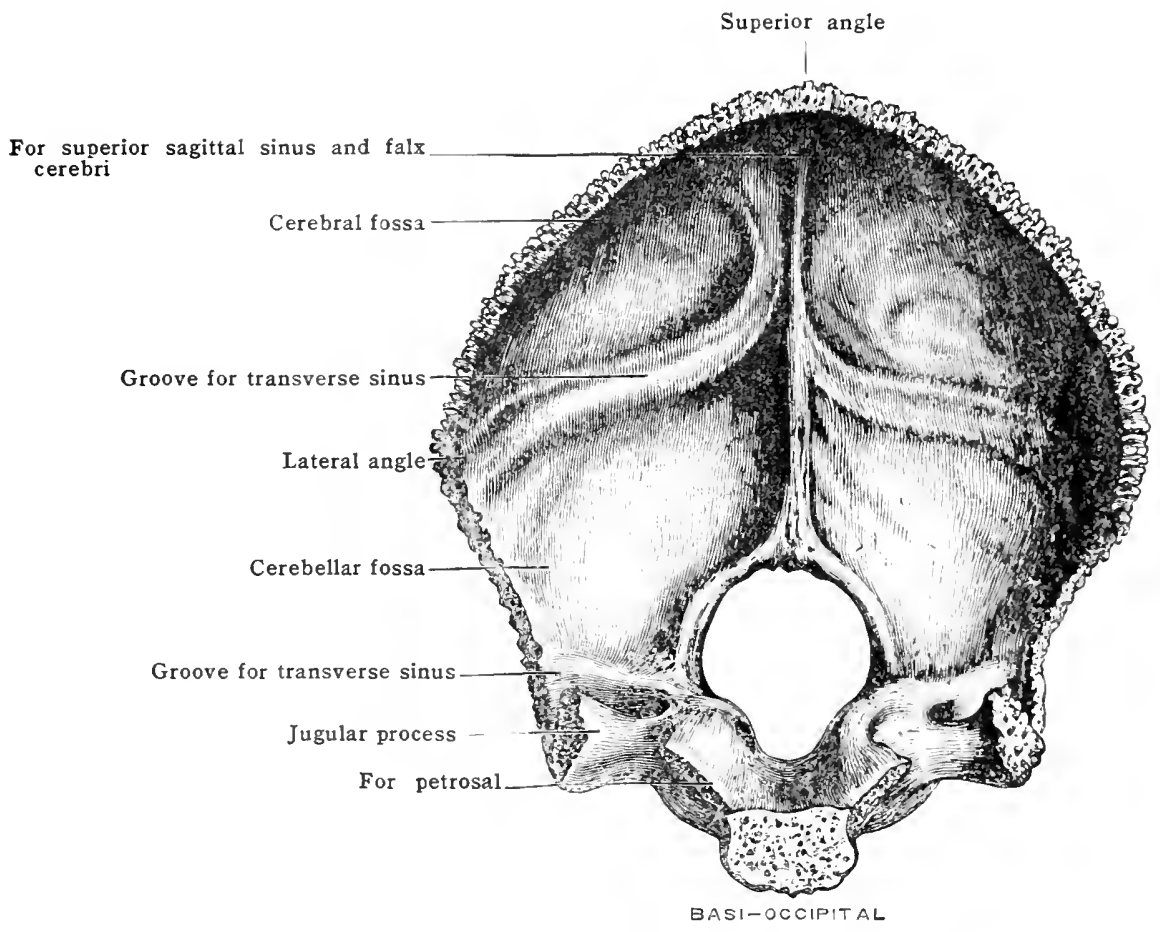

upper part of the vertical ridge is grooved [suleus sagittalis] for the superior sagittal (longitudinal) sinus and gives attachment, by its margins, to the falx cerebri; the lower part is sharp and known as the internal occipital crest, and affords attachment to the falx eerebelli. Approaching the foramen magnum the ridge divides, and the two parts become lost upon its margin. The angle of divergence sometimes presents a shallow fossa for the extremity of the vermis of the cerebellum, and is called the vermiform fossa. The two parts of the transverse ridge are deeply grooved [suleus transversus] for the transverse (lateral) sinuses, and the margins of the groove give attachment to the tentorim cerebelli. To one side of the internal oceipital protuberance is a wile spaee, where the vertical groove is continued into one of the lateral grooves more frequently the right), and this is termed the toreular Herophili; it is sometimes exactly in the middle line.

The squamous portion has three angles and four borders. The superior angle forming the summit of the bone is received into the space formed by the union of the two parietals. The lateral angles are very obtuse and corresponcl in situation with the lateral ends of the transverse ridges. Above the lateral angle on each side the margin is deeply serrated, forming the la mbdoid or superior border which extends to the superior angle and artieulates with the posterior border of the parietal in the lambdoid suture. The mastoid or inferior border extends 
from the lateral angle to the jugular process and articulates with the mastoid portion of the temporal.

The condylar or lateral portions [partes laterales] (ex-occipitals) form the lateral boundaries of the foramen magnum and bear the condyles on their inferior surfaces. The condyles are two convex oval processes of bone with smooth articular surfaces, covered with cartilage in the recent state, for the superior articular processes of the atlas. They converge in front, and are somewhat everted. Their margins give attachment to the capsular ligaments of the occipito-atlantal joints and on the medial side of each is a prominent tubercle for the alar (lateral odontoid) ligament. The anterior extremities of the condyles extend beyond the ex-occipitals on the basi-occipital portion of the bone. The hypoglossal (anterior conclyloid) foramen or canal [canalis hypoglossi] perforates the bone at the base of the condyle, and is directed from the interior of the cranium, just above the foramen magnum, forward and laterally; it transmits the hypoglosial nerve and a twig of the ascending pharyngeal artery.

The foramen is sometimes double, being divided by a delicate spicule of bone. Above the canil is a smooth convexity known as the tuberculum jugulare sometimes marked by an oblique groove for the ninth, tentl and eleventh cranial nerves. Posterior to each condyle is a pit, the

Fig. 67.-Cerebral Surface of the Occipital, Sirowing an Occasional Disposition of the Channels.

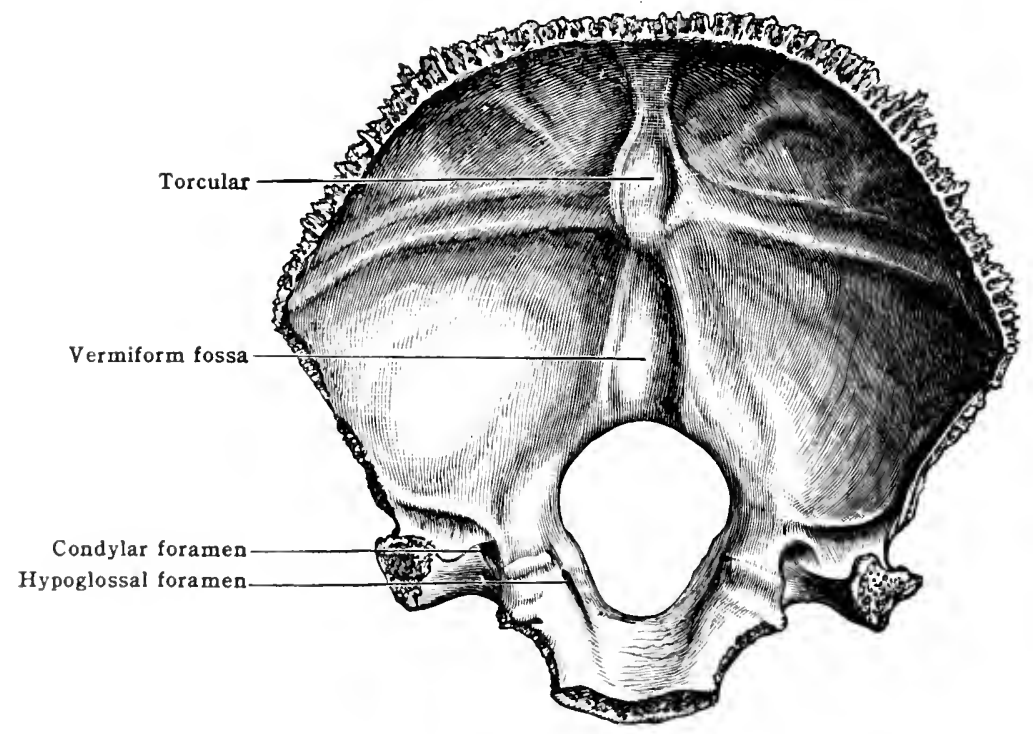

condylar fossa, which receives the hinder edge of the superior articular process of the atlas when the hearl is rextended. The floor of the depression is occasionally perforated by the condylar (jostrior conclyloid) canal or foramen [eanalis condyloideus], which transmits a vein from the transverse sinus. Projecting laterally opposite the condyle is a quadrilateral portion of bone known as the jugular process, the extrenity of which is rough for articulation with the jugular faced on the pretrous portion of the temporal bone. $U_{1}$ ) to twenty-five years the bones are united horr by neans of cartilage; about this age ossification of the eartilage takes place, and the jugular prome thes becomes fused with the petrosal. Its anterior border is deeply notebed to form the postrior bomdary of the jugular foramen, and the noteh is directly continuous with a groove (on the npy r surfare: which lodgos the termination of the transverse sinus. In or near the groove is secn the inner opming of the condylar foramen. The lower surface of the process gives attanement to the rectus rapitis lateralis and the oblique oecipito-atlantal ligament. Occasionally the mastoid a dir enlls extrond into this process and rarely a process of bone, representing the primmastoil prowes of many mimmals, projeets downwaril from its under aspect and may bo so long as lo join or artinulate with the transverse process of the atlas.

Tho basilar portion (Iasi-orecipital) is a quadrilateral plate of bone projecting forward and upward in front of the foramen magnum. Its superior surface presents a derep groove-the basilar groove [clivus]; it supports the medulla oblongata and gives attachment to the tectorial membrane (oceipito-axial ligarnent). 'l'he lower surfare presents in the midlle line a small clevation knwwn as the pharyngeal tubercle for the attachment of the fibrous raphe of the pharynx, and immodiatrly in front of the tubercle there is frequently a shallow 
fossa-the scaphoid fossa-which originally received the primitive anterior extremity of the foregut.

On each side of the middle line are impressions for the insertions of the longus capitis (rectus capitis anterior major) and rectus capitis anterior (minor), the impression for the latter being

Fig. 68.-The Foranex Magnum at the śnth Year.

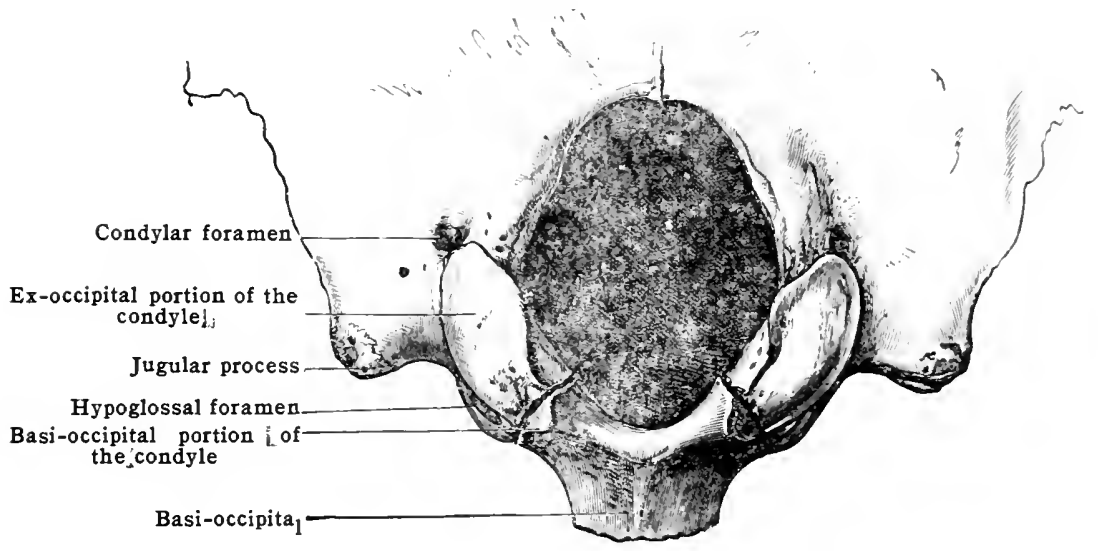

nearer to the condyle, and near the foramen magnum this surface gives attachment to the anterior occipito-atlantal ligament. Anteriorly the basilar process articulates by synchondrosis with the body of the sphenoid up to twenty years of age, after which there is complete bony. union. Posteriorly it presents a smooth rounded border forming the anterior boundary of the foramen magnum. It gives attachment to the apical odontoid ligament, and above this

\section{Fig. 69.-The Occipital at Birth. (Anterior view.)}

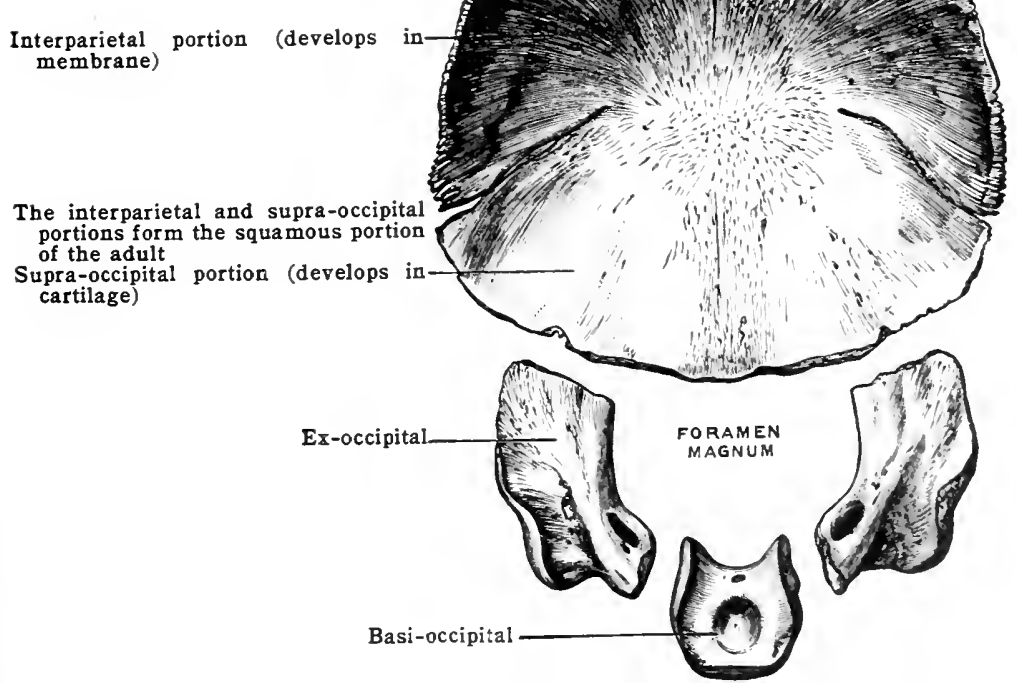

to the ascending portion of the crucial ligament. In the occipital bone at the sixth year the lateral extremities of this border are enlarged to form the basilar portion of the condyles. The lateral borders are rough below for articulation with the petrous portion of the temporal bones, but above, on either side of the basilar groove, is a half-groove, which, with a similar half-groove on the petrous portion of the temporal bone, lodges the inferior petrosal sinus. 
The foramen magnum is oval in shape, with its long axis in a sagittal direction. It transmits the medulla oblongata and its membranes, the accessory nerves (spinal portions), the rertebral arteries, the anterior and posterior spinal

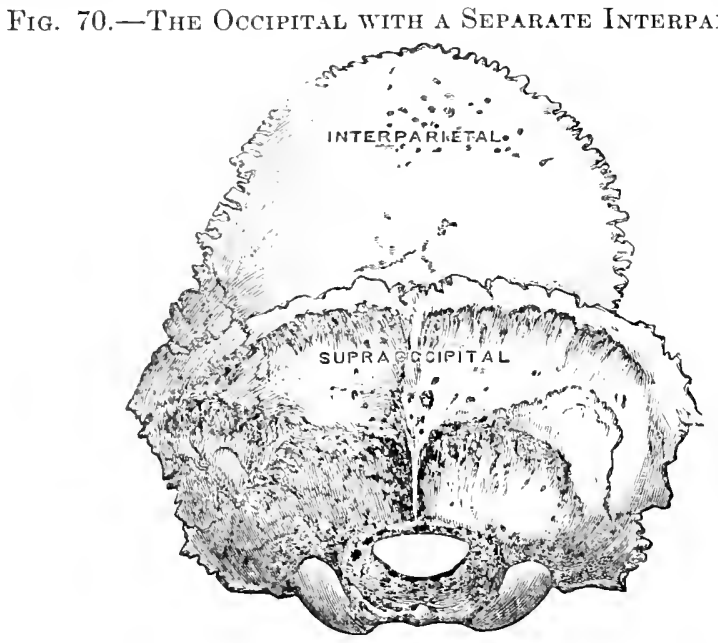

arteries, and the tectorial membrane (occipito-axial ligament). It is widest behind, where it transmits the medulla, and is narrower in front, where it is encroached upon by the condyles.

Fig. 71. - Shull showing a Pre-interparietal Bone (P.I.).

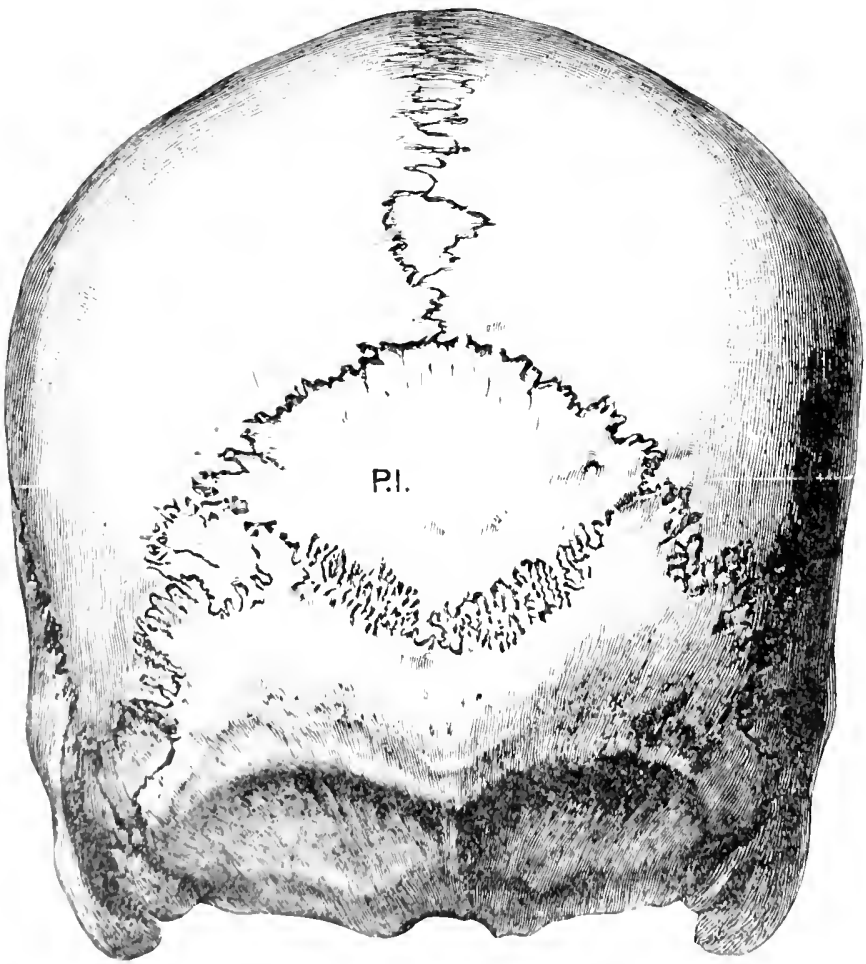

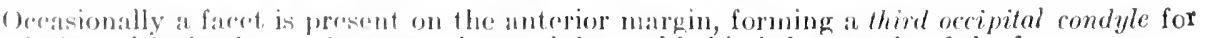
aptionlation with the dens. Bowwent the condyles and behind the margin of the foramen magwulu the posterior ocripito-atlantal ligament obtains attachment.

Blood-supply. - Tho occifital bone receives its blood-supply from the oceipital, posterior auricular, midilomeningeal, vertebal and the aseending pharyngeal arteries.

Articulations. - The ocripital bone is connected by suture with the two parietals, the two tomporals, and the sphenoid; the eondyles articulate with the athas, and exceptionally the oecipital articulates with the dens of the epistropheus by means of the thirrl occipital condyle. 
Ossification. - The occipital bone develops in four pieces. The squamous portion is ossified from four centres, arranged in two pairs, which appear about the eighth week. The upper pair are deposited in membrane, and this part of the squamous portion represents the interparietal bone of many animals. The lower vair, deposited in cartilage, form the true supra-occipital element, and the four parts quickly coalesce near the situation of the future occipital protuberance. For many weeks two deep lateral fissures separate the interparietal and supraoccipital portions, and a membranous space extending from the centre of the squamous portion to the foramen magnum partially separates the lateral portions of the supra-ceripital. This space is occupied later by a spicule of bone, and is of interest as being the opening through which the form of hernia of the brain and its meninges, known as occipital meningocele or encephalocele, occurs. The basi-occipital and the two ex-occipitals are ossified each from a single nucleus which appears in cartilage from the eighth to the tenth week.

At birth the bone consists of four parts united by strips of cartilage, and in the squamous portion fissures running in from the upper and lateral angles are still noticeable. The osseous union of the squamous and ex-occipital is completed in the fifth year, and that of the exoccipitals with the basi-occipital before the seventh year. Up to the twentieth year the basioccipital is united to the body of the sphenoid by an intervening piece of cartilage, but about that date ossific union begins and is completed in the course of two or three years. Occasionally the interparietal portion remains separate throughout life (fig. 70), forming what has been termed the inca bone, or it may be represented by numerous detached ossicles or Wormian bones. In some cases a large Wormian bone, named the pre-interparietal, is founi, partly replacing the interparietal bone (fig. 71). A pre-interparietal bone is found in some mammals, and it has occasionally been observed in the human fotal skull. In fig. 71 the bone is seen in an adult human skull-a distinctly rare condition.

\section{THE PARIETAL}

The two parietal bones (figs. 72, 73), interposed between the frontal before and the occipital behind, form a large portion of the roof and sides of the cranium. Each parietal bone [os parietale] is quadrilateral in form, convex externally, concave internally, and each presents for examination two surfaces, four borders, and four angles.

The parietal surface is smooth and is crossed, just below the middle, by two curved lines known as the temporal lines. The superior line gives attachment to the temporal fascia; the lower, frequently the better marked, limits the origin of the temporal muscle; whilst the narrow part of the surface enclosed between them is smooth and more polished than the rest. Immediately above the ridges is the most convex part of the bone, termed the parietal eminence [tuber parietale], best marked in young bones, and indicating the point where ossification commenced. Of the two divisions on the parietal surface marked off by the temporal lines, the upper is covered by the scalp, and the lower, somewhat striated, affords attachment to the temporal muscle. Close to the upper border and near to the occipital angle is a small opening - the parietal foramen-which transmits a vein to the superior sagittal (longitudinal) sinus.

The cerebral surface is marked with depressions corresponding to the cerebral convolutions and by numerous deep furrows, running upward and backward from the sphenoidal angle and the lower border, for the middle meningeal ressels (sinus and artery). A shallow depression running close to the superior border forms, with the one of the opposite side, a channel for the superior sagittal sinus, at the side of which are small irregular pits for the Pacchionian bodies; the pits are usually present in adult skulls, but are best marked in those of old persons. The margins of the groove for the superior sagittal sinus give attachment to the falx cerebri.

Borders.-The sagittal or superior border, the longest and thickest, is teeply serrated to articulate with the opposite parietal, with which it forms the sagittal suture. The frontal or anterior border articulates with the frontal to form the coronal suture. It is deeply serrated and bevelled, so that it is overlipped by the frontal above, but overlaps the edge of that bone below. The occipital or posterior border articulates with the eccipital to form the lambdoid suture, ancl resembles the superior and anterior in being markedly serrated. The squamosal or inferior border is divided into three portions:- the anterior, thin and berelled, is overlapped by the tip of the great wing of the sphenoid; the midule portion, arched and also bevelled, is overlapped by the squamous part of the temporal: and the posterior portion, thick and serrated, articulates with the mastoid portion of the temporal bone.

Angles.-The frontal or anterior superior, almost a right angle, occupies that part of the bone which at birth is membranous and forms part of the anterior 
fontanelle. The sphenoidal or anterior inferior angle is thin and prolonged downward to articulate with the tip of the great wing of the sphenoid. Its inner surface is marked by a deep groove, sometimes converted into a canal for a short

Fig. 72.-The Left Parietal. (Outer surface.)

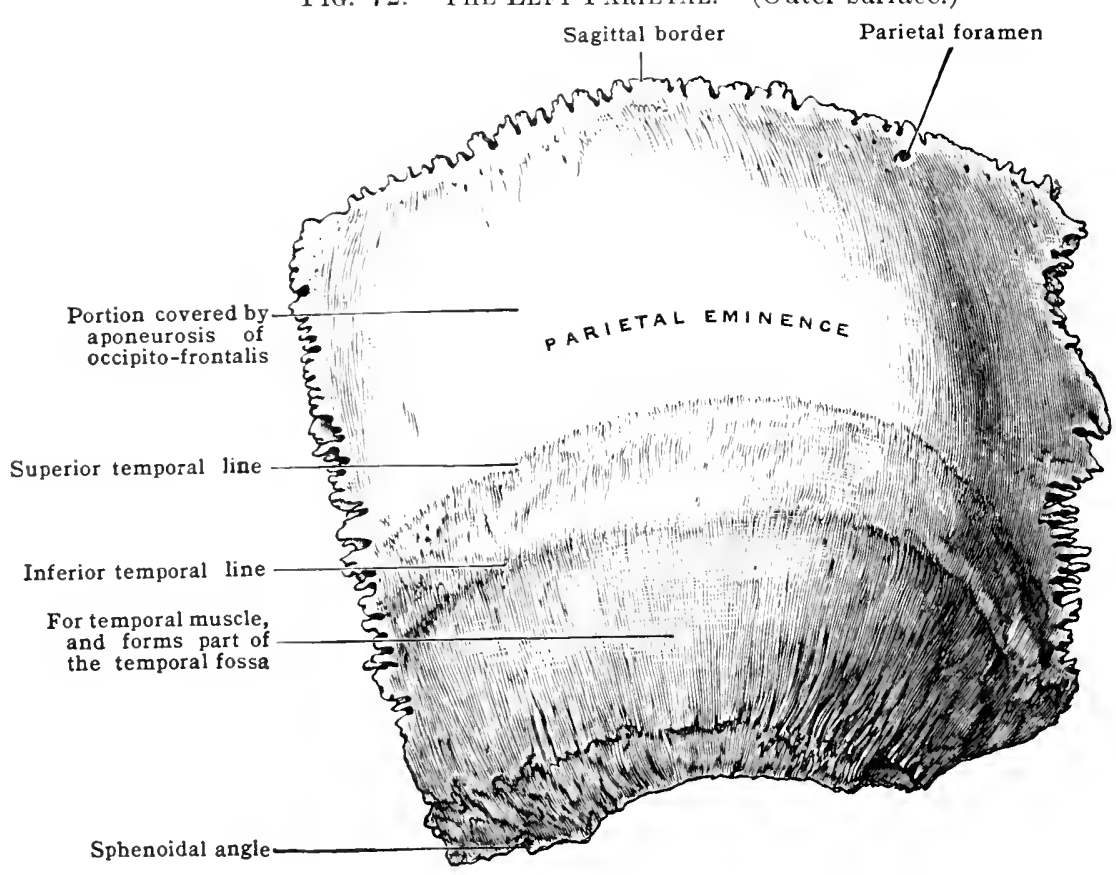

Fig. 73.-The Left Parietal. (Inner surface.)

Parietal foramen Groove for superior sagittal sinus Depressions for Pacchionian bodies

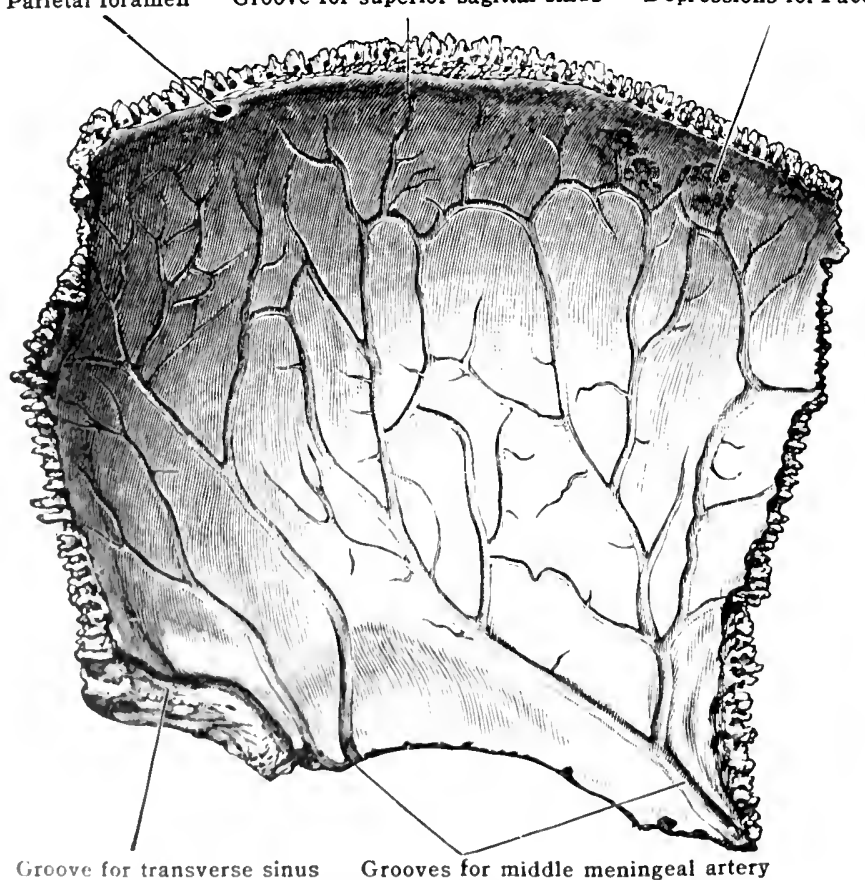

distance, for thr midllle moningeal vessols (chicofly for the simus). The occipital or posterior superior angle is ofituse and occupies that part which during foetal lifre mutre into formation of the posterior fontanclle. The mastoid or posterior 
inferior angle is thick and articulates with the mastoid portion of the temporal bone. Its inner surface presents a shallow groove which lorlges a part of the transverse (lateral) sinus.

Blood-supply.-The parietal bone receives its blood-supply from the middle meningeal, oceipital, and supra-orbital arteries.

Articulations. - The parietal artieulates with the occipital, frontal, sphenoirl, temporal, its fellow of the opposite side, and the epipterie bone when present. Occasionally the temporal and epipteric bones exelude the parietal from articulation with the great wing of the sphenoil.

Ossification.-The parietal ossifies from a single nucleus which appears in the outer layer of the membranous wall of the skull about the seventh week. The ossification radiates in such a way as to leave a eleft at the upper part of the bone in front of the occipital angle, the

Fig. 74.-Unusual Form of Parietal Exhibiting a Horizontal Sutere separating the Bone into Two Pieces, UTper and Lower.

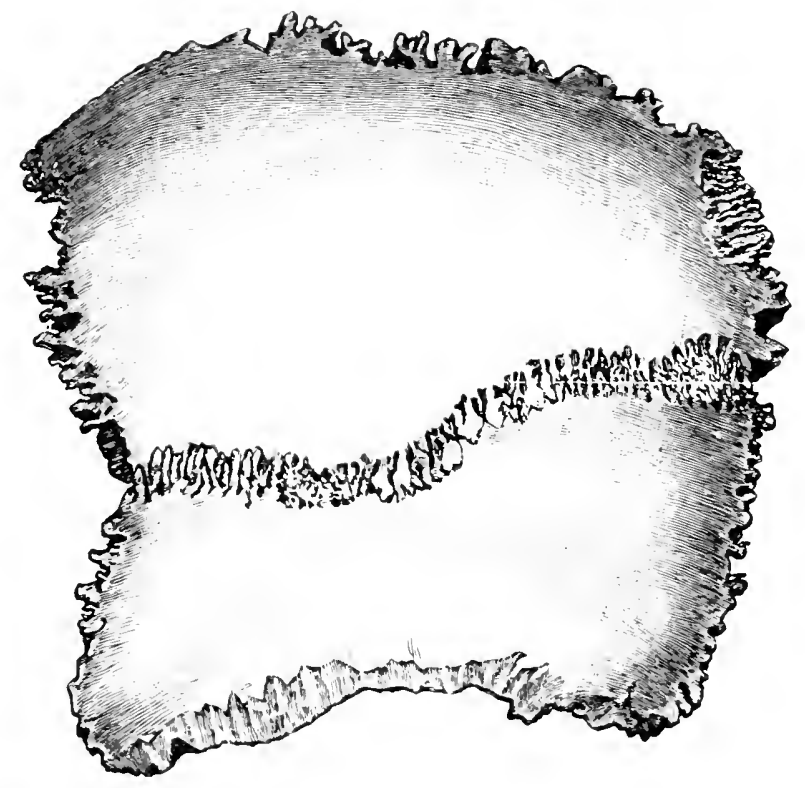

eleft of the two side forming a lozenge-shaped space aeross the sagittal suture known as the sagittal fontanelle. This is usually elosed about the fifth month of intra-uterine life, but traces may sometimes be recognised at the time of birth, and the parietal foramina are to be regarded as remains of the eleft. Aceording to Dr. A. W. W. Lea, a well-developed sagittal fontanelle is present in 4.4 per cent. of infants at birth. In such cases it closes within the first two months of life, but at times it may remain open for at least eight months after birth and possibly longer.

Rarely the parietal bone is composed of two pieces (fig. 74), one above the other, and separated by an antero-posterior suture (sub-sagittal suture), more or less parallel with the sagittal suture. In such eases the parietal is ossified from two centres of ossification.

\section{THE FRONTAL}

The frontal bone [os frontale] closes the cranium in front and is situated above the skeleton of the face. It consists of two portions-a frontal (vertical) portion [squama frontalis], forming the convexity of the forehead, and an orbital (horizontal) portion, which enters into formation of the roof of each orbit.

Frontal (vertical) portion.-The frontal surface is smooth and convex, and usually presents in the middle line above the root of the nose some traces of the suture which in young subjects traverses the bone from the upper to the lower part. This suture, known as the frontal or metopic suture, indicates the line of junction of the two lateral halves of which the bone consists at the time of hirth: in the adult the suture is usually obliterated except at its lowest part. On each side is a rounded elevation, the frontal eminence [tuber frontale], very prominent in young bones, below which is a shallow groove, the sulcus transversus, separating the frontal eminence from the superciliary arch. The latter forms an arched projection above the margin of the orbit and corresponds to an air-carity within the bone known as the frontal sinus; it gives attachment to the orbicularis oculi and the corrugator muscles. The ridges of the two sides converge towarl thr 
median line, but are separated by a smooth surface called the glabella (nasal eminence). Below the arch the bone presents a sharp curved margin, the supraorbital border, forming the upper boundary of the circumference of the orbit and separating the frontal from the orbital portion of the bone. At the junction of its medial and intermediate third is a notch, sometimes converted into a foramen, and known as the supra-orbital notch or foramen; it transmits the supra-orbital nerve, artery, and vein, and at the bottom of the notch is a small opening for a vein of the diploe which terminates in the supra-orbital. Sometimes, a second less marked notch is present, medial to the supra-orbital, and known as the frontal notch; it transmits one of the divisions of the supra-orbital nerve. The extremities of the supra-orbital border are directed downward and form the medial and zygomatic (lateral angular) processes. The prominent zygomatic process articulates with the zygomatic bone and receives superiorly two well-marked lines which converge somewhat as they curve downward and forward across the bone. These are the superior and inferior temporal lines, continuous with the

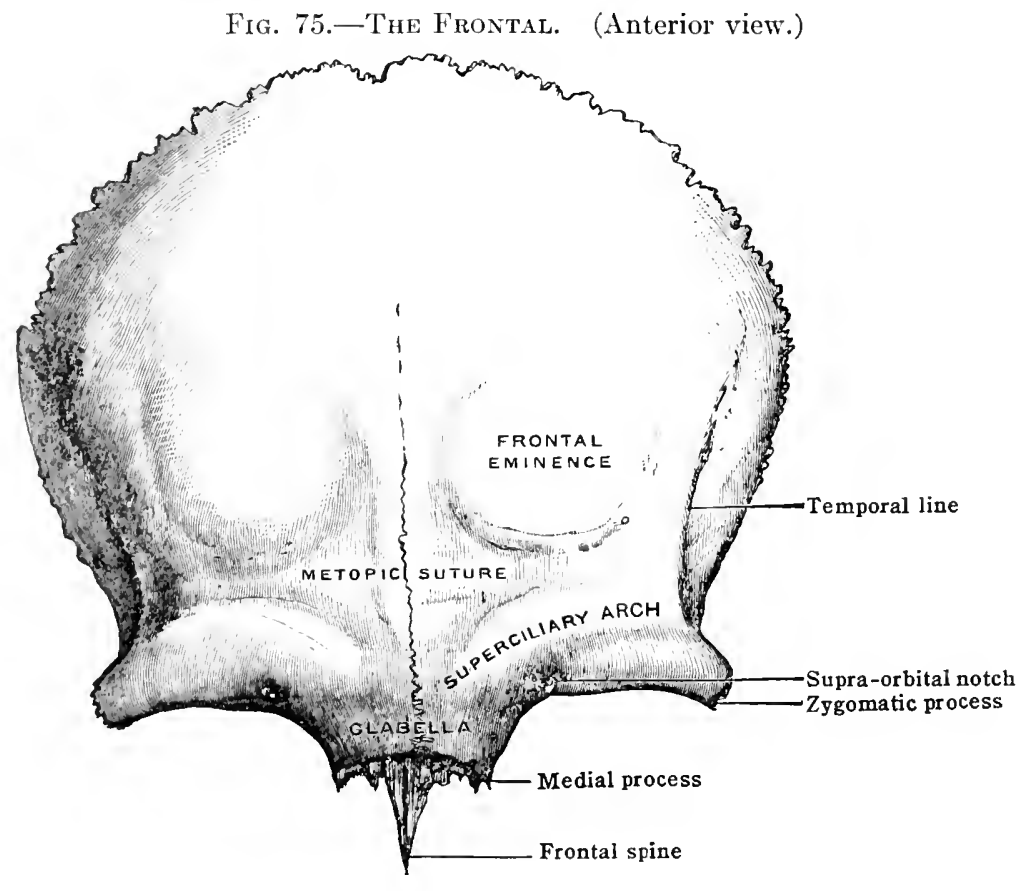

trmporal lines on the parietal bone, the upper giving attachment to the temporal fascia and the lower to the temporal muscle. Behind the lines is a slight concavity which forms part of the floor of the temporal fossa and gives origin to the temporal inusele. 'The medial angular processes articulate with the lacrimals and form the lateral limits of the nasal notch, bounded in front by a rough, semilnnar surface which articulates with the upper ends of the nasal bones and the frontit (nasial) processes of the maxillæ.

In the concibvity of the noteh lies the nasal portion of the frontal, which projects sonewhat formath the masil lones and the nasal processes of the maxilla. It is divisible into three parts: -it merlian frontal (nisil) spine, which descrols in the nasal septum between the erest of the natsal lenney in front and the vertical plate of the ethmoid behind, and, on the posterior aspreat of the loresss, two alæ, one on cither side of the median ridge from which the frontal

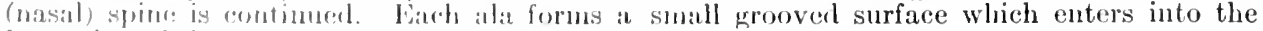
formation of the roof of the natsal fossat.

Ther cerebral surface presents in the midlllo line a vertical groove- the sagittal sulcus which ifreenels from the middle of the upper margin and lodges the superior sagittal (longiturlinal) sinus. Below, the groove is succeeded by the frontal crest, which triminates near the lower margin at a small notch, converted into a foramen by articulation with the ethmoid. 
The foramen is called the foramen cæcum, and is generally closed below, but sometimes transmits a vein from the nasal fossæ to the superior sagittal (longitudinal) sinus. The frontal crest serves for the attachment of the anterior part of the falx cerebri. On each side of the middle line the bone is deeply concave, presenting depressions for the cerebral convolutions and numerous small furrows which, running medially from the lateral margin, lodge branches of the middle meningeal vessels. At the upper part of the surface, on either side of the frontal sulcus, are some depressions for Pacchionian bodies.

The horizontal portion consists of two somewhat triangular plates of bone called the orbital plates, which, separated from one another by the ethmoidal

Fig. 76.-The Frontal Bone. (Inferior view.)

Frontal spine

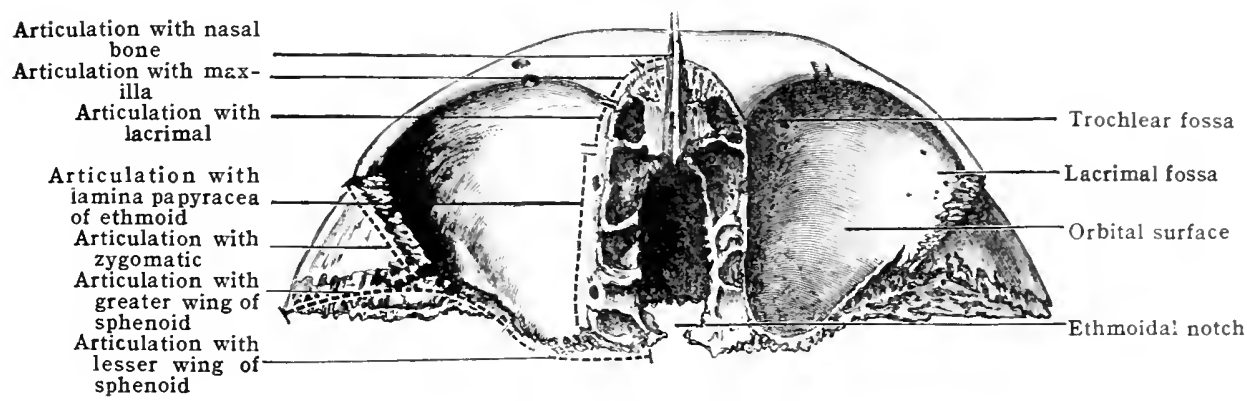

notch [incisura ethmoidalis], form the greater part of the roof of each orbit. When the bones are articulated, the notch is filled up by the cribriform plate of the ethmoid, and the half-cells on the upper surface of the lateral mass of the ethmoid are completed by the depressions or half-cells which occupy the irregular margins of the notch. Traversing these edges transversely are two grooves which complete, with the ethmoid, the anterior and posterior ethmoidal canals. The anterior transmits the anterior ethmoidal nerve and vessels; the posterior transmits the posterior ethmoidal nerve and vessels, and both canals open on the medial wall of the orbit. Farther forward, on either side of the nasal spine, are the openings of the frontal sinuses, two irregular cavities which extend within

Fig. 77.-The Frontal Bone at Brrth.

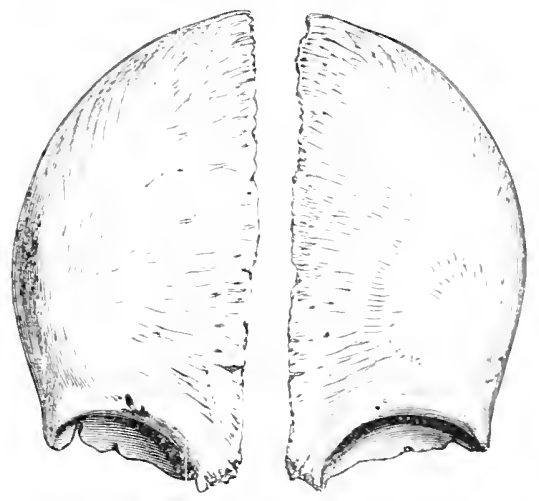

the bone for a variable distance and give rise to the superciliary arches (ridges). Each is lined by mucous membrane and communicates with the nasal fossa by means of a passage called the infundibulum.

The inferior surface of each orbital plate, smooth and concave, presents immediately behind the lateral angular process the lacrimal fossa, for the lacrimal gland. Close to the medial angular process is a depression called the trochlear fossa [fovea trochlearis], which gives attachment to the cartilaginous pulley for the superior oblique muscle. The superior surface of each plate is convex and strongly marked by eminences and depressions for the convolutions on the orbital surface of the cerebrum. 
Borders.- The artieular border of the frontal portion (parietal margin) forms a little more than a semicircle. It is thick, strongly serrated, and bevelled so as to overlap the parietal above and to be overlapped by the edge of that bone below. The border is continued inferiorly into a triangular rough surface on either side, which articulates with the great wing of the sphenoid. The posterior border of the orbital portion is thin and articulated with the lesser wing of the sphenoid.

Blood-supply. - The blood-vessels for the supply of the vertical portion are derived from the frontal and supra-orbital arteries, which enter on the outer surface, and from the middle and small meningeal, whieh enter on the cerebral surface. The horizontal portion receives branches from the ethmoidal, and other branches of the ophthalmic, as well as from the meningeal.

Articulations. - The frontal articulates with the parietal, sphenoid, ethmoid, lacrimal, zygomatic (malar), maxillat, and nasal bones: Also, with the epipteric bones when present, and oecasionally with the squamous portion of the temporal, and with the sphenoidal coneha. when it reaches the orbit.

Fig. 78.-Unusually Large Frontal Sinuses.

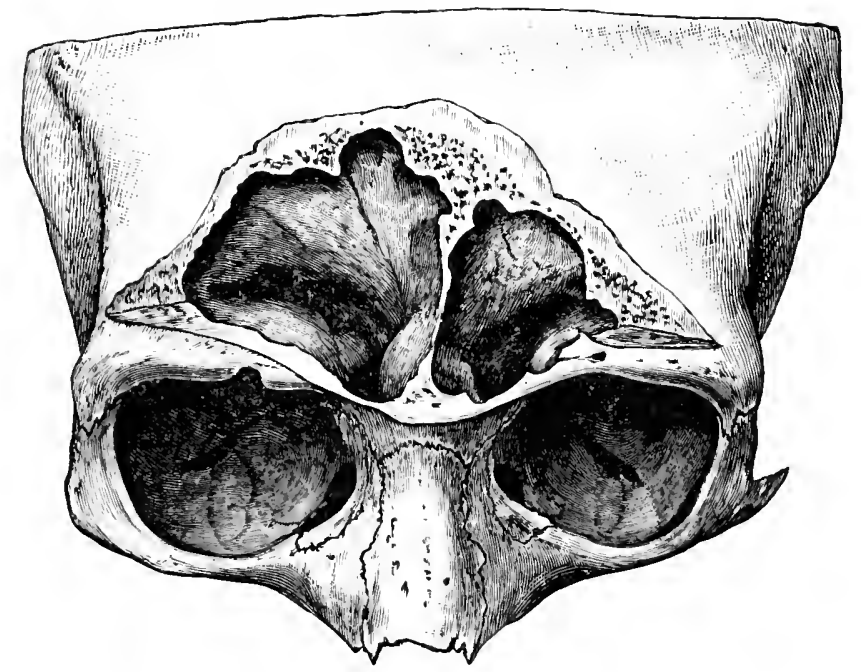

Ossification. - The frontal is ossified from two nuclei deposited in the outer layer of the membranous wall of the cranium, in the situations ultimately known as the frontal eminences. These muelei appear about the eighth weck, and ossification spreads quickly through the memJranc. At birth the bones are quite distinct, but sulsequently they articulate with each other in the median line to form the metopic suture. In the majority of eases the suture is obliterated by osscons union, which commences about the second year, though in a few eases the bones remain distinet throughout life.

After the two halves of the bonc have united, osscous material is deposited at the lower end of the metopic suture to form the frontal spine, which is one of the distinguishing features of the human frontal bone. The spine appears about the twelf th year, and soon consolielates with the frontal bone above. Accessory nuclei are sometimes seen between this bone and the lacrimal and may persist as Wormian ossicles.

The frontal sinuses appear about the seventh year as prolongations upward from the hiatus semilumaris and increase in size up to old age. As they grow they extend in three clircetions, viz., "lpward, laterally, and backward along the orbital roof. A bony septum, usually complete, scpirates the sinuses of the two sides, and they are larger in the male than in the female. The supereiliary arches are not altogether rediable guides as to the size of the sinuses, since examples are seren in which the arehes are low and the sinuses large. In fig. 78 an example of mustally large simmses is figmed, illustrating the extension upward, laterally, and backward.

\section{THE SPIHENOID}

The sphenoid [os sphemoidale] (figs. 79, 80, 81, 82) is situated in the base of the skull anel takes part in the formation of the floor of the anterior, middle, and posterior cranial fosse, of the temporal and natsal fossae, and of the cavity of the orthit. It is very irregular in shape and is reseribed as consisting of a central part or body, wo pairs of lateral expansions called the great and small wings, and a pair of processes which project downward, called the pterygoid processes.

The body, irregularly euboidal in shape, is hollowed out into two large eavities known as thr sphenoidal sinuses, scparated hy a thin sphenoidal septum and opening in front by two large apertures into the nasial fossiae. The superior sur- 
face presents the following points for examination: In front is seen a prominent spine, the ethmoidal spine, which artieulates with the hinder edge of the cribriform plate of the ethmoid. The surface behind this is smooth and frequently presents two longitudinal grooves, one on either side of the median line, for the olfactory bulbs; it is limited posteriorly by a ridge, the limbus sphenoidalis, which forms the anterior border of the narrow transverse optic groove [sulcus chiasmatis], above and behind which lies the optic commissure. The groove terminates on each side in the optic foramen, which perforates the root of the small wing and transmits the optic nerve and the ophthalmic artery. Behind the optic groove is the tuberculum sellæ, indieating the line of junction of the two parts of which the body is formed (pre- and post-sphenoid); and still further back, a deep depression, the hypophyseal fossa [sella turcica], which lodges the hypophysis cerebri. The floor of the fossa presents numerous foramina for blood-vessels, and at birth the superior orifice of a narrow pasiage called the basi-pharyngeal canal opens on the tubereulum. The posterior boundary of the fossa is formed by a quadrilateral plate of bone, the dorsum sellæ (dorsum

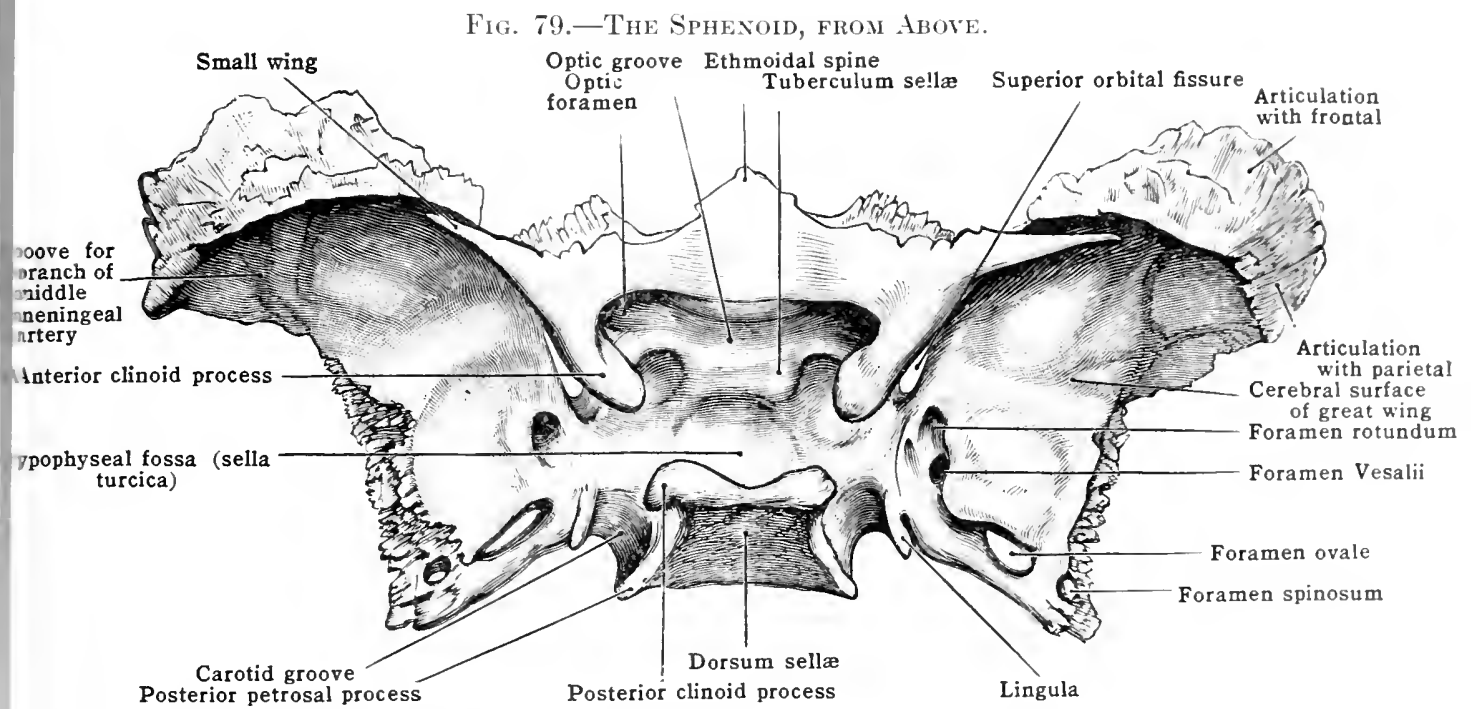

ephippii), the posterior surface of which is sloped in eontinuation with the basilar groove of the occipital bone. The superior angles of the plate are summounted by the posterior clinoid processes, which give attachment to the tentorium cerebelli and the interclinoid ligaments. Below the elinoid process, on each side of the dorsum sellæ (sometimes at the suture between the sphenoid and apex of petrosal), a noteh is seen, eonverted into a foramen by the clura mater, for the passage of the sixth eranial nerve, and at the inferior angle the posterior petrosal process, which articulates with the apex of the petrous portion of the temporal bone, forming the inner boundary of the foramen lacerum. The torsum sellix is slightly concave posteriorly (the elivus) and supports the pons Varolii and the basilar artery.

The inferior surface presents in the middle line a prominent ridge known at: the rostrum, which is reeeived into a deep depression between the ala of the vomer. On each side is the vaginal process of the medial pterygoid plate. directed horizontally and medially, whieh, with the alæ of the romer, cover the greater part of this surface. The remainder is rough and clothed by the mucous. membrane of the roof of the pharrnx.

The anterior surface is divided into two lateral halves by the sphenoidal crest, a vertical ridge of bone continuous above with the ethmoidal spine, below with the rostrum, and articulating in front with the perpendicular plate of the ethmoid. The surface on each side presents a rough lateral margin for articulittion with the lateral mass of the ethmoid and the orbital process of the palite bone. Elsewhere it is smooth, and enters into the formation of the roof of the 
nasal fossæ, presenting superiorly the irregular apertures of the sphenoidal sinuses.

The body is not hollowed until after the sixth year, but from that time the sinuses increase in size as age advances. Except for the apertures just mentioned, they are eloserl below and in front by the two sphenoidal conchæ (turbinate bones), originally distinct, but in the adult usually incorporated with the sphenoid.

The posterior surface is united to the basilar process of the occipital, up to the trentieth year, by a dise of hyaline cartilage forming a synchondrosis, but afterward this becomes ossified and the two bones then form one piece.

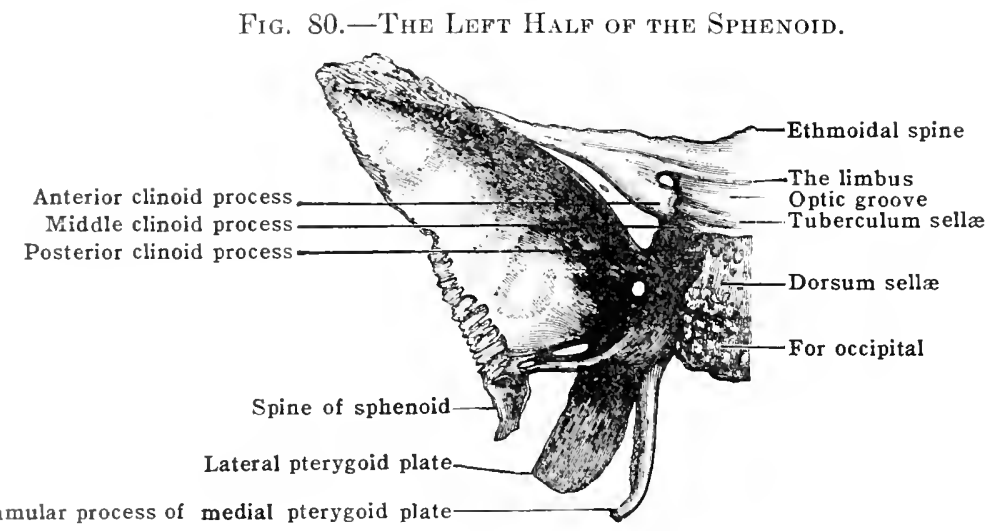

Hamular process of medial pterygoid plate

The lateral surface of the body gives attachment to the two wings, and its fore part is free where it forms the medial boundary of the superior orbital fissure and the posterior part of the medial wall of the orbit. Above the line of attachment of the great wing is a broad groove which lodges the internal carotid artery and the cavernous sinus, called the carotid groove. It is deepest where it curves behind the root of the process, and this part is bounded along its lateral margin by a slender ridge of bone named the lingula, which projects backward in the angle between the body and the great wing.

Fig. 81.-The Sphenoid. (Anterior view.)

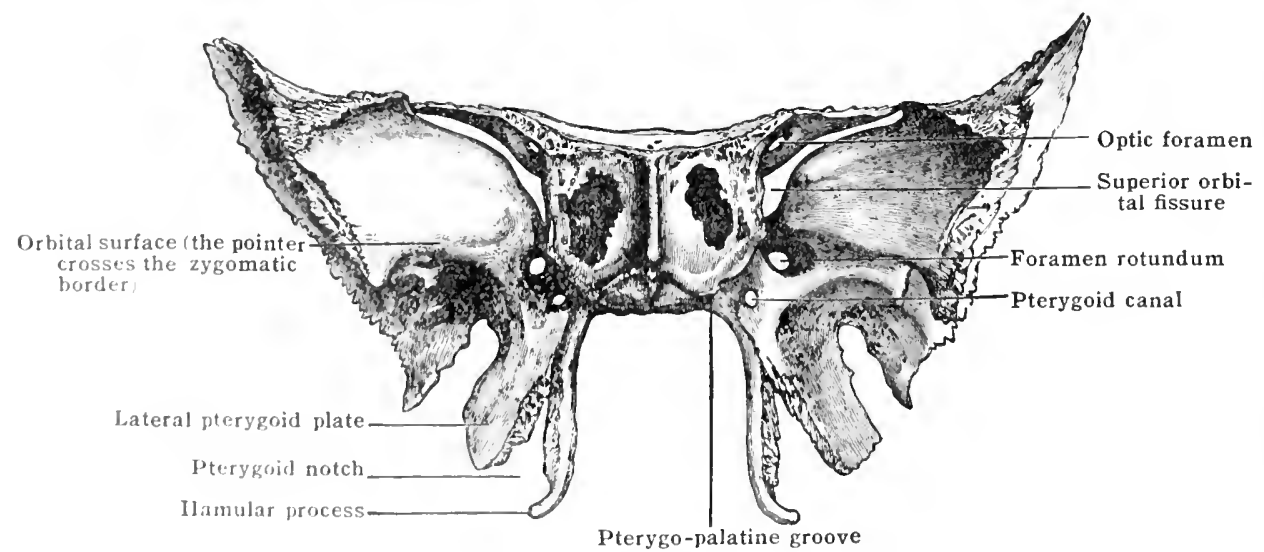

'Ther small or orbital wings [alie parve] are two thin, triangular plates of bone rextemling nexty horimontally and laterally on a level with the front part of the

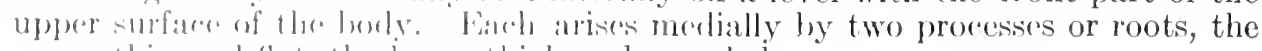
upenere thin and flat, tho lowere thick and romoled.

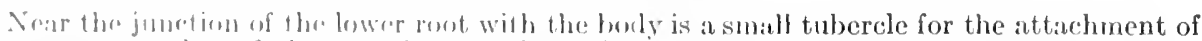

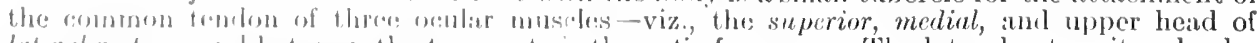

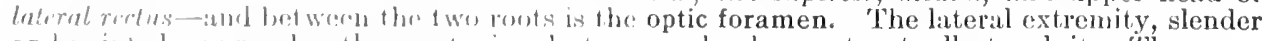

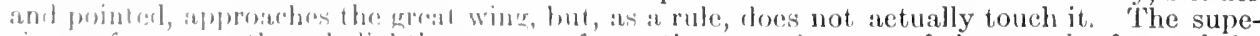

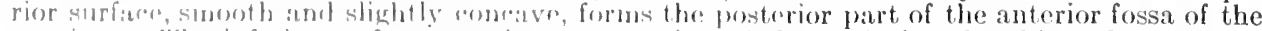
criname. The inferior surfare constitutes a portion of the roof of each orbit and overhangs 
the superior orbital (or sphenoidal) fissure, the elongated opening between the small and great wings. The anterior border is serrated for articulation with the orbital plate of the frontal, and the posterior border, smooth and rounded, is received into the Sylvian fissure of the cerebrum. Moreover, the posterior border forms the boundary between the anterior and middle cranial fossæ and is prolonged at its medial extremity to form the anterior clinoid process, which gives attachment to the tentorium cerebelli and the interclinoid ligaments. Between the tuberculum sellæ and the anterior clinoid process is a semicircular notch which represents the termination of the carotid groove. It is sometimes converted into a foramen, the caroticoclinoid foramen, by a spicule of bone which bridges across from the anterior clinoid to the middle clinoid process; the latter is a small tubercle frequently seen on each side, in front of the hypophyseal fossa, and slightly posterior to the tuberculum sellæ; the foramen transmits the internal carotid artery, and the spicule of bone which may complete the foramen is formed by ossification of the carotico-clinoid ligament.

The great or temporal wings [alæ magnæ], arising from the lateral surface of the body, extend laterally and then upward and forward. The posterior part is placed horizontally and projects backward into the angle between the squamous and petrous portions of the temporal bone. From the under aspect of its pointed extremity the spine, which is grooved medially by the chorda tympani nerve (Lucas), projects downward. The spine serves for the attachment of the sphenomandibular ligament and a few fibres of the tensor veli palatini. Each wing presents for examination four surfaces and four borders.

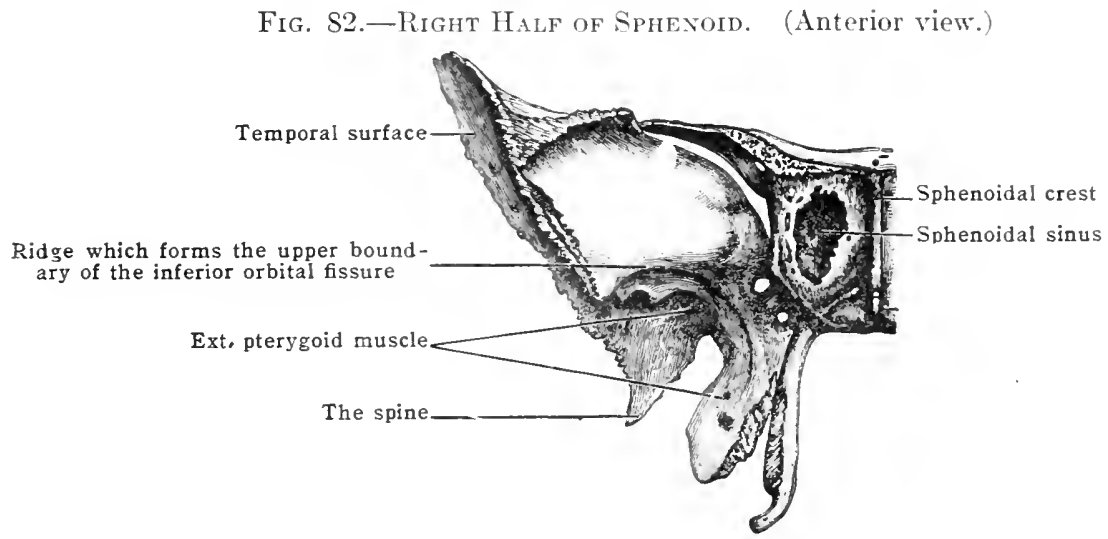

The cerebral or superior surface is smooth and concave. It enters into the formation of the middle cranial fossa, supports the temporo-sphenoidal lobe of the cerebrum, and presents several foramina. At the anterior and medial part is the foramen rotundum for the second division of the fifth nerve, and behind and lateral to it, near the posterior margin of the great wing, is the large foramen ovale, transmitting the third division of the fifth, the small meningeal artery, and an emissary vein from the cavernous sinus.

Behind and lateral to the foramen ovale is the small circular foramen spinosum, sometimes incomplete, for the passage of the middle meningeal vessels, and the recurrent branch of the third division of the fifth. Between the foramen ovale and the foramen rotundum is the inconstant foramen Vesalii, which transmits a small emissary vein from the cavernous sinus; and ou the plate of bone, behind and medial to the foramen ovale (spheno-petrosal lamina), a minute canal is occasionally seen-the canaliculus innominatus - through which the small superficial petrosal nerve escapes from the skull. When the canaliculus is absent, the nerve passes through the foramen ovale.

The anterior surface looks medially and forward and consists of two divisionsa quadrilateral or orbital surface, which forms the chief part of the lateral wall of the orbit, and a smaller, inferior or spheno-maxillary surface, situated above the pterygoid process and perforated $\mathrm{b}, \mathrm{v}$ the foramen rotundum; this inferior part forms the posterior wall of the pterygo-palatine fossa.

The lateral or squamo-zygomatic surface is divided by a prominent infratemporal ridge into a superior portion, which forms part of the temporal fossa and affords attachment to the temporal muscle, and an inferior part, which looks downward into the zygomatic fossa and gives attachment to the external pterygoid muscle; the inferior part joins the lateral surface of the lateral pterrgoid plate. and presents the inferior orifices of the foramen ovale, foramen spinosum, and foramen of Vesalius. 
Borders. - The posterior border extends from the body to the spine. By its lateral third it articulates with the petrous portion of the temporal bone, whilst the medial two-thirds form the anterior boundary of the foramen lacerum. The squamosal border is serrated behind and bevelled in front for articulation with the squamous portion of the temporal bone, whilst its upper extremity, or summit, is bevelled on its inner aspect, for the anterior inferior angle of the parietal. Immediately in front of the upper extremity is a rough, triangular, sutural area for the frontal, the sides of which are formed by the upper margins of the superior, anterior, and lateral surfaces respectively. The zygomatic or anterior border separates the orbital and temporal surfaces and articulates with the zygomatic, and by its lower angle, in many skulls, also with the maxilla. Below the anterior border is a short horizontal ridge, non-articular, which separates the spheno-maxillary and zygomatic surfaces. Above and medially, where the orbital and cerebral surfaces meet, is the sharp medial border, which forms the lower boundary of the superior orbital fissure, serving for the passage of the third, fourth, three branches of the first dirision of the fifth, and the sixth eranial nerves, the orbital branch of the middle meningeal artery, a recurrent branch from the lacrimal artery, some twigs from the cavernous plexus of the sympathetie, and one or two ophthalmic veins. Near the middle of the border is a small tubercle for the origin of the lower head of the lateral rectus muscle.

The pterygoid processes project downward from the junction of the body and the great wings. Each consists of two plates, one shorter and broader, the lateral pterygoid plate [lamina lateralis], the other longer and narrower, the medial pterygoid plate [lamina medialis]. They are united in front, but diverge behind so as to enclose between them the pterygoid fossa in which lie the internal pterygoid and tensor palati muscles. The lateral pterygoid plate is turned a little laterally and by its lateral surface, which looks into the zygomatic fossa, affords attachment to the external pterygoid muscle, whilst from its medial surface the internal pterygoid takes origin.

The posterior border of the lateral pterygoid plate frequently presents one or more bony projections, which represent ossified parts of the pterygo-spinous ligaments, and occasionally one may extend across to the spine and complete the bony boundary of the pterygospinous foramen. The medial ptervgoid plate is prolonged below into a slender, hook-like or hamular process, smooth on the under aspect for the tendon of the tensor palati, which plays round it. iuperiorly, the medial plate extends medially on the under surface of the body, forming the vaginal process, which articulates with the ala of the vomer and the sphenoidal process of the palate. The vaginal process presents, on the under surface, a small groove which, with the sphenoidal process of the palate, forms the pharyngeal canal for the transmission of branches of the spheno-palatine vessels and ganglion. The medial surface of the medial pteryoid plate forms part of the lateral boundary of the masal fossa, and the lateral surface, the medial boundary of the pterygoid fossa. The posterior border presents superiorly a well-marked prominence, the pterygoid tubercle, above and to the lateral side of which is the posterior orifice of the pterygoid canal. The latter pierees the bone in the sagital rlirection at the root of the medial pterygoid plate and transmits the Vidian vessels and nerve. Some distance below the tubercle is a projection, called the processus tubarius, which supports the cartilage of the tuba auditiva (Eustachian tube). From the lower third of the posterior border and from the hamular process, the superior constrietor of the pharynx takes origin, and from the depression known as the scaphoid fossa, situated in the upper part if thr. recess between the 1 wo pterygoid plates, the tensor palati arises.

Fig. 83.-The Spinnold at Birth.

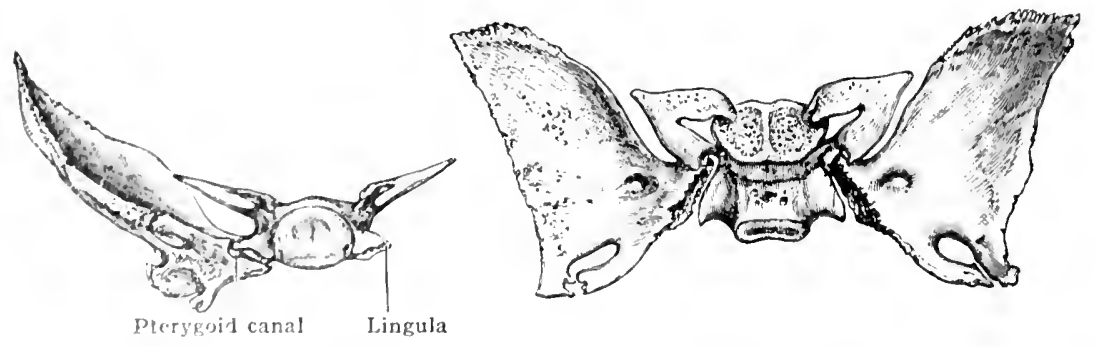

In frout, the two plates are joined above, but diverge below, leaving a gap-the pterygoid notch oreupied, in the artienlated skull, by the pyramidal process of the palate. Smprionly, they form a triangular surface which looks into the pteryge-palatine fosisa and presents the anterior orifice of the pterygoid canal. The anterion horder of the medial pterygoid plate articulates with the posterior borrar of the rertical plate of the palate.

Blood-supply. - The sphenoid is smphliod by hranches of the middle and small meningeal arterim, the derep temperal and other lmanclies of the internal maxillary artery-viz. the

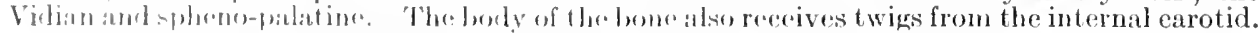

Articulations. - The sphenoid anticinlates with all the bones of the cranimm-viz., occipital, 
parietal, frontal, ethmoid, temporal, and sphenoidal conchæ. Also with the palate, romer, zygomatic, epipteric bone when present, and occasionally with the maxilla.

Ossification.-The sphenoil is divided, up to the seventh or eighth month of intra-uterine life, into an anterior or pre-sphenoid portion, including the part of the body in front of the tuberculum sella and the small wings, and a post-sphenoid portion, the part behind the tuberculum sellæ including the hypophyseal fossa and the great wings. The two portions of the body join together before birth, but in many animals the division is persistent throughout life.

The pre-sphenoid portion ossifies in cartilage from four centres, one of which gives rise to each lesser wing (orbito-sphenoid) and a pair to the body of the pre-sphenoid.

In the formation of the post-sphenoidal portion both cartilage and membrane bone participate, the pterygoid plates being formed in membrane, while the rest of the portion, together with the hamular process, ossifies from cartilage. (Fawcett.) At about the eighth week a

\section{Fig. S4.-The Jegum Sphenoidale.}

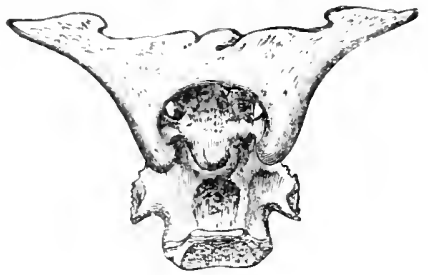

centre appears at the base of each greater wing (ali-sphenoid), and at about the same time a pair of centres appear in the body (basi-sphenoid) and later one in each lingula (sphenotic). The medial pterygoid plates are pre-formed in cartilage, in which a centre appears for the hamular process, but the rest of the plate is formed from membrane bone which invests the cartilage. The lateral plate is formed in nembrane and a considerable part of the greater wing is also membranous in origin (see epipteric bone).

At birth the bone consists of three pieces. The median piece includes the basi-sphenoid and lingulæ, conjoined with the pre-sphenoid, carrying the orbito-sphenoids.

The two lateral pieces are the ali-sphenoids, carrying the merlial pterygoid plates. The dorsum selly is cartilaginous. A canal, known as the basi-pharyngeal canal, extends into the

Fig. 85. -The Inferior Surface of Pre-sphenoid at the Sixth Year.

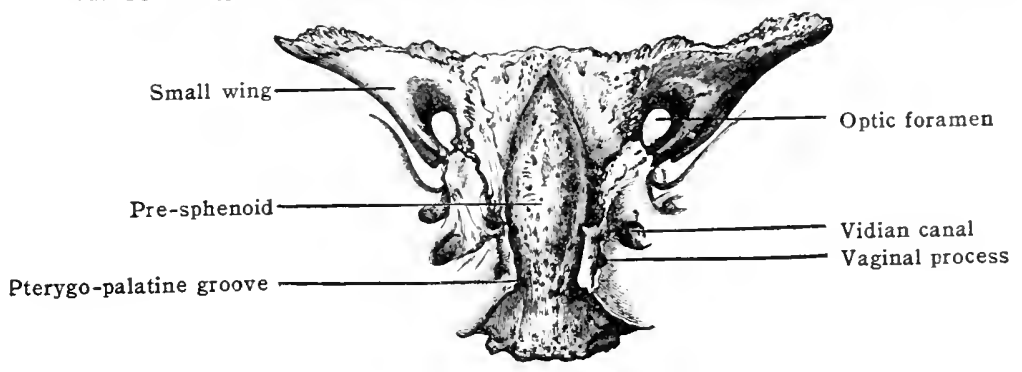

body from the sella turcica and sometimes reaches its under surface. It cuntains a process of dura mater, and represents the remains of the canal in the base of the cranium, through which the diverticulum of Rathke extended upward to form part of the hypophysis.

The great wings are joined to the lingula by cartilage, but in the course of the first year bony union takes place. About the same time the orbito-sphenoids meet and fuse in the inildle line to form the jugum sphenoidale, which thus excludes the anterior part of the pre-sphenoid from the cranial cavity. For some vears the body of the pre-sphenoid is broad and rounderl inferiorly (fig. S5). The posterior clinoid processes chondrify separately, a fact which throws some light on the occasional absence of these processes.

\section{THE SPHENOLDAL CONCHE}

The sphenoidal conchæ (or turbinate bones; bones of Bertin) (figs. S6, Si) 111y he obtained as distinct ossicles about the fifth year, and resemble in shape two hollow cones flattened in three planes. At this date each is wedged in between the under surface of the pre-sphenoid and the orbital and sphenoidal processes of the palate bone, with the apex of the cone directed backward as far as the vaginal process of the medial pteryolid plate. Of its three surfaces, the lateral is in relation with the pterygo-palatine fossa, and occasionally extencls upward between the sphenoid and the lamina papyracea of the ethmoid, to appear on the medial wall of the orbit (fig. 105). The inferior surface forms the upper boundary of the spheno-palatine foramen and enters into formation of the posterior part of the roof of the nasal fossa. The 
superior surface lies flattened against the under surface of the pre-sphenoid, whilst the base of the cone is in contaet with the lateral mass of the ethmoid.

The deposits of earthy matter from which the sphenoidal concha are formed appear at the If th month. At birth eaeh forms a small triangular lamina in the periehondrium of the ethmovomerine plate near its junetion with the presphenoid, and partially eneloses a small reeess from the mueous membrane of the nose, which becomes the sphenoidal sinus. By the third year the bone has surrounder the sinus, forming an osseous capsule, conical in shape, the circular orifice which represents the base beeoming the sphenoidal foramen. As the eavity enlarges the medial wall is absorbed, and the medial wall of the sinus is then formed by the pre-sphenoid.

Fig. S6-The Sphenoidal Concha at the Sixtit Year.

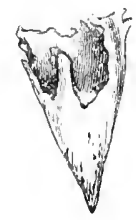

The bones are subsequently ankylosed in many skulls with the ethmoid, whence they are often regarded as parts of that bone. More frequently they fuse with the pre-sphenoid, and less frequently with the palate bones. After the twelf th year they can rarely be separated from the skull without damage. In many disarticulated skulls they are so broken up that a portion is found on the sphenoid, fragments on the palate bones, and the remainder attached to the ethmoid. Sometimes, even in old skulls, they are represented by a very thin triangular plate on each side of the rostrum of the sphenoid (fig. 87).

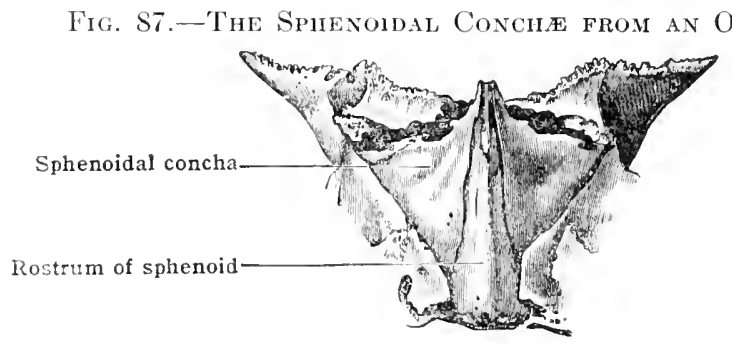

\section{THE EPIPTERIC: AND WORMIAN BONES}

The epipterics are scale-like bones which occupy the antero-lateral fontanelles. Each epipteric bone is wedged between the squamo-zygomatic portion of the temporal, frontal, great wing of sphenoid, and the parietal, and is present in most skulls between the second and fifteenth year. After that date it may persist as a separate osicle, or mite with the sphenoid, the frontal, or the squamo-zygomatic. The epiptrif bone is preformed in membrane, and appears as a series of bony granules in the rourse of the first year.

The Wormian or sutural bones [ossa suturarum] are small, irregularly shaped ossirles, of ten found in the sutures of the cranium, especially those in relation with the pariotal bones. They sometimes oceur in great numbers; as many as a hundroul have born counted in one skull. They are rarely present in the sutures of ther facer.

\section{THE TEMPORAI, BONE}

The temporal bone fos trmporale], situater at the side and the base of the cranium, rontains the orwan of hearing and articulates with the lower jaw. It is usually divided info three pallts - viz, Ihe squamous portion, forming the anterior and superior part of the hone, thin and rexpanded and prolonged externally into the zyendiatif broess; the mastoid portion, the thick conical posterior part, behinil the extrenal aperture of the carr and a pyramidal projection named the petrous portion, sifuafed in a hane feelow and to the merlial side of the two parts atready monliomenl, and forming bart of the base of the skull.

When it is consiblered in reforence tor its morle of development, the temporal bone is found

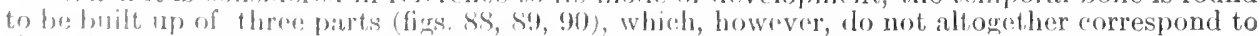
the arbitrary divisions of the adult bons. Thr thros parts are namert squamosal, petrosal, 
and tympanic, and a knowledge of their arrangement in the early stages of growth greatly facilitates the study of the fully formed bone.

The more important division of the temporal bone is the petrous portion. It is pyramidal in shape, and contains the essential part of the organ of hearing,

Fig. 88. - The Temporal Bone at Birth. Fig. 89.-Temporal Bone at Birth.

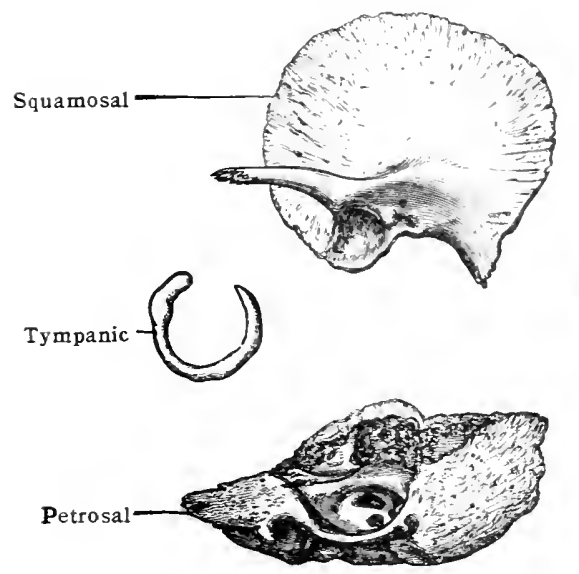

(Inner vier.)

Fig. 90.- The Temporal Bone at Birth. (Outer view.)

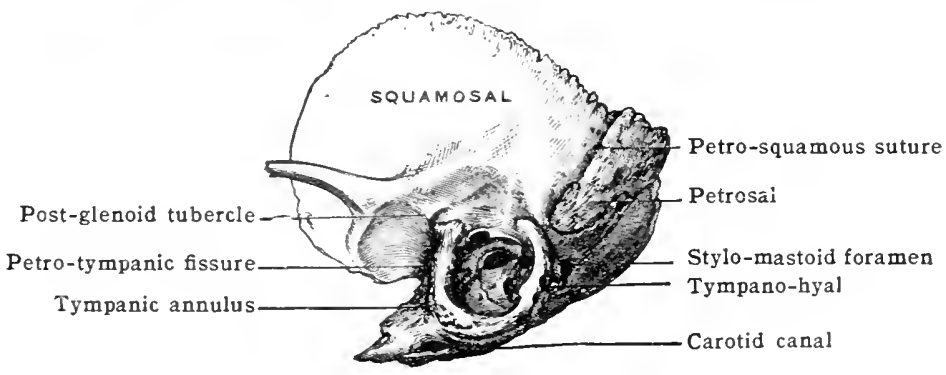

Fig. 91.-Right Temporal Bone at abott six Years.

The tympanic plate has been separated and drawn below. A portion of the post-auclitory process of the squamosal has been removed to show the mastoid antrum.

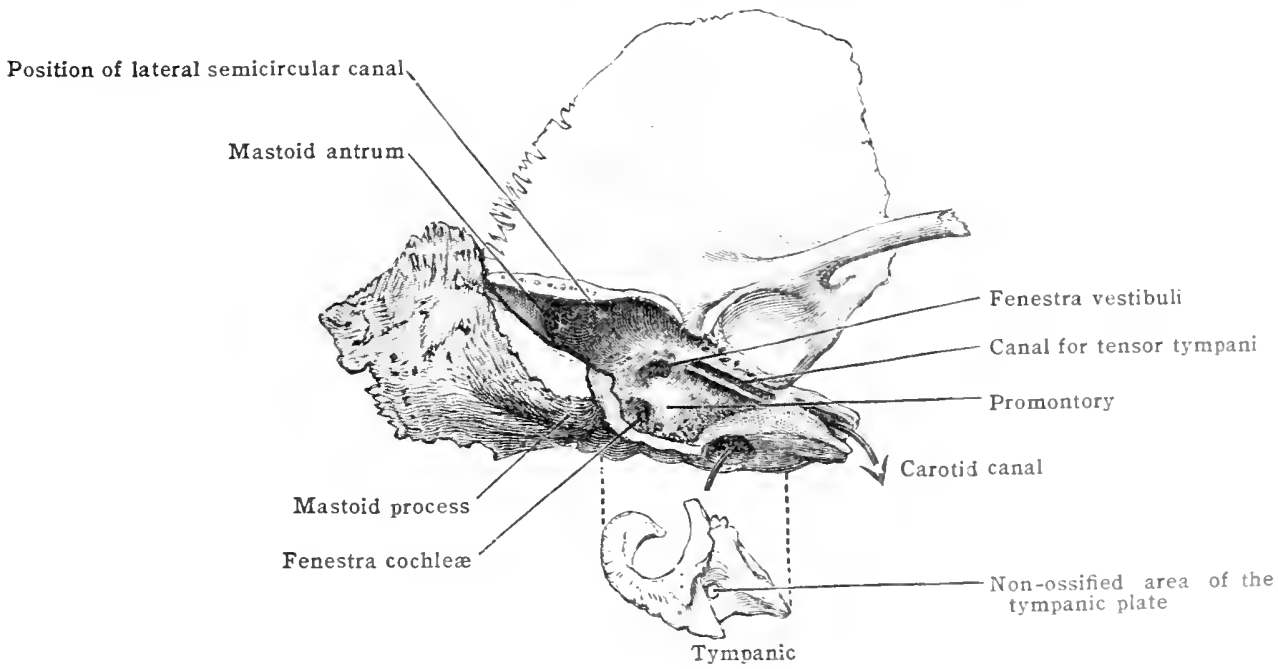

around which it is developed as a cartilaginous capsule. This is known as the periotic capsule or petrosal element, and its base abuts on the outer aspect of the 
cranium, where it forms a large part of the so-called mastoid portion of the temporal bone. Besides containing the internal ear, it bears on its cranial side a foramen for the serenth and eighth cranial nerves (internal auditory meatus), and on its outer side two openings - the fenestra vestibuli and fenestra cochleæ (fig. 91). The squamosal is a superadded element and is formed as a membrane bone in the lateral wall of the cranium. It is especially developed in man in consequence of the large size of the brain, and forms the squamous division of the adult bone, and by a triangular shaped process which is prolonged behind the aperture of the ear it also contributes to the formation of the mastoid portion. It is obvious, therefore, that the mastoid is not an independent element, but belongs in part to the petrous, and in part to the squamous. The tympanic portion, also superadded, is a ring of bone developed in connection with the external auditory meatus, and eventually forms a plate constituting part of the bony wall of this passage. These three parts are easily separable at birth, but eventually become firmly united to form a single bone which affords little trace of its complex origin. Lastly a process of bone, developed in the second visceral arch, coalesces with the under surface of the temporal bone and forms the styloid process.

Fig. 92.-The Left Temporal Bone. (Outer view.)

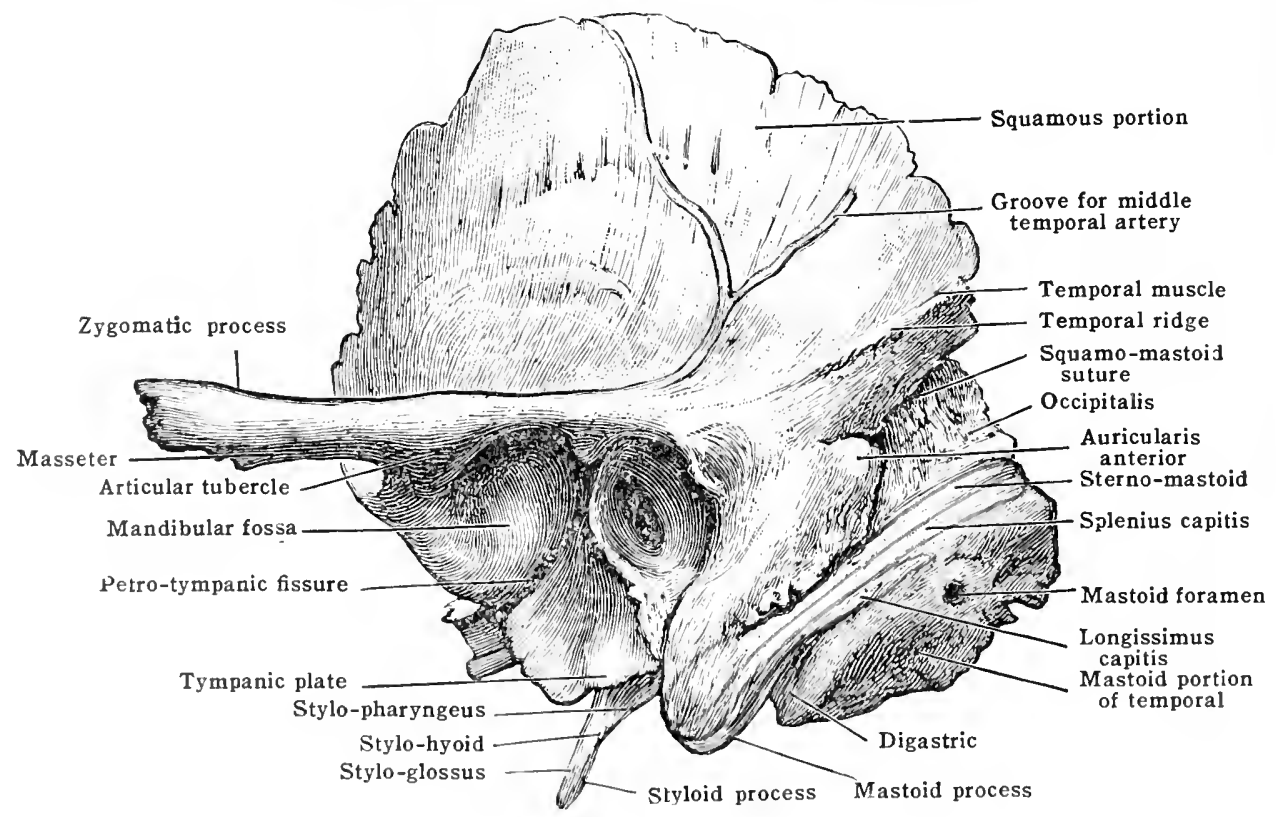

The squamous portion [scuama temporalis] is flat, scale-like, thin, and transluecut. It is attached almost at right angles to the petrous portion, forms part of the side wall of the skull and is limited above by an uneven border which descrilse athout two-thirds of a circle. The outer surface is smooth, slightly conver near the mindelle, and forms part of the temporal fossa. Above the "xtrrual anditory meatus it presents a nearly vertical groove for the middle tamprial altery. ('onnected with its lower part is a narrow projecting bar of lome known as the zygomatic process. At its base the process is broad, directed laterally, and flathencel from aloove downward. It soon, however, becomes twisted on itself and runs lorward, almost parallel with the squamous portion.

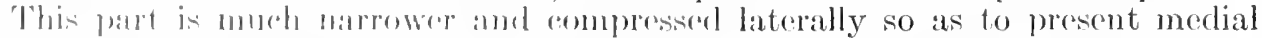
and lateral surfaces with mpere and lower margins. The lateral surfare is subcutancoms; the medial looks toward the temporal fossa and gives origin to the masseter muscle. The lower horder is comeave and rough for fibres of the same masede, whilst the uppere border, thin and prolonged further forward than the

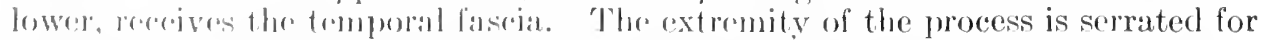
articalation with the zyematio hone. At its hase the zygomatic process presents three roots anterior, midelle, and posterior. 
The anterior, continuous with the lower border, is short, broad, convex, and directed medially to terminate in the articular tubercle, which is covered witl cartilage in the recent state, for articulation with the condyle of the lower jaw. The middle root, sometimes very prominent, forms the post-glenoid process. It separates the articular portion of the mandibular fossa from the external auditory meatus and is situated immediately in front of the petro-tympanic (Glaserian) fissure. The posterior root, prolonged from the upper border, is strongly marked and extends backward as a ridge above the external auditory meatus. It is called the temporal ridge (supra-mastoid crest), and marks the arbitrary line of division between the squamous and mastoid portions of the adult bone. It forms part of the posterior boundary of the temporal fossa, from which, as well as from the ridge, fibres of the temporal muscle arise. Where the anterior root joins the zygomatic process is a slight tubercle-the preglenoid tubercle-for the attachment of the temporo-mandibular ligament, and betwcen the anterior and middle roots is a deep oval depression, forming the part of the mandibular fossa for the condyle of the lower jaw. The mandibular fossa is a considerable hollow, bounded in front by the articular tubercle and behind by the tympanic plate which separates it from the external auditory meatus. It is divided into two parts by a narrow slit - the petro-tympanic (Glaserian) fissure. The anterior part [facies articularis], which belongs to the squamous portion, is articular, and, like the articular tubercle, is coated with cartilage. The posterior

Fig. 93.-The Left Temporal Bone. (Seen from the inner side and above.)

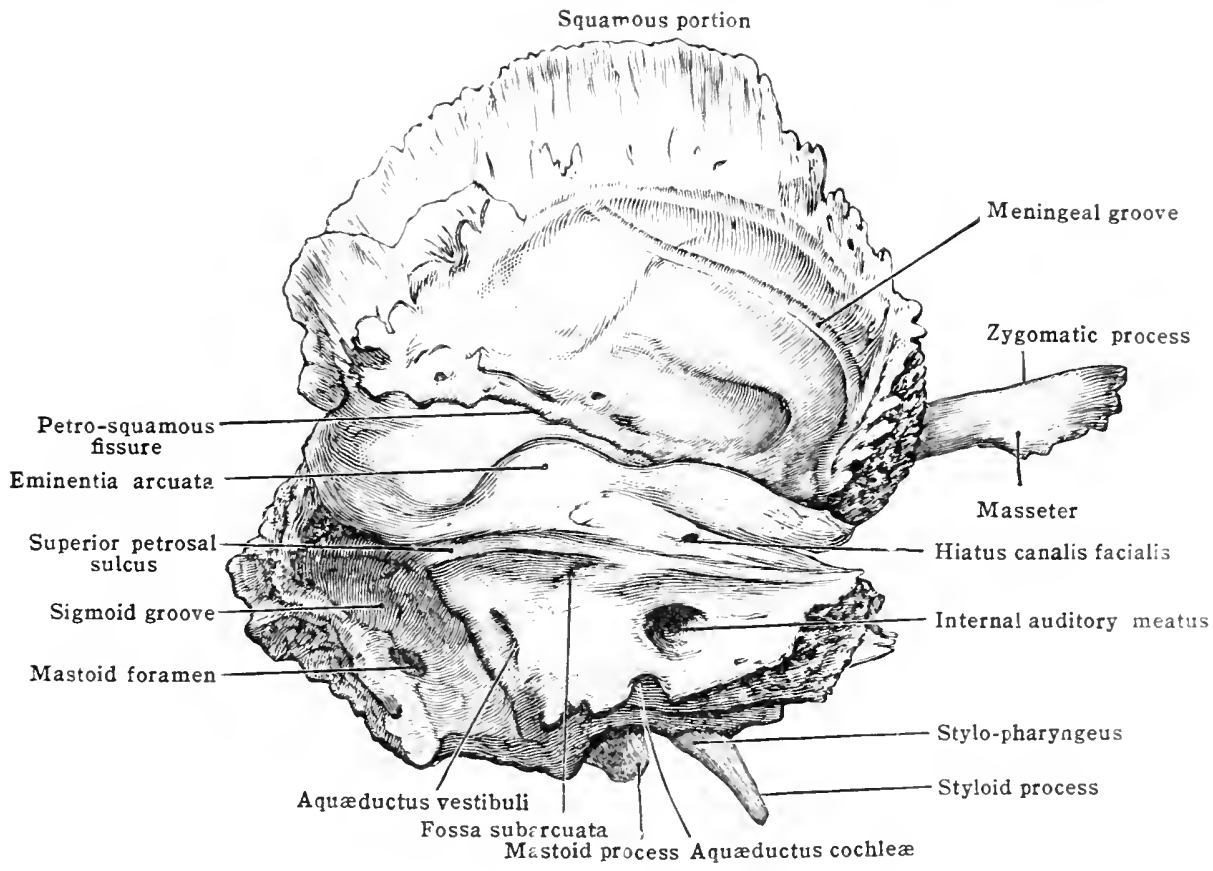

part, formed by the tympanic plate, is non-articular and lodges a lobe of the parotid gland. Immediately in front of the articular tubercle is a small triangular surface which enters into the formation of the roof of the zygomatic fossa.

The inner or cerebral surface of the squamous portion is marked by furrows for the convolutions of the brain and grooves for the middle meningeal vessels. It the upper part of the surface the inner table is deficient and the outer table is prolonged some distance upward, forming a thin scale, with the bevelled surface looking inward to overlap the corresponting edge of the parietal. Anteriorly the border is thicker, serlited, and slightly bevellerl on the outer side for articulation with the posterior borker of the great wing of the sphenoid. Posteriorly it joins the rough serrated margin of the mastoid portion to form the parietal notrh. The line separating the squamous from the petrous portion is indicater at the lower part of the inner surface by a narrow cleft, the internal petro-squamous suture, the appcarance of which varies in different bones according to the degree of persistence of the original line of division.

The mastoid portion [pars mastoidea] is rough and convex. It is hounded above by the temporal ridge and the parieto-mastoid suture; in front. hy the external auditory meatus and the tympano-mastoid fissure; and behind. by the suture between the mastoid and occipital. As already pointed out, it is formed by the squamous portion in front and by the base of the petrosal behind, the line of junction of the two component parts being indicated on the outer surface by the external petro-squamous suture (squamo-mastoil). The appearance of the suture varies, being in some bones searcely distinguishable, in others. a series 
of irregular depressions, whilst oecasionally it is present as a well-marked fissure (fig. 92) directed obliquely downward and forward. The mastoid portion is prolonged downward behind the external acoustic meatus into a nipple-shaped projection, the mastoid process, the tip of which points forward as well as downward. The process is marked, on its medjal surface, by a deep groove, the mastoid notch (digastric fossa), for the origin of the digastric muscle, and again medially by the occipital groove for the occipital artery.

The outer surface is perforated by numerous foramina, one, of large size, being usually situated near the posterior border and called the mastoid foramen. It transmits a vein to the transverse (lateral) sinus and the mastoid branch of the occipital artery. The mastoid portion gives attachment externally to the auricularis posterior (retrahens aurem) and occipitalis, and, along with the mastoid process, to the sterno-mastoid, splenius capitis, and longissimus capitis (trachelo-mastoid). Projecting from the postero-superior margin of the external auditory meatus there is frequently a small tubercle-the supra-meatal spine-behind which the surface is depressed to form the mastoid (supra-meatal) fossa.

The inner surface of the mastoid portion presents a deep curved sigmoid groove, in which is lodged a part of the transverse sinus; the mastoid foramen is seen opening into the groove. The interior of the mastoid portion, in the adult, is usually oeeupied by cavities lined by mucous membrane and known as the mastoid air-cells (fig. 97). These open into a small chamber-the mastoid antrum - which communicates with the upper part of the tympanic cavity. The mastoid cells are arranged in three groups: (1) antero-superior, (2) middle, and (3) apical. The apical cells, situated at the apex of the mastoid process, are small and usually contain marrow.

Borders.--The superior border is broad and rough for articulation with the hinder part of the inferior border of the parietal bone. The posterior border, very uneven and serrated, articulates with the inferior border of the occipital bone, extending from the lateral angle to the jugular process.

The petrous portion [pars petrosa; pyramis] is a pyramid of very dense bone presenting for examination a base, an apex, three (or four) surfaces, and three (or four) borders or angles. Two sides of the pyramid look into the eranial cavity, the posterior into the posterior cranial fossa, and the anterior into the middle eranial fossa. The inferior surface appears on the under surface of the cranium. The medial and posterior walls of the tympanic cavity in the temporal bone are sometimes described as a fourth side of the pyramid. The base forms a part of the lateral surface of the cranium; the apex is placed medially.

The posterior surface of the pyramid is triangular in form, bounded above by the superior angle and below by the posterior angle Near the middle is an oblicuely dirceted foramen [porus acusticus internus] leading into a short canalthe internal auditory meatus - at the bottom of which is a plate of bone, pierced by numerous foramina, and known as the lamina cribrosa. 'The eanal transmits the facial ancl auditory nerves, the pars intermedia, and the internal auditory artery. The bottom of the internal auditory meatus ean be most advantageously studied in a temporal bone at about the time of birth, when the canal is shallow and the openings relatively wide.

The fundus of the meatus is divided by a trinsverse ridge of bone, the transicrse crest, into a superior and inferior fossa. Of these, the superior is the smaller, and presents anteriorly the beginning of the facial canal (aqueduct of Fallopius), which transmits the seventh nerve. The rest of the surfite above the crest is dotter with small foramina (the superior vestibular area) which transmit norve-twigs to the recessus ellipticus (fovea henielliptica) and the ampullas of the superior and lateral semicircular canals (vestibular division of the auditory nerve). Bnow the erest there are two depressions and an opening. Of these, an anterior colrled tract (the spiral cribuform tract) with a central foranen (foranen entrale cochleare) marks the base of the cochlea; the central foramen imlieates the orifice of the canal of the modiolus, and the smaller formanat transmit the corhlear twigs of the aulitory nerve. The posterior opening (forancell singulare) is for the norve to the ampulla of the posterior semicirsular canal. The milldle depression (inferion v(stibular area) is dotted with minute foramina for the nerve-twigs to the sacenle, which is lorlged in the recessus sphariens (fove hemisphari$\mathrm{rat})$ The inforior fossa is subdivichol by a low vertionl crest. The fossa in front of the crest is the fossula cochloris, and the reoss behind it is the fossula vestibularis.

bohind and lateral to the meatus is a narrow fissure, the aquæductus vestibuli, covered by a scale of bone. In the fissure lies the ductus endolymphaticus, a suall arteriole and venule. and a process of connective tissies which unites the chra mater to the sheath of the internal ear. Oecasionally a bristle can be passul through it into the vestibule. Near the upper margin, and opposite a point about midway between the meatus and the aqueduct of the vesti- 
bule, is an irregular opening, the fossa subarcuata, the remains of the floccular fossa, a conspicuous depression in the foetal bone. In the adult the depression usually lodges a process of dura mater and transmits a small vein, though in some bones it is almost obliterated.

The anterior surface of the pyramid, sloping downward and forward, forms the back part of the floor of the middle fossa of the cranium.

Upon the anterior surface of the pyramid will be found the following points of interest, proceeding from the apex toward the base of the pyramid:--(1) a shallow trigeminal impression for the semilunar (Gasserian) ganglion of the trigeminal nerve; (2) two small grooves running backward and laterally toward two small foramina overhung by a thin osseous lip, the larger and medial of which, known as the hiatus canalis facialis, transmits the great superfi. cial petrosal nerve and the petrosal branch of the middle meningeal artery, whilst the smaller and lateral foramen is for the small superficial petrosal nerve; (3) behind and lateral to these is an eminence-the eminentia arcuata-best seen in young bones, corresponding to the superior semicircular canal in the interior; (4) still more laterally is a thin transulcent plate of bone, roofing in the tympanic cavity, and named the tegmen tympani.

Fig. 94.-The Foramina in the Fundes of the Left Internal Auditory Meates of a Child at Birth $\left(\begin{array}{l}\frac{1}{1} \\ 1\end{array}\right)$. (Diagrammatic.)

Superior fossa

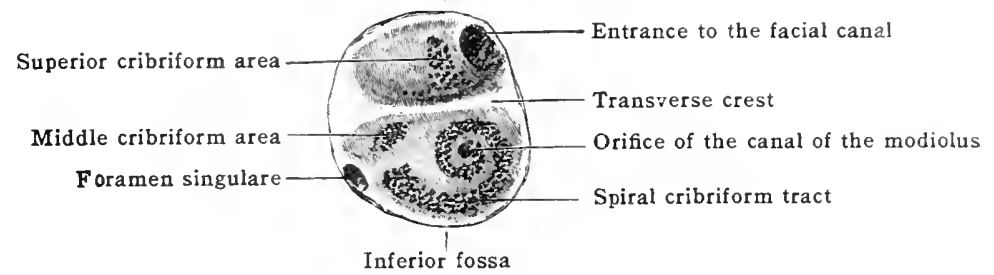

The inferior or basilar surface of the pyramid is very irregular. At the apex it is rough, quadrilateral, and gives attachment to the tensor tympani,levator veli palatini, and the pharyngeal aponeurosis. Behind this are seen the large circular orifice of the carotid canal for the transmission of the carotid artery and a plexus of sympathetic nerves, and on the same level, near the posterior border, a small three-sided depression, the canaliculus cochleæ, which transmits a small vein from the cochlea to the internal jugular. Behind these two openings is the large elliptical jugular fossa which forms the anterior and lateral part of the bony wall of the jugular foramen, in which is contained a dilatation on the commencement of the internal jugular vein; on the lateral wall of the jugular fossa is a minute foramen, the mastoid canaliculus, for the entrance of the auricular branch of the vagus (Arnold's nerve) into the interior of the bone. Between the inferior aperture of the carotid canal and the jugular fossa is the sharp carotid ridge, on which is a small depression, the fossula petrosa, and at the bottom of this a minute opening, the tympanic canaliculus, for the tympanic branch of the glosso-pharyngeal or Jacobson's nerve, and the small tympanic branch from the ascending pharyngeal artery. Behind the fossa is the rough jugular surface for articulation with the jugular process of the occipital bone, on the lateral side of which is the prominent cylindrical spur known as the styloid process with the stylo-mastoid foramen at its base. The facial nerve, and sometimes the auricular branch of the vagus, leave the skull, and the strlo-mastoid artery enters it by this foramen. Running backward from the foramen are the mastoid and occipital grooves already described.

The tympanic surface of the pyramid, forming the medial and posterior walls [paries labyrinthica] of the tympanic carity, is shown by remoring the tympanic plate (fig. 91). It presents near the base an excaration, known as the tympanic or mastoid antrum, covered by the triangular part of the sqummos: below and behind the temporal line. "The opening of the antrum intu the tympanic cavity is situated immediately above the fenestra vestibulis an oratshaped opening which receives the base of the stapes; below the fenestra restibuli is a convex projection or promontory, marked by grooves for the tympanic plexus of nerves and containing the commencement of the first turn of the cochlea. In the lower and posterior part of the promontory is the fenestra cochiea, closed in the recent state by the secondary membrane of the tympanum. Ruming downward and forward from the front of the fenestra restibuli is a thin curved plate of bone [septum canalis musculotubarii], separating two grooves converted 
into canals by the overlying tympanic plate. The lower is the groove for the Eustachian tube [semicanalis tubæ auditivæ], the communicating passage between the tympanum and the pharynx; the upper is the semicanalis $\mathrm{m}$. tensoris tympani, and the lateral apertures of both canals are visible in the retiring angle, between the petrous and squamous portions of the bone.

The apex of the pyramid is truncated and presents the medial opening of the carotid canal. The latter commences on the inferior surface, and, after ascending for a short distance, turns forward and medially, tunnelling the bone as far as the apex, and finally opens into the upper part of the foramen lacerum formed between the temporal and sphenoid bones. One or two minute openings in the wall of the carotid canal, known as the carotico-tympanic canaliculi, transmit communicating twigs between the carotid and tympanic plexuses. The upper part of the apex is joined by cartilage to the posterior petrosal process of the sphenoid.

The base is the part of the pyramid which appears laterally at the side of the cranium and takes part in the formation of the mastoid portion. It is described with that division of the bone.

Fig. 95.-The Left Temporal Bone. (Inferior view.)

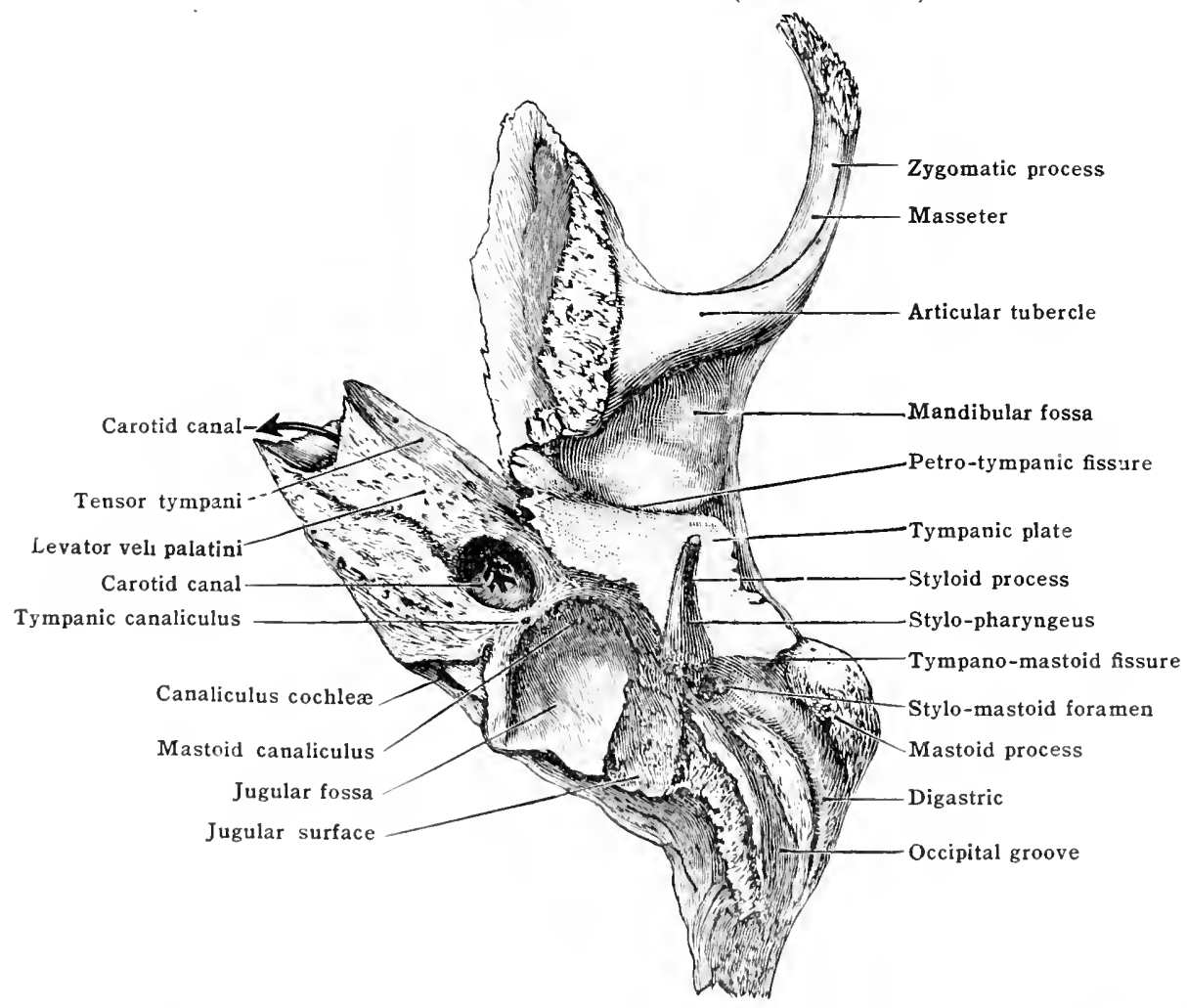

Angles.--Tho superior angle (border) of the pyramil is the longest and separates the posterior from the antrior surface. It is groover for the superior petrosal sinus, gives attachment to the tontorium coldicli, and presents near the apex a semilnuar noteh upon which the fifth cranial mervolius. Vear its mertial rmol there is often a small projection for the attachment of the pertro-splunomial liganont, which arehes over the inforior petrosal sinus and the sixth nerve. The posterior angle separates the justerior from the inferior surface, and when artembated with thromipital, forms the groove for the inforior potrosal sinus, and completes the jugular foramen formol by the temporit in front and on the literal side, and by the oceipital buhiml aurl on the meslial sirle. The jugular foramen is divisible into three compartments: an

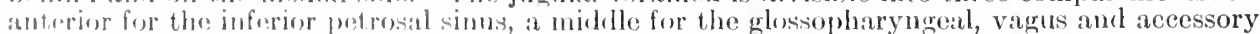

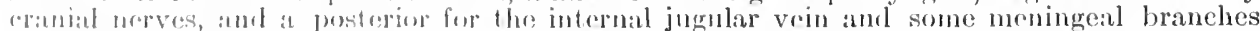
from throciphal aml ascomling pharyngeal arterios. The anterior angle is the shortest

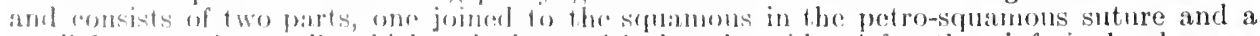

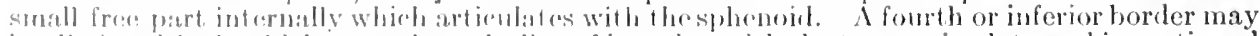
her distingushorl, whirh russ along the line of junction with the tympanic plate and is eontinued

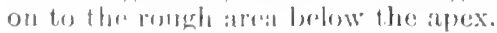


The tympanic portion [pars tympaniea] is quadrilateral in form, hollowed out above and behind, and nearly flat, or somewhat concave, in front and below. It forms the whole of the anterior and inferior walls, and part of the posterior wall. of the external auditory meatus, and is separated behind from the mastoid process by the tympano-mastoid (aurieular) fissure through which the auricular branch of the vagus in some cases leaves the bone.

In front it is separated by the petro-tympanic fissure from the squamous portion. Through the petro-tympanic fissure the tympanic branch of the internal maxillary artery and the socalled laxator tympani pass. The processus gracilis of the malleus is lodged within it, and is narrow subdivision at its inner end, known as the canal of Huguier, transmits the chorda tympani nerve. The tympanic part presents for examination two surfaces and four borders.

The antero-inferior surface, directed downward and forward, lodges part of the parotid gland. Near the middle it is usually very thin, and sometimes presents a small foramen (the foramen of Huschke), which represents a non-ossified portion of the plate. The posterosuperior surface looks into the external auditory meatus and tympanic cavity, and at its media] end is a narrow groove, the sulcus tympanicus, deficient above, which receives the membrana tympani.

The lateral border is rough and everted, forming the external auditory process for the attachment of the cartilage of the pinna; the superior border enters into the formation of the petro-tympanic fissure; the inferior border is uneven and prolonged into the vaginal process [vagina processus styloidei] which surrounds the lateral aspect of the base of the styloid process and gives attachment to the front part of the fascial sheath of the carotid ressels; the medial border, short and irregular, lies immediately below and to the lateral side of the opening of the Eustachian tube, and becomes continuous with the rough quadrilateral area on the inferior aspect of the apex.

The external auditory meatus is formed partly by the tympanic and partly by the squamous portion. It is an elliptical bony tube leading into the tympanum, the extrance of which is bounded throughout the greater part of its circumference by the external auditory process of the tympanic plate. Above. the entrance is limited by the temporal ridge or posterior root of the zygomatic process.

The styloid process is a slender, eylindrical spur of bone fused with the inferior aspect of the temporal immediately in front of the stylo-mastoid foramen. It consists of two parts, basal (tympano-hyal), which in the adult lies under cover of the tympanic plate, and a projecting portion (stylo-hyal), which varies in length from five to fifty millimetres. When short, it is hidden by the raginal process. but, on the other hand, it may reach to the hyoid bone. The projecting portion gives attachment to three muscles and two ligaments.

The stylo-pharyngeus arises near the base from the medial and slightly from the posterior aspect; the stylo-hyoid from the posterior and lateral aspect near the midrle; and the styloglossus from the front near the tip. The tip is continuous with the stylo-hyoid ligament, which runs lown to the lesser cornu of the hyoid bone. A band of fibrous tissue- the stylo-mandibular ligament-passes from the process below the origin of the stylo-glossus to the angle of the lower jaw.

Blood-supply. - The arteries supplying the temporal bone are derived from various sources.

\section{The chief are:-}

stylo-mastoid from posterior auricular: it enters the stylo-mastoid foramen.

Anterior tympanic from internal maxillary: it passes through the petro-tympanic fisture.

Superficial petrosal from middle meningeal: transmitted by the hiatus canalis facialis.

Carotico-tympanic from internal carotid whilst in the carotid canal.

Internal auditory from the basilar: it enters the internal auditory meatus, and is distributed to the cochlea and vestibule.

Other less important twigs are furnished by the middle meningeal, the meningeal brames of the occipital, and by the ascending pharyngeal artery. The squamous portion is supplied. on its internal surface, by the middle meningeal, and externally by the branches of the leep temporal from the internal maxillary.

Articulations. - The temporal bone articulates with the occipital, parietal, sphenuil, zygomatic, and, by a movable joint, with the mandible. Occasionally the squanous portion presents a process which articulates with the frontal. A fronto-squamosal suture is common in the skulls of the lower races of men, and is normal in the skulls of the chimp:mace, gorillit. and gibbon.

Ossification.-Of the three parts which constitute the temporal bone at hirth, the squamosal and tympanic derelop in membrane and the petrosal in cartilage. The squamosal is formed from one centre, which appears as carly as the eighth week, and osification extcnds into the zygomatic process, which grows concurrently with the squamosal. At first the $1 \mathrm{gm}$ panic border is nearly straight, but soon assumes its characteristic horseshoe shape. At birth the post-glenoid tubercle is conspicuous, and at the hinder ent of the squamosal there is a process which comes into relation with the mastoid antrum The centre for the tympanic element appears about the twelfth week. At birth it forms an incomplete ring, open above, and slightly ankylosed to the lower border of the squamosal. The anterior extremity terminates 
in a small irregular process, and the medial aspect presents, in the lower half of its cireumference, a groove for the reception of the tympanic membrane.

Up to the middle of the fifth month the periotic capsule is cartilaginous; it then ossifies so rapidly that by the end of the sixth month its chief portion is converted into porous bone. The ossific material is deposited in four centres, or groups of centres, named according to their relation to the ear-eapsule in its embryonic position.

The nuclei are deposited in the following order:-

1. The opisthotic appears at the end of the fifth month. The osseous material is seen first on the promontory, and it quickly surrounds the fenestra cochleæ from above downward, and forms the floor of the vestibule, the lower part of the fenestra vestibuli, and the internal auditory meatus; it also invests the cochlea. Subsequently a plate of bone arises from it to surround the internal carotid artery and form the floor of the tympanum.

2 . The prootic nucleus is deposited behind the internal auditory meatus near the medial limb of the superior semicircular canal. It covers in a part of the cochlea, the vestibule, and the internal auditory meatus, completes the fenestra vestibuli, and invests the superior semicircular canal.

3. The pterotic nueleus ossifies the tegmen tympani and covers in the lateral semicircular canal; the ossific matter is first deposited over the lateral limb of this canal.

4. The epiotic, often double, is the last to appear, and is first seen at the most posterior part of the posterior semicircular eanal.

At birth the bone is of loose and open texture, thus offering a striking contrast to the dense and ivory-like petrosal of the adult. It also differs from the adult bone in several other partieulars. The floceular fossa is widely open and conspicuous. Voltolini has pointed out that a small canal leads from the floor of the floccular fossa and opens posteriorly on the mastoid surface of the bone; it may open in the mastoid antrum. The hiatus canalis facialis is unclosed

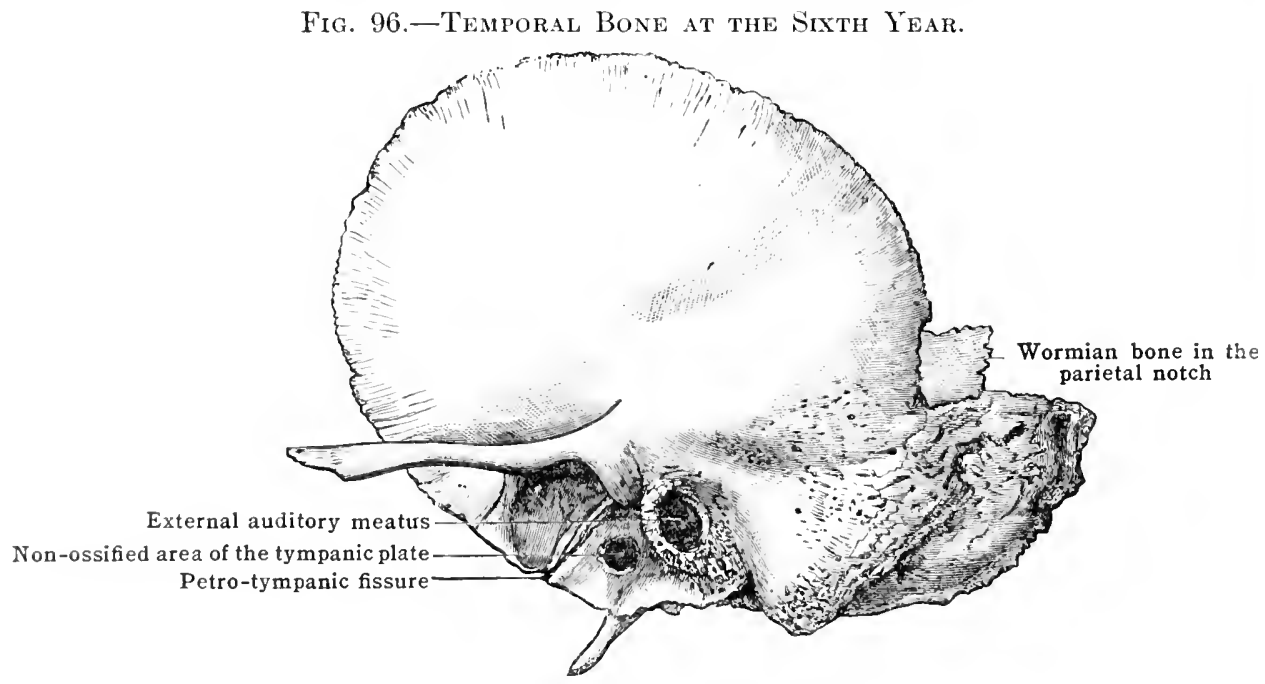

and the tympanum is filled with gelatinous connective tissue. The mastoid process is not develojed, and the jugular fossa is a shallow depression.

After birth the parts grow rapidly. The tympanum becomes permeated with air, the various clements fuse, and the tympanic annulus grows rapidly and forms the tympanic plate. Development of the tympanic plate takes place by an outgrowth of bone from the lateral asperet of the tympanis annulus. This outgrowth takes place most rapidly from the tubercles or spines at its mpper (xtremities, and in consequence of the slow growth of the lower segment a deep noteh is formed; graduilly the tubercles eoalesee, lateral to the noteh, so as to enclose a foramen which porsists until puberty, and sometimes even in the adult. In most skulls a eleft capable of receiving the nail remains brtween the tympanic element and the mastoid proeess; this is the tympano-inastrid fissure. The anterior portion of the tympanie plate forms with the inforior border of the srgumosial a eleft known as the petro-tympanie fissure, which is subserquently ancroached mon ly the growth of the petrosal. As the tympanic plate increases in size it joins the literal wall of the carotirl canal and presents a prominent lower edge, known as the vateinal proesess (sheath of threstyloid)

Thr mastoid process lwemes distinet alout the first year, eoineirlent with the obliteration of the petro-spuamons suture, and incroases in thickness by deposit from the periostem. Aecording to most writers, the process becomes pnemmatic about the time of puberty, but it has beon shown by Young and Milligan that the mastoid air-cells develep at a mueh earlior period than is usually silpmserl. These writers have deseribod specinens in which the air-cells were present, as smill pit-like diverticula from the matoid antrum, in a nine months' fortus and in an infant one your olı. In old skulls the air-cells nay extend into the jugular process of the orecipital bone.

At birth the mistoin antrum is relatively large and bounded laterally by a thin plate of bone belonging to the schumosal (post-anditory process). As the mastoid increases in thickness the antrun comes to lie at a greater depth from the surface and becomes relatively smaller. 
The styloid process is ossified in cartilage from two centres, one of which apprars at the base in the tympano-hyal before birth. This soon joins with the temporal bone, and in the second year a centre appears for the stylo-hyal, which, however, remains very small until puberty. In the adult it usually becones firmly united with the tympano-hyal, bist it may remain permanently separate.

\section{THE TYMPANUM}

The tympanum (middle ear) includes a cavity [carum tympani] of irregular form in the temporal bone, situated over the jugular fossa, between the petrous portion medially and the tympanic and squamous portions laterally. When fully dereloped, it is completely surrounded by bone except where it communicates with the external auditory meatus, and presents for examination six wallslateral, medial, posterior, anterior, superior (roof), and inferior (floor). The lateral and medial walls are flat, but the remainder are curved, so that they rum into adjoining surfaces, without their limits being sharply indicated.

The roof or tegmen tympani [paries tegmentalis] is a translacent plate of bone, forming part of the superior surface of the petrous portion and separating the tympanum from the middle fossa of the skull. The floor [paries jugularis] is the plate of bone which forms the roof of the jugular fossa.

The medial wall [paries labyrinthica? is formed by the tympanic surface of the petrous portion. In the angle between it and the roof is a horizontal ridge which extends backward as far as the posterior wall and then turns downward in the angle between the medial and posterior walls. This is the facial (Fallopian) canal, and is occupied by the facial nerve. The other features of this surface-viz., the fenestra vestibuli, the fenestra cochleæ, and the promontory -have previously been described with the anterior surface of the petrous portion of the temporal bone.

The posterior wall [baries mastoidea] of the tympannm is also formed by the anterior surface of the petrous portion. At the superior and lateral angle of this wall an opening

Fig. 97.-The Medial Wall of the Trapanum.

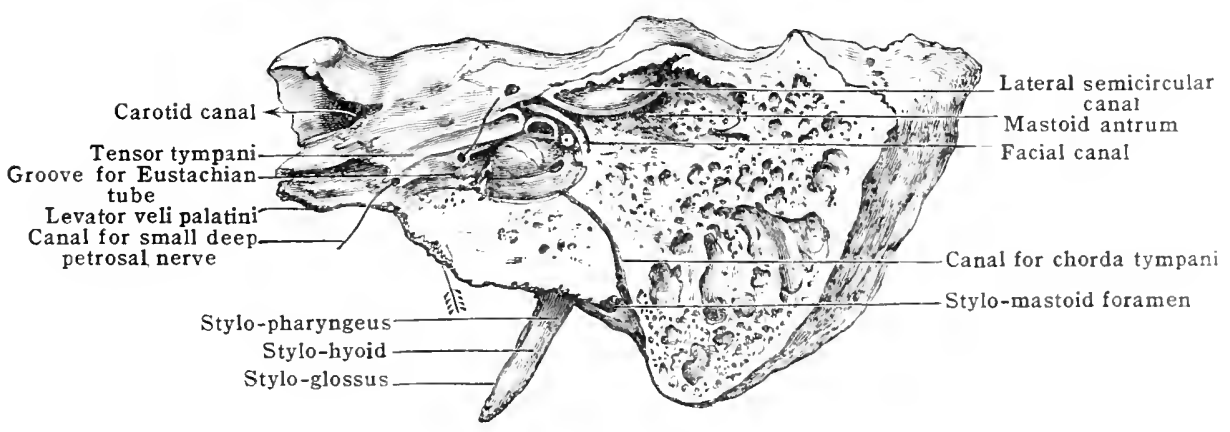

leads into the mastoid antrum. Immediately below this opening there is a small hollow cone, the pyramidal eminence, the cavity of which is continuous with the descending limb of the facial canal. The cavity is occupied by the stapedius and the tendon of the muscle emerges at the apex. One or more bony spicules often connect the apex of the pyramil with the promontory.

The roof and floor converge toward the anterior extremity of the tympanum. which is, in consequence, very low; it is occupied by two semicanals, the lower for the Eustachian tube, thw upper for the tensor tympani muscle. These channels are sometimes described together as the canalis musculo-tubarius. In carefully prepared bones the upper semicanal is a small horizontal hollow cone (anterior prramid), $12 \mathrm{~mm}$. in length; the apex is just in front of the fenestra vestibuli, and is perforated to permit the passage of the tendon of the muscle. As a rule, the thin walls of the canal are damaged, and represented merely by a thin ridge of bone. The posterior portion of this ridge projects into the tympanum, and is known as the processus cochleariformis. The thin septum between the semicanal for the tensor tympani and the tube is pierced by a minute opening which transmits the small deep petrosal nerve.

The lateral wall \{paries membranaceaj is occupied mainly by the external aulitory meatu: This opening is closed in the recent state by the trmpanic membrane. The rim of bone to which the membrane is attached is incomplete above, and the defect is know $n$ as the tympanic notch (notch of Rivinus). Anterior to this notch, in the angle between the squamous portion and the tympanic plate, is the petro-tympanic (Glaserian) fissure, and the small passiuce which transmits the chorda tympani nerve, known as the canal of Huguier.

Up to this point the description of the middle ear conforms to that in general usage. I3ut Young and Milligan have laid stress on the fact that the middle ear is reilly a cleft, namerl by them the "middle-ear cleft," which intervenes between the periotic capsule, on the one hand. and the squamo-zygomatic and tympanic elements of the temporal hone on the other. This cleft, as development proceeds, gives rise to three cavities:--(1) the mastoid antrum; (2) 
tympanum; and (3) the Eustachian tube. They point out that "the eleft is primarily eontinuous, and however much it may be altered in shape and modified in parts to form these three cavities, that continuity is never lost." It will be clear that the mastoid antrum, according to this riew, is not an outgrowth from the tympanum, but is simply the lateral end of the middleear cleft.

The tympanic cavity may be divided into three parts. The part below the level of the superior margin of the external auditory meatus is the tympanum proper; the portion above this level is the epitympanic recess or attic; it receives the head of the malleus, the body of the incus, and leads posteriorly into the recess known as the mastoid antrum. The third part is the downward extension known as the hypotympanic recess.

The tympanic or mastoid antrum.--The air-cells which in the adult are found in the interior of the mastoid portion of the temporal bone open into a small cavity termed the mastoid antrum. This is an air-chamber, communicating with the attic of the tympanum, and separated from the middle cranial fossa by the posterior portion of the tegmen tympani. The floor is formed by the mastoid portion of the petrosal, and the lateral wall by the squamosal, below the temporal ridge. In children the outer wall is exceedingly thin, but in the adult it is of considerable thickness. The lateral semicircular canal projects into the antrum on its

Fig. 98.-Temporal Bone at Birth Dissected from above and behind to show the Semiclrcular Canals and the Mastoid Antruil. (Enlarged $\frac{1}{3}$.)

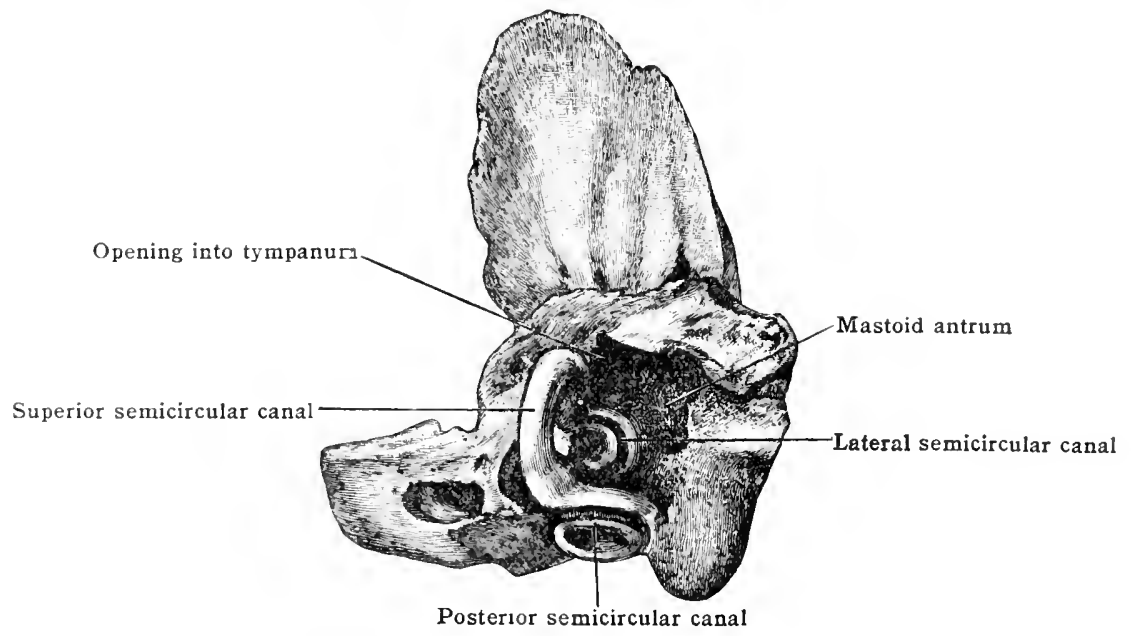

medial wall, and is very conspicuous in the foetus. Immediately below and in front of the canal is the facial nerve, contained in the facial canal.

'The mastoid antrum has somewhat the form of the bulb of a retort (Thane and Godlee) compressed laterally, and opening by its narrowed neck into the attic or cpitympanic recess. Its rimensions vary at different periods of life. It is well developed at birth, attains its maximum size about the third year, and diminishes somewhat up to adult life. In the adult the plate of bone which forms the liateral wall of the antrum is 12 to $18 \mathrm{~mm}$. ( $\frac{1}{2}$ to $\frac{3}{4} \mathrm{in}$.) in thickness, whereas at birth it is about $1.8 \mathrm{~mm}$. ( $(1$ in.) or less. 'The deposition of bone laterally occurs, therefore, at average rate of nearly $1 \mathrm{~mm}$. a year in thirkness. In the ardult the antrum is

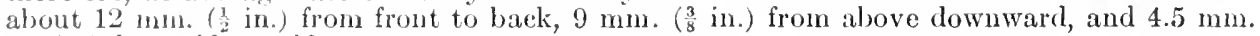
$(1$, in.) from side to side.

A canal occasionally learls from the mastoir antrum through the petrous bone to open in the recess which indicates the position of the flocenlar fossa; it is termed the petro-mastoid canal. (Gruber.)

The facial (Fallopian) canal.- This canal begins at the anterior angle of the superior fossa of the internal audjory meatus, and passes forward and laterally above the vestibular portion of the internal mar for it clistance of $1.5-2.0 \mathrm{~mm}$. At the lateral end of this portion of its course it becones dilated to atecommorlate the geniculate ginglion, and then turns abruptly backward and runs in a lorizontal ridge on the medial wall of the tympanum, lying in the angle betwoen it and the togmentympani, inmediately aloove the lenestra vestibuli, and extending

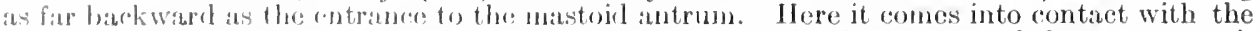
inforios aspect of the projection formod hy the lateral semicircular cinal, and then turns vertically downward, romning in the angle betwen the medial and posterior walls of the tympanum to torminate at the styformatstoil forimen.

Tho canal is traverserl by the facial nerve. Numerous openings exist in the walls of this patsilge. At its abrupt bend, or genu, the greater ambl smaller superficial petrosal nerves eseape from, and a branch from the midlle monimgeal artery enters, the canal, and in the vertical part of its enomse for: cavily of the pyramirl opens into it. There is also a small orifice by which the alurionlat biunch of the vagns joins the facial, and near its termination the iter chordæ posterius for the chorla tympani nerve leads from it into the tympanum. 
The small bones of the tympanum.-These bones, the malleus, incus and stapes, are contained in the upper part of the tympanic carity. Together they form a jointed column of bone connecting the membrana tympani with the fenestra vestibuli.

The malleus.-This is the most external of the auditory ossicles, and lies in relation with the tympanic membrane. Its upper portion, or head, is lodged in the epitympanic recess. It is of rounded shape, and presents posteriorly an elliptical depression for articulation with the incus. Below the head is a constricted portion or neck, from which three processes diverge. The largest is the handie or manubrium, which is slightly twisted and flattened. It forms an obtuse angle with the head of the bone, and lies between the membrana tympani and the mucous membrane covering its inner surface. The tensor tympani tendon is inserted into the manubrium near its junction with the neck on the medial side.

Fig. 99.-The Buxes of the Ear. (Modified from llenle.)

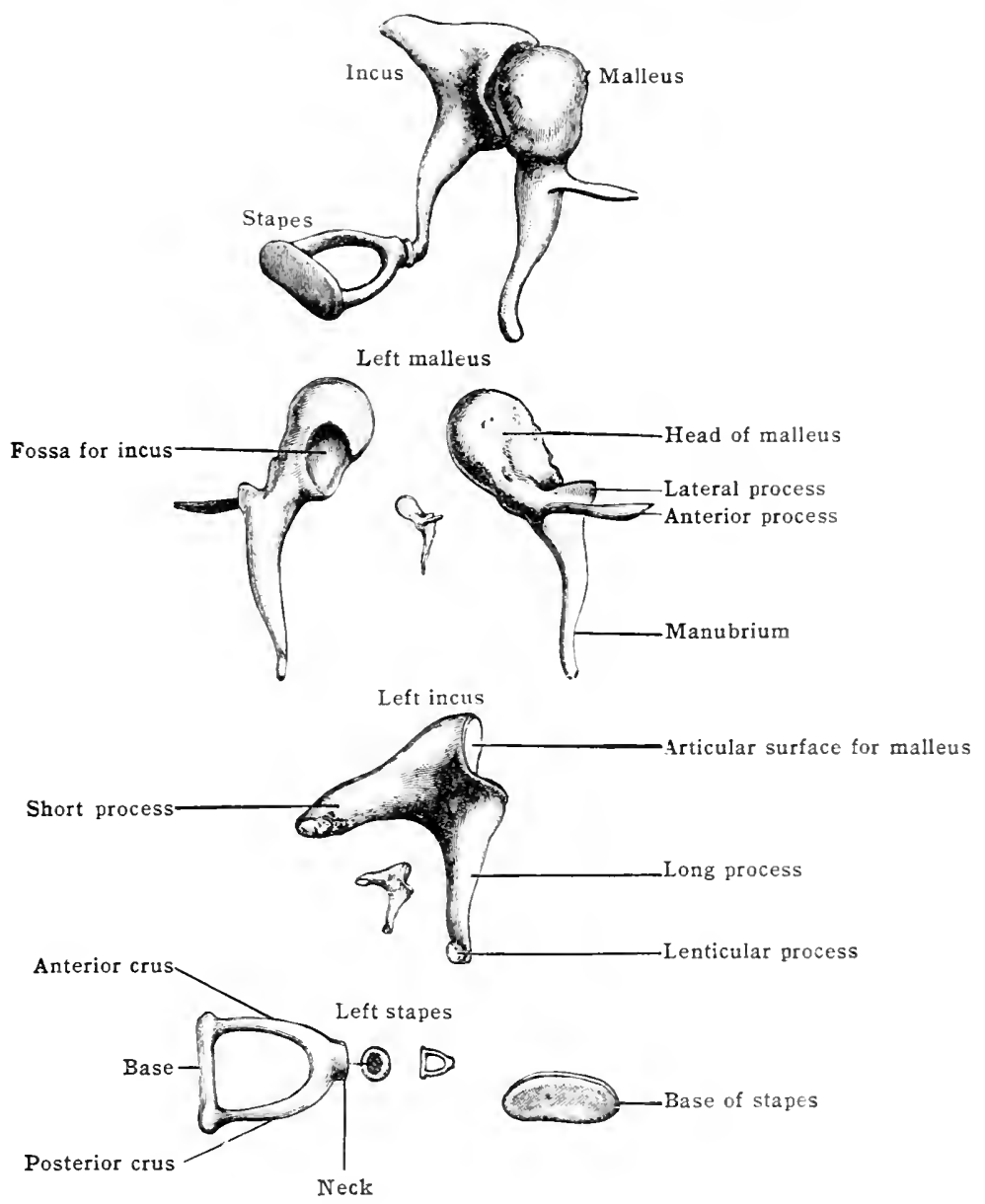

The anterior process (processus gracilis or Folii) is a long, slender, delicate spiculum of bone (rarely seen of full length except in the foetus). projecting nearly at right ingles to the anteriot aspect of the neck, and extending obliquely downward. It lies in the petro-tympanic fisure, and in the adult usually becomes converted into connective tissue, except a small basal stmmp. The lateral process is a conical projection from the lateral aspect of the hase of the manubrium. Its apex is connected to the upper part of the tympanic menhrane, and its base receives: the lateral ligament of the malleus. The malleus also gives attachment to a superior livinent and an anterior ligament, the latter of which was formerly describel as the laxator tympani muscle.

The incus. - This bone is situated between the malleus externally and the stapes internally. It presents for examination a body and two processes. The body is deeply exertitted anteriorly for the reception of the head of the malleus. The short process projects hackward, and is connected by means of ligamentous fibres to the posterior wall of the tympanum, near the entrance to the mastoid antrum. The long process is slender, and dirceteil downward and inward, and lies parallel with the manubrium of the malleus. On the medial aspect of the distal extremity of this process is the lenticular process (orbicular tubercle), separate in early life, but 
subsequently joined to the process by a narrow neck. Its free surface articulates with the head of the stapes.

The stapes is the innermost ossicle. It has a head directed horizontally outward, capped at its outer extremity by a disc resembling the head of the radius. The cup-shaped depression receives the lenticular process of the incus. The base occupies the fenestra vestibuli, and like this opening, the inferior border is straight, and the superior curved. The base is connected with the head by means of two crura, and a narrow piece of bone called the neck. Of the two crura, the anterior is the shorter and straighter. The crura with the base form a stirrup-shaped arch, of which the inner margin presents a groove for the reception of the membrane stretched across the hollow of the stapes. In the early embryo this hollow is traversed by the stapedial artery. The neck is very short, and receives on its posterior border the tendon of the stapedius muscle.

Development.-The tympanic cavity represents the upper extremity of the first endodermal branchial groove, which becomes converted into a blind pouch, the communication of which with the pharyngeal cavity is the tuba auditiva (Eustachian tube). The thin membrane which separates the endodermal from the ectodermal groove becomes the tympanic membrane, and it is from the upper extremities of the axial skeletons of the first and seeond branchial arches, which bound the groove anteriorly and posteriorly, that the auditory ossicles are formed, the malleus and incus belonging to the first arch and the stapes to the second (Reichert). The ossicles consequently lie originally in the walls of the cavity, but they are surrounded by a loose spongy tissue, which, on the entrance of air into the cavity, becomes compressed, allowing the cavity to enfold the ossicles. These therefore are enelosed within an epithelium which is continuous medially with that lining the posterior tympanic wall, and laterally with that lining the internal surface of the tympanic membrane.

The mastoid cells are outgrowths of the cavity into the adjacent bone, and are therefore lined with an epithelium continuous with that of the cavity.

\section{THE OSSEOUS LABYRINTH}

The osseous labyrinth [labyrinthus osseus] (fig. 100) is a complex cavity hollowed out of the petrous portion of the temporal bone and containing the membranous labyrinth, the essential part of the organ of hearing. It is incompletely divided into three parts, named the vestibule, the semicircular canals, and the cochlea.

Fig. 100.--The Left Osseous Labrrinth. (After Henle. From a cast.)

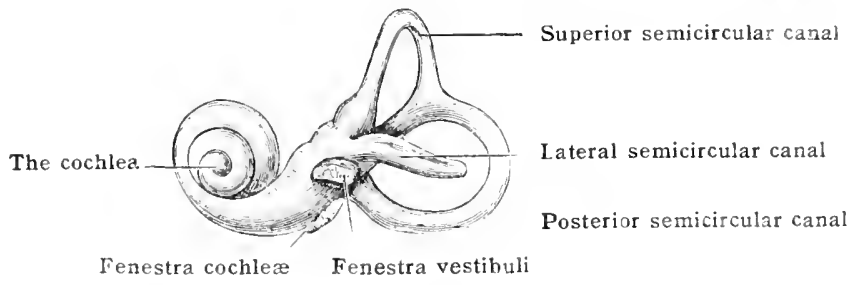

The vestibule. - This is an oval chamber situated between the base of the internal auditory meatus and the inedial wall of the tympanum, with which it communieates by way of the fonestra vestibuli. Anteriorly, the vestibule leads into the cochlea, and posteriorly it receives the extremities of the semicircular canals. It measures about $3 \mathrm{~mm}$. transversely, and is somewhat longer antero-posteriorly.

Its merlial wall presents at the anterior part a cireular depression, the spherical recess (foyea hemispheriea), which is perforated for the passage of nerve-twigs. 'This recess is separatel hy a vertical ridge (the crista vestibuli) from the vestibular orifice of the aquæductus

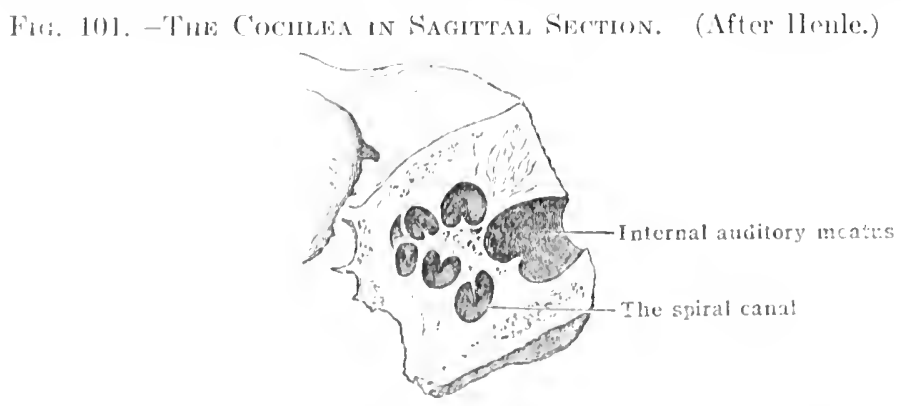

vestibuli, which passes ohliquely lackward to open on the posterior surface of the petrosal. 'lhe roff contains an oval clepression - the elliptical recess (fovea hemielliptica).

'The semicircular canals are three in number. Arranged in different planes, each forms abont two-thires of a circle. ()ne cxtremity of rach canal is dilated to form an ampulla.

The superior canal lies transversely to the long axis of the petrosal, and is nearly vertical; 
its highest limb makes a projection on the superior surface of the bone. The ampulla is at the lateral end; the medial end opens into the vestibule conjointly with the superior limb of the posterior canal.

The posterior canal is nearly vertical and lies in a plane nearly parallel to the posterior surface of the petrosal. It is the longest of the three; its upper extremity joins the medial limb of the superior canal, and opens in common with it into the vestibule. The lower is the ampullated end.

The lateral canal is placed horizontally and arches laterally; its lateral limb forms a prominence in the mastoid antrum. This canal is the shortest; its ampulla is at the lateral end near the fenestra vestibuli.

The cochlea. - This is a cone-shaped cavity lying with its base upon the internal aurlitory meatus, and the apex directed forward and laterally. It measures about five millimetres in length, and the diameter of its base is about the same. The centre of this cavity is occupied by a column of bone-the modiolus-around which a canal is wound in a spiral manner, making about two and a half turns. This is the spiral canal of the cochlea; its first turn is the largest and forms a bulging, the promontory, on the medial wall of the tympanum.

Projecting into the canal throughout its entire length there is a horizontal, shelf-like lamella, the lamina spiralis, which terminates at the apex of the cochlea in a hook-like process, the hamulus. The free edge of the lamina spiralis gives attachment to the membranous cochlea, a canal having in section the form of a triangle whose base is attached to the lateral wall of the spiral canal. By this the spiral canal is divided into a portion above the lamina spiralis, termed the scala vestibuli, which communicates at its lower end with the osseous vestibule, and a portion below, termed the scala tympani, which abuts at its lower end upon the fenestra cochlex. The two scalæ communicate at the apex of the cochlea by the helicotrema. Near the commencement of the scala tympani, and close to the fenestra rotunda, is the cochlear orifice of the canaliculus cochleæ (ductus perilymphaticus). In the adult this opens below, near the middle of the posterior border of the petrous bone, and transmits a small vein from the cochlea to the jugular fossa.

Measurements of the principal parts connected with the auditory organs:Internal auditory meatus...... Length of anterior wall, $13-14 \mathrm{~mm}$.

Length of posterior wall, $6.7 \mathrm{~mm}$.

External auditory meatus...... $14-16 \mathrm{~mm}$. (Gruber.)
Tympanum................. Length, $13 \mathrm{~mm}$.

Height in centre of cavity, $15 \mathrm{~mm}$.

Width opposite the membrana tympani, $2 \mathrm{~mm}$.

Width opposite the tubal orifice, $3-1 \mathrm{~mm}$. (Von Tröltsch.)

The capsule of the osseous labyrinth is in length $22 \mathrm{~mm}$. (Schwalbe.)

Superior semicircular canal measures along its convexity $20 \mathrm{~mm}$.

The posterior semicircular canal measures along its convexity $22 \mathrm{~mm}$.

The lateral semicircular canal measures along its convexity $15 \mathrm{~mm}$.

The canal is in diameter $1.5 \mathrm{~mm}$. (Huschke.)

The ampulla of the canal, $2.5 \mathrm{~mm}$.

Development. - The membranous internal ear arises in the embryo as a depression of the ectoderm of the surface of the head opposite the fifth neuromere of the hind-brain and later becomes a sac-like cavity, the otocyst, which separates from its original ectodermal connections and sinks deeply into the subjacent mesoderm, a part of which becomes incorporated with it. The rest of the mesolermal tissue which surrounds the otocyst becomes later the petrous portion of the temporal bone, the perilymph and the internal periosteal layer; the osseous labyrinth is therefore merely the portions of the petrous which enclose the cavity occupied by the membranous internal ear.

\section{THE ETHMIOID}

The ethmoid [os ethmoidale] is a bone of delicate texture, situated at the anterior part of the base of the cranium (figs. 102, 103, 104). Projecting downwarl from between the orbital plates of the frontal, it enters into the formation of the orbital and nasal fosse. It is cubical in form, and its extreme lightness and delicacy are due to an arrangement of very thin plates of bone surrounding irregular spaces known as air-cells. The ethmoid consists of four parts: the horizontal or cribriform plate, the ethmoidal labyrinth on each side, and a perpendicular plate.

The cribriform plate [lamina cribrosa] forms part of the anterior cranial fossa. and is received into the ethmoidal notch of the frontal bone. It presents on its upper surface, in the median line, the intra-cranial portion of the perpendicular plate, known as the crista galli, a thick, vertical, triangular process with the highest point in front, and a sloping border behind which gives attachment to the falx cerebri. The anterior border is short and in its lower part broadens out to form two alar processes which articulate with the frontal bone and complete the foramen cæcum. The crista galli is continuous behind with a median ridge, and on each side of the middle line is a groove which lodges the olfactory bulb. 
The cribriform plate is piereed, on each side, by numerous foramina, arranged in two or three rows, which transmit the filaments of the olfaetory nerves deseending from the bulb. Those in the middle of the groove are few and are simple perforations, through which pass the nerves to the roof of the nose; the medial and lateral series are more numerous and eonstitute the upper ends of small canals, which subdivide as they eourse downward to the upper parts of the septum and the lateral wall of the nasal fossa. At the front part of the eribriform plate is a narrow longitudinal slit, on each side of the crista galli, whieh transmits the anterior ethmoidal (nasal) braneh of the ophthalmic division of the fifth nerve. The posterior border articulates with the ethmoidal spine of the sphenoid.

Fig. 102.--Section through the Nasal Fossa to show the Mesethioid (Lamina Perpendicularis).

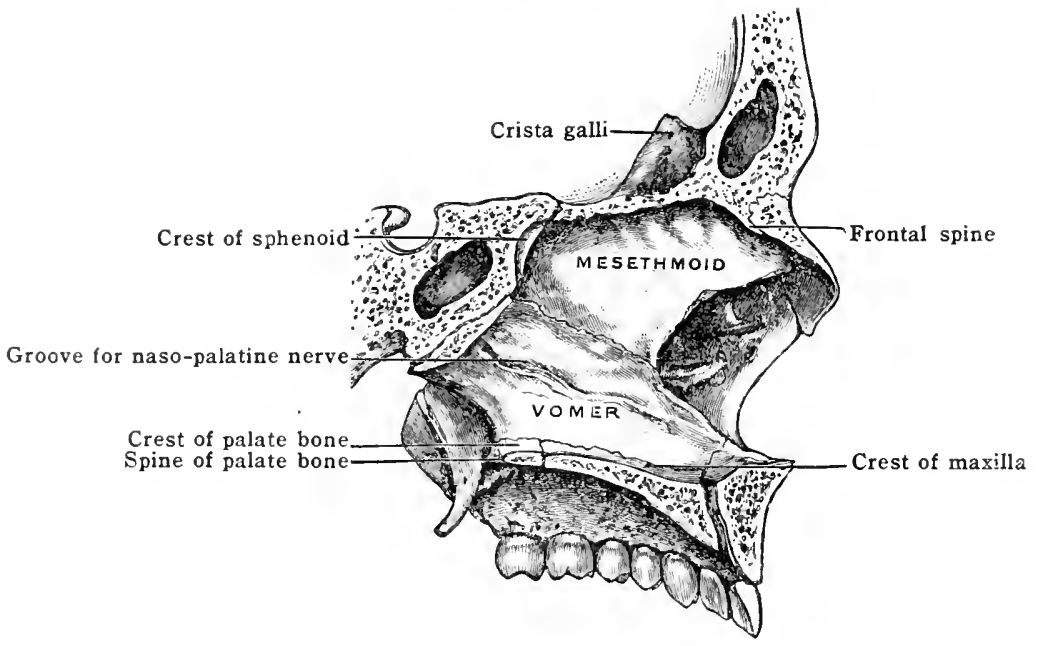

The perpendicular plate (mesethmoid) [lamina perpendicularis is directly continuous with the crista galli on the under aspect of the eribriform plate, so that the two plates cross each other at right angles. The larger part of the perpendicular plate is below the point of intersection and forms the upper third of the septum of the nose. It is quadrangular in form with unequal sides.

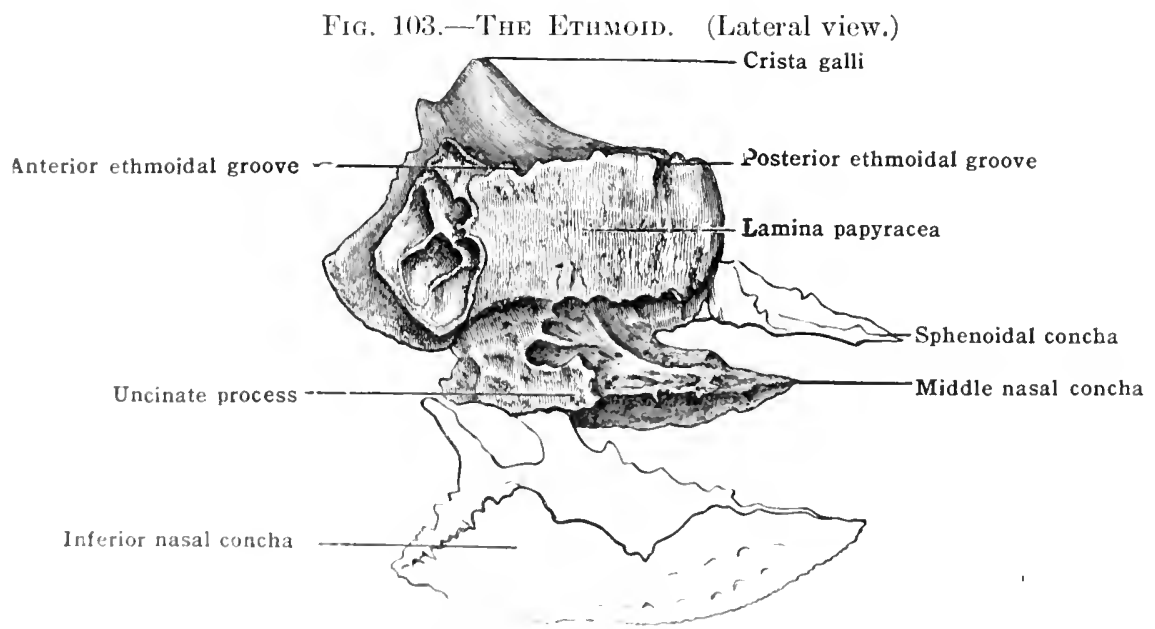

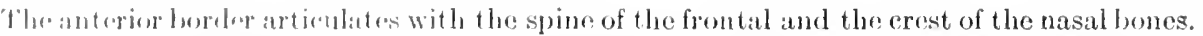
The inferior bereler artirulates in front with the septal cartilage of the nose and behind with the anterion' matrgin of the vomers. 'The posterios margin is very thin and articulates with the erest of thr. suhanofl. This plate, which is generally deflected a little to one side, presents above a number of grouves and minute canals which lead from the inner set of foramina in the cribriform plater and transmit the offactory nerves to the septum.

The labyrinth (lateral mass) is oblong in shape and suspended from the under aspect of the lateral part of the cribriform plate. It consists of two seroll-like 
pieces of bone, the superior and middle nasal conchæ (turbinate bones), and encloses numerous irregularly shaped spaces, known as the ethmoidal cells. These are arranged in three sets-anterior, middle, and posterior ethmoidal cells - and, in the recent state, are lined with prolongations of the nasal mucous membrane. Laterally the labyrinth presents a thin, smooth, quadrilateral plate of bone-the lamina papyracea (os planum)-which closes in the middle and posterior ethmoidal cells and forms a large part of the medial wall of the orbit.

By its anterior border it articulates with the lacrimal, and by its posterjor border with the sphenoid; the inferior border articulates with the medial margin of the orbital plate of the maxilla and the orbital process of the palate bone, whilst the superior border articulates with the horizontal plate of the frontal. Two notches in the superior border lead into grooves running horizontally across the lateral mass to the cribriform plate, which complete, with the frontal bone, the ethmoidal canals. The anterior canal transmits the anterior ethmoidal vessels and (nasal) nerve; the posterior transmits the posterior ethmoidal vessels and nerve.

Fig. 104.-Section throdgh the Nasal Fossa to show the Labrrinth of the Ethmoid. It shows also the lateral wall of the left nasal fossa.

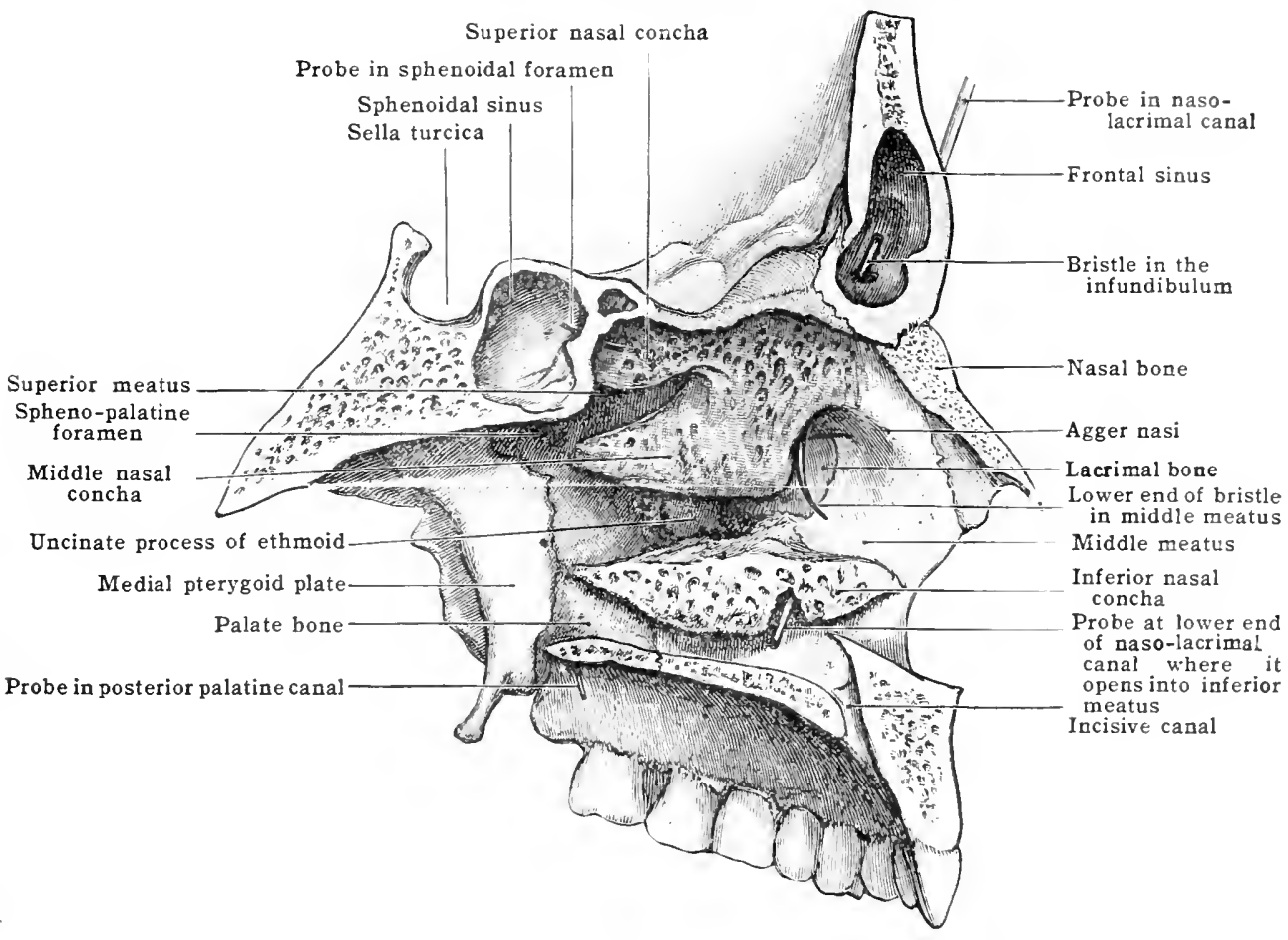

At the lower part of the lateral surface is a deep groove, which belongs to the middle meatus of the nose, and is bounded below by the thick curved margin of the inferior nasal concha. Anteriorly the middle meatus receives the infundibulum, a sinuous passage which descends from the frontal sinus through the anterior part of the labyrinth. The anterior ethmoidal cells open into the lower part of the infundibulum, and in this way communicate with the nose. whereas the middle ethmoidal cells open directly into the middle or horizontal part of the meatus. In front of the lamina papyracea are scen a few broken cells, which extend under, and are completed by, the lacrimal bone and the frontal process of the maxilla; from this part of the labyrinth an irregular lamina, known at the uncinate process, projects downward and backward. The uncinate proces: articulates with the ethmoidal process of the inferior nasal concha and forms a small part of the medial wall of the maxillary sinus.

Medially the labyrinth takes part in the formation of the lateral wall of the nasal fossa, and presents the superior and middle nasal conchæ (tuphinate processes), continuous anteriorly, but separated behind by a space directed forward from the posterior margin. This channel is the superior meatus of the nose and communicates with the posterior cthmoidal cells. The conchæ are corered 
in the recent state with mucous membrane and present numerous foramina for blood-vessels and, above, grooves for twigs of the olfactory nerves. Each concha has an attached upper border and a free, slightly convoluted, lower border, and in the case of the middle concha, the lower margin has already been noticed on the outer aspect, where it overhangs the middle meatus of the nose. The posterior extremity of the labyrinth articulates with the anterior surface of the body of the sphenoid and is commonly united with the sphenoidal concha.

A rounded prominence on the lateral wall of the middle meatus is known as the bulla ethmoidalis. Antero-inferior to the bulla is a large semilunar depression [hiatus semilunaris] which corresponds to the lower aperture of the infundibulum.

Wany of the ethmoidal cells are imperfect and are completed by adjacent bones. Those along the superior edge of the lateral mass are the fronto-ethmoidal; those at the anterior border, usually two in number, are known as lacrimo-ethmoidal. Those along the lower edge of the lamina papyracea are the maxillo-ethmoidal; and posteriorly, are the sphenoethmoidal, completed by the sphenoidal concha, and a palato-ethmoidal cell. The anterior extremity presents one or two incomplete cells closed by the nasal process of the maxilla.

Blood-supply. - The ethmoid receives its blood-supply from the anterior and posterior ethmoidal arteries and from the spheno-palatine branch of the internal maxillary.

Articulations. - With the frontal, sphenoid, two palate bones, two nasals, vomer, two inferior nasal conchæ, two sphenoidal conchæ, two maxillæ, and two lacrimal bones. The posterior surface of each labyrinth is in relation with the sphenoid on each side of the crest and rostrum, and helps to close in the sphenoidal sinus.

Ossification. - The ethmoid has three centres of ossification. Of these, a nucleus appears in the fourth month of intra-uterine life in each labyrinth, first in the lamina papyracea and afterward extending into the middle concha. At birth each lateral portion is represented by two scroll-like bones, very delicate and covered with irregular depressions, which give it a wormeaten appearance. Six months after birth a nucleus appears in the ethmo-vomerine cartilage tor the vertical plate which gradually extends into the crista galli, and the cribriform plate is formed by ossification extending laterally from this centre, and medially from the labyrinth. The three parts coalesce to form one piece in the fifth or sixth year.

The etlimoidal cells make their appearance about the third year, and gradually invade the labyrinths. In many places there is so much absorption of bone that the cells perforate the ethmoid in situations where it is overlapped by other bones. Along the lower border, near its articulation with the maxilla, the absorption leads to the partial detachment of a narrow strip known as the uncinate process. Sometimes a second but smaller hook-like process is formed, above and anterior to this, so fragile that it is difficult to preserve it in disarticulated bones. The relations of the uncinate process are best studied by removing the lateral wall of the maxillary sinus.

\section{THE INFERIOR NASAL CONCHA}

The inferior nasal concha (inferior turbinate) (fig. 105) is a slender, scroll-like lamina, attached by its upper margin to the lateral wall of the nasal fossa, and hanging into the cavity in such a way as to separate the midclle from the inferior

Frg. 105.-The Inferior Concha, Adult Sphenomal Turbinate, and Lacrimal Bones.

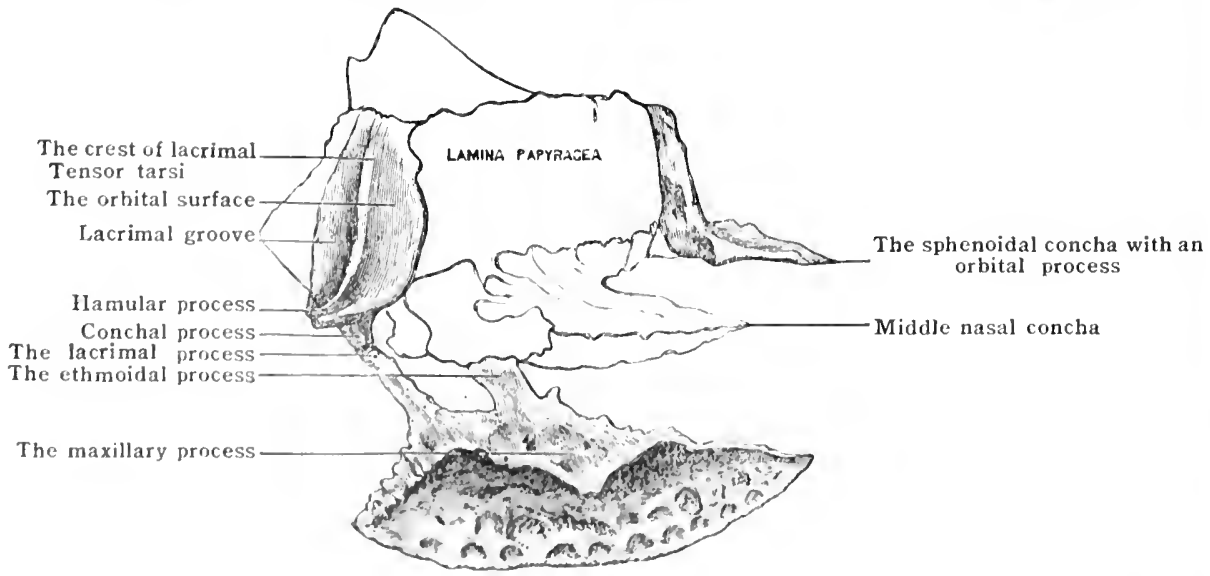

meatis of the nose. It may be reginded as a dismemberment of the ethmoidal labyrinth, with which it is edescly related. It presents for examination two surfirene, fwo loorders, and two extremities.

Ther lateral surface is concave, looks lowarl the lateral wall of the nasal fossa, 
and is overhung by the maxillary process. The medial surface is convex, pitted with depressions, and grooved for vessels, which, for the most part, run longitudinally. The superior or attached border articulates in front with the conchal crest of the maxilla, then ascends to form the lacrimal process, which articulates with the lacrimal bone and forms part of the wall of the lacrimal canal. Behind this, it is turned downward to form the maxillary process, already mentioned, which overhangs the orifice of the maxillary sinus and serves to fix the bone firmly to the lateral wall of the nasal fossa. The projection behind the maxillary process is the ethmoidal process, joined in the articulated skull with the uncinate process of the ethmoid across the opening of the maxillary sinus. Posteriorly the upper border articulates with the conchal crest of the palate. The inferior border is free, rounded, and somewhat thickened. The anterior extremity is blunt and flattened, and broader than the posterior extremity, which is elongated, narrow, and pointed.

Articulations. - With the maxilla, lacrimal, palate, and ethmoid.

Ossification.- The inferior nasal concha is ossified in cartilage from a single nucleus which appears in the fifth month of intra-uterine life. At birth it is a relatively large bone and fills up the lower part of the nasal fossa.

\section{THE LACRIMAL}

The lacrimal bone [os lacrimale] (fig. 105) is extremely thin and delicate, quadrilateral in shape, and situated at the anterior part of the medial wall of the orbit. It is the smallest of the facial bones.

The orbital surface is divided by a vertical ridge, the posterior lacrimal crest, into two unequal portions. The anterior, smaller portion is deeply grooved to form the lacrimal groove, which lodges the lacrimal sac and forms the commencement of the canal for the naso-lacrimal duct. The portion behind the ridge is smooth, and forms part of the medial wall of the orbit. The ridge gives origin to the orbicularis oculi (pars lacrimalis) muscle and ends below in a hook-like process, the lacrimal hamulus, which curves forward to articulate with the lacrimal tubercle of the maxilla and completes the superior orifice of the naso-lacrimal canal. The medial surface is in relation with the two anterior cells of the ethmoid (lacrimo-ethmoidal), forms part of the infundibulum, and inferiorly looks into the middle meatus of the nose. The superior border is short, and articulates with the medial angular process of the frontal. The inferior border posterior to the crest joins the medial edge of the orbital plate of the maxilla. The narrow piece, anterior to the ridge, is prolonged downward as the descending process to join the lacrimal process of the inferior nasal concha. The anterior border articulates with the posterior border of the frontal process of the maxilla and the posterior border with the lamina papyracea of the ethmoid.

The vessels of the lacrimal bone are derived from the infra-orbital, dorsal nasal branch of the ophthalmic, and anterior ethmoidal arteries.

Articulations. - The lacrimal articulates with the ethmoid, maxilla, frontal, and inferior nasal concha.

Ossification.--This bone arises in the membrane overlying the cartilage of the fronto-nasal plate, and in its mode of ossification is very variable. As a rule, it is formed from a single nucleus which appears in the third or fourth month of intra-uterine life. Not infrequently, the hamulus is a separate element, and occasionally the bone is divided by a horizontal cleft, a process of the lamina papyracea projecting between the two halves to join the frontal process of the maxilla. More rarely the bone is represented by a group of detached ossicles resembling Wormian bones.

The hamular process is regarded as representing the remains of the facial part of the lacrimal seen in lower animals.

\section{THE VOMER}

The vomer (fig. 106) (ploughshare bone) is an unpaired flat bone, which lies in the median plane and forms the lower part of the nasal septum. It is thin and irregularly quadrilateral in form, and is usually bent somewhat to one side, though the deflection rarely involves the posterior margin. Each lateral surface is covered in the recent state by the mucous membrane of the nasal carity, and is traversed by a narrow but well-marked groove, which lodges the naso-palatine nerve from the spheno-palatine ganglion. 
The superior border, by far the thickest part of the bone, is expanded laterally into two alæ. The groove between them receives the rostrum of the sphenoid, and the margin of each ala comes into contact with the sphenoidal process of the palate and the vaginal process of the medial pterygoid plate. The inferior border is uneren and lies in the groove formed by the crests of the maxillary and palate bones of the two sides. The anterior border slopes downward and forward and is grooved below for the septal cartilage of the nose; above it is united with the perpendicular plate of the ethmoid. The posterior border, smooth, rounded, and covered by mucus membrane, separates the posterior nares. The anterior and inferior borders meet at the anterior extremity of the bone which forms a short vertical ridge behind the incisor crest of the maxillæ. From near the anterior extremity, a small projection passes downward between the incisive foramina.

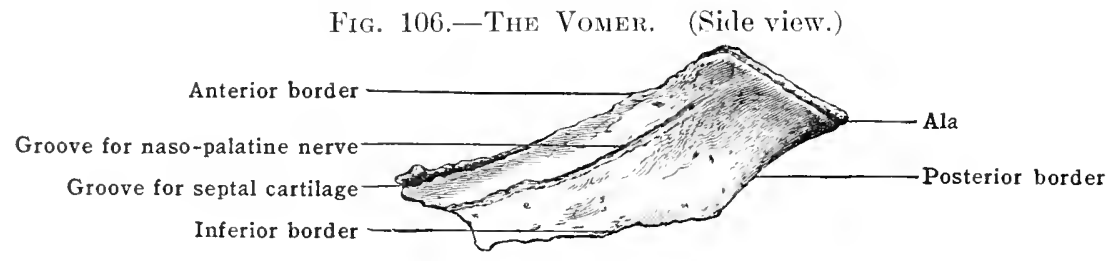

Blood-supply.-The arterial supply of the vomer is derived from the anterior and posterior ethmoidal and the spheno-palatine arteries. Branches are also derived from the posterior palatine through the foramen incisivum.

Ossification.- The vomer is ossified from two centres which appear about the eighth week in the membrane investing the ethmo-vomerine cartilage. The two lamellæ unite below during the third month and form a shallow bony trough in which the cartilage lies. In the process of growth the lamellie extend upward and forward and gradually fuse to form a rectangular plate of bone, the cartilage enclosed between them undergoing absorption at the same time. The ale on the superior margin and the groove in front are evidence of the original bilaminar condition.

\section{THE NASAL}

The nasal (figs. 107 and 108) are two small oblong bones situated at the upper part of the face and forming the bridge of the nose. Each bone is thicker and narrower above, thinner and broader below, and presents for examination two surfaces and four borders.
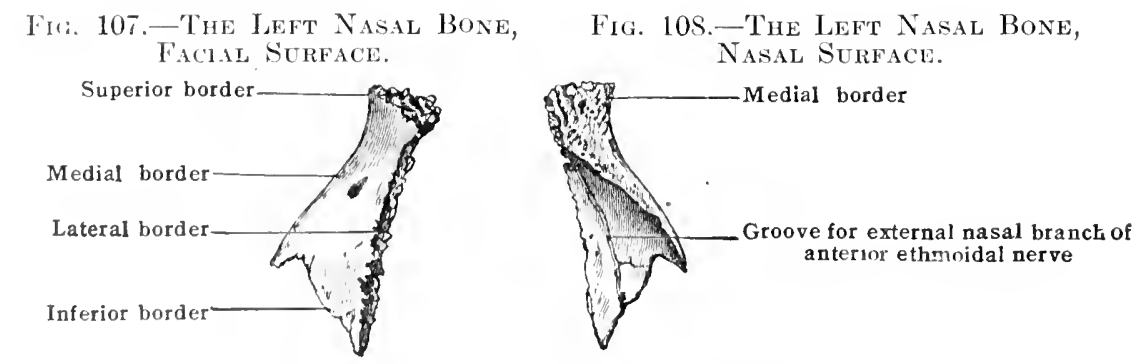

The facial surface is concave from above downward, convex from side to side, and near the contre is perforated by a small formen, which transmits a small tributary to the facial vein. The posterior or nasal surface, covered in the recent state hy mucous mombrame, is concave laterally, and traversed by a longitudinal greove [sulens ethmoidalisel for the anterior ethmoidal branch of the ophthatmic division of the fifth nere. The short superior border is thick and scrrated for articulation with the merlial part of the nasal noteh of the frontal. The inferior border is thin, and serves for the attachment of the lateral nasal cartilage. It is notelied for the extermal nasial branch of the anterior ethmoidal nerve. The nasal homes of the two silles are mnited by their medial borders, forming the internasal suture. The contiguous horder's are prolonged backward to form a crest which rests on the frontal spinc and the anteriof border of the perpendicular plate of the ofhmoid. The lateral border articulates with the frontal process of the maxillat. 
Blood-supply.- - Arteries are supplied to this bone by the nasal branch of the ophthalmic, the frontal, the angular, and the anterior ethmoidal arteries.

Articulations. - With the frontal, maxilla, ethmoid, and its fellow of the opposite side

Ossification.--Each nasal bone is developed from a single centre which appoars about the eighth week in the membrane overlying the fronto-nasal cartilage. The cartilage, which is continuous with the ethmoid cartilage above and the lateral cartilage of the nose below, subsequently undergoes absorption as a result of the pressure caused by the expanding bone. At birth the nasal bones are nearly as wide as they are long, whereas in the adult the length is three times greater than the wilth.

\section{THE MAXILLA}

The maxilla or upper jaw-bone (figs. 109, 110, 111) is one of the largest and most important of the bones of the face. It supports the maxillary teeth and takes part in the formation of the orbit, the hard palate, and the nasal fossa. It is divisible into a body and four processes, of which two-the frontal and zygomatic-belong to the upper part, and the palatine and alveolar to the lower part of the bone.

The body is somewhat pyramidal in shape and hollowed by a large cavity known as the sinus maxillaris (antrum of Highmore), lined by mucous membrane in the recent state, and opening at the base of the pyramid into the nasal cavity, the zygomatic process forming the apex. The anterior (or facial) surface looks forward and outward and is marked at its lower part by a series of eminences which indicate the positions of the fangs of the teeth. The eminence produced by the fang of the canine tooth is very prominent and separates two fossa. That on the medial side is the incisive fossa, and gives origin to the alar and transierse portions of the nasalis, and just above the socket of the lateral incisor tooth, to a slip of the orbicularis oris; on the lateral side is the canine fossa, from which the caninus (levator anguli oris) arises. Above the canine fossa, and close to the margin of the orbit, is the infra-orbital foramen, through which the terminal branches of the infra-orbital nerve and vessels emerge, and from the ridge immediately above the foramen the quadratus labii superioris takes origin. The medial margin of the anterior surface is deeply concave, forming the nasal notch, and is prolonged below into the anterior nasal spine.

A ridge of bone extending upward from the socket of the first molar tooth separates the anterior from the infratemporal (zygomatic) surface. This latter surface is convex and presents near the middle the orifices of the posterior alveolar canals, transmitting the posterior alveolar vessels and nerves. The posterior inferior angle, known as the tuberosity [tuber maxillare], is rough and is most prominent after eruption of the wisdom tooth. It gives attachment to a few fibres of the internal pterygoid muscle and articulates with the tuberosity of the palate.

The orbital surface [planum orbitale] is smooth, irregularly triangular, and forms the greater part of the floor of the orbit.

Anteriorly, it is rounded and reaches the orbital circumference for a short distance at the root of the nasal process; laterally is the rough surface for the zygomatic bone. The posterior border, smooth and rounded, forms the inferior boundary of the inferior orbital fissure. The medial border is nearly straight and presents behind the frontal process, a smooth rounded angle forming part of the circumference of the orbital orifice of the naso-lacrimal canal, and a notch which receives the lacrimal bone. The rest of the medial border is rough for articulation with the lamina papyracea of the ethmoid and orbital process of the palate bone.

The orbital surface is traversed by the infra-orbital groove, which, commencing at the posterior border, deepens as it passes forward and finally becomes closed in to form the infra-orbital canal. It transmits the second division of the fifth nerve and the infra-orbital vessels and terminates on the anterior surface immediately below the margin of the orbit. From the infra-orbital, other canals - the anterior and middle alveolar-run downward in the wall of the antrum and transmit the anterior and middle alveolar vessels and nerves. Lateral to the commencement of the lacrimal canal is a shallow depression for the origin of the inferior oblique.

The nasal surface takes part in the formation of the lateral wall of the nasal fossa. It presents a large irregular aperture which leads into the antrum and, immediately in front of this, the lacrimal groove, directed downward, backward, and laterally into the inferior meatus of the nose. The groove is converted 
into a canal by the lacrimal and inferior nasal concha and transmits the nasolacrimal duct.

In front of the groove is a smooth surface erossed obliquely by a ridge, the conchal crest, for articulation with the inferior nasal concha. The surface below the erest is smooth, coneave, and belongs to the inferior meatus; the surface above the crest extends on to the lower part of the frontal process and forms the wall of the atrium of the middle meatus. Behind the opening of the antrum the surface is rough for articulation with the vertieal plate of the palate bone, and erossing it obliquely is a smooth groove converted by the palate into the pterygopalatine canal for the passage of the (descending) palatine nerves and the descending palatine artery.

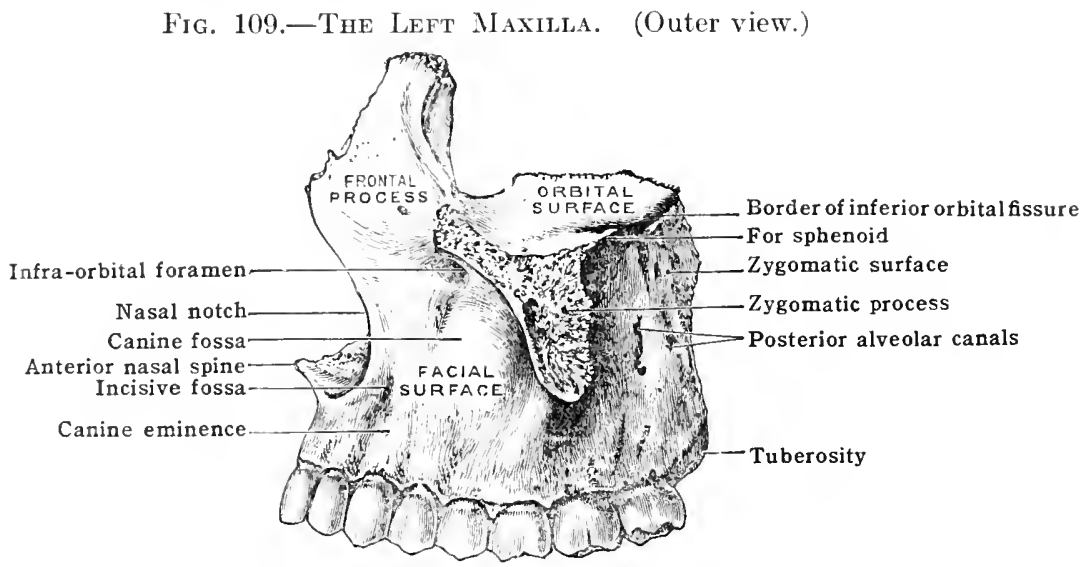

The frontal process, somewhat triangular in shape, rises vertically from the angle of the maxilla. Its lateral surface is continuous with the anterior surface of the body, and gives attachment to the orbicularis oculi, the medial palpebral ligament and the quadratus labii superioris (caput angulare). The medial surface forms part of the lateral boundary of the nasal fossa and is crossed obliquely by a low ridge, known as the agger nasi, limiting the atrium of the middle meatus.

The hinder part of this surface rests on the anterior extremity of the labyrinth of the ethmoirl and completes the maxillo-ethmoidal cells. The superior border articulates with the frontal; the anterior border articulates with the nasal bone; the posterior border is thick and vertically grooved, in continuation with the lacrimal groove, and lodges the lacrimal sac. The medial margin of the groove articulates with the lacrimal bone, and the junction of its lateral margin with the orbital surface is indicated by the lacrimal tubercle.

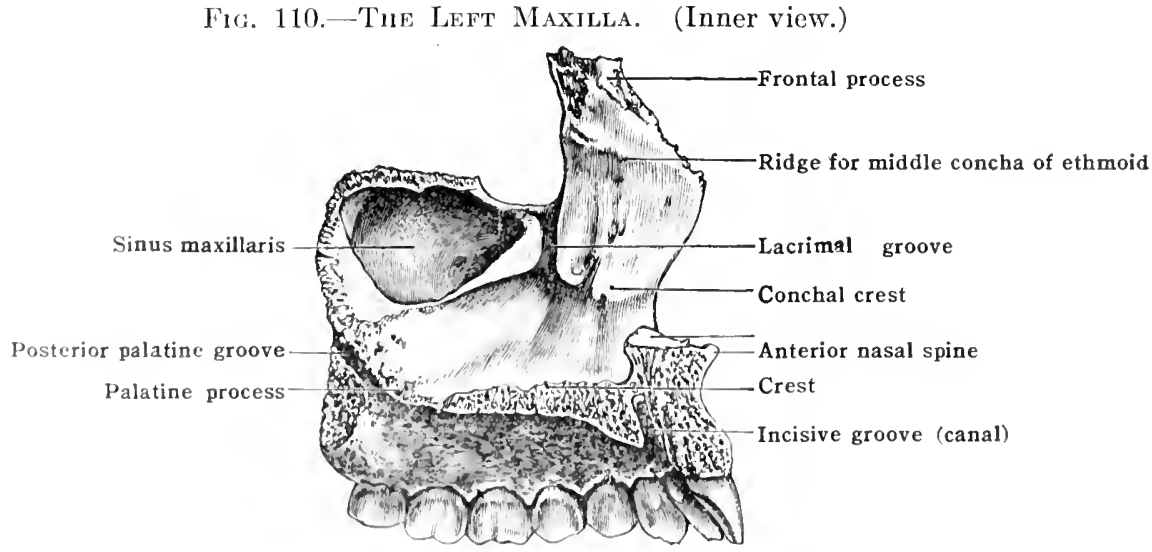

The zygomatic process, rough and triangular, forms the summit of the forminent ridge of bone sceatrating the anterior and infratemporal surfaces. It articulates above with the zygematic, and from its inferior angle a few fibres of 1he messeter take origin. 'The anterior and posterior surfaces are continuous with the anterior and infratempreral surfaces of the body.

'The palatine process projoets horizontally from the merlial surface and, with the ereresponding process of the opposite siele, forms about three-fourths of the hard palate. The sujuriol surface is mooth, concave from sicle to side, and 
constitutes the larger part of the floor of the nasal fossa. The inferior surface is vaulted, rough, and perforated with foramina for nutrient vessels. Near it: lateral margin is a longitudinal groove for the transmission of the ressels and nerves which issue at the posterior palatine canal and course along the lower aspect of the palate. When the bones of the two sides are placed in apposition, a large orifice may be seen in the middle line immediately behind the incisor teeth. This is the incisive foramen, at the bottom of which are four foramina. Two are small and arranged one behind the other exactly in the meso-palatine suture. These are the foramina of Scarpa and transmit the naso-palatine nerves, the left

Fig. 111.-Section of Maxille to show the Floor of the Maxillary Axtrci. (Reduced $\frac{1}{4}$.)

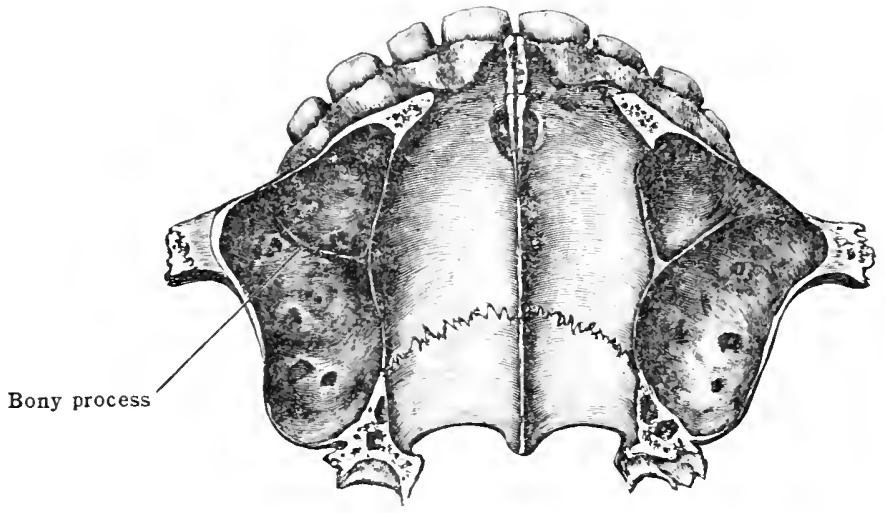

passing through the anterior and the right through the posterior aperture. The lateral and larger orifices are the foramina of Stenson, representing the lower apertures of two passages by which the nose communicates with the mouth; they transmit some terminal branches of the descending palatine artery to the nasal fossæ, and lodge recesses of the nasal mucous membrane and remnants of Jacobson's organs.

Fig. 112.-Maxilla and Zygonatic Bone, to show Muscular Attachments. (Poirier.)

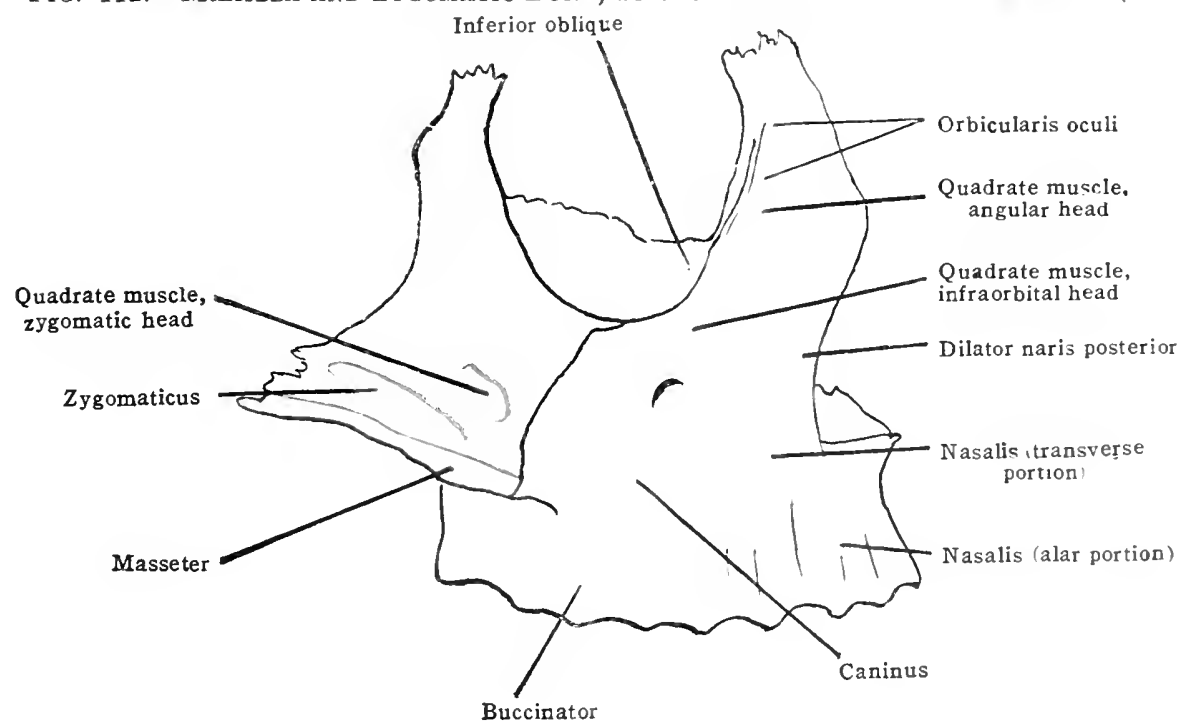

Running laterally from the incisive foramen to the space between the second incisor and canine tooth, an indistinct suture may sometimes be seen, indicating the line of junction of the maxillary and pre-maxillary portions of the bone. The premaxilla or incisive bone is the part which bears the incisor teeth and in some animals exists throughout life as an independent element. The posterior border of the palate process is rough and serrated for articulation with 
the horizontal plate of the palate bone which completes the hard palate. The medial border joins with its fellow to form the nasal crest upon which the vomer is received. The more elevated anterior portion of this border is known as the incisor crest, and is continued forward into the anterior nasal spine. The septal cartilage of the nose rests on its summit and the anterior extremity of the romer lies immediately behind it. At the side of the incisor crest is seen the upper aperture of the canal leading from the nose to the mouth (Stenson's canal), which in its course downward becomes a groove by a deficiency of its medial wall. Thus when the two bones are articulated a canal is formed (incisive) with the lower ends of two canals opening into it.

The alevolar process is crescentic in shape, spongy in texture, and presents cavities [alveoli dentales] in which the upper teeth are lodged. When complete

there are eight tooth-cavities (alveoli), with wide mouths, gradually narrowing as they pass into the substance of the bone, and forming exact impressions of the corresponding fangs of the teeth. The pit for the canine tooth is the deepest; those for the molars are the widest, and present subdivisions. Along the lateral aspect of the alveolar process the buccinator arises as far forward as the first molar tooth.

The maxillary sinus or antrum of Highmore, as the air-chamber occupying the body of the bone is called, is somewhat pyramidal in shape, the base being represented by the nasal or mediai surface, and the apex corresponding to the zygomatic process. In addition it has four walls: the superior is formed by the orbital plate, and the inferior by the alveolar ridge. The anterior wall corresponds to the anterior surface of the maxilla, and the posterior is formed by the infratemporal surface. The medial boundary or base presents a very irregular

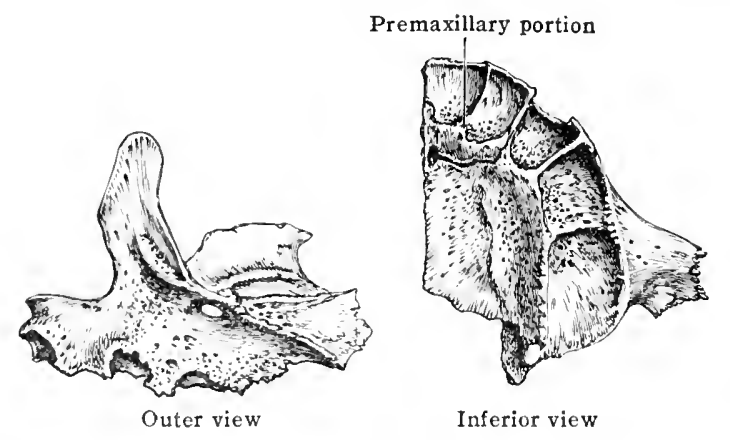

Fig. 113.-The Maxilla at Birth.

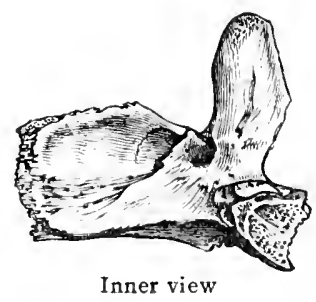

orifien at its posterior part; this is partially filled in by the vertical plate of the palate bone, the uncinate process of the ethmoid, the maxillary process of the inferior nasal concha, and a small portion of the lacrimal bone. Even when these benes are in their relative positions, the orifice is very irregular in shape, and repuires the musens membrane to form the definite rounded aperture (or apertures, for they arr offen multiple) known as the opening of the sinus through which the "avity ammunicates with the midelle meatus of the nose.

Thre ravity of the sinns varies considerably in size and slape. In the young, it is small and the walls are thek: as life arlvances it enlarges at the expense of its walls, and in old age they are ofterl extremely thin, se that oesisionally the eavity extends even into the substance of the zygomatir: bone. 'The flool of the simus is usually very uneven, due to prominenees corresponling to the routs of the molat tecth. In most ases the bone separating the teeth from thr simas is very thin, and in some cases the roots project into it. The toeth which eome into

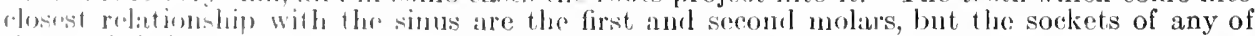
the forth lodgerl in the maxilla may, moler discased eonditions, communieate with it. As a rule, the "itvity of the simus is single, hut oceasiomally specinens are seen in which it is divided ly lony soptin into shambers, and it is not unommon to find recesses separated by bony proensis. The row of the sinns presents near its anterior aspeet what appears to be a thick rib of hone; this is hollow and corrosponds to the inf rat-orbital canal.

The mest satisfactory mothod of studying the relation of the bones closing in the base of

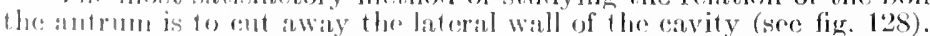

Blood-supply. -The maxilla is a very vascular bono and its arteries are numerous and larese. They are derived from the infra-orbital, alveolar, descending palatine, spheno-palatinc, othoriclal, frontal, nasal, and fiucial vessels.

Articulations.-With the frontal, nasial, lacrinal, ethmoid, palate, vomer, zygomatic, inferior nasal concha and its follow of the opposite side. Occasionally it articulates with the ureat wing, amel the pterygoid process, of the spleneid. 
Ossification.-The maxilla is developed from several centres which are deposited in melubrane during the second month of intrauterine life. Several pieces are formed which speedily fuse, so that at birth, with the exception of the incisor fissure separating the maxilla from the premaxilla, there is no trace of the composite character of the bone. The centres of ossification comprise-(1) the malar, which gives rise to the portion of bone outsicle the infra-orbital canal; (2) the maxillary, from which the greater part of the body and the frontal process are developed; (3) the palatine, forming the hinder three-fourths of the palatal process and arljoining part of the nasal wall; (4) the premaxillary, giving rise to the independent premaxillary bone (os incisivum), which lodges the incisor teeth and completes the anterior fourth of the hard palate. In the early stages of growth the premaxilla may consist of two pieces arising from two centres of ossification which Albrecht has named as follows:- the endognathion, or medial division for

Fig. 114.-Maxille at the exd of the First Dentition in both of which the Stteres between Maxilla and Preniaxilla, and Between the two Parts of the Premaxilla, ARE SEEN.

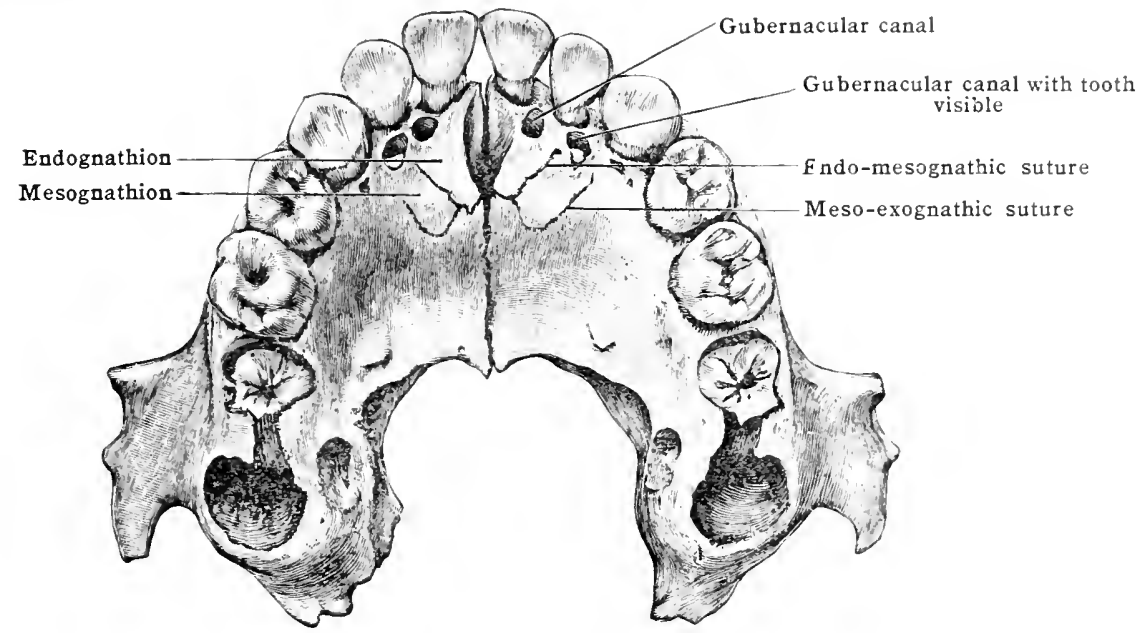

the central incisor, and the mesognathion, or lateral division for the lateral incisor; the rest of the maxilla is named the exognathion; (5) the prepalatine, corresponding to the infra-vomerine centre of Rambaud and Renault, forms a portion of bone interposed between the premaxillary in front and the palatine process behind. It gives rise to a part of the nasal surface and completes the medial wall of the incisive canal.

At birth the sinus is narrow from side to side and does not extend laterally to any appreciable extent between the orbit and the alveoli of the teeth. During the early years of life it. gradually enlarges, but does not attain its full growth until after the period of the second dentition.

\section{THE PALATE}

The palate bone [os palatinum] (figs. 115, 116) forms the posterior part of the hard palate, the medial wall of the nasal fossa between the maxilla and the medial pterygoid plate, and, by its orbital process, the hinder part of the floor of the orbit. It is somewhat L-shaped and presents for examination a horizontal part and a perpendicular part; at their point of junction is the pyramidal process, and surmounting the top of the vertical plate are the orbital and sphenoidal processes, separated by the spheno-palatine notch.

The horizontal part resembles the palatine process of the maxilla, but is much shorter. The superior surface is smooth, concave from side to side, and form: the back part of the floor of the nasal fossa; the inferior surface eompletes the hard palate behind and presents near its prosterior border a transwerse ridwe which gives attachment to the tensur veli palatini muscle.

The anterior border is rough for articulation with the palatine process of the maxilla; the posterior is free, curved, and sharp, giving attachment to the sof palate. Nedially it is thick and broad for articulation with its fellow of the opposite side, forming a continuation of the crest of the palatal processes of the maxille and supporting the vomer. The posterior extremity of the crest is the posterior nasal spine, from which the azygos uvelie arises. Laterally, at its" junction with the perpendicular part, it is grooved by the lower end of the pterygo-palatine canal.

The perpendicular part is longer and thinner than the horizontal plate. The lateral surface is in relation with the maxilla and is divided into two parts by 
a vertical groove which forms with the maxilla the pterygo-palatine canal for the transmission of the anterior palatine nerve and the descending palatine artery. The part of the surface in front of the groove articulates with the nasal surface of the maxilla and overlaps the orifice of the antrum by the maxillary process, a variable projection on the anterior border. Behind the groove the surface is rough for articulation with the maxilla below and the medial pterygoid plate above.

Fig. 115.-Palate Bone (Left). (Medial view.)

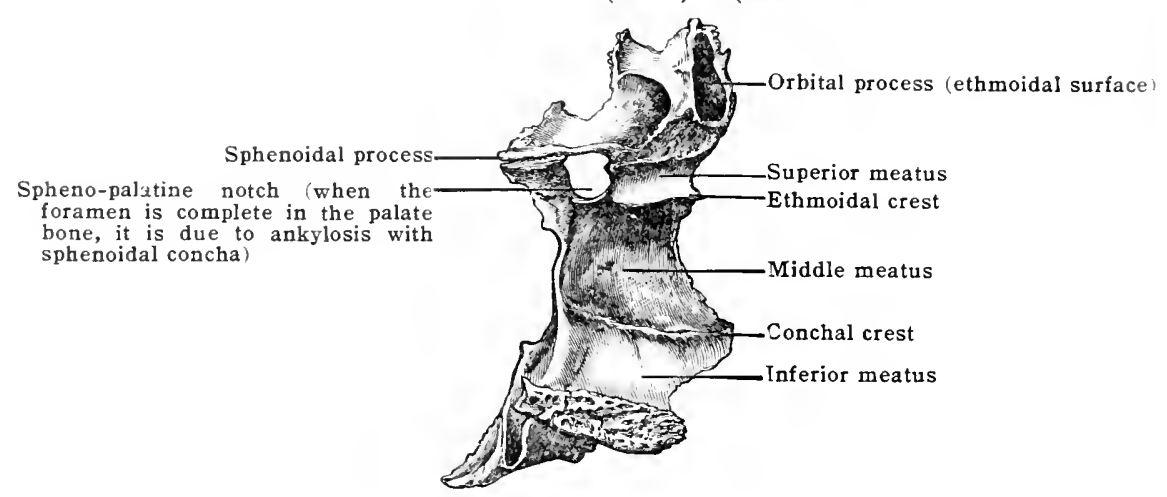

The medial or nasal surface presents two nearly horizontal ridges separating three shallow depressions. Of the depressions, the lower forms part of the inferior meatus of the nose, and the limiting ridge or conchal (inferior turbinate) crest articulates with the inferior nasal concha. Above this is the depression forming part of the middle meatus, and the ridge or ethmoidal (superior turbinate) crest, constituting its upper boundary, articulates with the middle nasal concha.

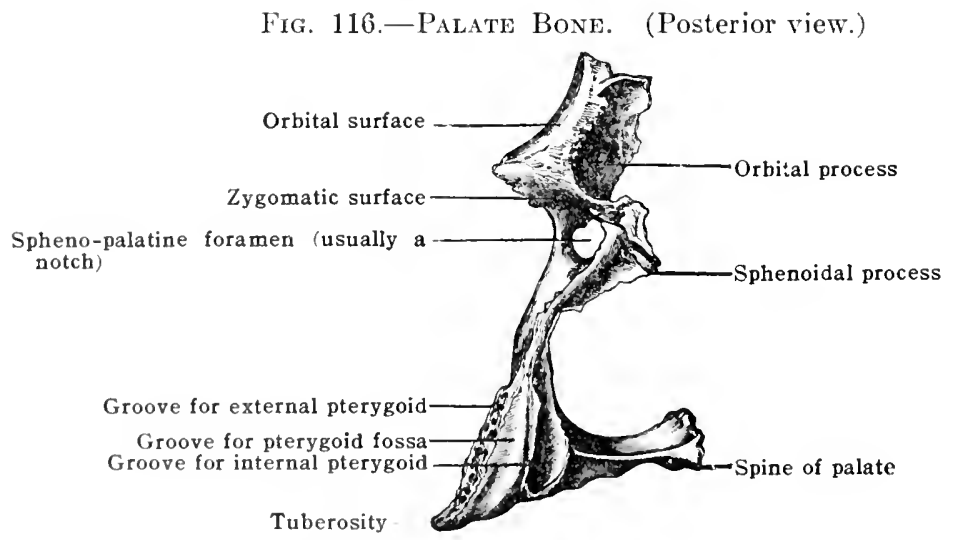

The upper growe is narrower and deeper than the other two and forms a large part of the superior novetis of the nose. The anterior borker of the vertical plate is thin and bears the maxillary process, a tongue-tike piece of bone, which extends over the opening of the maxillary sinns fron behind. This border is eontinuous above with the orbital process. The posterior border is rough and articulates with the anterior border of the medial pterygoid plate. It is continuous superiorly with the spbenoirlal process.

The pyramidal process or tuberosity fits into the noteh between the lower extremities of the pterygoil plates and presents posteriorly three grooves. The midelle, smooth and coneave, eompletes lhe pteryenid fossin, and gives origin to a few filses of the inlernal pterygoid; the medial and latreal grooves are rougl for articulation with the anterior border of the eorresponding prorgeil plite. Inferiorly, close to its junction with the horizontal plate, are the openings of the greater palatine and smaller palatine canals, of which the latter are the smaller and less constant; they transmit the palatine nerves. Nedially the pyramiclal process gives origin to a few fibres of the superior constrictor of the pharynx, and laterally a small part appears in the zy gornatiofossa between the tuberosity of the maxilla and the pterygoid process of the sphenoid.

'The: sphenoidal process, the smaller of the two proresses smmomnting the vertieal part, curves upward and monlially and presents three surfaces and two borders. 'The superior surface is in contart with the borly of the sphenoid, and the top of the medial pterygoid plate, where it completes the pharyngeal canal. The medial or inferior surface forms part of the lateral 
wall and roof of the nasal fossa, and at its medial end touches the ala of the vomer. The lateral surface looks forward and laterally into the pterygo-palatine (spheno-maxillary) fossa. Of the two borders, the posterior is thin and articulates with the medial pterygoid plate; the anterior border forms the posterior boundary of the spheno-palatine foramen.

The orbital process is somewhat pyramidal in shape, and presents for examination five surfaces, three of which-the posterior, anterior, and medial-are articular and the rest nonarticular. The posterior or sphenoidal surface is small and joins the anterior surface of the body of the sphenoid; the medial or ethmoidal articulates with the labyrinth of the ethmoid; and the anterior or maxillary, which is continuous with the lateral surface of the perpendicular part, is joined with the maxilla. Of the two non-articular surfaces, the superior or orbital, directed upward and laterally, is slightly concave, and forms the posterior angle of the floor of the orbit; the lateral or zygomatic, smooth and directed lateral, looks into the pterygopalatine (spheno-maxillary) and zygomatic fossæ, and forms the anteriol boundary of the spheno-palatine foramen. The process is usually hollow and the cavity completes one of the posterior ethmoidal cells or communicates with the sphenoidal sinus.

Fig. 117.-Maxilla and Palate Bones showing how the Infra-orbital Groove Runs Outward almost at Right Angles fron tie Neighbourhood of the Sphejopalatine Foramen on the Back of the Maxilia and the Orbital Process of the Palate. Posterior View. (E. Fawcett.)

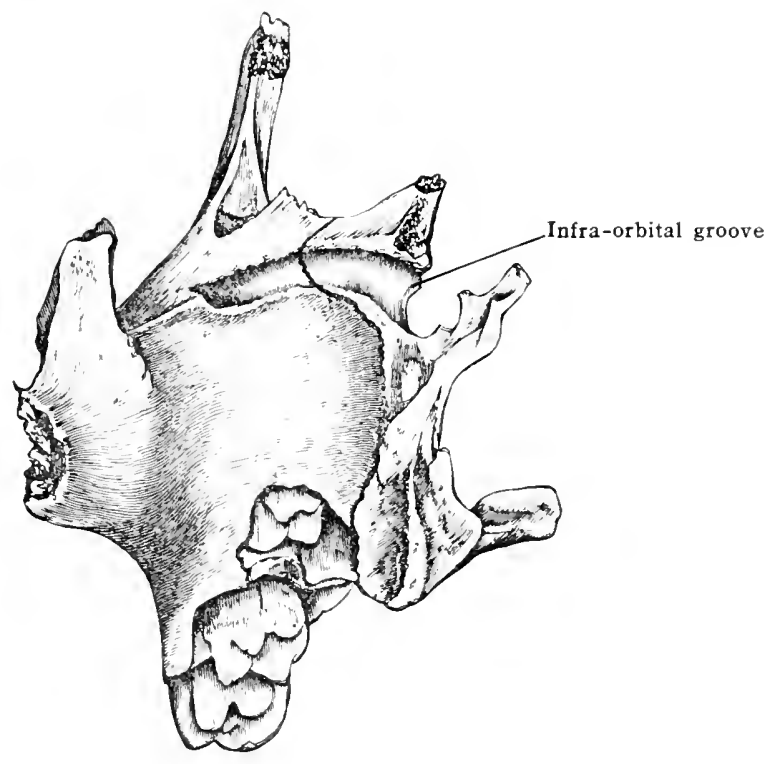

Between the orbital and sphenoidal processes is the spheno-palatine notch, converted by the body of the sphenoid, into a complete foramen. It leads from the pterygo-palatine fossa into the back part of the nasal cavity close to its roof, and transmits the medial branches from the spheno-palatine ganglion and the spheno-palatine vesscls.

Blood-supply. - The palate bone receives branches from the descending palatine and the spheno-palatine arteries.

Articulations. - With the sphenoid, maxilla, vomer, inferior nasal concha, ethmoid, and its fellow of the opposite side.

Ossification. - The palate is ossified in membrane from a single centre which appears about the eighth week at the angle between the horizontal and perpendicular parts. At birth the two parts are nearly equal in length, but as the nasal fosse increase in vertical depth, the perpendicular part is lengthened until it becomes about twice as long as the horizontal part.

\section{THE ZYGOMATIC}

The zygomatic [os zygomaticum] or malar bone (fig. 118) forms the prominence known as the cheek and joins the zygomatic process of the temporal with the maxilla. It is quadrangular in form with the angles directed rertically and horizontally. The malar (or external) surface is convex and presents one or two small orifices for the transmission of the zygomatico-facial nerves and ressels. It is largely covered by the orbicularis oculi and near the middle is slightly elevated to form the malar tuberosity, which gives origin to the zygomaticus and zygomatic head of quadrate muscle of upper lip.

The temporal (or internal) surface is concave and looks into the temporal and infratemporal fossæ; it is excluded from the orbit by a prominent curved plate 
of bone, the orbital process, which forms the anterior boundary of the temporal fossa. The lipper part gives origin to a few fibres of the temporal muscle, while at the lower part is a large rough area for articulation with the zygomatic process of the maxilla.

The orbital process is placed at right angles to the remaining part of the bone and forms the anterior portion of the lateral wall of the orbit. On the orbital

Fig. 118.-The Left Zygomatic Bone.

$A$, the malar surface. $B$, the temporal and orbital surfaces.

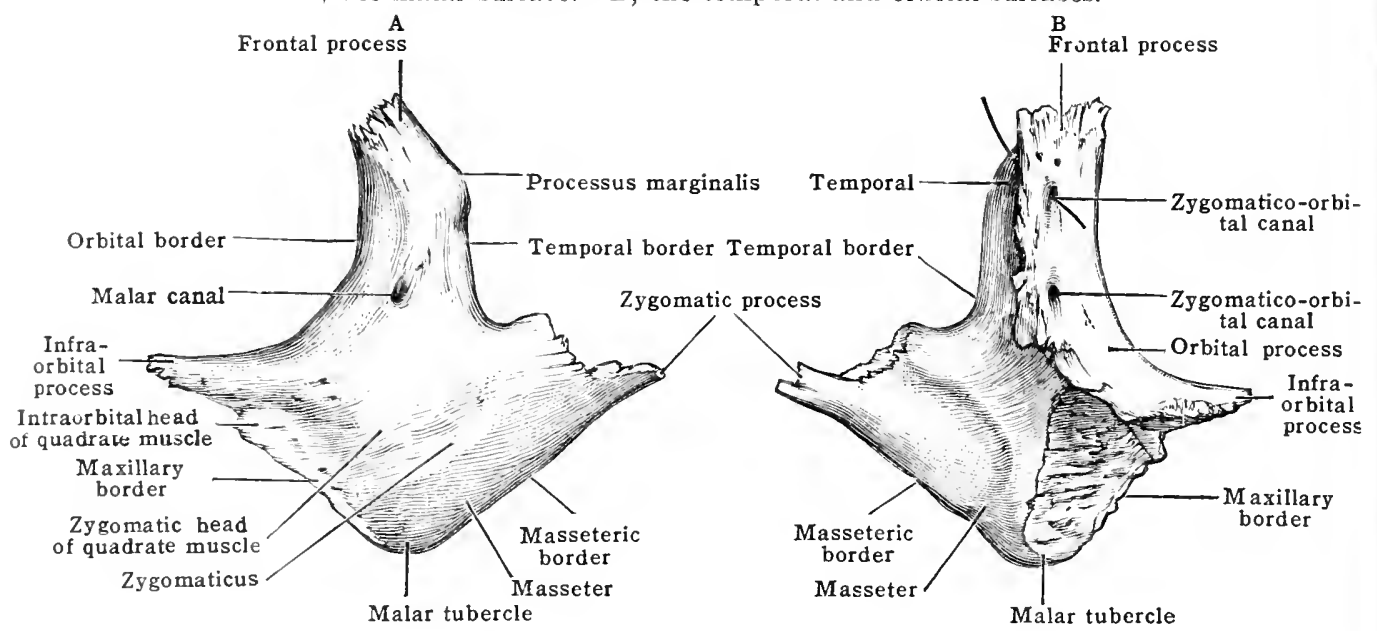

surface of the process are seen the foramina of two zygomatico-orbital canals, which transmit the zygomatico-facial and zygomatico-temporal branches of the zygomatic branch of the fifth, together with two small arteries from the lacrimal. In some cases, howerer, the canal is single at its commencement on the orbital plate and bifurcates as it traverses the bone. The rough free edge of the

Fig. 119. - Shill showing the Right Malar Bone divided into Two Parts by a HoriZONTAL SCTCRE. (From a specimen in the Museum of University College, London.)

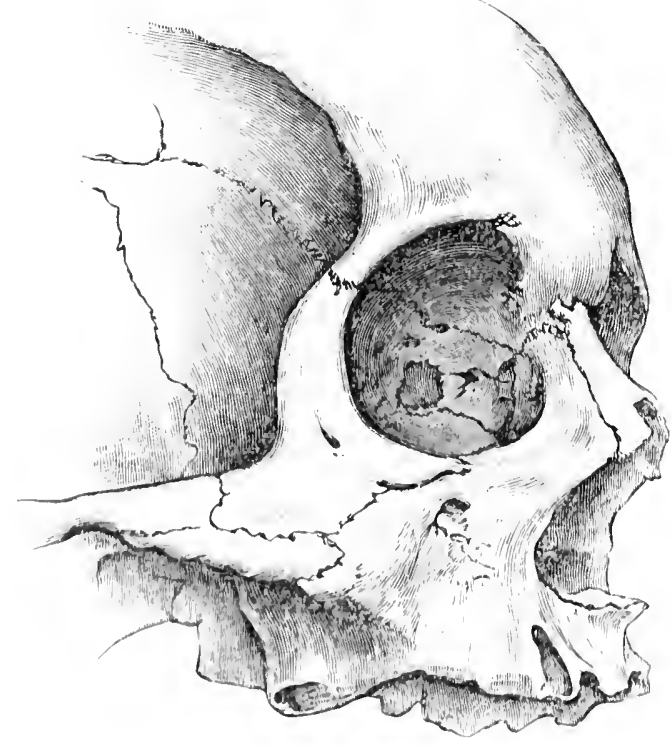

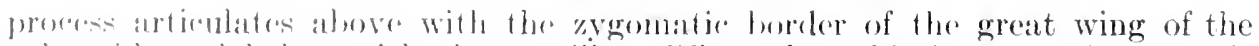

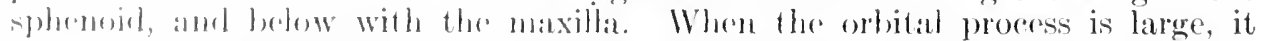
(xalndes the errat wing of the sphenoid from articulation with the maxilla, and the berres then presents near the midalle at short, non-serrated portion 
which eloses the anterior extremity of the inferior orbital (spheno-maxillary) fissure.

All the four angles of the zyromatic bone have distinguishing features. The superior, forming the fronto-sphenoidal process, is the most prominent, and is serrated for articulation with the zygomatic process of the frontal; the anterior or infra-orbital process, sharp and pointed, articulates with the maxilla and occasionally forms the superior boundary of the infraorbital foramen; the posterior or temporal process is blunt and serrated mainly on its medial aspect for articulation with the ztgomatic process of the temporal; the inferior angle, blunt and rounded, is known as the malar tubercle.

Of the four borders, the orbital is the longest and extends from the fronto-sphenoidal to the infra-orbital process. It is thick, rounded, and forms more than one-third of the circunference of the orbit; the temporal border, extending from the fronto-sphenoidal to the temporal process, is sinuously curved and gives attachment to the temporal fascia. Near the frontal angle is usually seen a slight elevation, the processus marginalis, to which a strong slip of the fascia is attached; the masseteric border, thick and rough, completes the lower edge of the zygomatic arch and gives origin to the anterior fibres of the masseter; the maxillary border, rough and concave, is connected by suture with the maxilla, and near the margin of the orbit gives origin to the infra-orbital head of the quadratus lntii superioris.

Blood-supply.- - The arteries of the zygomatic are derived from the'infra-orbital, lacrimal, transverse facial, and deep temporal arteries.

Articulations. - With the maxilla, frontal, temporal, and sphenoid.

Ossification.-The zygomatic is ossified in membrane from three centres which appear in the eighth week of intra-uterine life. The three pieces, which have received the names of prenıalar, postmalar, and hypomalar, unite about the fifth mon th. Occasionally the primary nuclei fail to coalesce, and the bone is then represented in the adult by two or three portions separated by sutures. In those cases in which the premalar and postmalar unite and the hypomalar remains distinct, the suture is horizontal; if the independent portion is the premalar, then the suture is vertical. The bipartite zvgomatic has been observed in skulls obtained from at least a dozen different races of mankind, but because of the greater frequeney in which it occurs in the crania of the Japanese (seren per cent.), the name of os Japonicum has been given to it.

\section{THE MANDIBLE}

The mandible [mandibula] or lower jaw-bone (figs. 120,121) is the largest and strongest bone of the face. It supports the mandibular teeth, and by means of a pair of condyles, moves on the skull at the mandibular fossa of the temporal bones. It consists of a horizontal portion-the body-strongly curved, so ats to somewhat resemble in shape a horseshoe, from the ends of which two branches or rami ascend almost at right angles.

The body is marked in the middle line in front by a faint groove which indicates the symphysis or place of union of the two originally separate halves of the bone. This ends below in the elevation of the ehin known as the mental protuberance, the lowest part of which is slightly depressed in the centre and raised on each side to form the mental tubercle. Each half of the mindible presents two surfaces and two borders. On the lateral surface, at the side of the symphysis, and below the ineisor teeth, is a shallow depression, the incisor fossa, from which the mentalis and the incisivis labit inferioris muscle arise: and more laterally, opposite the second bicuspid tooth, and midway between the upper and lower margins, is the mental foramen, which transmits the mental nerve and vessels. Below the foramen is the oblique line, extending backward and upward from the mental tuberele to the anterior border of the ramus: it divides the body into an upper or alveolar part and a lower or basilar part, and affords attachment to the quadratus labii inferioris and the triangularis oris.

The medial surface presents at the back of the symphysis four small projections, called the mental spine (genial tubereles). These are usually arranged in two pairs, one above the other; the upper comprising a pair of prominent spines, gives origin to the genio-glossi, and the lower, represented in some bones by a median ridge or only a slight roughness, gives origin to the genio-hyoid muscles. At the side of the symphysis near the inferior margin is an oval depresion, the digastric fossa, for the insertion of the digastric muscle. Commencing betow the mental spine, and extending upward and backward to the ramus, is the mylo-hyoid line, which becomes more prominent as it approaches, the alreolar border; it gives attachment along its whole length to the mylo-hyoid muscle, at its posterior fifth to the superior constrictor of the pharyn, and at the posterior extremity to the pterygo-mandibular raphe. Above this line at the sile of the symphysis is a smooth depression [fovea sublingualis] for the sublingual gland, and below it, farther back, is another for the submaxillary gland. 
The alveolar part or superior border is hollowed out into eight sockets or alveoli. These are conical in shape and form an exact counterpart of the roots of the teeth which they contain. From the lateral aspect of the alveolar process, as far forward as the first molar tooth, the buccinator muscle takes origin.

The base or inferior border is thick and rounded. In the anterior part of its extent it gives attachment to the platysma, and near its junction with the ramus is a groore for the external maxillary artery which here turns upward into the face.

The ramus is thimner than the body and quadrilateral in shape. The lateral surface is flat, gives insertion to the masseter, and at the lower part is marked by sereral oblique ridges for the attachment of tendinous bundles in the substance of the muscle. The medial surface presents near the middle the mandibular (inferior dental) foramen, leading into the mandibular (inferior dental) canal which traverses the bone and terminates at the mental foramen on the lateral surface of the body. From the canal, which in its posterior two-thirds is nearer to the medial, and in its anterior third nearer to the lateral, surface of the mandible,

Fig. 120.-The Mandible. (Lateral view.)

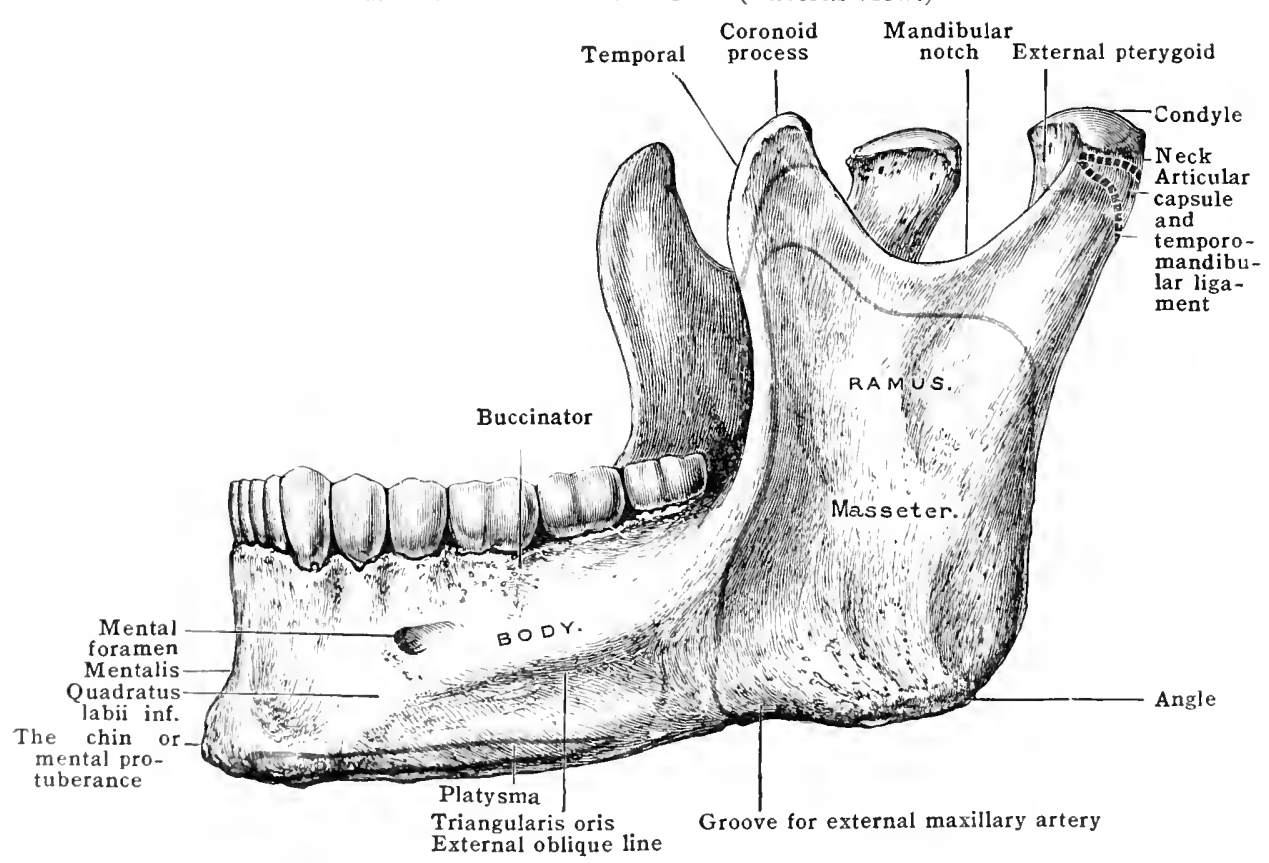

a series of small channels pass upward to the sockets of the posterior teeth and transmit hranches of the inferior alveolar (dental) vessels and nerve; in front of the mestal foramen a continuation of the canal extends forward and conveys the vorich and norves to the canine and incisor teeth. The mandibular foramen is bommed medially by a sharp) margin forming the lingula (mandibular spine), which gives attachment to the spheno-mandibular ligament.

'The postorior margin of the lingula is notehed. 'This notch forms the commencoment of a groove, the mylo-hyoid groove [suleus mylohyoideus], which runs oldigurely downward and forward and lodges the mylo-hyoid nerve and artery, :mol, in the cmbryo, Meckel's cartilage. Behind the spine is a rough area for the insertion of the internal pterygoid muscle.

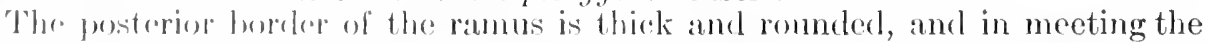
inforior horeter of the ramus forms the angle of the jaw, which is rough, ob tuse,

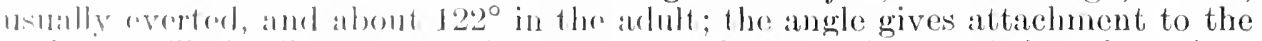
stylo-mandibular ligament. The inferior border is thick, rounded, and continuons with the base. 'The antrerior border is contimuous with the oblique line, whilst the uppror border presents two procosses separated by a doep concavity, the mandibular (sigmejil) notch. Of the processes, the anterior is the coronoid; the jostritior, the condylar. 
The condylar process consists of the condyle [capitulum mandibulæ] and the narrowed portion by which it is supported, the neck. The condyle is oval in shape, with its long axis transverse to the upper borker of the ramus, but obligue with regard to the median axis of the skull, so that the lateral extremity, which presents the condylar tubercle for the temporo-mandibular ligament of the temporo-mandibular articulation, is a little more formard than the medial oxtremity. The convex surface of the condyle is covered with cartilage in the recent

Fig, 121,--The Mandible. (Medial view.)

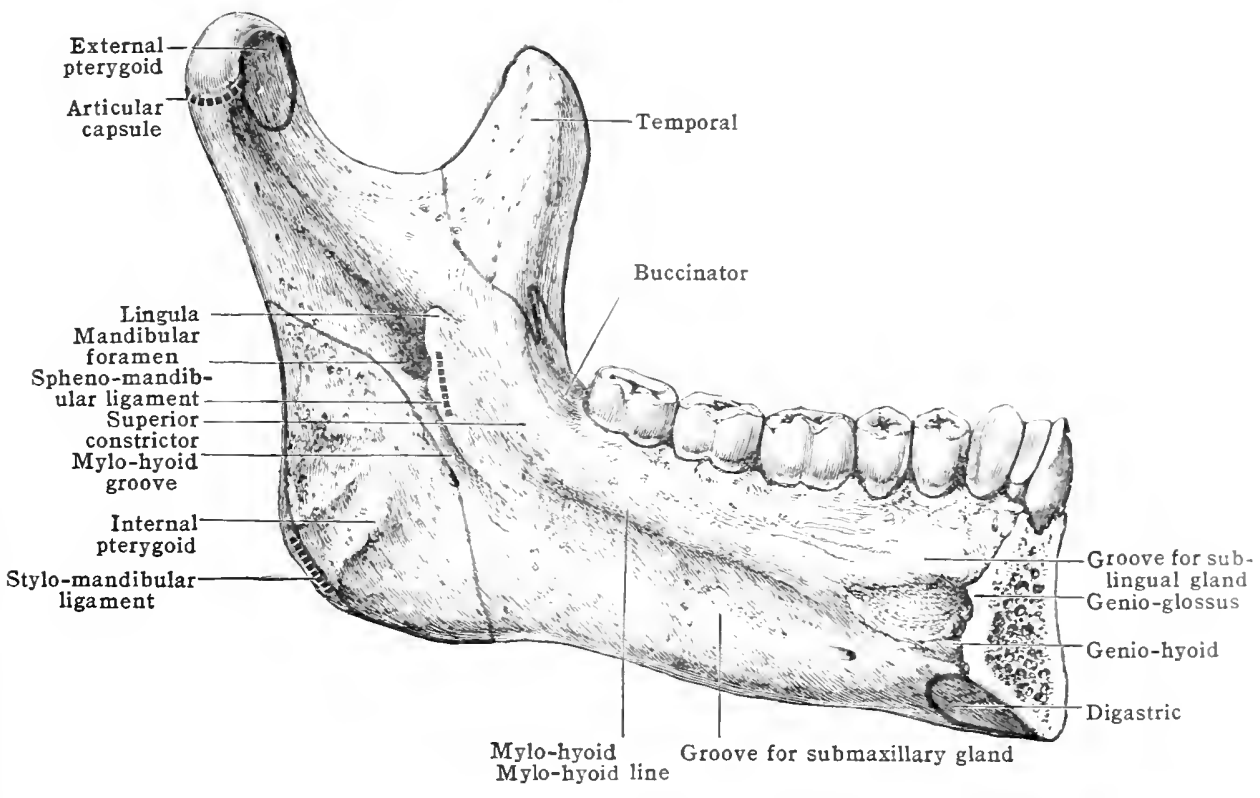

state, and rests in the mandibular fossa; the neck is flattened from before backward, and presents, in front, a depression [fovea pterygoidea] for the insertion of the external pterygoid muscle.

The coronoid process, flattened and triangular, is continued upward from the anterior part of the ramus. The lateral surface is smooth and gives insertion to the temporal and masseter muscles; the medial surface is marked by a rilge which descends from the tip and becomes continuous with the posterior part of the mylo-hyoid line. On the medial surface, as well as on the tip of the coronoid

Fig 122-Mandible showing Relations of Meckel's Cartilage ix Human Fetes of 8 cm. Crown-Rump Length. (After Kollmann, Handatlas der Entwickelungsgeschichte.)

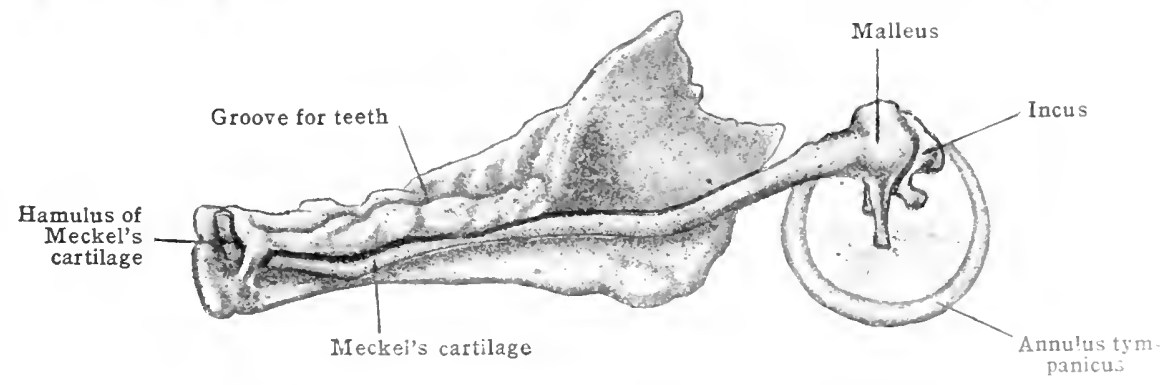

process, the temporal muscle is inserted. The mandibular notch, the leep senillunar excavation separating the coronoid from the condy-lar procesa. is crosact by the masseteric nerve and vessels.

Blood-supply. -Compared with other bones, the superficial parts of the mandible are not so freely supplied with blood. The ohief artery is the inferior alveolar which rums in the mandibular canal, and hence, as the bone is exposed to injury and sometimes actually linl hare in. its alveolar portion, it often neeroses, especially if the artery is involved at the same time 
Ossification.-The mandible is mainly formed by ossification in the fibrous tissue investing the cartilage of the first branchial arch or Meckel's cartilage, although a small portion of the cartilage itself is directly converted into bone.

It is now generally admitted that the lower jaw is developed in membrane as a single skeletal element. The centre of ossifieation appears in the outer aspeet of Meekel's eartilage and gives rise to the bony plate known as the dentary. This plate extends forward right up to the middle line in front, and from it a shelf grows upward for the support of the tooth germs.

Fig. 123.-The Mandible at Birth.
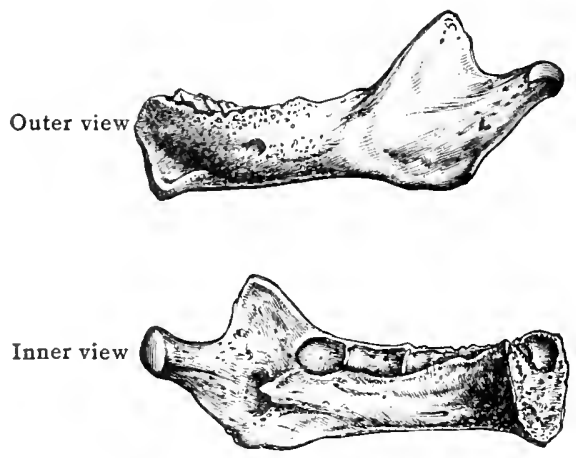

Meckel's eartilage lies below and medial to the dentary plate, and the inferior alveolar nerve passes forward between the two structures. Meckel's eartilage itself takes some small part in the formation of the luwer jaw. Ossification from the primary nucleus invades the cartilage at a point opposite the interval between the first and second tooth germs, and the resulting bone contributes to the formation of the alveolar margin opposite these two teeth. Behind this point the eartilage atrophies except in so far as it helps to form the spheno-mandibular ligament and the malleus and ineus. Behind the symphysis the anterior extremity of the cartilage does not enter into the formation of the jaw, but it usually persists throughout fotal

Fig. 124.-The Skull of a Woman Eighty-three Years Old, to show the Changes in the Mandibide and Maxilla.

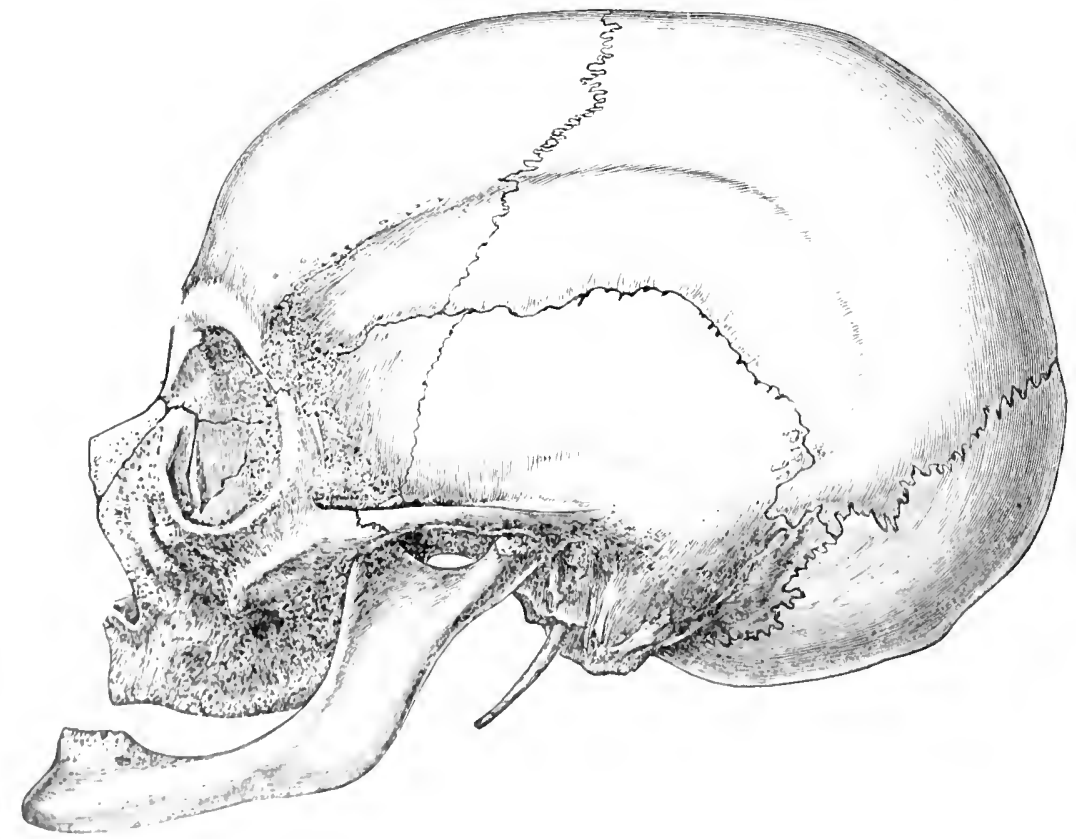

life as one or two small, rommlol, cartilaginous masses. Oecasionally they become ossified and giverise to acorser)y' ussicles in this situation. 'The lamella of bone situater on the medial side of Meckel's cartilitge, corrosponding to the dlistincet splenial element in some animals, arises in than ab an extrosion from the dentary element.

In connection with the eonly latr and coronoil proresses, eartilaginous masses are developed. These lo not, hewerer, indieati searate cloments, lut are allaptations to the growth of the lower juw. "Thry ate ossified hy an extension from the surrounding meinbrane bone. 
The process of ossification of the lower jaw commences very early, between the sixth and eighth week, and proceeds rapidly, so that by the fourth month the various parts are formed.

Age-changes.- At birth the mandible is represented by two nearly horizontal troughs of bone, lodging unerupted teeth, and joined at the symphrsis by fibrous tissue. The borly is mainly alveolar, the basal part being but little developed; the condyle and the upper edge of the symphysis are nearly on a level; the mental foramen is nearer the lower than the upper margin, and the angle is about $175^{\circ}$. The inferior alveolar nerve lies in a shallow groove between the splenial and dentary plates.

During the first year osseous union of the two halves takes place from below upward, but is not complete until the second year. After the first dentition, the ramus forms with the body of the mandible an angle of about $140^{\circ}$, and the mental foramen is situated midway between the upper and lower borders of the bone opposite the second milk-molar. In the adult, the angle formed by the ramus and body is nearer to a right angle, and the mental foramen is opposite the second bicuspid, so that its relative position remains unaltered after the first dentition. In old age, after the fall of the teeth, the alveolar margin is absorbed, the angle formed by the ramus and body is again increased, and the mental foramen approaches the alveolar maryin. in a young and vigorous adult the mandible is, with the exception of the petrous portion of the temporal, the densest bone in the skeleton; in old age it becomes exceedingly porous, and of ten so soft that it may easily be broken.

\section{THE HYOID BONE}

The hyoid bone [os hyoideum] or os linguæ (fig. 125), situated in the anterior part of the neck between the chin and the thyreoid cartilage, supports the tongue and gives attachment to numerous muscles. It is suspended from the lower extremities of the styloid processes of the temporal bones by two slender bands known as the stylo-hyoid ligaments, and is divisible into a body and two pairs of processes, the greater and lesser cornua.

The body, constituting the central portion of the bone, is transwersely placed and quadrilateral in form. It is compressed from before backward and lies obliquely so that the anterior surface looks upward and forward and the posterior surface in the opposite direction.

The anterior surface is convex and divided by a horizontal ridge into a superior and an inferior portion. Frequently it also presents a vertical ridge crossing the former at right angles, and just above the point of intersection is the glosso-hyal

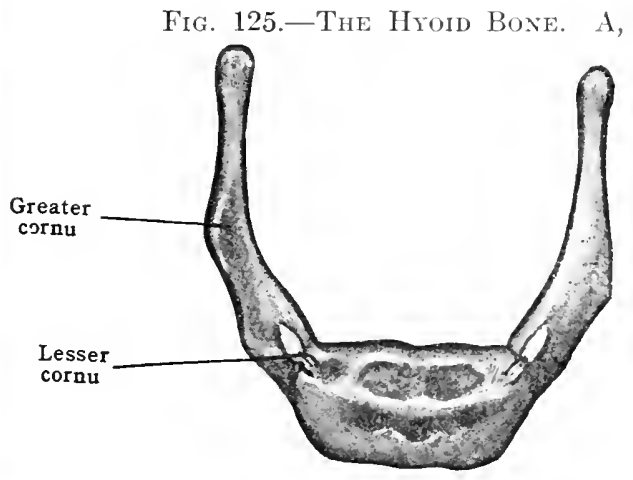

A

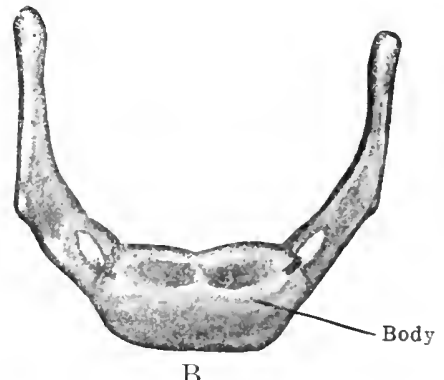

$\mathrm{B}$

process, the vestige of a well-developed process in this situation in the hroid bone of some of the lower animals (reptiles and the horse). In this way foul spaces or depressions for muscular attachments are marked off, two on either" side of the middle line. The posterior surface is deeply concave and separated from the epiglottis by the thyreo-hyoid membrane, and by some loose areolar tissue. The membrane passes upward from the thrreoid cartilage to be attached to the superior border, and interposed between it and the concavity on the back of the body is a small synovial bursa. The inferior border, thicker than the upper, gives insertion to muscles. The lateral borders are partly in relation with the greater cornua, with which they are connected, up to midille life, hy synchondrosis, but after this period, usually by bone. 
The greater cornua projects upward and backward from the sides of the body. They are fluttened from above downward, thicker near their origin, and terminate posteriorly in a rounded tubercle to which the thyreo-hyoid ligament is attached.

The lesser cornua are small conical processes projecting upward and backward opposite the lines of junction between the body and the greater cornua, and by their apices give attachment to the stylo-hyoid ligaments; they are connected to the body by fibrous tissue. Professor Parsons has shown that a joint with a synovial cavity is common between the smaller and geater cornua. The lesser cornua are sometimes partly or even completely cartilaginous in the adult.

Fig. 126.-Hyoid Bone Enlarged to show Muscular Attachients. (After F. G. Parsons.)

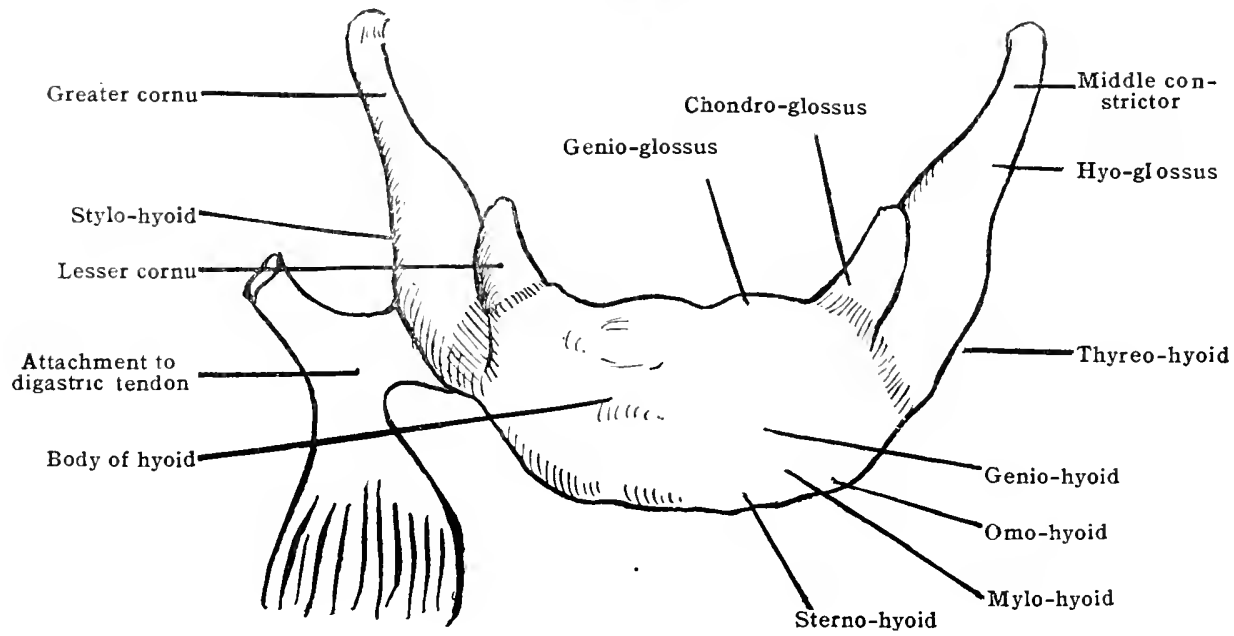

The muscles attached to each half of the hyoid bone may be enumerated as follows:-

Body.......... Genio-hyoid, genio-glossus, mylo-hyoid, sterno-hyoid, omo-hyoid, stylohyoid, thyreo-hyoid and hyo-glossus.

Greater cornu.....Thyreo-hyoid, middle constrietor, hyo-glossus, and digastric.

Lesser cornu...... Chondro-glossus, and middle constrictor.

Ossification.- - In the early months of intra-uterine life the hyoid bone is composed of hyaline eartilage and is directly continuous with the styloid processes of the temporal bones. Ossification takes place from six centres, of which two appear in the central piece of cartilage, one on either side of the middle line, either just before or just after birth; soon after their appearance, however, they coalesce to form the body of the bone (basi-hyal). The centre for each of the greater cornua (thyreo-hyals) appears just about the time of birth, and for each of the lesser cornua (cerato-hyals) some years after birth, even as late as puberty. (F. G. Parsons.) The greater cormua and the body unite in middle life; the lesser cornua rarely ankylose with the body and only in advanced age. Professor Parsons has shown, however, that the lesser cornua more frequently unite with the greater cornua.

\section{THE SKULI, AS A WHOLE}

The skull, formed by the union of the ranial and facial bones already deseribed, naty now be consielered as a wholr. 'Taking a general view, it is spheroidal in shape, smooth alowe, compressed from side to side, flattened and uneven below, and divisible into six regions: a superior region or vertex, a posterior or oecipital region, an anterior or frental region, an inferior region or base, and two lateral regions.

\section{(1) The SUPERor Region}

Viened from atove (morma verticalis) the skull presents an oval outline with the broaker chul bethind, and includes the frontal, parietals, and the interparietal pertion of the occipital. In a skull of average width the aygomatic arches are visible, but in very broand sulls they are obsemed. 
The sutures of the vertex are:-

The metopic, which is, in most skulls, merely a median fissure in the frontal bone just above the glabella; occasionally it involves the whole length of the bone. It is due to the persistence of the fissure normally separating the two halves of the bone in the infant.

The sagittal is situated between the two parietals, and extends from the bregma to the lambda.

The coronal lies between the frontal and parietals, and extends from pterion to pterion.

The lambdoid is formed by the parietals and interparietal portion of the occipital. It extends from asterion to asterion.

The occipital suture is only present when the interparietal exists as a separate element (figs. 70 and 71 ).

The more important points are:-

The bregma, which indicates the situation of the frontal (greater) fontanelle, and marks the confluence of the coronal, the sagittal, and, when present, the metopic sutures.

The lambda, where the sagittal enters the lambloid suture; it marks the situation of the occipital (lesser) fontanelle.

The obelion, a little anterior to the lambra, is usually indicated by a median or two lateral foramina.

\section{(2) The Posterior Region}

Viewed from behind (norma occipitalis) the skull is somewhat pentagonal in form. Of the five angles, the superior or median is situated in the line of the sagittal suture; the two upper lateral angles coincide with the parietal eminences and the two lower with the mastoid processes of the temporal bones. Of the sides, four are somewhat rounded, and one, forming the basal line, running between the mastoid processes, is flattened.

The centre is occupied by the lambda, and radiating from this point are three sutures, the sagittal, and the two parts of the lambdoid. Each half of the lambdoid suture bifureates at the mastoid portion of the temporal bone, the two divisions constituting the parieto-mastoid and occipito-mastoid sutures; the point of bifureation is known as the asterion.

In the lower part of the view is seen the external occipital protuberance (inion), the occipital crest, and the three pairs of nuchal lines, which give it a rough and uneven appearance. The occipital point is the point of the occiput furthest from the glabella in the median plane. It is situated above the external occipital protuberance.

\section{(3) The Lateral Region}

The lateral region (noma lateralis) (fig. 127) is somewhat triangular in shape, being bounded above by a line extending from the zygomatic process of the frontal, along the temporal line to the lateral extremity of the superior nuchal line of the occipital bone; this forms the base of the triangle. The two sicles are represented by lines drawn from the extremities of the base to the angle of the jaw. It is divisible into two portions, one in front, the other behind, the eminentia articularis [tuberculum articulare]. The posterior portion presents, in a horizontal line from behind forward, the mastoid portion of the temporal, with its process and foramen, the external auditory meatus, the centre of which is known as the auricular point, the mandibuiar fossa, and the condyle of the mandible

In the anterior portion are three fossa, (a) temporal, (b) infratemporal, (c) pterygo-palatine (spheno-maxillary), and two fissures, the inferior orbital (sphenomaxillary) and pterygo-palatine.

(a) The temporal fossa, somewhat semilunar in shape, is bounded above and bchind by the temporal line, in front by the frontal, zygomatic, and great wing of sphenoid, and laterally by the zygomatic arch, by which it is separated superficially from the infratemporal fossa; more deeply the infratemporal ridge separates the two fosse.

The fossa is formed by parts of five bones, the zygomatic, temporal, parietal, frontal, great wing of sphenoid, and is traversed by six sutures, coronal, spheno-zygomatic, spluenosquamosal, spheno-parietal, squamosal, and spheno-frontal. The point where the temporal ridge is crossed by the coronal suture is the stephanion, and the region whele the frontal, sphenoid, temporal, and parietal meet is the pterion. The latter is frequently oceupied in the adult by the epipteric bone.

The temporal fossa is concave in front, convex behind, filled by the temporal muscle, and roofed in by a strong glistening aponeurosis, the temporal fascia, which serves to bind down the muscle.

(b) The infratemporal fossa (zygomatic fossa), irregular in shape, is situated below and to the medial side of the zygoma, covered in part by the ramus of the mandible. It is bounded in front by the lower part of the medial surface of the zygomatic, and by the infratemporal surface of the maxilla, on which are seen the orifices of the posterior superior alveolar canals; behind by the posterior border of the lateral pterygoid plate, the spine of the sphenoid, and the articular tubercle; above by the infratemporal ridge, a small part of the squamous portion of 
the temporal, the great wing of the sphenoid perforated by the foramen ovale and foramen spinosum; beion by the alveolar border of the maxilla; laterally by the ramus of the mandible and the zygoma formed by zygomatic and temporal; medially by the lateral pterygoid plate, a line from which to the spine of the sphenoid separates the infratemporal fossa from the base of the skull. It contains the lower part of the temporal muscle and the coronoid process of the mandible, the external and in ternal pterygoids, the internal maxillary vessels, and the mandibular division of the fifth ne:ve with numerous branches. At its upper and medial part are seen the inferior orbital and pterygo-palatine fissures.

The inferior orbital (or spheno-maxillary) fissure is horizontal in position, and lies between the maxilla and the great wing of the sphenoid; laterally it is usually completed by the zygomatic, though in some cases the sphenoid joins the maxilla, and in this way excludes the zygomatic bone from the fissure; medially it is terminated by the infratemporal surface of the orbital process of the palate bone. Through this fissure the orbit communicates with the pterygopalatine (spheno-maxillary), infratemporal, and temporal fossæ. It transmits the infraorbital nerve and vessels, the zygomatic nerve, ascending branches from the spheno-palatine ganglion to the orbit, and a communicating vein from the ophthalmic to the pterygoid plexus.

Fig. 127.-The Skdll. (Norma lateralis.)

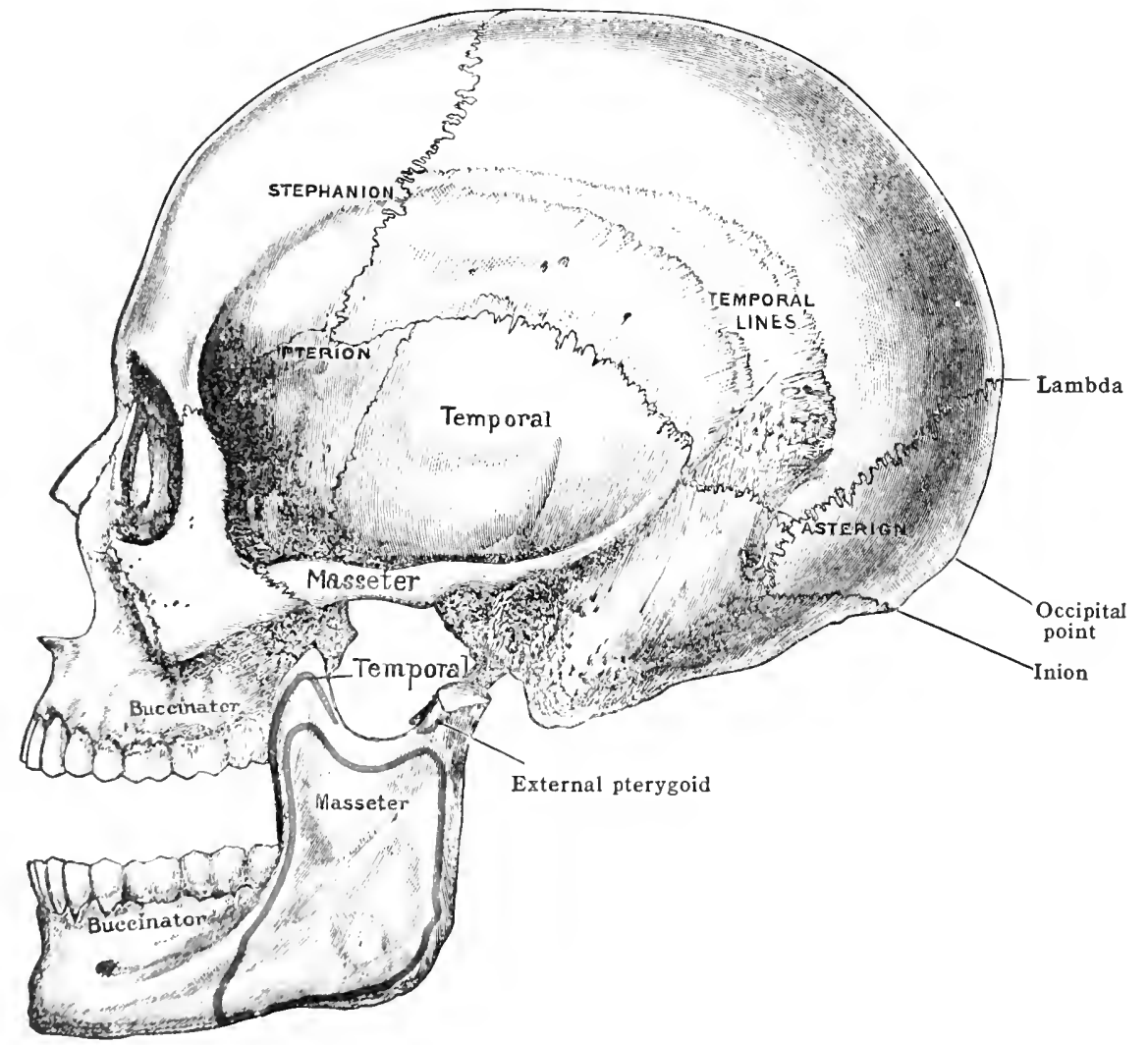

The pterygo-palatine (ptervgo-maxillary) fissure forms a right angle with the inferior orbital fissure and is situated foetwern tho maxilla and the anterior horder of the pterygoid presess of the sphenoid. It its lower angle, where the wo lips of the fissure approximate, the lateral pteryenid plate oceasionally articulates with the naxilla, hut they are usually separated by a thin portion of the pyranidal process of the palate. The pterygo-palatine fissure, which

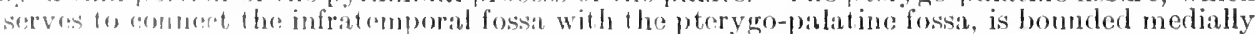
by the ferpondionlar part of the palate; it transmits branches of the internal maxillary artery, and the (o) responding veins, to and from the pteryog-padatine fossa.

(a) 'Th: pterygo-palatine (spheno-mitxillary) fossa is al small space, of the form of an invarterl pyrinid, situterl at the angle of jumetion of the inforior orbital (spheno-maxillary) with the pleryen-pabatins (ptorygo-maxillary) fissnre, below the apex of the orbit. It is boumderl in froml hy the inf ratemporal surface of the maxilla; behind, by the base of the pterygoid propess and the dower part of the anterior surface of the great wing of the sphenoid; medially by the perpondindar pat of the; palate: with its orhital and sphenoidat processes; above by the lower surface of the borly of the sphenoid. Threre lissures terminate in it-viz., the superior orlotal, pteryeo-palatime, and inforior arhital; throurh thesuperior orbital fissure it communicates with the ranimu, throunh the pteryen-palatime lissure with the infratemporal fossa, therent the inforior oribital fissure with the orfit, and through the spheno-palatine foramen on the modial wall it commeniontes with the mppor and back part of the nasal fossa. In- 
cluding the spheno-palatine foramen six foramina open into the fossa. Of these, three are on the posterior wall: enumerated from without inward, and from above downward, they are the foramen rotundum, the pterygoid (Vidian) canal, and the pharyngeal (pterygo-palatine) canal. The apex of the pyramid leads below into the pterygo-palatine canal and the accessory palatine canals which branch from it; and anteriorly is the orifice of the infra-orbital canal. The fossa contains the spheno-palatine ganglion, the maxillary nerve, and the terminal part of the internal maxillary artery, and the various foramina and canals in relation with the fossa serve for the transmission of the numerous branches which these vessels and nerves give off.

Fig. 128.-A Section of the Skull showing the Medial Wall of the Orbit, the Medial Wall of the Antrum, and the Pterygo-palatixe Fossa.

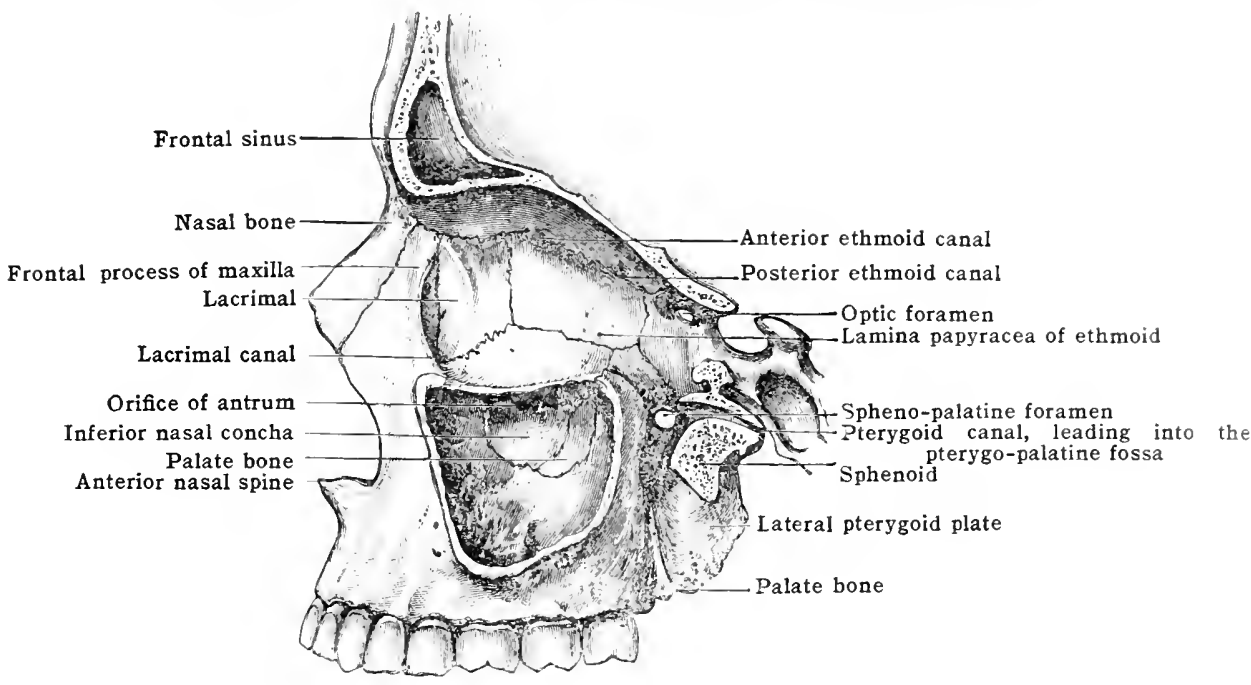

(4) Inferior Region or External Base of Skull

The external base of the skull (norma basilaris) (figs. 130, 131) extends from the incisor teeth to the occipital protuberance, and is bounded on each side by the alveolar arch, the zygomatic, the zygoma, the temporal, and the superior nuchal line of the occipital bone. It is very uneven and, excluding the lower jaw, divisible into three portions: (a) anterior, (b) midclle or subcranial, and (c) posterior or suboccipital.

Fig. 129.- - Hard Palate of a Child Five Years Old.

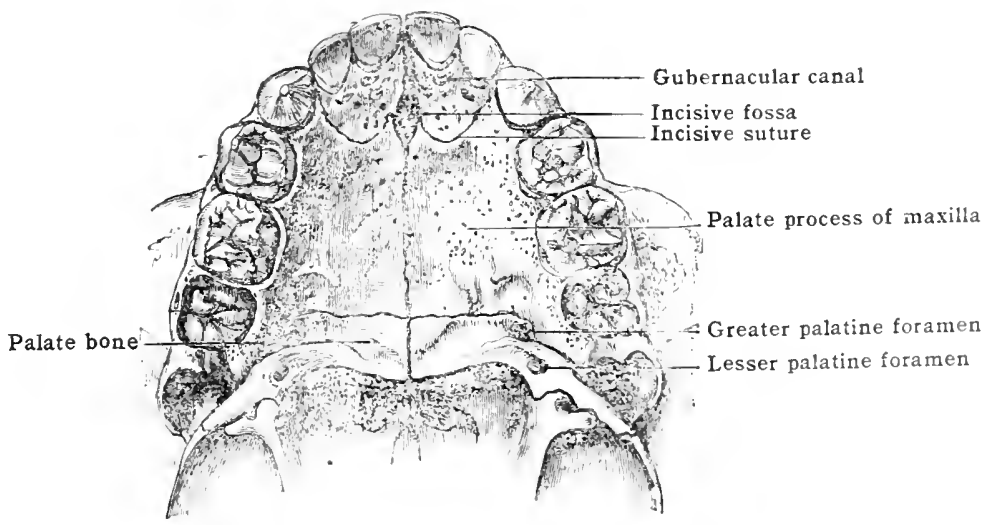

(a) The anterior division consists of the hard palate, the alveolar arch, and the choanæ (posterior nares).

When the skull is inverted, the hard palate stands at a higher level than the rest, and is bounded anteriorly and laterally by the alveolar ridges containing the teeth. The bones appearing in the intermediate space are the premaxillary and palatine portions of the maxillæ and the horizontal parts of the palate bones. 
Fig. 130.-The SkUll. (Norma basilaris.)

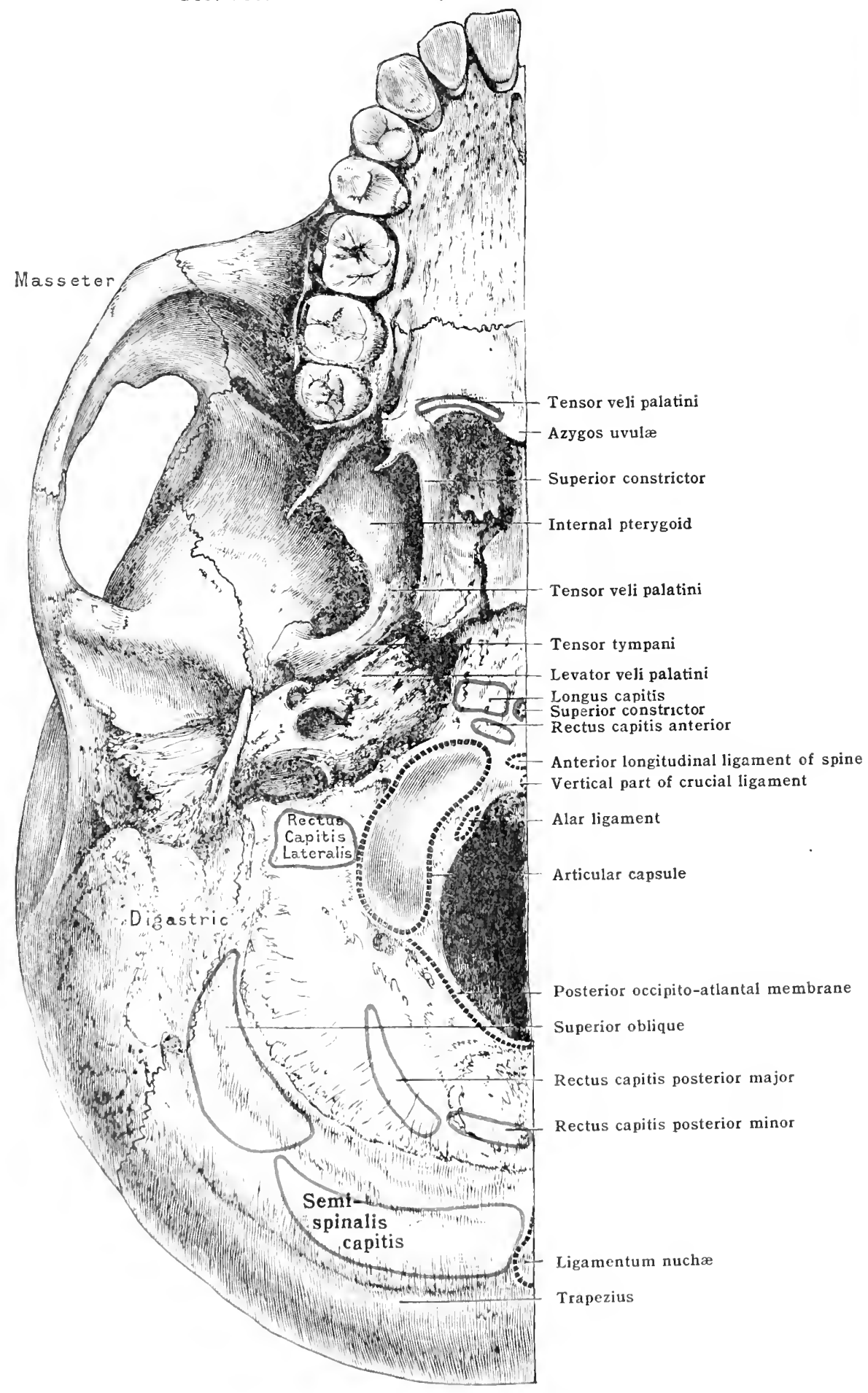


Fig. 131.-The Skcll. (Norma basilaris.)

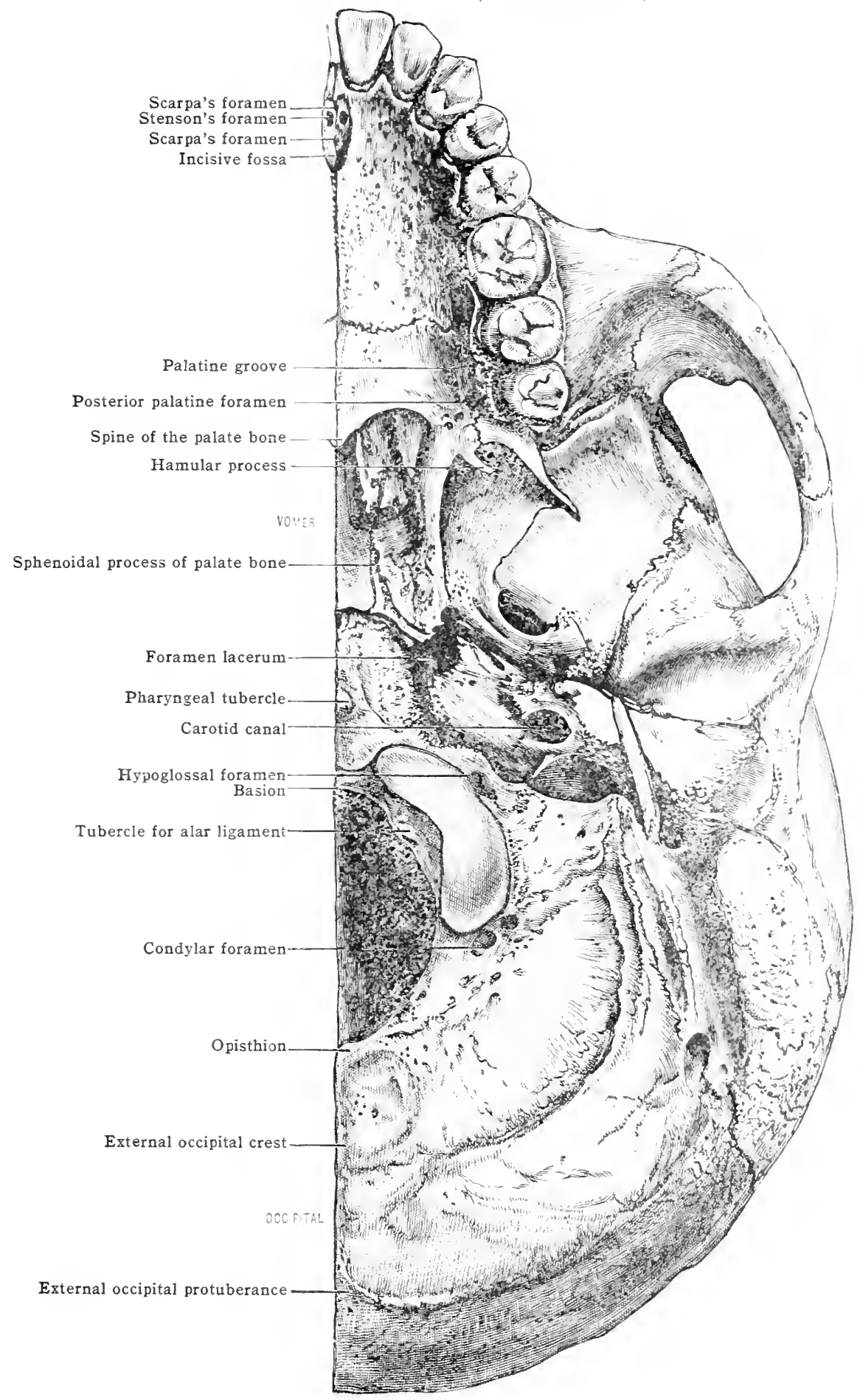


They are rough for the attachment of the muco-periosteum, and near the posterior margin is the ridge for the fibrous expansion of the tensor veli palatini. The following points are readily recognised (fig. 129):-

The meso-palatine suture commences at the alveolar point, traverses the ineisive fossa, and terminates at the posterior nasal spine.

The transverse palatine suture, between the palate bones and palatine processes of the maxilla.

In young skulls the incisive sutures, and behind the incisor teeth four small openings known as the gubernacular canals (see figs. 114 and 129 ).

The incisive fossa containing the termination of four canals: two small orifices, foramina of

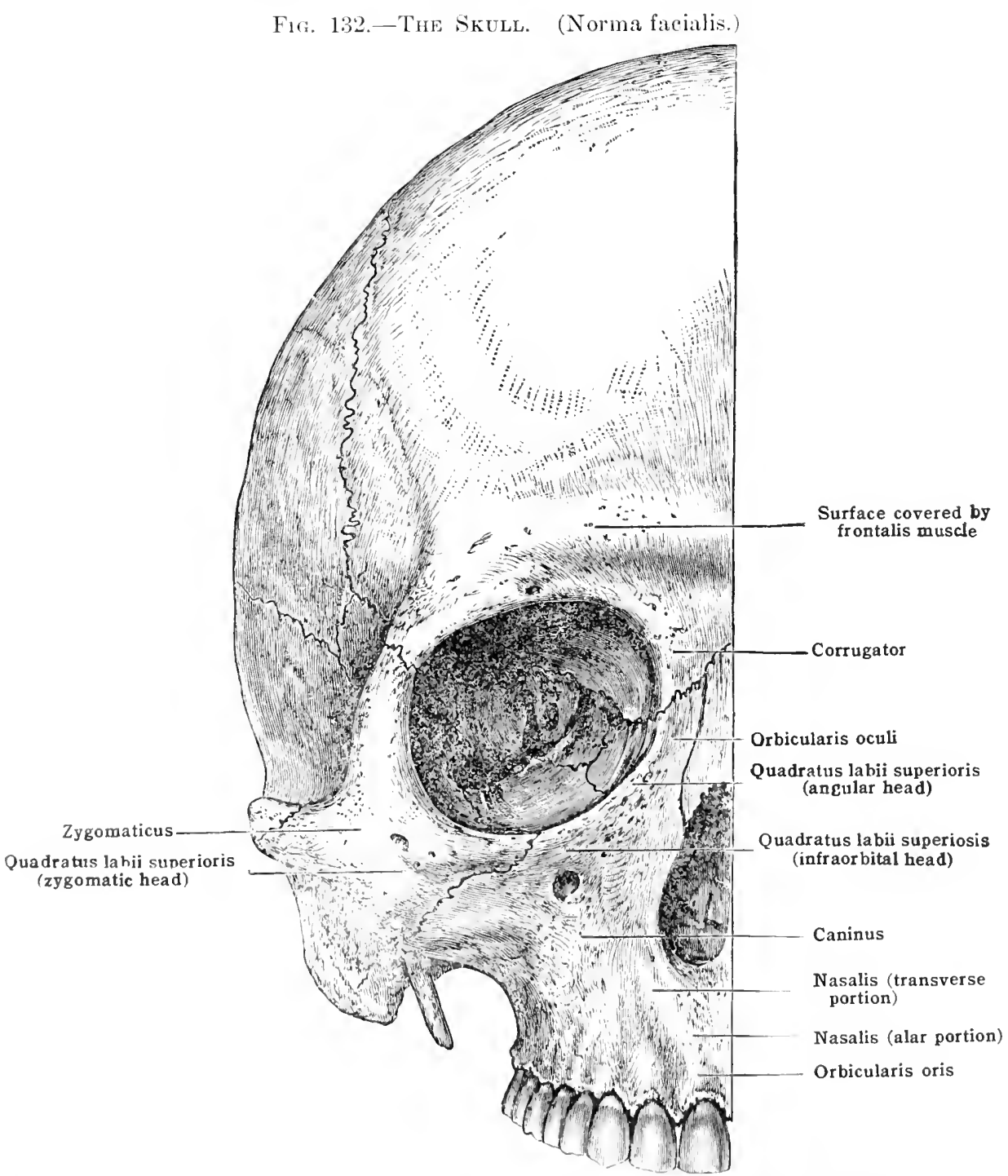

Scarpa, situltol mo: behiul the other in the meso-palatiur suture; and two larger openings, thr foramina of Stenson. The formina of Scarpa transmit the naso-palatine nerves, and those of stenson are in rolation (embloryonic) with the organs of Jacobson.

Al the postorior arghtes of the harr palate are the greater palatine foramina, through which

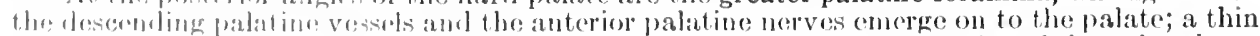
lip of home separibtes then from the lesser palatine foramen in the tuberosity of the palate bone on each sile, for the pusterior palatine nerve. 1:alato.

'The hamular process of thr: meslial pterygoid plate is the most posterior limit of the hard

1t the posterior rextromity of eath alvolar ridge is the tuberosity of the maxilla, and hetween

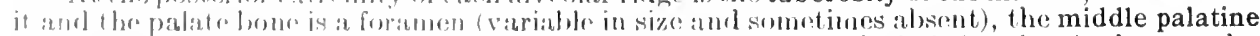
foramen, for the minldle palatino norve. This formen is of ten inchided under the lesser palalime fur:uniua (13Nil). 
Behind the hard palate are the choanæ (posterior nares), separated from each ot her lyy the vomer. Each is bounded laterally by the medial pterygoid plate; below by the horizontal plate of the palate bone; above by the under surfaee of the body of the sphenoid, with the ala of the vomer and a portion of the sphenoidal proeess of the palate bone.

Lateral to the choanæ there is on each side a vertieal fossa lying between the pterygoid plates. It extends upward to the under surface of the great wings of the sphenoinl; it is completed anteriorly by the eoalescence of the pterygoid plates and below by the pyramilal process of the palate bone. It contains the following points of interest:-

An elongated furrow, the scaphoid fossa, for the tensor veli palatini muscle and the cartilage of the Eustachian tube.

The general cavity of the pterygoid fossa whieh lodges the tensor veli palatini and internal pterygoid muscles.

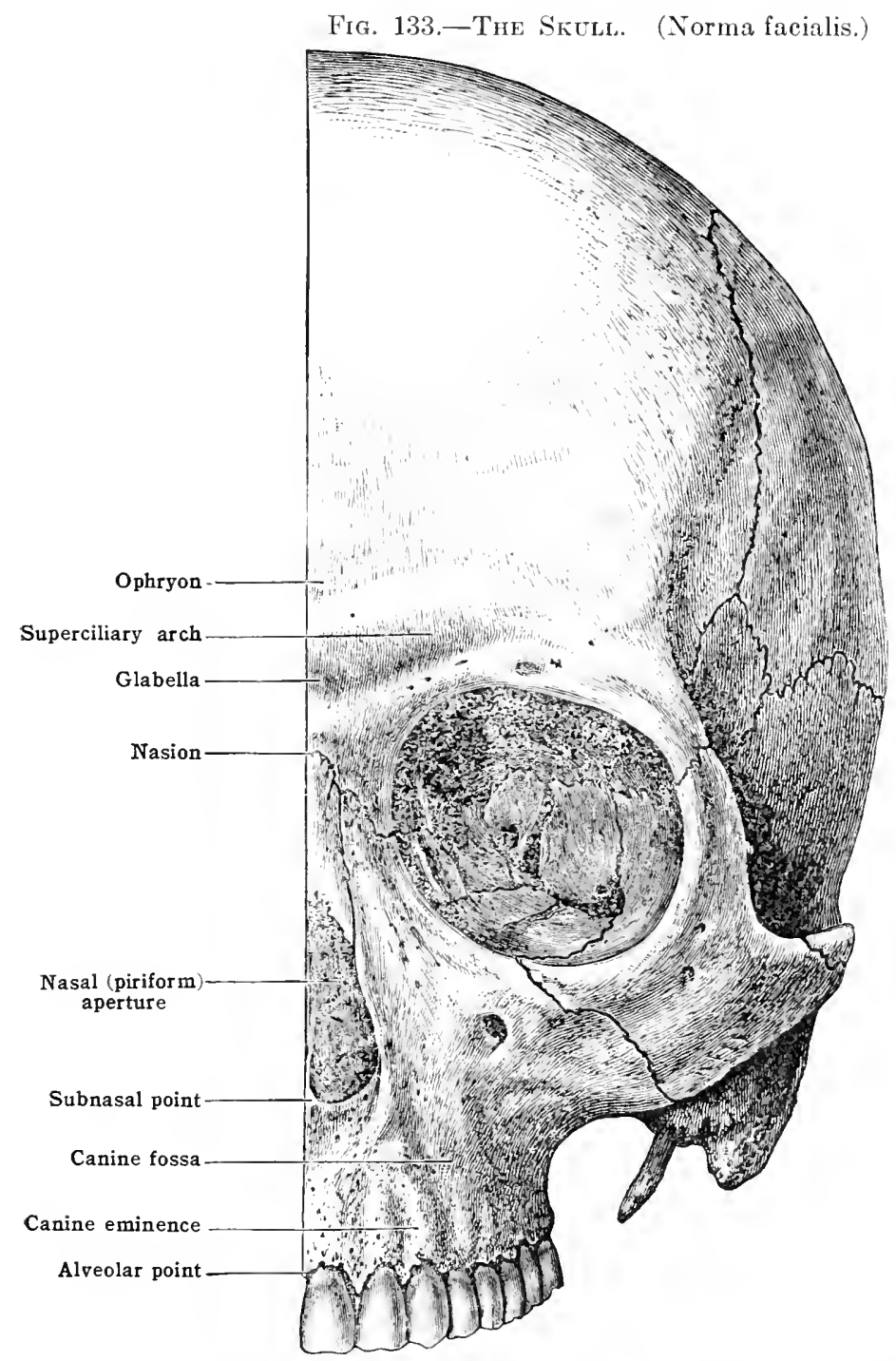

Frequently there is a notch in the lateral pterygoid plate close besile the foramen orale. The posterior termination of the pterygoid (Vidian) canal.

If a line be drawn across the base of the skull from one preglenoid tubercle to the other, it will fall immediately behind the lateral pterygoid plate and lisect the foramen spinosum on each side. A second transverse line, drawn across the opisthion or posterior margin of the foramen magnum, will fall behind the mastoid processes. The space between these arbitrary lines may be called the subcranial region; that behind the second line, the suboccipital region.

(b) The subcranial region is separated from the infratemporal fossa by a line drawn from the posterior margin of the lateral pterygoid plate to the spine of the 
sphenoid. It is formed by the inferior surface of the basilar process of the occipital and the body of the sphenoid, the petrous portion of the temporal bone, a small piece of the squamosal portion, the posterior part of the great wing of the sphenoid, and the condylar portions of the occipital bone. It presents the following points for examination (Figs. 95, 131):-

The pharyngeal tubercle.

The foramen magnum and the occipital condyles. The most anterior point of the foramen is termed the basion, and the most posterior point the opisthion.

On each side will be seen:-The hypoglossal foramen for the hypoglossal nerve and a meningeal branch of the ascending pharyngeal artery.

The condylar fossa with the condylar foramen (this foramen is not constant).

The under aspect of the jugular process, from which the rectus capitis lateralis takes origin.

The foramen lacerum and the orifice of the pterygoid (Vidian) canal.

The canalis musculo-tubarius for the tensor tympani muscle and Eustachian tube.

The carotid canal.

The quadrilateral area for the origin of the levator veli palatini and tensor tympani muscles.

The canaliculus cochleæ, or ductus perilymphaticus.

The jugular foramen and fossa for the glosso-pharyngeal, vagus, and spinal accessory nerves, the internal jugular vein, and a meningeal branch of the ascending pharyngeal artery.

The tympanic canaliculus for Jacobson's nerve (tympanic branch of glossopharyngeal).

The spine of the sphenoid; this is sometimes fifteen millimetres in length.

The mandibular fossa with the petro-tympanic fissure. This lodges the anterior process of the malleus, the tympanic twig of the internal maxillary artery. A small passage beside it, the canal of Huguier, conducts the chorda tympani nerve from the tympanum.

The external auditory meatus.

The auricular or tympano-mastoid fissure.

The tympanic plate and vaginal process.

The styloid process.

The stylo-mastoid foramen for the stylo-mastoid artery and the exit of the facial nerve and, in some cases, the auricular branch of the vagus.

The mastoid process with the digastric and occipital grooves.

(c) The suboccipital region is largely formed by the tabular portion of the occipital bone with its ridges and areas for muscular attachment. Laterally a small part of the mastoid portion of the temporal is seen, pierced by a small foramen, of variable size, the mastoid foramen, which transmits a vein from the transverse (lateral) sinus and a meningeal branch of the occipital artery.

\section{(5) The Anterior Region}

The anterior region (norma facialis) (figs. 132, 133) comprises the anterior end of the cranium or forehead, and the skeleton of the face; also the cavities known as the orbits, formed by the junction of the two parts of this region, and the nasal fossæ, situated on either side of the septum of the nose.

The upper part or forehead, narrowest between the temporal crests about half an inch above the zygomatic processes of the frontal, presents at this level the two transverse sulci; above are the frontal eminences, below the superciliary arches, and still lower the supra-orbital margins, interrupted near their medial ands by the supra-orbital notetres.

Briow the forehearl are the openings of the orbits, bounded laterally by the zygomatic bones constituting the prominences of the cheeks, and between them the lrielge of the nose, formed by the nasal bones and the frontal processes of the maxilla. TBelow the nasal bones is the apertura piriformis or anterior nasal aperture, learling into the nasal foswe. The tecth form a conspicuous feature in this vinw of the skull, the outline of which is completed below by the mandible.

Thro bones antering into formation of thro norme forinlis are:-the frontal, nasals, lacrimals, orbital surfaces of the small and the great wings, and a portion of the body of the sphenoid, the lamina palyracrar of the ethmoids, the orbital processes of the palate bones, the zygomaties, maxilla, inferiog nasial conche, and the mantible.

The sutures are nmmoroms, and for the most part mimportant:-

The transverse suture (fig. 1:3:3) extenels from one zyematic process of the frontal to the other. The upprer bat of the suture is formol by the fromtal home; below are the zygomatic, great and surall wings of the sphenoid, lamina papyraera, lacrimal, maxillary, and nasal bones. 1 portion of this complex suture, lying betwern the sphenoidal and frontal bones, appears in the anterior crantal fosiat.

()thro fissures an the intermasal, naso-maxillary, inter-maxillary and zygonatico-maxillary. The small sutures sere in the orhit are describerl with that cavity.

The foramina are:-the supra-orbital, infra-crbital, optic, zygomatico-facial, and mental;

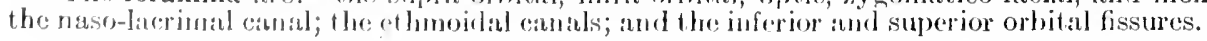


The following points may also be noticed:-

The glabella, a smooth space between the converging supcrciliary arches.

The ophryon, the most anterior point of the metopic suture.

The nasion, the middle of the naso-frontal suture.

The subnasal point, the middle of the inferior border of the pyriform aperture at the base of the nasal spine.

The alveolar point, the centre of the anterior margin of the upper alveolar arch.

\section{THE ORBITS}

The orbits [orbitæ] (fig. 134) are two cavities of pyramidal shape, with their bases directed forward and laterally and their apices backward and medially; their medial walls are nearly parallel, but their lateral walls diverge so as to be nearly at right angles to each other. Each cavity forms a socket for the eyeball and the muscles, nerves, and ressels associated with it.

Seven bones enter into formation of its walls, viz., the frontal, zygomatic, sphenoid, ethmoid, lacrimal, palate, and maxilla; but as three of these-the frontal, sphenoid, and ethmoid-are single median bones which form parts of each cavity, there are only eleven bones represented in the two orbits. Each orbit presents for examination four walls, a circumference or base, and an apex.

The superior wall or roof, vaulted and smooth, is formed mainly by the orbital plate of the frontal and is completed posteriorly by the small wing of the sphenoid. At the lateral angle it presents the lacrimal fossa for the larrimal gland, and at the medial angle a depression or ib spine for the pulley of the superior oblique musele.

Fig. 134.-The Medial Wall of the Orbit.

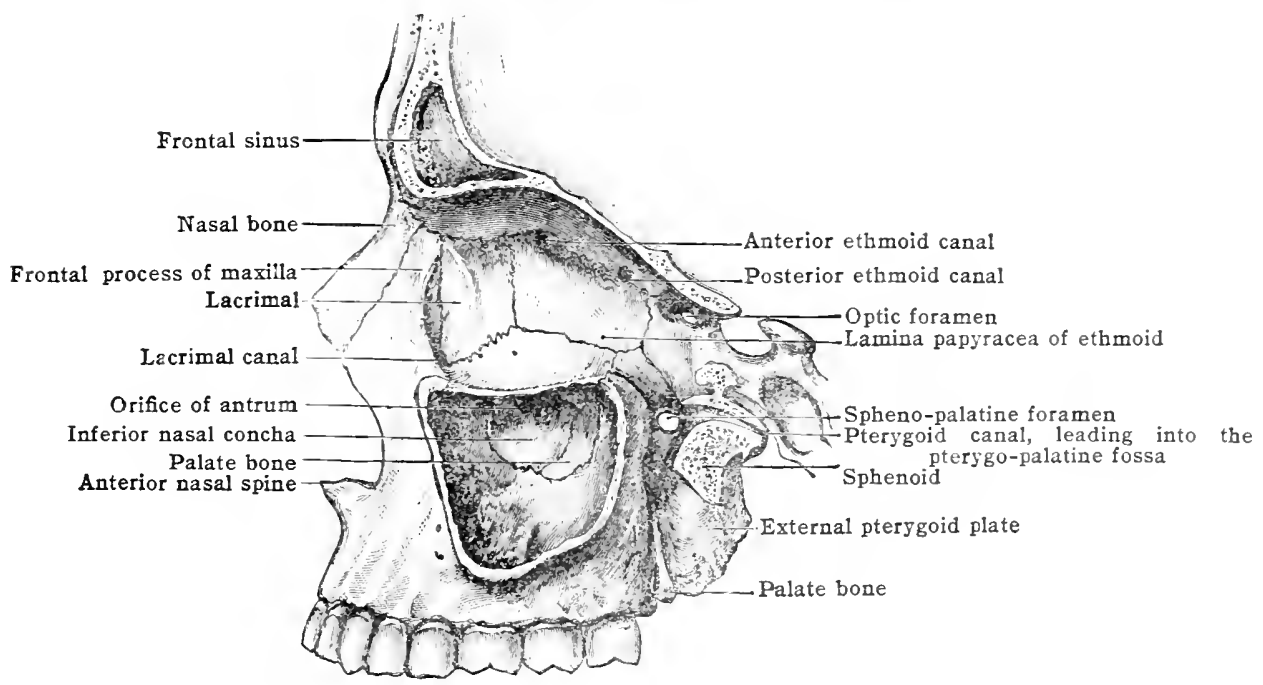

The inferior wall or floor is directed upward and laterally and is not so large as the roof. It is formed by the orbital plate of the maxilla, the orbital process of the zygomatic, and the orbital process of the palate bone. It its medial angle it prescnts the naso-lacrimal canal, and near this, a depression for the origin of the inferior obliqne muscle. It is markerl near the middle by a furrow for the infra-orbital artery and the second division of the fifth nerve, terminating anteriorly in the infra-orbital canal, though which the nerve and artery energe on the face. Near the commencement of the canal a narrow passage, the anterion atrooliz canal, runs forward and downward in the anterior wall of the antrum, transmitting nerves and vessels to th" incisor and canine teeth.

The lateral wall, directed forward and medially, is formed by the ortital surface of the great wing of the sphenoid, and the zygomatic. Between it and the roof, neir the apex, is the superior orbital (sphenoidal) fssure, by means of which the third, fourth, ophtbalnic division of the fifth, and sixth nerves enter the orbit from the cranial cavity; it also transmits some filaments from the cavernous plexus of the sympathetic, the orbitai branch of the middle meningeal artery, recurrent branches of the lacinal artery, and an ophthalmic vein. The lower margin of the fissure presents near the middle a small tubercle. from which the inferior head of the lateral rectus muscle arises. Between the lateral mall and the floor, near the apex, is the inferior orbital (spheno-maxillary) fissure, through which the second division of the fifth and the infra-orbital vessels pass from the pteryo-palatine fossa to enter the infra-orbital groove. At the anterior margin of the fissure the sphenoid oceasionally articulates with the maxilla, but 
the two are usually separated by the orbital plate of the zygomatic, and on the latter are seen the orifices of the zygomatico-temporal and zygomatico-facial canals, which traverse the zygomatic bone. The commencement of the zygomatico-temporal canal is sometimes scen in the spheno-zygomatic suture comnecting the sphenoid and zygomatic bones.

The medial wall, narrow and nearly vertical, is formed from before backward by the frontal process of the maxilla, the lacrimal, the lamina papyracea of the ethmoid, and the body of the sphenoid. At the junction of the medial wall with the roof, and in the suture between the ethmoid and frontal, are seen the orifices of the anterior and posterior ethmoidal canals, the anterior, transmitting the anterior ethmoidal vessels and nerve; and the posterior, the posterior vessels and nerve. Anteriorly is the lacrimal groove for the lacrimal sac, and behind this the lacrimal crest, from which the tensor tarsi arises. The medial wall, which is the smallest of the four, is traversed by three vertical sutures:- - one between the frontal process of the maxilla and the lacrimal, a second between lacrimal and lamina papyracea, and a third between the lamina papyracea and the sphenoid. Occasionally the sphenoidal concha appears in the orbit between the ethmoid and the body of the sphenoid.

The apex of each orbit corresponds to the optic foramen, a circular orifice which transmits the optic nerve and ophthalmic artery. The base or circumference is quadrilateral in form and is bounded by the frontal bone above, the frontal process of the maxilla and the medial angular process of the frontal on the medial side, the zygomatic bone and the zygomatic process of the frontal on the lateral side, and by the zygomatic and the body of the maxilla below. The following points may also be noted:-The suture between the zygomatic process of the frontal bone and the zygomatic; the supra-orbital notch (sometimes a complete foramen); the suture between the frontal bone and the frontal process of the maxilla; and in the lower segment, the zygomatico-maxillary suture.

The orbit communicates with the cranial cavity by the optic foramen and superior orbital fissure; with the nasal fossa, by means of the naso-lacrimal canal; with the zygomatic and pterygo-palatine fosse, by the inferior orbital fissure. In addition to these large openings, the orbit has five other foramina-the infra-orbital, zygomatico-orbital, and the anterior and posterior ethmoidal canals-opening into it or leading from it.

The following muscles arise within the orbit:- the four recti, the superior oblique, and levator palpebre superioris, near the apex; the inferior olslique on the floor of the orbit lateral to the naso-lacrimal canal; and the tensor tarsi from the lacrimal erest. The margins of the inferior orbital fissure give attachment to the orbitalis muscle.

\section{THE NASAI, FOSSA}

The nasal fossæ (figs. 135, 136) are two irregular cavities situated on each side of a median vertical septum. They open in front by the piriform aperture and communicate behind with the pharynx by the choanæ. They are somewhat

F1g. 135.- Section through the Nasal Fossa to show the Septua. Left Malf, with Septum looking toward Right Nasal Fossa.

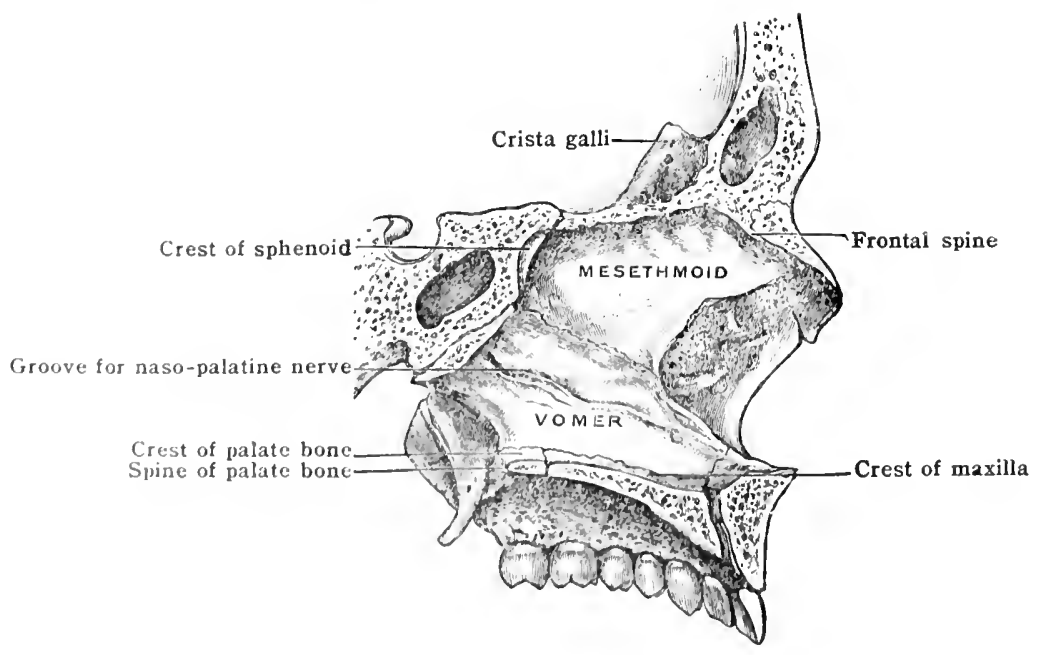

bl) hong in transwerse section, and extend vertically from the anterior part of the lask of the eranium alowe to the superior surface of the hard palate below. Their transverse extent is very limited, especially in the upper part. Each fossa presents for cxannination a roof, floor, medial and lateral walls, and conmunieates with the: sinmses of the frontal, sphenoid, maxilla, and ethmoid bones. 
The roof is horizontal in the mildle, but sloped downward in front and behind. The anterior slope is formed by the posterior surface of the nasal bone and the nasal process of the frontal; the horizontal portion corresponds to the cribriform plate of the ethmoid and the sphenoidal concha; the posterior slope is formed by the inferior surface of the body of the sphenoid, the ala of the vomer, and a small portion of the sphenoidal process of the palate. The sphenoidal sinus opens at the upper and back part of the roof into the spheno-ethmoidal recess, above the superior meatus.

The floor is concave from side to side, and in the transverse diameter wider than the roof, It is formed mainly by the palatine process of the maxilla and completed posteriorly by the hor izontal part of the palate bone. Near its anterior extremity, close to the septum, is the incisive canal.

The septum or medial wall is formed by the perpendicular plate of the ethmoirl, the vomer, the rostrum of the sphenoid, the erest of the nasal bones, the frontal spine, and the median crest formed by the apposition of the palatine processes of the maxillie and the horizontal parts of the palate bones. The anterior border has a triangular outline limited above by the perpendicular plate of the ethmoid and below by the vomer, and in the recent state the deficiency is filled up by the septal cartilage of the nose. The posterior border is formed by the

Fig. 136.-Section throdgh the Nasal Fossa to show the Lateral Wall with the Meatuses.

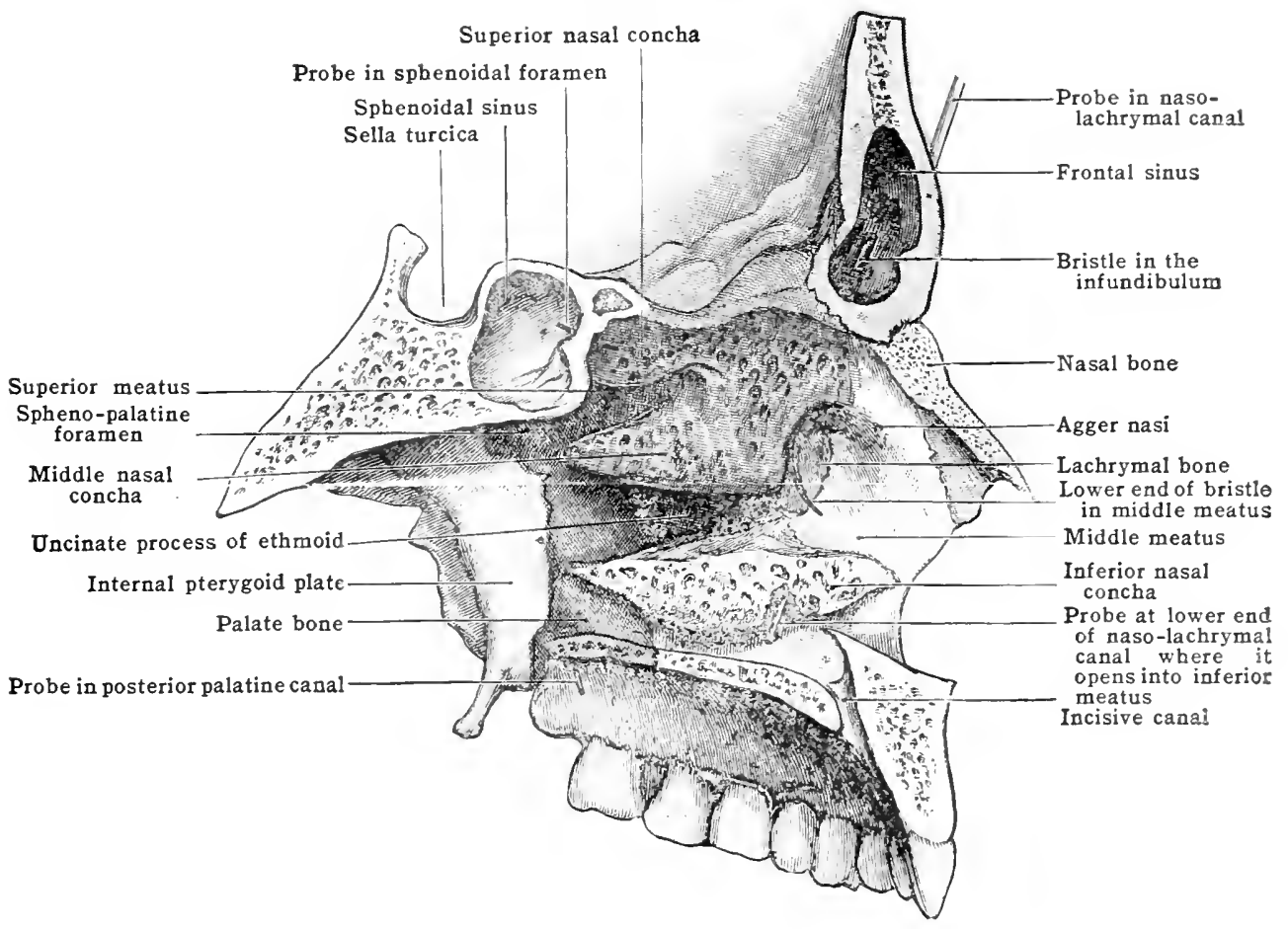

pharyngeal edge of the vomer, which separates the two choanx. The septum, which is usually deflected from the middle line to one side or the other, is occasionally perforated, and in some cases a strip of cartilage, continuous with the triangular cartilage, extends backward between the vomer and perpendicular plate of the ethmoid (posterior or sphenoidal, process).

The lateral wall is the most extensive and the most complicated on account of the formation of the meatuses of the nose. It is formed by the frontal process and the medial surface of the maxilla, the lacrimal, the superior and inferior conche of the ethmoid, the inferior nasal concha, the vertical part of the palate bone, and the medial surface of the medial ptergoid plate. The three conchr, which project medially, overhang the three recesses known as the meatuses of the nose. The superior meatus, the shortest of the three, is situated between the superior and middle nasal conchr, and into it open the orifice of the posterior ethmoidal cells and the spheno-palatine foramen. The middle meatus lies between the niddle and inferion conchæ. At its fore part it communicates with the frontal sinus by means of the infundibulum, and near the middle with the maxillary sinus (antrum); the communication with the sinus is very irregular and sometimes represented by more than one opening (fig. 136). Two sets of ethmoidal cells - the middle and anterior-also open into the middle meatus, the anterior in common with the infundibulum, the middle on an elevation known as the bulla ethmoidalis. The inferior meatus, longer than either of the preceding, is situated between the inferior nasal concha and the floor of the fossa, and presents, near the anterior part, the lower orifice of the canal for the naso-lacrimal duct. 
The nasal fossæ open on the face by means of the apertura piriformis, a heart-shaped or piriform opening whose long axis is vertical and whose broad end is below. The orifice is bounded above by the lower borders of the nasal bones, laterally by the maxillæ, inferiorly by the premaxillary portions of the maxille, and in the recent state the orifice is divided by the septal cartilage. Below, where the lateral margins slope inward to meet in the middle line, is the anterior nasal spine.

The choanæ (posterior nares) are bounded superiorly by the alæ of the vomer, the sphenoidal processes of the palate, and the inferior surface of the body of the sphenoid; laterally by the lateral pterygoid plates; and inferiorly by the posterior edge of the horizontal plates of the palate bones. "They are separated from each other by the posterior border of the vomer.

The nasal fossæ communicate with all the more important fossæ and the air-sinuses of the skull. By means of the foramina in the roof they are in connection with the cranial cavity;

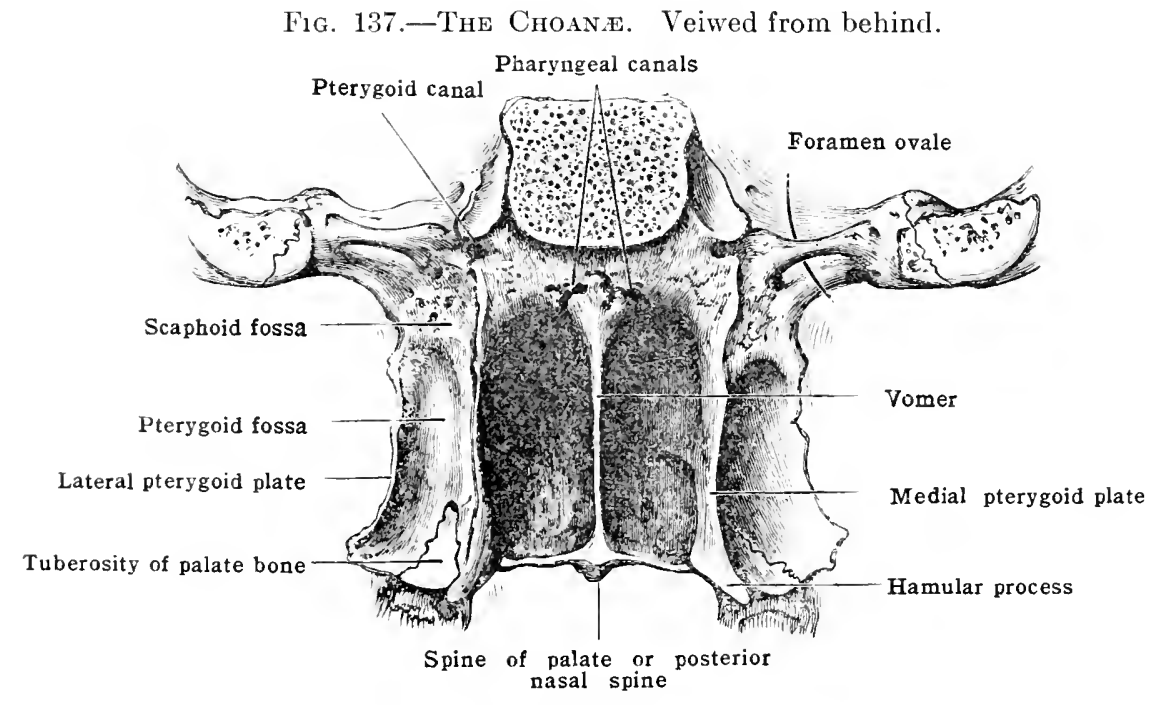

by the infundibulum each fossa is in communication with the frontal and anterior ethmoidal cells; the posterior ethmoidal cells open into the superior meatuses and the sphenoidal sinuses into the recesses above; the spheno-palatine foramina connect them with the pterygo-palatine fossa, and by means of an irregular orifice in each lateral wall they communicate with the maxillary sinuses. The canals for the naso-lacrimal ducts connect them with the orbits, and the incisive canals with the oral cavity.

\section{THE INTERIOR OF THE SKULL}

In order to study the interior of the skull it is necessary to make sections in three directions-sagittal, coronal, and horizontal. This enables the student to (xamine the various points with facility, and displays the great proportion the brain cavity bears to the rest of the skull. The sagittal section (fig. 138) should the made slightly to one side of the median line, in order to preserve the nasal septum. The black line (fig. 138) drawn from the basion (anterior margin of the foramen magnum) to the gonion (the anterior extremity of the sphenoid) represents the basi-cranial axis; whilst the line drawn from the gonion to the subnasal point lies in the basi-facial axis. These two axes form an angle termed the cranio-facial, which is useful in making comparative measurements of crania. I line prolongerl vertically upward from the basion will strike the bregma. This is the basi-bregmatic axis, and gives the greatest height of the cranial cavity. A line drawn from the ophryon to the occipital point indieates the greatest length of the resmintm.

Near its mirllle, the cranial avity is encroached upon by the petrous portion of the tentural bone on cash side; the walls are channelled vertically by narrow urooves for the mirlelle and small meningeat vessels, and toward the base and at the vertex arr hroader furrows for the venous sinuses.

The coronal section is most instructive when made in the basi-bregmatic axis. The section will pass through the petrous portion on each side in such a way as fo traverse the external auditory passage and expose the tympanum and vestibuln, and will also partially traverse the internal auditory meatus. Such 
a section will divide the parietal bones slightly posterior to the parietal eminences, and a line drawn transversely across the section at the mid-point will give the greatest transverse measurement of the cranial eavity. A skull divided in this way facilitates the examination of the parts about the choanæ (posterior nares).

The horizontal section (figs. 139, 140) of the skull should be made through a line extending from the ophryon to the occipital point, passing laterally a few millimetres above the pterion on each side. It is of great advantage to study the various parts on the floor of the eranial eavity in a second skull in which the dura mater and its various processes have not been removed.

The floor [basis eranii interna] of the cranial cavity presents three irregular depressions termed the anterior, middle, and posterior fossæ (figs. 139 and 140).

The Anterior Cranial Fossa.- The floor of this fossa is on a higher level than the rest of the cranial floor. It is formed by the horizontal plate of the frontal bone, the cribriform plate of the ethmoid, and the lesser wings of the

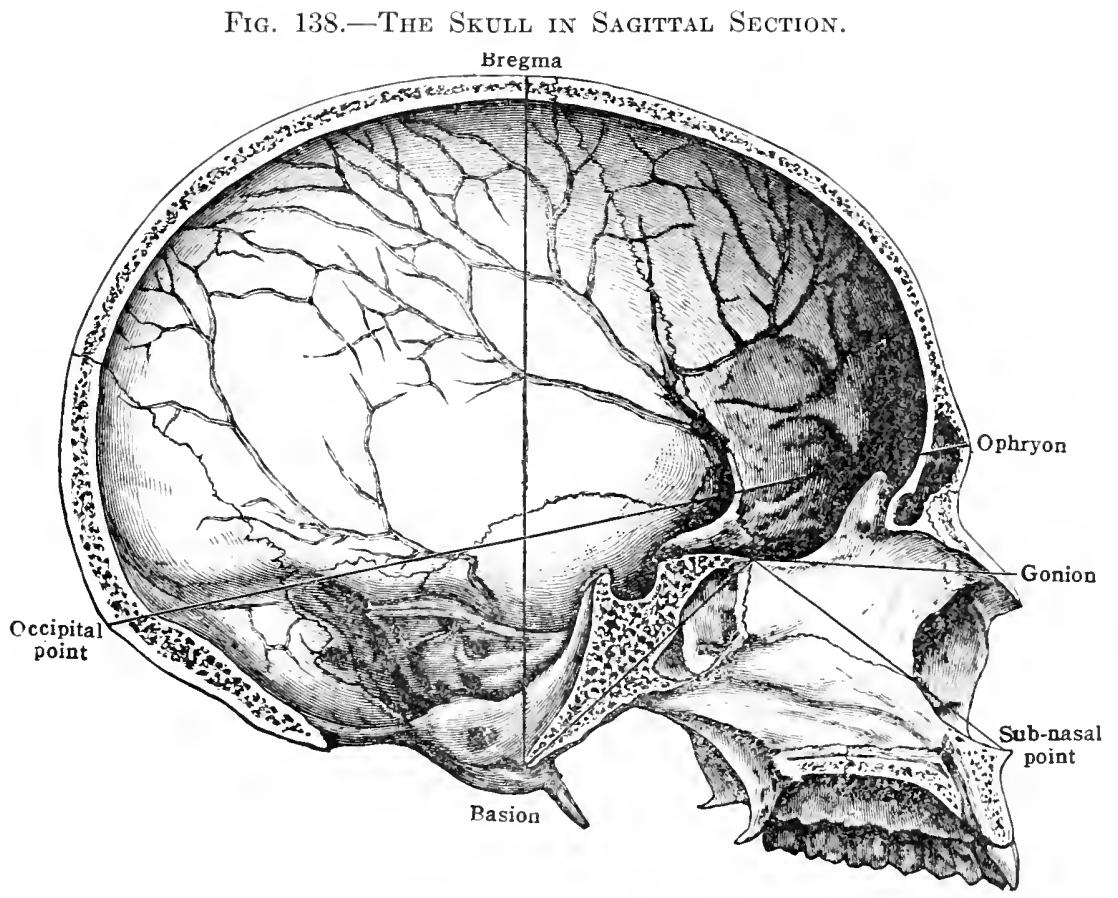

sphenoid, which meet and exclude the body of the sphenoid from the anterior fossa. The free margins of the lesser wings and the anterior margin of the optic groove mark the limits of this fossa posteriorly. The central portion is clepressed on each side of the crista galli, presents the numerous apertures of the cribriform plate, and takes part in the formation of the roof of the nasal fossæ; laterally, the floor of the anterior eranial fossa is convex; it forms the roof of the orbits, and is marked by irregular furrows. It supports the frontal lobes of the cerebrum. The sutures traversing the floor of the fossa are the fronto-ethmoidal, forming three sides of a rectangle, that portion of the transverse facial suture which traverses the roof of the orbit, and the ethmo-sphenoidal suture, the centre of which corresponds to the gonion. The other points of interest in the fossa are:-

A groove for the superior sagittal sinus.

The foramen cæcum which frequently transmits a small vein to the nasal carity

The crista galli.

The ethmoidal fissure for the anterior ethmoidal branch of the fifth nerve.

The cranial orifice of the anterior ethmoidal canal, trinsmitting the anterior ethmoidal branch of the fifth nerve, and a meningeal branch of the anterior ethmoiclal artery.

The cranial orifice of the posterior ethmoidal canal, transmitting a meningeal branch of the posterior ethmoidal artery.

The ethmoidal spine of the sphenoid.

Furrows for meningeal vessels. 
Fig. 139.-The Skull in Horizontal Section.

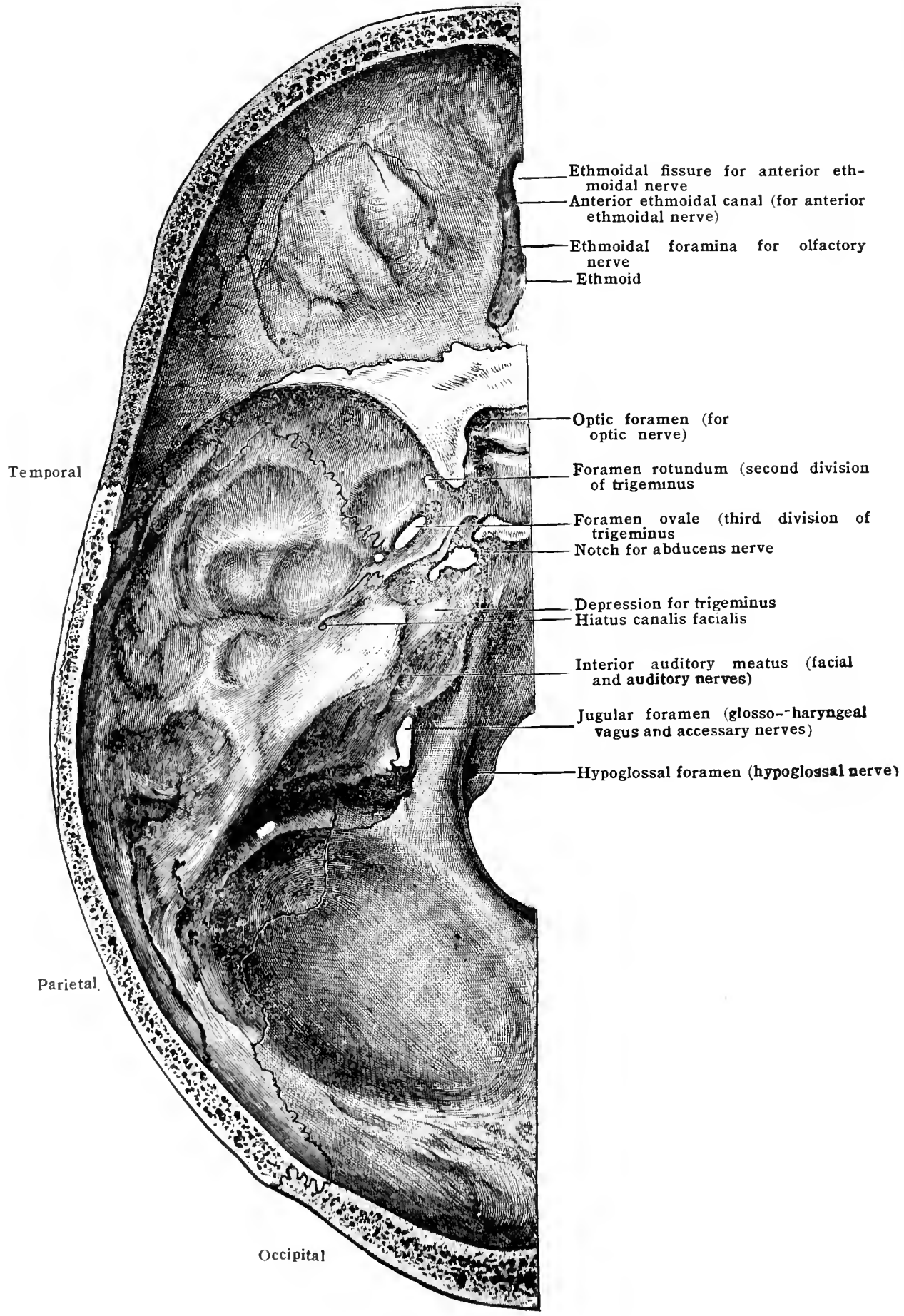


Fig. 140,-The sikull in Horizontal Section.

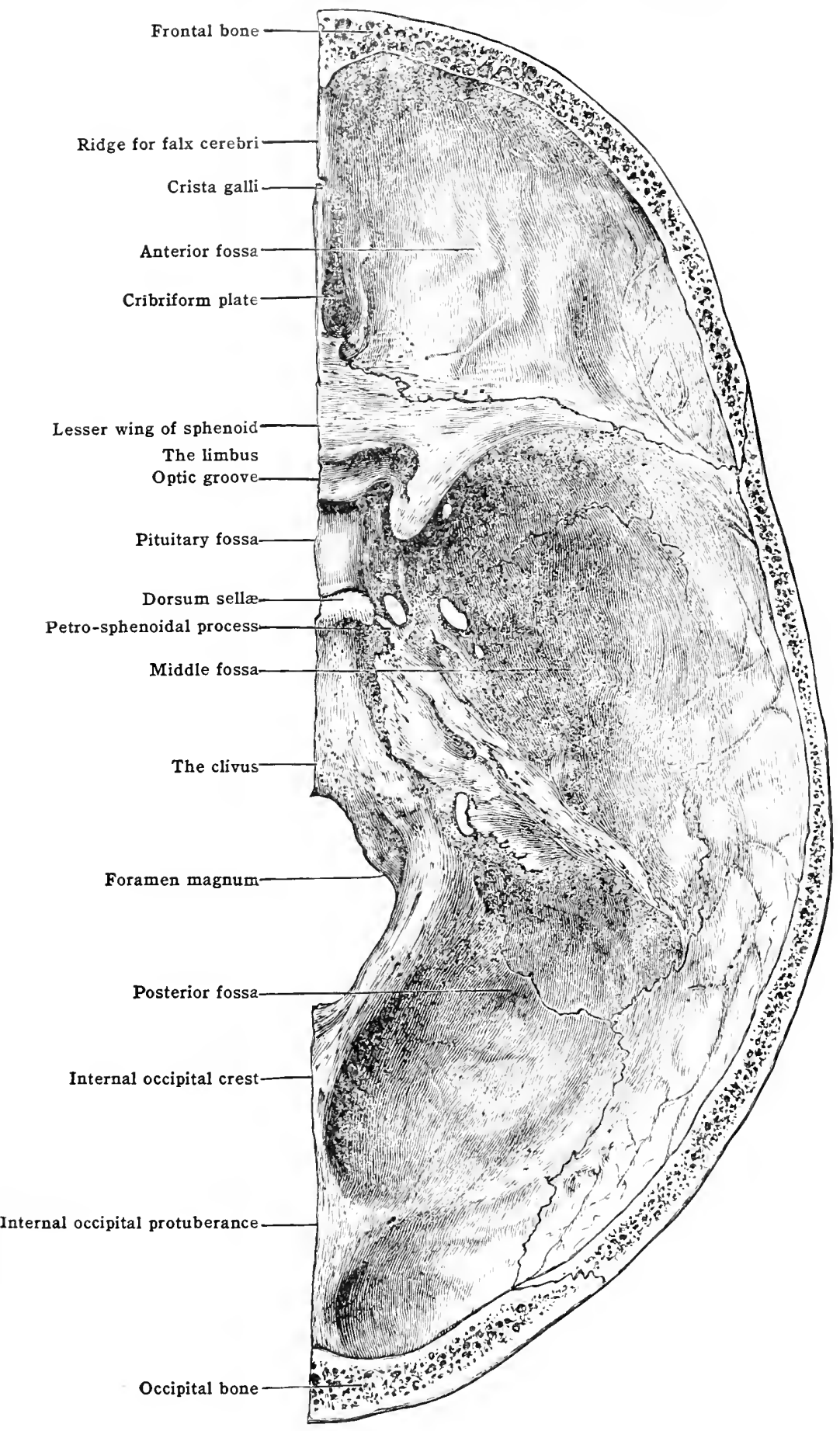


The Midde Cranial Fossa, situated on a lower level than the anterior, consists of a central and two lateral portions. In front it is limited by the posterior borders of the lesser wings of the sphenoid and the anterior margin of the optic groove, behind by the dorsum sellæ and the upper angle of the petrous portion of both temporal bones. Laterally it is bounded on each side by the squamous portion of the temporal, the great wing of the sphenoid, and the parietal bone, whilst the floor is formed by the body and great wings of the sphenoid and the anterior surface of the petrous portion of the temporals. It contains the following sutures:- spheno-parietal, petro-sphenoidal, squamo-sphenoidal, squamous, and a part of the transverse suture. The central portion of the fossa presents from before backward:

The optic groove, above and behind which is the optie chiasma.

The optic foramen on each side, transmitting the optic nerve and ophthalmic artery.

The tuberculum sellæ, indieating the line of junetion of pre- and post-sphenoid elements.

The anterior clinoid processes.

The fossa hypophyseos or sella turcica, with the middle clinoid processes, and grooves for the internal carotid arteries. The dorsum sellæ, with the posterior clinoid processes, and notches for the sixth pair of cranial nerves. Willis.

The central portion is in direct relation with the parts of the brain within the eircle of

The lateral portions are of considerable depth and marked by numerous elevations and depressions corresponding to the convolutions of the temporal lobes of the brain, and by grooves for the branches of the middle and small meningeal vessels. The following foramina are seen on each side:-

The superior orbital (sphenoidal) fissure, leading into the orbit and transmitting the third, fourth, three branches of the ophthalmic division of the fifth and sixth cranial nerves, some filaments from the cavernous plexus of the sympathetie, an ophthalmie vein, the orbital branch of the middle meningeal, and a recurrent branch of the lacrimal artery.

The foramen rotundum, for the passage of the seeond division of the fifth nerve into the pterygo-palatine fossa.

The foramen ovale, which transmits the third division of the fifth nerve with its motor root (mandibular nerve), the small meningeal artery, and the small superfieial petrosal nerve.

The foramen Vesalii (not always present) for a small vein.

The foramen spinosum, for the middle meningeal artery and its venæ comitantes; also the X. spinosus.

The foramen lacerum is the irregular aperture bctween the body and great wing of the sphenoid, and the apex of the petrous portion of the temporal. In the recent state it is closed below by a layer of fibro-cartilage which is perforated by the Vidian nerve, a meningeal branch of the ascending pharyngeal artery, and an emissary vein. The carotid eanal opens on its lateral wall and the pterygoid (Vidian) eanal in front.

On the anterior surface of the petrous portion of the temporal bone are seen:-

A depression which lodges the senilunar (Gasserian) ganglion.

The hiatus canalis facialis for the great superfieial petrosal nerve and the petrosal braneh of the midclle meningeal artery.

The accessory hiatus for the small superficial petrosal nerve.

A minute foramen for the external superficial petrosal nerve.

The eminentia arcuata, formed by the superior semicircular canal.

Anterior and slightly lateral to the eminentia arenata the bone is exeedingly thin and translucent, forming the roof of the tympanum (tegmen tympani). When the dura mater is in situ, the depression lodging the semilunar ganglion is converted into a foramen, traversed by the fifth nerve, and in the same way the notch on the side of the dorsum sellse is converted into a foramen for the sixth nerve. In many skulls the middle clinoid proeess is prolonged toward the anterior clinoid process, with which it may be joined to complete a foramen for the internal earotid artery. The grooves for the middle meningeal vessels are sometimes eonverted into canals or tumels for a short distance, especially in old skulls. The hones most deeply marked are the srquanous portion of temporal, the great wing of the sphenoid, and the parictal.

The Postemor ('maniar Fossa is the deepest and largest of the series. It is boumber in front by the dorsum sella of the sphenoid and on each side by the superior lomere of the petrosal, and the mastoid portion of the temporal bone, the posterior inforior angle of the parietal, and the groove on the oecipital bone for the transverse simus; eareh of the bones mentioned takes part in the formation of its floot.

In the recent state the fossa lorlges the cerebellum, pons, and medulla, and is roofeal in by the fontorium orebelli, a tent-like process of the dura mater attached to the ridges limiting the fossa alove. It eommunicates with the general cranial savity by means of the foramen ovale of Pacchionius, a large opening bounded in fromt lis the (livus (batilar groove) and behind by the anterior free edge of the tentorium. 
The posterior fossa is narked by several sutures, viz., petro-occipital, occipito-nastoid, parieto-mastoid, and in young skulls the basilar (oceipito-sphenoidal). In addition, the following points may be noted:-

The clivus, extending from the dorsum sellæ to the anterior margin of the foramen inagnum, and in relation with the basilar artery, the pons, the medulla, the sixth nerves, and the basilar sinuts.

The foramen magnum, occupied in the recent state by the lower end of the inedulla oblongata and its membranes, the vertebral, anterior spinal and posterior spinal arteries, the accessory (eleventh) eranial nerves, and the tectorial membrane.

The hypoglossal canal (foramen), sometimes divided by a spicule of bone in to two divisions, for the two parts of the hypoglossal nerve and a meningeal branch of the ascending pharyngeal artery.

The internal occipital crest, behind the foramen magnum, for the attachment of the falx cerebelli. It sometimes presents a depression known as the vermiform fossa.

The internal auditory meatus, for the seventh and eighth eranial nerves, the pars intermedia, and the internal aurlitory vessels.

The jugular foramen (foramen lacerum posterius), somewhat pyriform in shape, and divisible into three compartments. The anterior division, placed somewhat medially, transmits the inferior petrosal sinus and is sometimes completely separated by an intra-jugular process of bone; the middle division transmits three cranial nerves, the ninth, tenth, and eleventh; and, in the posterior division, placed somewhat laterally, the transverse sinus becomes continuous with the internal jugular vein. A meningeal branch of the aseending pharyngeal or oceipital artery enters the eranium through this division of the foramen.

The termination of the groove for the transverse sinus with the internal orifice of the mastoid foramen.

The aquæductus vestibuli and the fossa subarcuata, on the posterior surface of the petrous portion of the temporal.

The eranium of an average European has a capacity of 1450 e.e. The circumferere, taken in a plane passing through the ophryon in front, the occipital point bebind, and the pterion at the side, is $52 \mathrm{~cm}$. The length from the ophryon to the occipital point is $17 \mathrm{~cm}$, and the width between the parietals at the level of the zygomata is $12.5 \mathrm{~cm}$. The proportion of the greatest width to the length is known as the cephalic inder, i. e., index of breadth. A skull with an average cephalie index is mesaticephalic. When the index is above the average, it is brachycephalic (short and broad), and when below the average, dolichocephalic (long and narrow). The height from the basion to the bregma is nearly the same as the width at the level of the zygomata. The eranio-facial angle is about $96^{\circ}$.

\section{THE MORPHOLOGY OF THE SKULI}

In man the skull during development passes through three stages. At first the brain vesieles are enclosed in a sac of indifferent tissue which ultimately becomes tough and fibrous to form the membranous cranium. This, in turn, is partly converterl into the membrane or roof bones of the cranium, whilst the remainder is represented in the adult by the dura mater. At the sides and base of the membranous cranium, however, cartilage is deposited, chondro-cranium, in which, as well as in the membranous tracts, osseous tissue appears in due course. Eventually, as osseous box is formed, consisting of membrane bones and eartilage bones intricately interwoven.

A study of the skull in the chondral stage is very instructive. It consists of two parts:

(1) The skull proper and (2) the appendicular elements.

(1) The skull proper consists of three regions:-

(a) The notochordal region, which ultimately gives rise to the chief parts of the occipital bone and a part of the sphenoid. It is named notochordal because the notochord runs in it as far as the anterior extremity, i. e., the level of the fossa hypophyseos (sella turcica.)

(b) Anterior to the notochordal is the trabecular region, from which the remainder of the sphenoid is developed.

(c) The most anterior part of the prechordal portion of the base is the ethmo-vomerine region, from which the nasal septum and its cartilages arise. These three parts continue forward the line of the vertebral axis, and constitute a cranio-facial axis terminating, in front, in the premaxillie. Finally, wedged in on each side, between the notochorial and trabecular regions, is the complicated periotic capsule.

The chondro-cranium at the third month presents the following parts. Scen from above, the cartilage extends from the eranial base to a spot midway between the base and the vertex, shading off indefinitely on the membranous vall. The oval masses on each side are the periotic cartilages, in which the fosse subarcuate are conspicuous objects. Each periotic cartilage is joined to the sphenoid by a strip, termed the sphenotic cartilage, which usually persists in the adult skull. The cartilage for the orbito-sphenoid (the small wing) is co-extensive with the ali-sphenoid, and forms part of the lateral wall of the skull. The snout-like appeurance of the anterior part of the skull is caused by the fronto-nasal plate. On each side of the ethmo-romerine plate, near its anterior termination, are two small concave pieces of eartilage for Jacobson's organs. They are sometines referred to as the ploughshare cartilages, owing to their shape. Further details are given in fig. 141 .

(2) The appendicular elements of the skull are a number of cartilaginous rods surrounding the visceral cavity-i. e., nose, mouth, and pharynx-which undergo a remarkable metamorphosis, and are represented in the adult by the ear bones, the styloid process, and the hyoid bone. 
Fig. 141.- Model of the Chondro-cranidi of a Human Fotus $S$ cai. in Length. Cartilage in Blue. Viewed from Above. (After O. Hertwig.)

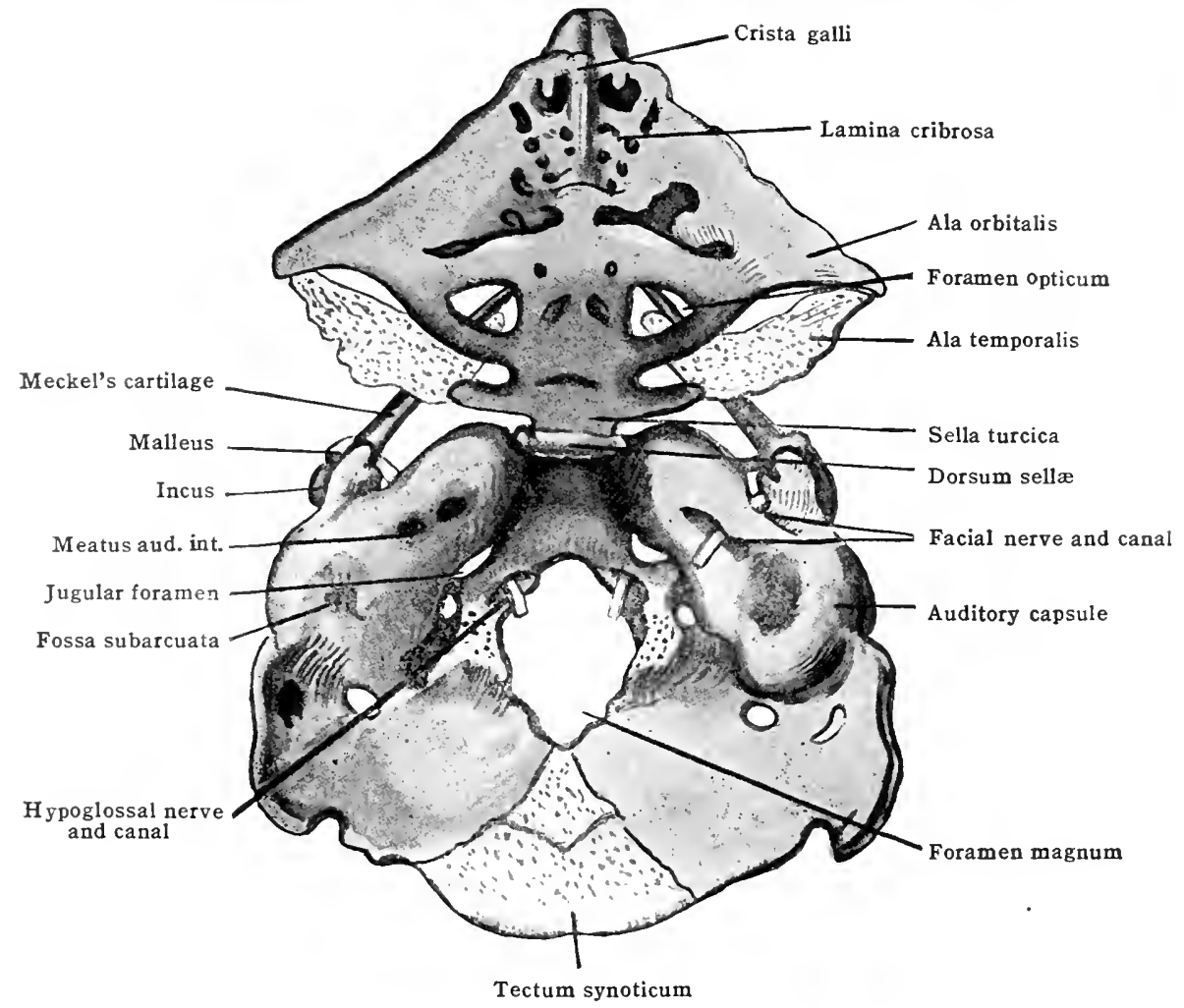

Fig. 142.-An Enlarged Portion of the Same Model of the Chondro-cranium as Shown in Fig. 141. Viewed From the Right Side, Showing the Skeleton of the Auditory Regrox. Cartilage in Blue. (After O. Hertwig.)

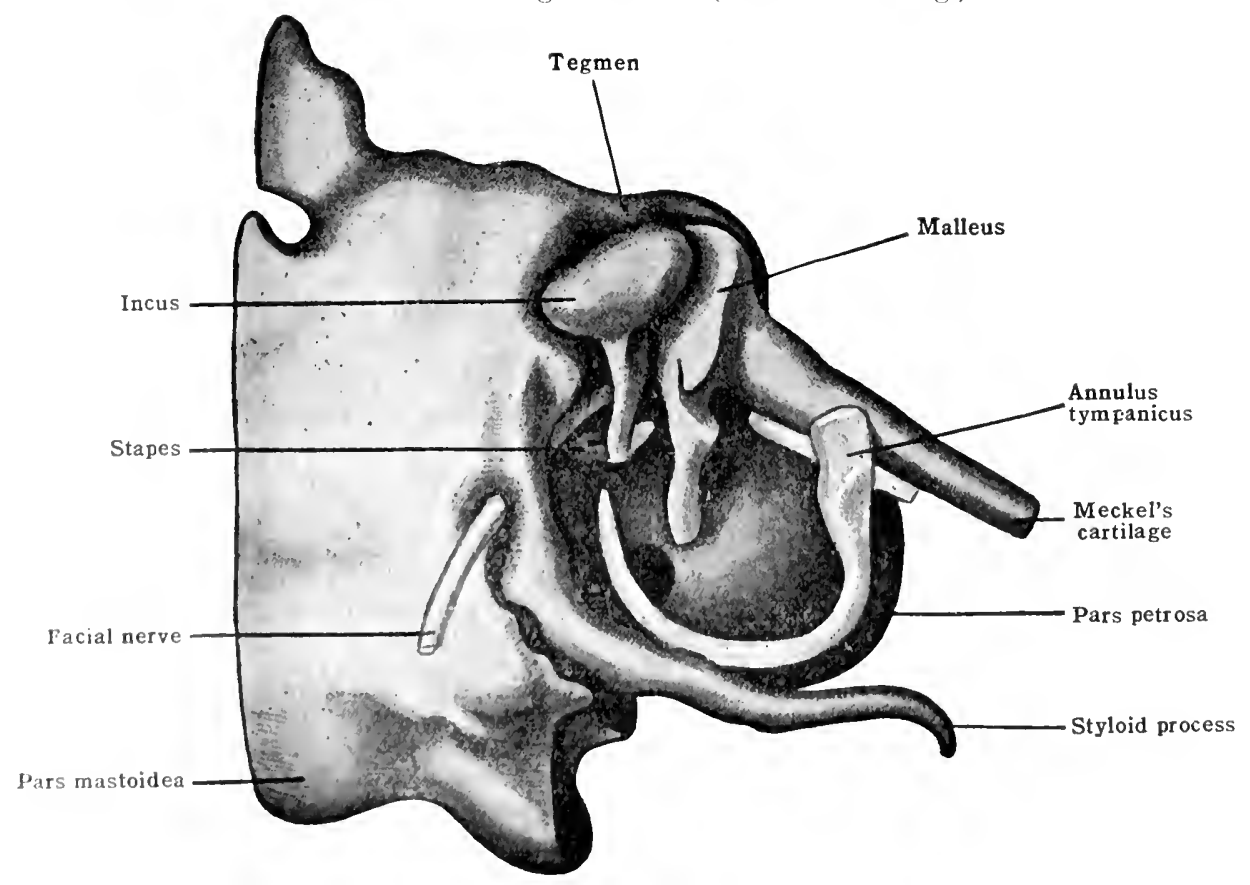




\section{Metamorphosis of the Branchial or Tisceral Bars}

These rods of cartilage are named, f om before backward, the mandibular, hyoid, and thyreoid bars. They may with care be easily dissected in the fœetus between the third and fourth months. Their metamorphosis is as follows:-

The two extremities of the mandibular bar (cartilago Meckelii) ossify; the distal end ultimately forms a portion of the mandible near to the symphysis (see p. 94); the proximal end ossifies as the malleus and incus. The intermediate portion disappears; the only vestige is a band of fibrous tissue, the spheno-mandibular ligament, extending from the spine of the sphenoisl to the spine of the mandible.

In the connective tissue surrounding the bar there appear, however, ossifications, one of which invests the bar to form the dentary plate; while a second, situated niore proximally, forms the tympanic bone.

The hyoid bar fuses distally with the thyreoid bar, and forms part of the hyoid bone. Its proximal end becomes the stapes, the tympano-hyal portion of the styloid process (fused with the petro-mastoid), and the stylo-hyal or free portion of the process. The succeeding portion (epi-hyal segment) is represented in the adult by the stylo-hyoid ligament, and the lowest serment, or cerato-hyal, by the small cornu of the hyoid.

The thyreoid bar forms the great cornu of the hyoid bone (thyreo-hyal). The body of the hyoid (basi-hyal) is regarded as representing the fused ventral ends of the hyoidean and thyreoidean arches.

In addition to these structures ossifications occur in the connective tissue of the maxillary process, a structure which may be regarded as forming the anterior part of the first branchial arch, and in the fronto-nasal process. The ossifications in the maxillary process give rise to the pterygoid (medial pterygoid process of the sphenoid), the palate, the maxilla, and the zygomatic, while that in the fronto-nasal process forms the premaxilla.

The bony elements of the head may therefore be arranged, according to their origin, in the following table:-

\section{Basilar Bones Developed in the Cartilaginous Crayidi}

Basi-occipital......... Basilar portion of the occipital bone.

Exoccipitals. . .......... Condylar parts of the occipital bone.

Supra-occipital........... Lower part of the squamous portion of the occipital.

Basi-sphenoid

Pre-sphenoid

Constituting the body of the sphenoid.

Ali-sphenoids ........... Greater wings and lateral pterygoid plates.

Orbito-sphenoids ......... Lesser wings.

Petro-mastoids............. Petrous and mastoid portions (excepting post-auditory processes) of the temporal bones.

\section{Roof Bones Developed in the Membranous Cravium}

Squamosals............ Squamous portions of temporals.

Parietals............ The two parietal bones.

Frontals................ United to form a median frontal bone.

Interparietal............ Upper part of squamous portion of occipital.

Epipterics............ The epipteric bones.

\section{Bones of the Nasal Region}

Mesethmoid...........Vertical plate of ethmoid developed in the cartilage of the cranio-facial axis.

Ethmo-turbinals........ Juperior and inferior conchal processes of ethmoid.

Maxillo-turbinals........ The inferior nasal conchæ.

Cribriform lamina........ Cribriform plate of ethmoid.

These elements are developed in the cartilage of the lateral nasal process.

Sphenoidal turbinals......Sphenoidal conchr. These are derivatives of the ethmoturbinals.

Lacrimals............ The lacrimal bones $\}$ Developed in the membrane over Nasals............... The nasal bones $\}$ the lateral nasal process.

Vomer................ The vomer. Ossified in the membrane investing the cartilage of the cranio-facial axis.

\section{Facial Bones}

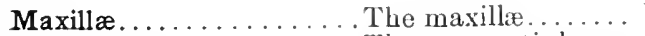

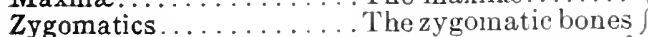

Developed in the connective tissue of the maxillary process.

Premaxillæ............. The incisor parts of the maxille. Formed at the anterior extremity of the cranio-facial axis in the tissue of the fronto-nasal process (proc. globulares). 


\section{T. Appendicular Elenents (Bones of the Visceral Arches)}

Malleus, Incus, and

Stapes............ The ossicula auditus.

Mento-Meckelian portion

of the lower jaw........ Small part on either side near to the symphysis menti.

Tympano-hyals and Stylo-

hyals................ Styloid processes of the temporal bones.

Epihyals.............. Stylo-hyoid ligaments.

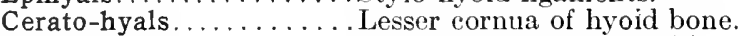

Thyreo-hyals........... Greater cornua of hyoid bone.

Basi-hyals............ Body of hyoid bone.

\section{(B) Membranous}

Mandible............ The lower jaw excluding a small portion near symphysis. Tympanics........... The tympanic plates.

Pterygoids........... The medial pterygoid plates.

Palatals.............. The palate bones.

\section{The Skull at Birth}

The skull at birth presents, when compared with the adult skull, several important and interesting fentures. Its peculiarities may be considered under three headings:- The peculiarities of the foetal skull as a whole; the construetion of the individual bones; the remnants of the ehondral skull.

\section{(1) The General Characters of the Fotal Skull}

iThe most striking features of the skull at birth are, its relatively large size in comparison with the body, and the predominanee of the cramial over the facial portion of the skull (8 to 1$)$; the latter is, in fact, very small.

Fig. 143.-The Cranium at Birth. (Viewed from above.)

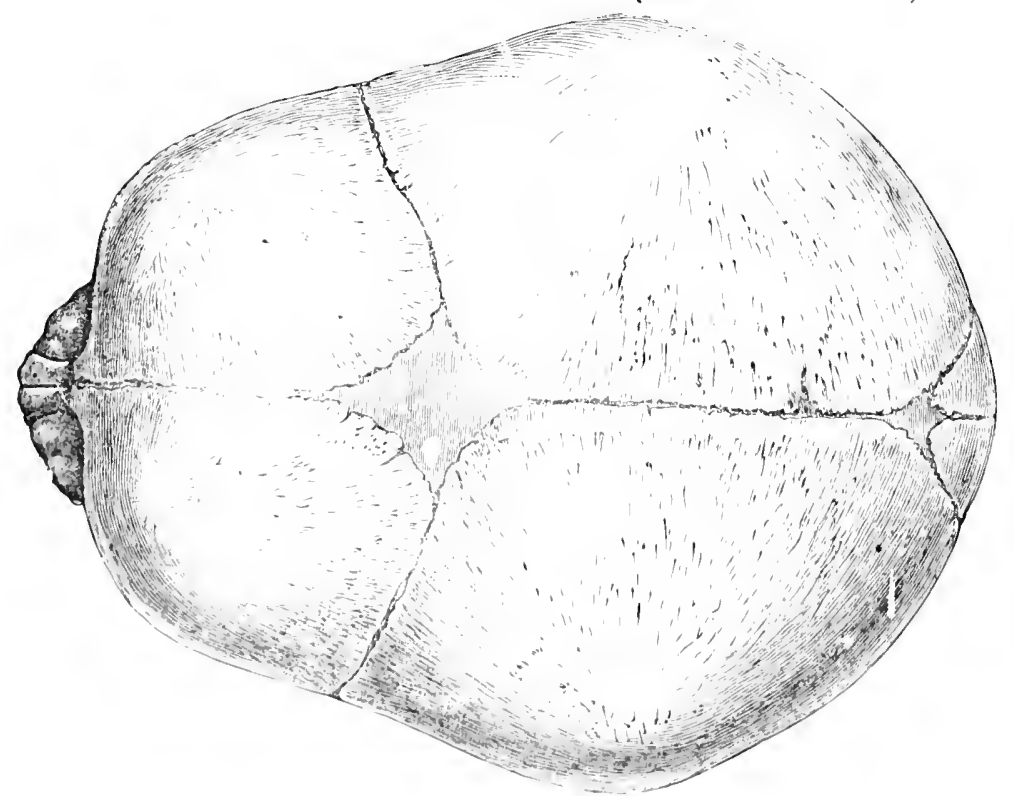

'The frontal and pariotal eninences are large and conspieuous; the sutures are absent; the arljasent margins of the bones of the vault are separated by septa of fibrous tissue continuous with the dora matre intcrually and the perieranimu externally; hence it is diflieult to separate

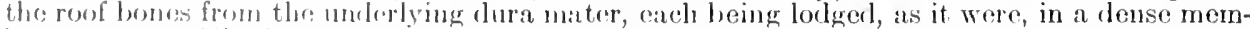

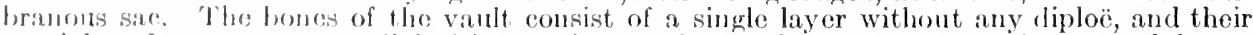
cranial surfiuces joresent uo ligital inpressions, six membranous spaces exist, named fontanollow: fwo are median, the frontal ffonticulus frontalis; major] being anterior and the occipital [fonticulus oeciphitalis; ninor] posterior. T'wo exist on raleh side, fermed anterior [fonticulus sphonoidatis and posterior fontiondus mastoidous] lateral fontanelles. Each angle of the pari-

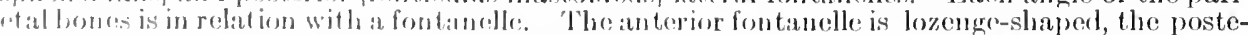
rior triangular. The lateral fontandles are irrogular in ontline. 'The lateral fontanelles close soon after hirth; theoeceipoital fontanello closes in the first year, and the froutal during the second yetir. 
Turning to the base of the skull, the most striking points are the absence of the mastoid processes, and the large angle which the pterygoid plates form with the skull-base, whereas in the adult it is almost a right angle. The base of the skull is relatively short, and the lower border of the mental symphysis is on a level with the occipital condyles.

The facial skeleton is relatively small in consequence of the small size of the nasal fossa, the small size of the maxillary sinus, and the rudimentary condition of the alveolar borders

Fig. 144.-The Cranium at Birth. (Lateral view.)

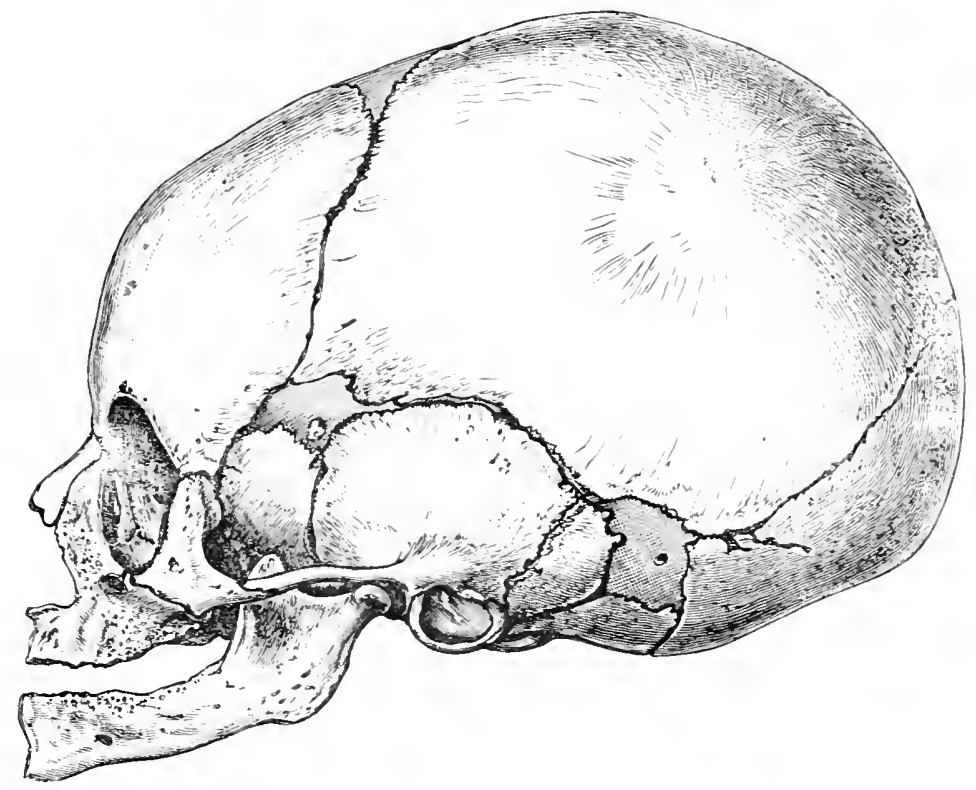

of the maxillæ and mandible; the nasal fossæ are as wide as they are high, and are almost filled with the conchæ.

Grow th takes place rapidly in the first seven years after birth. There is a second period of rapid growth at puberty, when the air sinuses develop, and this affects especially the face and frontal portion of the cranium.

Fig. 145.-The Crayici at Birth 1x Sagittal Section. (Sphenoidal concha indicated by a *)

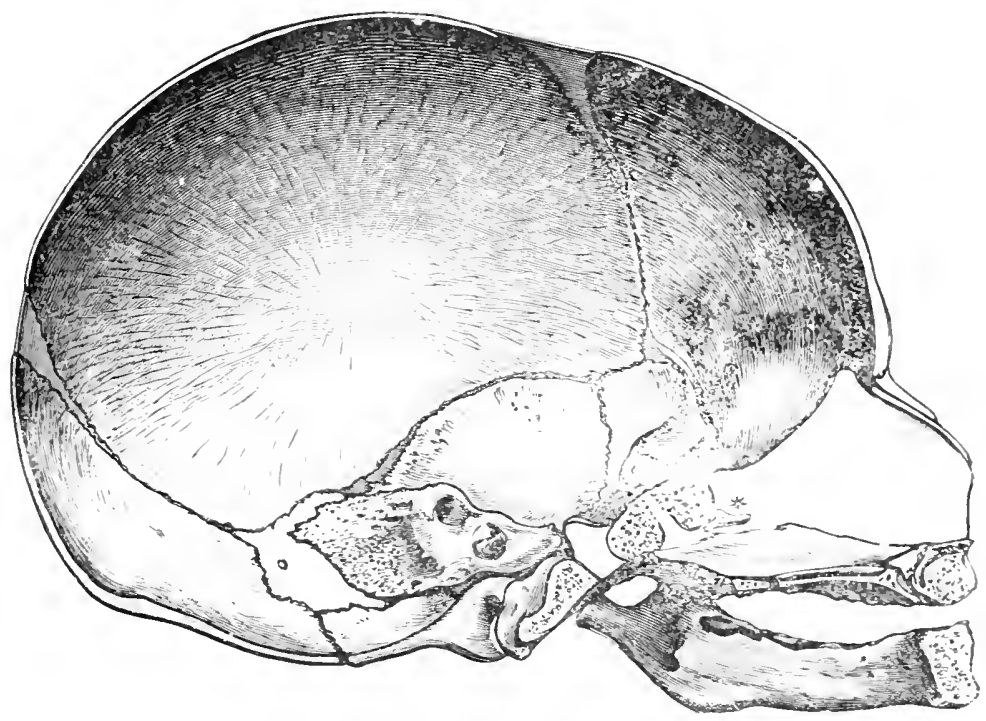

(2) The Peculiarity of Individual Bones at Birth

The occipital bone consists of four distinct parts, which have already been described. Compared with the adult bone, the following are the most important points of distinction:There is no pharyngeal tubercle or jugular process; the squamous portion presents two deep fissures separating the interparietal from the supra-occipital portion and extending medially 
as far as the occipital protuberance. The grooves for the transverse (lateral) sinuses are absent.

The sphenoid in a macerated fœetal skull falls into three pieces: (1) united pre- and postsphenoids, orbito-sphenoids, and lingulæ, and (2 and 3) the ali-sphenoids. The pre-sphenoid is quite solid and connected with the ethmo-vomerine cartilage, and presents no traces of the air sinuses which occupy this part in the adult skull. 'The pre-sphenoid by its upper surface forms part of the anterior cranial fossa, from which it is subsequently excluded by the growth of the orbito-sphenoids. The optic foramina are large and triangular in shape. The lingulæ

Frg. 146.-The Occipital at Birth.

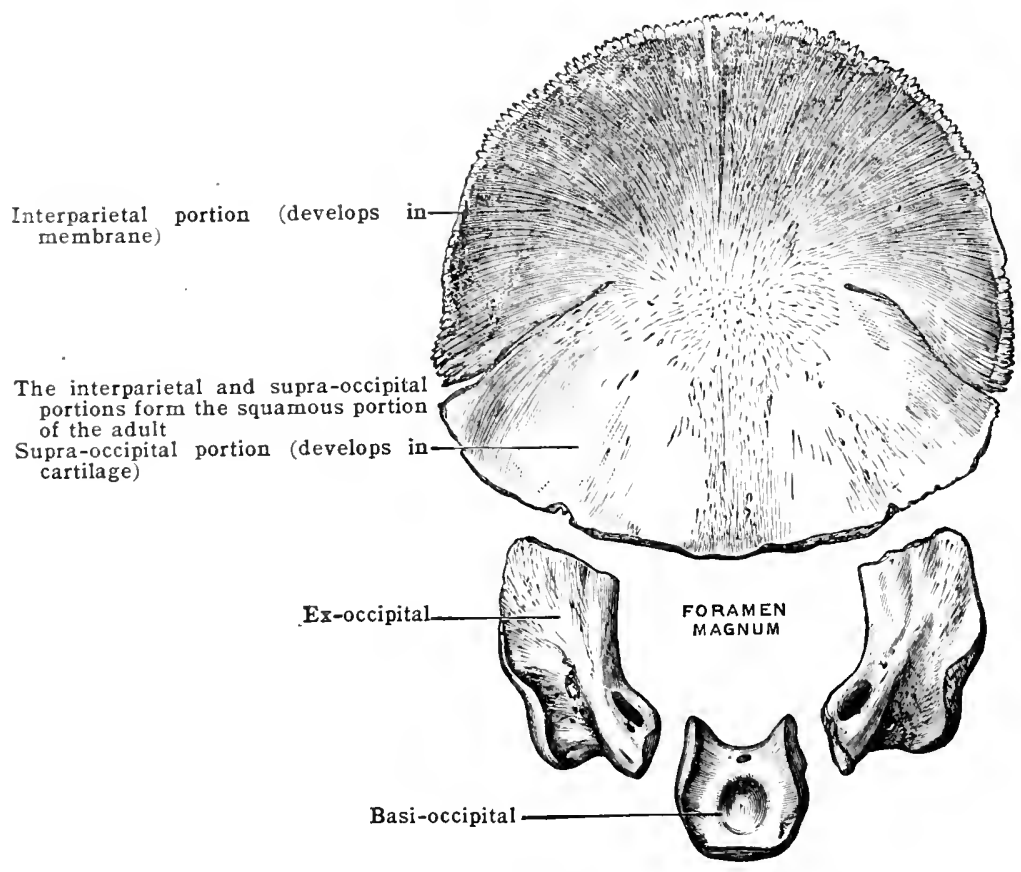

stand out from the basi-sphenoid as two lateral buttresses, and at the tuberculum sellæ is the basi-pharyngeal canal, which in the recent bone is occupied by fibrous tissue. The dorsum sellæ is still cartilaginous. The ali-sphenoids with the pterygoid processes are separated from the rest of the bone by cartilage. 'The foramen rotundum is complete, but the future foramen ovale is mercly a deep notch in the posterior border of the great wing, and there is no foramen spinosum. The pterygoid processes are short, and each medial pterygoid plate presents a broad surface for articulation with the lingula. The pterygoid canal is a groove between the medial pterygoid plate, the lingula, and great wing.

\section{Fig. 147.-The Sphienold at Birth.}

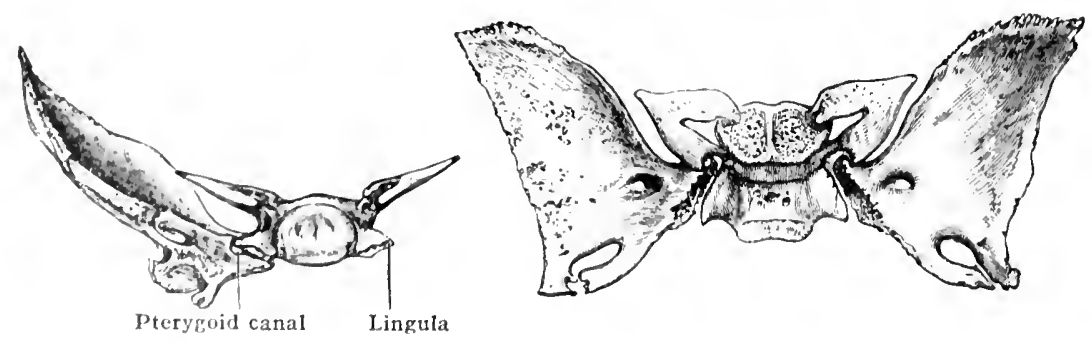

'The temporal bone at birth consists of three elements, the petrosal, squamosal, and tympanic. 'Tho petrosal presents a large and conspicuous floceular fossa; the hiatus Fallopii is it shallow bay lodging the geniculate ganglion of the facial nerve. There is a relatively large mustrid antrum, but no mastoin process. The styloid process is unossified, but the tympanohyal nity be fleterted as a minute rounded nodile of bone near the stylo-mastoid foramen.

'Tho squamosal has a very shallow mandibular fossa and a relatively large post-glenoid tubercle. rlie posterior part of the inferior borler is prolonged downward into an uncinate process (postanditory process) which closes the mastoid antrum laterally. 
The tympanic bone or annulus is a delicate, horseshoe-shaped ossicle, attached by it anterior and posterior extremities to the inferior border of the squamo-al

The ear-bones are chiefly of interest from their size, for they are as large at birth as in the adult. The anterior process (Folian process) may be $2 \mathrm{~cm}$. in length.

Fig 14S.-The Temporal Boxe at Birth.

\section{Fig. 149.--Temporal Boxe at Birth.}
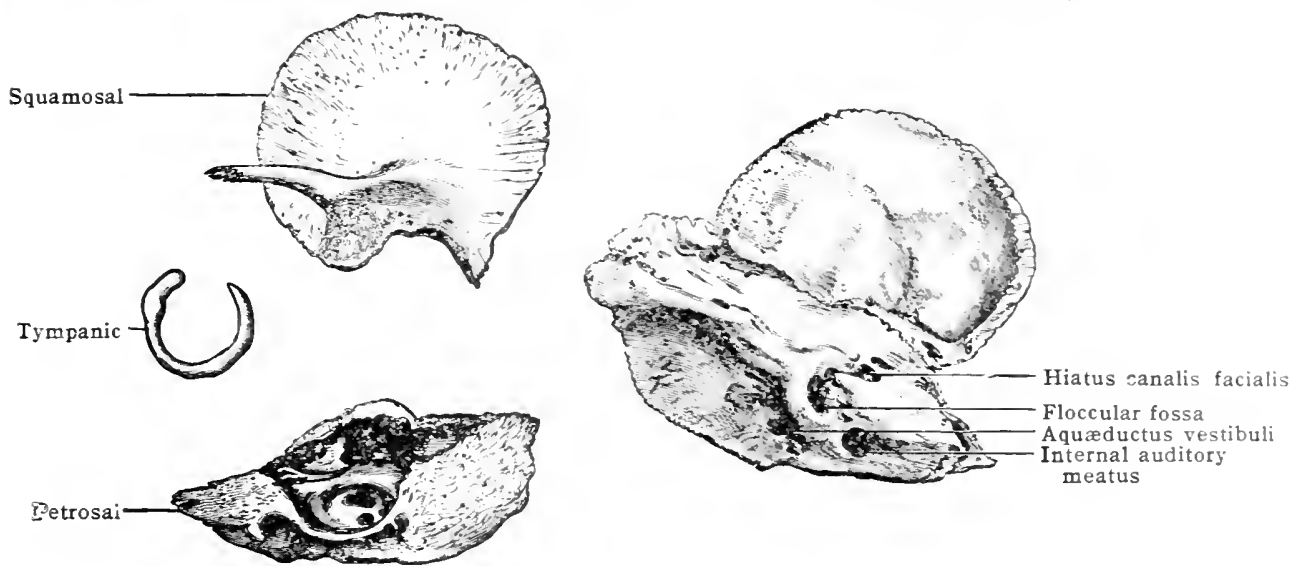

Fig. 150.-The Tempor.ll Bone at Birth. (Lateral view.)

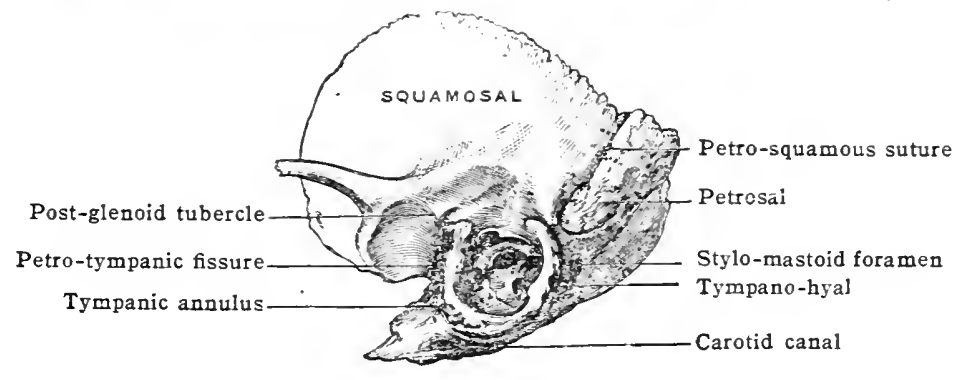

The frontal consists of two bones separated br a median vertical (metopic) suture. The frontal eminence is very pronounced, but the superciliary arches and frontal sinuses are wanting. The frontal spine, which later becomes one of the most conspicuous features of this bone, is absent. There is no temporal line.

Fig. 151.-The Frontal Bone at Birth.
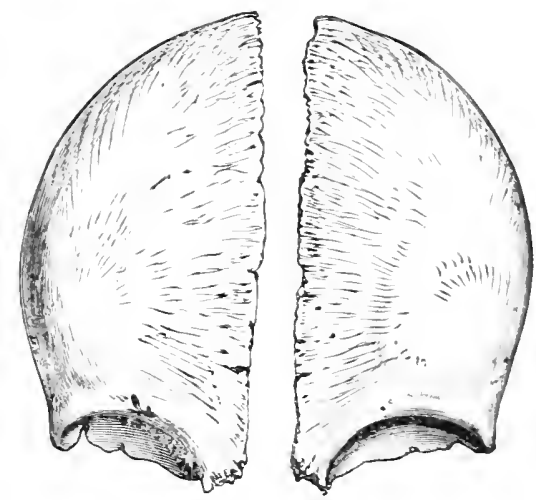

The parietal is simply a quadrilateral lamina of bone, concave on its inner and convex on the outer surface. The parietal eminence, which indicates the spot in which the ossification of the bone commenced, is large and prominent. The grooves for blood-sinuses, as in other cranial 
bones, are absent. Each angle of the parietal is in relation with a fontanelle. As in the adult, the anterior inferior angle of the bone is prolonged downward toward the ali-sphenoid.

The ethmoid consists of two lateral portions separated by the still cartilaginous ethmovomerine plate. The ethmoid cells are represented by shallow depressions, and the uncinate process is undereloped.

The sphenoidal conchæ are two small triangular pieces of bone lying in the perichondrium on each side of the ethmo-vomerine plate near its junction with the pre-sphenoid. (Indicated by the ${ }^{*}$ in fig. 1.5.)

The maxilla presents the following characters:-The incisive suture is visible on the palatine aspect of the bone. The alveolar border presents five sockets for teeth. The infra-orbital

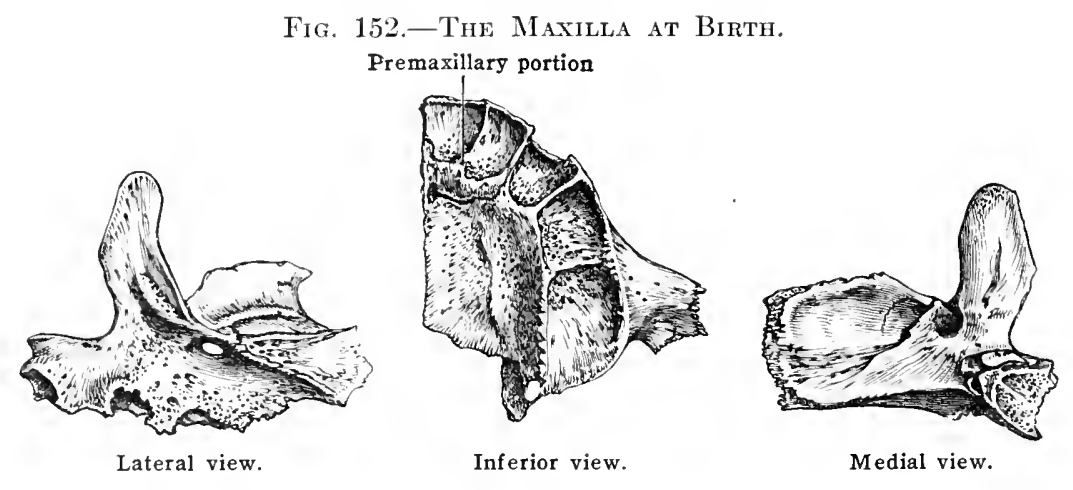

foramen communicates with the floor of the orbit by a deep fissure; this fissure sometimes persists in the adult. The sinus is a shallow depression.

The mandible at birth consists of two halves united by fibrous tissue in the line of the future symphysis. Each half is a bony trough lodging teeth. The trough is divided by thin osseous partitions into five compartments: of these, the fifth is the largest, and is often subdivided by a ridge of bone. The floor is traversed by a furrow as far forward as the fourth socket (that for the first milk molar), where it turns outward at the mental foramen. This furrow lodges the inferior alveolar nerve and artery, which enter by the large mandibular foramen. The condyle is on a level with the upper border of the anterior extremity of the bone.

The palate bones differ mainly from those in the adult in that the vertical and horizontal plates are of the same length; thus the nasal fosse in the fotus are as wide as they are high, whereas in the adult the height of each nasal fossa greatly exceeds the width.

Concerning the remaining bones little need be said. The vomer is a delicate trongh of bone for the reception of the inferior border of the ethno-vomerine plate; its inferior border,

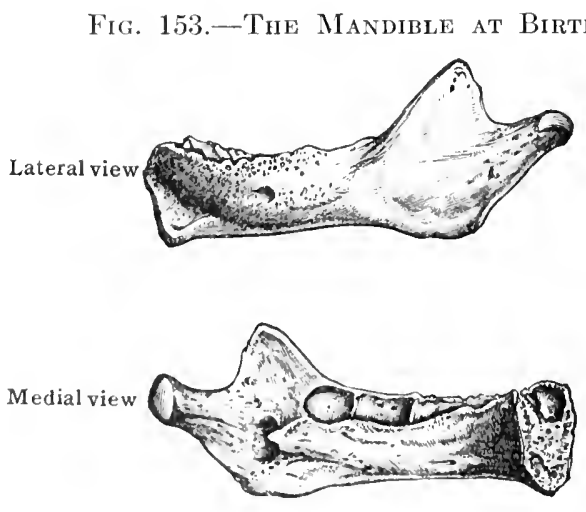

whirh rests upon thr: hard palate, is broal, and the bone presents quite a different appearance from that in the : alult. The nasal bones are slort and broad; the zygomatics and inferior concha are rentively vary linge; and the lacrimals are thin, frail, and delicate lamellat.

"Thro hyoid romsists of five parts. There is a merlian nucleus for the basi-hyal, and one on

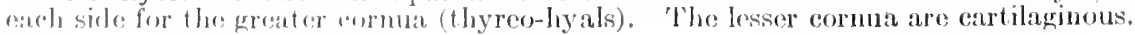

\section{(3) Jirmunts of the Carlilaginous Cranium}

It has alpouly loen pointerl out that at an early date the base of the skull and the face are represented by liyaline cartilage, which for the most part is replated by bone before birth. liven at hirti remmants of this jrimitive chondral skull are aloundant. In the cranium, cartiliginoms tracts rexist between the varions portions of the occipital bone, as well as at the line of 
junction of the occipital with the petrosal and sphenoid. The dorsum sella is entirely cartilaginous at birth, and the last portion of this cartilage disappears with the ankylosis of the basi-occipital and basi-sphenoid about the twentieth year. A strip of cartilage unites the alisphenoids with the lingulæ, and for at least a year after birtly this cartilage is continuous with that which throughout life occupies the foramen lacerum. A strip of cartilage exists along the posterior border of the orbito-sphenoid, and not unfrequently extends lateralward to the pterion. In the adult skull it is replaced by ligamentous tissue.

The ethmo-vomerine plate is entirely cartilaginous, and near the end of the nose supports the lateral nasal cartilages, remnants of the fronto-nasal plate. The fate of the ethmo-vomerine plate is instructive. The upper part is ossified to form the mesethmoid; the lower part atrophies from the pressure exerted by the vomer; the anterior end remains as the septal cartilage. The lateral snout-like extremities of the fronto-nasal plate persist as the lateral cartilages of the nose.

Among the appendicular elenrents of the skull, the styloid process and a large portion of the hyoid are cartilaginous at birth.

\section{The Nerve-foramina of the Skull}

The various foramina and canals in the skull which give passage to nerves may be arranger in two groups, primary and secondary. Primary foramira indicate the spots where the nerves leave the general cavity of the dura mater, and as this membrane indicates the limit of the primitive cranium, a cranial nerve, in a morphological sense, becom es extra-cranial at the point where it pierees this membrane. In consequence of the complicat ed and ext raordinary modifications the vertebrate skull has undergone, many nerves traverse, in the adult skull, bony tumnels and canals which are not represented in the less complex skulls of low vertebrates, such as sharks and rays. To such foramina and canals the terms secondary or adventitious may be applied.

Nerve-foramina are further interesting in that they oceupy sutures, or indicate the points of union of two or more ossifie centres. To this rule the foramen rotundum is the only exception in the human skull.

\section{The Primary Foramina}

1. Foramen magnum.-This is bounded by four distinct centres, the supra-, basi-, and two ex-occipitals. It transmits the accessory (eleventh) pair of cranial nerves, the vertebral arteries and their anterior and posterior spinal branches, the medulla oblongata and its membranes, and the membrana tectoria.

2. The hypoglossal. - At birth this is a deep notch in the anterior extremity of the exoccipital, and becomes a complete foramen when the basi-and ex-occipitals fuse. Oceasionally it may be complete in the ex-oceipital, but it indicates accurately the line of union of these two elements of the occipital bone. It transmits the hypoglossal nerve, the meningeal branch of the ascending pharyngeal artery, and its vene comitantes.

3. Jugular foramen. - This occupies the petro-oecipital suture, and is formed by the basiand ex-occipital in conjunetion with the petrosal. It transmits the glosso-pharyngeal, vagus, and accessory nerves, a meningeal branch of the ascending pharyngeal artery, and receives the transverse and inferior petrosal simuses.

4. Auditory.-This marks the point of confluence of the groups of centres termed pro-otic and opisthotic. It transmits the facial and auditory nerves, the pars intermedia, and the auditory twig of the basilar artery.

5. Trigeminal. - This is only a foramen when the dura mater is present in the skull. It is a notch at the apex of the petrosal converted into a foramen by the tentorium. The main trunk of the trigeminal nerve, with the small motor root (masticator nerve), traverses it.

6. Petro-sphenoidal. - This is a notch between the side of the dorsum selle and apex of the petrosal which becomes converted into a foramen by dura mater.

7. Optic.-This foramen is formed by the confluence of the orbito- and pre-sphenoidal centres. It opens into the orbit and transmits the optic nerve and ophthalmic artery.

\section{The Secondary Nerve-foramina}

Foramina transmitting the various subdivisions of the trigeminal nerve. - The primary foramen of exit for the trigeminal nerve is formed partly of bone and partly of membrane at the apex of the petrosal. The three divisions of the nerve issue through secondary foramina.

(a) The superior orbital (sphenoilal) fissure is an elongated chink, bounded above by the orbital wing and below by the great wing of the sphenoid, medially by the body of the sphenoid, and laterally by the frontal. It opens into the orbit, and transinits the third, fourth, first (ophthalmic) division of the trigeminal and abducens nerves, also the ophthalmic vein or veins.

(b) The foramen rotundum is the only exception to the rule relating to the formation of nerve-foramina; it is probably a segment of the superior orbital fissure. The foramen is really a canal running from the middle cranial fossa to the pterygo-palatine fossa, and transmits the second or maxillary division of the trigeminal.

(c) The foramen ovale at birth is a gap in the hinder border of the great wing (ali-sphenoid) of the sphenoid, and is converted into a formen by the petrosal; subsequently it becomes complete in the sphenoid. It transmits the third or mandibular division of the trigeminal and the small or motor root, the snrall superficial petrosal nerve (which occasionally passes through a separate foramen), and the small meningeal artery with its vene comitantes. 
The ethmoidal canals. - These commence in the suture between the lamina papyracea and the frontal bons, and traverse the space between the upper surface of the lateral mass of the ethmoid and the horizontal plate of the frontal, to emerge on the cribriform plate; they are situated outside the dura mater. The anterior foramen transmits the anterior ethmoidal branch of the ophthalmic, which subsequently gains the nasal cavity by passing through the ethmoidal fissure by the side of the crista galli

The infra-orbital canal indicates the line of confluence of the maxillary and malar centres of the maxilla; occasionally it is completed by the zygomatic; rarely it is incomplete above, and communicates by a narrow fissure with the orbit. It lodges the infra-orbital nerve and arterv.

The zygomatico-temporal foramen is situated in the suture between the zygomatic and the greater wing of the sphenoid (ali-sphenoid); it transmits the temporal branch of the zygomatic nerve and a branch of the lacrimal artery. In the adult this foramen may be wholly confined to the zygomatic bone.

The zygomatico-facial canals traverse the zygomatic bone, and indicate the line of confluence of the two chief centres for this bone. The facial twigs of the zygomatic nerve issue from them accompanied by arterial twigs.

The spheno-palatine foramen is a deep groove between the orbital and sphenoidal processes of the palate bone, converted into a foramen by the sphenoidal concha. It is traversed by the naso-palatine nerve and artery as they enter the nasal from the pterygo-palatine fossa.

Scarpa's foramina are two minute openings in the meso-palatine suture where it is in relation with the incisive fossa. They are traversed by the naso-palatine nerves.

The pharyngeal foramen is situated between the sphenoidal process of the palate bone, the medial pterygoid plate of the sphenoid, and the sphenoidal concha. The pharyngeal branch of the spheno-palatine ganglion and a branch of the spheno-palatine artery pass through it.

The pterygoid (Vidian) canal is trumpet-shaped: the narrower end is situated in the foramen lacerum; the broader orifice opens on the posterior wall of the pteryo-palatine fossa. The canal is $10 \mathrm{~mm}$. long; in the fotal skull it is a chink between the base of the medial pterygoid plate, the ali-sphenoid, and the lingula of the sphenoid. The canal is traversed by the Vidian branch of the spheno-palatine ganglion and the Vidian artery.

The posterior (greater) palatine canal is a passage left between the maxilla, the vertical plate and tuberosity of the palate bone and the medial pterygoid plate; it commences on the hard palate by the greater palatine foramen. The descending palatine nerve and artery traverse this canal. Several foramina open from it. In the suture between the vertical plate of the palate bone and the maxilla, two snall openings allow minute nerves to issue for the middle and inferior nasal conchæ. In the fissures between the tuberosities of the palate and maxillæ, and the pterygoid plates, the posterior and middle pala tine nerves issue. These are sometimes called the posterior and middle (smaller) palatine canals.

The mandibular or inferior dental canal runs in the mandible between the dentary and Meckel's cartilage of the mandible. The posterior orifice of the canal is the mandibular (inferior dental) foramen; the anterior orifice is the mental foramen. The inferior alveolar nerve and artery enter the canal at its posterior orifice; the mental foramen allows the mental nerve to escape from the canal accompanied by the mental artery.

Foramina transmitting the facial nerve and its branches.--The main trunk of the facial enters the internal auditery meatus and traverses the facial canal. In the early embryo the nerve lies on the petrosal, and is not covered in with bone until the fifth month of fotal life. The terminal orifice, the stylo-mastoid foramen, is situated between the tympanic, tympanohyal, and epiotic elements of the complex temporal bone.

'The 'iter chordæ posterius' is a chink between the squamosal and the tympanic elements, and allows the chorda tympani nerve to enter the tympanum. The fissure of exit for this nerve is the subdivision of the petro-tympanic fissure termed the canal of Huguier, or "iter chordæ anterius.' 'The petro-tympanic fissure lies between the tympanic plate and the squamosal. It transmits the tympanic branch of the internal maxillary artery, and lodges the anterior process of the malleus.

The inferior orbital (spheno-maxillary) fissure is situated between the posterior border of the ortital plate of the maxilla and a smooth ridge on the orbital surface of the great wing of the sphenoid. It transmits the superior maxillary division (second) of the fifth nerve, the zygomatic nerve, branches of the spheno-palatine ganglion to the orbit, and a communicating vein from the ophthalmic to the pterygoid plexus.

\section{(. THE THORAX}

The thorax is a bony cage formed by the thoracic vertebra already described, the ribs with their costal cartilages, and the sternum.

\section{THE RIBS}

The ribs [coste] (figs. 154, 155) twelve in number on each side, constitute a series of narrow, flattened bones, extending from the sides of the thoracic vertebræ towarl the median line on the anterior aspect of the trunk. The anterior ends of the first seven pairs are connected, by means of their eostal cartilages, with the sides of the sternum, and on this account the first seven ribs on each side are 
termed true or sternal ribs. The remaining five pairs, known as false or asternal ribs, may be arranged in two sets:- one, including the eighth, ninth, and tenth ribs, in which the cartilages of the anterior extremities are connected together, and the other, including the eleventh and twelfth, in which the anterior extremities, tipped with cartilage, are free. The eleventh and twelfth are known, in consequence, as the floating ribs. Thus, the first seven are vertebro-sternal; the eighth, ninth, and tenth, vertebro-chondral; the eleventh and twelfth, vertebral ribs.

The ribs increase in length from the first to the seventh, and decrease from the seventh to the twelfth. They also vary in their direction, the upper ones being less oblique than the lower. The obliquity is greatest at the ninth rib and gradually decreases from the ninth to the twelfth.

Typical characters of a rib (fig. 154).-The seventh is regarded as the most typical rib. It presents for examination a vertebral extremity or head; a narrow portion or neck; a sternal extremity; and an intermediate portion, the body or shaft.

The head [capitulum costæ] presents an articular surface made up of two articular facets separated by a horizontal crest [crista capituli]. The crest is connected by an interarticular ligament with an intervertebral disc, and the facets articulate with the costal pits on the sicles of the bodies of two vertebræ (sixth and seventh). As a rule, the lower facet is the larger, and articulates with the thoracic vertebra, to which the rib corresponds in number. This is the primary facet, and is the one represented in those ribs which possess only a single facet on the rib-head. The anterior margin is lipped for the attachment of the radiate ligament.

The neck [collum costæ] is that portion of the rib extending from the head to the tubercle. It is flattened from before backward and the posterior surface is in relation with the transverse process of the lower of the two vertebræ with which the head articulates; it forms the anterior boundary of the costo-transverse foramen, and is rough where it is attached to the neck (middle costo-transverse) ligament. The anterior surface is flat and smooth. The superior border of the neck, continuous with the corresponding border of the shaft, presents a rough crest [crista colli] for the anterior costo-transverse ligament. The inferior border of the neck is rounded and continuous with the ridge of the costal groove. This difference in the relation of the neck, to the upper and lower borders of the rib-shaft, is useful in determining to which side a rib belongs.

The tubercle, situated behind at the junction of the neck with the shaft, consists of an upper and lateral part, rough for the attachment of the posterior costotransverse ligament, and a lower and medial part, bearing a facet for articulation with a pit near the tip of the transverse process. The tubercle projects below the lower edge of the rib to form a crest, marking the beginning of the costal groove.

The body is strongly curved and presents for examination two surfaces and two borders. At first the curve is in the same plane as the neck, but it quickly turns forward at a spot on the posterior surface of the shaft known as the angle, where it gives attachment to the ilio-costalis muscle and some of its subdivisions. The rib has also a second or upward curve, beginning at the angle. These curves are expressed by describing the main curve as disposed around a vertical, and the second or upward curve around a second transverse axis.

When a rib, except the first, second, and twelfth, is laid with its lower border upon the table, the rib-head rises and the rib touches the table at two places, viz., at the anterior end, and in the neighbourhood of the angle.

Besides the two curves now described, the rib is slightly twisted on itself, so that the surfaces which look medially and laterally behind are placed obliquely in front and look downward as well as medially, and upward as well as laterally.

The external surface of the rib is convex, and gives attachment to muscles. Near its anterior extremity it forms a somewhat abrupt curve, indicated by a ridge on the bone, which gives attachment to the serratus anterior (magnus) muscle, and is sometimes called the anterior angle.

The internal surface is concave and presents near its inferior border the costal groove [sulcus costæ]. The groove is best marked near the angle, and gradually becomes shallower toward the anterior extremity of the rib, where it is finally lost; it lodges the intercostal vessels and nerve. The ridge limiting the 
groove above is continuous with the inferior border of the neck of the rib, and gives attachment to the internal intercostal muscle.

The superior border is rounded, and affords attachment to the internal and external intercostal muscles. The inferior border commences abruptly near the angle, and gives attachment to the external intercostal muscle.

The sternal end of the shaft is cupped for the reception of the costal cartilage.

Fig. 154.-The Seventh Rib of the Left Side. (Seen from below.)

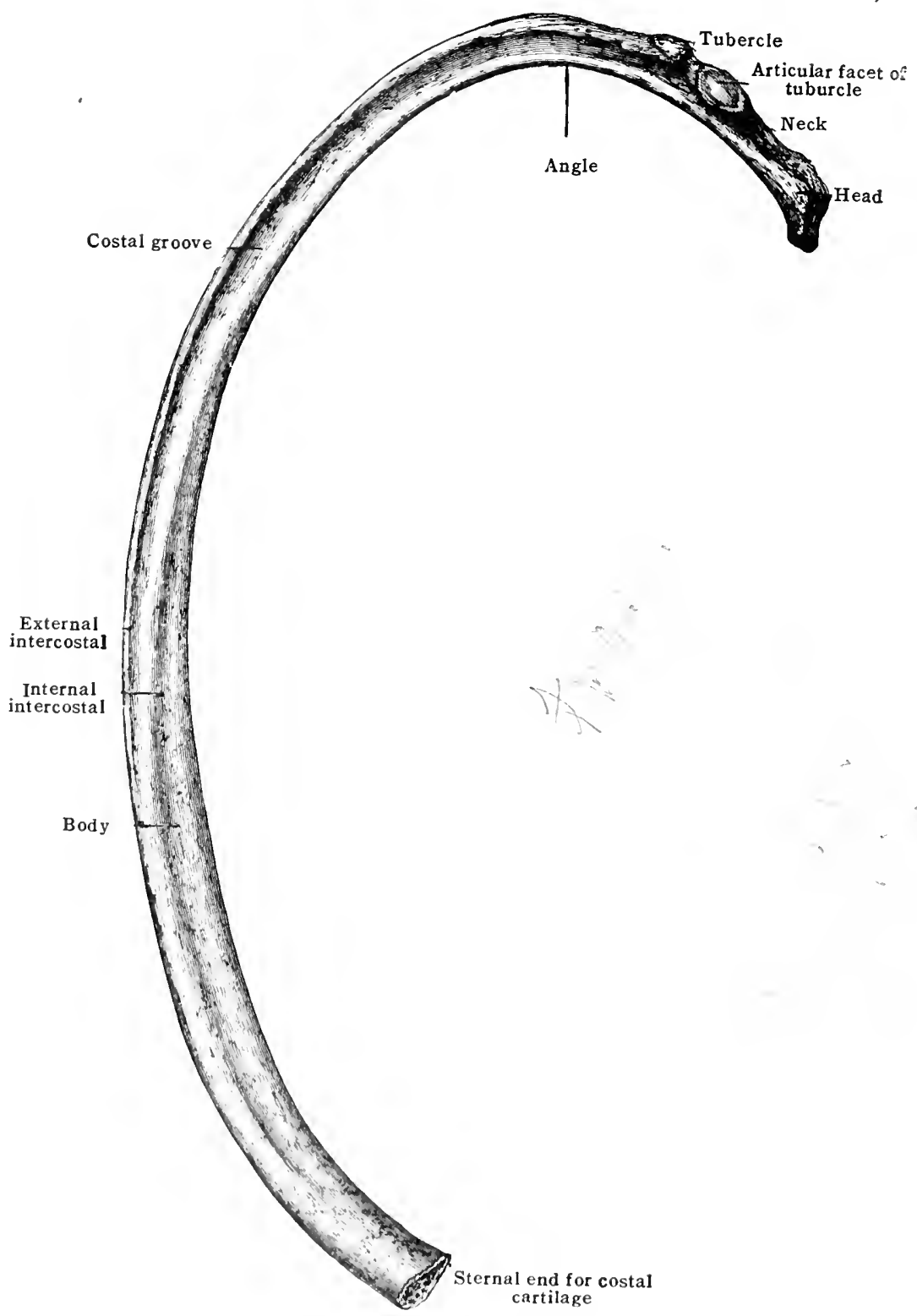

Blood-supply.-.-The rils are vory vascular and derive numerous branches from the intercostal arteris. The branches in the shaft run toward the vertebral end, whilst those in the beal and norek pun, ats at rule, towitrl the shaft. In the neighlourhoor of the tuberosity the Peculiar serm to have any constant arrangement.

Peculiar ribs(figs. 15i, liffi). Sevoral of tho ribs present eertain peculiarities and differ in many particulars from the general description given above. These are the first, second, tenth,
eleventh, and twelfth.

The first rib is thre broaldest, flattest, strongest, shortest, and nost curved of all the series. It, is not twisted, and is so placel that its smperior surfice looks forward as well as upward, and its inferior surface backwarl as wrll as downward. 'The heart is small, and as a rule is furnished 
with only one articular facet. The neck, longer than that of must of the ribs, is slouder and rounded. The tubercle is large and prominent. The shaft lies for its whole extent nearly in one plane, has no angle, and is curved in one direction only, i. e., around a vertical axis. The superior surface presents two shallow grooves, separated near the in ner border ly a rough surface (scalene tubercle or tubercle of Lisfrane) for the scalenus anterior muscle. The groove in front of this surface is for the subclarian vein, and the groore behind it is for the subclavian artery and a nerve trunk passing to the brachial plexus. Between the groove for the artery and the tubercle is a rough surface for the insertion of the scalenus medius, and between the groor. and the outer margin is an area for the origin of the serratus anterior (magnus). The inferior surface is uniformly flat and lacks a subcostal groove. By the lateral portion, which is rough, it gives attachment to the internal intercostal muscle; the remainder of the inferior surface is in relation to pleura and lung. The lateral border is thick and rounded, and gives attachment to the external intercostal muscle, whilst the medial border, thin, sharp, and concave, receir:the attachment of the fascia (Sibson's) corering the dome of the pleura. The anterior extremity is thick and broad, and its upper margin, as well as the cartilage to which it is joined, afforrl attachment to the costo-claricular ligament and the subclarius muscle. The costal cartilage: of this rib is directly united to the manubrium sterni, and occasionally the cartilage ant the adjoining part of the anterior extremity of the rib are replaced by fibrous tissue.

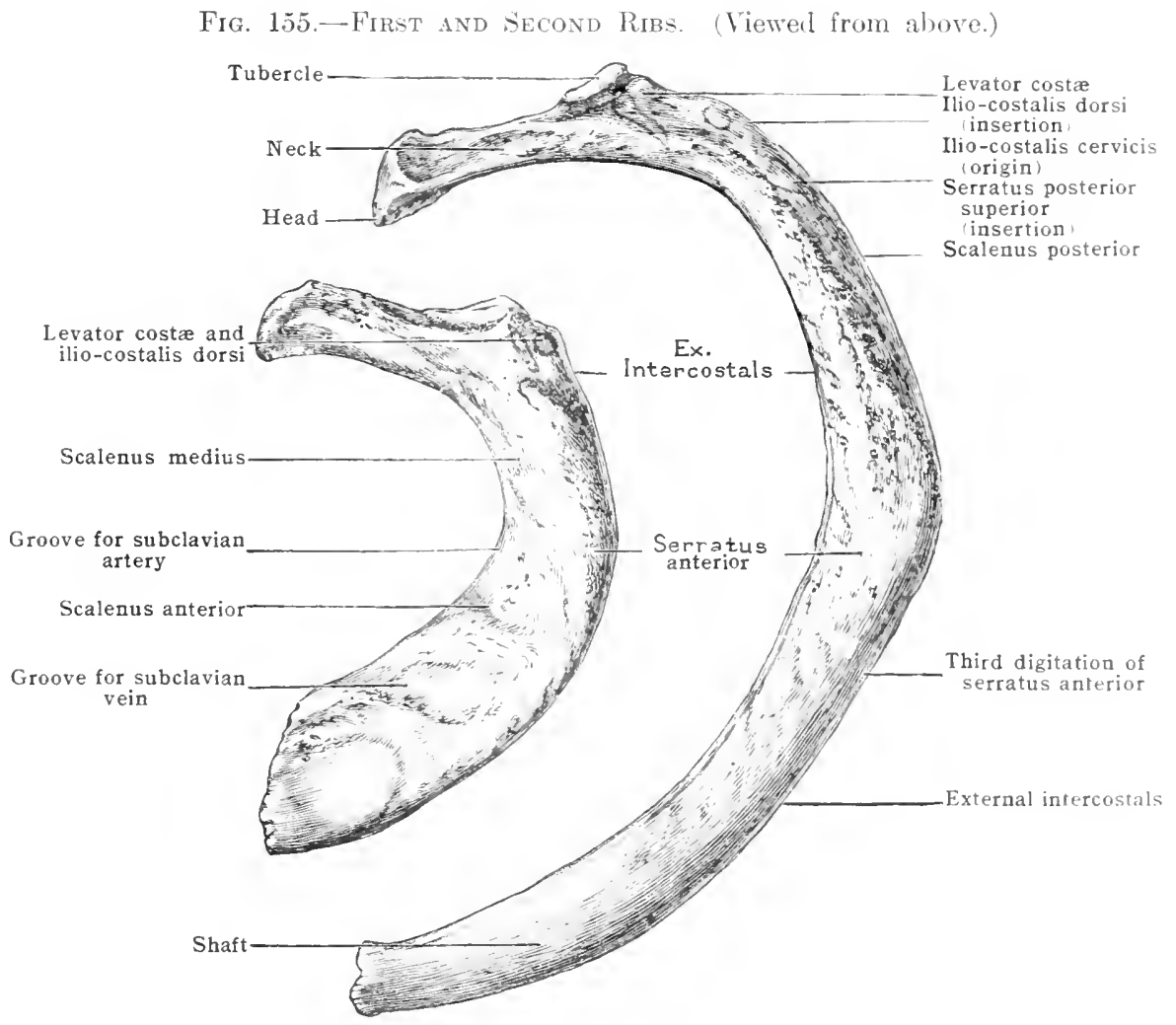

The rib derives its nutrition mainly from the superior intercostal branch of the subclavian artery.

The second rib is much longer than the first, and although like it in being strongly eurver round a vertical axis, in its form and general characters there is a closer resemblance to th" ribs lower down in the series. The head is round and presents two facets, the costal groorc is present, though faintly marked, and an angle is situated near the tubercle. The specially cli:tinguishing feature of the rib, howerer, is a well-marked tuberosity on its outer suface somewhat near the middle, for the origin of a part of the first digitation, and the whole of the secon il digitation of the serratus anterior (magnus). Between the tuberosity and the tubercle the onter surface is smooth and rounded and gives attachment to the scalenus postcrior, the scrutus posterior superior, the ilio-costalis cervicis (cervicalis ascendens), and the ilio-costalis dorsi acctssorius). The internal surface is smooth and in relation to the plema. The borlers atre attan. ment to the intercostal muscles, the upper, to those of the first space, the lower, to those of the second. The shaft of the second rib is not twisted on its own axis, so that both ends can lie flat on the table. The second rib receives vessels from the superior intercostal branch of the subclavian artery and the first wortic intereostal.

The tenth rib is distinguisherl by a single facet on the head for anticulation with the body of the tenth thoracic vertebra. Oecasionally there are two facets, in which cuse the rib articillates also with the ninth thoracic vertebra. The tenth rib, like the ribs immediately above, is long, curverl, presents a deep costal groove, a well-marked tuberosity and an angle. It nuy 
be noted, however, that the distance between the tubercle and the angle in this rib is greater than in the ribs above. Speaking generally, the distance between these points increases from above downward-a disposition which is useful in at once determining if any given rib belongs to the upper or lower end of the series.

The eleventh rib is peculiar in that it has a single facet on the head, a feebly marked angle some distance from the head, a shallow costal groove, no tubercle, and no neck. The tuberele is sometimes represented by a slight elevation or roughness without any articular facet. The interior extremity is pointed.

The twelfth rib has a large head furnished with one facet for articulation with the root (pedicle) of the twelf th thoracic vertebra. The shaft is narrow and extremely variable in length $(3$ to $20 \mathrm{~cm}$.). It is usually somewhat longer than the first rib, but it may be shorter. There is no tubercle, no angle, no neek, no costal groove. The anterior extremity is pointed. Posteriorly, the upper border is smooth and somewhat rounded; the lower border is sharp and rough.

The costal cartilages are bars of hyaline cartilage attached to the anterior extremities of the ribs, and may be regarded as representing unossified epiphyses. Like the shaft of a rib, each cartilage has an outer and inner surface. The outer surfaces give origin and insertion to large muscles, and the inner surfaces, from the second to the sixth inclusive, are in relation with the transversus thoracis (triangularis sterni). The upper and lower borders serve for the attachment of the internal intercostal muscles. The upper seven cartilages, and occasionally the eighth, are connected with the sternum. Of these, the first fuses with the manubrium sterni and the remaining six are received into small articular concavities, and retained by means of ligaments.

\section{Fig. 156.-The Vertebral Ends of Tenth, Eleventh, and Twelfth Ribs.}

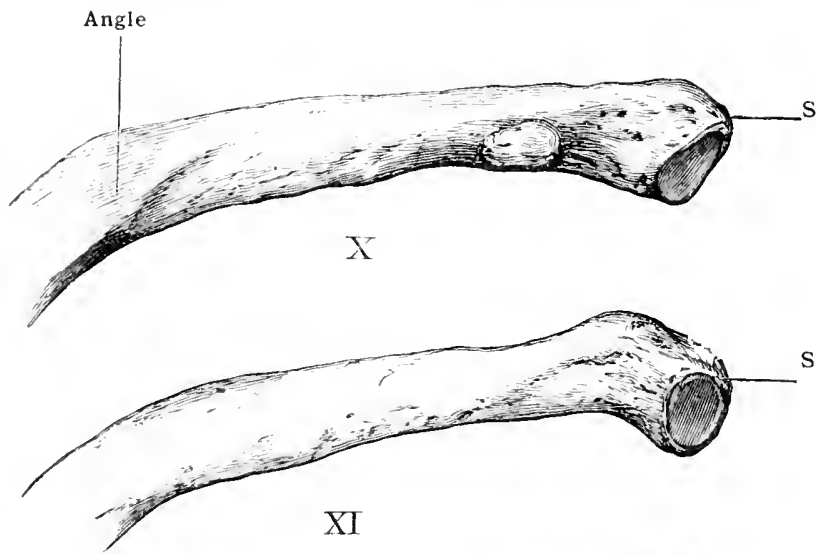

Single facet (sometimes two facets are present)

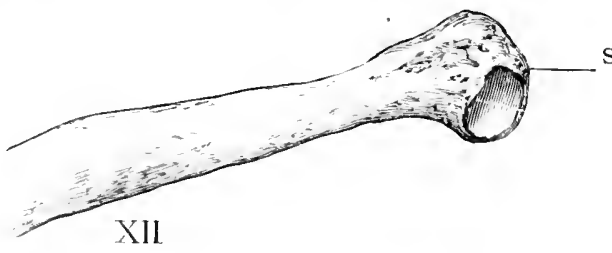

Single facet (this rib has an angle, but no tuberosity and no neck)

Single facet (this rib has neither tuberosity, angle, nor neck)

The cartilares of the vertebro-chondral ribs are united to one another and to the seventh costal cartilage by ligaments (sometimes by short vertical bars of cartilage), while those of the vertehral rils form no such attachment, but lie between the abdominal muscles. The inner surfaces of the lower six costal cartilages afford attachment to the diaphragm and the transversalis muscle.

Each of the second, third, fourth, and fifth costal cartilages articulates with the side of the stermum, at a point corresponding to the junction of two stemebrat. The sixth and seventh (and eighth when this reaches the sternum) are arranged irregularly. As a rule, the sixth lies in a recess at the side of the fifth sternelora; the seventh corresponds to the line of junetion of the meson and metastromm; and the cighth artienlates with the metasternm (see figs. 158, 161).

Blood-supply. - The costal cartilages derive their blowl-supply from the terminal twigs of the artic intercostals and from the internal mammary arteries.

Ossification. - It the eighth woek of intra-itcrine life the ribs are cartilaginous. About this date a nuclens appears nral 1 he angle of each rib, and spreads with great rapidity along the shaft, and by the fonrth month wimhes as far as the eostal cartilage. $\Lambda$ this date the length of rile-shaf bears the same propurtion to that of the costal cartilage as in adult life. Whilst the ribs are in a cartilaginoms romblition, the first eight reach to the side of the sternum, and even after ossification has taken place, the costal cartilage of the eighth rib, in many instanees, retains itsarticulation with the stermm wh to as late as the eighth month (fig. 158). This relationship may persist through life, but wsually the cartilage retrogresses, and is replaced by liganentous issue. About the fiftecnth year a secomclary rentre anpears for the heal of each rib, and a littla later one makes its appearance for the tubercle, except in the eleventh and twelf th ribs.

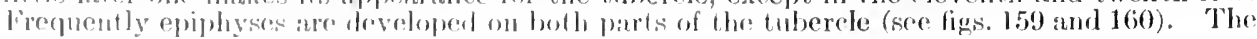


epiphyses fuse with the ribs about the twenty-third year. The rib-shaftincreases in length mainly at its line of junction with the costal cartilage.

\section{Variations in the Number and Shape of the Ribs}

The ribs may be increased in number by addition either at the cervical or lumbar end of the series, but it is extremely rare to find an additional rib or pair of ribs in both the cervical and lumbar regions in the same subject.

$$
\text { Fig. 157.-Rib at Puberty. }
$$

Epiphysis for the head. Appears at Epiphysis for tubercle. Appears at fifteen; fuses at twenty-three fifteen; fuses at twenty-three

The cartilaginous shaft commences to ossify at the eighth week of intrauterine life

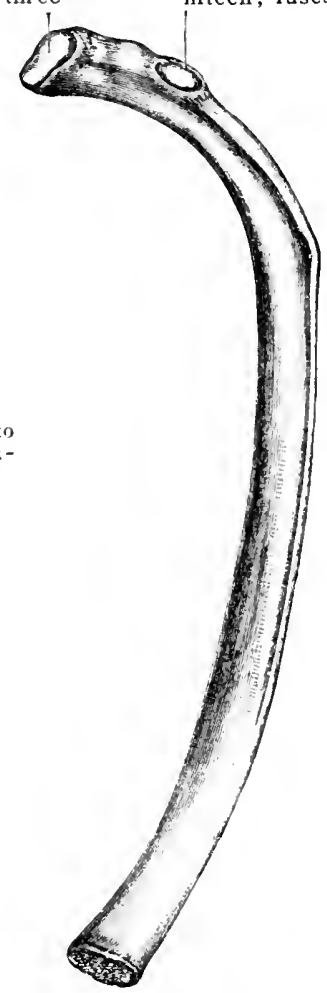

Fig. 158.-The 'Thorax at the Eighth F(etal Mon'th. (On the left sile eight cartilages reach the stermum.)

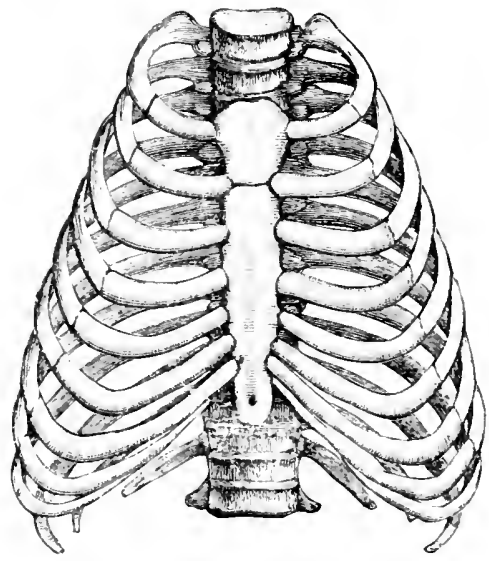

Cervical ribs are fairly rommon; as a rule, they are of small size and rarely exteni more than a few millimeters beyond the extremity of the transverse process (see p. 35). Rarely they exceed such insignificant proportions and reach as far as the sternum; between these two extremes many varieties occur. In one case Turner was able to make a thorough dissection of a specimen in which a complete cervical rib existed. Its head articulated with the body of the 
seventh cervical vertebra and had a radiate ligament. The tuberele was well developed, and articulated with the transverse process. The costal cartilage blended with that of the first thoracic rib, and gave attachment to the costo-clavicular ligament. Between it and the first thoracic rib there was a well-marked intercostal space occupied by intercostal muscles. It received the attachment of the scalenus anterior and medius muscles, and it was crossed by the subclavian artery and vein. The nerves of the intercostal space were supplied by the eighth cervical and first thoracic. The artery of the space was derived from the deep cervical, which, with the superion intercostal, arose from the root of the vertebral. The head of the first thoracic rib in this specimen articulated with the seventh cervical, as well as with the first thoracic vertebra. An interesting fact is also recorded in the careful account of this specimen. There was no movable twelf th thoracic rib on the same side as this well-developed cervical rib, and the twelfth thoracic vertebra had mammillary and accessory processes, and a strong elongated costal process, and was in linear series with the lumbar transverse processes.

Fig. 159.-Posterior Portion of the Sixth Rib in the Fifteenth Year. (After Toldt.)

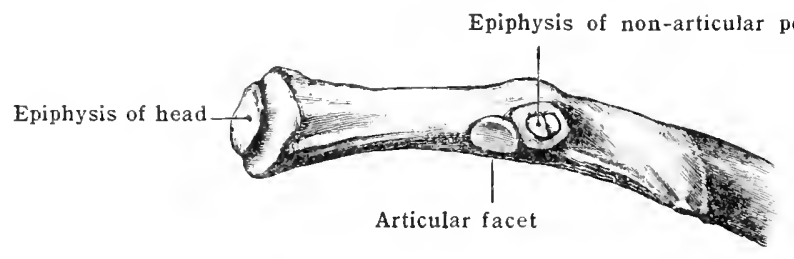

Gruber and Turner, from at careful and elaborate study of this question, summarise the variations in the cervical rib thus:-It may be very short and possess only a head, neck, and tubercle. When it extends beyond the transverse process, its shaft may end freely or join the first thoracic lib: this union may be effected by bone, cartilage, or ligament. In very rare instances it may have a costal cartilage and join the manubrium of the sternum. Nct unfrequently a process, or eminence, exists on the first thcracic rib at the spot where it articulates with a cervical rib.

Lumbar ribs are of less significance than cervical ribs and rarely attain a great length. Their presence is easily accounted for, as they are the differentiated costal elements of the transverse processes. They are never so complete as the cervical ribs, and articulate only with the transverse processes; the heal never reaches as far as the body of the vertebra, and there is no neck or tubercle. An extriu levator coste muscle is associated with a lumbar rib.

F1a. 160.-Posteliok Portion of the Saxth Rib in the Eighteentil Year. (After Toldt.)

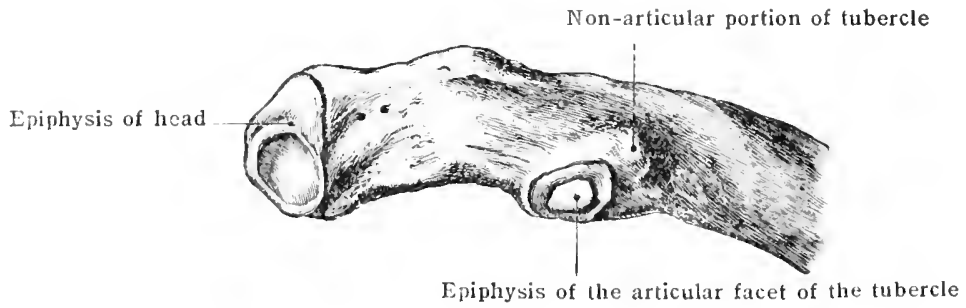

Vit the least interesting variation of a rib is that known as the bicipital rib. This condition Is sern exalusively in connection with the first thoracic rib. The verted)ral end consists of two limbs which lie in different transverse planes. These bicipital rils have been especially studied in whales and man. This abnormality is due to the fusion of two ribs, either of a cervical rib with the shaft of the first theracic; or the more common form, the fusion of the first and second true rilss.

Anong unusnal variations of rils should be mentioned the replacement of the costat cartilage: and a pertion of the rib-shaft by filbrous tissue, a process which oceurs normally in the case of the eighth rib aring its dovolopment.

Sometimes thes stafts of two or more ribs may lereome united by small quadrilateral plates

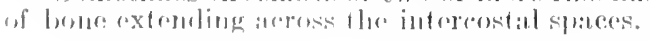

\section{'THE STLRNGM}

The sternum (figs. 16il, 16i2) is a flat, ololong plate of bone, situalted in the anderior wall of the thorax, and divisible into three parts, called respeetively-(1) the manubrium sterni (presternmm), (2) the gladiolus (mesosternum), constitutfur the body of the honc, and (3) the xiphoid (or (ansiform) process (metasternum).

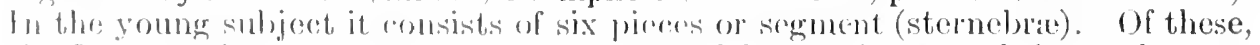

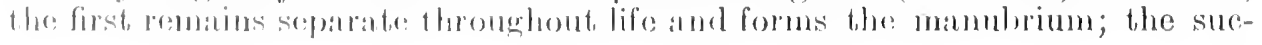


ceeding four segments fuse together, forming the body; whilst the lowest segment, also distinct until middle life, is represented by the xiphoid process.

In its natural position the sternum is inclined obliquely from above downward and forwarl, and corresponds in length to the spine from the third to the ninth thoracic vertebra. It is not of equal width throughout, being broader above at the manubrium and narrow at the junction of this piece with the body. Toward the lower part of the body the sternun again widlens, and then suddenly contracts at its junction with the xiphoid process which constitutes the narrowest part.

The manubrium or first piece of the sternum forms the broadest and thickest part of the bone, and is of a somewhat triangular form with the base directed upward and the apex downward. It presents for examination two surfaces and four borders. The anterior surface [planum sternale] is largely subcutancous. It is slightly convex and directed obliquely upward and forward, is smooth and gives origin on each side to the sternal head of the sterno-mastoid and the pectoralis major. The posterior surface, almost flat, and directed downward and backward, affords origin near the lateral margins on each side, to the sterno-hyoid muscle above and the sterno-thyreoid muscle below. Of the four borders, the superior is the longest and much the thickest. In the middle is a curved, non-articular depression, called the jugular (interclavicular) notch, to which the fibres of the interclavicular ligament are attached, and at either end is an oval articular surface [incisura clavicularis], somewhat saddle-shaped and direeted upward, backward, and laterally for the reception of the medial end of the clavicle. The circumference of the articular surface gives attachment to the sterno-clavicular ligaments. The lateral borders slope from above downward and medially and each presents an irregular surface above for the first costal cartilage and a small facet below, which, with an adjoining facet on the body, forms a notch for the second costal cartilage. The two articular surfaces are separated by a narrow curved edge in relation with the internal intercostal muscle of the first space. The lower border is thick and short and presents an oval rough surface which articulates with the upper border of the body, forming the sternal synchondrosis. The two opposed surfaces are separated by a fibro-cartilaginous disc, which may, however, become partially ossified in advanced age, and at the position of the joint there is usually an angle-the angle of the sternum-which can be felt as a transverse ridge beneath the skin. This is useful in locating the position of the second rib in the living subject.

The body (gladiolus) or second picce of the sternum is longer, narrower, and thinner than the manubrium. It is widest opposite the notches for the fifth costal cartilages and becomes narrower above and below. The anterior surface is flat, directed upward and forward, and marked by three transverse clevations which indicate the lines of junction of its four component parts. It gives attachment on each side to fibres of the pectoralis major, and occasionally presents a foramen-the sternal foramen-situated at the junction of the third and fourth pieces of the bone. The posterior surface is slightly concave, marked by lines corresponding to those on the anterior surface, and below gives attachment on each side to fibres of the transversus thoracis (triangularis sterni). The lateral borders present four whole notches [incisuræ costæ] and two half-notches on each side, which articulate with the costal cartilages of the second to the serenth ribs inclusive; the two half-notches are completed by corresponding notches on the manubrium and the xiphoid process. Between the articular depressions the lateral border is curved and in relation to the internal intercostal muscles.

In order to appreciate the nature of these articular notches, it is advantageous to study the sternum in a young subject. Each typical sternebra presents four angles at each of which is a demi-notch. Between every two sterneve there is an interstemebral disc so that when in position, each notch for a costal cartilage is formed by a sternebra above and helow and an intersternebral disc in the middle, thus repeating the relation of the rib-head to the vertebral centre. Later in life these fuse more or less together, except in the case of the first and second sternehra, which usually remain separate to the end of life. The first (pre-sternum) is the most modified of all the sternebræ, and differs from them in the fact that the costal cartilage of the first rib is continuous with it, and in fact that it supports the clavicles. Occasionally a rounded pisiform bone is seen on each side, medial to the articular notch for the clavicle; these are the supra-sternal bones.

The superior border of the sternal body presents an oval facet for articulation (synchondrosis) with the manubrium. The inferior border is short and articu- 
lated with the xiphoid process, forming the meso-metasternal joint, the two opposed surfaces being separated by a layer of cartilage so long as they are not united by bone.

The xiphoid (ensiform) process is the thin, elongated process projecting downward between the cartilages of the seventh ribs. It is the least developed

Fig. 161.-The Sternom. (Anterior view.)

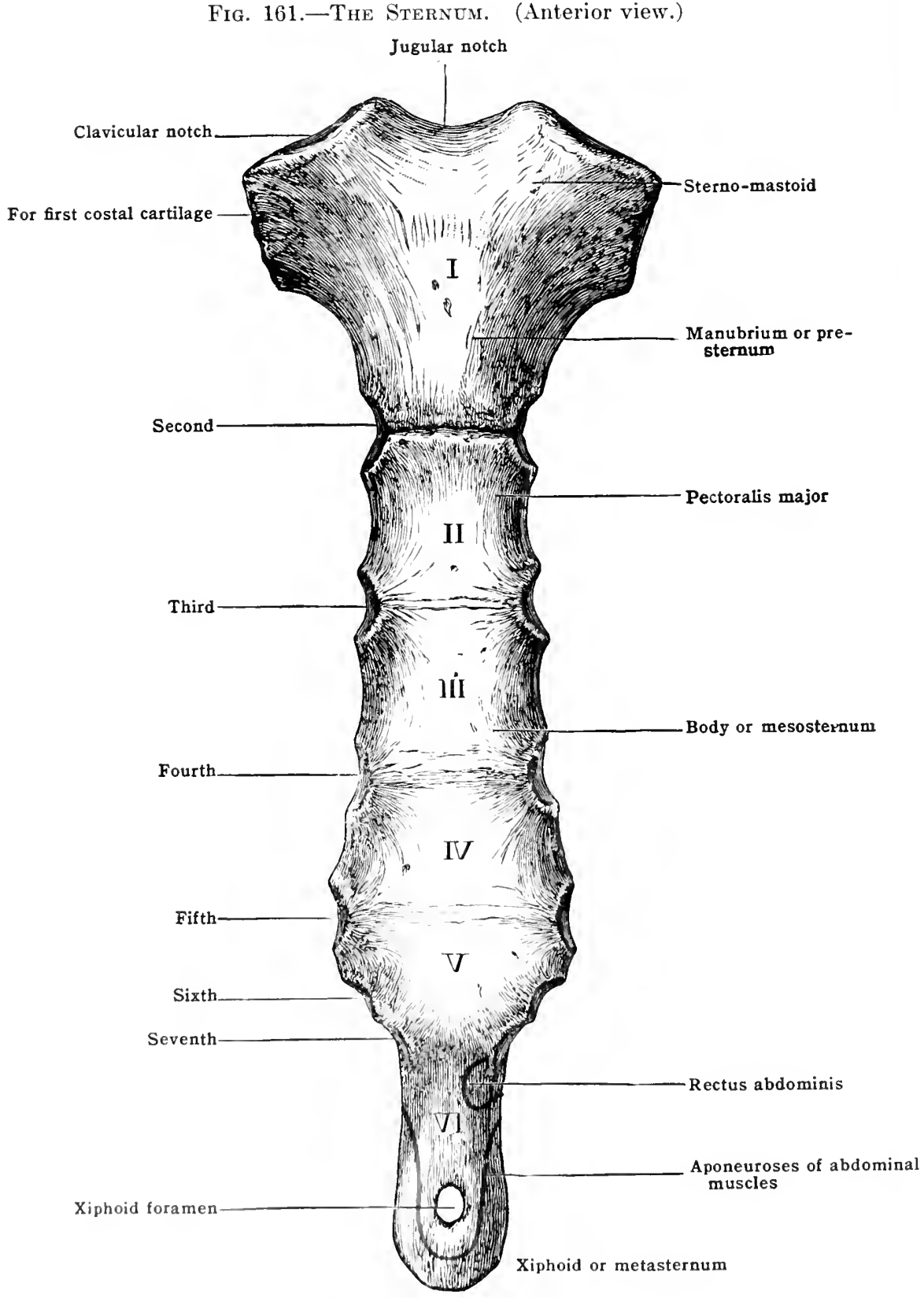

part of the sternum and is subject to many variations in form, being sometimes pointerl, broad and thin, occasionally bifid or perforated by a foramen, and sometimes bent forward, backward, or deflected to one side. In structure it is cartilaginous in early life, partially ossified in the adult, but in old age it tends to become ossified throughout and to fuse with the borly.

The anterior surface of the xiphoid procoss gives attachment to a few fibres of the rectus abdominis muscle and the chondro-xiphoid liganent, the posterior surface to the sternal fibres of the diaphragm, and the lowest fibres of the transversus thoracis (triangularis sterni), whilst 

the lateral margins receive the aponeuroses of the abdominal muscles. Its tip is directly con-
tinuous with the linea alba.

Differences according to sex.-The sternum differs somewhat in the two seres. The sternum is relatively shorter, the diminution being almost confined the two sexes. The female the body is more than twice as diminution being almost confined to the body. In the male than twice the length of the first piece.

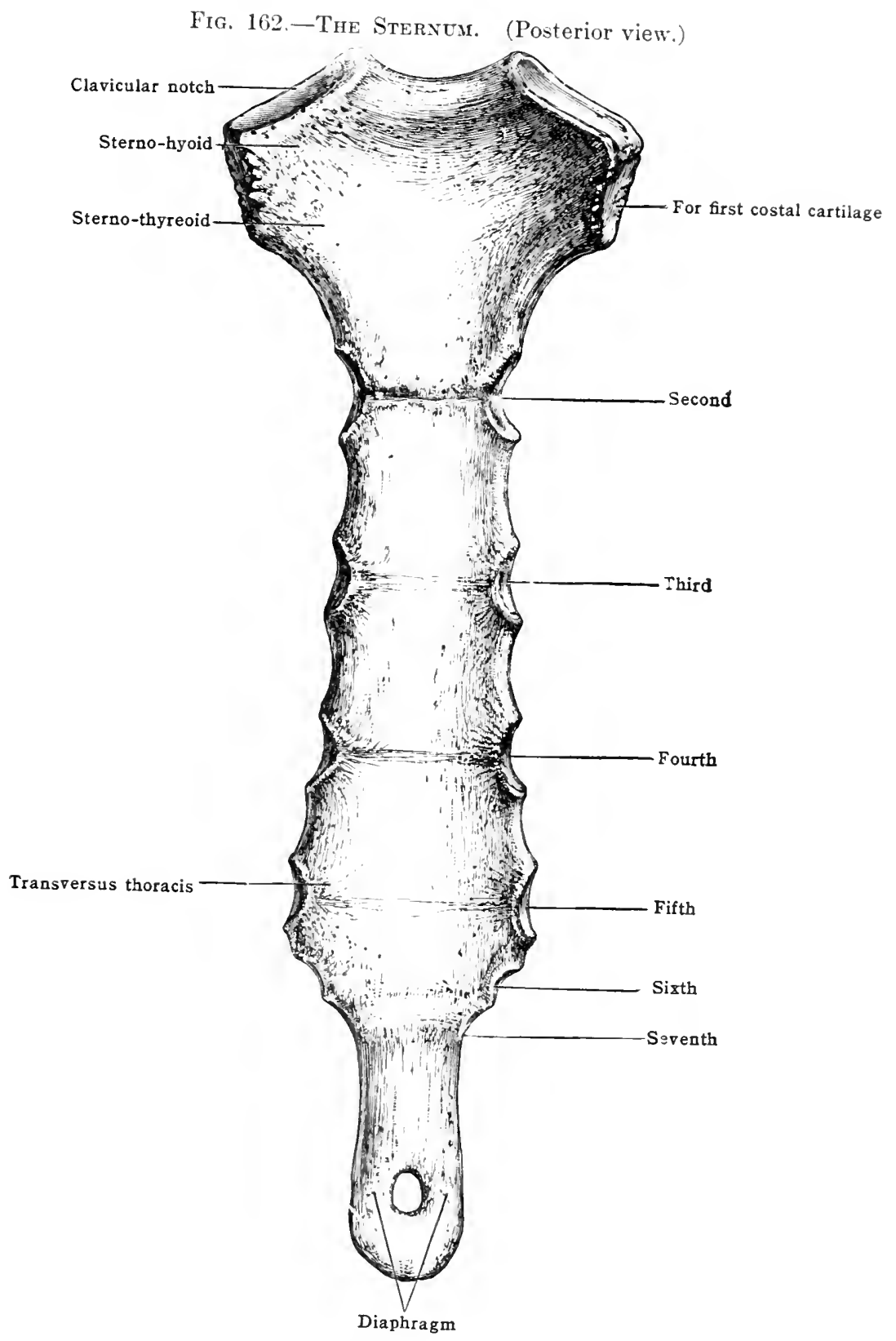

Structurally the sternum is composed of cancellous tissue covered with an outer laver of of the internal mammary. Its arterial supply is derived mainly from the sternal and perforating branches

\section{Development of the} segmented central sternal cartilage formed in the fernum is preceded by a continuous or nonfirst appear in the embryo, cartilage formed in the following way When the cartilaginous ribs dle line. For some time a median fissure ventral ends fuse together on either side of the midof cartilage with each of which at first nine is present, bordered by two sagittally directed strips strips come into contact in the middle line ribs are joined. As development proceeds the two sternal cartilage. The eighth cartille line and fuse from before backward to form a median cases it remains permanently articulaten ally loses its sternal attachment, although in some 
costal cartilage becomes subdivided, one part remaining attached to the sternum and forming the siphoid process, whilst the end still continuous with the rib acquires a new attachment to the eighth cartilage. The ends adherent to the sternum may remain separate and give rise to a bifid xiphoid process, though much more frequently they unite, leaving a small foramen.

At first, therefore, the sternum and costal cartilages are continuous. A joint soon forms between the presternum and mesosternum, and others between the costal cartilages and the sternum (except in the case of the first) quickly follow. The division of the mesosternum into segments is a still later formation and arises during the process of ossification.

Fig. 163.-Posterior Surface of the Manubridu (Pre-sternum), with Sternal Ends of Clavicles and the First Costal Cartilages.

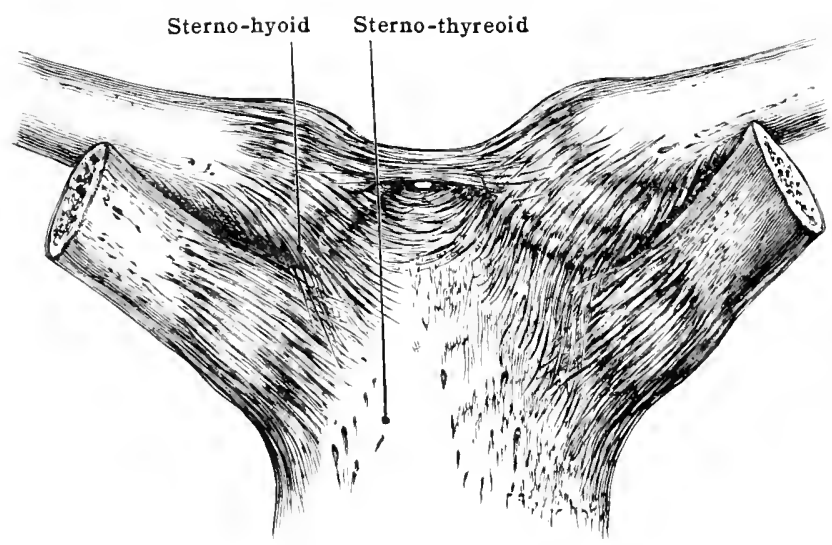

On the other hand, a view has been advanced by Professor A. M. Paterson that the sternum is not a bilateral structure, but is laikl down, as shown in human sterna of the third month, as a simple inedian band of hyaline cartilage, in complete fusion with the costal cartilages on each side and presenting no differentiation of its component parts. From a study of the earliest stages of the development of the sternum, its comparative anatomy and structure, Professor Paterson has, moreover, brought forward evidence which indicates its independence in the first instance of costal elements and its genetic association with the shoulder girdle.

Ossification.-The ossification of the sternum is slow and irregular. The process begins in the presternum (manubrium) by a single centre about the sixth month of intra-uterine life, though occusionally other accessory centres are superadded.

Fig. 164.-Two Stafes in the formation of the Cartilaginous Sternum. (After Ruge.)

A

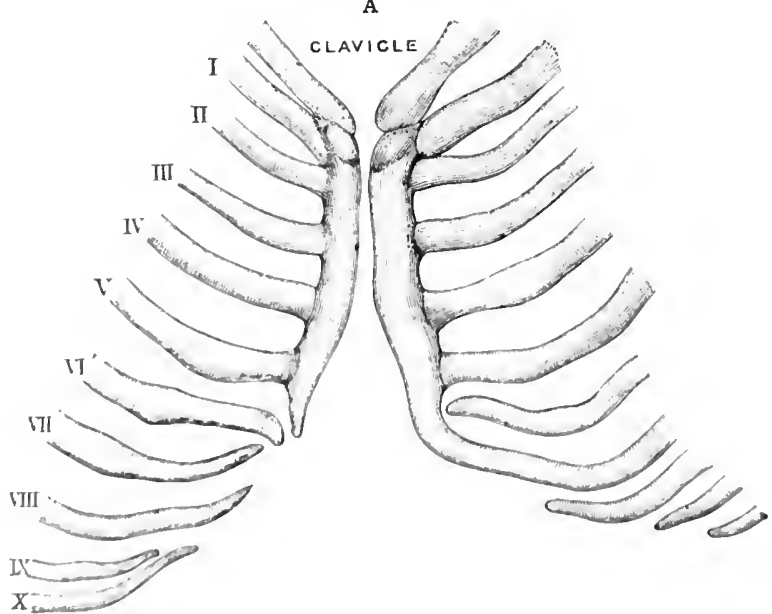

B

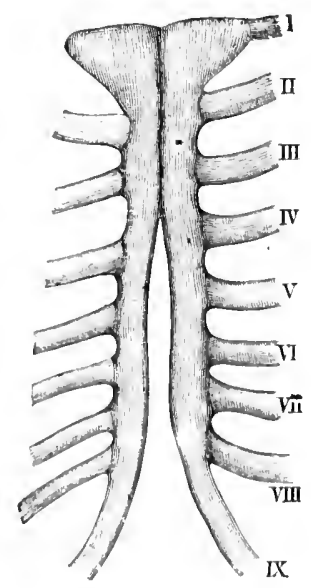

The mososternum (boly) usually ossifies from seven centres. The upper segment ossifies from a sitngle median nuclens about the eighth month, and below this, three pairs of ossific nuclei appear, which may remain for a long time separate. Of these, two pairs for the second and third segunents are visiblo at hirth, and those for the lower segment make their appearance towarl the end of the first your. The various litteral centres unite in pairs, so that at the sixth your the sternum consists of six sternobre, the lowest (metasternum) being cartilaginous. Very often, however, there are only four ecntres of ossification in the gladiolus, as shown in fig. 165. Cirmlually the four pieces representing the mesosternum fuse with one another, and 
Fig. 165.-Ossification of the Sternum.

A, common arrangement of the ossific centres. B, showing accessory centre in the manubrium sterni, and bilateral centres in the second, third, and fourth pieces of the body.
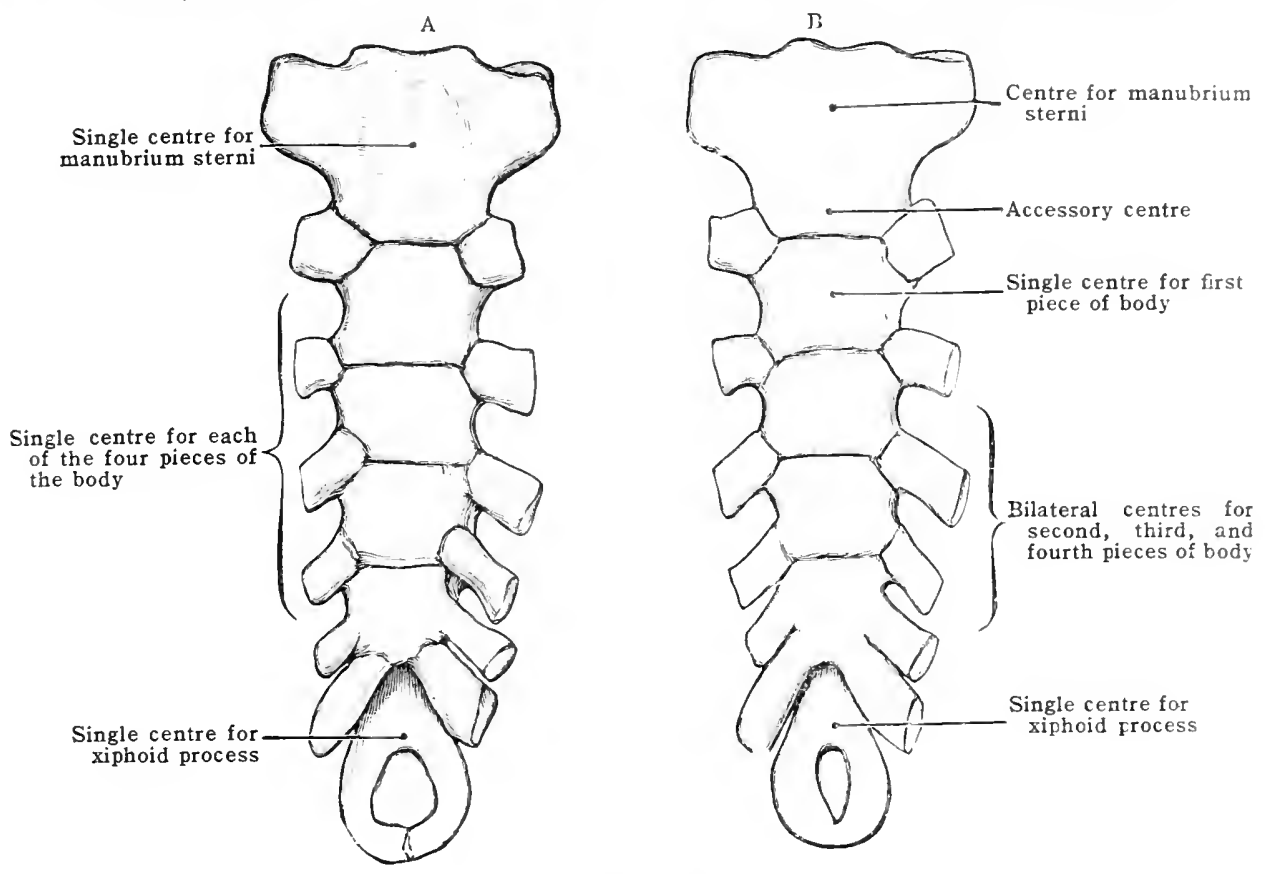

F1G. 166.-The Thorax. (Front view.)

Superior thoracic aperture

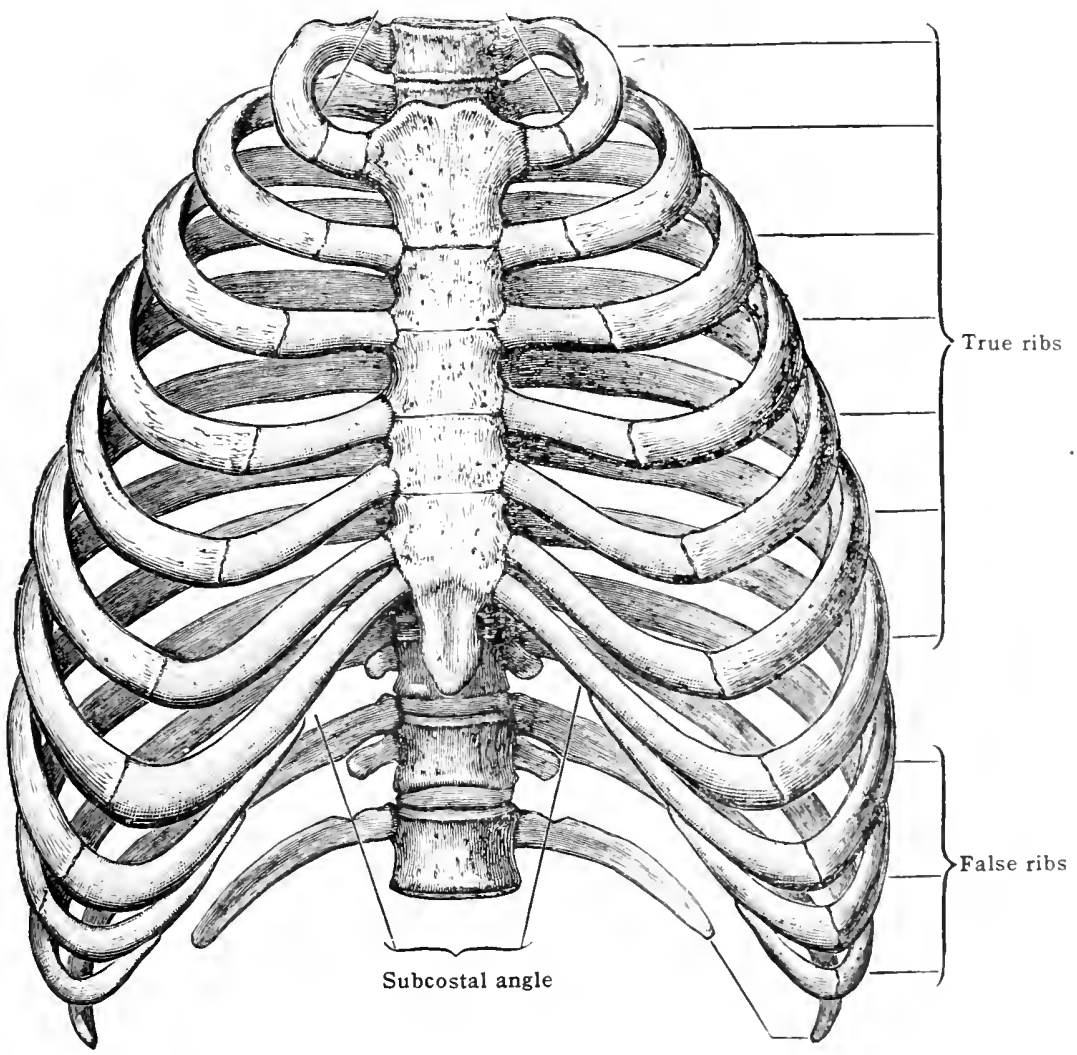

Floating ribs 
at twenty-five they form a single piece, but exhibit, even in advanced life, traces of their original separation. A sternal foramen is usually the result of non-union across the middle line or a defect of ossification.

The metasternum is always imperfectly ossified, and does not join with the mesosternum till after middle life. The presternum and mesosternum rarely fuse. The dates given above for the various nuclei, and for the union of the various segments, are merely approximate, hence the sternum affords very uncertain data as to age.

Abnormalities of the Sternum.-The mode of development of the sternum as described above is of importance in connection with some deviations to which it is occasionally subject. In rare instances the two lateral halves fail to unite, giving rise to the anomaly of a completely cleft sternum. The union of the two halves may occur in the region of the manubrium and fail below, whilst in other cases the upper and lower parts have fused but remain separate in the middle. The clefts are in many instances so small as not to be of any moment, and are not even recognised until the skeleton is prepared. In a few individuals, however, they have been so extensive as to allow the pulsation of the heart to be perceptible to the hand, and even to the eye, through the skin covering the defect in the bone.

$A$ common variation in the sternum is asymmetry of the costal cartilages. Instead of corresponding, the cartilages may articulate with the sternum in an alternating manner. The cause of this asymmetry is not known.

\section{THE THORAX AS A WHOLE}

The bony thorax (fig. 166) is somewhat conical in shape, deeper behind than in front and compressed antero-posteriorly, so that in the adult it measures less in the sagittal than in the transverse axis. The posterior wall, formed by the thoracic vertebra and the ribs as far

Fig. 167.-The Thorax. (Posterior view.) The scapulæ are drawn from an $X$-ray photograph of a man 33 years old.

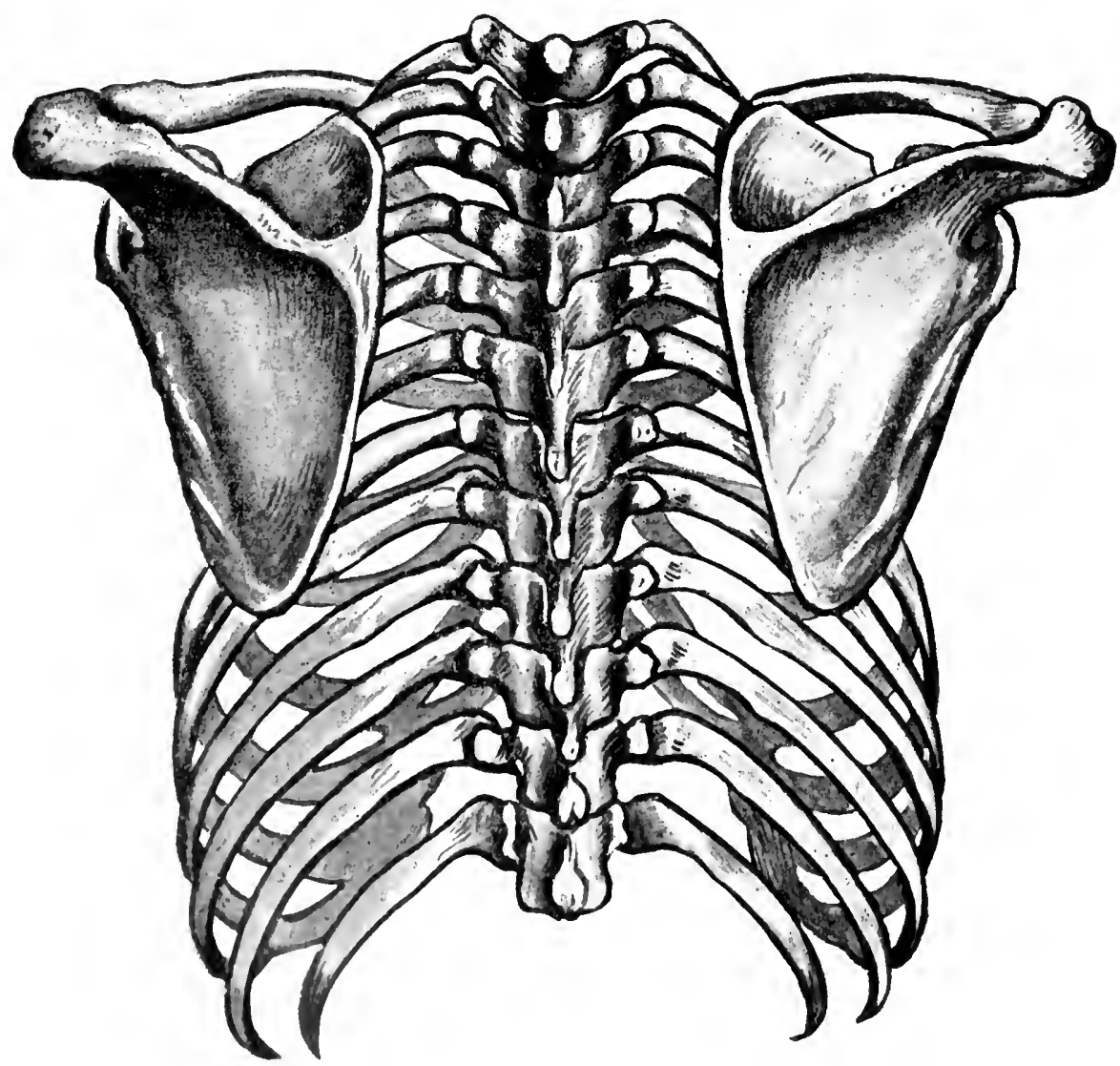

ontwarl as their angles, is convex from above downward, and the backward curve of the ribs producss on oach sicle of the vertedira a decp furrow, the costo-vertebral groove, in which the sacro-spinalis (erector spinar) muselo:unl its silulivisions are lodged. 'The anterior wall is formed by the stromm and costal cartilages. It is slightly convex and inclined forward in its lower part, forming an angle of albout, $20^{\circ}$ with the vertical plane. The lateral walls are formed by the ribs from the angles to the costal cartiliges. The top of the thorax presents an elliptical apreture, the superior thoracic aperture, which moisures on an average 12.5 centimetres (5 
inches) transversely and 6.2 centimetres ( $2 \frac{1}{2}$ inches) in its sagittal axis. It is bounded by the first thoracic vertebra behind, the upper margin of the manubrium sterni in front, and the first rib on each side. As the upper margin of the manubrium sterni is oftenest on a level with the disc between the second and third thoracic vertebræ, it follows that the plane of the opening is directed obliquely upward and forward. The angle of the sternum (angulus Ludovici) is usually opposite the body of the fifth thoracic vertebra and the xiphi-sternal junction corresponds to the disc between the ninth and tenth thoracic vertebræ. The lower aperture of the thorax is very irregular, and is formed by the twelfth thoracic vertebra behind, the twelfth ribs: laterally, and in front by two curved lines, ascending one on either side from the last rib, along the costal margin to the lower border of the gladiolus. The two borders form the costal arch, which in the median line below the sternum forms the infrasternal angle. From this angle the xiphoid process projects downward. The intervals between the ribs are the intercostal spaces, and are eleven in number on each side.

The ratio of the sagittal and the transverse dianeter of the thorax forms the thoracic index, which is higher in the female and in children, in whom the thorax is more rounded. In the embryo, the index is very much higher, the sagit tal diameter being greater than the transverse. In the early embryo, the index is nearly 200; at birth it is about 90 . In the adults it varies from 70 to 75 , averaging 2 or 3 per cent. lower in the male than in the female. It is also lower in the negro than in the white race. (Rodes, Zeitschr. f. Morph. u. Anthrop., Bd. 9.)

\section{THE APPENDICULAR SKELETON}

\section{A. BONES OF THE UPPER EXTREMITY}

The bones of the upper extremity may be arranged in four groups corresponding to the division of the limb into four segments. In the shoulder are the clavicle and the scapula, which together constitute the pectoral or shoulder girdle; in the arm is the humerus; in the forearm are the radius and ulna; and in the hand the carpus, the metacarpus, and the phalanges.

\section{THE CLAVICLE}

The clavicle [clavicula] or collar bone (figs. 168, 169) is situated immediately above the first rib and extends from the upper border of the manubrium sterni, laterally and backward to the acromion process of the scapula. It connects the upper limb with the trunk, and is so arranged that whilst the medial end rests on the sternum and first costal cartilage, the lateral end is associated with the scapula in all its movements, supporting it firmly in its various positions and preventing it from falling inward on the thorax.

The clavicle is a long bone, and when viewed from the front presents a double curvature, so that it somewhat resembles in shape the italic letter $f$. The medial curve, convex forward, extends over two-thirds of the length of the bone; the lateral, concave forward, is smaller and confined to the lateral part. For descriptive purposes the clavicle may be divided into a medial prismatic portion, a lateral flattened portion, and two extremities.

Prismatic portion. - The medial two-thirds of the bone, extending from the sternal extremity to a point opposite the coracoid process of the scapula, has the form of a triangular prism. This portion, however, is subject to considerable variations of form, being more cylindrical in ill-developed specimens and becoming almost quadrangular when associated with great muscular development. In a typical specimen it is marked by three borders separating three surfaces. Of these, the anterior surface is convex and divided near the sternal end by a prominent ridge into two parts, a lower, giving origin to the clavicular portion of the pectoralis major; an upper, for the clavicular portion of the sterno-cleidomastoid. Near the middle of the shaft the ridge disappears, the surface is smooth, and is covered by the platysma myoides. Occasionally this surface is pierced by a small canal, transmitting a cutaneous nerve from the cervical plexus. The posterior surface is concave, forming an arch over the brachial plexus and the subclavian artery, broadest medially and smooth in its whole extent. It gives origin near the sternal extremity to a part of the sterno-hyoid and occasionally to a few fibres of the sterno-thyreoid. Somewhere near the middle of this surface is a small foramen, directed laterally, for the chief nutrient artery of the bone, derived from the transverse scapular (suprascapular) artery. Sometimes the 
foramen is situated on the inferior surface of the bone, in the subclavian groove. On the inferior surface near the sternal end is a rough area, the costal tuberosity, about three-quarters of an inch in length, for the attachment of the costoclavicular ligament, by which the clavicle is fixed to the first rib. More laterally is a longitudinal groove for the subclavius, bordered by two lips, to which the sheath of the muscle is attached. To the posterior of the two lips the layer of deep cervical fascia which binds down the posterior belly of the omo-hyoid to the clavicle is also attached.

Of the three borders, the superior separates the anterior and posterior surfaces. Beginning at the sternal end, it is well-marked, becomes rounded and indistinct in the middle, whilst laterally it is continuous with the posterior border of the outer third. The posterior border separates the inferior and posterior surfaces and forms the posterior lip of the subclavian

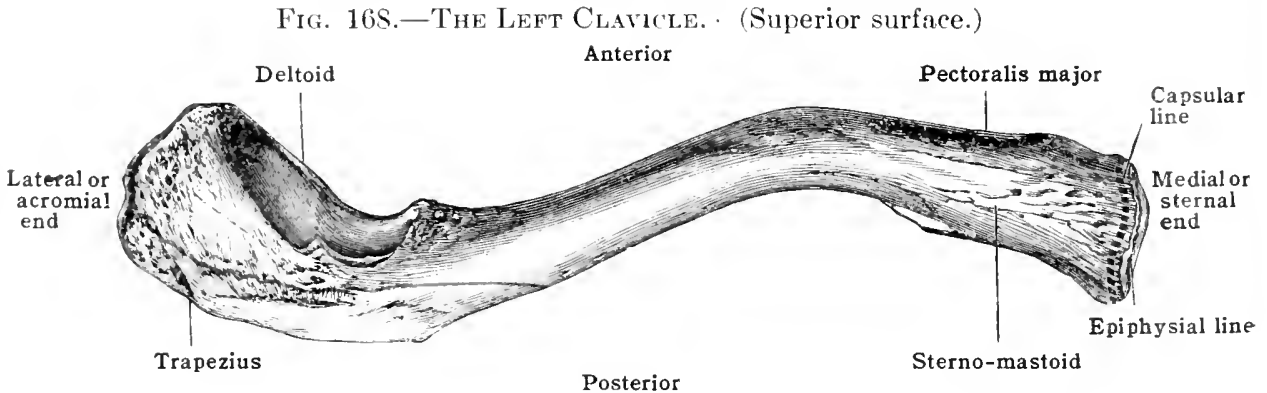

groove. It begins at the costal tuberosity and can be traced laterally as far as the coracoid tubercle, an eminence on the under aspect of the bone near the junction of prismatic and flattened portions. The anterior border is continuous with the anterior border of the flattened portion and separates the anterior and inferior surfaces. Medially, it forms the lower boundary of the elliptical area for the origin of the pectoralis major, and approaches the posterior border. Near the middle of the bone it coincides with the anterior lip of the subclavian groove.

Flattened portion.-The lateral third of the bone, extending from a point opposite the coracoid process of the scapula to the acromial extremity, is flat-

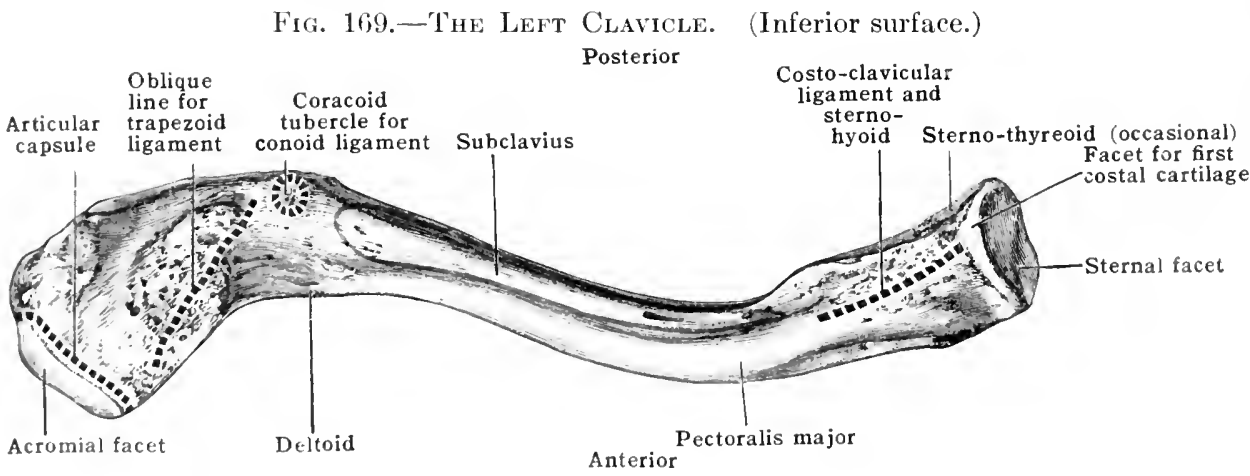

tened from above downward and presents two surfaces and two borders. The superior surface is rough and looks directly upward and gives attachment to the trapezius behind and the deltoid in front; between the two areas the surface is suldeutaneous. On the inferior surface, near the posterior border, is a rough revation, the coracoid (conoid) tubercle; it overhangs the coracoid process and gives attachment to the conoid ligament. From the roracoid tuberele, a prominont ringe, the trapezoid or oblique line, runs laterally and forward to near the lateral end of the bone. To it the trapezoid ligament is attached. The conoid and traperoid ligaments are the two parts of the coraco-clavieular ligament which binds the claviele down to the roracoid process.

'The anterior border is sharp, gives origin to the deltoid muscle, and frequently presents near the junction of the flattened and prismatic portions a projection known as the deltoid tubercle. 'The posterior border is thick and rounded, and receives the insertion of the upper fitores of the trapezius. 
Extremities.-The sternal extremity of the clavicle presents a triangular articular surface, directed medially, downward, and a little forward, slightly. concave from before backward and convex from above downward, which articulates with a facet on the upper border of the manubrium sterni through an interposed interarticular fibro-cartilage.

Of the three angles, one is above and two below. The postero-inferior angle is prolonger! backward, and so renders this surfare considerubly larger than that with which it articulates; the superior angle receives the attachment of the upper part of the filro-curtilage. The lower part of the surface is continuous with a facet on the under aspect of the bone, medial to the costal tuberosity, for the first costal cartilage. The circumference of the extremity is rough, and gives attachment to the interclavicular ligament above and the anterior and posterior sterno-clavicular ligaments in front and hehind.

The acromial extremity presents a smooth, oval, articular facet, flattened or convex, directed slightly downward for the acromion; its border is rough, for the attachment of the capsule of the acromio-clavicular joint.

Structure.-The clavicle consists externally of a compact layer of bone, much thicker in the middle and thinning out gradually toward the two extremities. There is no true medullary

Fig. 170.-The Sternal Ends of Two Clavicles with Epiphyses.

A, right clavicle from below and behind. B, left clavicle from below and behind.

(From Royal College of Surgeons Museum.) Sternal epiphyses
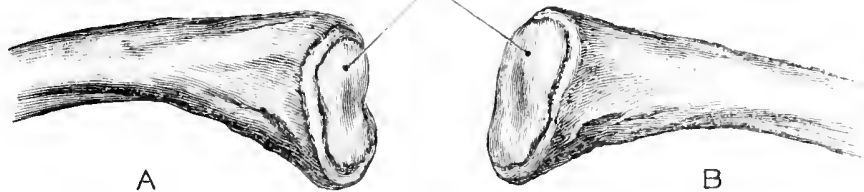

cavity, for the interior is occupied from end to end by cancellous tissue, the amount in the various parts of the bone being in inverse proportion to the thickness of the outer compact shell

Ossification.-From observations made by F. P. Mall, D. C. L. Fitzwilliams, and E. Fawcett it seems almost certain that there are two centres of ossification of the shaft of the clavicle, at the juncture of the middle and lateral thirds. They appear very early, about the fif th week of embryonic life, and rapidly fuse. The ossific process extends medially and lat erally along the shaft toward the medial and lateral extremities, respectively. About the eighteenth year at secondary centre appears at the sternal end and forms a small epiphysis which joins the shaft about the twenty-fifth year.

\section{'THE SCAPLLA}

The scapula (figs. 171, 172) is a large flat bone, triangular in shaye, situated on the dorsal aspect of the thorax, between the levels of the second and seventh ribs. Attached to the trunk by means of the clavicle and various muscles it articulates with the lateral end of the clavicle at the acromio-clavicular joint, and with the humerus at the shoulder-joint. The greater part of the bone consists of a triangular plate known as the body, from which two processes are prolonged: one anterior in position, is the coracoid; the other, posterior in position, is the spine, which is continued laterally into the acromion.

The body presents for examination two surfaces, three borders, and three angles. The costal (anterior) surface, or renter, looks considerably medialward, is deeply concave, forming the subscapular fossa, and marked by several oblique lines which commence at the posterior borter and pass oblicuely upward and laterally; these lines or ridges tivide the surface into several shallow grooves, from which the subscapularis takes origin, whilst the rilges give attachment to the tendinous intersections of that muscle. The lateral third of the surface is smooth and overlapped by the subscapularis, whilst medially are two small flat areas in front of the upper and lower angles respectively, but excluded from the subscapular fossa by fairly definite lines and joined by a ridge which runs close to the vertebral border. The ridge and its terminal areas serve for the insertion of the serratus anterior (magnus).

The dorsal (posterior) surface is generally convex and divided by a prominent plate of bone - the spine -into two unequal parts. The hollow above the spine is the supraspinous fossa and lodges the supraspinatus muscle. The part helow 
the spine is the infraspinous fossa ; it is three times as large as the supraspinous fossa, is alternately concave and convex, and gives origin to the infraspinatus. The muscle is attached to its medial three-fourths and covers the lateral fourth, without taking origin from it.

The infraspinous fossa does not extend as far as the axillary border, but is limited laterally by a ridge-the oblique line-Which runs from the glenoid cavity-the large articular surface for the head of the humerus - downward and backward to join the posterior border a short distance above the inferior angle. This line, which gives attachment to a stout aponeurosis, cuts off an elongated surface, narlow above for the origin of the teres minor, and crossed near its middle by a groove for the circumflex (dorsal) artery of the scapula; below, the surface is broader for the origin of the teres major and occasionally a few fibres of the latissimus dorsi. The two areas are separated by a line which gives attachment to an aponeurotic septum situated between the two teres muscles.

Fig. 171.-The Left Scapula. (Dorsal surface.)

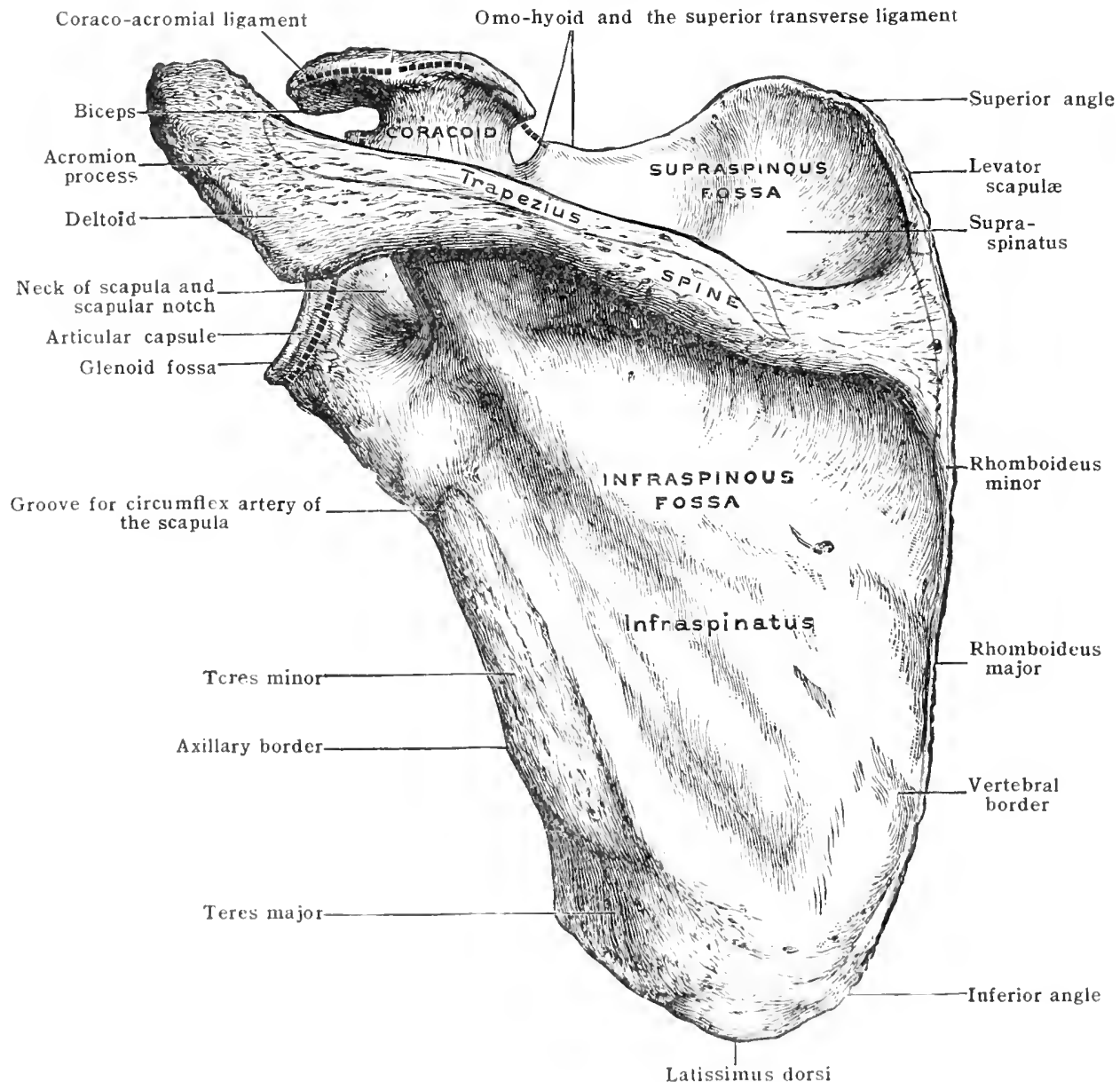

The : Ifprat and infraspinoms fosse communicate through the great scapular notch at the lateral horder of the spine, and through the noteh the supraseapular

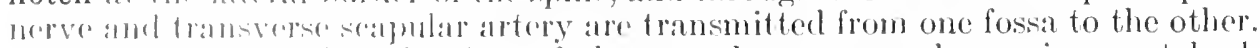

Borders. 'The: three horders of the seapula are named superior, vertebral, and axillary. The superior is short and thin and extends from the upper angle

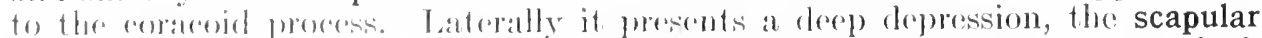

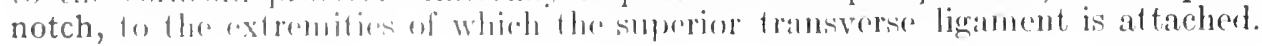

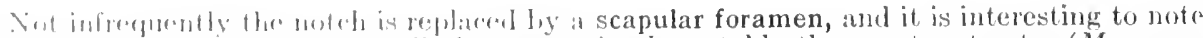
that a bony foramen orents momally in some animals, notably the great ant-eater (Myrmecophaga jubalo). Thes noteh or foranen transmits the suprascapular verve, whilst the transverse scapular artery uswally passes orer the ligament. From the adjacent margins of the noteh and from the ligament the pestorior bolly of the omo-hyoud takes origin. 
The vertebral border (sometimes called the base) is the longest, and oxtend: from the upper or medial to the lower angle of the bone. It is divisible into three parts, to each of which a muscle is attached: an upper portion, extending frons the medial (superior) angle to the spine, for the insertion of the levator scapula; a middle portion, opposite the smooth triangular area at the commencement of the spine, for the rhomboideus minor; and the lowest and longest portion. extending below this as far as the inferior angle, for the rhomboideus majoir. the attachment of which takes place through the medium of a fibrous arch.

The axillary border is the thickest, and extends from the lower marein of the glenoid cavity to the inferior angle of the bone. Near its junction with the glenoid cavity there is a rough surface, about $2.5 \mathrm{~cm}$. (1 in.) in length the infraglenoid tubercle, from which the long head of the triceps arises, and below

Fig. 172.-WThe Left Scapdla. (Ventral surface.

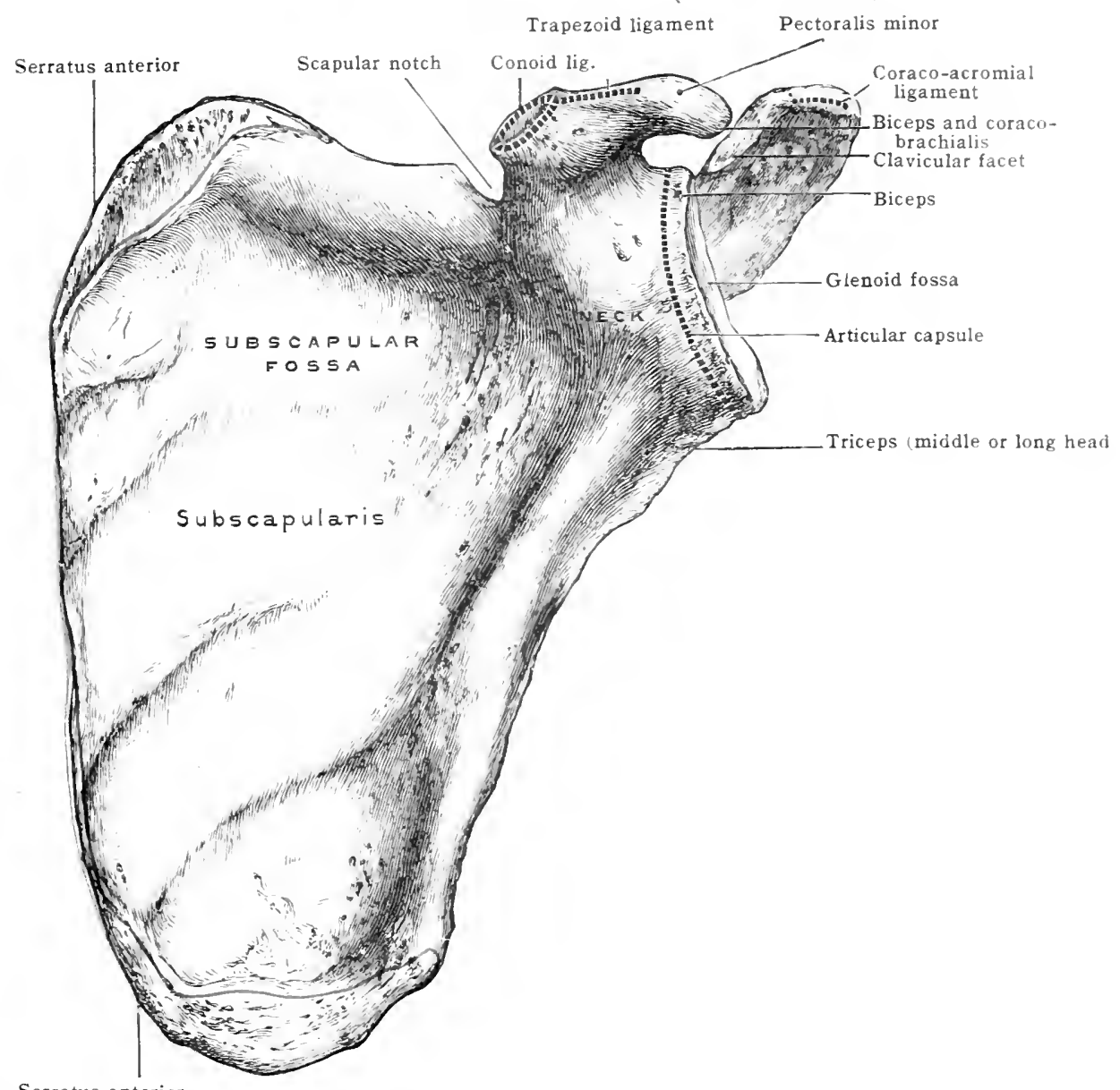

Serratus anterior

the tubercle is the groove for the circumflex (dorsal) artery of the scapula. The upper two-thirds of the border is deeply grooved on the ventral aspect and gives origin to a considerable part of the subscapularis.

Angles. - The three angles are named medial, inferior, and lateral.

The medial (or superior) angle, forming the highest part of the body, is thin, smooth, and either rounded or approsimating a right angle. It is formed by the junction of the superior and vertebral borders and gives insertion to a few fibres of the lcuator scapula. The inferior angle, constituting the lowest part of the body, is thick, rounded, and rougl. It is formed by the junction of axillary and vertebral borders, gives origin to the teres mujor. and is crossed horizontally by the upper part of the latissimus dorsi, the latter occasionally receiving from it a small slip of fleshy fibies.

The lateral angle forms the expanded portion of the bone known as the head, hearing the glenoid cavity, and supported by a somewhat constricterl neck. The 
glenoid cavity is a wide, shallow, pyriform, articular surface for the head of the humerus, directed forward and laterally, with the apex above and the broad end below. Its margin is raised, and affords attachment to the glenoid ligament, which deepens its concavity. The margin is not, however, of equal prominence throughout, being somewhat defective where it is overarched by the acromion, notched anteriorly, and emphasised above to form a small eminence, the supraglenoid tubercle, for the attachment of the long head of the biceps.

The circumference and adjoining part of the neck give attachment to the articular capsule of the shoulder-joint, and the anterior border to the three accessory ligaments of the capsule, known as the superior, middle, and inferior gleno-humeral folds. The superior fold (Flood's ligament) is attached above the notch near the upper end; of the two remaining folds, which together constitute Schlemm's ligament, the middle is attached immediately above the notch and the inferior below the notch. In the recent state the glenoid fossa is covered with hyaline cartilage. The neck is more prominent behind than before and below than above, where it supports the coracoid process. It is not separated by any definite boundary from the body.

Processes.-The spine is a strong, triangular plate of bone attached obliquely to the dorsum of the scapula and directed backward and upward. Its apex is situated at the vertebral border; the base, corresponding to the middle of the neck, is free, concave, and gives attachment to the inferior transverse ligament, which arches over the transverse scapular (suprascapular) vessels and suprascapular nerve. Of the two borders, one is joined to the body, whilst the other is free, forming a prominent subcutaneous crest. The latter commences at the vertebral border, in a smooth triangular area, over which the tendon of the trapezius glides, usually without the intervention of a bursa, as it passes to its insertion into a small tubercle on the crest beyond. Further laterally, this border is rough, and presents two lips - a superior for the insertion of the trapezius and an inferior for the origin of the deltoid. Laterally the erest is continued into the acromion.

The spine has two surfaces, the superior, which also looks medialward and forward, is concave, contributes to the formation of the supraspinous fossa, and gives origin to the supraspinatus muscle; the inferior surface, also slightly concave, is directed lateralward and backward, forms part of the infraspinous fossa, and affords origin to the infraspinatus muscle. On both surfaces are one or more prominent vascular foramina.

The acromion, a process overhanging the glenoid cavity, springs from the angle formed by the junction of the crest with the base of the spine. Somewhat crescentic in shape, it forms the summit of the shoulder and is compressed from above downward so as to present for cxamination two surfaces, two borders, and two extremities.

The posterior part sometimes terminates laterally in a prominent acromial angle (metacromion) and the process then assumes a more or less triangular form. Of the two extremities, the posterior is continuous with the spine, whilst the anterior forms the free tip. The upper surface, directed upward, hackward, and slightly lateralward, is rough and convex, and affords origin at its lateral part to a portion of the delloid; the remaining part of this surface is subcutaneous. The lower surface, lirected downward, forward, and slightly medialward, is concave and smooth. The medial border, continuous with the upper lip of the erest, presents, from behiud forward, an area for the insertion of the trapezius; a small, oval, concave artieular facet for the lateral end of the elavicle, the edges of which are rough for the acromio-clavicular liganents; and, beyond this, the anterior extrenity or tip, to which is attached the apex of the coraco-acromial liganuent. The lateral border, continuous with the inferior lip of the crest, is thick, convex, and presents thee or four tubercles with intervening depressions; from the tuberdes the fendincuss septa in tle arromial part of the delloid arise, and from the depressions, some fleshy filmes of the sime: muscle

Projerting upward from the neck of the scapula is the coracoid process, bent finger-like, pointing forward and laterally. It consists of two parts, ascending and horizontal, arrangerl at almost a right angle to each other.

The asecruting part arises l,y a wide ront, extends upward and nedially for a short distance, and is compressed from leche backwarl; it is rontimus alove with the horizontal part and below with the nock of thre scipulat; the lateral boreler lies ahove the glenoid ravity and gives attachenent to the coraco-huncral ligament; the medial border, which forms the lateral boundary of the srapular notch, gives attachment to the ronoid liganent above and the transverse ligament below. Ils anterior anrl postrior surfares are in relation with the subscapularis and supraspinulue respectively. 'The herizmelul purt of the proress runs forward and lateralward; it is compressed from alove downwarl so as to present two borders, two surfaces, and a free extremity. The medial borler gives insertion along its anterior half to the pectoralis minor and nearer the base to the costo-coricroid membrane; the lateral border is rough for the coracoarromial and corach-humeral figaments; the upper surface is irregular and gives insertion in 
front to the pectoralis minor, and behind to the trapezoid ligament; the inferior surface is smooth and directed toward the glenoid cavity, which it overhangs; the free extremity or apex gives origin to the conjoined coraco-brachialis and short head of the biceps.

The greater part of the body of the scapula and the central parts of the spinous process are thin and transparent. The coracoid and acromion processes, the crest of the spine and inferior angle, the head, neck, and axillary border, are thick and opaque. The young bone consists of two layers of compact tissue with an intervening cancellous layer, but in the transparent parts of the adult bone the middle layer has disappeared. The vascular foramina on the costal surface transmit twigs from the subscapular and transverse scapular (suprascapular) arteries; those in the infraspinous fossa, twigs from the circumflex (dorsal) and transverse scapular (suprascapular) arteries, the latter also giving off vessels which enter the foramina in the supraspinous fossa. The acromion is supplied by branches from the thoraco-acromial (acromiothoracic) artery.

The line of attachment of the spinous process to the dorsum of the scapula is known as the morphological axis, and the obtuse angle in the subscapular fossa opposite the spine as the

Fig. 173. -Ossification of the Scapula.

The right Scapula at the twelf th year, showing the subcoracoid element (a little larger than half

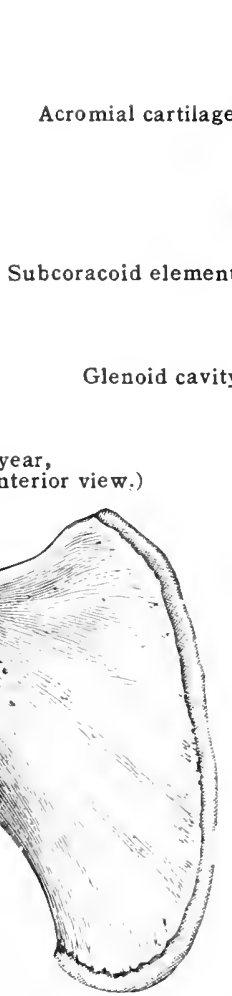

The Scapula at the third year.

showing the caracoid element. (Anterior view.)

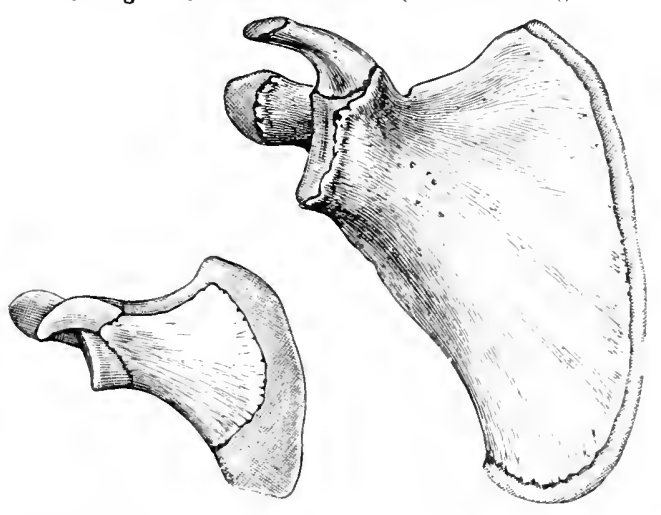

Tee Scapula at birth. (Anterior view.) the natural size, i. e. $\frac{\text { t) }}{7}$.

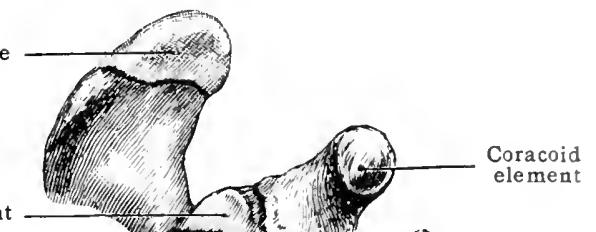

subscapular angle. From the axis three plates of bone radiate as from a centre, the prescapula forward, the mesoscapula laterally, and the postscapula backward, being named in accordance with the long axis of the body in the horizontal position. In the human subject the postscapulaz is greatly developed, and this is associated with the freedom and versatility of movement possessed by the upper limb.

Ossification. - The scapula is ossified from nine centres. Of these, two (for the body of the scapula and the coracoid) may be considered as primary, and the remainder as secondary. The centre for the body appears in a plate of cartilage near the neck of the scapulat about the eighth week of intra-uterine life, and quickiy forms a triangular plate of bone, from which the spine appears as a slight ridge about the middle of the third month. At birth the glenoid fossa and part of the scapular neck, the acromion and coracoid processes, the vertebral border and inferior angle, are cartilaginous. During the first year a nucleus appears for the coracoid, and at the tenth year a second centre appears for the base of the coracoid and the upper part of the glenoid cavity (subcoracoid, fig. 173).

During the fifteenth year the coracoid unites with the scapula, and about this time the other secondary centres appear. Two nuclei are deposited in the acromial cartilage, and fuse to form the acromion, which joins the spine at the twentieth year. The union of spine and acromion may be fibrous, hence the latter is sometimes found separate in macerated specimens. The cartilage along the vertebral border ossifies from two centres, one in the middle, and another at the inferior angle. A thin lamina is added along the upper surface of the coracoid process and 
occasionally another at the margin of the glenoid cavity. These epiphyses join by the twentyfifth year.

The occurrence of a special primary centre for the coracoid process is of morphological importance in that the process is the representative of what in the lower vertebrates is a distinct coracoid bone. This primarily takes part in the formation of the glenoid cavity and extends medially to articulate with the sternum. In man and all the higher mammals only the lateral portion of the bone persists.

\section{THE HUMERUS}

The humerus (figs. 174, 175, 176) is the longest and largest bone of the upper limb, and extends from the shoulder above, where it articulates with the scapula,

Fig. 174.-The Leff Humerds. (Anterior view.)

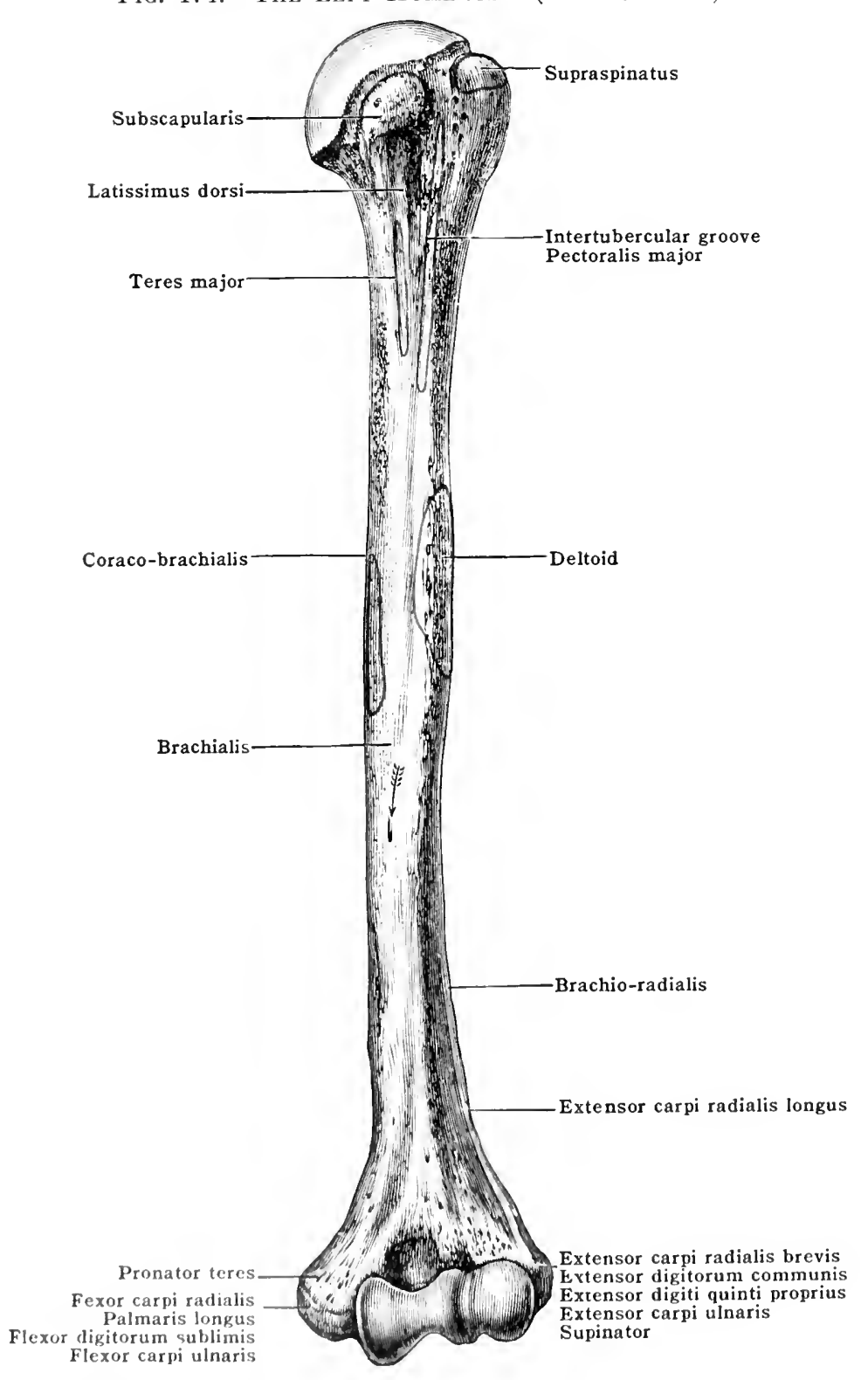

to the ellow [cubitus] below, where it articulates with the two bones of the forearm [anti-brachium]. It is divisible into a shaft and two extremities; the upper extremity ineludes the head [caput], neck [collum], and two tuberosities-great and small; the lower extremity includes the articular surface with the surmounting foskin in front and behind, and the two epicondyles. 
Upper extremity.--The head forms a nearly hemispherical articular surface, cartilage-clad in the recent state and directed upward, medially, and backward toward the glenoid cavity. Below the head the bone is rough and somewhat constricted, constituting the anatomical neck, best marked superiorly, where it forms a groove separating the articular surface from the two tuberosities. The circumference of the neck gives attachment to the capsule of the shoulder-joint and the gleno-humeral folds, the upper of which is received into a depression near the top of the intertubercular (bicipital) groove. 'The lowest part of the capsule

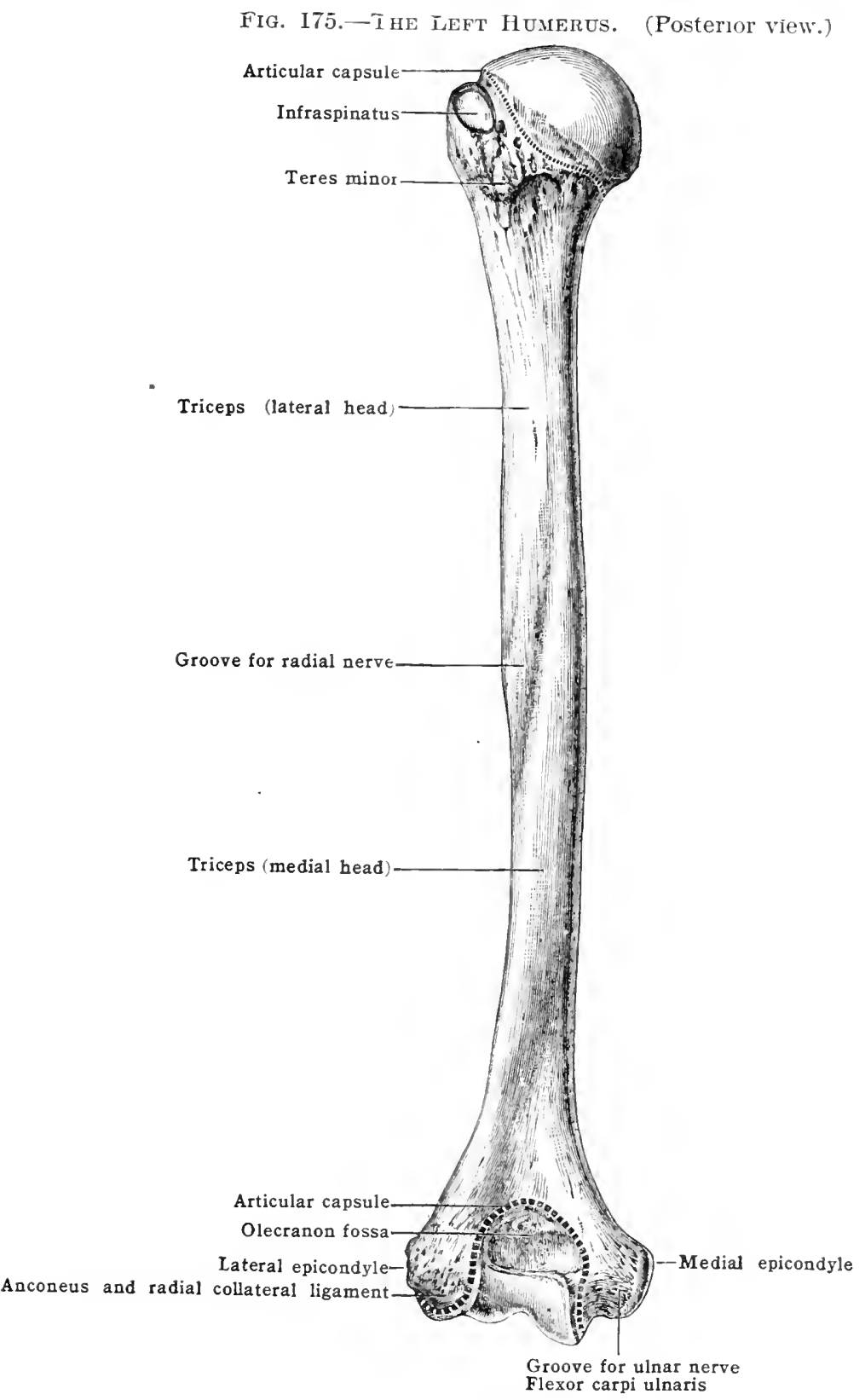

descends upon the humerus some distance from the articular margin. Laterally and in front of the head are the two tuberosities, separated by a deep furrow. The greater tuberosity [tuberculum majus], lateral in position and reaching higher than the lesser tuberosity [tuberculum minus], is marked by three facets for the insertion of muscles: an upper one for the supraspinatus, a middle for the in- 
fraspinatus, and a lower for the teres minor. The lesser tuberosity is situated in front of the head and is the more prominent of the two; it receives the insertion of the subscapularis. The furrow between the tuberosities lodges the long tendon of the biceps and forms the commencement of the intertubercular (bicipital) groove, which extends downward along the shaft of the humerus. Between the tuberosities the transverse humeral ligament converts the upper end of the groove into a canal. In addition to the long tendon of the biceps and its tube of synovial

Fig. 176.-The Left Humerus with a Supracondyloid Process and some Irregular Muscle Attachanents. (Anterior view.)

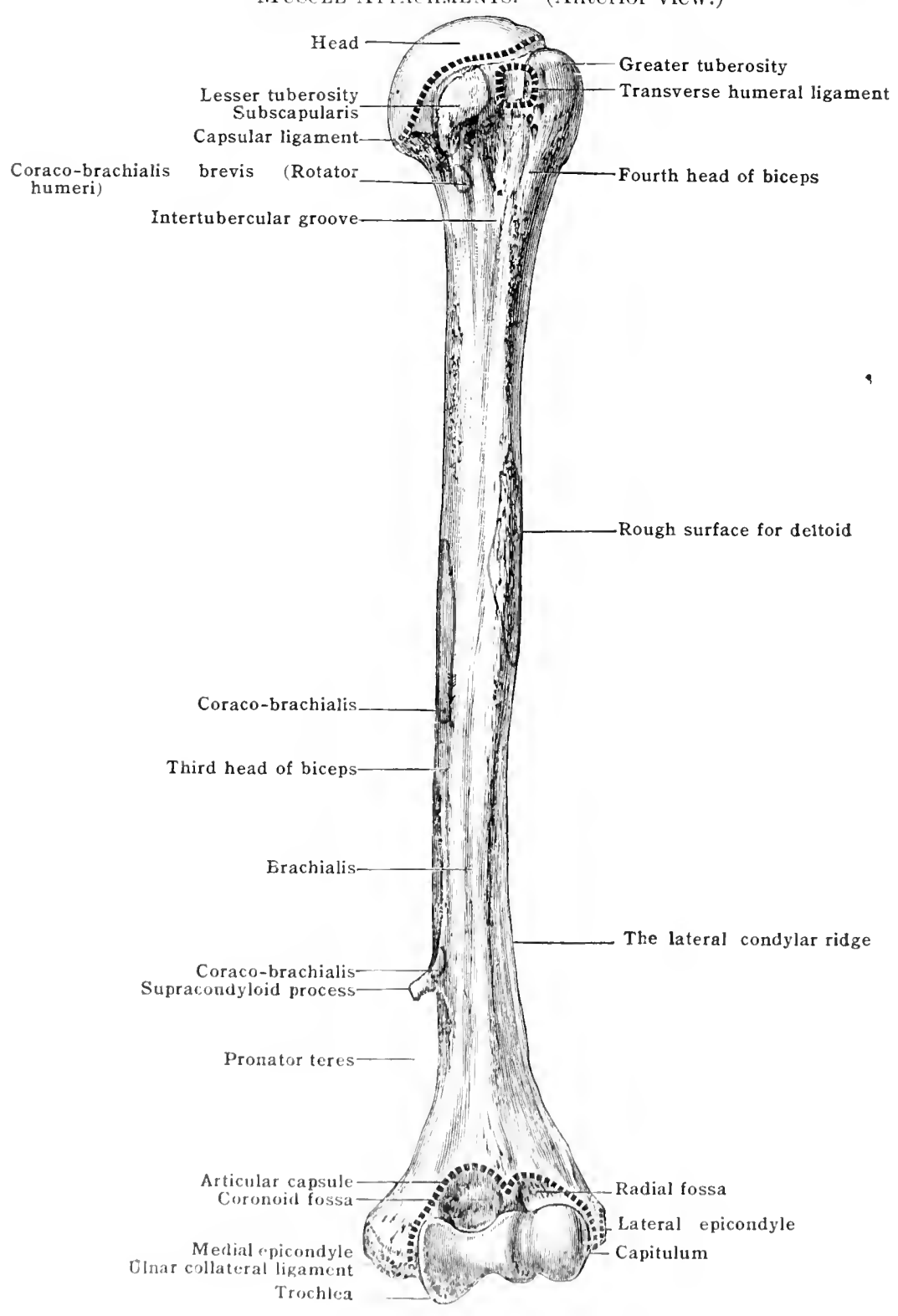

mombrane, the growe lransmits a braneh of the anterior circumflex artery. Immediately hedew the fwo tuberositios the bone becomes contrated and forms the surgical neck.

The shaft or body [ororpus humeri] is somewhat eylindrical above, flattened and prismatic below. Three borders and three surfaces may be recognised.

Borders. The anterior border commences above at the greater tuberosity, and its upler part, forming the crest of this tulperosity [crista tuberculi majoris], 
receives the pectoralis major. In the middle of the shaft it is rough and prominent and gives insertion to fibres of the deltoid; below it is smooth and rounded, giving origin to fibres of the brachialis, and finally it passes along lateral to the coronoid fossa to become continuous with the ridge separating the capitulum and trochlea. It separates the antero-medial from the antero-lateral surface. The lateral margin extends from the lower and posterior part of the greater tuberosity to the lateral epicondyle. Smooth and indistinct above, it gives attachment to the teres minor and the lateral head of the triceps; it is interrupted in the middle by the groove for the radial nerve (musculo-spiral groove), but the lower third becomes prominent and curved laterally to form the lateral supracondylar ridge, which affords origin in front to the brachio-radialis and the extensor carpi radialis longus; behind to the medial head of the triceps, and between these muscles in front and behind to the lateral intermuscular septum. It separates the antero-lateral from the posterior surface. The medial border commences at the lesser tuberosity, forming its crest which receives the insertion of the teres major, and continuing downward to the medial epicondyle. Near the middle of the shaft it forms a ridge for the insertion of the coraco-brachialis and presents a foramen for the nutrient artery, directed downward toward the elbow-joint. Below it forms a distinet medial supracondylar ridge, curved medially, which gives origin to the brachialis in front, the medial head of the triceps behind, and the medial intermuscular septum in the interval between the muscles. This border separates the antero-medial from the posterior surface.

Fig. 177.-A Diagrai showixg Pressure and Texion Curtes in the Head of the Henerus. (After Wagstaffe.)

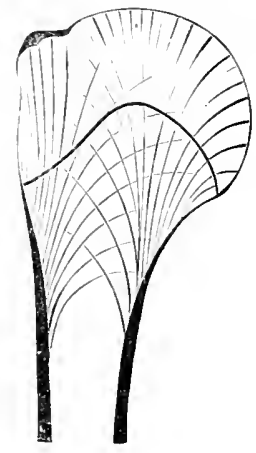

Surfaces. - The antero-lateral surface is smooth above, rough in the middle, forming a large impression for the insertion of the deltoid, below which is the termination of the groove for the radial nerve. The lower part of the surface gives origin to the lateral part of the brachialis. The antero-medial surface is narrow above, where it forms the floor of the intertubercular (bicipital) groove, and receives the insertion of the latissimus dorsi. Near the junction of the upper and middle thirds of the bone the groove, gradually becoming shallower, widens out and, with the exception of a rough impression near the middle of the shaft for the coraco-brachialis, the remaining part of the antero-medial surface is flat and smooth, and gives origin to the brachialis.

Occasionally, a prominent spine of bone, the supracondylar process, projects downward from the medial border about $5 \mathrm{~cm}$. (2 in.) above the medial epicondyle, to which it is joined by a band of fibrous tissue. Through' the ring thus formed, which corresponds to the supracondylar foraman in many of the lower animals, the median nerve and brachial artery are transmitted, though in some cases it is occupied by the nerve alone. The process gives origin to the pronator teres, and may afford insertion to a persistent lower part of the coraco-brachialis.

The posterior surface is obliquely divided by a broad shallow groove, which runs in a spiral direction from behind downward and forward and transmits the radial (musculo-spiral) nerve and the profunda artery. The lateral part of the surface above the groove gives attachment to the lateral head, and the part below the groove, to the medial head of the triceps.

The lower extremity of the humerus is flattened from before backward, and terminates below in a sloping articular surface, subdivided by a low ridge into the 
trochlea and the capitulum. The trochlea is the pulley-like surface which extends over the end of the bone for articulation with the semilunar notch (great sigmoid cavity) of the ulna. It is constricted in the centre and expanded laterally to form two prominent edges, the medial of which is thicker, descends lower, and forms a marked projection; the lateral edge is narrow and corresponds to the interval between the ulna and radius. Above the trochlea are two fossæ: on the anterior surface is the coronoid fossa, an oval pit which receives the coronoid process of

Fig. 178.-OSsification of the Humerus; the Figure also shows the Relations of the Epiphysial and Capsular Lines

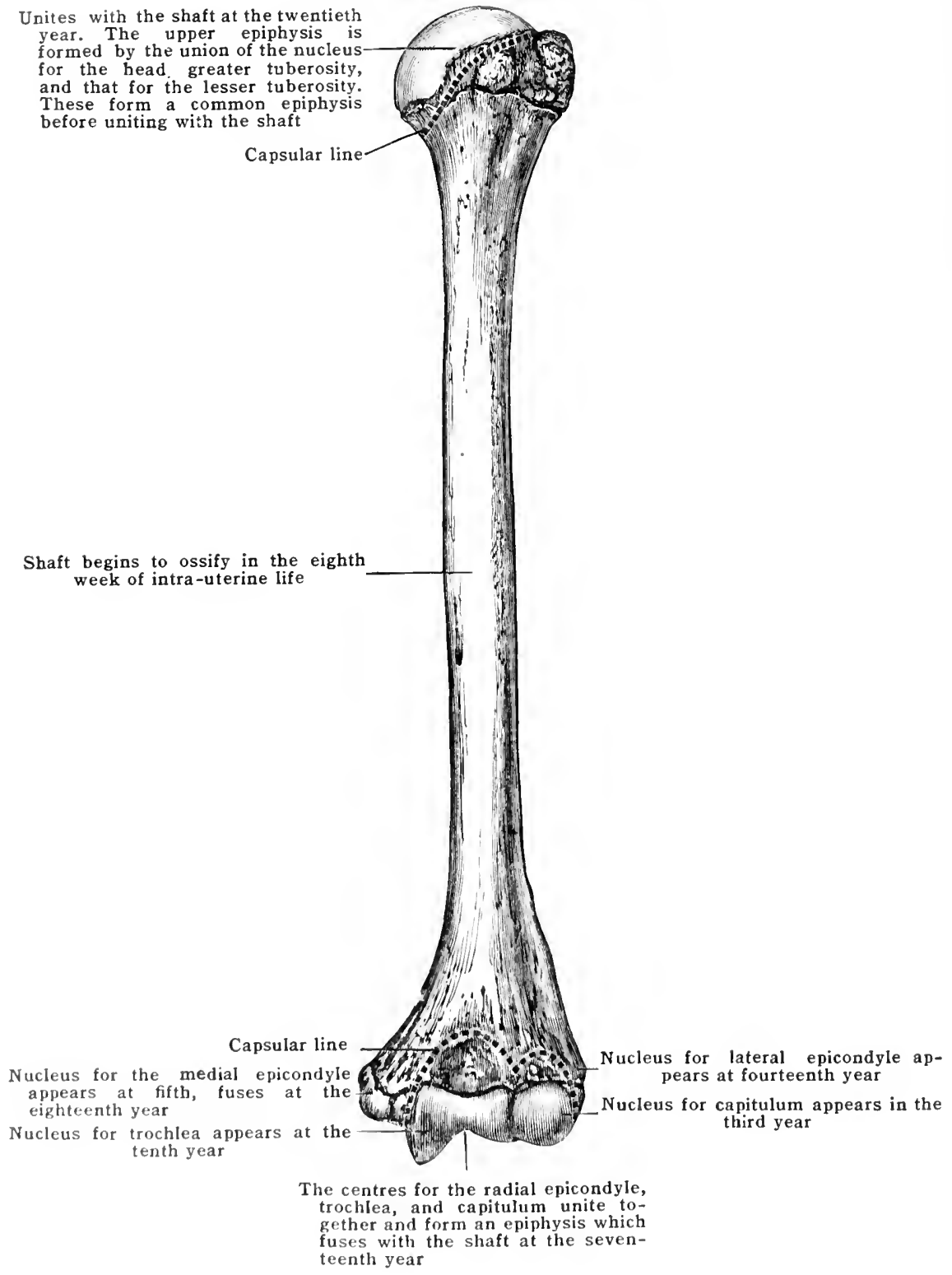

the ulna when the forearm is flexerl on the posterior aspect is the olecranon fossa, a deeplo hollow for the reerption of the anterior extremity of the olecranon in extension of the forcarm. These fosse are usually separated by a thin, translucent plate of bone, sometimes merely by fibrous tissue, so that in macerated specimens a perforation, the supratrochlear foramen, exists. The capitulum, or radial head, is mieh smaller than the trochlea, somewhat globular in shape, and limited to the anterior and inferior surfaces of the extremity. It articulates with the con- 
cavity on the summit of the radius. The radial fossa is a slight depression on the front of the bone, immediately above the capitulum, which receives the anterior edge of the head of the radius in complete flexion of the forearm, whilst between the capitulum and the trochlea is a shallow groove occupied by the medial margin of the head of the radius.

In the recent state the inferior articular surface is covered with cartilage, the fossæ are lined by synovial membrane, and their margins give attachment to the capsule of the elbor-joint. Projecting on either side from the lower end of the humerus are the two epicondyles. The medial one is large and by far the more prominent of the two, rough in front and below, smooth behind, where there is a shallow groove for the ulnar nerve. The rough area serves for origin of the pronator teres above, the common tendon of origin of the flexor carpi radialis, palmaris longus, flexor digitorum sublimis and flexor carpi ulnaris in the middle, and the ulnar collateral ligament below. The lateral epicondyle is flat and irregular. Above, it gives attachment to a common tendon of origin of the extensor carpi radialis brevis, extensor digitorum communis, extensor quinti digiti proprius, extensor carpi ulnaris, and supinator; to a depression near the outer margin of the capitulum, the radial collateral ligament is attached, and from an area below and behind, the anconeus takes origin.

Architecture. - The interior of the shaft of the humerus is hollowed out by a large medullary canal, whereas the extremities are composed of cancellated tissue invested by a thin compact layer. The arrangement of the cancellous tissue at the upper end of the humerus is shown in fig. 177. The lamellæ converge to the axis of the bone and form a series of superimposed arches which reach upward as far as the epiphysial line. In the epiphyses the spongy tissue forms a fine network, the lamellæ resulting from "pressure" being directed at right angles to the articular surface of the head and to the great tuberosity.

Blood-supply. - The foramina which cluster round the circumference of the head and tuberosities transmit branches from the transverse scapular (suprascapular) and anterior and posterior circumflex arteries. At the top of the intertubercular groove is a large nutrient foramen

Fig. 179.-The Head of the Humerus at the Sixth Year. (In section.)

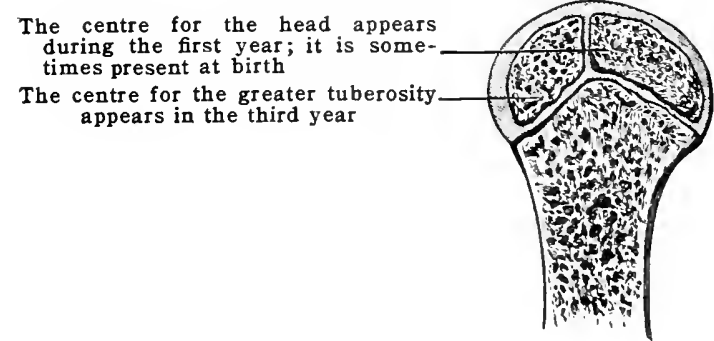

for a branch of the anterior circumflex artery which supplies the head. The nutrient artery of the shaft is derived from the brachial, and in many cases, an additional branch, derived from the profunda artery, enters the foramen in the groove for the radial nerve (musculo-spiral groove). The lower extremity is nourished by branches derived from the profunda (superior profunda), the superior and inferior ulnar collateral (inferior profunda and anastomotic), and the recurrent branches of the radial, ulnar, and interosseous arteries.

Ossification. - The humerus is ossified from one primary centre (diaphysial) and six secondary centres (epiphysial). The centre for the shaft appears about the eighth week of intrauterine life and grows very rapidly. At birth only the two extremities are cartilaginous, and these ossify in the following manner: Single centres appear for the head in the first year, for the greater tuberosity in the third year, and for the lesser tuberosity in the fifth year, though sometimes the latter ossifies by an extension from the greater tuberosity. These three nuclei coalesce at six years to form a single epiphysis, which joins the shaft about the twentieth year.

The inferior extremity ossifies from foar centres: one for the capitulum appears in the third year, a second for the medial epicondyle in the fifth year, a third for the trochlea in the tenth year, and a fourth for the lateral epicondyle in the fourteenth year. The nuclei for the capitulum, trochlea, and lateral epicondyle coalesce to form a single epiphysis which joins the shaft in the seventeenth year. The nucleus of the medial epicondyle joins the shaft independently at the age of eighteen years.

A study of the upper end of the humeral shaft before its union with the epiphysis is of intercat in relation to what is known as the neck of the humerus. The term neck is applied to three parts of this bone. The anatomical neck is the constriction to which the articular capsule is mainly attached, and its position is accurately indicated by the groove which lies internal to the tuberosities. The upper extremity of the humeral shaft, before its union with the epiphysis, terminates in a low three-sided pyramid, the surfaces of which are separated from one another by ridges. The medial of these three surfaces underlies the head of the bone, and the two lateral surfaces underlie the tuberosities. The part supporting the head constitutes the morphological neck of the humerus, whilst the surgical neck is the indefinite area below the tuberosities where the bone is liable to fracture. 


\section{THE RADIUS}

The radius (figs. 180-185) is the lateral and shorter of the two bones of the forearm. Above. it articulates with the humerus; below, with the carpus; and on the medial sicle with the uhna. It presents for examination a shaft and two extremities.

The upper extremity, smaller than the lower, includes the head, neck, and tuberosity. The head [capitulum], covered with cartilage in the recent state, is a circular disc forming the expanded, articular end of the bone. Superiorly it presents the capitular depression [fovea capituli] for the reception of the capitulum

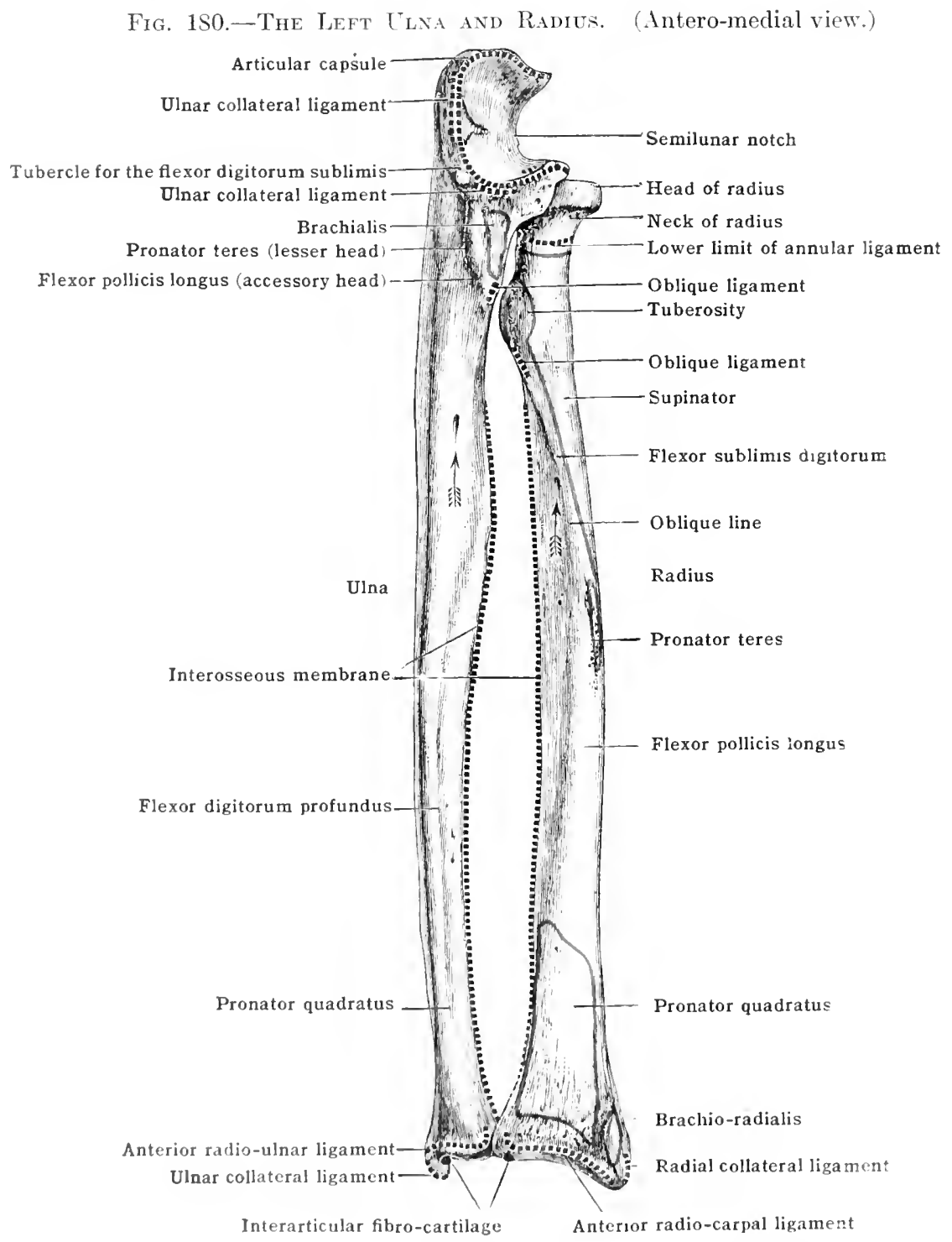

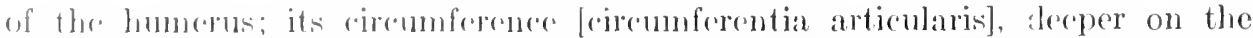
merlial asperet, artionlates with the radial noteh (lesser sigmoid cavity) of the ulna, and is narrow elsowhere for the anmular ligament by which it is cmbraced. Below the heal is a short rylindrical portion of bone, somewhat constricted, and known an the neck. 'T'he nipuer part is surrounderl by the ligament which embraces the lesal, and below this it gives insertion antero-laterally to the supinator. Below the mork, at the antero-medial aspert of the boue, is an oval minence, the radial tuberosity, divisible into two parts: a rough posterior portion for the insertion of 
the tendon of the biceps, and a smooth anterior surface in relation with a bur-a which is situated between the tendon and the tuberosity.

The body [corpus radii] or shaft is somewhat prismatic in form, gradually increasing in size from the upper to the lower end, and slightly curved so as to be concave toward the ulna. Three borders and three surfaces may be recognisal. Of the borders, the medial or interosseous crest [crista interossea] is best markert. Commencing at the posterior elge of the tuberosity, its first part is round and indistinct, and receives the attachment of the oblique cord of the radius; it is cont-

Fig. 1S1.-The Left Tlua axd Radies. (Postero-lateral viers.)

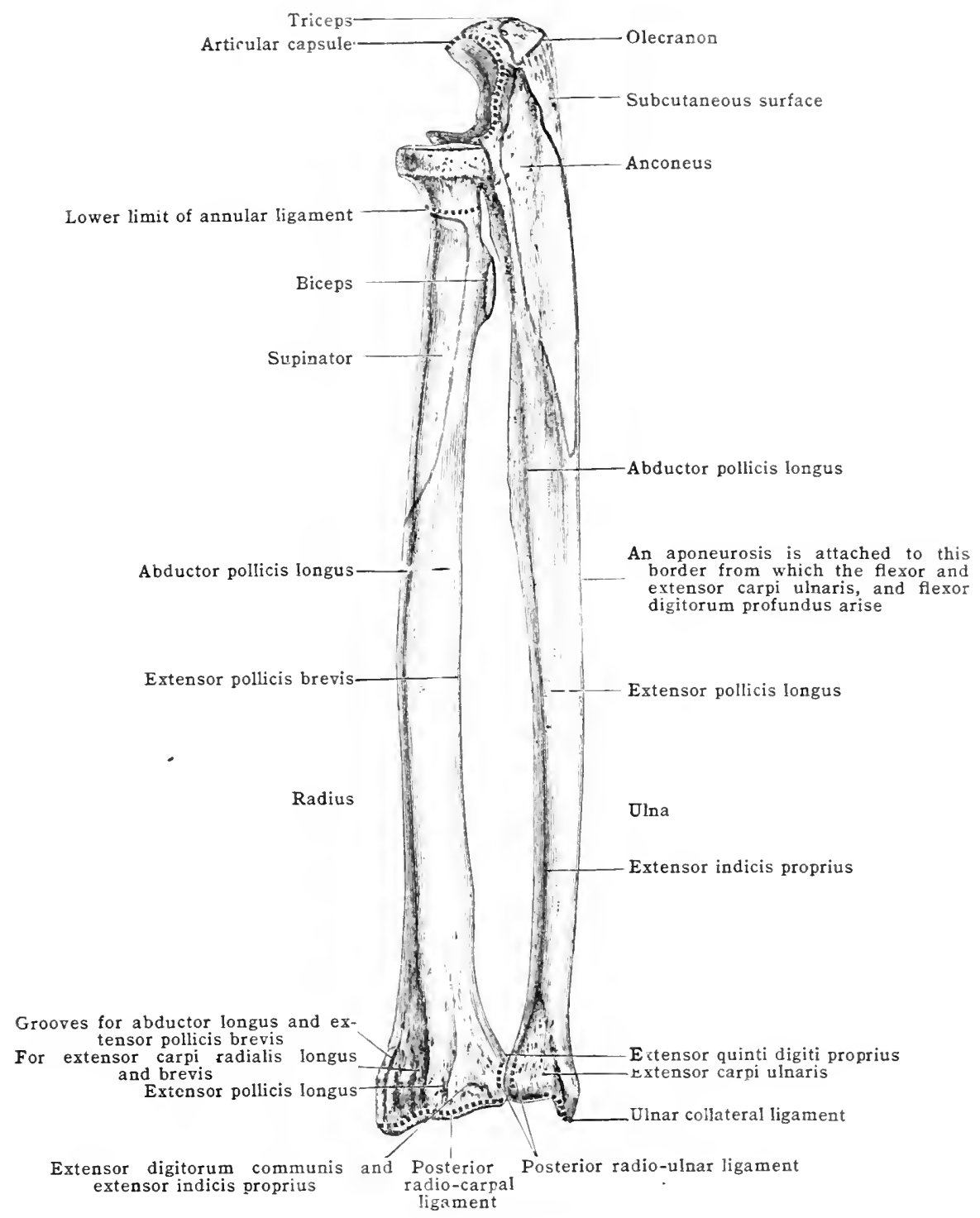

tinued as a sharp ridge which divides near the lower extremity to become continuous with the anterior and posterior margins of the ulnar notch (sigmoid carity). The prominent ridge and the posterior of the two lower lines give attachment to the interosseous membrane, whilst the triangular surface above the ulnar notch receives a part of the pronator quadratus. The interosseous crest separates the volar from the dorsal surface. The volar border [margo volaris] runs from the tuberosity obliquely downward to the lateral side of the bone and then descends vertically to the anterior border of the styloid process. The upper third, consti- 
tuting the oblique line of the radius, gives origin to the radial head of the flexor digitorum sublimis, limits the insertion of the supinator above, and the origin of the flexor pollicis longus below. The volar border separates the volar from the lateral surface. The dorsal border extends from the back of the tuberosity to the prominent middle tubercle on the posterior aspect of the lower extremity. Separating the lateral from the dorsal surface, it is well marked in the middle third, but becomes indistinct above and below.

Surfaces.- The volar (or anterior) surface is narrow and concave above; broad, flat, and smooth below. The upper two-thirds is oceupied chiefly by the flexor pollicis longus and a little less than the lower third by the pronator quadratus. Near

Fig. 182.-Articular Facets on the Lower End of Left Radius and Ulna.

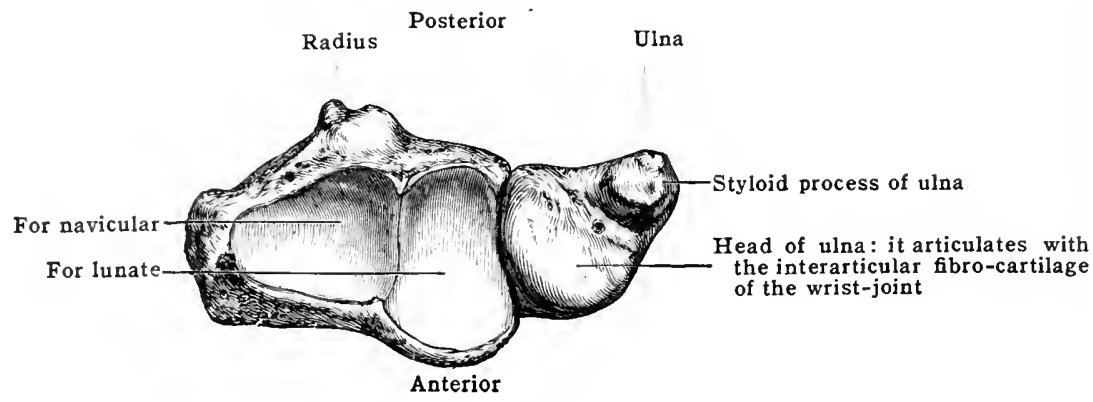

the junction of the upper and middle thirds of the volar surface is the nutrient foramen, directed upward toward the proximal end of the bone. It transmits a branch of the volar interosseous artery. The lateral surface is rounded above and affords insertion to the supinator; marked near the middle by a rough, low, vertical ridge for the pronator teres; smooth below, where the tendons of the extensor carpi radialis longus and brevis lie upon it, and where it is crossed by the abductor pollicis longus and extensor pollicis brevis. The dorsal (or posterior) surface, smooth and rounded above, is covered by the supinator; grooved longitudinally in the middle third for the abductor pollicis longus and the extensor pollicis

Fig. 183.-Dorsal View of the Lower End of the Radids and Ulna.

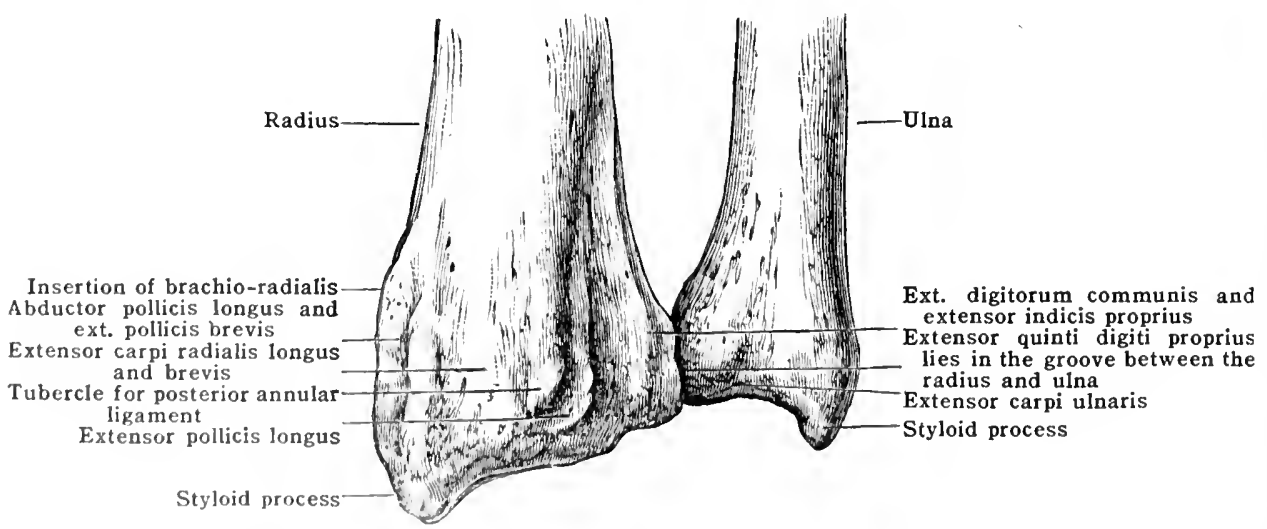

brenis; the lower third is broad, rounded, and eovered by tendons. The line which forms the upper limit of the impression for the abductor pollicis longus is known as the posterior oblique line.

The lower extremity of the radius is quadrilateral; its carpal surface [facies articularis carpea] is articular and clivided by a ridge into a medial quadrilateral portion, concave for articulation with the limate bone; and a lateral triangular portion, extending onto the styloid process for artieulation with the navieular (scaphoid) bone. The medial surface, also articular, presents the ulnar notch (sigmoid cavity) for the reception of the rounded margin of the head of the ulna. To the borler separating the unar and carpal articular surfaces the base of the 
articular disc is attached, and to the anterior and posterior borders, the anterior and posterior radio-ulnar ligaments respectively. The anterior surface is raised into a prominent area for the anterior ligament of the wrist-joint. The lateral surface is represented by the styloid process, a blunt pyramidal eminence, to the base of which the brachio-radialis is inserted, whilst the tip serves for the attachment of the radial (external) collateral ligament of the wrist. Its lateral surface is marked by two shallow furrows for the tendons of the abductor pollicis longus and extensor pollicis brevis. The posterior surface is convex, and marked by three prominent ridges separating three furrows. The posterior annular ligament is attached to these ridges, thus forming with the bone a series of tunnels for the passage of tendons.

The most lateral is broad, shallow, and frequently subdivided by a low ridge. The lateral subdivision is for the extensor carpi radialis longus, the medial for the extensor carpi radialis brevis. The middle groove is narrow and deep for the tendon of the extensor pollicis longus. The most medial is shallow and transmits the extensor indicis proprius, the extensor digitorum communis, the dorsal branch of the interosseous artery, and the dorsal interosseous nerve. When the radius and ulna are articulated, an additional groove is formed for the tendon of the extensor quinti digiti proprius.

Ossification. - The radius is ossified from a centre which appears in the middle of the shaft in the eighth woek of intra-uterine life and from two epiphysial centres which appear after birth. The nucleus for the lower end appears in the second year, and that for the upper end, which forms simply the disc-shaped head, in the fifth year. The head unites with the shaft at the seventeenth year, whilst the inferior epiphysis and the shaft join about the twentieth year.

\section{THE ULNA}

The ulna (figs. 180, 181, 189) is a long, prismatic bone, thicker above than below, on the medial side of the forearm and parallel with the radius, which it

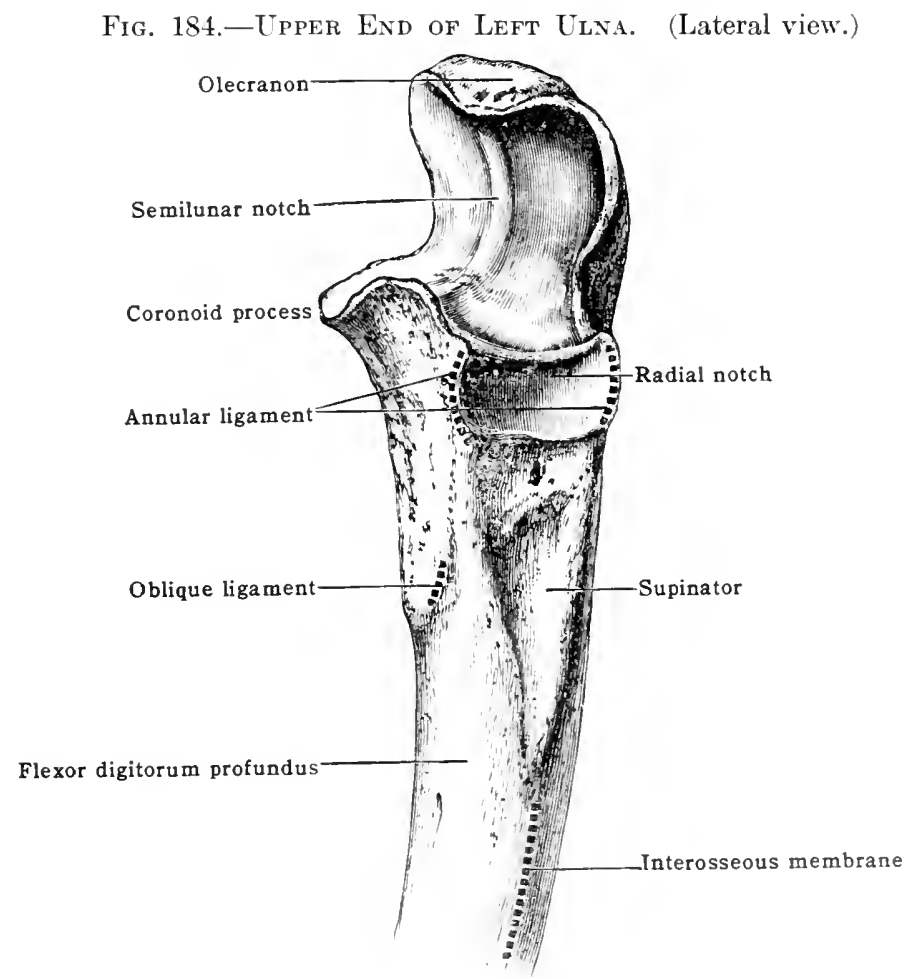

exceeds in length by the extent of the olecranon process. It articulates at the upper end with the humerus, at the lower end indirectly with the carpus, and on the lateral side with the radius. It is divisible into a shaft and two extremities.

The upper extremity is of irregular shape and forms the thickest and strongest part of the bone. The superior articular surface is concave from above downward, convex from side to side, and transversely constricted near the middle. It belongs 
partly to the olecranon, the thick upward projection from the shaft, and partly to the coronoid process, which projects horizontally forward from the front of the ulna. This semilunar excavation forms the semilunar notch (greater sigmoid cavity) and articulates with the trochlear surface of the humerus. The olecranon is the large curved eminence forming the highest part of the bone.

The superior surface of the olecranon, uneven and somewhat quarlrilateral in shape, reeeives behind, where there is a rough impression, the insertion of the triceps, and along the anterior margin the artieular capsule of the elbow-joint. The posterior surfaee, smooth and triangular in outline, is separated from the skin by a bursa. The anterior surface, covered with cartilage in the reeent state, is directed downward and forward, and its margins give attaehment to the articular capsule of the elbow-joint. This surface, as already noticed, forms the upper and back part of the semilunar notch. On the medial surface of the olecranon is a tubercle for the origin of the ulnar head of the flexor carpi ulnaris, and in front of this a fasciculus of the uhar eollateral ligument of the elbow-joint is attached to the bone; the lateral surface is rough, eoncave, and gives insertion to a part of the anconeus. The extrenity of the olecranon hies during extension of the elbow in the oleeranon fossa of the humerus.

Fig. 185.-Ossification of the Radius and Uluna; the Figure also shows the Relations of the Epiphysial and Capsular Lines.

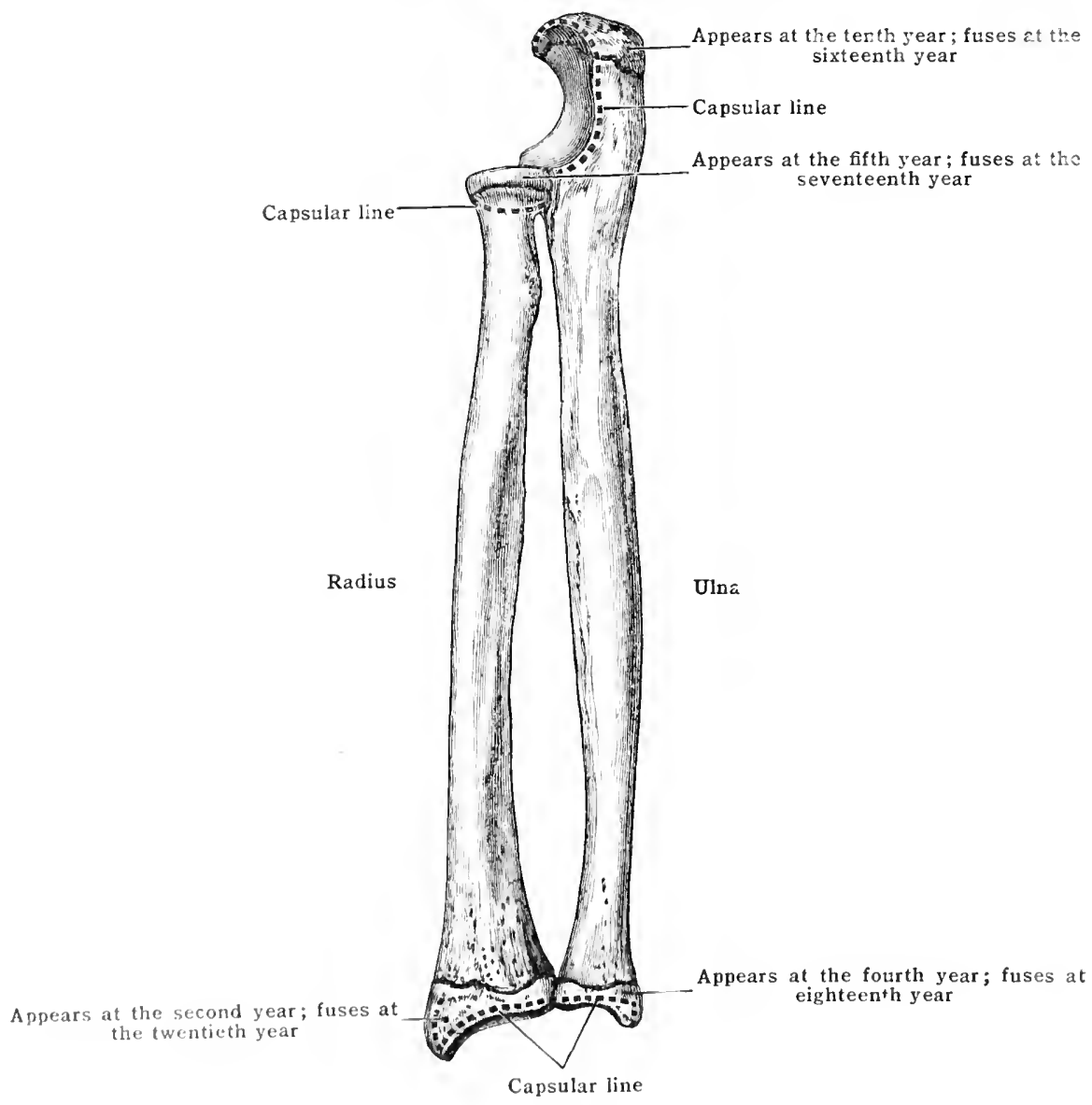

'The coronoid process, forming the lower and anterior part of the semilunar notch, has at superior articular surface continuous with the anterior surface of the oleranom, and, liko it, covered with cartilage. The inferior aspect is rough and concive, and gives insertion to the brachictis.

It is (ontinnons with the volar surface of the shaft, and near the junction of the two is a

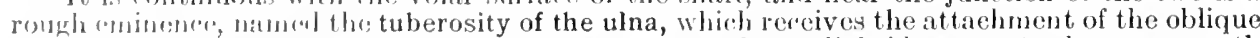
cord of the laulius and the insertion of the brachialis. The modial site presents above a smooth tuberele: for the origin of the nluar portion of the flexor digitorum sublimis, and a ridge below for the lesser hearl of the prometor teres and the rounded accessory bundle of the flexor pollicis lomgns, whilst immerliately behind the sublimis tubercle there is a triangular depressed surface for the nperor filines of the flexor digitorum profundus. 
On the lateral surface is the radial notch (lesser sigmoid cavity), an oblong articular surface which articulates with the circumference of the head of the radius, the anterior and posterior margins of which afford attachment to the annular ligament and the radial collateral ligament of the elbow-joint. In flexion of the elbow the tip of the process is received into the coronoid fossa of the humerus.

The body [corpus ulnæ] or shaft throughout the greater part of its extent is three-sided, but tapers toward the lower extremity, where it becomes smooth and rounded. It has three borders and three surfaces. Of the three borders, the lateral, the interosseous crest, is best marked. In the middle three-fifths of the shaft it is sharp and prominent, but becomes indistinct below; above it is continued by two lines which pass to the anterior and posterior extremities of the radial notch and enclose a depressed triangular area (bicipital hollow), the fore part of which lodges the tuberosity of the radius and the insertion of the biceps tendon during pronation of the hand, while from the posterior part the supinator takes origin. The interosseous crest separates the volar from the dorsal surface and gives attachment by the lower four-fifths of its extent to the interosseous membrane. The volar border is directly continuous with the medial edge of the rough surface for the brachialis and terminates inferiorly in front of the styloid process.

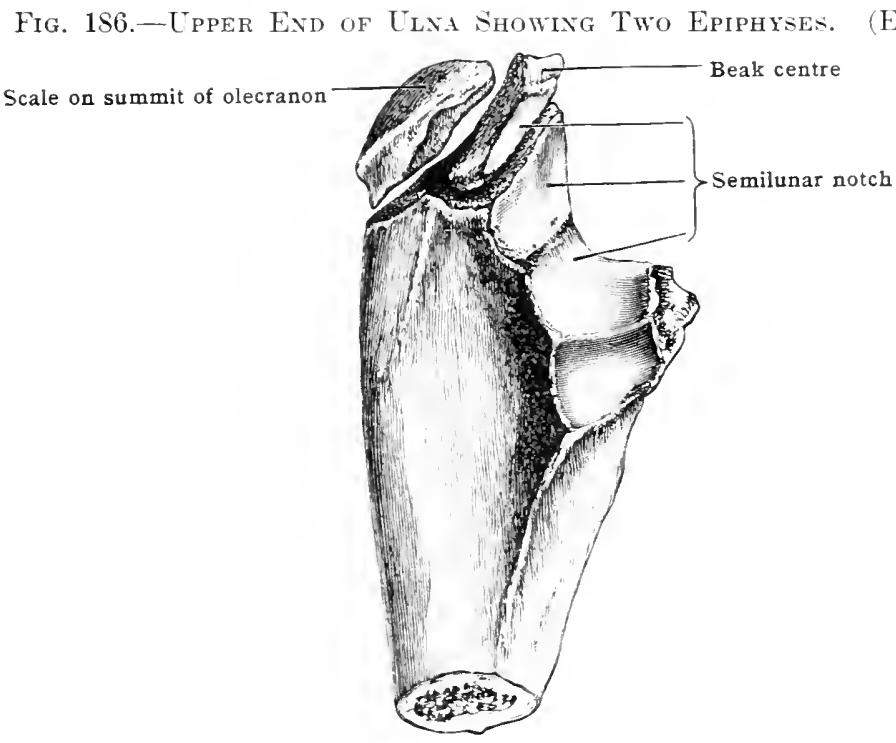

Throughout the greater part of its extent it is smooth and rounded, and affords origin to the flexor digitorum profundus and the pronator quadratus. It separates the volar from the medial surface. The dorsal border commences above at the apex of the triangular subcutaneous area on the back of the olecranon, and takes a sinuous course to the back part of the styloid process. The upper three-fourths gives attachment to an aponeurosis common to three muscles, viz., the flexor and extensor carpi ulnaris and the flexor digitorum profundus. This border separates the medial from the dorsal surface.

Surfaces.- The volar (or anterior) surface is grooved in the upper threefourths of its extent for the origin of the flexor digitorum profundus, narrow and convex below, for the origin of the pronator quadratus. The upper limit of the area for the latter muscle is sometimes indicated by an oblique line- the pronator ridge. Near the junction of the upper and middle thirds of the anterior surface is the nutrient foramen, directed upward toward the proximal end of the bone. It transmits a branch of the volar interosseous artery. The medial surface, smooth and rounded, gives attachment, on the upper two-thirds, to the flexor digitorum profundus, whereas the lower third is subcutaneous. The dorsal (or posterior) surface, directed laterally as well as backward, presents at its upper part the oblique line of the ulna running from the posterior extremity of the radial noteh to the dorsal border. 
The oblique line gives attachinent to a few fibres of the supinator and marks off the posterior surface into two unequal parts. That above the line, much the smaller of the two, receives the insertion of the anconeus. The more extensive part below is subdivided by a vertical ridge into a medial portion, smooth, and eovered by the extensor carpi ulnaris, and a lateral portion which gives origin to three museles, viz., the abductor pollicis longus, the extensor pollicis longus and the extensor indicis proprius, from above downward.

The lower extremity of the ulna is of small size and consists of two parts, the head and the styloid process, separated from each other on the inferior surface by a groove into which the apex of the articular disc is inserted. That part of the head adjacent to the groove is semilunar in shape and plays upon the articular disc which thus excludes the ulna from the radio-carpal or wrist-joint. The margin of the head is also semilunar, and is received into the ulnar notch of the radius. The styloid process projects from the medial and back part of the bone, and appears as a continuation of the dorsal border. To its rounded summit the ulnar collateral ligament of the wrist-joint is attached, and its dorsal surface is grooved for the passage of the tendon of the extensor carpi ulnaris. Immediately above the articular margin of the head the anterior and posterior radio-ulnar ligaments are attached in front and behind.

Fig. 1S7.-The Left Radius and Ulna in Pronation. (Anterior view.)

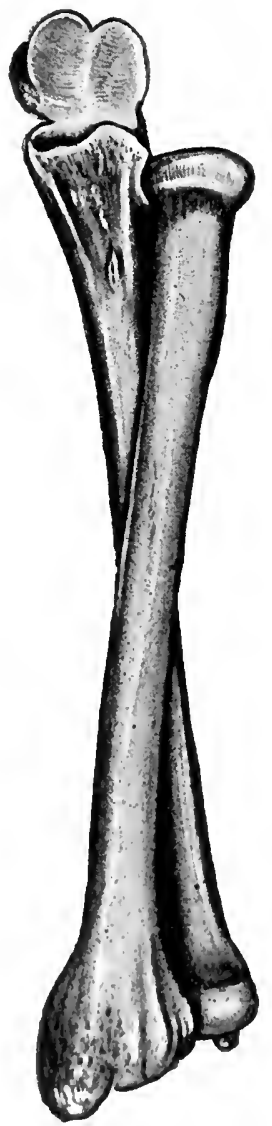

Ossification.- The nlna is ossified from three eentres. The primary nucleus appears near the midlle of the shaft in the eighth week of intri-uterine life. At birth the inferior extremity and the greater prortion of the olromon are cartilaginons. The nucleus for the lower end appears dluring the fourth year and the epiphysis joins with the shaft from the eighteenth to the twonticth year. 'The greater part of the ofecrinom is ossified from the shaft, but an epiphysis

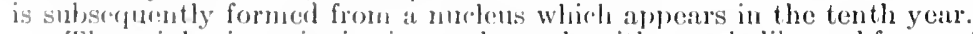

'Th: "piphysis varios in size, and may be either scale-like and form a thin plate on the summit, or involve the upper fourth of the vilecranon and the corresponding articular surface. In the litfor case the cpiphysis is probably composed of two parts fused together: (1) The seale on the summit of the olecranon process, and (2) the boak centre which enters into the formation of the apjer end of the semilumir noteh (soe fig. IS6). The epiphysis unites to the shaft in the sixternth or seventeenth year. 


\section{THE CARPUS}

The carpus (figs. 188, 189) consists of eight bones, arranged in two rows, four bones in each row. Enumerated from the radial to the ulnar side, the bones of the proximal row are named navicular (scaphoid), lunate (semilunar), triquetral (cuneiform), and pisiform; those of the distal row, greater multangular (trapezium), lesser multangular (trapezoid), capitate (os magnum), and hamate (unciform).

When the bones of the carpus are articulated, they form a mass somewhat quadrangular in outline, wider below than above, and with the long diameter transverse. The dorsal surface is convex and the volar surface concave from side to side. The concavity is increased by four prominences, which project forward, one

Fig. 188.-Bones of the Left Hand. (Dorsal surface.)

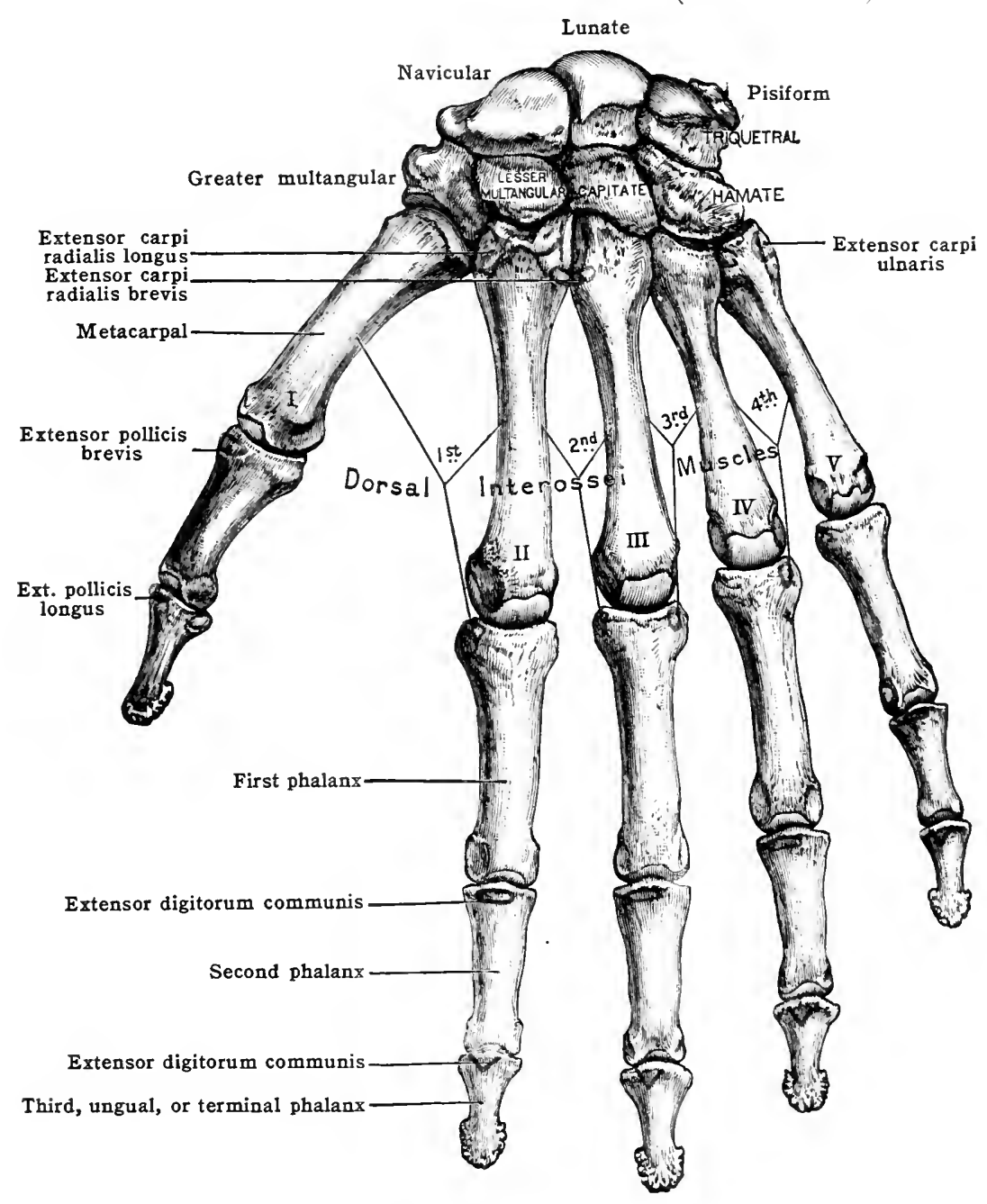

from each extremity of each row. On the radial side are the tuberosity of the navicular and the ridge of the greater multangular; on the ulnar side, the pisiform and the hook of the hamate. Stretched transversely between these prominences, in the recent state, is the transverse carpal ligament forming a canal for the passage of the flexor tendons and the median nerve into the palm of the hand. The proximal border of the carpus is convex and articulates with the distal end of the radius and the articular disc. The pisiform, however, takes no share in this articulation, being attached to the volar surface of the triquetral. The distal border forms an undulating articular surface for the bases of the metacarpal bones. The 
line of articulation between the two rows of the carpus is coneavo-convex from side to sicle, the lateral part of the navicular being received into the concavity formed by the greater multangular, lesser multangular, and capitate, and the capitate and hamate into that formed by the navicular, lunate, and triquetral bones.

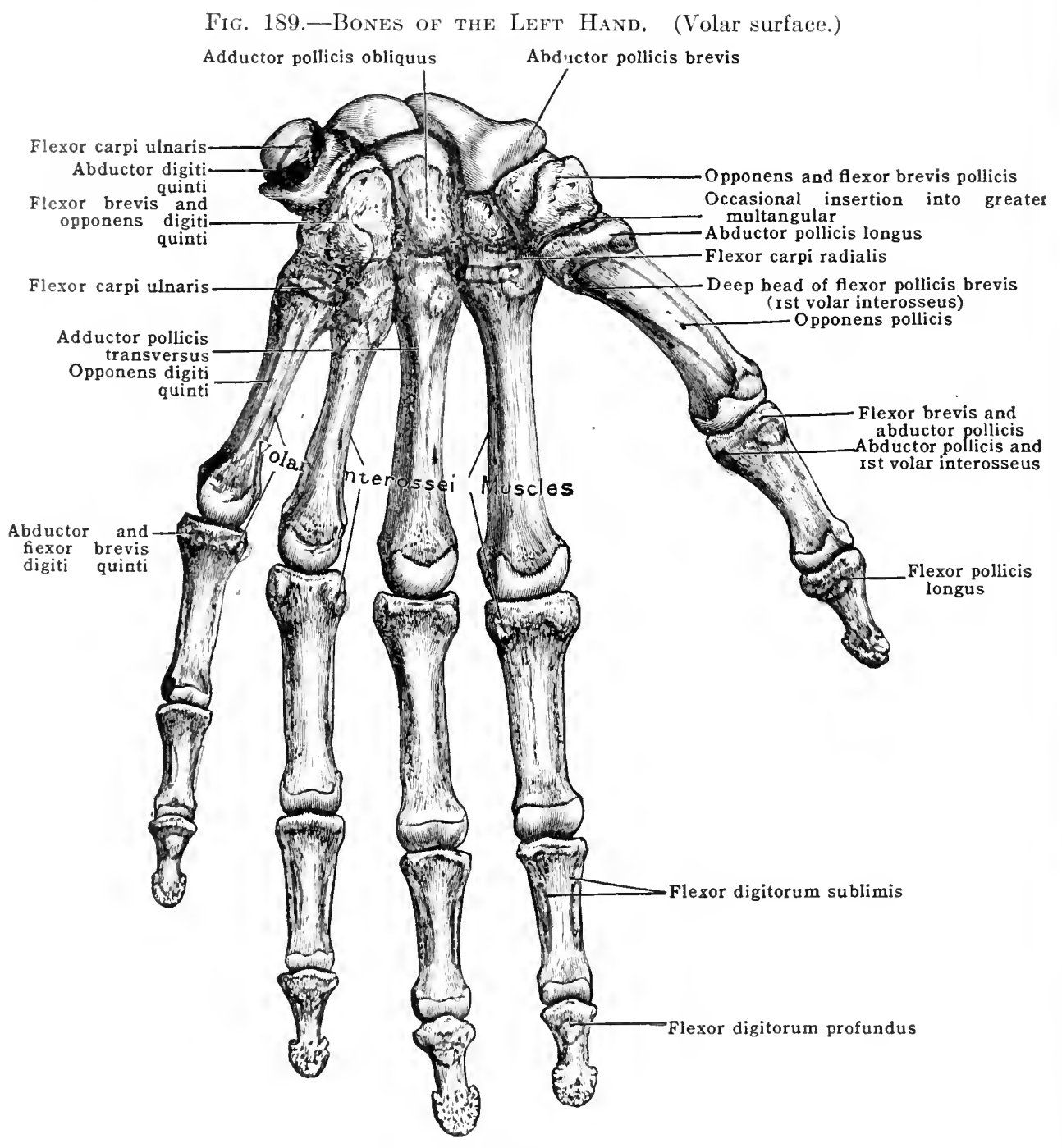

The individual carpal bones have several points of resemblance. Each bone (excepting the pisiform) has six surfaces, of which the anterior or volar and posterior or clorsal are rough for the attachment of ligaments, the volar surface being the broakder in the proximal row, the dorsal surface in the distal row. The superior and inferior surfaces are articular, the former being gencrally convex and the latter concave. The lateral surfates, when in contatet with adjacent bones, are also articular, but otherwise rough for the attachment of ligaments. Further, the whole of the carpus is artilaginous at birth and eath bone is ossified from a single: rentre.

\section{The Navieular}

The navicular [os naviculare] or scaphoid (fig. 190) is the largest bone of the proximal row, and so disposed that its long axis rums obliquely downward and lateralwarl.

The superior surface is anvex and somewhat triangular in shape for articulation with the lateril facet on the distal rnct of thrialius. The inferior surface, smooth and convex, is divided 
into two parts by a ridge running from before backward. The lateral part articulates with the greater multangular, the medial with the lesser multangular. The volar surface, rough and eoncave above, is elevated below into a prominent tubercle for the attachment of the transicess. carpal ligament and the abductor pollicis brevis. The dorsal surface is narrow, being reduced

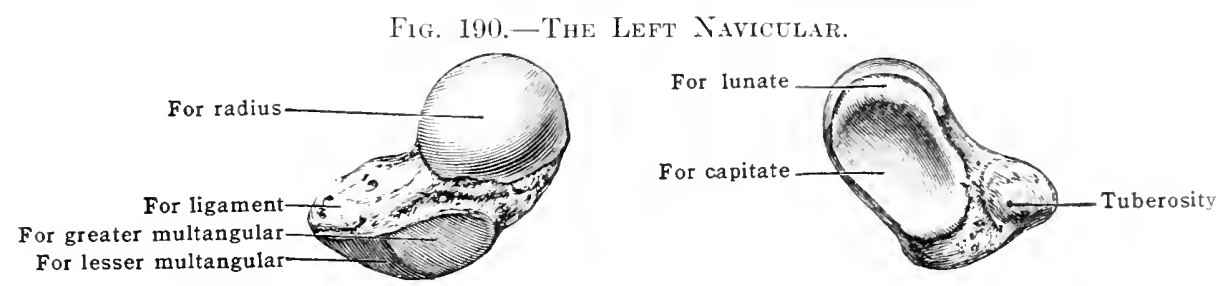

to a groove running the whole length of the bone; it is rough and serves for the attachment of the dorsal radio-carpal ligament. The medial surface is occupied by two articular farets, of which the upper is crescentic in shape for the lunate bone, whilst the lower is deeply coneare for the reception of the hearl of the capitate. The lateral surface is narrow and rough for the attachment of the radial collateral ligament of the wrist-joint.

Articulations. - With the radius above, greater and lesser multangular below, lumate and capitate medially.

\section{The Linate}

The lunate [os lunatum] or semilunar (fig. 191), placed in the middle of the proximal row of the carpus, is markedly crescentic in outline.

The superior surface is smooth and convex and articulates with the medial of the two facet: on the distal end of the radius. The inferior surface presents a deep concavity divided into two parts by a line running from before backward. Of these, the lateral and larger articulates with the capitate; the medial and smaller with the hamate. The volar surface is large and convex,

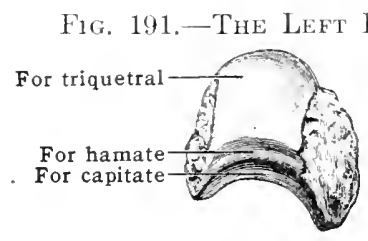

the dorsal surface warrow and flat, and both are rough for the attachment of ligaments. The medial surface is marked by a smooth quadrilateral facet for the base of the triquetral. The lateral surface forms a narrow crescentic articular surface for the lunate.

Articulations. - With the ralius above, capitate and hanate below, navicular laterally and triquetral medially.

\section{The Triquetral}

The triquetral [os triquetrum] or cuneiform (fig. 192) is pyramilal in shape and placed obliquely, so that its base looks upward and laterally and the apex downward and medially.

\section{Fig. 192.-The Left Trigletral.}

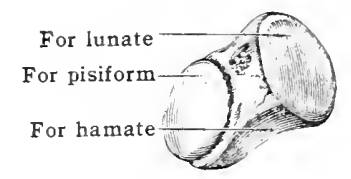

The superior surface presents laterally near the base a small, convex articular forcet which plays upon the articular dise interposed between it and the clistal end of the uhnt, and meelially. a rough non-articular portion for ligaments. The inferior surface forms a lalree, triangulit undulating facet for articulation with the hamate. The volar surface can be realily recomisicet by the conspicuous oval facet near the apex for the pisiform bone. The dorsal surface is rough for the attachment of ligaments. The medial and lateral surfaces are representerl by the hast and the apex of the pyramid. The base is marked by a flat quadrilateral facet for the lumate. The apex forms the lowest part of the bone and is roughered for the attachment of the ulnar collateral ligament of the wrist. above.

Articulations. - With the pisiform in front, Innate laterally, hamate below, articular dise 


\section{The Pisiform}

The pisiform [os pisiforme] (fig. 193), the smallest of the carpal bones, is in many of its characters a complete contrast to the rest of the series. It deviates from the general type in its shape, size, position, use, and development. Forming a rounded bony nodule with the long axis directed vertically, it is situated on a plane in front of the other bones of the carpus.

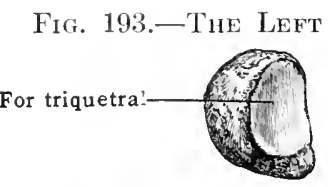

On the dorsal surface is a single articular facet for the triquetral which reaches to the upper end of the bone, but leaves a free non-articular portion below. The volar surface, rough and rounded, gives attachment to the transverse carpal ligament, the flexor carpi ulnaris, the $a b$ ductor quinti digiti, the piso-metacarpal and the piso-hamate ligaments. The median and lateral surfaces are also rough and the lateral presents a shallow groove for the ulnar artery. It is usually considered that the pisiform is a sesamoid bone developed in the tendon of the flexor carpi ulnaris, though by some writers it is regarded as part of a rudimentary digit.

\section{The Greater Multangular}

The greater multangular [os multangulum majus] or trapezium (fig. 194), situated between the navicular and first metacarpal, is oblong in form with the lower angle prolonged downward and medially.

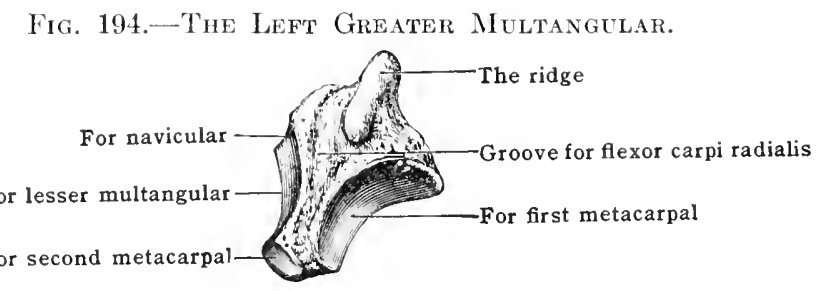

The superior surface is concave and directed upward and medially for articulation with the lateral of the two facets on the distal surface of the navicular, and on the inferior surface is a sarlde-shaped facet for the base of the first metacarpal. The volar surface presents a prominent rilge with a deep groove on its melial side which transmits the tendon of the flexor carpi radialis. The ridge gives attachment to the transverse carpal ligament, the abductor pollicis brevis, the opponens pollicis, and oceasionally a tendinous slip of insertion of the abductor pollicis longus. The dorsal and lateral surfaces are rough for ligaments. The medial surface is divided into two parts by a horizontal ridge. The upper and larger portion is concave and articulates with the lesser multangular; the lower - a small flat facet on the projecting lower angle-articulates with the base of the second metarcarpal.

Articulations. - With the navicular above, first metacarpal below, the lesser multangular and second metacarpal on the medial side.

\section{The Lesser Multangulak}

The lesser multangular [os multangulum minus] or trapezoid (fig. 195), the smallest of the bones in the distal row, is somewhat wedge-shaped, with the hroader end florsally and the narrow end ventrally.

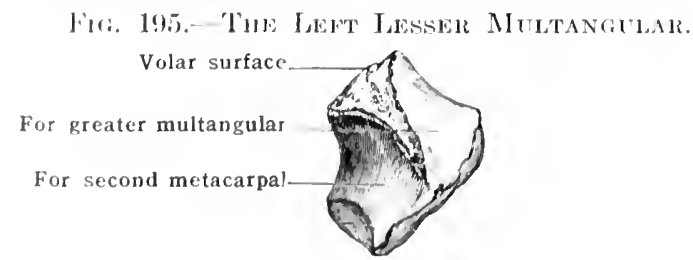

The superior surface is marked ly a small, qualrilatcral, concave facet, for the media of the two facets on the lower surface of the llavicular. The inferior surface is convex from side to sids: and coneave from leffore batek ward, forming a suldle-shaped articular surface for the bitse of the secend metacieplat. () the volar anel dorsal surfaces, the former is narrow and rough, 
the latter broad and rounded, constituting the widest surface of the bone, and both are rough for the attachment of ligaments. The lateral surface slopes downward and medially and is convex for articulation with the corresponding surface of the greater multangular. On the medial surface in front is a smooth flat facet for the capitate; elsewhere it is rough for ligaments.

Articulations. - With the naviculac above, second metacarpal below, greater multangulur laterally, and the capitate medially.

\section{The Capitate}

The capitate [os capitatum] or os magnum (fig. 196) is the largest bone of the carpus. Situated in the centre of the wrist, the upper expanded portion, globular in shape and known as the head, is received into the concavity formed above by the navicular and lunate. The cubical portion below forms the body, whilst the intermediate constricted part is distinguished as the neck.

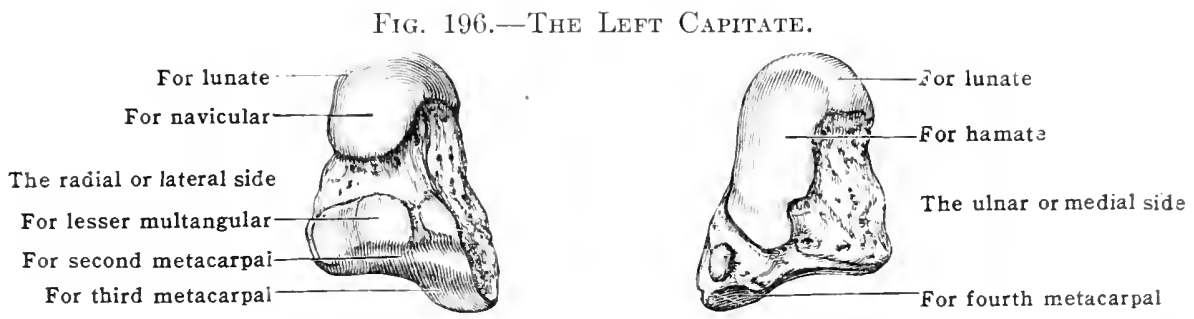

Of the six surfaces, the superior is smooth and convex, elongated from before backward for articulation with the concavity of the lunate bone. The inferior surface is divided into three unequal parts by two ridges. The middle portion, much the larger, articulates with the base of the third metacarpal; the lateral, narrow and concave, looks lateral as well as downward to articulate with the second metacarpal, whilst the medial portion is a small facet, placed on the projecting angle of the bone dorsally, for the fouth metacalpal bone. The volar surface is convex and rough, giving origin to fibres of the oblique adductor pollicis; the dorsal surface is broad and deeply concave. The lateral surface presents, from above downward:- (1) a smooth convex surface, forming the outer aspect of the head, with the superior surface of which it is continuous, for articulation with the navicular; (2) a groore representing the neck, indented for ligaments; (3) a small facet, flat and smooth, for articulation with the lesser multangular. Behind this facet is a rough area for attachment of an interosseous ligament. The medial surface has extending along its whole hinder margin an oblong articular surface for the hamate; the lower part of this smooth area sometimes forms a detached facet. 'The volar part of the surface is rough for an interosseous ligament.

Articulations. - With the lunate and navicular above, second, third, and fourth metacarpals below, lesser multangular laterally, and hamate medially.

\section{The Hamate}

The hamate [os hamatum] or unciform (fig. 197) is a large wedge-shaped bone, bearing a hook-like process, situated between the capitate and triquetral, with the base directed downward and resting on the two medial metacarpals.

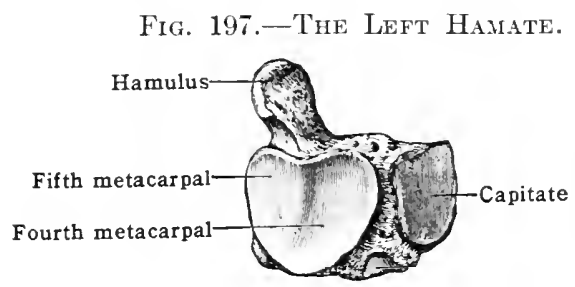

The apex of the wedge forms the narrow superior surface, directed upward and laterally for articulation with the lumate. The inferior surface or base is divided by a ridge in to two quadrilateral facets for the fourth and fifth metacarpal bones. The volar surface is triangular in outline and presents at its lower part a prominent hamulus (unciform process), a hook-like eminence, projecting forward and curved toward the carpal canal. It is flattened from side to side so as to present two surfaces, two borders, and a free extremity. To the latter the transverse carpal ligament and the flexor carpi ulnaris (by means of the piso-hamate ligament) are attached, whilst the medial surface affords origin to the flexorbrevis and the opponens digiti quinti. The lateral surface is concave and in relation to the flexor tendons. The dorsal surface is triangular and rough for ligaments. The lateral surface has extending along its upper and 
hinder edges a long flat surface, wider above than below, for articulation with the capitate. In front of this articular facet the surface is rough for the attachment of an interosseous ligament. The medial surface is oblong and undulating, i. e., concavo-convex from base to apex, for articulation with the triquetral. bones.

Articulations. - With the triquetral, lunate, capitate, and the fourth and fifth metacarpal

\author{
Ossification of the Carpal Bones \\ Capitate......... first year Greater multangular...... fifth year

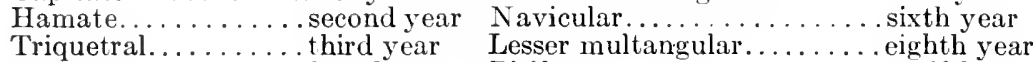

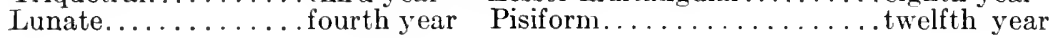

Additional carpal elements are occasionally met with. The os centrale occurs normally in the carpus of many mammals, and in the human fotus of two months it is present as a small cartilaginous nodule which soon becomes fused with the cartilage of the navicular. Failure of fusion, with subsequent ossification of the nodule, leads to the formation of an os centrale in the human carpus which is then found on the dorsal aspect, between the navicular, capitate, and lesser multangular. In most individuals, however, it coalesces with the navicular or undergoes suppression.

An additional centre of ossification, leading to the formation of an accessory carpal element, occasionally appears in connection with the greater multangular and the hamate. An accessory element (os resalianum) also occurs occasionally in the angle between the hamate and the fifth metacarpal, and others occur between the second and third metacarpals and the lesser multangular and capitate.

\title{
THE METACARPALS
}

The metacarpus (figs. 188, 189) consists of a series of five eylindrical bones [ossa metacarpalia], well deseribed as 'long bones in miniature.' Articulated with the earpus above, they descend, slightly diverging from each other, to support the fingers, and are numbered from the lateral to the medial side. With the exception of the first, which in some respects resembles a phalanx, they conform to a general type.

A typical metacarpal bone presents for examination a shaft and two extremities. The body or shaft is prismatic and curved so as to be slightly convex toward the back of the hand. Of the three surfaces, two are lateral in position,

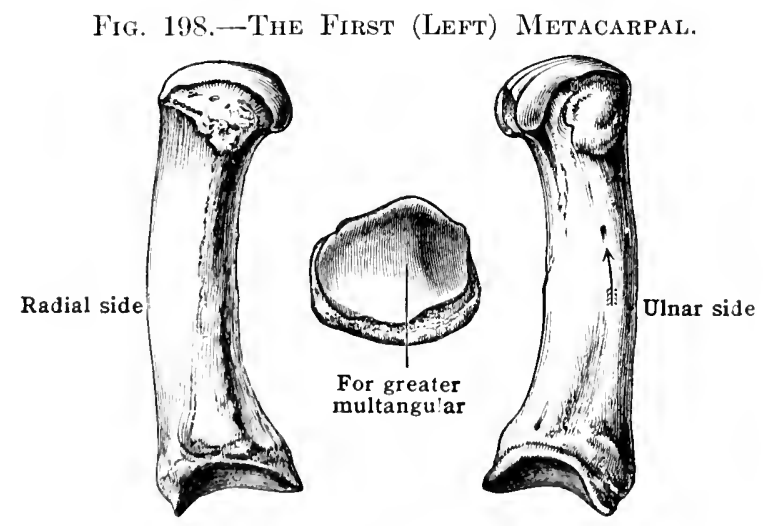

separated in the middle part of the shaft by a prominent palmar ridge, and coneave for the attarhment of interosseous nuscles. The third or dorsal surface prescnts for examination a large, smooth, triangular area with the base below and apex above, covered in the recent state by the extensor tendons of the fingers, and two sloping areas, near the carpal axtremity, also for interosseous muscles. The triangular area is bombled by. two lines, which commence below in two dorsal tuberctes, and, passing upward, converge to form a median ridge situated between the sloping areas on cither side. A little above or below the middle of the shaft, and near the volir horder, is the modullary foramen, entering the bone obliquely upwarl. 'Thr base or carpal extremity, broader behind than in front, is ruadrilateral, and both palmar and dorsal surfaces are rough for ligaments; it articulates above with the carpus and on cach sicle with the adjacent metacarpal bones. The head [anpitulumu] or digital extremity presents a large rounded articular surface, extronling further on the palmar than on the dorsal aspeet, for 
articulation with the base of the first phalanx. The volar surface is grooved for the flexor tendons and raised on each side into an articular eminence. On each side of the head is a prominent tubercle, and immediately in front of this a wellmarked fossa, to both of which the collateral ligament of the metacarpo-phalangeal joint is attached.

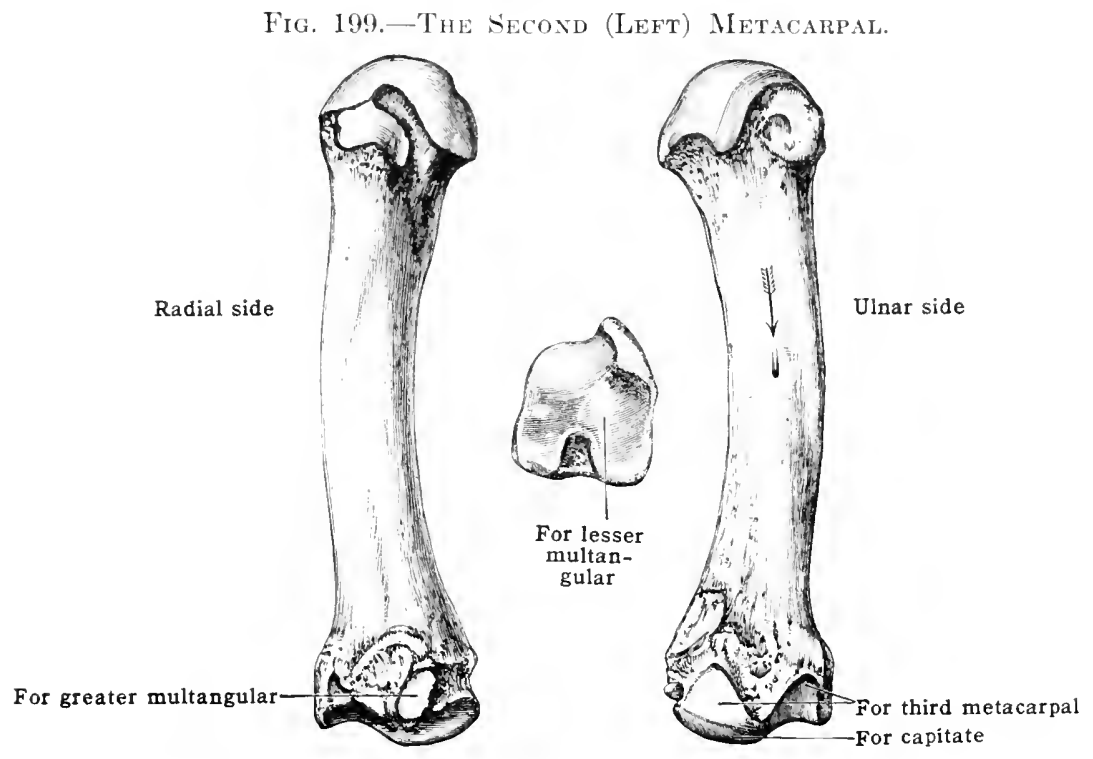

The second is the longest of all the metacarpal bones, and the third, fourth, and fifth successively decrease in length. The several metacarpals possess distinctive characters by which they are readily identified.

The first metacarpal (fig. 198) is the shortest and widest of the series. Diverging from the carpus more widely than any of the others the palmar surface is directed medially and marked

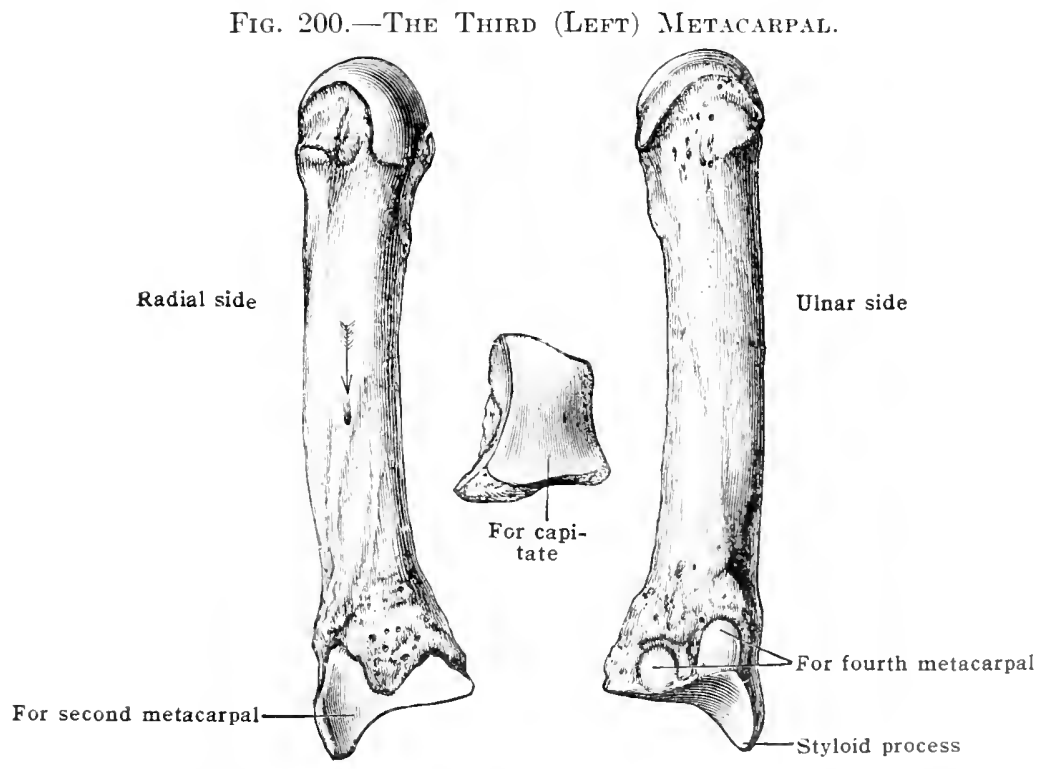

by a ridge placed nearer to the medial border. The lateral portion of the surfare slope- gently to the lateral border and gives attachment to the opponens pollicis; the medial portion, the smaller of the two, slopes more abruptly to the medial border, is in relation to the deep liead of the flexor pollicis brevis, and presents the nutrient foramen, directed downward toward the head of the bone and transmitting a branch of the arteria princeps pollicis. The dorsal surface, wide and flattened, is in relation to the tendons of the extensor pollicis longus and brevis. 
The base presents a saddle-shaped articular surface for the greater multangular, prolonged in front into a thin process. There are no lateral facets, but laterally a small tubercle receives the insertion of the abductor pollicis longus. Nedially is a rough area from which fibres of the inner head of the flexor pollicis brevis take origin. The margin of the articular surface gives attachment to the articular capsule of the carpo-metacarpal joint. The inferior extremity or head is rounded and articular, for the base of the first phalanx; the greatest dianeter is from side to side and the surface is less convex than the corresponding surface of the other metacarpal bones. On the volar surface it presents two articular eminences corresponding to the two sesamoid bones of the thumb. Of the two margins, the medial gives origin to the lateral head of the first dorsal interosseous, the lateral receires fibres of insertion of the opponens pollicis.

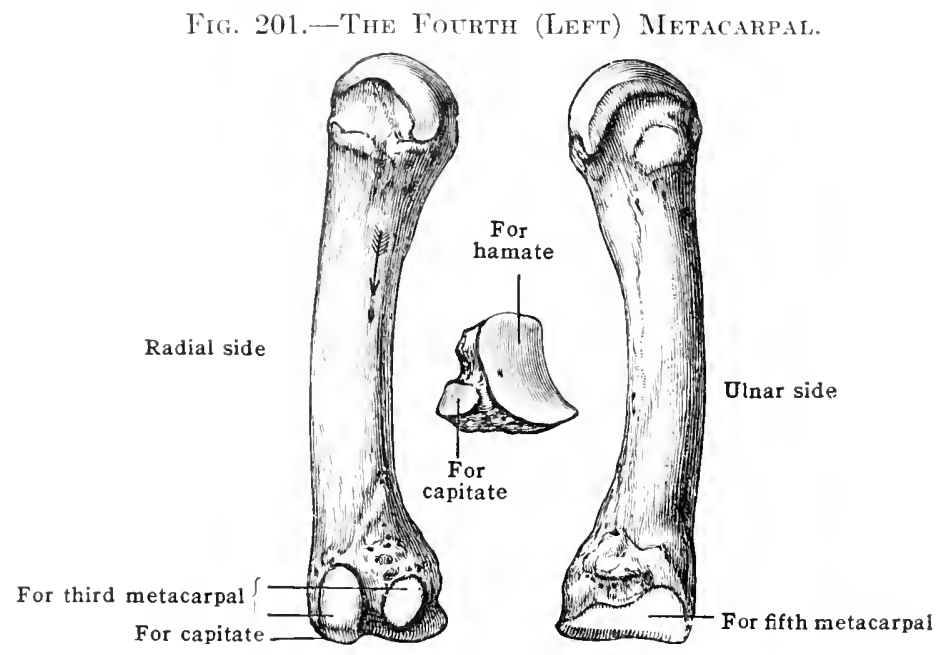

The second metacarpal (fig. 199). - The distinctive features of the four remaining metacarpals are almost exclusively confined to the carpal extremities. The second is easily recognised by its leeply cleft base. The terminal surface presents three articular facets, arranged as follows, from lateral to medial border:-(1) a small oval facet for the greater multangular; (2) a hollow for the lesser multangular; and (3) an elongated ridge for the capitate. The dorsal surface is rough for the insertions of the extensor carpi radialis longus and a part of the extensor carpi radialis brevis; the palmar surface receives the insertion of the flexor carpi radialis and gives origin to a few fibres of the oblique adductor pollicis. The lateral aspect of the extremity is rough and non-articular; the medial surface bears a bilobed facet for the third metacarpal.

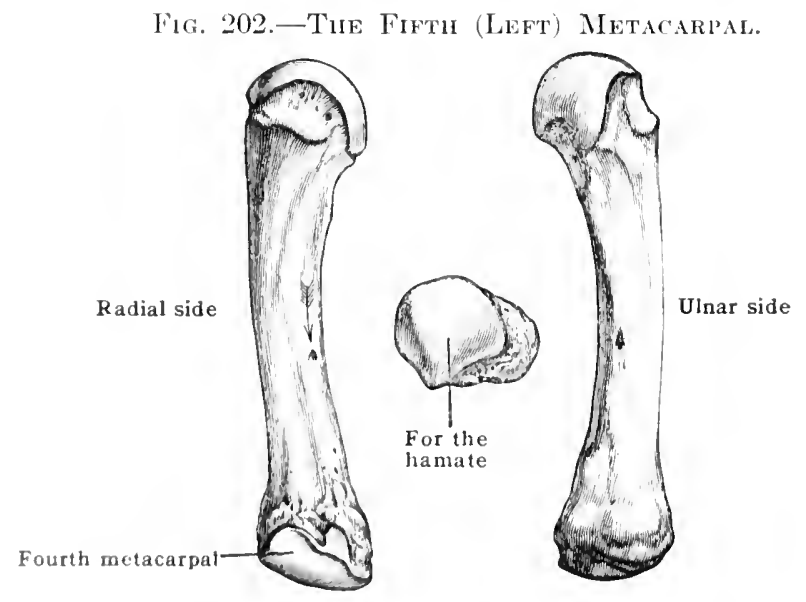

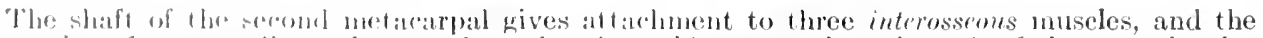
untrient foranen, directed ufward on the nluar side, transmits a branch of the second volar metirialpat antroy.

'The third metacarpal (fig. 200) is distinguisherl by the prominent styloid process projecting npwarl from the laterit and posterior angle of the base. Immediately below it, on the dorsal surfare, is a romgh implesion for the frtemsor corpi radialis brevis. The carpal surface is concave behiml and anvex in front, and artindates with the middle of the three facets on the inferior surface of the capitate. On the lateral sile is a biloberl articular facet for the second metarimpal, atul on the merlial sidre two small oval lacets for the fourth metacarpal. "lihe volar aspent of the bar is romgh and gives attandusent to fibres of the oblique adductor pollicis and 
sometimes a slip of insertion of the flexor carpi radialis. The shaft of the third metacarpal serves for the origin of the transverse adductor pollicis and two interosseous muscles. The nutrient foramen is directed upward on the radial side and transmits a branch of the seconsl volar metacarpal artery.

The fourth metacarpal (fig. 201) has a small base. The carpal surface presents two facets: a medial, large and flat, for articulation with the hamate, and a small facet, at the lateral and posterior angle, for the capitate. On the lateral side are two small oval facets for the corresponiing surfaces on the third metacarpal and a single concave facet on the medial side for the fifth metacarpal. The shaft of the fourth metacarpal gives attachment to three interosseous miscles. and the nutrient foramen, directed upward on the radial side, transmits a branch of the third volar metacarpal artery.

The fifth metacarpal (fig. 202) is distinguished by a semilunar facet on the lateral side of the base for the fourth metacarpal, and a rounded tubercle on the medial side for the extensor carpi ulnaris, in place of the usual medial facet. The carpal surface is saddle-shaperl for the hamate; the palmar surface is rough for ligaments including the piso-metacarpal prolongation from the flexor carpi ulnaris. The dorsal surface of the shaft presents an oblique line separating a lateral concave portion for the fourth dorsal interosseous muscle from a smooth medial portion covered by the extensor tendons of the little finger. The palmar surface gives attachment laterally to the third palmar interosseous muscle and medially to the opponens digiti quinti. The nutrient foramen is directed upward on the radial side and transmits a branch of the fourth volar metacarpal artery.

\section{THE PHALANGES}

The phalanges (fig. 203) are the bones of the fingers, and number in all fourteen. Each finger consists of three phalanges distinguished as first or proximal, second

Fig. 203.-The Phalayges of the Third Digit of the Haxid. (Dorsal view.) [The arrows indicate the direction of the nutrient canals.]

Third termina! or ungual phalanx
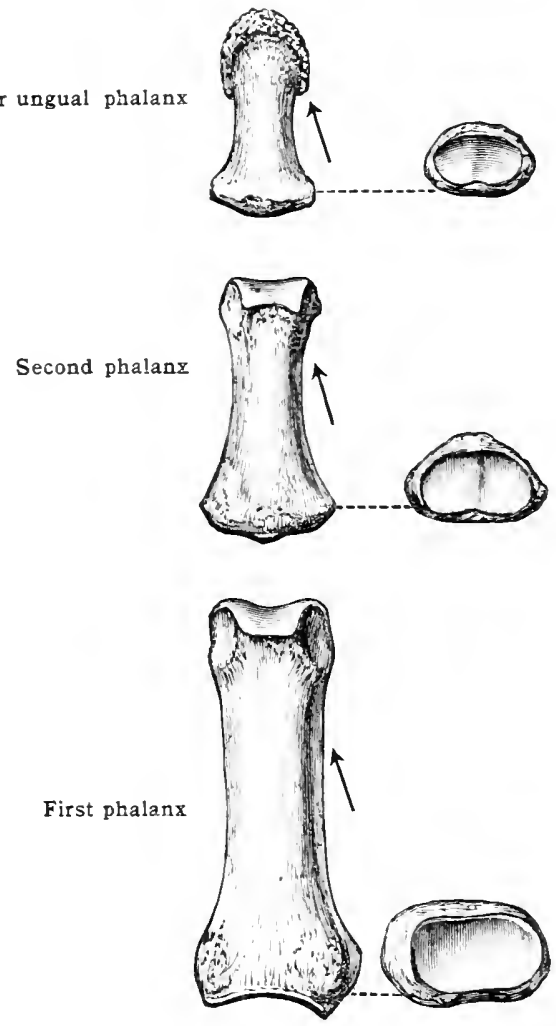

or middle, and third or distal. In the thumb, the second phalanx is ranting. Arranged in horizontal rows, the phalanges of each row resemble one another and differ from those of the other two rows. In all the phalanges the nutrient canal is directed downward, toward the distal extremity.

First phalanx, - The shaft of a phalanx from the first row is flat on the palmar surface. smooth and rounded on the dorsal surface, i. e., semi-cylindrical in shape. The borders of the palmar surface are rough for the attachment of the sheaths of the flexor tendons. The base or metacarpal extremity presents a single concave articular surface, oval in shape, for the 
convex head of the metacarpal bone. The distal extremity forms a pulley-like surface, grooved in the centre and elevated at each side to form two miniature condyles, for articulation with the base of a second phalanx.

Second phalanx. - The second phalanges are four in number and are shorter than those of the first row, which they closely resemble in form. They are distinguished, however, by the articular surface on the proximal extremity, which presents two shallow depressions, separated by a ridge and corresponding to the two condyles of the first phalanx. The distal end for the base of the third phalanx is trochlear or pulley-like, but smaller than that of the first phalanx. The palmar surface of the shaft presents on each side an impression for the tendon of the flexor digitorum sublimis, and the dorsal aspect of the base is marked by a projection for the insertion of the extensor digitorum communis.

Third phalanx.-A third phalanx is readily recognised by its small size. The proximal end is identieal in shape with that of a second phalanx, and bears a depression in front for the tendon of the flexor digitorum profundus. The free, flattened and expanded distal extremity presents on its palmar surface a rough semilunar elevation for the support of the pulp of the finger. The somewhat horseshoe-shaped free extremity is known as the ungual tuberosity [tuberositas unguicularis], and the bone is accordingly referred to as the ungual phalanx.

\section{Ossification of the Metacarpus and Phalanges}

Each of the metacarpal bones and phalanges is ossified from a primary centre for the greater part of the bone, and from one epiphysial centre. The primary nucleus appears from the eighth to the tenth week of intra-uterine life. In four metacarpal bones the epiphysis is distal, whilst

Fig. 204.-Ossification of the Metacarpals and Phalanges.

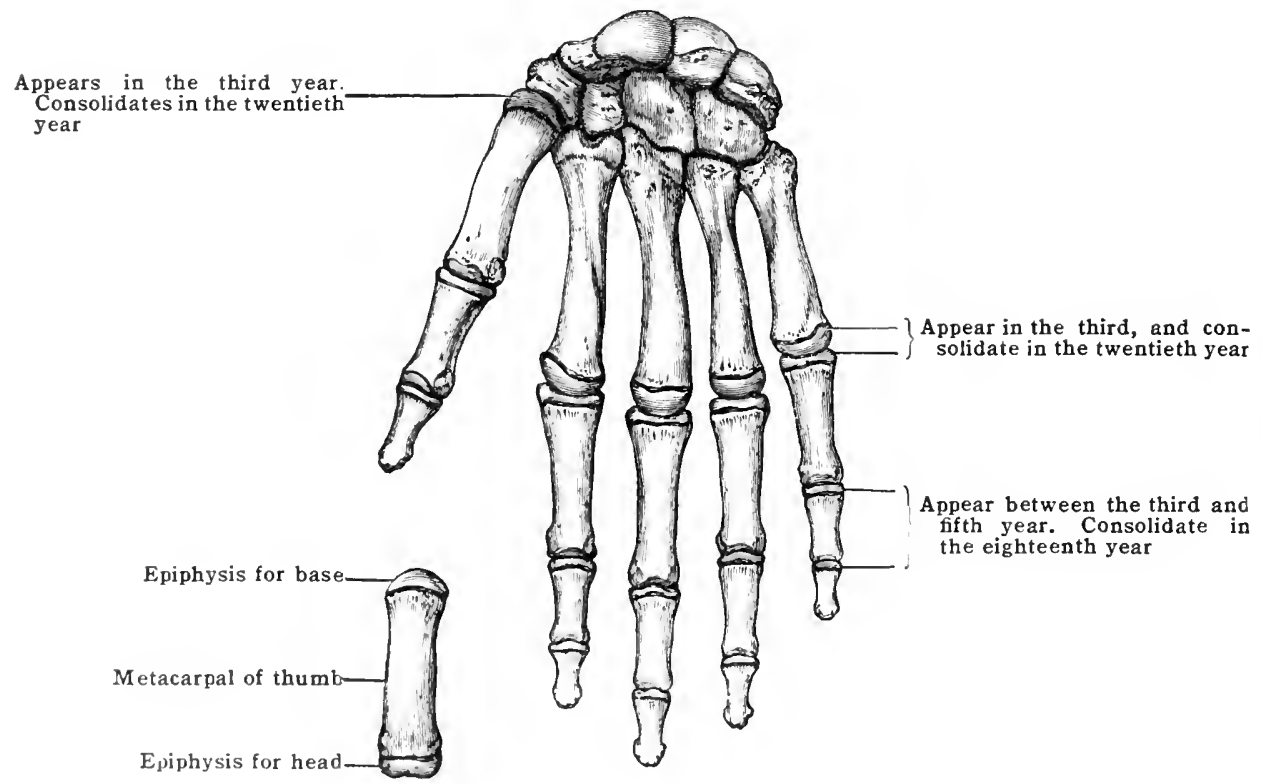

in the first metacinpal bone, and in all the phalanges, it is proximal. The epiphysial nuclei appear from the thirl to the fif th year and are united to their respective shafts about the twentieth year. In many cases the first metacarpal has two epiphyses, one for the base in the third year and an adrlitional one for the liead in the seventh year, but the latter is never so large as in the other meturarpal bones. The thirr metacarpal occasionally has an additional nucleus for the prominent styloil process which may remain distinct and form a styloid bone, and traces of a proximal cpiphysis have been observed in the second metacarpal bone. In many of the Cetarea (whalds, dolphins, and porpoises) and in the scal, epiplyyses ale found at both ends of the metararpal lomes ambl phalanges (Flower).

The ossification of a terminal phalanx is peculiar. Jike the other plabanges, it has a primary nucleus and a secondary nuclens for an apiphysis. But whereas in other phalanges the primary entre apuears in the mirldle of the shaft, in the case of the rlistal phalanges the earthy matter is depositerl in the free axtranity.

\section{SESAMOHI, THONES}

The sesanoin lones anc small and rommled and orour imbeded in certain tendons where they exert a consinlerable anount of pressiure on subjacont bony structures. In the hand five sesamoill brones are of almost constant occurrenco, namely, two over the metacarpo-phalangeal joint of the thumb in the tendons of the flexor pollicis lorevis, one over the interphalangeal joint of the thmmb, and one over the metararpo-phakangeal joints of the second and fifth fingers. 
Occasionally sesamoids occur over the metacarpo-phalangeal joint of the third and fourth cligits, and an additional one may occul over that of the fifth. radius.

Very rarely a sesamoid is developed in the tendon of the biceps over the tuberosity of the

\section{B. THE BONES OF THE LOWER EXTREMITY}

The bones of the lower extremity may be arranged in four groups corresponding to the division of the limb into the hip, thigh, leg, and foot. In the hip is the coxal or hip-bone, which constitutes the pelvic girdle [cingulum extremitatis inferioris], and contributes to the formation of the pelvis; in the thigh is the femur; in the leg, the tibia and fibula, and in the foot the tarsus, metatarsus, and phalanges. Associated with the lower end of the femur is a large sesamoid bone, the patclla or knee-cap.

\section{THE COXAL BONE}

The coxal (innominate) bone or hip-bone [os coxæ] (figs. 205, 206) is a large, irregularly shaped bone articulated behind with the sacrum, and in front with its fellow of the opposite side, the two bones forming the anterior and side walls of the pelvis. The coxal bone consists of three parts, named ilium, ischium, and pubis, which, though separate in early life, are firmly united in the adult. The three parts meet together and form the acetabulum (or cotyloid fossa), a large, cup-like socket situated near the middle of the lateral surface of the bone for articulation with the head of the femur.

The ilium [os ilium] is the upper expanded portion of the bone, and by its inferior extremity forms the upper two-fifths of the acetabulum. It presents for examination three borders and two surfaces.

Borders.- When viewed from above, the thick crest [crista iliaca] or superior border is curved somewhat like the letter $f$, being concave medially in front and concave laterally behind. Its anterior extremity forms the anterior superior iliac spine, which gives attachment to the inguinal (Poupart's) ligament and the sartorius; the posterior extremity forms the posterior superior iliac spine and affords attachment to the sacro-tuberous (great sacro-sciatic) ligament, the posterior sacro-iliac ligament, and the multifidus. The crest is narrow in the middle, thick at its extremities, and may be divided into an inner lip, an outer lip, and an intermediate line. About two and a half inches from the anterior superior spine is a prominent tubercle on its external lip.

The external lip of the crest gives attachment in front to the tensor fascio late; along its whole length, to the fascia lata; along its anterior half to the external oblique; and behind this, for about an inch, to the latissimus dorsi. The anterior two-thirds of the intermediate line gives origin to the internal oblique. The internal lip gives origin, by its anterior two-thirds, to the transversus; behind this is a small area for the quadratus lumborum, and the remainder is occupied by the sacro-spinalis (erector spina). The internal lip, in the anterior two-thirds, also serves for the attachment of the iliac fascia.

The anterior border of the ilium extends from the anterior superior iliac spine to the margin of the acetabulum. Below the spine is a prominent notch from which fibres of the sartorius arise, and this is succeeded by the anterior inferior iliac spine, smaller and less prominent than the superior, to which the straight head of the rectus and the ilio-femoral ligament are attached. On the medial side of the anterior inferior spine is a broad, shallow groove for the ilio-psoas as it passes from the abdomen into the thigh, limited below by the ilio-pectineal eminence, which indicates the point of union of the ilium and pubis.

The posterior border of the ilium presents the posterior superior iliac spine, and below this, a shallow notch terminating in the posterior inferior iliac spine which corresponds to the posterior extremity of the auricular surface and gives attachment to a portion of the sacro-tuberous (great sacro-sciatic) ligament. Below the spine the posterior border of the ilium forms the upper limit of the greater sciatic notch.

Surfaces.- The external surface or dorsum is concave behind, convex in front, limited above by the thick superior border or crest, and traversed by three gluteal lines. 
The posterior gluteal line commences at the erest about two inches from the posterior superior iliac spine and curves downward to the upper margin of the greater sciatic notch. The space included between this ridge and the crest affords origin at its upper part to the gluteus maximus, and at its lower part, to a few fibres of the piriformis, while the intermediate portion is smooth and free from muscular attachment. The anterior gluteal line begins at the crest, one inch behind its anterior superior iliac spine, and curves across the dorsum to terminate near the lower end of the superior line, at the upper margin of the greater sciatic notch. The surface of bone between this line and the crest is for the origin of the gluteus medius. The inferior gluteal line commences at the notch immediately below the anterior

Fic. 205.-The Left Coxal or Hip-Bone. (Lateral view.)

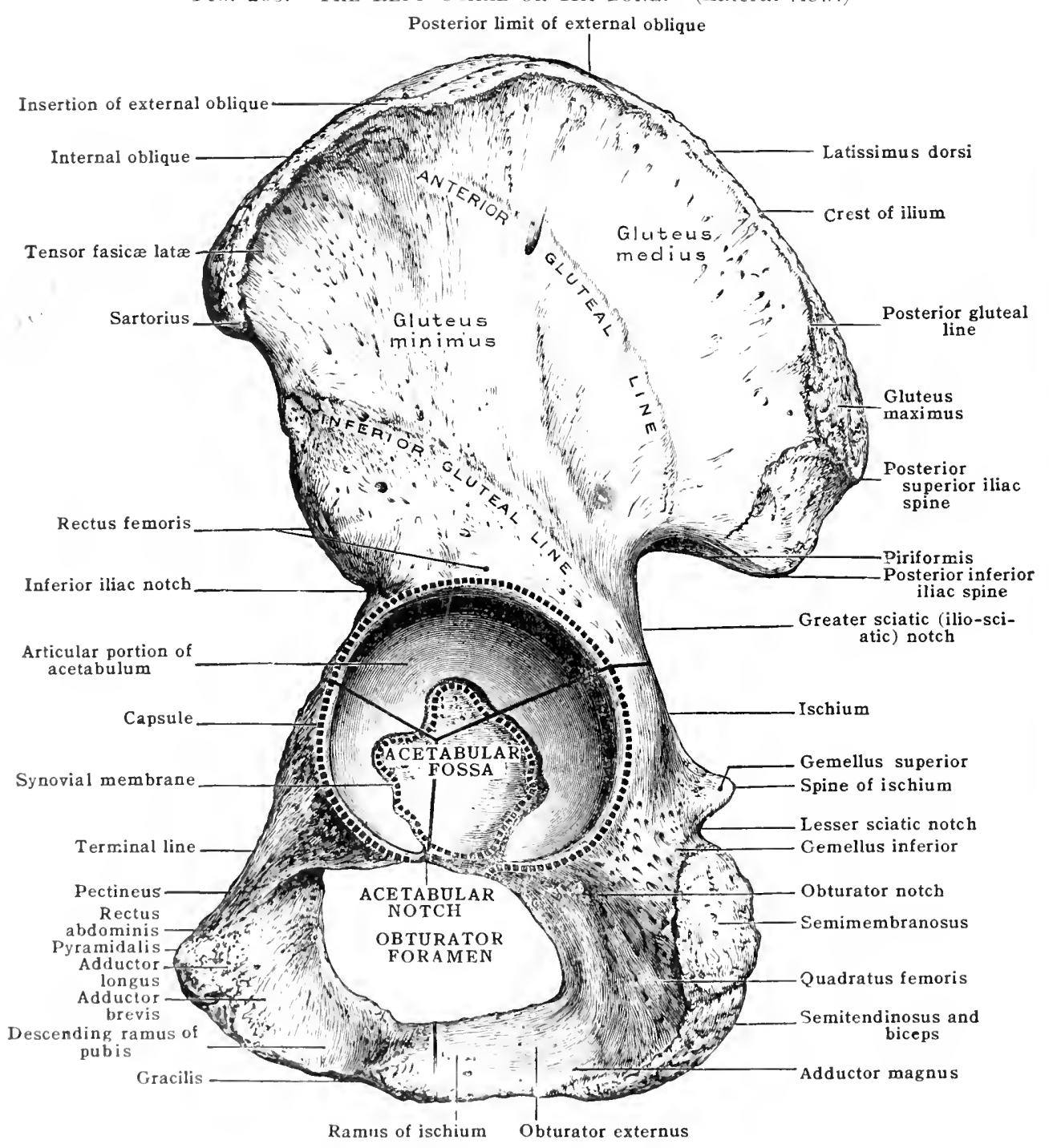

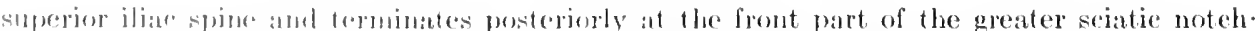
The spare between the anterior and inferior gluteal lines, with the exception of a small area inljawent to the anterion cond of the spine for the tensor fascia lata, gives origin to the gluteus memmes. Betwern the inferior gluteal line and the margin of the acetabuhum the surface affords attachuent to the rapsule of the hip-joint, and on a romgh area (sometimes a depression) towitrd its intrepior part, to tlare reflected tomdon of the rectus femoris.

'The internal surface presents in front a smooth concave portion termed the iliac fossa, which lodgers the iliacus musche. The fossa is limited below by linea arcuata, the iliac portion of the terminal (ilio-pectineal) line. This is a rounded boreler separating the fossa from a portion of the internal surface below the line, which gives attachenent to the obluralon introus and enters into the formation of the minor (true) pelvis. Behind the iliac fossa the bone is uneven and presents 
an auricular surface, covered with cartilage in the recent state, for articulation with the lateral aspect of the upper portion of the sacrum; above the auricular surface are some depressions for the posterior sacro-iliac ligaments and a rough area reaching as high as the crest, from which parts of the sacro-spinalis (erector spince) and multifidus take origin. The rough surface above the auricular facet is known as the tuberosity of the ilium.

The ischium [os ischii] consists of a body, a tuberosity, and a ramus. The body, which has somewhat the form of a triangular pyramid, enters superiorly into

Fig. 206.-The Left Coxal or Hip-bone. (Medial aspert.)

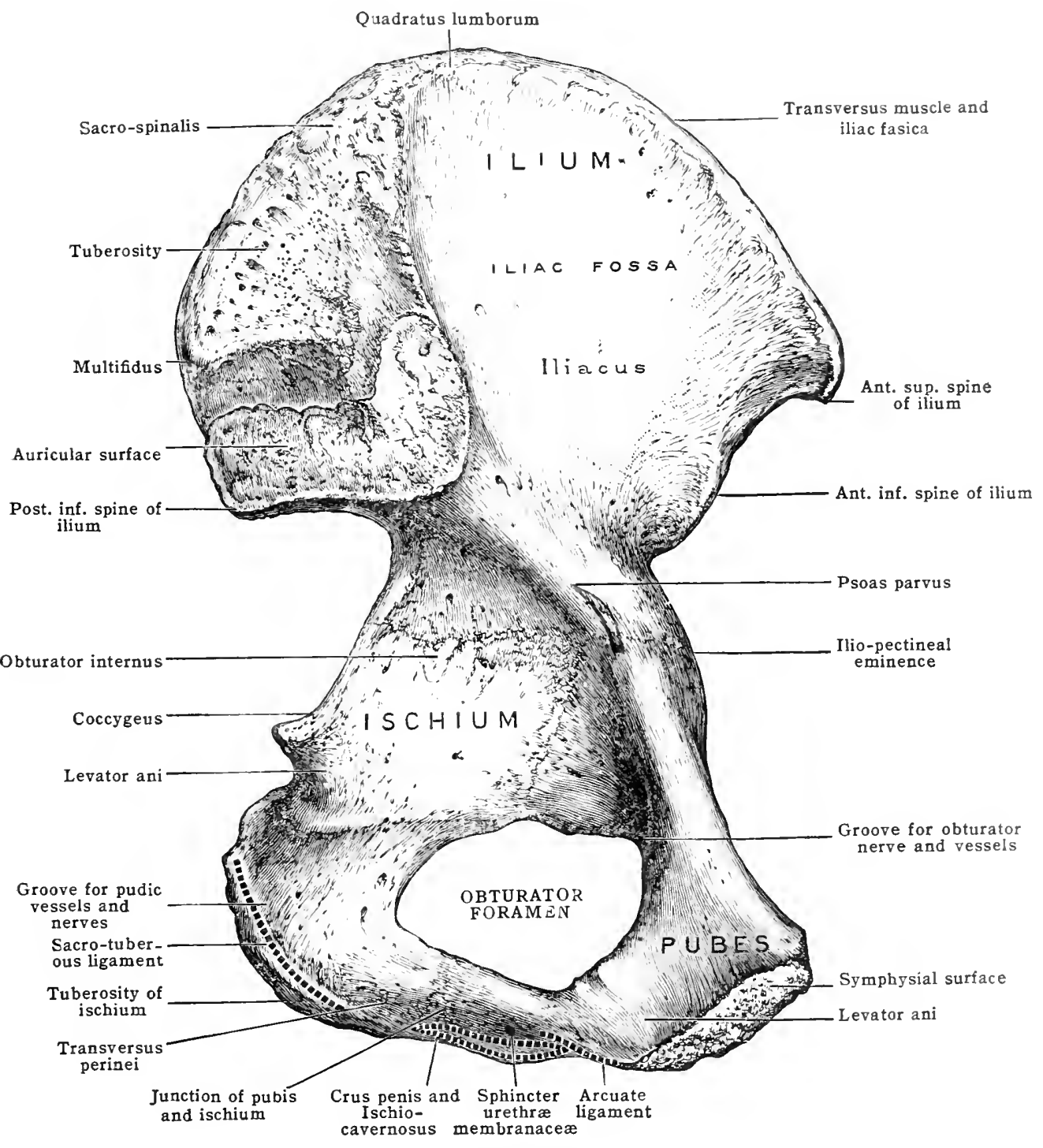

the formation of the acetabulum, to which it contributes a little more than twofifths, and forms the chief part of the non-articular portion or floor. The inner surface forms part of the minor (true) pelvis and gives origin to the obturator internus. It is continuous with the ilium a little below the terminal (ilio-pectineal) line, and with the pubis in front, the line of junction with the latter being frequently indicated in the adult bone by a rough line extending from the ilio-pectineal eminence to the margin of the obturator foramen. The outer surface in cludes the portion of the acetabulum formed by the ischium. The posterior surface is broad and bounded laterally by the margin of the acetabulum and behind 
by the posterior border. The capsule of the hip-joint is attached to the lateral part and the piriformis, the great sciatic and posterior cutaneous nerves, the inferior gluteal (sciatic) artery, and the nerve to the quadratus femoris lie on the surface as they leave the pelvis. Inferiorly this surface is limited by the obturator groove, which receives the posterior fleshy border of the obturator externus when the thigh is flexed. Of the three borders, the external, forming the prominent rim of the acetabulum, separates the posterior from the external surface and gives attachment to the glenoid lip. The inner border is sharp and forms the lateral boundary of the obturator foramen. The posterior border is continuous with the posterior border of the ilium, with which it joins to complete the margin of the great sciatic notch [incisura ischiadica major]. The notch is converted into a foramen by the sacro-spinous (small sacro-sciatic) ligament, and transmits the piriformis muscle, the gluteal vessels, the superior and inferior gluteal nerves, the sciatic and posterior cutaneous nerves, the internal pudic vessels and nerve, and the nerves to the obturator internus and quadratus femoris. Below the notch is the prominent ischial spine, which gives attachment internally to the coccygeus and levator ani, externally to the gemellus superior, and at the tip to the sacrospinous ligament. Below the spine is the small sciatic notch [incisura ischiadica minor], covered in the recent state with cartilage, and converted into a foramen by the sacro-tuberous (great sacro-sciatic) ligament. It transmits the tendon of the obturator internus, its nerve of supply, and the internal pudic vessels and nerve.

The rami form the flattened part of the ischium which runs first downward, then upward, forward and medially from the tuberosity toward the inferior ramus of the pubis, with which it is continuous. The rami together form an Lshaped structure with an upper vertical ramus [ramus superior] and a lower horizontal ramus [ramus inferior]. The outer surface of the rami gives origin to the adductor magnus and obturator externus; the inner surface, forming part of the anterior wall of the pelvis, receives the crus penis (or clitoridis) and the ischiocavernosus, and gives origin to a part of the obturator internus. Of the two borders, the upper is thin and sharp, and forms part of the boundary of the obturator foramen; the lower is rough and corresponds to the inferior ramus. It is somewhat ererted and gives attachment to the fascia of Colles, and the transversus perinei. To a ridge immediately above the impression for the crus penis (or clitoridis) and the ischio-cavernosus, the urogenital trigone (triangular ligament) is attached. The posterior and inferior aspect of the superior ramus is an expanded area forming the tuberosity [tuber ischiadicum].

The tuberosity is that portion of the ischium which supports the body in the sitting posture. It forms a rough, thick eminence continuous with the inferior horder of the inferior ramus, and is marked by an oblique line separating two impressions, an upper and lateral for the semimembranosus, and a lower and medial for the common tendon of the biceps and semilendinosus, while the lower part is markedly uneven and gives origin to the adductor magnus. The upper border gives origin to the inferior gemellus; the inner border, sharp and prominent, rereives the saro-tuberous (great sacro-sciatic) ligament, while the surface of the tuberosity immoliately in front is in relation with the internal pudic vessels and nerve. The outer borlor gives origin to the quadratus femoris.

The pubis [os pubjis] consists of a body and two rami-superior and inferior. Thro body is somewhat quadrilateral in shape and presents for examination two surfaces and three borders. The anterior surface looks downward, forward and slightly outward, and gives origin to the adductor longus, the adductor brevis, the ablurator externus, and the gracitis. The posterior surface is smooth, looks into thr pelvis, and affords origin to the lorator ami, the obturator interme, and the puboprotatic ligaments. The upper border or crest of the body is rough and presents latcially at prominent bony point, known as the tubercle [tulxereulum pubiomm] or spine, for the attachunent of the inguinal (Poupart's) ligament. The upper border extends from the pubic tuberele modialward to the upper end of the smmphysis, with which if forms the angle of the pubis. The upper border is a short lorizontal ridge, which gives attachnont to the reches abdominis and pyramidnlis. 'The medial border is oval in shapee, rough, and articular, forming with the bone of the opposite side the symphysis mbis [facies symphyseos]. The lateral border is sharp and forms part of the houndary of the obturator foramen.

"The inferior ramus, like the inferior ramus of the ischium, with which it is continuous, is thin and flattened. To its anterior surface are attached the 
adductor brevis, adductor magnus, and obturator extermus. The posterior surface is smooth and gives attachment to the crus penis or clitoridis, the sphincter urethre (urogenitalis), the obturator internus, and the urogenital trigone (triangular ligament). The lateral border forms part of the circumference of the obturator foramen, and the medial border forms part of the pubic arch and gives attachment to the gracilis.

The superior ramus extends from the body of the pubis to the ilium, forming by its lateral extremity the anterior one-fifth of the articular surface of the aretabulum. It is prismatic in shape and increases in size as it passes laterally. Above it presents a sharp ridge, the pecten or pubic portion of the terminal (ilio-pectineal) line continuous with the iliac portion at the ilio-pectineal eminence, and affording

Fig. 207.-An Immature Coxal (Inxominate) Bone, showng a Cutrloid Bone.

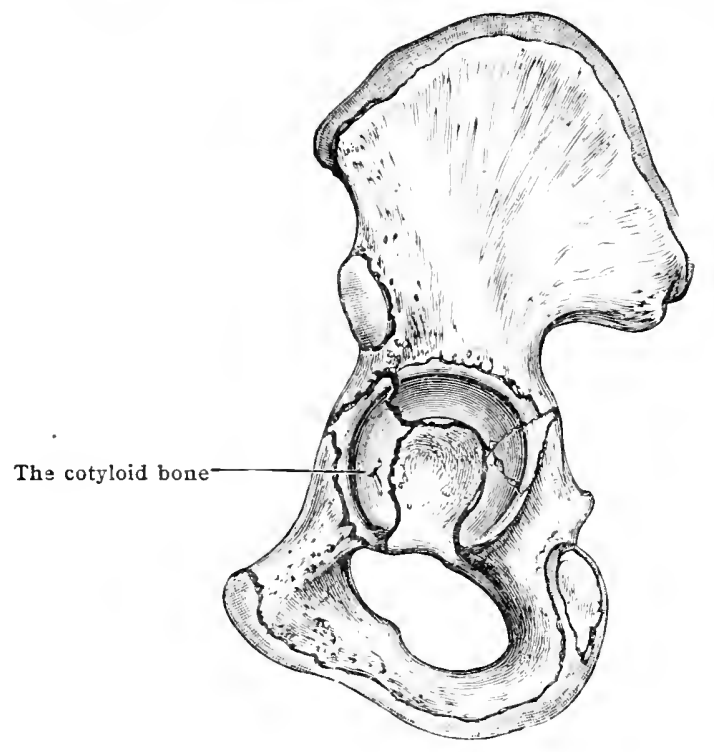

attachment to the conjoined tendon [falx aponeurotica inguinalis], the lacunar (Gimbernat's) ligament, the reflected inguinal ligament (fascia triangularis), and the pubic portion of the fascia lata; the iliac portion of the terminal (iliopectineal) line gives attachment to the psoas minor, the iliac fascia, and the pelvic fascia. Immediately in front of the pubic portion of the line is the pectineal surface; it gives origin at its posterior part to the pectineus, and is limited below by the obturator crest, which extends from the pubic tubercle to the acetabular notch. The inferior surface of the ascending ramus forms the upper boundary of the obturator foramen and presents a deep groove [sulcus obturatorius] for the passage of the obturator vessels and nerve. The posterior surface is smooth, forms part of the anterior wall of the pelric cavity, and gives attachment to a few fibres of the obturator internus.

According to the BNA, the body [corpus ossis pubis] is the portion corresponding to the acetabulum. The remainder of the bone is described as consisting of the ramus superior and the ramus inferior, which meet at the symphysis. Thus the divisions according to the BNA are different from those in the description above given.

The acetabulum is a circular depression in which the head of the femur is lodged and consists of an articular and a non-articular portion. The articular portion is circumferential and semilunar in shape [facies lunata], with the deficiency in the lower segment. One-fifth of the acetabulum is formed by the pulis. two-fifth by the ischium, and the remaining two-fifths are formed by the ilium. In rare instances the pubis may be excluded by a fourth element, the cotyloid bone. The non-articular portion [fossa acetabuli] is formed mainly by the ischium, and is continuous below with the margin of the obturator foramen. The articular portion presents a lateral rim to which the glenoich lip is attached, and a medial margin to which the synovial membrane which excludes 
the ligamentum teres from the synovial cavity is connected. The opposite extremities of the articular lunate surface which limit the acetabular notch are united by the transverse ligament, and through the acetabular foramen thus formed a nerve and vessels enter the joint.

The obturator (thyreoid) foramen is situated between the ischium and pubis. Its margins are thin, and serve for the attachment of the obturator membrane. At the upper and posterior angle it is deeply grooved for the passage of the obturator vessels and nerve.

Fig. 20S.-The Pelvis of a Feetus at Birth, to show the Three Portoxs of the COYAL BONEs.

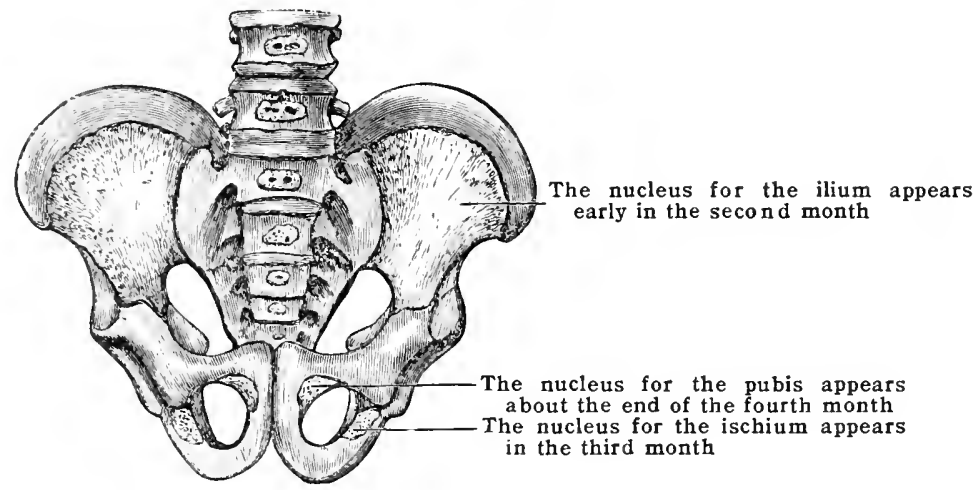

Blood-supply. - The chief vascular foramina of the coxal bone are found where the bone is thickest. On the inner surface, the ilium receives twigs from the jlio-lumbar, deep circumflex iliac, and obturator arteries, by foramina near the crest, in the iliac fossa, and below the terminal line near the greater sciatic notch. On the outer surface the chief foramina are found below the inferior gluteal line and the nutrient vessels are derived from the gluteal arteries. The ischium receives nutrient vessels from the obturator, internal and external circumflex arteries, and the largest foramina are situated between the acetabulum and the ischial tuberosity. 'The pubis is supplied by twigs from the obturator, internal and external circumflex arteries, and from the pubic branches of the common femoral artery.

Fig. 209.-Coxal or Hip-bone, showing Secondary Centres.

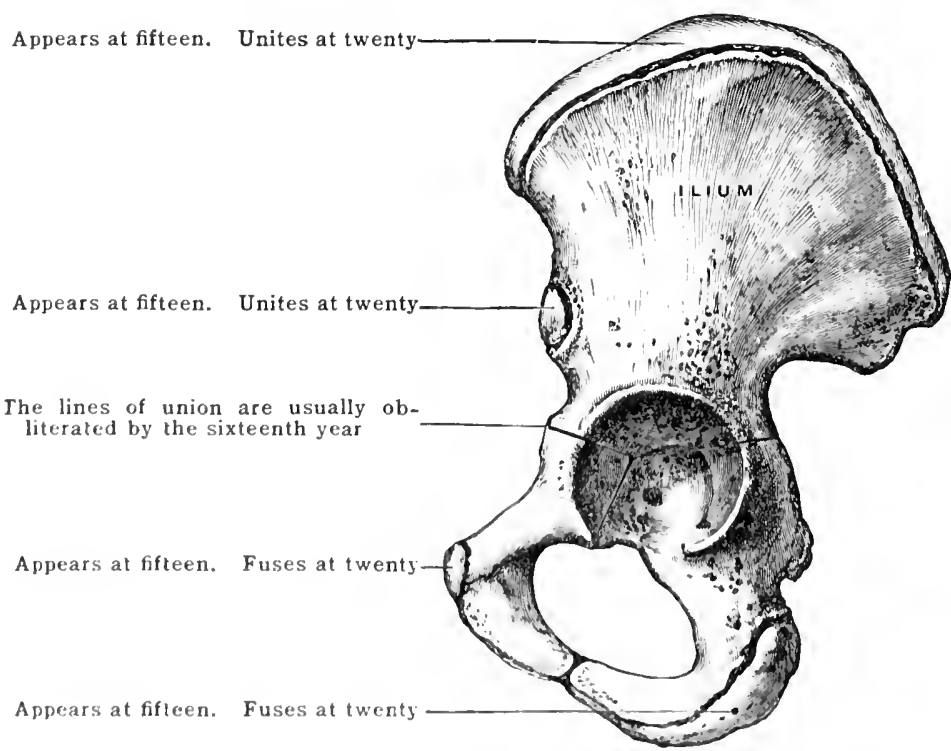

Ossification. - The cartilaginous representative of the hip-bone eonsists of thee distinct portions, an ilac, an ischiatic, and a pubic purtion; the ihiac and ischiatic portions first unite and latcr the puldic portion, so that eventually there is fomd a single cartiliginous mass. Early in the second month a contre of assification appears alove the acetabulum for the ilium. $\Lambda$ little later : secend muckous appears betow the cavity for the ischimm, and this is followed in the fourth nonth by aleposit in the pubic portion of the cartilage. $\Lambda$ t birth, the three nuelei 
are of considerable size, but are surrounded by relatively wile tracts of cartilage; ossification has, however, extended into the margin of the acetabulum. In the eighth year the rami of the pubis and ischium become united by bone, and in the twelf th year the triradiate cartilage which separates the three segments of the bone in the acetabulum begins to ossif y from several centres. Of these, one is more constant than the others and is known as the acetabular nucleus. The triangular piece of bone to which it gives rise is regarded as the representative of the colyloid or acetabular bone, constantly present in a few mammals. It is situated at the medial part of the acetabulum and is of such a size as to exclude entirely the pubis from the cavitr. With this bone, however, it eventually fuses, and afterward becomes joined with the ilium and

Fig. 210.-Coxal or Hip-bone (Inner Surface) at the Eighth Ýear.

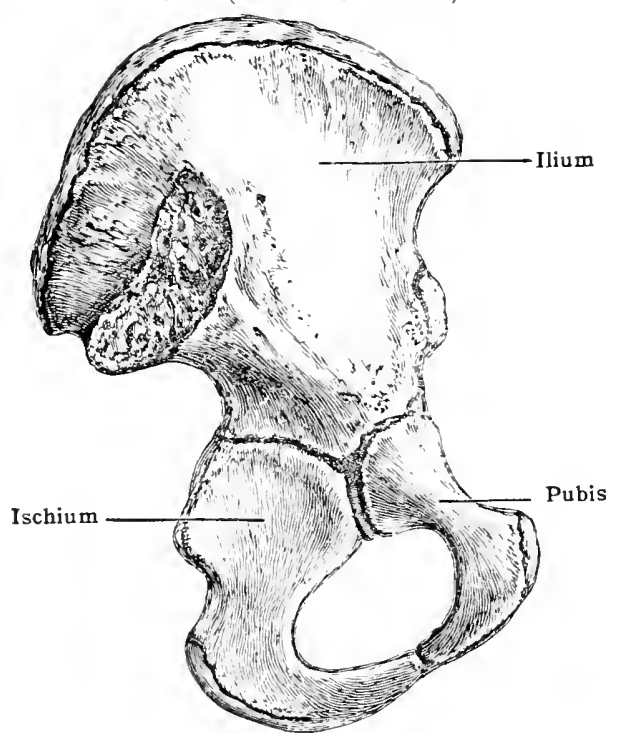

ischium, so that by the eighteenth or twentieth year the several parts of the acetabulum have become united. In the fifteenth year other centres appear in the cartilage of the crest of the ilium, the anterior inferior iliac spine, the tuberosity of the ischium, and the pubic pecten. The epiphyses fuse with the main bone about the twentieth year. The fibrous tissue connected with the tubercle of the pubis represents the epipubic bones of marsupials.

\section{THE PELVIS}

The pelvis (figs. 211, 212, 213, 214) is composed of four bones: the two coxal or hip-bones, the sacrum, and the coceyx. The hip-bones form the lateral and anterior boundaries, meeting each other in front to form the pubic symphysis [symphysis ossium pubis]; posteriorly they are separated by the sacrum. 'The interior of the pelvis is divided into the major and minor pelvic cavity.

The major (or false) pelvis is that part of the cavity which lies above the terminal (iliopectineal) lines and between the iliac fossæ. "This part belongs really to the abdomen, and is in relation with the hypogastric and iliac regions.

The minor (or true) pelvis is situated below the terminal (ilio-pectineal) lines. The upper circumference, known as the superior aperture (inlet or brim) of the pelvis, is bounded anteriorly by the tubercle and pecten of the pubis on each side, posteriorly by the anterior margin of the base of the sacrum, and laterally by the terminal lines. The inlet in normal pelves is heart-shaped, being obtusely pointed in front; posteriorly it is encroached upon by the promontory of the sacrum. It has three principal diameters; of these, the antero-posterior, called the conjugate diameter [conjugata], is measured from the sacro-vertebral angle to the simphyis. The transverse diameter represents the greatest width of the pelvic eavity. The oblique diameter is measured from the sacro-iliac symchondrosis of one side to the ilio-pectineal eminence of the other.

The cavity of the minor (true) pelvis is bounded in front by the pubes, behind by the sacrum and coccyx, and laterally by a smooth wall of bone formed in part by the ilium and in part by the ischium. The eavity is shallow in front, where it is formed by the pubes, and is deepest posteriorly. 
The inferior aperture, or outlet, of the minor pelvis is very irregular, and encroached upon by three bony processes: the posterior process is the coccyx, and the two lateral processes are the ischial tuberosities. They separate three notches. The anterior notch is the pubic arch, and is bounded on each side by the conjoined rami of the pubes and ischium. Each of the two remaining gaps, bounded by the

Fig. 211.-The Male Pelvis.

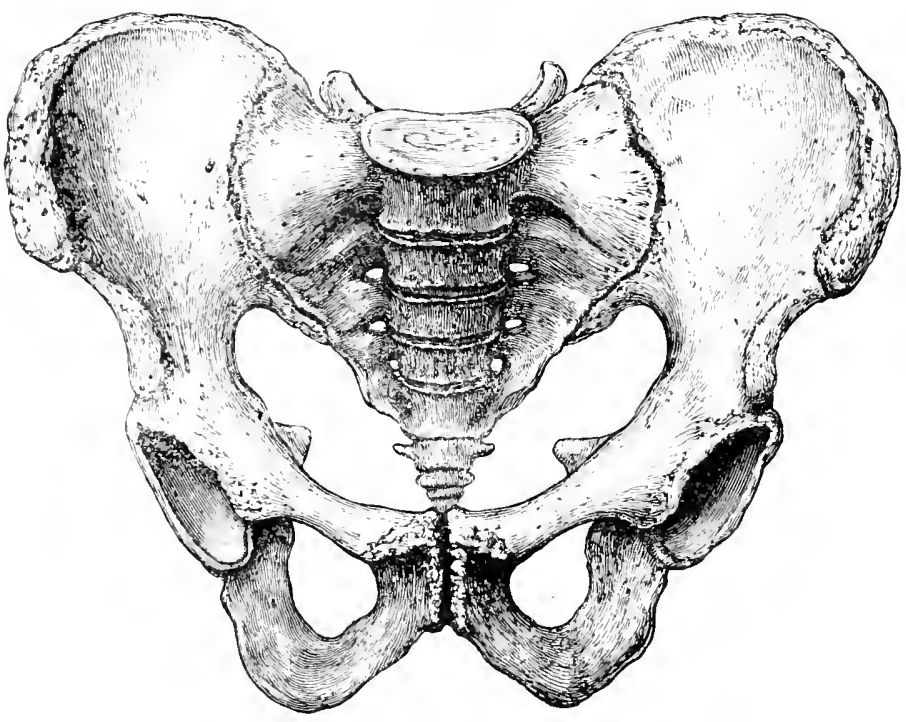

ischium anteriorly, the sacrum and coccyx posteriorly, and the ilium above, corresponds to the greater and lesser sciatic notches. These are converted into foramina by the sacro-tuberous (great sacro-sciatic) and sacro-spinous (small sacro-sciatic) ligaments.

The position of the pelvis. - In the erect position of the skeleton the plane of the pelvic inlet forms an angle with the horizontal plane, which varies in individuals from $50^{\circ}$ to $60^{\circ}$.

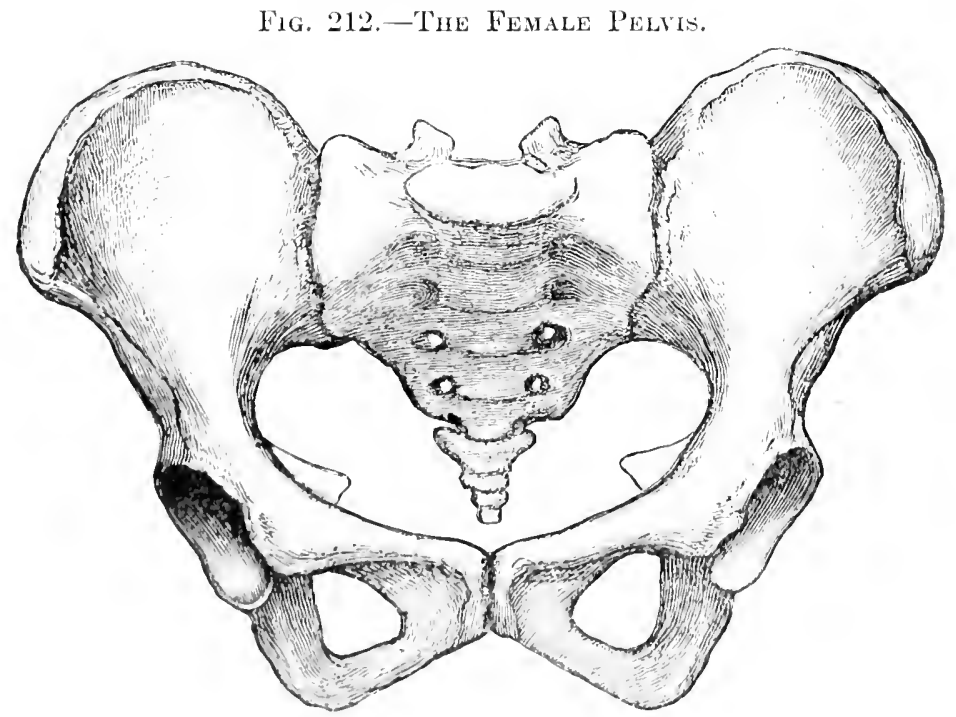

The base of the sarrmo in an average pelvis lies nearly ten centinetres (four inclres) above the upper margin of the symphysis puthis.

The axis of the pelvis. - This is an inaginary curved line drawn through the minor pelvis at right angles fo the planes of the inlet, cavity, and outlet through their central points.

As tho prosterior wall, formed by sacrum and coceyx, is nearly live inches long and concave, and the anterior wall at the sympliysis mubs one one and a half to two inches long, it follows that the axis must he curverl. 
The average measurements of the diameters of the minor pelvis in the three planes are given below:-

\section{Conjugate or} ANTERO-POSTERIOR.

Inlet............

Cavity..............

Outlet..........
$4 \frac{1}{4}$ inches $(10.6 \mathrm{~cm}$.) $4 \frac{3}{4} "$ (11.8 cm.) $3 \frac{4}{4} \quad "(9.0 \mathrm{~cm}$.

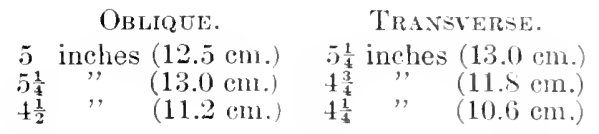

Fig. 214.-Fenale Pelvis. (Lateral view.)

Fig. 213.-Male Peltis. (Lateral view.)
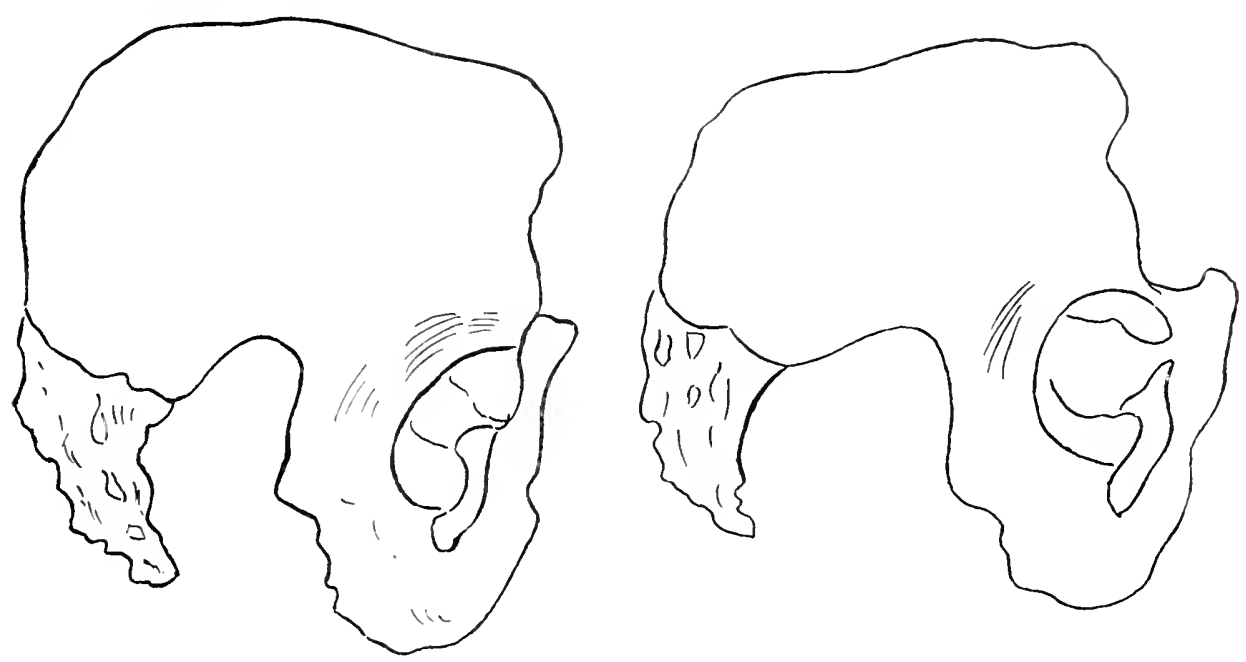

There is, however, a difference between the sexes, the diameters of the male pelvis in general averaging slightly less, and those of the female slightly greater than the figures above given.

Differences according to sex.-There is a marked difference in the size and form of the male and female pelvis, the pecularities of the latter being necessary to qualify it for its functions in parturition. The various points of divergence may be tabulated as follows:-

\section{Male.}

Bones heavier and rougher.

Ilia less vertical.

Iliac fossæ deeper.

Major pelvis relatively wider.

Minor pelvis deeper.

Superior aperture more heart-shaped.

Symphysis deeper.

Tuberosities of ischia inflexed.

Pubic angle narrow and pointed.

Margins of ischio-pubic rami more everted.

Obturator foramen oval.

Sacrum narrower and more curved.

Capacity of minor pelvis less.

\section{Female.}

Bones more slender.

Ilia more vertical.

Iliac fosse shallower.

Major pelvis relatively narrower.

Minor pelvis shallower.

" " wider.

Superior aperture more oval.

Symphysis shallower.

Tuberosities of ischia everted.

Pubic arch wider and more rounded.

Margins of ischio-pubic rami less everted.

Obturator foramen triangular.

Sacrum wider and less curved.

Capacity of minor pelvis greater.

The sexual characters of the pelvis as shown by A. Thomson are manifest as early as the fourth month of foetal life.

Quite recently attention has been drawn by D. Derry to some special points in which the os coxæ differ in the two sexes, and two figures are shown here in which one of these points is clearly brought out. It will be seen that the great seiatic notch is larger in the fenale, and that the sacrum projects less forward at $\mathrm{i}^{\text {t}} \mathrm{s}$ apex. Moreover the facies auricularis is smallev whilst below and in front of this surface, the sulcus preauricularis, a depression for the attachment of the ligamenta sacroiliaca anteriora, is usually more pronounced.

In comparison with the pelves of lower animals, which, speaking generally, are elongated and narrow, the human pelvis is characterised by its breadth, shallowness, and great capacity. Differences are also to be recognised in the form of the pelvis in the various races of mankind, the most important being the relation of the antero-posterior to the transverse liameter, measurcd at the inlet. This is expressed by the pelvic index $=100 \times$ conjugate diameter.

In the average European male the index is about 80 ; in the lower races of mankind, 90 to 95. Pelves with an index below 90 are platypellic, from 90 to 95 are mesatipellic, and above 95 dolichopellic. (Sir William Turner.) 


\section{THE FEMUR}

The femur or thigh bone (figs. 215, 216) is the largest and longest bone in the skeleton, and transmits the entire weight of the trunk from the hip to the tibia. In the erect posture it inclines from above downward and medially, approaching at the lower extremity its fellow of the opposite side, but separated from it above by the width of the true pelvis. It presents for examination a superior extremity, including the head, neck, and two trochanters, an inferior extremity, expanded laterally into two condyles, and a shaft.

The upper extremity is surmounted by a smooth, globular portion called the head, forming more than half a sphere, directed upward and medially for articulation with the acetabulum. With the exception of a small rough depression, the fovea, for the ligamentum teres, a little below and behind the centre of the head, its surface is covered with cartilage in the recent state. The head is connected with the shaft by the neck, a stout rectangular column of bone which forms with the shaft, in the adult, an angle of about $125^{\circ}$. Its anterior surface is in the same plane with the front aspect of the shaft, but is marked off from it by a ridge to which the capsule of the hip-joint is attached. The ridge, which eommences at the great trochanter in a small prominence, or tubercle, extends obliquely downward, and winding to the back of the femur, passes by the lesser trochanter and becomes continuous with the medial lip of the linea aspera, on the posterior aspect of the shaft. This ridge forms the intertrochanteric line or spiral line of the femur. The intertrochanteric line receives the bands of the ilio-femoral thickening of the capsule of the hip-joint. The posterior surface of the neek is smooth and concave and its medial two-thirds is enelosed in the capsule of the hip-joint. The superior border of the neek, perforated by large nutrient foramina, is short and thick, and runs downward to the great trochanter. The inferior border, longer and narrower than the superior, curves downward to terminate at the lesser trochanter.

The trochanters are the prominences which afford attachment to the rotator muscles of the thigh; they are two in number-great and lesser.

The great trochanter is a thick, quadrilateral process surmounting the junction of the neek with the shaft, and presents for examination two surfaces and four borders. The lateral surface is broad, rough, and continuous with the lateral surface of the shaft. It is marked by a diagonal ridge running from the posterosuperior to the antero-inferior angle, which receives the insertion of the gluteus medius. The ridge divides the surface into two triangular areas: an upper, covered by the gluteus medius, and occasionally separated from it by a bursa, and a lower, covered by a bursa to permit the free gliding of the tendon of the gluteus maximus. Of the medial surface the lower and anterior portion is joined with the rest of the bone; the upper and posterior portion is free, concave, and presents a deep depression, the trochanteric or digital fossa, which receives the tendon of the obturator externus. The fore part of the surface is marked by an impression for the insertion of the obturator internus and two gemelli.

Of the four borflers, the superior, thick and free, presents near the centre an oval mark for the insertion of the priformis; the anterior border, broad and irregular, receives the gluteus minimus; the posterior boreler, thick and rounded, is continuous with the intertrochanteric crest, the prominent ridge uniting the two trochanters behind. Above the middle of this line is an elevation, termed the tubercle of the quadratus, for the attachment of the upper part of the quadratus fommis. The inferior border corresponds with the line of junction of the base of the trochanter with the shaft; it is marked ly a prominent ridge for the origin of the upper part of the mostus latriolis:

The lesser trochanter is a conical cmincence projecting medially from the posterior anet medial asperet of the hone, where the neck is continuous with the shaft. Its summit is roumh and gives attachment to the tendon of the ilio-psoas. The fibres of the itincus extend beyond the trochanter and are inserted into the surface of thes shate immoriately ledow.

The body or shaft of the fomm is almost eylindrical, but is slightly flattened in front and strengthened behind by a projecting longitudinal ridge, the linea aspera, for the origin and insertion of museles. The linea aspera extends along the middle third of the shaft and presents a medial lip and a lateral lip separated by a narrow interval. When followed into the upper third of the shaft, the three parts diverge. The lateral lip becomes contimuous with the gluteal tuberosity and ends at the base of the great trochanter. 'The ridge affords insertion to the ghutens maximus, 
Fig. 215.-The Left Femur, (Anterior view.)

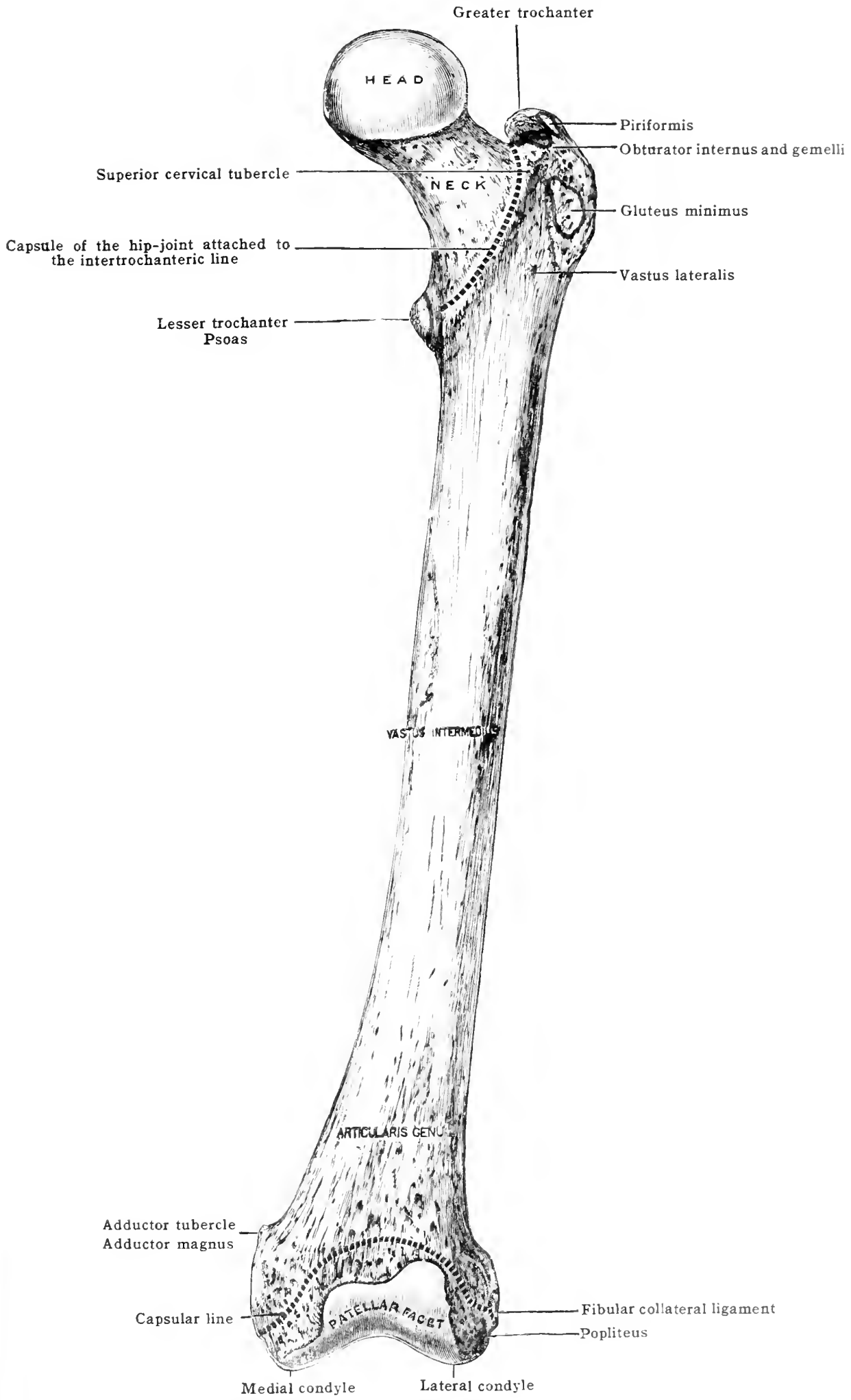


Fig. 216.-The Left Femur. (Posterior view.)

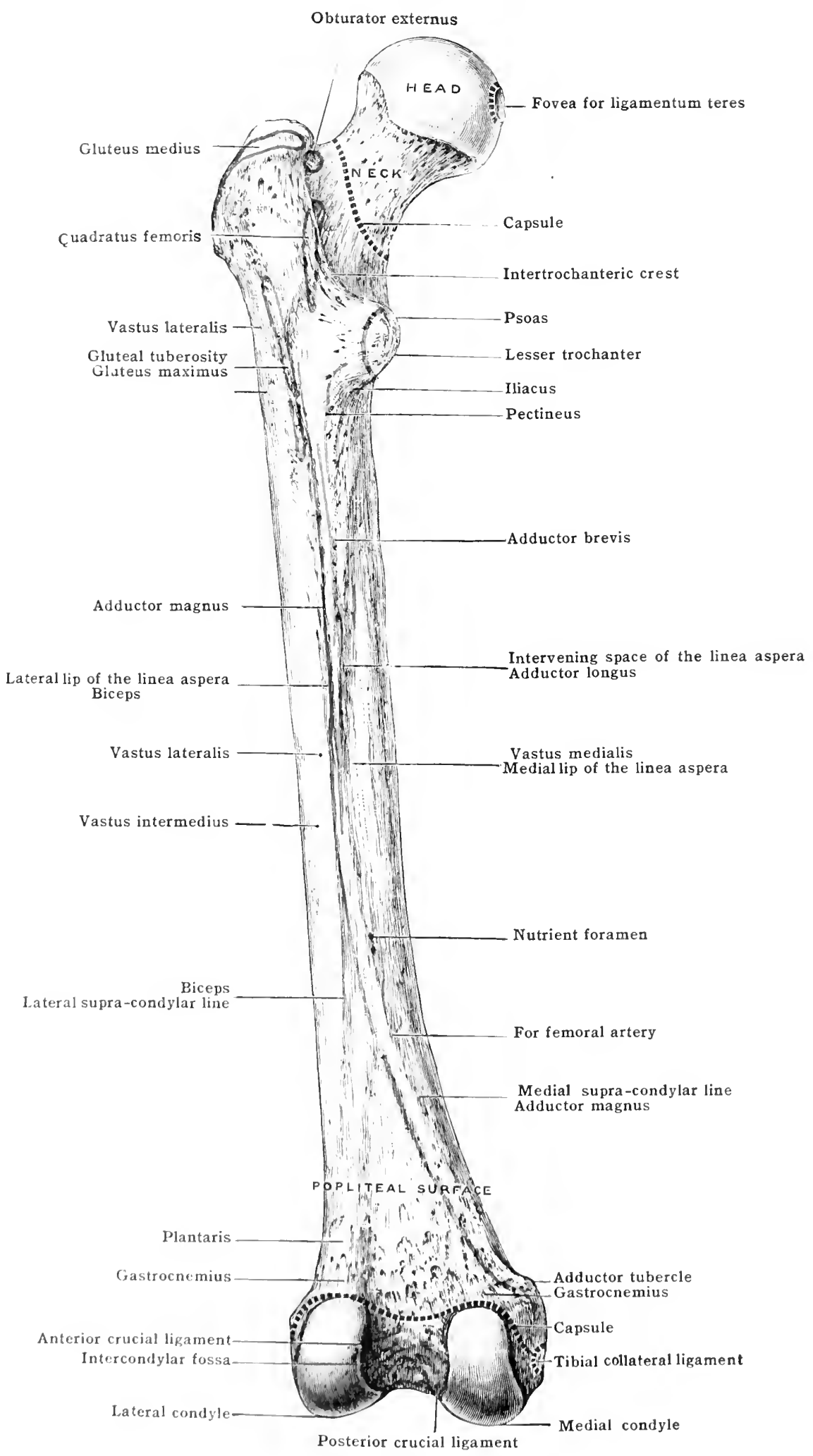


and when very prominent is termed the third trochanter. The medial lip curves medialward below the lesser trochanter, where it becomes continuous with the intertrochanteric line; the intervening portion bifureates and is continued upward as two lines, one of which ends at the small trochanter, and receives some fibres of the iliacus, whilst the other is the linea pectinea and marks the insertion of the pectineus musele.

Toward the lower third of the shaft the medial and lateral lips of the linea aspera again diverge, and are prolonged to the condyles by the medial and lateral supra-condylar lines, enclosing between them a triangular surface of bone, the popliteal surface [planum popliteum] of the femur, which forms the upper part of the floor of the popliteal space. The lateral line is the more prominent and terminates below in the lateral epicondyle. The medial one is interrupted above, where the femoral vessels are in relation with the bone, better marked below, where it terminates in the adductor tubercle, a small sharp projection at the summit of the medial epicondyle, which affords attachment to the tendon of the adductor magnus.

Fig. 217.-A Diagram to show the Pressure and Texsion Curves of the Fentr. (After Wagstaffe.)

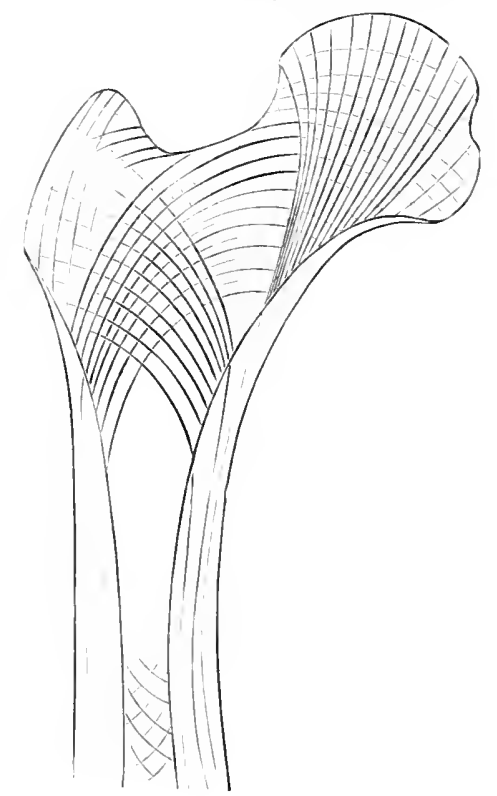

Near the centre of the linea aspera is the foramen for the medullary artery, directed upward toward the head of the bone.

From the medial lip of the linea aspera and the lower part of the intertrochanteric line arises the vastus medialis (internus), and from the lateral lip and the side of the gluteal ridge arises the vastus lateralis (externus). The adductor magnus is inserted into the mediai lip of the linea aspera, from the medial side of the gluteal tuberosity above, and the medial supracondylar line below. Between the adductor magnus and vastus medialis (internus) four muscles are attached: the pectineus and iliacus above, then the adductor brevis, and lowest of all, the adductor longus. Above, in the interval between the adductor magnus and the vastus lateralis (externus), the gluteus maximus is inserted; in the interval lower down is the short head of the biceps, taking origin from the lower two-thirds of the lateral lip of the linea aspera and the upper two-thirds of the lateral supra-condylar line. On the popliteal surface of the bone, just above the condyles, are two rough areas $1 \mathrm{mom}$ which fibres of the two heads of the gustrocnemius take origin. Above the area for the lateral head of the gastrocnemius is a slight roughnes for the plantaris.

For purposes of deseription it is convenient to regard the shaft of the femur as presenting anterior, medial, and lateral surfaces, although definite borders separating the surfaces from one another do not exist. All three surfaces are smooth and the anterior is not separated from the lateral by ridges of any kind. In the middle third of the shaft the medial and lateral surfaces approach one another behind, being separated by the linea aspera. 
The shaft is overlapped on its medial side by the vastus medialis (internus), and on its lateral side by the rastus lateralis (externus). The upper three-fourths of the anterior and lateral surfaces afford origin to the vastus intermedius (crureus), and the lower fourth of the anterior surface, to the articularis genu (sub-crureus). The medial surface is free from muscular attachment.

Fig. 21S.-Transterse Section of Shaft of Femer to show the Medullary Caytit.

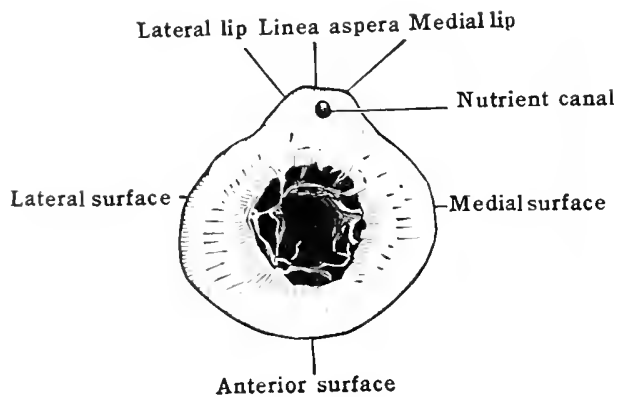

Anterior surface
Fig. 219.-Section of UpPer End of Feuidr to show the Calcar Femorale.

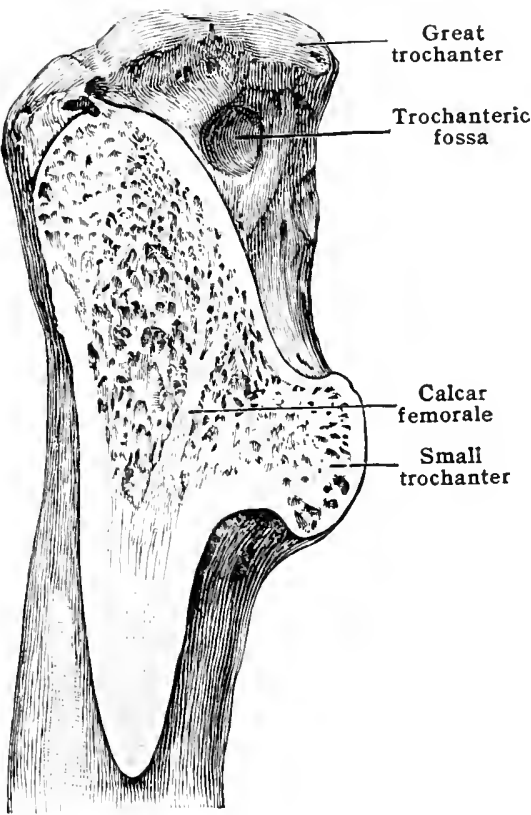

Fig. 220.-The Femur at Birth.
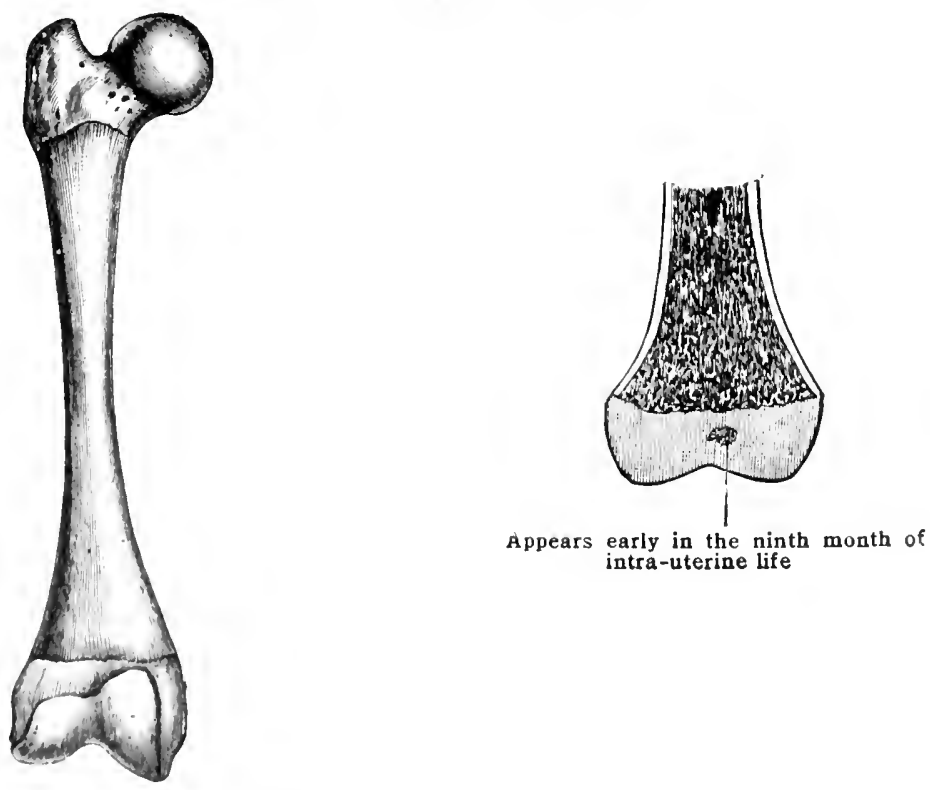

The lower extremity presents two eartilage-covered eminences or condyles, separated behind by the intercondyloid fossa. 'The lateral condyle is wider than its follow and more prominent anteriorly; the medial condyle is narrower, more prominent, and longer, to compensate for the obliquity of the shaft. When the femur is in the natural position, the inferior surfaces of the conclyles are on the 
same plane, and almost parallel, for articulation with the upper surfaces on the head of the tibia. The two condyles are continuous in front, forming a smooth trochlear surface [facies patellaris] for articulation with the patella. This surface presents a median vertical groove and two convexities, the lateral of which is wider, more prominent, and prolonged farther upward. The patellar surface is faintly marked off from the tibial articular surfaces by two irregular grooves, best seen while the lower end is still coated with cartilage. The lateral groove commences on the medial margin of the lateral condyle near the front of the intercondylar fossa, and extends obliquely forward to the lateral margin of the bone. The general direction of the medial groove is from front to back, turning medially in front and extending backward as a faint ridge which marks off from the

Fig. 221.-The Left Femur at the Twentieth Fear. (Posterior view )

The figure shows the relations of the epiphysial and capsular lines.

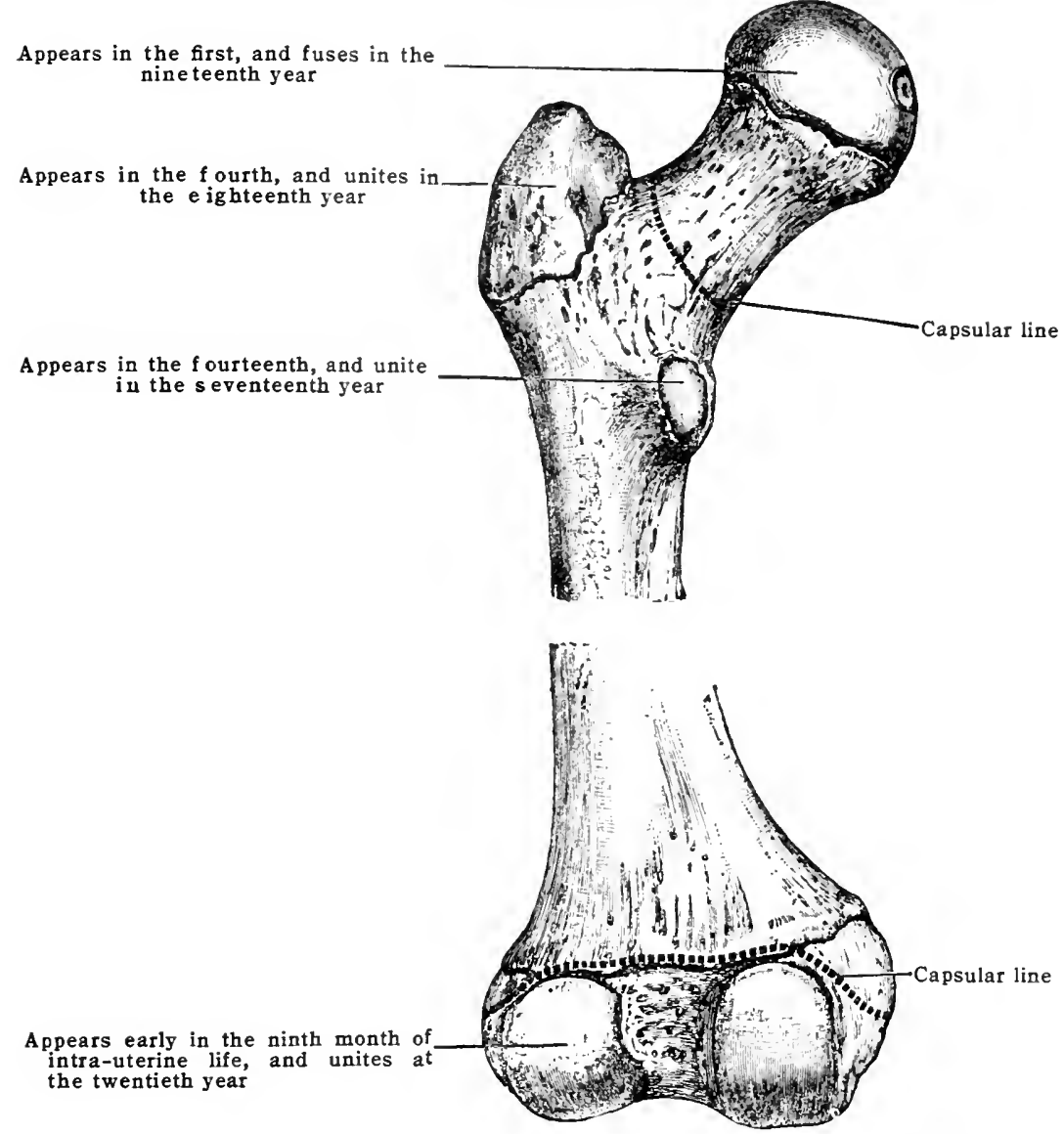

rest of the medial condyle a narrow semilunar facet for articulation with the medial perpendicular facet of the patella in extreme flexion. The grooves receive the semilunar menisci in the extended position of the joint. The tibial surfaces are almost parallel except in front, where the medial turns laterally to become continuous with the patellar surface.

The opposed surfaces of the two condyles form the boundaries of the intercondylar fossa and give attachment to the crucial ligaments which are lodged within it. The posterior crucial ligament is attached to the fore part of the lateral surface of the medial condyle and the anterior crucial ligament to the back part of the medial surface of the lateral condyle. The two remaining surfaces of the condyles are broad and convex, and each presents an epicondyle (tuberosity) for the attachment of lateral ligaments. The medial epicondyle, the larger of the two, is surmounted by the adductor tubercle, behind which is an impression for 
the medial head of the gastrocnemius on the upper aspect of the condyle; below and behind the lateral epicondyle is a deep groove which receives the tendon of the popliteus muscle when the knee is flexed, and its anterior end terminates in a pit from which the tendon takes origin. Above the lateral epicondyle is a rough impression for the lateral head of the gastrocnemius.

The interior of the shaft of the femur is hollowed out by a large medullary canal, and the extremities are composed of cancellated tissue invested by a thin compact layer. The arrangement of the cancelli in the upper end of the bone forms a good illustration of the effect produced by the mechanical conditions to which bones are subject. In the upper end of the bone the cancellous tissue is arranged in divergent curves. One system springs from the lower part of the neck and upper end of the shaft medially and spreads into the great trochanter "pressure lamellæ'). A second system springs from the lateral part of the shaft and arches upward into the neck and head ("tension lamella'), crossing the former almost at right angles. "A second set of pressure lamellie springs from the lower thick wall of the neck, and extends into the upper part of the head to end perpendicularly in the articular surface mainly along the lines of greatest pressure. A nearly vertical plate of compact tissue (calcar femorale) projects into the neck of the bone from the inferior cervical tubercle toward the great trochanter. This is placed in the line through which the weight of the body falls, and adds to the stability of the neck of the bone; it is said to be liable to absorption in old age. In the lower end of the bone the vertical and horizontal fibres are so disposed as to form a rectangular meshwork.

Blood-supply.- The head and neck of the femur receive branches from the inferior gluteal, obturator, and circumflex arteries, and the trochanters from the circumflex arteries. The nutrient vessel of the shaft is derived from either the second or third perforating artery, or there may be two nutrient vessels arising usually from the first and third perforating. The vessels of the inferior extremity arise from the articular branches of the popliteal and the anastomotic branch of the femoral (supremagenu).

Ossification.- The femur is ossified from one primary centre for the shaft and from four epiphysial centres. The shaft begins to ossify in the seventh week of intra-uterine life. Early in the ninth month a nucleus appears for the lower extremity. During the first year the nucleus for the head of the bone is visible, and in the fourth year that for the trochanter major. The centre for the lesser trochanter appears about the thirteenth or fourteenth year. The lesser trochanter joins the shaft at the seventeenth, the great trochanter at the eighteenth, the head about the nineteenth, and the lower extremity at the twentieth year.

The neck of the femur is an apophysis, or outgrowth from the shaft. The line of fusion of the condylar epiphysis with the shaft passes through the adductor tubercle.

The morphological relation of the patellar facet to the tibial portions of the condyles is worthy of notice. In a few mammals, such as the ox, this facet remains separated from the condyles by a furrow of rough bone.

The angle which the neck of the femur forms with the shaft at birth measures, on an average, $160^{\circ}$. In the adult it varies from $110^{\circ}$ to $140^{\circ}$; hence the angle decreases greatly during the period of growth. When once growth is completed, the angle, as a rule, remains fixed. (Humphry.)

\section{THE PATELLA}

The patella (fig. 222) or knee-pan, situated in front of the knce-joint, is a sesamoid hone, triangular in shape, developed in the tendon of the quadriceps femoris. Its anterior surface, marked by numerous longitudinal strix, is slightly convex, and

$$
\text { Fig. 222.-The Left Patella. }
$$
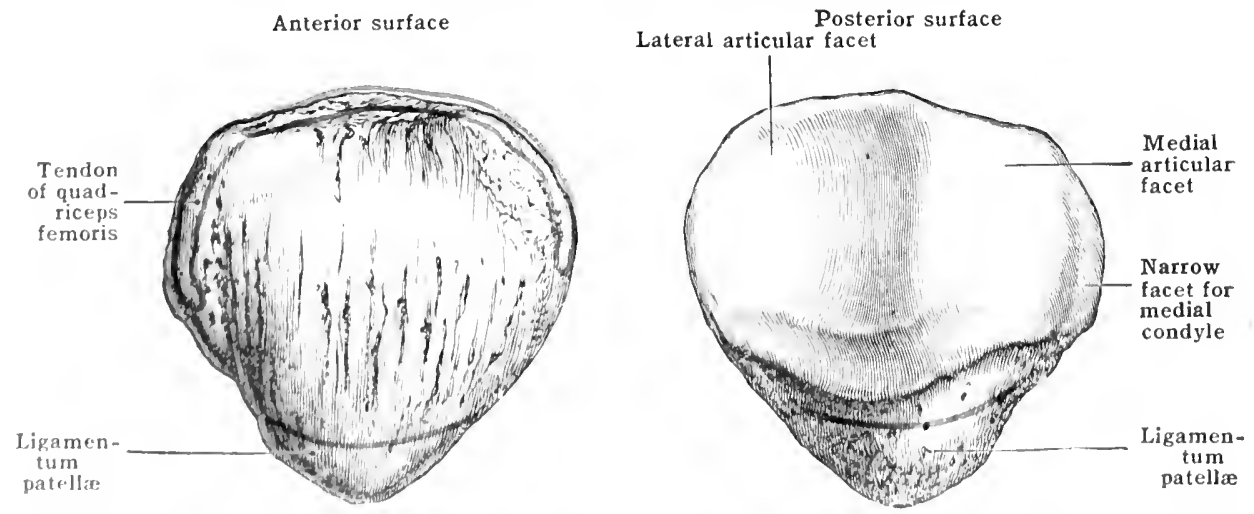

preforalol hy small oponings which transmit nutricut vessels to the interior of the fone. It is rovereal in the recont state hy a few filores prolonger from the common tenclon of insortion (smpra-patellat tendon) of the quadriceps femoris, into the ligamentum patollar (infrat-patcllar tondon), and is separated from the slin by one 
or more bursæ. The posterior surface is largely articular, covered with cartilage in the recent state, and divided by a slightly marked vertical ridge, corresponding to the groove on the trochlear surface of the femur, into a lateral larger portion for the lateral condyle, and a medial smaller portion for the medial condyle. Close to the medial edge a faint vertical ridge sometimes marks off a narrow articular facet, for the lateral margin of the medial condyle of the femur in extreme flexion of the leg. Below the articular surface is a rough, non-articular depression, giving attachment to the ligamentum patellæ, and separated by a mass of fat from the head of the tibia.

The base or superior border is broad, sloped from behind downward and forward, and affords attachment, except near the posterior margin, to the common

Fig. 223.-The Superior Border or Base of the Left Patelia.

Anterior surface

Area in relation with synovial membrane of knee-joint

tendon of the quadriceps. The borders, thimner than the base, converge to the apex below, and receive parts of the two vasti muscles. The apex forms a blunt point directed downward, and gives attachment to the ligamentum patellæ, by which the patella is attached to the tibia.

Structurally the patella consists of dense cancellous tissue covered by a thin compact layer, and it receives nutrient vessels from the articular branch of the suprema genu (anastomotic), the anterior tibial recurrent, and the inferior articular branches of the popliteal.

Ossification.-The cartilaginous deposit in the tendon of the quadriceps muscle takes place in the fourth month of intra-uterine life. Ossification begins from a single centre cluring the third year, and is completed about the age of puberty.

\section{THE TIBIA}

The tibia (figs. 224, 225) or shin-bone is situated at the front and medial side of the leg and nearly parallel with the fibula. Excepting the femur, it is the largest bone in the skeleton, and alone transmits the weight of the trunk to the foot. It articulates above with the femur, below with the tarsus, and laterally with the fibula. It is divisible into two extremities and a shaft.

The upper extremity (or head) consists of two lateral eminences, or condyles. Their superior articular surfaces receive the condyles of the femur, the articular parts being separated by a non-articular interval, to which ligaments are attached. The medial articular surface is oval in shape and concave for the medial condyle of the femur. The lateral articular surface is smaller, somewhat circular in shape. and presents an almost plane surface for the lateral condyle. The peripheral portion of each articular surface is overlaid by a fibro-cartilaginous meniscus of semilunar shape, connected with the margins of the condyles by bands of fibrous tissue termed coronary ligaments. Each semilunar meniseus is attached firmly to the rough interval separating the articular surfaces. This interval is broad and clepressed in front, the anterior intercondyloid fossa, where it affords attachment to the anterior extremities of the medial and lateral menisci and the anterior crucial ligament; elevated in the middle to form the intercondyloid eminence $\mathrm{Ol}^{\circ}$ spine of the tibia, a prominent eminence, presenting at its summit two compressed intercondyloid tubercles, on to which the condylar articular surfices are prolonged; the posterior aspect of the base of the eminence affords attachment to the posterior extremities of the lateral and medial semilunar menisei, and limits a deep noteh, inclined toward the medial condyle, known as the posterior intercondyloid fossa or popliteal notch. It separates the condyles on the posterior aspect of the head and gives attachment to the posterior crucial ligament, and part of the posterior ligament of the knee-joint. Anteriorly, the two condyles are confluent, and form a somewhat flattened surface of triangular outline, the apex of which forms the tuberosity of the tibia. The tuberosity is divisible into two parts. The upper 
part, rounded and smooth, receives the attachment of the ligamentum patellæ. The lower part is rough, and into its lateral edges prolongations of the ligamentum patellæ are inserted. A prominent bursa intervenes between the ligament and the anterior aspect of the upper extremity of the bone.

Fig. 224.-The Left Tibia and Fibula. (Anterior view.)

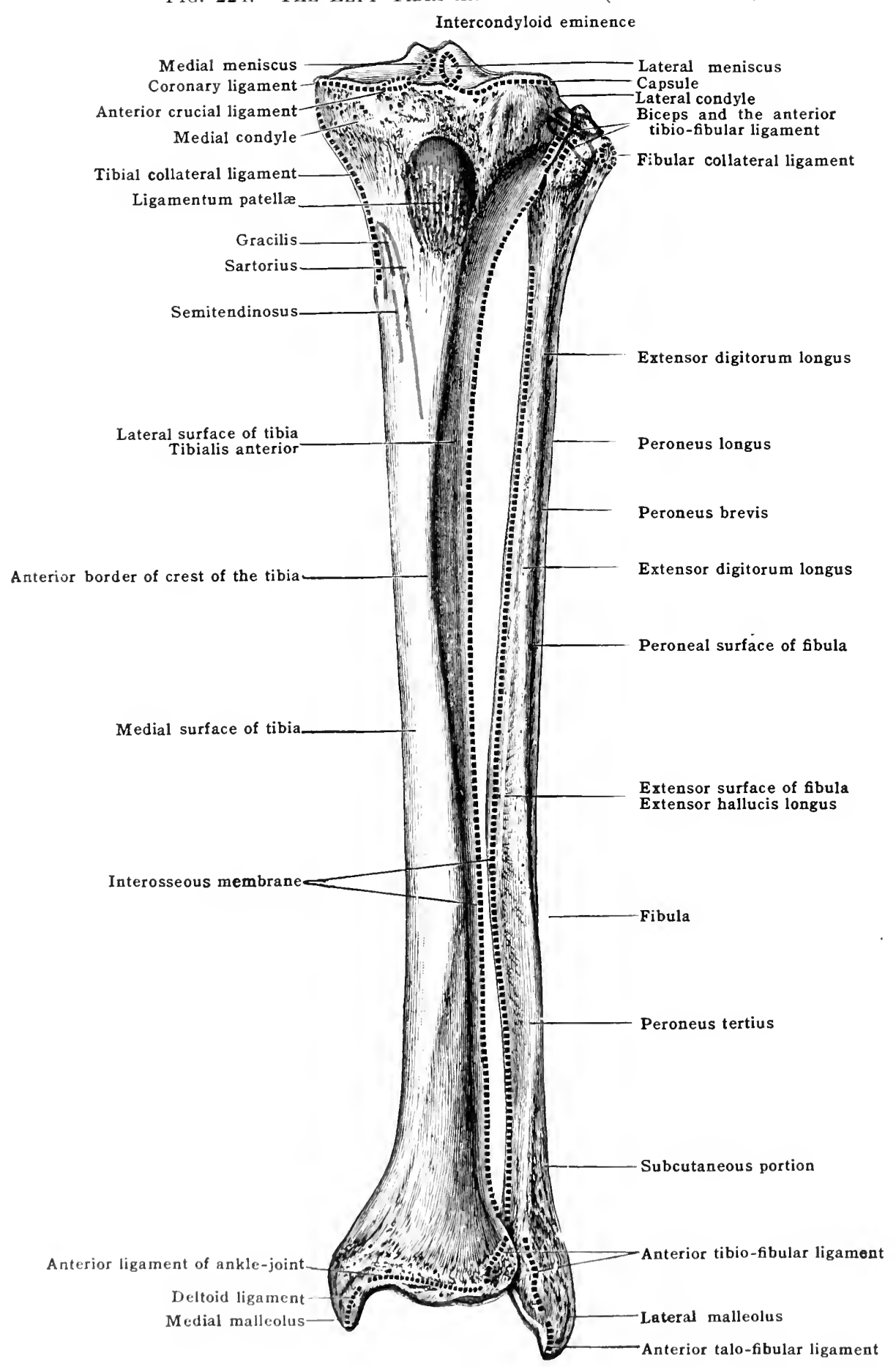

The meslial condyle is less prominent though more extonsive than the lateral, and near the pesterior part of its circumforence is a decp horizontal groove for the attachment of the central portion of the semimembranosus tendon. The margins of this groove, and the surface 
of bone below, give attachment to the tibial (internal) lateral ligament of the knee. On the under aspect of the lateral condyle is a rounded articular facet for the head of the fibula, flat and nearly circular in outline, directed downward, backward, and laterally. The circumference of the facet is rough and gives attachment to the ligaments of the superior tibio-fibular joint, while above and in front of the facet, at the junction of the anterior and lateral surface:

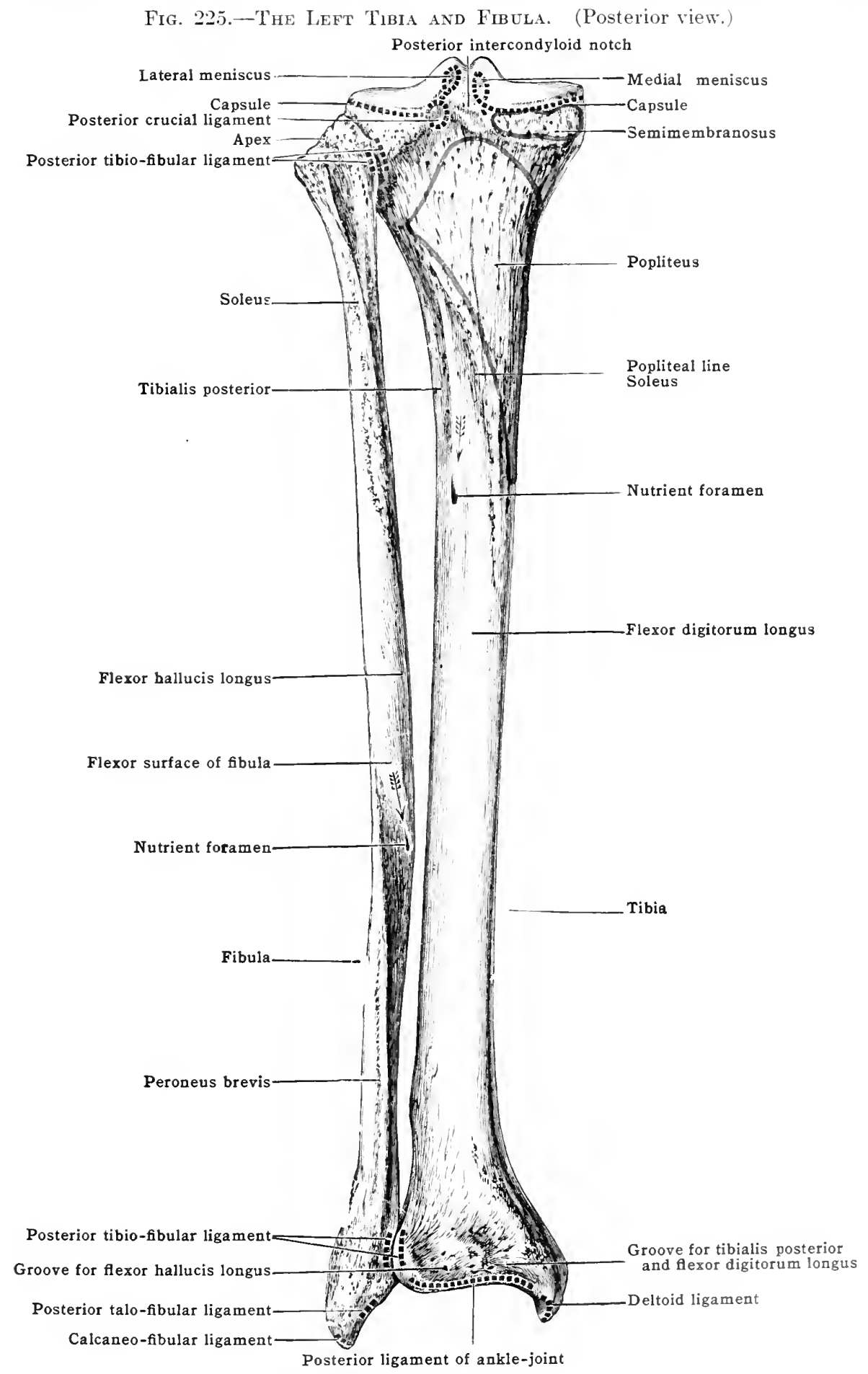

of the condyle, is a ridge for the ilio-tibial band. A slip from the tendon of the biceps and parts of the extensor longus digitorum and peroneus longus muscles are attached to the head below the ilio-tibial band. 
The shaft or body [corpus] of the tibia, thick and prismatic above, becomes thinner as it descends for about two-thirds of its length, and then gradually expands toward its lower extremity. It presents for examination three borders and three surfaces. The anterior border is very prominent and known as the anterior crest of the tibia. It commences above on the lateral edge of the tuberosity and terminates below at the anterior margin of the medial malleolus. It runs a somewhat sinuous course, and gives attachment to the deep fascia of the leg. The medial border extends from the back of the medial condyle to the posterior margin of the medial malleolus, and affords attachment above, for about three inches, to

Fig. 226. - The Tibia and Fibula at tile Sixteenth Year.

The figure shows the relations of the epiphysial and capsular lines.

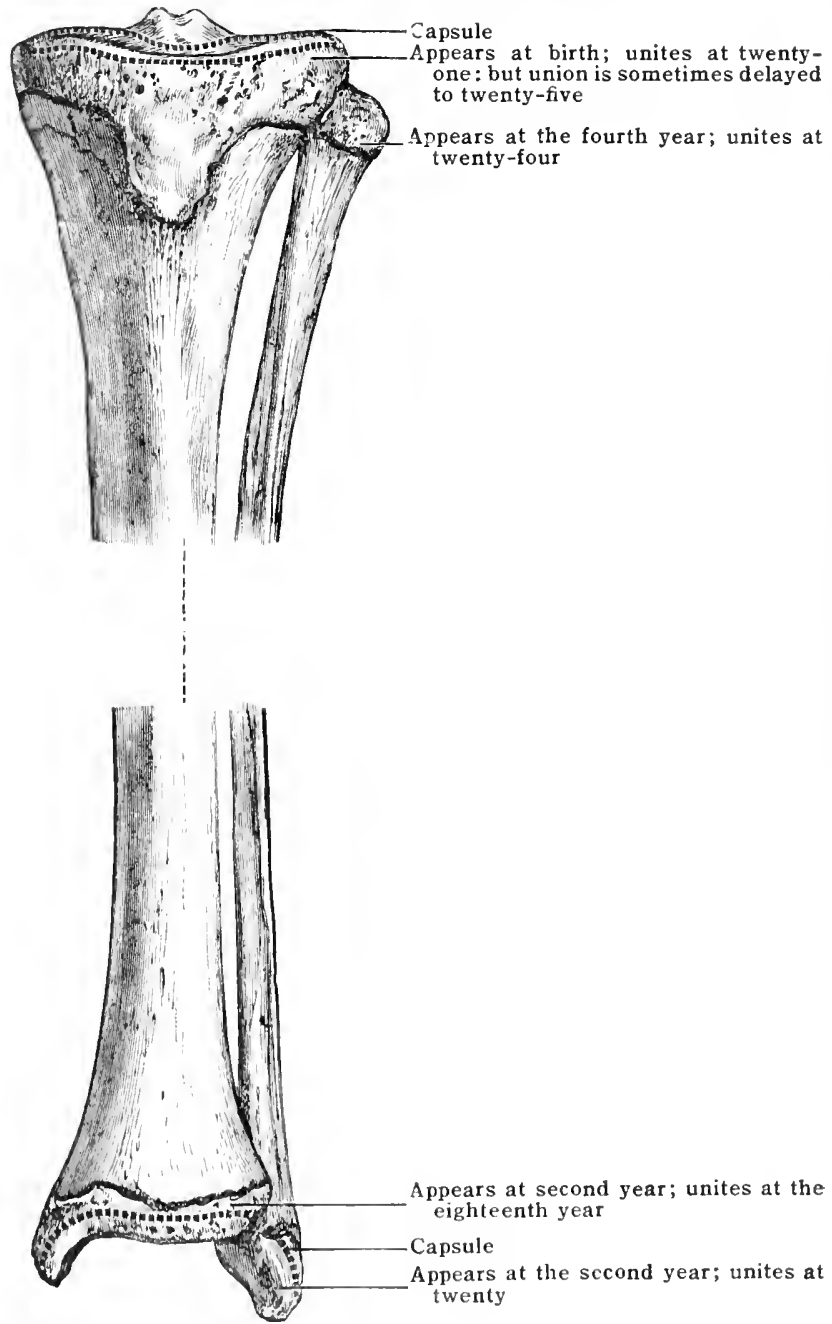

the tibial (intrenal) bateral liganent of the knee-joint and in the midelle third, to 1 he solens. 'The interosseous crest or lateral border, thin and prominent, gives attachment to the interoserous membrame. It commences in front of the fibular fareet, on the upper extronity, and towad its tormination bifureates to rnclose a trimgular area for the at andhuent of the interosieous ligament uniting the lower rouls of the tibia and filmbla.

'l'he medial surface is hounderl by the merlial margin and the anterior erest; it is brast alove, where it reerives the insertions of the sartorius, gracilis, and semitendimesns; vonvex and subertancous in the remainder of its extent. The lateral surface lies between the arest of the libial and the interosseous crest. The upper two-thircls presents a hollow for the origin of the libialis anterior; the rest of the 
surface is convex and covered by the extensor tendons and the anterior tibial vessels. The posterior surface is limited by the interosseous erest and the medial border. The upper part is erossed obliquely by a rough popliteal line, extending from the fibular facet on the lateral condyle to the medial border, a little above the middle of the bone.

The popliteal line gives origin to the soleus and attachment to the popliteal fascia, while the triangular surface above is occupied by the popliteus muscle. Descending along the posterior surface from near the middle of the popliteal line is a vertical ridge, well marked at its commencement, but gradually becoming indistinct below. The portion of the surface between the ridge and the medial border gives origin to the flexor digitorum longus; the lateral and narrower part, between the ridge and the interosseous border, to fibres of the titinilis posterior. The lower third of the posterior surface is covered by flexor tendons and the posterior tibial vessels. Immediately below the popliteal line and near the interosseous border is the large medullary foramen directed obliquely downward.

The lower extremity, much smaller than the upper, is quadrilateral in shape and presents a strong process called the medial malleolus, projecting clownwircl from its medial side. The anterior surface of the lower extremity is smooth and rounded above, where it is covered by the extensor tendons, rough and depressed below for the attachment of the anterior ligament of the ankle-joint. It sometimes bears a facet for articulation with the neck of the talus (astragalus). (A. Thomson.) The posterior surface is rough and is marked by two groores. The medial and deeper of the two encroaches on the malleolus, and receives the tendons of the tibialis posterior and flexor digitorum longus; the lateral, very shallow and sometimes indistinet, is for the tendon of the flexor hallucis longus. The lateral surface is triangular and hollowed for the reeption of the lower end of the fibula and rough for the interosseous ligament which unites the two bones, except near the lower border, where there is usually a narrow surface, elongated from before backward, covered with cartilage in the reeent state for articulation with the fibula. The lines in front of and behind the triangular surface afford attachment to the anterior and posterior ligaments of the inferior tibio-fibular articulation. The medial surface, prolonged downward on the medial malleolus, is rough, convex, and subcutaneous. The lateral surface of this process is smooth and articulates with the facet on the medial side of the talus (astragalus). Its lower border is notched, and from the noteh, as well as from the tip and anterior border, the fibres of the deltoid ligament of the ankle-joint deseend. The inferior or terminal surface, by which the tibia articulates with the talus, is of quadrilateral form, eoneave from before backward, wider in front than behind, and laterally than medially where it is continuous with the lateral surface of the malleolus.

The occasional facet on the anterior surface of the lower extremity of the tibia is a pressure facet, produced by extreme flexion of the ankle joint. It is therefore sometimes designated as the "squatting facet." (See fig. 333.)

Blood-supply.- The tibia is a rery vascular bone. The nutrient artery of the shaft is furnished by the posterior tibial, and is the largest of its kind in the body. The head of the bone receives numerous branches from the inferior articular arteries of the popliteal and the recurrent branches of the anterior and posterior tibial. The lower extremity receives twigs from the posterior and anterior tibial, the peroneal, and the medial malleolar arteries.

Ossification.- The tibia is ossified from one principal centre for the shaft, which appears in the eighth week of intra-uterine life, and two epiphyses, the centres for which appen in the cartilaginous head of the bone toward the end of the ninth month, and in the lower extremity during the second year. The latter unites with the shaft at eighteen, but the union of the head with the shaft does not take place until the twenty-first year, and it may even be delayed until twenty-five. The upper part of the tubercle of the tibia is ossified from the upper epiphysis, and the lower part from the diaphysis.

\section{THE FIBLLA}

The fibula (figs. 224, 225) is situated on the lateral side of the leg and, in proportion to its length is the most slender of all the long bones. It is placed nearly parallel to the tibia with which it is conneeted above and below. In man it is a rudimentary bone and bears none of the weight of the trunk, but is retined on account of the muscles to which it gives origin and its participation in the formation of the ankle-joint. Like other long bones, it is divisible into a shaft and two extremities.

The head [capitulum fibulæ], or upper extremity, is a rounded prominence. Its upper surface presents laterally a rough eminence for the attachment of the 
biceps tendon and the fibular (long external) collateral ligament of the knee-joint, medially it presents a round or oval facet [facies artieularis eapituli], directed upward, forward, and medially, for articulation with the lateral condyle (tuberosity) of the tibia. The margin of the facet gives attachment to the articular capsule of the superior tibio-fibular articulation. Posteriorly, the head rises into a pointed apex (styloid process), which affords attachment to the short lateral ligament of the knee-joint, and on the lateral side, to part of the biceps tendon.

The posterior aspect of the head gives attachment to the soleus, the lateral aspect, extending also in front of the eminence for the biceps, to the peroneus longus; from the anterior aspect fibres of the extensor digitorum longus arise, whilst the medial side lies adjacent to the tibia.

The shaft [corpus fibulæ], in its upper three-fourths, is quadrangular, possessing four borders and four surfaces, whereas its lower fourth is flattened from side to side, so as to be somewhat triangular. The borders and surfaces vary exceedingly so that their deseription is difficult. The anterior crest (or antero-lateral border) commences in front of the head and terminates below by dividing to enclose a subcutaneous surface, triangular in shape, immediately above the

Fig. 227.-The Upper End of the Left Fibula to show Muscular and Ligamentous AtTachuents $\times 2$. (G. J. Jenkins.)

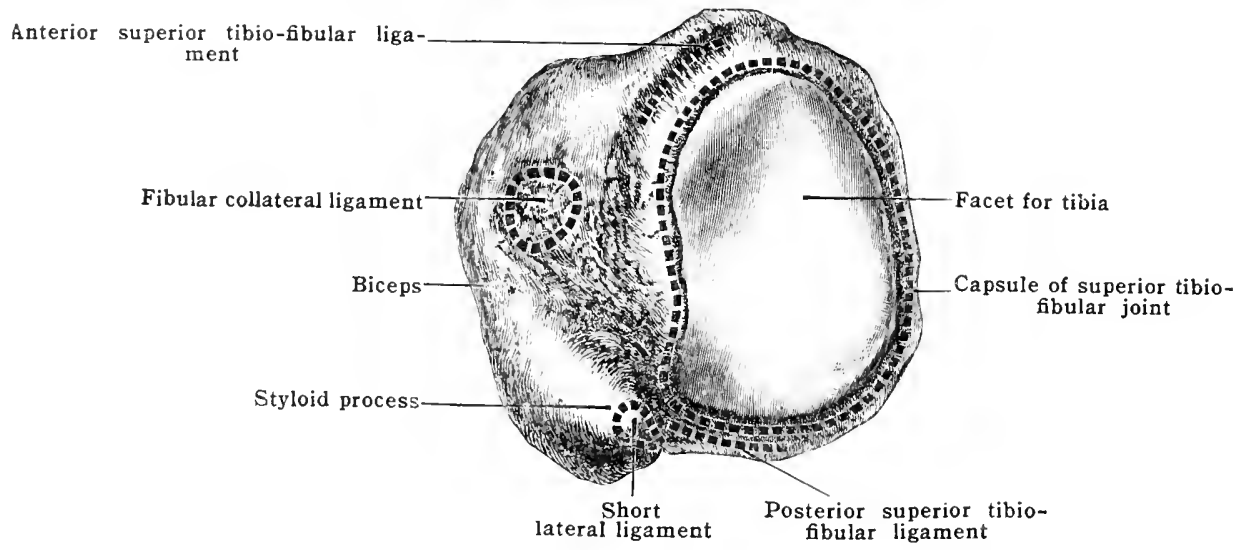

listeral malleolus. It gives attachment to a septum separating the extensor muscles in front from the peronei museles on the lateral aspect. The interosseous crest (or antero-medial border), so named from giving attachment to the interosseous membrane, also commences in front of the head, close to the anterior crest, and terminates below by dividing to enclose a rough triangular area immediately above the facet for the talus (astragalus); this area gives attachment to the inferior interosseons ligament, and may present at its lower end a narrow facet for articulation with the tibia. The medial crest (or postero-medial borker), sometimes deseribed as the oblique line of the fibula, commences at the medial side of the head and terminates below by joining the interosscous erest, in the lower fourth of the shaft. It gives attachment to an aponeurosis separating the tibialis posterior from the soleus and flexor hallueis longus. The lateral crest (or posterolateral bereler) runs from the batek of the head to the medial border of the peroneal grooveron the latek of the lower extremity; it gives attachment to the faseia separating the peromei from the flexor museles.

'The anterior or extensor surface is the interval between the interosseous and antrior arests. In the npuer third it is extremely narrow, but broadens out howe, where it is slightly groover longitulinally. It affords origin to three

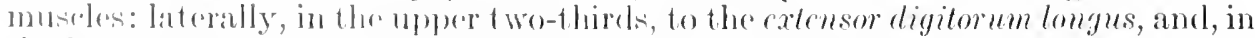
the lower third, to the gremens tertims; medially, in the midclle third, also to the axtrusm hallucis longus. Thu medial surface, situated between the interosseous and morlial crests, is narrow abowe and bolow, and broadest in the middle. It

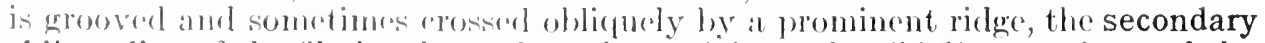
oblique line of the fibulat the surface gives origin to the tibialis posterior, and the ridge to at tendinous septum in the substance of the muscle. 'The posterior surface 
is the interval between the medial and lateral crests, and is somewhat twisted so as to look backward above and medially below. It serves, in its upper third, for the origin of the soleus, and in its lower two-thirds for the flexor hallucis longus. Near the middle of the surface is the medullary foramen, directed downward toward the ankle. The lateral surface, situated between the anterior and lateral crests, is also somewhat twisted, looking laterally above and backward below, where it is continuous with the groove on the back of the lateral malleolus. The surface is often deeply grooved and is occupied by the peroneus longus in the upper two-thirds and by the peroneus brevis in the lower two-thirds.

The lateral malleolus or lower extremity is pyramidal in form, somewhat flattened from side to side, and joined by its base to the shaft. It is longer, more prominent, and descends lower than the medial malleolus. Its lateral surface is convex, subcutaneous, and continuous with the triangular subcutaneous surface on the shaft, immediately above. The medial surface is divicled into an anterior and upper area [facies articularis malleoli], triangular in outline and convex from above downward for articulation with the lateral side of the talus (astragalus), and a lower and posterior excavated area, the digital fossa, in which are attached the transverse inferior tibio-fibular ligament and the posterior talo-fibular (posterior fasciculus of the external lateral) ligament of the ankle. The anterior border is rough and gives attachment to the anterior talo-fibular (anterior fasciculus of the external lateral) ligament of the ankle, and the anterior inferior tibio-fibular ligament. The posterior border is grooved for the peronei tendons, and near its upper part gives attachment to the posterior inferior tibio-fibular ligament. The apex or summit of the process affords attachment to the calcaneo-fibular (middle fasciculus of the external lateral) ligament of the ankle.

Blood-supply.-The shaft of the fibula receives its nutrient artery from the peroneal branch of the posterior tibial. The head is nourished by branches from the inferior lateral articular branch of the popliteal artery, and the lateral malleolus is supplied mainly by the peroneal, and its perforating and malleolar branches.

Ossification.--The shaft of the fibula commences to ossify in the eighth week of intrauterine life. A nucleus appears for the lower extremity in the second year, and one in the upper extremity during the fourth or fifth year. The lower extremity fuses with the shaft about twenty, but the upper extremity remains separate until the twenty-second year or even later.

It is interesting, in connection with the times of appearance of the two epiphyses of the fibula, to note that the ossification of the lower epiphysis is contrary to the general rule-viz., that the epiphysis toward which the nutrient artery is directed is the last to undergo ossification. This is perhaps explained by the rudimentary nature of the upper extremity. In birds the head of the bone is large and enters into the formation of the knee-joint; and in human embryos, during the second month, the fibula is quite close up to the femur.

The human fibula is characterised by the length of its malleolus, for in no other vertebrate does this process descend so far below the level of the tibial malleolus. On the other hand. in the majority of mammals the tibial descends to a lower level than the fibular malleolus. In the human embryo of the third month, the lateral is equal in length to the medial mallenlus. At the fifth month the lateral malleolus exceeds the medial by $1.5 \mathrm{~mm}$; at birth, the lateral malleolus is still longer; and by the second year it assumes its adult proportion.

\section{THE TARSUS}

The tarsal bones [ossa tarsi] (figs. 228, 229) are grouped in two rows:- a proximal row, consisting of the talus and calcaneus, and a distal row, consisting of four bones which, enumerated from tibial side, are the first, second, and third cuneiform bones and the cuboid. Interposed between the two rows on the tibial side of the foot is a single bone, the navicular; on the fibular side the proximal and distal rows come into contact.

Compared with the carpus, the tarsal bones present fewer common characters. and greater diversity of size and form, in consequence of the modifications for supporting the weight of the trunk. On each, however, six surfaces can generally be recognised, articular when in contact with neighbouring bones, elsewhere subcutaneous or rough for the attachment of ligaments. As regards ossification, they correspond in the main with that of the bones of the carpus. Each tarsal bone is ossified from a single centre, but the calcaneus has, in addition, an epiphysis for a large part of its posterior extremity, and the talus, an occasional centre for the os trigonum. 


\section{The Talus}

The talus (or astragalus) (figs. 230, 231) is, next to the calcaneus, the largest of the bones of the tarsus. Above it supports the tibia, below it rests on the calcaneus, at the sicles it articulates with the two malleoli, and in front it is received into the navicular. For descriptive purposes, it may be divided into a head, neck, and body.

Fig. 228.-The Left Foot. (Superior surface.)

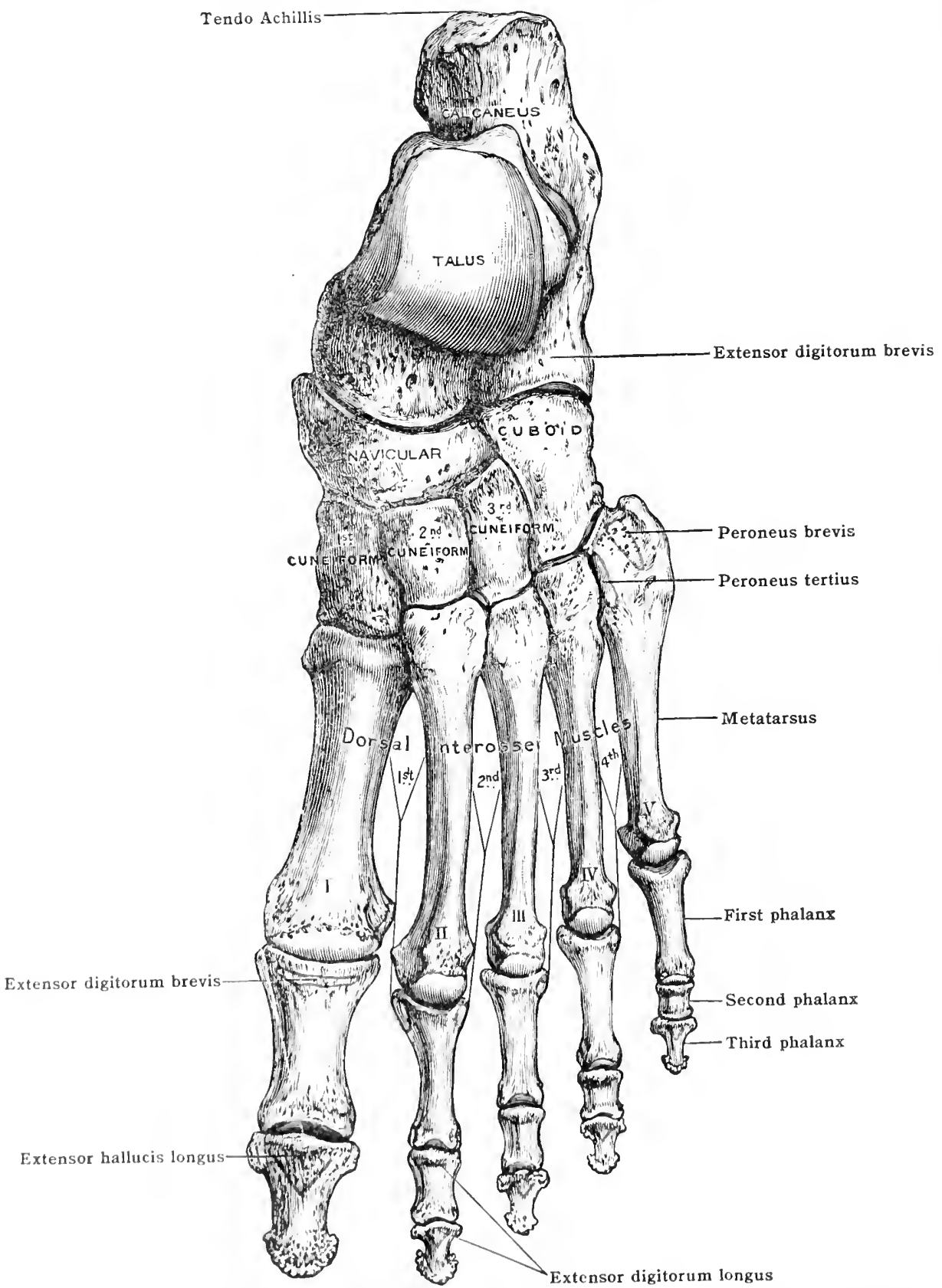

The body is somewhat guatrilateral in shape. The upper surface presents a broad, smooth arface for wider in front than behind. "The dimmution in width posteriorly is associated with an obliquity wher is directed medially as well as bickward and lownward. The inferior surface is oceupied by a transersely disposed ol, long facet [facies articulisis calcanea 
posterior], deeply concave from side to side, which articulates with a corresponding surface on the calcaneus. Of the malleolar surfaces, the lateral is almost entirely occupied by a large triangular facet, broad above, where it is continuous with the superior surface, concave from above downward, for articulation with the lateral malleolus; on the medial malleolar surface is a pyriform facet continuous with the superior surface, broad in front and narrow behind, which articulates with the medial malleolus. Below this facet the medial surface is rough for the attachment of the deep fibres of the deltoid (internal lateral) ligament of the ankle. The

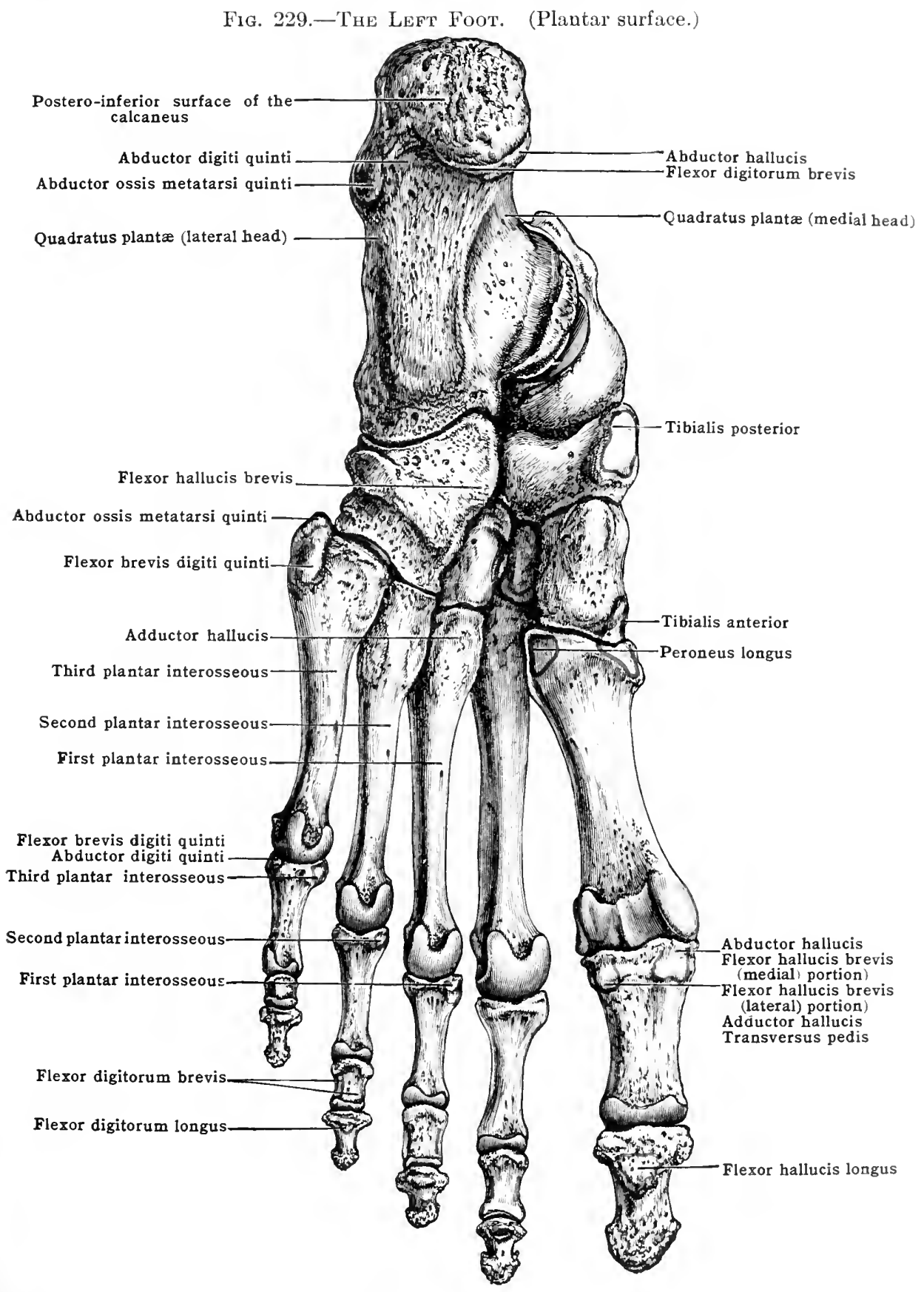

superior surface and the two malleolar surfaces together constitute the trochlea. The posterior surface is of small extent and marked by a groove which lodges the tendon of the flexor hallucis longus. Bounding the groove on either side are two tubercles, of which the lateral [processus posterior tali] is usually the more prominent, for attachment of the posterior talo-fibular ligament of the ankle-joint; the medial tubercle gives attachment to the medial talo-calcaneal ligament. Continuous with the anterior aspect of the body is the neck, a con- 
stricted part of the bone supporting the head. Above it is rough, and perforated by numerous vascular foramina. Below, it presents a deep groove [sulcus tali], directed from behind forward and lateralward. When the talus is articulated with the ealcaneus, this furrow is eonverted into a canal [sinus tarsi] in which is lodged the interosseous talo-ealeaneal ligament. The head is the rounded anterior end of the bone, and its large articular surface is divisible into three parts: in front, a smooth, oval eonvex area, direeted downward and forward for the navieular bone; below, an elongated facet, convex from front to back, for articulation with the sustentaculum tali of the calcaneus; and between these, is a small facet which rests on the calcaneo-

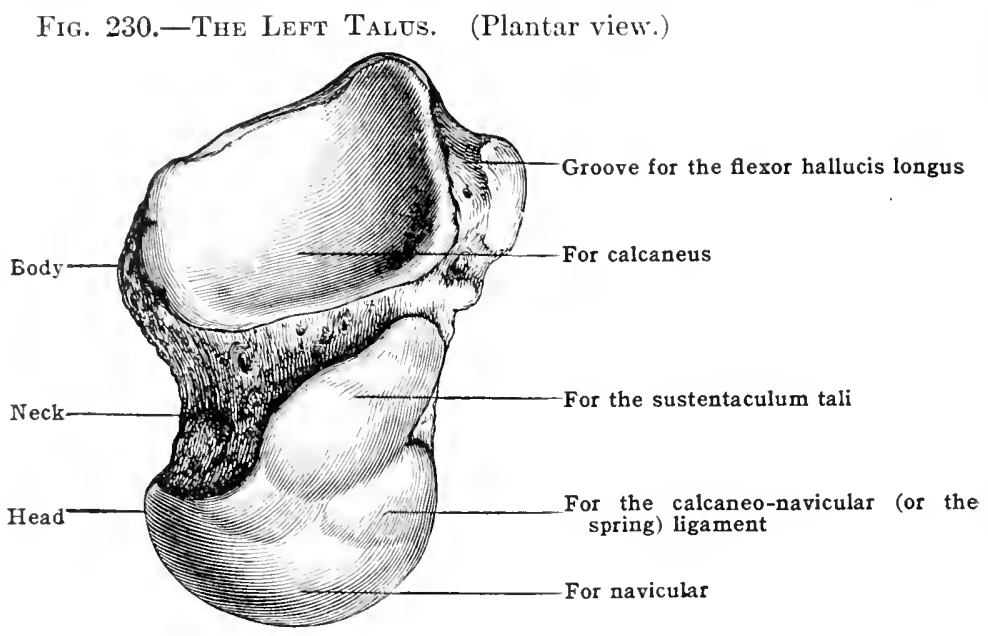

navicular ligament, separated from it by the synovial membrane of the talo-calcaneo-navicular joint.

Articulations.-The talus articulates with four bones and two ligaments. Above and medially with the tibia, below with the calcaneus, in front with the navicular, laterally with the fibula. The hearl articulates with the calcaneo-navicular ligament and the lateral border of the superior surface, at its posterior part, with the transverse ligament of the inferior tibiofibular joint.

The talus is a very vaseular bone and is nourished by the dorsalis pedis artery and its tarsa] braneh. It gives attachment to no museles.

Fig. 231.-A Talus with the Os Trigonum.

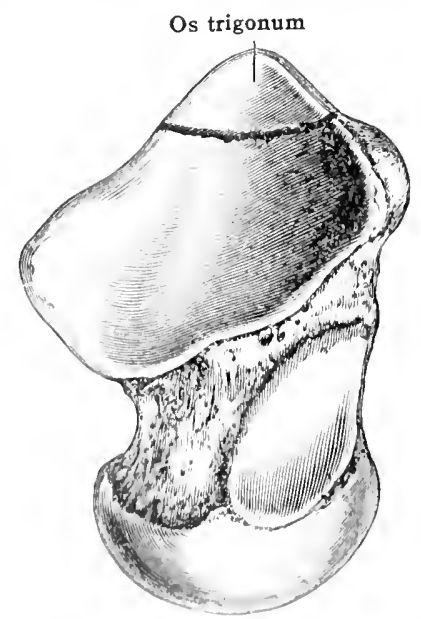

Ossification. The tulus is ossified from one, oecasionally from two, nuclei. The principal

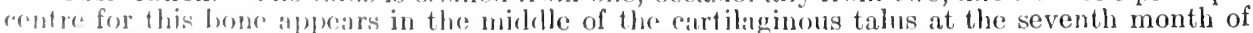
intra-uterine life. The alditional centre is deposited in the posterior portion of the bone, and forms the lateral posterior lulerele which may remain separate from the rest of the bone and form the os trigonum. At hirth, the talus presents some important peculiarities in the disposition of the artienlar fares on the tibial side of its borly, and in the oblinuity of its neck. If, in the aclult tahs, ane les drawn thromgh the mirldle of the superior trochlear surface parallel with its medial border, and a sorond line be drawn along the lateral side of the neek of the bone so as to intorsect the lirst, the anglo formed by these two lines will express the ollicquity of the neck of the bone. This in the arlut varies greatly, Jut the average may be taken as $10^{\circ}$. In the 
fœetus at birth the angle averages $35^{\circ}$, whilst in a young orang it measures $45^{\circ}$. In the normal adult talus the articular surface on the tibial side is limited to the body of the bone. In the fœtal talus it extends for some distane on to the neck, and sometimes reaches almost as far forward as the navicular facet on the head of the bone. This disposition of the medial malleolar facet is a characteristic feature of the talus in the chimpanzee and the orang. It is related to the inverted position of the foot which is found in the human foetus almost up to the period of birth, and is of interest to the surgeon in connection with some varieties of club-foot. (Shattock and Parker.)

\section{The Calcaneus}

The calcaneus (or os calcis) (figs. 232, 233) is the largest and strongest bone of the foot. It is of an elongated form, flattened from side to side, and expanded at its posterior extremity, which projects downward and backward to form the heel. It presents six surfaces, superior, inferior lateral, medial, anterior and posterior.

The superior surface presents in the middle a large, oval, convex, articular facet for the under aspect of the body of the talus. In front of the facet the bone is markerl by a deep

Fig. 232.-The Left Calcaneus. (Dorsal view.)

Facet for talus on the sustentaculum tali

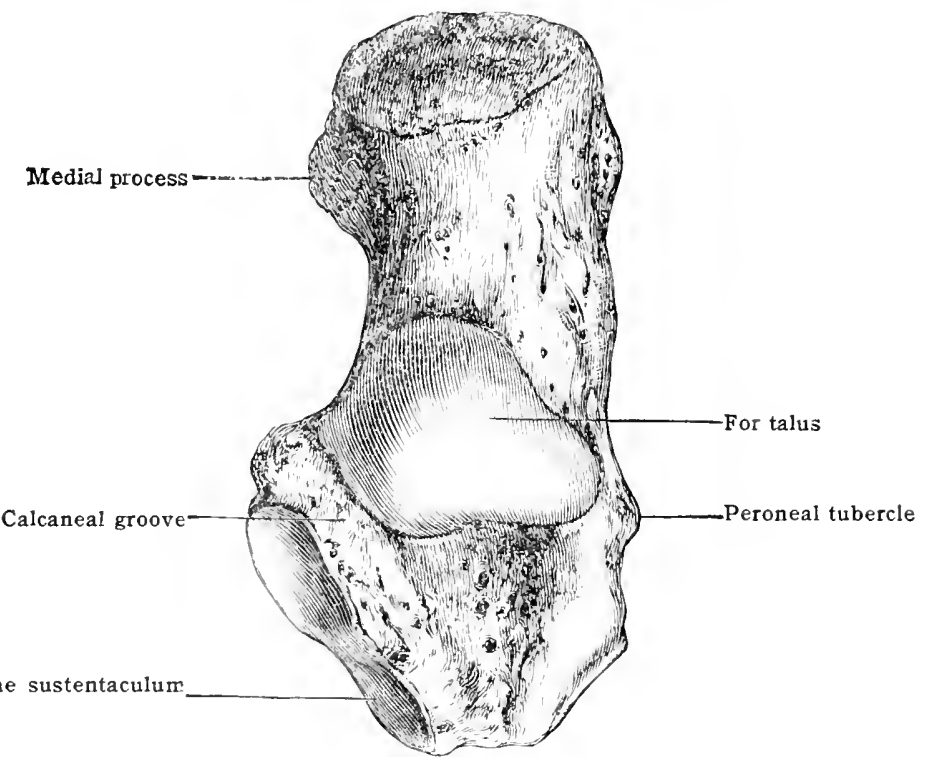

depression, the floor of which is rough for the attachment of ligaments, especially the talocalcaneal, and the origin of the cxtensor digitorum brevis muscle; when the calcaneus and talus are articulated, this portion of the bone forms the floor of a cavity called the sinus tarsi. Medially, the upper surface of the bone presents a well-marked process, the sustentaculum tali, furnished with an elongated concave facet, occasionally divided into two, for articulation with the under aspect of the head of the talus. The posterior part of the upper surface is nonarticular, convex from side to side, and in relation with a mass of fat placed in front of the tendo Achillis.

The inferior surface is narrow, rough, uneven, and ends posteriorly in two processes: the medial is the larger and broader, the lateral is narrower but prominent. The medial process affords origin to the abductor hallucis, the flexor digitorum brevis, and the abductor digiti quinti; the last muscle also arises from the lateral process and from the riclge of bone between. The rough surface in front of the tubercles gives attachment to the long plantar ligament (calcaneocuboid) and the lateral head of the quadratus planto. Near its anterior end this surface forms a rounded eminence, the anterior tubercle, from which (as well as from the shallow groove in front) the plantar (short) calcaneo-cuboid ligament arises. (According to the BNA nomenclature, the medial and lateral processes belong to the tuber calcanei or the posterior extremity of the bone.)

The lateral surface is broad, flat, and slightly convex. It represents near the midile a small eminence for the calcaneo-fibular ligament of the ankle-joint. Below and in front of this is a well-marked tubercle-the trochlear process [processus trochlearis] (or peroneil tubercle), separating two grooves, the upper for the peroneus brevis and the lower for the peroncus longus.

The medial surface is deeply concave, the hollow being increased by the prominent medial process behind and the overhanging sustentaculum tali in front. The latter forms a prominence of bone projecting horizontally, concave and articular above, grooved below for the tendon of the flexor hallucis longus, and giving attachment to a slip of the tenclon of the tibialis posterior, the inferior calcaneo-navicular ligament, and some fibres of the cleltoid ligament of the ankle-joint. The hollow below the process receives the plantar vessels and nerves and its lower part gives attachment to the medial head of the quadratus planto. 
The anterior surface is somewhat quadrilateral in outline with rounded angles, and presents a saddle-shaped articular surface for the cuboid.

The posterior surface is oval in shape, rough, and convex. It is divided into three parts:an upper, smooth and separated by a bursa from the tendo Achillis; a middle part giving attachment to the tendo Achillis and the plantaris, and a lower part in relation to the skin and fat of the heel. The expanded posterior extremity of the bone is known as the tuber calcanei. in front.

Articulations. - The calcaneus articulates with two bones, the talus above and the cuboid

Blood-supply.- The calcaneus is nourished by numerous branches from the posterior tibial and the medial and lateral malleolar arteries. They enter the bone chiefly on the inferior and medial surfaces.

Fig. 233.-The Calcaneus at the Fifteenth Year, showing the Epiphysis.

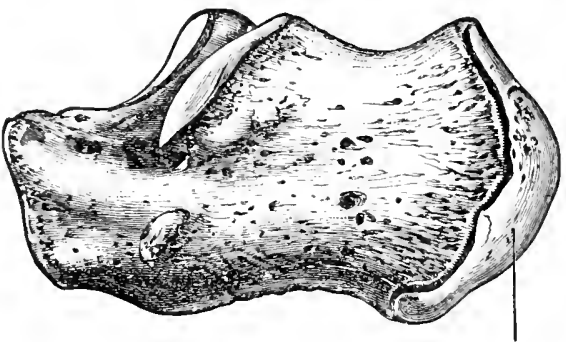

Appears at the tenth, and unites at the sixteenth year

Ossification.-The primary nucleus appears in the sixth month of intra-uterine life. The epiphysis, for its posterior extremity, begins to be ossified in the tenth year and is united to the body of the bone by the sixteenth year. It may extend over the whole of the posterior surface, as shown in fig. 233 , or over the lower two-thirds only, leaving a part above in relation to the bursa beneath the tendo Achillis, which is formed from the primary nucleus. The medial and lateral processes are formed by the epiphysis.

\section{The Navicular}

The navicular [os naviculare pedis] (figs. 234, 235) is oval in shape, flattened from before backward, and situated between the talus behind and the three cuneiform bones in front. It is characterised by a large oval, concave, articular

Fig. 234.-The Lefrt Navicular. (Anterior view.)

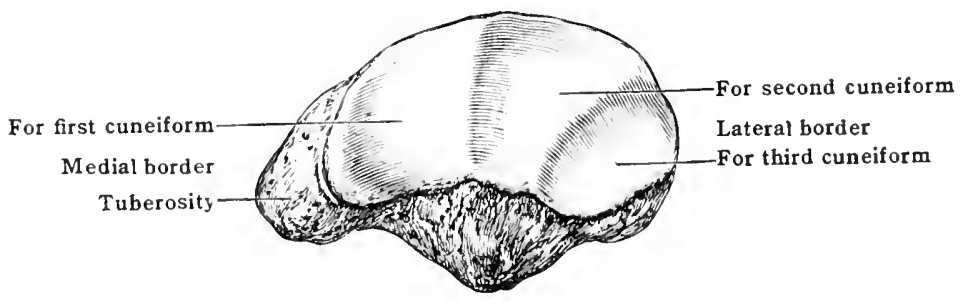

facet on the posterior surface, which receives the head of the talus; a broad, rough, rounded eminener on the medial surface, named the tuberosity of the navicular, the lower part of which projeets downward and gives insertion to the tendon of

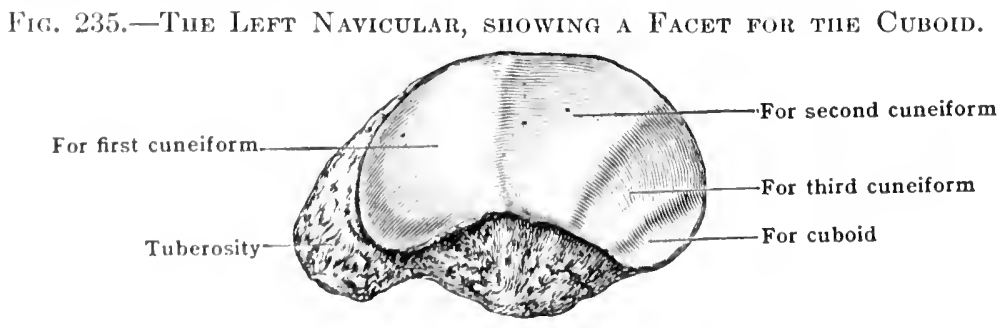

the tibialis posterior; and an ohlong-shaped anterior surface, convex and divided by two vortical ridges into three facets which articulate with the three cuneiform benes. The superior (dorsal) surface is rough, convex, and slopes downward to 
the tuberosity; the inferior (plantar) surface is irregular and rough for the attachment of the inferior calcaneo-navicular ligament, and the lateral surface is rough and sometimes presents a small articular surface for the cuboid.

Articulations. - With the talus behind, with the three cuneiform bones in front, and occasionally with the cuboid on its lateral aspect.

Ossification.-The nucleus for the navicular appears in the course of the fourth year. The tuberosity of the navicular, into which the tibialis posterior acquires its main insertion, occasionally develops separately, and sometimes remains distinct from the rest of the bone.

\section{The Cuneiforil Bones}

Of the three cuneiform bones, the first is the largest, the second is the smallest, and the third intermediate in size. They are wedge-shaped bones placed between the navicular and the first, second and third metatarsal bones. Posteriorly, the ends of the bones lie in the same transverse line, but in front, the first and third project farther forward than the second, and form the sides of a deep recess into which the base of the second metatarsal bone is received.

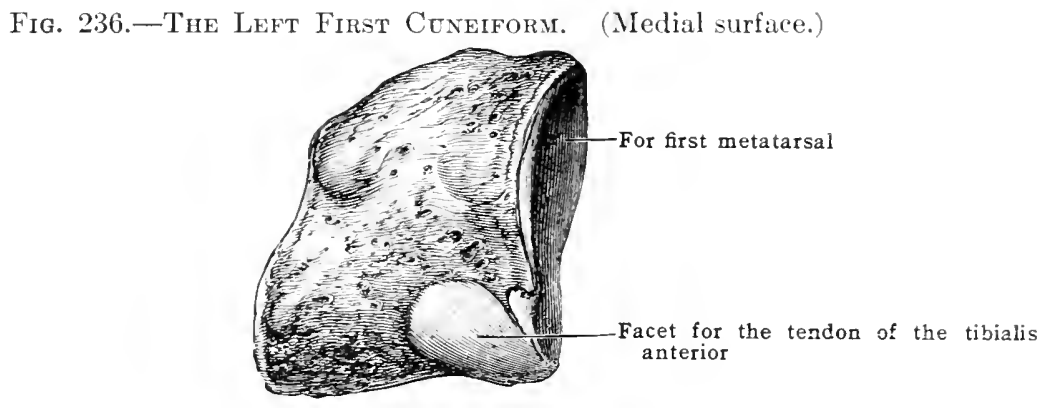

The first cuneiform [os cuneiforme primum] (figs. 236, 237) is distinguished by its large size and by the fact that when articulated, the base of the wedge is directed downward and the apex upward. The posterior surface is concave and pyriform for articulation with the medial facet on the anterior surface of the navicular. The anterior surface forms a reniform articular facet for the base of the first metatarsal. The medial surface is rough, and presents an oblique groove for the tendon of the tibialis anterior; this groove is limited inferiorly by an oval facet into which a portion of the tendon is inserted. The lateral surface is concave and presents along its superior and posterior borders a reversed L-shaped facet for articulation with the second cuneiform, and, at its anterior extremity, with the second metatarsal. Anteriorly it is rough for ligaments. The inferior surface is rough for the insertion of the peroneus longus, tibialis anterior, and (usually) the tibialis posterior. The superior surface is the narrow part of the wedge and is directed upward.

Fig 237.-The Left Finst Cuneiform. (Lateral aspect.)

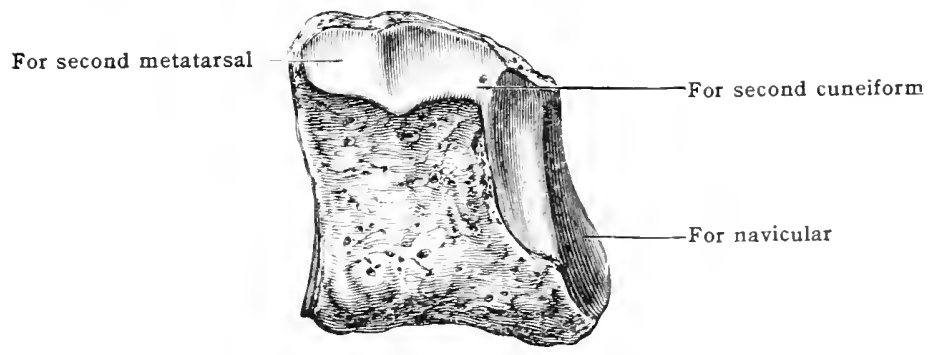

Articulations. - With the navicular behind, second cuneiform and second metatarsal on its lateral side, and first metatarsal in front.

Ossification.-From a single nucleus which appears in the course of the third year.

The second cuneiform [os cuneiforme secundum] (figs. 238,239 ) is placed with the broad extremity upward and the narrow end downward, and is readily recognised by its nearly square base. The posterior surface, triangular and concave, articulates with the middle facet on the anterior surface of the navicular. The anterior surface, also triangular, but narrower than the posterior surface, articulates with the base of the second metatarsal. The medial surface has a reversed L-shaped facet running along its superior and posterior margins for articulation with the corresponding facet on the first cuneiform, and is rough elsewhere for the 
attachment of ligaments. On the lateral surface near its posterior border is a vertical facet, sometimes bilobed, for the third cuneiform, and occasionally a second facet at the anterior inferior angle. The superior surface forms the square-cut base of the werlge and is rough for the attachment of ligaments. The inferior surface is sharp and rough for ligaments and a slip of the tendon of the tibialis posterior.

Fig. 23S.-The Left Second Cuneiform. (Medial surface.)

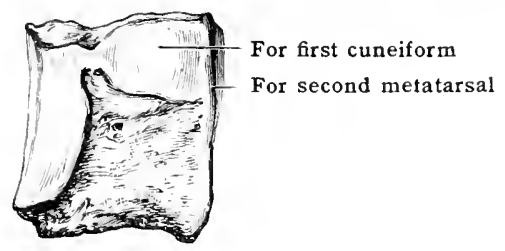

Articulations. - With the navicular behind, second metatarsal in front, third cuneiform on the lateral side, and first cuneiform on the medial side.

Ossification.-From a single mucleus which appears in the fourth year.

The third cuneiform bone (figs. 240,241 ) also placed with the broad end directed upward and the narrow end downward, is distinguished by the oblong shape of its base. Like the

Fig. 239.--Tie Left Second Cuneifora. (Lateral surface.)

Occasional facet for third cuneiform

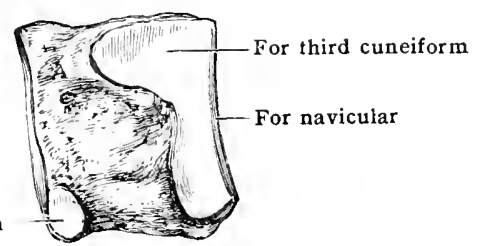

second runeiform, the posterior surface presents a triangular facet for the navicular; and the anterior surface a triangular facet, longer and narrower, for the third metatarsal. The medial surface has a large facet extending along the posterior border for the second cuneiform, and along the anterior border a narrow irregular facet for the lateral side of the base of the second metatarsal. Occasionally, a small facet is present near the anterior inferior angle for the second

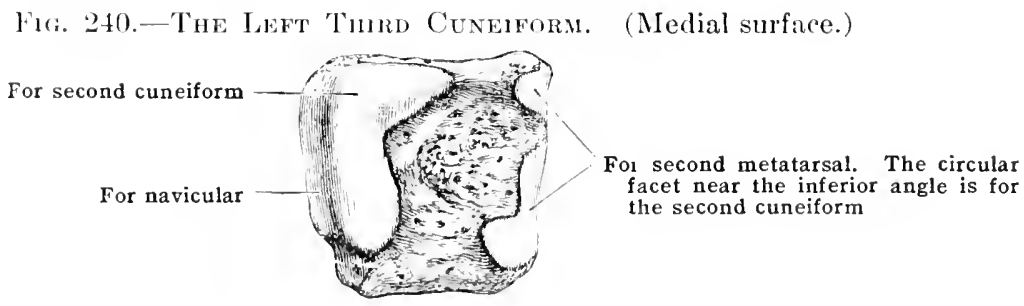

muneiform. The lateral surface has a large distinctive facet near its posterior superior angle for the rubirl, and at the anterior superior angle there is usually a small faret for the medial side of the base of the fourth metatirsal. The superior surface, olsong in shate, is rough for ligancents, and thr inferior, forming a rounded matgin, receives a slip of the tibialis posterior and gives origin to a fow fibles of the flexor halluris brevis.

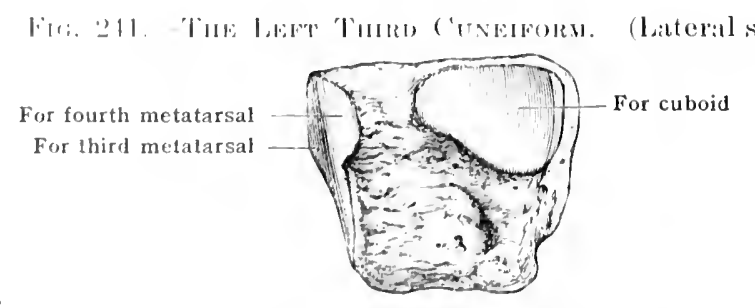

Articulations. - With thr navientar behind, thirr metartarsal in front, cuboid and fourth

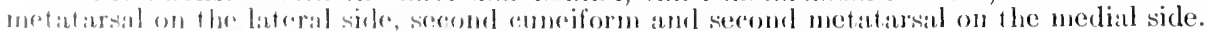

Ossification. A singlr nucleus appears in the course of the first year. 


\section{The Cuboid}

The cuboid (figs. 242, 243, 244), irregularly cubical in shape, is placed on the lateral aspect of the foot, forming a continuous line with the calcaneus and the fourth and fifth metatarsals.

Its posterior surface is somewhat quadrangular with rounded angles and presents a saddleshaped articular surface for the calcaneus. Its lower and medial angle is somewhat prolonged backward beneath the sustentaculum tali (calcaneal process of the cuboid), an arrangement to oppose the upward or outward movement of the bone. This process occasionally terminates

$$
\text { F1G. 242.-The Left Cubord. (Medial view.) }
$$

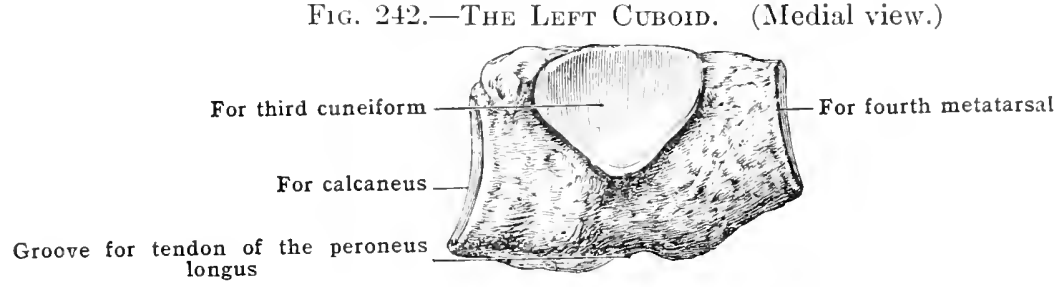

in a rounded facet which plays on the head of the talus lateral to the facet for the calcaneo navicular ligament. The anterior surface is smaller and divided by a vertical ridge into two articular facets, a lateral for the base of the fifth, and a medial for the base of the fourth metatarsal. The superior surface is rough, non-articular, and directed obliquely upward. The inferior surface presents a prominent ridge for the attachment of the long plantar (calcaneocuboid) ligament, in front of which is a deep groove-the peroneal groove-running obliquely. forward and medially and lodging the tendon of the peroneus longus. The ridge terminates laterally in an eminence, the tuberosity of the cuboid, on which there is usually a facet for a sesamoid bone of the tendon contained in the groove. The part of the surface behind the ridge is rongh for the attachment of the plantar (short) calcaneo-cuboid ligament, a slip of the tibialis posterior, and a few fibres of the flexor hallucis brevis.

Fig. 243.-The Left Cubord. (Medial view.)

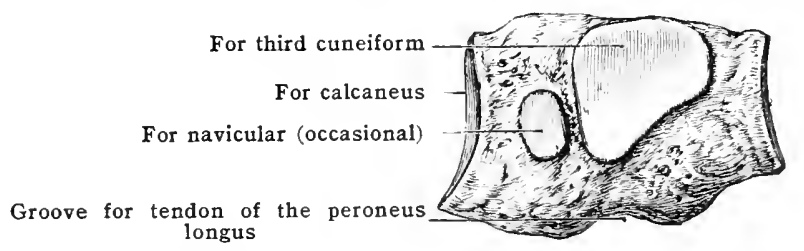

The medial surface presents, near its middle and upper part, an oval facet for articulation with the third cuneiform bone (fig. 242); behind this, a second facet for the navicular is frequently seen (fig. 243). Generally the two facets are confluent and then form an elliptical surface (fig. 244). The remainder of this surface is rough for the attachment of strong interosseous ligaments.

The lateral surface, the smallest and narrowest of all the surfaces, presents a deep notch which leads into the peroneal groove.

Articulations. - With the calcaneus behind, fourth and fifth metatarsals in front, third cuneiform and frequently the navicular on the medial side; occasionally also the talus.

Fig. 244.-The Left Cubord. (Medial view.)

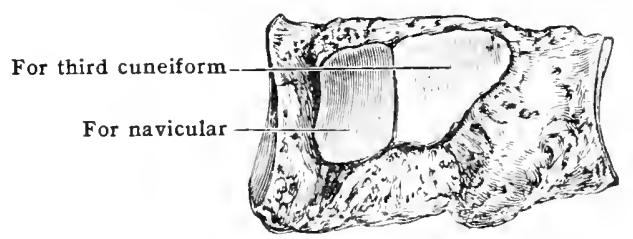

Ossification.-The cuboid is ossified from a single nucleus which appears about the tine of birth.

Accessory tarsal elements.-As in the carpus, a number of aclditional elements may occur in the tarsus. The most frequent of these is the os trigonum, which has already been noticed. Next in frequency is an additional first cuneiform, resulting from the ossification of the plantar half of that bone independently of the dorsal half, so that the bone is represented by a plantar and a dorsal first cuneiforn. Other additional elements may occasionally occur at the upper posterior angle of the sustentaculum tali; at the anterior superior angle of the calcaneus, between that bone and the navicular; in the angle between the first cuneiform and the first and second metatarsals; and in the fibular angle between the fifth metatarsal and the cuboid (os Vesalianum). 
The fibular portion of the navicular is sometimes united to the cuboid and quite separate from the rest of the navicular, the cuboid in such cases articulating with the talus. This condition suggests the recognition of the fibular portion of the navicular as a distinct accessory tarsal element, the cuboides secundarium, though it has not yet been observed as an independent bone in the human foot.

\section{THE METATARSUS}

The metatarsus [ossa metatarsalia] consists of a series of five somewhat eylindrical bones. Articulated with the tarsus behind, they extend forward, nearly parallel with each other, to their anterior extremities, which articulate with the toes, and are numbered aceording to their position from great toe to small toe. Like the corresponding bones in the hand, each presents for examination a three-sided shaft, a proximal extremity termed the base, and a distal extremity or head. The shaft tapers gradually from the base to the head, and is slightly eurved longitudinally so as to be convex on the dorsal and eoneave on the plantar aspect.

A typical metatarsal bone.-The shaft [corpus] is compressed laterally and presents for examination three borders and three surfaces. The two borders, distinguished as medial and lateral, are sharp and commence behind, one on each side of the dorsal aspect of the tarsal extremity, and, gradually approaching in the middle of the shaft, separate at the anterior end to terminate in the corresponding

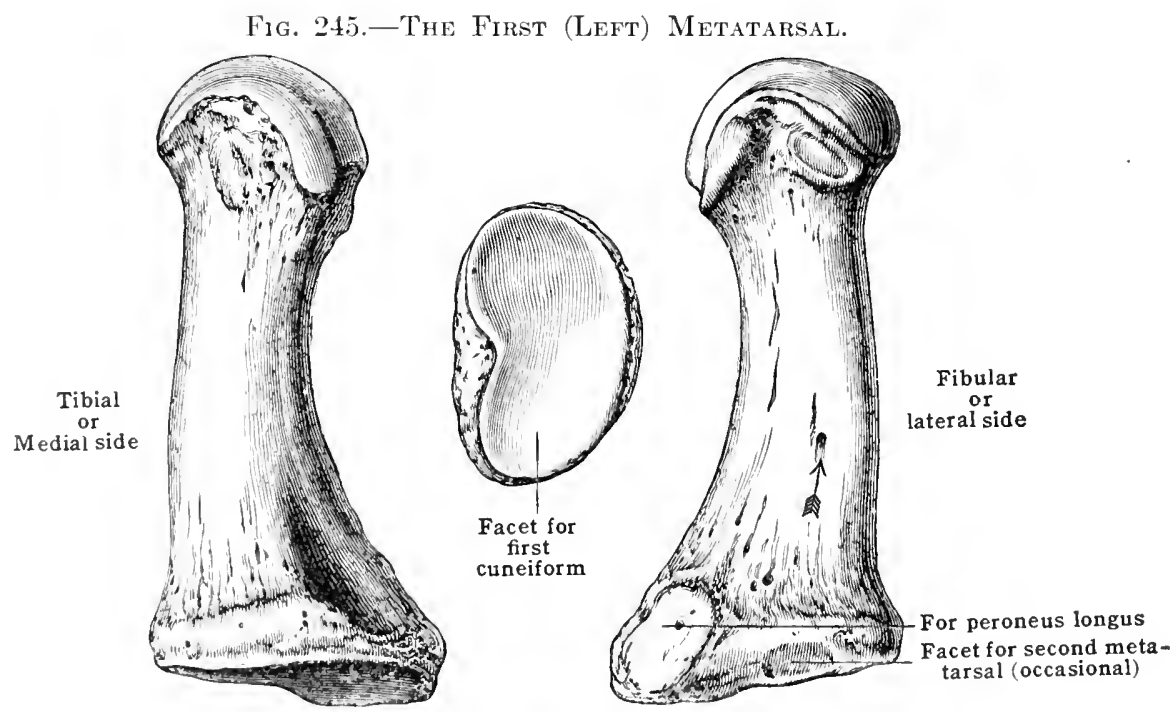

tubereles. The inferior border is thick and rounded and extends from the under aspect of the tarsal extremity to near the anterior end of the bone, where it bifureates, the two divisions teminating in the articular cminences on the plantar aspecet of the head. Of the three surfaces, the dorsal is narrow in the middle and wider at either cond. It is directed upward and is in relation with the extensor tendons. Thr medial and lateral surfaces, more extcnsive than the dorsal, corresponding with the interosseous spaces, are separated above, but meet together at the inforior border; they afford origin to the interosseous museles. The base is werlgr-shaped, articulating by its terminal surface with the tarsus, and on each side with the adjacent metatarsal bones. The dorsal and plantar surfaces are rough for the attachument of ligaments. The head presents a semicireular articular surface for the base of the first phalanx, and on each sirle a depression, surmominted by a tuberele, for the attachment of the lateral ligaments of the inetatarso-phalangeal joint. 'The inferior surface of the head is grooved for the passage of the flexortendons and is hounded by two eminences continuous with the terminal artirular surface.

The sevoral motatarials possess distinctive characters by which they ean be rearlily recognised. 
The first metatarsal (fig. 245) is the most modified of all the metatarsal bones, and deviates widely from the general description given above. It is the shortest, the thickest, the strongest, and most massive of the series. The base presents a large reniform, slightly concave facet for the first cuneiform and projects downward into the sole to form the tuberosity, a rough eminence into which the peroneus longus and a slip of the tibialis anterior are inserted. A little

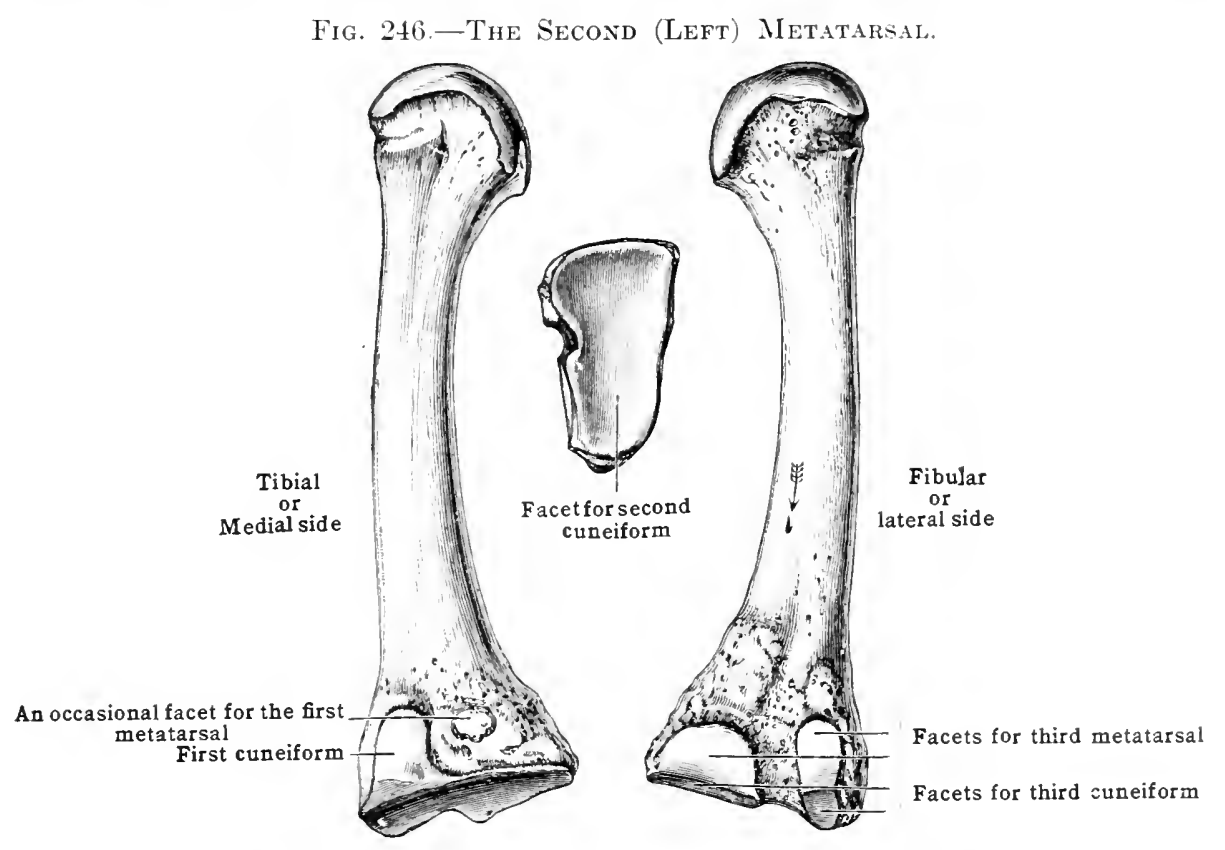

above the tuberosity, on its lateral side, there is occasionally a shallow, but easily recognised facet, for articulation with the base of the second metatarsal. The head is marked on the plantar surface by two deep grooves, separated by a ridge, in which the two sesamoid bones of the flexor hallucis brevis glide. The shaft is markedly prismatic. The dorsal surface is smooth, broad, and convex, directed obliquely upward; the plantar surface is concave longitudinally

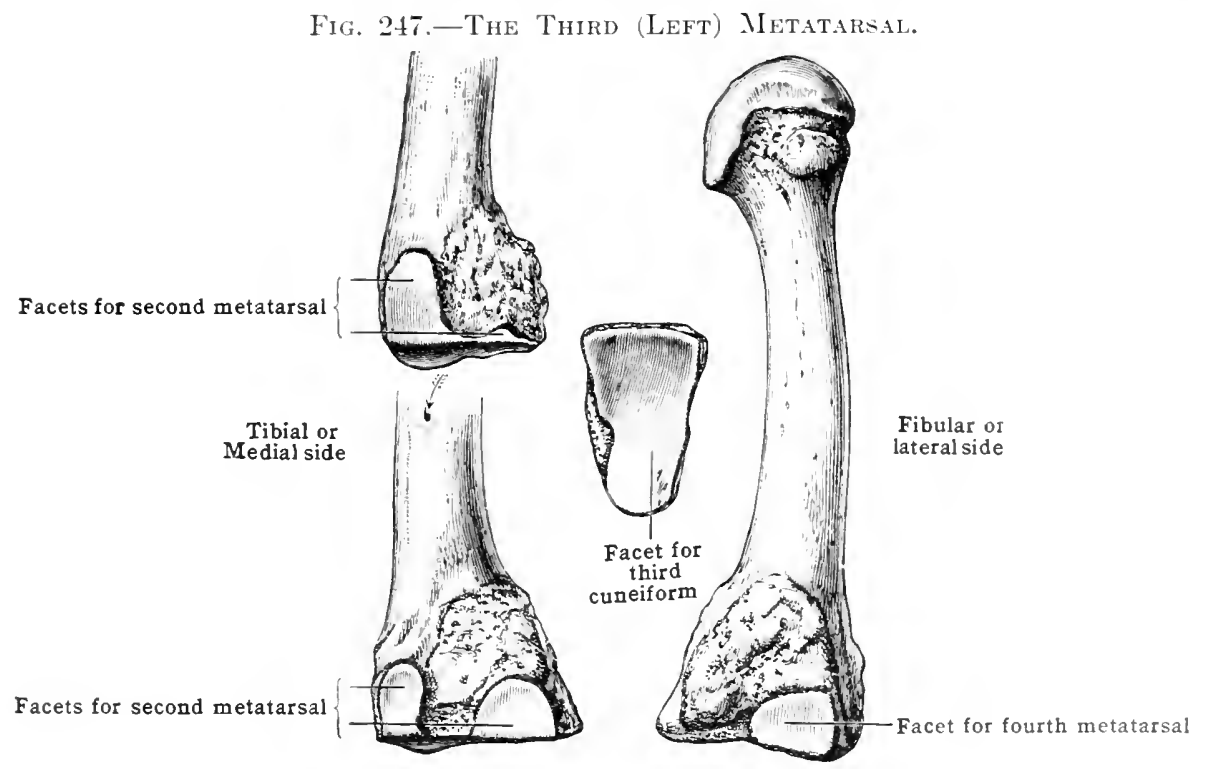

and covered by the flexor hallucis longus and brevis, whilst the lateral surface is triangular in outline, almost vertical, and in relation with the first dorsal interosscous and adductor hallucis obliquus. A few fibres of the medial head of the first dorsal interosseous vecasionally arise from the hinder part of the surface adjoining the base, or from the border separating the lateral from the dorsal surface. Somewhere near the middle of the shaft, and on its fibular side, is the nutrient foramen, directed toward the head of the bone. 
The second metatarsal (fig. 246) is the longest of the series. Its base is prolonged backward to occupy the space between the first and third cuneiform, and accordingly it is marked by facets for articulation with each of these hones. The tarsal surface is triangular in outline, with the base above and apex below, and articulates with the second cuneiform bone. On the tibial side of the base, near the upper angle, is a small facet for the first cuneiform, and occa-

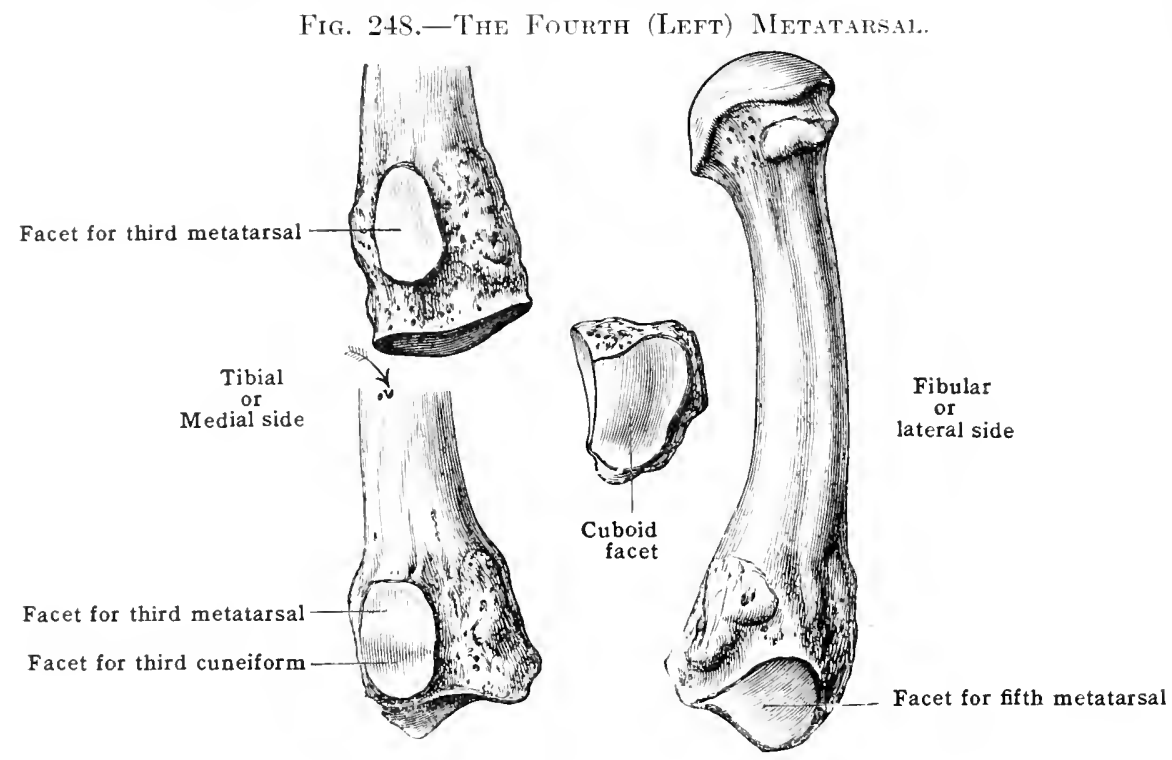

sionally another for the first metatarsal a little lower down. The fibular side of the base presents an upper and a lower facet, separated by a non-articular depression, and each facet is divided by a vertical ridge into two, thus making four in all. The two posterior facets articulate with the third cuneiform and the two anterior with the third metatarsal. The base gives attachment to a slip of the tibialis posterior and the adductor hallucis obliquus, whilst from the

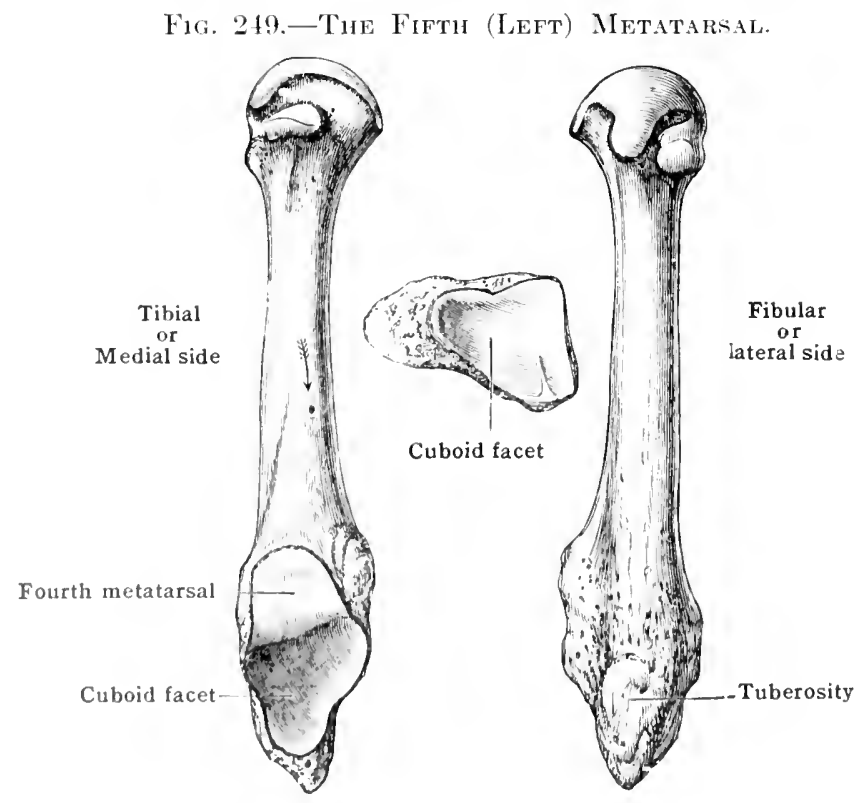

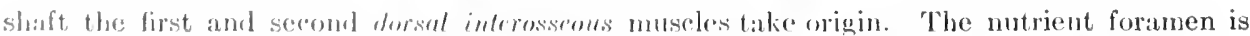
situated on the fibular side of the shaft near the midtle and is directed toward the base of the boue.

The: third metatarsal (fig. "217), a little shorter than the second, articulates by the triangular surface of its hase with the third runciform. On the medial side are two small facets, one below the other, for the soronet metatarsil, and on the lateral side, a single large facet for the fourth metatarsal. 'The: base gives attachment to a slip of the tibialis posterior and the rndurtor halluris obliques, and from the shaft three inleresscous muscles take origin. The motrent foranon is situated on the tihial side of the shaft and is clirerted toward the base. 
The fourth metatarsal (fig. 24S), smaller in size than the preceding, is distinguished by the quadrilateral facet on the base, for the cuboid. 'The medial side presents a large facet divided by a ridge into an anterior portion for articulation with the third metatarsal and a posterior portion for the third cuneiform. Occasionally the cuneiform part of the facet is wanting. On the lateral side of the base is a single facet for articulation with the fifth metatarsal.

The fifth metatarsal (fig. 249), is shorter than the fourth, but longer than the first. It is recognised by the large nipple-shaped process, known as the tuberosity, which projects on the lateral side of the base. It constitutes the hindmost part of the bone and gives insertion to the peroneus brevis on the dorsal aspect, and flexor brevis digiti quinti and the occasional abductor ossis metatarsi quinti on the plantar aspect. The fifth metatarsal articulates behind by an obliquely directed triangular facet with the cuboid, and on the medial side with the fourth metatarsal. The plantar aspect of the base is marked by a shallow groove which lodges the tendon of the abductor digiti quinti, and the dorsal surface, continuous with the superior surface of the shaft, receives the insertion of the peroneus tertius. The head is small and turned somewhat laterally in consequence of the curvature of the shaft in the same direction. The shaft differs from that of any of the other metatarsals in being compressed from above downward, instead of from side to side, so as to present superior, inferior, and medial surfaces. It gives origin to the lateral head of the fourth dorsal interosseous and the third plantar interosseous muscles. The nutrient foramen is situated on its tibial side and is directed toward the base.

Ossification. - Each metatarsal ossifies from two centres. The primary nucleus for the shaft appears in the eighth week of embryonic life in the middle of the cartilaginous metatarsal. At birth, each extremity is represented by cartilage, and that at the proximal end is ossified by extension from the primary nucleus, except in the case of the first metatarsal. For this, a nucleus appears in the third year.

The distal ends of the four lateral metatarsals are ossified by secondary nuclei which make their appearance about the third year. Very frequently an epiphysis is found at the listal end of the first metatarsal as well as at its base. The shafts and epiphyses consolidate at the twentieth year. The sesamoids belonging to the flexor hallucis brevis begin to ossify about the fifth year.

\section{THE PHALANGES}

The phalanges (fig. 250) are the bones of the toes, and number in all fourteen. Except the great toe, each consists of three phalanges, distinguished as first (proximal), second and third (distal); in the great toe the second phalanx is absent.

Fig. 250.-The Phalanges of the Midple Toe.
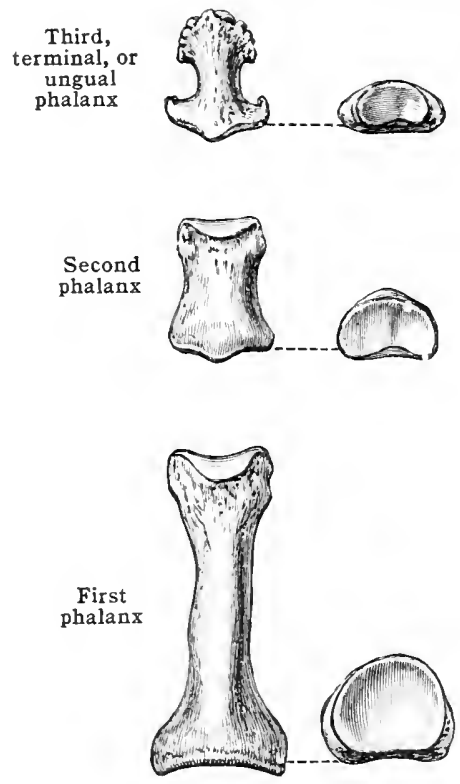

There is thus a similarity as regards number and general arrangement with the phalanges of the fingers. With the exception of the phalanges of the great toe, which are larger than those of the thumb, the bones of the toes are smaller and more rudimentary than the corresponding bones of the fingers. In all the phalanges, the nutrient foramen is directed toward the distal extremity.

The phalanges of the first row are constricted in the micldle and expanded at either extremity. The shafts are narrow and laterally compressed, rounded on the dorsal and concave 
on the plantar aspects. The base of each presents a single oval concave facet for the convex head of the corresponding metatarsal, whilst the head forms a pulley-like surface [trochlea phalangis], grooved in the centre and elevated on each side for the second phalanx.

The phalanges of the second row are stunted, insignificant bones. Their shafts, besides being much shorter, are flatter than those of the first row. The bases have two depressions, separated by a vertical ridge, and the heads present trochlear surfaces for the ungual phalanges.

The third, or ungual phalanges are easily recognised. The bases articulate with the second phalanges; the shafts are expanded, forming the ungual tuberosities which support the nails, and their plantar surfaces are rough where they come into relation with the pulp of the digits.

The nuscles attached to the various phalanges may be tabulated thus:-

The first phalanx of the hallux gives insertion to the flexor hallucis brevis; abductor hallucis; adductor hallucis transversus and obliquus; extensor digitorum brevis.

The first phalanx of second toe: The first and second dorsal interosscous.

The first phalanx of third toe: Third dorsal interosseous; first plantar interosseous.

The first phalanx of fourth toe: Second plantar interosseous; fourth dorsal interosseous.

The first phalanx of fifth toe: Third plantar interosscous; flexor digiti quinti brevis; and abductor digiti quinti.

The terminal phalanx of hallux: Flexor hallucis longus; extensor hallucis longus.

Fig. 251.-A Longitcdinal Section of the Bones of the Lower Limb at Birth.

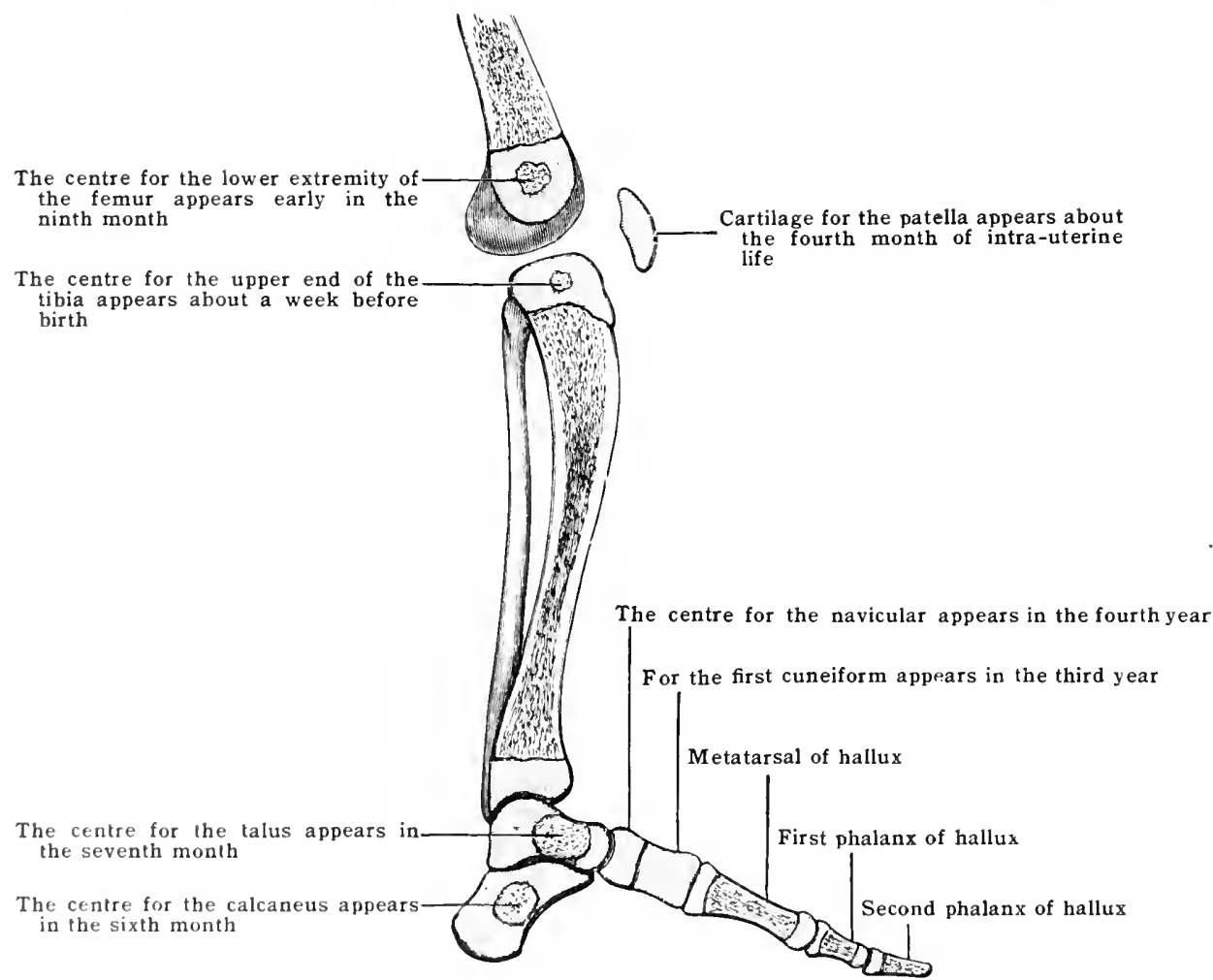

The second phalanges of the remaining toes: Dorsal expansion of the extensor tendons, including rextensor digitormm longus, extensor digitorum brevis (except in the case of the fifth toe), and (expancions from the interossei ambl lumbricales.

The third phalanges: lexor digitorum longus; dorsal expansion of the extensor tendon with the assereiatorl muscles.

Ossification.-- like the corresponding bones of the fingers, the phalanges of the toes ossify from it primary and in serondiury nuclens. In cach, the centre for the shaft appears during the cighth or ninth week of imbromic life. The secondary centre forms a seale-like epijhysis for the poxinat ond bet ween the fourth and eighth years, and union takes phare in the eighteenth or ninetecnth your i. e., corlier than the corresponding epiphyses in the fingers. 'The prinary "watros for the third phatangas appeatl at the rlistal extremities of the bones.

\section{TISAMOII BONB}

In the fort a pair of sesmoin bones is anstant over the metatamo-phalangeal joint of the grest tor: in the tenrlons of the flexor halluris lorevis. One sometimes oceurs over the interthalangeal joint of the same tor and over the metatarso-phalangeal joints of the second and fifth and rarely of the third and fourth toes. 
A sesamoid also occurs in the tendon of the peroneus longus, where it glides over the groove in the cuboid; another may be found, especially in later life, in the tendon of the tibialis anterior over the first cuneiform bone, and another in the tendon of the tibialis posterior over the medial surface of the head of the talus. Further a sesamoid, the fabella, sometimes occurs in the lateral head of the gastrocnemius, and another may be found in the tendon of the ilio-psoas over the pubis.

\section{BONES OF THE FOOT AS A WHOLE}

Although the foot is constructed on the same general plan as the hand, there is a marked difference in its architecture to qualify it for the different functions which it is called upon to perform. When in the erect posture, the foot forms a firm basis of support for the rest of the body, and the bones are arranged in an elliptical arch, supported on two pillars, a posterior or calcaneal pillar and an

Fig. 252.-The Secondary Ossific Centres of the Foot.

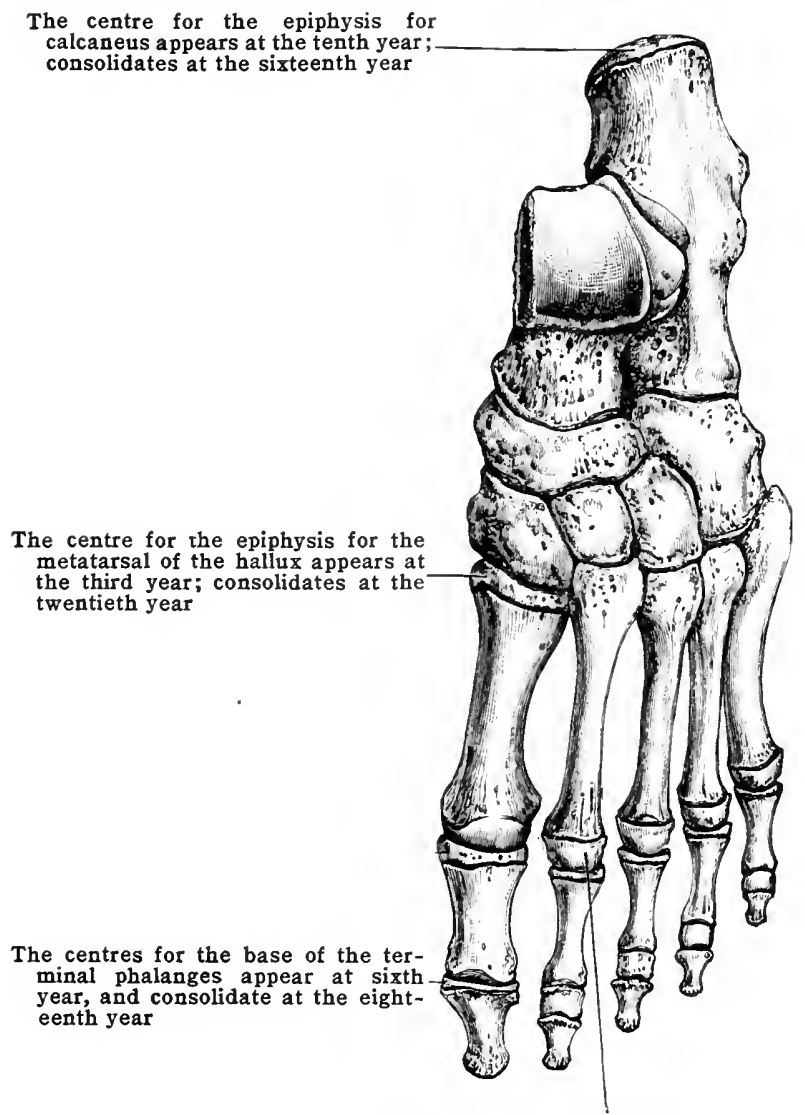

The entres for the heads of the metatarsals

appear at the third year, and consolidate at the twentieth year

anterior or metatarsal pillar. It is convenient, however, to regard the anterior part of the arch as consisting of two segments, corresponding to the medial and lateral borders of the foot respectively. The medial segment is made up of the three metatarsal bones, the three cuneiform, the navicular, and talus; the lateral segment is made up of the fourth and fifth metatarsal bones, the cuboid, and the calcaneus, and both segments are supported behind on a common calcaneal pillar. The division corresponds to a difference in function of the two longitudinal arches. Both are intimately concerned in ordinary locomotion. In addition, the medial, characterised by its great curvature and remarkable elasticity, sustains the more violent concussions in jumping and similar actions, whereas the lateral, less curved, more rigid, and less elastic arch forms, with the pillars in front and behind, a firm basis of support in the upright posture.

Both arches are completed and maintained by strong ligaments and tendons. The weakest part is the joint between the talus and navicular bone, and special 
provision is accordingly made, by the addition of a strong calcaneo-navicular ligament, for the support of the head of the talus. This ligament is in turn supported by its union with the deltoid ligament of the ankle, and by the tendon of the tibialis posterior which passes beneath it to its insertion.

Besides being arched longitudinally, the foot presents a transverse arch formed by the metatarsal bones in front and the distal row of the tarsus behind. It is produced by the marked elevation of the central portion of the medial longitudinal arch above the ground, whereas the lateral longitudinal arch is much less raised, and at its anterior end becomes almost horizontal. Both the longitudinal and transverse arches serve the double purpose of increasing the strength and elasticity of the foot and of providing a hollow in which the muscles, nerves, and vessels of the sole may lie protected from pressure.

\section{Homology of the Bones of the Limbs}

That there is a general correspondence in the plan of construction of the two extremities is apparent to a superficial observer, and this becomes more marked when a detailed examination of the individual bones, their forms and relations, their embryonic and adult peculiarities, is systematically carried out. In each limb there are four segments, the shoulder girdle corresponding to the pelvic girdle, the arm to the thigh, the forearm to the leg, and the hand to the foot. These parts have been variously modified, in adaptation to the different functions of the two limbs, particularly as regards the deviations or changes from what is regarded as their primi-

Fig. 253.-Diagramiatic Representation of the Bones of the Two Limbs, to show Homologous Parts. (Modified from Flower.)

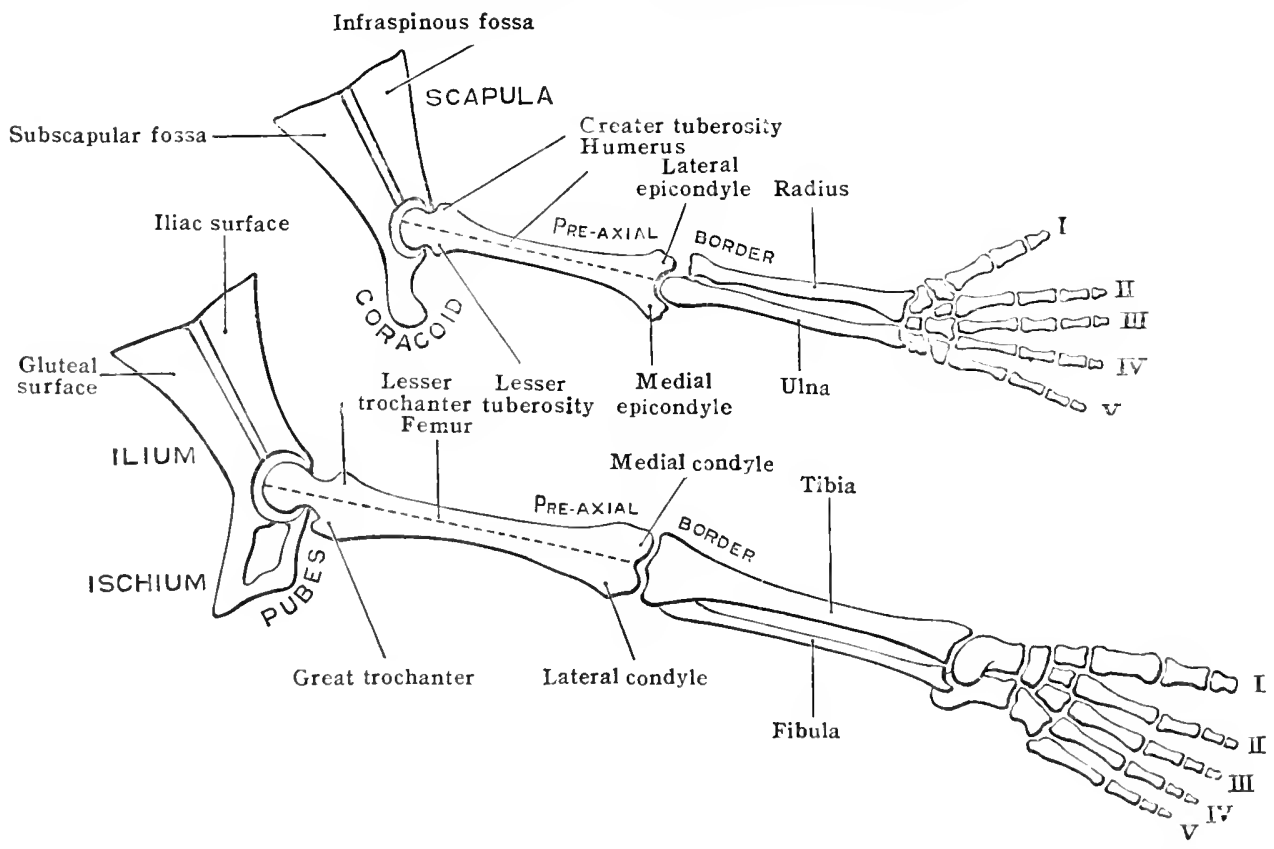

tive position, and as a knowlerlge of these ehanges is essential to a clear understanding of the homologous bones, it will be advantageous to refer briefly to the relations of the limbs in the arliest stages of development.

The limbs first appe:1r ats flattened, bud-like outgrowths from the sides of the trunk. Each prescents a dorsal or eetenser surface, and a ventral or flexor surface, as well as two borders, itll antrior, or crphalie, directed lowarl the head end of the embryo, and a posterior or candal, clirested toward the tail end. In reference to the axis of the limb itself, the borders have

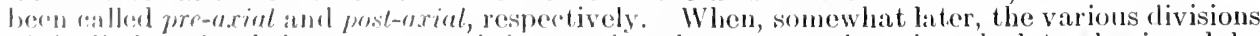
of the limb make their appearanee, it is seen that the greater tuberosity, the lateral epicondyle, the ratins, and the thmmb, lie on the pre-axial border of the anterior extremity, and the small trochatnfer, the merlial comlyle, the tibia, and the great toe on the pre-axial border of the posterior extremity. Further on the post-axial borter of the anterior extremity are seen the

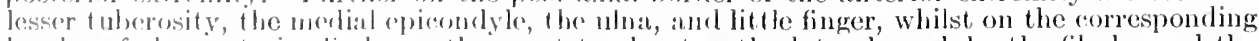

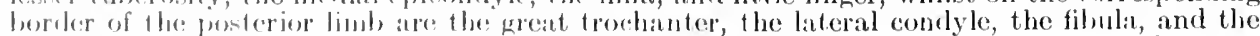
little: toe. 'flie parts new enumerated on the corresponding borders of the two limbs must therefore be regareled as serially homedogous (fig. 25)3). 
It is necessary to trace next the further changes which take place in the segments of the limbs up to the time when they assume their permanent positions. They may be arranged in stages as follows:-

(1) Each segment of the limb is bent upon the one above it. The humerus and femur remain unchanged. The forearm segment, however, is bent so that the ventral surface looks medially and the dorsal surface laterally. Moreover, the joints between these segments-i. c., elbow and knee-form marked projections. The terminal segments (hand and foot) are bent in the opposite direction to the middle one, so that the primitive position is retained, and the ends of the digits directed laterally. It will be noticed that in this series of changes the relations of the pre-axial and post-axial borders of the limbs remain as before.

(2) This stage consists in a rotation of the whole limb from the proximal end, though in an exactly opposite direction in each case. The anterior extremity is rotated backward so that the humerus lies parallel with the trunk; the elbow is directed toward the caudal end, the pre-axial (radial) border becomes lateral, and the post-axial border medial. The ends of the digits point backward. The posterior extremity undergoes a rotation forward to the same extent, so that the femur is also nearly parallel with the trunk; the knee is directed toward the head end, the pre-axial (tibial) border becomes medial, and the post-axial border lateral. The tibia and fibula are parallel, the ends of the digits are directed forward, the great toe is on the pre-axial and the little toe on the post-axial border of the limb, and in this position the posterior extremity remains, the changes being finally completed by the extension of the limb at the hip-joint as the body attains its full development.

(3) This stage affects the anterior extremity alone and consists in a rotation of the rarlius, carrying the hand round the ulna so that the digits are brought round from the back to the front of the limb, and in many animals the manus is thus placed permanently in the prone position. But in man, in whom the caparity for pronation and supination is highly developed, the hand can assume either position at will. In his case the final change is the extension which takes place at the shoulder-joint with the assumption of the upright posture, the limb dropping loosely at the side of the body, and being endowed with the greatest freedom of movenent.

Homological comparison of-

I. The shoulder and pelvic girdles.-Primarily the lateral half of each girdle consists of a curved bar or rod of cartilage placed at right angles to the longitudinal axis of the trunk and divisible into a dorsal segment, and a ventral segment, the point of division corresponding to the place of articulation with the limb-stalk-i. e., the glenoid and acetabular cavities. In the fore-limb the dorsal segment is the scapula, and the ventral segment the coracoid, whilst in the hind-limb the dorsal segment is the ilium and the ventral segment the ischium and pubis.

The dorsal segments of the two girdles-i. e., scapula and ilium-are accordingly regarded as homologous bones, the chief difference being that whereas the scapula is free from articulation with the vertebral column, the ilium is firmly jointed to the rib elements (lateral mass) of the sacrum. But the correspondence is not quite so clear with regard to the ventral segments. In the primitive condition the coracoid articulates with the side of the sternum, an arrangement which persists throughout life in certain animals, such as reptiles and Ornithorhynchus. But in all the higher mammals it undergoes reduction, withdrawing from the side of the sternum, and eventually forming a more or less rudimentary process attached to the scapula. In the more generalised form of shoulder girdle the ventral bar is double, consisting of coracoid and precoracoid elements, the latter being situated in front and almost parallel with the coracoid. 'The pre-coracoid in mammals is largely replaced by the development over it of the clavicle, a dermal or membranous splint-bone which eventually invades the underlying cartilage. Parts, however, remain distinct and form the sternal epiphysis of the clavicle, the inter-articular cartilage between it and the sternum, the supra-sternal bones, and the inconstant inter-articular cartilage in the acromio-clavicular joint.

It has already been noticed that in the hip girdle the ventral segment also consists of two elements, the pubis and ischium. Both take part in the formation of the acetabular cavity, and the pubis meets in the ventral median line the corresponding segment of the opposite side.

It is generally agreed that the coracoid and ischium are lomologous structures. The pubic portion of the ventral segment appears to correspond most closely with the pre-coracoid element of reptiles, so that there is no true homologue of the clavicle in the pelvis. If, however, the clavicle corresponds to the reptilian pre-coracoid, as believed by many anatomists, it then becomes the representative of the pubis.

From a consideration of the condition in cranio-cleido-dysostosis, Mr. Fitzwilliams has put forward the following riews regarding the homology of the shoulder girlle:-Coracoid bar is represented by (a) medial two-thirds of clavicle; (b) coraco-clavicular ligaments; and (c) sub-coracoid centre of coracoid process. The clavicula, a membranous bone, is represented by the lateral third of adult clavicle. The pre-coracoid har is represented by:-(a) the coracoirl process (less the sub-coracoid centre); and (b) the costo-coracoid ligament. The epi-coracoid is represented by the meniscus of the sterno-clavicular joint.

Moreover, it is possible to establish a somparison between the individual parts of the ilium and scapula. A reference to fig. 253 shows that both the scapula and ilium may be resolved into three-sided prismatic rods, each of which has three surfaces and three borders. In the primitive position of the limb one surface - the internal - is turned toward the vertebral column, the remaining surfaces are external, and named pre-axial and post-axial, corresponding to the borders of the limb. The borders separating the internal from the external surfaces are antero-internal (terminating in the acromion or pubis) and postero-internal (terminating in the coracoid or ischium). The two external surfaces are separated by a ridge, terminating below at the upper margin of the glenoid cavity or acetabulum (glenoid and cotyloid borders).

The primitive arrangement is lost by the marked growth of the borders of the rods leading to the formation of fossa and by the rotation of each rod, the scapula laterally and the ilium medially, in association with the rotation which takes place in the free part of the limb, so that 
the inner surface of the one comes to correspond with the outer surface of the other. It results that the primitive vertebral surface of the scapula is now the pre-scapular or supraspinous fossa, and the corresponding surface in the ilium is the sacral, which, on account of its close conneetion with the vertebral column, undergoes but little change in position. Further, the primitive pre-axial surfaces are the infraspinous fossa and the iliac fossa, which accordingly are to be regarded as homologous, as well as the two post-axial surfaces, the subscapular fossa and the dorsum ilii. The correspondence between the various parts of the scapula and ilium is shown in the appended table (after Flower).

\section{ScAPULA}

\section{Surfaces :}

II. Borders :
Supraspinous fossa. Infraspinous fossa. Subscapular fossa. Axillary or glenoid.

\section{Spine.}

Superior or coracoid.

Base.

\section{Prinitive Arrangement \\ Vertebral. \\ Pre-axial. \\ Post-axial. \\ External.}

Antero-internal.
Postero-internal.
Dorsal extremity.

\section{ILI UMI}

Sacral surface.

Iliae fossa.

Gluteal surface.

Cotyloid or anterior border.

Terminal line.

Posterior border.

Crest of ilium.

II. Bones of the arm and thigh, forearm, and leg.-It has already been pointed out in describing the deviation of the limbs from the primitive position that the humerus corresponds to the femur, the radius to the tibia, and the ulna to the fibula; also that in consequence of the rotation backward of the fore-limb, and forward of the hind-limb, the lateral side of the humerus corresponds with the medial side of the femur, the radial border of the forearm to the tibial border of the leg, and the ulnar (border of the forearm) to the fibular border of the leg. 'The corresponding parts are tabulated below:-

\begin{tabular}{cc}
\multicolumn{1}{c}{ Fore-Limb } & \multicolumn{1}{c}{ Hind-LinB } \\
Humerus & Femur \\
Greater tuberosity & Lesser Trochanter \\
Lesser tuberosity & Great Trochanter \\
Lateral epicondyle and capitulum & Medial Condyle \\
Medial epicondyle and trochlea & Lateral Condyle \\
Radius & Tibia \\
Ulna & Fibula \\
Not represented & Patella
\end{tabular}

III. Bones of the hand and foot.-It is obvious that the carpus and tarsus, the metacarpus and metatarsus, and the various digits, commencing at the thumb, in the hand, and at the great toe, in the foot, are serially homologous.

Fig. 254.-Dorsal Surface of the Right Manus of a IVater-tortorse, Chelydra serpentina. (After Gegenbaur.)

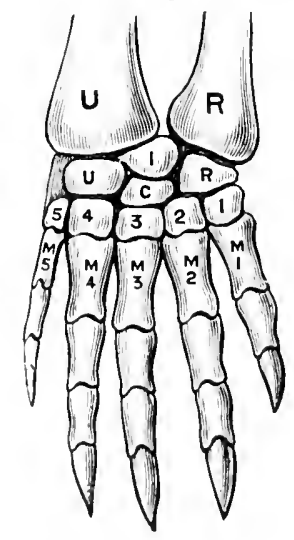

In order to trace the correspondence between the various elements of the carpus and tarsus it is envenient to refer in the first place to the primitive type of hand and foot as found in the water-tortoise and the lizaril (fig. 254). In each segment nine elements may be reeognised, arrangel in a proximal row of three, named respectively radiale or tibiale, intermedium, and ulnare, or fibulare, a clistal row of five carpalia, or tarsalia, numbered from one to five, commencing at the pre-axial borlor, and between the two rows an os centrale.

In man the carpus is ieriverl from the typical form in the following manner: The radiale forms the navicular, intermerlium the lunate, and the ulnare, the triquetral; carpale I forms the greater multangular, carpale II the lesser multangular, carpale III the capitate, whilst carpalia IV and $V$ coileser to form the hamate. The os eentrale is present in the human earpus at an early stige, but in the second nonth it joins the navicular. It is occasionally separatea normal arrangumont in most of the primates. 
In the tarsus, the tibiale and intermedium coalesce to form the talus, and the fibulare becomes the calcaneus. It is interesting to note that although in the human subject there are three bones in the first row of the carpus and two in the first row of the tarsus, in carnivores the navicular and lunate are united to form a naviculo-lunate bone-the homologue of the talus. In the human tarsus the intermedium occasionally remains distinct as the os trigonum.

Tarsale I forms the first cuneiform, tarsale II the second cuneiform, tarsale III the third cuneiform, and tarsale $I V$ and $V$ are joined to form the cuboid. The os centrale forms the navicular.

In addition to the carpal and tarsal elements enumerated above, brief mention must now be made of the sesamoid bones of the two segments, which are regarded by many anatomists as vestiges of suppressed digits. In the hand are the ulnar and radial sesamoids, the ulnar being represented by the pisiform and the radial probably by the tuberosity of the navicular. (In the mole and other allied species with fossorial habits, the radial sesamoid is greatly developed to form a sickle-shaped bone which has received the name of os falciforme.)

The corresponding structures in the foot are the tibial and fibular sesamoids, the tibial being most nearly represented by the tuberosity of the navicular and the fibular by the tuber of the calcaneus.

Table Showing the Honologous Bones of the Carpus and Tarsus. (After G. D. Thane in Quain's Anatomy.)

\section{Carpus}

Triquetral

Pisiform

Lunate

Navicular

Greater multangular Lesser multangular

Capitate

Hamate

\section{Primitive Nanes}

Unare
Unar sesamoid
Intermedium
Radiale
Radial sesamoid
Centrale
Carpale I
" II II
“
“ IV

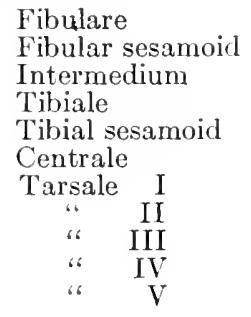

\section{TARSUS}

$\left\{\begin{array}{l}\text { Calcaneus } \\ \text { Talus } \\ \text { Navicular }\end{array}\right.$
First cuneiform
Second cuneiform
Third cuneiform
Cuboid

References.-For the development of the skeleton, consult the bibliography in Bardeen's article in Keibel and Mall's 'Human Embryology,' Vol. 1. For further references concerning the adult structure and morphology of the skeleton, the sections on osteology in the larger works on human anatomy by Quain, von Bardeleben, Rauber-Kopsch. Poirier-Charpy, etc., should be consulted. References to the most recent literature may be found in Schwalbe's Jahresbericht, the Index Medicus, and in the various anatomical journals. 


\section{SEC'I I O N I I I \\ THE ARTICULATIONS}

Revised for the Fifth Edition

By FREDERIC WOOD JONES, D.Sc., M.B., B.S.(Lond.), M.R.C.s.., L.R.C.P.

HEAD OF THE DEPARTMENT OF ANATOMY AND LECTURER IN THE LONDON SCHOOL OF MEDICINE FOR WOMEN.

\section{THE CONSTITUENTS OF AN ARTICULATION}

$\mathrm{T}^{\mathrm{n}}$

HE section devoted to the Articulations or Joints deals with the union of the various and dissimilar parts of the human skeleton. The following structures enter into the formation of joints.

Bones constitute the basis of most joints. The long bones articulate by their ends, the flat by their edges, and the short at various parts on their surfaces. The articular ends are usually expanded, and are composed of cancellous tissue, surrounded by a dense and strong shell of compact tissue.

This shell has no Haversian canals (the vessels of the cancellous tissue turn back and do not perforate it), or large lacunæ, and no canaliculi, and is thus well adapted to bear pressure. This "osteoid" layer may represent in part calcified cartilage rather than true bone.

The cartilage which covers the articular ends of the bones is called articular, and is of the hyaline variety. It is firmly implanted on the bone by one surface, while the other is smooth, polished, and free, thus reducing friction to a minimum, while its slight elasticity tends to break jars. It ends abruptly at the edge of the articulation, and is thickest over the areas of greatest pressure.

Another form of cartilage, the white fibrous, is also found in joints:-

(i) As interarticular cartilage in diarthrodial joints-viz, in the knee, mandibular, sterno-clavicular, radio-carpal, and occasionally in the acromio-clavicular joint. It is interposed between the ends of the bones, partially or completely dividing the synovial cavity into two. It serves to adjust dissimilar bony surfaces, adding to the security of, while it increases the extent of motion at, the joint; it also acts as a buffer to break shocks.

(ii) As circumferential or marginal fibro-cartilages, which serve to deepen the sockets for the reception of the heads of bones-e. g., the glenoid ligaments of the shoulder and hip.

Another form of marginal plate is seen in the accessory volar ligaments of the fingers and toes, which deepen the articulations of the phalanges and add to their security.

(iii) As connecting fibro-cartilage. The more pliant and elastic is the more cellular form, and is found in the intervertebral dises; while the less yielding and more fibrous form is seen in the sacro-iliac and pubic articulations, where there is little or no movement.

The ligaments which bind the bones together are strong bands of white fibrous tissue, forming a more or less perfect capsule [capsula articularis], round the articu. lation. They are pliant but inextensile, varying in shape, strength, and thick. ness according to the kind of articulation into which they enter. They are closely connected with the periosteum of the bones they unite. In some cases-as the ligamenta flava which unite parts not in contact-they are formed of rellow elastic tissue.

The synovial membrane [stratum synoviale] lines the interior of the fibrous ligaments, thus excluding them, as well as the cushions or pads of fatty tissue situate within and the tendons which perforate the fibrous capsule, from the articular cavity. It is a thin, delicate membrane, frequently forming folds and fringes which project into the cavity of the joint; or, as in the knee, stretches across the cavity, forming a so-called synovial ligament. In these folds are often found pads of fatty tissue, which fill up interstices, and form soft cushions between the contiguous bones. The amount of fat that is normally present within a joint varies greatly. It is an old observation that al though there is always fat in the hip- 
and knee-joints, there is usually none within the shoulder-joint. Sometimes these fringes become villous and pedunculated, and cause pain on movement of the joints. They contain fibro-fatty tissue, with an isolated cartilage cell or two. The synovial membrane is well supplied with blood, especially near the margins of the articular cartilages and in the fringes. It secretes a thick, glairy fluid like white of egg, called synovia, which lubricates the joint. Another variety of synovial membrane is seen in the bursæ, which are interposed between various moving surfaces. In some instances bursx in the neighbourhood of a joint may communicate with the synovial cavity of that joint.

\section{CLASSIFICATION OF ARTICULATIONS}

Joints may be classified:- (a) From an anatomical point of view, with regard to the substances and the arrangement of the substances by which the constituent parts are united. (b) From a physiological standpoint, with regard to the greater or smaller mobility at the seat of union. (c) From a physical standpoint, either the shapes of the portions in contact being mainly considered or the axes round which movement can occur. Or again $(d)$ a combination of the preceding methods may be adopted, and this is the plan most generally followed. None of the classifications hitherto used is quite satisfactory, but perhaps, on the whole, that suggested by Prof. Alex. Macalister is the least open to objection, and therefore with slight modification it is utilised here.

There are three chief groups of joints:-

1. Synarthroses. In joints of this class the bones are united by fibrous tissue.

2. Synchondroses. Or joints in which the uniting substance intervening between the bones is cartilage.

3. Diarthroses. The constituent parts of joints of this class are $(a)$ two or more bones each covered by articular hyaline cartilage; $(b)$ a fibrous capsule uniting the bones, and $(c)$ a synovial membrane which lines the fibrous capsule and covers any part of bone enclosed in the capsule and not covered with articular cartilage. An interarticular plate of cartilage may or may not be present.

Synarthroses. -

(a) Sutures or immovible joints, in which the fibrous tissue between the bones is too small in amount to allow movement.

(1) Harmonic. The edges of the bones are comparatively smooth and are in even apposition, c. g., vertical plate of palate and maxilla.

(2) Squamous. The margin of one bone overlaps the other, e. g., temporal and parictal.

(3) Serrate. The opposed edges interlock by processes tapering to a point.

(4) Dentute. The opposed edges are clovetailed, e. g., occipital and parietal.

(5) Limbous. 'The opposed edges alternately overlip, r. g., parietal and frontal.

(6) Schindylesis. A ridge or flattened process is received into a corresponding socket, $\cdots$ g., rostrum of sphenoid and vomer.

(7) Gomphosis. A peg-like process is lodged in a corresponding socket, e.g., the fangs of the teeth.

(b) Syndesmoses. Movalble joints in which the fibrous tissue between bones or cartilages is sufficiently lax to allow movenent between the connected parts, e. g., thyreo-hyoil membrane. Interosseons membranes of forearm and leg.

2. Synchondroses. - In all synchoudroses at certain amount of movement is possible, and they are often ealled amphiarthrosess.

(1) True synchondross's. The cartilage eonnecting the bones is the remains of the bar in which the bones were ossified, 9 . g., oecipito-sphenoidal joint.

(2) Fitse synchoudroses. The plate of cirtitage intervening between and connecting the bones is fibro-eirtilage and is unt part of the cartilage in which the bones were onsifierl, but is dreveloped sepatrately, c. ge, intervertebral joint and pubie symphysis. The articular end of calch bone maty be covered with hyaline cartiliage and there nuty be a more or lese well-mitrked eavity in the intervening plate of fil)r(y-rourtilisgr.

$\therefore$ Diarthroses. - In diarthondial joints the surfaces in eontact maty bo equal and similar or unerpal and dissimilar. In the former ease the joints are homomorphie; in the

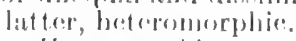

(A) Ilomemorylic:

(a) Plone or arthrodial. Flat surfaces, alduitting gliding movement, e. g.,

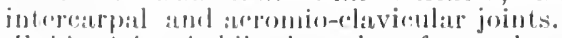

(b) Ephippinl. Sialdle-sld:tped surfares placed at right angles to each other, admitting free movenumt in all thrections, e. g., metsearpo-phalangeal joint of thuinh, 
(B) Heteromorphic.

(a) Enarthrodial. Ball-and-socket, allowing the most free movement, e. g., hipand shoulder-joints.

(b) Condylarthroses. The convex surface is ellipsoidal, and fits into a corresponding concavity, e. g., wrist and metacarpo-phalangeal joints.

(c) Ginglymi. One surface consists of two conjoined condyles or of a segment of a cone or cylinder, and the opposite surface has a reciprocal contour. In these joints movement is only permitted round one axis, which may be transverse; e. g., elbow, ankle; or it may be vertical, in which case the joint is trochoid; e. g., odontoid process of axis with atlas, radius with ulna.

Such a classification should be considered as being purely academic and the student must always remember that it is not enough to discuss a joint by assigning it to a particular class in any scheme; for he must be familiar with the actual conditions present in every joint. No classification, however perfect, must be taken as final, and each joint should be studied as a separate thing altogether apart from any general systematic arrangement.

\section{DEVELOPMENT AND MORPHOLOGY OF JOINTS}

The arrangement of the various parts which constitute an articulation is best appreciated by a study of the development of the various types of joints. In this way it is easy to recognise a primitive condition typical of each class; but it must be remembered that various modifications take place during growth, that these modifications vary in the individual joints, and produce adult departures from the primitive arrangement which are peculiar to each joint and which must be studied separately.

In the case of bones ossifying in membrane the articulation will be a suture, the ossifications from neighbouring centres extending until they practically come into contact.

Fig. 255.-Developuent of Joints

$A$. Stage in which primary embryonic tissue separates the developing cartilages.

$B$. Primary embryonic tissue transformed into cartilage (synchondrosis), or fibrous connective tissue (syndesmosis).

C. Degeneration of embryonic tissue with production of a joint cavity (diarthrosis).

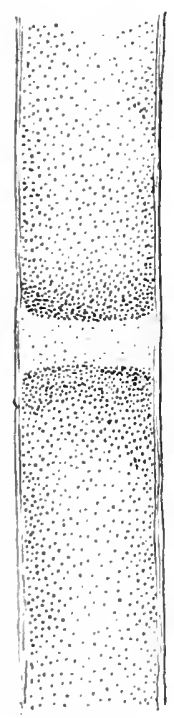

A

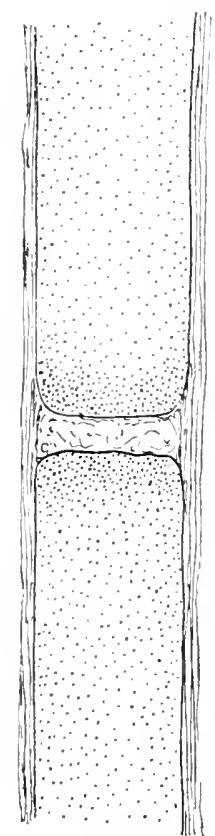

B

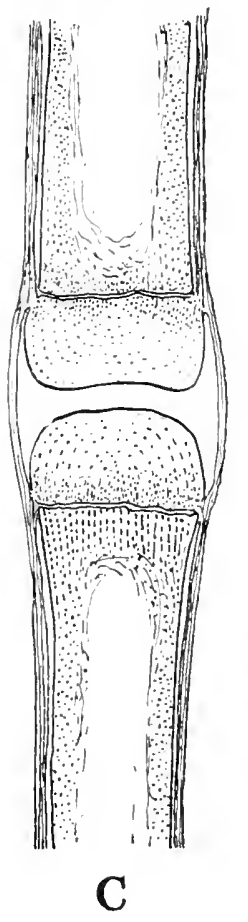

With cartilage bones the articulation may be either a syndesmosis, a synchondrosis, or a diarthrosis. The embryonic tissue in which the cartilage is to develop is at first continuous; centres of chondrification, corresponding in number to the bony elements which are destined to be formed, appearing in it. As the chondrifications approach each other a small portion of the primary embryonic tissue persists between them (fig. 255), and it is the subsequent fate of

(1) When the ossification of the cartilage occurs to form the articulating bones, the intermediate tissue may undergo transformation into cartilage (fig. 255), a synchondrosis being thus produced. (2) Or the intermediate tissue may be converted into fibrous connective-tissue 
(fig. 255), the result being a syndesmosis. (3) Or, finally, the central portion of the intermediate tissue may degenerate, so that an articular cavity is produced, the peripheral portions being converted into conmective tissue, forming a sleeve-like capsule surrounding the cavity, continuous at either extremity with the periosteum of the articulating bones (fig. 255). This is the articular capsule, and the connective-tissue cells arranging themselves in a layer upon its inner surface give rise to a synovial membrane. As the result of these processes a diarthrosis is produced, and from its mode of formation it is clear that the cavity of such an articulation is completely closed.

In a typical diarthrosis there is therefore a ligamentous capsule which entirely encloses the joint cavity, which is continuous with the periosteum of the bones entering into the articulation but which is not attached to nor reflected onto the cartilaginous ends of the bones which constitute the articulating surfaces. Such a capsule constitutes the primitive bond between the articulating bones and furnishes a complete lubricating bag in which these smooth cartilaginous ends glide over one another. This primitive capsule, however, becomes modified in most adult joints, (1) by unequal development of various parts of the capsule; and (2) by the more or less complete incorporation of other structures which are developmentally separate from the capsule. Under the first heading come specially thickened bands which may be so distinctly marked off from the rest of the capsule as to be named as separate ligaments (e. g., the temporo-mandibular ligament of the mandibular joint). Again certain thickened bands of capsule may, with alteration of joint contour, take up anatomical positions which are apparently separated from the rest of the capsule; advanced examples of this process are, in all probability, seen in the ligamentum teres of the hip-joint and the crucial ligaments of the knee. Under the second heading comes a series of ligaments derived from a great variety of sources; the most common origin being from the divorced or rearranged tendons of the muscles around the joint.

Muscles arising from, or inserted into, bones in the immediate vicinity of a joint tend to become metamorphosed into tenclon near their attachments, and a comprehensive study of myology in low vertebrate forms indicates that there is associated with this tissue-change a tendency for the muscle to alter its point of attachment; hence a muscle originally inserted below a joint may eventually come to have its insertion above the joint. In the same way, a muscle arising above a joint nay, as a result of altered environment, shift its origin to some point below the joint. To this change of position the term migration of muscles has been applied. In many instances a portion of the muscle equivalent to the distance between the original and the acquired attaclument persists as a fibrous band and fulfils the function of a ligament. This is well seen in the knee-joint, where the tibial collateral ligament is derived from the adductor magnus, this muscle having shifted its insertion from the tibia to the femur. In the same way the fluchur collateral ligament represents the tendon of the peroneus longus, which has migrated from the femur to the head of the fibula.

Anong other ligaments derived in a similar way from muscles may be mentioned the sacrotuberoms ligament. This was originally the tendon of origin of the biceps femoris. (H. Morris, Mel. Times and Gazette, 1877, p. 361.) The sacro-spinous is derived from the fibrous retrogression of portions of the coccygeus. The sacro-coccygeal ligaments represent the muscles which lift, lepress, and wag the tail in those mammals furmished with such an appendage; indeed, these ligaments are occasionally replaced by muscle-tissue.

The coraco-humeral ligament is derived from the original tendon of insertion of the pectoralis minor, and not unfrequently the muscle is inserted into the lesser tuberosity of the humerus, the ligament being then replaced by the tendon of the muscle. The coraco-clavicular, rhomboid, and gleno-humeral liguments are probably derived from modifications of the subclavius muscle.

Other anatomical structures besides muscles may, when degenerated or functionally altered, form the basis of ligaments in connection with joints. The spheno-mandibular ligament is the fibrous remnant of the cartilaginous manclibular bar.

The putpy substance in the centre of each intervertebal disc is lerived from the notochord; the apical ligamol passing from the tip of the dens to the anterior margin of the foramen magnimn is a remnant of the sheath of the notochord, and indicates its position as it passed from the vertehral column into the base of the cranium. The transverse ligament of the atlas (as pointed out by Professor Cleland) is a persistent and functional form of the posterior conjugal ligament miting the rib-hearls in soals and many other mammals, whilst the interosseous ligament of the liead of a rib in man is the fochle rejoresentative of this structure in the thoracic region of the spine. The ligamentum ronjugale costarum was deseribed by Mayer in 1834 (.Iïller's . Irchiv für Anatonie). Acrording to luscluka's account of this ligament it would secun as througl the posterior superior fitres of the rapsule of the costo-central joint represented it in man, rather than the inforosseous higament.

\section{T'HE' MOVEMENTS OF JOINT'S}

'Tlue movements which may lake place at a joint are either glicling, angular, rotatory, or circumeluetory.

Thro gliding motion is the simplest, and is rommon to all diarthrodial joints; it consists of a simple slibling of the apjosed surfices of the lunes upon one another, without angular or rotatory motion. It is the only kind of motion permited in the carpal and tarsal joints, and in those betweres the articular processes of the vertehis:

T'he angular unotion is more claborate, and increases or diminishes the angle between differant parts. There aro four varioties, viz., flexion and extension, which bend or straighten the varions joints, and take plawe in a forwarl and lownward direction (in a perfect hinge-joint this is the only motion pormited); atud adduction and abduction, which, exeept in the case of the fingers and fors, signifies an approas h to, or deviation from, the median plane of the body. In the 
case of the hand, the line to or from which adduction and abduction are made is drawn through the middle finger, while in the foot it is through the second toe.

Rotation is the revolution of a bone about its own axis without much change of position. It is only seen in enarthrodial and trochoidal joints. The knee also permits of slight rotation in certain positions, which is a distinctive feature of this articulation.

Circumduction is the movement compounded of the four angular movements in quick succession, by which the moving bone describes a cone, the proximal end of the bone forming the apex, while the distal end describes the base of the cone. It is seen in the hip and shoulder, as well as in the carpo-metacarpal joint of the thumb, which thus approximates to the ball-andsocket joint.

In some situations where a variety of motion is required, strength, security, and celerity are obtained by the combination of two or more joints, each allowing a different class of action, as in the case of the wrist, the ankle, and the head with the spine. Many of the long muscles, which pass over two or more joints, act on all, so tending to co-ordinate their movements and enabling them to be produced with the least expenditure of power. Museles also act as elastic ligaments to the joints; and when acting as such, are diffusers and combiners, not producers of movement; the short muscles producing movement, the long diffusing it, and thus allowing the short muscles to act on more than one joint.

Muscles are so disposed at their attachments near the joints as never to strain the ligaments by tending to pull the bones apart, but, on the contrary, they add to the security of the joint by bracing the bones firmly together during their action.

The articulations may be divided for convenience of description into those: 1 . of the Skull; 2. of the Trunk; 3. of the Upper Limb; and 4. of the Lower Limb.

\section{THE ARTICULATIONS OF THE SKULL}

The movable articulations of the skull comprise (1) the mandibular; and (2) those between the skull and the vertebral column, namely $(a)$ between the occiput and atlas; (b) between the atlas and epistropheus (axis); and $(c)$ the ligaments which connect the occiput and epistropheus.

The union of the atlas and epistropheus is described in this section because, (1) there is often a direct communication between the synovial cavity of the transverse epistrophic and the occipito-atlantal joints; $(2)$ the rotatory movements of the head take place around the dens (odontoid process); and (3) important ligaments from the dens pass over the atlas to the occiput.

\section{(1) THE MANDIBULAR ARTICULATION}

\section{Class.-Diarthrosis. Subdivision.-Condylarthrosis.}

The parts entering into the formation of this joint (figs. 256, 257) are:-the anterior portion of the mandibular fossa and glenoid ridge (eminentia articularis) of the temporal bone above, and the condyle of the lower jaw below. Both are covered with articular cartilage, which extends over the front of the glenoid ridge to facilitate the play of the interarticular cartilage. The ligaments which unite the bones are:
1. Articular capsule.
2. Articular disc.
3. Spheno-mandibular.
4. Stylo-mandibular.

The articular capsule is often described as consisting of four portions, anterior, posterior, lateral and medial, which are, however, continuous with one another around the articulation.

1. The anterior portion consists of a few stray fibres connected with the anterior margin of the articular disc, and attached below to the anterior edge of the condyle, and above to the front of the articular eminence. Some fibres of insertion of the external pterygoid pass between them to be inserted into the margin of the articular disc.

2. The posterior portion is attached above, just in front of the petro-tympanic (Glaserian) fissure, and is inserted into the back of the jaw just below its neck.

3. The lateral portion or temporo-mandibular (external lateral) ligament (fig. 256) is the strongest part of the capsule. It is broader above, where it is attached to the lower edge of the zygoma in nearly its whole length, as well as to the tubercle at th point where the two roots of the zygoma meet. It is inclined downward and backward, to be inserted into the condyle and neck of the mandible laterally. Its fibres diminish in obliquity and strength from before backward, those coming from the tubercle being short and nearly vertical.

4. The medial portion (or short internal lateral ligament) (fig. 257) consists of well-defined fibres, having a broad attachment, above to the lateral side of the spine of the sphenoid and medial edge of the mandibular fossa; and below, a narrow insertion to the medial side of the neck 
of the condyle. Fatty and cellular tissue separate it from the spheno-mandibular ligament which is medial to it.

The articular disc (fig. 258) is an oval plate of fibro-cartilage interposed between and adapted to the two articular surfaces. It is thinner at the centre than at the circumference, and is thicker behind, where it covers the thin bone at the bottom of the mandibular fossa which separates it from the dura mater, than in front, where it covers the articular eminence.

Fig. 256.-Lateral View of the Mandibular Joint.

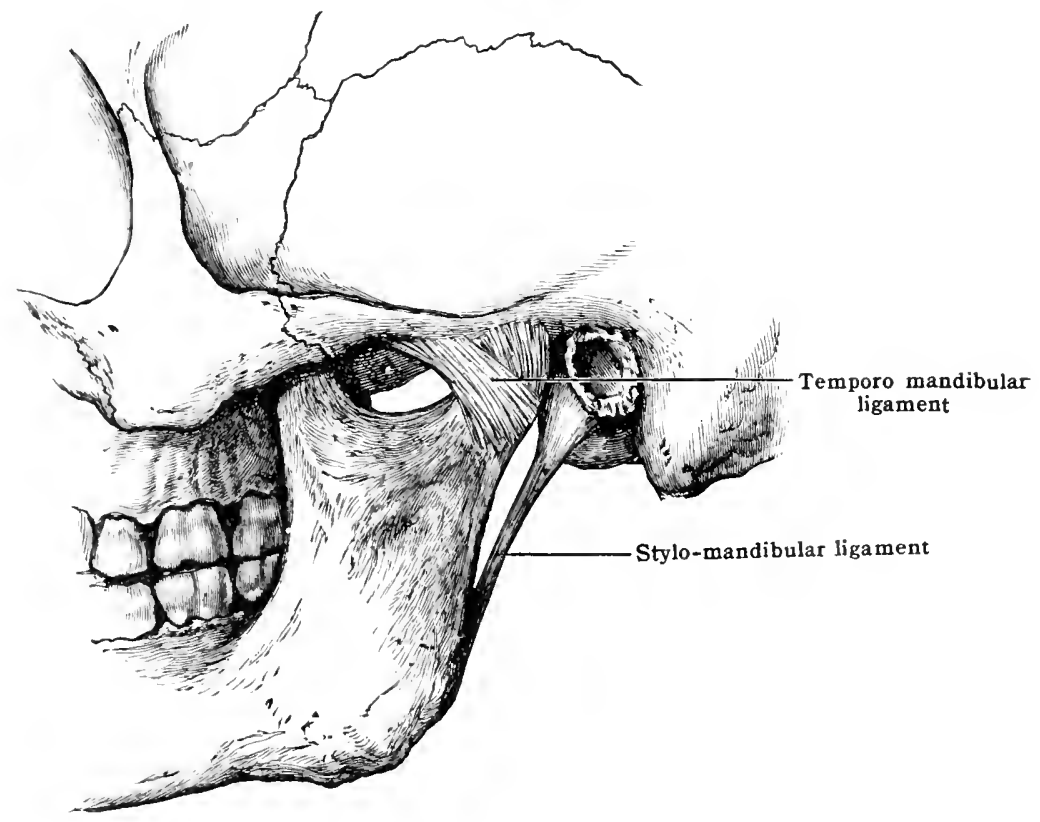

Fig. 257.- Medial View of the Mandibular Jonnt.

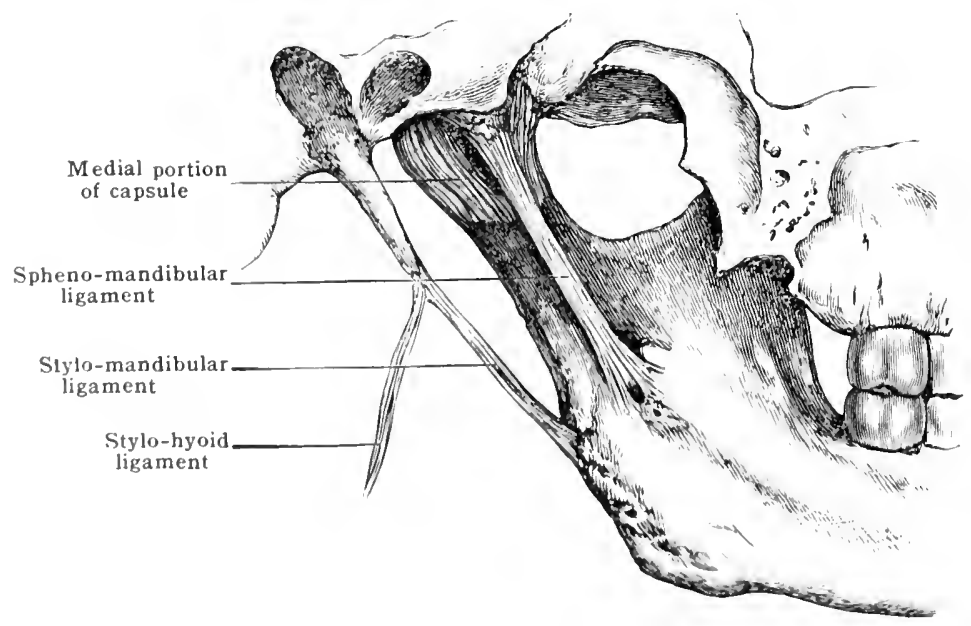

Its infrior surfuer is concave and fits on to the condyle of the lower jaw; while its superior surface is concavo-ennve from before backward, and is in contact with the articular surface of the temporal bono. It divides the joint into two separate synovial ravities, but is oceasionally perforated in the centre, and hlus allows then to communicate. it is connected with the articular capsule at its circumference, and has some fibres of the externalipterygoid muscle inserted into its anterior margin.

There are usially $t w 0$ synovial membranes (fig. 258), the superior being the larger and looser, passing down from the margin of the articular surface above, to the upper surface of the articular disc below; the lower and smaller one passes. 
from the articular disc above to the condyle of the jaw below, extending somewhat further down behind than in front. When the disc is perforated, the two sacs communicate.

The spheno-mandibular ligament (long internal lateral) (fig. 257) is a thin, loose band, situated some little distance from the joint. It is attached above to the spine of the sphenoid and contiguous part of the temporal bone, and is inserted into the lingula of the lower jaw.

It covers the upper end of the mylo-hyoid groove, and is here pierced by the mylo-hyoid nerve. Its origin is a little medial to, and immediately behind, the origin of the medial portion of the capsule. It is separated from the joint and ramus of the jaw by the external pterygoid muscle, the internal maxillary artery and vein, the inferior alveolar (dental) nerve and artery, the auriculo-temporal nerve, and the middle meningeal artery. It is really the fibrous remnant of a part of the mandibular (Meckelian) bar.

The stylo-mandibular ligament (stylo-maxillary) (figs. 256 and 257) is a process of the deep cervical fascia extending from near the tip of the styloid process to the angle and posterior border of the ramus of the jaw, between the masseter and internal pterygoid muscles. It separates the parotid from the submaxillary gland, and gives origin to some fibres of the stylo-glossus muscle.

Fig. 258.-Sagittal Section throdgh the Condyle of Jaw to show the Two Synoviai Sacs and the Articular Disc.

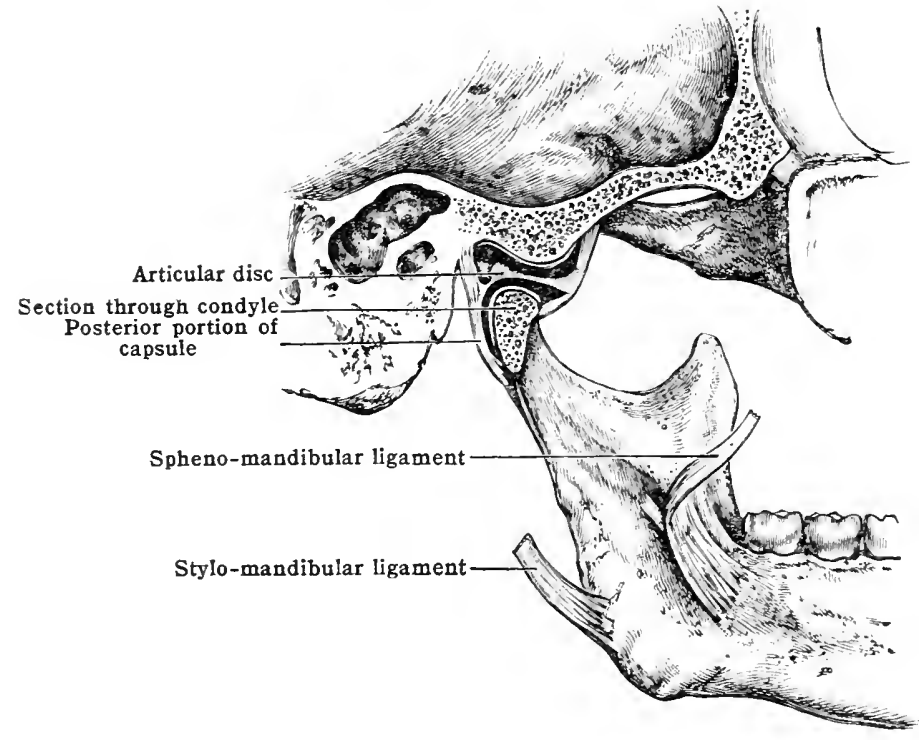

The arterial supply of the mandibular joint is derived from the temporal, middle meningeal and ascending pharyngeal arteries, and from the latter by its branches to the Eustachian tube. The nerves are derived from the masseteric and auriculo-temporal.

Movements. - The chief movement of this joint is of (i) a ginglymoid or hinge character, accompanied by a slight gliding action, as in opening or shutting the mouth. In the opening movement the condyle turns like a hinge on the articular disc, while at the same time the articular disc, together with the condyle, glides forward so as to rise upon the eminentia articularis, reaching as far as the anterior edge of the eminence, which is coated with articular cartilage to receive it; but the condyle never reaches quite so far as the summit of the eminence. Should the condyle, however, by excessive movement (as in a convulsive yamn), glide over the summit, it slips into the zygomatic fossa, the mandible is dislocated, and the posterior portion of the capsule is torn. In the shutting movement the condyle revolves back again, and the articular disc glides back, carrying the condyle with it. This combination of the hinge and gliding motions gives a tearing as well as a cutting action to the incisor teeth, without any extra muscular exertion.

There is (ii) a horizontal gliding action in an antero-posterior direction, by which the lower teeth are thrust forward and drawn back again: this takes place almost entirely in the upper compartment, because of the closer connection of the articular disc with the condyle than witl the squamosal bone, and also because of the insertion of the external pterygoid into both bone similarly engaged.

The third form of movement is called (iii) the oblique rotatory, and is that by which the grinding and chewing actions are performed. It consists in a rotation of the condyle about 
the vertical axis of its neck in the lower compartment, while the eartilage glides obliquely forward and inward on one side, and baekward and inward on the other, upon the articular surface of the squamosal bones, each side acting alternately. If the symphysis be simply moved from the centre to one side and back again, and not from side to side as in grinding, the condyle of that side mores round the vertical axis of its neck, and the opposite condyle and cartilage glide forward and inward upon the mandibular fossa. But in the ordinary grinding movement, one condyle advances and the other recedes, and then the first recedes while the other advances, slight rotation taking place in each joint meanwhile.

Relations.- The chief relations are: Behind, and overlapping the lateral side, the parotid gland. Laterally, the superficial temporal artery. Medially, the internal maxillary artery and auriculo-temporal nerve. In front, the nerve to the masseter muscle.

Muscles acting on the joint.-Elevalors of the mandible.-temporals, masseters, int. pterygoids.

Depressors.-Mylo-hyoids, digastrics, genio-hyoid, muscles connecting the hyoid bone to lomer points. Ext. pterygoids. The weight of the jaw.

Protraclors.- Ext. pterygoids, superfieial layer of masseters, anterior fibres of temporals.

Retractors.-Posterior fibres of temporals, slightly by the int. pterygoids and deep layer of the masseters.

\section{(2) THE LIGAMENTS AND JOINTS BETWEEN THE SKULL AND VERTEBRAL COLUMN, AND BETWEEN THE ATLAS AND EPISTROPHEUS}

\section{(a) The Articulation of the Atlas with the Occiput}

Class.-Diarthrosis. Subdivision.-Double Condylarthrosis.

This articulation [articulatio atlanto-oecipitalis] consists of a pair of joints symmetrically situated on either sicte of the middle line. The parts entering into their formation are the cup-shaped superior articular processes of the atlas and the condyles of the occipital bone. They are united by the following ligaments:--

1. Anterior atlanto-oecipital.

2. Posterior atlanto-occipital.

3. Two artieular eapsutes.

4. Two anterior oblique.

The anterior atlanto-occipital ligament [membrana atlanto-oceipitalis anterior] (fig. 259) is less than an inch (about $2 \mathrm{~cm}$.) wide, and is composed of densely woven fibres, most of which radiate slightly lateralward as they ascend from the front surface and upper margin of the anterior areh of the atlas to the anterior border of the foramen magnum; it is continuous at the sides with the articular eapsules, the fibres of which overlap its edges, and take an opposite direction medially and upwart.

The central fibres ascend vertically from the anterior tubercle of the atlas to the pharyngeal tubcrele on the occipital bone; they are thicker than the lateral fibres, and are continuous below with the superficial part of the anterior atlanto-epistrophic ligament, and through it with the anterior longiturlinal ligament of the vertebral column. It is in relation, in front, with the recli capilis antcriores; and behind, with the apical dental or suspensory ligament.

The posterior atlanto-occipital ligament (fig. 260) is broader, more membranous, and not so strong as the anterior. It extends from the posterior surface and upper border of the posterior arch of the atlas to the posterior margin of the foramen magnum from condyle to condyle; being incomplete on either side for the passage of tho vertebral artery into, and suboccipital nerve out of, the canal. It is somewhat thiekcued in the middle line by fibres, which pass from the posterior tubercle of the atlas to the lower end of the oecipital erest.

It is not tightly stretched hetween the bones, nor does it limit their movements; it corresponds with the position of the ligamentit flava, but has no elastic tissue in its composition. It is in relation in front with the clura mater, which is finly attached to it; and behind with the recti cupilis posteriores minores, and enters into the floor of the suboceipital triangle. Its lateral margins, which ro not reach the ocsipital bone hat terminate on the posterior end of the superior articular processes of the atlas, form the so-called oblique ligaments of the allas. The lafral margins of these liguments are free and they form the posterior boundaries of the ajertures through which the verteloral arteries enter and the suboceipital nerves leave the vertebral caual.

The atlanto-occipital articular capsules (figs. 259 and 260 ) are very distinet and strongly marked, exeept on the medial side, where they are thin and formed only of short membranous fibres. They are lax, and do not add mueh to the sereurity of the joint. 
In front, the capsule descends upon the atlas, to be attached, some distance belon the articular margin, to the front surface of the lateral mass and to the base of the transverse process; these fibres take an oblique course upward and medialward, overlapping the anterior atlant ooccipital. At the sides and behind, the capsule is attached above to the margins of the occipital condyles; below, it skirts the medial edge of the foramen for the vertebral artery, and behind is attached to the prominent tubercle overhanging the groove for that vessel; these latter fibres are strengthened by a band running obliquely upward and merlialward to the posterior margin of the foramen magnum.

The anterior oblique or lateral occipito-atlantal ligament is an accessory band which strengthens the capsule laterally (fig. 259). It is an ohlique, thick band of fibres, sometimes quite separate and distinct from the rest, passing upward and medialward from the upper surface of the transverse process beyond the costo-transverse foramen to the jugular process of the occipital bone.

The synovial membrane of these joints occasionally communicates with the synovial sac between the dens (odontoid process) and the transverse ligament.

The arterial supply is derived from twigs of the rertebral, and occasionally from twigs from the meningeal branches of the ascending pharyngeal.

Fig. 259.-Anterior View of the Upper End of the Vertebral Coltux.

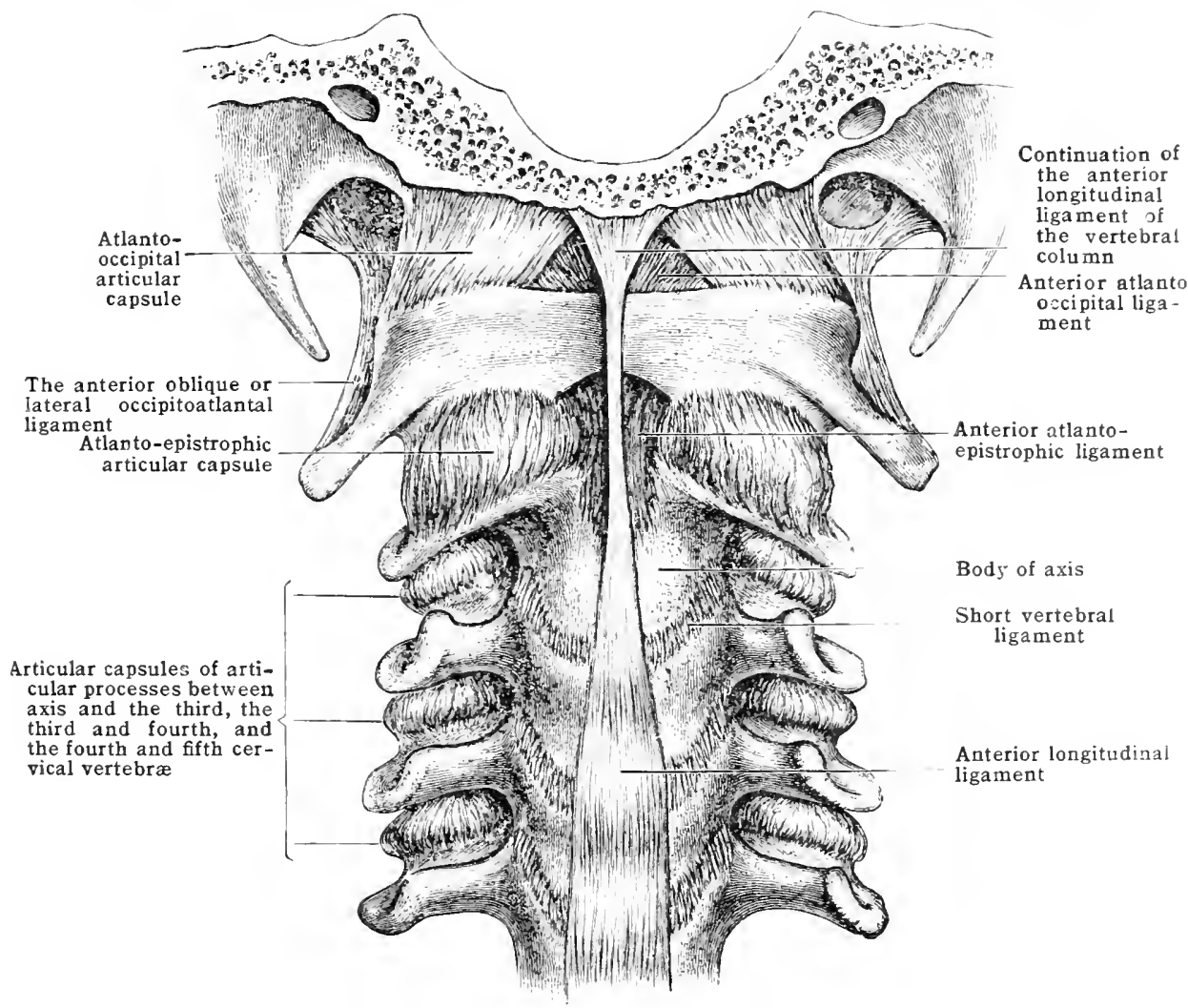

The nerve-supply comes from the anterior division of the suboccipital nerve.

Movements.- By the symmetrical and bilateral arrangement of these joints, security and strength are gained at the expense of a very small amount of actual articular surface; the basis of support and the area of action being equal to the width between the most distant borders of the joint.

The principal movement permitted at these joints is of a ginglymoid character, producing flexion and extension upon a transverse axis drawn across the condyles at their slightly constricted parts.

In flexion, the forehead and chin drop, and what is called the nodding morement is made; in extension, the chin is elevated and the forehead recedes.

There is also a slight amount of gliding movement, either directly lateral, the lateral edge of one condyle sinking a little within the lateral edge of the socket of the atlits, and that of the opposite condyle projecting to a corresponding degree. The head is thus tilted to one side, and it is even possible that the weight of the skull may be borne almost entirely on one joint, the articular surfaces of the other being thrown out of contact.

Or the movement may be obliquely lateral, when the lower side of the head will be a trifle 
in advance of the elevated side. In this motion, which takes place on the antero-posterior axis, one condyle adrances slightly and approaches the middle line, while the other recedes. This is of the nature of rotation, though there is no true rotation round a vertical axis possible between the occiput and atlas.

These lateral movements are checked by the alar ligaments and the lateral part of the capsules; extension is checked by the anterior atlanto-occipital and anterior oblique ligaments, and flexion by the posterior part of the capsile and the tectorial membrane.

Muscles acting upon the occipito-atlantal joint.- Flexion whereby the chin is approximated toward the sternum is produced by the weight of the anterior part of the head and by all muscles which are attached to the hyoid bone or to the bones of the skull in front of a transverse axis between the two condyles. These muscles take their fixed point below either from the vertebral column, the sternum, or the bones of the shoulder girdle. Before those connected with the mandible can act that bone must be fixed by the muscles of mastication which, therefore, also take part in the movements. It must be noted that the sterno-mastoid muscles are powerful flexors, although a part of their insertion is behind the transverse axis between the two condyles.

Extension is due to the action of muscles or portions of muscles inserted into the skull behind the transverse axis above mentioned, and connected below either with the vertebral column, shoulder girdle, or sternum.

Lateral movement is prodiced by the anterior and posterior groups of muscles on the same side acting simultaneously and aided by the rectus capitis lateralis of that side.

Fig. 260.-Median Sagittal Section of Tertebral Column showing Liganexts.

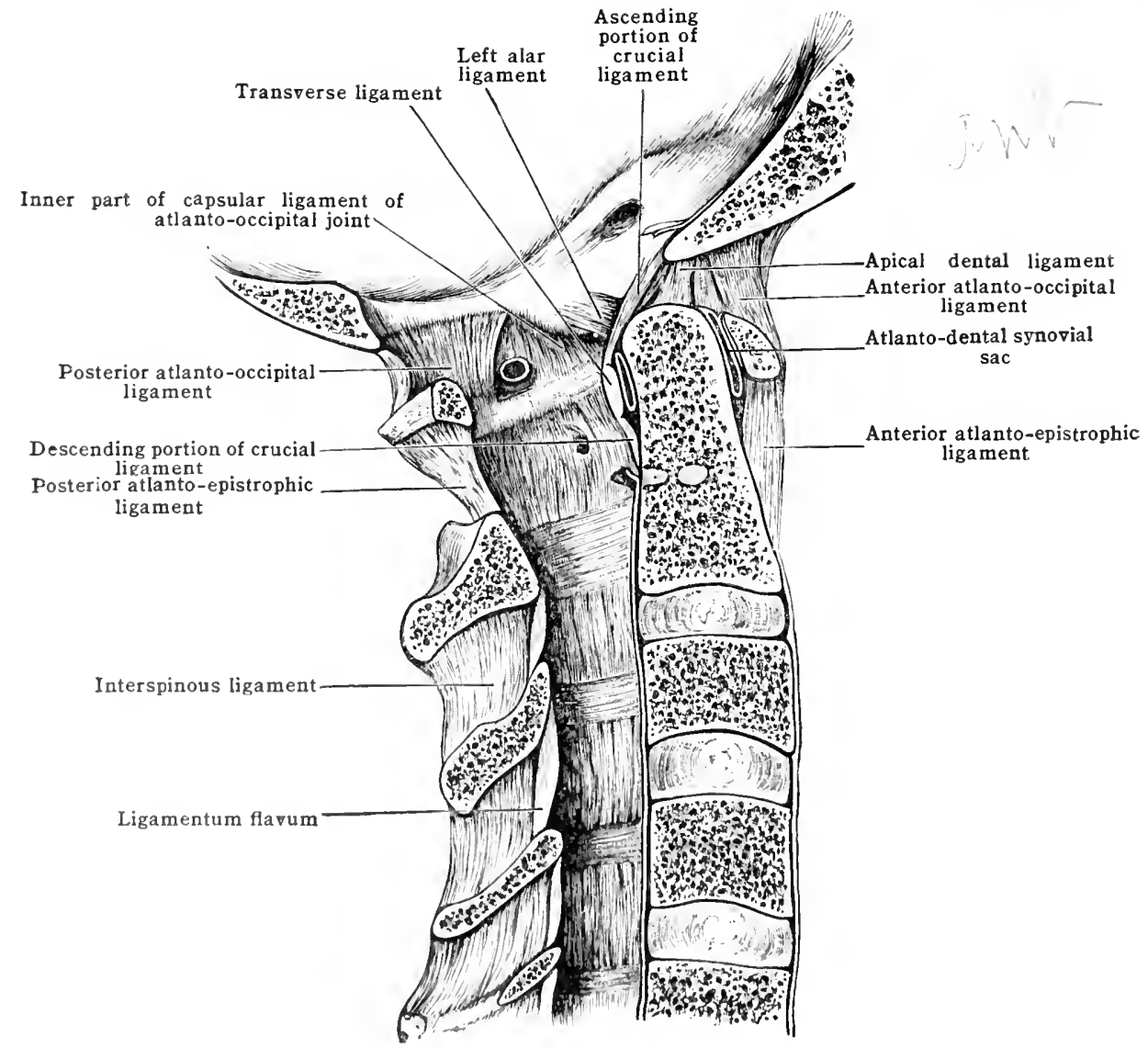

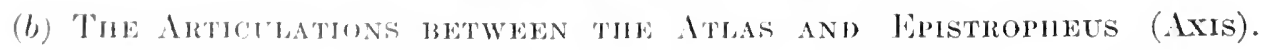

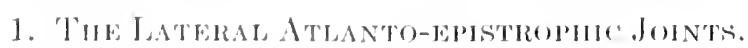

Class.-Diarthrosis.

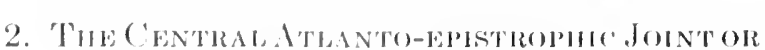
I'IE ITIANTO-DENTAI.

Subdivision.-Arthrodia.

Class.-Diarthrosis.

Subdivision.-T'rochoides.

The homes that enter into the formation of the lateral joints are the inferior articular propesses of the atlas and the superiol of the epistropheus (axis); the contral joint is formon hy tho dens coclontoid process) articulating in front with the atlas, and bethind with the transverse biganent. 
The ligaments which unite the epistropheus and atlas are:-
1. The anterior atlanto-epistrophic.
3. Two articular capsules (for lateral joints).
2. The posterior atlanto-epistrophic.
4. The transverse ligament.

\section{The atlanto-dental articular capsule.}

The anterior atlanto-epistrophic ligament (figs. 259 and 260) is a 11 arrow but strong membrane filling up the interval between the lateral joints. It is attached above to the front surface and lower border of the anterior arch of the atlas, and below to the transverse ridge on the front of the body of the epistropheus. Its fibres are vertical, and are thickened in the median line by a dense band which is a continuation upward of the anterior longitudinal ligament of the rertebral column.

This band is fixed above to the anterior tubercle of the atlas, where it becomes continuous with the central part of the anterior atlanto-occipital ligament (fig. 259); it is sometimes separated by an interval from the deeper ligament, and is often described as the superficial atlantoepistrophic ligament. It is in relation with the longus colli muscle.

The posterior atlanto-epistrophic ligament (fig. 260) is a deeper, but thinner and looser membrane than the anterior. It extends from the posterior root of the transverse process of one side to that of the other, projecting laterally beyond the posterior part of the capsules which are connected with it. It is attached above to the posterior surface and lower edge of the posterior arch of the atlas, and below to the superior edge of the laminæ of the epistropheus on their dorsal aspect.

It is denser and stronger in the median line, and has a layer of elastic tissue on its anterior surface like the ligamenta flava, to which it corresponds in position. It is connected in front with the dura mater; behind, it is in relation with the inferior oblique muscles, and is perforated at each side by the second cervical nerve.

1. The Lateral Atlanto-epistrophic Joints are provided with short, ligamentous fibres, forming articular capsules (fig. 259), which completely surround the lateral articular facets. Lateral to the canal they are attached some little distance from the articular margins, extending along the roots of the

Fig. 261.--Horizontal Section throdgh the Lateral Masses of the Atlas and the Top of the DeNs (Odontoid Process).

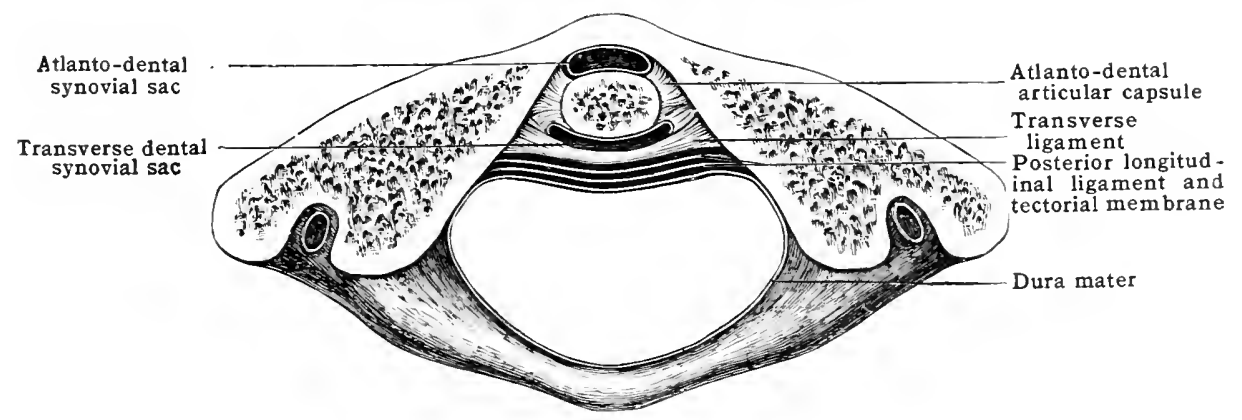

transverse processes of the epistropheus nearly to the tips, but between the roots they skirt the medial edge of the costo-transverse foramina. They are strengthened in front and behind by the atlanto-epistrophic ligaments.

Medially each capsule is thinner, and attached close to the articular margins, being strengthened behind by a strong band of slightly oblique fibres passing upwarl along the lateral edge of the tectorial membrane from the body of the epistropheus to the lateral mass of the at las behind the transverse ligament; some of these fibres pass on, thickening and blending with the atlantooccipital capsule, to be inserted into the margin of the foramen magnum. This band is sometimes called the accessory band (fig. 263).

There is a synovial membrane for each joint.

2. The Central Atlanto-epistrophic Joint, although usually described as one, is composed of two articulations, which are quite separate from one another:

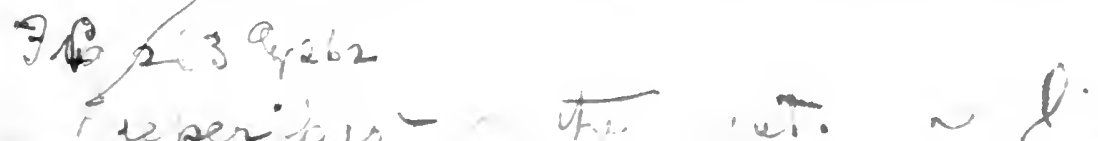


an anterior between the dens and the arch of the atlas, and a posterior between the dens and the transverse ligament.

The transverse ligament (figs. 260,261, and 263) is one of the most important structures in the body, for on its integrity and that of the alar ligaments our lives largely depend. It is a thick and verv strong band, as dense and closely woven as fibro-cartilage, about a quarter of an inch $(6 \mathrm{~mm}$.) deep at the sides, and somewhat more in the middle line. Attached at each end to a tubercle on the inner side of the lateral mass of the atlas, it crosses the ring of this bone in a curved manner, so as to have the concavity forward; thus dividing the ring into a smaller anterior portion for the dens and a larger posterior part for the spinal cord and its membranes, and the spinal accessory nerves.

It is flattened from before backward, being smooth in front, and covered by synovial membrane to allow it to glide freely over the posterior facet of the dens. Where it is attached to the atlas it is smooth and well rounded off to provide an easy floor of communication between the transverso-dental and occipito-atlantal joints.

To its posterior surface is added, in the middle line, a strong faseiculus of vertical fibres, passing upward from the root of the dens to the basilar border of the foramen magnum on its cranial aspect. Some of these fibres are derived from the transverse ligament. These vertical fibres give the transverse ligament a cruciform appearance; hence the name, the crucial ligament (figs. 260 and 263) applied to the whole.

The atlanto-dental articular capsule (fig. 261) is a tough, loose membrane, completely surrounding the apposed articular surfaces of the atlas and dens.

At the dens it blends above with the front of the alar and central occipito-odontoid ligaments, and arises also along the sides of the articular facet as far as the neck of the dens; the fibres are thick, and blend with the eapsules of the lateral joint. At the atlas they are attached to the non-articular part of the anterior areh in front of the tubercles for the transverse ligament, blending, above and below the borders of the bone, with the anterior atlanto-occipital and atlanto-epistrophic ligaments, as well as with the medial portion of the articular capsules. It holds the dens to the anterior areh of the atlas after all the other ligaments have been divided.

The synovial membranes (figs. 260 and 261) are two in number:-one for the joint between the dens and atlas; and another (transverso-dental) for that between the transverse ligament and the dens. This last often communicates with the atlanto-occipital articulations; it is elosed in by membranous tissue between the borders of the transverse ligament and the margin of the facet on the dens, and is separated from the front sac by the atlarito-dental articular capsile.

The arterial supply is from the vertebral artery, and the nerve-supply from the loop between the first and second cervical nerves.

Movements. - The chief and characteristic movement at these joints is the rotation, in a nearly horizontal plane, of the collar formed by the atlas and transverse ligament, round the dens as a pivot, which is extensive enough to allow of an all-round view without twisting the trunk. Partly on account of its ligamentous attachments, and partly on account of the shape of the articular surfaces, the eraniun must be carried with the atlas in these movements. The rotition is ehecked by the ligaments passing from the dens to the occiput (alar ligaments), and also by the atlanto-epistrophic. Owing to the fact that the facets of both atlas and epistrophens, which enter into the formation of the lateral atlanto-cpistrophic articulations, are convex from before backwarl, and have the articular cartilage thicker in the centre than at the cireumferenre, the motion is not guite horizontal but slightly eurvilinear. In the erect position, with the face looking liroctly forward, the most convex portions of the articular surfaces are alone in contact, there boing a consideralile interval between the elges; during rotation, therefore, the prominent portions of the condyles of the atlas descend upon those of the epistropheus, diminishing the spare between the lones, slackening the ligaments, and thus increasing the anount of rotation, without sacerificing the security of the joint in the rentral position.

Besides rotation, forwart and backward movenents and some lateral flexion are permitted between the atlis anrl cpistrophens, even to a greater extent than in most of the other vertebral joints.

The muscles acting upon the atlanto-epistrophic joints. - The muscles capable of producing rotation at the at lanto-(r)istroplin joints are those which take origin from near the mesial plane aither in front or behind aml which aro attached above either to the atlas or the skull, lateral to the athuto-rupistrophic jonts. Whan tho muscles which lie at the hack of the joint on one side anct they will torn the hearl fo the samesinte and will be aided by the muscles in front on the opposito side, If the musches in front and helind on the same side aret simultaneonsly, they will pull down the heal to that siele and will be aided hy muscles which pass more or less vertically

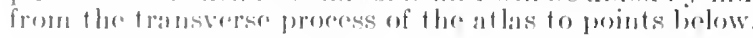


(c) The Ligaments uniting the Occiput and Epistropheus

The following ligaments unite bones not in contact, and are to be seen from the interior of the canal after removing the posterior arches of the epistropheus and atlas and posterior ring of the foramen magnum:-

1. The tectorial membrane.

2. The crucial ligament.

3. Two alar (or check) ligaments.

4. The apical dental ligament.

The tectorial membrane (occipito-cervical ligament) (figs. 261, 262, and 263) consists of a very strong band of fibres, connected below to the upper part of the body of the third vertebra and lower part of the body of the epistropheus as far as the root of the dens. It is narrow below, but widens out as it ascends, to be fastened to the basilar groove of the occiput. Laterally, it is connected with the accessory fibres of the atlanto-epistrophic capsule. It is really only the upward prolongation of the deep stratum of the posterior longitudinal ligament, the superficial fibres of which run on to the occipital bone without touching the epistropheus, thus giving rise to two strata. It is in relation in front with the crucial ligament.

Fig. 262.-The Stperficial Layer of the Posterior Longitudinal Vertebral Ligament has been Removed to show its Deep or Short Fibres. These Deep Fibres form the Tectorial Membrane. Tiewed from behind.

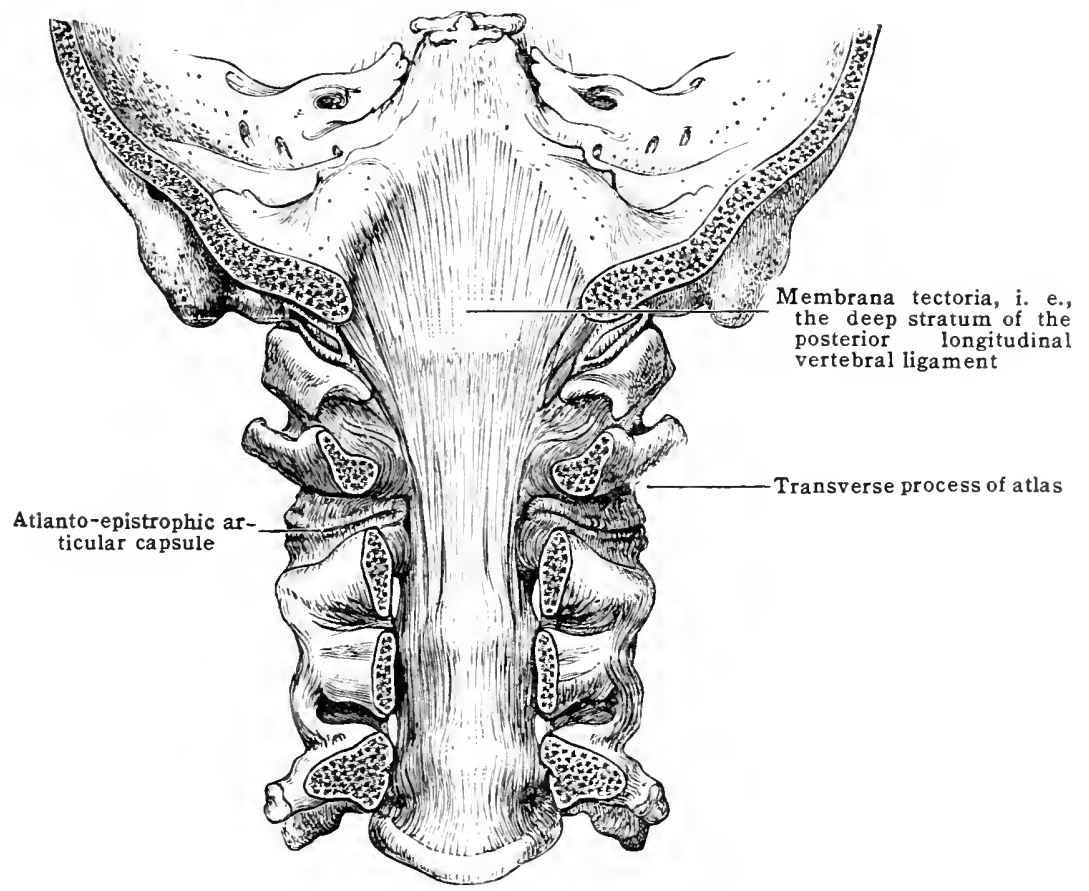

The crucial ligament has been already described (see p. 222).

The alar (or check) ligaments (figs. 260 and 263) are two strong rounded cords, which extend from the sides of the apex of the dens, transversely lateralward to the medial edge of the anterior portion of the occipital condyles.

They are to be seen immediately above the upper border of the transverse ligament, which they cross obliquely owing to its forward curve at its attachments to the atlas. Some of their fibres occasionally run across the middle line from one alar ligament to the other. At the dens they are connected with the atlanto-dental capsule, and at the condyles they strengthen the atlanto-occipital articular capsule.

The apical dental or suspensory ligament (figs. 260 and 263) consists of a slender band of fibres ascending from the suminit of the dens to the lower surface of the occipital bone, close to the foramen magnum. It is best seen from the front, after removing the anterior atlanto-occipital ligament, or from behind by drawing aside the crucial ligament. 
The apical ligament is tightened by extension and relaxed by flexion or nodding; the alar ligaments not only limit the rotatory movement s of the head and atlas upon the epistropheus, but by binding the occiput to the pivot, round which rotation occurs, they steady the head and prevent its undue lateral inclination upon the vertebral column. (See Transverse Ligament, p. 222.)

By experiments, it has been proved that the head, when placed so that the orbits look a little upward, is poised upon the occipital condyles in a line drawn a little in front of their middle; the amount of elevation varies slightly in different cases, but the balance is always to be obtained in the human body -it is one of the characteristics of the human figure. It serves to maintain the head erect without undue muscular effort, or a strong ligamentum nuchæ and prominent dorsal spines such as are seen in the lower animals. Disturb this balance, and let the muscles cease to act, the head will either drop forward or backward according as the centre of gravity is in front or behind the balance line. The ligaments which pass over the dens to the occiput are not quite tight when the head is erect, and only become so when the head is flexed; if this were not so, no flexion would be allowed; thus, muscular action, and not ligamentous tension, is employed to steady the head in the erect position. It is through the combination of the joints of the atlas and epistropheus, and occiput and epistropheus (consisting of two pairs of joints placed symmetrically on either side of the median line, while through the median line there passes a pivot, also with a pair of joints), that the head enjoys such freedom and celerity of action, remarkable strength, and almost absolute security against violence, which could only be obtained by a ball-and socket joint; but the ordinary ball-and-socket joints are too prone to dislocations by even moderate twists to be reliable enough when the life of the individual depends on the perfection of the articulation: hence the importance of this combination of joints.

Fig. 263.-Coronal Section of the Vertebral Column and the Occipital Bone TO SHOW LigAMENTS.

(The tectorial membrane (1), though shown as a distinct stratum, is really the deeper part of the posterior longitudinal ligament (2). The upper ends have been reflected upward, the lower downward. Viewed from behind.)

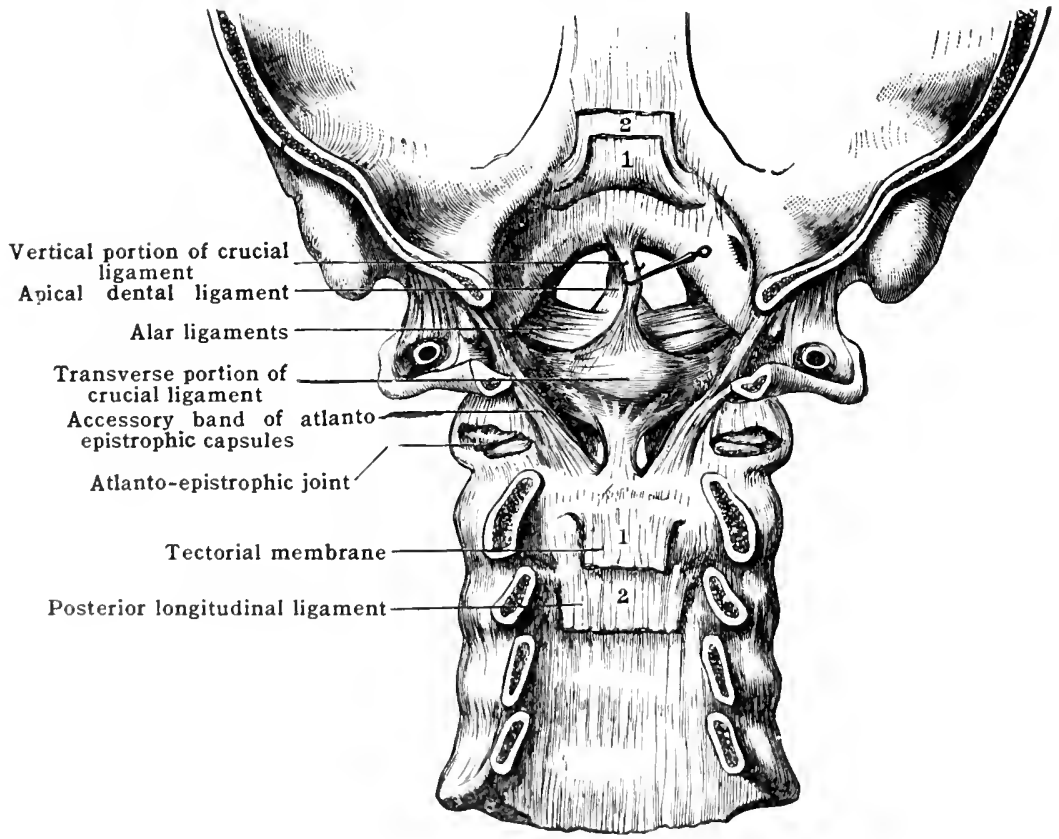

THE ARTICULATIONS OF THE TRUNK

These maty bre divided into the following sets:-

1. Those of thr verteloral column. Joints and ligaments connecting:

(a) The borlin.

(b) The articular processess.

(d) The spinous processes.

(c) The laminas.

(e) The transverse processes.

2. Vertebral column with the pelvis.

3. Pelvis.
(a) Sarro-iliar.
(c) Intereoceygeal.
(b) Siarero-cocerygentil.
(d) Symphysis pubis. 
4. Ribs with the vertebral column.

5. The articulations at the front of the thorax.

(a) Costal cartilages with the sternum.

(b) Costal cartilages with the ribs.

(c) Sternal.

(d) Certain costal cartilages with each other.

\section{THE ARTICULATIONS OF THE VERTEBRAL COLLMN}

There are two distinct sets of articulations in the vertebral column :--

(a) Those between the bodies and intervertebral discs which form synchondroses and which are amphiarthrodial as regards movement.

(b) Those between the articular processes which form arthrodial joints.

The ligaments which unite the various parts may also be divided into two sets, viz.--immediate, or those that bind together parts which are in contact; and intermediate, or those that bind together parts which are not in contact.

Immediate.

(a) Those between the bodies and dises.

(b) Those between the articular processes.

\section{Intermediate.}

(c) Those between the laminæ.

(d) Those between the spinous processes.

(e) Those between the transverse processes.

Fig. 264.-Horizontal Section throdgh an Intertertebral Fibro-cartilage and the Corresponding Ribs.

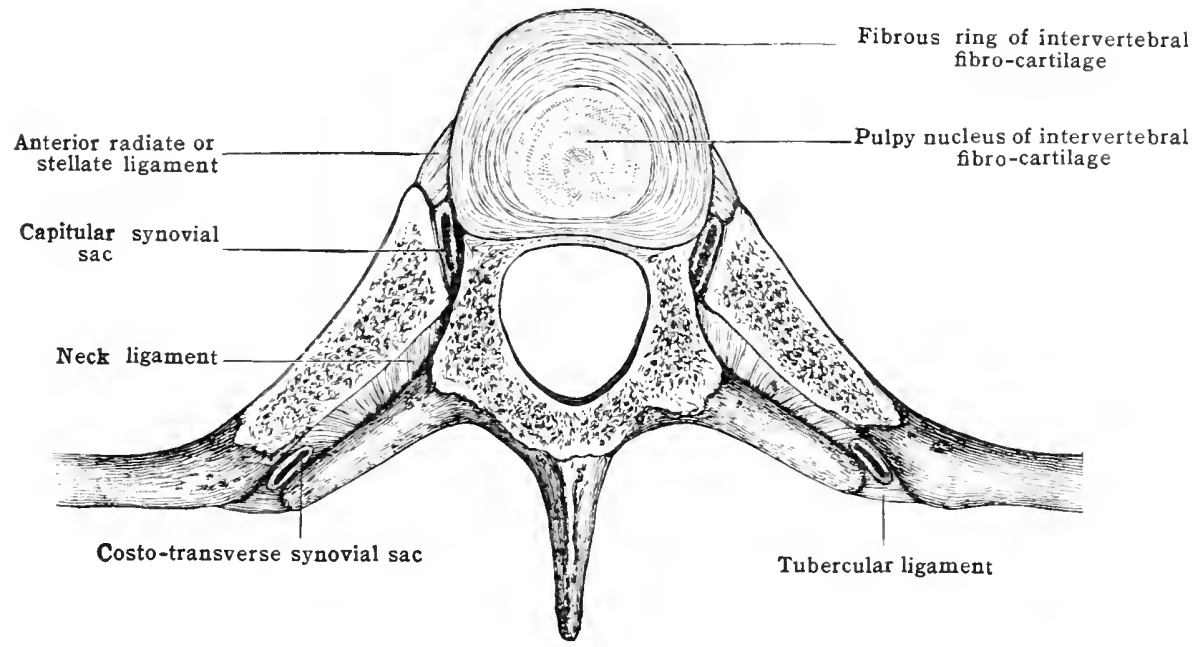

(a) The Articulations of the Bodies of the Vertebre

Class.-False Synchondrosis.

The ligaments which unite the bodies of the vertebræ are:-
Intervertebral fibro-cartilages.
Anterior longitudinal.
Short lateral ligaments.
Posterior longitudinal.

The intervertebral fibro-cartilages (figs. 260 and 261) are tough, but elastic and compressible discs of composite structure, which serve as the chief bond of union between the vertebræ. They are twenty-three in number, and are interposed between the bodies of all the vertebræ from the epistropheus to the sacrum (figs. 260 and 271). Similar discs are found between the segments of the sacrum and coccyx in the younger stages of life, but they undergo ossification at their surfaces and often throughout their whole extent. 
Each disc is composed of two portions-a cireumferential laminar, and a central pulpy portion; the former tightly surrounds and braces in the latter, and forms somewhat more than half the dise. The fibrous ring [annulus fibrosus] or laminar portion consists of alternating layers of fibrous tissue and fibro-cartilage; the component fibres of these layers are firmly connected with two vertebræ, those of one passing obliquely down and to the right, those of the next down and to the left, making an $\times$-shaped arrangement of the alternate layers. A few of the superficial lamellæ project beyond the edges of the bodies, their fibres being connected with the edges of the anterior and lateral surfaces; and some do not completely surround the rest, but terminate at the intervertebral foramina, so that on horizontal section the circumferential portion is seen to be thinner posteriorly. The more central lamellæ are incomplete, less firm, and not so distinct as the rest; and as they near the pulp they gradually assume its characters, becoming more fibro-cartilaginous and less fibrous, and have cartilage cells in their structure.

The pulpy nucleus [nucleus pulposus] or central portion is situated somewhat behind the centre of the disc, forming a ball of very elastic and tightly compressed material, which bulges freely when the confining pressure of the laminar portion is removed by either horizontal or vertical section. Thus, it has a constant tendency to spring out of its confinement in the direction of least resistance, and constitutes a pivot round which the bodies of the vertebræ can twist, tilt, or incline. It is yellowish in colour, and is composed of fine white and elastic

Fig. 265.-The Anterior Longitudinal Liganent, the Radiate, the Interarticular, and the Anterior Costo-transterse Ligaments.

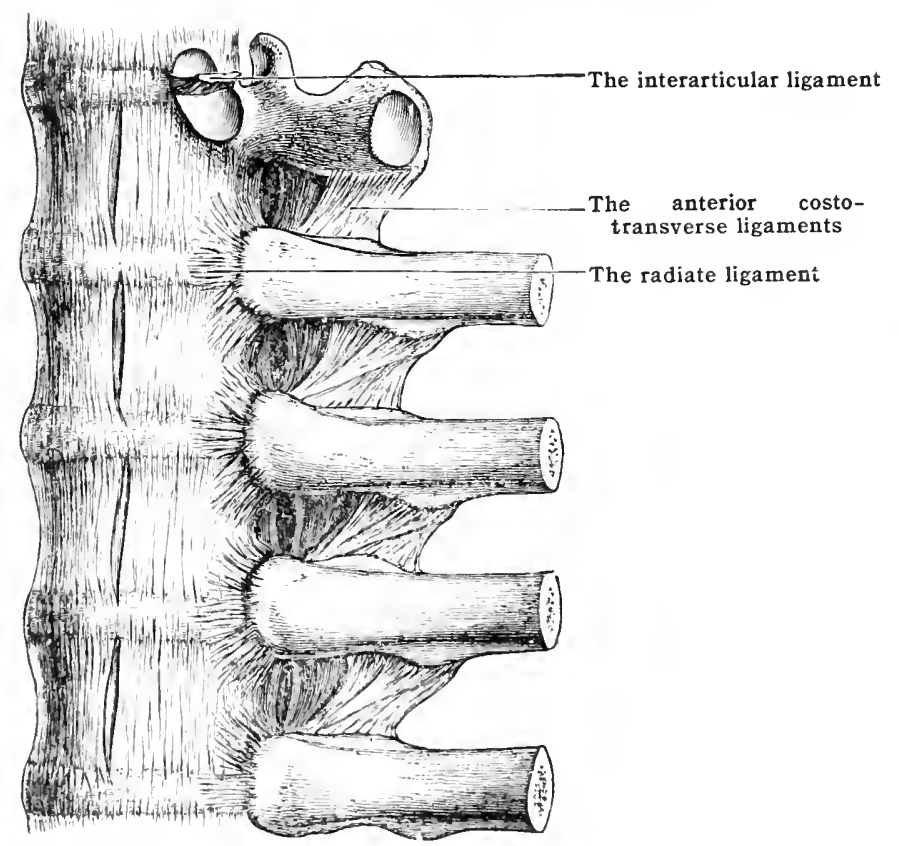

fibres amidst which are orlinary connective-tissue cells, and peculiar cells of various sizes which contisin one or more nuclei. Fogether with the most centril lamine, it is separated from immediate contact with the bone lyy a thin plate of articular eartilage. The central pulp of the intervertebral substance is the persistent part of the notochord.

The intervertetral substances vary in shane with the hodies of the vertebra they unite, and are widest and thickest in the lumbar region. In the cervical and lumbar regions they are thicker in front thin behind, and rause the convexity forwarl of the cervical, and increase that of the lumbar; the curve in the thoracie region, almost entirely clue to the shape of the bodies, is, however, somowhit. increased by the clises. Without the dises the column loses a quarter of its longth, and assumes a "urve with the concavity forward, most marked a little below the

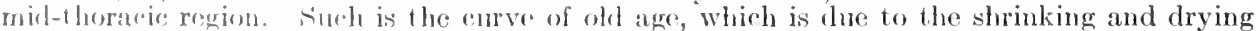
up of the introvertebal substanes. 'The lise hetween the epistropheus and third cervical is the thinnest of all (fig. 2(t) ; that bow weon the fifth lumbar and sacrum is the thickest, and is

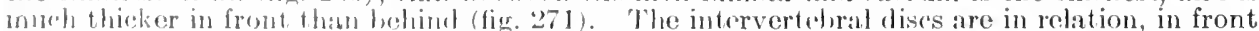
with the antorior lomgitulinat tignmont; hohind, with the posterior longitudinal ligament; laterally, with the short lateral; and in tho thoracos region, with the interarticular and radiate ligaments.

In the corvinal regrion latrial diathroulial joints are placed one on each side of the interverteliral discs. 'They are of snall extent and are confined to the intervals between the promi-

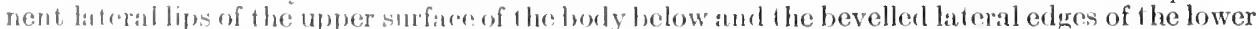

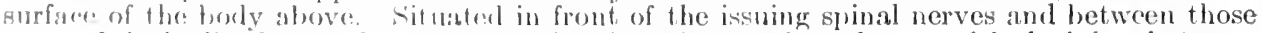
parts of the honling formed from the nemal aretwes, they are homologous with the joints between the atlas and coistropheres, and lectwern the attas and oceipital bone. 
The anterior longitudinal ligament (figs. 259 and 265) commences as a narrow band attached to the inferior surface of the occipital bone in the median line, just in front of the atlanto-occipital ligament, of which it forms the thickened central portion. Attached firmly to the tubercle of the atlas, it passes down as the central portion of the atlanto-epistrophic ligament, in the mid-line, to the front of the body of the epistropheus. It now begins to widen out as it descends. until it is nearly two inches $(5 \mathrm{~cm}$.) wide in the lumbar region. Below, it is fixed to the upper segment of the sacrum, becoming lost in periosteum about the middle of that bone; but is again distinguishable in front of the sacro-coccygeal joint, as the anterior sacro-coccygeal ligament.

Its structure is bright, pearly-white, and glistening. Its lateral borders are separated from the lateral bands by clefts through which blood-vessels pass; they are frequently indistinct and are best marked in the thoracic region. It is thickest in the thoracic region, and thicker in the lumbar than the cervical. It is firmly connected with the bodies of the vertebræ, and is composed of longitudinal fibres, of which the superficial extend over several, while the deeper pass over only two or three vertebræ. It is connected with the tendinous expansion of the prevertebral muscles in the cervical, and the crura of the diaphragm are closely attached to it in the lumbar region.

Fig. 266.-Posterior Longitudinal Liganent. (Thoracic region.)

(Pedicles cut through, and posterior arches of vertebræ removed.)

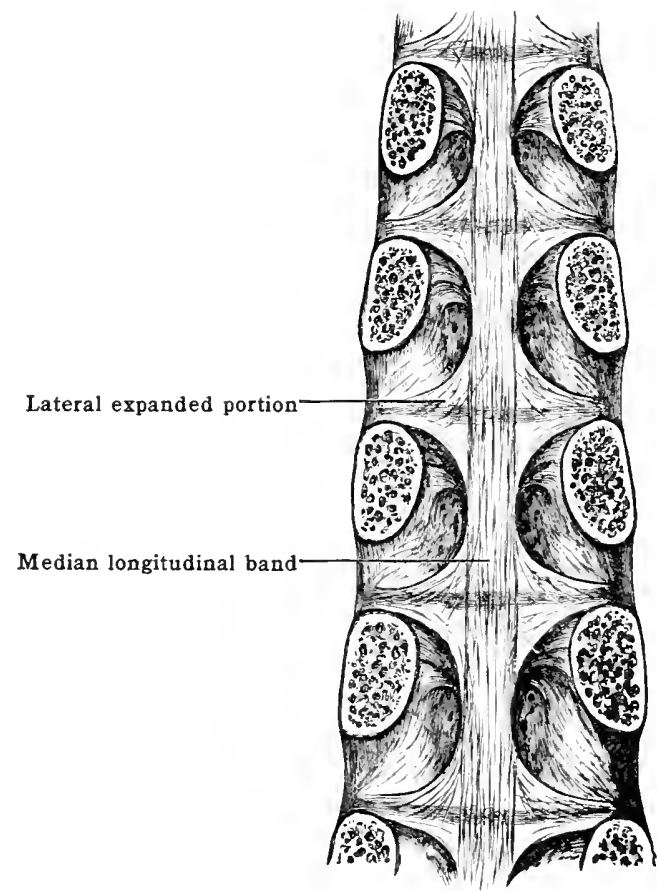

The posterior longitudinal ligament (figs. 263, 266, 267, and 274) extends from the occipital bone to the coccyx. It is wider above than below, and commences by a broad attachment to the cranial surface of the basi-occipital. In the cervical region it is of nearly uniform width, and extends completely across the bodies of the vertebræ, upon which it rests quite flat. It does, however, extend slightly further laterally on each side opposite the intervertebral dises. In the thoracic and lumbar regions it is distinctly dentated, being broader over the intervertebral substances and the edges of the bones than over the middle of the bodies, where it is a narrow band stretched over the bones without resting on them, the anterior internal vertebral venous plexus being interposed. The narrow median portion consists of longitudinal fibres, some of which are superficial and pass over several vertebræ; and others are deeper, and extend only from one vertebra to the next but one below.

The dentated or broader portions (fig. 267) are formed by oblique fibres which, springing from the bodies near the intervertebral foramina, take a curved course downward and back- 
ward over an intervertebral fibro-cartilage, and reach the narrow portion of the ligament on the centre of the vertebra next below; they then diverge to pass over another intervertebral dics to end on the body of the vertebra beyond, near the intervertebral noteh. They thus pass over two discs and three vertebræ. Deeper still are other fibres thickening these expansions of the longitudinal ligament, and extending from one bone to the next.

The last well-marked expansion is situated between the first two segments of the sacrum: below this, the ligament becomes a delicate central band with rudimentary expansions, being more pronounced again over the sacro-coceygeal joint, and losing itself in the ligamentous tissue at the back of the coccyx. The dura mater is tightly attached to it at the margin of the foramen magnum and behind the bodies of the upper cervical vertebræ, but is separated from it in the rest of its extent by loose cellular tissue which becomes condensed in the sacral region to form the sacro-dural ligament. The filum terminale becomes blended with it at the lower part of the sacrum and back of the coecyx.

Fig, 267.-Posterior Longitudinal Liganent. (Lumbar region.)

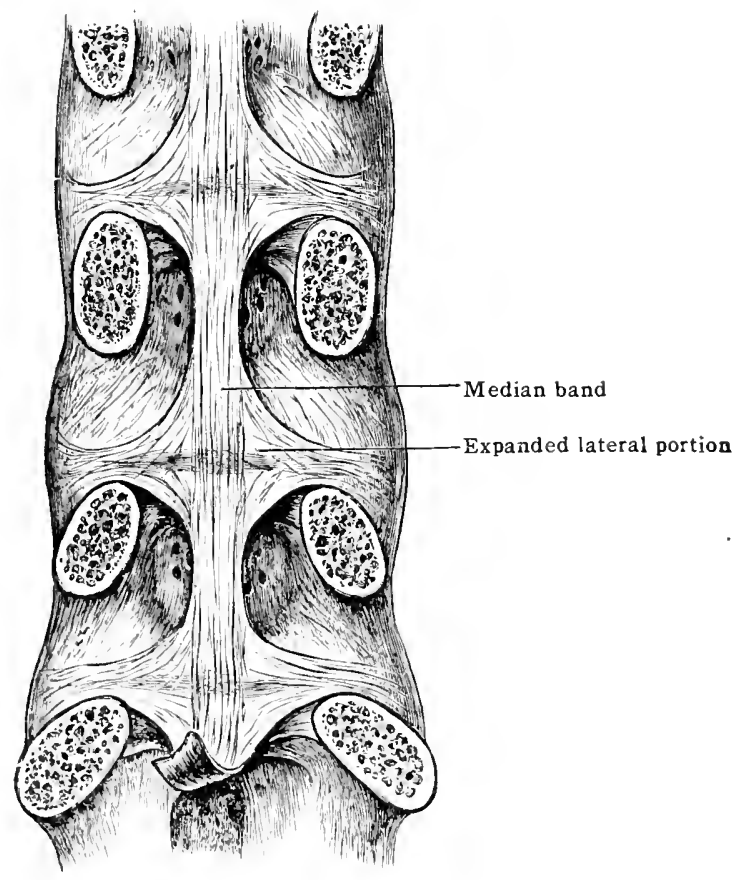

The lateral (or short) vertebral ligaments (fig. 265) eonsist of numerous short fibres situated between the anterior and posterior longitudinal ligaments, and passing from one vertebra over the intervertebral dise, to which it is firmly adhrerent, to the next vertebra below.

The more superficial fibres are more or less vertical, but the rleeper decussate and have a crucial arrangement. They are eonnected with the deep surface of the anterior longitudinal ligament, and so tie it to the edges of the bodies of the vertebra and to the intervertebral dises. They blend brhind with the expansions of the posterior longitudinal ligament, and so complete the casing rombl each amphiarthrodial joint. In the thoracic region, they overlie the radiate ligancont, and in the lumbar they radiate toward the transverse processes. In the cervical region thry are less well marked.

\section{(b) The Liganness Connecting the Articular Processes}

\section{Class.-Direrthrosis. Subdivision.-Arthrodia.}

The articular capsules (fig. 259) which unite these processes are composed partly of ycllow clastic: tissue and partly of white fibrous tissue. In the cervical region only the medial side of the capsule is formed by the ligamenta flava, whieh in the thoracis and lumbar rogions, however, extend anteriorly to the margins of the intervertebral foramina.

'l'he: purt formed of white fibrons tissue eonsists of short, well-marked fibres, which in the rerviral region passoblicundy downwarl and forwart over the joint, between the articular proe- 
esses and the posterior roots of the transverse processes of two contiguous vertebræ. In the thoracic region the fibres are shorter, and vertical in direction, and are attached to the bases of the transverse processes; in the lumbar, they are obliquely transverse. The articular capsules in the cervical region are the most lax, those in the lumbar region are rather tighter, and those in the thoracic region are the tightest.

There is one synovial membrane to each capsule.

\section{(c) The Liganents uniting the Lamine}

The ligamenta flava (fig. 268) are thick plates of closely woven yellow elastic tissue, interposed between the laminæ of two adjacent vertebræ. The first connects the epistropheus with the third cervical, and the last the fifth lumbar with

Fig. 268.-Ligalexta Flaya in the Lenbar Region, seen fron within the Vertebral Canal.

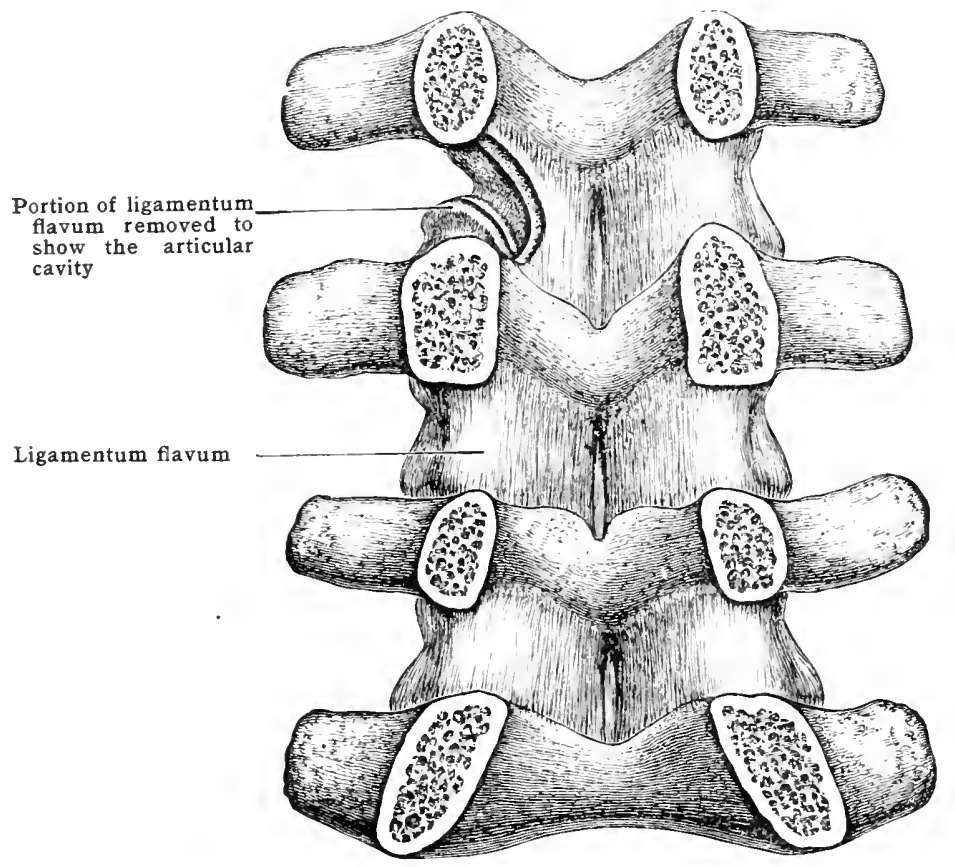

the sacrum. Each ligament extends from the medial and posterior edge of the intervertebral foramen on one side to a corresponding point on the other; above, it is attached close to the inner margin of the inferior articular process and to a well-marked ridge on the inner surface of the laminæ as far as the root of the spine; below, it is fixed close to the inner margin of the superior articular process and to the dorsal aspect of the upper edge of the laminæ.

Thus each ligamentum flavum, besides filling up the interlaminar space, enters into the formation of two articular capsules; they do so to a greater extent in the thoracic and lumbar regions than in the cervical, where the articular processes are placed wider apart. When seen from the front after removing the bodies of the vertebræ, they are concave from side to side, but convex from above downward; they make a more decided transverse curve than the arches between which they are placed. This concavity is more marked in the thoracic, and still more in the lumbar region than in the cervical; in the lumbar region the ligamenta flava extend a short distance between the roots of the spinous process, blending with the interspinous liganent, and making a median sulcus when seen from the front; there is, however, no separation betwren the two parts. In the cervical region, where the spines are bifid, there is a median fissure in the yellow tissue which is filled up by fibro-areolar tissue. The ligaments are thickest and strongest in the lumbar region; narrow but strong in the thoracic; thinner, broader, and more membranous in the cervical region.

\section{(d) The Liganents connecting the Spinous Processes}

These include supraspinous ligament, interspinous ligaments, and the ligamentum nuchæ. 
The supraspinous ligament (fig. 270) extends without interruption as a well-marked band of longitudinal fibres along the tips of the spines of the vertebræ from that of the seventh cervical downward till it ends on the median sacral crest.

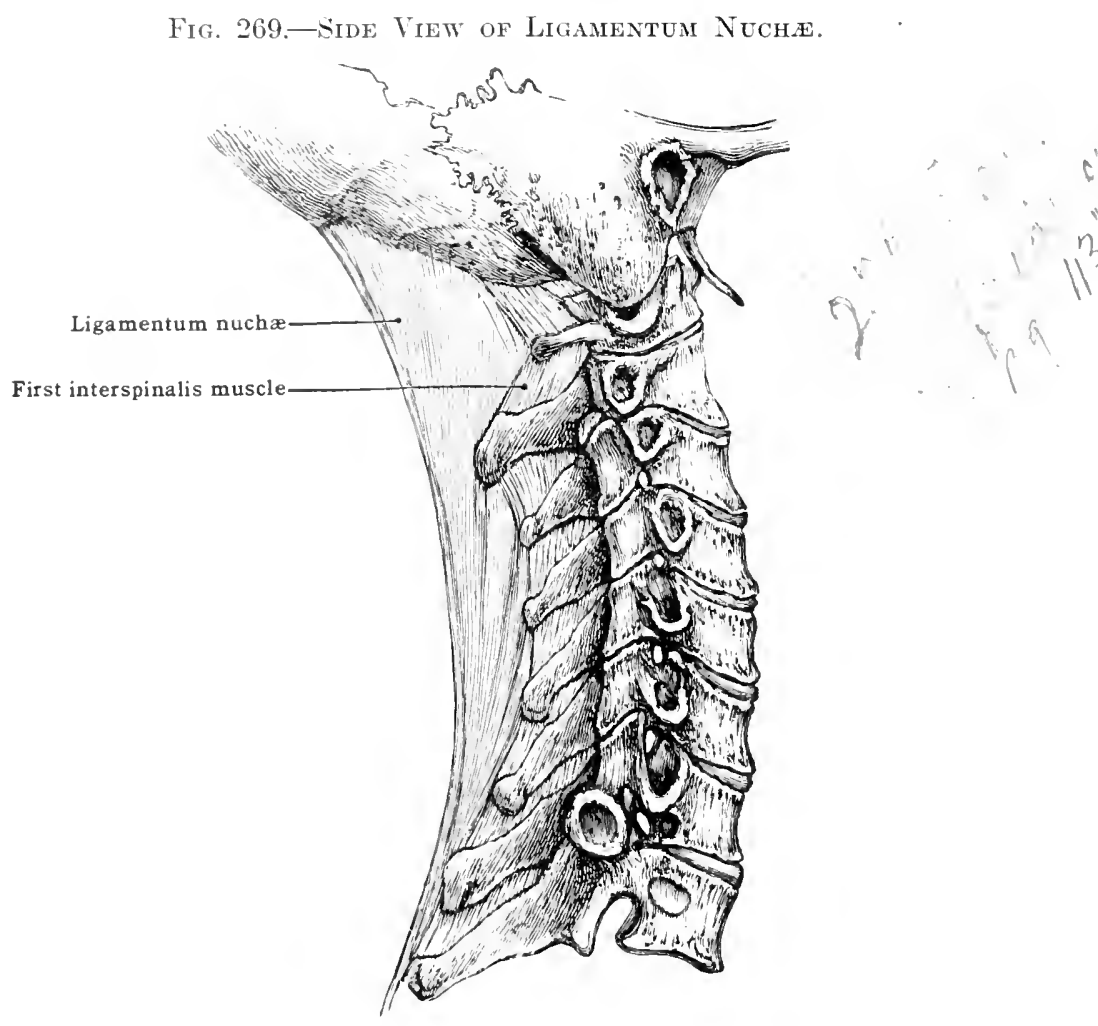

Fin, 270, - The Interspinous and Supraspinous Ligaments in the Lumbarigegion.

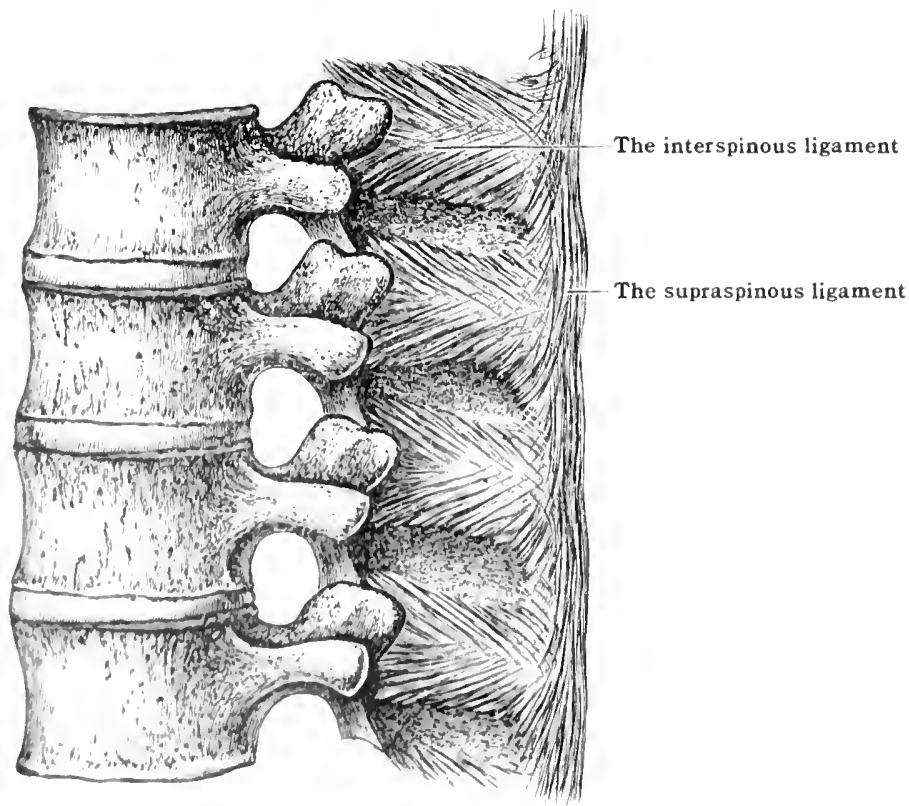

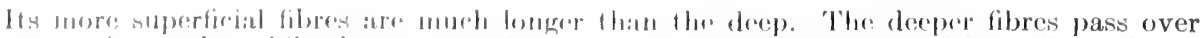

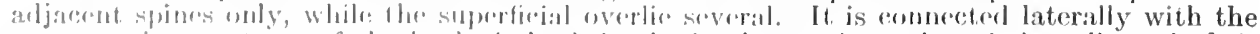
aponourstic struntures of the hask; indenel, in the lumbar region, where it is well marked, it 
appears to result from the interweaving of the tendinous fibres of the several muscles which are attached to the tips of the spinous processes. In the dorsal region it is a round slender cord which is put on the stretch in flexion and relaxed in extension of the back.

The ligamentum nuchæ, or the posterior cervical ligament (fig. 269), is the continuation in the neck of the supraspinous ligament, from which, however, it differs considerably. It is a slender vertical septum of an elongated triangular form, extending from the seventh cervical vertebra to the external protuberance and the crest of the oceipital bone. Its anterior border is firmly attached to the tips of the spines of all the cervical vertebræ, including the posterior tubercle of the atlas, as well as to the occiput. Its posterior border gives origin to the trapezii, with the tendinous fibres of which muscle it blends. Its lateral, triangular surfaces afford numerous points of attachment for the posterior muscles of the head and neck.

In man it is rudimentary, and consists of elastic and white fibrous tissues. As seen in the horse, elephant, ox, and other pronograde mammals, it is a great and important elastic ligament, which even reaches along the thoracic part of the spinal column. In these animals it serves

to support the head and neck, which otherwise from their own weight would hang down. Its rudimentary state in man is the direct consequence of his erect position.

The interspinous ligaments (fig. 270) are thin membranous structures which extend between the spines, and are connected with the ligamenta flava in front, and the supraspinous ligament behind.

The fibres pass obliquely from the root of one spine to the tip of the next; they thus decussate. They are best marked in the lumbar region, and are replaced by the well-developed interspinales muscles in the cervical region.

\section{(e) The Ligaments connecting the Transingse Processes}

\section{The intertransverse ligaments are but poorly developed.}

In the thoracic region they form small rounded bundles, and in the lumbar they are flat membranous bands, unimportant as bonds of union. They consist of fibres passing between the apices of the transverse processes. In the cervical region they are replaced by the intertransversarii muscles.

The arterial supply for the column comes from twigs of the vertebral, ascending pharyngeal, ascending cervical, superior and aortic intercostals, lumbar, ilio-lumbar, and lateral sacral.

The nerve-supply comes from the spinal nerves of each region.

Movements.-The vertebral column is so formed of a number of bones and intervertebral discs as to serve many purposes. It is the axis of the skeleton; upon it the skull is supported; and with it the cavities of the trunk and the limbs are connected. As a fixed colnmn it is capable of bearing great weight, and, through the elastic intervertebral substances, of resisting and breaking the transmission of shocks. Noreover, it is flexible. Now, the range of movements of the column as a whole is very considerable; but the movements between any two vertebræ are slight, so that motions of the spine may take place without any change in the shape of the column, and without any marked disturbance in the relative positions of the vertebrie. It is about the pulpy part of the intervertebral discs, which form a central elastic pivot or ball, upon which the middle of the vertebræ rest, that these movements take place.

The amount of motion is everywhere limited by the common vertebral ligaments, but it depends partly upon the width of the bodies of the vertebræ, and partly upon the depth of the discs, so that in the loins, where the bodies are large and wide, and the discs very thick, free motion is permitted; in the cervical region, though the discs are thinner, yet, as the bodies are smaller, almost equally free motion is allowed. As the ball-like pulpy part of the intervert cbral disc is the centre of movement of each vertebra, it is obvious that the motion would be of a rolling charactcr in any direction but for the articular processes, which serve also to give steadiness to the column and to assist in bearing the superincumbent weight. Were it not for these processes, the column, instead of being steady, endowed with the capacity of movement by muscular agency, would be tottering, requiring muscles to steady it. The influence of the articular processes in limiting the direction of inchination will appear from a study of the movements in the three regions of the spine.

In the neck all movements are permitted and are free, except between the second and third cervical vertebræ, where they are slight, owing to the shallow intervertebral disc and the great prolongation of the anterior lip of the inferior surface of the body of the epistropheus, which checks forward flexion considerably. On the whole, however, extension and lateral inclination are more free and extensive in this than in any other region of the column, whilst flexion is more limited than in the lumbar region. Rotatory movements are also free, but take place, on account of the position and inclination of the articular facets, not, as in the thoricic region, round a vertical axis, but round an oblique axis, the articular process of one side gliding upward and forward and that of the opposite side downward and backward.

In the thoracic region, especially near its middle, antero-posterior flexion and extension are very slight; and, as the concavity of the curve here is forward, the flat and nearly vertical surfaces of the articular processes prevent anything like sliding in a curvilincar manner of the 
one set of processes over the sharp upper edges of the other, which would be necessary for forward flexion. A fair amount of lateral inclination would be permitted but for the impediment offered by the iibs; while the position and direction of the articular processes allows rotation round a vertical axis which passes through the centres of the bodies of the vertebræ. This rotation is not very great, and is freer in the upper than in the lower part of the thoracic region.

In the lumbar region, extension and flexion are very free, especially between the third and fourth and fourth and fifth vertebrx, where the lumbar curve is sharpest; lateral inclination is also very free between these same vertebre. It has been stated that the shape and position of the articular processes of the lumbar and the lower two or three dorsal are such as to prevent any rotation in these regions; but, owing to the fact that the inferior articular processes are not tightly embraced by the superior, so that the two sets of articular processes are not in contact on both sides of the bodies at the same time, there is always some space in which horizontal motion can occur round an axis drawn through the central part of the bodies and intervertebral discs, but it is very slight. Thus, the motions are most free in those regions of the column which have a convex curve forward, due to the shape of the intervertebral discs, where there are no bony walls surrounding solid viscera, where the spinal canal is largest and its contents are less firmly attached, and where the pedicles and articular processes are more nearly on a transyerse level with the posterior surface of the bodies of the vertebræ.

For must the uses of the ligamenta flava be forgotten: these useful structures-(1) complete the roofing-in of the vertebral canal, and yet at the same time permit an ever-changing variation in the width of the interlaminar spaces in flexion and extension; (2) they also restore the articulating surfaces to their normal position with regard to each other after movements of the column; (3) and by forming the medial portion of each articular capsule, they take the place of muscle in preventing it from being nipped between the articular surfaces during movement.

Muscles which take part in the movements of the vertebral column.-Flexors: When acting with their fellows of the opposite side. Rectus abdominis, infra-hyoid muscles (slightly) sterno-mastoid, external oblique, internal oblique, intercostals, scalenus anterior, psoas major and minor, longus colli, longus capitis (rectus capitis anterior major).

Extensors: When acting with their fellows of the opposite side. Sacro-spinalis, quadratus lumborum, semispinalis, multifidus, rotatores, interspinales, serrati posteriores, the splenius, and with the scapula fixed the levator scapula and the upper fibres of the trapezius.

Muscles which help to incline the column to their own side.-Sacro-spinalis, quadratus lumborum, semispinalis, multifidus, the intercostals helping to fix the ribs, the external and internal oblinue muscles, levatores costarum, serrati posteriores, the scalenes, splenius cervicis, longus colli (oblique part), rotatores, intertransversales, psoas, and with the scapula fixed the levator scapulie and the upper and lower fibres of the trapezius.

Muscles which rotate the column and turn the body to their own side.-Splenius cervicis, internal oblique (the ribs being fixed), serratus posterior inferior, and with the scapula fixed the lower fibres of the trapezius.

Muscles which rotate the column and turn the body to the opposite side.-Multifidus, semispinalis, external oblique, the lower oblique fibres of the longus colli, and with the scapula and humerus fixed the latissimus dorsi and trapezius.

\section{THE SAC'RO-VERTEBRAL ARTICLLATIONA}

(a) Class.-False Synchondrosis.

(b) Class.-Diarthrosis. Subdivision.-Arthrodiu.

As in the intervertebral articulations, so in the union of the first portion of the sacrum with thr last lumbar vertebra, there are two sets of joints-viz. (a) a synchondrosis, between the bodies and intervertebral disc; and $(b)$ a pair of arthrodial joints, between the artienlar processes. The union is effected by the following ligaments, which are common to the vertebral colmmn:-(i) anterior, and (ii) postcrior longitudinal; (iii) lateral or short vertebral; (iv) capsular; (v) ligamentat flava; (vi) supraspinous and (vii) interspinous ligaments. 'Two sperial aceressory ligaments on cither side, viz., the sacro-lumbar and the iliolombar, connect the jelvis with the fourth and fifth lumbar vertebre.

'l'he sacro-lumbar ligament (figr. 271) is strong, and triangular in shape. Its apex is aboverand merlial, being attached to the whole of the lower border and front surface of the transweres proesse of the fifth lumbar vertehra, as well as to

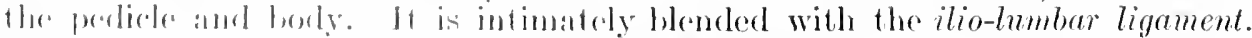

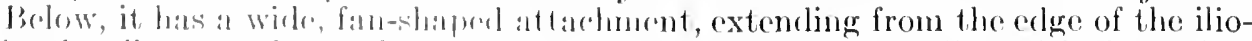
Imonhar ligamant forwalel to thr brim of the true pelvis; blending with the periostrum on the hase of the sarerum and in the iliae fossa, and with the superior sacroilian ligamurnt.

liy its sharp merlial border it limits laterally the foranen for the last lumbar nerve. It is

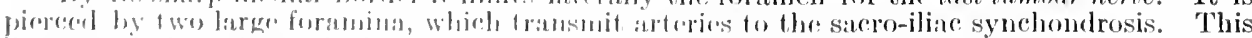

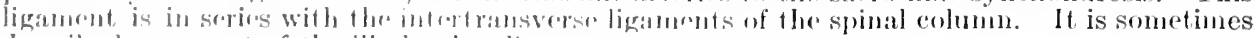
describud ats al part of the ilio-lombar ligimmont. 
The ilio-lumbar llgament (fig. 271) is a strong, dense, triangular ligament connecting the fourth and fifth lumbar vertebræ with the iliac crest.

It springs from the front surface of the transverse process of the fifth lumbar vertelura as far as the body, by a strong fascieulns from the posterior surface of the process near the tip, and also from the front surface and lower edge of the transverse process and pediele of the foirth lumbar vertebra, as far medialward as the body. Between these two lumbar vertebræ it is inseparable from the intertransverse ligament.

At its origin from the transverse proeess of the fifth lumbar vertebra it is closely interwoven with the sacro-lumbar ligament, and some of its fibres spread downward on to the body of the fifth vertebra, while others aseend to the dise above. At the pelvis it is attached to the inner lip of the erest of the ilium for about two inches $(5 \mathrm{~cm}$.). The highest fibres at the column form the upper edge of the ligament at the pelvis, those which come from the posterior portion of the transverse process of the fifth lumbar vertebra forming the lower, while the fibres from the front of the same proeess pass nearly horizontally lateralward. Near the column the surfaces

Fig. 271.-Anterior View of the Ligaments between Vertebre and Pelitis.

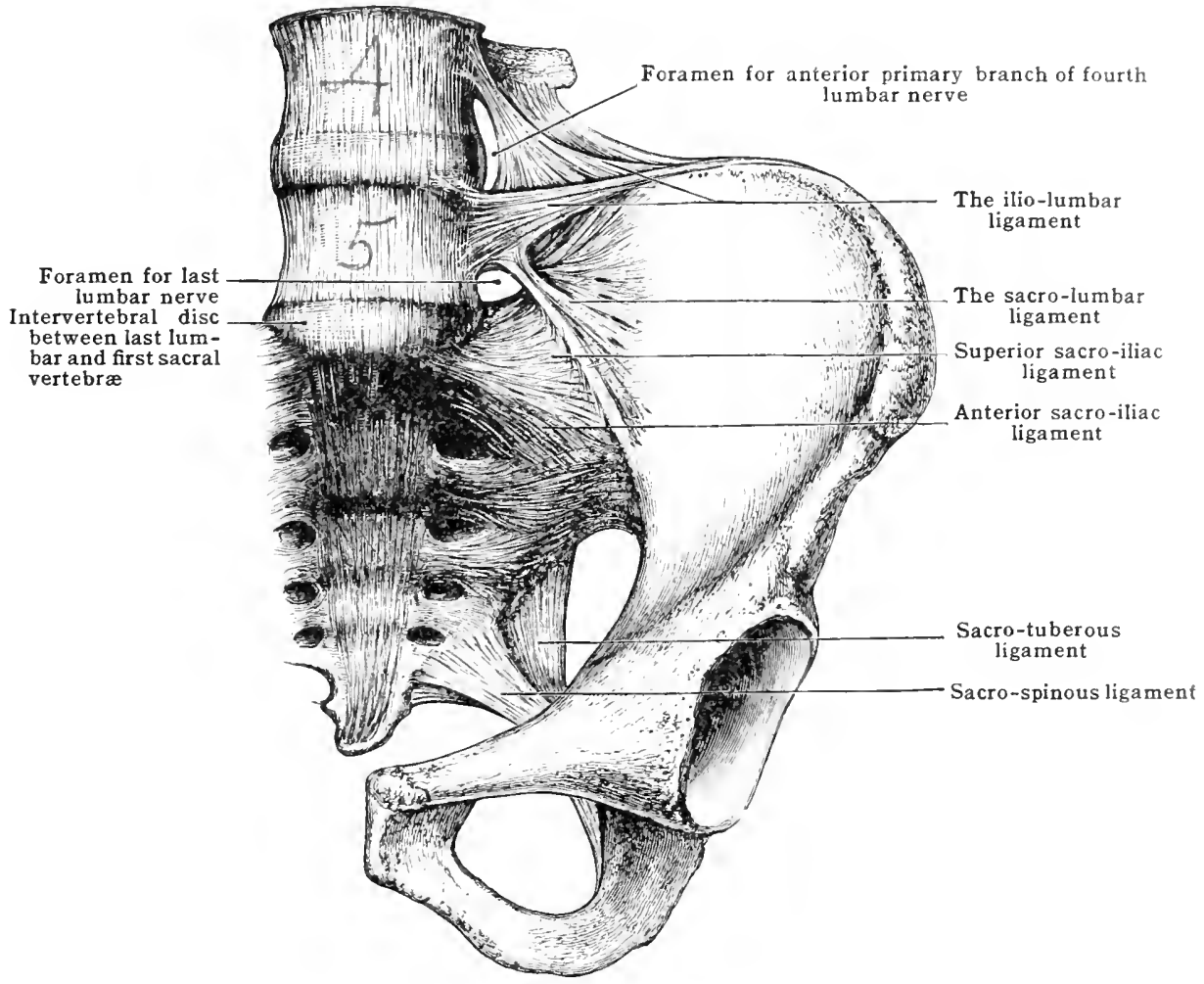

look direetly backward and forward, but at the ilium the ligament gets somewhat twisted, so that the posterior surface looks a little upward, and the anterior looks a little downward. The anterior surface forms part of the posterior boundary of the major (false) pelvis, and overlies the upper part of the posterior sacro-iliae ligament; the posterior surface forms part of the floor of the spinal groove, and gives origin to the multifidus musele. Of the borders, the upper is oblique, has the anterior lamella of the lumbar fascia attached to it, and gives origin to the quadratus lumborum; the lower is horizontal, and is adjacent to the upper edge of the saerolumbar ligament; while the medial is erescentic, and forms the lateral boundary of a foramen through which the fourth lumbar nerve passes.

The arterial supply is very free, and comes from the last lumbar, ilio-lumbar, and lateral sacral.

The nerve-supply is from the svmpathetic, as well as from twigs from the fourth and fifth lumbar nerves.

Movements. - The angle formed by the saerum with the spinal column is ealled the saerovertebral angle. The pelvic inclination does not depend entirely upon this angle, but in great part upon the obliquity of the coxal (innominate) bones to the saerum, so that in males in whom the average pelvic obliquity is a little greater, the average saero-vertebral angle is considerably less than in females.

The sacro-vertebral angle in the male shows that there is a greater and more sudden change in direction at the sacro-vertebral union than in the female. A part of this change in direction is due to the greater thickness in the anterior part of the intervertebral fibro-cartilage between the last lumbar vertebra and the sacrum. Owing to the greater thickness of the intervertebral 
disc here than elsewhere, the movements permitted at this joint are very free, being freer than those between any two lumbar vertebre. As the diameter of the two contiguous bones is less in the sagittal than in the frontal plane, the forward and backward motions are much freer than chose from side to side. The backward and forward motions take place every time the sitting is exchanged for the standing position, and the standing for the sitting posture; in rising, the back is extended on the sacrum at the sacro-lumbar union; in sitting down it is flexed.

The articular processes provide for the gliding movement incidental to the extension, flexion, and lateral movements; they also allow some horizontal movement, necessary for the rotation of the vertebral column on the pelvis, or pelvis on the column. The inferior articular processes of the fifth differ considerably from the inferior processes in the rest of the lumbar vertebræ, and in direction they resemble somewhat those of the cervical vertebræ; while the superior articular processes of the sacrum differ in a similar degree from the superior processes of the lumbar vertebre. This difference allows for the freer rotation which occurs at this joint.

The sacro-vertebral angle averages $117^{\circ}$ in the male, and $130^{\circ}$ in the female; while the pelvic inclination averages $155^{\circ}$ in the male, and $150^{\circ}$ in the female.

As already stated, the movements at the sacro-vertebral joint are the same as those in other parts of the spinal column, but more extensive, and the muscles which produce the movements are those mentioned in the preceding groups which cross the plane of the articulation.

\section{THE ARTICULATIONS OF THE PELVIS}

This group may again be subdivided into-

(a) The sacro-iliac.

(b) The sacro-coccygeal.

(c) The intercoccygeal.

(d) The symphysis pubis.

(a) The Sacro-iliac Articulation and Sacro-sciatic Ligaments

\section{Class.-Diarthrosis. Subdivision.-Arthrodia.}

It is now generally admitted that the sacro-iliac joint is a diarthrosis, the articular surface of each bone being covered with a layer of cartilage, whilst the eavity of the joint is a narrow cleft and the capsule is extremely thick posteriorly. The cartilage on the sacrum is much thicker than that on the ilium and the cartilages are sometimes bound together here and there by fibrous strands. The different character of the joint in the two sexes should be noted. Briefly, the female joint has strong ligamentous bonds with but little bony apposition, while the male joint gains its strength by virtue of extensive areas of bony contact and a slighter development of ligaments. This difference is, of course, a physiological one; for some laxity of the joint is demanded during pregnancy and labour. The bones which enter into the joint are the sacrum and ilium, and they are bound together by the following ligaments:-

$$
\begin{array}{ll}
\text { Anterior sacro-ilias. } & \text { Superior sacro-iliac. } \\
\text { Postrior sacro-iliae. } & \text { Inferior sacro-iliac. }
\end{array}
$$

Interosicous.

The anterior sacro-iliac ligament (figs. 271 and 272) consists of well-marked glistrning fihres wheh pass above into the superior, and below into the inferior, liginnents. It axtands from the first three bones of the sacrum to the ilium hatworn the hrim of the pelvis minor and the great sciatic notch, blending with the proristrum of thr sacrum and ilimn as it passes away from the united edges of the bones.

Thr superior sacro-iliac ligament (figs. 27 I and 272) extends across the mper margins of the joint, from the ala of the sacrum to the iliac fossa, being well matked along the brim of the polvis, where it is thickened by some closely parkml filures. lachiml, it is far st ronger, especially beneath the transverse process of the fifth humbar vertalura. This limament is connected with the strong sacrolombar ligament, which sproble lateralward and forward over the joint to reach the iliar fossa and frominal line. By some anthors it is deseribed as a part of the ilio-lumbur ligamment.

Thr posterior sacro-iliac ligament is cxtrumely strong and consists essentially of two sots of libres, diepe and superficial. 'The drep fibres (short posterior sacroiligr liganont) bass downwarl and molialwarl from the rough area of the 
ilium behind the auricular surface to the back of the lateral mass of the sacrum, both lateral to and between the upper foramina and to the upper saeral articular process, and the area between it and the first sacral foramen. The deepest fibres of this group constitute the so-called interosseous ligament. The more superficial fibres (long posterior sacro-iliac ligament) are oblique or vertical, and pass from the posterior superior iliac spine to the second, third, and fourth tubercles on the back of the sacrum, a more or less well-defined band which goes to the third and fourth sacral tubereles being ealled sometimes the oblique sacro-iliae band and sometimes the long straight band.

The inferior sacro-iliac ligament (fig. 272) is covered behind by the upper end of the sacro-tuberous ligament; it eonsists of strong fibres extending from the lateral border of the sacrum below the articular facet to the posterior iliac spines; some of the fibres are attached to the deep surface of the ilium and join the interosseous ligament.

Fig. 272.-Miedian Sagittal Section of the Pelvis, Showing Liganexts.

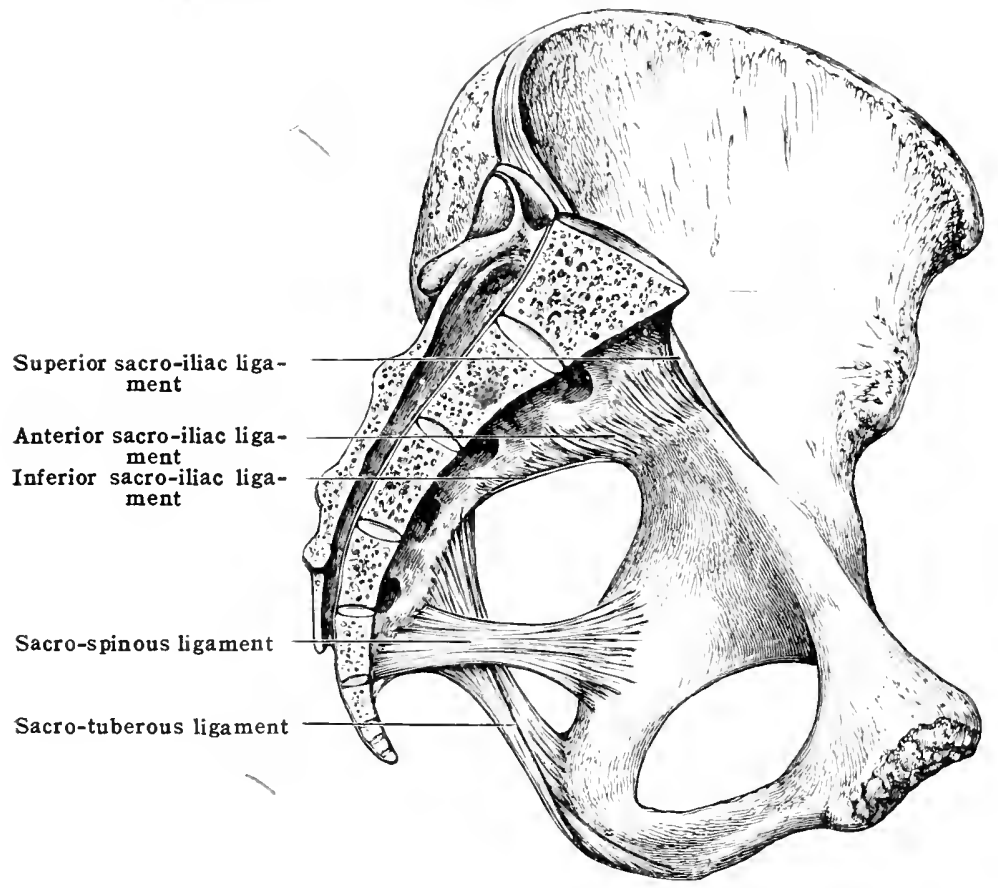

The interosseous ligament is the strongest of all, and consists of fibres of different lengths passing in various direetions between the two bones. Immediately above the interspinous notch of the ilium the fibres of this ligament are very strong, and form an open network, in the interstices of which is a quantity of fat in which the articular vessels ramify.

The ear-shaped cartilaginous plate, which unites the bones firmly, is arecurately applied to the auricular surfaces of the sacrum and ilium. It is about one-twelfth of an inch $(2 \mathrm{~mm}$.) thick in the centre, but becomes thinmer toward the edges. Though closely adherent to the bones, it tears away from one entirely, or from both partially, on the application of violence, sometimes breaking inregularly so that the greater portion remains connected with one bone, learing the other bone rough and bare. It is usually one mass, and is only occationally formed of two plates with a synovial cavity between them.

Because of the occasional presence of a more or less extensive synovial eavity within the fibro-cartilage, and also of a synovial lining to the ligaments passing in front and belind the articulation, the term 'diarthro-amphiarthrosis' has been given to this joint, and also to the symphysis pubis. Testut mentions certain folds of synovial membrane filling up gaps which here and there occur at the margin of the fibro-cartilage but they are not usually scen.

The sacro-tuberous (great sciatic) ligament (figs. 271, 272, and 273) is attached above to the posterior extremity of the crest of the ilimm and the lateral aspect of the posterior iliac spines. From this attachment some of its fibres 
pass downward and backmard to be attached to the lateral borders and posterior surfaces of the lower three sacral vertebræ and upper two segments of the coccyx; while others, after passing for a certain distance backward, curve forward and downward to the ischium, forming the anterior free margin of the ligament where it limits posteriorly the sciatic foramina. These fibres are joined by others which arise from the posterior surfaces of the lower three sacral vertebræ and upper pieces of the coccyx. At the ischium it is fixed to the medial border of the tuberosity, and sends a thin sharp process upward along the ramus of the ischium which is called the falciform process (fig. 273), and is a prolongation of the posterior edge of the ligament.

A great many fibres pass on directly into the tendon of the biceps muscle, so that traction on this musele braces up the whole ligament, and the coceyx is thus made to move on the sacrum. The ligament may not unfairly be described as a tendinous expansion of the musele, whereby its action is extended and a more alvantageous leverage given. It is broad and flat at its attached ends, but narrower and thicker in the centre, looking like two triangular expansions

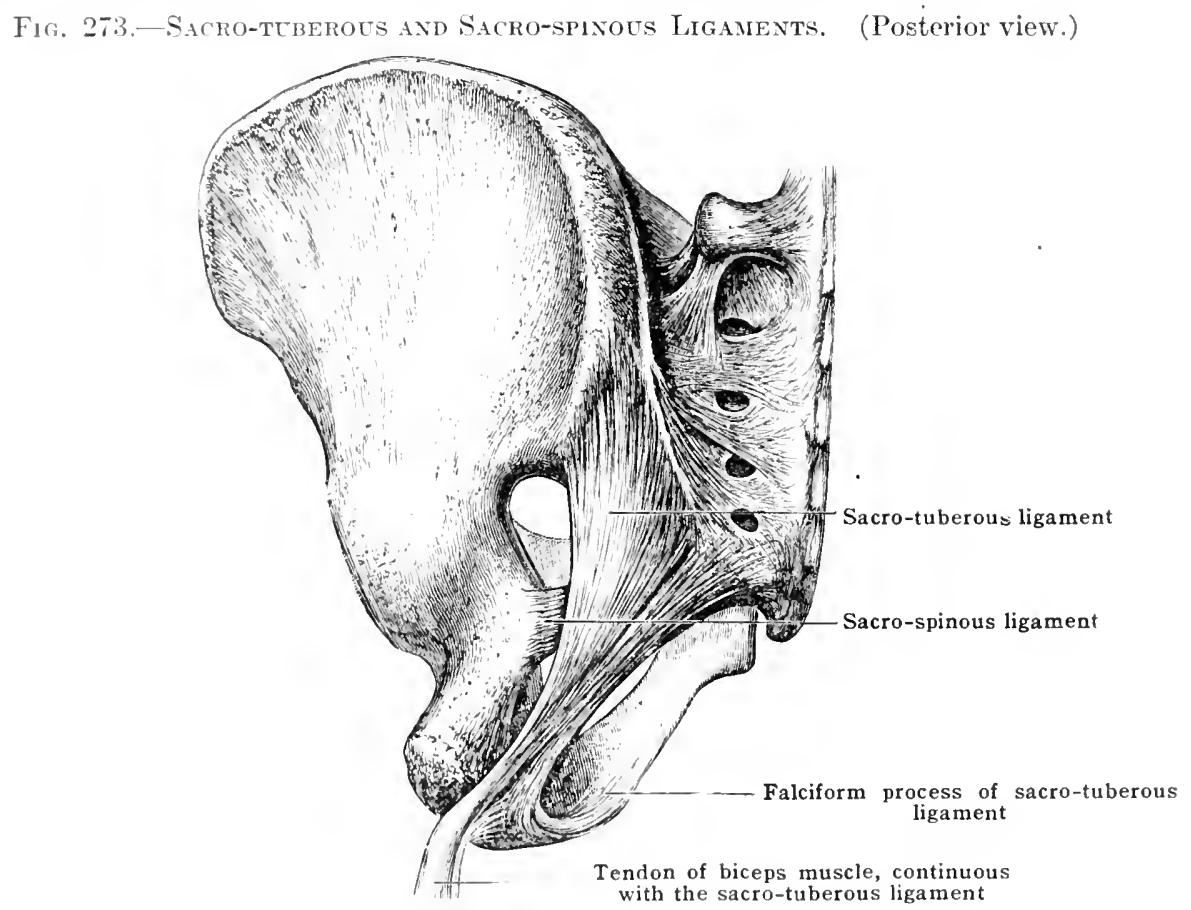

joinenl l,y a flat band, the larger triangle being at the ilimm, and the smaller at the ischimm The filors of the ligunent are twisted upon its axis ar the narrow part, so that some of the supreror lilores palss to the lower borter.

The postarios surfaco gives origin to the gluteus maximus musele, and on it ranify the loop; from the posterior hanclass of the sacral norves; its antrior surface is closely connected at its origin, with flo satrospinous ligument, and some filnes of the piriformis musele arise from its brow the oburater intermas passes out of the pelvis undor its cover, and the internal pudic vessols and urre prise in. It the ilimm, jts postorior edge is continuous with the vertebrad

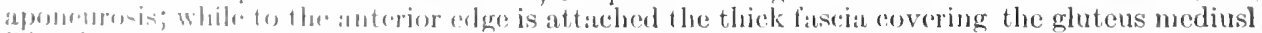

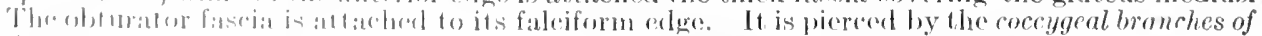

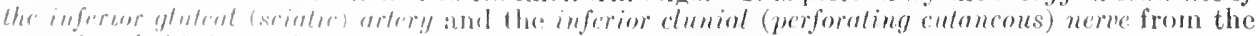
seronil and thirit suerul.

'Thr sacro-spinous (small suittic) ligament (figs. 271, 272, and 273) is triangular and thin, springing hy a broad hase from the bateral border of the saterum

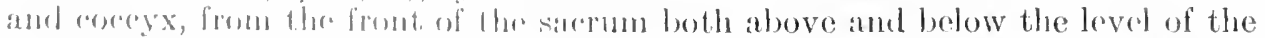
fourth sacral foramen, and from the ooceyx nearly as far as its tip. By its apex it is attacherl to the frout surfite and the lorelers of the isehial spine as far out-

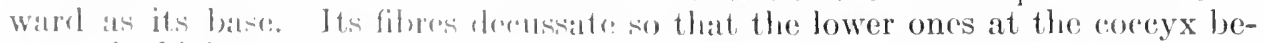
"ome the lighest at the ischial spine; muscular fibres are oftrn seen intermingled with the ligannentoms.

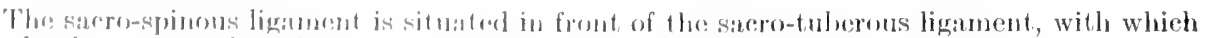

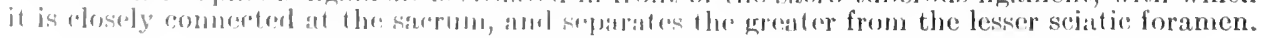


Its front surface gives attachment to the coccygeus muscle, which overlies it. Behind, it is connected with, and hidden by, the sacro-tuberous ligament, so that only the lateral inch or less $(2 \mathrm{~cm}$.) and a small part of its attachment to the coccyx can be seen; the internal pudic nerve also passes over the posterior surface.

The arterial supply of the sacro-iliac joint comes from the superior gluteal, ilio-lumbar, and lateral sacral.

The nerve-supply is from the superior gluteal, sacral plexus, and external twigs of the posterior divisions of the first and second sacral nerves.

Movements.- Recent investigations have shown that in spite of the interlocking of the articular surfaces and the strong ligaments connecting the bones together a slight amount of movement, both a gliding and rotatory, loes occur at the sacro-iliac joint. The gliding movement is both up and down, and forward and backward, and the latter is associated with a slight rotation round a transverse axis which passes through the upper tubercles on the back of the sacrum. The movement is but small in extent, nevertheless as the base of the sacrum moves

Fig. 274.-Ligaments connecting Sacrum and Coccyx posteriorly.

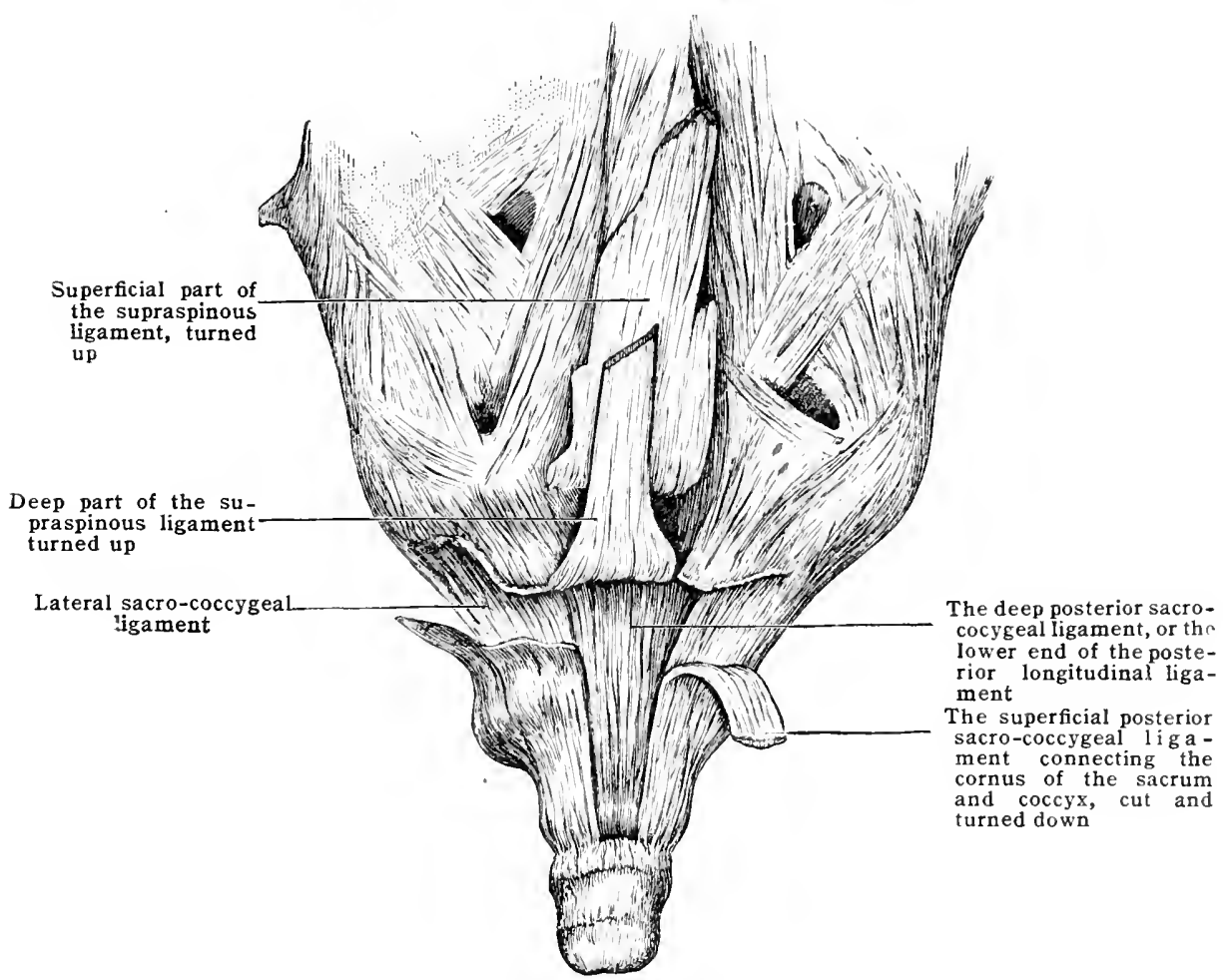

downward and forward the conjugate (antero-posterior) diameter of the pelvic inlet is diminished and at the same time, as the coccyx moves up and back, the conjugate diameter of the outlet is increased. This rotatory movement is limited principally by the sacro-sciatic (sacrotuberous and sacro-spinous) ligaments which prevent any extensive upward and backward movement of the coccyx and lower part of the sacrum.

Downward displacement of the sacrum when the body is in the sitting posture is prevented not only by the surrounding ligaments, but also by the wedge-like character of the sacrum, which is broader above than below. Downward and forward displacement of the sacrum in the erect posture is prevented by the ligaments and more particularly by the posterior sacroiliac bands, while backward displacement would be hindered by the breadth of the anterior as contrasted with the posterior part of the sacrum as well as by the anterior ligaments.

Relations. - The sacro-iliac joint is in relation above with psoas and iliacus. In front it is in relation at its upper part with the hypogastric vessels and obturator nerve, and at its lower part with the piriformis muscle.

\section{(b) The Sacro-coccygeal Articulation}

\section{Class.-False Synchondrosis.}

The last piece of the sacrum and first piece of the coccyx enter into this union [symphysis sacrococcygea] and are bound together by the following ligaments:Anterior sacro-coceygeal.

Superficial posterior sacro-coccygeal. Lateral sacro-coccygeal.

Intervertebral substance. 
The intervertebral fibro-cartilage is a small oval disc, three-quarters of an inch (about $2 \mathrm{~cm}$.) wide, and a little less from before backward, closely connected with the surrounding ligaments. It resembles the other discs in structure, but is softer and more jelly-like, though the laminæ of the fibrous portion are well marked.

The anterior sacro-coccygeal ligament is a prolongation of the glistening fibrous structure on the front of the sacrum. It is really the lower extremity of the anterior longitudinal ligament, which is thicker over this joint than over the central part of either of the bones.

The posterior sacro-coccygeal ligament (fig. 274) is divided into two layers of which one (the deep) is a direct continuation of the posterior longitudinal ligament of the column, consisting of a narrow band of closely packed fibres, which become blended at the lower border of the first segment of the coccyx with the filum terminale and cleep posterior ligament.

The superficial layer of the posterior sacro-coccygeal ligament (or supracormual ligament), (fig. 274) is the prolongation of the supraspinous which becomes inseparably blended with the aponeurosis of the sacro-spinalis (erector spinx) opposite the laminæ of the third sacral vertebra, and is thus prolonged downward upon the back of the coccyx, passing over and roofing in the lower end of the spinal canal where the laminx are deficient.

The median fibres (the supraspinous ligament) extend over the back of the coccyx to its tip, blending with the deep fibres of the posterior sacro-coccygeal ligament and filum terminale; the deeper fibres run across from the stunted laminæ on one side to the next below on the opposite side, and from the sacral cornua on one side to the coccygeal on the opposite, some passing between the two cornua of the same side, and bridging the aperture through which the fifth sacral nerve passes. Its posterior surface gives origin to the gluteus maximus muscle.

The lateral sacro-coccygeal or intertransverse ligament (fig. 274) is merely a quantity of fibrous tissue which passes from the transverse process of the coccyx to the lateral edge of the sacrum below its angle. It is connected with the sacrosciatic ligaments at their attachments, and the fifth sacral nerve escapes behind it. It is perforated by twigs from the lateral sacral artery and the coccygeal nerve.

The arterial supply of the sacro-coceygcal joint is from the lateral sacral and middle sacral arteries.

The nerves come from the fourth and fifth sacral and coccygeal nerves.

The movements permitted at this joint are of a simple forward and backward, or hingelike character. In the act of defecation, the bone is pushed back by the fæcal mass, and, in parturition, by the foetus; but this backward movement is controlled by the upward and forward pull of the levator ani and coceygeus. The external sphincter also tends to pull the coccyx forward.

\section{(c) Intercoccygeal Joints}

The soveral segments of the coccyx are held together by the anterior and posterior longitudinal ligaments, which completely cover the bony nodules on their anterior and posterior aspects. Laterally, the sacro-sciatic ligaments, being attached to mearly the whole length of the coccyx, serve to connect them. Between the first and second pieces of the coccyx there is a very perfect amphiarthrodial joint, with a woll-marked intervertebral substance.

Movements. - But little movement occurs as a rule at the sacro-roceygeal and intercoceyecul joints, but when the hear of the child is passing through the pelvie outlet at birth, the tip of the coscry is lisplacorl hackwarl, it may be to the extent of one inch.

\section{(d) 'The Sympiysis l’ubis}

\section{Class.-Fialse Synchondrosis.}

The bones antring into this joint are the pubie portions of the hip-bones.

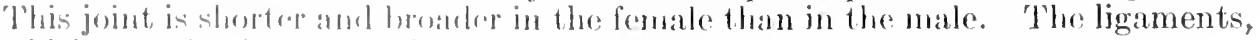
which complotely surromel thes articulation, alr:--

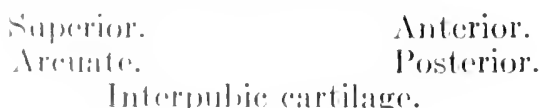

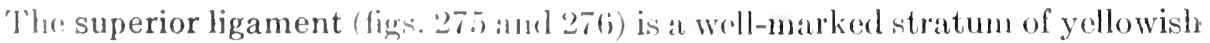
fibres which extends lateralward along the crest of the pubis on each side, blending in the midelle lime with the interosiseness cartilage. 
It is continuous in front with the deep traverse fibres of the anterior ligament, anrl behind with the posterior ligament. It gives origin to the rectus abdominis tendon.

The posterior ligament (fig. 277) is slight, and, excepting above and below, consists of little more than thickened periosteum.

Near the upper part is a band of strong fibres, reaching the whole width of the pubic bones, and continuous with the thickened periosteal fibres along the terminal line. Below, many of the upper and superficial fibres of the arcuate ligament ascend over the back of the joint, and interlace across the median line with fibres from the opposite side nearly as high as the middle of the symphysis.

Fig. 275.-Anterior View of the Sruphysis Pubis (Male), showing the Dectssation of the Fibres of the ANTERIor Ligament.

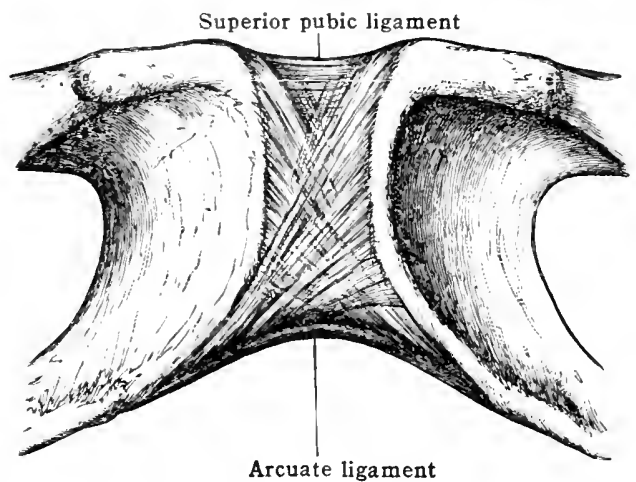

The anterior ligament (figs. 275 and 276 ) is thick and strong, and is closely connected with the fascial covering of the muscles arising from the body of the pubis. It consists of several strata of thick, decussating fibres of different degrees of obliquity, the superficial being the most oblique, and extending lowest over the joint.

The most superficial descending fibres extend from the upper border of the pubis, cros: others from the opposite side about the middle of the symphysis, and are attached to the ramus of the opposite bone. The most superficial ascending fibres come from the arcuate ligament,

Fig. 276.-Anterior View of the Symphysis Pubis (Female), showing greater Width BETWEEN THE Bones.

Superior pubic ligament

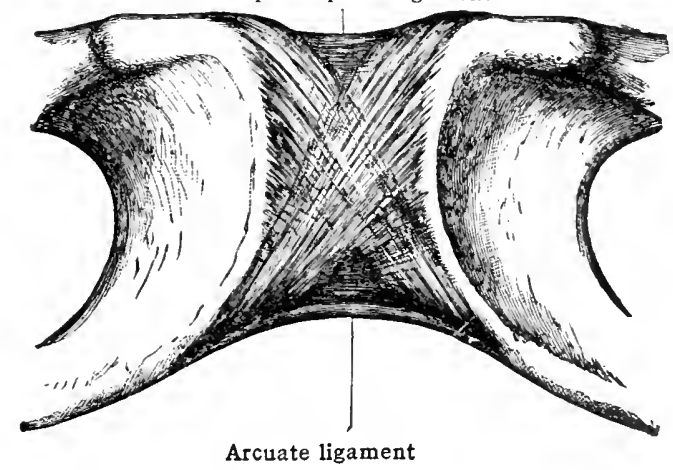

arch upward,"and decussate with other fibres across the middle line, and are lost on the opposite side beneath the descending set. There is another deeper set of descending fibres which arise below the angle, but do not descend so far as the superficial; and a deeper set of ascending. which decussate, and reach higher than the superficial set, and are connected with the arcuate ligament. Some few transverse fibres pass from side to side, especially above and below the points of decussation.

The arcuate (inferior or subpubic) ligament (figs. 275, 276, and 277 ) is at thick, arch-like band of closely packed fibres which fills up the angle between the pubic rami, and forms a smooth, rounded summit to the pubic arch. On section, it is yellowish in colour and three-eighths of an inch $(1 \mathrm{~cm}$.) thick in the middle line; it is inseparably connected with the interpubic cartilage. 
Both on the front and back aspects of the joint it gives off decussating fibres, which, by their interlacement over the anterior and posterior ligaments of the symphysis, add very materially to its security. In fact, the ligament may be said to split superiorly into two layers, one passing over the front, and the other over the back, of the articulation.

The interpubic fibro-cartilage varies in thickness in different subjects, but is thicker in the female than in the male. It is thicker in front than behind, and projects beyond the edges of the bones, especially posteriorly (see fig. 277), blending intimately with the ligaments at its margins. It is sometimes uninterruptedly woven throughout, but at others has an elongated narrow fissure, partially divicling the cartilage into two plates, with a little fluid in the interspace

Fig. 277.-Posterior View of the Sraphysis Pubis, showing the Decussation of the Fibres from the Arcuate Ligament.

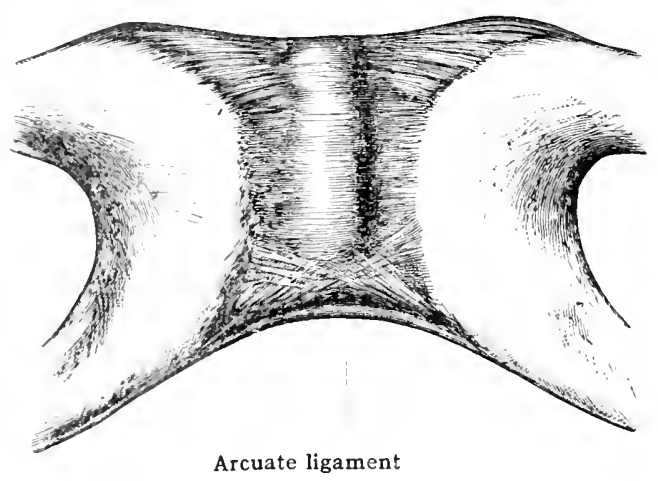

(fig. 278). This is situated toward the upper and posterior aspects, but does not usually reach either; it generally extends about half the length of the cartilage.

When this cavity is large, especially if it reaches or approaches very near to the circumference of the cartilage (which, however, it very rarely does), it is thought by some anatomists that it more nearly resembles a diarthrolial than an amphiarthrodial joint, and it is then classed with the sacro-iliac joint under similar conditions, as 'diarthroamphiarthrosis.' The interosseous cartilage is intimately adherent to the layer of hyaline cartilage which covers the medial surfare of catch pubic bone; the osseous surface is ridged to give a firmer attachment; and, on forcing the bones apart, it does not frequently split into two plates, but is torn from the bone on one sirle or the other.

Iig. 278.- Section of bimpilysis to show the Synovial Cavity.

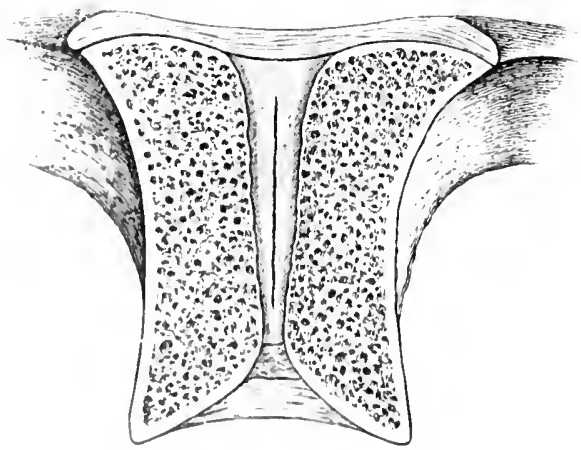

The arterial supply, of tho introulir joint is from twigs of the internal pudie, pubie hranches

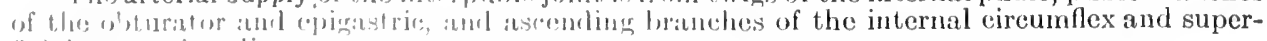
firial external purelice.

T'lus nerve-supply has not, lecen sutisfaclorily mats out, but it probably comes, in part, from the internal puldo and in part from the ilio-hypogastric and ilio-inguinal.

'The movements :unomb only to a slight, yieling of the cattilage; neither muscular force

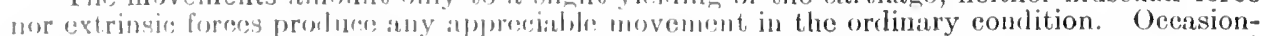
ally, as the result of ehild-boaring, the joint becomes unmaturally loose, and then walking and standiug are painfolly unstrably. It is known thal, during pregnancy and parturition, the 
symphyseal cartilage becomes softer and more vascular, so as to permit the temporary enlargement of the pelvis; but it must be remembered that the fibres of the oblique muscles decussate and thus, during labour, while they force the head of the fot us down, they strengthen the joint by bracing the bones more tightly together.

Relations. - The interpubic joint is in relation above with the linea alba. Behind with the prostate and the anterior border of the bladder. In front with the suspensory ligament of the penis or clitoris and below with the dorsal vein of the penis or clitoris and the upper border of the urogenital trigone (triangular ligament).

\section{THE COSTO-VERTEBRAL ARTICLLATIONS}

These consist of two sets, viz.:-

(a) The capitular (costo-central): i.e., the articulation of the head of the rib with the vertebræ.

(b) The costo-transverse, or the articulation of the tubercle (of each of the first ten ribs) with the transverse process of the lower of the two vertebræ, with which the head of the rib articulates: i. e., the one bearing its own number, as the first rib with the first thoracic vertebra, the second rib with the second thoracic vertebra, and so on.

Fig. 279.-The Capsular ligaments of the Costo-vertebral Jolnts.

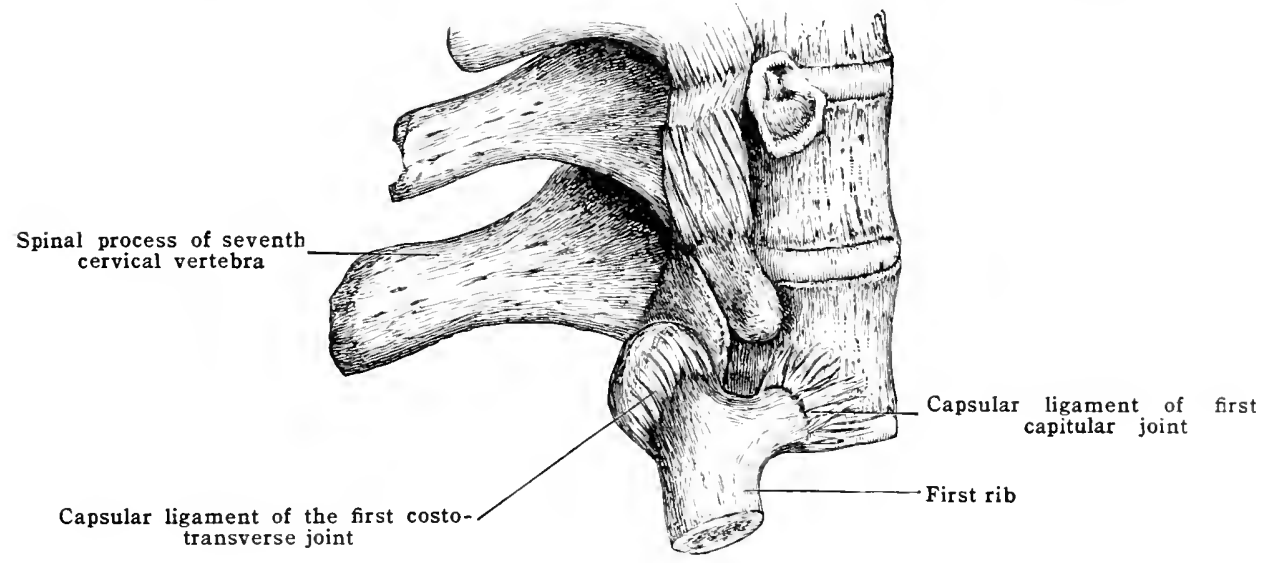

(a) The Capitular (Costo-central) Articulation

Class.-Diarthrosis. Subdivision.-Condylarthrosis.

It is a very perfect joint, into the formation of which the head of the rib and two vertebræ, with the intervertebral dise between them, enter. In the case of the first, tenth, eleventh, and twelfth ribs, it is formed by the head of the rib articulating with a single vertebra.

The ligaments are:-

Articular capsule.

Interarticular.

\section{Radiate.}

The articular capsule (fig. 279) consists of short, strong, woolly fibres, completely surrounding the joint, which are attached to the bones and intervertebral substances, a little beyond their articular margins.

At its upper part it reaches through the intervertebral foramen toward the back of the bodies of the vertebræ, being strengthened here by fibres which at intervals connect the anterior with the posterior longitudinal ligaments. The lower fibres extend downward nearly to the demi-facet (costal pit) of the rib below; behind, it is continuous with the neck ligament, and in front is overlaid by the radiate.

The interarticular ligament (fig. 280) consists of short, strong fibres, closely interwoven with the outermost ring of the intervertebral disc, and attatched to the transverse ridge separating the articular facets on the head of the rib. It completely divides the articulations into two parts, but does not brace the rib tightly to the spine, being loose enough to allow a moderate amount of rotation 
on its own axis. There is no interarticular ligament in the costo-vertebral joints of the first, tenth, eleventh, and twelfth ribs.

The radiate (or stellate) ligament, a thickening of the anterior part of the capsule (figs. 280 and 281), is the most striking of all, and consists of bright, pearly-white fibres attached to the anterior surface, and upper and lower borders of the neck of the rib, a little way beyond the articular facet; from this they radiate upward, forward, and downward, so as to form a continuous layer of distinct and sharply defined fibres.

The middle fibres run straight forward to be attached to the intervertebral dise; the upper ascend to the lower half of the lateral surface of the vertebra above, and the lower descend to the upper half of the vertebra below. The radiate ligament is overlapped on the vertebral bodies by the lateral (short) vertebral ligaments.

In the case of the first, tenth, eleventh, and twelfth ribs, each of which articulates with one vertebra, the ligament is not quite so distinctly radiate, but even in these the ascending fibres reach the vertebra above that with which the rib articulates.

Fig. 280.--Showing the Anterior Longitudinal Ligament, and the Connection of the Ribs With the Vertebr..

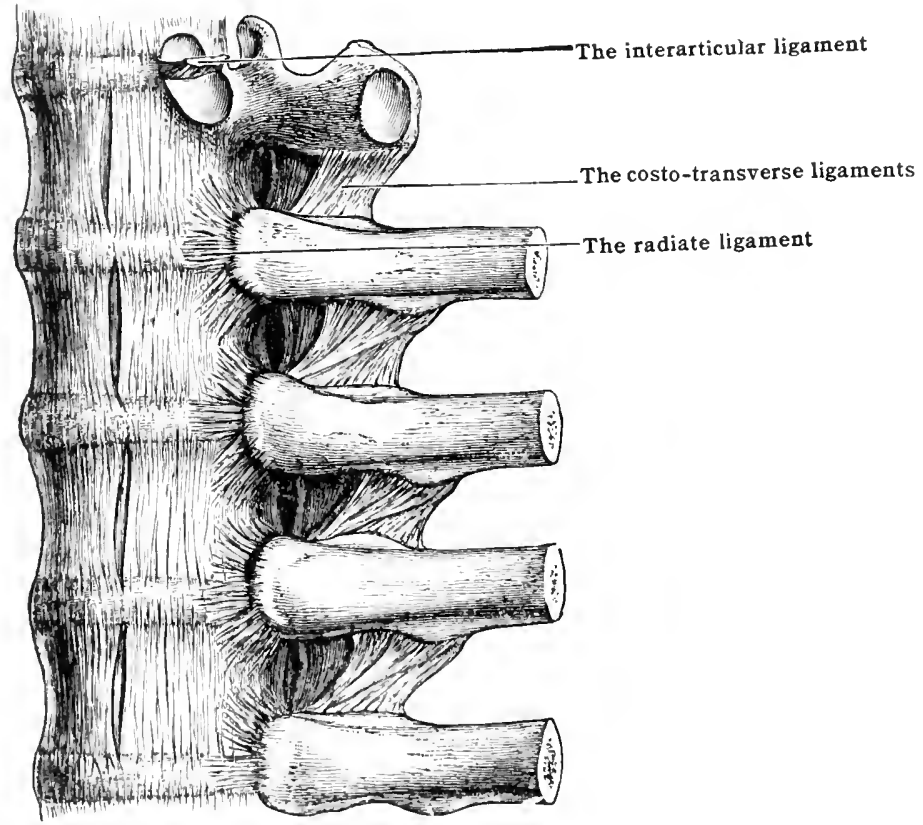

The synovial membranes (fig. 281) consist of two elosed sacs which do not communicate: one above, and the other below, the interarticular ligament. In the case of the first, tenth, eleventh, and twelf th articulations, there is but one symevial membrane, as these joints have no interarticular ligament.

'The arterial supply is from the intercostal arteries, the twigs piereing the radiate and capsialar ligauconts.

The nerve-supply coms from the anterior primary branches of the intercostal nerves.

These joints alprometh most nearly in their movements to the condylarthoses.

The movements are kinglymorl in character, eonsisting of a slight degree of clevation and fepression aromen an oliguely horizontal axis corresponding with the interarticular liganent; there is also a slight amomit of forwald and hackwarl gliding; and a slight degree of serewing or rotatory movernent is also possitile. There is a considerable differene in the degree of mobility of the difforent rils, for while the tirst ril, is almost immolile axcept in a very deep inspiration, the molility of the others incerases from theseroml to the last; the two flonting ribs being the most molibes of all. The heat of the rib is the mest fixed point of the costal areh, and upon it the whole areh rotates; the inforarliomlar ligament allows only a very limited amomnt of

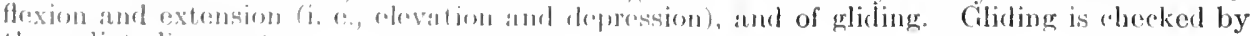
the rudiate ligament.

In inspiration, the rit, is clevalcel, and glides forward in its socket, too grat elevation being chesed not only hy the liganents, but also by the overhanging upper edge of the cavity itself. In expiration, the rih in desmensed, and glides lackward in its cavity. 


\section{(b) The Costo-transverse Articulation}

\section{Class.-Diurthrosts. Subdivision.-Arthrodia.}

This joint is formed by the tubercle of the rib articulating with the anterior part of the tip of the transverse process. The eleventh and twelfth ribs are devoid of these joints, for the tubercles of these ribs are absent, and the transverse processes of the eleventh and twelfth thoracic vertebræ are rudimentary.

The ligaments of the union are:-

Articular capsule.

Neck ligament.

Tubercular ligament.

Costo-transverse ligaments.

The articular capsule (figs. 279 and 281) forms a thin, loose, fibrous envelope to the synovial membrane. Its fibres are attached to the bones just beyond the articular margins, and are thickest below, where they are not strengthened by any other structure. It is connected medially with the neck ligament, above with the costo-transverse, and laterally with the tubercular (posterior costotransverse) ligaments. The eleventh and twelfth ribs are unprovided with costotransverse capsules.

Fig. 281.-Horizontal siection throtgh the Ixtertertebral Disc axd Ribs.

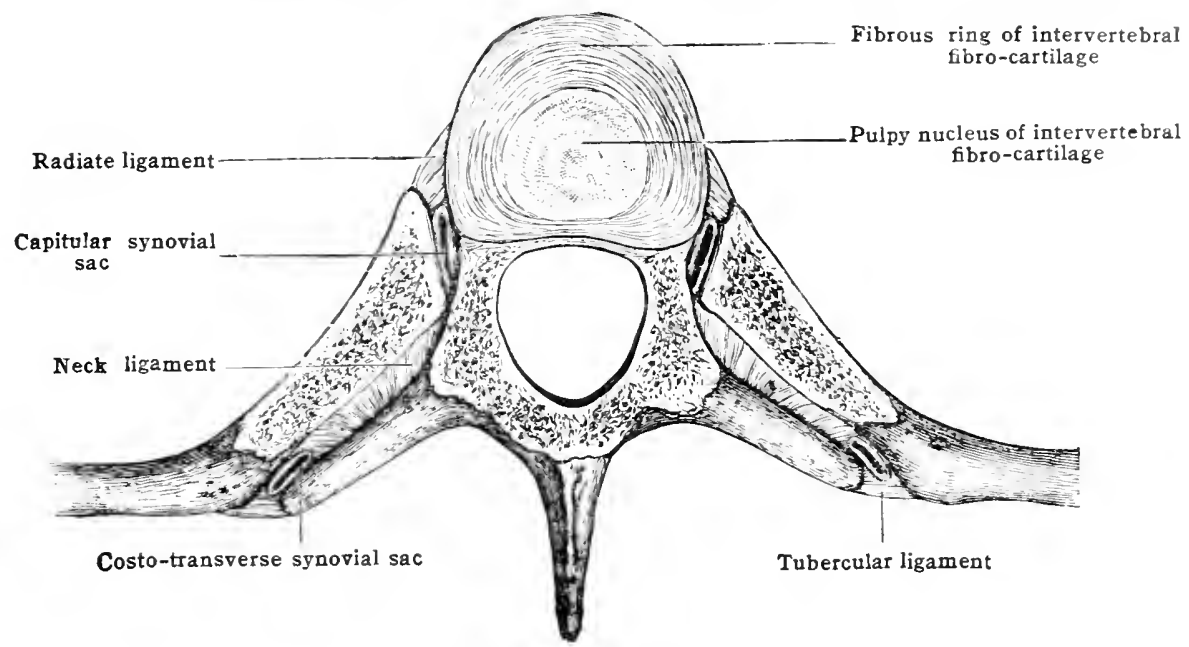

The neck ligament [lig. colli costæ] (middle costo-transverse, or interosseous ligament) (fig. 281), consists of short fibres passing between the back of the neck of the rib and front of the transverse process, with which the tubercle articulates. It extends from the capsule of the capitular joint to that of the costo-transverse. It is best seen on horizontal section through the bones. In the eleventh and twelfth ribs this ligament is rudimentary.

The tubercular ligament (posterior costo-transverse) (fig. 281) is a short but thick, strong, and broad ligament, which extends laterally and upward from the extremity of the transverse process to the non-articular surface of the tubercle of the corresponding rib. The eleventh and twelfth ribs have no posterior ligament.

The (superior) costo-transverse ligament (fig. 280) is a strong, broad band of fibres which ascends laterally from the crest on the upper border of the neck of the rib, to the lower border of the transverse process above. A few scattered posterior fibres pass upward and medially from the neck to the transverse process. The costo-transverse ligament is subdivided into a stronger anterior portion (anterior costo-transverse ligament) best seen from the front (fig. 280), and a weaker posterior portion (posterior costo-transverse ligament). Its medial border bounds the foramen through which the posterior branches of the intercostal vessels and nerves pass. To the lateral border is attached the thin aponeu- 
rosis covering the external intercostals. Its anterior surface is in relation with the intercostal ressels and nerve; the posterior with the longissimus dorsi. The first rib has no (superior) costo-transverse ligament.

The synovial membrane (fig. 281 ) is a single sac.

The arterial and nerve supplies come from the posterior branches of the intercostal arteries and nerves.

The movements which take place at these joints are limited to a gliding of the tuberele of the rib upon the transverse process. The exact position of the facet on the transverse process varies slightly from above downward, being placed higher on the processes of the lower vertebræ. The plane of movement in most of the costo-transverse joints is inclined upward and backward in inspiration, and downward and forward in expiration. The point round which these movements occur is the head of the rib, so that the tubercle of the rib glides upon the transverse process in the circumference of a circle, the centre of which is at the capitular joint.

\section{THE ARTICLLATIONS AT THE FRONT OF THE THORAX}

These may be clivided into four sets, viz.:-

(a) The intersternal joints, or the union of the several parts of the sternum with one another.

(b) The costo-chondral joints, or the union of the ribs with their costal cartilages.

(c) The chondro-sternal joints, or the junction of the costal cartilages with the sternum.

(d) The interchondral joints, or the union of five costal cartilages (sixth, serenth, eighth, ninth, and tenth) with one another.

\section{(a) The Intersternal Joints}

The sternum being composed, in the adult, of three distinct pieces-the manubrium, body, and the xiphoid process-has two articulations, viz., the superior, which unites the manubrium with the body (gladiolus), and the inferior, which unites the body with the xiphoid.

\section{The Superior Intersternal Articulation}

Class.-False Synchondrosis.

The lower border of the manubrium and the upper border of the body of the sternum present oval-shaped, flat surfaces, with their long axes transverse, and covered with a thin layer of hyaline cartilage. An interosseous fibro-cartilage is interposed hetwern the bony surfaces: it corresponds exactly in shape and intimately adheres to them. At each lateral border this fibro-cartilage enters into the formation of the second chondro-sternal articulation (fig. 282).

In romsistence if vilries, being in some cases uniform throurhout, in others softer in the centro 1 hath at the circunference, and in others again an oval-shaped synovial cavity is found towat its anteriof part. When such a cavity exists in the fibro-cartilage this joint has a

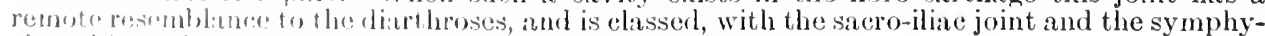
sis puhis under simitur conclitions, ats 'diarthro-amphiarthrosis.'

The poriostenum pistes muinterruptedly over the joint from one serment of the sternum to the ohere, forming a kiml of apsular liganent [membrana sterni]. This capsule is strength-

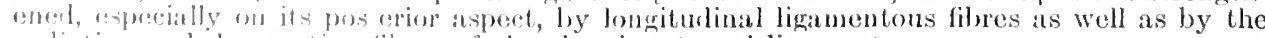

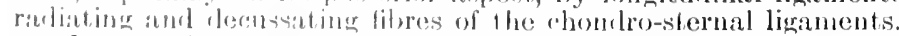

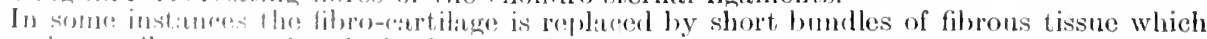

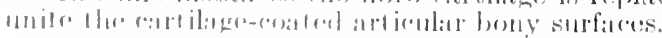

\section{2. 'The Inferior Intersternal Articulation}

Class.-Fulse Siynchondrosis.

The gladiolus is joincel to the xiphoicl cartilage by a thick investing membrane, by anterior and postorior longitudinal fibres, and by radiating fibres of the sixth and seventhe phomlro-stornal liganonts. The costo-xiphoid ligament also connects the xiphoirl with the anterior surface of the sixth and seventh costal cartilages, and thus indirectly with the glarliolus; and some fine fibro-areolar tissue also comnects the xiphoirl with the back of the seventh costal eartilage. 
The junction of the xiphoid with the sternum is on a level somewhat posterior to the junction of the seventh costal cartilage with the sternum. The union is a synchondrosis, each bone being covered by hyaline cartilage which is connected with the intervening fibro-cartilage plate.

\section{(b) The Costo-chondral Joints}

\section{Class.-Synarthrosis.}

The extremity of the costal cartilage is received into a cup-shaped depression at the end of the rib, which is somewhat larger than the cartilage. The two are joined together by the continuity of the investing membranes, the periosteum of the rib being continuous with the perichondrium of the cartilage.

\section{(c) The Sterno-costal Articulations}

\section{Class.-Diarthrosis.}

Subdivision-Ginglymus.

These articulations are between the lateral borders of the sternum and the ends of the costal cartilages. The union of the first rib with the sternum is synchondrodial, and therefore forms an exception to the others. From the second to the seventh inclusive, the articulations have the following ligaments, which together form a complete capsule:-

Radiate (anterior) sterno-costal. Posterior sterno-costal.

\section{Superior sterno-costal. Inferior sterno-costal.}

The radiate (anterior) sterno-costal ligament (fig. 282) is a triangular band composed of strong fibres which cover the medial half-inch of the front of the costal cartilage, and radiate upward and downward upon the front of the sternum. Some of the fibres decussate across the middle line with fibres of the opposite ligament. At its upper and lower borders it is in contact with the superior and inferior ligaments respectively.

The posterior sterno-costal ligament consists of little more than a thickening of the fibrous envelopes of the bone and cartilage, the joint being completed behind by a continuity of perichondrium with periosteum.

The superior and inferior ligaments are strong, well-marked bands, which pass from the upper and lower borders respectively of the costal cartilage to the lateral edges of the sternum. The sixth and seventh cartilages are so close that the superior ligament of the seventh is blended with the inferior of the sixth rib.

Deeper than the fibres of these ligaments are short fibres passing from the margins of the sternal facets to the edges of the facets on the cartilages; they are most distinct in the front and lower part of the joint, and may encroach so much upon the synovial cavity as to reduce it to a very small size, or almost obliterate it. This occurs mostly in the case of the sixth and seventh joints, especially the latter.

The interarticular ligament (fig. 282) is by no means constant, but is usually present in the second joint on one, if not on both sides of the same subject. It consists of a strong transverse bundle of fibres passing from the ridge on the facet on the cartilage to the fibrous substance between the manubrium and body; sometimes the upper part of the synovial cavity is partially or entirely obliterated by short, fine, ligamentous fibres.

The costo-xiphoid ligament (fig. 282) is a strong flat band of fibres passing obliquely upward and laterally from the front surface of the xiphoid cartilage to the anterior surface of the sternal end of the seventh costal cartilage, and most frequently to that of the sixth also.

Synovial membranes.-The union of the first cartilage with the sternum being synchondrodial, it has no synovial membrane; the second has usually two, separated by the interarticular ligament. The rest usually have one synovial membrane, which may occasionally be subdivided into two (fig. 282).

The arterial supply is derived from perforating branches of the internal mammary; and the nerves come from the anterior brauches of the intercostals.

Movements.-Excepting the first, the chondro-sternal joints are ginglymoid, but the motion of which they are capable is very limited. It consists of a hinge-like action in two directions: first, there is a slight amount of elevation and depression which takes place round a transverse axis, and, secondly, there is some forward and backward movement round an obliquely vertical axis. In inspiration the cartilage is elevated, the lowest part of its articular facet is pressed into the sternal socket, and the sternum is thrust forward so that the upper 
and front edges of the articular surfaces separate a little; in expiration the reverse movement takes place. Thus the two extremities of the costal arches move in their respective sockets in opposite directions.

This difference results necessarily from the fact that the costal arch moves upon the vertebral column, and, having been elevated, it in its turn raises the sternum by pushing it upward and forward.

The costo-xiphoid ligament tends to prevent the xiphoid cartilage from being drawn backward by the action of the diaphragm.

Fig. 282.- The Articulation at the Front of the Thorax.

(Left sile, showing ligaments; right side, the synovial cavities.)

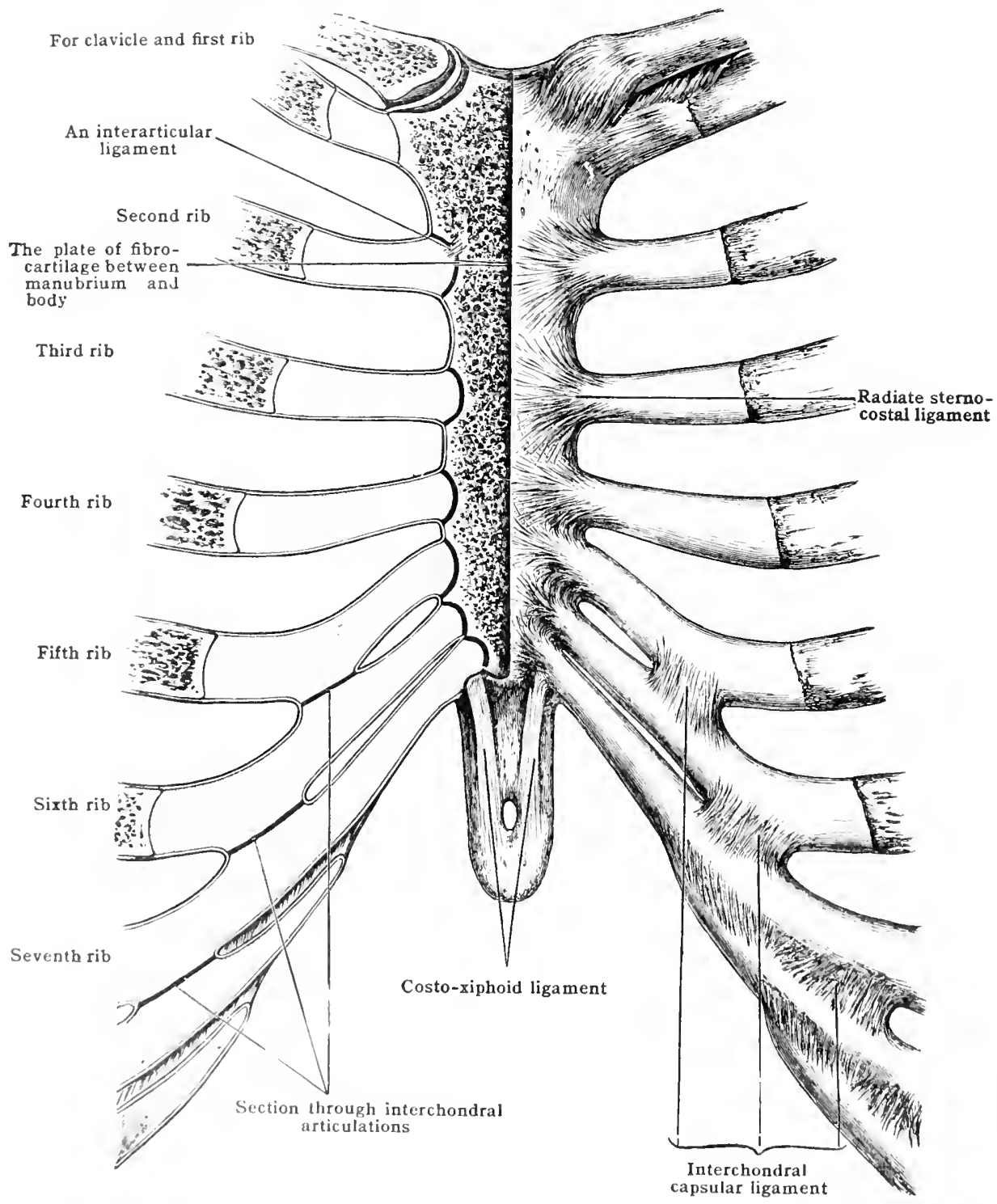

(d) 'T'HE INTHRCHONdrat Artieulations

Class. Dintherosis.

Subdivision.-. Hethrodia.

A little in front of the peint where the costal eartilages bend upward toward the median line the sixth is mnited with the seventh, the seventh with the eighth, the cighth with the ninth, and the ninth with the tenth.

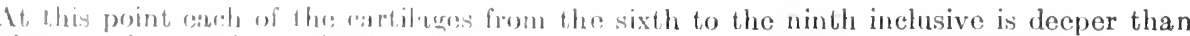

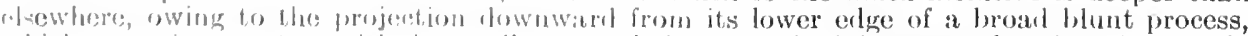

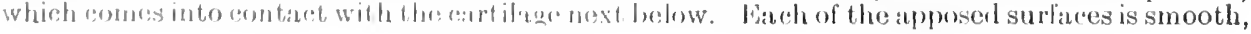


and they are connected at their margins by higamentous tissue, which forms a complete capsule for the articulation, and is lined by a synovial membrane (fig. 282). The largest of these "avities is between the seventh and eighth; those between the eighth and ninth, and ninth and tenth, are smaller, and are not free to play upon each other in the whole of their extent, being lield together by ligamentous tissue at their anterior margins. Sometimes this fibrous tissue completely obliterates the synovial cavity.

The arteries are derived from the musculo-phrenic, and the nerves from the intercostals.

Movements.-By means of the costal cartilages and interchondral joints, strength with elasticity is given to the wall of the trunk at a part where the cartilages are the only firm structures in its composition; while a slight gliding movement is permitted between the costal cartilages themselves, which takes place round an axis corresponding to the long axis of the cartilages. By this means, the outward projection of the lower part of the thoracic wall is incleased by deep inspiration.

\section{MOVEMENTS OF THE THORAX AS A WHOLE}

Before describing these movements as a whole, it must be premised that there are somt few modifications in the movements of certain ribs resulting from their shape. Thus the firs rib (and to a less extent the second also), which is flat on its upper and lower surfaces, revolves on a transverse axis drawn through the costo-vertebral and costo-transverse joints. During inspiration and expiration, the anterior extremities of the first pair of costal arches play up and down, the tubercles and the heads of the ribs acting in a hinge-like manner, the latter having also a slight screwing motion. By this movement the anterior ends of the costal arches are simply raised or depressed, and the sternum pushed a little forward; it may be likened to the movement of a pump-handle, as in fig. $283, a, b$.

The movements of the other ribs, particularly in the mid-region of the thorax, are more complex, for, besides the elevation of the anterior extremities, the bodies and angles of the

Fig. 283.-Diagram of Axis of Rib-movement. (After Kirkes.)

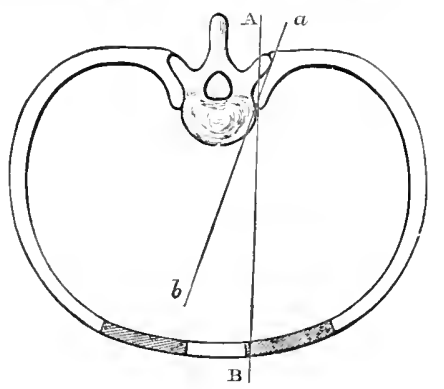

ribs rise nearly as much as the extremities themselves. In this"movement the tubercles of the ribs glide upward and backward in inspiration, and downward and forward in expiration; and the movement may be likened to that of a bucket handle, as in fig. $283, \mathrm{~A}, \mathrm{~B}$.

During inspiration, the cavity of the thorax is increased in every direction. The anteroposterior diameter is increased by the thrusting forward of the sternum, cansed by the elevation of the costal cartilages and fore part of the ribs, whereby they are brought to nearly the same level as the heads of the ribs. The transverse diameter is increased: (i) Behind, by the elevation of the middle part of the ribs; for when at rest the mid-part of the rib is on a lower level than either the costo-vertebral or chondro-sternal articulations. Owing to this obliquity the transverse diameter is increased when the rib is raised, and the increase is proportionate to the degree of obliquity. (ii) By the eversion of the lower border of the costal arch, which turns outward as the arch is raised. (iii) The transverse diameter is increased in front by the abduction of the anterior extremity of the rib at the same time as it is elevated and thrust forward.

The increase in the vertical diameter of the thorax is due to the elevation of the ribs, especially the upper ones, and the consequent widening of the intercostal spaces; but the chief increase in this direction is due to the descent of the diaphragn.

The greatest increase both in the antero-posterior and transverse diameters takes place where the ribs are longest, most oblique, and most curved at their angles, and where the bulkiest part of the lung is enclosed. This is on a level with the sixth, seventh, and eighth ribs.

At the lower part of the thorax, where the ribs have no relation to the lings, and do not affect respiration directly by their movements, it is important that the costal arches should be thrown well outward in order to counteract the compression of the abdominal viscera by the contraction of the diaphragm.

By widening and steadying the lower part of the thorax during inspiration, the attachments of the muscular fibres of the diaphragm are widened, and their power increased.

Muscles which take part in the movements of inspiration.-(a) Ordinary inspiration; The scalenes, serratus posterior superior, the external and interual (?) intercostals, the diaphrigm: the quadratus lumborum and serratus posterior inferior fixing the lower ribs, possibly the postcrior fibres of the external oblique also helping to fix the lower ribs. (b) Extraordinary inspiration: The superior extremities are raised and fixed. The cervical part of the vertebral column and the head are extended, and in addition to the muscles of ordinary inspiration, the following 
muscles also come into play: The pectoralis ninor, the muscles which extend the head and the cervical part of the vertebral column, the sterno-mastoid and the supra- and infra-hyoid muscles, the lower fibres of the pectoralis major, some of the lower fibres of the serratus anterior, and, when the clavicle is fixed, the subclavius.

Expiration is produced by the elasticity of the lungs and the weight of the thorax, aided by the elastic reaction and contraction of the external and internal oblique muscles, the recti and pyramidales, the transrersus abdominis, and the levatores ani and coccygei. In forcible expiration all muscles which depress the ribs and reduce the dimensions of the abdomen are thrown into action. The internal intercostals probably tend to contract the thorax, excepting the parts between the costal cartilages, which tend to expand the thorax.

\title{
THE ARTICLLATIONS OF THE UPPER EXTREMITY
}

The articulations of the upper extremity are the following:-
1. The sterno-costo-clavicular.
2. The scapulo-clavicular union.
3. The shoulder-joint.
4. The elbow-joint.
5. The radio-ulnar union.
6. The radio-carpal or wrist-joint.
7. The carpal joints.
8. The carpo-metacarpal joints.
9. The intermetacarpal joints.
10. The metacarpo-phalangeal joints.
11. The interphalangeal joints.

\section{THE S'TERNO-C'OSTO-CLAVICULAR ARTICLLATION}

\author{
Class.-Diarthrosis. \\ Subdivision.-Condylarthrosis.
}

At this joint the large medial end of the clavicle is united to the superior angle of the manulbrium sterni, the first costal cartilage also assisting to support the clavicle. It is the only joint between the upper extremity and the trunk, and take's part in all the movements of the upper limb. Looking at the bones, one would say that they were in no way adapted to articulate with one another, and rot they assist in constructing a joint of security, strength, and importance. The bones are nowhere in actual contact, being completely separated by an articular clise. The interval between the joints of the two sides varies from one inch to an inch and a half $(2.5-4 \mathrm{~cm}$.). The liganents of this joint are:-
(1) Articular (aifsule.
(3) Articular dise.
(2) Intrerclaviculiar.
(4) Costo-clavicular.

Th" articular capsule (fig. 2S4) consists of fibres, having varying directions aud being of varions strength and thickness, which completely surround the atriculation, and are firmly connected with the orlges of the interarticular fibrorartilitge.

The fithes at the bark of the joint, sometines styled the posterior sterno-clavicular ligament, alle stronger than those in front or below, and consist of two sets: a superficial, passing

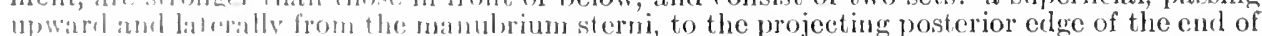
the "lavide, a fow lieimg prolongerl onward upon the posterior surface of the bone. $A$ deeper

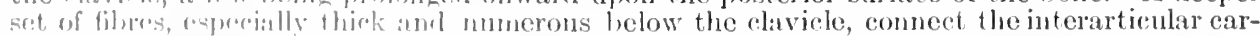
tilage with the rlaviolu and with the stromm, but do not extend from one hone to the other. 'l'he filires in front, l lir: anterior sterno-clavicular ligament, are well marked, but more lax and

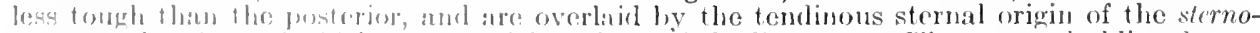

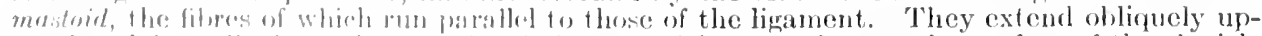
wark and latorally from the marein of the strenal facet to the anterior surface of the clavicle some litfle distame from lles articular matgin. "The fibres which cover in the joint below are

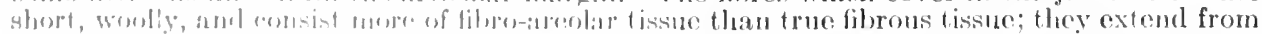

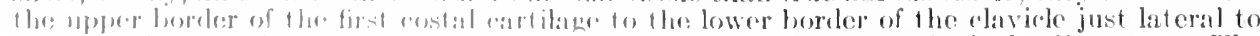

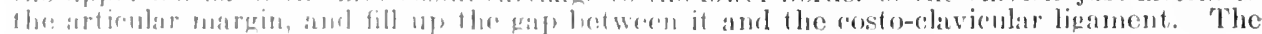
superior portion consists of short lomgh filmes passing from the stermun to the articular dise;

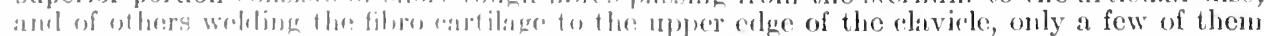

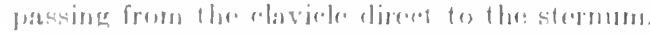

'The interclavicular ligament (fig. 2sit) is a strong, concave band, materially strengthening the superior jortion of the ralpule. It is noarly a quarter of an 
inch $(6 \mathrm{~mm}$.) deep with the concavity upward, its upper border tapering to a narrow, almost sharp edge. It is comnected with the posterior superior angle of the sternal extremity of each clavicle, and with the fibres which weld the interarticular cartilage to the clavicle; and then passes across from clavicle to clavicle along the posterior aspect of the upper border of the manubrium sterni. The lowest fibres are attached to the sternum, and join the posterior fibres of the capsule of each joint. In the middle line, between the ligament and the sternum, there is an aperture for the passage of a small artery and vein.

In addition to the interclavicular ligament Mr. Carwardine " Journal of Anatomy and Physiology," vol. 7, new series, p. 232) has described a special band of the upper portion of the sterno-clavicular capsule which he proposes to name the 'suprasternal ligament.' It descends from the upper border of the sternal end of the clavicle to the upper border of the sternum, and is of special importance as it encloses the suprasternal bones, when these rudiments are present.

The costo-clavicular or rhomboid ligament (fig. 284) is a strong dense band, composed of fine fibres massed together into a membranous structure. It extends from the upper (medial) border of the first costal eartilage (and rib),

Fig. 284.-Posterior View of the Sterno-costo-clavicular Joint.

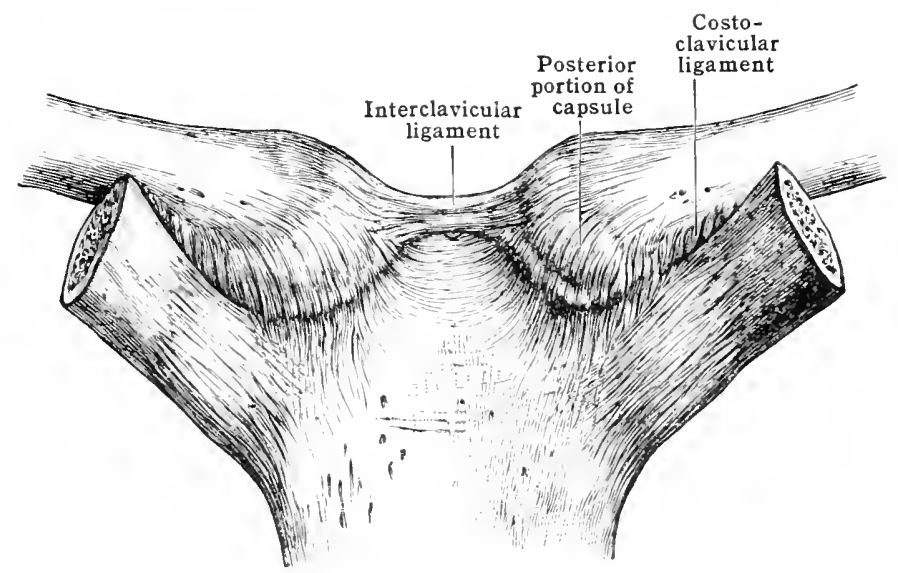

upward, backward, and distinctly laterally to the costal tuberosity on the under surface of the medial extremity of the clavicle, to which it is attached just lateral to the lower part of the eapsule. Frequently some of the lateral fibres pass upward and medially behind the rest, and give the appearance of decussating. It is from half to three-quarters of an ineh $(1.5-2 \mathrm{~cm}$.) broad.

The articular disc (fig. 285) is a flattened dise of nearly the same size and outline as the medial articular end of the clavicle, which it fairly accurately fits. It is attached above to the upper border of the posterior edge of the clavicle: and below to the cartilage of the first rib at its union with the sternum, where it assists in forming the socket for the elavicle. At its circumference it is connected with the articular eapsule, and this connection is verr strong behind, and still stronger above, where it is blended with the interelavicular ligament.

It is usually thinnest below, where it is connected with the costal cartilage. It varies in thickness in different parts, sometimes being thinner in the centre than at the circumference sometimes the reverse, and is occasionally perforated in the centre. It divides the joint into two compartments.

There are two synovial membranes (fig. 285); a lateral one, which is reflected from the clavicle and capsule cver the lateral aspect of the dise and is looser than the medial one; the medial is reflected from the sternum orer the medial side of the articular disc, costal eartilage, and capsule. Oecasionally a communication takes place between them.

The arterial supply is derived from branches-(1) from the internal mammary: (2) from the superior thoracic branch of the axillary; (3) twigs of a muscular branch often arising from the subclavian artery pass over the interclavicular notch; (1) twigs of the transterse scapular (suprascapular) artery.

The nerve-supply is derived from the nerve to the subclavius and sternal descending hranch of the cervical plexus. 
Relations.- In front of the joint is the sternal head of the sterno-mastoid. Belind it are the sterno-hyoid and sterno-thyreoid muscles. Still further back, on the right side, are the innominate and internal mammary arteries, and, on the left side, the left common carotid, the left subclavian, and the internal mammary arteries. Above and behind, between the sternomastoid and sterno-hyoid muscles, the anterior jugular vein passes back and laterally toward the posterior triangle.

The movements permitted at this joint are various though limited, owing to the capsular ligament being moderately tense in every position of the clavicle. Motion takes place in nearly every direction-viz, upward, downward, forward, backward, and in a circumductory manner. The upward and downward motions occur between the clavicle and the articular disc: during elevation of the arm the upper edge of the clavicle with its attached articular disc is pressed into the sternal socket, and the lower edge glides away from the disc; during depression of the limb, the lower edge of the clavicle presses on to the disc, while the rest of the articular surface of the clavicle inclines laterally, bringing with it to a slight degree the upper edge of the articular disc. These movements occur on an antero-posterior axis drawn through the outer compartment of the joint. The forward and backward motions take place between the articular disc and sternum, the elavicle with the dise gliding backward upon the sternum when the shoulder is brought forward, and forward when the shoulder is forced backward; these movements occur round an axis drawn nearly vertically through the sternal socket.

Fig. 255.-Anterior View of Sterno-costo-clavicular Joint, with Section showling Cavities opened on the Right Side.

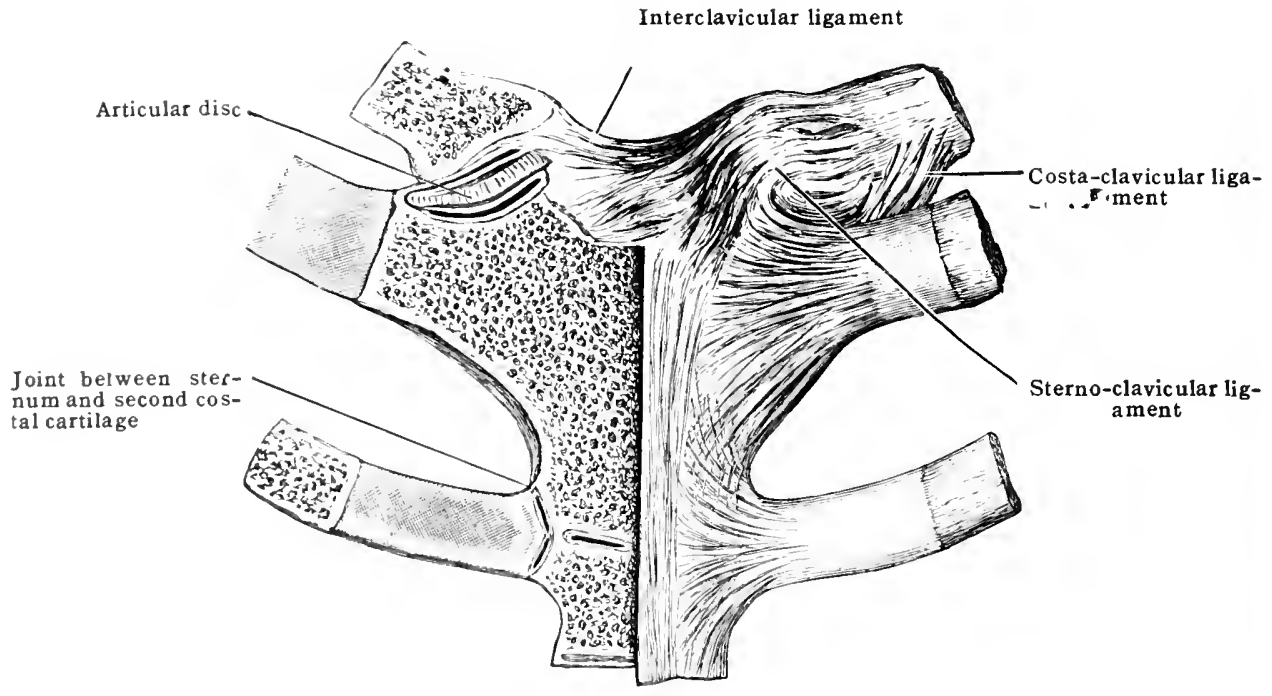

The articular disc serves materially to bind the bones together, and to prevent the media and 11 pward displaeements of the clavicle. It also forms an elastic buffer which tends to break shocks. The capsule, by being moderately tight, tends to limit movements in all directions, while the interchavicular ligament is a safeguard against upward displacement during depression of the arm. The costo-clavicular ligament prevents dislocation upward during elevation of the ariu, and resists displacements backward.

Muscles which move the clavicle at the sterno-clavicular joint.-Elevators.-Trapezius, Havioular part of sterno-mastoil, levator scapula, omo-hyoid, rhomboids.

Depressurs. - Subclicvius, pectoralis minor, lower fibres of trapezius and serratus anterior (magnis). Depression is alded by the weight of the upper extremity.

Protractors.-Pestoralis najor and minor. Serratus anterior (maguus).

Retractors. - latissimus dorsi, trapezius.

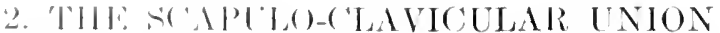

Thro scapula is ennocetrol with the chavicle by a synovial joint with its ligamonts at the aroonio-navicular articulation; and also by a set of ligaments pass-

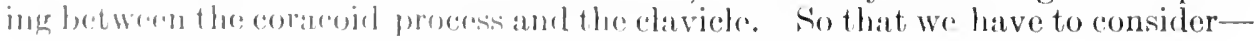

(a) 'The: acromio-clavicular articulation.

(b) 'Tlir coraco-clavicular ligaments.

(c) 'T'he proper scapular ligaments ar" also best describud in this sectionvi\%, the: coraco-acromial iurl transverse. 
(a) The Acromio-clavicular Joint

\section{Class.-Diarthrosis. Subdivision.-Arthrodia.}

The acromio-clavicular joint is surrounded by an articular capsule and frequently contains an articular disc.

The articular capsule (figs. 287 and 290) completely surrounds the articular margins, and is composed of strong, coarse fibres arranged in parallel fasciculi, of fairly uniform thickness, which are attached to the borclers as well as the surfaces of the bones. It is somewhat lax in all positions of the joint, so that the clavicle is not tightly braced to the acromion. The fibres extend three-quarters of an inch $(2 \mathrm{~cm}$.) along the clavicle posteriorly, but only a quarter of an inch $(6 \mathrm{~mm}$.$) anteriorly. Superiorly, they are attached to an oblique line joining$ these two points, while inferiorly they reach to the ridge for the trapezoid ligament with which they blend.

At the acromion they extend half way across the upper and lower surfaces, but at the anterior and posterior limits of the joint they are attached close to the articular facet. The anterior fibres become blended with the insertion of the coraco-acromial ligament. The fibres are strengthened above by the aponeuroses of the trapezius and deltoid muscles; and all run from the acromion to the clavicle medially and backward.

The articular disc is occasionally present, but is usually imperfect, only occupying the upper part of the joint; it may completely divide the joint into two cavities, or be perforated in the centre. It is usually thicker at the edge than in the centre, and some of the fibres of the articular capsule are blended with its edges.

The synovial membrane lining the joint is occasionally either partially or entirely divided into two by the articular disc.

Relations.-Superiorly skin and fascia and the tendinous intersection between the deltoid and the trapezius. Inferiorly, the coraco-acromial ligament and supraspinatus. Anteriorly, part of the origin of the deltoid. Posteriorly, part of the insertion of the trapezius.

Movements. - A certain amount of gliding movement occurs at this joint, but the most important movement is a rotation of the scapula whereby the glenoid cavity is turned forward and upward, or downward. As these movements occur the inferior angle of the scapula moves forward as the glenoid cavity turns upward and the superior angle recedes.

The forward movement of the inferior angle is produced mainly by the inferior fibres of the serratus anterior (magnus), aided by the inferior fibres of the trapezius, and it is by this movement that the arm is raised above the level of the shoulder forward. dorsi.

The reverse movement is produced mainly by the rhomboideus major aided by the latissimus

\section{(b) The Coraco-clavicular Union}

The coraco-clavicular ligament (figs. 286, 287, and 290) consists of two parts, the conoid and the trapezoid ligaments.

The conoid ligament is the medial and posterior portion, and passes upward and laterally from the coracoid process to the clavicle.

It is a very strong and coarsely fasciculated band of triangular shape, the apex being fixed to the medial and posterior edge of the root of the coracoid process just in front of the scapular notch, some fibres joining the transverse ligament. Its base is at the clavicle, where it widens out, to be attached to the posterior edge of the inferior surface, as well as to the coracoid tubercle. It is easily separated from the trapezoid, without being absolutely distinct. A small bursa of ten exists between it and the coracoid process; medially, some of the fibres of the subclavius muscle are often attached to it.

The trapezoid ligament is the anterior and lateral portion of the coracoclavicular ligament. It is a strong, flat, quadrilateral plane of closely woven fibres, the surfaces of which look upward and medially toward the clavicle, and downward and laterally over the upper surface of the coracoid process.

At the coracoid it is attached for about an inch $(2.5 \mathrm{~cm}$.) to a rough ridge which runs forward from the angle, along the anterior border of the process. At the clavicle it is attached to the oblique ridge which runs laterally and forward from the coracoid tubercle, reaching as far as, and blending with the inferior part of the acromio-clavicular ligament. Its anterior. edge is free, and overlies the colaco-acromial ligament; the posterior edge is shorter than the anterior, and is in contact with the posterior and lateral portion of the conoid ligament.

The arterial supply is derived from the transverse scapular (suprascapular), acromial branches of the thoraco-acromial, and the anterior circumflex.

The nerve-supply is derived from the suprascapular and axillary (circumflex) nerves. 
Movements. - In the movements of the shoulder girdle, the scapula moves upon the lateral' end of the clavicle, and the clavicle, in turn, carried by the uniting ligaments, moves upon the sternum; so that the entire scapula moves in the arc of a circle whose centre is at the sternoclavicular joint, and whose radius is the clavicle. The scapula, in moving upon the clavicle, also moves upon the thorax forward and backward, upward and downward, and also in a rotatory direction upon an axis drawn at right angles to the centre of the bone. Throughout these movements the inferior angle and base of the scapula are kept in contact with the ribs by the

Fig. 2S6.-Anterior View of Shodlder, showing also Coraco-clavicular and Coraco-ACromial Ligaments.

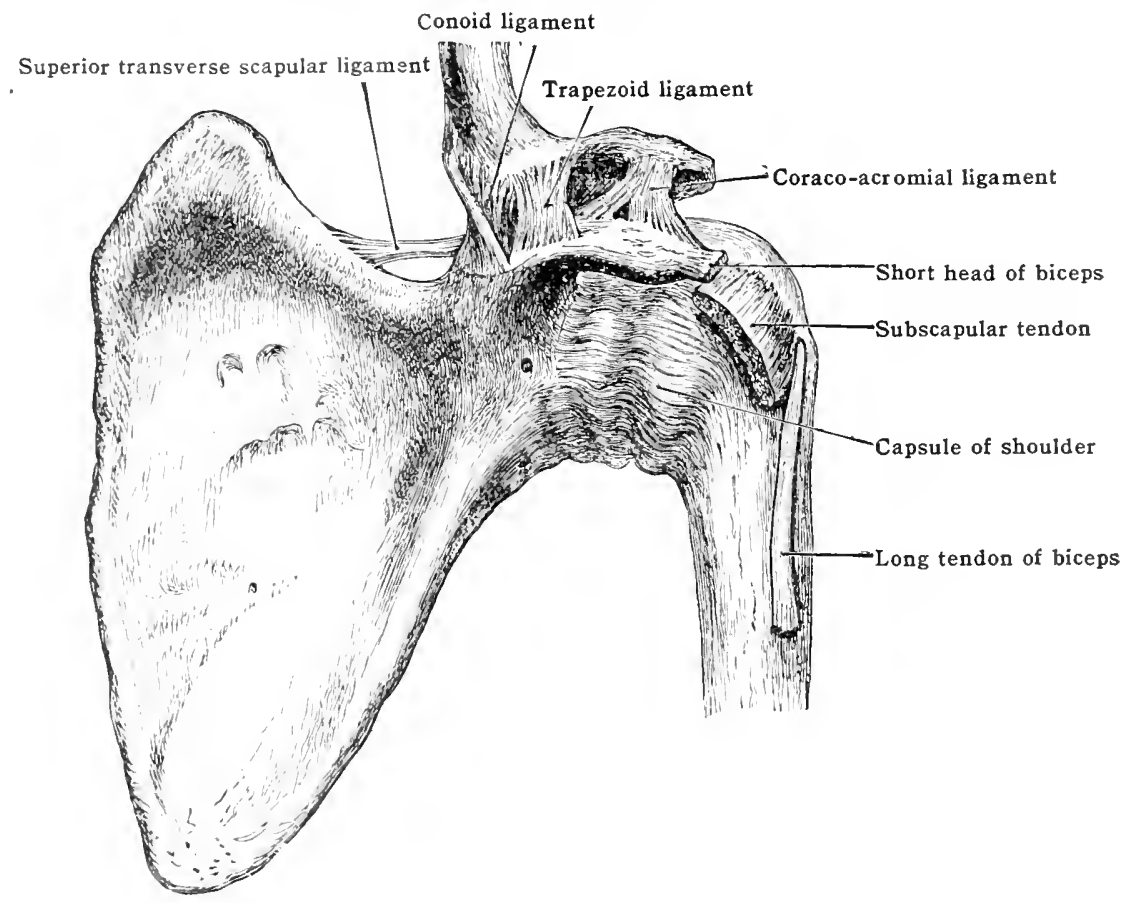

latissimus dorsi, which straps down the former, anch the rhomboids and serratus anterior (magnus), which brace lown thr latter. The glenoid eavity could not have preserved its obliquely forward ilirection hal there been no acromio-clavicular joint, but would have shifted round a vertical axis, and thus the shoulder would have pointed medialward when the scapula was arlvancerl, and lateralward when it was drawn backward. By means of the acromio-clavicular joint, the scapula can be foreibly alvaneed upon the thorax, the glenoid cavity all the time kreping its fuce duly forward. Thus the muscles of the shoulder and forearm can be with arlvantage combined, as, for' example, in giving a direct blow. 'The acromio-clavicular joint also bermits the lower ingle of the sciunla to be retained in contact with the chest wall during the rising and falling of the shoulder, the scapula turning in a hinge-like manner round the herpizent:al axis of thre joint.

'Ther" are mo atctions in which the seapula moves on a fixes clavicle, or the clavicle on a fixcrl scaptula; the two bones, bound together by their connecting liganent, must move in minisun.

\section{(c) The Ploper scapular Iigaments}

'There are three proprer ligaments of the scapula, which pass between different, portions of the burs, viz.- -

$$
\text { ('oracerateromial. Superior transverse. }
$$

lufrerior transverse.

The coraco-acromial ligament (figs. 2sf; and 290) is a flat, triangular band

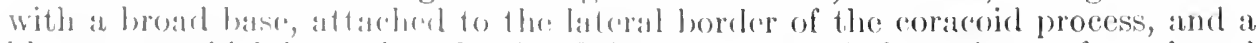
blunt andex which is fixed to the tip of the atromion. It is made up of two broad marginal bamk, and at smallor and thinner intervening portion. The anterior band, which arises from the anteriog portion of the coracoid process, is the stronger, and some of its marginal fibres ran of ton be traced into the short head

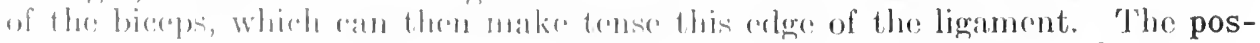
terior band, coming from the pustorion patt of the coracolis process, is also strong. 
The intermediate part, of variable extent, is thin and membranous, containing but few ligamentous fibres; it is often incomplete near the coracoid process. leaving a small gap (fig. 286).

The superior surface of the ligament looks upward and a little forward, and is covered by the deltoid muscle; the inferior looks downward and a little backward, and is separated from the capsule of the shoulder-joint by a bursa and the tendons of the supraspinatus and sutscapularis muscles. At the coracoid process it overlies the coraco-humeral ligament. It is barely one-third of an inch $(8 \mathrm{~mm}$.) above the capsule of the shoulder, and in the undissected state there is scarcely a quarter of an inch $(6 \mathrm{~mm}$.) interval. The anterior band projects over the centre of the head of the humerus, and is continued into a tough fascia under the deltoid; the posterior band is continuous with the fascia over the supraspinatus muscle. It binds the

Fig. 287.-Posterior View of the Sihoulder-joint, silowing also the Acromio-clavicular Jont and the Śpecial Ligaiexts of tile ścaptla.

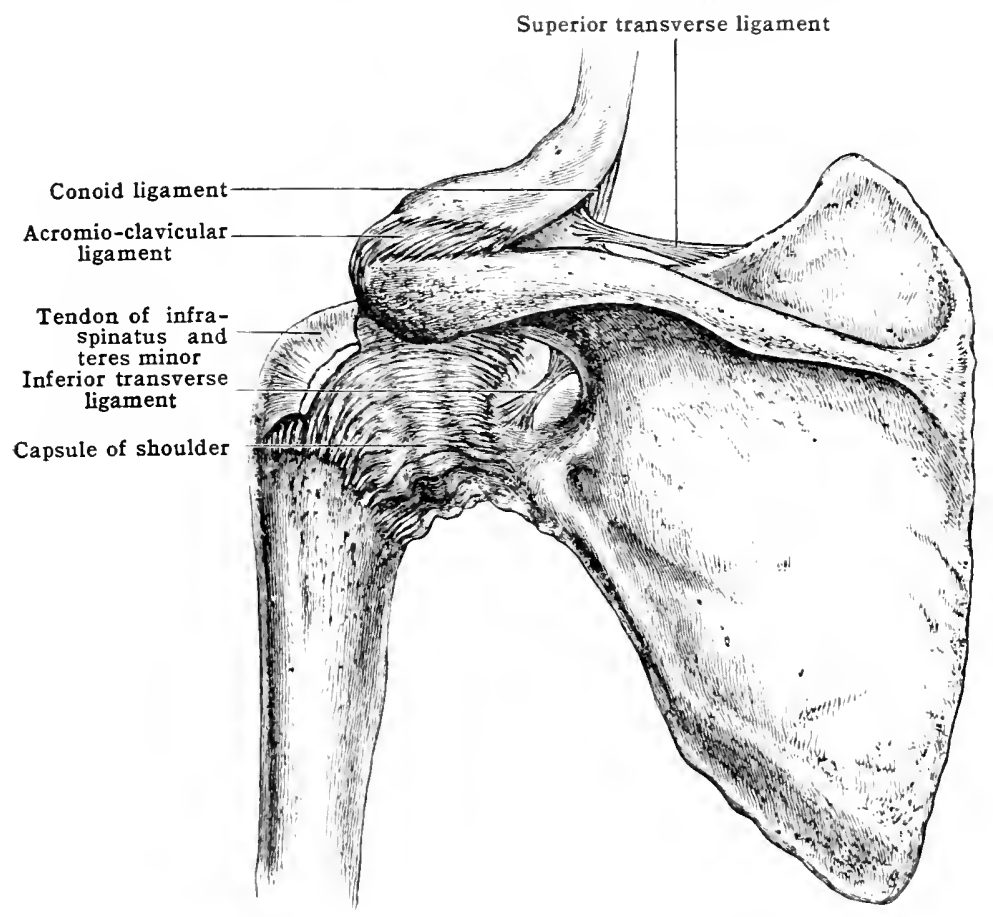

two processes firmly together, and so strengthens each; it holds the deltoid off the capsule of the shoulder, and protects the joint from slight injuries directed downward and backward against it.

The superior transverse (coracoid, or suprascapular) ligament (figs. 2s6, 287 , and 288) is a small triangular band of fibrous tissue, the surfaces of which look forward and backward; and its edges, which are thin and sharp, are turned upward and downward. It continues the superior border of the scapula, bridging over the scapular notch.

It is broader medially, where it springs from the upper border of the seapula on its dorsal surface; and narrow laterally, where it is attached to the base of the coracoid process; some of its fibres are inserted under the edge of the trapezoid ligament, and others pass upward with the conoid to reach the clavicle. The transverse scapular (suprascapular) artery passes orer it, and the suprascapular nerve beneath it. IIedially, some fibres of the omo-hyoid muscle arise from it.

The inferior transverse (spino-glenoid) ligament (fig. 285) reaches from the lateral border of the spine of the scapula to the margin of the glenoid cavity, and so forms a foramen under which the transverse scapular (suprascapular) vessels and suprascapular neree grain the infraspinous fossa. It is usually a weak membranous structure with but few ligunentous fibres.

\section{THE SHOLLDER-JOINT}

Class.-Diarthrosis.

Subdivision.-Enarthrodia.

The shoulder [articulatio humeri] is one of the most perfect and most morable 
of joints, the large upper end of the humerus playing upon the shallow glenoid cavity. Like the hip, it is a ball-and-socket joint. It is retained in position much less by ligaments than by muscles, and, owing to the looseness of its capsule, as well as to all the other conditions of its construction and position, it is exceedingly liable to be displaced; on the other hand, it is sheltered from violence by the two projecting processes-the acromion and coracoid.

The ligaments of the shoulder-joint are:-
Articular capsule.
Coraco-humeral.
Gleno-humeral.
Glenoid.

The articular capsule (figs. 286, 287, and 288) is a loose sac, insufficient in itself to maintain the bones in contact. It consists of fairly distinct but not coarse fibres, closely woven together, and directed, some straight, others obliquely, between the two bones, a few circular ones being interwoven amongst them. At the scapula, it is fixed on the dorsal aspect to the prominent rough

Fig. 259.- Vertical śection throdgh the Shoulder-Joint to show the Gleno-humeral. LIGAMENT.

(The joint is opened from behind.)

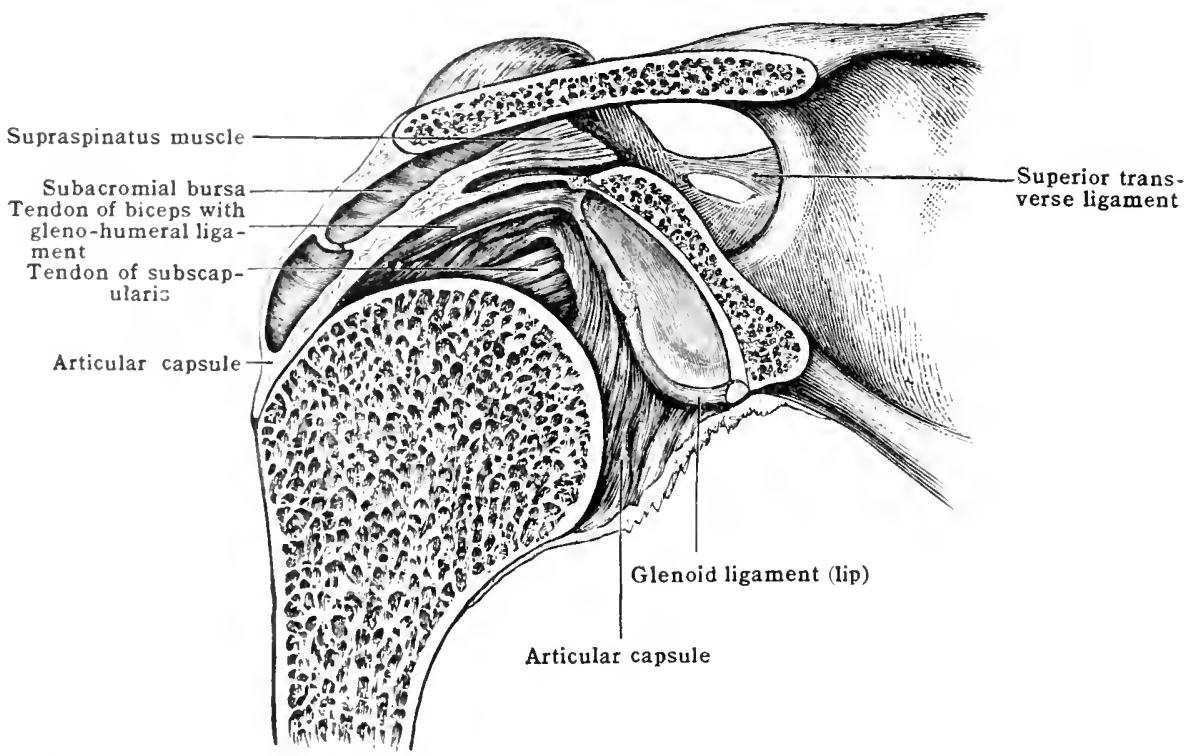

surface around the margin of the glenoid eavity, reaching as far as the neck of the bone. Simperiorly, it is attached to the root of the eoracoid process; anteriorly, to the ventral surface, at a variable distance from the articular margin, of ten reaching half an inch $(12 \mathrm{~mm}$.) upon the neck of the bone, and thus allowing the formation of a pouch; it may not, however, extend for more than a (fuart ( $\mathrm{r}$ of an inch $(6 \mathrm{~mm}$.) beyond the articular margin; inferiorly, it blends with the origin of the long head of the triceps. At the humerus, the superior half is fixed to the anatomical neck, sending a prolongation downward between the two tuberoities which attenuates as it descends, and covers the transverse humeral ligament. 'The lower half of the capsule deseends upon the humerus further from the articular margin, some of the deeper fibres being refleeted upward so ats to lwe at ached close to the articular edge, thus forming a kind of fibrous inventument for the neck of the humerus. This ligament is more uniform in thickness thath that of the hip.

Gleno-humeral bands of the capsule (figs. 288 and 289).-There are three aresory binds, known as the superior, middle and inferior gleno-humeral bands, which project towarl the interior of the joint from the fore part of the eapsule and arre rencerguently best seen when the joint is opened from behind.

'The midle banl maches from the anterior margin of the glenoil carity along the lower

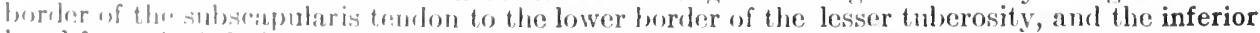
hand from the inforior part of the glenoid eavity to the inferior part of the neck of the humerus. 
The superior band, known also as the gleno-humeral ligament, runs from the edge of the glenoid cavity at the root of the coracoid process, just medial to the origin of the long tendon of the biceps, and, passing laterally and downward at an acute angle to the tendon, for which it forms a slight groove or sulcus, is fixed to a depression, the fovea capitis humeri, above the lesser tuberosity of the humerus. It is a thin, ribbon-like band, of which the superior surface is attached to the capsule, while the inferior is free and turned toward the joint. In the foetus it is often, and in the adult occasionally, quite free from the capsule, and may be as thick as the long tendon of the biceps (fig. 2s9).

The tendons of the supra- and infra-spinatus, teres minor, and subscapularis muscles strengthen and support the capsule, especially near their points of insertion, and can be with difficulty dissected off from it. The long head of the triceps supports and strengthens the capsule below. The capsule also receives an upmard slip from the pectoralis major. The supraspinatus often sends a slip into the capsule from its upper edge (fig. 285).

The coraco-humeral ligament (fig. 290) is a strong broad band, which is attached above to the lateral edge of the root and horizontal limb of the coracoid process nearly as far as the tip. From this origin it is directed backward along the line of the biceps tendon to blend with the capsule, and is inserted into the greater tuberosity of the humerus.

Seen from the back, it looks like an uninterrupted continuation of the capsule, while from the front it looks like a fan-shaped prolongation from it overlying the rest of the liganent. At its origin there is sometimes a bursa between it and the capsule.

The glenoid ligament or lip [labrum glenoidale] (figs. 288 and 292) is a narrow rim of dense fibro-cartilage, which surrounds the edge of the glenoid socket and deepens it. It is about a quarter of an inch $(6 \mathrm{~mm}$.) wide above and below, but. less at its sides. Its peripheral edge is inseparably welded, near the bone, with

Fig. 289.-Fetal Shodlder-joint, showing the Gleno-humeral Ligament, and also the Short Head of the Biceps, BeiNg continuous with the Coraco-acromial Liganent.

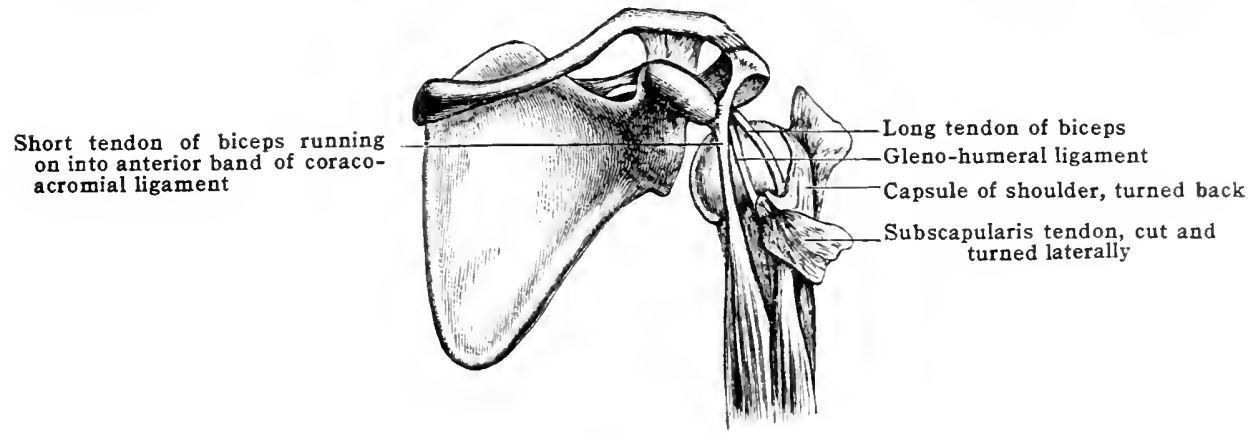

the articular capsule. Its structure is almost entirely fibrous, with but few cartilage cells intermixed. At the upper part of the fossa the biceps tendon is prolonged into the glenoid ligament, the tendon usually dividing and sending fibres right and left into the ligament, which may wind round nearly the whole circumference of the socket. It may, however, sencl fibres into one side only, usually into the lateral.

The articular cartilage covering the glenoid fossa is thicker at the circumference than in the centre, thus tending to deepen the cavity. It is usually thickest at the lower part of the fossa; over the head of the humerus the cartilage is thickest at and below the centre.

The synovial membrane lines the glenoid ligament, and is then reflected over the capsule as far as its attachment to the humerus, from which it ascends as far as the edge of the articular cartilage. The tendon of the biceps receives a long tubular sheath, which is continuous with the synovial membrane, both at its attached extremity and at the bicipital groove, but is free in the rest of it: extent. The synovial cavity almost always communicates with the bursil under the subscapularis, and sometimes with one under the infraspinatus muscle.

It also sends a pouch-like prolongation beneath the coracoid process when the fibrous capsule is attached wide of the margin of the glenoid fossa. A few fringes are seen near the edge of the glenoid cavity, and there is often one which runs down the medial edge of the biceps tendon, extending slightly below it and making a slight groove for the tendon to lie in. 
The transverse humeral ligament (fig. 290) is so closely connected with the capsule of the shoulder that, although it is a proper ligament of the humerus, it may well be described here. It is a strong band of fibrous tissue, which extends

Fig. 290.-Lateral View of the Shollder-Joint, showing the Coraco-humeral and Transverse Humeral Ligaments.

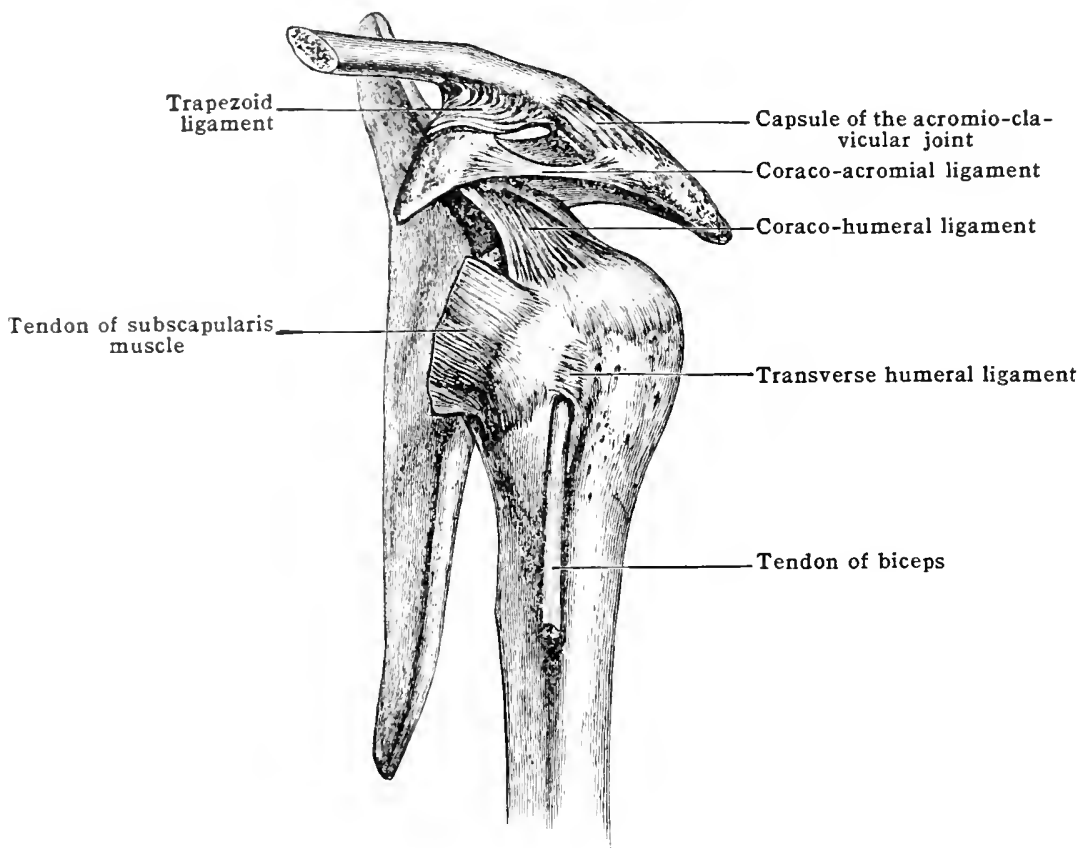

Fig. 291.-The Upper Exthemity of the Humerus, Anterior View, to Show the Relatiox of tife Articular Capsule of the Shoulder-joint (in red) to the Epiphysial Line.

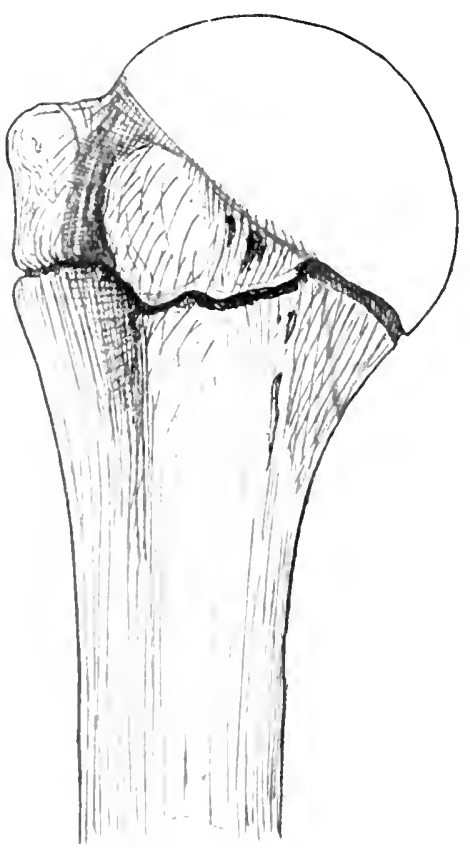

betwern the two tuberosities, bofing in the intertubercular (bjeipital) groove. It is enverest hy at thin expansion of the anpsule. It is limited to the portion of the

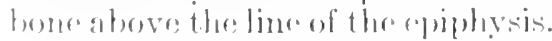


Relations.-The following muscles are in contact with the capsule of the shoulder-joint. In front, the subscapularis; above, the supraspinatus; above and behind, the infraspinatus; behind, the teres minor; below, the long head of the triceps and the teres major. In the interval between the subscapularis and the supraspinatus the subacromial bursa is close to the capsule and occasionally its cavity communicates with the cavity of the joint.

The axillary (circumflex) nerve and posterior circumflex artery pass beneath the capsule in the interval between the long head of the triceps, the humerus, and the teres major. When the arm is abducted, the long head of the triceps and the teres major are drawn into closer relation with the capsule and help to prevent dislocation of the humerus.

The axillary vessels, the great nerves of the axilla, the short head of the biceps, and the coraco-brachialis are separated from the joint by the subscapularis, whilst the deltoid forms a kind of cap, which extends from the front to the back over the more immediate relations.

The arterial supply is derived from the transverse scapular (suprascapular), anterior and posterior circumflex, subscapular, circumflex scapular (dorsalis scapulæ), and a branch from the second portion of the axillary artery.

The nerve-supply is derived from the suprascapular, by branches in both fossæ; and from the axillary (circumflex) and subscapular nerves.

The movements of the shoulder-joint consist of flexion, extension, adduction, abduction, rotation and circumduction.

Flexion is the swinging forward, extension the swinging backward, of the humerus; abduction is the raising of the arm from, and adduction depression of the arm to, the side. In flexion and extension the head of the humerus moves upon the centre of the glenoid fossa round an

Fig. 292.-Biceps Tendon, Bifurcating and Blending on each Side with the Glenoid Ligament.

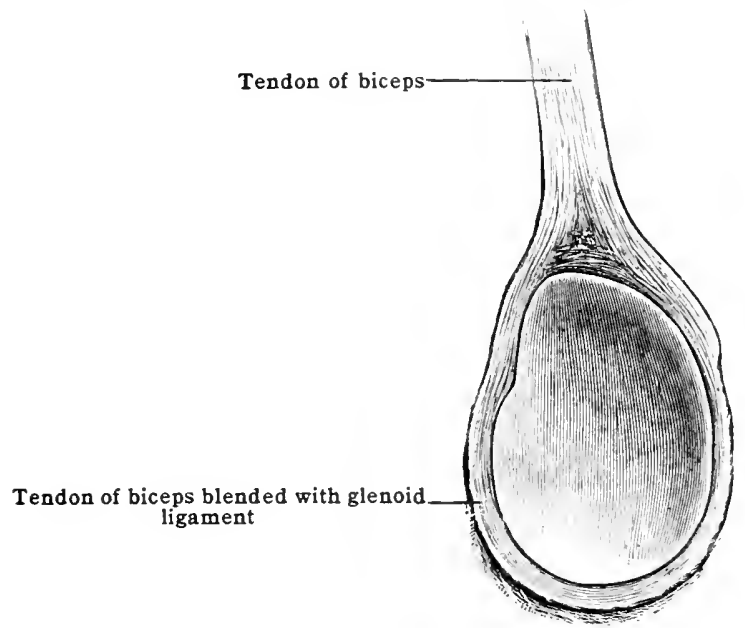

oblique line corresponding to the axis of the head and neck of the humerus, flexion being more free than extension, and in extreme flexion the scapula follows the head of the humerus, so as to keep the articular surfaces in apposition. In extension the scapula moves much less, if at all.

In abduction and adduction the scapula is fixed, and the humerus rolls up and down upon the glenoid fossa; during abduction the head descends until it projects beyond the lower edge of the glenoid cavity, and the greater tuberosity impinges against the arch of the acromion; during adduction, the head of the humerus ascends in its socket, the arm at length reaches the side, and the capsule is completely relaxed.

In circumduction, the humerus, by passing quickly through these movements, describes a cone, whose apex is at the shoulder-joint, and the base at the distal extremity of the bone or limb.

Rotation takes place round a vertical axis drawn through the extremities of the humerus from the centre of the head to the inner condyle; in rotation forward (that is, medialward) the head of the bone rolls back in the socket as the great tuberosity and shaft are turned forward; in rotation backward (that is, lateralward) the head of the bone glides forward, and the tuberosity and shaft of the humerus are turned backward, i. e., lateralward.

Great freedom of movement is permitted at the shoulder, and this is increased by the mobility of the scapula. Restraint is scarcely exercised at all upon the movements of the shoulder by the ligaments, but chiefly by the muscles of the joint.

In abduction, the lower part of the capsule is somewhat, and in extreme abduction considerably, tightened; and in rotation medialward and lateralward, the upper part of the capsule is made tense, as is also, in the latter movement, the coraco-humeral ligament.

The movements of abduction and extension have a most decided and definite resistance offered to them other than by muscles and ligaments, for the greater tuberosity of the humerus, by striking against the acromion process and coraco-acromial ligament, stops short any further advance of the bone in these directions, and thus abduction ceases altogether as soon as the arin 
is raised to a right angle with the trunk, and extension shortly after the humerus passes the line of the trunk.

Further elevation of the arm beyond the right angle, in the abducted or extended position, is effected by the rotation of the scapula round its own axis by the action of the trapezius and serratus anterior muscles upon the sterno-clavicular and acromio-clavicular joints respectively.

The acromion and coracoid process, together with the coraco-acromial ligament, form an arch, which is separated by a bursa and the tendon of the supraspinatus from the capsule of the shoulder. Beneath this arch the movements of the joint take place, and against it the head and tuberosities are pressed when the weight of the trunk is supported by the arms; the greater tuberosity and the upper part of the shaft impinge upon it when abduction and extension are carried to their fullest extent.

No description of the shoulder-joint would be complete without a short notice of the peculiar relation which the biceps tendon bear's to the joint. It passes over the head of the humerus a little to the medial side of its summit, and lies free within the capsule, surrounded only by a tubular process of synovial membrane. It is flat, with the surfaces looking upward and downward, until it reaches the intertubercular (bicipital) groove, when it assumes a rounded form. It strengthens the articulation along the same course as the coraco-humeral ligament, and tends to prevent the head of the humerus from being pulled upward too' forcibly against the inferior surface of the acromion. It also serves the purpose of a ligament by steadying the head of the humerus in various movements of the arm and forearm, and to this end is let into a groove at the upper end of the bone, from which it cannot escape on account of the abutting tuberosities and the strong transverse humeral ligament which binds it down. Further, it acts like the four shoulder muscles which pass over the capsule, to keep the head of the humerus against the glenoid socket; and, moreover, it resists the tendency of the pcctoralis major and latissimus dorsi muscles, in certain actions when the arm is away from the side of the body, to pull the head of the humerus below the lower edge of the cavity.

Muscles which act upon the shoulder-joint.-Flexors or protractors.-Deltoid (anterior fibres), pectoralis major (clavicular fibres), coraco-brachialis, biceps (short head), subscapularis (upper fibres).

Extensors or retractors.-Latissimus dorsi, deltoid (posterior fibres), teres major, teres minor, infraspinatus (lower fibres).

Abductors.-Deltoid, supraspinatus, biceps (long head).

Adductors.-Pectoralis major, latissimus dorsi, subscapularis, infraspinatus, teres major, teres miror, coraco-brachialis, biceps (short head), triceps (lower head).

Medial rotators.-Pectoralis major, latissimus dorsi, teres major, subscapularis, deltoid (anterior fibres).

Lateral rotators.-Deltoid (posterior fibres), infraspinatus, teres minor.

Circumductors.-The above groups acting consecutively.

\section{THE ELBOW-JOINT}

Class.-Diarthrosis.

Subdivision.-Ginglymus.

The elbow [articulatio cubiti] is a complete hinge, and, unlike the knee, depends for its sccurity and strength upon the configuration of its bones rather than on the number, strength, or arrangement of its ligaments. The bones composing it are the lower end of the humerus above, and the upper ends of the radius and ulna below; the articular surface of the humerus being received partly within the scmilunar notch (great sigmoid cavity) of the ulna, and partly upon the cup-shaped area (fovea) of the radial head. The ligaments form one large and capacious capsule [capsula articularis], which, by blending with the anmilar ligament, and then passing on to be attached to the neck of the radius, cmbraces the elbow and the superior radio-ulnar joints, uniting them into one. Latcrally, it is considerably strengthened by superadded fibres arising from the epicondyles of the humerus and inseparably connected with the capsule. For convenience of decription it will be spoken of as consisting of four portions:-

$$
\begin{array}{ll}
\text { Antrior. } & \text { Medial. } \\
\text { P'osterior. } & \text { Lateral. }
\end{array}
$$

The anterior portion (fig. 29:) is attached to the front of the humerus above the artieular surfirer and corongid fossa, in an inverted $\boldsymbol{V}$-shaped manner, to two very faintly maklinl ridgen whel start from the front of the medial and lateral

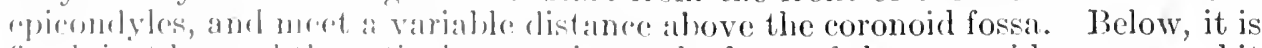
fixerl, just brgenerl the anticular margin, to the front of the coronoid process and it is intimatcly benderl with the front of the anmular ligament, a few fibres passing (s) to the neek of the radius.

It varies in strength and thickness, being sometimes so thin as barcly to cover the synovial mombranc; at othors, thick and strong, and formed of coarse decussating fibres, the nuajority of which desend from the merlial side laterally to the radius. 
The posterior portion (fig. 294), thin and membranous, is attached superiorly to the humerus, in much the same inverted $\mathbf{V}$-shaped way as the anterior; ascending from the medial epicondyle, along the medial side of the olecranon fossa nearly to the top; then, crossing the bottom of the fossa, it descends on the lateral side, skirting the lateral margin of the trochlear surface, and turns laterally along the posterior edge of the capitulum. Inferiorly, it is attached to a slight groove

Fig. 293.-Medial View of the Elbow-Joint.

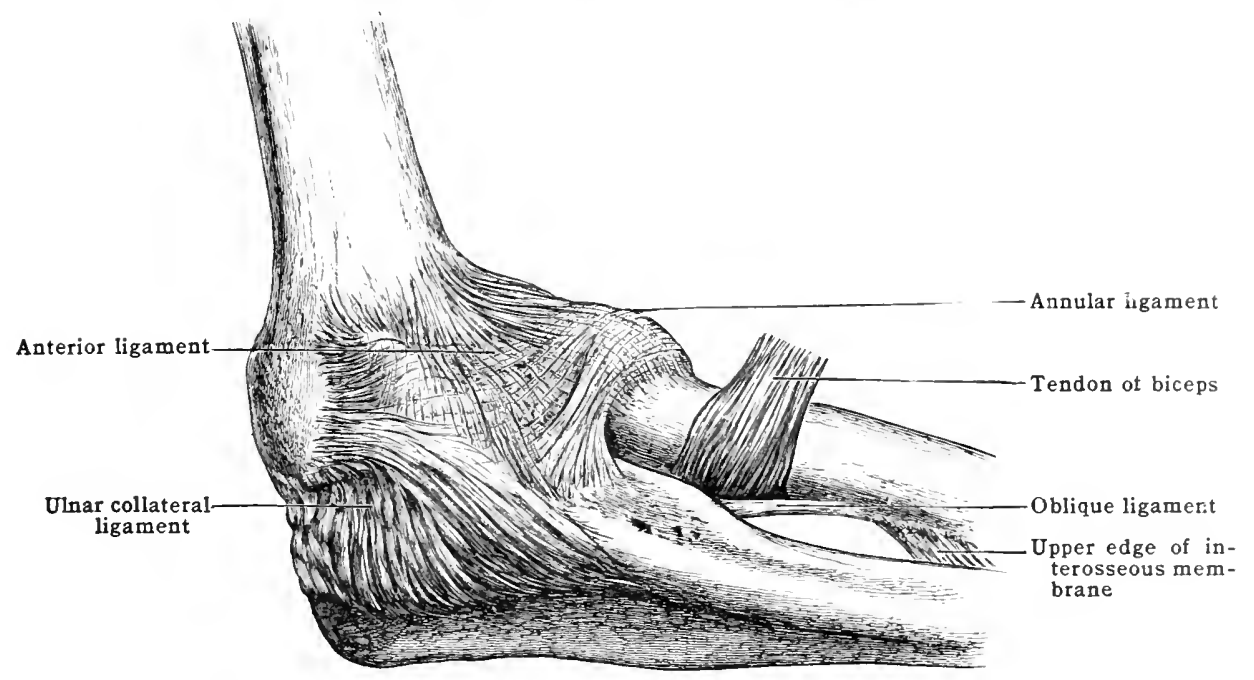

along the superior and lateral surfaces of the olecranon, and the rough surface of the ulna just beyond the radial notch, and to the annular ligament, a few fibres passing on to the neck of the radius.

It is composed of decussating fibres, most of which pass vertically or obliquely downward, a few taking a transverse course at the summit of the olecranon fossa where the ligament is usually thinnest.

Fig. 294.-Lateral View of the Elbow-Joint.

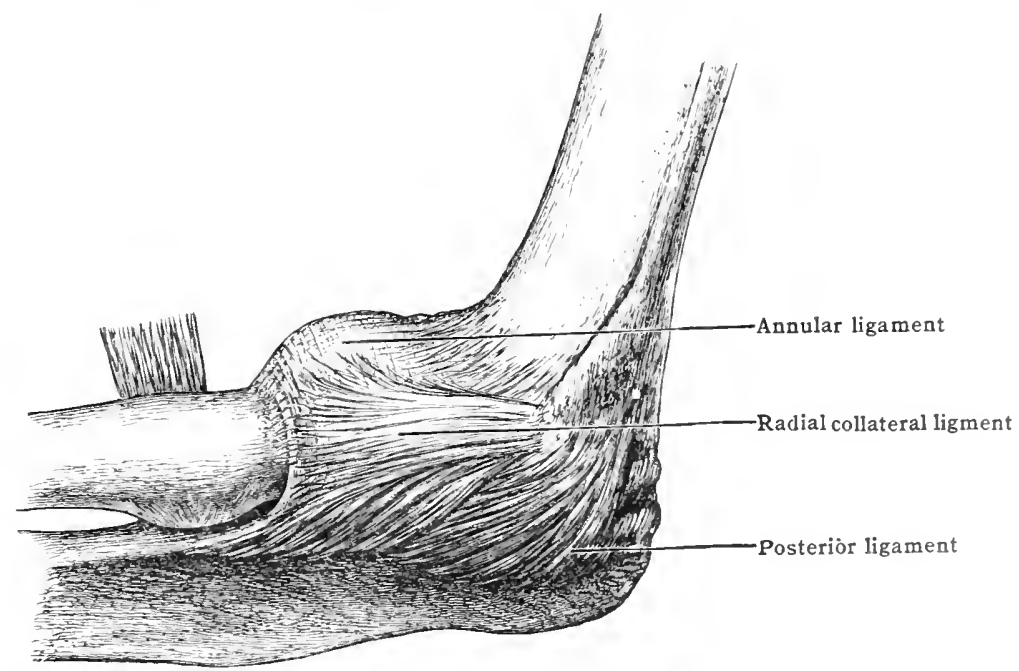

The medial portion, the ulnar collateral ligament (fig. 293), is thicker, stronger, and denser than either the anterior or posterior portions. It is triangular in form, its apex being attached to the anterior and under aspect of the medial epicondyle, and to the condyloid edge of the groove between the trochlea and the condyle. The fibres radiate downward from this attachment, the anterior passing forward to be fixed to the rough overhanging medial edge of the coronoid 
process; the middle descend less obliquely to a ridge running between the coronoid and olecranon processes, while the posterior pass obliquely backward to the medial edge of the olecranon just beyond the articular margin.

Fig. 295. - Lother Extremity of the Humerus, to show the Relation of the Articular Capsule of the Elbow-Joint (IN Red) to the Epiphysial Lines.

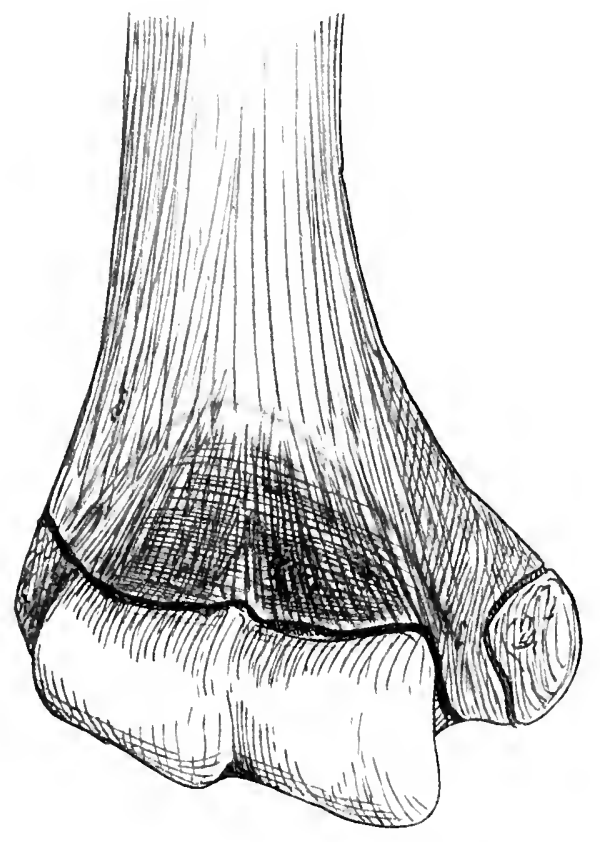

Fig. 296. - The Upper Extremity of the Ulna, to show the Relation of the Articdlar Capsule of the Elbow-Joint (IN RED) to the Epiphysial Lines.

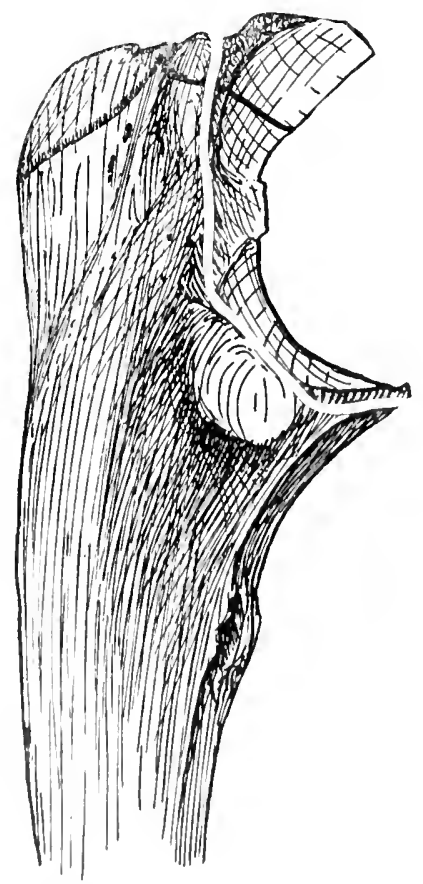

An oblique band (the oblique ligament of sir $\Lambda$ stley Cooper) connects the margin of the olecranon process with the margin of the "oronoid process. It lies superficial to the posterior fibres of the ulnar collateral ligament. 'The anterior fibres are the thickest, strongest, and most pronouncel. 
The lateral portion, the radial collateral ligament (fig. 294), is attached above to the lower part of the lateral epicondyle, and from this the fibres radiate to their attachment into the lateral side of the annular ligament, a few fibres being prolonged to reach the neck of the radius. The anterior fibres reach further forward than the posterior do behind. It is strong and well-marked, but less so than the medial portion.

The synovial membrane lines the whole of the capsule, and extends into the superior radio-ulnar joint, lining the annular ligament.

Outside the synovial membrane, but inside the capsule, are often seen some pads of fatty tissue; one is situated on the medial side at the base of the olecranon, another is seen on the lateral side projecting into the cavity between the radius and ulna; this latter, with a fold of synovial membrane opposite the front of the lateral lip of the trochlea, suggests the division of the joint into two parts-one medially for the ulna, and anotler laterally for the radius. There are also pads of fatty tissue at the bottom of the olecranon and coronoid fossæ, and at the tip of the olecranon process.

The arterial supply is derived from each of the vessels forming the free anastomosis around the elbow, and there is also a special branch to the front and lateral side of the joint, from the brachial artery, and the arterial branch to the brachialis also feeds the front of the joint.

The nerve-supply comes chiefly from the musculo-cutaneous; the ulnar, median, and radial (musculo-spiral) also give filaments to the joint.

Relations. - In front of the joint, and in immediate relation with the capsule, are the brachialis, the superficial and deep branches of the radial (musculo-spiral) nerve, the radial recurrent artery, and the brachio-radialis. The brachial artery, the median nerve, and the pronator teres are separated from the capsule by the brachialis. Directly behind the capsule are the triceps, the anconeus, and the posterior interosseous recurrent artery. On the medial side are the ulnar nerve, the superior ulnar collateral (posterior ulnar recurrent) artery, and the upper parts of the flexor carpi ulnaris and flexor digitorum sublimis. On the lateral side lie the extensor carpi radialis longus and the upper part of the common tendon of origin of the superficial extensors of the wrist and fingers.

The movements permitted at the elbow are those of a true hinge joint, viz., flexion and extension. These movements are oblique, so that the forearm is inclined medially in flexion, and laterally in extension; they are linited by the contact respectively of the coronoid and olecranon processes of the ulna with their corresponding fossæ on the humerus, and their extent is determined by the relative proportion between the length of the processes and depth of the fossæ which receive them, rather than by the tension of the ligaments, or the bulk of the soft parts over them. The anterior and posterior portions of the capsule, together with the corresponding portions of the collateral ligament, are not put on the stretch during flexion and extension; but, although they may assist in checking the velocity, and thus prevent undue force of impact, they do not control or determine the extent of these movements. The limit of extension is reached when the ulna is nearly in a straight line with the humerus; and the limit of flexion when the ulna describes an angle of from $30^{\circ}$ to $40^{\circ}$ with the humerus.

The obliquity of these movements is due to the lateral inclination of the upper and back part of the trochlear surface, and the greater prominence of the medial lip of the trochlea below; thus the plane of motion is directed from behind forward and medially, and carries the hand toward the middle third of the clavicle. The obliquity of the joint, the twist of the shaft of the humerus, and the backward direction of its head, all tend to bring the hand toward the midline of the body, under the inmediate observation of the eye, whether for defence, employment, or nourishment. This is in striking contrast to the lower limb, where the direction of the foot diverges from the median axis of the trunk, thus preventing awkwardness in locomotion. In flexion and extension, the cup-like depression of the radial head glides upon the capitulum, and the medial margin of the radial head travels in the groove between the capitulum and the trochlea. This allows the radius to rotate upon the humerus while following the ulna in all its movements. In full extension and supination, the head of the radius is barely in contact with the inferior surface of the capitulum, and projects so much backward that its posterior margin can be felt as a prominence at the back of the elbow. In full flexion the anterior edge of the radial head is received into, and checked against, the depression above the canitulum; while in mid-flexion the cup-like depression is fairly received upon the capitulum, and in this position, the radius being more completely steadied by the humerus than in any other, pronation and supination take place most perfectly.

Muscles which act upon the elbow-joint.-Flexors.-Brachialis, biceps, brachio-radialis, pronator teres, flexor carpi radialis, palmaris longus, flexor digitorum sublimis, flexor carpi ulnaris.

Extensors.-Triceps, anconeus, and the muscles which spring from the lateral epicondylo

\section{THE UNION OF THE RADILS WITH THE L'LNA}

The radius is firmly united to the ulna by two joints, and an intermediate fibrous union, viz.:-

(a) The superior radio-ulnar-whereat the head of the radius rotates within the radial notch and annular ligament.

(b) The union of the shafts-the mid radio-ulnar union.

(c) The inferior radio-ulnar-whereat the lower end of the radius rolls ronend the head of the ulna. 


\section{(a) The Superior Radio-ulnar Joint}

\section{Class.-Diarthrosis. Subdivision.-Trochoides.}

The bones which enter into this joint (which is often included with the elbowjoint) are, the ulna by its radial notel and the radius by the smooth vertical border or rim on its head. There is but one ligament special to the joint, viz.:-

\section{Annular.}

The annular ligament consists of bands of strong fibres, somewhat thicker than the capsule of the elbow-joint, which encircle the head of the radius, retaining it against the side of the ulna. The bulk of these fibres forms about threefourths of a circle, and they are attached to the anterior and posterior margins of the radial notch; some few are continued round below the radial notch, and form a complete ligamentous circle.

The ligament is inseparably conneeted along its upper edge and lateral (i. e., its nonarticular) surface with the anterior, posterior, and lateral portions of the eapsule of the elbow, a few of the fibres of these portions, especially of the lateral, descending to be attached to the neck of the radius. The lower part of the articulation is covered in anteriorly, posteriorly, and laterally by a thin independent membranous layer, which passes from the lower edge of the annular ligament to the neck of the radius, strengthened on the lateral side by those fibres passing down from the capsule. They are loose enough to allow the bone to rotate upon its

Fig. 297.-Annular Ligament.

(The head of themradius removed to show the membranous connection of this ligament with the radius.)

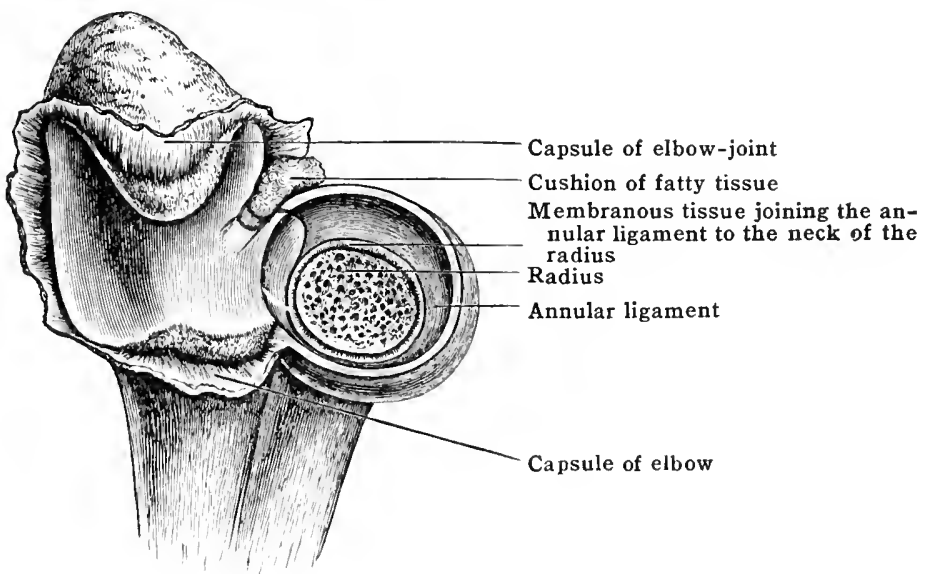

own axis (fig. 297). Nedially and below the cavity is closed in by a loose membrane, the ligamentum quadratum, which passes from the lower border of the radial noteh to the neek of the rarlius.

'Thr synovial membrane is the same as that of the elbow-joint, and, after lining the annular ligament, passes on to the neck of the radius, and thence up to the lower margin of the articular cartilage.

The arterial aml nerve-supply are the same as those to the lateral part of the elbow-joint. Relations. - lichind lices the anconeus and in front the lateral border of the brachialis.

\section{(b) THir Mil) Radio-ULnar Union}

\section{Class. - Symurthrosis. Subdivision.-Syndesmosis.}

There are two introsseous ligaments which pass between the shafts of the honess and anite them firmly together, viz.:-
())lique cord.
Interosseous membrane.

'The oblique cord [chorrla oblicfua] (figs. 293 and 298) is a fairly strong, narrow lanel, which passes from the lower end of the rough lateral border of the coronoid 
process, downward and laterally to be attached to the posterior edge of the lower end of the tuberosity of the radius and the vertical ridge running from it to the medial border of the bone.

Some of its fibres blend with the fibres of insertion of the biceps tendon; behind, it is in close contact with the supinator; below, a thin membrane passes off from it to the upper edge of the interosseous membrane; the posterior interosseous vessels pass in the space betwcen it and the interosseous membrane; occasionally a slip is continued in to the annular ligament of the superior radio-ulnar articulation (see fig. 298).

The interosseous membrane (fig. 293) is attached to the ulna at the lowest part of the ridge in front of the depression for the supinator, and along the whole length of the interosseous border as far as the inferior radio-ulnar articulation, approaching the front of the bone in the lower part of its attachment. To the radius it is attached along the interosseous border, from an inch $(2.5 \mathrm{~cm}$.) below the tuberosity to the ulnar notch for the lower end of the ulna.

It is strongest and broadest in the centre, where the fibres are dense and closely packed; it is also well marked beneath the pronator quadratus, and thickens considerably at the lower end, forming a strong band of union between the two bones. Its fibres pass chiefly downward and medially, from the radius to the ulna, though some take the opposite direction; at the lower end some are transverse. On the posterior surface are one or two bands, which pass downward and laterally from the ulna to the radius, and frequently there is a strong bundle as large as the

Fig. 298.-Upper Portions of Left Ulna and Radius, to show an Occasional Slip from the Oblique Cord to the Lower Part of the Annular liganent. This condition is present in the spider monkey (Ateles), which has no external thumb but only rudimentary bones of one.

(From a dissection by Mr. W. Pearson, Royal College of Surgeons, England.)

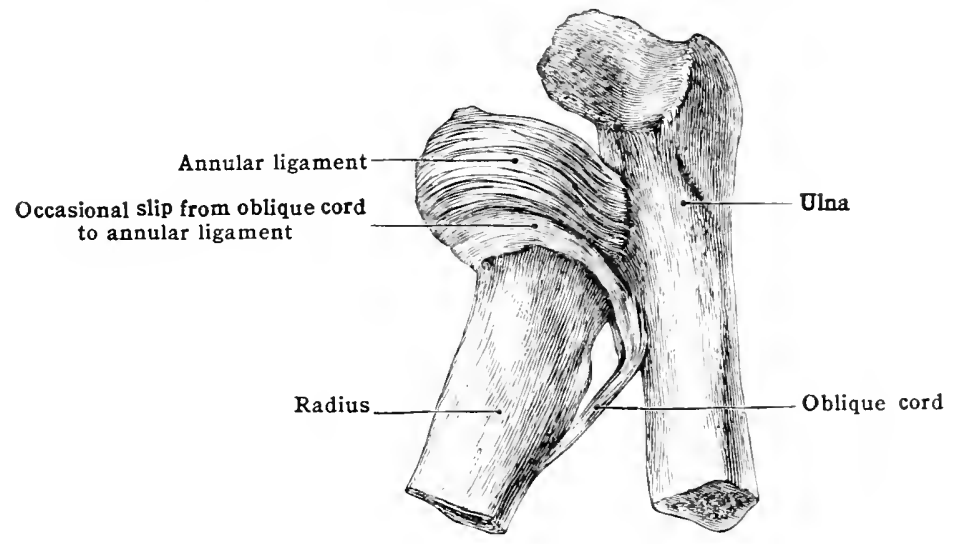

oblique cord; this, which may be called the inferior oblique ligament (fig. 303), stretches from the ulna, an inch and a half above its lower extremity, downward and laterally to the ridge above and behind the ulnar notch of the radius.

At its attachment to the bones, the interosseous membrane blends with the periosteum. Its upper border is connected with the oblique cord by a thin membrane, which is pierced by the posterior interosseous vessels; and the lower border, which stretches across between the two bones just above the inferior radio-ulnar articulation, assists in completing the capsuie of that joint. Its anterior surface is in relation with the flexor digitorum profundus and flexor pollicis longus in the upper three-quarters, the lower fourth being in relation with the pronator quadratus. The anterior interosseous vessels and nerve descend along the middle of the membrane, the artery being bound down to it. About an inch from the lower end it is pierced by the anterior interosseous artery. The posterior surface is in relation with the supinator, abductor pollicis longus (extensor ossis metacarpi pollicis), extensor pollicis longus and brevis, and the extensor indicis proprius; at its lower part, alse with the posterior branch of the anterior interosseous artery, and the deep branch of the radial nerve (posterior interosseous).

\section{(c) The Inferior Radio-ulnar Joint}

\section{Class.-Diarthrosis.}

Subdivision.-Trochoides.

This is, in one respect, the reverse of the superior; for the radius, instead of presenting a circular head to rotate upon the facet on the ulna, presents a concave facet which rolls round the ulna. The articulation may be said to consist of two 
parts at right angles to each other; one between the radius and ulna, and the other between the ulna and the articular disc (triangular fibro-cartilage).

\section{The ligaments are:- \\ Anterior radio-ulnar. \\ Articular disc. \\ Posterior radio-ulnar.}

The articular disc (triangular fibro-cartilage) (figs. 303 and 304) assists the radius in forming an areh under which is received the first row of carpal bones. Its base is attached to the margin of the radius, separating the ulnar notch from the articular surface for the carpus, while its apex is fixed to the fossa at the base of the styloid process of the ulna. It gradually and uniformly diminishes in width from base to apex, becoming rounded where it is fixed to the ulna; it is joined by fibres of the ulnar collateral ligament of the wrist.

The articular disc is about three-eighths of an inch $(1 \mathrm{~cm}$.) wide, and the same from base to apex; thicker at the circumference than in the centre; smooth and concave above to adapt

Fig. 299.-Lower Extremities of the Radius and Ulna to Show the Relation of the Articular Capsule of the Wrist Joint (in red) to the Epiphysial Lines. Note the upward extension of the membrana sacciformis.

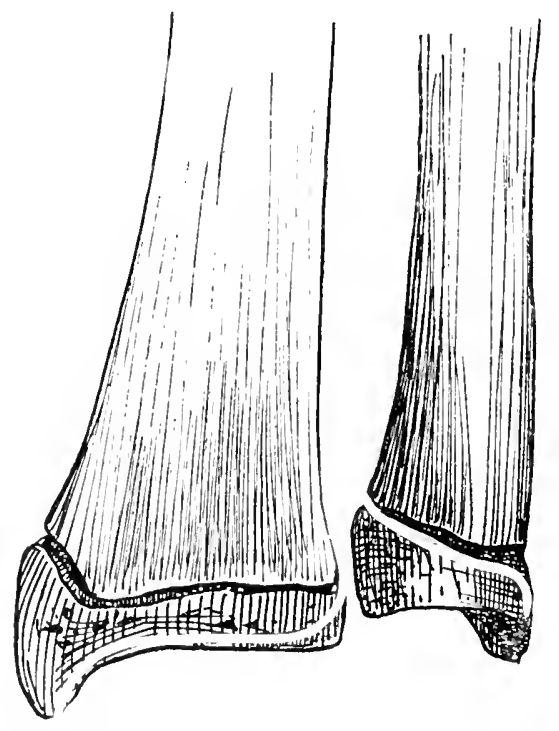

itself to the ulna, and smooth and slightly coneave below to fit over the triquetral bone. Its anterior and posterior borders are united to the anterior and posterior radio-ulnar and radiocarpal ligaments. It is the most important structure in the inferior radio-carpal articulation, as it is a very firm bond of union between the lower ends of the bones, and serves to limit their movements upon one another more than any other structure in either the upper or lower radioulnar joints. Its structure is fibrous at the circumference, while in the centre there is a preponderance of cells. It differs from all other fibro-cartilages in entering into two distinet artieulations; and separates entirely the synovial niembrane of the radio-uinar joint from that of the wrist.

The lower end of the interosseous membrane extends between the ulna and rarlius immediately above their points of contact. Transverse fibres between the two bones form a sort of arch above the concave articular facet of the radius, and, joining the anterior and posterior radio-ulnar ligaments, complete the articular capsule of the inforior radio-ulnar joint. The ligaments represent merely thickenings of the capsule.

The anterior radio-ulnar ligament (fig. 300 ) is attached by one end to the anterior edge of the ulnar notch of the raslius, and by the other to the rough bone above the artieular surface of the una as far medially as the notch, as well as into the anterior margin of the trianguar cartilage from base to aluex.

The posterior radio-ulnar ligament (fig. 301) is similarly attaehed to the posterior margin of the ulnar noteh at one (sul, and at the other to the rough bone above the artieular surface of the extrinity of the una as far medially as the groove for the extensor carpi ulnaris, with the sheath of which it is connected, as woll as into the whole length of the posterior margin of the articular rlisc. lioth the rarlio-ulnar liganents consist of thin, almost scattered, fibres. 
The synovial membrane, sometimes called the membrana sacciformis, is large and loose in proportion to the size of the joint. It is not only interposed between the radial and ulnar articular surfaces, but lines the terminal articular surface of the ulna and the upper surface of the articular disc.

The arterial supply is derived from the volar interosseous artery and branches of the volar carpal rete.

The nerve-supply comes from the volar interosseous of the median, and the deep branch of the radial (posterior interosseous).

Relations.-Behind lies the tendon of the extensor digiti quinti proprius and in front the flexor digitorum profundus.

The movements of the radius. - The upper end of the radius rotates upon an axis drawn through its own head and neck within the collar formed by the radial notch and the annular ligament, while the lower end, retained in position by the articular disc, rolls round the head of the ulna. This rotation is called pronation, when the radius from a position nearly parallel to the ulna turns medialward so as to lie obliquely across it; and supination, when the radius turns back again, so as to uncross and lie nearly parallel with the ulna. In these movements the radius carries with it the hand, which rotates on an axis passing along the ulnar side of the hand; thus, the hand when pronated lies with its dorsum upward, as in playing the piano, while when supinated, the palm lies upward-the attitude of a beggar asking alms. Ward thus expresses the relations of the two extremities of the radius in pronation and supination: 'The head of the radius is so disposed in relation to the sigmoid cavity (ulnar notch) at the lower end that the axis of the former if prolonged falls upon the centre of the circle of which the latter is a segment;' the axis thus passes through the lower end of the ulna at a point at which the articular disc is attached, and if prolonged further, passes through the ring finger. Thus the radius describes, in rotating, a blunt-pointed cone whose apex is the centre of the radial head, and whose base is at the wrist; partial rotation of the bone being unaccompanierl by any hinge-like or antero-posterior motion of its head, and pronation and supination occurring witliout disturbance to the parallelism of the bones at the superior radio-ulnar joint. Associated with this rotation in the ordinary way, there is some rotation of the humero-ulnar shaft, which causes lateral shifting of the hand from side to side; thus, with pronation there is some abduction, and with supination some adduction combined, so that the hand can keep on the same superficies in both pronation and supination. The power of supination in man is much greater than pronation, owing to the immense power and leverage obtained by the curve of the radius. and by the attachment of the biceps tendon to the back of the tuberosity. For this reason all our screw-driving and boring tools are made to be used by supination movements.

In the undissected state, the amount of rotation it is possible to obtain is about $135^{\circ}$, so that neither the palm nor the fore part of the lower end of the radius can be turned completely in opposite directions; yet in the living subject this amount can be greatly increased by rotation of the humero-ulnar shaft at the shoulder-joint.

Pronation is checked in the living subject by (a) the posterior inferior radio-ulnar ligament, which is strengthened by the connection of the sheath of the extensor tendons with it; (b) the lowermost fibres of the interosseous membrane; (c) the back part of the ulnar collateral and adjacent fibres of the posterior ligament of the wrist, and (d) the meeting of the soft parts on the front of the forearm.

Supination is checked mainly (a) by the medial ulnar collateral ligaments of the wrist, but partly also by (b) the oblique cord; (c) the anterior inferior radio-ulnar ligament, and (d) the lowest fibres of the interosseous membrane.

The interosseous membrane serves, from the direction of its fibres downward and medially from the radius to the ulna, to transmit the weight of the body from the ulna to the radius in the extended position of the elbow, as in pushing forward with the arms extended, or in supporting one's own weight on the hands, the ulna being in intimate contact with the humerus, but not at all with the carpus; while the area of contact of the radius wịth the humerus is small. and that of the radius with the carpus large. Hence the weight transmitted by the ulna is communicated to the radius by the tightening of the interosseous membrane. Conversely, in falls upon the hand with the arm extended, the interosseous membrane acts as a sling to lireak the violence of the shock, and prevents the whole force of the impact from expending itself directly upon the capitulum.

Muscles which act upon the radio-ulnar joints.-Pronators.-Pronator teres, pronator quadratus, flexor carpi radialis, palmaris longus.

Supinators.-Biceps, supinator, extensor pollicis longus.

The brachio-radialis is chiefly a flexor of the elbow-joint, but it takes part in the initiation of the movement of supination when the hand is fully pronated and of pronation when the hand is fully supinated.

\section{THE RADIO-CARPAL OR IVIST-JOIN T}

\section{Class.-Diarthrosis.}

Subdivision.-Condylarthrusis.

The wrist-joint is formed by the union of the radius and articular disc above, articulating with the navicular, lunate, and triquetral bones below; the ulna being excluded by the intervention of the articular disc. The radius and disc together present a smooth surface, slightly concave both from before backward, and from side to side, whilst the three bones of the carpus present a smooth, 
convex surface, made uniformly even by the interosseous ligaments which bind them together.

The capsule of the wrist-joint has been usually described as four separate ligaments, and it will be convenient for the sake of a complete description to follow this method; but it must be understood that these four portions are continuous around the joint, extending from styloid process to styloid process on both its aspects.

The four portions are:-

Volar radio-carpal.

Dorsal radio-carpal.
Ulnar collateral. Radial collateral.

The volar (or anterior) radio-carpal (fig. 300) is a thick strong ligament, attached superiorly to the raclius immediately above the anterior margin of the terminal articular facet, to the curved ridge at the root of the styloid process of the radius, and to the anterior margin of the articular disc, blending with some fibres of the capsule of the inferior radio-ulnar joint. It passes downward and in a medial direction to be attached to both rows of carpal bones, especially the second, and to the volar intercarpal ligament.

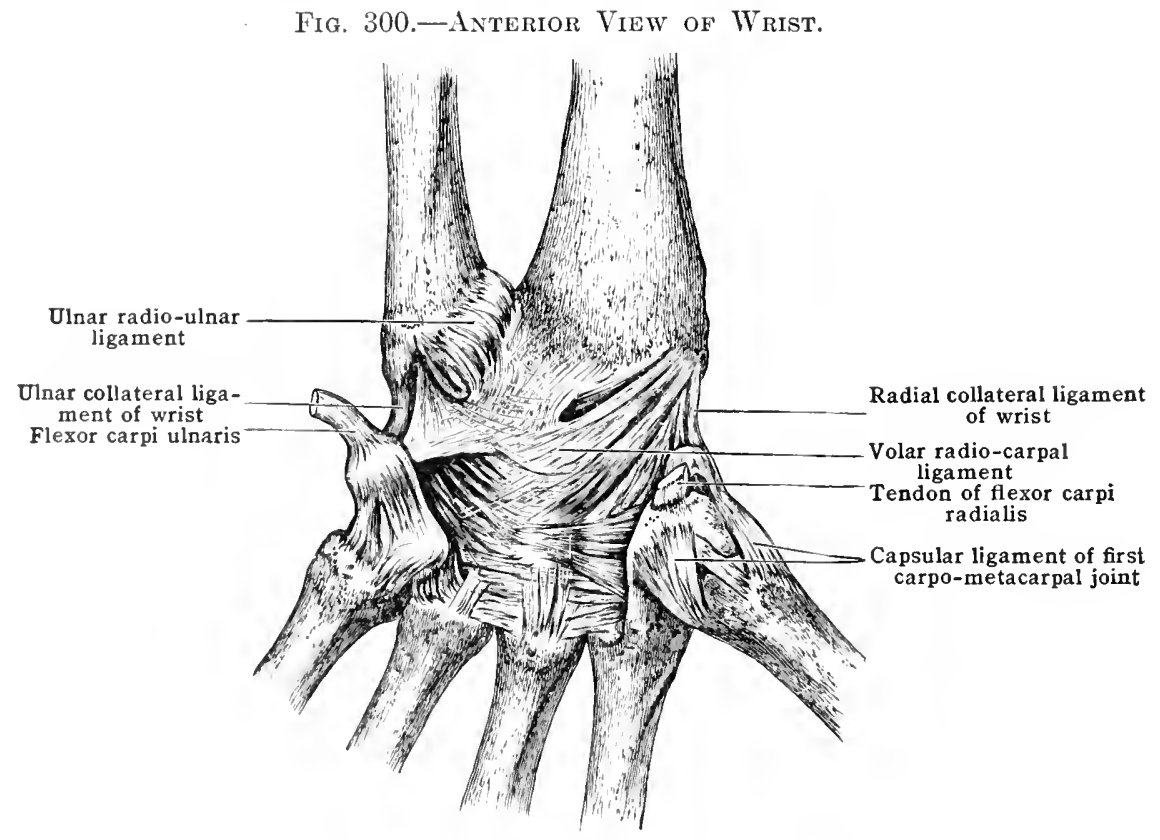

The strongest and most olblique fibres arise from the root of the styloid process of the radius, and pass oblifiuely over the navicular, with which only a few fibres are connected, to be inserted into the linate, cippitate, and triquetral bones. Another set, less oblique, passes from the margin of the facet for the lonate fo he attached to the adjacent parts of the capitate, hamate, and triquetral hones. lbetween the two sets of fibres, small vessels pass into the joint.

The: dorsal (or ponturior) radio-carpal ligament (fig. 301) is attached above to the dorsal ealge of the lower end of the radius, the back of the styloid process, and the postcrior marein of the fibro-cartilage. It passes downward and in a moliat dirution to be (andected with the first row of the earpal bones, chiefly with the hunte and trignetral, and the clorsal interearpal ligament. This liganornt is thin and mombranous.

It is strengthend liy (i) strong fibres passing from the back of the articular dise where

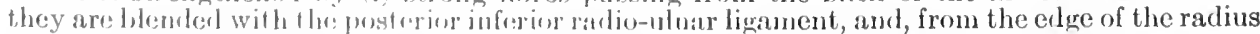

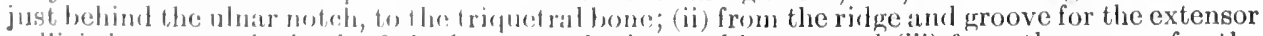
pollicis Iongus to the back of the lunate and trifurtral hones; and (iii) from the groove for the rarlial extensors to the luack of the mavioular and lunate. It is in relation with, and strengthened by, the cxtensor temdons which jatss over it.

The ulnar collateral ligament (fig. 301) is fan-shaped, with its apex above, at thes styloid proeess of the ulna, to which it is attatehed on all sides, blencling with 
the apex of the articular disc. Some of the fibres pass forward and laterally to the base of the pisiform bone and to the medial part of the upper border of the transverse carpal ligament, where it is attached to the pisiform bone; they form a thick, rounded fasciculus on the front of the wrist. Other fibres descend vertically to the medial side of the triquetral bone, and others again laterally to the dorsal surface of the triquetral. The tendon of the extensor carpi ulnaris is posterior to, and passes over, part of the fibres of the ligament.

The radial collateral ligament (fig. 300) consists of fibres which radiate from the fore part and tip of the styloid process of the radius. Some pass downward and medially, in front, to the navicular and adjacent edge of the capitate; some downward, a little forward and medially, to the tubercle of the navicular and ridge of the greater multangular; and others downward and laterally to the rough dorsal surface of the navicular.

The fibres of this ligament are not so long and strong, nor do they radiate so much as those of the ulnar collateral ligament. It is in relation with the radial artery, and the abductor pollicis longus (extensor ossis metacarpi pollicis) and extcnsor pollicis brevis, the artery separating the tendons from the ligament.

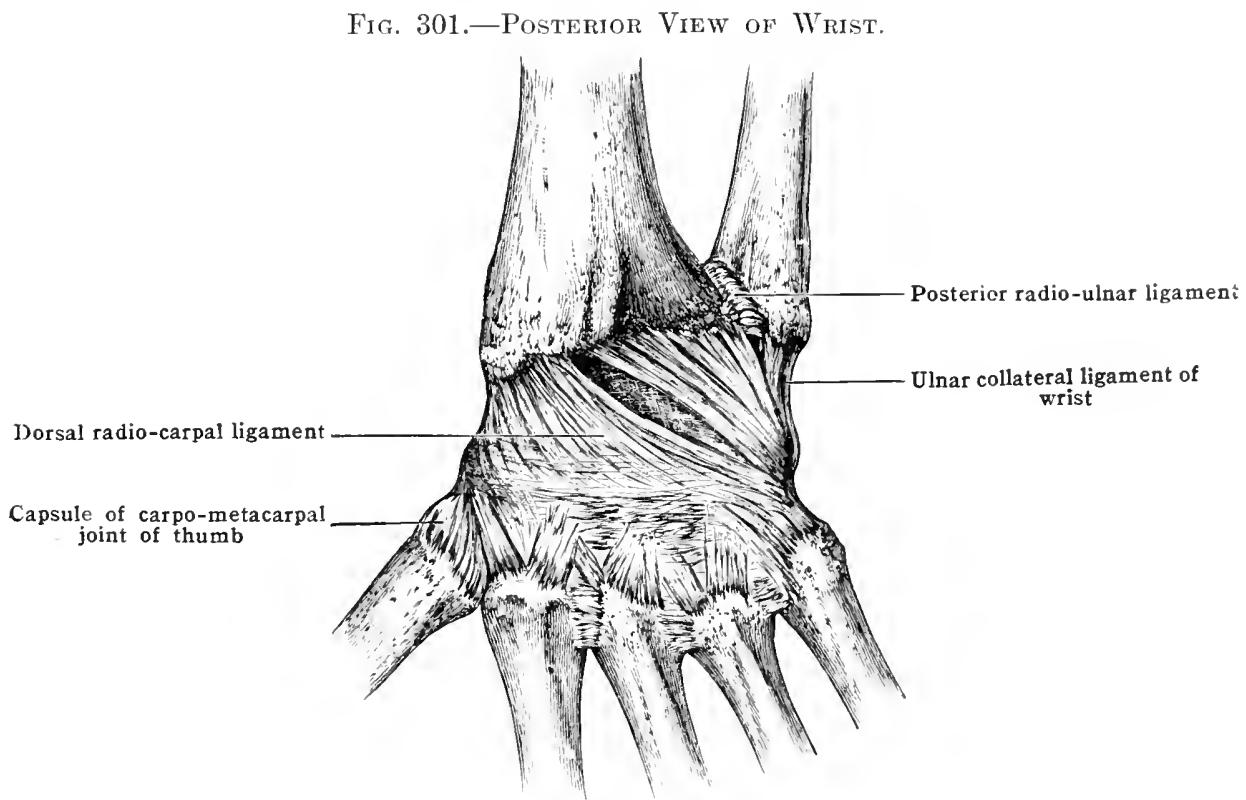

The synovial membrane is extensive, but does not usually communicate with the synovial membrane of the inferior radio-ulnar joint, being shut out by the articular disc. It is also excluded, in almost every instance, from that of the carpal joints by the interosseous ligaments between the first row of carpal bones. The styloid process of the radius is cartilage-covered medially, and forms part of the articular cavity, while that of the ulna does not.

The arterial supply is derived from the anterior and posterior carpal rami, the dorsal division of the volar interosseous, and from twigs direct from the radial and ulnar arteries.

The nerve-supply is derived from the ulnar and median in front, and the deep franch of the radial (posterior interosseous) behind.

Relations. - In front of the radin-carpal joint are the tendons of the flexor muscles of the wrist and fingers, the synovial sheaths associated with them, the radial and ulnar arteries, and the median and ulnar nerves.

Behind the joint are the majority of the tendons of the extensor muscles of the wrist and fingers, with their synovial sheaths, the terminal part of the anterior and posterior interosseous arteries, and the deep branch of the radial nerve (posterior interosseous). On the radial side lie the tendons of the abductor pollicis longus (extensor ossis metacarpi pollicis) and the extensor pollicis brevis. On the ulnar side the joint is subcutaneous and it is crossed by the dorsal cutaneous branch of the ulnar nerve.

Movements.- The wrist is a condyloid joint, the carpus forming the condyle. It allows of movements upon a transverse axis, i. e., flexion and extension; and around an antero-posterior axis, i. e., abduction and adduction; together with a combination of these in quick succes- 
sion-circumduction. Lacking only rotation on a vertical axis, it thus possesses most of the movements of a ball-and-socket joint, without the weakness and liability to dislocation which are peculiar to these joints. This deficiency of rotation is compensated for by the movements of the radius at the radio-ulnar joints, viz., supination and pronation. Its strength depends chiefly upon the number of tendons which pass over it, and the close connection which exists between the fibrous tissue of their sheaths and the capsule of the wrist; also upon the proximity of the medio-carpal and carpo-metacarpal joints, which permits shocks and jars to be shared and distributed between them; another source of strength is the absence of any long bone on the distal side of the joint. In flexion and extension the carpus rolls backward and forward, respectively, beneath the arch formed by the radius and articular disc; flexion being limited by the dorsal ligament and dorsal portions of the collateral; extension by the volar, and volar portions of the collateral ligaments. In adduction and abduction the carpal bones glide from the ulnar to the radial side and from the radial to the ulnar side, respectively. Abduction is more limited than adduction, and is checked by the ulnar collateral ligament and by contact of the styloid process of the radius with the greater multangular; adduction is checked by the radial collateral ligament alone. One reason for adduction being more free than abduction is that the ulna does

Fig. 302.-Front of Wrist with Transverse Carpal Ligament.

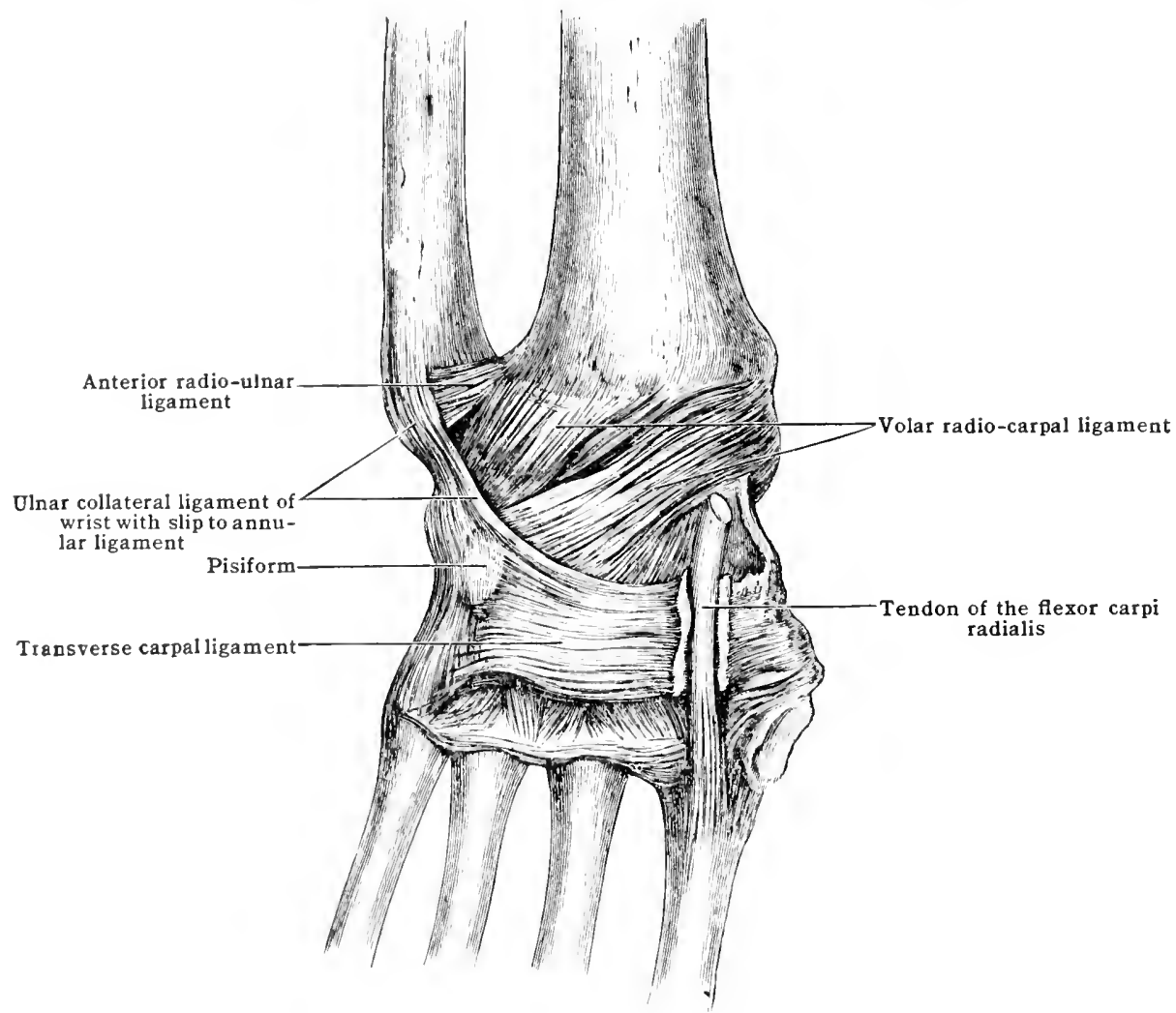

not reach so low down as the radius, aud the yichling articular dise allows of greater movement upwarl of the ulnar end of the carmus. In circmuluction the hand moves so as to describe a cone, the apex of which is at the wrist. 'These movements are made more easy and extensive hy the slight gliding of the carpal hones upon one another, and the comparatively free motion at the medio-carpal joint. The oblique direction of the fibres of the collateral ligaments prevents any rotution at the ralio-carpal joint, while it permits considerable freedom of abduction und aelduetion.

Muscles which act upon the radio-carpal joint.-Flexors.-The flexors of the carpus and the long flexors of the fingers and the thumb, and the palmaris longus. Extensors.-The extensors of the carpus and fingers. Alulucters. - Ixtensor carpi radialis longus, the abductor pol-

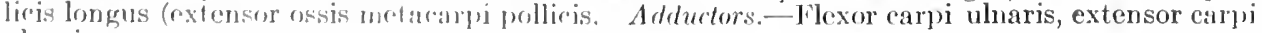
ulnaris.

\section{7. 'TIE C IRPAL, JOIN'TS}

The joints of the carpus may be subrlivided into-

(a) 'The joints of the first row.

(b) The joints of the second row.

(r) The medio-carpal, or junction of the two rows with each other. 


\title{
(a) The Joints of the Finst Row of Carpal Bones
}

\author{
Class.-Diarthrosis. \\ Subdivision.-Arthrodia.
}

The bones of the first row, the pisiform excepted, are united by two sets of ligaments and two interosseous fibro-cartilages.

$$
\text { Dorsal. Volar. }
$$

\section{Interosseous.}

The two dorsal intercarpal ligaments extend transversely between the bones, and connect the navicular with the lunate, and the lunate with the triquetral. Their posterior surfaces are in contact with the posterior ligament of the wrist.

The two volar intercarpal ligaments extend nearly transversely between the bones connecting the navicular with the lunate, and the lunate with the triquetral. They are stronger than the dorsal ligaments, and are placed beneath the anterior ligament of the wrist.

The two interosseous intercarpal ligaments (fig. 304) are interposed between the navicular and lunate, and the lunate and triquetral bones, reaching from the dorsal to the volar surfaces,

Fig. 303.-Posterior View of the Wrist, with Capsule cut to show Articular Surfaces.

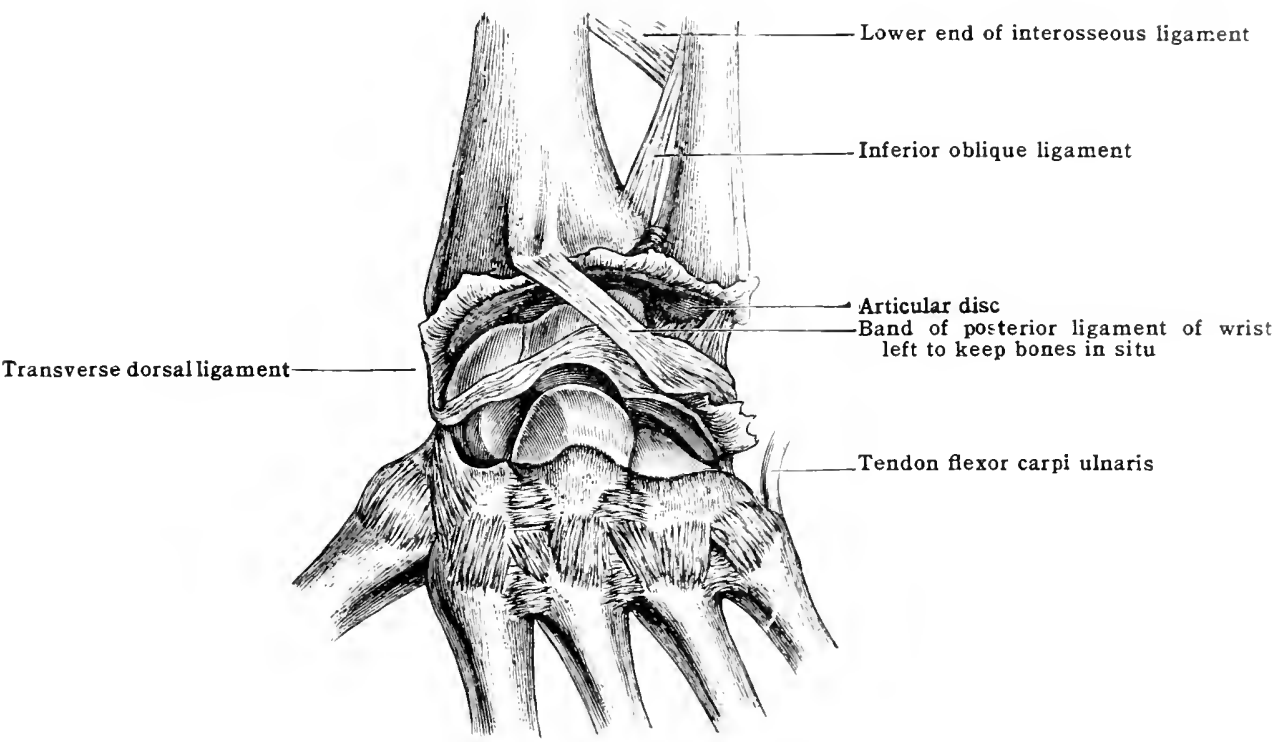

and being connected with the dorsal and volar ligaments. They are narrow fibro-cartilages which extend between small portions only of the osseous surfaces. They help to form the convex carpal surface of the radio-carpal joint, and are somewhat wedge-shaped, their bases being toward the wrist, and their thin edges between the adjacent articular surfaces of the bones.

The synovial membrane is a prolongation from that of the medio-carpal joint.

The arterial and nerve-supplies are the same as for the medio-carpal joint.

\section{The Joint of the Pisiform Bone with the Triquetral}

This is an arthrodial joint which has a loose fibrous capsule attached to both the pisiform and triquetral bones just beyond the margins of their articular surfaces.

It is lined by a separate synovial membrane. Two strong rounded or flattened bands pass downward from the pisiform, one to the process of the hamate [lig. pisohamatum], and the other [lig. pisometacarpeum] to the bases of the third to fifth metacarpals; these are regarded as prolongations of the tendon of the flexor carpi ulnaris, and the pisiform bone may be looked upon in the light of a sesamoid bone developed in that tendon.

(b) The Joints of the Second Row of Carpal Bones

$$
\text { Class.-Diarthrosis. Subdivision.-Arthrodia. }
$$

The four bones of this row are united by three dorsal, three palmar, and three interosseous ligaments. 
The three dorsal ligaments (fig. 303) extend transversely and connect the greater with the lesser multangular, the lesser multangular with the capitate, and the capitate with the hamate.

The three volar ligaments are stronger than the dorsal, and are deeply placed beneath the mass of flexor tendons; they extend transversely between the bones in a similar manner to the dorsal ligaments.

Three interosseous ligaments connect the bones of the lower row of the carpus together. Two are connected with the capitate, one uniting it with the hamate (fig. 304) and the other binding it to the lesser multangular. The third ligament joins the greater and lesser multangular.

The synovial membrane is a prolongation of that lining the medio-carpal joint.

The arterial and nerve-supplies are the same as for the medio-carpal joint.

\section{(c) The Medio-carpal Joint, or the Union of the Two Rows of the Carpus WITH EACH OTHER}

(I) Class.-Diarthrosis.

(II) Class.-Diarthrosis.

\author{
Subdivision.-Arthrodia. \\ Subdivision.-Condylarthrosis.
}

The inferior surfaces of the bones of the first row are adapted to the superior articular surfaces of the bones of the second row. The line of this articulation is concavo-convex from side to side, and is sometimes described as having the course of a Roman S placed horizontally, $\boldsymbol{s}$, a resemblance by no means strained. (i) The lateral part of the first row consists of the navicular alone; it is convex, and bears the greater and lesser multangulars. (ii) Then follows a transversely elongated socket formed by the medial part of the navicular, the lunate, and triquetral, into which are received- $(a)$ the head of the capitate, which articulates with the navicular and lunate; $(b)$ the upper and lateral angle of the hamate, which articulates with the navicular; and (c) the upper convex portion of the medial surface of the hamate, which articulates with the lateral and concave portion of the inferior surface of the triquetral. (iii) The medial part of the inferior surface of the triquetral bone is convex, and turned a little backward to fit into the lower portion of the medial surface of the hamate, which is a little concave and turned forward to receive it. The central part, which forms a socket for the capitate and hamate, has somewhat the character of a condyloid joint, the capitate and hamate being the condyle, to fit into the cavity formed by the navicular, lunate, and triquetral; the other portions are typically arthrodial. The ligaments are:-(1) radiate or anterior medio-carpal; (2) posterior medio-carpal; (3) transverse dorsal.

The radiate, anterior or volar medio-carpal is a ligament of considerable strength, consisting mostly of fibres which radiate from the capitate to the navicular, lunate, and triquetral; some few fibres connect the greater and lesser multangular with the navicular, and others pass between the hamate and triquetral. It is covered over and thickened by fibrous tissue derived from the sheatlis of the flexor tendons and the fibres of origin of the small muscles of the thumb and little finger.

The posterior or dorsal medio-carpal ligament, consists of fibres passing obliquely from the bones of the first row to those of the second. It is stronger on the ulnar side than on the radial, but is not so strong as the volar ligament.

The transverse dorsal ligament (fig. 303) is an additional band, well marked and often of consildrable strength, which passes arross the head of the capitate from the navieular to the trichetral lone; besides binding down the head of the capitate, it serves to fix the upper and latcral anglo: of the hanate in the socket formed ly the first row.

'The dorsal liganents, like the volar', are strengthened by a ginantity of fibrous tissue belonging to the sheaths of the cxtensor temlons, and by an extension of some of the fibres of the capsule of the wrist. 'There are no proper collateral medio-carpal ligaments; they are but prolongations of the collixtral ligaments of the wrist.

The synovial membrane (lig. :301) of the (arpus is common to all the joints of the carpus, and extends to the latses of the four nodial netacarpal bones. Thus, besides lining the inter-or medio-carpal joint, it sents two proresses upward between the three bones of the first row, and three downward l, w ween the contignous surfaces of the lesser and greater multangular, the lesser multangular and "apitate, amel cajutate ambl hamate. From these latter, prolongations extend

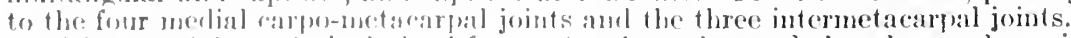

The arterial supply is lepivel from- (a) the volar and dorsal carpal rami of the radial and ulnar arteriog; (b) the carpal l,anch of the volar interosseons; (c) the recurrent branches from the does baluar arol. 'The terminal twigs of the volar and dorsal interosseous arteries supply the juint on its dorsal an piret.

'lihe nerve-supply comes from the ulnar on the mluar side, the median on the radial side, and

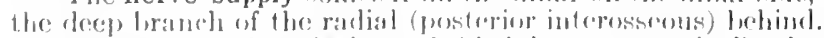

Relations. - The relations of this joint are practically the same as those of the radio-carpal joint, exeept that tho flexor carpi uluarig does not ross the front, the ulnar artery is separated 
from it by the transverse carpal ligament, and the radial artery passes across its lateral border instead of in front.

The movements of the carpal articulations between bones of the same row are very limited and consist only of slight gliding upon one another; but, slight as they are, they give elasticity to the carpus to break the jars and shocks which result from blows or falls upon the hand.

The movements of one row of bones upon the other at the medio-carpal joint are more extensive, especially in the direction of flexion and extension, so that the hand enjoys a greater range of these movements than is permitted at the wrist-joint alone. At the wrist, extension is more free than flexion; but this is balancel by the greater freedom of flexion than of extension at the medio-carpal joint, and by flexion at the carpo-metacarpal joint, so that on the whole: the range of flexion of the hand is greater than that of extension.

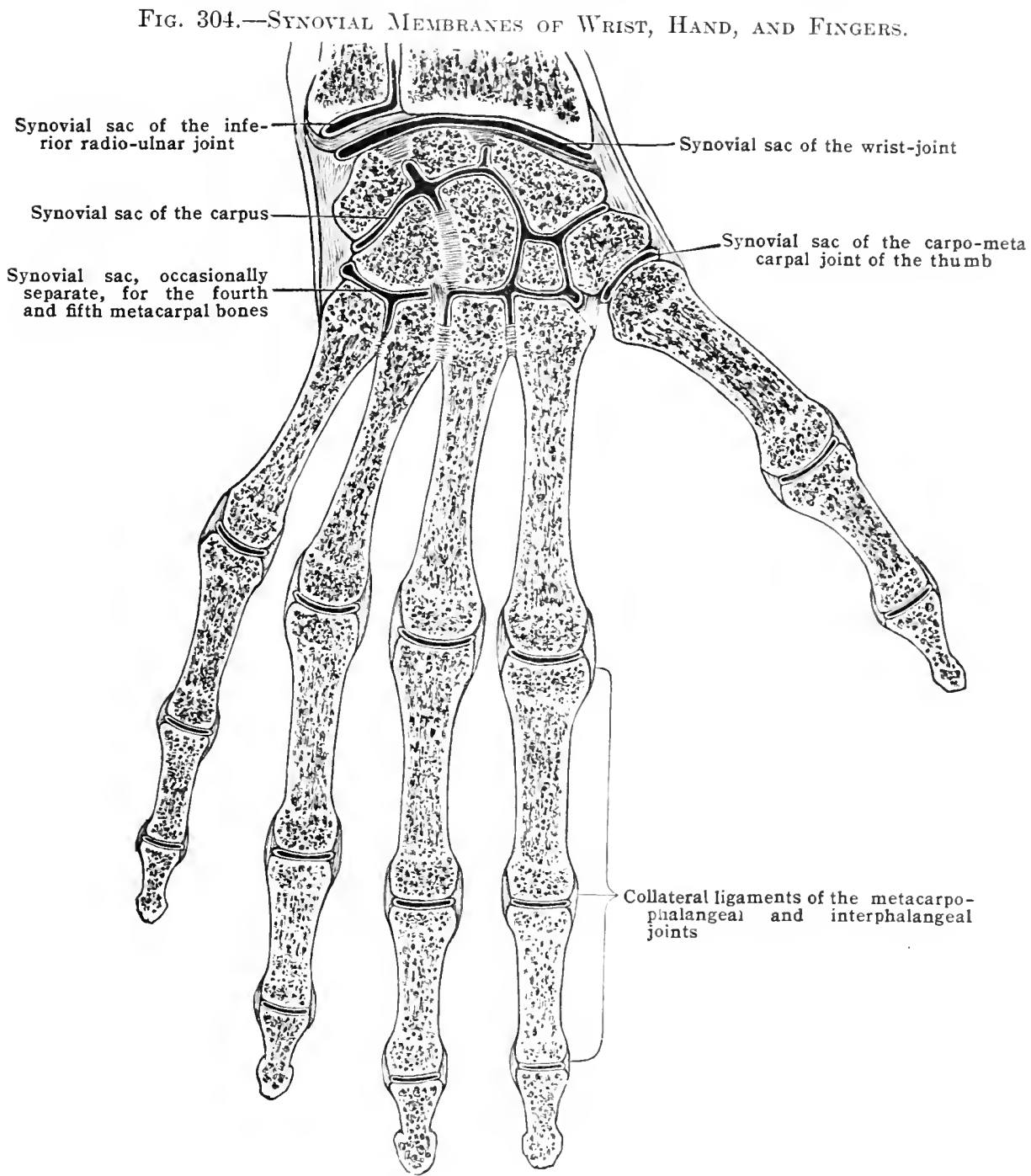

A slight amount of side to side motion accompanied by a limited degree of rotation also takes place; this rotation consists in the head of the capitate and the superior and lateral angle of the hamate bone rotating in the socket formed by the three bones of the upper row, and in a gliding forward and backward of the greater and lesser multangular upon the navicular.

In addition to the ligaments, the undulating outline and the rariety of shapes of the apposed facets render this joint very secure.

Bearing in mind the mobility of this medio-carpal joint and of the carpo-metacarpal, we see at once the reason for the radial and ulnar flexors and extensors of the carpus being prolonged down to their insertion into the base of the metacarpus, for they produce the conbincd effect of motion at each of the three transverse articulations:- (1) at the wrist; (2) at the medio-carpal; (3) at the carpo-metacarpal joints.

Muscles which act upon the mid-carpal joint.-The muscles which act upon this joint are the same as those which act upon the radio-carpal joint, except the flexor carpi ulnaris, which is inserted into the pisiform bone. 


\section{THE CARPO-METACARPAL JOINTS}

These may be divided into two sets, namely:-

(a) The carpo-metacarpal joints of the four medial fingers.

(b) The carpo-metacarpal joints of the thumb.

The inferior surfaces of the bones of the second row of the carpus present a composite surface for the four medial metacarpal bones; the greater multangular presents in addition a distinct and separate saddle-shaped surface for the base of the metacarpal bone of the thumb.

\section{(a) The Four Medial Carpo-metacarpal Joints}

\section{Class.-Diarthrosis. \\ Subdivision.-Arthrodia.}

These joints exist between the greater and lesser multangular, capitate, and hamate bones above, and the four medial metacarpal bones below. The ligaments which unite them are, dorsal, volar, and interosseous.

The dorsal ligaments (fig. 303). - Three dorsal ligaments pass to the second metacarpal bone: one from each of the carpal bones with which it articulates, viz., the greater and lesser multangular, and capitate. Two dorsal bands pass from the capitate to the third metacarpal bone. Two dorsal bands pass to the fourth bone: viz., one from the hamate, and another from the capitate; the latter is sometimes wanting. The fifth bone has only one band passing to it from the hamate.

The volar ligaments (fig. 300).-One strong band passes from the second metacarpal bone to the greater multangular medial to the ridge for the transverse carpal ligament; it is covered by the sheath of the flexor carpi radialis.

Three bands pass from the third metacarpal: one laterally to the greater multangular, a middle one upward to the capitate, and a third medially over the fourth to reach the fifth metacarpal and the hamate bones.

One ligament connects the fourth bone to the hamate.

One ligament connects the fifth bone to the hamate, the fibres extending medially, and connecting the dorsal and volar ligaments. The ligament to the fifth bone is strengthened in front by the prolonged fibres of the flexor carpi ulnaris and the strong medial slip of the ligament of the third metacarpal bone; and posteriorly, by the tendon of the extensor carpi ulnaris.

The interosseous ligament (fig. 304) is limited to one part of the articulation, and consists of short fibres connecting the contiguous angles of the hamate and eapitate with the third and fourth metacarpal bones toward their volar aspect. There is, however, a thick strong ligament. connecting the edge of the greater multangular with the lateral border of the base of the second metacarpal hone; it helps to separate the carpo-metacarpal joint of the thumb from the common carpo-metacarpal joint, and to close in the radial side of the latter joint.

The synovial membrane is a continuation of the medio-carpal joint; occasionally there is a separate membrane between the hamate and fourth and fifth metacarpal bones (fig. 304); while that between the fourth and capitate is lined by the synovial sac of the common joint.

The arteries to the four medial carpo-metacarpal joints are as follows:-

(1) For the index finger: twigs are supplied by the trunk of the radial on the dorsal and volar aspects, and by the dorsal and volar metacarpal branches.

(2) For the mirdlle finger: the first dorsal metacarpal by the branch which passes upward to join the dorsal carpal arch, and a branch from the deep volar arch which joins the volar carpal arch.

(3) For the ring finger: the deep volar arch and recurrent twigs from the second dorsal inetararpal in the same manner as for the middle finger.

(4) For the little finger: the ulnar and its deep branch; also twigs from the second dorsal metacarpal.

The nerves are supplierl to these joints by the deep volar branch of the ulnar, the deep branch of the rarlial (posterior interosserus), and the median.

Relations. In front of the four medial carpo-metacarpal joints are the flexors of the fingers with their symovial sheath. The flexor carpi radialis crossing in front of the lateral part of the joint and the fibres of the obligue adductor pollieis which spring from the capitate and lesser inultangular are also anterior relations. Behind the joints are the extensors of the wrist and fingers with their synovial sheat hs and the dorsal metacarpal arteries. $\Lambda$ the lateral border of the joints between the index and lesser multangular lies the radial artery.

The movements permitterl it these joints, though slight, serve to increase those of the medio-carpal and wrist-joints. The joint leetween the fifth metacarpal and the hamate bones approaches somewhat in shane and mobility the first carpo-metacarpal joint; it has a greater range of flexion and extorstion, but its side fo side movement is nearly as limited as that of the three ot her metacarpal henes; the promess of the hanate bone limits its flexion. Motion toward the uluar side is chereked hy the strong palmar band which unites the base of the fifth metacarpal to the base of the thirel, and the strong transverse ligament at the head of the bones. The morhility of the secound, third, and fourth metararpal bones is very limited, and consists almost rutirely of a slight glicling upon the cirpal bones, i. e., flexion and extension; that of the third and fourth bones is extremely slight, as there is no long llexor attached to either; but, 
owing to the close connection of the bases of the metacarpal bones, the radial and ulnar flexors and extensors of the carpus act on all by their pull on the particular bone into which they are inserted.

Abduction, or movement toward the radial side, is prevented by the impaction of the secomd bone against the greater multangular; a little adduction is permitted, and is favoured by the slope given to the hamate and fifth metacarpal bones.

There is also a slight gliding between the fourth and fifth bones, when the concavity they present toward the palm is deepened to form the 'cup of Diogenes.'

Muscles which act upon the four medial carpo-metacarpal joints are the flexors and extensors of the wrist and fingers, except the flexor carpi ulnaris.

\section{(b) The Carpo-metacarpal Joint of the Thumb}

\section{Class.-Diarthrosis.}

\section{Subdivision.- Saddle-shaped Arthrodia.}

The bones entering into this joint are the base of the first metacarpal and the greater multangular. The first metacarpal bone diverges from the other four, contrasting very strongly with the position of the great toe. It is due to this divergence that the thumb is able to be opposed to each and all the fingers. The ligament which unites the bones is the

\section{Articular capsule.}

The articular capsule (figs. 300 and 301) consists of fibres which pass from the margin of the articular facet on the greater multangular, to the margin of the articular facet at the base of the first metacarpal bone.

The fibres are stronger on the dorsal than on the palmar aspect. They are not tense enough to hold the bones in close contact, so that while they restrict they do not prevent motion in any direction. The medial fibres are stronger than the lateral. carpus.

The synovial membrane is lax, and distinct from the other synovial membranes of the

The arteries of the carpo-metacarpal joint of the thumb are derived from the trunk of the radial, the first volar metacarpal, and the dorsalis pollicis.

The nerves are supplied by the branches of the median to the thumb.

Relations. - Behind are the long and short extensor tendons of the thumb, and behind and laterally the tendon of the abductor pollicis longus (extensor ossis metacarpi pollicis). The tendon of the flexor pollicis longus is in front and fibres of the flexor pollicis brevis and opponens pollicis muscles are also anterior relations. To the medial side is the radial artery as it passes forward into the palm of the hand.

The movements of this joint are regulated by the shape of the articular surfaces, rather than by the ligaments, and consist of flexion, extension, abduction, adduction, and circumduction, but not rotation. In flexion and extension the metacarpal bone slides to and fro upon the multangular; in abduction and addluction it slides from side to side or, more correctly, revolves upon the antero-posterior axis of the joint. The power of opposing the thumb to any of the fingers is due to the forward and medial obliquity of its flexion movement, which is by far its most extensive motion. Abduction is very free, while adduction is limited on account of the proximity of the second metacarpal bone. The movement of the greater multangular upon the rest of the carpus somewhat increases the range of all the movements of the thumb.

Muscles which act upon the carpo-metacarpal joint of the thumb.-Flexors.- Flexor pollicis brevis, flexor pollicis longus, opponens pollicis. Extensors.-Extensores pollicis brevis and longus and abductor pollicis longus. Abductors.-Abductores pollicis longus and breris. Adductors.- The transverse and oblique adductor pollicis, opponens, first dorsal interosseous. Muscles producing opposition.--Opponens, flexor brevis, oblique adductor.

\section{THE INTERAIETACARPAL ARTICLLATIONS}

\section{Class.-Diarthrosis. \\ Subdivision.-Arthrodia.}

The metacarpal of the thumb is not connected with any other metacarpal bone. The second, third, fourth, and fifth metacarpal bones are in actual contact at their bases, and are beld firmly together by the following ligaments (in addition to the articular capsule):-

$$
\text { Dorsal. }
$$

Volar.

\section{Interosseous ligaments.}

The dorsal ligaments (fig. 302) are layers of variable thickness of strong, short fibres, which pass transversely from bone to bone, filling up the irregularities on the clorsal surfaces.

The volar ligaments are transverse layers of ligamentous tissue passing from bone to bone; they cannot be well differentiated from the other ligaments and fibrous tissue covering the bones.

The interosseous ligaments (fig. 304) pass between the apposed surfaces of the bones, and are attached to the distal sides of the articular facets, so as to close in the synorial cavities on 
this aspect; where there are two articular facets, the fibres extend upward between them nearly as far as their carpal facets. That between the fourth and fifth is the wealiest.

The synovial membrane is prolonged downward from the common carpal sac.

The arteries to the intermetacarpal joints are twigs from the volar and dorsal metacarpal arteries; the twigs pass upward between the interosseous muscles.

The nerves are derived from the ulnar and the deep branch of radial (posterior interosseous).

\title{
The Union of the Heads of the Metacarpal Bones
}

The distal extremities of these bones are connected together on their palmar aspects by what is called the transverse ligament [lig. capitulorum]. This consists of three short bands of fibrous tissue, which unite the second and third, third and fourth, and the fourth and fifth bones. They are rather more than $6 \mathrm{~mm}$. ( $\frac{1}{4}$ in.) deep, and rather less in width, and limit the distance to which the metacarpal bones can be separated. They are continuous above with the fascia covering the interosseous muscles; below, they are connected with the subcutaneous tissue of the web of the hand. They are on a level with the front surface of the bones, and are blended on either side with the edges of the glenoid ligament in front, with the lateral ligaments

Fig. 305.-Anterior and Posterior Views of Ligaments of the Fingers.
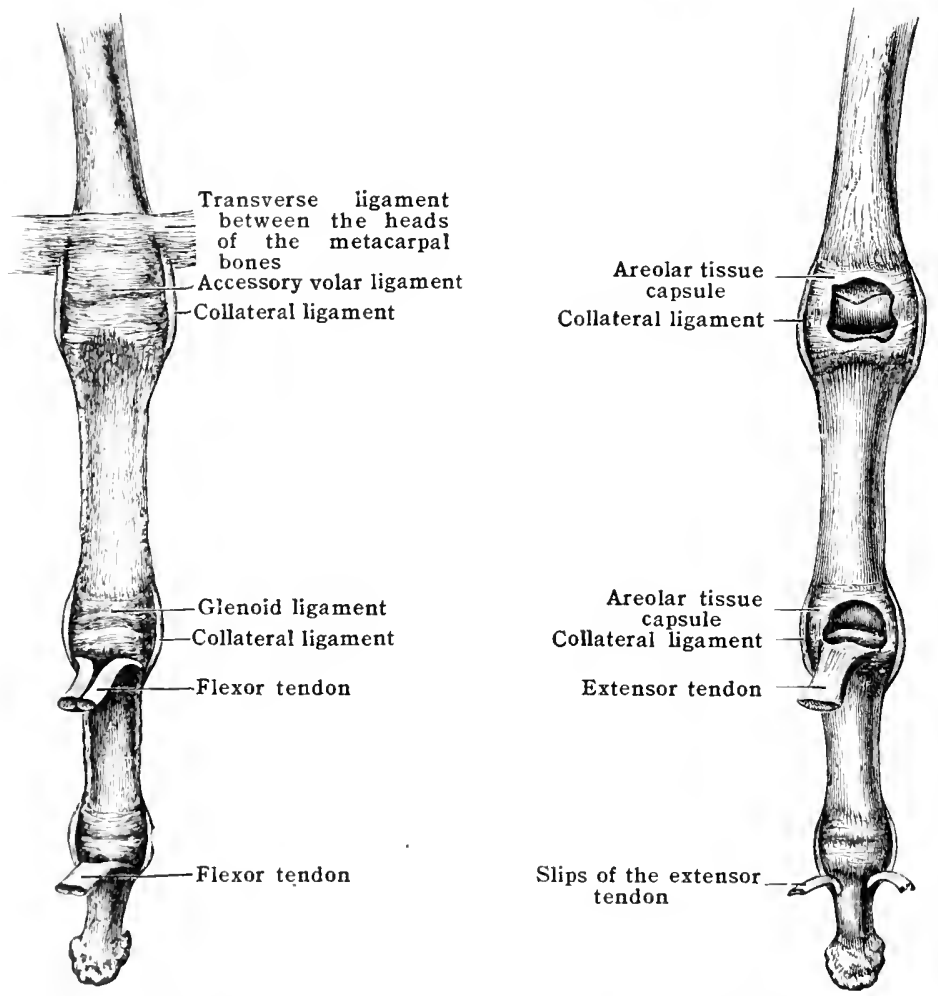

of the metacarpo-phalangeal joint, and also with the sheaths of the tendons. In front, a lumbrical muscle passes with the digital arteries and nerves; while behind, the interossei muscles pass to their inscrtions.

\section{THE METACARPO-PHALANGEAL JOINTS}

\section{(a) 'THE Metachrpo-pindangeal Joints of the Four Medial Fingers}

\author{
Class.-Diarthrosis. \\ Subdivision.-Condylarthrosis.
}

In these joints the "un-shaped extremity of the base of the first phalanx fits on to the romedod hrad of the metacarpal bone, and is united by the following ligaments (in aclition to the articular rapsule):-

$$
\text { ('ollatrial. Volar accessory. }
$$

The volar accessory (or wlound) ligament (fig. 3015) is a fibro-cartilaginous plate which gecms more intenderl to incresse: the depth of the phalangeal articular facet in front, than to unite the two boues. It is much nore firmly atlached to the margin of the phalanx than to the metacarpal bore, being only loosely combected with the palmar surface of the latter by some loose areolar tissue which eovers in the syuovial membrane, here prolonged some little distance upon the surfare of the hene. At the sides, it is comected with the collateral ligaments and the 
transverse metacarpal ligament. It corresponds to the sesamoid bones of the thumb; a sesamoid bone sometimes exists at the medial border of the joint of the little finger.

The collateral ligaments (304 and 305) are strong and firmly connect the bones with one another; each is attached above to the corresponding tubercle, and to a depression in front of the tubercle, of the metacarpal bone. From this point the fibres spread widely as they descend on either side of the base of the phalanx; the anterior fibres are connected with the glenoid ligament; the posterior blend with the tendinous expansion at the back of the joint.

The joint is covered in posteriorly by the expansion of the extensor tendon, and some loose areolar tissue passing from its under surface to the bones (fig. 305).

The synovial membrane is loose and capacious, and invests the inner surface of the ligaments which connect the bones.

The arteries come from the digital or volar metacarpal vessels of the deep arch.

The nerves are derived from the digital branches, or from twigs of the branches of the ulnar to the interosseous muscles.

Relations.- - I. The metacarpo-phalangeal joints of the middle three digits. In front, the tendons of the flexor profundus and flexor sublimis digitorum. On the radial side, a lumbrical, an interosseous muscle, and digital nerves and vessels; on the ulnar side, an interosseous muscle and digital vessels and nerves. Behind, the common extensor tendon and in the case of the index digit the tendon of the extensor indicis.

II. The metacarpo-phalangeal joint of the little finger. In front, the flexor quinti digiti brevis and the tendons of the flexor profundus and sublimis digitorum muscle which go to this digit. Behind, the extensor digiti quinti to a slip of the extensor digitorum communis sometimes. On the radial side, a lumbrical, the third palmar interosscous muscle, digital vessels and nerves. On the ulnar side, digital vessels and nerves.

The movements permitted at these joints are flexion, extension, abduction, adduction, and circumduction. Flexion is the most free of all and may be continued until the phals $\mathrm{nx}$ is at a right angle with the metacarpal bone. It is on this account that the articular surface of the head of the bone is prolonged so much further on the palmar aspect, and that the synovial membrane is here so loose and ample. Extension is the most limited of the movements, and can only be carried to a little beyond the straight line. Abduction and adduction are fairly free, but not so free as flexion. Flexion is associated with adduction, and extension with abduction. This may be proved by opening the hand, when the fingers involuntarily separate as they extend, while in closing the fist they come together again. The free abduction, adduction, and circumduction which are permitted at these joints are due to the fact that the long axes of the articular facets are at right angles to one another.

Muscles acting on the middle three digits.-Flexors.-Flexor digitorum profundus, flexor digitorum sublimis. Extensors.-Extensor digitorum communis and on the index digit the extensor indicis. Abductors.-Dorsal interossei. Adductors.-Volar interossei.

Muscles acting on the metacarpo-phalangeal joint of the little finger.-Flexors.-Flexor quinti digiti brevis, flexor digitorum sublimis, flexor digitorum profundus. Extensors.-Extensor digitorum communis, extensor quinti digiti. Abductor.-Abductor quinti digiti. Adductor. -Third volar interosseous.

\section{(b) The Metacarpo-phalangeal Joint of the Thumb}

\section{Class.-Diarthrosis. Subdivision.-Condylarthrosis.}

The head of the metacarpal bone of the thumb differs considerably from the corresponding ends of the metacarpal bones of the fingers. It is less convex, wider from side to side, the palmar edge of the articular surface is raised and irregular, and here on either side of the median line are the two facets for the sesamoid bones. The base of the first phalanx of the thumb, too, is more like the base of the second phalanx of one of the other fingers. The ligaments are:-

$$
\text { Collateral. }
$$

Dorsal.

\section{Articular capsule.}

The collateral ligaments are short, strong bands of fibres, which radiate from depressions on either side of the head of the metacarpal bone to the base of the first phalanx and sesamoid bones. As they descend they pass a little forward, so that the greater number are inserted in front of the centre of motion.

The dorsal ligament consists of scattered fibres which pass across the joint from one collateral ligament to the other, completing the articular capsule and protecting the synovial sac:

The sesamoid bones are two in number, situated on either side of the middle line, and connected together by strong transverse fibres which form the floor of the groove for the long flexor tendon; they are connected with the base of the phalanx and head of the netacarpal bone by strong fibres. Anteriorly they give attachment to the short uuseles of the thumb, and posteriorly are smooth for the purpose of gliding over the facets. The collateral ligaments are partly inserted into their sides.

The arteries and nerves come from the digital branches of the thumb.

Relations. - Of the metacarpo-phalangeal joint of the thumb: In front and externally abductor pollicis brevis and superficial head of flexor pollicis brevis. In front and medially oblique and transverse adductors and deep head of flexor pollicis brevis. Directly in front flexor pollicis longus and terminal branches of first volar metacarpal artery. Behind, extensor pollicis brevis and longus tendons. On either side, the dorsal digital vessels and the digital nerves. 
The movements are chiefly fexion and extension, very little side to side movement being permitted, and that only when the joint is slightly bent. Thus this joint more nearly approaches the simple hinge character than the corresponding articulations of the fingers. The thumb gets its freedom of motion at the carpo-metacarpal joint; the fingers get theirs at the metacarpo-phalangeal, but they are not endowed with so much freedom as the thumb enjoys.

Muscles which act upon the metacarpo-phalangeal joint of the thumb.-Flexors.-Flexor pollicis brevis, flexor pollicis longus. Extensors.-Extensor pollicis brevis, extensor pollicis longus.

\title{
11. THE INTERPHALANGEAL ARTICULATIONS
}

\author{
Class.-Diarthrosis.
}

Subdivision.-Ginglymus.

The ligaments which unite the phalanges of the thumb and of the fingers are (in addition to the articular capsule) :-

\author{
Accessory volar. \\ Collateral.
}

The accessory volar (or glenoid) ligament (fig. 305), sometimes called the sesamoid body, is very firmly connected with the base of the distal bone, and loosely, by means of fibro-areolar tissue, with the head of the proximal one. It blends with the collateral ligaments at the sides, and over it pass the flexor tendons. Occasionally a sesamoid bone is developed in the cartilage of the interphalangeal joint of the thumb.

The collateral ligaments (figs. 304 and 305 ) are strong bands which are attached to the rough depressions on the sides of the upper phalanx, and to the projecting margins of the lower phalanx of each joint. They are tense in every position, and entirely prevent any side to side motion; they are connected posteriorly with the expansion of the extensor tendon.

Dorsally (fig. 305) the joint is covered in by the deep surface of the extensor tendon, and a little fibro-areolar tissue extends from the tendon, and thickens the posterior portion of the synovial sac, completing the articular capsule.

The synovial membrane is loose and ample, and extends upward a little way along the shaft of the proximal bone.

The arteries and nerves come from their respective digital branches.

The relations of the interphalangeal joints are the flexor and extensor tendons and the digital vessels and nerves.

The movements are limited to flexion and extension. Flexion is more free, and can be continued till one bone is at a right angle to the other, and is most free at the junction of the first and second bones; the second phalanx can be flexed on the first through $110^{\circ}$ to $115^{\circ}$ when the latter is not flexed. 'The greater freedom of flexion is due to the greater extent of the articular surface in front of the heads of the proximal bones, and to the direction of the fibres of the collateral ligaments, which pass a little forward to their insertion into the distal bone.

The muscles which act upon the interphalangeal joints are the extensors and flexors of the digits.

\section{THE ARTICULATIONS OF THE LOWER LIMB}

The articulations of the lower limb are the following:-

1. The hip-joint.

2. The knee-joint.

3. The tibio-fibular union.

4. The ankle-joint.

5. The tarsal joints.

(i. The tarso-metatarsal joints.

7. The intermetatarsal joints.

8. The metatarso-phalangeal joints.

!. The interphalangeal joints.

\section{THES HHP-JOINT}

Class. Jirrithrosis.

Subdivision.-Emarthrodia.

The hip is the most typical (xample of a hall-and-socket joint in the body, the

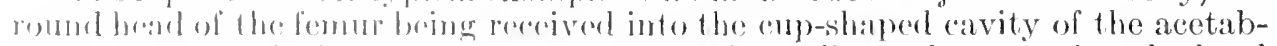

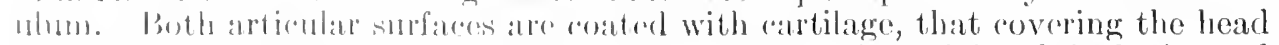
of the former boing thickin atwore where it has to bear the weight of the body, and

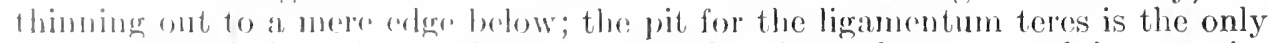
part muncoaterl, but the cartilage is somewhat heaped up around its margin. Covering the aretabulum, the cirtilage is horseshoe-shaped, and thicker above than forlow. loring defieiont over the depression at the bottom of the acetabulum, 
where a mass of fatty tissue-the so-called synovial or Haversian gland-is lodged.

The ligaments of the joint are:-
Articular capsule.
Transverse.
Ligamentum teres.
Glenoid lip.

The articular capsule is one of the strongest ligaments in the body. It is large and somewhat loose, so that in every position of the body some portion of it is relaxed. At the pelvis it is attached, superiorly, to the base of the anterior inferior iliac spine; curving backward, it becomes blended with the deep surface of the reflected tendon of the rectus femoris; posteriorly, it is attached a few millimetres from the acetabular rim; and below, to the upper edge of the groove between the acetabulum and tuberosity of the ischium. Thus it reaches the

Fig. 306.-Anterior View of the Articular Capsule of the Hip-joint.

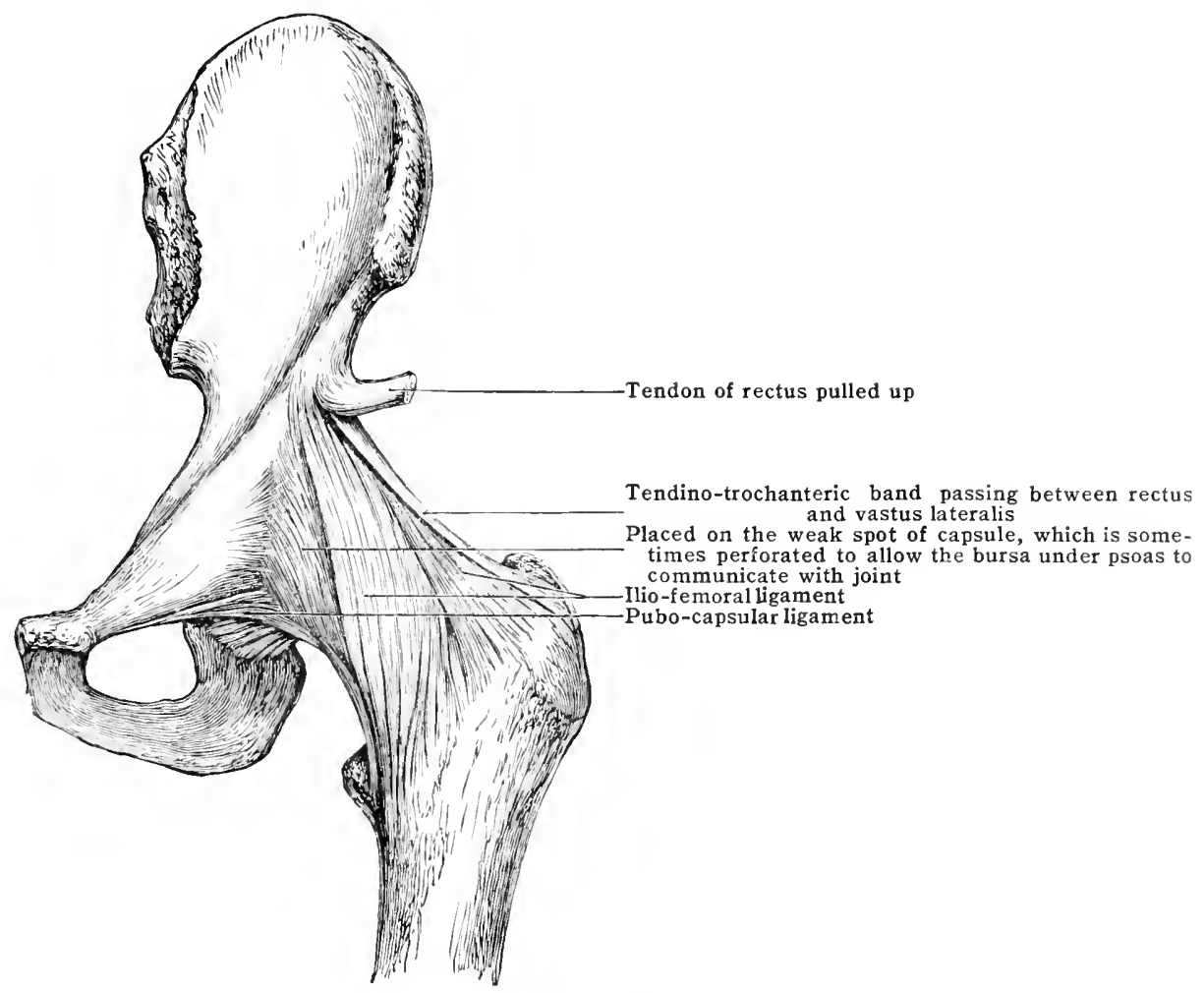

transverse ligament, being firmly blended with its outer surface, and frequently sends fibres beyond the notch to blend with the obturator membrane. Anteriorly it is attached to the pubis near the obturator notch, to the ilio-pectineal eminence and thence backward to the base of the inferior iliac spine.

A thin strong stratum is given off from its superficial aspect behind; this extends beneath the gluteus minimus and small rotators, to be attached above to the dorsum of the ilium higher than the reflected tendon of the rectus, and posteriorly to the ilium and ischium nearly as far as the sciatic notch. As this expansion passes over the long tendon of the rectus, the tendon may be described as being in part contained within the substance of the capsule.

At the femur, the capsule is fixed to the anterior portion of the upper border of the great trochanter and to the cervical tubercle. Thence it runs down, the intertrochanteric line as far as the medial border of the femur, where it is on a level with the lower part of the lesser trochanter. It then runs upward and backward along an oblique line about $1.6 \mathrm{~cm}$. ( $\frac{2}{3} \mathrm{in}$.) in front of the lesser trochanter, and continues its ascent along the back of the neck nearly parallel to the intertrochanteric crest, and from 12 to $16 \mathrm{~mm}$. ( $\frac{1}{2}$ to $\frac{2}{3}$ in.) above it; finally, it passes along the medial side of the trochanteric fossa to reach the anterior superior angle of the great trochanter. 
On laying open the capsule, some of the deeper fibres are seen reflected upward along the neck of the femur, to be attached much nearer the head: these are the retinacula. One corre. sponds to the upper, and another to the lower, part of the intertrochanteric line; a third is seen at the upper and back part of the neck. They form flat bands, which lie on the femoral neck.

Superadded to the capsule, and considerably strengthening it, are three auxiliary bands, whose fibres are intimately blended with, and in fact form part of, the capsule, viz., the ilio-femoral, ischio-capsular, and pubo-capsular ligaments.

The ilio-femoral ligament (fig. 306) is the longest, widest, and strongest of the bands. It is of triangular shape, with the apex attached above to a curved line on the ilium immediately below and behind the anterior inferior spine, and its base below to the anterior edge of the greater trochanter and to the spiral line as far as the medial border of the shaft. The highest or most lateral fibres are coarse, almost straight, and shorter than the rest; the most medial fibres are also thick and strong, but oblique. This varying obliquity of the fibres, and their accumulation at the borders, explain why this band has been described as the Y-shaped ligament; but it

Fig. 307.-Upper Extremity of the Femur (Anterior View), to snow the Relation of the Articular Capsule of the Hip-joint (in red) to the Epiphysial lines.

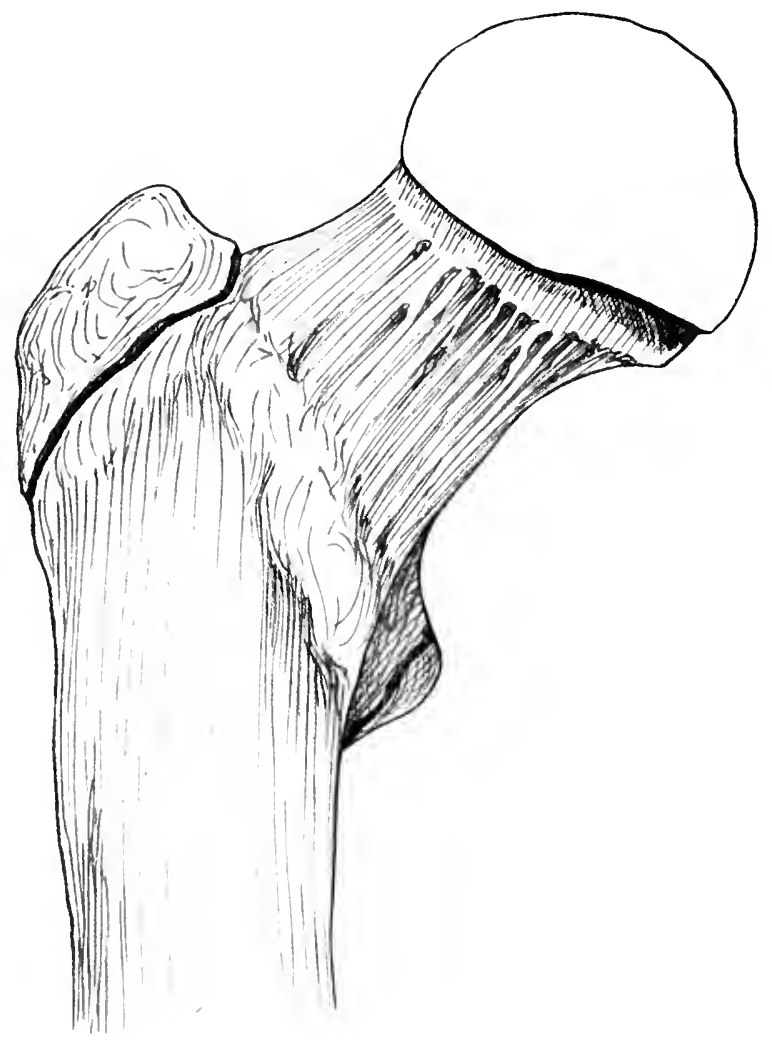

shonlel be noter] that thrs $\mathrm{Y}$ is inverted. About the centre of its base, near the femoral attachutent, is an ajerture transmitting an articular twig from the ascending branch of the external circumflex artery.

The ischio-capsular ligament (fig. 308) is formed of very strong fibres attached all along the upper horler of the groove for the external obturator, and to the ischial margin of the acetabulum above the groove. The highest of these incline a little upward as they pass laterally to be fixed to the grestrer trochanter in front of the insertion of the piriformis tendon, while the

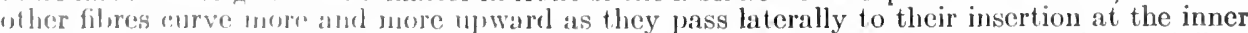
side of the trochanteriv fossi, blending with the insertion of the external rotator tendons. When the joint is in flexion, these fihres futss in nearly straight lines to their femoral attachment, and sprearl out mniformly over the hrarl of the femur; lut in extension they winl over the back of the femur in a zomilar manuer [zona orbienlaris], embracing the posterior aspect of the neck of the fomur.

'I'he pubo-capsular (pectineo-femoral) band (fig. 306) is a distinet but narrow set of fibres which arc indivinhally less marked than the fiturs of the other two bands; they are fixed above to the obturator crest and fo the anterior bortor of the ilio-pectineal eninence, reaching as far

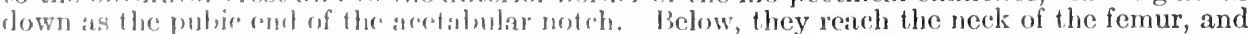
are fixed above and hehind the bowermost fibres of the ilio-femoral hand, with which they blend. 
In thickness and strength the capsule varies greatly; thus, if two lines be drawn, one from the anterior inferior spine to the medial border of the femur near the lesser trochanter, and the other from the anterior part of the groove for the

Fig. 308.-Posterior View of the Articular Capsule of the Hip-joint.

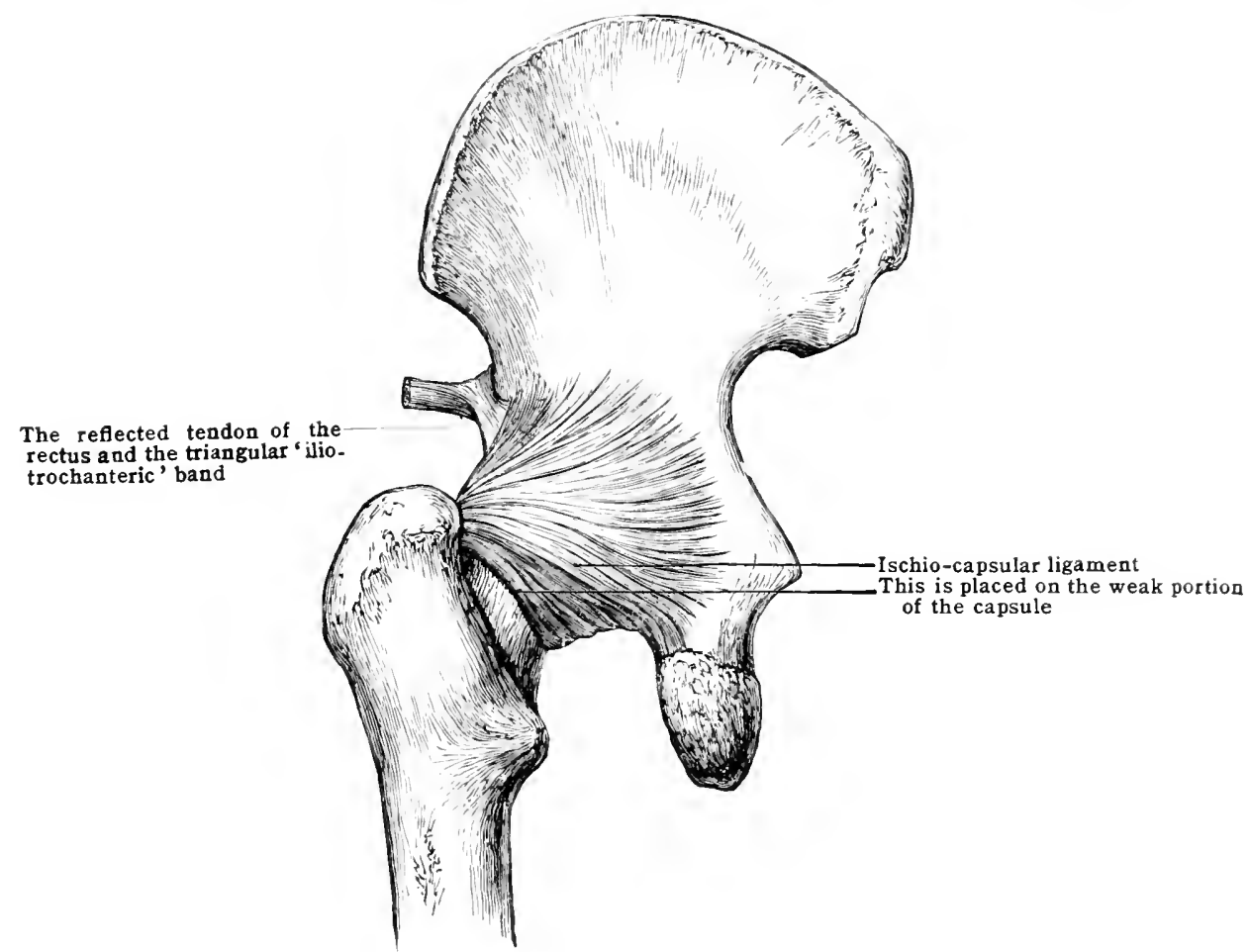

Fig. 309.--Section throdgh the Hip-Joint, showing the Glenold Lip, Liganentui Teres, and Retinacola.

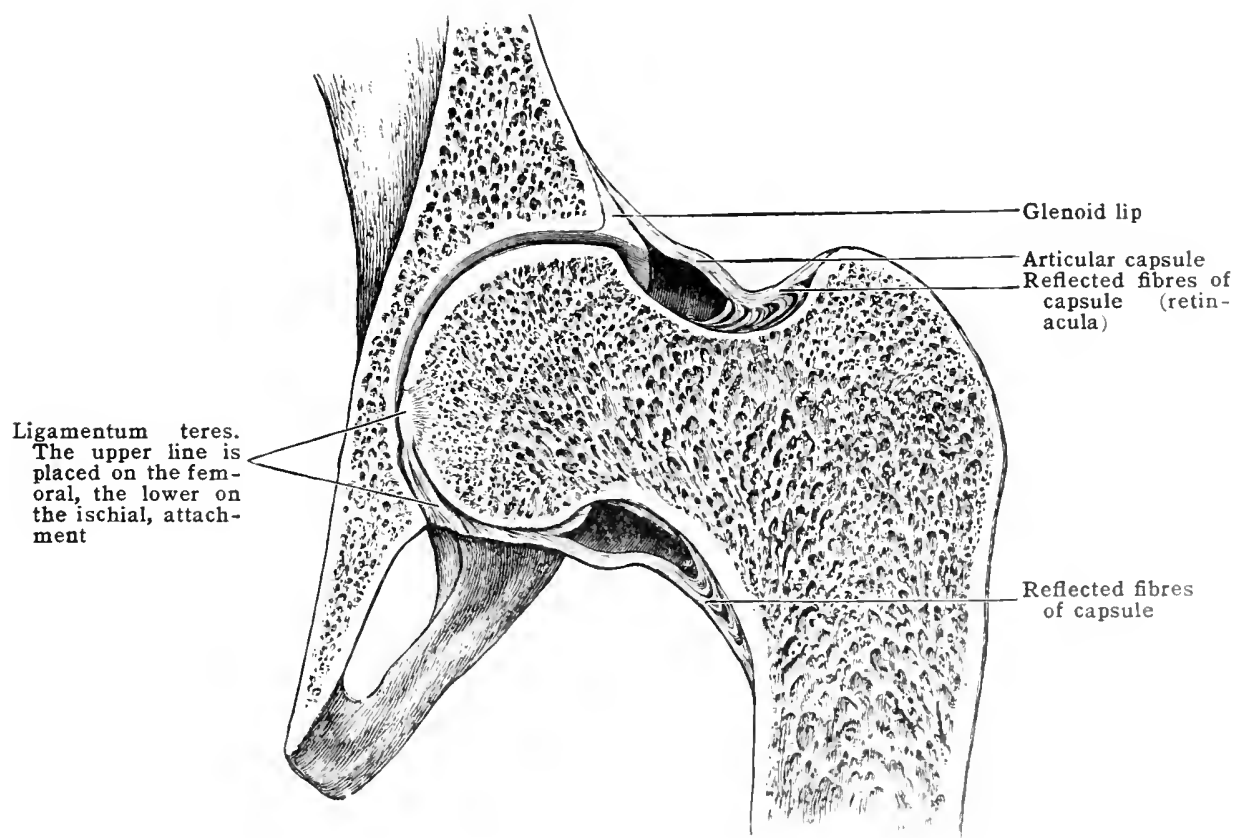

external obturator to the trochanteric fossa, all the ligament between these lines on the lateral and upper aspects of the joint is very thick and strong, while that below and to the medial side, except at the narrow pubo-capsular ligament, is 
thin and weak, so that the head of the bone can be seen through it. The capsule is thickest in the course of the ilio-femoral ligament, toward the lateral part of which it measures over $6 \mathrm{~mm}$. ( $\frac{1}{4} \mathrm{in}$.). Between the ilio-femoral and ischio-capsular ligaments the capsule is very strong, and with it here, near the acetabulum, is incorporated the reflected tendon of the rectus, and here also a triangular band of fibres runs downward and forward to be attached by a narrow insertion to the ridge on the front border of the greater trochanter near the gluteus minimus (the ilio-trochanteric band) (fig. 308).

The capsule is strengthened also at this point by a strong band from the under surface of the gluteus minimus, and by the tendino-trochanteric band which passes down from the reflected tendon of the rectus to the vastus lateralis (externus) (fig. 306). This is closely blended with the capsule near the lateral edge of the ilio-femoral ligament.

The thinnest part of the capsule is between the pubo-capsular and ilio-femoral ligaments; this is sometimes perforated, allowing the bursa under the psoas to communicate with the joint. The capsule is also very thin at its attachment to the back of the femoral neck, and again opposite the acetabular notch.

Fig. 310.-Hip-joint after Dividing the Articular Capsule and Disarticulating the FeMur.

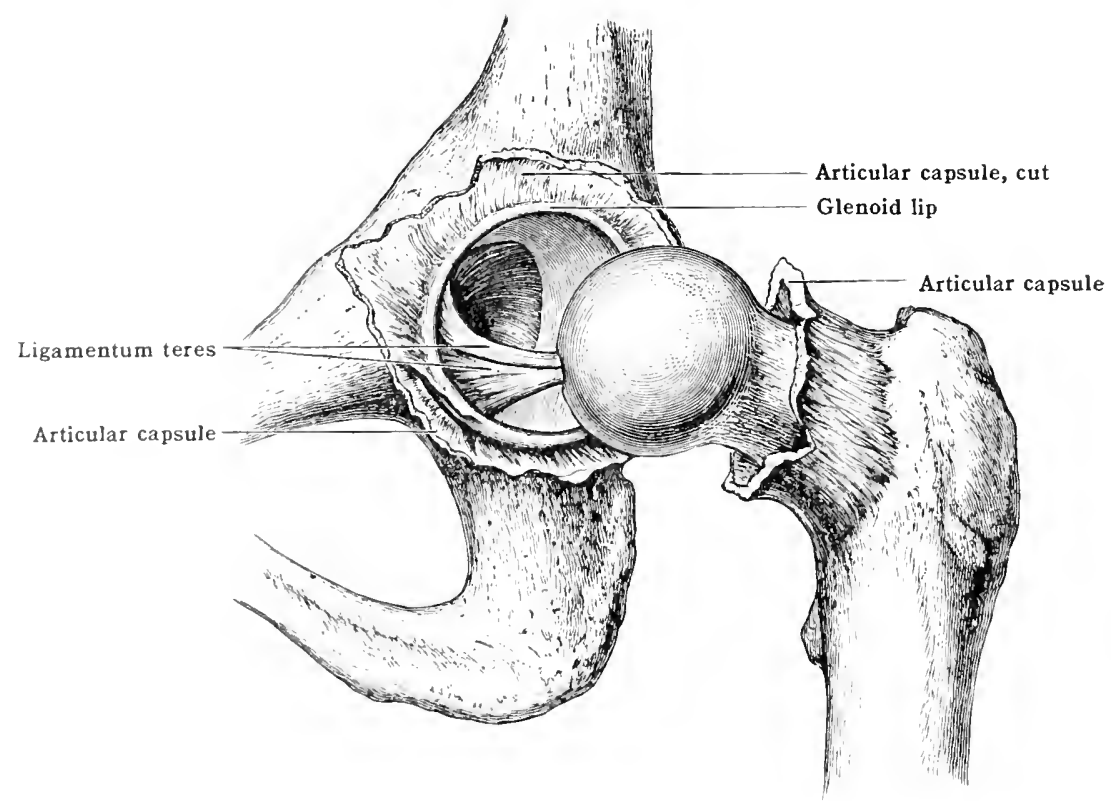

The ligamentum teres (figs. 309 and 310) is an interarticular flat band which extronds from the accetabular fossa to the head of the femur, and is usually about 3.7 (all. ( $1 \frac{1}{2} \mathrm{in}$.) long. It has two bony attachments, one on either side of the acctabmar notch immediately below the articular cartilage, while intermediate fibres suring from the lower surface of the transverse ligament. The ischial portion is the stronger, and has several of its fibres arising outside the cavity, below and in connection with the origin of the transverse ligament, where it is also continums with the rapsule and periostem of the ischium. At the fomur it is fixed to the fromt part of the depression on the head, and to the cartilage round the margin of the depression.

It is covered hy a prolongation of synovial membrane, which also covers the cushion of fat in the recess of the areetabulnu; the portion of the membrane reflected over the fatty tissue does not cling closcly to the round ligament, lut forms a triangubar fold, the apex of which is at the fommr.

Thr transverse ligament (fig. 311) pisses across the acetabular noteh and converts it into a foramern; it supports fart of the glenoid filmo-cartilage, and is connecterl with the liganentum tres and the capsule. It is eomposed of decussating filsers, which arise from thre margin of the acetabulum on cither side of the Hoteh, those coming from thr bubis leming more superficial, and passing to form 
the deep part of the ligament at the ischium, while those superficial at the ischium are deep at the pubis. It thus completes the rim of the acetabulum.

The glenoid lip (cotyloid fibro-cartilage) (figs. 309 and 310) is a yellowishwhite structure, which deepens the acetabulum by surmounting its margin. It

Fig. 311.--Portions of Ischium and Pubis, showing the Acetabular Notch axd the Ligamentum Teres at'Tached outside the Acetabulum.

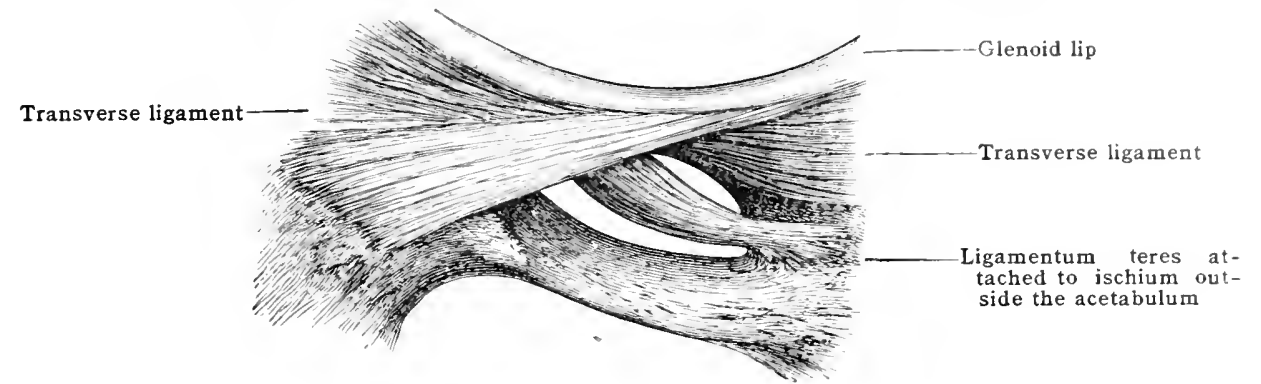

varies in strength and thickness, but is stronger at its iliac and ischial portions than elsewhere. Its base is broad and fixed to the bony rim as well as to the articular cartilage of the acetabulum on the inner, and the periosteum on the outer, side of it, and blends inseparably with the transverse ligament which supports it over the acetabular notch.

Fig. 312.--The Upper Extremity of the Femur (Posterior View), to show the Relation of the Articular Capsule of the Hip-joint (in red) to the Epiphysial Lines.

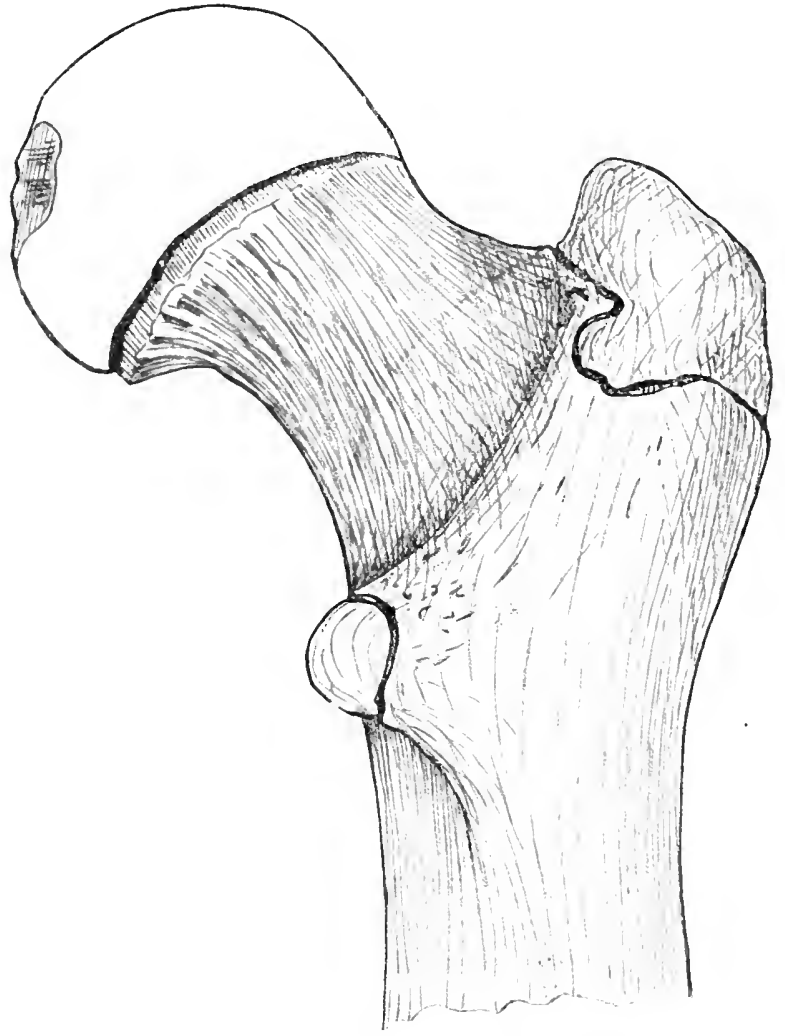

Its free margin is thin; on section it is somewhat lunated, having its outer surface convex and its articular face concave and very smooth in adaptation to the head of the bone. which it tightly embraces a little beyond its greatest circumference. It somewhat contracts the aperture of the acetabulum, and retains the head of the femur within its grasp after division of the muscles and capsular ligament. It is covered on both aspects by synorial membrane. 
The synovial membrane lines the capsule and both surfaces of the glenoid lip, and passes over the border of the acetabulum to reach and cover the fatty cushion it contains. The part covering the fatty cushion is unusually thick, and is attached round the edges of the rough bony surface on which the cushion rests. The membrane is loosely reflected off this on to the ligamentum teres, along which it is prolonged to the head of the femur; thus the fibres of the round ligament are shut out from the joint cavity. From the capsule the synovial membrane is also reflected below on to the neck of the femur, whence it passes over the retinacula to the margin of the articular cartilage. A fold of synovial membrane on the under aspect of the neck often conveys to the head of the femur a. branch of an artery-generally a branch of the medial circumflex.

The arterial supply comes from- $(a)$ the transverse branches of the medial and lateral circumflex arteries; $(b)$ the lateral branch of the obturator sends a branch through the acetabular notch beneath the transverse ligament, which ramifies in the fat at the bottom of the acetabulum, and travels down the round ligament to the head of the femur; $(c)$ the inferior branch of the deep division of the superior gluteal; and $(d)$ the inferior gluteal (sciatic) arteries. The branch from the obturator to the ligamentum teres is sometimes very large when the branch from the medial eircumflex does not also supply the ligament.

The superior and inferior gluteal send several branches through the innominate attachment

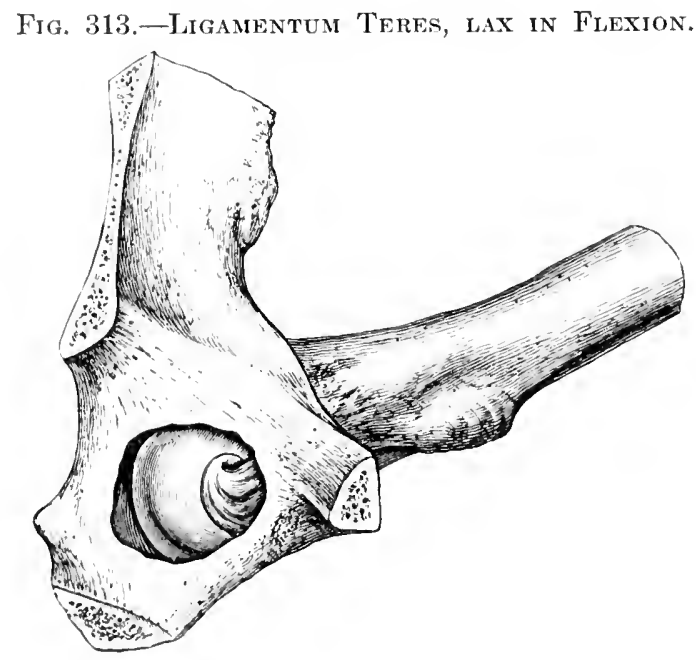

of the articular capsule: these anastomose freely bencath the capsule around the outer aspect of the acelabulum, and supply some branches to enter the bone, and others which enter the substance of the glenoid lip. There is quite an arterial crescent upon the posterior and posterosuperior jortions of the acetabulum; but no vessels are to be seen on the inner aspect of the glenoid lip.

The nerve-supply comes from-(a) femoral (anterior erural), (b) anterior division of the olturator, $(c)$ the accessory obturator, and $(d)$ the sacral plexus, by a twig from the nerve to the quatratus femoris, or from the upper part of the great seiatic, or from the lower part of the sacral plexus.

Relations. - In front and in contact with the capsule are the psoas bursa, the tendinous part of the psois magnus, and the iliacus. Still more anteriorly and not in contact are the femoral artery, the femoral (anterior crumal) nerve, the rectus femoris, the sartorius, and the tensor fasciar latat.

Abome and in chose relation with the eapsule are the piriformis, the obturator internus and the gemelli, and the reflecterl heal of the reetus fenoris, whilst more superficially lie the gluteus minimus and merlius.

Batind and in close rolation with the capsule are the obturator externus, the gemelli and oturator interms, um] the piriformis. More superficially lie the puarlatus femoris, the seiatic norves, ant the glutrols maximus.

Bifom the vbturator (x) relation with the chusule.

The movements. The hip-joint, like the shoulder, is a ball-and-socket joint, but with a much more complete socliet ant a corresponding limitation of movement. lach variety of movement is permitted, vi\%. flexion, expension, aluluction, alduetion, circumbluction, and rotation; and any two or more of thess: movements not heing antagonistie can he combined, i. e.,

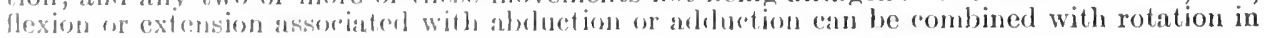
(1) (3)1. 
It results from the obliquity of the neck of the femur that the movements of the head in the acetabulum are always more or less of a rotatory character. This is more especially the case during flexion and extension, and two results follow from it. First, the bearing surfaces of the femur and acetabulum preserve their apposition to each other, so that the amount of articular surface of the head in the acetabulum does not sensibly diminish pari passu with the transit of the joint from the extended to the flexed position, as would necessarily be the case if the movement of the femoral head, like that of the thigh itself, was simply angular, instead of rotatory and angular. Secondly, as rotation of the head can continue until the ligaments are tight without being checked by contact of the neck of the thigh bone with the rim of the acetabulum, flexion of the thigh so far as the joint is concerned is practically unlimited. Flexion is the most important, most frequent, and most extensive movement, and in the dissected limb, before the ligaments are disturbed, can be carried to $160^{\circ}$, and is then checked by the lower fibres of the ischio-capsular ligament. In the living subject simple flexion can continue until checked by the contact of the soft parts at the groin, if the knee be bent; if the knee be straight, flexion of the hip is checked in most persons by the hamstring museles at nearly a right angle. This is very evident on trying to touch the ground with the fingers without bending the knees, the chief strain being felt at the popliteal space. This is due to the shortness of the hamstrings. Extension is limited by the ilio-femoral ligament.

Fig. 314.-Liganentum Teres, very lax in Complete Extensiox.

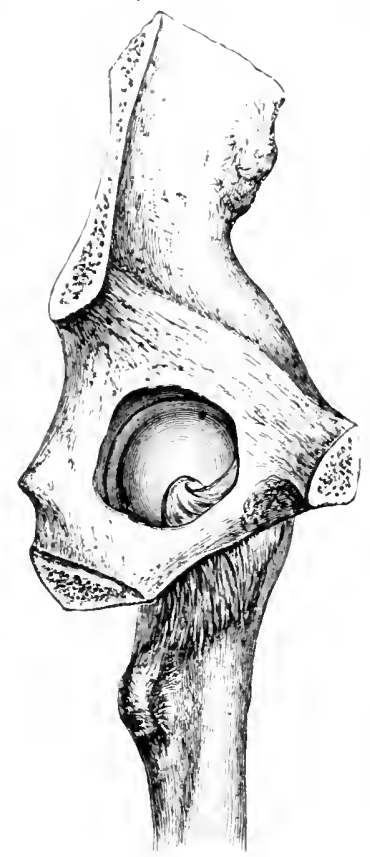

Abduction and lateral rotation can be performed freely in every position of flexion and extension-abduction being limited by the pubo-capsular ligament; lateral rotation by the ilio-femoral ligament, especially its medial portion, during extension; but by the lateral portion, as well as by the ligamentum teres, during flexion.

Adduction is very limited in the extended thigh on account of the contact with the opposite limb. In the slightly flexed position adduction is more free than in extension, and is then limited by the lateral fibres of the ilio-femoral band and the superior portion of the capsule. In flexion the range is still greater, and limited by the ischio-capsular ligament, the ligamentum teres being also rendered nearly tight. Medial rotation in the extended position is limited by the lower fibres of the ilio-femoral ligament; and in flexion by the ischio-capsular ligament and the portion of the capsule between it and the ilio-femoral band.

The ilio-femoral band also prevents the tendency of the trunk to roll backward on the thigh bones in the erect posture, and so does away with the necessity for muscular power for this purpose; it is put on stretch in the stand-at-ease position.

The ligamentum teres is of little use in resisting violence or in imparting strength to the joint. It assists in checking lateral rotation, and adduction during flexion. A ligament can only be of use when it is tight, and it was found by trephining the bottom of the acetabulum. removing the fat, and threading a piece of whipcord round the ligament, that the ligament was slack in simple flexion, and very loose in complete extension, but that its most slack condition was in abduction. It is tightest in flexion combined with adduction and lateral rotation and almost as tight in flexion with lateral rotation alone, and in flexion with adduction alone (figs. $313-315)$.

Muscles which act upon the hip-joint.-Flexors.-The psoas and iliacus, the rectus femoris, the pectineus, the adductors, the sartorius, the tensor fasciæ latæ, and the gluteus medius. 
Fig. 315.-Ligamentum Teres, drawn Tight in Flexion Combined with Lateral Rotation and Adduction.

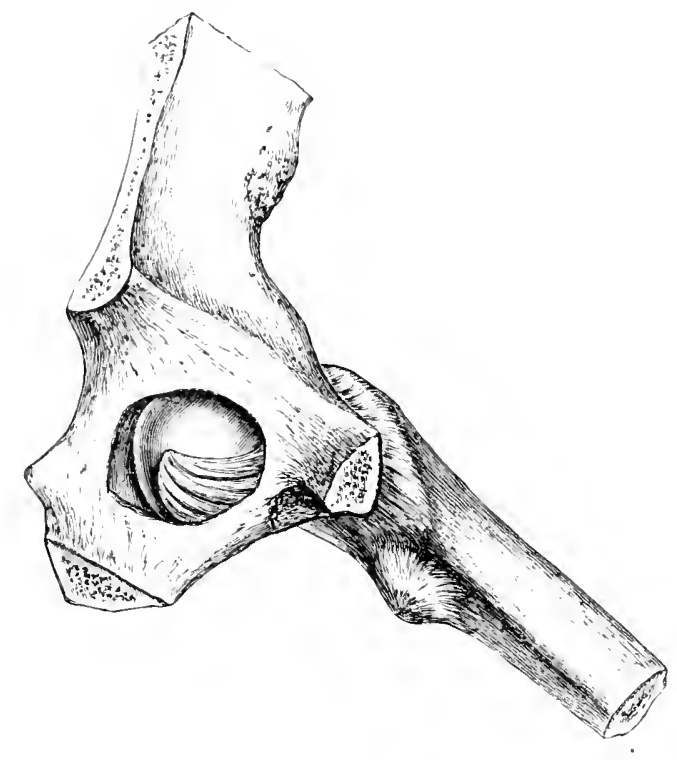

Extensors.-The gluteus maximus, the posterior fibres of the glutei medius and minimus, the biceps, the semitendinosus, the senimembranosus, and the ischial fibres of the adductor magnus; also (slightly) the piriformis, obturator internus and gemelli. Abductors.-Gluteus maximus (upper fibres), tensor faseiæ latæ, gluteus medius, gluteus minimus, and, when the joint is flexed, the piriformis, obturator internus, the gemelli, and the sartorius also become abductors. Adductors.-Adductores magnus, longus, brevis, and minimus, semitendinosus, biceps, the gracilis, the pectineus, the quadratus femoris, and the lower fibres of the gluteus maximus. Medial rotators.-Psoas (slightly), adductor magnus, semimembranosus, the anterior fibres of the gluteus medius and minimus, and the tensor fasciæ latæ. Lateral rotators.-Gluteus maximus, posterior fibres of gluteus medius and minimus, the adduetors, obturator externus, quadratus femoris, obturator internus, the gemelli, and the piriformis when the joint is extended.

\section{THE KNEE-JOINT}

Class.-Diarthrosis.

Subdivision.-Ginglymus.

The knee is the largest joint in the body. It is rightly described as a ginglymoid joint, but there is also an arthrodial element; for, in addition to flexion and extension, there is a sliding backward and forward of the tibia upon the femoral condyles, as well as slight rotation round a vertical axis. It is one of the most superficial, and, as far as adaptation of the bony surfaces goes, one of the weakest joints, for in no position are the bones in more than partial contact. Its strength lies in the number, size, and arrangement of the ligaments, and the powerful muscles and fascial expansions which pass over the articulation and enable it to withstand the leverage of the two longest bones in the body. It may be said to consist of two articulations with a common synovial membrane-the patellofemoral and the tibio-fenoral, the latter being double. It is composed of the condyles and trochlear surface of the femur, the condyles of the tibia, and the patella, united by the following ligaments, which may be divided into an external and internal set:-

\section{EXTERNAL}

(1) Wibrous expansion of the extrnsors.

(2) Articular capsule.

(i) ()blicue poplitrat ligament.

(1) libular collateral.

(i) Tibial collateral.

(6) Ligancutum patella:

\section{INTERNAL}

(1) Anterior crucial.

(2) Posterior erucial.

(3) Merlial meniseus.

(4) Iateral meniscus.

(5) Coronary

(6) Transverse. 


\section{External Ligaments}

Superficial to the fibrous expansion of the quadriceps extensor tendons the fascia lata of the thigh covers the front and sides of the knee-joint.

The deep fascia of the thigh, as it descends to its attachment to the tuberosity and oblique lines of the tibia, not only overlies but blends with the fibrous expansion of the extensor tendons. The oblique lines of the tibia curve upward and backward from the tuberosity on each side to the postero-lateral part of the condyles. The process of fascia attached to the lateral riilge of the tibia and to the head of the fibula descends from the tensor fascix late and is very thick and strong. It is firmly blended with the tendinous fibres of the vastus lateralis. The fascia lata, on the medial side of the patella, besides being attached to the medial oblique ridge of the tibia, sends some longitudinal fibres lower down to become blended with the fibrous expansion of the sartorius. The fascia is much thinner on the medial side of the patella than on the lateral, and blends much less with the tendon of the vastus medialis than the lateral part of the fascia does with the vastus lateralis. A thin layer of the fascia lata in the form of transverse or arciform fibres passes over the front of the joint. These filbres are specially well marked orer the ligamentum patellæ, and blend here with the central portion of the quadriceps extensor fibres.

Fig. 316.-The Lower Extremity of the Fenur (Posterior View), to show the Relation of the Articular Capsule of the Knee-Joint (in red) to the Epiphisial line.

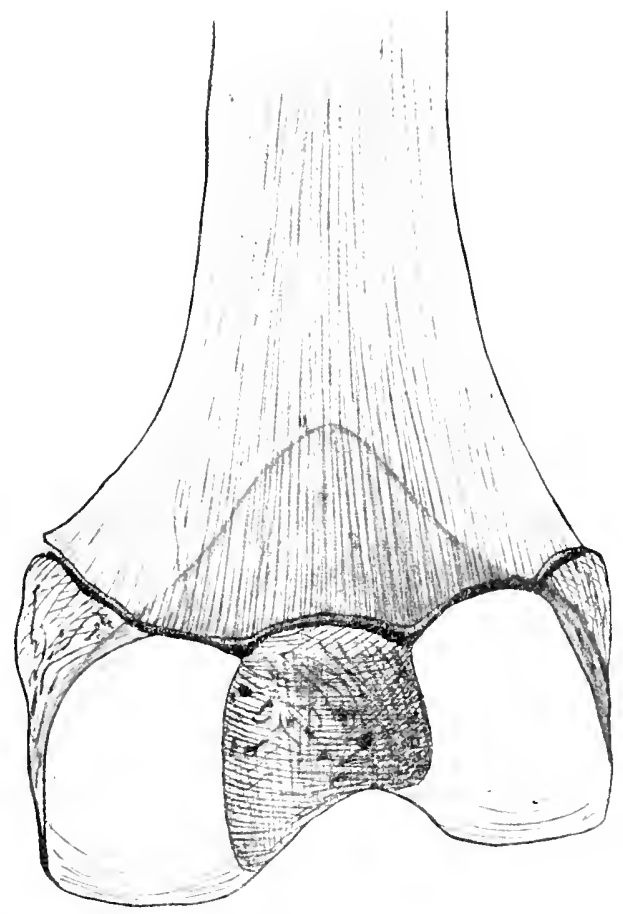

The fibrous expansion of the extensor tendons consists-(1) of a central portion, densely thick and strong, $3.7 \mathrm{~cm}$. ( $1 \frac{1}{2} \mathrm{in}$.) broad, which is inserted into the anterior two-thirds of the upper border of the patella, many of its superficial fibres passing over the subcutaneous surface of the bone into the ligamentum patellæ; (2) of two side portions thimner, but strong.

The side portions are inserted into the patella along its upper border on either side of the central portion and also into its medial and lateral borders, nearer the anterior than the posterior surface, as low down as the attachment of the ligamentum patelle; passing thence along the sides of the ligamentum patellæ to the tibia, they are attached to the oblique lines which extend from the tuberosity to the medial and lateral condyles, and reach as far as the tibial and fil,ular collateral ligaments. On the lateral side, the fibres blend with the ilio-tibial band of the fascia lata, and on the medial they extend below the oblique line to blend with the periostemn of the shaft. Thus there is a large hood spread over the whole of the front of the joint, investing the patella, and reaching from the sides of the ligamentum patellæ to the colliteral ligaments, attached below to the tibia, and separated everywhere from the synovial membrane hy a layer of fatty tissue.

The ligamentum patellæ (fig. 320) is the continuation in line of the central portion of the conjoined tendon, some fibres of which are prolonged orer the front 
of the patella into the ligament. It is an extremely strong, flat band, attached above to the lower border of the patella; below, it is fixed to the lower part of the tuberosity and upper part of the crest of the tibia, somewhat obliquely, being prolonged downmard further on the lateral side, so that this border is fully 2.5 $\mathrm{cm}$. (1 in.) longer than the medial, which measures $6.7 \mathrm{~cm} .\left(2 \frac{1}{2} \mathrm{in}.\right)$ in length. Behind, it is in contact with a mass of fat which separates it from the synovial membrane, and a small bursa intervenes between it and the head of the tibia. In front, a large bursa separates it from the subcutaneous tissue, and at the sides it is continuous with the fibrous expansion of the extensors.

The tibial (internal) collateral ligament (fig. 317) is a strong, flat band, which extends from the depression on the tubercle on the medial side of the medial

Fig. 317.-Posterior View of the Knee-Joint.

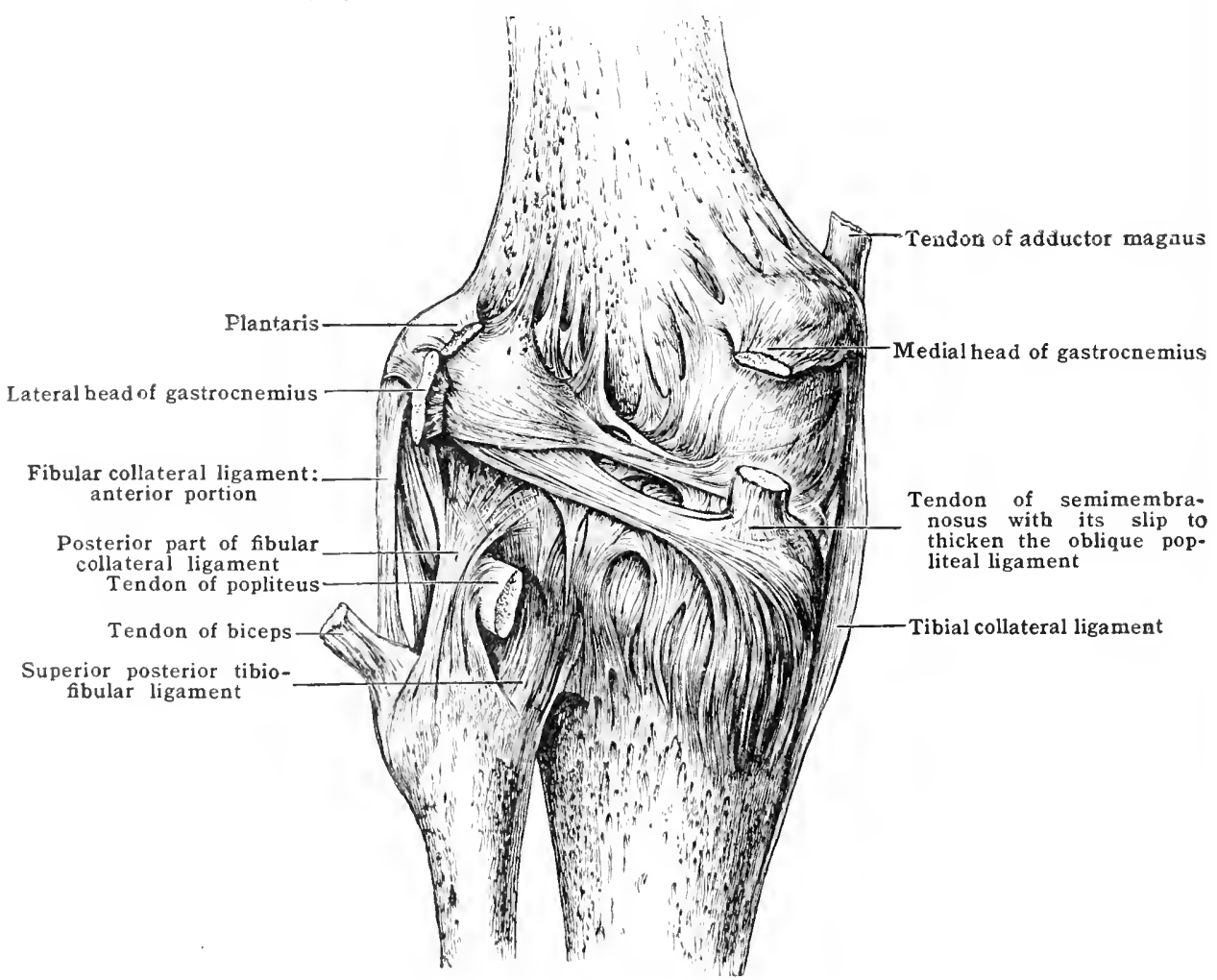

epicondyle of the femur, to the medial border and medial surface of the shaft of the tilsia, $3.7 \mathrm{~cm}$. ( $1 \frac{1}{2} \mathrm{in}$.) below the condyle. It is $8.7 \mathrm{~cm}$. ( $3 \frac{1}{2} \mathrm{in}$.) long, well defined anteriorly, where it blends with the expansion of the eonjoined extensor tendons; but not so well defined posteriorly, where it merges into the oblique popliteal ligament.

Somo of the lower fibres blend with the descending portion of the semimembranosus tendon, Its de(p) surface is firmly adlicrent to, the edge of the medial meniscus and coronary ligament. while part of the somimembranosus lindon and inferior medial arlicular vessels and nerve pass between it and the bone. Superficially, a bursa separates it from the tendons of the graeilis and srmiterdimosus muscles and from the aponeurosis of the sartorius nuscte.

The fibular (exterial) collateral ligament (fig. 317) eonsists of two portions: the anterior, which is the longer and bether marked, is a strong, rounded cord, abont $5 \mathrm{~cm}$. (2 in.) long, attacherl above to the tubercle on the lateral side of the latrial epicondyle of the fomur, just below and in front of the origin of the lateral hearl of the gastrocnemias, whilst the tendon of the popliteus arises from the groove braw and in fromt of it. Below, it is fixed to the middle of the lateral

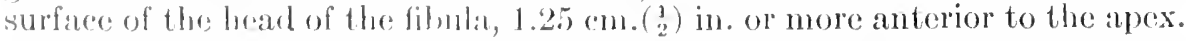

Suprefirially is the tendon of the biceps, which sulits to embrace its lower extremity; while beneath it pass the poptiteus tondom in its sheath, and the inferion lateral arlieular vessels and nerve. 
Some fibres of the peroneus longus occasionally arise from the lower end of the ligament. The posterior portion is $8 \mathrm{~mm}$. ( $\frac{1}{3} \mathrm{in}$.) behind the anterior. It is broader and less defined; fixed below: to the apex of the fibula, it inclines upward and somewhat backward, and ties down the popliteus against the lateral condyle of the tibia, blending beneath the lateral head of the gastrocnemius with the oblique popliteal ligament of the knee, of which it is really a portion.

The oblique popliteal ligament or ligamentum Winslowii (fig. 317) is a broad dense structure of interlacing fibres, with large orifices for vessels and nerves. It is attached above to the femur close to the articular margins of the condyles, stretching across the upper margin of the intercondyloid fossa, to which it is connected by fibro-fatty tissue; it thus reaches across from the tibial to the fibular collateral ligaments. Below, it is fixed to the border of the lateral condyle of the tibia, to the bone just below the posterior intercondyloid notch, and to the shaft of the tibia below the medial condyle, blending with the descending slip of the semimembranosus and tibial collateral ligament.

Superficially, an oblique fasciculus from the semimembranosus runs across the centre, passing upward and laterally from near the back part of the medial condyle of the tibia to the lateral

Fig. 318.-The Lower Extremity of the Femur (Anterior View) to show the Relation of the Articular Capsule of the linee-Joint (in red) to the Epiphysial Line.

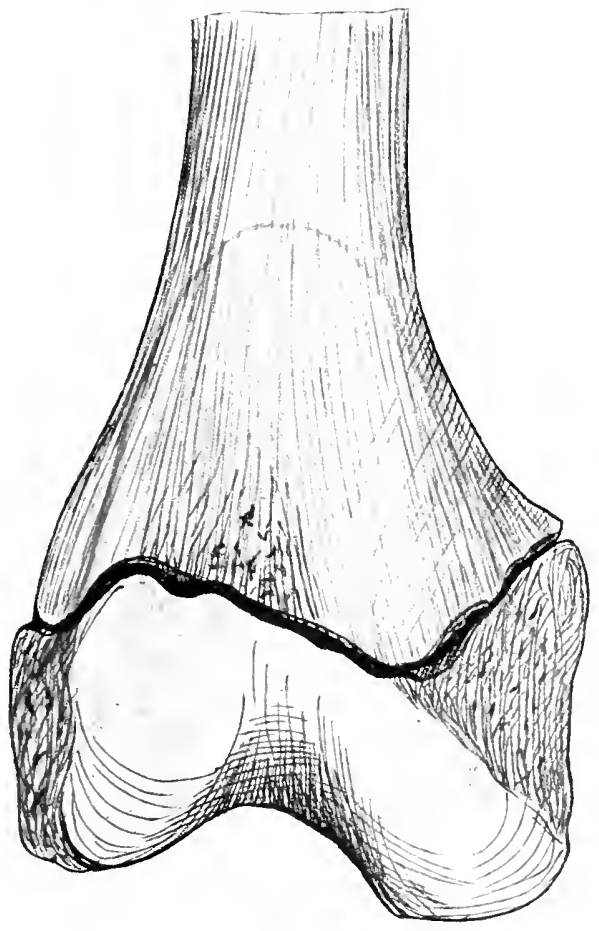

epicondyle of the femur, where it joins the lateral head of the gastrocnemius, a sesamuid plate being sometimes developed at the point of junction. This slip greatly strengthens the oblique popliteal ligament, of which, if not the chief constituent, it is at least a very important part.

Its deep surface is closely connected with the semilunar menisci (especially the medial) and coronary ligaments, and in the interval betweeu the cartilages with the posterior crucial ligament and fibro-fatty tissue within the joint. Superficially it forms part of the floor of the popliteal space. A special band, the arcuate ligament, is sometimes found extending from the lateral epicondyle to the oblique ligament.

The articular capsule (fig. 319) is thin but strong, covering the synovial membrane, and looking like a loose sac. It is attached to the femur near the articular margin on the medial side, but further away on the lateral; it passes beneath the fibular collateral ligament to join the sheath of the popliteus. Medially it joins the tibial collateral ligament. Below, it is fixed to the upper as well as the medial and lateral borders of the patella and the anterior border of the head of the tibia. It is strengthened superficially between the femur and patella by an expansion from the articularis genu (sub-crureus) and is separated from 
the fibrous expansion of the extensor tendon by a layer of fatty tissue. The synovial membrane lines its deep surface, and holds it against the borders of the semilunar menisci; it is also attached to the coronary ligaments.

\section{Internal Ligaments}

The anterior crucial ligament (figs. 319 and 320) is strong and cord-like. It is attached to the medial half of the fossa in front of the intercondyloid eminence of the tibia, and to the lateral border of the medial articular facet as far back as the medial intercondrloid tubercle. It passes upward, backward, and laterally to the back part of the medial surface of the lateral condyle of the femur. 'To

ig. 319.-Anterior View of the Internal Ligaments of the Knee-joint.

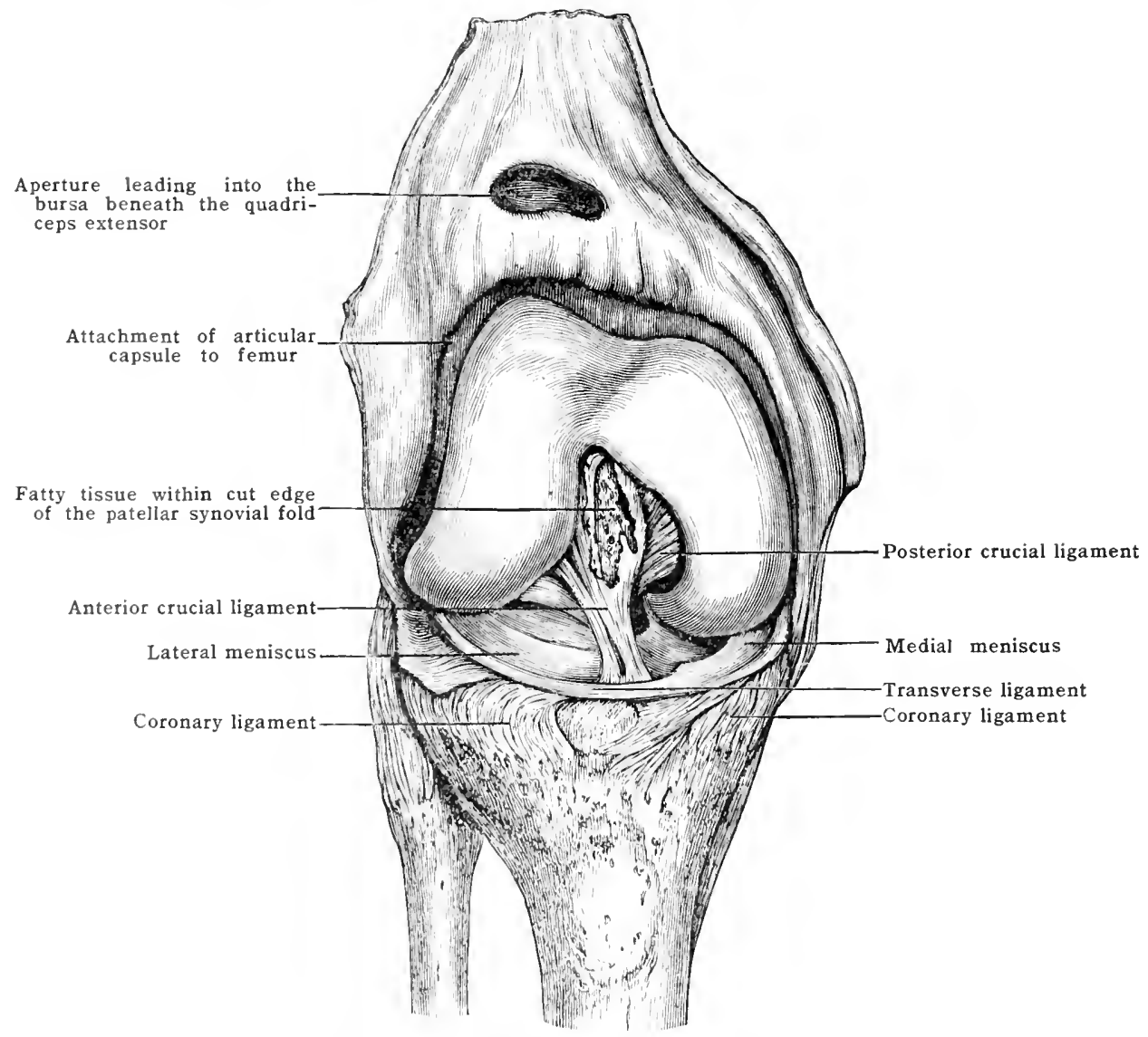

the tibia, it is fixed behind the anterior extremity of the medial semilunar meniscus. Jielind and to the lateral side it has the anterior extremity of the lateral meniscus, a fow filmes of which blend with the lateral erlge of the ligament.

Its anterior filpres at the tillial end are strongest and longest, being fixed highest on the fommr; while the postrier, springing from the interendy foid eninence, are shorter and more

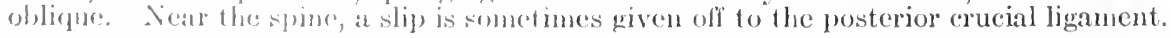

The posterior crucial ligament (fig. 319, :320, and 322) is stronger and less ol)licque than the anterior. It is fixed below to the greater portion of the fossa leehind the intereomelyloil rminenes of the tibia, especially the lateral and postrerior portion, and then morlially along the posterior intercondyloid fossa; being joined by fibres which aniso betworn the intereondyloid tubereles, it ascends to the anterior part of the lateral surface of the medial condyle of the femur,

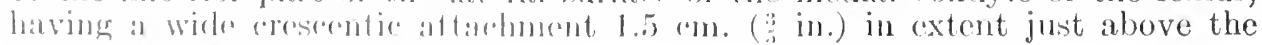
articular surface.

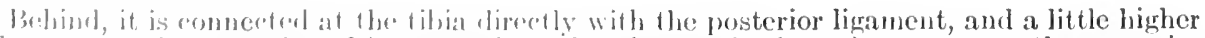

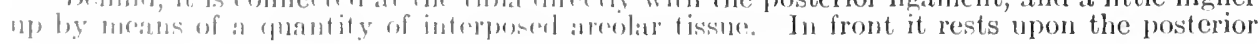


horn of the medial semilunar meniscus, and receives a large slip from the lateral meniscis, which ascends along it, either in front or behind, to the femur; higher up in front it is connected with the anterior crucial ligament.

Until they rise above the intercondyloid eminence of the tibia the two crucial liganents are closely bound together, so that no interspace exists between their tibial attachments and the point of decussation; the only space between them is therefore a $\mathbf{V}$-shaped one corresponding to the upper half of their $X$-shaped arrangement, and this is a mere chink in the undissected state, and can be seen from the front only, owing to the fatty tissue beneath the synovial membrane which surrounds their femoral attachment.

The interarticular menisci or semilunar fibro-cartilages (figs. 319 and 320) are two crescentic clises resting upon the circumferential portions of the articular facets of the tibia, and moving with the tibia upon the femur. They somewhat deepen the tibial articular surfaces, and are dense and compact in structure, becoming looser and more fibrous near their extremities, where they are firmly fixed in front of and behind the intercondyloid eminence of the tibia. The circumferential border of each is convex, thick, and somewhat loosely attached to the borders of the condyles of the tibia by the coronary ligaments and the reflexion of the synovial nembrane. The inner border is concave, thin, and free. Half an inch $(1.3 \mathrm{~cm}$.) broad at the wirlest part, they taper somewhat toward their

Fig. 320.-Śtructures lying on the Head of the Tibia. (Right knee.)

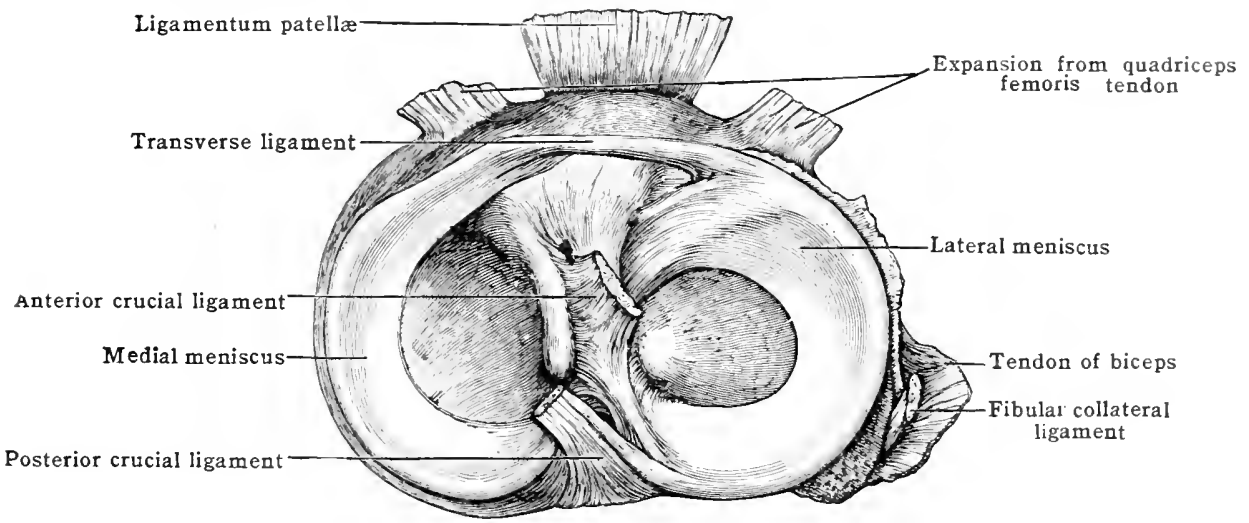

extremities, and cover rather less than two-thirds of the articular facets of the tibia. Their upper surfaces are slightly concave, and fit on to the femoral condyles, while the lower are flat and rest on the head of the tibia; both surfaces are smooth and covered by synovial membrane.

The lateral meniscus (fig. 320) is nearly circular in form and less firmly fixed than the medial, and consequently slides more freely upon the tibia. Its anterior cornu is attached to a narrow depression along the lateral articular facet, just in front of the lateral intercondyloid tubercle of the tibia, close to, and on the lateral side of, the anterior cruc ial ligament; a small slip from the cornu is often fixed to the tibia in front of the crucial ligament. The posturior cornu is firmly attached to the tibia behind the lateralintercondyloid tubercle, blending with the posterior crucial ligament, and giving off a well-marked fasciculus, which runs up along the anterior border of the ligament to be attached to the femur (ligament of Wrisberg). It also sends a narrow slip into the back part of the anterior crucial ligament. Its outer border is grooved toward its posterior part by the popliteus tendon, which is held to it by fibrous tissue and synovial membrane, and separates it from the fibular collateral ligament. From its anterior border is given off the transverse ligament.

The medial meniscus (fig. 320 ) is a segment of a larger circle than the lateral, and has an outline more oval than circular. Its anterior cornu is wide, and has a broad and oblique attachment to the anterior margin of the head of the tibia. It reaches from the margin of the condrle toward the middle of the fossa in front of the intercondyloid eminence, being altogether in front of the anterior crucial ligament. The posterior cornu is firmly fixed by a broad insertion in an antero-posterior line along the medial side of the posterior intercondyloid fossi, from the medial tubercle to the posterior margin of the head of the tibia. Its convex border is connected with the tibial collateral ligament and the semimembranosus tendon.

The transverse ligament (figs. 319 and 320) is a rounded, slencler, short cord, which extends from the convex border of the lateral meniscus to the concave border or anterior cornu of the medial, near which it is sometimes attached to the bone. It is an accessory band of the lateral meniscus, and is situated beneath the synovial membrane. 
The coronary ligaments (fig. 319) connect the margins of the semilunar discs with the head of the tibia. The lateral is much more lax than the medial, permitting the lateral clisc to change its position more freely than the medial. They are not in reality separate structures, but consist of fibres of the several surrounding ligaments of the linee-joint which become attached to the margins of the dises as they pass over them.

The synovial membrane (fig. 324) of the knee forms the largest synovial sac in the body. Bulging upward from the patella, it follows the capsule of the joint into a large cul-de-sac benenth the tendon of the extensor muscles on the front of the femur. It reaches some distance beyond the articular surface of the bone, and communicates very frequently with a large bursa interposed between the tendon and the femur abore the line of attachment of the articular capsule. After investing the circumference of the lower end of the femur, it is reflected upon the

Fig. 321.-The Upper Extremity of the Tibia (Anterior View), to show the Relatiox of the Articdlar Cajsule of the Knee-Joint (in red) to the Epiphysial Line.

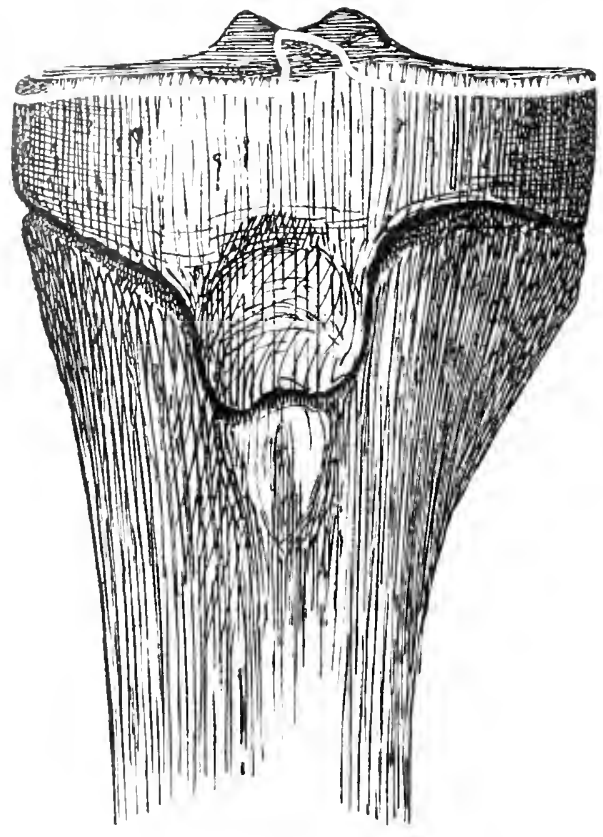

fibrous concelope of the joint lormed by the capsular, posterior, and collateral ligaments.

The symoviat memtmane eovers a great portion of the erucial ligaments, but leaves uncovered the hate of the posterior cructial where the latter is ronnected with the posterior ligament, and

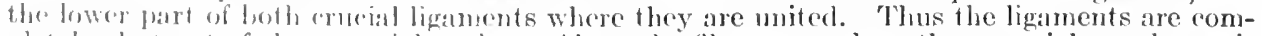

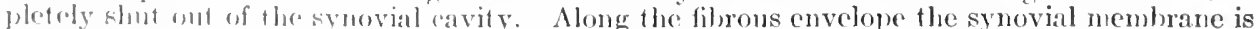

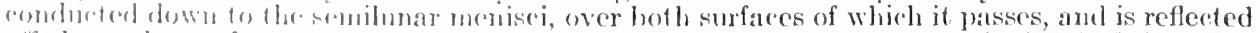
otf the muder surfares on to the coromaly tigaments, and thenee down to the head of the tibia,

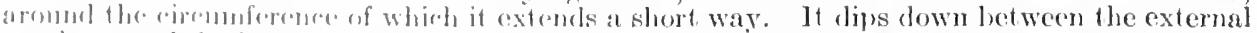

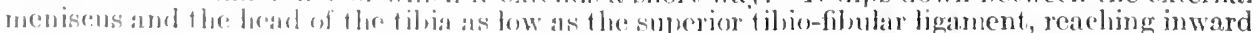
nearly as far as the interomdyloid notoh, and forming a hursa for the play of the popliteal tendon.

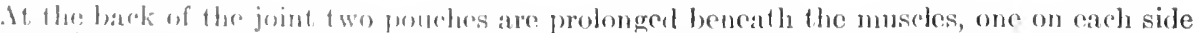

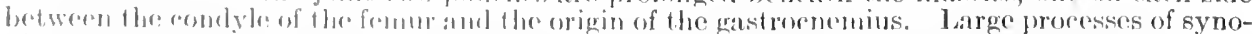

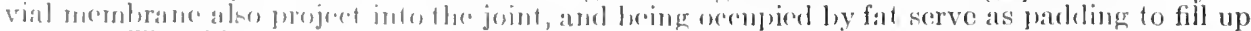

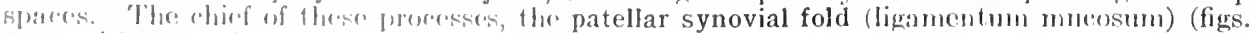

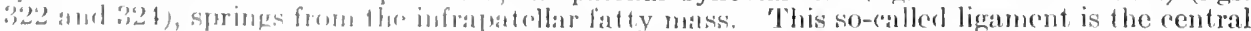

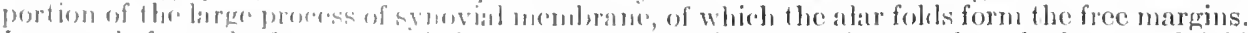

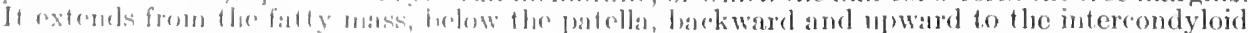
moth of the femmr, where it is atlanhed in front of the anterior crucial, and lateral to the poste-

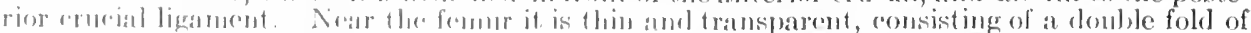

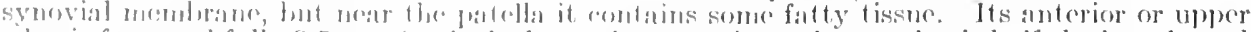

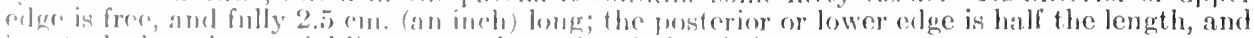

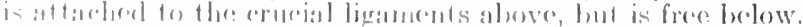


Passing backward from the capsule on each side of the patella is a prominent crescentic fold formed by reduplications of the synovial membrane - these are the alar folds (fig. 322). Their free margins are concave and thin, and are lost below in the patellar fold. There is a slight fossa above and another below each ligament.

Fig. 322.-Anterior View of the Knee-joint, showixg the Srnovial Liganexts. (Anterior portion of capsule with the extensor tenron thrown downward.)

Synovial pouch under tendon of quadriceps femoris

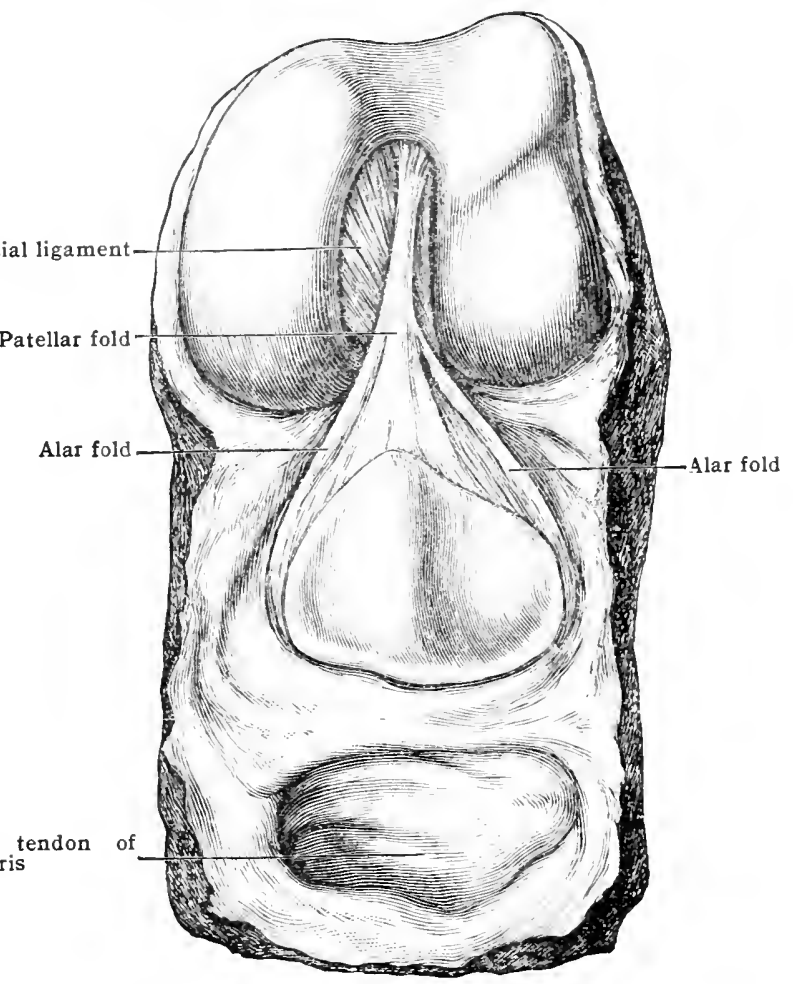

Fig. 323.-The Upper Extrenity of the Tibia (Posterior Yiew'), to shon the Relatiox of the Articular Capsele of the hinee-ioint (in red) to the Epiphysial Line.

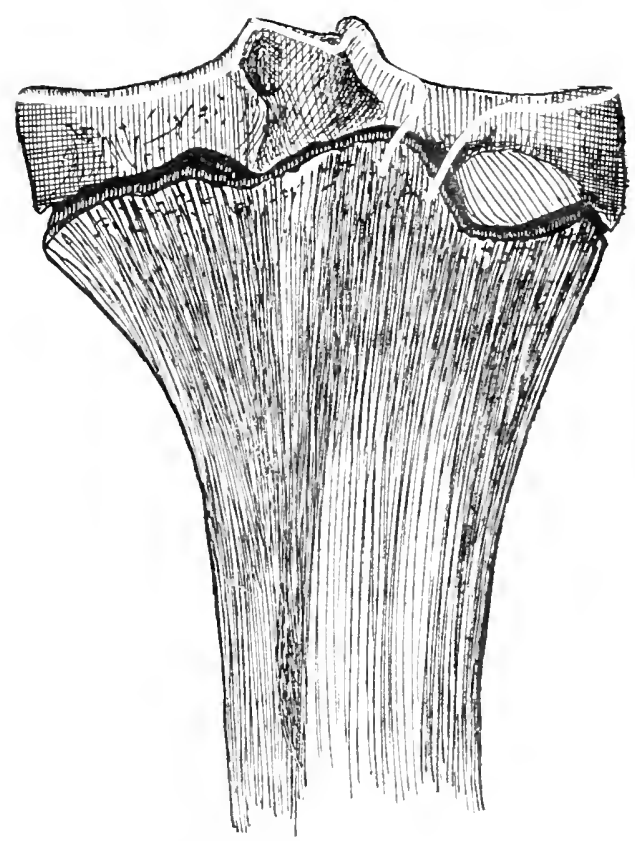

The arterial supply is derived from the art. genu suprema (anastomotica); the superior and inferior medial and lateral articular; the medial articular; the descending branch of the lateral circumflex; the anterior recurrent branch from the anterior tibial; and the posterior tibial recurrent. 
The nerve-supply comes from the great sciatic, femoral, and obturator sources. The great sciatic gives off the tibial and common peroneal; the tibial sends two, sometimes three branches - one with the medial articular artery; one with the inferior medial, and sometimes one with the superior medial articular artery; the common peroneal gives a branch which accompanies the superior, and another which accompanics the inferior articular artery, and a recurrent branch which follows the course of the anterior recurrent branch of the anterior tibial artery. The femoral sends an articular hranch from the nerve to the vastus lateralis; a second from the nerve to the vastus medialis; and sometimes a thirl from that to the vastus intermedius. Thus there are three articular twigs to the knee derived from the muscular branches of the femoral. The obturator by its deep division sends a branch through the adductor magnus on to the popliteal artery, which enters the joint posteriorly.

Fig. 324.-Sigittal Section of the Knee-Joint. (The bones are somewhat drawn apart.)

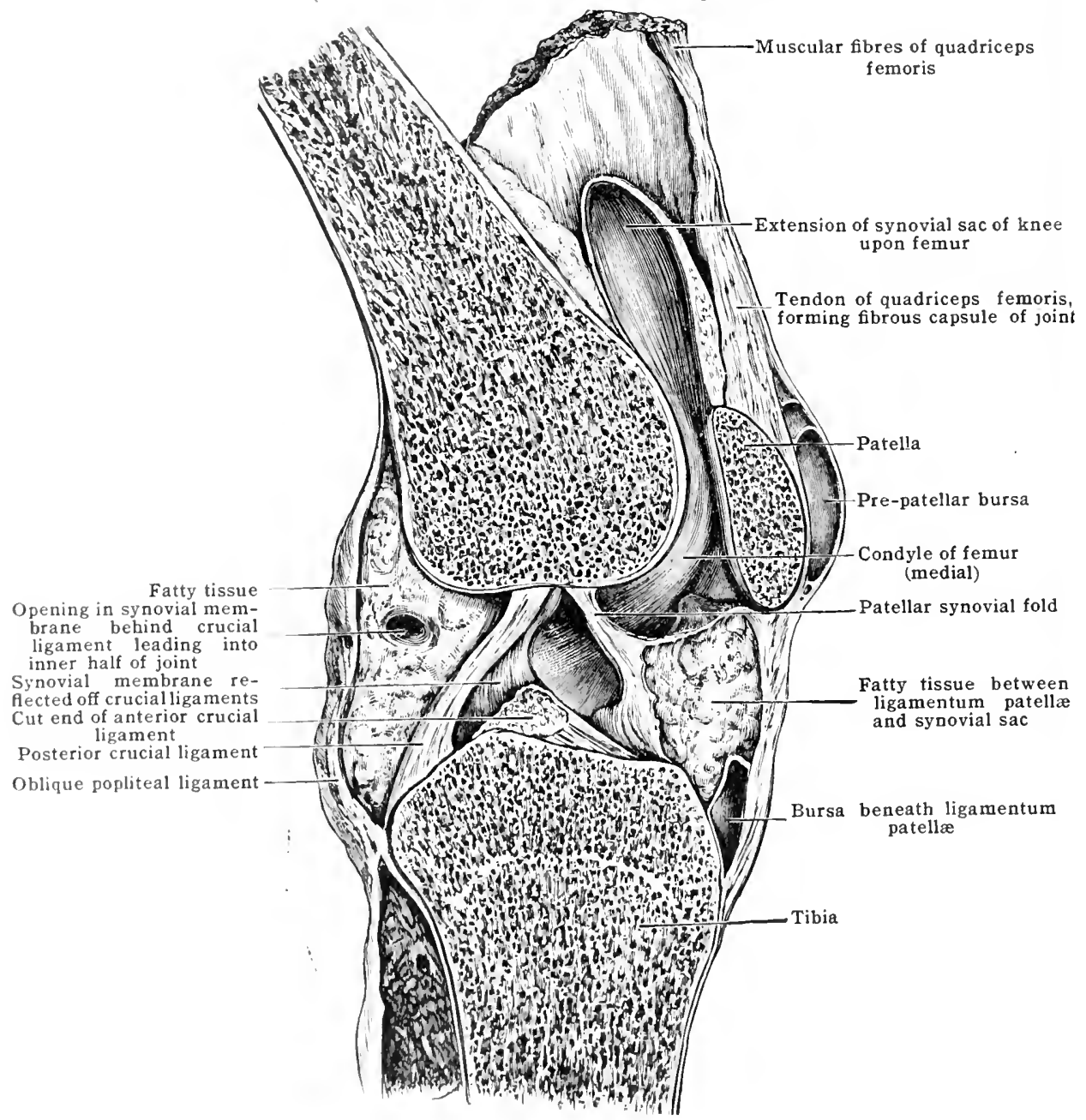

Relations. - Anteriorly aml at the siles the knee-joint is merely covered am protected iby skin, fascia, ant the tordinoms expansions of the quarleceps extensor muscle. laterally and postoriorly it is aressol hy the hiceps fomlon. Nerlially and posteriorly lie the sartorins and

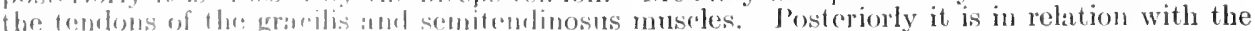

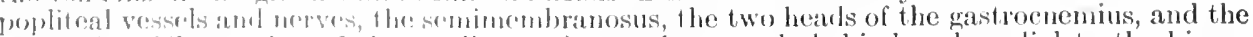
plantaris. The fomelon of thropplitens pirrers the capsule behind and medial to the biceps temitorl.

The movements which went at the knop-joint are flexion and extension, with some slight annonnt of robation in the lent pustion. These movements are not so simple as the corresponding ones at the ellow, for the knes is met a simple hinge joint. The movements of rotation

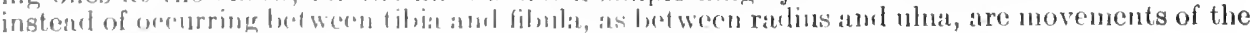

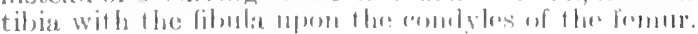

The kure rliffors from in trur: hinge joint, like the ellow or ankle, in the following particulars:

1. The points of contant of the fomm with the tibia are constantly ehanging. Thus, in 
the flexed position, the posterior part of the articular surface of the tibia is in contact with the rounded back part of the femoral condyles; in the semiflexed position the middle parts of the tibial facets articulate with the anterior rounded part of the condyles; while in the fully extended. position the anterior and middle parts of the tibial facets are in contact with the anterior flattened portion of the condyles. So with the patella: in extreme flexion the medial articular facet rests on the lateral part of the medial condyle of the femur; in flexion the upper pair of facets rests on the lower part of the trochlear surface of the femur; in mid-flexion the middle pair rests on the middle of the trochlear surface; while in extension the lower pair of facets on the patella rests on the upper portion of the trochlear surface of the femur.

Fig. 325.-The Collateral Liganents of the Knee in Flexion and Extexision.
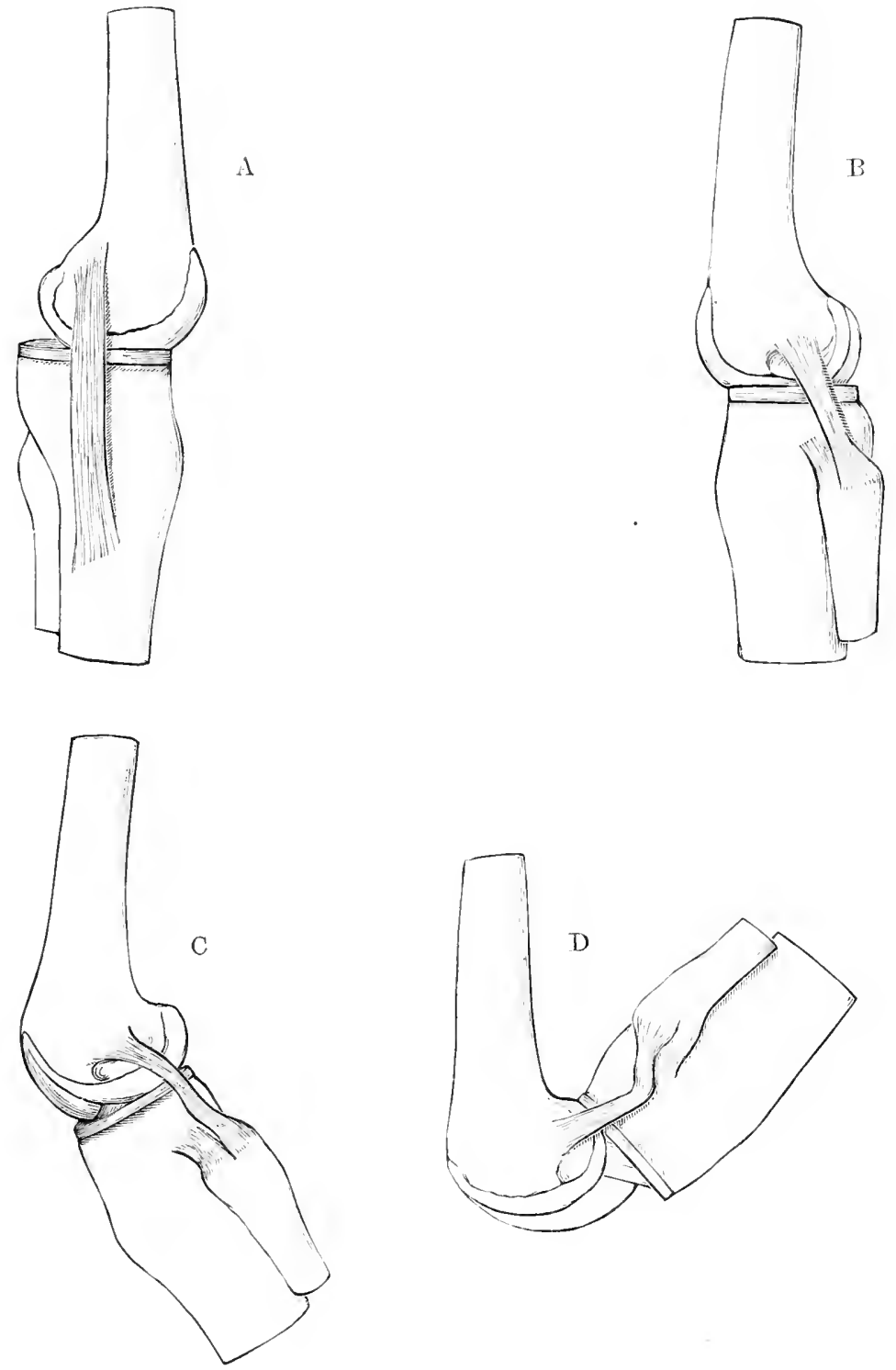

This difference may be described as the shifting of the points of contact of the articulin surface.

2. It differs from a true hinge in that, in passing from a state of extension to one of flexion, the tibia does not revolve round a single transverse axis drawn through the lower end of the femur, as the ulna does round the lower end of the humerus. The articular surface of the tibia slides forward in extension and backward in flexion; thus the axis round which the tibia revolves upon the femur is a shifting one, as is seen by reference to fig. $325, \mathrm{~B}, \mathrm{C}, \mathrm{D}$.

3. Another point of difference is that extension is accompanied by lateral rotation, and flexion by medial rotation. This rotation occurs round a vertical axis drawn through the middle of the lateral condyle of the femur and the lateral condyle of the tibia, and is most marked at the termination of extension and at the commencement of flexion. This rotation of the leg at the knee is a true rotation about a vertical axis, and thus differs from the obliquity of the flexion 
and extension movements at the elbow which is due to the oblique direction of the articular surfaces of the bones.

4. The antero-posterior spiral curve of the femoral condyles is such that the anterior part is an are of a greater circle than the posterior; hence certain ligaments which are tightened during

Fig. 326.-Section of Kinee, shomixg Crucial Liganents in Extension.

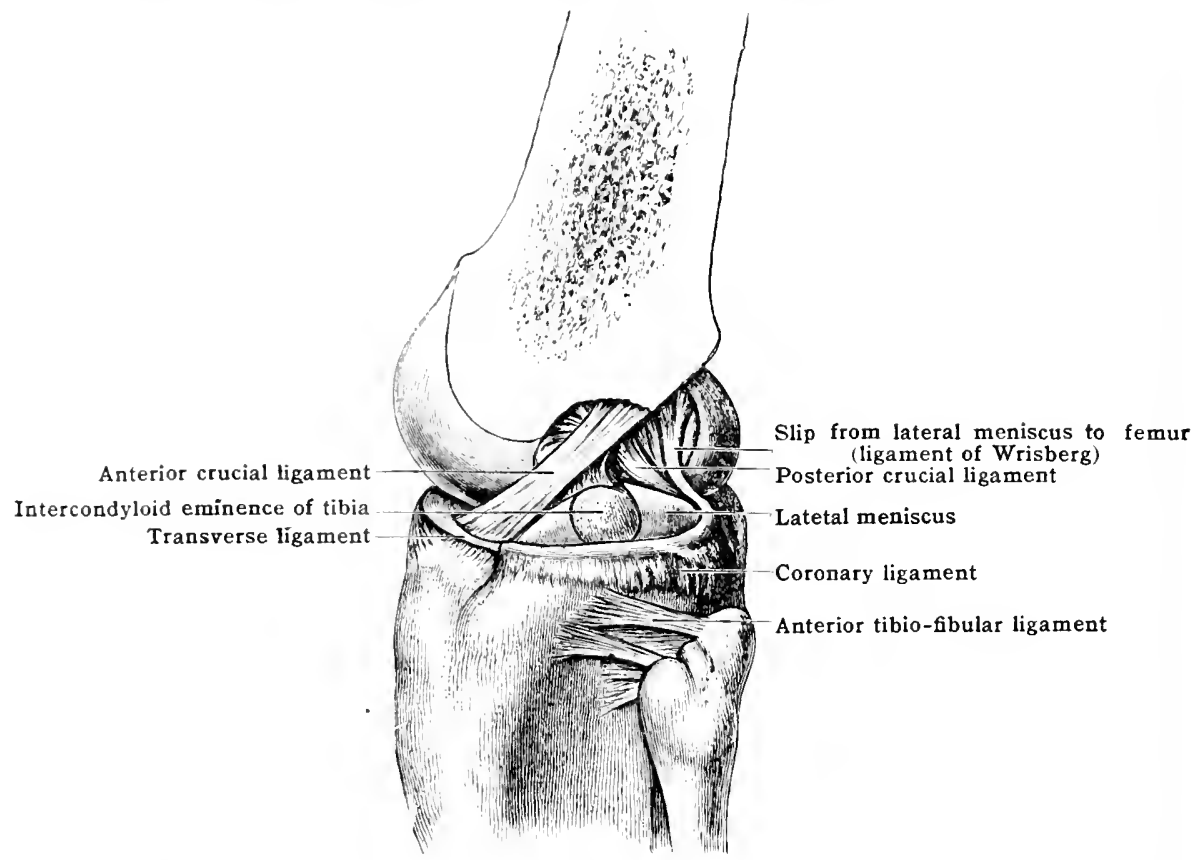

extension are relaxed during flexion, and thereby a considerable amount of rotatory movement is permitted in the flexad position. The axis of this rotation is vertical, and passes through the medial intercondyloid tubercle of the tibia, so that the lateral condyle moves in the are of a larger circle than does the medial, and is therefore required to move more freely and easily;

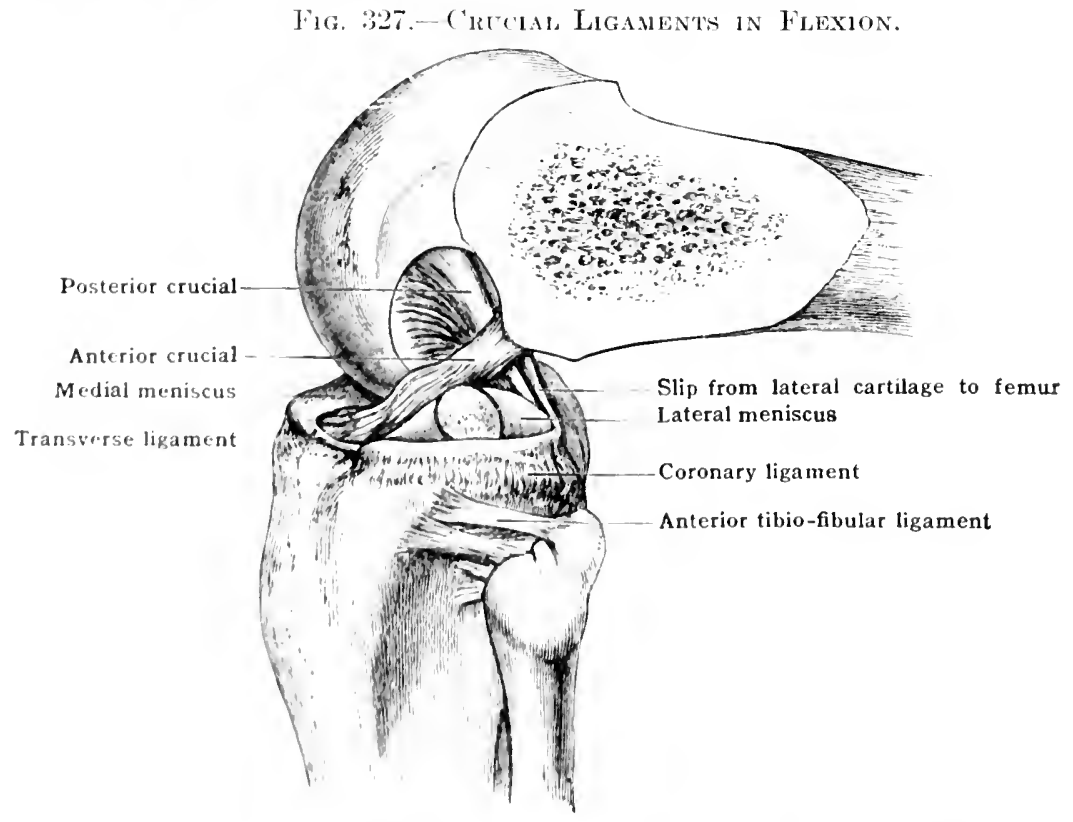

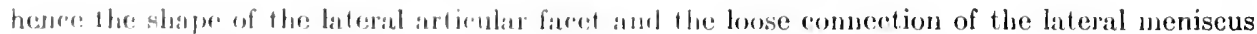
which is ataphen to it.

In extension, all the liginuchts are on the stretch with the exception of the ligamentum

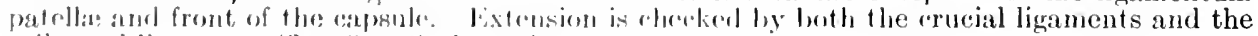

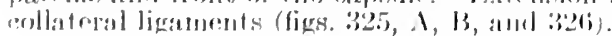


In flexion the ligamentum patella and anterior portion of the capsule are on the stretch; so also is the posterior crucial in extreme flexion, though it is not quite tight in the semiflexed state of the joint. All the other ligaments are relaxed (fig. $325, \mathrm{C}, \mathrm{D}$ ), although the relaxation of the anterior crucial ligament is shight in extreme flexion (fig. 327). Flexion is only checked during life by the contact of the soft parts, i. e., the calf with the back of the thigh.

Rotation medially is checked by the anterior crucial ligament; the collateral ligamenta being loose.

Rotation laterally is checked by the collateral ligaments; the crucial ligaments have no controlling effect on it, as they are untwisted by it.

Sliding movements are checked by the crucial and collateral ligaments-sliding forward especially by the anterior, and sliding backward by the posterior crucial.

Muscles which act upon the knee-joint.-Flexors.-Biceps, semimembranosus, semitendinosus, sartorius, gastrocnemius, plantaris, and popliteus. Extensor.-Quadrices extensor. Medial Rotators.- Sartorius, gracilis, semitendinosus, semimembranosus, popliteus. Lateral Rotator.-Biceps.

\section{THE TIBIO-FIBULAR UNION}

The fibula is connected with the tibia throughout its length by an interosseous membrane, and at the upper and lower extremities by means of two joints. Very little movement is permitted between the two bones.
(a) The superior tibio-fibular joint.
(b) The middle tibio-fibular union.
(c) The inferior tibio-fibular joint.
(a) The Superior Tibio-fibular Joint

\section{Class.-Diarthrosis. Subdivision.-Arthrodia.}

The superior tibio-fibular joint is about $6 \mathrm{~mm}$. ( $\frac{1}{4} \mathrm{in}$.) below, and quite distinct from, the knee at its upper and anterior part; but at its posterior and superior aspect, where the border of the lateral condyle of the tibia is bevelled by the popliteus muscle, the joint is in the closest proximity to the bursa beneath the tendon of that muscle, and is only separated from the knee-joint by a thin septum of areolar tissue. There is often a communication between the synovial cavities of the two joints. The ligaments uniting the bones are:-
Articular capsule.
Anterior tibio-fibular.

\section{Posterior tibio-fibular.}

The articular capsule is a well-marked fibro-arcolar structure; it is attached close round the articular margins of the tibia and fibula. In front it is shut off completely from the knee-joint by the capsule of the knee and the coronary ligament; but behind, it is often very thin, and may communicate with the bursa under the popliteus tendon.

The anterior tibio-fibular (capitular) ligament (fig. 326) consists of a few fibres which pass upward and medially from the fibula to the tibia. It lies beneath the anterior portion of the tendon of the biceps.

The posterior tibio-fibular (capitular) ligament (fig. 317) consists of a few fibres which pass upward and medially between the adjacent bones, from the head of the fibula to the lateral condyle of the tibia.

The superior interosseous ligament consists of a mass of dense yellow fibroareolar tissue, binding the opposed surfaces of the bones together for $2 \mathrm{~cm}$. ( $\frac{3}{4}$ in.) below the articular facets. It is continuous with the interosseous membrane along the tibia.

The biceps tendon is divided by the fibular collateral ligament of the knee; of the two divisions the anterior is by far the stronger, and is inserted into the lateral condyle of the tibia as well as to the front of the head of the fibula, and thus the muscle, acting on both bones, tends to brace them more tightly together; indeed, it holds the bones strongly together after all other connections have been severed.

The synovial membrane which lines the joint sometimes communicates with the knec-joint through the bursa beneath the popliteus tendon.

The arterial supply is from the inferior lateral articular and recurrent tibial arteries.

The nerve-supply is from the inferior lateral articular, and also from the recurrent branch of the common peroneal.

Relations. - In front, the upper ends of the tibialis anterior, the extensor digitorum longus, and the peroneus longus. Behind, the tendon of the popliteus overlapped by the lateral head of the gastrocnemius. Laterally, the biceps tendon and the common peroneal nerve. Below and medially, the anterior tibial vessels.

The movements are but slight, and consist merely of a gliding of the two bones upon each other. The joint is so constructed that the fibula gives some support to the tibia in transmitting 
the weight to the foot. The articular facet of the tibia overhangs, and is received upon the articular facet of the head of the fibula in an oblique plane. This joint allows of slight yielding of the lateral malleolus during flexion and extension of the ankle-joint, the whole fibula gliding slightly upward in flexion, and downward in extension, of the ankle.

\section{(b) The Midule Tibio-fibular Union}

\section{Class.-Synarthrosis. \\ Subdivision.-Syndesmosis.}

The interosseous membrane is attached along the lateral border of the tibia and the interosseous border of the fibula. It is deficient above for about $2.5 \mathrm{~cm}$. ( 1 in.) or more, measured from the under aspect of the superior joint. Its upper border is concave, and over it pass the anterior tibial vesscls.

The membrane consists of a thin aponeurotic and translucent lamina, formed of oblique fine fibres, some of which run from the tibia to the filuula, and some from the fibula to the tibia, but all are inclined downward. They are best marked at their attachment to the bones, and gradually grow denser and thicker as they approach the inferior interosseous ligament. The

Fig. 32S.-Lower Ends of Left Tibia and Fibula, showing the Ligaments. The synovial fold between these bones has been removed to show the transverse ligament forming part of the capsule of the joint, and the deeper fibres of the anterior lateral malleolar ligament which come into contact with the talus.

(From a dissection by Mr. W. Pearson, of the Royal College of Surgeons' Museum.)

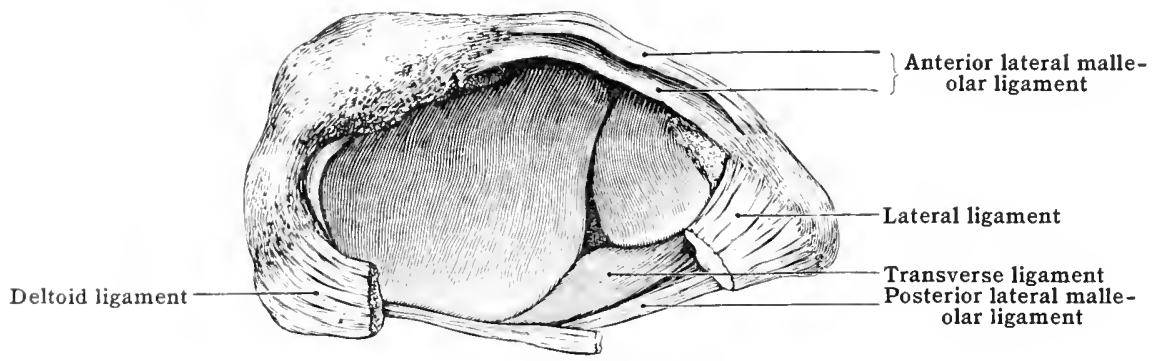

chief use of the membrane is to afford a surface for the origin of muscles. It is continuous below with the inferior interosseous ligament.

In front of the interosseous membrane lie the tibialis anterior, the extensor digitorum longus, the extensor hallucis longus, and the anterior tibial vessels and nerves. Behind it is in relation with the tibialis posterior, the flexor hallucis longus, and the peroneal artery.

\section{(c) 'Tile Inferior Tibio-fibular Articulation}

\section{Class.-Diarthrosis. Subdivision.-Arthrodia.}

This junction is formed by the lower ends of the tibia and fibula. The rough triangular sirface on each of these bones formed by the bifureation of their interosseous lines is closely and firmly united by the inferior interosseous ligament. 'The fibula is in actual contact with the tibia by an articular facet, which is small in siz", erescentic in shape, and continuous with the articular facet of the malleolus.

'The ligaments which unite the bones are:-

1. Anterior lateral malleolar ligament.

2. T'osterior lateral malleolar ligament.

3. 'T'ransverse ligament.

1. Inferion introosseons liganont.

'The: anterior lateral malleolar ligament (anterior inferior tibio-fibular ligaincent) (figs. :328 and :3i.t) is a strong triangular band abont $2 \mathrm{~cm}$. ( $\frac{3}{4} \mathrm{in}$.) wide, and is attached to the lower rextremity of the tibia at its anterior and fateral angle, close to the margin of the faced for the talus and passes clownwart and 
laterally to the anterior border and contiguous surface of the lower end of the fibula, some fibres passing along the edge nearly as far as the origin of the anterior talo-fibular ligament.

The fibres increase in length from above downward. In front it is in relation with the peroneus tertius and deep fascia of the leg, and gives origin to fibres of the anterior ligament of the ankle-joint. Behind, it lies in contact with the interosseous ligament, and comes into contact with the articular surface of the talus (see figs. 328 and 329 ).

The posterior lateral malleolar ligament (figs. 328 and 33t) is very similar to the anterior, extending from the posterior and lateral angle of the lower end of the tibia downward and laterally to the lowest $1.5 \mathrm{~cm}$. ( $\frac{1}{2} \mathrm{in}$.) of the border separating the medial from the posterior surface of the shaft of the fibula, and to the upper part of the posterior border of the lateral malleolus. It is in relation in front with the interosseous ligament; below, it touches the transverse ligament.

The inferior interosseous ligament is a dense mass of short, felt-like fibres, passing transversely between and firmly uniting the opposed rough triangular surfaces at the lower ends of the

Fig. 329.-Right Ankle-Joint, showing the Ligamexts.

(From dissection by Mr. W. Pearson, of the Royal College of Surgeons' Museum.)

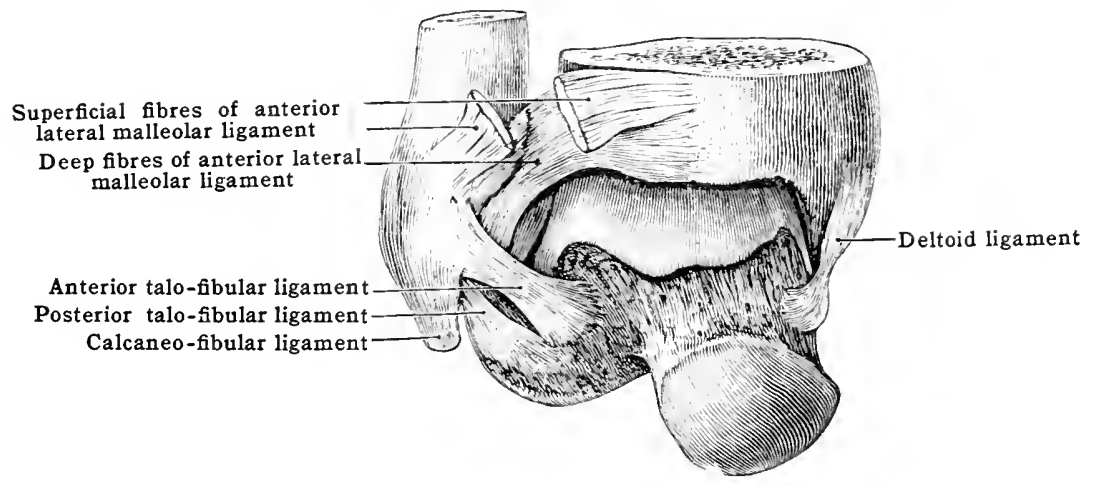

tibia and fibula, except for $1 \mathrm{~cm}$. ( $\frac{3}{8}$ in.) at the extremity, where there is a synorial cavity. It extends from the anterior to the posterior lateral malleolar ligaments, reaching upmard $4 \mathrm{~cm}$. ( $1 \frac{1}{2}$ in.) in front, but only half this height behind.

The transverse ligament (fig. 331) is a strong rounded band, attached to nearly the whole length of the inferior border of the posterior surface of the tibia, just above the articular facet for the talus. It then inclines a little forward and downward, to be attached to the medial surface of the lateral malleolus, just above the fossa, and into the upper part of the fossa itself.

The synovial membrane is continuous with that of the ankle-joint; it projects upward between the bones beyond their articular facets as high as the inferior interosseous ligament.

The nerve-supply is the same as that of the ankle-joint; the arterial supply is from the peroneal and the anterior peroneal, and sometimes from the anterior tibial, or its lateral malleolar branch.

Relations. - In front of the inferior tibio-fibular joint are the anterior peroneal artery and the tendon of the peroneus tertius, and behind it are the posterior peroneal artery and the pad of fat which lies in front of the tendo Achillis.

The movement permitted at this joint is a mere gliding, chiefly in an upward and downward direction, of the fibula on the tibia. The bones are firmly braced together and yet form a slightly yielding arch, thus allowing a slight side to side expansion during extreme flexion, when the broad part of the talus is brought under the arch, by the upward gliding of the fibula on the tibia. To this end the direction of the fibres of the lateral malleolar ligaments is downward from tibia to fibula. This mechanical arrangement secures perfect contact of the articular surfaces of the ankle-joint in all positions of the foot.

\section{THE ANKLE-JOINT}

Class.-Diarthrosis.

Subdivision.-Ginglymus.

The ankle [articulatio talo-cruralis] is a perfect ginglymus or hinge joint. The bones which enter into its formation are: the lower extremity and medial malleolus of the tibia, and the lateral malleolus of the fibula, above; and the upper 
and lateral articular surfaces of the talus (astragalus) below. The ligaments (supplementing the articular capsule) uniting the bones are:-
Anterior.
Posterior.
Deltoid.
Lateral ligament.

The anterior ligament (fig. 334) is a thin, membranous strueture, which completes the eapsule in front of the joint. It is attached above to the anterior border of the medial malleohs, to a crest of bone just above the transverse groove at the lower end of the tibia, to the anterior lateral malleolar ligament, and to the anterior border of the lateral malleolus. Below, it is attached to the rough upper surface of the neck of the talus (astragalus). Medially it is thicker, and is fixed to the talus close to the facet for the medial malleolus, being continuous with the deltoid ligament, and passing forward to blend with the talo-navicular ligament. Laterally it is attached to the talus, just below and in front of the angle between the superior and lateral facets, close to their edges, and joins the anterior talofibular ligament.

It is in relation, in front with the tibialis anterior muscle, the anterior tibial vessels and nerve, the extensor tendons of the toes, and the peroneus tertius; and behind with a mass of fat and synovial membrane.

Fig. 330.-Medial View of the Ankle and the Tarsus, showing the Groove for the Tendon of the Tibialis Posterior.

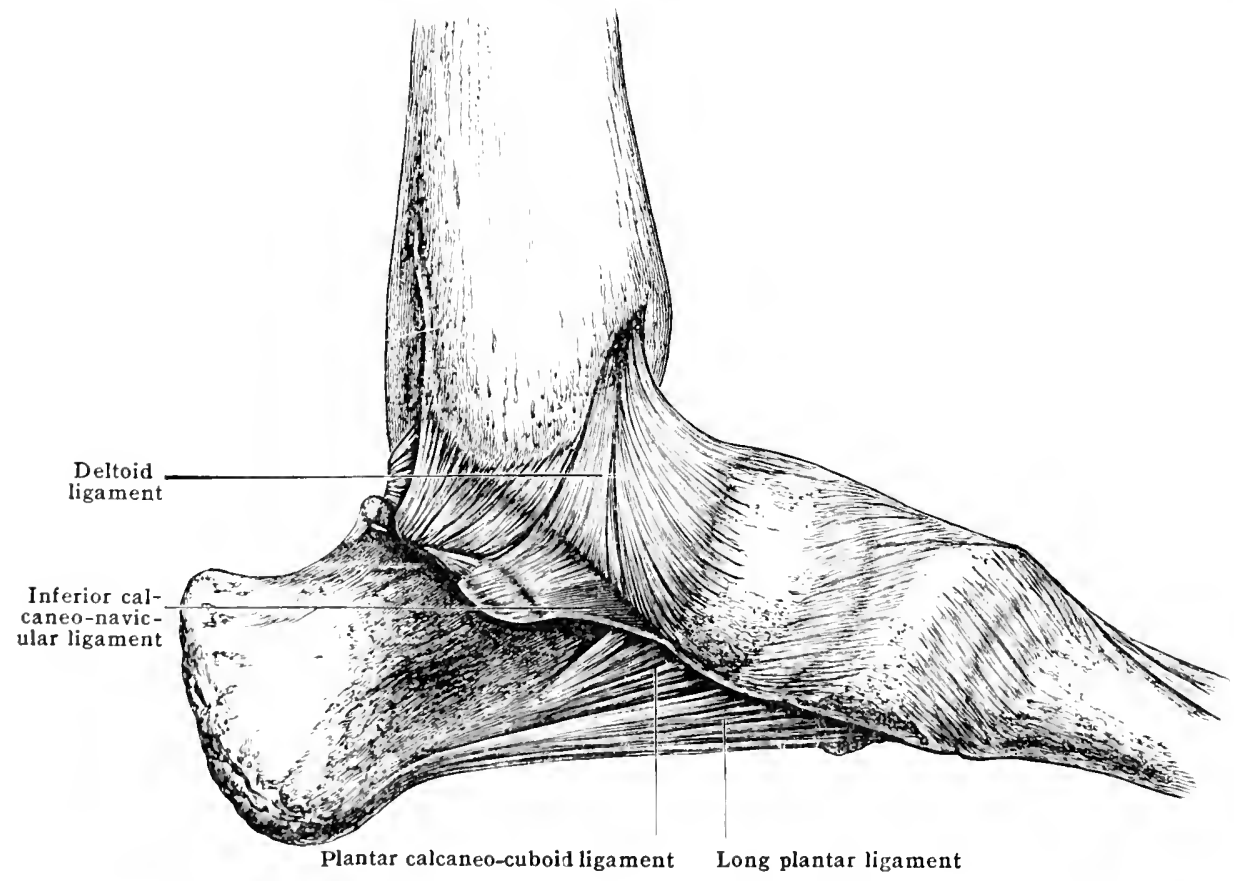

The posterior ligament (fig. 331) is a very thin and disconnected membranous structure, connected alove with the lateral malleolus, medial to the peroneal groove; to the posterior margin of the lower end of the tibia lateral to the groove for the tibialis posterior; and to the posterior lateral malleolar ligament. Below, it is attardued to the posterior surface of the talus from the deltoid to the lateral ligaments. 'The passage of the flexor hallucis longus tendon over the back of the joint sarves the purpose of a mueh stronger posterior ligament.

The deltoid ligament (fig. 330 ) is attached superiorly to the medial malleolus along its lower border, and to its anterior surface sujerficial to the anterior ligament; some very strong fibmes are fixed to the notel in the lower border of the malleolus, and, getting attachment brew to the rough depression on the medial side of the talus, form a deep portion to the ligament. The ligament radiates; the posterior fibres are short, and incline a litte backward to be fixed to the rough merlial surfare of the talus, elose to the superior artienar facet, and into the 
tubercle to the medial side of the flexor hallucis longus groove. The fibres next in front are numerous and form a thick and strong mass, filling up the rough depression on the medial surface of the talus, whilst some pass over the talocalcaneal joint to the upper and medial border of the sustentaeulum tali. The fibres which are connected abore with the anterior surface of the malleolus pass downward and somewhat forward to be attached to the navicular and to the margin of the calcaneo-navicular ligament.

The lateral ligament (figs. 329 and 334) consists of three distinet slips (fasciculi). The anterior talo-fibular ligament (anterior fascieulus), is ribbon-like and passes from the anterior border of the lateral malleolus near the tip to the rough surface of the talus in front of the lateral facet, and overhanging the sinus pedis. The calcaneo-fibular ligament (micldle fasciculus), is a strong roundish bundle, which extends downward and somewhat backward from the anterior border of the lateral malleolus close to the attachment of the anterior fascieulus, and from the lateral surface of the malleolus, just in front of the apex, to a tubercle on the middle of the lateral surface of the calcaneum. The posterior talo-

Fig. 331.--Ligaments seen fron the Back of the Ankle-joint.

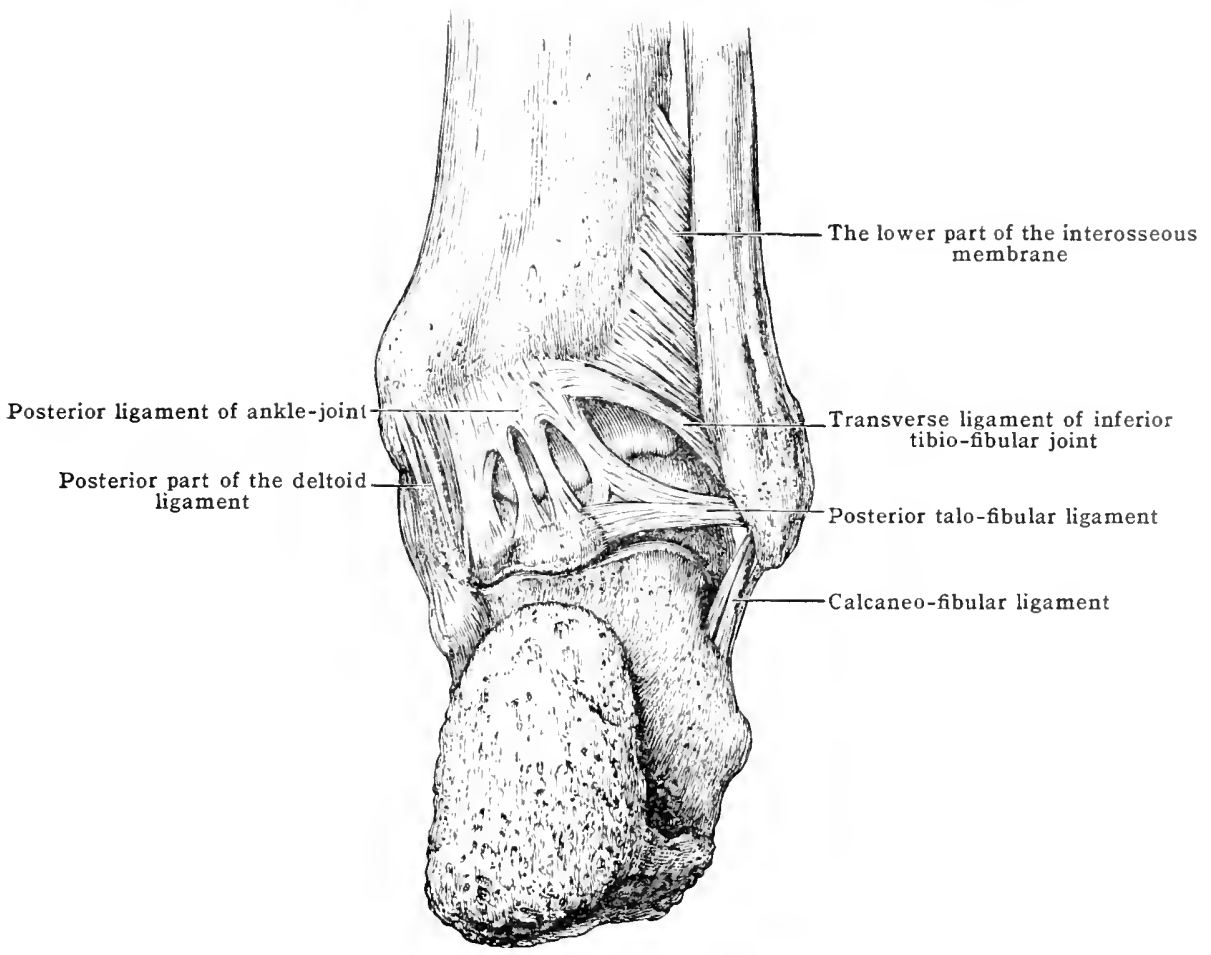

fibular ligament (posterior faseieulus), is almost horizontal; it is a strong, thick band attached at one end to the posterior border of the malleolus, and slightly to the fossa on the medial surface; and at the other end to the talus, behind the articular facet for the fibula, as well as to a tuberele on the lateral side of the groove for the flexor hallucis longus.

The middle fasciculus is covered by the tendons of the perone $i$ longus and brevis; and in extension, the posterior fasciculus is received into the pit on the medial surface of the lateral malleolus.

The synovial membrane is very extensive. Besides lining the ligaments of the ankle, it extends upward between the tibia and fibula, forming a short culde-sac as far as the interosseous ligament. Upon the anterior and posterior ligaments it is very loose, and extends beyond the limits of the articulation. It is said to contain more synovia than any other joint.

The nerve-supply is from the saphenous, posterior tibial, and the lateral division of the anterior tibial. 
The arterial supply comes from the anterior tibial, the anterior peroneal, the lateral malleolar, the posterior tibial, and posterior peroneal.

Relations.- In front and in contact with the anterior ligament, from medial to lateral aspects, are the tendons of the tibialis anterior, the tendon of the extensor hallucis longus, the anterior tibial vessels, the anterior tibial nerve, the tendons of the extensor digitorum longus, and the tendon of the peroneus tertius. To the medial side of the tibialis anterior and to the lateral side of the peroneus tertius the joint is subcutaneous anteriorly. Behind and laterally are the tendons of the peroneus longus and brevis. Behind and medially, from medial to lateral side, are the tendon of the tibialis posterior, the tendon of the flexor digitorum longus, the posterior tibial vessels, the posterior tibial nerve, and the tendon of the flexor hallucis longus. Directly behind is a pad of fat which intervenes between the tendo Achillis and the joint. Below and on the lateral side, crossing the middle fasciculus of the lateral ligament, are the tendons of the peroneus longus and brevis. Below and on the medial side, erossing the deltoid ligament, are the tendons of the tibialis posterior and the flexor digitorum longus.

Movements.- This being a true hinge joint, flexion and extension are the only movements of which it is capable, there being no side to side motion, except in extreme extension, when the narrowest part of the talus is thrust forward into the widest part of the tibio-fibular arch.

Fig. 332.-The Lower Extremity of the Tibia (Anterior view), to Show the Relation of the Articular Capsule of the Ankle-Jornt (in red) to the Epiphysial Line.

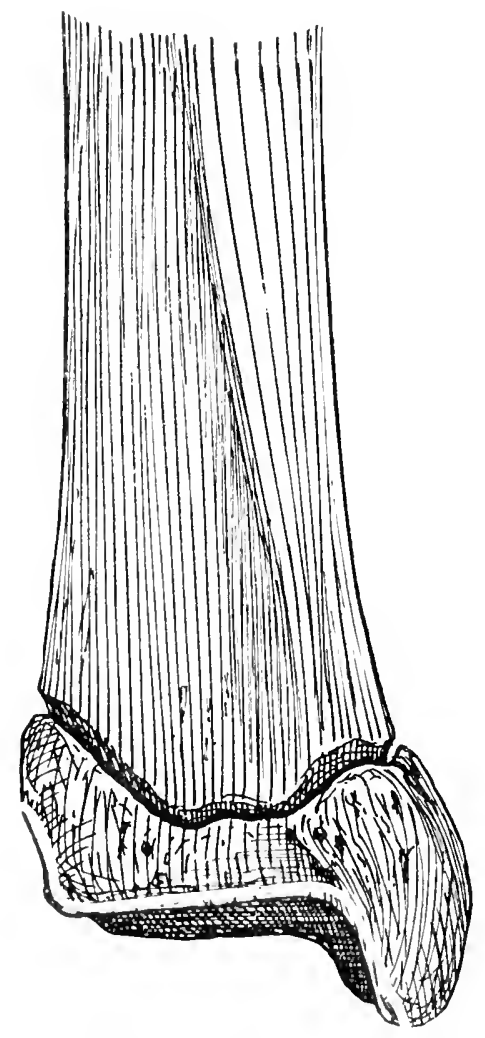

In flexion the talus is tightly embraced by the malleoli, and side to side movenent is impossible. Ilexion of the ankle-joint is limited by:- (i) nearly the whole of the filores of the deltoid ligament, none but the most anterios being relaxed; (ii) the posterior and middle portions of the lateral ligament, especially the posterior; (iii) the posterior liganent of the ankle. It is also limited by the neck of the talus ahutting on the elge of the tibia.

In most Enpopean ankle-joints the anterior edige of the lower end of the tibia is kept from actual montact with the nerk of the lalus in positions of extrene flexion by the intervention of a pad of fat situater bencath the anterior extension of the anterior liganent. In races which aldopt a spuatting posture, however, an actual articulation ma be developed between these two bony surfaces, a facef being present both npon the anterior margin of the tibia and upon the neck of the talus. These farchs are known as "squating facets" (fig. $333, \Lambda$ ) and are of common ocenrrence in ancient bones and in the hones of modern oriental people.

lixtension of the ankle-jont is limited hy:- (i) the anterior fibres of the deltoid ligament; (ii) the anterior and mirlelle portions of the lateral liganent; (iii) the medial and stronger fibres of the anterior liganent. It is also limited hy the posterior portion of the falus meeting with the tibia. Thus the mirlde portion of the lateral liganent is always on the streteh, owing to its obliguely hackward direction, whorely it limits flexiom; and its attachment to the fibula in front of the malteolar apex, wherehy it prevents over-extension as soon as the foot begins to twist 
medialward. This medial twisting, or alduction of the foot, is partly due to the greater posterior length of the medial border of the superior articular surface of the talus, and to the less proportionate height posteriorly of the lateral borcler of that surface, but chiefly to the side to side movement in the talo-calcaneal joints. Flexion and extension take place round a transverse axis drawn through the body of the talus. The movement is not in a direct antero-posterior plane, but on a plane inclined forward and laterally from the middle of the astragalus to the intermetatarsal joint of the second and third toes.

Muscles which act on the ankle-joint.-Flexors.-Tibialis anterior, extensol hallucis longus, extensor digitorum longus, peroneus tertius. Extensors.-CTibialis posterior, flexor digitorum longus, flexor hallucis longus, peroneus longus, peroneus brevis, soleus, gastrocnemius, plantaris.

Fig. 333.-Anterior Aspect of the Lower Extremity of tile Tibia.

In $A$, the articular surface is prolonged upward in front, forming a "squatting facet" which articulates with a corresponding iacet on the neck of the talus. In $B$ (the usual condition) the articular surface is confined to the lower aspect of the bone.
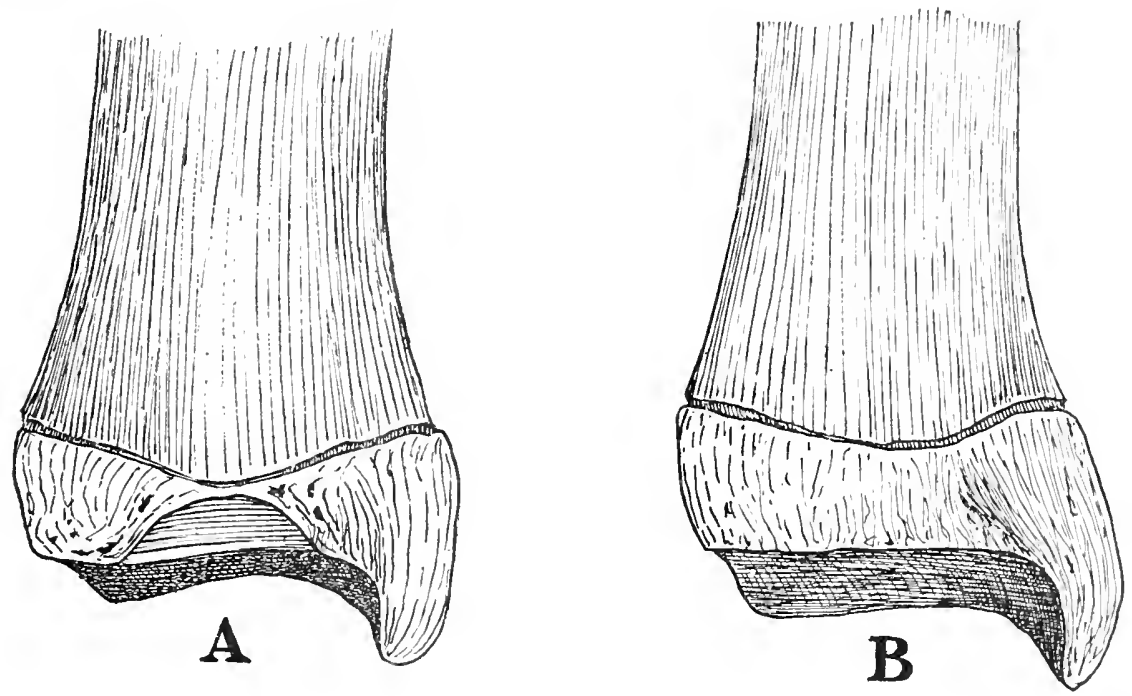

5. THE TARSAL JOINTS

These may be divided into the following sub-groups:-

(a) The talo-calcaneal union.

(b) The articulations of the anterior portion of the tarsus.

(c) The medio-tarsal joint.

\section{(a) The Talo-calcaneal Union}

There are two joints which enter into this union-viz., an anterior and a posterior.

\section{(i) The Posterior Talo-calcancal Joint}

\section{Class.-Diarthrosis.}

Subdivision.--Arthrodia.

The calcaneus articulates with the talus by two joints, the anterior and posterior: the former communicates with the medio-tarsal; the posterior is separate and complete in itself. At the latter joint the two bones are united by an articular capsule with the following ligaments:-

Interosseous.

Posterior talo-calcaneal.
Lateral talo-calcaneal.

Medial talo-calcancal.

The interosseous ligament (figs. 334 and 335) is a strong band connecting the apposed surfaces of the calcaneus and talus along their oblique grooves. It is composed of several vertical laminæ of fibres, with some fatty tissue in between. 
It is better marked, leeper, and broader laterally. Strong laminæ extend from the rough inferior and lateral surfaces of the neck of the tahus to the rough superior surface of the ealcaneus anteriorly, forming the posterior boundary of the anterior talo-calcaneal joint; these have been described as the anterior (interosseous) ligament. The posterior laminæ extend from the roof of the sinus pedis to the calcaneus immediately in front of the lateral facet, thus forming the anterior part of the capsule of the posterior joint.

The lateral talo-calcaneal ligament (fig. 33t) extends from the groove just below and in front of the lateral articular facet of the talus, to the calcaneus some little distance from the articular margin. Its fibres are nearly parallel with those of the calcaneo-fibular ligament of the ankle, which passes over it and adds to its strength. It fills up the interval between the calcaneofibular and anterior talo-fibular ligaments, a considerable bundle of its fibres blending with the anterior border of the calcaneo-fibular.

The posterior talo-calcaneal ligament passes from the lateral tubercle of the talus and lower edge of the groove for the flexor hallucis longus to the calcaneus, a variable distance from the articular margin.

The medial talo-calcaneal ligament includes two portions. The first is a narrow band of well-marked fibres passing obliquely downward and forward from the medial tubercle oi the talus, just behind the medial end of the sinus tarsi, to the calcaneus behind the sustentaculum tali, thus completing the floor of the groove for the flexor hallucis longus tendon. The second portion, which is often considered a separate ligament, is described below with the anterior talo-calcaneal joint.

The synovial sac is distinct from any other.

The nerve-supply is from the posterior tibial or one of its plantar branches.

The arteries are, a branch from the posterior tibial, which enters at the medial end of the sinus pedis; and trigs from the tarsal, lateral malleolar, and the peroneal, which enter at the lateral end of the sinus.

(ii) The Anterior Talo-calcaneal Joint
Class.-Diarthrosis.
Subdivision.-Arthrodia.

This joint is formed by the anterior facet on the upper surface of the calcaneus and the facets on the lower surface of the neck and head of the talus; it is bounded on the sides and behind by ligaments, and communicates anteriorly with the talo-navicular joint. The ligaments are:-

\section{Interosseous. \\ Medial talo-calcaneal. Lateral calcaneo-navicular.}

The interosseous ligament by its anterior laminæ limits this joint posteriorly. It has been already described.

The medial talo-calcaneal ligament (second portion; see above) consists of short fibres attached above to the medial surface of the neck of the talus, and below to the upper edge of the free border of the sustentaculum tali, blending posteriorly with the medial extremityof the interosseous ligament, and anteriorly with the upper border of the plantar calcaneo-navicular ligament. It is strengthened by the deltoid ligament, the anterior fibres of which are also attached to the plantar calcanco-navicular ligament.

The lateral calcaneo-navicular (figs. 334 and 335) limits this, as well as the talo-navicular joint. on the litteral side. It is a strong, well-marked band, cxtending from the rough upper surface of the calcaneus, lateral to the anterior facet, to a slight groove on the lateral surface of the mavioular near the posterior nargin. It blends below with the plantar ealcaneo-navicular, :1m] alove with the talo-navicular ligament. Its fibres run obliquely forward and medially. The: heloidl ligament and middle fasciculus of the lateral ligament of the ankle-joint also add to the security of these two joints, and assist in limiting movements between the bones by passing over the tialus to the caleanens.

The synovial membrane is the same as that of the talo-navicular joint. The arteries and nerves are dorived from the same sources as those of the medio-tarsal joints.

'The: movements of which these two joints are (apable are adduction and abduction, with sonc anount of rotation. Arlunction, or inclination of the sole medialward, is combined with some merlial rotition of the toes, and some lateral rotation of the heel; while albluction, or inclimation of the foot latralwarl, is associated with turning of the toes laterally and the heel medially. 'I'hus the varicty and the range of novenents of the foot on the leg, which at the ankle

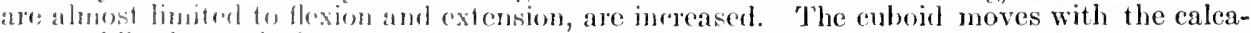
neus, while: the navienlar revolves on the head of the talus.

In walking, the lienl is lirst placed on the ground; the foot is slightly adelueted; but as the horly swings forwarl, firs the latral then the medial toes touch the groumb, the talus presses against the navoular anul sinks ugun the plantar (aldoneo-navioular ligament; the foot then lecomes slightly abelurtorl. When the font is firmly placed on the ground, the weight is trans-

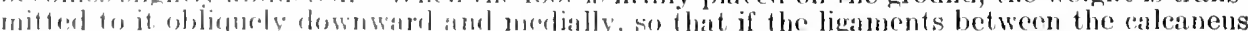

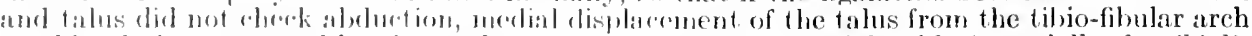

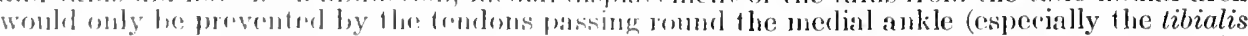

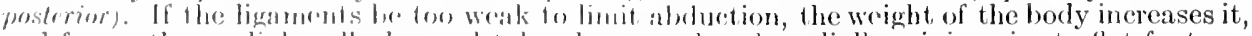
and forees the medial malloohs and talus downward and noclially, giving rise to flat foot.

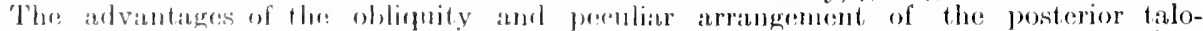
ralesucal articulation are secon in walking:---(i) for the posterior facet of the caleaneus receives 
the whole weight of the body when the lieel is first placed on the ground; (ii) by the upward pressure of this facet against the talus it transfers the weight to the ball of the toes as the heel is raised, the posterior edge of the sustentaculum tali and the anterior and lateral part of the upper surface of the calcaneus preventing the talus from being displaced too far forward by the superincumbent weight; and (iii) the calcaneus serves to suspend the talus when, with the heel raised by muscular action, the other foot is being swung forward.

Fig. 334.-Lateral View of the Ligaments of the Foot and Ankle.

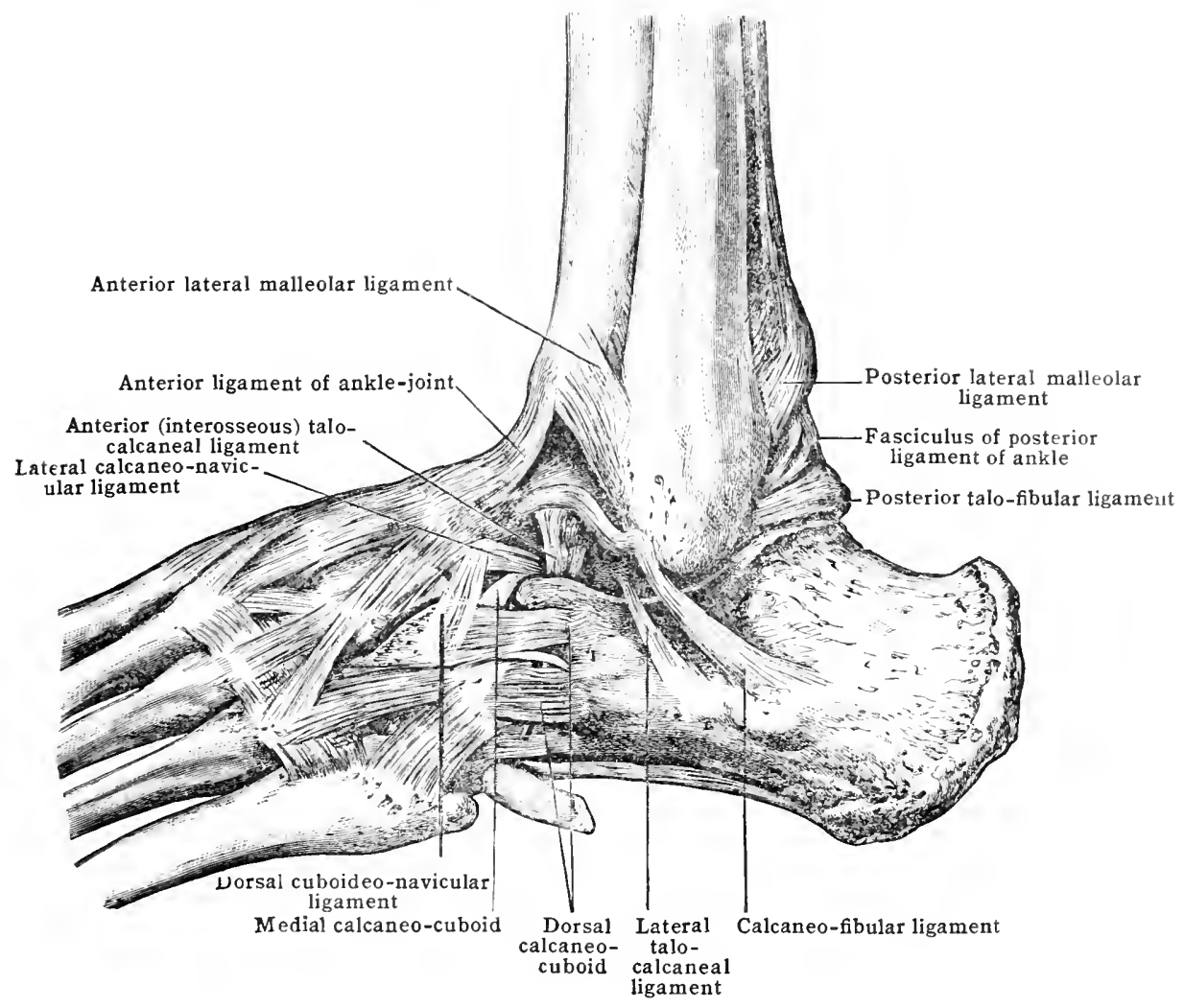

(b) The Articulations of the Anterior Part of the Tarsus

These include (i) the cuboideo-navicular; (ii) cuneo-navicular; (iii) intercuneiform; and (iv) cuneo-cuboid joints.

\title{
(i) The Cuboideo-navicular Union
}

\author{
Class.-Diarthrosis. \\ Subdivision.-Arthrodia.
}

The joint cavity is only occasionally present and this joint is often included in the transverse tarsal.

The ligaments which unite the cuboid and navicular are:-
Dorsal.
Plantar.
Interosseous.

The dorsal cuboideo-navicular ligament (fig. 334) runs forwarl anil laterally from the lateral end of the dorsal surface of the lavicular to the middle third of the medial border of the cuboid on its dorsal aspect, passing over the posterior lateral angle of the third cuneiform bone. It is wider laterally.

The plantar cuboideo-navicular ligament is a well-marked strong banil, which runs forward and laterally, from the plantar surface of the navicular to the depression on the medial surface of the cuboid, and slightly into the plantar surface just below it.

The interosseous cuboideo-navicular ligament is a strong band which passes between the apposed surfaces of these bones from the dorsal to the plantar ligaments. Some of its postcrior fibres reach the plantar surface of the foot behind the cuboirleo-navicular ligament, and raliate laterally and backward over the medial border of the cuboid to blend with the anterior extremity of the plantar calcaneo-cuboid ligament. 


\section{(ii) The Cuneo-navicular Articulation}

Class.-Diarthrosis.

Subdivision.-Arthrodia.

The ligaments uniting the navicular with the three cuneiform bones are:-

Dorsal.

Plantar.

\section{Medial.}

The dorsal cuneo-navicular ligament is very strong, and stretehes as a continuous strueture on the dorsal surface of the navicular, between the tubercle of the navicular on the medial side, and the dorsal cubodeo-navicular ligament laterally, passing forward and a little laterally to the dorsal surfaces of the three cunciform bones.

The medial cuneo-navicular ligament is a very strong thick band which connects the tubercle of the navicular with the medial surface of the first cuneiform bone. It is continuous with the dorsal and plantar ligaments. Its lower border touches the tendon of the tibialis posterior.

The plantar cuneo-navicular ligament forms, like the lorsal, a continuous structure extending between the lantar surfaces of the bones. Its fibres pass forward and laterally. It is in relation below with the tendon of the tibialis posterior.

It must be noticel that the expanded tendon of insertion of the tibialis posterior, and the ligaments uniting the navicular with the euboid and euneiform bones, pass forward and laterally, while the peroneus longus tendon and the ligaments uniting the first and second rows of bones, except the medial hatf of the dorsal talo-navieular ligaments, pass forward and medially. This arrangement is admirably adapted to preserve the arches of the foot, and especially the transverse arch. Had these tendons and ligaments run directly forward, all the strain on the transverse arch would have fallen on the interosseous ligaments, but as it is, the areh is braced up by the above-mentionel structures.

\section{(iii) The Intercuneiform and (iv) The Cuneo-cuboid Articulations}

Class.-Diarthrosis.

Subdivision-Arthrodia.

The uniting ligaments of these bones are divided into three sets:-

Dorsal.

Plantar.

\section{Interosseous.}

The dorsal ligaments are three in number, two, the dorsal intercuneiform, connecting the three "uneiform bones, and a third, the dorsal cuneo-cuboid, miting the third cuneiform with the cuboill. They pass between the contiguous margins of the bones, and are blended behind with the dorsal ligaments of the cuboideo-navieular and cuneo-navieular joints.

The plantar ligaments are two in number: a very strong one, the plantar intercuneiform, basses laterally and forward from the lateral side of the base of the first euneiform to the apex of the secoml cumeiform, winding somewhat to its lateral side. The second, the plantar cuneocuboid, connerts the apex of the thind cuneiform with the anterior half of the medial surface of the cubujel along its plantar border, joining with the plantar cuboideo-navieular ligament lechind.

The interosseous ligaments are three in number. They are strong and deep masses of ligunertoms tissue whicll connect the second cuneiform with the first and third cuneiform bones, and the third cunciform with the cuboid; oecupying all the non-artienlar portions of the apposed surfaces of the lones. The ligaments extend the whole vertical depth between the second euneiform and the third, and the thirl cuneiform and the enboid, and blend with the dorsal and Hantar ligaments; thry are situated in front of the artieular facets, and completely shut off

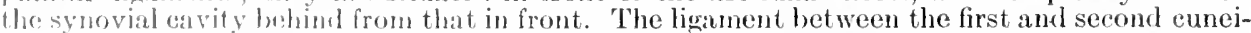
form bones ocenpies the infrerior and anterior two-thirets of the apposed surfaces, and does not

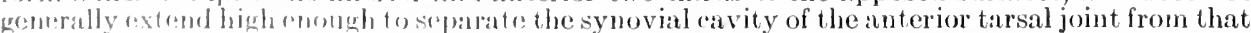
of the soromel and thirel motatistal and coneiform bones. If it does extend to the dorsal surfare, if diviles the fircots complofoly from one another, making a seventh synovial sae in the fort.

'l'he: synovial cavity will be descrilued later on.

The arterial supply is from lihe motatarsal amol plantar arteries.

'The nerves are lorivol from the deop peroneal and merlial and lateral plantar.

The movement permitful in lluse joints is very limited, and exists only for the purpose of adrling to the gentral plianey and ristieity of the tarsus without allowing any sensible alloratiun in thr: position of the lifferent parts of the foot, as the medio-tarsal and talo-ealrancal joints do. It is simply a gliding motion, and either decpens or widens the transverse

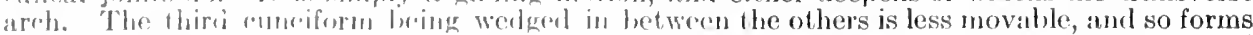

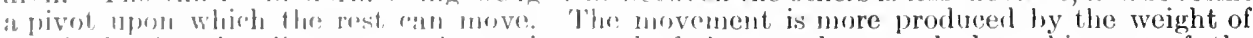

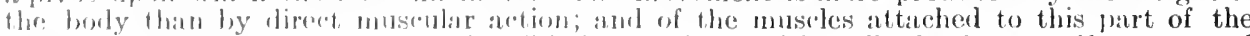

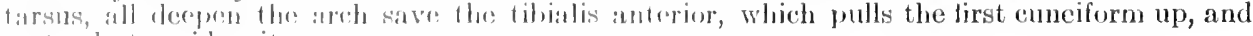
sor tencle to wirlen it. 


\section{(c) The Transverse Tarsal Joints}

The articulations of the anterior and posterior portions of the tarsus, although in the same transverse line, consist of two separate joints, viz., (i) a medial, the talo-navicular, which communicates with the anterior talo-calcaneal articulation; and (ii) a lateral, the calcaneo-cuboid, which is complete in itself. The morements of the anterior upon the posterior portions of the foot take place at these joints simultaneously. It will be most convenient to deal with the joints separately as regards the ligaments; while the arteries, nerves, and movements will be considered together.

\section{(i) The Talo-navicular Articulation}

Class.-Diarthrosis.

Subdivision.-Enarthrodia.

This is the only ball-and-socket joint in the tarsus. It communicates with the anterior talo-calcaneal articulation, and two of the ligaments which close it in do not touch the talus, but pass from the calcaneus to the navicular. The uniting ligaments include, in addition to the articular capsule, the following:-

Lateral calcaneo-navicular.

Plantar calcaneo-navicular

Talo-naricular.

The lateral calcaneo-navicular has been already described (p. 302).

The plantar calcaneo-navicular ligament (figs. 335 and 336 ) is an exceedingly dense, thick plate of fibro-elastic tissue. It extends from the sustentaculum tali and the under surface of the calcaneus in front of a ridge curving laterally to the anterior tubercle of that bone, to the

Fig. 335.-View of the Foot from above, with the Talus renoved to show the Plantar and Lateral Calcaneo-naycular Liganents

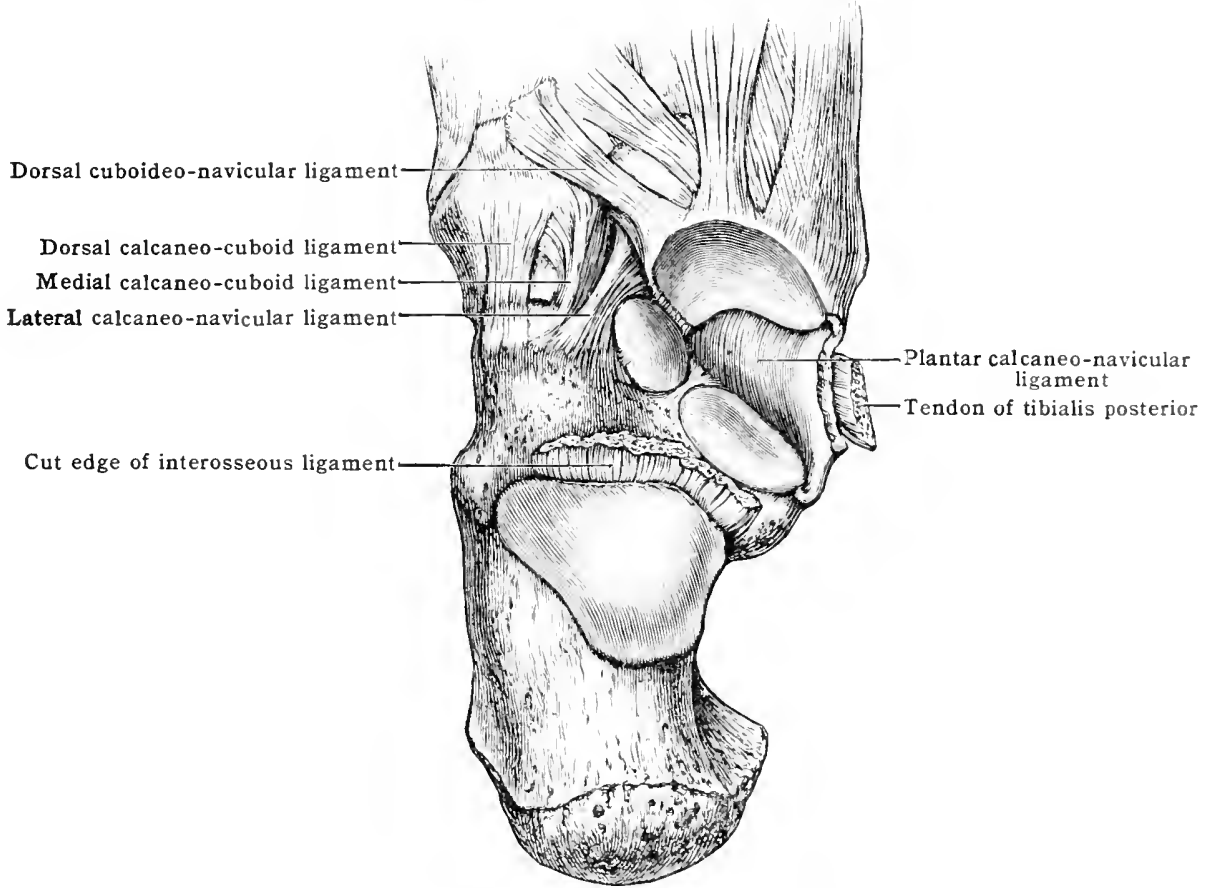

whole width of the inferior surface of the navicular, and also to the medial surface of the navicular behind the tubercle. Medially it is blended with the anterior portion of the deltoid ligament of the ankle, and laterally with the lower border of the lateral calcaneo-navicular ligament. It is thickest along the medial border. Its upper surface loses the well-marked fibrous appearance which the ligament has in the sole, and becomes smooth and faceted. In contact with the under surface of the ligament the tendon of the tibialis posterior passes, giring considerable support to the head of the talus by assisting the power and protecting the spring of the ligament. The fibres of the ligament run forward and medially. On account of its elasticity it is sometimes termed the spring ligament. 
The talo-navicular ligament is a broad, thin, but well-marked layer of fibres which passes from the dorsal and lateral surfaces of the neck of the talus to the whole length of the dorsal surface of the navicular. Many of the fibres converge to their insertion on the navicular. The fibres low down on the lateral side blend a little way from their origin with the upper edge of the lateral calcaneo-navicular ligament, and then pass forward and medially to the navicular; those next above pass obliquely and with a distinct twist over the upper and lateral side of the head of the talus to the centre of the dorsum of the navicular, overlapping fibres from the medial side of the talus as well as some from the anterior ligament of the ankle-joint.

Synovial membrane.-The talo-navicular is lined by the same synovial membrane as the anterior talo-calcaneal joint.

\section{(ii) The Calcaneo-cuboid Articulation}

\section{Class.-Diarthrosis. \\ Subdivision.-Saddle-shaped Arthrodia.}

The ligaments which are supplementary to the articular capsule and unite the bones forming the outer part of the medio-tarsal joint are:-
Medial calcaneo-cuboid.
Dorsal calcaneo-cuboid.
Long plantar.
Plantar calcaneo-cuboid.

The medial calcaneo-cuboid ligament (fig. 335) is a strong band of fibres attached to the calcaneus a long the medial part of the non-articular ridge above the articular facet for the cuboid, and also to the upper part of the medial surface close to the articular margin, and passes forward to be at tached to the depression on the medial surface of the cuboid, and also to the rough angle

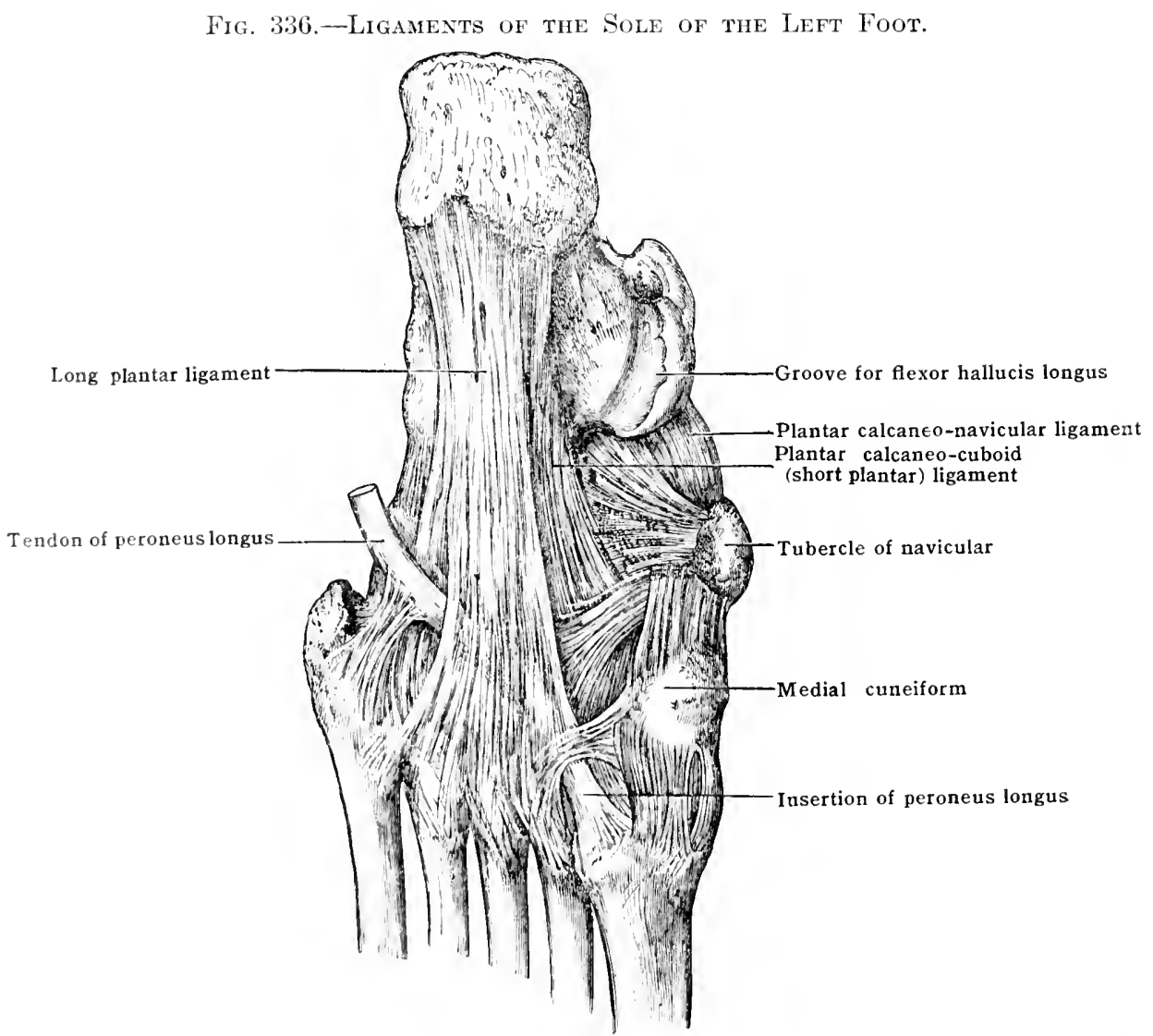

betwen the medial aurl inforior surfaces. At the calcaneus this ligament is closely connected

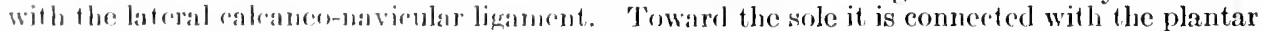
ealeanco-ruboirl ligament, and superiorly with the dorsal calcaneo-culoid.

The dorsal calcaneo-cuboid (fig. 3.35$)$ is attachel to the dorsal surfares of the two bones, extemling low down laterally to blend with the lateral part of the plantar calcaneo-cuboid ligament. Over the meelial hialf, or more, the liganent stretches some distance beyond the margins of the articular surfares, realing well forward upon the cuboid to be attached about indway letween its anterior and posterior lowelers; hut toward the lateral side, the ligament

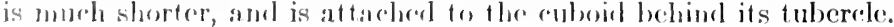


The long plantar ligament (fig. 336) is a strong, dense band of fibres which is attacherl posteriorly to the whole of the inferior surface of the calcaneus between the posterior tubercles and the rounded eminence (the anterior tubercle) at the anterior end of the bone. Most of its fibres pass directly forward, and are fixed to the lateral two-thirds or more of the oblique ridge behind the peroneal groove on the cuboid, while some pass further forward and medially, expanding into a broad layer, and are inserted into the bases of the second, third, fourth, and medial half of the fifth metatarsal bones. This anterior expanded portion completes the canal for the peroneus longus tendon, and from its under surface arise the obliquc adductor hallucis and the flexor quinti digiti brevis muscles.

The plantar calcaneo-cuboid (short plantar) (fig. 336) is attached to the rouncled eminence (anterior tubercle) at the anterior end of the under surface of the calcaneus, and to the bone in front of it, and then takes an oblique course forward and medially, and is attached to the whole of the depressed inferior surface of the cuboid behind the oblique ridge, except its lateral angle. It is strongest near its lateral edge, and is formed by dense strong fibres.

The synovial membrane is distinct from that of any other tarsal joint.

The arterial supply of the medio-tarsal joints is from the anterior tibial, from the tarsal and metatarsal branches of the dorsalis pedis, and from the plantar arteries.

The nerve-supply of the medio-tarsal joints is from the lateral division of the deep peroneal, and occasionally from the superficial peroneal or lateral plantar.

Relations. - On the dorsal aspect of the mid-tarsal joint lie the tendons of the tilialis anterior, extensor hallucis longus, extensor digitorum longus, and peroneus tertius, the muscular part of the extensor digitorum brevis, the dorsalis pedis artery, and the anterior tibial nerve. On its plantar aspct are the tendons of the flexor digitorum longus and hallucis longus, quadratus plantæ (accessorius), and the medial and lateral plantar vessels and nerves. It is crossed laterally by the tendons of the peroneus longus and brevis and medially by the tendon of the tibialis posterior.

The movements which take place at the medio-tarsal joints are mainly flexion and extension, with superadded side-to-side and rotatory movements. Flexion at these joints is simultaneous with extension of the ankle. and vice versa. Flexion and extension do not take place upon a transverse, but round an oblique, axis which passes from the medial to the lateral side, and somewhat backward and downward through the talus and calcaneus.

Combined with flexion and extension is also some rotatory motion round an antero-posterior axis which turns the medial or lateral border of the foot upward. There is also a fair amount of side-to-side motion whereby the foot can be inclined medially (i. e., adducted) or laterally (i. e., abducted).

These movements of the medio-tarsal joint occur in conjunction with those of the ankle and talo-calcaneal joints. Rotation at the talo-calcaneal joint is, however, round a vertical axis in a horizontal plane, and so turns the toes medially or laterally; whereas at the mediotarsal union the axis is antero-posterior and the medial or lateral edge of the foot is turned upward. Gliding at the talo-calcaneal joint elevates or depresses the edge of the foot, while at the medio-tarsal it adducts or abducts the toes without altering the relative position of the calcaneus to the talus.

Thus flexion at the medio-tarsal joint is associated with adduction and medial rotation of the foot, occurring simultaneously with extension of the ankle; and extension at the mediotarsal joint is associated with abduction and lateral rotation, occurring simultaneously with flexion of the ankle.

Flexion and medial rotation are far more free than extension and lateral rotation, which latter movements are arrested by the ligaments of the sole as soon as the foot is brought into the position in which it rests on the ground.

Although the talo-navicular is a ball-and-socket joint, yet, owing to the union of the navicular with the cuboid, its morements are limited by the shape of the calcaneo-cuboid joint; this latter being concavo-convex from above downward, prevents rotation round a vertical axis, and also any side-to-side motion except in a direction obliquely downward and medially, and upward and laterally. This is also the direction of freest movement at the talo-navicular joint. Iorement is also limited by the ligamentous union of the calcaneus with the navicular. The twisting movement of the foot, such as turning it upon its medial or lateral edge, and the increase or diminution of the arch, take place at the tarsal joints, especially the medio-tarsal and talocalcaneal articulations. Here too those changes occur which, owing to paralysis of some muscles or contraction of others, result in talipes equino-varus, or valgus.

Muscles which act on the mid-tarsal joint. - Medial rotators.- Tibialis anterior and posterior acting simultaneously; they are aided by the flexor digitorum longus and flexor hallucis longus. Lateral rotators.-The peronei longus, brevis, and tertius, acting simultaneously. They are aided by the extensor digitorum longus.

\section{THE TARSO-METATARSAL ARTICLLATIONS}

There may be said to be three articulations between the tarsus and metatarsus, viz.:-

(a) The medial, between the first cuneiform and first netatarsal bones.

(b) The intermediate, between the three cuneiform and second and third metatarsal bones.

(c) The lateral, or cubo-metatarsal, between the cuboid and fourth and fifth metatarsal bones. 


\section{(a) The Medial Tarso-metatarsal Joint}

\section{Class.-Diarthrosis. Subdivision.-Arthrodia.}

A complete articular capsule unites the first metatarsal with the first cuneiform, the fibres of which are very thick on the inferior and medial aspects; those on the lateral side pass from behind forward in the interval between the interosseous ligaments which connect the two bones forming this joint with the second metatarsal. The ligament on the plantar aspect is by far the strongest, and blends at the cuneiform bone with the cuneo-navicular ligament.

\section{(b) The Intermediate Tarso-hetatarsal Jolnt}

\section{Class.-Diarthrosis. Subdivision.-Arthrodia.}

Into this union there enter the three cuneiform and second and third metatarsal bones, which are bound together by the following ligaments (supplementary to the articular capsule): dorsal, plantar, interosseous.

The dorsal ligaments. - 1 . Some short fibres cross obliquely from the lateral edge of the first cuneiform bone to the medial border of the base of the second metatarsal bone; they take the place of a dorsal metatarsal ligament, which is wanting between the first and second metatarsal bones.

2. Between the second cuneiform and the base of the second metatarsal bone some fibres run directly forward.

3. The third cuneiform is connected with (1) the lateral corner of the second metatarsal bone by a narrow band passing obliquely medially; (2) with the third metatarsal by fibres passing directly forward; and (3) with the fourth metatarsal by a short band passing obliquely laterally to the medial edlge of its base.

The plantar ligaments. - A strong ligament unites the first cuneiform and the bases of the second and third metatarsal bones. The tibialis posterior is inserted into these bones close beside it. Other slender ligaments connect the second cuneiform with the second, and the third cuneiform with the third metatarsal bones.

The interosseous ligaments.-(1) A strong broad interosseous ligament extends between the lateral surface of the first cuneiform and the medial surface of the base of the second metatarsal bone. It is attached to both bones below and in front of the articular facets, and separates the intermediate from the medial tarso-metatarsal joint. (2) A second band is attached behind to a fossa on the anterior and lateral edge of the third cuneiform and to the interosseous ligament between it and the culoid, and passes horizontally forward to be attached to the whole depth of the fourth metatarsal bone behind its medial facet, and to the opposed surfaces of the third and fourth below the articular facets upon their sides. It separates the middle tarsometatarsal, and intermetatarsal between the third and fourth bones, from the cubo-metatarsal joint. It is more firmly connected with the third bone than with the fourth. (3) A slender ligament composed only of a few filmres often passes from a small tubercle on the medial and anterior edge of the thirl ameiform to a groove on the lateral edge of the second metatarsal bone between the two facets upon their sides.

The synovial membrane is prolonged forward from that of the naviculari-cuneiform and inter-euneiform articulations.

The arteries for the tarso-metatarsal joints are derived:-(1) for the medial, from the dorsahis pedis and medial plantar; (2) for the rest, twigs from the arcuate and deep plantar arch.

The nerve-supply comes from the deep peroneal and plantar nerves.

The movements permitter at these joints are flexion and extension of the metatarsus on the tarsus; and at the medial and lateral rlivisions, slight arlduetion and abduction. In the lateral, the side-to-side motion is freer than in the medial joint, and freest between the fifth

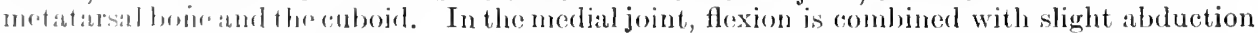
and "xtension with aluluction.

There is it so : littlo gliding, which allows the transverse arch to be increased or dininished in deplb; the modial and lateral two bones sliding downwarl, amd the two middle a little upwarl, when the anh is increascel; and vice versa when the areh is flattened.

\section{(c) THE LATERAL, ar ('UBO-METATARSAI, JOINT}

\section{Class. Jinthrosis. Subdivision. Arthrodia.}

The lones amurising this joint are the fourth and fifth metatarsal and the antrior surfare of the cubsid, firmly commeted on all sides by the articular capsule, strengthened ly the following ligaments:-
Jorsial.
Plantar.
Interosseous.

The plantar cubo-metatarsal ligament is a lorad, well-markel ligament, which extends from the (notuil behind to the bases of the fourth alud fifth metatarsal bones in front. It is 
continuous along the groove at the base of the fifth metatarsal bone with the dorsal ligament, and as it passes round the lateral border of the foot it is somewhat thickened, and may be described as the lateral cubo-metatarsal ligament. On its medial side it joins the interosseous ligaments, thus completing the capsule below. It is not a thick structure, and to see it the long plantar ligament, the peroneus longus, and lateral slip of the tibialis posterior must be remored; the attachment of these structures to the fourth and fif th metatarsal bones considerably assists to unite them with the tarsus.

The dorsal cubo-metatarsal ligament is composed of fibres which pass obliquely outward and forward from the cuboid to the bases of the fourth and fifth metatarsal bones. They complete the capsule above, and are continuous laterally with the lateral cubo-metatarsal ligament.

The interosseous ligament shuts off the cubo-metatarsal from the middle tarso-metatarsal joint. It is attached to the third cuneiform behind, and to the whole depth of the fourth metatarsal behind its medial facet, and to the apposed surfaces of the third and fourth bones below their articular facets. It is continuous below with the plantar ligament.

The synovial membrane is separate from the other synovial sacs of the tarsus, and is continued between the fourth and fifth metatarsal bones.

Relations.-The line of the tarso-metatarsal joints is crossed dorsally by the tendons of the long and short extensor muscles of the toes and the tendon of the peroneus tertius. On the plantar aspect it is in relation with the oblique adductor of the great toe, the short flexor of the great toe, the lateral plantar artery, and the tendon of the peroneus longus. Its medial end is subcutaneous except that it is crossed, near the plantar surface, by a slip of the tendon of the tibialis anterior, and its lateral end is crossed by the tendon of the peroneus brevis.

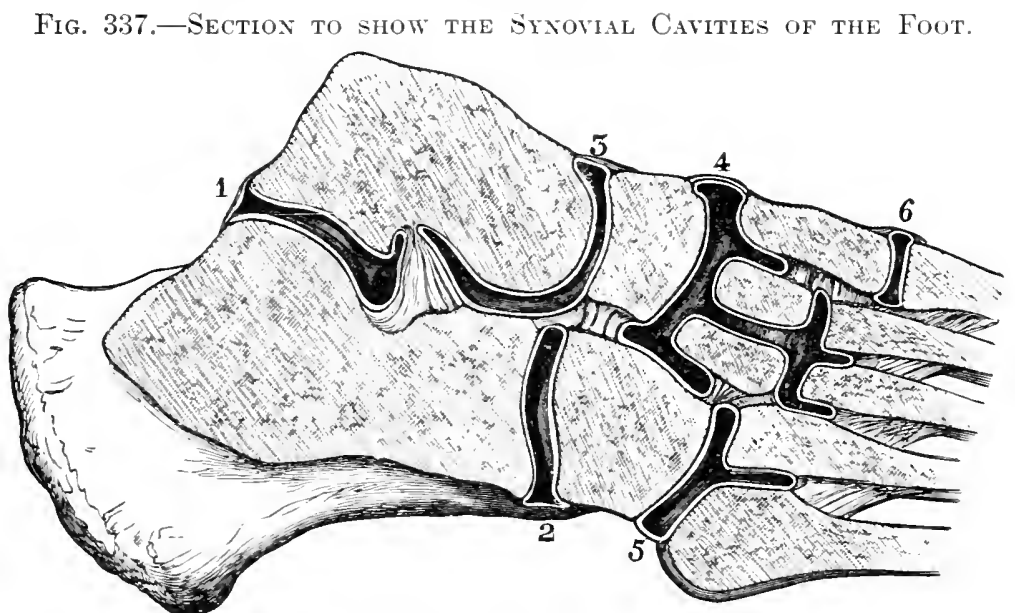

1. Posterior talo-calcaneal. 4. Tarsal.
2. Calcaneo-cuboid. 5. Cubo-metatarsal.
3. Anterior talo-calcaneo-navicular. 6. First metatarso-cuneiform.

\section{THE INTERMETATARSAL ARTICLLATIONS}

\section{Class.-Diarthrosis.}

Subdivision.-Arthrodia.

The bases of the metatarsal bones are firmly held in position by dorsal, plantar, and interosseous ligaments, supplementing the articular capsules. The first occasionally articulates by means of a distinct facet with the second metatarsal (figs. 245 and 246).

The dorsal ligaments are broad, membranous bands passing between the four lateral toes on their dorsal aspect; but in place of one between the first and second metatarsal bones, a ligament extends from the first cuneiforn to the base of the second metatarsal bone.

The plantar ligaments are strong, thick, well-marked ligaments which connect the bones on their plantar aspect.

The interosseous ligaments are three in number, very strong, and are situated at the points of union of the shaft with the bases of the bones, and fill up the sulci on their sides. They limit the synovial cavities in front of the synorial facets.

The common synovial membrane of the tarsus extends between the second and third, and third and fourth bones; that of the cubo-metatarsal joint extending between the fourth and fifth.

The arterial and nerve-supply is the same as for the tarso-metatarsal joint:

The movements consist merely of gliding, so as to allow the raising or widening of the transverse arch. Considerable flexibility and elasticity are thus given to the anterior part of the foot, enabling it to become moulded to the irregularities of the ground.

\section{The Union of the Heads of the Metatarsal Bones}

The heads of the metatarsal bones are connected on their plantar aspect by the transverse ligament [Ligg. capitulorum transversa], consisting of four bands 
of fibres passing transversely from bone to bone, blending with the fibro-cartilaginous or sesamoirl plates of the metatarso-phalangeal joints, and the sheatlis of the flexor tendons where they are connected with the fibro-cartilages. It differs from the corresponding ligament in the hand by having a band from the first to the second metatarsal bone.

\section{THE METATARSO-PHALANGEAL ARTICULATIONS}

\section{(a) The Metatarso-phalangeal Joints of the Four lateral Toes}

$$
\text { Class.-Diarthrosis. }
$$

\section{Subdivision.-Condylarthrosis.}

These joints are formed by the concave proximal ends of the first phalanges articulating with the rounded heads of the metatarsal bones, and united by articular capsules strengthened by the following ligaments:-

\section{Collateral. Dorsal. Plantar accessory.}

The two collateral ligaments are strong bands passing from a ridge on each side of the head of the metatarsal bone to the sicles of the proximal end of the first phalanx, and also to the sides of the sesamoid plate which unites the two bones on their plantar surfaces. On the dorsal aspect they are united by the dorsal ligament.

The dorsal ligament consists of loose fine fibres of areolo-fibrous tissue, extending between the collateral limiments, thus completing a capsule. It is connected by fine fibres to the under surface of the extensor tendons, which pass over and considerably strengthen this portion of the ("apsule.

The plantar accessory ligament or sesamoid plate helps to deepen the shallow facet of the phalanx for the head of the metatarsal bone, and corresponds to the accessory volar ligament of the fingers. It is firmly connected to the collateral ligaments and the transverse ligament, and is grooved inferiorly where the flexor tendons pass over it. It serves to prevent dorsal dislocation of the phalanx.

The scrond metatarso-phalangeal joint is $6 \mathrm{~mm}$. ( $\frac{1}{4}$ in.) in front of both the first and third metatarso-phalangeal joints.

The third metatarso-phalangeal joint is $6 \mathrm{~mm}$. ( $\frac{1}{4} \mathrm{in}$.) in front of the fourth, and the fourth 9 $\mathrm{mm}$. ( $\frac{3}{4}$ in.) in front of the fifth.

The heal of the fifth metatarsal is in line with the neck of the fourth.

Thus the lateral side of the longitudinal arch of the foot is shorter than the medial, it is also distinctly shallower.

\section{(b) The Metatarso-phalangeal Joint of the Great Toe}

The metatarso-phalangeal joint of the great toe differs from the rest in the following particulars:-

(1) The hones arr on a larger soale, and the articular surfaces are more extensive.

(2) There are two grooves on the plintar surface of the metatirsal bone, one on each side of the merlian line, for the sesamoirl hones.

(3) The sesamoid bones replace the acessory phantar ligament (sesamoid plate). They are two small lemispleriral bones developed in the tendons of the flexor hallucis brevis, convex below lint flat above where they play in grooves on the hearl of the metatarsal bone; they are unitrol by astrong transverse ligamentoms band, which is smooth below and forms part of the rhammin along which the long flexor trmion plays. They are firmly mited to the base of the phalanx lye strong short filmes, but to the metatalsal bone they ane joined by somewhat looser

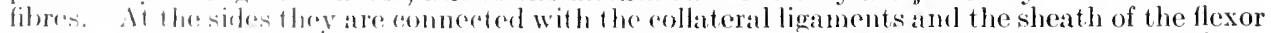
fondom. Threy providr shiftine leverage for the flexor hallucis brevis as well as for the flexor halluris longus.

flin: arteries omm: from the digital and metatarsal hranches; and the nerves from the cuta-

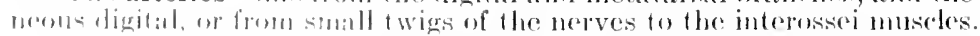

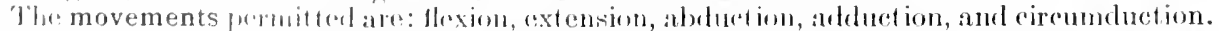

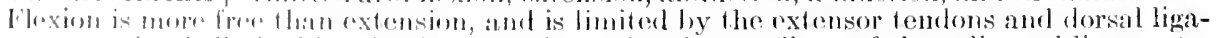
ments; extorsion is limiterl hy the flexor tondons, the plantar litres of the collateral ligaments,

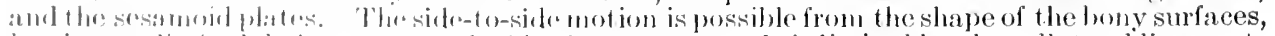

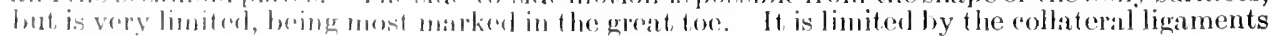
alul sorsambinl platers.

\section{THE INTERPIALAN(BEAL, JOINT'S}

\section{Class. Jinilluresis.}

Subdivision. Conglymus.

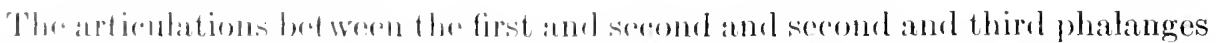
of the lowe are sinnilar to thoif of the fingers, with this important difference, that 
the bones are smaller and the joints, especially between the second and third phalanges, are often ankylosed. The ligaments which unite then include, in addition to the articular capsule:-
Collateral.
Dorsal.
Accessory plantar.

The two collateral ligaments are well marked, and pass on each side of the joints from a little rough depression on the head of the proximal, to a rough border on the side of the base of the distal phalanx of the joint.

The dorsal ligament is thin and membranous, and extends across the joint from one collateral ligament to the other beneath the extensor tendon, with the deep surface of which it is connected and by which it is strengthened.

The accessory plantar ligament covers in the joint on the plantar surface. It is a fibrocartilaginous plate, connected at the sides with the collateral ligaments, and with the bones by short ligamentous fibres; the plantar surface is smooth, and grooved for the flexor tendons.

The arteries and nerves are derived from the corresponding digital branches.

The only movements permitted at these joints are flexion and extension.

At the interphalangeal joint of the great toe there is very frequently a small sesamoirl bone which plays on the plantar surface of the first phalanx, in the same way as the sesanoid bones of the metatarso-phalangeal joint play upon the plantar surface of the head of the metatarsal bone.

Relations of the muscles acting on the metatarso-phalangeal and interphalangeal joints of the foot.-If the student will refer to the accounts given of the relations of the corresponding joints in the hand and of the actions of the muscles upon those joints, and if he contrasts and compares the muscles of the hand with those of the foot, he will readily be able to construct tables of the relations of the metatarso-phalangeal and interphalangeal joints of the foot, and tables of the muscles acting upon the joints.

References.-A complete bibliography for the joints is given in the "Handbuch der Anatomie und Mechanik der Gelenke," by Professor Rudolf Fick (in ron Bardeleben's Handbuch der Anatomie). References are also given in the larger works on human anatomy by Quain, Rauber-Kopsch, Poirier-Charpy, etc. References to the most recent literature may be found in Schwalbe's Jahresbericht, the Index Medicus and the various anatomical journals. 



\section{SEC'TION IN \\ THE MUSCULATURE}

Revised fOR The Fifth Edition

BY C. R. BARDEEN, A.B., M.D.

PROFESSOR OF ANATOMY IN THE UNIVERSITY OF WISCON SIN

$\mathrm{M}$

USCLES, the movements of which are under the control of the will, almost completely envelope the skeletal framework of the body; close in the oral, abdominal, and pelvic cavities; separate the thoracic from the abdominal cavity; surround the pharynx and the upper portion of the csophagus; and are found connected with the eye, ear, larynx, and other organs. 'They constitute about two-fifths to three-sevenths of the weight of the body.

In this section an account is given of the gross anatomy of the musculature attached to the skeleton and the skin, with the exception of certain of the muscles which are more conveniently treated in connection with the organs to which they are appended. Thus, the muscles of the eye, the ear, the pharrnx, the larynx, and the intrinsic muscles of the tongue are described in the sections devoted to those structures.

Relations to the skin.-Beneath the skin is a sheet of connective tissue, the tela subcutanea. In this, in some regions of the bodv (the head, neck, and palm), thin, flat, subcutaneous muscles are embedded. Superficial muscles of this kind constitute a panniculus carnosus, much more extensive in the lower mammals than in man. The tela subcutanea is separated from the more deeply seated musculature by areolar tissue, which, in most places, is loose in texture orer the muscles. In some regions, as over the upper part of the back, the tela subcutanea is firmly united to the underlying musculature and is less freely movable. In the tela subcutanea more or less fat is usually embedded. This constitutes the panniculus adiposus, which varies greatly in thickness in different parts of the body. As a rule, it is much more developed over muscles than over those regions where bone and joints lie beneath the skin. From the tela subcutanea of the eyelids, penis, and scrotum fat is absent. The deeper layer of the tela subcutanea is more or less free from fat, and in it run the main trunks of the cutaneous nerves and vessels. In some regions, as over the lower part of the abdomen, one or more fibrous membranes are differentiated in this deeper layer.

To the tela subcutanea the term superficial fascia has been commonly applied, but since this leads to a confusion with the superficial fascix which immediately invest the muscles, it seems better to restrict the term fascia to the membranes connected with the muscular system, and to use the term tela subcutanea for the layer of connective tissue which underlies the skin and is continuous over the whole surface of the body.

In several places where the skin overlies bony prominences well-marked synovial bursæ, or sacs (bursæ mucosæ), are developed in the tela subcutinea .

Since the skin and the subcutaneous tissue must be removed in order to study the muscles of various regions, the tela subcutanca and subcutaneous bursip mair be conveniently described in connection with the muscles, and brief references will, therefore, be made to them in connection with the musculature of various regiuns.

Muscle fasciæ.- The musculature of the body, with the exception of some of the subcutaneous muscles, is ensheathed by fibrous tissue, which, in certain regions forms distinct membranes, while in other regions it is delicate and not clearly to be distinguished from the superficial connective tissue of the muscles, the periny- 
sium externum. The membranes, or muscle fasciæ, are united to various parts of the skeleton, either directly or by means of intermuscular septa, and, where strong, keep the underlying musculature in place. In some regions they are united to the muscles; in others they are separated from the underlying musculature by loose areolar tissue. which allows free movement between the surface of the muscles and the oyerlying fascia. The best example of a strong fascia of this nature is that which envelopes the extensor muscles of the thigh. Where the fasciæ are well developed, the main bunlles of constituent fibres take a course directly or obliquely transverse to the direction of the underlying museles. They may be composed of several successive layers of fibrous tissue, the fibres of one layer taking a different direction from those of the next layer.

The function of the fascice is the mechanical one of restraining or modifying muscle action. The direction of the main component fibre-bundles indicates the direction of the greatest stress to which the fascize are subjected. Indirectly the fascin promote the circulation of the blood and lymph in places where the ressels lie between the contracting muscles and the overlying fascia.

Intermuscular septa.-- Iuscle fasciæ enclose not only the external layer of the musculature of the body, but also the various groups of more deeply seated muscles. In addition, between the individual muscles, and between the different layers and groups of muscles, there intervenes a greater or less amount of ronnective tissue, sometimes loose in texture, sometimes dense in structure. In these intermuscular septa run the chief nerves and blood-vessels of the region in which the musculature lies.

Gross structure of the muscles.-The muscles are composed of bundles of redlish fibres surrounded by a greater or less extent of white and glistening connective tissue. They are attached by prolongations of this tissue in the form of tendons or aponeuroses usually to the bony skeleton, but also in places to cartilages, as in the thorax and larynx; to the skin, as in the face; to mucous membranes, as in the tongue and cheeks; to the tendons of other museles, as in the case of the lumbrical muscles; to muscle fasciæ, as in the case of the oblique and transverse muscles of the aldomen; and to other structures, as, for instance, to the eyeball.

The fleshy portion of the musele is called the belly. The belly is usually attached at one extremity to a portion of the skeleton or to some other structure which serves as a support for its action on the structures to which its other extremity is attached. The attachment to the more fixed part is called the origin of the mirele; the attuchment to the structure chiefly acted on is called the insertion. Thus the origin of the biceps muscle, the chief flexor of the forearm at the elbow, is from the scapula; the insertion is into the radius and into the fascia of the forearm. The part of the muscle attached to the origin is ealled the head of the mus"le. The part attached to the insertion is sometimes called the tail, but this term is murlh less freguently used than the former.

The muscles vary greatly in size and form. Thus the stapedius muscle of the mirldle atr is a slender little strurture, only a few millimetres long, while the ghlutens maximus muscle of the hip is a large, rhomboid strueture often several centimetres thick amb with a surface area of over 500 square centimetres. The length of a monscle fiom origin to insert ion may be much less than the width of the musele, as in the inferestal muscles; or much greater than the width, as in most of the long museles of the limbs. The thickness of a muscle is usually less than the width so murb so in some instances that the musele is described as flat, sheet-like, or rihbrolike: white in other instances the belly is cylindrical. In flat muscles the

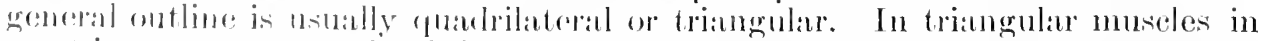
most instances ons angle of the fritugle matsis the insertion of the muscle, while

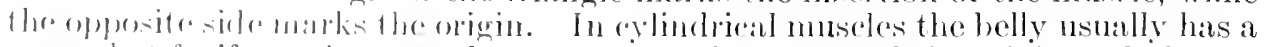
sommothal fusiform shalm, and grows smaller both foward the origin and the insertion of the muscles.

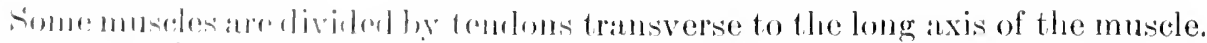

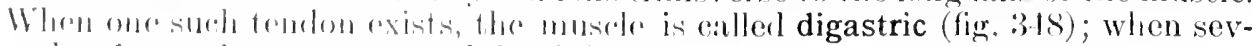

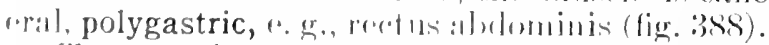

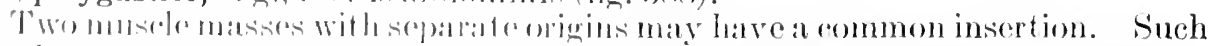

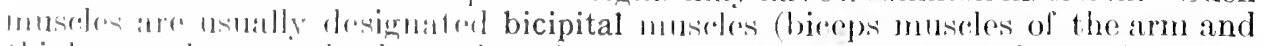

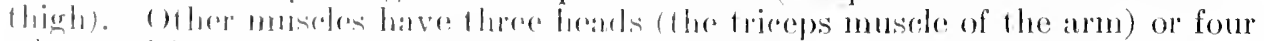

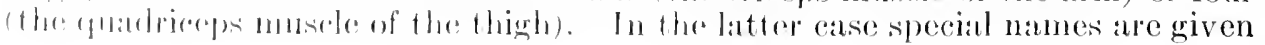


to the four parts or muscles which constitute the quadriceps as a whole. In aridition to these comparatively simple compound muscles there are others in which the various component fasciculi and the tendons of origin and insertion are numerous and complexly interrelated. The intrinsic muscles of the bark offer goor illustrations of muscles of this nature.

In addition to muscles with distinet regions of origin and insertion, there are at few voluntary muscles which surround hollow viscera or their orifices and have a circular or tube-like form (sphincter muscles, voluntary muscles of the cesophagus. etc.).

Number of muscles. - A logical constancy does not appear always to have been followed in the commonly accepted division of the musculature into muscles inclividually designated. Most of the muscles are symmetrically placed in pairs, one on each side of the body. Authors not only vary in the extent to which they carry the subdivisions of the musculature on each side of the body into individual muscles, but also in describing muscles placed near the median line cither as single muscles with bilateral halves or as paired muscles. In addition some muscles are not constantly present, and there are differences of opinion as to which of these less constant muscles should be classed with the normal musculature. The BNA recognises 347 paired and two unpaired skeletal muscles, and 47 paired and two unpaired muscles belonging to the visceral system and organs of special sense. Of the skeletal muscles the head has 25 paired and one umpaired; the neck 16 paired; the back 112 paired; the thorax 52 paired, one unpaired; the abdomen and pelvis 8 paired; the upper extremity, 52 paired; the lower extremity, 62 paired (Eisler).

Finer structure of muscles.-While no attempt can be made here to describe in detail the finer microseopic features of inuscle structure, some of the more general features of muscle arehiteeture may be briefly mentioned.

The eontractile cells of voluntary muscle are long, slender, multinucleated 'fibres,' the protoplasm of which exhibits both eross and longitudinal striation. The longitudinal striation is due to the presence of fibrils situated in the sarcoplasma. The eross striation is due to alternate segments of singly and doubly refracting substance in these fibrils. The length of these fibres in the human body varies from a few millimetres to sixteen centimetres or more, and the thickness from ten to eighty microns. Each muscle-fibre is surrounded by an especially differentiated sheath, the sarcolemma. Outside of this is a layer of delicate connective tissue, the perimysium internum or endomysium, the fibres of which are in part inserted into the sareolemma. This conneetive tissue, which is especially developerl at the ends of the fibres, serves to attach them either directly to the structures on which the muscle acts or to the skeletal framework of the muscle.

In the simplest mammalian muscles the muscle-fibres take a paralkel eourse from tendon to tendon, and are not definitely bound into secondary groups. An example may be seen in fig. 338 , a, which represents two segments of the rectus abdominis muscle of a mouse. More often, however, the inclividual fibres do not run the entire distance from tendon to tendon, but insteat they interdigitate, and the interdigitating fibres are bound up into secondary and tertiar'y anastomosing fibre-bundles by connective tissue, in which there is usually a consilerable anount of elastic tissue. Fig. 338, b, represents cliagrammatically this interdigitation of fibre-bundles as seen in the abdominal musculature of one of the larger mammals.

In most of the flat muscles of the body the fibre-bundles either take a nearly parallel course from tendon to tendon or they converge from the tendon of origin toward the tendon of insertion (see fig. 338, c-e). The greater the distance from tendon to tendon, the more marked is the interdigitation of the eonstituent fibre-bundles.

In elongated muscles the tendons of origin and insertion may either arise near the extremities of the muscle or may extend for a considerable distance on the surface or within the substance of the musele. In the former case the belly of the muscle is composed of bundles of interdigitating fibres which take a course parallel with the long axis of the muscle. 'This is shown diagrammatically in fig. 338 , f. An example may be seen in the sartorius muscle of the thigh (fig. 411 ). When the tendons extend far on the surface or within the substance of the muscle, the ronstituent fibre-bundles take a course oblique to the long axis of the muscle. When they take a course from a tendon of origin on one side toward a tendon of insertion on the other, the muscle is called unipenniform (see fig. 338, g, ant the extensor digitorum longus, fig. 415 ). In other instances the fibre-bundles converge from two sides toward a central tendon. Surh a muscle is called bipenniform (see fig. $338, \mathrm{~h}$, and the flexor hallucis longus, fig. 416). When there are several tendons in the muscle between which the fibre-bundles run obliquely, the muscle is ealled multipenniform. In fusiform muscles the tendons usually either embrace the extremity of the muscle like a hollow cone, or they extend far on the surface or within the substanee of the muscle. In such muscles the fibre-bundles take a curved cource from one temion to the other. The bundles which arise highest on one tentlon are inserted highest on the other, and the fibre-bundles of lowest origin have the lowest insertion. This structure is diagrammatically shown in fig. 338, i. A good example may be found in the rectus femoris muscle (fig. 411).

Many other arrangements of the fibre-bundles are found, and the arrangements here shown may be variously combined. In most muscles the architecture is deciledly complex. In the 
more complex muscles dense connective-tissue septa, or intramuscular fasciæ, serve to separate different regions of the muscle from one another. In general there are groups of muscle fibrebundles surrounded by a greater amount of connective tissue, or perimysium internum, than that surrounding the individual fibre-bundles, and the latter are surrounded by a denser connective

Fig. 338.-Diagramatic Outlines to Illustrate Various Types of Muscle Architecture and the Relations of the Main Nerve Branches to the Fibre-bundles of THE MISCLE.

a. Two segments of the rectus abdominis muscle of a small mammal. b. Portion of sheet-like musele with two nerve-branches and intramuscular nerve plexus. c. Typical quadrilateral muscle with nerve passing across the muscle about midway between the tendons. $d$ and $e$. Two triangular muscles with different types of innervation. f. Long ribbon-like muscle with interdigitating fibre-bundles. g. Unipenniform muscle. h. Bipenniform musele. i. Typical fusiform muscle. The main intramuscular nerve-branches are distributed to the fibre-bundles about midway between their origins and insertions. $\mathrm{N}$, nerve.

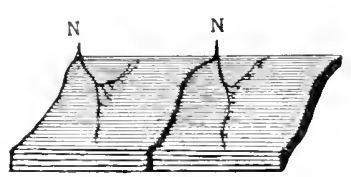

$\boldsymbol{\alpha}$

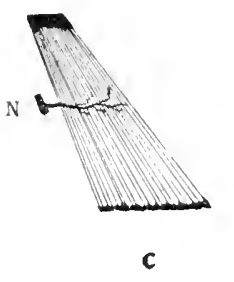

C

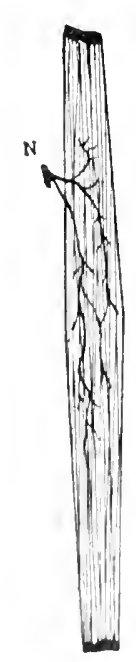

f
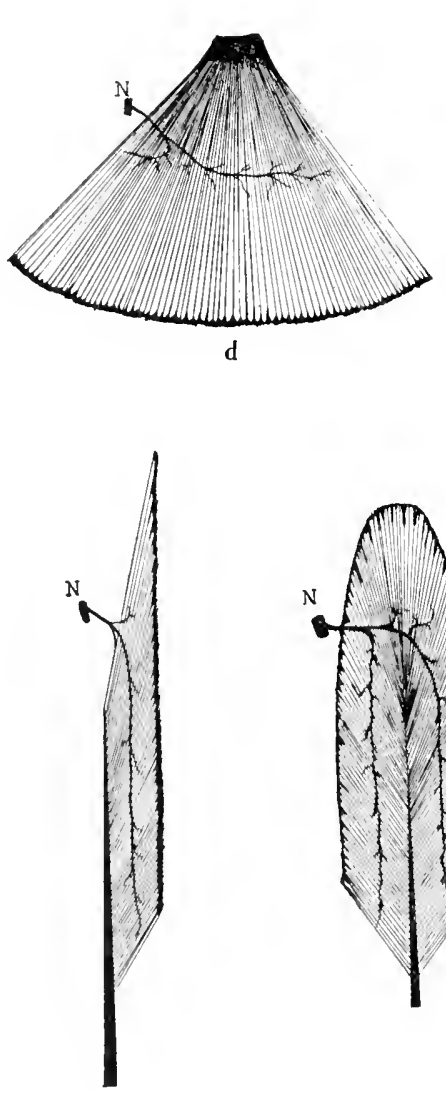

$\$$

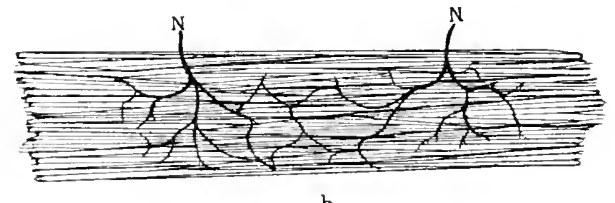

b
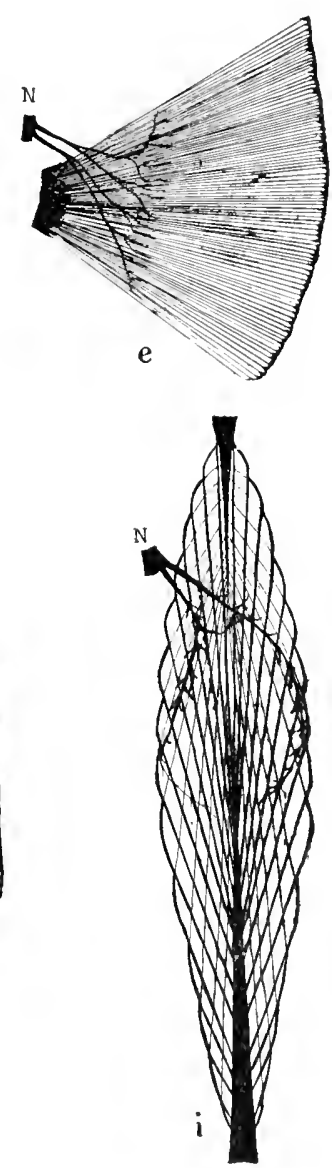

tissue than that surromuling the component muscle-fibes. The muscles are surroundel externally by a more or less feris: slect of conncetive lissue called the perimysium externum, or epinysium, which is rontinnous with the comective tissue within the muscle, the perinysium internum. In the following pages 'muscle fibre-bundle' is used to denote sunall groups of musclo-fibres, 'fasciculus' to denote large, more or less isolated, groups of fibre-bundles.

Embryonic development of muscles.-The voluntary museles are of mesodermal origin. The museles of the trunk arise ahiefly from the nyotomes, those of the head and limbs ehiefly from the mesendryme in these regions. New muscle fibres are formed mainly before birth. After birth, growth of muscles repends on growth of individual muscle fibres. 
Tendons.-Muscles vary not only in general form and in the relations of the constituent fibre-bundles to the intrinsie skeletal framework, but also in the mode of attachment to the parts on which they act. In many instances the fibre-bundles impinge, perpendieularly or obliquely, directly upon a bone or cartilage. The tendinous tissue arising from the fibre-bundles of the musele here is attacherl to the periosteum or perichondrium or to the bone directly. A broad attachment is thus offered the muscle. Instances of this mode of attachment may be seen in the attachment of the intereostal muscles and of many of the muscles attached to the shoulder and hip girdles.

In the ease of most thin, flat muscles the muscle is continued at one or both extremities into thin, tendinous sheets called aponeuroses, composed of connective tissue. Well-marked instances may be seen in the transverse muscle of the abdomen (fig. 390), and the trapezius and latissimus dorsi museles of the back (fig. 355). The extent of development of these aponeuroses is generally inversely proportional to the development of the muscle-the more extensively developed the muscle is in a given individual, the less extensive the aponeurotic sheet.*

Most muscles are eontinued at one or both extremities into dense, tendinous bands which may be comparatively short and thick, like the tendon of Achilles (fig. 413), or very long and narrow, like the tendon of the palmaris longus (fig. 370). In this latter case the tendon represents in part the remnants of musculature more highly developed in the lower vertebrates. In most instances, however, the tendons are structures specifically differentiated for definite functions and are composed of bundles of parallel connective-tissue fibrils held together by an interlacing fibrous-tissue framework. The tendons usually contain a relatively small amount of elastic tissue.

The tendons are attached to the skeleton early in embryonic development. As the bones enlarge the tendons become in part incorporated in the substance of the bone and ossified.

In some tendons sesamoid bones are developed in the neighbourhood of joints over which the tendons pass. Examples of these are the patella at the knee-joint (fig. 412) and the sesamoid bones of the thumb and great toe.

Where museles or tendons closely envelope a joint, there is usually formed a elose union between the connective tissue of the capsule of the joint and that of the musele or the tendon. Special bands may develop in the direetion of the pull of the muscle (lig. popliteum obliquum).

Where tendons run for some distance across or beneath a fascia, they are usually either bound to the fascia by a special investment, as near the wrist and knee (fig. 366 and fig. 414), or are fused with the fascia, as in the case of the iliotibial band. Fibrous tracts in the fascia may indicate stress under muscle eontraction (the lacertus fibrosus of the fascia of the forearm).

Often in broad aponeurotie attachments of muscles there is formed in the tendon near the attachment a fibrous arehway [arcus tendineus] for the passage of blood-vessels, nerves, muscles, or tendons. The tendinous arch is either fastened at both ends to the bone, or at one end it is connected with a joint eapsule or other membrane. The dorsal attachment of the diaphragm (fig. 391) and that of the adductor magnus to the femur (fig. 409) offer good examples of tendon arehes.

In digastric and polygastric museles the transverse tendons which separate the bellies are often composed of narrow, incomplete bants of fibrous tissue. Such a transverse band is ealled an inscriptio tendinea (see Rectus Abdominis Muscle, fig. 388).

Tendon sheaths. - The tendons are held in place by sheath composed of dense connective tissue. These sheaths vary in different regions. In the most complete form they confine tendons in osseous grooves which they convert into osteofibrous canals on the flexor surface of the digits. The sheath is here called a vagina fibrosa tendinis. It is strengthened by tendinous band.s (vaginal ligaments). In other regions special dense bands or ligaments, retinacula tendinum, confine a series of tendons in place, as at the ankle (fig. +17 ), or fascice may be modified for this purpose, as at the back of the wrist (fig. 366). A tendinous loop,

* The terms fascia and aponeurosis are often loosely and interchangeably used. It seems best to make a distinction by restricting the term fascia to membranous sheets of investment, and aponeurosis to broad tendons. The latter may, however, be inserted into and form a part of the former. 
annulus fibrosus, may hold a tendon in place, as, for instance, the trochlea of the tendon of the sumerior oblique muscle of the eye.

Synovial bursæ [bursæ mucosæ].- Where there is freedom of action between muscles and tendons and the surrounding parts, there intervenes a loose connective tissue. In regions where the pressure is great or considerable friction would result were these conditions retained, there are developed special cavities with smooth surfaces and containing fluid. Most of these bursæ are developed from the intervening connective tissue at a period in embryonic life preceding muscular activity, but special burse may later be developed as the result of unusual pressure or muscular activity after birth. An instance of a bursa lying in a region of friction may be seen in the bursa intervening between the tendinous posterior surface of the ilio-psoas muscle and the ilio-femoral ligament. As an instance of a bursa lying in a region of intermittent pressure may be cited that between the tendon of Achilles and the calcaneus.

Most synovial burse intervene between a tendon and a bone, a tendon and a ligament, or between two tendons (subtendinous bursæ mucosæ). Others lie between two muscles, a muscle and some skeletal part, or between a muscle and a tendon (submuscular bursæ mucosæ); or below a fiscia (subfascial bursæ mucosæ). Subcutaneous bursæ have been referred to in comnection with the tela subcutanea (see p. 313). Most bursæ are developed near joints. The bursæ may so expand during active life that they come to communicate with other burse or with a neighbouring joint cavity.

Synovial sheaths [vaginæ mucosæ tendinum].-Wynovial sheaths are developed about tendons where the latter are confined in osteo-fibrous canals, as in the fingers. The wall of the canal and the enclosed tendon, or tendons, are each covered by a smooth membrane which at the extremities of the canal is reflected from the wall to the tendon. Between the membrane covering the tendon and that lining the canal is a symovial cavity. An interesting feature of these tendonsheaths is the presence of mesotendons, delicate bands of vascular connective tissue which run in places from the osseous groove to the tendon and carry bloodvessels and nerves.

Trochlex.-Where a tenton passes at an angle about a bone, the tissue in the groove in which the tendon runs frequently is composed of hyaline eartilage instead of bone. An example may be seen in the trochlear process of the calcaneus.

Nerves.-To each muscle of the body a nerve containing motor and sensory fibres is distributed. I few muscles receive two or more nerves. Sherrington has estimated that in the musele-nerves of the cat two-fifths of the fibres are sensory and three-fifths motor.

The muscles of the head and in part those of the neck are supplied by branches of the cranial nerves. The intrinsie muscles of the neck, back, thorax, and abdomon are supplied by branches which arise fairly directly from the spinal nerves. The muscles of the limbs are supplied by branches from nerve-trunks which arise from plexuses formed by the spinal nerves in the regions near which the limbs are attached.

'The main nerve-trunks lie beneath the superficial muscles. 'They usually run in the interminsmbar sopta which separate the deeper gromps of muscles from one another and from the sufuerfirial muscles. 'Tle nerve-branches which enter a given musele usually pass in where the larger intrumbeular septa approach the surface of the musele, and then ramify through the perinysium intermum, the smaller manches heing distributed in the finer layers of connective fissue whicl. surromel and separate the prinary muscle fibre-bundles, to the constituent musclefibres of whinh terminal hranches are given. Special sensory emb organs are tistributed ehiefly in the large inframusular septa, in the tendons and in the muscles near the tendons. Simple sensory endiugs ane fontul on the molsele fibres.

The size of a norve supplying at musele is mot proportional to the size of the latter, but rather to the romendexity of movoments in which the musele plays a part.

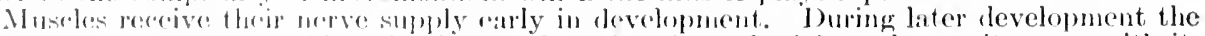
musele may wabler at considerathe distance from its place of origin ans earry its nerve with it.

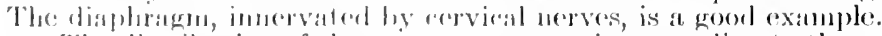

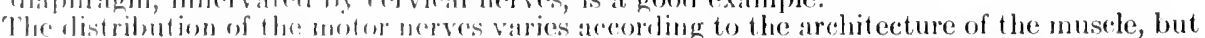
in groferal it appears that the nerves aro so distributed as to earry the main branches of distri-

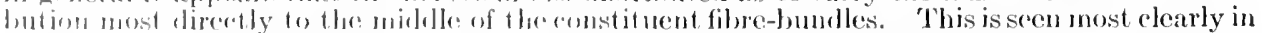
muselos with remparatively short libre-fumbles, where the individual muscle-fibres run nearly

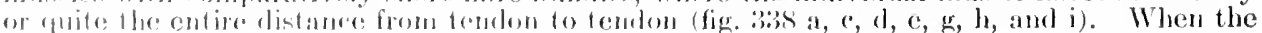
distance is long, a matked plexiform arrangemont is fomml (lig. 333s, b and f). To each musele 
fibre there is distributed a terminal nerve-fibre which passes through the sarcolemma and end: in a motor end organ (musele plate). Oceasionally there are two such nerve-fibres to one murclefibre.

Vessels.-The muscles are richly supplied with blood. In many instance- the larger blood-vessels accompany the larger nerve-trunks as ther enter the muscle, and their primary branches are distributed in the larger intramuscular septa. Often, however, the main blood-vessels approach a muscle from a direction different from that taken ly the nerves. Each muscle has, however. its own biool supply. There is little anastomosis between the blood-vessels of a musele and those of a neighbouring structure, but the anastomosis between the ressels within the muscle is exceedingly rich. Teins, as a rule, accompany all but the smallest arteries within the muscle. The veins are richly supplied with valyes, so that muscle contraction promotes the flow of hlood through the muscle. Rich anpillary plexuses surround the muscle-fibres. The capillaries are of unusually small diameter.

During contraction, the blood is forced from the muscles; during expansion it rushes in through dilated arteries which furnish five or six times as much blood to muscles during exereise as that supplied te them during rest.

The connective-tissue sheathis, the larger intramuscular septa, and the tembur of muscles are richly supplied with lymphatics. There are no lymphatios within the muscle bundles or in small muscles.

Nomenclature.-The names of the various muscles and their classification are less satisfactory than is desirable. The muscular system was first carefully studied in the human body, and names based sometimes upon the shape, structure. size, or position, at other times upon the supposed function or other associaterl facts, were applied to the muscles found in rarious regions. Sometimes two or more names were applied to a muscle to indicate several of these factors. Thus trapezius and triangularis indicate the shape of the corresponding muscles: biceps or triceps indicates the origin by two or three heads; rcctus, obliques, and transversus represent the direction taken by a muscle or its constituent fibre-bundles; magnus and minimus indicate size; sublimis (superficial) and profundus (leep) represent the relative positions occupied; stemo-cleido-mastoid indicates structures to which the muscle is attached; flexor and extensor indicate function; and sartorius indicates that the corresponding muscle was supposed to be of use to tailors.

Since careful study has been devoted to the comparative anatomy of the muscles in various vertebrates, it has beeome apparent that a simple and more consistent numenclature applieable to corresponding muscles found in various animals would be of great value. A satisfactory nomenclature of this sort has not, however, as yet been devised and adopted in comparative anatomy, and the established usage of the terms now familimly applied to the muscles of the human body makes it seem improbable that even if such a system were lerised for comparative anatomy it eould be brought into extensive use in human anatony. For many of the museles in the human body varions synonyms have been in use in different cointries. The Anatomical Congress assembled at Basel in 1895, to simplify the nonenclature of human anatomy, adopted in large part the terms in familiar use in England and America. In the following pages the terms approved by the Congress will be employed, but where they differ materially from those previously in use, the synonym will be given in parentheses.

Classification.-The nuseles are usually treated strictly aceording to the region of the hody in which they are found. This method of consideration is still of value in a dissector's guide and in text-books of topographical anatomy. But in studying the museles seientifically it is of importance also to consider them in their more fundamental genetic relationships to one another and to the nervous system. Embryology and comparative anatomy have proved of the greatest value in revealing these relationships. Studies of this nature have revealed well-narkal relationships in the adult human musculature which are of praetieal as well as scientifie importance The voluntary musculature may be broadly divided into that of the skeletal axis, the limbs, and the visceral orifices. The nuseulature of each of these divisions has a different and in generil simpler form in the lower than in the higher vertebrates, and in the embryos of the higher vertebrates than in the adult. The museulature of the spinal region of the borly axis of fishes, the tailed amphibia, and all vertebrate mbryos is metamerically segmented; that is, it is livided along the axis of the body into a series of components corresponding with the segmentit ion of the vertebral column. Although marked alterations take place in the subsequent ontogenetic differentiation in higher vertebrates, traces of this primitive segmentation are still to he found in the adult; in man, for instance, in the intereostal muscles and the segments of the rewtus ahdominis. In the region of the head conditions are complex, owing to the concurrent presence of museles which primitively eorrespond in nature with the segmental spinal musulature, and museles non-segmental in character, which surround the visceral orfices. This also is true of the anus and external genitalia, where, however, the conditions are simpler. Emlnology and comparative anatomy have done much to elear up puzzling features in both regions.

The muscles of the limbs are metamerieally arranged in no adult vertehrate. In some of the lower forms a series of axial muscle segments, myotomes, furnishes material from which the 
musculature of the limbs is differentiated. In the mammals this appears not to be the case, and the muscles are differentiated from the non-segmental tissue of the limb-buds.

Where mammalian musculature is primitively segmental, each segment becomes associated with a corresponding spinal nerve or, in the head, with a nerve which corresponds in series with a spinal nerve. Even when subsequent differentiation brings about marked alterations in the axial musculature, the nerves maintain to a considerable degree a segmental distribution.

In to each of the limbs, where the intrinsic musculature is at no time segmental, there extends during embryonic development a series of segmental spinal nerves, so that in them, as in the region of the body axis, a certain segmentation in the nerve-supply can be made out in the adult. That part of the limb nearest the head in early embryonic development has its muscles supplied by the most cranial, that part nearest the caudal extremity of the body by the most caudal, of the nerves which supply the limb musculature. There is here, however, considerable overlapping of the segmental areas.

Variation.-In man some variation in the arrangement of the muscles is met with in every individual, and often marked deviations from the normal conditions are found. The muscles vary in their mode of origin or insertion, and in the extent to which muscles of a given group are fused with one another or to which the chief parts of a complex muscle are isolated from one another. Some muscles, like the palmaris longus and the plantaris, are frequently entirely absent, and other muscles generally absent are frequently present.

In addition to these frequent variations there are others so rare that many authors prefer to speak of them as anomalies rather than variations. Sometimes muscles may be found doubled by longitudinal division, or two or more muscles normally present may be fused into a single indivisible muscle. Occasionally there occur muscles constantly present in some of the lower animals, but normally not met with in the human body (anomalies of reversion or of convergence). In such instances the muscle may be normally represented by a tendon or fascia. At times the anomalies are supposed to be not a reversion to an ancestral condition, but a distinct step in advance. This, however, is difficult to prove. At other times no phylogenetic relation is apparent, and the anomaly is looked upon as a monstrous sport or as the result of some pathological condition.

The nerve-supply of the muscles is of value in the study of muscle variations. There is, however, not infrequent variation in the nerves with relation to the supply of the muscles.

Physiology.-From the standpoint of morphology the muscles are grouped aceording to their intimate relations to one another and to the peripheral nerves, relations, as noted above, that are made more clear by a study of comparative anatomy aud embryology. From the physiological aspect a different grouping of the muscles is required, because muscles belonging morphologically in one group may have different physiological functions in the animal body. The chief features of the inechanical action of muscles may be briefly considered here.

Nost muscles act on the bones as levers. In physics three types of levers are recognised In levers of the first type (fig. 339, I) the fulcrum (F) lies between the place where power $(P)$ is exerted on the lever and the point of resistance or load (L). Levers of this kind are frequently met with in the body. A good example is seen in the attachment of the skull to the vertebral column. The fulcrum lies at the region of attachment; the weight of the skull tends to bend the head forward, while the force exerted by the dorsal muscles of the neck serve to keep the head upright or to bend it baek.

In levers of the sceond class (fig. 339 II) the point on which power is exerted moves through a greater distance than the point of resistance. Speed of movement is thus sacrificed to power. Levers of this type are exceedingly rare in the animal body. An example in the human body is the foot when the body is raiserl on the toess.

In levers of the third cliss (fig. 339, III) the point on which force is exerted moves at less distance than the point of resistance. Power is thus sacrificed to speed. This is the common form of leverage found in the body. $\Lambda$ good exatmple is found in the action of the muscles which flex the forearm on the arm. 'The region in which the hiceps and brachialis are attached is but a short distance from the ellow-joint or fulerum, while the hand may be looked upon as the region of resistance to the force excrted. A movement of the point $\mathrm{P}$ throngh a short distance will cause $\mathrm{I}$, to move through a great distance.

'The: more: he: angle betwecu an insche or its tendom and the bone on which it acts approaches at right ingle, the greater is the puwer of movement exerted by the inuscle. The arin in fig. 339 , 111, is in the prosition of groutest anvantage for the aretion of the biceps on the forearm. All broys know that it is casier to '(hin' oneself after the arm is partly bent than when hanging 
straight from a bar. Many of the muscles run nearly parallel with the parts on which they act, but the tendons before their attachment are usually either carried over a bony prominence or some fascia or ligament acts as a pulley so that the tendon is inserted at an oblique angle. At other times a process for the attachment of the tendon projects from the bone and causes the force of the contracting muscle to be more advantageously exerted on the bone. It may, of course, readily be seen that the greater the distance of the attachment of a muscle from the joint over which it acts, the greater will be the power exerted by the muscle.

In considering the movements of the body, it is convenient to recognise two groups, simple and complex. To the former, which alone can be considered in a text-book of anatomy, belong such movements as flexion, extension, adduction, rotation, etc., while to the latter belong those associated movements which give rise to changes in the positions of the body as a whole or of extensive regions of the body.

In flexion the extremities of the trunk or limbs or special portions of these regions are bent near to one another; in extension the reverse movement is brought about. The parts are straightened or even bent beyond the straight position (over-extension).

Fig. 339.-Three Diagrays (after Testut) to Illustrate Different Types of Levers in their Relations to the Mechanical Action of the Muscles.
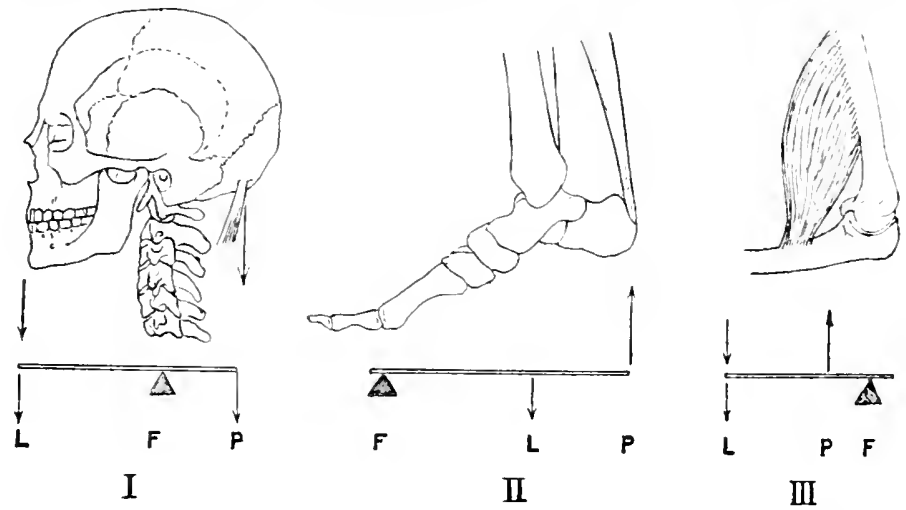

In abduction transverse movements are made, a part being bent away from the median line of the body or limb; in adduction the reverse movement is brought about.

In rotation a part is turned on its longitudinal axis. The rotation of the femur at the hip-joint is called medial rotation when the toes are turned medialward, lateral rotation when the toes are turned lateralward. Rotation at the shoulder-joint is called medial when the thumb is turned forward and medialward toward the body, lateral when the reverse movement takes place. These movements are also carried out at the elbow-joint, but here medial rotation is called pronation, lateral rotation, supination. Fick prefers these terms also for the rotation at other joints as at the shoulder, hip and knee.

At the shoulder-joint the swinging of the arm toward the back is called extension; toward the front, flexion; and from the side, abduction. Moving the arm toward the mid-dorsal or mid-ventral line is called adduction.

Taking the body as a whole the musculature may be divided into two main divisions, an expander division and a contractor division. In general the extensors, abductors and lateral rotators expand, the flexors, adductors and medial rotators contract.

In the most expanded condition the head and spine are extended or even slightly hyperextended (flexed dorsally), and the limbs project laterally from the body with the backs of the hands and feet facing dorsalward, the palms and soles ventralward, and the digits spreat out. In the fully formed human body it is not possible to put the lower extremity in the completely expanded position, although it is in this position early in embryonic derelopment. As development proceeds the lower extremity is adducted and rotated medialward and the girdle is so fixed that full abduction becomes no longer possible. In many of the lower vertebrates full abluction is possible throughout life in the lower extremities just as it is throughout life in the upper extremities in man. Full extension of the spinal column in man is also hindered in the thoracic region by the thorax, and in the sacro-coceygeal region by the osseous union of the vertebra with one another as well as by the attachment of the hip girdles. The lumbar region in man is in a condition of permanent hyper-extension. 
In the fully contracted condition the head and spinal column are strongly flexed, and the digits are adducted, the various segments of the limbs are flexed and the limbs are adducted, flexed and rotated medialward toward the middle of the trunk. The body approaches a ball in form. It is the position taken by a gymnast when turning a somerset in the air, and is in marked contrast to the fully expanded condition which would be assumed could man fly like a bat or glide like a flying squirret.

In general, the muscles which tend to put the body or a part of the body into the expanded position form a distinct group as contrasted with those which tend to put the body into the contracted position. The chief musculature which extends the head and trunk lies dorso-lateral to the spinal column and is supplied by the dorsal divisions of the spinal nerves. The chief musculature which flexes the head and trunk lies ventro-lateral to the spinal column and is supplied by ventro-lateral divisions of the spinal nerves. The chief muscles which abduct, extend and rotate the limbs lateralward arise during embryonic development on the lorsal sides of the limb buds and are innervated by branches from the dorsal sides of the brachial and lumbo-sacral nerve plexus. The chief muscles which flex, adduct and rotate the limbs medialward arise on the ventral sides of the limb buds and are supplied by nerves which arise from the ventral sides of the limb plexuses. To these general rules there are some exceptions, the most marked of which is at the hip-joint where rotation of the girdle has brought about a condition in which the primitive action of the flexor and extensor groups is partly reversed. The chief flexors (the ilio-psoas and rectus femoris) belong to the dorsal division and some of the chief extensors (the hamstring muscles) belong to the ventral division. At the ankle-joint the exception is more apparent than real. What is usually called flexion at the ankle-joint is really hyper-extension and the reverse movement is the nearest we can come to real flexion. In the extremely contracted position of the body as a whole the feet are extended (flexed plantarward) at the ankle-joint.

Muscles which produce a movement in a common direction are called synergists, while those whose contraction produces opposite movements are called antagonists; e. g., the flexors and extensors are antagonists. In the actual working of the muscular system, however, when a set of museles is contracting to produce a movement, the antagonists also contract to a :ertain (legree. The movement is the result of nerve impulses sent simultaneously to all the muscles which act on the part moved.

The relation of the internal architecture of a muscle to the movements to which its contraction gives rise is a complex subject, the details of which cannot be entered into here. In general it may be said that when the fibre-bundles run directly from one attachment to the other, as in fig. 338 , a and $f$, the force exerted by the contraction of the individual muscle-fibres is most efficiently utilised and the extent of the movement varies direetly as the length of the fibres, while the force exerted varies directly with the number of the fibres.

In muscles of the types indicated in fig. 33S, g, h, i, a certain amount of the extent of movement and of the force exerted by the contraction of the individual fibres is not effectively exerted on the parts moved by the museles, as may be seen by applying to this action the laws of the parallelogram of forces. In such museles, however, the great number of short musclefibres composing them makes possible the exertion of great power with some loss of speed of contraction in the muscle as a whole.

The dircetion of the movements which result from muscular contraction is in large part determined by the shape of the articular surfaces, none of which are to be looked upon as simple fulera, but instead, during a given movement, the fulerum shifts from one region to another of the joint.

In different muscles the extent of contraction of the constituent fibre-loundles during activity varies considerably. While usually the length of the contracted fibre-bundles is half that of those in the extended state, the amount of shortening in some muscles is only 25 to 35 per rent.

Functional aetivity is necessary for the full development or for the maintenance of development in muscles. Mluscles atropliy if their nerve supply is injured or if they are passively prevented from contracting.

Order of treatment.- The muscles and fascix are here treated in the following order:- (1) those of the head and neck and shoulder girdle (p. 323); (2) those of the upper (xtremity (p. 360); (3) those of the back (p. 410); (4) those of the thorax and abrlomen (p. 422); (5) those of the pelvic outlet (p. 439); (6) those of the lower extremity (p. 452). The reason for taking up the musculature in the order named is, that during ombronic devolopment nusculature belonging primitively to the head comms to overlap that of the neck; that of the neck spreads over the rregion of the latek and thorax, and becomes attached to the shoulder girdle; that of the arm extents over the region of the thorax, abdomen, and back; that of the back partially over the region of the thorax; while that of the abdomen chters into intinate relation with the pelvie girclle. So far as practicable the musculature of these varions regions will be taken up according to fundamental morphological relationships.

Since a morphological grouping of the muscles does not accord perfectly with a physiologieal grouping, there is given at the end of this section a table showing what muscles are concerned in performing the simpler voluntary movements. 
The topographical relations of the muscles in various regions of the body are illustrated in the series of cross-sections given for each region.

Tables illustrating the relations of the central nervous system and the peripheral nerves to the muscles are given in the section on the nervous system (Section VI).

Fig. 340.-Human Embryo (Lr) 42 mim. Lowg. (After His.)

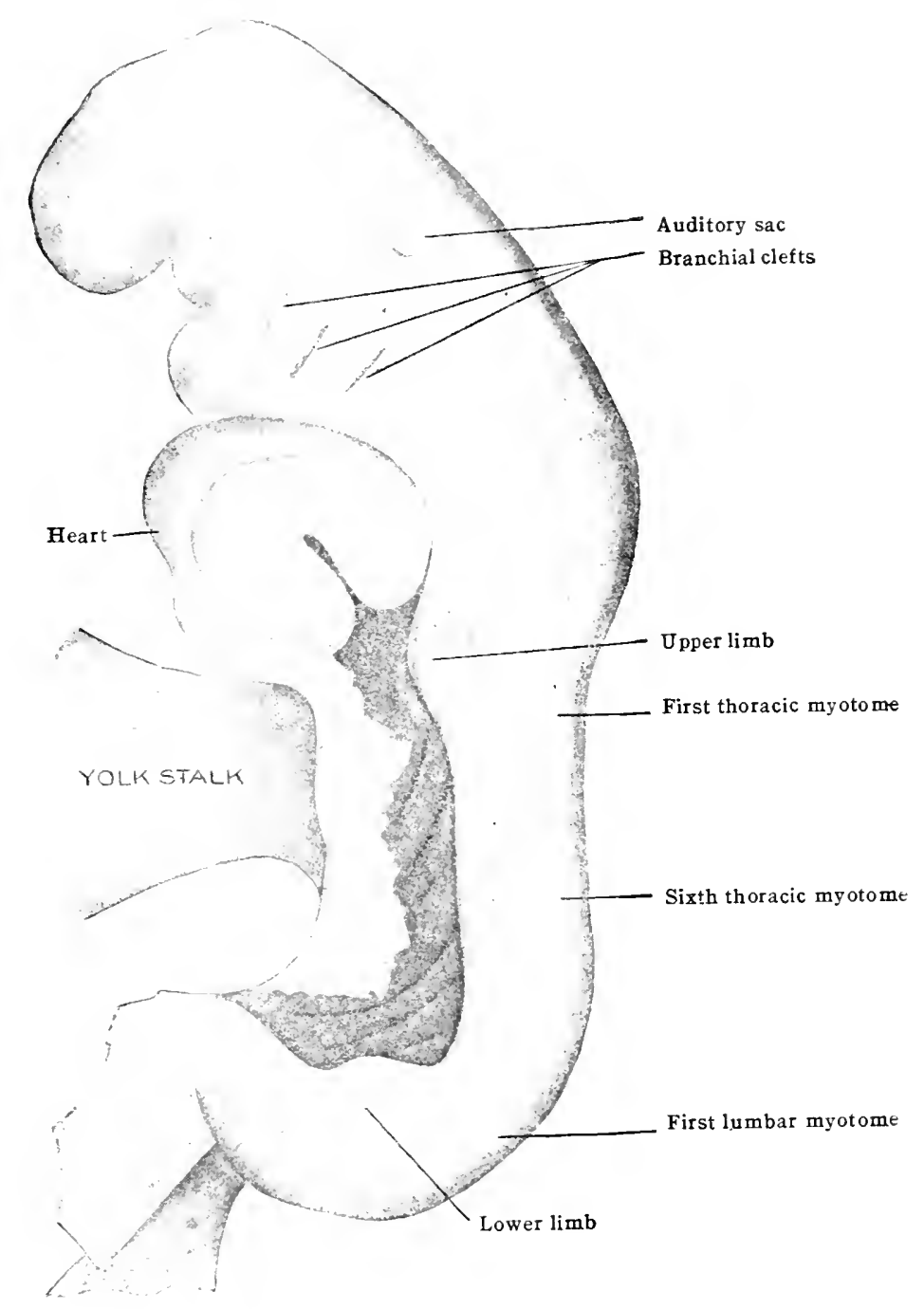

\section{MUSCULATURE OF THE HEAD, NECK AND SHOULDER GIRDLE}

\section{PHYSIOLOGICAL AND MORPHOLOGICAL ASPECTS}

The head, situated at the anterior end of the trunk in bilaterally symmetrical animals, is primitively that part of the body first brought into contact with new surroundings as the animal moves formard. We therefore find developed here the most highly differentiated organs of special sense, those of vision, hearing, and smell, through which the animal is put in touch with an enviromment more or less removed from immediate contact with the hody. In connection with these 
organs of special sense, the brain is developed. In most animals the head also is the chief organ for the prehension of food and for attack and defense. The neck is a part of the trunk differentiated to give freedom to the movements of the head. The forelimbs, relatively unimportant as the forefins in the fishes, become important organs of locomotion in the land animals. In the fishes there is no true neck, but the forefins are developed at the sides of the cervical part of the trunk. In the higher vertebrates the forelimbs are also first differentiated at the sides of the cervical region (fig. 340) but, as embryonic development goes on, they shift caudalward to the sides of the cranial (anterior) part of the thorax. The cervical region is thus left free for movement but the musculature and nerves of the upper extremity remain intimately related to it.

In man, with the assumption of the erect posture, the head no longer has to bear the brunt of the new surroundings as the body moves forward. There is, however, a distinct advantage in having those organs of special sense, which put the individual into touch with the more distant parts of the environment, situated high above the ground, and a motile neck is of great value in directing the organs of special sense toward various parts of the environment. The development of the superior extremities as organs for the prehension of food and as organs of attack and defense reduces the value of the head for these purposes, but still leaves it the important functions of the reception of food and air and the preparation of food for gastric and intestinal digestion. The head, furthermore, assumes a new and most important function as an organ for the expression of the emotions and of speech.

The expression of the emotions, such as anger, fear, affection and the like,* is brought about largely through the action of flat, subcutaneous "facialis", muscles which underlie most of the skin of the face and head and extend down under that of the neck (figs. 341 and 344). They also line the mucous membrane of the lips and cheeks. Most of them arise from the surface of the skull and are inserted into the slin, which they pull in various directions eausing it to become smooth or wrinkled, according to the direction of the pull. The various muscles are grouped about the buccal, nasal and aural orifices and about the orbit of the eye. Some of the fibre-bundles are arranged so as to constrict the orifices, others radiate out so as to dilate them.

The chicf groups of muscles of the head and neck, in addition to the facialis group just mentioned, are the muscles of the orbit and middle ear, the muscles used in mastication and swallowing (cranio-mandibular, supra- and infrahyoid groups, muscles of the tongue, soft palate and pharynx), the muscles of the larynx, and the ventral and dorsal groups of museles which lie in the region of neek, extend over the thorax and move the head, neck and shoulder girdle. A brief summary of these groups will be given before proceeding to a more detailed account.

Facialis group.-The muscles are especially well developed about the mouth, a sphincter muscle (orbicularis oris) serving to close, the radiating muscles to open the lips (quadratus labii superioris and inferioris), to pull the corners of the inouth in various directions, as, for instance, upward to express bitterness (caninus) or pleasure (zygomaticus), or lateralward and downward to express grief or pain (risorius, triangularis, platysma) or to protrude the lips as in pouting (mentalis and incisive inuseles). The buccinator, which radiates out from the corner of the mouth and lines the mueous membrane of the cheek, is used in mastication and whistling.

Abont the orbit and in the eyelids a circular musculature (orbicularis oculi) is broadly developerl. It is used to close the eyes, and to contract the skin about the orbit. Associated with the orlicularis are muscles which produce perpendicular furrows in the skin of the forehear aloove the nose (moserus, corrugator). The skin is drawn upward from the orbit and horizontal furrows are caused in the skin of the forehead by muscles attached to the scalp (epieranius). 'Two of these inuscles, the occipilales, arise one on each side from the occipital bone and are attacherl to an aponeurosis which lies beneath the scalp to which it is firmly united. Two of the muscles, the frontales, extend one on each side from this aponeurosis to the skin above the eyelorows.

About the nasal orifices there are weak constrictors (alar part of the nasalis, depressor alo nasi) and dilators (dilator naris anterior and posterior, transverse part of the nasalis, angular head of the quadratus labii suprrioris). L'rmin the ear (aturicle) three flat muscles radiate, one lankwarl (auriculeris posterior), one upward (auricularis suprrior) and one forward (anricularis antrior). These muscles are selulom functionally develoyed. They pull the anricle in their respertive rlirections. They may lo looked upon as (primitively) dilators of the anral orifice. On the cartilige of the auricle are several rudimentary "intrinsic" museles which may be looked ufom as remints of a constrictor of this orifice.

* See Darwin: The Expression of the Emotions in Man and Animals. 
In the orbital cavity there are six muscles which are attached to and move the eyeball and one muscle (the levator palpebre superioris) which extends into and raises the upper lid (fig. 341). Of the muscles which move the eyeball five arise like the levator of the lid, from the back of the orbit. Four of these, the rectus muscles, are inserted respectively into the superior, inferior, medial and lateral sides of the eyeball and direct the pupil upward, downward, medialward and lateralward. One, the superior oblique, sends a tendon through a loop at the upper, front part of the nasal side of the orbit and thence to the upper surface of the eyeball. Another muscle, the inferior oblique, arises from the nasal side of the front of the lower part of the orbit and is attached to the lower part of the eyeball. The oblique muscles prevent the rectus muscles from rotating the eyeball. These muscles are supplied by the third, fourth and sixth cranial nerves. They are described in the section on the eye, $p$. 1067. In the middle ear are two small muscles (the tensor tympani and the stapedius) attached respectively to the malleus and stapes and supplied by fifth and seventh cranial nerves. They are described in the section on the ear, p. 1091

Mastication and swallowing.-The complex musculature used in biting, masticating and swallowing food is used also in speech in conjunction with the muscles of the larynx and the lips. The two movable bones of the skull concerned with these functions are the mandible and the hyoid bone. The mandible articulates with the skull on each side, just in front of the external auditory meatus. The hyoid bone is connected on each side by the stylo-hyoid ligament with the styloid process of the temporal bone, which descends just behind the external auditory meatus. A powerful group of muscles, the cranio-mandibular muscles (figs. $344,345,346,347 \mathrm{c}$ ), or muscles of mastication, arise from the temporal fossa (temporal muscle), the zygomatic arch (masseter muscle) and the pterygoid process (external and internal pterygoid muscles) and are inserted into the coronoid process of the inandible (temporal muscle), the outer side of the ramus (masseter muscle), the inner side of the ramus (internal pterygoid), and into the condyle of the jaw (external pterygoid). These muscles raise the jaw, move it forward and from side to side, and are used in biting and chewing the food. They are innervated by the fifth cranial (masticator) nerve.

Another less powerful group of muscles, the suprahyoid group (fig. 348), is divisible into two subdivisions, hyo-mandibular which extends in front between the hyoid bone and the ramus of the jaw (anterior belly of the digastric, genio-hyoid, mylo-hyoid) and a hyo-temporal group which extends between the hyoid bone and the temporal bone back of the external auditory meatus (stylo-hyoid, posterior belly of the digastric). Two of the hyo-mandibular muscles (the anterior belly of the digastric and the mylo-hyoid) are innervated by the trigeminal; the genio-hyoid by the hypoglossal nerve. The two hyo-temporal muscles (posterior belly of the digastric and stylo-hyoid) are innervated by the facial nerve. Morphologically therefore, as indicated by this innervation, the muscles of this group are diverse. Physiologically they are closely united. The group, acting as a whole, elevates the hyoid bone and with this the larynx and the tongue. If, however, the hyoid bone be fixed by contraction of the neck muscles (infrahyoid muscles) attached to its lower border, the suprahyoid muscles act as antagonists of the cranio-mandibular muscles and depress the jaw. The hyo-mandibular muscles form, together with the tongue, the muscular floor of the inouth. When acting with the hyo-temporal muscles they help the tongue to pass food into the pharynx. When acting alone the hyo-mandibular muscles draw forward the hyoid bone and with it the base of the tongue and the larynx and thus open the passage from the pharynx into the cesophagus. The two hyo-temporal muscles, acting in conjunction with the middle and inferior constrictors of the pharynx, draw the hyoid bone and larynx backward, as well as upward, and thus constrict the pharynx while giving free passage for air from the naso-pharynx into the larynx. The chief functions of the suprahyoid group are, therefore, to play a part in deglutition and respiration.

Closely associated with the muscles of the suprahyoid group in the performance of these important functions are the muscles of the tongue, the pharynx and the soft palate. The bulk of the tongue (fig. 349) is made up of muscles which have their origin on each side from the inner surface of the front part of the mandible (genio-glossus), the hyoid bone (hyo-glossus and chondro-glossus) and the styloid process of the temporal bone (stylo-glossus). MIuscles also connect the tongue with the palate (glosso-palatinus) and with the pharynx (glosso-pharyngeus). These muscles, together with intrinsic longitudinal, transverse and perpendicular fibre-bundles, enable the tongue to perform the complex activities associated with mastication and swallowing and with speech. During mastication the tongue passes the food from side to side between the teeth. When the food has been masticated the tongue forms a bolus of it and then this is passed into the pharynx by a sudden elevation of the dorsum of the tongue produced in part by the muscles of the tongue, in part by the suprahyoid group of muscles. The muscles of the tongue are described on p. 345 .

The pharynx is the dilated upper part of the alimentary canal into which open the Eustachian tubes, the nasal passages, the mouth and the larynx. The walls of the side and back of the pharynx are composed mainly of muscular tissue. The chief museles are three "constrictor" muscles on each side, a superior, a middle and an inferior, and an elevator and dilator, the stylo-pharyngeus (fig. 894). The ihree constrictor muscles are attached to the median raphe* which extends in front of the spinal column from the base of the occipital bone to the sixth cervical vertebra. The supcrior constrictor muscle is attached to the pterygoid process, the pterygo-mandibular ligament, the mandible and the side of the root of the tongue (fi...34:3); the middle constrictor to the hyoid bone; and the inferior constrictor to the laryn. These muscles constrict the pharyngeal orifice and thus force food into the oesophagus. The stylo-pharyngeal muscle, which extends from the styloid process into the lateral wall of the pharynx, serves to

* The attachments to the raphe are usually spoken of as the insertions, those to the bones in front as the origins of these muscles. The raphe is, however, a more fixed structure than most of the structures to which the constrictors are attached in front. 
elevate and dilate the pharynx and elevate the larynx. The muscles of the pharynx are described on page 11 ist.

The orifices of the various passages into the pharynx are dilated or constricted by muscular action. The orifices of the nasal passages, the Eustachian tubes, and the mouth are controlled mainly by the musculature of the soit palate and pharynx. The orifice of the larynx is controlled by special muscles which act in conjunction with those of the suprabyoid group, the tongue, and the pharynx.

The soft palate is a muscular partition which is continued backward from the hard palate between the buccal eavity and the naso-pharyngeal orifice and then bends downward between the back part of the mouth and the nasal part of the pharynx, terminating in a median projection, the uvula. Above, on each side, back of the fold of tissue (pliea salpingo-palatinus) which descends from the ventral border of the orifice of the Eustachian tube and whieh marks laterally the passage from the nose into the pharynx, there is a muscle, the levator veli palatini (fig. 343 ). This arises from the petrous portion of the temporal bone and from the Eustachian tube descends to the middle of the side of the soft palate and then spreads out broadly on its dorsal side. The musele from each side interdigitates to some extent with that of the other side. These muscles raise the soft palate toward the upper part of the posterior wall of the nasopharynx and thus shut off the nose from the buceal portion of the pharynx during cleglutition. The sides of this portion of the pharynx are, meanwhile, constricted by the superior constrictors of the pharynx and by the pharyno-palatinus muscles deseribed below. Contraction of the levator veli palatini tends to cause folds of tissue to elose firmly the opening of the Eustachian tube. This is counteraeted by the tensor veli palatini museles (fig. 343). One of these arises on each side from the pterygoid region of the sphenoid bone, and is inserted into the anterior part of the soft palate by a tendon which passes beneath the hamular process of the pterygoid process. Contraction of this pair of muscles flattens the anterior part of the soft palate and exerts a traction which dilates the orifice of the Eustachian tube. Most authorities state that the Eustachian tube is thus opened each time we swallow. As air is admitted into the middle ear the tensor tympani muscle contratets so as to prevent too sudden an effect on the ear drum (Jonnes'o.)

Dorsal to the fibres of the elevator of the palate in the soft palate next the median line on each side there extends from the hard palate into the uvula a small muscle, the muscle of the uvula, which lifts the tip of this and shortens the soft palate from front to back thus enlarging the opening from the mouth into the pharynx. On each side of the uvula the posterior edge of the soft palate is continued backward and downward into a fold, the arcus pharyngo-palatinus, which contains a muscle, the pharyngo-palatinus (fig. 865). This arises from the soft palate, passes downward and backward on the inner side of the lateral wall of the pharynx and divides into two fascieuli, onc of which is attached to the larynx, the other to the median raphe. The muscle constriets the pharynx at the junction between the nasal and buceal portions and elevates the larynx. As the bolus of food is passed from the dorsum of the tongue into the pharynx the bucco-pharyngeal opening is dilated by the eontraction of the elevators of the palate and uvvlar muscles and the opening into the naso-pharynx is elosed not only by the soft palate being raiserl against the posterior wall of the naso-pharynx but also by the lateral folds raised on each side by the pharyngo-palatinus against the uvula. Meanwhile the larynx is raised by the pharyngo-palatinus and the stylo-pharyngeus, as well as by the suprahyoid museles, and carried forward by the hyo-mandibular subdivision of the latter muscles so that the opening from the phirynx into the rsophagus is dilated for the passage of food. At the same time the opening into the larynx is constricted from above, the larynx being carried forward beneath the tongue so that the epiglottis slants somewhat backwarl. This backward slant is aided by the constriction of the thyreo-hyoid muscle which raises the thyreoid eartilage toward the hyoid bone and bry the stylo-glossus inuscle which pulls the tongue backward over the larynx. The apening into the larynx is constricted at the sides and behind by the contraction of museles which run in the aryepiglottic folls and by the thyreo-arytenoid and transverse arytenoid musi:les. At the end of deglutition the larynx is pulled back from beneath the base of the tongue by the iniddle and inferior constrictors of the pharynx and the opening is again dilated. The bucral cavity may be shut off from the phitrynx by the action of the museles whieh pass in the glosso-palatal folds from the soft palate to the mouth in front of the tonsils. These glosso-palulal muscles elevate the folds in which they lic, depress the soft palate, and, if the lorsum of the tongue be raised, shut off the buceal eavity. The muscles of the soft palate are described on p. 113.

The uvular muscle, the levator veli palaini, the glosso-palatinus and the pharyngopalatinus muscles are supplied by the pharyngeal plexus. The tensor veli palatini is supplied by the mandibular division of the fifth nerve. The pharyngeal museles are supplied by the glessis-pharyngeal, the vagus, and the spinal aecessory eranial nerves.

The larynx lines in the neck, but since the intrinsic muscles of the larynx from the standpoint of embryology and comparative anatomy belong with the museulature of the head, it is eonvenient to refer to them briefly here rather than to treat of them with the intrinsic muscles of the nerk. $\Lambda$ fill rlescription of the laryngeal muscles is given in the section on the larynx (fig. 981). They develop from tissue, which corresponts with that which in fishes gives rise to the muscles of the gills and are inrervated ly the nerves which in the fishes innervate the gills, the tenth pair (vagus) of cranial nerves. The movements of the laryngeal cartilages are such as to approximate or draw apart the voral corils and to loosen or make them tense. The approximation of the voral cords is prorlured hy the rotation medialward of the vocal processes of the arytenoid cartilages bromght shout hy the latcral crico-arytenoid and tronsverse arytenoid muscles. The drawing atpart if the voral cords is produced by the posterior crico-arytenoids. The voral cords are made long, thin and tense by the crico-thyreoid. They are shortened and thickened by the thyren-arytcnoid (extermus) and the vocalis. 'The inferior laryngeal braneh of 
the vagus supplies all the muscles but the crico-thyreoid. This is supplied by the superior laryngeal branch of the vagus.

Metamerism.-The muscles thus far considered are essentially visceral muscles, althongh all are composed of striated muscle cells and all are more or less directly under the control of the will. From the morphological standpoint the muscles of the orbit, the tensor tympani, the muscles of mastication, the hyo-mandibular muscles and the muscles of the tongue have been grouped with the ordinary voluntary skeletal muscles while the facialis musculature, the stapedius, the hyo-temporal muscles and the muscles of the soft palate, pharynx and laryux are looked upon as of a more purely visceral origin. A primitive characteristic of the voluntary skeletal muscles is metameric segmentation. This is maintained through life in the trunk musculature of fishes and of tailed amphibia and is passed through as a temporary stage in all the higher vertebrates. The embryonic segmented muscles are called myotomes (see fig. 340). In some regions the metamerism is retained throughout life even in the higher forms, as, for instance, in the intercostal muscles and the intertransverse muscles. But for the most part the primitive metamerism is so lost during the differentiation of the definitive truuk musculature that only traces of it remain here and there as, for instance, in the segments of the rectus abdominis muscle. In the lower forms the myotomes give rise during embryonic development to material utilized in the formation of the limb musculature, but even in the fishes all traces of trunk metamerism are lost in the differentiated limb musculature and in the higher forms, as in man, the limb musculature appears to differentiate directly from the unsegmented tissue in the limb-buds. In the head the musculature is differentiated directly, as in the limbs, without undergoing a preliminary metameric or myotomic stage. Attempts have been made to show that in primitive forms the cranial voluntary skeletal musculature, in the narrower morphological sense mentioned above, passes through a metameric stage comparable with the myotomic metamerism of the trunk. This attempt has been partially successful as regards the development of the muscles of the eve in some of the lower forms. There is also good evidence that the spinal region of the skull and associated structures represent a part of the metameric trunk fused with a more primitive head so that the musculature of the tongue and the hyo-mandibular muscles belongs morphologically with the primitively metameric trunk musculature. The rest of the cranial musculature gives little evidence of a primitive metameric segmentation and hence is probably to be classed morphologically with the unsegmented visceral musculature.

Of the muscles of the neck, the most superficial, the platysma (fig. 341), is a subcutaneous muscle belonging to the facialis group of the head from which it grows down during enbryonic development. It is supplied by the seventh cranial (facial) nerve. It extends from the corner of the mouth and the side of the mandible over the clavicle. It depresses the corner of the mouth, wrinkles up the skin of the neck and aids the circulation by relieving pressure on the underlying veins.

Beneath the platysma there lies a layer composed of two flat muscles (fig. 314) which extend from the base of the skull behind the ear to the shoulder girdle. One of these muscles, the sterno-cleido-mastoid, arises in front from the sternum and clavicle and is inserted into the mastoid process of the temporal bone and the skull behind this. The other, the trapezius, arises from the base of the skull, and from the ligamentum nuchæ and vertebral spines of the cervical and thoracic regions, and is inserted into the spine of the scapula, the acromion and the lateral third of the clavicle. These two muscles constitute the superficial shoulder-girdle musculature. They extend the head, bend it toward the same side and rotate it toward the opposite side. The sterno-cleido-mastoid and the upper part of the trapezius raise the shoulder girdle and thorax and hence are of use in forced inspiration. The trapezius draws the scapula toward the spine and rotates the inferior angle of the scapula lateralward. The lower part of the trapezius acting alone draws the scapula downward and dorsalward while rotating the inferior angle lateralward. The trapezius is therefore used when the arm is raised high or carried backward. The two muscles of this group are innervated partly by the spinal accessory, and partly by the ventral divisions of the second, third and fourth cranial nerves. They represent in part musculature which in the lower vertebrates is associated with the visceral musculature of the gills (hence the innervation by the spinal accessory, a derivative of the vagus nerve) and in part metameric musculature of the second, third, and fourth cervical segments. During embryonic development this musculature therefore spreads out widely from its origin, the upper cervical region. The lower part of the trapezius varies greatly in the extent of its development caudalward. It may reach only half way down the thoracic region or it may extend into the lumbar region. The deeper musculature of the neck is derived from the cervical myotomes.

The primitive segmental musculature of the neck, like that of the whole trunk, becomes divided at an early embryonic stage into two divisions, a dorsal, supplied by the dorsal divisions of the spinal nerves, and a ventro-lateral supplied by the ventral divisions. The trapezius, although it covers the intrinsic dorsal musculature of the cervical region, insofar as it is of cervical origin, belongs to the ventro-lateral musculature and is derived, apparently, from the first three cervical myotomes. There is also a deeper layer of muscles attached to the shoulder girdle which arise from the ventro-lateral divisions of the lower five or six cervical myotomes but which, with one exception, the levator scapule (fig. 353), wander over the thorax during embryonic development. This group is described below as the deep shoulder-girdle musculature. The rest of the muscles derived from the ventro-lateral divisions of the cervical myotomes are divisible into three groups, the infra-hyoid, the scalene and the prevertebral.

The infra-hyoid group lies at the front of the neck, superficial to the larynx and trachea (fig. 348), and is composed of four flat muscles, the sterno-hyoid, sterno-thyreoid, thyreo-hyoid and omo-hyoid (scapulo-hyoid), the names of which indicate the origin and insertion. The chief function of this group of muscles is to depress the hyoid bone, the larynx and the associated structures. When the supra-hyoid group of muscles contracts at the same time, the infra-hyoid muscles help to depress the lower jaw, or if this in turn is fixed by the cranio-mandibular group, to flex the head. The muscles of this group are derived from the ventral portions 
of the first three cervical myotomes and are innervated by the first three cervical nerves through the ansa hypogloss:. The primitive segmental origin of these muscles is frequently indicated by transverse tendons (inscriptiones tendineæ). They correspond morphologically with the rectus abdominis nusculature.

The scalene group (fig. 352) lies at the side of the neck and extends to the first and second ribs from the transverse processes of the lower six cervical vertebræ. The muscles of this group bend the neck toward the side, or if the neck be fixed, elevate the thorax. They come from the lateral parts of the ventro-lateral divisions of the lower five cervical myotomes and are innervated by the lower five cervical nerves. They correspond morphologically with the intercostal and with the lateral abdominal musculature.

The prevertebral group lies back of the pharynx and osophagus and in front of the bodies and transverse processes of the cervical veltebra. The muscles of this group arise not only: from the transverse processes and bodies of the cervical vertebre, but also in part from the bodies of the first three thoracic vertebræ and are inserted in part into the cervical vertebræ (longus colli) and in part into the base of the occipital bone (longus capitis). This musculature flexes the neck and the head. When acting on one side it rotates the liead toward the same sitle. It is innervated by the first six cervical nerves.

The deep shoulder-girdle musculature.-This becomes differentiated from the ventro-lateral divisions of the lower five or six cervical myotomes. Like the muscles of the superficial layer those of the deeper layer spread out widely from their origin. There are four muscles in the deeper group, all of which become attached to the dorsal border of the scapula. Of these, one, the levator scapula (fig. 353), remains in the cervical region, extending from the upper cervical transverse processes to the medial angle of the scapula. Two, the rhomboids (fig. 353), extend over the intrinsic dorsal nusculature and are attached to the upper thoracic and lower cervical vertebral spines; while the fourth, the serratus anterior (fig. 354), extends over the side of the upper part of the thorax beneath the scapula and is attached to the first nine ribs. These muscles all, however, through their innervation, reveal in the adult their primitive cervical origin. They are supplied by branches from the third to the seventh cervical nerves. The levator scapula elevates the scapula, the rhomboid muscles retract it and the serratus anterior draws it forward. The levator and rhomboid muscles rotate the shoulder girdle so as to depress the shoulder, the serratus anterior, like the trapezius, rotates it so as to raise the shoulder. The two former muscles are an aid in extending the arm, the latter in flexing and abducting it. When the group, as a whole, contracts action is exerted on the ribs so that the group is of use in forced inspiration.

The intrinsic dorsal musculature of the neck, innervated by the dorsal divisions of the cervical nerves, is separated from the scalene muscles by the levator scapulie. Dorsally it is covered by the trapezius and the rhomboid muscles. It is to be looked upon as a specialized portion of the system of intrinsic dorsal muscles which extend from the sacrum to the base of the skull on each side of the vertebral column. The primary function of this muscle system is to extend and to rotate the spine and the skull. In the thoracic region three main subdivisions may be recognised, a lateral, the ilio-costal; an intermediate, the longissimus; and a medial, the transverse-spinal group (fig. 381). In the cervical region these three groups may likewise be recogni-ed and, in addition, there is a superficial group, the splcnius (fig. 380), not represented in the lower thoracic region. The splenius arises from the upper thoracic and lower cervicla spines and is inserted into the transverse processes of the upper cervical vertebra and into the mastoid processes of the temporal bone and the neighbouring part of the occipital. It acts with the sterno-cleido-mastoid, by which it is crossed siear the head, in extending the head, bending it toward the side, but tends to rotate it foward the same side instead of toward the opposite side. Literally beneath the splenius the ilio-costalis rrvicis extends from the upper part of the thorax to the transverse processes of the sixth to the fourth rervical vertebre, and the longissimus cervicis and capitis extend from the same region to the transverse processes of the mid-cervical vertebra and to the mastoid process of the temporal bone (fig. 381). These muscles likewise extend and henl the head and neek laterally and rotate it toward the same side. Medially on each sicle the strong semispinalis capitis (fig. 381), arises from the upper thoracie and the lower cervical verteline, spreads out and is inserted into the squamous portion of the ureipital bone. It is a powerful extensor of the head. Beneath it numerous fasciculi extend from the transverse proceses to the spines of the cervical vertehre. These fasciculi, the more superficial of which are the lon est, constitute the scmispinales cervicis, multifidus, and rotatores museles. They extend and rotate the neck.

Between the sucessive spines and the transverse process there are short muscles (inter-

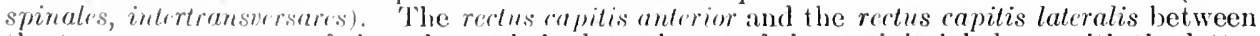
the trasserse poress of the atlas and the lateral part of the occipital belong with the latter series.

Between the bave of the skll bohind and the first two vertebra there are four deep-seated specialized mmseles whinh ronstitute the suboccipital group (fig. 382). The rectus capitis posterior mojor and minne sperad ont respectively from the spines of the atlas and epistropheus and are inserted hereath the inforior muchal line of the ofecipital. The obliques capitis inferior arises from the spino of the eristmophens and is inserted into the transverse process of the atlas; the oblinums copilis suprior arios from this and is inserted into the lateral part of the

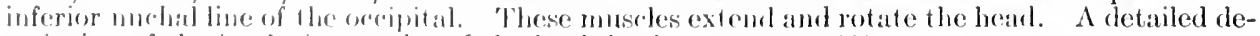
scriftion of the intrinsis monseles of the hack is given on page 410.

'The muscle fascia in the luarl and neck are well developed in comnection with most of

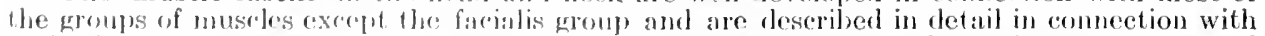
rach of these gromps. In the hearl we maty here call atiention merely to the dense temporal fiscia which ervers over thr: comporal fossa and hirles from view the temporal muscle. In the reck the fascis are of romiderable prantical importance. It is convenient to think of them as divisithe into several lavers although the varins layers fuse to some extent. 'The external layer (fig. 350) may be looked upon as completely ensheathing the neck and as dividing on each 
side into two layers which ensheath the sterno-cleido-mastoid and trapezius muscles. As a free fascia it is attached to the lower jaw, to the clavicle and sternum, and to the hyois bone which divides it into a submaxillary and an infra-hyoid portion. It is connected with the fibrous sheath of the parotid and submaxillary glands. The middle layer of cervical fascia is composed of two laminæ, one extending between the sterno-hyoid and omo-hyoid and another more delicate one beneath this, ensheathing the thyreo-hyoid and sterno-thyreoid muscles and fused with the fibrous sheath which encloses the carotid artery, internal jugular vein and the vagus nerve. The deeper muscles of the side and front of the neck and the intrinsic muscles of the back of the neck are likewise ensheathed by muscle fasciæ.

Of the various groups of muscles mentioned above, some, for the sake of convenience, are treated in connection with the organs to which they belong. Thus the muscles of the eye and ear are taken up in section VIII; those of the palate, pharynx and larynx in Sections IX and $\mathrm{X}$; the deep dorsal musculature of the neck will be taken up in the section on the intrinsic muscles of the back, p. 410, The remaining groups of muscles will be taken up in the following order:-
1. The facial group p. 329.
2. The cranio-mandibular group p. 338.
3. The supra-hyoid musculature p. 343 .
4. The muscles of the tongue p. 345 .
5. The superficial shoulder-girdle musculature p. 347 .
6. The infra-hyoid musculature p. 350 .
7. The scalene musculature p. 353 .
8. The prevertebral musculature p. 355 .
9. Anterior and lateral intertransverse muscles p. 356.
10. Deep musculature of the shoulder girdle p. $356 *^{*}$

\section{THE FACIALIS MUSCULATURE}

$$
\text { (Figs. 341, 344) }
$$

The muscles of this group are intimately connected with the scalp, with the skin of the face and neck, and with the mucous membrane lining the lips and the cheeks. Most of the muscles have an osseous origin and a cutaneous insertion, but there are exceptions. Both origin and insertion may be cutaneous, or the attachment may be to an aponeurosis instead of directly to the skin. The deeper musculature about the mouth is attached to the mucous membrane.

The muscles are composed of interdigitating muscle-fibres which are grouped in bundles that take a nearly parallel or slightly converging course and give rise to thin muscle-sheets. The extent of development of the various muscles of the group and their independence varies greatly in different individuals.

The region from which the facial musculature originates in the embryo is, in the main at least, that of the hyoid arch immediately below the ear. From here the musculature spreads with the development of the facial nerve, dorsally to the occipital region behind the ear, distally over the neck, ventrally over the face, and upward toward the eye, forehead, and the side of the skull. The course of the development is indicated by the branches of the facial nerve. A somewhat similar phylogenetic development is indicated by conditions found in the inferior mammals and lower vertebrates. According to Ruge and Gegenbaur, the facial musculature is to be looked upon as derived from two muscle-sheets, of which in man the deeper has disappeared in the region of the neck while it is differentiated into the deeper facial muscles in the region of the head. The deeper layer of transverse fibres in the neck, the sphincter colli, is found in several of the mammals. The complex development of the facial muscles in man is characteristic of the human species, and is associated with the use of these muscles as a means of expression of the emotions, a physiological function superadded to the primitive function of opening and closing visceral orifices. There is much individual variation in the differentiation of the muscles.

Fasciæ.- The skin of the head and neck is, in most regions, firmly fused with the tela subcutanea. This is composed of a dense fibrous tissue united by a looser areolar tissue to the underlying structures. But a slight amount of fat is embedded in the subcutaneous tissue of the scalp, forehead, and nose. Considerable fat nay be embedded in the region of the cheelis, the back of the neck, and the under surface of the chin (double chin). The constantly repeated action of various muscles of the facialis group usually results by middle hife in the production of permanent wrinkles due to alterations in the structure of the tela subcutanea and the cutis.

The subcutaneous muscles of the cranial vault and the neck are invested with fascial membranes. That covering the cranial musculature externally is firmly fused to the subcutane-

* The pectoral muscles and the latissimus dorsi, which extend from the skeleton of the limb to the front and side of the thorax and the lower part of the back, arise from the limb-bud diring embryonic development, are innervated through the brachial plexus, and will, therefore, be taken up in considering the intrinsic musculature of the upper limb, p. 360. 
ous tissue of the scalp. That covering the subcutaneous muscle of the neck is less firmly fused with the subcutaneous tissue. In the facial region the more superficial muscles are so closely embedded in the subcutaneous tissue that no distinct fascia intervening between the muscles and the skin can as a rule, he distinguishel. Of the leeper muscles of the facialis group, the buccinator alone possesses a distinct fascia. This muscle lies upon the mucous membrane of the lateral wall of the mouth, and is covered externally by a fascia continued into the fascia investing the superior constrictor of the pharynx.

Bursæ.-Bursa subcutanea prementalis. Between the periosteum at the tip of the chin and the overlying tissue. Bursa subcutanea prominentiæ laryngeæ. In front of the junction of the right and left lamine of the thyreoid cartilage.

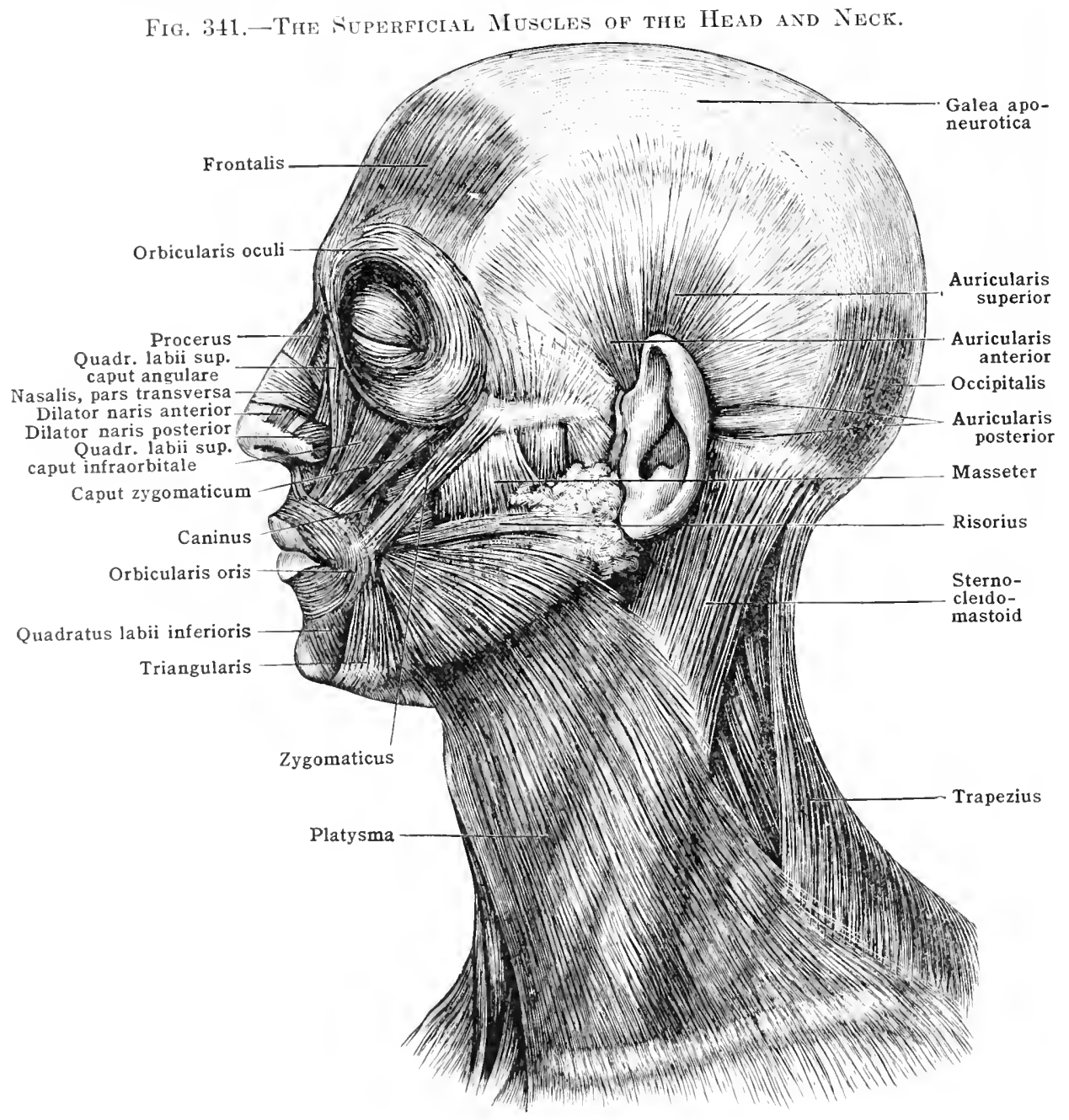

\section{MUSC'LLS'}

Themuseles of the fatcialis gromp may be eonveniently sublivided as follows:-

(a) Cervical: the platysmil. (b) Oral: the orbiculiris oris and the incisivus labii superistis and inferioris; the (puadratus labii superioris and inferioris; the "aninus, zygomaticus, risoriss, and triangularis; and the buecinator. $(c)$ Mental. (d) Nasal: the nasidis, depressor septi, and the dilatores naris. (e) Periorbital: the orthicularis oculi, corrugator, and procerus. $(f)$ Epicranial : the frontalis and oncipitalis, with the gatea aponemotica. (g) Auricular: anterior, smperior, and posterior. With these the temporalis superficialis is also deseribed.

\section{(a) C'ERVIC AL, MLSCLE}

The platysma is a large, thin, (fuaclangulatr muscle which runs obliquely from the chin, the cornor of the month, and the lower part of the check across the 
mandible and the neck to the proximal part of the thorax and shoulder. The muscles of each side interdigitate across the chin. A short distance below the chin, in the neck, the ventral margins diverge (fig. 341).

Origin.-From the tela subcutanea by somewhat seattered bundles-(1) along a line extending from the cartilage of the second rib to the acromion, and (2) along the dorsal niargin of the muscle.

Insertion.-Into-(1) the mental protuberance of the mandible and the inferior margin of the mandible; and (2) into the skin of the lower part of the cheek and at the corner of the mouth, where it fuses more or less with the quadratus labii inferioris and the orbicularis oris.

Nerve-supply. - The cervical branch (ramus colli) of the seventh cranial nerve forms beneath the muscle a plexus to which the cutaneus colli nerve contributes sensory branches.

Relations.-The muscle is situated beneat h the panniculus adiposus, to which in the neck it is not very firmly attached. For the most part it is separated from the external layer of the cervical fascia by loose areolar tissue. The main cutaneous rami of the cervical plexus and the external jugular vein lie beneath the muscle.

Action.-It wrinkles up the skin of the neck, depresses the corner of the mouth, and thus plays a part in expression of sadness, fright, and suffering. It aids the circulation by relieving pressure on the underlying veins.

Variations.-Either the facial or the distal development of the muscle may be more extensive than that described above. On the other hand, it may be less developed than usual, and rarely it is absent. Accessory slips have been seen going to the zygoma, the auricle, or the mastoid process, etc., and to the clavicle and sternum. Rarely a deep transverse layer is found in man.

Fig. 342.-Diagrair to Illustrate the Architecture of the Orbicularis Oris. (After T. D. Thane.)

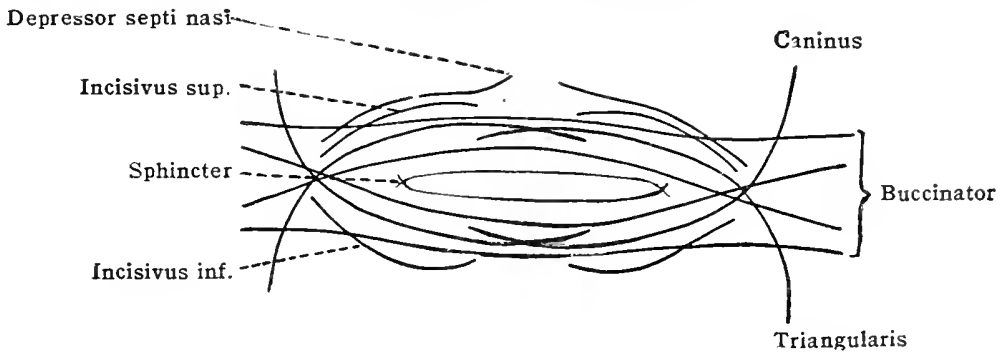

\section{(b) ORAL MUSCLES}

The muscles of the mouth belonging to the facialis system include several intralabial muscles:- a sphincter, the orbicularis oris; a transverse, the compressor labii; and four deep submucous muscles which pass from the sides of the lips to the alveolar juga of the upper canine and lower lateral incisor teeth, the incisivi labii superioris and inferioris. From each corner of the mouth there radiate out several muscles; the caninus and zygomaticus upward to the maxilla and zygomatic bone; the risorius lateralward over the cheek; the platysma and the triangularis downward over the side of the jaw; and the buccinator, lateralward over the side of the oral cavity. From each of these fibre-bundles are continued into the more peripheral and superficial portions of the orbicularis. In addition to these muscles there are two retractors or quadrate muscles, one of which, the quadratus labii superioris, extends from the upper lip medial to the angle to the bridge of the nose, the lower margin of the orbit, and the zygomatic bone; while the other, the quadratus labii inferioris, extends from a corresponding position in the lower lip to the side of the chin. The orbicularis oris. compressor labii, and incisive muscles close the lips; the other muscles open them and pull them in various clirections. The buccinator, however, plays a part in the closing of the mouth by offering support for the orbicularis.

\section{Intralabial Múscles}

The orbicularis oris (figs. $308,341,342,343$ ) is a complex muscle which surrounds the oral orifice and forms the chief intrinsic museulature of the lips. Immediately about the orifice, and on the deep surface of the muscle, is a fairly well-defined sphincter, although at the corners of the mouth the fibre-bundles of one lip cross those of the other and are inserted into the mucosa, and to a less extent into the skin. In the mid-line the fibre-bundles end partly in the perimysium, partly in the skin. About this sphincter area and between its outer margin and 
the skin is a complex musculature comprised partly of fibre-bundles prolonged from the muscles which radiate from the corners of the mouth. The more superficial portion of the muscle in the upper lip is composed of fibre-bundles from the triangularis (depressor anguli oris), the more superficial portion of that in the lower lip by fibre-bundles from the canimus (levator anguli oris). These fibre-bundles form commissures at the angles of the mouth and extend toward the median line, where many of them interdigitate with those of the opposite side, and are attached to the skin of the lips. The deeper portions are partly formed by fibre-bundles prolonged from the buccinator, the mandibular fibre-bundles of the latter muscle going mainly to the upper lip, the maxillary fibre-bundles mainly to the lower lip. These fibre-bundles are attached chiefly to the mucosa, near the corners of the mouth.

The compressor labii, or muscle of Klein, is composed of bundles of fibres which take a course transverse to those of the orbicularis, and pass obliquely from the skin surrounding the oral orifice toward the mucosa which bounds its inner margin. It is said to be best marked in infants.

The incisivus labii superioris is a small musele-bundle which passes from the alveolar jugum of the upper canine tooth to the back of the orbicularis near the corner of the mouth.

The incisivus labii inferioris passes similarly from the alveolar jugum of the lower lateral incisor tooth to the back of the orbicularis in the lower lip.

Terve-supply.-These muscles are supplied by the buceal branches of the facial nerve which enter the orbicularis on the lateral border.

Relations.-The main mass of intrinsic musculature of the lips is placed slightly nearer the mucosa than the skin. On its deep surfar e lie the labial arteries.

Action.-The orbicularis draws the upper lip downward, the lower lip upward. The incisive muscles draw the corners of the lips medialward, and the compressor flattens the lips. Together they serve to close the mouth. Acting separately they may draw different parts of it in the directions indicated by their structure. The circumferential portion of the orbicularis acting with the incisive muscles makes the lips protrude. The central portion of the orbicularis draws the lips together, and when the buccinator also acts, draws them against the teeth. It is this portion of the muscle that has chiefly to do with nutritive functions. The more peripheral parts of the musele are chiefly utilised in the expression of the emotions.

\section{Retractors of the Lips or Quadrate Muscles}

(Fig. 341)

The quadratus labii superioris is a thin, quadrangular muscle with three heads, all of which are inserted into the skin and musculature of the upper lip.

The caput zygomaticum (zygomaticus minor) is long and slender and arises from the lower part of the external surface of the zygomatic bone beneath the lower border of the palpebral portion of the orbicularis oculi. It passes obliquely forward over the caninus and orbicularis oris muscles, and extends to a cutaneous and muscular insertion in the upper lip medial to the corner of the mouth. It lies medial to the zygomaticus.

The caput infraorbitale (levator labii superioris), a broad, flat muscle, arises from the infraorbital margin of the maxilla, where it is concealed by the orbicularis oculi. It extends obliquely forwarl over the caninus and beneath the caput angulare to the skin and musculature of the lateral half of the upper lip.

'The caput angulare (levator labii superioris alæque nasi) arises from the root of the nose, where it is fused with the frontalis. As it descends it divides into two fasciculi, one of which is attached to the skin and the alar cartilage of the nose; the other passes obliquely downward over the caput infraorbitale to the skin and musculature of the lateral half of the upper lip.

Vroe-supply.-The zygomatic ramus of the seventh nerve sends branches to enter the deep surface of each of the divisions of the muscle.

1 ctions. - It raises the lateral half of the upper lip and the wing of the nose. It is of value in inspiration, serves to express the emotion of discontent, and comes into play in violent weeping.

Irariations. The caput zygomaticum is often absent. It may be fused with the zygomaticus (najor). It may be doubled. Its origin may extend to neighbouring struetures. The other louts, though more stable, vary considerably, especially in the extent of their fusion with neighbouring museles.

The quadratus labii inferioris (depressor labii inferioris) is a thin, rhomboid muscle which arises lodow the canine and licuspid tecth from the base of the mandible, between the mental protuleranceand the mental formen, and extends obliquely upward in a medial direction to the orticularis oris, throwgh which its fibre-bundles pass. Its more medial fibres cross at their insertion with those of the nuscle of the other side. It is attached to the skin and mucosa of the lower lip. It jis coscontially a part of the platysma, and is superficially united to the skin except where coscued l,y the triangularis (depressol anguli oris). It croses the mental vessels and uerves and a part if the mentalis (levator menti).

Nerve-supply.- The mandibular branch of the facial sends twigs into its deep surface near the laterial buriler.

Action.- If draws down and crerts the lower lip. It is an antagonist of the mentalis (levator menti). It hays a pant in the exprossion of teror, irony, great anger, and similar enotions.

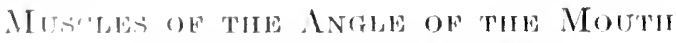

$$
\begin{aligned}
& \text { (lig. 311, 312,314, 315) }
\end{aligned}
$$

The caninus (Jevator angmli oris) is a flat, guadrilatcral muscle which arises from the canine fossa of the maxilla and runs beneath the qualdatus (levator) habii superioris to the corner of 
the mouth, where it becomes attached to the skin and sends some fasciculi into the orbicularis of the lower lip. Between the caninus and the quadratus labii superioris there is a certain amount of fatty areolar tissue through which the infraorbital vessels and nerves run. Its deep surface extends over the canine fossa, the buccinator muscle, and the mucosa of the lip. The external maxillary (facial) artery passes over its inferior extremity,

The zygomaticus (z. major) is a long, ribbon-shaped muscle which arises by short tenclinous processes from the zygomatic bone near the temporal suture under cover of the orbicularis oculi. It passes obliquely to the corner of the mouth, where it is attached to the skin and mucosa. The body of the muscle is subcutaneous and is usually surrounded by fat. It crosses the masseter and buccinator muscles and the anterior facial vein.

The risorius is a thin, triangular, subcutaneous muscle which extends across the middle of the cheek and lies in a more superficial plane than the platysma, with which it is of ten fused. It arises from the tela subcutanea above the parotid fascia. Its fibres converge across the masseter muscle toward the angle of the mouth and are attached to the skin and mucosa in this vicinity. It lies above the anterior facial vein and external maxillary artery.

The platysma has been described ahove.

The triangularis (depressor anguli oris) is a broar, flat, well-developed, subcutaneous muscle which arises from the base and external surface of the body of the mandible below the canine, bieuspid, and first molar teeth. From here its fibres converge toward the corner of the mouth, where they are in part inserted into the skin and in part are continued into the orbicularis oris of the upper lip. It overlies the buccinator and the quadratus (depressor) labii inferioris muscles. Not infrequently ( 58 out of 92 bodies--LeDouble) some fasciculi are continued into

Fig. 343. (After Eisler.) Buccinator Muscle and Pterygomandibular Raphe, As SEEN FroM THE BUCCAL SIDE.

The alveolar processes of both jaws have been removed in the region of the molar teeth. The soft palate and its muscles have been removed

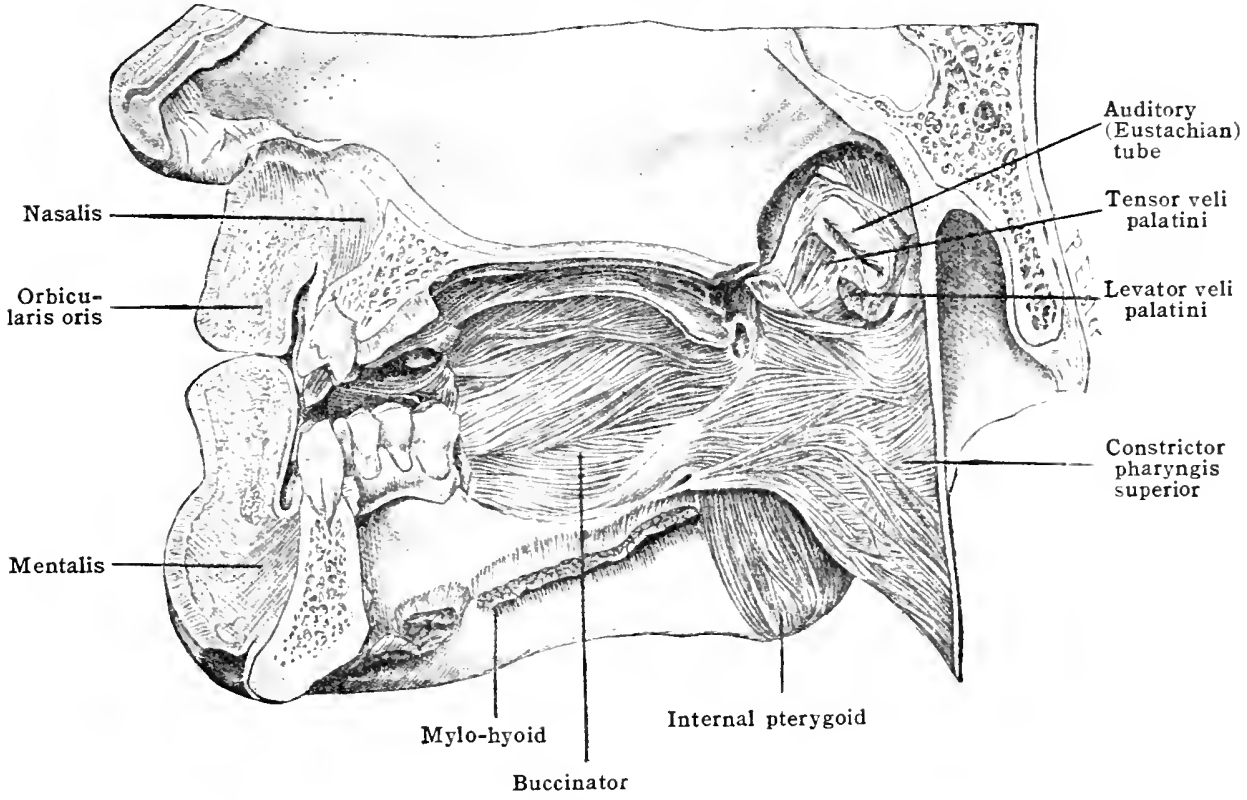

the neck as the transversus menti, a fibro-muscular band formed by the interdigitation of the slips prolonged from each side below the chin and superficial to the platysma. Santorini described the transversus menti as an independent though inconstant muscle. According to Eisler the true transversus menti muscle is to be distinguished from aberrent slips of the triangularis or of the platysma in this region. In one instance Eisler found a slender nerve emerging through the platysma and passing to this muscle.

Nerve-supply. - The zygomatic branch of the seventh nerve supplies the canine (levator anguli oris) and zygomatic (major) muscles. Branches enter the middle of the deep surface of the latter muscle and the superficial surface of the former near its lateral horier. The risorius is supplied by branches from the buccal rami of the seventh nerve, which enter its deep surface. The triangularis (depressor anguli oris) is supplied by the buccal branch through branches which enter its deep surface near the posterior margin.

Action.-The caninus (levator anguli oris) and zygomatic (z. major) museles raise the coruer of the mouth, the former at the same time drawing it medially, the latter, laterally. The caninus gives rise to expression of bitterness or menace. The zygomaticus is active in smiling or laughing. When contracted greatly it elevates the cheek and the lower eyelid and produces crow's-foot wrinkles at the corner of the eye. The risorius draws the angle of the mouth laterally. In spite of its name it is not used to express pleasure, but instead gives rise to an expression of pain. The triangularis (depressor anguli oris) depresses the corner of the mouth and draws it laterally, giving rise to the expression of grief. 
Tariations.-The risorius is very inconstant in its development, and in its relations to neighbouring musrles, and is not infrequently quite small. The zy gomaticus is rarely absent Its origin may extend to the temporal or masseteric fascix. It may be doubled throughout its length or at one extremity. Frequently the triangularis is divided into three fasciculi.

The buccinator (fig. 343) arises from-(1) the molar portion of the alveolar process of the maxilla; (2) the buccinator crest of the mandible, and (3) the pterygo-mandibular raphe of the bucco-pharyngeal fascia. This narrow fibrous band, which separates the buccinator from the superior constrictor of the pharynx, extends from the pterygoid hamulus to the buccinator crest of the mandible. The fibre-bundles are divisible into four sets. The most cranial extend directly into the orbicularis of the upper lip. The next pass through the commissure at the corner of the lips into the orbicular is of the lower lip; the third through the commissure into the orbicularis of the upper lip, and the fourth directly into the orbicularis of the lower lip. The muscle is attached chiefly to the mucosa of the lips near the angle of the mouth. Some fibrebundles extend to the more medial portion of the mucosa and some through the orbicularis to the skin.

Nerve-supply.-By the buccal branch of the facial nerve through filaments which enter the posterior half of its outer surface.

Relations. - The muscle is covered externally by the thin bucco-pharyngeal fascia; internally by the mucosa of the mouth. Above its onter surface lie the zygomatic (z. major), risorius, and masseter muscles. Between the last and the buccinator lies a large pad of fat (the buccal fat pad). The parotid duct passes forward over the muscle, and slightly in front of its centre pierces it and passes into the mouth. It is crossed by the external maxillary (facial) artery and anterior facial vein and by the buccal artery and nerve.

Actions.-It draws the corner of the mouth laterally, pulls the lips against the teeth, and flattens the cheek. It is of use in mastication, swallowing, whistling, and blowing windinstruments.

Variations.-Occasionally it consists of two laminx, a condition found in many mammals. It may be continuous in part with the superior constrictor of the pharynx, as in the eat.

\section{(c) MENTAL MUSCLE}

The mentalis (levator menti) (fig. 343) is a short, thick muscle which arises from the alveolar jugum of the lower lateral incisor tooth and the neighbouring region of the mandible under cover of the quadratus (depressor) labii inferioris and beneath the oral mucosa, where this is reflecterl from the lips to the gums. It extends to the chin, where it is fused with the muscle of the opposite side and is attached to the skin of the chin.

Nere-supply.- The mandibular branch of the seventh nerve sends terminal twigs into this muscle.

Actions.-It draws up the skin of the chin and thus indirectly causes the lower lip to protrude. It is of use in articulation, in forcing bits of food from between the gums, and in the expression of various emotions (musele of pride).

Variations.- It varies greatly in size and generally is fused with the platysma.

\section{(d) NASAL MUSCLES}

$$
\text { (Figs. } 341 \text { and 344) }
$$

Toward the nasal apertures several muscles converge. Those extending from above elevate and dilate, those from below depress and contract, the nostrils. To the former belongs the pars transversa of the nasalis (compressor naris), a triangular muscle extending from the bridge of the nose to the naso-labial sulcus; the caput angulare of the quadratus labii superioris (levator labii superioris alieque nasi), which arises from the root of the nose and sends a fasciculus to the wing of the nose; and the dilatores naris, described helow; to the latter, the pars alaris of the nasalis (depressor ala nasi), which extends from the alveolar juga of the upper lateral incisor and canine tecth to the dorsal margin of the nostril; and the small depressor septi nasi.

The nasalis comsists of tivo parts, the pars trinsversa and the pars alaris. The pars transversa (compressor naris) is triangular. It lies on the side of the nose above the wing. Its fihre-fumbles arise from anl aponcurosis which overlies the bridge of the nose, is adherent to the skin, and is unt elosely at tached to the nuderlying cartilage. From this aponenrosis the fibrebundles eonverge foward the back of the wing, where they are attached to the skin along the line which separates the wing from the check (naso-labial suleus). Its insertion is covered by the nasal process of the raput angulare (levator lal,ii superioris alerque nasi) of the quadratus lathii superioris (p. 3:?':2), with which its filmes interdigitate. An attachnent (origin) is also described by many as laking place in the lower part of the eanine fossa of the maxilla.

Tho pars alaris (foproson ala nasi) (fig. 313 ), is a small quadrangular muscle situated below the aperture of the nose, lestween this and the alveolar portion of the maxilla. It is covered by the mueosa of the gunn, by the orticularis oris and the enadratus (levator) labii superioris, and latcrally is fased with the jurs transwersa (compressor maris). It arises from the alveolar juga of the litteral incisor and the canime taeth. Its fibre-bumlles extend vertically to the skin of the dorsal margin of the nostril, from the elorsal bart of the cartilage of the wing to the septum

The depressor septi is a flat, triangulat muscle which extends from the orbicularis oris to the lower relge of the nisal septum. It may arise from the jugmm alveolare of the medial incisor. 
The dilator naris posterior is a thin, triangular muscle which lies on the side of the wing of the nose. It arises from the skin of the naso-labial groove and is attached to the inferior border of the wing of the nose.

The dilator naris anterior is a very small, thin muscle which runs from the lower margin of the cartilage at the front of the wing of the nose to the skin. It is not usually clearly marked.

Nerve-supply. - The muscles of this group are supplied by the infra-orbital and buccal branches of the facial nerve.

Actions.-The transverse portion of the nasalis (compressor naris) acts with the angular head (levator labii superioris aleque nasi) of the quadratus labii superioris in drawing lateral-

Fig. 344.-The Deeper Muscles of the Face and Neck.

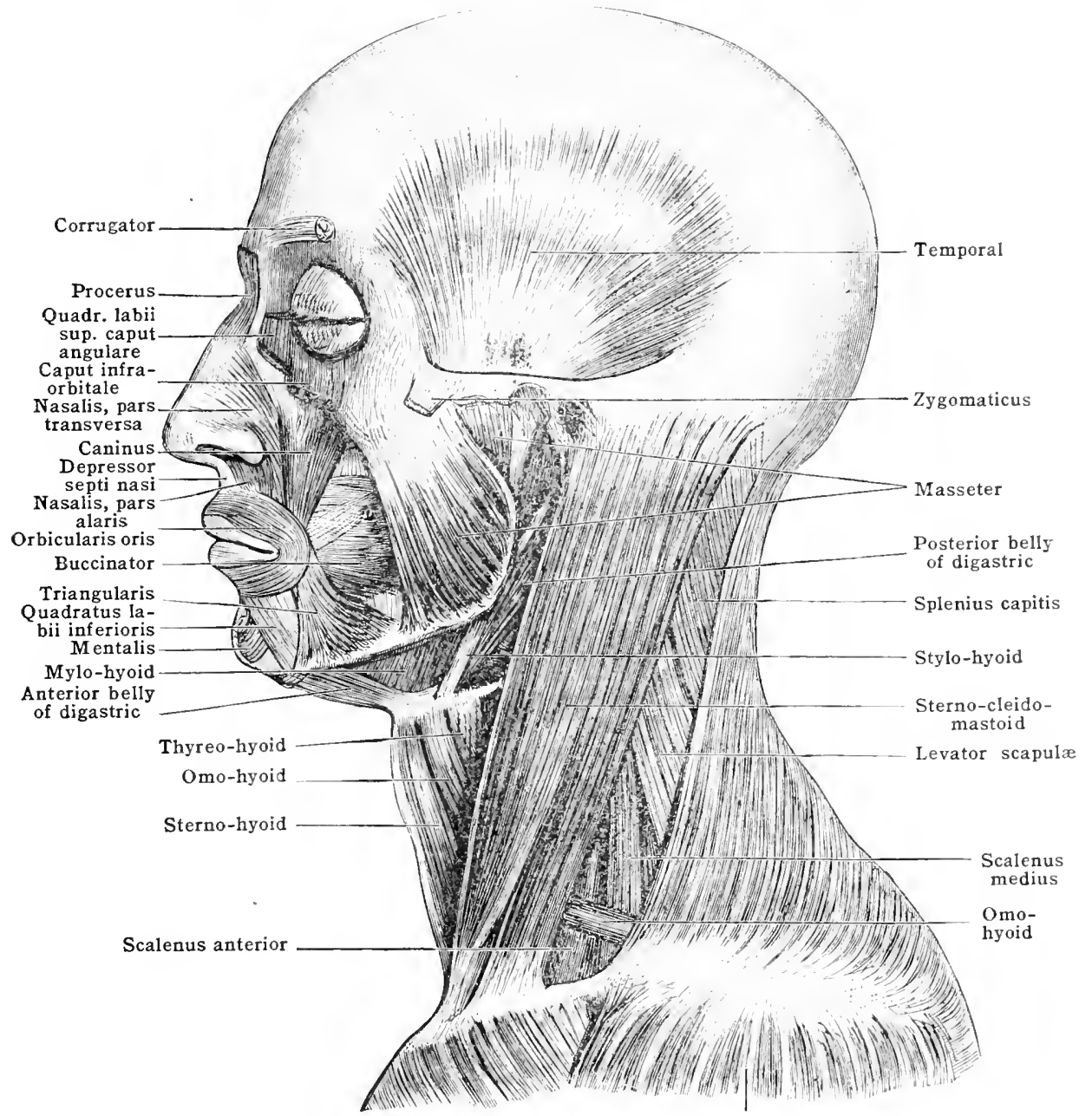

ward and up the lateral margin of the wings of the nose, and gives rise to the expression of sensuality. (Poirier.) This accords with the electrical experiments of Duchenne. However, acting in conjunction with the alar portion, the transverse portion of the nasalis may constrict the nostrils. The alar portion (depressor alæ nasi) of the nasalis and the depressor septi nasi draw down the nostril. The former tends to contract it from side to side, the latter from front to back, and at the same time to depress the tip of the nose. They play a part in the expression of anger and of pain. The functions of the other muscles are indicated by their names.

Variations.-The muscles of the nose vary considerably in extent of development, and one or more may be absent. Authors differ considerably in their description of several of the muscles. The anomalus is a longitudinal muscle strip occasionally found running from the frontal process to the body of the maxilla near the lateral margin of the nasal aperture.

\section{(e) PERIORBITAL MUSCLES}

(Figs. 341, 34t)

The muscles which encircle the orbit constrict the entrance of the orbit so as to shut out light and protect the eye against foreign bodies. To these belong 
the orbicularis oculi, the corrugator, and the procerus. The orbicularis oculi is a large, flat, elliptical muscle which lies in the eyelids and over the bone surrounding the orbit. Three parts are recognised, a palpebral, an orbital and a lacrimal. The quadrangular corrugator extends from the nasal portion of the frontal bone to the skin of the middle half of the eyebrow; the narrow procerus (pyramidalis nasi) from the bridge of the nose to the skin at the root. The muscles which have an antagonistic action are the levator palpebra superioris and the epicranius. The levator palpebræ is described in the chapter on the Ere (see Section VIII), the epicranius in the following subsection.

The orbicularis oculi.-The palpebral portion arises from the ventral surface and margins of the lateral portion of the medial palpebral ligament (tendo oculi), and from the covering of the lacrimal sac. The fibre-bundles spread out as they pass into the eyelids and again are concentrated toward their insertion into the outer surface of the lateral palpebral ligament. Many of the fibre-bundles interdigitate here without being inserted into the ligament. The muscle in each evelid lies between the tarsal plate and the skin, separated from both by loose tissue. The superficial muscle-fibres nearest the margin of the lids constitute the ciliary muscle, or muscle of Riolan. They are very small fibres and probably act on the eyelashes and Meibomian glands.

The orbital portion arises by a superior origin from the medial palpebral ligament (tendo oculi), the nasal portion of the frontal bone, and the anterior lacrimal erest of the maxilla, and by an inferior origin from the medial palpebral ligament and the medial portion of the inferior rim of the orbit. The fibre-bundles form a flat ring which surrounds the orbit for a considerable distance, especially inferiorly. The muscle is adherent to the overlying skin. It lies over the bones surrounding the margin of the orbit and over the attachments of several of the facial muscles attached to these bones. With these muscles some of the fibre-bundles are usually continuous.

The lacrimal portion (tensor tarsi or Horner's muscle) arises from the posterior lacrimal crest of the lacrimal bone and passes down on the dorsal surface of the lacrimal sac and the medial palpebral ligament (tendo oeuli). It bifurcates and furnishes a fascieulus attached to each tarsal plate. Some of the fibre-bundles surround the lacrimal canaliculi and some surround the ducts of the tarsal glands and the roots of the eyelashes.

The corrugator arises from the frontal bone near the fronto-nasal suture. It extends obliquely upward to be inserted into the skin of the middle half of the eyebrow. The fibrebundles of insertion interdigitate with those of the frontalis. The muscle lies relatively deep. It is covered by the procerus (pyramidalis nasi), the frontalis, and the orbicularis. Under it lie the supra-orbital vessels and nerves.

The procerus (pyramidalis nasi) overlies the nasal bone. It arises from the lateral cartilage of the nose through a fibrous membrane and also directly from the nasal bone, and is attached to the skin over the root of the nose, where its fibres interdigitate with those of the frontalis. The medial margins of the muscles on each side are more or less fused.

Nerve-supply.-The muscles of this group are supplied by temporal and infraorbital branches of the facial nerve which enter the deep surfaces near the lateral margins.

Action.-The palpebral portion of the orbicularis closes the eyelids, of which the upper moves more freely than the lower. It also serves to dilate the lacrinal sac and allow the tears to flow away readily. The tensor tarsi probably contracts the sac and forces the tears into the nose. The upper half of the orbital portion of the orbieularis contracts and depresses the tissue overhanging the orbit, and stretches the skin of the forehead. The corrugator draws the skin of the brow downward and medially, thus aiding the preeeding muscle. It causes the perpendicular furrows characteristic of frowning. The proccrus (pvramidalis nasi) draws down the skin of the forehead and wrinkles the skin across the root of the nose. The lower half of the orbital portion of the orbicularis raises the skin of the check, eausing the wrinkles seen to radiate from the corner of the eye. The whole set of muscles comes into play in the forcible closure of the eyes. In case of violent expiratory efforts, as in shouting, sneezing, coughing, etc., the eye is thus usually forcilly elosed. The pressure thus exerted on the eyeball prevents a too violent flow of blood to the vessels of the eye. Pressure is thought at the same time to be exrred on the laerimal gland so as to cause the exeessive flow of tears often experienced at such times.

lariations. - The muscles of this group vary in extent and differentiation, and may be more or less finserl with one another or with neighbouring muscles. The orbital portion of the orbicularis, the cormentor, and the procerus have been foumd absent.

\section{(f) TIIE FPIC RANIAL, MUSCLLATURE}

(Fig. 3.11)

The epicranius (oceipito-frontalis) is formed of the two frontal muscles, which lif on warh sirle of the forchead, the two occipital muscles, which oceupy corresponding positions on the oceipital bone, and of the epicranial atponeurosis, the galea aponeurotica, which extends between these. The occipital muscles arise from the supreme nuchal line aud are inserted into the galea aponeurotica. The frontal muscles arise from the latter and are inserted into the skin near the eyebrows. The ehief function of these muscles is to elevate the brows. The 
muscles and the intervening aponeurosis lie between two layers of fascia, the external of which is fused to the skin, while the internal moves freely orer the periosteum, to which it is loosely attached. Hæmorrhages and abscerses spread freely between the deep layer of fascia and the periosteum.

The frontalis is a large, thin muscle with convex upper and coneave lower border. It arises from the epicranial aponeurosis midway between the coronal suture and the orbital areh, and is inserted into the skin of the eyebrow and of the root of the nose. 'The medial fibre-bundles take a sagittal direction; the lateral converge obliquely toward the brow. The medial margins of the muscles of each side are approximated near the attachment. The more medial fibre-bundles are continuous with those of the procerus (pyramidalis nasi) and the angular portion (levator labii superioris alæque nasi) of the quadratus labii superioris; the more lateral interlace with those of the corrugator and orbicularis muscles. The branches of the vessels and nerves of the frontal region pierce the muscle and are distributed between it and the skin.

The occipitalis, flat and quadrangular, lies on the occipital bone above the supreme nuchal line. It rises by tendinous fibres from the lateral two-thirds of this line and from the postcrior part of the mastoid process of the temporal bone, and is inserted into the epicranial aponeurosis. The medial fibre-bundles run sagitally, while the lateral run obliquely forward. The oceipital artery and nerve lie between the musele and the skin. The lateral border of the muscle romes in contact with the posterior auricular muscle. The muscles of each side are usually separated by a strip of aponeurosis.

The galea aponeurotica (epicranial aponeurosis) is a fibrous membrane which extends between the occipital museles and from them anteriorly to the frontal muscles. In the area between these two sets of museles it is composed largely of sagitally running fibres into which coronal fibres radiate from the region of the muscles of the ear. Between the two oecipital muscles the aponeurosis is attached to the supreme nuchal line and external occipital protuberance. Laterally the fascia covering it is continued as a special investment of the auricular muscles, beyond which it is attached to the mastoid process, the zygoma, and to the external cervical and the masseteric fasciæ.

Nere-supply. - The frontalis is supplied by the temporal branches of the facial nerve, the occipitalis by the posterior auricular branch. "The branches enter the deep surface of each of these muscles near its lateral border.

Action.-The occipitalis serves to draw back and to fix and make tense the epicranial aponeurosis. The frontalis, with its aponeurotic extremity fixed, elevates the brows and throws the skin of the forehead into transverse wrinkles as in the expression of attention, surprise, or horror. When both muscles contract forcibly there is, in addition, a tendency to make the hair stand on end beeause the hair-bulbs of the occipital region slant forward, those of the frontal region backward. The frontalis when fixed below pulls the sealp forward.

Variations.-The occipitalis is occasionally absent, a condition normal in ruminants. The muscles of the two sides may be fused in the median line (normal in dogs). It may be fused with the posterior auricular. The frontalis is rarely missing. The frontalis may send slips to the medial or lateral angles or the orbital arch of the frontal bone, to the nasal process of the maxilla or to the nasal bone. The fibre-bundles of the frontalis may interdigitate across the median line.

The transversus nuchæ, or occipitalis minor, is a small muscle, frequently present (2 7 per cent., Le Double), which runs from the oceipital protuberance toward the posterior auricular muscle, with which it may be fused. It may lie over or under the trapezius.

\section{(g) ACRIC'TLAR MESCLES}

(Fig. 341)

The intrinsic muscles of the auricle are described in section VIII. There are three 'extrinsic' auricular muscles which converge from regions anterior, superior, and posterior to the auricle and are inserted into it.

The auricularis anterior (attrahens aurem) is a small, flat, triangular musele which arises between the two layers of the fascia of the galea aponemotica, extends over the zygomatic arch, and is attached to the ventral end of the helix. The fibre-bundles converge from the origin toward a tendon of insertion. The area of origin of this muscle is often marked by a fibrous band tangential to its component fibres. From this band muscle fibre-bundles radiate out toward the frontal region of the skull. To the muscle formed of these radiating fibres the names epicranio-temporalis (Henle), temporalis superficialis (Sappey) and auriculo-frontalis (Gegenbaur) have been given.

The auricularis superior (attollens a urem) is a large, thin, triangurar muscle which, from its tendinous insertion on the eminence of the triangular fossa of the car, radiates upward into the fascia of the galea aponeurotica, between the layers of which it takes oigin near the temporal ridge. It lies over the temporal faseia and the periosteum of the parietal bone.

The auricularis posterior (retrahens aurem) is a thin, band-like nusele which extends over the insertion of the sterno-cleido-mastoid from the base of the mastoid process and the aponeurosis of the sterno-cleido-mastoid musele to the convexity of the eoneha, where it has a tendinous insertion. It is usually composed of two fascieuli, and is contained between two layers of fascia derived from the galea aponeurotica.

Nerve-supply.-The auricularis anterior and superior are supplied by the temporal braneh of the facial, the auricularis superior and posterior by the posterior auricular branch. The twigs of supply run to the deep surface of the muscles. 
Relations.-The superficial ascending branch of the auriculo-temporal nerve usually runs superficial to the anterior and superior auricular nuscles. The superficial temporal vessels run at first beneath these muscles and the lateral expansion of the galea aponeurotica, then between the two fascial layer's which enclose the muscles. Their branches of distribution finally come to lie between the muscles and aponeurosis and the skin. The posterior auricular artery and nerve usually run under cover of the auricularis posterior.

Action.-The anterior muscle is a protractor, the superior an elevator, and the posterior a retractor of the ear, but usually in man they are inactive.

Fariations.-These muscles vary much in development. The most constant of them is the superior. The posterior frequenty is increased in size and may be fused with the occipitalis, which originally was probably an ear muscle. From the anterior muscle a special deep fasciculus is occasionally isolated. Each of the muscles is occasionally, though rarely, absent, the anterior most frequently. An inferior auricular muscle is very rarely found in man, though present in many of the lower mammals. A slip of the posterior auricular may run beneath the ear to the parotid fascia.

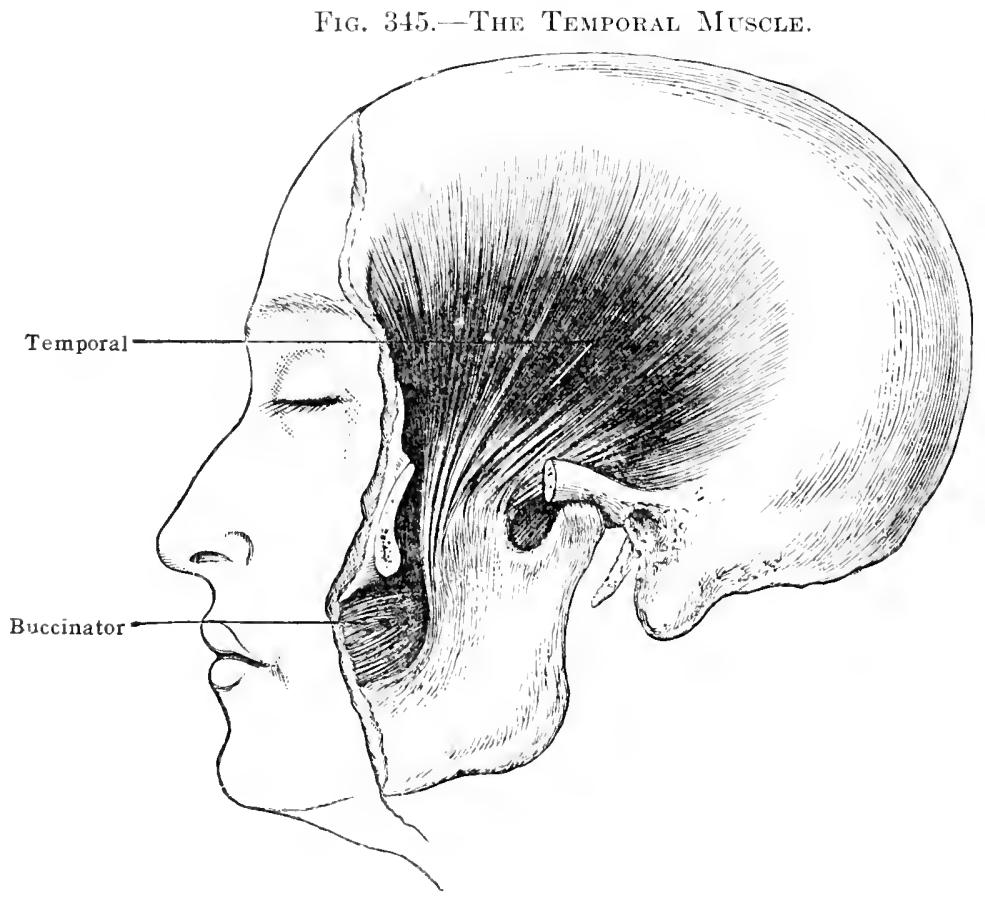

\section{CRANIO-MANDIBULAR MUSCULATURE}

(Iigs. 344, 345, 3.16, and 347)

'The cranio-mandibular muscles, or muscles of mastication, pass from the base of the skull to the lower jaw. They are represented in the selachians by a single muscle mass, the alductor mandibrila (Cegenbaur), but in the higher vertebrates this musele mass hecomes variously subdivided during embryonie development. 'The musches are innervated by the masticator nerve (motor root of the trigeminal ('tulial nerve, the nerve of the mandibular areh). In man four muscles are reogenised, the temporal, masseter, and internal and external pterygoids.

The temporal and masseter muscles are situated on the lateral surface of the

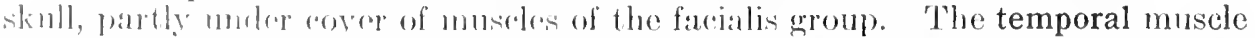

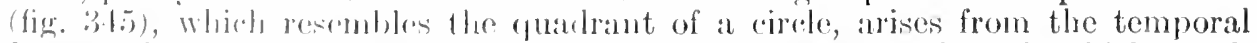
forsat and is inseptal inte the coromoisl process of the mandible; the thick, quadrilatcral masseter (lig. 31.1$)$ muscho arises from the zygomatic areh and is insorted inte the laterial surface of the rannus and angle of the mandible. The

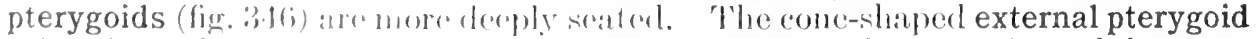

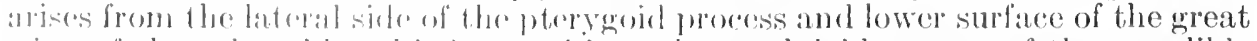
wing of the sphemoid and is inserted into the andytoid process of the mantible and the rapsule of the joint. The thick, guadrilateral internal pterygoid parallels

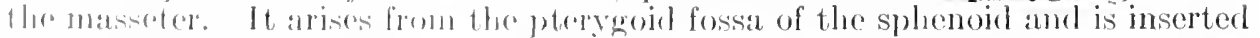
intes the inner side of the angle of the mamblible. It will be noted that the tem- 
poral, masseter, and internal pterygoid muscles have approximately vertical ares of contraction and adduct the lower jaw, while the external pteryolic has an approximately horizontal axis of contraction and draws the jaw forward and, when acting on one side, toward the opposite side.

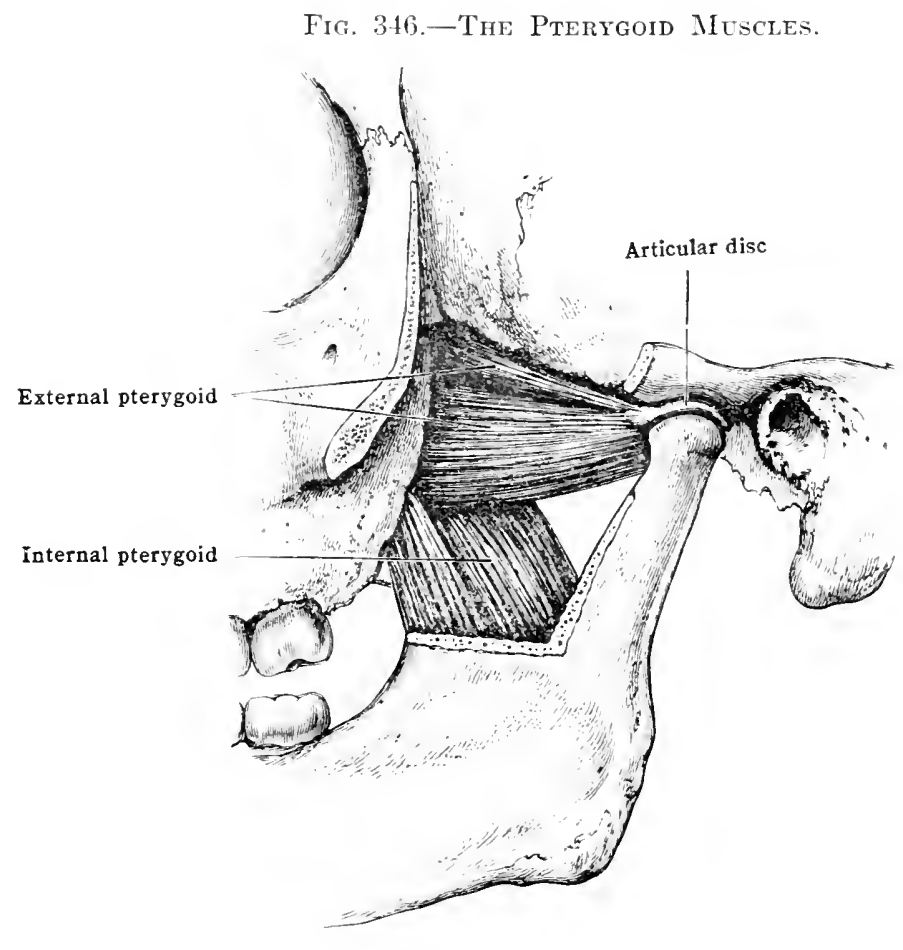

FASCIE

The temporal fascia arises from the temporal line of the frontal bone and from the superior temporal line of the parietal and the periosteum immediately below this. It extends to the zygomatic arch. In its inferior quarter the fascia divides into two lamellæ, one of which passes to the outer, the other to the inner, surface of the arch, but at the superior margin of the arch these two lamellæ are united by dense fibrous tissue. Between the two lamellæ above the arch lies a fatty areolar tissue in which the middle temporal artery often runs. The outer surface of the fascia is covered by the superficial temporal and anterior and superior auricular muscles, and by a thin layer of fascia from the galea aponeurotica, with which, toward the zygomatic arch, it becomes merged. The superficial temporal artery and auriculo-temporal nerve cross it.

The masseteric fascia represents essentially a continuation of the temporal fascia from the inferior margin of the zygomatic arch over the masseter muscle which it covers. It is less thick than the temporal fascia, but is firm and strong. It is attached dorsally to the dorsal margin of the mandible, inferiorly to the inferior margin, and ventrally to the body and to the rentral margin of the ramus and the coronoid process of the mandible. In part it extends over the fat pad of the cheek to the buccinator fascia. The parotid gland, covered by the parotid extension of the external cervical fascia, extends over the posterior portion of this fascia. The parotid fascia becomes fused to its external surface at the anterior margin of the gland. Over it lie the parotid duct, the transverse facial artery, branches of the facial nerve, the zygomaticus (major), risorius, and platysma muscles.

The pterygoid muscles are each surrounded by a delicate membrane. In acdition an interpterygoid fascia separates the two muscles. This arises from the sphenoidal spine and follows the internal surface of the externai pterygoid to the mandible. Nedially it is attached to the lateral lamella of the pterygoid process; posteriorly and laterally it presents a free margin which forms with the neck of the mandihular condyle, an orifice for the passage of the internal maxillary artery, the auriculo-temporal nerve, and several veins. Its posterior margin is strengthened into the spheno-mandibular ligament, which runs from the spine of the spherioid to the lingula of the mandible.

The pharyngeal region is separated from the pterygoid by a dense membrane, the lateral pharyngeal fascia. This extends from the depth of the pterygoid fossa to the prevertebral fascia, and separates the tensor veli palatini from the internal pterygoid muscle. It is attached above along a line extending from the external margin of the carotid canal to the internal margin of the oval foramen. 

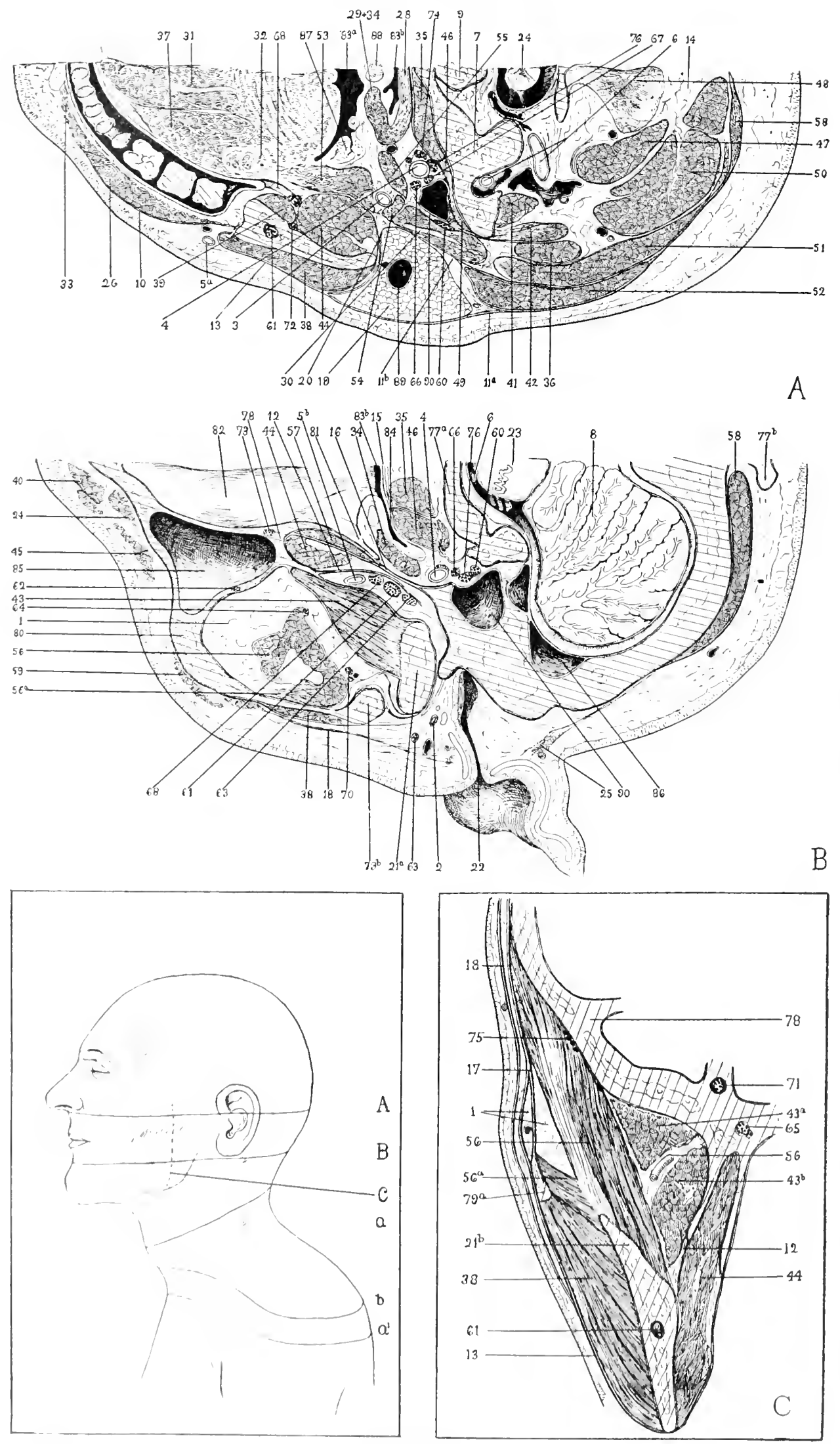
The sigmoidal septum is a thin membrane which occupies the incisura mandibuland andilrates the masseter from the external pterygoid muscle.

\section{MUSCLES}

The temporalis (fig. 345).-Origin.-(1) From the whole of the temporal fossa, with the exception of that part formed by the body and temporal process of the zygomatic (malar) bone; and (2) from the fascia covering the fossa. Insertion is into the tip, dorsal and ventral borders, and the whole internal surface of the coronoid process of the mandible and the ventral portion of the medial surface of the ramus.

In structure, the muscle is thin near its superior margin, but becomes thick as its insertion is approached. The fibre-bundles arising from the medial surface of the fossa and from the fascia converge upon the medial and lateral surfaces and the margins of a thick, broad tendon which begins very high in the muscle, becomes visible laterally some distance above the zygomatic arch, and is inserted into the tip, edges, and internal surface of the coronoil process. On the ventral and dorsal margins of the tendon the insertion of fibre-bundles continues to the coronoid process, while medially the insertion of the fibre-bundles is continued on the medial surface of the coronoid process and often on the ramus as far as the body of the bone.

Nerve-supply.-Usually three branches from the anterior branch of the mandibular division of the fifth nerve curve upward over the temporal surface of the great wing of the sphenoid and enter the deep surface of the muscle. The posterior and middle nerves pass above the external pterygoid; the anterior, which springs from the buccinator nerve, passes between the two heads of the external pterygoid before curving upward.

Relations. - The muscle is covered by the temporal fascia and the zygomatic areh. Below the temporal fossa the pteryoid muscles and the buccinator lie medial to it. The temporal fossa in front of the muscle is filled with a fatty areolar tissue and this also extends between the muscle and the temporal fascia. Fatty tissue likewise lies between the muscle and the buccinator. Nedial to the muscle run the deep temporal vessels and nerves, the bucrinator nerve and the spheno-mandibular ligament. The masseteric nerve passes lateralwall lehind and below the tendon.

The masseter (fig. 343) is composed of two liners. The superficial layer arises by an aponeurosis from the anterior two-thirds of the lower border of the zygomatic (malar) bone. The fibre-bundles arise from the reep surface of this aponeurosis and its tendinous prolongations pass obliquely downward and backward, and are inserted into the lower half of the external surface of the ramus, into the angle, and into the neighbouring portion of the borly of the man-

Fig. 347.*-A and B are Transterse Sections and C. (after Tentet), a Frontal section throdgh the Left side of the Head, ix the Regions indicated in the Diagram. $a$ and $b$ in the diagram indicate the regions through which pass sections $A$ and $B$, fig. 351 : and $a^{1}$, section A, fig. $35 \%$.

1. Adipose tissue. 2. Arteria temporalis superficialis. 3. A. carotis externa. 4. A. carotis interna. 5a. A. maxillaris externa (facial). 5b. A. maxillaris interna. 6. A. vertebralis. 7. Atlas. \&. Cerebellum. 9. Epistropheus (axis). 10. Fascia buccopharyngea. 11. F. cervicalis, $a$ (superficial layer), $b$, deep parotid process. 12. F. interpterygoidea. 13. F. masseterica. 14. F. nuchæ. 15. F. pharyngobasilaris. 16. F. pharyngis lateralis. 17. F. temporalis. 1S. Galea aponeurotica. 19. Glandula parotica. 20. Ligamentum stylomandibularis. $21 a$. Nandible, capitulum; $b$, coronoid process. 22. Meatus acusticus ext. 23. Medulla oblongata. 24. Medulla spinalis (spinal cord). 25. Musculus auricularis posterior (retractor auris). 26. M. buccinator. 27. M. caninus (levator anguli oris). 2S. II constrictor pharyngis medius. 29. M. constrictor pharyngis superior. 30. M. digastricus. 31. M. genio-glossus. 32. M. hyo-glossus. 33. M. incisivus labii inferioris. 34. M. levator veli palatini. 35. M. longus capitis rectus capitis anticus major). 36. II. longissimus capitis (trachelo-mastoid). 37. M. longitudinalis interior. 35. M. masseter. 39. M. mylo-hyoideus. 40. M. nasalis (alar portion). 41. M. obliquus capitis inferior. 42. M. obliquus capitis superior. 43. M. pteryoideus externus $-a$, superior fasciculus; $b$, inferior fasciculus. 4t. M. pteryoidens internus. 45. $M$. quadratus (levator) labii superioris. 46. MI. rectus capitis anterior (ninor). 47. $M$. rectus capitis posterior major. 4S. II. rectus capitis posterior minor. 49. M. rectus capitis lateralis. 50. M. semispinalis capitis (complexus). 51. M. splenius capitis. 52. M. sterno-cleido-mastoideus. 53. M. strlo-glossus. 5t. M. stylo-hyoirlens. 55. M. stylo-pharyngeus. 56. M. temporalis (a, fasciculus from zygoma). 57. M. tensor veli palatini. 5S. M. trapezius. 59. M. zroomaticus (najor). 60. Nervus accessorius (spinal accessory). 61. N. alveolaris inferior (dental). 62. N. alveolaris posterior superion' (dental). 63. ․ auriculo-temporalis. 64. N. buceinatorius. 65. N. canalis pterteniclei (Vidian nerve). 66. $\mathrm{X}$. glossonharvngeus. 67. $\mathrm{X}$. hypoglossus. 65. $\mathrm{Y}$. lingualis. 69. N. mandibularis. 70. ₹. masseteric nerve 71. N. maxillary nerve. 72. X. nylohyoid nerve. 73. X. palatinus. 74. Srmpathetic trunk. 75. X. temporalis profunitus. 76. N. vagus. 77. Os occipitale-a, hasilar portion; $b$. external protuherance. $i$. ( $_{5}$ sphenoidale. 79. Os temporale- $a$, processus zygomaticus; $b$, tubercle. $\$ 0$. () zyonmaticum (malar). S1. Pharrngeal orifice of tuba auditira (Eustachian tule. \$2. Palatum durum (hard palate). \&3. Pharyn-a, oral portion; $b$, nasal portion. 84. Pharyngeal recess. S5. Sinus maxillaris (antrum of Highmore). s6. Sinus transversus (lateral). S7. Tonsila palatina. SS. Uvula. S9. Tena facialis posterior (temporomaxillary). $90 . \mathrm{T}$. jugularis interna.

* This and the following series of cross-sections are taken from a thin, not rery muscular, adult male. The fascie are represented in most instances disproportionately thick. 
dible-the more anterior directly, the posterior by means of an aponeurosis. The deep layer arises from the lower border and internal surface of the zygomatic arch. The fibre-bundles pass nearly vertically downward, and are inserted upon the upper half of the external surface of the ramus. The origin and insertion are by tendinous bands, to which the fibre-bundles are attached in a multipenniform manner. The two layers are fused near the origin and insertion and in front. From the temporal surface of the zygomatic bone and the neighbouring part of the deep layer of the temporal fascia there arises a fasciculus which is separated by a pad of fat from the main body of the temporal inuscle, and is inserted into the lateral surface of the lower extremity of the tendon of the temporal muscle and into the ventro-lateral surface of the tip of the coronoid process. This fasciculus, sometimes described as a part of the temporal muscle, is innervated by the masseteric nerve.

Nerve-supply. - The branch arises in common with the posterior nerve to the temporal muscle from the motor root of the trigeminal (the masticator nerve). It passes above the external pterygoid, through the mandibular (sigmoid) notch, and enters the deep surface of the muscle near the dorsal margin.

Relations.--It is covered by the masseteric fascia (see above). It lies upon the ramus of the jaw and ventrally is separated by a pad of fat from the buccinator muscle. At the mandibular (signoid) notch the sigmoid septum separates it from the external pterygoid muscle. The parotid gland partly overlaps its posterior border.

The pterygoideus externus (figs. 343-346) consists of two fasciculi. Each is thick and triangular. The superior is flattened in a horizontal, the inferior in a vertical, plane. At their origin they are separated by a narrow cleft. Near the insertion they become more or less fused. The superior fasciculus arises by short tendinous processes from the infratemporal (pterygoid) crest and from the neighbouring portion of the under surface of the great wing of the sphenoid. Its fibre-bundles converge toward the insertion, which takes place by short tendinous processes into-(1) the capsular ligament in front of the articular disc and (2) the upper third of the front of the neck of the condyle. The inferior fasciculus is the larger. It arises by short tendinous processes from the lateral surface of the lateral lamina of the pterygoid process, from the pyramidal process of the palate bone, and from the adjacent portions of the maxillary tuberosity. The fibre-bundles converge toward their insertion into a depression on the front of the neck of the condyle.

Nerie-supply. - A branch from the masticator nerve (motor root of the trigeminus) approaches the muscle near the upper border of the medial surface of the superior fasciculus and gives branches to both portions.

Relations. - It is partly covered by the maxillary fasciculus of the internal pterygoid and by the temporal and masseter muscles. Medial to it lies the chief fasciculus of the internal pterygoid muscle. The masseteric and the posterior and middle temporal nerves usually pass above the muscle, the anterior temporal and the buccinator nerves and frequently the internal maxillary artery between the two fasciculi. The internal maxillary vessels usually pass below the lower border of the muscle and across its external surface; and the auriculo-temporal, lingual, and inferior alveolar (dental) nerves cross the deep surface of the muscle.

The pterygoideus internus (fig. 346).-Origin.-From (1) the pterygoid fossa, and (2) from the maxillary tuberosity and the pyramictal process of the palatine, where these adjoin.

Structure and Insertion.-From the medial and lateral laminæ of the pterygoid process there arise aponeuroses and from the palatine bone at the lower margin of the fossa, and from the maxillary tuberosity and palatine bone in front of the external pterygoid, there arise short tendons. From these aponeuroses and tendons and directly from the fossa the fibre-bundles take a nearly parallel course downward, backward, and outward, and are inserted in part in a multi-penniform manner into the lower half of the internal surface of the ramus of the mandible. The insertion extends to the mylo-hyoid ridge. The muscle is divided at its origin into two fasciculi hy the distal margin of the external pterygoid.

Nerve-supply.-The internal pterygoid nerve arises from the back of the mandibular nerve near the foramen ovale. It passes near or through the otic ganglion, and thence to the medial surfare of the muscle near the dorsal edge. Both the buccinator and lingual nerves are also rescribel as sending filaments to this musele.

firletions:-Laterally the muscle is covered by the interpterygoid fascia and the sphenomanlibular ligament, the external pterygoid, temporal, and masseter muscles, and the ramus of the mamlible. The inferior alveolar (dental) and lingual nerves and the corresponding vessels run across this surfare. Medial to the muscle lie the lateral pharyngeal fascia, the tensor veli palatini muscle, and the superior constrictor of the pharynx.

Artim.--The muscles of this group adduct the lower jaw and serve to carry it forward and barkward and from side to side. The elevation is produced by the masseter, temporal, and intermat ptery arid muscles. 'The suprahyoid muscles and the external pterygoid are the feeble antagonists. The forwarl movement of the jaw is produced by the simultaneous action of the two cxternal pteryonils (slightly hy the superficial layer of the masseter, and the anterior fibres of the trmpiril) while the inferior posterior portions of the temporal inuscles carry the jaw at the frmmoro-riscoirlal joint somewhat barkward. Oblicue lateral rotatory movenents are profluces chicfly l,y the action of one of the external pterygoids. The alternate action of thesc two msincles associated with the elevating action of the other muscles of the group, gives rise to the grimling movenent of the nolar teeth. Purely lateral movements of the jaw

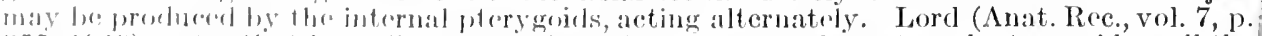

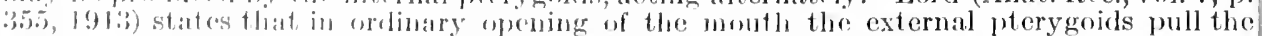
articular disces and rendyles forwarrl while the jaw rotates about an axis passing through the insertions of the sty fo-mandibular ligaments.

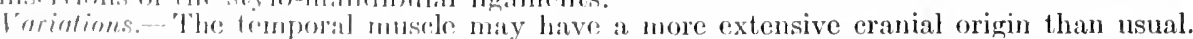
It may be formel of two superimposed layers. It may he more or less fused with the external pteryeroid, or semel a fascinulus to the cormonid process. The masseter may be rompletely 
divided into two fasciculi, a condition normal in many manmals. A special faseiculus may arise from the temporo-mandibular articulation or from the zygomatic (nalar) bone. Its deepest fibres may be fused with the temporal muscle. The two fasciculi of the external pterygoid may be distinet, as in the horse. It has been seen fused with the temporal and with the digastric muscle. The internal pterygoil may send a fasciculus to the masseter. It may give origin to the stylo-glossus. Inconstant fasciculi (accessory pterygoirls) extending from the body of the sphenoid to the pteryoil process represent perhaps remnants of the muscles which act on the movable pterygoids possessed hy many inferior vertebrates.

\section{SUPRAHYOID MUSCULATURE (Fig. 3ts)}

From the hyoid bone there extend to the base of the skull on each side four muscles which form a fairly well-defined group. They are situated external to

Fig. 348.-Anterior and Lateral Ceritcal Muscles.

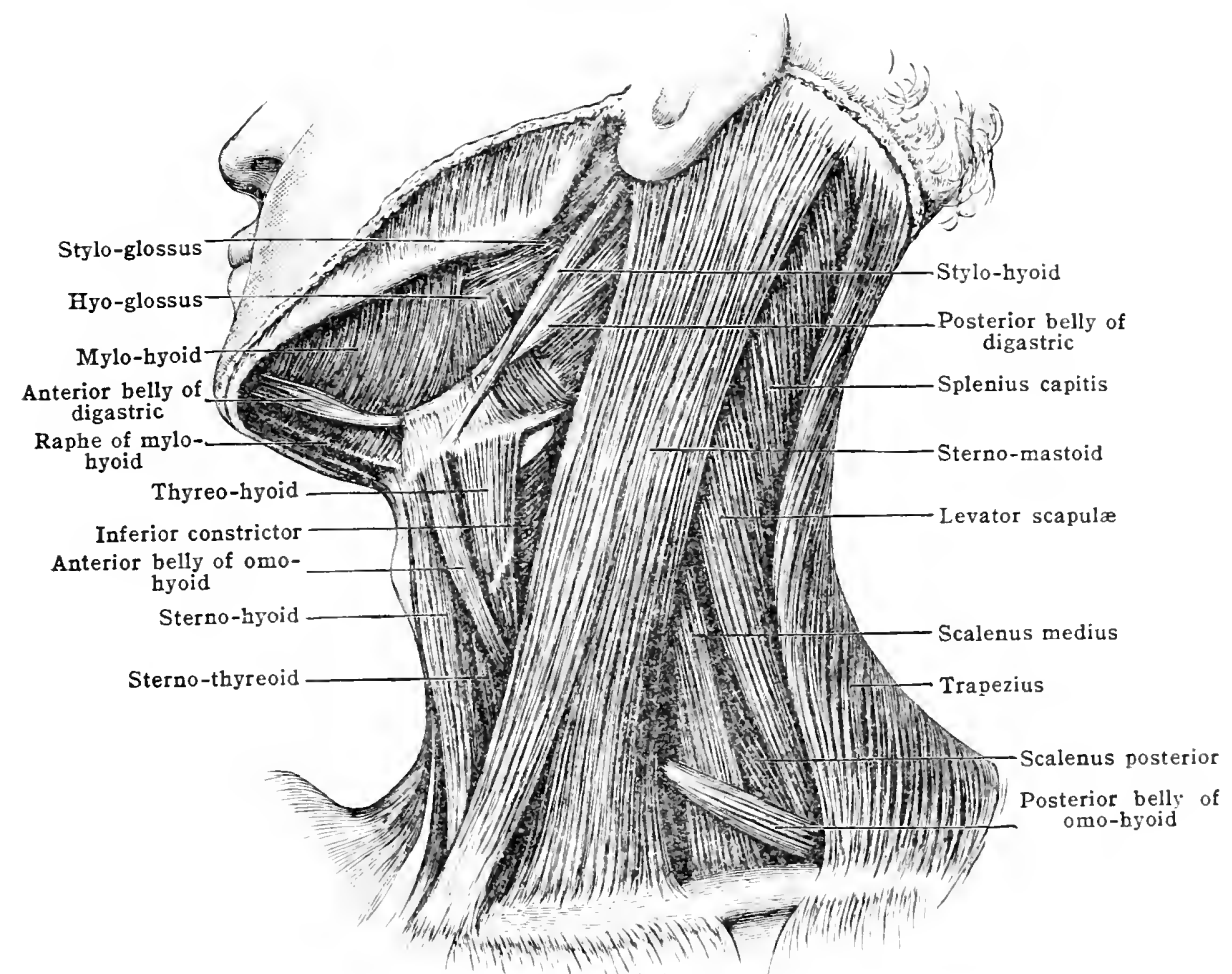

the musculature of the tongue and pharynx. They elerate the hyoid bone and larynx and depress the mandible. The most superficial of the group is the slender, fusiform stylo-hyoid, which arises from the styloid process of the temporal bone and is inserted into the body of the hroid. Immediately behind this is the flattened posterior belly of the digastric, which extends from its origin in the mastoid notch to a tendon that runs between two divisions of the tenclon of the stylo-hyoid and is attached to the hyoid bone by an aponeurotic process. From the digastric tendon the flat, triangular anterior belly is continued to the back of the ventral portion of the inferior margin of the mandible. Internal to this anterior belly the thin, quadrangular mylo-hyoid arises from the inner surface of the body of the mandible and is inserted into a median raphe extending from the mandible to the hroid. Still more internally the triangular genio-hyoid extends from the hyoid to the mental spine of the mandible. The last two muscles form the muscular floor of the mouth. The motor innervation of the posterior belly 
of the digastric and of the stylo-hyoid is from the seventh cranial nerve, the sensory innervation probably from the glosso-pharyngeal cranial nerve. The mrlo-hyoid and the anterior belly of the digastric are supplied by the masticator (fifth) cranial nerve; the genio-hyoid from the hypoglossal by a branch, the fibres of which are possibly derived through anastomosis from the first cervical nerve.

From the morphological standpoint, therefore, the stylo-hyoid and the posterior belly of the digastric belong to the facialis group; the anterior belly of the digastric and the mylo-hyoid to the group of mandibular muscles, and the genio-hyoid to the muscles of the tongue innervated by the hypoglossal, or, if we consider the nerve-fibres of the nerve to the genio-hyoid as derived from the first cervical nerve, to the same group as the infra-hyoid muscles. It is convenient, however, to follow the usual custom of considering these muscles as a suprahyoid group.

\section{FASCIA}

The muscles of this group lie internal to that portion of the external cervical fascia which extends above the hyoid bone. This fascia, which is described on p. 347 , comes into contact merely with the tendon, the anterior belly, and to a slight extent with the posterior belly of the digastric muscle. Above the tendon it sends inward a process which curves down internal to the tendon, and is inserted into the external surface of the hyoid bone. The individual muscles of the group are covered by delicate adherent menbranes. An aponetrotic membrane usually extends between the anterior bellies of the digastric muscles of each side.

\section{MUSCLES}

\section{(Fig. 348)}

The stylo-hyoideus.-Origin.-From the lateral and dorsal part of the base of the styloid process by a rounded tendon which soon becomes a hollow cone to the internal surface of which the fibre-bundles of the muscle are attached. Structure and Insertion.- The fibre-bundles are inserted on both sides of a slender tendon which divides to let the tendon of the digastric pass through and then is attached to the ventral surface of the body of the hyoid bone near its junction with the great colnu.

Nerve-supply.-From the facial nerve as it cmerges from the stylo-mastoid foramen a small

twig is given off which enters the proximal third of the deep surface of the muscle. The glossopharyngeal nerve also gives to it a small twig, probably sensory.

Relations.-It descends immediately in front of the posterior belly of the digastric. Externally lie the parotid and submaxillary glands. Medially it crosses the internal and external carotid artery, the hypoglossal nerve, the stylo-pharyngeus muscle, the superior constrictor of the pharyix, and the hyo-ghossus muscle. The posterior auricular artery passes between it and the posterior belly of the digastric and the external maxillary artery crosses over it.

The digastricus. - The posterior belly arises by tendinous processes from the mastoid (digastric) not ch of the temporal bone. The fibre-bundles form a riblon-like belly which converges on the intermediate tendon. This begins as a scmiconical laminar process on the outer surface of the muscle a short distance above the hyoid bone. The anterior belly arises by short tendinous processes from the digastric fossa of the mandilble. This at achment is often described as an insertion. The fibres converge on both surfaces of the flattened anterior end of the intermediate tendon. The intermediate tendon lies a variable distance above the hyoid bone, usually less than a contimetre. It curves upwad toward each belly of the musele. It is united to the outer surface of the body and to the base of the great corvin of the hyoid bone by an aponeurotic expansion from it inferion margin. Other expansions are usually continued into the interligastrio annourotio membrane. Oecasionally the intermediate tendon of the

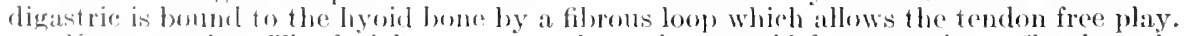

Noresupply. - The farial nerve neat the stylo-mastoid foramen gives off a branch which chitars the froximal third of the anterior masgin of the muscle, from this a ramus may be

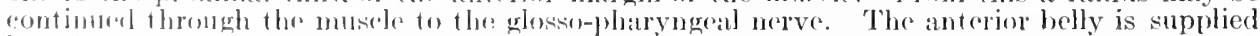
by a lorawh of the nerve to the mylo-hyoid musde. This enters the midelle of the lateral part of the derpesufale. Fery rarely the vagus may supply the anterior belly, the hypoghossal, thes posterion lints.

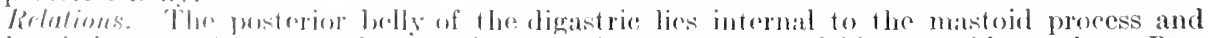

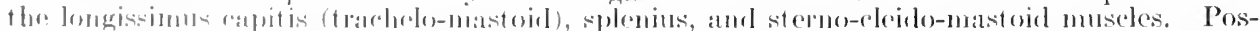

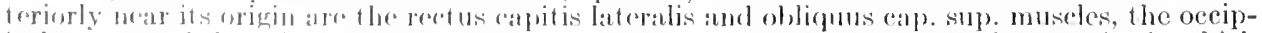

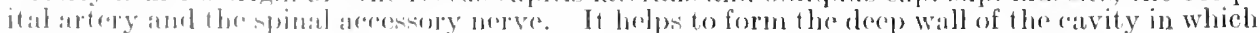

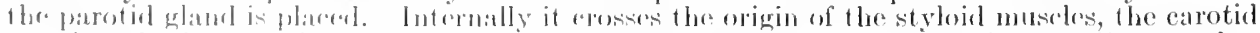

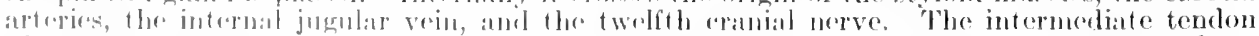
of insertion lins bokw the inforior margin of the submaxillary glaturl, and erosses the hyo-

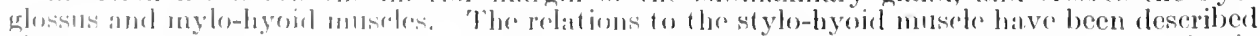

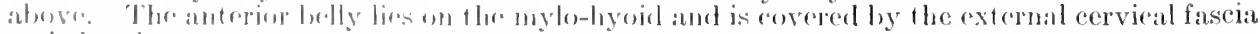
and the platysuras.

'The mylo-hyoideus. Crigin. - l'om the mylo-hyoid ridge of the mandible. Structure

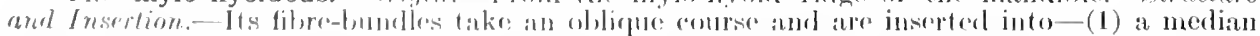

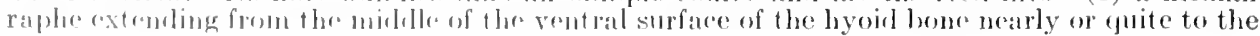


dorsal surface of the inferior margin of the mandible, and (2) into the ventral surface of the hyoid bone. Some of the fibre-bundles may cross the median line. The museles of the two sides form a sheet with a downward convexity which lies between the inner surface of the bouly of the mandible and the hyoid bone. On the diaphragm thus formed rest the tongue.

Nerve-supply.-From the mylo-hyoid branch of the inferior alveolar (dental) nerve several filaments enter the under surface of the muscle.

Relations. - The mylo-hyoid muscle is covered externally by the submixillary gland, the anterior belly of the digastric, and the external cervical fascia. It is crossed by the submental artery. With the genio-hyoid and the genio-glossus muscles it helps to bound a compartment in which are lodged the sublingual gland, the duct of Wharton, and the deep portion of the submaxillary gland. Its deep surface also faces the stylo-glossus and hyo-glossus muscles, the lingual and hypoglossal nerves, and to a slight extent the buccal mucosa.

The genio-hyoideus (fig. 349).-Origin.-By short tendinous fibres from the mental spine of the mandible. Structure and Insertion.-The fibre-bundles diverge and are inserted into the ventral surface of the body of the hyoid bone. Usually a special fasciculus goes to the great cornu of the hyoid bone.

Nerve-supply.- The hypoglossal nerve sends a filament to the middle third of the deep surface of the muscle. The nerve-fibres are thought to be derived chiefly from the first cervical nerve.

Relations.- It lies between the genio-glossus and mylo-hyoid muscles. It adjoins it: fellow of the opposite side and is of ten fused with it. Lateral to it lie the sublingual and submaxillary glands and the hypoglossal nerve.

Action.-The muscles of this group all elevate the hroid bone and, through this, the laryns and inferior part of the pharynx, and thus play a part in the act of swallowing. The stylohyoid and posterior belly of the digastric serve also to draw the hyoid bone in a dorsal direction; the ventral belly of the digastric and the genio-hyoid, in a ventral direction. The digastric, genio-hyoid, and mylo-hyoid depress the mandible, when the hyoul bone is fised. The posterior belly of the digastric has a shight power to bend the head backward.

rariations. - The stylo-hyoid tendon frequently passes ent irely in front of and less frequently entirely behind the digastric muscle. Its insertion may be of greater extent than usual. i special fasciculus to the lesser cornu is not very infrequent; more rarely one extends to the angle of the jaw or to other regions. The muscle may arise from the petrous portion of the temporal or from the occipital bone, as in some lower vertebrates. It may be doubled or absent, or fused with the posterior belly of the digastric. The anterior belly of the digastric may be missing; the posterior belly may be inserted into the angle of the jaw. The intermediate tendons of the digastric of each side may be connected by a fibrous arch. The anterior bellies of the muscles of each side may be unit ed by a fasciculus or fused. The anterior belly is frequently: doubled. The posterior belly may be divided by a tendinous inscription. Fasciculi may pasis from either belly to neighbouring structures. "The mylo-hyoid may not extend quite to the hyoid bone. It may be more or less fused with neighbouring muscles. Rarely it is absent. The genio-hyoid is frequent ly more or less fused with the muscles of the tongue or with the geniohyoid of the opposite side. A considerable number of infrequently found muscles have been described superficial to the stylo-hyoid and digastric museles. Most of them are innervated by the glosso-pharyngeal nerve or by the facial nerve.

\section{t. MIUSCLES OF THE TONGUE}

(Fig. 349)

The tongue is a flexible organ, composed chiefly of various muscles, some of which lie entirely within its substance, while others axtend to be attached to neighbouring parts of the skeleton. To the former the term intrinsic, to the latter the term extrinsic, is frequently applied. In this section the extrinsic muscle will alone be taken up. The intrinsic muscles are described in the section on the Digestre srster. Certain pharyngeal and palatal muscles which are continued into the tongue are described in connection with the pharynx. The extrinsic musculature of the tongue is concealed below hy the suprahyoid musculature and the sublingual gland. It is covered on the fres surface of the tongue by the mucosa.

The musculature of the tongue is supplied by the hypoglossal nerre, which is in series with the motor roots of the spinal nerves. It is, primitively at least. derived from the ventral portion of myotomes in series with the spinal myotomes.

Four extrinsic muscles are recognised on each side. The stylo-glossus is at slender muscle, which arises from the styloid process and is inserted into the side of the tongue. It is crlindrical near its origin, flat and triangular near its insertion. The thin, quadrilateral hyo-glossus arises from the body and great comm of the hyoid bone and is inserted into the dorsum of the tongue. The chondroglossus arises from the lesser cornu of the hyoid bone and joins the superior and inferior longitudinal muscles of the tongue. The genio-glossus genio-hroglossus), which forms the main part of the body of the tongue, arises from the mental spine of the mandible, from which the fibre-bundles racliate out torvard the whole length of the dorsum of the tongue and to the hroid bone. 
Under the mucous membrane of the tongue is a dense layer of fibrous tissue, the lingual fascia. In the borly of the tongue there is a sagittal septum linguæ, which separates the two genio-glossus muscles. A transverse fibrous lamella, the hyo-glossal membrane, helps to unite the tongue to the hyoid bone. Delicate membranes invest the free portions of the extrinsic muscles of the tongue.

\section{MIUSCLES}

The stylo-glossus. - This arises from the front of the lower end of the styloid process of the temporal bone and from the upper part of the stylo-mandibular ligament. Insertion.-It runs obliquely downmard, forward, and medially, with slightly diverging fibre-bundles, to the lateral margin of the tongue, where it gives rise near the anterior pillar of the fauces to two fasciculi. The larger, lateral, longitudinal fasciculus runs superficially along the lateral margin of the tongue to the tip. The fibre-bundles are attached to the overlying mucosa and underlying musculature. The smaller, inferior, transverse fasciculus gives rise to diverging fibrebundles which pass medially through the hyo-glossus into the base of the tongue. The most posterior of these diverging bundles may extend to the hyoid bone.

The hyo-glossus. - This arises from-(1) the lateral part of the ventral surface of the body of the hyoid bone and (2) from the upper border of the great cornu. The fibre-bundles take a nearly parallel course upward, diverging, however, slightly. Near the upper margin of the back

Fig. 349.--Side View of the Muscles of the Tongue.

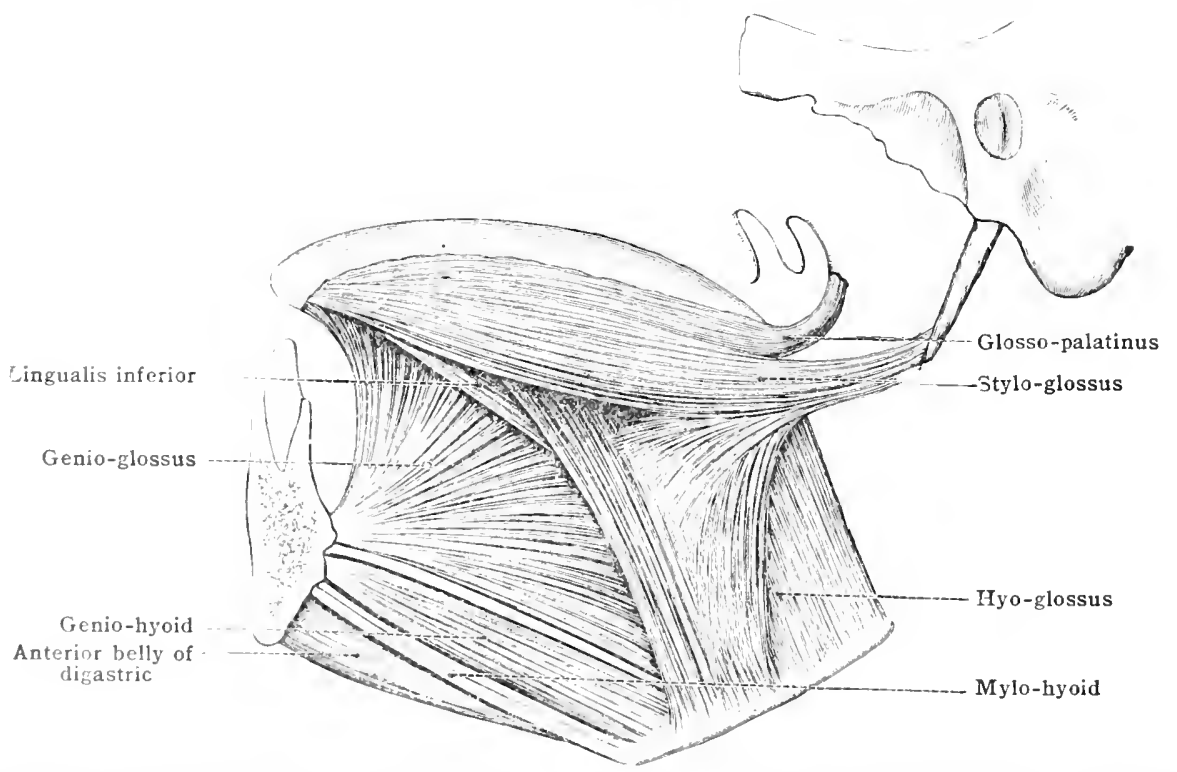

part of the tongue they curve medianward and interlace with the intrinsic musculature of this region. The dorsal fibre-bundles pass trinsversely, the midcle obliquely, the ventral longitudimally. 'They are inserted into the fibrous tissue which forms the skeletal framework of the tongurs.

'The chondro-glossus is a small muscle which arises from the lesser cornu of the hyoid bone and gives rise to fasciculi which join the longitudinalis inferior and the longitudinalis superior of the: tomgnes drescriled in Section IX.

The genio-glossus. This arises from the mental (genial) svine of the mandible partly directly, parth ly moans of a short, trimenlar tendon. The more inferior fibre-bundles radiate towarl the tipi of the tongue; the intermediate exteml directly towarl the dorsum of the tongue, whroe they are inserted into the lingual fascia amol skeletal framework. 'The inferior curve back to be inserted on the ancelian pate of the superior borter of the hyoid bone.

Nerve-supply... Twigs from the hypoglossal nerve ranter the lateral surfaces of the muscles "ff this group.

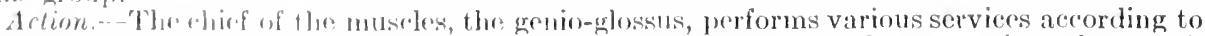

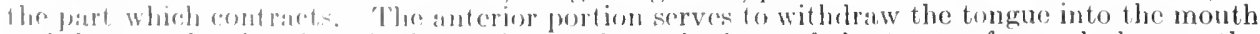

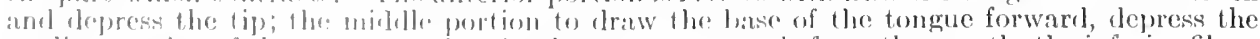

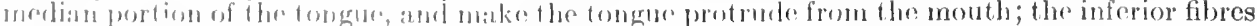

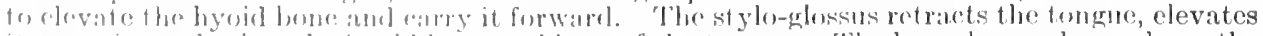

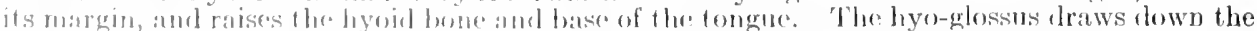

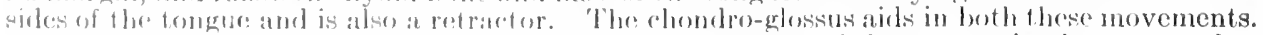

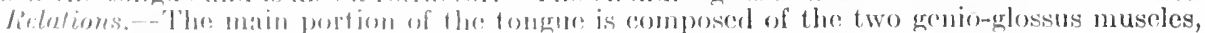

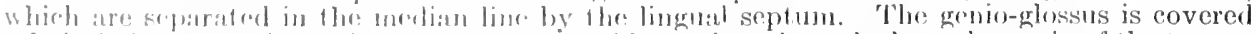

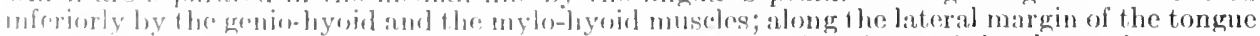

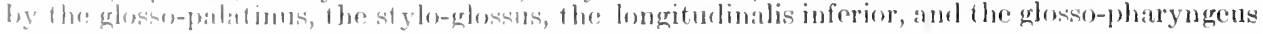


muscles; and posteriorly by the hyo-glossus, and the chondro-glossus. Below it forms a part of the medial wall of the space in which the sublingual gland is lodged. Over the dorsum and tip of the tongue it is covered by the mucosa. This likewise covers laterally, in the region of the base of the tongue, the stylo-glossus, hro-glossus, and the longitudinalis inferior. The hingual artery runs between the hyo-glossus and the genio-glossus, and along the boundary between the longitudinalis inferior and the genio-glossus to the tip of the tongue. The lingual vein, which lies lateral to the hyo-glossus muscle, takes a similar although much more irregular course. The glosso-pharyngeal nerve passes down medial to the stylo-glossus muscle to the root of the tongue. The lingua! nerve passes along the laterul margin of the tongue external to the styloglossus, hyo-glossus, and inferior longitudinal muscles. The hypoglossal nerve lies lateral to the inferior portion of the hyo-glossus muscle and then sinks into the genio-glossus.

The hyo-glossus muscle is covered laterally below the free portion of the tongue by the mylohyoid, digastric, and stylo-hyoid muscles and by the deep part of the submaxillary gland. Medially it covers in part the middle constrictor of the pharynx.

The stylo-glossus muscle above the tongue lies medial to the stylo-hyoid and the internal pterygoid muscles and the parotid gland, and between the internal and external carotid arteries. It lies lateral to the superior constrictor of the pharynx.

Variations.-The genio-glossus often sends a slip to the epiglottis (levator epiglottidis). It may send some bundles into the superior constrictor of the pharynx (genio-pharyngeus) or to the stylo-hyoid ligament. Various parts of the muscle may be more or less isolated. Of these, a fasciculus from the mental (genial) spine to the tip of the tongue is the most frequent (longitudinalis linguæ inferior medius). The hyo-glossus exhibits considerable variation in structure. Some authors consider the chondro-glossus but a portion of this muscle, while Poirier considers it merely the origin of the longitudinalis inferior. The stylo-glossus may be absent on one side or on both. Its origin varies considerably and may be from the angle of the jaw. The muscle may be doubled.

\title{
5. SUPERFICIAL MUSCULATURE OF THE SHOULDER GIRDLE AND THE EXTERNAL CERVICAL FASCIA
}

\author{
(Figs. 348, 355)
}

The sterno-cleido-mastoid is a strong, band-shaped muscle, bifurcated below, which arises from the medial third of the clavicle and the front of the manubrium and is inserted into the mastoid process of the temporal bone and the neighbouring part of the occipital. The large, flat, triangular trapezius arises from the occipital bone and the spines of the cervical and thoracic vertebræ and is inserted into the lateral third of the clavicle and into the acromion and spine of the scapula. The two muscles lie in a well defined layer of fascia which ensheaths the neck beneath the platysma, the external cervical fascia. Both muscles bend the head and neck toward the shoulder, rotate and extend the head, and raise the shoulder. The sterno-cleido-mastoid also elevates the thorax and flexes the neck.

These two superficially placed muscles represent differentiated portions of a musculature found in elasmobranchs and in the amphibia and all higher vertebrates. In sharks this musculature is associated with the musculature of the branchial arches, and, like them, is innervated by the vagus nerve. In the higher vertebrates it is innervated by the vagus or by the spinal accessory nerve, developed in connection with the vagus. To this innervation by a cranial nerve, innervation by cervical nerves is added in those higher vertebrates in which the musculature is more extensively developed. In the human embryo the muscles migrate from their origin in the upper lateral cervical region to the positions found in the adult.

\section{FASCIE}

The fasciæ of the neck and the relations of the muscles are shown in cross-section in figs. 347 , and 351 .

The tela subcutanea of the head and neck in the upper dorsal region is thick, fibrous, and closely adherent to the underlying muscle fascia. Ventrally in the cervical region it contains the platysma.

The external cervical fascia (fig. 350) lies beneath the subcutaneous tissue and the platysua, completely invests the neck and extends sranialward over the parotid gland to the zyoma and the masseteric fascia. The trapezius lies between two closely adherent laminx of the fasia. From the ventral margin of the trapezius it is continued as a thin but strong membrane acruss the posterior triangle of the neck, between this muscle and the sterno- cleido-mastoil, and is attached below to the clavicle. It invests the sterno-cleido-mastoid with two alherent laminie and extends from the ventral margin of this muscle across the anterior triangle to the mid-line where it is continued into that of the opposite side. In this triangle the fascia is bond to the hyoid bone, and is thus divided into a submaxillary and an infrahyoid portion. The infrahyoid portion is simple and is attached below to the front of the manubrium. The submaxillary portion is attached to the inferior margin of the mandible. It covers the submaxillary gland. and along the inferior margin gives rise to a strong, membranous 'process which passes inward below the gland and, after extending around the tendon of the digastric muscle, becomes united 
to the superior margin of the hyoid bone. This process ventrally becomes fused with the perimysium of the ventral belly of the digastric. Dorsally it extends over the posterior end of the submaxillary gland and becomes attached to the angle of the jaw. Here it is strengthened by fibrous tissue which extends in from the ventral margin of the sterno-cleido-mastoid and serves to separate the parotid from the submaxillary gland. This 'mandibular process' is continued into the stylo-mandibular ligament.

Fig, 350.-FAscif of THE NECK. (After Eisler.) The superficial fascia has been removed in places in order to show the leeper fascix; the sterno-cleido-mastoid has been partly removed; the submaxillary gland, almost wholly; the parotid gland, as far as the duct.

1. Submaxillary space. 2. Parotid space. 3. Sterno-cleido-mastoid. 4 Supra-clavicular fossa. 5. Supra-stemal space. 6. External jugular vein. 7. Anterior jugular vein. 8. Median colli rein. 9. $\mathrm{T}$ occipitalis minor. $10, \mathrm{~N}$. auricularis magnus. 11. Deltoid. 12. Proc. coracoideus. 13. Fascia coraco-clavicularis.

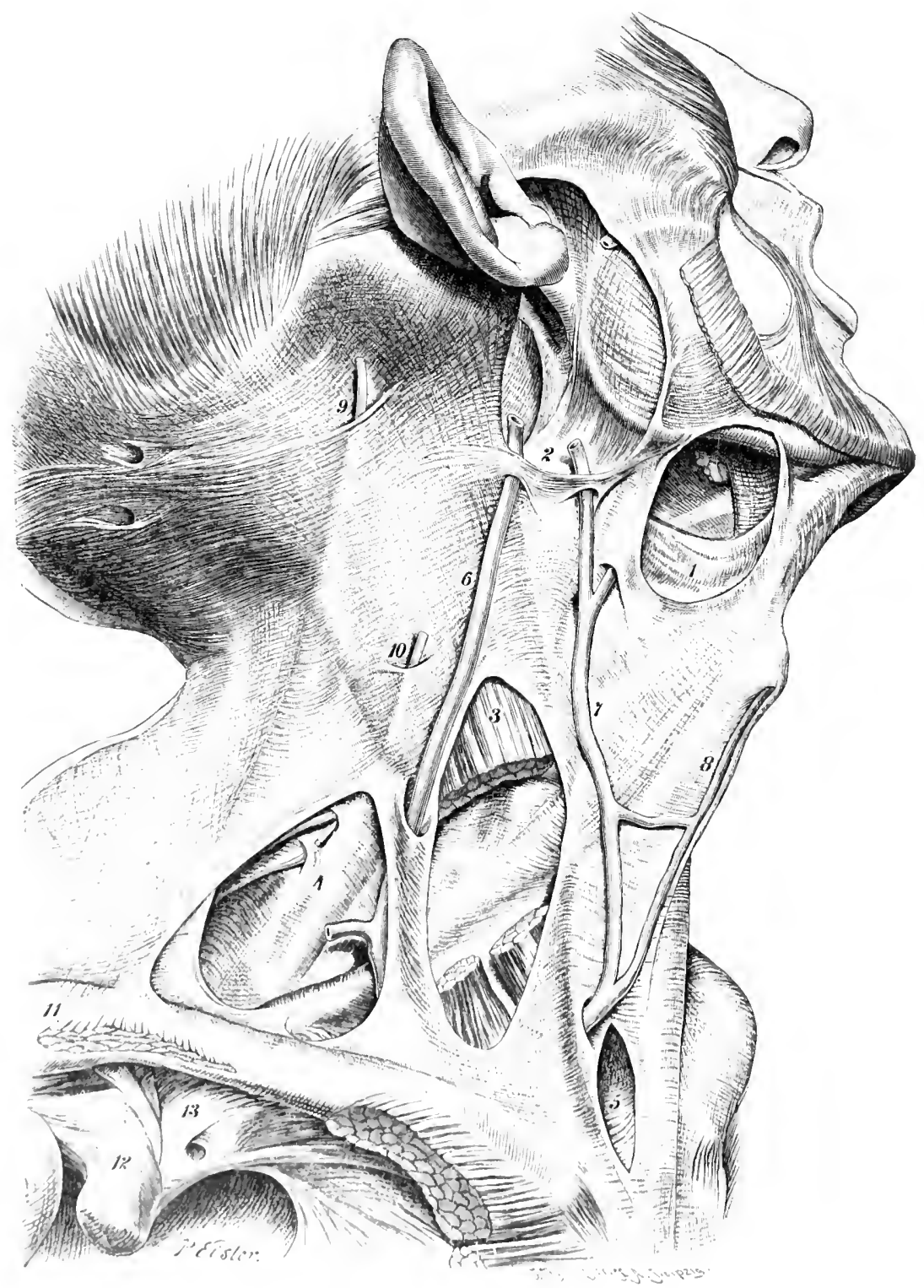

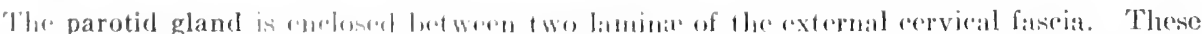

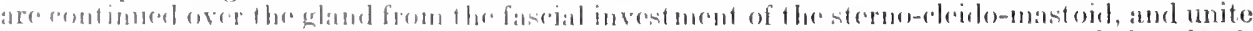

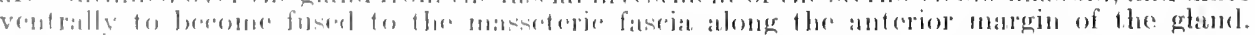

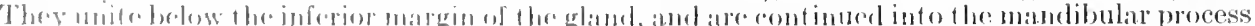

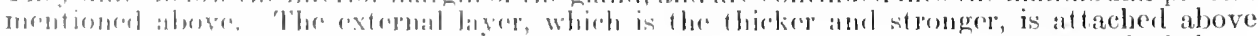

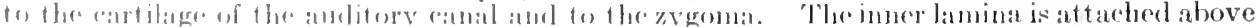


to the base of the temporal bone. It is incomplete and is more or less fused to the posterior belly of the digastric muscle, the styloid process, and the muscles arising from this process. Between the styloid process and the angle of the jaw this lamina is strengthened to form the stylo-mandibular ligament.

In the back, beyond the spine of the scapula, the fascia arising from the investing adherent fascial sheath of the trapezius muscle is continued laterally across the fascia investing the infraspinatus muscle, and becomes fused with the most superficial lityer of this fascia and more distally with that of the latissimus dorsi muscle. Near this lateral line of fusion it is usually closely adherent to the tela subcutanea.

\section{MLSCLES}

The sterno-cleido-mastoideus (fig. 345).-Origin.-By a medial (sternal) head from the front of the manubrium and by a laterial (clavicular) head from the upper border of the median third of the clavicle. Between the two origins there intervenes a triangular area covered by the external cervical fascia. Its insertion is-(1) on the anterior border and outer surface of the mastoid process, and (2) on the lateral half of the superior nuchal line of the oceipital bone.

Structure.-The tendons are comparatively short, the longest being that on the anterior surface of the sternal attachment. The fibre-bundles of the muscle take a nearly parallel course from origin to insertion. Five fasciculi may be more or less clearly recognised. In a superficial layer-(1) a superficial sterno-mastoid; (2) a sterno-occipital; and (3) a cleidooccipital. In a deep layer-(4) a deep sterno-mastoid and (5) a cleido-mastoid.

Nerve-supply.-(1) From the spinal accessory nerve, which gives it branches during it: course through the deep portion of the muscle, and (2) by branches from the anterior primary divisions of the second and third (?) cervical nerves. These branches enter the deep surface of the upper half of the muscie.

Action.-To bend the head and neck toward the shoulder and rotate the head toward the opposite side. When both muscles act, the neck is flexed toward the thorax and the chin is raised; or, with fixed head, the sternum is raised, as in forced respiration. When the head is bent back, the two muscles may further increase the hyperextension.

Relations.-The muscle and its sheath are covered extermally by the tela subcutanea, which here contains the platysma and the external jugular vein, as well as the superficial branches of the cervical plexus. Beneath the muscle lie the sterno-hyoid, sterno-thrreoid, omo-hroid. levator scapulæ, scaleni, splenius, and digastric muscles, the cervical plexus, the common carotid artery, internal jugular vein, and the vagus nerve. The spinal accessory nerve usually runs through its deep cleido-mastoid portion.

Variations. - There is considerable variation in the extent of independence of the main fasciculi of the muscle. In many of the lower animals the cleido-mastoid portion of the muscle is quite distinct from the sterno-mastoid portion, and this condition is frequently found in man. The cleido-occipital portion of the muscle is that most frequently absent (Irood found it present in 37 out of 102 instances). The clavicular portion of the muscle varies greatly in width. The sternal head has been seen to extend as far as the attachment of the fifth rib. Slips from the muscle may pass to various neighbouring structures. The main fasciculi of the muscle may be doubled. Sometimes one or more tendinous inseriptions eross a part or the whole of the superficial layer of the muscle.

The trapezius (fig. 355).-Origin.-By a flat aponeurosis from the superior nuchal line and external protuberance of the occipital bone, the ligamentum nuche, and the vertebral spines and supraspinous ligament from the seventh cervical to the twelf h thoracic vertebra. The. aponeuroses of the right and left muscles are continuous across the middle line. Between the middle of the ligamentum nuche and the second thoracic vertebra, the aponeuroses give rise to an extensive quadrilateral tendinous area. At the distal extrenity of the muscle they are also well developed.

Structure and Insertion.-The superior fibre-bundles pass obliquely downward, lateralward, and forward to the postero-superior aspect of the Jateral third of the clavicle; the middle fibrebundles, transversely to the medial edge of the acromion and the upper border of the spine of the scapula; the lower fibre-bundles, obliquely upward and laterally to terminate through a flat, triangular tendon on a tubercle at the medial end of the spine of the scapula.

Nerve-supply.-The external branch of the spinal accessory nerve descends for a listance near the superior border of the trapezius muscle and then along the ventral surface. Soon it gives rise to ascending branches for the superior portion of the muscle and descending branches for the middle and inferior portions. The main branches of distribution run about midway between the origin and insertion of the fibre-bundles. The branches from the second (?), thiril and fourth cervical nerves anastomose with the trunk of the spinal aceessory, sonetimes as it passes along the margin of the muscle, at other times within the substance of the upper portion of the muscle.

Action. - When the whole muscle contracts, it draws the scapula toward the spine and turns it so that the inferior angle points laterally, the lateral angle upward. In addition the upper portion draws the point of the shoulder upward, and with the scapula fixed extends the head, bends the neck toward the same side, and turns the face to the opposite side. The lower portion of the muscle tends to draw the scapula downward and inward and at the same tinc to rotate the inferior angle of the scapula outward.

Relations.- It is covered merely by skin and fascia. It lies external to the semispinalis, splenii, rhomboidei, latissimus dorsi, levator scapulæ, supraspinatus, and a small portion of the infraspinatus muscles.

Variations.-The lower limit of attachment of the muscle may be as high as the fourth thoracic vertebra. The right and left muscles are seliom symmetrical. The upper attachment may not extend to the skull. The clavicular attachment may be much more extensive 
than normal or may be missing. The attachmeuts to the scapula show considerable variations. Occasionally the cerrical and thoracic portions are separate, a condition normal in many mammals. Ventrally the trapezius may become continuous with the sterno-cleido-mastoid in the neck, or send a fasciculus to it or to the sternum. Aberrant fasciculi are not infrequent. Rarely a transverse tendinous inscription is found in the cervical or in the thoracic portion of the muscle. Sometimes a fasciculus is sent into the deltoid. The innervation of either the sterno-cleido-mastoid or the trapezius may be by cervical nerves only. The omo-cervicalis (levator claviculce) is a fasciculus frequent in the lower mammals, but rarely found in man. It usually extends from the acromial end of the clavicle to the atlas and axis, but may extend to more distal cervical vertebre. It is innervated by a ramus from the cervical branches to the trapezius. The supra-clavicularis proprius is a muscle rarely found. It extends on the cranial surface of the clavicle from the sternal to the acromial end and is innervated by the third cervical nerve. It is said to make tense the superficial layer of the cervical fascia.

A bursa is of ten found between the base of the spine of the scapula and the tendon of insertion of the thoracic portion of the trapezius. Another bursa is also frequently found between the insertion of the transverse portion and the supraspinous fascia.

\title{
6. INFRAHYOID MUSCULATURE
}

\author{
(Figs. 348 and 351)
}

The four infrahyoid muscles constitute a well-defined group of muscles which depress the hyoid bone, the larynx, and the associated structures. They lie beneath the sterno-cleido-mastoid muscle and the external cervical fascia. Two strata may be recognised. In the superficial stratum are comprised the omohyoid, a narrow, ribbon-like digastric muscle which arises from the superior margin of the scapula and is inserted into the hyoid bone; and the thin, quadrangular sterno-hyoid, which arises from the superior margin of the sternum and the medial end of the clavicle and is inserted into the hyoid bone. Between these two muscles is an aponeurotic membrane which constitutes the main part of the middle layer of the cervical fascia, and represents possibly a retrograde portion of a single muscle, of which the two above named are but the ventral and dorsal margins. Beneath this superficial musculature the thin, quadrangular thyreo-hyoid descends from the hyoid bone to the thyreoid cartilage, and the ribloon-like sterno-thyreoid arises from the dorsal surface of the manubrium and is inserted into the thyreoid cartilage.

All these muscles are supplied by branches from the ansa hypoglossi. The nerve-fibres arise from the first three cervical nerves.

The muscles of this group are derived from the ventral portions of the ventro-lateral divisions of the first three cervical myotomes, and correspond with the rectus abdominis muscle, which is derived from the ventral portions of the eighth to the twelf th thoracic myotomes. 'This musculature is characterised by metameric segmentation, which may be more or less obscured, and by a general longitudinal direction taken by the component fibre-bundles. The course of the filmes in the omo-liyoid may be looked upon as a secondary condition due to the shifing laterally of the distal attachment of the muscle. Musculature of this nature is not deriven from the lower cervical and upper thoracic myotones in man, but in some of the lower vertebrates it forms a continuous ventral band. Even in man occusional traces of this ventral musculatur: nay, however, be seen as muscular and aponemotic slips on the upper part of the thoraric wall, abeve the ribs and the aponeurosis of the external intercostal muscles.

\section{FASCIA}

\section{(Figs. 351 and 357 )}

'The: middle cervical fascia is composed of two lamine. Of these, the superfieial, which ensheaths the sterno-hyoid and omo-hyoul muscles and fills in the intervening area, is much the stronger and ledfer lifferentiafed. The more delicate deep lamina ensheaths the thyreo-hyoid and stemo-fliyrouil muscles, and laterally extends out to become fused with the superficial lamina. It is also nume of less (losely bound to the sheath which covers the internal jugular vein, ciroticl artery, and vagus hrove.

The midlle cervint fastia is attaried above to the hyoid bone. Beyond the lateral edge of the omo-hyoded it herentes fureal with the deep lamima of the external layer of the cervieal

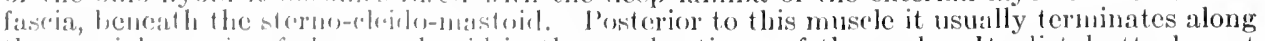
the crantat margin of the rmo-hyosil in the areolar tissue of the neck. Its distal attachment

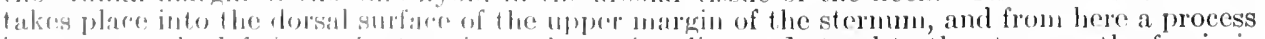

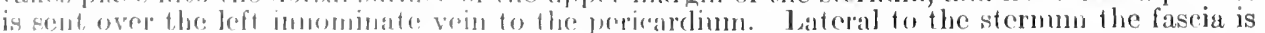

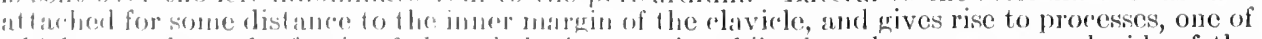
which extends to the fascia of the subntivius muscle, while the others pass on ench side of the suludivian voin to the first ril. Sill more laterally the fascia is fused atong the lower margin of the scapulat liedly of the omo-liyojel to the mulerlying dense, fatty areolar tissue. 


\title{
MUSCLES
}

\author{
(Figs. 348 and 351)
}

The sterno-hyoideus.-Origin.-From (1) the deep surface of the medial extremity of the clavicle; (2) the costo-clavicular (rhomboid) ligament; and (3) the neighbouring part of the sternum. The origin may extend to the cartilage of the first rib. Structure and instionThe fibre-bundles take a nearly parallel course upward. The muscle belly, however, contract. slightly in width and increases slightly in thickness and slants somewhat toward the median line. The insertion takes place directly upon the inferior margin of the body of the livoid lateral to the mid-line. Not infrequently a tendinous inscription near the junction of the mildle and inferior thirds more or less eompletely divides the muscle into two portions. A recond inscription is sometimes found at the level of the oblique line of the thyreoid cartilage. Vervesupply. - One or more branches from the ansa hypoglossi enter the lateral margin of the muscle. Frequently one goes to the upper third, another to the lower third, of the musele.

The omo-hyoideus.-Origin.-From the superior margin of the scapula near, and occasionally also from, the superior transverse ligament of the scapula. Insertion.-The lower border of the hyoid bone lateral to the sterno-hyoid muscle. Structure.-The inferior belly of the musele near its origin is thick and fleshy. It contracts as it passes ventrally across the posterior triangle of the neek. Beneath the sterno-cleido-mastoid it is attached to a short tendon from which, as it bends upward toward the hyoid bone, the superior belly takes origin and thence expands toward the insertion. The tendon of attachment is short. The fibre-bundles of both bellies take a nearly parallel course. The "entral tendon of the musele is held in plare by a strong process in the middle layer of the cervical faseia. This process is attacherl to the dorsal surface of the clavicle and to the first rib. Nerce-supply.-The superior belly is supplied by a branch which enters its deep surface near the medial margin somewhat below the centre; the inferior by a branch which enters the proximal third of its deep surface. These branches arise from the ansa hypoglossi.

The sterno-thyreoideus.--Origin.-Partly directly, partly by tendinous fibres, from-(1) the dorsal surface of the manubrium from the middle line to the notch for the first rib; (2) the dorsal surface of the cartilage of the first rib. Occasionally also from the back of the cartilage of the second rib or from the claviele. Structure and insertion.-The fibre-bundles take a nearly parallel course upward and slightly lateralward. The muscle is inserted by short tendinous fibres into the oblique line on the lamina of the thyreoid eartilage. A transverse tendinous inseription near the upper border of the interclavicular ligament not infrequently divides the belly of the muscle more or less completely into two parts. Sometinies a second transverse inscription is found at the level of the lower margin of the thyreoid cartilage. Nerve-supply.By one or two branches from the ansa hypoglossi, which enter the ventral surface of the nuscle near the lateral margin. One branch usually goes to the upper, another to the lower, third of the muscle.

The thyreo-hyoideus.-Origin.-From the oblique line on the lamina of the thyreoid cartilage. Structure and insertion.-The fibre-bundles take a parallel course and are inserted on the inferior margin of the lateral third of the body of the hyoid bone and the external surface of the great cornu. Many fibre-bundles are continuous with those of the sterno-thyreoid. Nerve-supply.-By a branch of the hypoglossal which enters the muscle near the middle of its lateral border. The fibres are said to be derived from the first cervical nerve.

Action.-The sterno-hyoid and omo-hyoid depress the hyoid bone; the sterno-thyreoid depresses the thyreoid eartilage; and the thyreoid-hyoid approximates the bone to the cartilage. The omo-hyoid tends to draw the hyoid bone somewhat laterally. In this it is aided by the posterior belly of the digastric and the stylo-hyoid and is opposed by the stemo-thyreoid and thyreo-hyoid muscles, and the anterior belly of the digastric.

Relations.-The muscles of this group lie beneath the external cervieal fascia. The sternocleido-mastoid musele crosses the omo-hyoid, the sterno-hyoid, and sterno-thyreoid muscles. The latter two museles extend for a distance behind the manubrium of the sternim. The onnohyoid is partly eovered by the trapezius, crosses the sealene muscles, the brachial plexus, the internal jugular vein, earotid artery, and the stemo-thyreoid and thyreo-hyoid muscles. The sterno-hyoid extends over the sterno-thyreoid musele, the thyreoid gland, crico-thrreoid muscle, and the thyreoid cartilage. The sterno-thyreoid lies over the imnominate rein, the trachea, and thyreoid gland. It is partly covered by the sterno-hyoid and omo-hyoid muscles. The thyreo-hyoid is largely covered by the omo-hroid and stemo-hyoid museles, and lies upon the hyo-thyreoid membrane and the upper part of the thyreoid cartilage.

Variations.-.The muscles vary in extent of development and may he niore or less fured with one another. The sternal attachment of the sterno-hyoid is more frequently abient than the clavicular attachment. The region between the omo-hyoid and sterno-hyoid may locomposed of muscle instead of fascia. Eacr of the muscles may be longitudinally divileil into two distinct fascieuli, may send fasciculi to one another or to the midlle laver of the cervical fiascial, or may have an abnormal origin or insertion. The ono-hyoid is the one of the group nuost frequently absent. One of the bellies is much more frequently absent than both. The intermediate tendon of the omo-hyoid may be reduced to a tendinous inscription or eren lisanpur entirely. The distal attachment may take place on the scapular spine, the aroundon, the coracoid process, or even the first rib or elavicle. An extra fasciculus from the clavicle is found in 3 per cent. of instances. (Le Double.). Not very infrequently a muscle innervated by a branch of the descendens hypoglossi is found extending from the sternum to the claticle belind the origin of the sterno-cleido-mastoid. It may also extend from the stermum or alaricle in various directions upward toward the head. 
Fig. 35̃1, A and B.-Traxsterse Sections Through the Left side of the Neck avd Shoulder in the Regions indicated in the Diagram.

$a$ and $b$ in the diagram indicate sections $A$ and $B$ of fig. 347 (p. 340), a, that of section A, fig. 357 (p. 366).
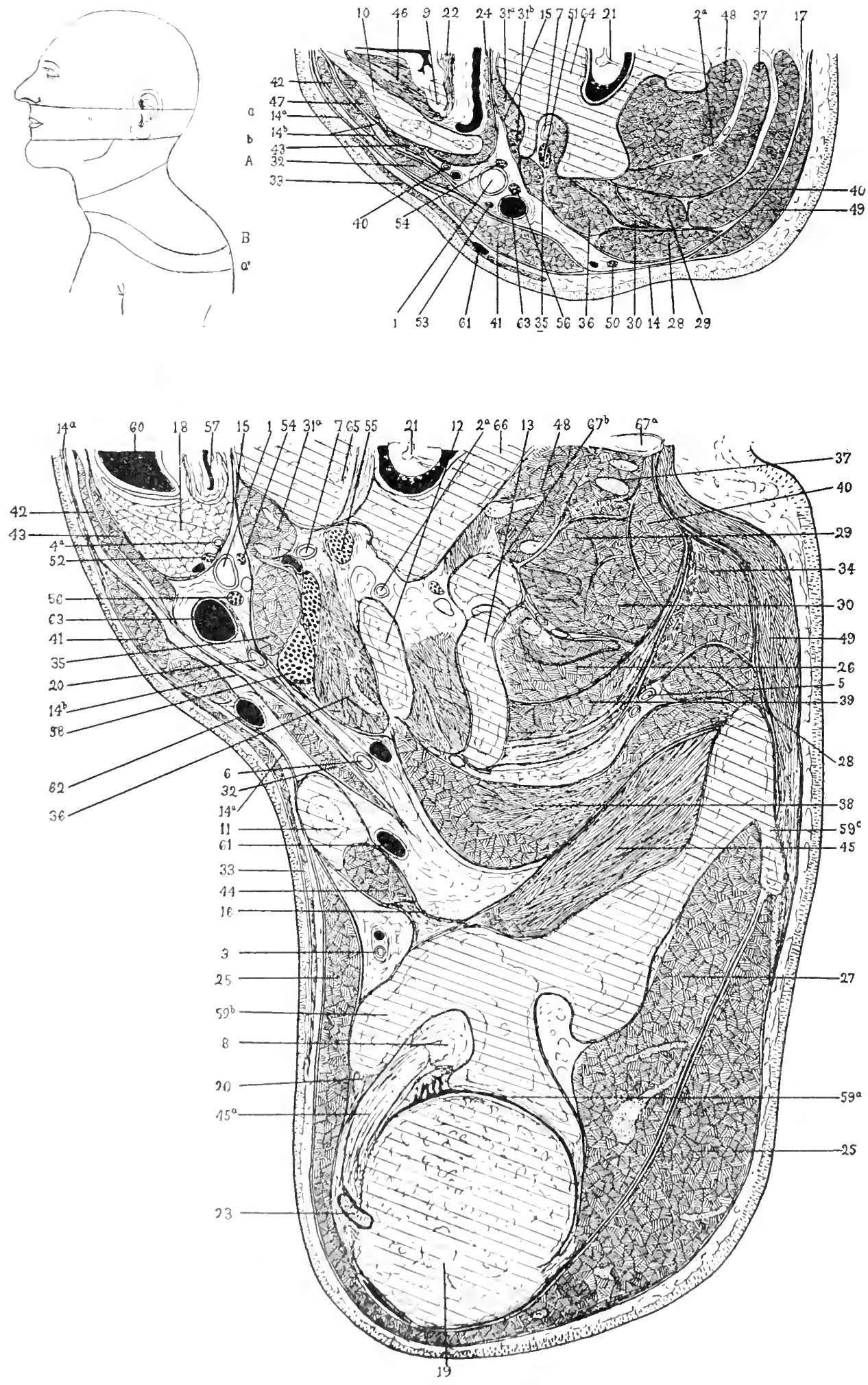


\section{BURSE}

The bursa $\mathrm{m}$. sterno-hyoidei is in constantly found between the lower margin of the hyoid bone and median hyo-thyreoid ligament and the sterno-hyoid muscle and external cervical fascia. It is better developed in men than in women and is found either on each side of the median line or fused in the median line.

The bursa $\mathrm{m}$. thyreo-hyoidei is frequently found between the greater cornu of the hyoid bone and hyo-thyreoid membrane and the thyreo-hyoid muscle.

\section{SCALENE MUSCULATURE (Figs. 348 and 352)}

The three muscles which form this group constitute a triangular mass which extends in front of the levator scapulie and intrinsic dorsal musculature and behind the prevertebral musculature from the first two ribs to the transverse processes of the cervical vertebræ. They cover laterally the apex of the pleural cavity. They bend the neck and fix the first two ribs or raise the thorax. In front lies the scalenus anterior, which extends from the first rib to the fourth to sixth vertebræ. Behind this the scalenus medius extends from the first rib to the lower six vertebræ. The most dorsal of the group, the scalenus posterior, extends from the second rib to the fifth and sixth vertebræ.

These muscles are supplied by direct branches of the cervical nerves. They are probably derived from the lateral portions of the cervical myotomes. According to Gegenbaur, the two more ventral are homologous with intercostat muscles, the dorsal with the levatores costarum. It is to be noted, however, that the anterior muscle lies in front of the brachial plexus, i. e., in a position similar to that of the subcostal musculature. The scalene musculature is morphologically closely related to the deep shoulder-girdle musculature, p. 356.

\section{FASCIA}

(Figs. 351, 357)

From the front of the bodies of the cervical vertebræ the prevertebral fascia is continued laterally over the longus colli and the scalene muscles, and extends dorsally into the fascia covering the levator scapulie. Between the muscles fascial processes are sent in to become attached to the cervical vertebra. Inferiorly the fascia extends to the outer surface of the thorax.

\section{MUUCLES}

\section{(Fig. 352)}

The scalenus anterior.-This arises from the ventral part of the inferior border of the transverse processes of the fourth, fifth, and sixth cervical vertebre, usually also from the third, rarely from the seventh, by means of long, slender tendinous processes. From each tendon arises a fasciculus composed of nearly parallel fibre-bundles. The fasciculi soon fuse to form a muscle belly which contracts somerhat toward the insertion. This takes place by means of

1. Arteria carotis communis. 2a. A. cervicalis profunda. 2b. A. cervicalis superficialis 3. A. thoracoacromialis (acromial branch). ta. A. thyreoidea inferior. 4b. A. thyreordea superior. 5. A. transversa colli. 6. A. transversa scapule. T. A. vertebralis. \&. Bursa m. subscapularis. 9. Cartilago arytenoidea. 10. Cartilago thyreoidea. 11. Clavicle. 12. Costa 1. 13. Costa II. 14. Fascia cervicalis-a, superficial layer; $b$, middle layer. 15. Deep or prevertebral layer. 16. Fascia coraco clavicularis. 17. Fascia nuche. 18. Glandula thyreoidea. 19. Humerus. 20. Ligamentum coracolnumerale. 21. Medulla spinalis (spinal cord). 22. Musculus arytenoideus transversus. 23. M. biceps brachii, tendon long head. 24. M. constrictor pharyngis inferior. 25. M. deltoideus. 26. M. llio-costalis. 27. M. infraspinatus. 28. M. levator scapulæ. 29. M. longissimus capitis (trachelo-mastoid). 30. M. longissimus cervicis. 31a. MI. longus colli. 31b. M. longus capitis (rectus capitis anticus major). 32. M. omo-lryoideus. 33. M. platysma. 34. II. rhomboideus minor. 35. M. scalenus anterior. 36. M. scalenus medius. 37. M. semispinalis capitis (complexus). 3S. M. serratus anterior. 39. MI. serratus posterior superior. 40. M. splenius. 41. MI. sterno-cleido-mastoideus. 42. M. sterno-hyoideus. 43. MI. sterno-thyreoideus. 44. II. subclavius. 45. M. subscapularis; $a$, tendon. 46. M. thyreo-arytenoideus (and vocalis). 47. M. thyreo-hroideus. 48. M. transverso-spinales. 49. M. trapezius. 50. Nervous accessorius. 51. N. cervicalis IT. 52. N. laryngeus inferior. $53 . \mathrm{N}$. descendens hypoglossi. 54. Sympathetic trunk. 55. N. thoracalis $\mathrm{I}$. 56. N. vagus. 57. CEsophagus. 58. Plexus brachialis. 59. Scapula-a, glenoil carity; $b$, coracoid process; $c$, spine. 60. Trachea. 61. Vena transversa colli. 62. T. jugularis externa. 63. V. jugularis interna. 64. Vertebra cervicalis V. 65. Vertebra cervicalis VII. 66. Vertebra thoracalis 1 , arch. 67. Vertebra thoracalis I $-a$, spine; $b$, transverse process. 
a tendon which sends a fibrous lamina a short distance upward on the outer surface of the muscle. The tendon is inserted into the scalene tuberele on the upper surface of the body of the first rib.

The scalenus medius. - This arises usually from the third to the seventh, sometimes from all seven or from merely the last four or five cervical vertebræ. The origin takes place from the posterior part of the lateral border of the transverse processes by means of a slender tendon from each of the upper and directly by a muscular fasciculus from each of the lower vertebræ. The fasciculi become combined into a compact muscle belly which is inserted in a manner similar to the scalenus anterior into the upper surface of the first rib behind the subclavian groove. The insertion usually extends to the second rib.

The scalenus posterior arises by short tendons from the posterior tubercles of the transverse processes of the fifth and sixth cervical rertebrie. The origin may extend as high as the fourth vertebra, or as low as the seventh. It is inserted by a short tendon into the lateral surface of the second rib. Occasionally it extends to the third rib.

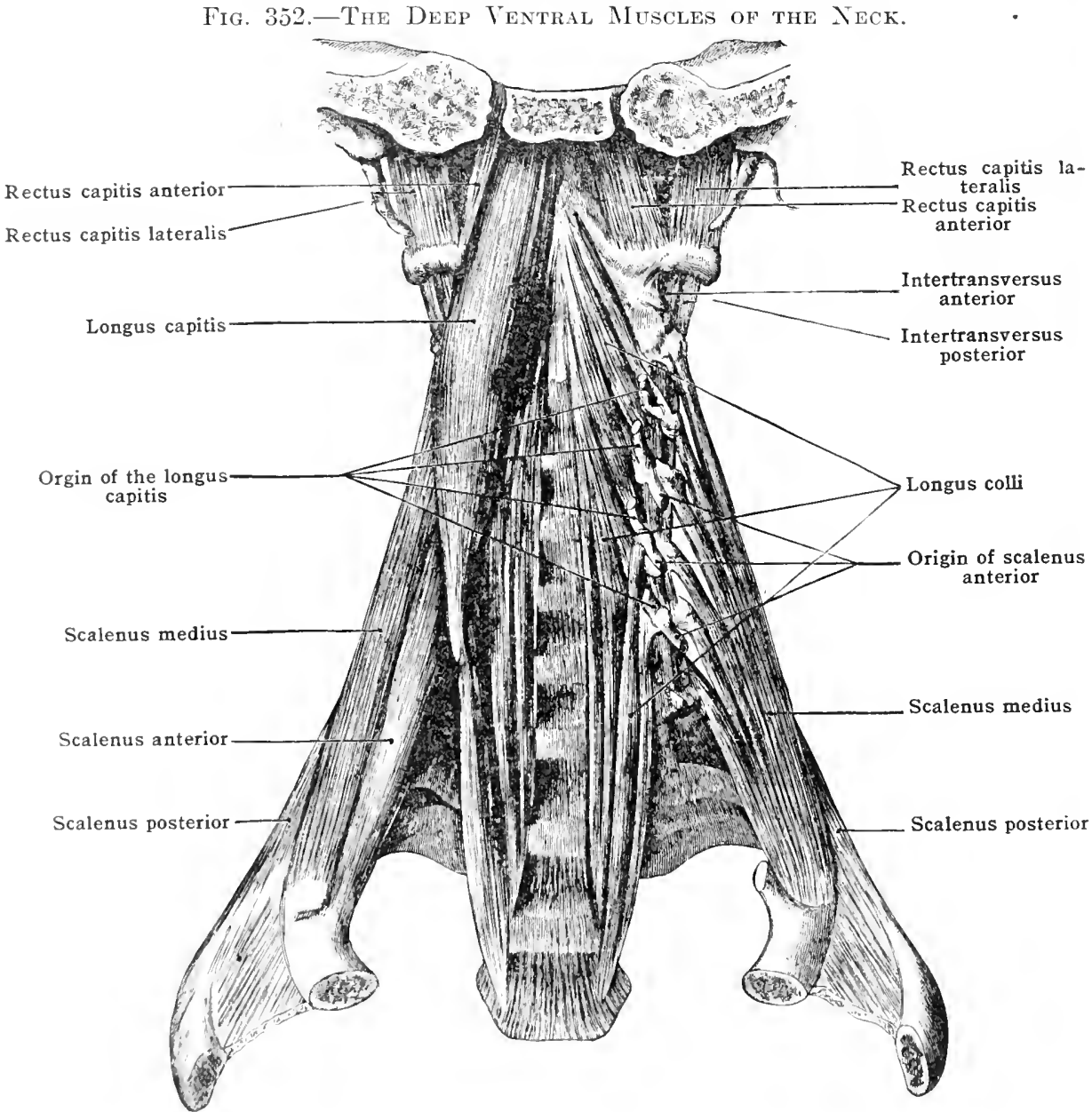

Norve-supply.- The sealenus anterior is innervated by loranches from the fifth, sixth, and seventh cervical nerves; the middle by the fourth, fifth, sixth, seventh, and eighth eervical nerves; the posterior liy the seventh or eighth nerves.

Action. With the Horax fixerl the scidene muscles hend the neck to the side and slightly forwarl and turn it slightly towall the opposite side. With the neck fixed they serve to lift the first two ribs and are of use in enforeel inspiration. In quiet inspiration they serve to fix the first two ribs.

Relations.- The longus erolli lies medial to the sealenus anterior. Dorsally the sealene muscles; modially the pharyx, thyreoid gland, amd trachea; ventro-laterally the sterno-cheido-

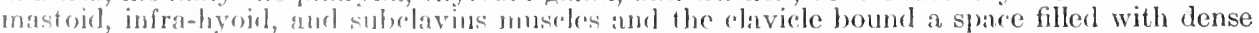
fatty areolar tissne in which arr rontaned the suhelavian and earotid arteries, the subelavian and internal jugular veins, the vagus, phrenic, and sympathetic nerves, and numerous smaller

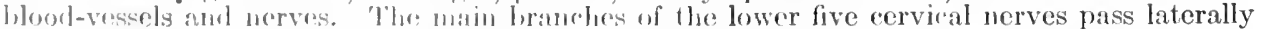
hetween the sealenus anterior and medius. The subdavian artery passes behind, the subrlavian vein in front of the attalloment of the sealemus anterior. 'The sealenus medius above and the scalenus posterior below entre into relations dorsally with the levator seapule and the

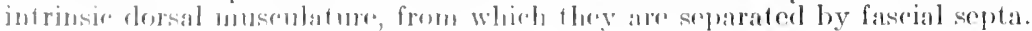


$V$ ariations.-The scaleni present numerous variations in the extent of the costal and rertebral attachments. The degree of fusion of the various fasciculi likewise varies so much that different authors have described varying numbers of muscles into which the sealenus mass should be subdivided. A muscle frequently present is the scalenus minimus. This arises from the anterior tubercle of the sixth or sixth and seventh cervical vertebre, and is inserted into the first rib behind the sulcus for the subclavian artery. It sends a process (Sibson's fascia) to the pleural cupola and serves to make the pleura tense. Zuckerkandl found it in 22 out of 60 bodies on both sides; 12 times on the right side only, 9 times on the left. It is innervated by the eighth cervical nerve. When absent, a ligamentous band takes its place. An intertransversarius lateralis longus, may extend from the posterior tubercles of the 3-5 transverse processes to the tip of the seventh transverse process and divide the muscle fasciculi near their origin into dorsal and ventral divisions.

\title{
8. THE PREVERTEBRAL MUSCULATURE
}

\author{
(Fig. 352)
}

This deep-seated musculature extends along the ventro-lateral surfaces of the three upper thoracic and the cervical vertebra to the skull. It is composed of two muscles. The longus colli arises from the bodies of the three thoracic and from the bodies and transverse processes of the third to the sixth cervical rertebræ, and is inserted into transverse processes and bodies of the cervical vertebræ. The longus capitis (rectus capitis anterior major) arises from the transverse processes of the fourth, fifth, and sixth cervical vertebræ, and is inserted into the basilar process of the occipital bone. These muscles flex, abduct, and rotate the head and neck. All of them are supplied by direct branches from the anterior divisions of the cervical nerves. They are probably specialised from the ventrolateral portions of the cervical myotomes. Similar muscles are found in all vertebrates with well-developed necks. The rectus capitis anterior (minor) represents an anterior cervical intertransverse muscle.

\section{FASCIA}

\section{(Figs. 351, 357)}

The muscles are firmly bound to the vertebral column by the prevertebral fascia described in connection with the scalene muscles and by the septa which extend in between the nuscles of this group and between them and the scalenus anterior.

\section{MUSCLES}

(Fig. 352)

The longus colli.-This musele may be compared to a triangle, the base of which extends from the anterior tubercle of the atlas to the body of the third thoracic vertebra and the apex of which is the transverse process of the fifth cervical vertebra. The complex construction of the muscle makes it advisable to consider it as divided into three parts.

The supero-lateral portion consists of fasciculi which arise from the anterior tubercles of the transverse processes of the third, fourth, fifth, and sixth cervical vertebre and from the body of the third thoracic and become fused into a belly which is inserted into the anterior tubercle of the atlas.

The median portion is formed of muscle fasciculi which arise from the antero-lateral parts of the bodies of the first three thoracic vertebræ and the last three cervical vertebra by tendinous processes. These fasciculi fuse into a belly which terminates by three flat tendinous fasciculi on the antero-lateral surfaces of the bodies of the second, third, and fourth cervical vertebræ.

The infero-lateral portion is applied to the inferior lateral surface of the median portion. It arises from the lateral parts of the bodies of the first three thoracic vertebrx and is inserted by tendinous processes into the transverse processes of the fifth and sixth cervical vertebra.

Nerve-supply.-By branches from the second to sixth cervical nerves which send rami to the various constituent fasciculi of the muscle.

The longus capitis (rectus capitis anterior major).-Origin.-By cylindrical tentons from the tips of the anterior tubercles of the third, fourth fifth, and sixth cervical verteliri. The tendons send up aponeurotic expansions on the outside of the fasciculi, which arise from them. These fasciculi fuse into a dense muscular belly to which is usually added a fasciculus from the longus colli. The insertion takes place into the impression on the inferior surface of the bisilats portion of the occipital bone, extending lateral to the pharyngeal tubercle outwari and forward. The insertion of the fibre-bundles from the third vertebra is direct; the other fibrebundles are inserted largely into a tendinous lamina which covers the midile of the ventral surface of the muscle and from which, in turn, other fibre-bundles arise. It is an incomplete digastric muscle. Nerve-supply.-The first, second, third, and fourth cerrical nerves send branches into the ventral surface of the muscle. 
Actions.- The longus colli serves to bend the neck forward; the supero-lateral portion, when acting on one side only, serves slightly to bend the neck toward that side and to rotate it; the infero-lateral portion serves especially to prevent hyperextension. The longus capitis bends the head forward; one side acting alone rotates the head toward that side.

Variations.-There is considerable variation in the number of vertebre to which the tendons of origin and insertion of the longus colli and longus capitis may be attached and in the extent of fusion of the different fasciculi composing them. There may be fusion with the scalenus anterior. The atlantico-basilaris internus in 4 per cent. of eases extends from the anterior tubercle of the atlas to the base of the skull.

\section{ANTERIOR AND LATERAL INTERTRANSVERSE MUSCLES}

(Fig. 352)

The anterior intertransverse museles extend successively between the anterior tubereles of the eervical vertebra. They lie in front of the anterior divisions of the eervical nerves and are supplied by branches from these divisions. They are usually more or less bound up with the insertions of the sealene and prevertebral museles into these tubereles. The musele between the atlas and epistropheus is frequently missing; when present, it passes in front of the lateral artieulation between these vertebræ. 'The reetus eapitis anterior (minor) may be considered a eontinuation of the series. The lowest muscle may extend between the seventh cervical vertebra and the first rib. The lateral intertransverse muscles lie immediately behind the ventral divisions of the spinal nerves and lateral to the dorsal divisions and are supplied by branehes from the ventral divisions. The reetus eapitis lateralis belongs to this series. The rectus capitis anterior (minor) arises from the lateral mass of the atlas and is inserted into the base of the oecipital bone. The rectus capitis lateralis runs from the transverse proeess of the atlas to the lateral part of the oceipital. For the posterior intertransverse museles see p. 417.

The rectus capitis anterior (minor).-This arises from the upper surface of the lateral mass of the atlas in front of the articular process and partly from the neighbouring transverse process. From a tendon the fibre-bundles extend in a nearly parallel direction upward and medially to be inserled on the inferior surface of the basilar portion of the occipital bone in front of the condyle Nere'supply.-From the first (and second) cervical nerves. Action.-The rectus capitis anterior (minor) serve to bend the head forward and, when the muscles on one side only are contracted, to rotate the head toward the same side.

Relations. - The muscles of this group are closely applied to the vertebral column. Between the fascia covering them and the fascia surrounding the pharynx which lies in front is a region in which merely a slight amount of loose areolar tissue is found. Dorso-medially the longus colli below and the longus capitis above help to bound the space in which the chief vessels and nerves extend between the thorax and the head.

The rectus capitis lateralis (fig. 352).-Origin.-From the upper surface of the transverse process of the atlas.

Siructure and insertion.- The fibre-bundles give rise to a quadrilateral sheet which passes upwitrl to be inserted on the under surface of the pars lateralis of the ocripital bone.

Neref-supply.-The ventral branch of the suboceipital (first cervical) nerve gives twigs to its ventral surface.

Artion.-To flex the head laterally.

Rilatims.-In front lie the anterior primary division of the suborcipital nerve and the internal jugular vein. Jehind the muscle lie the superior oblique and the longissimus capitis (trarbluclo-mastoid) musrles and the atlanto-oceipital joint.

\section{I) JEP MUSCULATURE OF THE SIIOULDER GIRDLE} (Figs. 348, 353, 354, 388)

To this gromp belong four muscles which arise in the lateral cervieal region during conbryonit; devolopment and hecome secondarily attaehed to the vertebral margin of the scapulat. ( no of these museles, the band-like levator scapulæ (fig. 3.53), ramains in the corvinal region. It cxtends beneath the sterno-eleidomastoil, the trapezios, and the intervening fascia from the transverse proeesses of thr first four eervional vertroria to the medial angle of the seapula. A second, the lalke, qualrilatcral serratus anterior (magnus) (fig. 35.4), romes to lie beneath the blate of the scapnla and wanders with this to the thoracie region. It arises, in the adult, from the first nime ribs and is inserted into the vertcbral margin of the salpulat. 'The Hat, flatlangular rhomboideus major and rhomboideus 
minor (fig. 353) arise from the spines of the last cervical and first four or five thoracic vertebræ, pass obliquely downward across the deep dorsal muscles beneath the trapezius and are inserted into the vertebral margin of the scapula. The third to the seventh cerrical nerves supply this set of

Fig. 353.-The Levator Scaptle axd Rhonboidei.

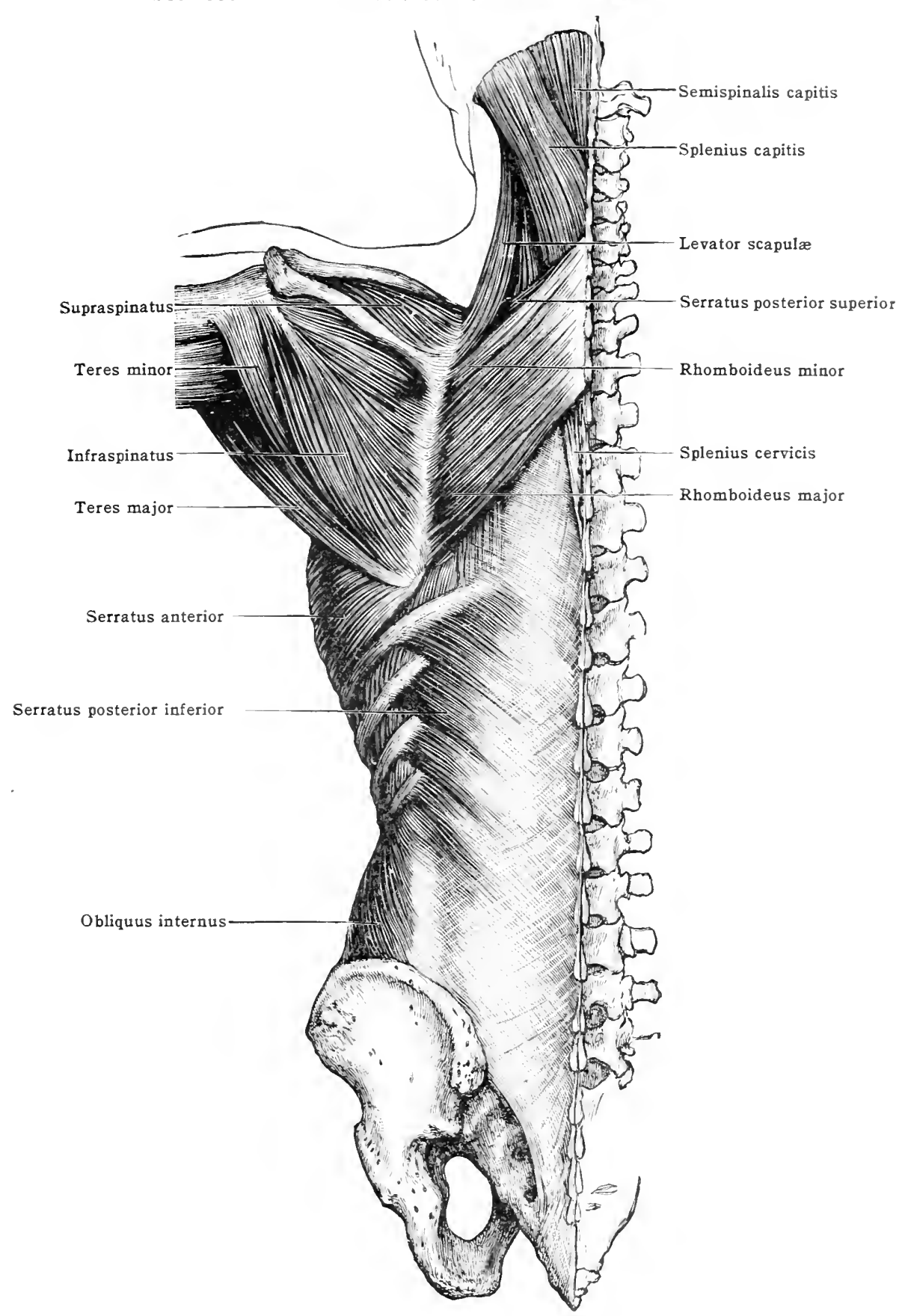

muscles. The levator scapulæe is supplied by the third and fourth cerrical nerves, the rhomboids by the fifth (dorsal scapular), the serratus anterior by the fifth to the seventh (long thoracic nerve). The muscles of this group elevate the scapula, rotate it, and draw it backward (rhomboidei) or formard (serratus anterior). When all contract together they raise the thorax. 
The levator scapule and the serratus anterior (magnus) are two differentiated parts of a muscle which is a continous mass in many of the lower mammals. A muscle corresponding to the rhomboideus is found in some of the reptiles and many of the higher vertebrates. In some of the mammals it has a more extensive cervical attachment than in man.

\section{FASCIE}

The fasciæ investing these muscles are shown in cross-section in fig. 357.

The levator scapulie is invested by fascial membranes, the external and stronger of which is continued dorsally from the fascial investment of the scalene muscles. The thinner layer on its deep surface lies next the fascial investment of the intrinsic museles of the back. Cranialward from the rhomboid muscles the faseial investment of the levator scapulæ is fused dorsally with the fascia covering the splenius cervicis. Where the dorsal margin of the levator comes in contact with the rhomboideus minor, the fascia is continued over into the thin fascial mem-

\section{Fig. 35t.- Serrates ANterior.}

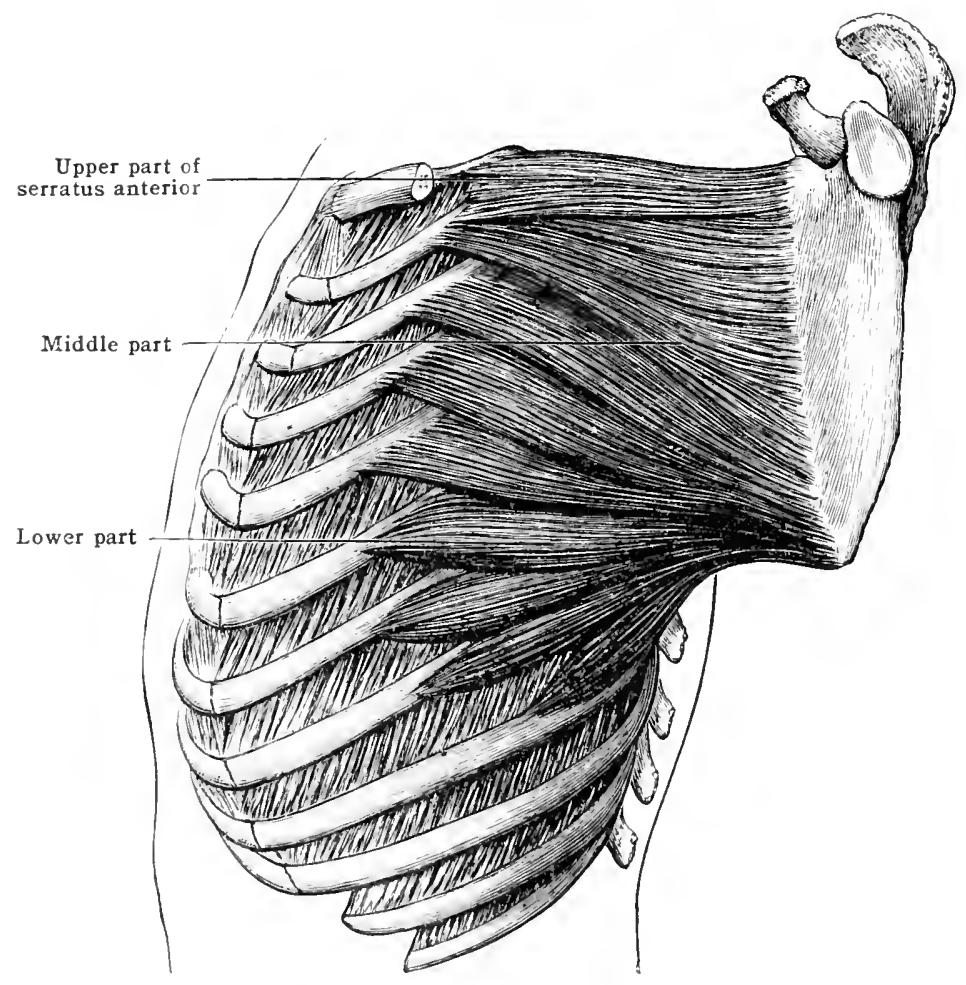

branc which invests both surfaces of the rhomboidei. Similarly the investing fascia of the levator is continued ventrally into the fascia investing both surfaces of the serratus anterior (magmus). Within the internal fascial investment of this group of museles, near the insertion of the levator, run the transversa colli artery and the dorsal scapular nerve.

\section{MUSCLES}

The rhomboideus minor (figr. 353).-Origin.-Lower part of the ligamentum nuchs, the spines of the seventh cervical and lirst thoracic vertebra, and the intervening supraspinous ligament. Insertim. - Vertebral borter of the seapula near the spine.

The rhomboideus major (fig. 35:3). - Vrigin.- Spines of the first four or five thoracie vertohas. Insertion. linteloral horder of the seapula opposite the infraspinous fossa.

Structure. Ther: 1 wo muscles are included between two adherent fascial lavers which bridge wrer the greater or loss spare that may intervene between them. The fibre-bundles take a barallel course oldigudy clownward and lateralward from the vertebra. Trom the vertebral spinrs the museles arise by an aponcurosis which varies in width. The attachment to the seapula is by short tendimus morrsses. The attachment of the rhomboideus major is firmest towart the inferior anglo of the soapmlit.

Nerne-supply- The dorsal scapular nerve, which usually arises chiefly from the fifth rervical nerve, enters the suproriormangin of the rhomboideus minor and then eourses distally near the deep ventral surfare of the two moscles and about midway between the tendons of origin and in:-rition. 
Action.-The two muscles draw the scapula upward and medialward toward the spine and rotate it so as to depress the shoulder.

Relations.-Over the muscles lies the trapezius. Under them lie the serratus posterior superior and the splenius cervicis, the longissimus dorsi, the ilio-costalis, serratus posterior superior and external intereostal muscles. The descending ramus of the transversa colli artery descends on the deep surface. Blood-vessels for the trapezius pass to this muscle between the two rhomboids.

Variations. - There is much variation in the extent of the rertebral attachment. The minor is frequently, the major occasionally, absent. The two rhomboids are frequently fused with one another or may be divided into several distimet fasciculi. Frequently ( 80 per cent., Balli) a fasciculus extends obliquely on the deep surface of the R. major from the cranial part of the origin to the distal part of the insertion. slips may be sent to the latissinus dorsi or the teres major. An accessory slip may pass between the trapezius and splenius muscles to the occipital bone (occipito-scapularis). A muscle corresponding to this fasciculus is normally found in many mammals.

The levator scapulæ (figs. 353, 385).-Origin.-By short tendons from the dorsal tubercles of the transverse processes of the first four cervical vertebræ, between the attachments of the splenius cervicis and scalenus medius muscles. The tendons from the third and fourth cervical vertebræ are fused for a short distance with those of the longissimus cervicis. Structure ard insertion.- The fibres run in parallel bundles in a dorso-lateral direction downward to the ver. tebral border of the scapula opposite the supraspinous fossa. The fibre-bundles are inserted directly into the periosteum. As a rule, the flat fasciculi arising from the different vertebræ are easily separated.

Nerve-supply.-By rami chiefly from the third and fourth cervical nerves. These rami enter the ventral margin of the muscle and extend obliquely across the dorsal surface of the constituent fasciculi about midway between the tendons of origin and insertion. Frequently anastomosing branches pass between the nerves. The lowest fasciculus is usually supplied by branches from the nerve to the rhomboid muscles (dorsal scapular).

Action.-Draws the scapula upward and tends to rotate it so that the inferior angle approaches the spine. When the scapula is fixed, the muscle serves to bend the neck laterally and slightly to rotate it toward the same side aud extend it.

Relations.-Externally the sterno-cleido-mastoid and, in part, the splenius capitis cover it above; the trapezius, below; and the external cervical fascia, its middle portion. Internally lie the splenius cervicis, longissimus and iliocostalis cervicis (transversalis cervicis), and serratus posterior superior muscles and the ramus descendens of the transversa colli artery. In front lie the scalene muscles.

Variations.-The number of cervical vertebræ from which the muscle springs varies from two to seven. The most constant are the slips of origin from the first two vertebræ. The muscle may send slips to the temporal or the occiptal bone or to the trapezius, the serratus anterior (magnus), serratus posterior superior, aud other muscles, or to the clavicle, first or second rib, etc. Often the parts' of the muscle running to each vertebra are separated for the whole distance. A bundle of fibres that appears to be a detached slip of the levator scapulie may run from the first two or from lower cervical vertebra to the lateral eud of the clavicle and to the acromion. This represents the levator claviculæ found normally in many vertebrates. According to Le Double, it is innervated by a branch from the cervical branches to the trapezius group.

The serratus anterior (magnus) (figs. 354, 388).-First Part.-The origin is by two digita. tions from the first and second ribs and from a fibrous arch uniting these two attachments. The fibre-bundles converge to be inserted on an oval space on the costal surface of the scapula near its medial angle. Second Part.-This arises by two or three digitations from the second, third, and sometimes the fourth ribs. The fibre-bundles spread out into a thin sheet which is inserted along the vertebral border of the scapula. Third Part.- This, the strongest part of the muscle, arises by digitations from the fourth or fifth to the eighth or ninth ribs. The attachments of the digitations are longest on the upper border of each rib. The interdigitate with the attachments of the external oblique muscle of the abdomen. The fibre-bundles converge to be inserted on the large oval space on the costal surface near the inferior angle of the scapula.

Nerve-supply.-From the proximal portions of the anterior divisions of the fifth, sixth, seventh, and sometimes the eighth cervical nerves branches arise which fuse into the long thoracic nerve. This nerve usually passes laterally through or behind the scalenus medius muscle, courses along the outer surface of the serratus anterior midway between the origin and insertion, and gives rise to numerous twigs to supply the various divisions. The fibres to the upper portion come mainly from the fifth cervical nerve; those to the widdle from the fifth and sixth; and those to the lower from the sixth and serenth.

Action.-The muscle holds the scapula against the thorax and draws it forward and laterally and, by its highly developed inferior portion, rotates the bone so as to raise the point of the shoulder. It is of especial importance in abduction of the arm. It also aids, to a slight. degree, in forced inspiration.

Relations.-Superficial to the muscle lie the pectoralis major anıl minor, subscapularis, teres major, and latissimus dorsi muscles, the subclavian and axillary ressels, and the brachial plexus. Between the latissimus dorsi and pectoral muscles it is corered by skin and fascia inferiorly, and superiorly by the fatty areolar tissue of the axillary fossa. T'nlel it lie the external intercostal, serratus posterior superior, and the lower extremity of the scalenus melius and posterior muscles.

Variations. - The digitations may extend to the teuth or only to the serenth rib. The muscle may be continuous with the levator scapule as it is in the carnirora, or some of its upper digitations may be wanting. Slips may be continued into neighbouring muscles. The lower digitations may be partially replaced by digitations innervated by intercostal nerves. 


\section{MUSCULATURE OF THE UPPER LIMB}

The upper limbs in man, relieved of the function of locomotion which is their chief office in most of the lower mammals, have become endowed with great

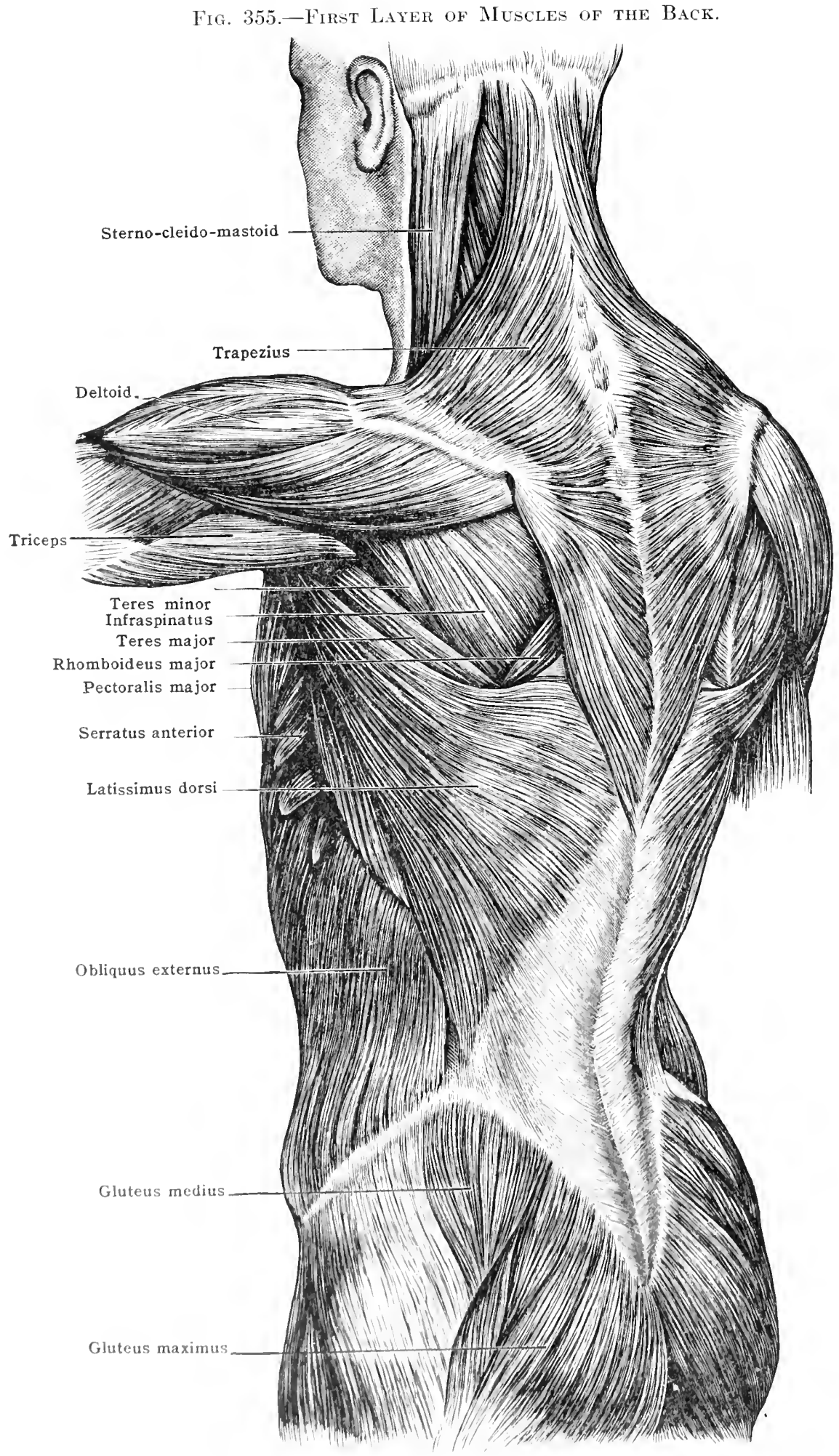


freedom of movement which permits their developing many important functions. Primitively of value in climbing, in seizing food, preparing it for eating and carrying it to the mouth, in attack and defense, their importance has been greatly increased through the invention and use of tools, at first simple but constantly increasing in complexity. They are also used as a means of social expression, as seen primitively in the shrugging of the shoulders, or in the varied movements of the arms which aceompany heated discourse, and as finally developed in the art of writing. In order to understand the muscles which are called into play in the performance of these varied funetions it is necessary to consider the various types of movement which take place at each of the joints. Since, however, most muscles act on more than one joint and the different parts of a muscle may act differently on the same joint, it is convenient to take up the muscles of each region of the limb in groups, based not so much upon the action of the muscles on any one joint as upon the development of the group and the innervation of the muscles composing it.

Movement of the scapula is of essential importance in the movements of the arm. The scapula is kept against the thorax by muscular attachments and atmospheric pressure, but it may be moved forward, backward, upward, and downward, and may be rotated so that the glenoid fossa, with which the head of the humerus articulates, is pointed forward when the arins are carried forward, lateralward when the arms are abducted, upward when the arms are raised high and somewhat downward when the arms are carried backward, thus greatly increasing the extent of movement in these various directions. The acromio-claviculir, and sterno-elavicular joints both allow limited movements in various directions so that they resemble physiologically limited ball and socket joints. The part plinyed by the superficial and deep shoulder-girdle muscles in the various movements has been clescribed above, p. 356 , in connection with these groups of muscles. The action of these muscles is aided by the "pectoral muscles," (figs. 360, 388 ) and by the latissimus dorsi (fig. 355) described below. 'These muscles depress the scapula*

At the humero-scapular or shoulder-joint the arm may be carried outward or abducted, bodyward or adducted, forward or flexed and backward or extended. The last is much more limited in degree than the other two. The arm may also be partially rotated at this joint. These various movements are brought about by the scapulo-humeral muscles (figs. $355,356,363$ ) and by the latissimus dorsi (fig. 355) and the pectoralis major, (fig. 360) assisted by the muscles of the arm which arise from the scapula. They are produced in association with the movements of the scapula described above. At the ulno-humeral joint the movenents are relatively simple, consisting of flexion and extension. Extension is produced at the elbow by the dorsal muscles of the arm (fig. 363), flexion is produced not only by the ventral muscles of the arm, which are inserted into the radius and ulna (fig. 364), but also by the more superficial of both the main groups of muscles of the forearm. The pronation of the forearm, whereby the palm is turned downward, and supination, whereby it is turned upward, take place in the joints between the radius and ulna at each extremity and between the radius and the lower end of the humerus. At the upper radio-ulnar joint the radius is turned on its long axis, at the lower joint it is carried about the lower end of the ulna. Pronation is produced chiefly by muscles belonging to the ulno-volar group of for earm museles (fig. 370); supination is produced by the biceps of the arm (fig. 364) in conjunction with some of the muscles of the radio-dorsal group) of the forearm (fig. 367). At the wrist joints (radio-carpal, intercarpal), the morements are those of flexion, extension, radial abduction and ulnar abduction. Volar flexion takes placee chiefly at the radio-carpal joint, dorsal flexion at the intercarpal joint (Frohse). Extension is produced by those muscles of the radio-dorsal group of the forearm, which send tendons to the wrist and digits, flexion by the corresponding muscles of the ulno-volar group, radial abduction is produced by the radial carpal extensors (fig. 367), and flexor ulnar abduction by the ulnar carpal extensor and flexor (fig. 370). The varied movements of the thumb and fingers, flexion, extension, abduction, and adduction are produced partly by muscles of the two chief groups of forearm muscles, partly by the intrinsic muscles of the hand. Of chief interest here are the free movements of the metacarpal of the thumb and the limited movements of the other metacarpals, that of the little fingers being the most movable, as seen in spreading or cupping the hand. In flexion and extension of the metacarpal of the thumb the movement is such as to bring the thumb into opposition to the fingers. In the metacarpo-phalangeal joints those of the fingers admit of much greater freedom of movement. flexion, extension, abduction, and adduction, than that of the thumb. The interphalangeal joints are pure hinge joints and permit merely flexion and extension.

Divisions.-The muscles described in this section as the museles of the upper limb are all differentiated from the blastema of the embryonic limb bud. Iost of them are differentiated in connection with the skeleton of the limb and extend between the various bones which compose it, but a few grow out from the limb bud over the trunk and become secondarily attached at one extremity to the trunk, while the other extremity remains attached to the skeleton of the limb. Thus the pectoral muscles (fig. 360), extend from the limb bud orer the front of the thorax and the latissimus dorsi extends over the side and back of the trunk

* The upper sternal part of the pectoralis major, however, acting alone clevates the scapula. and the glenoid fossa, the latissimus dorsi draws the scapulabackwarl, the pertorial nuscles draw it forward. 
as far as the iliae erest (fig. 355). The muscles of the limb may be divided into two great divisions, a dorsal division, innervated by nerves arising from the back of the brachial plexus (supra- and subscapular, axillary and radial nerves) and a ventral division innervated by nerves arising from the front of the plexus (subclavian, anterior thoracic, musculo-eutaneous, median and ulnar). The former, which eorrespond with the museulature on the back of the shark's fin, are in the main extensors; the latter, which correspond with the musculature on the front of the shark's fin are in the main flexors. The bellies of the muscles of each division are found in the region of the shoulder and thorax, the arm, the forearm, and the hand.

The shoulder muscles belong to the dorsal division. They arise from the lateral third of the elavicle and from both surfaces of the seapula and are inserted into the upper part of the humerus. They include the deltoid (fig. 355), the chief abductor of the arm; the supraspinatus, the infraspinatus and the teres minor (fig. 363), all lateral rotators; the subscapularis (fig. 356), the ehief medial rotator; and the teres major (fig. 355), a medial rotator and adductor. With these may be elassed the latissimus dorsi (a medial rotator, adductor and extensor) (fig. 355 ), which arises from the dorsolumbar faseia and the erest of the ilium and is inserted into the upper part of the shaft of the humerus. These muscles are supplied by the supraseapular, the subseapular, and the axillary nerves.

The pectoral group belongs to the ventral division. It includes the pectoralis major (fig. 360), a powerful flexor and adductor of the arm arising from the anterior chest wall and inserted into the shaft of the humerus; the pectoralis minor (fig. 388), which arises from the chest wall and is inserted into the coracoid process of the scapula, and the subclavius (fig. 361), which extends from the first rib to the claviele. These muscles are supplied by the subclavian and the anterior thoracic nerves.

In the arm the dorsal division is represented by the triceps and anconeus, (fig. 363). The triceps arises from the seapula and the back of the humerus and is inserted into the oleeranon process of the ulna. The anconcus arises from the radial epicondyle of the humerus and is inserted into the olecranon process. Both museles extend the forearm. The triceps also adduets the arm. They are supplied by the radial nerve.

The ventral division is marle up of the eoraco-brachialis (fig. 365); the biceps (fig. 364); and the brachialis (fig. 365). The coraco-brachialis (fig. 365), arises from the tip of the coracoid process of the elaviele and is inserted into the shaft of the humerus. It adduets and flexes the arm. The biceps (fig. 364), arises by a short head from the coracoid process and by a long head from the scapula above the glenoid fossa and is inserted into the radius and the faseia of the forearm. It flexes and supinates the forearm. The long head is an abductor, the short head an adductor and flexor of the arm. The brachialis (fig. 365), arises from the lower part of the shaft of the humerus and is inserted into the ulna. It is a flexor of the forearm.

The two main divisions of the musculature of the forearm give rise to the prominences on each sicle of the clbow-joint. Their peeuliar arrangement with respect to the humerus is because in man, as in most tetrapods, the normal position of the forearm is one of pronation and in this position the back of the forearm is in line with the radial epicondyle, the front with the ulnar epicondyle. The Jorsal or (xtrinsor muscles, springing from the lower end of the humerus (fig. 367), gret the most lirect purchase when attached to the radial epieondyle, and the ventral or flexor muscles (fig. 370), the most direct purehase when attached to the ulnap cpicomlyte. 'The two divisions of the musculature may therefore here be dresignated the radio-dersal and the nlno-volar or volar divisions. The main bulk of the musculatine is found in the mpper part of the forearm. At the wrist numeroms temelons pass over to the wrist, palm and digits. 'This arrangement faccilitates movement of the hanel.

'The muscles of the dorsal division (figs. $367,368,369$ ), are divisible into two gromps, it superficial and it horp mroup. Those of the superficial group arise from the radial side of the lower ond of the humerus and are inserted in to the dorsal

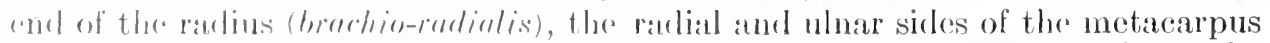

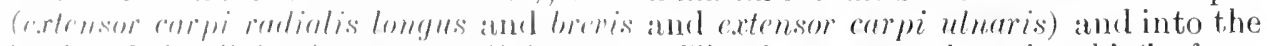
biaks of the digits (extensores digitorum.). The deeper museles arise ehiefly from 
the ulna and are inserted into the radius (supinator), the thumb (abductor pollicis longus, extensor pollicis longus and brevis) and index-finger (extensor indicis proprius, fig. 369). All are supplied by the radial nerve. The chief function of the brachio-radialis is to flex the forearm. The chief functions of the other muscles are indicated by their names.

The volar musculature (figs. 370, 371, 372, 375) arises from the medial side of the lower end of the humerus and from the front of the radius and ulna and is divisible into four planes. The muscles of the most superficial plane, pronator teres, flexor carpi radialis, palmaris longus, and flexor carpi ulnaris, arise from the humerus and are inserted respectively into the radius, the radial side of the metacarpus, the palmar fascia and the ulnar side of the metacarpus. In the second layer the flexor digitorum sublimis arises from the humerus and the upper part of the radius and ulna and sends tendons to the second row of phalanges of the fingers. In the third layer the flexor digitorum profundus and flexor pollicis longus arise from the radius and ulna and send tendons to the terminal row of phalanges. In the fourth layer a single muscle, the pronator quadratus (fig. 377), extends in the lower part of the forearm from the radius to the ulna. These muscles are supplied mainly by branches of the median nerve but the ulnar nerve supplies the flexor carpi ulnaris and a part of the flexor profundus digitorum. The chief functions of these muscles are indicated by their names.

In the hand (figs. $368,375,376,377,379$ ) there are several sets of intrinsic muscles. About the metacarpal of the thumb is grouped a set of muscles which arise from the carpus and metacarpus and are inserted into the metacarpal and first phalanx of the thumb (flexor brevis pollicis, opponens pollicis, abductor pollicis brevis, adductor pollicis). A similar set of muscles is grouped about the metacarpal of the little finger (abductor digiti quinti, opponens digiti quinti, flexor brevis digiti quinti). These sets of muscles give rise respectively to the thenar and hypothenar eminences. Between the metacarpals two sets of interosscous muscles arise; a volar, adductor toward the middle finger and a dorsal, abductor group. They are inserted into the sides of the bases of the first row of phalanges and into the extensor tendons. They also flex the first row of phalanges and extend the other two rows. From the tendons of the deep flexor muscle of the fingers, a series of lumbrical muscles extends to the radial sides of the extensor tendons. They flex the first row of phalanges and extend the other two. Over the thenar eminence there is a subcutaneous muscle, the palmaris brevis. The muscles of the hand are supplied by the ulnar nerve, with the exception of the two more radial lumbricals and the abductor, opponens, and flexor brevis of the thumb, which are supplied by the median nerve.

Fasciæ.-The muscle fasciæ of the upper extremities are well developed. The deltoid and latissimus dorsi are contained in a fascial sheet which extends between them. The deeper muscles which arise from the scapula are covered by strong fasciæ. Of the pectoral muscles the pectoralis major is covered by a delicate fascia, while the subclavius and pectoralis minor are contained within the dense costo-coracoid membrane (fig. 358) which extends into the fascia covering the axillary fossa. The latter (fig. 359), is thin and is intimately fused to the tela subcutanea. The muscles of the arm are enveloped in a cylindrical sheath which in the lower half of the arm is united to the humerus by intermuscular septa.

In the forearm near the wrist and on the back of the hand the tela subcutanea contains little fat. The antibrachial fascia forms a cylindrical enclosure for the muscles of the forearm. Near the wrist it becomes strengthened dorsally to form the dorsal ligament of the carpus (posterior annular ligament). This ligament converts the grooves on the back of the rarlius into canals for the tendons of the extensors of the wrist and fingers. On the back of the hand and fingers the fascia is intimately connected with these tendons. On the volar side near the wrist the fascia is strengthened to form the volar ligament of the carpus. Beneath the ligament lies the transverse ligament of the carpus which extends from the pisiform and hamate bones to the tuberosities of the navicular and greater multangular bones. It completes an osteo-fibrous canal for the tendons of the long flexors of the fingers. On the palm of the hand the fascia is firmly bound to the bones by intermuscular septa, which separate the thenar and hypothenar regions from a central palmar region. On the volar sides of the fingers the fascia forms the vaginal ligaments of the flexor tendons.

\section{A. MUSCULATURE OF THE SHOULDER}

(Figs. 355, 356, 357, 363, 388)

The muscles belonging to this group are the deltoid, the teres minor, the infraand supraspinatus, the latissimus dorsi, the teres major, and the subscapularis. 
The deltoid (fig. 355) is a large, shield-shaped musele which covers the shoulder. It arises from the spine of the scapula, the acromion, and lateral third of the clavicle and is inserted into the deltoid tubercle of the humerus. It abducts the arm.

The teres minor, infra- and supraspinatus form a group of muscles (fig. 363) which arise from the back of the seapula, pass over the eapsule of the shoulderjoint, to which their tendons are adherent, and, under cover of the deltoid, are inserted into the top and the dorsal margin of the great tuberele of the humerus. The band-like teres minor arises from the upper two-thirds of the axillary border of the scapula, and has the lowest insertion on the tubercle. The triangular infraspinatus (fig. 363) arises from the whole infraspinous fossa except the axillary border, and is inserted above the teres minor. The pyramidal supraspinatus (fig. 363) arises under cover of the trapezius from the supraspinous fossa, and has the highest insertion on the tuberele. The teres minor, supraspinatus and infraspinatus act as lateral rotators of the arm, the supraspinatus also as an abductor.

The latissimus dorsi, the teres major, and the subscapularis form a group of muscles attached to the lesser tuberele of the humerus and to the erest which

Fig. 356.-Front View of the Scapular Muscles.

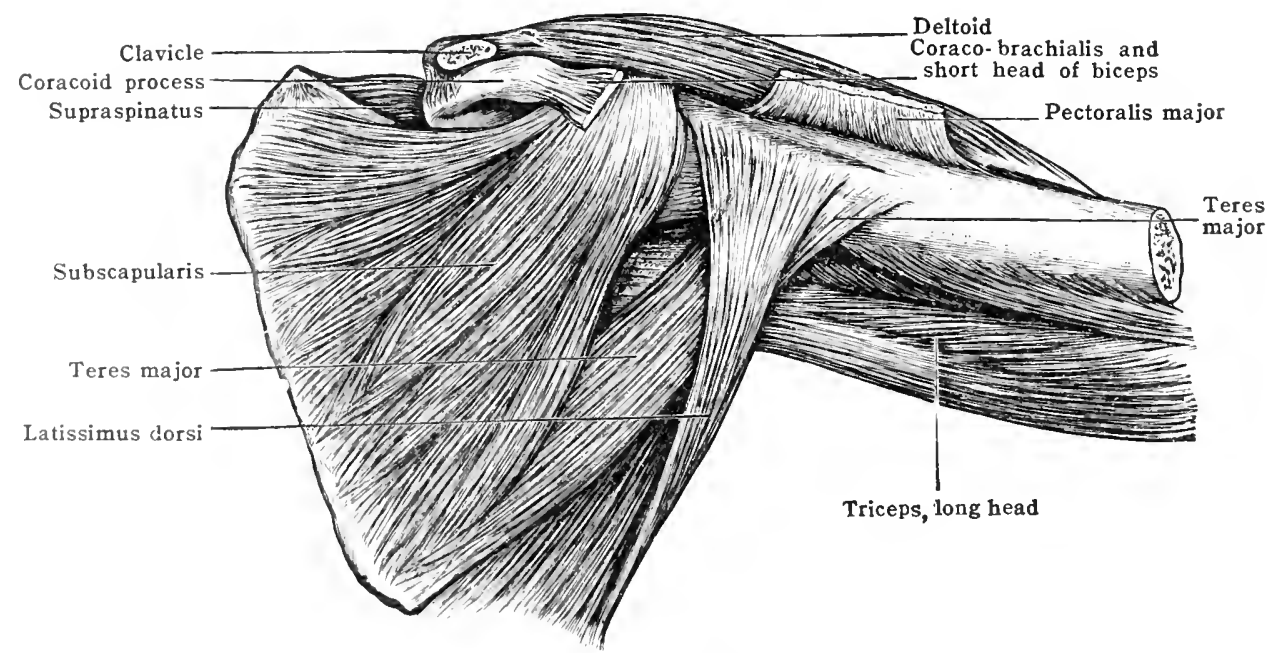

extends distally from this on the medial side of the intertubereular (bieipital) groove. The latissimus dorsi (figs. 355,356 ) is a large, flat, triangular musele, which ariks from an aponeurosis covering the lumbar and the lower half of the thoracic regions of the back and from the posterior part of the iliae crest, and is inserted into the intertubereular (bicipital) groove. The teres major (figs. $35.5,356$ is is thick, ribbon-shaped muscle which arises from the dorsal surface of the inforior angle of the scapula and is inserted behind the latissimus dorsi into the distal two-thirds of the crost of the small tubercle of the humerus. The subscapularis (fig. 355) is a thick, triangular muscle which extends from the subscapular fosisil to the small tuberele of the humerus. These museles adduet the arm and rotate it merlialwarl. The latissmus dorsi is also the chief extensor of the arm.

Noar thoir himmoral attachments these two groups of muscles are separated helow by the long hearl of the triceps. The supraspinatus is separated from the subserpularis by the hase of the coracoid process and by the intertubereular (bicipital) groove. The tomlons of the latissimus clorsi, teres major, and subscaplularis are crosind ventrally by the main vesseds and nerves of the arm and by the short hearl of the hicens and the coraceo-brachialis.

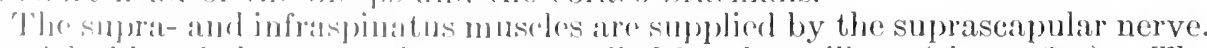
'the delteid and the teres minor are suppliod by the axillary (cireunflex). The subseapulatis, the tores major, and the lat issinus dorsi are supplind by subscapular norvere. That to the latissimms dorsi is called the dorsal thoracic nerve. 
The deltoid in many of the mammals and the lower vertebrates is represented by separate scapulo-humeral and eleido-humeral portions. The cleido-mastoid in some mammals is (o)ntinued into the deltoid. The teres ninor, which is innervated by the same nerve, ma lie lumed upon as a derivative of the deltoid, although in man it is anatomically more intimately connecterl with the infraspinatus. The teres major may be looked upon as a speeialised portion of the more primitive latissimus dorsi. The comparative anatomy of the shoukder muscles throughout the vertebrate series is a somewhat intricate subject, owing to the great variations exhibiter in the form and attachment of the shoulder girdle.

The muscles of this group show more or less marked resemblances to certain muscles of the lower limb. The deltoid and the teres minor probably represent the tensor fascia latie, the gluteal faseia, and the upper part of the gluteus maximus; the latissimus dorsi and teres major, the lower portion of the gluteus maximus; and the subscapularis, the gluteus medius and minimus, and the piriformis. The subscapular and axillary nerves, which supply the arm muscles mentioned, therefore represent in the main the nerves to the gluteal muscles, and the gluteal branch of the posterior cutaneous nerve of the thigh. The infraspinatus muscle probably represents the iliacus; the supraspinatus possibly the pectineus muscle of the lower limb.

\section{FASCIE}

$$
\text { (Figs. 351, 357, 359, 362) }
$$

The tela subcutanea eovering the regions oecupied by these muscles contains considerable fat. In most regions it is not readily separable into two distinct layers. In the neighbourbood of the shoulder-joint it is adherent to the underlying musculature and the axillary fascice. Over the acromion there is a well-marked subcutaneous bursa, bursa subcutanea acromialis.

Muscle fasciæ.-The deltoid and latissimus dorsi muscles are throughout the greater part of their extent superficially placed. They are covered by an adherent fascial layer, which, above, is attached to the elavicle and to the spine of the scapula. Ventrally it is continued over and fuses with the fascia covering the pectoralis major, serratus anterior, and external oblique muscles. On the back it extends as a thin sheet between the dorsal margin of the deltoid and the upper margin of the latissimus dorsi, and is continued dorsally into the fascial investment of the rhomboid muscles. The lateral fascial extension of the trapezius becomes fuser to the dorsal surfaee of this sheet. Toward the armpit the fascial investment of the deltoid and latissimus dorsi muscles is continued into the axillary fascia, and on the back of the arm it is continued into the faseial investment of the triceps.

The supraspinatus muscle lies beneath the trapezius. It is covered by a dense adherent faseial layer which is separated from the trapezius by loose connective tissue which usually contains a considerable amount of fat.

The infraspinatus and the two teres muscles lie beneath the musculo-fascial layer composed of the deltoid, the latissimus dorsi, and the fascial sheet describerl above. Each of the three museles has a speeial faseial investment which is bound to the scapula about the region of attachment of the muscle to the bone. Where two of the muscles arljoin, their fascice gives rise to intermuscular septa. Septa of this nature are found between the infraspinatus and each of the teres muscles, and between the teres minor and the teres major. The intermuscular septum between the infraspinatus and teres minor muscles is often incomplete. The fascia covering the teres major is so delicate as hardly to deserve the name, except near the origin of the nuscle. Near the spine the fascia covering the deep surface of the deltoid is often fused to that eovering the infraspinatus.

The subseapularis muscle is invested by a moderately dense fascia which is bound to the scapula along the periphery of the attachment of the muscle. For a short distance this fascia is fused with the fascial in vestment of the teres major near the origin of the latter muscle, so that an intermuseular septum is formed. From the ventro-lateral margin of the fascia covering the subscapularis muscle a sheet of fascia is continued below the axillary fascia into the fascia covering the serratus anterior (magnus).

\section{MUSCLES}

The deltoideus (figs. 355, 356, 360).--Origin.-Fleshy from the lateral border and upper surface of the acromion and from the ventral border and upper surface of the lateral thind of the clavicle, and tendinous from the spine of the scapula. Some fibre-bundles also at times arise from the deep fascia of the muscle where it overlies and is fused to the fascia of the infraspinatus muscle near the spine.

Insertion.-Into the deltoid tuberosity of the humerus by a strong tendon arising from numerous tendinous bands within the muscle (fig. 36t).

Structure. - In structure the deltoid muscle is complex. Three portions may be recognised: - a clavicular, an acromial, and a spinous. The first and last are composed of loug fibre-bundles which take a slightly converging course and are inserted by aponeurotic tendons respectively on the front and back of the V-shaped area of insertion of the muscle. The acromial portimi, on the other hand, is multipenniform in composition. Four or five tendinous expansions descend into the muscle from the acromion, and three up into the muscle from the tenton of insertion. From the acromion and from the descending tendinous processes fibre-bundles run to be inserted on the sides of the ascending processes and into the tendons of insertion of the clavicular and spinous portions of the muscle.

Nerve-supply. - The axillary (circumflex) nerve passes across tho costal surface of the muscle near the tendon of insertion and gives off rami which enter lateral to the midlle of the muscle. The nerve fibres are derived from the (fourth), fifth, and sixth cervical nerves.

Action.-When the whole muscle contracts, the arm is ablucted (rised laterally) to a 


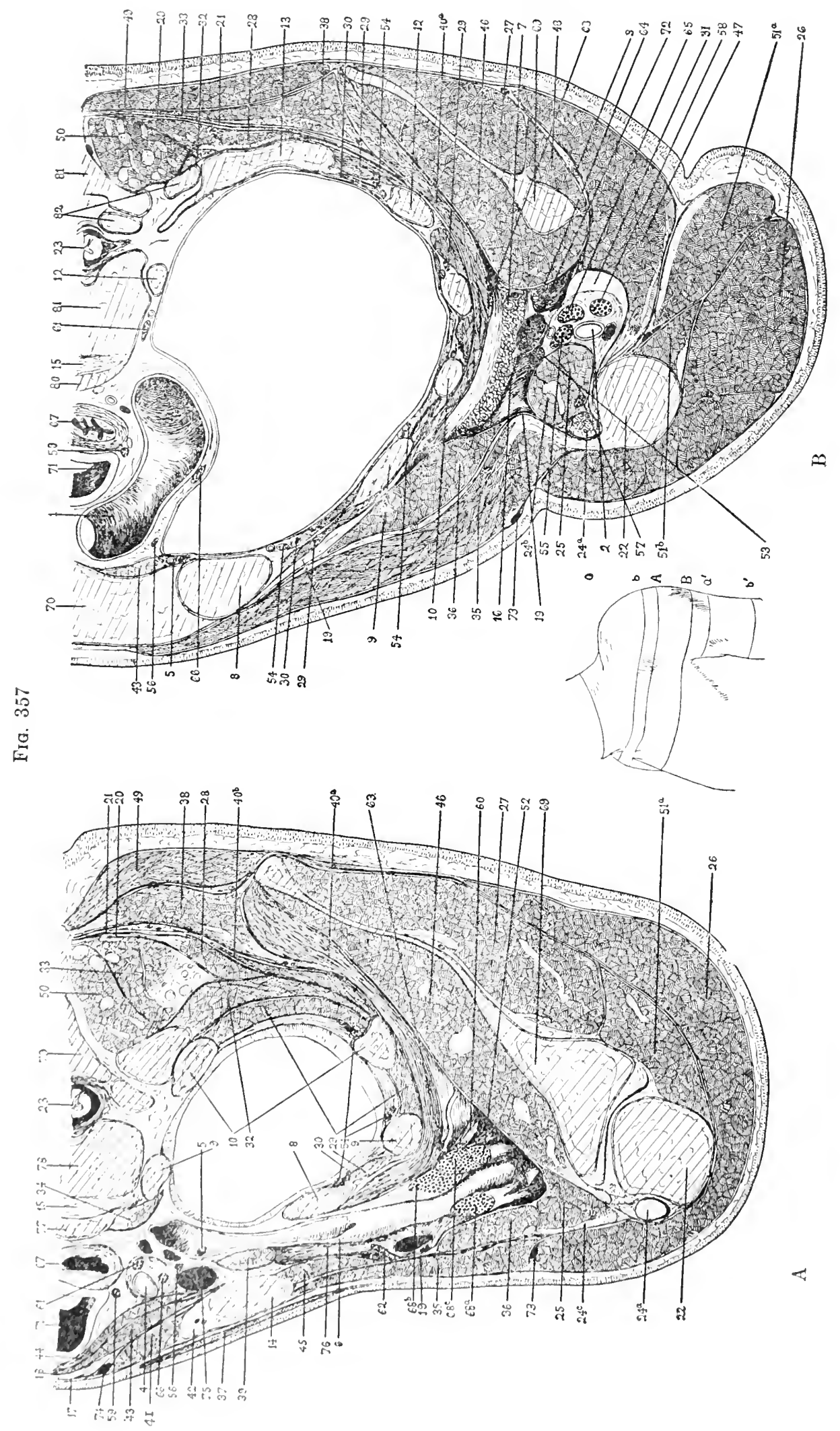


horizontal position. When the clavicular and acromial parts act, the arm is raiserl and flexerl (brought forward toward the chest). When the acromial and spinous parts act, the arm is raised and extended (carried toward the back), but in this instance the arm is not brought to a level with the shoulder-joint, but only about $45^{\circ}$ from the hanging position. The inferior part of the serratus anterior and the trapezius act in conjunction with the deltoid in abduction. Abduction is greatest when the arm is rotated lateralward. The ventral portion rotates the arm medially, the dorsal portion laterally. When the arm is fixed, the deltoid tends to carry the inferior angle of the scapula toward the spinal column and away from the thorax.

Relations. - On its ventral border the deltoid is in contact with the pectoralis major muscle. Near the clavicle the cephalic vein and a small artery pass between the tro muscles. 1 ts dorsal border is continued into a dense fascial sheet which overlies the infraspinatus muscle. Its tendon of insertion passes between the biceps and triceps muscles. The deltoid overlies the coracoid process and upper extremity of the humerus, the coraco-clavicular and coraco-acromial ligaments, and the insertions of the supraspinatus, infraspinatus, and teres minor muscles, the origins of the biceps and coraco-brachialis, and a part of the long and lateral heads of the triceps. Beneath it run the posterior circumflex artery and axillary (circumflex) nerve.

Variations.-The clavicular portion is frequently separate from the rest of the muscle. The three portions may be distinctly separate - a condition normal in some of the lower mammals. The clavicular and acromial portions have been found missing. The deep portion of the muscle may be separated as a distinct layer and inserted either into the capsule of the joint or into the humerus. Accessory fasciculi may pass into the muscle from the fascia over the infraspinatus and from the vertebral and axillary borders of the scapula. Not infrequently fasciculi are continued into the muscle from the trapezius-a condition normal in animals witl ill-developed clavicles. An accessory tendon of insertion may extend to the radial side of the forearm. Bundles of fibres from the axillary border of the scapula have been seen to cross the deep surface of the deltoid and be inserted in to the deltoid fascia. The deltoid may be fused with neighbouring muscles, the pectoralis major, trapezius, infraspinatus, brachialis, brachio-radialis.

The teres minor (fig. 363).-Origin.-From the upper two-thirds of the axillary border of the infraspinous fossa, and from the septa lying between it and the infraspinatus on the one side and the teres major and subscapularis on the other. The origin is in part fleshy, in part from an aponeurotic band on its ventral surface toward the subscapularis muscle.

Structure and insertion.-The fibre-bundles from this origin take a slightly converging course toward a tendon of insertion which extends for some distance on the dorsal surfare of the muscle. The musele is adherent to the capsule of the joint, and terminates on the inferior of the three facets of the great tubercle of the humerus and the postero-lateral aspect of that bone for two or three centimetres below the facet.

Nerve-supply.-From a branch of the axillary (circumflex) nerve which enters the muscle on its lateral margin about midway between its extremities. A 'ganglion' is usually found upon this nerve. A branch from the nerve to the teres major has also been reported. 'The nerve fibres are derived from the fifth cervical nerve.

Action.-It acts conjointly with the infraspinatus to rotate the arm laterally. It is a flexor when the arm is down and an extensor when it is abducted. It is also an adductor.

Relations.-The muscle is in part covered by the deltoid. Ventrally it enters into relations with the long head of the triceps, the teres major, and the subscapularis. Superiorly, the circumflex (dorsal) scapular vessels run between it and the axillary border of the scapula.

Fig. 357. A and B.-Transyerse Sections through the Left Shoulder in the Regions indiCATED IN THE DiagraM.

In the neighbourhood of the brachial plexus in each section some of the adipose and lrmphatic tissue has been removed. In section $B$ the fascia covering the apex of the axillary fossa is thus revealed from above. $a$ and $b$ in the diagram indicate the regions through which pass sections $A$ and $B$, fig. 351 (p. 352); $a^{\prime}$ and $b^{\prime}$, the regions through which pass sections $A$ and $B$, fig. 362 (p. 375).

1. Aorta. 2. Arteria brachialis. 3. A. cincumflexa scapula (dorsalis scapulæ). 4. A. carotis communis. 5. A. mamnaria interna. 6. A. subchavia. 7. A. thoracalis lateralis (long thoracic). 8. Costa I. 9. Costa II. 10. Costa III. 11. Costa IV. 12. Costa. V. 13. Costa VI. 14. Clavicle. 15. Fibrocartilago intervertebralis (intervertebral disc). 16. Fascia axillaris. 17. Fascia cervicalis (superficial laver). 1S. Niddle laver. 19. I coraco-clavicularis. 20. F. lumbo-dorsalis. 21. Fascia of posterior serrati. 22. Humerus 23. Medulla spinalis (spinal cord). 24. Nusculus biceps-a, long head; $b$, short head $c$, tendon of short head. 25. M. coraco-brachialis. 26. M. deltoideus. 27. M. infraspinatus. 28. M. ilio-costalis dorsi (accessorius). 29. M. intercostales externi. 30. M. intercostales interni. 31. M. latissimus dorsi, tendon. 32. M. levator coste. 33. M. longisimus dorsi. 34. M. longus colli. 35. M. pectoralis major. 36. M. pectoralis minor. 37. M. platysma. 38. M. rhomboideus major. 39. M. scalenus anterior. 40a. M. serratus anterior. $40 b$ M. serratus posterior superior. 41. M. sterno-mastoideus. 42. M. elcido-mastoideus. insertion. 43. M. sterno-hyoideus. 44. M. sterno-threoideus. 45. M. subclavius. 46. M. subscapularis. 47. M. teres major. 4S. M. teres minor. 49. M. trapezius. 50 ? M. transverso-spinales. 51. MI. triceps-a, long head; $b$, lateral head. 52. Nerris axillaris 53. N. cutaneus antebrachii medialis (internal cutaneous). 54. a-e, Nn. interostales $\mathrm{I}-\mathrm{V} .55$. N. medianus. 56. N. phrenicus. 57. N. musculocutaneus. 5. N. radialis (musculo-spiral). 59. $\mathrm{N}$. recurrens. 60. $\mathrm{N}$. subscapularis. 61. Sympathetic trunk. $62 . \quad N$. thoracalis anterior. 63. N. thoracalis longus. 64. N. thoractelersalis (l)ng subscapular). 65. N. unaris. 66. N. vagus. 67. Gsophagus. 6s. Plexus brachialis$a$, lateral fasciculus; $b$, medial; $c$, posterior. 69. Scapula. 70. Sternum. 71. Trarhea. 72 Venæ brachiales, 73. V. cephalica. 74. V. jugularis anterior. 75. V. jugularis inferior. 76. V. subclavia. 77. Vertebra I. 78. Vertebra II. 79. Vertebra III. 80. Vertebra IV. S1. Vertebra V. S2. Vertebra VI. 
Variations.-Aside from its frequent fusion with the infraspinatus, there has also been reported an isolation of a special fasciculus to the subtubereular attachment.

The infraspinatus (fig. 363).-Origin.-From the vertebral three-fourths of the infraspinous fossa, from the under surface of the spine, from the enveloping fascia and from intermuscular septa between it and the two teres museles.

Structure and insertion.- The fibre-bundles converge toward the lateral angle of the seapula to be attached to a deep-seated tendon which is adherent to the capsule of the joint and is attached to the middle facet of the great tubercle. The fibre-bundles arising from the inferior surface of the spine and the fascia near this form a distinct faseiculus which descends on and covers the tendon of insertion.

Nerve-supply.-From the suprascapular nerve, which passes beneath the supraspinatus muscle and enters the deep surface of the infraspinatus in the lateral part of the midde third of its upper margin. From here rami spread out toward the vertebral border of the musele and toward the humeral insertion. The nerve fibres are derived from the fifth and sixth cervical nerves.

Action.-This muscle is the chief lateral rotator of the arm, a movement that can be carried through $90^{\circ}$. The upper part of the muscle is an abductor, the lower part an adductor of the arm. The muscle is also a flexor.

Relations.-The deltoid and trapezius, and sometimes the latissimus dorsi museles, cover a portion of the dorsal surface. Over most of it extends the complex fascia described above. Laterally it adjoins the teres minor and major muscles. Under the muscle lie the transverse (suprascapular) and cireumflex (dorsal) seapular vessels.

Variations.- These are rare, aside from a greater or less independence of the bundles arising from the spine and a greater or less complete fusion with the teres minor. A fasciculus has been seen extending to the muscle from the deltoid.

The supraspinatus (fig. 363).-Origin.-Fleshy from the medial two-thirds of the supraspinous fossa and from the deep surface of the enveloping faseia near the vertebral end.

Structure and insertion.- The fibre-bundles converge upon a deep-seated tendon nearly to its attachment into the highest of the three facets on the great tubercle of the humerus.

Nerve-supply.-Two branches from the suprascapular nerve enter the middle third of the deep surface of the muscle. The nerve fibres are derived from the fifth cervical nerve.

Action.- It aids the deltoid in abdueting the arm. It is also a weak lateral rotator and flexor. It keeps the head of the humerus in place during abduction of the arm.

Relations. - The muscle is covered by the trapezius, the acromion, and the coraco-acromial ligament. Bevond the base of the spine of the scapula it comes into contact with the infraspinatus muscle. Beneath the muscle pass the suprascapular nerve and transverse scapular (supraseapular) vessels.

Variations.- The muscle shows slight variations. Its tendon may be fused with that of the infraspinatus. Its belly may be reinforeed by fibre-loundles from the coraco-acromial ligament.

The latissimus dorsi (figs. 355, 356, 387, 388).-Origin.-(1) From an aponeurosis attached to the spines and interspinous ligaments of the five or six last thoracic and the upper lumbar vertebre, to the lumbo-dorsal fascia, and to the posterior third of the external lip of the crest of the ilium; (2) from the external surface and upper margin of the last three or four ribs by muscular slips which interdigitate with those of the external oblique. In the lumbar region the aponeuroses of the right and left museles are connected by fibrous fasciculi which cross the mid-dorsal line above the supraspinous ligament.

structure and insertion. - From this extensive area of the origin fibre-bundles converge toward the tenton of insertion. In the region of the dorsal wall of the axillary fossa the musele is concentrated into a thick, libbon-like band which winds about the teres major and passes to the ventral surface of that musele. As this takes place the fibre-bundles become applied to each surface of a flat tendon, which, after emerging from the muscle, is six to eight cm. long and three to frve em. broad, and is inserted into the ventral side of the crest of the lesser tubercle of the humerus and into the depth of the intertubercular (bicipital) groove immediately ventral to the tendon of the teres major. With this it is more or less closely bound, although between the tentons there lies a serous bursa. Some of the fasciculi of the tendon extend to the erest of the greater tubercle. Frequently a tendon ship passes from the inferior margin of the tenflon to the tendon on the posterior surface of the long head of the triceps or into the brachial fascia (see lutissimo-condyloidens, p. 379).

like the teres major, with which it is closely associated, the latissimus dorsi muscle undergoes it torsion between its origin and its insertion, so that the dorsal surface of the muscle is continued into the ventral surface of the tenlon and the most cranially situated of the fibrebundles are most distally attached to the humerus, and vire versa. The muscle either directly or throngh its fascial extension is of ten alherent to the inforior angle of the seapula.

Nerve-supply. - Fon the dorsal thoracic (long subseapular) nerve (from the sixth, seventh and eighth cervical nerves). This nerve, which may arise in eonjunetion with the axillary nerve, passes to the defe surface of the muscle in the lower part of the axilla, and here gives rise to rani which diverge as the musele expands toward its tendons of origin. Though soon embedded in the muscle substance, two main branches may be followed for a considerable distance near the decp strface of the muscle. One usially extends near the lateral, the other near the superior, borler of the muscle, and from these large rami pass into the intervening region. Branches of the dorsal thorative artory and vein acompany the nerve.

Actim.-With the trunk fixerl, the lat issimus dorsi draws the raised arm down and backward and rotates it medialwarl (swimning movement). When the am is hanging by the side, the artion of the musclo is on the scapulat. The upper third of the muscle draws the seapula towarl the spine, the inferior two-thirds depress the shomliler. When the humerus is fixed, the latissimus serves to lift the trunk and pelvis forwated, as in climbing, lt also aids in foreed inspiration through its costal attachments. 
'Relations.-The trapezius covers a small portion of the musele in the mid-thoracie region of the back. Over a large area it is subcutaneous, and its fascial investment is adherent to the skin. As it winds about the teres major its tendon comes to lie behind the coraco-brachialis muscle. The main nerves and vessels of the arm here pass across its ventral surface. The muscle covers in part the rhomboideus major, the infraspinatus, teres major, serratus posterior inferior, the lower ribs, the external intercostal museles, the dorsal border of the external and internal oblique museles, and the lower dorsal part of the serratus anterior (magnus).

Variations.- It may show considerable variation in the extent of its fleshy portion and in the attachment of its aponeurosis to the vertebral column, erest of the ilium, the ribs, and the seapula. Its origin may be merely from the ribs. It may be divided into separate fasciculi. Frequently a fasciculus arises from the inferior angle of the scapula. The musele is often intimately united to the teres major. For an account of the muscular slip which extencls from the latissimus dorsi across the axillary fossa to the tendon of the pectoralis major near the intertubereular (bicipital) groove see the latter muscle (p.374); and for the slip continued from the tendon of the latissimus dorsi to the olecranon see the Triceps MuscLe (p. 379).

The teres major (figs. 356, 3S8).-Origin.-Direetly from the dorsal surface of the inferior angle of the scapula and from the septa which lie between this inuscle and the subscapularis, teres minor, and infraspinatus muscles.

Insertion.-For about five or six $\mathrm{cm}$. from the lower borler of the small tubercle of the humerus, along the medial lip of the intertubereular (bicipital) groove. Proximally the fibrebundles are attached direetly to the tuberele; more distally the attachment is by means of a flat tendon which extends for some distance on the dorsal surface of the muscle.

Structure.-The nearly parallel fibre-bundles pass upward in a spiral direction so that the musele undergoes a torsion on its axis. The fibre-bundles which have the highest attachment to the scapula have the lowest humeral attachment, and vice i'tra.

Nerve-supply. - By a branch of the lower subscapular nerve which enters the muscle near the middle of its seapular border. The nerve fibres are derived from the fifth, sixth (and seventh) cervical nerves.

Action.-It aids the latissimus dorsi in addueting the arm, and in some positions of the arm acts as a medial rotator and as an extensor.

Relations.-Dorsally the muscle is covered by the latissimus dorsi and by the faseia which extends from this musele to the deltoid and rhomboid muscles. It is also crosser by the long head of the triceps. Its lower border and ventral surface are largely covered by the latissimus dorsi and its tendon. Its upper border helps to bound a triangular space the other sides of which are the borders of the seapula and the humerus. In front lies the subseapularis, and behind, the teres minor. Across this space passes the long head of the triceps. Lateral to this head lie the humeral eircumflex vessels and axillary (circumflex) nerve; and medial, the circumflex (dorsal) seapular artery.

Variations. - The teres major may be connected with the latissimus dorsi by a fasciculus, or it may be fused with that musele or its tendon. Slips have also been seen extending to the triceps and into the fascia of the arm. The musele is rarely absent.

The subscapularis (figs. 356, 385).-Origin.-The fibre-bundles spring-(1) directly and by means of tendinous bands from the costal surface of the seapula, exeept near the neck and at the upper and lower angles; and (2) from intermuseular septa between it and the teres major and teres minor museles.

Insertion.-The tendon of insertion as it passes over the capsule of the joint is intimately bound to this. It is inserted into the lesser tuberele of the humerus and into the shaft immediately below this.

Structure.-The fibre-bundles arising from the tendinous bands attached to the bone (")nverge upon several tendinous laminæ which extend into the musele from the tendon of insertion, thus forming small penniform fasciculi. The fibre-bundles arising directly from the bone converge toward the extremities of the tendinous laminx, thus forning triangular bundles interdigitating with the penniform fascieuli. The faseiculus which arises highest on the axillary border goes directly to the humerus.

Nerve-supply. -By two or three subseapular branches from the back of the brachial plexus. One or more of these may arise in association with the axillary (cireunflex) nerve. From the main nerves rami sprearl out to enter the ventral surface of the musele near the junction of the lateral and middle thirds. The nerve fibres come from the fifth and sixth rervical nerves.

Action. - It is the ehief medial rotator of the arm. It strengthens the shoulder-joint by drawing the humerus against the glenoid cavity. It is an extensor when the arm is at the side. a flexor when the arm is abducted. The upper portion of the muscle, however, acts as a flexor in both positions. The upper part acts as an abductor but when the arm is ablucted the musele is an adductor.

Relations.-Ventrally it forms the greater part of the posterior wall of the axillary fossa, and enters into relation with the serratus anterior (magnus) and the combined tenion of the coraco-brachialis and bieeps. On it he the axillary vessels, the brachial plexus, and numerou. lymph-vessels and glands. At its lateral border lie the teres major, the humeral circunflex vessels, axillary (circumflex) nerve, and cireumflex (dorsal) seapular ressels. Behind it lie the long head of the triceps and the teres minor musele.

Variations. - It may be divided into several distin ct segments. A faseiculus may be sent to the tendon of the latissimus dorsi and another to the brachial fascia. The subscapularis minor arises from the axillary border of the seapula and is inserted into the articular "apsule (capsular ligament) of the shoulder-joint or into the erest of the lesser tubercle of the himerus.

\section{Burs杘}

B. subacromialis.-A large bursa, nearly constantly found, between the acromion and coraco-acromial ligament and the insertion of the supraspinatus muscle and capsule of the joint 
Processes extend orer the greater and lesser tubercles.

B. supracoracoidea.- I bursa sometimes found between the coracoil process and the clavicle and the deltoid muscle.

B. m. subscapularis.-Between the glenoid border of the scapula and the subscapularis muscle. Communicates with the joint calvity. A small portion of this bursa may be isolated adjacent to the base of the coracoid process (b. subcoracoidea).

B. m. infraspinati.-Between the tendon of the infraspinatus and the capsule of the joint or the great tubercle.

B. m. latissimi dorsi.-Constant between the tendons of the latissimus dorsi and the teres major.

B. m. teretis majoris.- Under the insertion of the tendon of the teres major muscle.

\section{B. PECTORAL, MUSCLES AND AXILLARY FASCIA}

(Figs. 357, 358, 360, 361, 388)

The muscles belonging to this group are the pectoralis major, pectoralis minor, and the subclarius. Of these, the largest and most superficial is the

Fig. 35S.-Deep Fascia of the Breast. (After Eisler). The Pectoralis Major Has Beex in Large Part Removed, 1, Deltojd; 2, Pectoralis Major, Abdominal Part; 3 , Pectoralis IItior; 4, Coraco-Brachialis.

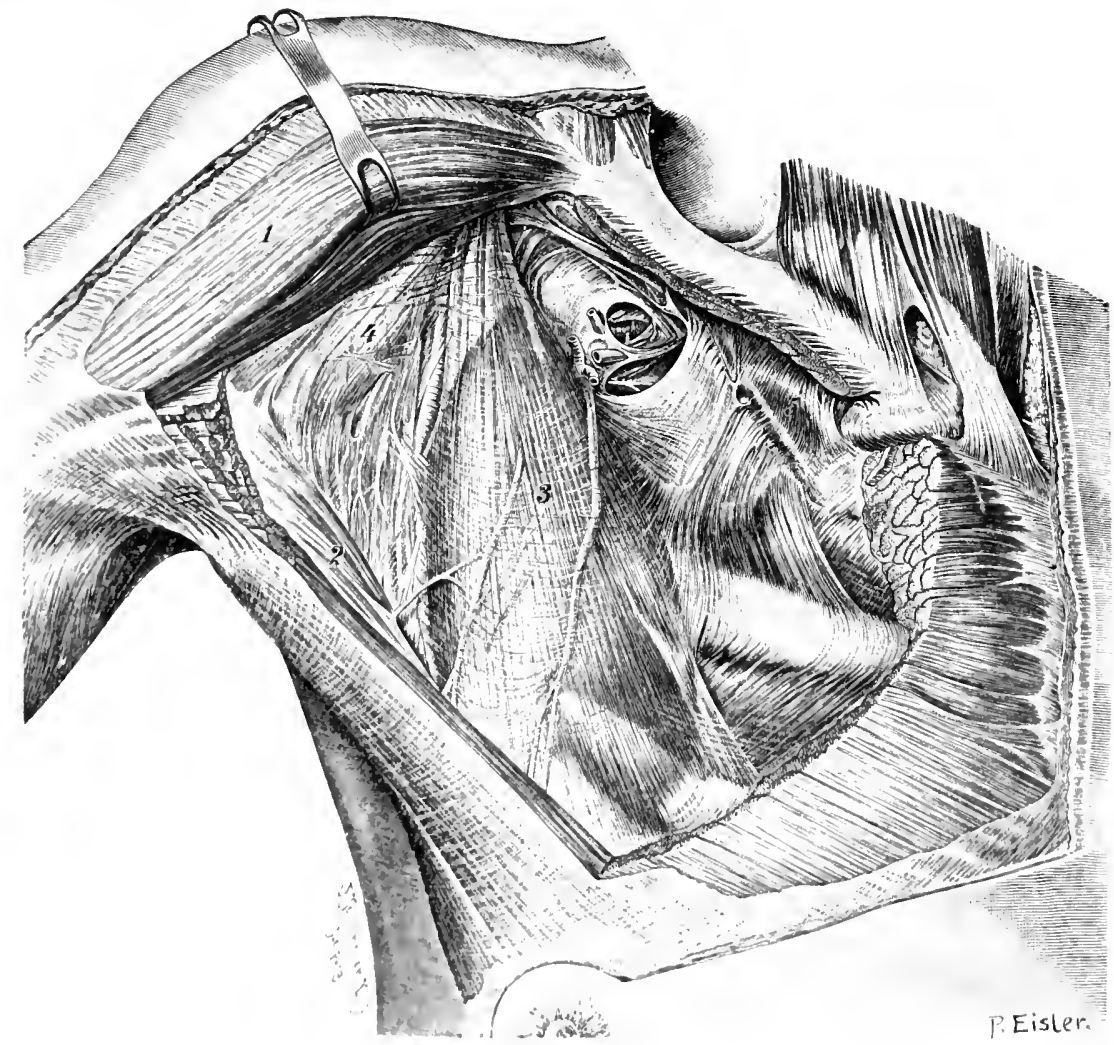

triangular pectoralis major (fig. 3600), which arises from the secomd to the sixth

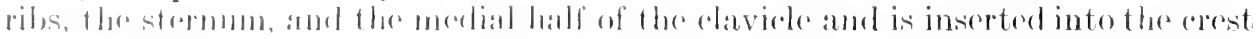

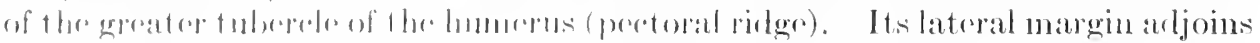

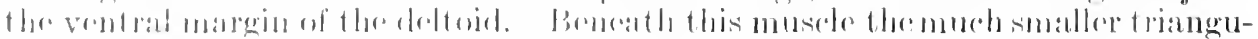

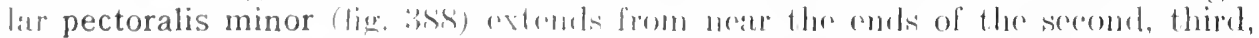

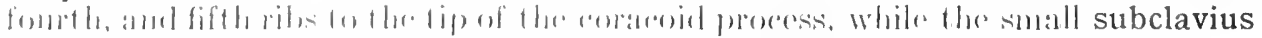

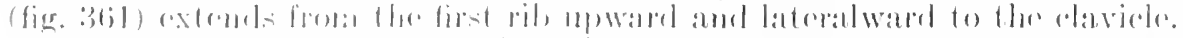

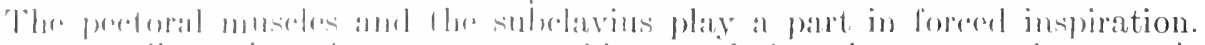

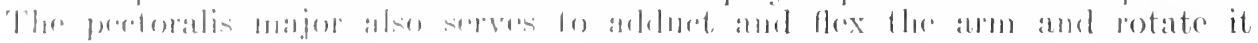
minlialmarrl.

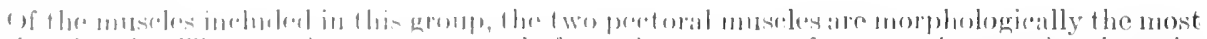

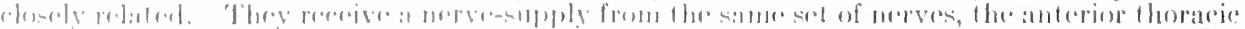

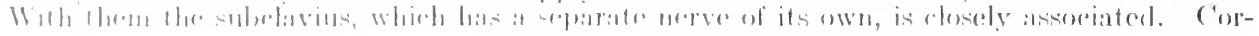


responding musculature, at hough variously modified in different forms, is found throughout the vertebrate series. In the lower forms it seems to be differentiated firectly from the negmental trunk musculature and seeondarily attached to the shoulder girdle, like the superficial atil deep, musculature of the shoulder girille previousty described. In man, however, the muscle mass from which these muscles arise is at all times in intimate union with the skeleton of the upper limb, and the nerves which supply it are in mueh more intimate union with the brachial plexus than are those of the shoulder-girdle museles. For these reasons the three muscles are "lassed with the intrinsic muscles of the arm. They have no eertain representatives in the lower limb, although the clavicular portion of the pectoralis major is considered by some to represent certain adductor muscles of the thigh. Possibly they correspond in their embryonie origin with the obturator internus group of the lower limb.

In many of the mammals a subcutaneous musele arises from the pectoral muscle niass and extends over the axilla and the trunk. In man this musculature is frequently represented by abnormal slips of muscles, of which the 'axillary arch' and possibly the 'sternalis' are representatives. A list of some of the abnormal museles which are innervated from the anterior thoracic nerves and are evidently derivatives of the pectoral muscle mass is given at the end of this seetion

Fig. 359.-(After Eisler). Fascia of the Axillary Fossa.

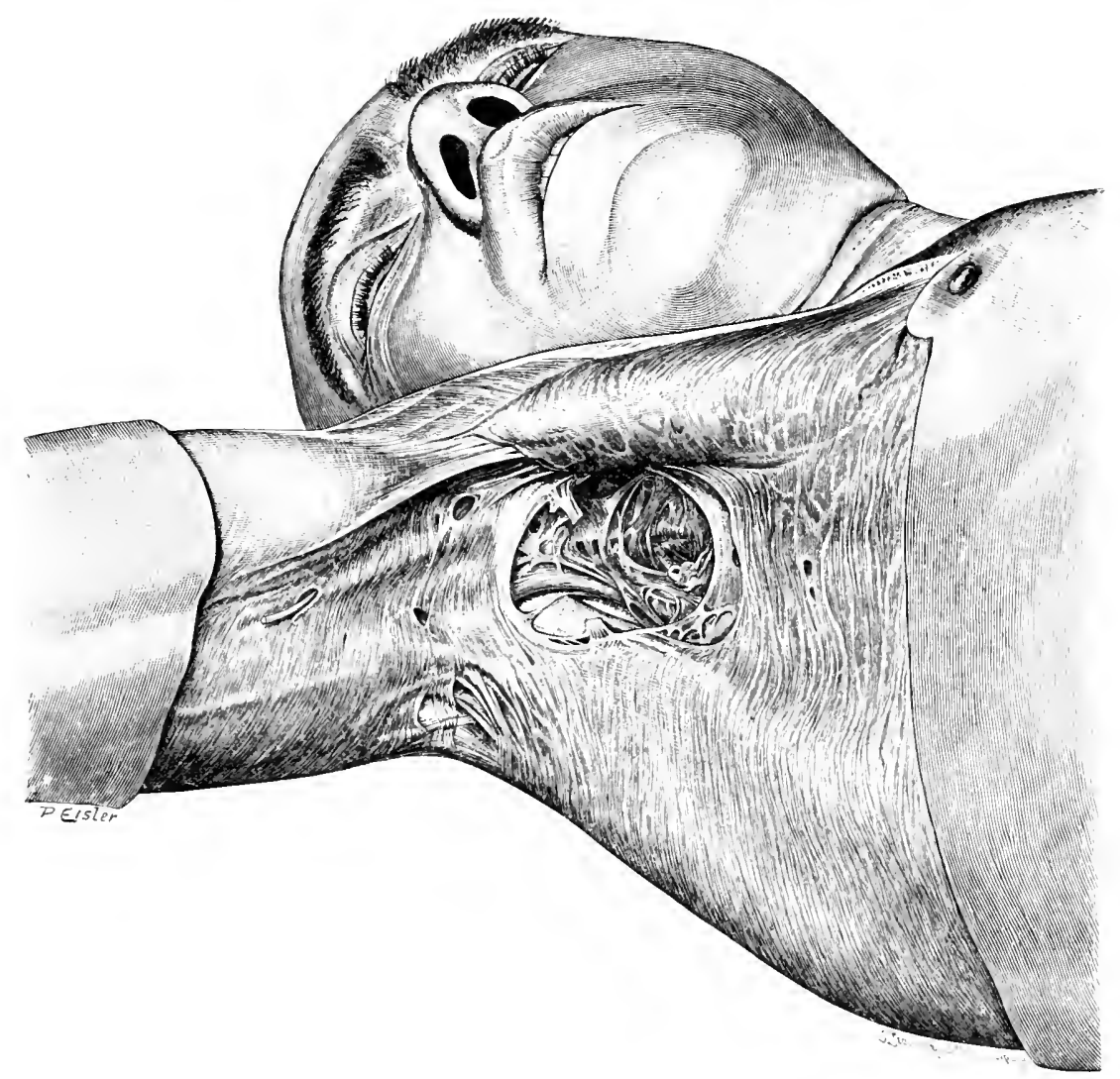

FASCLE

In the tela subcutanea of the pectoral region the mammary gland is embediled between two layers which ensheath the gland and are connected by dense fibre-bands. To a greater or less extent the platysma extends into the tela of this region from above the clavicle.

Muscle fasciæ. - The pectoralis major is invested with a thin, adherent membrane, fascia pectoralis, attached to the clavicle and the sternum and continued into the fascial investment of the external oblique, the serratus anterior (magnus), amel the deltoil muscles, and in to the axillary fascia. More impertant is the coraco-clavicular (costo-ccracoid) fascia fig. 358. This arises from two fascial sheets which invest the subelivius muscle and are attached to the clavicle. From the inferior margin of this muscle the membrane is continued to the superior margin of the pectoralis minor. Between the coracoid process and the first costal cartilage it is strengthened to form the costo-coracoid ligament. Between this and the? pectoralis minor it is thin. At the superior margin of this muscle it again ulirides to form tro adherent fascial sheets, which, at the axillary margin of the muscle, once more unite to form at firm membrane continued into the fascial investment of the coraco-brachialis and short head of the biceps and into the axillary fascia. Ahove, dorsally, the membrane is a dherent to the sheath of the axillary vessels and nerves.

Axillary fascia (fig. 359 ... The alm-pit, or axillary fossa, is a prramilal space bounded by the pectoralis major and minor and coraco-brachialis muscles in front; hy the latissimus 
dorsi, teres major, and subscapularis muscles behind; by the subscapularis muscle toward the joint; and by the serratus anterior (magnus) toward the thoracic wall. In the groove between the coraco-brachialis and the subscapularis and tendons of the latissimus lorsi and teres major muscles run the main nerves and vesscls of the arm. These are surrounded by a considerable amount of comnective tissue in which numerous blood- and lymph-vessels, lymph-nodes, nerves, and masses of fat are embedded.

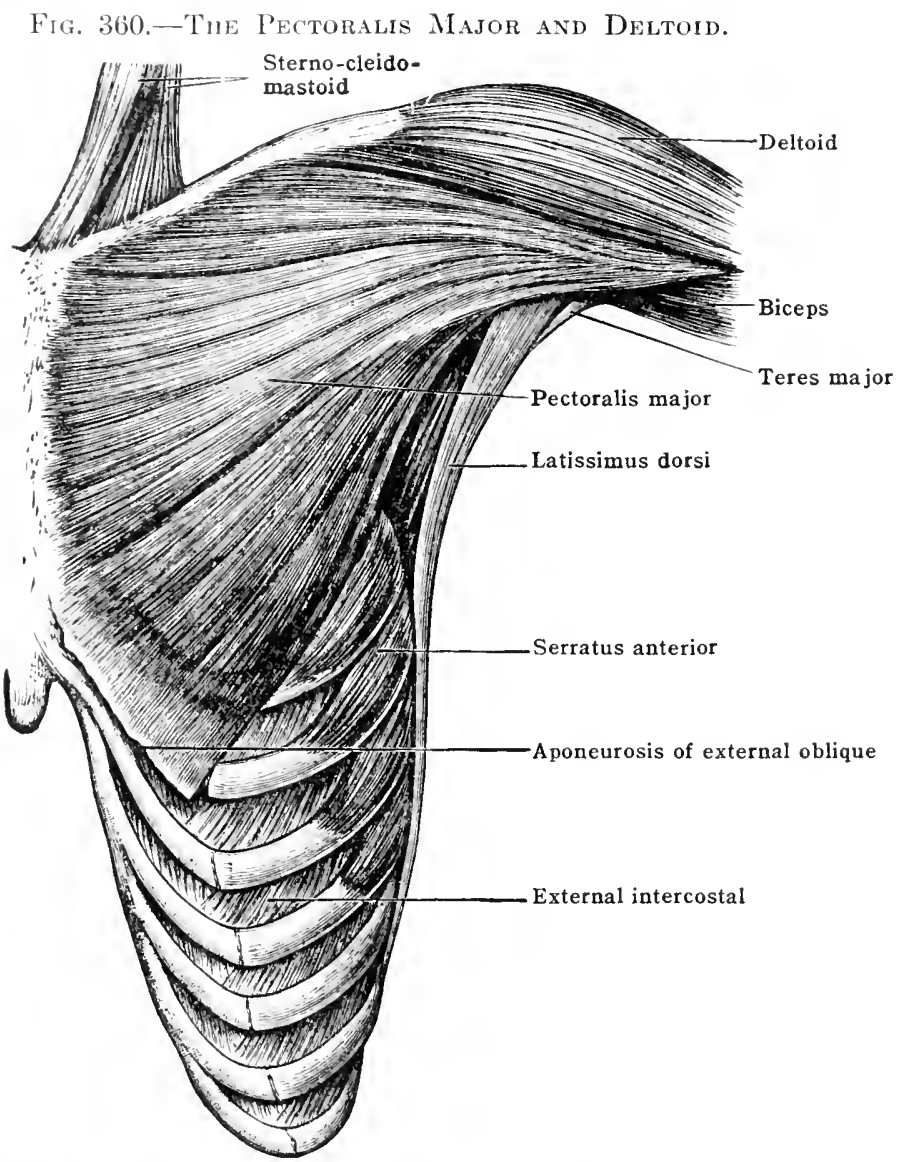

(1)e this commective tissue the fascia covering the musculature of the neighbouring portion of the shoulder and thorax is continued into the fascia eovering the musculature of the medial side of the arm. Thus the fascia covering the pectoralis minor, the eoraco-clavicular fascia, strengthened by a reflection of the fasciat investment of the pectoralis major and deltoid muselesis contimuel alcosss the vental margin of the arm-pit into the fascia which covers the coracofrachialis and bireps muscles in the arm. Similarly, dorsally, the fascia covering the latissimus Jors ambl feres major is continued over the arm-pit jnto that covering the long head of the triceps in the arn. The ventral is comnected with the lorsal fascia hy a thin membrane which is

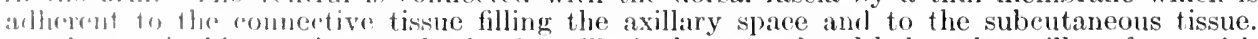
1h the: lrunk this membranc, the fascia axillaris, heromes fused helow the axillary fossa with the fuscit of the sopratus anterior (magnus). In the arm it becomes fused with the fascia over

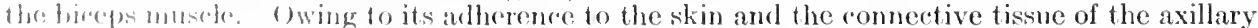
forit, investigutors luse disseded out and figured the axillary fascia in different ways.

\section{MUSCLES}

'Tw pectoralis major (fig. 3600 .-Crigin.-(1) From the medial half of the claviole; (2) from the sulc and fromt of the stemum as fal as the sixth costal rattilage; (3) from the front of

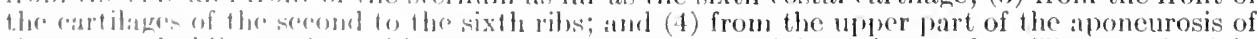
the extermat obliguse where this extomls over the rectus ablominis mosele. The costal origin

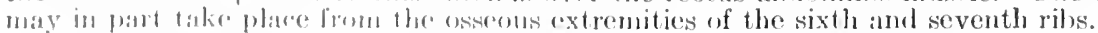

Instion. ('rest of the grratre fulderele (outer lip of the hicipital groove) of the humerus from the tolserele to the insertion of the deltoirl (fig. 174). Some of the tenclon fibres are also

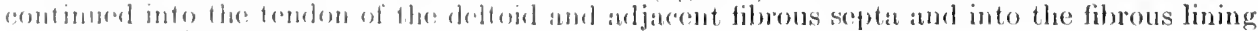

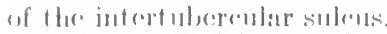

Sirueture.- The musalo is divisiblo into a sories of overlapping latyers spread out like a fan.

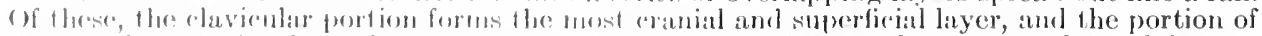

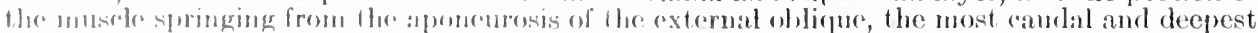

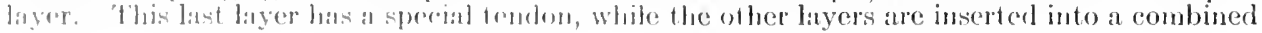


tendon lying rentral to this. The two tendons are continuous at their distal margins. Lewis.)

Nerve-supply.-From the external and internal anterior thoracic nerves, branches of which enter the sterno-eostal portion of the muscle about midway between the tendons of origin and insertion, and the clavicular portion in the proximal third. The nerve fibres are derised from the (fifth), sixth, seventh and eighth cervical and first thoracic nerves.

Action.- With the thorax fixed, the musele adducts and flexes the arm and rotates it medialward. The clavicular portion draws the arm forward, upward, and medialward; the sternocostal portion draws the arm downward, medialward, and forward. When the arm is pendent. the upper portion elevates, the lower depresses, the shouller. With the arm fixed, the muscle draws the chest upward toward it. It is of value in forced inspiration.

Relations.-It lies over the coracoid process, the subclavius, pectoralis minor, intercostal, and serratus anterior (magnus) muscles, the coraco-clavieular (costo-coracoid) fascia, and the thoraco-acromial vessels. It forms the main part of the ventral wall of the axillary fossa, and laterally it enters into relation with the deltoid, biceps, and eoraco-brachialis muscles.

Variations.-In considering variations the muscle may be looked upon as composed of four portions-a clavicular, a sternal, a costal, and an abdominal, the last being that portion which arises from the aponeurosis of the external oblique. These portions vary in the extent of their attachments and in the degree of separation which they present. The abdominal portion may extend to the umbilicus. Huntington eonsiders this portion a derivative of the pannicular muscle of the lower mammals. On the sternum the museles of the two sides may decussate across the middle line. The sterno-costal portions of the inusele are more frequently deficient or missing than the clavicular, but in rare cases the entire muscle is absent. The clavicular portion of the muscle may be fused with the deltoid. The sterno-costal may extend laterally to the latissimus dorsi. There may be an intimate fusion of the abdominal portion with the rectus abdominis or the external oblique. Sometimes a slip may run from the pectoralis major to the biceps, the pectoralis minor, coracoid process, eapsule of the joint, or brachial fascia.

The pectoralis minor (fig. 3S8).-Origin.-By aponeurotic slips from the second, third, fourth, and fifth ribs near the costal cartilages.

Fig. 361.-The Subclavies axd the Lpper Portion of the Serrates Axterior.

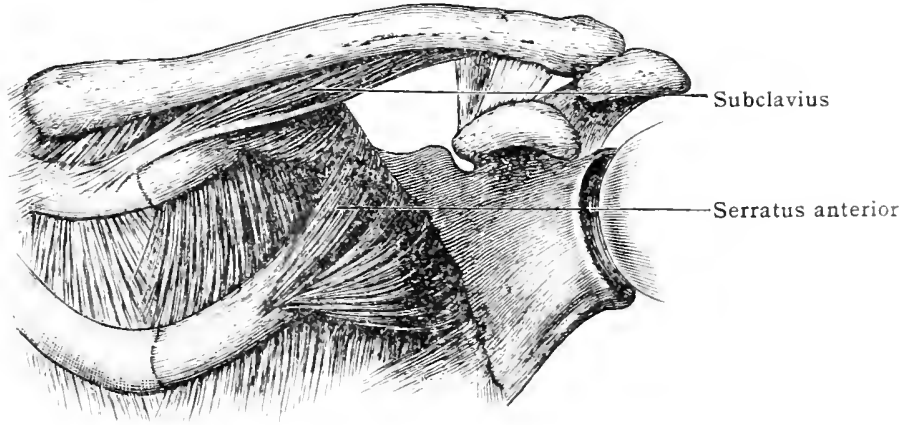

Structure and insertion.-The fibre-bundles converge upwarl and outward to a flattened tendon which is attached to the medial border and upper surfare of the coracoid process of the scapula.

Nerve-supply.-From the internal anterior thoracic nerve which enters the upper part of the middle third of the deep surface by several branches. Some of the branches extend through to the pectoralis major. The nerve fibres arise from the seventh and eighth cervical nerves.

Action. - When the thorax is fixed, the pectoralis minor pulls the scapula forward, the lateral angle of the bone downward, and the inferior angle dorsalward and upward. When the scapula is fixed, the muscle aids in foreed inspiration.

Relations. - It is covered by the pectoralis major. Near its insertion the fibrous investment of the chief nerves and vessels of the arm is adherent to its enveloping fascia.

Variations. - The origin may extend to the sixth rib or may be reduced to one or two ribs. In the primates below man the insertion of the musele takes place normally into the humerus. In man its insertion may be continued (in more than 15 per cent of bodies- Wood) orer the coracoid process to the eoraco-acromial or coraco-humeral ligaments, to the tenclon of the suthscapularis muscle, or to the great tubercle of the humerus. It may be livided into two superimposed fasciculi. Fasciculi may extend from the muscle to the subclavius or the pectoralimajor.

The subclavius (fig. 361).-Origin.--From a flat tendon attached to the first rib and its cartilage near their junction.

Structure and insertion.-The fibre-bundles arise in a penniform manner from the tenton of origin which extends for some distance along the lower border of the muscle. Fhey are inserted in a groove which lies on the lower surface of the clavicle between the costal tuherosity and the coracoid tuberosity. The nedial fibre-bundles are inserted directly, the lateral by al strong tendon.

Nerve-supply.-By a branch which arises usually from the fifth or fifth and sixth cervical nerves and enters the middle of the back part of the milscle.

Action. - When the first rib is fixed, the subclarius depresses the clavicle and the point of 
the shoulder. When the clavicle is fixed, the muscle aids in forced inspiration. It also serves to keep the clavicle against the sternum.

Relations.- It is concealed by the clavicle and pectoralis major muscle. Behind it lie the subclavian ressels and the brachial plexus.

Variations.- It may be replaced by a ligament or by a pectoralis minimus muscle (see below). It may be doubled or may be inserted into the coracoid process, coraco-acromial ligament, the acromion, or the humerus. The subclaitus posticus arises near the subclavius, passes backward over the subclavian ressels and brachial plexus and is inserted into the cranial margin of the scapula near the base of the coracoid process.

\section{Abnormal Muscles of the Pectoral Group}

The following muscles are usually innervated by the anterior thoracic nerves and are probably generally abnormal derivatives of the pectoral mass. Frequently they represent muscles normally found in lower mammals.

The sternalis.-A flat muscle somewhat frequently seen on the surface of the pectoralis major, usually nearly parallel to the sternum. It arises from the sheath of the rectus and from some of the costal cartilages (thirrl to seventh) and terminates on the sterno-cleido-mastoid, on the sternum, or on the fascia covering the pectoralis major. When present on both sides, the two muscles may be fused across the sternum. This muscle is found in 4 per cent. of normal individuals and 48 per cent. of anencephalic monsters. (Eisler.) Rarely, corresponding muscle slips have been found innervated by the intercostal nerves. These probably represent remains of a thoracic 'rectus' muscle.

The pectoro-dorsalis (axillary arch). - This muscle in its most complete form extends from the tendon of the pectoralis major over the axillary fossa to the tendon of the latissimus dorsi, to the fascia covering the latissimus dorsi, to the teres major or even more distally. It may, however, be more or less fused with either of the last two muscles mentioned, and it presents a great variety of forms. It may extend from the latissimus dorsi to the brachial fascia over the coraco-brachialis or biceps, to the long tendon of the biceps, to the axillary fascia, to the axillary margin of the pectoralis minor, or to the coracoid process, ete. It is found in about 7 per cent. of bodies. (Le Double.) When supplied from the anterior thoracic nerves, it probably represents a portion of the thoraco-humeral subcutaneous (pannicular) muscle of the lower primates. It is also sometimes supplied by the medial brachial cutaneous or the intercosto. brachial (humeral) nerve and frequently is partly or wholly supplied by the dorsal thoracic (long subscapular) nerve. The part of the muscle supplied by the dorsal thoracic nerve is probably derived from the latissimus dorsi musculature.

The costo-coracoideus. - A muscular slip which arises from one or more ribs or from the aponmurnis of the external oblique between the pectoralis major and latissimus dorsi muscles, and is inserted in the coracoid process.

The chondro-humeralis (epitrochlearis).- This is a slip which springs from one or two rib cartiliges or from the thoraco-abdominal fascia beneath the pectoralis major, or from its lower border or temlon, and extends on the medial side of the arm to the intertubercular (bicipital) groove, the braclial fascia, the intermuscular septum, or the medial epicondyle. It is found in 12 to 211 per cent. of hodies (Le Double), and occurs normally in many of the lower mammals.

The pectoralis minimus (sterno-chondro-scapularis). - From the cartilage of the first rib and sternecm to the eoracoid process.

'The sterno-clavicularis. - From the manubriun of the sternum to the clavicle between the pectoralis major and the coraro-clavidular (costo-coracoid) fascia. In 2 per cent. to 3 per cent of borlies. (Gruber.)

'The scapulo-clavicularis.-From the coracoid process of the scapula to the outer third of the riviriele.

Thr infra-clavicularis. - From alowe the rlavicular part of the pectoralis major to the fascial over the deltoicl.

\section{BIRS.E}

B. m. pectoralis majoris.--Between the tendon of insertion of the pertoralis major and the long hrearl of the hiceps. Frecuent.

$$
\begin{aligned}
& \text { ( . MUSCUIATURE OF THE ARM } \\
& \text { ( } 1 \text { igs. } 355,356,3(32,363,364,365,367,370,372)
\end{aligned}
$$

The museles includerl in this soetion are the trieces and anconeus, colaco-

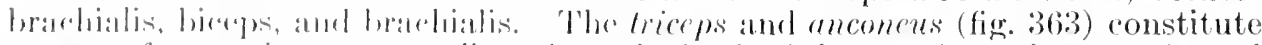

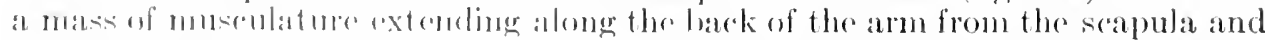

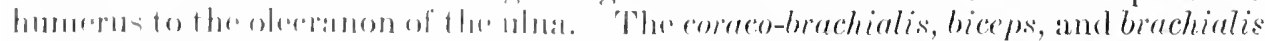

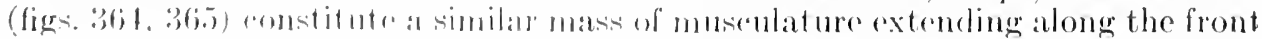

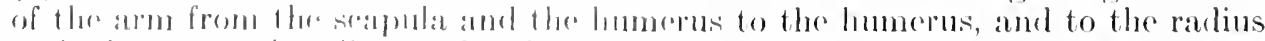
and ulua mar the olhow. In the mplere hall of the arm the two groups are

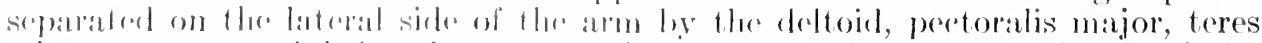
minor, supra- amb inlrasumatus museles, and hy the greater tuberele of the

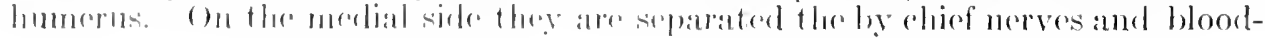




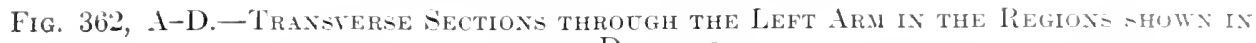
The Diagrail.

$a$ and $b$ in the diagram indicate the regions through which pass section $A$ and $B$, fin. 3.51 (p. 352); $a^{\prime}$ and $b^{\prime}$, the regions through which pass sections $A$ and $B$, fig. 357 ( $p$. 366 : and $a^{11}$ the region through which passes section $\mathrm{A}$, fig. 366 (p. 385).

1. Arteria brachialis. 2. Bursa subcutanea olecrani. 3. Fascia brachialis. 4. Humerus. 5. Musculus anconeus. 6. M. biceps- $a$, long head; $b$, short hearl; $c$, tendon of insertinn. 7. M. brachialis. 8. M. brachio-radialis. 9. M. roraco-brachialis. 10. M. deltoiden. 11. M. extensor carpi raclialis brevis. 12. M. extensor carpi radialis longus. $13 \mathrm{M}$. extensor digitorum communis. 14. M. flexor carpi radialis. 15. M. flexor carpi ulnaris.. 16. 1. flexor digitorum sublimis. 17. M. flexor digitorum profundus. 18. M. palmaris longus. 19. M. pronator teres. 20. M. triceps-a, lateral head; $b$, long head; $c$, medial head. $21 a . \mathrm{N}$. cutaneus antibrachii medialis (internal cutaneous). 21b. $\mathrm{N}$. cutaneus antibrachii dorsalis. 22. $\mathrm{N}$. musculo-cutaneus. 23. $\mathrm{N}$. medianus. 24. $\mathrm{N}$. radialis $-a$. muscular branch. 25. X. ulnaris. 26. Lymphatic gland. 27. Olecranon. 2S. Septum intermusculare laterale. 29. Septum intermusculare mediale. 30. Vena cephalict. :31. V. basilica. 32. Tv, brachiales.

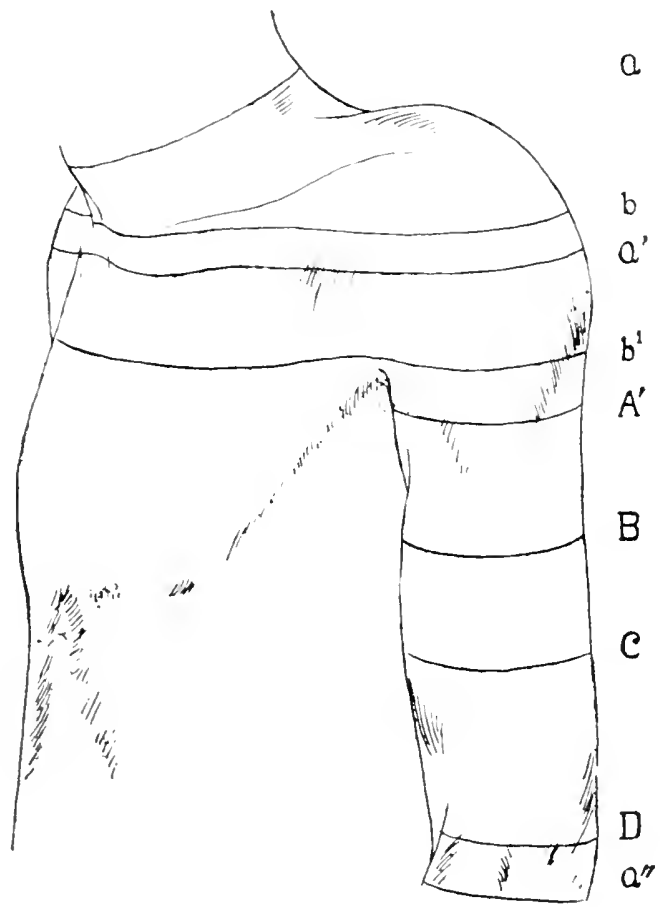

A

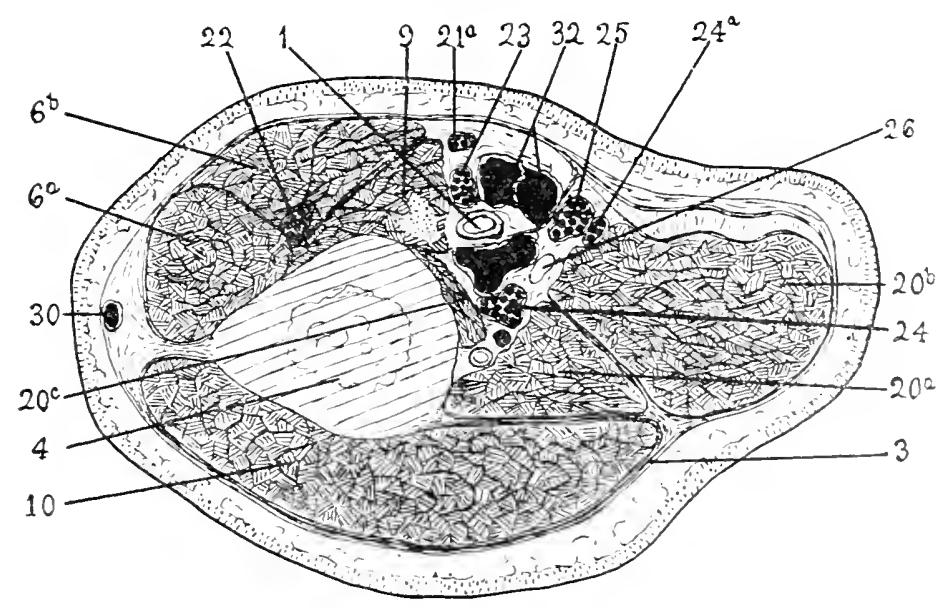




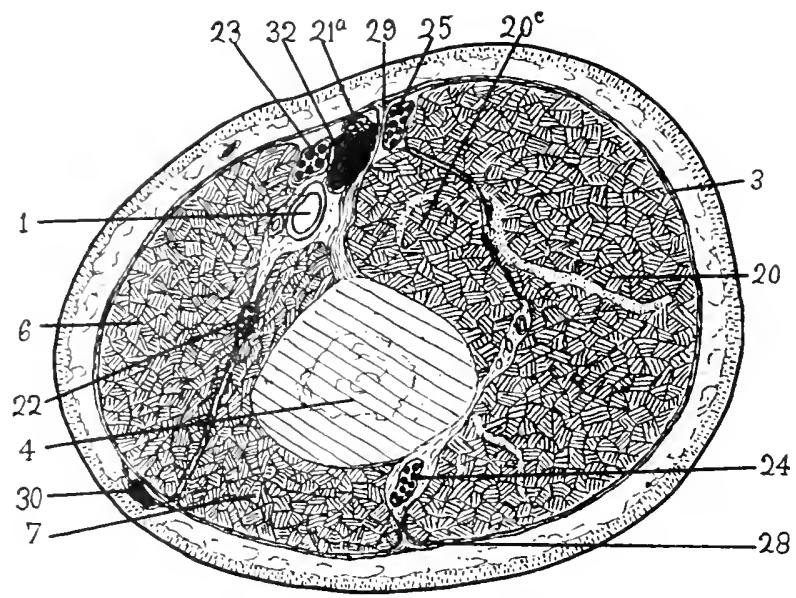

C

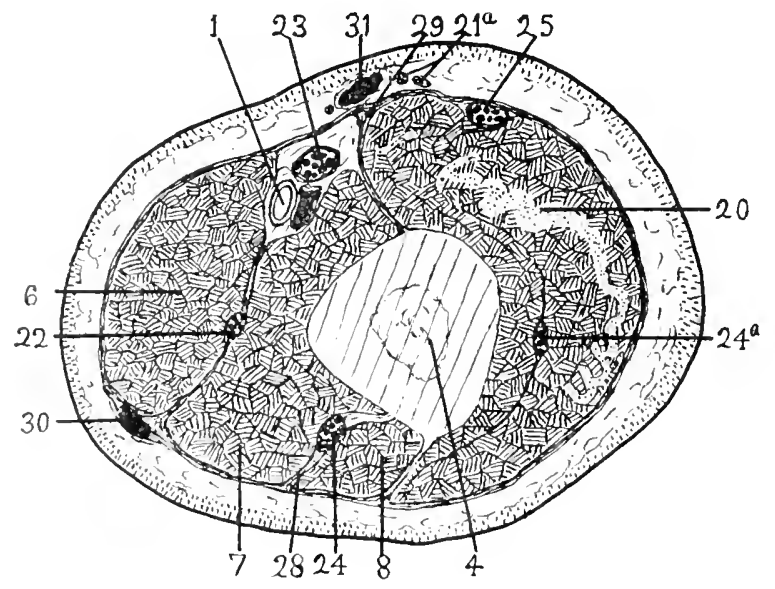

I)

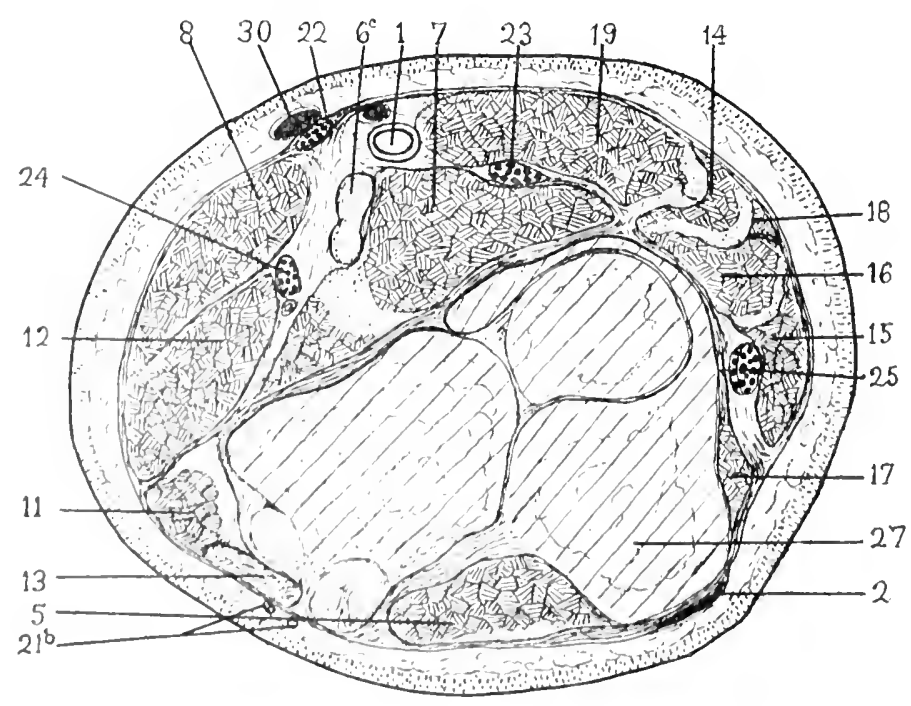


vessels of the arm and by the tendons of the latissimus dorsi, teres major, and subscapularis muscles. In the distal half of the arm they are separated merlially. by the medial intermuscular septum (described below) and by the medial epienndyle and the ulno-volar group of muscles of the forearm. On the lateral sidc of the arm they are separated by the lateral intermuscular septum, by the lateral epicondyle, and by the brachio-radialis and the extensor muscles of the forearm which take origin from the lateral epicondyle.

\section{FASCIE}

The fasciæ and the general relations of the muscles of the arm are shown in the rrossections in fig. 362 .

The tela subcutanea of the arm is fairly well developed and contains a considerable amount of fat, especially near the shoulder. It is but loosely bound to the muscle fascia, except near the insertion of the deltoid, where the union may be more intimate.

Bursæ.-B. subcutanea epicondyli lateralis.- Between the lateral epicondyle and the skin. Rare. B. subcutanea epicondyli medialis. - Between the medial epicondyle and the sin. Inconstant. B. subcutanea olecrani.--Between the olecranon process of the ulna and the skin. Nearly constant.

The brachial fascia forms a cylindrical sheath about the muscles of the arm. It contains circular and longitudinal fibres, the former being the better developed. The fascia is strong over the dorsal muscles, especially near the two epicondyles of the humerus. Proximally the fascia of the arm is continued into the axillary faseia and into the fascial investment of the pertoralis major, deltoid, and latissimus dorsi muscles; distally it is continued into the fancial investment of the forearm. It is intimately bound to the epieondyles and to the dorsal surface of the olecranon. It is separated by loose areolar tissue from the bellies of the museles which it covers. From the tendons of the deltoid, pectoralis major, teres major, and latissimus dorsi muscles, however, fibrous bundles are continued into the brachial fascia. There are a number of orifices in the fascia for the passage of nerves and blood-vessels. Of these, the largest is that for the basilic vein and two or three large branches of the medial antibrachial (internal) cutaneous nerve. This lies on the ulnar margin of the arm in the lower third. On the radial margin lie the cephalic vein in a double fold of the fascia, orifices for branches of the musculocutaneous nerve, and more dorsally orifices for branehes of the radial. From the fascia septa descend between the muscles which it invests. Of these septa, the most important are the medial and lateral intermuscular septa, which separate the dorsal group of muscles from the rentrial in the distal half of the arm. The medial intermuscular septum is the stronger. It is attarhed to the medial epicondyle and to the medial margin of the humerus proximal to this. It is: continued proximally into the tendon of insertion of the coraco-brachialis and the investing fascia of this muscle. Into it longitudinal bundles of fibres descend from the tenrlon. It separates the brachialis and pronator teres muscles from the medial head of the triceps. The lateral intermuscular septum is attached to the lateral epicondyle and to the lateral margin of the humerus. It is continued proximally into the dorsal surface of the tendon of insertion of the deltoid muscle, and into the septa between the deltoid and the triceps. It seprarites the triceps from the brachialis in the third quarter of the arm and from the brachio-racialis and extensor carpi radialis longus in the distal quarter. The median nerve and hrachial vessels lie in front of the medial septum. The ulnar nerve and the superior ulnar collateral (inferior profunda) artery are bound to its dorsal surface.

\section{MLSCLES}

\section{Dorsal or Extensor Group}

Two muscles are included in this group, the triceps brachii and the anconeus. The triceps is a complex muscle in which proximally three heads, a long or scaptular, a lateral humeral, and a medial humeral, may be distinguished. The long head arises from the infraglenoid tuberosity of the scapula, the lateral head fron the humerus above and laterally to the groove for the radial nerve (musculospiral groove), the medial head from the lower half and medial margin of the posterior surface of the humerus. Distally these heads fuse and are insertal by a common tendon into the olecranon of the ulna. The anconeus lies chinfly. in the forearm, but physiologically and morphologically it belongs with the triceps, and hence is described in connection with the muscles of the arm. It is al triangular muscle, which arises from the lateral epicondyle and is inserted into the olecranon and adjacent part of the shaft of the ulna. Both muscles are supplied 
by branches of the radial (musculo-spiral) nerve. They extend the forearm. The long head is also an adductor of the arm.

The triceps, variously modified, is found in the amphibia and all higher vertebrates. The anconens is found in the prosimians and all higher forms. The triceps muscle is homologous with the quadriceps of the thigh. The long head is equivalent to the rectus femoris. The anconeus is not represented in the lower limb.

The triceps brachii (figs. $355,356,363$ ).-The long head arises from the infraglenoid tuberosity of the scapula by a strong, broad tendon, some of the fibres of which are connected with the inferior portion of the capsule of the shoulder-joint. The tendon soon divides into two lamellax, which extend distally, one a short distance on the deep surface, the other much farther

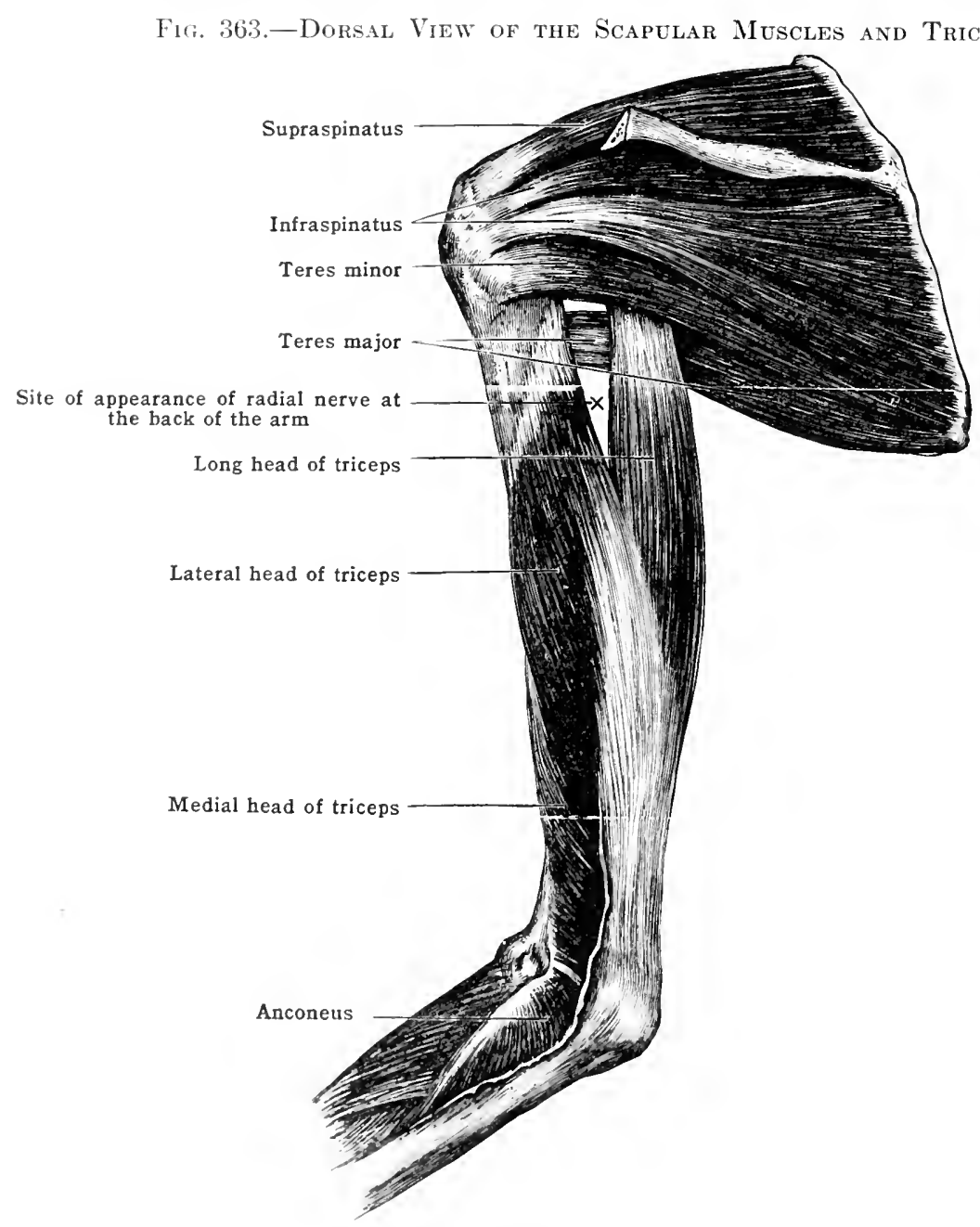

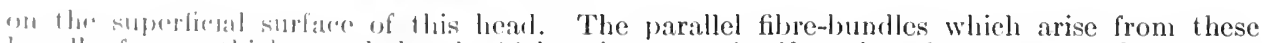
lamellat form at thick muscle-baud which twists mpon itself so that the ventral surface at the origin berentes dorso-mocial at the insertion. At the insertion the long head becomes applind to an apenomosis whinh extends npward from the main tendon of insertion of the triceps.

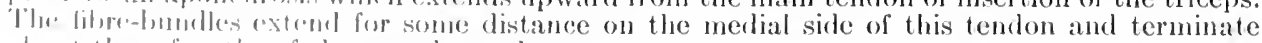
ahesut therefenthts of the waty down the arm.

Thr lateral head has a trindinoms origin from the superior lateral portion of the posterior surfare of the humbrus along a line cxtenting from the insertion of the teres minor as far as the gromer for thr radial (musculo-spiral) nerve, and from the aponcurotic arch formed by the lateral intermascolat septum as it rosses this groove. The comstituent filme-bundles descend, the superior vertically, the inforiof obliguncly, fo be inserted on the dorsal and ventral surfaces of the prexime-lateral matrgin of the rembun femlon of insertion of the triceps.

'Thr medial head has it lleshy arigin from the posterior surface of the humerus below the

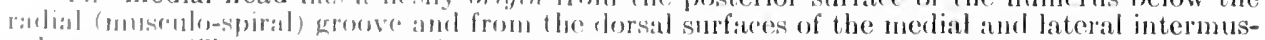

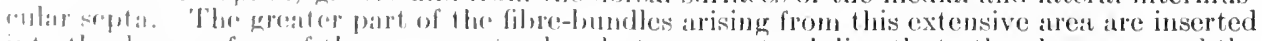
intos the deep surface of the common tendons, hut some extend directly to the olecranom and the

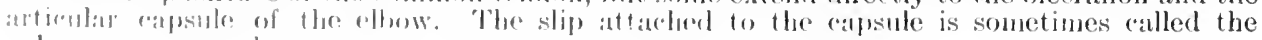
subanconeus inlisito. 
Insertion.-The tendon of insertion of the triceps forms a flat band covering the dorsal surface of the distal two-fifths of the muscle. It also extends proximally between the long and lateral heads and on the deep surface of the former. This tendon is inserted into the olecranon and laterally, by a prolongation over the anconeus, into the dorsal fascia of the forearm.

Nerve-supply.-From the radial (musculo-spiral) nerve. The branch to the long heal aris:in the arm-pit and enters that margin of the muscle which is prolonged down from the lateral edge of the tendon, but which, because of the torsion of the muscle, comes to lie on the media! side. The nerve usually enters through several rami about the middle of the free portion of the long head. Somewhat more distally the radial nerve gives off a branch that enters, by two or three branches, the proximal portion of the medial head. A similar branch is given to the lateral head and other branches are given to the lateral and medial heads from that portion of the radial (musculo-spiral) nerve lying in the radial (musculo-spiral) groove. The nerve fibres arise from the sixth, seventh, and eighth cervical nerves.

Relations.- - Near the shoulder the triceps is covered by the deltoid muscle. The long heal passes between the teres major and teres minor muscles. The circumflex (dorsal) scapular vessels here pass medial, the circumflex humeral vessels and the axillary (circumflex) nerve lateral, to this head. More distally the muscle lies beneath the brachial fascia. It covers the radial groove of the humerus, in which run the radial (musculo-spiral) nerve and (superior) profunda brachii artery. Ventro-lateral to the muscle lie the deltoid, brachialis, brachio-radialis, and extensor carpi radialis muscles; ventro-medial, the coraco-brachialis, biceps, and brachialis muscles.

Action.--It extends the forearm. The leverage is of such a nature that force is sarrificed for speed of movement. The long head of the triceps also serves to extend and to adduct the arm and to hold the head of the humerus in the glenoid cavity.

Variations. - The scapular attachment may extend for a considerable distance clown the axillary border of the scapula. Each of the heads may be more or less fused with neighbouring muscles. Frequently a fourth head is found. This may arise from the humerus, from the axillary margin of the scapula, from the capsule of the shoulder-joint, from the coracoid process, or from the tendon of the latissimus dorsi.

The latissimo-condyloideus (dorso-epitrochlearis).-This muscle is found in about 5 per cent. of bodies. When well developed, it extends from the tendon of the latissimus dorsi to the brachial fascia, the triceps muscle, the shaft of the humerus, the lateral epicondyle, the olec. ranon, or the fascia of the forearm. It is innervated by a branch of the radial (musculo-spiral) nerve. It is a muscle normally present in some one of the forms above mentioned or in some similar form, in a large number of the inferior mammals. In the human body it is normally represented by a fascial slip from the tendon of the latissimus to the long head of the triceps on the brachial fascia.

The anconeus.- - Origin.-By a short narrow tendon from the distal part of the back of the lateral epicondyle and the adjacent part of the capsular ligament of the elbow-joint.

Structure and insertion. - The tendon of origin is prolonged on the deep surface and lateral border of the muscle. From this the fibre-bundles spread, the proximal transversely, the more distal obliquely, to be inserted into the radial side of the olecranon and an adjacent inpression on the shaft of the ulna. Its superior fibre-bundles are usually continuous with those of the n edial head of the triceps.

Nerve-supply.-By a long branch which arises in the radial (musculo-spiral) groove from the radial (musculo-spiral) nerve, passes through the medial head of the triceps, to which it gives branches, and enters the proximal border of the anconeus. The nerve fibres arise from the seventh and eighth cervical nerves.

Action.-It aids the triccps in extending the forearm and draws the ulna laterally in pronation of the hand.

Relations.-The muscle lies immediately beneath the antibrachial fascia. It extends over the head of the supinator (brevis) and the elbow-joint and upper radio-ulnar joint.

Variations.-The extent of fusion of the muscle with the medial head of the triceps varies a good deal. It may also be fused with the extensor carpi uhnaris. It has been reported missing.

\section{BURS.E}

B. intratendinea olecrani.-Within the tendon of the triceps near its insertion. Ilore frequent than the following:-

B. subtendinea olecrani.-Between the tendon of the triceps and the olecranon and dur $-a !$ ligament of the elbow-joint. Inconstant.

B. epicondyli medialis dorsalis. - Between the medial epicondyle, the erlae of the triceps. and the ulnar nerve. Rare.

B. m. anconei.- Between the tendon of origin of the muscle and the hearl of the ramlins: Frequent.

\section{Vextral or Flexor Grolp}

$$
\text { (Figs. 364, 365, 370, 372) }
$$

The muscles of this group are the coraco-brachialis, the biceps, ant the hrathialis. The coraco-brachialis (fig. 365 ) is a band-like muscle whith arises from the coracoid process and is inserted into the middle third of the shat of the humerus. The biceps (fig. 36t) arises by two heads: a short head, dosely associated with the coraco-brachialis, from the coracoid process: a long head. by an 
extended tendon, from the supraglenoid tuberosity of the scapula. The fusiform belly which arises from the fusion of these two heads is inserted into the radius and into the fascia of the forearm. The brachialis (fig. 365) extends under cover of the biceps from the lower three-fifths of the shaft of the humerus to the coronoid process of the ulna. The muscles of this group are supplied by the musculocutaneous nerve. The brachialis also usually receives a branch from the radial nerve. The coraco-brachialis and short head of the biceps flex and adduct the arm at the shoulder; the biceps and brachialis flex the forearm at the elbow. The long head of the biceps abducts the arm at the shoulder.

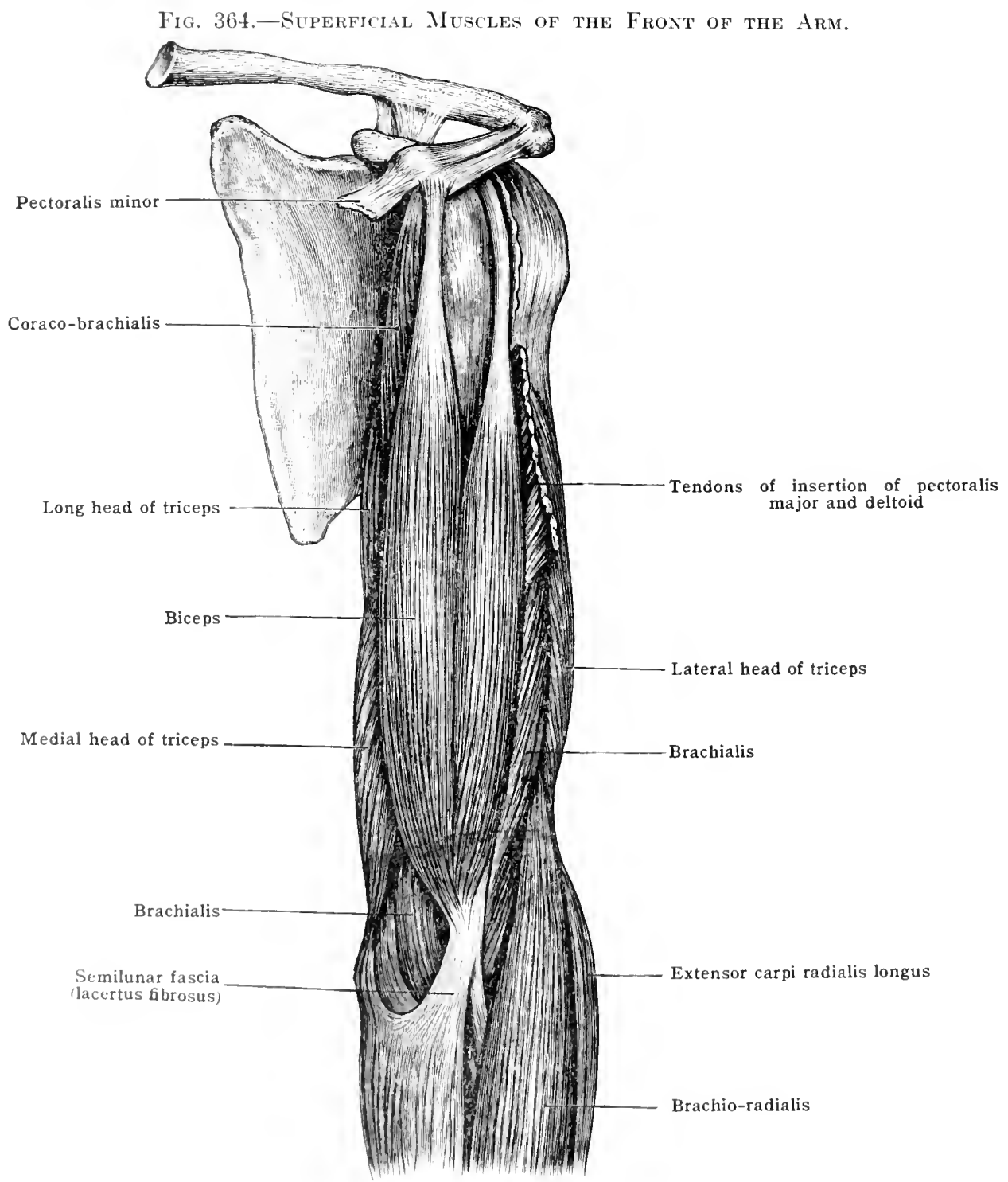

The muscles of this gromp are fomm in most of the limbel vertebrates. In many of the lower forms the coram-turathialis, which allyears farther down in the vertebrate series than the hiceps, has a more extensive insertion than in man. li matexteml to the ulna (lizards) and maty besmbelivided into varions muselos which correspond with the adductors of the thigh. The

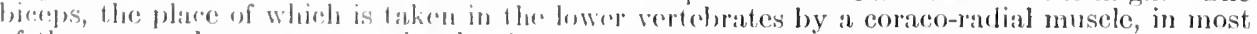

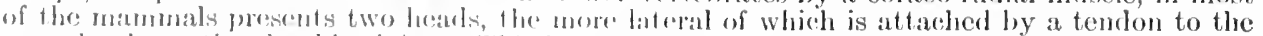

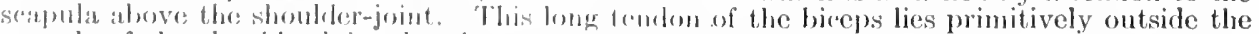
capsule of the shonlder-joint, lut in somo of Ho higher mammals has come to lie within the rapsule. In the biceps four clemente may low forognised:- a coraco-radial, coraco-ulnar, glenorardial, and glemombar. (Kranso.) "llic dovelopmont of these elements varies in different matminits 
The coraco-brachialis (fig. 365).-Origin.-(1) By a short tendon from the tip of the coracoid process of the scapula and (2) from the tenclon of the short head of the biceps.

Insertion.-(1) By means of a strong tendon into the medial surface of the humerus immediately proximal to the middle of the shaft, and $(2)$ of ten above this also into an aponeurotic band which extends from the tendon along the medial margin of the humerus, arches over the tendons of the latissimus dorsi and teres major, and is attached to the lesser tubercle of the humerus. When the attachment to the tubercle does not take place, the band becomes closely applied to the deep surface of the muscle.

Structure.-From the tendons of origin, which are usually closely associated, the fibrebundles take an oblique, nearly parallel, course and are attached to the aponeurotic band above

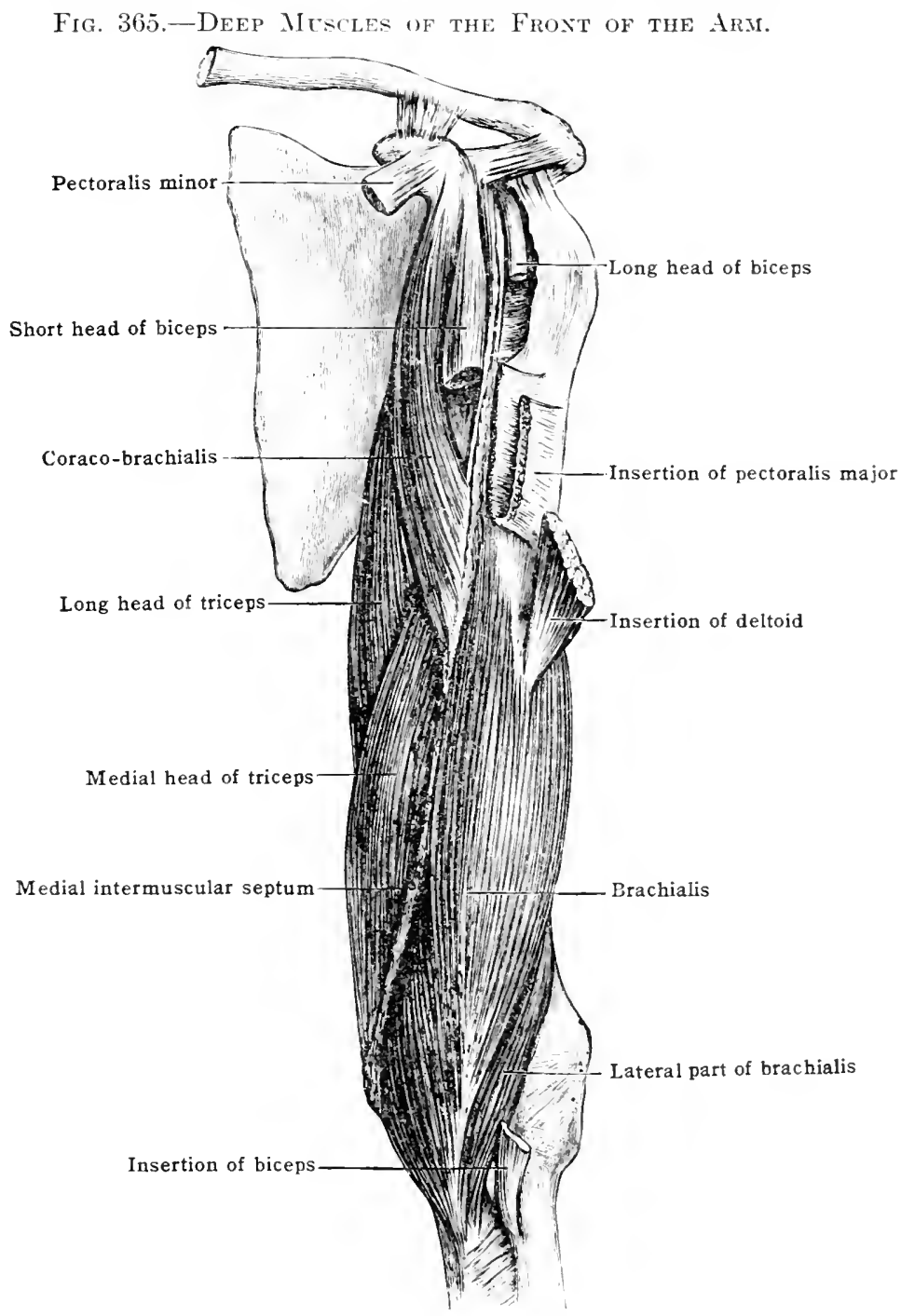

mentioned and to both surfaces of the flat tendon of insertion. This extends high into the muscle. The belly of the muscle usually shows some separation into a superficial and a deep portion, between which runs the musculo-cutaneous nerve. When this separation is well marked, the tendon of origin of the superior fasciculus mav be distinct from that of the inferior fasciculus and the short head of the biceps, and the tendon of insertion may give a separate lamina to each fasciculus.

Nerve-supply.-A branch of the musculo-cutaneous nerve, or of the brachial plexus near the origin of this nerve, enters the upper third of the medial border of the muscle, and passe: across the constituent fibre-bundles about midway between their attathments. The nerve fibres arise from the sixth and seventh cervical nerves.

Action.-Adducts and flexes the arm at the shoulder and helps to keep the head of the humerus in the glenoid fossa. When the am has been rotated lateralward, it acts as a medial rotator.

Relations.-The coraco-brachialis is largely covered by the deltoid and pectoralis major muscles. Below the inferior border of the latter it becomes superficial. Near its origin it lie: 
between the pectoralis minor and the subscapularis muscles. More distally it lies medial to the humerus and in front of the chief brachial vessels and nerves. The musculo-cutancous nerve usually runs through it.

Tariations. - The humeral insertion of the muscle varies considerably. According to Wool, the coraco-brachialis consists primitively of three parts, which arise from the coracoid process and are inserted respectively into the upper, the middle, and the distal part of the humerus along the medial side. The superior division is most deeply, the inferior the most superficially, placed. In man the muscle is composed of parts of the middle and inferior divisions. The inferior division may be completely developed as far as the medial epicondyle. 'The superior division of the muscle is occasionally found. Slips from the coraco-brachialis to the brachialis have been seen. Complete absence of the muscle has been recorded.

The biceps brachii (figs. 364,370 ). - The short head arises by a flat tendon closely associated with that of the coraco-brachialis from the coracoid process. From the dorso-medial surface of this tendon the fibre-bundles descend nearly vertically, though increasing in number, toward their attachment to the tendon of insertion. The fibre-bundles which arise highest on the tendon of origin are inserted highest on the tendon of insertion, while those which have the lowest origin have the lowest insertion.

The long head arises from the supraglenoid tuberosity and from the glenoid ligament by a long tendon $(9 \mathrm{~cm}$.) bifurcated at its origin. The tendon at first passes over the head of the humerus within the capsule of the joint, and then passes into the intertubercular (bicipital) groove, which is covered by the capsule of the joint and an expansion from the tendon of the pectoralis major. To this point the tendon is surrounded by the synovial membrane of the joint. After emerging from this the tendon slowly expands and from its dorsal concave surface arise fibre-bundles which, increasing in number, extend, somewhat obliquely, toward the tendon of insertion. As in case of the short head, here also the fibre-bundles which arise highest on the tendon of origin have the highest insertion.

Insertion.- The tendon of insertion begins usually in the distal quarter of the arm as a vertical septum between the two heads of the muscle. More distally this broadens out on each side into a flattened aponeurosis. The fibre-bundles are inserted into the sides of the septum and on each surface of the aponeurosis-those of the long head chiefly on the deep surface, those of the short head chiefly on the superficial surface. The aponeurosis is continued into a strong, flattened tendon which descends between the brachio-radialis and pronator teres muscles to be inserted on the dorsal half of the bicipital tuberosity of the radius. From the medial border of the tendon an aponeurotic expansion, the lacertus fibrosus (semilunar fascia), is continued into the fascia of the ulnar side of the forearm.

Nerie-supply.-By a branch from the musculo-cutaneous nerve for each head. These hranches may be bound in a common trunk for some distance. They enter the deep surface of the muscle in the proximal part of the middle third of each belly of ten by several rami. Usually there is a distinet intramuscular fissure for the reception of the branches to each head and the blood-vessels which accompany them. The nerve fibres come from the fifth and sixth cervical nerves.

Action.- It is a chicf flexor of the arm at the elbow and is also a supinator of the forearm. This last action is most marked when the forearm is flexed and pronated. Both heads are flexors and medial rotators of the arm at the shoulder. The long head is an abductor and s) also is the short head when the arm is greatly abducted, otherwise the short head is an arlductor.

Retations.- The tendons of origin are concealed by the pectoralis major and del toid muscles. boyond this the muscle is covered by the fascia brachii. In the lower part of the arm it hies "Ion the lorachialis muscle. Cpon the medial margin lie the coraco-brachialis muscle, the brachial veswels. and the median nerve.

Tarialmus. - Variations are frequent. The whole muscle or either head may be missing, hit such cases are rare. The long hear inay extend only to the bicipital groove. Frequently' the muscle is partially divided into the four prinitive portions mentioned above. The two heats maly be separate from origin to insertion. There may be an acessory head (1 in 10 suljorts - le bouble) which arises from the coracoid process, the capsule of the joint, the tendon of thr jorloralis maj:r, or the shaft of the humerus near the insertion of the coraco-brachialis. In must instaners the origin takes place above the origin of the brachialis from the humerus.

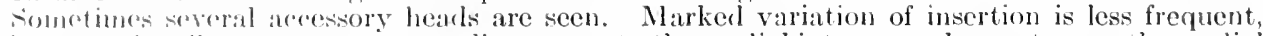
but occasimally a supernumerary slip may go to the medial intermuscular septum or the medial (a)iandyle. The fusion of the bireps with neighlooming museles (pectoralis major and minor, coraco-brachialis, brachialis, palmaris longus, pronator teres, brachioradialis) by means of

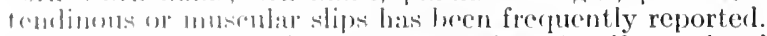

'The brachialis (fig. 36.5).- ()rigin.-(1) Fon the distal three-fifths of the front of the

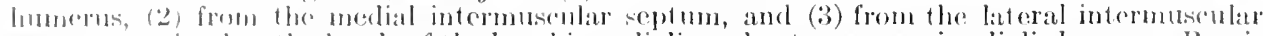
septum poximal to the heads of the brachio-raulialis and extensor carpi radialis longus. P'oximally if semle up a pointed promess on the lateral side of the insertion of the deltoid and another

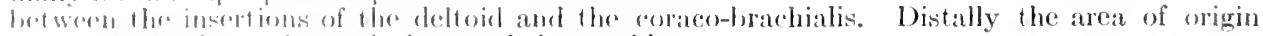

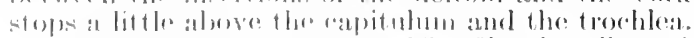

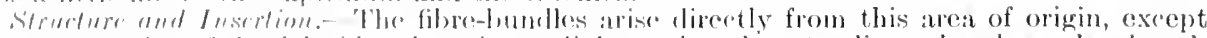

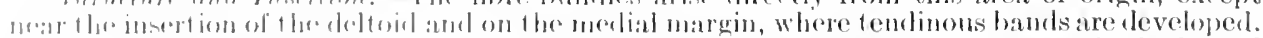

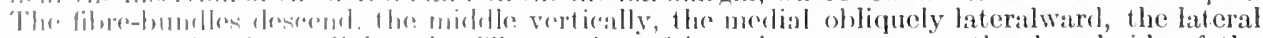

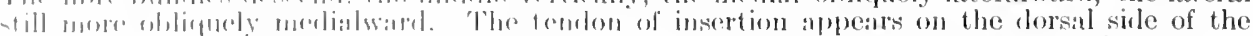

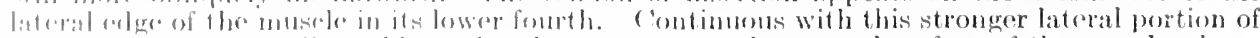

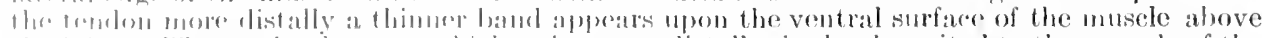

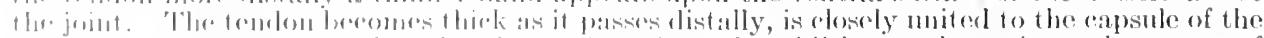

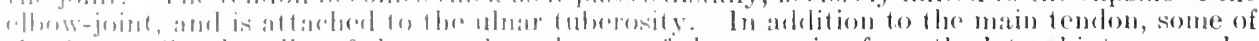

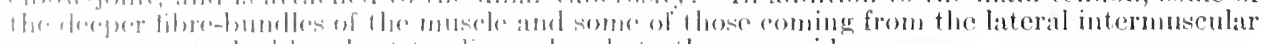

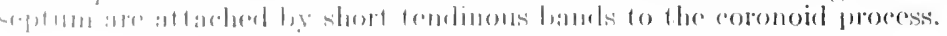


Nerve-supply.-From the musculo-cutaneous nerve by a branch which enters the ventrat surface of the muscle near the junction of the upper and middle thirds of the medial border. In addition the radial (musculo-spiral) nerve usually sends a small branch into the distal lateral portion of the muscle. A branch from the median nerve frequently supplies the medial sile of the muscle near the elbow-joint (Frohse).

Action.-To flex the forearm.

Relations.- It lies behind the biceps, on each side of which it projects. The distal latera! portion of the muscle is grooved by the brachio-radialis, which here is elosely applied to it. The radial (musculo-spiral) nerve runs between these two muscles. On the medial side run the brachial vessels and median nerve.

Variations. - It may be divided into two distinct heads continuous with the projections on each side of the deltoid tuberosity. A great number of supernumerary slips have been recorded. These may be attached to the radius, una, fascia of the forearm, capsule of the joint, brachioradialis, and extensor carpi radialis muscles. It may be partially fused with neighbouring muscles. It has also been reported absent.

\section{BuRsie}

B. m. coraco-brachialis.-Between the subscapularis muscle, the tendon of the coracobrachialis, and the coracoid process. Frequent.

B. bicipito-radialis.-Between the ventral half of the radial tuberosity and the tendon of the biceps. Constant.

B. cubitalis interossea.-Between the tendon of the biceps and the ulna and the neighhouring muscles. Frequent.

\section{MUSCULATURE OF THE FOREARM AND HAND}

(Figs. 366-379)

The muscles of the forearm arise in part from the humerus, in part from the radius and ulna. Their bellies lie ehiefly in the proximal half of the forearm. They are divisible into two groups:- - a radio-dorsal, composed of extensors of the hand and fingers and supinators of the forearm; and an ulno-volar, eomposed of flexors of the hand and fingers and pronators of the forearm. The brachioradialis, which belongs morphologically with the former group, is physiologically a flexor of the forearm.

The two groups are separated on the medial side of the back of the forearm by the dorsal margin of the ulna (figs. 366,369 ). Ventrally they are separated by the insertions of the biceps and brachialis and by an intermuscular septum (figs. 366, 370).

In the hand, in addition to the tendons of the museles of the forearm mentioned above (fig. 376), there are several sets of intrinsie muscles. About the metacarpal of the thumb (figs. $375,376,377$ ) is grouped a set of muscles which arise from the earpus and metacarpus and are inserted into the metacarpal and first phalanx of the thumb. A similar set of museles is grouped about the metacarpal of the little finger (figs. 375, 376). These sets of muscles give rise respectively to the thenar and hypothenar eminences. Between the metacarpals lies a series of dorsal and palmar interosseous museles (figs. 377, 378, 379) which are inserted into the first row of phalanges and into the extensor tendons. From the temdons of the deep flexor of the fingers a series of lumbrical muscles passes to the rarlial side of the extensor tendons (figs. 373, 375). These various muscles abluct, adduct, flex, and extend the digits. In addition to these deeper skeletal muscles of the hand there is a subcutaneous muscle over the hypothenar eminenee (fig. 375). Of the muscles of the hand, all are supplied by the ulnar nerve exeept most of those of the thumb and the two more radial lumbricals, which are supplied by the median nerve.

An arrangement of the muscles of the forearm in which the dorsal extensol-supinator musculture extends proximally on the raclial side of the arm to the distal extremity of the humerus. and the volar flexor-pronat or musculature similarly on the ulnar side, is characteristic of all limbed vertebrates and is associater with the pronate position of the forelinb characteristic of quadrupeds. In amphibia and reptiles the musculature terminates distally on the carpus and in the aponeuroses of the hand. In the higher forms special tendons are differentiated for those muscles of the forearm which act on the fingers. On the back of the hand in many vertehrate: short extensor muscles are found running from the carpus to the phalanges. On the volin surface a complex musculature is found in all forms which bave freelr movable fingers. In animals which walk on the ends of the fingers, especially in the hoofed animats, the intrinsis musculature of the hand is greatly reduced. The phytogenetic development of the num tes of 
the forearm and hand is too eomplex a subject to be briefly summarised. The phylogeny of the forearm flexors and the palmar musculature has been studied by McMurrich. In his papers a summary of the literature on the subject may be found.

\section{FASCIÆ}

The fasciæ and the general relations of the musculature of the forearm and hand may be followed in the cross-sections fig. 366.

The tela subcutanea contains a moderate amount of fat in the upper part of the forearm. This grows less in amount as the wrist is approached. On the back of the hand it contains little fat. In the palm and on the volar surface of the fingers a moderate amount of fat is embedcled between dense vertical bundles of fibres which unite the skin to the fascia. Except on the volar surface of the hand and on the backs of the terminal phalanges, the tela is but loosely united to the underlying fascia.

The bursa subcutanea olecrani lies over the dorsal surface of the olecranon. Subcutaneous bursp are also frequently found over the knuckles (b. subcutaneæ metacarpophalangeæ dorsales) and the proximal joints of the fingers (b. subcutaneæ digitorum dorsales).

The antibrachial fascia encloses the muscles of the forearm in a cylindrical sheath, composed in the main of circular fibre-bundles, but strengthened by longitudinal and oblique bundles extending in from the epicondyles of the humerus, the olecranon, the lacertus fibrosus of the biceps, and the tendon of the triceps. The fascia of the forearn is attached to the dorsal surface of the olecranon and to the subcutaneous margin of the ulna. Above, it is continued into the fascia of the arm; below, into the fascia of the hand. From the antibrachial fascia in the upper half of the foreirm a fibrous septum extends between the radio-dorsal and the ulno-volar muscle group to the radius. In the radial septum below the elbow a branch of communication extends between the superficial and deep veins of the arm. That part of the fascia overlying the radio-rorsal group of muscles is much denser than that covering the volar group, exeept where the latter is strengthened by the lacertus fibrosus. In addition to the main raclial septum other septa descend between the underlying muscles from the antibrachial fuscial. These septa are best marked near the attachment of the muscles to the humerus. Here the fascia is firmly fused to the muscles.

Dorsilly the antibrachial fascia is strengthened at the wrist by transverse fibres which extend from the radius to the styloid process of the ulna, the triquetrum (cuneiform), and pisiform, and give rise to the dorsal ligament of the carpus (posterior annular ligament). From this ligament septa descend to the radius and uha and convert the grooves in these bones into osteo-filmous canals which lodge the tendons of the various muscles extending to the wrist and hanrl.

On the back of the hand there is spread a fascia composed of two thin fascial sheets between which the extensol tendons are contained. Between the tendons these sheets are more or less fuserl. On the backs of the fingers the fascia blends with the extensor tendons and the associated aponeurotic expansions from the interosseous and lumbrical inuscles. Between the fingers it is continued into the transverse fascieuli of the palmar aponeurosis. At the sides of the hand the fascia is rontinued into the thenar and hypothenar fascia. Each dorsal interosseous in usirle is covered by a special fascial membrame which is separated by loose tissue from the fascia investing the extensor tendons.

\section{lig. 366, d-I1.-Transverse Sections throdgi the Llft Forearm and Hand.}

II. Transverse section through the first phalanx of the middle finger, diagrammatie, with the (atvity of the synovial sheath of the flexor tendons distended.

The regions through which these sections pass are indicated in the diagram. $c$ and $d$ in the diagram show the regions through which pass sections $\mathrm{C}$ and $\mathrm{D}$, fig. 362 (p. 375).

1. Aponmosis palnaris. 2. Arteria radialis. 3. A. unaris. 4. Bursa bicipito-radialis. 5 J)is:ls articularis. 6. Iigamentum carpale dorsale. 7. L. carpi transversum. 8. L. "arpi voline. 9. lascia antibrachii. 10. Musculus abduetor pollicis brevis. 11. M. abructor follicis longus-a, tendon. 12. M. abductor digiti quinti. 13. M. adductor pullicis. J. . M. anconeus. 15. M. hiceps, tendon. 16. M. brachialis, tendon. 17. M. frachio-radiatis-at tendon. 18. M. extensor carpi radialis brevis-a, tendon. 19. M. oxtensor "arpi radialis longus-a, tendon. 20. M. extensor carpi ulnaris. 21. M. extomson digiturun communis-a, tondon for second finger; $b$, tendon for the third finger; $c$, rencton for fonth linger; d, tendon for fifth finger; $\mathrm{e}$, digital aponcurosis. 22. M. extensor digiti aunti moprius. 23. M. extonsor indicis proprius. 24. M. extensor pollicis brevis

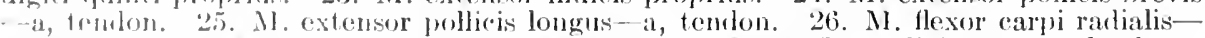
a, temdnt. 27. M. flexor carpi uhnaris-a, tenton. 28. M. flexor digitorum profundusa, tomlon for second finger; b, tendon for third finger; c, tendon for fourth finger; d, tendon for fifth finger. 2!). M. Ilexor digitortum sublimis-a, teudon for second linger; b, tendon for thimel finger; a, fondon for fourth finger; d. tendon for fifth tinger. 30. M. 1lexor digiti

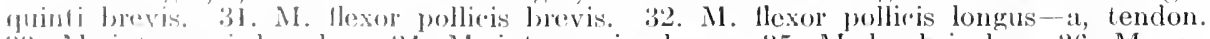
3.3. 11. interossci forsales. 31. M. interostei volares. 35. M. lumbricales. 36. M. opponens pollecis. :37. M. opponens digiti quinti. 35. M. palmaris brevis. 39. M. palmaris longus a, trindon. Ho. M. monalor quadratus. H. M. promator teres. 42. M. supi-

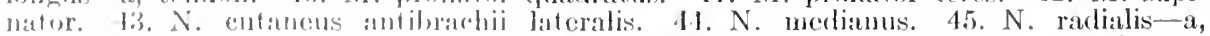

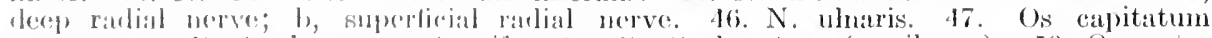
(magnmm). Is. () hamafum (unciform). 19). Os lunatum (semilumar). 50. Os meta-

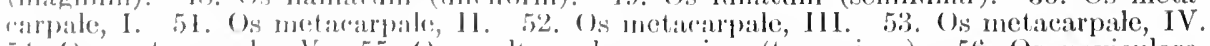
5. (1) metarapale, V. 5\%. () multanglum majus (trapegium). 56. Os naviculare.

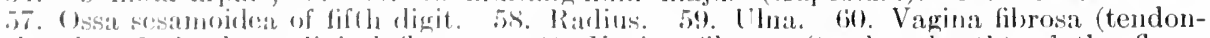

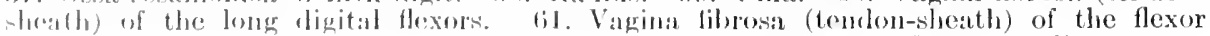

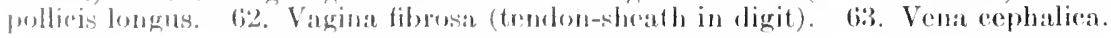



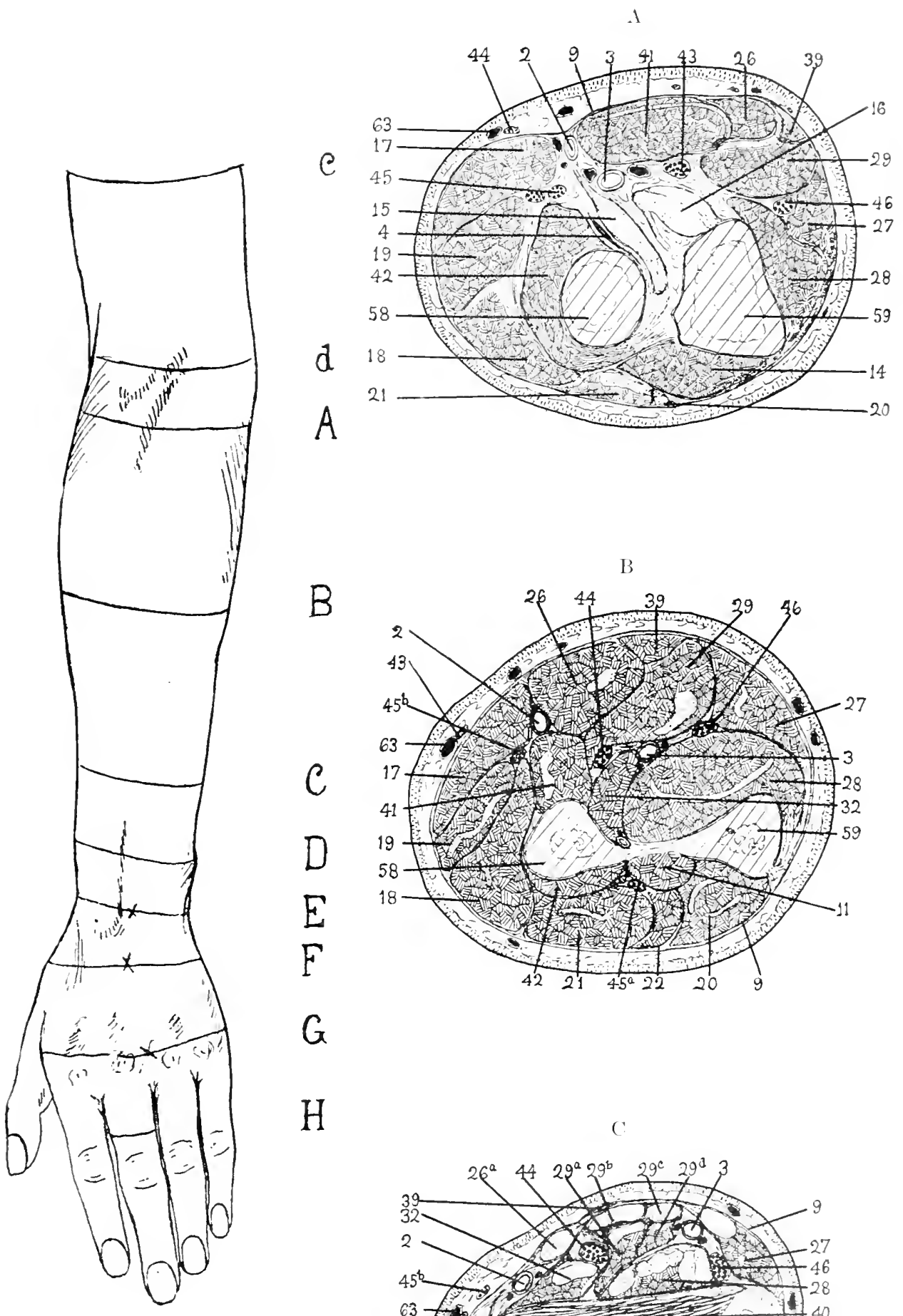

H

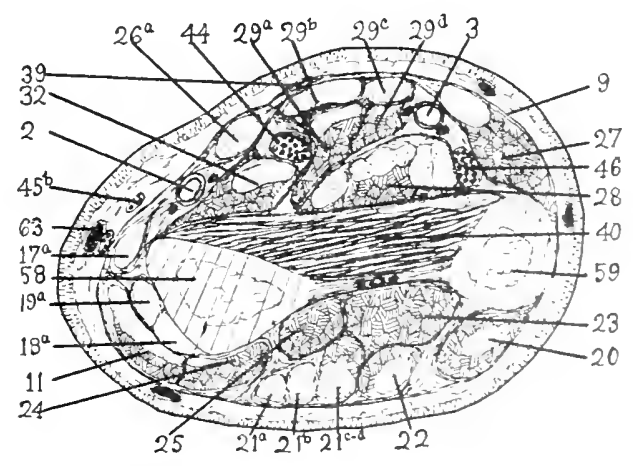


D

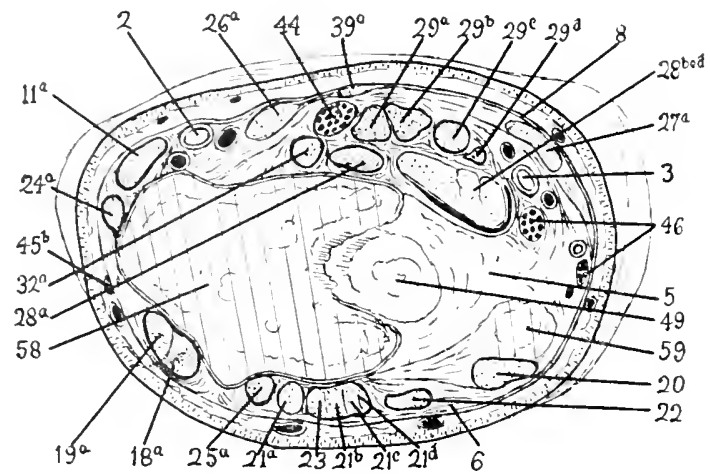

E)

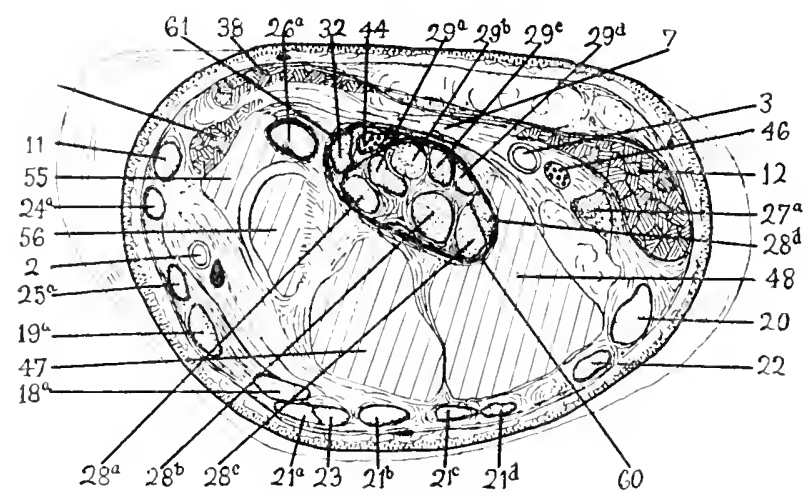

F

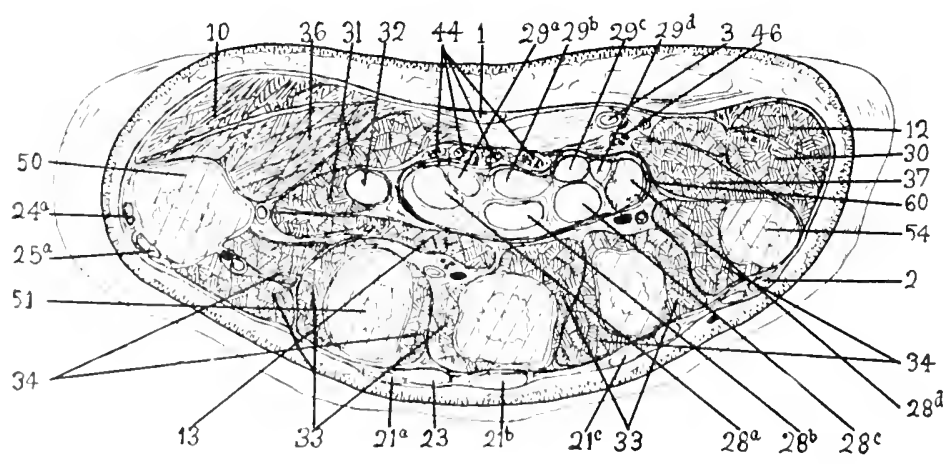

$(i$

H
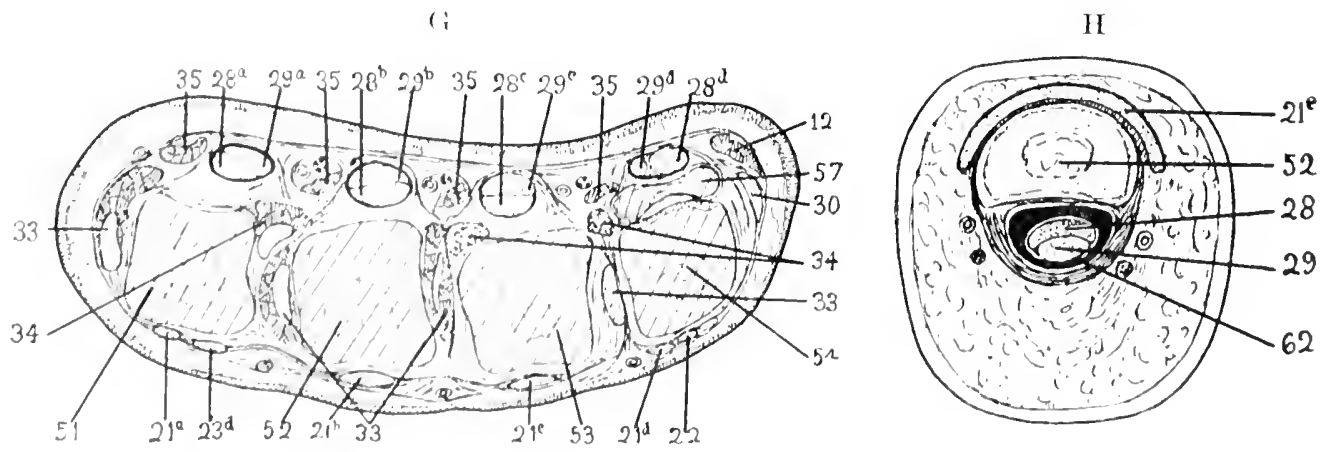
On the volar side of the forearm for some distance above the wrist the tendons of the flexor carpi radialis, the pahmaris longus, and the flexor carpi ulnaris run between two hyers of the fascia. The fascia is much strengthened at the wrist by transverse fibres which give rise to the volar ligament of the carpus. Beneath it lies the transverse ligament of the carpus (anterior annular ligament). This dense band is broader than the volar ligament but like it extends from the pisiform bone and the hamulus of the hamatum (unciform) to the tuberosity of the navicular and the tuberosity of the greater multangular (trapezium). It serves to complete an osteo-fibrous canal through which pass the flexor tendons of the fingers. Between the two ligaments which are partially fused with one another run the ulnar artery and nerve.

On the palm of the hand the ensheathing fascia presents three distinct areas a central, a lateral, and a medial.

The central portion, the palmar aponeurosis, is composed chiefly of bundles of fibrous tissue which radiate superficially toward the fingers from the tendon of the pahmaris longus or from a corresponding region of the forearm fascia when this muscle is absent. Between these bundles are others which arise from the transverse ligament. The deep surface of the fascia is composed of a thin incomplete layer of transverse fibres which continue the transverse fibres of the forearm fascia. Near the capitula of the metacarpals this layer becones much stronger and constitutes a ligamentous band (superficial transverse ligament of Poirier). Near the bases of the digits bundles of transverse fibres (fasciculi transversi) lie in the rebs of the fingers and constitute an incomplete transverse ligament separated by a distinct interval from the superficial transverse ligament.

From the palmar aponeurosis processes are sent in toward the deeper structures. Of these, the most important are those continued into a fibrous sheath which surrounds the space containing the long flexor tendons and the lumbrical nuscles. This deuse fibrous sheath is united by fibrous processes to the third, fourth, and fifth metacarpals. As the flexor tendons diverge and the ends of the metacarpals are approached, numerous processes descend from the pahnar aponeurosis to the transverse capitular ligament. These hold the tendons in place. (In the volar surface of the fingers the faseia serves to complete osteo-fibrous canals for the long flexor tendons. The ventral surface of the first and second phalanges of each finger is slightly grooved. The fascia is firmly united on each side to the margin of the groove, and over the groove forms a semicylindrical, strong, fibrous sheath, the vaginal ligament of the finger. This sheath is strengthened by transverse bands over the bases of the first and second phalanges (annular ligaments) and by cruciate bands over the shafts of the phalanges (cruciate ligaments). Over the interphalangeal joints the sheath is thin, but is strengthened by rrucial bands which permit of freedom of motion.

The thenar fascia is a thin membrane covering the short muscles of the thumb. It is continued above into the fascia of the forearm, medially is fused with the tendon of the palmaris longus and the palmar aponeurosis, and extends as a septum to be attached to the third metacarpal. Laterally it is attached to the first metaearpal and is continted into the lorsal fascia of the hand. It is fused with an aponeurosis from the tendon of the abductor pollicis longus. Distally it is continued into the vaginal ligament of the long flexor of the thumb. Superficially it is closely adherent to the skin.

The hypothenar fascia invests the palmar museles of the little finger. It is continued from the ulnar margin of the fifth metacarpal over the muscles of the little finger to the palmar aponeurosis, and, by means of a septum, to the radial side of the fifth metacarpal. Proximally, it is attached to the hamatum (unciform) and extends into the fascia of the forearm, distally, it extends into the vaginal ligament of the tendon of the fifth cligit.

A deeply seated suprametacarpal fascial layer, or deep palmar fascia, covers the interosseous muscles and is attached to the volar surface of the metararpal bones.

In addition to the fascix mentioner, intermuscular septa serve to separate m re or less completely the various intrinsie muscles of the hand.

\section{MLSCLES}

\section{Rado-Dorsal Divismon}

The muscles of this group lie in two chief layers, a superficial and a decp.

\section{a. SUUPerfichal LaYer}

(Figs. 367, 370, 371)

The muscles of this layer, elosely associated at their origins, extent from the radial side of the distal end of the humerus to the distal extremity of the ralius. the carpus, and the fingers. They are elivisible into a radial, an intermediate. and an ulnar set.

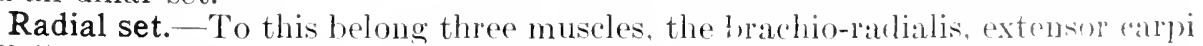
radialis longus and brevis. The brachio-radialis (fig. 370), a forearm Hexor, is it superficial fusiform musele which arises from the lateral ppicondylar rielge of the humerus and is inserted into the base of the styloid process of the ratius. The extensor carpi radialis longus (fig. 371) is a nurrow, fusiform muscle which extends 
along the radial margin of the forearm, partly under cover of the brachio-radialis. It arises from the lateral epicondylar ridge of the humerus, and is inserted into the second metacarpal bone. The extensor carpi radialis brevis (fig. 367) is a band-like muscle more dorsally placed than the last at the radial side of the arm. It arises from the lateral epicondyle and is inserted into the bases of the second and third metacarpals. These muscles are supplied by branches of the radial nerve which arise proximal to the passage of the deep radial (posterior interosseous) through the supinator muscle. Distally this set of muscles is separated from the intermediate set by the long abductor and the extensors of the thumb, which pass from an origin under the latter set over the tendons of the radial extensors to the thumb.

The intermediate set.-This consists of the thick, flattened extensor digitorum communis and the slender extensor digiti quinti proprius (fig. 367). They arise from the lateral epicondyle, and are inserted into the backs of the fingers.

The ulnar set consists of one muscle, the fusiform extensor carpi ulnaris, which arises from the lateral epicondyle of the humerus and is inserted into the back of the base of the fifth metacarpal.

The intermediate and ulnar sets of muscles are supplied by branches from the ramus profundus of the radial nerve after this has passed through the supinator muscle.

In the leg the lateral set of the superficial layer is represented by the tibialis anterior. The intermediate set is represented by the long extensors of the toes. The single muscle which constitutes the medial set is represented by the peroneal muscles.

The brachio-radialis (supinator radii longus) (figs. 367, 370).-Origin.-From the upper two-thirds of the lateral epicondylar ridge of the humerus and from the front of the lateral int ermuscular septum.

Insertion.-Into the lateral sile of the base of the styloid process of the radius.

structure.-The constituent fibre-bundtes arise directly from the septum and by short tendinous bands from the epicondylar ridge, extend downward and ventralty, and terminate in al penniform manner on a tendon which extends high on the deep surface of the muscle. This tendon becomes free about the mildle of the forearm as a broal, flat band. This be(")mes narrow as the tendon winds about the radius from the volar to the lateral surface. Before its insertion it expands laterally and is connected with neighbouring ligaments. The free sirface of the muscle faces laterally at its origin, but, owing to the torsion, ventrally in the forcarm. The tendon, however, is turned again so that at the insertion it faces laterally once yilu'e.

Nerre-supply.-From a branch of the radial nerve (musculo-spiral) which enters the proximal third of the muscle on its deep surface. The nerve fibres arise from the fifth and sixth cervical nerves.

Action.-To flex the forearm. This action is strongest when the forearm is pronated. It acts as a supinator onty when the arm is extended and pronated. It then serves to put the alm in is state of semi-promation. When the forearm is flexed, it acts as a pronator.

Relations. - The muscle is superficially placed on the ventro-lateral surface of the forearm. Its tendon of insertion, however, is covered by the long abductor and the short extensor of the thumb. Near its origin (fig. 367) it lies lateral to the brachialis. In the intervening tissue run the radial nerve and the terminal branch of the profunda brachii artery. Dorsally and laterally line the medial head of the trieeps. More distally the muscle overlies the extensor carpi radialis longus. It rrosses the supinator, pronator teres, and flexor pollicis longus muscles. Beneath its medial edge lie the randial vessels and nerve.

I'teriations.-The humeral origin maty extend half-way up the shaft. The radial insertion may be as high ts the middle of the shiff or descend to the lesser multangular, navicular, or third metarcarpal. In ahout 7 per cent. of bodles (Le Double) the tendon of insertion clivides into two or three slips which are inserted on the styloid process of the radius. Oeenasionally the ratlial nerve passes between these slips. An aceessory stip may pass to the fascia of the forearm. The muscle may be doubled thronghout its length and it may be missing. It may be

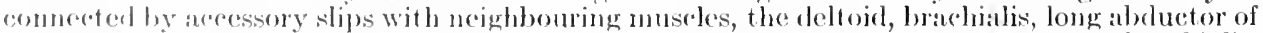
the thumbl, ir hong ranlial cearpal extensor. The slip most frectuently found goes to the brachialis.

The extensor carpi radialis longus (figs. $367,368,371$.) - Origin.-From the lower third of the lateral epiomblyar ridge, the laterat intermuscular septum, and from the front of the tendons of the extensor rarpi radialis brevis and the extensor communis digitorum which arise from the lateral epicondyle.

siructure and insertion.- The fibre-bundles are inserted in a penniform manner on both

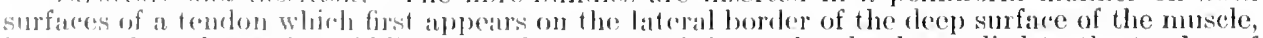
becomes free atrove the midrle of the forearm, ind deseends, chesely applied to the tendon of the short radial carpal extensor, to the second compartment beneath the dorsal carpal ligament, throngh whinh it patseses lo its insertion into the base of the seeond metararpal near the radial berrler. The guter surface of the muscte faces at first laterally, then ventrally.

Nirer-supply. - lay one on two brandhes which arise from the radial (musculo-spiral) nerve as it patses betwern the brardialis and hrachion-radialis. 'The nerve enters the deep surfare of the: muscle in the proximal third. 'The nerve filmes arrise from the (fifth), sixth and seventh areviral nerves.

Antime - To extend and abluet the hand. It steadies the wrist when the flexors anct on 
the fingers. It is a flexor of the forearm; a supinator when the forearm is extended, a pronator when it is flexed.

Relations.-It is covered by the brachio-radialis near the elbow. Below it becomes supuficial except where crossed by the tendons of the muscles of the thumb. (For the relations to the short radial carpal extensor see below.)

Fig. 367.-Muscles of the Radial Side and the Back of the Forearm.

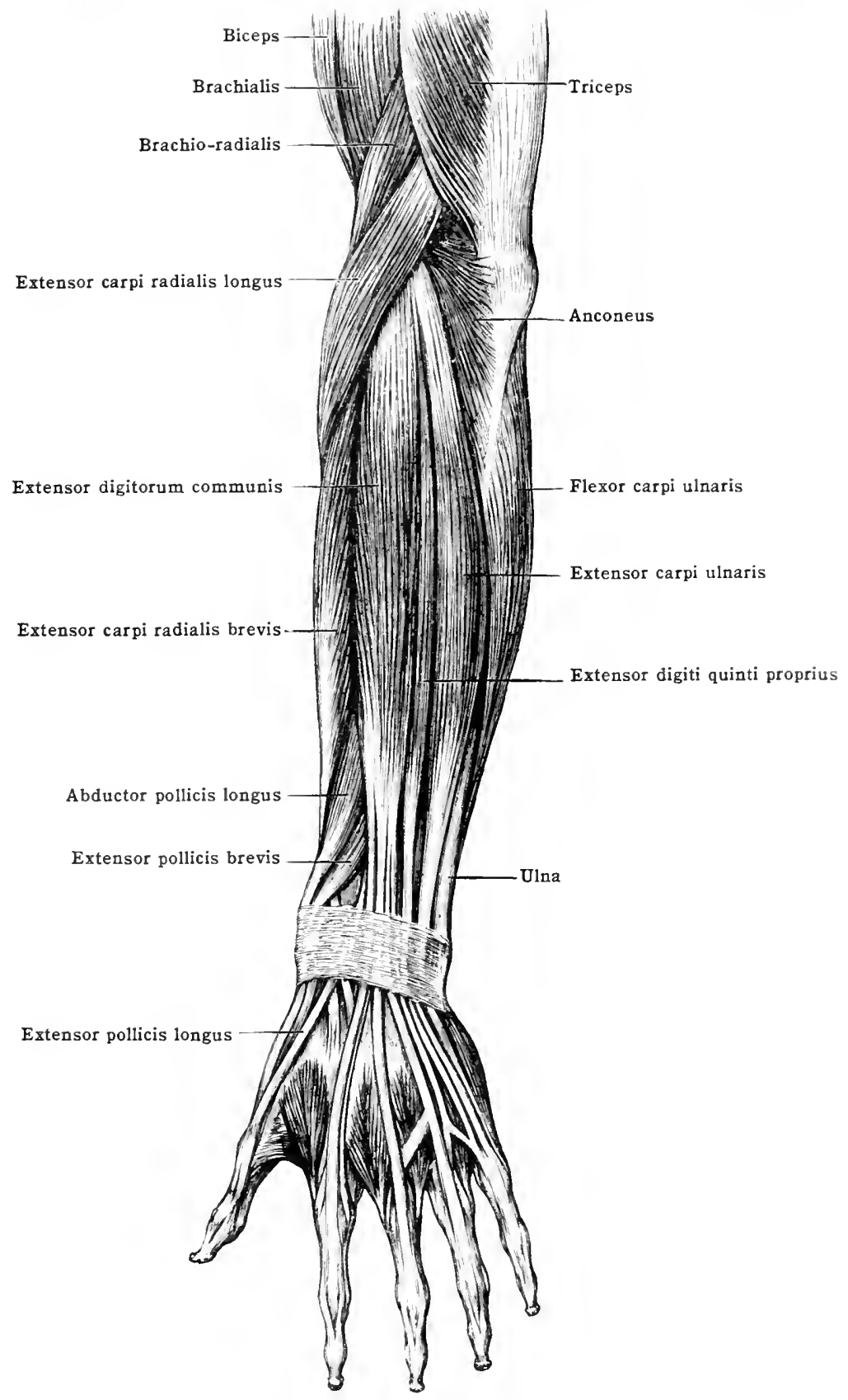

Variations.-The humeral attachment may be more extensive than that indicated above. The tendon of insertion may send a band to the third or to the fourth metacarpal or to the 11niltangulum majus (trapezium). The muscle may be fused, partly or completely, with the short radial extensor. It may send a slip to the abductor pollicis longus or to some of the interossei.

The extensor carpi radialis brevis (figs. 367, 368).-Origin.-From in band which clescends on its deep surface from the common extensor tendon attached to the lateral epicondyle, from the intermuscular septa surrounding its head, and from the radial collateral ligament of the elbow-joint. 
Structure and insertion. - The fibre-bundles converge obliquely toward a tendon which appears high up on the dorso-lateral surface of the muscle. Toward the lower third of the forearm this tendon becomes a free, strong band closely applied to the under surface of the tendon of the long radial extensor, and with this passes through the second compartment beneath the dorsal ligament of the carpus, diverging as it does so toward its insertion into the back of the bases of the second and third metacarpal bones.

Fig. 368.-Tendons upon the Dorsum of the Hand.

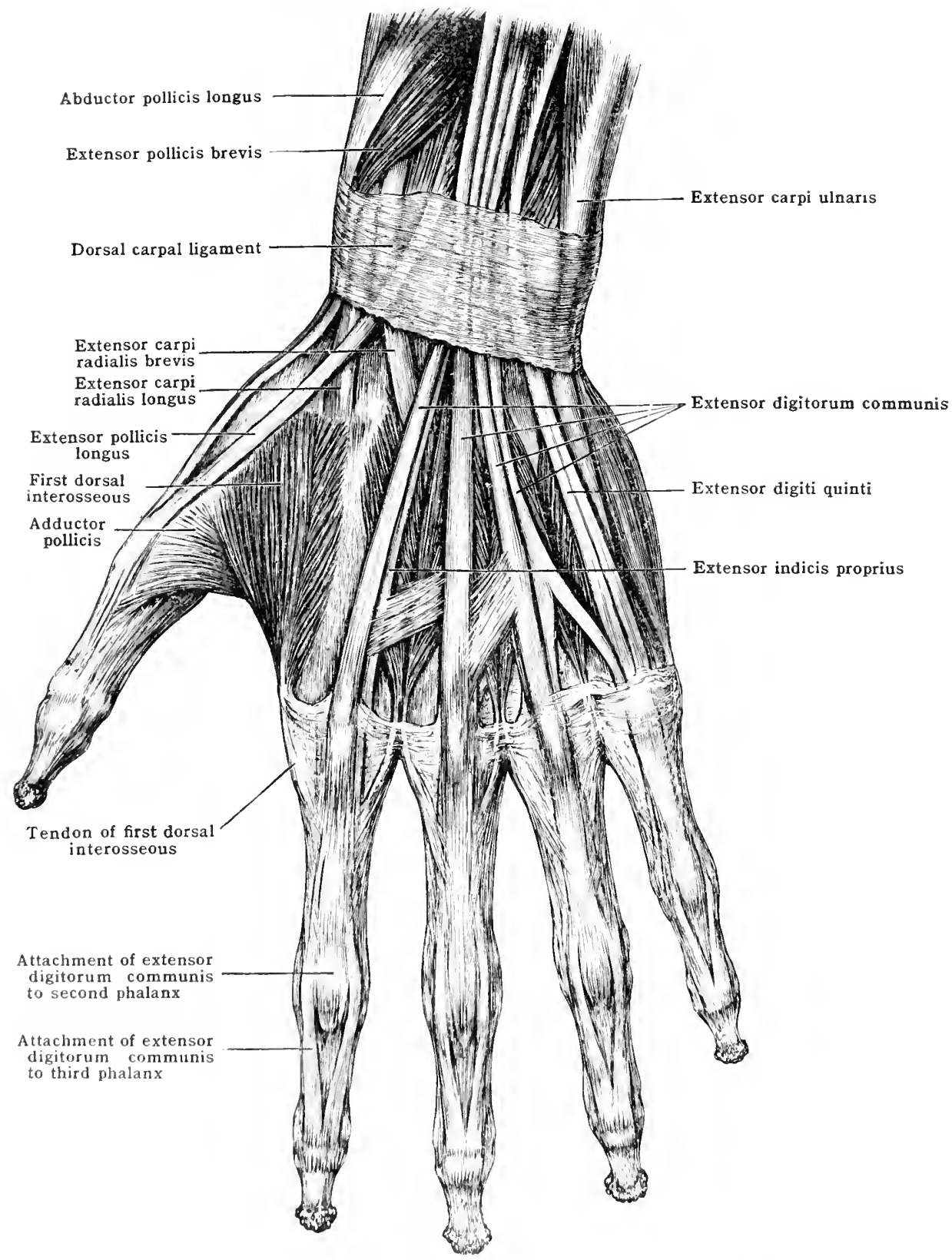

Cirr-supuly.- - A branch is supplicel to the musele from the deep radial (posterior interossenus) nerve hefore this enters the supinator (brevis). The branch enters the middle third of thr: mexlial margin of the muscle by savelal rami. The nerve filmes arise from the (fifth), sixth and seventh cervieal norves.

frlion.-'T'o extend the hand and, to in slight, extent, to flex the forearm.

lirlatims.-In its proximal portion the mmsele is placerl with a medial surface toward

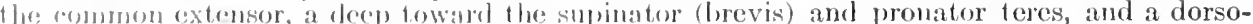
litteral towarl the long raslial extensor. More distally the muscle and its tendon become flattened about the radius and partly roverest hy the long radial extensor and its tendon. 
In the distal quarter of the forearm the tendons of these two muscles are crossed by the long abductor and the short extensor of the thumb. Beneath the dorsal carpal ligament the tendon of the short radial extensor is crossed by the tendon of the long extensor of the thumb.

Variations.-The tendon of ten sends no slip to the second metacarpal. Fusion of the two radial extensors is frequent. The fused muscle may have from one to four tendons. The extensor carpi radialis intermedius of Wood is a muscle which arises, rarely directly from the humerus, but not infrequently as a slip from one or both radial extensors. It is inserted into the second or third metacarpal bone or into both. The extensor carpi radialis accessorius is a muscle which has an origin like the extensor intermedius, but which terminates on the base of the metacarpal or first phalanx of the thumb, the short abductor of the thumb, or some neighbouring structure.

The extensor digitorum communis (figs. 367, 368).--Origin.-From a tendon attached to the lateral epicondyle, and from intermuscular septa which lie between the head of the muscle and the short radial extensor, the extensor of the little finger, and the supinator muscle.

Insertion.-By four tendons into the bases of the phalanges of the fingers.

Structure.-The fibre-bundles arise from the interior of the pyramidal case formed by the tendon, the fascia, and intermuscular septa, and pass distally to converge on four tendons which begin in the middle of the forearm, become free a little above the wrist, pass under the dorsal carpal ligament in a groove common to them and the tendon of the extensor indicis proprius, and diverge to the backs of the fingers. Opposite the metacarpo-phalangeal joint each tendon gives rise on its under surface to a band which becomes attached to the base of the first phalanx of its respective digit. The tendon is also closely bound to the joint by fibrous bands connected with the palmar fascia. On the dorsum of the first phalanx the tendon expands and is bound to an aponeurotic extension from the interosseous and lumbrical muscles. The tendon divides into three bands. The middle band passes to the base of the second phalanx, the lateral bands pass laterally around the joint to be inserted into the back of the base of the third phalanx. The lateral bands are bound to the second joint by a thin layer of transverse and oblique niores.

An obliquely transverse band usually passes from the tendon of the index to that of the middle finger above the heads of the metacarpals. The tendon to the index finger is united to the tendon of the extensor indicis proprius opposite the metacarpo-phalangeal articulation. The tendon to the ring finger usually sends a slip to join the tendon of the middle finger. The fourth tendon lies near that of the ring finger and divides into two slips, one of which joins the tendon of the ring finger and one goes to the little finger to join the tendon of the extensor digiti quinti proprius.

Nerve-supply.-From a branch which arises from the deep radial (posterior interosseous) nerve as it emerges from the supinator (brevis) muscle. From this several twigs enter the deep surface of the middle third of the belly. Often the nerve is bound up with the nerve to the extensor of the little finger and the ulnar extensor. On the other hand, there may be several separate branches to the muscle. The nerve fibres arise from the sixth, seventh, and eighth cervical nerves.

Action.-The muscle extends the two terminal phalanges on the basal, the basal on the metacarpus, and the hand at the wrist. The extensor action is strongest on the first phalanx. The cross-bands between the tendons hinder the independent extension of the middle and ring fingers, while the special extensors of the index and little fingers makes the movements of these fingers freer. When the hand is abducted toward the radial side, the extensor muscles tend to draw the fingers ulnarward. When the hand is abducted toward the ulnar side, the muscles tend to draw the fingers toward the thumb. When the hand is in the mid-position the ring finger and little finger are abducted and the index-finger is adducted. (Frohse.)

Relations.-It is superficially placed. Under it lie the deep muscles of the back of the forearm, the interosseous vessels, and the deep radial (posterior interosseous) nerve. It lies between the short radial carpal extensor and the extensor of the little finger.

Variations. - There is considerable variation in the extent of isolation of the parts going to the various fingers. That to the index-finger is the one most frequently isolated. At times the tendon to the index or little finger may be wanting. More frequently one or more of the tendons subdivides to be attached to two or more fingers or to the thumb. 'The connections between the tendons on the back of the hand vary greatly.

The extensor digiti quinti proprius (extensor minimi digiti) (figs. 367, 368).-Origin.Chiefly from the septum between it and the common extensor, but also in part from the septum between it and the extensor ulnaris and from the overlying fascia.

Structure and insertion.-The fibre-bundles descend in a narrow band which begins near the neck of the radius. They are inserted into the side of a tendon which begins high on the ulnar margin of the muscle. The most distal fibre-bundles extend nearly to the wrist-joint. The tendon passes through the fifth compartment beneath the dorsal carpal ligament, and extends on the back of the fifth metacarpal to the base of the first phalanx of the little finger, where it is joined by a slip from the fourth tendon of the common extensor. The insertion of the tendon is like that of the tendons of the common extensor.

Nerve-supply. - By a branch or branches from the deep radial (posterior interosseous) nerve. The nerve filaments enter the middle third of the fleshy portion of the muscle on its deep surface. The innervation of this muscle is intimately related to that of the preceding.

Action.-It acts as a portion of the common extensor, but, owing to its separation, independent movement of the little finger is possible.

Relations.- It lies between the common extensor and the ulnar extensor and upon the deep muscles of the back of the forearm.

Variations. - Absence is not very frequent; blending with the common extensor is frequent. Its tendon often divides into two or more slips. The belly may also be doubled. It may have a supplementary origin from the ulna. A tendon slip to the ring-finger is frequently found.

The extensor carpi ulnaris (figs. 367, 368).-Origin.-By two heads: one from the inferior dorsal portion of the epicondyle by an aponeurotic band attached below the tendon of the 
common extensor, from the enveloping fascia, and from the septa between it and the extensor digiti quinti, anconeus, and supinator (brevis); the other from the proximal three-fourths of the clorsal border of the ulna.

Structure and insertion.-The fibre-bundles descend in an osteo-faseial compartment bounded by the dorsal surface of the ulna, the fascia of the forearm, the dense fascia overtying the ulnar origin of the muscles of the thumb, and the origin of the extensor indicis. The tendon commences high in the muscle and appears on the radial border of the middle third of the back of its belly. The fibre-bundles are inserted in a penniform manner on the ulnar border and deep surface of the tendon as far as the wrist. Here the tendon enters the sixth osteo-fibrous eanal beneath the dorsal carpal ligament in a special groove on the outer side of the styloid process of the ulna. It is inserted int o the base of the fifth metacarpal.

Nerve-supply.-By a branch which arises from the deep radial (posterior interosseous) nerve as this emerges from the supinator (brevis) musele. Several filaments enter the deep surface of the muscle in the middle thirc. The nerve fibres arise from the sixth, seventh and eighth cervical nerves.

Action.-To extend and abduct the hand ulnarward.

Relations. - It occupies a superficial position on the ulnar sicle of the extensors of the forearm. Beneath it lie the deep muscles of the back of the forearm and the posterior surface of the ulna.

Tariations.-It mav receive a slip from the triceps or be fused with the anconeus or with the extensor of the little finger. More frequently it is doubled, partially or completely. An accessory tendon may go to the first phalanx of the little finger, to the head of the fifth metacarpal, to the fourth metacarpal, to the extensor tendon of the little finger, or to the fascia over the opponens digiti quinti. The muscle may be reduced to a fibrous band. The ulnaris digiti quinti is a rare muscle arising from the dorsal surface of the ulna and inserted into the base of the first phalanx of the little finger. It may be represented by a fasciculus or an extra tendon from the ulnar extensor.

\section{b. Deep Layer}

\section{(Fig. 369)}

The muscles of this group extend from the ulna to the radius, thumb, and indexfinger. They are the supinator, abductor pollicis longus, extensor pollicis longus and brevis, and extensor indicis proprius. The supinator is a rhomboid muscle which arises from the lateral epicondyle of the humerus and the supinator crest of the ulna winds laterally around the radius and is inserted into its volar surface. The abductor pollicis longus is a fusiform muscle which arises from the middle third of the ulna, the interosseous membrane, and the radius, and is inserted into the base of the first metacarpal. The extensor pollicis brevis arises from the radius distal to the preceding muscle, and is inserted into the base of the first phalanx of the thumb. The extensor pollicis longus is a narrow muscle which arises from the middle third of the dorsal surface of the ulna and is inserted into the base of the second phalanx of the thumb. The extensor indicis proprius is a narrow, fusiform muscle arising from the shaft of the ulna and inserted into the dorsal aponeurosis of the index-finger. These muscles are supplied from branches of the deep radial (posterior interosseous) nerve while this is passing through or after its exit from the supinator.

The extensor pollicis longus is represented by the extensor hallueis longus of the leg. The abductor pollicis longus and extensor pollicis brevis are represented by the alonormal abductor hallucis longus and extensor primi internodii hallueis museles, the rudinents of which are perhaps normally present in the tibialis anterior. The supinator and the extensor indieis muscles are not represented in the leg. On the other hand, the extensor digitorum brevis, normal in the foot, is only occasionally found on the back of the hand.

The supinator (brevis) (figs. 366, 369, 372). -Origin.-From (1) the inferior dorsal portion of the lateral epieondyle by a tentinous band which is adherent to the deep surface of the cendons of origin of the raclial and common extensors and to the raclial collateral ligament of the joint; and (2) the 11 ma by a superfirial aponeurosis and by fibre-bundles attaehed directly to the depression below the radial noteh aud to the supinator crest.

Insertion. - The lateral and volar surfaces of the raclius from the tuberosity to the attachment of the promater teres.

Structure. - From theil origin the filsre-buntles descend spirally in a muscular sheet whieh mwraps the radius (fig. 36it). The attachment extends to the obligue line. The muscle is dividral into a superficial and a decp plane by a septum in which the deep radial (posterios interoscous) nerve russ. 'The rudial attachments of these two portions are separated by an ossends arra into which no fibre-hundlos are inserted. The fibre-bundles of the superfieial layer have an Indeh mole verticial rourse and are longer than those of the deep layer.

Nervesupply.- liy hranches which atrise from the decp radial (josterior interosseous) nerve before it passes luet wern the two hayess of the supinator muscle. The nerve fibres arise frem the fifth, sixth, and seventh ervient nerves.

Artion.-Tos supinate the forearm.

folations.- The supinator is covered by the superticial group of extensor museles above deseribed and by the anomeus. 
I Variations. - The extent of separation of the museles into two portions varies. Accencry fasciculi of origin are not uncommon. These may spring from the annular ligament, tensor ligamenti annularis anterior ( 5 per cent. or more of bodies-Le Double), the lateral epicondyle, the tendon of the biceps, the tuberosity of the radius, etc. A sesamoid bone may lie in the tendon of origin. The tensor ligamenti annularis posterior is a slip generally present and of ten independent of the supinator. It runs from the ulna behind the radial not ch to the innular ligament of the radio-ulnar joint.

The abductor pollicis longus (extensor ossis metacarpi pollicis) (fig. 369), - Origin.-From (1) the lateral margin of the dorsal surface of the ulna in the proximal portion of the middle third,

Fig. 369.-The Deep Muscles of the Back of the Forearm.

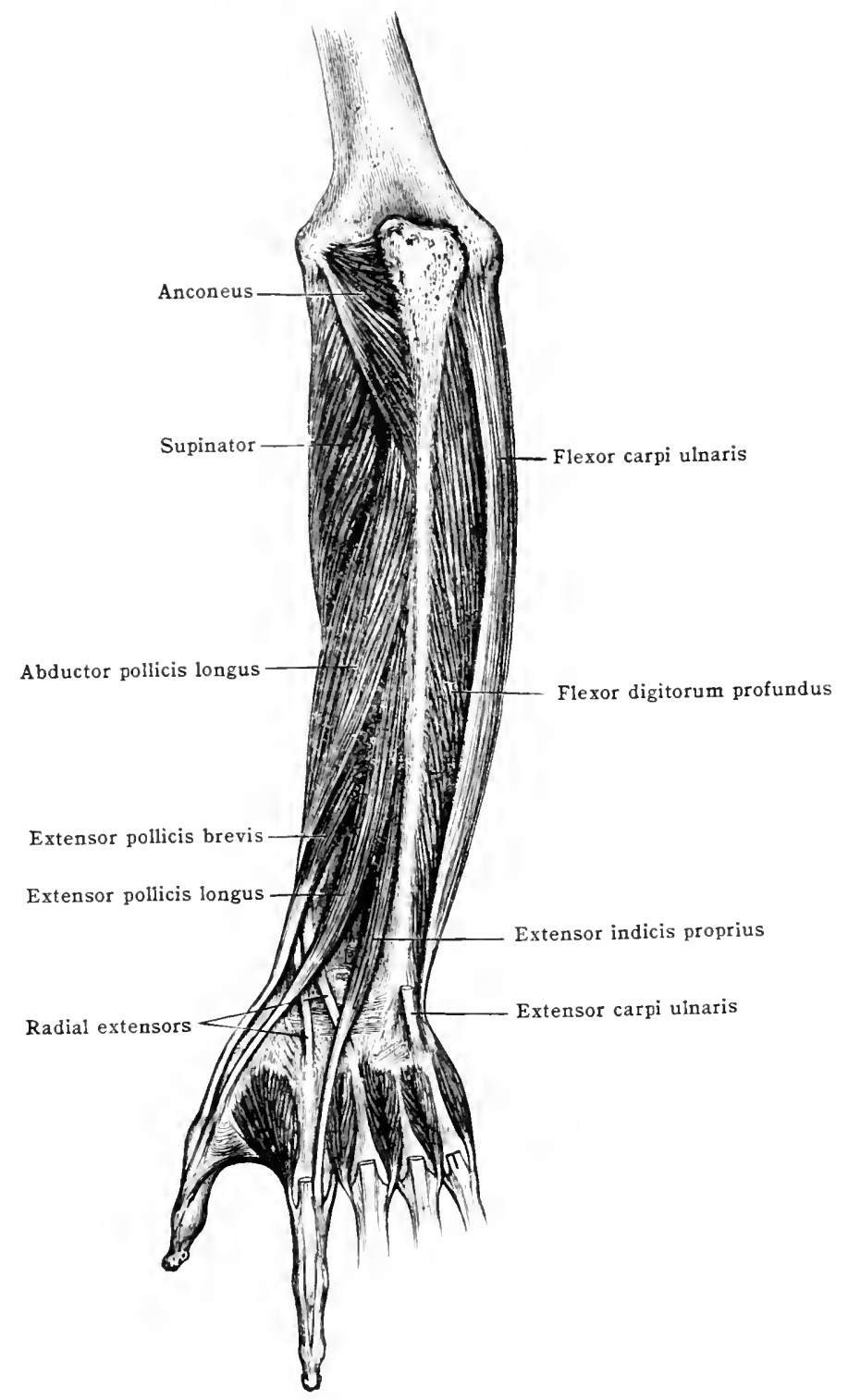

and the adjacent interosseous membrane, (2) the dorsal surface of the radius distal and medial to the attachment of the supinator, and (3) at times, from the septa lying between it and the supinator, extensor carpi ulnaris, and extensor pollicis longus.

Structure and insertion. - The fibre-bundles from this extensive area of origin converge in a bipenniform manner upon a tendon which appears as an aponeurosis on the leep surface of the muscle about the middle of the forearm. The tendon as it descenils becomes rounded. The insertion of fibre-bundles continues nearly to the wrist. Here, together with the tendon of the short extensor, it enters the first osteo-fibrous canal beneath the dorsal carpal ligament upon the lateral surface of the distal extremity of the radius. Upon leaving this canal the tendon extends to be inserted on the radial side of the base of the first metacarpal bone.

Nerve-supply. - By one or more branches from the deep radial (posterior interosseous) nerve 
after it has emerged from the supinator. The branches enter the muscle on the superficial surface in the proximal third. The nerve fibres come from the sixth, seventh (and eighth) cervical nerves.

Action.-It carries the first metacarpal radialward and forward. At the height of its contraction it flexes and abducts the hand at the wrist.

Relations.- Near its origin the muscle is covered by the superficial extensors of the forearm. More distally, accompanied by the short extensor, it passes radially, becomes superficial, and crosses the tendons of the two radial carpal extensors.

I'ariations. - The muscle or its tendon may be doubled. An accessory tendon may be applied to the multangulum majus (trapezium), the transverse ligament of the carpus, the superficial muscles of the thenar eminence, or the first metacarpal. Of these, the attachment to the short abductor and short flexor is the most frequent ( 7 out of 36 bodies-Wood). There may be three or more tendons. The musele may be fused with the short extensor.

The extensor pollicis brevis (fig. 369).-Origin.-From the distal part of the middle third of the medial portion of the dorsal surface of the radius and from the neighbouring portion of the interosseous membrane. Rarely its origin extends to the ulna.

Structure and insertion. - The fibre-bundles converge on a tendon which appears on the radial border. The fibres are inserted as far as the dorsal carpal (posterior annular) ligament. The tendon lies parallel to the ulnar side of that of the abductor pollicis longus, and, in close connection with it, passes through the first eompartment beneath the dorsal carpal ligament, and crosses the metacarpo-phalangeal joint on the radial side of the long extensor tendon. It is inserted on the base of the first phalanx of the thumb or into the capsule of the metacarpophalangeal joint.

Nerie-supply.-From a branch derived from the deep radial (posterior interosseous) nerve. This branch is usually given off in common with or near the nerve to the abductor pollicis longus, and many traverse that muscle to reach the extensor pollicis brevis, whieh it enters in the proximal third of its radial border. The nerve fibres come from the sixth, seventh (and eighth) cervical nerves.

Action.-To extend the thumb at the metacarpo-phalangeal joint and to abduct the first metacarpal. It likewise acts as a weak supinator of the forearm.

Relations.- It lies between the abductor pollicis longus and the extensor pollicis longus, by which its origin is partly overlapped. In company with the former musele it passes medially from beneath the common extensor of the fingers and over the tendons of the radial carpal extensors to reach its osteo-fibrous canal under the dorsal carpal ligament.

Variations.-The head of the musele may be fused with the long abductor. Its tendon of insertion may give rise to a slip inserted on the first metacarpal (in 2 out of 85 bodies-Le Double) or into the terminal phalanx. Its tendon is of ten united with that of the long extensor. It may be fused with the long abductor of the thumb and has been found missing. It may be doublèd.

The extensor pollicis longus (fig. 369).-Origin.-From the middle third of the lateral part of the dorsal surface of the ulna; from the neighbouring part of the interosseous membrane; and from the septa between it and the extensor indicis proprius, and the extensor carpi ulnaris.

structure and insertion. - The fibre-bundles converge in a bipenniform manner on the two sides of a tendon which appears high on the dorsal surface of the musele. They extend as far as the dorsal carpal (posterior annular) ligament. The fusiform body of the muscle descends somewhat obliquely on the dorsal surface of the forearm. The tendon enters the third osteofibrous canal beneath the dorsal carpal (posterior annular) ligament. On emerging from the canal it passes very obliquely across the dorsal surface of the carpus, over the tendons of the radial extensors, to the ulnar side of the first metacarpal. It passes along this and on the lorsal surface of the first phalanx, expands to be inserted into the base of the second phalanx. The aponemrosis of insertion receives tendinous slips from the short muscles of the volar surface of the thismb.

Lirm-supply.-By a twig from the deep radial (posterior interosseous) nerve. The braneh gives rise to twigs which enter the proximal third of the radial border of the musele. The fibres arise from the sixth, seventh, and eighth cervical nerves.

Action. - To extend the second phalanx on the first, and this on the metacarpal. . It also draws the whole thumb when extended toward the seeond metacarpal. It may have a slight sipinat or action on the forearm.

Relutions.- The head of the innsele is partly overlapped by the long abductor of the thumb. It lies between this and the extensor pollicis brevis on one side, and the extensor indicis proprius () n the other. Over it lie the extensors of the fingers and the ulnar carpal extensor.

Fariations.-.'The tenclon may give a slip to the base of the first phalanx of the thumb, (1) the dorsil carpal ligunent, or to the index linger. It may receive an accessory slip from the "ommon extensor of the fingers or the short extensor of the thumb. It is frequently! doubled. In arditional atomsor is foumd in about ti per cent. of bodies between the extensorf of the index finger and that of the thumb. It has a rouble tendon and insertion into both digits (extensor communis pollicis et indicis).

The extensor indicis proprius (fig. 369).-Origin.- From the proximal part of the distal thirel of the posterior surface of the ana, medial and thistal to that of the preceding musele, from the adjarent juterosseous mombrane, and from the septum between it and the extensor pollieis longus.

Siruchure and insertion. The filse-bundles are inserted on a tendon which first appears on the rachal horder of the muscla. The: insertion of fibre-bundles extemds nearly to the dorsal "arpal (posterior anrular) ligancont. IJore the tendon passes beneath that of the extensor of the littlo finger aud enters the fourth ostoofibroms anal beneath the lateral tendons of the common extensor. It passes across the wrist heneath the tendon from the exterisor communis to the indrex finger, and is inserted on the uhar side of this into the dorsal aponeurosis of the inder finger opposite the base of the first phalanx. 
Nerve-supply.-By a twig from the deep radial (posterior interosseous) nerve. This twig enters the proximal third of the radial border of the muscle. It frequently arises from a branch to the extensor pollicis longus. The nerve fibres come from the sixth, seventh, eighth cervical nerves.

Action.-To extend the first phalanx on the metacarpal. Like the common extensor it has a limited action on the two terminal phalanges. It also adducts the index finger and is a weak supinator of the forearm.

Relations. - It is covered by the superficial extensor group.

Variations.-These are frequent. It may be absent. There may be two heads, or the muscle may be completely doubled. It may receive an accessory slip from the ulna or the carpus. The tendon may give accessory slips to the middle finger, the ring finger, or the thumb. The accessory tendon to the middle finger is the most frequent. The tendon to the index finger may be inserted on the metacarpus.

\section{Abnormal Muscles of the Back of the Wrist and Hand}

The extensor medii digiti is a small muscle which arises from the ulna beneath the extensor of the index finger, with which it is more or less fused. It sends a tendon to the extensor aponeurosis of the middle finger or slips both to this finger and the index finger. It is present in about 10 per cent. of bodies (Le Double).

The extensor digiti annularis is a muscle similar to the extensor medii digiti, but much rarer.

The extensor digitorum brevis, which resembles the muscle of corresponding name on the dorsum of the foot, may have from one to four fasciculi, but most frequently one. The most common fasciculus is one which sends a tendon to the extensor tendon of the index finger. One for the middle finger is nearly as frequent. Others are rare. A fasciculus for the thumb has not been reported. (Le Double.) The fasciculi usually arise from the bones of the ulnar half of the carpus-lunatum (semilunar), triquetrum (cuneiform), hamatum (uneiform), and capitatum (magnum), and from the dorsal ligaments uniting these bones. The tendons are inserted either into the corresponding extensor tendons or into the metacarpals. The muscle is found in about 10 per cent. of bodies (Wood).

\section{BURSE}

B. $m$. extensoris carpi radialis brevis.-Between the tendon and the base of the third metacarpal.

B. m. abductoris pollicis longi.--Between the tendons of the long and short radial extensors and the tendons of the abductor pollicis longus and extensor pollicis brevis. Another bursa lies beneath the tendon of insertion of the abductor.

B. intermetacarpo-phalangeæ.-Between the lateral surfaces of the heads of the metaearpal bones of neighbouring fingers dorsal to the transverse capitular ligament.

B. tendinum $\mathrm{m}$. extensoris digitorum communis.--Small bursa are sometimes found beneath the tendons to the index and little fingers near where they begin to diverge from the common tendon.

B. $m$. extensoris carpi ulnaris. - A small bursa may be found under the tendon of origin of this muscle.

B. m. supinatoris.-Between the supinator and the tendon of the extensor muscles.

B. m. extensoris pollicis longi.-Between the tendon and the first metacarpal.

\section{Synovial Tendon-sheaths}

Vagina tendinum mm. extensorum carpi radialium.-Synovial sheaths cover the tendons of the two radial carpal extensors as they pass beneath the dorsal carpal (posterior annular) ligament. In the adult these sheaths usually are more or less fused and communicate with the sheath of the extensor pollicis longus where this crosses them.

Vagina tendinum mm. extensol is digitorum communis et extensoris indicis.-A synovial sheath surrounds the tendons of these muscles as they pass beneath the dorsal carpal (posterior annular) ligament. This sheath extends for some distance on the tendons as they diverge.

Vagina tendinis $m$. extensoris digiti quinti. - A synovial sheath extends on the tendon of this muscle from above the dorsal carpal (posterior annular) ligament to the base of the metacarpal.

Vagina tendinis $\mathrm{m}$. extensoris carpi ulnaris.-This sheath commences above the carpal (posterior annular) ligament and extends to the insertion of the tendon.

Vagina tendinum mm. abductoris pollicis longi et extensoris pollicis brevis.-The sheaths which surround these two tendons beneath the dorsal carpal (posterior annular) ligament usually communicate freely.

Vagina tendinis $\mathrm{m}$. extensolis pollicis longi.-A long synovial sheath surrounds this tendon. Where it crosses the tendons of the radial extensors, a communication is found with the sheath of the latter.

\section{Ulno-Volar Division}

The muscles on the volar side of the forearm lie in four layers.

\section{a. First Layer}

(Fig. 370)

Of the four muscles of associated ulnar epicondylar origin which constitute this layer the pronator teres is a strong, band-like muscle which is inserted into 
the lateral surface of the middle third of the shaft of the radius; the fusiform flexor carpi radialis sends a tendon to the base of the second metacarpal; the slender palmaris longus is inserted into the palmar fascia; and the medially situated, fusiform flexor carpi ulnaris into the pisiform bone and the palmar fascia. The pronator teres is the most powerful pronator of the forearm. When

Fig. 370.-Front of the Forearm: First Layer of Muscles.

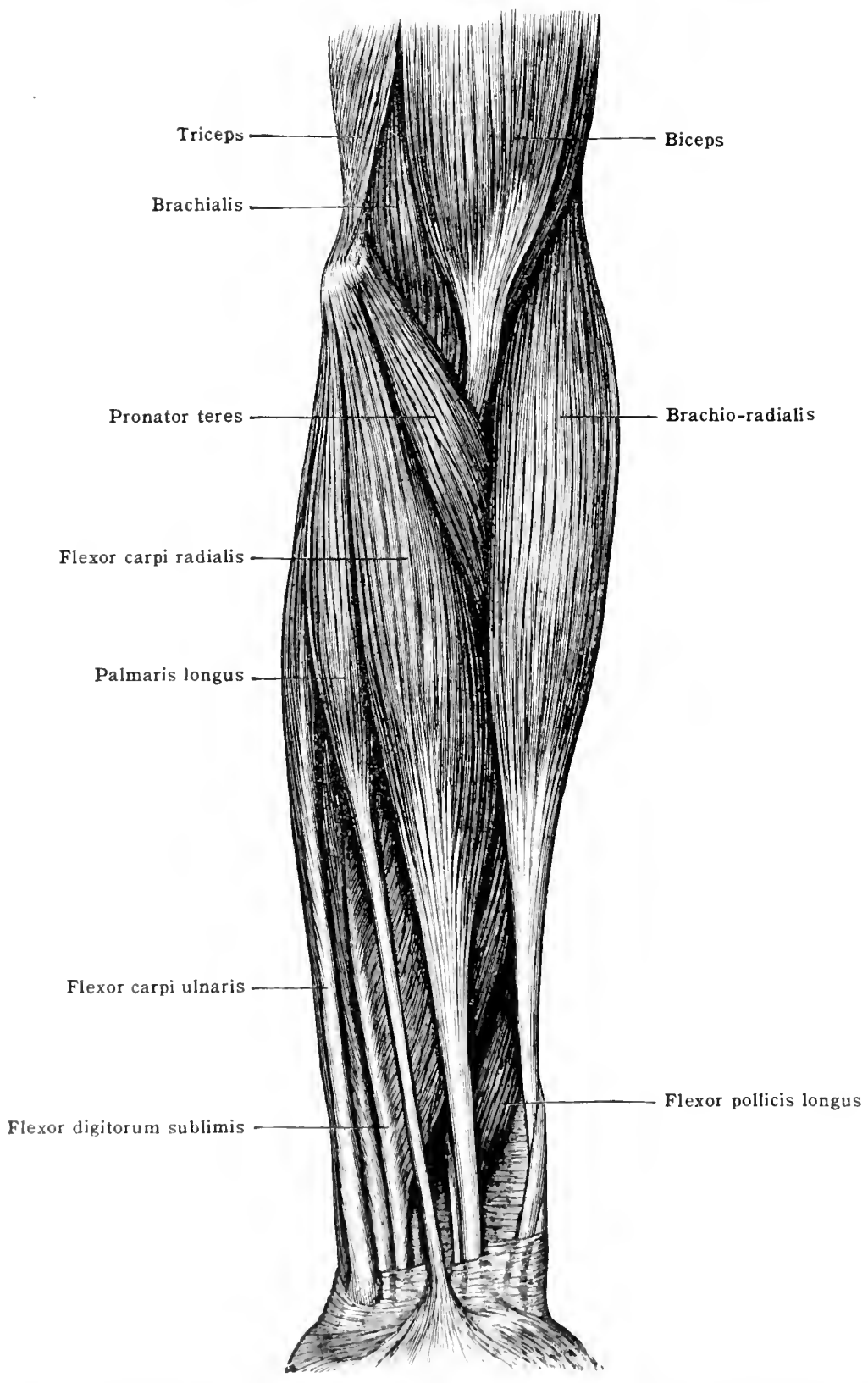

the hand is slightly flexed the nhar carpal flexor abducts ulnarward. When the hand is greatly flexed lateral movement is diflicult. 'The ulnar flexor is supplied by the ulnar nerve, the other muscles by the median.

'The pronator teres probahly compesends with the popliteus of the leg. The flexor carpi

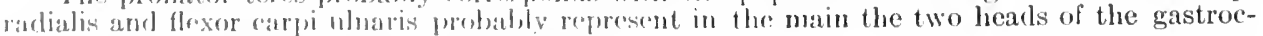
urmins, and the palmatris longus, the plantaris.

The pronator teres (fig. 370), (rigin.-13y two heads:-(1) The humeral or chief heart arises loy a tomfon from the smperior half of the ventral surface of the medial epieondyle and directly from tho overlyong fascia and from the jutermusular sopta between it and the medial 
head of the triceps and the flexor carpi radialis. (2) The ulnar, deep or accessory, head arises by an aponeurotic band attached to the inmer border of the coronoid process medial to the tendon of the brachialis. Between the humeral and ulnar heads is a fibrous arch beneath which the median nerve passes.

Structure and insertion.- The fibre-bundles of the humeral head are inserted in a penniform manner on a tendon which begins near the midile of the belly of the muscle on the superficial

Fig. 371.-Front of the Foreari: Second Layer of Mescles.

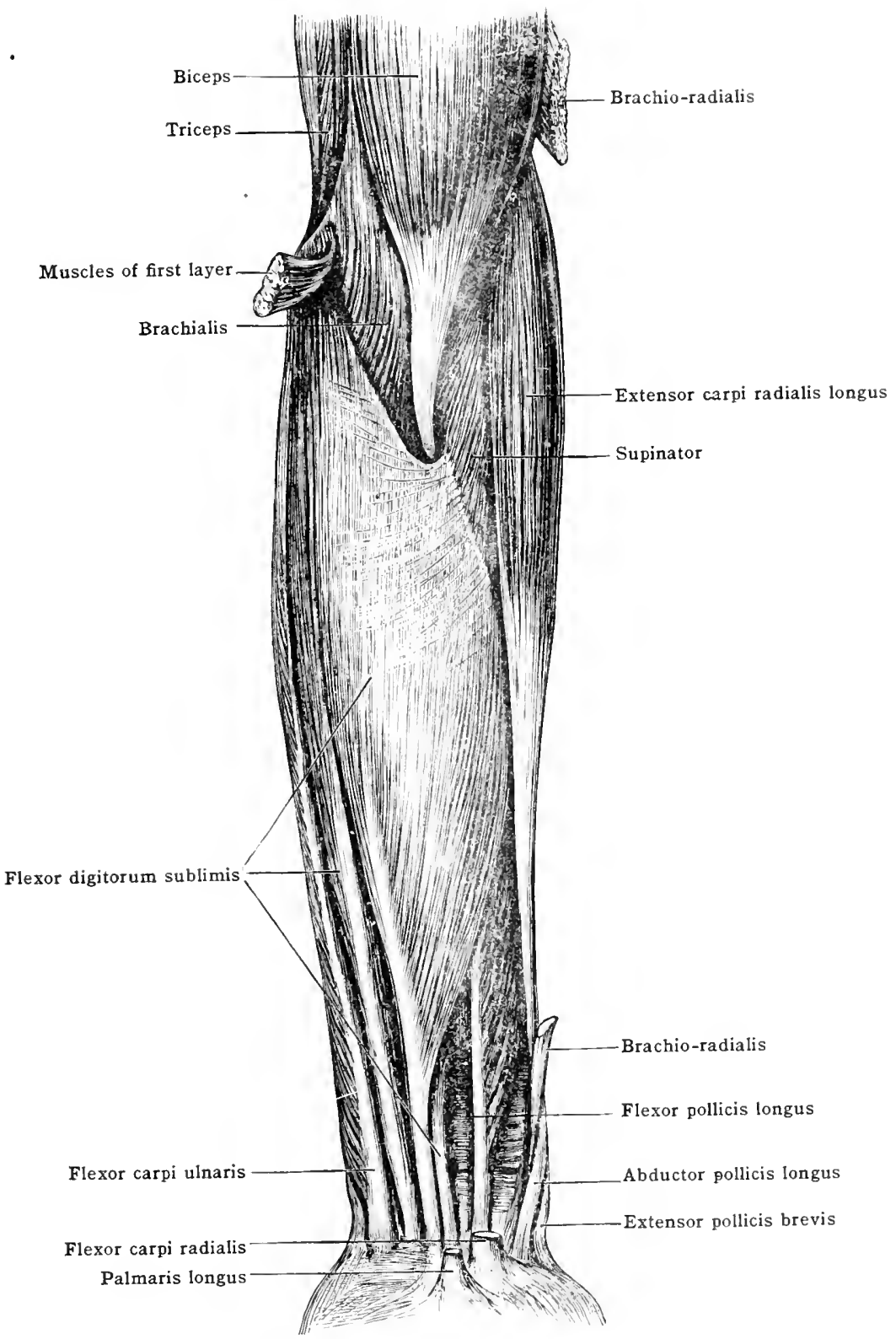

surface along the radial border. The tendon gradually hecomes broader, winds about the rolar surface of the radius, and is insertect into the niddle third of its lateral surface. The attach列 form a slender fasciculus which is inserted into the radial side of the deep surface of the humeral head.

Nerve-supply.-By a branch derived from the median nerve before it passes between the two heads of the muscle. The nerve enters the proximal part of the middle third of the main belly of the muscle on its deep surface near the radial border. The branch to the ulnar head usually enters this portion of the muscle somewhat proximal to its fusion with the humeral head. The nerve fibres arise from the sixth and seventh cervical nerves.

Action.-To pronate and flex the forearm. 
Relations.-The muscle is superficially placed. Near its origin it is covered by the lacertus fibrosus of the biceps, and near its insertion by the radial vessels and nerve and the brachioradialis and radial extensor muscles. It is the most radial of the group of muscles under consideration. The radial border helps to bound an angular space, the cubital fossa, in which lie the brachial vessels, median nerve, and the tendon of the biceps. The median nerve passes between its humeral and ulnar heads. The muscle overlies the supinator, the brachialis, and the radial origin of the flexor digitorum sublimis muscles and the ulnar artery.

Variations. - Supplementary fascieuli may arise from the humerus, the medial intermuscular septum of the arm, the flexor carpi radialis, the flexor sublimis, or the brachialis muscles. The two portions of the muscle may be distinct from origin to insertion. Either part of the muscle may be doubled. 'The ulnar head may be absent. The radial insertion may be extensive. Fasciculi may extend to the long flexor of the thumb. There may be a sesamoid bone in the tendon of origin from the bumerus.

The flexor carpi radialis (fig. 370).-Origin.-From (1) the common tendon attached to the medial epicondyle; and (2) the septa between its head and the pronator teres, the flexor sublimis, and the palmaris longus.

Structure and insertion.- The fibre-bundles descend to converge upon a tendon at first intramuscular, but which in the middle of the arm appears on the volar surface of the muscle and soon becomes free from the attachment of fibre-bundles. The fibre-bundles from the epicondyle descend nearly vertically to the front and sides of the tendon, while those from the intermuscular septa take an oblique course to the deep surface of the tendon. The tendon is at first flat, but soon becomes crlindrical, bound to the superficial muscle fascia, and enters the hand through a special osteo-fibrous canal formed mainly by the groove in the os multangulum majus (trapezium) and the transverse carpal (anterior anmular) ligament. It is inserted into the base of the second metacarpal. It usually also sends a tendon slip to the third.

Veresupply. - By a branch from the median nerve which divides into several twigs that enter the muscle near the junction of its proximal and middle thirds on the deep surface. The nerve usually arises near the elbow. The nerve fibres arise from the sixth, seventh (and eighth) cervical nerves.

Action.-To flex the hand at the wrist. To a slight extent it may also act as a pronator of the forcarm and a flexor of the forearm on the arm.

Relations.- It is superficial except near its insertion. The belly of the muscle lies between the pronator teres and the palmaris longus and upon the flexor digitorum sublimis. The tendon of the muscle passes over the flexor pollicis longus, and near the wrist is a guide to the radial artery, which here lies lateral to it. In the hand the tendon lies beneath the thenar muscles and is crossed by the tendon of the long flexor of the thumb.

rariations. - It may receive a fasciculus from the brachialis or biceps muscles or from the ranlius or ulna. It may send tendon slips to the multangulum majus (trapezium), navicular, the transverse carpal (anterior annular) ligament, or the fourth metacarpal. The insertion mar take place viriously into these structures.

The palmaris longus (fig. 370).-Origin.-From the common tendon attached to the medial epicondyle and from the surrounding intermuscular septa.

Structure and insertion. - The fibre-bundles take a nearly parallel course to a tendon which appears high in the midtlle thind of the forearm on the volar surface of the muscle. In the middle of the forcarm the attachment of fibre-bundles usually ceases, the tendon becomes bound to the overtying fascia, and descends parallel with that of the ralial flexor. Near the proximal bodder of the transverse carpal (anterior annular) ligiment the tendon expands into raliating bundles of fil,res of which the medial and lateral are attacherl to the fascia over the intrinsic muscles of the thumb) and little finger, while the middle, much more developed, (on. stitute the rhicf portion of the palmar aponeurosis.

Virre-supply. - From a branch which usually arises in company with the nerve to the proximal part of the flexor sublimis. It frequently traverses the superficial fibres of the flexor sulblinis. The nerve onters the middle third of the muscle.

Action.-To flex the liand. It is also a weak flexor and pronator of the forearm.

Rolution. - lt is placed between the rarlial and ulnar flexors over the flexor sublimis. In the distal part of the forearm the tendon lies over the median nerve.

larialions.- It is absent in 11.2 per cont. of instances (Le Domble). It may lo highly deverpored of redured to a temlinous band. The belly of the musele may lie in the distal instead of in the proximal part of the forearm. It mathe digastric. It may Je fused wit heightomring mmscles. It may arise from the medial intermuscular septum of the arm or from the lacertus filmosis, from the ranlin, from the coronoid proeess, from the radial or uhar flexor, or from the flexor sublinis muscles. The temdon may terminate in the fascia of the forearm, the thenar cominener, the carpus, or the abductor of the thumb. 'The musele maty be partly or wholly [isul)]al.

The flexor carpi ulnaris (lig. 370).-Origin.-13y two heals:- (1) the humeral head arises

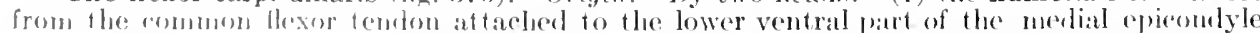

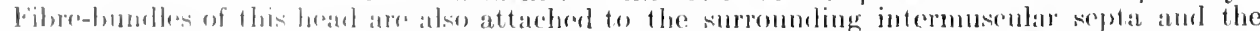

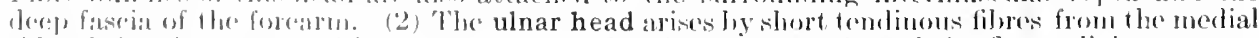

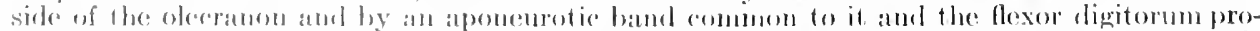

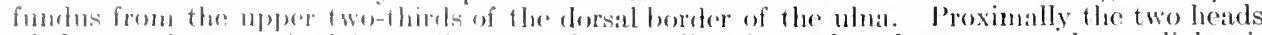

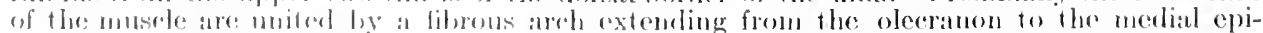

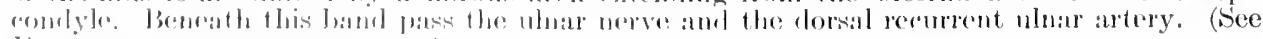

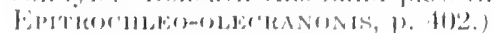

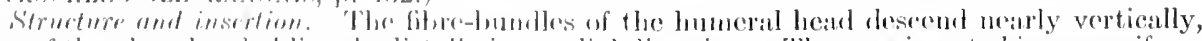

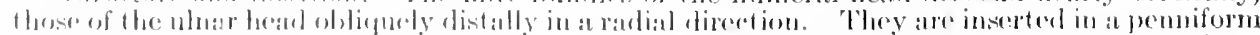

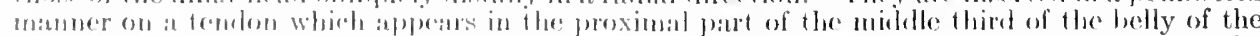

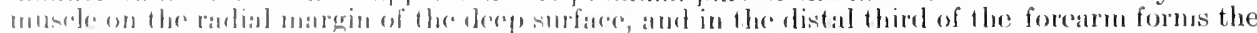

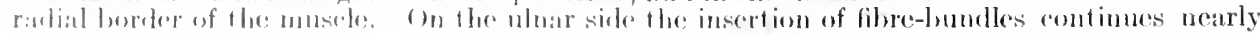


to the pisiform bone. The insertion of the tendon takes place chiefly into the pisiform bonte, but from it tendinous bundles extend to the palmar aponeurosis, volar ligament of the carpus, to the pisohamate ligament (pisi-unciform), and to the bases of the fifth, fourth, and third metacarpals.

Nerve-supply.-From two or three branches of the unar nerve, the most proximal of which arises near the elbow-joint. These branches, which may arise by a single trunk, enter the deers surface of the proximal third of the muscle and send long twigs distally across the mithle thiril of the constituent fibre-bundles. The nerve fibres arise from the seventh and eighth cervical and first thoracic nerves.

Action.-To flex the hand and to abduct the hand uharward.

Relations.-It is superficially placed. Its aponeurotic origin is adherent to the fasciat of the forearm. It lies medial to the palmaris longus and flexor sublimis and upon the flexor profundus. Beneath the muscle lies the uhnar nerve. The ulnar artery extends along the radial border of the tendon near the wrist.

Variations. - These are rare. Slips from the tendon may pass to the metacarpo-phalangeal articulation of the little finger. (See, however, ABNormal Mluscles, p. 402. )

\section{b. SECOND LATER}

This is composed of one muscle, the flexor digitorum sublimis, which, although in part covered by the muscles of the preceding layer, is in part superficial. It arises from the medial epicondyle of the humerus, and from the radius and the ulna, and sends tendons to the second row of phalanges of the fingers. It corresponds probably with the soleus and the tendons of the flexor digitorum brevis in the leg and foot.

The flexor digitorum sublimis (figs. 371, 373, 375).-Origin.-By two heads: the ulnar or chief head arises (1) by the tendon common to it and the superficial group of nuscles from the medial epicondyle, and by short tendinous bands fron the ventral surface of the epicondyle; (2) from the ulnar collateral ligament of the elbow, the ulnar tuberosity, the medial border of the coronoid process, and the inferior extremity of the tendon of the brachialis; and (3).from the intermuscular septum between the flexor sublimis and the overlying muscles. The radial head arises from an oblique line on the volar surface of the radius, and from the midile third of the anterior border.

Insertion.- Into the sides of the volar surface of the shafts of the second row of phalanges of the fingers.

Structure.-The fibre-bundles of the ulnar head and the upper part of the radial head converge, the ulnar fibre-bundles nearly vertically, the radial obliquely, to form a common belly the deep surface of which on the ulnar side is backed by a dense tendinous band. On the radial side of this a less dense membrane covers over an oval canal which passes distally along the line of junction of the two heads and lodges the ulnar artery and the median nerve.

The fibre-bundles of the ulnar head form a superficial and a deep group. The superficial portion near the middle of the forearm divides into a lateral and a medial division, the former being inserted on a tendon that goes to the middle and the latter on one that goes to the ring finger. The fibre-bundles of the radial head join with the lateral division of the superficial layer of the ulnar head and are inserted on the tendon of the middle finger nearly as far as the wrist. A small muscle fasciculus of the superficial portion of the ulnar head is usually united by a tendon to the long flexor of the thumb.

The deep portion of the ulnar head about the middle of the forearm terminates in large part on the volar surface of the dense tendinous band above mentioned. From this in turn two muscle bellies arise. One of these is inserted in a bipenniform manner on a tendon going to the index finger, the other on a tendon going to the little finger. A muscle fasciculus also usually passes from the region of the tendon band to that portion of the superficial fascieulus which terminates on the tendon of the ring finger.

The four tendons pass together through the carpal canal under the transverse carpal (anterior annular) ligament, those to the middle and ring fingers lving at first superficial to the other two. The tendons then diverge, and each tendon, together with and above a tendon of the flexor profundus, passes orer the metacarpo-phalangeal joint into an osteo-fibrous callal on the palmar surface of the first phalanx of the finger for which it is destined. Here the tendon becomes flattened about the round tendon of the flexor profundus. Opposite the niridle of the phalanx the tendon divides into two slips, between which the tendon of the flexor profundus passes. The divided halves of the sublimis tendon fold about the profundus tendon so that their lateral edges come to meet in the mid-line beneath this tendon opposite the phalingeal joint (figs. 375,376 ). They then again separate, extend distally, and are attached one on each side into a ridge at the middle of the lateral border of the second phalanx. The temlons are also attached by vincula tendinum, a ligamentum breve, between the tendon and the hearl of the first phalanx and the joint, and a ligamentum longum, between the tendon and the rolar surface of the first phalanx.

Nerve-supply.-Before the median nerve passes between the two heads of the pronator teres a branch arises which accompanies the nerve through the pronator and sends several branches into the proximal third of the ulnar head of the muscle. As the median nerve passes beneath the muscle, one or more branches are given to the radial head, and a long branch is given to the fasciculus of the second and from this one to that of the fifth digit. Occasionally, the median nerve in the distal third of the forearm gives rise to branches for these fasciculi. The nerve fibres arise from the seventh and eighth cervical and first thoracic nerves.

Action. - Chiefly to flex the second phalanx of each finger on the first; secondarily, to flex the fingers on the hand and the hand on the forearm. 
Relations.-The belly of the muscle is covered by the pronator teres, flexor carpi radialis, and palmaris longus, but is superfieial along a narrow strip between the flexor carpi ulnaris and the palmaris longus, and on each side of the tendon of the flexor carpi radialis. The musele rests on the flexor pollieis longus and flexor digitorum profundus, the median nerve (see deseription given above) and ulnar vessels. The median nerve emerges from beneath the radial border of the musele in the lower third of the forearm. In the palm the tendons lie beneath the

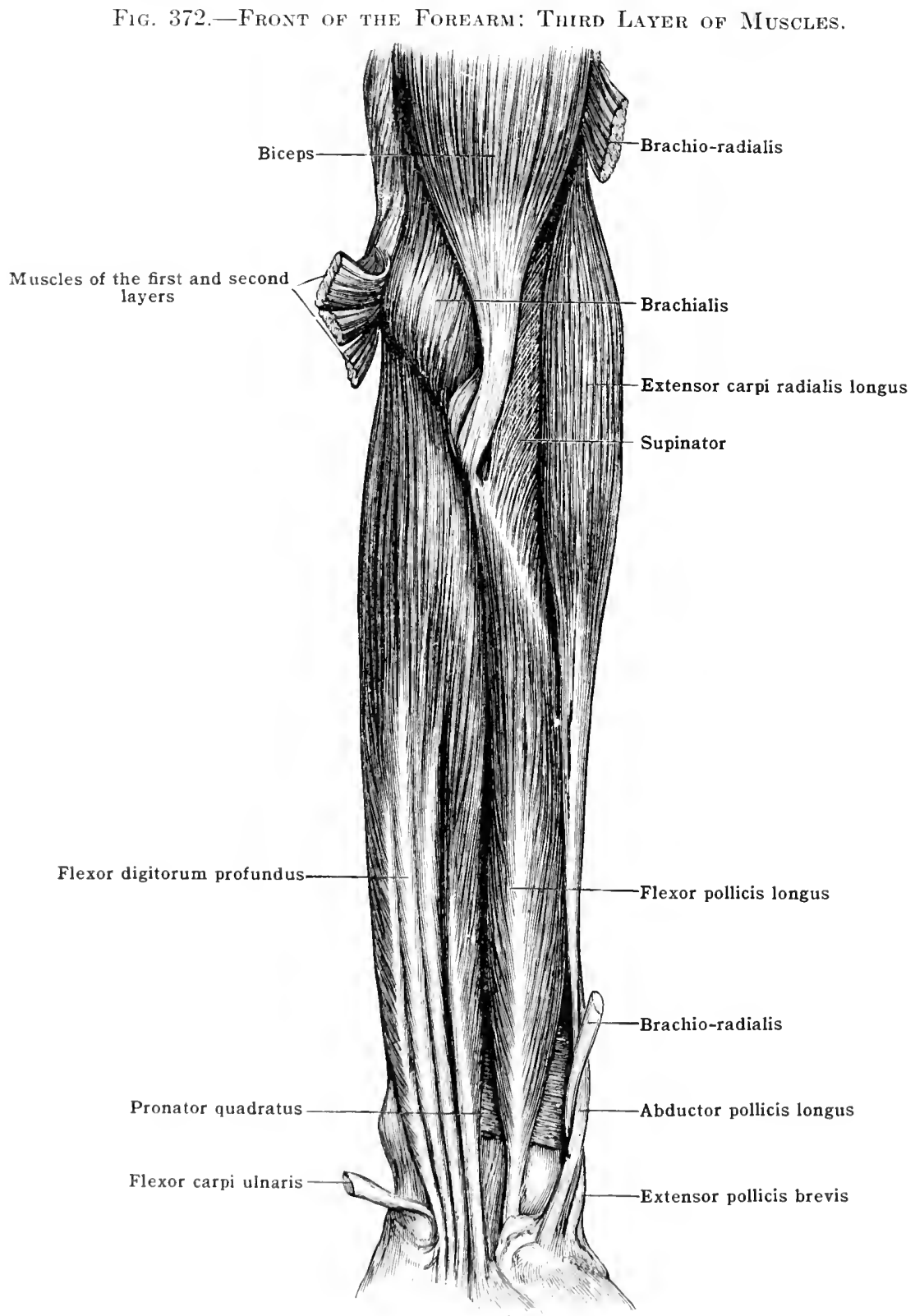

Palluar apromenrosis, the superficial palmar arde, and the branches of the median nerve, white they lice in front of the trmelons of the flexor profumlus, with which they are closely associated into a common bundle by loose fihmens tissue. The digital relations of the tendons are deseribed ab)(ar.

Fariations. The whole musele ma lw rendered digastric by a transverse tendon. A fascinalus of the flexor sublimis may replace the palmaris lomgus or the two may coexist. A

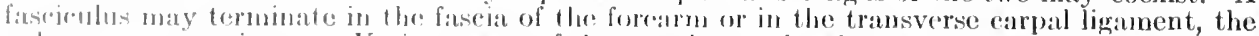
palmar aponemrosis, cec. Varions parts of the muscle may be alsent or more independent than nswal. The extront of the rarlal attarbment varies greatly and may be missing. A speeial

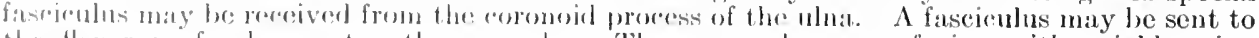
the Ilexor frofundus or to other muscles. 'There may be some fusion with noighbouring muscles. 


\section{c. ThiRd LAYER}

(Figs. 372-376)

The two muscles which constitute this layer may be looked upon as differentiated from a single deep flexor muscle. The flexor digitorum profundus is a strong, broad muscle which arises from the upper three-fourths of the volar surface of the ulna and gives rise to tendons which are inserted into the bases of the third row of phalanges of the fingers. The flexor pollicis longus, likewise broad and flat, arises from the volar surface of the radius and is inserted into the base of the second phalanx of the thumb. Both muscles are supplied by the median nerve and the flexor profundus is also supplied by the ulnar nerve.

These muscles correspond to the flexor digitorum longus and the flexor hallucis longus of the leg.

The flexor digitorum profundus (figs. 372-376).-Origin.-(1) Through an aponeurotic septum between it and the flexor carpi ulnaris from the dorsal border of the ulna; (2) directly from the proximal two-thirds of the medial surface and the proximal three-fourths of the volar surface of the ulna and from the adjacent interosseous membrane; and (3) inconstantly, from a small area on the radius below the bicipital tuberosity.

Structure and insertion. - The fibre-bundles descend nearly vertically and give rise to a common belly which soon divides into four portions, each of which is attached about midway down the forearm in a semipenniform manner to the dorsal surface of a tendon. The attachment of fibre-bundles continues nearly to the wrist. The digital divisions of the muscle vary in the height to which they extend. That belonging to the index finger is usually the one most exten-

Fig. 373.-Insertions of the Texdons of the Muscles which act ox the Fixger. (After Toldt, Atlas of Human Anatomy, Rebman, London and New York.)

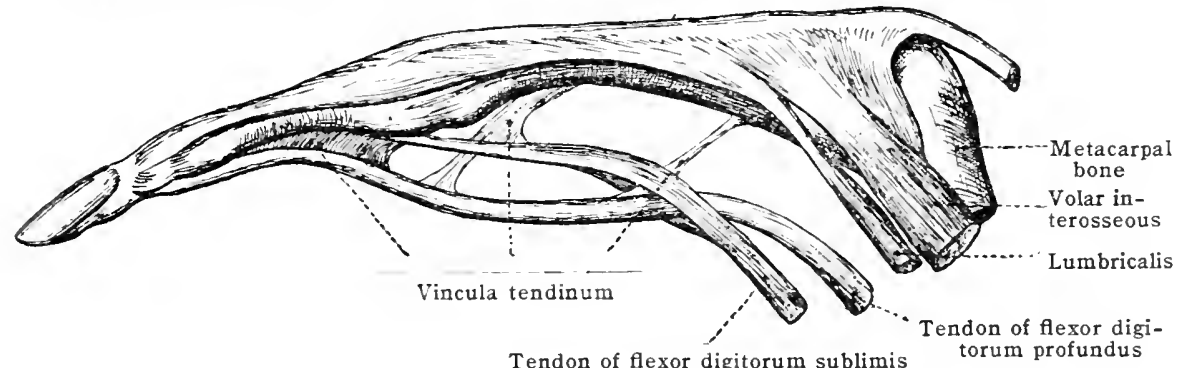

sively isolated, and that to the little finger is the next most so. The tendons pass side by side under the transverse carpal (anterior annular) ligament, and then diverge to the bases of the fingers. At the metacarpo-phalangeal joints, they enter the osteo-fibrous canals described above (p. 387). On the volar surface of the first phalanx each tendon passes through the slit in the sublimis tendon. The tendon then is continued over the second phalanx to the base of the third. Vincula tendinum are described passing to the capsule of the second interphalangeal joint (ligamentum breve) and to the tendon of the flexor sublimis (ligamentum longum). The lumbrical muscles arise from the tendons while they are in the palm.

Nerve-supply. - The interosseous branch of the median nerve arises usually before the nerve passes through the pronator teres and accompanies the main trunk. This branch as it passes beneath the flexor sublimis gives off a branch (or two) from which several twigs spring. These twigs enter the muscle near the radial border and pass in across the middle third of the constituent fibre-bundles of the fasciculi to the index and middle fingers. The ulnar nerve near the elbow gives rise to a branch which enters the volar surface of the muscle near the junction of the proximal and middle thirds of that portion of the belly, giving tendons to the ring and little fingers. There is some variation in the extent of the innervation by the branches of the ulnar and those of the median nerve. To a greater or less extent throigh anastomosis their territories overlap. The nerve fibres arise from the seventh and eighth rerriual and first thoracic nerves.

Action.-To flex the terminal phalanx of each finger on the second and the sepond on the first, while that of the superficial flexor is to flex the second phalanx on the first. The action of the two flexors on the first phalanx is somewhat more limited. The interosseous muscles, aided by the lumbricals, are the chief flexors of the first row of phalanges. The flexor profundus acts, though not powerfully, as a flexor of the wrist.

Relations.-The flexor profundus muscle lies beneath the flexor sublimis and the flexor carpi ulnaris muscles, the median nerve, and the ulnar vessels and nerve. Inder the muscle lie the ulna, the interosseous membrane, and the pronator quadratus muscle. Lnder the transverse carpal (anterior annular) ligament the tendons lie beneath those of the flexor sublimis in the same synovial sac. In the palm the tendons with the associated lumbrical muscles lie upon the interosseous muscles, the adductor of the thumb, and the deep palmar arch, and beneath the flexor sublimis tendons. For the relations to the synovial burse see p. 403 . 
Variations. - There is considerable variation in the extent of the radial origin and in the extent of the independence and fusion of the different fasciculi. In the prosimians a common tendon extends as far as the hand. The division in the higher forms is associated with refinement of movements of the fingers. One or more special faseiculi not infrequently join the muscle from the flexor sublimis, the flexor pollicis longus, the medial epicondyle, or the ulna. The accessorius ad flexorem digitorum profundum is a fasciculus which arises from the coronoid process of the ulna and sends a tendon to join the tendon of one of the fingers, most frequently the middle or index. It is found in 20 per cent. of bodies.

The flexor pollicis longus (fig. 372).-Origin.-The attachment extends along the oblique line and the ventral border of the radius from slightly below the bicipital tuberosity to within $5 \mathrm{~cm}$. of the wrist. Medially it is continued into the interosseous membrane. Proximally the tendon frequently extends to the distal radial margin of the coronoid process of the ulna and gives rise to fibre-bundles connected with the muscle, as well as to a fasciculus of the flexor profundus.

Structure and insertion. - The fibre-bundles descend obliquely to be inserted in a penniform manner on a tendon which begins high up on the volar surface near the ulnar border of the muscle, and descends as a broad band which near the wrist becomes cylindroid. The insertion of fibres continues nearly to the point where the tendon passes under the transverse carpal ligament. Here the tendon enters the carpal canal radial to the tendons of the flexor profundus, and passes beneath the superficial head of the short flexor of the thumb, then between the thumb sesamoids into the osteo-fibrous canal of the thumb, in which it is continued to the base of the terminal phalanx.

Nerve-supply.-Usually from two branches of the volar interosseous ramus of the median nerve. These enter the proximal half of the ulnar margin of the muscle. The nerve fibres arise from the sixth, seventh (and eighth) cervical nerves.

Action.- - It is a strong flexor of the second phalanx on the first and has less powerful aetion on the metacarpo-phalangeal joint and on the wrist.

Relations.- It lies beneath the flexor sublimis, the flexor carpi radialis and brachio-radialis muscles, and the radial artery. Near the wrist it crosses over the insertion of the pronator quadratus. In the hand the tendon runs beneath the opponens pollicis and the superficial head of the flexor brevis, and across the deep head of the latter.

Tariations. - It may be fused or united by fasciculi with the flexor profundus, the flexor sublimis, or the pronator teres. It may be partially doubled, giving rise to an accessory tendon which extends to the index finger. The origin may extend to the medial epicondyle of the humerus (epitrochlear bundle).

\section{d. Fourth Layer}

This layer consists of a single quadrilateral muscle which passes transversely across the lower part of the forearm from the ulna to the radius. In the leg there is no corresponding muscle.

The pronator quadratus (fig. 377).-Origin.-Medial side of the volar surface of the lower fourth of the ulna.

structure and insertion.-From the ulna a strong aponeurosis extends a third of the way across the volar surface of the muscle. From this membrane and from the bone fibre-bundles extend transversely to be inserter on the distal quarter of the volar surface of the radius and on the triangular area above the ulnar notch. The decper fibre-bundles which arise directly from the ulna are inserted into the radius by means of an aponeurosis. The superficial and deep portions of the muscle are of ten separated. The muscle is thicker distally than proximally.

Nrrer-supply.-The volar interosseous nerve descends along the interosseous nembrane, passes hehind the middle of the proximal margin of the muscle, and sends branches into its deep surfare. The nerve fibres arise from the (sixth), seventh and eighth cervical and first thoracic nerves.

Action.-To pronate the forearm.

liflations.- The muscle lies immediately beneath the muscles of the third layer and upon the radius and unin, the interosseous membrane, and radio-ulnar joint. The radial artery and ulnar nerve pass in front of it, the volar interosseous artery behind it.

l'ariations. - It may be missing or may extend further up the forearm than usual or down upon the arpus. It may he triangular or divided into parts the filre-bundles of which take different direntions. I1 may send fascienli to the carpus or metacarpus or be fused with the flexor carpi rartialis brevis (see below).

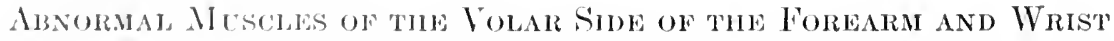

The epitrochleo-olecranonis (anconcus internus), - $\Lambda$ musele fasciculus, distinct from the dist al margin of the tricels, which runs from the medial epicondyle to the olecranon over the groove for the mluar nerve, l,y a branch of which it is supplied. It takes the place of the fibrois areh normally extending hetwen the epieondylar and ulnar heads of the flexor carpi ulnaris. It oreurs in about 25 jer (nont. of bodies ('Testut), and represents an adductor of the olecranon of the lower mammals. ()orasionally the medial head of the triceps may descend over the ulnar groove, but this forms amother type of muscle variation.

The flexor carpi ulnaris brevis (uhn-(miprus).- $\Lambda_{n}$ abnormal musele which arises from the distal guarter of the volar surface of the what and is inserted into the hamatum (uneiform), the pisiform, the abduetor of the litthe finger, of the superior extremity of the fifth metacarpal. 
The unci-pisiformis. - A short, thick band of muscle which runs from the pisiform to the tip of the hamulus of the os hanatum (unciform) parallel with the pisohamate (pisi-unciform) ligament. It is innervated by the ulnar nerve.

The flexor carpi radialis brevis (radio-carpeus).-An abnormal muscle found in about 5 per cent. of bodies (Le Double). It arises from the lateral or the volar surface of the distal half of the radius. Some of the fibre-bundles may spring from the pronator quadratus, the fascia of the forearm, or the ulna. It is inserted into the carpus or metacarpus, and occasionally even into the first phalanx of the index finger, etc. It is supphied by a branch of the volar interosseous nerve. It serves to flex the wrist. It is said to represent the tibialis posterior of the leg.

\section{Bursæ}

B. m. flexoris carpi ulnaris.-Between the tendon of this muscle and the pisiform bone.

B. m. flexoris carpi radialis.-Between the tendon of this muscle and the tubercle of the navicular bone.

Fig. 374.-Synovial Sheaths of the Tendons of the Loxg Flexors of the Fingers A. Frequent type; B. normal type; C. fœtal type. (After Poirier and Charpy.)

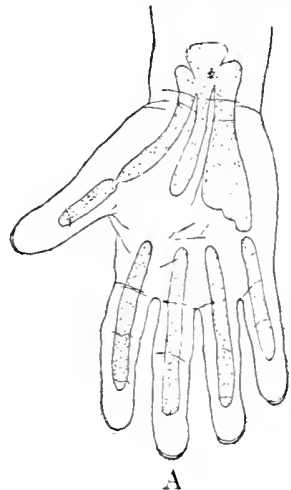

A

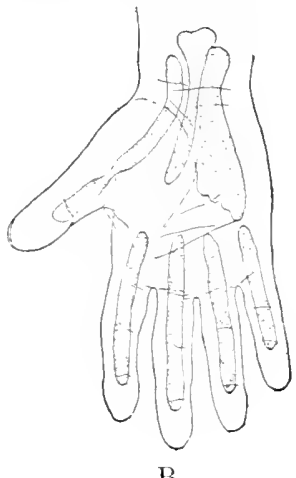

B

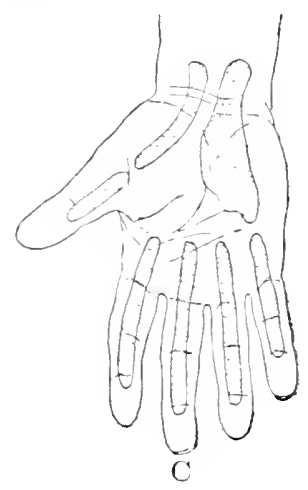

A bursa is often found between the tendon of the deep flexor of the index finger and the carpus. This bursa is frequently in communication with the radial and ulnar tendon sheaths.

A bursa is also often found between the deep and superficial tendons of the index finger.

\section{Synovial Tendon Sheaths}

$$
\text { (Figs. } 366 \text { and 374) }
$$

Vagina tendinis $\mathrm{m}$. flexoris carpi radialis.-About the tendon as it passes beneath the transverse carpal ligament.

Vaginæ tendinum mm. flexorum digitorum.-The osteo-fibrous canals of the digits are lined by a synovial membrane which is reflected by means of a fold (cul-de-sac) to the tendons at each end and over the vincula tendinum, in which blood-vessels and nerves for the tendons are contained. The synovial cavity of the first and usually that of the fifth digit communicate with those of the palm.

In the wrist and palm two large synovial sacs may usually be recognized, although the number may be raised to five or reduced to one.

The radial sac, vagina tendinis $\mathrm{m}$. flexoris pollicis longi, surrounds the long flexor tendon of the thumb in the wrist and palm and usually communicates with that of the thumb. In the palm a well-marked mesotendon usually extends to the deep ulnar side of the tendon from the parietal layer of the sheath.

The ulnar sac, vagina tendinum mm. flexorum communium, surrounds the tendons of the long flexors of the fingers. It begins proximal to the transverse carpal ligament and extends nearly or quite to the synovial sheath of the little finger on the ulnar side and on the radial side to the centre of the palm.

\section{Musculature of the Hand}

(Figs. 366, 368, 375-379)

The intrinsic muscles of the hand are taken up in the following groups:-

$a$ The subcutaneous muscle of the palm.

$b$ The muscles of the little finger.

$c$ The muscles of the thumb.

$d$ The lumbrical muscles.

$e$ The interosseous muscles. 
The ulnar nerve supplies the muscles of the little finger, the interossei, the medial lumbrical muscles, and two of the muscles of the thumb; the median nerve supplies most of the muscles of the thenar region and the lateral lumbrical muscles.

\section{(a) Subcutaneous Muscle}

(Fig. 375)

The palmaris brevis is a small, trapezoid sheet situated between the hypothenar fascia and the skin. It arises at the lateral edge of the palmar aponeurosis from tendinous slips which may be traced through the aponeurosis to the navicular and greater multangular. It is composed of nearly parallel fibre-bundles, and extends into the deep surface of the skin along the ulnar border of the palm. It is generally taken to be a subcutaneous muscle like the superficial muscles of the head and neck. It has, however, been suggested that it represents the remnants of a short flexor of the digits corresponding with the flexor digitorum brevis of the foot.

Nerve-supply.-The superficial branch of the palmar division of the ulnar nerve gives rise to a twig which enters the deep surface of the muscle. The fibres come from the (seventh and) eighth cervical and first thoracic nerves.

Action. - The action of the muscle is to draw the skin of the ulnar side of the hand toward the centre of the palm. It is said that it thus helps to form a cup-shaped hollow when the hand conveys fluid to the mouth. The contraction of the muscle by raising a ridge over the ulnar nerve and artery when an object is grasped hard serves, according to Henle, to protect these structures.

Variations.-It varies in size. In about 2 per cent. of bodies it is absent (Le Double). It may send tendinous slips to the pisiform bone. (For a thenar subcutaneous muscle, see variations of the abductor pollicis brevis.)

\section{(b) Muscles of the Liille Finger}

(Figs. 375, 376, 377)

In the hypothenar eminence are three muscles, the abductor, the flexor brevis, and the opponens digiti quinti. The abductor digiti quinti is a flat, fusiform muscle which arises from the pisiform and is inserted into the ulnar border of the first phalanx and into the dorsal aponeurosis through which it helps to flex the first and extend the second and third phalanges of the little finger. The fusiform flexor brevis arises from the hamatum (unciform) and adjacent part of the transverse carpal (anterior annular) ligament and is inserted into the ulnar side of the hase of the first phalanx. The triangular opponens likewise arises from the hamatum (unciform) and the transverse (anterior annular) ligament. It is inserted into the ulnar border and the head of the fifth metacarpal.

The abductor of the little funger corresponds with that of the little toe. A part of the opponens beneath the ulnar nerve corresponds with that of the lit tle toe, while the more superficial portion is unrepresented in the font. The flexor brevis of the little toe corresponds with a part if the leep portion of the opponens of the little finger. 'The flexor lrevis of the little finger is nurepresented in the foot. (Cumningham.)

The abductor digiti quinti (fus. 375, 376).-Origin.-From the distal half of the pisiform, the ligaments letween this and the hamatmm, the temion of the flexor carpi ulnaris, and often from the transverse (arpal (anterior anmular) ligament.

Structur and insertion. The fibre-bundles clescend vertically, at first increasing in number and then concentrated, towart two short tendons one of which is inserted into the ulnar border of the first phalanx of the little fiuger and the other iuto the aponemosis of the extensor tendon of the little finger.

Nirm-supply.- From the decep pahnar division of the ulnar nerve before it passes through the opuonens, of from the supcrficial malmar branch, arise one or more twigs which enter the ratial side of the matsele on its derp surfare in the proximal third. The nerve fibres arise from

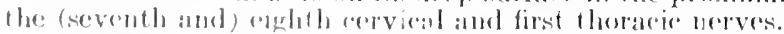

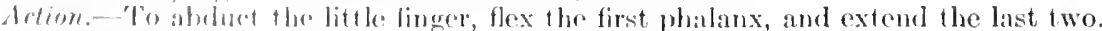

firletions. It rverlies the opponens and llexor brevis. Simerficially it is covered by fascia and the palmaris brevis musele. Along the proximal pat of its rasliat margin run the deep

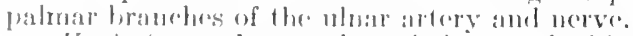

Veriolions - It may be: nissing or lombled. It may be fused with the short flexor or resecive fascicouli form the balmaris longus, the uluar flexor, the fascia of the forearm, etc.

The flexor digiti quinti brevis (figs. 376,377 ).- Grigin.-13y a short temlon from the hook of the hanatim (utwiform) and from the aljacent parts of the transerse carpal (anterior annular) liganument.

Siructure and insertion. -The fibrobumbles take a nearly parallel course and are inserted 
by a short tendon which is fused with that of the abductor and is inserted into the ulnar sirle of the base of the first phalanx of the little finger. A sesamoid bone may lie in the tendon.

Nerve-supply. A branch from the superficial or deep palmar division of the ulnar nerve enters the deep surface of the muscle in its proximal half. The nerves to the abductor and flexor may arise in common from the ulnar. The nerve fibres arise from the (seventh and) eighth cervical and first thoracic nerves.

Fig. 375. - The Superficial Muscles of the Palm of the Haxd.

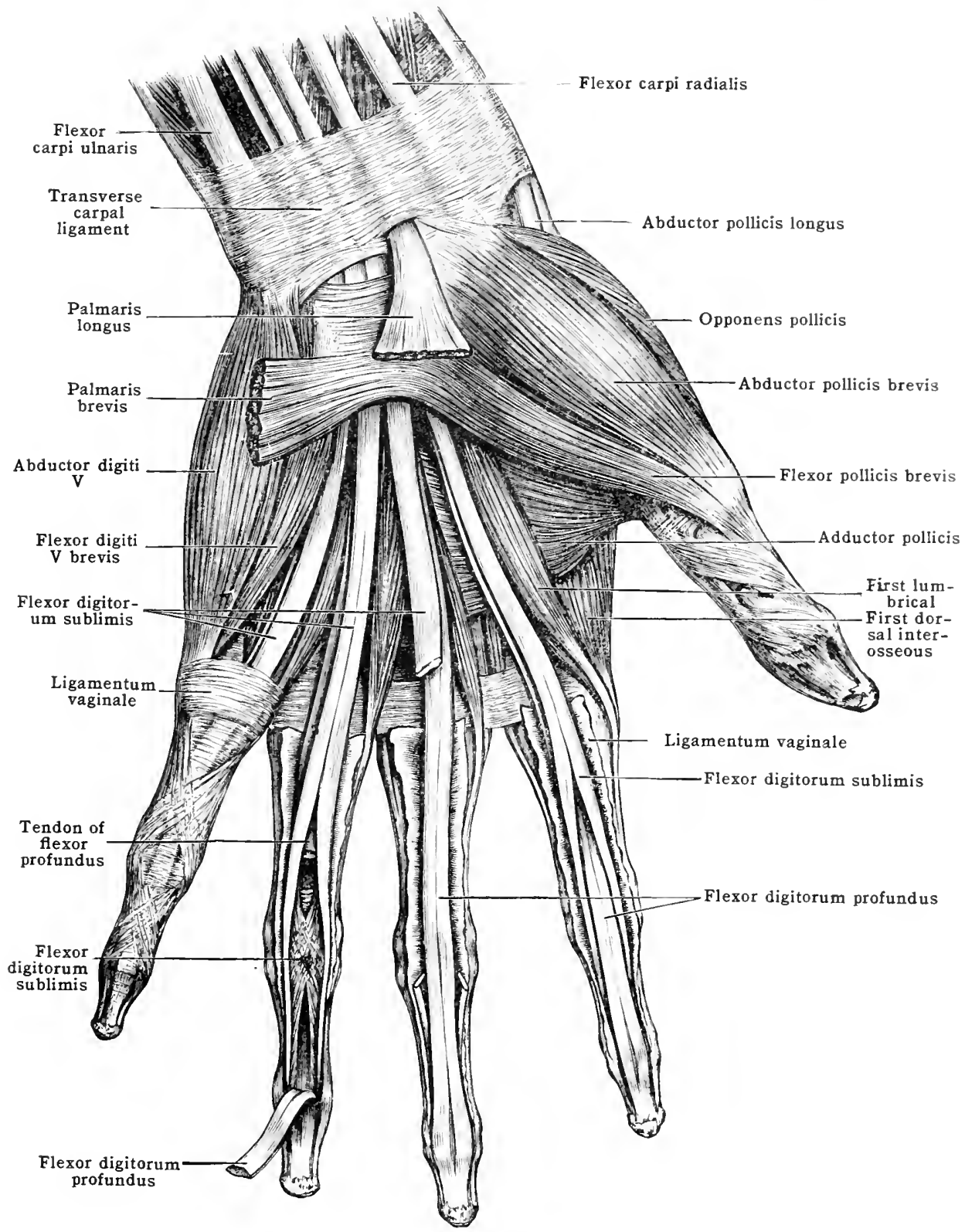

Action.-To flex the first phalanx of the little finger. When it sends a tendon slip to the aponeurosis of the extensor of the finger it helps to extend the two terminal phalanges.

Relations.-The muscle closely adjoins and is partly covered by the abductor. The palmaris brevis and the lateral volar digital artery to the fifth finger lie superficial to it. Cnder it lies the opponens.

Variations. - The muscle may be wanting or may be closely fused with the abductor or the opponens. It may receive an accessory slip from the forearm fascia. It may give a tendon slip to the extensor aponeurosis or to the head of the fiftl metacarpal.

The opponens digiti quinti (fig. 377).-Origin.-Partly tendinous, from the distal ulnar border of the hook of the hamatum (unciform) and from the adjacent transverse carpal (anterior annular) ligament. 
Structure and insertion.-The fibre-bundles diverge, the proximal short and horizontal, the distal long and oblique, and are inserted on the whole of the ulnar border and on a part of the head of the fifth metacarpal. Often the muscle is divisible into two portions between which the ulnar nerve runs.

Nerve-supply.-Before the deep palmar branch passes through the muscle it gives rise to a twig which enters its volar surface in the middle third near the ulnar margin. The nerve fibres arise from the (seventh and) eighth cervical and first thoracie nerves.

Action.-To flex, adduct, and slightly rotate the fifth metacarpal; as, for example, in 'cupping' the hand to drink from it.

Relations. - The opponens lies beneath the abductor and flexor brevis muscles. The deep branches of the ulnar nerve and artery pass through the opponens near its carpal origin and then under it extend into the palm.

\section{Fig. 376.-The Defper Muscles of the Palm of the Hand.}

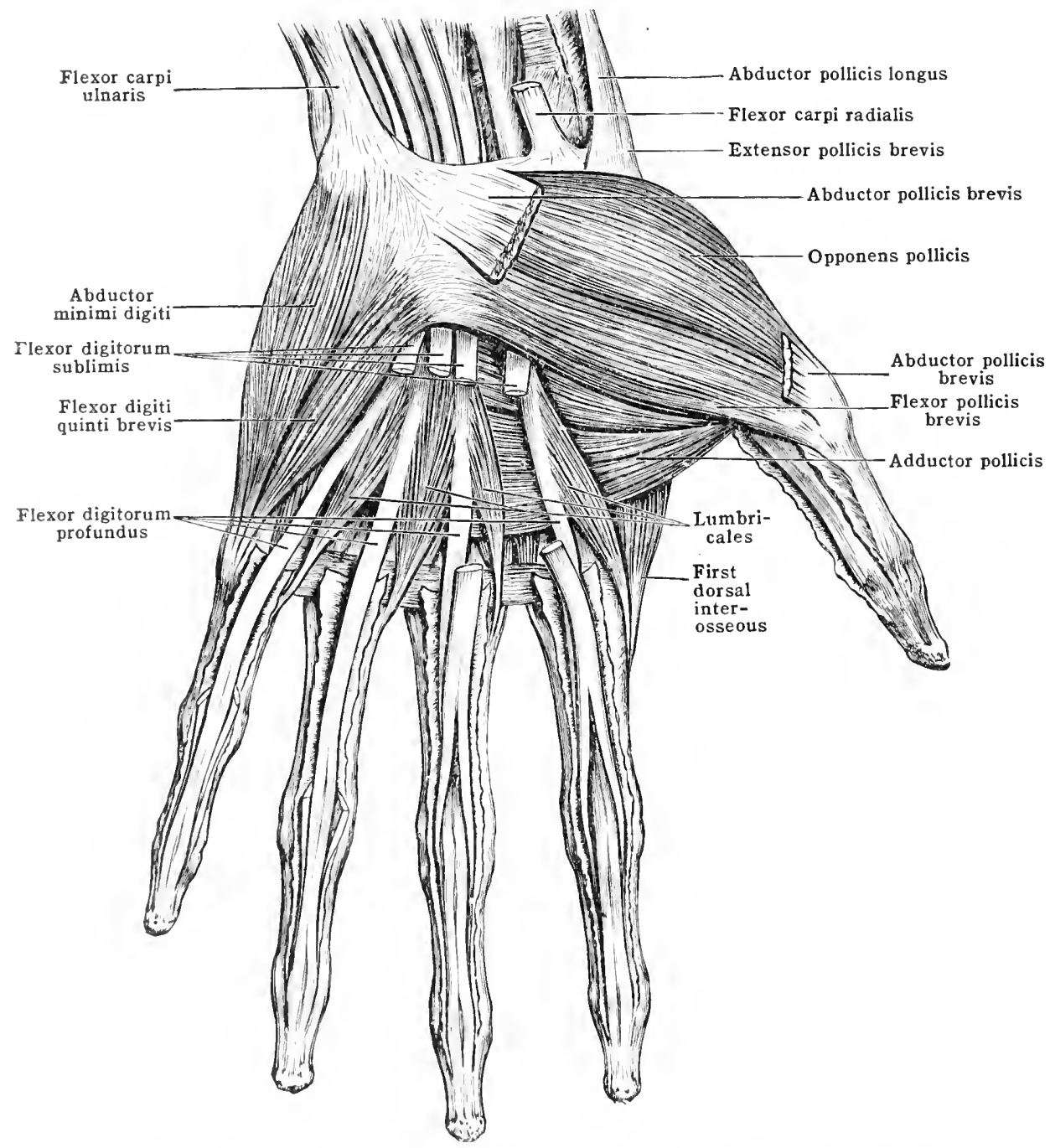

Variations.-1t. may be fused with neighbouring muscles or receive aceessory slips.

The tensor capsularis articulationis metacarpo-phalangei digiti quinti is a slender musele which arises from the liganents which unite the pisiform to the hamatum, and is inserted into the volar surfare of the nuctararpo-phabungeal joint of the little finger.

\section{(c) Muscles of the Thumb

$$
\text { (1igs. } 375,376,377 \text { ) }
$$

In the thenar regrion there are four muscles. Of these, the abductor pollicis brevis is the most superficial. Then come the opponens pollicis and the short flexor, and beneath the last the ardluctor pollicis. All are triangular in form. 'The abductor pollicis brevis arises from the radial side of the volar surface of the 
carpus and is inserted into the radial side of the base of the first phalanx of the thumb. The opponens is a thick muscle extending from the transverse carpal (anterior annular) ligament to the radial side of the first metacarpal. The flexor pollicis brevis arises by two heads, a "deep" and a "superficial" from the carplis and is inserted into the radial side of the base of the first phalanx. The adductor pollicis arises from the carpus and the second and third metacarpals and is inserted into the ulnar side of the first phalanx of the thumb. From the tendons of insertion of the abductor and flexor brevis slips are continued into the dorsal aponeurosis of the thumb so that they aid in extending the second phalanx.

In the foot an opponens hallucis oceurs as an abnormal musele. The abductor, flexor brevis and adductor of the thumb are represented by the corresponding muscles of the big toe, although

Fig. 377.-The Pronator Quadratus and Deep Muscles of the Palis.

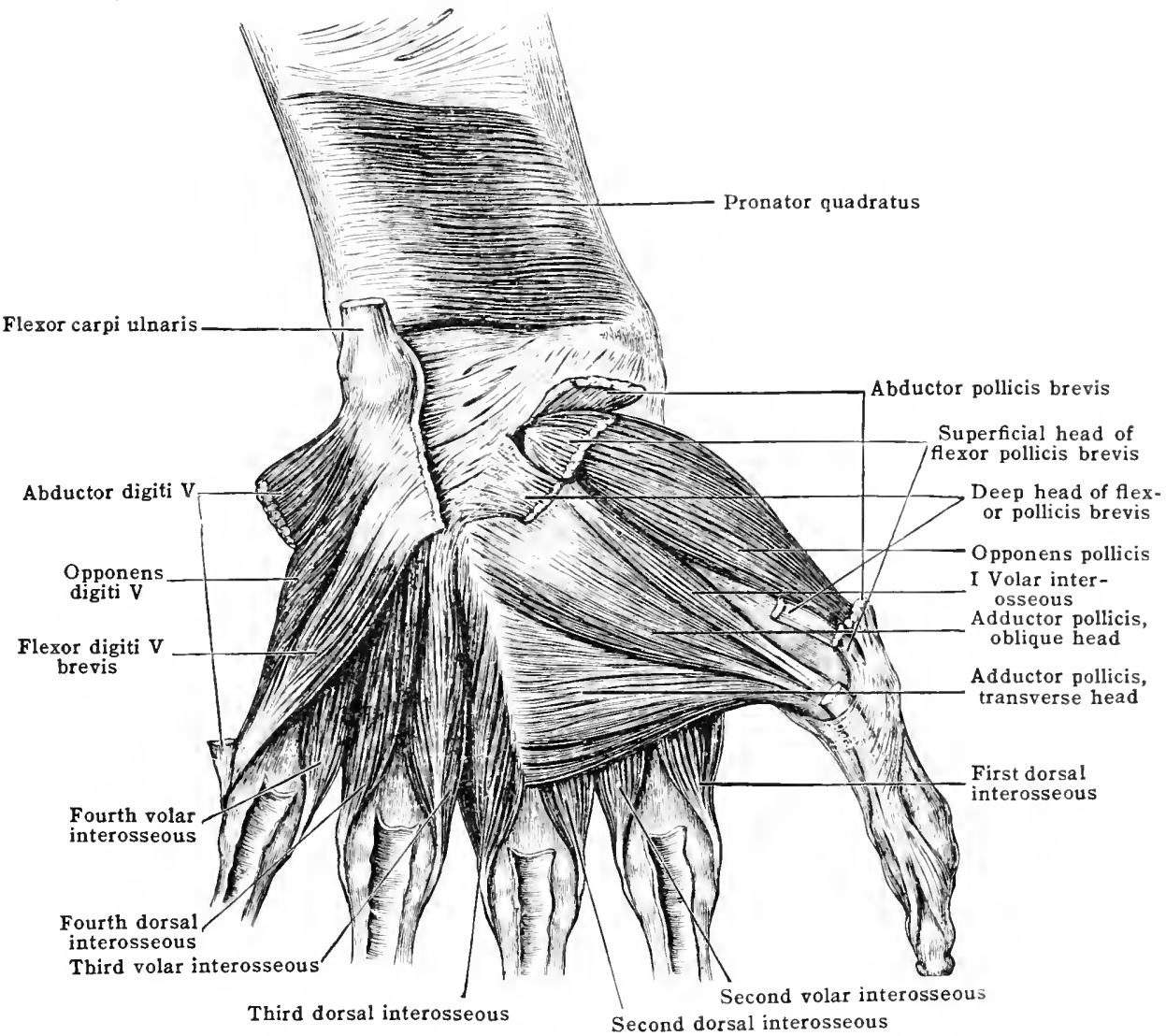

the last two muscles are not perfectly homologous in the hand and foot.

The abductor pollicis brevis (fig. 375).-Origin.- From the volar surface of the transverse earpal (anterior annular) ligament, and from the greater multangular bone (trapezium). Also often from the navicular bone and from a tendon slip of the long abductor.

Structure and insertion.-The fibre-bundles converge upon a flat tendon with two lamellie, the deeper of which is inserted into the rachial side of the base of the first phalanx of the thumb and the superficial into the aponeurosis of the extensor pollicis longus.

Nerve-supply.-By a branch of the first volar digital ramus of the median nerve. This branch passes over or through the flexcr brevis and enters the muscle on the volur surface in the middle third near its ulnar border.

Action. - To abduct the thumb, flex the first phalanx, and extend the terminal phakan.

Relations. - It lies beneath the thenar fascia lateral to the superficial head of the flexor brevis and over the opponens. The superficial volar artery usually perforates the nuscle.

Variations. - It may be wanting or may be dividerl into two divisions. The origin may extend to the faseia of the forearm or styloid process of the radius. It may receive an accessory slip from the long radial extensor, the opponens, or the short extensor of the thumb. A thenar subcutaneous muscle is oceasionally present. It is narrow, is closely associated with the short abductor of the thumb, and extends from the radial sicle of the base of the first metacarpal into the skin of the thenar eminence. 
The opponens pollicis (fig. 377).-Urigin.-From the volar surface of the transverse carpa (anterior annular) ligament and from the tuberele of the greater multangular bone (trilpezium).

Structure and Insertion. - The fibre-hundles extend obliquely in a nearly parallel direction to their insertion along the whole lateral border of the volar surface of the shaft and the head of the first metaearpal.

Nerit-supply. - By a braneh of the first volar digital ramus of the median nerve. This branch passes over or through the superficial division of the flexor brevis near the origin of the muscle. One or two twigs enter the deep surface of the proximal third of the opponens near its ulnar border. The nerve fibres arise from the sixth and seventh cervieal nerves.

Action.-To flex, adduct, and rotate medialward the first metacarpal bone. The volar surface of the thumb is thus brought to face the volar surface of the other digits.

Relations.-It lies beneath the thenar fascia and the abductor brevis. The flexor brevis overlies its ulnar border.

Tariations.-It may be absent or it may be divided into two heads. It is usually more or less fused with the short flexor.

The flexor pollicis brevis (figs. 376, 377). - The muscle is divided by the tendon of the long flexor into a superficial and a deep portion. The superficial head arises from the greater nultangular bone (trapezium), the adjacent part of the transverse carpal (anterior annular) ligament, and the tendon sheath of the flexor earpi radialis. The fibre-bundles descend closely applied to the opponens, and terminate by a tendon which is attached to the lateral side of the front of the ba:e of the first phalanx. Over the joint a sesamoid bone lies in the tendon. The deep head has a tendinous origin from the os multangulum minus (trapezoid) and the os capitatum (magnum). The fibre-bundles take an oblique eourse, to be inserted into the tendon of the superficial part. A musele fasciculus which arises from the ulnar side of the base of the first metacarpal and the neighbouring carpal ligaments and is inserted on the ulnar side of the base of the first phalanx, is sometimes considered to be the deep head of the flexor brevis. It is closely bound up with the carpal head of the adductor pollicis and they have a eommon tendon. Some fibres of the medial division of the tendon may be traced into the aponeurosis of the extensor tendon. It is probable that this portion of the musele represents a first volar interosseous, and it is so deseribed later with the interosseous museles. There is mueh dispute as to what fascieuli should be included in the flexor brevis.

Nerv-supply. - The musele is usually supplied by twigs derived from a branch from the first volar digital ramus of the median nerve as this branch passes through its substance, and by twigs from the deep branch of the ulnar. Brookes found this supply in 19 out of 29 instances, in 5 by the median alone, and in 5 by the ulnar alone. The nerve fibres come from the sixth and seventh cervical nerves.

Action.-To flex, adduct, and rotate medialward the metacarpal of the thumb; flex the first phalanx; and extend the seeond phalanx.

Relations.-Proximally the short flexor is grooved for the tendon of the long flexor, beneath which more distally the deep head of the muscle passes laterally. The superficial portion of the muscle lies beneath the skin. The ulnar border of the deep head is fused proximally with the adductor.

I'ariations.-The deep head may be absent. Either or both heads may be double. The superficial head may be fused with the abductor brevis, and is usually more or less fused with the opponens.

The adductor pollicis (fig. 377).-Origin.-By two heads. The carpal or oblique head arises from the deep carpal ligaments, the capitatum and the bases of the second and third metacarpals; the metacarpal or transverse head, from the crest of the third metacarpal, from the supranetacarpal faseia of the third interspace, and sometimes also from that of the fourth interspace and from the eapsules of the second, third, and fourth metacarpo-phalangeal articulations.

Siructure and insertion.- The fibre-bundles eonverge toward a tendon which is inserted into the uluar sicle of the front of the base of the first phalanx of the thumb. A sesamoid bone lies in thr tenclon over the joint.

Serv-supply.-One or more twigs from the deep palmar braneh of the ulnar enter the middle thirel of the musele on its cleep surface. There may also be an anastomosing braneh from the molliun nerve. "The nerve fibres come from the sixth, seventh and eighth eervical and first thoracice nerves.

Artion.- To adduet and flex the first metararpal and flex the first phalanx of the thumb. When thro thumb is in an extreme position of apposition, it acts as an abductor.

Lirlations.- Simperficial to the nuscle lie some of the temdons of the deep flexor of the fingers and the first two lumbrimal muscles. It extends over the two more lateral intermetacarpal spacese, and is in part subcutancous on the dorsal surface. The deep palmar arch extends betweren the two locids and berrath the oblique hrad. The oblique head of the musele is closely unitul to the first volar interosisens, so that the latter by some is considered a part of the andiretor.

linintions.- The extent of the attachments of origin of the muscle vary considerably. The two heads of the muscho may loc more or less completely separated from one another. Each

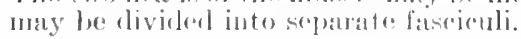

\section{(d) Inumbrical Muscles}

From the deep flexor tendons in the palm of the hand arise the lumbrieal muscles, four in number, which arre attacherl by small tendons to the radial side of thre extensor trorlons (figs. 373, 375). 'These fumbrical muscles have homologues in the sole of the foot. 
The lumbricales (figs. 375, 376).-Origin.-The two lateral arise from the radial side of the volar aspect of the first and second tendons of the flexor digitorum profundus; the two medial arise from the adjacent sides of the second and third and third and fourth tendons.

Structure and insertion.-The fibre-bundles of each muscle arise dircetly from the flexor tendons near the distal border of the transverse carpal (anterior annular) ligament. They. converge as far as the metacarpo-phalangeal joint, upon a small tendon which begins about the middle of the muscle. The tendon passes out between the palmar aponeurosis and the transverse capitular ligament, winds about the metacarpo-phalangeal joint, expands, and is at tacherl along the side of the first phalanx to the radial border of the tendon of the extensor digitorum communis.

Nerve-supply. - Branches from the median nerve enter the middle third of the radial border of the first two or three lumbrical museles. The last one or two are supplicd by branches from the deep volar branch of the ulnar nerve, which enter the middle third of the deep surface. The third lumbrical and sometimes one or more of the others may receive a branch from both nerves. The nerve fibres come from the eighth cervical and first thoracic nerves.

Action.-Together with the interosseous muscles ther flex the basal phalanges on the metacarpal bones and extend the terminal and middle phalanges. They also adduct the fingers toward the thumb.

Relations.- The muscles run between the tendons of the flexor profundus and beneath the palmar aponeurosis. They lie upon the fascia covering the interosseous muscles, the capitular ligaments, and the septum over the adductor and deep head of the flexor pollicis brevis.

Variations.- These are very frequent, especially in case of the third and fourth. Fach may be doubled or missing. They may arise from the tendons of the flexor sublimis or from the belly of the deep flexor. The first lumbrical may come from the tendon of the long flexor, from the opponens, or the metacarpal of the thumb. The tendon of insertion may go to the ulnar side of the base of the digit opposite that to which the tendon is usually attached, or the tendon may divide and go to the adjacent sides of two fingers. Kopsch has found that in 110 bodies all four lumbricals were inserted on the radial side of their respective digits in 39 per cent. In 35 per cent. the first, second, and fourth were so inserted, while the third sent slips to the adjacent sides of the middle and ring fingers. An accessory fasciculus has been found to arise from the tendon of the flexor pollicis longus and go to the base of the index finger.

\section{(e) Interosseous Muscles (figs. 377, 378, 379)}

These muscles lie between the metacarpal bones and are covered dorsally and ventrally by fasciæ attached to the metacarpals. In each interspace are two muscles, a dorsal and a palmar. The volar interossei are inserted into all the fingers

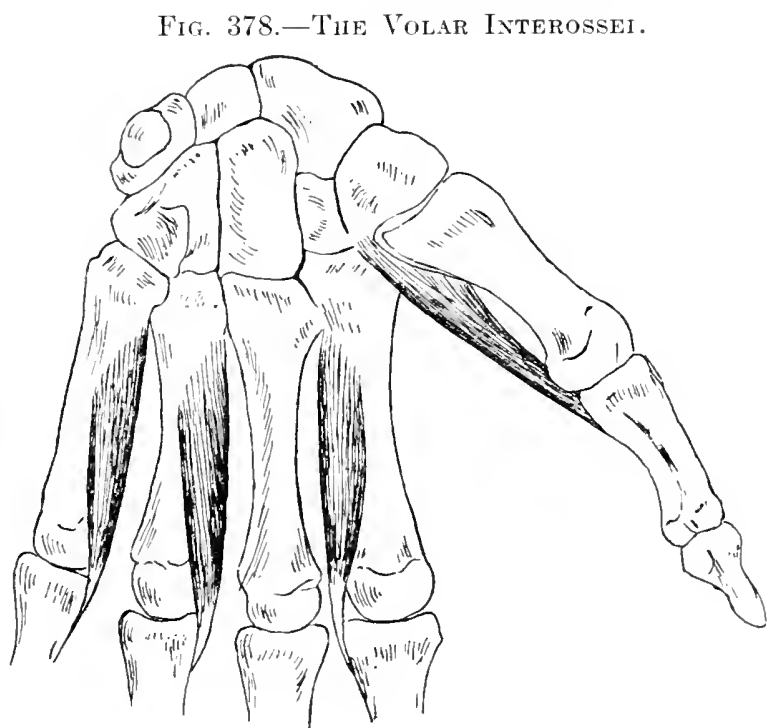

except the middle finger, and are adductors toward an axis passing through the middle finger; the dorsal in terossei are inserted into both sides of the midclle finger and into the radial side of the second and the ulnar side of the fourth finger, and are abductors. All also serve as flexors of the first row of phalanges and extensors of the second and third. In the foot the axis to and from which the interosseous muscles adduct and abduct the toes passes through the second toe.

The interossei volares arise from the sides toward the middle finger and the front of the shafts of the first, second, fourth, and fifth metacarpals. The first arises from near the base, the 
others from three-fourths of the shaft. The fibre-bundles of each muscle converge in a penniform manner upon a tendon which is inserted into the aponeurosis of the digital extensor tendon and the base of the first phalanx on the middle finger side of the corresponding digit (see fig. 373). The first volar interosseous is often described as a division of the flexor pollicis brevis or of the adductor pollicis.

The interossei dorsales arise from the adjacent sides of the metacarpal bones in each interspace. On the sides nearest the middle finger they cover three-fourths of the bone, on the opposite sides much less. The fibre-bundles converge in a bipenniform manner upon a tendon which begins high in the muscle and is inserted into the aponeurosis of the extensor muscles and the base of the first phalanx on each side of the middle finger, on the thumb side of the index finger, and the ulnar side of the ring finger. The interosseous muscle in the first interspace is thick and strong and forms with the adductor pollicis the fleshy web between the base of the thumb and the palm.

Nerve-supply.-By branches of the deep palmar division of the ulnar nerve. As a rule, a branch to each volar interosseous enters the proximal third of the muscle. To each dorsal interosseous a branch is given which enters between the two heads. These branches may be variously combined before entering the interosseous muscles. The nerve fibres arise from the eighth cervical and first thoracic nerves.

Fig. 379.-The Dorsal Interossei.

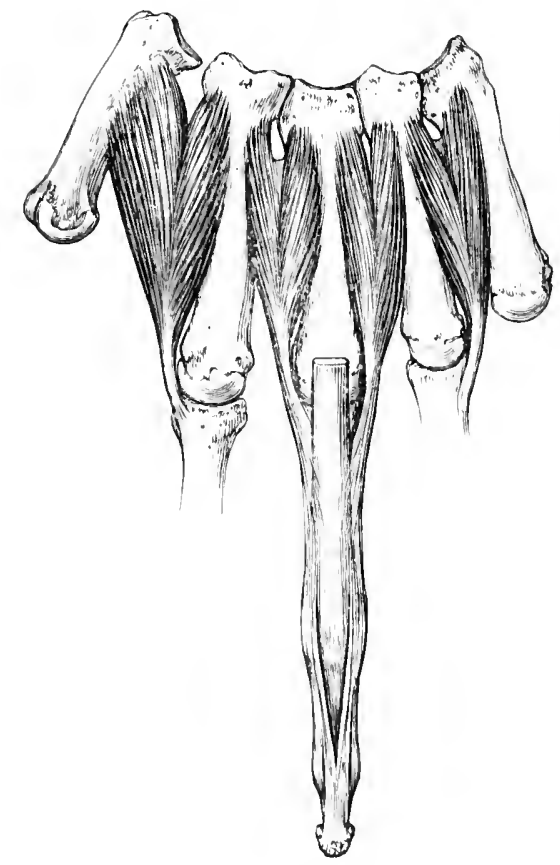

Action,-To move the fingers toward the ralial and ulnar sides, to flex the first phalanx and extend the second and third. The volar interossei move the fingers toward the median axis, the dorsal from it.

Relations.- The volar interossei lie volarward from the dorsal interossei. The two sets of musctes are bound in place by the dorsal and volar metacarpal fasciæ. The tendons pass out on the rlorsal sirle of the transverse capitular ligament and are closely applied to the metacarpophalangeal juints. The muscles of the first two interspaces lie immediately dorsal to the adductor of the thimb; the others dorsal to the flexor tendons.

Variutions. - The tendon slip from an interosseous niusele to the base of the first phalanx of a digit may be missing. This is more frequent in case of the volar than in that of the dorsal introssej, and in the medial than the lateral muscles. Either a volar or a dorsal interosseous muscle may be domble or missing. Rarely the insertions of the interosseous muscles eliaraeteristic of the foot (soe , 499 ) maty loe fomid in the hand.

\section{SPINAL MUSCULA'TURE}

$$
\text { ( ligs. 380, 381, 382, 38:3) }
$$

'Throspinal (vertehral) column is of special interest as the segmented longitudinal axial support of the looly which has given rise to the term "vertebrates" as appliefl to the class of animals of which man is the highest form. The segmentation in fishes permits the latoral movements of the borly which are their chief means of propmlsiom. In the land vertehrates, with the exception of snakes, the limbs are leveloped as the chicf orgins of propulsion but flexibility of the column 
is retained for the sake of freedom of movement. In man the spinal column, with the exception of the sacral region, may be readily extended (bent backward) and flexed (bent forward), abducted (bent to the side) and rotated. Freedom of movement is greatest in the cervical and lumbar regions and is restricted by the thorax in the thoracic region. The cervical region allows consiclerable flexion. extension and rotation, but a more limited abduction. In the thoracic region rotation and abduction are freer than flexion and extension. The lumbar region is that in which the chief flexion and extension of the trunk takes place, but abduction and rotation are limited, especially the latter. In the isolated articulated spinal column freedom of movement of the various parts depends chiefly upon the thickness and elasticity of the intervertebral discs, upon the conformation of the articular processes, and upon the elasticity or arrangement of the various ligaments uniting the vertebræ. In the living body freedom of movement is further restricted by the musculature and skeletal apparatus attached to the column. There is much individual variation in the flexibility of the vertebral column.

The various movements of the column are produced partly by muscles which act directly on it and partly by muscles which act on it through the head, thorax or pelvis. Most of the muscles which act on it directly belong to the intrinsic dorsal musculature; that is, to musculature which is derived from the dorsal divisions of the myotomes and is innervated by the dorsal divisions of the spinal nerves. This musculature extends from the sacrum to the skull and is closely applied on each side of the mid-dorsal line of the body to the backs of the vertebræ and the back of the thorax (fig. 381). Its chief function is to extend the spinal column and head, hence the old term applied to the superficial portion of this musculature "erector spinæ." During the development of the body, muscles belonging to the ventro-lateral thoracic musculature and to the upper extremity come to overlie in part the intrinsic dorsal musculature. The trapezius and rhomboid muscles which cover it in the cervical and thoracic regions, and the latissimus dorsi which covers it in the thoracic and lumbar regions belong to the shoulder girdle and arm and have already been described, p. 360. The serratus posterior superior, which overlaps it in the upper thoracic region, and the serratus posterior inferior, which overlaps it at the junction of the thoracic and lumbar regions, are derived from the intercostal musculature which is described below, p. 422 (fig. 380 ). All of these muscles are innervated by the ventro-lateral divisions of the spinal nerves. The levatores costarum (fig. 380), which extend from the transverse process of the thoracic vertebræ to the ribs, and which, in spite of their name, act chiefly on the spinal column, are derived from the external intercostal musculature and are innervated by the intercostal nerves.

Ventral to the spinal column and closely applied to it there are a few muscles, the chief function of which is to flex the column. All are supplied by branches from the ventro-lateral divisions of the spinal nerves. Of these the longissimus colli and longissimus capitis and scalene muscles have been described in connection with the muscles of the neck, p. 353. In the thoracic region there are no muscles of this type. In the lumbar region there are four muscles on each side, the pillars of the diaphragm, fig. 391, the psoas minor, fig. 391, the psoas major, fig. 391, and the quadratus lumborum, fig. 391. All of these muscles are flexors of the spine, excent the quadratus, which is an extensor. The psoas major muscle is also a flexor of the thigh. Even more powerful flexors of the column than those above mentioned are some of those which work indirectly upon it through the leverage offered by the skull (sterno-cleido-mastoid described above, p. 347), and the thorax (the ventro-lateral abdominal musculature).

Abduction and rotation of the spine are produced by contraction of muscles on one side while the corresponding muscles on the other side are relaxed. See Table, p. 502.

In the present section we shall confine our attention to the intrinsic dorsal musculature, leaving for consideration elsewhere the other musculature which acts on the vertebral column.

The intrinsic dorsal musculature is attached to the sacrum, to the ilium, to the spines, transverse, and articular processes and laminæ of the lumbar, thoracic, and cervical vertebræ, to the backs of the ribs and to the base of the skull. 'Two great longitudinal subdivisions may be recognised, a lateral, supplied by lateral branches of the posterior divisions of the spinal nerves, and a medial, supplied by medial branches. The lateral portion is further divisible into a superficial division, consisting chiefly of systems of rnuscles extending laterally from the spines of the vertebræ upward toward the transverse processes of the vertebre, the ribs, and the mastoid process of the skull; and a deep division, consisting of muscles which extend between successive transverse processes. The medial portion likerise consists of two parts; a superficial medial composed of fasciculi extending from inferior to superior spines, best developed in the dorsal region, and a deep portion consisting mainly of muscle fasciculi which pass from the transverse processes upward toward the spines of vertebra situated more cranially. In the neck the more superficial extend to the base of the skull. Between the base of the skull and the first two vertebræ there are several specialised muscles. There is also frequently present the rudimentary sacro-coccygeus posterior described on p. 448 , which represents an extension into the caudal region of the intrinsic dorsal musculature. 
The superficial lateral dorsal musculature consists of the splenius and the sacrospinalis. The splenius (fig. 380) is a flat, somewhat triangular muscle, which extends from the cervical and upper thoracic spines to the upper cervical transverse processes and to the mastoid process of the temporal bone and the neighbouring part of the occipital. The sacro-spinalis (erector spinæ) (fig. 381) is the name given to a mass of musculature which takes its origin from the ilium, the sacrum, and the lumbar spines. In the lumbar region this muscle divides into its two chief portions, the ilio-costalis and the longissimus. The ilio-costalis (fig. 382) is attached to the lumbar transverse processes and to the ribs near the angles, and is continued upward by accessory faseiculi along the back of the thorax to the transverse processes of the cervical vertebre. The longissimus (fig. 382) extends upward between the ilio-costalis and the spines of the lumbar and thoracic vertebræ. It is attached to the transverse processes of the lumbar and thoracic vertebræ and to the ribs lateral to the transverse processes. It is continued to the transverse processes of the cervical vertebræ and to the skull by accessory muscle ships.

The deep lateral dorsal musculature consists of the dorsal intertransverse muscles. The intertransverse muscles are best developed in the cervical and lumbar regions. In the cervical region intertransverse muscles belonging to the dor. sal musculature extend between the successive dorsal tubercles, while intertransverse muscles belonging to the ventral musculature extend between the ventral tubercles. The latter, as well as the rectus capitis anterior and rectus capitis lateralis, which belong in the series, have been deseribed above (p. 356). In the lumbar region there are also two sets of intertransverse muscles, one belonging to the ventral and one to the dorsal musculature.

The superficial medial dorsal musculature consists of the spinalis dorsi and cervieis. The spinalis dorsi (fig. 381) is intimately fused with the longissimus. It extends from the lower to the upper thoracic spines, and is derived from the medial dorsal musculature. The inconstant spinalis cervicis, which extends from the upper thoracic to the lower cervical spines, is likewise derived from the medial dorsal museulature, but is less intimately related to the longissimus.

The deep medial dorsal musculature (fig. 383) lies in the groove between the transverse processes and the spines of the sacral, lumbar, thoracic, and cervical vertebre. It extends from the sacrum to the skull, and is best developed in the lumbar and cervical regions. It is subdivided into a vertebro-occipital muscle (semispinalis eapitis), a transverso-spinal group, and the interspinal muscles. The semispinalis capitis (complexus) (fig. 381) arises from the transverse processes of the third cervical to the sixth thoracic vertebra and from the spines of the upper thoracic vertebre and is inserted into the base of the skull. The transverso-spinal group (fig. 383) extends from the sacrum to the second cervical vertebra. It is more or less artificially divisible into several layers. In the superficial layer, the semispinalis dorsi et cervicis, which extends from the tweifth thoracic to the second cervical vertebra, the constituent fasciculi extend from the transverse process of one vertebra to the spine of a vertebra four to six segments above. In the middle layer, the multifidus, the faseiculi extend over from two to four vertebræ. In the deepest layer, the rotatores, the faseieuli extend to the next vertebra (short rotators) or to the second vertebra above (long rotators). The interspinal muscles extend between successive spines.

The muscles which pass from the first two vertebra to the base of the skull behind, or subuccipital muscles (fig. 382), consist of the rectus capitis posterior minor, from the spine of the atlas to beneath the inferior nuchal line of the occipital and rectus capitis posterior major, from the spine of the epistropheus (axis) to beneath the infroror nuchal line, lateral to the preceling; of the obliquas capitis inferior, from the spine of the epistrophens (axis) to the transverse process of the atlas, and the obliqums copilis superior, from the transverse process of the atlas to the base of the lateral part of the inferior nuchal line of the occipital above the iectus mojor.

The mimitive condition of the dorsal musculature is one of metameric segmentation. This is chitranteristio of fishes, matuy amphiliat, and of the embryos of all higher vertebrates. In

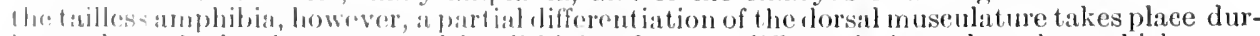
ing andoryonis devolopment, and in all highor forms a differentiation takes place whieh eorrespomb in many ways to that rescribud above for man. Acoording to Favaro, the splenius is differentiatier] from the merlial dorsal systen, but its imervation should place it with the lateral systern. In tho human embryo the dorsal seguncutal musculature extends into the tail region, but afterward lare: undergoes retrograde motamorplusis. 


\section{FASCI E}

The intrinsic musculature of the back serves to extend, bend from side to side, and to rotate the spinal column and head. The muscles attached to the ribs depress the thorax.

Fig. 3S0.-The Third and Fourth Layers of the Muscles of the Back. (Intrinsic Dorsal Musculatere)

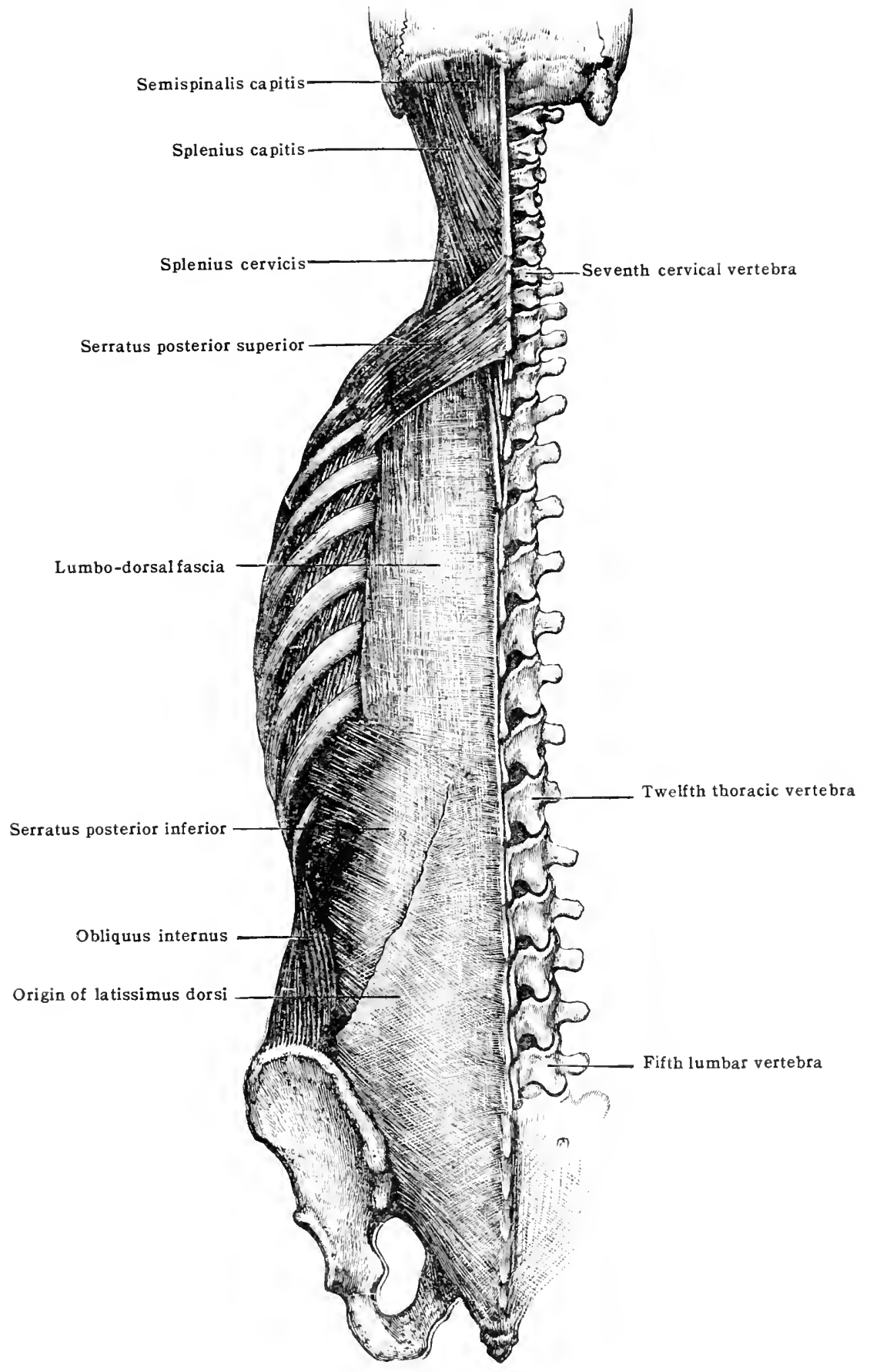

\section{FASCIE}

The fasciæ and the general relations of the muscles of the back may be followed in the crosssections shown in figs. $347,351,357,384$, and 407 .

The tela subcutanea of the upper dorsal region has been described in connection with the muscles of the shoulder girdle (p. 347). It is thick, fibrous, and adherent. In the lower dorsal 
region it is somewhat less compact, but is thicker and contains more fat. It is usually divisible into two layers, of which the deeper is adherent to the lumbodorsal fascia.

The splenius (fig. 380 ) is enveloped in a thin, adherent fascial covering. The sacro-spinalis is covered by a fascia, the fascia lumbo-dorsalis (fig. 380), which inferiorly is attached to the iliac erest, the distal and lateral margins of the sacrum, and the sacral spines. In the lumbar and thoracic regions it is attached medially to the vertebral spines. Laterally, in the lumbar region, it is reflected around the muscle to its ventral surface, where a 'ventral' or 'deep' layer forms an intermuscular septum (fig. 384) between the quadratus lumborum and the sacrospinalis. This intermuscular septum (fig. 383) extends from the twelf th rib to the iliac crest and the ilio-lumbar ligament, and is attached medially to the transverse processes of the lumbar vertebræ, from which fibre-bands extend laterally into it. It is strengthened above by fibrebundles which pass from the first and second lumbar vertebræ to the twelfth rib (lumbo-costal ligament). (For the relation of the abdominal museles to this fascia see p. 328.)

In the thoracic region (fig. 381 ) the lumbo-dorsal fascia is attached to the ribs lateral to the ilio-costal muscle. In the cervical region (fig. 351) the fascia is contiuued into the intermuscular septa which surround the muscles of this group in the neck.

The transverso-spinal muscles are covered throughout their extent by a fascial membrane which serves to separate them from the longissimus in the sacral, lumbar, and thoracic regions.

In the dorsal region of the neck (figs. $347,351,357$ ) the muscles are covered on each surface by adherent fascial sheets, fascia nuchæ, and are arranged in several concentric layers, each of which is separated from its neighbour's by dense fatty areolar tissue. The deepest of the layers is formed by the muscles of the transverso-spinal group. This is covered by a dense membrane, and is separated from the semispinalis capitis (complexus) by a thick layer of areolar tissue containing the chief blood-vessels and nerves of the neck. The semispinalis capitis (complexus) is covered on each surface by a more delicate adherent membrane, and is separated from the splenius by loose tissue. The splenius has a somewhat denser adherent fascial covering into which the fascia of the levator scapulæ is continued. Separated from this by areolar tissue lies the trapezius. The cervical and thoracic portions of the semispinalis are separated by delicate membranous septa from the semispinalis eapitis (complexus), the levator scapulæ, and the splenius. The muscles of each side are separated in the dorsal median plane by the dense ligamentum nuchæ, into which the various cervical septa and fasciæ extend. The suboccipital muscles are covered by fascial sheaths which are so fused as to constitute a special fascia for these muscles. Distally this is continued into the fascia of the transversospinal muscles.

\section{MUSCLES}

\section{A. Superficial Lateral Dorsal System}

The splenius (fig. 380). - The two parts of which this muscle is composed may be separately considered.

The splenius cervicis.-Origin.-By a narrow aponeurotic band from the spinous processes and the supraspinous ligament of the third to the sixth thoracic vertebra.

Structure and insertion.- The fibre-bundles extend upward and laterally and give rise to a flat muscle sheet from which fasciculi arise that are inserted by short tendinous processes on the posterior tubercles of the transverse processes of the first two or three cervical vertebræ. The processes are often united with those of the levator scapula and the longissimus cervicis.

The splenius capitis.-Origin.-From the ligamentum nuchæe in the region of the third to the seventh cervical vertelire and from the spinous processes and the supraspinous ligament of the first two to five tholacic vertebre.

Structure and insertion.-The fibre-bundles form a sheet which continues cranialward that of the splenius cervicis. The fibre-bundles converge somewhat and are inserted by a short, broad, thick tendon into-(1) the back, the side, and the tip of the mastoid process below the sterno-cleido-mastoid muscle, and (2) into the neighbouring part of the occipital bone.

Relations. - The splenius lies dorsal to the semispinalis capitis (complexus) and to the cervical (trausversalis cervieis) and the cranial (trachelo-mastoid) portions of the longissimus and the cervical portion (cervicalis ascendens) of the ilio-costalis and to the levator scapulie, and is partly covered by the trapezius, sterno-cleido-mastoid, serratus posterior superior, and the rhomboids. In the triangie bounded by the trapezius, sterno-cleido-nastoid, and the levator scupulic it is subeutaneous

Nerer-supply--The lateral branches of the posterior divisions of the second, third and fourth (sometines idso of the first, the fifth and the sixth) (cervical nerves give off rami which enter the deep surface of the musele.

Action.- Tu incline and rotate the head and neck toward the side on which the muscle is placerl. When lwth muscles act, the head and neck are extended.

lariations. ']le extent of separation and of fusion of the two museles varies. Absence of either muscle is rate. The splenius eapitis may be divided into mastoid and oceipital portions. The attanhment of the muscle also varies somewhat. Oceasionally the spinal origin of the splenins may exteml to the "ranial end of the liganentum mohe. The origin may extend laterally wer the fascia covering the decper lorsal muscles. An acessory slip, the splenius cervicis accessorius, separated from the main muscle by the tendon of the serratus posterior superior, is freguently (s per cent. of instunces, led)ouble) found to run from the lower eervical or upper thoracic vertobar to the trusterse process of the atlas.

The sacro-spinalis (ercetor spina:).-Origin.-(1) from a strong aponeurosis attached to He spines of the lmmbar, and the sacral vertebre, to the ligunent passing from the sacrum to the coceys, to thr; lateral sacral crest, the sacro-tuberous ligament, the long posterior sacro-iliac ligunent, and to the dorsal fifth of the iliate erest; (2) directly from the iliae crest in front of and buterial to the atumbent of the aponeurosis; and (3) from the short posterior sacro-iliac 
ligaments. The aponeurosis covers the muscles of the sacral region and is there united to the overlying fascia by more or less dense areolar tissue. Opposite the iliac crest fibre-bundle: begin to take origin from the lateral margin of the dorsal surface as well as from the deep or

Fig. 381.-The Fifth Layer of the Muscles of the Back.

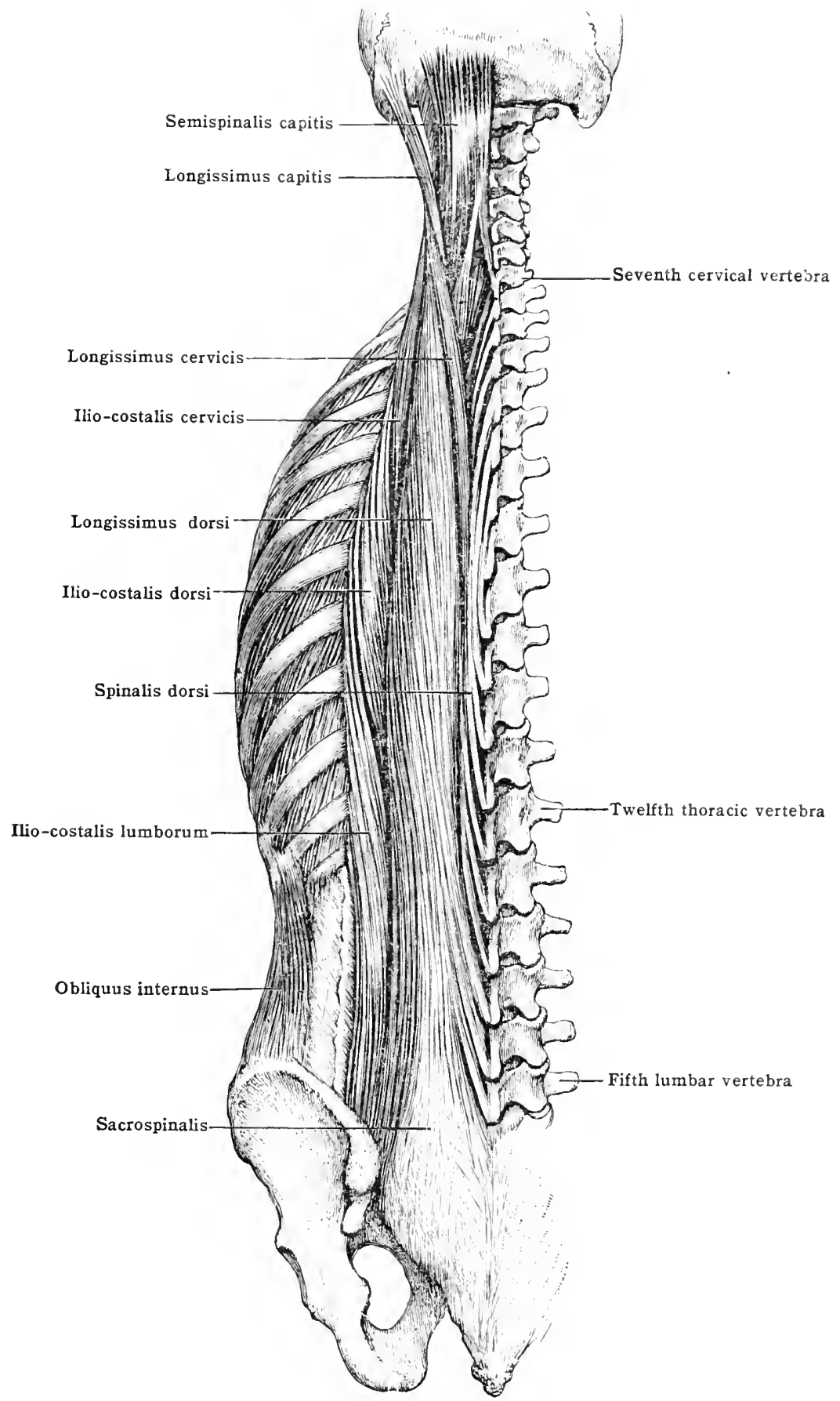

ventral surface of the aponeurosis of origin, and gradually the line of dorsal attachment extends medially until, in the lower thoracic region, the tendon becomes completely embedded in the muscle-fasciculi which take their origin from it. The aponeurosis, which is the strongest in the lower lumbar region, is composed chiefly of fibres which take a direction upward and somewhat lateralward. 
In the lower lumbar region the sacro-spinalis (erector spinæ) muscle begins to show a listinet division into its two chief component parts, the ilio-costalis and the longissimus. The parts of which the ilio-costalis and longissimus are composed will be taken up separately.

The ilio-costalis lumborum (figs. 381, 382).-Origin.-(1) Chiefly from the baek of the sacrospinal aponeurosis, medial to and eranialward from the iliae crest, and (2) from the iliac crest directly: The deep medial surface of the muscle is closely united in the lumbar region to the longissinus.

Structure and insertion.-From the mass of fibre-bundles which compose the musele, fasciculi are given off which are attached ehiefly by tendinous slips to-(1) the tips of the transveree processes of the lumbar vertebra; $(2)$ the fibrous processes which extend lateratward from the tips of the transverse processes of the upper lumbar vertebræ into the anterior layer of the lumbodorsal fascia; (3) the inferior margin of the last six or seven ribs near the angles. The insertions int o the lumbo-dorsal fascia and the twelf th rib are usually fleshy. The portions attached to the lumbar vertebra are by some considered to belong to the longissimus (Eisler).

Relations.-The muscle lies on the lateral margin of the longissimus and upon the ribs and the external intercostal and levatores costarum muscles, and under the axio-appendicular muscles described above.

The ilio-costalis dorsi (accessorius).-Origin.-By fleshy faseieuli from the superior borders of the lower seven ribs medial to the angles.

Structure and insertion.-The slips of origin lie beneath the preceding portion of the muscle, pass medial to and partly fuse with it, and give rise to a belly from which tendinous slips extend to be inserted into the upper seven ribs near their angles and to the transverse process of the seventh cervical vertebra.

Relations.-The muscle lies upon the ribs and the external intercostal museles lateral to the longissimus.

The ilio-costalis cervicis (cervicalis ascendens).-Origin.-By fleshy slips from the upper borlers near the angles of the seventh to the third (sometimes to the second or first) ribs.

Structure and insertion.--The slips of origin are eovered by the slips of insertion of the dorsal portion (accessorius). They emerge medial to them and give rise to a fleshy belly from which tendons pass to the backs of the transverse processes of the sixth to the fourth cervieal vertebræ.

Relations.-The scalenus posterior lies in front, the levator scapula at the side, and the splenius and longissinus (transversalis) eervicis medial to this muscle.

A bursa is frequently found between the muscle and the tubercle of the first rib.

The longissimus dorsi (figs. 381, 382).-Origin.-(1) From the deep surfaee of the saerospinal aponeurosis; (2) from the short posterior sacro-iliae ligaments; and (3) through accessory lips which arise from the transverse processes of the first two lumbar and the last five or six thoracic vertebrie. In the lumbar region it is fused dorso-laterally with the ilio-eostalis.

Structure and insertion.-From the muscle mass arise fasciculi which are inserted partly directly, partly by means of tendons, into-(1) the lower border of the baek of the transverse processes of the lumbar vertebre and the inferior margins of the ribs lateral to the tubercles; and (2) the accessory tubercles of the lumbar and the tips and inferior margins of the transverse processes of the thoracic vertebre. The attachment to the first rib is usually wanting. The attachment to the first five ribs may fail. The medial attachments seldom extend to the first vertebra.

Relations.-The lateral margin of the muscle is covered by the ilio-eostalis. Medially it overlies the transverso-spinal museles. The lateral branches of the clorsal veins, arteries, and nerves pass mainly in the fibrous tissue whieh separates the longissimus from the ilio-eostalis, the medial branches chiefly between the longissimus and the transverso-spinal muscles. 'The relations to the axio-appenilicular museles and to the dorsal fascia have been pointed out above. Ventrally it lies upon the intertransverse museles, the external intercostals, and the levatores ('ostarum.

The Iongissimus cervicis (transversalis cervicis).-Origin.-By tendinous slips from the transverse processes of the first four to six thoracic vertebre.

Structure and insertion. - The fasciculi which arise from these slips give rise to a musele belly from which tendons of insertion extend to the posterior tubereles of the transverse processes of the mirl-rervical (second to sixth) vertebra.

liclations:- This muscle lies between the longissimus dorsi and capitis with which it is to some cxtent fused and the ilio-costalis dorsi (accessorius) and cervicis (cerviealis aseendens) minseless.

The longissimus capitis (trachelo-mastoid). - Origin.-By tendinous slips from the transrorse processes of the first three or four thoracic vertebra and the articular processes of the last four rervional.

Sirurlure and insertion. - The muscle fasciculi arising from these tendons form a belly which is united to the mastoid process by a short tendon. A tendinous inseription of ten crosses the ImIlsisele.

lirtations.- It lins ventral to the splenius aptis, lateral to the semispmalis capitis (com-

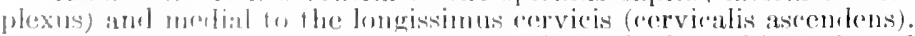

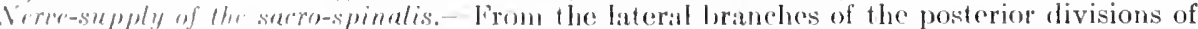
the spinal nerves. Ther axart distribution of these brandhes is ton complex to be treated here. The nerves forthe ilie-entatis arise from the eighth repviad to the first lumbar, those for the lengisimas from the first arerviral to the fifth lambar.

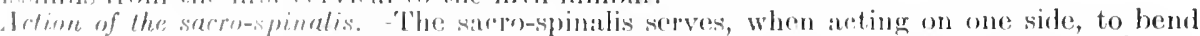
the spinal colunn towarl that side, and when ateting on both sides, to extent the spinal column. The rantal portions of the musele serve to inchine the locul towarl the same sirle, and when

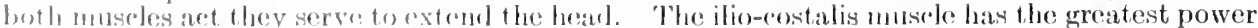
for profucing laterial inclination. The ilio-costalis lumborum dopresses the ribs, while the

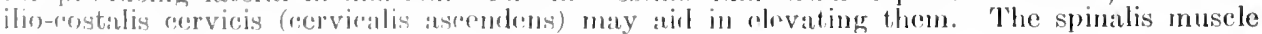
serves merely ity an extensor. 
Variations of the sacro-spinalis.-The slips of origin and insertion of the various parts of - this muscle and the extent of fusion of the various parts vary greatly. Statistical data from which the most frequent conditions might be determined are wanting. Tendinous inscriptions may extend across the longissimus cervicis and other parts of the sacro-spinalis.

\section{B. Deep Lateral Dorsal System}

The intertransversarii.-These are vertical bands composed of short bundles which pass between the transverse processes of the cervical, lumbar, and the lower thoraric vertebre.

(a) Cervical (fig. 349).- Ventral, lateral and dorsal muscles are found in the cervical region The ventral and lateral muscles run between the ventral tubercles and tips of the transverse processes of the vertebræ, are homologous with the intercostal nuscles, are supplied by branches from the anterior divisions of the corresponding spinal nerves, and have leen descrited above (p. 356). The dorsal muscles run between the dorsal tubercles and belong to the intrinsic. dorsal musculature. They are supplied by the lateral branches of the posterior divisions of the cervical nerves.* ${ }^{*}$ The three sets of muscles are, however, more or less fused. The first pair of muscles extends between the atlas and axis, the lowest passes to the transverse process of the first thoracic vertebra, or to the frst rib close to this. The obliquus capitis superim (described later) belongs, however, to the posterior set of muscles, the rcctus capitis lateralis (p. 3.56) to the lateral set. The vertebral artery runs vertically between each pair of muscles above the sixth, and the anterior division of each cervical nerve passes laterally between the artery and the dorsal muscle in each space, and then out between the ventral and lateral muscles. "The posterior division of each cervical nerve passes medial to each dorsal muscle.

(b) Thoracic.- Small muscle fasciculi may extend between the transverse processes of the thoracic vertebræ and between the last thoracic and first lumbar. They are most frequent in the upper and lower thoracic regions. Often they are replaced by tendinous bands. In the second interspace the insertion may extend to the rib near the transverse process. The innervation is from the lateral branches of the posterior divisions of the spinal nerves.

(c) Lumbar (fig. 3S3). - In the lumbar region there is a lateral set of muscles connecting the adjacent margins of the transverse processes and a medial comnecting the mammary tubercle of one vertebra to the maminary or the accessory tubercle of the vertebra next above. They extend between each two of the five lumbar vertebre and sometimes also to the first sacral. They lie between the sacrospinalis and psoas muscles. The medial muscles are supplied by the lateral branches of the posterior divisions of the spinal nerves. The lateral muscles are supplied by branches from the junction between the two divisions of the corresponding spinal nerves. These branches probably belong to the anterior divisions.

Action.-The intertransverse muscles bend the spinal column laterally, and when acting on both sides, make it rigid.

Variations.-The number of intertransverse spaces occupied by the museles varies, especially in the thoracic region. They may be doubled or extend over more than one interspace.

\section{Superfictal Medial Dorsal Sistem}

The spinalis dorsi.-Origin.-By tendinous bands from the tips of the two upper lumbar and the last two thoracic spines.

Structure and inscrtion.-From the deep surface of the tendinous bands there arises a long slender muscle belly which is fused laterally with the longissimus dorsi. It is attached by tendinous processes to the spines of the upper thoracic vertebre, usually the second or third to the ninth.

Nerec-supply.-From the medial divisions of the sixth to ninth thoracic nerves.

The spinalis cervicis.--A muscle of inconstant development which arises from the spines of the two upper thoracic and two lower cervical vertebra and extends to the spines of the second to the fourth cervical vertebre. The nerve supply is from the dorsal divisions of the lower cervical nerves.

Action.-To extend the vertebral column.

Variation.-There is great variation in the development of the spinalis muscles. Similar fasciculi are sometimes found in the lumbar region and in the cervical region sometimes extend to the skull.

\section{Deep Mediat, Dorsal, System}

\section{Vertebro-occipital Muscle}

The semispinalis capitis (complexus) (fig. 381). - This muscle is usually separaterl from the semispinalis muscles of the back and neek by a well-marked septum and has a distinctive structure.

Origin.-(1) By long tendinous fasciculi from the tips of the transverse processes of the upper five or six thoracic vertebrie and of the seventh cervical vertebra; (2) by short fleshy processes from the articular processes and bases of the transverse processes of the third to the sixth cervical vertebræ; and (3) by delicate fleshy fasciculi from the spinous processes of the upper thoracic vertebrs.

Structure and insertion.-The slightly diverging fibre-bundles form a long, flat belly which is inserted, partly by means of an aponeurosis which covers the muscle laterally, into the lower

* According to Lickley, both sets of cervical intertransverse muscles are supplied by the anterior divisions of the spinal nerves. 
surface of the squamous portion of the occipital, between the superior and inferior nuchal lines. There is often a transverse tendinous inscription across the muscle opposite the sixth cervical vertebra, and less frequently one between the upper and middle thirds of the muscle. These

Fig. 382.-The Fifth Layer of the Muscles of the Back, after separating the Longissinus and Ilio-costalis Divisions.

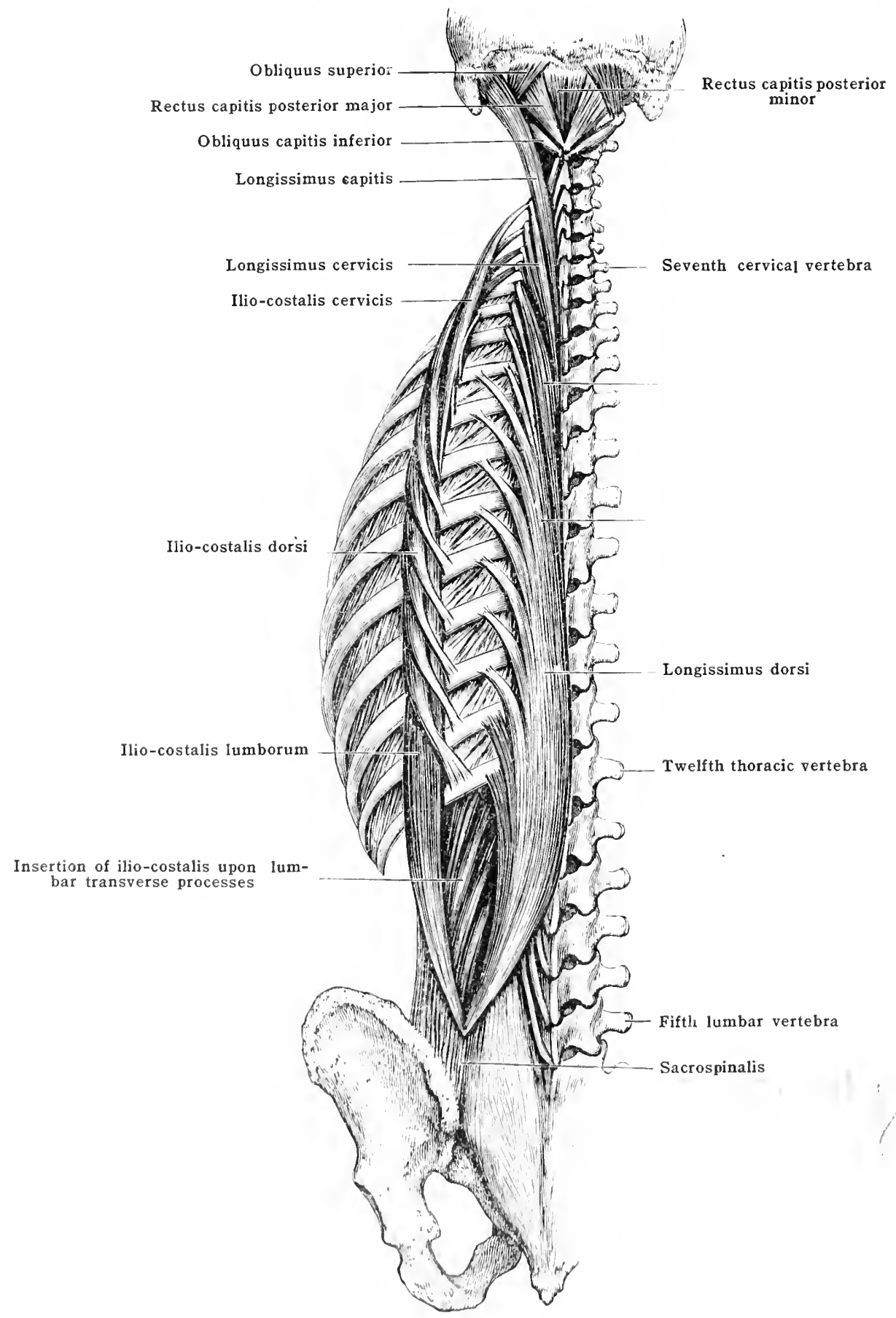

are best marked in the medial portion of the muscke, which eomes from the thoracic vertebræo and is sometines separately rlesignaten as the spinalis eapitis (biventer cervicis).

Wrres-supply.-It is supplienl chiefly by the medial branches of the posterior divisions of the first fonr or five cervical nerves. The muscle also gets some twigs from the lateral branches. 
Relations.-It lies dorso-lateral to the suboccipital muscles and to the semispinalis cervicis. From this latter it is separated by a septum containing the descending branch of the occipital artery, the deep cervical artery, and the medial dorsal branches of the cervical nerves. It is covered laterally by the longissimus capitis (trachelo-mastoid), and dorsally by the splenius, and above the upper margin of the splenius by the trapezius.

Action.-To extend the head and to incline it slightly toward the same side.

Variations. - The origiu of the muscle may extend to the eighth thoracic vertebra or merely to the first thoracic. It may be fused with the longissimus (transversalis) cervicis. A special fasciculus may run beneath the muscle from the upper thoracic vertebræ to the head. 'The origin from the spinous processes of the thoracic vertebræ is not constant. The part of the muscle arising from this origin may be looked upon as a spinalis capitis.

\section{Transverso-spinal Muscles}

The semispinalis dorsi et cervicis (fig. 383).-This superficial transverso-spinal muscle sheet extends from the twelf th thoracic to the second cervical vertebra. The fasciculi which compose it arise by short tendons from the backs of the transverse processes, and are inserted by short tendons into the spines.

The semispinalis dorsi.-Origin.-From the sixth to the tenth or twelf th thoracic vertebræ.

Insertion.- The upper four to six thoracic and the last two cervical vertebræ. The fasciculi extend over four to six vertebræ.

Nerve-supply. - Third to sixth thoracic.

The semispinalis cervicis.-Origin.-From the upper five or six thoracic vertebræ.

Insertion. - Into the fifth to the second cervical vertebre. The fasciculi extend over four to five vertebræ.

Nerve-supply. - Third to sisth cervical.

Relations. - This muscle lies beneath the longissimus dorsi and the semispinalis capitis (complexus) and over the following musculature.

Variations.-A semispinalis lumborum is a muscle rarely found extending from the lumbar to the lower thoracic vertebræ.

The multifidus (fig. 383).- This second layer of transverso-spinal musculature extends from the sacrum to the second cervical vertebra. It is best developed in the lumbar region and least so in the thoracie.

Origin.-(1) From the groove on the back of the sacrum between the spines and the articular elevations, from the dorsal sacro-iliac ligaments, from the dorsal end of the iliac crest, and from the deep surface of the aponeurosis of the sacrospinal muscle; (2) from the mammary and accessory processes of the lumbar vertebræ; (3) from the backs of the transverse processes of the thoracic vertebre; and (4) from the articular processes of the fourth to the seventh cervical vertebræ and the back of the transverse process of the seventh.

Insertion.- Spinous processes of the lumbar, thoracic, and lower six cervical vertebræ.

Structure.-The more superficial fasciculi arise by short tendinous processes, the deeper ones directly. The more superficial fasciculi extend to the fourth or fifth vertebra above, the middle to the third, and the deepest to the second above.

The rotatores. - These, the third layer of transverso-spinal muscles, extend from the sacrum to the second cervical vertebra. They are composed of short fleshy fasciculi which extend to the second vertebra above (rotatores longi) and to the first above (rotatores breves). The fasciculi arise from the back and upper borders of the transverse processes or their homologues, and are inserted into the laminæ of the preceding vertebræ. They are best developed in the thoracic region. Some authors consider the rotatores breves confined to the thoracic region. In the cervical region the fasciculi usually run from articular processes to the bases of the spines, in the lumbar region from the mammary processes to the caudal margin of the laminæ of the arches.

\section{The Interspinal Muscles}

The interspinales consist of short fasciculi which extend from the upper surface of the spine of each vertebra near its tip to the lower surface of the spine of the vertebra above. In the neck the muscles lie in pairs between the bifid extremities of the vertebræ. In the lumbar region they form broad bands attached to the whole length of the spinous processes and are separated by the interspinous ligaments. Iu the thoracic region they usually are undeveloped.

Nerve-supply of medial dorsal muscles.-These are all supplied by the medial branches of the posterior divisions of the spinal nerves.

Action of medial dorsal muscles.-These muscles extend the spinal column when acting on both sides. When acting on one side, they produce a movement of rotation toward the opposite side.

\section{E. Suboccipital Muscles}

$$
\text { (Figs. 382, 383) }
$$

The rectus capitis posterior major.-Origin.-From the upper surface of the spine of the epistropheus.

Structure and insertion.-The muscle-fibres diverge to form a broad triangular band which is inserted into the lateral half of the inferior nuchal line of the occipital bone and the area below it. Its insertion is immediately below that of the obliquus superior.

The rectus capitis posterior minor.-Origin.-From the upper part of the side of the posterior tubercle of the atlas. 
Structure and insertion.-The fibre-bundles diverge to form a flat, triangular sheet inserted below the medial third of the inferior nuchal line of the occipital bone on the inferior surface of the squama occipitalis.

The obliquus capitis inferior.-Origin.-From the upper part of the side of the spine of the epistropheus (axis).

Structure and insertion.-The fibre-bundles form a fusiform belly which is inserted by a short tendon into the lower part of the tip of the transverse process of the atlas.

Fig. 383,-The Transverso-spinalis.

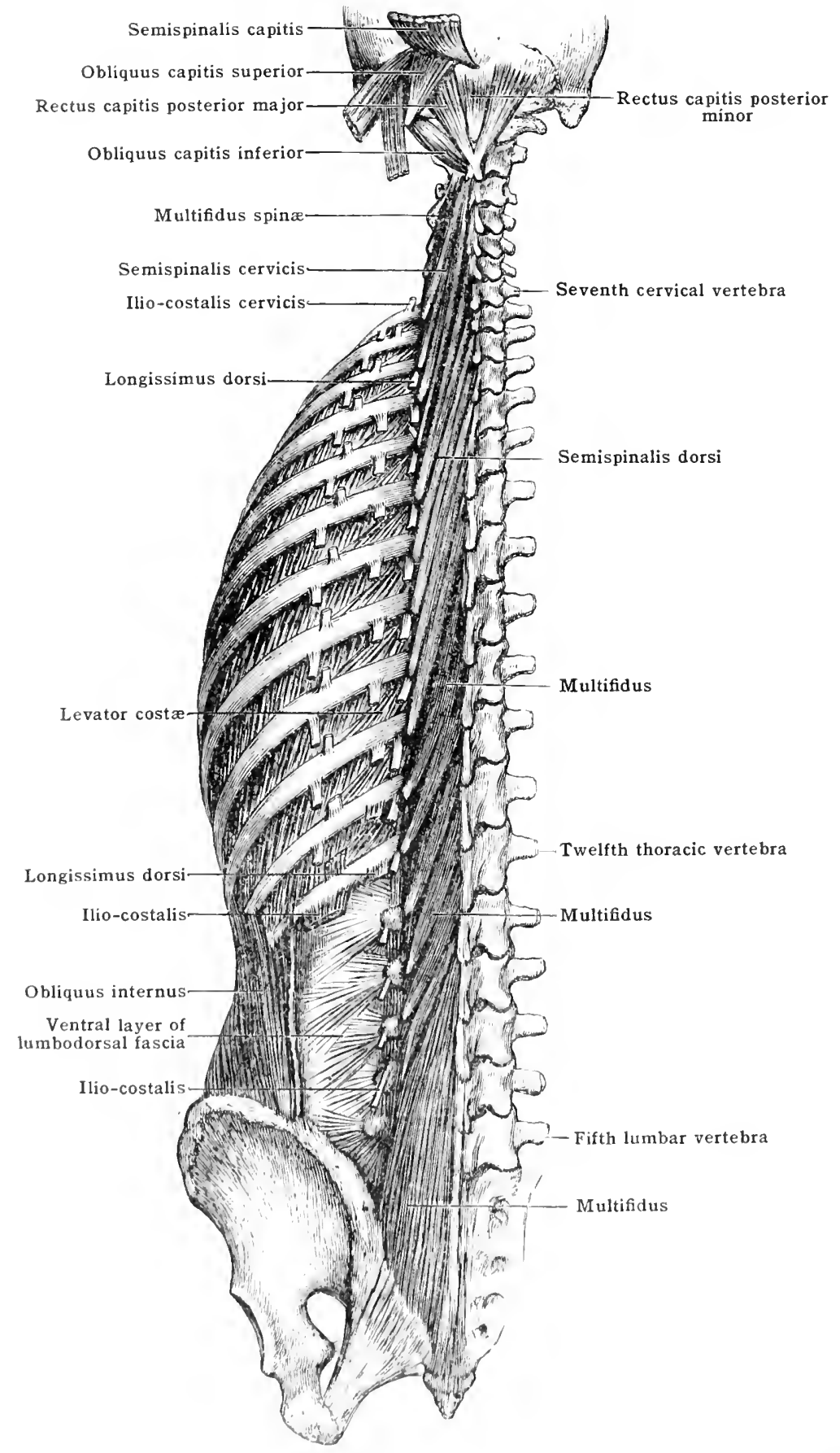

The obliquus capitis superior. (Jigin. From the back of the upper part of the trans-

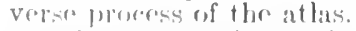

stemetere amb insertion. The fibre-bundles diverge to form a flat, triangular muscle, insertorl into the lateral third of the inforior mulual line of the ocripital bone, and above the lateral part of the insertion of the rectus calpitis posterior major. 
Fig. 384, A and B.-Sections throvgh the Left Side of the Trunk in the Regrons showa in the Diagrair.

The muscles of the body wall have been slightly pulled apart in order to reveal the relations of muscles, fasciæ, and aponeuroses. $a$ and $b$ in the diagram indicate sections $A$ and $B$, fig. 351 (p. 352); $a^{2}$ and $b^{2}$, sections $A$ and $B$, fig. 357 (p. 366); $a^{22^{4}}$ and $b^{2}$, sections $A$ and $B$, fig. 407 (p. 45 S).

I. Aorta. 2. Arteria mammaria interma. 3. Costa VI-a, cartilage. 4. Costa VII-a, eartilage. 5. Costa VIII. 6. Costa IX. 7. Costa X. 8. Costa XI. 9. Descending colon. 10. Diaphragm - a, costal portion; b, lumbar portion; $c$, sternal portion; d, centrum tendineum. 11. Fascia lumbodorsalis-a, anterior layer; b, posterior layer. 12. Faseia transversalis. 13. Flexura colica sinstra (splenic flexure). 14. Kidney. 15. Liver. 16. Linea alba. 17. Museuli intercostales externi-a, ligament. 15. MIm. intercostales interni. 19. M. ilio-costalis. 20. M. latissimus dorsi. 21. MI. levator coste. 22. MI. longissimus dorsi. 23. M. obliquus abrlominis externus. 24. M. obliquus abdominis internus. 25. M. psoas major. 26. MI. quadratus lumborum. 27. MI. rectus abdominis. 28. M. serratus posterior inferior. 29. MI. subcostalis. 30. MI. transrersus thoracis. 31. MI. transversus abdominis. 32. MIm. transverso-spinales. 33. MI. trapezius. 34. Nervus lumbalis I. 35. $\mathrm{N}$. thoracalis VI. 36. $\mathrm{N}$. thoracalis VII. $37 . \mathrm{N}$. thoracalis VIII. 38. $\mathrm{N}$. thoracalis IX. 39. $\mathrm{N}$. thoracalis $\mathbf{X}$. 40. $\mathrm{N}$. thoracalis $\mathrm{XI}$. 41. N. thoracalis XII. 42. Sympathetic trunk-a, great splanchnic nerve. 43. Omentum majus. 44. Esophagus. 45. Searpa's fascia. 46. Spleen. 47. Stomach. 48. Ureter. 49. Vertebra lumbalis II. 50. Vert. lumbalis III. 51. Vert thoracalis X.
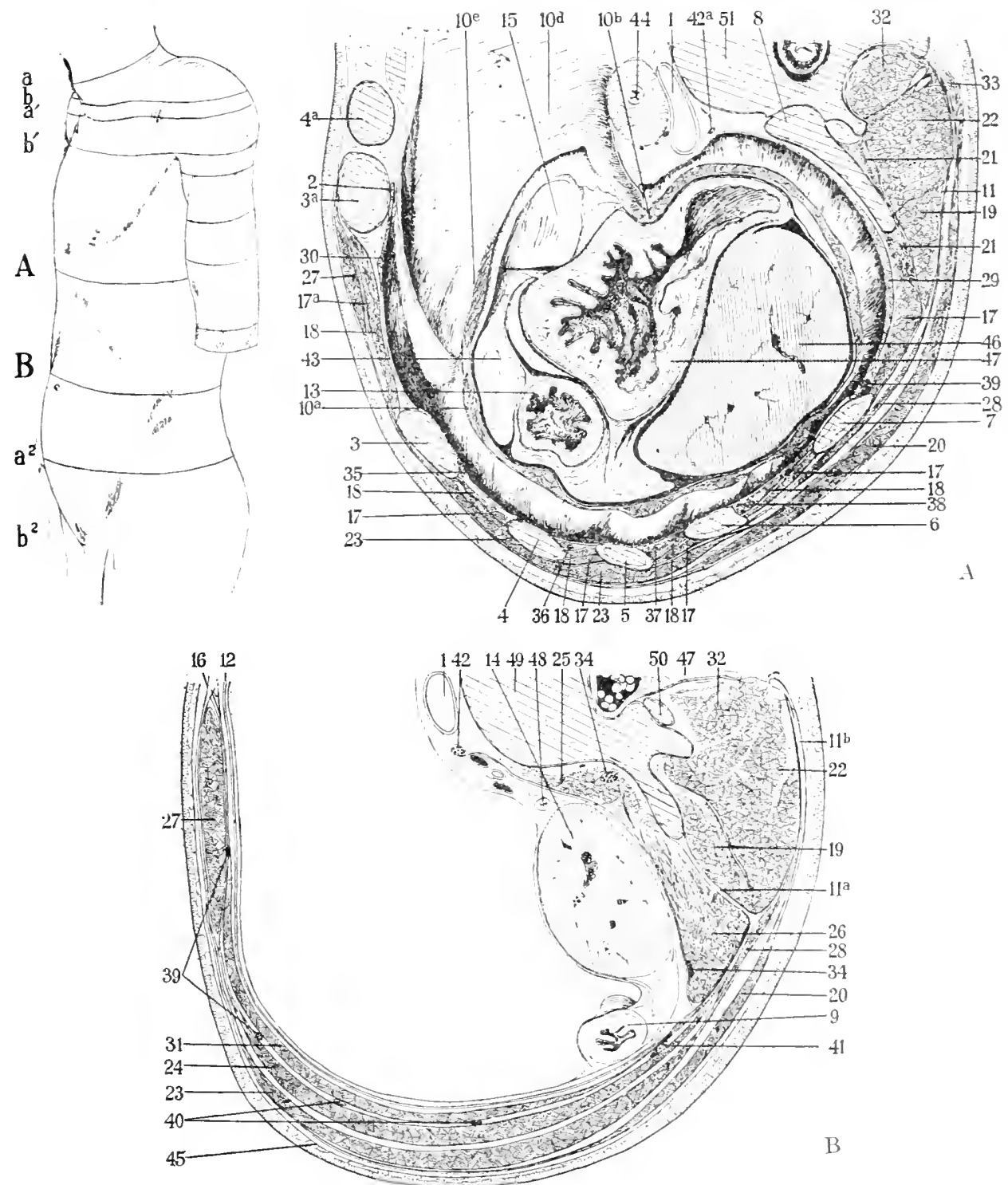
Nerve-supply.-These muscles are all supplied by the posterior branch of the suboccipital (first cervical) nerve. The branch to the two rectus muscles passes across the dorsal surface of the major rectus and supplies branches to the middle of the dorsal surface of each muscle. The branch to the superior oblique muscle enters the middle of the medial margin, that to the inferior oblique about the middle of its superior margin. The inferior oblique and major rectus muscles usually, the other muscles oceasionally, receive branches from the second cervical nerve.

Relations.-The two oblique muscles with the rectus major serve to bound a small triangular space, the suboccipital triangle, through which pass the dorsal division of the suboccipital nerve and the vertebral artery. The two minor recti lie on the atlanto-occipital membrane in the upper part of the space bounded by the major recti. The muscles are covered medially by the semispinalis capitis (complexus), laterally by the longissimus and splenius capitis. In front of the two oblique muscles and the major rectus runs the vertebral artery. The great occipital nerve runs betreen the semispinalis capitis (complexus) and the inferior oblique and the two recti in a dense fatty connective tissue containing the extensive suboccipital venous plexus.

Action.-The rectus muscles and the superior oblique draw the head backward. The rectus major and the inferior oblique, when acting on one side, rotate the face toward that side.

Tariations.-Each of these nuscles may be doubled by longitudinal division. Accessory slips may connect the two recti with the semispinalis capitis. The atlanto-mastoid is a small muscle frequently found. It passes from the transverse process of the atlas to the mastoid process.

\section{IIV. THE THORACIC-ABDOMINAL MUSCULATURE}

The thoracic and abdominal viscera are contained within cavities, the ventrolateral walls of which may be contracted and expanded by muscular action. The skeletal support for the intrinsic musculature of these walls consists of the ribs, the sternum and the vertebral column and the pelvis. The intrinsic musculature in the thoracic walls is situated chiefly between the ribs (intercostal muscles, figs. 385,386 ) while in the region of the abdomen it extends in broad sheets from the lower part of the thorax to the pelvis (the quadratus lumborum and the external and internal oblique, transverse, and rectus muscles, figs. 387, 388, 390, 406). Between the two cavities, attached to the lower part of the thorax and to the lumbar vertebræ lies the dome-shaped diaphragm (fig. 391). The thoracic cavity extends on each side slightly above the first rib. The abdominal cavity extends downward and backward into the pelvis, as the pelvic cavity.

The function of the intercostal muscles is to expand and contract the thoracic cavity for the sake of respiration. The shape of the ribs and their articulations with the vertebræ are such that a slight rotation of the neck of each rib will cause the shaft to swing outward and upward or in the reverse direction. The costal cartilages are elastic enough to permit this movement, and at the same time are strong enough to make the thorax an effective skeletal apparatus. Ninety joints are called into play in the movements of the thorax ( 24 between the heads of the ribs and the vertebræ, 20 between the tuberosities and the transverse processes of the vertebræ, 24 between the ribs and costal cartilages, 14 between the costal cartilages and the sternum, 6 between the costal cartilages and 2 intrasternal). When the shafts of ribs are swung outward and upward the thorax is enlarged in the antero-posterior and transverse axes. In the adult when standing the sternum may be raised nearly $3 \mathrm{~cm}$, and protruded $1 \mathrm{~cm}$. The cartilages of the lower ribs may be raised 4 to $5 \mathrm{~cm}$. The side of the thorax at the level of the second rib may be protruded $3 \mathrm{~cm}$., and at the level of the eighth rib nearly as far. This extent of movernent, however, is found only in forced respiration. In ordinary quiet respiration it is far less, the sternum being raised merely 3 or $4 \mathrm{~mm}$. and protruded $2 \mathrm{~mm}$., and the thorax is enlarged at the side merely $5 \mathrm{~mm}$. (R. Fiek). The chief muscles used in quiet inspiration are the external intercostals and the intercartilaginous parts of the internal intercostals.

During inspiration the diaphragm contracts so that the thoracic eavity is further enlarged perpendicularly. The extent of movement of the upper part of the diaphragm is estimated by R. lick at from $1 \frac{1}{2}-3 \mathrm{~cm}$.

The ventro-literal abdominal museles contract the thoracic cavity by depressing the thorax and by pushing the diinphragm upward. They direetly contract the abdominal eavity. Contraction of the alidominal eavity is of aid in defecation and parturition. The abdominal muscles are also of value in flexion, abduction, and rotation of the vertebral column and pelvis.

The therax, with ite intrinsic musculature, is in large part covered by the museulature which extends from the trunk to the shoukder girdle and arm; dorsally by the trapezius and rhomboids, ventrally ly the pectoral museles, and laterally by the scrratus interior and the latissimus dorsi, as well as by the seapula and the muscles which pass from it to the humerus. The upper extremity on cach side is largely supported from the spine by the trapezins, rhomboid and levator sc:apula muscles but it none the less exerts some pressure on the thorax and interferes to some extent with respiration. If the girdle and arm are fixed or raised the muscles which yass from them to the thorax are an aid in fored inspiration. Aclvantage of this is taken when in artificial respiration the arms are raised so as to lift the ribs through traction by the latissimus dorsi, the pectoralis muscles and the subelivius. Some of the museles of the neck, especially the scalene muscles mot the sterno-cleido-mastoid, are likewise of value in forced inspiration. 
Expiration is produced not only by the part of the internal intercostals which lie between the bony ribs, and by the abdominal museles, but also by the lumbar ilio-costales and by the quad. ratus lumborum.

The intrinsic muscles of the thorax and abdomen are derived from the trielve thoracic myotomes and the first one or two lumbar and are innervated by the corresponding nerves, while the musculature of the shoulder girdle and arm which covers the intrinsic muscles of the thorax is of cervical origin and is innerrated by cervical nerves. The diaphragm is likewise of cervical origin and is innervated by the phrenic nerve from the cervical plexus.

The intrinsic muscles of the back extend over the thoracic musculature (external intercostals and levators of the ribs, fig. 383) and in turn are in part covered by muscles which extend dorsally from the thoracic region (posterior serrate muscles, fig. 380).

The intrinsic thoracic-abdominal muscles are composed laterally of three layers of sheet-like muscles.

In the external layer the fibre bundles run downward and ventralward. This layer is represented in the thoracic region by the external intercostal muscles, the levators of the ribs and the posterior serrate muscles. The fibre-bundles of the external intercostals (fig. 385), extend between each pair of ribs but between the costal cartilages are replaced by fibrous tissue, the external intercostal ligaments. The levatores costarum (fig. 383), extend from the transverse process of one vertebra to the rib which articulates with the next vertebra below and in some instances the fibre bundles are continued to the second rib below.

The serratus posterior superior and inferior (fig. 380), are derivatives of the external oblique which during development wander in part over the intrinsic dorsal musculature. The superior serrate arises from the spines of the last two cervical and first two thoracic vertebra and is inserted into the second to the fifth ribs. The inferior serrate muscle arises from the spines of the last two thoracic and first two lumbar spines and is inserted into the last four ribs. The fibrebundles of this muscles therefore take a direction opposite to that of the other muscles of the group. The muscles aid in inspiration. In the abdominal region the external layer is represented by the external oblique muscle (fig. 387). This arises by digitations from the last seven ribs and is inserted into the crest of the ilium and by means of a broad flat aponeurosis into the linea alba in the midventral line and into the inguinal ligament below. The external intercostal, levatores costarum, and posterior serrate muscles are innervated from branches which arise near the tubercles of the ribs. The external oblique muscles are innervated by branches which in large part arise in conjunction with or from the lateral branches of the anterior divisions of the last seven thoracic nerves and frequently also by branches from the ilio-hypogastric.

The middle layer of the lateral thoraco-abdominal musculature is composed of fibre-bundles which run downward and backward obliquely across the fibre-bundles of the external layer. In the thoracic region it is represented by the internal intercostal and subcostal muscles. The internal intercostal (fig. 385) muscles lie between the costal cartilages and between the ribs as far dorsalward as the angles, beyond which they are replaced by membranous tissue and by the subcostal muscles. The latter, instead of extending from one rib to the next rib below, extend to the second or third rib below. They are best developed in the lower part of the thoracic cavity. In the abdominal region the middle layer is represented by the internal oblique muscle (fig. 388). This arises from the lumbo-dorsal fascia, the crest of the ilium and the inguinal ligament and is inserted into the sheath of the rectus abdominis muscle and into the inferior margins of the ventral extremities of the three lower ribs. The aponeurosis, which helps to form the sheath of the rectus, divides in the upper abdominal region into two layers, one of which passes in front and the other of which passes behind the rectus to be inserted into the linea alba in the mid-ventral line. In the lower third of the ventral abdominal wall both layers pass in front of the rectus. The fibre-bundles which compose the internal oblique muscles do not all follow the usual course of the fibre-bundles of this layer. At the level of the iliac crest they pass nearly transversely across the body and below here they slant downward and forward. Just above the inguinal ligament and medial to its centre the internal oblique muscle is continuous with the thin cremaster muscle (fig. 389), which is prolonged over the spermatic cord and the tunica vaginalis of the testis and epididymis in the male and over the 
ligamentum teres in the female. The cremaster muscle is attached laterally to the inguinal ligament, medially to the outer layer of the sheath of the rectus near the insertion of the latter.

The inner layer of the thoraco-abdominal musculature is composed of fibre bundles which take a course transversely across the body. In the thoracic region it is represented by the transversus thoracis (fig. 386), a slightly developed muscle which arises from the costal cartilages of the third to sixth ribs and is inserted into the lower part of the sternum and in to the xiphoid process. In the upper portion of the muscle the fibre-bundles extend obliquely downward and forward instead of transversely. In the abdomen this layer is represented by the transversus abdominis (fig. 390) which arises from the cartilages of the lower seven ribs, from the lumbo-dorsal fascia, the iliac crest and lateral part of the inguinal ligament and is inserted into the linea alba by means of an aponeurosis which lies behind the rectus in the upper two-thirds of the ventral wall of the abdomen and in front in the lower third. It is intimately fused with the aponeurosis of the internal oblique.

The main trunks of the anterior divisions of the last five or six thoracic nerves give rise to branches which supply the muscles both of the middle and inner layers of the lateral thoraco-abdominal musculature. In the abdominal region these trunks run in the main between the two layers. Some muscular branches are usually also supplied from the ilio-hypogastric and ilio-inguinal nerves. In the thoracic region the intercostal nerves run external to the subcostal muscles, through the substance of the costal part of the internal intercostal muscles, and internal to the parts of the internal intercostals which lie between the costal cartilages. Eisler includes the subcostal muscles and that part of the internal intercostals which lies internal to the nerve trunk, with the inner rather than with the middle layer of the thoracic musculature.

The ventral part of the muscular thoraco-abdominal wall is represented by a single muscle on each side, the rectus abdominis muscle, except just above the symphysis pubis where the rudimentary pyramidalis is usually found. The rectus abdominis muscle (fig. 388), is a band-like muscle which arises from the ventral surfaces of the fifth to the seventh costal cartilages and from the xiphoid process and is inserted into the superior ramus of the pubis. It is ensheathed by the aponeuroses of the lateral abdominal musculature described above. The component fibre-bundles run nearly parallel with the mid-sagittal line. Transverse inscriptions partially divide the muscles into segments. It is innervated by the last six or seren thoracic nerves. The pyramidalis (fig. 388) is a small muscle which arises from the superior pubic ramus and is inserted into the linea alba for about a third of the distance to the umbilicus.

The lateral intertransverse muscles of the lumbar region described on p. 417 probably belong to the ventro-lateral musculature of the trunk. The nerves supplying them come from the junction between the posterior and anterior clivisions of the spinal nerves.

The inguinal (Poupart's) ligament and the inguinal canal, described in detail below, are of consideral,le practical interest because of the frequency of hernias in this region. In the quadrupeds the pressure of the weight of the abdominal viscera crntres toward the umbilicus while in man it centres toward the ventral part of the line of attachment of the abdominal wall to the pelvis. The lower margin of the aponeurosis of the external ohlique muscle is here strengthened to form the inguinal (Poupart's) ligament which extends from the anterior superior iliac spine to the pubie tuberele. Near the Iatter it is reflected (curves medialward) to the pulvic "rest forming the triangular lacunar ligament (Cimbernart's). The modial half of the inguinal ligament helps to bound a slit-like space, inguinal canal through which in the male the spermatic corl passes to the scrotum, and in the female, the round ligament passes to the labium majus. This canal begins on the inner side at the (internal) abolominal ring, which is situated above and medial to the "roter of the inguinal ligannent. The anal, which is about 4 em. long, cxtends medialward and fownward to the subeutaneous (cxternal abdominal) ring, at stit-likr. opening in the aponemosis of the external obligue just above the inguinal ligament. The canal is homeded ventrally by the aponeurosis of the ex- 
ternal oblique and the cremaster muscle, below by the reflected portion of the inguinal ligament, dorsally by the transversalis fascia and above by the transversus. internal oblique, and cremaster muscles.

The quadratus lumborum (fig. 405), which extends from the twelf th rib to the ilium and ilio-lumbar ligament, is supplied by direct branches of the lumbar nerves in series with the nerves supplying the musculature of the abdominal wall. It will, therefore, be taken up with the intrinsic thoraco-abdominal muscles. It depresses the thorax and abducts and extends the spine. The psoas muscle. on on the other hand, which also lies at the back of the abdominal cavity, represents an extension of the intrinsic musculature of the limb to the spinal column (sce p. 455$)$.

The diaphragm (fig. 391), a dome-shaped muscle which is attached to the distal margin of the thorax and to the upper lumbar vertebre, and separates the thoracic and abdominal cavities, arises in the embry in the region of the neck, and maintains cervical relations through its innervation by the phrenic nerves, which spring one on each side usually from the third to fifth cervical nerves. It does not belong morphologically with the other muscles considered in this section, but is here included because of its physiological and anatomical relations and the conveniences of treating it in connection with the intrinsic thoraco-abdominal muscles. A diaphragm completely separating the thoracic from the abdominal carities is found only in the mammals. The central portion of the diaphragm is an aponeurosis or central tendon with a convex ventral and concave dorsal margin. Into this tendon is inserted the musculature which arises on each side from the xiphoin cartilage, the cartilages and tips of the last six or seven ribs and by means of three crura from the sides of the first four lumbar vertebre.

In fishes and tailed amphibians the musculature of the body wall is composed of metamerically segmented musculature. In all higher vertebrates it is likewise at an early embryonic stage segmental, being composed of the rentro-lateral portions of the myotomes. "The ventral ends of the myotomes give rise to a ventral longitudinal muscle which runs on each sicle of the body next the mid-line in front, and retains more or less of the primitive segmentation. The rectus abdominis and the infrahyoid muscles represent this system in man. Tery frequently traces of the system may also be seen on the upper thoracie wall in the form of slender musculait and aponeurotic slips. 'The rectus muscle in man is usually developed from the last seven thoracic myotomes. The pyramidalis becomes split off from its lower end. The lateral part of the ventro-lateral portions of the thoracic myotomes usually gives rise to several strat a of muscles which vary somewhat in different vertebrates, although quite similar among the mammals. In man the twelve thoracic and first two lumbar myotomes give rise to the lateral musculature of the thoraco-abdominal wall.

The quadratus lumborum represents the ventro-lateral portions of the lumbar myotomes with the exception of that portion of the first two which enter into the lateral abdominal musculature and of the fifth, which probably undergoes retrograde metamorphosis.

It will be noted that the abdominal wall is composed of musculature which has an origin chiefly from the thoracic myotomes. At an early stage of embryonic development both the thoracic and the abdominal viscera are covered by a non-nuscular membrane. The myotomes extend into this from the thoracic region, and as the musculature is differentiated, it approaches the median line in front and extends distally to the pelvis. Owing to the rotation of the limbs the abdominal musculature is stretched ventrally orer an area corresponding to the lumbar and sacral regions dorsally The last part of the thoraco-abdominal wall to be furnished with musculature is that about the umbilicus. Occasionally the process fails to be completed in this region.

Each spinal nerve supplies primarily the musculature derived from the nyotome which lay caudal to it, and at first the musculature lies wholly superficial to the nerves. "With subsequent differentiation the metamerism is somewhat olscured by anastomosis of nerves and fusion of myotomes; and a part of the internal oblique layer and all the transverse layer of the lateral musculature comes to lie on the inner side of the main nerve-trunks.

\section{FASCIE}

The fasciæ and the topographical relations of the thoraco-abdominal muscles may be followed in the sections shown in figs. 357,384 , and 407.

Tela subcutanea.- As mentioned abuve, most of the intrinsic thoracic musculature is corered by other muscles, while the superficial layer of the abdominal musculature is subcutaneous. A panniculus adiposus, Camper's fascia, in which much fat may be deposited is usually easily distinguishable, especially in the lower part of the ventral wall of the abdomen, from a membranous fascial sheet which is loosely attached to the underlying fascial envelopment of the muscles. To this membrane has been applied the term Scarpa's fascia. Near the groin it is separated from the panniculus adiposus by blood-vessels and lymphatic glands. It is closely bound to the linea alba between the two rectus muscles, to the fibrous structures in front of tie pubic bone, to the fascia lata below the inguinal ligament, and to the crest of the ilium.

Over the scrotum of the male and vulva of the female both layers of the tela subcutanea are continued. In the male the fat of the more superficial layer disappears and the two layers 
blend with the fundiform (suspensory) ligament and fascia of the penis and the dartos and septum of the scrotum.

Muscle fasciæ and sheaths.-The posterior serrate muscles (fig. 380) are enveloped by two adherent layers of an aponeurotic sheet that extends as a single membrane between them and is attached lateralward to the ribs and medialward to the spines of the thoracic vertebræ. 'The membrane between the muscles may represent the rudiment of a primitive continuous muscle such as is found in some lower vertebrates. This membrane may usually be easily separated from the aponeurosis of the latissimus dorsi on its superficial surface and the lumbo-dorsal faseia beneath

The intercostal muscles are covered by delicate, adherent membranes on each surface. The external intercostal muscles are continued as aponeurotic bands between the, costal cartilages. These serve here as fascia for the internal intercostals.

Fig. 3S5.-The Intercostal Muscles.

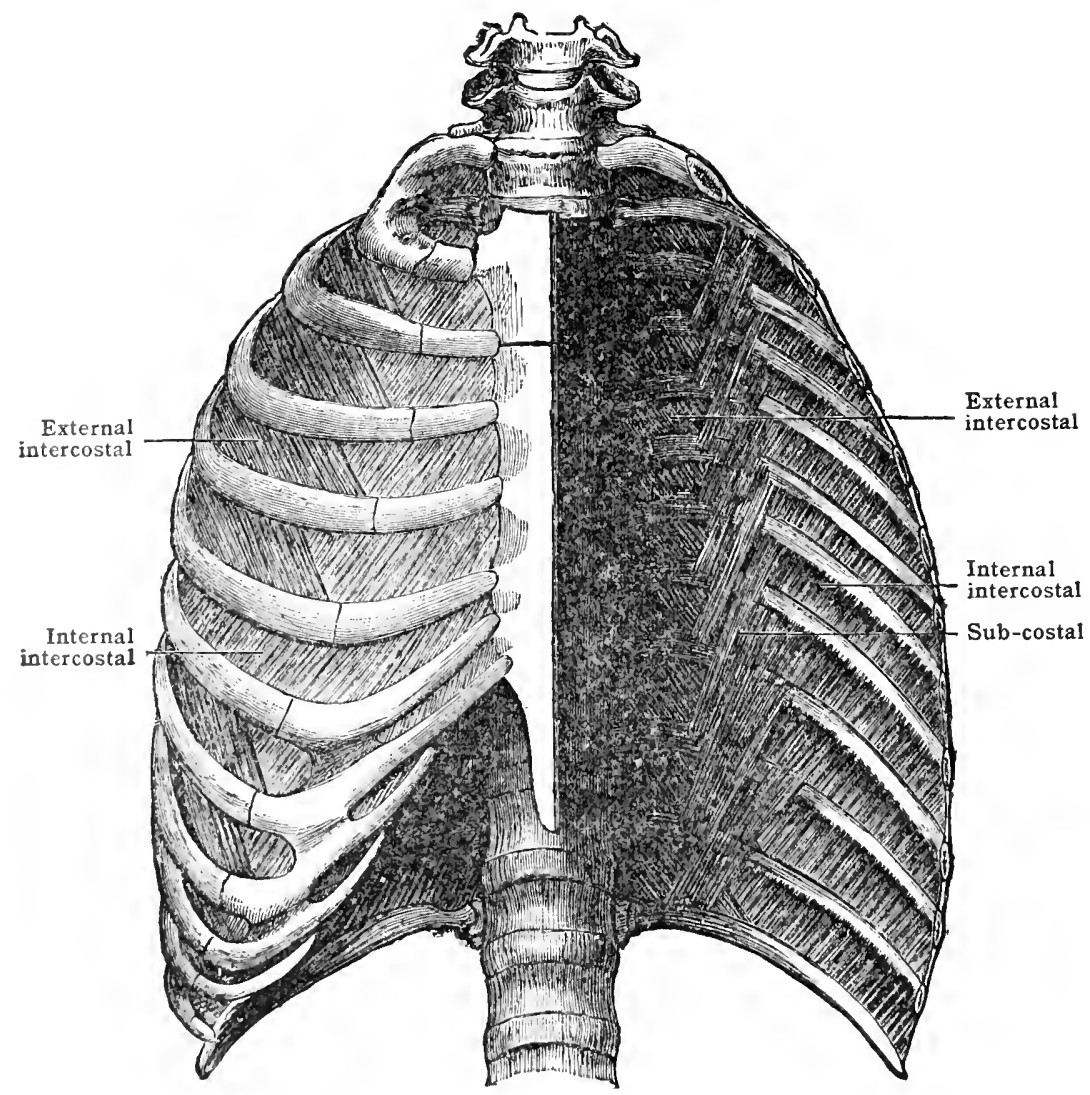

The external oblique muscle is covered exterually by a dense, adherent membrane and intermally fuy a more delieate membrane except where the muscle is attached to the ribs or fused with the external intercostal inuscles. Ventrally and distally these memloranes are fused beyond the fleshy portion of the in usele to the broal aponeurosis that serves to ensheath the rectus muscle and cover the lower part of the abdominal wall (fig. 389). Dorsally the membranes are in part attiuched to the rils and in part are fused to form a membrane which becomes adherent to the locep surface of the latissimus dorsi in the thoracic region and to the lumbo-dorsal fascia in the lombar region.

The infertal obligue musele and the transversus ablominis have similar membranous coverings which are fused to the aponeuroses of origin and insertion of these muscles. The inembranes on the musples are, however, much more delicate than that of the external oblique. More or less fusion hetwen the two muscles with disappearance of the membranes eovering the opposing surfares takes jalae, esperially in the lower part of the abdominal wall. The superfieial nuscle fascice of the external oblique and the lascie of the internal oblique are continued into the thin cremasteric fascin which covers the eremasterie muscle, spermatic cord and testis.

'The diaphragm is covered on osch surface by a more or less well-marked adherent inembrane.

The transversalis fascia is a thin membrane which lies external to the peritonewm of the abfominal wall. It covers the peritoneal surface of the transversus muscle and its aponeurosis. Ventrally it, is continned across the median line internal to the rectus abdominis. In the lumhar region the fascia cliviless at the lateral margin of the quadratus lumborum (fig. 384), one laminat of $\mathrm{t}$ passing dorsal to this muscle to be attared to the lumbo-dorsal fascia. The other lanina extends over the ventral surfare of the qualratus and becomes fuserl with the psoas fascia. P'roxinally the transversalis fuscia becomes fused with the fascial membrane adherent 
to the diaphragm. In the region of the iliac fossa the transversalis fascia is reflected from the transversus muscle to the ilio-psoas fascia, with which it usually becomes fused. Sometimes, however, it may be traced as a very delicate membrane over the iliac artery and yein. As these vessels pass below the inguinal ligament a process from the transversalis fascia is usually reflected into their sheath.

The sheath of the rectus (figs. 384,407 ) is formed externally in the upper portion of its extent by the aponeurosis of the external oblique which fuses distal to the costal margin with the external layer of the aponeurosis of the internal oblique. In the lower portion of the abdomen this fusion takes place nearer the linea alba than in the upper portion. In the lower third of its extent the rectus is covered ventrally by the fused aponeuroses of the two oblique muscles conjoined with that of the transversus. Internally the rectus is covered in the upper two-thirds of the abdomen by the inner layer of the aponeurosis of the internal oblique conjoined with that of the transversus and by the transversalis fascia. In the lower third of the abdomen the aponeurosis of the internal oblique, together with that of the transversus, passes in front of the rectus, leaving the rectus in this portion of its abdominal surface covered merely by the transversalis fascia and the peritoneum. The line which marks the lower limit of the dorsal ensheathment of the rectus by the aponeurosis of the transversus muscle is called the linea semicircularis,

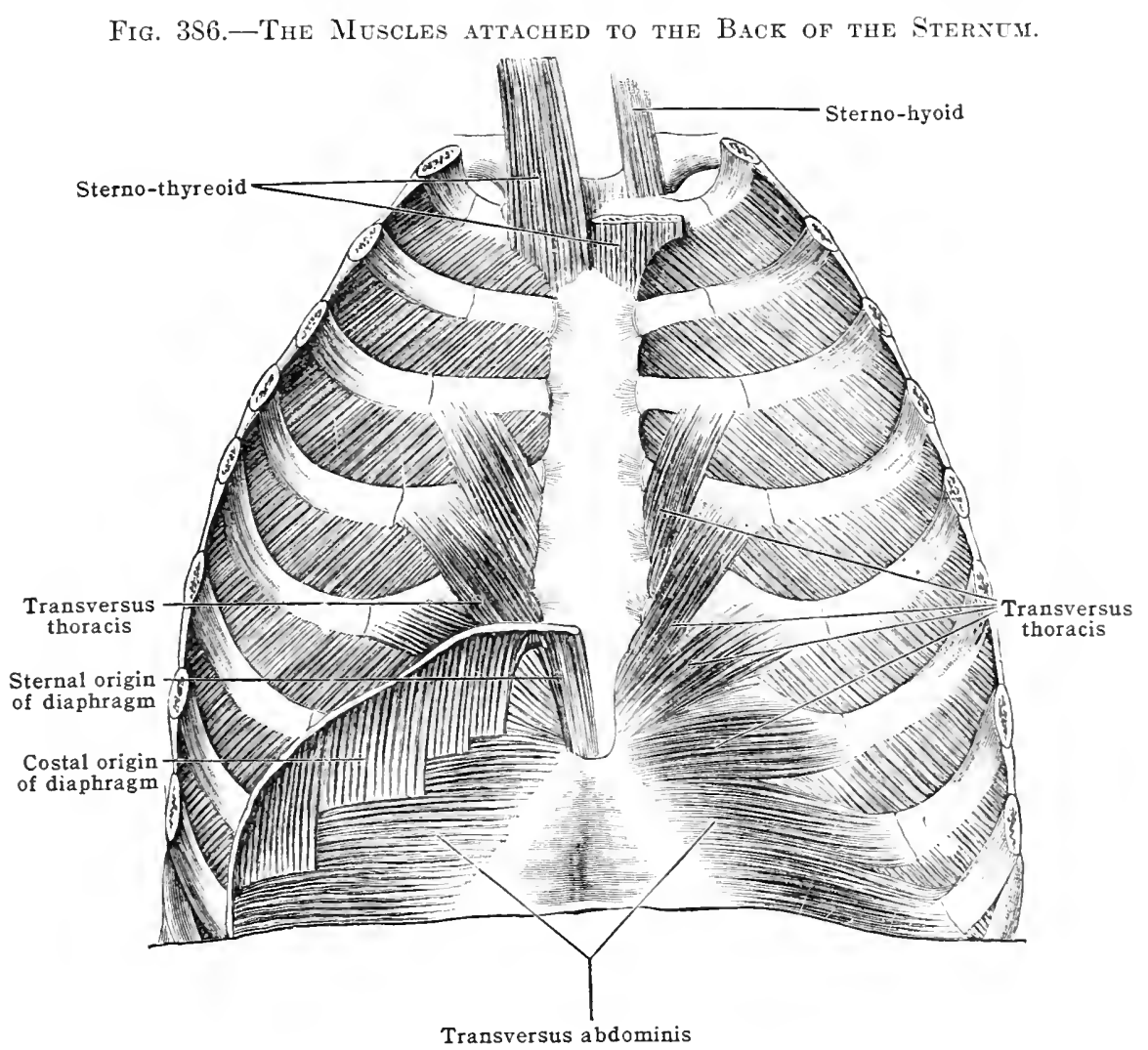

or fold of Douglas. Between the transversalis fascia and the rectus just above the pubis there is a space filled with loose connective tissue or with fat.

The pyramidalis lies beueath the ventral layer of the sheath of the rectus. From the latter it is sometimes separated by a distinct fascial layer.

Between the rectus muscles of each side the investing aponeuroses are firmly united into a dense tendinous band, the linea alba (fig. 389). This is broadest opposite the umbilicus. Above this it gradually grows narrower toward the xiphoid process to the ventral surface of which it is attached. From the tip of the xiphoid process it is often separated by a bursa. Toward the symphysis pubis it extends as a narrow line. Just above the symphysis it divides to be attached on each side to the tubercle (spine) of the pubis. Behind it broadens into the adminiculum linea alba which is attached on each side to the pubis. The linea alba is composed mainly of the interlacing of the fibres which pass into it from the aponeurotic sheaths of the rectus abdominis. From it and Scarpa's fascia, a few centimetres above the symphysis, there arises a broad elastic band, the fundiform ligament (superficial suspensory ligament) of the penis, which sends a fasciculus on each side of the penis. Below the penis these fasciculi unite. * At the umbilicus there is a circular opening encircled by dense fibrous tissue and filled with a thick connective tissue, extending from the tela subcutanea to the subserosa.

* Alex. Hagenton has shown that the linea alba varies much in width. It is relatively wide in fat people and in fœtuses. 
The ventral layer of the lumbo-dorsal fascia and its relations to the abdominal muscles also merit attention. This lies between the intrinsic dorsal musculature and the quadratus lumborum muscle and extends from the twelf th rib to the ilio-lumbar ligament. It is strengthened by the lumbo-costal ligament, which extends between the transverse processes of the first and

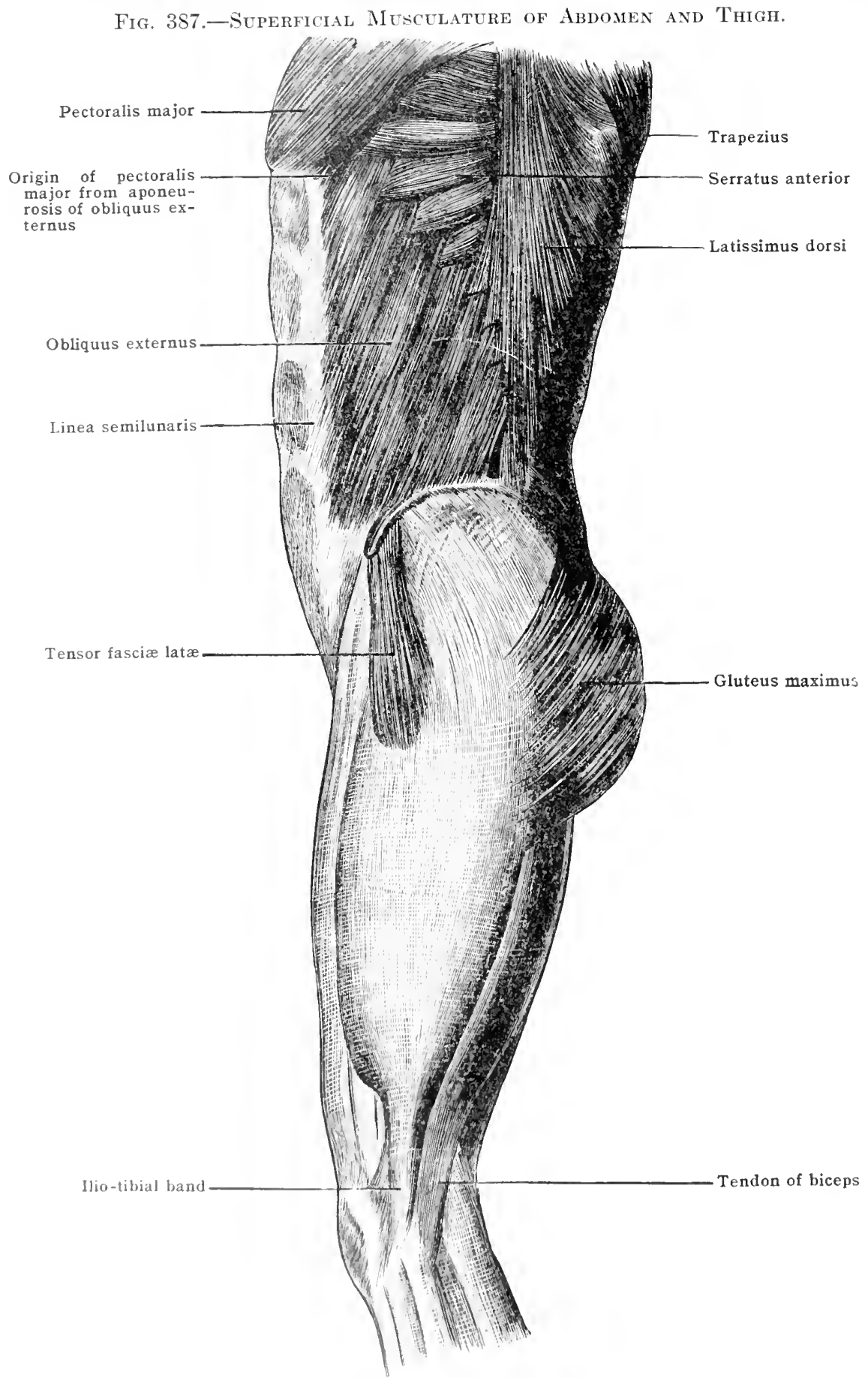

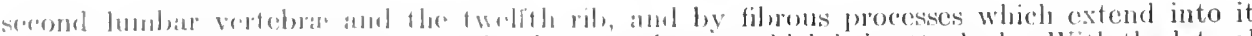

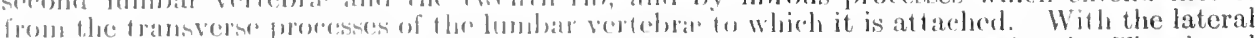
margin of this ventral layer the dostat later of the lombordorsal fascia is lused. The dorsal

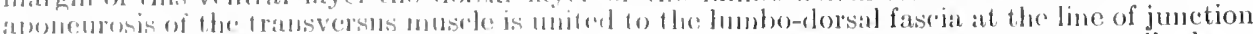

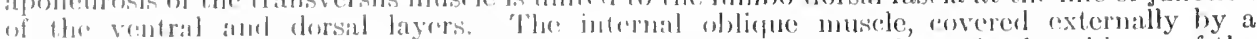

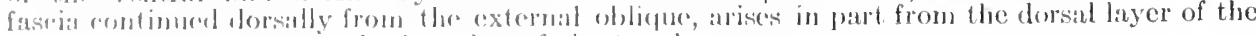

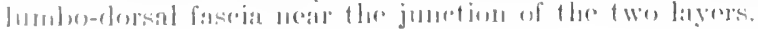


The inguinal ligament (Poupart's ligament) (figs. 387, 389, 390) is a strong band which extends along the distal margin of the aponeurosis of the external oblique from the anterior superior iliac spine to the pubic tubercle. Internally the iliac fascia is fused to it. Distally the fascia lata of the thigh is attached to it. The deeper lateral abdominal muscles in part

Fig. 388.-The Pectoralds Minor, Obliquus Internus, Pyramidalis, and Rectus ABdominis.

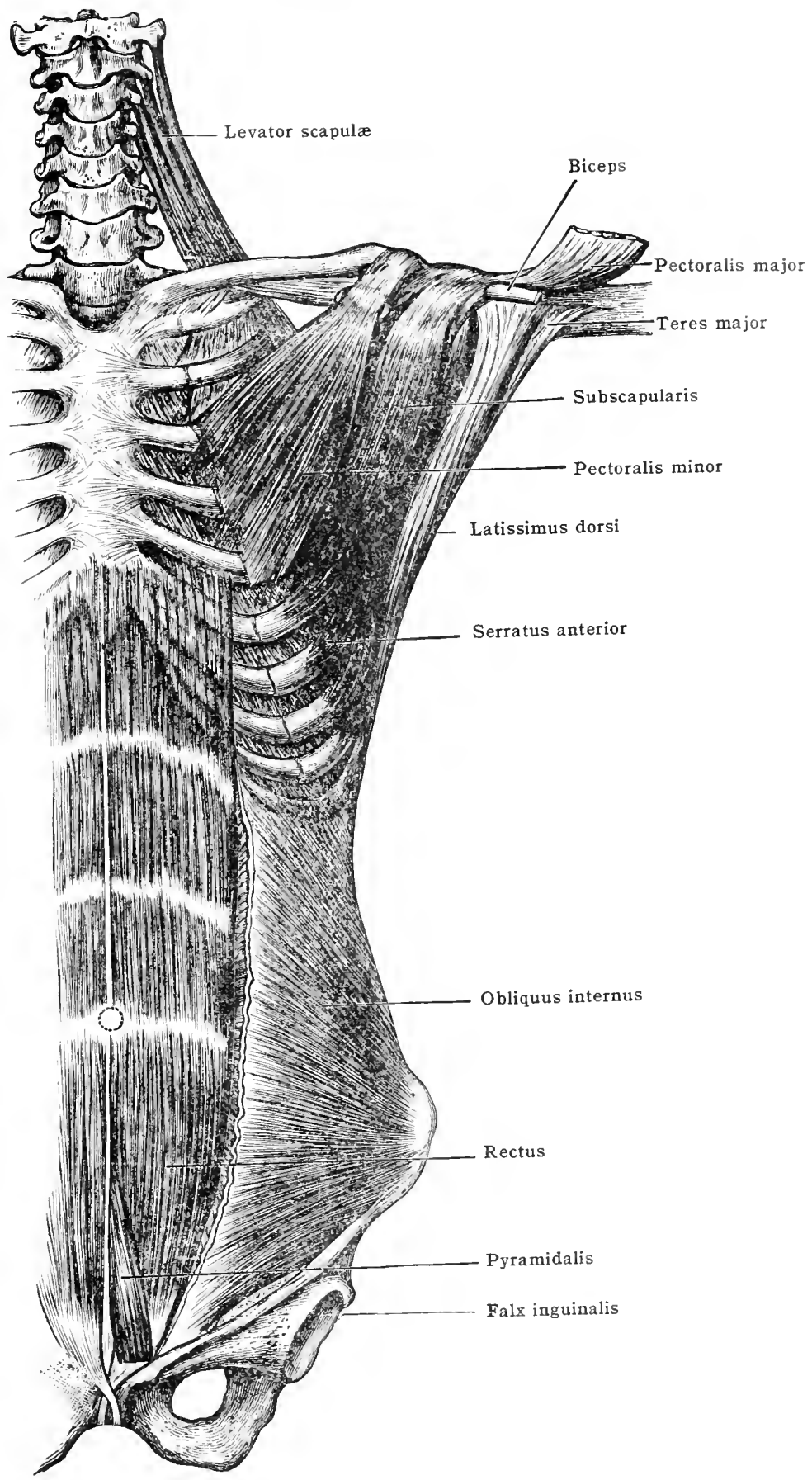

arise from it. Medially near the attachment of the ligament to the pubic tubercle (spine) arise from it. Medially near the attachment of the ligament to the pubic tubst of the pubis and give rise to the triangular lacunar ligament (Gimbernat's ligament). This is fused with the fascia of the pectineus muscle and bounds the femoral ring. Above the inguinal ligament near its medial extremity lies the external opening of the inguinal canal, the subcutaneous (external) 
inguinal ring [annulus inguinalis subeutaneus]. This opening is formed by the diverging of the lower medial fibres which compose the aponeuroiss of the external oblique muscle. The superior fibres form the upper boundary, superior crus, of the ring and pass to the front of the symphysis pubis. The inferior fibres form the inferior boundary, inferior crus, of the ring and pass to the pubic tubercle (spine). Between these two fibre bands intercrural (intercolumnar) fibres arch about the lateral boundary of the ring and serve to strengthen the anterior and inferior walls of the inguinal canal. Some of the fibres of the superior crus, intermingled with other fibres cross to the opposite side of the body and are inserted into the tubercle (spine) and crest of the pubis and into the superior crus of the opposite side. The structure thus formed is called the reflected inguinal ligament (Colles's ligament, or triangular fascia).

Inguinal canal [canalis inguinalis]. - This term is applied to the slit in the lower margin of the abdominal wall through which, in the male, the spermatic cord passes, and in the female, the ligamentum teres. It is not a true canal. The inner end begins at the (internal) abdominal ring [annulus inguinalis abdominalis]. This is situated just above and slightly medial to the middle of the inguinal (Poupart's) ligament. Below the ligament in this region lies the femoral canal through which the femoral vessels pass into the thigh. The (internal) abdominal ring is covered by the peritoneum and the transversalis fascia. The latter here sends a shallow funnel-like extension outward to be attached to the spermatic cord. The base of this funnellike depression toward the inguinal (Poupart's) ligament is formed by a thickened band of tissue, the tractus ilio-pubicus. Medially and laterally the bundles of fibrous tissue which constitute this tract spread out fan-like, medially over the sheath of the rectus and toward the pubis, laterally over the transversus muscle and toward the crest of the ilium. The transverse abdominal muscle arises from the inguinal ligament nearly as far as the lateral margin of the abdominal ring. The fibre-bundles of this portion of the muscle course ventralward above the base of the funnel mentioned above and are inserted by tendons forming a more or less complete aponeurosis, the "conjoined tendon" [falx inguinalis], common to it and the internal oblique into the ventral sheath of the rectus abdominis muscle, into the tubercle, crest and pecten of the pubis and sometimes into the pectineal fascia or the lacunar (Gimbernat's) ligament. Tendinous bands from the transversalis muscle curve downward medial to the (internal) abdominal ring and help to strengthen the transversalis fascia here. These bands constitute the interfoveolar ligament [ligamentum interfoveolare, Hesselbachi]. The fibrous bands constituting this ligament are attached to the lacunar ligament and the pectineal fascia.

From the internal ring the spermatic cord (or in the female the ligamentum teres) passes downward and forward in a space (inguinal canal) about $4 \mathrm{~cm}$. long and then through the subcutaneous (external abdominal) ring which has been described in connection with the inguinal ligament. The ventral wall of the inguinal canal is composed of the aponeurosis of the external oblique, the intercrural fibres, and the cremaster muscle. Laterally it is also covered by the caudal portions of the internal oblique and transversus muscles. The caudal wall or floor of the space is formed ehiefly by the lacunar (Gimbernat's) ligament and laterally also by the iliopubie tract. Cranialward the lateral part of the space is covered by the transversus and internal oblique muscles, the medial part by the cremaster muscle. The dorsal (internal) wall is formed mainly by the transversalis fascia. Medially the lacunar (Gimbernat's) ligament and the conjoined tendon (falx inguinalis), when this is well developed, help to form the dorsal wall. Lateral to these structures the dorsal wall is thinner but may be strengthened by a well developed ilio-pulic tract. Near the (internal) abdominal ring it is strengthened by the interfoveolar ligament, and sometimes by muscle slips (interfoveolar muscle).

Abdominal fossæ in the inguinal region.-The hernias so frequent in this region make a special stuty of the inner surface of the abdominal wall of considerable practical importance. Ifeclial to the abrlominal (internal) inguinal ring the inferior internal epigastric vessels give rise to a slight fold (plica epigastrica) which slants medialward and upward toward the rectus muscle. From the lateral margin of the tendon of insertion of the rectus muscle upward toward the [unbilins orer the obliterated umbilieal artery there extends a better marked fold, the plica umbiticalis lotralis. Lateral to the pliea epigastrica lies the fovea inguinalis lateralis, with the internal inguinal ring. Between the plica epigastriea and the pliea umbiliealis lateralis lies the fovea inguinalis medialis. In the latter region the fascia transversalis which here forms the inner wall of the inguiual cunal is strengthened by two longitudinal fibrous bands belonging to the aponemposis of the transversalis muscle and described above, the ligament interfoveolare at the medial side of the (internal) ibdominal ring, and the falx inguinalis (conjoined tendon) lateral to the rectus muscle. These bands vary in width. When they are narrow the part of the internal wall of the inguinal canal covered merely by the thin transversalis fascia and the perifomeun is rolatively latge and, since this region lies behind the subcutaneous (external aldominal) ring, opportunity is offered for direct inguinal hernia.

\section{MUSCLES}

\section{A. Ventrat, Division}

The rectus abdominis (fig. 3sis).-Origin-Ventral surfare of the fifth to seventh costal eartilagess, the xiphoitl proeses, and the costo-xiphoid ligament.

Inseriom. The upper lowder of the body of the pubis and the ventral surface of the symphysis.

Sitructure. - The muscle: is long, flat, ambl somewhat triangular in form. Cranialward it is

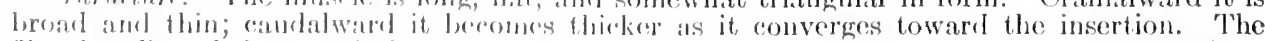

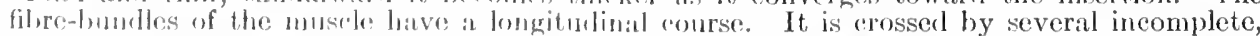
zigzalg, transwerse fondincus limuls, inscriptiones tendineæ, better developed on the ventral than on the dorsal surface of the muscle amb intimatcly united to the ventral sheath of the rectus. che of these, corresponding segnentally to the fenth rib, is usually situated opposite the um- 
bilicus. Another, corresponding to the ninth rib, is situated midway between this and the lower margin of the thoracic wall, and one corresponding to the seventh rib is found at the level of the xiphoid process. Between this and the one corresponding to the ninth rib an additional inscription is frequently found. Below the umbilicus an inscription corresponding with the eleventh rib is often found ( 30 per cent.). In these inseriptions many of the fibre-bundles have their origin and insertion. The thoracic attachments take place by means of band-like fasciculi which extend upward from the highest inscription, the fibre-buudles of these fasciculi being inserted by short tendinous bands. The pubic attachment of the muscle takes place by a short, thick tendon, usually divisible into two portions, of which the broader, lateral portion is inserted into a rough area extending from the pubic tubercle (spine) to the symphysis, while the more slender medial portion is attached to the fasciæ in front of the symphysis pubis, where its fibres interdigitate with those of the opposite side. In addition to the attachments mentioned, some of the fibre-bundles are attached to the sheath of the rectus and many, after interdigitating, terminate in the intramuscular framework.

Nerve-supply. - The anterior branches of the six or seven lowermost intercostal nerves enter the deep surface of the muscle near its lateral edge. The cutaneous branches pass obliquely through its substance, while the muscular branches give rise to an intramuscular plexus. As a rule, the chief ventral branch of the tenth thoracic nerve enters the substance of the muscle slightly below the umbilical transverse inscription. The branches of the eleventh and twelfth nerves enter at a lower level. The main branch of the ninth nerve enters slightly below the preumbilical inscription; the eighth nerve, between this and the lower margin of the thorax. Either the sixth or seventh nerve may supply the fasciculi of origin. In addition to the main branches other smaller branches of the nerves of the abdominal wall are also usually distributed to the muscle. Each segment, either directly or through intramuscular plexuses, has a supply from more than one spinal nerve.

Action.-To depress the thorax and flex the spinal column. When the thorax is fixed the rectus serves to flex the pelvis upon the trunk.

Relations.- It lies between the transversalis fascia and the tela subcutanea and is ensheathed by the aponeuroses of the lateral abdominal muscles, as above described. The epigastric artery runs on its deep surface.

Variations. - The rectus muscle varies in the number of its tendinous inscriptions and in the extent of its thoracic attachment. It may extend farther than usual on the thorax. Frequently aponeurotic slips or slips of muscle on the upper part of the thorax indicate a more primitive condition in which the muscle extended to the neck. Absence of a part or the whole of the muscle has been noted. The muscles of the two sides may be separated by a considerable interval in the neighbourhood of the umbilicus. The muscle is relatively thicker in men than in women.

The pyramidalis (fig. 388).-Origin.-Upper border of the body of the pubis.

Structure and insertion.- The fibre-bundles extend toward and are inserted into the linea alba for about a third of the distance to the umbilicus, and give rise to a flat, triangular belly.

Nerve-supply.- Usually through a branch of the twelfth thoracic, which may extend into the muscle through the rectus abdominis. Not infrequently a special branch extends into the muscle from the ilio-hypogastric or ilio-inguinal or, rarely, from the genito-femoral.

Action.-To draw down the linea alba in the median line.

Relations. - It lies between two laminæ of the anterior layer of the sheath of the rectus.

Variations.- It is missing in about 16 per cent. of instances (Le Double). Dwight has found it absent in 81 out of 450 males and in 60 out of 223 females dissected at the Harvard Medical School. It may extend upward to the umbilicus or be but very slightly developed. It may be double. In many of the mammals it is missing. It is well developed in the marsupials and monotremes.

\section{B. Lateral Division}

\section{Serratus Group (fig. 380)}

The serratus posterior superior.-Origin.-By a broad, thin aponeurosis from the ligamentum nuchæ and the spines of the last one or two cervical and the first two or three thoracic vertebræ.

Structure and insertion.-The fibre-bundles take a nearly parallel course downward and lateralward and give rise to a flat belly which ends by four fasciculi on the upper margin of the second to the fifth ribs, lateral to the ilio-costalis.

Nerve-supply.-Through branches from the first four intercostal nerves. These nerves give rise to a plexus which passes across the deep surface of the muscle in the middle third between the tendons of origin and insertion.

Action.-To elevate the ribs to which the muscle is attached, and through then to enlarge the thorax.

Relations.-It lies upon the wall of the thorax and the intrinsic dorsal musculature and beneath the levator scapulæ, rhomboids, serratus anterior, and trapezius. Its fasciculi extend on the ribs to those of the serratus anterior (magnus).

The serratus posterior inferior.--Origin.-Through an aponeurosis, fused medially and inferiorly with the lumbo-dorsal fascia, from the last two or three thoracic and first two or three lumbar spines.

Structure and insertion.-From the aponeurosis arise four flat bands which are successively attached to the inferior margins of the last four ribs, lateral to the ilio-costalis.

Nerve-supply.-From the ninth to eleventh intercostal nerves arise branches which form a plexus that extends across the deep surface of the muscle in the middle third between the tendons of origin and insertion.

Action.-To depress and draw outward the four lower ribs and through them to enlarge 
the thorax. Together with the serratus posterior superior and the eonnecting aponeurotic faseia it aids in keeping the intrinsic dorsal muscles in place.

Relations.- It lies upon the intrinsic dorsal musculature, the lower dorsal part of the thorax, and the lumbo-dorsal fascia, and beneath the latissimus dorsi, the trapezius, and their aponeuroses.

Variations. - The fasciculi of both muscles vary in number and may be replaced by aponeurotic slips. Aberrant muscle faseieuli, supracostales posteriores, may be found in the faseia which connects the two muscles. In several of the lower mammals the two muscles are norinally continuous.

\section{External Oblique Group}

The intercostales externi (fig. 355).- These muscles extend in the intereostal spaces from the tubereles of the ribs to the costal cartilagess. The intermediate muscles do not, however, of ten quite reach the cartilages. The first intereostal muscle may extend to the sternum. The others are continued through the intercostal region by thin aponemroses, the external intercostal ligaments, the fibres of which have a direction corresponding to that of the muscle fibrebundles. Dorsally the museles are fused with the levatores, and ventrally the lower seven muscles are more or less fused with the corresponding fasciculi of the external oblique.

Origin.-From the lower margin of each rib external to the costal suleus.

structure and insertion.-The fibre-bundles take a parallel eourse obliquely forward and downward to the upper margin of the next rib. The proximal fibre-bundles are more oblique than the distal, and the muscles are best developed in the dorsal part of the intercostal spaces.

Verve-supply. - By several branches from the corresponding intercostal nerves.

Action.-To elevate the ribs and enlarge the thorax.

Relations.- They are covered externally by the peetoral muscles, the serratus anterior, inul serrati posteriores, the levatores costarum, the sacro-spinalis (erector spina), and the extcmal oblique museles. Internally they are separated by a slight amount of loose tissue from the internal intereostals, the membranes which continue these muscles medially, and from the subcostal muscles.

I"arintions. - When the twelfth rib is very small or is lacking, the eleventh intercostal muscle may be missing. When there is a supermmerary cervical or thirteenth thoracic rib. there nay be an extra external intercostal musele. Next to the first intereostal, the fourth most freruently reaches the stermum.

The levatores costarum (fig. 383). - These consist of a series of flat, triangular muscles, each of which arises from the tip and inferior margin of a transverse process and extends laterally with diverging fibre-bundles to be inserted into the dorsal surface of the rib below, from the tubercle to the angle. The first extends from the transverse process of the seventh eervical vertebra to the first rib. They increase successively in size from this to the last, whieh is attached to the twelf th rib. Those arising from the transverse processes of the eighth to the eleventh thoracic vertebra send their more medial fibre-bundles across the rib below to join the lateral margin of the succeeding muscle (levatores longi). The levatores costarum are elosely mited to the external intereostals and are innervated by the intercostal nerves which pass forwarl in the corresponding intercostal spaces. The first muscle is innervated by the eighth rervical nerve.

Action.-To bend laterally and extend the spinal eolumn.

Relutinns.- They are covered dorsally by the longissimus dorsi and the ilio-costalis.

Irariations.- The first levator may be continued into the scalenus posterior. When greatly

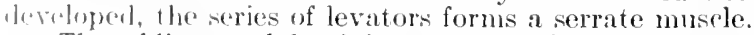

The obliquus abdominis externus (fig. 387).-Oriqin.-By eight fleshy digitations from 1 lue external surface of the lower cight ribs immediately lateral to where they join the cartilages. The first fire slips interligitate with the serratus anterior (magms), the last three with the latisimus dorsi.

lustion.-(1) By a strong aponcurosis which extencls over the rectus to the linea alba,

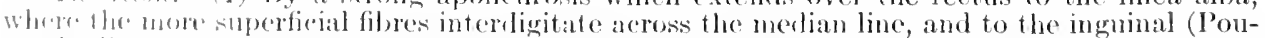
burt'A bigancut; and (2) direetly into the onter lip of the arest of the ilium. 'The aponeurosis over thr protus is asually partly fused with the aponeurosis of the internal oblique.

Structur. The fibre-fumbles which compose the llat fascienli of origin diverge slightly as they ghas forwall and lownward, and ly fusion of their edges give rise to a flat sheet of maseli. 'The fasiculus taking origin from the fifth rib passes nearly direetly ventrally, but the surereding fascindi incline somewhat downward, those from the seventh to the ninth ribs howing 1 hogratest downward inclination. The lower margin of the fascienlus which arises from

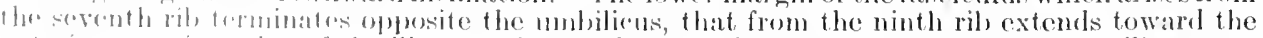

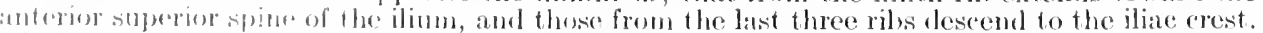

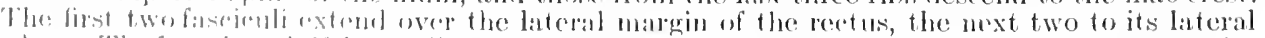

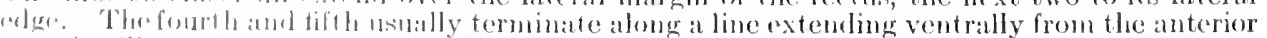

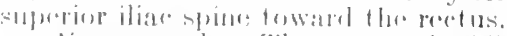

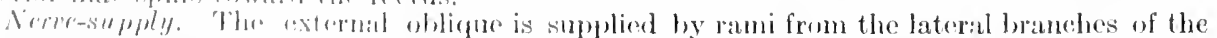

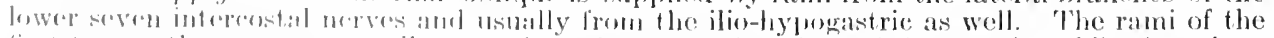

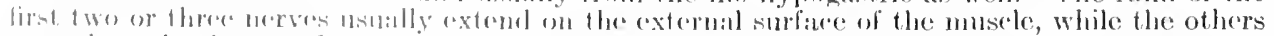

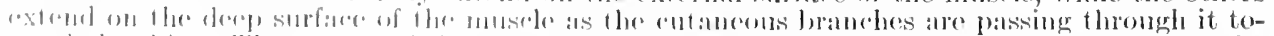

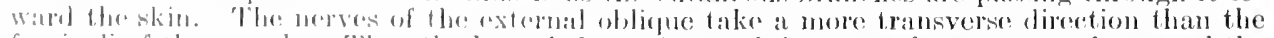
fiscisuli of the mosele. Thus the hamele from the tenth interestal nerve extenels toward the umbilins and that of the I welfth towatrl a mint midway between the mubilins and the sym-

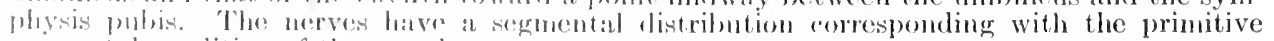
sogmental comblition of the muscele.

Irtim. - (1) To compress the abrlomen; (2) to depress the thorax; (3) to flex the spinal 
column; and (4) to rotate the column toward the opposite side. With the thorax fixed it serves to flex and rotate the pelvis.

Relations.-It lies superficial to the lower ventro-lateral margin of the thorax and the internal oblique muscle. It is partly covered by the latissimus dorsi muscle behind. Otherwise it is subcutaneous.

Variations.-It may have a more or less extensive origin from the ribs. Broarl fasciculi not infrequently are separated by loose tissue from the main belly of the muscle either on its deep or superficial surface. Occasionally tendinous inseriptions are found. These transverse inscriptions are constant in many of the smaller mammals. The supracostalis anterior is a rare fasciculus sometimes found on the upper portion of the thoracic wall. It is usually supplied by branches of the upper thoracic nerves and seems to be a continuation upward of the external oblique muscle. In some prosimians the external oblique extends normally to the first or second rib.

\section{Internal Oblique Group}

The intercostales interni (figs. 355, 386, 385).- These extend in the intercostal spaces from the angles of the ribs to the sternal ends of the spaces. The upper and lower muscles are usually continued dorsally slightly beyond the angles of the ribs, while the intermediate muscles frequently do not quite reach them. Dorso-medially the internal intercostals are continued in

Fig. 359.-Structures of Inguinal Region.

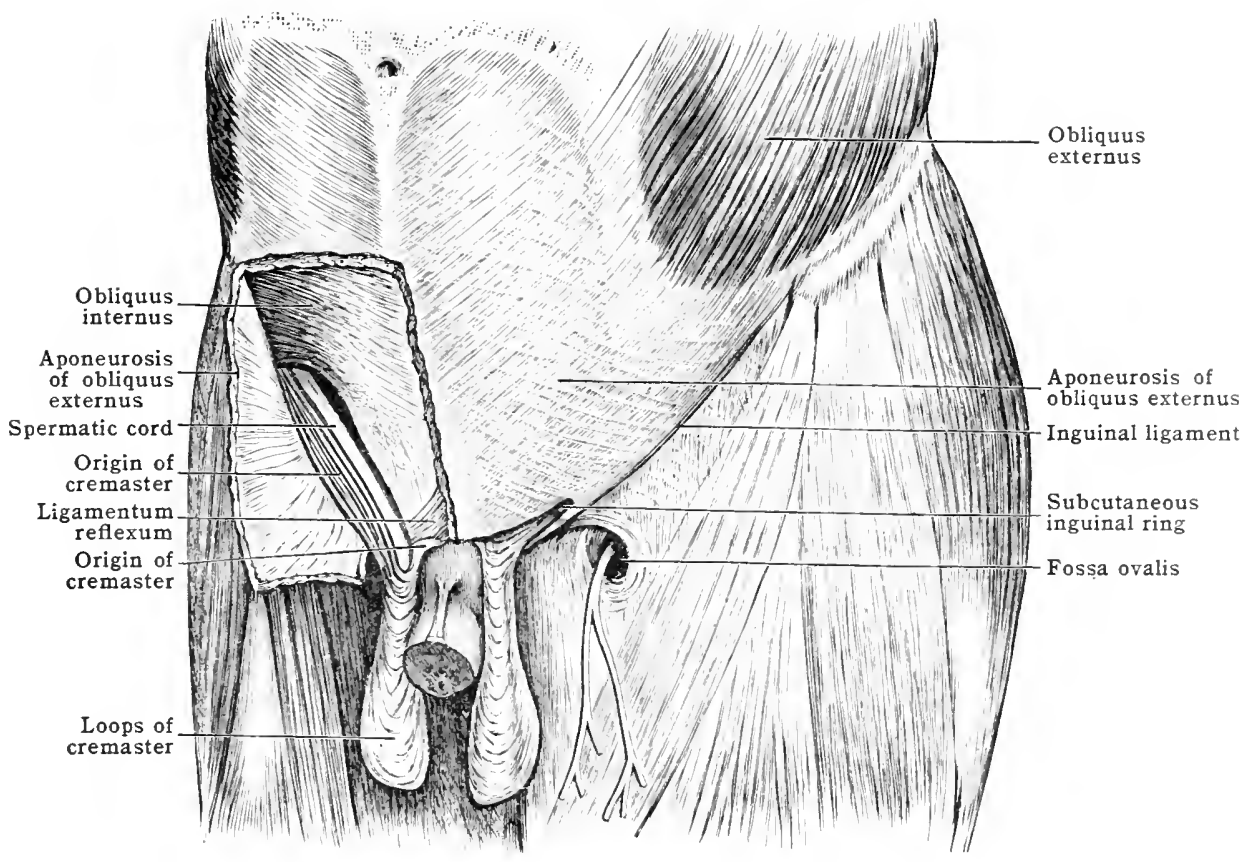

the form of thin fascial sheets across the inner surface of the external intercostals and become fused with the subcostals.

Origin.- Near the angles of the ribs they arise from the internal lip of the costal sulcus. More ventrally they arise mainly from the external lip of the sulcus, but also in part from the internal lip.

Structure and insertion.-The fibre-bundles take a parallel course downward and dorsalward to the upper margin of the rib below. They are less obliquely placed than those of the external intercostals. The muscles are thicker in front and grow thinner dorsally. They contain less fibrous tissue than the external intercostals.

Nerve-supply.-From numerous branches of the corresponding intercostal nerves.

Action. - Investigators disagree as to the functions. It is probable that the portions of the muscles between the ribs serve to contract, those between the costal cartilages to expand; the thorax.

Relations.-Between the ribs they are covered by the external intercostal muscles and between the costal cartilages by the external intercostal ligaments. Between the intermal and external muscles there is some loose areolar tissue. Proximally, for a short distance, the intercostal nerve in each interspace runs between the external and internal intercustal muscles, but more distally it runs first in the substance of and then on the internal surface of the internal intercostal. Eisler distinguishes that portion of the internal intercostal muscle which lies external to the nerve as the intercostalis intermedius, that which lies internal as the true internal intercostal. The terminal branches of the first six nerves, however, pass through the muscle on their way to the skin, while the last six pass beneath the inferior maryin of the thorax. Internal to the internal intercostal muscles lie the transtersus (triangularis sterni) and sub- 
costal muscles, the diaphragm, and the pleural membranes. The more distal internal intercostal muscles are continuous with the internal oblique and the subcostal muscles.

Variations. - The tenth and eleventh internal intercostal muscles normally are but slightly developed and often may be wanting. The internal intercostals of the first three spaces may extend to the vertebræ.

The subcostales (fig. 385).- These muscles are due to an extension over two or more intercostal spaces of those fibre-bundles of the internal intercostal muscles which lie in the proximal part of the interspaces. They arise near the angles of the ribs, and are usually well developed only in the lower part of the thorax. The component fibre-bundles keep the general direction of the internal intercostals, but they converge toward the tendons of insertion, which are attached in each case to the second or third rib below, between the angle and the neck.

Nerve-supply. - The main nerve of supply for each muscle comes from the intercostal nerve running below the rib from which the muscle takes origin.

Action.-To depress the ribs and contract the thorax.

Relations. - They lie on the inner side of the internal and external intercostals and the ribs, and are covered by the pleural membranes.

I'ariations, - They vary much in development. Next to the lower fasciculi, the fasciculi in the cranial part of the thorax are those usually best developed.

The obliquus abdominis internus (fig. 388).-Origin.-From the lumbo-dorsal faseia the intermediate lip of the rentral two-thirds of the iliac erest, and the lateral half of the inguinal ligament.

Strueture and insertion.-From the origin the fibre-bundles radiate forward in a flat sheet. The most dorsal extend to the lower three ribs, where they become continuous with the internal intercostals. The rest extend toward the lateral margin of the rectus, the upper ones toward the xiphoid process, the intermediate toward the umbilicus, the lower ones somewhat obliquely downward across the lower part of the abdomen. The fibre-bundles which extend toward the rectus terminate in an aponeurosis which in its upper two-thirds divides into two layers, one of which passes in front of and the other behind the rectus muscle to the linea alba. In the lower third the aponeurosis passes as a single membrane in front of the rectus. In the neighbourhood of the subcutaneous inguinal (external abdominal) ring the muscle is continued into the cremaster. Medial to the ring some fasciculi are attached to the tubercle of the pubis and to the symphysis.

Nerve-supply.-From branches of the last three intercostal and the ilio-hypogastric, ilioinguinal and genito-femoral (?) nerves as these pass between this muscle and the transversus.

Aetion.-To depress the thorax, flex the vertebral column, and bend and rotate it toward the side on which the muscle is placed. When the thorax is fixed, the muscle serves to flex and rotate the pelvis.

Relations. - It lies between the external oblique and the transversus. The trigonum lumbale (trimgle of Petit) is an area, variable in size, between the posterior margin of the external obligue, the lateral margin of the latissimus dorsi, and the crest of the ilium. In this area the internal oblique is subcutancous.

lariations.- The attachments and the extent of development of the fleshy part of the muscle vary considerably. Occasionally tendinous inscriptions are found in the muscle which indicate a primitive segmental condition.

The cremaster (fig. 389).-The cremaster musele is found well developed only in the male. It represents an extension of the lower border of the internal oblique muscle and possibly also of the transverse over the testis and spermatic cold.

Origin.-(1) Lateral, thick and fleshy, from about the miclde of the upper border of the inguinal ligament, and (2) medial, thin and tendinous, from the sheath of the rectus muscle and the tubercle (spine) of the pubis.

Structure. The lateral head is applied to the lateral side, the medial hearl to the medial side, of the spermatic cord. Both pass with this through the subcutaneous (external ahdominal) ring of the inguinal canal and become spread in loops over the test is. Ensheathing the muscle and fortacen the somewhat seattered fibre-bundes which compose it, there extends a thin, monhanoms laver of connective tissue, the cremasteric (Cowper's) fascia.

Virr-supply.-The genital nerve (external spermatic), usually joined by a ramus from the inguinal nerve, gives rise to hranches which spreat over the muscle.

Artim. To lift the test is toward the subcutaneous inguinal (external abdominal) ring.

liflotims. - It is covered by the aponeurosis of the extemal oblique, the cremasterie fascia, thr dartos, and the skin. It covers the spermatic corel and the testis.

lariations. In the female: the muscle is represented by a few fascienli on the round ligament. It mal arise wholly from the transvorsalis fascia or be somewhat fused with the transversus muscle. The lattre condition is especially frequent in museular indiviluals.

\section{Trunserersus Group}

The transversus thoracis (triangularis sterui) (fig. 3\$6).-Origin.-Dy aponeurotic bands from the dorsal surfare of the lower half of the hody of the stemum and the xiphoid process. Sirueture and instion. The muscle is composed of several flat, thin fascieuli, partly fibrous, more or loss isolated, which are inseldol by aponemotic bamb into the dorsal surface of the cartilages of the seromd or thirel to the sixth ribs, and oreasionally also into the tips of the bony portions of the ribs. 'The lower fasciculus is elesely related to the cranial margin of the transversus ablominis.

Vorer-supply. - liy rami from the vontral portions of the secomel to the sixth intereostal norves. Throse norves give rise to a domgitudinal plexus aross the deep surface of the muscle near the middle of the constitucnt fasciculi. 
Action.-To depress the ribs in expiration.

Relations.-The sternum, the costal cartilages, internal intercostal muscles, and the internal mammary vessels lie in front and the pleura and pericardium behind the musele.

Variations. - It is an exceedingly variable muscle, both in the extent of its attachments and in the development of the individual fasciculi. The fasciculi vary in number from one to six. With this musele Eisler would elass the subcostal museles and those portions of the internal intercostal muscles which lie internal to the intereostal nerves.

The transversus abdominis (figs. 386, 390).-Origin.-Directly from-(1) the inner side of the cartilages of the lower six ribs by dentations which interdigitate with the attachments of the diaphragm; (2) the internal lip of the iliac crest and lateral half of the inguinal ligament; and (3) through an aponeurosis from the lumbo-dorsal fascia.

Siructure and insertion.-The fibre-bundles give rise to a broad, thin belly and take a nearly transverse course across the inner side of the abdominal wall. The most distal fibres, however, are inclined obliquely toward the pubis. The fleshy portion of the muscle terminates in a strong aponeurosis along a curved line, which extends above well under the rectus and emerges

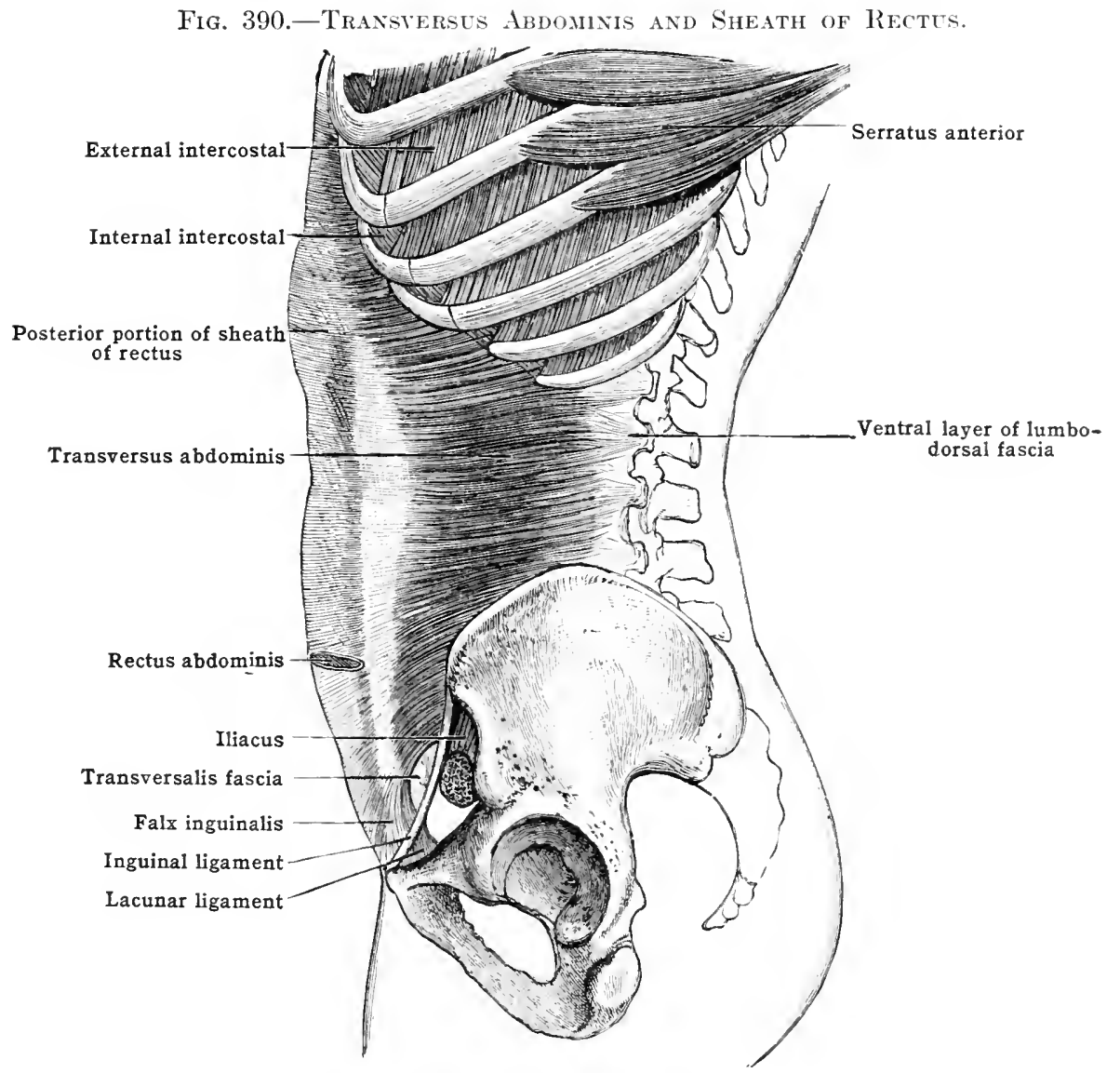

lateral to the rectus opposite the umbilicus, whence it extends toward the middle of the inguinal ligament. In the upper two-thirds of the abdomen the aponeurosis extends behind the rectus to the linea alba and fuses with the inner lamina of that of the internal oblique. In the lower third of the abdomen it extends in front of the rectus to the linea alba, and is here also fused with the aponeurosis of the internal oblique. some of the fibres are continued into the aponeurosis of the muscle of the opposite side. The lower attachment of the muscle is somemhat more complex. The fibre-bundles here bend around the spermatic cord, on the medial side of which they are spread out to be attached to the lacunar (Gimbernat's) ligament and pectineal fascia, the pubis, and the sheath of the rectus. The attachment to the lacumar ligament and pectineal fascia takes place by means of an aponeurotic band, the more lateral fibres of which are dense and curve below the spermatic cord to the lacunar ligament and the pectineal fascia below this. This band is called the interfoveolar ligament. It is composed partly of bundles of fibres prolonged from the aponeurosis of the opposite transversus, and bounds the abdominal ring medially and below. Medially the transversus is united to the upper part of the os pubis, and to the sheath of the rectus by an aponeurotic band, the falx inguinalis (conjoinerl tendon). Between the interfoveolar ligament and the falx inguinalis the transversalis fascia forms the posterior wall of the inguinal canal. In this area a detached band of muscle-fibres is sometimes found. This is called the musculus interfoveolaris.

Nerve-supply. - The transversus is supplied with nerves by the last five or six thoracic and 
the ilio-hypogastric, inguinal and genito-femoral nerves as these course forward between this muscle and the internal oblique.

Action.-The chicf function is to compress the abdominal viscera. Through the portions extending between the lower margins of the thorax on each side it serves to contract the thorax and so may aid in expiration.

Rclations.-It lies on the inner side of the lower ribs, the internal oblique and rectus muscles, and is covered on the deep surface by the transversalis fascia.

Tariations. - It is very rarely absent. It shows considerable variation in the extent of its development. The pubo-peritonealis is a similar muscle which may pass from the pubic crest to the transversus near the umbilicus. The pubo-transversalis is a small muscle which may extend from the superior ramus of the pubis to the transversalis fascia near the abdominal inguinal ring. The tensor laminæ posterioris vaginæ musculi recti abdominis, essentially like the preceding, may extend from the inguinal ligament to the rectus sheath on the deep surface of the rectus muscle near the umbilicus. The tensor laminæ posterioris vaginæ musculi recti et fasciæ transversalis abdominis likewise extends from the transversalis fascia near the abdominal inguinal ring to the fold of Douglas.

\section{Lumbar Muscle}

The quadratus lumborum (fig. 406).-Origin.-From-(1) the internal lip of the iliac crest near the junction of the middle and dorsal thirds, and the iliolumbar ligament; (2) the transverse processes of the three or four lower lumbar vertebræ; and (3) the lumbo-dorsal fascia.

\section{Fig. 391.-Diaphragm.}

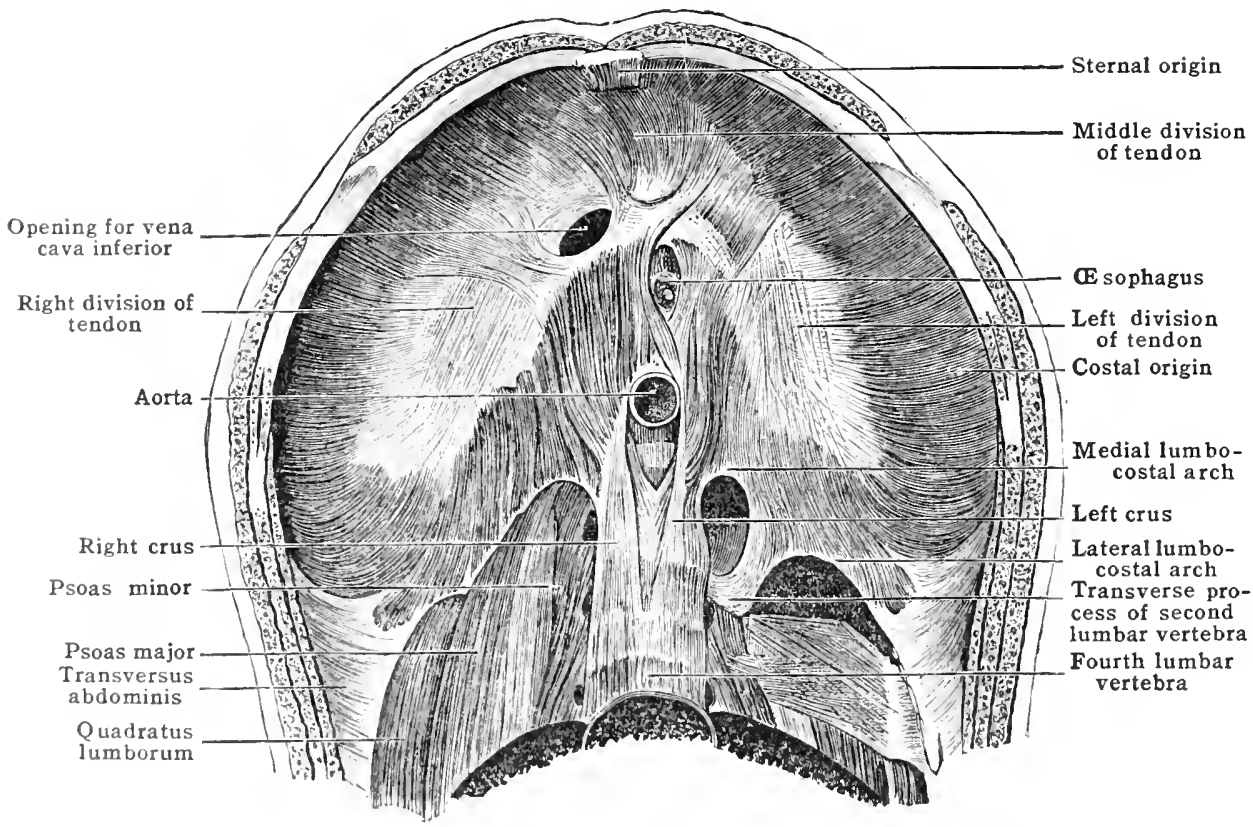

Structure and insertion.-From the origins therc arises a complex quadrangular muscle belly from which spring the fasiculi of termination. These extend to-(1) the transverse professes of the upper three or four lumbar vertehrir; (2) to the fibre-bands which extend out literally in the lumbar fascia from the trinsverse processes; and (3) to the medial part of the lower borker of the twelfth rib.

Nerve-supply.- Throm ent lirect branches from the first three or four lumbar nerves.

Action. - It serves primarily to produce lateral flexion of the spinal column. When both muscles at tognther, they prodice extension of the column. 'The nusele also serves to depress itud fix the twelfth rib.

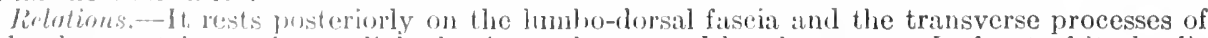
the lumbar verteluris. Its medial eden is partly avered by the psoas. In front of it also lie the kilney, the intostines, aml the lumbar arteries and nerves. It is ensheathed by membranes

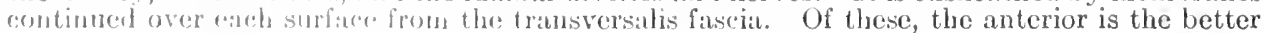
markerl and is callerl the lumbar fascia.

lariations. - There is mmm inlividual variation in the internal structure of the muscle and in its attarhments.-Its insertion naty coteme to the eleventh rib.-

'I'he psoas major and minor lrelong essentially to the musculature of the lower limb and are there alescribed (1, 15ii).

\section{D). 'THF DIAPHRAGM}

The diaphragm (figs. 346,391 ).- This loute-shaped musculo-membranous slıcet has, when

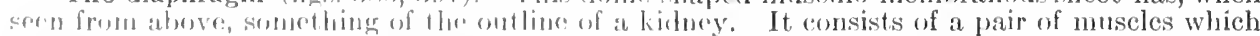

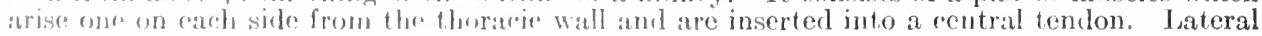


to the tendon the diaphragm projects higher into the thoracic cavity than in the central area. On the right, in moderate expiration, it extends in adults to the height of the medial extremity of the fifth rib, and on the left to the fifth interspace.

Origin.-On each side from-(1) the lower border and back of the xiphoid process and the adjacent aponeurosis of the transversus abdominis or from the tendinous arch extending from the tip of the xiphoid process to the cartilages of the fifth and sixth ribs, (sternal portion); (2) the lower border and inner surfaces of the cartilages of the seventh and eighth ribs, the cartilages and osseous extremity of the ninth rib) and the osseous extremities of the last three ribs (costal portion); and (3) from the lumbar vertebre (lumbar portion). The lumbar portion is divided somewhat irregularly into three crura, between which pass blood-vessels and nerves.

The lateral crus arises from the lateral surface of the bodies of the first two lumbar vertebrx and from fibrous thickenings of the fascia over the psoas and quadratus lumborum muscles. Of these, one, the medial lumbo-costal arch (internal arcuate ligament), extends from the body of the second lumbar vertebra to the transverse process of the same vertebra; the other, the lateral lumbo-costal arch (external arcuate ligament), extends from the tip of the transverse

Fig. 392.-The Perineal Muscles in the Female.

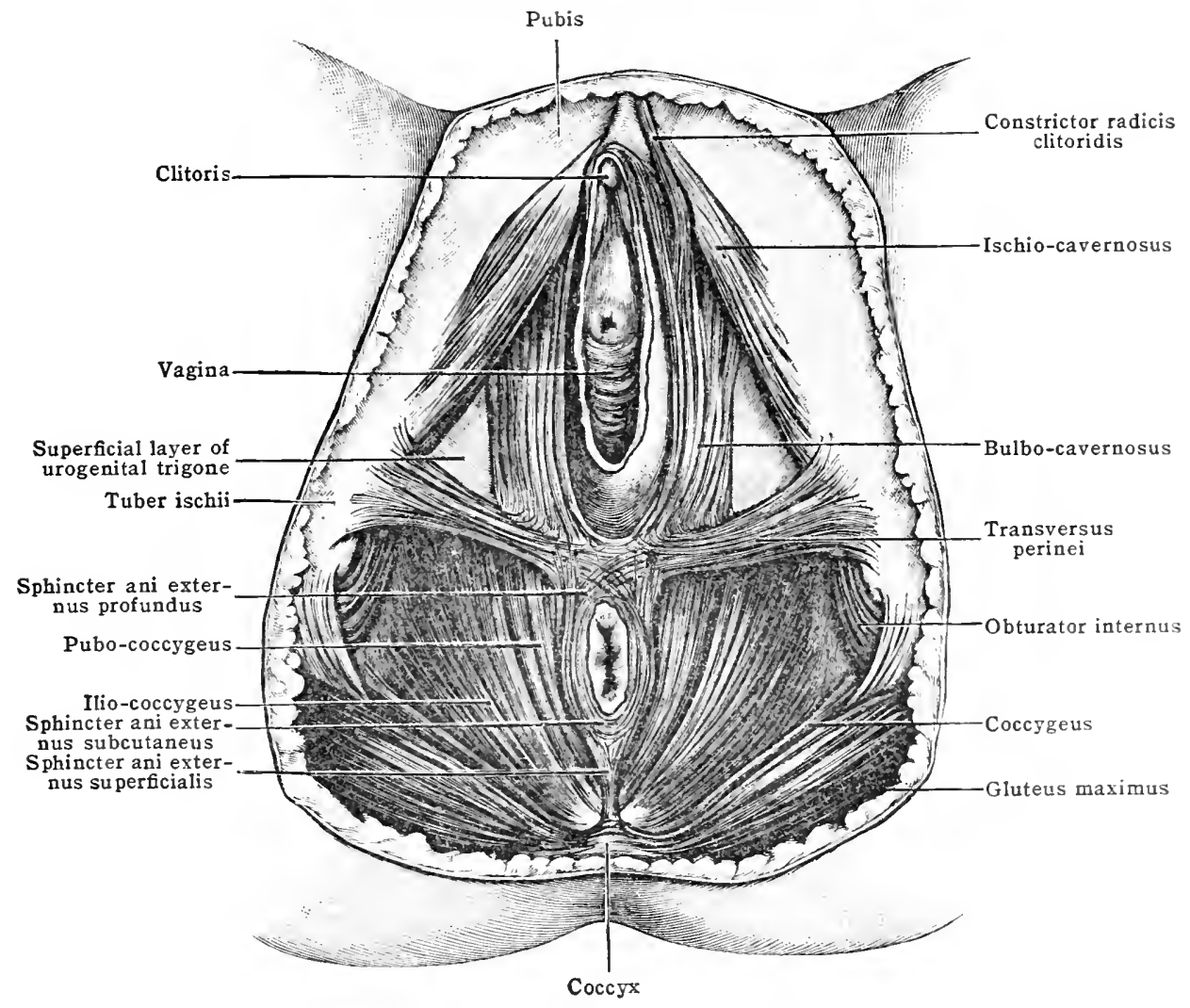

process of the second lumbar vertebra to the twelfth rib. The lateral crus is only inconstantly attached to this. The intermediate crus arises from the ventro-lateral surface of the body of the second lumbar vertebra from the sides of the bodies of the first two lumbar vertebræand from the intervening discs. The medial crus arises from the front of the bodies of the third and the fourth lumbar vertebræ. On the left side it usually extends only to the third vertebra, and it does not always extend to the fourth on the right. The extremity and medial margin of this crus are tendinous, the lateral portion fleshy. On the second, third, and fourth, and the lower part of the first lumbar vertebrie the medial crus of each side is separated from its fellow by the hiatus aorticus (for the aorta and thoracic duct). Over the first lumbar vertebra they are fused by a process which extends from the right crus into the fower ventral surface of the left. Above here the right crus may be divided into two parts, one of which, fused with the left crus, passes on the left of the hiatus œsophageus, while the other passes on the right. Sometimes the hiatus œsophageus lies between the right and left crura. Frequently the left crus gives off a slip which passes to the ventral surface of the right below the hiatus.

The costal portion arises by a series of dentations which do not correspond perfectly in number with the ribs. Some costal cartilages have two dentations attached to them. It interdigitates with the transversus abdominis but in part arises from tendinous arches which bridge the origin of the transversus in the last three interspaces.

Structure and insertion. - The central tendon has somewhat the shape of a trifoliate leaf, 
the place of the stem being taken by the region oceupied by the vertebral column, one leaflet lying on each side of this and one in front. The ventral part is usually placed somewhat to the left and is more or less completely fused with the left leaflet. Between the ventral and the right leaflets there is a large opening through which passes the inferior vena cava, the foramen venæ cavæ. The leaflets are fused in front and behind this.

Fig. 393.-Textral Coccrgeal Muscles (After Eisler.)-1. M. sacrococcygeus anterior. 2. M. coecrgeus. 3. M. piriformis. 4. M. obturator internus 5. Fascia iliaca, above the iliopsoas. 6. Fibroeartilago intervertebralis lumbosacralis. 7. Ventral trunk of first saeral nerve. y. Sacral plexus.

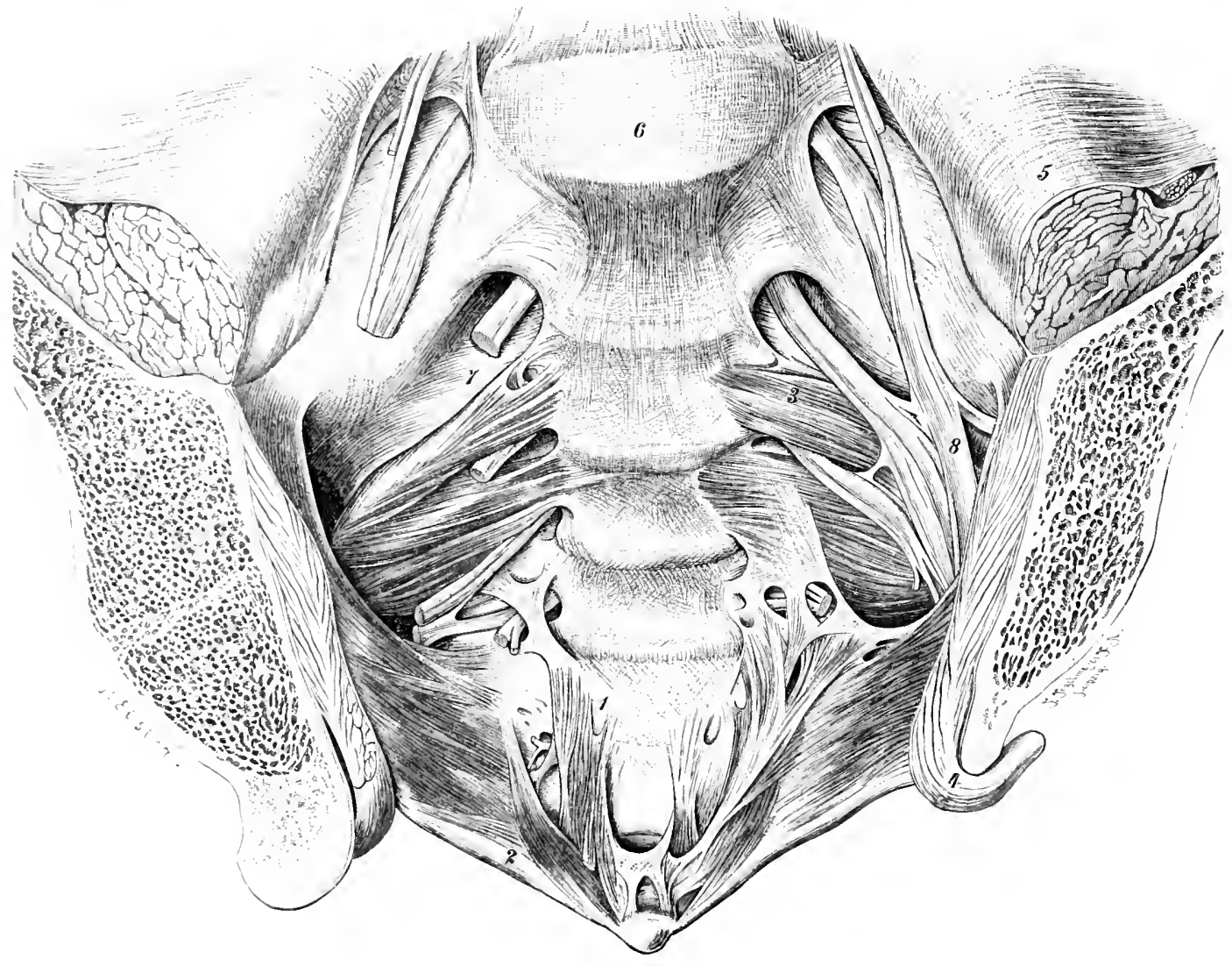

The flowy portion of the muscle is composed of fibre-bundles which pass at first nearly vertically upwarland ther arch over to be attached to the margins of the central tendon. The stermal pretion of the muscle is the shortest. It is often separated from the eostal portion by a small space through which the superiol cpigastric vessels pass.

Nerep-supply. - From the phrenic nerves, one of which arises on each side from the third to the fifth eervical nerves. Warh nerve penctrates the diaphragm lateral to the central tendon and braks ap into an extensive plexus on the inferior surface of the muscle. Some of the lower intercostal nerves also contribute to the sensory innervation of the margin of the muscle and possibly also slightly to the motor innervation. The sympathetie nerves furnish fibres for the blood-vesseds.

Actom.-'Jn colarge the theracic ravity and thus cause inspiration. According to R. Fick, however, the diaphragn plays a less important part in inspleation than is usually assumed for

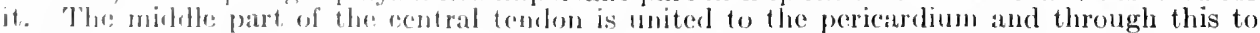
the errveal fasriat, and is, threfore, not very movidble. In the contraction of the musele it is the dorsal and lateral pretions which in the main are flattened. The diaphagm aids in defecaion, parturition and voniting, ly the pressme it exerts on the abdominal viscera. It also acts as a constriefor of the asophlagus.

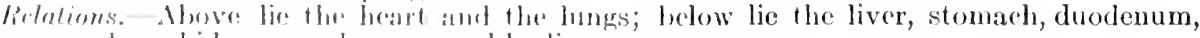
panerras, sploen, kidneys, and suprarenal bodies.

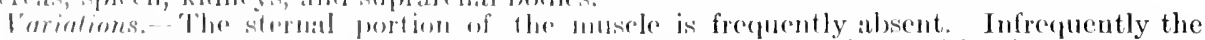
riaphragen is incompledely developed lorsally on the left sirle. This condition is rarer on the right side. The extent of the varions insertions of the diaphragm shows eonsiderable individual lifferences. 'The vertebral port ion of the muscle mat be slightly fused with the psoas or with the

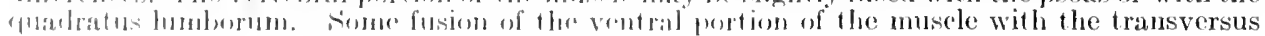


thoracis has also been seen. Small fasciculi may pass to neighbouring structures: the esophagus, stomach, liver, mesentery, etc. Muscle fasciculi are frequently found in the central tendon.

\section{r. MUSCULATURE OF THE PELNIC OLTLET}

In order to understand the musculature of the pelvic outlet it is necessary first to consider briefly the structure of the pelvis. It is bounded laterally and in front by the ilium below the terminal (ilio-pectineal) line, the ischium and the pubis, and by the obturator membrane and the sacro-spinous (small sciatic), sacro-tuberous (great sciatic) and the interpubic ligaments. The pubis, ischium and the obturator membrane are covered by the obturator internus muscle (figs. 392, 401) which here takes its origin and which converges toward and passes through the lesser sciatic notch on its way to its insertion on the great trochanter of the femur. The piriformis muscle (figs. 393, 396), which arises from the sicles of the pelvic surface of

Fig. 394.-The Male Perineum. (Modified from Hirschfeld and Leveillé.

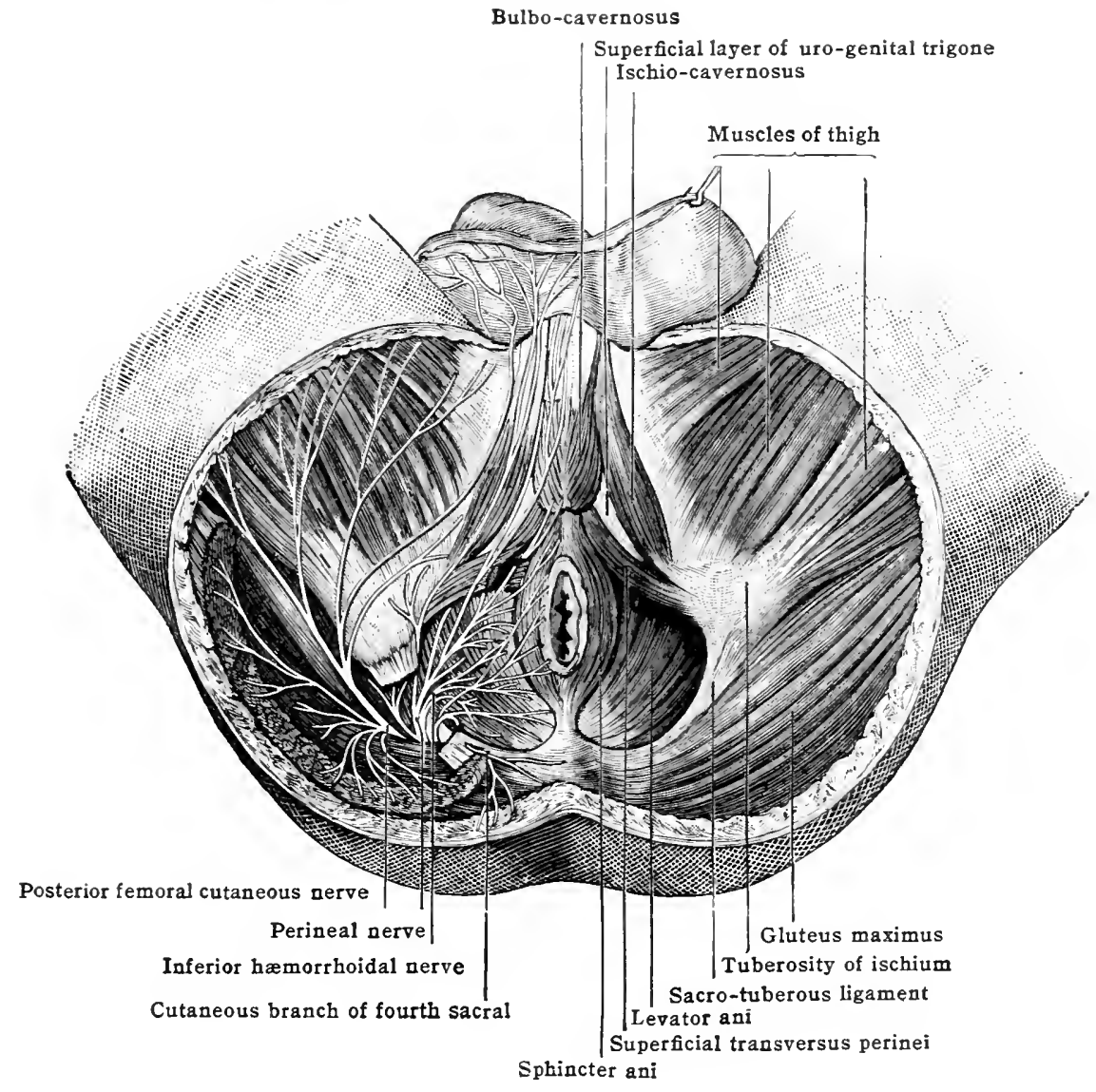

the sacrum, from the posterior border of the great sciatic notch and the neighbouring part of the sacro-tuberous (great sciatic) ligament nearly fills up the great sciatic notch on its way to its insertion on the great trochanter. The walls of the pelvis are thus padded by muscles which belong to the limb. The muscles are covered by fascia best developed over the obturator internus muscle as the obturator fascia. The gluteus maximus muscle (figs. 392, 394, 400, 401), which arises from the back of the ilium, the sacrum, and the coccyx, and is inserted into the femur and the fascia of the thigh overlaps to some extent the sacro-tuberous ligament, and in the standing position the tuberosity of the ischium so that its lower margin forms an accessory boundary to the pelvic outlet. 
The outlet of the pelvis thus bounded by bone, ligaments and by muscles belonging to the lower extremity prescnts two triangles (figs. 392, 394), an anterior or urogenital triangle, with the base between the two ischial tuberosities and the apex below the symphysis pubis, and a posterior or rectal with the base between the ischial tuberosities and the apex at the cocerx which projects into it here. The outlet is closed by a special musculature divisible into three groups of muscles and fascia; those of the pelvic diaphragm and anus, those of the urogenital diaphragm, and those of the external genitalia.

The pelvic diaphragm [diaphragma pelvis] extends from the upper part of the pelvic surface of the pubis and ischium to the rectum which passes through it to be surrounded by the external sphincter. The urogenital trigone or urogenital diaphragm [diaphragma urogenitale] lies between the ischio-pubic rami superficial to the pelvic diaphragm and surrounds the membranous urethra and in the female also the ragina. The external genital muscles lie superficial to the trigone.

The muscles of the pelvic diaphragm are two in number on each side, the coccygeus, and the levator ani (figs. 395, 396, 397). The coccygeus arises from the

Fig. 395.-The Pelvic Diaphragm in the Female, from below and behind.

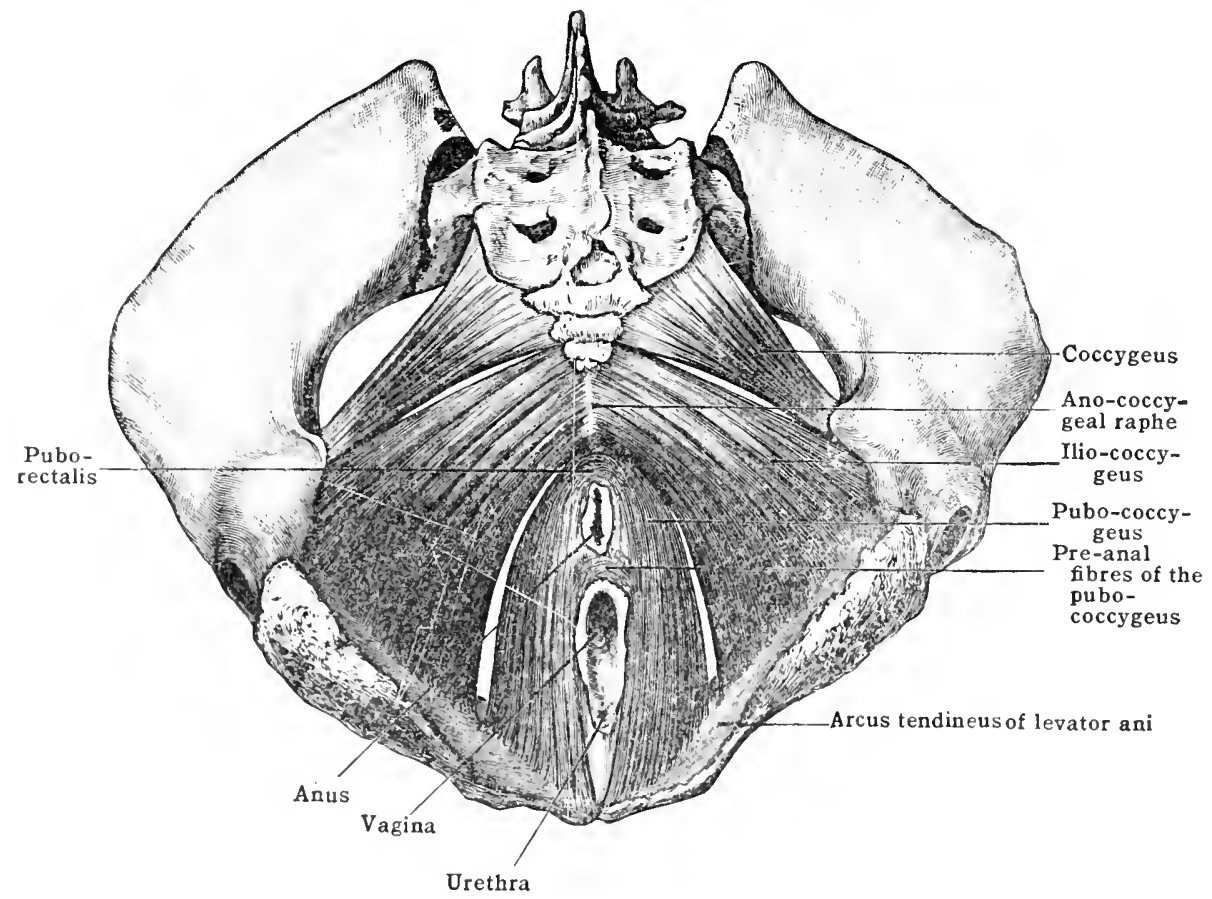

ischial spine and is inserted into the lateral margin of the lower sacral and the upper coceygral vertebrip. It is closcly applied to the pelvic surface of the sacrospinous (smatl sciatic) ligament. In so far as it is active it flexes and abducts the coceys.

'The levator ani arises (figs. 395, 3969, 397) from the innor side of the pubis, along a line exteruling laterally from the inferior margin of the symphysis to the obturator canal, and Prom the obturator fatscia along a line, the arcus tendineus, extenfing from the publs to the spine of the ischium. The levator ani is inserted into the merlian raphe hick of thr anus, the ano-coceygeal raphe, in to the tip and sides of the coreyz and into an aponemesis, which is attached to the anterior salrococeygrat ligimurnt. It is divisible into three portions, a pubo-coccygeal, an ilinecocygrol, and a puberectul. 'The levator ani muscles of the two sides are separated l,y it slit which exteruts from the reckum to the symphysis pubis and in which in the: mate lie the lower part of the prostate, and the membranous urethra (fig. $3996)$, and in the fomalo the vaginal and urethra (fig. 395). Back of the rectum some of the fibre-lumbles from the museles of the two sides interdigitate, while 
others terminate in the ano-coccrgeal raphe. A few fibre-bundles also interdigitate across the median line, in front of the rectum (pubo-coceygeal, fig. 39.5) and some are inserted into the walls of the rectum. The levator ani and coccygeal muscles of the two sides form a funnel-shaped muscular support for the pelvic viscera (fig. 399). When the abdomino-thoracic diaphragm contracts, as luring inspiration, the pressure on the viscera is transmitted to the pelvic diaphragm which resists the pressure and elevates the viscera when the abdomino-thoracic diaphragm relaxes. The levator ani muscle also constricts the rectum and pulls it forward and in the female constricts the vagina from side to side.

As it passes through the pelvic diaphragm, the rectum for about two and a half centimetres is surrounded by a special external sphincter muscle (figs. 393, 394, 397), divisible into three concentric layers as described below. This muscle, especially differentiated from the primitive sphincter of the cloaca,

Fig. 396.--Lateral Viet of Muscles of the Floor of the Pelvis.

(A portion of the ischial and pubic bones sawn away.)

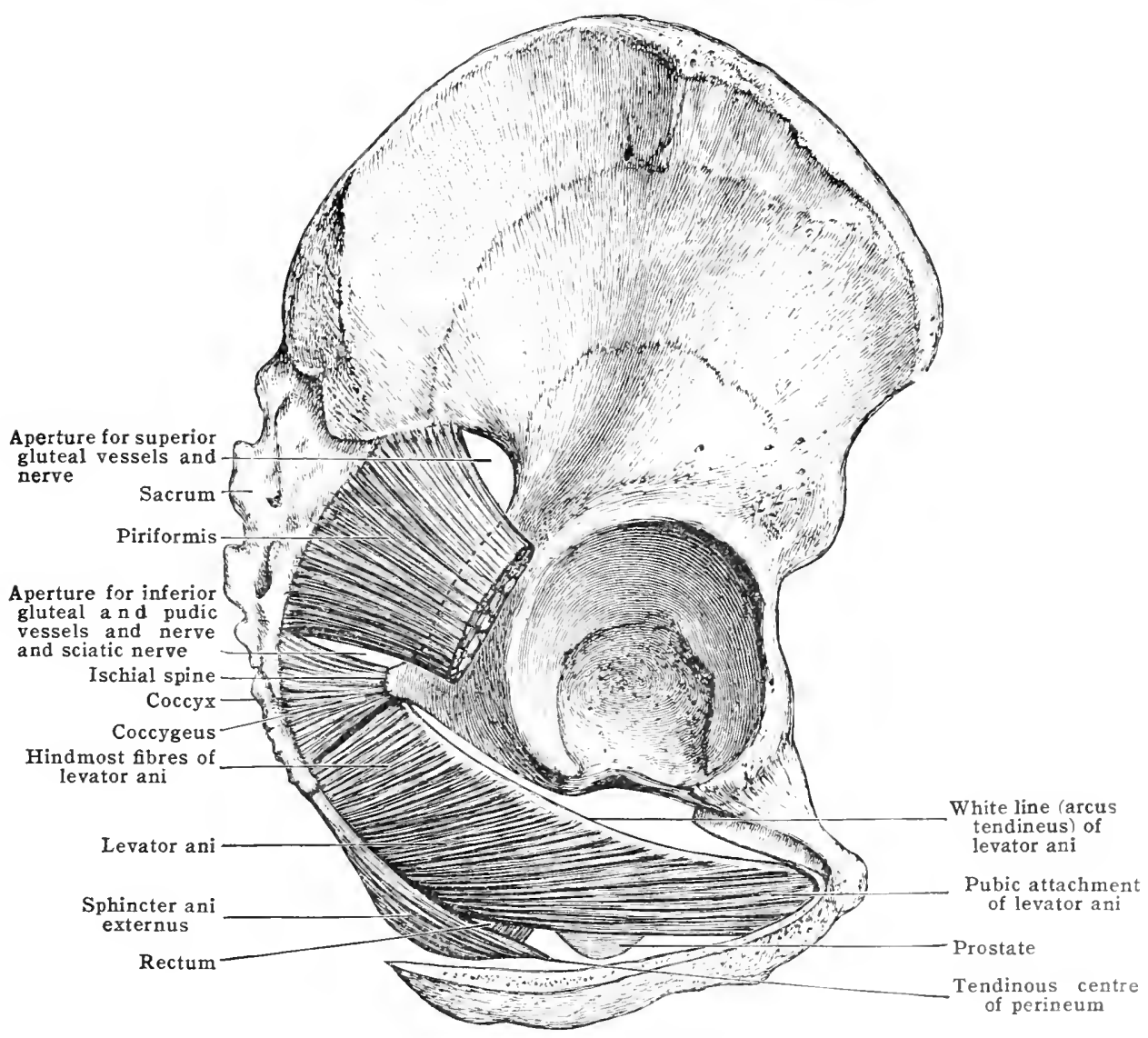

serves to close the rectum. It is supplemented by a sphincter of smooth muscle which lies immediately beneath the mucous membrane of the anus. It is attached behind to the coccygeus, and in fropt to the central tendon of the perincum described below.

The lateral origin of the levator ani, as above described and as shown in figs. 396 and 399, is considerably above the osseous and muscular margin of the pelric outlet. The muscles of each side converge toward the post-anal region so that a space is left between the lateral wall of the pelvis, and the levator ani and external sphincter (fig. 399). This space, the ischio-rectal fossa, is filled with fat (fig. 400 , 401, 402). It is deepened laterally by the lower margin of the gluteus maximus muscle (fig. 400). In the fascial canal (Alcock's canal) in the lateral wall of the 
fossa run the internal pudic ressels and nerves (fig. 401). Above the pelvic diaphragm in the median part of the pelvic eavity are found the bladder, the ampulla of the rectum, and the prostate gland (in the male) or the vagina and uterus (in the female). I saterally on each side there is a subperitoneal space, filled with connective tissue and containing blood-vessels and nerves (fig. 402). Fasciæ invest each surface of the pelvic diaphragm (diaphragmatic fascia) and extend about the viscera (endopelvic fascia).

Fig. 397. - Sagittal Sectiox of the Peluis to Show the Peluic Diaphragua and External Sphincter ANi.

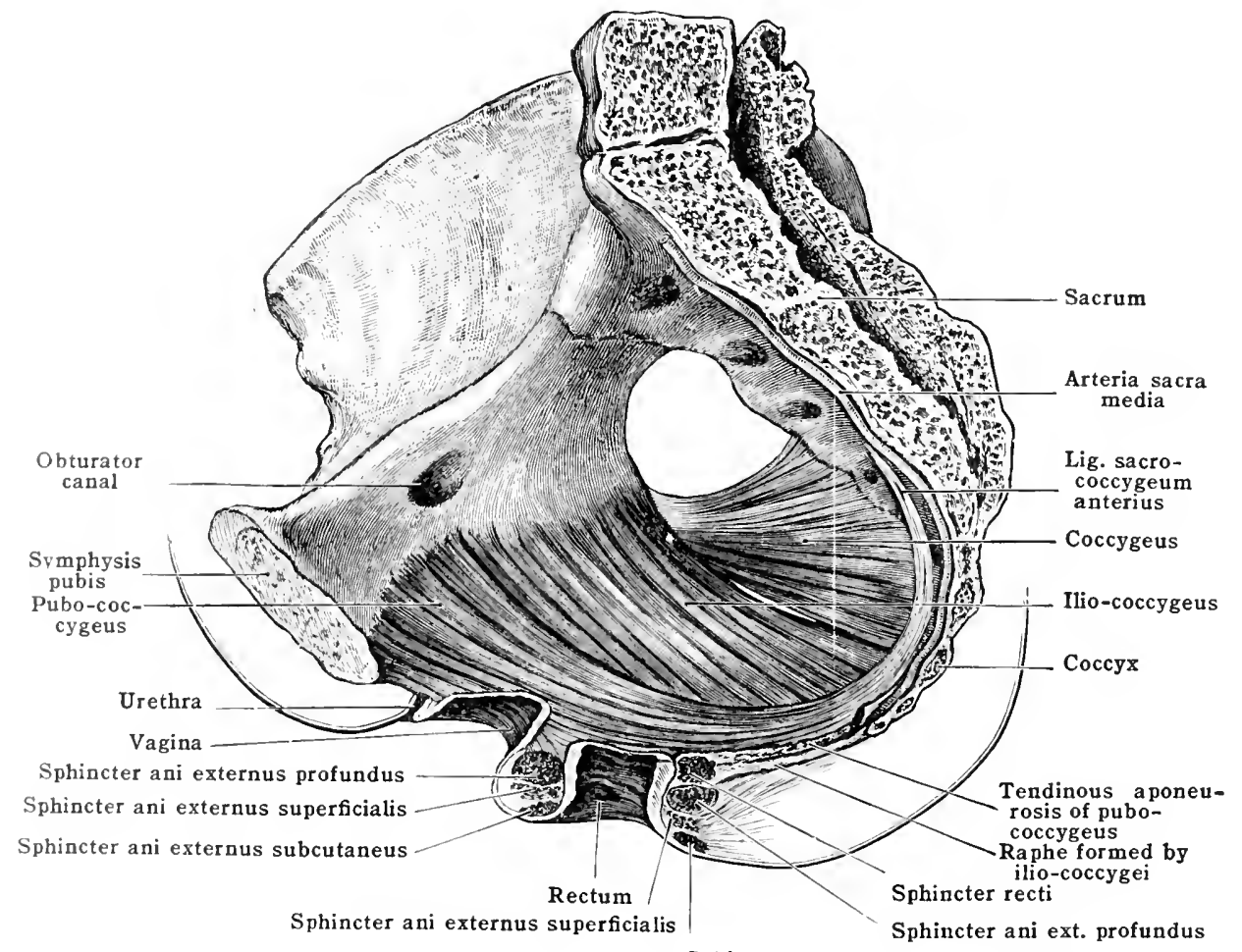

Sphincter ani externus subcutaneus

Thr muscular apparatus of the anterior or urogenital triangle of the pelvic outlet is much more complicated than that of the posterior or rectal triangle just described. We have seen that between the levator ani muscles of each side in front of the rectum there is a slit whieh extends to the symphysis pubis and that through it, the lower part of the prostate and the urethra extend in the male, the urethri and the vagina in the female. Between the ischio-pubic rami there is stretehed a triangular muscular and fibrous membrane, which likewise surrounds these urogenital ducts and which serves to strengthen the pelvie wall in this region. This structure is known as the urogenital trigone (figs. 398, 400, 403). 'The museulature within it, (allenl by Holl the aceessory or urogenital diaphragm, includes two muscles (fig. 3988), the sphineter urogenitalis (urethro) and the deep transverse perineal muscle. The sphincler embraces the urethra and associated structures. 'The component fihre-bundles arise ehiefly from the fibrous tissue in the angle beneath the symphysis pubis, but partly also from the descending pubie rami. They pass analivarl and morlialward on cach side of the urethra and then partly intrereligitate aneses the incelian line, partly terminate in a median raphe. Some fibre-bundles enbrace in the male the lower part of the prostate and (jowper's graml. In the female the fibre-bundles of the sphincter partly terminate in the wall of the vagina. Some of them are continued clownward on each side of the vilgina and interligitate with fihre-bundles from the deep transverse perineal muscle. 'The deep trensiverse perineal muscle (fig. 398) arises on rach side from the ischio-pulice ramus. It constitutes a flat hand of musele, the fibre-bundles of 
which in part interdigitate across the median line, and in part are inserted into a median raphe.

The musculature of the urogenital diaphragm is enclosed between two woll marked fascial layers (fig. 400, 403), the deep (superior) and superficial (inferior) layer's of the urogenital trigone (triangular ligament). 'The anterior margins of the two fascial layers are fused to form the transverse ligament of the pelvis which extends between the inferior pubic rami, beneath the dorsal nerves and veins of the penis (clitoris). At the anal margin of the musculature these two lavers are also fused with one another. The deep layer of the urogenital trigone forms the floor of the anterior recess of the ischio-rectal fossa (fig. 400).

Superficial to the urogenital trigone lie the external genitalia (figs. 392, 394). Voluntary muscle is here found in conneetion with the crura of the penis (elitoris) and the bulb of the penis (vestibule). Although the musculature in the two sexes is fundamentally similar, nevertheless, owing to the differences in the structure of the genitalia in the two sexes, it is convenient to take up first the external genital musculature in the male and then that in the female.

Fig. 398.-Muscles between the Two Layers of the Urogenital Trigone (Male.)

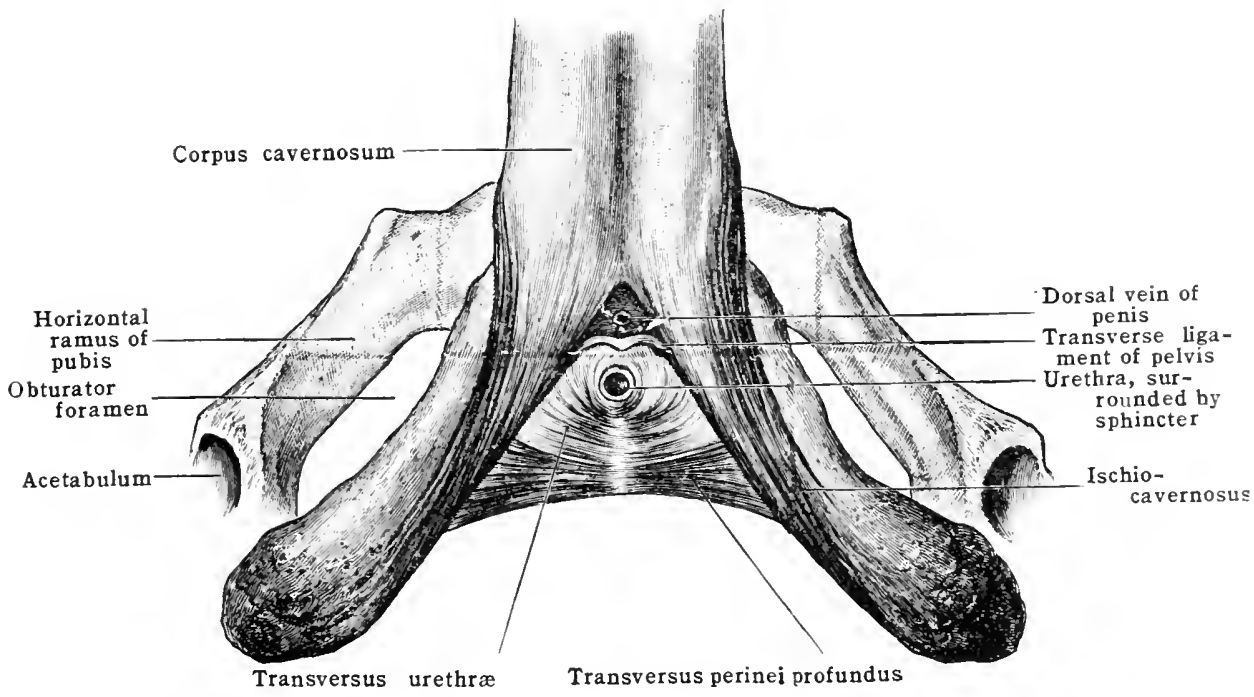

In the male the crus penis, the posterior part of the eorpus cavernosum, is relatively large. It lies in the groove between the ischio-pubic ramus and the urogenital trigone (fig. 398), to the former of which it is firmly united. It is enwrapped on its free medial surface by the ischio-cavernosus muscle (crector penis) (figs. 398, 402). The fibre-bundles of this muscle arise from the ischial tuberosity and from the ischio-pubic ramus on each side of the attachment of the crus. It is inserted into the medial and ventral surfaces of the crus near the attachment of the suspensory ligament. Some of the fibre-bundles may frequently be traced to the dorsal surface of the root of the penis (levator penis muscle).

The corpus spongiosum [corpus cavernosum urethræ] terminates posteriorly in the bulb which lies on the urogenital trigone between the two crura (figs. 39. 402). It is united to the superficial layer of the trigone (fig. 402). It is cnveloped by the bulbo-cavernosus muscle, composed of right and left halves united by a median raphe on the superficial surface of the bulb (fig. 394). Each half consists of several superimposed layers of fibre-bundles deseribed below. The component fibre-bundles arise from the superficial layer of the urogenital trigone, from fibrous tissue on the dorsum of the bulb in the angle between the two crura, from the lateral surface of the corpus cavernosum penis in front of the ischiocavernosus and from the dorsal surface of the penis. It is inserted into a tendinous structure situated in front of the anus, the central tendon of the perineum, 
and into the median raphe on the free surface of the bulb. By its contraction the bulbo-cavernosus forces semen or urine from the bulbous part of the urethra.

The superficial transverse muscle of the perineum (figs. 392, 394) arises on each side from the ascending ramus of the ischium and is inserted into the central tendon of the perineum. It is frequently weakly developed. It acts with the deep transverse perineal muscle in fixing the perineum and thus offeringsupport for the action of other muscles.

In the female (fig. 392) the ischio-cavernosus does not differ markedly from that in the male although usually it is smaller. The superficial transverse muscles are. on the other hand, usually relatively better developed. The central tendon of the perineum is likewise usually better developed in women and is more elastic, a characteristic of value in childbirth.

The chief difference in the musculature in the two sexes is found in the bulbo-cavernosus (fig. 392). This, in the female, arises from the back of the clitoris, the corpus cavernosum and the trigone. It covers the outer side of the bulb of the vestibule and the gland of Bartholin. It is inserted into the central tendon of the perineum. The chief function of the pair of muscles is to constrict the vagina.

The external genital muscles are covered by a deep layer of the tela subcutanea,

Fig. 399.-Diagran to show the Fascief of the Pelvis in Section. (After Holl.)

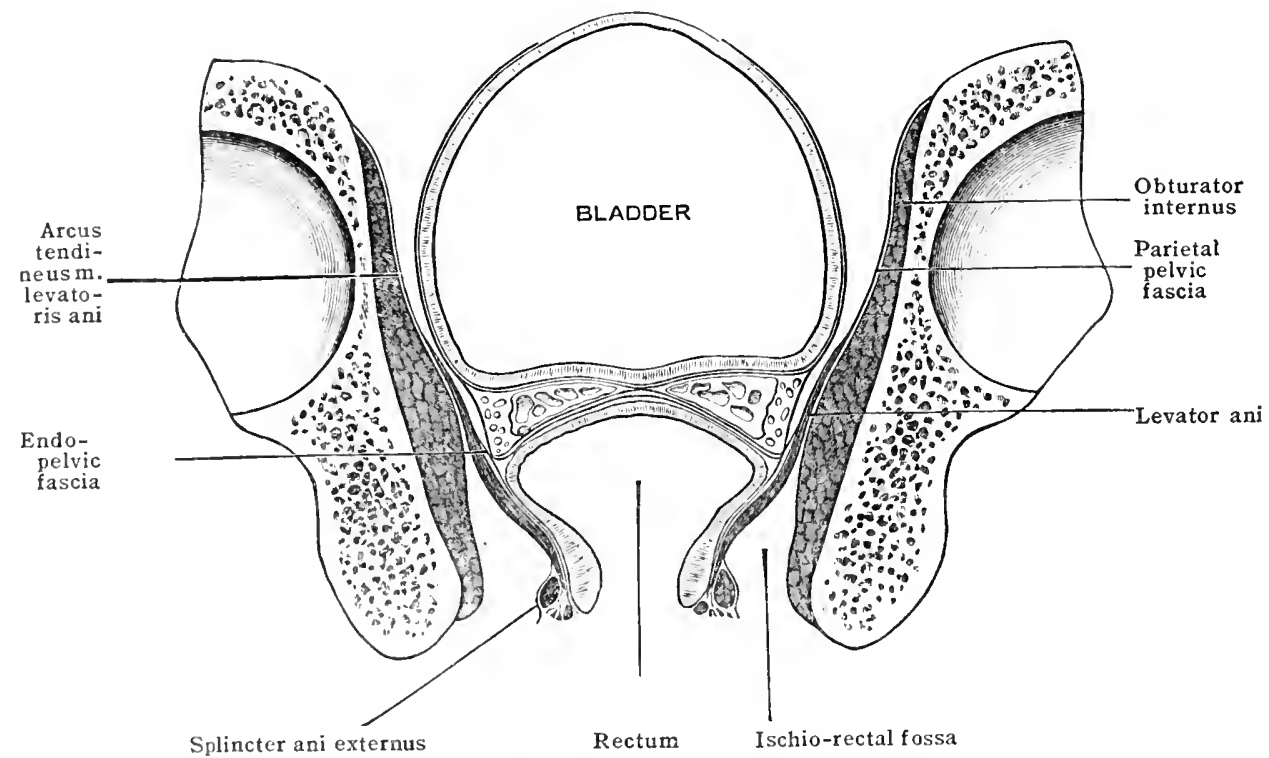

Colles' fascia, which is firmly fused with the two layers of the urogenital trigone at the anal margin of the latter.

\section{MORPHOLOGICAL REMARKS}

While the shoulder-grirlle and the muscles which extend from this and from the trunk to the upper ext renity aresuperficially placed with respect to the trunk, and do not interrupt the trunk musculature the peverse is true of the hip-girdle and the musculature of the lower extremity. 'The hip-girdle is firmly united to the spinal column at the sacrum. The museles which arise from the trunk and are attached to the lower limbs are few in number compared with those of the upper extrenity and, unlike the latter, are decply placed. Thus the psoas major muscle (fig. (1)(i) arises on cach side of the lumbar region of the spinal column at the back of the abdominal (abvity and is inselted into the femur and the piriformis (fig. 406) arises from the front of the sacrum at the lasek of the pelvic cavity and is inserted into the great trochanter of the fommr. The skeleton and musculature of the lower extrenity, furthermore, markedty interfere with the continuty of the trunk musculature which in the lower vertebrates and in the huinan conloryo may be followed ontinuously to the caudal end. The interruption is much less narked behind than in front. 'fhe intrinsic dorsal spinal musculature extends well down over the Janck of the sacrum, hut on the herek of the lowel end of the sacrum and on the back of the

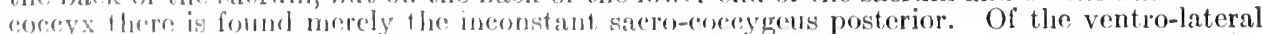
mosmbature the musenlature of the aludominal wall, as is indieated by its innervation, is derivel from the lower thoracio and the first one or two lombar myotomes; the quadratus lumbormm, at the bark of the aldominal eavity (fig. 406), from the first three or four lumbar myo- 
tomes. Beyond here there is an interruption until we come to the musculature of the pelvic outlet which, in part, mav be looked upon as modified trunk musculature belonging to the last three sacral myotomes. "The intervening region is "cut out" for the reception of the base of the lower extremity.

It is of interest to note that more and more of the ventro-lateral wall of the trunk is "cut out" as the mid-ventral line is approached. Thus while the quadratus lumborum behind represents spinal segments as far caudal as the third or fourth lumbar, the rectus abdominis in front represents segments merely as far caudal as the twelf th thoracic. Similarly while the

Fig. 400.-Sagittal Section throdgh the Urogenital 'Trigonf axd Ischio-rectal Fossa to the Left of the Midde Lixe. (Diagrammatic.)

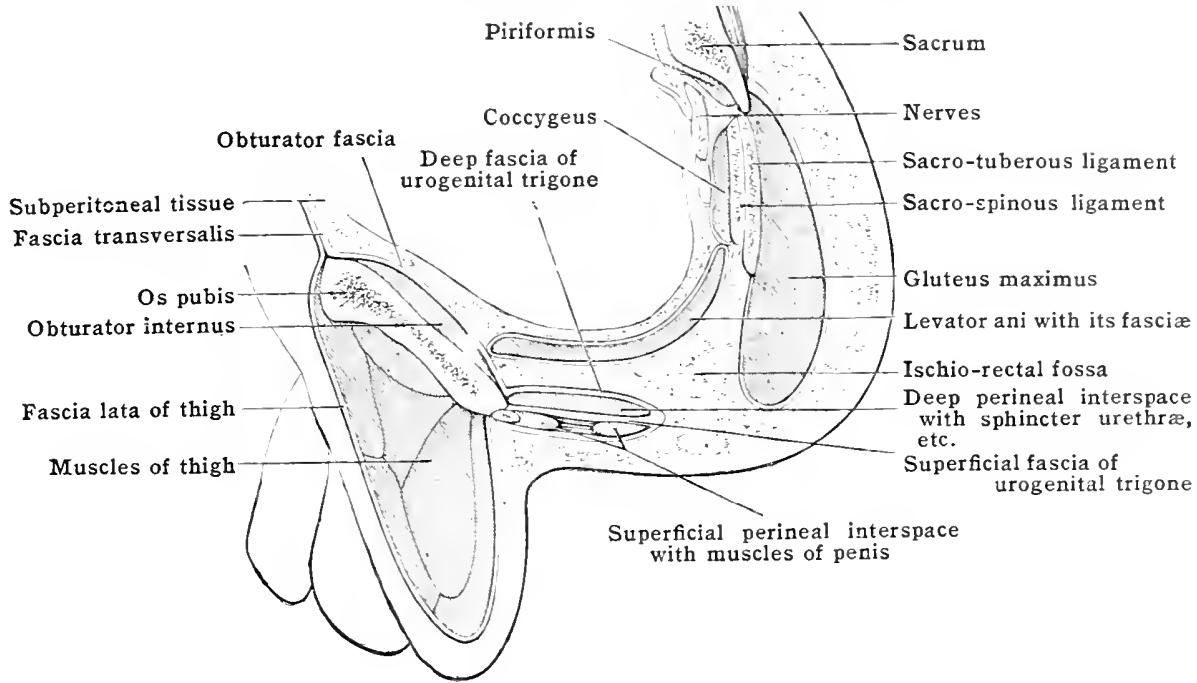

coccygeus at the back part of the pelvic outlet represents the third and fourth sacral segments, the levator ani at the front represents chiefly the fourth.

The musculature which in the tailed mammals is used to move the tail as well as to wall off the pelvic cavity and close rectal and urogenital openings, in man is modified wholly for the latter functions. It constitutes the pelric diaphragm.

The musculature of the urogenital diaphragm of the external genitalia and anus in man is differentiated from the primitive sphincter of the cloaca.

\section{FASCIE}

The tela subcutanea in the male perineal region contains many bundles of smooth muscle fibres continuous with and similar to the lartos of the scrotum (corrugator cutis ani). At the sides where it passes over the lower margin of the gluteus maximus it contains a large amount of fat, but in the dorsal region over the coccyx and sacrum, as in the mid-perineal region, the fat is limited in amount. In the labia majora of the female perineu $n$ there is much fat in the tela subcutanea.

The ischio-rectal fossa (figs. 401, 402) is bounded laterally by the obturator internus muscle and fascia, the tuberosity of the ischium and the ischio-pubic ramus, medially by the levator ani and coccygeus muscles and fasciæ, ventrally by the dorsal aspect of the urogenital trigone and dorsally by the gluteus maximus muscle. An anterior recess extends forward well toward the body of the pubis between the levator ani, the ischio-pubic ramus and the urogenital trigone. A posterior recess may likewise be traced backward covered by the lower edge of the gluteus maximus (figs, 400,401). The fossa is filled with loose fatty tissue continuous with that of the tela subcutanea. Through it pass the hæmorrhoidal, and long and short perineal hranches of the pudic artery and nerve. The main trunks of these vessels and nerves lie in il special fascial compartment (Alcock's canal) in the lateral wall (fig. 401).

The external genital org:nns are covered by a special deep laver of the tela subcutanea, the superficial perineal (Colles') fascia (fig. 402). 'This is attached on each side to the lower margin of the ischio-pubic ramus and to the ischial tuberosity. At the posterior margin of the superficial transverse perineal muscle it fuses with the two fascial layers of the trigone. It is wherent to the central tendon of the perineum and to the raphe of the bulb. Anteriorly it is continuous with the deep layer of the tela subcutanea covering the scrotum, the penis, and the lower part of the abdominal wall. In rupture of the urethra urine is prevented, by the attachments of the tela, from getting further back than the posterior edge of the trigone, but anteriorly it may extend to the surface of the abdomen. Here it may extend upward for a considerable listance, but it is kept from the thighs by the attachment of the deep layer of the tela subeutanea (Acarpa's fascia) to the inguinal ligament. Beneath the superficial perineal fascia are found the crura of 
the penis and their muscles, the bulb of the corpus spongiosum and its muscles, the superficial transverse perinei muscles, and the perineal vessels and nerves (fig. 402).

Muscle fasciæ.-The muscles of the urogenital diaphragm, the urogenital (urethral) sphincter and the transversus perinei profundus, are contained between two fascia layers which constitute the superficial (inferior) and deep (superior) layers of the urogenital trigone (the superficial or inferior and the deep or superior layers of the triangular ligament).

Fig. 401.-Section showing the Ischio-rectal Fossa in its Relations to the Pelvid VISCERA.

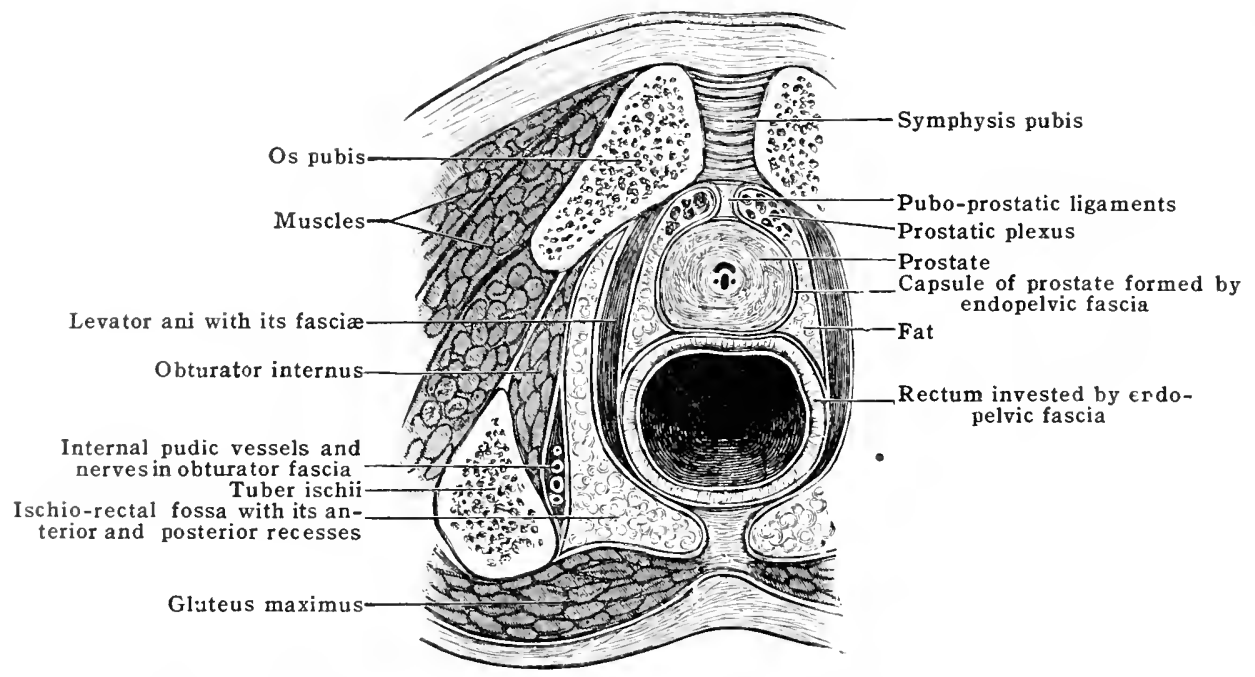

The superficial (inferior) layer (figs. 392, 394, 400, 402, 403) which lies between the external genitalia and the urogenital diaphragm, is composed of strong bands of fibrous tissue which extend transversely across the subpubic arch and are attached to a ridge on the ischio-pubic rami. It is separated from the arcuate (subpubic) ligament by a mass of fibrous tissue through which the dorsal veins and nerves of the penis (clitoris) run, and in which there is a venous plexus.

Fig. 402.- Vertical Frontal Section of the Pelis, showing Fascie. (Modified from Braune.)

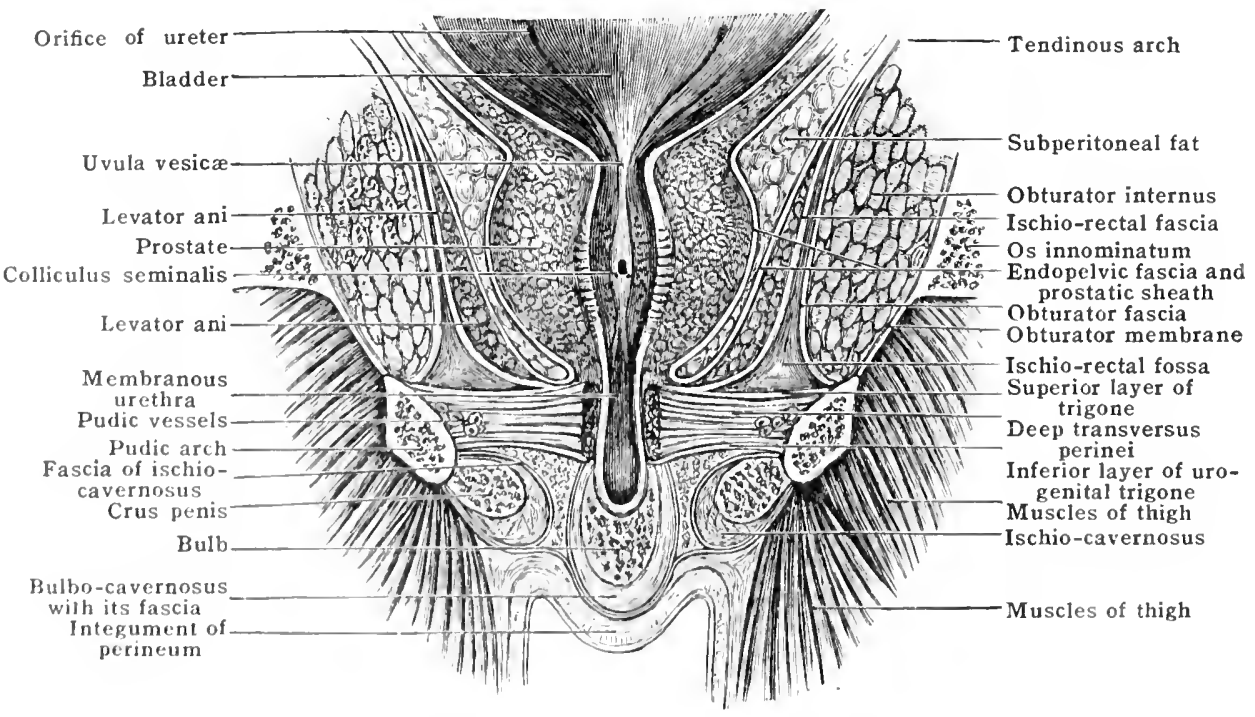

Inomath this tissur: a fitmons hamb, the lianserse ligament of the pubis, extends between the

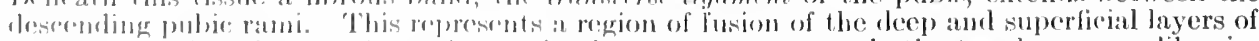

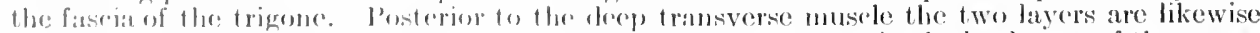

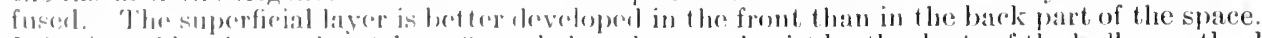

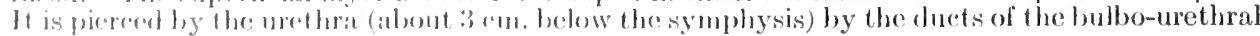


(Cowper's) glands, the arteries of the bulb, and the dorsal nerves and arteries of the penis. In the female it is pierced by the vagina as well as by the structures mentioned above.

Beneath the superficial layer of the fascia of the trigone, in addition to the muscles of the urogenital diaphragm, there are found the membranous urethra, the bulbo-urethral gland(Cowper's), the internal purlic arteries and the pudic nerves (in part).

The deep (superior) layer of the urogenital trigone (figs. 400, 402, 403) lies between the muscles of the urogenital diaphragm and the ischio-rectal fossa and levator ani. It may be looked upon as a continuation of the obturator fascia across the pubic arch. Posterior to the deep transverse perineal muscle it fuses with the superficial layer of the fascia of the urogenital trigone. In this region in the male it fuses with a fascial membrane, the prostatico-perineal fascia, which extends upward between the rectum and prostate, and is attached to the posterior wall of the latter. In the female it is fused with the fibrous tissue which lies between the vagina and the rectum.

The muscle fasciæ of the pelvis (figs. 399, 400, 401, 402, 407, B) have been descriled in various ways by different authors. They may be subdivided into parietal and diaphragmatic.

Fig. 403.-Diagram of the Superficial and Deep Layers of the Urogexital Trigone.

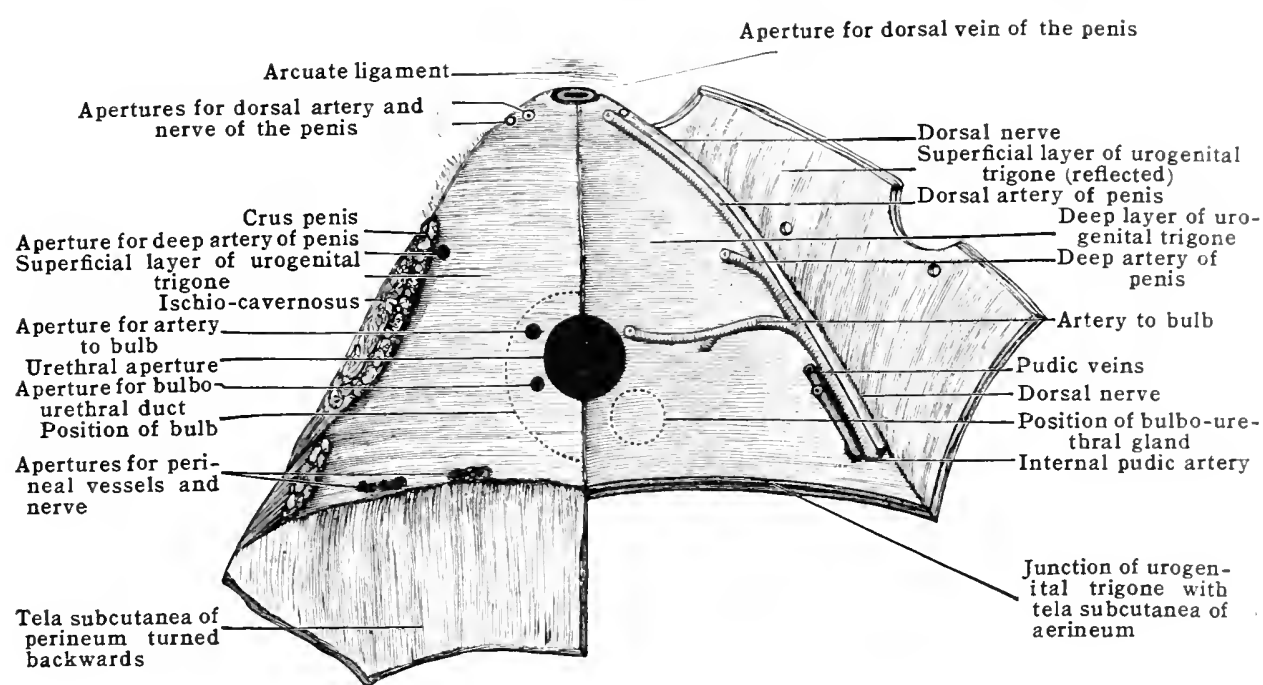

The parietal fasciæ (fig. 399) cover the muscles which extend from the interior of the pelvis to the thigh (the obturator internus and piriformis muscles). Above, the fascia on each side is attached to the linea terminalis and is continuous with the fascia transversalis and the iliac fascia. It is attached to the margins of the greater and lesser sciatic notches and to the ischiopubic ramus and the body of the pubis. Between the ischio-pubic rami it is stretched across the subpubic arch and forms the superior or deep layer of the urogenital trigone described above. The portion of parietal pelvic fascia over the obturator internus muscle is called the obturator fascia.

The diaphragmatic pelvic fasciæ cover both surfaces of the pelvic diaphragm and are reflected upon the viscera. The fascise covering the two surfaces of the levator ani are attacheil to the parietal (obturator) fascia along the line of origin of the muscle.

The line of attachment of the levator ani divides the obturator fascia into two parts (fig. 399), a pelvic part above the line of attachment, covered by peritoneum, and an ischio-rectal part below the line of attachment. The latter bounds the lateral wall of the ischio-rectal fossa. The former part is much the thicker. It consists morphologically of two fused membranes, the obturator fascia proper and the aponeurosis of the ilio-coccygeal portion of the levator ani, which although usually fused with the obturator fascia, may frequently be traced to the terminal (ilio-pectineal) line from which in tailed mammals this portion of the levator takes origin. The two layers of fascia also become continuous at the medial margin of the muscle where this faces the urogenital passage (fig. 399). Posteriorly, the inner layer fuses with the tendinous insertion of the pubo-coccygeus portion of the muscle and the fascie of the muscles of each side are continuous. It also fuses with a fascia covering the coceygeus muscle.

The thin perineal layer of the levator fascia behind the rectum fuses with that of the onposite side and is attached to the coccyx and the ano-coccrgeal raphe. About the anus it lielps to form a covering for the external sphincter. Ventratly it is attached to the ischio-pubic rani. It forms the medial wall of the ischio-rectal fossa.

Endo-pelvic fascia (figs. 401, 402).-The peritoneum is reflected from the pelvic wall onto the viscera much higher up than the level at which the viscera are attached to the pelvic diaphragm. Between the pelvic fascia covering the deep surface of the pelvic diaphramm (levator ani and coccygeus muscles) and the peritoneum there is thus left a space, subperitoneal space (fig. $467 \mathrm{~B}$ ). In the median plane in this region in the male are found the bladder, prostate, seminal vesicles, the ureter and ductus deferens in their course near the bladder, and the ampulla of the rectum. In the female we find here the bladder, the vagina, the uterus, and the ampulla of the rectum. Between these medially placed viscera and the lateral wall of the pelvis 
there is an irregularly shaped space, cavum pelvis subperitoneale, bounded above by peritoneum, below by the fascia covering the pelvic diaphragm and filled with connective tissue of varying density. The tissue in this space in the female is continuous with that between the two peritoneal surfaces of the broad ligament. Between the viscera in the subperitoneal region and about their walls the connective tissue is more or less definitely condensed into membranes which constitute the endopelvic fascia, variously described by different authors. The fascia covering the pelvic diaphragm, especially that on the deep surface, is fused to the endopelvic fascia where the viscera pass through the pelvic diaphragm. In the connective tissue of the subperitoneal space are found the hypogastric artery and vein and their chief branches, and various risceral nerves. The subperitoneal space above the pelvic diaphragm is to be compared with the subcutaneous space below the pelvic diaphragm known as the ischio-rectal fossa and described above.

\section{MUSCLES}

\section{A. Mtscles of the Pelvic Diaphraga, Coccra, and Anus}

The coccygeus (figs. 393, 395, 397, 400).-Origin.-From the ischial spine and the neighbouring margin of the great sciatic notch. Structure and insertion. - The fibre-bundles diverge to be inserted partly directly, partly by means of an aponeurosis, into the lateral margin of the fourth and fifth sacral vertebre and of the coccyx. Usually the muscle is composed in considerable part of tendinous connective tissue, especially on the dorsal side of the cranial portion, and the ventral side of the caudal portion.

Nerve-supply.-From the pudendal plexus several small nerves enter the cranial margin and pelvic surface of the muscle. They arise usually from the third and fourth sacral nerves.

Action.-Insofar as the muscle is active it flexes and abducts the coccyx.

Relations.- Ventrally the muscle bounds the pelvic cavity, from which it is separated by the pelvic fascia, beneath which runs the nerve to the levator ani muscle. The dorsal surface is partly covered by the sacro-spinous (lesser sciatic) ligament and helps to bound the ischiorectal fossa (posterior recess).

Variations.--The muscle varies greatly in the extent of its fleshy development. It may be doubled. It may be partially fused with the levator ani. Occasionally it is absent.

The sacro-coccygeus anterior (fig. 393).- This inconstant muscle, when well developed, arises from the sides of the fourth and fifth sacral and from the front of the first coccygeal vertebra and from the sacro-spinous ligament. The short fibre-bundles which compose it make up a somewhat irregular belly which is inserted into the anterior sacro-coccygeal ligament and into the second to fourth coceygeal vertebra dorsal to the insertion of the levator ani. The innervation is from the fourth and fifth sacral nerves.

The sacrococcygeus posterior is an inconstant muscle consisting of a few muscle bundles which extend from the dorsal surface of the lower sacral vertebræ or from the posterior iliac spine to the dorsal surface of the coccyx. It lies beneath the superficial layer of the sacrotuberous (great sciatic) ligament.

The levator ani (figs. 392, 394, 39.5, 396, 399, 401) is divisible into three portions, the iliococcygeus, the pubo-coccygeus and the pubo-rectalis.

The ilio-coccygeus (fig. 397) arises from the ischial portion of the arcus tendincus (white line). This extends from the ischial spine and posterior part of the arcuate line to the superior ramus of the pubis near the obturator canal, curving downward for a variable distance below the olsturator canal. The constituent fibre-bundles form a muscular sheet which is inserted into the side of the eoceyx and into the median raphe (ano-coccygeal) which extends from the tip of the coccyx to the rectum. Many fibre-bundles cross the median line.

The pubo-corygeus (figs. 395, 397) arises from the inner surface of the os pubis, along a line extendheg from the lower margin of the symphysis pubis to the obturator canal, and from the areis tendineus as far backward as the origin of the ilio-coceygeus. The fibre-bundles form a sheet of nusele which passes backward, downward, and medialward past the urogenital organs ant the rectum on each sicte ant is insertcd by means of an aponeurosis into the anterior sacro-coceygeal ligament. Back of the rectum some of the fibre-bundles of the muscle sheets of e:th side interdigitate across the median line. Some of the more superficial fibres are insertorl into the leep part of the mo-coceygeal raphe. Some of the fibre-bundles which arise nearest the sympliysis are inserted on each side into the rectum. The pubo-coceygeus lies to some extent on the pelvie surfare of the insertion of the ilio-coceygeus.

The pulu-rertalis (fig. 395) arises (a) from the body and descending ramus of the pubis beneath the origin of the pubn-coccygeus, (b) from the neighlouring part of the obturator faseia and (s) from the fatseia rovering the pelvie surfare of the urogenital trigone. The fibre-bundles

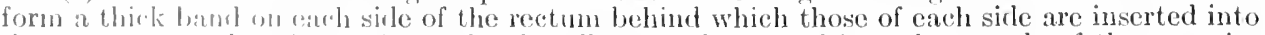

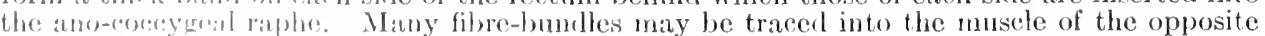
sirle. Sime of 1 he more superficial fibre-bundles are reflected medialward in front of rectum and may be followed into the superficial transverse perineal inusele, others may be followed into the sphineter ani extroms, or even to the skin.

Nerve-supply. - liy at spmial nerve which arises usually from the fourth sacral, runs across the pelve surfare of the muscle and gives a special branch to each portion.

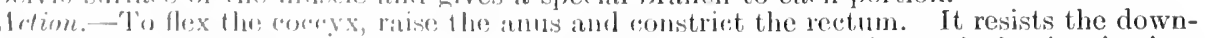

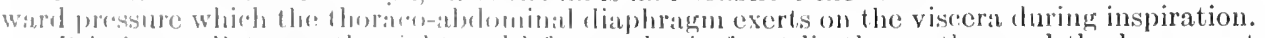

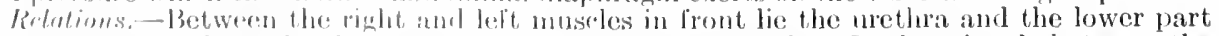
of the prostate in the mals, the urotha mol vagina in the female. In the triangle between the isshio-pulso rami of earh sicle lies the urogenital cliaphragm separated from the pubo-rectal part of the moselo: l,y the deep latyos of the trigone from which some of the fibres of the latter arise. back of the urrigenital itiaphragm the muscle helps to bound the isehio-rectal fossa. 
Variations.-The muscle shows great individual variation in structure which causes it to be variously described by different authors.

The sphincter ani externus (figs. 392, 394, 396, 397, 399) is made up of bundles of muscle fibres which surround the anus for nearly two centimetres. It is elliptical in form. Behind the anus the fibre-bundles of each side in part interdigitate, forming a ring. They are attached to the skin, and in part are attached through a tendon, the ligamentum ano-coccygeum, to the back of the coccyx. In front of the anus the fibre-bundles also in part interdigitate with one another, in part are inserted into the skin and in part interdigitate with the fibre-bundles of the transverse perineal and bulbo-cavernosus muscles. At the point where these muscles meet, about two and a half centimetres in front of the anus, there may be a visible mass of fibrous tissue, the central tendon of the perincum, but this is not always distinct. It is usually better developed in the female than in the male perineum. The external sphincter is divisible into three portions, a subcutaneus, a superficial and a deep (fig. 397). The three parts are connected by fibre-bundles, and are not always distinct. The subcutaneous division is small and immediately encircles the anal orifice. The superficial division lies external to the subcutaneous ring and descends further toward the rectum. It is shown in figs. 392, 394. It is the only part attacherl to the coccyx. In front it is attached to the central tendon of the perineum, but some fibres are continued into the bulbo-cavernosus. The deep portion forms a heavy ring above the rectum beneath the superficial part. It is distinctly, though not completely, separated from the pubo-rectal portion of the levator ani by fascial tissue containing the inferior hæmorrhoidal vessels. Some of the fibre-bundles of the deep portion may be traced in front of the anus across the mid-line to the ascending ramus of the opposite side and form part of the superficial transverse perineal muscle.

Nerve-supply.-From the inferior hæmorrhoidal branches of the pudendal (internal pudic) and frequently also by a perineal branch from the fourth sacral.

Action.-To keep the anus closed.

Relations.-Externally it is surrounded by the fat of the ischio-rectal fossa, internally near the skin it surrounds the sphincter ani internus, composed of smooth muscle, deeper it lies next the mucous membrane, for a distance of two centimetres from the skin.

Variations.-The muscle shows considerable individual variation in structure.

The rccto-coccygeus or muscle of Treitz, is a triangular bundle of smooth muscle fibres. The origin of the muscle is from the second and third coccygeal vertebrie. It is inserted by its apex into the posterior wall of the rectum and the perirectal fascia. It retracts and elevates the rectum.

\section{B. Muscles of the Urogenital Diaphragm}

The urogenital diaphragm is composed of two closely united muscles, the deep transverse perineal muscle and the urogenital sphincter.

The transversus perinei profundus (fig. 39S) is a flat muscle which arises from the inner side of the inferior ischial ramus and is inserted into the median raphe. Many of the fibre-bundles interdigitate with those of the opposite side and some may be followed into the external sphincter of the anus and into the urogenital spincter and other perineal museles.

Nerve-supply.-By the perineal branch of the pudendal (internal pudic).

Action.- The pair of muscles draw back and fix the central tendon of the perineum and thus give firm support for the action of the urogenital sphincter.

Relations.-The inferior surface is separated (often incompletely) by the inferior layer of the urogenital trigone from the superficial transverse perineal muscle. The superior surface is covered by the deep layer of the urogenital trigone, into which the superficial layer is reflected about the anal margin of the muscle.

Variations.- The muscle is variable in structure and may be absent. (It is more frequently absent in the female than in the male.)

The sphincter urogenitalis differs in the male and female owing to the passage of the vagina through the perineum in the latter. In each sex it is convenient to consider the muscle as divided into two parts, a peri-urethral and an infra-urethral (vaginal).

In the male (fig. 398) the peri-urethral part, the $m$. sphincter urcthre membranacere is composed of fibre-bundles which are circularly placed about the membraneous urethra. The more external fibre-bundles are attached to the crura of the penis near their junction, to the transverse ligament of the pubis and to the fasciæ of the trigone. Some of them partially ensheath the lower part of the prostate, and others envelop the bulbo-urethral (Cowper's) glands. Some of the fibre-bundles take a longitudinal course along the urethra. Bundles of smooth muscle fibres are intermingled with the striated, and the fibrous framework of the musculature is marked by the large amount of elastic tissue which it contains. The infra-urethral part, the $m$. transversus urethro, is closely associated with the urethral part. The fibre-bundles arise on each side from the inferior ramus of the pubis. They pass for the greater part beneath the urethra and interdigitate with that of the opposite side or are inserted into a median raphe. A few fibrebundles may pass above instead of below the urethra. The transverse urethral muscle, first described by Guthrie (On the anatomy and diseases of the neck of the bladder, London, 1831) is inconstant. Its existence as a normal constituent of the male perineal musculature hils been disputed by Delbet (Poirier and Charpy) and others.

In the female the peri-urethral part, sphincter urcthre, differs in no essential respects from the corresponding muscle in the male. Some of the fibre-bundles form a true sphincter about the urethra. The infra-urcthral part, on the other hand, seems to vary greatly in difierent individuals so that the descriptions given by different authors are somewhit contradictory. It is better developed in women who have not borne children than in those who have. It may be looked upon as composed of two portions, a $m$. transversus vagince and an $m$. constrictor vagina. 
The transversus vagina arises from the ischio-pubie rami and is inserted into the lateral wall of the vagina. Some of the fibre-bundles pass above and some below the vagina. This musele corresponds with the transversus urethre of the male but is, apparently, seldom fully developed. The $m$. constrictor vagince, on the other hand, seems to be more constant. It is composed of fibre-bundles which embrace the lateral wall of the vagina and are inserted above into the periurethral framework, below into the raphe between the two deep transverse perineal muscles. some of the fibre-bundles are attached to the vaginal wall. Some interdigitate with the sphincter urethræ, others with the deep transverse perineal muscle and with the transversus vaginæ.

Nerve-supply. - By a branch from the perineal nerve.

Action.- To compress or close the urethra and in the male to compress the prostate and Cowper's glands, in the female to compress the vagina and Bartholin's glands.

Relations.-On the pelvic side it is separated from the levator ani by the deep layer of the urogenital trigone, and on the perineal side it is separated from the superficial muscles by the superficial layer of the trigone. Toward the anus it is closely associated with the deep transverse perineal muscle. Tenous plexuses are well developed near the sphincter urethræ in both sexes, but especially in the female.

Frg. 404.-Bulbo-Cavernosus in the Male.

The two halves have been reflected from the median raphé, and the bulb turned downward after division of the corpus spongiosum. (The ischio-bulbosus is not present on the right side.)

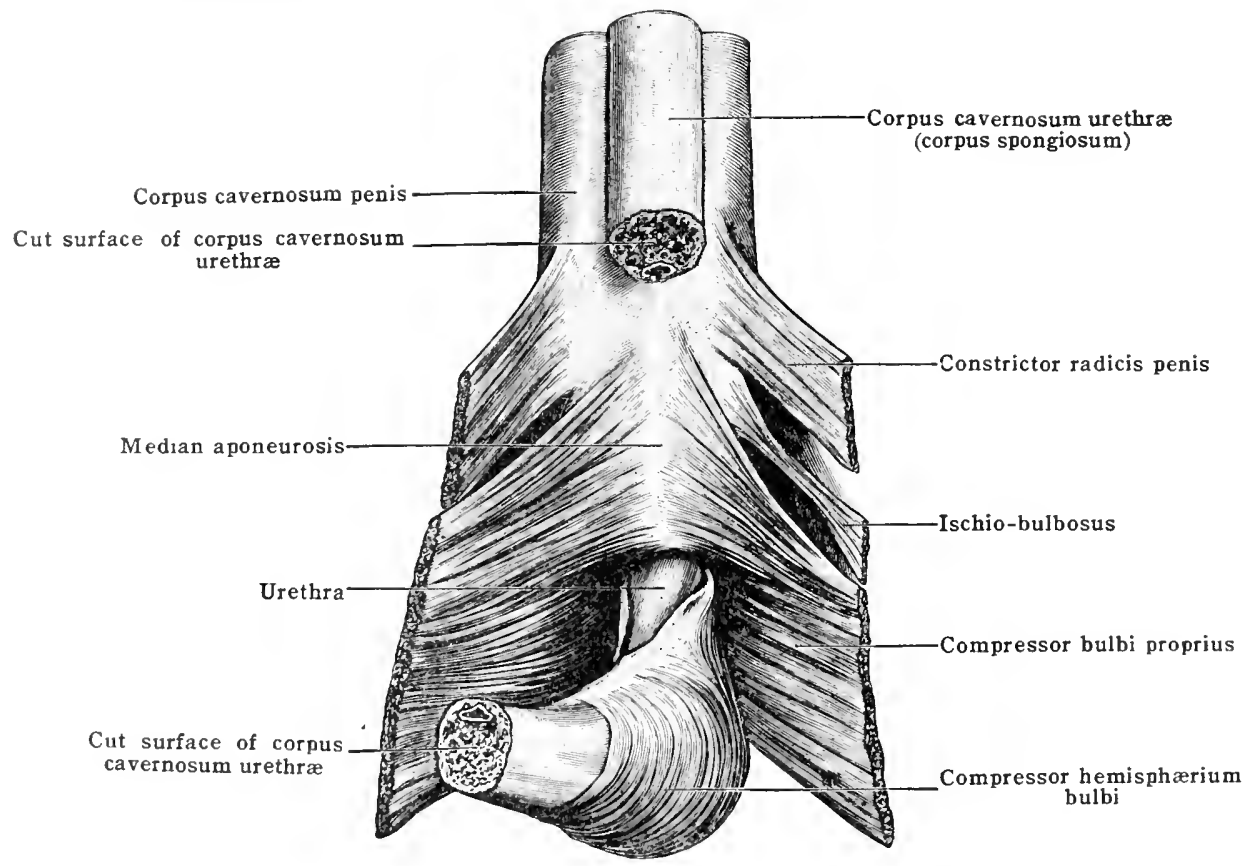

Tariations. - It has already been pointed out that there is considerable variation in the muscles composing urogenital sphincter. Occusionally a rulimentary ischio-pubicus is found arising from the ischio-pubic ramus and terminating in a tendon which unites with that of the uppreste side bencath the dorsal vein of the penis (clitoris). The tendon may be present as thr transvere liganent of the belvis when the muscle itsolf is absent. It represents the eompressor of the dorsal vein fomm in lower mammals.

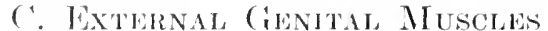

The bulbo-cavernosus (figs. 39., (1). in the male ensheaths the bult,. The fibre-bundles arise foum the dense fissue eovering the eorpus cavernostum at the root of the penis and from the

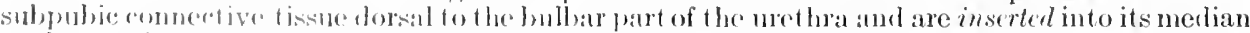
raphe on the ventral side of the bulh and into the crintral tendon of the perineum. Several

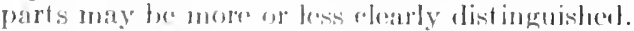

1. The comstrictor radicis whis arises ustatly from the bateral surfare of the corpus cavernosmm prois at the batio of the prois, hut maty arise from the under surface or from the dorsal

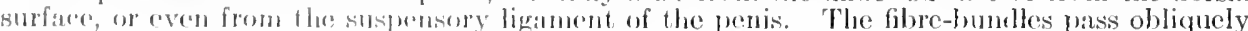
backwarl and motiatwart and are inserted into the median raphe on the perineal surface of the lulk.

2. The compressor bulbi proprins arises (1) from a strong fibrous aponeurosis situated betwern the corpus spongiosum and the united arura of the penis and firmly artherent to the former, and (2) from the sulperficial haye of the frigone. The fibre-bundles ensheath the bulb ind are insertal into the posteries part of the median raphe and into the centrat tendon of the 
perineum. To a greater or less extent, depending on the development of the two muscles, the compressor covers the more posterior part of the constrictor.

3. The compressor hemispharium bulbi arises from a tendon common to the muscles of the two sides on the dorsum of the bulbous part of the urethra near the membranous part. The fibre-bundles embrace the hemisphere of the bulb and are inserted into the median raphe. This muscle is covered by the preceding. It not only compresses the bulb, but also is a sphincter of the urethra.

4. The ischio-bulbosus is placed by Holl in this group. It arises from the pelvic surface of the tuberosity and of the inferior ramus of the ischium and when well developed is inserted into the median raphe, superficial to the compressor bulbi proprius or the constrictor radicis proprius. Frequently, however, it does not extend over the bulb but is inserted into the inferior surface of the corpus cavernosum. It is more frequently absent than present. (Nee fig. 404.)

Nerve-supply. - The perineal division of the pudic nerve sends several branches to the bulbocavernosus.

Action.--It compresses the bulb and at the same time the bulbous portion of the urethra. The turgescence of the penis is thus increased and urine or semen is expelled from this portion of the urethra.

Relations.--It lies beneath the skin and subcutaneous tissue.

Variations.-The muscle is variable in structure as is indicated by the different descriptions given by different authors. The compressor vence dorsalis described by Houston is composed of

Fig. 405.-Diagramiatic Representation of the Perineal Structures in the Female.

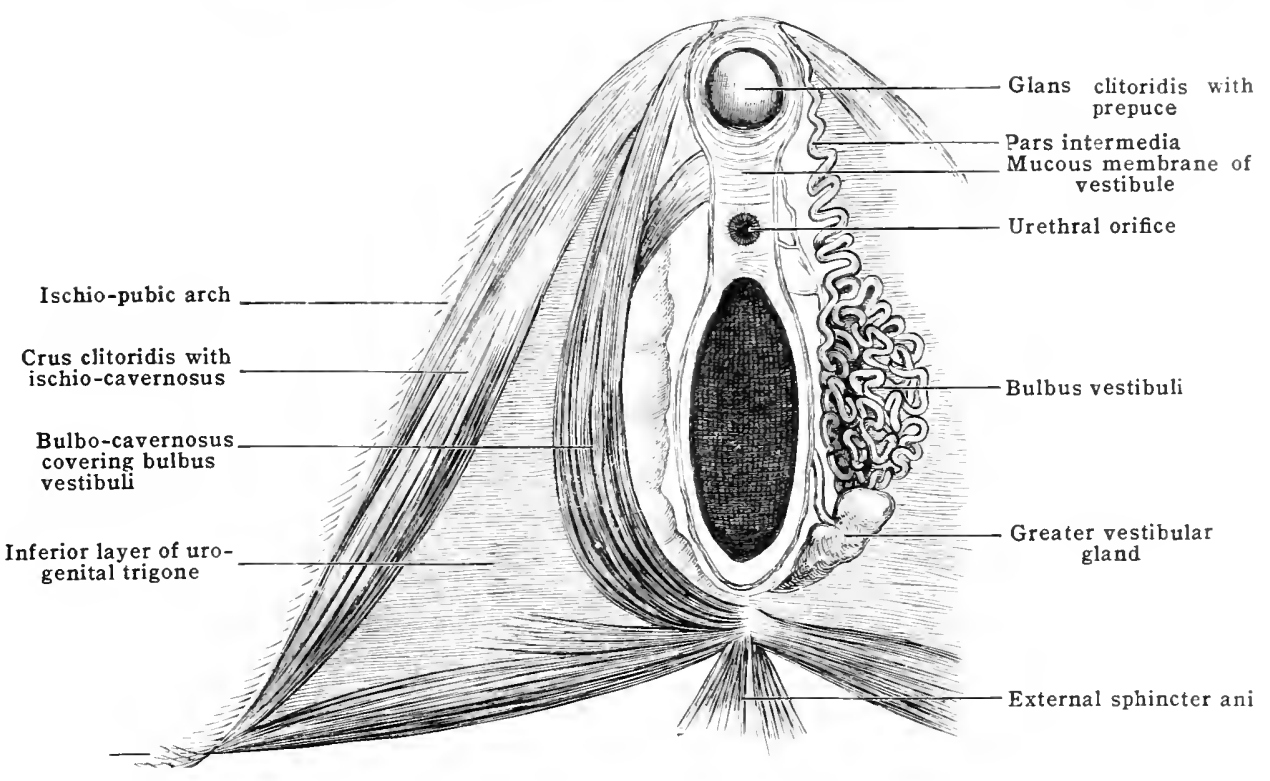

a few fasciculi which arise from the sheath of the corpus spongiosum, and from the median raphe and are united to those of the opposite side by a tendon which passes over the dorsal vein.

The bulbo-cavernosus (sphincter vagina) (fig. 392, 405) in the female arises (1) from fibrous tissue dorsal to the clitoris, (2) from the tunica fibrosa of the corpus cavernosum and from the superficial layer of the urogenital trigone in the angle between the crura of the clitoris. The fibre-bundles form a band of tissue about two centimetres wide at the side of the vagina and are inserted into the posterior part of the superficial (inferior) layer of the trigonum and into the central tendon of the perineum where some of the fibre-bundles interdigitate with those of other muscles attached here. The fibre-bundles arising from the back of the clitoris correspond with those of the constrictor radicis penis in the male. The other fibre-bundles correspond with those of the compressor bulbi proprius in the male.

Nerve-supply.-From the perineal division of the pudic.

Action.-To compress the vagina.

Relations. - It covers the bulb of the vestibule and the great vestibular gland (Bartholin": It is covered by skin and superficial fascia.

The ischio-cavernosus (figs. 395, 405) (erector penis or clitoridis) arises from the pelvio surface of the tuberosity and inferior ramus of the ischium, back and on each side of the attachment of the crus. The fibre-bundles form a thin sheet which is spread over the crus into thes medial and inferior surfaces of which it is inserted near the symphysis pubis. It is better developed in the male than in the female.

Nerve-supply.-By branches of the perineal nerve.

Action.-By constrieting the erus to maintain turgeseence of the penis or clitoris.

Relations.-Superficially it is covered by shin and subcutaneous tissue. Laterilly it lies next the ischio-pubic ramus. Medially it bounds a space lying between the erms and the bulb and filled with fat. 
Variations.-The muscle in the male is much larger than in the female. Some of the more anterior fibre-bundles may extend to the dorsal surface of the penis (clitoris) and form a pubocavernosus or levator penis muscle.

The transversus perinei superficialis (figs. 392, 394, 405) arises from the inferior ischial ramus. The fibre-bundles extend in front of the rectum superficial to the deep transverse muscle and are inserted into the central tendon of the perineum. Some cross to the opposite side. Some of the fibre-bundles are continuous with those of the external sphincter or of the puborectalis of the opposite side.

Action.- It acts with the deep transverse muscle in fixing the central part of the perineum. Nerve-supply.-By a branch from the perineal division of the pudic.

Variations. - It is frequently absent or poorly developed.

\section{THE MUSCULATURE OF THE LOWER LIMB}

The lower limbs are used chiefly for the support and propulsion of the body. Variety of movement is subordinated to strength and precision. In contrast with the upper limbs, which perform a vast variety of complex movements under conscious control, the lower limbs are called upon to perform chiefly the relatively simple movements which are used in walking or running, without our paying much attention to them.

The contrast between the two extremities is best marked in the girdles, the relations of which to the trunk have already been described, p. 444. The shoulder girdle is constantly called upon for movements in various directions which increase the freedom of action of the whole extremity. The sterno-clavicular and acromio-clavicular joints are movable so that the scapula can be carried in various directions over the thorax. The bones of the hip-girdle on each side, on the other hand, are ossified into a single hip-bone (os innominatum). The two hip-bones are almost immovably united to one another in front by the symphysis pubis and behind each is united to the sacrum by a joint which, although a diarthrosis, likewise permits but slight movement. The sacrum in turn is composed of vertebrx firmly ossified together. The pelvis, composed of the two hip-bones and the sacrum forms a strong support for the trunk. Such movements as it makes are due chiefly to the lumbo-sacral joint and to a less extent to the joints between the lumbar vertebræ. These joints permit the pelvis, in a limited manner, to be flexed and extended, abducted, adducted, and rotated. Flexion is produced by the rectus and the oblique muscles of the abdomen (fig. 387) and by the psoas muscles (fig. 406), extension is produced by the quadratus lumborum (fig. 406) and the sacrospinalis (fig. 381). Rotation and abduction are produced when these muscles act on one side only. The weight of the body in the sitting posture is transmitted through the sacrum and hip-bones to the ischial tuberosities. In this position the pelvis is flexed. The weight of the body in the standing position is transmitted to the femora through the acetabulum on each side. In this position the pelvis is extenderl. In walking the pelvis is rotated forward toward the limb that is being advanced.

The hip-joint is a true ball-and-socket joint, but freedom of movement is greatly limited by the powerful musculature which surrounds it, as well as by the ligaments. Movements here, however, are freer than at the shoulder-joint, if the shoulder girdle be left out of consideration. At the hip-joint the most frequent and most free movements are those of flexion and extension, the main movements in'walking or lunning; but abduction, adduction, circumduction, and rotation are of the greatest importance in balancing the body.

At the knee-joint the main movenents are also those of flexion and extension and the musculature is so arranged that the chief flexors of the knee which lie at the back of the thigh are extensors of the hip (fig. 408) while the extensor musculature of the knee which lies at the front of the thigh flexes the hip (fig. 411). Flexion of the hip, however, through the action of gravity on the foot passively brings about flexion at the knee, while flexion of the linee likewise passively brings about flexion of the hip, since the flexed knee tends to swing forward. These passive movenents, lue to gravity, are of importance in walking. The gastrocnemius (fig. 413), the most powerful extensor of the ankle-joint, is also a powerful flexor of the knee-joint. At the knee-joint, in adlition to flexion and extension, some rotation is possible, best marked when the knee is flexed. This rotation is of value in walking over rough ground in that it helps to accommerlate the fout to the ground. It is also of value in sitting on a flat surface. While there is thus sume rotation at the knee-joint not found at the elbow-joint, the free movement of the ralits about the nlna which aceompanies pronation and supination in the forearm, is unrepresentent in the leg where the fibula is firmly united to the tibia at each end.

The joint betwern the bones of the lea and the tarsus permits mercly of flexion and extension in contrast to the wrist-joint which also permits of adduction and abluction. Flexion and extension are also more limited at the ankle than at the wrist. On the other hand, the movements of inversion and eversion which take place in the intertarsal joints are not neerled in the wrist heatuse of the pronation and supination of the forearm. Inversion and eversion of the fuest are of value ju walking on rough gromel.

The movements of the tores resemble those of the fingers except that they are, in most indivinluals, far morre restriefol. The greatest restriction is seen at the joint between the metatarsal of the hig foe ambl the farsus, as compuned with that between the metatarsal of the thumb and the callus.

The musculature of the inforior extremity, like that of the superior, can be divided arecording to its development and innervation into two great subdivisions 
which correspond with the musculature on the dorsal and ventral sides of the (shark's fin. The dorsal musculature is supplied by nerve branches which arise from the back of the lumbo-dorsal plexus (femoral, gluteal, and peroneal nerves), the ventral musculature by branches which arise from the front of the plexus obturator and tibial nerves). Owing, however, to the rotation which the limb makes during embryonic development, the musculature which primitively lies on the dorsal side of the limb-bud comes to lie on the front and lateral side of the extremity and the musculature of the ventral side of the limb-bud comes to lie on the back and medial side of the extremity or in the sole of the foot. The side of the limb which primitively was towand the head becomes the medial side of the limb, and that which faced caudalward comes to lie laterally. While this makes the primitive relations of the musculature of the limb at first somewhat confusing, it is possible to approximate these primitive conditions by abducting the limb and rotating it so that the sole of the foot faces forward. An understanding of the innervation of the limb is thus greatly facilitated.

In the region of the hip the musculature of the dorsal division is that which arises from the spinal column and ilium and is inserted into the upper part of the femur and into the fascia of the thigh. It includes the chief flexor of the thigh, the ilio-psoas (fig. 406), and the most powerful extensor, the gluteus maximus (fig. 413), as well as several important rotators and abductors, gluteus medius and minimus, piriformis and tensor fascice late (fig. 408). The ilio-psoas is innervated by nerves from the back of the lumbar, the other muscles by nerves from the back of the sacral plexus. The musculature of the ventral division arises from the pubis and ischium, is inserted into the femur near the great trochanter and serves to adduct the thigh and rotate it lateralward, obturator internus, gemelli, quadratus femoris (fig. 408) and obturator externus (fig. 406). The obturator externus is innervated by the obturator nerve from the front of the lumbar plexus, the other muscles by special branches from the front of the sacral plexus.

In the thigh there are three well-marked groups of muscles, an anterior or extensor group (fig. 411), a medial or adductor group (fig. 411), and a posterior or flexor group (fig. 408). The anterior group belongs to the primitive dorsal division, the other two groups to the ventral division.

The muscles of the anterior group (fig. 411) the sartorius and quadriceps arise from the ilium and the shaft of the femur and are inserted into the tibia. The quadriceps flexes the thigh and extends the leg. The sartorius flexes both the thigh and the leg and rotates the former lateralward, the latter medialward. They are innervated by the femoral nerve. The muscles of the medial group (fig. 411), gracilis, pectineus, adductor brevis, longus, and magnus, arise from the pubis and the inferior ramus of the ischium and are inserted into the shaft of the femur. They adduct and flex the thigh. They are innervated by the obturator nerve. The adductor magnus gets part of its nerve-supply from the sciatic. The pectineus usually gets all or most of its supply from the femoral. The reasons for including it in this group are given below. The posterior group (fig. 408) consists of the semitendinosus and semimembranosus, which arise from the ischial tuberosity, and of the biceps, one head of which also arises from the ischial tuberosity while the other arises from the shaft of the femur. The semimembranosus and semitendinosus are inserted into the tibia, the biceps into the fibula. They are innervated by branches of the sciatic. They extend the thigh and flex the knee. The semitendinosus rotates the leg medialward, the biceps lateralward.

In the leg there are also three groups of muscles, an anterior, a lateral and a posterior. The two former belong to the dorsal division and are innervated by the peroneal nerve. The last belongs to the ventral clivision and is innervated by the tibial nerve. The muscles of the anterior group (fig. 415), the tibialis anterior, extensor digitorum longus, peroneus tortius and extensor hallucis longus, arise from the tibia and fibula and are inserted into first and fifth metatarsals and into the two distal rows of phalanges. They flex the ankle and extend the toes. The extensor digitorum longus and peroneus tertius evert the foot. The muscles of the lateral group (fig. 415), the peroneus longus and brevis, arise from the fibula. send tendons behind the lateral malleolus and are inserted respectively into the first and the fifth metatarsals. They extend and evert the foot. The posterior group (figs. 413, 416) may be separated into two subdivisions, a superficial and a deep. The superficial subdivision (fig. 413) consists of the gastrocnemius, which 
arises from the two epicondyles of the femur, and the soleus which arises from the tibia and fibula. These powerful extensors of the ankle are inserted by means of the tendon of Achilles into the calcaneus. The gastrocnemius is a flexor of the knee as well as an extensor of the ankle. A rudimentary muscle, the plantaris, arises near the lateral head of the gastrocnemius and is inserted into the fibrous tissue of the heel.

The deep group (fig. 416) consists of one muscle, the popliteus, a medial rotator and flexor of the leg, which arises from the lateral condyle of the femur and is inserted into the tibia; and of three muscles, the flexor digitorum longus, flexor hallucis longus and tibialis posterior, which arise from the tibia and fibula, send tendons behind the medial malleolus and are inserted into the plantar surface of the tarsus and into the terminal phalanges of the toes. They invert the foot and flex the toes.

In the foot one muscle on the dorsum represents the primitive dorsal division, the extensor digitorum brevis (fig. 418), supplied by a branch from the peroneal nerve. On the other hand the primitive ventral division is well represented in the sole of the foot, not only by the muscles associated with the long flexor tendons, quadratus plante, lumbricales (fig. 420), but also by the short flexor of the toes (fig. 419). by the special musculature of the big and little toes (fig. 421) and by the interosseous muscles (fig. 422). The flexor digitorum brevis (fig. 419), the most superficial of these muscles, arises from the calcaneus and is inserted into the second row of phalanges of the four more lateral toes. The quadratus plante arises from the calcaneus and is inserted into the tenclon of the long extensor of the toes. It makes the action of the tendon on the digits more direct. The four lumbrical muscles run from this tendon to the medial sides of the four lateral toes. They flex the digits. Of the intrinsic muscles of the great toe (figs. 419, 421), the abductor arises from the calcaneus; the flexor brevis from the cuneiform bones; and the adductor, by one head from the long plantar ligament, by the other from the capsules of the metatarso-phalangeal joints. All are inserted into the base of the first phalanx. Of the muscles of the little toe (figs. 419-421), the abductor arises from the calcaneus, the flexor and opponens from the cuboid. The two former are attached to the base of the first phalanx, the last to the fifth metatarsal. The interosseous muscles which arise between the metatarsals are so arranged that the three plantar abduct and the four dorsal adduct the four lateral toes to and from an axis passing through the second toe. The muscles of the sole of the foot which send tendons to the sides of the bases of the first row of phalanges help to flex the rligits on the metatarsals and to extend the toes at the first row of interphilangeal joints. These are much less effective extensors of the phalanges than arr the corresponding inuscles of the hand and, unlike the latter, seem, in most. indivirluals, to exert but little extensor action on the third row of phalanges. The musclos of the sole of the foot are supplied by the lateral and medial plantar branches of the tibial nerve.

The muscle fasciæ of the inferior extremity are well developed. The fascia lata, which eneloses the musculature of the back of the hip and the museulature of the thigh, is especially -trong on the lateral side where it includes the longitudinal bundles of fibres which eompose the ilio-tibial hand. From the fuscia lata strong intermuscular septa extend on each side of the quadriceps group of muscles to the femur. Medially beneath the sartorius muscle (fig. 410), septa help to bound IIunter's canal in which lies the femoral artery on its way to the popliteal spare behind the knee. In the leg there is likewise a strong eylindrical faseial sheath which encloses the musculature and sends septa on each side of the peroneal group to the fibula. $\Lambda$ transverse septum also separates the deep from the superfieial muscles of the ealf. The fasciat of the log is esperially well developerl near the ankle where it helps to hold in place the tendons which jass from the muscles of the leg into the foot. Muscle fasciae are well developed both on the dorstum and in the sole of the foot.

\section{A. MLAR'CHATURE OF' 'THE' HIP'}

\section{ILIO-HFMORAL, MUSCULATURE}

'The iliac blarke divides these muscles into an anterior group (ilio-psoas), supplied by nerves from the lumbar plexus, and a posterior group (the gluteal mustres, piriformis, and tensor fasciar latar, supplied by nerves from the sacral plexus. 
In most of the limbed vertebrates these two groups of muscles are represented, but they present marked specific variations in the different forms. Primitively, the iliacus group lies on the proximal portion of the lateral surface of the ilium.

\section{(a) Anterior Group}

(FIGS. 406, 411)

The fan-shaped iliacus muscle arises from the iliac fossa. The fusiform psoas major muscle arises from the sides of the last thoracic and of the lumbar vertebr:e and extends along the medial margin of the iliacus muscle. The two muscles are inserted by a common tendon into the lesser trochanter of the femur. Together they constitute the ilio-psoas muscle. The small, flat, fusiform psoas minor lies on the medial surface of the psoas major and extends from the twelf th thoracic vertebra to the ilio-pectineal eminence. The ilio-psoas flexes the thigh at the hip and the pelvis on the trunk. The psoas minor aids in flexing the pelvis.

The ilio-psoas muscle arises in the human embryo from a blastema which at first surrounds the femoral nerve and later extends proximally over the ilium (iliacus) and toward the lumbar vertebræ (psoas). The iliacus is phylogenetically the more primitive. In the shoulder it is probably represented by the infraspinatus. The psoas minor is much better developed in many of the lower mammals than in man.

\section{FASCIE}

The fasciæ and the relations of these muscles are shown in figs. 384 and 407.

The iliac and psoas muscles are covered by a dense fascia which is but slightly adherent to the underlying muscles. It is best developed in the pelvic region, where it extends from the iliac crest and ilio-lumbar ligament to the iliac portion of the linea arcuata and is called the iliac fascia. Superiorly it is continued over the psoas muscle as the psoas fascia and is attached medially to the sacrum and the lumbar region of the spinal column. Laterally it unites with the lumbar fascia and superiorly it is strengthened to form the medial lumbo-costal arch (fig. 391). Infiriorly the ilio-pectineal fascia extends over the ilio-psoas muscle to its femoral insertion. It is firmly united on each side of the muscle to the capsule of the hip-joint and to the femur. As it passes beneath the inguinal ligament it is united to this by tendinous processes. Beyond the ligament it is less dense than in the pelvic region.

\section{MUSCLES}

The psoas major (figs. 406, 411).--Origin.--(1) By a series of thick fasciculi from the intervertebral discs between the twelf th thoracic and the fifth lumbar vertebra, from the adjacent parts of the bodies of these vertebræ and from tendinous arches which bridge over the middle of the sides of the first four lumbar vertebre; and (2) by a series of more slender fasciculi from the lower borders and ventral surfaces of the transverse processes of the lumbar vertebra.

Structure and insertion. - From these origins parallel fibre-bundles descend nearly vertically and give rise to a fusiform muscle which lies at the side of the vertebral bodies and extends along the border of the true pelvis toward its insertion. A tendon arises deep in the muscle near the last lumbar vertebra, and becomes free on its dorso-lateral surface slightly above the inguinal (Poupart's) ligament. On the medial side the attachment of fibre-bundles continues to the insertion of the muscle into the small trochanter. The iliacus muscle is attached to the lateral side of the tendon from near the ilio-pectineal eminence downward.

Nerve-supply.-Delicate branches pass into the psoas muscle from the trunks which unite to form the femoral (anterior crural) nerve, i. e., from the fourth, third, second, and often the first lumbar nerves.

The iliacus (figs. 406, 411).-Origin.--(1) From the iliac crest, the ilio-lumbar ligament, and the greater part of the iliac fossa, the anterior sacro-iliac ligaments, and of ten from the sacrum, and (2) from the ventral border of the ilium between the two anterior spines.

Structure and insertion.-From these areas of origin the fibre-bundles pass to be inserted(1) in a penniform manner on the lateral surface of the tendon which emerges from the psoas above the inguinal (Poupart's) ligament, and (2) directly on the femur immediately distal to the small trochanter. The lateral portion of the muscle arise from the ventral border of the ilium and is adherent to the direct tendon of the rectus femoris and the capsule of the hip-joint. It is sometimes more or less isolated (m. iliacus minor, ilio-capsulo-trochantericus, ete.).

Nerve-supply. - Nerve branches, often united in a plexiform manner, arise from the femoral (anterior crural) nerve and pass across the surface of the iliacus muscle about midway between the crest of the ilium and the combined ilio-psoas tendon. Special nerve branches are usually likewise distributed from the main trunk of the femoral nerve to the fleshy portion of the muscle which extends over the acetabulum and the head of the femur.

Relations. - The psoas major lies lateral to the lumbar vertebre and in front of the quadratus lumborum and intertransverse muscles. The psoas minor passes downward across its ventral surface. Both psoas muscles are crossed by the crura of the diaphragm. The kidney with its adipose capsule lies lateral to them opposite the first two lumbar vertebra. For the rest, their fascia is covered ventro-laterally by retro-intestinal and retro-peritoneal tissue in which the vena cava inferior runs in front of them on the right side, the inferior mesenteric vein in front of them on the left side, and the ureter, the spermatic or ovarian, and the renal and colic vessels on each side. The external iliac artery lies medial to the psoas major in the pelvis, and beyond the inguinal (Poupart's) ligament the femoral artery lies ventral to it. The lumbar plexus arises 
between its origins from the vertebral bodies and discs and those from the transverse processes. The nerves springing from the lumbar plexus take courses subject to much individual variation through the muscle on the way to their destinations. Fasciculi of the muscle may thus be separated by the femoral (anterior crural) nerve or other branches of the lumbar plexus.

The iliacus muscle in the region of the pelvis is covered by retro-peritoneal fat. The psoas muscle crosses its medial margin and from between the two muscles the femoral nerve usually emerges to pass into the thigh above the iliacus. Beyond the inguinal ligament the iliacus lies in front of the capsule of the hip-joint and the straight tendon of the rectus femoris, and is crossed by the sartorius.

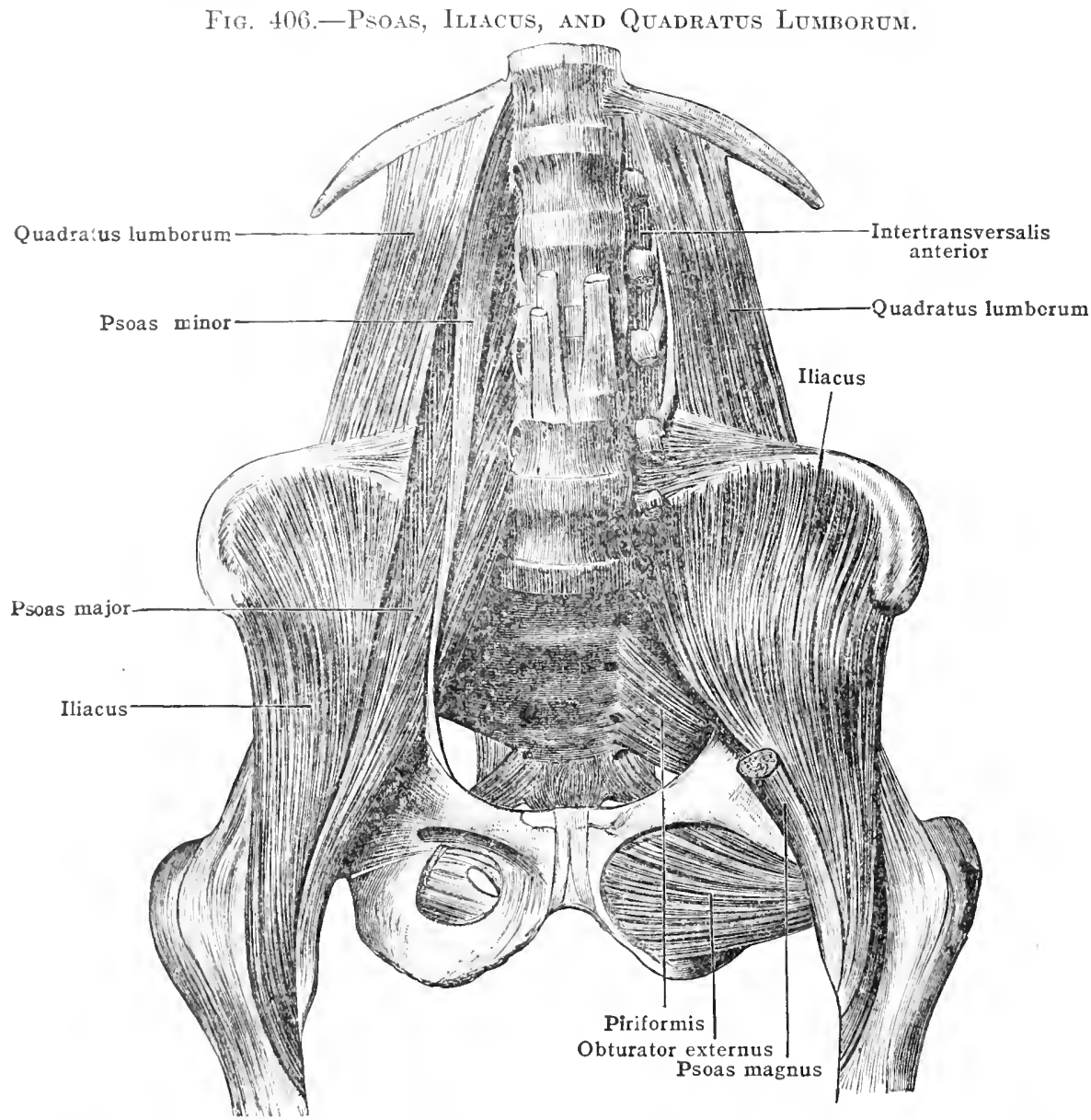

Action.-The ilio-psons is a powerful flexor of the thigh at the hip and a weak medial rotator and arlductor. It also serves to flex the lumbar region of the spine.

l'ariations. The psoas muscle may be separated from the iliams as far as the femoral insertion. The part of the psoas arising from the distal lumbar vertebra may form a distinet muscle. Slips may pass from the psoas major to the psoas minor. A separate lamina of the jliarus muss le mity le attahed to the iliac fascia. From the anterior inferior iliac spine a small Inusele slip may run to the intertrochanteric line or the ilio-femoral ligament. To this slip the term iliacus minor has been applied as well as to the harger fasciculus nentioned above.

The psoas minor (fig. 4(1)6).-Origin.-Fron the twelf th tholacic and first lumbar vertebra and the interrening disce.

Sitrueture and insertion. - The fibre-bunclles pass to be attached as far as the level of the fifth lumbar vertehrato a flat temclon which appears alout the mid-lumbar region and is inserted

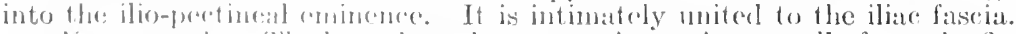

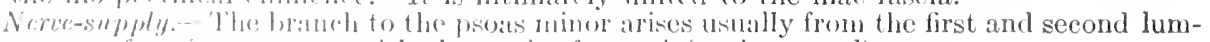

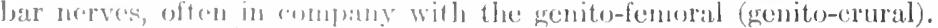

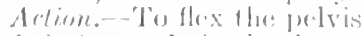

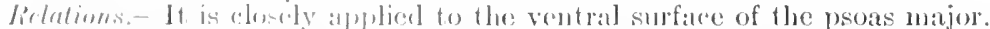

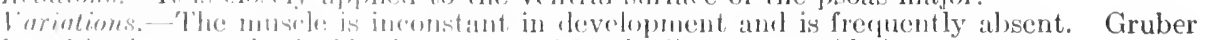

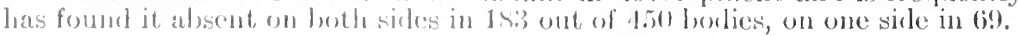

\section{IBIIRSA}

B. iliopectinea. I largo bursa luefwoen the ilio-psoas muscle, the ilio-peetineal eminence, and the capsule of the hip-joint. B. iliaca subtendinea. $-\Lambda$ small bursa between the tendon of insertion of the ilio-penstes and the lesser trowhanter. 


\section{(b) Posterior Group}

(Figs. 387, 407, 408, 413)

The muscles of this group arise from the ilium and sacrum, cover the dorsolateral surface of the hip, and are inserted into the great trochanter and shaft of the femur and into the ilio-tibial band. They lie in three planes. In the first layer (fig. 387) are the flat, quadrilateral tensor fasciæ latæ, which arises from the front of the crest of the ilium and is inserted into the ilio-tibial band, and the thick, rhomboid gluteus maximus, which arises from the dorsal portion of the iliac ala, the lumbo-dorsal fascia, the sacrum and coccyx, and the sacro-tuberous (great sacro-sciatic) ligament, and is inserted in part into the ilio-tibial band and in part into the back of the upper part of the shaft of the femur. The ilio-tibial band is a flat tendon which descends, closely fused with the fascia lata, to the lateral side of the upper extremity of the tibia. In the second layer (fig. 408) are the flat, thick, triangular gluteus medius and the 'pear-shaped' piriformis The former arises from the upper and back part of the outer surface of the ala of the ilium, the latter from the ventral surface of the sacrum and the posterior border of the great sciatic notch. Both are inserted into the top of the great trochanter. The third layer (fig. 409) is composed of the triangular gluteus minimus, which arises from the inferior ventral portion of the outer surface of the ala of the ilium, and is inserted into the front of the great trochanter of the femur.

The muscles of this group extend, flex, abduct, and rotate the thigh at the hip. The gluteus maximus and medius are in part extensors, the gluteus minimus and the tensor fasciæ latæ are flexors of the hip-joint. All the muscles serve to abduct, the gluteus maximus acting thus when the hip is flexed. When the thigh is extended the lower part of the gluteus maximus is an adductor. The gluteus maximus and posterior part of the gluteus medius and the piriformis act as lateral, the anterior part of the gluteus medius, the gluteus minimus, and the tensor fasciæ latæ as medial, rotators. The gluteus maximus and the tensor fasciæ latæ through the ilio-tibial band keep the extended knee-joint firm. The gluteus maximus is supplied by the inferior gluteal nerve, the piriformis by special nerves, and the other muscles of the group by the superior gluteal nerve. All these nerves arise from the upper part of the back of the sacral plexus.

The gluteus medius, gluteus minimus, and piriformis form a group of muscles which in the embryo have a common origin and are more or less fused in the adult. The gluteus maximus arises in two distinct, though associated, portions, and the tensor fasciæ latæ as another distinct portion. The two museles, however, are probably to be considered as parts of a primitive caudo-pelvo-tibial musculature, while the gluteus medius group is represented in the lower forms by an ilio-femoral musculature. The former group is often closely associated with the extensor muscles of the thigh in the lower forms (frog), and in some of the lower mammals extends its insertion to the plantar fascia (ornithorhynchus). In the arm this group is perhaps represented by the deltoid, the latissimus dorsi, and the teres major, while the gluteus medius group is represented by the subscapularis.

\section{FASCI I}

The tela subcutanea of the gluteal region is very thick, contains much fat, and is often divisible into two layers, of which the deeper is closely adherent to the fascia lat a and through this to the gluteus maximus. Over the great trochanter a subcutaneous bursa is usually found (bursa trochanterica subcutanea).

Muscle fascia.- The muscles of the hip and thigh are enclosed in a dense fascia, the fascia lata (figs. 387,407 ). This arises from the tuber ischii, the sacro-tuberous (great sacro-sciatic) ligament, the back of the sacrum and the coccyx, the crest of the ilium, the inguinal (Poupart's) ligament, and the pubic and ischial rami, and extends to the tibia and the fascia covering the muscles of the leg. It is composed mainly of bundles of fibres running transversely to the long axis of the limb. In the region of the gluteal groove it is strengthened by a transverse fibrous band which arises from the tuberosity of the ischim and arches upward over the lower border of the gluteus maximus muscle.

In the region of the hip the fascia lata invests both surfaces of the tensor fasciæ latæ and the gluteus maximus, and is closely bound to these muscles through intramuscular septa. Between these two muscles the fascia covers the fascia of the ghteus medius, to which it is adherent near the iliac crest, but from which it is separated by loose tissue more distally. Anteriorly the fascia is fused with the ilio-pectineal fascia and the inguinal (Poupart's) ligament. 
More distally the tendons of the tensor fasciæ latæ and of the superficial portion of the gluteus maximus become incorporated with the deep surface of the fascia lata and give rise to the ilio-tibial band [tractus iliotibialis].

Fig. 407, A and B.-Traxsverse Sections throdgh the Left Side of the Pelvis in the Regions Indicated in the Diagram.

C. Section through the muscles of the left inguinal region parallel to the inguinal (Poupart's) ligament (after Spalteholz). $b$ in the diagram indicates Section $B$, fig. 384, p. 421; $a^{\prime}$ and $b^{\prime}$ indicate sections $A$ and $B$, fig. 410, p. 465. (For legends, sce p. 459.)
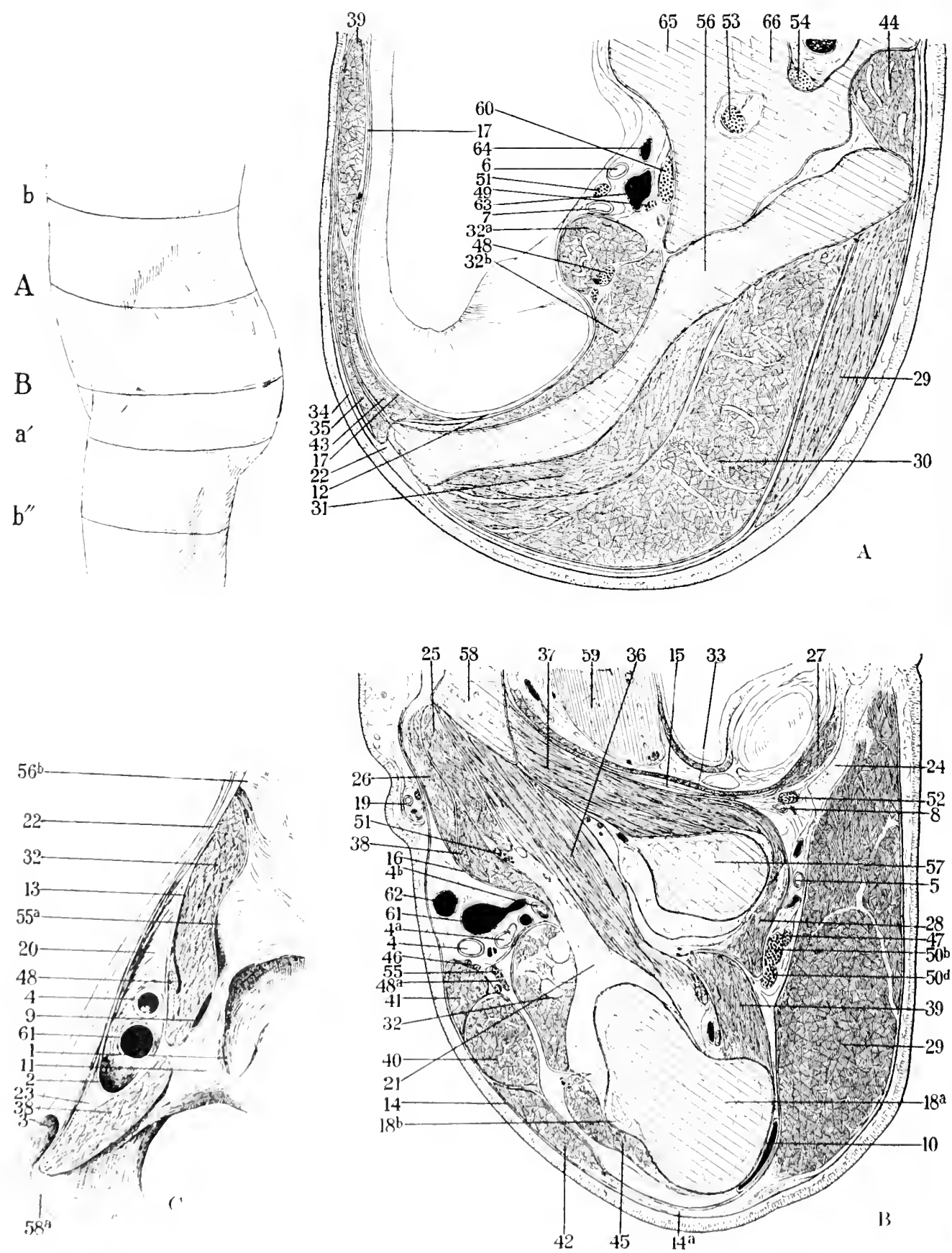

Tlet glutems medius and minimus museles are invested by alherent fascial shects which, vent rally betwern the two muscles, maty be combined into an intermuscular septum or be so

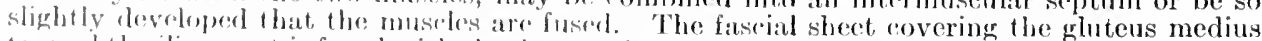
towarl 1 lo iliac crest is fused wilh the focp surface of the fascia lata. This fusion results in the formation of septa betweren the glulous medius and the glutens maximus and tensor fascix latx. 
The piriformis in the pelvic cavity is covered on the anterior surface by a special slightly developed fascia. This fascia also covers the pelvic surface of the sacral plexus. Outside the pelvis the piriformis is covered by an adherent membrane which usually is separated by loose tissue from the surrounding structures.

\section{MUSCLES}

\section{First Layer}

The tensor fasciæ latæ (figs. 387, 411)._Origin.-(1) By a tendinous band from the external lip of the iliac crest, and the upper part of the notch between the anterior superior and anterior inferior spines of the ilium, and (2) from the septum between it and the gluteus merlius.

Structure and insertion.-The nearly parallel fibre-bundles pass distally and laterally and are united to tendon fasciculi which become incorporated with the ilio-tibial band (tractus iliotibialis) about one-third of the way down the thigh.

Nerve-supply.- The superior gluteal nerve sends a branch through the ventral margin of the gluteus minimus to terminate in the middle third of the deep surface of the tensor fascice latæ near its dorsal border.

Action.-To rotate medially, flex, and abduct the thigh, and to make tense the fascia lata.

Relations. - It lies over the gluteus medius, the proximal part of the rectus femoris, and the vastus lateralis.

Variations.- It may be divided into two parts, one rising from the anterior superior spine, the other from the iliac crest. Accessory slips may arise from the inguinal ligament, the crest of the ilium, or the fascia over the lower part of the abdominal wall. Union of the musele with the gluteus maximus has been observed, thus making a muscle much resembling the deltoid of the shoulder. By some the fascia lata between the tensor and the gluteus maximus is considererl an atrophied part of a deltoid of the hip.

The gluteus maximus (figs. 387, 413).-Origin.-(1) From the dorsal fifth of the outer lip of the iliac crest, the outer surface of the ilium dorsal to the posterior ghteal line, the lumbodorsal fascia between the posterior superior spine of the ilium, and the side of the sacrum, and (2) from the lateral portions of the fourth and fifth sacral and the coceygeal vertebra and from the back of the sacro-tuberous (great sacro-sciatic) ligament.

Insertion. - Into (1) the ilio-tibial band; (2) the gluteal tuberosity of the femur and the adjacent part of the tendinous origin of the vastus lateralis (fig. 407).

Structure.-The large fibre-bundles of which the muscle is composed take a somewhat parallel course from origin to insertion. From the areas of origin and the enveloping fascia fibrous bands extend into the muscle. The belly is divisible into two portions, a superficial and a deep. The division may be much more clearly recognised in the embryo than in the adult. The superficial portion is the larger, and includes all of that part of the muscle which spring from the ilium and the more superficial portion of that arising from the sacrum and the upper part of the coccyx. The deep portion includes that part of the muscle attached to the side of the sacrum and the coccyx, and to the sacro-tuberous ligament. The superficial portion and some of the fibre-bundles of the deep portion terminate in the ilio-tibial band along a line extending from the great trochanter to the end of the upper third of the femur. The deep portion is inserted chiefly by a flat tendon into the gluteal tuberosity, and also directly into the adjacent portion of the origin of the vastus lateralis.

Nerve-supply. - Two branches (inferior gluteal) arising from the sacral plexus either separately or united, are usually given to the muscle. One of these curves anteriorly across the deep surface of the proximal superficial portion of the muscle in the middle third between the tendons

1. Acetabulum. 2. Annulus femoralis. 3. Annulus inguinalis subcutaneous (ext. abdominal ring). 4. Arteria femoralis. 4a. A. profunda femoris. 4b. A. circumflexa femoris medialis. 5. A. glutea inferior. 6. A. hypogastrica (internal iliac). 7. A. iliaca externa. 8. A. pudena interna (pudic). 9. Bursa ilio-pectinea. 10. B. trochanterica 11. glutæi maximi. 11. Eminentia iliopectinea. 12. Fascia iliaca. 13. F. ilio-pectinea. 14. F. lata-a, iliotibial band. 15. F. obturatoria. 16. F. pectinea. 17. F. transversalis. 15. Femur-a, trochanter major; $b$, trochanter minor. 19. Funiculus spermaticus (spermatic cord). 20.-Lacuna vasorum. 21. Ligamentum ilio-femorale. 22. L. inguinale (Poupart's ligament), 23. L. lacunare (Gimbernat's). 24. L. sacro-tuberosum (great sciatic). 25. Musculus adductor brevis. 26. M. adductor longus. 27. M. coccygeus. 28. M. gemellus inferior. 29. M. gluteus maximus. $30 . \mathrm{M}$. gluteus medius. 31. MI. glutens minimus. 32. II. iliopsoas- $a$, psoas; $b$. iliacus. 33 . M. levator ani. 34. II. obliquus abdominis externus, aponeurosis. 35. M. obliquus abdominis internus. 36. M. obturator externus. 37. M. obturator internus. 3S. M. pectineus. 39. M. quadratus femoris. 40. M. rectus femoris. 41. M. sartorius. 42. M. tensor fascia latæ. 43. M. transversus abdominis. 44. M. transverso-spinales (multificlus). 45. M. vastus lateralis. $46 . \mathrm{N}$. eutaneus femoris anterior (middle cutaneous). $47 . \mathrm{N}$. cutaneous femoris posterior (small sciatic). 48. N. femoralis (anterior crural). 49. N. gluteus superior. 50. N. ischiadicus (great sciatic) - a, peronseus communis (external popliteal); $b$, tibialis (internal popliteal). 51. N. obturatorius. 52. N. pudendus. 53. N. sacralis 1. 54. N. sacralis II. 55. N. saphenus. 56. Os ilium-a, spina anterior superior; $b$, spina anterior inferior. 57. Os ischium. 5S. Os pubis-a, spina (tubercle). 59. Prostata. 60. Truncus lumbo-sacralis. 61. Vena femoralis. 62. V. saphena magna. 63. V. iliaca externa. 64. V. hypogastrica (internal iliac). 65. Vertebra sacralis I. 66. Vertebra sacralis 11 . 
of origin and insertion, the other descends to enter the middle third of the distal deep portion of the muscle.

Action.-It is the most powerful extensor of the thigh. It also serves slightly to rotate the limb lateralward and to make tense the fascia lata, and through the ilio-tibial band to keep the extended knee-joint steady. When the thigh is extended the major part of the musele is an adductor but the upper part is a weak abductor. The whole muscle is an abductor when the thigh is flexed. It is brought powerfully into play in climbing and in walking up hill.

Fig. 40S.-The Lateral Rotators and the Hamstring Muscles.

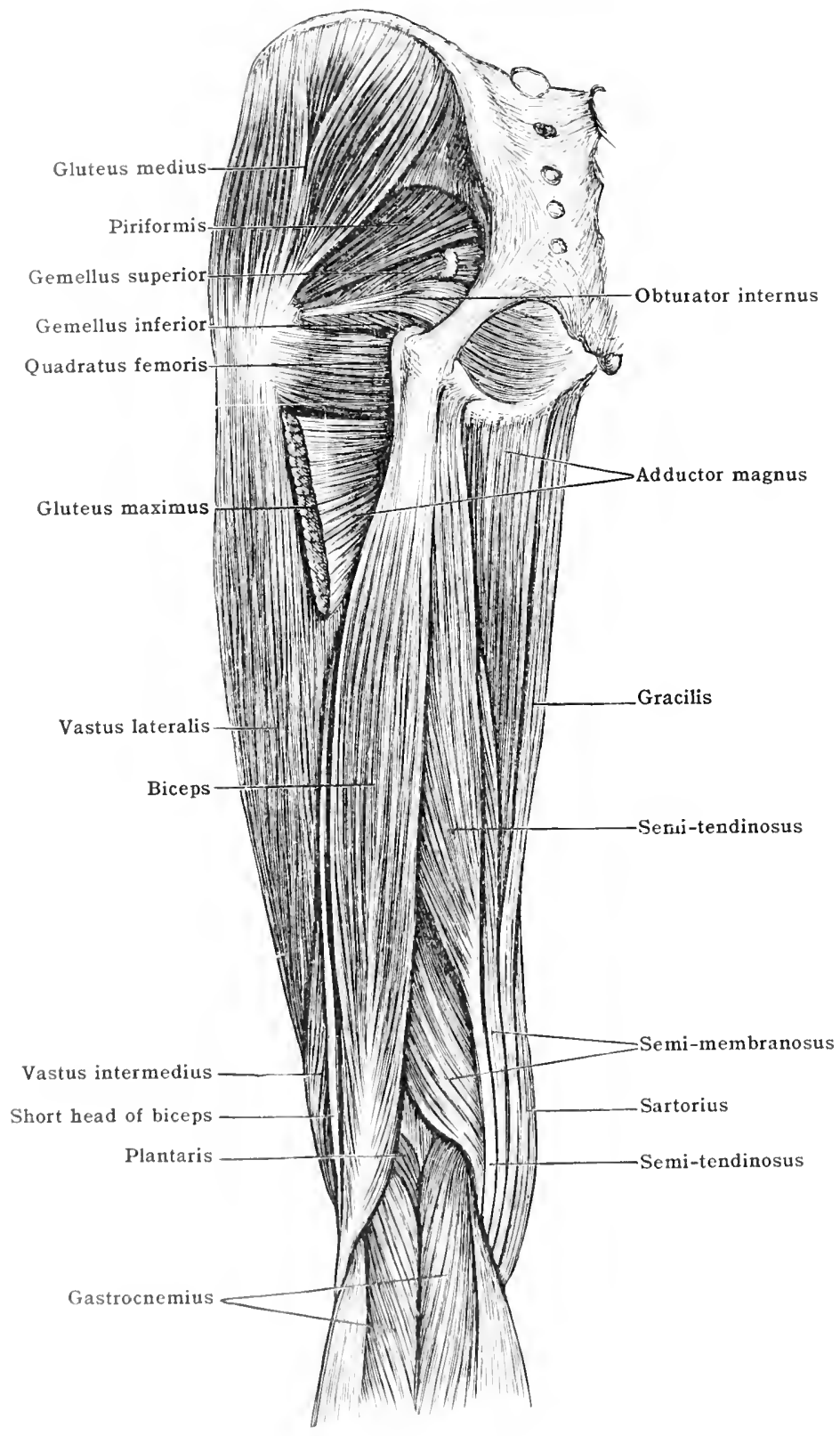

Relations,-It is creverel hy the fatty superficial tissue of the buttock. It extends over the posterior yortion of the ilim, He lateral surface of the sacrum and eoceyx, the sacro-tuberous figanent, and the great truchanter. It covers the tuber of the isehium in the stauding but not in the sitfing position. Immerlatuly beneath the nusele lie portions of the ghitens medius, piriformis, obturator interms, genolli, cuadratus femoris, oloturator externus, and hamstring inuseles, and of the ghateal vessels and nervers and the seiatie nerve.

l'ariations. - lew unomalios are recorded. The decp distal portion of the muscle may be more isolited than normal in the atult. A special coceygeo-femoral musele may run from the esery $x$ to the linea aspera, or from the sicro-tuberous ligament to the fascia of the leg. A 
special fasciculus, the ischio-femoralis, may arise from the tuberosity of the ischium and become inserted into the lower border of the muscle near the great trochanter. The sacral, ischial, or coccygeal origin may be lacking, or the origin of the muscle may be from the sacrum only.

\section{SECOND LAYER}

The muscles of this layer are the gluteus medius and the piriformis.

The gluteus medius (fig. 408).-Origin.-From (1) the ventral three-fourths of the iliac crest, and the outer surface of the ilium between the anterior and posterior gluteal lines and (2) the investing fascia.

Structure and insertion.-The fibre-bundles converge upon both surfaces of a broad tendon nearly to its insertion on an oblong impression on the postero-superior angle and the external surface of the great trochanter. The more posterior fibre-bundles of the superficial stratum of the ventral portion of the muscle cross obliquely those of the deeper dorsal portion near the tendon of insertion. From the tendon an aponeurotic extension is usually continued into the tendon of the vastus lateralis.

Nerve-supply. - From the superior gluteal nerve a branch passes to the dorsal portion of the muscle and one or more twigs of the branch to the tensor fasciæ latæenter the ventral portion of the muscle. The branches enter the middle third of the muscle between its tendons of origin and insertion. The nerve-fibres arise usually from the fourth and fifth lumbar and first sacral nerves. The branch to the dorsal portion of the muscle has a lower spinal origin than those to the ventral portion.

Action.-To abduct the thigh. The anterior portion of the muscle is a flexor and a medial rotator, the posterior a lateral rotator and an extensor. When the muscle acts as a whole, it is a medial rotator.

Relations.-Upon the muscle lie the tensor fasciæ latæ and gluteus maximus muscles and the fascia lata; beneath it lie the gluteus minimus muscle, the superior gluteal nerve and vessels, and the great trochanter.

Variations.- It may be divided into two distinct portions, or it may be fused with the piriformis or the gluteus mimimus or both. A special fasciculus may extend to the superior portion of the great trochanter.

The piriformis (fig. 408).-Origin.-From (1) the lateral part of the ventral surface of the second, third, and fourth sacral vertebræ; (2) the posterior border of the great sciatic notch; and (3) the deep surface of the sacro-tuberous (great sacro-sciatic) ligament near the sacrum.

Structure and insertion.-The fibre-bundles converge upon a tendon which is inserted upon the anterior and inner portion of the upper border of the great trochanter. The insertion of fibre-bundles continues nearly to the great trochanter. An accessory slip of insertion may pass to the gluteus minimus.

Nerve-supply.-From a nerve which arises either directly from the first or second sacral nerve or from a loop between them. The nerve enters the deep surface of the muscle in its middle third. There mav be two or more nerves.

Action.- It is an extensor, abductor, and lateral rotator of the thigh. It causes medial rotation when the hip is flexed.

Relations.- Its ventral surface faces the sacral plexus, the rectum, and the hip-joint. It is covered dorsally by the gluteus maximus. It lies between the gluteus medius and the superior gemellus. Between the piriformis and the superior gemellus the sciatic nerve usually passes into the thigh. The superior gluteal nerve and vessels pass dorsally above its superior margin; the inferior nerve and vessels beneath its inferior margin.

Variations. - It is rarely absent. The origin may extend to the first sacral or to the fifth sacral vertebra and the coccyx. It may be fused with the gluteus medius or minimus or more rarely with the superior gemellus. Its tendon of insertion may be fused with that of the gluteus medius or the obturator internus. In about 20 per cent. of bodies it is divided partly or completely into two portions, between which the sciatic nerve or its peroneal (external popliteal) division usually passes. Rarely the tibial instead of the peroneal portion may pass between the two fasciculi, or the muscle may be divided into three or more fasciculi, between which the branches of the sciatic nerve pass.

\section{ThIRd LAYER}

The gluteus minimus (fig. 409).-Origin.-From the outer surface of the ilium between the anterior and inferior gluteal lines; (2) from the septum between it and the gluteus merlius near the anterior superior iliac spine; and (3) from the capsule of the hip-joint.

Structure and insertion. - The fibre-bundles converge upon a tendon which appears on the middle of the ventral border and gradually spreads over the lateral surfare. The muscle is thickest in front, where it is usually bound by an intermuscular septum to the gluteus medius. The tendon is inserted into the ventral surface of the great trochanter of the femur.

Nerve-supply.-From twigs of the branch of the superior gluteal nerve which goes to the tensor fasciæ latæ. These twigs enter the middle third of the muscle as the tensor branch passes across it.

Action.-To abduct the thigh and rotate it medialward. The anterior part of the muscle is a flexor, the posterior an extensor.

Relations.-It is covered by the gluteus medius and piriformis muscles. Beneath it lie the inferior part of the iliac ala, the hip-joint (to the capsular ligament of which it is bound), and the direct tendon of the rectus femoris muscle.

Variations. - It may be fused with the gluteus medius or the piriformis. It may send a slip to the fascia lata or the vastus lateralis. It may be divided into two distinct divisions, 
an anterior and a posterior. Very frequently from the anterior margin of the muscle a special fasciculus is more or less isolated (the scansorius, invertor femoris, small anterior gluteal, etc.) The accessorius of the gluteus minimus is a small musele fasciculus which may lie under cover of the gluteus minimus and extend to be inserted into the capsule of the hip-joint.

\section{BURS.E}

B. ischiadica m. glutei maximi.-A small ineonstant bursa between the tuber isebii and the gluteus maximus muscle. B. trochanterica $\mathrm{m}$. glutei maximi.-A large bursa constantly

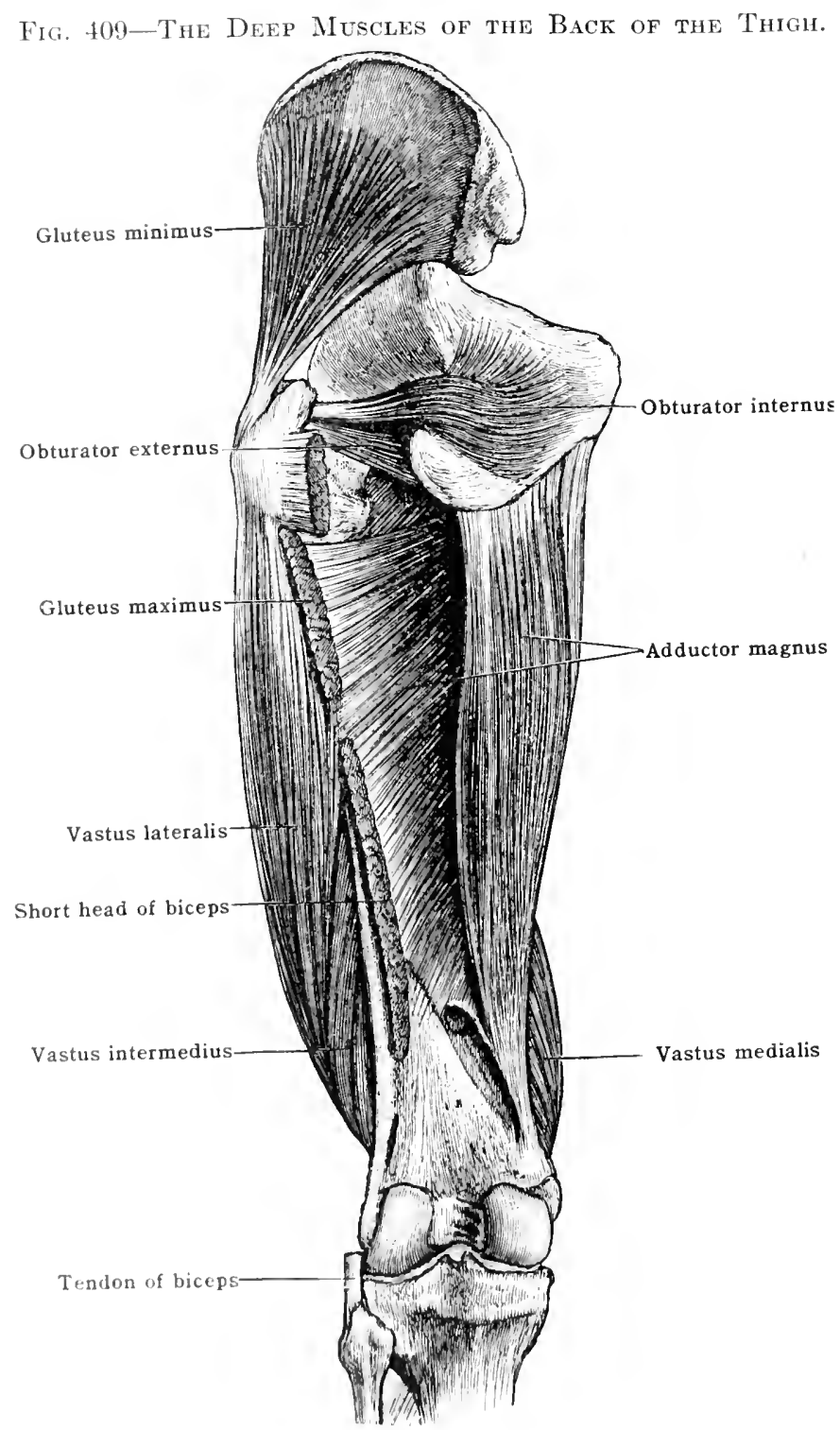

present between the fiscial tondon of the gluteus maximus and the posterior lateral surface of the reat trochanter and the origin of the vastus bateralis muscle. B. gluteofemorales. Two or three small bursa on cach sile of lle tendon of attachment of the gluteus maximus to the femur. B. trochanterica m. glutei medii anterior. $-\Lambda$ small bursi constantly present between the tenrlon of the ghateus molius musere and the lateral surface of the great troehanter. $B$. trochanterica $\mathrm{m}$. glutei medii posterior. -1 small bursa frequently present letween the tendons of the piriformis and the ghatrus medius. B. trochanterica m. glutei minimi. $-\Lambda$ fairly large bursa generally present betwern the mangin of the great trochanter and the tendon of this muscle B. m. piriformis. $-\lambda$ small hursa frefuently present between the tendons of the piriformis ard superior gemellus museles and the fommr. 


\section{Ischio-pubo-fenoral Musculature of the Hip}

The muscles belonging to this group (the obturator internus, the two gemelli. the quadratus femoris and the obturator externus, extend from the pubis and ischium across the back of the hip-joint to the great trochanter and the neighbouring part of the shaft of the femur. They are powerful lateral rotators of the thigh. The obturator internus (fig. 409), a large, flat, triangular muscle. arises from the pelvic surface of the immominate bone and from the obturator membrane. At the lesser sciatic notch its tendon is joined by the two gemelli (fig. 408), one of which arises on each side from the bony projections which makr the notch, and the combined tendon is inserted into the trochanteric (digital, fossa. The quadratus femoris (fig. 408) passes from the tuber of the ischium to the femur behind and below the great trochanter. These muscles are supplied by special nerves which arise from the front of the sacral plexus and enter the deep surfaces of the muscles. A fifth muscle, attached to the greater trochanter and associated with this group, the obturator externus, is differentiated near the adductor muscles of the thigh and is supplied by a branch from the obturator nerve. It arises from the outer surface of the bones bounding the ventral twothirds of the obturator foramen and is inserted by a tendon into the trochanteric (digital) fossa.

These muscles seem to have no certain representatives in the arm, where the shoulder-joint is entirely ensheathed by the dorsal musculature. It is possible that the pectoral group has a corresponding enbryonic origin. The group is represented, with marked variations, in the lower extremities of amphibia and all higher vertebrates.

\section{FASCIE}

Within the pelvis the obturator internus lies on the obturator membrane. It is covered by the obturator fascia, which is attached to the body of the pubis, to the iliac portion of the arcuate line, to the ventral margin of the great sciatic noteh, to the ischial spine, to the sacrotuberous (great sacro-sciatic) ligament, and with the falciform process of that ligament, to the ischial and pubic rami. Near the upper part of the obturator foramen the fascia instead of being attached to bone is reflected over the muscle and attached to the obturator membrane. It here helps to bound the canal for the obturator vessels and nerve. The upper part of the fascia lies beneath the pelvic peritoneum and the levator ani. The lower part forms the outer boundary of the ischio-rectal fossa. The fascia is continued as a thin, adherent membrane over the obturator internus and the gemellns muscles to their attachment. The quadratus femoris is invested by a thin adherent fascial sheet.

\section{MUSCLES}

The obturator internus (fig. 409).-Origin.-From (1) the pelvic surface of the pubic rami near the obturator foramen; (2) the pelvic surface of the ischium between the foramen and the great sciatic notch; (3) the deep surfaee of the obturator internus fascia; (4) the fibrous arch which bounds the canal for the obturator vessels and nerve; and $(5)$ the pelvic surface of the obturator membrane except in the lower part.

Structure and insertion.-From this extensive area of origin the fibre-bundles converge toward the lesser sciatic notch and become applied to the broad tendon of insertion. At the notch the muscle curves laterally and extends outward and upward to its insertion into the fore part of the trochanteric fossa of the femur. The tendon is formed of five or six bands which begin high in the musele and converge into a common tendon situated on the deep surface of the muscle as the latter curves abont the ischium. The tendon bands at first throw the tendon into folds which run in ridges in the fibro-eartilage which lines the notch. The attachment of fibre-bundles continues upon the dorsal surface of the tendon to half way between the lessel. sciatic noteh and the great trochanter.

Nerve-supply.-A special nerve to the obturator internus arises from the front of the sacral plexus, usually from the lumbo-saeral eord and the first and second sacral nerves. This nerve passes lateral to the sacro-spinous (lesser seiatic) ligament, then re-enters the pelvis through the lesser seiatic notch and sends out branches of distribution on the pelvic surface of the obturator internus.

Action.- This muscle with its two companions, the gemelli, is a powerful lateral rotator of the thigh. It is also an extensor and abductor when the thigh is bent at a right angle.

Relations. - The chief pelvic relations have been described in connection with the obturator fascia which completely rovers the medial surface of the muscle. The muscle passes out bintween the two sacro-ischial (saero-sciatic) ligaments. Outside the pelvis the gemellus muscles run on each side of the tendon, which is here elosely applied to the eapsule of the joint. Dorsal to it lie the gluteus maximus, the sacro-tuberous (great sacro-sciatic) ligament, the inferior gluteal (sciatic) vessels, and the seiatie and posterior cutaneous nerves. The nerre of the quadratus femoris runs beneath the obturator internus and gemellus muscles.

Variations. - It varies in the extent of its insertions. It may be divided into two parts, 
a pubic and an ischial. Fasciculi may be sent to the postero-inferior part of the ilio-pectineal eminence, the tendon of the psoas minor, the tuber ischii, the sacro-tuberous (great sacro-sciatic) ligament, the ischial spine, etc.

The gemellus superior (fig. 40s).-Origin.--From the outer surface of the ischial spine and the neighbouring edge of the lesser sciatic noteh.

Structure and insertion.- The fibre-bundles encircle the upper border and ventral aspect of the tendon of the obturator internus. They are inserted into the upper border of this tendon, and sometimes also into the trochanteric fossa.

Nerve-supply.-From a small nerve which arises either directly from the plexus or as a branch of the nerve to the obturator internus or of that to the quadratus femoris. This nerve usually enters the deep surface of the muscle near the junction of its ischial and middle thirds. Action. - It is essentially a part of the obturator internus.

Relations. - It lies between the piriformis and the tendon of the obturator internus. Proximally it adjoins its fellow beneath this tendon; distally, the two gemelli enclose the tendon in a musculo-tendinous sheath.

Variations. - It may be wanting or may have a more extensive origin than usual. It may be joined to the piriformis or to the gluteus minimus or be joined more closely than usual to the obturator tendon.

The gemellus inferior.-Origin.-From the upper part of the inner border of the tuberosity of the ischium, the sacro-tuberous (great sacro-sciatic) ligament and from the neighbouring edge of the lesser sciatic notch.

Structure and insertion. - The fibre-bundles converge upon the inferior border of the tendon of the obturator internus, and are inserted by tendon-fibres into this or into the great trochanter below the obturator internus tendon.

Nerve-supply. - From a branch of the nerve to the quadratus femoris. This branch enters the deep surface of the muscle near the junction of the ischial with the middle third.

Action.-It is essentially a part of the obturator internus.

Relations. - It lies between the quadratus femoris and the tendon of the obturator internus.

Variations.-It is rarely absent. It may be joined to the quadratus femoris. It is frequently closely bound up with the obturator internus. It may be doubled.

The quadratus femoris (fig. 408).- Origin. - From the upper part of the outer border of the tuber of the ischium.

Structure and insertion.-The fibre-bundles take a nearly parallel course and are inserted into the vertical ridge which terminates above on the inferior dorsal angle of the great trochanter.

Nervc-supply. - From a nerve which arises usually from the lumbo-sacral cord and the first sacral nerve and passes under the gemelli and the tendon of the obturator internus. The nerve enters the deep surface of the muscle near the junction of the ischial and middle thirds.

Action.- - It is a powerful lateral rotator and a weak adductor of the thigh.

Relations. - It is covered by the gluteus maximus. Between this muscle and the quadratus femoris runs the sciatic nerve. The obturator externus muscle lies in front. The inferior gemellus extends along its superior border. The adductor minimus adjoins it distally.

Variations.- It is absent in from 1 to 2 per cent. of instances. (Schwalbe and Pfitzner.) It may be double near its femoral insertion. It may be fused with the inferior gemellus or the adductor magnus. It may send a fasciculus to the semimembranosus.

The obturator externus (figs. 407, 409).-Origin.-From the lateral surface of the pubic and ischial rami, where they bound the obturator foramen, and from the surface of the obturator membrane.

Structure and insertion.-Often the muscle is distally divided into three fasciculi, a superior from the superior pubic ramus, a middle from the inferior pubic ramus and the obturator membrane, and an inferior from the ischium. The fibre-bundles converge upon a tendon which is at first deeply buried, then appears on the lateral surface of the muscle and is continued as a roumded tendon over the capsule of the joint to its insertion into the dorsal part of the trochanteric fossa.

Nerve-supply. - The obturator nerve gives rise, usually in the obturator canal, to a branch which bifurcates to enter the superior border. and ventral surface of the muscle in its middle third.

Action.-It is a powerful lateral rotator of the thigh and is also a weak adductor.

Relations.-It is covered by the pectincus, the ilio-psoas, and the adductor magnus muscles in front, and by the quardratus femoris behind near its insertion. It covers over the obturator membrane. The oluturator nerve passes either above the muscle or through its upper portion.

Varialions. The reported variations are few. It may be joined by a slip from the adructor lirevis.

\section{Butes}

B. m. obturatoris interni. - A fitirly large bursa constantly present between the tendon of the olfurator infermus musele and the lesser sciatic noteh. It may extend on each side beneath the gemellus muscles. B. m. quadrati femoris. $-\Lambda$ small bursa frequently found between this muscle and the small trochanter. B. m. obturatoris externi.- $\Lambda$ bursa is sometimundes of between the tenton of this musete and the capsule of the joint.

\section{B. MUSCLLS OF' THE 'THIGH}

In the thigh three groups of musceles may be recognised, an anterior or extrensor (figs. 111, 112), a medial or adductor (figs. 409, 411, 412), and a posterior, flexor of hamstring gromp (figs. 408, 413). 
Fig. 410, A-D.-Transterse Sections through the Left 'Thigh in the Regions inditated IN THE DragraM.
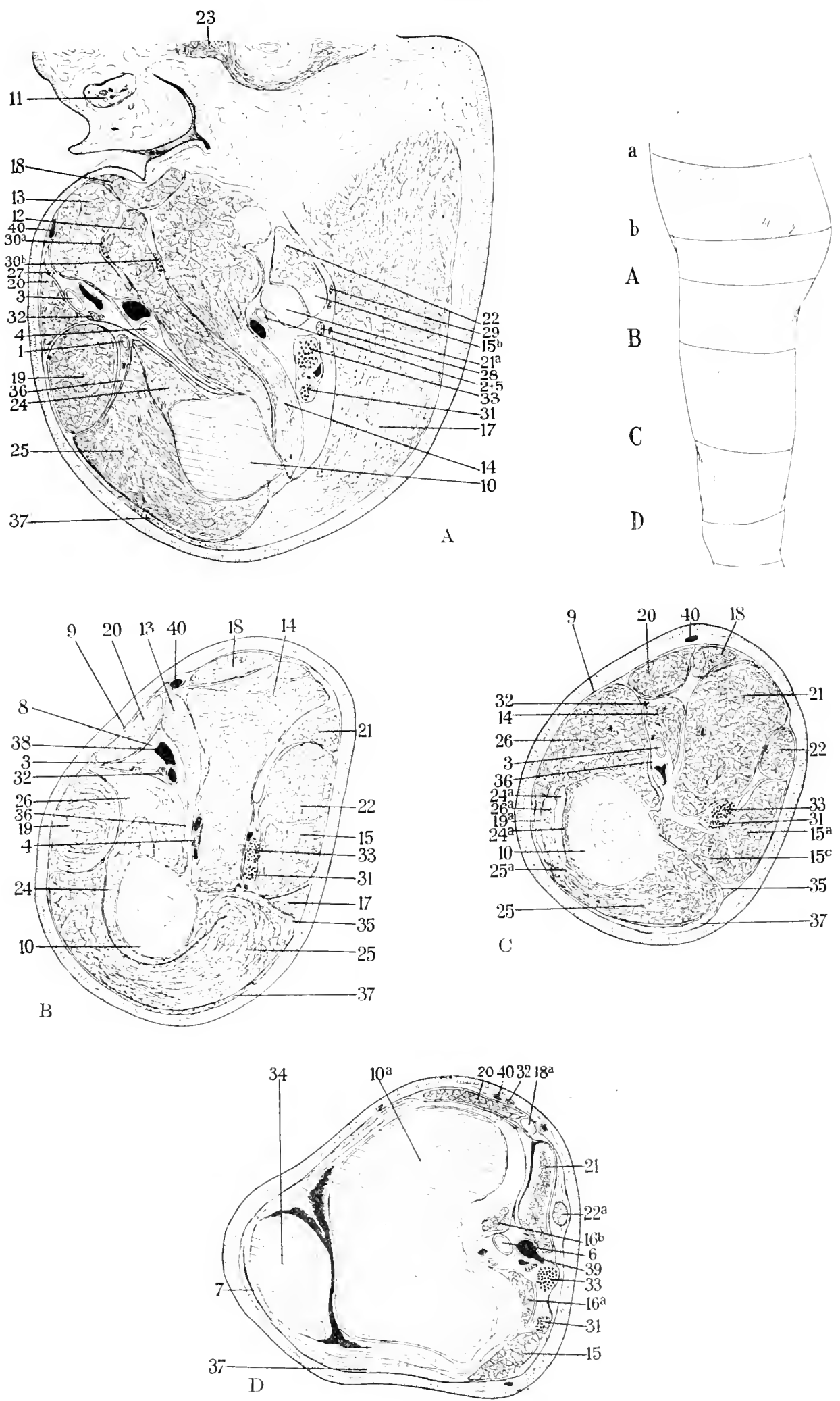
In the proximal part of the thigh the anterior group of muscles is separated from the medial group by the ilio-psoas muscle (fig. 411) and by the femoral blood-vessels and nerve, and from the posterior group by the gluteus maximus (fig. 413). More distally it is separated from the medial group by the medial intermuscular septum and from the posterior by the lateral intermuscular septum (see p. 468). The medial and posterior groups are closely associated. The adductor magnus belongs ontogenetically to both.

The three groups of muscles, with numerous modifications, are represented in the thighs of amphibia and all higher vertebrates. In the human arm they are likewise represented, the adductor group in a much reduced form by the coraco-brachialis. The quadriceps is represented by the triceps in the arm, the long head of the triceps corresponding with the rectus femoris. The hamstring muscles are represented by the biceps and the brachialis.

\section{FASCIE}

The fasciæ and the relations of the musculature of the thigh may be followed in the crosssections figs. $40 \bar{\tau}, 410,414$.

The tela subcutanea of the thigh varies considerably in thickness in different regions, but is well developed throughout and contains a considerable amount of fat. Over the front of the thigh, especially in the upper medial region, one or more deeper membranous layers may usually be separated from the superficial adipose layer. Between the former and the latter are situated the inguinal lymphatic nodes and the saphenous vein. The deepest layer near the inguinal (Poupart's) ligament is fused with the fascia lata (see below). Medially it is attached to the pubic arch. Thus fluids beneath the tela subcutanea of the abdomen and perineum do not realily pass into the region of the thigh.

Over the lower half of the patella a subcutaneous bursa (b. præpatellaris subcutanea) is found. Another is usually found over the upper end of the patellar ligament (b. infrapatellaris subcutanea).

The muscles of the thigh are enclosed in a dense fascial sheet, the fascia lata (figs. 387, 410). The gluteal portion of this and the ilio-tibial band have already been described ( $p$. 457). The ventral portion of the fascia, composed chiefly of transverse fibres, is a dense, fibrous membrane. Above it is attached to the inguinal ligament from the anterior superior spine to the pubie tubercle. Below it extends over the knee, where it is united to the capsule of the joint and is strengthened by expansions from the vastus lateralis and medialis. Between the front of the patella and the fascia is a bursa (b. præpatellaris subfascialis). Above the knee the fascia is strengthened by an arciform process which extends obliquely distally across the fascia from the ilio-tibial band to the capsule of the knee. This gives rise to a fold in the skin when the leg is extended and the muscles are not tense. Over the medial and posterior regions of the thigh the fascia is less dense. It extends from the body and inferior ramus of the pubis, the inferior ramus and tuber of the ischium, and the sacro-tuberous ligament into the fascia of the back of the leg. Above the popliteal space it is strengthened by a transverse band of fibres. Near the knee the tendons of the quadriceps, sartorius, gracilis, and semitendinosus become bound to the fascia by membranous laminie.

The relations of the fascia lata to the inguinal ligament and the iliac fascia are somewhat complex. The fascia of the ilio-psoas muscle extends over the muscle to its femoral insertion. Above the inguinal ligament this fascia is called the fascia iliaca; below the ligament, the fascia ilio-pectinea. This fascia is firmly united to the lateral extremity of the inguinal ligament. The pectineus muscle is likewise invested with a fascial membrane which extends over the muscle from the pubis to the femur and is fused laterally with that of the ilio-psoas. This combined fascia is firmly bound between the two muscles to the ilio-pectineal eminence. The ilio-pectineal fascia divides the space beneath the inguinal ligament into a lateral lacuna musculorum, which contains the ilio-psoas muscle and the femoral (anterior crural) nerve, and a medial lacuna vasorum, which contains the femoral artery and vein. Medial to the vein is the femoral ring, bounded medially by the lacunar (Gimbernat's) ligament. This is closed off from the abdominal cavity by a septum derived from the transversalis fascia, the femoral septum, but oflers passage for lymph-vessels.

a and $b$ in lle diagram indicate the regions through which pass sections $\Lambda$ and $\mathrm{B}$, fig. 407 (p. 458);

1. Arteria riremmlexa fenomis lateralis. 2. A. eircumllexa femoris methalis. 3. A. femoralis. 4. A. fomoralis mofunda. 5. A. ghutea inferior (sciatic). 6. A. poplitea. 7. Bursa priplatellaris sulfascoiatis. 8. Adkluctor (Ilunter's) canal. 9. Fascia lata. 10. Femur-a, distal cxtronity. 11. Funiculus spermaticus (spermatic cord). 12. Museulus arlductor brevis. 13. M. affluctor longus 1.1. M. adductor magnus. 15. M. biceps femoris-a, long hearl; I, lendorn of origin; (c, short, head. 16. NI. gastrocnemius-a, lateral head; l), medial learl. 17. M. gluteus maximus. 18. M. gracilis-il, tenton. 19. M. rectus femoris-a,

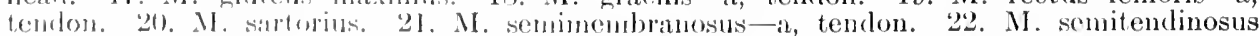
- it, tondon. 23. M. sphincle ani. 24. M. vastus intermedius (crureus)-a, tendon. 25. M. vastus latcralis al, tomlon. 215. M. vatstus motialis-a, tendon. 27. Nervus cutineous femoris anterior. 2s. ‥ antanous femoris posterior (small sciatic). 29. N. gluteus inferior. 30. N. olfuratorius-at, stuperficial bratuch; h, eleep branch. 31. N. peroneus communis (external popliteal). 32. N. saphenus (great saphenous). 33. N. tibialis (internal popliteal). :31. Patcllil. :55. Septum intermuseulare laterale. 36. Septum intermusculare mediale. 37. Trartas ilintibialis (ilin-tilnial buml). 3\%. Vena femoralis. 39. Vena poplitea. 40. V.

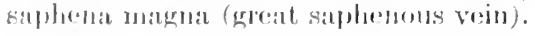


Beyond the inguinal ligament the fasciæ of the ilio-psoas and pectineal muscles line a triangular space, the ilio-pectineal fossa, ${ }^{*}$ through which run the femoral vessels (fig. 407). The sartorius muscle partly overlies the distal lateral margin of this fossa. The fascia lata is here reflected from the surface of the sartorius to the ilio-psoas fascia, and becomes fused with it. From the medial margin of the sartorius a process of the fascia is continued over the lateral and upper part of the fossa, and is attached to the inguinal and lacunar (Gimbernat's) liga-

Fig. 411.-MIuscles of the Front of the Thigh.

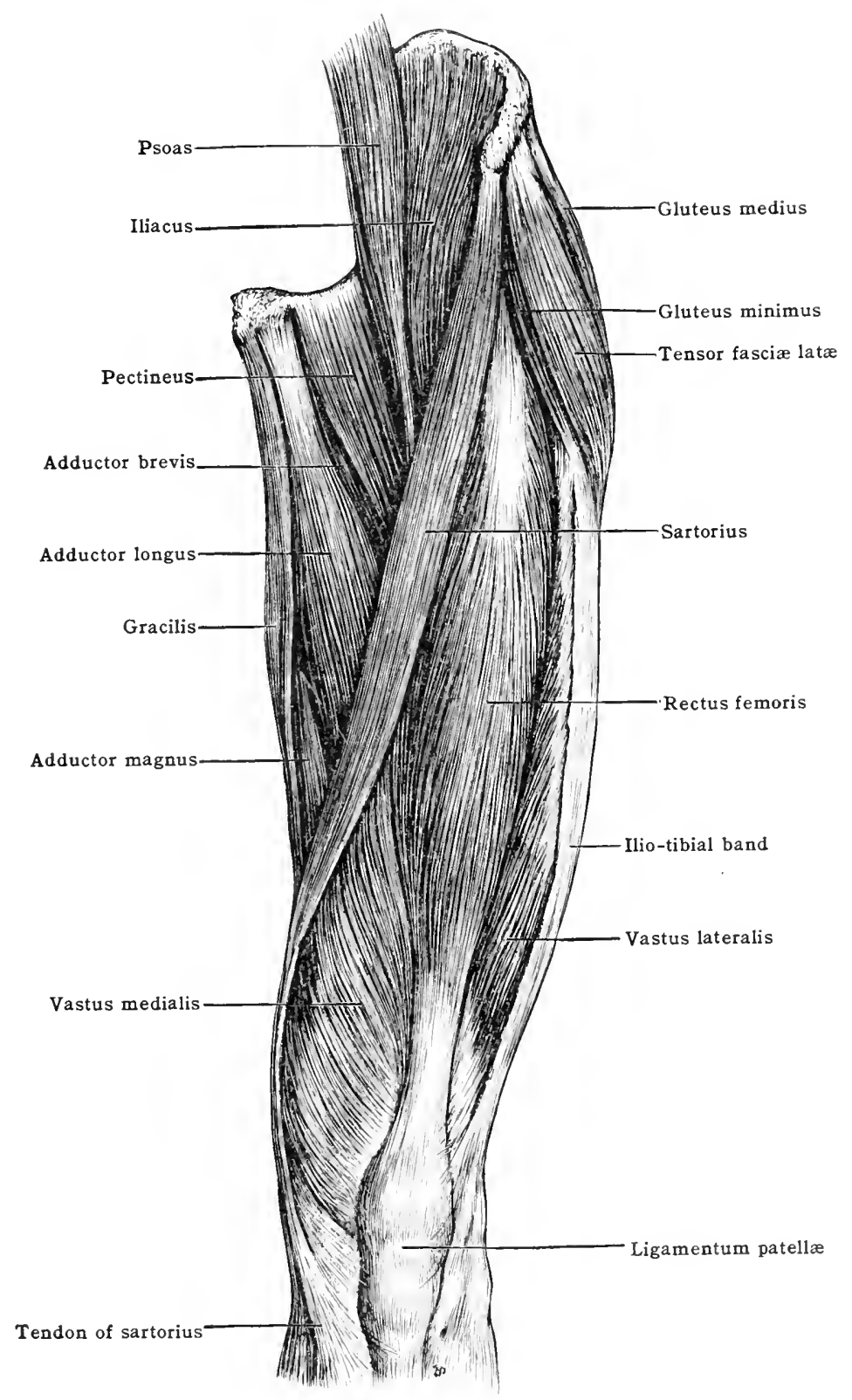

ments (fig. 389). Over the lower extremity of the fossa a process is continued medially into the pectineal fascia. On the medial margin of the fossa the fascia lata is continued directly into the pectineal fascia. The lateral concave margin of the fascia overlying the fossa is called the falciform margin; the upper extremity of this, the superior cornu; the distal extremity, the inferior cornu. The oval space bounded by the margo falciformis is called the fossa ovalis (saphenous opening). This is covered by the fascia cribrosa, which some consider a deep layer

* This lies within Scarpa's triangle [trigonum femorale], a space bounded by the inguinal (Poupart's) ligament and the sartorius and long adductor muscles. 
of the tela subcutanea and others a portion of the faseia lata. This fascia cribrosa contains many openings for the passage of blood-vessels and lymphatics. The space which lies medial to the femoral vessels between the femoral ring and the fossa ovalis is ealled the femoral canal (crural canal).

From the faseia intermuscular septa descend in between the underlying muscles. Of these, the medial and lateral intermuscular septa are the best marked (fig. 410).

The lateral intermuscular septum separates the extensor museles from the hamstring group. It extends from the tendon of the gluteus maximus to the lateral epicondyle. It is composerl chiefly of longitudinal fibres and is thiekest distally. The vastus lateralis is united to its ventro-lateral surface; the short head of the biceps, to its dorso-medial surface.

It will be noted that this septum serves to divide primarily ventral from primarily dorsal musculature, with the exception of the short head of the biceps, which, though primarily dorsal, occupies a position, perhaps secondarily acquired, with the primarily ventral muscles.

The medial intermuscular septum serves to divide the anterior extensor from the medial arluctor musculature. It is perhaps simplest in the region immediately distal to the iliopectineal fossa (fig. $410 \mathrm{~B}$ ). Here a well-marked septum may be seen extending to the femur between the sartorius and quadriceps on the one side, and the adductor longus and brevis on the other. The septum here, next the muscles, has on each side a membranous lamina. Between the two laminx there is a looser tissue in which run blood-vessels and nerves. A fibrous membrane extends between the reetus and sartorius to the septum.

More distally the sartorius eomes to overlie the septum (fig. $410 \mathrm{C}$ ). The sheath of the sartorius on the lateral margin becomes fused with the faseia of the vastus medialis, and on the medial margin to a membrane that covers the ventral surfaces of the adductor longus and magnus. Beneath the sartorius and between the adduetor longus and the vastus medialis is a triangular space bounded by the sheaths of these muscles, and filled with a loose areolar tissue in which run the chief blood-vessels of the thigh. This space, first described by John Hunter, is known as Hunter's canal, or the adductor canal. Still more distally the vessels with their surrounding fibrous tissue pass through the hiatus tendineus, between the long tendon of the arductor magnus and the femur, to the back of the thigh. The septum here passes behind the posterior surface of the vastus medialis to the femur.

\section{MUSCLES}

\section{The Anterior Group}

(Figs. 411,412 )

This group, which forms a semi-conical mass pointed upward, is composed of the quadriceps femoris and the sartorius muscles, innervated by the femoral nerre.

The sartorius is a long, ribbon-like musele which arises from the anterior superior spine of the ilium and extends along the medial margin of the quadriceps, passing obliquely across the upper part of the thigh, and then deseending to the dorse-medial side of the knee, whence its tendon curves forward to be inserted into the ventro-medial surface of the superior extremity of the tibia.

The quadriceps femoris is eomposed of four museles ilifferentiated from a common cmbryonic origin. Of these, the rectus femoris, which arises from the ventro-lateral margin of the ilium by two tendons, is the most superficial and the most eompletely differentiated. 'The vastus lateralis, which arises from the superior extremity of the rentral surface of the shaft of the femur and from the lateral lip of the linea aspera; the vastus medialis, which arises from the medial lip of the lincia aspera and from the intertrochanterie line; and the vastus intermedius (anrous), which arises between these two and beneath the rectus from the surfare of the fomme, are less distinctly differentiated from one another. The vatus intermedius and vastus lateralis are partly fused at the insertion, the intremerdius and monlialis at there origins. From the four museles arises a tendon whele is insertal into the fuberosity of the tibia. In this tenton, which is

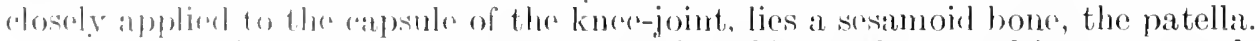

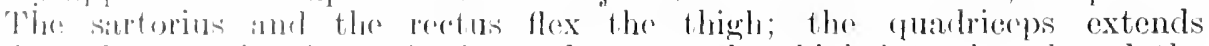
the lage: the sartorius flexps the lege and rotates the thigh lateralward and the leg mordialwarl.

In the cunbryo thr surtorias has an migin distinct from that of the guadriceps. In the anthropoid apes it is marh more devaloper than in man.

In arldition to supplying the muscles of this gromp, the femoral nerve also gives branches to the iliacus muscle (p, 155$)$ and the perdincus musele (p. 472).

The sartorius (fig. HI). ()rigin. From the anterior superior spine of the ilium and the area immediatcly bolow this.

Insertion. - Into the modial surfare of the libia near the tuberosity and into the neighbouring faseria of the lege. 
Structure.-The muscle arises by short tendinous strands. The fibre-bundles take a neinly parallel course. The component muscle-fibres are said to be the longest in the body. Nent the medial epicondyle of the femur the tendon of insertion makes its appearance on the deep aspect of the muscle. On the superficial surface of the tendon the muscle-fibres are inserted as far as the distal margin of the knee-joint. From there the tendon turns forwarel to it: insertion.

Nerve-supply.-Usually two branches enter the deep surface of the proximal third of the sartorius. One or both of them may be bound up with an anterior cutaneous nerve passing

Fig. 412.-The Deep Muscles of the Front of the Thigh.

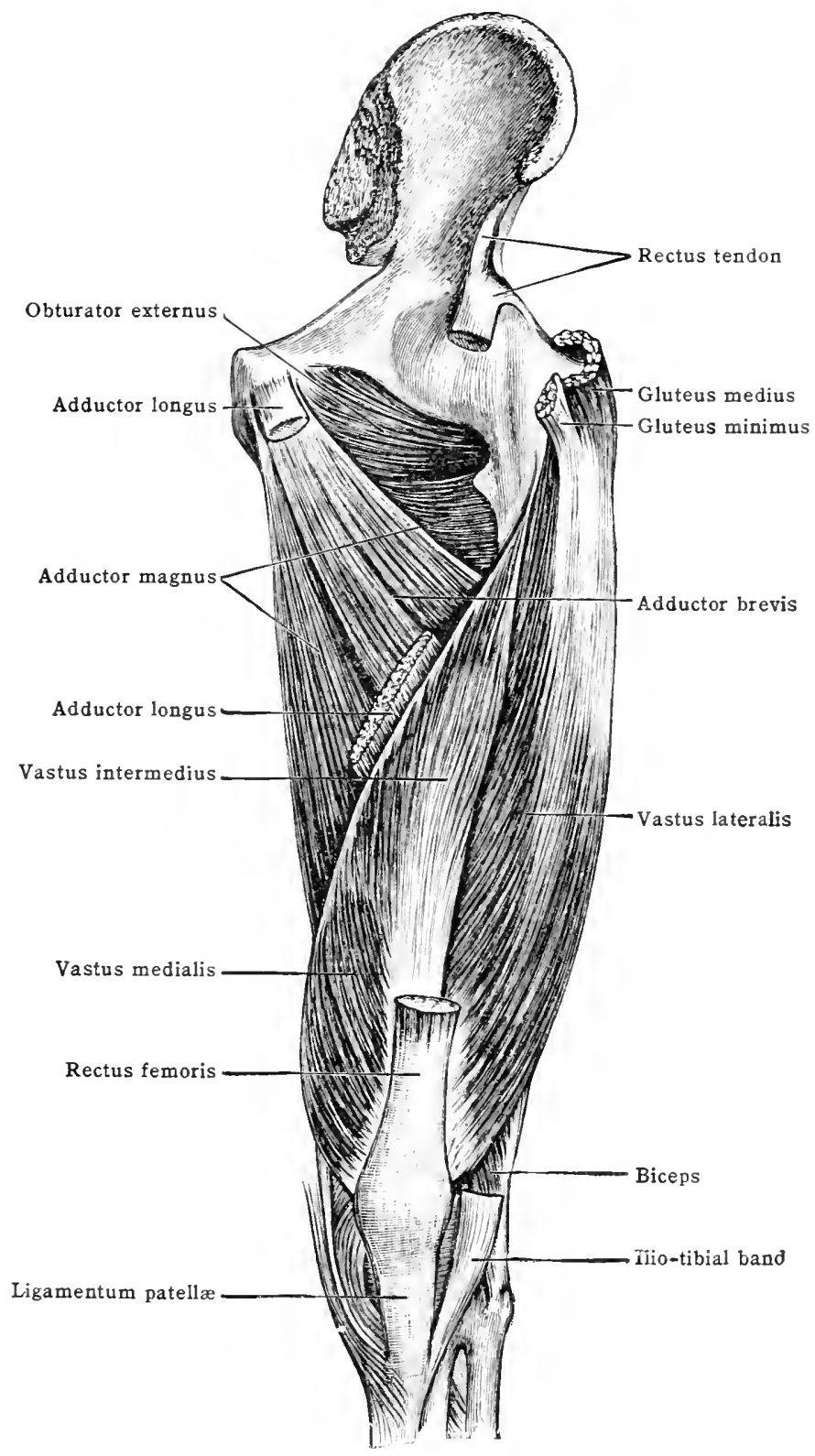

through the muscle. The first of the branches is distributed chiefly to the lateral and proxinal, the second to the medial and distal, portions of the muscle. Within the muscle is a complex plexus.

Action.-(1) To flex the thigh at the hip, abduct and rotate it lateralward; (2) to flex the leg and rotate it slightly medialward; $(3)$ to make tense the medial part of the fascia lata.

Relations. - The sartorius lies in a fascial canal bounded by the fascia lata and by intermuscular septa which descend from this. It crosses the rectus femoris, ilio-psoss, the adductor 
longus and magnus, and the vastus medialis muscles, the femoral vessels and nerve, and the knee-joint. At its insertion its tendon covers the gracilis and semitendinosus.

Variations. - It may arise from the inguinal ligament or be inserted into the fascia lata, the medial epicondyle, or the capsule of the knee-joint. It may be longitudinally divided into two parts. The tendon of the secondary slip is in such instances usually attached to the capsule of the knee-joint, but sometimes is attached to the fascia over the vastus medialis or to the anterior wall of the adductor canal. More frequently the muscle is partly divided proximally or distally. The secondary tendon of origin may arise from the anterior inferior spine, the ilio-pectineal eminence, etc. The muscle is very rarely absent. It may be crossed by a tendinous inscription, or more rarely it is rendered digastric by an intervening tendon.

The quadriceps femoris (figs. 411, 412).-This, as pointed out above, is composed of the rectus femoris and the vastus lateratis, intermedius, and medialis.

The rectus femoris (fig. 411).-Origin.-By two tendons. The anterior 'straight' tendon is attached to the anterior inferior spine of the ilium; the posterior 'reflected' tendon to the postero-superior surface of the rim of the acetabulum. The two tendons unite so as to form a small arch above the capsule of the joint.

Structure and instrtion.-From this arch an aponeurotic expansion descends upon the front of the muscle nearly to the middle of the thigh. This expansion is broad above, becomes narrower as it descends, and is continued a short distance as a narrow intramuscular tendon after it disappears from the surface. The tendon of insertion begins on the back of the muscle above the middle of the thigh, expands into a broad aponeurosis, and finally becomes a strong band which is inserted into the proximal border of the patella. The fibre-bundles pass in a bipenniform manner from the back and sides of the tendon of origin to the front and sides of the tendon of insertion.

Nerve-supply. - As a rule, two branches enter the muscle. One of these enters the deep surface of the muscle in its upper fourth, and is distributed mainly to the proximal part of the lateral half. The other enters the medial margin of the muscle near the junction of the proximal and middle thirds, and is distributed chiefly to the medial half and distal portion of the muscle.

The vastus lateralis (vastus externus) (fig. 412),-Origin,-From-(1) the shaft of the femur along the antero-inferior margin of the great trochanter and in front of the gluteal tuberosity; and (2) the lateral intermuscular septum along the upper half of the linea aspera.

Insertion.-By a flat tendon into-(1) the proximo-lateral borcler of the patella; and (2) the front of the lateral condyle of the tibia and the fascia of the leg.

Structure. - The fibre-bundles arise partly from the bone, partly from an aponeurosis which covers the proximal two-thirds of the muscle, and from the lateral intermuscular septum. They take a parallel course distally in a ventro-medial direction, and are inserted into an aponeurosis which lies on the deep surface of the muscle and receives fibres until within a few centimetres of the patella. Ventrally this aponeurosis fuses with the rectus tendon, laterally with that of the vastus medialis, and dorsally it receives some of the fibre-bundles of the vastus intermedius. Commonly the muscle is distinctly divisible for the greater part of its course into two sheets, a superficial and a deep. The deep sheet is often subdivided into two laminæ.

Nerve-supply. - Usually there are three nerves, one of which, accompanied by blood-vessels, runs on the inner surface of the superficial sheet midway between the tendons of origin and insertion, the second between the two lamine of the decp layer, and the third passes through the innermost lamina to be distributed in part to the vastus intermedius (crureus) muscle.

The vastus medialis (vastus internus) (fig. 412 ). - Origin.- From the whole extent of the merlial lip of the linca aspera and from the distal half of the intertrochanteric line. The origin takes place by means of an aponeurosis which is adherent to the tendons of insertion of the adluctor muscles.

Structure and insertion. - The fibre-bundles arise from the deep surface of this aponeurosis and are inserted on the medial surface and margin of a tendon which begins on the deep surface of the muscle about its middle near the lateral margin. On the distal lateral border of the muscle it is inserted into the medial half of the proximal margin of the patella and into the medial condyle of the tibia and the fascia of the leg. For some distance near the knee the lateral margin of the tendon is united to those of the vastus intermedius (crureus), lateralis (extermis) ind the rectus.

Nerve-supply. - The nerve to this musele descends on its medial surface, often bound up with the saphenous nerve for a part of its course. It gives off successive branches and finally sinks into the muscle substance. These branches enter about midway between the origin and insertion of the fibre-lundles of the muscle.

The vastus intermedius (crureus) (figs. 409, 412).-Origin.-From (1) the clistal half of the lateral margin of the linea aspera and its lateral bifurcation; (2) the antero-lateral surface of the shaft of thr: femmr. Between the origin of the vastus intermedius (crureus) and that of the vastus medialis the shaft of the femur is free from muscle attachment.

Strueture ame insertion.-( )n the ventral surface of the muscle lies an aponeurosis which extends from its proximal fourth to the proximal margin of the patellat. The fibre-bundles of the muscle are inserted into the leep surfare of this and into the deep surface of the aponeurosis of insertion of tho vastus lateralis. The proximal filme-lundles descend vertically, the merlial and lateral, especially the latter, obliquely to their insertion. Merlially the tendon is more or less fuserl with that of the vastus medialis, and laberally with that of the vastus lateralis. The intusele is composed of musclo lamella superimposed concentrieally about the shaft of the femur. The deeprest, most distal of these is callerl the articularis genu (subcrureas). The filire-bundles of this layer are inserted into the rapsule of the joint or into the superior margin of the patella.

Norne-supply.- Several hranclies are usually distributed to this muscle. To the lateral region at banch from the norve to the vastus lateralis is usually given; to the middle of the musclo another branch desends from the femoral (anterior crural) nerve; to the medial portion there extrubl severalitwigs from the norve to thr vastus medialis. 
Tendon of the quadriceps.-The quadriceps tendon may be more or less distinctly divided into layers, of which the superficial layer belongs to the rectus, the deep to the vastus intermedius, and the intermediate to the vastus lateralis and medialis. Some of the more superficia fibres of the tendons of the two vasti, however, cross in front of the rectus tenclon. The combined tendon of the quadriceps is in part attached to the superior and lateral margins of the patella, and in part extends over the patella into the patellar ligament. A part of the tendon fibres of the vastus lateralis and medialis run on each side of the patella to the ventral surface of the condyles of the tibia. These form the retinacula patellæ mediale and laterale. The mediat is the broader and better developed. With the retinacula are included bundles of fibres which run from the epicondyles to the patella and into which some muscle fibre-bundles are inserterl. From the apex of the patella to the tuberosity of the tibia the quadriceps tendon is continuel as the patellar ligament (fig. 415 ).

Nerve-supply.-The relations of the branches of distribution to the various parts of the muscle have been pointed out above in connection with each head. The general relations of these branches of the femoral nerve are as follows:- From the femoral nerve near the proximal end of the vastus medialis the branches for the vastus lateralis, vastus intermedius (crureus), anil rectus pass distally and laterally between the rectus and vastus intermedius (crureus) to be distributed to the muscles named, while the chief nerve for the vastus medialis descends on the medial side of this muscle in company with the saphenous nerve. The branches to the vastus lateralis and intermedius are commonly bound up in a single nerve-trunk for some distance. The branches to the rectus are usually bound up with this trunk for a shorter distance. The nerve to the vastus medialis may be united to this trunk for a slight distance, but more frequently it is more or less bound up with the saphenous nerve.

Action.-The quadriceps is the extensor of the leg. The rectus femoris also flexes the thigh at the hip and is a weak abductor of the thigh. The articularis genu makes tense the capsule of the knee-joint.

Relations.-The quadriceps is covered ventrally immediately by the fascia lata. The sartorius runs along its medial margin; the tensor fasciæ latæ lies over the proximal quarter of its lateral surface. Dorsal to the vastus lateralis lie the gluteus maximus and biceps; dorsomedial to the vastus medialis, the three adductor muscles and the semimembranosus. Next the vastus medialis lies the adductor canal with the femoral vessels and the saphenous nerve.

Variations.- The variations of this muscle, aside from a greater or less fusion of its parts, are not marked. The attachment of the rectus femoris to the anterior inferior spine, which takes place in the embryo later than its insertion above the acetabulum, may be wanting. On the other hand, this tendon may extend to the anterior superior spine. Occasionally the deep reflected tendon may be wanting. The rectus accessorius is a fasciculus rarely found, which arises by a tendon from the rim of the acetabulum and is inserted into the ventral edge of the vastus lateralis. It is innervated by a twig from the branch to the rectus.

\section{BURSA}

B. m. recti femoris (superior).-A small bursa between the deep tendon of the rectus femoris and the edge of the acetabulum. Rare. B. m. recti femoris (inferior).-Between the tendon of the rectus and the combined tendon of the vastus lateralis and medialis. Occasional. B. præpatellaris subtendinea.-A bursa between the tendon of the quadriceps and the periosteum of the patella. Of the three præpatellar bursæ-the subcutaneous, subfascial, and subtendinous-as a rule only one occurs. When two or three exist, they usually communicate freely with one another. B. suprapatellaris.-A bursa between the anterior surface of the lower end of the femur and the tendon of the quadriceps. It usually communicates with the joint cavity. B. infrapatellaris profunda.-A bursa between the patellar ligament and the tibia. It seldom communicates with the joint cavity. B. m. sartorii propria. - A bursa, fairly large, between the tendon of the sartorius and the tenclons of the semitendinosus and gracilis muscles. This usually communicates with the bursa anserina (see p. 474).

\section{The Medial (Adductor) Group}

(Figs. 409, 411, 412)

To this group of muscles belong the gracilis, the pectineus, the adductors breris, longus, and magnus, and the obturator externus. The most superficial of the group is the gracilis (figs. 408, 411). This ribbon-shaped muscle arises from the inferior pubic and ischial rami, extends along the medial side of the thigh, and gives rise to a tendon which curves forward from behind the medial condrle of the femur to be inserted under the tendon of the sartorius into the medial side of the upper extremity of the tibia. The quadrilateral pectineus arises from the body and superior ramus of the pubis; the triangular adductor longus from the superior ramus medial to this (fig. 411). The pectineus is inserted into the pectineal line of the femur; the adductor longus into the middle third of the linea aspera. The triangular adductor brevis (fig. 412) arises from the inferior pubic ramus below the adductor longus. It is inserted into the pectineal line and the upper third of the linea aspera. The large, triangular adductor magnus (figs. 409,412 ) arises from the inferior ramus and the tuber of the ischium and is 
inserted behind the short and long adductors into the whole length of the linea aspera, and by a special tendon into the adductor tubercle of the femur. The deepest muscle of the group, the obturator externus, which arises from the outer surface of the bones bounding the ventral two-thirds of the obturator foramen, and is inserted by a tendon into the trochanteric (digital) fossa, has been deseribed in connection with the ischio-pubo-femoral muscles of the hip.

All the muscles of this group adduct the thigh. The gracilis, obturator externus, adductor brevis and the lower part of the adductor magnus (when the thigh is extended) rotate it lateralward. The pectineus, adductor longus, and the adductor magnus rotate it medialward. Those attached to the pubis flex the thigh. The gracilis flexes the leg and rotates it medialward. The inferior part of the adductor magnus extends the thigh.

The muscles of this group are supplied by the obturator nerve, except the pectineus, which usually gets its whole supply from the femoral (anterior crural) nerve, and the adductor magnus, which gets a part of its supply from the sciatic nerve.

In embryonic development the pectineus arises in close conjunction with the obturator group, and in the adult it mar get the whole or a part of its nerve-supply from the obturator nerve or from the accessory obturator nerve. In the lower mammals the nerve-supply may come from the femoral (anterior crural) or the obturator nerve or from both. It is not certain whether the innervation from the femoral nerve indicates that the musele belongs phylogenetically, if not ontogenetically, with the primitive dorsal musculature of the limb. By some it is considered to be derived in part from the primitive dorsal, in part from the primitive ventral, musculature. The adduetor magnus arises in the embryo as two distinet portions, one connected with the flexor group of muscles, the other with the adductor group. These two portions later become fused. Primitively the seiatie portion of the adductor magnus and the semimembranosus constitute a single medial flexor muscle.

The gracilis (figs. 408, 411).-Origin.-By a flat tendon from the medial margin of the inferior ramus of the pubis and the pubic extremity of the inferior ramus of the ischium.

Structure and insertion.- The nearly parallel fibre-bundles which arise between two lamina of the tendon form it thin band of inuscle which is narrower and thicker distally than proximally. They are inserted on a tendon which begins as an aponeurosis on the posterior border and medial surface of the muscle in the distal third of the thigh, becomes free as a rounded cord a little proximal to the melial condyle of the femur, runs behind the condyle, and then turns forward to be inserted by an expanded process into the tibia below the medial condyle.

Nerve-supply.-The nerve enters the deep surface of the muscle near the junction of the superior and middle thirds.

Action.-To addluct, flex and (slightly) rotate the thigh lateralward, and flex the leg. With the knee flexed, it acts as a medial rotator of the leg.

Relations.-It occupies a position beneath the fascia lata and superficial to the adductor hrevis, longus, and magnus museles. Distally the sartorius lies in front, the semimembranosus behind. Its tendon erosses the tibial collateral ligament of the knee-joint and the tendons of the semitendinosus and the semimembranosus, and is overlapped by that of the sartorius.

I'arintions.--The pubie origin of the musele may be much reduced or may be double. Its tendon of insertion may give rise to an accessory fascieulus which extends distally in the leg. In some of the apes the tendon deseends normally much farther down the leg than in man.

The pectineus (fig. 411.)-Origin.-(1) From the pecten (erest) of the os pubis, the bone in front of this, and the pectineal fascia near this origin; and (2) from the anterior margin of the obturator sulcus and from the pubo-capsular ligament. Laterally the two areas of origin are usually separated by most of the superior surfare of the body of the pubis. Medially they rome togrither.

Structure and insertion.-From each area of origin a separate lamina arises. The fibre-

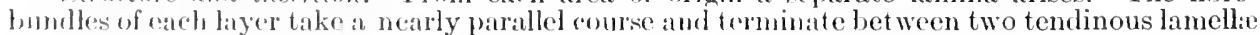
Which fuse to be inserted into the upper half of the pertineal line behind the small trochanter.

The fibre-bundles of the sunerfitial layer cross those of the deep slightly oblinguely. The muscle fares ventrally at its origin, laterally at its inscrtion.

Neree-supply.-lirom a branch of the fomoral (anterior crural) nerve, which passes behind the femoral artery and vein and through the pertineal fascia to enter the ventral surface of the muscle. It maty also be supplied by the ateressory obturat or nerve, when present, or by a branch from the oldturitor. When both the femoral (anterior crural) and obturator nerves supply this muscle, the femoral sujplies the superficiat, the obturator, the deep lamina (Paterson).

fetion.-To flex and adduct the thigh (ats in (rossing the legs).

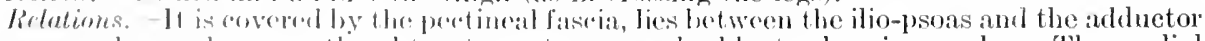

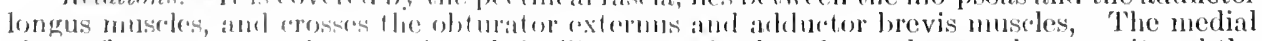
cirenmflex artery runs between it and the ilio-psosis, the deep femoral artery between it and the arliluctor lomgus.

l'ariatims.-The extent of the division of the pectineus into superfuial and deep portions varies considerably. It may also lo divided into a lateral and a medial division. Often the

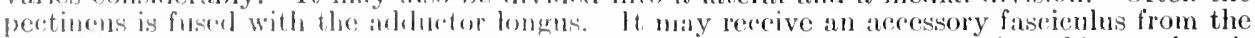
eapsule of the hip-joint, the iliacus musclo, the oblurator exterums, or the adeluetor brevis

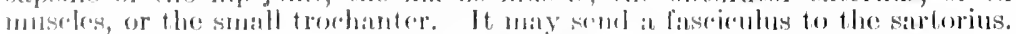

The adductor longus (fig. 111).- Crigin. - From the modial corner of the superior ramus 

of the pubis by a strong tendon which extends for some distance on the medial border of the
muscle.

Structure and insertion.-From this tendon the fibre-bundles diverge toward their insertion.

Fig. 413.-Superficial Muscles of tile Back of the Thigh and Leg.

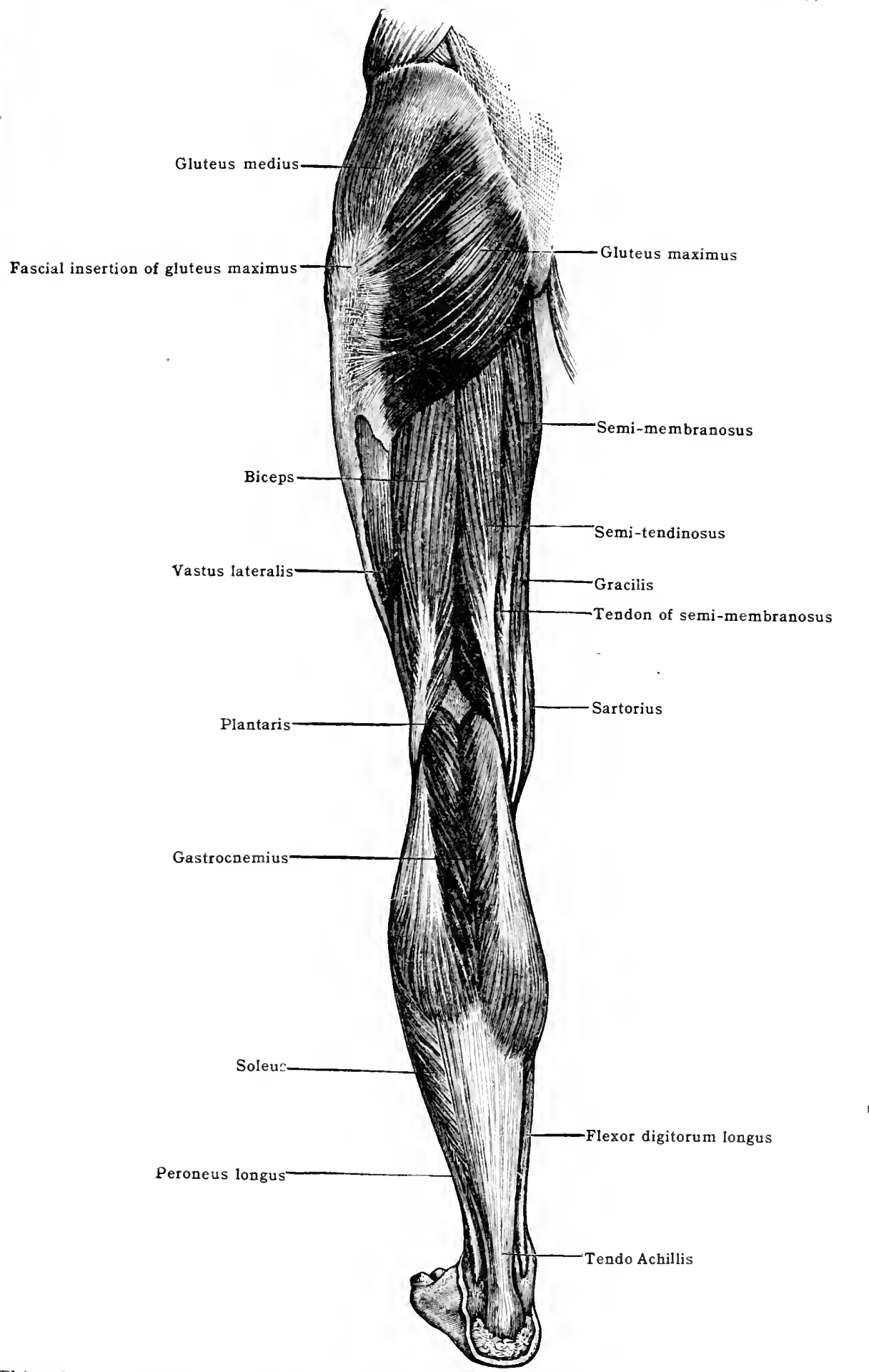

This takes place between two lamellæ of a short tendon attached to the middle third of the linea aspera. The tendon is usually fused to the medial intermuscular septum and sends an expansion 
Nerve-supply. - A branch from the anterior division of the main obturator trunk gives off several twios which enter the middle third of the deep surface of the muscle. Occasionally a small branch from the femoral (anterior crural) nerve enters the muscle. This is probably sensory in nature.

Action.-To adduct and flex the thigh, and rotate it medialward.

Relations. - The sartorius, the vastus medialis, and the femoral vessels lie antero-lateral to it. Behind it lie the adductor brevis and adductor magnus muscles. Between these and the longus run the profunda vessels. Its lateral border touches the pectineus above, but is separated from it toward the insertion.

I ariations. - It may be fused with the other adductors, including the pectineus. It may be doubled. The femoral insertion may extend to the medial epicondyle.

The adductor brevis (fig. 412). - Origin.-From the medial part of the outer surface of the inferior ramus of the pubis directly, and by means of short tendinous processes or a short flat tendon.

Structure and insertion.-From their origin the fibre-bundles diverge into a sheet which is inserted by short tendinous bands into the distal two-thirds of the pectineal line and the upper third of the linea aspera. 'The muscle is more or less completely divided into two fasciculi near its insertion. The place of division is near where the intertrochanteric line curves away from the linea aspera.

Tere-supply.-Usually from the anterior but also sometimes from the posterior branch of the main obturator trunk. The rami enter the middle third of the muscle near the proximal border. thigh.

Action.-It is chiefly an adductor and to a less extent a flexor and a lateral rotator of the

Relations.-In front lie the pectineus and adductor longus; behind, the obturator externus quadratus femoris and adductor magnus. It is crossed by the profunda artery. The first perforating artery passes usually between the two fasciculi of the insertion.

Tariations. - It may be fused with other members of the group. It may be divided completely into two fasciculi, rarely into three.

The adductor magnus (figs. 409, 412).-The origin of this muscle begins on the inferior ramus of the pubis posterior to the origins of the adductor brevis and gracilis muscles. From here it extends backward along the inferior margin of the ventro-lateral surface of the isehium to the tuberosity. The muscle in passing from this curved origin to its extensive femoral insertion presents posteriorly a longitudinal groove in which rest the hamstring muscles. The adductor magnus is composed of three superimposed fasciculi, of which the first is frequently fairly distinct and is called the adductor minimus, while the other two are normally fused, but are occasionally distinct.

The superior fasciculus (adductor minimus) arises directly from the inferior rami of the pubis and ischium. From here the fibres diverge to form a thin sheet inserted by tendinous bands to the medial side of the gluteal ridge and the superior part of the linea aspera. The middle fasciculus arises directly from the inferior margin of the ventro-lateral surface of the inferior ramus and the tuber of the ischium, and from a tendon which descends along the dorsomedial margin of the muscle from the tuber ischii. The fibre-bundles diverge to be inserted between the lamellie of a narrow flat tendon attached to the distal three-fourths of the linea aspera. This tendon is pierced by the perforating vessels. The inferior fasciculus arises dorsal to and in common with the middle fasciculus. The fibre-bundles converge toward a strong tendon which begins in the distal third of the thigh and is inserted into a tubercle at the distal encl of the medial supracondylar ridge.

Nerve-supply. - The chief nerve-supply is from the posterior ramus of the obturator. This caters by one or more branches the proximal portion of the ventral surface of the muscle about midway between its pubic and femoral attachments. It also receives a branch from the sciatic which enters the dorsal surface of the muscle in the middle third of the thigh. To the adduetor minimus a branch may be sent from the nerve to the quadratus femoris.

Action.- It is the strongest of the adductors. The superior and middle fasciculi rotate the thigh nedialward and flex it; the inferior rotate it Iateralward when the thigh is extended, but melialwarl when the thigh is flexed. The latter also extend the thigh.

Rilutions.- In front are the pectineus, the short and long adluctor and the vastus merlialis muscles, and the profunda artery. Behind lie the hamstring muscles and the gluteus maximus. Medially lies the gracilis muscle. The femoral and perforating arteries pass through its attachnent to the shaft of the femur.

l'arintions:- The divisions of the muscle may be more or less distinet. It may be partly fuserl or cxohatuge fasciculi with neighbouring muscles- the semimembranosus, quadratus femoris, adductor lovevis, and adductor longus.

\section{Burste}

B. m. pectinei.- $\Lambda$ small bursa frequently present between this muscle and the ilio-psoas and small trochanter. B. anserina. $-\Lambda$ fairly large bursa which lies between the tendons of the sirtorius, grarilis, and semitendinosus museles and the tibial collateral ligament of the knce-

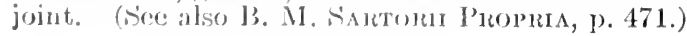

\section{Time Posterior (Hamstring) Group}

$$
\text { (Figs. 408, 413) }
$$

The muscles of this group are the semitendinosus, semimembranosus, and bireps. 'Thref flex thr log and extrend and ardduct the thigh. The semitendinosus 
and semimembranosus rotate the thigh and the leg medialward; the biceps, lateralward. The semitendinosus and the long head of the biceps constitute a superficial layer; the semimembranosus and the short head of the biceps a deep layer. The semitendinosus and the long head of the biceps arise by a common tendon from the tuber of the ischium. The somewhat fusiform semitendinosus gives rise to a tendon in the lower half of the thigh. The tendon curves forward behind the knee to be inserted under that of the sartorius into the medial side of the tibia. The penniform short head of the biceps arises from the linea aspera in the lower part of the thigh, and is inserted, together with the fusiform long head, into a tendon that passes over the lateral side of the knee and is attached to the head of the fibula. The semimembranosus arises from the tuber ischii through a long, flat, triangular tendon. The belly of the muscle increases in thickness toward the knee. It is inserted by a strong tendon on the back of the medial condyle of the tibia. From the tendons of all the hamstring muscles expansions are sent into the crural fascia.

The muscles of this group are all supplied by the tibial portion of the sciatic, except the short head of the biceps, which is supplied from the peroneal portion.

The femoral head of the biceps is characteristic of the anthropoid apes and man. In many mammals its place is taken by a slender muscle, the tenuissimus, which extends from the caudal vertebræ, the sacro-tuberous (great sacro-sciatic) ligament, or the gluteal fascia to the fascia of the back of the leg. In some forns this muscle is broad instead of slender. According to Testut, the long head of the biceps may be looked upon as arising by two fasciculi, one primitively attached to the posterior part of the ilium, the other to the caudal vertebra or coccyx. The sacro-tuberous (great sacro-sciatic) ligament represents the reduced upper portion of this muscle. In the foetus the origin of the muscle extends higher on the sacro-tuberous ligament than in the adult. In many of the lower mammals the origins of the semimembranosus and semitendinosus take place in part from the sacro-caudal vertebræ.

In the mammals below man the insertion of the biceps, gracilis, and semitendinosus takes place chiefly into the fascia of the back of the leg, and extends more distally than in man. This insertion of these flexor muscles is associated with a permanent position of flexion of the leg at the knee. In the human embryo likewise these muscles are inserted more distally than in the adult. In the lower primates the semimembranosus is chiefly a medial rotator of the leg.

Biceps femoris (Figs. 408, 413). - - Long head.-Origin.- From a tendon common to it and the semitendinosus. This tendon arises from the more medial of the two facets on the back of the tuber of the ischium and from the sacro-tuberous (great sacro-sciatic) ligament. It is continued for a third of the distance to the knee as a septum between the biceps and the semitendinosus, and for a short distance as an aponeurotic sheath on the deep surface of the biceps.

Structure and insertion.- The fibre-bundles begin to arise from the tendon some distance from the ischium. They form a thick fusiform belly which is inserted into the deep surface of a tendon that begins laterally on the back of the muscle about the middle of the thigh. The insertion of the fibre-bundles of the long head continues on the medial margin of the deep surface of the tendon nearly as far as the lateral condyle of the femur.

Short head.-Origin.-By short tendinous fibres from the lateral lip of the linea aspera of the femur from the middle of the shaft to the bifurcation of this line, the proximal two-thirds of the supracondylar ridge, and the lateral intermuscular septum.

Structure and insertion.-The fibre-bundles take a nearly parallel course, to be inserted on the deep surface of the common tendon of insertion. The most distal fibres are inserted nearly to the skeletal attachment of the tendon. The tendon is inserted into the superior extremity of the head of the fibula, into the lateral condyle of the tibia, and into the fascia of the leg.

Nerve-supply.-Commonly two branches are given to the long head of the biceps. One of these branches is given off proximal to the ischium, and enters the proximal third of the deep surface of the muscle. The other is given off more distally and usually enters the middle third. Either or both branches may be doubled or the two may be combined for some distance in a common trunk. The nerve-fibres arise usually from the first, second, and third sacral nerves. The branch to the short head arises from the peroneal (external popliteal) portion of the sciatic nerve about the middle of the thigh. It enters the posterior surface near the lateral margin of the muscle, and passes distally across the muscle bundles about midway between the tendons of origin and insertion. The nerve-fibres come chiefly from the fifth lumbar, first and second sacral nerves.

Action.-To extend and adduct the thigh and flex the leg. The short head acts only on the leg. The long head acts as a lateral rotatcr of the thigh, and of the leg when flexed.

Relations.--The upper extremity of the muscle is covered by the gluteus maximus. Below this the long head and tendon of insertion lie beneath the fascia lata and overlie the short head. Ventral to the muscle lie the tendon of origin of the semimembranosus, the adductor magnus and vastus lateralis muscles, and the lateral head of the gastrocnemius. The medial border is in contact with the semitendinosus and semimembranosus. Distally it forms the upper lateral border of the popliteal space. The sciatic nerve runs between it and the adductor magnus.

Variations.-The short head is rarely absent. It may be more isolated from the long head than usual, and at times has a separate tendon of insertion. It may itself be divided into two distinct laminæ. Its origin may take place higher up on the femur than usual or from the fascia lata. Variations of this sort suggest the tenuissimus muscle of some of the lower mammals 
(see above). The long head of the biceps may receive accessory fasciculi from the coccyx, sacrum, sacro-tuberous (great sacro-sciatic) ligament, tuber of the ischium, or the deep surface of the gluteus maximus. These fasciculi suggest the iliac and sacro-coccygeal origin of the muscle found in lower vertebrates (see above). Inferiorly, a muscle fasciculus may take the place of the fibrous prolongations from the tenclon of the biceps into the sural fascia (the tensores fasciæ suralis). This may extend to the tendon of Achilles. The long head may have a tendinous inscription similar to that of the semitendinosus.

The semitendinosus (figs. 40s, 413).- Origin.-Partly from a medio-dorsal facet on the distal margin of the tuber of the ischium by direct implantation of the fibre-bundles, and partly from the medial surface of the tendon common to it and the long head of the biceps.

Strueture and insertion.-The fibre-bundles spreal out to form a flat, fusiform belly which, about the middle of the thigh, again contracts toward the tendon of insertion. This begins on the medial margin and dorsal surface of the muscle, becomes free from the muscle slightly above the medial condyle of the femur, passes behind this and curves forward to be inserted by a triangular expansion into the proximal part of the medial surface of the tibia behind and distal to the insertion of the gracilis. An aponeurotic expansion is continued into the fascia of the leg. About the middle of the muscle a narrow irregular tendinous inscription more or less completely divides the belly into proximal and distal divisions.

Nere-supply. - To the muscle two nerves are commonly given. One arises from the sciatic nerve or directly from the plexus, proximal to the tuber of the ischium, sometimes in company with a branch to the long head of the biceps. It enters the middle third of the deep surface of the proximal portion of the muscle. The other branch arises from the sciatic nerve, usually distal to the ischial tuber, sometimes in common with a nerve to the biceps or the scmimembranosus. It enters about the middle of the deep surface of the distal half of the muscle. Either or both branches may be represented by two nerves. The nerve fibres of the first branch arise chiefly from the first and second sacral nerves, those of the second from the fifth lumbar and first sicral nerves.

Action.-To extend and adduct the thigh and rotate it medialward and to flex the leg, and with knee flexed, to rotate the leg medialwart.

Relations.- It is covered by the gluteus maximus and fascia lata; on the lateral side lies the biceps; and in front, the semimembranosus and adductor magnus.

Fariations.-It may be completely separater from the biceps at its origin. It may be fused with neighbouring muscles. There may be two tendinous inscriptions. It may have a femoral head (a condition characteristic of many bir(s). $\Lambda$ muscle fasciculus may extend from the body of the muscle to the fascia of the back of the leg.

The semimembranosus (fig. 408).-Origin.-By a long, flat tendon which lies beneath the proximal half of the semitendinosus, and which arises from the more lateral of the two facets on the back of the tuber of the ischimm, between the tendons of the biceps and the quartratus fomoris. The tendon is at first adherent to the tendon of the adductor magnus in front and to that of the biceps and semitendinosus behind. It descends to the midale of the muscle.

structure and insertion.-From both surfaces of the medial side and distal extremity of the tendon of origin filse-bundles arise which take an oblique course to their insertion on the aponeurosis of the tendon of insertion. This appears on the deep surface and medial margin of the muscle opposite the end of the tendon of origin and descends on the medial side and deep surface of the muscle. Near the back of the medial condyle of the femur the insertion of musclefibres ceases and the tenton is inserted directly on the back of the medial condyle of the tibia, and by aponeurotic expansions into the capsule of the joint, int o the lateral condyle of the femur, into the tibial rollateral ligament, and into the fascia of the poplitens muscle.

Nerve-supply.-By several brinches from the sciatic nerve, which usually arise from a common trunk in conpany with the branches to the adductor magnus. These branches enter the deep surfice of the muscle about midway between the origin and insertion of the constituent fibre-linulles.

Action. - To flex the log and rotate it mediatward and to extend and adduct the thigh and retate it nodialwath

Relations.- It is covered ly the glutous maximus, the long hoad of the bieeps, the semitronlingsis, and the fiscria latit. It lies dorsal to the quadratus femoris, the adductor magnus, and the kisero-joint.

Variations. - It naty be fused with the semitendinosus or the adduetor magnus. It may be donblod. Its tondons may have a more extensive attahnont than usual. The extent of

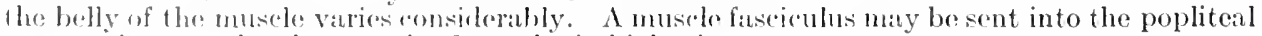
spater. An cextra head maty arise from the is thial spine.

\section{JUURSA}

B. m. bicipitis femoris superior. - I fair-sized hursin which frequently lies between the troulon of origin of the long hearl of the biceps and semitendinosus and the tendon of the semimonbranosis and the ischial tuber. B. m. bicipitis femoris inferior. - 1 small bursa which scoparates the temelon of insertion from the lifular collateral ligament of the knee-joint. B. m. bicipitis gastrocnemialis.- I lursit infrequently fommt between the tondon of the biceps and the tembons of origin of the lateral head of the gastroenemius and the plantaris museles. $B$. m. semimembranosus. 'This is a large domble lursil constantly present. One part extends between the: scmincmbranosss, the modial head of the gastrocremius, and the knee-joint. With the cavity of the jont it frequently communieates. The other part extends between the

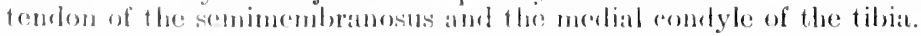




\section{MUSCULATURE OF THE LEG}

(Figs. +13-422)

The musculature of the leg arises in part from the distal end of the femur, but in the main from the tibia and fibula. The muscle-bellies are best developed in the proximal half of the leg, where they give rise to the 'calf' behind and to less well-marked ventral and lateral protrusions. Toward the ankle the musclebellies give way to tendons which attach the muscles of the leg to the skeleton of the foot.

The musculature is divisible into an anterior, a lateral and a posterior group of muscles. The anterior and literal groups are separated from one another by an intermuscular septum. The antero-lateral groups are separated from the posterior group by the tibia and fibula, the interosseous membrane, and by an intermuscular septum which extends from the lateral margin of the shaft of the fibula to the fascia enveloping the leg. Medially the separation is well marked by the broad medial surface of the tibia. Laterally the line of division is not so clearly marked externally. In the proximal part of the leg the dorsal musculature protrudes somewhat ventrally; in the distal part the lateral musculature pasies dorsal to the lower end of the fibula. The posterior group is divided by a trinsrerse septum into superficial and deep divisions.

While in the forearm the extensor-supinator muscles extend proximally on the rarlial side of the arm to the humerus, and the flexor-pronator muscles on the ulnar side, in the leg both of the corresponding sets of muscles extend primitively on the fibular side of the leg to the femur. In the higher vertebrates the superficial layer of the flexor musculature of the leg takes origin from both sides of the distal extremity of the femur, and the origin of the extensor musculature ceases to extend to the femur. The crural musculature is primitively inserted into the bones of the leg, the tarsus, and the aponeuroses of the foot. On the extensor side of the leg the musculitture ultimately becomes attached wholly to the foot by means of tendons differentiated, in part at least, from the dorsal aponeurosis. The lateral portion of the extensor musculature, which primitively extends from the femur to the fibula, in the higher vertebrates extends from the fibula to the tarsus and metatarsus (peroneal musculature). On the flexor side of the leg the more superficial musculature maintains a tarsal attachment through the tendon of Achilles. The deeper musculature in part extends from the femur and fibula to the tibia, in part arises from the fibula and tibia, and is inserted into the metatarsus and the digits through tendons differentiated from the plantar aponeuroses. The musculature of the sole of the foot is highly developed in five-toed vertebrates, but in those which walk on the toes, and especially in hoofed animals, it is very greatly reduced.

\section{FASCIE OF THE LEG}

The tela subcutanea of the leg contains a considerable amount of fat where it overlies the muscles, but less where it overlies the bones and joints. subcutaneous burse are found over the tuberosity of the tibia (b. subcutanea tuberositatis tibiæ) and over each of the malleoli (b. subcutanea malleoli medialis et lateralis). Over the dorsum of the foot the tela contains comparatively little fat, but on the sole of the foot and plantar surface of the toes it contains much fat interposed between dense fibrous tissue. The b. subcutanea calcanea lies beneath the tuber calcanei.

The crural fascia, or external laver of fascia of the leg, extends from the knee to the ankle. It forms an enveloping cone-like sheath for the muscles and is adherent to the periosteum of the medial surface of the tibia. It is formed of transverse, oblique, and longitudinal fibres and is thickest in front.

Ventrally the fascia of the thigh, to which the tendons of the quadriceps, sartorius, gracilis. semitendinosus, and biceps muscles and the ilio-tibial bant are closely united, becomes attacherl with these tendons to the tibia and fibula. From these attachments, therefore. the fascia of the front of the leg may be said to arise. Into it extend processes from the tendons mentioned. Dorsally the fascia of the thigh is continued uninterruptedly into that of the lex. Distally the crural fascia is attached to the two malleoli and to the posteriol surface of the calcaneus.

In the proximal part of the leg in front the underlying nusces in part take origin from the fascia; in other places the fascia is separated from the underlying muscles by loose tissue.

From the fascia two main intermuscular septa arise. One, the anterior intermuscular septum, extends between the extensor digitorum longus and peroneal muscles to the anterior crest of the fibula; the other, the posterior intermuscular septum, between the peroneal muscles: and the soleus to the lateral crest of the fibula. These septa separate compartments for the anterior, lateral, and posterior groups of muscles.

As the heads of the gastrocnemius pass over the back of the knee they are held in place by a special deep lamina of the fascia lata, which distally becomes fused with the crural fascia (fig. 414 A). 
Fig. 414, A-F.-Transyerse Sections throdgh the Left Leg in the Regions shown in THE Diagram.

$d$ In the diagram indicates the region through which passes section D, fig. 410 (p. 465); $a^{\prime}, b^{\prime}, c^{\prime}$, $d^{\prime}$, the regions through which pass sections A, B, C, D, fig. 417 (p. 488).

1. Arteria peronea. 2. A. poplitea. 3. A. tibialis anterior. 4. A. tibialis posterior. 5 . Bursa anserina. 6. Bursa m. sartorii propria. 7. Fascia eruralis. 8. Fibula. 9. Ligamentum crurale transversum. 10. Lig. patellæ. 11. Nembrana interossea. 12. Musculus biceps femoris-tendon. 13. M. extensor digitorum longus-a, tendon. 14. M. extensor hallucis longus. 15. M. flexor digitorum longus. 16. M. flexor hallucis longus. 17. M. gastrocnemius-a, lateral head; $b$, medial head. 1S. M. gracilis, tendon. 19. M. peroneus brevis. 20. M. peroneus longus-a, tendon. 21. M. peroneus tertius. 22 . M. plantaris-a, tendon. 23. M. popliteus. 24. M. sartorius, tendon. 25. M. semimembranosus, tendon. 26. M. semitendinosus, tendon. 27. M. soleus-a, fasciculus accessorius. 2S. M. tibialis anterior-a, tendon. 29. M. tibialis posterior-a, tendon. 30. N. cutaneus suræ lateralis. 31. N. cutaneus suræ medialis. 32. N. peroneus communis (external popliteal). 33. N. peroneus profundus (anterior tibial). 34. N. peroneus superficiales (musculo-cutaneus). $35 . \mathrm{N}$. plantaris lateralis (external plantar). 36. N. plantaris medialis (internal plantar). 37. N. suralis (external saphenous). 38. N. tibialis (posterior tibial). 39. Septum intermusculare (anterior). 40. S. intermusculare (posterior). 41. S. suræ transversum. 42. Tendo Achillis (calcanei). 43. Tibia. 44. Vena saphena magna. 45. V. saphena parva.

d

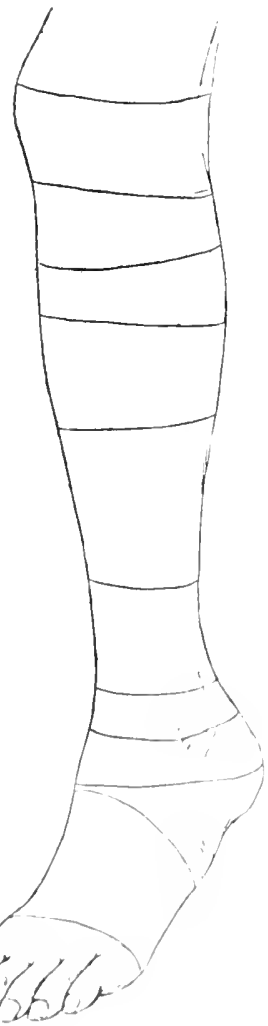

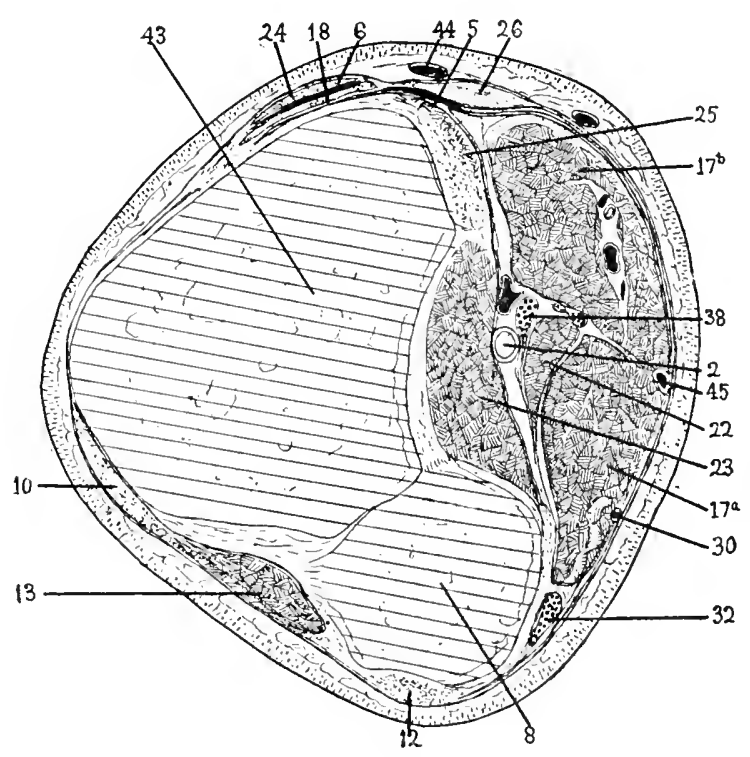

A

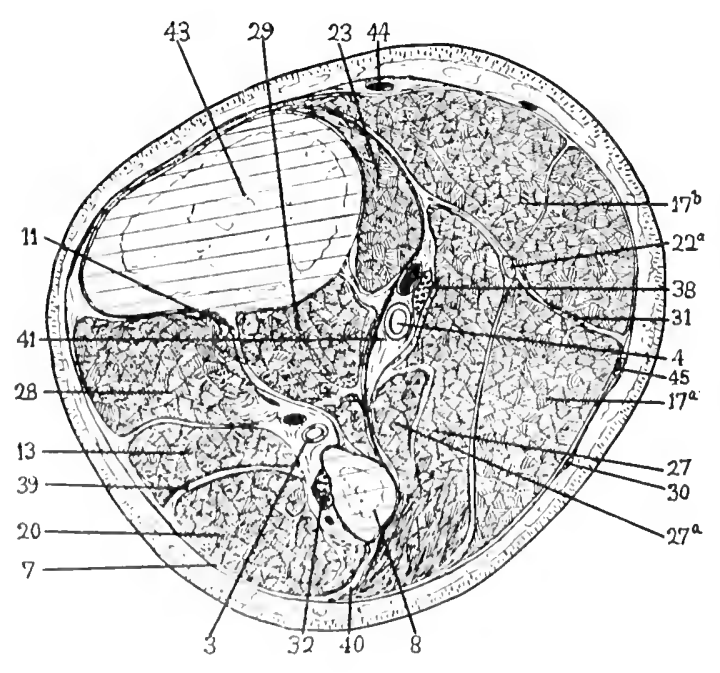




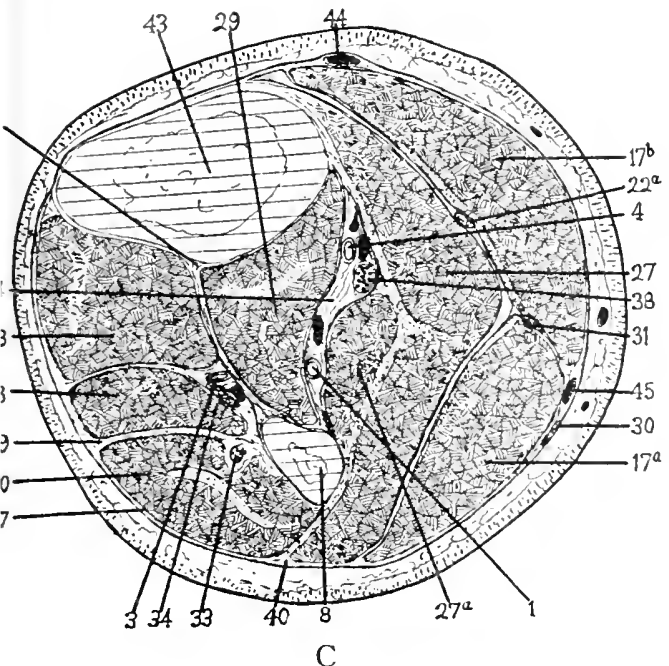

$\mathrm{C}$

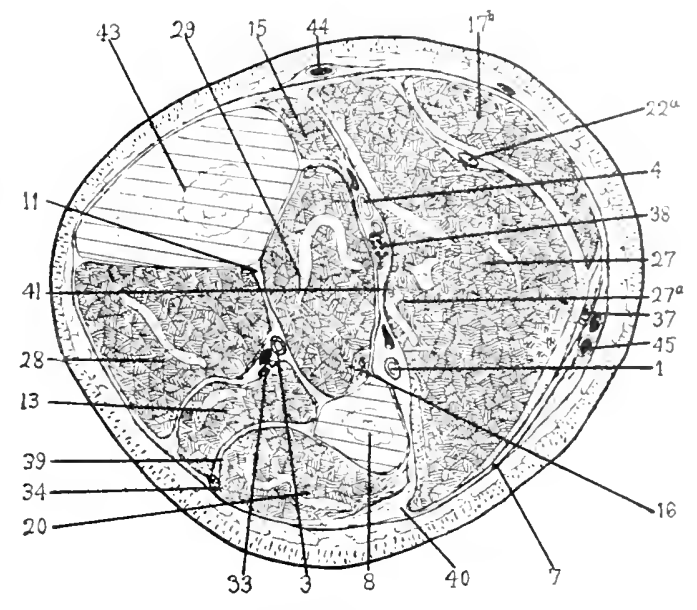

$\mathrm{D}$
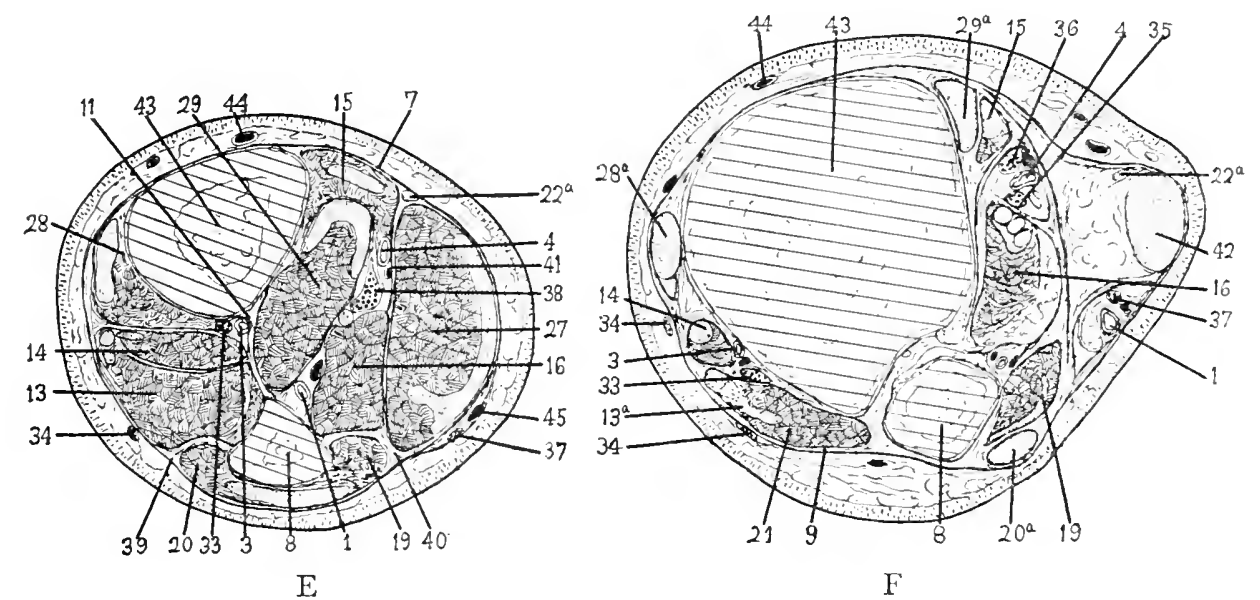

i The semimembranosus has a special fascial investment which, on the back of the knee becomes bound on each side of the muscle and its tendon to the capsule of the joint. This fascia extends into a transverse septal membrane which is continued over the deep muscles of the back of the leg to the ankle. It is united on one side to the tibia, on the other to the fibula. Proximally the fibres are continued into it from the tendon of the semimembranosus. Over the back of the tibia the septum is interrupted by the attachment of the soleus to the popliteal line. Beyond the tibial origin of the soleus it is fused on the medial side of the flexor digitorum longus to the crural fascia.

In addition to the two intermuscular septa and the longitudinal transverse septum, other septa serve to separate the individual muscles of the different groups.

Above the ankle the fascia is enforced by bands of tissue so that ligaments are formed which serve to retain in position the various tendons which pass from the leg into the foot.

The transverse crural ligament (upper part of anterior annular ligament) (fig. 415) lies on the front of the lower part of the leg above the ankle. It is composed of fascia strengthened by transverse bundles which pass from the medial side of the tibia to the ventral margin of the fibula. From its deep surface a strong, broad septum descends to the tibia and divides the underlying space into two osteo-fibrous canals, a medial for the tibialis anterior and a lateral for the long extensor muscles. The lateral compartment is further subdivided by a slightly marked septum into a medial division for the extensor hallucis longus and a lateral for the extensor digitorum longus and the peroneus iertius.

The cruciate ligament (lower part of anterior annular ligament) (fig. 415) serves to hold the tendons of the anterior muscle group in place as they pass to the dorsum of the foot. In part it is formed by a dense fibrous band lying in the fascia over the ankle, in part of a ligament which passes from the bones of the ankle to the deep surface of this band. The superficial band is V-shaped. It arises from the lateral surface of the body of the calcaneus and passes across the dorsum of the foot, one arm of the $\mathrm{V}$ going to the medial malleolns, the other to the side of the foot, where it terminates in the fascia over the first cuneiform bone. The apex of the $\mathrm{V}$ lies over the tendons of the extensor digitorum longus and peroneus tertius muscles. The distal arm extends over the tendons of the extensor hallucis longus and tibialis anterior 
muscles. The proximal arm passes over the tendon of the extensor hallucis longus and then divides into two layers, between which the tendon of the tibialis anterior passes. The deeper ligament mentioned above arises from deep within the tarsal sinus, some of its fibres even from the sustentaeulum tali. It then passes forward and medially beneath the long extensor tendons, and divides into two parts, one of which eurves about the medial margin of the tenclon of the extensor digitorum longus, the other about the extensor hallueis longus tendon to the under surfaee of the proximal arm of the V-shaped band.

The peroneal retinacula are strengthened regions in the fascia which serve to hold the tendons of the peroneal museles in place. The superior extends from the lateral malleolus into the fascia on the back of the leg, and to the lateral surface of the ealcaneus. The inferior orerlies the tendons on the lateral surface of the ealcaneus, and is attached to this bone on each side of them. Between the tendons it sends a septum to the bone. It is eonneeted with the superficial layer of the eruciate ligament.

The laciniate ligament (internal annular) (fig. 416) is found on the medial side of the ankle. Hele the faseia is strengthened by fibre-bands which form a well-marked ligament that holds in place the tendons of the deep dorsal cruro-pedal muscles. This ligament extends from the dorsal and distal margins of the medial malleolus to the caleaneus. It is closely bound to the tibia and the talo-tibial (tibio-astragaloid) ligament until the tendon of the tibialis posterior is reached. It passes over this and becomes bound to the bony struetures on the posterior margin of the tendon. From this attaehment two layers, a deep and a superficial, extend hackward. The superficial layer extends to the tuber calcanei, and is eonneeted superiorly with the crural fascia. The decp layer, which represents a continuation distally of the transrers septum, extends over the tendons of the flexor digitorum longus and flexor hallueis longus to the medial surface of the calcaneus, and is closely united to the underlying bone on each side of these tendons, thus giving rise to osteo-fibrous eanals.

\section{MUSCLES}

\section{Muscles of tilf Front of the Leg}

(Figs. 415, 418)

The anterior musculature of the leg consists of four muscles, the tibialis anterior, extensor digitorum longus, peroneus tertius, and extensor hallueis longus. The tibialis anterior has a quadrangular prismatic belly which arises from the lateral side of the tibia and adjacent interosscous membrane in the proximal half of the leg. The tendon passes over the front of the tibia to the first metatarsal. The extensor digitorum longus is a transversely flattened, fusiform muscle, which arises from the superior extremity of the tibia, the anterior crest of the fibula, and the adjacent interosscous membrane, and gives rise to a tenton which passes over the front of the distal extremity of the tibia and sends tendons to the two teminal phalanges of the four more lateral toes. The peroneus tertius represents a more or less completely differentiated portion of the preceding muscle. Its tencton passes laterally through the same osteofibrous canal in the same synovial sheath and terminates on the fifth metatarsal. The extensor hallucis longus is a narrow musche which arises from the distal half of the medial surface of the fihnla and the interosseous membrane. Its tendon rxtends over the ankle to the great toe. The tendons of these muscles are held in place by the transwerse and erueiate ligaments deseribed above.

All the muscles of this group flex the foot. The extensors extend the toes; the pronensis tertius and the extensor digitorum longus evert the foot. The nerve silphly is from the deep peroncal (anterior tilsial) nerve.

'The fibialis anterior is represented in the arm probably by the brachio-radialis and the two l'arlial cxtensors; the extensor digitorum longus by the extensor digitorum communis and

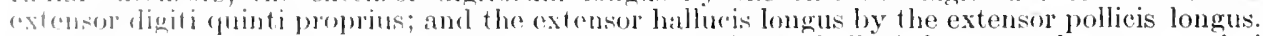
T'wo abmonat muscles not infreguently foumd, the abductor hallue is longus and extensor primi informolit halluris, represent probably the arresponding normal museles of the hand.

The tibialis anterior (fig. 415).-Grigin.- From the distal sufface of the lateral condyle of the tibin, ame the lateral surface of the proximal half of the shaft of the tibia, the adjacent introsents numbram, the overlying fascia near the condyle (tuberosity) of the tibia, and the

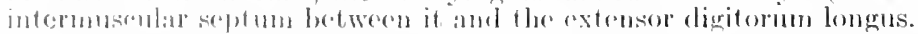

stemature lipenniform. The tibre-bumlles comverge upon a tlat tendon which begins

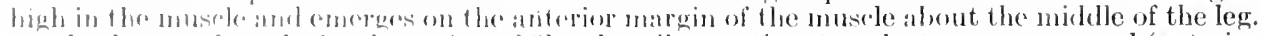

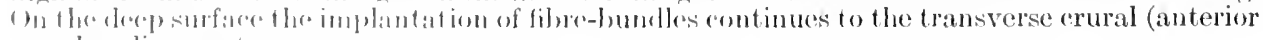
anmular, ligamment.

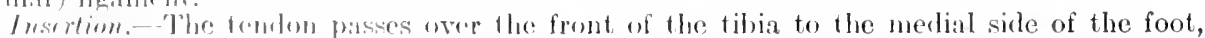
where it is inserted into the merlial surface of the first cuneiform and the base of the first molatarsal.

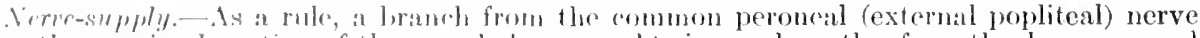
antors the proximal portion of the musclo h,y soveral twigs, and amother from the deep peroneal (antropor tibial) entris near the midkle of the belly on the lateral colge. 
Relations.- In the proximal half of the leg the extensor digitorum longus lies lateral to it; and between the two muscles, the anterior tibial artery and vein. It is covered by the crural fascia and rests on the interosseous membrane. Distally it lies over the extensor hallucis longus. The tendon passes in special compartments beneath the transverse and the cruciate (anterior annular) ligaments.

Fig. 415.-The Muscles of the Front of the Leg.

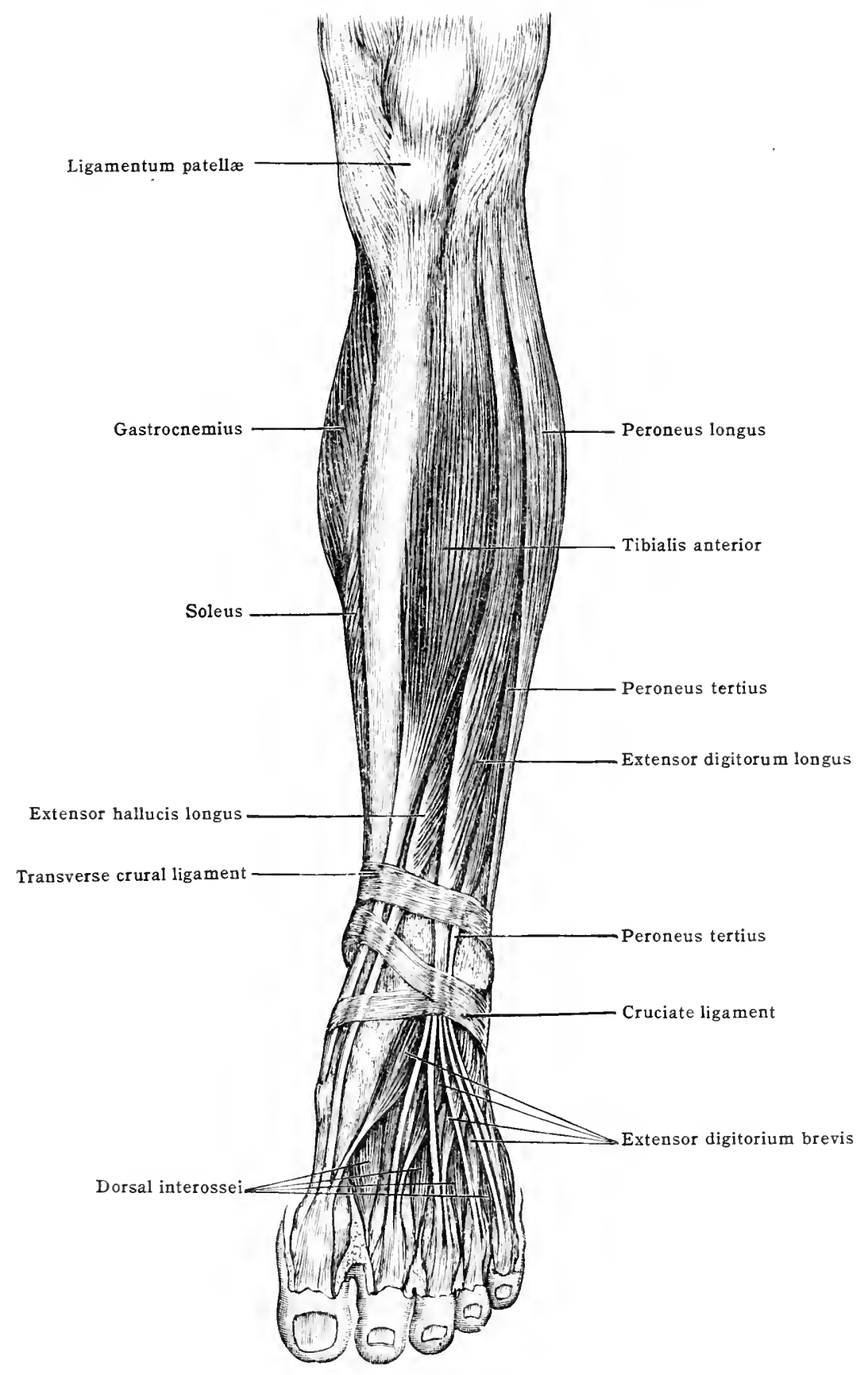

The extensor digitorum longus (fig. 415).-Origin.-From the lateral condyle of the tibia, the anterior crest (surface) of the fibula, the intermuscular membrane betwe it and the tibialis anterior, the lateral margin of the interosseous membrane, the septum between it and the peroneus longus, and the fascia of the leg near the tibial origin.

Structure.-Penniform. The fibre-bundles converge upon the posterior surface of a tendon which begins at the middle of the leg. The implantation of fibres continues nearly to the 
ankle. Usually at the distal margin of the transverse (anterior annular) ligament the tendon divides into two parts which pass between the two layers of the cruciate (lower part of anterior annular) ligament, and then each divides again into two parts, thus giving rise to four slips, one for each of the four lateral toes.

Insertion.-Each tendon on the dorsal surface of the toe to which it goes divides into three fasciculi: an intermediate, which is attached to the dorsum of the base of the second phalanx; and two lateral, which convelge to the dorsum of the base of the third phalanx. The margins of the tendon are also bound by fibrous tissue to the sides of the back of the first phalanx.

Nerve-supply. - Most frequently two branches of the deep peroneal (anterior tibial) enter the deep surface of the muscle, one near its tibial origin, one about the centre of the belly.

Relations.-In the proximal half of the leg it lies on the interosseous membrane, and beneath the fascia of the leg, and adjoins medially the tibialis anterior, laterally the peroneus longus. Distally it lies over the extensor hallucis longus and adjoins laterally the peroneus brevis. The tendon passes beneath the transverse crural and the superficial layer of the cruciate (anterior annular) ligaments and over the extensor digitorum brevis muscle. The superficial peroneal (musculo-cutaneous) nerve runs in the septum between it and the peroneal museles; the anterior tibial artery and deep peroneal nerve pass beneath the head of the muscle, and then between it and the tibialis anterior.

The peroneus tertius (fig. 415).-Origin.-From the distal third of the medial surface of the fibula, the neighbouring interosseous membrane, and the anterior intermuseular septum.

Structure.-It is essentially a fasciculus of the extensor digitorum longus, from which it is seldom completely differentiated. The fibre-bundles descend obliquely forward to be inserted in a penniform manner on a tendon which runs along the lateral margin of the tendons of the extensor digitorum. 'The attachment of fibre-bundles continues to the cruciate ligament (lower part of anterior annular ligament).

Insertion.- On the base of the fifth metatarsal and often also on the base of the fourth.

Nerve-supply.-The more distal nerve to the extensor digitorum continues into this musele.

Relations.--It lies lateral to the extensor digitorum longus. Its tendon passes into the foot beneath the transverse crural and the superficial layer of the cruciate ligament in the same compartments with those of the extensor longus.

The extensor hallucis longus (fig. 415).-Origin.-From the middle two-fourths of the medial surface of the fibula near the interosseous crest, and from the distal half of the interosseous membrane.

Structure.-Penniform. The fibre-bundles are attached as far as the eruciate ligament to the back and sides of a tendon which begins on the antero-medial margin of the distal third of the muscle.

Insertion.-On the base of the second phalanx of the big toe. On the back of the first phalanx the margins of the tendon are attached to the bone by bands of fibres.

Nerve-supply. - As a rule, a branch from the deep peroneal (anterior tibial) nerve enters the deep surface of the muscle near the junction of the upper and middle thirds, and passes distally across the middle of the obliquely running muscle fibre-bundles.

Relations.-It lies on the distal half of the interosseous membrane, partly covered by the extensor digitorum longus and the tibialis anterior muscles. Its tendon passes over the front of the distal extremity of the tibia and the medial side of the dorsum of the foot and is held in place by the transverse and cruciate ligaments and by a strengthening band in the fascia over the base of the first metatarsal. In the distal part of the leg the anterior tibial artery and the decp peroneal (anterior tibial) nerve pass bencath the musele to enter the foot on the lateral side of its tenclon.

Actions. - The muscles of this group all flex the ankle. The tibialis anterior and extensor hallucis longus evert the foot at the talo-ealcaneo-navieular joints, and invert it at the talonavicular, calcanco-cuboid joints. In certain positions the tibialis anterior may, however, invert the foot at these joints. The peroneus tertius and the long extensor evert the foot. The force of the extensor hallucis longus is exerted powerfully on the first phalanx and weakly on the second. The short muscles of the big toe aid in extending the second phalanx. The extensor digitorum longus extends the first phalanx of each toe powerfully, but exerts less force on the serond and third. The lumbrical muscles assist in extending the last two phalanges.

Variations. - The origin of the tilialis anterior may extend to the femur. Its tendon of insortion maly give aressory slips to the cuneiforms, metatarsals, and phalanges. More rarely its belly is diviled into two portions, one of which sends a tendon to the first euneiform and one to the first metatursal. A slip, the tensor fasciæ dorsalis pedis (Wood), may pass to the dorsal fascia of the fort. Anotlier, the tibio-astragalus anticus (Gruber), to the talus (astragalus) or calcaneus. 'The bellies or' the tendons of the extensor hallucis and extensor digitorum may be more or less completely fuserl, or tendon slips nay pass from the tendon of one muscle to that of the other". 'Trmlon slips may pass to the metatiusal bones or from the tendon of one toe to that of ancighlmuring tor: The tendon to each toe may be doubled. The belly of the extensor digitorun longus naty he more or less completely subdivided to correspond with the tendons to indivindal toes. The uroneus fortius is frequently fused with the long extensor. It nuay ledoubled. More offon its fombon may fifurcate or trifurcate and be inserted into the extensor tendons of the fifth tore or into the fonth or thire netatarsal. It is absent in about 8.5 per cent. of borlies (I te Donble)

Abnormal Huscles. The abductor hallucis longus is rarely found as a completely independent muscle. It usually arisis as a fasciculus of the extensor digitorum longus, extensor hallucis lonetss, or the tibialis anterior. It is inserterl into the base of the first metatarsal. The extensor primi internodii hallucis (extensor hallucis lorevis) has an origin similar to that of the long abductor above descrilsed. It is inserterl into the dorsum of the base of the first phalanx of the hig tre. It is not to be confomaled with that portion of the extensor digitorum brevis connered with the great toe and also sometimes ealled the extensor hatheis brevis. 


\section{BursÆ}

B. subtendinea m. tibialis anterioris.-A small bursa between the medial surface of the first cuneiform bone and the tendon of the tibialis anterior. B. subtendinea m. extensoris hallucis longi.-A small bursa beneath the tendon near the tarso-metatarsal articulation. It may communicate with the synovial sheath of the tendon. B. sinus tarsi.-A large bursa in the sinus tarsi and on the lateral surface of the neck of the talus (astragalus) beneath the tendons of the extensor digitorum longus and the fibrous bands between the talo-calcaneal and the cruciate ligaments. It extends back to the talo-crural, forward to the talo-navicular joint, and may communicate with the joint cavity of the latter.

\section{Synovial Tendon-Sheaths}

Vagina tendinis $m$. tibialis anterioris.-This sheath surrounds the tendon from above the transverse crural ligament to the talo-navicular joint. Vagina tendinis m. extensoris hallucis longi.- The sheath begins above the proximal arm of the cruciate ligament, and ends near the tarso-metatarsal joint beneath a band-like thickening of the dorsal fascia of the foot. Vagina tendinum $\mathrm{m}$. extensoris digitorum longi.- This sheath surrounds the tendons of the long digital extensor and the peroneus tertius from above the cruciate ligament to the middle of the third cuneiform bone.

\section{Lateral Musculature of the Leg}

(Figs. 416, 422)

The lateral muscles consist of the peroneus longus and the peroneus brevis. They extend and evert the foot. The thick prismatic belly of the peroneus longus arises from the proximal half of the lateral surface of the fibula and from neighbouring structures, while the smaller belly of the peroneus brevis arises from the middle third of the lateral surface of this bone. The peroneus longus partly covers the peroneus brevis. The tendons of the two muscles pass behind the lateral malleolus, held in place by special retinacula (p. 480). There the tendon of the peroneus longus lies at first lateral to and then crosses behind that of the peroneus brevis and curves about the lateral side of the calcaneus and across the sole of the foot closely applied to the cuboid and to the tarso-metatarsal articulations, and terminates on the base of the first metatarsal. The tendon of the peroneus brevis terminates on the lateral side of the foot at the base of the fifth metatarsal. The nerve supply is from the superficial peroneal (musculo-cutaneous) nerve.

The two muscles are probably represented in the arm by the extensor carpi ulnaris. In some of the lower animals the head of the peroneus longus extends to the femur. The fibular collateral ligament of the knee-joint probably represents in man the femoral head of the peroneus longus.

The peroneus longus (figs. 416, 422).-Origin.-Anterior head: tendinous from the anterior tibio-fibular ligament, the neighbouring part of the lateral condyle of the tibia, and the head of the fibula; fleshy from the proximal third of the anterior intermuscular septum and the crural fascia near the tibia. Posterior head: fleshy from the proximal half of the lateral surface of the shaft of the fibula and from the posterior intermuscular septum.

Structure.-Bipenniform. The fibre-bundles converge upon a tendon which begins high in the muscle. The constituent fibre-bundles of the anterior head are long and take a nearly vertical course. The fibre-bundles of the posterior head take a more oblique course and their attachment extends more distally on the tendon. The tendon emerges on the surface of the muscle in the distal half of the leg. The fibre-bundles of the posterior head extend to within a few centimetres of the lateral malleolus. The tendon passes through the retro-malleolar groove, passes across the lateral face of the calcaneus, to and through the peroneal groove of the cuboid, and crosses the second and third tarso-metatarsal joints. Where the tendon enters the groove in the cuboid it contains a fibro-cartilaginous nodule which may become a sesamoid bone.

Insertion.-On the inferior surface of the first cuneiform and on the supero-lateral border and base of the first metatarsal. From the region of the fibro-cartilaginous nodule above mentioned a fibrous slip is usually sent to the base of the fifth metatarsal.

Nerve-supply.- Most commonly the peroneal (external popliteal) nerve before dividing gives off two branches. One of these enters the deep surface of the middle third of the anterior head, the other passes across the middle third of the constituent bundles of the posterior head. The latter branch may arise from the superficial peroneal (musculo-cutaneous) nerve, and it may extend to supply the peroneus brevis.

The peroneus brevis (fig. 416).-Origin.-From the middle third of the lateral surface of the fibula; (2) from the septa which separate it from the anterior and posterior groups of muscles.

Structure-Penniform. The fibre-bundles converge upon a tendon which begins high in the muscle and becomes visible on the lateral surface of the distal half of the belly. Behind the lateral malleolus the tendon becomes free, then passes forward below the malleolus and, across the calcaneus and cuboid. 
Insertion.--Into the tip of the tuberosity of the fifth metatarsal.

Nerve-supply.- The nerve arises from the superficial peroneal (musculo-cutaneous) nerve, or from a branch to the peroneus longus. It enters the proximal margin of the muscle and passes distaliy across its eonstituent fibre-bundles.

Relations. The peroneal muscles in the leg are contained in a compartment bounded by the anterior and posterior intermuscular septa, by the fibula, and by the fascia of the leg. The peroneus longus to a considerable degree overlies the peroneus brevis. Beneath the upper part of the peroneus longus the peroneal (external popliteal) nerve bifurcates into its two chief branches. The deep peroneal (anterior tibial) nerve passes medially beneath the anterior head of the muscle. The superficial peroneal (musculo-cutaneous) nerve extends in the interval between the areas of the attachment of the two heads of the peroneus longus, and along the anterior marcin of the peroneus brevis to the anterior intermuscular septum, through which it passes to its superficial distribution. The tendon of the peroneus longus at first lies lateral to and slightly overlaps that of the peroneus brevis. Toward the tip of the malleolus it lies almost directly posterior to this tendon. On the lateral surface of the calcaneus the tendon of the brevis lies superior to that of the longus, from which it is separated by a bony spine, the processus trochlearis of the calcaneus. The tendon of the longus is separated from the deep surface of the abductor of the little toe, and is held in place in the groove in the euboid by the long plantar ligament.

Action.-The peroneus brevis everts the foot. The peroneus longus extends, abducts, and everts the foot, and supports the arch of the foot. The peroneus brevis also extends the foot when this is greatly flexed.

Tariations. - The two neroneal muscles may be more or less fused. The origin of the peroneus longus may extend to the femur. The two heads of origin may be fused. Its tendon of insertion may send slips to the second, third, and rarely to the fourth and fifth metatarsals. The tendon may be united to that of the tibialis posterior (12 out of 45 bodies-Picou). Sesamoid cartilages or bones are occasionally found in the retro-malleolar and calcaneal portions of the tendon. The tenton of the peroneus brevis may send a slip to the second or third phalanx or to the head of the metatarsal of the fifth toe, to its extensor tendon, or to the cuboid. It may also send a fasciculus to the fourth metatarsal or the extensor tendon of the fourth toe.

Accessory peroneals.- Poirier considers these all varieties of a muscle which in its simplest form arises from the distal fourth of the fibula and is inserted by a tendon into the fifth toe. A corresponding muscle is normally found in many of the monkeys (peroneus digiti quinti). In man in one form or another it is a frequent anomaly. It may be so fused with the peroneus brevis that only its terrlon of insertion is apparent. It may appear as a special muscle fasciculus of the peroneus longus or brevis. It may be merely a tendinous band, or it may be tendinous at origin and insertion, with an intermediate belly. Instead of being attached to the fifth toe, it may le inserted into the fifth metatarsal, the cuboid, the tendon of the peroneus longus, the calcancus, lateral malleohs, or posterior talo-fibular ligament.

\section{Srnovial Tendon-sheaths}

Vagina tendinum peroneorum communis.-There is a double sheath for the tendons of the pringeal muscles as they pass back of the lateral malleolus. From this region of union the sheath semls proceses along each tendon proximally above the malleolus and distally over the latrat surfare of the calcaneus. This process on the tendon of the peroneus longus often communicates with the following sheath. Vagina tendinis $\mathrm{m}$. peronæi longi plantaris. This shrath hegins in the peroneal groove of the euboid and ends near the medial border of the long plantar ligament.

\section{Musculature of the Back of the Leg}

\section{a. Siperfictal Group (fig. 413)}

l'o this group belong the gastrocnemius, soleus, and plantaris muscles. They rextont the foot and flex the log. The two ovoid heads of the gastrocnemius arise me on carch side from abore the condyles of the femur, extend about to the middle of the back of the lowe and are inserted into the posterior surface of the tendon of Irhilles, and through this into the back of the ealcaneus. The broad, flat, ovoid soleus arises leneath the gastrocnemius from the tibia and fibula, and is insertert inte the freep surface of the tendon of Achilles ats far as the ankle. The two hearls of the gatstroenemiun and the soleus romstitute the triceps suræ. The plantaris is a slender musclo which passes along the medial matrin of the lateral

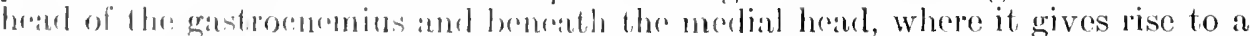

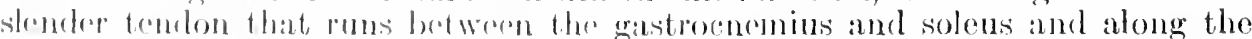
morlial margin of the tomblon of dehilles to the fatty fibrous tissue of the heet. 'The norre-supply is from the tilial nerve.

f'Thr museles of this grong have a common embryone origin, and are first differentiated un the fibular side of the Jeg, whenre: hore extend over the posterior tibial vessels and nerve to

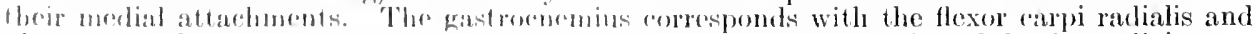
ularise, the plantaris with the palmaris longus, the soleus with a portion of the flexor digitorum 
sublimis of the forearm. In many of the monkeys and in the prosimians the plantaris is much more developed than in man.

The gastrocnemius (fig. 413).-Medial head.-Origin.-From a facet on the back of the medial condyle of the femur above the articular surface, from an area on the back of the femur superior and lateral to this, and from the femoral margin of the capsule of the knee-joint. Lateral head.-Origin.-From a facet on the proximal portion of the postero-lateral surface of the lateral condyle of the femur and from a rough area situated more medially and at a greater distance from the joint.

Structure and insertion. - The heads of the gastrocnemius are similar in structure. From the condylar facets there descend aponeurotic bands, one on the medial margin and the medial side of the posterior surface of the medial head, the other on the lateral margin and the lateral side of the posterior surface of the lateral head. These bands descend about two-thirds of the way down the muscle. In the tendon of the lateral head a sesamoid bone is frequently found. The fibre-bundles of the muscle pass obliquely from the supracondylar areas of origin and from the deep surface of the aponeurosis on each side to the tendon of insertion. This tendon begins as a septum between the two heads, and as a lamina on the deep surface of cach head. The septum and laminæ soon fuse with the broad aponeurosis which covers the dorsal surface of the soleus. The attachment of fibre-bundles continues to about the middle of the back of the leg. The attachment of the medial head extends more distally than that of the lateral hearl. As a rule, the medial head is also the broader and thicker of the two.

The soleus.-Origin.- (1) By a fibular head from the back of the head and the proximal third of the posterior surface of the shaft of the fibula, and from the intermiscular septum between it and the peroneus longus; and (2) by a tibial head from the transverse seytum over the distal margin of the popliteus, from the popliteal line, and from the middle third of the medial border of the tibia.

Structure and insertion.-From the fibular and tibial origins arise broad aponeuroses which unite proximally on the deep surface of the muscle so as to form a fibrous arch over the posterior tibial vessels and nerves. Distally they diverge and become more narrow, but the fibular aponeurosis is continued on the fibular side and the tibial aponeurosis on the tibial side of the muscle as far as the distal quarter of the leg. The main portion of the belly of the muscle is formed by fibre-bundles which arise from the posterior surface of these aponeuroses and pass obliquely to be inserted in a bipenniform manner on the deep surface of the tendon of Achilles. This tendon begins as a broad aponeurosis which covers the greater part of the posterior surface of the muscle, and gradually converges into a heavy fibrous band that is inserted into the calcaneus. The bundles of fibres of the tendon take a slightly spiral course. Those on the posterior surface run from the medial margin toward the lateral surface of the calcaneus; those on the anterior surface in a reverse direction. The attachment of the fibrebundles continues to within a short distance of the heel. A few of the fibre-bundles arise directly from the fibula and the posterior intermuscular septum. On the deey surface of the belly of the muscle there is an accessory fasciculus which is formed by fibre-bundles that suring on each side from the anterior surface of the aponeuroses of origin of the muscle and have a bipenniform insertion on each side of a thin, oblique tendinous lamina which inferiorly becomes united to the deep surface of the tendon of Achilles.

The plantaris (fig. 413).-This muscle arises from the distal part of the lateral line of bifurration of the linea aspera, in close assoriation with the lateral head of the gastrocnemius. The fibre-bundles give rise to a flat, short, fusiorm belly, and are united to a narrow tendon which extends along the medial edge of the tendon of Achilles to the lateral part of the dorsa] surface of the calcaneus, where it terminates in the neighbouring fibrous tissue.

Nerve-supply. - From the tibial (internal popliteal) part of the sciatic nerve in the popliteal space nerves arise for each head of the gastrocnemius. Each nerve enters the middle third of the deep surface of the head near the proximal margin. The nerve-supply for the soleus is from two sources. One nerve arises in the popliteal space, often in company with the nerve to the lateral head of the gastrocnemius. It enters the posterior surface of the muscle near the proximal border and divides into two branches, one for each head of the muscle. The tibial (posterior tibial) nerve gives rise to a branch which, about half-way down the leg, enters the deep surface of the muscle and fumishes branches for the deep portion of the muscle on each side. The nerve-supply of the plantaris is by a branch from the tibial (internal popliteal) portion of the sciatic. This arises in the popliteal space and enters the deep surface of the muscle.

Relations.-The semimembranosus winds about the medial margin of the medial head of the gastrocnemius to its deep surface. The biceps passes to the lateral side of the lateral head of the gastrocnemius, and the plantaris along its medial margin. The semimembranosus and biceps above, the medial head of the gastrocnemius and the plant aris below, bound the ponliteal space. The peroneal (external popliteal) nerve passes from the popliteal space obliquely across the plantaris and the lateral head of the gastrocnemius. The medial sural (short saphenous) nerve and the small saphenous vein pass between the heads of the gastrocnemius to the surfact and thence to the lateral side of the ankle. From the peroneal (external popliteal) nerve in thr popliteal space the lateral sural (communicans peronei) nerve extends distally over the calf. The (posterior) tibial nerve and posterior tibial artery and vein run between the two heads of the gastrocnemius, and then beneath the soleus to the medial side of the ankle. In the region of the tendon of Achilles a considerable space filled with fatty tissue intervenes between the tendon and the transverse septum.

Action.-The contraction of the triceps sura produces extension, adduction, and inversion of the foot. The gastrocnemius is also a flexor of the leg. The plantaris has no known function in man. In some animals it is an extensor of the plantar fascia.

Variations.- There is considerable variation in the extent of the separation of the different parts of the triceps suræ. The tendons of the three heads may be separate nearly to the heel. Either or both heads of the gastrocnemius or the soleus may be doubled. A slip tron the biceps 
or semimembranosus, from the linea aspera, or popliteal space may join the triceps and give rise to a quadriceps suræ. On the other hand, one of the heads of the gastrocnemius or the tibial head of the soleus may be missing. A supernumerary fasciculus may extend from the deep surface of the soleus to the calcaneus. The plantaris is exceedingly variable in origin, structure, and insertion. The origin may be from the capsule of the knee-joint, the fascia of the leg, or from the tibia. Its tendon may terminate at almost any part of its course in neighbouring structures. It may be represented by a fibrous band. It is absent in about 7 per cent. of instances (Le Double).

\section{Burs $A$}

B. $\mathrm{m}$. gastrocnemii lateralis.-A bursa is often found between the tendon of the lateral head of the gastrocnemius and the capsule of the joint. It may communicate with the joint cavity. B. m. gastrocnemii medialis.-A bursa usually lies between the tendon of origin of the medial head of the gastrocnemius, the condyle of the humerus, and the capsule of the joint. Another bursa (b. m. semimembranosi) extends between the semimembranosus and the medial head of the gastrocnemius muscle. The two bursæ frequently communicate with one another and with the joint. B. tendinis calcanei.-This lies between the tendon of Achilles and the upper part of the back of the calcaneus. Between the back of the tendon and the crural fascia another bursa is frequently present.

\section{b. Deep Group}

The deep posterior musculature is separated from the superficial by the transverse septum described above (p. 479). The museles covered by this septal fascia are the popliteus, the flexor digitorum longus, the flexor hallucis longus, and the tibialis posterior. An intermuscular septum between the popliteus and the tibialis posterior, and the attachment of the soleus to the popliteal line on the back of the tibia serve to separate the popliteus from the other deep posterior museles which lie distal to this region and send tendons into the sole of the foot. The deep posterior musculature may thus be considered as divided into a proximal femoro-tibial and a distal eruro-pedal group. Both sets of muscles are supplied by branches of the tibial nerve.

\section{Femoro-tibial Muscle}

The popliteus (fig. 416).-A triangular muscle which arises from an ovoid facet at the inferior extremity of the groove on the outer side of the lateral condyle of the femur and is inserted into the proximal lip of the popliteal line of the tibia and the surface of the shaft of the tibia proximal to this. It rotates the leg medialward and flexes it.

Structure.-From the origin a broad tendon glides over the condyle within the capsule of the joint, then over the lateral fibro-cartilage and through a groove on the back of the tibio-fibular articulation. From both surfaces of this tendon, fibre-bundles diverge toward the area of insertion. The tendon is more or less intimately united to several structures with which it cones in contact about the joint. Ritrely it contains a sesamoid bone. The fibres of insertion terminate in part in the fascia covering the muscle. The popliteus is homologous with the pronator teres of the arm, or, according to some investigators, with the deep portion of that muscle.

Nerve-supply. $-\Lambda$ nerve which arises either independently or in conjunction with that to the posterire tilial muscle enters the popliteus near the middle of its distal edge. Sometimes a branch from the ehief nerve to the knee-joint enters the proximal edge of the muscle.

Action.--To flex and rotate the leg medially.

Relations.-The popliteus lies within a compartment bounded by the transverse septum, the cansules of the knee and superior tibio-fibular joints, the back of the tibia, and a septum extemling to the popliteal line (sce alove). On the transverse septum run the popliteal vessels and the tilial nerve. The proximal margin of the soleus overlaps the distal margin of the popliteis. The synovial membrane of the knee-joint sends a prolongation between its tendon and the back of the lateral conclyle of the tibia.

Variations.-It is rarely alsent. An accessory head may arise from the medial side of the lateral condyle or from some neighbouring strueture. The fibulo-tibialis (peroneo-tibialis) is a small muscle found by Gruber in one lody in seven. It arises from the medial side of the hear of the fibula and is inserted into the posterior surface of the tibia bencath the popliteus.

$$
\text { Cruro-pedal Muscles (figs. 416, 420) }
$$

Of the three muscles of this group, the fiexor digitorum longus lies on the tibial sirle of the log, the flexor hallucis longus on the fibular side, and the tibialis posterior upon the introsscous inembrane, partly eovered by the other two 
muscles, beneath the former of which it crosses, distally, to the tibial side of the leg. Septa separate the flexor muscles from the tibialis. The tendons of the three muscles pass behind the medial malleolus, held in place by the transverse septum and the deep layer of the laciniate (internal annular) ligament. They lie

Fig. 416.-The Deep Muscles of the Back of the Leg.

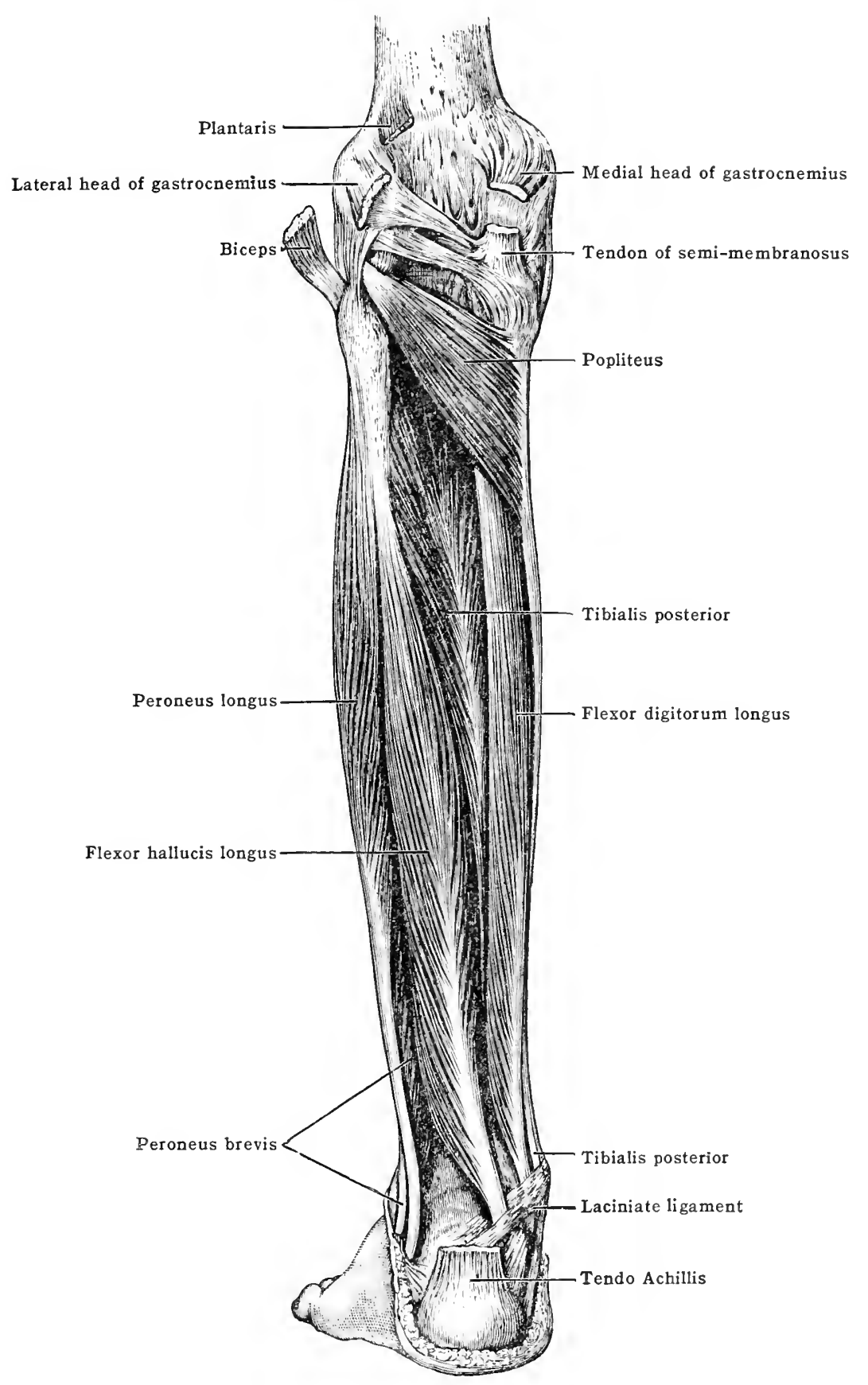

in compartments divided by septa which descend to the tibia. The compartment for the tibialis posterior is the most medial. It is partly overlapped by that for the flexor digitorum. At the ankle the tendon of the tibialis passes above, the tendon of the flexor digitorum medial to, and that of the flexor hallucis below, the sustentaculum tall, each in a separate osteo-fibrous canal bounded 
Fig. 417. A-D.-Transverse Sections througin the Foot in the Regions Shown in the Diagram.

$f$ in the diagram indicates the region through which passes section F, fig. 414 (p. 478).

1. Arteria peronea. 2. A. plantaris medialis (internal). 3. A. plantaris lateralis (external). 4. A. tibialis anterior. 5 . Aponeurosis plantaris. 6. Calcaneus. 7. Fascia pedis dorsalis. S. F. plantaris-a, lateral; b, intermediate; $c$, medial. 9. Ligamentum cruciatum (anterior annular). 10 . L. laciniatum (internal annular). 11. Malleolus lateralis (external). 12. Malleolus medialis (internal). 13. Musculus abductor hallucis-a, tendon. 14. M. abductor quinti digiti-a, insertion. 15. M. adductor hallucis-a, oblique head, origin; b, transverse head. 16. M. extensor digitorum brevis-a, tendons. 17. M. extensor digitorum longus, tendons. 1S. M. extensor hallucis longus, tendon. 19. MI. flexor digitorum brevis-a, tendon. 20. M. flexor digiti quinti brevis-a, tendon. 21. M. flexor digitorum longus, tendion. 22. II. flexor hallucis brevis tendon. 23. M. flexor hallucis longus. 24. M. interossei dorsales. 25. M. interossei plantares. 26. M. lumbricales. 27. M. peroneus brevis. 25. M. peroneus longus. 29. M. peroneus tertius-a, tendon. 30. II. planaris, tendon. 31. M. quadratus plantx. 32. M. tibialis anterior, tendon. 33. II. tibialis posterior, tendon. 34. Nervus peroneus profundus. 35. N.peronaus superficialis (musculo-cutaneous). 36. N. plantaris medialis (internal). 37. N. plantaris lateralis (external). 35. $\mathrm{N}$. suralis (external saphenous). 39. Os cuneiform I, 40. Os cuneiform III. 41. Oscuboid. 42. Os metacarpale I. 43. Os metacarpale II. 44. Os metacarpale III. 45. Os metacarpale IV. 46. Os metacarpale $\mathrm{V}$. 47. Os naviculare. 48. Ossa sesamoidea. 49. Os talus (astragalus). 50. Tendo Achillis 51. Retinacula mm. peroneorum. 52. Septum intermusculare laterale. 53. S. intermusculare mediale. 54. Tena saphena magna.
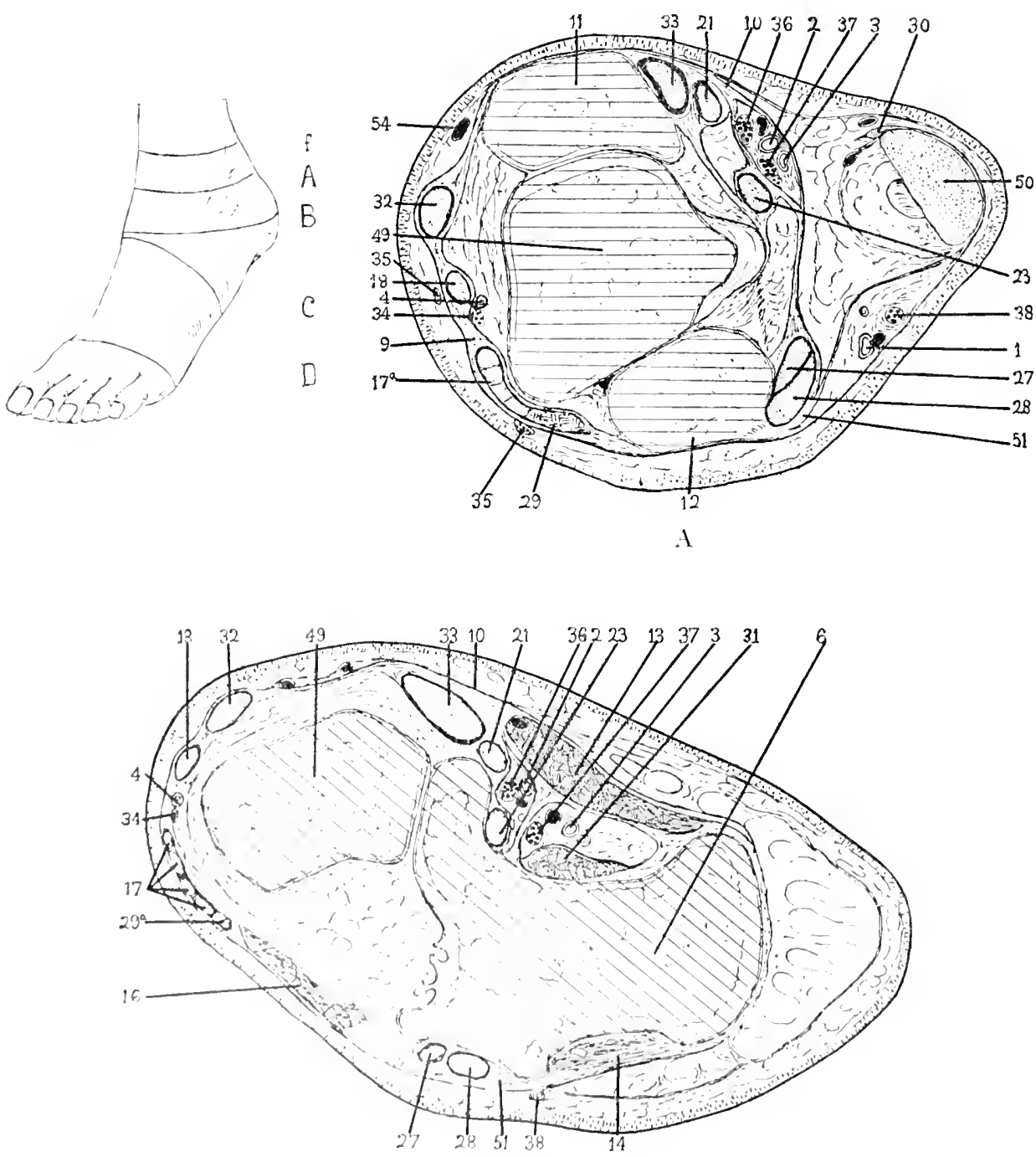


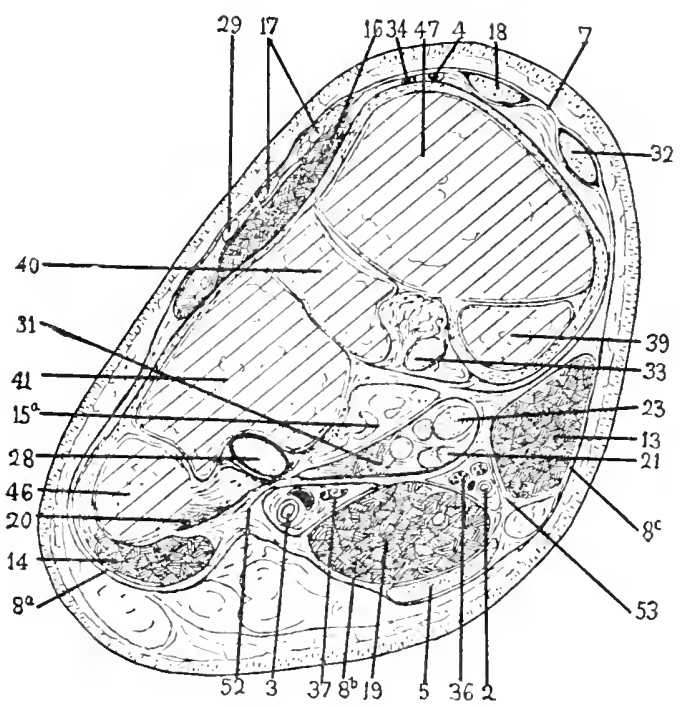

$\mathrm{C}$

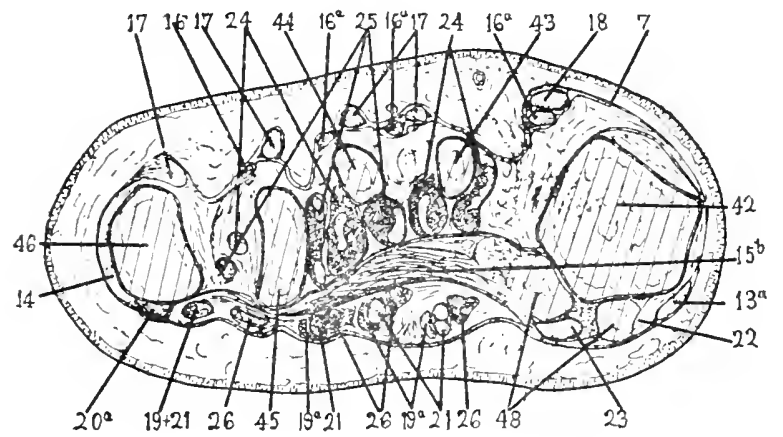

$\mathrm{D}$

externally by the laciniate (internal annular) ligament. In the sole the tendon of the long flexor of the big toe passes under (deeper than) the tendon of the flexor digitorum, to which it gives a slip, and is inserted into the terminal phalanx of the big toe. The tendon of the long flexor of the toes passes obliquely across the sole, is joined by the quadratus plante (flexor accessorius), and gives rise to a tendon for the terminal phalanx of each of the four lateral toes. From these tendons the lumbrical muscles arise. The tilialis posterior has an extensive insertion on the plantar surface of the tarsus.

The long flexors act chiefly on the toes. Together with the tihialis posterior they invert and extend the foot.

The long flexors of the toes probably represent the flexor profundus and the flexor pollicis longus of the forearm. The tendons of the deep flexors of the forearm do not, however, cross like those of the long flexors of the toes. In the lower mammals there is much variation in the toes to which the tibial and fibular flexors are distributed. The tibialis posterior has no certain representative in the forearm. The rare ulno-carpens may represent it.

The flexor digitorum longus (figs. 416, 420).-Origin.- From the popliteal line, the medial side of the second quarter of the dorsal surface of the tibia, the fibrous septum betreen the muscle and the tibialis posterior, and the fascia covering its proximal extremity.

Structure and insertion. - From these areas of origin the fibre-bundles run obliquely to be inserted in a penniform manner on a tendon which begins in the proximal quarter of the muscle as a narrow septum, and more distally becomes a strong band on the medial margin. The insertion of the fibre-bundles continues nearly to the medial malleolus. From here the tendon passes behind the medial malleolus, dorso-lateral to the tendon of the tibialis posterior, crosses the posterior talo-tibial ligament, and passes along the medial margin of the sustentaculum tali into the sole of the foot. Here it crosses the tendon of the flexor hallucis longus, from which it receives a tendinous slip, and divides into four parts, which pass to the second to the fifth toes. Each tendon is bound to the phalanges of the toe to which it passes by a fibrous sheath. Superficial to it in the sheath lies a tendon of the flexor digitorum brevis, which the 
flexor longus tendon perforates as it passes to the base of the terminal phalanx. The tendon is connected, like those of the fingers, by vineula tendinum, to the phalanges of the toes.

Nere-supply. - From the tibial (posterior tibial) nerve a branch arises, often in company with nerves to some other or others of the museles of this group. The nerve divides into two branches, one of which passes to the lateral side of the musele, where it extends along near the middle of the fibre-bundles of that side, while the other branch passes along near the middle of the fibre-bundles of the medial side of the muscle.

Relations.-In the proximal half of the leg it lies on the tibia, in the distal half on the posterior tibial muscle. Between it and the flexor hallucis lie the posterior tibial vessels and nerve. Near the ankle the plantar vessels and nerves cross the tendon of the muscle, separated from it by the deep layer of the laciniate (internal annular) ligament. In the upper two-thirds of its extent it is covered by the triceps suræ. In the lower third of the leg it emerges medial to the soleus and the tendon of Achilles. The relations of its tendon at the ankle have been described above. The tendon lies beneath the origin of the abductor hallueis muscle and in the sole is covered by the flexor digitorum brevis, crosses the tendon of the long flexor and the oblique adductor of the big toe and the interosseous museles, is joined by the quadratus plantæ (llexor accessorius), and gives origin to the lumbrical muscles.

The flexer hallucis longus (figs. 416, 420).-Origin.-From the distal two-thirds of the posterior surface of the fibula, the septa between it and the tibialis posterior and peroneal museles, and the fascia above its proximal extremity.

Structure and insertion. - The fibre-bundles converge upon a tendon which begins in the second quarter of the musele, within its substance, and emerges upon the postero-medial margin in its distal half. The insertion of the fibre-bundles continues to the end of the tibia. From here the tendon passes over the dorsal talo-tibial (tibio-astragaloid) ligament, and through the groove on the posterior surface of the talus and the under surface of the sustentaculum tali, where it lies on the fibular side of the tendon of the flexor digitorum longus. It then crosses the deep surface of this tendon, to which it gives a slip, passes over the plantar surface of the medial head of the flexor hallucis brevis, and between the sesamoid bones of this muscle into the osteo-fibrous canal on the plantar surface of the big toe. It is inserted into the base of the terminal phalanx of the big toe.

Nerve-supply. - The nerve arises from the tibial (posterior tibial) nerve, often in company with the nerve to the flexor digitorum longus or the other muscles of the group. It runs along the deep surface of the muscle and sends twigs into the middle third of its constituent fibre-bundles. Sometimes two nerves are furnished to the muscle.

Relations.-It lies on the fibular side of the distal two-thirds of the leg. Proximally it diverges from the preceding musele so as to disclose the tibialis posterior, which is more deeply situated. Between it and the tibialis posterior lie the peroneal vessels. Distally its tibial margin approarhes the flexor digitorum longus, but between them lie the posterior tibial vessels and nerve. Lateral to it lie the peroneal museles. It is covered in the leg by the soleus. In the distal part of the leg its tendon lies medial to the tendon of Achilles. On entering the foot the tendon crosses beneath the abduetor hallueis muscle and the lateral plantar vessels and nerve. The other relations of the tendon have been deseribed above.

The tibialis posterior (figs, 416, 422).-Origin.-From-(1) the lateral half of the distal margin of the popliteal line and the middle third of the posterior surface of the tibia; $(2)$ the medial side of the hearl and of that part of the body of the fibula next the interosseous membrane in the proximal two-thirds; (3) from the whole of the proximal and the lateral portion of the distal part of the posterior surface of the interosseous membrane; and (4) from the septa between its proximal portion and the long flexor muscles.

Structure.-From this extensive area of origin the fibre-bundles converge upon a tendon which is at first deep seated within the muscle-belly, but about the middle of the leg cmerges on the medial unargin of the muscle. The fibular portion of the musele is much more extensive than the tibial. The proximal fibres take a nearly perpendicular, the most distal (from the fitula) a nearly transverse, coursc. The insertion of filores stops a little proximal to the medial malleolus. The tendion then extends to the medial side of the tendon of the long

$\checkmark$ flexor of the toes, passes through the groove on the back of the malleolus, across the medial talo-tilial (tibio-astragaloid) ligament, and above the sustentaculum tali to the sole.

Insertion.- The tenton divides into two ehief divisions, a decp and a superficial. (1) The drep purtion liceomes attached chiefly to the tubercle of the navieular bone, and usually in part also to the first runciform. (2) The superficial spreads out to be attached chicfly to the third enneiform and the base of the fourth metatarsal, but also in part to the second euneiform, to the citpsule of the natrieulo-euneiform joint, to the sulcus of the euboid, and usually also to the origin of the short flexor of the lig toe and the base of the second metatarsal. Slips may, however, also lie given to other struetures. $A$ sesamoid bone is usually found in the tendon eithere norar the calcanos-navieular ligament or the navieular bone.

Neresuply. - Thro nerve arises from the tihial (posterior tilial) in eompany often with branches to the oflier museles of the group. It enters the posterior surface of the muscle in its proximal third, and gives off one or two branches for the titial fasciculus. The main trunk Hesernots arross the midelle third of the fasciculi arising from the fibula.

firlations.- The musele covers the posterior surface of the interosseous membrane, and extents distally over thr posterior surfare of the tibia beneath the flexor digitorum longus. It is covered proximally by the solens, distally hy the two long digital flexors. 'The posterior tibial aml peromedl arteries and thr tibial (posterior tibial) nerve run upon its posterior surface. The tondon in the sols is under cover of the origin of the plantar muscles of the big toe.

Artion.-The tibialis posterior adducts the foot and slightly inverts it. The flexor digitorum longus flexes the treminal phalanx on the seeond and the second on the first, and at the height of its erontraction the first on thr metalarsals. It also rotates medially to some extent the enrls of thre fourth and fifth toes, and inverts the foot. The flexor hallucis longus flexes
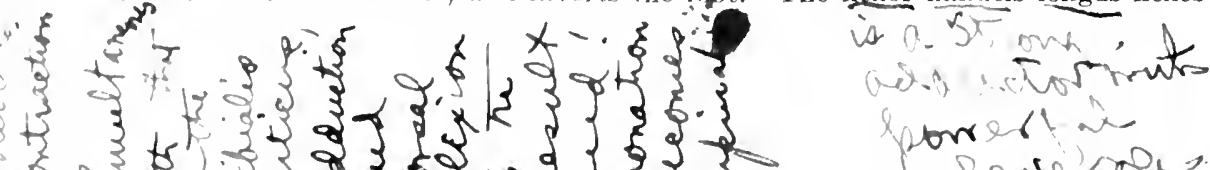
the second phalanx of the big toe on the first, and, less energetically, the first on the metatarsal. It also inverts the foot. All three muscles extend the foot. The flexor hallucis is the strongest of the three in this respect.

Variations.-The muscles of the group may be more or less fused with one another or be united by fasciculi. This is especially common between the two flexors of the toes. The individual muscles vary in development. The flexor digitorum longus may be more or less divided into separate fasciculi for the individual toes. The slip from the flexor hallucis longus to the flexor digitorum longus varies greatly in extent, but usually passes mainly to the second and third toes, more rarely to the second, third, and fourth, and very rarely to the fifth. In most of the apes the tibial flexor (flexor digitorum) sends tendons to the second and fifth, the fibular flexor (flexor hallucis) to the first, third, and fourth toes. This condition is also sometimes found in man. A slip may pass from the tendon of the flexor digitorum to that of the flexor hallucis longus. There may be a sesamoid bone in the tendon of the flexor hallucis longus as it passes over the talus (astragalus) and calcaneus. The tibialis posterior may be doubled. Aberrant fasciculi may arise from various regions on the back of the leg and join any one of the three muscles of the group.

Abnormal muscles.- The soleus accessorius.-Arises by a tendon from the head of the fibula beneath the soleus. It is usually a slender muscle inserted into the medial surface of calcaneus. The tibialis secundus (tensor of capsule of ankle-joint). - A small muscle which arises from the tibia beneath the flexor digitorum and is inserted into the capsule of the anklejoint. The fibulo-calcaneus medialis (peroneo-calcaneus internus of MacAlister, flexor accessorius long. dig. long., etc.).-A fasciculus which arises from the lower third of the body of the fibula and gives rise to a tendon which passes beneath the laciniate ligament to the quadratus plantæ or to the tendon of the flexor digitorum longus.

\section{BuRSE}

B. subtendinea m. tibialis posterioris.-A small bursa between the navicular fibro-cartilage and the tendon.

\section{Synovial Tendon-sheaths}

Vagina m. flexoris digitorum longi.-The tendon is surrounded by a synovial sheath from the back of the medial malleolus to where it crosses the tendon of the flexor hallucis longus below the navicular bone. It may communicate with the sheath of the tibialis anterior or with that of the flexor hallucis longus. Vaginæ tendinum digitales.-The tendons of the long flexor, together with those of the short flexor, are surrounded by synovial sheaths from the heads of the metatarsals to the insertions of the tendons. In structure these resemble those of the fingers. Vagina $\mathrm{m}$. flexoris hallucis longi.- The tendon is surrounded by a sheath from the back of the medial malleolus to the crossing of the tendon of the flexor digitorum longus. Another sheath surrounds the tendon from the middle of the first metatarsal to its insertion. Vagina $\mathrm{m}$. tibialis posterioris.-The tendon is surrounded by a synovial sheath extending from a region proximal to the medial malleolus to the insertion of the tendon.

\section{MUSCULATURE OF THE FOOT}

On the dorsum of the foot there is a muscle not represented in the hand, the extensor digitorum brevis (fig. 418). In the sole of the foot there is a highly developed musculature which may be subdivided into the flexor digitorum brevis (fig. 419); the muscles connected with the long extensor of the toes, quadratus plantæ and lumbricales (fig. 420); the intrinsic muscles of the great toe, (figs. 419,421 ); the intrinsic muscles of the little toe (figs. 419,421 ); and the interosseous muscles (fig. 422). These muscles abduct and adduct the toes, flex them at the metacarpophalangeal joints and flex and extend them at the first row of interphalangeal joints. On the second row of interphalangeal joints they seem to exert relatively little action. All the movements, excepting flexion, are weak in most individuals. The extensor digitorum brevis is innervated by the deep peroneal (anterior tibial) nerve. The muscles of the sole of the foot are all innervated by the lateral (external) plantar, except the flexor digitorum brevis, the most medial of the lumbrical muscles, and the abductor and flexor brevis of the great toe, which are innervated by the medial (internal) plantar.

\section{FASCIE}

Tela subcutanea.-Over the dorsum of the foot the tela subcutanea contains little fat. On the sole of the foot and the plantar surface of the toes it contains much fat embedded in dense fibrous tissue.

Muscle fasciæ.-Over the dorsum of the foot a fascial membrane extends from the cruciate ligament mentioned above to the toes, where it is continued as fibrous sheaths for the extensor tendons. Laterally and medially it is continued into the plantar fascia. Where 
it overlies skeletal structures it becomes adherent to them. In the main this fascial sheet is thin. Over the base of the first metatarsal it is strengthened by a band which runs from the medial side of this bone over the extensor tendons of the big toe to the base of the second metatarsal. The extensor digitorum brevis is covered by an adherent fascial sheet. The dorsal surface of each dorsal interosseous muscle is likewise covered by an adherent membrane.

The plantar surface of the foot is invested by a fascia in which three distinct regions may be observed, a central, a lateral, and a medial. The central region is greatly thickened by bands of fibrous tissue, the plantar aponeurosis, which diverge toward the toes from the medial half of the tuber calcanei. These bands become distinct from one another as the toes are approached, and each finally terminates partly in the skin over the head of the corresponding metatarsal and in the digital sheath of the flexor tendons. Some of the fibres are continned into the transverse capitular ligaments, the others extend through near the metat arsophalangeal articulation to the dorsum of the foot. Broader, thicker bands go to the three middle toes than to the big and little toes. At the margins of this central area some fibres radiate into the fascia of the lateral and medial area, some extend laterally into the skin, and some sink into the intermuscular septa described below. Near the toes well-marked transverse bundles of fibres may be seen between the digital bands. The central area of the plantar fascia is not densely adherent to the skin.

The digital sheaths of the flexor tendons of the toes correspond essentially with those previously described (p. 357) for the fingers.

The medial plantar fascia is thin and adherent to the skin. It extends between the central plantar and the dorsal fascia over the intrinsic muscles of the big toe. The lateral plantar fascia is thick and well developerl near the heel, thin as the little toe is approached. A dense band, the calcaneo-metatarsal ligament, strengthens it between the calcaneus and the tuberosity of the fifth metatarsal.

At the junction of the lateral with the central region of the plantar fascia the lateral intermuscular septum sinks in to be attached to the first cuneiform, the navicular and the tendon of the posterior tibial. A similar medial intermuscular septum sinks in between the medial and central regions of the plantar fascia and is attached to the long plantar ligament, the tendon sheath of the peroneus longus and the base of the fifth metatarsal. The fascia of each of these regions in considerable part extends int o these septa instead of becoming continuous across them.

The sole is thus divided into three great fascial compartments by these septa, a lateral, a central, and a medial. In the lateral lie the intrinsic pedal muscles of the little toe; in the medial the abductor and the flexor brevis of the big toe and the distal end of the tendon of the flexor hallucis longus. The central compartment is subdivided by transverse septa into several sub-compartments. In the most superficial compartment lies the flexor digitorum brevis; in the second, the tendons of the flexor digitorm longus and its associated muscles, the quadratus planto (flexor accessorius) and the lumbrical muscles; in the third, the adductor muscles of the big toe; and in the fourth, the interosseous muscles.

The first two sub-compartments are most clearly marked in the region of the tarsus. Distally they become merged by the disappearance of the intervening transverse septum, and longiturlinally subdivided by fibrous septa which serve to make a complete sheath over each ligit for the flexor tendons. The sheath over the adductor muscle of the big toe is a thin membrane continued laterally from the medial intermuscular septum. Where the two heads of the adductor muscle arlvance upon their tendon of insertion, the medial septum has no skeletal attachment, so that the adductor sub-compartment of the middle fascial compartment communifates freely with the medial compartment. Over the cunciform bones the tendon of the flexor hallue is longus passes from the long flexor region of the middle compartment into the medial compartment. Hore the medial intermusenlar septum divides into two layers, which form a sheath for the terdon as it passes to the plantal surface of the flexor hallucis brevis.

MILSCIAS

\section{MISCLE OF THE DORSUM OH THE FOOT}

The extensor digitorum brevis (fig. 118).-.This muscle is broat and thin, lies benerth the temelons of the lone extensor muselo on the tarsus, lateral to the natrindar and the heal of the talus, and semels tendons to the four more medial tores. It atrise from thre malemens. Its nerve-supply is from the deep peroneal.

Origin. - Fom the fatrul and superior surfaces of the body of the calcaneus and lrom the apex of the remeiatre ligatuent.

Strurture and insertiom. The fibre-bundles arise directly from the ligament, and by short

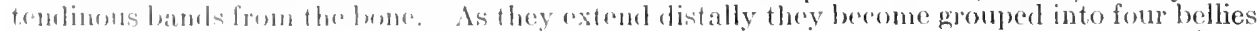
Those of the most merlial and lererest lialy, the extensor hallucis brevis, berome inserted in a

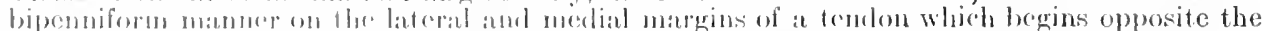

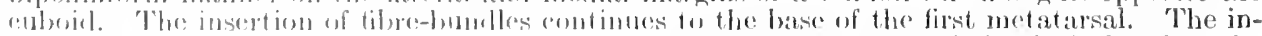

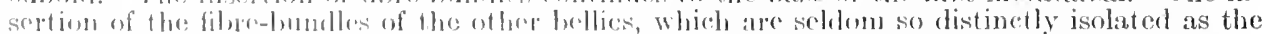
first, takes place in a prontiform manner into their respective fondors, but the exact mode of

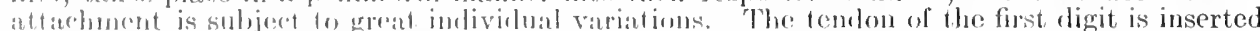

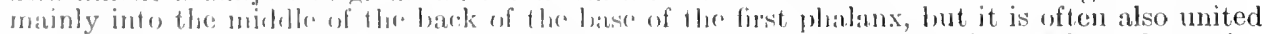

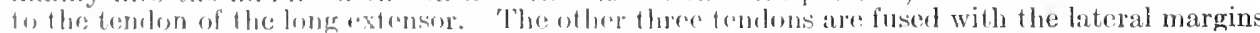

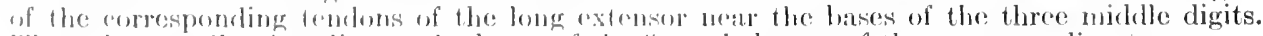

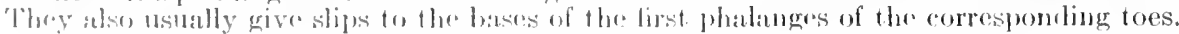


Nerve-supply.--The deep peroneal (anterior tibial) nerve, which, accompanied by the anterior tibial artery, passes beneath the medial belly of the muscle, gives off a branch which passes transversely across the middle of the deep surface of the muscle and sends twigs into it.

Relations.--It lies on the lateral side of the tarsus, beneath the long extensor tendons of the toes. The relations of its tendons have been described above.

Action.--It aids the long extensors in extending the first phalanx of each of the four medial digits. It has but a limited action on the second and third phalanges. It serves also to pull the ends of the toes to which its tendons go toward the little toe.

Fig. 418.-The Muscle of the Dorsum of the Foot.

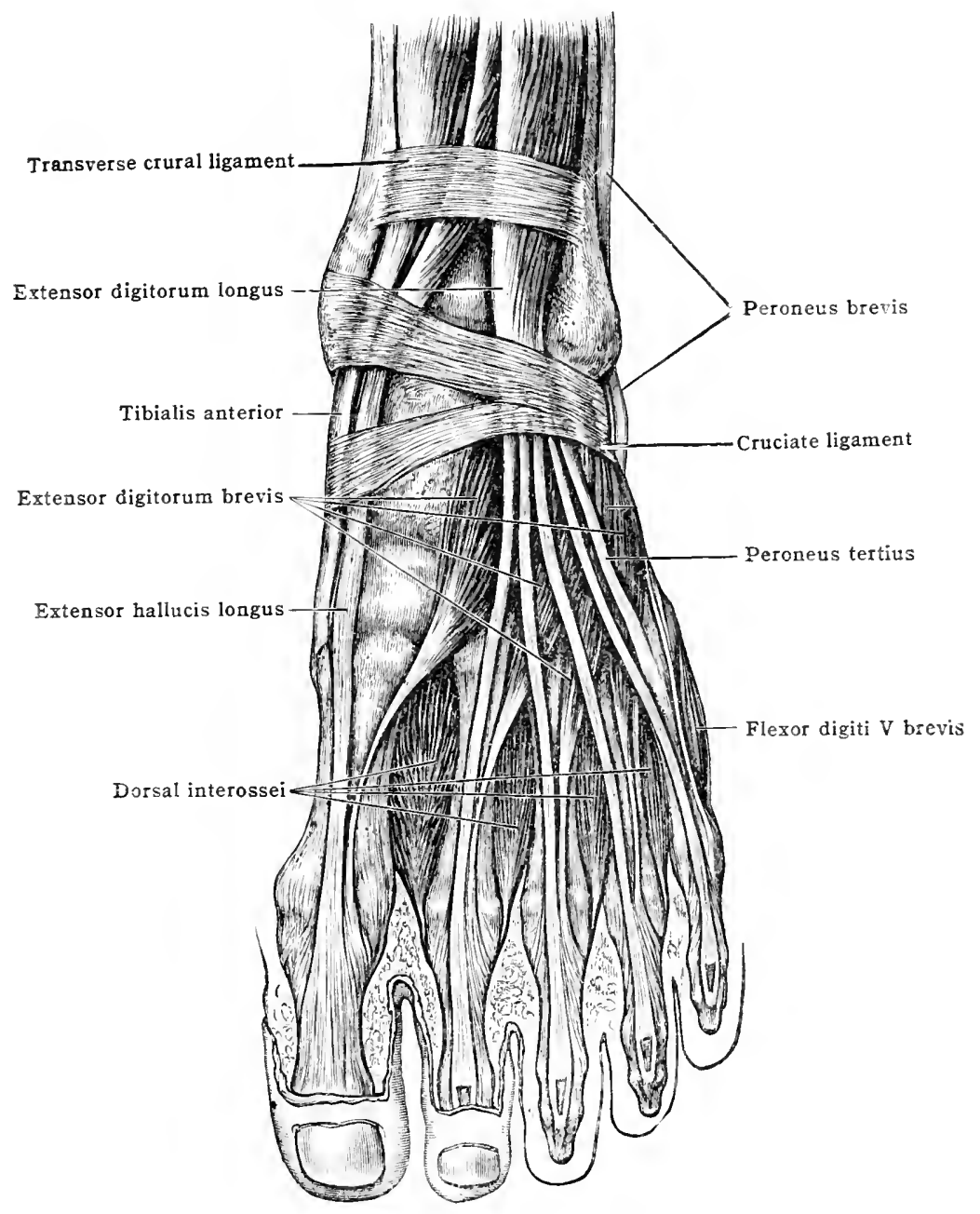

Variations.-The muscle shows great variation in development. Rarely the whole muscle, more frequently one or more of its digital divisions, may be missing. On the other hand, it may be more highly developed than usual. Accessory fasciculi vary greatly in origin and ternination. Most frequently their tendons go to a metacarpo-phalangeal articulation or to the second or the fifth toe.

\section{Muscles of the Sole of the Foot \\ a. Flexor Digitorum Brevis (fig. 419)}

The flexor digitorum brevis, the most superficially placed of the plantar muscles, lies in the mid-plantar region beneath the plantar fascia and over the tendons of the long flexor of the toes and its associated muscles. It arises from the calcaneus, and has a flat, elongated belly, which toward the middle of the sole is prolonged into four processes, each of which has a special tendon that is inserted into the second phalanx of one of the four lateral toes. The tendons of the muscle correspond to those of the flexor sublimis in the palm. The belly of the flexor 
sublimis is supposed to be represented by the soleus. The nerve supply is from the medial (internal) plantar.

Origin.-From (1) the medial process of the tuber ealcanei; $(2)$ the posterior third of the plantar aponeurosis; and (3) the medial and lateral intermuseular septa.

Structure.-The constituent fibre-bundles pass distally in a compact mass. The tendons of insertion begin within the muscle substance, and as the fibre-bundles beeome inserted on them, the separate fasciculi become more and more distinct. The faseieuli for the second and third toes are larger and arise more superficially than those for the fourth and fifth toes. The fasciculus for the fifth toe is often very small, and its tendon takes an oblique course to the insertion.

Insertion.-The tendons of the short flexor pass superficial to those of the long flexor into the osteo-fibrous canals on the flexor surface of the digits. Upon the first phalanx of each toe the tendon of the short flexor divides and forms an opening (chiasma tendinis) through which

Fig. 419.-First Layer of the Muscles of the Sole

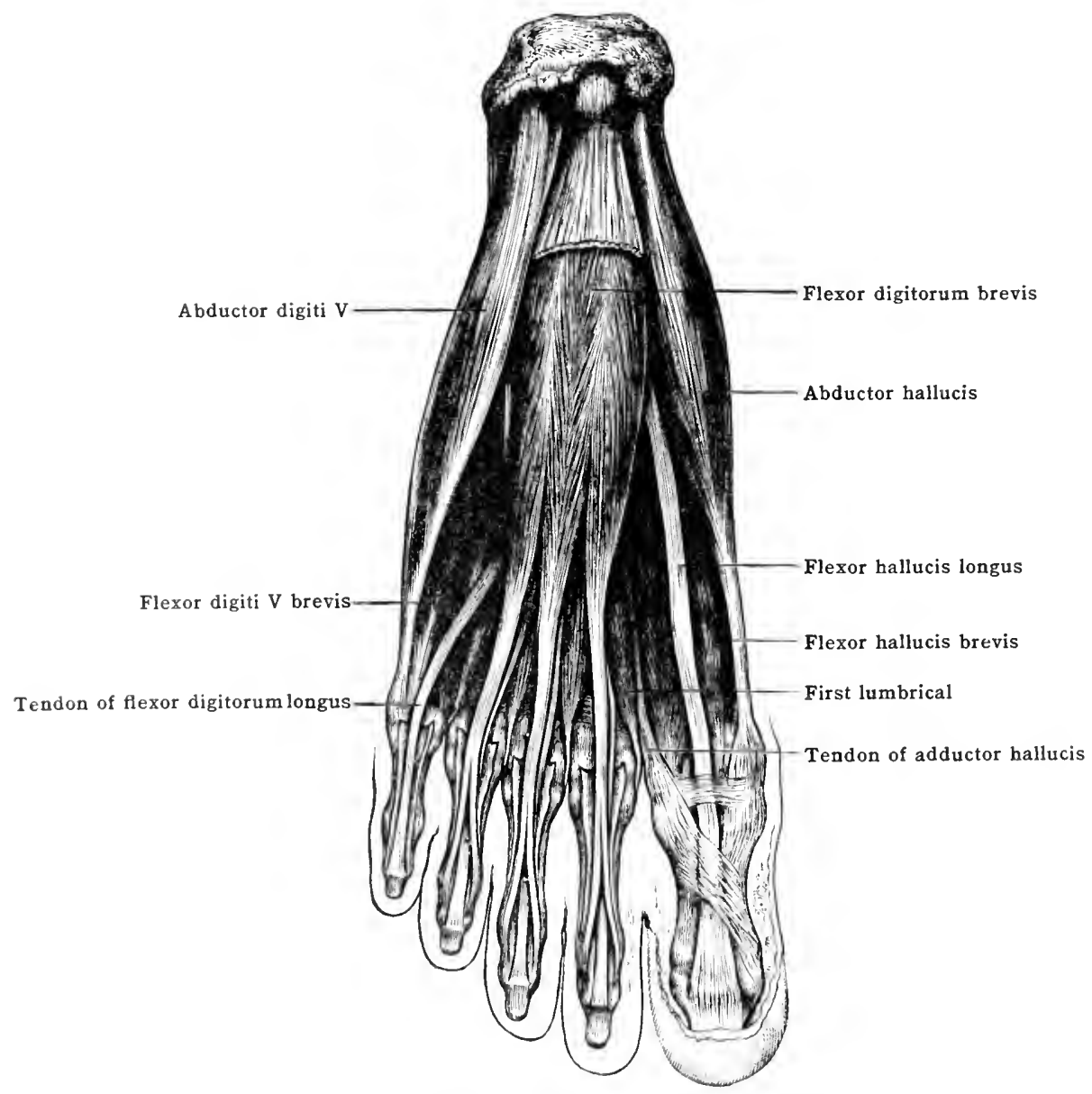

the tencon of the long flexor passes, while the tendon of the short flexor becomes attached to the base of the second phalanx. The arrangement is essentially like that deseribed at length for the flexors of the fingers (p. 401).

Nerve-supply.-From the medial plantar nerve by a branch which enters the middle third of the deep surface near the medial margin of the muscle.

Action.-It is a strong flexor of the second row of phalanges.

fielations. - The short flexor is separated from the abluctors of the big toe and little toe by strong intermuscular septa (p. 492), and from the long flexor tendons and the quadratus planta (flexor accessorius) by it transverse septum in which the lateral plantar vessels and nerve cross the foot. In its distal two-thirds it is separated from the plantar fascia by loose tissue.

l'ariations.-The muscle shows a tendency toward reduction, one or more of its fasciculi being frequently alsent, and occasionally the whole muscle. The fasciculus for the fifth toe is alsent in about 20 per cent. of bordies (le Druble). When a fascieulus is absent, its tendon is usually replaced by an accessory tendon from the long flexor. 'The muscle or its tendons may be more or less fused to the tendons of the flexor digitorum longus. 


\section{b. Muscles Attached to the Tendons of the Flexor Digitorum} LoNGUS (fig. 420)

The muscles belonging in this group are the quadratus plantæ (flexor accessorius), a flat, quadrangular, bicipital muscle which runs from the medial and plantar surface of the body of the calcaneus to the dorso-lateral margin and deep surface of the long flexor tendon; and the lumbricales, four slender bipinnate muscles which run from the medial sides of the digital slips of the tendon to the medial sides of the four more lateral toes. The quadratus aids the long flexor muscle; the lumbricales extend the last two phalanges and flex the first phalanx of each of the digits to which they pass. The lumbrical muscles correspond to those of the hand. The quadratus is not there represented. The nerve-supply is from the lateral (external) plantar nerve except that for the first lumbrical muscle which gets its supply from the medial (internal) plantar.

The quadratus plantæ (flexor accessorius) (fig. 420).-This muscle arises by two heads. The lateral head springs by an elongated tendon from the calcaneus in front of the lateral process of the tuber, and from the lateral margin of the long plantar ligament. The medial head arises directly from the medial surface of the body of the calcaneus as far back as the medial process of the tuber calcanei, and from neighbouring ligaments.

Structure and insertion.-The two heads are separated at their origin by a short triangular space. They soon fuse to form a single belly, but the fibre-bundles of each head in the main are separately inserted. Those from the lateral head diverge to be attached to the lateral margin of the flexor tendon. Those from the medial head are inserted on a tendon that begins on the medial margin and deep surface of this head, becomes broader, and is inserted as a flat aponeurosis on the deep surface of the flexor tendon. There are great individual variations in the structure of this muscle. The fibres of either part may be inserted with those of the other part.

Nerve-supply.-From a branch of the lateral plantar nerve which passes obliquely across the superficial surface of the muscle parallel with the tendon of the flexor digitorum longus.

Relations. - The muscle lies in a fascial compartment with the long flexor tendons. This compartment is bounded on each side by intermuscular septa, deeply by the tarsus, and plantarward by a septum which intervenes between it and the flexor digitorum brevis, and in which the lateral plantar nerve and vessels cross to the lateral side of the foot.

Action.-It assists the long flexor tendon in flexing the toes. It makes the direction of traction on the toes parallel with the long axis of the foot.

Variations.- It is frequently reduced in size. The lateral head is not infrequently missing, the medial head or the whole muscle much more rarely. The mode of attachment to the tendon varies. It may be inserted in part or wholly into the long flexor of the great toe. It may receive, in about one body in twenty (Wood), an accessory slip of origin from the fibula, one of the muscles of the leg, the fascia of the leg or foot, or the medial surface of the calcaneus, etc.

The lumbricales.--The three lateral muscles arise from the contiguous sides of the digital tendon-slips of the flexor digitorum longus in the angles of division. The first lumbrical arises on the medial margin of the tendon to the second toe. The fibre-bundles of each muscle converge on both sides of a tendon which becomes free near the metatarso-phalangeal joint and is attached to the medial side of the first phalanx of the toe to which the muscle belongs. A tendinous expansion is sent into the aponeurosis of the extensor muscle.

Nerve-supply. - The three lateral lumbrical muscles are most frequently supplied by branches of the deep ramus of the lateral plantar nerve, the medial by the first common plantar digital branch of the medial plantar nerve. The latter nerve may supply the two more medial muscles or the more medial muscles may receive a double supply. The branches of the lateral plantar nerve enter the deep surfaces of the muscles in the middle third. The branches of the medial plantar enter the medial borders of the muscles near the junction of the proximal and middle thirds.

Relations.-The lumbrical muscles lie in a plane with the long flexor tendons deeper than the flexor brevis tendons and superficial to the adductor hallucis. The deep branches of the lateral plantar nerve and vessels pass across their deep surface; superficial branches of both plantar nerves across the superficial surface.

Action.-To extend the last two phalanges of the toes and to flex the first.

Variations.-One or more of the muscles may be absent. Sometimes a muscle is doubled. This is more frequently the case with the third and fourth muscles. The first may arise wholly from the tendon of the posterior tibial muscle or from this and the long flexor of the big toe. The third lumbrical may arise from the flexor digitorum brevis. The second and fourth lumbricals may be inserted into the tendons of the flexor digitorum brevis.

\section{c. Intrinsic Muscles of the Great Toe (figs. 419-121)}

These muscles are the abductor, flexor brevis, and adductor. Of the three muscles, the first two lie in the medial fascial compartment, while the last lies in the middle compartment covered by the flexor digitorum longus and its associated muscles. 
The abductor hallucis (fig. 419), the largest and most superficial of these muscles, lies on the border of the sole medial to the short flexor muscle. It passes from the calcaneus across the tendons of the long flexor muscles, and is inserted into the medial side of the base of the first phalanx of the great toe and into the medial side of the long extensor tendon. It is partly fused to the medial belly of the flexor hallucis brevis. The flexor hallucis brevis (fig. 421) is a bicaudal muscle which lies over the first metatarsal. It arises in the region of the cuneiformbones and is inserted on each side of the base of the first phalanx. Between

Fig. 420.-Second Layer of the Muscles of the Sole.

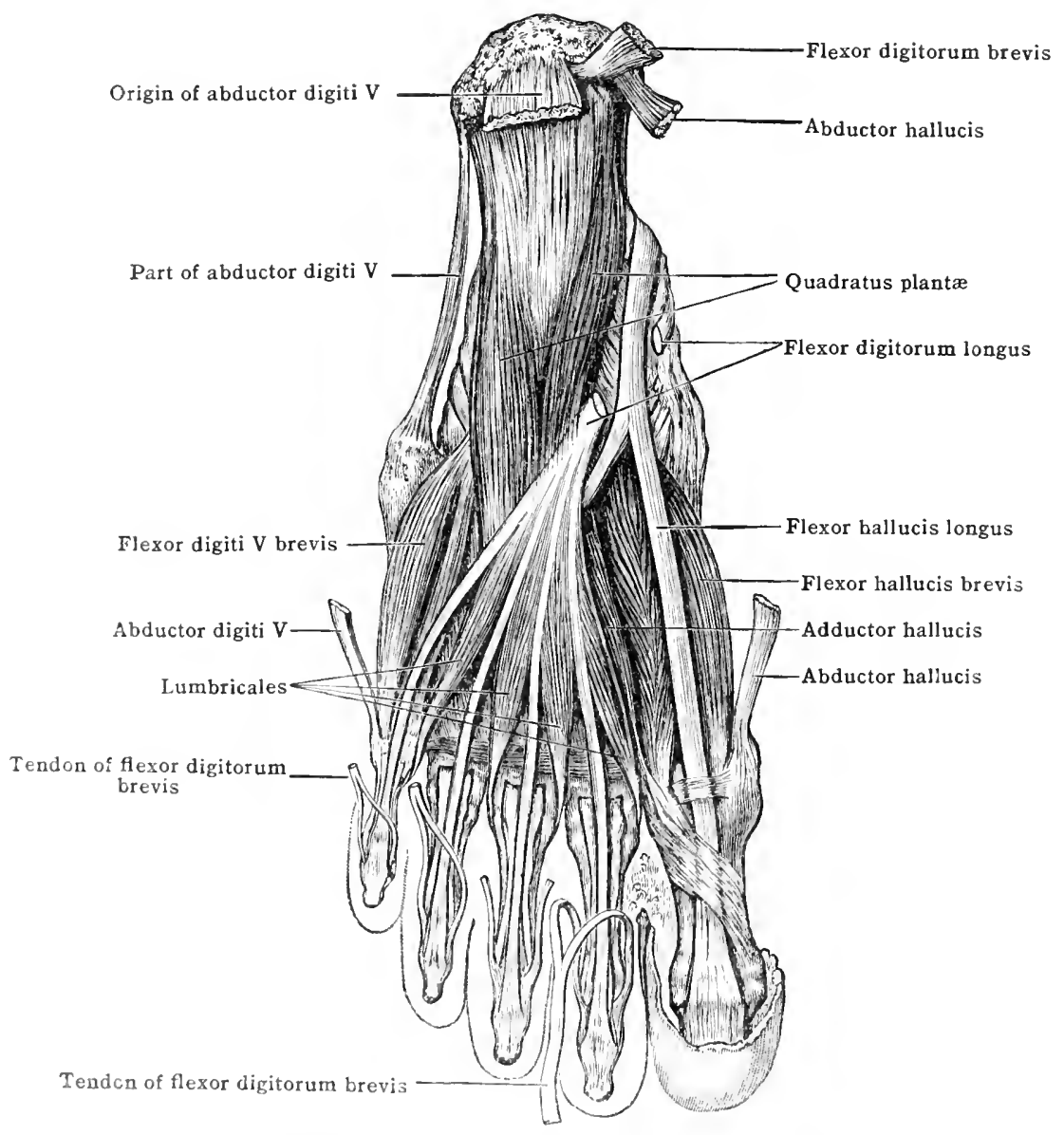

its two bellies and insertions runs the tendon of the long flexor of the great toe. Proxinally and merlially the llexor brevis is crossed by the abductor hallucis. Its tomblons are fused with those of the abductor and the oblique head of the addector. The adductor hallucis (fig. 121) is composed of two distinct heads, an oldirpe and at transwerse. The oldirgue head extemls from the long plantar ligament murler aster of the temlons of the flexor digitorum longus and the lumbrieal

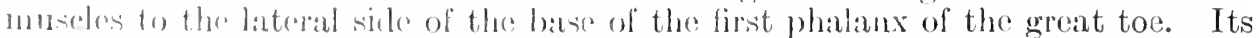

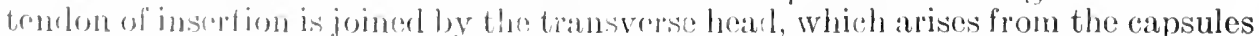
of the thimel to the fifth metatarso-phalangal joints. Beneath the adduetor lie

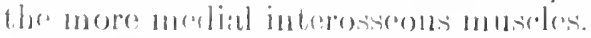

These museles proform not only the functions indicated by their names, but

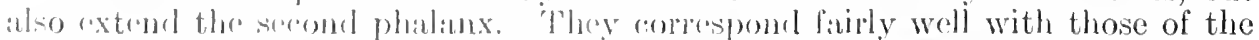
thand). 'The oppenens is not nomatly present in the foot. The nerve supply for the aldustor is from the lateral (exterial) plantar nerve; that for the other muscles is from the merlial (intormal) plantitr.

The abductor hallucis (fir. 119).- () rigin. From (1) the medial process of the tuber

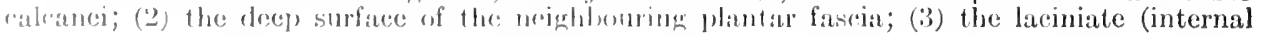


annular) ligament; (4) the septum between the muscle and the flexor digitorum brevis; and (5) a fibrous arch which extends on the deep surface of the muscle over the plantar vessels and nerves and the long flexor tendons from the calcaneus to the navicular bone.

Structure.-From the medial process of the tuber calcanei a tendinous band passes to the deep, lateral side of the muscle. Numerous tendinous bands arise from the other areas of origin. The fibre-bundles arise from these tendons and directly from the fibrous arch. They are attached in a penniform manner to numerous tendinous slips which extend far up in the muscle. These slips become gradually fused into a tendon which appears on the superficial plantar aspect of the muscle. Opposite the distal half of the first metatarsal bone the tendon leaves the belly of the muscle and becomes closely bound to the medial belly of the flexor hallucis brevis.

Fig. 421.- Third Layer of the Muscles of the Sole.

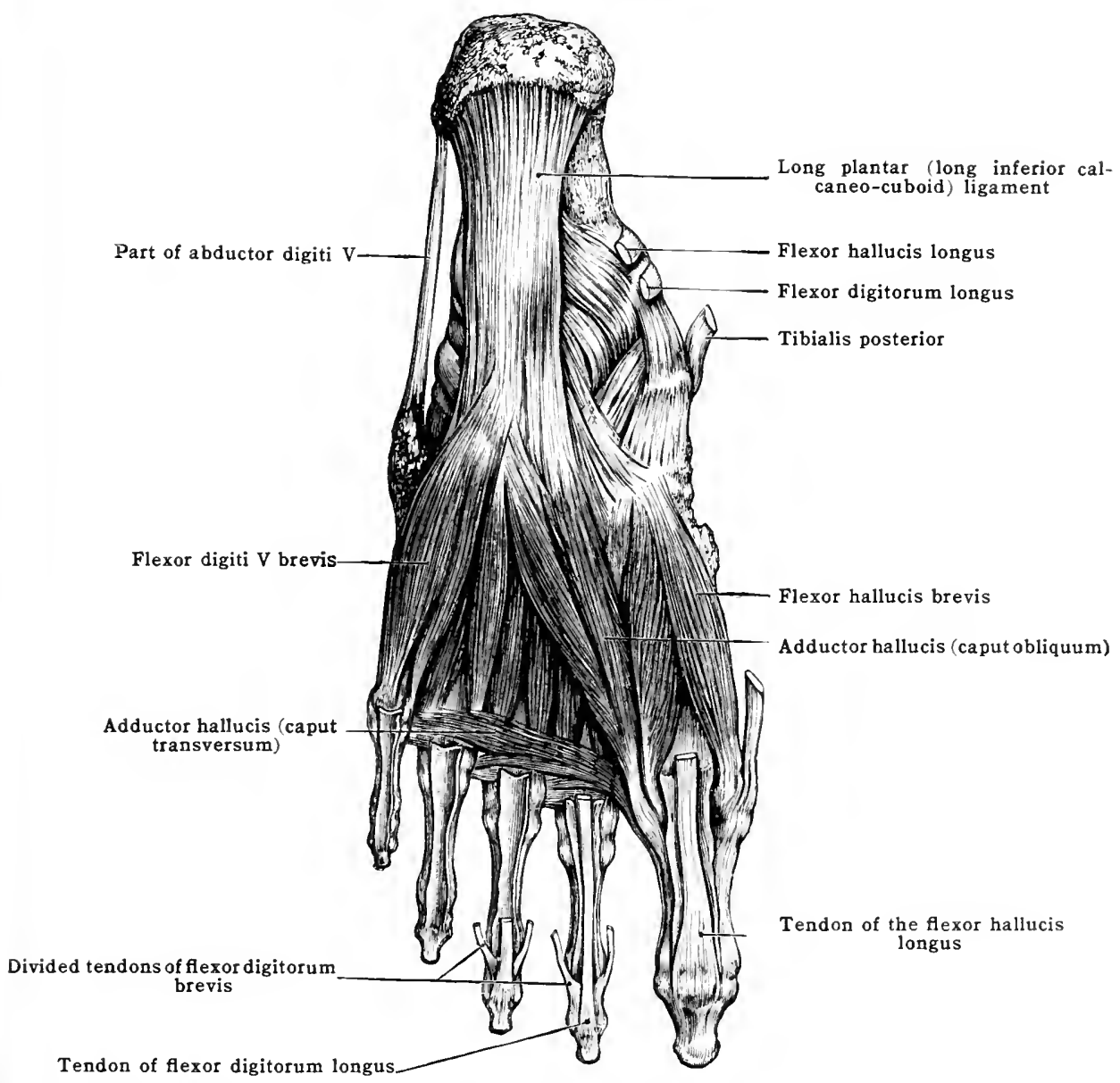

Insertion.- In conjunction with the tenclon of the medial belly of the flexor brevis into the base of the first phalanx. It usually sends an expansion to the extensor tendon.

Nerve-supply. - A branch from the medial plantar nerve usually enters near the middle of the lateral border of the muscle.

Relations.-It is covered by the plantar fascia and is separated from the muscles of the median compartment by the medial intermuscular septum. It erosses the tendons of the tibialis anterior, tibialis posterior, flexor digitorum longus, and flexor hallucis longus muscles and the plantar vessels and nerves.

The flexor hallucis brevis (fig. 421).-Origin.-From a tendon attached to the first (internal), second and third cuneiform bones. The more lateral of its fibres are continued into the plantar calcaneo-cuboid ligament and the more medial into the expansion of the tendon of the posterior tibial muscle.

Structure and insertion.-The fibre-bundles give rise to two bellies, a medial and a lateral. Those of the medial belly pass obliquely medially to be inserted into the tendon of the abductor hallucis, and by a short tendon fused with this into the medial side of the plantar surface of the base of the first phalanx. This tendon contains a sesamoid bone. Those of the lateral converge upon the tendon of the oblique head of the adductor, and the two muscles are inserted by a common tendon, which contains a sesamoid bone, into the lateral side of the plantar surface of the base of the first phalanx. 
Nere-supply. - A branch from the medial plantar (or first plantar digital) nerve divides over the plantar surface of the muscle and gives a twig to each belly near the middle third. Rarely the lateral belly may receive a branch from the lateral plantar nerve.

Relations.- The abductor hallucis covers it medially; the tendon of the flexor hallucis longus passes between its two heads. Branches of the medial plantar vessels and nerve lie on its superficial surface.

The adductor hallucis (fig. 421).-The oblique head.-Origin.-From (1) the tuberosity of the euboid and the sheath over the tendon of the peroneus longus muscle; (2) the plantar calcaneo-cuboid ligament; (3) the third cuneiform; (4) the bases of the second and third metatarsals and (5) a fibrous arch which extends from the plantar calcaneo-cuboid ligament to the interosseous fascia.

Structure and insertion.-From short tendon-slips the fibre-bundles pass forward to form a thick, fusiform belly which is attached in a bipenniform manner to a flat tendon. The tendon begins about the middle of the plantar surface of the muscle and is inserted in common with that of the flexor brevis into the lateral side of the plantar surface of the base of the first phalanx, and by a slip into the aponcurosis of the long extensor muscle on the back of the big toe.

Verve-supply. - A branch from the deep ramus of the lateral plantar nerve enters the middle third of the lateral border of the muscle on its deep surface.

The transverse head arises from the joint-capsules of the third, fourth, and fifth metatarsophalangeal joints and from the transverse capitular ligaments.

Structure and insertion. - Of the three fasciculi, that to the little toe lies nearest the heel, that to the middle toe the most distally. The fibre-bundles take a nearly parallel course to be attached to tendon-slips which are fused into a common tendon that splits and passes on each side of the tendon of the oblique head and is inserted into the sheath of the tenclon of the long flexor of the great toe (Leboucq).

Nerve-supply. $\rightarrow$ A branch from the deep ramus of the lateral plantar nerve enters the middle third of the deep surface of the muscle.

Relations. - The adductor hallucis is crossed superficially by the tendons of the flexor digitorum longus and by the lumbrical muscles. On its deep surface lie the interosseous museles, and the deep plantar vessels and nerves.

Action.- The actions of the muscles of this group are indicated by the names of the individual muscles. The abductor and the oblique head of the adductor are also flexors of the first phalunx. All the muscles of the group aid in extending the second phalanx. The transverse head of the adductor serves to draw together the heads of the metatarsals after they have been separated by the weight of the body during the tread.

lariations. - The extent of fusion of the abductor and adductor with the two heads of the short flexor varies considerably. The abductor may receive an accessory fascieulus from the medial border of the foot. Either the adductor or the flexor brevis may send a tendon to the base of the first phalanx or to the short flexor tendon of the second toe. The adductor shows frequent variations in relation to its metatarsal attachments, owing to the fact that originally a fasriculus from the borly of the seeond (and third) metatarsal was probably normally present and the transverse head was more developed (Leboucq). The opponens hallucis is a fascieulus occasionally found which extends from the short flexor or the medial intermuscular septum to the body of the first metatarsal. This muscle is normal in some monkeys. An adductor digiti secundi has becn seen to arise from various sourees and beeome attached to the lateral side of the plantar surfare of the base of the first phalanx of the second toe. This muscle may be fused with the oblique adductor. A eorresponding muscle is found normally in some apes, and in some of the lower amimals there is a special adductor for cach toe.

\section{d. Intrinsic Muscles of the Little Tok (figs. 419-421)}

In this group belong three muscles, an abductor, a flexor and an opponens. 'The largest of these, the abductor digiti quinti (fig. 419), extenels superficially over the lateral inargin of the foot from the lateral sicle of the tuber calcanei to the bass of the little toe. The flexor digiti quinti brevis (fig. 421) is a small, flat muscle: which lies on the plantar surface of the fifth metatarsal. The opponens is a small muscle lying lateral to this. The two, which are of ten fused, arise from thr anbicl. The flexor hrevis is inserted into the plantar side of the base of the first phatanx of the litfle toc. The opponems is inserted into the lateral surface of the metatiarsal. 'The abluator correspones with the abductor of the little finger. The opponens and flexor brevis correspond probably with the deep part of the opponens of the little finger. "The nerve supply is from the lateral plantar nerve.

The abductor digiti quinti (fig. 119).- Origin.- From (1) the lateral process of the tuber ralcanci and the lat roml and platur surfare of the body of the bone in front of this; (2) the lateral

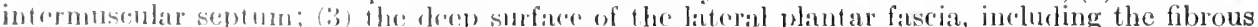

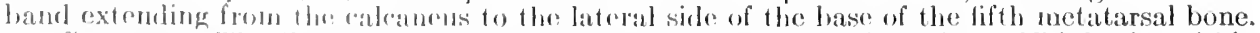

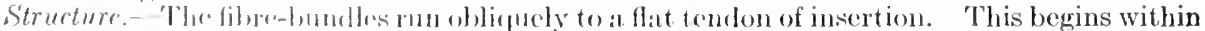

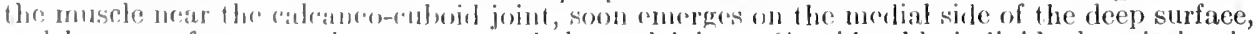

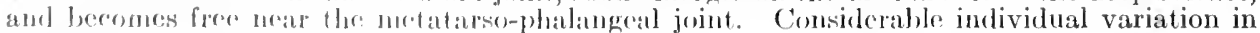
structure is fommel.

Insertion.-On Ho lateral surfare of 1 lo forst phalanx of the little toe and the metatarsophalungeal capsule. (often a slip is sent to the rextensol tenton. While usually the muscle 
glides over the tuberosity of the fifth metatarsal, it frequently sends a second fasciculus to be attached to this bone (abductor ossis metatarsi quinti). A special fasciculus from the tuberosity often constitutes the lateral margin of the muscle.

Nerve-supply.-The nerve arises from the lateral plantar. It may be distributed either near the deep or the superficial surface of the muscle. The former appears to be the case when the muscle is slightly developed. The chief intramuscular branches then extend aeross the middle third of the constituent fibre-bundles near the deep surfare. In case the calcaneo-metatarsal bundles are well developed, the nerve enters the proxinual margin of the muscle and its chief branches extend across the middle third of the more supcrficial muscle-bundles, finally terminating in the distal margin of the muscle.

Relations. - It is ensheathed by the plantar fascia and the lateral intermuscular septum. It lies superficial to the quadratus planta (flexor aceessorius), the opponens and flexor brevis of the little toe, the long plantar ligament, and the tendon of the peroneus longus muscle.

The flexor digiti quinti brevis (fig. 421). - Origin.-From the sheath of the peroneus longus, the tuberosity of the cuboid, and (3) the base of the fifth metatarsal.

Structure and insertion.-The fibre-bundles take a nearly parallel course, although the belly is slightly fusiform. They are attached by short tendinous bands to the base of the first phalanx of the little toe, the capsule of the corresponding joint, and the aponeurosis on the dorsal surface of the toe.

Nerve-supply. - A branch of the superficial ramus of the lateral plantar nerve sends $t w i g s$ to the middle third of the plantar surface of this and the following muscle.

Relations.- It is covered medially by the plantar fascia, laterally by the abductor of the fifth toe. Medially it lies superficial to the third plantar interosseous muscle.

The opponens digiti quinti.-This muscle arises from the sheath of the peroneus longus and the tuberosity of the cuboid by a slender tendon which passes over the tuberosity of the fifth metatarsal and gives rise to fibre-bundles which are inserted on the lateral surface of the fifth metatarsal.

Nerve-supply.-From branches of the nerve to the flexor brevis.

Relations. - It is covered by the abductor of the fifth toe.

Actions.-The abductor and flexor brevis abduct the little toe and flex the first phalanx. They act as extensors of the second phalanx. The opponens serves to draw the little toe medially in a plantar direction.

Variations. - The museles of this group may be more or less completely fused. The abductor, in addition to the variations mentioned above, may send tendons to the third and fourth metatarsals. The opponens is frequently missing. The abductor accessorius digiti quinti is a rare muscle which arises from the lateral process of the tuber of the calcaneus and is inserted into the lateral surface of the base of the first phalanx of the little toe.

\section{e. The Interosseous Muscles (fig. 422)}

Two groups of interosseous muscles are recognised, a dorsal and a plantar. The dorsal are the larger and fill the interspaces. The first two are inserted into each side of the base of the first phalanx of the second toe; the third and fourth into the lateral sides of the bases of the first phalanges of the third and fourth toes. The plantar interossei lie on the medial side of the ventral surfaces of the third, fourth, and fifth metatarsals, and are inserted each on the medial side of the base of the first phalanx of the corresponding toe. In the hand the axis about which the interosseous muscles are arranged passes through the middle finger, in the foot through the second toe. The nerve-supply is from the lateral plantar nerve.

The interossei dorsales.- Each of the three lateral dorsal interosseous muscles arises from -(1) the sides of the shaft and the plantar surface of the bases of the metatarsal bones bounding the space in which it lies; (2) from the fascia cuvering it dorsally; and (3) from fibrous prolongations from the long plantar ligament. The first has a similar origin except that it is at tached medially to the base of the first metatarsil and to a fibrous arch extending from the base to the head.

Structure. - The component fibre-bundles of each muscle are inserted bipinnately on a tendon which begins high in the muscle and becomes free near the metatarso-phalangeal joint.

Insertion:- The first and second on each side of the base of the first phalanx of the second toe. The third and fourth on the lateral side of the bases of the proximal phalanges of the third and fourth toes. Each tendon is adherent to the capsule of the neighbouring joint. They send no well marked processes to the extensor tendons, as do those of the hand.

The interossei plantares. - Each plantar interosseus arises-(1) from the proximal third of the medial plantar surface of the shaft and from the base of the metatarsal on which it lies; and (2) from expansions of the long plantar ligament.

Structure and insertion.- The obliquely placed fibre-bundles are longer than those of the dorsal interossei, and are inserted in a tendon which lies near the medial border of the muscle, becomes free near the metatarso-phalangeal joint, and is inserted into a tubercle on the medial side of the base of the first phalanx of the digit to which it goes.

Nerve-supply. - From the deep branch of the lateral plantar nerve several rami are given off for the interossei. The nerve of each muscle enters the plantar surface in the proximal third. The interosseous muscles of the fourth interspace, however, are usually supplied by a branch from the superficial ramus of the lateral plantar nerve. 
Relations.-The interosseous muscles are covered on the plantar surface by a thin fascia on which the deep branches of the lateral plantar nerve and vessels run. The first dorsal interosseous adjoins medially the flexor hallucis brevis and laterally on the plantar surface of the second metatarsal, adjoins the second dorsal interosseous. Dorsal and plantar interossei then alternate across the plantar surface of the foot until the fifth metatarsal is reached. Here the third plantar interosseous adjoins the flexor brevis of the little toe.

Fig. 422.-Fourth Layer of the Muscles of the Sole.

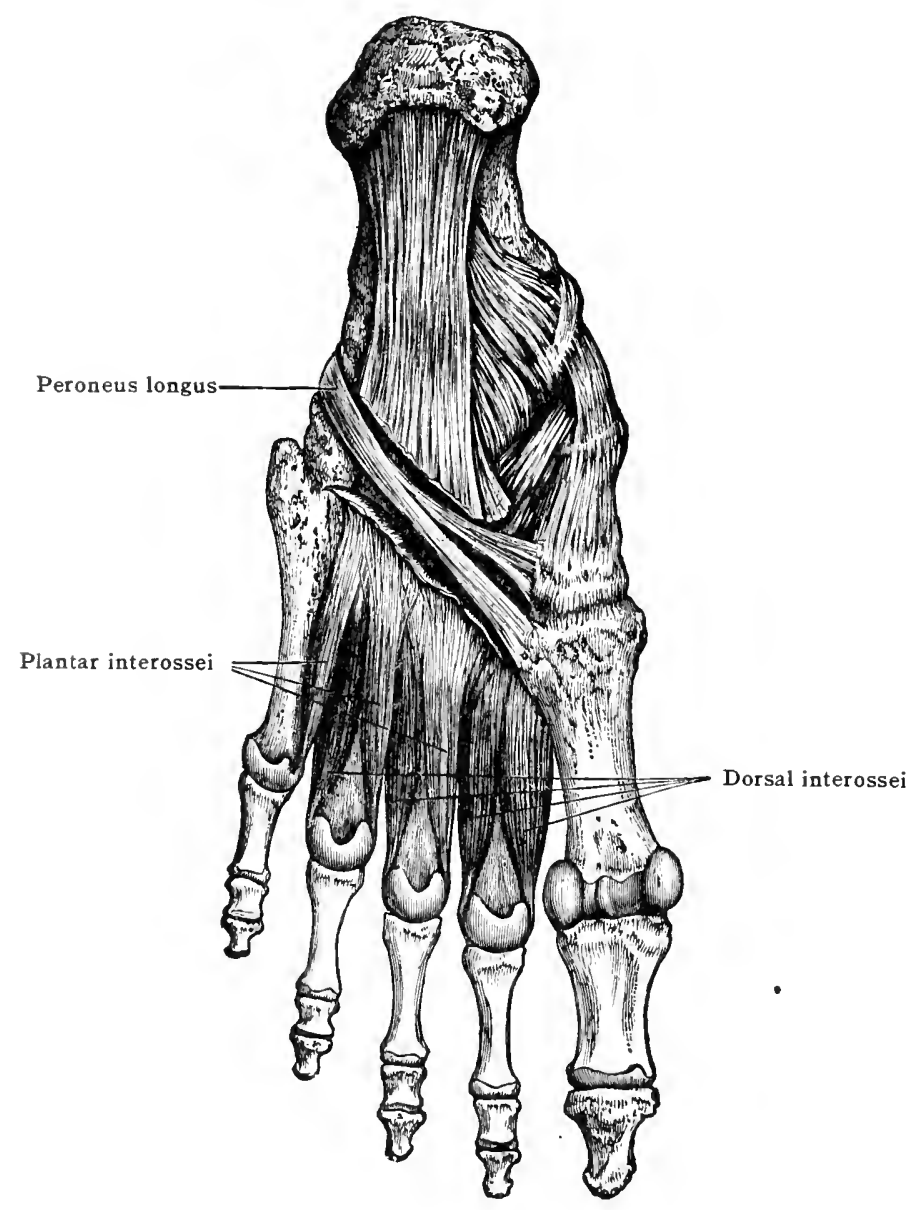

Action.--The chief axis of the foot may be taken to extend through the second toe. The Inrsal interosseous museles abduct--pull the digits to which they are attached away from this axis; the plantar interosscous muscles adduct-pull the digits toward the axis. The interossei all flex the first row of phalanges.

Variations. - The second dorsal interosseous may have no attachment to the third metatarsal.

\section{BURSA}

B. intermetatarsophalangeæ.-Four bursa between the neighbouring sides of the heads of the metatarsal bones and dorsal to the transverse capitular ligaments. B. mm. lumbricalium. - Between the ends of the tendons of the lumbrical muscles and the transverse capitular ligaments. The thrce mertial are more constant than the lateral.

For other bursie in the foot, see pp. 4 S:3 and 491.

\section{MUSCIES GROUPED ACCORIDING TO FUNCTION}

The exact functions of many of the museles have not yet been decisively determined. Anatomical studies, the construction of mechanical models, the electrieal stimulation of the musculature, and observation of the muscular activities of normal individuals and of individuals in whom given muscles or sets of museles are absent or paralysed, have all proved valuable methods of investigation, but cach methou has its drawbarks, and knowledge of the part actually played by individual museles in the normal activities of the body is as yet merely approxi- 
mate. Owing to the influence of gravity, the relations of other muscles to the skeleton, and similar factors, a given muscle may perform functions which would not be deduced from a simple study of the relations of the muscle to the skeleton. Thus the iliacus serves to flex not only the hip, but also the knee, and the hamstring muscles may flex the hip while flexing the knee. The functions ascribed to various muscles in the following tables, although an attempt has been made to base them upon the more recent work on the action of the muscles, must be taken to be merely approximately correct. So far as possible the muscles are given in order of their power in effecting the various movements. In this we have utilized chiefly the work of R. Fick: "Anatomie und Mechanik der Gelenke unter Berücksichtigung der bewegenden Muskeln" in von Bardeleben's Handbuch der Anatomie des Menschen.

In this table have been included not only the voluntary muscles described in the preceding section, but also several described in other parts of the book.

\section{Facial muscles.}

These serve essentially to contract the various visceral orifices of the liead or to retract Ear.

Orbit. the tissue surrounding them.

Retractors: auricularis anterior, superior, and posterior.

(a) Retractor: Epicranius (occipito-frontalis). The levator palpebra superioris, innervated by the third cranial nerve, serves to raise the upper lid of the eye.

(b) Contractors: orbicularis oculi, corrugator, and procerus.

Nasal orifice.

(a) Dilators: angular head of the quadratus labii superioris, transverse portion of the nasalis, and the dilatores naris.

(b) Contractors: pars alaris of the nasalis and the depressor septi nasi.

Oral orifice.

(a) Retractors:

Upward: zygomaticus, quadratus labii superioris, caninus.

Lateralward: zygomaticus, risorius, platysma, triangularis, buccinator.

Downward: triangularis, quadratus labii inferioris, platysma.

(b) Contractors: orbicularis oris, compressor labii, incisivus labii inferioris and superioris.

(c) Protractors of the lips: incisivus labii inferioris and superioris, mentalis.

2. Muscles acting on the eyeball (see Section on Eye).

To adduct the pupil: rectus medialis.

To abduct the pupil: rectus lateralis.

To direct the pupil upward: rectus superior, in association with the obliquus inferior.

To direct the pupil downward: rectus inferior, in association with the obliquus superior.

3. Muscles acting on the lower jaw.

(a) To raise it: masseter, temporal, internal pterygoid.

(b) To lower it: external pterygoid, digastric, mylo-hyoid, genio-hyoid, and the infrahyoid muscles. The weight of the jaw also plays a part in this movement.

(c) To protract it: external pterygoid, internal pterygoid, masseter and the anterior part of the temporal.

(d) To retract it: the inferior dorsal portion of the temporal and the digastric.

(e) To produce lateral movements: the external pterygoid acting on one side rotates the chin and carries the jaw toward the opposite side. The rotation may be aided by the digastric of the opposite side. The masseter draws it slightly toward the side on which the muscle lies. This action of the masseter is counterbalanced by the internal pterygoid (Riegner).

4. Muscles acting on the hyoid bone.

(a) To elevate it: digastric, stylo-hyoid, stylo-glossus, mylo-hyoid, genio-hyoid, genio-glossus, hyo-glossus, and the middle constrictor of the pharynx.

(b) To depress it: thyreo-hyoid, sterno-hyoid, omohyoid, sterno-thyreoid.

(c) To protract it: genio-glossus (inferior portion), genio-hyoid, anterior belly of digastric, and the mylo-hyoid.

(d) To retract it: posterior belly of digastric, stylo-hyoid, and the middle constrictor of the pharynx.

5. Muscles acting on the larynx (see Section IX).

(a) To elevate it: thyreo-hyoid, stylo-pharyngeus, pharyngo-palatinus, the inferior constrictor of the pharynx, and the elevators of the hyoid bone.

(b) To depress it: sterno-thyreoid, sterno-hyoid, and omo-hyoid.

(c) To approximate the vocal cords: crico-arytenoideus lateralis; rocalis;

(d) To make the vocal cord tense: crico-thyreoideus.

(e) To widen the rima glottidis: crico-arytenoideus posterior.

(f) To shorten and thicken the vocal cords: thyreo-arytenoideus (externus), vocalis. 
(g) To constrict the aditus and vestibule of the larynx: aryepiglotticus, thyreo-arytenoideus.

(h) To widen the aditus and vestibule of the larynx: thyreo-epiglottideus

6. Muscles acting on the tongue (see Section IX).

(a) To elevate it: stylo-glossus (especially along the sides), glosso-palatinus, glosso-pharyngeus, and the elevators of the hyoid bone.

(b) To depress it: genio-glossus (in the centre), hyoglossus (at the sides), chondroglossus, and the depressors of the hyoid bone.

(c) To protrude it: genio-glossus (middle and inferior portions).

(d) To retract it: genio-glossus (anterior portion), stylo-glossus, chondroglossus.

(e) To shorten it and make it bulge upwards: longitudinalis superior and inferior.

(f) To narrow it and make it bulge upwards: transversus linguæ.

(g) To flatten it: verticalis lingux.

When the muscles work symmetrically, these movements are symmetrical; when they do not work symmetrically, the tongue is moved from side to sicle, rotated, etc.

7. Muscles acting on the palate and pharynx (sce Section IX).

(a) To narrow the pharyngeal opening of the tuba auditiva (Eustachian tube): levator veli palatini.

(b) To widen the isthmus of the tuba: levator veli palatini.

(c) To open the tube: tensor veli palatini, pharyngo-palatinus.

(d) To raise and shorten the uvula: $m$. uvula.

(e) To depress the soft palate: glosso-palatinus, pharyngo-palatinus.

(f) To make tense the soft palate: tensor veli palatini.

(g) To lift the sof palate: levator veli palatini.

(h) To approximate the glosso-palatine arches (anterior pillars of the fauces): glosso-palatinus.

(i) To approximate the pharyngo-palatine arches (posterior pillars of the fauces): pharyngo-palatinus, superior constrictor of the pharynx.

(j) To constrict the pharynx: superior, middle, and inferior constrictors.

(k) To willen the pharynx: stylo-pharyngeus and the muscles which protract the hyoid bone.

(l) To clevate the pharynx: stylo-pharyngeus, pharyngo-palatinus.

8. Muscles acting on the head.

(a) To flex it: the supra- and infrahyoid muscles, rectus capitis anterior, longus capitis, rectus capitis lateralis.

(b) To extend it: sterno-cleido-mastoid, trapezius, splenius capitis, longissinus capitis, semispinalis capitis, obliquus capitis superior, rectus capitis posterior major and minor. When the hyoid bone and lower jaw are fixed by contraction of the hyomandibular and infrahyoid muscles, the posterior belly of the digastric aids the extensors of the hearl in opening the mouth.

(c) To bend it laterally: stemo-cleido-mastoid, rectus capitis lateralis, splenius capitis, longissinus capitis, semispinalis capitis, obliquus capitis superior.

(d) To rotate it: stcrno-cheido-mastoid, trapezius, splenius capitis, longissimus capitis, semispinalis capitis, obliquus capitis superior and inferior, rectus capitis postcrior major.

9. Muscles acting on the spinal columin.

(a) To flex it: sterno-cleido-nastoid, longus colli, longus eapitis, psoas major and minor, scaleni, rectus abdominis, obliques abdominis cxtermus and internus, the crura of the diaphragm, levator ani, and the roceryens.

(b) To extend it: splenius capitis, splenius cervicis, spinalis, sacro-spinalis, semispinalis corsi, cervicis and capitis, multifidus, rotatores, interspinales, intertransversirii, levatores costarum, quadratus limborium.

(c) 'T'o bent it latcrally and extend it: quadratus humborum, splenius, iliocostalis, lomgissimus dorsi, repvicis aml capitis, semispinales, multifirlus, rotatores, levitores costarmm, intertransversarii.

(d) J'o Jernd it laterally and flex it: scalcue, stemo-eleido-mastoid, oblicfuns alulominis externus and internus, intercostales, psoas major ancl minor.

"licu the arm and shoulder girtle are fixed the trapezius, levatur stipular, latissimus dorsi and rhomboirls aid abduction.

(e) To rotate it to the right: r. internal oblique, l. external olslicue, r. splenius, 1. stremerlejolo-mastoirl, r. lomgissimms capitis, r. ilio-costalis, 1. somisprinatis, 1. multifichs, l. rotatores (except the lumbar), longus rolli (r. alfove, l. loclow), l. serratus anferior and rhomboils, r. levatores rositamut. 
10. Muscles of respiration.

Quiet inspiration: the external intercostals, intercartilaginous parts of internal intercostals, diaphragm.

Enforced inspiration: in addition to the muscles mentioned above, the scaleni, sterno-cleido-mastoid, serratus posterior superior and inferior, rhomboids, serratus anterior, latissimus dorsi, subclavius, pectoralis major and minor, and the extensors of the spinal column, the trapezius and the levator scapuli.

Quiet expiration: interosseous parts of internal intercostals, subcostales, and transversus thoracis.

Enforced expiration: in addition to the muscles mentioned above, the abdominal muscles, ilio-costalis lumborum and dorsi, longissimus dorsi, and the quadratus lumborum.

The chief muscles of respiration are the intercostals; the diaphragm plays a minor part (Fick).

11. Muscles acting on the abdomen.

(a) Constriction of the abdominal cavity: obliquus abdominis externus and internus, the transversus and rectus abclominis, and the diaphragm, levator ani, and coccygeus.

(b) Reduction of pressure in the abdominal cavity: the muscles of inspiration, with the exception of the diaphragm, serve to lessen the compression of the abdominal viscera.

12. Action of the muscles of the perineal region.

(a) To close anal canal: sphincter ani externus.

(b) To constrict the anal portion of the rectum: levator ani (pubo-cocygeal portion).

(c) To constrict the bulbus urethræ and the corpus cavernosum urethræ (corpus spongiosum): bulbo-cavernosus.

(d) To elevate the prostate glanil: levator ani.

(e) To constrict the vagina: bulbo-cavernosus, levator ani (pubo-coccygeal portion), constrictor vaginæ.

(f) To cause erection of penis and clitoris: ischio-cavernosus, bulbo-cavernosus, and sphincter urethræ membranaceæ.

(g) To compress the urethra and the bulbo-urethral (Cowper's) or the great vestibular (Bartholin's) gland: sphincter urethræ menbranace: and the transversus perinei profundus.

(h) To support and lift the pelvic floor: levator ani, coceygeus, transversus perinei profundus and superficialis.

13. Muscles acting on the shoulder-girdle.

The two joints acted upon are the sterno-clavicular and the acromio-clavicular. The movements produced consist in lifting and lowering the scapula, carrving it forward and backward and rotating it.

(a) Elevation: trapezius (upper portion), levator scapulie, sterno-cleido-mastoid, rhomboidei, pectoralis major (upper sternal part), serratus anterior (middle portion), omo-hyoid.

(b) Depression: trapezius (lower portion), pectoralis major (lower portion), pectoralis minor, subclavius, latissimus dorsi, serratus anterior (lower part). The weight of the limb is likewise a factor.

(c) Forward movement: serratus anterior, pectorales major and minor.

(d) Backward movement: trapezius, rhomboidei, latissinus dorsi.

(e) Rotation:

Associated with abduction of the arm: serratus anterior. (inferior portion), trapezius.

Associated with adduction of the arm: rhomboidei, pectoralis major (pectoral portion), latissimus dorsi, pectoralis minor, levator scapulæ.

14. Muscles acting on the arm at the shoulder-joint.

(a) To flex it,

When the arm is at the side: pectoralis major (upper part), deltoid (anterior part), short head of biceps, coracobrachialis, infraspinatus, long head of biceps, teres minor, subscapularis (upper part), supraspinatus.

When the arm is abducted $60^{\circ}$ : pectoralis major, deltoid, subscapularis, short head of biceps, coracobrachialis, long head of biceps. infraspinatus, supraspinatus.

The movement is aided by the trapezius and the serratus anterior.

(b) To extend it.

When the arm is at the side: latissimus dorsi, deltoid (posterior part), teres major, subscapularis (lower part), triceps.

When the arm is abducted $60^{\circ}$ : latissimus dorsi, deltoid, teres major, triceps, teres minor.

The upper and middle portions of the trapezius and the levator scapulie play

(c) To abduct it. an important part in extension of the arm.

When the arm is at the side: deltoid, supraspinatus, long head of hiceps, subscapularis, infraspinatus (upper part).

When the arm is abducted $60^{\circ}$ : deltoid, supraspinatus, infraspinatus (upper part), long head of biceps, short head of biceps. 
The subscapularis is an adductor when the arm is abducted. The inferior part of the serratus anterior and the trapezius are important

(d) To adduct it, in abduction of the arm.

When the arm is at the side: pectoralis major, latissimus dorsi, deltoid (posterior and anterior parts), teres major, triceps, coracobrachialis, short head of biceps, teres minor, infraspinatus.

When the arm is abducted: pectoralis major, latissimus dorsi, teres major, triceps, subscapularis, deltoid (dorsal and ventral parts), coracobrachialis.

(e) To rotate it lateralward (supinate),

When the arm is at the side: infraspinatus (upper part), the dorsal part of the deltoid, teres minor, supraspinatus.

Then the arm is abducted $60^{\circ}$ : teres minor, infraspinatus, deltoid (dorsal part), coracobrachialis.

(f) To rotate it medialward (pronate).

With the arm at the side: latissimus dorsi, pectoralis major, subscapularis, deltoid (ventral part), long head of biceps, teres major, short head of biceps.

With the arm abducted $60^{\circ}$ : latissimus dorsi, pectoralis major, subscapularis, teres major, deltoid (ventral part).

When the arms are raised high the power of rotation at the shoulder becomes slight.

15. Muscles acting on the forearm at the elbow-joint (arranged according to R. Fick).

(a) Flexion at elbow.

Forearm supinated: brachialis, long head of biceps, short head of biceps, brachio-radialis, pronator teres, extensor carpi radialis longus, flexor carpi radialis, extensor carpi radialis brevis, palmaris longus.

Forearm in mid-position or pronated: brachialis, long head of biceps, short head of biceps, brachio-radialis, extensor carpi radialis longus, pronator teres, flexor carpi radialis, extensor carpi radialis brevis, palmaris longus.

(b) Extension at elbow: triceps (lateral, medial, and long heads), anconeus.

(c) Pronation of forearm.

Forearm extended: flexor carpi radialis, pronator teres, pronator quadratus, palmaris longus.

Forearm at right angles: pronator teres, flexor carpi radialis, brachio-radialis, pronator quadratus, extensor carpi radialis longus, palmaris longus.

Forearm flexed: pronator teres, brachio-radialis, flexor carpi radialis, pronator quadratus, extensor carpi radialis longus, palmaris longus.

(d) Supination.

Forearm extended: short head of biceps, supinator, long head of biceps, brachio-radialis, extensor carpi radialis longus, abductor pollicis longus, extensor pollicis brevis, extensor pollicis longus, extensor indicis proprius.

Forearm at right angles: short head of biceps, long head of biceps, supinator, abductor pollicis longus, extensor pollicis brevis, brachioradialis (in promation), extensor pollicis longus, extensor indicis proprius.

Forearm flexed: short head of biceps, long head of biceps, supinator, abductor pollicis longus, extensor pollicis brevis, extensor pollicis longus, extensor indicis proprius.

16. Muscles acting on the hand at the wrist (arranged according to R. Fick).

(a) 'To flex it: flexor digitorum sublimis, flexor digitorum profundus, flexor carpi ulnaris, flexor pollicis longus, flexor carpi radialis, abductor pollicis longus, palmaris longus.

(b) To extend it: 'axtensor digitorum communis, extensor carpi ulnaris, extensor carpi radialis longus and brevis, extensor indicis proprius, extcusor pollicis longus.

(c) Radial abduction: extensor carpi radialis longus, extensor carpi radialis brevis, alductor pollicis longus, Ilexor carpi radialis, extensor indicis proprius, extensor pollic is longus, extensor pollicis brevis.

(d) Thar abluetion: extensor carpi ulnaris, flexor carpi ulnaris.

17. Muscles acting on the palm:

(a) T'oflex the ulinar side: opponens, long and short flexors of the little finger.

(b) To extend the ulnat sido: cxtensor carpi uluaris, extensor fligiti quinti.

(r) To adeluct the ulatr side: third volar interosseous.

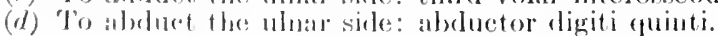

for action on the raclial side see "muscles acting on the thumb." Movements of the second, third and fourth metwearpals are produced by the Iong flexors and the dorsal interosseous muscles.

18. Muscles acting on the thumb.

(a) 'T'oppose the thmmb: adduetor, opponens, flexor brevis, flexor longus, adductor lirevis.

(b) 'l'o repose the thumb: long abductor, short extensor. 
(c) To flex all joints: flexor pollicis longus; the carpo-metacarpal and metacarpophalangeal joints; flexor brevis, the adductors, abductor brevis; the carpo-metacarpal joints: opponens pollicis, abduct or longus:

(d) To extend: all joints, extensor pollicis longus; the carpo-metacarpal and metacarpo-phalangeal joints, extensor pollicis brevis; the interphalangeal joint, abductor brevis, flexor brevis.

(e) To adduct: the adductor, flexor brevis, opponens, first dorsal interosseous, extensor longus.

(f) To abduct: the long and short abductors.

19. Muscles acting on the fingers.

(a) To flex: all the joints, flexor cligitorum profundus; all but the last, flexor digitorum sublimis; the metacarpo-phalangeal joint only, flexor digiti quinti brevis, the lumbricales, and interossei.

(b) To extend the fingers: extensor digitorum communis, extensor indicis proprius, extensor digiti quinti proprius; to extend the two interphalangeal joints: the lumbricales, interossei, and frequently the flexor digiti quinti brevis.

(c) To abduct from the axis passing through the centre of the middle finger: dorsal interossei, first two lumbricales, abductor digiti quinti, the long extensor of the fingers.

(d) To adduct toward this axis: volar interossei, last two lumbricales, opponens and flexor digiti quinti brevis.

20. Muscles acting on the pelvis.

(a) To flex it: rectus abdominis, obliquus abdominis externus and internus, psoas major and minor.

(b) To extend it: sacro-spinalis, multifidus, latissimus dorsi and quadratus lumborum.

(c) To bend it laterally and rotate it: abdominal muscles, quadratus lumborum, psoas muscles, and latissimus dorsi acting on one side.

21. Muscles acting on the thigh at the hip-joint (arranged according to R. Fick).

(a) To flex it: ilio-psoas, rectus femoris, adductor longus, adductor brevis, obturator externus, tensor fasciæ latæ, pectineus, sartorius, gluteus minimus, adductor magnus (upper part), gracilis, quadratus femoris.

(b) To extend it: gluteus maximus, adductor magnus (posterior lower part), biceps, semitendinosus, semimembranosus, gluteus medius, piriformis, obturator internus.

(c) To adduct it: adductor magnus, gluteus maximus, adductor brevis, adductor longus, quadratus femoris, obturator externus, gracilis, adductor magnus (upper part), pectineus, biceps, semitendinosus, obturator internus and gemelli, semimembranosus.

(d) To abduct it: gluteus medius and minimus, the piriformis, rectus femoris, tensor fasciæ latæ, sartorius; and when the hip is flexed, the gluteus maximus, obturator internus, and gemelli.

(e) To rotate it medialward: gluteus medius (anterior portion), gluteus minimus, ilio-psoas, adductor magnus (upper part), pectineus, adductor longus, semitendinosus, semimembranosus, tensor fasciæ late.

(f) To rotate it lateralward: gluteus maximus, quadratus femoris, obturator internus, piriformis, rectus femoris, adductor brevis, arlductor magnus (lower part), biceps, sartorius, obturator externus gracilis, gluteus medius (posterior part).

22. Muscles acting on the leg at the knee-joint (arranged according to R. Fick).

(a) To flex it: semimembranosus, semitendinosus, biceps, gastrocnemius, gracilis, sartorius, popliteus.

(b) To extend it: quadriceps femoris (the tensor fascia latce and gluteus maximus through the ilio-tibial band keep the extentled leg fixed).

(c) To rotate it medialward (when flexed): semimembranosus, semitendinosus, sartorius, popliteus, gracilis.

(d) To rotate it lateralward (when flexed): biceps, tensor fascixe latx.

23. Muscles acting on the foot at the ankle-joint (arranged according to R. Fick).

(a) To flex it: tibialis anterior, extensor digitorum longus, peroneus tertius, extensor hallucis longus.

(b) To extend it: gastrocnemius, soleus, flexor hallucis longus, peroneus longus, tibialis posterior, flexor digitorum longus, peroneus brevis.

(c) To invert the foot at the inferior articulation of the talus (art. talo-calcanea and talc-calcaneo-navicularis): gastrocnemius, soleus, tibialis posterior, flexor hallucis longus, flexor digitorum longus, tibialis anterior.

(d) To evert the foot at the inferior articulation of the talus: peroneus longus, peroneus brevis, extensor digitorum longus, peroneus tertius, extensor hallucis longus, tibialis anterior.

(e) To invert the foot at Chopart's (talo-navicular-calcaneo-cuboid) joint: tibialis anterior, tibialis posterior, flexor digitorum longus, flexor hallucis longus, extensor hallucis longus.

(f) To evert the foot at Chopart's joint: peroneus longus, peroneus brevis, extensor digitorum longus, peroneus tertius. 
24. Muscles acting on the toes (arranged according to R. Fick).

(a) To flex: all the joints, flexor hallucis longus, quadratus plante, and flexor digitorum longus; the first interphalangeal and the metatarsophalangeal joints of the four lateral toes, flexor digitorum brevis; the metacarpo-phalangeal joints, the lumbricales, interossei, abductor hallucis, adductor hallucis (oblique head), flexor hallucis brevis, abductor digiti quinti, flexor digiti quinti brevis.

(b) To extend: all joints, extensor digitorum longus, extensor hallucis longus, extensor digitorum brevis; the interphalangeal joints, the lumbricales, and the adductors and abductors of the big and lit tle toes.

(c) To abduct from an axis passing through the second toe; abductor hallucis, dorsal interossei, abductor digiti quinti, first lumbrical.

(d) To adduct toward this axis: adductores hallucis, plantar interossei, three more lateral lumbricals.

(e) To draw together the ends of the metatarsals: the transverse head of the adductor of the big toe.

References.-For development of the muscular system, consult the list given by IV. H. Lewis, Development of the Muscular System, in Keibel and Mall's Human Embryology; for cariations: Le Double, Traité des variations du systeme musculaire de l'homme; for action of muscles: R. Fick, Handbuch der Anatomie und Mechanik der Gelenke unter Berücksichtigung der bewegenden Muskeln, in von Bardeleben's Handbuch, and H. Strasser, Lehrbuch der Muskel und Gelenkmechanik; for the extremities: Frohse und Fränkel, Die Muskeln des menschlichen Armes und Beines, in von Bardeleben's Handbuch; for the head and trunk: Eisler, Die Muskeln des Stammes, in von Bardeleben's Handbuch; for the pelvis: Holl, Die Muskeln und Fascien des Beckenausganges. Further references to the literature upon the muscular system may be found in PoirierCharpy's Traité d'anatomie humaine. 


\title{
SEGTION V \\ THE BLOOD-I ISCULAR SYSTEM
}

Revised for the Fifth Edition

\author{
BY H. D. SENIOR, M.B., F.R.C.S.
}

PROFESSOR OF ANATOMY, NEW YORK UNIVERSITY

$\mathrm{T}$ HE organs of circulation consist of a system of tubes or vessels which during life are filled with fluid constantly moving in one direction. The major portion of the system is concerned with the continuous distribution of blood throughout the body and is called the hæmal or blood-vascular system. A circumscribed part of the hæmal circulation is differentiated into a rhythmically contracting propulsory organ called the heart. The minor portion of the system is called the lymphatic system. The lymphatic vessels convey fluid, the lymph, from the tissues to the hæmal system.

The essential functions of the blood-vascular system are performed by the smallest of all the blood-vessels, the capillaries [vasa capillaria], which form a network pervading practically all the tissues of the body. Blood is carried to and from the capillaries by larger vessels called the arteries and veins respectively. The heart receives blood from the veins and propels it, in turn, into the arteries.

One of the primary functions of the blood is the transmission of oxygen from the atmosphere to the tissues. In order to do this the blood must of necessity pass through the respiratory organ before being delivered to the body at large. In gill-breathing vertebrates, the blood, having received oxygen in its passage through the gills, passes on directly to the tissues. 'The entire circuit is here accomplished by a single continuous chain of vessels in which capillaries occur twice, once in the gills and again in the organs and tissues in general. In man, as in other higher vertebrates, lungs assume the function of the gills. Having received oxygen in the lungs the blood is returned again to the heart before being redistributed throughout the hody. There are thus in man two separate circuits or systems of blood-ressels, one traversing the lungs and a second ramifying throughout the body. The former is known as the pulmonary circulation; the latter as the systemic. Each has its own arteries, capillaries and veins; the heart is common to both. From the time of birth the heart is longitudinally divided into right and left halves, each of which contains its own independent stream of blood. The blood entering the left side of the heart has issued from the pulmonary circulation and is driven into the systemic; that in the right side, having traversed the systemic eircuit, is returned again to the lungs.

The heart and blood-ressels have a continuous lining of flattened cells called endothelium; the hæmal system is, therefore, a closed circuit. ${ }^{*}$ 'The main thiekness of the heart, arteries and veins consists of additional tissue developed around the endothelial lining. It is due to this tissue that the blood is continuously delivered to and withdrawn from the capillaries under suitable pressure and velocity. The heart is mainly composed of rhythmically eontracting muscle and its valves are so arranged that the contained blood is driven intermittently in one direction only. The walls of the largest arteries are formed to a great extent of elastic tissue, and, being constantly under tension from within, are instrumental in converting the stream, intermittently received from the heart, into a continuous flow. The walls of the medium sized to smallest arteries are mainly muscular. The smallest arteries are microscopic in size and known as arterioles [arteriole]. The muscular arteries are eapable of general or local alterations of calibre regulated by the nervous system; they are thus largely concerned in the maintenance of the blood pressure and in the regulation of the volume of blood entering given loealities under varying conditions. The reins have much thimner walls than the arteries; the blood in them is under low tension upon which they exercise little or no control.

When an artery divides, the combined calibre of its branches is greater than that of the vessel itself. Since the arteries divide repeatedly the bed of the blood-stream increases in proportion as the vessels diminish in size. The rate of increase, slow at first, becomes enormous in the arterioles. Conversely, the bed of flow undergoes contraction as the heart is approached from the venous side. The velocity of flow in the capillaries must necessarily be much lower

* In the spleen and bone marrow the blood-channels intermediate between the arteries and veins are possible exceptions to this statement, but the essential conditions here are still imperfectly understoorl. 
than in the great arteries and veins. From the relative slowness of the blood flow in the systemic capillaries, it has been estimated that their total bed is eight hundred times greater than the bed of the main arterial stem.

Variations in the course and arrangement of the adult arteries and veins, originally studied by the surgeon for utilitarian purposes only, now furnish one of the most stimulating fields for anatomical research. Text-books can provide, at best, catalogues of the arrangement commonly found in the adult body and of the most ordmary variations. That no text-book description can fit any indiridual case in all particulars, and that unusual distribution of vessels does not necessarily shorten life are among the earliest lessons learned in the anatomical laboratory. The adult vascular pattern is derived from a symmetrical arrangement in the early embryo of which scarcely a trace remains. The intervening changes are so numerous and profound that the general uniformity of vascular distribution in different individuals is more remarkable than the occurrence of occasional wide variations from the usual type.

In early stages of development all vessels have a similar structure; they consist, in fact, of a single layer of endothelium. Some vessels, however, are larger than others; these act as arteries or veins (according to the direction of flow) while the smaller channels perform the office of capillaries. The early principal vessels do not necessarily persist, for many of these dwindle or are lost. New channels are meanwhile in continuous process of formation and some of these may, in turn, become main channels. It thus follows that the main vessels of the aduIt must be looked upon rather as selected channels through a plexus of possible pathways, than as separate entities which must necessarily conform to given rules of distribution and branching.

In time, no doubt, most of the commoner variations from the usual adult type will receive a rational explanation; at present enough has been done to indicate the value of the embryological method. The list of variations in the arteries and veins respectively is preceded by a brief account of the morphogenesis of these vessels.

In the case of the heart anomalies frequently result in early death, so that subjects of developmental irregularities are seldom seen in the anatomical laboratory. The anomalies usually consist in improper development of the septa which normally divide the heart and main arterial trunk into their pulmonary and systemic halves. A short account of the morphogenesis of the heart is appended to the description of the adult organ.

In the following section the heart and pericardium will first be considered followed by the arteries and veins.

\section{A. THE HEART AND PERICARDIUM}

\section{THE HEART}

The heart [eor] is a hollow organ principally eomposed of musele, the myocardium. It is lined internally by endocardium which is continuous with the intima of the blood-vessels. Externally, it is covered by the epicardium, a serous membrane continuous with the serous lining of the pericardium. The form of the heart, when removed from the body without previous hardening, is that of a fairly regular truncated cone. The base [basis cordis] is poorly circumseribed but corresponds, in a general way, to the area occupied by the roots of the great vessels and the portion of the heart-wall between them. The base of the heart is held in position* chiefly by the great vessels, which are attached to the pericardium; the remainder of the organ is capable of free movement within the pericardial cavity.

The interior of the heart is longitudinally divided, into right and left cavities, by a septum passing from base to apex. Fach eavity is subdivided into an atrium [atrinn cordis] and a ventricle [ventriuulus cordis], the former receiving the ultimate vonous trunks and the latter giving rise to the main arteries. Thus the loft atrimm reecives the four pulmonary veins, and the right atrium the superior and infrrior vena cava and the coronary sinus; the aorta issues from the left ventricle and the pulmonary artery from the right. The ventrieles, which constitute the major portion of the heart, may be recomised by their very thiek walls. The atria have thinner walls and are less capacious than the ventricles; projecting from earh is a divertieulum or auricle [arreula cordis]. The aurictes (whinh receive their name from thrir resemblance to dog's ears) partially embrace the roots of the pulmonaty artery and abotat.

Orientation of the heart. - The apex of the heart [apex cordis] points forward, to the left and lownwarl. The hase is lirected backward, to the right and upward. 'The longitudinal axis of the hoart forms an angle of about $40^{\circ}$ with the horizontal plane and also with the merlian sagittal plane of the body.

* Not neressarily fixerl, for during systole the hase performs a greater excursion than does the apex. 
The long axis of the heart is therefore slightly more horizontal than vertical, and slightly more antero-posterior than transverse. The atria are posterior to rather than above the ventricles. To arrive approximately at the longitudinal axis, it is necessary to select the central point of the base. By cutting the vessels short in several hearts, hardened by formalin before removal, a point immediately to the left of the left lower pulmonary vein was selected in determining the data above given. A steel pin was passed through this point to the apex cordis, and the angles controlled by frontal and transverse sections of the thorax. Mention of angular measurements of the axis of the heart could be found only in the text-books of Testut and Luschka; the former gives $40^{\circ}$ to the horizontal plane, the latter $60^{\circ}$ to the mid-sagittal. Luschka's angle appear to be too large; but further investigation in this direction is desirable.

Fig. 423.-Sterno-costal Surface of the Heart.

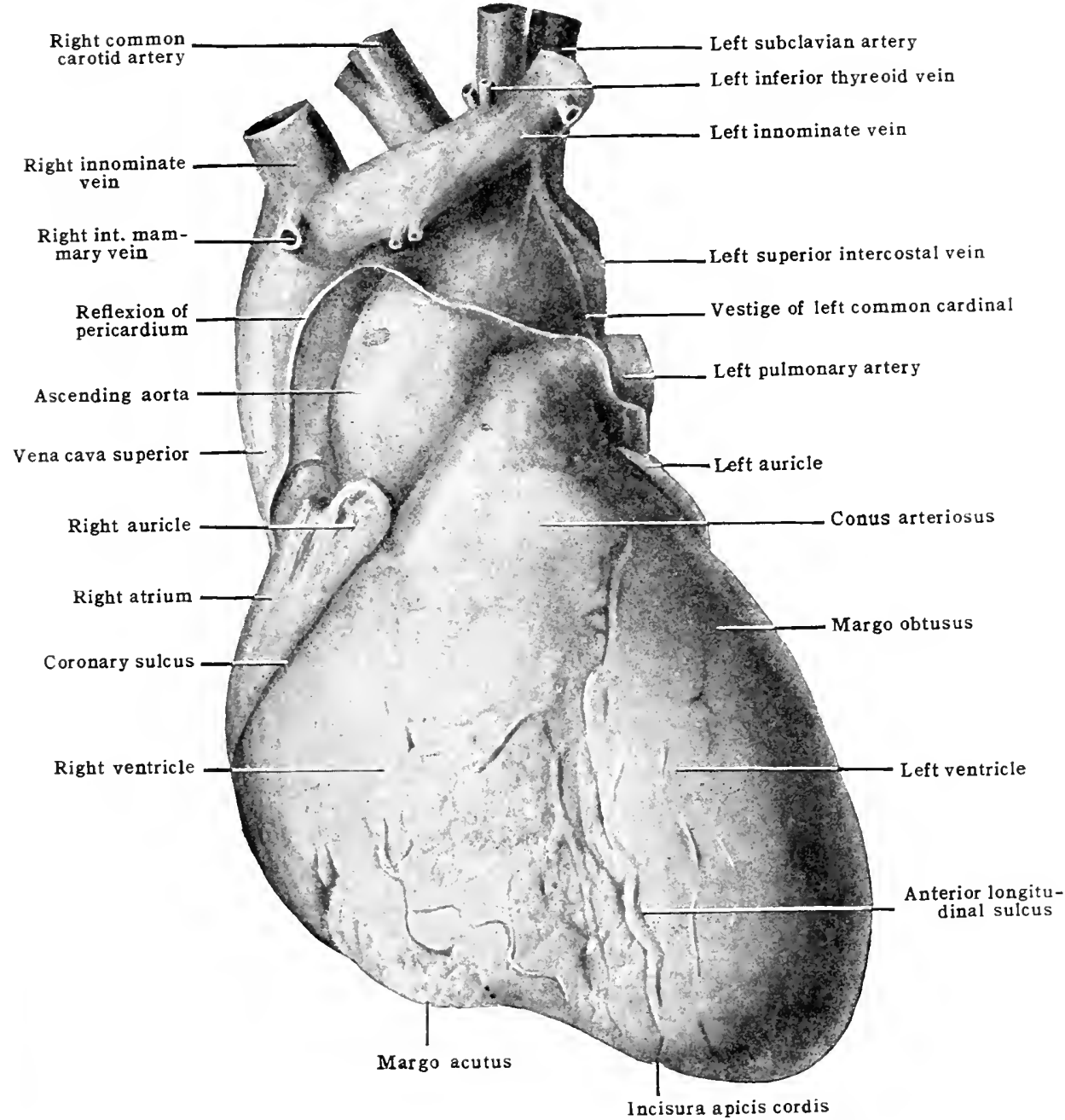

Size and weight.- In the adult the heart measures about $12.5 \mathrm{~cm}$. ( $5 \mathrm{in}$.) from base to apex, $8.7 \mathrm{~cm}$. ( $3 \frac{1}{2} \mathrm{in.}$ ) across where it is broadest, and $6.2 \mathrm{~cm} .\left(2 \frac{1}{2} \mathrm{in}\right.$.) at its thickest portion. In the male its weight averages about $312 \mathrm{gm}$. (eleven ounces), and in the female about $255 \mathrm{gm}$. (nine ounces). It increases both in size and weight up to advanced life, the increase being most marked up to the age of twenty-nine years. The proportion of heart-weight to body-weight is about $1: 205$ in the adult.

\section{EXTERIOR OF THE HEART}

In hearts which have been hardened by injection before removal from the body, the regularity of the heart-cone is disturbed by a well-marked triangular facet, imparted by contact with the diaphragm. This facet is the diaphragmatic surface [facies diaphragmatica], which is directed downward and slightly backward (fig. 424). It ends abruptly along a sharp margin extending from the apex 
toward the right. This margin is the margo acutus (fig. 423); it separates the diaphragmatic surface from the sternocostal surface. The other margin of the diaphragmatic surface is more rounded and shates gradually into the very wide margo obtusus (fig. 423), which passes almost insensibly into the sternocostal surface. The convex sternocostal surface [facies sternocostalis] (fig. 423), directed forward and somewhat upward and to the right, is triangular and bounded below by the margo acutus. To the left it goes over into the margo obtusus along a line extending from the apex of the heart to the root of the pulmonary artery. The margo obtusus corresponds to the rounded left side of the left ventricle.

The interventricular sulcus is a slightly marked groove indicating the separation of the ventricles upon the exterial of the heart. It lodges coronary bloodvessels and a moderate quantity of fat which can be seen through the epicardium

Fig. 424.-Base and Diaphragmatic surface of the Heart. (After His.)

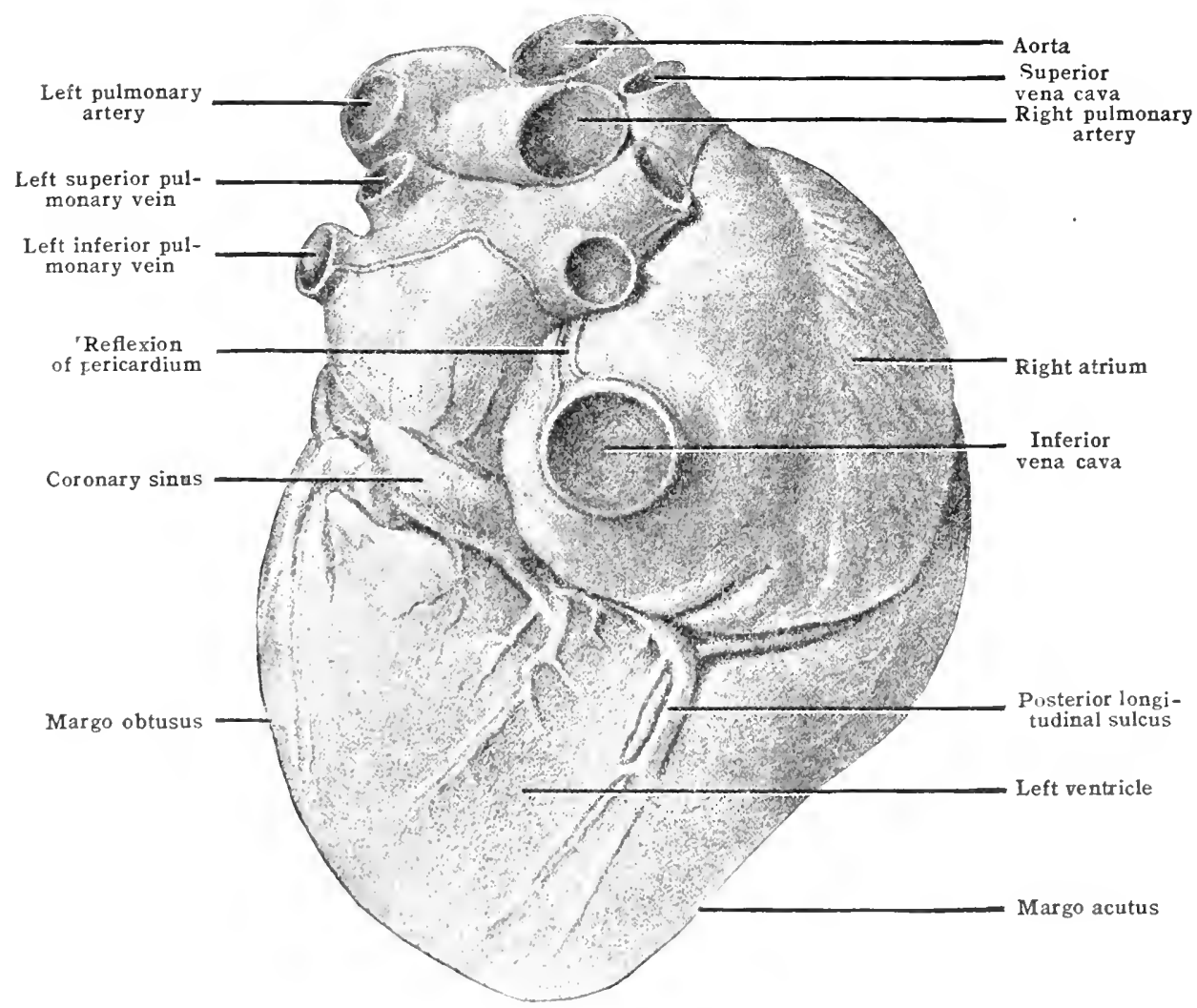

The anterior part of this groove, sulcus longitudinalis anterior, beginning posteriorly, runs obliguely over the mper pald of the margo obtusus on to the sternocostal surfices. ('rossing the mirgo acutes to the right of the apex, it is continuous with the sulcus longitudinalis posterior upon the diaphragnatie surface. The diaphragmatic strfiane is formed about erpually by the right and left ventricles,

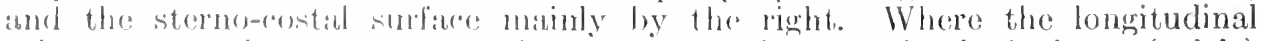
suleas crosises the margo acutus it produces a slight noteh, the incisura (apicis) cordis.

'The atriat are sepatrated axtronally from the ventrieles by the sulcus coronarius. This is a horseshor-shapenl groove well marked betow and haterally, and interrupted above lyy the roots of thr pulmonary artery and aorta. It lodges the coponary simbs, smaller coromary vessels amel liat. 


\section{ATRIAL, PORTION}

The atrial portion of the heart is situated behind, and slightly to the right of and above, the ventricular portion. The separation between the right and left atrium is not indicated behind except in distended hearts (such as that shown in fig. 424); in these it is marked by a slight groove connecting the left sides of the superior and inferior venic cave. In front, the aurieles are separated by the deep notch which lodges the aorta and pulmonary artery. A wight groore on the back of the right atrium which connects the right sides of the superior and inferior venæ cavæ, is the sulcus terminalis (figs. 424, 425). This represents the right limit of what was, in the embryo, the sinus venosus. It also indicates that the embryonic sinus venosus has become an integral part of the adult right atrium. The superior and inferior cave have each a nearly vertical direction and join the posterior part of the right atrium above and below, respectively. The coronary sinus runs downward, backward and to the right to join the lower part of the right atrium anterior to the inferior vena cava. The four pulmonary veins run nearly transversely and somewhat forward into the right and left sides of the left atrium.

Fig. 425.-Atria Opened Posteriorly to show the septum Atriorum.

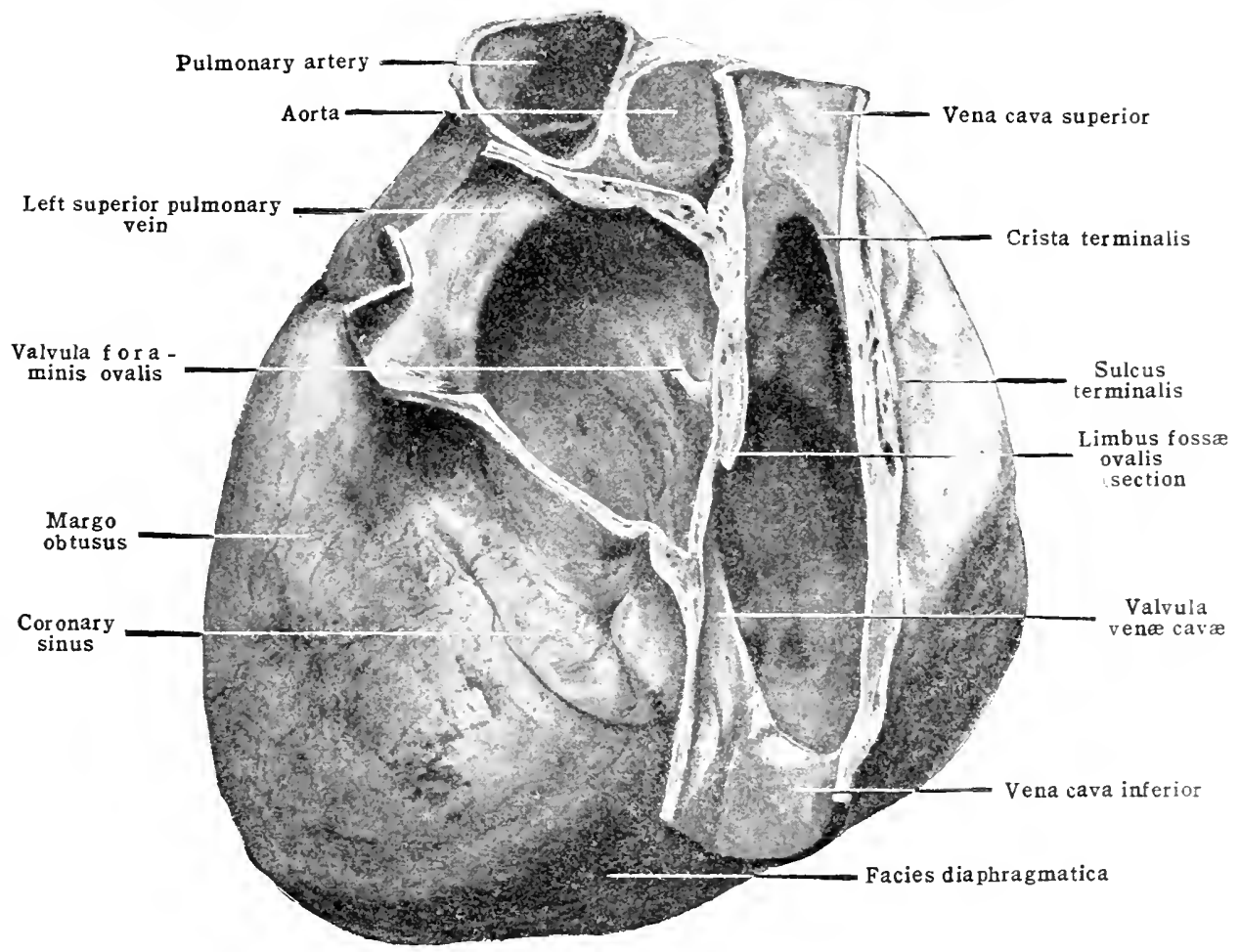

The interior of the atrial portion of the heart is divided into right and left cavities by the septum atriorum. This septum is a composite structure, having been developed (see morphogenesis of the heart) in two independent parts, each forming an incomplete septum in itself. The two incomplete septil, however, partly overlap one another so that, by the lateral fusion at the time of birth, they together produce the impervious structure of the adult heart (fig. 425). Of these septa, the first to be formed is the membranous septum [pars membranacea septi atriorum]. Later there is formed to the right of this the muscular septum, the margin of which forms, in the adult atrium, the greater part cf the limbus fossæ ovalis. The margin of the membranous septum is recognizable as a fold 
of endocardium on the septal wall of the left atrium; it is called the valvula foraminis ovalis.

Posteriorly into the right atrium [atrium dextrum (fig. 425)], above and below, respectively, open the superior and the inferior vena cava. Upon the septal wall, immediately above the inferior cava is the fossa ovalis, a depression of

Fig. 426.-Section of the Ventricles in Systole and Diastole. (After Krehl.)
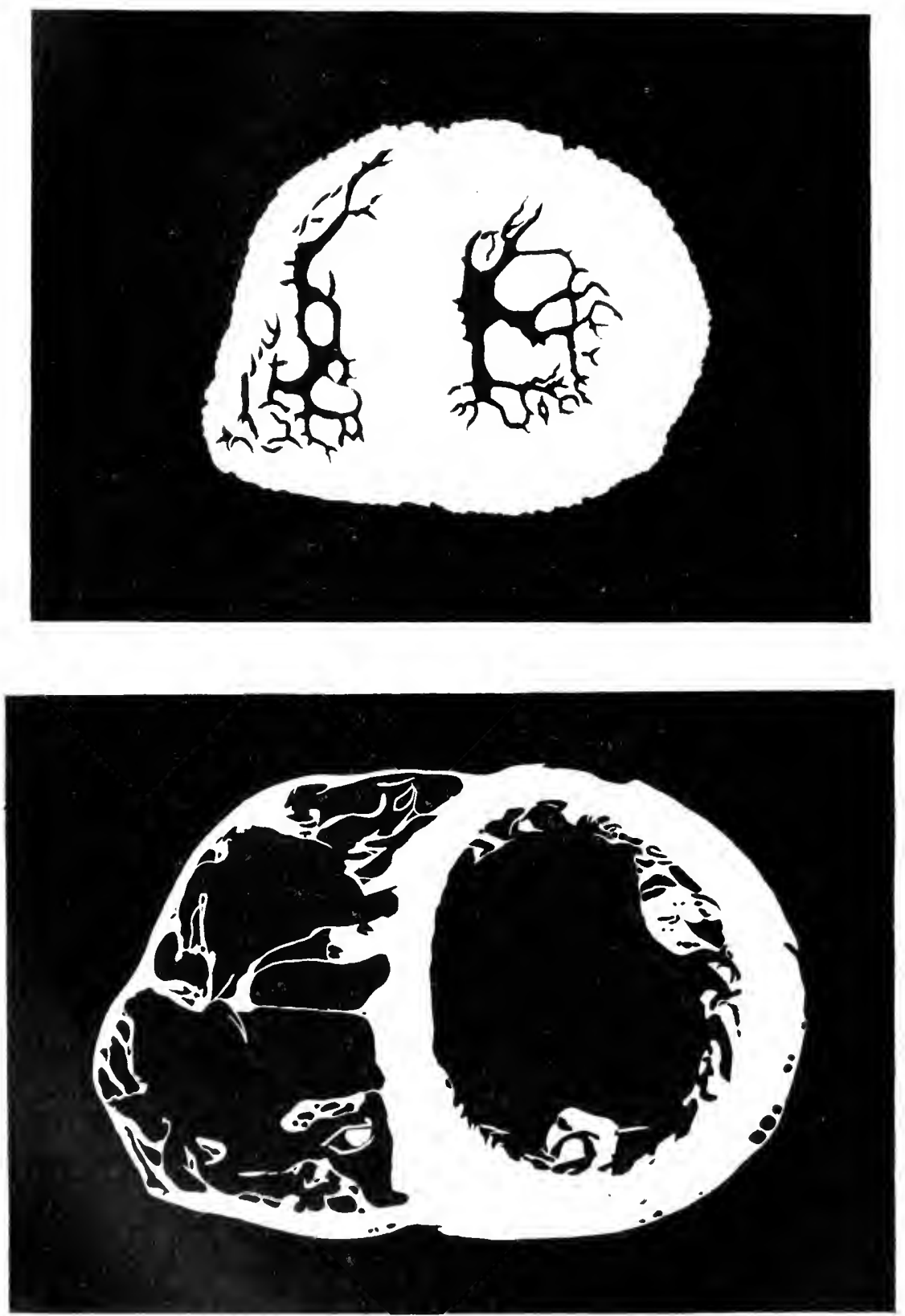

which the floor is formed by the membramous septum. Surrounding the fossa

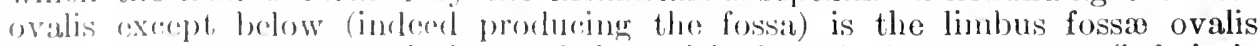
which is eontinuons anteriorly and below with the valvula venæ cavæ (inferioris Hustachii). Just anterior to the fossa ovalis is the orifice of the coronary sinus guarderl hy the valvula sinus coronarii ('Thelesii) (fig. 428). Leading from the 
front of the atrium forward and slightly downward and to the left is the ostium venosum (right atrio-ventricular orifice) guarded by the tricuspid valve. Above and behind this is the auricle, the exterior of which is in contact medially with the root of the aorta. To the right of the superior and inferior caval orifices there is a vertical ridge, the crista terminalis, which corresponds to the sulcus terminalis on the exterior (figs. 425, 428).

The portion of the atrium medial to the crista is smooth and is called the sinus venarum; in the embryo it is separated from the atrial cavity proper by the right and left simus valves. The crista terminalis marks the original line of attachment of the right sinus valve. The valve itself has disappeared, except at the lower part where it persists as the caval and coronary valves. These valves vary in size considerably in different specimens, and are frequently netlike from numerous perforations.

The conversion of a portion of a single valve into two separate valves, which meet at an acute angle, is brought about by an attachment between the sinus valve and an embryonic structure called the sinus-septum. This septum is a ridge dividing the right horn of the sinus venosus from the transverse portion of the sinus (the coronary of the adult); it probably con-

Fig. 427.-The Interior of the Ventricles, Anterior Half. (After His.)

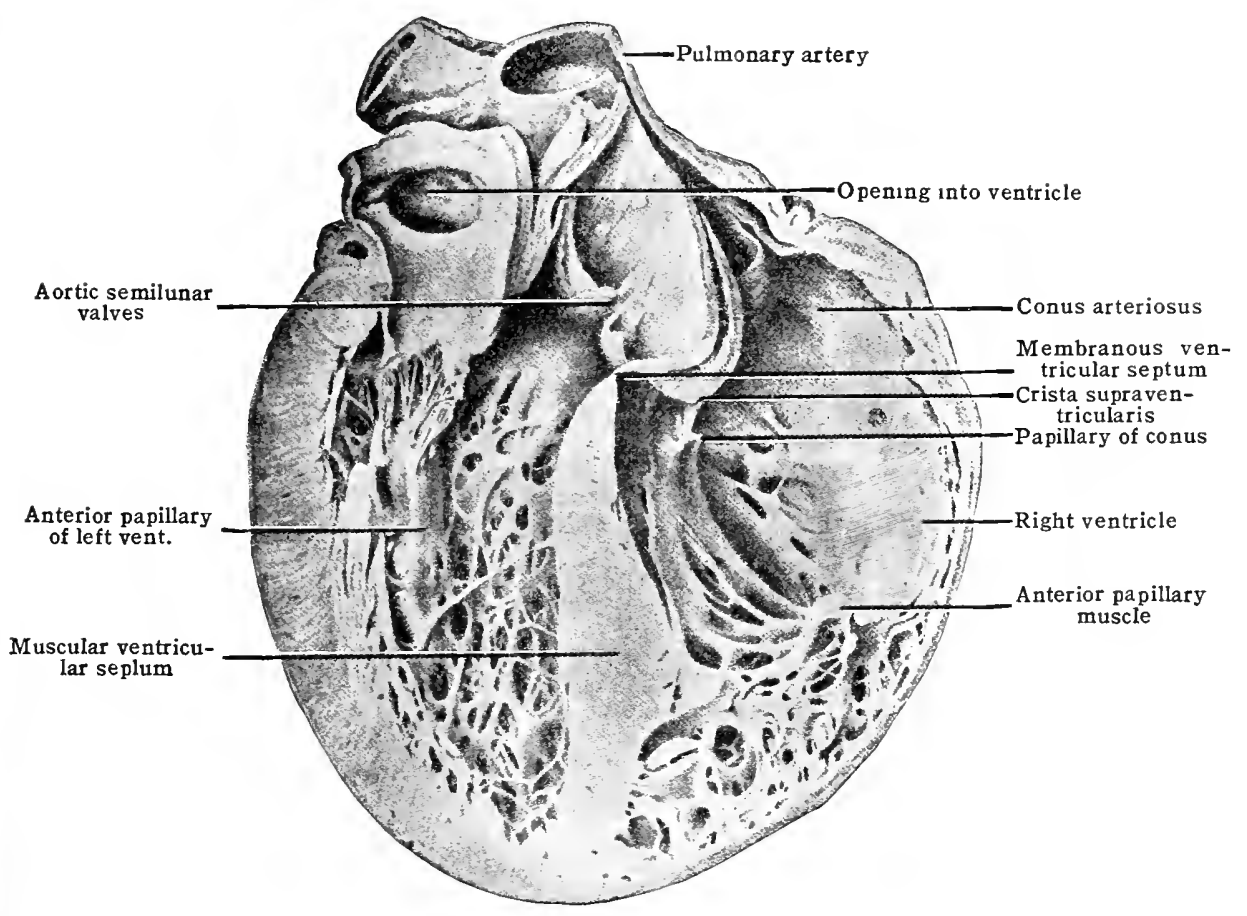

tributes somewhat to the formation of both the coronary and caval valves. The left sinus valve usually disappears by blending with the septum atriorum on which it unites with the limbus fossæ ovalis; it occasionally remains partially separate in the adult.

The interior of the right auricle and of the portion of the atrium Iateral to the crista terminalis is thrown into ridges (musculi pectinati) by prominent bands of the atrial myocardium. The musctili pectinati end abruptly by joining the crista. The orifice of the superior cava has no valve and is directed downward and somewhat forward; below it, on the posterior wall of the atrium, there has been described a tubercle or ridge, the tuberculum intervenosum (Loweri).

Apart from the posterior circumference of the superior cava itself and the limbus fossæ ovalis, the human heart appears to contain nothing in this region that could be described as a tubercle. With regard to the segregation of the streams entering the foetal right atrium from the superior and inferior cavæ, respectively, in which the tubercle of Lower has been supposed to participate, it is to be noted that the fossa ovalis is just above (almost within) the inferior 
caval orifice. Also that the caval opening and the fossal ovalis (containing the foetal foramen ovale) are, in hearts well hardened before removal, situated in a distinct diverticulum to the left of the remainder of the atrium. Between this diverticulum and the atrium proper, the caval valve and the limbus fosse ovatis form a prominent flange, better marked in the fœetus than the adult. Opening into the right atrium, particularly upon the septal and right lateral walls, are numerous foramina venarum minimarum (Thebesii).

The left atrium [a. sinistrum] (fig. 425) is to the left and somewhat posterior to the right. It is behind the root of the aorta and its auricle is to the left of the

Fig. 42S.-Interior of the Right Atriuni and Ventricle.

The atrio-ventricular bundle is dissected out.

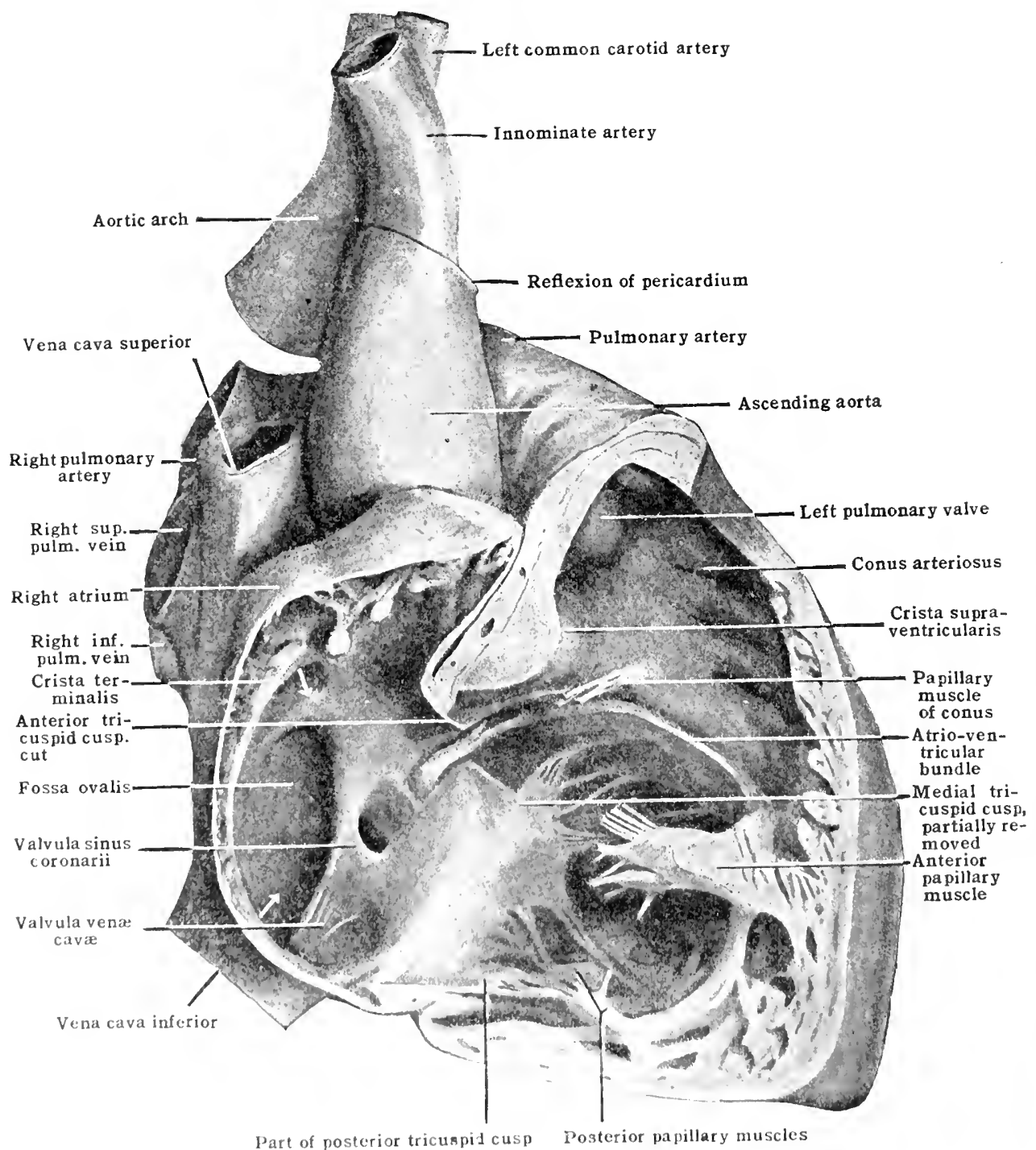

Part of posterior tricuspid cusp Posterior papillary muscles

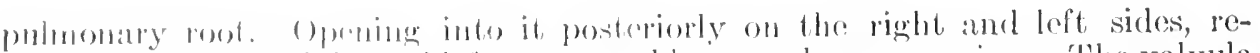

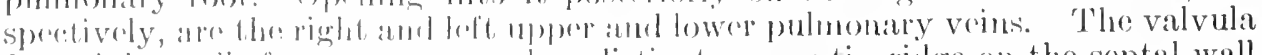

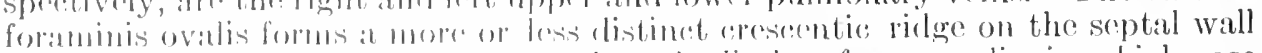

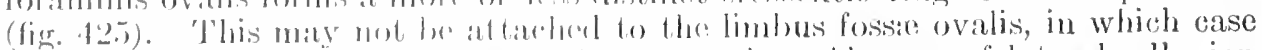

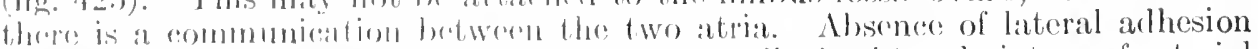

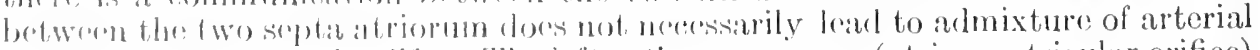

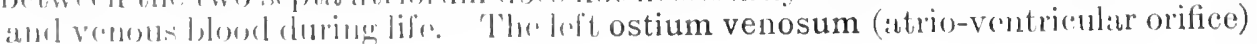


guarded by the mitral valve leads from the anterior part of the atrium forward and slightly downward and to the left. The interior of the left atrium is smooth except in the auricle, in which musculi pectinati are well marked.

Fig. 429.-Left Tentricle and Part of the Atrium.

The arta is opened through the anterior cusp of the mitral valve. The plainly visible left limb of the atrio-ventricular bundle has been accentuated.

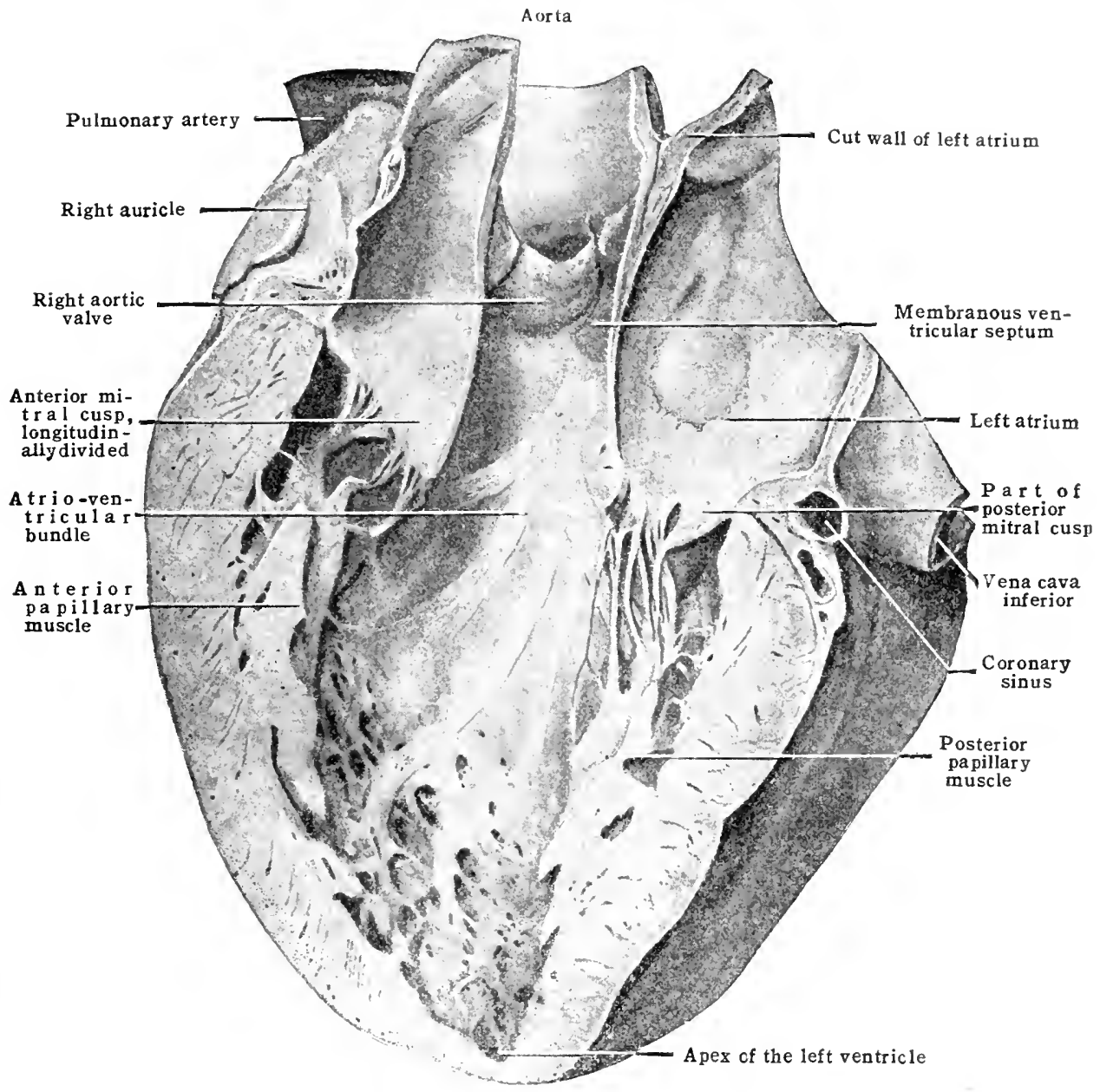

\section{ATRIO-VENTRICULAR VALVES}

The atrio-ventricular valves (figs. $427,425,429,431$ ) are attached around the venous ostia of the ventricles in such a way as to open freely into the ventricles, but to prevent regurgitation of the blood into the atria during ventricular systole. Each valve is continuous along its line of attachment, but its free edge is notehed so as to produce an irregular margin; some of the notehes are so deep as to partially divide the valve into cusps. The right atrio-ventricular valve is commonly divided by three deep notches into three cusps; this valve is therefore called the tricuspid [valvula tricuspicialis]. The left is similarly divided into two cusps and is called the bicuspid [r. bicuspidalis] or mitral. "The depth of the notches, however, is very variable and there may be an increase or (more rarely) a diminution in the number of cusps; the ardlition of small subsidiary eusps is quite common. Each valve cusp is tied down to the papillary muscles $[\mathrm{mm}$. papillares] of the ventricle by chordæ tendineæ. The latter are fibrous cords, generally branched, of varying thickness. The thinnest cords are attached to the free margin of the eusp; those of intermediate thickness to the rentricular surface a few millimetres from the margin, and the thickest to the ventricular surface 
near the attached margin. The valves are smooth and glistening on the atrial aspeet, but rough and fasciculated, from the attachment of the chordæ, on the ventrieular. The cusps of the mitral valve are called anterior and posterior; those of the tricuspid, anterior, posterior and medial. Each cusp receives chordæ from more than one papillary muscle and each papillary muscle sends chordæ to more than one cusp. The chordæ tendineæ of the mitral valve are thicker than those of the tricuspid (figs. 428, 429).

\section{VENTRICULAR PORTION}

The ventricles form the greater portion of the heart. In the adult the relation of the ventrieles to one another is as follows. The left [ventriculus sinister] has the form of a narrow cone, the apex of which is the apex of the heart. The right ventricle [ventriculus dexter] is erescentie in section and appears to be partially wrapped around the right or lower wall of the left ventricle which forms the septum ventriculorum (fig. 426). The left ventricle forms the margo obtusus of the heart, about half the diaphragmatic surface, and a slight part of the sterno-costal surface. The right ventricle forms about half the diaphragmatic surface and the major part of the sterno-costal surface; it takes no share in the formation of the apex of the heart.

The interventricular septum [septum ventriculorum] is thick and museular except for a small area near the root of the aorta which is membranous [septum membranaceum ventriculorum]. The latter ean be seen from the left ventricle in the angle between the attached edges of the right and posterior aortic valves (fig. 429). The membranous septum is partly concealed from the right heart by the medial cusp of the tricuspid valve which is attached to it near its upper part. The portion of the membranous septum above the medial trieuspid eusp is therefore atrio-ventricular, i. e., between the right atrium and left ventricle.

The membranous septum is the extreme lower part of the independent septum (s. aorticum) which divides the aortic root from the pulmonary artery and conus arteriosus (and partially subdivides, also, the right ventricle by separating the conus arteriosus from the remainder of the ventricle). The relation of the part of the aortic septum between the conus arteriosus and aortic root to the septum ventriculorum is beautifully shown by His, in fig. 427 .

The greater part of the interior of the ventricles is thrown into ridges by myocardial bundles of large size. These fasciculi [trabeculæ cordis] either stand out in relief only, or, by being undermined, form bands covered except at either end by endothelium. A careful examination of the endocardium of fresh hearts will reveal a plexiform network of Purkinje fibres. These fibres, belonging to the atrio-ventricular conducting system, become very obvious when the endocardium has been exposed to the air long enough to beeome partially dry.

The wall of the right ventricle [ventriculus dexter] (figs. 427, 428) is mueh thicker than that of the atria, but less so than that of the left ventricle. The upper and anterior part of the right ventricle is in relation posteriorly with the root of the aorta. This portion of the ventricle is ealled the conus arteriosus and is separated from the remainder of the right ventricle by a museular spur whieh ext'nuls from the back of the conus to the right venous ostium. The spur is the crista supraventricularis; its relation to the partition between the conus and aorta, and to the septum membranaceum, shows that it is the free edge of the embryonic aortic septum (see morphogenesis of the heart).

T'wo papillary museles in the right ventricle are constant in position, the large anterior papillary muscle, and the small papillary muscle of the conus (Luschka). The anterior papillary is situated on the sterno-eostal wall, near the junction of this with the septal wall. The papillary of the conus is placed just below the septal end of the crista supraventrieularis. The posterior papillary muscles form an irregular group springing from the diaphragmatie wall. Some chordes tendinear stroteh rirectly from the septal wall (with or without small muscolar olevations at their hases) to the medial cusp of the trienspid valve. The chorda tendinea from the anterior papillary go to the anterior and posterior cusps; those from the ronus papillary to the inedial and anterior, and those from the postarior papillary muscles to the medial and posterior casps of the trieuspid valve, respordively.

Theme is frequently a band of myorardimm cxtending from the septal wall of the right ventricle to the anforior malllary muscle noar its midelle. This is the moderator band, which contains a part of the right limb of the atrio-ventricular bundle. If the moderator band joins 
the anterior papillary near its base, as it frequently does, it is difficult to distinguish it from the ordinary trabeculæ in this situation.

The term moderator band was originally applied to this bridge or band of muscle under the. impression that it prevented overdistention of the ventricle. Subsequent discovery of the conducting system of the heart makes it plain that there is always a band conducting the right limb of the atrio-ventricular bundle from the septum to the anterior papillary muscle. Whether the band is isolated from the other trabecula, and therefore readily recognizable, appears to depend somewhat upon the relation of the base of the papillary muscle to the septum ventriculorum.

The wall of the left ventricle [ventriculus sinister] (figs. 427, 429) is very thick except at the extreme apex, and at the membranous septum. In the left ventricle are two large papillary muscles, generally known as anterior and posterior; both send chordæ tendineæ to each cusp of the mitral valve. On the septal wall of the ventricle the left limb of the atrio-ventricular bundle can usually be seen as a broad, flattened band beneath the endocardium. The band appears just below the septum membranaceum and divides into strands which go to the two papillary muscles. The strands in many places bridge across part of the ventricle to reach the papillary muscles covered only by tubes of endocardium.

These bridging strands connecting the papillary muscles with the septum ventriculorum, which were formerly called "false chordxe tendinex," are exactly comparable to the moderator band of the right ventricle which occasionally consists of atrio-ventricular bundle and endocardium only.

\section{SEMILUNAP VALVES}

The semilunar valves [valvulæ semilunares] guard the arterial ostia of the ventricles. The aortic ostium is directed upward and slightly forward and to the right; the pulmonary backward and slightly upward and to the left. Each valve, of which there are three to each ostium, is a pocket-like fold of endocardium strengthened by fibrous tissue (fig. 430). The free edge of each valve is directed away from the ventricle, so that excess of pressure within the great vessels brings

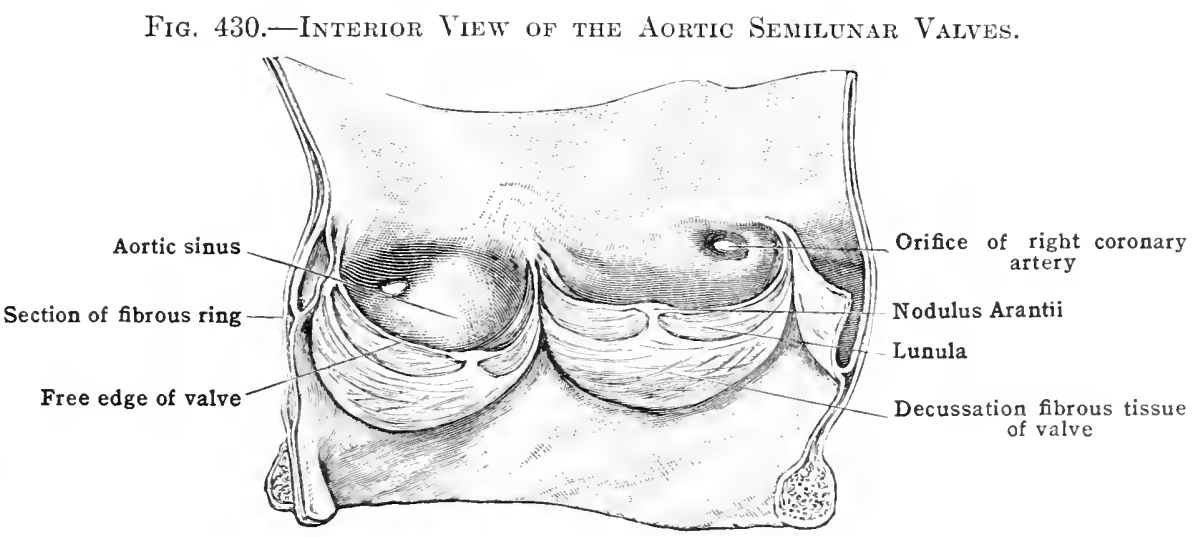

the three valves of either ostium into mutual apposition. In the middle of the free edge of each valve there is a small fibro-cartilaginous nodule; radiating from this toward the entire fundus, and along the extreme free edge of the valve, are fibrous thickenings. On either side of the nodule, between the thicker margin and fundus, the valve is thin over a crescentic area called the lunula.

The aortic valves are called the right, left, and posterior; the pulmonary valves. the right, left, and anterior.* The aortic semilunar valves are stronger than the pulmonary; opposite them there are three dilatations in the aortic wall, the artic

* The BNA names of the aortic and pulmonary valves are not based upon their relative positions in the body. From transverse sections through the thorax (see any good atlas) it may be seen that one aortic valve is anterior, one pulmonary valve posterior, and the other aortic and pulmonary valves are right and left. If the removed heart is held so that the ventricles are on the right and left of the septum, respectively, the valves take the positions indicated by the BNA. The names given by the BNA to the valves, although conventional (like many other terms of orientation applied to parts of the heart), are convenient, particularly from a developmental standpoint. 
sinuses [sinus aortæ] or sinuses of Valsalva. From the right and left sinuses the right and left, coronary arteries, respectively, arise.

After ventricular systole the increased pressure in the great vessels distends the valves with blood. The noduli meet in the centre and the lunulæ, coming into mutual contact, produee a tri-radiate line of eontact between the valves.

\section{ARCHITECTURE OF THE MYOCARDIUM}

In the adult heart the myocardium of the atria is separate from that of the ventricles. There is, between the atria and ventrieles, a fibrous partition, the upper and lower surfaces of which give attachment to the muscle fibres of these eavities, respectively.

The fibrous partition (fig. 431) is thickest in the triangle formed by the meeting of the aortie, and right and left atrio-ventricular ostia. This interval is filled by a mass of fibrous tissue, which in the angles between the aortic and the left atrio-ventricular ostium forms two thiekened triangular masses, the trigona fibrosa. The fibrous mass is continued to the pulmonary ostium as the tendon of the conus. Below the point of junetion of the trigona and the tendon of the conus these structures blend with the septum membranaceum ventriculorum. The septum membranaceum, tendon of the conus, and part of the trigona are derived from the aortic septum (pp. 516,527). The trigona give off laterally, on either side, atrio-ventricular rings which encircle the venous ostia and give attachment to the atrio-ventrieular valves. There are also weak

Fig. 431. Base of a Well Developed Heart showing the Course of the Superficial Muscle Flbres.

From $\mathrm{X}$ to $\mathrm{K}^{\prime \prime}$ around the front of the aorta indicates the course of the aortic septum. (Mlall, $\frac{3}{4}$ nat. size.)

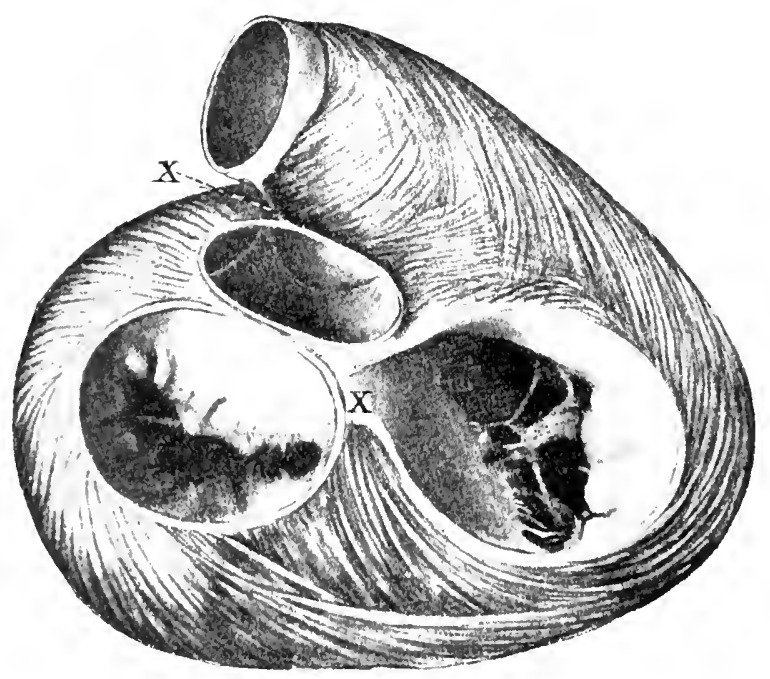

rings surrounding the pulmonary and anrtic orifues; the antic and left atrio-ventricular rings being partly confluent. 'The rings surrounding the arterial and venous ostia are the annuli fibrosi.

The atrial musculature is attached to the trigona and atrio-ventricular rings only. The superficial fibres are attached to both rings and either ('ncircle both atria in one loop, or enter the septum and form a figure 8 . 'l'he deejer filmes are attached to one ring and encircle one atrium only; some filres encircle only tho amicle.

The ventricular musculature is very complex and consists of numerous superimposed layers distinguisherl from one another ly the direction taken by the muscle fibres. In a general way", the fibres of the deepest layer have a direction arosing those upon the surface of the same area at a right angle. The intervening layel's of libres pass through all stages of obliquity.

Reerent wrok upon the origin and distribution of the ventrienlar fibres bas resulted in the recognition of a certain minformity of belavior, thus:-

1. All filmes arise from, and are inserted into, the librous partition at the base. The attarhment inay lecelirecoly to the trigona or anmoli, or indireetly to them hy means of the ehorda tendingate and atrin-ventricular valves.

2. The more superficial filors (fig. 132) teml to cucircle the entire heart, passing over the

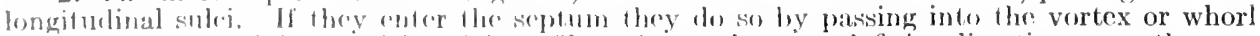
at the apex of the left velificle. These lifers have always a definite direction upon the sur-

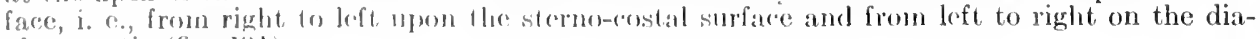
phragmatic (fig. li31).

: The teeper fibres all anter the septum in a clirection oblique or perpenticular to its

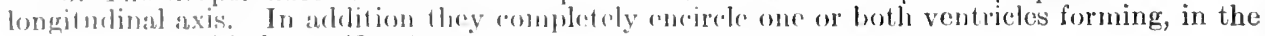
latter case, louble loops (fig. 1:3:3). 
During systole, as a result of this arangement:-(1) The papilary muscles and the longitudinal and antero-posterior axes of the ventrieles are simultaneously shortened. (2) There is a movement of torsion ol "wringing" which reduces the ventricular cavities to their minimum dimensions.

Conducting system.-Although the ordinary myocardium of the atria is distinct from that of the ventricles there is, at one place, a connection between them. This connection is by means of a small band of muscle which differs histologieally from ordinary heart muscle. It is known as the atrio-ventricular bundle, and serves to transmit the atrial rhythm of contraction to the ventricles.

The atrio-ventricular bundle begins in the septal wall of the atrium a short distance in front of the coronary orifices (fig. 42S). It has an expanded free end, the atrio-ventricular node, from which branches pass to be quickly lost in the atrial myoeardium. The bundle passes forward covered by endocardium and by one or two millimetres of myocardium, and passes beneath the medial cusp of the tricuspid valve. In passing from the atrium to the rentricle, the bundle skirts the lower margin of the septum membranaceum. Immediately in front of the septum membranaceum it divides into a left and right limb, of which the former pierces the muscular interventricular septum. The right limb now passes beneat he crista supraventricularis and above the papillary muscle of the cunus, giving off branehes to the latter and to other small papillaries on the septum (fig. 42S). Bending somewhat toward the apex, it enters the moderator band which conducts it to the large anterior papillary musele. From here it passes along one of the trabecule connected with the sterno-costal wall of the ventricle, or in the wall itself, to reach the posterior papillary muscle or muscles. The right limb is compact and rounded and in the intact heart is usually invisible except, sometimes near the root of the moderator band or in the band itself.

The left limb of the bundle appears in the left ventriele a little below the septum membranaceum. It is a wide band immediately beneath the endocardium, which cannot usually be

Fig. 432.-Diagram of ONE ANTERIOR and one Posterior Superficial Bundle of Cardiac Muscle Fibres seen from Benind. (After MacCallum.)
Fig. 433.-DIAGRA OF A DEEPER Bunder of M USCle Fibres. (After IacCallum.)

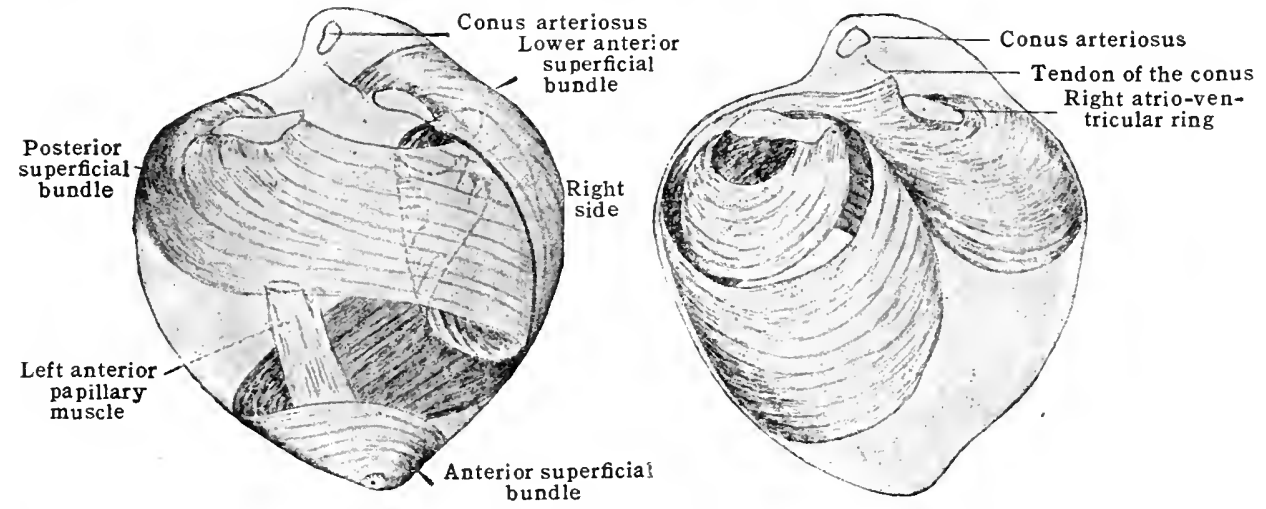

stripped off without injuring the bundle (fig. 429). It passes along the septal wall toward the apex and divides into two parts, which again subdivide to be distributed to the anterior and the posterior papillary muscles. The branches for the papillary muscles may reach them through thick trabeculæ, or they may form thin strands which, covered only by endocardium, bridge from septum to papillary muscle.

In addition to the comparatively distinct branehes to the papillary muscles of both ventricles, the bundle gives off finer fibres which form a sub-endocardial plexus. This plexus, visible to the naked eye (p. 516) is made up of fibres having a strueture similar to those of the ventricular portion of the bundle. The fibres were described by Purkinje as long ago as $1545,{ }^{*}$ but it was not until 1906, thirteen years after the discovery of the bundle by W. His, Jr., that Tawara recognised their significance.

There is another node of muscle having characters similar to that of the conducting system, although not connected with it except by myocardium of the ordinary character. This is the sinus-node which is situated at the upper end of the crista terminalis of the right atrium. Unanimity is still lacking with regard to the physiological sigmificance of this structure.

\section{Tessels and Nertes of the HeArt}

The arteries.-The two coronary arteries arise from the right and left simuses of the aorta.

The right coronary artery [a. coronaria dextra] passes forward between the pulmonary artery and the right atrium, and then follows the right coronary suleus to the diaphragmatic surface of the heart (fig. 435), to anastomose with the left eolonary artery. The posterior descending branch [ramus descendens posterior] arises at the posterior longitudinal suleus. It

* Arch. f. Anat., Physiol. u. wissensehaftliche Medizin.

$\dagger$ Das Reitungssystem des Saügertierherzens, Fischer, Jena, 1906. 
passes in the furrow between the ventricles toward the apex, near which it anastomoses with branches derived from the left coronary artery. In this course the right coronary artery supplies branches to the right atrium and roots of the pulmonary artery and aorta, as well as one that descends near the margo acutus (right marginal), and a second (preventricular) to the anterior wall of the right ventricle. It supplies both ventricles and the septum.

The left coronary artery [a. coronarius sinistra] passes for a short distance forward, between the pulmonary artery and the left auricle, and then divides into two principal branches, one of which runs in the anterior longitudinal sulcus to the apex of the heart, the anterior descending branch [r. descendens anterior], around which it sends branches to anastomose with the right coronary; whilst the other, the circumflex [ramus circumflexus], winds to the diaphragmatic surface in the coronary groove, to auastomose with the corresponding twigs of the right artery. In this course it gives off a branch which follows the margo obtusus (left marginal) as well as smaller branches to the left atrium, both ventricles, and the commencement of the aorta and pulmonary ressels.

Fig. 434.- Stererno-costal Surface of the Heart, showing its Arteries and Veins. (After Spalteholz.)

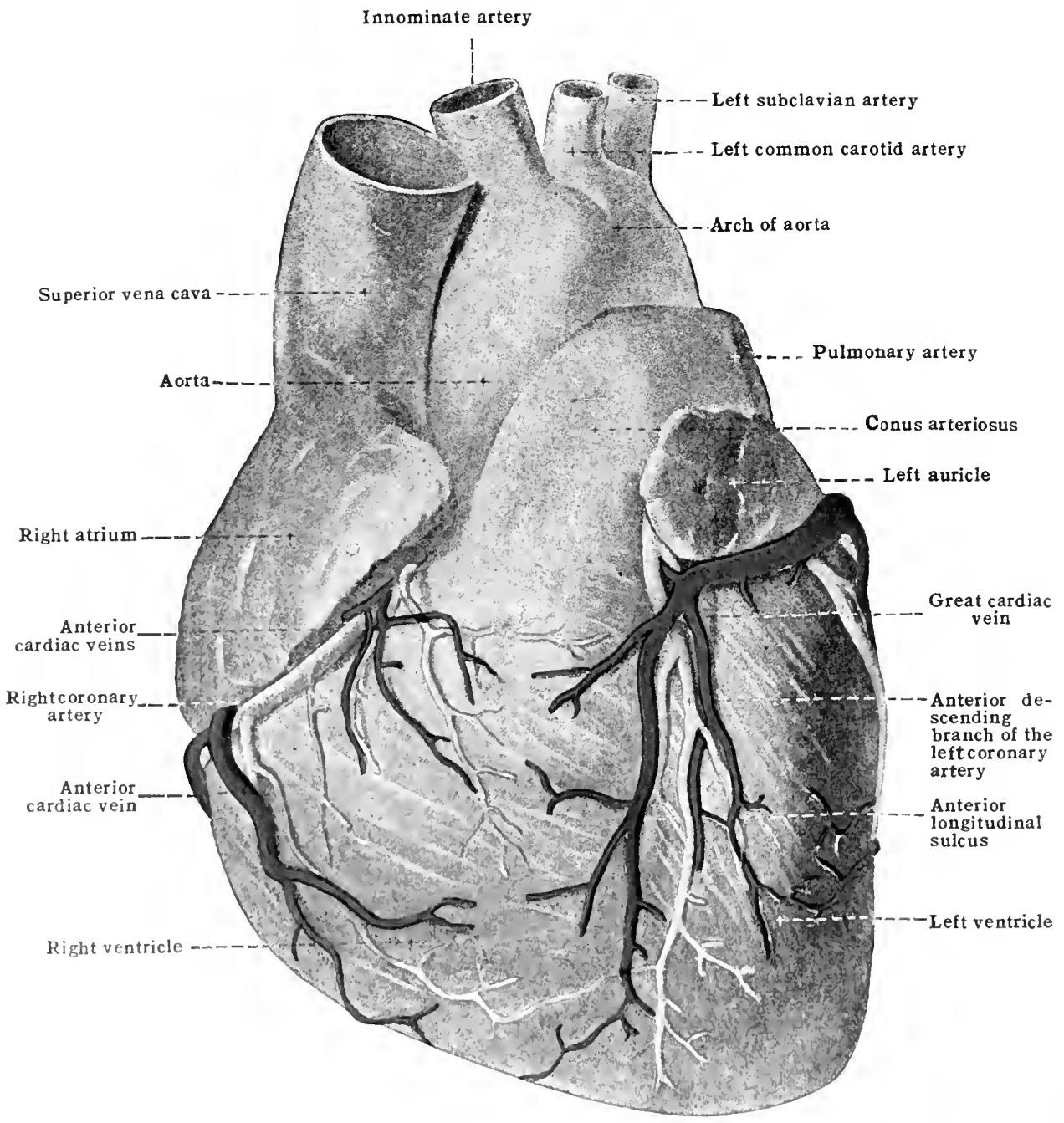

The cardiac or coronary veins acempany the comonary arteries and return the blood from ther: walls of the herith.

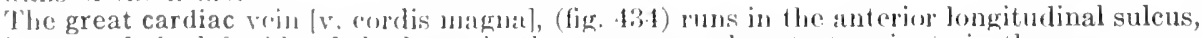
bassing round the loft sile of the heart in the cobonary sulews to terminate in the commencement of the (o) renuse the pesterior vein of the left ventricle, with of her smaller veins from the left atrium and bentricle, all of which are guarded ly valyes

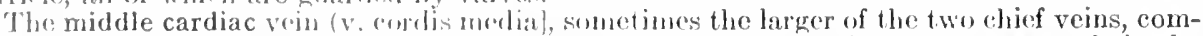

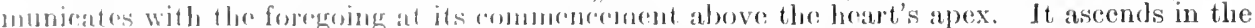

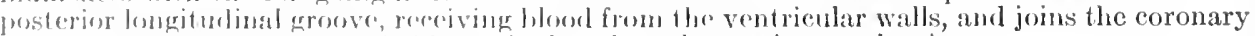
sinus fhrough an orifiere guardoel hy a single valve, alose to its formination, 
The posterior vein of the left ventricle [r. post. ventriculi sinistri], lies upon the posterior surface of the ventricle and, receiving branches from it, passes upward to terminate directly. in the coronary sinus.

The anterior cardiac veins [vv. cordis anteriores] consist of several small branches from the front of the right ventricle, which vary in number and either open separately into the right atrium or join the lesser cardiac vein (fig. 434).

The small cardiac vein [ $\mathrm{r}$. cordis parva] is a small vessel which receives branches from both the right atrium and ventricle, and winds around the right side of the heart, in the coronary sulcus, to terminate in the coronary sinus.

The coronary sinus [sinus coronarius] (fig. 435) may be regarded as a much dilated terminal portion of the great cardiac rein. It is about $2.5 \mathrm{~cm}$. (1 in.) in length, is covered by muscular. fibres from the atrium, and lies in the coronary sulcus below the base of the heart. Its cardiac orifice, with the coronary (Thebesian) valve, has already been described. Besides the tributary veins already named, a small oblique vein [v. obliqua atrii sinistri] of the left atrium may some-

Fig. 435.-Base and Diaphragmatic Surface of the Heart, showing its Arteries axd VEINs. (After Spalteholz.)

\section{Right pulmonary artery}

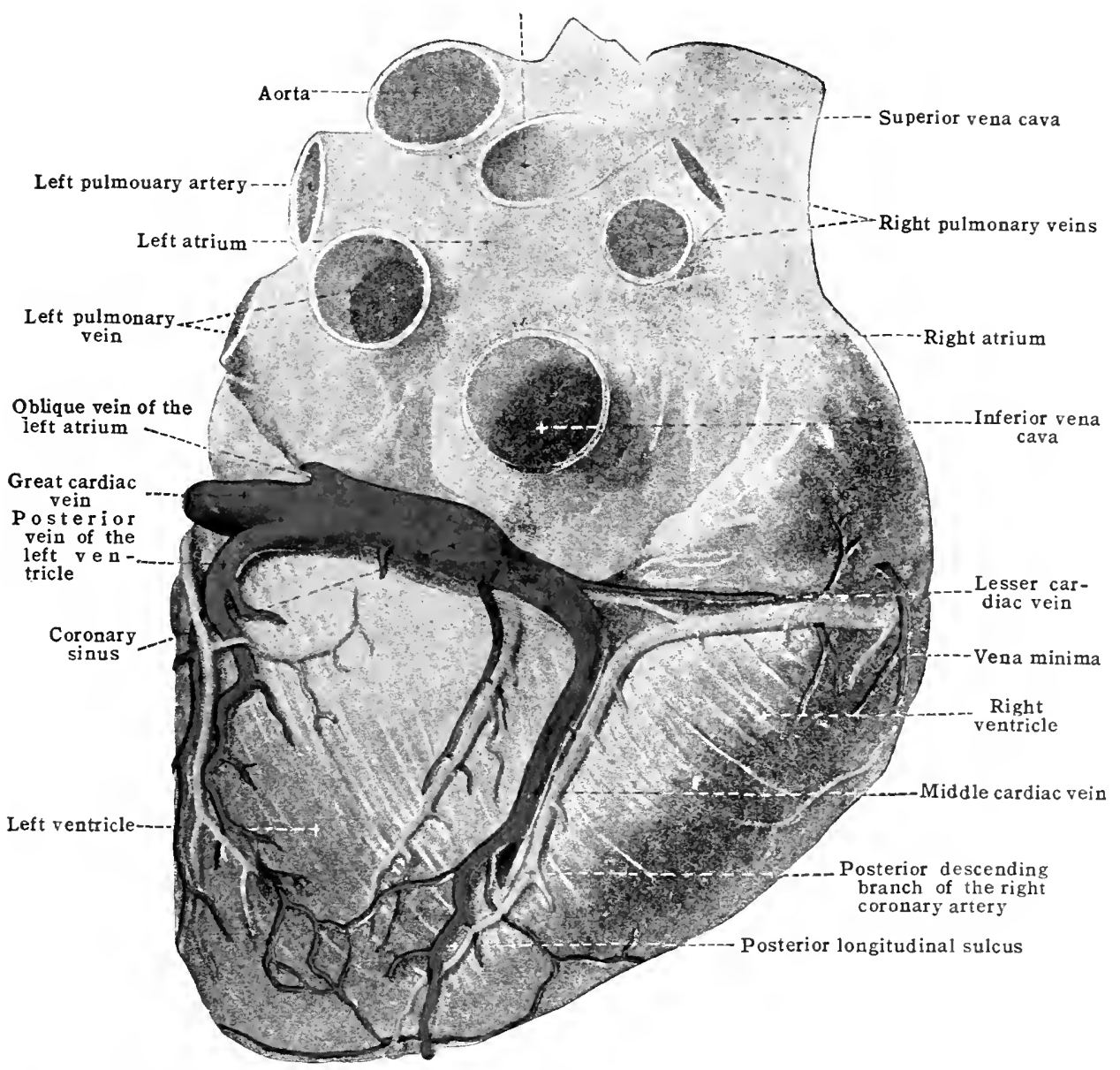

times be traced, on the back of the left atrium, from the ligament of the left rena cara (Marshall to the sinus. This little vein, which is not always pervious or ensy of demonstrition, never possesses a valve at its orifice, and, like the coronary sinus, formed a part of the left superion vena cava of early foetal life.

The smallest cardiac reins [rv cordis minima] drain blood from septum and lateral walls of the atria, particularly the light; also from the conus arteriosus. They open directly into the right atrium.

Although anastomoses occur between the two coronary arteries, these are by no means extensive, and are not sufficient to allow of the establishment of a satisfactory collateral circulation in the case of the blocking of one coronary artery. Consequently scich interference with the cardiac circulation produces rapid pathological changes in the heart musculature, provided it is sudden in occurrence. If the obliteration of the artery take place gradually, however, some relief may be afforded by the establishment of a collateral circulation through the venæ minimæ, which open out from both the atrial and ventricular cavities and communicate 
with the finer branches of the cardiac veins, and also with the general capillary network in the heart's walls.

The lymphatic vessels of the beart pass chiefly through the anterior mediastinal lymphnodes into the broncho-mediastinal trunk. (See Section VI.)

The cardiac nerves, derived from the vagus and the cervical sympathetic, descend into the superior mediastinum, passing in front of and behind the arch of the aorta; they unite in the formation of the superficial and deep cardiac plexuses. The superficial plexus lies above the right pulmonary artery as the latter passes beneath the aortic arch. The deep plexus lies between the trachea and the arch of the aorta, above the bifurcation of the pulmonary trunk. For the connections of the plexuses see section on Nerrous Srstem.

\section{THE PERICARDIUM}

The pericardium is a cone-shaped, fibro-serous sac which surrounds the heart and contains a small amount of fluid [liquor pericardii]. Its apex is above at the root of the great ressels, and its base below, adherent to the diaphragm. Its connection with the diaphragm is in part to the central tendon and in part to the muscle, especially on the left side. It consists of an outer fibrous layer and an inner serous layer. The virtual space between the serous pericardium and the epicardium is commonly called the pericardial cavity.

Fig. 436.-Lefe Posterior View of the Heart to show the Reflections of the PeriCARDIUM.

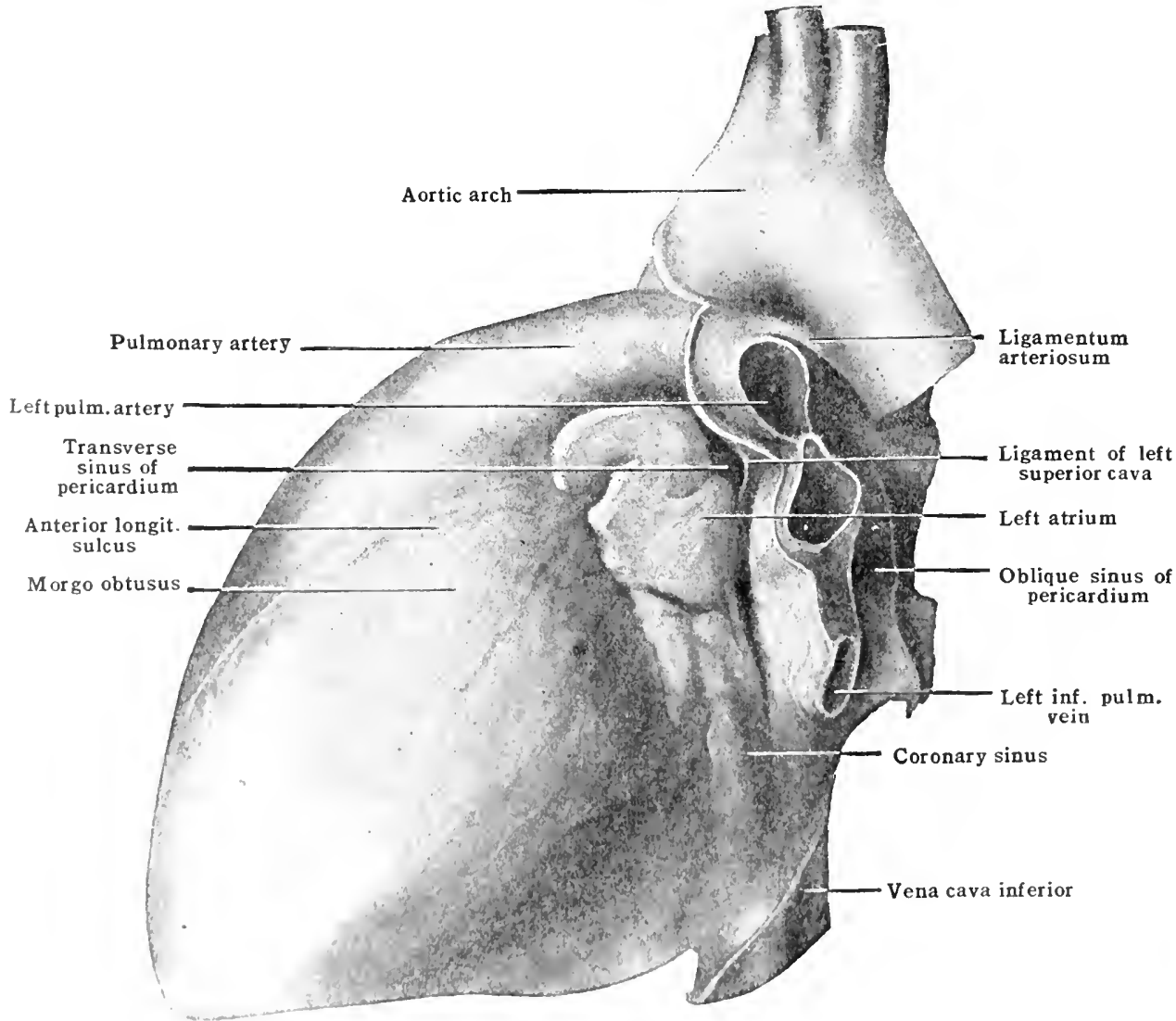

The fibrous layer is strome and inclastic, made of intorlacing libres. Lis connection with the contral temlon of the liaphragm is intimate, waticularly in the region of the caval opening,

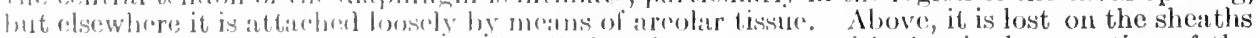
of thrs gront vessels, all of which poreive, distinct investments, with the single exception of the inforior verat cavat, which pierese it from below. The acorta, superior vena cava, the pulnonary artery, and the four molmonary veins, are all ansheatherl in thismanner. The pericardium is

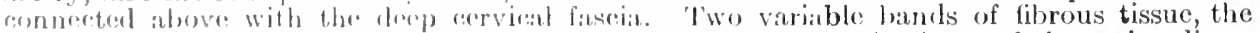
sterno-pericardial ligaments |ligre. sterno-perimelian:al, (onmet the front of the pericardium, above and holew, with the posterior surface of the stermum. 
The serous layer is smooth and glistening and consists of connective tissue, rich in elastic fibres, covered by endothelium. It lines the interior of the fibrous layer and is continuous with the epicardium or serous covering of the heart. The reflexion of the serous layer from the heart to the fibrous layer of the pericardium occurs at both the arterial and venous attachments of the heart. At the arterial attachment a simple tube of epicardium is reflected along the pulmonary artery and aorta. At the venous attachment the serous layer is reflected from the front of the pulmonary veins on the left, and from the front of these and from the roots of the venæ cava on the right. This reflexion is separated above from that around the aorta and pulmonary artery (figs. 424, 436). Around the lower margin of the left lower pulmonary vein (fig. 436) and the root of the inferior vena cava, this reflexion is continuous with an arched reflexion from the back of the atria (figs. 424,436). The latter reflexion forms a pocket posterior to the atria which is sometimes called the oblique sinus of the pericardium.

Between the reflexions of the epicardium at the arterial and venous attachments of the heart there is a dorsal communication between the right and left sides of the pericardial cavity. This is the transverse sinus of the pericardium [s. transversus pericardii]; it passes behind the aorta and pulmonary artery and in front of the superior cava and left atrium.

During early embryonic life the sinus transversus is closed by the dorsal mesocardium (see p. 527). The primitive ventral mesocardium, which divides the right and left sides of the pericardial cavity ventrally, is lost very early.

The ligament of the left superior cava [lig. venæ cavæ sinistræ] (figs. 423, 436) is a doubling of the serous layer which passes between the left pulmonary artery above and the left superior pulmonary vein below. It contains, besides some fatty and areolar tissue, the shrunken remains of the left superior vena cava. It is usually connected above with the left superior intercostal vein by means of a small tributary of the latter. Passing from its lower end to the left end of the coronary sinus is the small vena obliqua atrii sinistri (oblique vein of Marshall). The root of the left superior intercostal (and the adjacent part of the left innominate) vein; the vein passing from the superior intercostal to the lig. venie cavæ sinistræ; the oblique vein of the left atrium, and the coronary sinus all represent parts of the embryonic left vena cava superior.

Relations.- - In front of the pericardium are found the thymus gland or its remains, areolar tissue, the sterno-pericardial ligaments, the left transversus thoracis muscle, the internal mammary vessels, the anterior margins of the pleural sac and lungs, and the sternum. Laterally, it is overlapped by the lungs with their pleural sacs, and it is in contact with the phrenic nerves and their accompanying vessels. Posteriorly, it is in relation with the cesophagus and vagus nerves, the descending aorta, the thoracic duct and vena azygos, and the roots of the lungs. Below it is separated by the diaphragm from the stomach and the left lobe of the liver.

Vessels. - The arteries of the pericardium are derived from the pericardiac, oesophageal, and bronchial branches of the thoracic aorta and from the internal mammary and phrenic arteries.

\section{RELATIONS OF THE HEART AND PERICARDIUM TO THE THORACIC IVALL}

Heart (fig. $437 \mathrm{~A}$ and B).-The base of the heart corresponds posteriorly to the fifth, to the ninth thoracic vertebre. Anteriorly the apex is in the fifth intercostal space, 7.5 to $8 \mathrm{~cm}$. (3 to $3 \frac{1}{4}$ in.) from the medan line. The base (above) corresponds to a line (A) drawn from a point $1 \mathrm{~cm}$. ( $\frac{2}{5} \mathrm{in}$.) below the second left chondro-costal articulation, and $3 \mathrm{~cm}$ ( $1 \frac{1}{5} \mathrm{in}$. from the median line, to another point (the same distance from the median line) $1 \mathrm{~cm}$. above the right third chondro-sternal articulation. The margo acutus, or lower border corresponds to a line (B) drawn from the apex through the xiphi-sternal articulation, to a point on the sixth costal cartilage $2 \mathrm{~cm}$. to the right of the median line. The right border of the heart may be indicated approximately by a line (slightly convex to the right) joining the right ends of $\mathrm{A}$ and $\mathrm{B}$. The left border corresponds to a line (slightly ronvex to the left) joining the left end of $\mathrm{A}$ to the apex.

If a line be drawn from the upper margin of the left third chondro-sternal articulation to the right edge of the sternum in the fifth intercostal space, the upper end of the line will lie over the centre of the pulmonary ostium, and the lower two-thirds of it (approximately) will overlie the main axis of the tricuspid ostium. The aortic ostium is immediately to the left of the above line with its centre at the left edge of the sternum opposite the third space. The mitral ostium is very largely behind the third left interspace; its upper end is behind the third cartilage, its lower behind the left margin of the sternum opposite the fourth cartilage and space.

Of the ostia of the heart, the pulmonary is nearest the anterior thoracic wall, the aortic is slightly in advance of the mitral, and the tricuspid is the deepest of all.

The pericardium follows the heart closely. The upper end (apex) in the subject used in preparing fig. 437 extended up, behind the sternum, to the lower margin of the first costal cartilage on the right and the upper margin of the second on the left.

\section{MORPHOGENESIS OF THE HEART AND PERICARDIUM}

The heart is formed by the blending in the median line of two longitudinal endothelial tubes lying ventral to the fore-gut of the early embryo. Each tube is partially surrounded laterally by the splanchnic mesoderm which forms a septum between the right and left sides of 
Fig. 437.-A, Teleroentgenogram of a Formalin Preparation of the Axterior Thoracic Wall With the Heart, Pericardium and Diaphragi in situ. (Le Wald, $\left.\times \frac{1}{3}\right)$. B, Explanatory Outline Drawing, Traced from the Negative and ConTROLled bi Stereoscopic Views.

The ostia have been accurately fitted with wire rings. $\mathrm{P}$, pulmonary ostium; $M$, mitral; $T$, tricuspid; aortic ostium is unlabelled; I-VII, right costal cartilages.

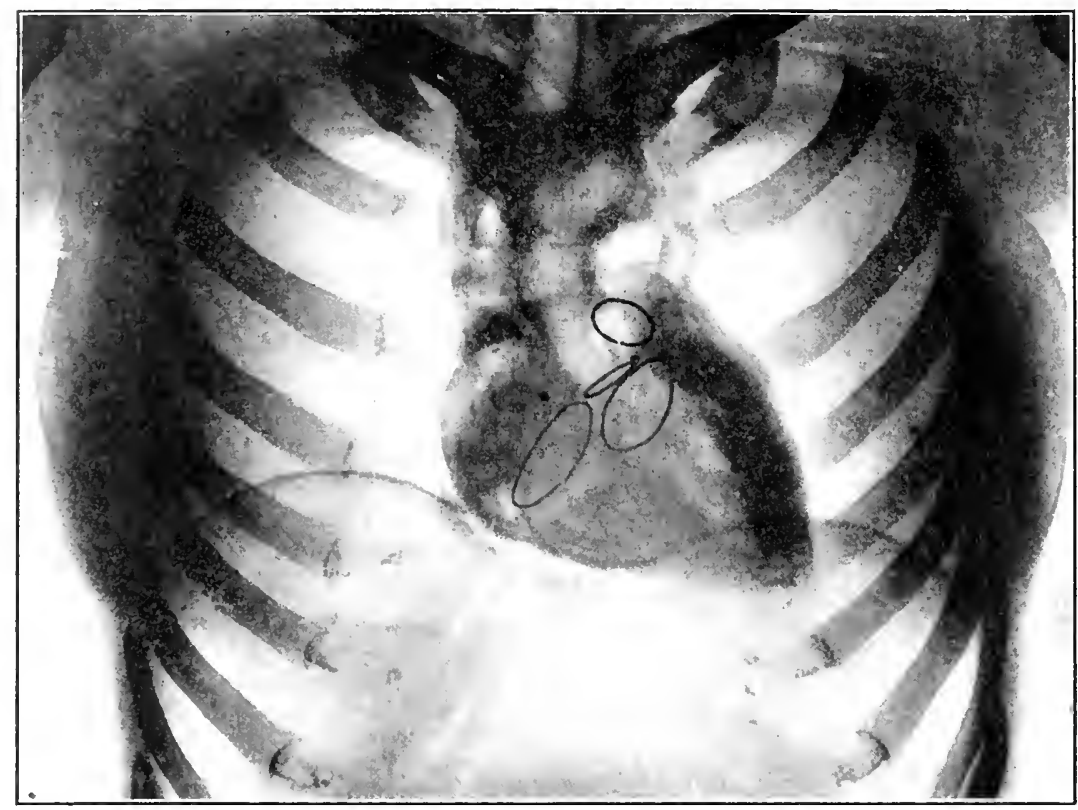

A

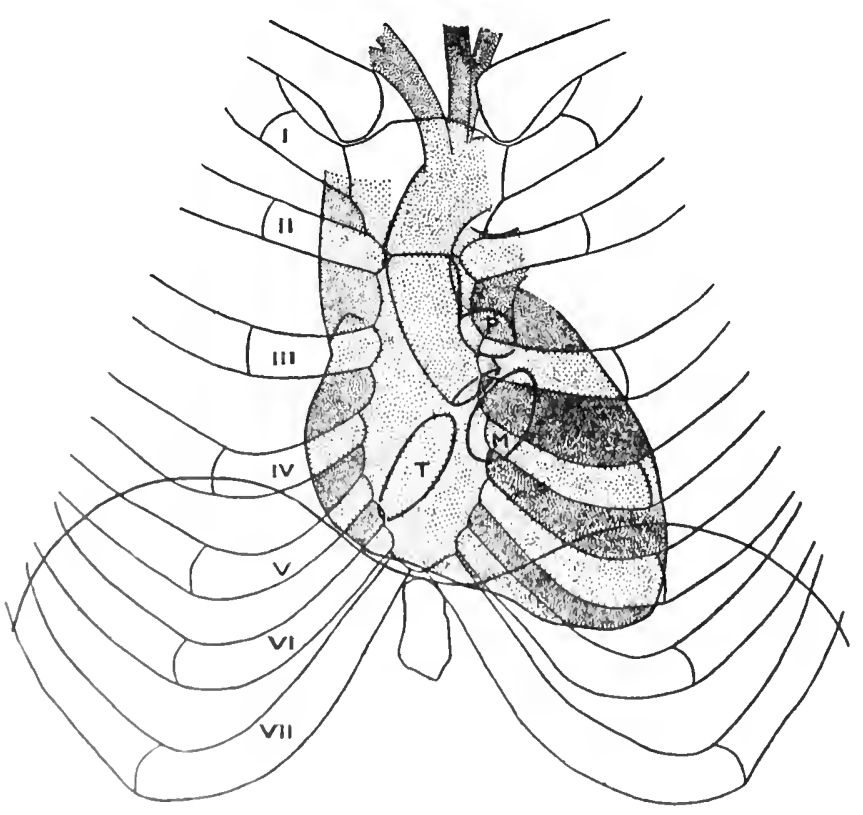


the cœlomic cavity. The blended endothelial tubes form the endocardium. The splanchnic mesoderm in relation to the endocardium becomes the myoepicardium, and the double layer connecting the heart dorsally and ventrally with the somatic mesoderm becomes the (temporary) dorsal and ventral mesocardia. The somatic mesoderm of the heart region becomes the pericardium.

The originally straight heart-tube grows rapidly and becomes tortuous on account of its increasing length between the limits assigned by its fixed arterial and venous ends. Its arterial end is continued into the truncus arteriosus, which is later divided into the pulmonary artery and the ascending aorta. Its venous end receives the vitelline and umbilical veins, and, later on, the common cardinals also. By the formation of a series of alternate bulgings aud constrictions the heart becomes differentiated into the sinus venosus, atrium, ventricle and conus arteriosus, counting from the venous to the arterial end. These parts, after going through a process of progressive differentiation and shifting (fig. 43S) take up relative positions somewhat approaching those of the adult.

Fig. 438.-Models showisg the Developaent of the Heart. (After His.)

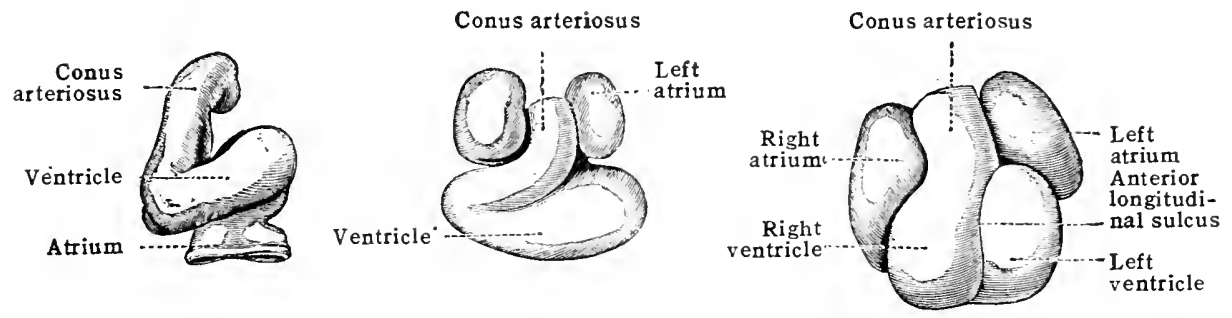

The sinus venosus lies on the dorsal wall of the atrium, and is composed of right and left horns united by a transverse portion. The sinus is separated from the atrium by a sagitally directed slit-like opening, guarded by right and left lateral valves which project into the atrium. The atrium is wide, being prolonged into a ventrally projecting pouch on either side, the future right and left auricles. The ventricle is situated caudal and somewhat ventral to the atrium. The right limb of the common ventricle, which leads into the conus arteriosus, is the future right ventricle; the left limb, connected with the atrium, is the future left ventricle. The

Fig. 439.-Sagittal Section throdgh a Reconstruction of the Hearti of a 9 aim. Human Embryo seen frod THE LeFt Side. (Tandler, $X 75$. )

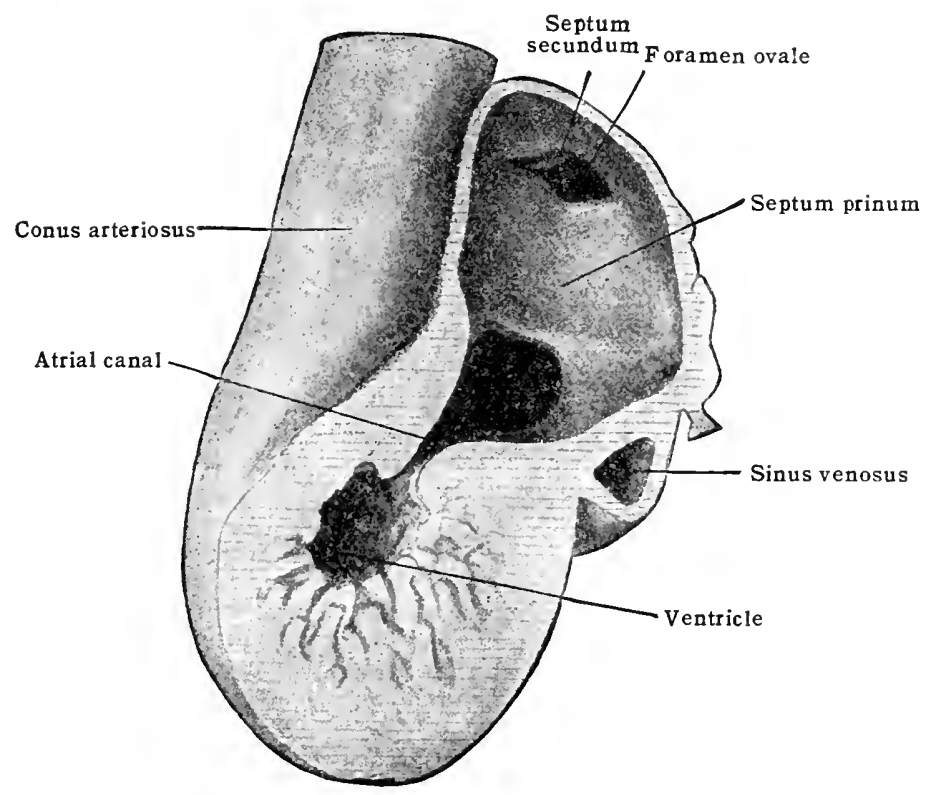

communication between the atrium and the ventricle, known as the atrial canal, is indicated on the exterior by a constriction; its interior consists of a transversely placed slit. The conus arteriosus is continued from the ventricle without obvious constriction and passes over into the truncus arteriosus.

The sinus venosus early loses its bilateral symmetry owing to the rapid enlargement of the right horn. This horn soon receives, through the proximal portion of the right vitelline vein (inferior vena cava), all the blood coming from the left vitelline and both umbilical veins. The right common cardinal also gains ascendency over the left and becomes the superior vena cava. 
The left horn and transverse part, now only draining the dwindling left common cardinal, (left superior cava) and the coronary veins, become the coronary sinus. The right horn gradually becomes absorbed into the right end of the atrial cavity until the superior and inferior cava and the coronary sinus acquire separate openings into that chamber. Between the opening of the coronary sinus and thit of the inferior cava there is a ridge, the sinus-septum (between the right horn and transverse parts of the sinus), which becomes attached to the lower part of the right sinus valve.

In the atrium a septum begins early to grow from the ventro-cephalic wall of the atrium, toward the atrial canal. As the interatrial communication around the edge of the septum (ostium primum) is becoming narrow, a perforation occurs near the attached margin of the septum (ostium secundum). This first septum (septum primum) is incomplete because when its edge reaches the atrial canal the atria still communicate through ostium secundum. To the right of the septum primum another septum (s. secundum) is formed later; this never stretches completely across the atrium and is rather a crescentic ridge than a true septum. Until the free edges of the two septa overlap one another there is a direct passage leading from one side of the atrium to the other; eventually they do overlap and the communication becomes oblique but persists until birth. (For adult relations of septa, see p. 511.) The cavities resulting from the division of the common atrium are the right and left atria of the adult. The oblique channel connecting the atria (foramen ovale) is bounded on the right side by the s. secundum the free edge of which forms the limbus fossæ ovalis. The channel is bounded on the left by the s. primum which slants into the left atrium. The free edge of the s. primum becomes the valvula foraminis ovalis; the remainder, the membranous atrial septum of the adult.

Fig. 440.-Reconstruction of the Heart of an 11 m. Human Embryo viewed from BeLow. (Mall, 50.)

The lower part of the ventricular portion has been cut off. Connective tissue septa colored yellow. Ao, aorta; $A p$, anterior papillary muscle; $L a$, left atrium; $L o$, left venous ostium; $L p$. large (anterior) papillary muscle of riglt ventricle; $1 / \mathrm{pm}$, medial papillary muscle; $P P$, posterior papillary muscle; $P$, pulmonary artery; $R A$, right atrimm.

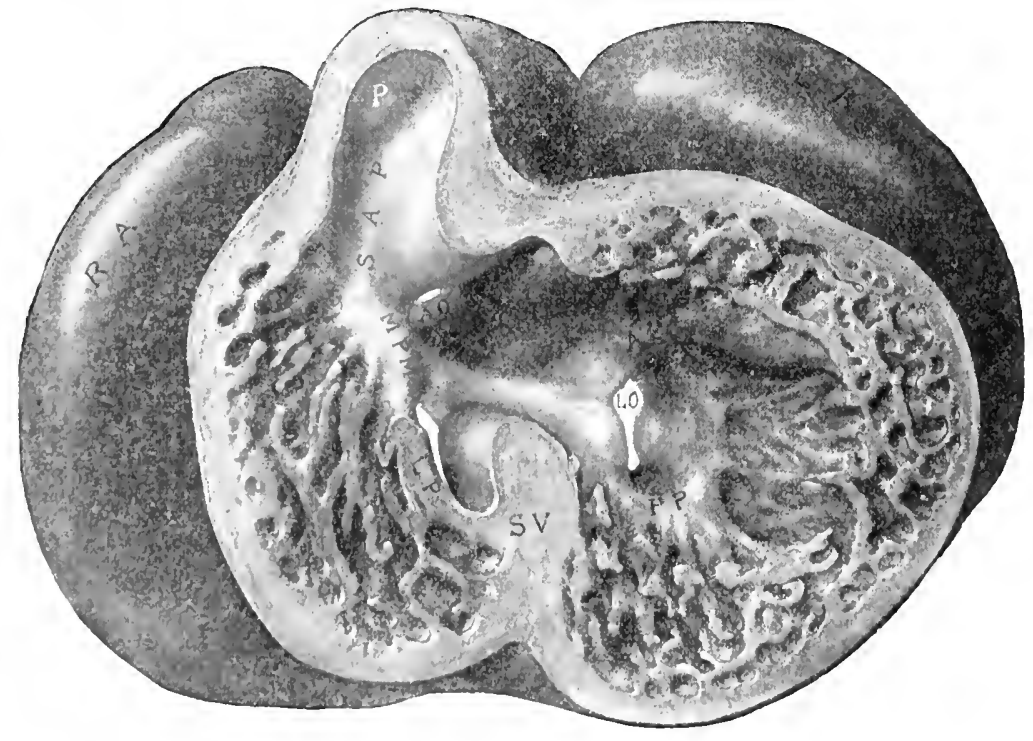

The portion of the dorsal wall of the right at rium immediately adjoining the septa is derived from the sinus vousus. This part of the atrium (the simus venalmm) receives the great venous openings. The? Ieft side of the loft sinns-valve is attached to both septa and assists the septum socomblum in the formation of tha limbus forminis onalis. The cephalie part of the right sinus-

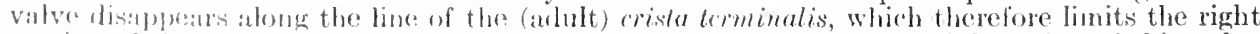
pertion of the right atrinm derived from the sinus venosus. The caublal portion of this valve porsists ats the inforior andel and commary vales. These are drawn ont of their original align-

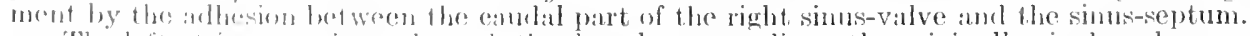

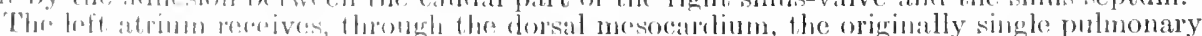

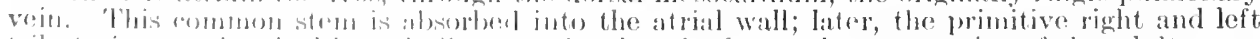

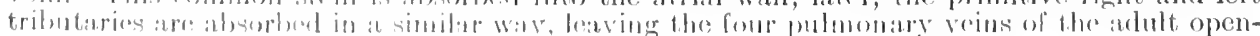

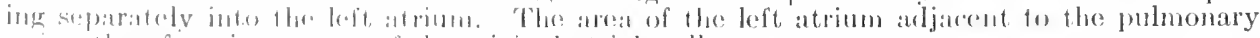

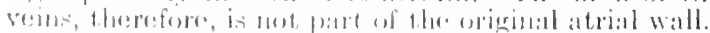

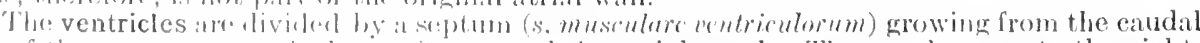

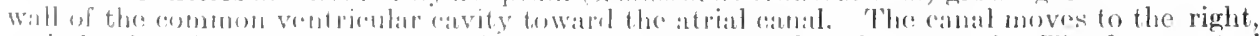

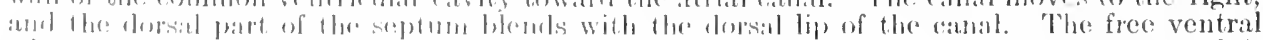

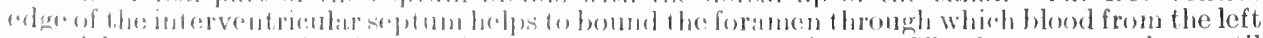
ventricle monst entor the right on its way to the rombs arteriosus. The foranen porsists until

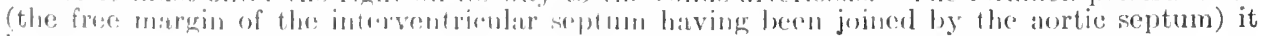

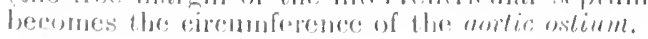


The aortic septum is a composite structure formed partly by a septum growing between the fourth and sixth pairs of aortic arches, and partly by swellings growing in the interior of the contis and truncus arteriosus. When fully formed it extends spirally along the truncus and conus, and enters the right half of the common ventricular cavity, where it joins the right side of tho free edge of the interventricular septum. The septum is arranged in such a way that the blool from the left ventricle passes no longer through the right ventricle but along its own channel (the aorta) through the conus and truneus to the first four pairs of aortic arches. The blood from the right ventricle passes through the pulmonary division of the conus and truncus arteriosus, anterior and to the left of the aorta, into the sixth arches. Further differentiation brings about the external separation of the aorta from the pulmonary artery, but their common covering of epicardium persists as such in the adult. The lower end of the aortic septum persist: in the adult as the septum membranaceum ventriculorum and the crista supraventricularis, the relations of which to the septum musculare are well shown in fig. 42S. During the formation of the aortic septum four endocardial swellings appear at the distal part of the interior of the conus. These are arranged as smaller and larger opposite pairs; the smaller and larger swellings. therefore, alternating around the lumen. The larger pair of swellings assists (by partial blending) in the formation of the aortic septum. When the septum is complete, half of each of the larger swellings is contained in the aorta and half of each in the pulmonary artery. One of the smaller swellings remains in the aorta and one in the pulmonary artery, so that there are now three swellings in each vessel. Each of the six swellings becomes undermined to form a semilunar valve of the adult.

The atrio-ventricular valves.--The interior of the ventricular cavity, which is at first smooth, becomes undermined in an irregular way, to form a system of myocardial trabeculæ. The lips of the transversely directed atrial canal become thickened in to prominent anterior and posterior endocardial cushions; these project into the ventricular cavity and become involved in its myocardial trabecular system. The atrial canal, which has now moved to the right, becomes divided sagittally, into right and left venous ostia, by the septum primum. The interventricular septum joins the ventricular side of the posterior endocardial cushion. The anterior and posterior endocardial cushions, where they blend with one another and with the septum primum on the medial side of each venous ostium, form an atrio-ventricular valve-cusp on either side, viz., the anterior cusp of the mitral in the left ostium, and the medial cusp of the tricuspid in the right. The posterior cusp of the mitral and the anterior and posterior of the tricuspid are formed later, partly, by lateral tubercles developing in either ostium, and partly by undermining of the ostia from the rentricular side. The atrial musculature extends in to the atrio-ventricular valves and, until a late stage, is continuous with the trabecular system of the ventricles. Gradually, however, this connection between atrial and ventricular musculature is lost, leaving only the chordæ tendinea connecting the papillary muscles with the valves Muscle is found at the basal region of the valve-cusps in the adult, and occasionally persists in the chordæ tendineæ.

The connection between the atrial and ventricular musculature is not confined to that occurring by means of the valves and trabecular system. The original myocardial connection between the atrial and ventricular portions of the heart remains complete until the embryo has reached the length of about $11 \mathrm{~mm}$. From that time on the epicardium begins to blend with the fibrous annuli of the venous ostia. Neanwhile the atrial nusculature rapidly loses its connection with that of the ventricles until they are connected in one place only, i. e., the site of the atrio-ventricular bundle.

The pericardial cavity is the original cephalic end of the intraembryonic colom. The somatic mesoderm of the pericardial region forms the adult pericardium. The splanchnic mesoderm persists only in the part which furnishes the myo-epicardium. The ventral and dorsal mesocardia, both of which are formed by the splanchnic mesoderm, are, in the main, transitory. The early disappearance of the ventral mesocardium unites the right and left sides of the pericardial cœlom ventral to the heart. The dorsal mesocardium persists at the arterial and venous ends of the heart only. The loss of the dorsal mesocardium between the latter points gives rise to the sinus transversus pericardii of the adult.

During development, the heart and pericardium migrate from a point opposite the cephalic end of the pharynx to one opposite the caudal end of the cesophagus; in fact, from the neck well into the thorax. In the adult, instead of being at the cephalic end of the colom, the heart and pericardium are contained between the right and left layers of the ventral mesentery of the œsophagus; the pericardial pleura of the adult.

The cranio-caudal migration is evidenced in the adult by the course of the recurrent and of the cardiac nerves, and also by the apparent migration of the ressels derived from some of the dorsal segmental arteries.

\section{B. THE ARTERIES AND VEINS}

The arteries [arteriæ], proportionately to their size, have much thicker walls than the veins. After death they retain their natural form, but are contracted and contain usually a small amount of pale clot. In a very general wity the thickness of wall is proportional to calibre. Some arteries, however, are constantly thicker or thinner than could be predicted from size alone.

The larger arteries usually take a direct course and branch dichotomousy. In descriptive anatomy if dichotomous branches are of nearly equal size it is common for each to take another name; if one branch preponderates in size, it is apt to retain the name of the parent trunk while the smaller is regarded as a collateral branch [vis collaterale]. There are numerous 
exceptions to dichotomous branching; branches may run perpendicularly or recurrently to the vessel from which they arise; or several branches may arise simultaneously.

There is less tendency to anastomosis between large or medium sized arteries than in veins of corresponding magnitude. Anastomoses do occur, however, particularly in the form of arches, such as the palpebral, plantar and volar arches, or the arches between the intestinal arteries. This form of anastomosis is sometimes called inosculation. Between smaller arteries anastomosis is usually free as in the case, for instance, of the articular retia. In some organs anastomosis (excepting capillary) between neighbouring arteries can scarcely be said to exist at all; the a. centralis retina affords a good example of this, as do the arteries of the brain, spleen, and kidner; such arteries are called terminal.

The larger arteries are supplied by vasa vasorum, frequently arising from their own recurrent branches.

The veins [renæ] have thin walls, and after death are either collapsed or filled with elot or stained serum. They are characterized by the presence of valves and frequent anastomoses.

Frequent anastomoses occur between veins of all sizes; plexuses are common, such, for instance, those of the pelvis. Vene comitantes are veins which, usually in pairs, accompany many arteries; they communicate with one another, around the artery, very freely. Veins do not primitively accompany arteries. In the case of the extremities the primitive veins are superficial. The deep veins of the limbs are of later formation and to them the superficial veins subsequently become tributary.

The veins from the stomach, spleen, pancreas and intestine are collected into a large trunk, the portal vein. This does not open into the inferior vena cava directly, but breaks up into numerous smaller ressels in the liver. From these the blood is returned, through the hepatic reins, to the inferior cava.

Many veins are provided with valves, the free borders of which are directed toward the heart. In the small veins the valves are single; in the larger veins they are usually double, rarely treble. Valves are much more numerous in the veins of infants than those of the adult, they seem to disappear progressively with advancing age. The venous valves are most numerous in the superficial veins, and in the deep veins of the extremities; in many veins of the head and neck they occur only at their point of termination in a larger trunk.

The cranial venous sinuses are modified veins, consisting of intima only which lines channels in the fibrous dura mater. The venous spaces in cavernous tissue, such as the corpora cavernosa, may be looked upon as specially modified veins.

The larger veins, like the arteries, have vasa vasorum.

The arteries and veins will be considered in the following order: 1, pulmonary artery and veins; 2 , the systemie arteries; and, 3 , the systemic veins. At the ends of the second and third divisions, the development and variations are considered.

\section{THE PULMONARY ARTERY AND VEINS}

The pulmonary artery [a. pulmonalis] (fig. 441) passes from the right ventricle to the lungs. It differs from all other arteries in the body in that it contains venous blood. It arises as a short, thick trunk from the conus arteriosus of the right ventricle, and, after a course of about $5 \mathrm{~cm}$. (2 in.) within the pericarlium, divisles into a right and a left branch. These branches pass to the right ancl the left lung respectively.

The trunk of the pulmonary artery at its origin is on a plane anterior to the asermling atorta, and slightly overlaps that vessel. Thence it passes upward, backward, and to the left, forming a slight eurve around the front and left side of the ascencling portion of the aorta; and, having reached the concavity of the aortic areh, on a plane posterior to the ascending aorta, it divides into its right and left branche's, which liverge from each other at an angle of about $130^{\circ}$. The division of the pulmonary artery occurs immediately to the left of the second left chondesternal articulation.

In the fortus, the pulmonary artery continues its course upward, backwarl, and to the left mmer the name of the ductus arteriosus (Botalli), and opens into the descending aorta just bolow the origin of the left subelavian artery. After birth, that portion of the pulmonary artery which extends to the anta becomes obliterated, and remains merely as a fibrous cord, the ligamentum arteriosum (fig. 136).

Relations.-In front, the trumk of the pulmonary artery is covered by the remains of the thymus gland, and the pericarlium. The artery lies, at its eommencement, behind the upper margin of the third Ioft chondro-stermal articulation. The right margin of the artery is behind the second piece of stermm but the greater part of the vessel is behind the medial end of the secomd intereostal space.

Behind, it liessucessively upon the asending aorta and the left atrium.

'To the right are the ascending aorta, the right atrimm, the right coronary artery, and the cardiac nerves. 
To the left are the pericardium, the left pleura and lung, the left auricle, the left coronary artery, and the cardiac nerves.

The right pulmonary artery [ramus dexter] longer than the left, passes almost horizontally under the arch of the aorta to the root of the right lung, where it divides, eitber directly or after repeated division, into three branches, one for each lobe. These branches follow the course of the bronchi, dividing and subdividing for the supply of the lobules of the lung. The terminal branches do not anastomose with each other.

Relations.--In its course to the lung it has in front of it the ascending aorta, the superior vena cava, the phrenic nerve, the anterior pulmonary plexus, and the reflexion of the pleura. Behind are the right bronchus and the termination of the azygos vein. Above is the arch of the aorta, and below are the left atrium and the upper right pulmonary vein.

At the root of the lung it has the right bronchus above and behind it; the pulmonary veins below and in front. Crossing in front of it and the other structures forming the root of the lung are the phrenic nerve and the anterior pulmonary plexus; behind are the azygos vein, the vagus nerve, and the posterior pulmonary plexus.

The left pulmonary artery, shorter and slightly smaller than the right, passes in front of the descending aorta to the root of the left lung, where it divides into two branches for the supply of the upper and lower lobes respectively. These divide and subdivide as on the right side.

Relations.-At the root of the lung it has the left bronchus behind and also below it, in consequence of the more vertical direction taken by the left bronchus than by the right. Below and in front are the pulmonary veins, while passing from the artery and the upper left pulmonary vein is the ligament of the left superior cava. Crossing in front of it and the other structures forming the root of the lung are the phrenic nerve, the anterior pulmonary plexus, and the reflexion of the left pleura; crossing behind, are the descending aorta, the left vagus nerve, and the posterior pulmonary plexus.

The pulmonary veins [vv. pulmonales] (figs. 424, 441) return the aërated blood from the lungs to the heart. They are usually four in number, superior and inferior, of the right and left sides. Occasionally, however, there are three pulmonary veins on the right side, the result of the vein from the middle lobe of the right lung opening separately in to the left atrium instead of joining as usual the upper of the two right pulmonary veins. The relations of the pulmonary veins to the pulmonary arteries and bronchi in the lungs are given with the anatomy of the lungs (Section $\mathrm{X}$ ).

The pulmonary veins are about $15 \mathrm{~mm}$. in length. In the pericardium the right pulmonary veins [vv. pulmonales dextræ] both pass behind the superior vena cava. The superior vein receives the vein from the right middle lobe and runs below and in front of the right pulmonary artery.

The left pulmonary veins [vv. pulmonales sinistræ] enter the left atrium about $3 \mathrm{~cm}$. in front of the veins of the right side. The superior vein is below the left pulmonary artery.

\section{THE SYSTEMIC ARTERIES}

\section{THE AORTA}

The aorta (fig. 442) is the main systemic arterial trunk, and from it all the systemic arteries are derived. It begins at the left ventricle of the heart, and ascends near the anterior thoracic wall as high as the second right chondro-sternal articulation [aorta ascendens]. It then turns backward and to the left forming an arch [arcus aortæ] which reaches the posterior thoracic wall at the left side of the fourth thoracic vertebra. From here it runs downward along the vertebral column [aorta descendens] through the thorax and abdomen and ends by dividing, opposite the fourth lumbar vertebra, into the right and left common iliac arteries. From the point of bifurcation a small vessel, the middle sacral, is continued down the middle line in front of the sacrum and coccyx. The middle sacral represents the sacral and coccygeal aorta.

\section{The Ascending Aorta}

The ascending aorta [aorta ascendens] (fig. 442) begins at the upper part of the left ventricle, on a level with the third intercostal space, and ascends behind 
the sternum to the upper border of the right second chondrosternal articulation. It measures about 5 to $5.5 \mathrm{~cm}$. (2 to $2_{4}^{1} \mathrm{in}$.), forming, as it aseends, a gentle eurve with its convexity to the right. It is enclosed for the greater part of its length in the pericardium, being invested, together with the pulmonary artery, in a common sheath formed by the serous layer of that membrane. A dilatation known as the bulbus aortæ occurs immediately above the heart upon which are three localized bulgings, known as the aortic sinuses (sinuses of Valsalva); they are placed, one to the right, one to the left, and one posteriorly. From the right and eft are derived the eoromary arteries of the heart. (See Heart.)

Fig. 441.-The Great Vessels of the Thorax.

(Modified from a dissection in St. Bartholomew's Hospital Museum.)

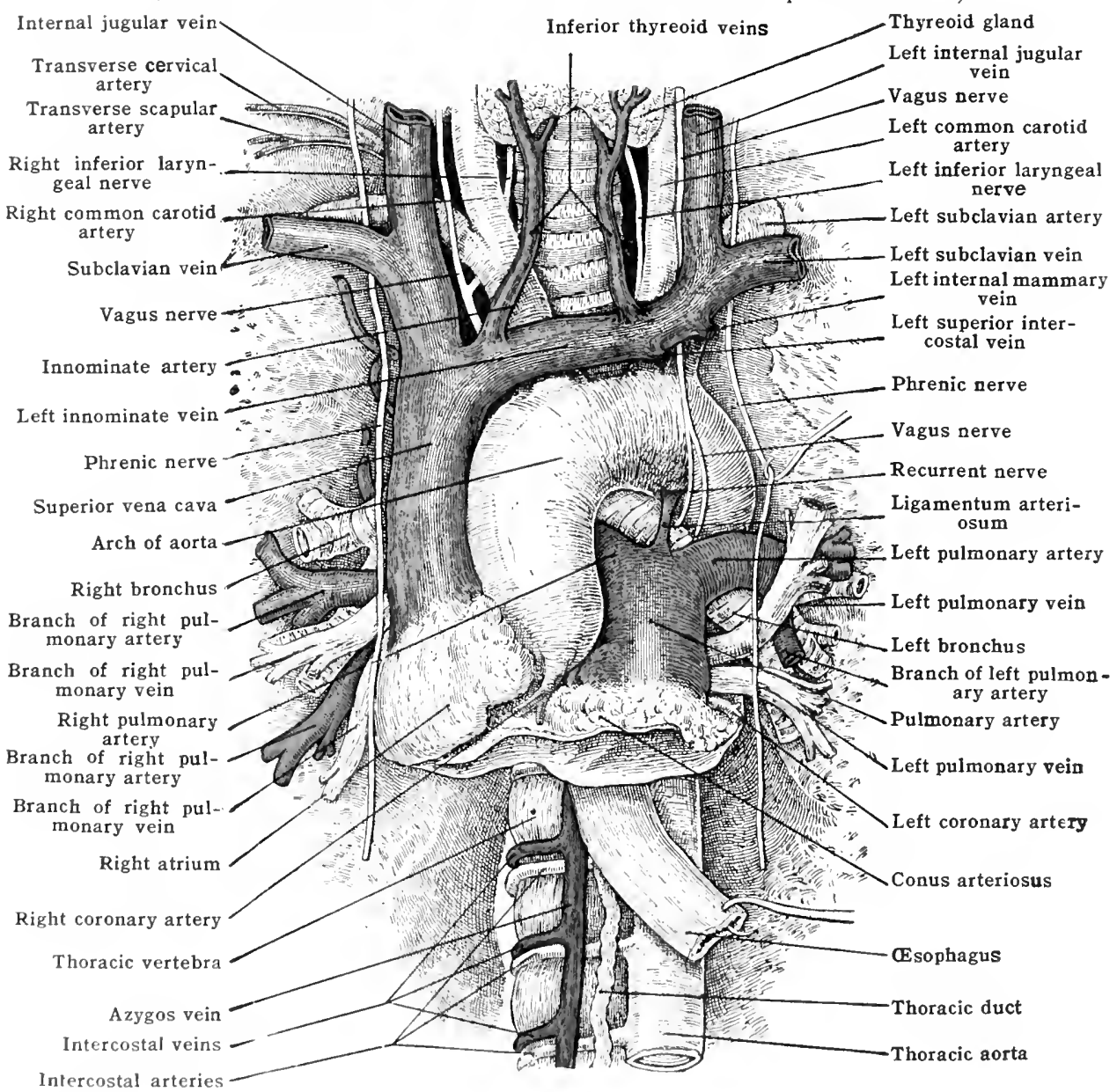

Relations.--In front, it is overlapperl at its commencement by the right auricle, conut arteriosus anl pulnonary artery. Jligher up, as the pulmonary artery and auricle diverge, is is separterl from the mambrimm by the pericarlimu, the remains of the thymus gland, and by the loros tissus and fat in the superior mediast inum, and is here slightly overlapped by the right plenrit and hy tho colge of the right lomg in full inspiration. The root of the right coronary artery is also in fornt

Behind are thre left atrimm of the heart, the right pulmonary artery, the right bronchus,

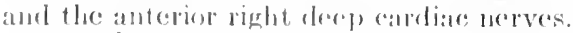

()n the right side it is in molact, below with the right atrium, and above with the superior lenit rivat.

(1) the left side are the pulnomaly artery and the bounches of the right superficial cardiac ne?vers.

Branches. 'The right, anl loft wornaly arteries have already been described (p). 519).

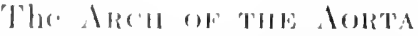

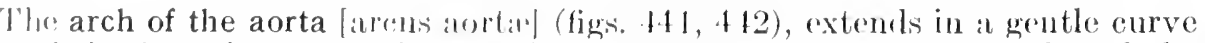

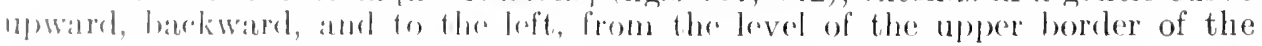


second right costal cartilage to the lower borler of the fourth thoracic vertebra. Attached to the concavity of the arch, just beyond the origin of the left subclavian artery, is the ligamentum arteriosum (vestige of the dorsal part of the left sixth areh). Between the left subclavian artery and the ligamentum arteriosum there is sometimes a definite constriction of the arch (isthmus aortæ) situated opposite the third thoracic vertebra. When the isthmus is well marked, it is succeeded by a dilatation (aortic spindle) which begins in the neighbourhood of the ligamentum arteriosum and passes over into the descending aorta. Passing under the arch are the left bronchus, the right pulmonary artery, and the left recurrent (inferior laryngeal) nerve. It measures about $4.5 \mathrm{~cm}$. (1\% in.).

\section{Fig. 442.-The Thoracic axd Abdomisal Aorta.}

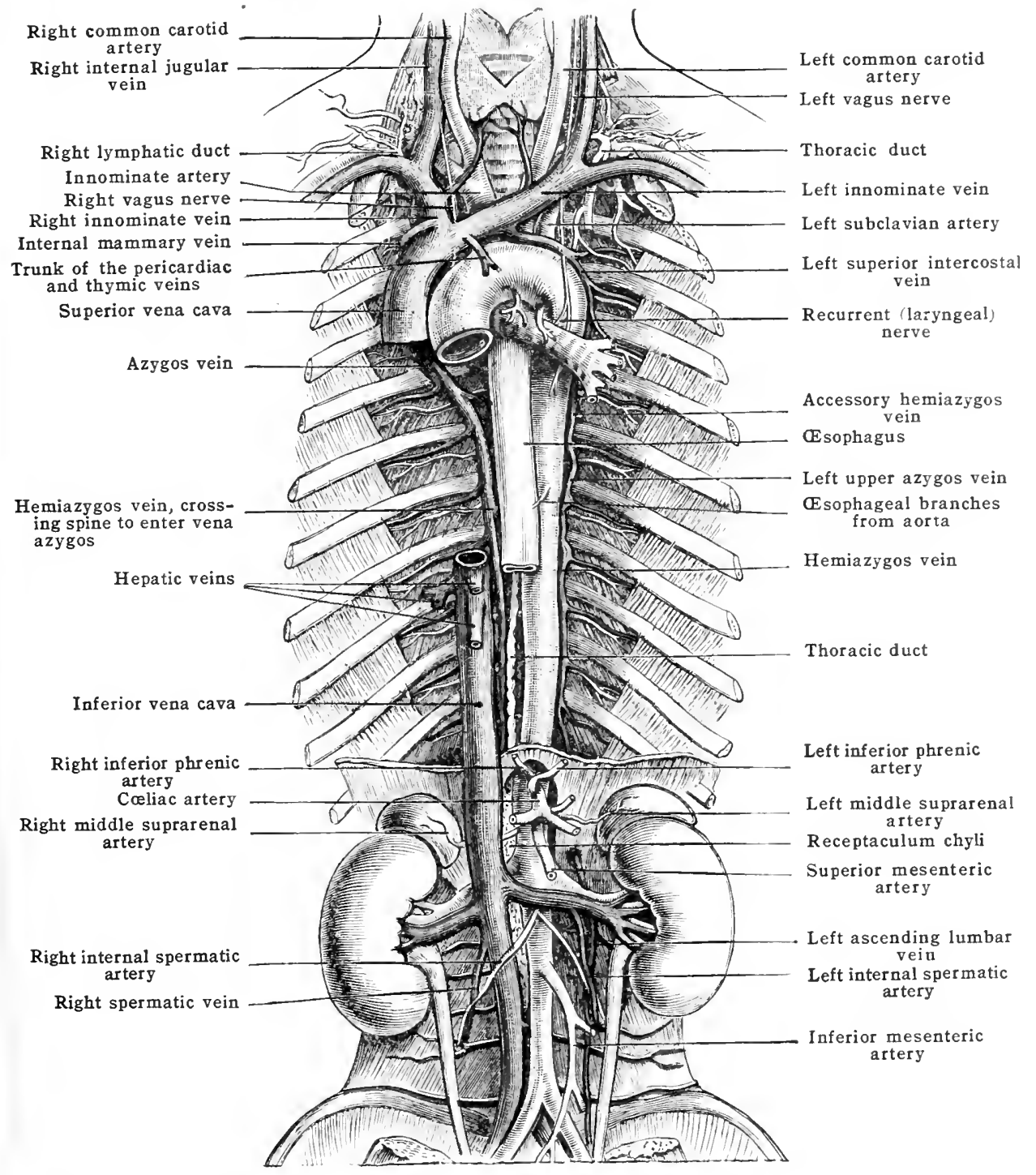

Relations.-In front and to the left, it is slightly overlapped by the right pleura and lung, and to a greater extent by the left pleura and lung. It is crossed in the following order from right to left, by the left phrenic nerve, by the cardiac branches of the ragus nerre, the cardiac branches of the sympathetic nerve, by the left vagus nerve, and by the left superior intercostal vein as it passes up to the left innominate vein.

Behind and to the right are the trachea, the cesophagus, the thoraeic duct, the deep cardiac plexus which is situated on the trachea just above its bifurcation, and the left recurrent (inferior laryngeal) nerve.

Above it are the three chief branches for the head, neek, and upper extremities, namely, the innominate, the left carotid, and the left subclavian arteries, and the left innominate veim. 
Below it-that is, in its concavity-are the bifurcation of the pulmonary artery, the left bronchus, the left recurrent (inferior laryngeal) nerve, the ligamentum arteriosum, the superficial cardiac plexus, two or more bromchial lymphatic glands, and the reflexion of the pericardium.

The branches of the aortic arch are:- the innominate, the left common carotid, and the left subclavian arteries. The innominate and left carotid arise close together-indeed, so close that, when seen from the interior of the aorta, the orifices appear merely separated by a thin septum. The left subclavian arises a little less close to the left carotid.

\section{THE INNOMINATE ARTERY}

The innominate [a. anonyma] or brachio-cephalic artery (fig. 441), the largest branch of the arch of the aorta, extends from near its commencement upward and a little forward and to the right, as high as the upper limit of the right sterno-clavicular joint where it bifurcates into the right common carotid and right subclavian arteries. It lies obliguely in front of the trachea, and measures from 3.7 to $5 \mathrm{~cm}$. ( $1 \frac{1}{2}$ to $2 \mathrm{in}$.).

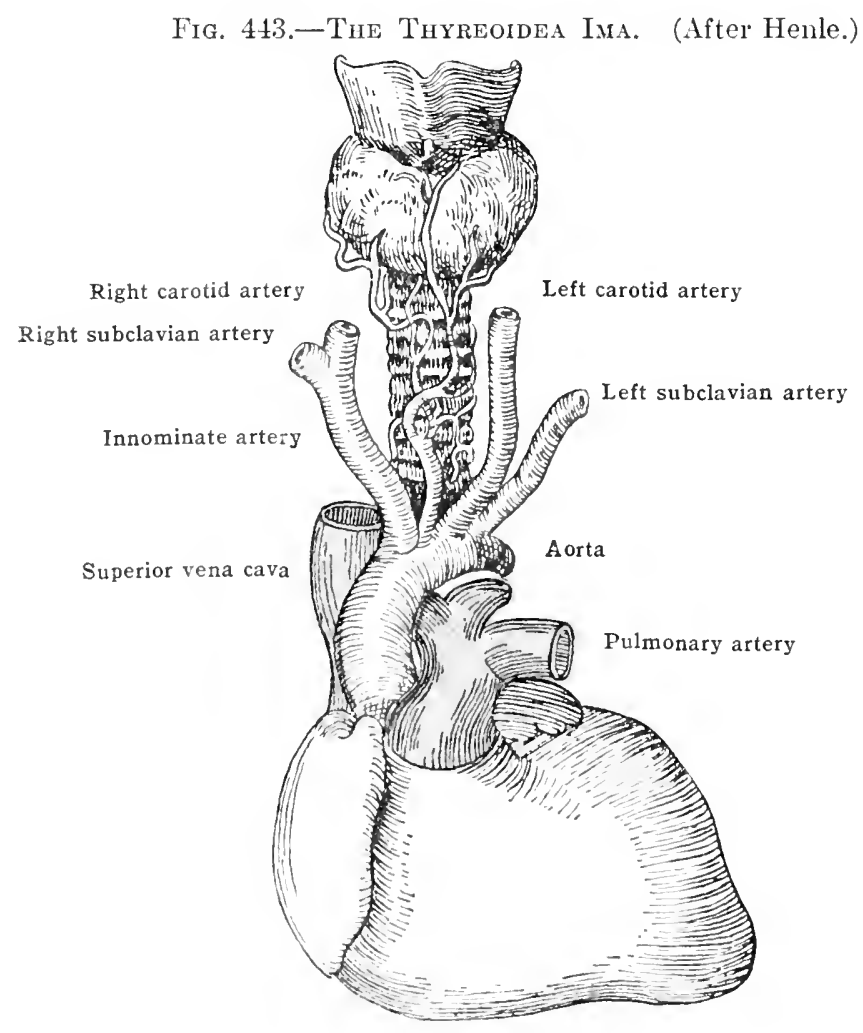

Relations.- In front of the artery are the manubrium, the origins of the sterno-hyoid and sterno-thyreoirl muscles, the right sterno-clavicular joint, and the remains of the thymus gland. The left inmoninate vein erosses the root of the vessel, and the inferior thyreoid and thyreoidea imat veins descend olliguely over it to end in the left innominate vein. The inferior cervical carcliac bramches of the right vagus nerve pass in front of it on their way to the deep cardiac plexus.

Behind, it lies on the trachea, crossing that tube oblicuely from left to right, and coming into eontast above with the right pleara.

To the right side are the right innominate vein, the right vagns, and the pleura.

'To the left side are the loft common caroticl, the remains of the thymus gland, the right inferion thy reosid vein; : ind, higher, the trachea.

The branches of the innominate artery are:-(1) The right common carotid; and (2) thr right suldelavian. 'T'hese are terminal branches. There are usually no collateral branches from this vessel, but at times the thyreoidea ima may arise from it. 
The thyreoida ima artery, which occurs in about 10 per cent. of subjects, ascends on the front of the trachea to the thyreoid gland. It may be large in which case it might complicate the low operation of tracheotomy. It does not always arise from the innominate, but occasionally from the arch of the aorta (fig. 443) or from the right common carotid.

\section{THE COMMON CAROTID ARTERIES}

The common carotid arteries [aa. carotides communes] pass up deeply from the thorax on either side of the neck to about the level of the upper border of the thyreoid cartilage, where they divide into the external and internal carotid arteries. The external carotid supplies the structures at the upper part of the front and side of the neck, the larynx, pharynx, tongue, face, the upper part of the back of the neck, the structures in the pterygoid region, the scalp, and in chief part the membranes of the brain. The internal carotid gives off no branch in the neck, but enters the cranium and supplies the greater part of the brain, the structures contained in the orbit, and portions of the membranes of the brain.

The common carotid artery on the right side arises from the bifurcation of the innominate at the upper limit of the sterno-clavicular joint; on the left side from the arch of the aorta a little to the left of the innominate artery, and on a plane somewhat posterior to that vessel (fig. 441). The portion of the left common carotid artery which extends from the arch of the aorta to the upper limit of the sterno-clavicular articulation lies deeply in the chest, and requires a separate description; but above the level of the sterno-clavicular joint the relations of the right and left carotids are practically the same, and are given under the account of the right common carotid.

\section{THORACIC PORTION OF THE LEFT COMMON CAROTID ARTERY}

Within the thorax the left common carotid is deeply placed behind the manubrium of the sternum, and is overlapped by the left lung and pleura. It arises from the middle of the aortic arch, close to the left side of the innominate artery, and a little posterior to that vessel, and ascends obliquely in front of the trachea to the left sterno-clavicular articulation, above which its relations are similar to those of the right common carotid (fig. 442).

Relations.- - In front, but at some little distance, are the manubrium and the origins of the left sterno-hyoid and sterno-thyreoid muscles, whilst in contact with it are the remains of the thymus gland, and the loose connective tissue and fat of the superior mediastinum. Crossing its root is the left innominate vem.

Behind, it lies successively upon the trachea the left recurrent (inferior laryngeal) nerve, the œsophagus (which bere inclines a little to the left), and the thoracic duct.

To its right side is the root of the innominate artery, and higher up are the trachea and the inferior thyreoid veins.

To its left side, but on a posterior plane, are the left subclavian artery and the left vagus nerve; and, slightly overlapping it, the edge of the left pleura and lung.

\section{THE COMMON CAROTID ARTERY IN THE NECK}

The common carotid artery in the neck extends from the sterno-clavicular articulation to the upper border of the thyreoid cartilage on a level with the fourth cervical vertebra, where it divides into the external and internal carotid arterics. A line drawn from the sterno-clavicular joint to the interval between the mastoid process and the angle of the jaw would indicate its course. The artery is at first deeply placed beneath the sterno-mastoid, sterno-hyoid, and sterno-thrreoid muscles, and at the level of the top of the sternum is only $2 \mathrm{~cm}$. ( $\frac{3}{4} \mathrm{in}$.) distant from its fellow of the opposite side, and merely separated from it by the trachea. As the carotid arteries run up the neck, however, they diverge in the form of a $V$ and become more superficial, though on a plane posterior to that in which they lie at the root of the neck, and are separated from each other by the larynx and pharynx. At their bifurcation they are about $6 \mathrm{~cm} .\left(2 \frac{1}{4} \mathrm{in}\right.$.) apart. The common carotid is contained in a sheath of fascia common to it and the internal jugular vein and vagus nerve. The artery, vein, and nerve, however, are not in contact, but separated from one another by fibrous septa, which divide the common sheath into three compartments: one for the artery, one for the vein, and one 
for the nerve. The vein, which is larger than the artery, lies to the lateral side, and somewhat orerlaps it. The ragus nerre lies behind and between the two vessels. The artery on the right side measures about $9.5 \mathrm{~cm} .\left(3 \frac{3}{4} \mathrm{in}\right.$.); on the left side, about $12 \mathrm{~cm} .\left(4_{4}^{\frac{3}{4}}\right.$ in.) in length.

F1g. 44.-The Collateral Circulation after ligature of the Comion Carotid and ŚLBClatiax Arteries.

(A ligature is placed on the common carotid and on the third portion of the subclavian artery.)

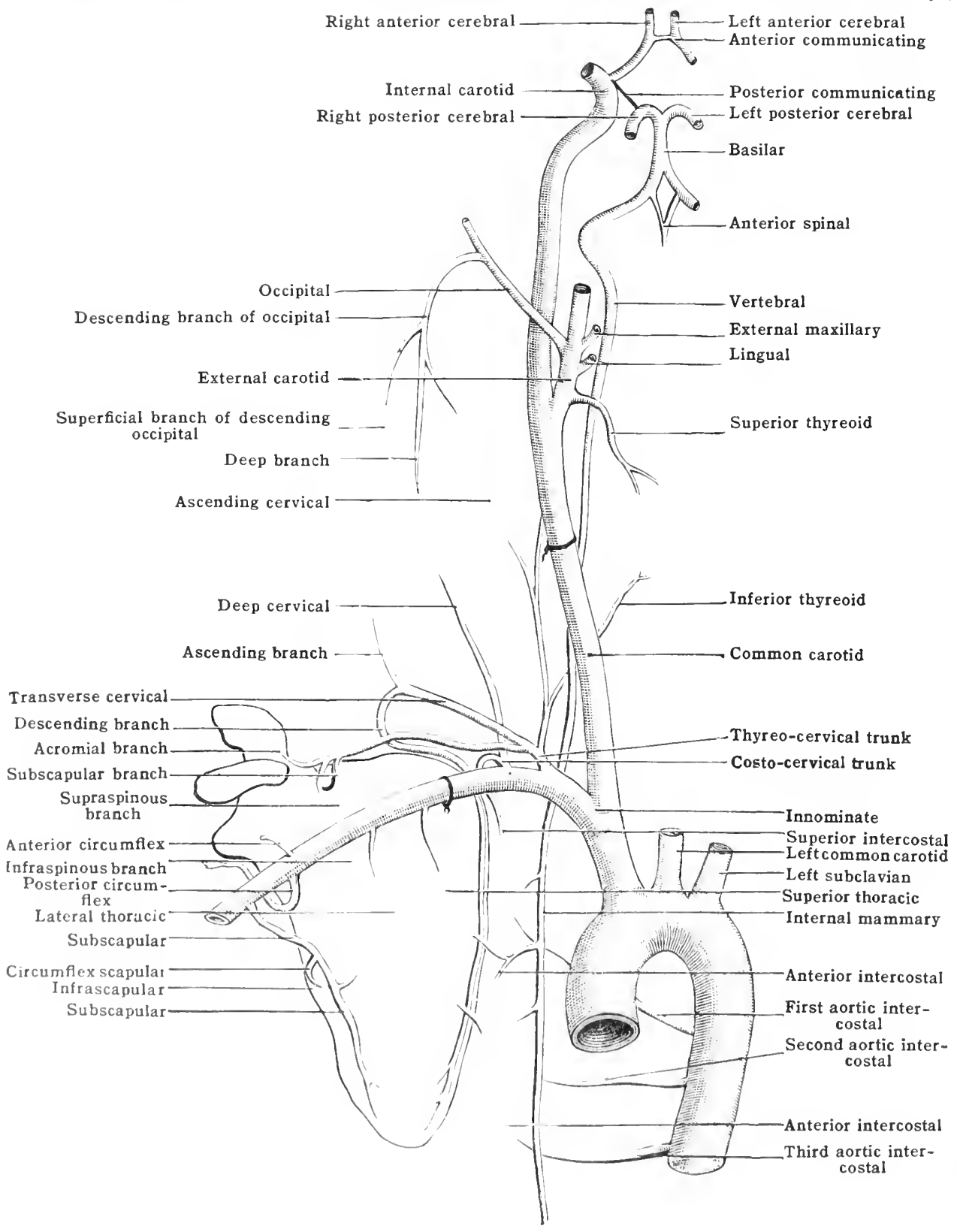

Relations. - In front the :ntery is avered by the skin, superficial fascia, platysma, and

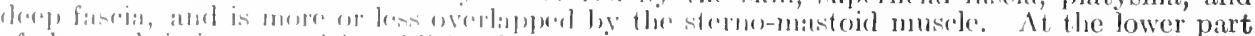

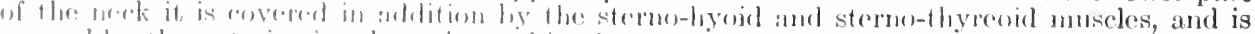

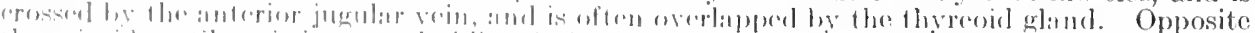

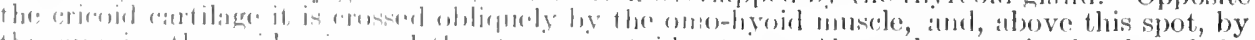

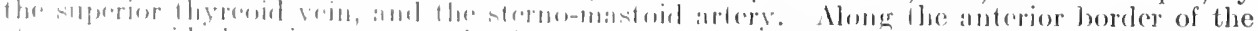

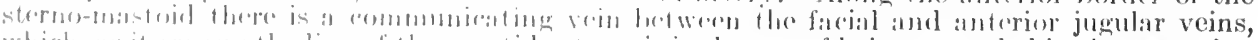

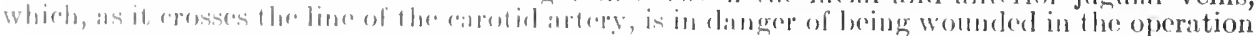


of tying the carotid. The ramus descendens n. hypoglossi generally descends in front of the carotid sheath, being there joined by one or two communieating branches from the second and third cervical nerves. At times this nerve runs within the sheath. There are usully two lymphatic glands about the bifurcation of the artery. These are often found enlarged and infiltrated in eaneer of the lip and tongue.

Behind, the eommon carotid lies on the longus colli and sealenus anterior below, and longus eapitis (rectus eapitis anterior major) above. Posterior to the artery, but in the same sheath, is the vagus nerve; and posterior to the sheath, the cervical sympathetic and the cervical

Fig. 445.-Arteries of the Head and Neck. (After Toldt, "Atlas of Human Anatomy," Rebman, London and New Tork.)

Transverse facial artery

Supraorbital artery

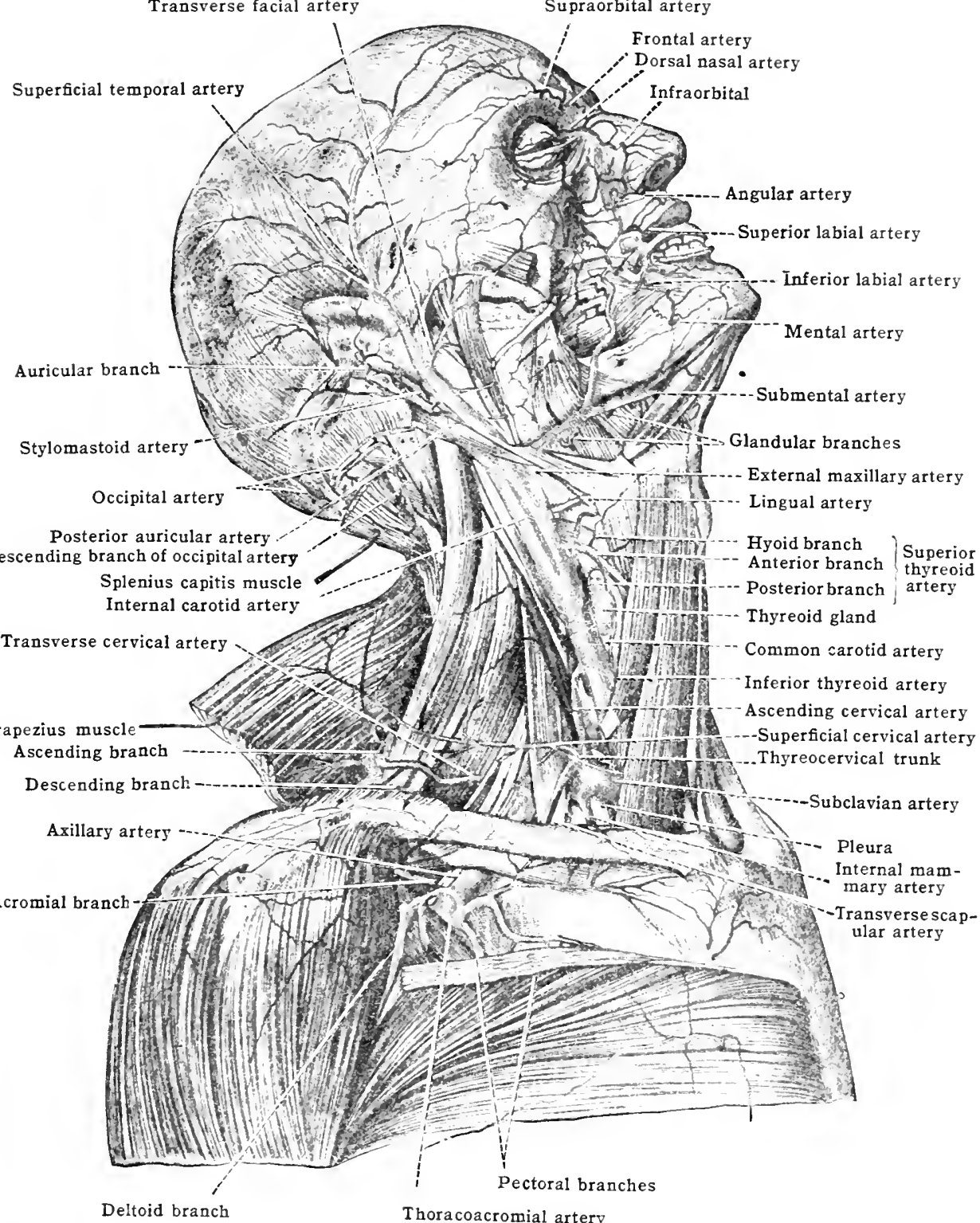

Deltoid branch

Thoracoacromial artery

cardiae branches of the sympathetic and vagus nerves. At the lower part of the neek the inferior thyreoid artery courses obliquely behind the carotid, as does likewise the inferior (recurrent) laryngeal nerve.

Medially, from below upward, are the trachea and cesophagus, with the inferior (recurrent) laryngeal nerve in the groove between them, and the terminal branches of the inferior thyreoid artery, the lateral lobe of the thyreoid ghand, the ericoid eartilage, the thyreoid cartilage, and the lower part of the pharynx. At the angle of bifureation is the carotid gland [glomus earoticum].

Laterally are the internal jugular vein and the vagus nerve. On the right side, at the root of the neek, the vein diverges somewhat from the artery, leaving a space in which the vagus 
nerre and vertebral artery are exposed. On the left side the vein approaches and somewhat overlaps the artery, thus leaving no interval corresponding to that on the right side.

The cricoid cartilage is, as a rule, taken as the centre of the incision in the operation for ligature of the common carotid artery. The incision is made in the line of the vessel parallel to the anterior margin of the sterno-mastoid muscle. The omo-hyoid forms one of the chief rallying points in the course of the operation for ligature of the artery above that muscle, the usual situation. The artery is found beating at the angle formed by the omo-hyoid with the sterno-mastoid.

Branches.-(1) External and (2) internal carotid arteries. The common carotid gives off no lateral branch, and consequently does not diminish in size as it runs up the neck. It is of ten a little swollen just below its bifurcation, a condition that should not be mistaken for an aneurismal dilation.

The collateral circulation (fig. 444), after ligature of the common carotid, is carried on chiefly by the anastomosis of the internal carotid with the internal carotid of the opposite side through the circle of IVillis; by the vertebral with the opposite vertebral; by the inferior thyreoid with the superior thyreoid; by the deep cervical branch of the costo-cervical trunk (superior intercostal) with the descending branch of the occipital; by the superior thyreoid, lingual, external maxillary (facial), occipital, and temporal, with the corresponding arteries of the opposite side, and by the ophthalmic with the angular. The anastomosis between the deep cervical branch of the costo-cervical trunk with the descending branch of the occipital is an important one; it is situated deeply at the back of the neck, and is to be found lying between the semispinalis capitis (complexus) and cervicis muscles.

\section{THE EXTERNAL CAROTID ARTERY}

The external carotid artery [a. carotis externa] (fig. 445), the smaller of the two branches into which the common carotid divides at the upper border of the thyreoid cartilage, is distributed to the anterior part of the neck, the face, and the cranial region, including the skin, the bones, and the dura mater. It is at first situated medial to the internal carotid; but as it ascends in the neck it forms a gentle curve, with its convexity forward, and, running slightly backward as well as upward, terminates opposite the neck of the mandible just below the condyle, by dividing into the internal maxillary and superficial temporal arteries. It here lies superficial to the internal carotid, from which it is separated by a portion of the parotid gland. At its origin it is overlapped by the anterior margin of the sterno-mastoid, and is covered by the superficial fascia, platysma, and deep fascia. Higher up the neck it is deeply placed, passing beneath the stylo-hyoid muscle, the posterior belly of the digastric muscle, and the hypoglossal nerve; and finally becomes embedded in the parotid gland, where it divides into its terminal branches. It is separated from the internal carotid artery posteriorly by the stylo-pharyngeus and stylo-glossus museles, the glosso-pharyngeal nerve, the pharyngeal branch of the vagus nerve, a portion of the parotid gland, and the stylo-hyoid ligament; or, if the styloid process is abnormally long, by that process itself. It measures about $6.5 \mathrm{~cm} .\left(2 \frac{3}{5} \mathrm{in}.\right)$.

Relations.--In front, in addition to the skin, superficial fascia, platysma, and deep fascia, it has the hypoglossal nerve, the lingual, common facial and posterior facial veins, the posterior belly of the digastric and stylo-hyoid muscles, the superior cervieal lymphatic glands, branches of the facial nerve, and the parotid gland. The sterno-mastoid also overlaps it in the natural state of the parts.

Behind, it is in relation with the internal carotid, from which it is separated by the styloglossus and stylo-pharyngeus muscles, the glosso-pharyngeal nerve, the pharyngeal branch of the vagus nerve, the stylo-hyoid ligament, and the parotid gland. The superior laryngeal nerve crosses bohind both the external and internal carotid arteries.

Medially, it is in relation with the hyoid bone, the pliaryugeal wall, the ramus of the mandible, the stylo-mandibular ligament which separates it from the submaxillary gland, and the parsticl glimil.

Laterally, in the first part of its course, it is in contact with the internal carotid artery.

'I'h' branches of the external carotid are usually given off in the following orrler, from bolow upwarl:

1. Asconcling phatyngeal.

2. Simperior thyreoid.

$\therefore$ Iingual.

1. Hxternal maxillary (facial).

5. Siternocleidomastoid.

f. ()coipital.

7. J'osterior auricular.

8. Simperficial temporal.

9. Internal maxillary. 


\section{THE ASCENDING PHARYNGEAL ARTERY}

The ascending pharyngeal artery [a. pharyngea ascendens] (fig. 446) is usually the first or second branch of the external carotid. Occasionally it comes off at the bifurcation of the common carotid from the common carotid itself. It is a long slender vessel which runs deeply seated up the neck to the base of the skull, having the walls of the pharynx and the tonsil medially, the internal carotid artery laterally, and the vertebral column, the longus capitis (rectus capitis anterior major), and the sympathetic nerve posteriorly. In front it is crossed by the stylo-glossus (fig. 446) and the stylo-pharyngeus muscles and the glossopharyngeal nerve.

\section{Branches of the Ascending Pharingeal Arter}

The branches of the ascending pharyngeal artery are small and variable. They supply the longus and rectus capitis muscles, the upper cervical sympathetic ganglion and adjacent lymph-nodes, as well as the pharynx, soft palate, ear, cranial nerves, and meninges.

The pharyngeal branches [rami pharyngei] supply the superior and middle constrictor muscles and the mucous membrane lining them. These vessels anastomose with branches

Fig. 446.-Scheme of Right Ascending Pharxngeal Artery. (Walsham.) The internal carotid artery is hooked aside.

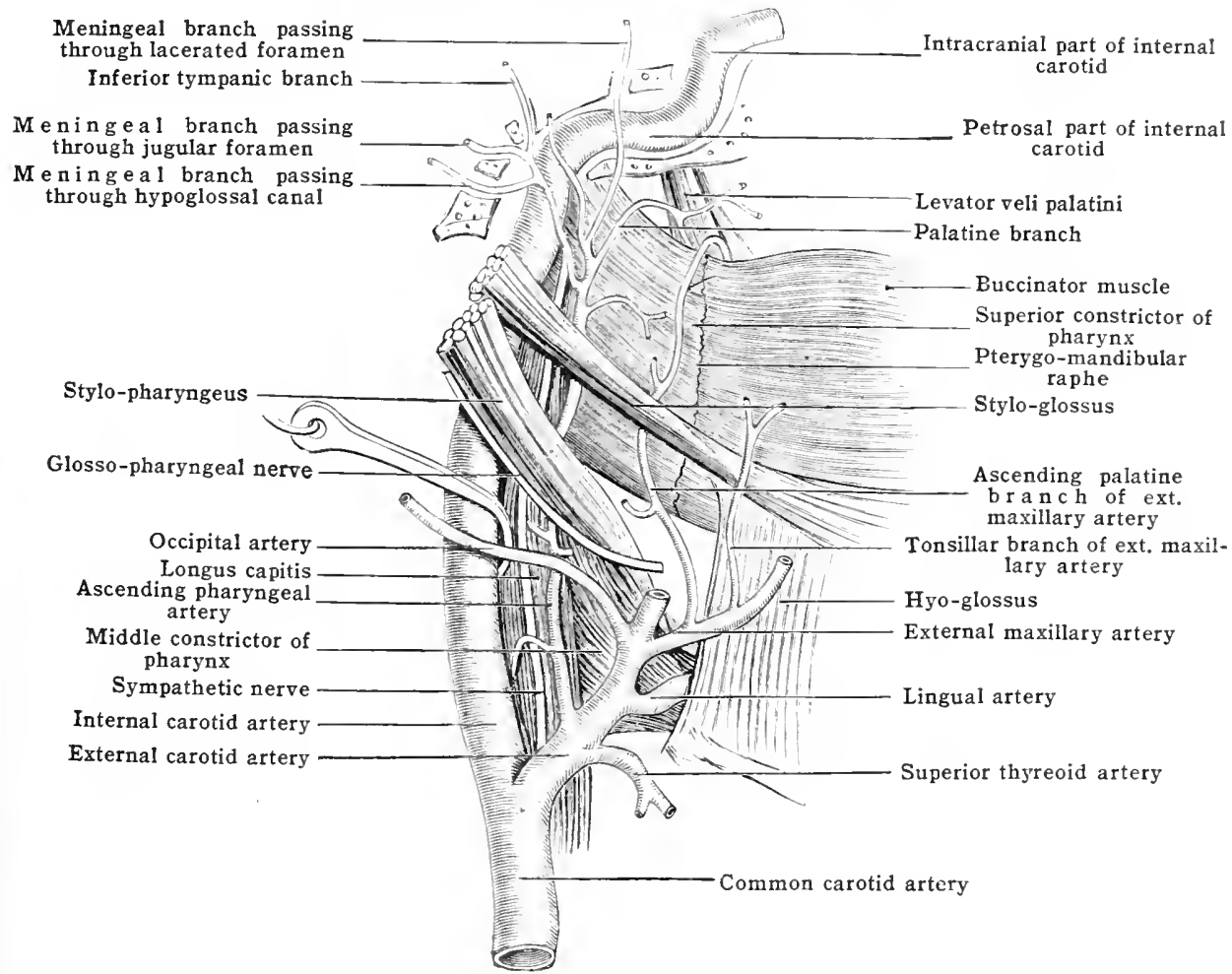

of the superior thyreoid. One branch (tho palatine) passes over the upper edge of the superior constrictor to the soft palate and its muscles. This branch follows a course similar to that taken by the ascending palatine artery, and when the latter is small may take its place. It generally gives off small twigs to the Eustachian tube and tonsil. The inferior tympanic artery [a. tympanica inferior] accompanies the tympanic branch of the glosso-pharyngeal nerve through the tympanic canaliculus into the tympanum, and anastomoses with the other tympanic arteries. The posterior meningeal artery [a. meningea posterior] is distributed to the membranes of the brain. Some twigs pass with the jugular vein through the jugular foramen into the cranium, and supply the dura mater in the posterior fossa of the skull. Others occasionally reach the same fossa through the hypoglossal (anterior condyloid) canal in company with the hypoglossal nerve; while others pass through the cartilage of the lacerated foramen and supply the middle fossa of the skull. 


\section{THE SUPERIOR THYREOID ARTERY}

The superior thyreoid artcry [a. thyreoidea superior] (figs. 445, 447) arises from the front of the external carotid a little above the origin of that vessel, and, coursing forward, medially, and then downward, in a tortuous manner, supplies the depresor muscles of the hyoid hone, the larynx, the thyreoid gland, and the lower part of the pharynx. The artery at first runs forward and a little upward, just beneath the greater cormu of the hyoid bone. In this part of its course it lies in the superior carotid triangle, and is guite superficial, being covered only with the integument, fascia, and platysma. It next turns downward, and passes beneath the omo-hyoid, sterno-hyoid, and sterno-thyreoid muscles, and ends at the upper part of the thyreoid gland by breaking up into terminal glandular branches. The superior thyreoid rein passes beneath the artery on its way to the intermal jugular vein. The superior thyreoid is the artery most commonly divided in cases of suicidal wounds of the throat.

\section{Branches of the Superior Thyreold Artery}

The named branches of the superior thyreoid artery are:-(1) The hyoid; (2) the sterno-mastoid; (3) the superior laryngeal; (4) the erico-thyreoid; (5) anterior; (6) posterior; and (7) glandular.

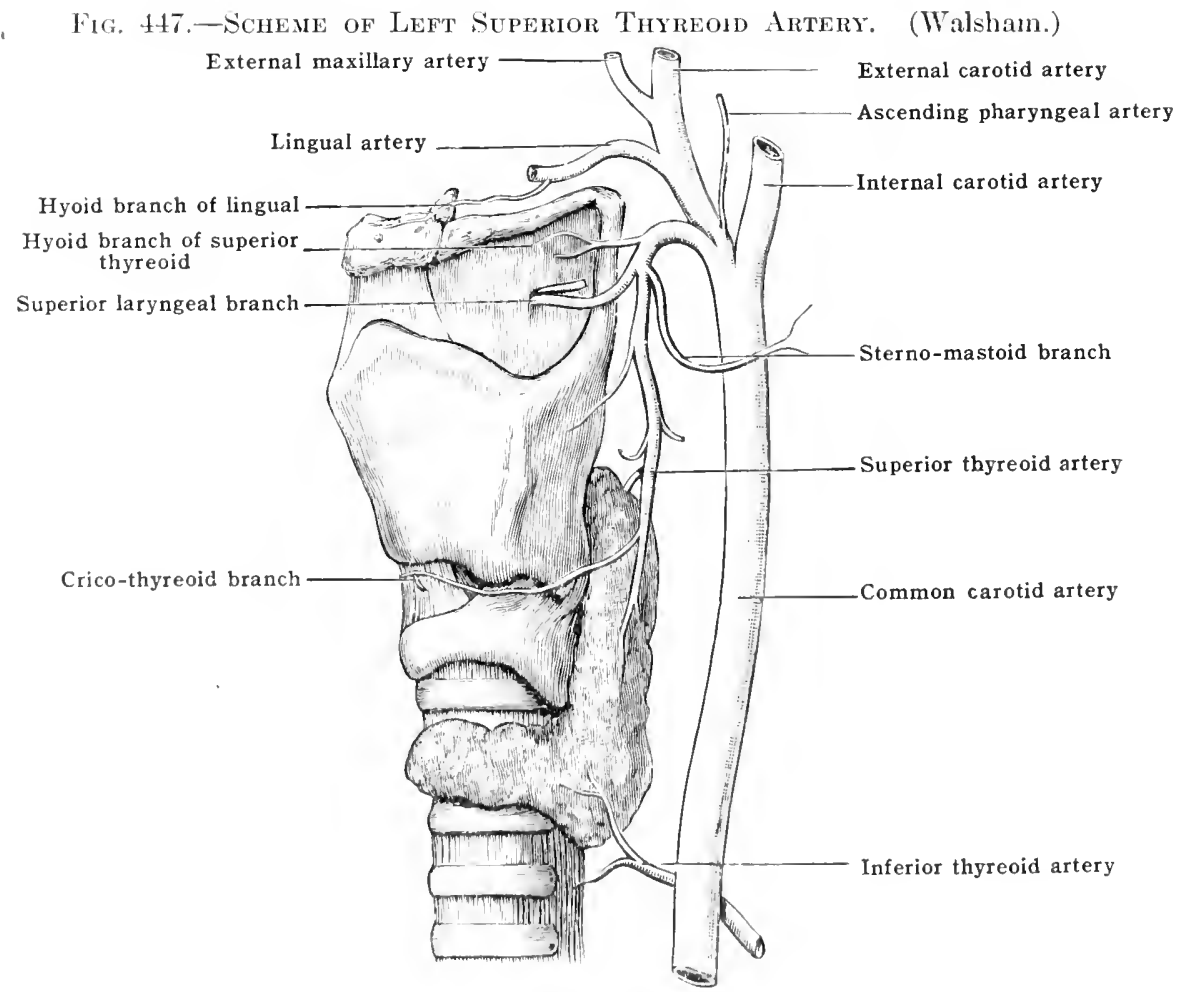

(1) Thre hyoid [ramus hyohdeus] is nstally a smal] twig which passes along the lower border

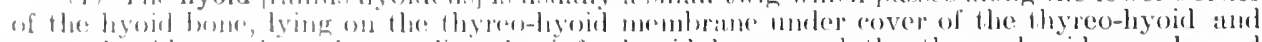

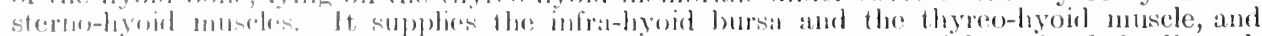

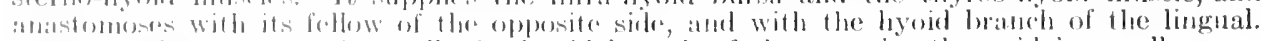

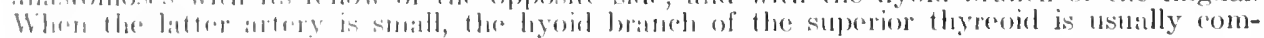
paratively larges, and rine rersin.

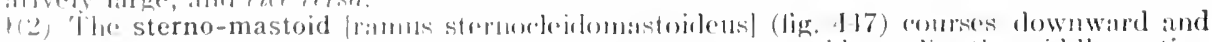

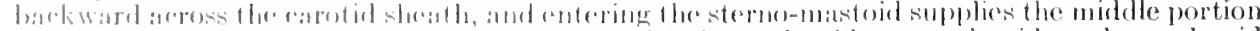

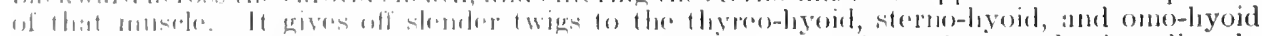

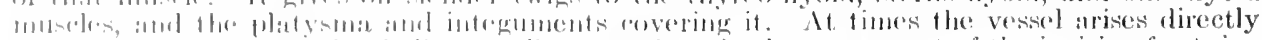

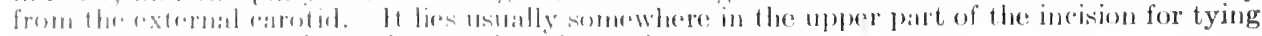

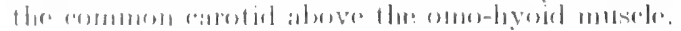

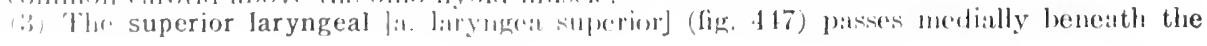


thyreo-hyoid muscle, and, perforating the thyreo-hyoid membrane along with the internal branch of the superior laryngeal nerve, supplies the intrinsic muscles and mucous lining of the larvnx. Its further distribution within the larrnx is given with the description of that organ. This branch sometimes arises from the external carotid direct. It may enter the larym by passing through a foramen in the thyreoid cartilage.

(4) The crico-thyreoid [ramus cricothyreoideus] passes across the crico-thyreoid membrane immediately beneath the lower border of the thyreoid cartilage. It anastomoses with its fellow of the opposite side, and usually sends a small branch through the membrane into the interior of the larynx. Occasionally a considerable twig descends over the cricoid cartilage to enter the isthmus of the thyreoid gland. The crico-thyreoid has, however, frequently been seen of comparatively large size-once as large as the radiak, and crossing the membrane obliquely. In order to avoid injuring the crico-thyreoid artery in the operation of laryngotomy, it is usual, if the operation has to be done in a hurry, to make the incision through the crico-thyreoid membrane in a transverse direction, and as near to the cricoid cartilage as possible.

(5) The anterior branch [ramus anterior] is the terminal branch supplying the isthmus and the neighbouring part of the lateral lobe of the thyreoid gland.

(6) The posterior branch [ramus posterior], the other terminal, supplies the posterior part of the lateral lobe, and sends branches to the inferior constrictor of the pharynx and to the œsophagus. It anastomoses with the ascending branches of the inferior thyreoid artery.

(7) The glandular branches [rami glandulares] are the ultimate twigs, arising from the anterior and posterior terminal branches, for the supply of the thyreoid gland.

\section{THE LINGUAL ARTERY}

The lingual artery [a. lingualis] (fig. 448) arises from the front of the external carotid, between the superior thyreoid and external maxillary (facial) arteries, often as a common trunk with the latter vessel, and nearly opposite or a little below the greater cornu of the hyoid bone. It may, for purposes of description, be divided into three portions: the first, or oblique, extends from its origin to the posterior edge of the hyo-glossus muscle; the second, or horizontal, lies beneath the hyo-glossus; the third, or ascending, beneath the tongue. The first or oblique portion is situated in the superior carotid triangle, and is superficial, being covered merely by the integument, platysma, and deep fascia. Here it lies on the middle constrictor muscle and superior laryngeal nerve. After ascending a short distance, it curves downward and forward beneath the hypoglossal nerve, and, in the second part of its course, runs horizontally along the upper border of the hyoid bone, beneath the hyo-glossus, by which it is separated from the hypoglossal nerve and its vena comitans, and the posterior belly of the digastric and the stylo-hyoid muscles. In this part of its course it lies successively on the middle constrictor of the pharynx and the genio-glossus muscle, and crosses a small triangular space known as 'Lesser's triangle,' the sides of which are formed by the tendons of the digastric, the base by the hypoglossal nerve, and the floor by the hyo-glossus muscle, in which situation it is usually tied. In the third part of its course it ascends tortuously, usually beneath the anterior margin of the hyo-glossus, to the under surface of the tongue, and is thence continued to the tip of that structure lying between the lingualis and the genio-glossus muscles. From the anterior edge of the hyo-glossus to its termination it is only corered by the mucous membrane of the under surface of the tongue. This part of the vessel is sometimes called the ranine artery. The lingual artery is accompanied by small venæ comitantes.

\section{Branches of the Lingual Artery}

The named branches of the lingual artery are:-(1) The hyoid: (2) the dorsal lingual; (3) the sublingual; and (4) the deep lingual (ranine).

(1) The hyoid branch [ramus hyoideus] (fig. 4tS) is a small vessel which arines from the first part of the lingual, and courses along the upper border of the hyoid bone, superficial to the hyoglossus, but beneath the insertion of the posterior belly of the digastric and the stylo-hyoid. It anastomoses with its fellow of the opposite side, and with the hyoid branch of the superior thyreoid artery, and supplies the contiguous muscles.

(2) The dorsalis linguæ (fig. 448) arises from the second portion of the lingual artery, usually under cover of the posterior edge of the hyo-glossus muscle. It ascends to the back of the dorsum of the tongue, and, dividing into branches, supplies the mucous membrane on each side of the $\mathbf{V}$ formed by the vallate papille. It also supplies the pillars of the fauce: and the tonsil, where it anastomoses with the other faucial and tonsillar arteries. Insteal of a single artery, as above described, there may be several small vessels ruming directly to the parts mentioned. The artery anastomoses in the mucous membrane by very small branches with the 
vessel of the opposite side; but the anastomosis is so minute that when one lingual artery is injected the injection merely passes across to the opposite side at the tip of the tongue; and when the tongue is divided accurately in the middle line, as in the removal of one-half of that organ, practically no hæmorrhage occurs.

(3) The sublingual artery [a. sublingualis] (fig. 448) usually comes off from the lingual at the auterior margin of the hyo-glossus. It passes beneath the mylo-hyoid to the sublingual gland, which it supplies, and finally it usually anastonoses with the submental artery, a branch of the external maxillary (facial). It also supplies branches to the side of the tongue, and gives off a terminal twig, which anastomoses beneath the mucous membrane of the floor of the mouth (to which it also gives twigs) with the artery of the opposite side. The artery of the frænum is usually derived from this vessel (fig. 448).

(4) The deep lingual [a. profunda linguæ], the termination of the lingual, courses forward beneath the mucous nembrane, on the under surface of the tongue, to the tip. It lies lateral to the genio-glossus, between that muscle and the inferior lingualis, and is accompanied by the lingual vein and terminal branch of the lingual nerve. It follows a very tortuous course, so that it is not stretched when the tongue is protruded. Branches are given off from it to the contiguous muscles and mucous membrane. Near the tip of the tongue it communicates with its fellow of the opposite side, as shown by the fact that when the lingual artery of one side is injected, the injection fluid passes into the branches of the artery of the other side.

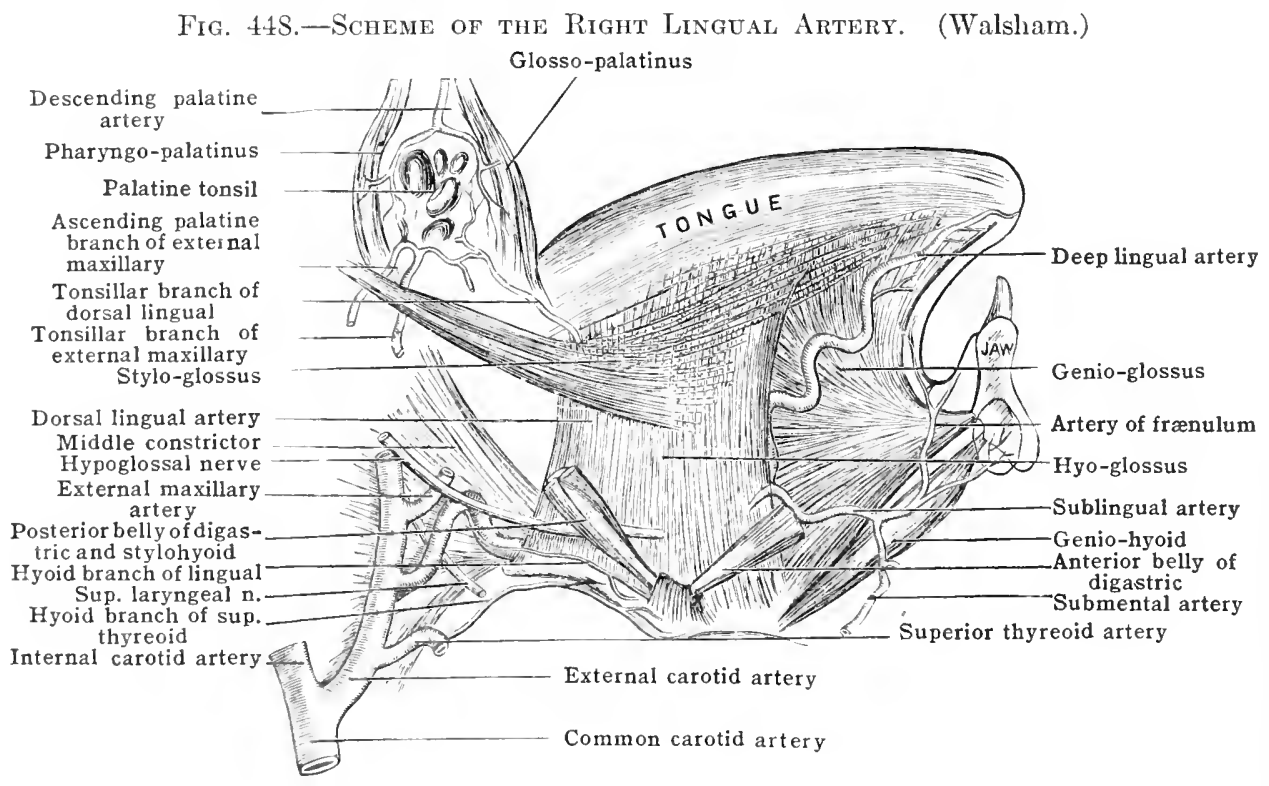

\section{THE EXTERNAL MAXILIARY (FACIAL) ARTERI}

The external maxillary or facial artery [a. maxillaris externa] (fig. 449) arises immediately above the lingual from the fore part of the external carotid, at times as at common trunk with the lingual. It courses forward and upward in a tortuous manner to the mandible, and, passing over the body of this bone at the anterior edge of the masseter musele, winds oblicguely upward and forward over the face to the medial angle of the eye, where it anastomoses, under the name of the angular artery, with the dorsal nasal branch of the ophthalmic. It is usually divided into two portions - the cervieal and the facial.

The cervical portion (fig. 149) ascends tortuously from its origin from the extrmal camblid nuward and forward beneath the posterior belly of the digastrie and stylo-hyoid muscles, and usially also beneath the hypoglossal nerve, and then, making a tirn, runs horizontally forward for a short way beneath the jaw, either imbedded in or lying umeler the submaxillary gland. It has here the mylo-hyoid and stylo-glossis leencath it. On leaving the cover of the gland it forms a loop passing first downwarl and then upward over the lower border of the jaw immediately in front of the masseter muscle, whore it is superficial, being merely covrerol by the integument and phatysmat. Here it can be felt beating, and ean be rearlily compressed. In the atove conrse it lies in the posterior part of the submaxiliary triangle, and, in addition to the structures already mentioned as crossing it, is covered by the skin, superficial fascia, and platysma, and by one or two smbmaxilary lymplatic nodes. The vein is separater from the artery by the 
submaxillary gland, the posterior belly of the diagastric muscle, the stylo-hyoid muscle, and the hypoglossal nerve.

The facial portion (fig. 449) of the external maxillary artery ascends tortuously forward toward the angle of the mouth, passing under the platysma (risorius), the zygomatic muscle, the zygomatic head of the quadratus labii superioris (zygomaticus minor), and the zygomatic and buccal branches of the facial nerve. It here lies upon the jaw and the buccinator muscle. Thence it courses upward by the side of the nose toward the medial angle of the eye, passing over or under the infraorbital and angular heads of the quadratus labii superioris, and under the infraorbital branches of the facial nerve. It lies on the caninus (levator anguli oris) and the infraorbital branches of the fifth nerve. The anterior facial vein takes a straighter course than the external maxillary artery, is separated from it by the zygomatic muscle, and lies lateral to it.

\section{Branches of the External Maxillary Artery of the Neck}

The branches of the external maxillary artery in the neck are:-(1) The ascending palatine; (2) the tonsillar; (3) the glandular; (4) the submental.

(1) The ascending palatine [a. palatina ascendens] (figs. 448, 449) - the first branch of the external maxillary, but often a distinet branch of the external carotid-ascends between the internal and external carotids, and then between the stylo-glossus and stylo-pharyngeus muscles, and on reaching the wall of the pharynx is continued upward between the superior constrictor and internal pterygoid muscles toward the base of the skull as high as the levator veli palatini, where it divides into two branches, a palatine and a tonsillar. One of these branches, the palatine, passes with the levator veli palatini over the curved upper margin of the superior constrictor to the soft palate, where it is distributed to the tissues constituting that structure, and anastomoses with its fellow of the opposite side and with the descending palatine branch of the internal maxillary, and the ascending pharyngeal, which vessel of ten to a great extent supplies the place of this artery. The other branch, the tonsillar, supplies the tonsil and the Eustachian tube, anastomosing with the tonsillar branch of the external maxillary (facial) and ascending pharyngeal arteries. The ascending palatine artery supplies the muscles between which it runs on its way to the palate.

(2) The tonsillar branch [ramus tonsillaris] (fig. 449) ascends between the stylo-glossus and internal pterygoid muscles to the level of the tonsil, where it perforates the superior constrictor muscle of the pharynx, and ends in the tonsil, anastomosing with the tonsillar branch of the ascending palatine and with the other tonsillar arteries (fig. 448). It gives branches also to the root of the tongue.

(3) The glandular branches [rami glandulares] are distributed to the submaxillary gland as the artery is passing through or beneath that structure. A small twig from one of these branches usually supplies the submaxillary (Wharton's) duct.

(4) The submental artery [a. submentalis] (fig. 449) comes off from the external maxillary as the latter vessel lies under cover of the submaxillary gland, and, passing forward on the mylo-hyoid muscle between the base of the jaw and the anterior belly of the digastricus, supplies these structures and the overlying platysma and integuments. It anastomoses with the sublingual artery. The external maxillary also supplies the adjacent muscles of the neck.

\section{Branches of the External Maxillary Artery on the Face}

From the lateral or concave side of the artery are given off branches which supply the masseter muscle and anastomose with the masseteric and buccinator branches of the internal maxillary artery, the transverse facial artery, and the infraorbital arteries.

From the medial or convex side the following larger and named vessels are given off:- (1) The inferior labial; (2) the superior labial; and (3) the angular.

(1) The inferior labial artery [a labialis inferior] arises at the angle of the mouth and runs in the under lip within the substance of the orbicularis oris, close to the mucous membrane. It anastomoses with the artery of the other side. Frequently an additional branch passes from the external maxillary to the lower lip.

(2) The superior labial artery [a. labialis superior] arising from the facial a little higher than the inferior, passes forward beneath the zygomaticus, and then, like the inferior labial, courses tortuously along the lower margin of the upper lip between the orbicularis oris and the

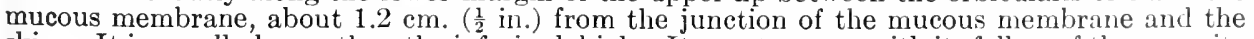
skin. It is usually larger than the inferior labial. It anastomoses with its fellow of the opposite side, and gives off a small artery to the septum-arteria septi nasi. Compression of this vessel will sometimes control hæmorrhage from the nose.

(3) The angular artery [a. angularis] (fig. 449) is the terminal branch of the external maxillary. It supplies the nose and anastomoses at the medial angle of the eye with the dorsal nasal branch of the ophthalmic. It is accompanied by the anterior descending vein from the scalp. 
It lies to the medial side of the lacrimal sac and supplies that structure and the lower part of the orbicularis oculi, beneath which a branch anastomoses with the infraorbital artery. The situation of the artery to the medial side of the lacrimal sac should be borne in mind in opening a lacrimal abscess.

Fig. 449.- Ścheme of the Right External Maxillary Artery. (Walsham.)

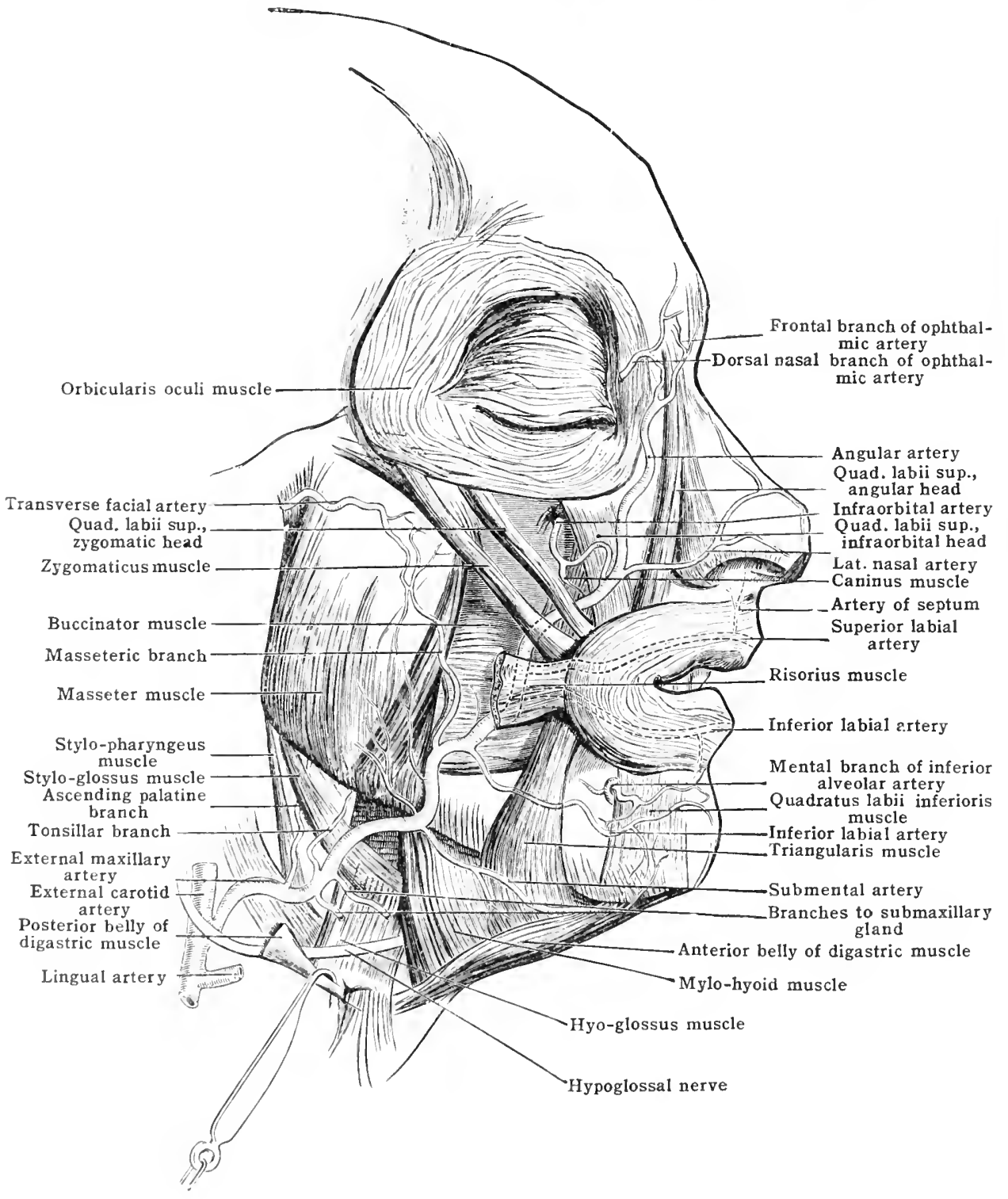

\section{PHESTHRNo(}

The sternocleidomastoid artery ta. strmocleiclomastoicleal arises from the

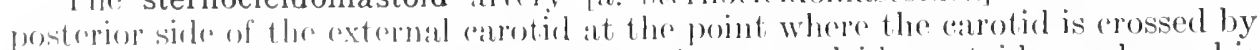

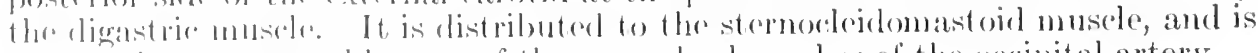

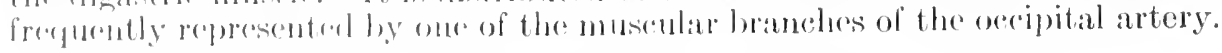

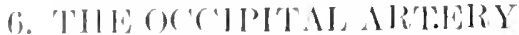

Ther occipital artery [a. orespitalis] (fig. fiso) is usually a vesion of consicterab]e size. It remes off firom the posterior part of the cetcomal caroticl opposite the rxternal maxillaty (factal), or alse a little higher than that vessel. It then winds 
upward and backward to the interval between the mastoid process of the temporal bone and transverse process of the atlas, and, after running horizontally backward in a groove on the mastoid portion of the temporal bone, again turns upward, and ends by ramifying in the scalp over the back of the skull, extending as far forward as the vertex.

The vessel may be divided into three parts-viz., that anterior to the sternomastoid muscle; that beneath the sterno-mastoid; and that posterior to the sterno-mastoid.

In the first part of its course the occipital artery is covered by the integuments and fascia, and is more or less overlapped by the posterior belly of the digastric muscle, the parotid gland, and posterior facial (temporo-maxillary) vein. It is crossed by the hypoglossal nerve as the latter winds forward over the carotid vessels to reach the tongue. It successively crosses in front of the internal carotid artery, the hypoglossal nerve, the vagus nerve, the intemal jugular vein, and the spinal accessory nerve.

In the second part of its course it sinks deeply beneath the digastric muscle into the interval between the mastoid process of the temporal bone and the transverse process of the atlas. It is here covered by the sterno-mastoid, splenius capitis, and longissimus capitis muscles and by the origin of the digastric; and lies, first on the rectus capitis lateralis, which separates it from the vertebral artery, then in a groove, the occipital groove, on the mastoid portion of the temporal bone, and then on the insertion of the superior oblique muscle.

In the third part of its course it enters the triangular interval formed by the diverging borders of the splenius capitis and the superior nuchal line of the occipital bone. Here it lies bencatb the integuments and the aponeurosis uniting the oecipital attachments of the sterno-mastoid and trapezius, and rests upon the semi-spinalis capitis (complexus) just before the insertion of that muscle into the occipital bone. In company with the greater occipital nerve, it perforates either this aponeurosis, or less often the posterior belly of the epicranius (occipito-frontalis), and follows roughly, but in a tortuous course, the line of the lamboid suture, lying between the integument and the cranial aponeurosis. In the sealp it divides into several lirge branches, which ramify over the back of the skull and rearlt as far forward as the vertex. They anastomose with the corresponding branches of the opposite side, and with the posterior auricular and the superficial temporal arteries.

\section{Branches of tile Occipital Artery (Fig. 450)}

The branches of the occipital artery are:-(1) The muscular; (2) the meningeal; (3) the auricular; (4) the mastoid; (5) the descending; (6) the occipital.

(1) The muscular branches [rami musculares] (fig. 450) supply the stemocleidomastoid and adjacent muscles. One of these branches may take the place of the sterno-mastoid branch of the external carotid. The hypoglossal nerve then, as a rule, loops round it instead of round the occipital.

(2) The meningeal branches [rami meningei] (fig. 450), one or more in number, are long slender vessels which leave the occipital artery as it crosses the internal jugular vein and, ascending along the vessel, pass with it through the jugular or hypoglossal foramen, and are distributed to the dura mater lining the posterior fossa of the skull.

(3) The auricular branch [ramus auricularis] ascends over the mastoid process to the back of the ear, and supplies the pima and concha. It sometimes takes the place of the posterior auricular artery (fig. 450 ).

(4) The mastoid branch [ramus mastoideus] is a small twig that passes into the skull through the mastoid foramen, supplying the dura mater, the diploë, the walls of the transverse sinus, and the mastoid cells.

(5) The descending or princeps cervicis [ramus descendens] (fig. 450), the largest of the branches of the occipital, arises from that artery just before it emerges from beneath the splenius, and, descending for a short distance between the splenius and semi-spinalis capitis (complexus), divides into a superficial and a deep branch. The superficial branch perforates the splenius, supplies branches to the trapezius, and anastomoses with the ascending branch of the transverse cervical artery. The deep branch passes downward between the semi-spinalis capitis (complexus) and colli, and anastomoses with the deep cervical branch of the costo-cervical trunk and with branches of the vertebral. The anastomoses between the above-mentioned arteries form important collateral channels after higature of the common carotid and subclavian arteries (fig. 444).

(6) The occipital or terminal branches [rami occipitales] (fig. 450 ), usually two in number, named from theix position medial and lateral, ramify over the scalp, and have already heen described. The medial branch generally gives off a twig which enters the parietal foramen (parietal artery) and is distributed to the dura mater. The occipital artery may also give off the stylo-mastoid, the posterior auricular, or the ascending pharyngeal arteries.

\section{THE POSTERIOR AURICULAR ARTERY}

The posterior auricular artery [a. auricularis posterior] (fig. 4.50) arises from the posterior part of the external carotid artery, usually immediately above the 
posterior belly of the digastric, about the level of the tip of the styloid process. Occasionally it arises under cover of the digastric, quite close to, or as a common trunk with, or as a branch of, the occipital. It courses upward and backward in the parotid gland to the notch between the margin of the external auditory meatus and the mastoid process, where it divides into branches. In this course it rests on the styloid process, crosses the spinal accessory nerve, and is crossed by the facial nerve.

Fig. 450.-Scheme of Left Occipital and Posterior Auricular Arteries. (Walsham.)

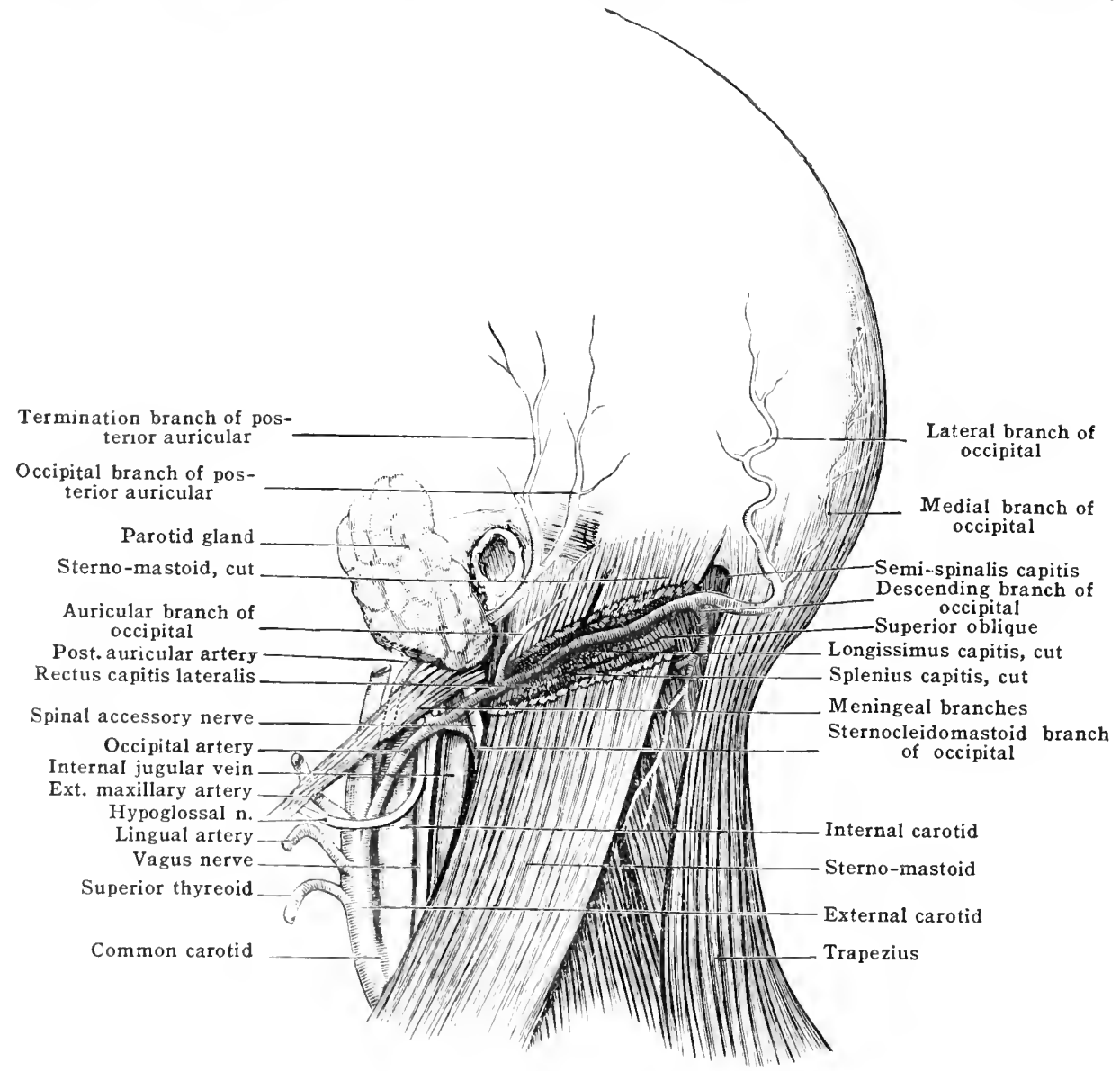

Branches of the Posterior duricular Artery

The branches of the posterior auricular artery are:-(1) the stylo-mastoid; the auricular; (3) the occipital (fig. 450).

The posterior auricular also gives branches to the parotid gland and the adjacent museles, namely, the posterior belly of the digastrie, the stylo-hyoid, and auricularis posterior (retrahens aturem).

(1) 'The stylo-mastoid artery [a. stylomastoiclea] comes off from the posterior aurieular' artery just before it rearhes the notch between the margin of the external auditory meatus and the mastoid process, and, following the far ial nerve upward, enters the stylo-mastoid foramen in the temporal hone. In the facial canal (aqueduct of Fallopius) it gives olf the following Hamerl twigs:-(a) meatal, to the external anrlitory meatus; $(b)$ mastoid [rami mastoidei], to the mastoid cells and tymuanic antrum; $(c)$ stapedic [ranus stapedius], which runs forward to the stiumelins muscle; (d) posterior tympanic [a. tympanica posterior], which anastomoses with the anteriog tympanic branch of the internal maxillary, forming with it in the foetus a vaseular circle aronm] the membrana tympani; (e) vestibular, to the vestibule and semicircular canals; and (f) terminal, a small twig which leavens the facial canal (by the hiatus) with the great super. ficial petrosal nerve, and anastomoses with the superior petrosal branch of the middle meningeal artery.

(2) 'The auricular branch [ramus aurioularis] passes upward behind the ear and beneath the ancionlaris posterior (retrahens aturem), supplying the medial surface of the pinna and adjacent 
skin. It anastomoses with the posterior branch of the superficial temporal artery. The branches to the pinna not only supply the back of that structure, but some perforate the cartilage, and others turn over its free margin to supply the lateral surface; there they anastomose with the anterior auricular branches from the temporal.

(3) The occipital branch [ramus occipitalis] passes upward and backward, crossing the aponeurotic insertion of the sterno-mastoid muscle. It gives a branch to the posterior belly of the epicranius (occipito-frontalis), and anastomoses with the occipital artery.

\section{THE SUPERFICIAL TEMPORAL ARTERY}

The superficial temporal artery [a. temporalis superficialis] (fic. 445), is the smaller of the two teminal divisions of the external carotid, though apparently the direct continuation of that ressel. It arises opposite the neck of the mandible and, under cover of the parotid gland, passes upward in the interval between the condyle and the external auditory meatus to the zygoma, lying on the capsule of the temporo-mandibular" joint. "Thence it ascends over the posterior'

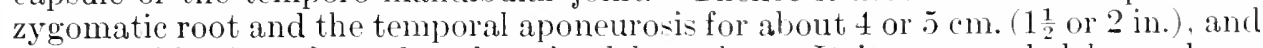
there divides into frontal and parietal branches. It is surrounded by a dense plexus of sympathetic nerves, and is accompanied by the auriculo-temporal nerve, which lies beneath and generally a little behind it. "It is crossed by the temporal and zygomatic branches of the facial nerve, and by the auricularis anterior attrahens aurem) muscle. As it (rosses the zygoma it can be readily felt pulsating immediately in front of the ear, and in this situation can be compressed against the bone. It is here quite superficial, being merely corered by the integuments and a delicate prolongation from the cervical fascia (fig. 445).

\section{Branches of the Superficial Temporal Artery}

The branches of the superficial temporal artery are:-(1) The parotirl; (2) the transverse facial; (3) the anterior auricular; (4) the zygomatico-orbital; (5) the middle temporal; (6) the frontal; ( 7 ) the parietal.

(1) The parotid branches [rami parotidei] are small twigs given off in the substance of the parotid gland.

(2) The transverse facial [a. transversa faciei] is the largest branch of the temporal. It sometimes arises from the external carotid as a common trunk with the temporal. It is at first deeply seated in the substance of the parotid gland, but soon emerging from the upper part of the anterior border of the gland known, courses transversely across the masseter muscle about a finger's breadth below the zygoma. The parotid duct runs below it, and the zygomatic (infraorbital) branches of the facial nerve above it. It supplies the parotid gland, the masseter muscle, and the skin of the face, and anastomoses with the infraorbital, the buccal, and the external maxillary (facial) arteries.

(3) The anterior auricular branches [rami auriculares anteriores] are three or four in number and supply the tragus, the pinna, and the lobule of the ear, and to some extent the external auditory meatus.

(4) The zygomatico-orbital artery [a. zygomaticoorbitalis] (fig. 445), at times a branch of the deep temporal, passes forward along the upper border of the zygoma in the fat between the superficial and deep layers of the temporal aponeurosis, and, after giving branches to the orbicularis oculi, sends one or more twigs into the orbit through foramina in the zygomatic (malar) bone to anastomose with the lacrimal and palpebral branches of the ophthalmic.

(5) The middle temporal artery [a. temporalis media] (fig. 453), arises just above the zygoma, and, perforating the temporal aponeurosis and temporal muscle, ascends on the squamous portion of the temporal bone, and anastomoses with the posterior deep temporal artery.

(6) The frontal or anterior terminal branch [ramus frontalis] ramifies tortuously in an upward and forward direction over the front part of the skull. It lies first between the skin ant temporal fascia and then between the skin and epicranial aponeurosis. It supplies the anterior belly of the epicranius (occipito-frontalis) and the orbicularis oculi muscles, and anastomoses with the supraorbital and frontal branches of the ophthalmic, and with the corresponding artery of the opposite side. The secondary branches given off from this ressel to the scalp run from before backward.

(7) The parietal or posterior terminal branch [ramus parietalis] ramifies on the side of the head between the skin and temporal fascia. Its branches anastomose, in front with the antertior terminal branch; behind, with the posterior anricular and occipital arteries; and alhove, acrus the vertex of the skull, with the corresponding artery of the opposite side.

\section{THE INTERXAL MAXILLARY ARTERY}

The internal maxillary artery [a. maxillaris interna] (fig. 451) is the larger of the two terminal divisions of the external caroticl. It arises opposite the neek of the mandible in the substance of the parotid gland, and, passing first between the mandible and the spheno-mandibular ligament and then between the external 
and internal pterygoid muscles, sinks deeply into the pterygo-palatine (sphenomaxillary) fossa, and there breaks up into its terminal branches. It is divided into three portions: a mandibular, a pterygoid, and a pterygo-palatine.

(1) In the first part of its course (the mandibular portion) the artery lies between the neck of the mandible and the spheno-mandibular ligament, taking a horizontal course forward, nearly parallel to and a little below the auriculotemporal nerve and the external pterygoid muscle. It is here embedded in the parotid gland, and usually crosses in front of the inferior alveolar (dental) nerve.

(2) In the second part of its course (the pterygoid portion) the artery may be placed superficial or deep to the external pterygoid muscle. In the first case it passes between the two pterygoid muscles and the ramus of the jaw, and then turns upward over the lateral surface of the external pterygoid, medial to the temporal muscle to gain the two heads of the external pterygoid, between which it

Fig. 451.-Scheme of Left Internal Maxillary. (Walsham.)

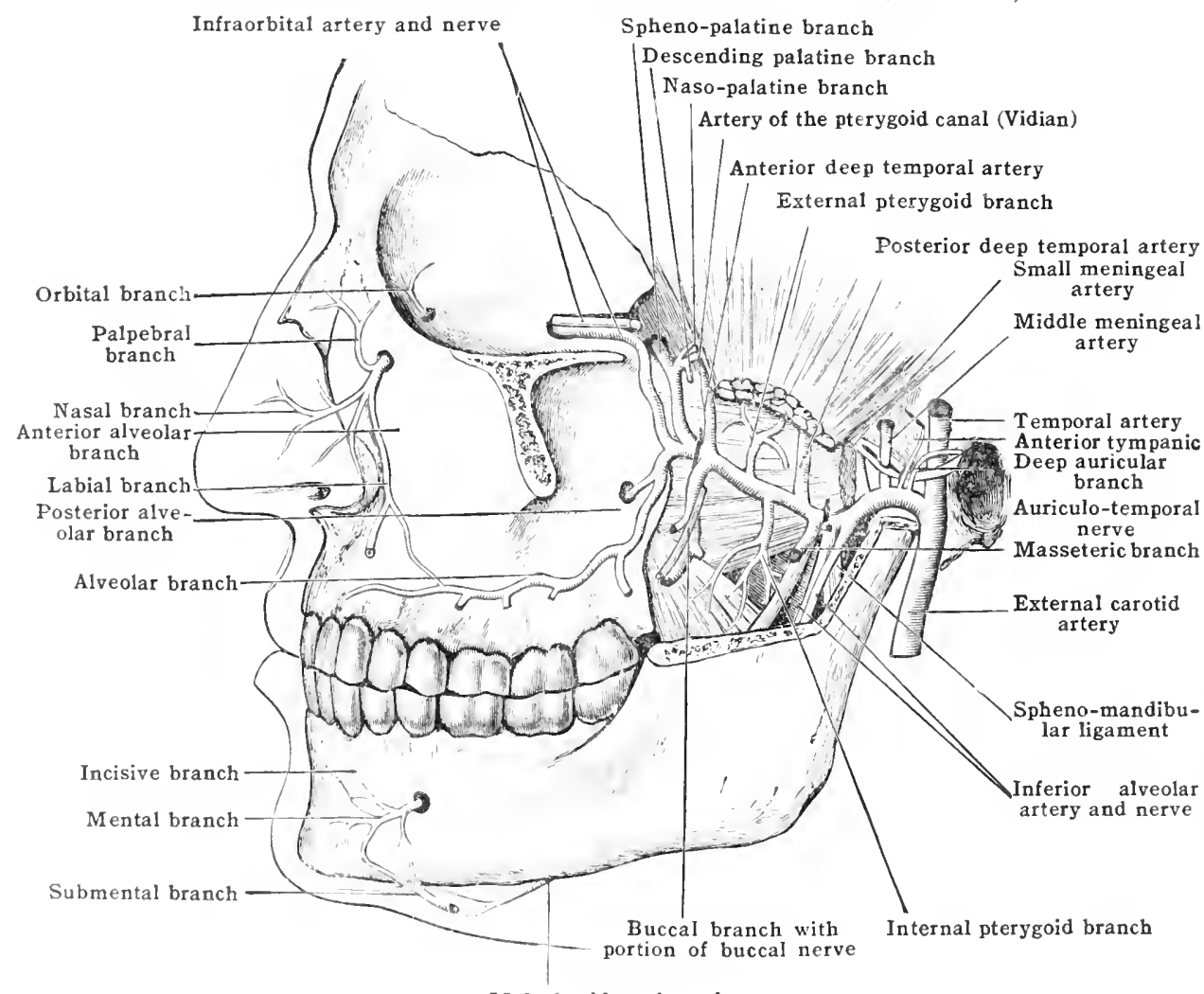

Mylo-hyoidean branch

sinks into the pterygo-palatine fossa. In the second case it passes medial to the external pterygoid, and is covered hy that muscle till it reaches the interval between its two heads, where it then of ten forms a projecting loop as it turns into the pteryg(i-palatine fossil.

(3) In the third part of its course (the pterygo-palatine portion) the artery lies in the pteryen-palatine fossa beneath the maxiltary division of the fifth nerve and in closc relationship with the spheno-palatine (Meckel's) ganglion, and there breaks up into its forminal branclues.

\section{Branches of thie Internat Maxiluary Artery}

'The branches of the internal maxillary artery are:-

(A) From the first part:--(1) 'The deep anricular; (2) the anterior tympanie; (3) the mirldle meningeal; (4) the inforior alveolar (dental); (5) the accessory moningeal (sometines). All these vessels pass through bony or cartilaginous ainals. 
(B) From the second part:-(1) The masseteric; (2) the posterior leep temporal; (3) the pterygoid; (4) the buccal; and (5) the anterior deep temporal. All these branches supply muscles.

(C) From the third part:-(1) The posterior superior alveolar (dental); (2) the infra-orbital; (3) the descending palatine; (4) the a. canalis pterygoidei or Vidian; and (5) the spheno-palatine. All these branches pass through bony canals.

\section{Branches of the First Part of the Internal Maxillary Artery}

(1) The deep auricular artery [a. auricularis profunda] (fig. 451) passes upward in the substance of the parotid gland behind the capsule of the temporo-mandibular joint, and, perforating the bony or cartilaginous wall of the external auditory meatus, supplies the skin of that passage and the membrana tympani. It at times gives a branch to the joint as it passes behind the temporo-mandibular articular capsule.

Fig. 452.-The Middle Meningeal Artery within the Skull. (After Spalteholtz.) Middle meningeal artery

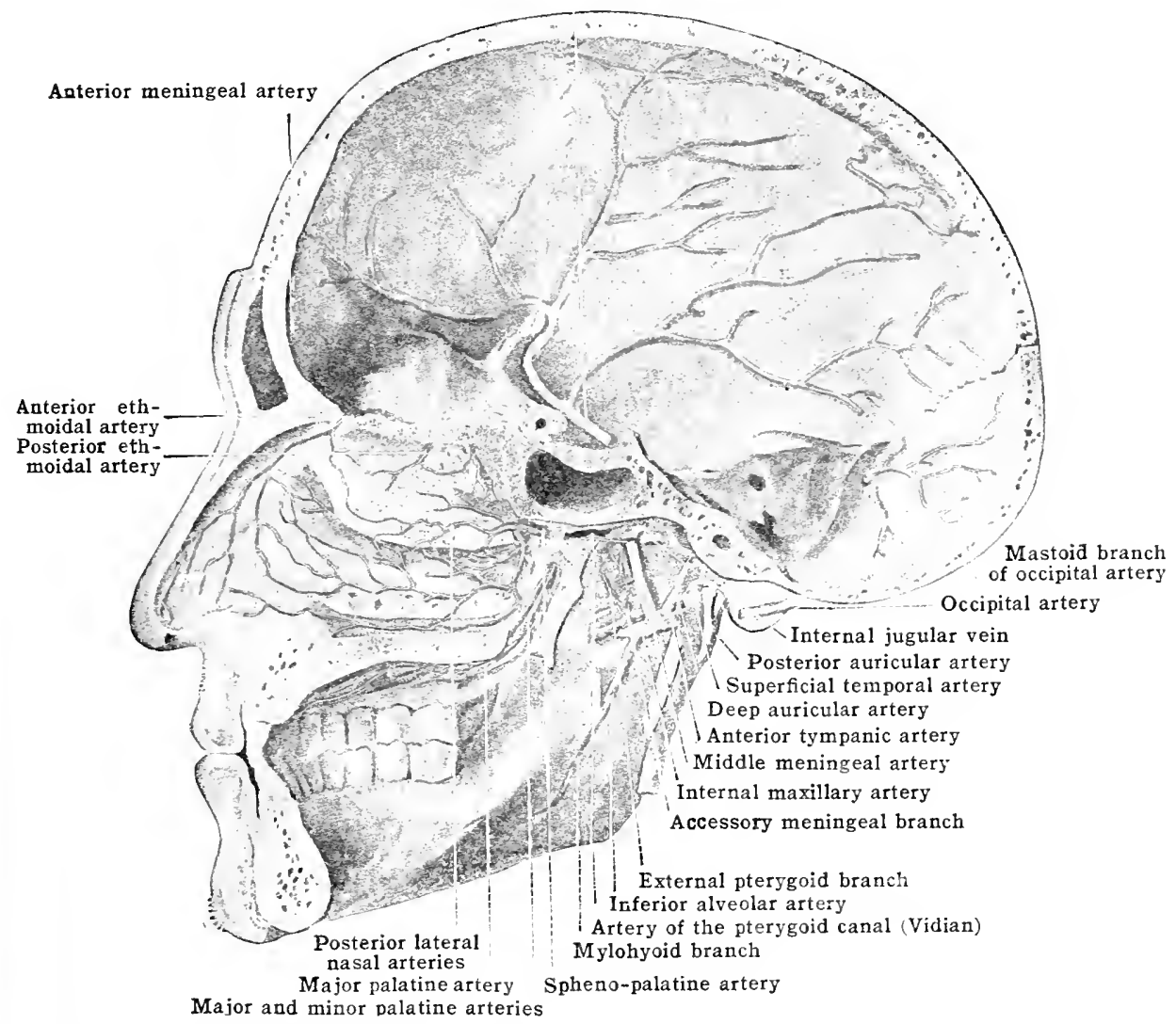

(2) The anterior tympanic artery [a. tympanica anterior] is a long slender vessel, which runs upward behind the condyle of the jaw to the petro-tympanic (Glaserian) fissure, through which it passes to the interior of the tympanum. Here it supplies the lining membrane of that cavity and anastomoses with the other tympanic arteries, forming with the posterior tympanic branch of the stylo-mastoid artery a vascular circle around the membrana tympani. This circle is more distinct in the fœtus than in the adult.

(3) The middle meningeal artery [a. meningea media] is the largest branch of the internal maxillary artery. It comes off from the vessel as it lies between the spheno-mandibular liga. ment and the ramus of the jaw, and under cover of the external pterygoid passes directly up. ward to the foramen spinosum, through which it enters the interior of the cranium. In this part of its course it is crossed by the chorda tympani nerve; and just before it enters the foramen is embraced by the two heads of origin of the auriculo-temporal nerve (fig. 451).

The trunk of the mandibular division of the fifth nerve, as it emerges from the foramen ovale, lies in front of the artery. As the artery passes upward it is surrounded by filaments of the sympathetic nerve, and is accompanied by two veins. On entering the skull it ramifies between the bone and dura mater, supplying both structures. It at first ascends for a short 
distance in a groove on the greater wing of the sphenoid, and then divides into two hranches, an anterior and a posterior.

The anteriot branch passes upward, in the groove on the greater wing of the sphenoid, on to the parietal bone at its anterior and inferior angle; at this spot the groove becomes deepened and of ten bridged over by a thin plate of bone, being converted for 6 to $12 \mathrm{~mm}$. ( $\frac{1}{4}$ to $\frac{1}{2}$ in.) or more into a distinct canal. The situation of the artery is here indicated on the exterior of the skull by a spot $3.7 \mathrm{~cm}$. ( $1 \frac{1}{2} \mathrm{in}$.) behind, and about $2.5 \mathrm{~cm}$. (1 in.) above, the zygomatic process of the frontal bone. The anterior branch is continued along the anterior border of the parictal bone nearly as far as the superior sagittal sinus, and gives off in its course, but especially posteriorly, large branches which ramify in an upward and backward direction in grooves on the parietal bone (fig. 452 ).

The posterior branch passes hackward over the squamous portion of the temporal bone; and thence on to the parietal bone, behind the anterior branch. This branch and its collaterals extend upward as far as the sagittal sinus, and backward as far as the transverse (lateral) sinus.

In addition to its terminal anterior, and terminal posterior branches, the middle meningeal gives off:- (a) Ganglionic branhecs to the semilunar (Gasserian) ganglion and its sheath of lura mater. (b) A superficial petrosal branch [ramus petrosus superficialis], which enters the hiatus of the facial canal in company with the large superficial petrosal nerve and anastomoses with the teminal branch of the stylo-mastoid artery. (c) A superior tympanic artery [a. trmpanica superior], which enters the canal for the tensor tympani, and supplies that muscle. (d) An orbital or lacrimal branch, which enters the orbit at the outermost part of the superior orbital (sphenoidal) fissure, or sometimes through a minute foramen, just lateral to that fissure, and anastomoses with the lacrimal branch of the ophthalmic. (e) Anastomotic or perforating branches which pierce the greater wing of the sphenoid bone, and anastomose with the deep temporal arteries.

(4) The inferior alveolar artery [a. alveolaris inferior] (fig. 451), arising from the internal maxillary as it lies between the spheno-mandibular ligament and neck of the jaw, courses downward to the mandibular foramen, which it enters in company with, and a little behind and lateral to, the inferior alveolar nerve. It then passes along the canal in the interior of the bone, giving off branches to the molar, premolar, and canine teeth. On reaching the mental foramen it divides into two branches, the incisive and the mental. The incisive continues its course in the bone, supplies branches to the incisor tecth, and anastomoses with the artery of the opposite sicle. The mental branch [ramus mentalis] passes through the mental foramen in company with the mental branch of the inferior alveolar (dental) nerve, and emerges on the chin uncler cover of the quadratus labii inferioris. It anastomoses above with the inferior labial (coronary), and below with the submental, and also with the inferior labial. Near its origin the artery gives off $(a)$ a lingual or gustatory branch, which accompanies and supplies the lingual nerve, and ends in the mucous nembrane of the mouth; and, just before it cnters the manlibular (dental) foramen in the lower jaw, (b) a mylo-hyoidean branch [ramus mylohyoideus], which accompanies the nerve of that name along the groove in the lower jaw, and, after supplying the mylo-hyoid muscle, anastomoses with the sublingual and submental arteries.

(i) The accessory or small meningeal branch [ramus meningens accessoria] arises either from the internil maxillary a little in front of the middle meningeal, or as a branch of the latter vesicel. It passes upward along the course of the mandibular division of the fifth nerve, and, ('ntring the skull through the foramen ovale, is clistributed to the semilunar (Gasserian) ganglion, and to the walls of the avernous sinus and the dura mater in the neighbourhood.

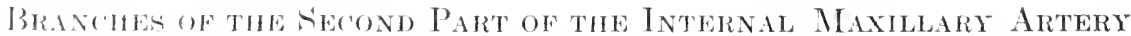

"Tle banches of the second portion of the internal maxillary all supply muscles. They an: (1) Thes masseteric; (2) the posterior decp temporal; (3) the pterygoid; (4) the buceal; amb (j) the anterior deep temporal.

(1) Tho masseteric artery [a, masseterical comes off from the internal maxillary as the latter

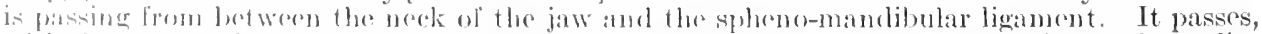

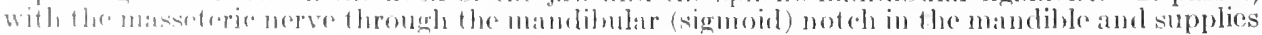

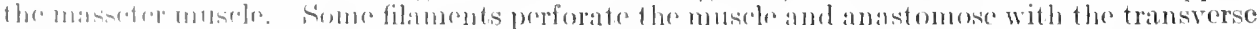

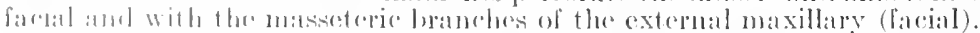

3) Tha posterior deep temporal artery fa, temporalis pofumlat posterior] arises, as a rule,

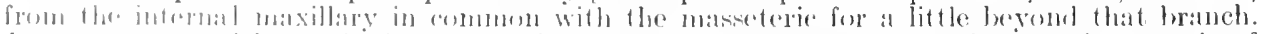

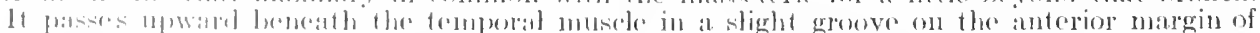

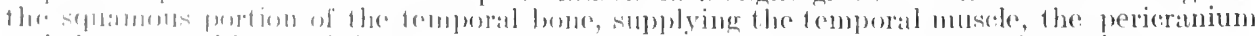

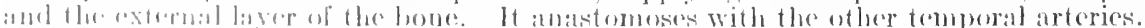

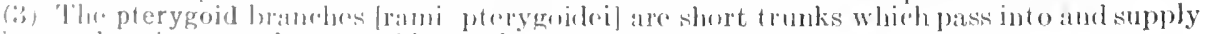

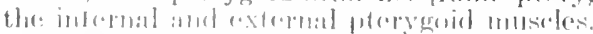

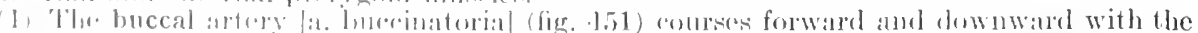

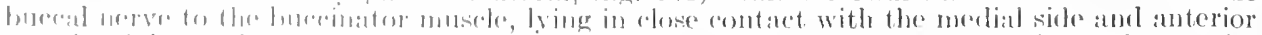

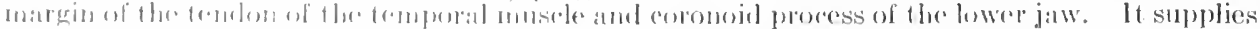

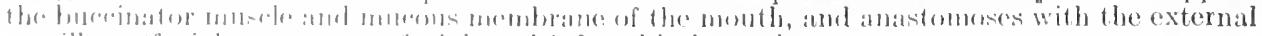

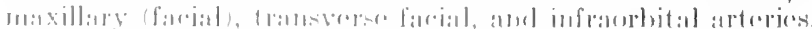

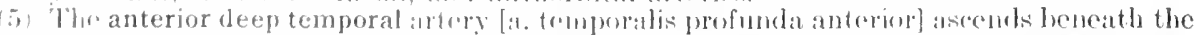

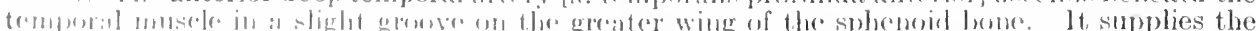

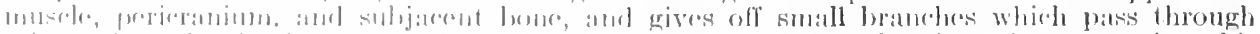

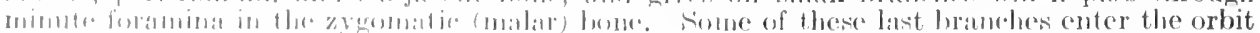

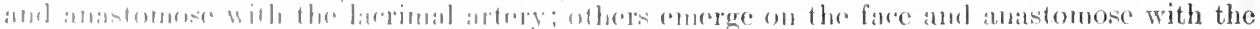

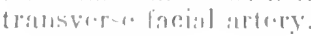




\section{Branches of the Third Part of the Internal Maxillary Artery}

The branches of the third part of the intemal maxillary artery, like those of the first part, all pass through bony canals. They are the following:-(1) 'The posterior superior alveolar (dental); (2) the infraorbital; (3) the descending palatine; (4) the artery of the pterygoid canal (Vidian); and (5) the sphenopalatine.

(1) The posterior superior alveolar (dental) artery [a. alveolaris superior posterior] arikes from the internal maxillary as the latter is passing into the pterygo-palatine (spheno-maxillary) fossa, and descends in a tortuous manner in a gloove on the back of the body of the maxilla. It gives off branches to the maxillary sinus, to the molar and premolar teeth, the gums, and to the buccinator muscle.

(2) The infraorbital artery [a. infraorbitalis] arises from the internal maxillary, generally as a common trunk with the posterior alveolar (dental). It passes forward and a little upwari through the pterygo-palatine (spheno-maxillary) fossa; then forward in company with the infraorbital branch of the fifth nerve, first along the groove, and then through the canal in the orbital plate of the maxilla; and finally, emerging on the face at the infraorbital foramen, under cover of the quadratus labii superioris, is distributed to the structures forming the uppes lip, the lower eyelid, the lacrimal sac, and the side of the nose. It anastomoses with the superior labial (coronary) and angular branches of the external maxillary (facial), with the nasal and lacrimal branches of the ophthamic, and with the transverse facial. It gives off small branches supplying the fat of the orbit and the inferior rectus and inferior oblique muscles. The anterior superior alveolar branch [a. alveolaris superior anterior] passes downward through a groove in the anterior wall of the maxilla, together with the anterior alveolar branch of the infraorbital nerve, and supplies branches to the incisor and canine teeth and the mucous membrane of the maxillary sinus. It has also nasal branches which pass through the foramina in the nasal process of the maxilla.

(3) The descending palatine artery [a. palatina descendens] descends in the ptervgopalatine canal with the anterior palatine branch of the spheno-palatine ganglion. On energing on the palate at the greater (posterior) palatine foramen, it divides into the following branches. - (a) The major palatine artery [a. palatina major]. which courses forward in the muco-periosteum at the junction of the hard palate with the alveolar process as far as the incisive (anterior palatine) foramen, where it anastomoses with the spleno-palatine artery; and (b) minor palatine arteries [aa. palatinx minores], which pass backward and downward into the soft palate, contributing to the supply of that structure, and anastomosing with the ascending palatine artery. After the operation for cleft palate, serious hamorrhage occasionally oceurs from the descending palatine artery. The foramen is situated a little belind, and meclial to, the last molar tooth, and almost immediately in front of the hamular process (fig. 452).

(4) The arteria canalis pterygoidei or Vidian artery is a long slender branch which passes backward through the pterygoid (Tidian) canal in company with the nerve of the same name into the cartilage of the lacerated foramen. It gives off branches which supply the roof of the pharynx, and anastomose with the ascending pharyngeal and spheno-palatine arteries; also a branch which is distributed to the Eustachian tube; and one which enters the tympanum, and anatomoses with the other tympanic arteries.

(5) The spheno-palatine [a. sphenopalatina], the terminal branch of the internal maxillary. passes with the naso-palatine branch of the spheno-palatine gangfion from the pterygo-palatine (spheno-maxillary) fossa into the nose through the spheno-palatine foramen. Crossing the roof of the nose in the muco-periosteum, it passes on to the septum, and then runs forward and downward in a groove on the vomer toward the incisive (anterior palatine) foramen, where it anastomoses with the anterior palatine artery, which enters the nose through the lateral compartment of that foramen (the canal of Stenson). In this course it gives off branches to the roof and contiguous portions of the pharynx, and to the sphenoidal cells. It has also posterior lateral nasal branches [aa. nasales post. laterales], which ramify over the nasal concha (turbinate bones) and lateral walls of the nose, and give twigs to the ethmoidal and frontal sinuses and the lining membrane of the maxillary sinus; and posterior septal branches [aa. nasales post. septi], which run upward and forward, giving small twigs to the mucous membrane covering the upper part of the septum, and which pass through the cribriform plate of the ethmoid, and anastomose with the ethmoidal arteries (perforating or meningeal branches).

\section{THE INTERNAL CAROTID ARTERY}

The internal carotid artery [a. carotis interna] (figs. 453 and 454 ) arises with the external carotid at the bifurcation of the common carotid, opposite the upper border of the thyreoid cartilage, on a level with the fourth cervical vertebra. It is at first placed a little lateral to the external carotid, but as it ascends in the neck the external carotid becomes more superficial and in front of the intermal. The internal carotid passes up the neck, in front of the transverse proceses of the uppor cervical vertebra, lying upon the longus capitis (rectus capitis ant. nuajor), to the carotid foramen, thence through the carotid canal in the petrous portion of the temporal bone, making at first a forward and medial turn and then a second turn upward, and enters the craniun through the foramen lacerum. It makes a sigmoid curve on the sicle of the body of the sphenoid bone, and terminates, after perforating the dura mater, by dividing opposite the anterior clinoid processes 
in the lateral fissure (fissure of Sylvius), into the anterior and middle cerebral arteries.

In its course up the neck it often forms one or more curves, especially in old people. Between the internal and the external carotids, at their angle of divergence, is situated the carotid body or gland [glomus caroticum].

The internal carotid is the contimuation upward of the primitive dorsal aorta, and supplies the greater part of the brain, the contents of the orbit, and parts of the internal ear, forehead, and nose. It is divided into three portions:-(1) a cervical; (2) a petrosal; and (3) an intracranial.

\section{Time Cervical Portion}

Relations.-In the neck (fig. 453) the artery is at first comparatively superficial, having in front of it, as it lies in the superior carotid triangle, the skin, superficial fascia, platysma and

Fig. 453.-The Carotid Arteries. (After Toldt, "Atlas of Human Anatomy," Rebman London and New York.)

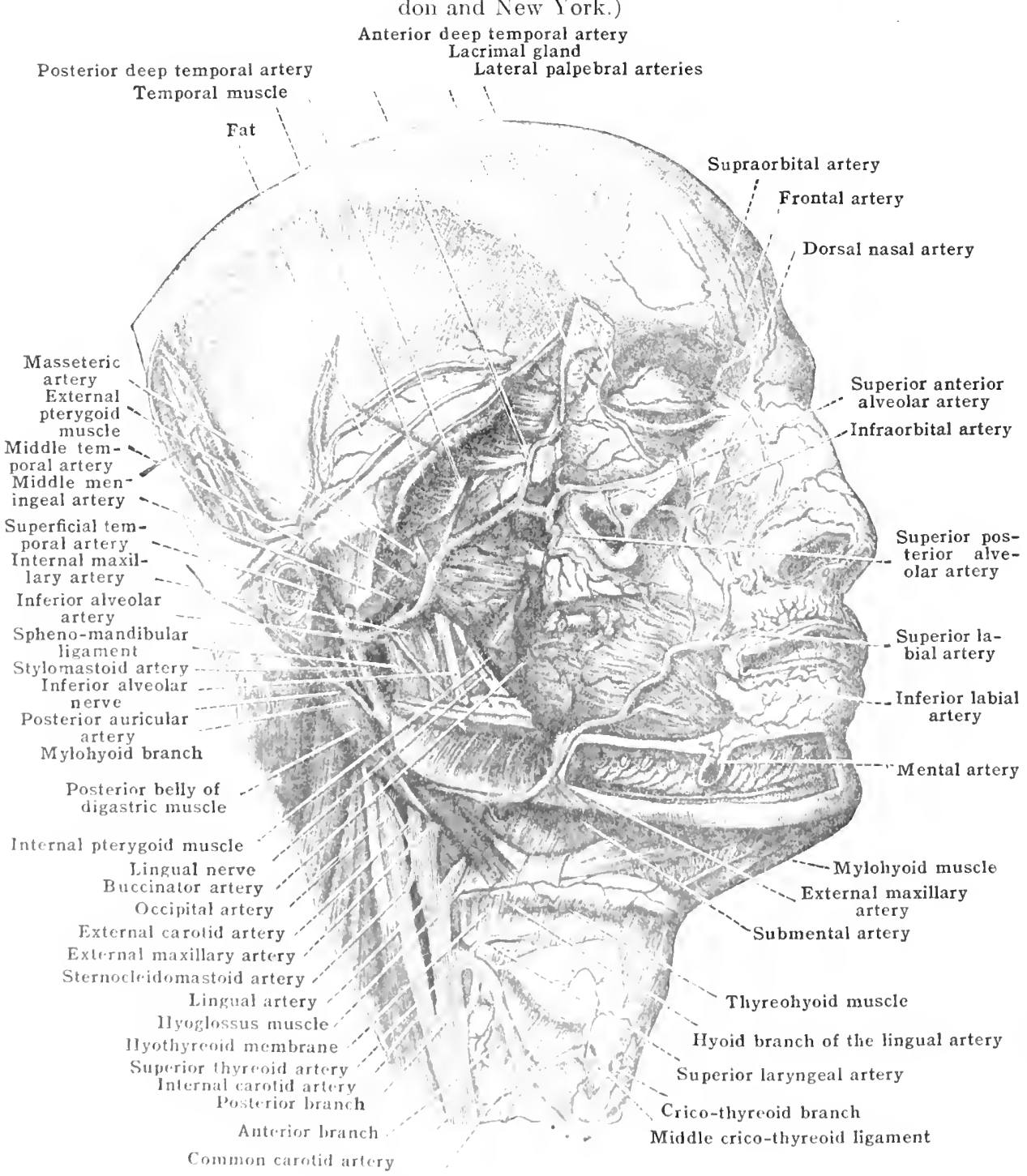

Thyreohyoid muscle

leep fascia, and the overlapping edlge of the sterno-mastoid muscle. IIigher up, as it sinks be-

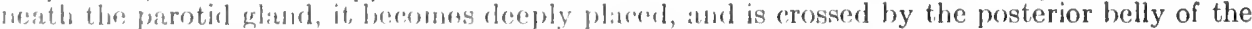
digastric and stylo-hyoid museles, the hypoglossal nerve, and the occipital and posterior auricular arteries; whilst still higher it is sejarated from the external carotid artery, which here gets 
in front of it, by the stylo-glossus and stylo-pharyngeus nuscles, the glosso-pharyngeal nerve, the pharyngeal branch of the vagus nerve, and by the stylo-hyoid ligament.

Behind, it lies upon the longus capitis (rectus capitis anticus major), which separates it from the transverse processes of the three upper cervical vertebræ, on the superior cervical ganglion of the sympathetic nerve, and on the vagus nerve. Near the base of the skull, the hypoglossal, vagus, glosso-pharyngeal, and spinal accessory nerves cross obliquely behind it, separating it here from the internal jugular vein, which, as the artery is about to enter the carotid canal, also forms one of its posterior relations.

On its lateral side are the internal jugular vein and vagus nerve.

On its medial side it is in relation with the pharynx, the superior constrictor muscle separating it from the tonsil. The ascending pharyngeal and ascending palatine arteries, and at the base of the skull the Eustachian tube and levator palati muscles, are also medial to it.

\section{Thf Petrosal Portion}

The petrosal portion (fig. 454) is situated in the carotid canal in the petrous portion of the temporal bone. It is here separated from the walls of the canal by a prolongation downward of the dura mater. In this part of its course it first ascends in front of the tympanum and cochlea of the internal ear; it then turns forward and medially, lying a little medial to and behind the Eustachian tube, and enters the cranial cavity by turning upward through the fora-

Fig. 454.-The Internal Carotid Artery in the Canal. (After Spalteholz.)

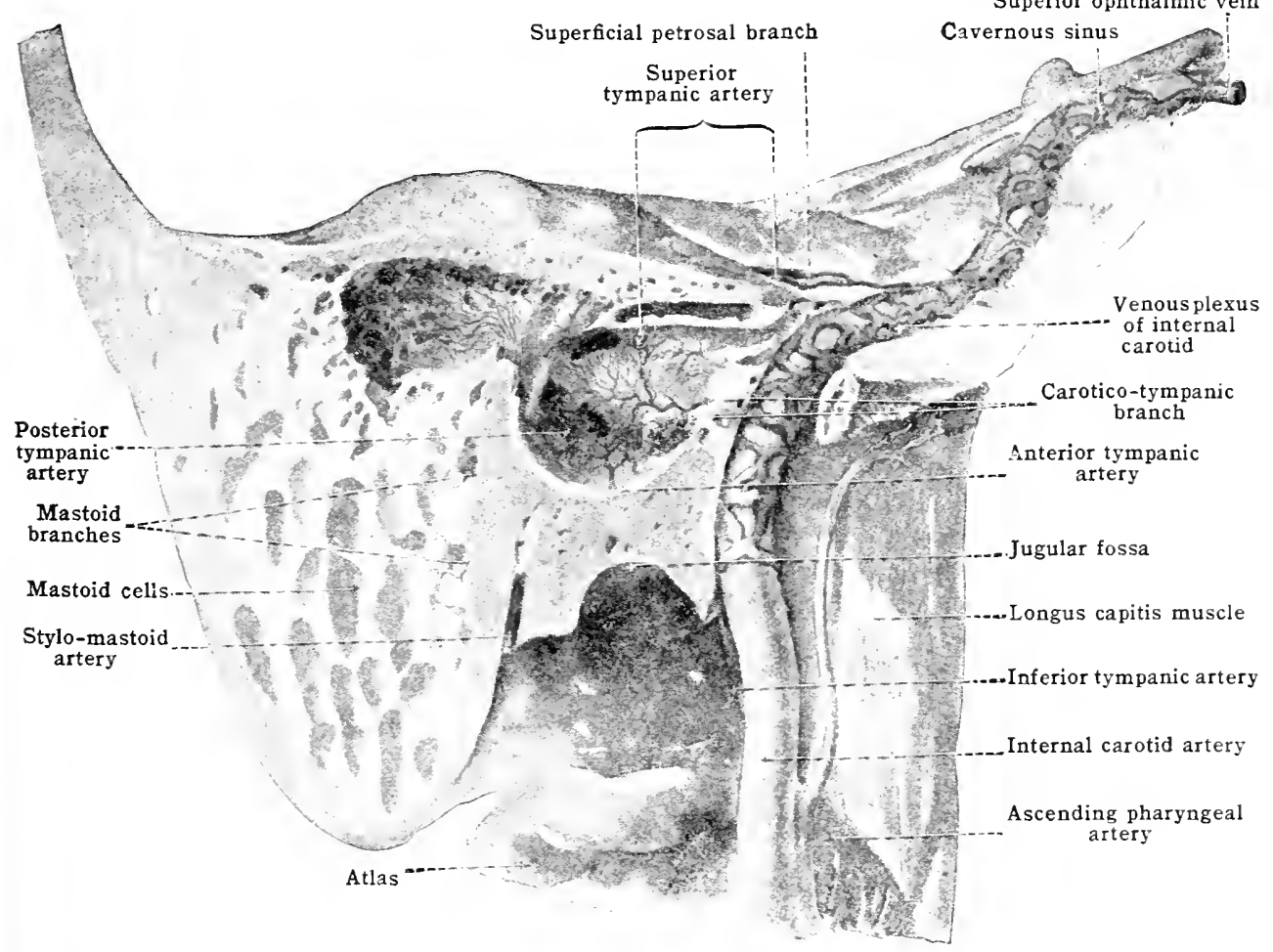

men lacerum, lying upon the lingula of the sphenoid bone. In this part of its course it is accompanied by the ascending branches from the superior cervical ganglion of the sympathetic. These form a plexus about the artery, but are situated chiefly on its lateral side. It is also surrounded by a number of small veirs, which receive tributaries from the tympanum and open into the cavernous sinus and internal jugular vein.

\section{The Intracranial Portion}

On entering the cranium through the foramen lacerum, the internal carotid first ascends to reach the lateral part of the body of the sphenoid medial to the lingula. It then follows the carotid sulcus forward and slightly downward along the medial wall of the cavernous sinus (fig. 454). Here it has the sixth nerve immediately lateral to it, and is covered by the lining membrane of the sinus. Again turning upward, it pierces the dura mater on the medial side of the anterior clinoid process, and, passes between the second and third nerves to the anterior perforated substance. At the medial end of the lateral (Sylvian) fissure it pierces the arachnoid and divides into its two terminal branches, the anterior and middle cerebral. As it lies in the 
foramen lacerum the artery is crossed on its lateral side by the great superficial petrosal nerve as the latter goes to join the great leep petrosal from the carotid plexus to form the nerve of the pterygoil canal (Vidian).

\section{Branches of the Internal Carotid Artery}

The cervical portion gives off no branch. The petrosal portion gives off the caroticotympanic. The branches of the intracranial portion are:-(2) ophthalmic; (3) posterior communieating; (4) chorioid; (5) anterior cerebral; (6) midalle erebral.

As the internal carotid artery lies on the medial side of the cavernois sinus, it also gives off the following small branches-branches to the walls of the eavernous inus; to the pituitary body; to the semilumar (Gasserian) ganglion; to the dura mater. These anastomose with anterior branches of the midlle meningeal.

\section{THE CAROTICOTYMPANIC ARTERY}

The caroticotympanic enters the tympanum through a small foramen in the posterior wall of the carotid canal, and contributes its quota to the blood-supply of that cavity. It anastomoses with the tympanie branches of the stylo-mastoid, internal maxillary, and middle meningeal arteries.

\section{THE OPHTHALMIC ARTERY}

The ophthalmic artery (fig. 455) comes off from the internal carotid immediately below the anterior clinoid process just as the latter vessel is passing through the ilura matter. Entering the orbit through the optic foramen below and lateral to theo ptic nerve, it at once perforates the sheath of dura mater whieh is prolonged through the optic foramen on both artery and nerve. It then runs in a gentle ("urve with a lateral convexity below the optic nerve and lateral rectus, being here crossed by the naso-ciliary (nasal) nerve. Tuming forward and upward, it passes over the optic nerve, to its medial side. Thence it runs obliquely beneath the superior reetus in front of the naso-ciliary (nasal) nerve under the lower border of the superior olligue, hut above the medial rectus, and continues its course under the pulley for the superior oblique and reflected tendon of that muscle to the merlial palpeloral region, where it divides into the frontal and nasal branches.

\section{Branciles of the Ophthalailc Artery}

Thu' branches of the ophthalmic artery are:-(1) the lacrimal; (2) the supraorbital; (3) the central altery of the retina; (4) the museular; (5) the ciliary; (6) the postrerior ethmoidal; (7) the anterior othmoidal; (8) the medial patpeJial; (9) the frontal; and (10) the clorsal nasal.

(1) Thu lacrimal artory fal lacrinalis], is usually the first and often the largest hraneh of

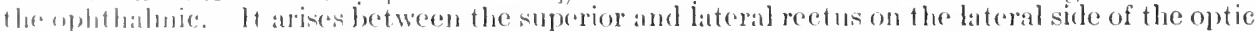

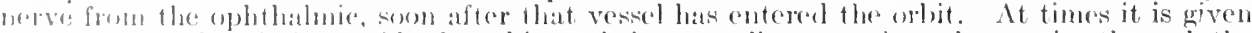

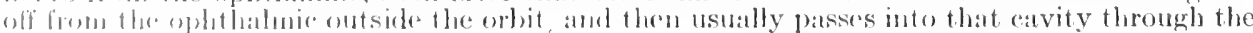

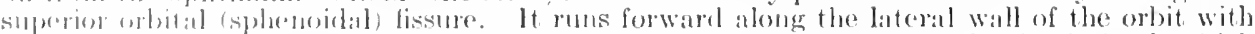

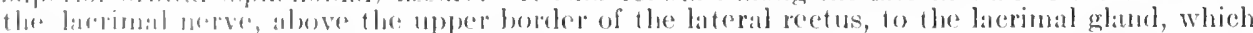
it supplixs. In this anuse it furnishes the following branches:- - (a) Recurrent, one or more

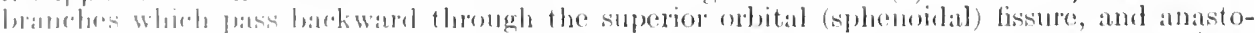

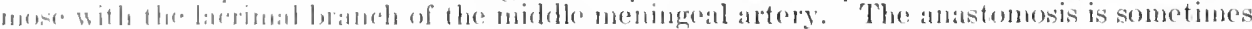
of large size, and theol talies the chice share in the formation of the lacrimal artery. (b) Mus-

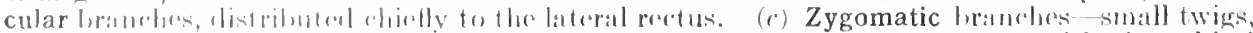

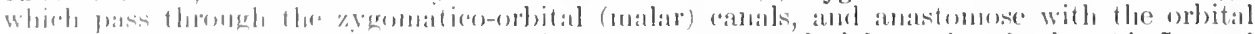

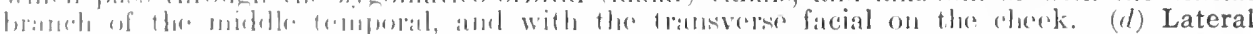

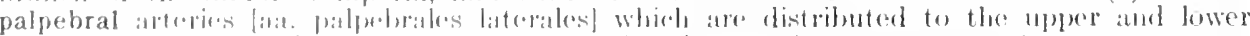

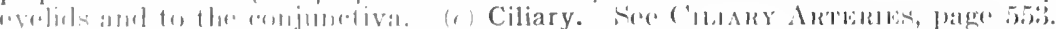

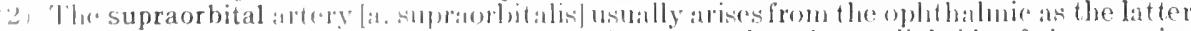

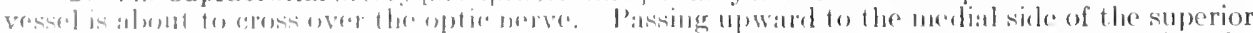

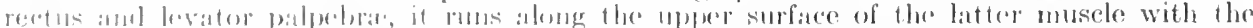

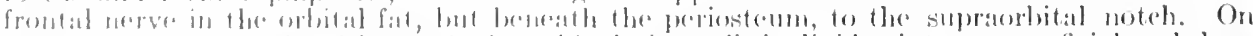

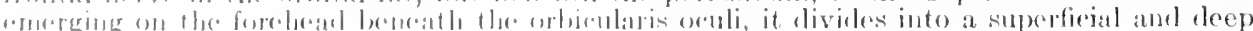

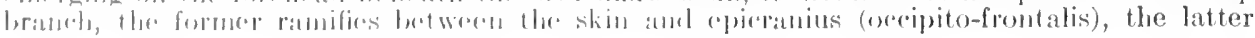


between the epicranius and the pericranium. Both branches anastomose with the anterior branches of the superficial temporal, the angular branch of the external maxillary (facial, and the transverse facial artery. The branches of the supraorbital are:- $(a)$ periosteal, to the periosteum of the roof of the orbit; $(b)$ muscular, to the levator palpebrix and superior rectus; (c) diploic, given off as the artery is passing through the supraorbital notch and, entering a minute foramen at the bottom of the notch, is distributed to the diploe and frontal sinuses; (d) trochlear, to the pulley of the superior oblique; $(e)$ palpebral, to the upper eyelid.

(3) The arteria centralis retinæ, a small hut constant branch, eomes off from the oph. thatmic close to the optic foramen, and, perforating the optic nerve about $6 \mathrm{~mm}$. (3 4 in.) behind the globe, runs forward in (the substance of the nerve) to the eveball, supplying the retina. Its further description is given in the section on the ExE.

(4) The muscular branches [rami museulares] are very variable in their origin and distribution. They may be roughly divided into superior and inferior sets. The superior or smaller set supply the superior oblique, the levator palpebræ, and superior rectus. The inferior pass forward, between the optic nerve and the inferior rectus, supplying that muscle, the medial rectus, and the inferior oblique. From the muscular branches are given off the anterior ciliary arteries. (See Ciliari Arteries.)

(5) The ciliary arteries are divided into three sets:-The short posterior, the long posterior, and the anterior. (i) The short posterior [aa. ciliares posteriores breves], five or six ill number', come off chiefly from the ophthatmic as it is crossing the optic nerve. They run forward about

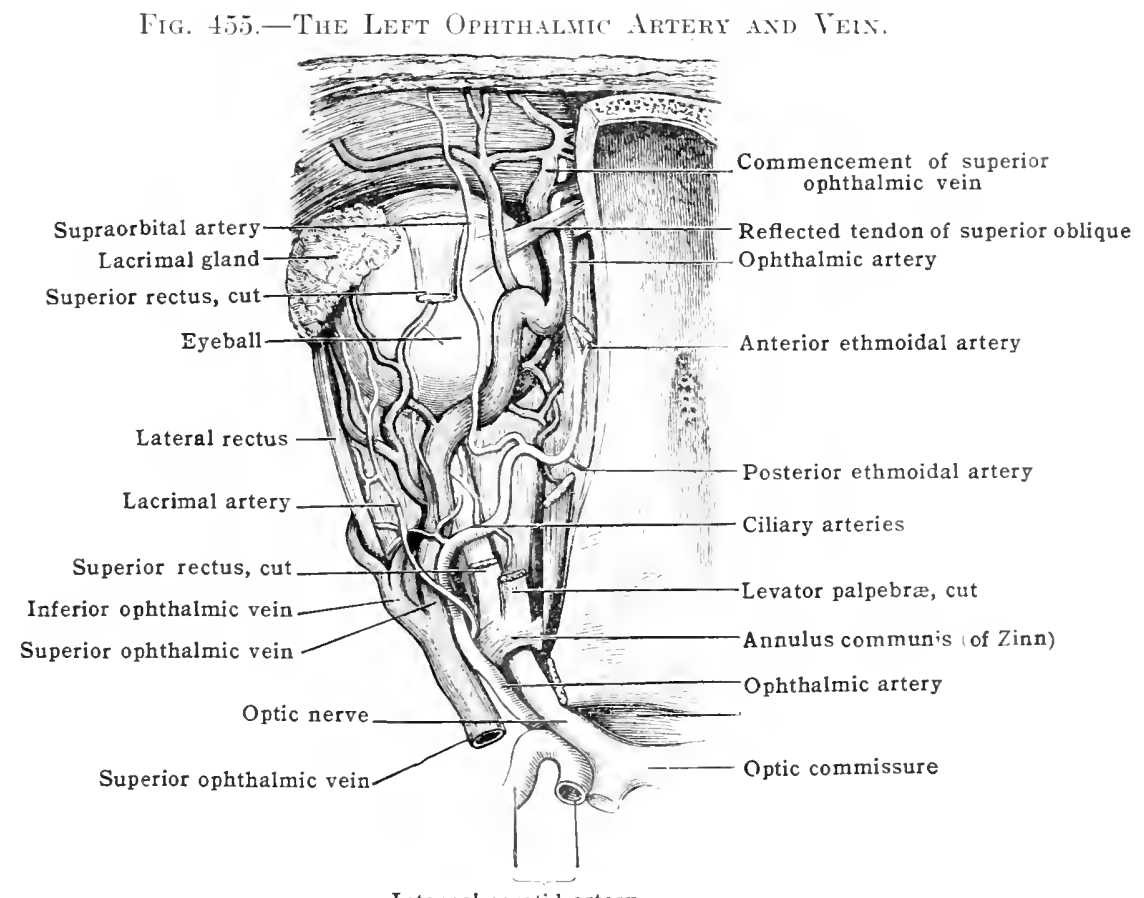

the nerve, dividing into twelve or fifteen small vessels, which perforate the sclerotic around the entrance of the optic nerve, and are distributed to the chorioid coat. (ii) The long posterior ciliary arteries [aa. ciliares posteriores longa], usually two, sometimes three, in number, come off from the ophthalmic on either side of the optic nerve, and run forwand with the short ciliary to the sclerotic. On piercing the sclerotic, they course formard, one on either side of the evelutll between the sclerotic and the chorioid to the ciliary processes and iris. Their further distrihution is given under the anatomy of the ErE. (iii) "The anterior ciliary arteries [ala. ciliares anteriores] are derived from the muscular branches and from the hacrimal. They rum to the ghise along the tendons of the recti, forming a zone of radiating vessels bentath the conjunctiva Some of them, the episcleral arteries [an. episclerales]; perforate the sclerotic about $6 \mathrm{~mm}$ ( $\frac{1}{4}$ in.) behind the comea, and supply the iris and ciliary processes. It is these vessels that are enlarged and congested in iritis, forming the circumcormeal zone of reshess so chararteristic of that disease. They then differ from the tortuous ressels of the conjunctiva in that they are straight and parallel. The remainder constitute the anterior conjunctival arteries [ati. conjunctivales anteriores].

(6) The posterior ethmoidal artery [a. ethmoidalis posterior] (fig. 455) runs medially between the superior oblique and medial rectus, and, leaving the orbit hy the posterion ethnioinis canal, together with the posterior ethmoidal branch of the naso-ciliary na-al nerve, enters the posterior ethmoidal cells, whence it passes through a transverse slit-like aperture between the sphenoid bone and cribriform plate of the ethmoid bone into the aranim. It givesoff $(a)$ ethmoidal branches to the posterior ethmoilal cells; $(b)$ meningeal brinches to the dura mater lining the cribriform plate; and $(c)$ nasal branches, which pass through the rribiform plate to 
the superior meatus and upper spongy bones of the nose, and anastomose with the nasal branches of the spheno-palatine artery (fig. 452).

(7) The anterior ethmoidal artery [a. ethmoidalis anterior] (fig. 452), a larger branch than the posterior ethmoidal, arises in front of the latter, passes medially between the superior oblique and medial rectus, and, leaving the orbit through the anterior ethmoidal canal, in company with the anterior ethmoidal nerve, enters the cranial cavity. After running a short distance beneath the dura mater on the cribriform plate of the ethmoidal bone, it passes into the nose through the horizontal slit-like aperture by the side of the crista galli. Its terminal branch passes along the groove on the under surface of the nasal bone, and emerges on the nose between the bone and lateral cartilage, terminating in the skin of that organ. It gives off the following branches in its course:-(i) Ethmoidal, to the anterior ethmoidal cells; (ii) anterior meningeal artery, [a. meningea anterior] to the dura mater of the anterior fossa; (iij) nasal, to the middle meatus and anterior part of the nose; (iv) frontal, to the frontal sinuses; (v) cutaneous, or terminal, to the skin of the nose.

(S) The medial palpebral arteries [aa. palpebrales mediales] arise either separately or by a common trunk from the ophthalmic artery opposite the pulley for the superior oblique, just as the latter vessel is about to divide into its terminal branches. They pass, one above and one below, the medial palpebral ligament and then skirt along the upper and lower eyehids respectively, near the free margin between the palpebral tarsi and the orbicularis muscle, and form a superior and an inferior tarsal arch [arcus tarsus superior et inferior] by anastomosing with the lateral palpebral branches of the lacrimal. The upper also anastomoses with the supraorbital artery and orbital branch of the temporal artery; the lower with the infraorbital, the angular branch of the external maxillary (facial), and the transverse facial arteries. A branch from the lower palpebral passes with the ductus nasolacrimalis as far as the inferior meatus. Small twigs, the posterior conjunctival arteries [aa. conjunctivales posteriores], are also given to the caruncula lacrimalis and conjunctiva.

(9) The frontal artery [a. frontalis], the upper of the terminal branches of the ophthalmic, pierces the superior tarsus at the medial angle of the orbit, passes upward over the frontal bone beneath the orbicularis oculi, supplies the structures in its neighbourhood, and anastomoses with its fellow of the opposite side, with the supraorbital, and with the anterior division of the superficial temporal artery.

(10) The dorsal nasal [a. dorsalis nasi], the lower of the terminal branches of the ophthalmic, leaves the orbit at the medial angle by perforating the tarsus above the medial palpebral ligament. It then descends along the dorsum of the nose, beneath the integuments, and anastomoses with the angular and lateral nasal branches of the external maxillary (facial). It gives off a lacrimal branch as it crosses the lacrimal sac, and a transverse nasal branch as it crosses the root of the nose; the latter vessel anastomoses with its fellow of the opposite side.

\section{THE POSTERIOR COMMUNICATING ARTERY}

The posterior communicating artery [a. communicans posterior] (fig. 456) is given off from the internal carotid just before the division of that vessel into the anterior and middle cerebral arteries; oceasionally it arises from the middle cerebral itself.

It is as a rule a slender vessel which runs backward over the optic tract and pedunculus cerchri along the sille of the hippocampal gyrus to join the posterior cerebral. At times, however, it is of considerible size, and contributes chiefly to form the posterior cerchral, the portion of the latter vessel between the basilar and posterior communicating being then as a rule redued to a nere rulliment. It gives off the following branches:- $(a)$ the hippocampal, to the gyrus of that nanc; and (b) the middle thalamic, to the optic thalimus.

\section{TIIE CIIORIOID ARTERY}

The chorioid artery [a. chorioidea] is a small but constant vessel which arises as a rule from the bark part of the internal carotid just lateral to the origin of the postrerior communicating.

It passes harkwarl on the opt ic tract and the perlunculus cerebri, at first lying parallel and lateral to the postorior anmmuncating artery. It then dips under the edge of the uncinate grves and, entering the chorioid fissure at the lower end of the inferior cornu of the lateral ventricle, ends in the choriend plexus and supplies the hippocampus and fimbria.

\section{THE ANTERIOR CIREBRAL ARTERY}

The anterior cerebral artery [a. corchri anterior] (figs. 456, 459), one of the terminal branches into which the internal arotid divides in the lateral fissure (fisture of sylvius), supplies a part of the cortex of the frontal and parietal lobes of the loran innd a small part of the basal ganglia. It passes at first anteriorly and medially across the anterior perforated substance between the olfactory and optic nerves to the longiturlinal fissure where it approaches its fellow of the opposite side 
and communicates with it by a short transverse trunk, about five mm. long, known as the anterior communicating artery [a. communicans anterior] (fig. 456). Onward from this point it runs side by side with its fellow in the longitudinal fissure round the genu of the corpus callosum; then, turning backward, it continues along the upper surface of that commissure, and, after giving off large branches to the frontal and parietal lobules, anastomoses with the posterior cerebral artery.

\section{THE MIDDLE CEREBRAL ARTERY}

The middle cerebral artery [a. cerebri media] (figs. 456, 460), the larger of the terminal divisions of the internal carctid, supplies the basal ganglia and a part of the cortex of the frontal and parietal lobes. It passes obliquely upward and lateralward into the lateral (Sylvian) fissure, and opposite the insula divides into cortical branches.

\section{Circulus Arteriosus}

The four arteries which supply the brain, namely, the two internal carotid arteries and the two vertebrals (which unite to form the basilar), form a remark-

Fig. 456.-The Arteries of the Brain.

(The cerebellum has been cut away on the left side to show the posterior part of the cerebrum.. From a preparation in the Museum of St. Bartholomew's Hospital.)

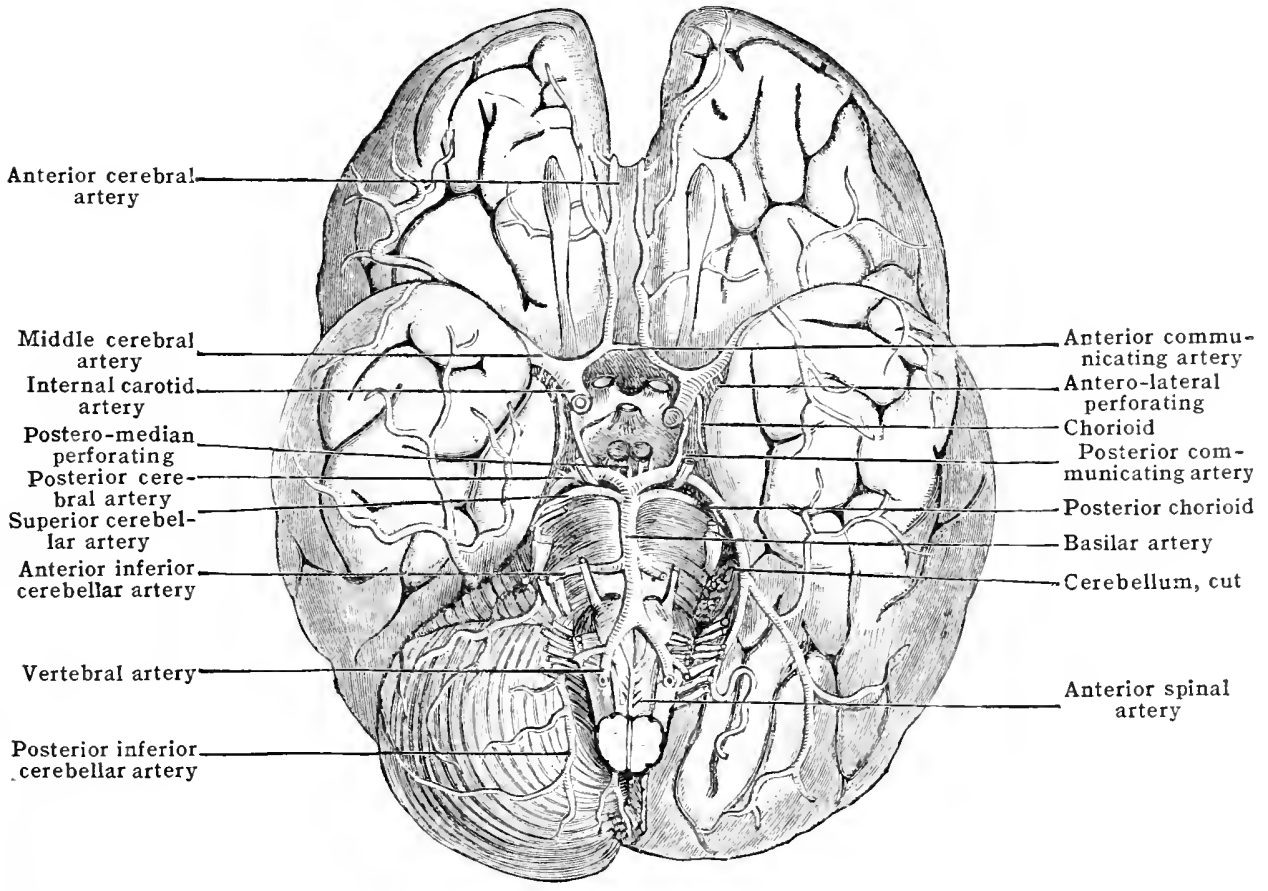

able anastomosis at the base of the brain known as the circle of Willis [circulus arteriosus (IVillisi)]. This so-called circle, which has really the form of a heptagon, is formed, in front, by the anterior communicating artery uniting the anterior cerebral arteries of opposite sides; laterally, by the internal carotids and the posterior communicating arteries stretching between these and the posterior cerebrals; behind, by the two posterior cerebrals diverging from the bifurcation of the basilar artery (fig. 456).

This free anastomosis between the two internal carotid and the two vertebral arteries serves to equalise the flow of blood to the various portions of the brain; and, should one or more of the arteries entering into the formation of the circle be temporarily or permanently obstructed, it ensures a flow of blood to the otherwise deprived part through some of the collateral arteries. Thus, if one carotid or one vertebral is obstructed, the parts supplied by that vessel receive their blood through the circle from the remaining pervious vessels. Indeed, one rertebral artery alone has been found equal to the task of carrying sufficient blood for the supply of the 
brain after ligature of both the carotids and the other vertebral artery. Further, the circle of IVillis is the only medium of comnunication between the ganglionic or central and the peripheral or cortical brinches of the cerehral arteries, and between the various ganglionic branches themselves. The ganglionic and the cortical branches form separate and distinct systems, and do not anastomose with each other; and the ganglionic, moreover, are so-called end-vessels, and do not anastomose with the neighbouring gauglionic branches. The three cerebral arteries, anterior, midclle, and posterior may be regarded as branches of the circle of Willis. (For details concerning the (listribution of the ecrebral arteries sec p. 562.)

\section{THE SLBCLAVIAN ARTERI}

The subclavian artery on the right side [a. subclavia dextra] arises at the bifureation of the innominate opposite the upper limit of the right sterno-clavicular articulation. On the left side it arises from the arch of the aorta, and, as far as the medial border of the scalenus anterior, is situated deeply in the ehest. The first portion of the left subelavian artery is deseribed separately.

Beyond the medial border of the scalen us anterior the artery has the same relations on both sides. It courses from this point beneath the elaviele in a slight curve across the root of the neek to the lateral border of the first rib, there to end in the axillary artery. Thus the course of the artery in the neek will be indicated by a line drawn from the stemo-elavieular joint in a eurve with its convexity upward to the micllle of the clavicle. The height to which the artery rises in the neek varies. It is perhaps most commonly about $1.2 \mathrm{em}$. ( $\frac{1}{2} \mathrm{in}$.) above the clavicle. If the curved line above mentioned is drawn to represent part of the eircumferenee of a circle having its eenter at a point on the lower margin of the clavicle $3.7 \mathrm{~cm}$. ( $1 \frac{1}{2}$ in.) from the sternal end of that bone, the line of the artery will be suffieiently well indieated for all practical purposes. In its eourse the artery arehes over the dome of the pleura and gains the groove on the upper surface of the first rib by passing between the scalenus anterior and medius muscles. The artery is aceompanied by the subclavian vein, the latter vessel lying in front of the scalenus anterior, anterior to the artery, and on a slightly lower plane.

The subclavian artery is divided into three portions-as it lies medial to, posterior to, or lateral to, the sealenus anterior muscle.

\section{THE FIRST OR THORAC'IC PORTION OF THE LEFT SUBCLAVIAN ARTERY}

The left subclavian artery [a. subclavia sinistra] (fig. 457) arises from the left ("nul of the arch of the aorta. The first part of the left subelavian is consequently longer than the first part of the right, which arises at the bifurcation of the inmominate artery. The artery at its origin is situated deeply in the thorax, and as it arises from the aorta is on a plane posterior to and a little to the left of the thomede portion of the left common carotid. It first ascends almost vertically ont of the chest, and at the root of the neck eurves laterally over the apex of the left plonlat and long to the interval between the anterior and midelle sealene mus-

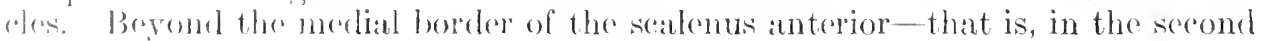
and third portions of its course -its relations are similar to those of the right subwatian artery.

Relations. In front it is covered by hlor left plenra and lumg, whilst more superfeial are

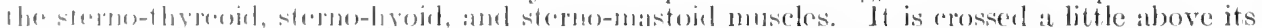

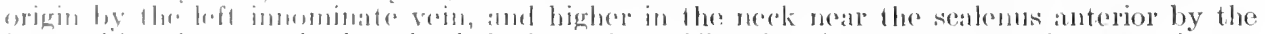

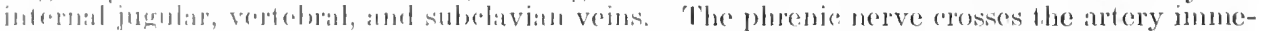

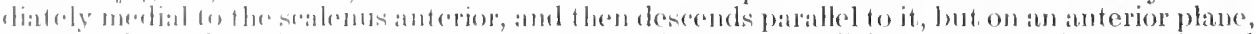

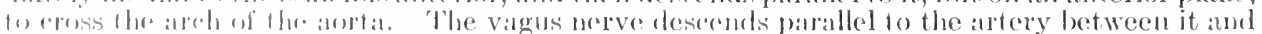

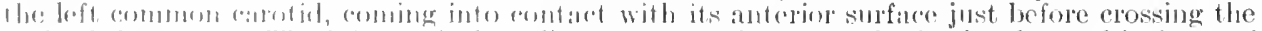

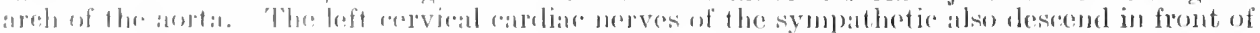

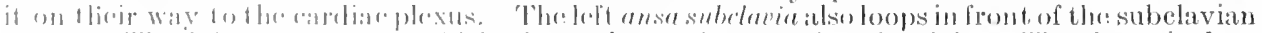

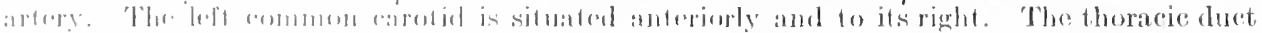

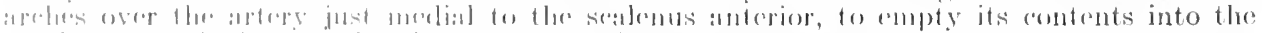

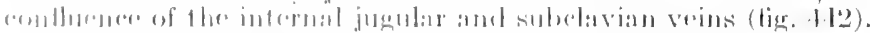

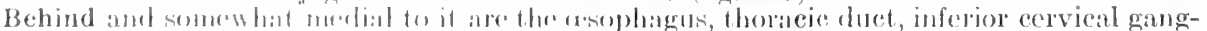

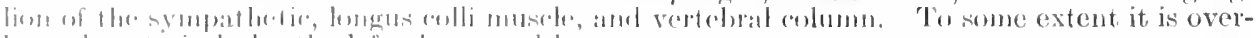

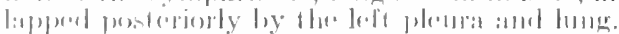

(1) ils right side ane the I ranhea and the inferior laryngeal nerve, and, higlere up, the asopha-

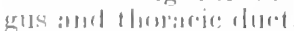

(1) jts left side ane the heft ploistat and lung. 
Branches.-The vertebral, internal mammary, and thrreo-cervical trunk (thrreoid axis) usually arise from the first portion on the left side. (see p. 5.59.)

\section{THE FIRST PORTION OF THE RIGHT SUBCLAVIAN ARTERI}

The first portion of the right subclavian artery (fig. 457) extends from its origin at the bifurcation of the innominate, behind the upper margin of the right sterno-

Fig. 457.-The Subclavian Artery. (After Toldt, "Atlas of Iluman Anatomy," Rebman, London and New York.)

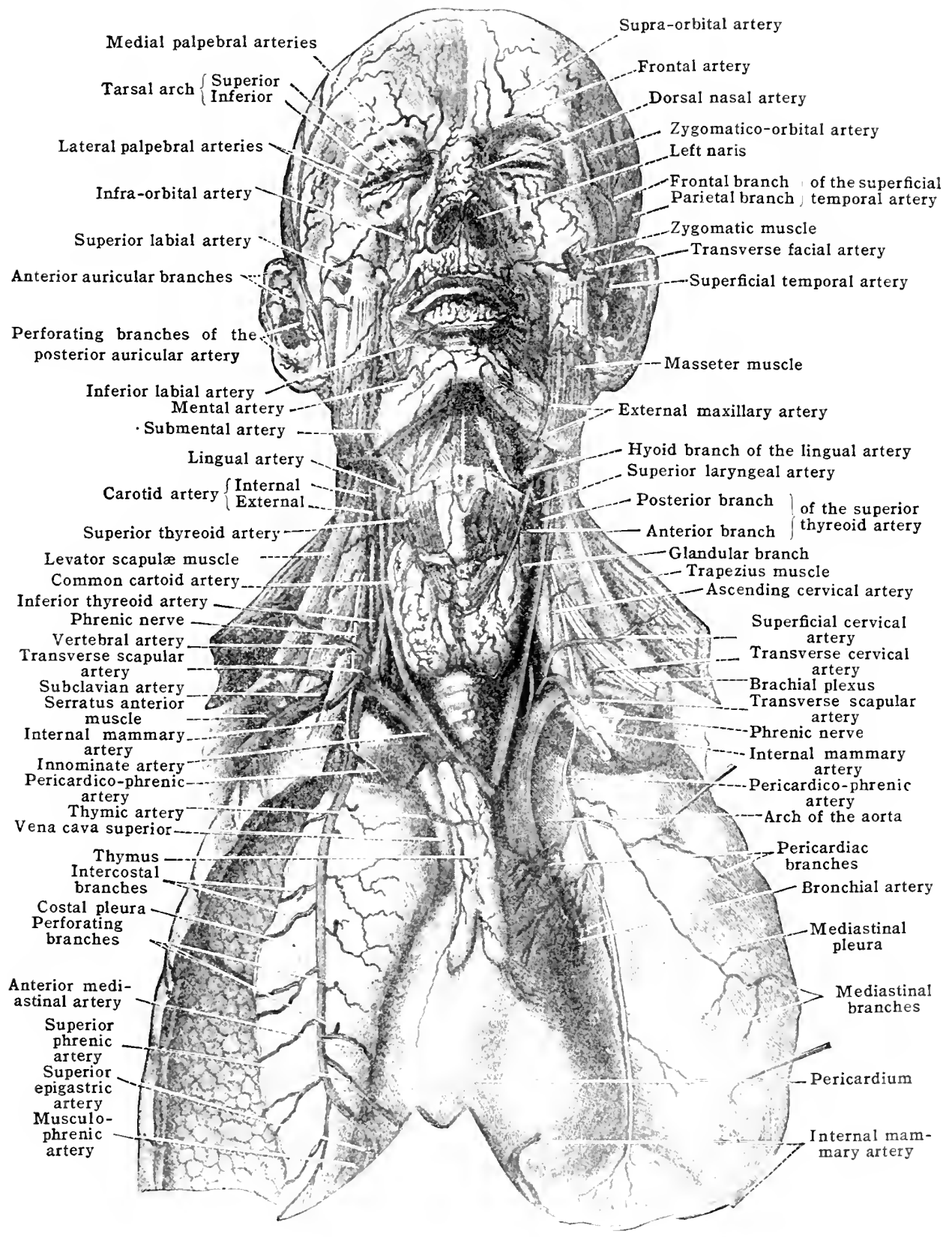

clavicular joint, upward and laterally in a gentle curve over the apex of the right lung and pleura to the medial border of the sealenus an terior. It measures about $3 \mathrm{~cm}$. (1 $1 \frac{1}{4} \mathrm{in}$.). In this course it ascends in the neck a variable distane above the clavicle, but is so deeply placerl, so surrounded by important structures, and gives 
off so many large branches, that it is now seldom or never selected for the application of a ligature.

Relations.- In front it is corered by the integuments, the superficial fascia, the platysma, the anterior layer of the deep fascia, the clavicular origin of the sterno-mastoid, the sterno-hyoid and sterno-thyreoid muscles, and the deep cervical fascia. It is crossed by the commencement of the innominate, by the internal jugular, and by the vertebral veins; and, in a medio-lateral direction, by the vagus and phrenic nerves, and the superior cardiac branches of the sympathetic nerve. A loop of the sympathetic nerve itself also crosses the artery, and forms with the trunk of the sympathetic a ring around the vessel known as the ansa subclavia (annulus of Vieussens).

Behind, but separated from the artery by a cellular interval, are the longus colli muscle, the transverse process of the seventh cervical or first thoracic vertebra, the main chain of the sympathetic nerve, the inferior cardiac nerves, the recurrent laryngeal nerve, and the apex of the right lung and pleura.

Below, it is in contact with the pleura and lung and the loop of the recurrent laryngeal nerve, which winds round the artery from the vagus and ascends behind it to the larynx. The subclavian vein is below the artery and on an anterior plane.

Branches.- The vertebral, internal mammary, superficial cervical, and thyreocervical trunk (thyreoid axis) arise from this part of the vessel on the right side. (See p. 559.) Not uneommonly a small aberrant artery also takes origin from this portion of the artery and descends to the left behind the œsophagus to join a branch of the aorta opposite the third or fourth thoracic vertebra. This vessel is probably the remains of the right dorsal aorta.

\section{THE SECOND PORTION OF THE SUBCLAVIAN ARTERY}

The second portion of the subclavian artery lies behind the scalenus anterior muscle. It measures about $2 \mathrm{~cm} .\left(\frac{3}{4} \mathrm{in}\right.$.) in length and here reaches highest in the neck. The subclavian vein is separated from the artery by the scalenus anterior, and lies on a lower and anterior plane (fig. 463).

Relations.-In front it is covered by the skin, superficial fascia, platysma, anterior layer of deep fascia, the clavicular origin of the sterno-mastoid, posterior layer of deep fascia, and by the scalenus anterior. The phrenic nerve-which, in consequence of its oblique course medially downward, crosses a portion of both the first and second part of the subclavian-is separated from the second portion by the scalenus anterior muscle, as is also the subclavian vein which courses on a somewhat lower plane.

Behind the artery are the apex of the pleura and lung, and a portion of the scalenus medius; also the scalenus minimus (partially or entirely fibrous, known as Sibson's fascia, see p. 355).

Above is the brachial plexus.

Below are the pleura and lung.

One branch only-the costo-cervical trunk (superior intercostal) - is, as a rule, given off from this portion of the subclavian; oceasionally the transverse cervical or the descending branch of the transverse cervical (posterior scapular artery) arises from it.

\section{THE THIRD PORTION OF THE SUBCLAVIAN ARTERY}

The third portion of the subclavian artery extends from the lateral margin of the scalenus anterior muscle to the lateral border of the first rib. It is more superficial than rither the first or seconrl portions; it is in relation with less important structures, and as a rule gives off no branch, and for these reasons is the part selecterl when practicable for the application of a ligature. It is the longest of the throe prortions of the subclavian artery, and lies in a triangle-the subclavian triangle founded by the sterno-mastoid, the omo-hyoid, and the claviele (fig. 445).

Relations. - In front it is covered by skin, superficial fascia, platysma, supra-clavieular nerves (descenting superficial branches) of the cervical plexus; the anterior layer of deep frscia which descends from the onno-hyoid to the elavicle; and the posterior layer of deep fascia which descends from the onne-hyojel to the first rib and passes over the sealenus anterior and phrenic nerve. Isotween the two hayers of fascia is a variable amount of cellular tissue and fat, and running in this is the transversescapular (supra-scapular) artery. The subclivian is crossed by this artery unless the arm is drawn well downward. Close to the lateral margin of the sterne-matoin, the extermal jugnlar vein pierces the fascia, and crosses the subclavian artery to open into the suldaclavian vein. As this vein lies between the two layers of fiscia, it receives on its latteral sifte the transverse scapular (supra-seapular), transverse cervical, and other veins of the nerk, which together form a plexus of large veins in front of the artery. The nerve to

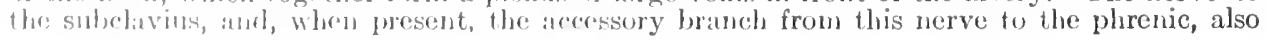


here cross in front of the artery. In very muscular subjects the clavicular head of the sternomastoid may be larger than usual, and in such a case will form one of the coverings of the artery.

Behind, the artery is in contact with the scalenus medius, and with the lower trunk of the brachial plexus. rib.

Below, the artery rests in the posterior of the two grooves on the upper surface of the first

Above is the brachial plexus of nerves and the posterior belly of the omo-hyoid muscle. The trunk formed by the fifth and sixth cervical nerves is also above the artery, but on a somewhat anterior plane. It is close to the vessel, and has been mistaken for the artery in the application of a ligature.

As a rule there is no branch given off from the third portion of the subclavian. At times, however, the transverse cervical or the descending branch of the transverse cervical (posterior scapular artery) may arise from the third portion of the subclavian instead of from the thyreo-cervical trunk (thyreoid axis) and from the transverse cervical respectively, as here described.

There is considerable variation in the branches of the subclavian artery and Bean (Am. Jour. Anat., Vol. 4, p. 303) has shown that the branches are arranged in a different way on the two sides of the body. The usual form on the right side is for the vertebral, internal mammary, the superficial cervical and the common trunk of the inferior thyreoid and transverse scapular arteries to arise from the first part of the subclavian. In this case the ascending cervical is a branch of the inferior thyreoid, while the transverse cervical and costo-cervical arise from the second portion. There are no branches from the third portion. On the left side the usual form is for the vertebral and internal mammary, and thyreo-cervical trunk, to arise from the first part. The thyreo-cervical trunk divides into inferior thyreoid, transverse scapular, and transverse cervical arteries; the superficial cervical is absent, and the costo-cervical trunk arises from the first part.

There are three more types of origin of the branches; in one, the vertebral, internal mammary, costo-cervical, and inferior thyreoid come from the first part, while the transverse cervical arises from the second part, and the transverse scapular comes either from the third part or the axillary artery; in the second, the inferior thyreoid, transverse scapular and transverse cervical arise in a common stem from the first part; while in the third, which is the rarest form, the inferior thyreoid and superficial cervical arteries come by a common trunk from the first part, while the transverse scapular artery arises from the internal mammary.

\section{THE VERTEBRAL ARTERY}

The vertebral artery [a. vertebralis] (fig. 458) the first, largest, and most constant branch, arises from the upper and posterior part of the first portion of the subclavian, on the right side, about $2 \mathrm{~cm}$. ( $\frac{3}{4} \mathrm{in}$.) from the origin of the latter vessel from the innominate, on the left side, from the most prominent part of the arch of the subclavian, close to the medial edge of the scalenus anterior muscle. It first ascends vertically to the foramen transversarium of the sixth cervical vertebra, and, having passed through that foramen and those of the next succeeding cervical vertebræ as high as the epistropheus (axis), it turns laterally and then ascends to reach the foramen in the transverse process of the atlas; after passing through that foramen it turns backward behind the articular process, lying in the groove on the posterior arch of the atlas. It next pierces the posterior occipito-atlantoid membrane and the dura mater, and enters the cranium through the foramen magnum. Here it passes upward, at first lying by the side of the medulla, then in front of that structure, and terminates at the lower portion of the pons by anastomosing with the vertebral of the opposite side to form the basilar.

The vertebral artery may be divided for purposes of description into four parts: the first, or cervical, extending from its origin to the transverse process of the sixth cervical vertebra; the second, or vertebral, situated in the foramina transversaria; the third, or occipital, contained in the suboccipital triangle; and the fourth, or intracranial, within the cranium.

The first or cervical portion.-The artery here lies between the scalenus anterior and longus colli muscles. In front it is covered by the vertebral and internal jugular veins, and is crossed by the inferior thyreoid artery, and on the left side, in addition, by the thoracic duct, which runs over it medio-laterally. Behind, the artery lies on the transverse process of the seventh cervical vertebra and the sympathetic nerve. To its medial side is the longus colli. To its lateral 
side is the scalenus anterior. It gives off as a rule no branch in this part of its course. Oecasionaly, however, a small branch passes into the foranen tranversarim of the seventh cervieal vertebra.

The second or vertebral portion.-As the artery passes through the foramina transversaria, it is surriunded by a plexus of veins and hy branches of the sympathetie nerve. The cervieal nerves lie behind it. Betwcen the transverse proeesses it is in contact with the intertransverse muscles.

The third or occipital portion.-The artery here lies in the subuccipital triangle, bounded by the superior oblique, inferior oblique, and reetus eapitis posterior major muscles. As it winds round the groove on the atlas, it has the rectus capitis lateralis, the articular process, and the posterior occipito-atlantoid membrane in front of it; the superior oblique, the reetus rapitis posterior major, and the semispinalis eapitis (complexus) behind it. Separating it from the areh of the atlas, is the first cervical or subociipital nerve.

The fourth or intracranial portion extends from the aperture in the dura mater to the lower border of the pons, where it pierces the arachnoid and unites with its fellow to form the basilar attery. It here winds round from the side to the front of the medulla, lying in the

Fig. 455.-Scheme of the Left Vertebral Artery. (I'alsham.)

The internal jugular and vertebral veins are hooked aside to expose the artery.

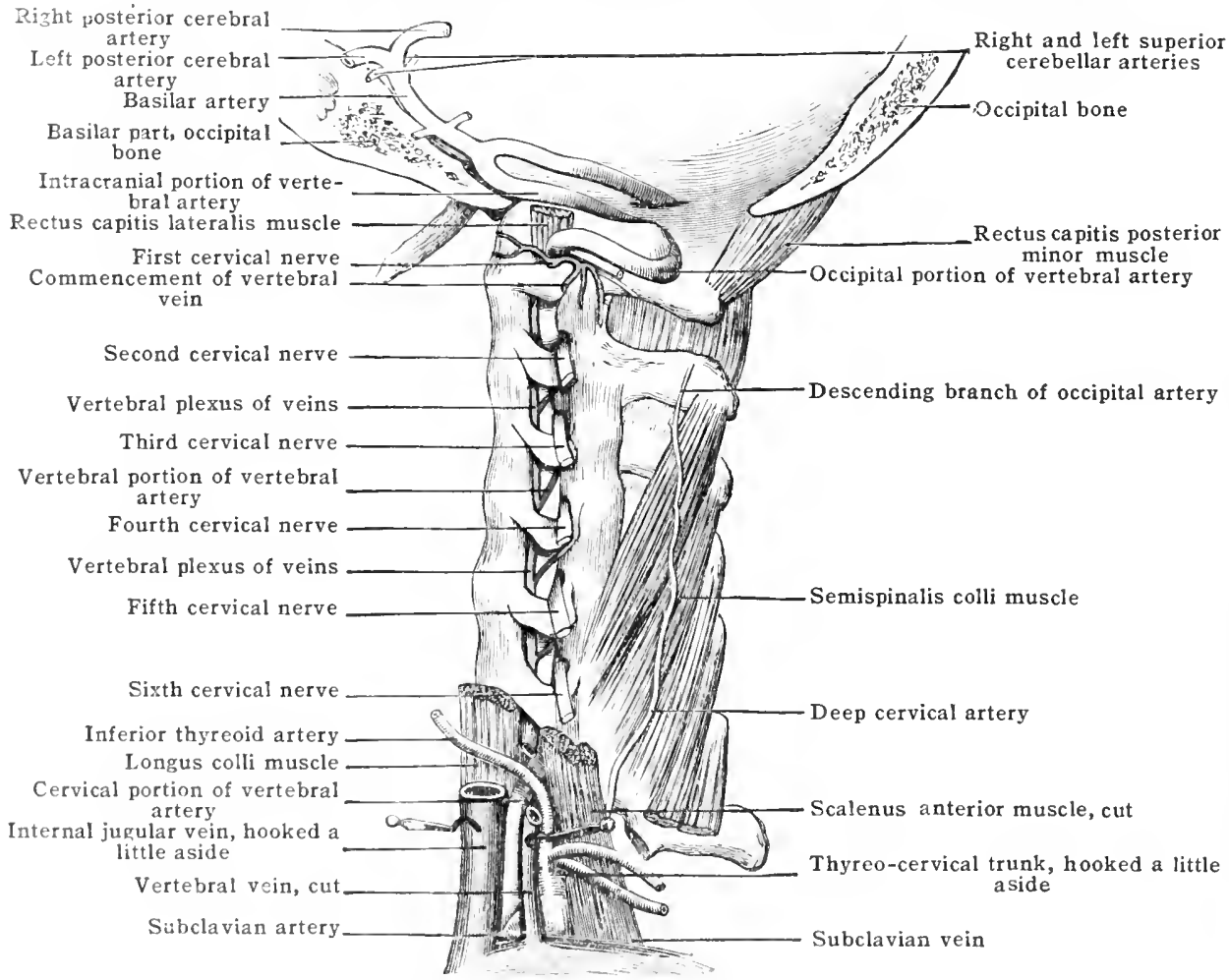

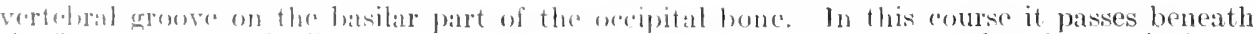

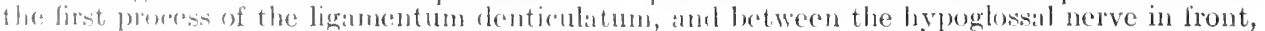
and the anterion roots of the suboceipital nerve bohind.

\section{DBRANCHES OF THE VERTERRAL IRTERY}

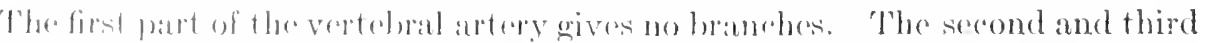

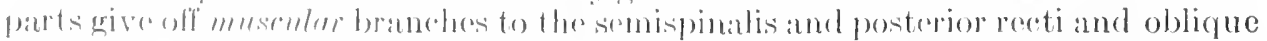

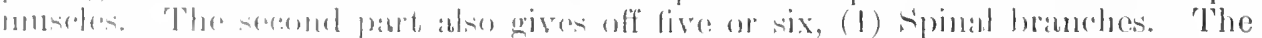

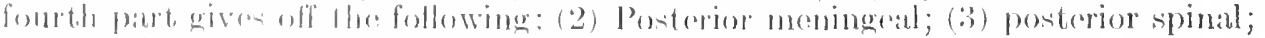

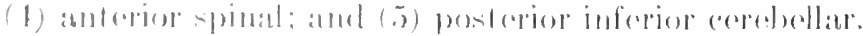

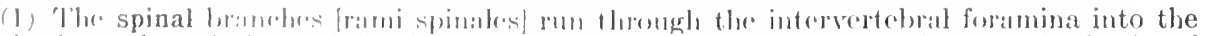

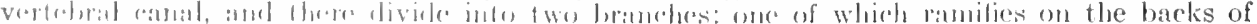

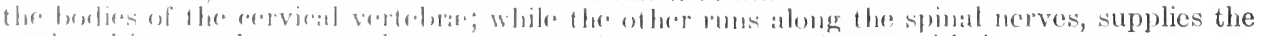

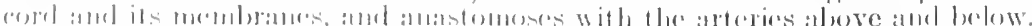

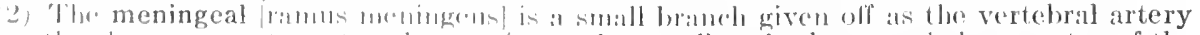

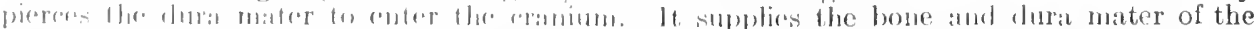

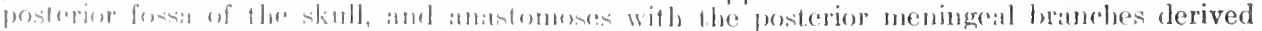

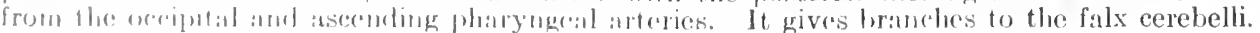


(3) The posterior spinal artery [a. spinalis posterior] runs downward obliquely along the side of the medulla to the back of the cord, down which it passes behind the roots of the spinal nerves, being reinforced by spinal branches accompanying these nerves, in the neck, the thoracic, and in the lumbar region. It can be traced as low as the end of the spinal cord.

(4) The anterior spinal artery [a. spinalis anterior] comes off from the vertebral a little below its termination in the basilar artery. Descending with a medial slant in front of the medulla, it unites on a level with the foramen magnum with its fellow of the opposite side. The single vessel thus formed runs downward in front of the spinal cord beneath the pia mater as far as the termination of the cord, being reinforced by the spinal branches on the way down. The spinal arteries are described in detail with the anatomy of the spinal cord.

(5) The posterior inferior cerebellar [a. cerebelli inferior posterior] (fig. 456) - the largest branch of the vertebral-arises from that vessel just before it joins its fellow to form the basilar artery. At times it may come off from the basilar itself. It runs, at first laterally across the restiform body between the origin of the vagus and hypoglossal nerves, and, descending toward the vallecula, there divides into two branches, medial and lateral. (a) The medial branch runs backward between the vermis and the lateral hemisphere of the cerebellum. It supplies the vermis, and anastomoses with the artery of the opposite side, and with the superior vermian of the superior cerebellar. (b) The lateral branch runs laterally and, ramifying over the under surface of the cerebellar hemisphere, supplies its cortex and anastomoses along its lateral margin with the superior cerebellar arteries.

From the undivided trunk of the posterior inferior cerebellar artery branches are given to the medulla oblongata, supplying the chorioid plexus and the fourth ventricle.

\section{THE BASILAR ARTERY}

The basilar artery [a. basilaris] is formed by the confluence of the right and left vertebral arteries, which meet at an acute angle at the lower border of the pons. It runs forward and upward in a slight groove in the middle line of the pons, and divides at the upper border of that structure at the level of the tentorial notch into the two posterior cerebral arteries, which take part in the formation of the circle of Willis (fig. 456).

\section{Branches of the Basilar Artery}

The branches of the basilar artery are:-1. Pontine; 2. internal auditory; 3. anterior inferior cerebellar; 4. superior cerebellar; 5 . posterior cerebral.

(1) The pontine branches [rami ad pontem] are numerous small vessels which come off at right angles on either side of the basilar artery, and, passing laterally over the pons, supply that structure and adjacent parts of the brain.

(2) The internal auditory artery [a. auditiva interna], a long slender vessel, accompanies the auditory nerve into the internal auditory meatus (fig 514). It here lies between the facial and auditory nerves, and at the bottom of the meatus passes into the internal ear, and anastomoses with the other auditory arteries. (See INTERNAL EAR.)

(3) The anterior inferior cerebellar [a. cerebelli inferior anterior] arises from the basilar soon after its origin, passes laterally and backward across the pons, and then over the brachium pontis to the front part of the under surface of the cerebellum. It anastomoses with the posterior inferior cerebellar artery (fig. 456).

(4) The superior cerebellar [a. cerebelli superior] comes off from the basilar immediately behind its bifurcation into the posterior cerebral arteries. It courses laterally and backward over the pons, in a curve roughly corresponding to that of the posterior cerebral artery, from which it is separated by the third cranial nerve; but, soon sinking into the groove between the pons and the pedunculus cerebri, it curves round the latter onto the upper surface of the cerebellum, lying nearly parallel to the fourth nerve. Here it divides into two branches medial and lateral. (a) The medial branch courses backward along the superior vermis, anastomosing with its fellow of the opposite side, and, at the posterior notch of the cerebellum, with the inferior vermian branch of the posterior inferior cerebellar artery. (b) The lateral runs to the circumference of the cerebellum, anastomosing with the lateral branch of the inferior posterior cerebellar artery.

Branches are given off from the main trunk of the superior cerebellar artery, or from its medial branch to the anterior velum (valve of Vieussens), the corpora quadrigemina, the pineal body, and the chorioid plexus.

(5). The posterior cerebral arteries [aa. cerebri posteriores] are the two terminal branches into which the basilar bifurcates at the upper border of the pons, immediately behind the posterior perforated substance. Each artery runs at first laterally and a little forward across the pedunculus cerebri immediately in front of the third nerve, which separates it from the superior cerebellar artery. After receiving the posterior communicating artery, which runs backward from the internal carotid, the posterior cerebral turns backward onto the under surface of the cerebral hemisphre, where it breaks up into branches for the supply of the temporal and occipital lobes.

The branches of the posterior cerebral artery are described below in connection with those of the other cerebral arteries. 


\section{Distribution of the Cerebral Arteries}

Although the brain receives its blood supply from two distinct sources, namely, from the internal carotids and from the vertebrals, it is convenient to consider together the distribution of the various cercbral branches derived from these stems. The formation of the circulus arteriosus (circle of Willis) and the origin of the anterior, middle and posterior cerebral arteries has already been described (pp. 554, 561). The detailed distribution of these vessels will now be considered. In general, their branches may be divided into central or ganglionic and peripheral or cortical.

The anterior cerebral artery has but a limited central distribution. It gives off a few inconstant branches which enter the anterior perforated substance and supply the anterior end of the caudate nucleus. One or two of these run to the corpus callosum and septum pellucidum. The anterior communicating branch is a transverse trunk which commects the two arteries and thereby completes the circulus arteriosus in front. It lies in front of the optic chiasm, and varies considerably in length and size. It may give off some of the branches to the anterior perforated substance. The cortical branches supply the gyrus rectus, the olfactory lobe and a part of the orbital gyri on the ventral surface. On the medial surface branches supply the cortex as far back as the parieto-occipital fissure. These branches are given off as the artery

Fig. 459.-The Arteries of the Mlesial Surface of the Brain. (After Spalteholz.)

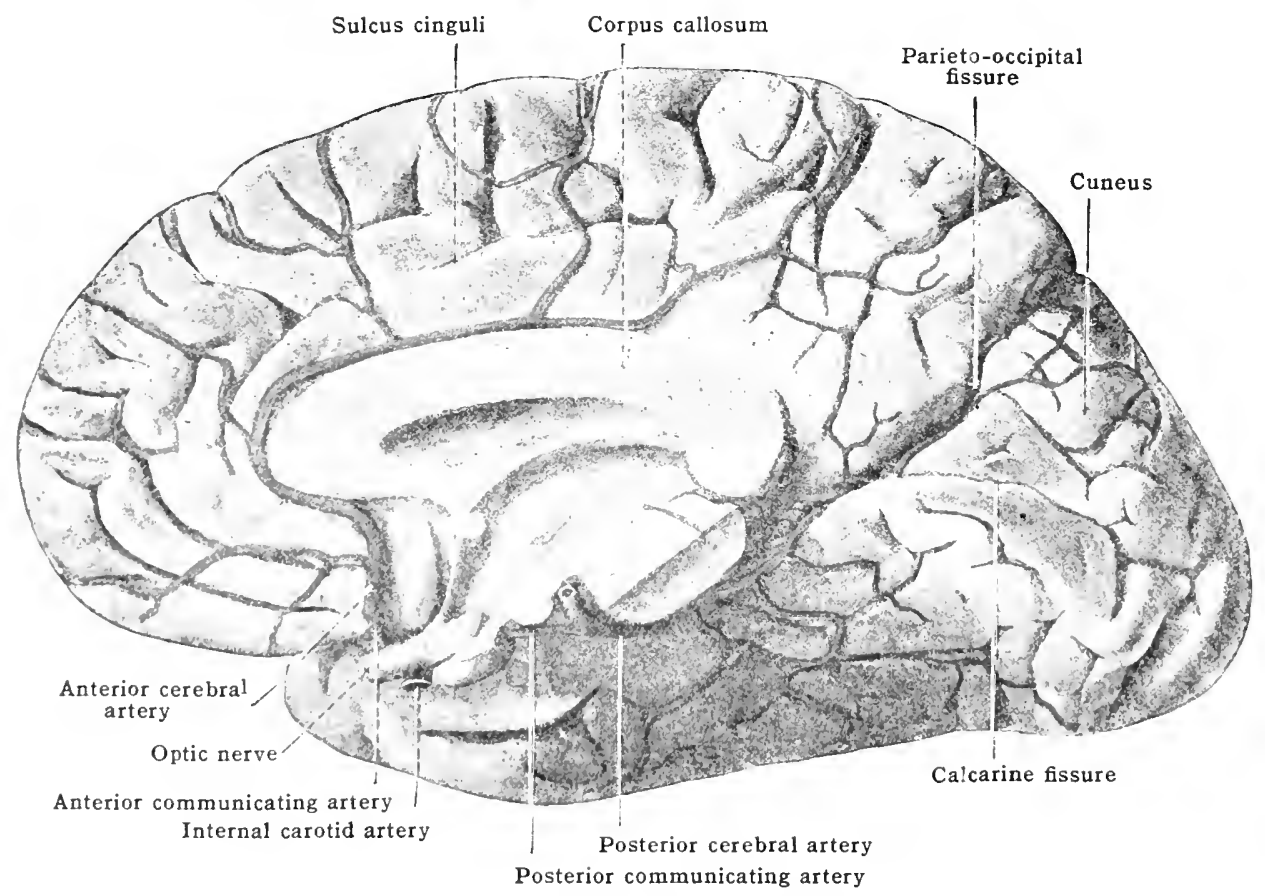

curves around the corpus callosum and sone of them curve over onto the lateral surface and supply the superior anel mildle temporal eonvolutions. I3ranches from the anterior cerebral artery also supply the corpus callosum (fig. 459).

The middle cerebral artery gives off nost of the brinches to the basal ganglia and supplies the greater part of the lateral surface of the brain. It rums through the lateral fissure (fissure of silvius) (fig. 4ti()). The branches of the middle cer(bral include the following:

The central branches are:-(i) The caudate, two or thee small branches, which arise from the medial aspret of the artery and pass through the medial part of the floor of the lateral fissure (fissure of Siylvius) to the hearl of the caudate nucleus. (ii) The antero-lateral are numerous smalt arleries which pass thromgh the anterior perlorated substane and supply the candate muleres (except its hourl), the internal capsule, and part of the optic thalamus. (iii) The lenticulostriate, a langer branch of the antero-lateral set, passes through a separate aperture in thro lateral part of the anterior porforated substance, runs mpward between the lentieular nucleus, which it supplies, and the cxtornal capsule, perforates the internal capsule, and terminates in the

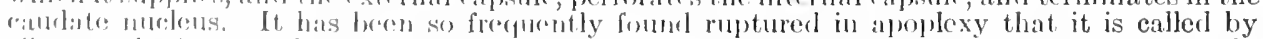

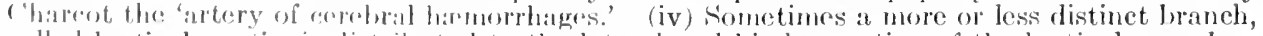
adlecl lenticulo-optic, is distributorl to the biteral and hinder portion of the lenticular mueleus atmel the litteral portion of thre oputie thatamus.

The cortical branches come off apposite the insulit. They supply the insula, the inferior frontal grit, the central gyri (anterior and posterior), the parietal folules, superior and in-

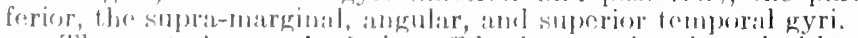

The posterior cerebral give off hoth entral and cortical bramches. The central branches are the postero-median, postcrior chriricl, and the postero-lateral. The postero-median 
enter the posterior perforated substance and supply the medial portion of the optic thalamus, and the walls of the third ventricle; the posterior chorioid pass through the transverse fissure to the tela chorioidea (velum interpositum) and chorioid plexus; the postero-lateral run to the posterior part of the optic thalamus and give branches to the cerebral peduncles and the corpora quadrigemina.

The cortical branches of the posterior cerebral supply the entire occipital lobe and all of the temporal lobe except the superior temporal gyrus (fig. 459).

In regard to the cerebral arteries in general it may be said that there is no anastomosis between the cortical and central branches, the two forming distinct and separate systems. The cortical may or may not anastomose with each other, but the communication between the neighbouring cortical branches is seldom sufficient to maintain the nutrition of an area when the vessel that normally supplies it is obstructed. The central branches are so-called endvessels and do not anastomose with each other. Hence obstruction of the middle cerebral artery leads to softening of the area supplied by its central branches, but not always to sof tening of the region supplied by its cortical branches. Indeed, the cortical region may escape completely, although the ceutral area is irreparably disorganised. The gross anastomosis of the posterior cerebral with the anterior cerebral arteries through the circulus arteriosus has already been described. To sum up the distribution of the cerebral arteries, the branches of each are divided into the central, or ganglionic and the peripheral or cortical. The central branches arise at the commencement of the cerebral arteries about the circulus arteriosus whilst the cortical are derived chiefly from the termination of these vessels.

Fig. 460.-The Arteries of the Lateral Surface of the Brain. (After Toldt, "Atlas of Human Anatomy," Rebman, London and New York.)

Central sulcus (Rolandi)

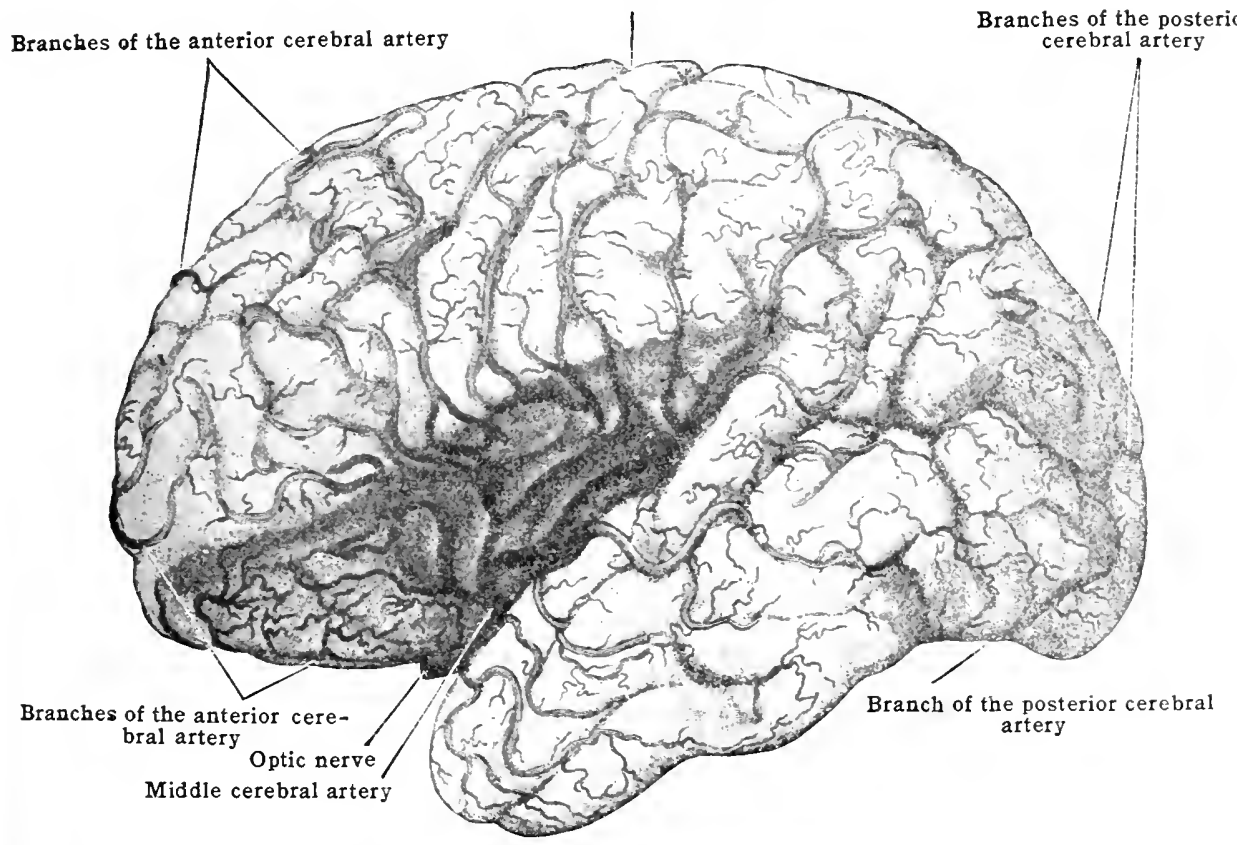

(A) The central branches are divided into four sets-two median and two lateral. 1 The two median are-(1) The antero-median, which arise from the anterior cerebral and the anterior communicating, and supply the fore end of the caudate nucleus, and (2) the posteromedian, which arise from the posterior cerebral and supply the medial part of the optic thalamus and neighbouring wall of the third ventricle. 2. The two lateral are:-(1) The antero-lateral arise from the middle cerebral, and, passing through the anterior perforated substance, supply the lenticular nucleus, the posterior part of the caudate nucleus, the internal and external capsules, and the lateral part of the optic thalamus. (2) The postero-lateral arise from the posterior cerebral, and supply the hinder part of the optic thalamus, the pedunculus cerebri, and the corpora quadrigemina.

(B) The cortical branches ramify in the pia mater, giving off branches to the cortical substance, some of which extend through it to the underlying white substance.

It will be seen that the middle cerebral supplies the somasthetic area of the cortex. It also supplies the cortical auditory centre, and, in part, the higher visual centre. The anterior cerebral supplies only a small part of the somæsthetic area, namely, the part of the leg centre that occupies the paracentral lobule and the highest part of the anterior central gyrus. 'The posterior cerebral supplies the visual path from the middle of the tract backward, and the half vision centre in the occipital lobe. It supplies also the corpora quadrigemina and the sensory part of the internal capsule.

The branches which supply the cerebellum and brain stem are given in connection with the vertebrals on page 561 . 


\section{THE THYREOCERVICAL TRUNK}

The thyreocervical trunk [truncus thyreocervicalis] or thyreoid axis arises from the upper and front part of the subclavian artery, usually opposite the internal mammary, and slightly medial to the scalenus anterior. It is a short thick trunk, and divides almost immediately into three radiating branches-namely, the inferior thyreoid, the transverse scapular, and the transverse cervical (figs. 444, 457). This is the usual form only on the left side (see page 559). It may give off also the ascending cervical.

\section{THE INFERIOR THYREOID ARTERY}

The inferior thyreoid artery [a. thyreoidea inferior] is the largest of the three branches into which the thyreocervical trunk (thyreoid axis) divides, and may arise in a common trunk with the transverse scapular, or as a branch of the subclavian. It ascends tortuously passing medially in front of the vertebral artery, the inferior laryngeal nerve and the longus colli muscle, and behind the common carotid and the sympathetic nerve or its middle cervical ganglion, to the thyreoid gland, where it anastomoses with the superior thyreoid artery and the artery of the opposite side.

The branches of the inferior thyreoid artery are:-(1) Muscular; (2) œsophageal and pharyngeal; (3) tracheal; (4) inferior laryngeal; (5) glandular; and (6) ascending cervical.

(1) The muscular branches supply the scalenus anterior, longus colli, sternohyoid, sternothyreoid, and omo-hyoid muscles, and the inferior constrictor muscle of the pharynx.

(2) The œsophageal and pharyngeal branches [rami cesophagei et pharyngei] of the inferior thyreoid artery supply the oesophagus and pharynx and anastomose with the other arteries supplying those structures.

(3) The tracheal branches [rami tracheales] ramify on the trachea, where they anastomose with the tracheal branches of the superior thyreoid and bronchial arteries.

(4) The inferior laryngeal artery [a. laryngea inferior] passes along the trachea to the back of the cricoid cartilage in company with the inferior laryngeal nerve. It enters the larynx beneath the inferior constrictor. Its further distribution in that organ is described under LARYNX.

(5) The glandular branches [rami glandulares] supply the thyreoid gland.

(6) The ascending cervical artery [a cervicalis ascendens] (figs. 444, 457) is given off from the thyreocervical trunk or from the inferior thyreoid as that vessel is passing beneath the carotid sheath. It ascends between the sealenus anterior and the longus capitis (rectus capitis anterior major), lying parallel and medial to the phrenic nerve and behind the internal jugular vein. It anastomoses with the vertebral, ascending pharyngeal, and occipital arteries, and supplies branches to the deep muscles of the neck [rami musculares], to the spinal canal [rami spinales], and to the phrenic nerve. Two veins accompany the ascending cervical artery and ond in the innominate vein.

\section{THE TRANSVERSE SCAPULAR ARTERY}

The transverse scapular or suprascapular [a. transversa scapulæ] artery passes laterally arross the root of the neck, lying first beneath the sterno-mastoid, and then in the subclavian triangle behind the clavicle and subcalvius muscle. At the latral angle of this space it is joined by the supraseapular nerve, sinks benrath the posterior belly of the omo-hyoid, and passes over the ligament bridging the scapular notch, the nerve passing through the notch (fig. 461). It then ramifies in the supraspinous fossa of the scapula, and, winding downward round the base of the spine ovor the neck of the scapula, enters the infraspinous fossa, and torminates by anastomosing with the circumflex (dorsal) scapular a rtery, and the descending lranch of the transverse cervical (posterior scapular) artery.

As it lies under cover of the sterno-mastoid muscle, it erosses the phrenie nerve and the scalenus anterior; and as it couses through the subclivian triangle, it is separated by the corvicul fascia which descenls from the ono-hyoil to the first rib, from the subclavian artery and hrichial plexus of nerves. If this artery is sen in tying the sulchivian it should not be irijurerl, as it is one of the chicf vessels by which the collateral circulation is carried on after ligature of the subchian in the third part of its course. At the hateral part of the subclavian triangle it is covered by the trapezius, and after passing over the transverse seapular ligament it pierces the supraspinous fascia and passes beneath the supra-spinatus inusele, ramifying lowwen it and the bone. In the infraspinons fossa it lies between the infra-spinatus and the lone. The artery is aecompanied by two veins. 
The branches of the transverse scapular are:-(1) the nutrient, to the clavicle; (2) the acromial [ramus acromialis] to the arterial rete or plexus on the acromial process, to reach which it pierces the trapezius; (3) the articular, to the acromio-clavicular joint and shoulderjoint; (4) the subscapular, given off as the artery is passing over the transverse scapular ligament, descends to the subscapular fossa between the subscapularis and the bone, and anastomoses with the infrascapular branch of the cireumflex (dorsal) scapular artery, and with the subscapular and transverse cervical arteries; (5) the supraspinous branches, which ramify in the supraspinous fossa, and supply the supra-spinatus muscle and the periosteum, and the nutrient artery to the bone; (6) the infraspinous branches, which ramify in a similar way in the infraspinous fossa, giving off twigs to the infra-spinatus muscle, the periosteun, and the bone.

Fig. 461.-Scheme of Anastomoses of the Right Scapdlar Arteries. (Malsham.)

Subscapular branch of transverse scapular artery

Supraspinous branch of transverse scapular artery

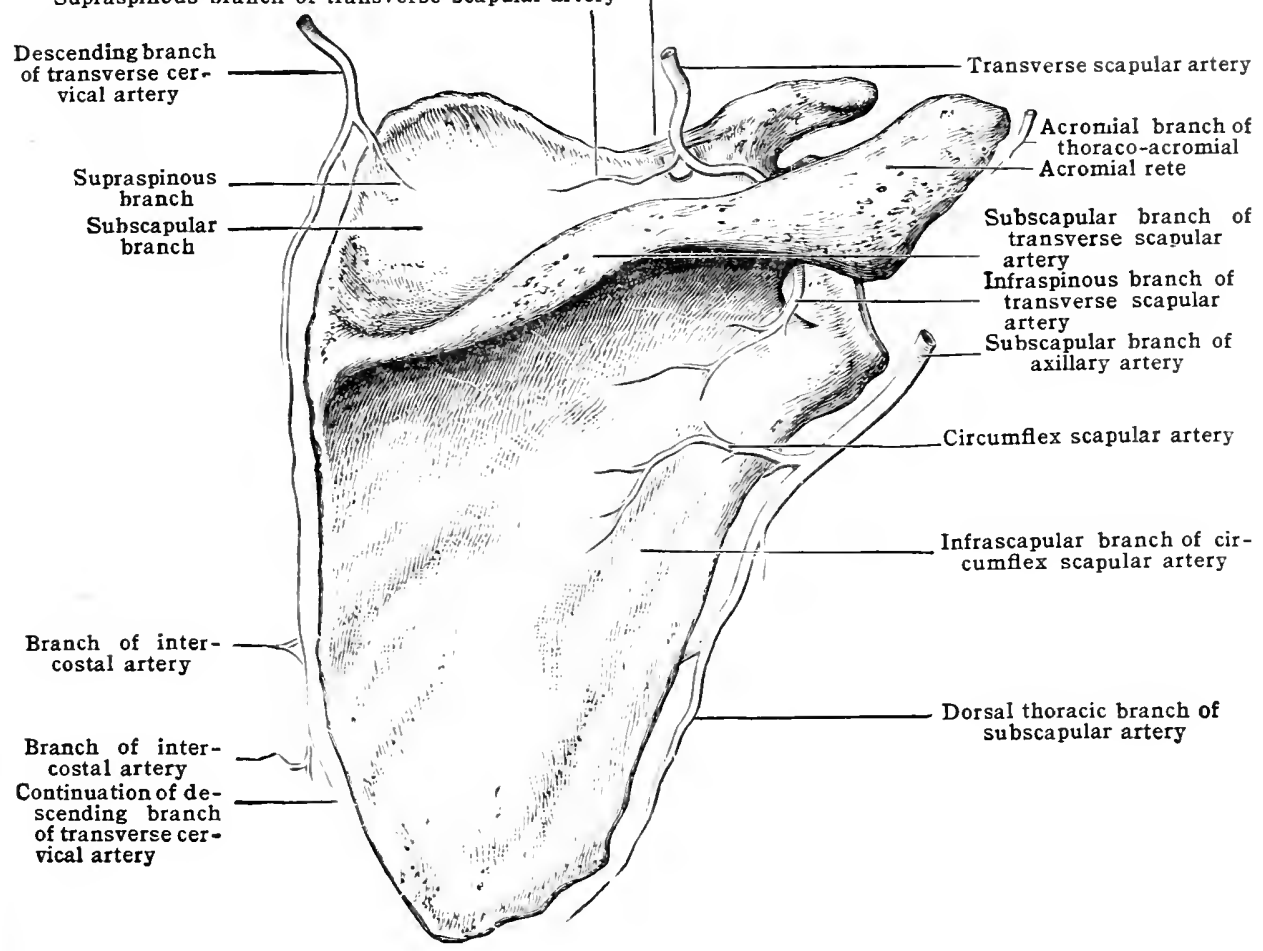

THE TRANSVERSE CERVICAL ARTERY

The tranverse cervical artery [a. transversa colli], somewhat larger than the transverse scapular (suprascapular), runs like the latter vessel laterally across the root of the neck, but on a slightly higher transverse plane, and a little above the clavicle. At its origin from the thyreo-cervical trunk (thyreoid axis) it lies under the sterno-mastoid; on leaving the cover of this muscle, it crosses the upper part of the subclavian triangle, lying here only beneath the platysma and cervical fascia; further laterally, it passes beneath the anterior margin of the trapezius and omo-hyoid muscle, and at the lateral margin of the levator scapula divides into a descending (posterior scapular) and an ascending (superficial cervical) branch. In this course it crosses the phrenic nerve, the scalenus anterior, the brachial plexus, and the scalenus medius. Sometimes it passes between the cords of the brachial plexus.

The branches of the transverse cervical artery are:-(1) a descending (posterior scapular); and (2) an ascending (or superficial) cervical. The descending branch occasionally arises from the third portion of the subclavian artery.

(1) The descending branch, or posterior scapular [ramus descendens] the apparent continuation of the transverse cervical artery, begins at the lateral bolder of the levator scapule, and, continuing its course beneath this muscle to the upper and posterior angle of the scapula, turns downward and skirts along the posterior border of the scapula, between the serratus anterior 
(magnus) in front and the levator scapulæ and rhomboideus minor and major behind, to the inferior angle, where it anastomoses with the subscapular artery. It gives off the following branches:-- (a) Supraspinous, which ramifies between the supraspinous muscle and the trapezius, and sends branches through the muscle into the fossa, to anastomose with the transverse scapular artery. (b) Infraspinous branches, one or more of which enter the infraspinous fossa, and anastomose with the circumflex (dorsal) scapular. (c) Subscapular branches, which enter the subscapular fossa, and anstomose with the branches of the transverse scapular and subscapular arteries. (d) Muscular branches, to the muscles between which it runs and to the latissimus dorsi. These branches anastomose with the posterior divisions of the intercostal arteries.

(2) The ascending branch or superficial cervical artery [ $r$. ascendens], smaller than the descending branch, ascends under the anterior margin of the trapezius, lying upon the levator scapulæ and splenius muscles. It supplies branches to the trapezius, levator scapulæ, and splenius muscles, and the posterior chain of lymphatic glands. It anastomoses with the superficial branch of the descending branch of the occipital between the splenius and semispinalis capitis (complexus). It is accompanied by two veins. This artery may arise directly from the thyreoid axis, or from the third part of the subclavian artery.

\section{THE IN'TERNAL MAMMARY ARTERY}

The internal mammary artery [a. mammaria interna] (figs. 457,462) comes off from the lower part of the first portion of the subelavian, usually opposite the

Fig. 462.-Scheme of the Rigit Internal Mammary Artery. (Walsham.)

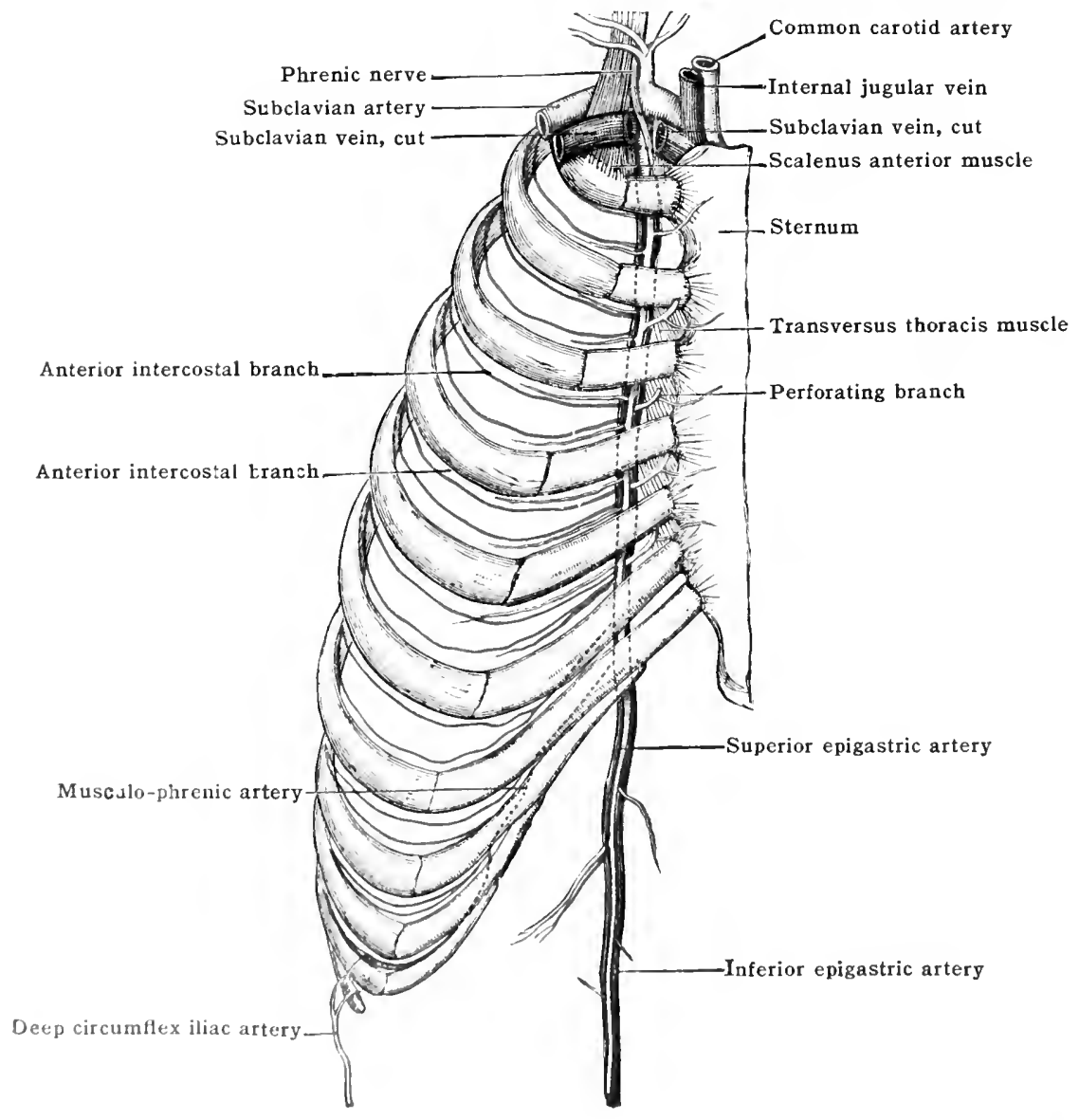

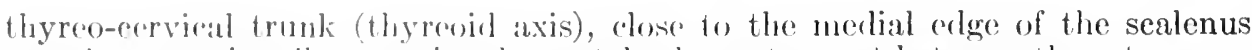
anterior, ocrasionally opjosite the vertebral, or at a spot between these two vesscls. It descends with at slight inclination forward and medialward, under eover

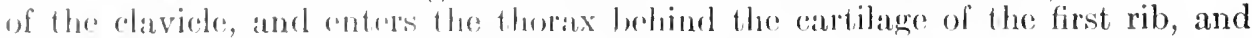
thence passes down belinel the certilagesol" the next sueceding ribs, about $1.2 \mathrm{~cm}$.

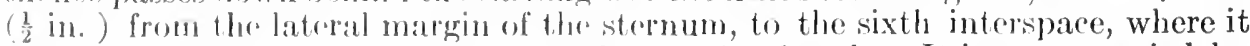
divilus into the superior epigastric and musculo-phrenic. It is accompanied by two veins, which unito into one trunk bohind the first intercostal muscle; this 
passes to the medial side of the artery into the corresponding vena innominata, or occasionally on the right side into the vena cava superior direct. The artery may be divided into two portions, the cervical and the thoracic.

The cervical portion is covered by the sterno-mastoid muscle, subclavian vein, and internal jugular vein, and is crossed obliquely, in the latero-medial direction, by the phrenic nerve. It rests upon the pleura and courses around the upper part of the innominate vein. There is no branch from this part of the artery.

The thoracic portion lies behind the cartilages of the six upper ribs, and in the interspace between the ribs has in front of it the pectoralis major and the internal intercostal muscles and external intercostal ligaments. Behind, it is in contact above with the pleura, but it is separated from it lower down by slips of the transversus thoracis (triangularis sterni). On the left side, the artery between the fourth and sixth ribs may be said to be in the anterior mediastinum, the pleura here forming a notch for the heart. In the first, second, and third spaces the artery, if wounded, can be easily tied; but in the fourth space the operation is attended with more difficulty. The remaining spaces are so narrow that a portion of the cartilage would have to be removed to expose the vessel.

The branches of the internal mammary artery are:-(1) The pericardiophrenic; (2) the anterior mediastinal and thymic; (3) the bronchial; (4) the pericardiac; (5) the sternal; $(6)$ the anterior intercostals; $(7)$ the perforating; $(8)$ the lateral costal; (9) the superior epigastric; and (10) the musculo-phrenic.

(1) The pericardio-phrenic artery [a. pericaridiophrenica], is a long slender vessel which comes off from the internal mammary just after it has entered the chest, and descends with the phrenic nerve, at first between the pleura and innominate vein; then (on the right side) between the pleura and the vena cava superior; and lastly, between the pleura and the pericardiun to the diaphragm, where it anastomoses with the other diaphragmatic arteries. It gives branches both to the pleura and pericardium.

(2) The anterior mediastinal and thymic arteries [aa. mediastinales anteriores et thymicæ] come off irregularly from the internal mammary. They are of small size, and supply the connective tissue, fat, and lymphatics in the superior and anterior mediastina and the remains of the thymus gland.

(3) The bronchial branches [rami bronchiales] are often wanting. When present they are supplied to the bronchi and the lower part of the trachea.

(4) The pericardiac branches are distributed to the anterior surface of the pericardium.

(5) The sternal branches [rami sternales] enter the nutrient foramina in the sternum, and also supply the transversus thoracis (triangularis sterni).

(6) The anterior intercostal branches [rami intercostales] (figs. 463, 478)-two in each of the five or six upper intercostal spaces-run laterally from the internal mammary artery, along the lower border of the rib above and the upper border of the rib below, and anastomose with the corresponding anterior and collateral branches of the aortic intercostals. Each pair of branches sometimes arises by a common trunk from the internal mammary, which in this ease soon divides into an upper and a lower branch, as above described. They lie at first between the internal intercostal muscles and the pleura; afterward between the external and internal intercostal muscles. They supply the contiguous muscles, the pectoralis major, and the ribs.

(7) The perforating or anterior perforating branches [rami perforantes]-five or six in number, one corresponding to each of the five or six upper spaces-come off from the front of the internal mammary, between the superior and inferiol anterior intercostals, and, perforating the internal intercostal muscles, pass forward between the costal cartilages to the pectoralis major, which they supply [rami musculares]. The terminal twigs perforate that muscle close to the sternum, and are distributed to the integument [rami cutanei]. The second, third, and fourth perforating supply the inner and deep surface of the mammary gland, and become greatly enlarged during lactation [rami mammaria]. They frequently require ligation in excision of the breast.

(8) The lateral costal branch [ramus costales lateralis] is given off close to the first rib, and descends behind the ribs just external to the costal cartilages. It anastomoses with the upper intercostal arteries. This vessel is of ten of insignificant size, or absent.

(9) The superior epigastric artery [a. epigastrica superior] (fig. 462), or medial terminal branch of the internal mammary artery, leaves the thorax behind the seventh costal cartilage by passing through the costo-xiphoid space in the diaphragm. It is the direct prolongation of the internal mammary downward. In the abdomen it descends behind the rectus muscle, between its posterior surface and its sheath, and, lower, entering the substance of the muscle, anastomoses with the inferior epigastric, a branch of the external iliac. It gives off the following small branches:- (a) The phrenic, to the diaphragm; (b) the xiphoid, which crosses in front of the xiphoid cartilage, and anastomoses with the artery of the opposite side; (c) the cutaneous, which perforate the anterior layer of the sheath of the rectus and supply the integuments: (d) the muscular, to the rectus muscle, some of which perforate the rectus sheath laterally, and are distributed to the oblique muscles; $(e)$ the hepatic (on the right side only), which pass along the falciform ligament to the liver, and anastomose with the hepatic artery; $(f)$ the peritoneal, which perforate the posterior layer of the sheath of the rectus, and ramify on the peritoneum.

(10) The musculo-phrenic artery [a. musculophrenica], or lateral terminal branch of the internal mammary artery, skirts laterally and downward behind the costal cartilages of the false ribs along the costal attachments of the diaphragm, which it perforates opposite the ninth rib. It terminates, much reduced in size, at the tenth or eleventh intercostal space by anastomosing with the ascending branch of the deep circumflex iliac artery. It gives off in its course the following small branches:- $(a)$ The phrenic for the supply of the diaphragm; $(b)$ the anterior intercostals, two in number for each of the lower five or six intercostal spaces, are dis- 
tributed like those to the upper spaces, already deseribed, and anastomose like them with the corresponding anterior branches of the lower aortic intercostals; $(c)$ the muscular for the supply of the oblique muscles of the abdomen.

\section{THE COSTO-CERVICAL TRUNK}

The costo-cervical trunk [truncus costocervicalis] (figs. 444, 463) is a short stem which arises usually from the back part of the second portion of the subclavian artery, behind the scalenus anterior on the right side, but commonly just medial to that muscle on the left side. Its course is upward and backward above the dome of the pleura and then downward toward the thorax, before entering which it divides into its two terminal branches.

The branches of the costo-cervical trunk are:-(1) the superior intercostal and (2) the deep cervical.

(1) The superior intercostal [a. intercostalis suprema] (fig. 463) continues the direction of the costo-cervical trunk, passing downward into the thorax in front of the neck of the first rib. It sometimes terminates opposite the first intercostal space by becoming the first intercostal artery. Usually, however, it is prolonged downward over the neck of the second rib and supplies the second intercostal space in addition. It communicates with the highest aortic intercostal artery. As it erosses the neck of the first rib the superior intercostal lies anterior (ventral) to the first intercostal nerve and lateral to the superior thoracic ganglion of the sympathetic.

Fig. 463.-Scheme of the Right Costo-cervical Trunk. (Walsham.)

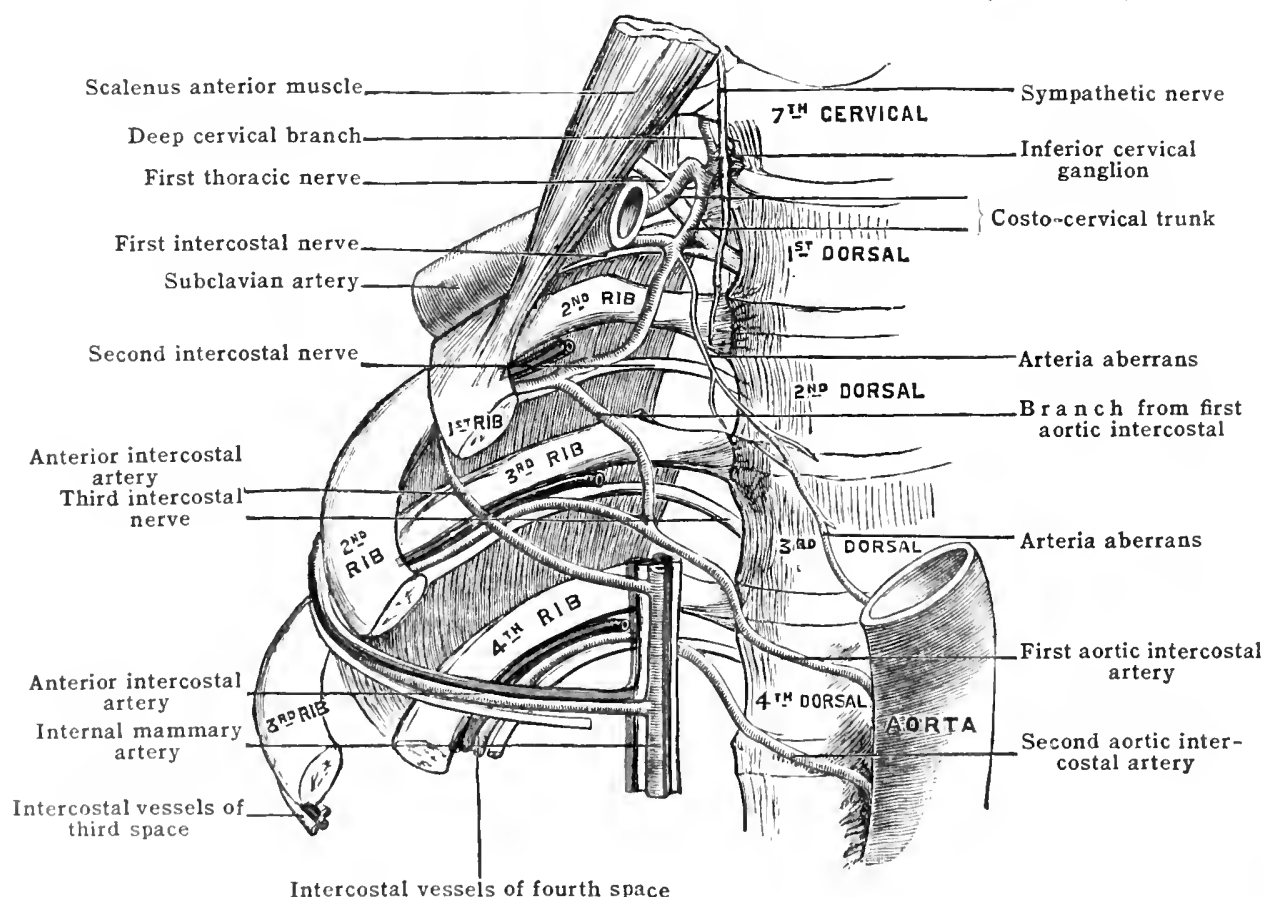

The branches to the first and second intercostal spaces resemble in course and distribution the succeding intereostals derived from the thoracic aorta (see p. 588). Like the aortic intercostals they give off dorsal [rr. dorsales] and spinal branches [rr. spinales]. An arteria aberrans, when present, arises from the medial side of the right superior intercostal, or occasionally from the right subchivian itself. It descends as a slender vessel into the thorax, passing downward and merlially behind the asophagus as far as the third or fourth thoracic vertebra, where in gonc eases it andustomoses with a similar slenfler branch arising from the aorta below the ligamentum arteriosum. This anastomosis represents the remains of the enbryonie right dorsal aortic arch, and it is by its oceasional enlargement that the anomaly of the right subdivian artery rising from the descending portion of the aortic arch oecurs (see p. 637).

(2) The deep cervical artry [i. cervicalis profunda] passes dijeetly backward, first between the seventh and eighth cervirul unerves, and then between the transverse process of the seventh cervieal vertebra and the neck of the first rib, latving the body of the seventh eervieal vertebra to its medial side, and the intertransverse musele to its liateral side. It then turns upward in the gronve between the fransverse and spinous processes of the cervieal vertebra lying upon the semispinalis colli. It is eovered by the semispinalis capitis (complexus). Between these muscles it anastomoses with the deep branch of the descending branch (prineeps cervicis) of the occipital artery. It gives off a spinal branch which enters the vertebral canal through the intervertebral forancen with the eighth cervioul nerve. 


\section{THE AXILLARY ARTERY}

The term axillary is applied to that portion of the main arterial stem of the upper limb that passes through the axillary fossa. The axillary artery [a. axillaris] (fig. 464) therefore is continuous with the subclavian above and with the brachial below. It extends from the lateral border of the first rib to the lower edge of the teres major muscle, and has the shoulder-joint and the neck of the humerus to its lateral side. When the arm is placed close to the side of the body, the artery forms a gentle curve with its convexity upward; but when the arm is carried out from the side at right angles to the trunk in the ordinary dissecting position, the vessel takes a nearly straight course, which will then be indicated by a line drawn from the middle of the clavicle to the groove on the medial side of the coracobrachialis and biceps muscles. The axillary artery is at first deeply placed beneath the pectoral muscles, but in its lower third it is superficial, being covered

Fig. 464.-The Axillari Artery. (After Spalteholz.)

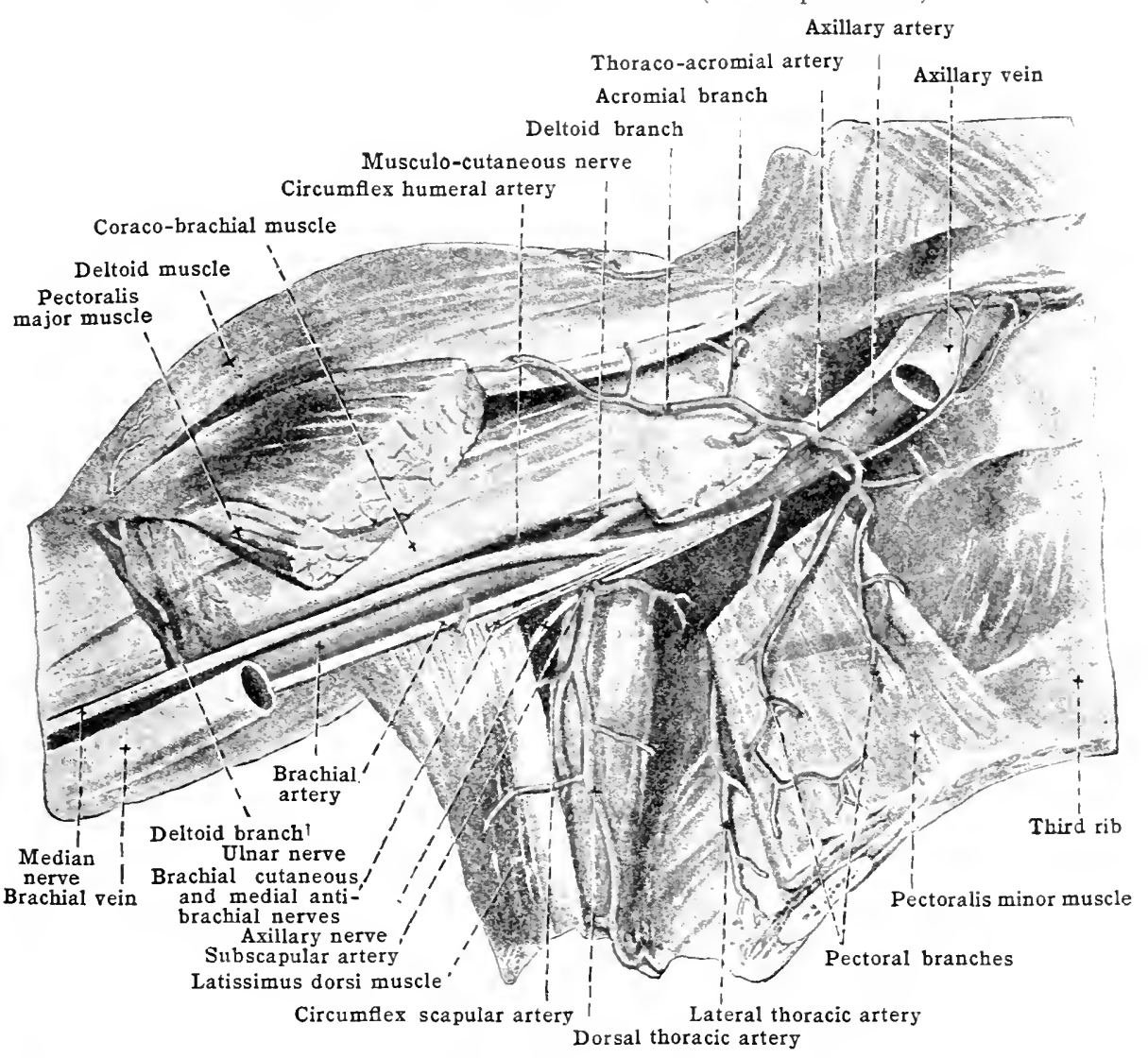

only by the skin and the superficial fascia and deep fascia. It is divided into three parts, first, second, and third, according as it lies respectively above, beneath, or below the pectoralis minor.

\section{The First Part of the Axillary Artery}

The first part of the axillary artery extends from the lateral border of the first rib to the upper border of the pectoralis minor. It measures about $2.5 \mathrm{~cm}$. (1 in.) in length.

Relations.- In front it is covered by the skin, superficial fascia, lower part of the platysma, the deep fascia, the pectoralis major, the coraco-clavicular (costo-coracoid) fascia, the subclavius muscle and the clavicle when the arm hangs down by the side. The cephalic and thoraco-acromial veins, the external anterior thoracic nerve, and the axillary lymphatic trunk, cross over it. A layer of the deep cervical fascia which has passed under the clavicle also descends in front of it. 
Behind, it rests upon the first intercostal space and first intercostal muscle, the first digitation and sometimes a portion of the second digitation of the serratus anterior (magnus) muscle, and a part of the second rib. The long thoracic nerve, on its way to the serratus anterior muscle, passes behind it.

To its lateral side, and somewhat on a higher plane, are the cords of the brachial plexus.

To its medial side, and on a slightly anterior plane, is the axillary vein. The internal anterior thoracic nerve courses between the rein and the artery.

\section{The Second Part of the Axillary Artery}

The second part of the axillary artery (fig. 464) lies beneath the pectoralis minor deep in the axilla. It measures $3 \mathrm{~cm}$. (a little more than $1 \mathrm{in}$.) in length.

Relations. - In front, in addition to the pectoralis minor, it is covered by the pectoralis major and the integuments.

Behind, it is separated by a considerable interval, containing loose connective tissue and fat, from the subscapularis muscle; whilst behind, and in contact with it, is the posterior cord of the brachial plexus.

To the medial side, but separated from the artery by the medial cord of the brachial plexus, is the axillary vein.

To the lateral side is the lateral cord of the brachial plexus, and at some little distance the coracoid process.

It is thus seen that the second portion of the auxillary artery is surrounded on three sides by the cords of the brachial plexus-one behind, one medial, and one lateral.

\section{The Third Part of the Axillary Artery}

The third part of the axillary artery (fig. 464) extends from the lower border of the pectoralis minor to the lower border of the teres major. Its upper half lies deeply placed within the axilla, beneath the lower edge of the pectoralis major muscle, but its lower half is in the arm external to the axilla, and is uncovered by muscle. It measures about $7.5 \mathrm{~cm}$. (3 in.) in length.

Relations.-In front it has, in addition to the skin and superficial fascia, the pectoralis major above, and lower down the deep fascia of the arm. It is crossed obliquely by the medial root of the median nerve and by the lateral brachial vena comitans.

Behind, it lies successively upon the subscapularis, the latissimus dorsi, and teres major muscles. From the first-named muscle it is separated at first by a considerable mass of fat and cellular tissue. The radial (nutsculo-spiral) and axillary (circumflex) nerves intervene between the artery and the muscles.

On its lateral side it is separated from the bone by the coraco-brachialis, by which it is partly overlapped, this muscle and the short head of the biceps serving as a guide to the artery in ligature. For a part of its course it has also the musculo-cutaneous nerve and the lateral root of the median nerve to its lateral side.

To its medial side it has the axillary vein, the ulnar nerve, the medial antibrachial (internal) and brachial (lesser internal) cutaneous nerves, and the medial root of the median nerve. The ulnar nerve is between the artery and the vein. The medial intibrachial (internal) cutaneous nerve is a little in front of the artery as well as medial to it.

\section{Branches of the Axillary Artery}

The branches of the axillary artery are exceedingly variable. In fig. 465 is shown what Hitzrot has found the usual type, in which the second portion of the artery has no named branches. The figure brings out the segmental relation of the branches of the axillary artery to the chest wall and suggests how one of the branches may supply the place of another. If the lateral thoracic arises directly from the axillary, it is generally from the second part as described below. In allition to the larger branches of the artery small twigs are supplied to the serratus anterior, coraeo-brachialis, and subscapularis; also to the axillary lymphnodis.s.

The first part gives off.-(1) The superior thoracie; and (2) the thoracoalcromial.

The second part gives off :-(3) The lateral thoracic.

The third part gives off: -(1) The subscilpular; (5) the anterior humeral circumflex; and (6) the posterior humeral circumflex.

\section{Branches of THE AXIhLARY ARTERY}

1. 'The superior thoracic [at. thoracalis suprema] is variously given off from the axillary artery, ustally aithor as a common trunk with the next branch, the 
thoraco-acromial, or a little above. It passes behind the axillary vein across the first intercostal space, supplying the intercostal muscles and the upper portion of the serratus anterior, and anastomoses with the intercostal arteries. At times it sends a branch between the pectoralis major and minor, which then, as a rule, more or less takes the place of the pectoral branch of the thoraco-acromial (figs. 464 and 465).

2. The thoraco-acromial or acromio-thoracic axis [a. thoracoacromialis] arises from the front part of the axillary just above the upper border of the pectoralis minor. It is a short trunk, and, coming off from the front of the artery, pierces the coraco-clavicular fascia, and then divides into three or four small branches, named from their direction:- $-(a)$ the acromial; $(b)$ the deltoid; $(c)$ the pectoral, and $(d)$ the clavicular.

Fig. 465.-The Branches of the Axillary Artery. (After Hitzrot.)

The numbers $1-5$ indicate the intercostal spaces.

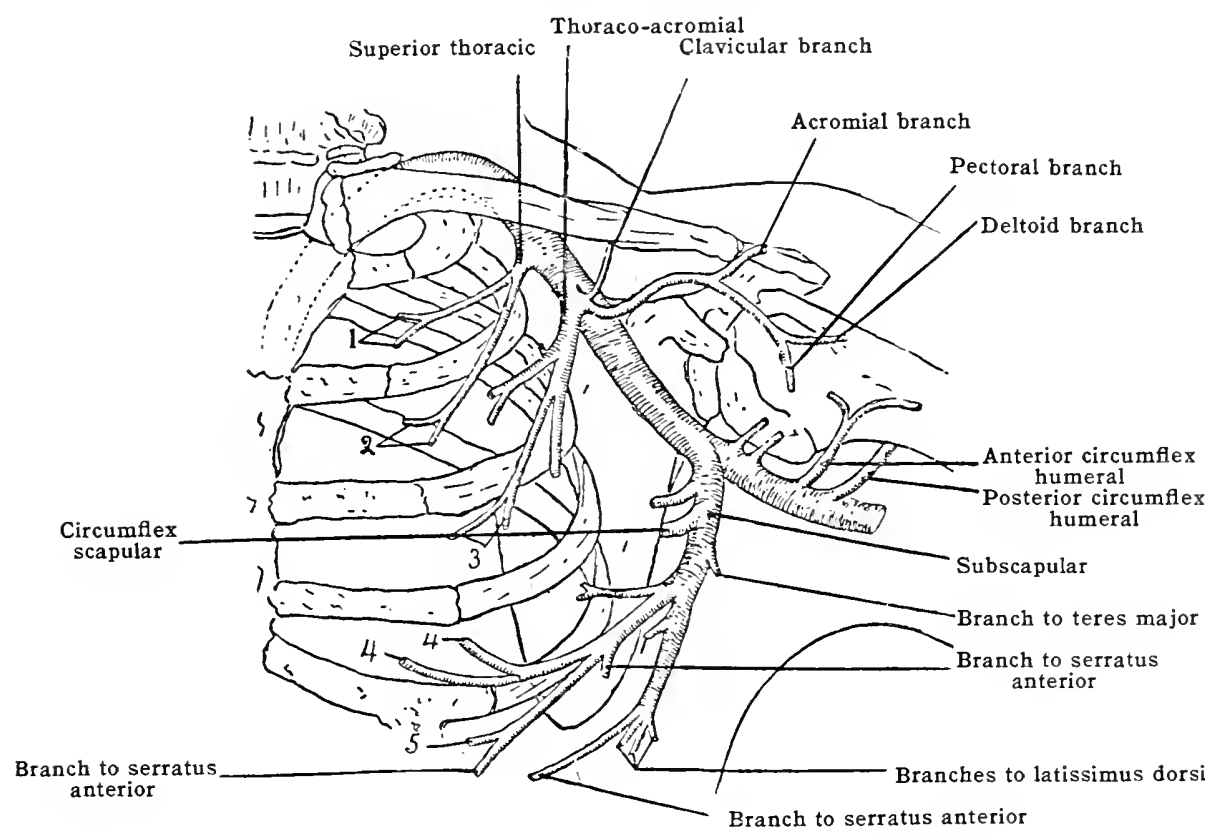

(a) The acromial branch [r. acromialis] or branches pass laterally across the coracoid process, frequently through the deltoid muscle, which they in part supply, to the acromion, where they form, by anastomosing with the anterior and posterior circumflex and transverse scapular (suprascapular) arteries, the so-called acromial rete, or plexus of vessels on the surface of that process.

(b) The deltoid branch [r. deltoideus] runs downward with the cephalic vein in the interval between the pectoralis major and the deltoid, and, supplying lateral offsets to these muscles and the adjacent integument, anastomoses with the anterior and posterior circumflex humeral arteries.

(c) The pectoral branch [r. pectoralis] passes between the pectoralis major and minor muscles, both of which it supplies. In the female, one or more branches which perforate the pectoralis major are often of large size, and supply the superimposed mammary gland.

(d) The clavicular branch passes upward beneath the clavicle, supplies the subclavius muscle, and anastomoses with the transverse scapular artery.

3. The lateral thoracic artery [a. thoracalis lateralis] descends along the lower border of the pectoralis minor, under cover of the pectoralis major, to the chest wall. It supplies both pectoral muscles and the serratus anterior (magnus), sends branches around the lower border of the pectoralis major to the mammary gland, and terminates in the intercostal muscles by anastomosing with the aortic intercostals and the internal mammary. It also furnishes branches to the lymph-nodes of the axillary fossa. The branches to the mammary gland in the female are often of large size.

4. The subscapular artery [a. subscapularis] is the largest branch of the axillary. It arises opposite the lower border of the subscapularis, and runs in a 
downward and medial direction along the anterior border of that muscle under cover of the latissimus dorsi. It supplies the subscapularis, teres major, latissimus dorsi, and serratus anterior (magnus) muscles, and gives branches to the nodes in the axillary fossa. The course of this large vessel along the posterior border of the axillary fossa should be remembered in opening abscesses in the fossa, and in removing enlarged nodes from it. It is accompanied by two veins, which usually unite and then receive the circumflex (dorsal) scapular vein, and open as a single vein of large size either into the axillary or at the confluence of the medial brachial vena comitans with the basilic vein.

About 2.5 or $3.7 \mathrm{~cm}$. ( 1 or $1 \frac{1}{2} \mathrm{in}$.) from its origin, the subscapular artery divides into two end branches, (1) the circumflex (dorsal) scapular, and (2) the dorsal thoracic.

Fig. 466.-The Anastomoses abodt the Scapdla.

Subscapular branch of transverse scapular artery

Supraspinous branch of transverse scapular artery

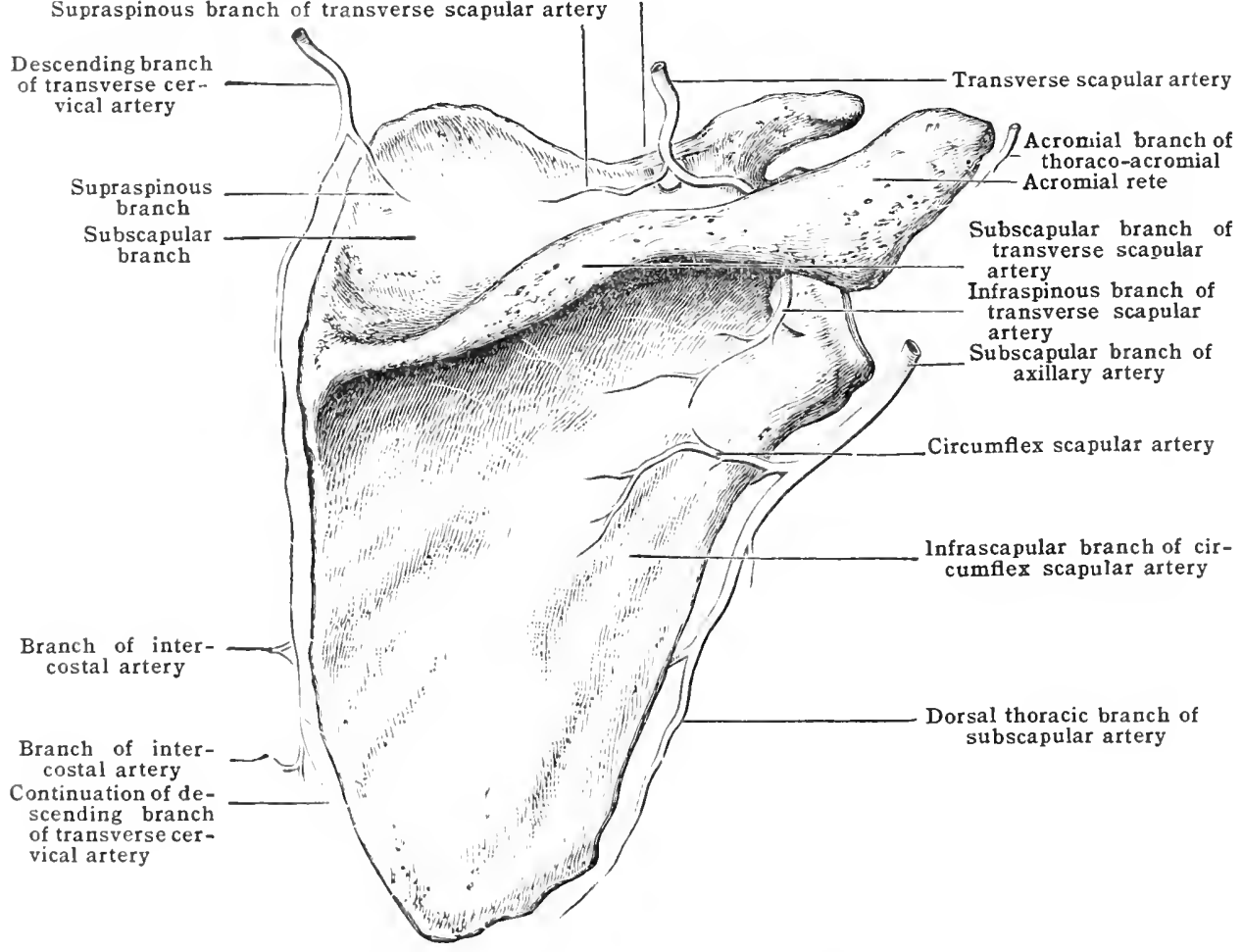

(1) The circumflex scapular artery [a. circminflexa scapulie], or dorsal scapular, arising from the sulscapular, usually at the point above mentioned, passes backward through the triangular space bounded by the subscipularis above, the teres major below, and the long head of the triceps laterally, and then between the teres minor and the axillary border of the scapula, which it commonly grooves. It thus reaches the infraspinous fossa, where, under cover of the infra-spinatus, it anastomoses with the transverse scapular (suprascapular) artery and the descending branch of the transverse cervical (posterior seapular) (fig. 466). As it passes through the triangular space, it gives off a ventral branch which ramifies between the subscapularis and the bone, supplying branches to the subscapularis, to the scapula, and to the shoulderjoint. A second branch is often given off ne:u the triangular space and passes downward between the teres major and teres minor, supplying both nuscles (fig. 467).

(2) 'Tho dorsal thoracic artery' [a. thoracolorsatis] contimes in the course of the subscapular as far as the angle of the scapula, where it anastomoses with the circumflex seapular, the descending branch of the transverse cervical (posterior scapular), the lateral thoracic, and intereostal arteries.

5. 'The anterior circumflex humeral artery [a. circumflexa humeri anterior], usially quitr: a small vessel, comes off from the lateral side of the axillary artery, Enenally opposite the posterior cireunflex. It passes beneath the coracobrachialis and short and long hrads of thr biceps, winding transversely round the front of the surgical neck of the humerus, across the intertubereular (bicipital) grocive, and anastomoses with the posterior circumflex and thoraco-acromial arteries. It gives off the following small branches: 
(a) The bicipital or ascending, which runs up the intertubercular groove to supply the long tendon of the biceps and the shoulder-joint; and $(b)$ a pectoral or descending branch, which runs downward along the insertion of the pectoralis major, and supplies the tendon of that muscle. The anterior circumflex artery, in consequence of its being close to the bone, is sometimes difficult to secure in the operation for excision of the shoulder-joint.

6. The posterior circumflex humeral artery [a. circumflexa humeri posterior] (fig. 467) arises from the posterior aspect of the axillary, just below the lower border of the subscapularis muscle. It passes through the quadrilateral space, bounded by the teres minor above, the latissimus dorsi and teres major below, the humerus laterally, and the long head of the triceps medially, and, winding round the back of the humerus beneath the deltoid, breaks up under cover of that muscle into a leash of branches, which for the most part enter its substance. The axillary (circumflex) nerve and two venæe comitantes run with it. It anastomoses with the anterior circumflex, the arteries on the acromion, and the profunda artery.

Fig. 467.-The Arteries of the Shoulder. (After Spalteholz.)

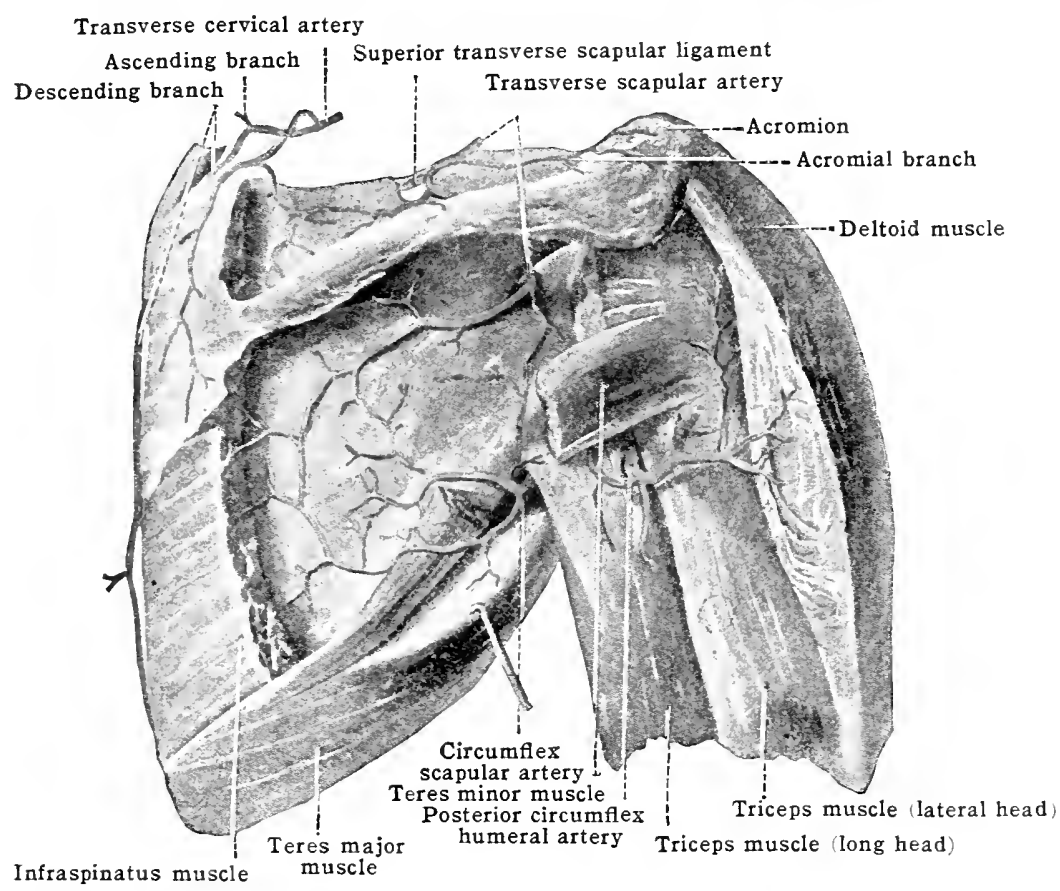

In addition to the leash of ressels to the deltoid, it gives off the following small branches: - (a) nutrient, to the greater tuberosity of the humerus; $(b)$ articular, to the back of the shoulderjoint; (c) acromial, to the plexus on the acromion; and $(d)$ muscular, to the teres minor and long and short heads of the triceps. One or more of these branches to the triceps descend either between the lateral and long head or in the substance of that muscle, to anastomose with an ascending branch from the profunda artery. It is by means of this anastomosis that the collateral circulation is chiefly carried on when the axillary or the brachial artery is tied between the origins of the posterior circumflex and profunda arteries.

\section{THE BRACHIAL ARTERI}

The brachial artery [a. brachialis] (fig. 468), the continuation of the axillary, extends from the lower border of the teres major to a little below the centre of the crease at the bend of the elbow, where it divides, opposite the junction of the head with the neck of the radius, into the radial and ulnar arteries. The artery is situated at first medial to the humerus; but as it passes down the arm it gradually gets in front of the bone, and at the bend of the elbow lies midway between the two epicondyles. Hence, in controlling hæmorrhage, the artery should be compressed laterally against the bone in its upper third, laterally and backward in its middle third, and directly backward in its lower third. Throughout the greater part of its course the artery is superficial, being merely overlapped slightly on 
its lateral side by the coraco-brachialis and biceps muscles; but at the bend of the elbow it sinks deeply beneath the lacertus fibrosus of the biceps into the triangular interval (antecubital space) bounded on either side by the brachio-

Fig. 468, - The Brachial Artery. (After Toldt, "Atlas of Human Anatomy" Rebman, London and New York.)

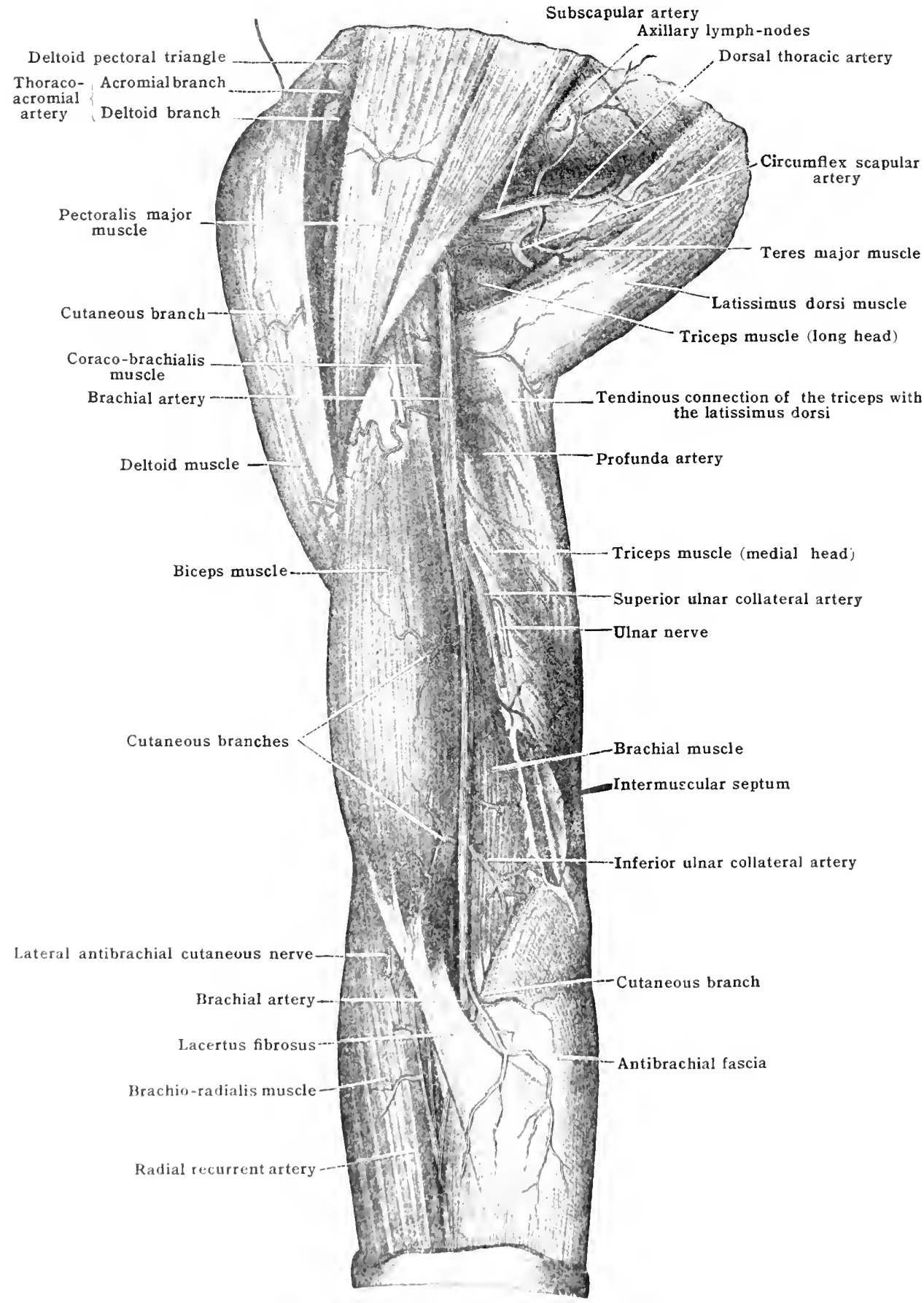

rarlialis and pronator tros, and at its biluration is more or less under cover of these muscless (fig. 469). The sheath of the brachial artery is elosely incorporated with the fascia covering the bierps muscle, and it is for this reason that in the operation for ligaturing the vessed is apt to be retracted with the muscle. 
A line drawn from the groove medial to the coraco-brachialis and biceps muscles to midway between the epicondyles of the humerus will indicate its course. It is accompanied by two veins which frequently communicate across the artery. In addition to the branches named below the brachial artery gives off numerous muscular branches and, occasionally, the nutrient artery to the humerus. The muscular branches usually come off from the lateral side of the artery; one in particular, which supplies the biceps muscle, is frequently of large size.

Relations.- In front, the artery is covered by the integument and superficial and deep fasciæ, and at the bend of the elbow by the lacertus fibrosus of the biceps, and in muscular subjects by the overlapping margins of the brachio-radialis and pronator teres. In the middle third of the arm it is crossed obliquely from the lateral to the medial side by the median nerve, and at the bend of the elbow by the median cubital vein, the bicipital fascia intervening (fig.475).

Behind, it lies successively on the long head of the triceps (from which it is separated by the radial (musculo-spiral) nerve and profunda artery), on the medial bead of the triceps, on the insertion of the coraco-brachialis, and thence to its bifurcation on the brachialis muscle.

Fig. 469.-The Brachial Artery at the Bend of the Elbow, Left Side, Front View.

(From a mounted specimen in the Anatomical Department of Trinity College, Dublin.)

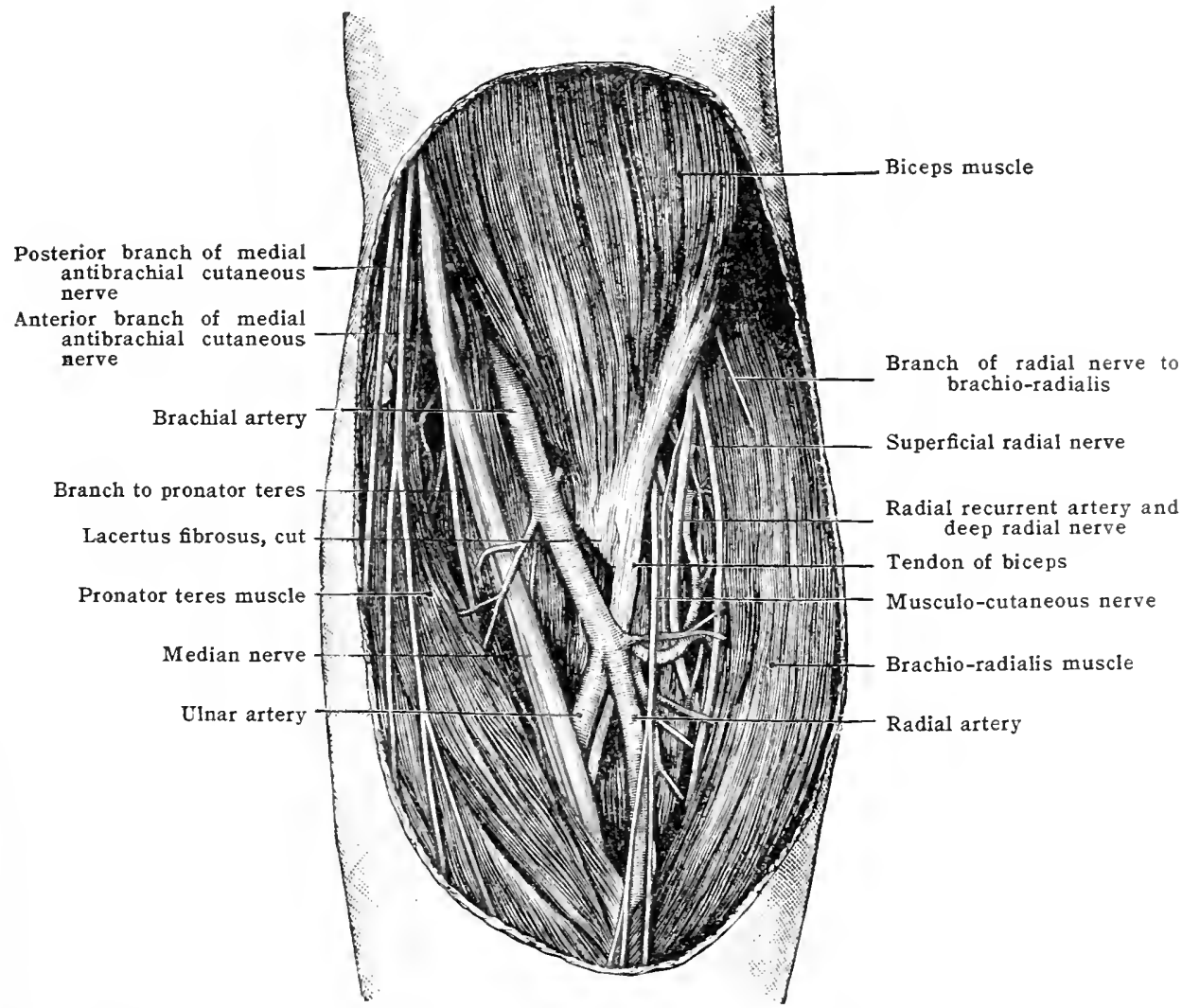

Lateral to the artery is the coraco-brachialis above, and the muscular belly of the biceps below, both of which slightly overlap the vessel, and at the bend of the elbow the tendon of the biceps. The lateral vena comitans is also to its lateral sicle. The median nerve is in close contact with the lateral side of the artery in the upper third of its course, but in the middle third crosses the artery obliquely to gain the medial side.

Medial to the artery in the upper part of its course are the medial antibrachial (internal) cutaneous and the ulnar nerves; the latter nerve, however, leaves the artery about the origin of the ulnar collateral (inferior profunda) branch, to make, with that vessel, for the medial epicondyle. Lower down, the medial antibrachial cutaneous nerve also leaves the artery, by piercing the deep fascia. The median nerve is in close contact with the medial side of the artery in its lower third and at the bend of the elbow. The basilic vein is superficial to it, and a little to its medial side in the greater part of its course, but separated from it by the deep fascia. The medial vena comitans runs along its medial side.

\section{Branches of the Brachial Artery}

The branches of the brachial artery are:-(1) The profunda brachii; (2) the superior ulnar collateral (inferior profunda); (3) the inferior ulnar collateral 
(anastomotica magna); and (4) the terminal branches-the radial and ulnar arteries.

\section{(1) The Profunda Artery}

The profunda brachii (superior profunda) is the largest branch of the brachial. It arises from the medial and hinder aspect of that artery, a little below the inferior border of the tendon of the teres major. It at first lies to the medial side of the brachial, but soon passes behind that vessel, and, sinking between the medial and long heads of the triceps with the radial (musculo-spiral) nerve, curves around the humerus in the groove for the nerve, lying in contact with the bone between the medial and lateral heads of the triceps. On reaching the lateral supracondyloid ridge of the humerus it perforates the lateral intermuscular septum, and, continuing forward between the brachio-radialis and brachialis to the front of the lateral epicondyle, ends by anastomosing with the radial recurrent artery (figs. 468 and 474).

It gives off the following branches:-

(a) The deltoid branch [r. deltoideus] which may also arise from the brachial itself or from the superior ulnar collateral. It runs across the anterior surface of the humerus, under cover of the coraco-brachialis and biceps, and supplies the brachialis and deltoid.

(b) The middle collateral artery [a. collateralis media] runs in the substance of the middle head of the triceps as far as the elbow, where it terminates in the articular rete.

(c) The radial collateral artery [a. collateralis radialis] arises about the middle of the upper arm, and runs behind the lateral intermuscular septum to the rete at the elbow-joint.

(d) A nutrient humeral artery [a. nutritia humeri], which may come from the brachial itself or from a muscular branch, enters a canal in the humerus.

\section{(2) The Superior Ulnar Collateral Artery}

The superior ulnar cóllateral artery [a. collateralis ulnaris superior] (inferior profunda) arises from the medial side of the brachial, usually about the level of the insertion of the coraco-brachialis, at times as a common trunk with the profunda. It passes with the ulnar nerve medially and downward through the medial intermuscular septum, and then along the medial head of the triceps to the back of the medial epicondyle, where, under cover of the deep fascia and the origin of the flexor carpi ulnaris from the olecranon and medial epicondyle, it enters into the anastomoses around the elbow-joint. It frequently supplies the nutrient artery to the humcrus. It gives branches to the triceps, to the elbowjoint, and a branch which passes in front of the medial epicondyle to anastomose with the anterior ulnar recurrent.

\section{(3) The Inferior Ulnar Collateral Artery}

The inferior ulnar collateral artery [a. collateralis ulnaris inferior] or anastomotica magna arises from the medial side of the brachial, ahout $5 \mathrm{~cm}$. (2 in.) above its bifureation in to the radial and ulnar arteries, and, running medially and downwarl across the brachialis, divides into two branches, a posterior and an anterior. The posterior pierees the medial intermuscular septum, winds round the medial condyloid rielge of the humerus, and pierees the triceps, between which and the bonc it anatstomoses with the articular branch of the profunda artery, and to a lesser extent with the interosseous recurrent, forming an arterial arch or rete around the upper border of the olceranon fossa. 'The anterior branch passes merlially and fownwarl between the brachialis and pronator teres, and anastomoses in front of the medial apicondyle, but beneath the pronator teres, with the anterior ulnar rorurrent. From this branch a small vessel passes down behind the medial epirondyle to anastomose with the posterior ulnar recurrent and superior ulnar collatian arteries (fig. 47.t).

\section{TIIE ULNAR ARTERY}

The ulnar artery [a. ulnaris] (fig. 170) the larger of the two terminal branches of the brachial, begins opposite the lower border of the head of the radius in the midclle line of the forearm. 'Thence through the upper half of the forearm it runs 
beneath the pronator teres and superficial flexor muscles, and, having reached the ulnar side of the arm about midway between the elbow and the wrist, it passes directly downward, being merely overlapped by the flexor carpi ulnaris. Crossing the transverse carpal (anterior annular) ligament immediately to the radial side of the pisiform bone, it enters the palm, where it divides into two branches, which enter respectively into the formation of the superficial and deep rolar arches. The artery is accompanied by two veins, which anastomose with each other by frequent cross branches, and usually terminate in the brachial venie comitantes. The ulnar nerve is at first some distance from the artery, but approaches the vessel at the junction of its upper and middle thirds, and then lies close to its medial or ulnar side. The course of the artery in the lower two-thirds of the forearm is indicated by a line drawn from the front of the medial epicondyle to the radial side of the pisiform bone; and in the upper third of the forearm by a line drawn in a gentle curve with its convexity to the medial side from $2.5 \mathrm{~cm}$. ( 1 in.) below the centre of the bend of the elbow to a point in the former line at the junction of its upper with its middle third. The artery throughout its course is best reached through the interval between the flexor carpi ulnaris and the flexor digitorum sublimis. hand.

The relations of the artery will be given in detail in the forearm, and in the palm of the

\section{The relations in the forearm are:-}

In front.-In the upper half of the forearm the uhnar artery is deeply placed beneath the pronator teres, the flexor carpi radialis, the palmaris longus, and the flexor digitorum sublimis. In the lower half it is comparatively superficial, being merely overlapped above by the tendon of the flexor carpi ulnaris, whilst the last inch or so of the vessel is only covered as a rule by the skin and superficial and deep fascix. As the artery lies beneath the pronator teres, it is crossed from the medial to the lateral side by the median nerve, the cleep head of origin of the muscle usually separating the nerve from the artery. The lower part of the artery is crossed by the palmar cutaneous branch of the ulnar nerve.

Behind.-For about $2.5 \mathrm{~cm}$. (1 in.) of its course the artery lies upon the brachialis; but thence, as far as the transverse carpal (anterior annular) ligament, upon the flexor digitorum profundus, which separates it above from the interosseous membrane and bone, and at the wrist from the pronator quadratus. The artery is bound down to the flexor cligitorum profundus by bands of fascix.

To the lateral side in the lower two-thirds of its course is the flexor digitorum sublimis.

To the medial side in the lower two-thirds is the flexor carpi ulnaris, the guicle to the vessel. The uhnar nerve, as it enters the forearm from behind the medial epicondyle, is at first some distance from the artery, being separated from it in its upper third by the flexor digitorum sublimis, but in its lower two-thirds is in close contact with the vessel and on its ulnar side.

The branches of the ulnar artery in the forearm are:-1. The ulnar recurrent arteries. 2. The common interosseous. 3. Muscular. 4. Dorsal ulnar carpal. 5. Volar ulnar carpal.

1. The ulnar recurrent arteries [aa. recurrentes ulnares] are two, the volin, and dorsal. The volar is a small branch which arises from the medial side of the ulnar artery, or the dorsal ulnar recurrent, and, running between the lateral edge of the pronator teres and the brachialis. anastomoses in front of the medial epicondyle with the inferior and superior ulnar collaterals. It supplies branches to the muscles between which it runs, and to the skin. The dorsal, larger than the volar, comes"off from the medial side of the ulnar artery, either a little below the latter branch, or else as a common trunk with it, and, passing between the flexores digitorum sublimis and profundus, turns upward to the back of the medial epicondyle, where it lies with the uhnar nerve between the two heads of origin of the flexor carpi ulnaris. It supplies the contiguous muscles-the flexor carpi ulnaris, the palmaris longus, and the flexores digitorum sublimis and profundus - the elbon-joint, and the ulnar nerve, and anastomoses with the inferior and superior ulnar collaterals, and with the interosseous recurrent forming the so-called rete olecrani.

2. The common interosseous artery [a. interossea communis] is a short thick trunk $1.2 \mathrm{~cm}$. ( $\frac{1}{2} \mathrm{in}$.) or so in length, which comes off from the lateral and back part of the ulnar artery about $2.5 \mathrm{~cm}$. ( $1 \mathrm{in}$.) from its origin, and just befor that artery is erossed by the median nerve. It passes backward and downward between the flexor pollicis longus and the flexor digitorum profundus, toward the triangular interval bounded by the upper border of the interosseous membrane, the oblique ligament, and the lateral border of the ulna, where it divides into the volar and dorsal interosseous arteries.

(a) The volar interosseous artery [a. interossea volaris], smaller than the clorsal, but apparently the direct continuation of the common trunk, courses downward in front of the interosseous membrane. It lies under cover of the overlapping edges of the flexor ligitorum profundus and flexor pollicis longus, to both of which muscles it supplies brinches. It the 
upper border of the pronator quadratus it divides into two branches, an anterior terminal and a posterior terminal (fig. 473 ).

The volar interosseous artery is accompanied by two veins and by the deep branch of the median nerve which lies to its radial side. The artery is bound down to the interosseous membrane by aponeurotic fibres.

Fig. 470.-The Tolar Arteries of the Forearm and Hand. (After Toldt, "Atlas of Human Anatomy," Rebman, London and New York.)

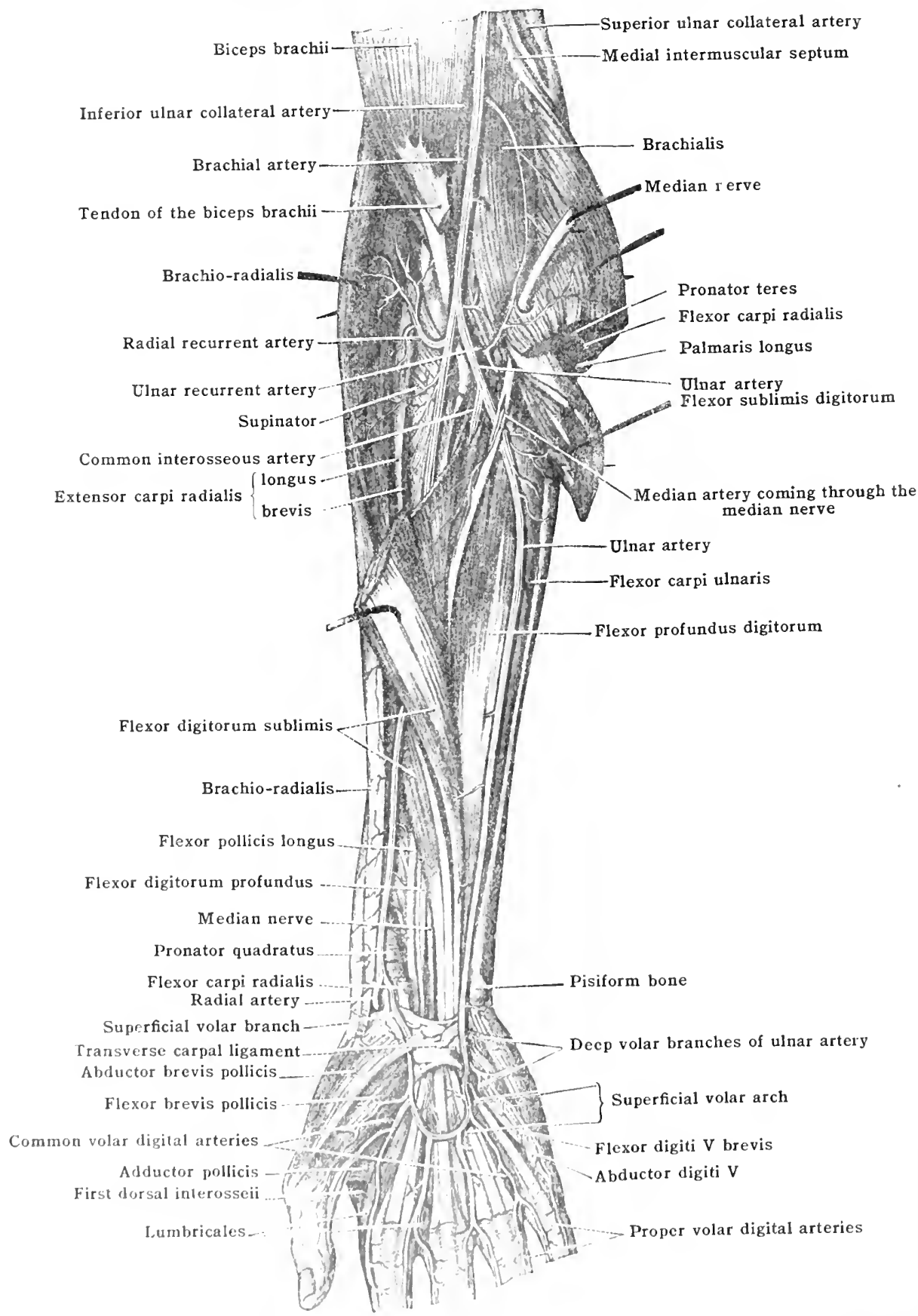

Tho branches of the volar interosseous artery are:-(i) The median artery [a. mediana]

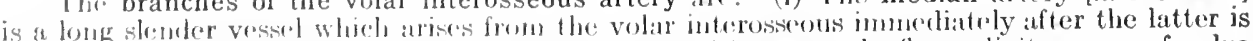

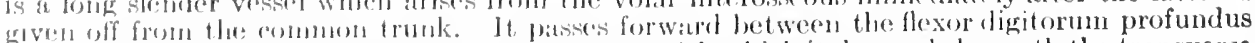
and the floxor pollicis lomgus to the morlian nerve, with which it descents beneath the transverse carpal (anterior asmular) liganont into the palu, and when of large size sometimes enters into the formation of the smumericial palmal arch. At times the artery arises from the common 
interosseous before its division. (ii) The nutrient arteries of the radius and ulna are usually derived from this vessel. (iii) The volar terminal division of the volar interosseous artery passes either in front of or behind the pronator quadratus, but in either case in front of the interosseous membrane, and anastomoses with the volar carpal branches of the radial and ulnar arteries, and with the recurrent branches from the deep volar arch, forming the so-called volar carpal rete. (iv) The dorsal terminal, the larger division, pierces the interosseous membrane, and continues its course downward behind the interosseous membrane, under cover of the extensor muscles, to the back of the wrist, where it ends by anastomosing with the dorsal

Fig. 471.-The Back of the Left Forearir, with the Dorsal Interosseous Artery and Branches of the Radial at the Back of the Wrist.

(From a dissection in the Hunterian Museum.)

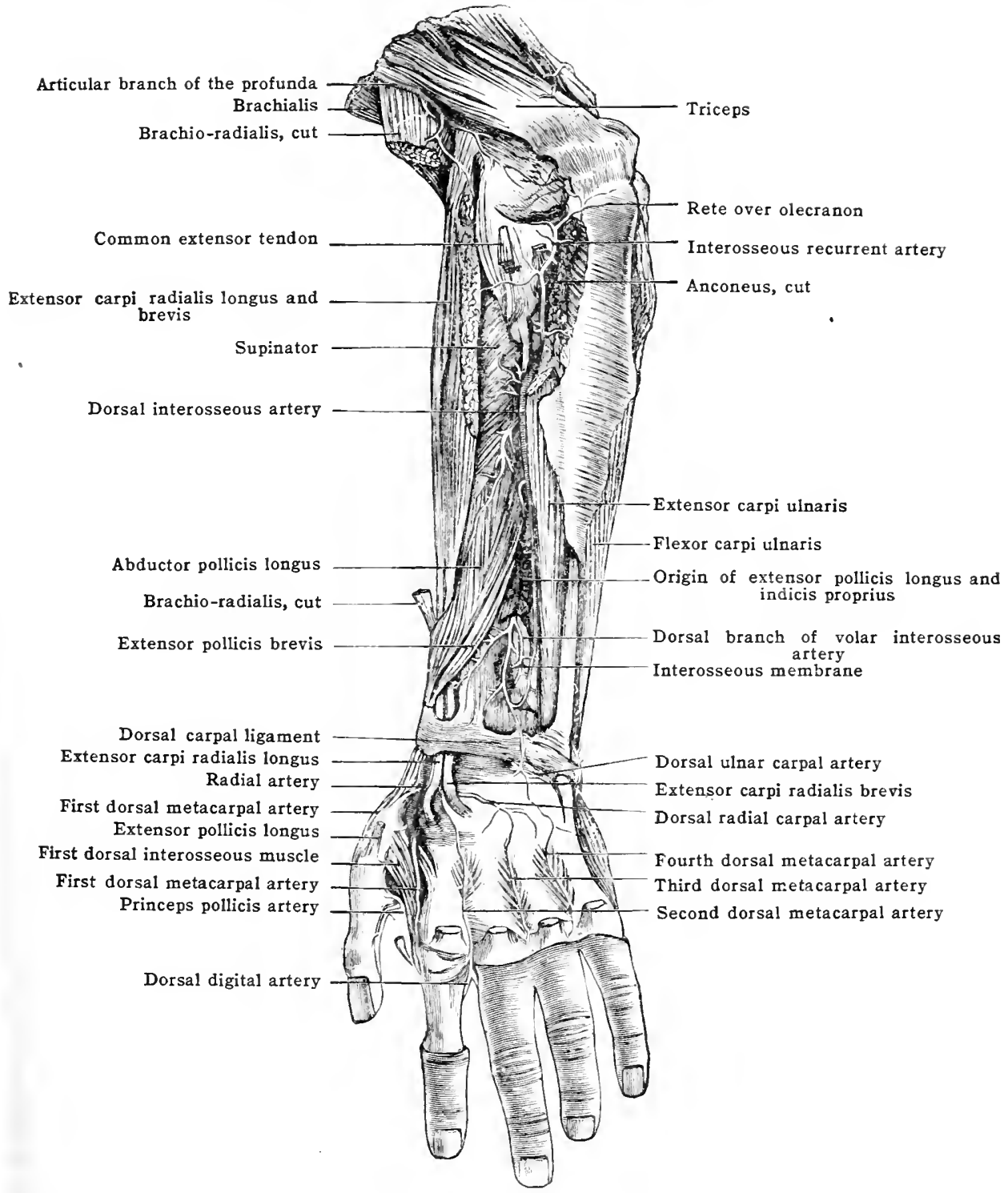

carpal branches of the radial and uhar arteries, forming the so-called dorsal carpal rete. This branch anastomoses, as soon as it pierces the interosseous membrane, with the dorsal interosseous artery.

(b) The dorsal interosseous artery [a. interossea dorsalis], the larger division of the common interosseous, turns backward through the triangular interval bounded by the interosseous membrane below, the oblique ligament above, and the ulna on the medial side, and energing at the back of the forearm between the abductor pollicis longus and the supinator, under cover of the superficial extensors of the forearm, descends between the superficial and the deep muscles, crossing in this course the abductor pollicis longus, the extensor pollicis brevis, the extensor pollicis longus, and the extensor indicis proprius (fig. 471). It anastomoses at the lower border 
of this muscle and just above the wrist joint, with the dorsal branch of the volar interosseous which here, as above described, has perforated the interosseous membrane. It is separated from the deep radial nerve at first by the radius and supinator, and on the back of the forearm by the extensores pollicis longus and indicis proprius.

The chief branch of the dorsal interosse ous artery, the interosseous recurrent artery [a. interossea recurrens] arises from the dorsal interosseous as the latter emerges from beneath the supinator. It runs upward between the anconeus and supinator, usually under cover of the former, to the interval between the lateral epicondyle and the olecranon, where it anastomoses with the profunda, inferior ulnar collateral, radial recurrent, and dorsal ulnar recurrent arteries. and gives branches to the retiform plexus over the olecranon-the rete olecrani.

Fig. 4i2.-Anastonoses and Distribution of the Arteries of the Hand. (Walsham.)

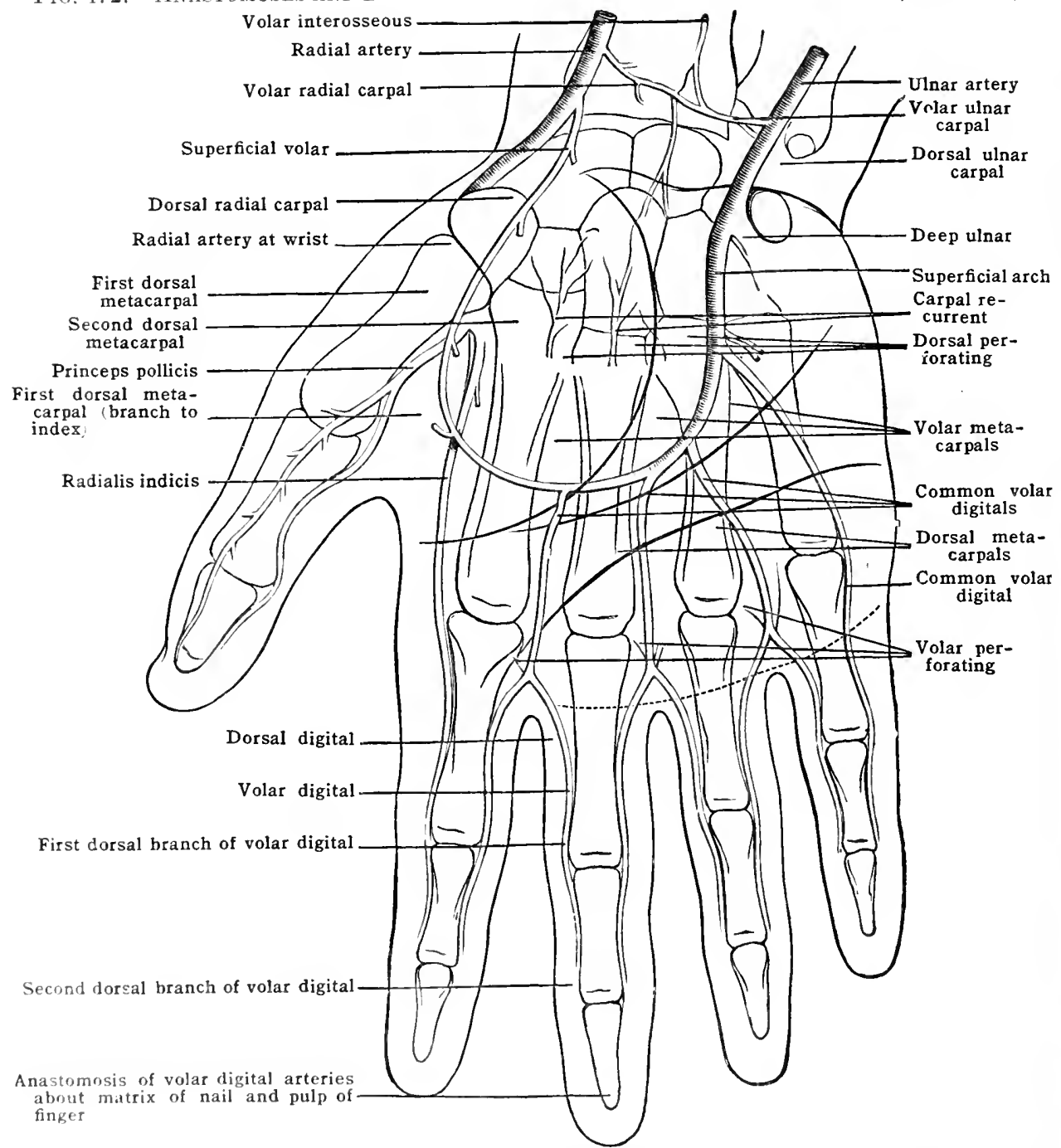

$\because$ The muscular branches [rami musculares] are mumerous. They supply

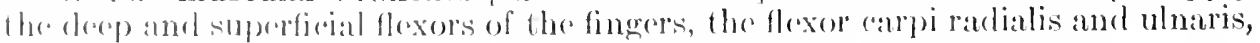
amel the promator raclii trers.

1. Thre dorsal ulnar carpal [ramus anpere dorsalis] eomes off from the ulnar artery a lithlo alowe the transwerse captal (anterior ammular) ligamont, and,

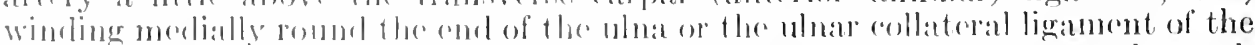
wrist, beneath the flexor calpi ulnaris, ramifies on the back of the earpus beneath

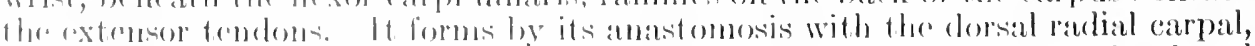
with the dorsal ferminal liranch of the volar interosseous and with the dorsal

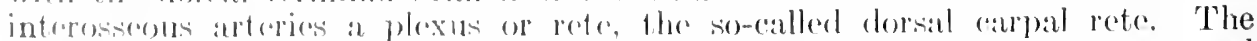
hranches given off from this plexus or areh are deseriber with the dorsal carpal branch of the raclial antery. 
5. The volar ulnar carpal [ramus carpeus volaris] is a small branch given off from the ulnar artery opposite the carpus. It passes beneath the flexor digitorum profundus to anastomose with the volar radial carpal, with teminal twigs of the volar branch of the volar interosseous, and with recurrent branches from the deep volar arch, forming an anastomotic arch across the front of the carpus-the volar carpal arch or rete.

Fig. 473.-The Arteries of the Right Forearm and the Deep Volar Arch.

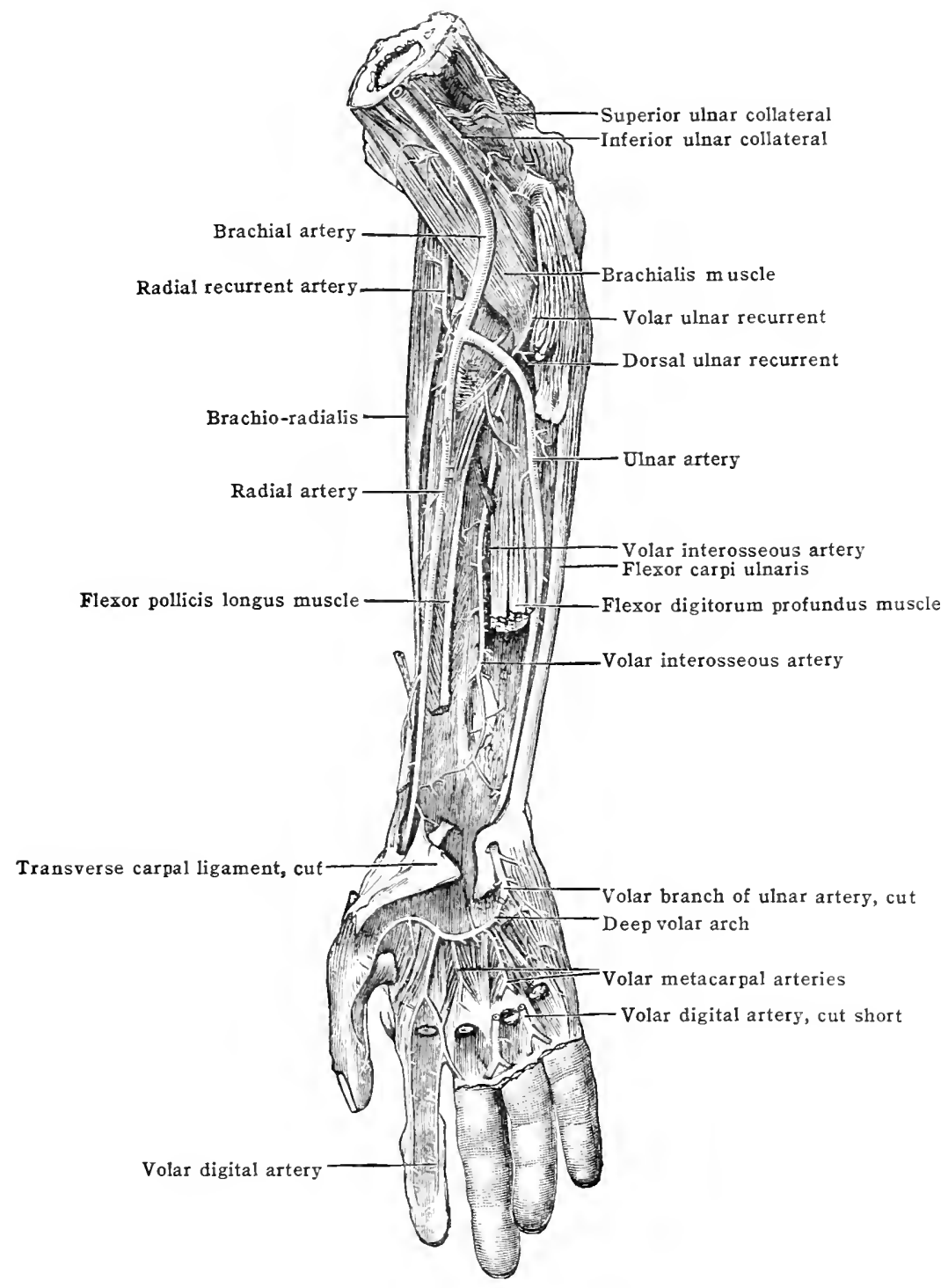

The Uluar Arteri at the Wrist

The ulnar artery at the wrist may be said to extend from the upper to the lower border of the transverse carpal (anterior annular) ligament upon which it rests. It here lies immediately to the radial side of the pisiform bone, and to the ulnar side of the hook of the hamate (unciform), the two bones forming for the vessel a protecting channel, which is further converted into a short canal by the expansion of the flexor carpi ulnaris passing from the pisiform to the hook of the hamate (unciform). The ulnar nerve in this situation is immediately to the ulnar sicle of the artery. 


\section{The Ulnar Artery in the Pali (Superficial Volar Arch)}

The ulnar artery, on entering the palm, divides into two branehes, the superficial and deep.

The superficial branch (fig. 472), the direct continuation of the vessel, anastomoses with the superfieial volar, a branch of the radial, forming what is then known as the superficial volar arch. After descending a short distance toward the eleft between the fourth and fifth fingers, it turns toward the thumb, forming a curve with its convexity toward the fingers and its concavity toward the muscles of the thumb, and anastomoses opposite the cleft between the index and middle fingers, at the junction of the upper with the middle third of the palm, with the superficial volar branch of the radial artery to complete the areh. A line drawn transversely aeross the palm on a level with the metacarpo-phalangeal joint of the thumb will roughly indicate the situation of the arch.

Relations.--In front: in addition to the skin and superficial fascia, the vessel is crossed successively, by the palmaris bevis, the palmar branch of the ulnar nerve, the palmar aponeurosis and the palmar branch of the median nerve.

Behind, it rests successively upon the short muscles of the little finger, the digital branches of the ulnar nerve, the flexor tendons, and the digital branches of the median nerve.

The branches of the superficial volar arch. In addition to small muscular and cutaneous branches the superficial volar supplies:-

The common digital arteries [aa. digitales volares communes]. These, usually four in number, arise from the convexity of the superficial arch and, running downward through the palm, give off the digital arteries proper to both sides of the little, ring, and middle fingers, and the ulnar side of the index finger. The radial side of the index finger and the thumb are supplied by the first volar metacarpal branch of the radial artery.

The most ulnar of the common digital arteries passes distally over the museles in the ulnar border of the palm, and thence along the ulnar borter of the little finger. The remaining arteries pass distally in the three ulnar intermetacarpal spaces to within about $6 \mathrm{~mm}$. ( $\frac{1}{4} \mathrm{in}$.) of the clefts between the fingers, where they divide into branches, the digital arteries proper [aa. cligitales volares propriæ], which supply the sides of contiguous fingers.

As the common digital arteries pass through the palm, they lie between the flexor tendons, on the digital nerves and lumbrical museles, and beneath the palmar aponeurosis. Just before bifureating they pass under the transverse fasciculi, and are joined hy the volar metacarpal branches from the deep volar arch (fig. 472). At this spot they also receive the volar perforating branches from the dorsal metacarpal vessels. On the sides of the fingers the proper digital arteries lie between the palmar and dorsal digital nerves. They anastomose by small branches, forming an arch across the front of the bones on the proximal side of each interphalangeal joint. They supply the flexor tendons and the integuments, and terminate in a plexiform manner beneath the pulp of the finger and around the matrix of the nail. A dorsal digital branch is given off to the back of the fingers about the level of the middle of the first phalanx, and a second but smaller dorsal digital br:mch about the level of the middle of the second phalanx.

The deep branch of the ulnar artery, also called the communicating artery, sinks deeply into the palm between the abductor and flexor quinti digiti brevis, and joins the radial to form the deep volar areh. (See Tine Randal Antery.)

\section{THE RADIAL ARTERY}

'The radial artery-the smaller of the two arteries into which the brachial divides at the bend of the elbow-appears as the direct continuation of the brachial. It runs, at first curving laterally, along the radial side of the forearm as far as the styloik process, then, roiling over the radial collateral ligament and the lateral and laak part of the wrist, enters the palm of the hand from behind be1.ween the first and seromel metatearpal bones, and ends by anastomosing with the deep branch of the uhar to form the decep volar arch. Henee the artery is divisible into thresparts: that in the forcarm, that at the wrist, and that in the palm of the hatud. There contse of the artery is indieated by a line drawn from a point 2.5 (mo. (1 in.) bedow the contre of the ellow to a point situated just medial to the styloirl prosess of the ranlins.

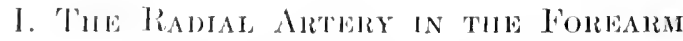

In its course through the forearm (fig. 170) the radial artery is found in the most latroal of the intromuscoular sprares, and it is only necessary to divide the 
skin, superficial and deep fascia, to expose the vessel, and in addition in the upper third to separate the brachio-radialis from the pronator teres.

Relations. - In front, the artery is at first overlapped by the brachio-radialis, but for the rest of its course it is nerely covered by the skin, superficial and deep fasciæ, by some cutaneous veins, and by cutaneous branches of the musculo-cutaneous nerve.

Behind, it lies successively from above downward on the tendon of the biceps, the supinator. from which it is separated by a layer of fat, the insertion of the pronator teres, the radial origin of the flexor digitorum sublimis, the flexor pollicis longus, the pronator quadratus, and the volar surface of the lower end of the radius. It is in this last situation, where the artery lies upon the bone and can therefore be easily pressed against it, that the pulse is usually felt.

Fig. 474.-Diagran of the Relation of the Arteries of the Left Forearil to THE BoNes. (Walsham.)

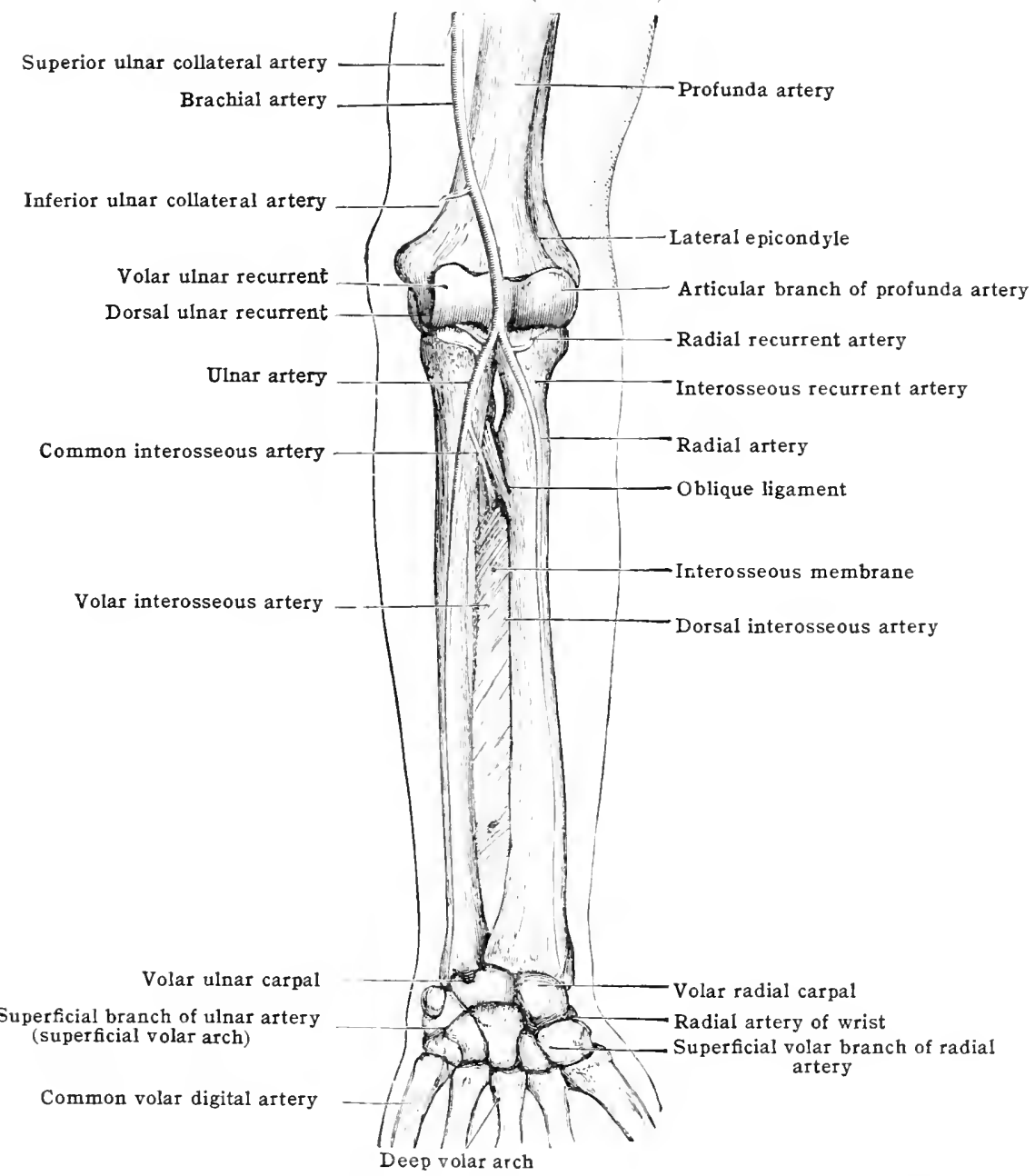

On its lateral side it has, throughout the whole of its course, the brachio-rachialis muscle. the guide to the artery in ligature, and the lateral vena connitans; in its middle third, the superficial radial nerve as well. In its lower third the superficial radial nerve is to its lateral side, but separated from it by the brachio-radialis and fascia.

On its medial side, in the upper third is the pronator teres, in the lower third the tendon of the flexor carpi radialis, and throughout the whole of its course the medial vena comitins.

The branches of the radial artery in the forearm are:-(1) The radial recurrent; (2) the muscular; (3) the volar radial carpal; (4) the superficial volar.

(1) The radial recurrent [a. recurrens radialis] usually arises from the lateral side of the radial just below its origin from the brachial. It at first runs laterally on the supinator and then divides into three chief branches (fig. 475). One of these continues laterally through the fibres of the radial (musculo-spiral) nerve, or between the superficial (radial) and deep radial (posterior. interosseous) nerves when the radial (musculo-spiral) divides higher than usual, into the brachioradialis and extensor carpi radialis longus and brevis, and anastomoses with the interosseons recurrent. A second ascends between the brachialis and brachio-radialis, with the radial 
(musculo-spiral) nerve, and anastomoses with the profunda artery. A third descends with the superficial radial nerve under cover of the brachio-radialis, supplying that muscle. The radial recurrent also gives off branches to the elbow-joint.

(2) The muscular branches |rami musculares| come off irregularly to supply the contiguous muscles on the lateral side of the forearm

(3) The volar radial carpal branch [ramus carpens volaris] arises from the merlial side of the radial arterv about the level of the lower borler of the pronator quadratus. It crosses the front of the radius beneath the flexor muscles, and anastomoses with the volar carpal branch of the ulnar, forming the volar earpal rete. This plexus is joined above by terminal twigs from the volar interosseous artery, and below by recurrent branches from the deep volar arch. It supplies branches to the lower end of the radius, and to the wrist and earpal joints.

(4) The superficial volar branch [ramus volaris superficialis] leaves the radial artery as the latter vessel is about to tum over the radial collateral ligament to the back of the wrist. It courses forward over the short muscles of the ball of the thumb, and anastomoses with the superficial.

Fig. 475.-The Bend of the Elbow, Left Side.

(From a dissection by Dr. Alder Smith in the Museum of St. Bartholomew's Hospital.)

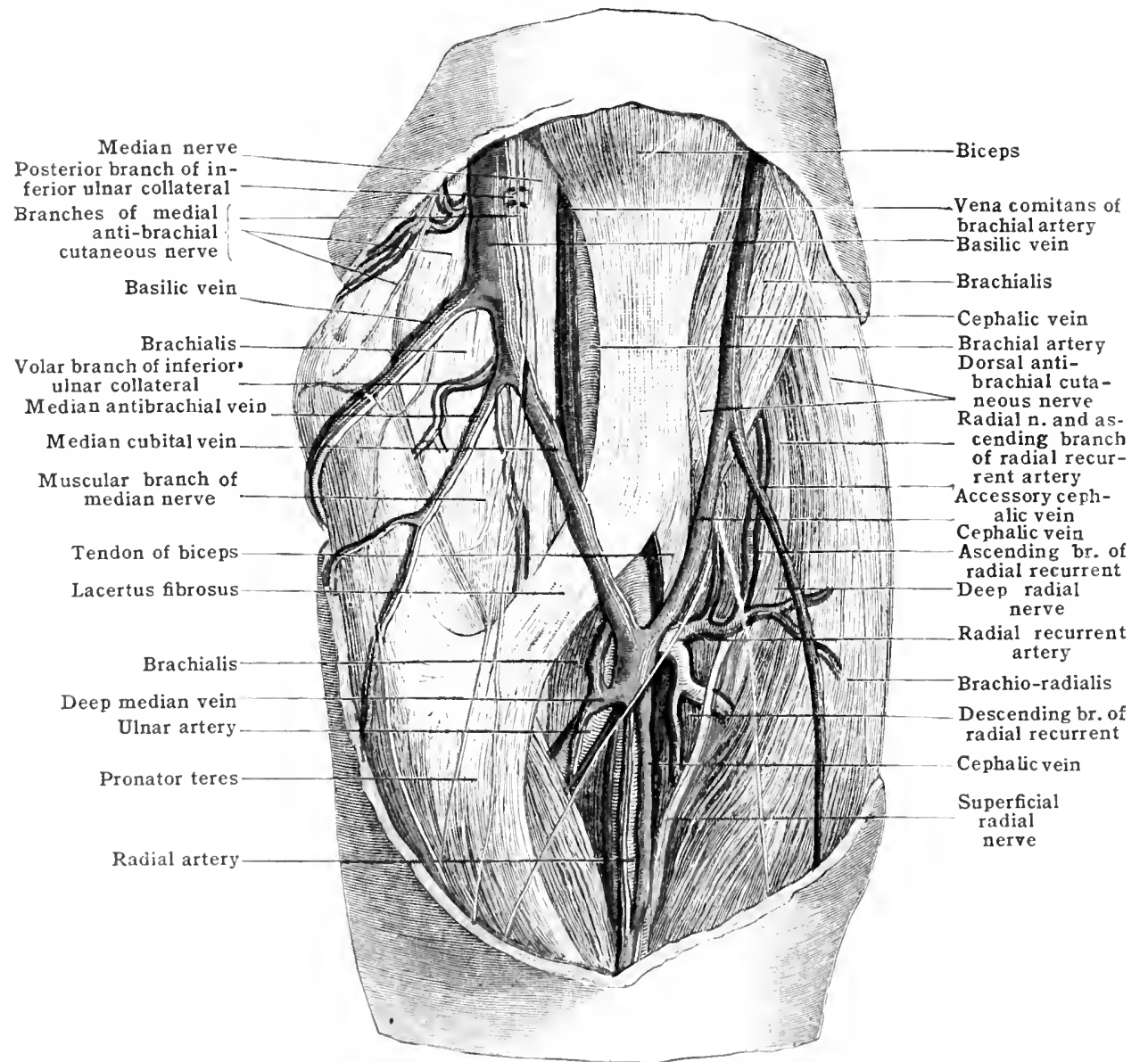

branch of the nhat artery to complete the smperfocial rolar ardh, It supplies small branches

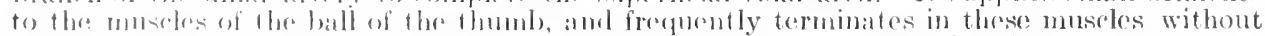

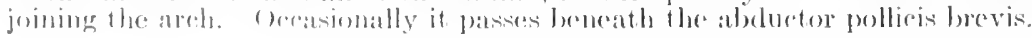

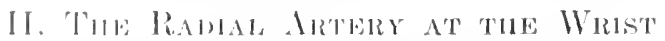

The radial artery at the wrist winds over the radial side of the earpurs, under

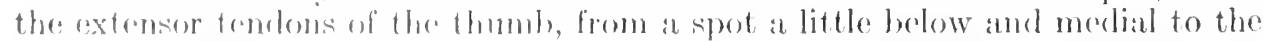

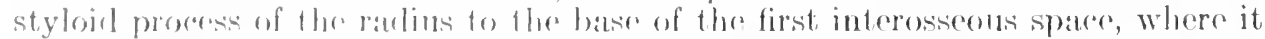

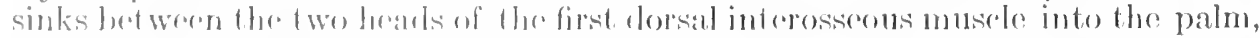

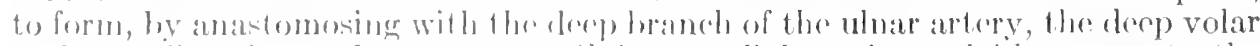

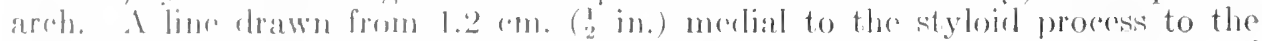

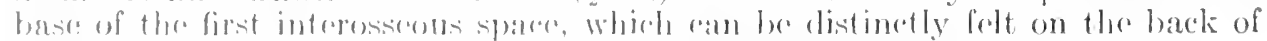

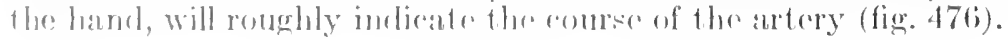


IRelations. - The artery is covered successively by the abductor pollicis longus and extensor pollicis brevis, by branches of the superficial ratial nerve and veins, and, just before it sinks between the two heads of the interosseous muscle, by the tendon of the extensor pollicis longus. The branches of the superficial radial nerve to the thumb and index finger cross it. It is at first somewhat deeply placed beneath the first-mentioned extensor muscles of the thumb; but subsequently it lies quite superficial, and can be felt pulsating in a little triangular depression bounded on either side by the extensores pollicis longus and brevis, and above by the lower end of the radius. The artery lies successively on the rachial collateral ligament of the wrist, on the navicular (scaphoid), the greater multangular (trapezium), the base of the first metacarpal bone, and on the dorsal ligaments uniting these bones. It has usually with it two companion veins, and a few branches of the musculo-cutaneous nerve.

Fig. 476.-The Radial Arteri at the Wrist, Left Foreari.

(From a dissection in the Hunterian Museum.)

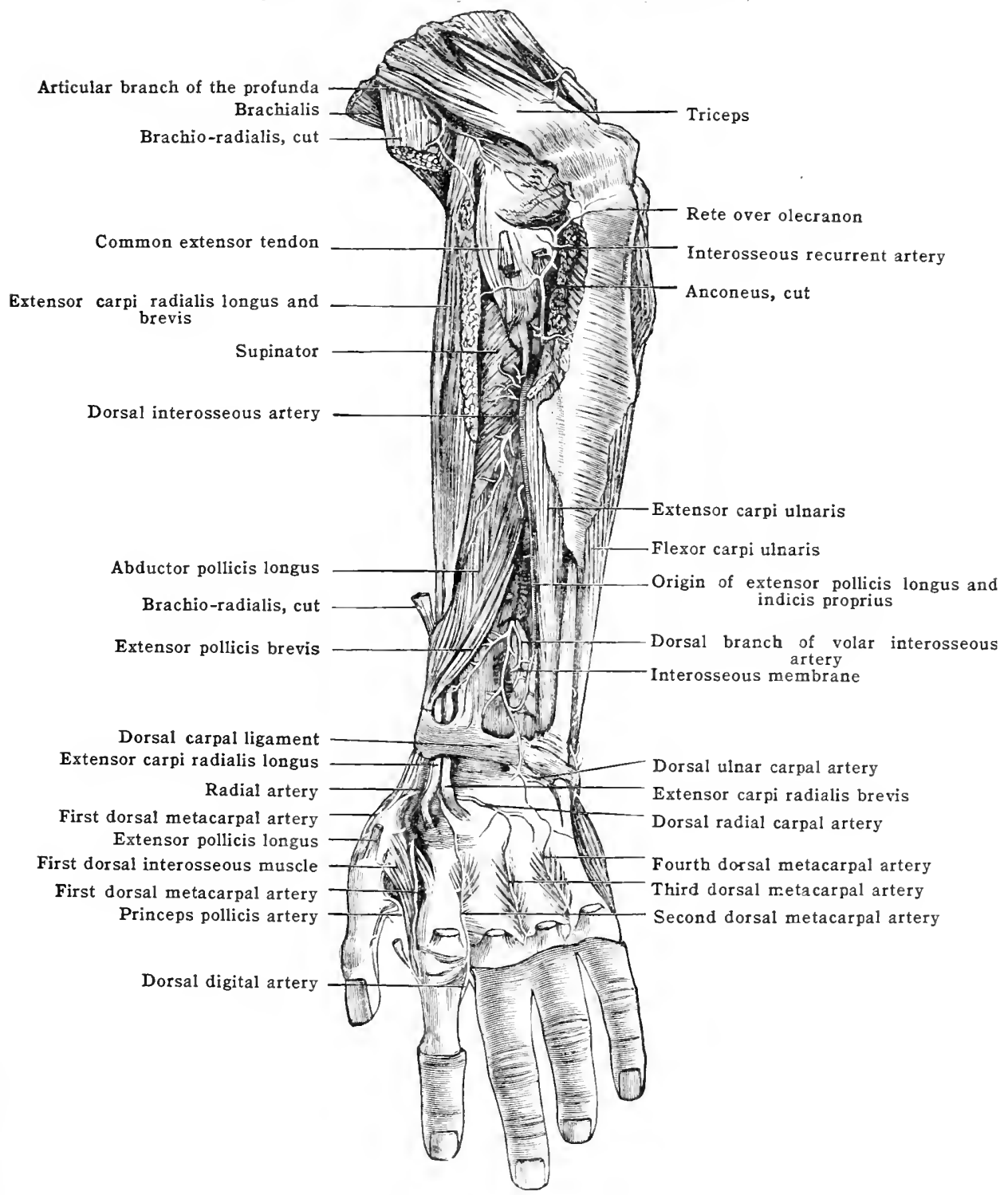

The branches of the radial artery at the wrist are:-(1) The lorsal radial carpal; (2) the first dorsal metacarpal.

(1) The dorsal radial carpal branch [ramus carpeus dorsalis] arises from the radial as the latter vessel passes under the abductor pollicis longus, and runs medially beneath the extensor carpi radialis longus and brevis, and the extensor pollicis longus, across the lorsal surface of the carpus, to anastomose with the dorsal uhar carpal and with the terminal twigs of the posterior branch of the volar interosseous artery. This anastomosis is called the dorsal carpal 
rete [rete carpi dorsale]. From this rete are given off the second, third, and fourth dorsal metacarpal arteries to the second, third, and fourth internetacarpal spaces respectively. These vessels rum downward on the dorsal interosseous muscles as far as the flexure of the fingers, and there divide into two branches (dorsal digital), which run along the sides of the contiguous fingers on their dorsal aspect. Near their proximal ends they anastomose with the dorsal perforating branches of the deep volar arch. Distally they are connected by volar perforating branches with the digital arteries or the corresponding spaces. The branches which run along the backs of the fingers anastomose with the dorsal branches of the first dorsal digital arteries derived from the volar common digital vessels (fig. 476)

(2) The first dorsal metacarpal (figs. 472,476 ) is given off by the radial shortly before it passes between the two heads of the first clorsal interosseous muscle. It quickly divides into two branches which supply the dorsal surface of the thumb and the radial side of the indexfinger toward its dorsal surface.

\section{The Radial Artery in the Palm (Deep Volar Arch)}

The radial artery enters the palm between the first and second metacarpal bones at the base of the first interosseous space, by passing between the two heads of the first dorsal interosseous muscle. It then runs medially between the transverse and oblique heads of the adductor pollicis muscle and continuing its course in a slight curve with the convexity forward, across the base of the metacarpal bones and interosseous muscles, it anastomoses with the deep branch of the ulnar, forming the deep volar arch [arcus volaris profundus]. The arch may be said to extend from the first interosseous space to the base of the metacarpal bone of the little finger, and is a finger's breadth nearer the wrist than the superficial arch. It is covered by the superficial and deep flexor tendons, by the superficial head of the flexor pollicis brevis, and by part of the flexor quinti digiti brevis. It is accompanied by the deep branch of the ulnar nerve, and two small venæ comitantes (figs. 472,473 ).

The branches of the deep volar arch are:-(1) The princeps pollicis; (2) the radialis indicis; (5) the volar metacarpals (three in number); (4) the recurrent carpal; (3) the dorsal perforating. The first two are usually spoken of as coming off from the radial artery in the palm; the last three from the deep volar arch.

(1) The arteria princeps pollicis arises from the radial artery as it enters the palm between the two heads of the first dorsal interosseous muscle. It passes downward between the atductor pollicis transversus and the first dorsal interosseous muscle, parallel to the metacarpal bone, and between the two portions of the flexor pollicis brevis unter cover of the flexor pollicis longus. Opposite the metacarpo-phalangeal joint it usually divides into two branches, one of which is distributed to each side of the thumb on its volar aspect. These vessels anastonose with each other at the end of the thumb, like the other digital arteries.

(2) 'The arteria radialis indicis comes off from the radial artery a little lower than the former vessel, or as al common trunk with it, and passes forward between the first clorsal interosseous and alductor pollicis transversus, parallel to the radial side of the second metacarpal bone. After energing from beneath the adductor pollicis transversus it continues its course along the raclial side of the index-finger, on its volar aspect, as far as the tip, anastomosing in this course with the digital artery on the opposite side of the finger in a way similar to that of the other digital arteries. It freepuently communicates, at the lower border of the adductor pollicis, with the superficial volar arch and princeps pollicis. It gives off a dorsal branch, which anastomoses with the branch fron the first dorsal metacarpal to the index finger.

(3) 'The volar metacarpal arteries [aa. metacarped volares], thrce in number, come off from the ronvexity of the deep anch, and, conrsing downward in the centre of the second, third, and fonrth introsseons spaces on the interosseous museles, terminate near the cleft of the fingers by anastomosing with the ligital arteries from the superficial arch. These vessels supply the interossents musclos and the bones, and the second, third, and fourth lumbrieales.

(1) The recurrent branches come off from the concavity of the arch, and consist of two or threes suall vesseds which run upward toward the wrist, and anastomose with the volar branch of the volar interosseous, and the volur radial and uhar carpal arteries.

(5) Thr dorsal perforating branches (rr. porforantes), which are usually thrce in number, pass from the areh ilirectly through the second, third, and fourth interosseous spaces between

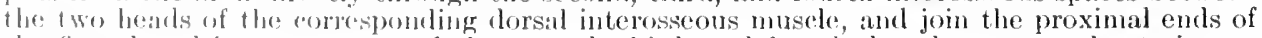
the first dorsal introssons, and the secomd, third, and fourth dorsal metacarpat arteries resurectively.

\section{THE THORACIC AORTA}

The thoracic aorta faterta thoracalis) (fig. 177) is the thoracic portion of the aorta leserendens. It extents from the termination of the arortic areh at the lower border of the hesty of the fourth thoracic vertelora to the lower border of the horly of thre twelfth thoracie vertebra, where it passes between the medial 
crura of the diaphragm, and is thence continued under the name of the abdominal aorta. It is at first situated a little to the left of the vertebral column, but as it descends, approaches the front of the column, at the same time following the backward curve of the spine, and at the diaphragm is almost in the middle line. It lies in the posterior mediastinum, having the oesophagus at first a little to the right of it, then in front of it, and just above the tenth thoracic vertebra, where this tube pierces the diaphragm, a little to its left side.

Fig. 477.-The Arch of the Aorta, the Thoracic Aorta, axd the Abdonisal Aorta, with the Superior and Inferior Vexi Caya and the Inxominate and Azygos Veins.

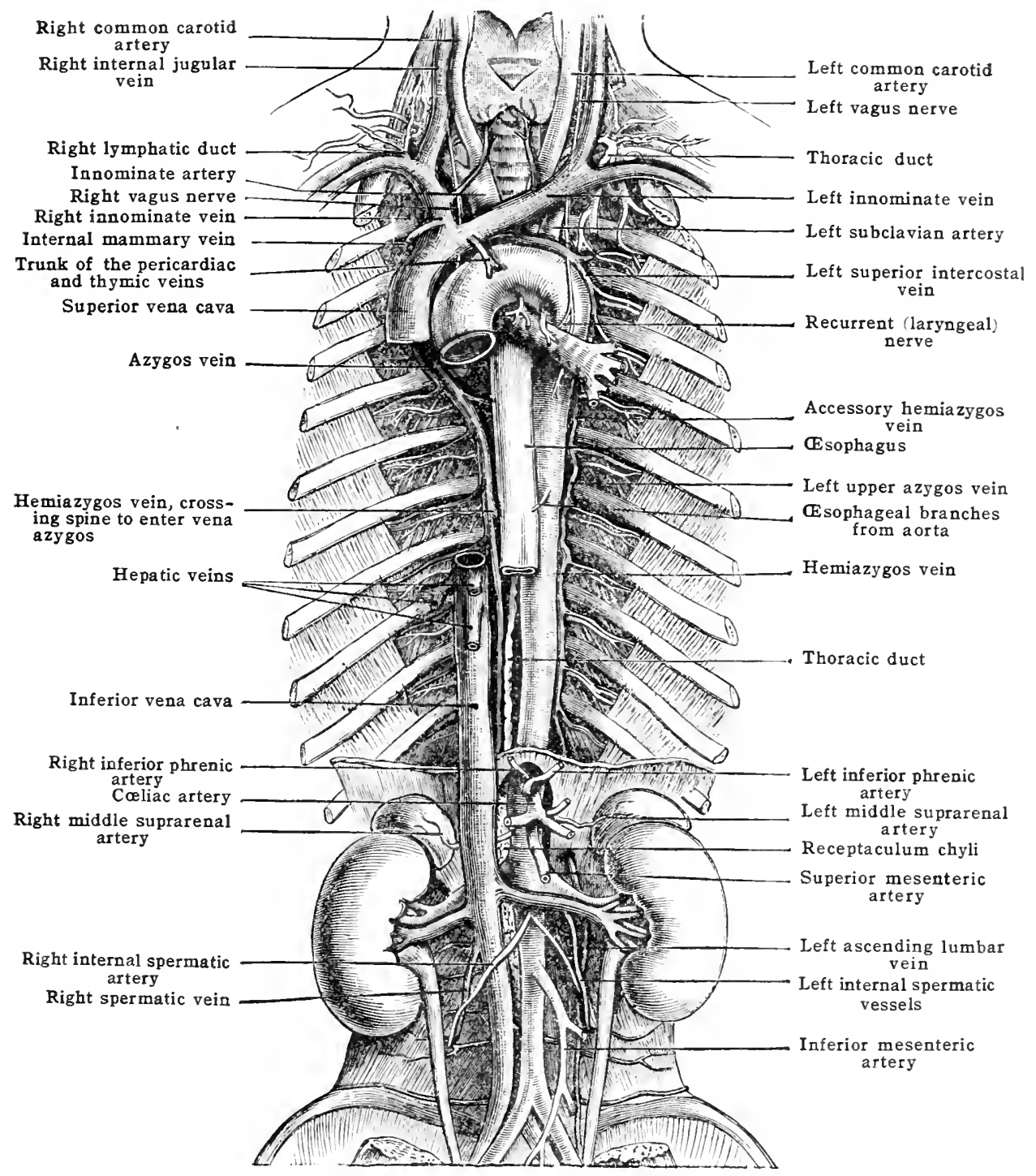

Relations. - In front it is crossed from above downward by the root of the left lung, by the wophagus, which separates it from the pericardium and heart, and by the diaphragm.

Behind, it lies upon the lower seven thoracic vertebra, and is crossed obliquely opposite the seventh or eighth thoracic vertebra by the the vena hemiazygos (azygos minor) and opposite the fifth or sixth vertebra by the accessory hemiazygos vein, or by one or wore of the intercostal veins.

On the right side it has, above, the osophagus and vertebral colmun; lower down the right pleura and lung. The vena azyos and thoracic duct also lie to the right, but on a somewhat posterior plane.

On the left side it has the left lung and pleura above, and the asophagus below. The vena hemiazygos and the accessory hemiazygos vein are also to the left, but on a posterior plane. 


\section{Branches of the Thoracic Aorta}

The branches of the thoracic aorta may be divided into the visceral and the parietal. The visceral are:-(1) The pericardiae; (2) the bronchial; and (3) the asophageal. The parietal are:-(1) The intereostal; (2) the superior phrenic; and (3) the arteria aberrans.

\section{A. Tisceral Branches}

(1) The pericardiac branches [rami perieardiaci] - two or three small branches, irregular in their origin, eourse, and distribution-pass to the posterior surface of the pericardium to supply that structure, and anastomose with the other pericardiae branches. They give small twigs to the posterior mediastinal glands.

(2) The bronchial arteries [aa. bronchiales] supply the bronchi and the lung substance. They vary considerably in their origin, course, and distribution; they are usually three in number-one on the right side, and two on the left.

(a) The right bronchial generally arises either from the first right aortic intercostal, or else as a common trunk with the left upper bronchial from the front of the aort a just below the level of the bifurcation of the trachea. It passes laterally on the back of the right bronchus, and is distributed to the bronchi and lung substance. (b) The left upper bronchial arises from the front of the aorta just below the bifurcation of the trachea, or as a common trunk with the right bronchial. (c) The left lower bronchial arises from the front of the aortit just below the level of the left bronchus. Like the corresponding artery on the right side, the left bronchial arteries rum laterally on the left bronchus, and, after dividing and subdividing on the back of the bronchi, supply the bronchi themselves and the lung substance. Small twigs are given off from the bronchial arteries to the bronchial glands and to the osophagus.

(3) The œsophageal arteries [aa. osophagec], four or sometimes five in number, arise at intervals from the front of the descending thoracic aorta, the first coming off just below the left lower bronchial. They usually increase in size from above downward, the upper coming off more toward the right side of the aorta, the lower more toward the left side. They pass forward to the (xsophagus, supplying that tube and anastomosing with each other and with the descending cesophageal branches of the inferior thyreoid above, and with the ascending cesophageal branches of the phrenie and gastric arteries below, thus forming a chain of anastomoses along the whole length of the tube.

\section{B. Parietal Brancies}

(1) The intercostal arteries [aa. intereostales], usually ten in number on each side, supply the lower intercostal spares, the two upper spaces (oceasionally the first only) being supplied from the costo-eervieal trunk of the subchavian artery. The lowest artery iecompanies the twelfth thoracie nerve below the last rib and is threfore called the subcostal artery. Its distribution is similar to that of the lumbar arteries (p. 593) except that it commonly erosses the anterior surface, rather than the posterior, of the cuatratus lumborum.

The intereostals arise in pairs from the back part of the aorta, and at once turning, the one to the right, the other to the left, wind backward over the front and sides of the vertebral bodies to reach the intereostal spaces. In foetal life these ateries run almost transversely backward, or even with a slight inclination downwarel, to the intereostal spaces; hut alter the first year, in conseguence of the dispropertionate growth of the aorta and vertebral column, the upper interrostals have to as seresel to reach their respective spaces.

The arteries in theip course aroment the vertchere differ on the two sicles of the borly. On the right side the arteries - and cspecially the upper, in eonsequenee

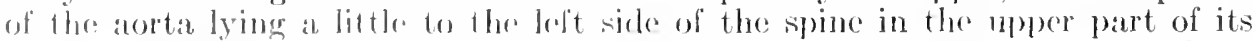
(o)

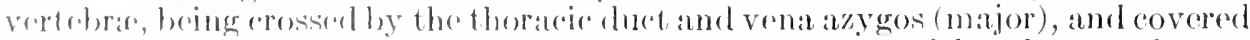

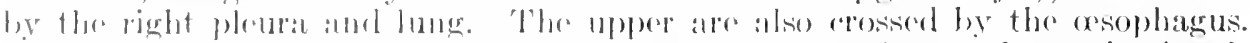
Tilacy give off small hranches to the borlies of the vertebra and anterior longiturlinal ligamont. () th the left side, as the interostals wind aromel the sides of

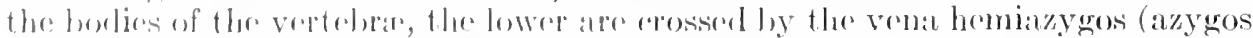
ininor), the two upper by the loft superior interostal vein, and the two next by 
the accessory hemiazygos rein when this is present. They are all corered by the left pleura and lung (tig. 478).

The branches of the intercostal arteries are:-(a) anterior, (b) posterior.

(a) The anterior branches [rami anteriores] at first cross the intercostal space obliquely, in consequence of the downward direction of the ribs, toward the angle of the rib above, and thence are continued forward in the costal groove, and anastomose with the superior branches of the anterior intercostals from the internal mammary in the upper spaces, and from the musculo-phrenic in the lower spaces. They lie at first on the external intercostal muscles, being covered in front by the pleura and lung, the entothoracic fascia, and the subcostal muscles. Opposite the heads of the ribs they are crossed by the srmpathetic nerve. At the angle of the ribs they pass under cover of the internal intercostal muscles, and thence to their termination lie between the two intercostal muscles. Their situation in the wirlsure as far as the angle of the rib should be remembered in performing paracentesis thoracis. To avoid the risk of injuring the vessels, the puncture should not be made further back than the angle of the ribs. They are accompanied by a nerve and vein, the vein lying above and the nerve below, except in the upper spaces, where the artery, having to ascend to reach the space, at first lies below the nerve which runs more horizontally. The uppermost branch anastomoses with the costo-cervical artery from the subclavian, and at times supplies almost entirely the second intercostal space. The arteries to the tenth and eleventh spaces on reaching the end

Fig. 478.-Scheme of Intercostal Artery. (W'alsham.)

Longissimus dorsi

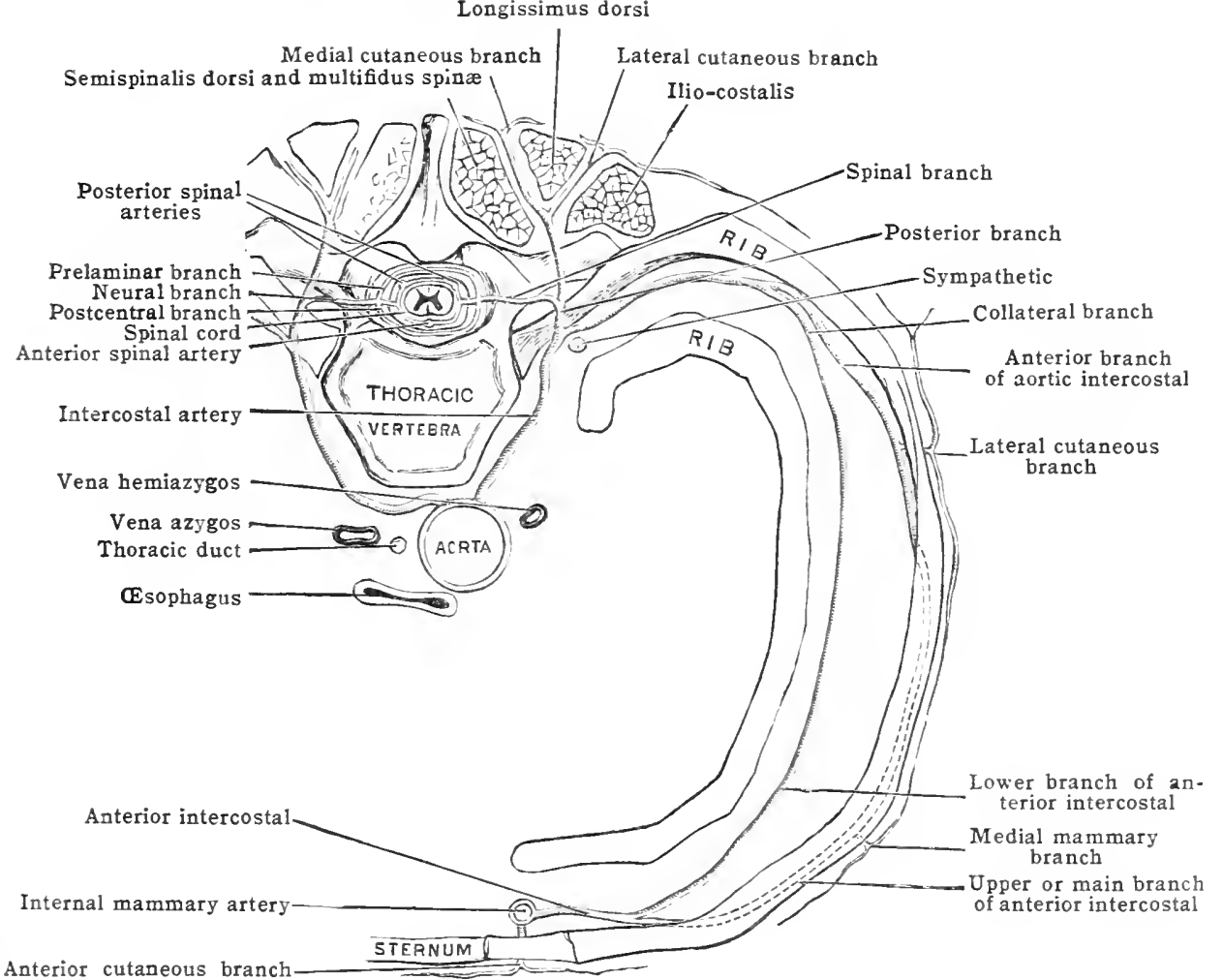

of their respective ribs pass between the abdominal muscles, and anastomose with the inf. epigastric artery from the external iliac, and with the lumbar arteries from the abdominal aorta. The artery beneath the twelfth rib anastomoses with the humbar arterics and with the external circumflex iliac.

Each anterior branch gives off the following:- i) The collateral branch which comes off near the angle of the rib and runs forwirl, between the cxternal and internal interostals. along the upper border of the lower rib enclosing the space. It is smaller than the main anterior branch and anastomoses with the lower anterior intereostal in each spuce. ii Muscular branches [rami musculares] supply the intercostal, pectoral and abolominal muscles. iii The lateral cutaneous branches [rami cutanei laterales], both pectoral and alubminal, rum with the corresponding branches of the intereostal nerves throngh the extemal interwotal and serratus anterior muscles. They then divide into anterior and postrior branches which turn formard and backward, respectively, to supply the integument. The anterior branches from the third, fourth and fifth spaces supply lateral mumary branches [rr. mammarii laterales] to the lateral region of the breast. (iv) Anterior cutaneous branches [rami cutanei anteriores] pierce the extemal intercostal ligament and the pectoralis major just lateral to the stermum. 
They are distributed to the skin and give medial mammary branches [rr. mammarii mediales] to the medial region of the breast.

(b) The posterior branches [rimi posteriores].-These large branches are given off from the intercostals opposite the quadrilateral space bounded by the transverse process of the vertebra above, the neck of the rib below, the body of the vertebra medially, and the anterior costotransverse ligament laterally. Passing backward toward this space with the dorsal branch of the corresponding intercostal nerve, they divide opposite the intervertebral foramen into a muscular and a spinal branch. (i) The muscular branch [r. muscularis] passes backward through the quadrilateral space, and soon subdivides into a medial and a lateral branch. The former passes between the longissimus dorsi and ilio-costalis, and, after supplying these muscles, gives off medial cutaneous branches [rr. cutanei mediales]. The latter branch pierces the multifidus spinæ, and, emerging between the longissimus dorsi and semispinalis dorsi near the spinous processes, gives off lateral cutaneous branches [rr. cutanei laterales]. It supplies the muscles in its course.

(ii) The spinal branch [r. spinalis] enters the intervertebral foramen with the spinal nerve of the corresponding segment. The disposition of the spinal branch is similar to that of the spinal branches entering the canalis vertcbralis in other regions and may be described here:-

\section{ARTERIES OF THE VERTEBRAL CANAL}

spinal arteries are derived from the vertebral, ascending cervical and costo-cervical arteries, from the dorsal rami of the intercostal (fig. 478) and lumbar arteries, and from the ilio-lumbar and lateral sacral arteries. The spinal branch in each case divides into three branches, postcentral, prelaminar and neural.

Each post-central branch divides on the lateral part of the posterior longitudinal ligament into an ascending and a descending branch by which means a bilateral series of anastomosing arches are formed throughout the length of the canal. From the concavities of the opposite arches transverse connecting stems are formed which are again connected by a median longitudinal channel.

The pre-laminar branches also divide and form an anastomosis in front of the laminx and ligamenta flava. This is similar in character to the post-central, but much less regular.

The neural branches enter the dura mater and are usually small and end by supplying the nerve roots. A variable number of these (5-10 on a side) are larger than the others and reinforce the longitudinal anterior and posterior spinal arteries given off from the vertebrals within the cranium. (For arteries of the spinal cord, sce Section VII.)

(2) The superior phrenic arteries [aa. phrenicx superiores], are small twigs coning off from the thoracic aorta immediately above the diaphragm. They are distributed to the vertebral portion of the diaphragm on its upper surface.

(3) The arteria aberrans is a small twig which, arising from the thoracic aorta near the right bronchial artery, passes upward and to the right behind the (x'sop)hagus and trachea, and is oreasionally found to anastomose on the ocsophagus with the arteria aberrans of the superior intereostal artery (see p. 568). It is regarded as the remains of the right aortic dorsal stem (fig. 506).

(4) The mediastinal branches [rami mediastinales], numerous, but small, are distributed to the pleura, and the vessels, nerves and lymph-nodes of the posterior mediastinum.

\section{THE ABDOMINAL AORTA}

The abdominal aorta [aorta abdominalis] (fig. 479), the abdominal portion of throrerending aorta, breins at the aortic opening in the diaphragm opposite the lower broder of the twelf th thoracic vertebra, and ends usually opposite the middle of the body of the fourth lumbar vertebra by dividing into the right and left (a)mmon iliac arteries. It is at first centrally placed between the medial crura of the diaphragm, but as it descends in front of the lumbar vertebra it leaves the midrlle line, and, at its bifurcation, lies a little to the left side of the spine.

Thar blare at which the aorta bifureates may be somewhat roughly indicated on the surface

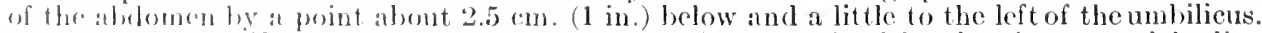

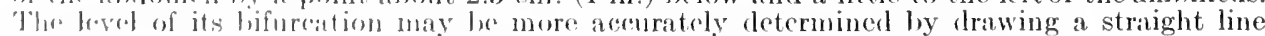
arross thr front of the aluenmon joining the highest points of the iliare erests.

'The inforiol vena cava, which aceompanies the abdominal aorta, lies to its right sisk. IBrlow, the voin is in contant with the artery and on a somewhat postrior plame; but above, it is soparated from the aorta by the right medial erus of the diaphragm, and, in conserpuence of the eaval opening in the diaphragm bering blares forther forward than the opening for the arorta, is on an anterior planc. 
Relations.-In front, the aorta is successively crossed from above downward by the right lobe of the liver, the coliac (solar) plexus, the lesser omentum, the termination of the cesophagus in the stomach, the aseending layer of the transverse meso-colon, the splenie vein or commencement of the portal vein, the panereas, the left renal vein, the third portion of the duodenum, the mesentery, the aortic plexus of the sympathetie nerve, the internal spermatic or ovarian arteries, the inferior mesenteric artery, the nedian lumbar lymphatic nodes and lymphatic vessels, and the small intestines.

Of these struetures the coliae (solar) plexus, the aortic plexus, the splenie vein or the commencement of the portal vein, the pancreas, the left renal vein, the duodenum, the lymphaties, the spermatic or ovarian arteries, and the peritoneal reflexions are in contact with the aorta.

Behind, the aorta lies upon the bodies of the lumbar vertebra and intervening intervertebral eartilages, the anterior longitudinal ligament, the origin of the left medial crus of the diaphragm, and the left lumbar veins.

Fig. 479.-The Abdominal Aorta and its Branches, with the Inferior Vena Caya and its Trubutaries.

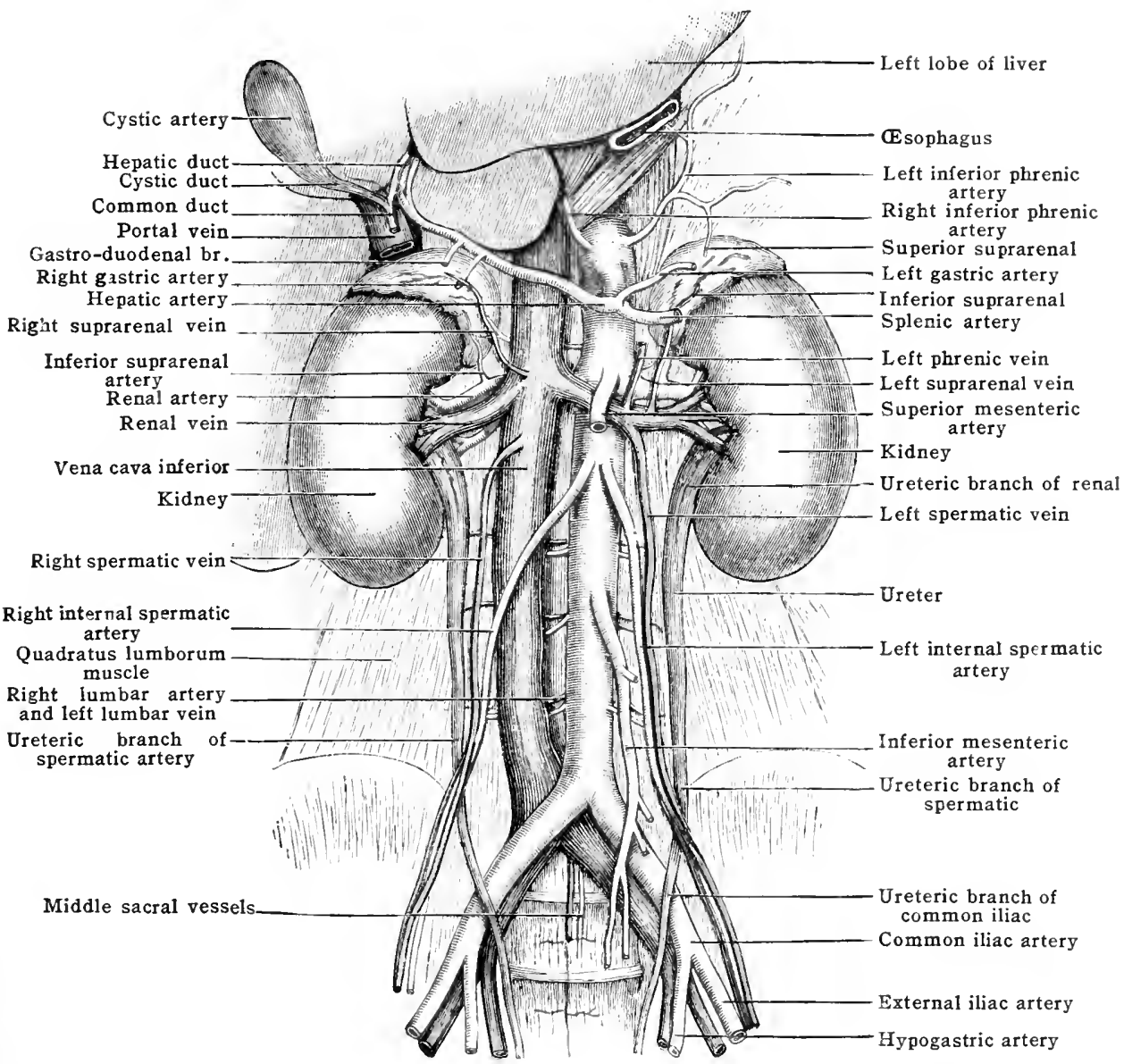

On the right side from above downward are the right medial erus of the diaphragm, the great splanchnie nerve, the eaudate lobe of the liver, the receptaculum ehyli and beginning of the thoracic duct (the two latter structures are on a posterior plane), the right eceliac (semilunar) ganglion, and the inferior vena eava.

On the left side are the left medial crus of the diaphragm, the left splanchnic nerve, and the left ecliac (semilunar) ganglion. The pancreas is also in contact with the aorta on the left side, and the small intestines are separated from it only by peritoneum.

\section{Branches of the Abdominal Aorta}

The branches of the abdominal aorta usually arise in the following order from above downward (figs. 479, 480):-

(1) Right and left inferior phrenic; (2) celiac; (3) right and left middle suprarenal; (4) right and left first lumbar; (5) superior mesenteric; (6) right and 
left renal: ( 7 ) right and left internal spermatic: (8) right and left second lumbar; (9) inferior mesenteric; (10) right and left third lumbar; (11) right and left fourth lumbar; (12) right and left common iliac; (13) middle sacral.

The above branches may be divided into the parietal, the visceral, and the terminal.

The parietal branches are distributed to the abdominal walls. They are the right and left phrenics, and the four right and left lumbars.

The visceral branches supply the viscera. Three of these are given off singly from the front of the arorta, namely, the celiac, the superior mesenteric, and the inferior mesenteric; and three are given off in pairs, namely, the two suprarenals, the two renals, and the two spermatics.

The terminal branches are the middle sacral and the right and left common iliac arteries.

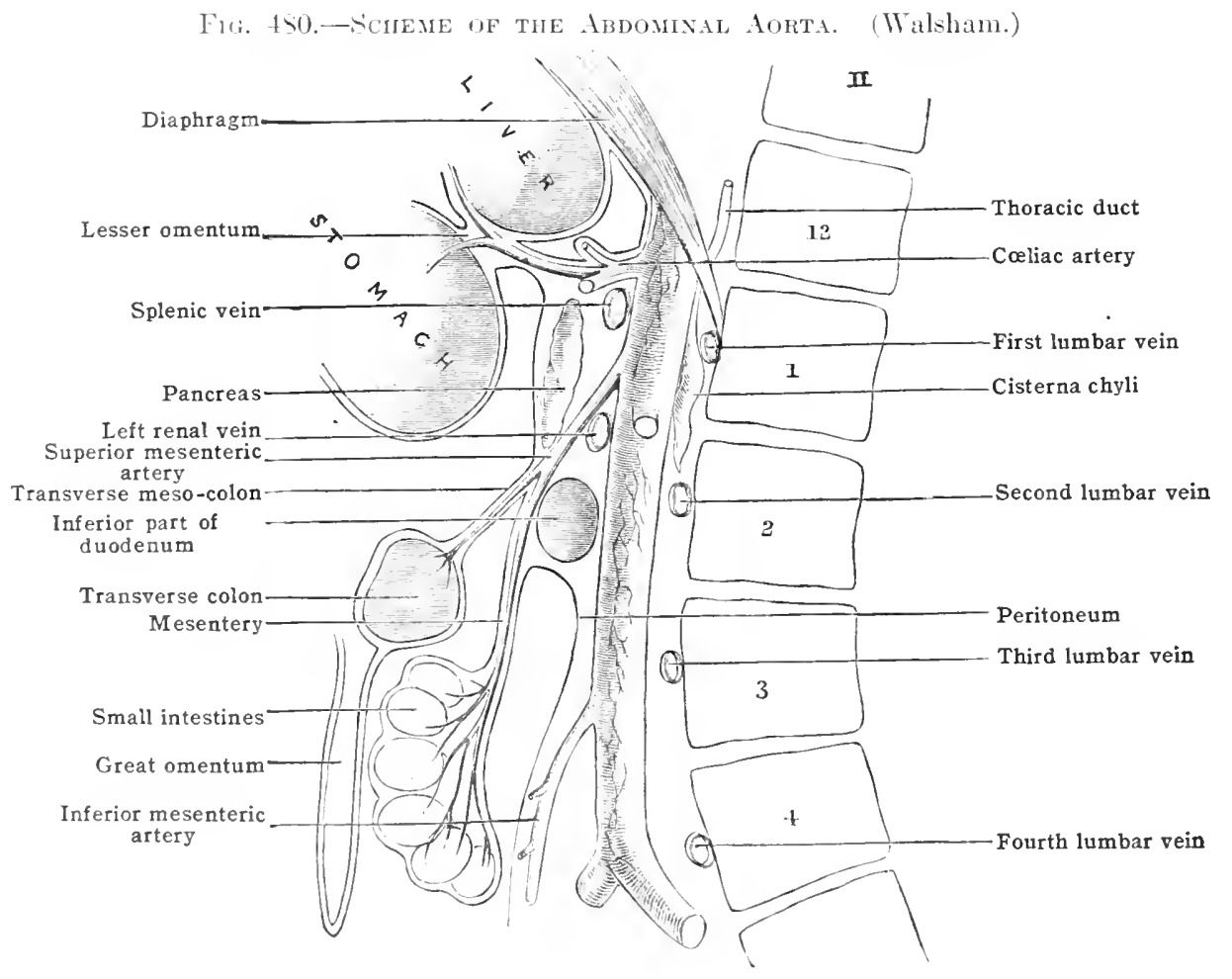

\section{A. The Partetal Branches of the Abdominal Aorta \\ 1. THE ANEERIOR PHIRENT ARTERIES}

l'ho inferior phrenic artery [a. phreniea inforior] usually arios from the aorta

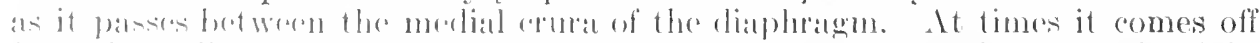

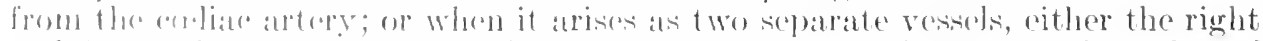
on left ressid maty ande from this atrtery, or lrom other of the apper branches of tha alshominal arortat.

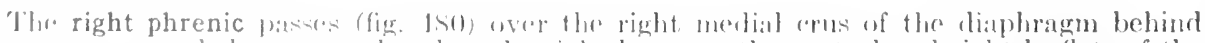

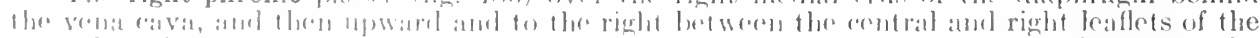

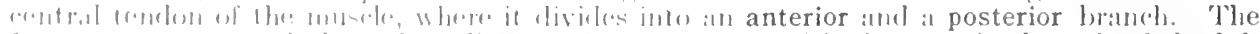

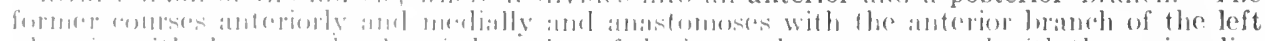

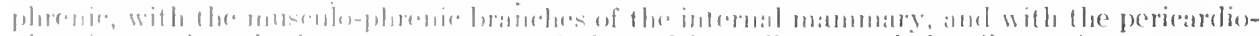

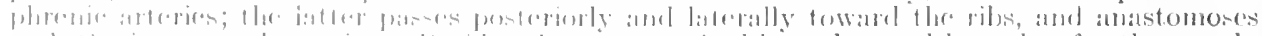

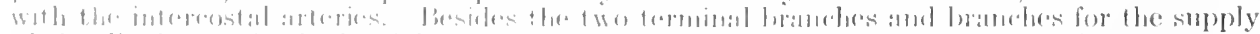

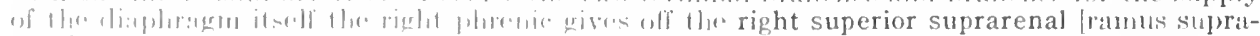

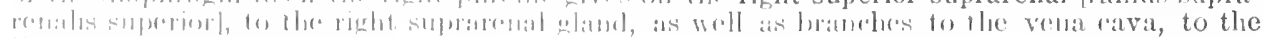

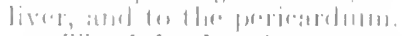

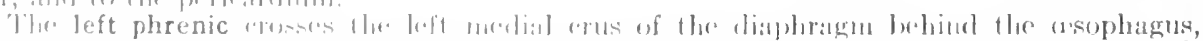

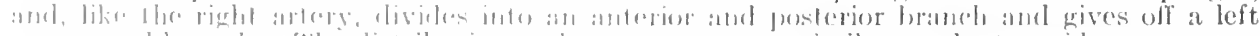

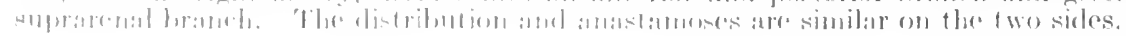




\section{THE LUMBAR ARTERIES}

The lumbar arteries [aa. lumbales] (fig. 479), usually eight in number, four on each side, come off in pairs from the posterior aspect of the abdominal aorta, opposite the bodies of the four upper lumbar vertebra. A fifth pair of lumbar arteries, generally of small size, frequently arises from the middle sacral artery opposite the fifth lumbar vertebra. The lumbar arteries, which are rather longer on the right than on the left side, in consequence of the aorta lying a little to the left of the median line, wind more or less transversely around the bodies of the vertebra to the space between the transverse processes, where they give off each a dorsal branch, and then, coursing forward between the abdominal muscles, terminate, by anastomosing with the other arteries of the abdominal wall.

Relations.-As they wind around the bodies of the vertebræ they pass beneath the chain of the sympathetic nerve trunk, and the upper two beneath the crura of the diaphragm. The right arteries also pass beneath the vena cava inferior, and the two upper on that side beneath the receptaculum chyli. The arteries on both sides then dip beneath the tendinous arch thrown across the sides of the bodies of the vertebra by the psoas, and continue beneath this muscle until they arrive at the interval between the transverse processes of the vertebra and the medial edge of the quadratus lumborum. While under cover of the psoas they are accompanied by two slender filaments of the sympathetic nerve and by the lumbar veins. A little anterior to the transverse processes they are crossed by branches of the lumbar plexus. and here usually cross in front of the ascending lumbar vein. They now pass behind the quadratus lumborum, with the exception sometimes of the last, which may pass in front of the muscle. At the lateral edge of the quadratus they run between the transversus and the internal oblique, and then, after perforating the internal oblique between the internal and external oblique. Finally, much diminished in size, they enter the rectus, and give off one or more anterior cutaneous branches, which accompany the last thoracic and the ilio-hypogastric nerves to the skin. 'They' anastomose with the lower intercostals, ilio-lumbar, deep circumflex iliac, and inf. epigastric arteries.

The branches of the lumbar arteries are:-

(a) Vertebral branches which supply the bodies of the vertebre and their connecting ligaments.

(b) Muscular branches to the psoas, quadratus lumborum, and oblique muscles of the abdomen.

(c) The dorsal branch [r. dorsalis]. This is of large size, and passes backward in company with the dorsal nerve between the transverse processes above and below, the intertransversalis medially and the quadratus lumborum laterally, to the muscles of the back. On reaching the interval between the longissimus dor'si and multifidus spinæ, it divides into a lateral and a medial branch. The former ends in the multifilus, the latter and larger supplies the sacrospinalis, and gives branches which accompany the termination of the dorsal nerves to the skin. Just before the artery passes between the transverse processes it gives off a spinal branch $\mathrm{r}$. spinalis], which accompanies the lumbar nerve through the intervertebral foramen into the vertebral canal (see p. 590 ).

(d) Renal branches of small size pass forward in front of the quadratus lumborum to the capsule of the kidney. They anastomose with the renal artery. A communication is thus established between the renal arteries and the arteries supplying the lumbar region.

\section{B. The Visceral Branches of the Abdominal Aorta}

\section{THE CELIAC ARTERY}

The cœliac artery [a. cœliaca] - or cœliac axis, as it is commonly called, because it breaks up simultaneously into three branches which radiate from it like the spokes of a wheel from the axle-is a short thick trunk given off from the front of the aorta between the medial crura of the diaphragm a little below the aortic opening. It passes horizontally forward above the upper margin of the pancreas for about half an inch, and then breaks up into three branches for the supply of the stomach, duodenum, spleen, pancreas, liver, and gallbladder (fig. 481).

Relations.-In front is the lesser omentum; behind, the aorta; above, the right lobe of the liver; below, the pancreas; to the right, the right coliac (semilunar) ganglion and caudate lobe of the liver; to the left, the left coeliac (semilunar) ganglion and the cardiac end of the stomach. It is closely surrounded by the dense coeliac (solar) plexus of sympathetic nerves.

Branches of the cœliac artery.-The coliac artery divides into the left gastric, the hepatic, and the splenic arteries.

\section{The Left Gastric Artery}

The left gastric [a. gastrica sinistra] (fig. 481), the smallest of the three branches into which the coliac artery divides, courses at first upward and to the 
left toward the cardiac end of the stomach, where it turns sharply round, and then, following the lesser curvature of the stomach, descends from left to right toward the pylorus. It anastomoses with the right gastric branch of the hepatic artery, which has proceeded from the opposite clirection, the two branches thus forming a continuous arterial arch corresponding to the lesser curvature of the stomach.

The artery at first lies behind the posterior layer of the omental bursa of peritoneum (fig. 480), but on reaching the cardiac end of the stomach it passes, between the layers of peritoneum reflected from the diaphragm onto the asophagus, into the lesser omentum in which it then runs to its terminal anastomosis with the pyloric. It is surrounded by a plexus of sympathetic nerves.

It supplies both surfaces of the stomach around the lesser curvature and gives off small œsophageal branches [rami osophagei] which anastomose with the oesophageal branches from the thoracic aorta.

Fig. 4S1.-The Celiac Artery and its Branches.

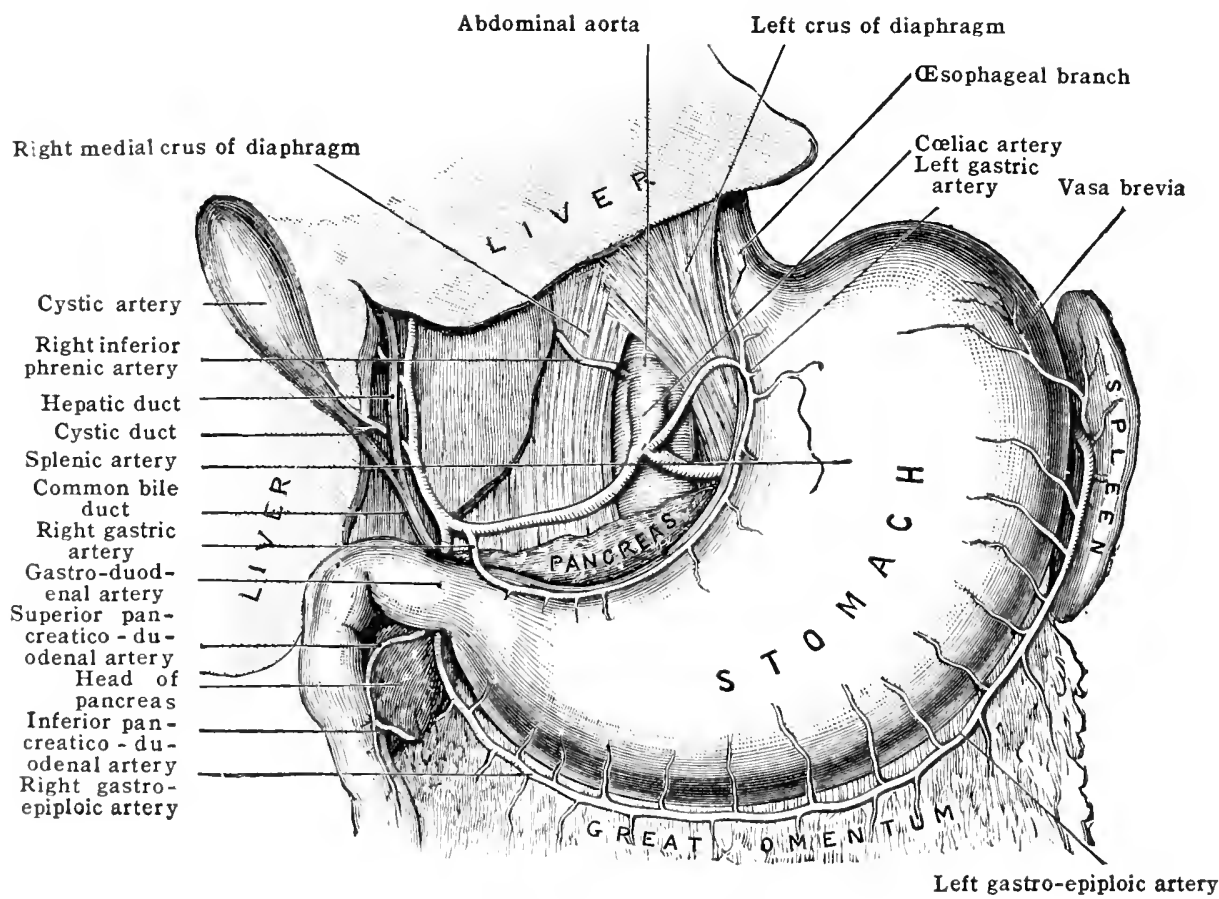

\section{The Hepatic Artery}

The hepatic artery [a. hepatical, the largest branch of the eocliac artery in the fretus, but intermediate in the arlult between the left gastrie and the splenie, comes off on the right side of the eceliac artery, and, winding upward and to the right to the porta (portal fissure) of the liver, there breaks up into two ehief branches for the supply of the right and left lobes of that organ. It at first courses forward and to the right along the upper border of the head of the panereas, behind the posterior latyer of the peritoneal omental bursia, to the upper margin of the cluodentum, where it passes forward beneath the layer of peritoneum forming the floor of the cpiploie foramon (of Winslow). It thus runs between the two layers of the lesser onnentum, and aseonds along with the hepatie duct which lies to its right, and with the portal vein which lies lehind it (figs. 480, 481).

'The branches of the hepatic artery are:--(1) The right gastrie; (2) the gastro-

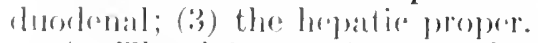

(1) The right gastric artery [a. gastrica dextra] comes off from the hepatic just

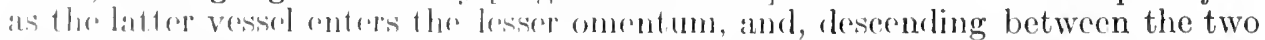
layers of that fold of peritomomm to the pylorus, there turns to the left, and, ascending from right to left, anastomoses along the lesser ceurvature of the stomateh, as aldealy mentioned, with the left, gastrie artery, which descends from the opposite direction.

(2) 'The gastro-duodenal artery [a. gastroduodenalis] arises from the hepatic 
a little beyond the pyloric. It descends behind the superior portion of the duodenum to the lower border of the pylorus, where it divides into the right gastro-epiploic and the superior pancreatico-duodenal. It varies from 1.2 to $2.5 \mathrm{~cm}$. ( $\frac{1}{2}$ to $1 \mathrm{in}$.) in length.

(a) The right gastro-epiploic artery [a. gastroepiploica dextra] passes from right to left along the greater curvature of the stomach between the layers of the great omentum, and anastomoses with the left gastro-epiploic branch of the splenic. From this anastomotic arch are given off:-(i) Ascending or gastric branches, which supply the anterior and posterior surfaces of the stomach, and anastomose with the descending gastric branches of the arteries along the lesser curvature. (ii) Epiploic [rami epiploici] or omental branches-long slender vessels which descend between the two anterior layers of the great omentum, and then, looping upward, anastomose with similar slender branches given off from the middle and left colic, and passing down in like manner between the two posterior layers of the great omentum.

(b) The superior pancreatico-duodenal [a. pancreaticoduodenalis superior]-the smaller division of the gastro-duodenal-arises from that vessel as it passes behind the first portion of the duodenum, and courses downward behind the peritoneum, in the anterior groove between the second portion of the duodenum and the pancreas, to anastomose with the inferior pancreatico-duodenal, a branch of the superior mesenteric. Both the inferior and superior pancreatico-duodenal give off duodenal [rami duodenales] and pancreatic branches [rami pancreatici] to supply these organs.

(3) The hepatic artery proper [a. hepatica propria] is the continuation of the hepatic after the gastro-duodenal has arisen. It ascends between the layers of the lesser omentum, preserving the relations of the main artery to the portal vein and common bile (and hepatic) duct, and divides, near the porta hepatis, into right and left branches.

(a) The right branch [r. dexter], given off at the porta (portal fissure) of the liver, runs to the right either behind the hepatic and cystic ducts, or between these strucures. At the right end of the porta it divides into or more branches, which again subdivided as they enter the liver substance for the supply of the right lobe. As it crosses the cystic duct it gives off the cystic artery.

The cystic artery [a. cystica] courses forward and downward through the angle formed by the union of the hepatic and cystic ducts, and just before it reaches the gall-bladder divides into a superficial and deep branch. The former breaks up into a number of small vessels, which ramify over the free surface of the gall-bladder beneath the peritoneal covering, and furnish branches to the muscular and mucous coats. The deep branch ramifies between the gallbladder and the liver-substance, supplying each, and anastomosing with the superficial branch.

(b) The left branch [r. sinister], the simaller division of the hepatic artery, runs medialward toward the left end of the porta hepatis, and, after giving off a distinct branch to the caudate (Spigelian) lobe, enters the left lobe of the liver.

\section{The Splenic Artery}

The splenic artery [a. lienalis]-the largest branch of the coeliac arteryarises from the left side of the termination of that vessel below the left gastric, and passes along the upper border of the pancreas in a tortuous manner to the spleen. It at first lies behind the ascending layer of the transverse meso-colon, but on nearing the spleen enters the lieno-renal ligament, and there breaks up into numerous branches, which enter the hilus and supply the organ. In this course it crosses in front of the left medial crus of the diaphragm and the upper end of the left kidney and is placed above the splenic vein.

The branches of the splenic artery are:-(1) The pancreatic; (2) the left gastro-epiploic; (3) the vasa brevia; and (4) the terminal.

(1) The pancreatic branches (rami pancreatici) come off from the splenic at varying intervals as that vessel courses along the upper margin of the pancreas. They enter and supply the organ. One larger branch usually arises from the splenic about the junction of its niddle with its left third. Entering the pancreas obliquely, it runs from left to right, commonly above, and a little behind, the pancreatic duct, which it supplies together with the substance of the organ.

(2) The left gastro-epiploic [a. gastroepiploica sinistra] arises from the splenic near the greater curvature and below the fundus of the stomach, and, passing between the anterior layers of the great omentum, descends along the greater curvature of the stomach from left to right, and anastomoses with the right gastro-epiploic. Like that ressel, it gives off ascending or gastric branches to the anterior and posterior surfaces of the stomach respectively, and long slender descending epiploic or omental branches to the great omentum which anastomose with like branches from the right and left colic arteries.

(3) The vasa brevia [aa. gastric:e breves] come off from the splenic just before it clivides into its terminal branches, oftentimes from some of these terminal branches themselves. Passing from between the folds of the lieno-renal ligament into those of the gastro-lienal, they thus reach the fundus of the stomach, where, ramifying over both its anterior and posterior surfaces, they anastomose with the left gastric and left gastro-epiploic arteries. 
(4) The splenic or terminal branches, five to eight or more in number, are given off from the splenic as it lies in the lieno-renal ligament, and, entering the spleen at the hilum, are distributed in the way mentioned in the description of that organ.

\section{THE SUPERIOR MESENTERIC ARTERY}

The superior mesenteric artery [a. mesenteriea superior] is given off from the front of the aorta a little below the eceliae, which it nearly equals in size; sometimes it forms a common trunk with the coeliac. Lying at first behind the pancreas and splenic vein, it soon passes forward between the lower border of that gland and the upper border of the inferior portion of the rluodenum, and, crossing in front of the duodenum, enters the mesentery, in which it runs from left to right, in the form of a curve with its convexity to the left, to the cæcum, where it anastomoses with its ileo-colie branch. It s vein lies to its right side above, having

Fig. 482.-The Superior Mesenteric Artery and Tein.

(The colon is turned up, and the small intestines are drawn over to the left side.)

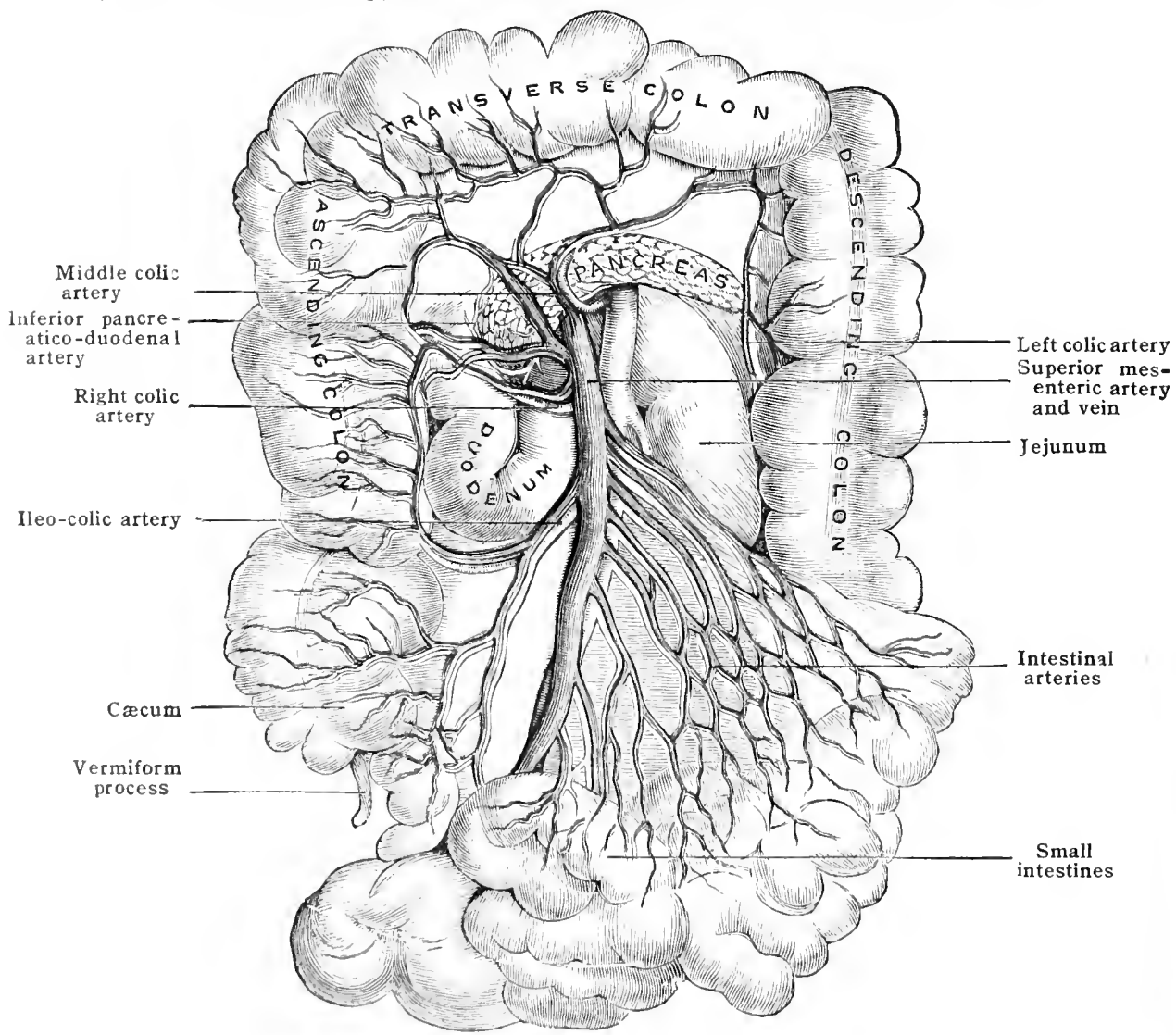

previously crossed obliguely in frout of the artery from left to right. It is surrounded by the mosenterie plexus of nerves. The areessory portion of the head of the pancreas dips in behingl the vesisl.

The branches of the superior mesenteric are, in their primitive order:(1) the inferior pancoration-duodenal; (2) the intestinal arteries; (3) the ileocolie; (4) the right colic; and (5) the midklle colie.

(1) 'The inferior pancreatico-duodenal [a. pancreatico duodenalis inferior] arises either from the superior mesentrice as that vassel cmerges from the contignous margins of the pancreas and inforior part of the hodernm or from its first intestinal branch. Crossing behind the superior mescoteric vain, it courses upwarl and to the right between the head of the pancreas and the ductenum, and leneath the aseconding layer of the transverse meso-colon, to anastomose with the suprerior pancreatico-duserlonal.

(2) The intestinal arteris [ar. intrestinales] arise from the convex side of the superior mesenteric, amb, varying from twolve to sixto'n in mumber, radiate in the mesentery, where 
Fig. 483.-The Blood-vessels of the Ileo-cacal Region. (From Kelly.)

(Arteries red, veins blue.) The peritoneal covering is removed so as to show the vessels more clearly. Above and to the right are seen the cut ends of the ileo-colic artery and vein. This artery gives off a branch to the ascending colon and a posterior and anterior cacal artery, the latter descending through the ileo-colic fold. A short anastomosis connects the ileocolic with the mesenteric. The artery of the vermiform process (appendix) is seen to arise from the posterior cæeal artery, $2 \mathrm{~cm}$. above the ileum. It passes behind the ileum in the free border of the mesappendix and gives off five branches (long appendices have 8-12, short appendices, 2-3), which traverse the mesappendix at fairly regular intervals in the direction of the hilus of the appendix, where they divide into anterior and posterior branches. The branches in the mesappendix are sometimes seen to anastomose, forming loops of varying size. The terminal branch curves around the tip. The creco-appendicular junction is supplied by a separate branch arising likewise from the posterior ileo-ciecal trunk. This branch may or may not anastomose with the proximal appendicular twig and while in some cases it supplies only the crecum, in others, as in the present case, it sends a few delicate branches into the appendix. At the place where this cæco-appendicular artery crosses the ileo-cæcal fold it is seen to give off a delicate recurrent twig to this structure Throughout their entire course the arteries are accompanied by veins.

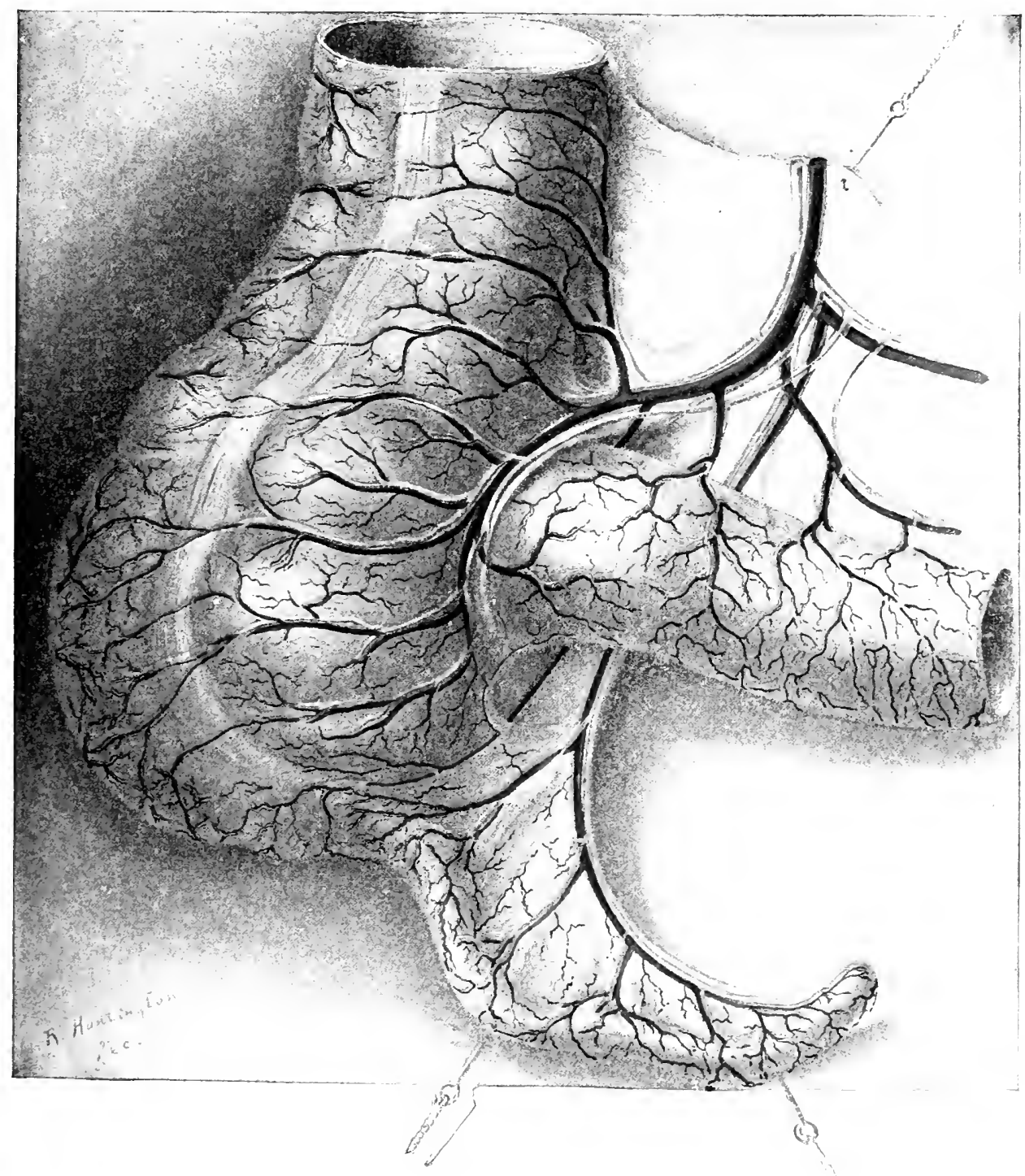


each divides into two branches, which inosculate with similar branches given off from the branch above and below. From the primary loops thus formed, secondary loops are derived in like manner, and from these tertiary, and at times quaternary, or even quinary loops. From the ultimate loops terminal jejunal and iliac branches [aa. jejunales et ilieæ] pass on to the muscular coat of the gut. These terminal vessels bifurcate, the two branches encircling the intestine, and thus forming with those above and below a series of vascular rings surrounding the small intestine throughout its whole length. The first intestial artery anastomoses with the pancreatico-duodenal artcries, and the last (the continuation of the main artery) with the ileo-colic. These branches of the superior mesenteric in their course to the intestine also supply the mesentery and the mesenteric glands.

(3) The ileo-colic [a. ileocolica] descends behind the peritoneum toward the cæcum, where it divides into a colic branch which tracks upward beneath the peritonemm to anastomose with the descending branch of the right colic; and into an iliac branch which passes between the layers of the mesentery and anastomoses with the termination of the superior mesenteric artery. Near the site of division the ileo-colic gives off anterior and posterior cæcal branches. From the latter of these arises a ceco-appendicular artery, to the cacum and root of the vermiform process, and a main appendicular artery [a. appendicularis] (fig. 483).

(t) The right colic [a. colica dextra]-sometimes given off as a common trunk either with the middle colic or with the ileo-colic-passes to the right behind the peritoneum to the back of the ascending colon, where it divides into an ascending branch, which anastomoses with the descending branch of the middle colic, and a descending branch which anastomoses with the ascending or colic branch of the ileo-colic.

(5) The middle colic [a. colica media], arising from the concavity of the superior mesenteric a little below the pancreas, enters the transverse meso-colon, and divides into two branchesone of which passes to the left and anastomoses with the ascending branch of the left colic; the other, winding downward and to the right, anastomoses with the ascencling branch of the right colic.

\section{THE RENAL ARTERIES}

The renal arteries [aa. renales] come off one on each side of the abdominal aorta, a little below the superior mesenteric and first lumbar arteries, on a level with the first lumbar vertebra. They pass laterally across the crura of the diaphragm to the kidneys, the right being on a slightly lower plane and somewhat longer than the left, and passing behind the inferior vena eava. In front of each is the corresponding renal vein, and behind, at the hilus of the kidney, is the commencement of the ureter. Each artery as it enters the hilus usually divides into three main stems, one of which passes toward the upper part of the pelvis, a second to its midlle portion, and a third to its lower. Each of these primary stems then divides so that there result from seven to nine secondary branches, the majority of which pass anterior to the pelvis, while the remainder are posterior to it (fig. 484). No anastomoses take place between the branches of the anterior and posterior seeondary stems and hence a longitudinal ineision into the kidney along its curved border, half way between the anterior and posterior ealices, will cut only terminal arteries.

The branches of the renal arteries are:-

(1) The inferior suprarenal [a. suprarenalis inferior] which ascents to the suprarenal body.

(2) The capsular or peri-renal branches to the capsule of the kidney and peri-renal fat.

(3) The ureteral branch to the upper end of the ureter.

\section{THE MIDDLE SUPRARENAL AR'TERIES}

The middle suprarenal artery [a. suprarenalis media] comes off, one on each side from the aorta, just above the first lumbar artery, and passes laterally to the supratrenal hody, acrosis the medial crura of the diaphragm a little above the renal arterics. In the fortis they equal the renals in size. In the adult they are much smaller.

They anastomose with the superior and inferior suprarenal arteries from the inferior phrenic and renal arteries respectively. For the distribution of the suprarenal vessels within the suprarenal bodics, see Section XII.

\section{THE INTERSAL, SPERMATIC ARTERIES}

The internal spermatic artories [a. spermatica interna], (fig. 479), right and left, come off from thre fromt of the aldominal atorta. They diverge from each

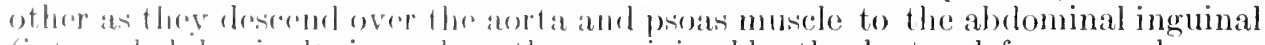
(internat aldenninat) ring, where they are joined by the duetus deferens, and, pass- 
ing with it through the inguinal canal and out of the subcutaneous inguinal (external abdominal) ring, run downward in to the scrotum in a tortuous course to the testes. They terminate in branches to the epididymis and body of those organs. Within the abdomen they lie beneath the peritoneum, and cross in their descent over the ureters and distal ends of the external iliac arteries; the right being super-

Fig. 484.-A. The Renal Artery and the Distribution of its Branches in Relation to the Pelvis. B. Transterse Section through the Middee of the Same Kidney. (After Brödel, Johns Hopkins Hospital Bulletin.)

$a$, renal artery; $a^{\prime}$ and $a^{\prime \prime}$, its anterior and posterior branches; $b$, branches to pyramids; $c$, line of division between anterior and posterior pyramids. The arrow and dotted line indicate the line of separation between the terminals of the anterior and posterior branches.
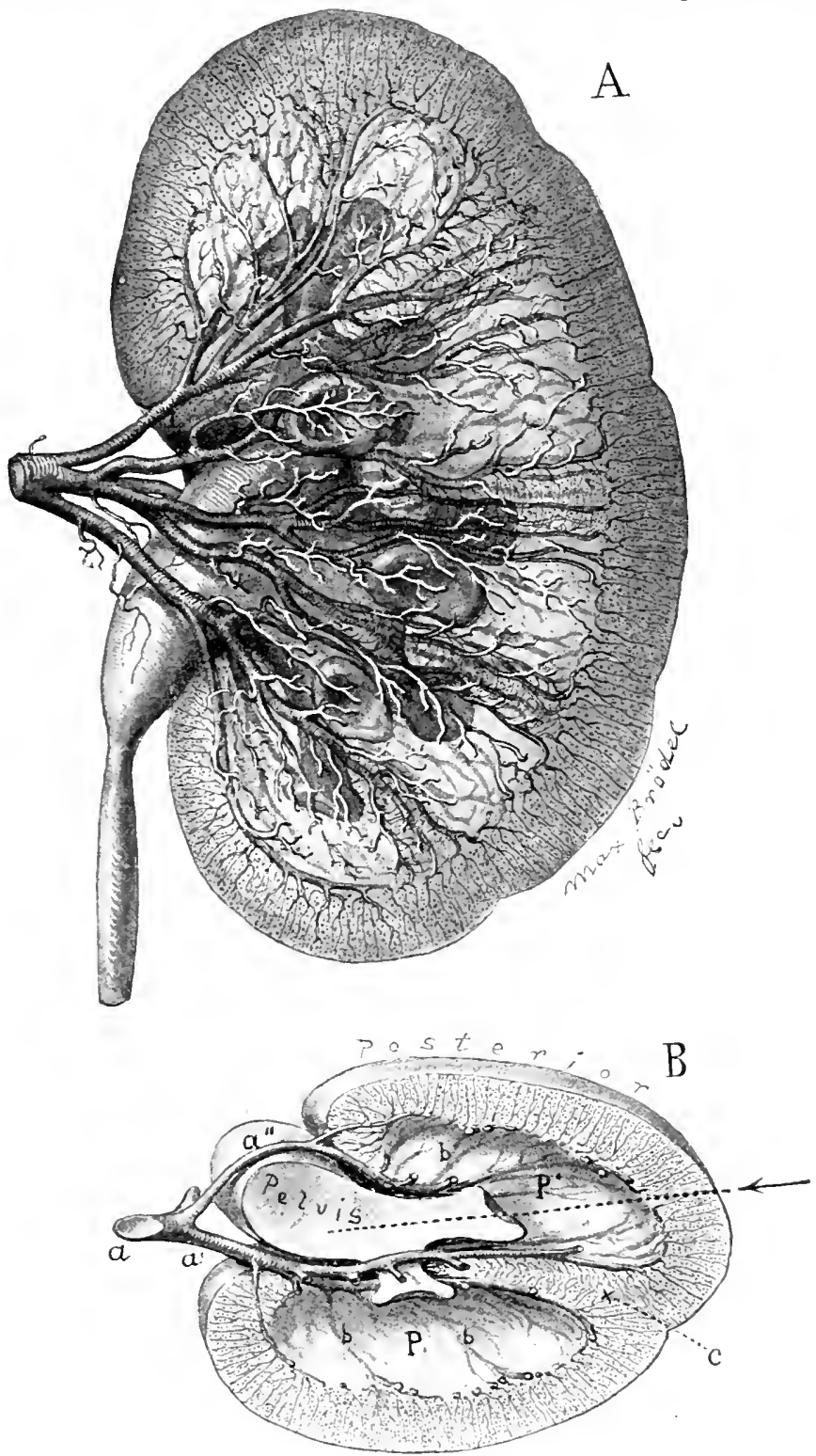

ficial to the vena cava, and behind the termination of the ileum; and the left beneath the sigmoid colon. In the inguinal canal and in the scrotum the spermatic veins lie in front of the artery, and the ductus deferens lies behind it.

In the fotus these vessels pass in a transversely lateral direction to the testis, which in early fotal life lies in the loin in front of the kilney; but as the testes 
Fig, 485,-The Vheclar Trexks of the Lower dboonen. (From Kelly, by Brödel.)

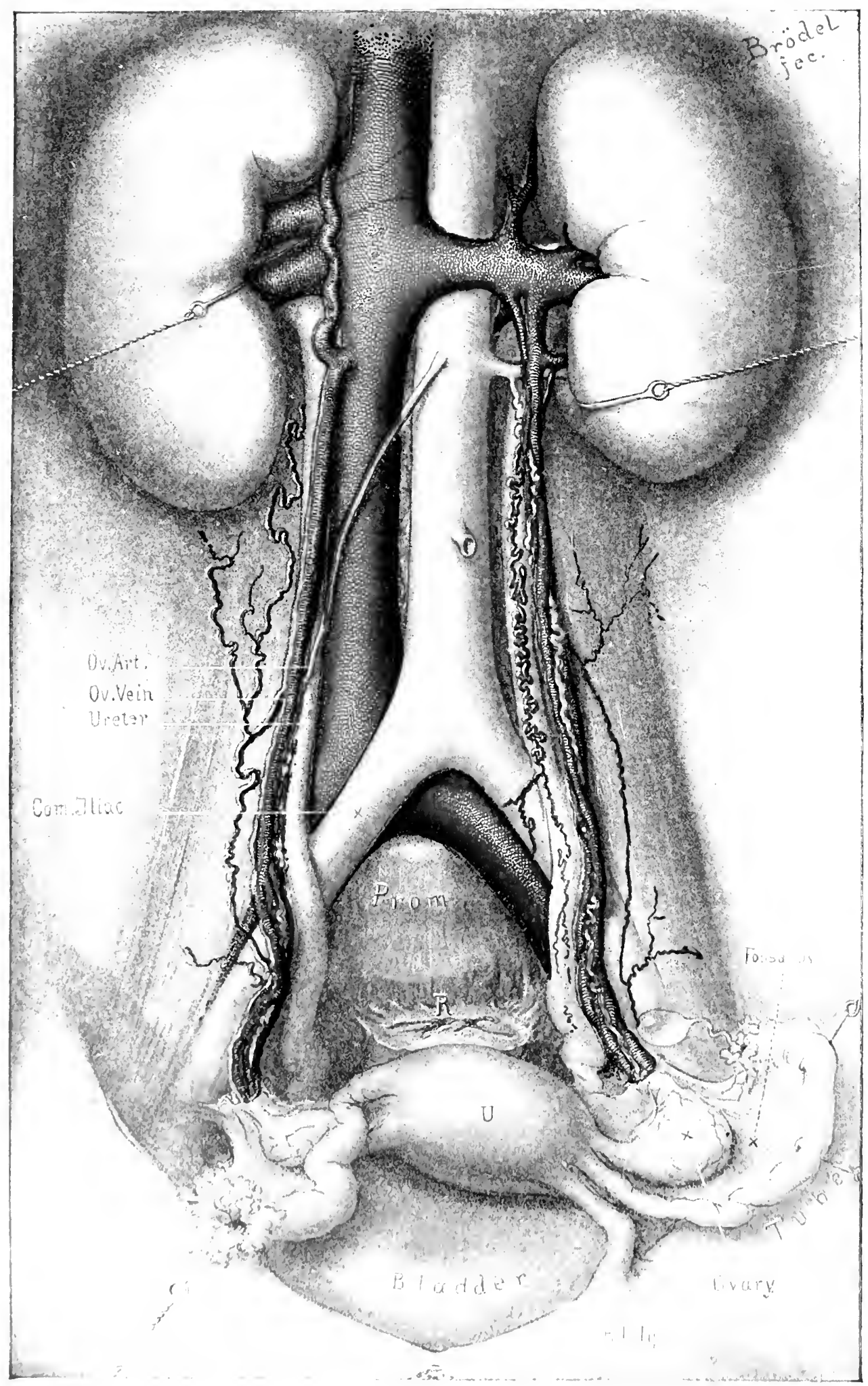


descend to the scrotum, the vessels become elongated, and are drawn with the testis into the scrotum.

The branches of the internal spermatic artery are:-(1) Ureteral; (2) cremasteric; (3) epididymal; and (4) testicular.

(1) The ureteral are small branches given off to the ureter as the spermatic artery crosses it. They anastomose with the other ureteral branches derived from the renal, common iliac,

(2) The cremasteric are small branches given off to the cremaster muscle; they anastomose with the cremasteric branch of the inf. epigastric.

Fig. 486.-The Ovarian Vessels. (After Clark.)

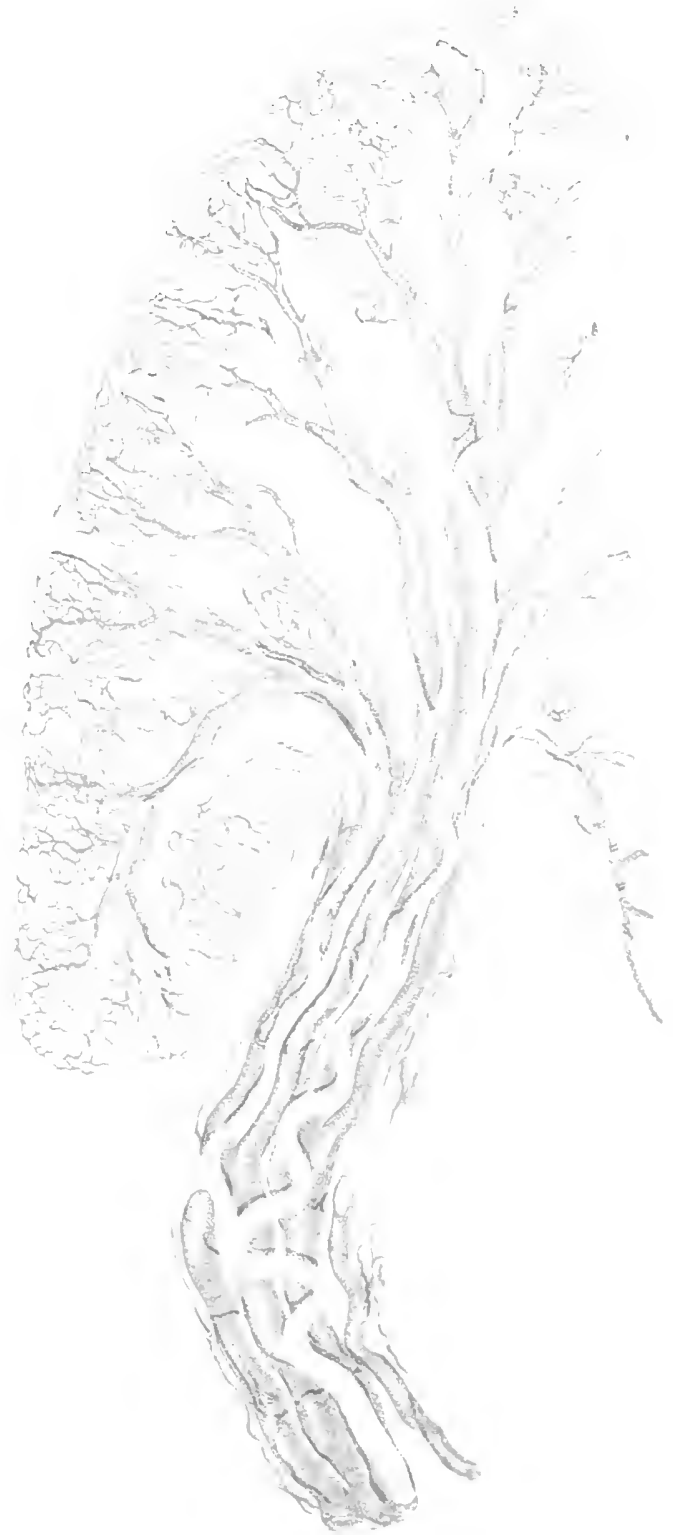

(3) The epididynal are distributed to the epididymic, and anastomose with the deferential. artery.

(4) The testicular arteries [aa. testiculares] are the terminal branches of the spermatic; they perforate the tunica albuginea posteriorly, and are distributed to the body of the organ in the way mentioned in the section on the Testis.

The external spermatic artery is a branch of the inferior epigastric artery (p.611). 


\section{THE OTARIAN ARTERIES}

The ovarian arteries [aa. ovarica], are the homologues of the internal spermatic arteries in the male, and correspond in their relations in the upper part of their course. They diverge somewhat less, however, and, on reaching the level of the common iliac artery, turn medialward over that vessel and descend tortuously into the pelvis between the folds of the broad ligament to the ovaries. In the broad ligament the ovarian artery lies below the Fallopian tube, and on reaching the ovary turns backward and supplies that organ. In fig. 486 is shown how the artery enters the hilus of the ovary and breaks up into branches which determine the lobules of the organ.

The branches of the ovarian arteries are:-(1) Ureteral; (2) tubal; (3) uterine; and (4) ligamentous.

(1) The ureteral is distributed, as in the male, to the ureter.

(2) The tubal supplies the isthmus and ampulla of the tuba uterina (Fallopian tube) and its fimbriated extremity.

(3) The uterine runs beneatl the tuba uterina (Fallopian tube) to the uterus, supplying the upper part of the fundus, and anastomosing with the uterine arteries from the hypogastric.

(4) The ligamentous is distributed to the round ligament, passing with that structure through the inguinal canal, and anastomosing with the superficial external pudendal artery.

Like the spermatic, the ovarian arteries in the foetus come off at right angles to the aorta, and pass transversely lateralward to the ovaries, which are formed, as are the testes, in the right and left loin in front of the kidneys. They elongate as the ovaries descend into the pelvis. During pregnancy these arteries undergo great enlargement.

\section{THE INFERIOR MESENTERIC ARTERY}

The inferior mesenteric artery [a. mesenterica inferior], smaller than the superior, arises from the front of the abdominal aorta about $3.7 \mathrm{~cm}$. ( $1 \frac{1}{2} \mathrm{in.}$ )

Fig. 4S7.-The Inferior Mesenteric Artery and Vein.

(The colon is turned up, and the small intestines are drawn to the right side.)

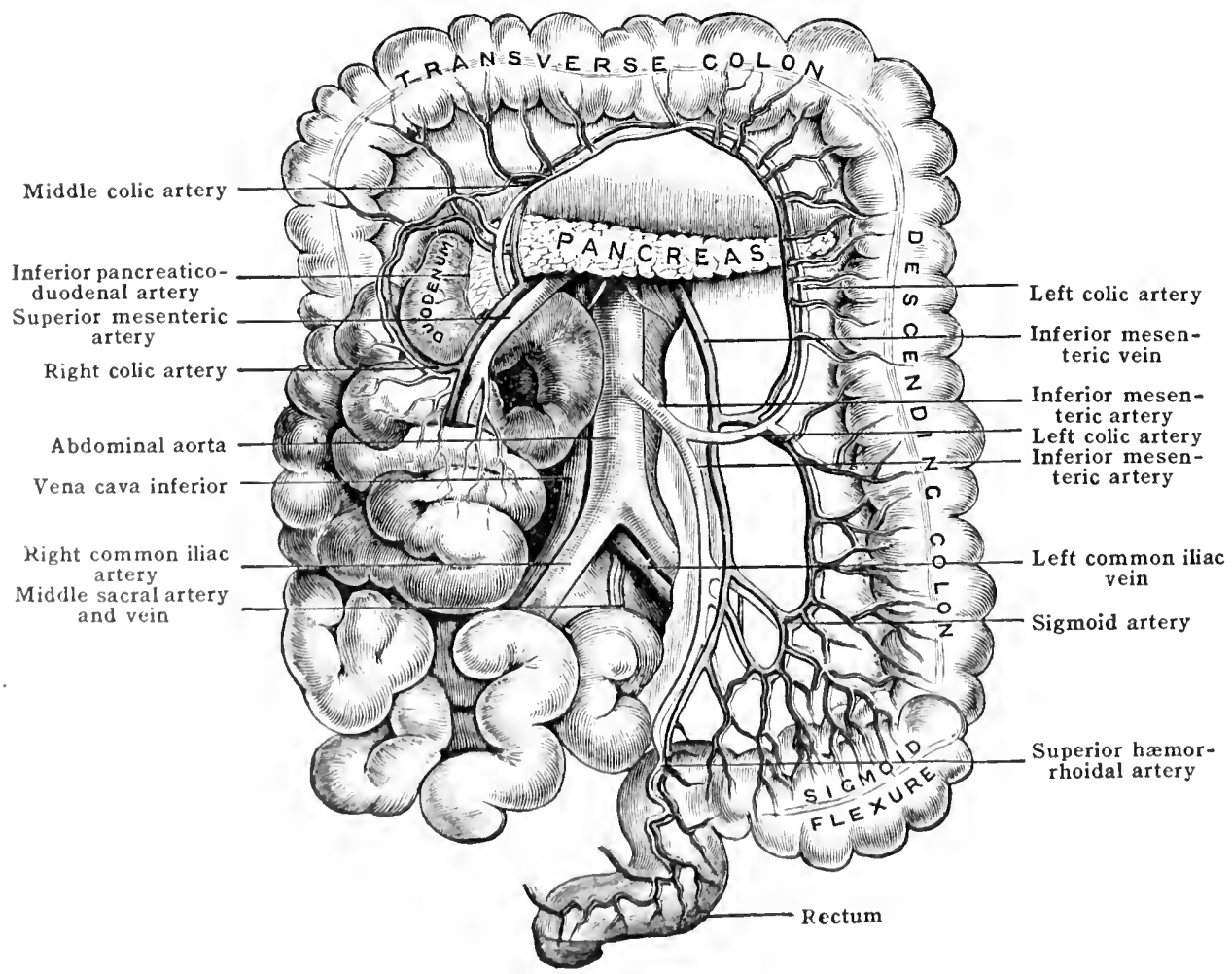

above Hae bifurcation of that vessel. It runs obliquely downward and to the left, lendind the preritonemm, across the lower part of the abdominal aorta and then orer the left woats muscle and left common ilias artery. It descends into the 
pelvis between the layers of the sigmoid meso-colon, and terminates on the rectum in the superior hæmorrhoidal artery. It supplies the lower half of the large intestine. Its vein lies at first close to the left side, but soon passes upward on the psoas, away from the artery, to end in the splenic vein (fig. 487).

The branches of the inferior mesenteric are:-(1) The left colic; (2) the sigmoid; and (3) the superior hæmorrhoidal.

(1) The left colic artery [a. colica sinistra] runs transversely to the left, beneath the peritoneum, and divides into two branches, one of which, entering the transverse meso-colon, ascends upward and to the right, to anastomose with the middle colic. The other descends, and, entering the sigmoid meso-coion anastomoses with the ascending branch of the sigmoid artery.

The distribution of this artery, and of the next, to the colon is similar to that of the colic branches of the superior mesenteric, and does not require a separate description. (See pp. $597,598$.

(2) The sigmoid artery [a. sigmoidea] runs downward and to the left over the psoas muscle and, entering the sigmoid meso-colon, divides into two brauches; the upper anastomosing with the left colic, the lower with the superior hremorrhoidal.

(3) The superior hæmorrhoidal artery [a. hæmorrhoidalis superior] is the continued trunk of the inferior mesenteric. It descends into the pelvis, behind the rectum, between the layers of the sigmoid meso-colon. On reaching the wall of the bowel it bifurcates, one branch proceeding on either side of the gut, to within 10 or $12 \mathrm{~cm}$. ( 4 or $5 \mathrm{in}$.) of the anus. Here each again divides, and the branches, piercing the muscular coat, descend between that coat and the mucous membrane, forming with each other, and with the middle hæmorrhoidal arteries-derived from the hypogastric (internal iliac) - a series of small vessels, running longitudinally to the rectum, and parallel to each other as far as the level of the internal sphincter, where, by their anastomosis, they form a series of loops around the lower part of the rectum.

\section{The Terminal Branches of the Abdominal Aorta}

\section{THE MIDDLE SACRAL ARTERY}

The middle sacral artery [a. sacralis media], is, anatomically, the continuation of the aorta. The coccygeal glomerulus [glomus coccygeum], in which it terminates, is believed to contain the rudiments of the caudal aorta. The artery extends from the bifurcation of the aorta to the tip of the coccyx. As it passes downward into the pelvis, it runs behind the left common iliac vein, the hypogastric plexus of the sympathetic nerve, and the peritoneum. It lies successively upon the intervertebral disc between the fourth and fifth lumbar vertebræ, the fifth lumbar vertebra, the intervertebral disc between that vertebra and the sacrum, and lower down upon the anterior surface of the sacrum and coccyx.

Branches.- The branches of the middle sacral artery are:-

(1) The lowest lumbar artery [a. lumbalis ima], which, when present, usually comes off from the middle sacral artery. Each vessel of this pair runs laterally beneath the common iliac artery and vein; and, after giving off a dorsal branch, ramifies over the lateral part of the sacrum, and ends in the iliacus muscle by anastomosing with the circumflex iliac artery. The dorsal branch passes to the back between the last lumbar vertebra and the sacrum and ramifies in the gluteus maximus, anastomosing with the lumbar arteries above, and the superior gluteal artery below.

(2) Lateral sacral branches, are usually four in number. They are serially homologous with the intercostal and lumbar arteries given off by the aorta. They run laterally, and anastomose with the lateral sacral branches of the hypogastric (internal iliac) artery. They give off small spinal branches, which pass through the sacral foramina, and supply the sacral canal and back of the sacrum.

(3) Rectal or hæmorrhoidal branches pass forward beneath the peritoneum or in the sigmoid meso-colon to the rectum, which they help to supply, and anastomose with the other hæmorrhoidal or rectal arteries.

\section{THE COMMON ILIAC ARTERIES}

The common iliac arteries [aa. iltacæ communes] arise opposite the left side of the middle of the body of the fourth lumbar vertebra, at the bifurcation of the abdominal aorta, and, diverging from each other in the male at about an angle of $60^{\circ}$, and in the female at an angle of $68^{\circ}$, terminate opposite the lumbo-sacral articulation by bifurcating into the external iliac, which is continued along the brim of the pelvis to the lower limb, and into the hypogastric (internal iliac), which passes through the superior aperture of the pelvis and descends into that cavity (fig. 488).

The relations differ slightly on the two sides, and may be considered separately. 
Fig. 4SS.-The Relations of the Common Iliac trteries. (Aiter Toldt, "Atlas of Human Anatomy," Rebman, London and New York.)

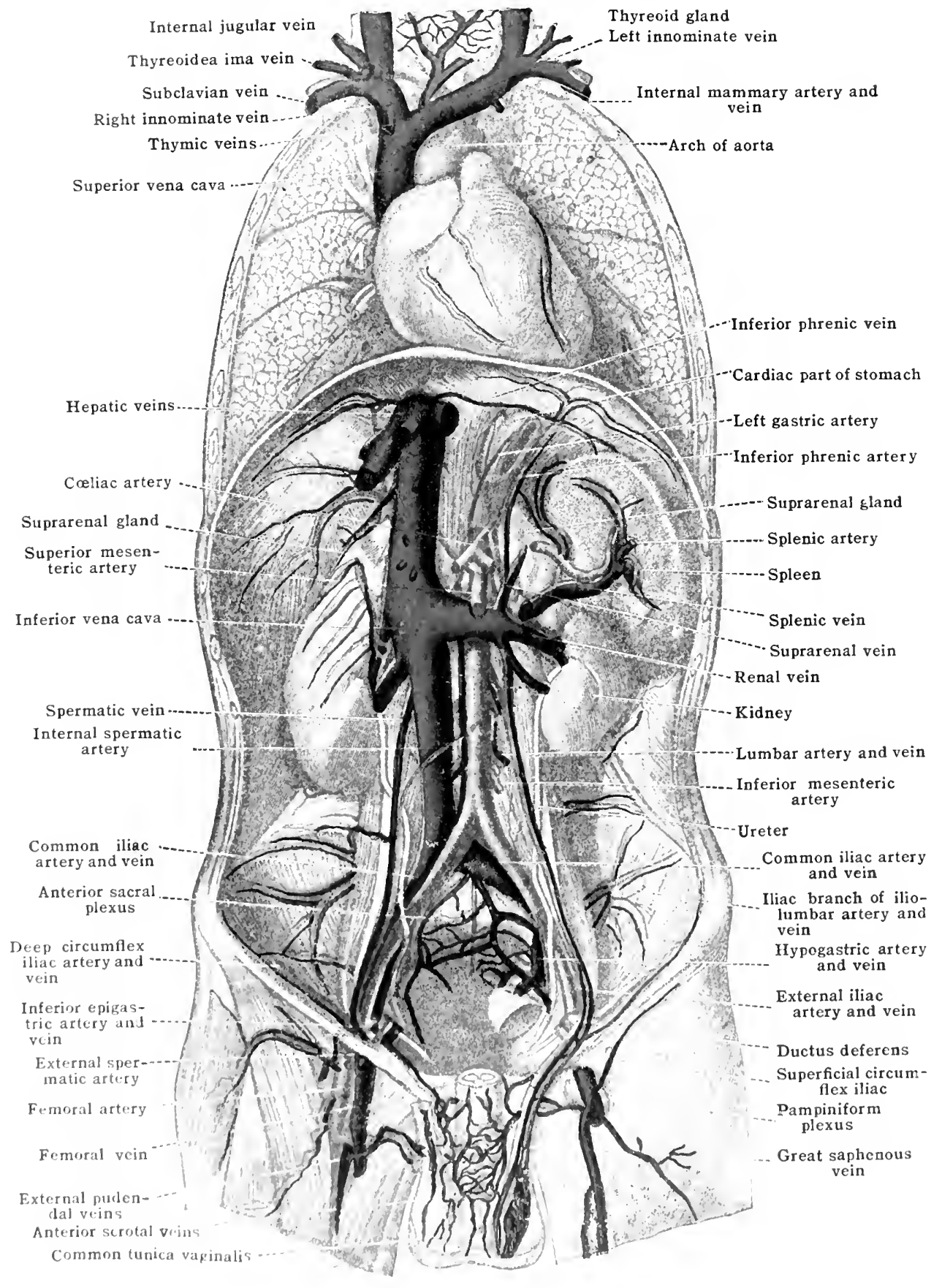




\section{The Right Common Iliac Artery}

The right common iliac measures about $5 \mathrm{~cm}$. (2 in.) in length, and is rather longer than the left, in consequence of the aorta bifurcating a little to the left of the median line.

Relations.- In front it is covered by the peritoneum, and is crossed by the right ureter a little before its bifurcation, by the ovarian artery in the female, by the termination of the ileum, by the terminal branches of the superior mesenteric artery, and by branches of the sympathetic nerve descending to the hypogastric plexus.

Behind, it lies on the right common iliac vein, the end of the left common iliac vein, and the commencement of the inferior vena cava, which separate it from the fourth and fifth lumbar vertebræ and their intervening disc, the psoas muscle, and the symuathetic nerve; whilst still deeper in the groove between the fifth vertebra and the psoas are the lumbo-sacral trunk, the obturator nerve, and the ilio-lumbar artery.

To the right side are the beginning of the inferior vena cava, the end of the right common iliac vein, and the psoas muscle, which, however, is separated from the artery by the vena cava inferior at its upper part.

To the left side are the right common iliac vein, the termination of the left common iliac vein, and the hypogastric plexus.

\section{The Left Common Ilac Artery}

The left common iliac artery, $4 \mathrm{~cm}$. (14 in.) in length, is a little shorter and thicker than the right.

Relations.-In front it is covered by the peritoneum, which separates it from the intestines, and is crossed by the ureter, the ovarian artery in the female, branches of the sympathetic nerve descending to the hypogastric plexus, the termination of the inferior mesenteric artery, the sigmoid colon, and the sigmoid mesocolon.

Behind are the lower border of the body of the fourth lumbar vertebra, the disc between the fourth and fifth lumbar vertebra, the body of the fifth lumbar vertebra, and the disc between it and the sacrum. Crossing deeply behind the artery between the fifth lumbar vertebra and the psoas, is the obturator nerve, the lumbo-sacral trunk, and the ilio-lumbar artery.

To the left side is the psoas muscle.

To the right side are the left common iliac vein, the hypogastric plexus, and the middle sacral artery.

\section{Collateral Circulation}

The collateral circulation after obstruction or ligature of the common iliac artery is carried on chiefly (fig. 497) by the anastomosis of the middle sacral with the lateral sacral; the internal mammary with the epigastric; the lumbar arteries of the aorta with the ilio-lumbar and deep circumflex iliac; the pubic branch of the epigastric with the pubic branch of the obturator; the posterior branches of the sacral arteries with the superior gluteal (gluteal); the superior hæmorrhoidal from the inferior mesenteric, with the hæmorrhoidal branches of the hypogastric (internal iliac) and pudic; the ovarian arteries from the aorta with the uterine branches of the hypogastric (internal iliac); and by the anastomosis across the middle line of the pubic branch of the obturator with the like vessel of the opposite side; the lateral sacral with the opposite lateral sacral; and the vesical, hæmorrhoidal, uterine, and vaginal branches of the hypogastric with the corresponding branches of the opposite hypogastric (internal iliac).

\section{Branches of the Common Iliac Artery}

The branches of the common iliac artery are:-(1) The hypogastric (internal iliac); and (2) external iliac.

There are a few small, unimportant branches distributed to the peritoneum and subperitoneal fat. They anastomose with vessels given off from the lumbar, inferior phrenic, and renal arteries, forming a subperitoneal arterial anastomosis. The ureter receives small insignificant twigs as it crosses the artery. 'They anastomose with the ureteral arteries given off from the internal spermatic above, and with those derived from the vesical arteries below.

\section{THE HYPOGASTRIC ARTERY}

The hypogastric or internal iliac artery [a. hypogastrica], arises at the bifurcation of the common iliac opposite the lumbo-sacral articulation. It descends into the pelvis for about $3 \mathrm{~cm}$. ( $1 \frac{1}{4} \mathrm{in}$.) and then divides, opposite the upper margin of the great sciatic foramen, into an anterior and a posterior division. The anterior division commonly gives off the obturator, inferior gluteal, umbilical, 
inferior vesical, deferential, midlle hæmorrhoidal, uterine (in the female), and internal pudendal arteries. From the posterior division the ilio-lumbar, lateral sacral, and superior gluteal arteries arise. These vessels are elassified, for description, as parietal and visceral.

In the adult the hypogastric is smaller than the external iliac; in the fotus it is much larger and through it the foetal blood is returned to the placenta. The adult hypogastric and common iliac arteries of either side represent the proximal portion of each of the embryonic umbilical arteries. The remainder of the umbilical artery within the body is represented by the umbilical branch of the hypogastric which runs to the navel. At birth, when the circulation in the umbilical cord ceases, the lumen of the umbilical branch of the hypogastric becomes obliterated except a small channel which remains pervious as the superior vesical of the adult.

Relations.-Behind, the hypogastric artery rests on the termination of the external iliac vein, the hypogastric vein, the medial margin of the psoas muscle, the lumbo-sacral trunk, the obturator nerve, and the sacrum.

In front, it is covered by the peritoneum, and is crossed by the ureter.

Fig. 489.-The Hypogastric Artery. (After Henle.)

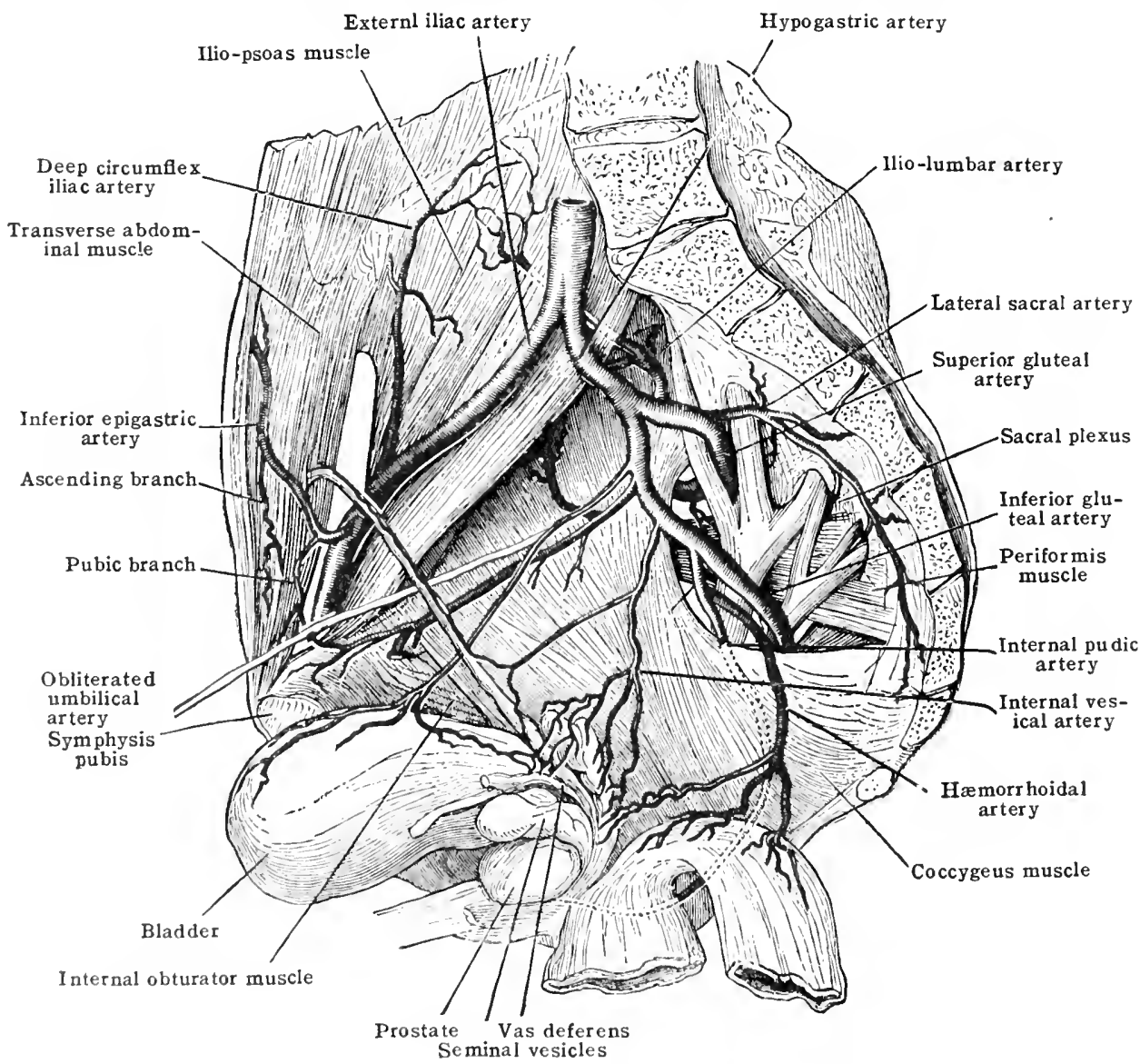

The branches of the hypogastric artery may be divided into parietal and visceral sets. The parietal branches are:-(1) 'The ilio-lumbar; (2) the lateral sacral; (3) throlsturator; and (4) the ghteal arteries.

The visceral loranches are:-(1) The umbilical; (2) the inferior vesical; (3) the middle hamorrobidil; (4) the uterine; and (5) the internal pudendal.

\section{Pairlital, Brancheg of the Ifrpogastric Amtery}

\section{THE IIAO-LUMBAR ARTERY}

Tho ilio-lumbar artry [at iliolumbalis] - a short vessel coming off from the posterior bart of the hypogastric artery -rons upward and laterally beneath the common ilias artery, first between the lumbo-sacral trunk and obturator nerve, 
and then between the psoas muscles and the vertebral column. On reaching the superior aperture of the pelvis it divides into two branches, an iliac and a lumbar (fig. 489).

The iliac branch [ramus iliacus] passes laterally beneath the psoas and the femoral (anterior crural) nerve and, perforating the iliacus, ramifies in the iliac fossa between that muscle and the bone. It supplies a nutrient artery to the bone, and then breaks up into several branches which radiate from the parent trunk, upward toward the sacro-iliac synchondrosis, laterally toward the crest of the ilium, downward toward the anterior superior spine, and medially toward the pelvic cavity. The first anastomoses with the last lumbar; the second with the external circumflex and gluteal; the third with the deep circumflex iliac from the external iliac; the fourth with the iliac branch of the obturator. The lumbar branch [ramus lumbalis] ascends beneath the psoas, and, supplying that muscle and the quadratus lumborum, anastomoses with the last lumbar artery. It sends a spinal branch (ramus spinalis) into the vertebral canal through the intervertebral foramen between the last lumbar vertebra and the sacrum; this branch anastomoses with the other spinal arteries. The ilio-lumbar artery is serially homologous with the lumbar arteries. Hence the similarity in its course and distribution.

\section{THE LATERAL SACRAL ARTERIES}

The lateral sacral artery [a. sacralis lateralis], commonly arises as two vessels from the posterior division of the hypogastric. The superior artery, when two

Fig. 490.-The Gluteal Arteries. (After Toldt, "Atlas of Human Anatomy," Rebman, London and New York.)

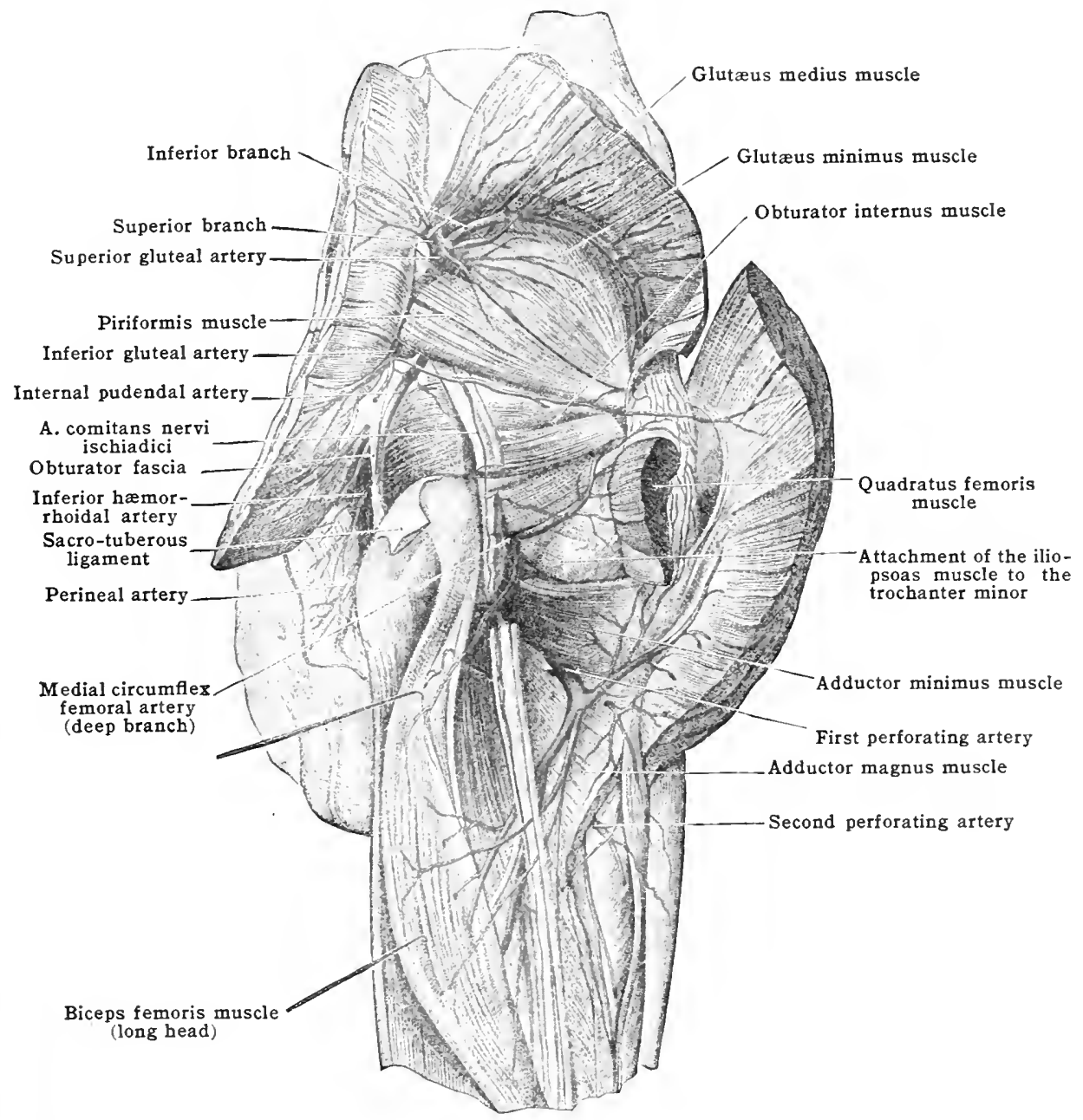

are present, runs downward and medially to the first anterior sacral foramen, through which it passes; and, after supplying the spinal membranes and anastomosing with the other spinal arteries, passes through the first posterior sacral 
foramen, and is distributed to the skin over the back of the sacrum, there anastomosing with branches of the superior and inferior gluteal arteries. The inferior lateral sacral descends on the side of the sacrum, lateral to the sacral chain of the sympathetic, and medial to the anterior sacral foramina, crossing in its course the slips of origin of the piriformis muscle and the first anterior sacral nerve. On reaching the coccyx it anastomoses in front of that bone with the middle sacral artery, and with the inferior lateral sacral of the opposite side (fig. 489).

In this course it gives off:-Spinal branches [rami spinales], which enter the second, third and fourth anterior sacral foramina, and, after supplying the spinal membranes and anastomosing with each other, leave the spinal canal by the corresponding posterior sacral foramina, and are distributed to the muscle and skin over the back of the sacrum; and rectal branches which run forward to the rectum.

At times the lateral sacral arteries are exceedingly small, the spinal branches then coming chiefly from the middle sacral. The anastomosing branches between the lateral sacral and middle sacral are usually regarded as sacral arteries diminished in size, and serially homologous with the lumbar and intercostal arteries.

\section{THE OBTURATOR ARTERY}

The obturator artery [a. obturatoria], usually arises from the anterior division of the hypogastric. It runs forward and downward a little below the brim of the pelvis, having the obturator nerve above and the obturator vein below. It here lies between the peritoneum and the endo-pelvic fascia, but later it passes through the obturator canal, the aperture in the upper part of the obturator membrane. In this course it is crossed by the ductus deferens. On emerging from the obturator canal the artery divides into two branches, anterior and posterior, which wind around the margin of the obturator foramen beneath the obturator externus muscle.

The branches of the obturator artery are:-(1) The iliac or nutrient branch; (2) a vesical branch; (3) the pubic branch; (4) the anterior, and (5) posterior terminal branches.

(1) The iliac or nutrient branch ascends to the iliac fossa, passing between the iliacus muscle and the bone. It supplies a nutrient vessel to the ilium, and anastomoses with the medial branch of the iliac division of the ilio-lumbar artery.

(2) The vesical branch or branches are small vessels which run in the lateral false ligament of the bladder to that organ, where they anastomose with the other vesical arteries.

(3) The pubic branch [ramus pubicus] comes off from the obturator as that vessel is leaving the pelvis by the obturator canal. It runs upward and medially behind the pubis, anastomosing with its fellow of the opposite side of the body, and with the pubic branch of the inferior epigastric artery. One of the anastomosing channels between the pubic branch of the obturator and pubic branch of the inferior epigastric arteries is sometimes of large size, a fact of surgical interest in that the enlarged vessel may then run around the medial side of the femoral ring (pp. 615 and 636).

(4) The anterior branch [ramus anterior] runs around the medial margin of the obturator foramen, and anastomoses with the posterior branch and with the medial circumflex artery. It supplies branches to the obturator and adductor muscles.

(5) The posterior branch [ramus posterior] skirts the lateral margin of the obturator foramen, lying between the obturator externus and the obturator membrane. At the lower margin of the foramen it divides into two branches. One branch continues its course around the lower margin of the foramen, and anastomoses with the anterior branch of the obturator and with the niclial circumflex. The other branch turns laterally below the acetabulum, and ends in the muscles arising from the tuberosity of the ischium. It anastomoses with the inferior gluteal artriry. This branch gives off a small twig, the acetabular artery [a. acetabuli], which passes muler the transverse liganent into the hip-joint, where it supplies the synovial membrane, the liganentum teres, and the fat in the fossa at the bottom of the acetabulum.

\section{THE GLUTEAL, ARTERIES}

Thre are two gluteal arteries, the superior and inferior. The superior gluteal artery [a. glutea superior], the largest branch of the posterior division of the hypogastric comes off as a short, thiek trunk from the lateral and back part of that vessel, of which indeed it may be regarded as the eontinuation. Passing backward between the first sacral nerve and the lumbo-sacral trunk through an osser)-trenlinous arch formed by the margin of the bone and the upper edge of the cnclo-jelvic fascia, it laves the pelvis through the great seiatie foramen above the piriformis muscle in company with its vein and the superior gluteal nerve. At its exit postoriorly from the great sciatic foramen it lies under cover of the gluteus 
maximus and beneatl the superior gluteal vein, and in front of the superior gluteal nerve. It here breaks up into two chief branches, a superficial and a deep. Its emergence from the pelvis is indicated on the surface by a point situated at the junction of the posterior with the middle third of a line drawn from the anterior superior to the posterior superior spine of the ilium.

The branches of the superior gluteal artery are:-

(a) Within the pelvis, branches are distributed to the obturator internus, the piriformis, the levator ani, the coceygeus, and the pelvic bones.

(b) External to the pelvis, the artery divides into a superior and an inferior branch.

(i) The superior branch [ramus superior] breaks up into a number of large vessels for the supply of the upper portion of the gluteus maximus, some of them piercing the muscle and supplying the skin over it, and anastomosing with the posterior branches of the lateral sacral arteries; whilst one of larger size, emerging from the muscle near the iliac crest, anastomoses with the deep circumflex iliac artery. The lower branches to the muscle anastomose with branches of the inferior gluteal (sciatic).

(ii) The inferior branch [ramus inferior] subdivides into two branches-One skirts along the line of origin of the gluteus minimus (fig. 490), between the gluteus medius and the bone, and, emerging in front from beneath these muscles under cover of the tensor fasciæ latæ, anastomoses with the ascending branch of the lateral circumflex and the deep circumflex iliac arteries. The other passes forward between the gluteus medius and minimus, accompanied by the branch to the tensor fascie latæ of the inferior division of the superior gluteal nerve, toward the greater trochanter, where it anastomoses with the ascending branch of the lateral circumflex. It supplies branches to the contiguous muscles and to the hip-joint. The inferior branch before its division gives off the external nutrient artery of the ilium.

The inferior gluteal [a. glutea inferior], is one of the terminal branches of the anterior division of the hypogastric artery. It leaves the pelvis below the piriformis muscle, and immediately breaks up into a number of diverging branches. The largest enter the gluteus maximus muscle, where they anastomose with the superior gluteal branches. Others pass to the hip-joint and the deep muscles around it; a third group passes downward to the hamstring muscles and anastomoses with the medial and lateral circumflex and first perforating; a fourth slender branch, the sciatic artery [a. comitans n. ischiadici], accompanies the sciatic nerve (fig. 490).

\section{Visceral Branches of the Hypogastric Artery}

\section{THE UMBILICAL ARTERY}

The umbilical artery in the foctus is the continuation of the hypogastric. Passing forward along the side of the pelvis, it runs beneath the lateral reflexion of peritoneum from the bladder, where, after giving off one or more vesical branches, it ceases to be pervious and passes on to the side and upper part of the bladder. Thence it ascends in the lateral umbilical fold, as a fibrous cord [ligamentum umbilicale laterale], to the umbilicus, where it is joined by its fellow of the opposite side. As it lies lateral to the bladder it is crossed by the ductus deferens.

The branches of the umbilical artery are:-(1) Superior vesical arteries, the lowest of which is sometimes called (2) the middle vesical artery (fig. 489).

The superior vesical arteries [aa. vesicales superiores] ramify over the upper surface of the bladder, anastomosing with the artery of the opposite side and with the middle and inferior vesical below. They give off the following branches:-(a) The urachal branches which pass upward along the urachus. (b) 'The ureteric branches pass to the lower' end of the ureter, and anastomose with the other ureteric arteries. (c) The middle vesical may come off from one of the superior vesicals or from the umbilical. It is distributed to the sides and base of the bladder, and anastomoses with the other vesical arteries.

\section{THE INFERIOR VESICAL ARTERY}

The inferior vesical artery [a. vesicalis inferior] arises from the anterior division of the hypogastric, frequently in common with the middle hicmorrhoidal, and passes downward and medially to the fundus of the bladder, where it breaks up into branches which ramify over the lower part of the viscus. It gives off branches to the prostate, which supply that organ and anastomose with the arteries of the opposite side by means of descending arteries which pass through 
the prostatic plexus of reins, but outside the capsule of the prostate, and with the inferior hrmorrhoidal branches of the internal pudic. At times one of these prostatie branches is of large size, and supplies certain of the parts normally supplied by the int. pudendal. It is then known as the accessory pudendal and most commonly terminates as the dorsal artery of the penis.

The inferior vesical usually gives off the deferential, or artery of the ductus deferens [a. deferentialis]. This vessel, which may come off from the superior vesical, divides, on the ductus deferens, into an ascending and a descending branch. The ascending branch follows the ductus through the inguinal canal to the testis, where it anastomoses with the internal spermatic artery. The descending branch passes downward to the dilated portion of the ductus and vesiculæ seminales.

\section{THE MIDDLE HEMORRHOIDAL ARTERY}

The middle hæmorrhoidal artery [a. hæmorrhoidals media], variable in origin, perhaps most commonly arises from the anterior division of the hypogastric along with the inferior vesical. It runs medially to the side of the middle portion of the reetum, dividing into branches which anastomose above with the superior hæmorrhoidal derived from the inferior mesenteric, and below with the inferior hæmorrhoidal derived from branches of the internal pudendal. Its corresponding rein terminates in the inferior mesenteric vein. In the female it also sends branches to the vagina.

\section{THE UTERINE ARTERY}

The uterine artery [a. uterina], arises from the anterior division of the hypogastric close to or in conjunction with the middle hemorrhoidal or inferior vesical. It runs downward and medially through the pelvic connective tissue, crossing the ureter about $12 \mathrm{~mm}$. ( $\frac{1}{2}$ in.) from the cervix uteri. It then turns upward and aseends in the parametrium between the layers of the broad ligament at the side of the uterus in a coiled and tortuous manner, and, after giving off a number of tortuous branches which ramify horizontally over the front and back of the uterus, supplying its substance, anastomoses with the uterine branch of the ovarian artery.

In addition to the branches to the uterus the branches of the uterine artery are:-(1) Cervical. - This branch comes off from the uterine as the latter artery crosses the ureter to turn upward on to the uterus. It is directed medially, and divides into three or four branches which yass on to the cervix at right angles to it; one branch anastomosing with its fellow of the opposite side in front and hehind the neck, forming the so-called coronary artery of the cervix. (2) Tubal [ramus tubarius]. - This rourses along the lower surface of the tuba uterina (Fallopian tube) as far as its fimbriated extremity, and may also semd a branch to the ligamentum teres. (3) Ovarian [ramts ovarii]. - This runs along the at tached horder of the ovary, sending branches to that stricture, and terminates by anastomosing widely with the ovarian artery. Usually the vaginal antry also alises from the utrine. (4) The vaginal artery [a. vaginalis] corresponds to the inforior vesian artrery of the male, and may arise directly from the hypogastric artery, close to the origin of the nterine, or from the superior vesical. It passes medially, behind the ureter, to the mper part of the vagina, and sends mumerous branehes to that strueture and also somer to the mosteriol palet of the fumdus of the bladeder.

'The hranches (1) the vagina tomel to anastomose with one another and with the cervical branch of the utrine, to form a moreor fess perferet vertical stem in the median line of the vagina, loth bark ind front. Thisstem is sometimes termed the azygos artery of the vagina. Branches also pass to the vagina from the midale hamorrhoidal artery.

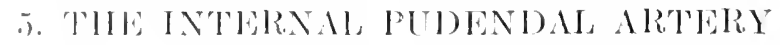

Tho internal pudendal (puclic) artory |a. pudenda internal (figs. 492, 493, 494) is one of the torminal hranches of the anterior division of the hypogatstric artery

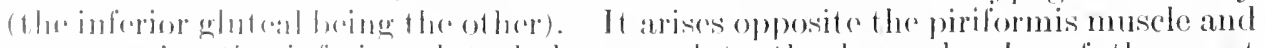

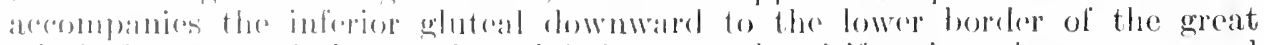

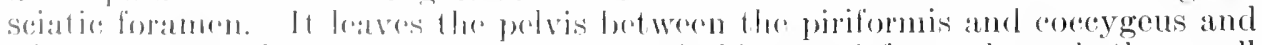
wints over the ischial spime to conter the ischio-pectal losid through the small sciatic: formune Romming forwarl in the ischio-rectal fosis medial to the lower

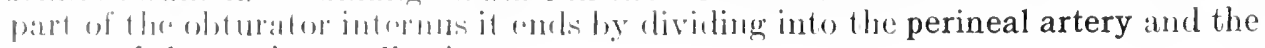
artery of the penis (or clitoris). 
Relations.-- Within the pelvis, the artery is anterior to the piriformis muscle and the sucrat plexus of nerves, and lateral to the inferior gluteal artery. It passes between the piriformis and coccygens, with the gluteal artery and pudemlal nerve medial to it, and the nerve to the ol, turator internus lateral. The seiatic and pusterior femoral cutaneous (lesser sciatic) nerves are still more lateral. (In the ischial spine the artery retains its relations to the pudental nerve (which often dividesin this situation into its two terminal branches) and the nerve to the ob)turitor intermus. It is accompanied by vens comitantes and rovered by the gluteus maximus

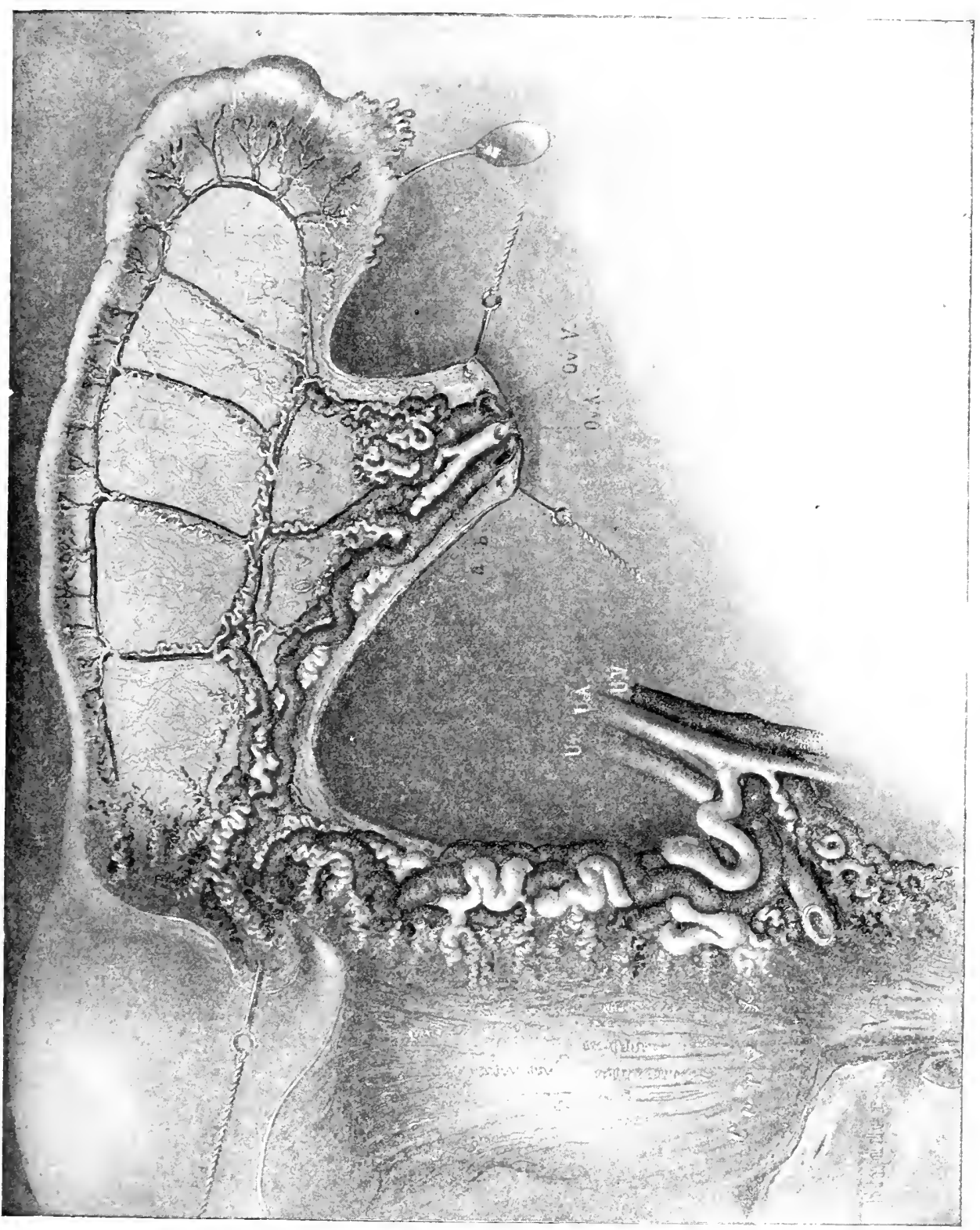

muscle. In the ischiorectul foss the artery is placest on the literal wall about $3.5 \mathrm{~cm}$. $1^{1}$ in $)$ above the tuberosity of the isehimm. It is alcompanied in al camal in the obturator fuscia (Alcock's canal) by the dor al nerve of the penis and the perineal nerve, which are respectively
above and below the artery.

The branches of the internal pudendal artery are:-(1) Small lianches to the gluteal region; (2) the inferior hemorrhoilal arteries; and the terminal branches (3) perineal; and (4) artery to the penis or clitoris. 
Fig. 492.-The Intersal Pedexdal Artery. (From Kielly, by Brödel.)

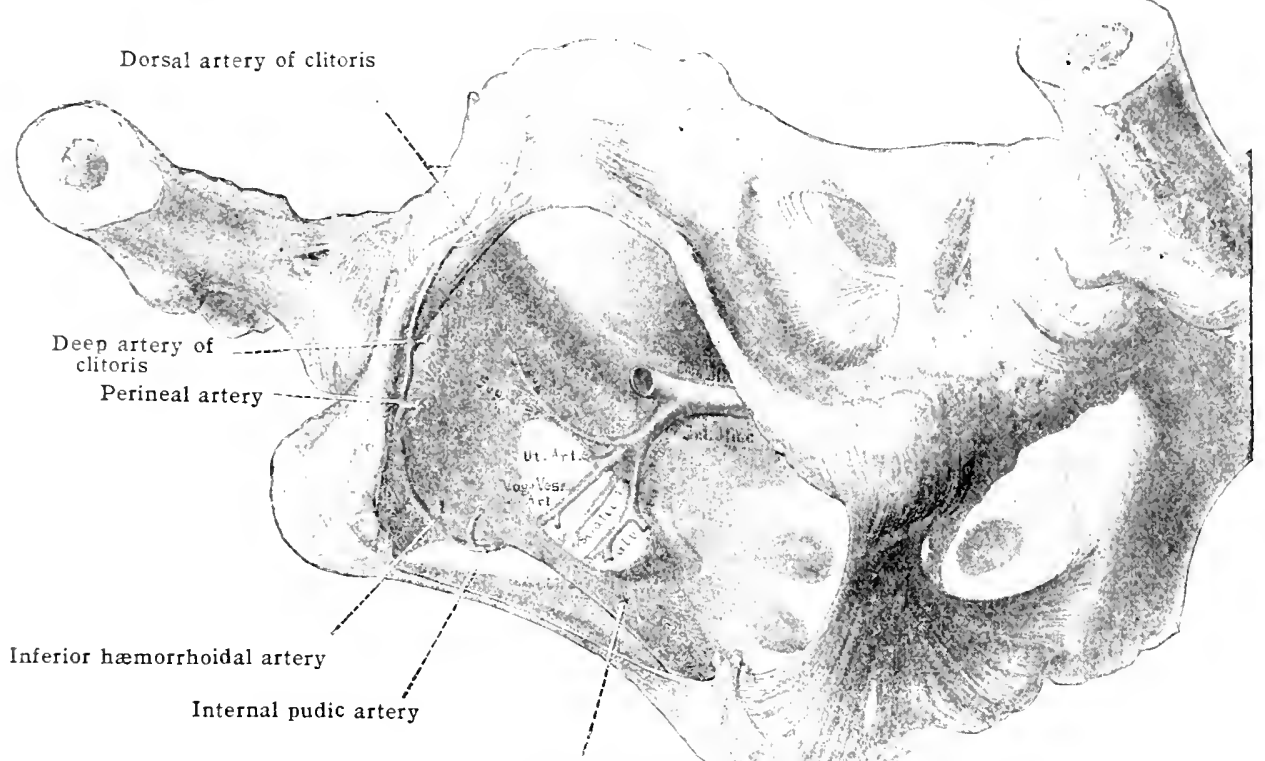

Sacro-spinous ligament

Fig. 493.-The Perineal and Hemorrhoidal Branches of the Internal Pudendal Arteries. (From Kelly, by Brödlel.)

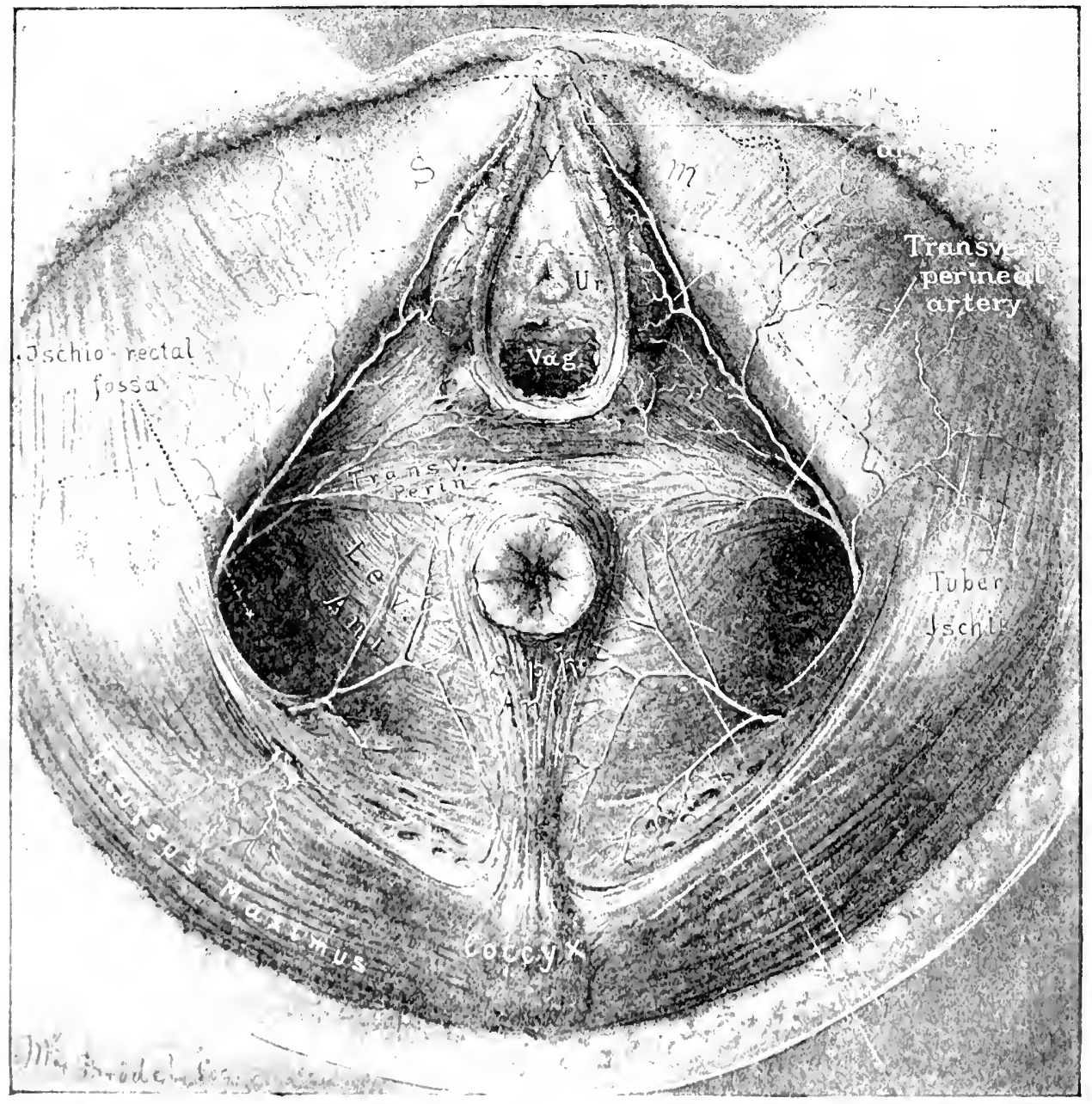


(1) The branches of the gluteal region are: (a) twigs to the gluteus maximus; $(b)$ branches accompanying the nerve to the obturator internus; $(c)$ a sacral branch which pierces the sacrotuberous ligament, and anastomoses with the inferior gluteal artery.

(2) The inferior hemorrhoidal artery (a. hrmorrhoidalis inferior] (figs, 493, 49 4 ) arises at the posterior part of the ischio-rectal fossa and, perforating the obturator fascia, at once breaks up into several branches. These, running medially toward the anus, traverse the ischio-rectal fat and supply the fascia, skin and the levator ani and external sphincter muscles. The inferior hæmorrhoidal branches anastomose with those from the middle and superior hamorrhoidal, and from the gluteal and perineal arteries.

(3) The perineal artery [a. perinei] (figs. 493, 494), one of the terminal arteries of the internal pudendal, arises at the anterior part of the ischio-rectal fossa. It pierces the base of the urogenital diaphragm (triangular ligament) anterior or posterior to the superficial transverse perineal muscle, and enters the space deep to Colles's fascia. Here it runs forward between the ischio- and bulbo-cavernosus muscles to the scrotum or labium majus and divides into numerous terminal branches. Immediately after piereing the diaphragm, the perineal artery gives off a constant transverse perineal branch which runs toward the median line along the superficial transverse perineal muscle. The terminal branches of the perineal are the posterior scrotal or labial arteries [aa. scrotales, or labiales posteriores] which ramify on the scrotum or labia majora (according to sex) and anastomose with external pudendal arteries.

(4) The artery of the penis, or clitoris [a. penis or clitoridis] (figs. 493,491) pierces the free border of the urogenital diaphragn and runs forward between the layers of the diaphragm with the dorsal nerve of the penis along the inferior ramus of the pubis. It traverses the fibres of the deep transverse perineal muscle and of the sphincter of the membranous urethra and

Frg. 494.-The Arteries of the Male Perindeui.

On the right side Colles's fascia has been turned back to show the perineal artery. On the left side the perineal vessels have been cut away with the inferior layer of the urogenital diaphragm to show the artery of the penis.

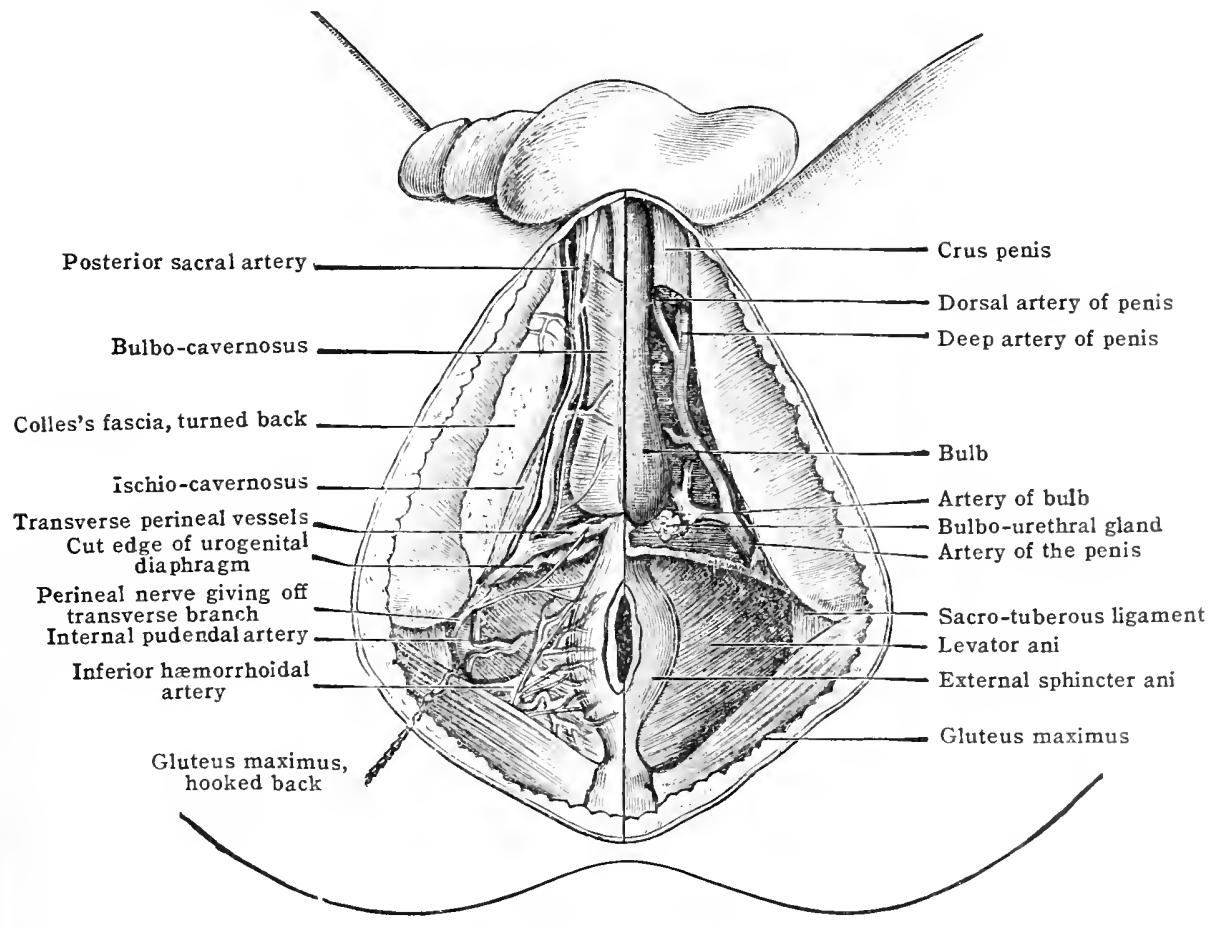

ends by dividing into cleep and dorsal arteries of the penis, or clituris, according to sex.

The branches of the artery of the penis (or clitoris) are: $(a)$ The artery to the bulb; $(b)$ the urethral artery; and $(c)$ the terminal, decp artery of the penis or clitoris.

(a) The artery of the bulb [a. bulbi urethrx or vestibuli vagina] takes a medial direction through the fibres of the $\mathrm{m}$. transversus perinei profundus. It then pierces the inferior fascia of the urogenital diaphragm to reach the bulb, the erectile tissue of which it supplies, in either sex. This vessel also supplies branches to the bulbo-urethral gland (Cowperi) or the glanil of the vestibule (Bartholini).

The situation of the artery to the bulb should be remembered in performing the operation of lateral lithotomy, particularly as it may arise far back. When the artery arises, as it occasionally does, from the accessory pudendal it pierces the urogenital diaphragm further forward and is out of danger in the ordinary low operation.

(b) The urethral artery [a. urethralis] is a small branch which passes into the corpus spongiosum and anastomoses with branches from the artery of the bulb. 
(c) The deep artery of the penis or clitoris [a profunda penis or clitoridis], larger in the male sex, pierces the inferior layer of the urogenital diaphragm near the inferior limms of the pubis. It enters the crus of the penis (fig. 194) or clitoris, and is distributed in the corpus cavernosum urethrie.

(d) The dorsal artery of the penis or clitoris [a. dorsalis penis or clitoridis] (figs. 492, 494), perforates the inferior fascia of the urogenital diaphrigm near its apex. The dorsal nerve is lateral to the artery and both join the dorsal vein (which lies between the arteries of either side) on the dorsum of the penis or clitoris. The artery is much larger in the male than the female; in either sex it supplies the glans, coronil, and prepuce and anastonoses with the external pudendal artery.

\section{THE EXTERNAL ILIAC ARTERY}

The external iliac artery [a. iliaca externa] - the larger in the adult of the two vessels into which the common iliac divides opposite the lumbo-sacral articulation - extends along the superior aperture of the pelvis, lying upon the medial border of the psoas muscle, to the lower margin of the inguinal ligament, where, midway between the anterior superior spine of the ilium and the symphysis pubis, it passes into the thigh, and takes the name of the femoral.

It measures 8.5 to $10 \mathrm{~cm}$. ( $3 \frac{1}{2}$ to $4 \mathrm{in}$.) in length. The course of the vessel is indicated by a line drawn from $2.5 \mathrm{~cm}$. (1 in.) below and a little to the left of the umbilicus to a spot miclway between the symphysis pubis and the anterior superior spine of the ilium. If this line is divided into thirds, the lower two-thirds indicate the situation of the external iliae, the upper third the common iliac. The external iliac vein, the continuation upward of the femoral vein from the thigh, lies to the medial side of the artery, but on a slightly lower plane, and, just before its termination, gets a little behind the artery on the right side.

Relations.--In front, the artery together with the vein is covered by the parietal peritoneum descending from the abdomen into the pelvis, and by a layer of condensed subperitoneal tissue (Abernethy's fascia). It is crossed by the termination of the ileum on the right side, and by the sigmoid colon on the left. The external spermatic (genital) branch of the genitofemoral (genito-crural) nerve runs obliquely over its lower third, and just before its termination it is crossed transversely by the deep circumflex iliac vein. The internal spermatic or ovarian vessels lie for a short distance on the lower part of the artery, and the ductus deferens in the male curves over it to descend to the pelvis. It is sometimes crossed at its origin by the ureter. The external iliac lymphatic nodes lie along the course of the artery. The commencement of its inferior epigastric branch is also in front.

Behind.-At first the artery lies partly upon its own vein; lower down upon the medial border of the psoas; and just before it passes through the lacuna vasorum, beneath Poupart's ligament, upon the tendon of the psoas. The continuation of the iliac into the endo-pelvic fascia is also below it.

To its medial side is the external iliac vein, the peritonemm, and the ductus deferens in the male, or the ovarian vessols in the female.

To its lateral side is the proas muscle and the iliac fascia.

The collateral circulation is carried on (fig. 497) when the external iliac is tied, by the anastomosis of the ilio-lumbar and lumbar arteries with the circumflex iliac; the internal mammary with the inferior epigastric; the obturator with the medial circumflex; the inferior gluteal with the medial circumflex and superior perforating; the gituteal with the lateral circumflex; the arteria comitans nervi ischiadici from the inferior gluteal, with the perforating branches of the profunda; the external purlenal with the internal pudendal; the pubic branch of the obturator with the pubic branch of the epigastric.

The branches of the external iliac artery are:-(1) The inferior epigastric; (2) the deep circumflex iliac; and (3) several small and insignifieant twigs to the neighbouring psoas muscles and lymphatic gland.

\section{(1) The Inferiolr Epigastric Artery}

The inferior or deep epigastric artcry [a. epigastrica inferior] (fig. 495) usually comes off from the external iliac just above the inguinal (Poupart's) ligament. Immediately after its origin, the cluctus deforens in the male, and the round ligament in the fomale, loop around it on their way to the polvis. It here lies medial to the abdominal inguinal (intornal abrlominal) ring, behind the inguinal ranal, and a little above: and lateral te the femoral ring. 'Thence it aseends with a slightly morlial dirention passing above and to the lateral side of the subeutaneons inguinal (external abelominal) ring, lying between the faseia transversalis and the peritonemm. Having piored the fascia transversalis at this point, it 
passes in front of the linea semicircularis (Douglass' fold) and turns upward between the rectus and its sheath. Higher, it enters the substance of the muscle, and anastomoses with the superior epigastric, descending in the rectus from the internal mammary.

The situation of the artery between the two inguinal rings should be borne in mind in the operation for strangulated inguinal hernia, and its near proximity to the upper and lateral side of the femoral ring should not be forgotten in the operation for femoral hernia. The artery is accompanied by two reins which end in a single trunk before opening into the extemal iliac vein.

The branches of the inferior epigastric are small and include:- (a) The external spermatic [a. spermatica externa], which runs with the ductus through the inguinal canal, supplies the cremaster muscle, and anastomoses with the internal spermatic, external pudendal, and perineal arteries. In the female a corresponding artery [a. lig. teretis uteri] accompanies the round liga-

Fig. 495.-The Ixferior (Deep) Epig.sistric Artery. (From Kelly, by Brödel).

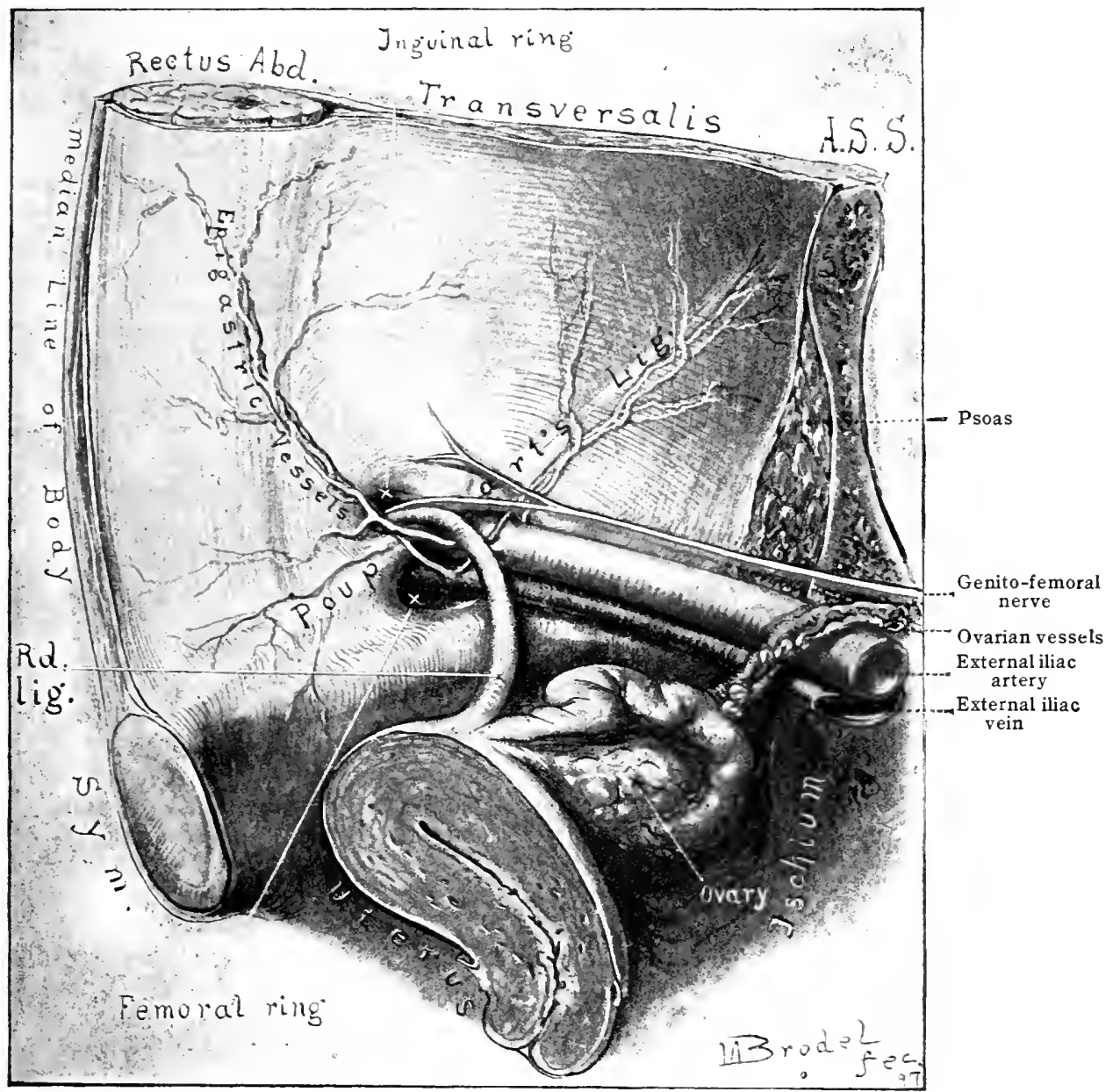

ment of the uterus through the inguinal canal and anastomoses in a similar manner. (b) The pubic [ramus pubicus], which passes below, or sometimes above, the femoral ring to the back of the pubis, where it anastomoses with the pubic branch of the obturator. This branch, though usually smahl, is occasionally considerably enlarged, when its exact course becomes of great interest to the surgeon. Thus it may descend immediately medial to the vein, and therefore lateral to the femoral ring, or it may course medially in front of the femoral ring and turn downward either behind the os pubis or immediately behind the free edge of the lacumar (Gimbernat's) ligament, in which situation it would be exposed to injury in the operation for the relief of a strangulated femoral hernia. In such cases the obturator may lose its connection with the hypogastric and actually arise from the inferior epigastric. Very rarely the inferior epigastric loses its connection with the external iliac and arises from the obturator. This abnormal origin of the obturator is said to occur once in every three subjects and a half; but the abnormal 
artery only courses around the medial side of the ring-in which situation it is liable to injury in the operation for femoral hernia-in exceptional cases. According to Langton (Holden's 'Anatomy'), the ehances are about seventy to one against this oecurring. But even when it takes the abnormal course, it lies $3 \mathrm{~mm}$. or so from the margin of the ring, and will probably escape injury in the division of the stricture if several short notehes are made in place of a single and longer ineision.

\section{(2) The Deep Circumflex Iliac Artery}

The deep circumflex iliac artery [a. circumflexa ilium profunda], arises from the lateral side of the external iliac artery either opposite the epigastric or a little below the origin of that vessel. It courses laterally just above the lower margin of Poupart's ligament, lying between the fascia transversalis and the peritoneum, or at times in a fibrous canal formed by the union of the fascia transversalis with the iliac fascia. Near the anterior superior spine of the ilium, it perforates the transversus, and then courses between that muscle and the internal oblique, along and a little above the crest of the ihum. It finally gives off an ascending branch, which anastomoses with the lumbar and lower intereostal arteries, and runs backward to anastomose with the ilio-lumbar artery. It is accompanied by two veins. These unite into one trunk, which then crosses the external iliae artery to join the external iliae vein.

The branches of the deep circumflex iliac artery are as follows:- (a) Muscular branches which supply the psoas, iliaeus, sartorius, tensor fascix latx, and the oblique and transverse museles of the abdomen. One of these branches, larger than the rest, usually arises about $2.5 \mathrm{~cm}$. ( $1 \mathrm{in}$.) behind the anterior superior spine of the ilium and aseends perpendicularly between the transversus musele and the internal oblique. It has received no name but is important to the surgeon, as it indicates the intermuseular plane between the two muscles. $(b)$ Cutaneous branehes, which supply the skin over the course of the vessel, and anastomose with the superficial cireumflex iliae, the superior gluteal, and the ascending branch of the lateral cireumflex.

\section{THE FEMORAL ARTERY}

The femoral artery (fig. 496) is the continuation of the external iliac, and extends from the lower border of Poupart's ligament, down the anterior and medial aspeet of the thigh, to the tendinous opening in the adduetor magnus, through which it passes into the popliteal space, and is then known as the poplitcal. The femoral artery is at first quite superficial, being merely covered by the skin, and superficial and deep fascia; but, after thus passing about $13 \mathrm{~cm}$. (5 in.) downward through the space known as the femoral trigone (Scarpa's triangle), it sinks at the apex of that triangle beneath the sartorius muscle, and thenee to its termination continues beneath the sartorius, coursing deeply between the vistus medialis and adductor muscles in the space known as the adductor (Hunter's) canal. It at first rests upon the brim of the pelvis and head of the thigh bone, from wlich it is merely separated by the capsule of the hip-joint and the trendon of the psoas. Here it can be readily compressed. Owing to the oblingity of the neck of the femur and the direct course taken by the artery, it lin's lower down on muscles only, at somo little distance from the bone. At its tormination, in conseguence of the shaft of the femur inclining toward the middle line of the borly, the artery lies close to the bone, but to the medial side. The course of the vessel when thr thigh is slightly flexed and abdueted-the position in which the limb is plared when the vessel is ligatured-is indieated by a line drawn from a spot mislway betwen the anterior superior spine of the ilium and the srmphysis pubis to the andaretor tuberele. Whon the thigh is in the extended pusition and parallel to its follow, the conrse of the artery will rorrespond to a line drawn from the spot alove mentioned to the modial border of the patella.

About 4-5 ('m. (1 1 - 2 in.) below the inguinal ligament the fomoral artery gives off a large branch ralled the profunda fomoris. 'The portion of the artery proximal fo the origin of the profunda is sometimes callod the common femoral, and the continuation of the vessel the superficial femoral.

T'he suprerfoial femoral varies in length areording to the distance that the profunda is given

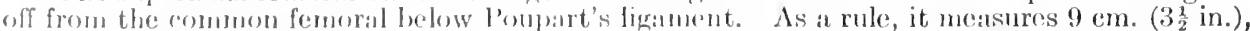

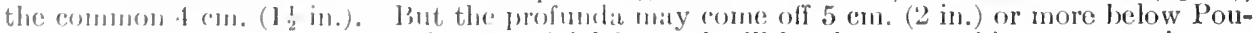
fart's liganent, in whin rase the sulerficial femoral will be shorter to this extent; or it may 
come off less than $3.7 \mathrm{~cm}$. ( $1 \frac{1}{2} \mathrm{in.}$ ) below Poupart's ligament, or even from the external iliac above Poupart's ligament, when the superficial will be longer than normal. The practical point to remember is that it is more usual to meet with a short than with a long common femoral and that if the superficial femoral is tied at the apex of the femoral trigone-i. e., the spot where the sartorius comes into contact with the adductor longus-there is nearly always a sufficient

Fig. 496.-The Femoral Artery. (After Toldt, "Atlas of Human Anatomy," Rebman London and New York.)

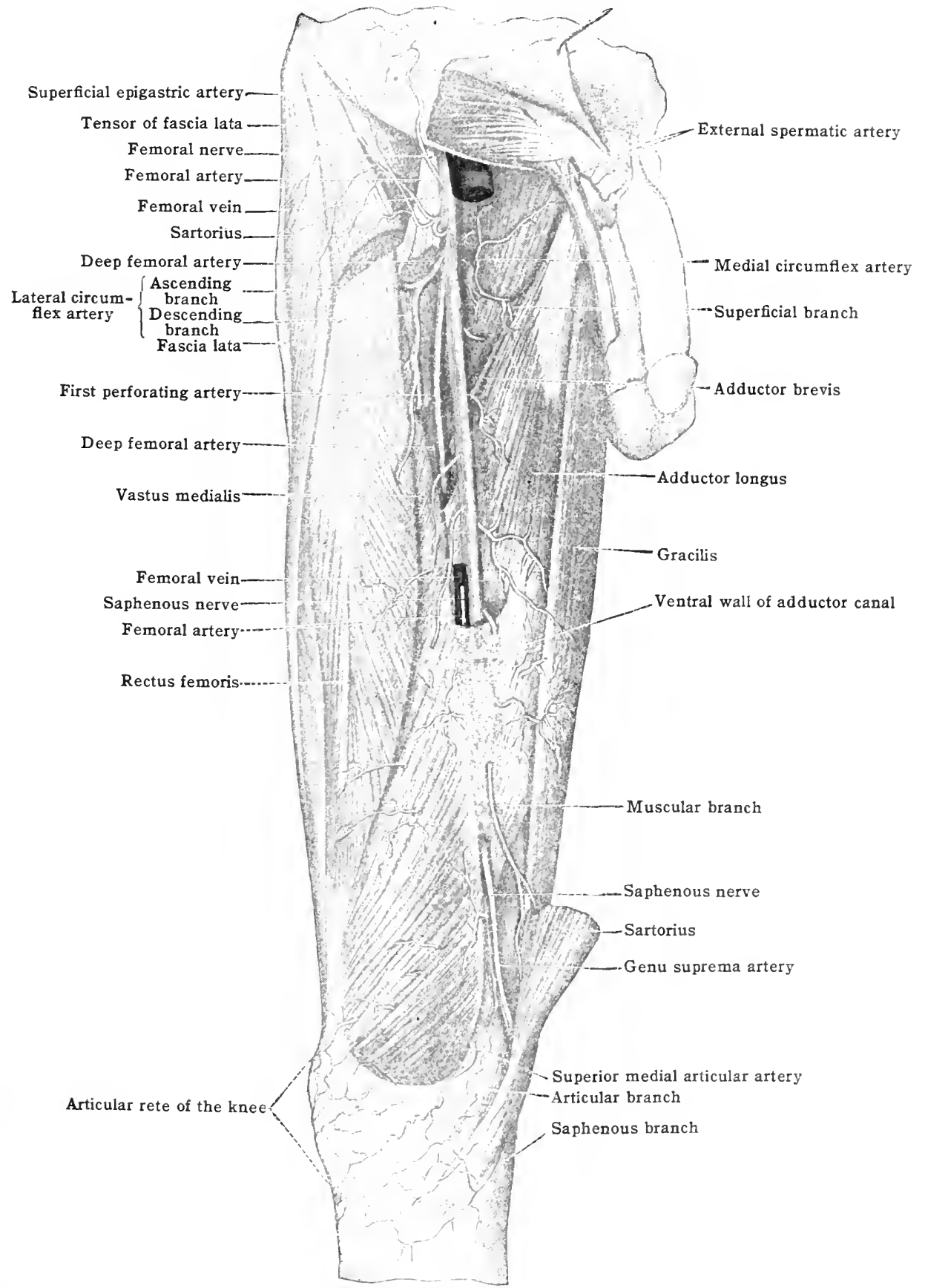

length of that vessel above the ligature to ensure a firm internal clot and consequently, as far as this point is concerned, a successful result.

The relations of the femoral artery in the femoral trigone.-In front, the femoral artery (fig. 496) is covered by the skin, the superficial fascia, the iliac portion of the fascia lata, and the lumbo-inguinal (crural) branch of the genito-femoral nerve. The superficial circumflex iliac vein, and sometimes the superficial epigastric vein, descend over the artery from the medial to 
the lateral side. Just above the sartorius, the artery is crossed by the most medial of the anterior cutaneous branches of the femoral nerve. The fascia transversalis, which is continued downward into the thigh beneath the inguinal ligament, is also in anterior relation, but it soons becomes indistinguishable from the sheath of the vessel.

Behind, the artery rests from above upon the tendon of the psoas muscle, which separates it from the brim of the pelvis and capsule of the hip-joint; the pectineus, and adductor longus. The artery is partially separated from the pectineus by the femoral vein and the profunda vein and artery, and from the alductor longus by the femoral vein which is almost directly behind the artery near the apex of the femoral trigone. 'The small nerve to the pectineus crosses behind the artery to reach its medial side.

A similar prolongation to that derived from the fascia transversalis in front, descends behind the ressel from the iliac fascia; but this, like the anterior prolongation or fascia, soon blends with the sheath of the ressels.

To the medial side is the femoral vein. This is separated above from the artery, where the two vessels lie in the femoral sheath, by a thin fascial septum. Below, the vein is somewhat behind the artery.

To the lateral side.-Above, the common stem of the femoral (anterior crural) nerve is about $1 \mathrm{~cm}$. ( $\frac{1}{3} \mathrm{in}$.) lateral to the artery. When the femoral nerve gives off its branches, the saphenous nerve and the nerve to the vastus medialis accompany the artery on the lateral side.

The adductor canal is the somewhat triangularly shaped space bounded by the vastus medialis on the lateral side, the adductors longus and magnus posteriorly, and by an aponeurosis thrown across from the adductors to the vastus medially and in front. Below, the canal terminates at the tendinous opening in the adductor magnus; above, its limit is less well defined, as here the aponeurosis between the nuscles becomes less tendinous, and gradually fades away into the perimuscular fascia. The transverse direction of the fibres of the aponeurotic covering at the lower two-thirds of the canal is characteristic, and serves as a rallying-point in tying the artery in this part of its course. Lying superficial to the aponeurosis is the sartorius muscle. The femoral artery, in the adductor (Hunter's) canal, has the following relations :-

In front, in addition to the skin, superficial and deep fascia, are the sartorius muscle and the aponeurotic fibres of the canal. The saphenous nerve crosses in front of the artery from the lateral to the medial side, lying in the wall of the canal.

Behind, the artery is in contact with the adductor longus, and just above the opening in the adductor magnus, usually with the latter muscle.

The femoral vein lies behind the artery, but gets a little lateral to it at the lower part of the canal. It is here very firmly and closely attached to the artery, embracing it as it were on its posterior and lateral aspect. Hence it is very liable to be punctured on ligaturing the artery in this part of its course. Such an accident is best avoided by opening the sheath of the vessels well to the medial side of the front of the artery, and by keeping the point of the aneurysm needle closely applied to the vessel in passing it between the vein and the artery. There are sometimes two veins, which then more or less surround the artery.

To the lateral side are the vastus medialis, the nerve to the vastus medialis, and at the lower part of the canal, the femoral vein.

\section{Branches of the Femoral Artery}

\section{The branches of the femoral artery are:-}

(1) The superficial epigastrie; (2) the superficial circumflex iliac; (3) the external purlendal; (4) the inguinal; (5) the profunda; (6) muscular branches; and (7) the suprema genu (anastomotica magna).

(1) the superficial epigastric artery [a. epigastrica superficialis], comes off from the femoral about $1.2 \mathrm{~cm}$. ( $\frac{1}{2} \mathrm{in}$.) below the inguinal ligament. At its origin it is beneath the fascia lata, but almost at once passes through this fascia, or else through the fossa ovalis, and courses in an upward and slightly medial direction in front of the cxternal oblique muscle almost as far as the umbilicus.

It ends in numemous small twigs, which anastomose with the cutancous branches from the inferior epigastric and internal mammary. In its course it gives off small branches to the inguinal glands and to the skin and superficial fascia. Rumning with it is the superficial epigastric vein, which rudls in the great saphenous just before the latter pisses through the fossa ovalis (saphenous opening).

(2) The superficial circumflex iliac artery [i. circumflexa ilium superficialis], (fig. 496), usually smaller than the superficial epigastric, arises either in common with that vessel, or clse as a separate branch from the femoral. It passes laterally over the iliacus, and, soon perforating the faseia lata at little to the lateral side of the fossia ovalis, runs more or less parallel to the inguinal ligament about as far ats 1 he crest of the ilinm, where it culls in branches which anastomose with the derep airemuffex ilian atrtery.

In its course it gives off branches to the iliacus and sartorius muscles, to the inguinal glands, and to the fascia and skin. Its companion vein ends in the great saphenous vein just before the latter patsons through the fossa ovalis (sitphenous opening). 
(3) the external pudendal arteries [aa. pudendxe externæ], arise from the medial side of the femoral. Some of them pass either through the fascia lata, or

Fig. 497.-To show the Axastomoses of the Arteries of the Lower Extremitr,

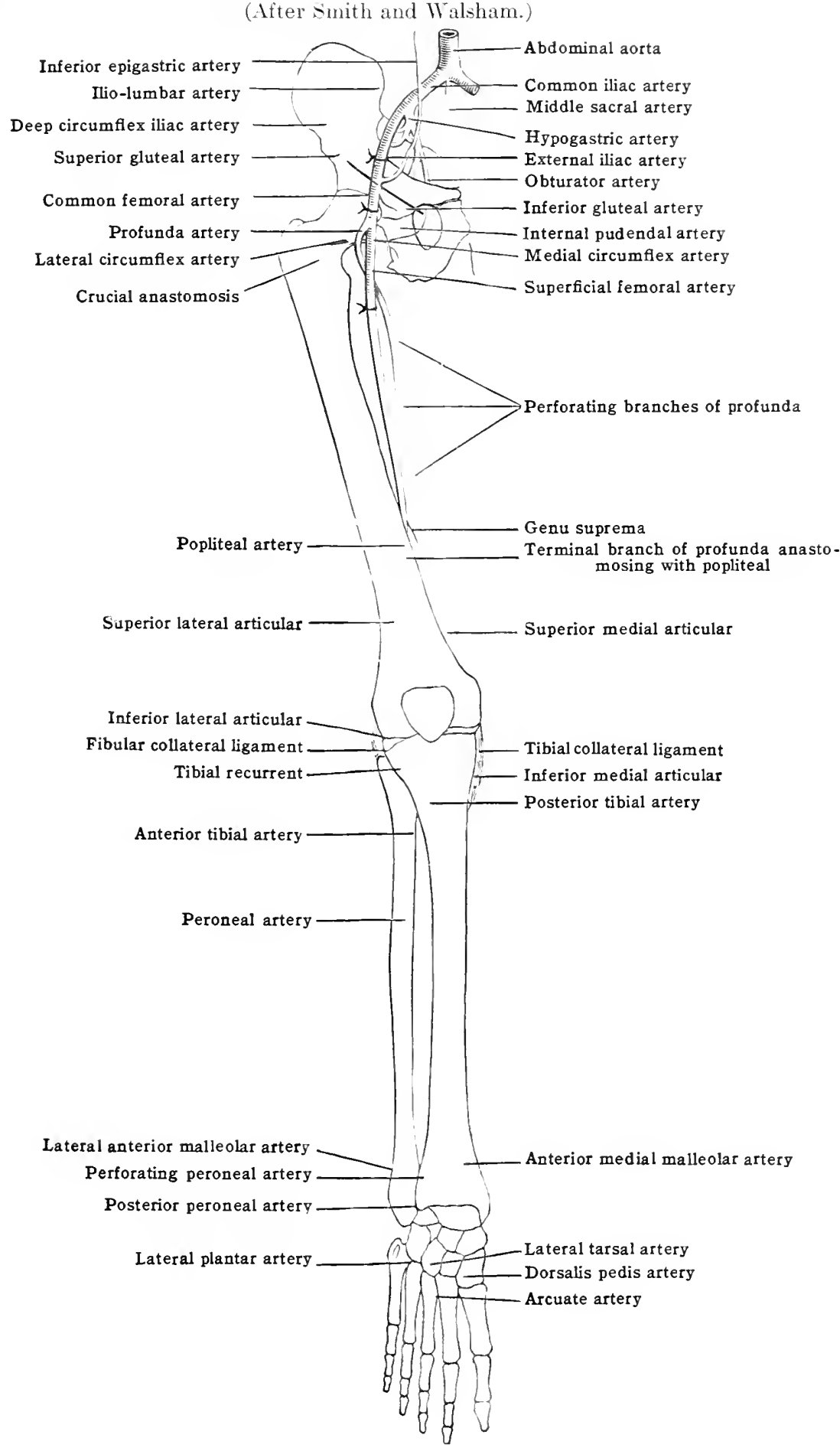

through the fascia covering the fossa ovalis (saphenous opening) and cross the spermatic cord in the male, or round ligament in the female, to reach and supply the integument above the pubes. One branch descends along the penis lateral 
to the dorsal artery, with which, and with the corresponding artery of the opposite side, it anastomoses at the corona. In the female, this branch terminates in the preputium clitoridis, anastomosing with the dorsal artery of the clitoris.

Other branches run medially beneath the deep fascia, across the pectineus and adductor longus muscles, and, perforating the fascia close to the ramus of the pubis, supply the skin of the scrotum or the labium majus, in the female [aa. scrotales or labiales anteriores] anastomosing with the posterior serotal or labial branches of the perineal artery. The external pudendal supplies small twigs to the pectineus and adductor muscles. Its companion veins terminate as a single trunk in the great saphenous.

(t) The inguinal branches [rami inguinales], a series of five or six small branches arise a short distance below the inguinal ligament. They supply the subinguinal lymph-nodes, and the skin and muscles in this region.

(5) The profunda artery [a. profunda femoris] (figs. 496, 497), is the chief nutrient ressel of the thigh. It is usually given off from the back and lateral part of the common femoral, about $4 \mathrm{~cm}$. ( $1 \frac{1}{2} \mathrm{in}$.) below the inguinal (Poupart's) ligament. At first it is a little lateral to the femoral, but as it runs downward and backward it gets behind that artery and closer to the bone. On reaching the upper border of the adductor longus muscle, it leaves the femoral, and, passing beneath the muscle, pierces the adductor magnus. Finally, much reduced in size, it ends in the hamstraing muscles, anastomosing with the third perforating and muscular and articular branches of the popliteal.

Relations.-Behind, the artery lies successively upon the iliacus, the pectineus, the adductor brevis, and adductor magnus muscles. In front, at first it is superficial, being merely covered by the skin, superficial and deep fasciæ, and branches of the femoral (anterior crural) nerve; but as it sinks behind the femoral artery, it has in front of it both the femoral and the prof unda veins and lower down the adductor longus muscle. Laterally is the femur at the angle of union of the adductors longus and brevis. Medially is the pectineus at the upper part of its course.

Branches of the profunda.- The profunda gives off the following branches:(a) The lateral circumflex; $(b)$ the medial circumflex; and $(c)$ the three perforating. The termination of the artery is sometimes called the fourth perforating branch.

(a) The lateral circumflex [a circumflexa femoris lateralis] a short trunk, but the largest in diameter of the branches of the artery, arises from the lateral side of the profunda as it lies on the iliacus muscle, about $2 \mathrm{~cm}$. ( $\frac{3}{4} \mathrm{in}$.) below the origin of that vessel from the femoral. It passes in a transversely lateral direction over the iliacus, under the sartorius and rectus, and between the branches of the femoral (anterior crural) nerve. In this course it gives off branches to the rectus and vastus intermedius (crureus), and then divides into two chief sets of branches-ascending and descending.

The ascending branch [ramus ascendeus] either breaks up at once into numerous branches or it may arise as several vessels some of which are apt to come from the profunda itself or even from the femoral. These run upward under the sartorius and tensor facia latæ or laterally under the rectus femoris. The highest branches reach the gluteus medius and minimus and anastomose with the gluteal and deep circumflex iliac arteries; one branch runs beneath the rectus femoris to the hip-joint, and the others cross the vastus intermedius and pierce the vastus lateralis to anastomose with the first perforating and the medial eircumflex.

'The descending branches [rami descendentes] l'un directly downward along with the nerve to the vastus lateralis musele. They lie beneath the rectus muscle and on the vastus intermedius (crureus) or vastus lateralis, some of them heing just under cover of the anterior edge of the latter inuscle. They are distributed to the vastus lateralis, vastus intermedius, and rectus, one branch usually runing along the anterior border of the vastus lateralis as far as the knee-joint, where it anastomoses with the superior lateral articular branch of the popliteal (fig. 499); another, entering the vastus intermedius, anastomoses with the termination of the profunda and with the genu suprema (anastomotica magna).

(b) 'The medial circumflex artery [a. circumflexa femoris medialis] comes off from the baek and medial aspect of the profunda artery on about the same level as the lateral circumflex; sometines as a common trunk with that vessel. $A$ s it winds around the medial side of the femur to reach the region of the trochanters, it lies successively, first, between the psoas and pectineus, then between the ol,urator externus and adductor brevis; finally, between the adductor magnus and guadratus femoris, where it anastomoses with the lateral circmuflex, with the inferior grluteal (sciatice), and with the suprerior perforating, forming the so-called crucial anastomosis. Thile still in the femoral trencone it gives off a superfieial branch [r. superficialis] which runs in a transversely medial dirention to sipply the pectinens adduetor longus and brevis, and the gracilis. The remainder of the artery is designated as the deep braneh [r. profundus]. An acetalmilar lorinch |r. accialuli| courses upward beneath the fendon of the psoas, and enters the lip-joint beneath the transverse ligament, and, together with the articular branch of the obturator, supplies the fatty tissue in the acetalulum, and sends branches to the synovial membrane. 'The medial circumflex veins join the profundis vein.

(c) The perforating arteries of the profunda are so called because they perforate, in a more or less regular manner from alove downward, certain of the adductor muscles. 'They form a series 
of loops by anastomosing with one another (fig. 497), and with the superior gluteal, medial circumflex, and inferior gluteal arteries above, and with the muscular and articular branches of the popliteal below. They are distributed chiefly to the hamstring muscles, but send twigs along the lateral intermuscular septum to supply the integuments at the back and lateral parts of the thigh. Other branches perforate the lateral intermuscular septum and the short head of the biceps, and, entering the vastus intermedius (crureus) and vastus lateralis, anastomose with the descending branch of the lateral circumflex. All the perforating arteries, moreover, contribute to reinforce the artery of the sciatic nerve, a branch of the inferior gluteal (sciatic) artery. They are each accompanied by two veins which terminate in the profunda.

The first perforating artery [a. perforans prima] is given off from the profunda as that vessel sinks beneath the adductor longus. It either pierces the adductor brevis, or else runs between the pectineus and adductor brevis, and then passes through a small aponeurotic opening in the adductor magnus close to the medial lip of the linea aspera. In this course it supplies branches to the adductors, and, after perforating the adductor maguus, is distributed to the lower part of the gluteus maximus and the hamstring muscles, one branch commonly running upward beneath the gluteus maximus to anastomose with the lateral circumflex, medial circumflex, and inferior gluteal (sciatic) arteries, forming the crucial anastomosis at the junction of the neck of the femur with the great trochanter (fig. 497). A second branch descends to anastomose with the ascending branch of the second perforating.

The second perforating artery [a. perforans secunda] which is given off from the profunda as it lies behind the adductor longus, pierces the adductor brevis, and then passes through a second aponeurotic opening in the adductor magnus a little below that for the first perforating artery, and also close to the linea aspera. It supplies the hamstring muscles, sends a branch upward to anastomose with the descending branch of the first perforating, and another downward to anastomose in like manner with the ascending branch of the third perforating.

The third perforating artery [a. perforans tertia] also arises from the profunda as it lies under the adductor longus, usually about the level of the lower border of the adductor brevis. It turns beneath this border, and then, like the first and second perforating, passes through an aponeurotic opening in the adductor magnus close to the linea aspera. It also supplies the hamstring muscles, and divides into two branches, which anastomose above with the second perforating, and below with the termination of the profunda.

Two nutrient arteries to the femur [aa. nutritiæ femoris superior et inferior] arise from the perforating arteries. The superior generally arises from the first perforating, the inferior usually from the third.

(6) The muscular branches [rami musculares], of the femoral artery supply the sartorius, the rectus, the vastus medialis, the vastus intermedius (crureus), and the adductor muscles.

(7) The genu suprema (or anastomotica magna) arises from the front and medial side of the femoral just before the latter perforates the adductor magnus muscle, and almost immediately divides into branches, $(a)$ saphenous, $(b)$ muscular, and $(c)$ articular. These branches may sometimes come off separately from the femoral.

(a) The saphenous branch [a. saphena] pierces the aponeurotic covering of the adductor canal, passes between the sartorius and gracilis muscles along with the saphenous nerve, and, perforating the deep fascia, supplies the skin of the upper and medial side of the leg and anastomoses with the inferior medial articular branch of the popliteal and the other vessels forming the plexus or rete at the medial side of the knee. In its course it gives twigs to the lower part of the sartorius and gracilis muscles.

(b) The muscular branches [rr. musculares] run downward in front of the adductor magnus tendon, burrowing amongst the fibres of the vastus medialis as far as the medial condyle. They break up into numerous twigs which supply the lower ends of the vasti muscles and adductor magnus. One branch runs laterally across the lower end of the femur to end in the vastus lateralis.

(c) The articular branches [rr. articulares] come off from the saphenous and muscular branches and enter the arterial rete on the medial and lateral sides of the knee. They anastamose with the medial and lateral superior articular branches of the popliteal and the anterior tibial recurrent and, like other vessels of the rete, supply branches to the joint.

\section{THE POPLITEAL ARTERY}

The popliteal artery [a. poplitea] (fig. 498) runs through the popliteal space or ham. It is a continuation of the iemoral, and extends from the aponeurotic opening in the adductor magnus at the junction of the middle with the lower third of the thigh to the lower border of the popliteus muscle, where it terminates by dividing into the anterior and posterior tibial arteries. This division is on a level with the lower border of the tuberosity of the tibia. As the artery passes through the opening in the adductor magnus, it is accompanied by the popliteal vein, and at times by the branch of the obturator nerve to the knee-joint. The vein throughout is behind the artery, at first lying a little lateral to it, but as the vessels pass through the popliteal space the vein crosses obliquely orer the artery, 
and at the termination of the artery lies a little to its medial side. The tibial (internal popliteal) nerve is superficial to both artery and vein. As it enters the space it is well to the lateral side of the vessels, but as it descends it gradually approaches them, crosses behind them, and at the lower part of the space lies to their medial side. The artery in the whole of its course is deeply placed and covered by a considerable amount of fat and cellular tissue.

Relations (fig. 498).-In front, the artery lies successively on the popliteal surface of the femur (from which it is separated by a little fat and sometimes one or two small glands); on the posterior ligament of the knee; on the hinder edge of the articular surface of the head of the tibia; and on the popliteus muscle. From the latter muscle it is separated by the expansion from the semi-membranosus which covers the muscle, and is attached to the popliteal line on the tibia.

Behind, the artery is covered, above by the semi-membranosus; in the centre of the space by the skin, superficial and deep fascia; and below, by the medial head of the gastrocnemius. The popliteal vein is behind it in the whole of its course. The tibial (internal popliteal) nerve crosses behind it obliquely, from the lateral to the medial side, about the centre of the space. As the artery divides into the anterior and posterior tibial, it is erossed by the aponeurotic areh of the soleus which stretches between the tibial and fibular origins of that muscle.

To the medial side are the semi-membranosus above, and the medial head of the gastroenemius and the tibial (internal popliteal) nerve below.

To the lateral side are the biceps and the tibial (internal popliteal) nerve above, and the lateral head of the gastrocnenins and the plantaris below.

\section{Branches of the Popliteal Artery}

The branches of the popliteal include the following:-(1) the sural; (2) the articular; and (3) the terminal.

(1) The sural arteries [aa. surales] arise irregularly from the popliteal and supply the muscles of the calf, sending branches upward to the muscles bounding the upper part of the popliteal space. From the sural arteries also arise the superficial sural or cutaneous branches which pass downward between the two hearls of the gastrocnemius, and, perforating the deep fascia, supply the skin and fascia of the ealf. A branch, usually of moderate size, accompanies the small saphenous vein, and is sometimes called the posterior saphenous artery.

(2) The articular, five in number, are divided into two superior (medial and lateral), two inferior (medial and lateral), and the middle or azygos. The superior and inferior come off transversely in pairs from either side of the popliteal, the superior above, the inferior below the joint. Winding round the bones to the front of the knee, they form - by anastomosing with each other and with the genu suprema (anastomotica magna), the termination of the profunda, the descending branch of the lateral circumflex, and the anterior tibial recurrent-a superficial and (leep) arterial rete (fig. 499). The superfieial anastomosis or rete lies betwern the skin and fascia round about the patella (patellar rete), which it supplies, the larger branches cutering it from above. The rleep anastomosis or articular rete [rete articularis genu] lies on the surface of the bones around the articular surfaces of the femur and tibia, supplying branches to the contiguous bones and to the joints. The midlle articular is a single short trunk coming off from the deep surface of the popliteal artery. It at once passes through the posterior lignment inte the joint.

(a) The superior lateral articular artery [at. genu superior lateralis], the larger of the two

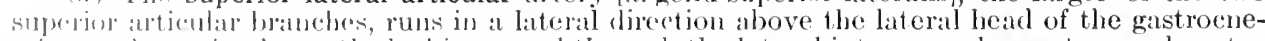
mius, and, passing beneath the bireps and though the lateral intermuscular septum and vastus

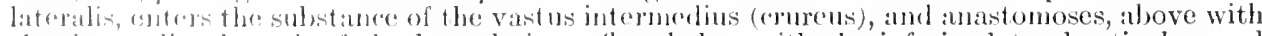

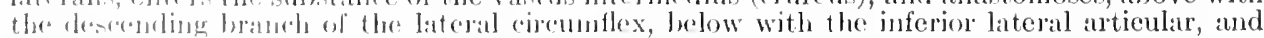

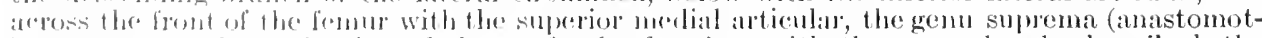
ir:a matgra), and topmination of the pofmula, forming with them, as alrealy described, the

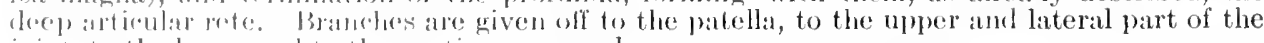
joint, to the lumu, and to the contiguous muscles.

(ii) The superior medial articular artery [a, genu superior medialis] (fig. 199) runs medlially

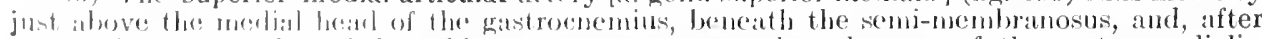

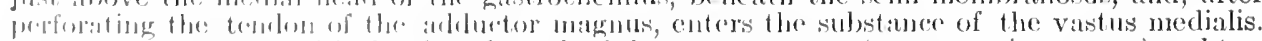

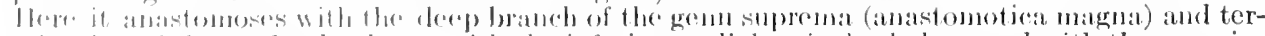

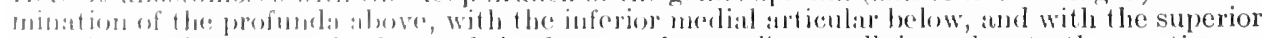

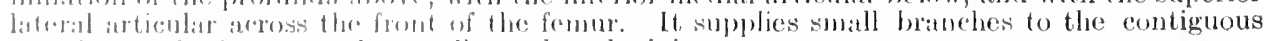

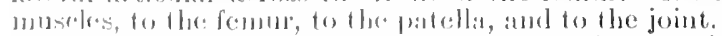

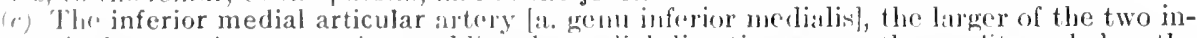

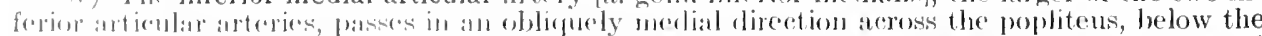
modial comely (tuherosity) of the filia and beneath the tibial collateralligannent to the fromt and 
medial side of the knee-joint. Here it anastomoses (fig. 499), above with the superior medial articular and the superficial branch of the genu suprema (anastomotica magna), and across the front of the tibia with the inferior lateral articular. It supplies branches to the lorer and medial part of the joint.

$(d)$ The inferior lateral articular artery [a. genu inferior lateralis] passes laterally above the head of the fibula, along the tendon of the poplitens muscle, beneath the lateral head of the gastrocnemius, and then under the tendon of the biceps, and between the long and short fibular

Fig. 49S.-Relations of the Popliteal Artery to Bones and Muscles, Left side.

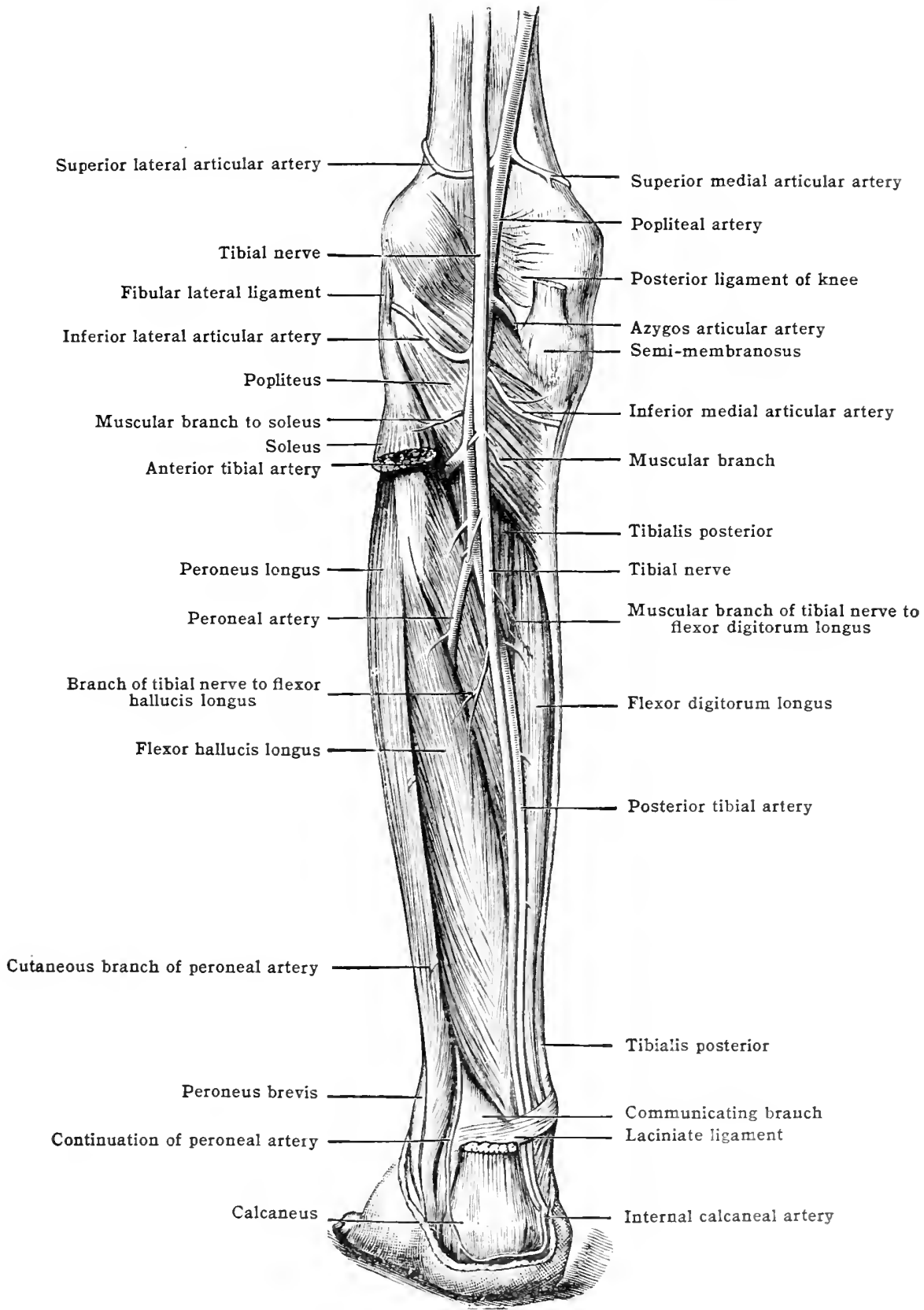

collateral ligaments. Then winding to the front of the joint, it anastomoses above with the superior lateral articular, below with the anterior tibial recurrent, and across the front of the tibia with the inferior medial articular. It also supplies branches to the lateral and lomer part
of the joint.

(e) The middle or azygos articular artery [a. genu media] arises from the deep surface of the popliteal artery, and passes, with the articular branch of the obturator nerve, through the 
popliteal ligament, directly into the knee-joint, where it supplies the crucial ligaments, and the patellar synovial and alar folds. It anastomoses with the intrinsic branches of the other articuJar arteries.

(3) The terminal branches of the popliteal are the posterior and the anterior tibial arteries.

Fig. 499.-The Anastomosis abodt the Left Knee-joint. (Walsham.) (Semi-diagrammatic.)

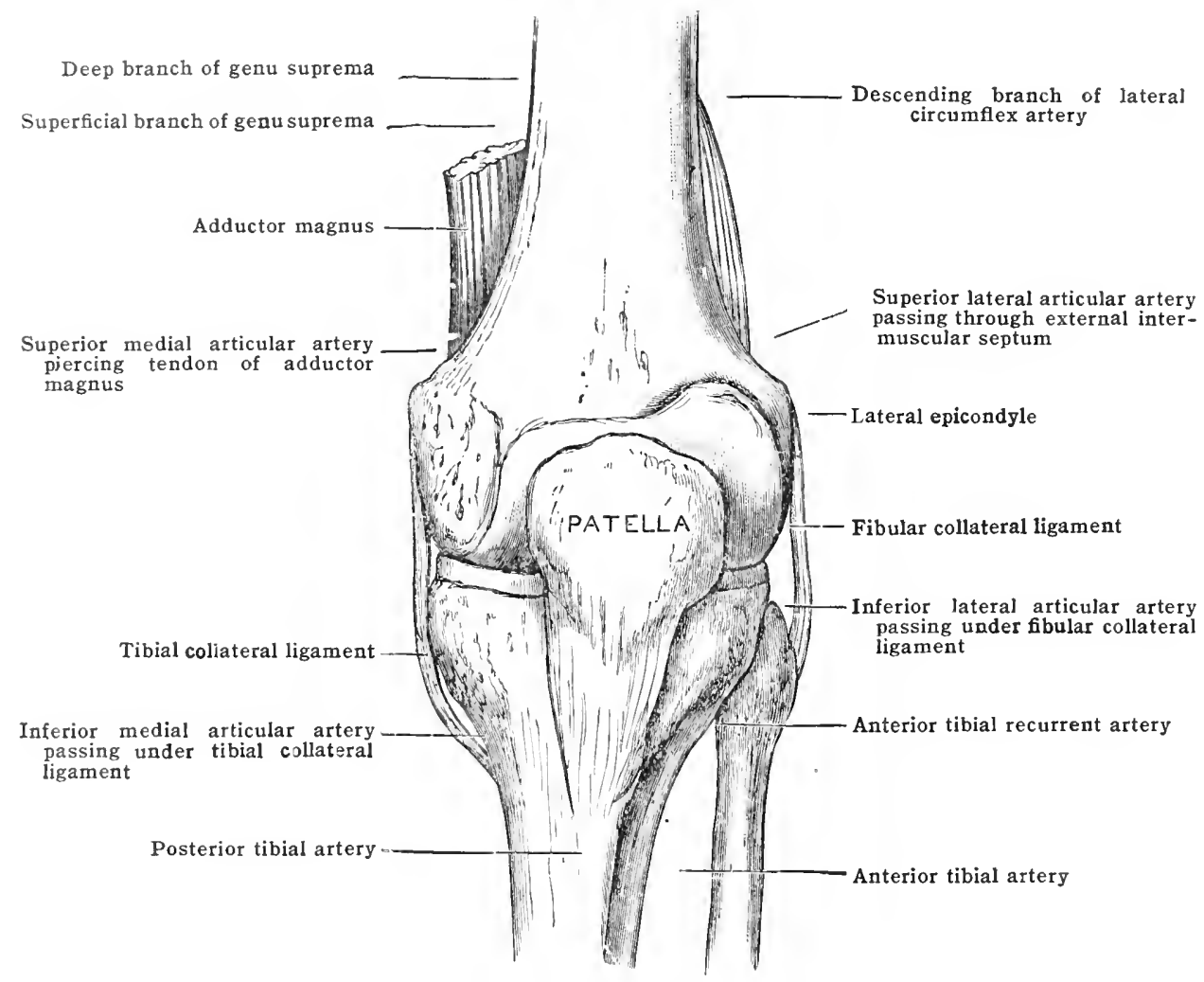

\section{THE POSTERIOR TIBIAL ARTERY}

The posterior tibial artery [a. tibialis posterior] (fig. 500), the larger of the two branches into which the popliteal divides at the lower border of the popliteus muscle, runs downward on the flexor aspect of the leg between the superficial and deep muscles to the back of the medial malleolus. Midway between the tip of the nalloolus and the calcancus, and under cover of the origin of the abductor hallucis as it arises from the laciniate (internal annular) ligament, it divides into the nnedial and lateral plantar arteries.

The artery is first situated midway between the tibia and fibula, and is deeply placed beneath the muscles of the calf. As it passes downward it inclines to the medial sidn and at the lower third of the leg is superficial, being only covered by the skin anrl fasciae. At the ankle it lies beneath the laciniate ligament, and at its bifurcation also bencath the abductor hallucis. A line drawn from the centre of the poplituis spuere to a spot midwily between the medial malleolus and point of the hecel will indicute its course. In addition to the branches named below it supplies the inuscles between which it passes, and the integument of the lower medial region of the leng.

Relations. - Anteriorly, from above downward, it lies successively on the tibialis posterior, the flexor thigitorun longus, the posterior surface of the tibia, and the deltoid ligament of the ankle-joint.

Posteriorly, it is covered by the skin and fascia, the gastrocnemius and soleus, and the deep or intermascular fascin of the leg, by which it is tightly bound down to the mulderlying muscles. It is crosserl by the tibial nerve about 4 ('m). (13 in.) below its origin, after it has given off its 
peroneal branch; the nerve first lies on the medial, and for the rest of its course on the lateral side of the vessel. It is accompanied by two veins, which send numerous anastomosing branches across it. In the lower third of the leg the artery is superficial, being covered only by the skin and-by the superficial and deep fascix.

Fig. 500.-The Popliteal, the Posterior Tibial, and the Peroneal Arteries. (After Toldt, "Atlas of Human Anatomy," Rebman, London and New York.)

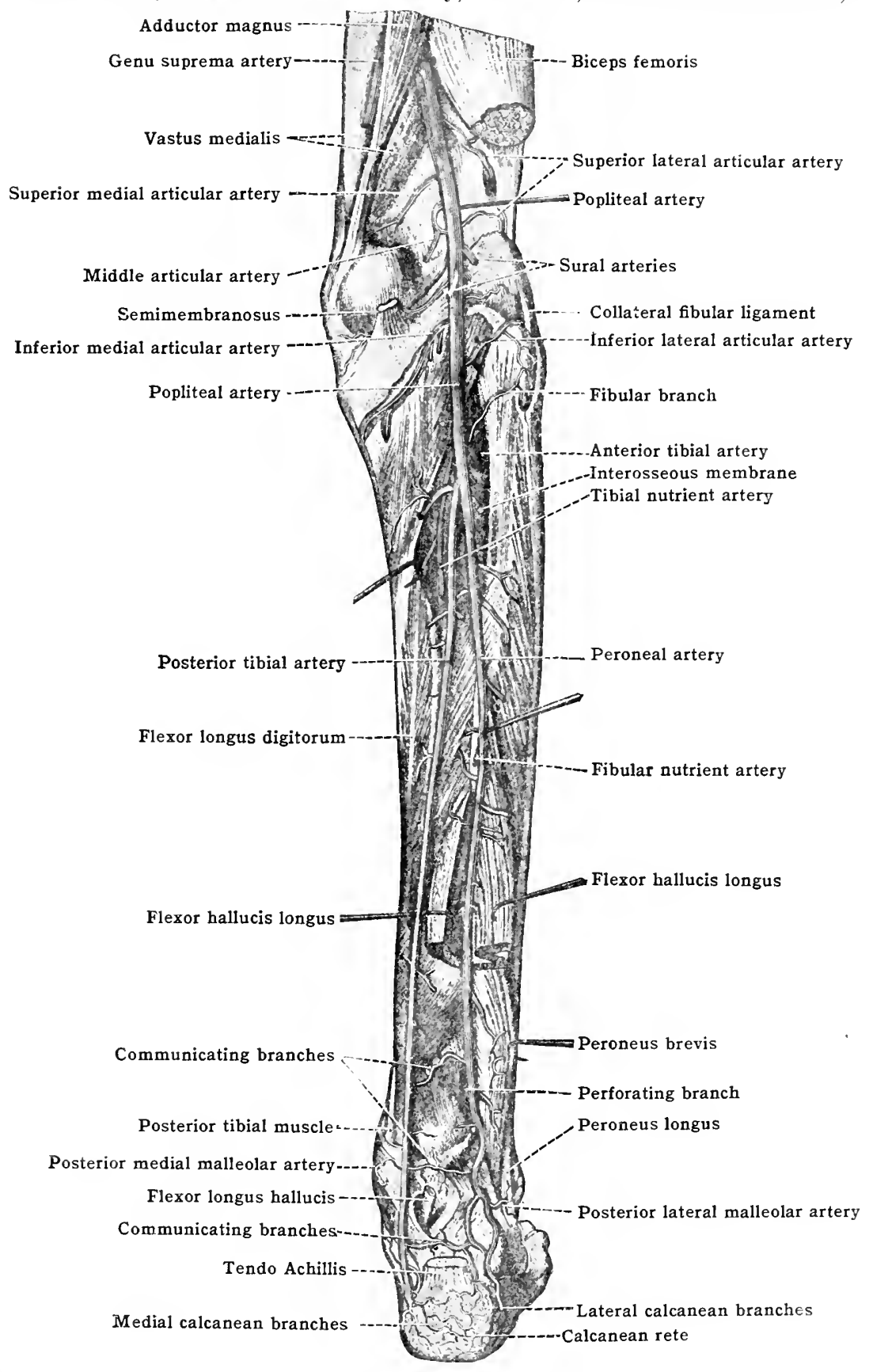

At the medial malleolus it lies beneath the laciniate (internal annular) ligament and abductor hallucis upon the deltoid ligament of the ankle-joint. Here it has the tibialis posterior and flexor digitorum longus in front of it, and the tibial nerve and the flexor hallucis longus behind and to its lateral side.

At times the tibial nerve divides higher than usual, when one branch lies on the medial side of the artery and the other branch on the lateral side. 
The branches of the posterior tibial artery are:-(1) The fibular; (2) the peroneal; (3) the tibial nutrient; (4) the communicating; (5) the posterior medial malleolar; (6) the medial calcanean, and (7) the terminal, medial and lateral plantar.

(1) The fibular or superior fibular branch [ramus fibularis], which frequently arises from the beginning of the anterior tibial, runs upward and laterally toward the head of the fibula. It is small and gives twigs to the soleus, peroneus longus, and extensor digitorum longus, and anastomoses with the inferior lateral articular and the lateral sural arteries.

(2) The peroneal artery [a. peronea] is a large vessel which (figs. 498, 500), arises from the posterior tibial about $2.5 \mathrm{~cm}$. ( $1 \mathrm{in}$.) below the lower border of the popliteus muscle. At first forming a gentle curve convex laterally, it approaches the fibula, and continues its course downward close to that bone as far as the lower end of the interosseous membrane, where it gives off a large branch, the perforating (anterior peroneal), and then, passing over the back of the inferior tibio-fibular joint, terminates by breaking up into a network, which is distributed over the back of the lateral malleolus and lateral surface of the calcaneus (figs. 500, 504). It is accompanied by two venæ comitantes. Besides the named branches it supplies twigs to the flexor hallucis longus, tibialis posterior, tibialis anterior, peronei and soleus; also to the integument on the lateral side of the leg.

Relations.-At its upper part it is deeply placed between the tibialis posterior and soleus muscles, and beneath the deep or intermuscular fascia. For the rest of its course to the ankle it lies beneath, or sometimes in the substance of, the flexor hallucis longus in the angle between the fibula and interosseous membrane. After giving off the perforating branch, it is only covered, as it lies behind the tibio-fibular articulation, by the integuments and deep faseia, and in this part of its course is sometimes called the posterior peroneal.

The branches of the peroneal artery are:- $(a)$ The perforating (anterior peroneal); (b) the fibular nutrient; $(c)$ the communicating; $(d)$ the lateral malleolar; $(e)$ the lateral calcanean; and $(f)$ the terminal.

(a) The perforating (or anterior peroneal) branch [ramus perforans] arises from the front of the peroneal artery at the lower part of the interosseous space, and, passing through the interosseous membrane, runs downward over the front of the inferior tibio-fibular joint, beneath the peroneus tertius, and supplies this muscle and the inferior tibio-fibular joint. It anastomoses with the tarsal, arcuate (metatarsal) and lateral malleolar branches of the anterior tibial artery, and with the lateral plantar artery on the lateral side of the foot, forming a plexus over the ankle (fig. 503).

(b) The fibular nutrient [a. nutritia fibulæ] enters the nutrient foramen of the fibula.

(c) The communicating branch [ramus communicans] passes medially in front of the tendo Achillis to anastomose with the communicating branch of the posterior tibial. The usual situation of this communication is from 2.5 to $5 \mathrm{~cm}$. ( 1 to $2 \mathrm{in}$.) above the ankle-joint.

(d) The lateral posterior malleolar artery [a. malleolaris poster. lateralis] anastomoses on the lateral malleolus with the anterior lateral malleolar of the anterior tibial artery to form the lateral malleolar rete.

(e) The lateral calcaneal branches [rami calcanei laterales] come off from the peroneal below the point at which the perforating is given off, and are distributed over the lateral surface of the calcancus.

$(f)$ The terminal branch or posterior peroneal, the continuation of the peroneal artery, anastomoses with the other arteries distributed to the lateral malleolus and heel.

(3) The tibial nutrient artery [a. nutritia tibia], a vessel of large size, leaves the posterior tibial at its upper part, pierees the tibialis posterior, and enters the nutrient foramen in the 1upper third of the posterior surface of the tibia. In the interior of the bone it divides into two branches: an ascending or smaller, which runs upward toward the head of the bone; and a descending or larger, which courses downward toward the lower end. It gives off two or three musenlar twigs to the tibialis posterior before it enters the foramen. The nutrient artery of the tilin is the largest nutrient artery of bone in the body, and is accompanied by a nerve given off by the nerve to the poplitens.

(4) The communicating branch [ramus communicans] arises from the posterior tibial about is cri. (2 in.) above the medial malleolus, and, passing transversely aeross the tibia beneath the flexor hallucis longus and tendo Achillis, anastomoses with the communicating branch of the peroneal.

lrepunstly an inferior eommmicating branch between the posterior tilsial and peroneal arteries is likewiks present in the loose connective tissue beneath or behind the tendo Achillis.

(5) The posterior medial malleolar branch [ramus malleolaris posterior medialis] divides for distribution ow.r thr merlial malleolus, anastomosing with the other arteries entering into the modial mallowar rete [rete malleolare nediale] which is formed over the portion of bone. In its course to the malleolus it rums beneath the flexor digitorum longus and tibialis posterior muscles.

(6) The medial calcanean branches [rani calcanei mediales] are distributed to the soft parts over the ancerdial sirle of the ealcaneus. These branches come off from the posterior tibial just hefore its bifureation, and anastomose with the medial malleolar and peroneal arteries.

(7) The terminal branches are the lateral and medial plantar arteries. 


\section{THE LATERAL PLANTAR ARTERY}

The lateral plantar artery [a. plantaris lateralis] (figs. 501, 502) 一 the larger of the two branches into which the posterior tibial divides beneath the laciniate (internal annular) ligament-passes at first laterally and forward across the sole of the foot to the base of the fifth metatarsal bone, where it bends medially, and still running forward sinks deeply into the foot and terminates at the proximal end of the first interosseous space by anastomosing with the deep plantar (communicating) branch of the dorsal artery of the foot. In its course to the fifth metatarsal bone the artery runs in a more or less straight line obliquely across the foot; whilst its deep portion, extending from the fifth metatarsal bone to the proximal

Fig. 501.-The Plantar Arteries, Left Foot.

(From a dissection in the Museum of St. Bartholomew's Hospital.)

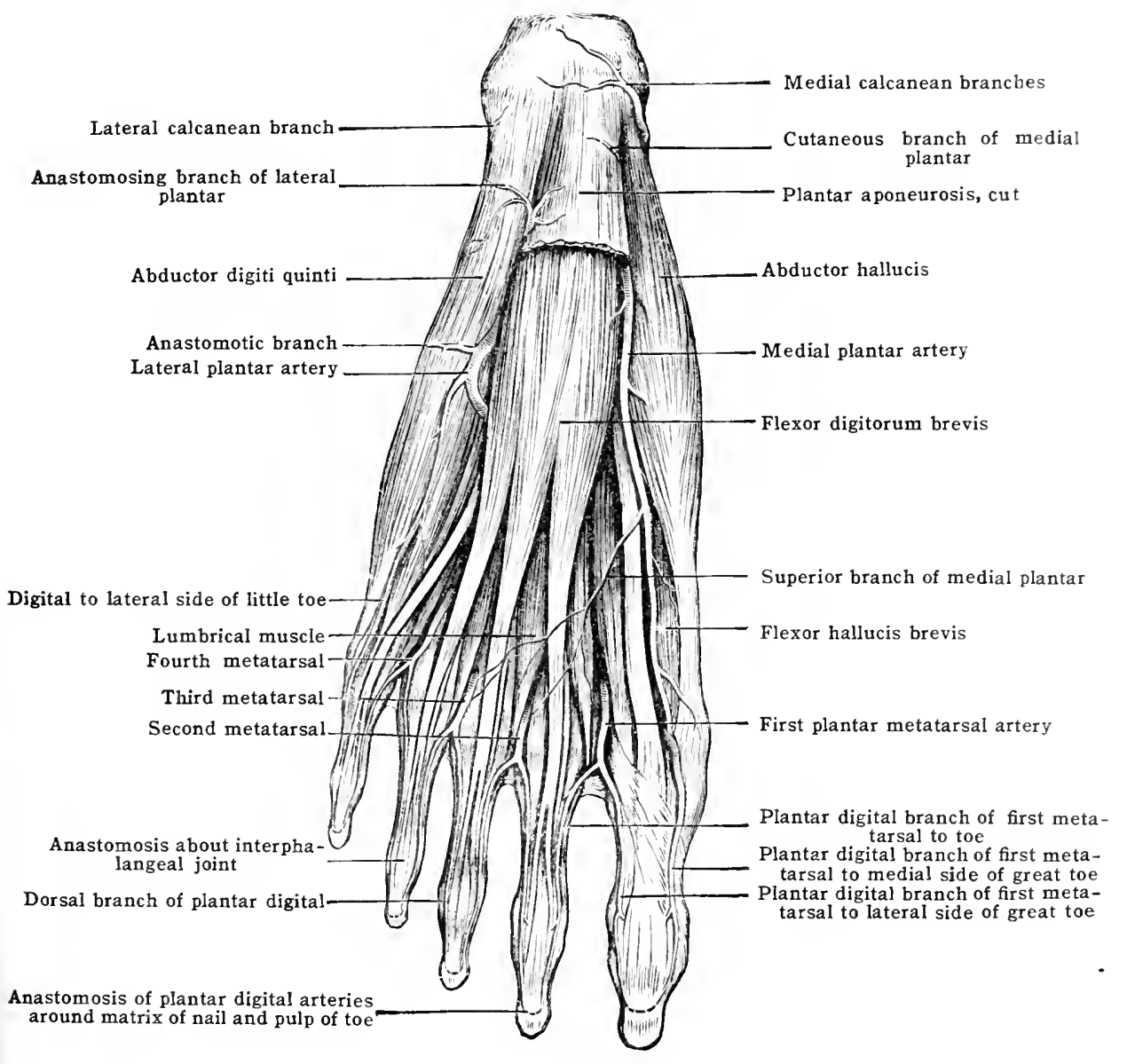

end of the first interosseous space, forms a slight curve with the convexity forward, and is known as the plantar arch. The plantar arch is comparable to the deep volar arch formed by the deep branch of the ulnar anastomosing with the radial through the first interosseous space. This homology is at times more complete in that the deep plantar (communicating) branch of the dorsalis peclis, the homologue of the radial in the upper limb, takes the chief share in forming the arch. The lateral plantar artery is accompanied by two veins. The course of the artery is indicated by a line drawn across the sole of the foot from a point midway between the tip of the medial malleolus and the medial tubercle of the calcaneus to the base of the fifth metatarsal bone, and thence to the lateral side of the base of the first metatarsal.

The lateral plantar artery, besides the branches named below gives twigs to supply the muscles between which it passes, and the tarsal joints. It also gives 
branches to the integument of the lateral side of the sole, some of which anastomose with arteries on the lateral side of the dorsum.

Relations. - In the first part of its course from the medial malleolus to the base of the fifth metatarsal hone, the artery is covered successively by the abductor hallucis and the flexor digitorum brevis, by which it is separated from the plantar aponeurosis, and may be slightly overlapped in muscular subjects by the abductor quinti digiti. As it approches the base of the fifth metatarsal bone it lies, as it turns medially before sinking into the foot, in the interspace between the flexor digitorum brevis and the abductor quinti digiti, and is here covered only by the skin and superficial fascia and the plantar aponeurosis. It lies upon the calcaneus, the quadratus plantæ (flexor accessorius), and the flexor digiti quinti brevis. It is accompanied by the lateral plantar nerve, the smaller of the two divisions into which the tibial nerve divides. In this part of its course it gives off small branches to the contiguous muscles and to the heel.

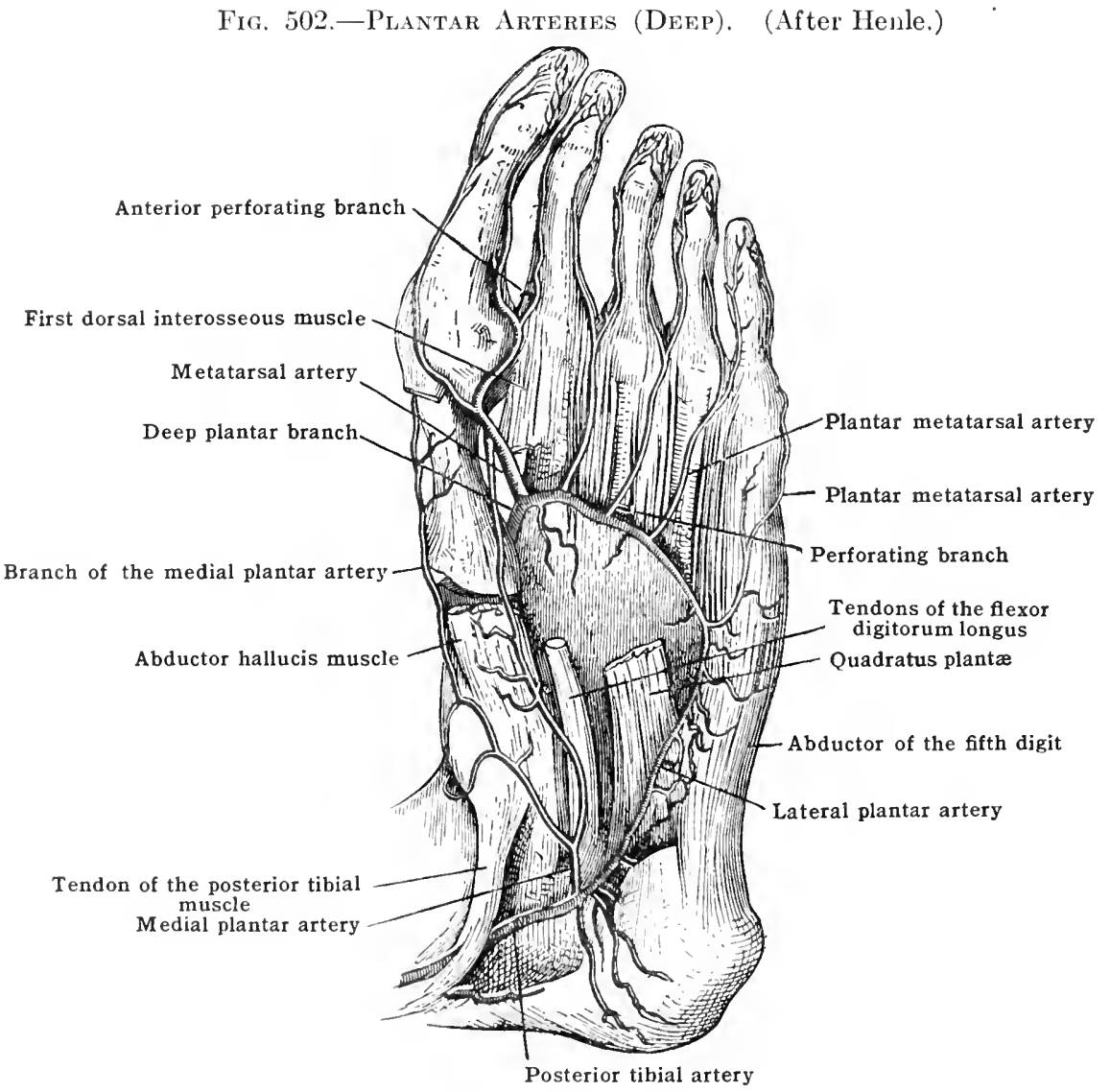

In the second part of its course the artery, which is here known as the plantar arch larcus plantaris], sinks into the sole, and is covered, in addition to the skin, superficial fascia, plantar aponemresis, and flexor digitorum brevis by the tentons of the flexor digitorum longus, the lumbricales, branches of the medial plantar nerve, and the adductor hallucis. It lies upon the proximal culs of the second, third, and fourth motatarsal bones and the eorresponding interosseous museles.

The branches of the lateral plantar artery are:-(1) Perforating; and (2) plantar mentataral (digital).

(1) The perforating branches [rr. performites], thrce in numbers, ascend through the proximal end of the second, thirl, and fourth spares, between the two heads of the correspondingly named dorsal interosseous muscles, and communicate with the proximal ends of the first, ferond, and third dorsal metatarsal (interosseous) arteries (fig. 502).

(2) 'The plantar metatarsal arteries [at. metatamea plantares] are usuatly four in number, and piss forward in the four intermetatamal spares, which are numbered from the medial side. They rest ujon the interosseous museles of their spates, and ane at first moler cover of the lumbrieals, hit as they apuroarh the clefts of the toes cach divicles into two brameloes, the plantar digital arteries [aid. digitales plantares], which supply the contiguous sides of the toes. The plantar digital branch for the merlial side of the great toe is usually given off by the first plantar metatarsal; that for the lateral side of the little toe is usually a separate branch from the lateral encl of thre plantar areh. 
The plantar metatarsal arteries, immediately before they bifurcate, send to the dorsum of the foot a perforating branch each to the corresponding dorsal metatarsal arteries. They anastomose by many small twigs with the dorsal metatarsal arteries, which also run along the sides of the metatarsal bones, but more toward the dorsal aspect. Immediately above each phalangeal joint the plantar digital vessels communicate by cross branches, forming a rete for the supply of the articular end of the phalanges and the contiguous joints. At the distal end of the toes they also freely anastomose with each other, forming a rete beneath the pulp and around the matrix of the nail. The metatarsal and digital arteries are each accompanied by two small veins.

\section{THE MEDLAL PLANTAR ARTERY}

The medial plantar artery [a. plantaris medialis] (figs. 501, 502)-much the smaller of the two divisions into which the posterior tibial divides, passes forward along the medial side of the sole of the foot usually to the first interosseous space. Here it ends by anastomosing either with the first plantar metatarsal artery derived from the plantar arch, or with the branch given off by the first plantar metatarsal to the medial side of the great toe.

Relations. - The artery is at first under cover of the abductor hallucis, but afterward hes in the interval between that muscle and the flexor digitorum brevis. It is covered by the skin and superficial fascia, but not by the plantar aponeurosis, since it lies between the central and medial portions of that structure.

The branches of the medial plantar are:-(1) The deep and (2) the superficial branches.

(1) The deep branch [ramus profundus], which at once divides-or it may come off as several branches - to supply the muscles, articulations, and integument of the medial side of the sole. Some of these branches form an anastomosis around the medial margin of the foot, with branches of the dorsalis pedis.

(2) The superficial branch [ramus superficialis] breaks up into very small twigs which accompany the digital branches of the medial plantar nerves, and anastomose with the plantar metatarsal arteries in the first, second, and third spaces. At times a twig from one of these branches joins the lateral plantar artery to form a superficial plantar arch.

\section{THE ANTERIOR TIBIAL ARTERI}

The anterior tibial artery [a. tibialis anterior] fig. 503-the smaller of the two branches into which the popliteal artery divides at the lower border of the popliteus muscle-at first courses forward between the two heads of origin of the tibialis posterior, and, after passing between the tibia and fibula above the upper part of the interosseous membrane, runs downward on the front and lateral aspect of the leg, between the anterior muscles, as far as the front of the ankle-joint. Below the joint it is known as the dorsalis pedis. The course of the vessel is indicated by a line drawn from the front of the head of the fibula to a point midway between the two malleoli.

The artery is accompanied by two veins which communicate with each other at frequent intervals across it. It is also accompanied in the lower three-fourths of its course by the deep peroneal nerve. The nerve, which winds round the head of the fibula, and pierces the extensor digitorum longus, first comes into contact with the lateral side of the artery about the upper third of the leg; in the middle third it is a little in front of the artery, and in the lower third again lies to its lateral side. In addition to the named branches the anterior tibial artery supplies muscular twigs to the extensors of the toes and the tibialis anterior.

Relations. - The artery at first lies in the triangle formed by the two heads of the tibialis posterior and the popliteus muscle; and, as it passes above the interosseous membrane, it has the tibia on one side and the fibula on the other. It is separated from the deep peroneal (anterior tibial) nerve at its commencement by the neck of the fibula and the extensor digitorum longus. This arrangement is homologous witi that met with in the forearm in the case of the posterior interosseous artery and deep radial (posterior interosseous) nerve.

Posteriorly in its course down the leg it lies in its upper two-thirds upon the interosseous membrane, to which it is closely bound by fibrous bands; and in its lower third upon the front of the tibia and the ankle-joint.

To its medial side along its upper two-thirds is the tibialis anterior muscle; but at the lower third it is crossed by the tendon of the extensor halhucis longus and then for the rest of its course has this tendon overlapping it or to its medial side.

On its lateral side it is in contact in its upper third with the extensor digitorum longus muscle; in its middle third with the extensor hallucis longus; but, as this muscle crosses to the medial side of the artery, the vessel usually for a very short part of its course comes again 
into contact with the extensor digitorum longus. At the upper and lower thirds of its course on the front of the leg the artery has the deep peroneal (anterior tibial) nerve to its lateral side.

In front the artery is covered by the skin, superficial and deep fascia. In its upper twothirds it is deeply placed in the cellular interval between the tibialis anterior on the medial side and the extensor digitorum longus and extensor hallucis longus on its lateral side; and in its lower third it is crossed in the latero-medial direction by the tendon of the extensor

Fig. 503.-The Anterior Tibial Artery, Dorsal Artery of the Foot, and Perforating (Anterior) Peroneal Artery, and their Branches, Left Side.

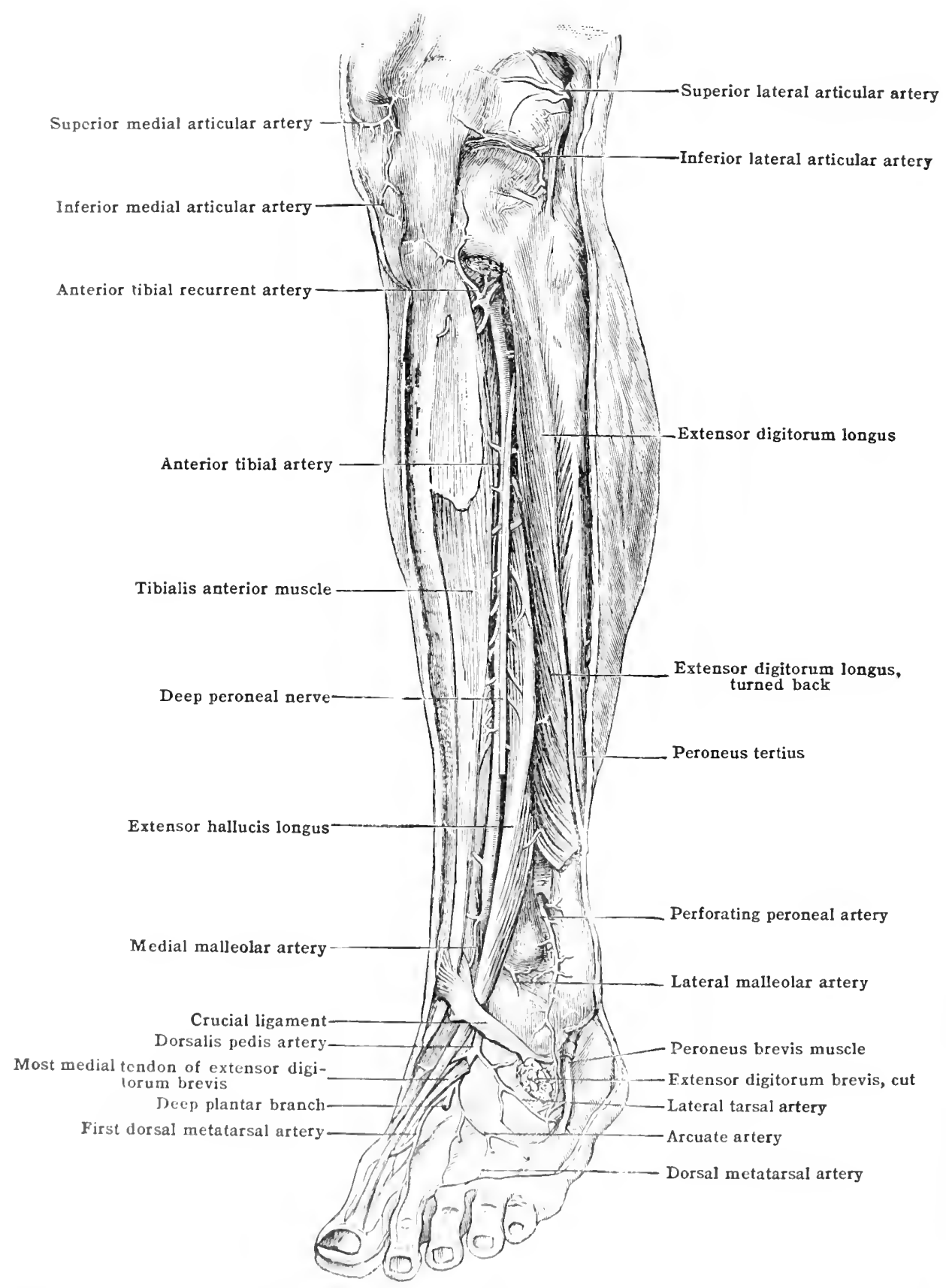

Inallucis longus, and lies bencath the cruciate (antwrior anmular) ligament of the ankle-joint 'lie deep peroneal nerve is usually in front of the artery in the middle third of the leg.

The branches of the anterior tibial artery are:-(1) The posterior tibial recurrent: (2) the anterior tibial recurrent; (3) the medial malleolar; and (4) the 
Fig. 504.-Scheme of the Distrdiution and Anastomoses of the Arteries of the Right Fоот. (Walsham.)

(The plantar arteries are shown in dotted outline; the dorsal in solid red.)

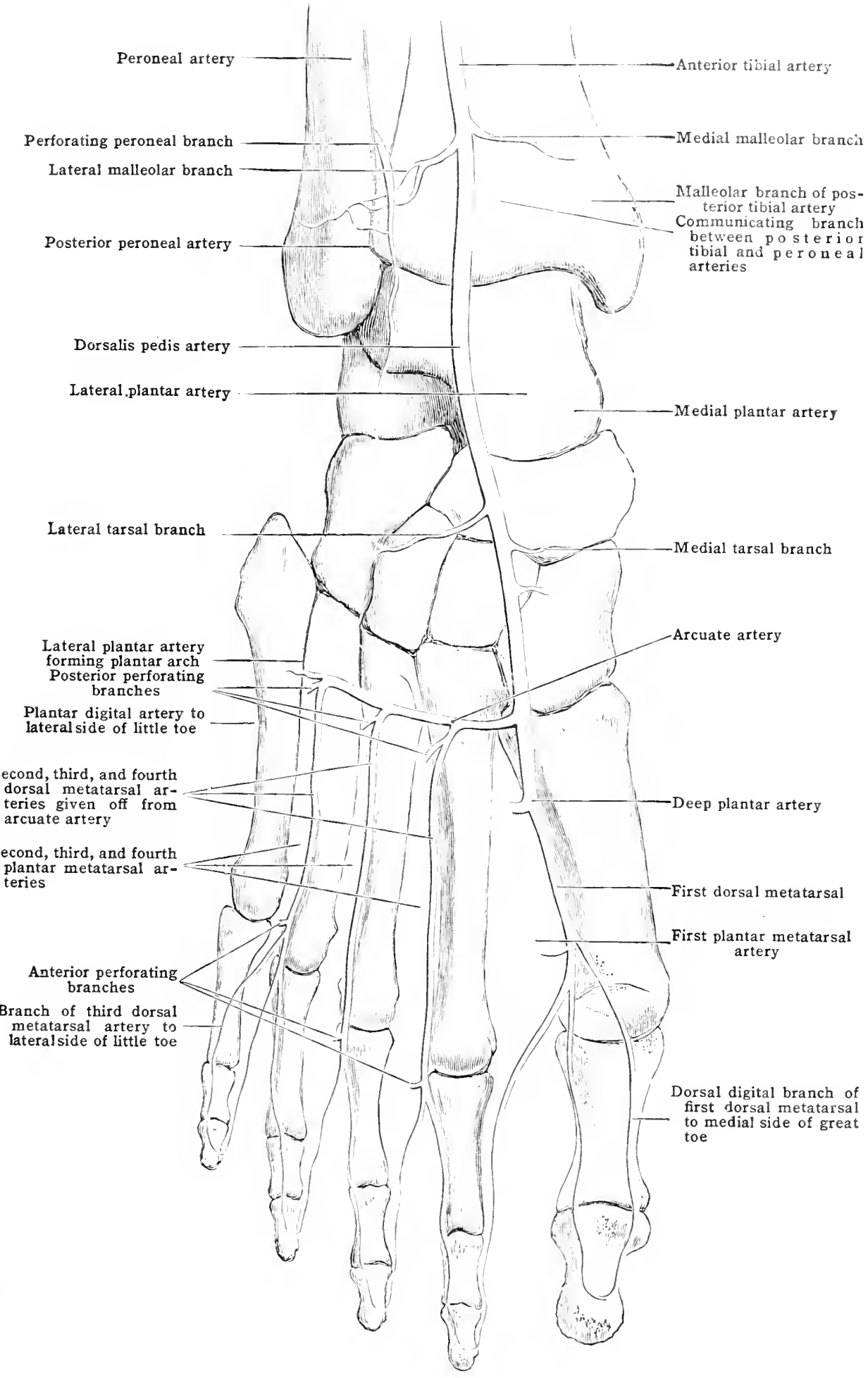


lateral malleolar. In addition, ten or twelve muscular branches are given off irregularly to the adjacent muscles along the artery.

(1) The posterior tibial recurrent artery [a. recurrens tibialis posterior] is occasionally absent. It ascends between the popliteus muscle and the popliteal ligament of the knee-joint, supplying these structures and the superior tibio-fibular joint. It anastomoses with the inferior lateral articular branch of the popliteal, and to a less extent with the inferior medial articular branch.

(2) The anterior tibial recurrent [a. recurrens tibialis anterior] is given off from the anterior tibial artery immediately after that vessel has passed above the interosseous membrane. It winds tortuously through the substance of the tibialis anterior muscle, over the lateral condyle (tuberosity) of the tibia elose to the bone; and, perforating the deep fascia, ramifies on the lower and lateral part of the capsule of the knee-joint. It anastomoses with the inferior and superior lateral articular branches of the popliteal, with the descending branch of the lateral circumflex, and somewhat less freely with the medial articular branches of the popliteal and with the genu suprema (anastomotica magna). It gives off small branches to the tibialis anterior, the extensor digitorum longus, the knee-joint, and the contiguous fascia and skin. It forms one of the collateral channels by which the blood is carried to the limb below in obstruction of the popliteal artery (fig. 503).

(3) The medial malleolar [a. malleolaris anterior medialis], the smaller of the two malleolar branches, arises from the lower part of the anterior tibial artery a little higher than the lateral, usually about the spot where the tendon of the extensor hallueis longus crosses the anterior tibial artery. It winds over the medial malleolus, passing beneath the tibialis anterior, and joins the medial malleolar rete anastomosing with branches from the posterior tibial artery.

(4) The lateral malleolar artery [a. malleolaris anterior lateralis], larger than the medial, arises from the lateral side of the anterior tibial artery, usually on a lower level than the medial malleolar. It winds downward and laterally round the lateral malleolus, passing beneath the extensor digitorum longus and peroneus tertius, and joins the lateral malleolar rete by anastomosing with the perforating peroneal, the termination of the peroneal, and the lateral tarsal branch of the dorsalis pedis (fig. 503).

The anastomosis between the lateral malleolar and perforating peroneal is sometimes of considerable size, supplying the blood to the dorsal artery of the foot; the anterior tibial, then much reduced in size, usually ends at the place of origin of the lateral malleolar.

\section{THE DORSALIS PEDIS ARTERY}

The dorsalis pedis artery [a. dorsalis pedis] (fig. 503) is a continuation of the anterior tibial. It extends from the front of the ankle-joint to the proximal end of the first interosscous space, where it ends, as the deep plantar branch, by joining the lateral plantar artery to complete the plantar arch. It is accompanied by two venx comitantes. The course of the artery is indicated by a line drawn from a point midway between the two malleoli to the proximal end of the first metatarsal space.

Relations.-Behind, the artery from above downward lies suceessively on the talus (astragalus), navicular, sceond cuneiform, and the base of the second metatarsal bones, and the ligaments uniting these bones. At times its course is a little more lateral, lying either partly on the second cuneiform bone, or on the dorsal ligaments uniting the second cuneiform to the first "unciform. It is more or less bound down to the bones by aponeurotic fibres derived from the deep fascia.

In front, the artery is eovered by the crucial (anterior annular) ligament, sometimes by the cxtensor hallucis longus, hy the skin, the superficial and deep fascia, and, just before its termination, by the tendon of the extensor hallucis brevis. The angle formed loy this tendon with the extensor hallucis longus is the best guide to finding the artery in the process of ligature (fig. 503).

To its lateral side is the most medial tendon of the extensor digitorum longus, and lower down the tenden of the extensor hallucis brevis. The deep peroneal (anterior tibial) nerve is also, fo its lateral side.

'T" its medial side is the extensor hallueis longus, except at times for aloout half an inch below, whers the temlon of the extensor hallucis brevis, having crossed the artery, may lie between it ind this tendon.

The branches of the dorsalis pedis artery are:-(1) The tarsal; (2) the areuat te; and (i, the de(e) platitiar.

(1) The tarsal branches may be divided into (a) the lateral and (b) the medial. (a) The lateral tarsal artrey la tarsea lateralis| runs latcrally over the navieular and cuboid bones beneath the extroser digitorum brevis. It supplies branclies to that muscle, and to the bones and the artionlations between them, and anastomoses above with the lateral malleolar and perforating (anterich) permeal, below with the arenate (metatursal) and, over the lateral border of the foot, with the anastomotic lnanches of the lateral plantar atery. (b) The medial tarsal arteries [at. tarsea: mediales] consists of a few small branches which run over the medial side of the foot, supplying the skin and articulations, and anastomose with the mexlial malleolar.

(i) The arcuate (metatarsal) artrery [at areuatal (figs. 503, 50.4) runs literally across the fout, in a slight curve with the convexity forwarl, over the bases of the metatamal lones, and bencath the extensor tendons and the cxtensor cligitormm brevis. At the lateral border of the fort it anastomoses, with the latral tarsal, amd with branches of the lateral plantar. 
From the convexity of the arch it gives off four dorsal metatarsal (intelosseous) arteries, which run forward on the dorsal interosseous muscles in the centre of the four interosseous spaces to the cleft of the toes, where they bifurcate for the supply of the contiguous sides of the toes. The artery to the first space is large, and gives off the digital artery to the medial side of the great toe. This vessel continues the direction of the dorsalis pedis and is commonly known as the dorsalis hallucis artery. The most lateral of the interosseous branches gives off a small vessel for the supply of the lateral side of the little toe. At the proximal end of the second, third, and fourth interosseous spaces each artery receives a perforating branch from the lateral plantar artery, and immediately before they bifurcate a second perforating artery through the distal end of the interosseous space from the corresponding digital.

The dorsal digital arteries [aa. digitales dorsales], into which the dorsal metatarsal arteries divide at the cleft of the toes, run along the side of each toe toward the dorsal aspect, anastomosing with each other across the dorsum of the toes and by frequent branches with the digital branches of the plantar metatarsal arteries, which also run along the sides of the toes, but nearer the plantar surface. At the end of the toes they anastomose with each other around the quick of the nail.

(3) The deep plantar branch [ramus plantaris profundus] comes off from the dorsalis pedis with the first dorsal metatarsal (into which arteries indeed the dorsalis pedis may be said to divide). At the back of the first interosseous space it dips into the sole between the two heads of the first dorsal interosseous muscle, and communicates with the termination of the lateral plantar artery, completing the plantar arch, in a manner similar to that in which the radial artery, passing through the first dorsal interosseous muscle in the hand, completes by anastomosing with the ulnar the deep palmar arch.

\section{MORPHOGENESIS AND VARIATIONS OF THE ARTERIES}

\section{A. ARTERIES OF THE HEAD AND TRLNK}

\section{MORPHOGENESIS}

In conformity with the branchiomeric and metameric development of the head and trunk (see p. 15) the arteries are developed in two sets, the branchiomeric (aortic arches) and metameric (segmental arteries).

Fig. 505.-Model of the Pharmx and Aortic Arches of a Human Eirbryo 5 ma. Long. (Tandler, $\times 75$.)

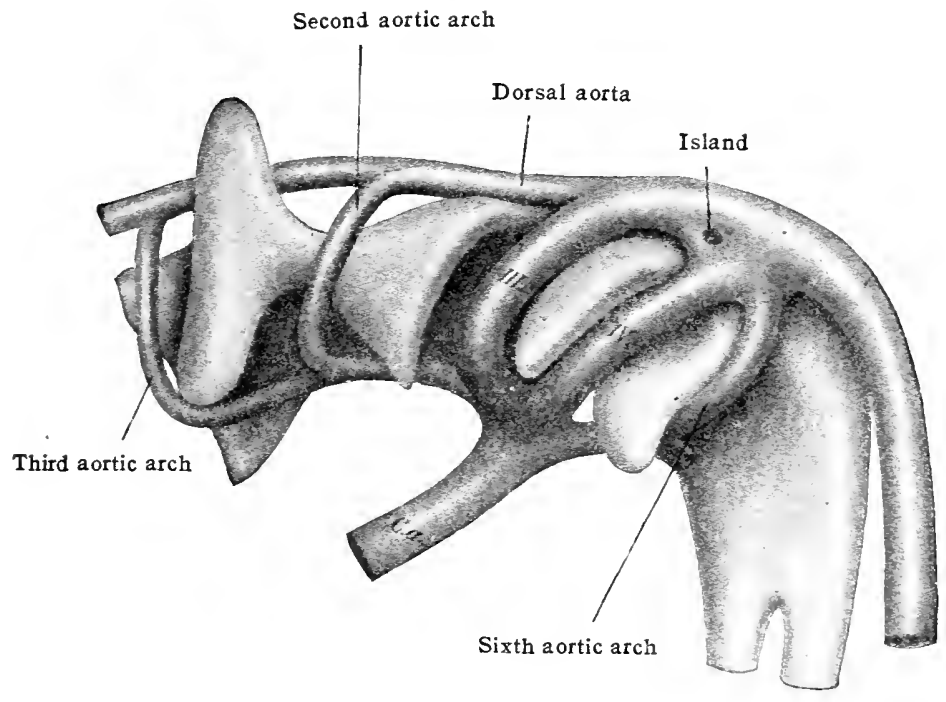

(1) The system of aortic arches consists of five pairs of arteries which spring from the ventral aorta, or aortr, and pass around the pharynx in the branchial arches to join the paired dorsal aortæ. Some of the arches are very transitory, but all those that give rise to permanent vessels are present in embryos about five millimetres in length. Fig. 505 shows their distribution and rlations to the pharyngeal pouches at this stage; the arches which appear fifth in order are regarded as the sixth because (like the sixth arches in lung-fish and amphibia) they give 
off the pulmonary arteries. The true fifth arches are probably not always developed, but when they occur they are later in development, imperfeet, and very transitory. The dorsal aorta, originally paired, are now united to form a single vessel as far forward as a place slightly caudal to the sixth arches.

During the separation of the heart into right and left halves (p 526.), the primitive ventral aorta is divided by the aortic septum into two vessels, the main pulmonary arlery and the ascending aorta of the adult. The pulmonary trunk becomes connected with the sixth pair of arches only; the other arches then communicate, by means of the aorta, with the left ventricle. The further changes which occur in the arches to bring about the conditions found in the adult are shown diagrammatically in fig. 506. The right and left pulmonary arteries arise from the corresponding sixth arches. The portion of the sixth arch dorsal to the pulmonary artery disappears on the right, on the left it persists until birth as the ductus arteriosus (lig. arteriosum of the adult). The fourth arch, including the short ventral stem between the fourth and sixth arch, becomes the permanent aortic arch on the left side, and the innominate and proximal portion of the subelavian upon the right. The dorsal longitudinal stem disappears on both sides between the third and fourth arches, and on the right side from the sixth arch back to the unpaired dorsal aorta. A trace of the latter portion of the right dorsal stem frequently persists in the adult as a small vessel (a. aberrans) connecting the dorsal aorta, directly or indirectly, with the right subelavian artery (p. 590). The ventral stems between the fourth and third arehes form the common carolids; those between the third and first become the external carotids. The inlernal carotids are formed by the third arehes and the dorsal stems between the third and first arches. The first and second arches disappear early, contributing somewhat to the formation of the branches of the internal and external carotids.

Fig. 506.-Diagrams showing the Method of Normal Development of the Aortic (Arches, and Indicating the Mechanism of Some Variations.)

The primitive aortic arches (1-6), and some of the cervical dorsal segmentals (V-VIII) are shown in all the diagrams but numbered in $\mathrm{Y}$ only. $\mathrm{X}$., abnormal: the aortic areh is on the right; the left'subelavian takes the dorsal course; the right vertebral arises direct from the aortic arch. Y., normal; Z., abnormal: the right subclavian arises from the sixth cervical dorsal segmental; the left from the sixth and seventh. A, ascending aorta; AA, aortic areh; $\mathrm{AD}$, dorsal aorta; CC, common carotid; CE, external carotid; CI, internal carotid; $\mathrm{D}$, ductus arteriosus; IN, innominate; S, subclavian; T, costo-cervical; V, vertebral.

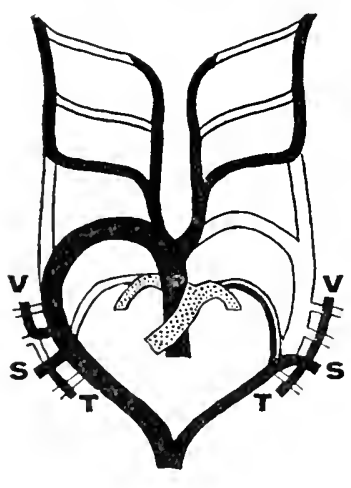

$\mathrm{X}$

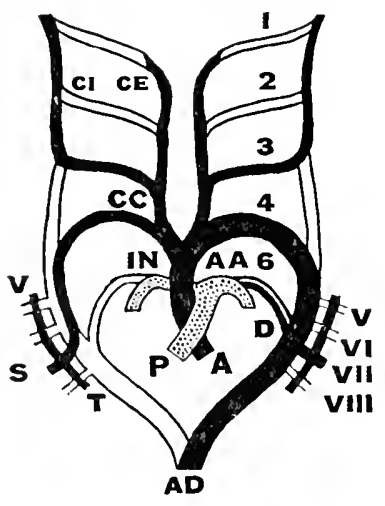

Y

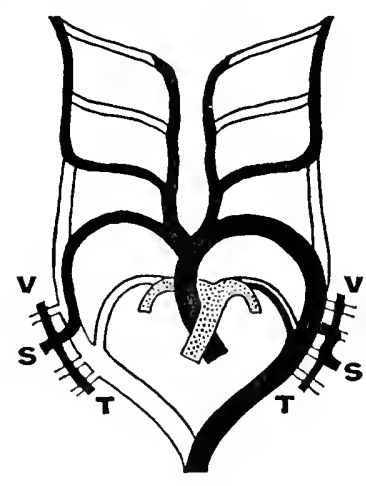

Z

In early development the segmental arteries are caudally placed with regard to the aortic arch vessels. As the latter, however, become shifted following the migration of the heart from the neck into the thorax, the persistent seventl dorsal cervical segmental (subelavian) reaches the neighbourhood of the sixth aortic arch.

Little is known of the share taken by the first and second aortic arehes in the formation of the branches of the internal and extemal carotid arteries. It has been shown by Tandler that the internal maxillary is primarily a branch of the internal carotid, (the first and second arehes taking a share in its formation). The prinitive vessel is known as the stapedial since it passes between the crura of the developing stapes. It gives off supraorbital, infraorbital, and mandibular branches; the latter two arising from the main artery by a common trunk. 'The common trunk is later joined by a branch fron the external carotid and, together with the supraorbital, becomes the middle meningral. An anastonosis between the supraorbital and the ophthalmic persists so that in the adnlt the anterior branch of the meningeal frequently takes a considerable share in the blood-supply of the orbit. The stipledial trunk undergoes retrogression and is represented in the adult hy the carotiro-tympanic of the internal carotid and by the superior tympanic of the midellemeningeal. The infranthital binch of the staperlial beeomes the seeond and third parts of the internal maxillary and gives off branches accordingly. The mandibular branch becomes the inferior alveolar of the arlutt.

(2) The segmental system (fig. 507) (onsists of arteries printarily arising from the aorta in three longitudinal series, lorsal, literal, and ventral on either sile. The segmental arrangement is much less perfect in the ventral and lateral groups thin in the dorsal. So mueh so, in fact, that the tem segnential is used for the ventral and lateral groups rather as a matter 
of convenience than as indicating a strict numerical correspondence between segments and vessels.

The dorsal segmental arteries primarily supply the central nervous system but later give off two sets of vessels to the body wall; these persist in the adult as the anterior and posterior main branches of the intercostal and lumbar arteries. The remainder of each segmental artery is represented in the adult by the spinal ramus which accompanies the corresponding nerve root through the intervertebral foramen. The tendency to form intersegmental anastomoses between these vessels (and their branches) gives rise to many of the important longitudinal stems of adult anatomy. Thus, the spinal ramus gives rise to a pre- and postneural anastomosing channel on either side, the (primarily paired) anterior and posterior spinal arteries. The anterior branches have each a longitudinal precostal anastomosis, and, as they grow forward with the developing body wall, their ends are connected to form the mammary anastomosis.

Between the posterior rami, a postcostal and a postvertebral anastomosis may be formed. In addition, the anterior rami give off lateral and anterior perforating branches (fig. 507).

Two dorsal segmental arteries have been recognized in the occipital region, the first disappears and the second, the hypoglossus artery, follows the hypoglossal nerve to the ventral surface of the brain where it is connected with the termination of the internal carotid of its own side by means of a longitudinal stem the a vertebralis cerebralis. The hypoglossus artery, by shifting forward to the third aortic arch, itself acquires a secondary origin from the internal carotid.

In the cervical region, the spinal ramus of segmental cervical I forms the third, or suboccipital, part of the vertebral artery. Cervical segmentals I to VI lose their connection with the aorta and a postcostal anastomosis between them forms the second part of the same artery. The first part of the vertebral is formed by the posterior ramus of cervical VI and its precostal anastomosis with cervical VII (subclavian) (fig. 508).

Fig. 507.-Scheme of the Trpical Arrangenent of the Branches of the Aorta. (After Quain.)

Longitudinal anastomoses: 1 , precostal; 2 , postcostal; 3 postvertebral; 4, preneural; 5 , postneural; 6 , mammary.

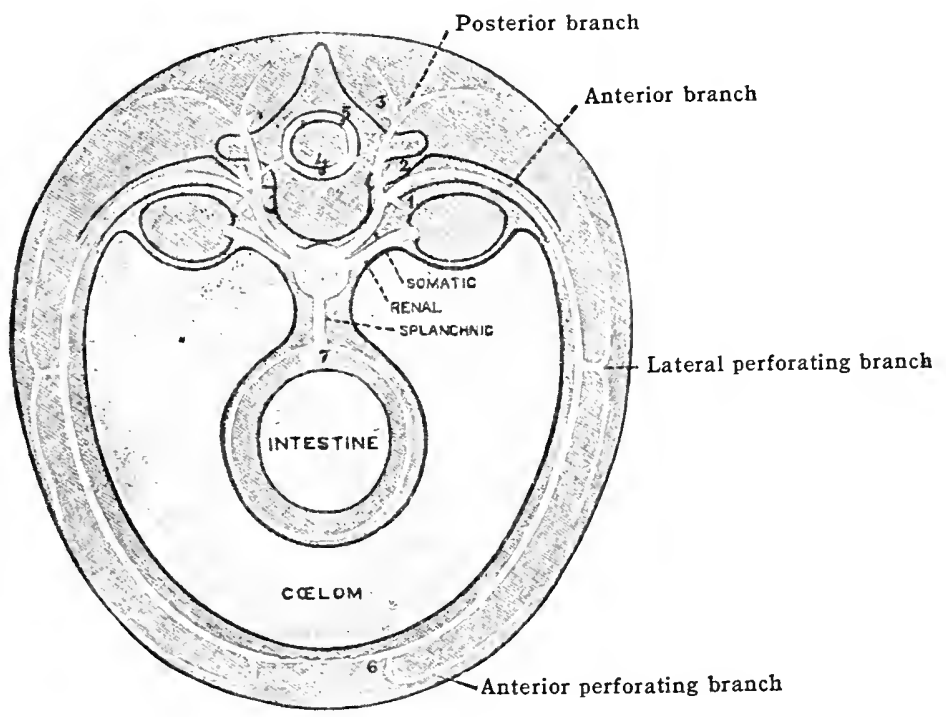

The anterior ramus of cervical VII forms the entire first part of the subclavian on the left, and the distal portion of it upon the right (see system of aortic arches). The second part of the subclavian is formed by the lateral branch of the anterior ramus of cervical VII, while the portion of the anterior ramus ventral to this becomes the root of the internal mammary. The anterior ramus of cervical VIII disappears, but the precostal anastomosis connecting it with the subclavian (cervical VII) persists to form the costo-cervical of the adult. The posterior ramus of cervical VIII forms the root of the deep cervical, and, by a postvertebral anastomosis with the other posterior cervical rami and with the occipital, forms the remainder of the deep cervical and the descending branch of the occipital artery.

In the thoracic and lumbar regions, the embryonic conditions very largely persist (fig. 508). The anterior rami of thoracic segmentals I and II, however, lose their connection with the aorta and, by a precostal anastomosis with cervical VIII, become secondarily connected (through the costo-cervical trunk) with the subclavian. The superior intercostal of the adult is thus formed. The fifth lumbar segmental apparently joins the umbilical artery (of the ventral segmental series) to form the external iliac which, in the adult, provides the chief arterial supply to the lower extremity. The inferior gluteal (sciatic), which is the primitive artery of supply for the lower extremity, if it is segmental at all, belongs to the sacral region. The free ends of the anterior rami of all the thoracic and the upper four lumbar segmentals become united, as they grow out with the body wall, to form the longitudinal mammary anastomosis (fig. 508). This anastomosis, by its connection with the anterior ramus of cervical 
VII (subclavian) and with the anterior ramus of lumbar $V$ (external iliae), forms the internal mammary (with its superior epigastric branch) and the inferior (deep) epigastric arteries of the adult.

In the sacral region, the adult shows evidence of segmental vessels in branches of the middle and lateral'sacral arteries; the latter probably representing a precostal anastomosis. Whether the parietal branches.may be derived directly from segmental sources, or whether they are vessels of new formation, has not been determined embryologically. The obturator would appear to be segmentalifor it contributes a branch to the mammary anastomosis which persists in the adult (pubic branches of obturator and inferior epigastric). If the connecting branch with the inferior epigastric is large, the obturator may lose its connection with the hypogastric, in which case the latter is said to arise from the former, or from the external iliac.

One of the most interesting of the longitudinal anastomoses in connection with the dorsal segmentals is the primitively bilateral preneural anastomosis extending ventral to the spinal cord'and connected, beyond the first spinal segment, with each internal carotid by means of the right and left aa. cerebrales vertebrales. The hypoglossus artery (p. 635) having lost its connection with the internal carotid, leaves the spinal ramus of cervical I (third part of the subclavian) to take over the major share of the cerebral supply. A process of blending by anas-

Fig. 508.-Diagran to Show the Develophent of the Arteries of the Trunk from the Aortic Arches and Segnental Arteries.

The arteries which persist are black; those which degenerate are in outline; those newly formed are shaded. (After Mall.)

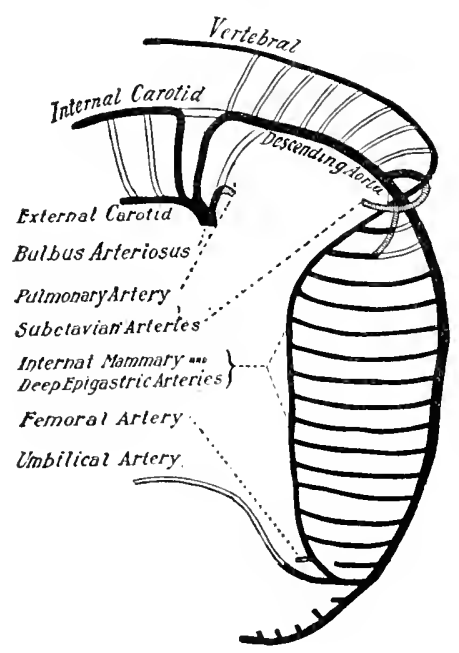

tomosis now occurs resulting in the single basilar and anterior spinal arteries of the adult. The posterior communicating, proximal portions of the posterior cerebrals, the fourth part of the vertebrals, and the right and left roots in the anterior spinals of the adult alone retain the primitive arrangement and testify to the clouble nature of the original anastomosis. Asymmetry in the vertebrals and other irregularities in the adult can usually be explained on developmental gromids. The postneural anastomosis, which joins the preneural at about the first eejvical segmont, retains its bilaterality throughout to form the pareal posterior spinal arteries of the adult.

The lateral segmental arteries take origin from the atorta in series, intermediate in position between the domsal and ventral segmentals. 'They reach their fullest development in embryos of alout 8 mm., when they extend from the seventh ecrvical to the twe f th thoracie segment and supply the mesonephros. At this stage Broman found twenty arteries on each side, many of which wore non-segmental. As the suprarenals and gonals develop, they each receive branches from several mesonephric arteries. The latter arteries now undergo rapid retrogression and the smprarenal and gonarlic branches are shifted audally through the mesonephric series to uewly former (urn-segmental) arteries opposite the upper lumbar segments. Finally there rmain three suprarenal arteries opposite the twelf th thoracic and first and second lumbar srangunts and a gonarlic artery (ommian or internal spermatic of the atolt) opposite the third himlar segment. Lll of these vessels now appear to be direct branches from the aorta. Of the Horecosuprarenal branchis, the upper and lower each gives a large branch to the chaphragm and

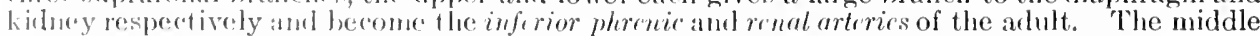
lecomes the mildle supromal of the alult. Felix puts as somewhat different interprefation upon the origin of the vesseds nersisting in the humbar region after the disappearance of the thoracie mosonphric arleries. Ile fimls in an embryo of $18 \mathrm{~mm}$. nine arteries on either side, extending forn thes ninth thoracie to the thiml lumbar segment, all of which he looks upon as mesonephric. 'l'hese low classilies inte there gromp:-Cranial, which reach the mesonephros by passing dorsal fo the stuprarenal; eamelal which pass ventral to the suprarenal, and middle which pass through it. Juasmuch as the artorios anastomose in the mosonephros there is great liability to variation in the number and prosition of 1 lor stroms which persist in the adult. 'The suprarenal arteries 
are usually derived from the caudal group, the renals from the caudal or middle and the spermatics from the middle. When accessory renals or spermatics occur in the adult their place of origin and course will generally indicate the group from which they are derived.

The ventral segmental arteries appear very early. In an embryo of seven somites (ca. 2 $\mathrm{mm}$.) described by Dandy* there was a right and a left series of twelve arteries, each arising from the still ununited dorsal aortx, the artery at the caudal end of each series being the umbilical, and the remainder vitelline arteries. In an embryo of $4.9 \mathrm{~mm}$. (35 somites) described by Ingalls $\uparrow$ the originally paired vitelline arteries had united (as had the dorsal aortæ in part) to form unpaired vessels. There were unpaired ressels as follows: one opposite the seventh cervical segment (coliac); five opposite the first four thoracic (omphalo-mesenterics, united by a longitudinal anastomosis), and one vessel of doubtful significance opposite the fifth and sixth thoracic segments. The paired umbilical arteries were opposite the first lumbar segment. No other ventral arteries were present.

It has been found from more fully developed stages that the inferior mesenteric artery is distinguishable at a stage of $8 \mathrm{~mm}$. opposite the second lumbar segment. Also that the ventral segmental vessels undergo a process of migration until they reach their definitive positions, i. e., the coliac opposite the twelf th thoracic segment, the superior mesenteric opposite the first, the inferior mesenteric opposite the third, and the umbilicals opposite the fourth lumbar segments, respectively. The cesophageal arteries of the adult do not belong to this series; but seem to be vessels of later formation.

The umbilical arteries, by means of secondary anastomosis, move laterally upon the aorta so as to pass lateral to the Wolffian ducts instead of medial. The proximal portion of each umbiical artery becomes the common iliac of the adult; its continuation is represented by the hypogastric and its umbilical branch. The external iliac appears to be derived from the dorsal segmental artery of the fifth lumbar segment, and the parietal branches of the hypogastric from corresponding sacral segmentals acquired by anastomosis. How such anastomoses between the umbilicals and the dorsal segmentals come about has not been ascertained.

\section{TARIATIONS}

Aorta and pulmonary artery.-The variations met with in the arch of the aorta are usually to be explained as persistent foetal conditions, and are often associated with abnormalities of the heart. Many of the variations are due to different modes of transformation of the primitive system of aortic arches. Since the aorta and pulmonary artery develop from a common conus and truncus arteriosus, irregular and imperfect development of the aortic septum may also produce numerous variations.

It has been seen that at one stage of development two fourth arches, a right and a left, are present, and such a condition is occasionally persistent in the adult. In such cases, owing to the portion of the aorta derived from the bulbus arteriosus being directed uprard and to the right and the descending aorta lying in the left side of the vertebral column, the right arch passes from right to left behind the osophagus, which thus seems to perforate the aortic arch.

Another variation occasionally seen is the occurrence of an aortic arch curving to the right instead of the left. This may be due to a persistence of the lower portion of the right dorsal longitudinal stem and the disappearance of the left, as shown in fig. 506; or it may be associated with a complete inversion of all the viscera, a situs inversus.

If the lower portion of the right dorsal longitudinal trunk should persist, and the part of it which normally forms the proximal part of the right subclavian should disappear, the right subclavian would arise from the descending portion of the aortic arch. It is to be noted that in such cases the subclavian passes behind the osophagus and below the right inferior laryngeal nerve. Partial persistence of the lower portion of the right dorsal longitudinal trunk is represented in the arteria aberrans (see p. 590 ).

Another group of variations is based on the persistence of the ductus arteriosus, which is derived from the sixth aortic arch. With this group belong the cases in which the pulmonary artery arises from the aorta; that is, where the blood of the pulmonary arteries passes from the aorta through the ductus arteriosus.

Variations in the number and the position of the vessels arising from the arch are extremely great, and many of these conditions are found normally in other mammals or birds. There may be from one to six branches. The case of one branch is the normal in the horse. It involves the fusion of the two aortic stems and the shortening of the fourth arch so that the left subclavian joins with the common stem. The avian form with two innominate arteries is extremely rare. A more common form is the one found in most apes, in which the innominate and left carotid form one branch; in rare instances the three branches are the two subclavians and a general carotid artery. When there are more than three branches the vertebral arteries are added, or the extra branch may be the thyreoidea ima (fig. 443). The commonest form with four vessels is the one in which the left vertebral arises between the left carotid and subclavian. A rarer form is to be found when the order is right subclavian, right carotid, left carotid, and left subclavian. Where there are five arteries, the estra ones are the right subclavian and left vertebral. The case of six branches is due to the separate origin of both vertebrals and both subclavians. The manner in which the vertebral artery may arise from the adult aortic arch is indicated in fig. 506.

The innominate artery may be absent, or mar give off additional branehes (see AORTA). It may be longer than usual and, bending to the left, ascend in front of the trachea (or more rarely behind the trachea and oesophagus) to turn again to the right. The thyroidea ima has been referred to (p. 532).

Carotid arteries.- - The common carotid may be absent or bifurcate higher or lower than usual.

* Am. Journ. Anat., Vol. 10, 1910.

† Arch. f. mikr. Anat., Bd. 70, 1907. 
It may not bifurcate at all, in which case the branches usually arising from the external carotid are derived from the common. The ascending pharyngeal and superior thyreoid occasionally arise from an otherwise normal common carotid. Unusual origin of the common carotids has been reierred to (see AORTA).

Branches of the carotid arteries. - The superior thyreoid, lingual and external maxillary sometimes have a common stem of origin. The superior thyreoid artery varies in size inversely with the inferior. The external maxillary occasionally terminates in its submental branch. In such cases the main supply of the face is taken over by an abnormally large dorsal nasal branch of the ophthalmic, or transverse facial branch of the temporal artery. The occipital sometimes arises from the internal carotid or from the ascending cervical. The ascending pharyngeal is very variable in its place of origin from the external carotid, it may arise from the common or internal.

Out of 447 arteries examined, the second portion of the internal maxillary passed lateral to the external pterygoid muscle in 55 per cent., and medial to it in 45 per cent. of cases. When medial to this muscle the internal maxillary sometimes passes medial to the inferior alveolar and lingual nerves and occasionally between them. The variability in the course of this artery appears to depend on a tendency to reduplication of the infraorbital branch of the stapedial artery (p. 634) in the neighbourhood of the mandibular nerve. Such a condition was found by Thyng in a $17 \mathrm{~mm}$. human embryo. When the internal maxillary passes medial to the external pterygoid there is often a parallel anastomosing channel between the posterior deep temporal and buccal branches.

The ophthalmic artery may arise, wholly or in part, from the middle meningeal, or vice versa. This is due to the anastomosis between the supraorbital branch of the stapedial and the oplthalmic in the embryo.

Subclavian artery.--Irregularities of origin have been referred to (see AorTA).

The branches of the subclavian artery are very variable in their place of origin (p, 559). The vertebral may arise directly from the arch of the aorta (p. 537) or take an unusual course in the neck. It may enter the foramen transversarium of the fourth or fifth cervical vertebra instead of the sixth; this arises from substitution of an embryonic precostal anastomosis in these segments for the usual postcostal. By a converse substitution it may enter the seventh. The aa. transvers colli and scapule vary inversely in size. The arteria aberrans connecting the right subclavian with the dorsal aorta has been referred to (p. 6:34).

The thoracic aorta.- Transposition, and the arteria aberrans have been referred to above.

Branches of the thoracic aorta.--The intercostal arteries are liable to numerical variation, evidently owing to the occurrence of precostal intersegnental anastomoses between the embryonic dorsal segmentals. A common longitudinal stem may even take over the vessels of both sides. The anterior spinal artery usually shows lack of median symmetry which indicates the bilaterality of its origin (p. 636). The arrangement of the bronehial arteries is liable to much variation; this has not received adequate explanation.

The abdominal aorta sometimes divides as low as the fifth lumbar vertebra, occasionally higher than usual, depending upon the definitive position taken by the umbilical arteries (p. 637 ). Cases are on record of accessory pulmonary arteries arising by a single stem from the abdominal aorta, which passes into the thorax along the oesophagus. The aorta and vena cava inferior may be transposed either as a part of situs inve:sus or as an abnormality of tho venous system.

Branches of the abdominal aorta.-The lumbar arteries are subject to the same type of variation as occurs in the intercostals. There may be a loop connecting the coliac and superior mesenteric arteries. Any or all of the branches of the coliac may arise from the superior mesenteric (colio-mesenteric in the latter case) or directly from the aorta. The instability of the coliac and superior mesenteric branches is favored by the rapid cranio-caudal migration of the two trunks; intersegmental anastomosis, in some cases, may be a factor also. There is very great variation in the number of branches given ofi by the superior mesenteric and in the details of their arrangement. This is a natural result of the number of possible routes which may be taken by the blood; these resemble, in their variety, those of an embryonic circulation. The region of supply of the inferior mesenterie artery is sometimes taken over entirely or in part (c. g., iniddle colic) by the superior mesenteric. An omphalo-mesenteric artery, in rare cases, arises from the superior mesenteric or one of its branches. It passes to the navel and anastomoses with inferior epigastric and with the small arteries accompanying the round ligament of the liver or the urachus.

Accessory renal arteries are very common; as many as six have been recorded. These may arise from the aorta, middle sacral, inferior phrenie, middle suprarenal or internal spermatic. Aceording to Felix, these are to be regarded as persistent mesomephric arteries. Those arising above the regular renal frequently enter the kidney dorsal to the hilum. Those below it are more apt to be ventrally pliced.

Nearly all possible varieties of origin are net with in the inferior phrenic, middle suprarenal, interual spermatic aud accessory renal arteries which find explanation in the caudal migration of, and andatomosis between, the embryonie representatives of these vessels. The occasional origin of the inferior phrenic from the caliac (or its branches) or from the superior mesenteris; of the internal spermatic or the mirldle suprarenal from the lumbar arteries, or of in accessory renal from the inferior mesenterie must be taken as indicating embryonic anastomoses between the dorsal, literal, or ventral segmental arteries, as the case may be.

The iliac and hypogastric arteries. - The length of the common iliae depends upon the site of aortic bifurcation (p. 5!) ; also upon the site of division of the common iliac into external iliac and liypogastric. If these spring directly from the aorta (ats they do in rare cases) the common ilise is absent. The trunk formed by the common iliac and hypogastric is the proximal portion of the cmbryonic unbilieal artery. 'T'he manner in which this takes over a dorsal segmental artery (probably the fifth lmubar) to beconne the external iliac is not sufficiently undersood to aceount for variations in this region. 
The branches of the hypogastric artery show great variation in their origin, and there is frequently no separation of the hypogastric into anterior and posterior divisions. Rarely the branches all take origin from the external iliac, in which case the hypogastric (as such) is absent. The obturator artery may arise from the inferior epigastric, or vice versa (p. 615). The arteria comitans $n$. ischiadici may be larger than usual and form a very pronounced anastomosis with the popliteal. In rare cases the main blood-supply of the lower limb is thus derived from the inferior gluteal which is the primitive embryonic condition (p. 640). The vesical and vaginal arteries are liable to variation in their relative areas of distribution. The internal pudendal is sometimes small and may terminate as the perineal artery, in these cases the urogenital region is supplied largely by the accessory pudendal (p. 610).

\section{B. ARTERIES OF THE EXTREMITIES}

\section{MORPHOGENESIS}

The arteries of the adult extremities represent surviving channels resulting from the selection of a chosen path traversing the perineural arterial plexuses of the early embryonic limb.

At present there is little unanimity of opinion as to whether the pattern of the developing nerve trunks is specifically reproduced by the primitive arterial plexuses or whether the undoubted similarity between the two is of a more general nature. There occurs in either extremity one case in which an artery of fundamental importance follows a course practically independent of nerve distribution. The volar interosseous, in the forearm, and the peroneal, in the leg, are accompanied by insignificant nerves ( $\mathrm{n}$. to pronator quadratus, and $\mathrm{n}$. to fexor hallucis longus respectively) which, moreover, do not extend the full length of the arteries in question.

The blood of a developing limb, having traversed the proximal segment by means of the arterial plexus around a single nerve, has the choice of several possible paths by which to reach the digits. The selected chanuel becomes, for the time, the principal artery of the distal segment. This presently gives way to a second favoured route, which may persist or again give way to a third. Thus, finally, the adult arrangement is established. This process of alternation is the cause of many of the commoner variations for, if it does not proceed to its usual termination, a small vessel, commonly rated as a branch, may testify to its earlier importance by appearing as one of the chief ressels of the part.

In the upper extremity the blood first traverses the peri-median plexus (which becomes later the axillo-brachial trunk) and flows to the digits mainly by the volar interosseous route. Next the volar interosseous dwindles in favour of the median. The median afterward rehinquishes its function to the radial and ulnar.

In the lower extremity the main blood-flow at first follows the peri-sciatic plexus from which it is delivered to the digits chiefly by the peroneal artery. The peroneal artery passes from the sole to the dorsum of the foot through the sinus pedis, and from here supplies the digits. The anterior and posterior tibial are at first small, the latter supplying the plantar digital arteries. At a stage of 10 millimetres the femoral artery is represented by a peri-saphenous plexus which anastomoses with the peri-sciatic plexus near the knee. The peri-femoral plexus rapidly consolidates into the femoral and genu suprema arteries. The femoral later takes over the poplileal as its direct continuation, and the origin of the genu suprema marks the boundary between the femoral and ischiadic zones of the main trunk. Finally the peroneal gives place to the anterior and posterior tibial arteries. The portion of the peroneal perforating the tarsus disappears. In so cloing it leaves the original termination of the peroneal artery connected with the dorsalis pedis to become the arcuate branch of the latter.

\section{VARIATIONS}

The variations of the arteries of the upper extremity may be divided into two categories, A certain number of them, particularly those occurring in the forearm and hand, are directly traceable to the unusual persistence of one or more of the embrionic channels; or, when variation involves magnitude only, to reciprocal variations in the size of the normal vessels. The commoner and more important variations of the arterial distribution, however, arise in a manner much less susceptible to ready explanation. They depend, in fact, upon variations in the course taken by the single or double route which, surviving from the intricacies of the peri-median plexus, persists to maturity. These will be referred to later.

The volar interosseous artery may be unusually large. It may reinforce a deficient radia or ulnar through the volar carpal artery, or its dorsal carpal branch may join the radial at the back of the wrist. In very rare cases the volar interosseous, together with a large ulnar artery, replaces the radial altogether.

A large median artery may participate in the palmar supply of the fingers, either by joining the superficial volar arch or (the arch being absent) by breaking directly into digital branches. The median, when large, occasionally replaces the ulnar, very rarely the radial, and frequently the superficial volar.

The superficial volar arch may be small, with compensation by the deep, or absent. In the latter case the digital arteries may come directly from the ulnar and radial, ulnar and median or median and radial. In the absence of the superficial volar, which is very frequent, the superficial arch is completed by the princeps pollicis or the volaris radialis indicis. 
Cases are on record in which the ulnar artery, arising in the middle of the arm passes behind the medial epicondyle to follow the nerve in the forearm as usual. The ulnar artery here replaces the superior ulnar collateral and the ulnar recurrent. This anomaly is explained in a striking way by the account given by de Vriese of the development of the vessels of the upper extremity.

Several important variations in the distribution of the main vessels belong to the second category. It is not uncommon for two arteries to arise from the primitive peri-median plexus of the arm. In such cases one artery usually takes a course clorsal to the median nerve, i. e., it is crossed medio-laterally by the medial head of the nerve and in the contrary direction by the nerve itself. Its course corresponds to that taken by the ordinary axillo-brachial trunk; it is known as the dcep brachial artery. The other vessel takes a course ventral to the median, nerve, and is known as the superficial brachial. The superficial brachial may join its companion artery, at or above the elbow, or one of the forearm vessels arising from it. In either case the superficial brachial is referred to as a "vas aberrans." Persistence of the superficial brachial further operates as a frequent cause of abnormality in the forearm in that it is often continued directly into one or more of the chief arteries of the latter, the deep brachial taking the remainder. 'This condition is classified as a high origin of the radial, ulnar, etc., as the case may be.

There is another type of variation belonging to the same category. In this, one large artery only occurs above the elbow which, instead of following the normal course of the brachial, passes, entirely or in part, ventral to the median nerve. In the first case this vessel represents the superficial brachial, the deep being absent. In the second it corresponds in its upper part to the deep brachial and in its lower to the superficial, the two components varying in inverse proportion.

E. Müller*, who has made a study of the variations belonging to this category, classifies the abnormal artery occurring in cases of vas aberrans, of high origin of forearm-vessels, and of single abnormal brachial, according to the proportion of superficial brachial present in any particular example, as a. brachialis superficialis superior media, inferior, or ima. In an embryo of 11.7 millimetres he found a system of arterial channels in relation with the median nerve out of which any variation of this category might have been produced cluring further development.

In cases in which the superficial brachial alone persists, the branches of the axillary (and sometimes the profunda brachii and superior ulnar collateral) arise from a common (deep brachial) trunk called the profunda axillaris. In cases in which the deep and superficial brachial co-exist examples of continuation of the superficial brachial into the radial are rather common, continuation into the ulnar less so. Continuation of the superficial brachial into the median, interosseous, or of posterior interosseous arteries occasionally occur, but they are rare. In any case of high origin a cross branch may connect the high vessel with the deep brachial in the neighbourhood of the elbow. The ulnar artery when arising high is often superficial to the forearm flexors (a fact which has not been explained on embryological grounds), the interosseons arising from the radial.

The variations occurring in the arteries of the lower extremity are usually compensatory, or dne to persistence of alternative embryonic channels. The sciatic (inferior gluteal) very rarely persists as the main artery of supply. In such cases the small femoral ends as the genu suprema which then appears to be a branch of the profunda.

The profunda is irregular; its origin may occur anywhere between the inguinal ligament and a point four inches below it. The median or lateral circumflex may arise from the femoral. The branches of the latter commonly arise separately from the profunda, or from the femoral. The popliteal does not vary much in its point of division. High division is commoner than low, but is never higher than the lower epiphyseal hine of the femur.

The anterior tibial may be small and only reach the middle or lower part of the leg. In such ases an enlarged anterior peroneal may end as the dorsalis peclis, or the dorsal metatarsal arteries may be supplied from the plantar arch. Ciases in which the anterior peroneal supplies the dorsum of the foot do not represent a direct inheritance of the embryonic method by which the peroneal artery performs this office. The embryonic route of the peroneal to the dorsum of the foot is transtarsal. The anterior tibial artery niay reach the extensor surface of the leg by accompanying the peroneal nerve. This ease, like that of the uhnar artery passing around the medial epironflyle, is interesting in comnection with the work of de Vriese.

'The pesterior libial artery nitay be absent or' small, the peroneal replacing it, or reinforeing it by means of the ramus communicans. Nosence of the peroneal has been recorded by Otto and W. Kinuse, hut these cases are explained by Barkow as being suppression of the posterior tibial artery between the origin of the peroneal and the communicating branch (Quain).

The latrol plontar is sometimes very small, in which case the plantar arch may be supplied by a large deep plantar. In rare cases there is a superficial plantar arch as in the embryo.

\section{3. 'THE SYSTEMIC' VEINS'}

The systemic veins are maturally divided into three groups-(1) the veins of the heart; (2) the volla cara superior and its tributaries, namely the veins of the heal, neck, mppel extremity, and thorax; and (i) the vena cava inferior and its tributarios, namely, the portal system, and the veins of the abdomen, pelvis, and lower axtromity.

* Ji. Mïller, Mnat. IIefte, No. 22, 1903. 


\title{
I. THE VEINS OF THE HEART
}

The veins of the heart have already been described (p. 520).

\section{THE VENA CAVA SUPERIOR AND ITS TRIBUTARIES}

\author{
THE VENA CATA SUPERIOR
}

The vena cava superior (fig. 509) carries to the heart the blood returned from the head and neck and upper extremities through the right and left innominate veins, and from the walls of the thorax, either directly through the azygos vein, or indirectly through the innominate veins. It is formed (fig. 509) by the confluence of the right and left innominate veins behind the first right sterno-chondral articulation. Descending from its origin in a gentle curve with its convexity to the right and in a direction slightly backward behind the sternal end of the first and second intercostal spaces and second costal cartilage, it terminates in the right atrium of the heart on a level with the third right costal cartilage in front and the seventh thoracic vertebra behind. It measures about 7 to $8 \mathrm{~cm}$. (3 in.) in length. A little more than its lower half $(4 \mathrm{~cm}$.) is contained within the pericardium, the serous layer of that membrane being reflected obliquely over it immediately below the spot where it is joined by the vena azygos, and on a lower level than the reflexion of the pericardium on the aorta. The superior vena cava contains no valves.

Relations.-In front, in addition to the first and second intercostal spaces and the second costal cartilage, it is covered by the remains of the thymus gland, the intrathoracic fascia, and the pericardium, and is overlapped by the right pleura and lung.

Behind (fig. 509) are the vena azygos (major), the right bronchus, the right pulnonary artery, and the superior right pulmonary vein; and below, the fibrous layer of the pericardium. The serous layer is reffected over the front and sides of the vessel, but not over its posterior part.

To the right side are the right lung and pleura and the phrenic nerve.

To the left side are the innominate artery and the ascending aorta.

Tributaries.-In addition to the right and left innominate veins and the vena azygos it receives small veins from the mediastinum and pericardium.

\section{THE INNOMINATE VEINS}

The innominate or brachio-cephalic veins [rv. anonymæ] return the blood from the head and neck and upper extremity. They are formed on each side by the confluence of the internal jugular and subclavian veins behind the sternal end of the clavicle. They terminate behind the first costal cartilage on the right side by uniting to form the vena cava superior. The innominate veins have no valves.

The right innominate vein [v. anonyma dextra] (fig. 509) measures about 2 to $3 \mathrm{~cm}$. ( 1 to $1 \frac{1}{2} \mathrm{in}$.) in length, and descends from its origin behind the sternal end of the clavicle, very slightly forward and medially, along the right side of the subclavian and innominate arteries, to its junction with the left vein behind the first costal cartilage close to the sternum. It is superficial to the imnominate artery.

Relations.--In front are the origins of the sterno-hyoid and sterno-thyreoid muscles, the clavicle, the first costal cartilage, and the remains of the thymus gland.

Behind are the pleura and lung.

To the right are the right pleura and lung and the phrenic nerve.

To the left (fig. 509) are the right subclavian artery, the innominate artery, the right vagus nerve, and the trachea.

The left innominate vein [v. anonyma sinistra] (fig. 509) measures 6 to $7.5 \mathrm{~cm}$. ( $2 \frac{1}{2}$ to $3 \mathrm{in}$.) in length, and extends from its origin behind the sternal end of the left clavicle obliquely across the three main branches of the arch of the aorta, to unite with the right immominate vein behind the cartilage of the first rib close to the sternum to form the vena cava superior. In this course it runs from left to right with an inclination downward and slightly backward. A line drawn obliquely across the upper half of the manubrium of the sternum, from the sterno- 
clavicular articulation on the left side to the lower border of the first costal cartilage at its junction with the sternum on the right side, will indicate its course. The left innominate vein is on a level with the top of the sternum at birth.

Relations.-In front, in addition to the manubrium of the sternum, it has the origins of the sterno-hyoid and sterno-thyreoid muscles, and the remains of the thymus gland, the sternal end of the left clavicle, and the sterno-clavicular articulation.

Behind are the three chief arteries arising from the arch of the aorta, the trachea, and the left phrenic and left vagus nerves.

Below it is the arch of the aorta.

Above it are the cervical fascia, the inferior thyreoid, and thyreoidea ima veins.

Tributaries.- In addition to the internal jugular and subclavian veins, by the confluence of which the innominate veins are formed, each vein receives on its upper aspect the vertebral, the deep cervical, and inferior thyreoid veins; and

Fig. 509.-The Vena Cava Superior and the Innominate Veins.

(Modified from a dissection in St. Bartholomew's Hospital Museum.)

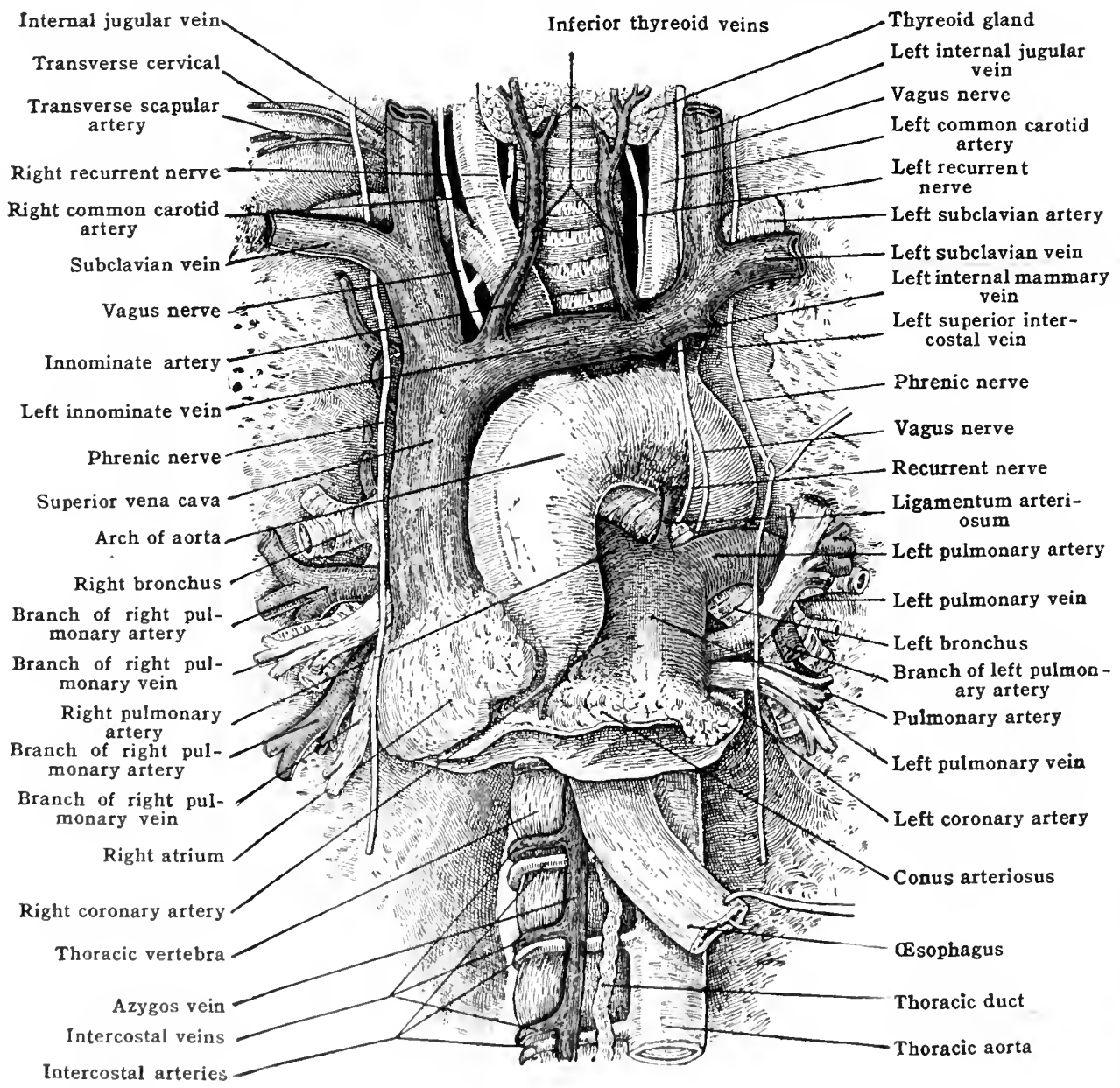

on its lower aspect the internal mammary vein. The left vein, moreover, is joined by the thyreoilea ima, the left superior intercostal, and by the thymic, tracheal, osophageal, superior phrenic, anterior mediastinal, and pericardiac veins. At the confluence of the internal jugular and subclavian veins on the right side the three lymphatic trunks or the right lymphatic duct open; on the left side the thoracic duct.

\section{THE VEINS OF TIIE IIEAD AND NECK}

The veins of the head and neck may be divided for purposes of description into the superficial, which return the hlool from the external parts of the head and 
neck; and the deep, which return the blood from the deeper structures. All the veins, whether superficial or deep, terminate in the internal jugular or subclavian, or open directly into the innominate veins at the root of the neck. Through the latter all the blood from the head and neck ultimately passes on its way to the heart.

\section{THE SUPERFICIAL VEINS OF THE HEAD AND NECK}

The venous blood from the anterior part of the scalp and integument of the face is returned, through the anterior and posterior facial veins, to the common facial, a tributary of the internal jugular vein. From the posterior part of the scalp and from the integument of the neck venous blood is returned, through the external jugular and its tributaries, to the subclavian vein.

\section{A. The Anterior Facial Vein}

The anterior facial vein [v. facialis anterior] (fig. 510) begins a little below the medial end of the eyebrow where it is formed by the union of the frontal and

Fig. 510.-The Superficial Veins of the Face and Scalp. (After Quain.)

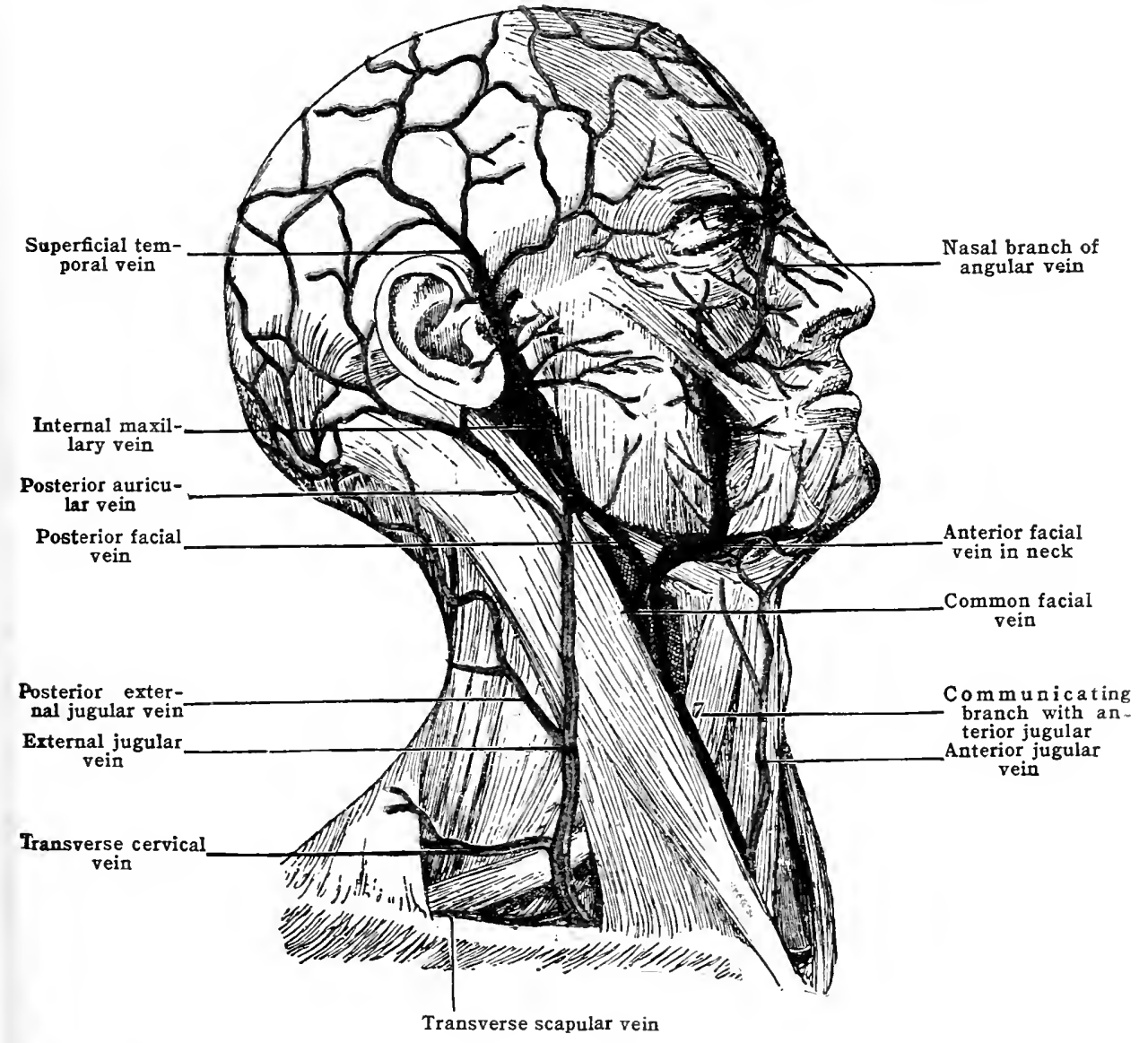

supraorbital veins. It descends near the medial angle of the orbit, and then by the side of the nose to the cheek, which it crosses obliquely, to the anterior edge of the masseter muscle. Thence it passes through the digastric triangle to the upper border of the hyoid bone, where it terminates in the common facial vein. In this course it is reinforced by numerous collateral veins, and gradually increases in size. It has, moreover, numerous communications with the deep veins. The portion of this vein above the lower margin of the orbit is called the angular [ $\mathrm{v}$. 
angularis]. In the remainder of its course over the face and neck it is termed the anterior facial vein.

The angular vein skirts around the medial margin of the orbit, lying with the angular artery on the frontal (nasal) process of the maxillary bone slightly medial to the lacrimal sac. Branches pass from the posterior part of the angular vein into the orbit to join the ophthalmic.

The angular, the facial, and the ophthalmic veins contain no valves. The blood, therefore, can pass either forward from the ophthalmic into the angular, or backward through the facial and angular into the ophthalmic, and so on to the cavernous and other venous sinuses of the cranium. Hence in certain tumours in the orbit and cranium, the congestion of the angular and facial reins; and the danger in facial carbuncle and anthrax of septic thrombi spreading backward through the angular and ophthalmic veins to the cranial sinuses.

The anterior facial vein runs in a more or less direct line behind its corresponding artery, the external maxillary (facial), which itself pursues a tortuous course. It usually passes deep to the zygomatic muscle, the zygomatic head of the quadratus labii superioris, and the risorius, but superficial to the other muscles. At the anterior edge of the masseter it meets the external maxillary artery, lying immediately posterior to it. In the neck it lies beneath the platysma and cerrical fascia, and is usually separated from the external maxillary artery by the submaxillary gland and the stylo-hyoid and posterior belly of the digastric muscles, below which it is joined by the posterior facial, to form the common facial vein.

Tributaries. - It receives, from above downward:-(a) the frontal vein; (b) the supraorbital vein; (c) the superior palpebral veins; (d) the external nasal reins; (e) the inferior palpebral veins; (f) the superior labial vein; (g) the inferior labial vein; (h) the masseteric veins; (i) the anterior parotid veins; (j) the palatine vein and $(\mathrm{k})$ the submental vein.

(a) The frontal vein [v. frontalis] (fig. 510) begins about the level of the coronal suture in a venous plexus which communicates with the anterior division of the temporal vein. Soon forming a single trunk, it passes vertically downward over the frontal bone, a short distance from the middle line and parallel to its fellow of the opposite side, to the medial end of the eyebrow where it terminates in the angular vein.

(b) The supraorbital vein [v. supraorbitalis] begins over the frontal eminence by intercommunication with the middle temporal vein. It receives tributaries from the forehead and eyebrow, and, running obliquely, medially and downward, opens into the termination of the frontal vein to form the angular. It communicates with the ophthalmic vein, and receives the frontal vein of the diploë as the latter vein issues from the bone at the bottom of the supraorbital noteh.

(c) The superior palpebral veins [vv. palpebrales superiores] arise in the upper eyelid and open into the lateral side of the angular vein. They communicate with the middle temporal vein.

(d) The external nasal veins [vv. nasales externa] form three or four stems on either side. The upper veins run upward into the angular and the lower, from the ala, pass more horizontally into the anterior facial vein.

(e) The inferior palpebral veins [vv. palpebrales inferiores] arise in the lower eyelid, and, passing medially and lownward over the cheek from which they receive tributaries, open into the lateral sirle of the anterior facial vein. They communicate with the infraorbital vein.

(f) 'T]e superior labial vein [v. labialis superior] and (g) the inferior labial vein [v. labialis infering] ariso from venous plexuses in the upper and lower lips. They rum laterally to open into the medial side of the facial vein.

(h) The masseteric veins [vv. masseterica] and (i) the anterior parotid veins [vv. parotid:e anteriofes], of small size, drain the rheek over the masseteric and parotid regions,

(j) 'The palatine vein [v. palatina] atcompanies the ascending palatine or tonsillar artery from the vomus jolexus about the tomsil and soft palate, and joins the anterior facial vein just below the borty of the mandihle.

(k) The submental vein [v. submentalis] lies on the mylo-hyoirl muscle superficial to the suburntal antery. Romning back in the submental triangle, it joins the anterior facial vein just aftor the datiol has passerl over the borly of the mandible. It communicates with the interior jugular vein.

Communications. - The tributaries of the anterior facial vein communicate freely with

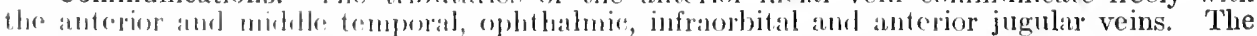
main trunk has a lith communicating branch with the pterygoid plexus. This vein, some-

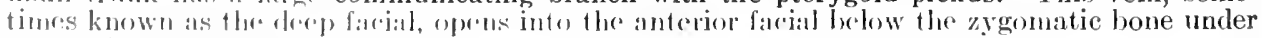

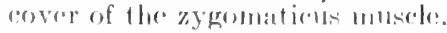

\section{B. The Posterior Factal Vein}

'The posterior facial (trmporo-maxillary) vein [v. facialis posterior] is formed in in the region of the root of the zygoma by the mion of the superficial and middle temporal veins. It passes downward behind the ramus of the mandible 
through the substance of the parotid gland--here lying lateral to the superficial temporal and external carotid arteries. At the angle of the mandible it runs medially and somewhat forward, and, passing either deep or superficial to the stylo-hyoid and digastric muscles, joins the anterior facial to form the common facial vein.

The tributaries received by the posterior facial vein are:-(a) the superficial

Fig. 511.-The Veins of the Head, Neck, and Axilla. (After Toldt, "Atlas of Human Anatomy," Rebman, London and New York.)

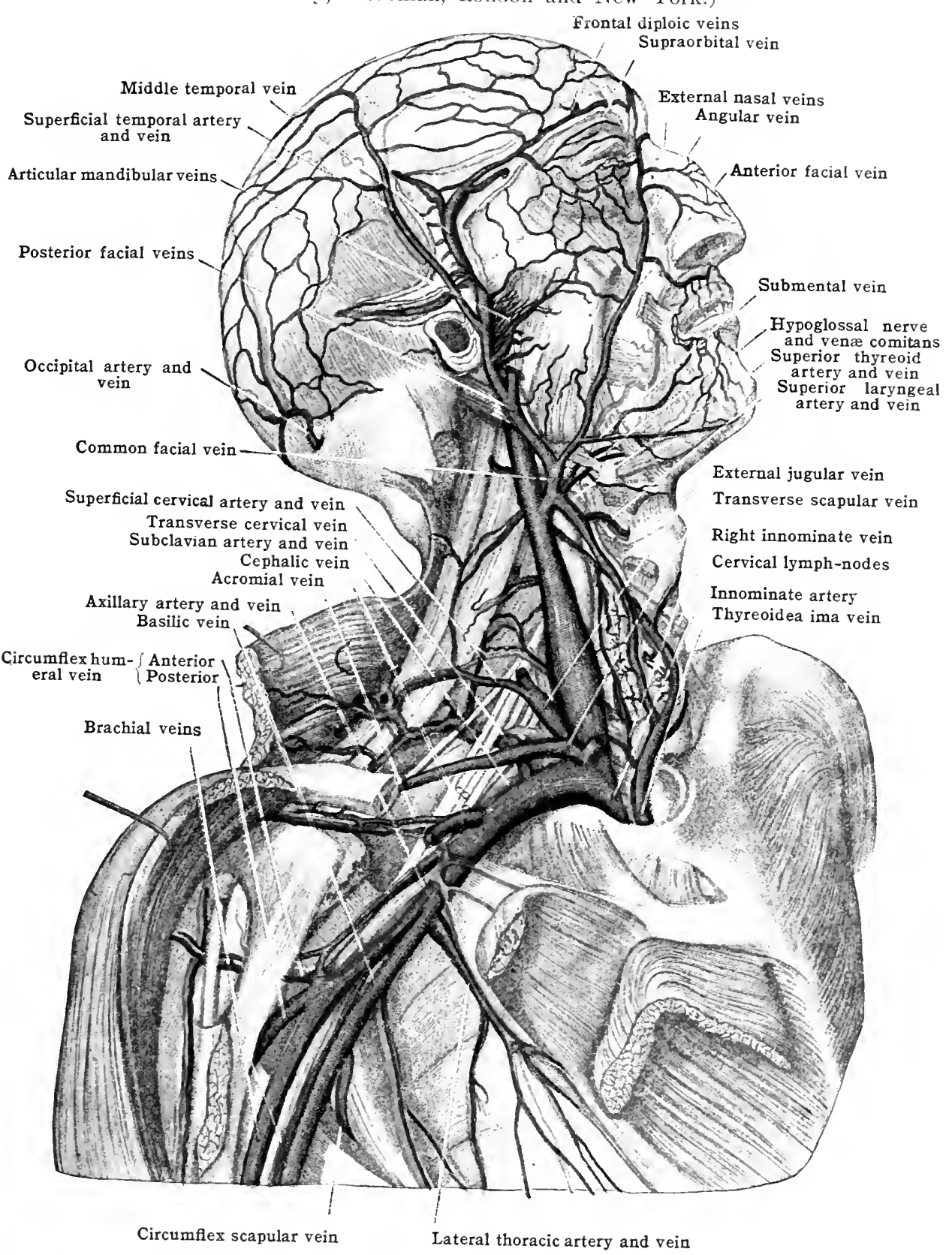

temporal veins; (b) the middle temporal rein; (c) the transverse facial rein: (d) the articular veins; (e) the posterior parotid veins; (f) the anterior auricular veins; $(\mathrm{g})$ the stylo-mastoid rein; and $(\mathrm{h})$ the internal maxillary vein through which occurs the principal drainage of the pterygoid plexus. 
(a) The superficial temporal vein [v. temporalis superficialis] returns the blood from the parietal region of the scalp. It is formed by the union of an anterior and a posterior branch: the former communicates with the supraorbital and frontal veins; the latter with the posterior auricular and occipital veins and the temporal vein of the opposite side. These branches lie superficial to the corresponding branches of the superficial temporal artery, which they roughly though not accurately follow. Like the artery, they lie between the skin and the cranial aponeurosis, and descend over the temporal fascia to unite a little above the zygoma, and just in front of the auricle of the ear, to form the superficial temporal trunk. The vein thus formed continues its course downward with the trunk of the temporal artery, and opposite the zygoma is joined by the middle temporal vein to form the common temporal vein.

(b) The middle temporal vein [v. temporalis media] corresponds with the orbital branch of the temporal artery, and communicates in front with the ophthalmic vein, the external palpebral veins, and the infraorbital veins, and then runs backward between the layers of the temporal fascia to join the superficial temporal vein. The middle temporal vein communicates with the deep temporal veins, and through them with the pterygoid venous plexus.

(c) The transverse facial vein [v. transversa faciei] corresponds to the transverse facial artery. (d) Articular veins [vv. articulares mandibulæ] form the plexus around the temporomandibular joint; this plexus receives the tympanic veins [vv. tympanicæ), which, together with its corresponding artery, passes through the petrotympanic fissure. (e) Posterior parotid veins [vv. parotideæ posteriores] emerge from the substance of the parotid gland. (f) Anterior auricular veins [vv. auriculares anteriores], from the auricle of the ear. (g) Stylo-mastoid vein [v. stylomastoidea] from the facial canal. (h) The internal maxallary vein accompanies the first part of the internal maxillary artery. It begins at the posterior confluence of the veins forming the pterygoid plexus, and passes backward between the stylo-mandibular ligament and the neck of the mandible. It ends by joining the posterior facial vein.

The pterygoid plexus [plexus pterygoideus] is formed by the veins which correspond to the branches of the internal maxillary artery. It is situated, partly on the medial surface of the internal pterygoid muscle, and partly around the external pterygoid muscle. The veins entering into this plexus are:- the two middle meningeal veins [vv. meningeæ mediæ], which accompany the artery of that name; the posterior superior alveolar (dental); the inferior alveolar (dental); the masseteric; the buccal; the pterygoid veins from the pterygoid muscles; the deep temporal veins [vv. temporales profundæ], by which the plexus communicates with the temporal plexus; the spheno-palatine vein; the infraorbital; the superior palatine; a branch of communication with the lower branch of the ophthalmic vein, which courses through the inferior orbital (spheno-maxillary) fissure; and the rete foraminis ovalis and Vesalian vein, through which the plexus communicates with the cavernous sinus. The plexus ends posteriorly in the internal maxillary vein, which joins the posterior facial vein, and anteriorly in a communicating vessel (the deep facial vein), which passes forward and downward between the buccinator and masseter muscles to join the anterior facial vein.

The above-mentioned veins, forming by their confluence the pterygoid plexus, correspond in their course so nearly with that of their companion arteries that a detailed description is not necessary. Although for convenience described with the superficial veins, they are all deeply placed.

Near the angle of the mandible there is almost always a communicating branch between the posterior facial and the external jugular veins. When large, this branch may drain the greater part of the blood from the posterior facial.

\section{The Common Facial Vein}

The common facial vein [v. facialis communis] is a short thick stem contained within the carotid triangle. It is formed, just below the angle of the mandible, by the union of the anterior and posterior facial veins. It ends opposite the hyoid bone, by opening into the internal jugular vein. In addition to the vessels which form it, sometimes it receives the superior thyreoid, the pharyngeal, and the lingual or the sublingual veins.

\section{Time External Jugular Vein}

The external jugular vein [v. jugularis externa] (fig. 510) is formed by the confluence of the posterior auricular and a short communieating trunk from the posterior facial near the angle of the mandible. It runs obliquely downward and backward aeross the sterno-mastoid muscle to a point opposite the middle of the clavicle, where it terminates as a rule in the subelavian vein. A line drawn from a point midway between the mastoid process and angle of the jaw to the middle of the clavicle will indicate its course. It is eovered by the skin, superficial fascia, and platysina, and is crossed by a few branches of the eervical plexus, the great auricular nerve running parallel to it at the upper part of the neck. It is separated from the sterno-mastoill by the anterior layer of the deep cervieal faseia.

Just above the clavicle it perforates the cervical fascia, by which it is prevented from readily collapsing, the fascia being attacherl to its walls. It then opens into the subclavian vein, occasionally in to the internal jugular, or into the confluenec of the subclavian and internal jugular 
veins. It contains a pair of valves about 2.5 to $5 \mathrm{~cm}$. (1 to 2 in.) above the clavicle, and a second pair where it enters the subclavian vein. Neither of these valves is sufficient to prevent the blood from regurgitating, or injections from passing from the larger vein into the external jugular.

Tributaries and communications.-These include;-(a) The posterior auricular vein; (b) the occipital vein; (c) a branch of communication with the posterior facial vein; (d) the posterior external jugular vein; (e) the transverse scapular vein; and (f) the anterior jugular vein.

(a) The posterior auricular vein [v. auricularis posterior] begins in a venous plexus on the posterior part of the parietal bone. This plexus communicates with the vein of the opposite side across the sagittal suture, and with the posterior branch of the superficial temporal vein in front, and with the occipital vein behind. It descends over the back part of the parietal bone and the mastoid process of the temporal bone, lying with its artery behind the ear, and joins a branch from the posterior facial vein to form the external jugular.

Fra. 512.-The Veins of the Face. (After Toldt, "Atlas of Human Anatomy," Rebman, London and New York.)

Deep temporal veins

Infraorbital artery and vein

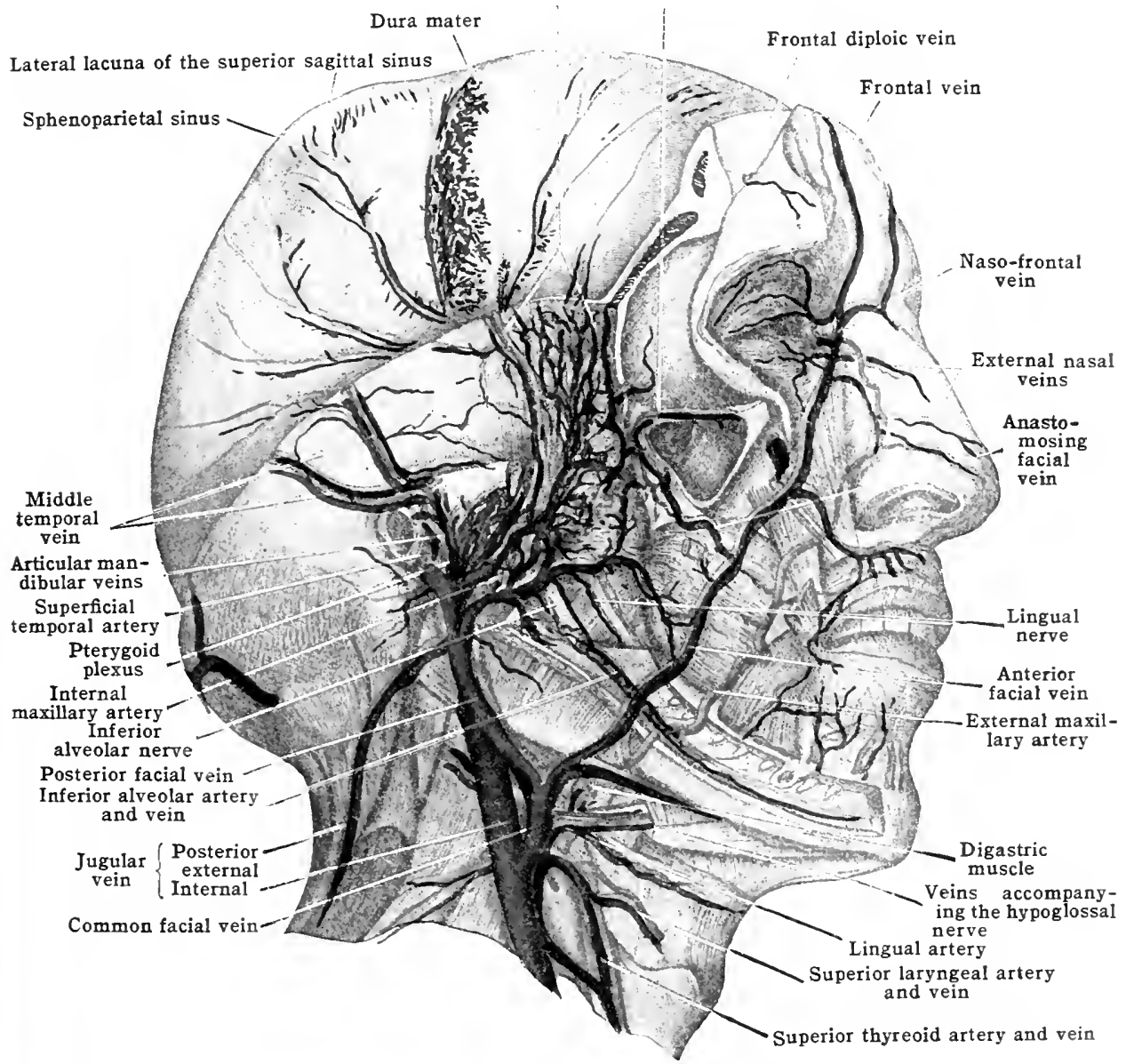

(b) The occipital vein [v. occipitalis] begins at the back of the skull in a venous plexus which anastomoses with the posterior auricular and the posterior branch of the superficial temporal veins. It passes downward over the occipital bone, and usually perforates the trapezius with the occipital artery, to join a plexus drained by the deep crevical and vertebral veins. It also communicates with the posterior auricular, and in many cases this forms the chief path of drainage. One of its branches, usually the most lateral, receives a mastoid emissary vein [emissarium mastoideum] which issues through the mastoid foramen of the temporal bone, and in this way forms a communication with the transverse sinus.

(c) The branch of communication with the posterior facial vein occurs a short distance below the point at which the posterior facial receives the internal maxillary vein. It is very constant and is placed immediately behind the angle of the mandible. Through it the external jugular 
usually receives a considerable proportion of the blood returning from the temporal and pterygoid regions.

(d) The posterior external jugular vein (fig. 512) descends from the upper and back part of the neck, receiving small tributaries from the superficial structures and muscles. At times it communicates with the occipital, or may appear as a continuation of that vein. It opens into the external jugular as the latter vein is leaving the sterno-mastoid muscle.

(e) The transverse scapular vein [v. transversa scapulæ] corresponds to the transverse scapular (suprascapular) artery. If double, these venæ comitantes usually form one trunk before they open into the external jugular vein. They contain well-marked valves.

(f) The anterior jugular vein [v. jugularis anterior] begins below the chin by communicating with the mental, submental, inferior labial, and inferior hyoid veins. It descends a little lateral to the midelle line, receiving branches from the superficial structures at the front and side of the neck, and occasionally a branch from the larynx and thyreoid body. Just above the clavicle it turns laterally, and, piercing the fascia, passes beneath the sterno-mastoid muscle and opens into the external jugular vein just before the latter joins the subclavian; at times it opens into the subclavian vein itself. In its course down the neck it communicates with the external jugular; and, as it turns laterally beneath the sterno-mastoid, sends a branch across the trachea, between the layers of cervical fascia, to join the anterior jugular of the opposite side. This communicating vein, the jugular venous arch [arcus venosus juguli], may open directly into the external jugular or into the internal jugular vein; occasionally one or both ends may open into the subclavian or innominate vein. It may be divided in the operation of tracheotomy, and is then often found greatly engorged with blood. Another branch, often of considerable size, courses along the anterior margin of the sterno-mastoid and joins the anterior facial vein. When the anterior jugular vein is large, the external jugular is small, and vice versa. It is usually also of large size when the corresponding vein on the opposite side is absent, as is frequently the case. It contains no valves.

\section{THE DEEP VEINS OF THE HEAD AND NECK}

The deep veins of the head and neck may be divided into:-(1) the veins of the diploë; (2) the venous sinuses of the dura mater encephali; (3) the veins of the brain; (4) the veins of the nasal cavities; (5) the veins of the ear; (6) the veins of the orbit; (7) the veins of the pharynx and larynx; and (8) the deep veins of the neck. The veins of the diploè terminate partly in the superfieial veins already described, partly in the venous sinuses of the cranium, and partly in the deep veins of the neck. The venous sinuses open into the deep veins of the neck. The veins of the brain terminate in the venous sinuses. The veins of the nasal cavities terminate partly in the deep, and to some extent in the superfieial veins. The veins of the ear join both the superficial and deep veins and the venous sinuses. The veins of the orbit terminate partly in the superfieial veins, but ehiefly in the venous sinuses. The veins of the pharynx and larynx enter the deep veins of the neck.

\section{THE VEINS OF THE DIPLOE}

The veins of the diploë [venx diploice] (fig. 513) are contained in bony channels in the cancellous tissue between the external and internal laminae of the skull. They are of comparatively large size, with very thin and imperfect walls, and form numerous irregular comnunicating channels. They have no valves. They terminate in four or five main and descending chamnels, which open, some outward through the external cranial lamina into some of the superficial and deep veins of the head and face, and some inward through the internal lamina in to the venous sinnses. They are divided into the frontal, anterior temporal, posterior temporal, and oecipital.

'T'he: frontal diploic veins are contained in the anterior part of the frontal bone. They ronverge anterionly to a singlo vein [v. diploiea frontalis] which passes downward, perforates the extcrnal table thromgl a small aperture in the roof of the supraorbital not ch, and terminates in the suprandital rein. Thery alse eommmineate with the superior sagital sinus.

The anterior temporal [v. diploim temporalis ant.] are contaned in the posterior part of the frontal and in the antrorior part of the parietal bone. They pass downard, and end, partly in the leep temunial veins hy perforating the greater wing of the sphenoid bone, and partly in tles: spheno-parietal sims.

'T'les posterior temporal [v. diploiea tomporalis post.] ramifies in the parietal bone, and, coursing downourl to the postrerion inferiol angle of that bone, passes either through a foramen in its infer taldre, or through the mastoid formmen into the transverse sinus.

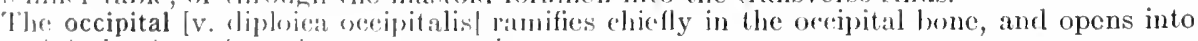

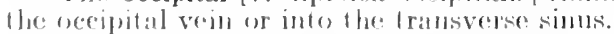

The diplese veins frerdy anastomese with one another in the adull; but in the foetus, before the benes lave united, cachls systeme of veins is distinet. 


\section{THE VENOUS SINUSES OF THE DURA MATER}

The venous sinuses of the dura mater [sinus duræ matris] are endothelially lined blood-spaces, situated between the periosteal and meningeal layers of the dura mater. They are the channels by which the blood is conveyed from the cerebral veins, and from some of the veins of the meninges and diploë, into the veins of the neck. The sinuses at the base of the skull also carry the chief part of the blood from the orbit and eyreball to the jugular veins. At certain spots the sinuses communicate with the superficial veins by small vessels known as the emissary veins, which run through foramina in the cranial bones.

The venous sinuses are sixteen in number, six being median and unpaired, the remaining ten consisting of five lateral pairs. The median sinuses are:-(1) the superior sagittal; (2) the inferior sagittal; (3) the straight; (4) the occipital; (5) the circular; and (6) the basilar plexus. The lateral and paired sinuses are:-(7) the two transverse; (8) the two superior petrosal; (9) the two inferior petrosal; (10) the two cavernous; and (11) the two spheno-parietal. Occasionally there are two additional sinuses, the two petro-squamous.

(1) The superior sagittal (or longitudinal) sinus [sinus sagittalis superior] (fig. 515) lies in the median groove on the inner surface of the cranium along the attached margin of the falx cerebri. It extends from the foramen crecum to the

Fig. 513.-The Veiss of the Diplói.

(From a specimen in St. Bartholomew's Hospital Museum.)

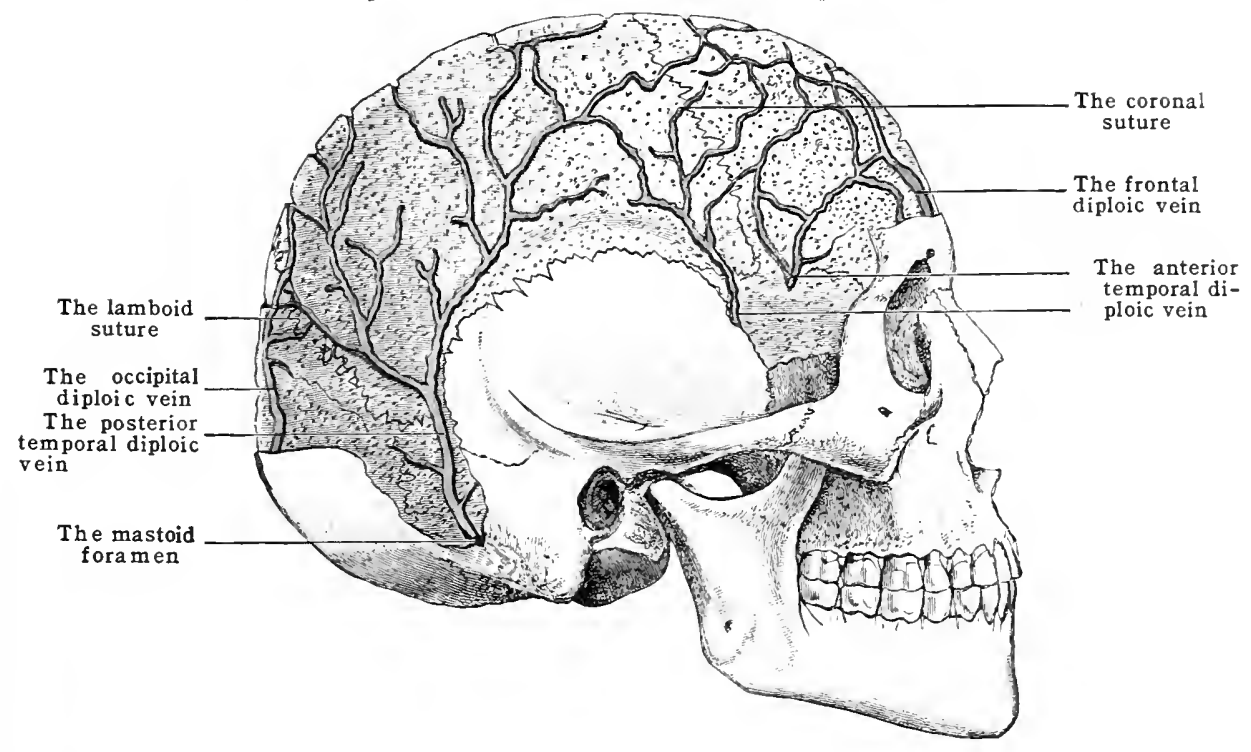

internal occipital protuberance. It grooves from before backward the frontal bone, the contiguous sagittal margins of the parietal bones, and the squamous portion of the occipital bone In the fotus, and occasionally in the adult, it communicates (through the foramen cæcum) with the nasal veins. It communicates throughout life with each superficial temporal vein by means of a parietal emissary vein [emissarium parietale] which passes through the parietal foraman. It is triangular on section, the base of the triangle corresponding to the bone. Crossing it are a number of fibrous bands known as the chords of Willis, and projecting into it in places are the arachnoidal (Pacchionian) granulations. The parts of the sinus into which the arachnoidal granulations project are irregular lateral diverticula from the main channel known as the lacunce laterales (fig. 517). In front the sinus is quite small, but it increases greatly in calibre as it runs backward. It receives at intervals the superior cortical cerebral veins and the veins from the falx. The former, for the most part, open into it in the direction opposite to that in which the blood is flowing in the sinus. Ther pass for some distance in the walls of the sinus before opening into it. Posteriorly, at the internal occipital protuberance, the superior sagittal sinus usually turns sharply to 
the right, and ends in the right transverse (lateral) sinus; the straight sinus then usually terminates in the left transverse (lateral) sinus.

Occasionally, however, the superior sagittal sinus ends in the left transverse sinus, the straight then passing into the right. At the angle of union between the superior sagittal sinus and the transverse sinus into which it empties there is a dilation, the confluens sinuum or torcular Herophili. At this point there is a communication between the right and left transverse sinuses. In some cases the communication is so free that the blood from the sagittal sinus flows almost equally into each transverse sinus. The confluens may communicate with the occipital vein through the occipital emissary vein [emissarium occipitale], which, when present passes through a minute foramen in the occipital protuberance.

(2) The inferior sagittal (or longitudinal) sinus [sinus sagittalis inferior] (fig. 515) is situated at the free margin of the falx cerebri. Beginning about the junction of the anterior with the middle third of the falx, it is continued backward along the concave or lower margin of that process to the junction of the falx with the tentorium, where it ends in the straight sinus. The sinus is cylindrical in

Fig. 514.-The Venous Sinuses.

(From a dissection by W. J. Walsham in St. Bartholomew's Hospital Museum.)

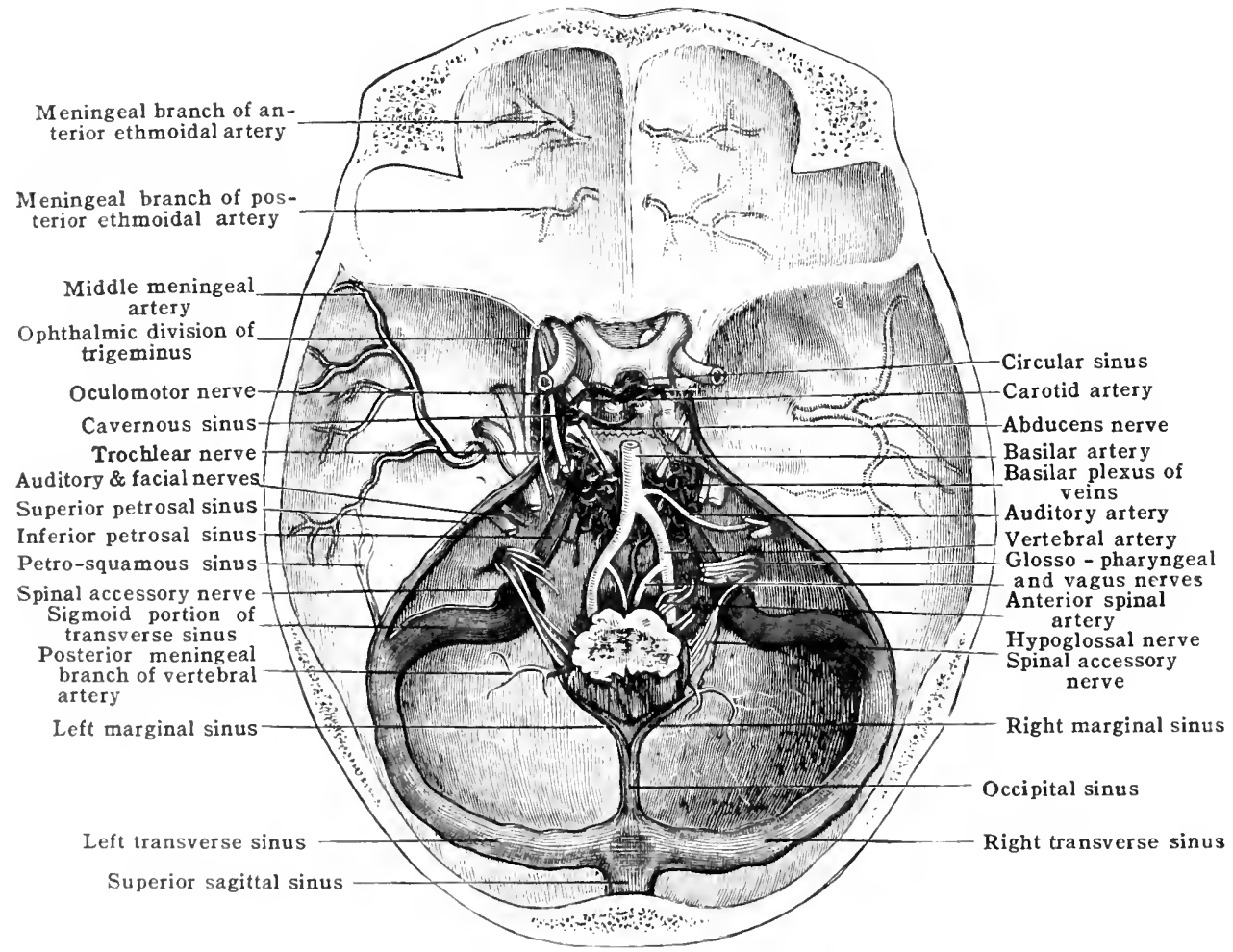

shape and of small size, and receives some of the inferior frontal veins of the brain, some of the veins from the medial surface of the brain, and some of the veins of the falx.

(3) The straight sinus [sinus rectus] lies along the junction of the falx cerebri with the tentorium cerebelli. It is formed by the union of the great cerebral vein (of Galen) and the inferior sagittal sinus. It receives in its course branches from the tentorium cerebelli and from the upper surface of the cerebellum. It runs downward and backward to the internal oceipital protuberance, where it ends in the transverse sinus opposite to that joined by the superior sagittal sinus. On section it is triangular in shape, with its apex upward.

(4) 'The occipital sinus [sinus occipitalis] (fig. 514) ascends at the attached margin of the falx cerebelli, along the lower half of the squamous portion of the occipital bone from near the posterior margin of the foramen magnum to the internal occipital protuberance. It usually begins in a right and a left branch, known as the marginal sinuses. 'These proceed from the termination of each 
transverse sinus, run around the foramen magnum, where they communicate with the venous vertebral retia, and unite at a variable distance from the internal occipital protuberance to form the single occipital sinus. Sometimes they remain separate as far as the occipital protuberance, then forming two occipital sinuses. One of the two marginal sinuses may be much smaller than the other, or be entirely absent. At the point where the marginal sinuses unite to form the single occipital sinus, there is a communication with the venous vertebral retia. The occipital sinus ends in the confluens sinuum. It receives in its course veins from the tentorium cerebelli, and from the inferior surface of the cerebellum. It communicates. through the plexus of veins which surrounds the hypoglossal nerve [rete canalis hypoglossi] in the hypoglossal (anterior condyloid) canal with the vertebral vein and the longitudinal vertebral venous sinuses.

(5) The circular sinus [sinus circularis] (fig. 516) encircles the hypophysis cerebri. It consists of the two cavernous sinuses and their communications across

Fig. 515.-The Venous Sinuses. (Longitudinal section.)

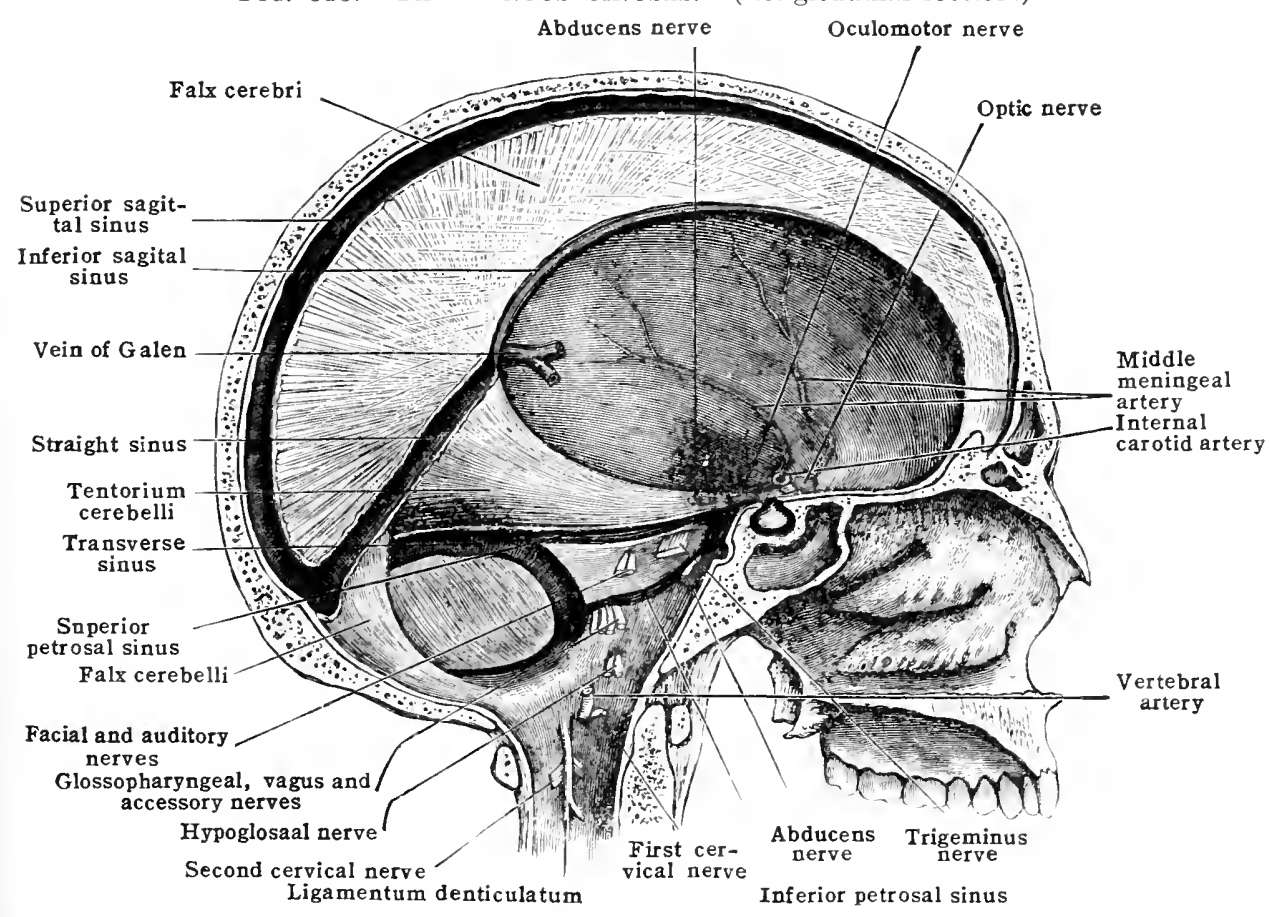

the median line by means of the anterior and posterior intercavernous sinuses. The intercavernous sinuses are small and cross the median line in front of and behind the hypophysis, respectively.

(6) The basilar plexus [plexus basilaris] is a venous plexus in the substance of the dura mater over the basilar part of the occipital bone. It extends from the cavernous sinus to the margin of the foramen magnum below. It communicates laterally with the inferior petrosal sinus, and inferiorly with the internal vertebral venous plexuses. One of the larger of the irregular venous channels forming the plexus passes transversely from one inferior petrosal sinus to the other. This venous plexus is serially homologous with the longitudinal vertebral venous sinuses on the posterior surfaces of the bodies of the vertebræ.

(7) The transverse (or lateral) sinus [sinus transversus] (figs. 514, 516) extends from the internal occipital protuberance to the jugular foramen. In this course it lies in the groove (which has been named after it) along the squamous portion of the occipital bone, the posterior inferior angle of the parietal bone, the mastoid portion of the temporal bone, and the jugular process of the occipital bone. It at first runs laterally and forward horizontally between the two layers of the tentorium cerebelli, following the curve of the groove on the occipital and on the mastoid angle of the parietal bone. On reaching the groove in the mas- 
toid portion of the temporal bone it leaves the tentorium and eurves medially and downward and then forward over the jugular process of the occipital bone, and ends in the posterior compartment of the jugular fossa in the superior bulb of the internal jugular vein. The S-shaped part of the sinus which lies on the mastoid portion of the temporal and jugular portion of the occipital bone is sometimes known as the sigmoid sinus. The transverse sinus receives the internal auditory veins [ $\mathrm{r} v$. auditive interna] from the labyrinth, which emerge from the internal auditory meatus. It also receives veins from the temporal lobe of the cerebrum, some of the superior and inferior cerebellar veins, some of the veins of the medulla and pons, the occipital, and the posterior temporal and occipital veins of the diploë. At the point where it leaves the tentorium it drains the superior petrosal sinus and, when present, the petro-squamous sinus. It communicates with the occipital and rertebral veins through the mastoid and posterior condyloid foramina by means of the mastoid and condyloid emissary veins. As the transverse sinus lies between the layers of the tentorium it is on section prismatic in shape. The sigmoid portion is semicylindrical.

The right transverse sinus is usually the larger and the direct continuation of the superior sagittal sinus, and hence conveys the chief part of the blood from the cortical surface of the brain and vault of the skull. The left transverse sinus is usually the smaller and the direct continuation of the straight sinus, and hence returns the chief part of the blood from the central ganglia of the brain. The right and left sinuses communicate opposite the internal occipital protuberance.

The relation of the lateral sinus to the outside of the skull, especially to the mastoid process of the temporal bone, is of importance with reference to the operations of trephining the mastoid cells, opening the tympanum, and exposing the sinus itself, in septic thrombosis, etc. The course of the sinus corresponds to a line drawn from the external occipital protuberance to the base of the mastoid process, or to the asterion, and thence over the back of the mastoid process in a curved line toward its apex.

(8) The superior petrosal sinus [sinus petrosus superior] (figs. 514, 515) runs at the attached margin of the tentorium cerebelli, along the upper border of the petrous portion of the temporal bone. It connects the cavernous with the transverse sinus. Leaving the lateral and back part of the eavernous sinus just below the fourth nerve, it crosses the fifth nerve, and, after grooving the petrous bone, ends in the transverse sinus as the latter turns downward on the mastoid portion of the temporal bone. It receives veins from the temporal lobe of the cerebrum, veins from the cerebellum, veins from the tympanum through the squano-petrosal fissure, and sometimes the anterior temporal veins of the diploë.

(9) The inferior petrosal sinus [sinus petrosus inferior] (figs. 514, 516) runs along the line of the petro-occipital suture, and connects the eavernous sinus with the commene'ment of the internal jugular vein. It is shorter than the superior petrosal, but considerably wider. As it crosses the anterior compartment of the jugular foramen, it separates the glosso-pharyngeal from the vagus and accessory nerves. It receives veins from the inferior surface of the cerebelium, from the medulla and pons, and from the internal ear. The last, the vein of the cochlear canaliculus [v. eanaliculi cochlear], issues through the eanaliculus cochlea.

(10) The cavernous sinus [sinus eavernosus] (fig. 516) is an irregularly shaped venoms space situated between the meningeal and periosteal layers of the dura mater on the side of the borly of the sphenoid bone. It extends from the medial end of the superior orbital (sphenoidal) fissure in front to the apex of the petrous bone behind. Its lateral wall is the more distinet, and contains the third and fourth nerves, and the ophthalmic division of the fifth nerve. The nerves take the abovernentioned order from above downward, and in the medio-lateral direction. 'The internal carotirl artery and the sixth nerve also pass through the sinus, being separatod from the blood by the condothelial lining. The right and left ravernous sinuses communicate across the middle line with the opposite sinus in frent and behinel the hypophysis cerebri as before mentioned.

The caveluous simus is traversod by numerous traberule or fibrous bands, so that there is no central space, fut rather a number of endothelial-lined irregular lacunar cavities commu-

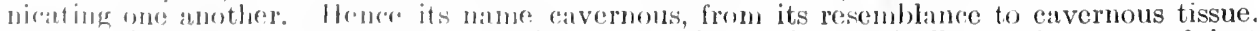
In front it receives the ophlahhoie: vein, with which it is practically continuous, and just

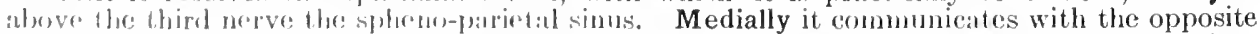
sinus, and posteriorly it ouds in the suprofor and inferior petrosal sinuses. It also receives veins from the inferior surfase of the fmont bobe of the bran, and some of the middle cerebral veins. 'Throngh the Vusilian vein, which rums in anmute formen in the spinous process of 
the sphenoid bone, the sinus communicates with the pterygoid plexus of veins; through the venous plexus around the petrosal portion of the internal carotid [plexus venosus caroticus internus], with the internal jugular vein; and through a venous rete which leaves the cranium by the foramen ovale [rete foraminis oralis] and by small veins passing through the foramen lacerum medium, with the pterygoid and pharyngeal plexuses.

(11) The spheno-parietal sinus [sinus sphenoparietalis] runs in a slight groove on the under surface of the lesser wing of the sphenoid bone. It originates in one of the meningeal veins near the apex of the lesser wing, and, running medially, passes through the sphenoidal fold of dura mater above the third nerve into the front part of the cavernous sinus. It generally receives the anterior temporal veins from the diploë.

Fig. 516.-The Venous Sinuses at the Base of the Brain. The dura mater has not been removed. (After Toldt, "Atlas of Human Anatomy," Rebman, London and New York.)

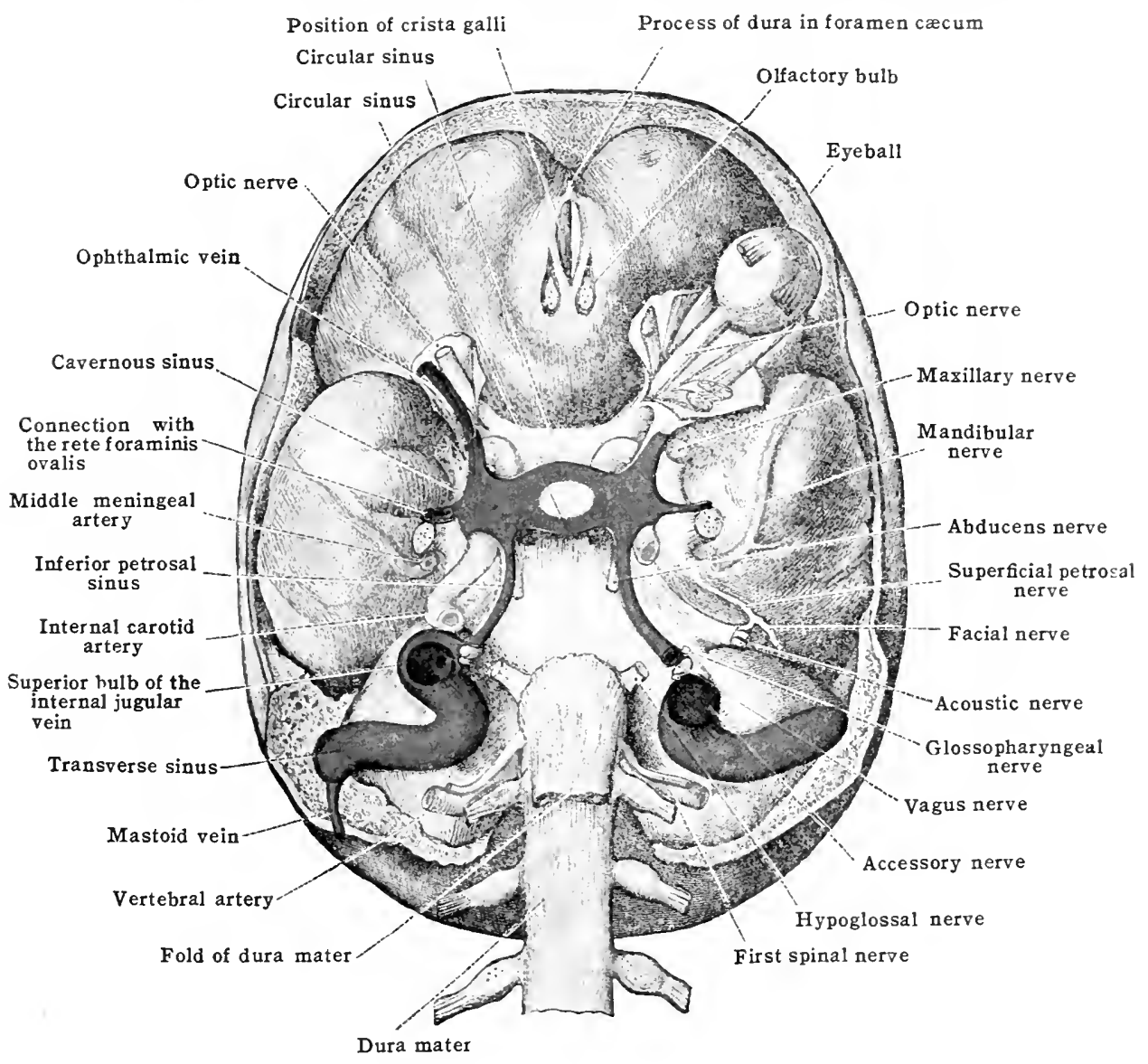

The petro-squamous sinus is occasionally present. It lies in a groove along the junction of the petrous and squamous portions of the temporal bone. It opens posteriorly into the transverse sinus at the spot where the latter enters on its sigmoid comse. In front it sometimes, though very rarely, passes through a formen in the squamous portion of the temporal bone between the mandibular fossa and the external auditory meatus into the temporal vein.

\section{THE TEINS OF THE BRAIN}

The veins of the brain present the following peculiarities:- (a) They do not accompany the cerebral arteries. (b) Ascending veins do not, is in other situations, run with descending arteries, but with ascending arteries, and vice versa. (c) The deep veins do not freely communicate. (d) The veins have very thin walls, no muscular coat, and no valves. (e) The reins opening into the saigittal, and some of those opening into the transverse (lateral) sinus pour in their blood in a direction opposite to the current in the sinuses, so impeding the flow in both 
vein and sinus. (f) The flow of blood in the sinuses is further retarded by the trabeculæ stretching across their lumen, and in the sagittal sinus by the blood having to ascend, when the body is erect, through the anterior half of its course.

The veins of the brain may be divided into the cerebral and the cerebellar.

Fig. 517.-The Veins of the Brain, Superior Surface. (After Toldt, "Atlas of Human Anatomy," Rebman, London and New York.)

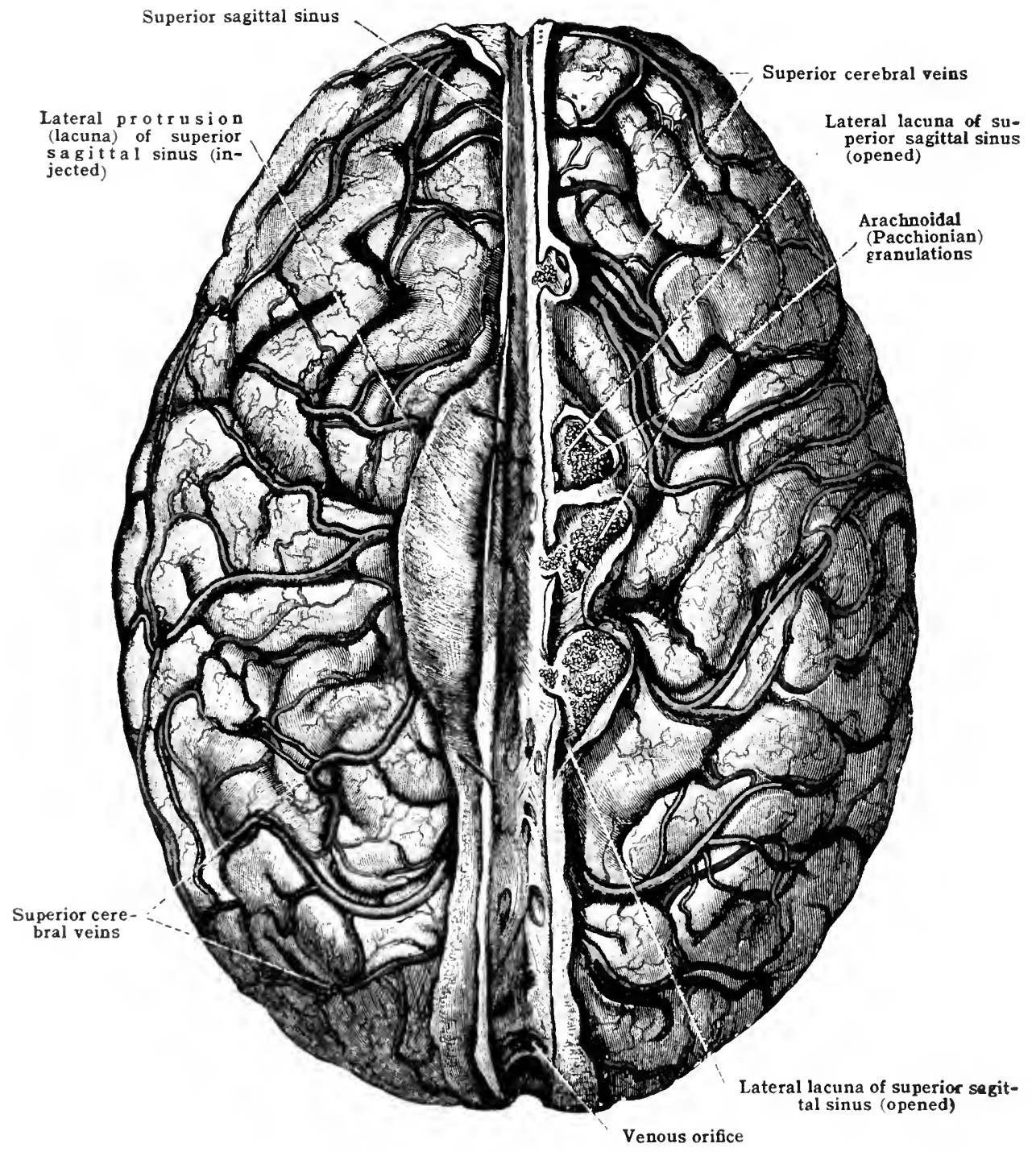

'Tine Celrebrat, Veins

The cerebral veins, like the cerebral arteries, may be divided into the cortical and the central.

The cortical or superficial veins ramify on the surface of the brain and return the blood from the cortical substance into the venous sinuses. They lie for the most part in the sulei between the gyri, but some pass over the gyri from one sulcus to another. 'They consist of two sets: a superior and an inferior.

(1) The superior cerebral veins [vence cerebri superiores] (fig. 517), some eight to twelve in number on each side, are formed by the union of branches from the convex and medial surfaces of the cerebrum. Those from the convex surface pass medially and forward toward the longitudinal fissure, where they aro joined by the branches eoming from the medial surface. After receiving a sheath from the arachnoid, they enter obliquely into the superior sagittal 
sinus, running for some distance in its walls. These veins freely communicate with each other, thus differing from the cortical arteries. They also communicate with the inferior cortical veins. They may be roughly divided into $(a)$ frontal; $(b)$ paracentral; $(c)$ central; $(d)$ occipital.

(2) The inferior cerebral veins [venæ cerebri inferiores] (fig. 518), ramify on the base of the hemisphere and the lower part of its lateral surface. Those on the inferior surface of the frontal lobe pass, in part into the inferior sagittal sinus, and in part into the cavernous sinus. Those on the temporal lobe enter in part into the superior petrosal sinus, and in part into the transverse sinus, passing into the latter from before backward. A large vein from the occipital lobe winds over the cerebral peduncle and joins the great cerebral vein (of Galen) just before the latter enters the straight sinus. One of the inferior cortical veins is called the middle cerebral vein [v. cerebri media]; it runs in the lateral fissure (of Sylvius) and ends in the cavernous sinus. This vein is sometimes called the superficial Sylvian vein. Another, the great anasto-

Fí. 518.-The Veins of the Brain, Inferior Surface. (After Toldt, "Atlas of Human Anatomy," Rebman, London and New York.)

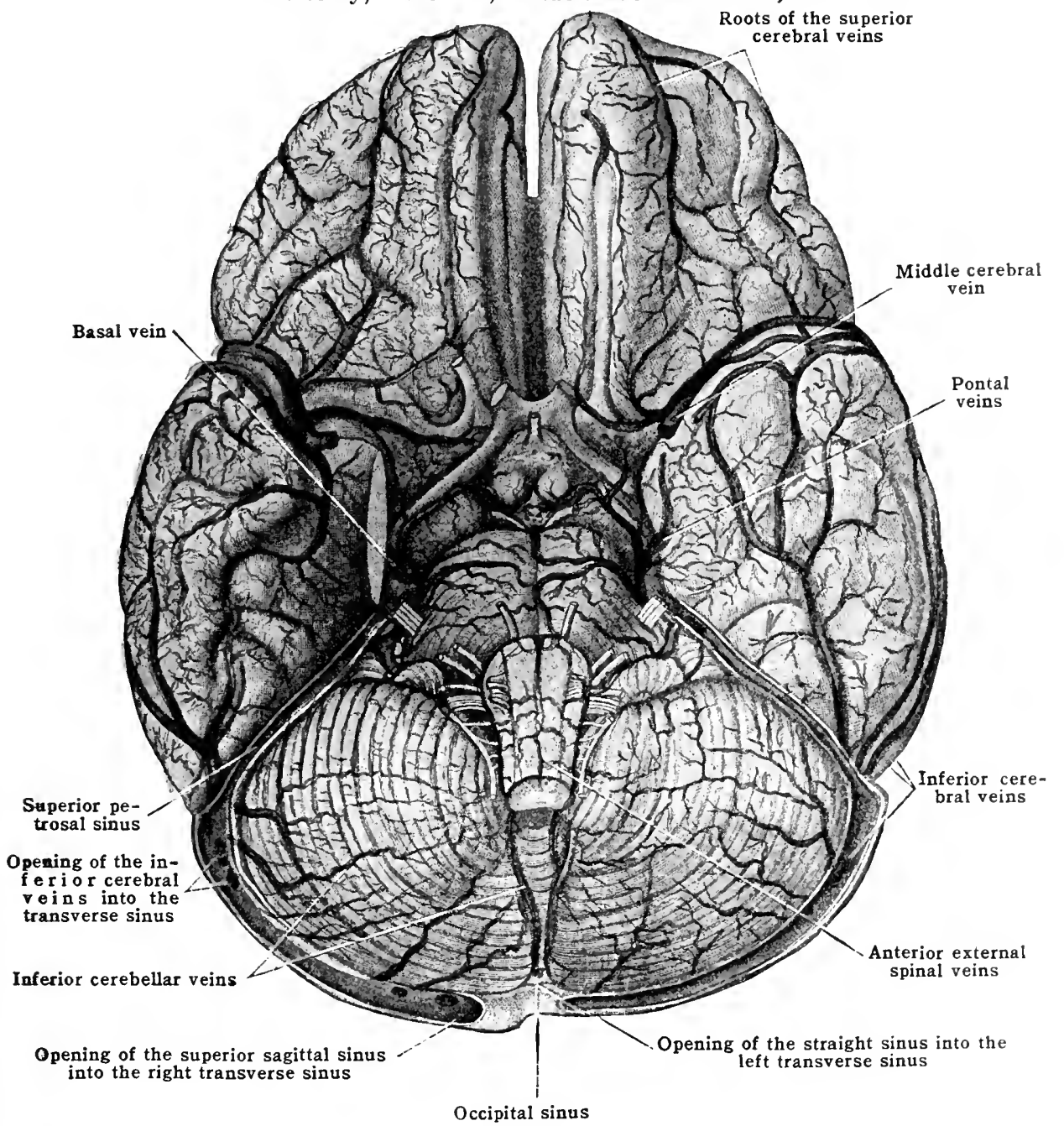

mosing vein of Trolard, a branch of the middle cerebral, establishes a communication between the superior sagittal and cavernous sinuses by anastomosing with one of the superior cortical veins. A second anastomotic vein, that of Labbé, is also a tributary of the middle cerebral, and connects the veins over the temporal lobe with the transverse sinus.

A small inferior cerebral vein, the ophthalmomeningeal vein, establishes a communication between the cerebral veins and those of the orbit. It communicates with the veins of the base and is usually drained by the superior ophthalmic vein. It occasionally opens into the superior petrosal sinus.

The central or deep (ganglionic) veins return blood from the internal parts of the cerebrum, and converge to the great cerebral vein. 
Fig. 519.--The Veins of the Brain, Lateral Surface. (After Toldt, "Atlas of Human Anatomy," London and New York.) Superior cerebral veins Dura mater

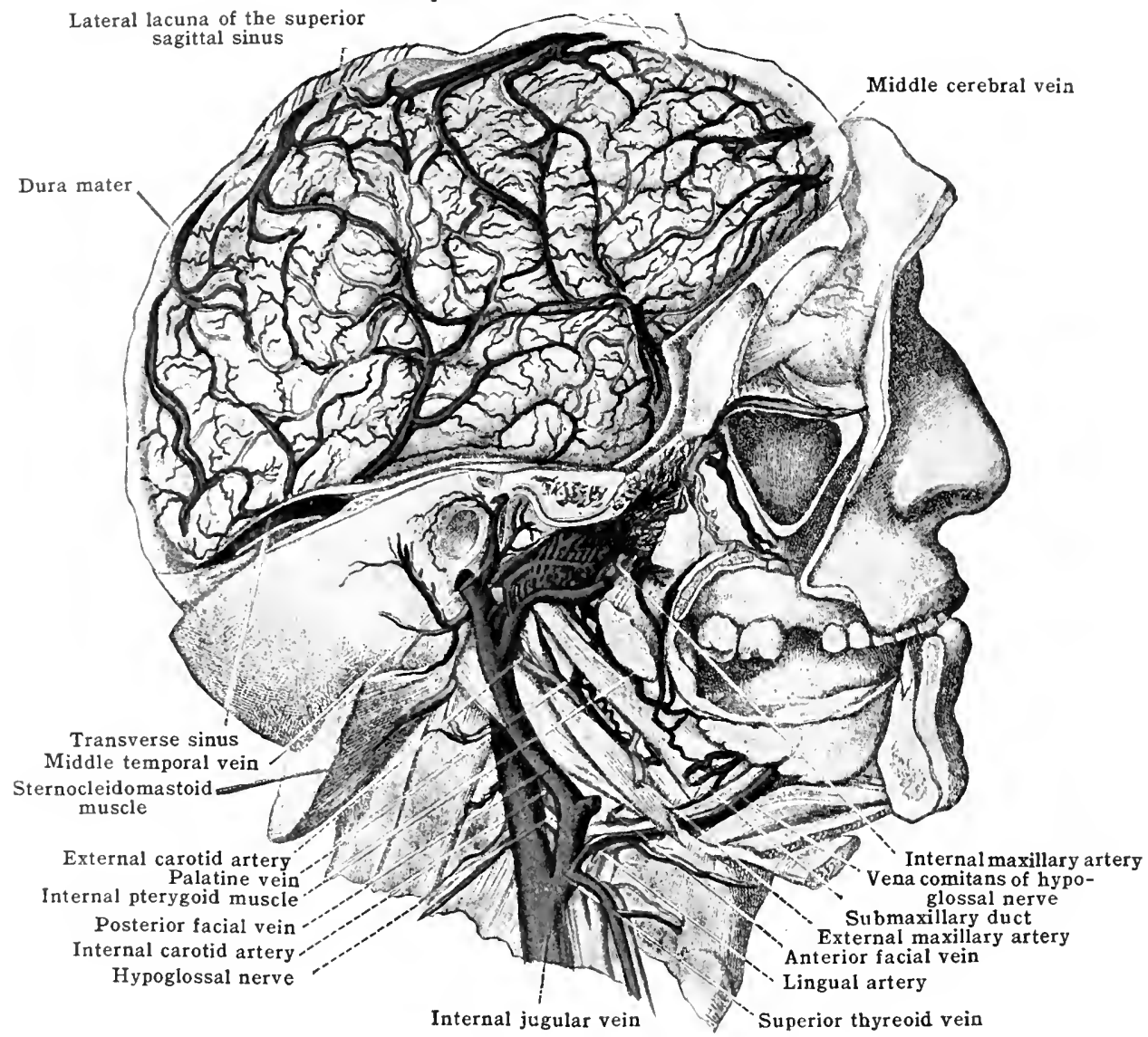

Frg. 520.-The Ophthalaic Veins. (After Quain.)

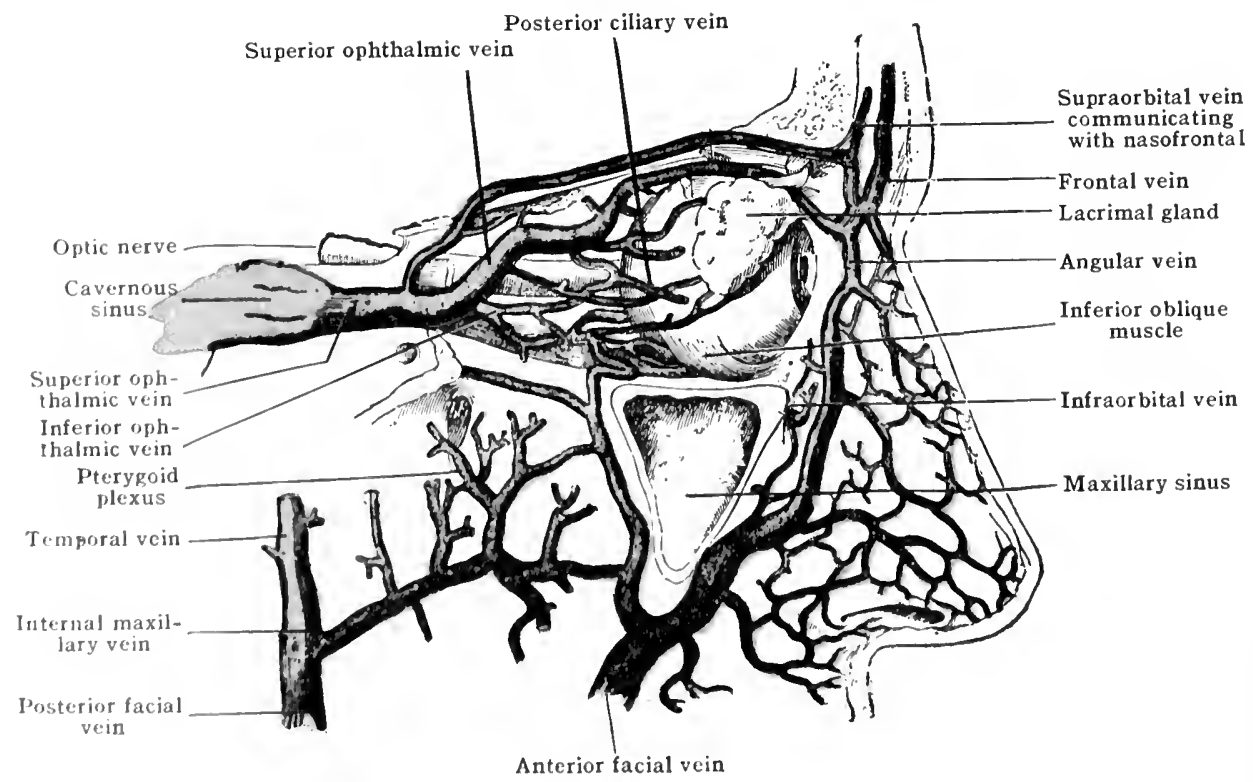


(3) The internal cerebral veins [vv. cerebri internæ] are two large venous trunks (the venæ Galeni) which leave the brain at the transverse fissure, that is, between the splenium of the corpus callosum and the corpora quadrigemina. In this region they unite to form the great cerebral vein [v. cerebri magna, Galeni], which opens into the anterior end of the straight sinus. The internal cerebral veins are formed by the union of the chorioid vein with the vena terminalis near the interventricular foramen. From this spot they run backward parallel to each other, between the layers of the tela chorioidea, and terminate in the way above mentioned.

Tributaries of the internal cerebral veins. - In addition to the vena terminalis and the chorioidal, the internal cerebral veins also receive the basal vcin, the veins of the thalmus, the vein of the chorioid plexus of the third ventricle, and veins from the corpus callosum, the pineal body, the corpora quadrigemina, and posterior horn of the lateral ventricle. The united trunk, or great cerebral vein, receives veins from the upper surface of the cerebellum, and one of the posterior inferior cerebral veins.

The chorioid vein [v. chorioidea] runs with the chorioid plexus. It begins in the inferior cornu of the lateral ventricle, and ascends on the lateral side of the chorioid plexus along the margin of the tela chorioidea to the interventricular foramen, where it unites with the vena terminalis to form the internal cerebral vein. It receives tributaries from the hippocampus, corpus callosum, and fornix.

The terminal vein (or vein of the corpus striatum) [v. terminalis], formed by veins from the corpus striatum and thalamus, runs forward in the groove between those structures, passing in its course beneath the stria terminalis, and joins the chorioid (choroid) vein at the interventricular foramen. Tributaries.-It receives, in addition to the veins from the corpus striatum, thalamus and fornix, the vena septi pellucidi which receives blood from the septum pellucidum, and anterior cornu of the lateral ventricle.

The basal vein [v. basalis], runs backward over the cerebral peduncle, and enters the internal cerebral vein near the union of that vessel with the vein of the opposite side.

Tributaries. - A vein, the deep Sylvian, from the insula and surrounding convlutions; the inferior striate veins from the corpus striatum, which they leave through the anterior perforated substance; and the anterior cerebral veins from the front of the corpus callosum. It is also joined by interpenduncular veins from the structures in the interpeduncular space; ventricular veins from the inferior cornu of the lateral ventricle; and by mesencephalic veins from the mid-brain.

\section{The Cerebellar Veins}

\section{The cerebellar veins are divided into the superior and inferior.}

The superior [vv. cerebelli superiores] ramify on the upper surface of the cerebellum; some of them run medially over the superior vermis to join the straight sinus and great cerebral vein; others run laterally to the transverse and superior petrosal sinuses.

The inferior [vv: cerebelli inferiores], larger than the superior, run, some forward and laterally to the inferior petrosal and transverse sinuses, and others directly backward to the occipital sinus.

\section{The Veins of the Medulla and Pons}

The veins from the medulla oblongata and the pons terminate in the inferior petrosal and transverse sinuses.

\section{THE VEINS OF THE NASAL CAVITIES}

The venous plexuses on the inferior nasal concha (turbinate bone) and back of the septum are described with the NosE. The veins leaving the nasal cavities follow roughly the course of their corresponding arteries. Thus the sphenopalatine veins pass through the spheno-palatine foramen into the pterygoid plexus; the anterior and posterior ethmoidal veins join the ophthalmic. Small veins accompany branches of the external maxillary artery through the nasal bones and frontal processes of the maxillary bones, and end in the angular and anterior facial veins; and other small veins pass from the nose anteriorly into the superior labial, and thence to the anterior facial.

\section{THE VEINS OF THE EAR}

The veins from the external ear and external auditory meatus join the posterior facial and posterior auricular veins. The veins from the tympanum open into the superior petrosal sinus and posterior facial vein. The blood from the labyrinth flows chiefly through the internal auditory veins [vv. auditivie internæ], which lie with the internal auditory artery in the internal auditory meatus, and enters the transverse or inferior petrosal sinus. Some of the blood from the labyrinth, however, passes through the vestibular vein which lies in the aquæductus 
vestibuli, into the inferior petrosal sinus. Some also passes through the vena canaliculi cochleæ which traverses the canal of the same name and empties into the commencement of the internal jugular vein.

\section{THE VEINS OF THE ORBIT}

The blood from the eyeball and orbit is returned by the superior ophthalmic vein into the eavernous sinus. This vein and its tributaries have no valves, and communicate with the frontal, supraorbital, inferior cerebral, and other veins. Hence under certain conditions, as from pressure on the cavernous sinus, the blood

Fig. 521.-The Veins of the Orbit.

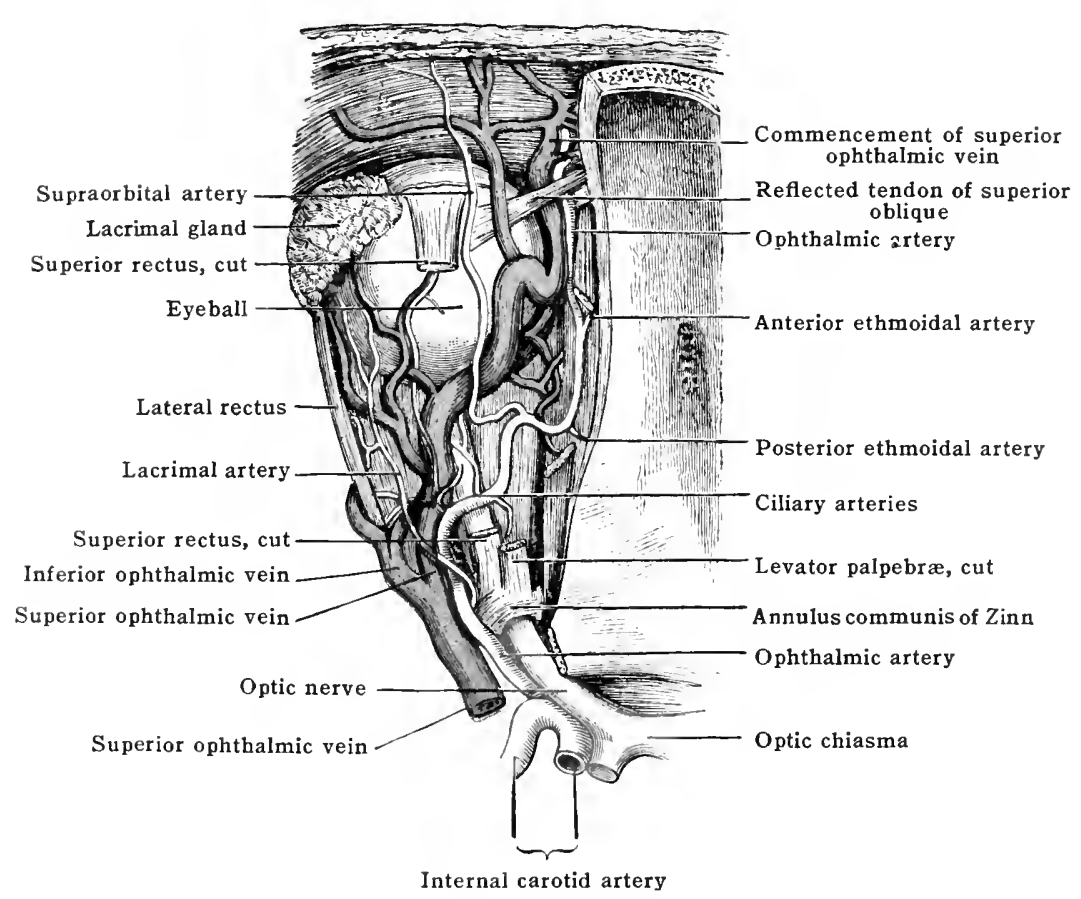

may flow in the contrary direction to the normal-i. e., from behind forward into the frontal and supraorbital, and thence through the angular vein into the anterior facial; or upward into the cerebral venous system. In this way pressure on the retinal veins is quickly relieverl, and little or no distension occurs in eases of obstruction in the cavernous sinus.

The superior ophthalmic vein [v. ophthalmica superior] begins at the medial angle of the eyelid by a free communication with the frontal, supraorbital, and angular veins, and thence runs backward and laterally with the ophthalmie artery across the optie nerve to the medial end of the superior orbital (sphenoidal) fissure, where it is usually joined by the inferior ophthalmic vein. It then passes backward between the two heads of the lateral rectus muscle below the sixth nerve, leaves the orbit through the medial end of thesuperior orbital (sphenoidal) fissure and enters the front part of the cavernous sinus. In this course it lies anterior and superficial to the ophthalmic artery.

Tributaries. - (1) 'The naso-frontal vein; (2) the superior museular veins; (3) the veins of the lids and conjunctiva; (4) the ciliary veins; (5) the anterior and postrrior rethmojalal veins; (6) the lacrimal vein; (7) the central vein of the retina; and (8) the infrerior ophthalmic vein.

(1) The naso-frontal vein [v. 11:tso-frontalis] begins by a free communication with the supra-

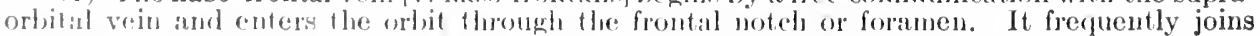

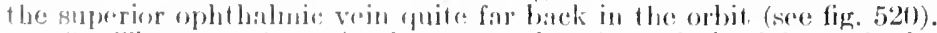

(2) 'l'ts muscular voins [vv. musculares] are derived from the levator palpebra, superior rectus, supurior shlicule, and unodial rectus.

(3) Thlu palpebral and conjunctival veins [vv. palpelerales; vv. conjunctivales ant. et post.], both anteriog and posterior, open into the superior ophthalmice.

(1) 'lla: ciliary veins, thro voins of the "yebitl, are divided into two sets. An anterior [vv. ciliares ant.] anerge from the eychall with the anterior eitiary arteries, and open 
into the muscular veins returning the blood from the four recti. They form a circumcorneal ring of episcleral yeins [rv. episclerales]. The posterior set, which drain the venæ vorticosæ, leave the globe midway between the cornea and the entrance of the optic nerve. The latter veins are four or five in number, the upper ending in the superior, the lower in the inferior ophthalmic vein (fig. 520).

(5) The anterior and posterior ethmoidal veins ( $\mathrm{rv}$. ethmoidales ant. et post.), correspond in their course with the arteries of the same name. They enter the orbit through the anterior and posterior ethmoidal foramina, and join either the ophthalmic direct, or one or other of the superior muscular branches.

(6) The lacrimal vein [v. lacrimalis] returns the blood from the lacrimal gland, and corre. sponds in its course to the lacrimal artery.

(7) The central vein of the retina [v. centralis retinæ] runs with the central artery in the optic nerve. It joins the superior ophthalmic at the back of the orbit.

(S) The inferior ophthalmic vein [v. ophthalmica inferior], smaller than the superior, is formed near the front of the orbit by the confluence of the inferior muscular with the lower posterior ciliary veins. It runs backward below the optic nerve, along the floor of the orbit, and either joins the superior ophthalmic vein, or opens separately into the cavernous sinus. A large communicating branch passes downward through the inferior orbital (spheno-maxillary) fissure to join the pterygoid plexus of veins. It receives muscular twigs from the inferior and lateral rectus and from the inferior oblique, and some posteior ciliary reins.

\section{THE VEINS OF THE PHARYNX AND LARYNX}

The pharyngeal veins [rv. pharyngex] are arranged in the form of a plexus, between the constrictor muscles and the pharyngeal or prevertebral fascia. The pharyngeal plexus receives branches from the mucous membrane, the pterygoid canal [vv. canalis pterygoidei] from the soft palate, the Eustachian tube and the anterior recti and longus colli muscles. Above, it communicates with the pterygoid plexus of veins; below it drains into the internal jugular vein.

The veins of the larynx end partly in the superior laryngeal vein [v. laryngea superior], which opens into the internal jugular vein, and partly in the inferior laryngeal vein [v. laryngea inferior], which terminates in the plexus thyroideus impar. The laryngeal plexus of veins communicates with the pharyngeal plexus.

\section{THE DEEP VEINS OF THE NECK}

The deep veins of the neck include the internal jugular, vertebral, deep cervical, erior thyreoid, thyreoidea ima, thymic, tracheal, and cesophageal veins.

\section{The Internal Jugular Vein}

The internal jugular vein [v. jugularis interna] begins at the jugular fossa, and is the continuation of the transverse sinus. It passes down the neck, in company first with the internal carotid artery and then with the common carotid artery, to a point a little lateral to the sterno-clavicular articulation, where it joins the subclavian to form the innominate vein. At its commencement in the larger: posterior and lateral part of the jugular foramen, it is somewhat dilated, forming the superior bulb of the jugular vein [bulbus v. jugularis superior] (fig. 522). This dilated part of the internal jugular vein lies in the jugular fossa of the temporal bone and is therefore in immediate relation to the floor of the tympanum. At first the internal jugular lies in front of the rectus capitis lateralis, and behind the internal carotid artery, from which it is separated by the hypoglossal, glossopharyngeal, and vagus nerves, and by the carotid plexus of the sympathetic. As it descends it passes gradually to the lateral side of the internal carotid, and retains this relation as far as the upper border of the thyreoid cartilage. Thence it runs to its termination along the lateral side of the common carotid artery, being contained in the same sheath with it and the vagus nerve, but separated from these structures by a distinct septum. The vein generally overlaps the artery in front. About $2.5 \mathrm{~cm}$. ( $1 \mathrm{in}$.) above its termination it contains a pair of imperfect valves below which a second dilation usually occurs in the vein. This, the inferior bulb [bulbus v. jugularis inferior], extends as low as the junction of the internal jugular with the subclavian. It not infrequently receives the termination of the external jugular vein.

Tributaries.- At the superior bulb the internal jugular vein receives the inferior petrosal sinus; the vein of the cochlear canaliculus, and a meningeal 
rein; opposite the angle of the jaw, reins from the pharyngeal plexus, and of ten a communicating branch from the external jugular vein; opposite the bifurcation of the carotid it is joined by the common facial, and a little lower down by the lingual, sternomastoid, and the superior thyreoid veins. At the level of the cricoid cartilage by the middle thyreoid when this vein is present.

The inferior petrosal sinus is described with the other sinuses of the brain ( $p$. 652); the pharyngeal plexus with the veins of the pharynx (see p. 659); and the common facial vein with the superficial veins of the scalp and face (p. 646).

The lingual vein [v. lingualis], begins near the tip of the tongue, where it accompanies the arteria profunda lingux. It lies at first beneath the mucous membrane covering the under surface of the tongue. It then passes backward medial to the hyo-glossus, and in company with the lingual artery. After receiving the sublingual vein [v. sublingualis] and the dorsal

Fig. 522.-The Internal Jugular Vein. (After Henle).

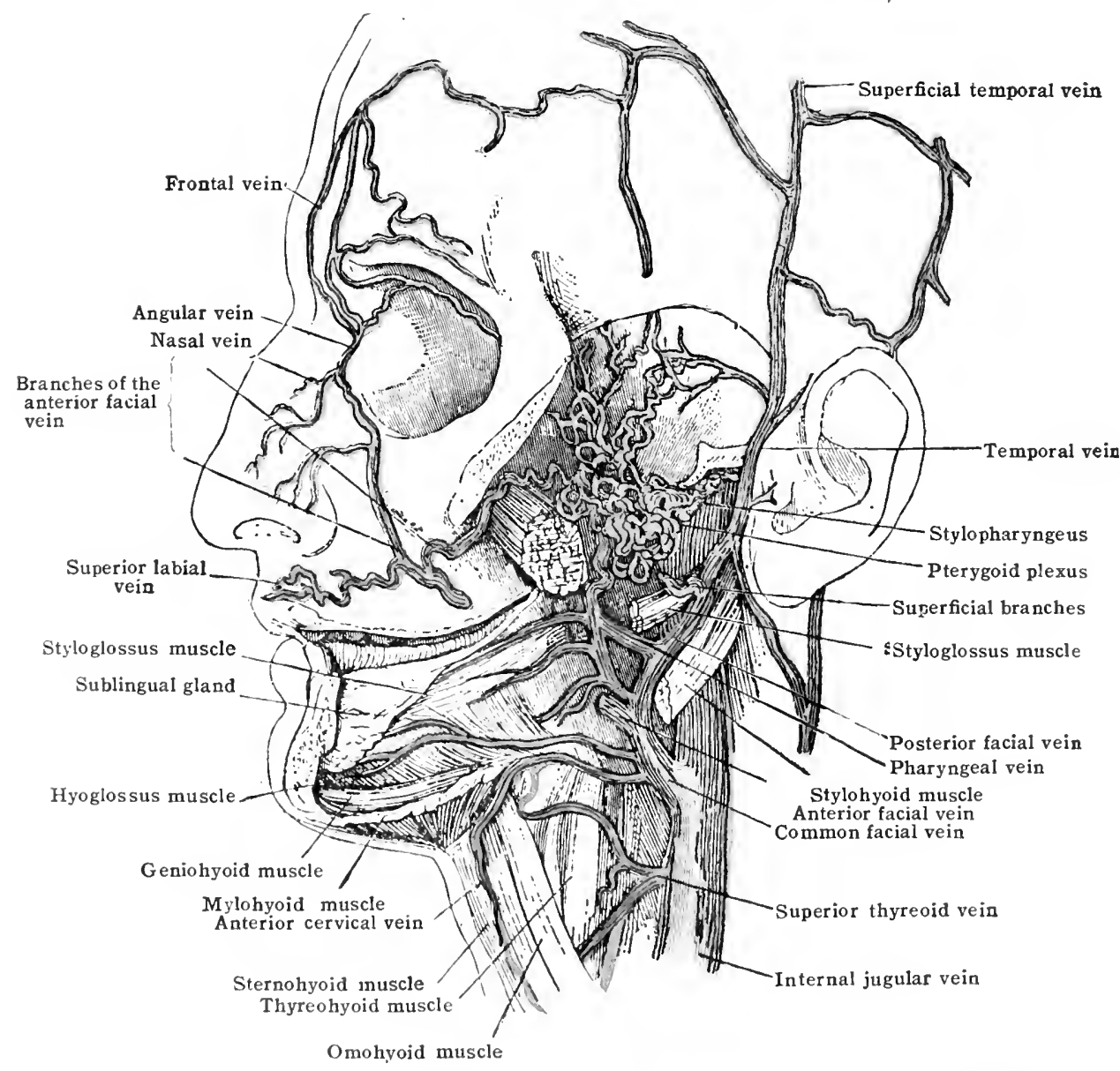

lingual veins [vv. dorsales linguce], which roughly correspond to their respective arteries, it is joined l,y the small v. comitans nervi hypoglossi which follows the upper border of the liypoglossal nerve. 'Tla trunk finally crosses the common carotid artery and opens into the internal jugular vein. 'lle lingual vein comumieates with the pharyngeal veins and with tributaries of the anterior facial. It occisionally terminates in the posterior or in the common facial vein. The sternomastoid vein [v sternocleilomastoidea] accompanies the artery of the same name and ernptirs into the internal jugular.

'Tle superior thyreoid vein [v. thyreoidea superior] emerges from the upper part of the thyreoid gland, in which if freely anstomoses with the other thyreoir veins. This anastoinosis, the plexus thyreoideus impar, oecurs both in the substance of the organ and on its surface beneath the capsule. 'The vein then passes upward and laterally into the internal juglatar vein, crossing the rommon cillotid artery in its course. At times it forms a common trink with the common facial vein. Its tributaries are the sterno-hyoid, sterno-thyreoid, and thyreo-loyoir veins from the musclos benring those names; and the erico-thyreoid and superior laryngeal veins which correspond with the crico-thyreoid and superior laryngeal arteries respentively. 'Tliese require no sperisl ileseription. 
A separate vein frequently passes out from the capsule of the thyreoid gland near the lower part of the lateral lobe, crosses the common carotid, and opens into the main superior thyreoid vein or into the internal jugular vein a little below the cricoid cartilage. In the former case it is regarded as part of the superior thyreoid vein system; in the latter it is generally known as the middle thyreoid vein.

\section{The Vertebral Tén}

The vertebral vein [v. vertebralis] does not accompany the vertebral artery in its fourth stage, that is, within the skull, but begins in the posterior vertebral venous plexus of the suboccipital triangle. It then enters the foramen in the transverse process of the altas, and passes with the vertebral artery through the foramina in the transverse processes of the cervical vertebre, forming a plexus around the artery. On leaving the transverse process of the sixth cervical vertebra it crosses in front of the subclavian artery and opens into the innominate vein. It has one or two semilunar valves at its entrance into the innominate vein. In the suboccipital triangle it communicates with the internal vertebral venous plexuses, with the deep cervical, and occipital veins, and is joined by veins from the recti and oblique muscles and the pericranium.

Tributaries.-As it passes down the neck it receives (1) intervertebral veins, which issue along with the cervical nerves, from the spinal canal; (2) tributaries from the anterior and posterior vertebral venous plexus from the bodies of the cervical vertebræ and their transverse processes; and (3) tributaries from the deep cervical muscles. Just before it terminates in the innominate it is joined by (4) the anterior vertebral vein, a small vein which accompanies the ascending cervical artery, and, sometimes, by the deep cervical vein.

\section{The Deep Cervical Vein}

The deep cervical vein [v. cervicalis profunda], larger than the vertebral, passes down the neck posterior to the cervical transverse processes. It corresponds to the deep cervical artery from which it is separated by the semispinalis cervicis muscle.

It ${ }^{-}$begins in the posterior vertebral venous plexus and receives tributaries from the deep muscles of the neck. It communicates with, or entirely drains, the occipital vein by a branch which perforates the trapezius muscle. The deep cervical vein then passes forward beneath the transverse process of the seventh cervical vertebra to open into the innominate vein near the vertebral, or into the latter near its termination. Its orifice is guarled by a pair of valves.

\section{The Inferior Thyreoid and Thyreoidea Iha Veins}

The inferior thyreoid veins [vv, thyreoidea inferiores] descend from the lower part of the thyreoid gland obliquely lateralward to the innominate veins. The right vein crosses the innominate artery just before its bifurcation, and ends in the right innominate vein a little above the superior vena cava. It receives inferior laryngeal veins and veins from the trachea, and has valves at its termination in the innominate. The left vein passes obliquely over the trachea behind the sterno-thyreoid muscle, and opens into the left innominate vein. It also receives laryngeal and tracheal veins, and sometimes the thyreoidea ima; it is guarded by valves where it opens into the innominate trunk.

The thyreoidea ima vein [v. thyreoidea ima] is single and placed approximately in the median line. It begins in the thyreoid isthmus from the plexus thyreoideus impar, runs downward upon the anterior surface of the trachea, and opens into the left innominate vein or into the left inferior thyreoid.

\section{The Thymic, Tracheal and Cesophageal Veins}

These small veins usually open into the left innominate vein. The thymic veins [vv. thymicæ], small in the adult, open into the left innominate or into the inferior thyreoid or thyreoidea ima vein. The tracheal veins [vr. tracheales] anastomose with the laryngeal and bronchial veins. The œsophageal veins [vv. œsophagex] from the upper part of the œsophagus, anastomose with the lower œsophageal veins and with the pharyngeal plexus. 


\section{THE VEINS OF THE THORAX}

\section{THE SUPERFICIAL VEINS OF THE THORAX}

The superficial veins of the front of the thorax can be seen in fig. 537. They form a plexus over the entire chest which the portion over the mammary gland is called the mammary plexus. The laterally placed lateral thoracic and costoaxillary veins drain the mammary plexus and communicate with the thoracoepigastric vein. These three veins terminate in the axillary vein (p.671). The veins nearer the median line are drained by the internal mammary vein and its anterior intercostal and superior epigastric tributaries. The veins over the entire thorax are in free communication with the superficial veins of the abdominal wall (p. 683).

\section{THE DEEP VEINS OF THE THORAX}

The deep veins of the thorax are:- the pulmonary veins, and the vena cava superior and its innominate and other tributaries. Of these veins, the pulmonary, the vena cava superior, and the innominate veins have already been described, as have the tributaries of the latter arising in the neek.

The following veins are described below:-(1) The azygos and ascending lumbar veins, which discharge their blood into the vena cava superior; (2) the veins of the vertebral column, which are tributary to the azygos veins through the intercostals; (3) the internal mammary veins, and (4) the superior phrenic, anterior mediastinal and pericardiac veins, all of which open into the innominate veins.

\section{THE AZYGOS AND ASCENDING LUMBAR VEINS}

The azygos veins are longitudinal veins, the remnants of the posterior cardinals, which are the main collecting trunks for the posterior part of the body in the embryo. They lie along the sides of the thoracic vertebræ, and collect the blood from the intercostal veins; they are the upward continuation of longitudinal anastomotic trunks, the ascending lumbar veins which take origin in the abdomen. The azygos veins are three in number, the azygos (azygos major) on the right side, and the hemiazygos (azygos minor) and accessory hemiazygos (azygos tertia) on the left.

The azygos vein [v. azygos] begins in the abdomen as a continuation upward of the ascending lumbar vein. Through this means it connects with the iliac veins and it has also an anastomosis with the vena cava inferior which may become very important in cases of obstruction of the vena cava. It runs up through the posterior mediastinum on the right side of the front of the bodies of the thoracic vertelure as high as the fourth thoracie vertebra, in this part of its course lying to the riglit of the alorta and thoracie duct; it then curves forward over the root of the right lung, and opens into the vena cava superior immediately before the latter pieres the perieardium.

It risually contains an imperfeet pair of valves at the point where it turns forwarl from the fourth thoracie vertebra to areh over the root of the lung; and still more imprerect valves are found at varying intervals lower down the vein.

It rercives the intereostal veins of the right side, exeept the first two or three. These voins (usially excepting the first) are collected into a common trunk before joining the azygos vein. It also receives the hemiazygos and aceessory hemiazygos, the right posterior bronchial vein, and small oesophageal and posterior inerliastinal veins.

'The hemiazygos vrin [ $\mathrm{v}$. hemiazygos] begins in the abdomen by communicating, like the azygos vein, with the ascencling lumbar vein of its own side. It conrses up the posterior mediastinum to the left of the bodies of the lower thoracie vertobre as high as the oighth or ninth, where it turns obliquely to the right, and, crossing in front of the vartebral column behind the aorta and the osophagus, opens into the vena azygos. In its course it crosses over three or four of the lower left interonstal arteries, and is eovered by the pleura. 
Tributaries.-(1) The lower four or five left intercostal veins; (2) the lower end of the accessory hemiazygos vein (sometimes); (3) small left mediastinal veins; and (4) the lower left cesophageal veins.

The accessory hemiazygos [v. azygos accessoria] varies considerably in size, position, and arrangement, and is often continuous with, or drained by, the left superior intercostal vein. It lies in the posterior mediastinum by the left side of the bodies of the fifth, sixth, and seventh or eighth thoracic vertebræ, and is more

Fig. 523.-The Superior and Inferior Venæ Cava, the Innominate Veins, and the Azygos Veins.

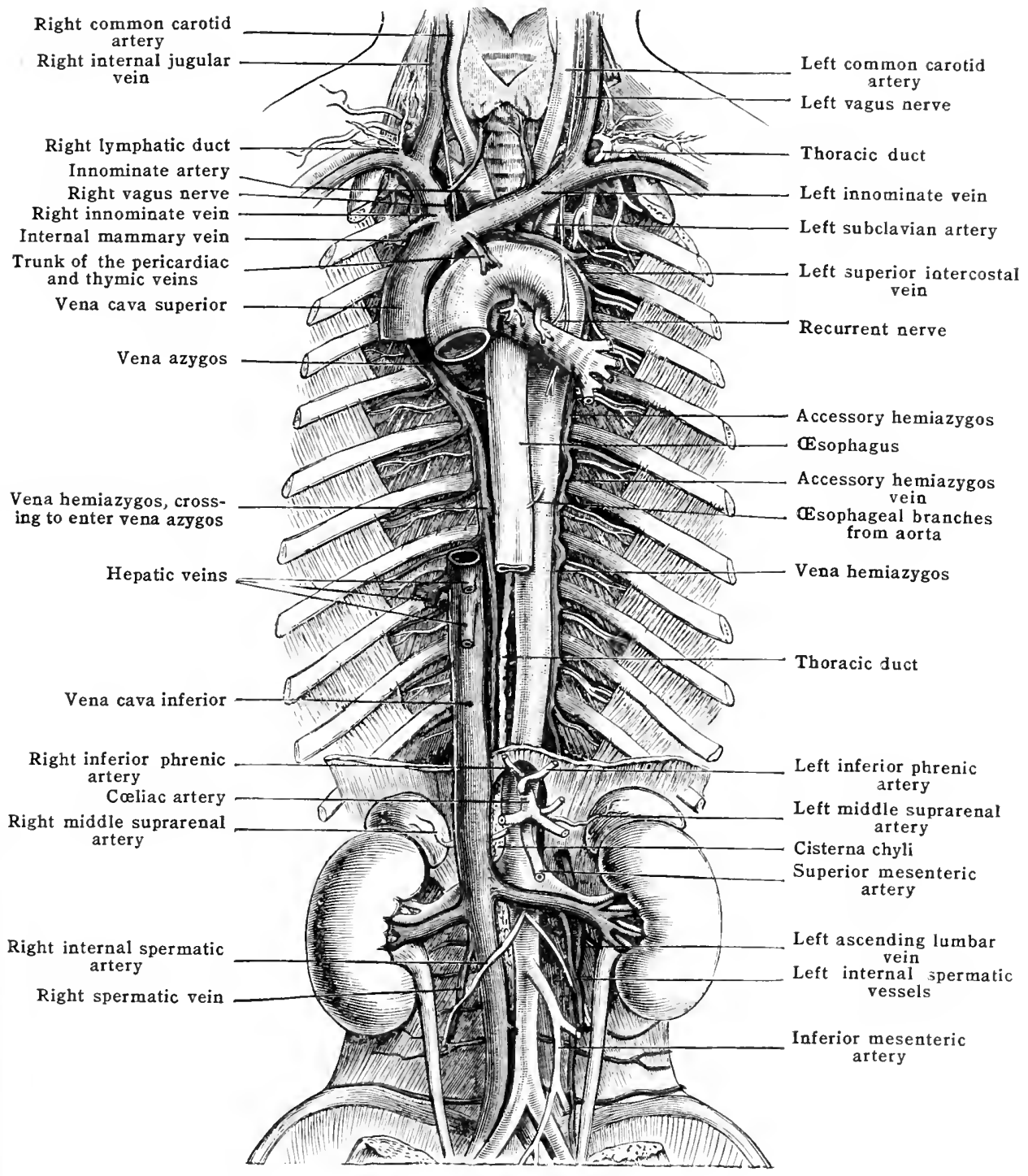

or less vertical in direction. It communicates above with the left superior intercostal vein, and below either joins the hemiazygos or passes obliquely across the seventh or eighth thoracic vertebra to join the azygos vein. It crosses the corresponding left intercostal arteries, and is covered by the pleura.

Tributaries.-(1) The fourth, fifth, sixth, seventh, and sometimes the eighth intercostal veins; and (2) the left posterior bronchial vein.

The ascending lumbar vein [v. lumbalis ascendens] begins, on either side, in the neighbourhood of the sacral promontory. It is here in free communication, by 
means of the anterior sacral plexus, with the middle and lateral sacral veins, and with the common iliac, hypogastric and ilio-lumbar veins. It ascends in front of the lumbar transverse processes communicating with the lumbar veins, the vena cava inferior and, usually, with the renal vein. The right vein enters the thorax between the aorta and the right medial crus of the diaphragm, and is continued upward as the vena azygos. The left vein pierces the lef $t$ medial crus and becomes the hemiazygos.

The intercostal veins [vv. intercostales]. -The intercostal veins are twelve in number on each side, the last one being subcostal. They correspond to the intercostal arteries. There is one vein to each artery, the vein lying above the artery whilst in the intercostal space. Each vein receives a dorsal tributary which accompanies the posterior ramus of an intercostal artery between the transverse process of the vertebræ and the neck of the rib. These dorsal branches not only return the blood from the muscles of the back, but receive a spinal branch from the vertebral venous plexuses. The intercostal veins also receive small tributaries from the bodies of the vertebræ. The termination of the intercostal veins is different on the two sides and also varies greatly in different individuals. The intercostal vein from the first space on either side may join the superior intercostal vein, but commonly opens directly into the innominate or one of its tributaries, most frequently the vertebral.

On the right side.-The second intercostal vein joins with the third or with the third and fourth to form the right superior intercostal vein [v. intercostalis suprema dextra]. This vein opens into the azygos vein as the latter is arching over the root of the right lung. The rest join the azygos directly. The upper of these have well-marked valves where they join the azygos vein; in the lower veins these valves are imperfect. All the intercostal veins are provided with valves in their course between the nuscles.

On the left side the second intercostal vein joins the third and fourth to form a single trunk, the left superior intercostal vein [v. intercostalis suplema sinistra]. This vein passes upward across the areh of the aorta and opens into the left innominate vein. The left superior intercostal frequently communicates at its lower end with the accessory hemiazygos vein, which is occasionally tributary to it. In most cases a small tributary runs up over the front of the aortic arch to join the superior intercostal vein; it is a vestige of the left conmon cardinal and from it a small fibrous cord can often be traced through the vestigial fold of the pericardium to the oblique vein of the left atrium (p. 523).

The left fifth, sixth and seventh intercostal veins commonly open into the accessory hemiazygos, and the eighth or ninth and succeeding veins into the hemiazygos. 'The method of termination of the intercostal veins of the left side is subject to such variation that a normal arrangement can scarcely be said to exist at all. The eighth may open directly into the azygos, as may the seventh and ninth or even more of the veins; the hemiazygos and accessory hemiazygos being correspondingly reduced in size.

The posterior bronchial veins [vv. bronchiales posteriores] correspond to the bronchial arteries, but do not retum the whole of the blood carried to the lungs by those vessels - that part which is distributed to the smaller bronchial tubes and the alveola being brought back by the pulnonary veins. The posterior bronchial veins issue from the lung substance behind the structures forming the root of the lung. The right vein generally joins the vena azygos just before the latter vein enters the superior vena cava. 'The left vein opens into accessory hemiazygos vein. The bronchial veins at the root of the lung receive sinall tributaries from the bronchial glands, from the trachea, and from the posterior mediastinum.

The œsophageal veins [vv. nesophage:e] from the thoracic portion of the osoplagus end in part in the vena azygos, and in part in the vena hemiazygos. 'They anastomose with the upuer orsophageal veins, and with the coronary vein. veins.

The posterior mediastinal veins, small and numerous, open into the azygos and hemiazygos

\section{TIIE VEINS OF THE VERTEBRAL COLUMN}

The venous plexuses around and within the vertebral column extending from the cranium to the coceyx may be divided into two categories:-- (1) the external and (2) tho internal vertebral venous plexuses. 'Tho external plexuses consist of two parts, the anlerior rertobral venous plexuses situated on the anterior aspect of the vertebral bodins and the posterior vertebral venous plexuses ramifying over the posterior aspect of the vertebral arehes, spines, and transverse processes. 'The intermal plexuses consist of two lomgitudinal venous sinuses situated between the vertehre and the pesterior Iongitudinal ligament, and of two vertebral venous retiv placed immediatrly external to the dura mater. The sinuses of the internal plexuses communieate freely with one another and with the internal retia and external plexuses. Thery rereive the reternal spinal veins and the basivertebral veins from the loodies of the vertobre. The venous cireulation of the vertebral 
column is drained by the vertebral, intercostal, lumbar and sacral veins either directly or by means of (3) the intervertebral reins.

1. The external vertebral venous plexuses [plexus venosi vertebrales externi] include the following:

(a) The anterior vertebral venous plexuses [plexus venosi vertebrales anteriores] (fig. 524) consist of small veins ramifying in front of the bodies of the vertebræ. These veins communicate with the basivertebral veins and are larger in the cervical region than elsewhere.

(b) The posterior vertebral venous plexuses [plexus venosi vertebrales posteriores] (fig. 524) are situated around the transverse, articular, spinous processes and laminæ of the vertebræ. Communications take place between the plexuses of each segment and with the veins of the neighbouring muscles and integuments. Branches are also sent, through the ligamenta flava, to the internal vertebral venous plexuses, and, between the transverse processes, to the intervertebral veins.

2. The internal vertebral venous plexuses [plexus venosi vertebrales interni] (fig. 524):-

(a) The two longitudinal vertebral sinuses [sinus vertebrales longitudinales] run through. out the entire length of the vertebral canal. They are situated behind the bodies of the vertebræ or either side, between the bone and the posterior longitudinal ligament. The sinuses have

\section{Fig. 524.-The Veins of the Vertebral Colunis.}

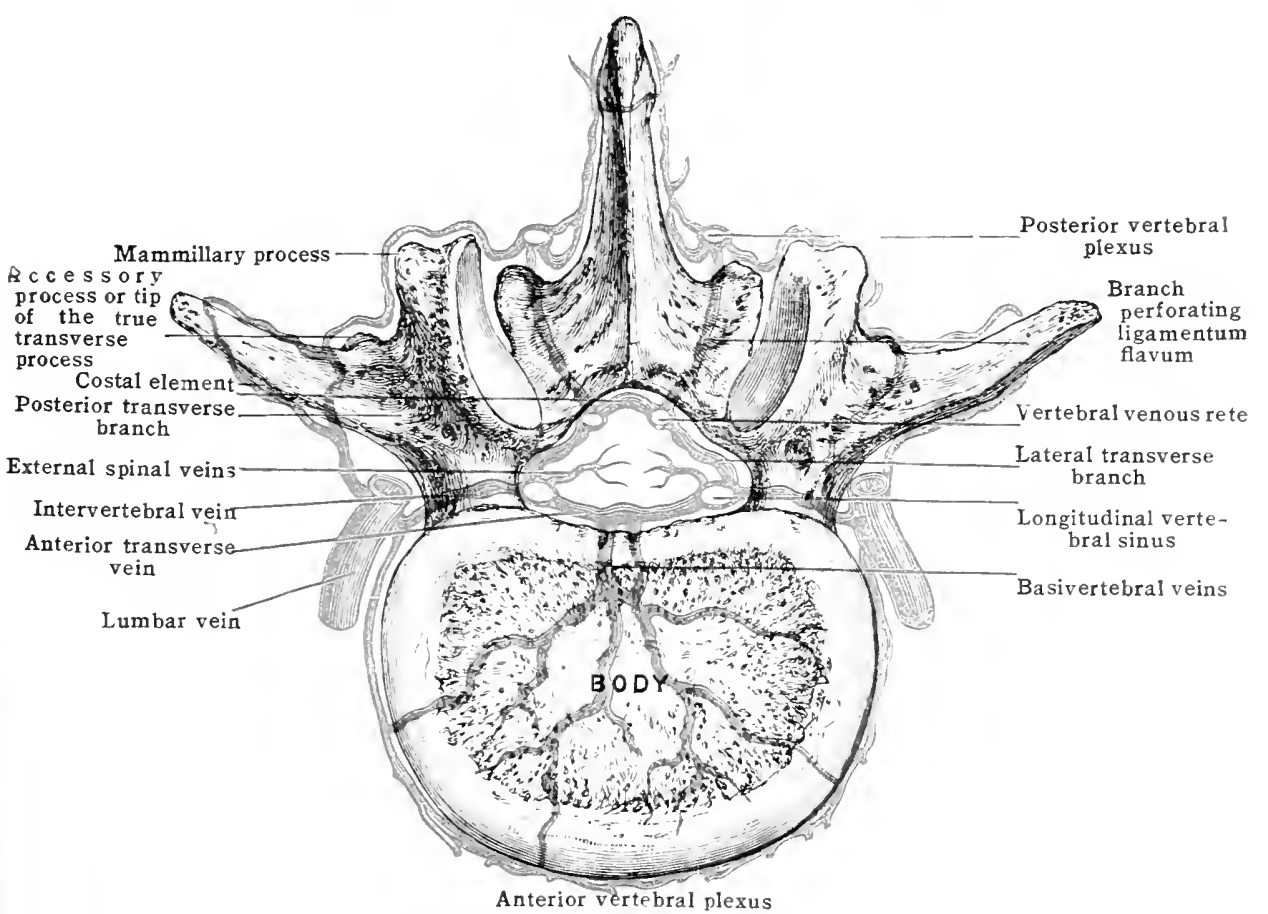

extremely thin walls, and their interior is made irregular by numerous folds but no true valves are present. The calibre of the longitudinal sinuses is reduced by constrictions opposite the intervertebral discs; the constrictions alternating with dilatations opposite the vertebral bodies. At each dilatation there occurs a cross communication between the longitudinal sinuses of either side, and each receives a basivertebral vein from the corresponding vertebral body. Opposite every intervertebral foramen and anterior sacral foramen each longitudinal sinus is joined by the corresponding intervertebral vein. The longitudinal sinuses communicate very freely with one another, and with the vertebral retia. At the foramen magnum they communicate with the basilar plexus and, by means of the rete canalis hypoglossi, with the internal jugular vein.

(b) The venous rete of the vertebræ [retia venosa vertebrarum] (fig. 524) extend from the foramen magnum to the coccyx. They consist of two main retia situated posteriorly and laterally to the dura between the latter and the vertebral arch. They communicate very freely with one another across the median line; with the posterior external plexus by means of twigs perforating the ligamenta flava; and with the longitudinal vertebral sinuses by means of lateral branches. At the foramen magnum they communicate with the occipital sinus.

(c) The external spinal veins consist of two sets-anterior and posterior-which are drained by means of veins following the nerve roots, in to the internal vertebral venous plexus.

The anterior external spinal veins [vv. spinales externæ anteriores] form a tortuous anastomosing vessel in the region of the anterior median fissure.

The posterior external spinal veins [vv. spinales externa posteriores], smaller than the anterior run longitudinally on the posterior surface of the cord.

The external spinal veins form a wide-meshed plexus in the pia mater which drains the internal spinal veins [vv. spinales internæ] (see SPINAL CORD). 
(d) The basivertebral veins [vv. basivertebrales] (fig. 524) collect the blood from the cancellous tissue of the bodies of the vertebra, and consist of a tunica intima only. They take a radial direction converging to the transverse vessels connecting the longitudinal vertebral sinuses. They communicate with the anterior external plexus and with the intercostal veins.

3 The intevertebral veins [rv. intervetebrales] (fig. 524), emerge from each longitudinal

Fig. 525.-The Vertebral Venous Plexuses. (After Henle.)

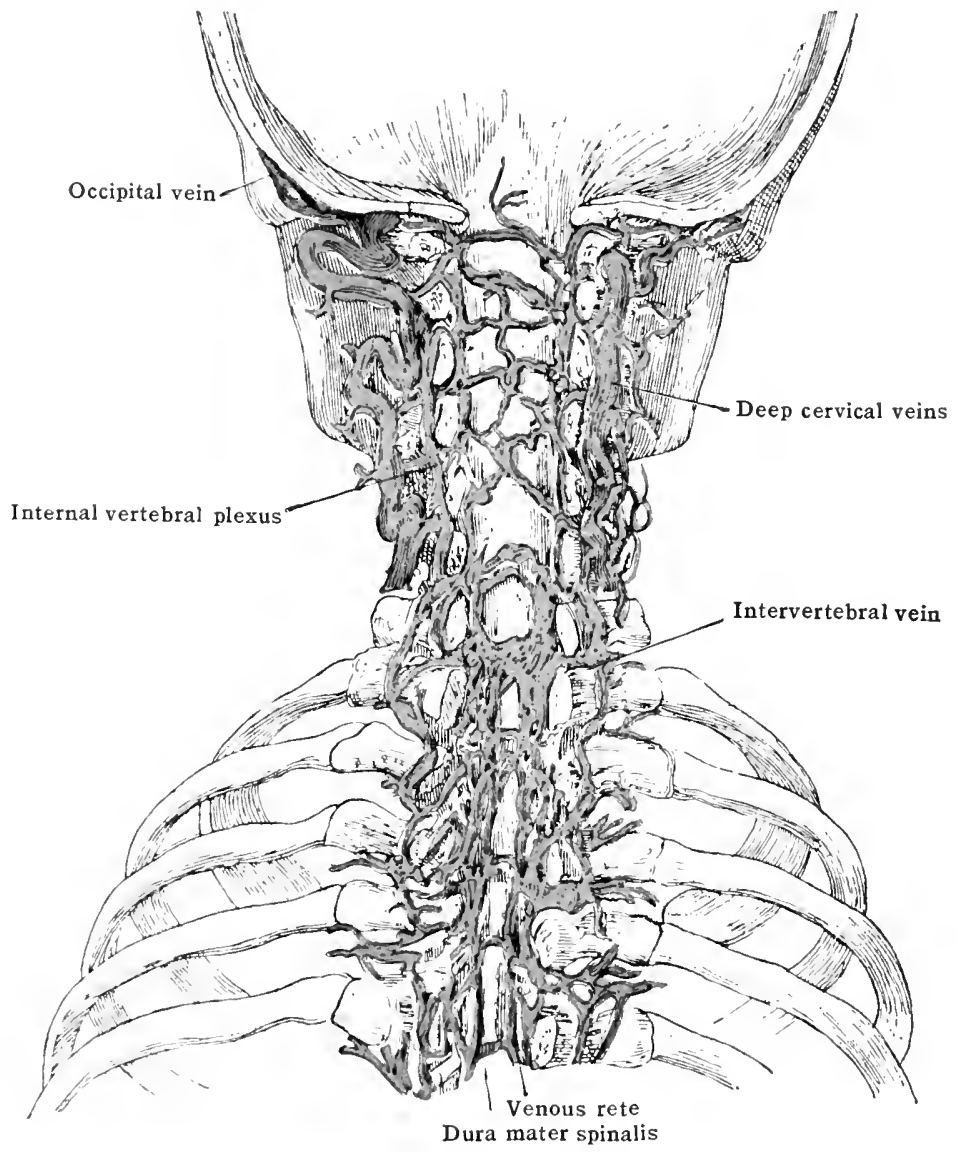

sinus and pass out through the intervertebral or anterior sacral foramina. They open into the vertebral, intercostal, limblar or sacral veins accorling to region and receive numerous tributaries from the anterior and posterior external vertelual venous plexuses. They are instrumental in draning the venous system of the vertebral column and spinal cord.

\section{THE' INTERNAL, MAMATARY VEIN}

The internal mammary voin [r. matmmaria interna] is formed by the union of thr vende comitantes corresponding to the suprrior epigastrie and museulo-phrenie arteries. The right and left interial mammary voins pass upward, in company with the corresponding arteris's, to open into the right and left innominate respertively.

Tributaries. In adclition to the superficial veins of the thorax, the internal inammary reins recrive the anterior intereostal, anterior bronchial and perirartliac veins.

Tho superior epigastric voin [v. (phigastrica superior] assists in the drainage of the subcu-

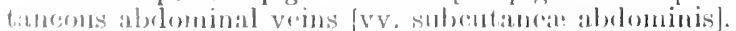

The anterior bronchial vins [vV honchintes anteriores] arise in the bronehial walls and rommonicate with the trachal and posterior hronchial veins. 


\section{THE SUPERIOR PHRENIC, ANTERIOR MEDIASTINAI, AND PERICARDIAC VEINS}

The superior phrenic [vv. phrenicx superiores], the anterior mediastinal [vv mediastinales anteriores], and pericardiac [vv. pericardiace] veins are small vessels, corresponding to the arteries of those names. They pass over the arch of the aorta and open into the lower and anterior part of the left innominate.

\section{THE VEINS OF THE UPPER EXTREMITY}

The veins of the upper limb consist of two sets-a superficial and a deep. The superficial veins ramify in the subcutaneous tissue above the deep fascia, and they do not accompany arteries. The deep reins accompany the arteries, and have practically the same relations as those vessels. The superficial and deep veins communicate at frequent intervals through the intermuscular veins which run between the muscles and perforate the deep fascia. Both sets of veins are provided with valves, but the valves are more numerous in the deep than in the superficial. There are usually valves where the deep veins join the superficial. The superficial veins are larger than the deep, and take the greater share in returning the blood.

\section{THE SUPERFICIAL VEINS OF THE UPPER EXTREMITY}

The superficial veins begin in two irregular plexuses, one in the palm and the other on the back of the hand. The plexus in the palm is much finer, and communicates with the superficial volar veins of the fingers. The latter discharge their blood into the dorsal venous rete by means of the veins of the folds between the fingers, or the intercapitular veins [vv. intercapitulares] (fig. 426).

The veins of the back of the hand begin in a longitudinal plexus over the fingers, and at the bases of the fingers the reins of the adjacent digits are connected by digital venous arches [arcus venosi digitales], from which arise the dorsal metacarpal veins [vv. metacarper dorsales]; these form upon the back of the hand a dorsal venous rete [rete venosum dorsale manus] (fig. 427).

Of the veins of the arm, two stand out prominently, the basilic and the cephalic. Both of these arise from the veins of the back of the hand, curve around to the volar surface of the forearm, and pass to the upper arm (fig. 426).

The basilic vein [v. basilica], ${ }^{*}$ arises on the back of the hand from the ulnar end of the dorsal venous rete, which usually forms an arch. It curves around the ulnar side of the forearm to the volar surface and passes to the elbow and the upper arm, where it lies in the median bicipital sulcus. It extends up to about the middle third of the sulcus, and, piercing the brachial fascia, joins the brachial vein.

The cephalic vein [v. cephalica],* begins at the radial end of the dorsal venous rete or arch and curves around the radial border of the forearm to the volar surface not far above the thumb. It passes to the elbow and the upper arm, but, unlike the basilic, it maintains its superficial course up to the shoulder, lying first in the lateral bicipital sulcus and then in the groove between the pectoralis major and the deltoid. Just below the clavicle it turns into the depth, and empties into the axillary vein.

In the forearm plexus one or more longitudinal veins besides these are usually distinct. One lateral to the cephalic is known as the accessory cephalic [ $\mathrm{r}$. cephalica accessoria] (formerly the radial) vein; one near the centre is known as the median antibrachial [v. mediana antibrachii], (formerly the anterior ulnar) vein.

At the elbow there is usually an oblique connecting branch, the median cubital vein [v. mediana cubiti] (formerly termed median basilic) which extends

* The basilic vein here described corresponds to the posterior ulnar and basilic; the cephalic corresponds to the median, median cephalic and cephalic of the older terminology employed in English text-books. The BNA terminology has the great advantage that it can be readily used to described any form of venous pattern. The English terminology applies only to cases in which the $\mathbf{M}$-shaped arrangement occurs upon the volar surface of the elbow. Berry and Newton find the latter arrangement in only 13 per cent. out of 300 cases examined. 
from the cephalic up to the basilic. In some cases this anastomosis is made by a division of the median antibrachial into two branches, a median cephalic and Fig. 526.-The Superfichal Veiss of the Arm and Forearm. (After Toldt, "Atlas of Human Anatomy," Rebman, Uondon and New York.)

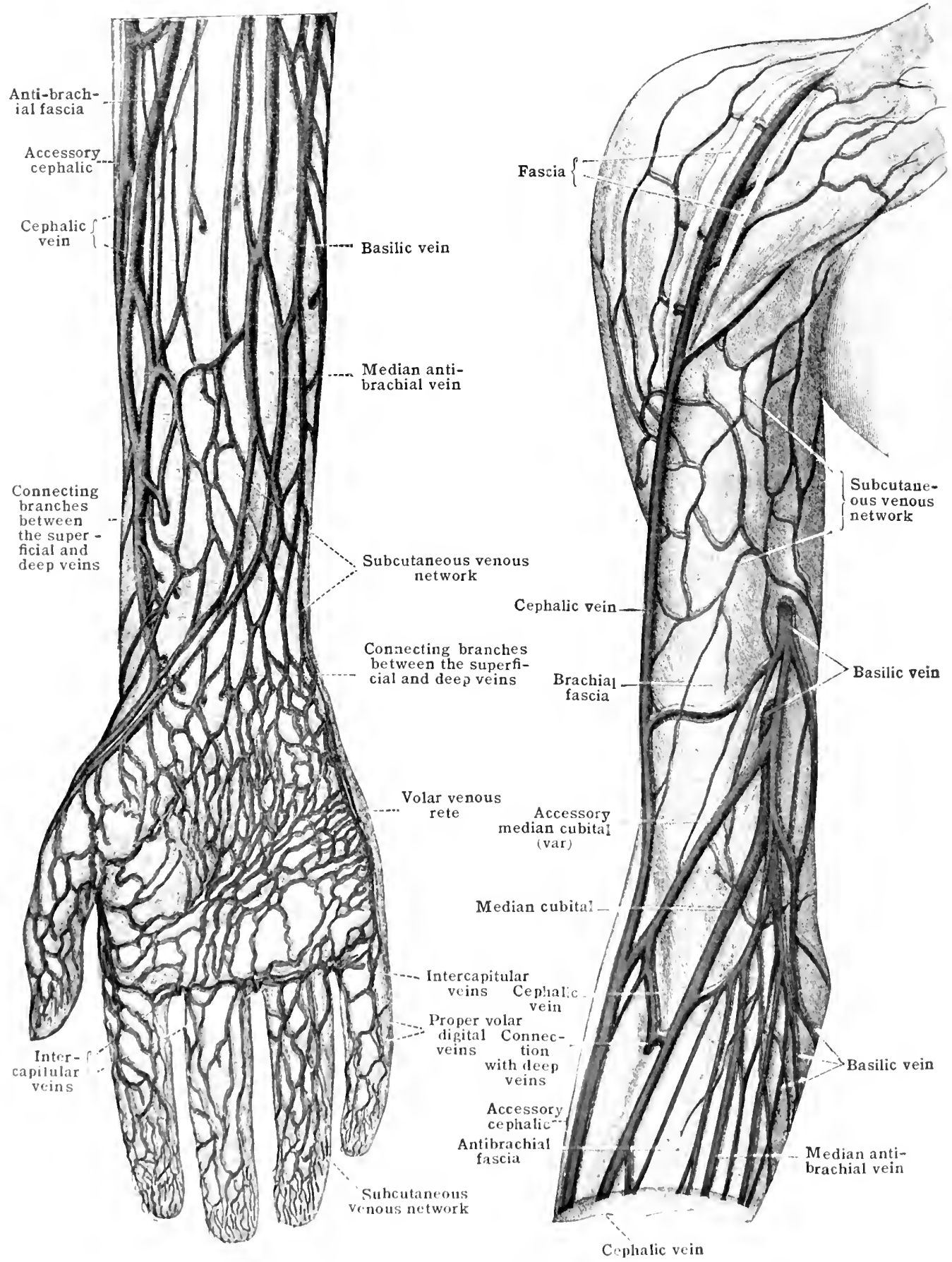

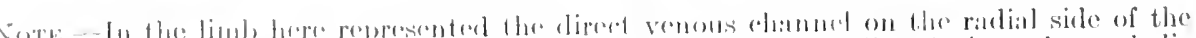

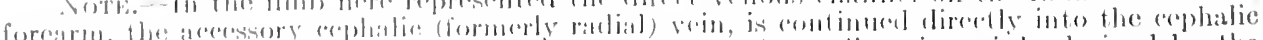

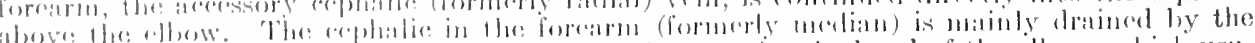

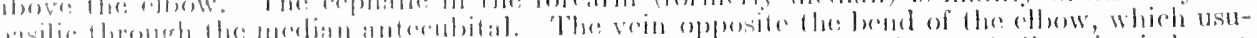

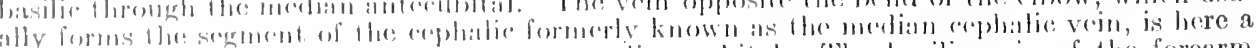
Aly

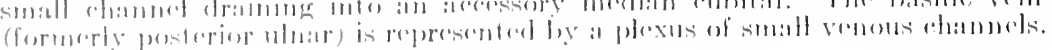


median basilic. Occasionally the cephalic in the upper arm is reduced to a small tributary, which takes the course of the cephalic in the forearm, but bends ulnarward at the elbow to form the basilic. Numerous connections occur between the deep and the superficial veins at the elbow.

The superficial plexus of veins in the upper arm consists of small vessels that pass to the cephalic vein.

Fig. 527.-Veins of the Back of the Forearir. (After Toldt, "Atlas of Human Anatomy," Rebman, London and New York.)

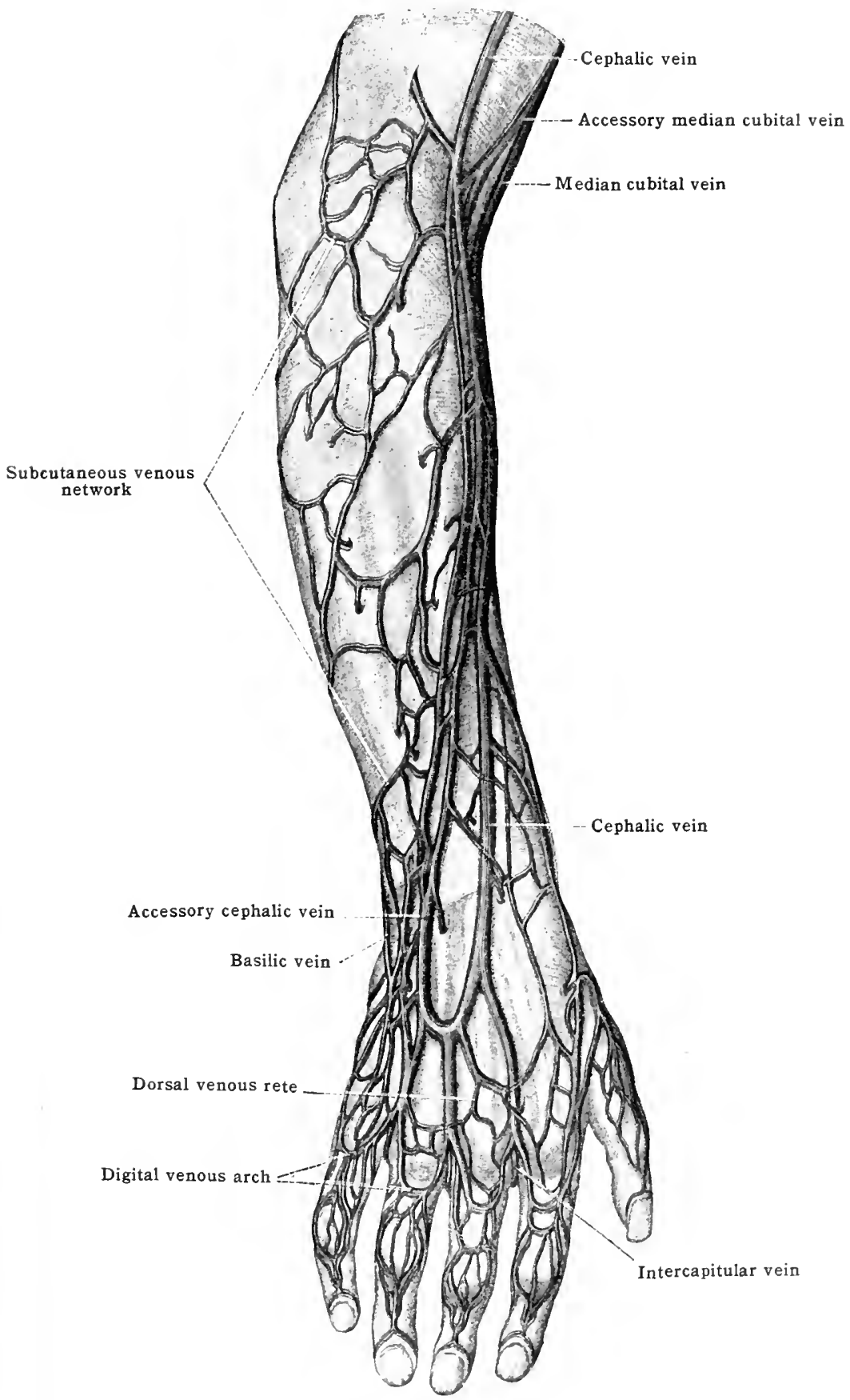




\section{THE DEEP VEINS OF THE UPPER EXTREMITY}

The deep veins of the upper extremity accompany their corresponding arteries. There are two veins to each artery below the level of the axilla, known as the venæ comitantes. The deep veins all contain numerous valves, and Fig. 528,-Deep Veins of the Arir and Axilla. (After Toldt, "Atlas of Human Anatomy," Rebman, London and New York.)

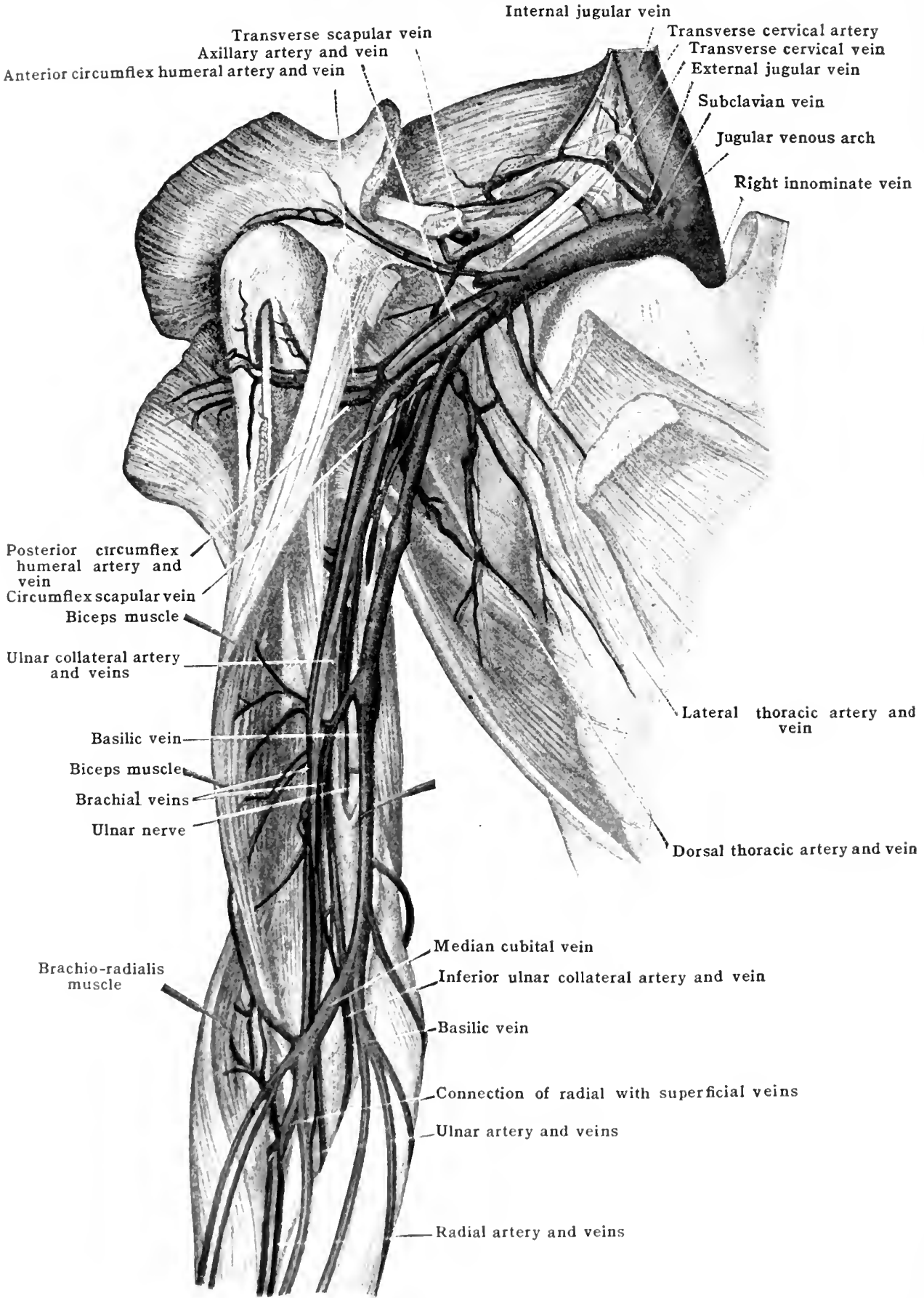

commmnimate at frepuent intrevals through intermuscular veins with the superficial versisels. 
Beginning at the fingers, two minute proper volar digital veins [venæ digitales volares propria], accompany each digital artery along the sides of the fingers, and uniting at the cleft, form common volar digital veins [vv. digitales volares communes], which join the venæ comitantes of the arteries, forming the superficial palmar arch. In like manner the veins accompanying the arteries forming the deep arch receive tributaries, the volar metacarpal veins [vv. metacarpeac volares], corresponding to the branches of that arch. A superficial and a deep volar venous arch [ arcus volaris venosi superficialis et profundus] are thus formed accompanying the arterial arches. The venwe comitantes from the ulnar sicle of the superficial and deep arches unite at the spot where the ulnar artery divides into the superficial and deep branch to form two ulnar venæ comitantes [vv. ulnares]; whilst those on the radial side of the superficial and deep arch accompany the superficial volar artery and the termination of the radial artery respectively, and unite at the spot where the superficial volar is given off from the radial artery, to form the radial venæ comitantes [vv. radiales]. The ulnar and radial venæe comitantes thus formed course up the forearm with their respective arteries, receiving numerous tributaries from the muscles amongst which they run, and giving frequent communications to the superficial veins. They finally unite at the bend of the elbow to form the brachial venæ comitantes [vv. brachiales]. The ulnar venæ comitantes receive, before joining the radial, the companion veins of the interosseous arteries. At the bend of the elbow the deep veins are connected with the basilic or with the median antibrachial vein by a short, thick trunk (fig. 528).

The brachial venæ comitantes accompany the brachial artery. At the lower border of either the teres major or subscapularis muscle, the more medial vein receives the more lateral and the basilic vein, to form a single axillary vein.

The venæ comitantes of the arteries of the arm anastomose with one another by frequent cross branches.

The axillary vein [v. axillaris], is formed by the junction of the medial brachial vena comitans with the basilic vein at the lower border of either the teres major or subscapularis muscle. It is a vessel of large size, conveying as it does nearly the whole of the returned blood from the upper extremity. It accompanies the axillary artery through the axillary fossa, lying to its medial side and, at the upper part of the space, on a slightly posterior plane. At the lateral border of the first rib it changes its name to the subclavian. It has one or two axillary lymphatic nodes in close connection with it, and is liable, if care is not taken, to be wounded in removing these glands. The vein contains a pair of valves, usually placed near the lower border of the subscapularis muscle.

Tributaries:-(1) The subscapular veins which accompany the subscapular artery; (2) the circumflex veins accompanying the circumflex arteries; (3) the lateral thoracic vein [v. thoracalis lateralis] a large vein which accompanies the lateral thoracic artery and receives numerous thoraco-epigastric veins [vv. thoracoepigastricæ] from the epigastric and lower thoracic regions; (4) the costoaxillary veins [vv. costoaxillares] the radicles of which arise in the pectoral region from the mammary plexus [plexus venosus mamillæ]; and (5) the cephalic vein.

The subclavian vein [v. subclavii] (fig. 528), is the continuation of the axillary. It begins at the lateral border of the first rib, and terminates by joining the internal jugular to form the innominate vein opposite the lateral end of the sterno-clavicular articulation. It lies anterior to the subclavian artery and on a lower plane, and is separated from the artery in the second part of its course by the scalenus anterior muscle. The subclavian vein, just before it is joined by the external jugular, contains a pair of valves.

Tributaries. - The subclavian vein receives the thoracoacromial vein near its distal end, and the external jugular voin near the lateral border of the sternomastoid muscle. The transverse cervical veins terminate in the subclavian near the external jugular, or in the latter vein, or in a plexiform arrangement formed between the transverse scapular, transverse cervical and external jugular veins. The external jugular vein is described with the superficial veins of the head and neck (p. 646).

The thoracoacromial vein [v. thoracoacromialis], receiving tributaries corresponding to the branches of the artery of the same name, terminates near the lateral border of the first rib. 
The transverse cervical veins [vv. transversæ eolli] receive tributaries eorresponding in distribution to the branches of the transverse eervieal artery. They emerge from beneath the trapezius muscle, cross the posterior triangle, and usually terminate in the subelavian vein. They usually terminate as a single vein the orifice of which is guarded by a pair of valves. Oecasionally the eephalic vein, or a branch from the cephalic (the jugulo-cephalic), passes over the clavicle to the subclavian.

\section{THE VENA CAVA INFERIOR AND ITS TRIBUTARIES}

All the veins of the abdomen, pelvis, and lower extremities, with the exception of the superior epigastric (p. 666), and ascending lumbar vein ( $p .521$ ), which join with the superior caval system, enter directly or indirectly into the vena cava inferior. The veins corresponding to the parietal branches of the abdominal aorta, except the middle sacral vein, open directly into the vena cava inferior; the middle sacral vein only indirectly through the left common iliae vein. Of the visceral veins corresponding to the viseeral branches of the abdominal aorta, those which return the blood from the stomach, intestines, pancreas, and the spleen end in a common trunk called the portal vein.

The portal vein [vena portæ] enters the liver and there breaks up into a network of smaller vessels somewhat after the manner of an artery. This network contains venous blood, and is moulded upon the tissue-elements of the organ itself. The smaller vessels consist, like capillaries (from which they differ in developmental history) of intima only; they are ealled sinusoids. The venous blood is returned from the sinusoidal plexus by the hepatic veins which open into the vena cava inferior as that vessel lies in the fossa venæ cavæ of the liver.

Of the other viseeral veins, both renals, the right suprarenal, and the right spermatic or ovarian open directly into the vena cava inferior; whilst the left suprarenal and left spermatic or ovarian are drained through the left renal.

Two of the superficial veins of the lower part of the anterior abdominal wall, the superficial epigastric and superficial cireumflex iliac, enter the great saphenous vein; and two of the deep veins from the like situation, the inferior epigastric and deep eircumflex iliac, enter the external iliac vein. The blood in these vessels, however, ean flow upward as well as in the normally downward direction. In obstruction of the vena cava inferior they become greatly enlarged, and form, with the superior epigastric vein and with other superficial veins of the thorax with which they anastomose, one of the chief channels for the return of the blood from the lower limbs.

The veins of the polvis, which receive the veins from the perinæum and gluteal region, join the hypogastric vein.

\section{THE VENA CAVA INFERIOR}

The vena cava inferior (fig. 529) is the large vessel which returns the blood from the lower extremities and the abdomen and pelyis. It is formed by the eonfluence of the right and left common iliac veins opposite the body of the fifth lumbar vertebra, aseends in front of the lumbar vertebre to the right of the abdominal aorta, passes through the caval opening in the diaphragm, and ends in the lower and batek part of the right atrium of the heart on a level with the lower border of the ninth thoracic vertebra. At its origin it lies behind the right rommon iliac: artery on a plane posterior to the aorta, but as it ascends it passes slightly forwird and to the right, reaching a plane anterior to the aorta, and becoming separated from that artery by the right medial crus of the diaphragm and the candiate lobre of the liver. While in eontact with the liver it lies in a deep groove [fossa venie mave] on the posterior surface of that organ, the groove being often converterl into a clistinet canal by a thin portion of the hepatic substanee bridging aroross it. Is it passes through the diaphragm its walls aro attached to the tendinoms margins of the eaval opening, and are thus held apart when the muscle contracts. On the thoracie side of the diaphragm it lies for about 1.2 ('m. ( ${ }_{2}^{1} \mathrm{in}$.) within the pericardium, the serous layer of that membrane being reflected over it. 
Relations.-In front it is covered by the peritoneum, and crossed by the right spermatic artery, branches of the aortic plexus of the sympathetic, the transverse colon, the root of the mesentery, the duodenum, the head of the pancreas, the portal vein, anl the liver. The median group of the lumbar lymphatic nodes are also in front of it below, and at its commencement the right common iliac artery rests upon it.

Behind, it lies on the lumbar vertebræ, the right lumbar arteries, the right renal artery, the right coliac (semilunar) ganglion, and the right medial crus of the diaphragm.

To the right are the peritoneum, liver, and psoas muscle.

To the left is the aorta, and higher up the right medial crus of the diaphragm.

Tributaries.-The vena cava inferior receives the following veins:-(1) the renal veins; (2) the right suprarenal vein; (3) the right spermatic or the right

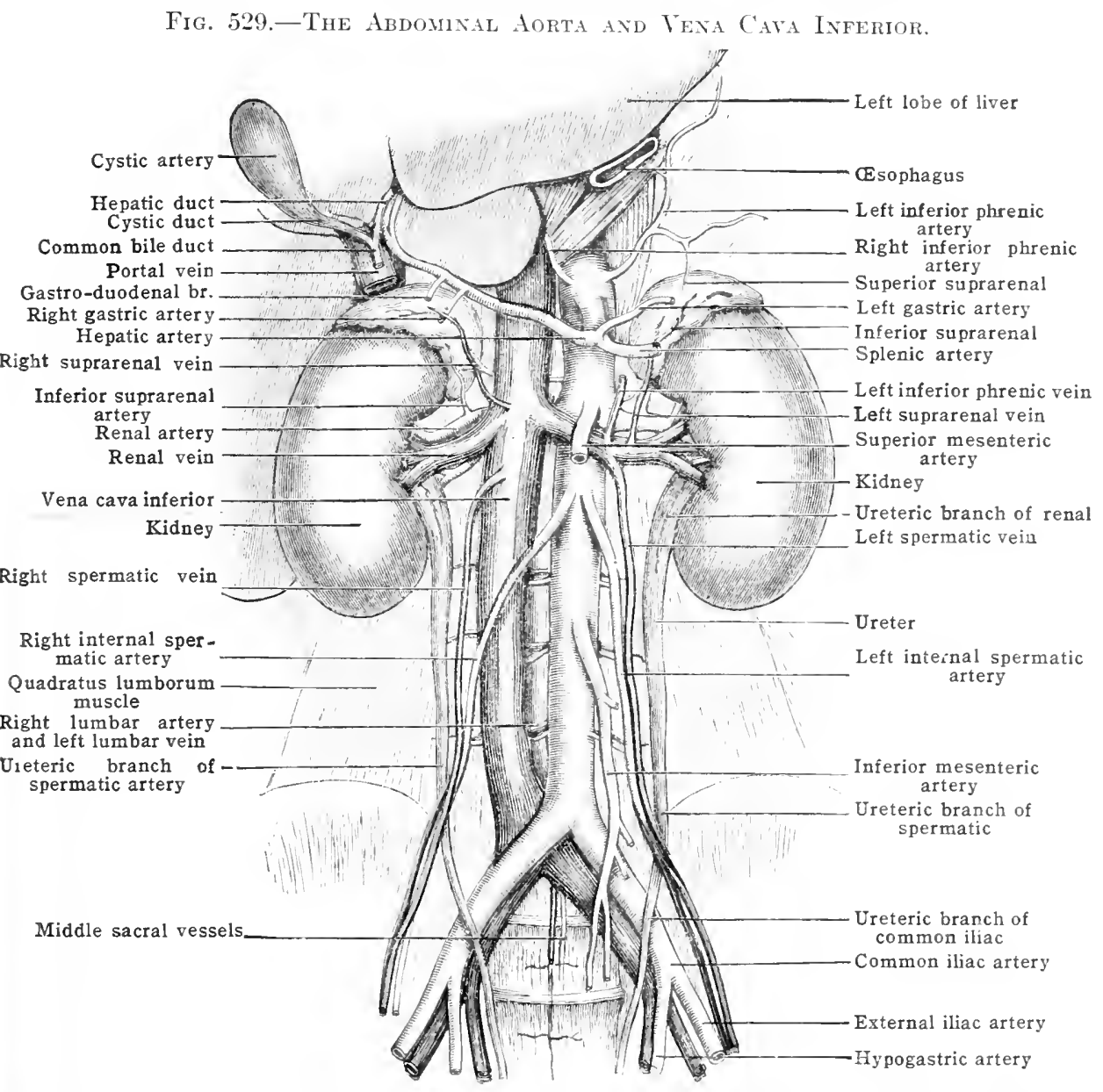

ovarian vein; (4) the lumbar veins; (5) the inferior phrenic veins; (6) the hepatic veins; and $(\bar{\gamma})$ the right and left common iliac veins.

(1) The renal veins [vv. renales] (fig. 529) return the blood from the kidners. They are short but thick trunks, and open into the vena cava nearly at right angles to that vessel. The vein on the left side, like the kidner, is a little higher than on the right, and is also longer. in consequence of its having to cross the aorta.

Each renal vein lies in front of its corresponding artery. The left rein crosses in front of the aorta, just below the origin of the superior mesenteric artery. It is covered by the inferior portion of the duodenum, and receives the left spermatic, or the left ovarian in the female, and usually the left suprarenal, and sometimes the left phrenic. There are rudiments of valves in each vein where it joins the vena cava. Those on the right side, however, are less well
marked.

(2) The suprarenal veins [vv. suprarenales] (fig. 529).-There is usuatly only one suprarenal vein on each side to return the blood brought to the suprarenal body by the three suprarenal arteries. On the right side the vein opens directly into the vena cava, above the opening of the right renal vein. On the left side, it opens into the left renal. 
(3) The spermatic veins [vv. spermatica] (fig. 529) return the blood from the testis. They begin by the confluence of small branches from the body of the testis and epididymis. As they proceed up the spermatic cord, in front of the intermal spermatic artery and ductus deferens, they become dilated and plexiform, constituting the pampiniform plexus [plexus pampiniformis] (fig. 541). After passing through the subcutaneous inguinal ring, the inguinal canal, and the abdominal inguinal ring, the plexus communicates with the inferior epigastrie vein and is continued as two veins. Along with the artery the veins pass up beneath the peritoneum, and on the left side also beneath the sigmoid colon, across the psoas muscle and ureter. They receive small tributaries from the ureter and peritonemn, and proceed as a single trunk, on the right side to the vena cava inferior, and on the left side to the left renal vein. There are commonly a number of imperfect valves in the spermatic plexus and a perfect pair at the termination of each spermatic vein. On the left side, however, the terminal valve may be wanting.

Fig. 530.-The Veins of the Female Pelisis. (After Toldt, "Atlas of Human Anatomy," Rebman, London and New York.)

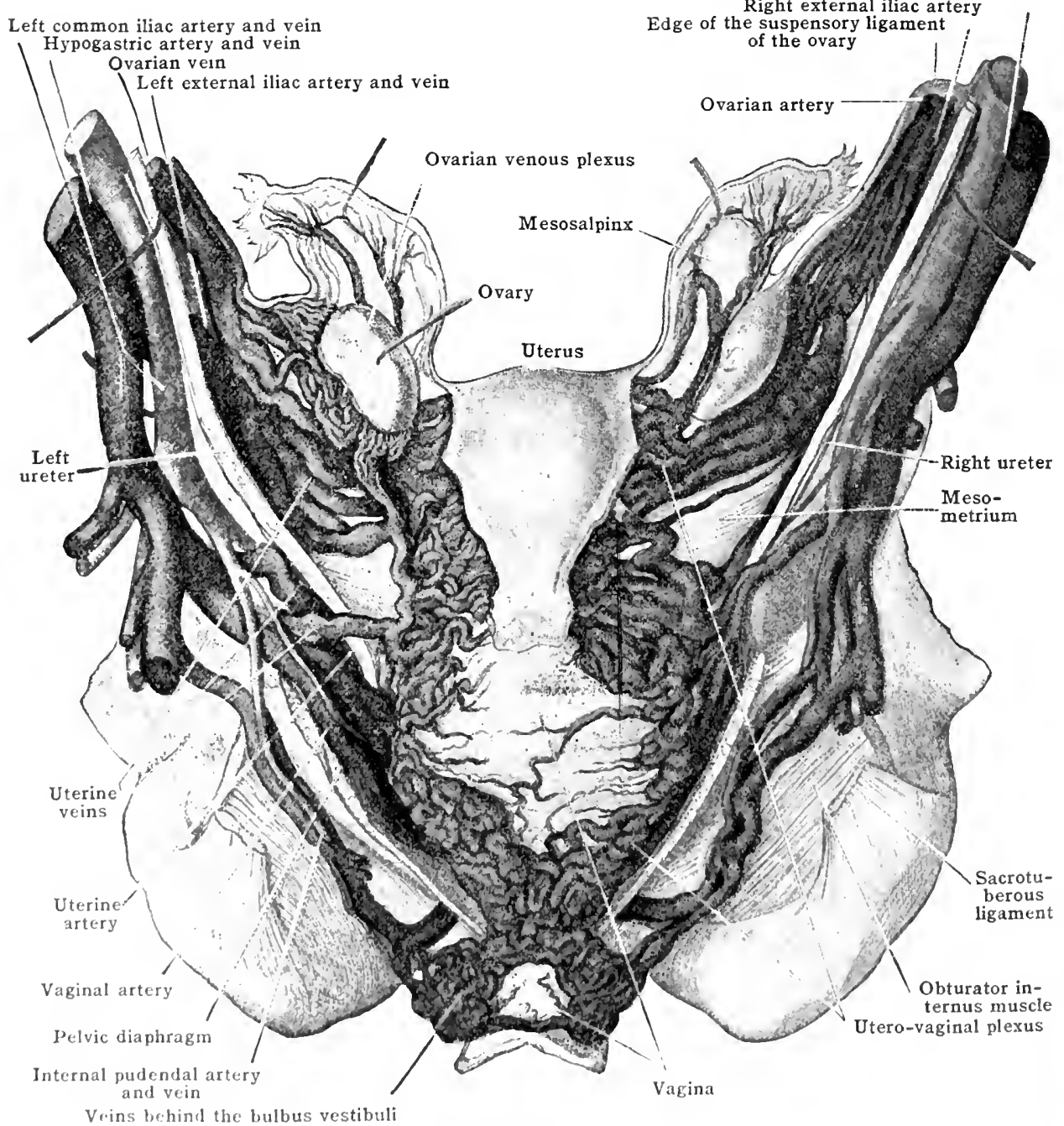

Right common iliac artery and vein

']lug ovarian veins [rv. ovarime legin at the plexus pampiniformis near the ovary,

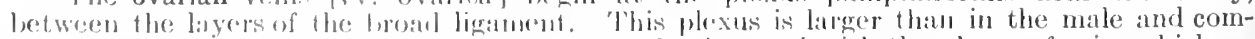
municutes freely with the llfere-variat plexus of veins, and with the plexus of veins which exfonds from the liblus of the ovary into the ovirian ligament (lig. 486). After passing from

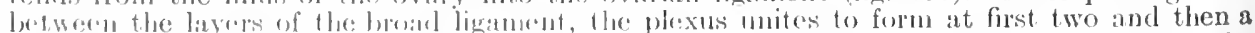

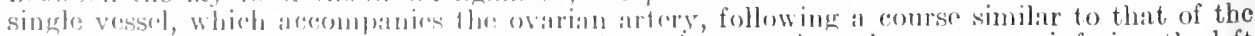

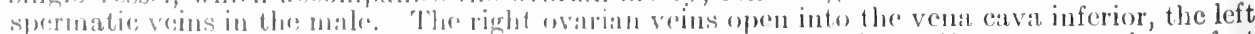
into the loft romal. They usmally contain imprefort volves in their plexiform part, and a perfect

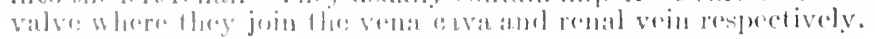


(4) The lumbar veins [vv. lumbales], four to five on either side accompany the lumbar arteries and collect venous blood from the muscles of the back and abdomen. They terminate by passing beneath the tendinous arches of the psoas major, along the sides of the lumbar vertebræ, and opening into the vena cava inferior. The veins of the left sicle are longer than those of the right and pass behind the aorta. Each vein receives a dorsal tributary corresponding in distribution to the dorsal branch of the lumbar artery. Between the dorsal tributaries and the posterior vertebral venous plexus there occurs a free communication. There is also an anastomosis between the main lumbar veins and the anterior vertebral venous plexus around the bodies and transverse processes of the lumbar vertebræ. By means of these communications the intervertebral reins, the internal and external vertebral and spinal plexuses are partly drained. In addition to these anastomoses the lumbar veins are connected with one another and with common iliac, hypogastric, ilio-lumbar, renal, azygos and hemiazygos veins by means of the ascending lumbar vein (p.663).

(5) The inferior phrenic veins [v. phrenica inferior] follow the course of the inferior phrenic arteries; the right opens into the vena cava direct; the left into the suprarenal, the left renal, or the vena cava.

(6) The hepatic veins [vv. hepaticæ], the largest tributaries of the vena cava, return the blood from the liver. Commencing in the substance of the liver (see Liver), they converge as they approach its posterior surface, and unite to form two or there large trunks, which open into the vena cava as it lies in the fossa venæ cavæ. Some smaller vessels from the caudate lobe, and other parts of the liver in the nighbourhood of the caval fossa, open directly into the vena cava. The hepatic veins contain no valves, but, in consequence of opening obliquely into the vena cava, a semilunar fold occurs at the lower magin of each orifice.

\section{THE PORTAL VEIN}

The veins corresponding to the inferior mesenteric, the superior mesenteric, and to some of the branches of the cœliac artery, do not join the vena cava inferior direct, but unite to form a common trunk - the portal vein.

This vein enters the liver, and breaks up in its substance into sinusoids from which the blood is again ultimately collected by the hepatic veins, and carried by them into the vena cava inferior. The terminal branches of the hepatic artery also empty into the hepatic sinusoids, and their blood likewise finds its way finally into the hepatic veins, and thence into the vena cava inferior. The portal vein and its tributaries have no valves.

The portal vein [v. portæ] (fig. 531), is a thick trunk 7 or $8 \mathrm{~cm}$. (3 in.) in length. It is formed behind the head of the pancreas, opposite the right side of the body of the second lumbar vertebra, by the union of the superior mesenteric with the splenic veins. It passes upward and to the right behind the superior part of the duodenum, and then between the layers of the lesser omentum. In the latter situation it passes in front of the foramen epiploicum and is accompanied by the hepatic artery and the hepatic duct. Finally it enters the porta of the liver, and there divides into a right and a left branch. In this course the hepatic artery and the common bile duct are in front, the former to the left, the latter to the right. It is surrounded by branches of the hepatic plexus of the sympathetic nerve, and by numerous lymphatic vessels and some glands. The connective tissue sheath enclosing these structures is called the fibrous capsule of Glisson [capsula fibrosa, Glissoni]. Just before it divides it is somewhat dilated, the dilated portion being called the sinus of the portal vein. The division into right and left branches takes place toward the right end of the porta of the liver. The right branch is shorter and thicker than the left, and supplies the right lobe of the liver and a branch to the quadrate lobe. The left branch is longer and smaller than the right, and supplies the left lobe, and gives a branch to the caudate (Spigelian) and quadrate lobes. It is joined, as it crosses the left sagittal fossa, by a fibrous cord, known as the ligamentum teres hepatis (obliterated vena umbilicalis), and posteriorly by a second fibrous cord, the ligamentum venosum (oblietrated ductus venosus). The position of the original course of the umbilical vein across the left portal is marked, in adult life, by a dilation of the latter vein, called the umbilical recess.

Tributaries.-The pyloric, the coronary (gastric), the cystic, the superior mesenteric, and the splenic.

The pyloric vein begins near the pylorus in the lesser curve of the stomach, and, running from left to right with the right gastric artery, opens directly into the lower part of the portal vein. It receives branches from the pancreas and duodenum.

The coronary vein [v. coronaria ventriculi] (fig. 533) runs with the left gastric artery at first from right to left, among the lesser curvature of the stomach, toward the cardiac end, and then, turming to the right, passes across the spine from left to right to end in the portal trunk a 
Fri, 531. - The Portal Vers. (From Kelly, by Brödel.)

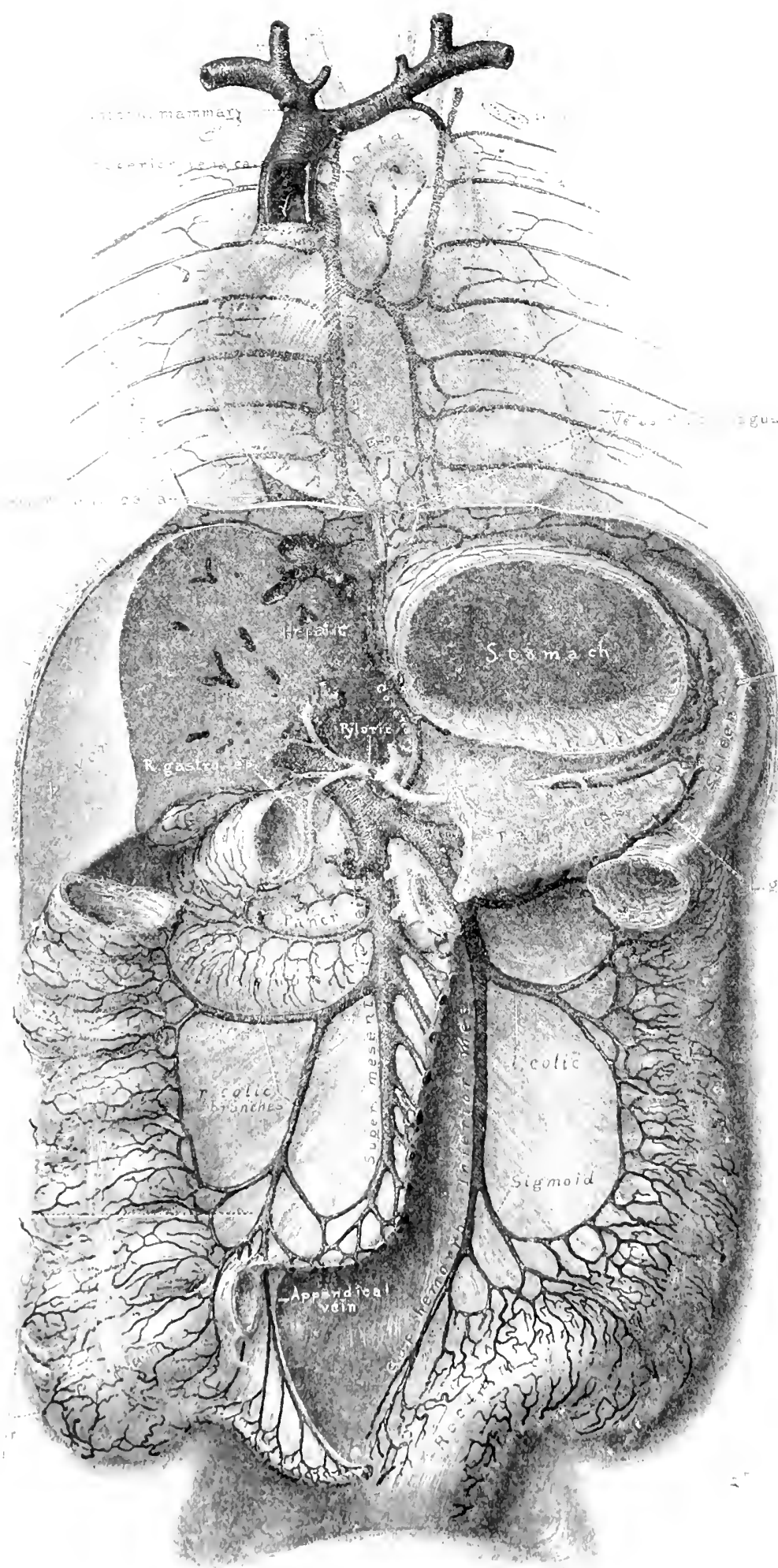


little higher than the pyloric vein. At the cardiac end of the stomach it receives small branches from the oesophagus.

The cystic vein [v. cystica] (fig. 53:3) returns the blood from the gall-bladiler. It usually opens into the right branch of the portal vein.

The superior mesenteric vein [v. mesenterica superior] (fig. 534) begins in tributaries which correspond with the branches of the superior mesenteric artery. It courses upward a little in front and to the right of the artery, passing with that vessel from between the layers of the mesentery. It passes in front of the inferior portion of the duodenum, and behind the pancreas, where it joins the splenic vein to form the portal trunk (fig. 531).

Tributaries.--In addition to the tributaries corresponding to the branches of the superior mesenterie artery-viz. the ileo-colica, colicadextra, colica media, and vence intestinales (fig. 534) -it receives the right gastro-epiploic and the pancreatico-duodenal veins just before its termination in the portal vein.

The right gastro-epiploic vein [v. gastroepiploica dextra] (fig. 533) accompanies the artery of that name. It runs from left to right along the greater curvature of the stomach, receiving branches from the anterior and posterior surfaces of that viscus, and from the great omentum. and, passing behind the superior portion of the duolenum, ends in the superior mesenteris vein just before that vessel joins the portal trunk.

Fig. 532.- The Portal Velx within the Liver. (After Rex.)

Ascending branch

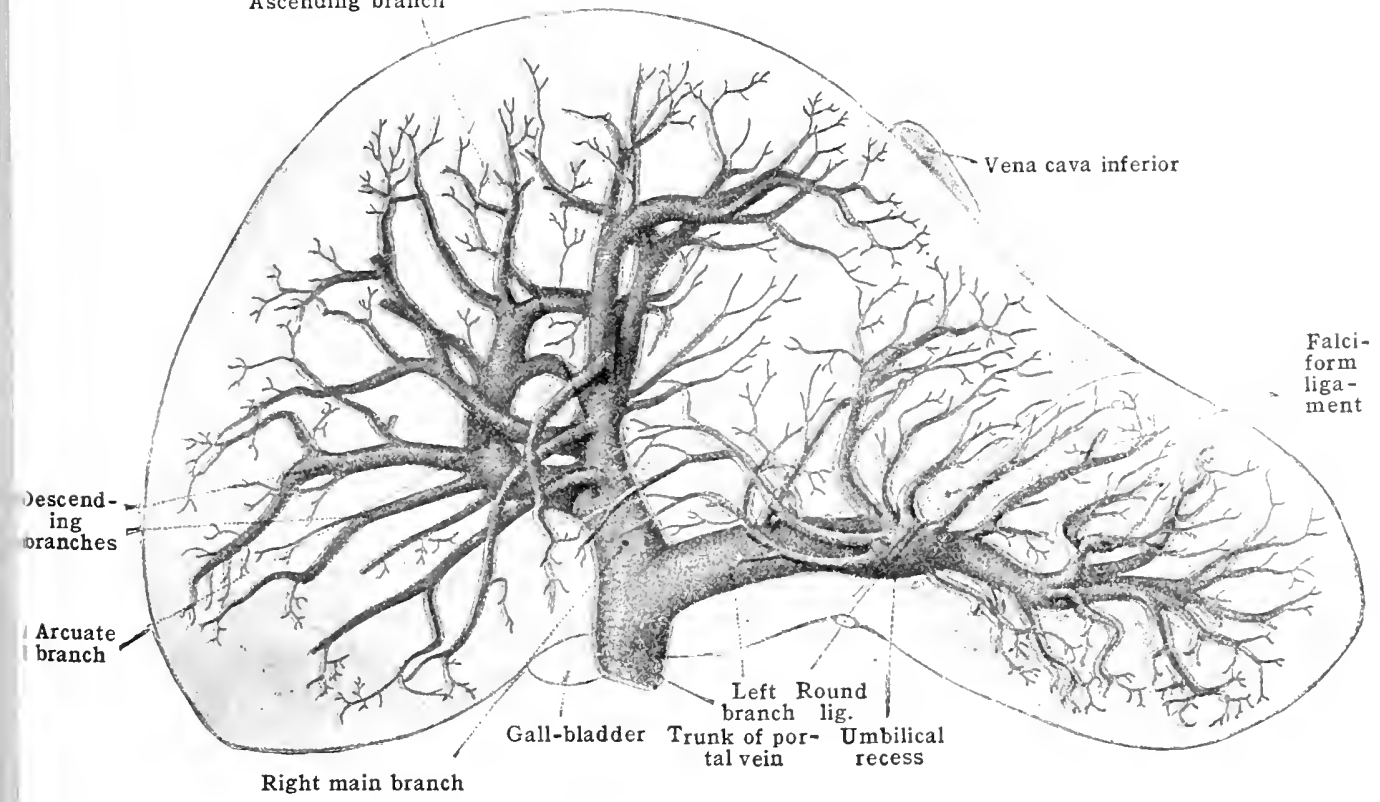

The pancreatio-duodenal veins [vv. pancreatico-cluodenales] (fig. 531) run with the superior and inferior pancreatico-duodenal arteries between the head of the pancreas and the second portion of the duodenum. They receive pancreatic and duodenal veins [vv. pancreaticx et duodenales] and are collected into a single stem which follows the inferior pancreatico-duodenal artery and ends in the superior mesenteric vein a little below the right gastro-epiploic vein.

The splenic vein [v. lienalis] (fig. 531) issues as several large branches from the hilus of the spleen. These soon unite to form a large trunk, which passes across the aorta and spine in company with the splenic artery, below which it lies, to join at nearly a right angle the superior mesenteric vein. In this course it lies behind the pancreas; and at its union with the superior mesenterie to form the vena portæ in front of the vena cava inferior.

Tributaries. - It receives the short gastric veins [vv. gastricie breves], from the fundus of the stomach, the left gastro-epiploic vein, and the inferior mesenteric vein. As it lies in contact with the pancreas it receives some small pancreatic veins [vv. pancreatice].

The left gastro-epiploic vein [v. gastroepiploica sinistra] (fig. 533) accompanies the left gastro-epiploic artery. It runs from right to left along the greater eurvature of the stomach, receives branches from the stomach and omentum, and opens into the commencenent of the splenic vein. 
The inferior mesenteric vein [v. mesenterica inferior] (fig. 531) begins at the rectum as the superior hæmorrhoidal vein. This emerges from the hæmorrhoidal plexus in which it communicates freely with the middle and inferior hæmorrhoidal veins. It passes out of the pelvis with the inferior mesenteric artery; but, after receiving the sigmoid and left colic veins [vv. sigmoidex et v. colica sinistra] which accompany the arteries of the same names, it leaves the artery and runs upward on the psoas to the left of the aorta and behind the peritoneum. On approaching the pancreas it turns medially, and passes obliquely behind that gland to join the splenic vein just before the latter unites with the superior mesenteric to form the vena portæ.

Fig. 533.-The Veins of the Stomach and the Portal Vein.

(From a dissection by W. J. Walsham.)

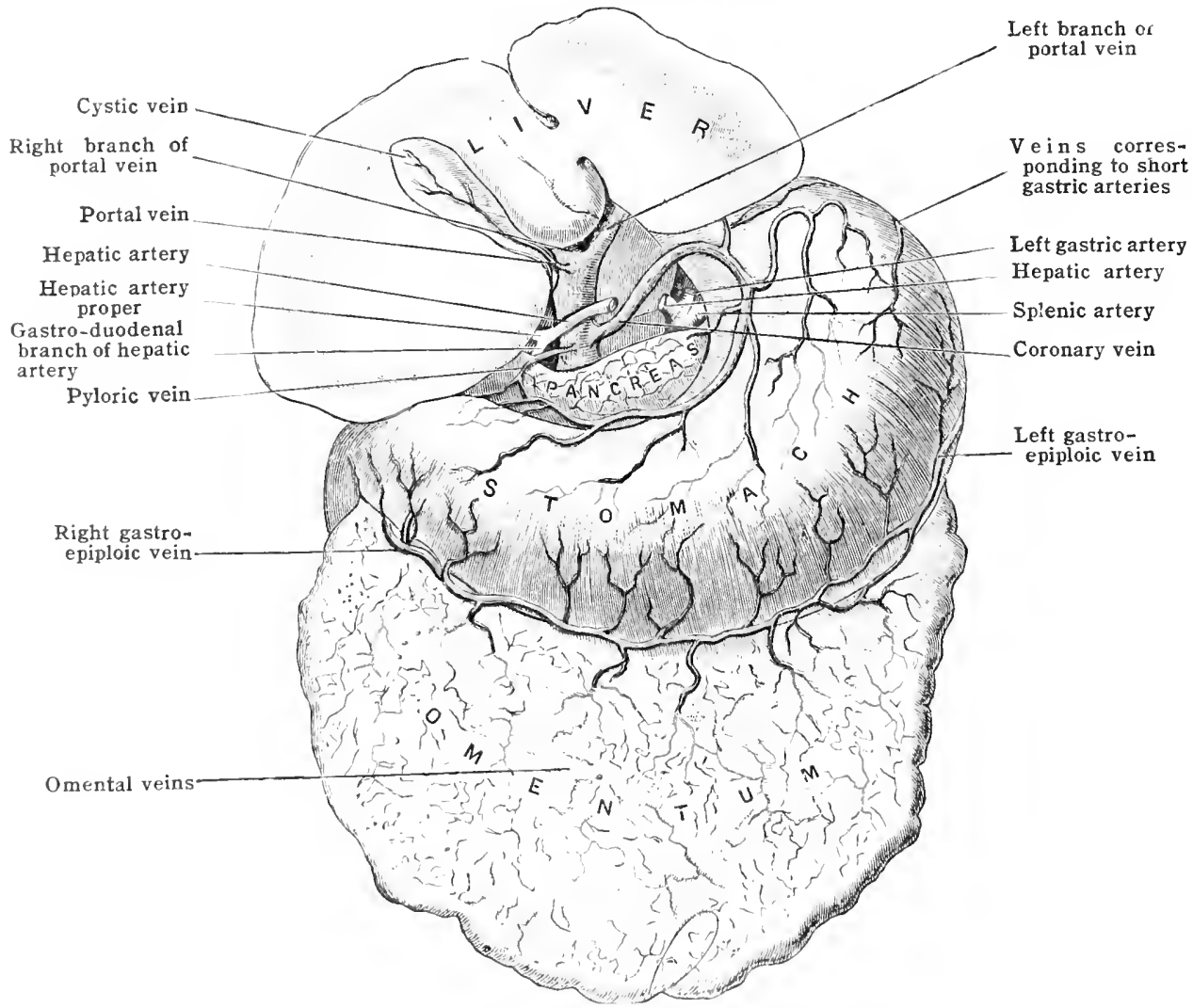

T'hes alut portal vein and its tributaries contain no valves, a circumstance which adversely affects the circulation of blood within this system. The liability to excessive pressure in the most anemdent part of the prortal system is evidenced by the great frequeney of the condition known as piles, due to dilutation of the veins of the internal harmorhoidal plexus. In early life valves are present in the veins of the stomach and of the intestinal wall but these undergo retrogression.

The accessory portal veins. - Since the blool returning from the alsclominal portion of the digentive t ract amb spleon must pass thromgh the hepatic capillaries before returning to the heart,

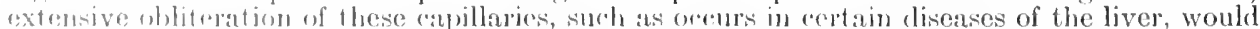
prevent the return of the portal hood to the heart were it not for anastomoses between tributaries of the portal vein and those of the caval systems, (oonstituting what have been termed accescory prortal veins. Some of the more importint of these are-(1) between the branches of i.ho (ormatry vein of the stomach and the wsophageal veins which open into the vena azygos;

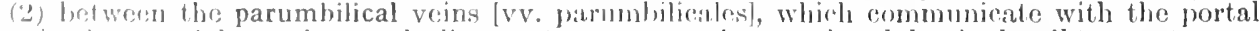

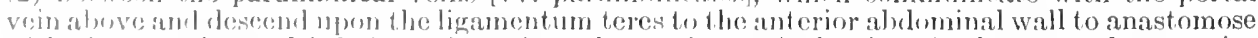
with the suporior and inforior epigastrio and superior vesical veins; (3) between the superior

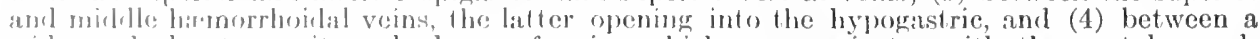
wide-meshed retro-perituneal plexus of veins which ommmuicates with the portal vessels over the posterior surface of the liver and the voins of the pancreas, duodenum and ascending and lowseconding eolon on the portal side, and with the phrouic and azygos veins on the systemic. 


\section{THE COMMON II,IAC VEINS}

The common iliac veins [vv, iliacæ communes], (fig. 536) are formed opposite the sacro-iliac articulation by the confluence of the external iliac and hypogastric (internal iliac) veins. They converge as they ascend, and unite opposite the upper border of the fifth lumbar vertebra and a little to the right of the median line to form the vena cava inferior.

Fig. 534.-The Superior Mesenteric Vein.

(The colon is turned up, and the small intestines are drawn over to the left side.)

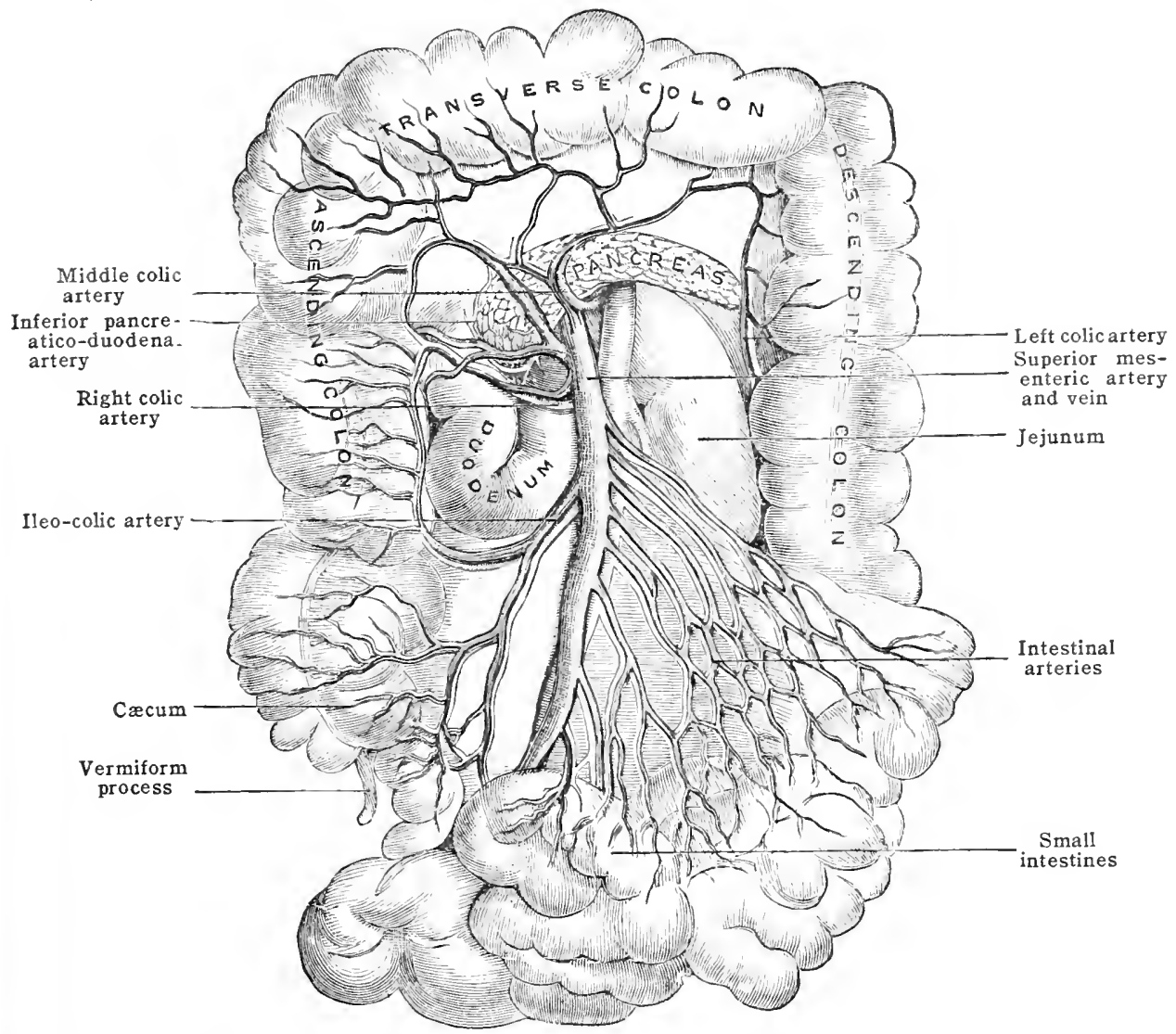

The right vein, shorter and more vertical in direction than the left, passes obliquely behind the right common iliac artery to its lateral side, where it is joined by the left common iliac vein.

The left vein lies to the medial side of the left common iliac artery, and, after crossing in front of the promontory of the sacrum and the fifth lumbar vertebra below the bifurcation of the aorta, passes beneath the right common iliac artery to join the right vein and form the vena cava inferior. The left vein may contain an imperfect valve.

Tributary.--The ilio-lumbar veins may enter the lower part of the common iliac, or open into the hypogastric vein. The left vein receives the middle sacral vein.

The middle sacral vein [v. sacralis media] opens usually as a single trunk into the left common liiac vein. The venæe comitantes which form it ascend on either side of the middle sacral artery in front of the sacrum. They communicate with the lateral sacral veins, forming the anterior sacral plexus [plexus sacralis anterior] which receives the sacral intervertebral veins, and anastomoses freely with the neighbouring lumbar and pelvic veins. Below, the middle sacral veins communicate with the hæmorrhoidal veins.

\section{THE HYPOGASTRIC VEIN}

The hypogastric (internal iliac) vein [v. hypogastrica] (fig. 536) is formed by the confluence of the veins (except the umbilical) corresponding to the branches 
of the hypogastric artery. It varies considerably in length, but is usually quite a short trunk, extending from the upper part of the great sciatic foramen to the sacro-liac articulation, where it joins the external iliac to form the common iliac vein. It lies behind and a little medial to the hypogastric artery. It contains no valre.

Tributaries. - The hypogastric vein receives directly or indirectly the following vessels; the superior gluteal, ilio-lumbar, lateral sacral, obturator, inferior

Fig. 535. - The Inferior Mesenteric Vein.

(The colon is turned up, and the small intestines are drawn to the right side.)

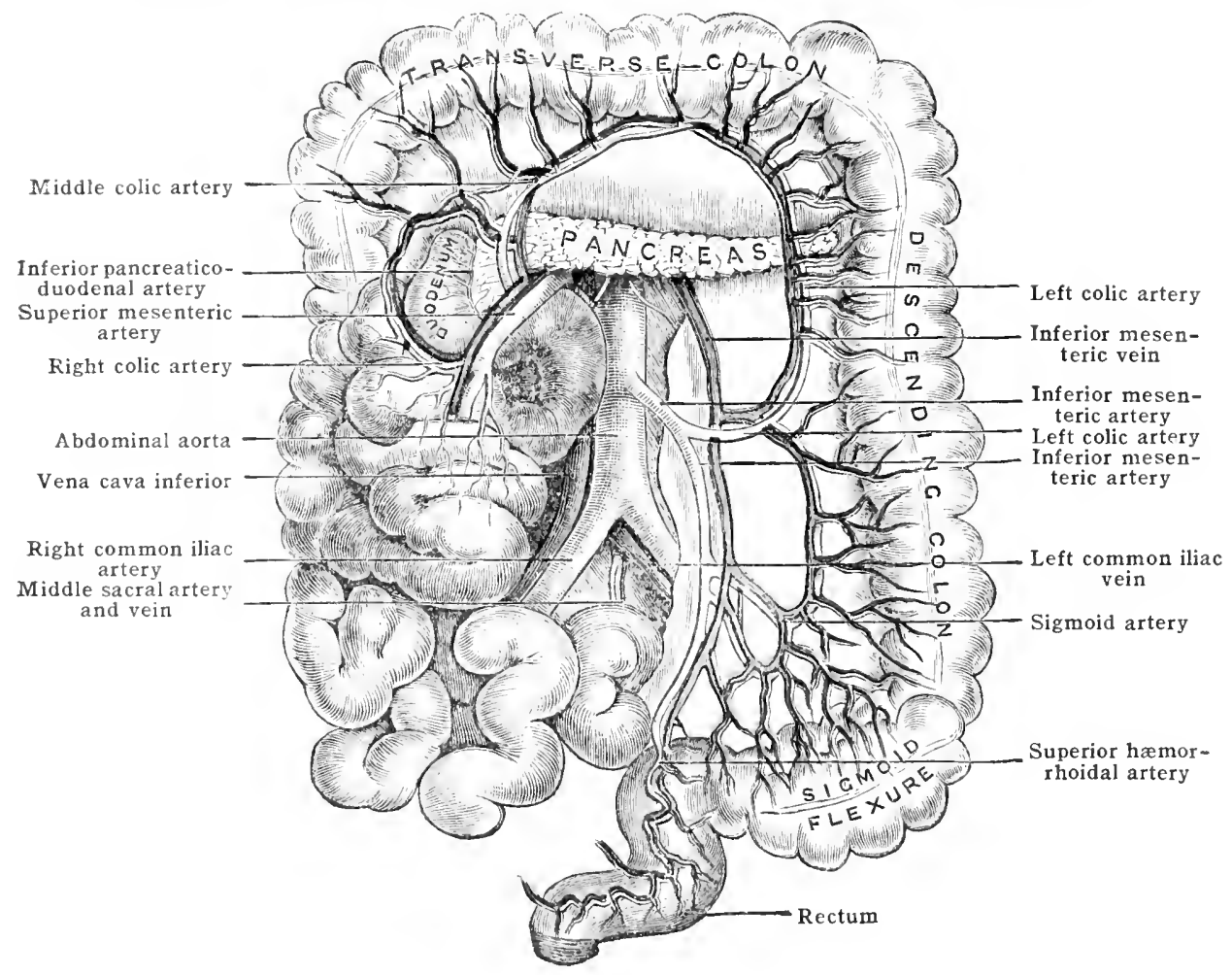

gluteal (sciatic), internal pulendal, and (in the female) the uterine veins; also branches from the pudendal, vesical, and hemorrhoidal plexuses. The single umbilical vein - the vein "orresponding to the right and left hypogastrie arteries and their continuation. the umbilical arterios-does not enter the pelvis, but, leaving the umbilical arteries at the navel, passes along the falciform ligament to the liver. After birth it is converted into the liganentum teres hepatis. (Sore PokTh, Vein, p. (675.)

The superior gluteal veins [vv. glutese superiores] aceompany the superior gluteal artery and, passing throngh the upper part of the great sciatic formen, open into the hypogastrie vein near its lerminalion, either separately or as a single trunk.

The ilio-lumbar voins [vv. ilio lumbiles] open into the hypogastric a little higher than the susperior gluteal. It times they join the eommon iliac vein.

The lateral sacral veins fvv. siucrules laterales] (fig. 5isij) join the superior ghteal or tho hypugastrio at or abmat the same situation as the gluteal. They form with the mirllle sacral vins a plexus in front of the sacrum, which receives tributaries from the sacral canal.

The obturator vein [r. olsturatorial (fig. 536), which lies ledow the olsturator artery as it croses the side of the polvis, opens into the front of the hypogastric vein a little below the suprover glateal. lis branches rorresponel to those of the artery.

'l'he inferior gluteal veins / vv. ghotcae inferiones] acompany the inferior gluteal (sciatic) attery, and, as a rukr, mnite fo form it single trunk lefore joining the hypogastric a little below lhe oliturator voin.

All the above veins so dosely follow the ramifoutions of their respective arteries that no

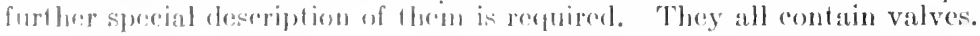


The internal pudendal vein [v. pudenda interna] (fig. 53h) begins at the termination of the deep veins of the penis [r. profundie penis] which issue from the corpus cosvernosum penis with the artery of that body. These veins conmunicate with the dorsal vein at the root of the penis In its course the internal pudendal vein runs with the internal pudental artery, receiving tributaries corresponding to the branches of that vessel. It terminates in the lower part of the hypogastric vein.

Fig. 536.-The Veiss of the Pelvis, Male. (After Toldt, "Atlas of Human Anatomy," Rebman, Londun and New York.

Abdominal aorta

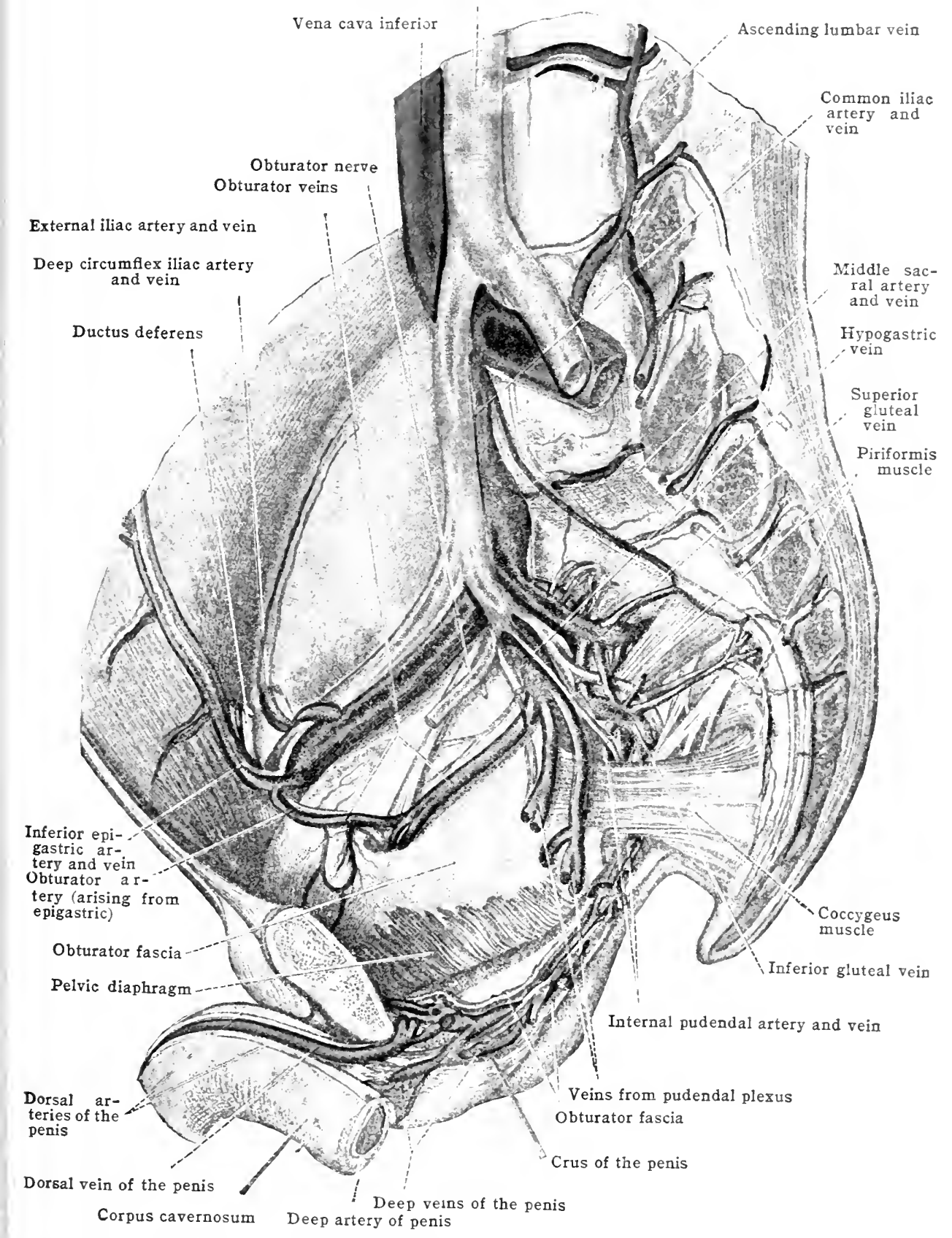

The dorsal vein of the penis [v. dorsalis penis] (fig. 536) begins iu a plexus around the corona glandis, then runs along the centre of the dorsum of the penis between the two dorsal arteries. In this course it receives large tributaries from the interior of the orwan. which, emerging for the most part between the corpus cavernosum urethre and corpus carernosum penis, wind dorsal vein. At the root of the of the latter structure to the dorsum of the penis to end in the of the dors. At the root of the penis the dorsal rein communicates with the subcutaneous veins of the dorsum of the penis and, leaving the arteries, passes straight backward hetween the two layers of the fundiforn (suspensory) ligament. It then goes hetwen the subpubie linament 
and the upper part of the fascia of the urogenital diaphragm (fig. 542). Here it bifurcates, each branch passing backward and downwaril to the pudendal plexus of veins. At times the dorsal vein begins as two branches, which run between the dorsal arteries and only unite to form a single trunk about $3.7 \mathrm{~cm}$. ( $1 \frac{1}{2}$ in.) from the symphysis. After dividing into a right and a left branch within the pelvis, each vessel generally communicates with the obturator vein by a branch passing over the back of the pubis to the obturator foramen.

Fig. 537.-The Subcutaneous Arteries and Veins of the Anterror Body Wall. (After Toldt, "Atlas of Human Anatomy," Rebman, Lonion and New York.)

Anterior jugular vein , Subcutaneous venous net of the neck

Edge of superficial cervical fascia Arch of the jugular vein Superficial cervical artery and vein
Cephalic vein opening into the deep

vein of neck (variation)

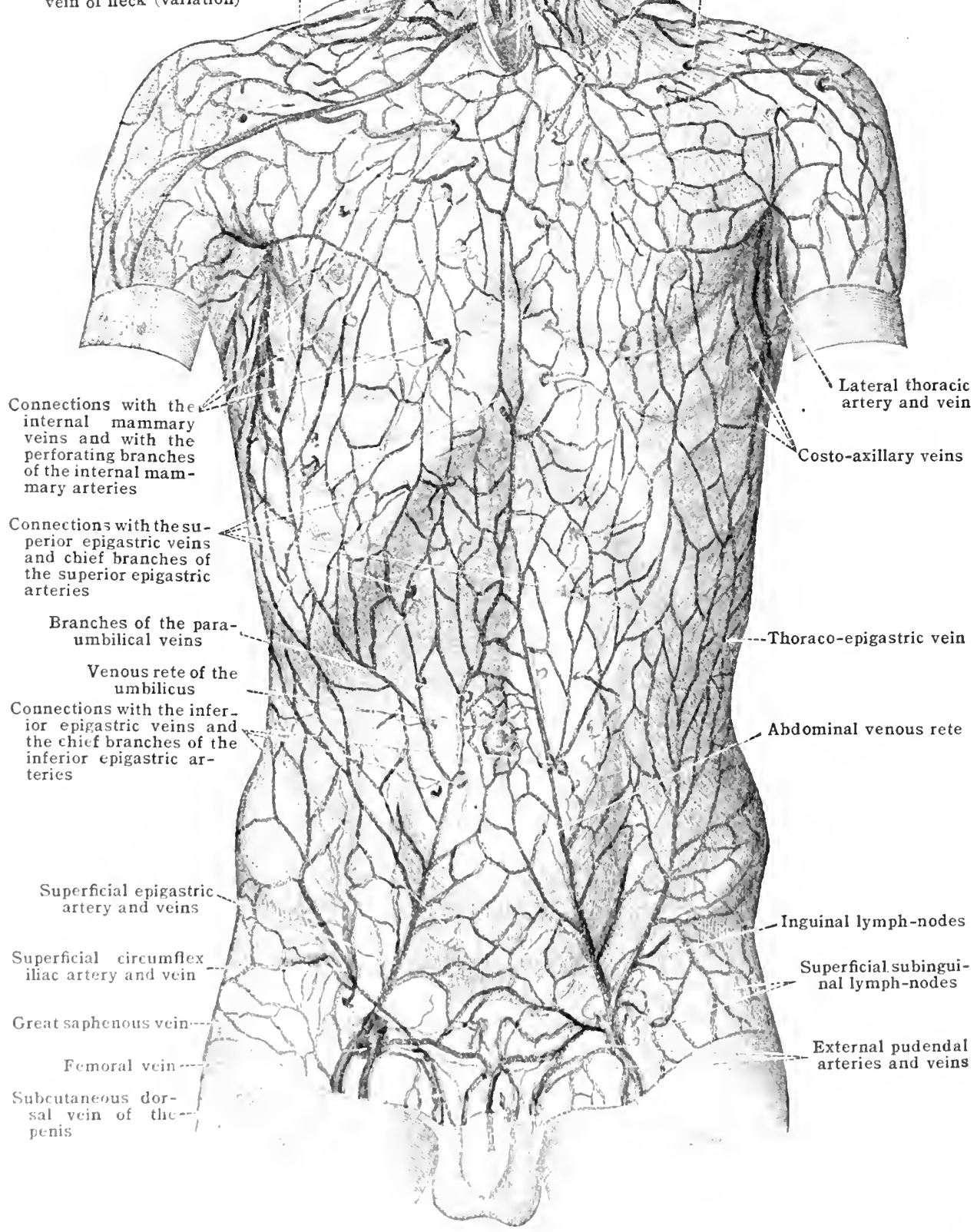

The pudendal plexus folmus pulmolitis] surrommls the prostate and the neck and fundus uf the blaller. It rocesves in front the right and left divisions of the dorsal veins of the penis, ant commonicates with thopusterior scrotal voins [vv. serotales posteriores] and with the hamorrheblal plexws. The prostatio veins and the vesioal plexus operin into it, and it also communicatru with the interual purbublal vein. The vrins forming the plexus are of large size, especially

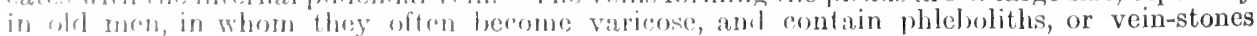


The plexus is surrounded by a kind of capsule formed by the superior fascia of the pelric diaphragm. It terminates in a single stem on each side which opens into the hypogastric vein.

In the female the smaller pudendal plexus surrounds the urethra and receives the dorsal and deep veins of the clitoris [rv. dorsales et profunda clitoridis], veins from the vestibule, and the posterior labial veins [vv. labiales posteriores]. It communicates freely with the uterovaginal plexus and is drained by the hypogastric veins.

The vesical plexus [plexus vesicalis] surrounds the apex, the sides, and the anterior and posterior surfaces of the bladder. It is situated between the muscular coat and the peritoneum, and where the bladder is uncovered by peritoneum external to the muscular coat in the pelvic cellular tissue. It opens into the pudendal plexus.

The utero-vaginal plexus [plexus uterovaginalis] connects with the himorrhoidal, vesical, and uterine plexuses. Its lower part drains through the internal pudendal veins and the pudendal plexus, and its upper protion largely through the ovarian veins, and partly through the uterine veins [vv. uterinæ] to the hypogastric (fig. 530).

The hæmorrhoidal plexus [plexus hæmorrhoidalis] surrounds the rectum, and is situated at the lower part of that tube. It consists of two portions, one of which, the internal hæmorrhoidal plexus, is situated between the muscular and mucous coats, while the other, the external hæmorrhoidal plexus, rests upon the outer surface of the muscular coat. The veins of this latter plexus terminate in the inferior, middle, and superior hæmorrhoidal veins. The inferior [vv. hæmorrhoidales inferiores] join the internal pudendal; the middle [r. hixmorrhoidalis media] accompanies the middle hæmorrhoidal artery and opens into the hypogastric and superior hæmorrhoidal veins; the superior (p. 67s) forms the commencement of the inferior mesenteric vein, and through this the blood gains the portal vein. Yone of these veins have any valves, hence the enlargement of the inferior hemorrhoidal veins, when the portal vein is obstructed, as in cirrhosis of the liver. Through the hamorrhoidal veins a free communication is established between the systemic and portal system of veins.

\section{THE EXTERNAL ILIAC VEIN}

The external iliac vein [v. iliaca externa] (fig. 536), is the upward continuation of the femoral. Beginning at the lower border of the inguinal ligament, it accompanies the external iliac artery medially upward along the brim of the minor pelvis, lying at first on the superior ramus of the pubis, and then on the psoas major muscle. It terminates by joining the hypogastric vein behind the hypogastric artery, opposite the lower border of the sacro-iliac articulation, to form the common iliac vein. It lies at first medial to the external iliac artery, and on the left side remains medial to the artery throughout its course. On the right side, however, as it ascends, it gradually gets behind the artery. It contains one or two valves.

In addition to the femoral, the external iliac receives the inferior epigastric vein [v. epigastrica inferior] (fig. 536) and the deep circumflex iliac vein [v. circumflexa ilium profunda] (fig. 541), which accompany the arteries of the same name.

\section{THE SUPERFICIAL VEINS OF THE ABDOMINAL WALL}

The plexus of superficial veins of the anterior abdominal wall is continuous with that of the thorax (fig. 537). Its main channels are the superficial circumflex iliac, the superficial epigastric, and the external pudendal, all of which open into the great saphenous vein. These communicate, by means of subcutaneous abdominal veins, with the superior epigastric vein, and, by means of the thoracoepigastric veins, with the lateral thoracic and costo-axillary. The superficial veins communicate very freely with the deeper veins of the abdominal wall, and, by means of parumbilical veins, they communicate to a slighter extent with the portal system.

The superficial veins of the lumbar region form an abundant plexus which drains through the dorsal and lateral perforating branches of the intercostal, lumbar, and sacral veins.

\section{THE VEINS OF THE LOWER EXTREMITY}

The veins of the lower extremity are divided into the superficial and the deep. The superficial veins lie in the subcutaneous tissue superficial to the deep fascia, through which they receive numerous communicating branches from the deep veins. They are collected chiefly into two main trunks, which, beginning on the foot, extend upward, one, the great saphenous, lying antero-medially, and the 
other, the small saphenous, postero-laterally. The former finally joins the femoral vein by passing through the deep fascia at the groin; the latter, the popliteal by perforating the fascia at the ham. The deep veins, on the other hand, aceompany their eorresponding arteries. All the veins of the lower limb have valves which are more numerous than in the veins of the upper extremity and in the deep than in the superficial veins.

\section{THE SUPERFICIAL VEINS OF THE LOWER EXTREMITY}

The superficial veins of the lower limb begin in the plexuses of the foot. The dorsal digital veins [rv. digitales pedis dorsales] collect blood from the dorsal surfaces of the tocs and unite in pairs, around each eleft, to form the dorsal metatarsal veins [vv, metatarsex dorsales pedis]. The dorsal metatarsal veins, of which the first and fifth are larger than the others, join the dorsal venous arch [arcus renosus dorsalis pedis]. This arch is eonvex toward the toes and crosses near the bases of the metatarsal bones. From the medial and lateral ends of the arch the great and small saphenous veins, respectively, take origin. The area of the dorsum of the foot contained between the areh and the two saphenous veins is covered by the dorsal venous rete [rete venosum dorsale pedis] which extends as high as the ankle-joint (fig. 539).

On the plantar surface the plantar digital veins [vv. digitales plantares] return the venous blood to the elefts of the toes and unite to form the common digital reins [vv. digitales communes pedis]. The common digital veins join freely with one another on the sole to form the plantar venous rete [rete venosum plantare]. There are numerous communications between the superficial veins of the dorsum and sole. These oceur both in the clefts of the toes, by means of the intercapitular veins [vv. intercapitulares], and around the margins of the foot. Communications between the superficial and deep veins of the foot are very free (fig. 540).

The great (or internal) saphenous vein [v. saphena magna] (fig. 538) commences as the medial end of the dorsal venous arch, and, after receiving branches from the sole which join it by turning over the medial border of the foot, passes upward in front of the medial malleolus, and then obliquely upward and backward about a finger's breadth from the posterior border of the tibia in company with the saphenous nerve, which becomes superfieial just below the knee. Continuing its course upward, it passes behind the medial epicondyle, and then runs upward on the medial side of the front of the thigh to about $3.7 \mathrm{~cm}$. ( $1_{4}^{1} \mathrm{in}$.) below the inguinal ligament, where it dips through the fossa ovalis (saphenous opening) in the fascia lata, and ends in the femoral vein.

Tributaries. - In its course up the leg and thigh it receives numerous unnamed cutancous trihutaries. As it passes up the thigh it of ten receives a large vein, the femoro-popliteal which communicates with the small saphenous, and several of the cutaneous veins on the lateral part of the thigh, and a second vein, the accessory saphenous [v. saphena accessoria], formed by the union of the cutancous veins from the medial and back part of the thigh (fig. 538). The great saphenous vein contains from ten to twenty valves.

Immediately before entering the fossa ovalis the great saphenous vein receives the superfieial epigastric, superficial circumflex iliac, and external puclendal veins, though any of these veins - or all of them - may pieree the fascia separately and enter the femoral vein.

The superficial epigastric vein [v. epigastrica superficialis] anastomoses with the superficial abdominal, and partumbilical veins.

The superficial circumflex iliac vein [v. circunflex ilium superficialis] anastomoses with the thoraco-epigastric and the superficial circumflex iliac veins.

'The external pudendal veins [vv. puldendiv externiv] collect venous blood from the anterior scrotal or labial voins, which anastomose with the posterior serotal or labial veins, and from the subcutaneous veins of the dorsum of the penis [vv. clorsales penis subentanex].

'The small saphenous vein [v. saphena parva] (fig. 539) begins at the lateral end of the vemons are $h_{1}$ on the dorsum of the foot. Niter receiving branches from the sole, which tarm over thre lateral border of the foot, it passes behind the lateral mallowlus, and then mpward and, lying at first along the lateral sicle of the tendo Achillis, afterward along the back of the calf, in company with the sural (short saphenous) norve, to albout the lower part of the centre of the popliteal space, where it perforates the derep fasciat, and, sinking between the two heads of the gastroenemius, opens into the poppliteal vein. 
Tributaries.-As it passes up the calf between the superficial and deep fascia, it receives numerous cutaneous veins from the heel, and the lateral side and back part of the leg, and

Fig. 538.-The Seperficial Veins and Lymphatics of the Left Lower Limb. (Walsham.)

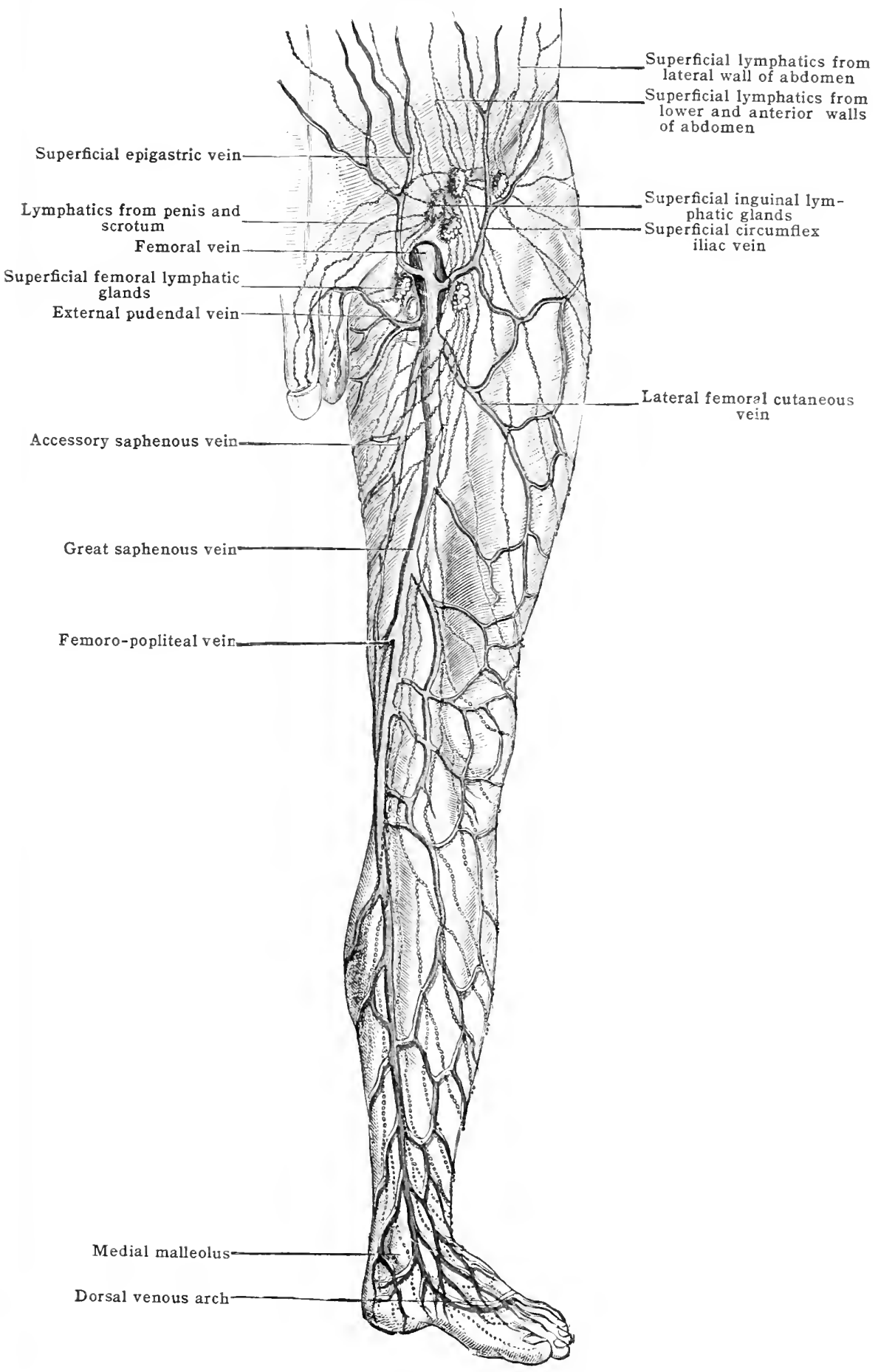

communicates at intervals, through transverse or intermuscular branches, with the deep reins accompanying the peroneal artery. Just before perforating the deep fascia, it receives a large descending branch, the vena femoropoplitea, from the lower and back part of the thigh. This 
communicates with a plexus of reins upon the posterior and lateral regions of the thigh and with the great saphenous. In many cases the small saphenous vein is entirely drained, by means of the femoro-popliteal, into the great saphenous. Under these circumstances the usual place of termination of the small saphenous is marked by a small vein opening into the popliteal. A small offshoot from the inferior sural branch of the popliteal artery accompanies this vein for a

Fig. 539.-The Veiss of the Dorsum of the Foot. (After Toldt, "Atlas of Human Anatomy," Rebman, Lonclon and New York.)

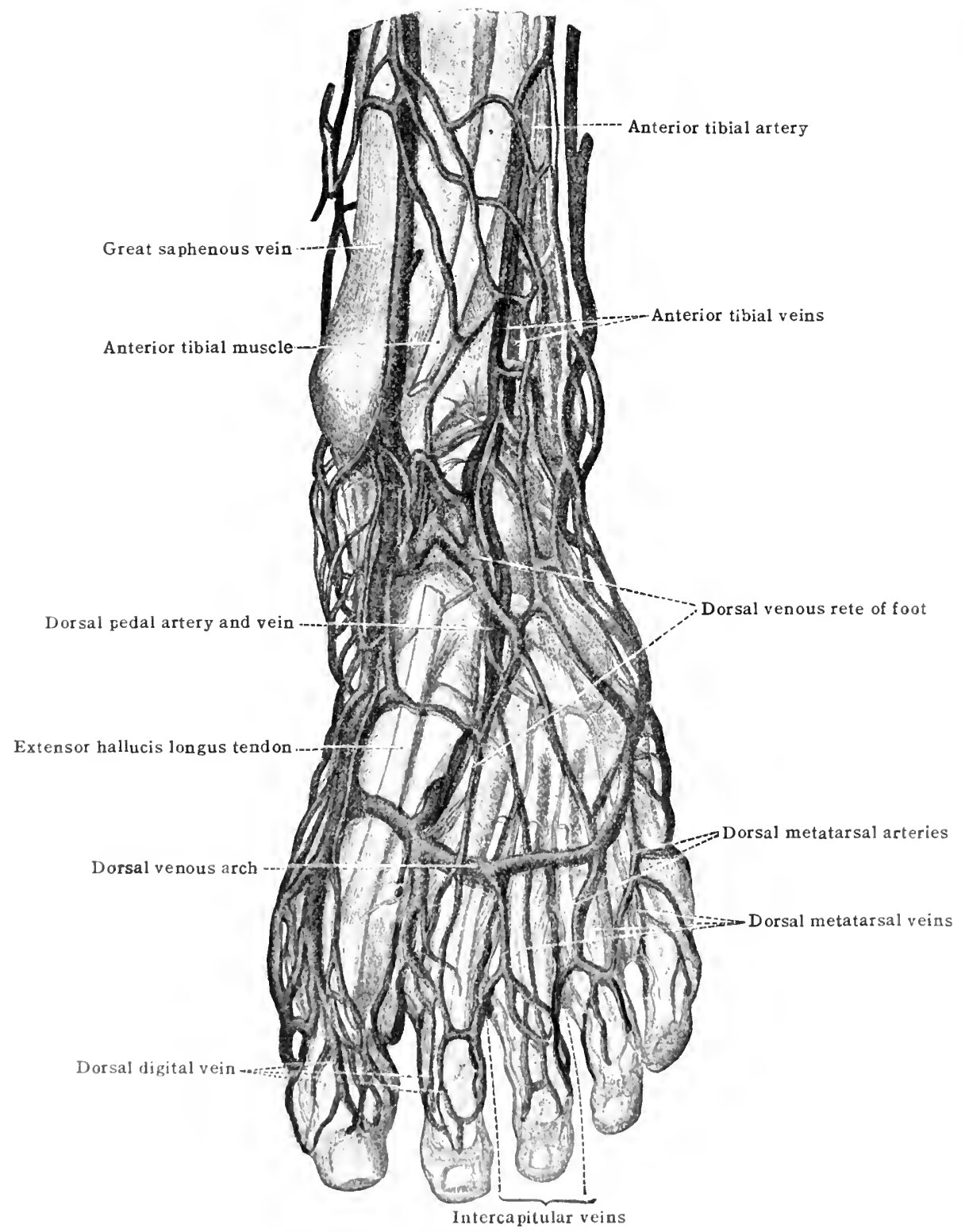

short distance down the batk of the calf. The small saphenous vein contains from nine to twolve valves.

\section{II. 'THE DEEP' VEINS OF THE LOWER EXTREMITY}

The deep veins of the lower extremity alecompany the arteries, and have recoiver corresponding names. From the foot to the knee there are two veins to rach artery. 'These vains run on cither side of the corresponding artery, and com- 
municate at frequent intervals with each other across it. They are known as the venæ comitantes. From the knee upward there is a single main vein to each artery, except at the back of the thigh and in the gluteal region, where there are commonly two.

Fig. 540.--The Veins of the Sole of the Foot. (After Toldt, "Atlas of Human Anatomy", Rebman, London and New York.)

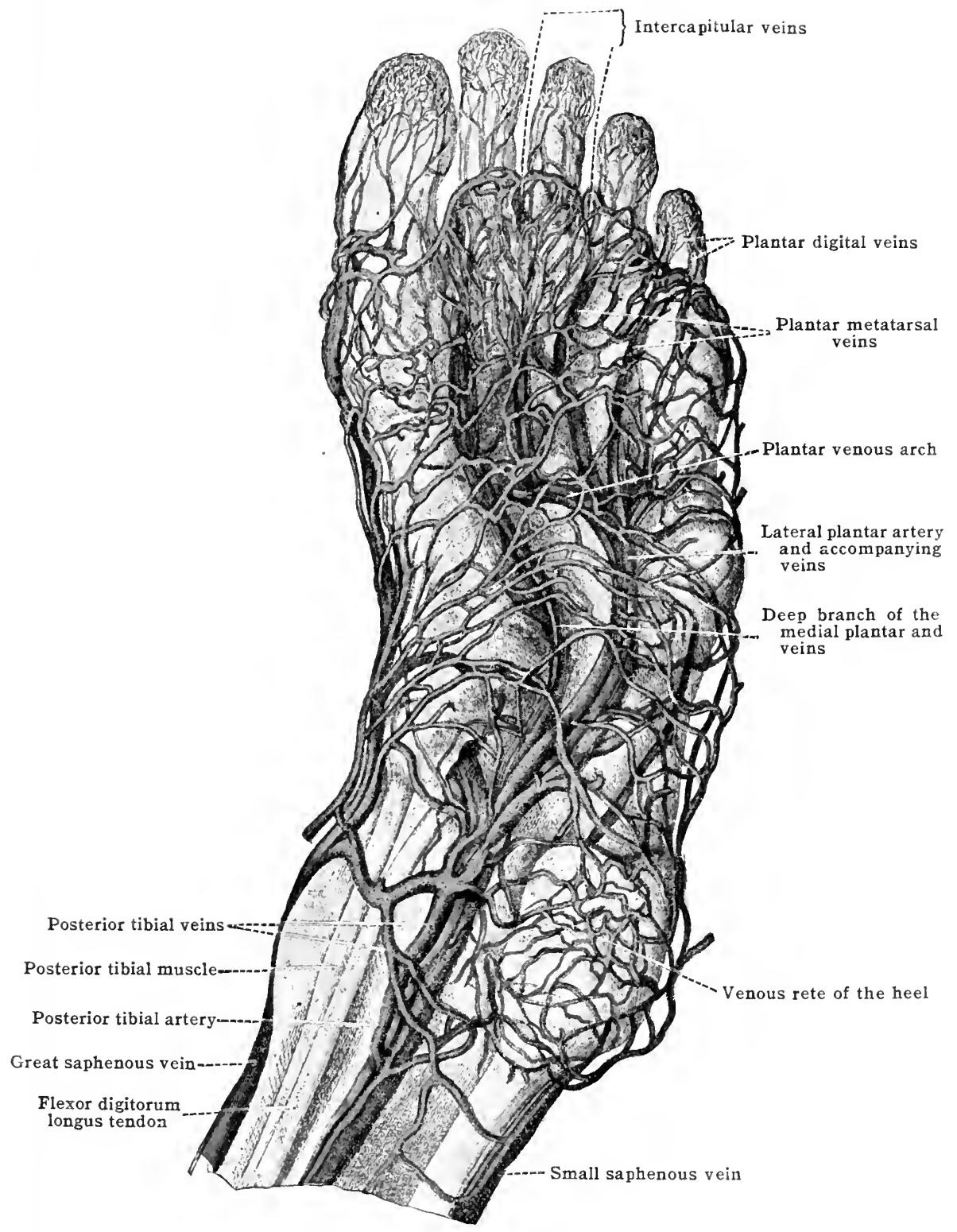

The veins of the foot and leg.-The deep veins of the foot become separated from the superficial where the plantar metatarsal veins [vv. metatarseæ plantares] leave the plantar digital and intercapitular veins to accompany the plantar metatarsal arteries. The plantar metatarsal veins empty into the plantar venous arch [arcus venosus plantaris] which accompanies the arterial plantar arch in the depth of the sole. (fig. 540) 
The posterior tibial veins [vv tibiales posteriores] drain the plantar venous arch and the superficial rete (fig 542).

They follow the posterior tibial artery up the leg, receiving tributaries corresponding to its branches, the largest of which are the peroneal veins [vv. peroneæ]. They unite with the anterior tibial vence comitantes at the lower border of the popliteus muscle.

The anterior tibial veins [vv. tibiales anteriores] begin in the dorsal venous rete and accompany the anterior tibial artery up the leg receiving tributaries corresponding to branches of the artery.

F1g. 541.-The Femoral Vein. (After Toldt, "Atlas of Human Anatomy," Rebman, London and New York.)

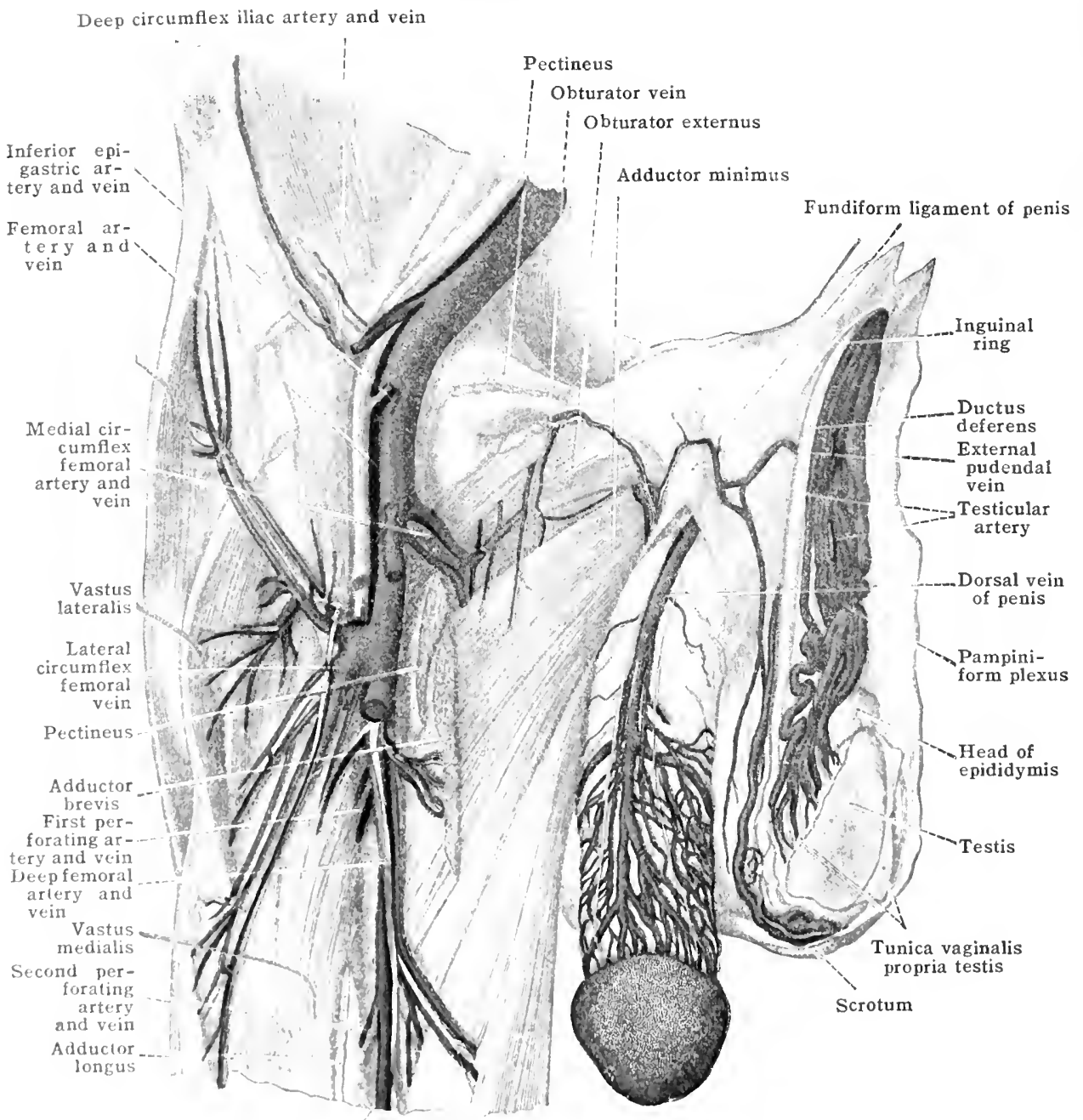

Deep femoral artery and vein

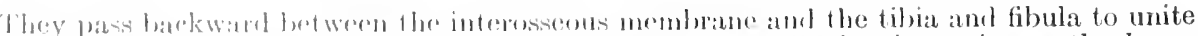
with the prosterior tibial verus. The pusterion and anterior tibial veins unite at the lower

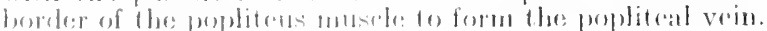

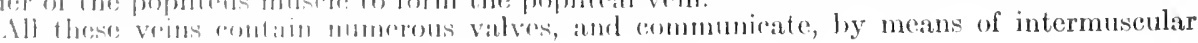

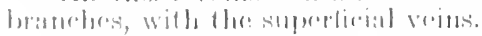

The popliteal vin / v. propliteal (fig. 512), is formed by the confluenee of the ventro contantes of the anterion and posterior tibial arteries at the lower border of the poplitros, and rextends upwarl to the opening in the adductor magnus at the junction of the mildle: and lower thirel of the thigh, where it changes its name 11) fomorial. 
It accompanies the popliteal artery, lying superficial to it in the whole of its course, and tightly bound down to it by its fascial sheath. At the lower part of the space it is a little medial to the artery, but, crossing the vessel obliquely as it ascends, lies a little lateral to it at the -upper part of the space. The tibial (internal popliteal) nerve lies superficial to the vein, being lateral to it above, then posterior to it, and then a little to its medial side. The popliteal vein contains two or three valves.

Fig. 542.-The Deep Veiss of the Leg. (After Toldt, "Atlas of Human Anatomy," Rebman. London and New York.)

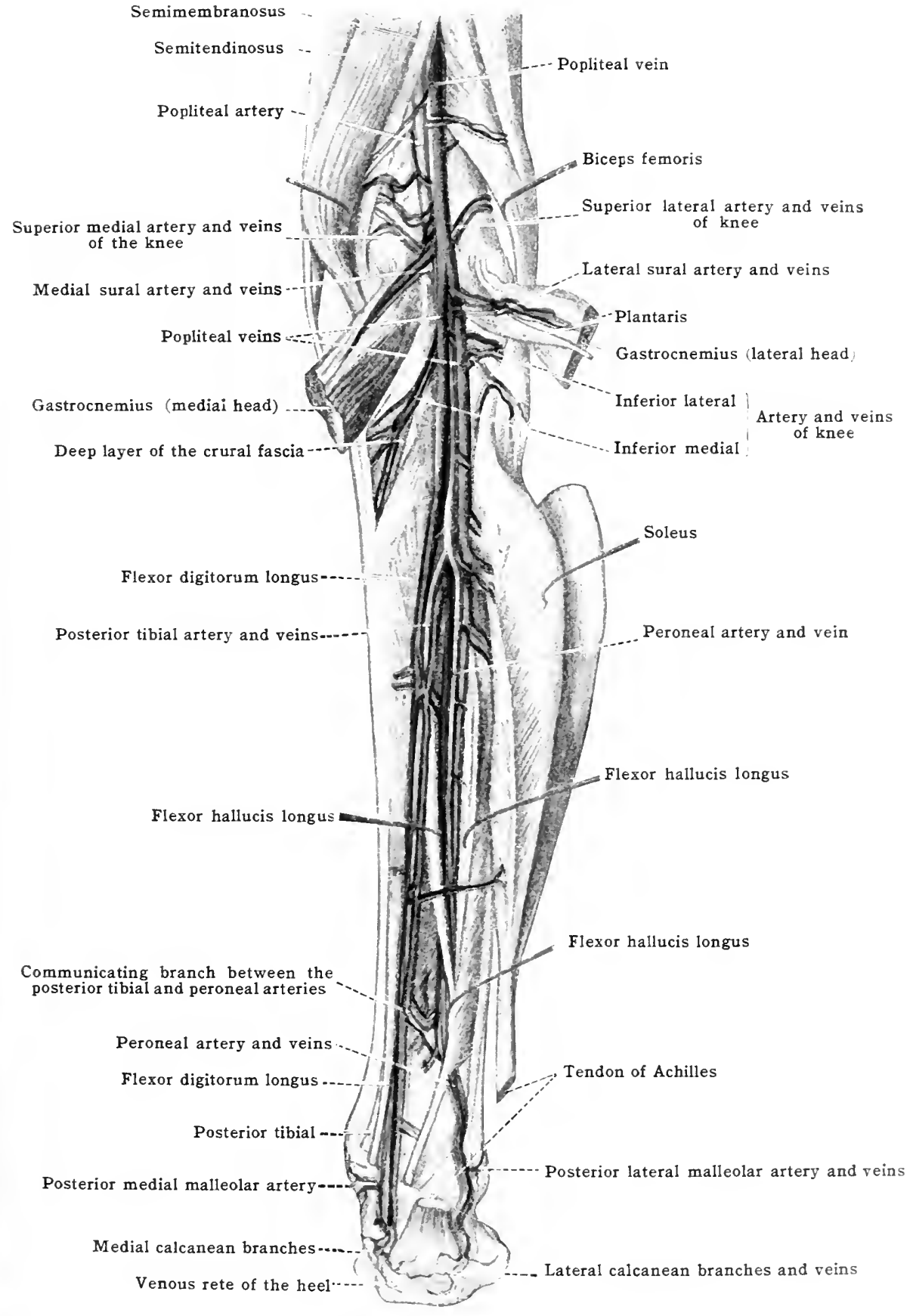

The popliteal receives the small saphenous vein. It is also joined on its lateral and medial sides by the accessory popliteal veins [vv. popliteæ accessoriæ] which form common trunks of cermination of the sural and articular veins of the respective sides. The medial vein receives $\mathrm{n}$ addition, through a plexus extending as high as the opening in the adductor magnus, the veins accompanying the a. genu suprema. 
The femoral vein [v. femoralis], the continuation of the popliteal upward, extends from the tendinous opening in the adductor magnus to the inguinal ligament. In this course its relations are similar to those of the femoral artery. As the vein passes through the adductor canal, it lies behind and a little lateral to the artery. At the apex of the femoral trigone (Scarpa's triangle) it is still posterior to the artery, but gradually passes to the medial side as it ascends through the trigone (fig. 541).

In the neighbourhood of the inguinal ligament the femoral vein lies on the same plane as the artery from which it is separated by a delicate prolongation of the fascia stretching between the front and back layers of the femoral sheath. On the medial side the vein is separated by a similar septum from the femoral canal. The femoral vein contains five pairs of valves.

Tributaries.- The femoral vein receives (in addition to the great saphenous vein, and, in some cases the superficial veins of the epigastrium and groin) the prof unda veins and a variable number of small femoral venæ comitantes.

The profunda femoris veins [vv. profundæ femoris] arise from the venæ comitantes eorresponding to branches of the profunda femoris artery. The medial and lateral circumflex veins [vv. eircumflex femoris mediales et laterales] collect blood from the muscles of the adductor and lateral rotator regions. The perforating veins anastomose with femoro-popliteal and other veins of the posterior femoral region, and with the circumflex and accessory popliteal veins. They return blood from the femur and the adductor, hamstring and vasti muscles.

The venæ comitantes, much smaller than the main femoral vein, accompany the femoral artery on either side. They anastomose with one another, with the femoral, and of ten with the popliteal vein. They terminate in the femoral a short distance above the profunda veins.

\section{MORPHOGENESIS AND VARIATIONS OF THE VEINS}

The veins of the adult human body tend to accompany the arteries; this tendency is more pronounced in the trunk, neck, and extremities than in the cranium. Developmental history shows that the primitive distribution of the veins of the trunk resembles that of the arteries of the same region in its bilateral symmetry only. Also that the changes which modify the primitive bilateral symmetry of the chief veins are not only more extensive but of a different nature from those producing a similar effect upon the arteries. In both cases the main bodyvessels begin as a pair of main longitudinal trunks and end as a main unpaired channel (or channels in the case of the venous system) situated near the median plane of the body. In the case of the venous system the change results from wholesale destruction of the vessels on the left of the body accompanied by enlargement of those upon the right. In the arterial system destruction occurs to a much more limited extent; the definitive channel results mainly from blending of the two primitive aortx.

The main venous channels of the cranium and extremities are primitively superficial; in the cranium they remain so. In the extremities new veins are formed which follow the main arterics; to these the more primitive channels become tributary.

The heart, as soon as it assumes the simple tubular form is found to receive four veins. 'These, the two vitelline and two umbilical veins, enter the sinus venosus, a vitelline and an umbilical vein on either side. The umbilical veins are lateral to the vitellines, and are paired within the body only; they arise from the placenta, and traverse the belly-stalk as a single trunk. The vitelline veins return blood from the yolk sac, and, at first, are independent throughout.

At a later period two other pairs of veins arise for the venous drainage of the embryonic borly. They are the pre- and post-eardinals which drain the cephalic and caudal regions respectively. 'The right pre-cardinal vein unites with the right post-eardinal to form the right common cardinal (duct of Cuvier). The latter runs in a medial direetion to join the sinus venosus lateral to the right umbilieal. On the left side the arrangement matehes that on the right to produce a primitively symmetrical pattern.

During levelopment ehanges are brought about in the primitive veins which end in the probluction of the adult venous system as follows: the common and pre-cardinals, together with the subchivian veins and the cephalic ends of the post-cardinals, are transformed into the vena cava superior and its larger tributaries. The remainder of the post-cardinal system is instrumental in the production of the vena cava inferior and its tributaries. Finally the intra-cmbryonic portions of the vitelline and umbilieal veins participate in the formation of the portal and hepatio systems of veins together with the proximal end of the vena cava inferior.

The following lriof aceount of morphogenesis and variations is divided into three headings (1) vena cava superior and its tributaries; (2) vena cava inferior and its tributaries, and (3) the prortal system.

\section{A. TIIE VENA (AVA SUPERIOR ANI) ITS TRIBUTARIES}

\section{MORPIIOGENESIS}

Tho pre-cardinal voins at first returu bloof from the head only, but as the heart recedes into the thorax the rarrlinal veins migrate with it. In so doing the conmon eardinals lag somewhat behind and in consecpuence their direction, primitively transverse, approaches the lon- 
the right and left $\mathrm{v}$. cerebralis anterior unite to from a median vein, the definitive superior sagittal sinus, which at first drains into the cavernous sinus. There are two other primitive cerebral veins; the $\mathrm{v}$. cerebralis media and $\mathrm{v}$. cerebralis posterior. The first receives blood from the cerebellar region and drains into the cavernous sinus. The second, the v. cerebralis posterior, also receives blood from the hind-brain and, leaving the skull through the jugular foramen, joins the pre-cardinal (internal jugular) vein in the neck. Several changes occur from now on (fig. 543) which bring about the definitive relations of the dural sinuses and transfer the main venous exit from the stylomastoid to the jugular foramen. The right v. cerebralis posterior joins the superior sagittal sinus and this becomes the right transverse sinus. The left $r$. cerebralis posterior communicates with the junction of the superior sagittal and right transverse simuses (now the confluens sinuum) and becomes the left transverse sinus. The confluens receives the sinus rectus, which forms its adult connections with the inferior petrosal. sinus and great cerebral vein. The v. cerebralis media joins the transverse sinus to become the superior petrosal sinus. The latter forms a new (intracranial) means of drainage for the cavernous sinus and its tributaries. The original drainage channel of the cavernous sinus (v. capitis lateralis), having been supplanted. disappears. The superior cerebral veins drain into the superior sagittal sinus. The remaining portion of the interrupted v. cerebralis anterior Irains the middle cerebral vein and spheno-parictal sinus. The inferior petrosal sinus arises de novo.

In the upper extremity the venous drainage is at first superficial and opens into the postcardinal and umbilical veins. The ulnar limb of the loop-litie early venous channel (marginal vein) becomes the primitive ulnar vein, but does not open into the pre-cardinal until a stage later than that of 10 millimetres. The primitive ulnar forms the basilic, part of the brachial, the axillary, and subclavian veins. It receives the large thoraco-epigastric trunk. The cephalic vein, which at first joins the external jugular, is of secondary formation. The venæ comitantes are formed later still.

\section{VARIATIONS}

The great veins of the thorax may present variations from the normal as a result of absence of the left innominate ein. In this case there are two superior cavie, not necessarily of equal size, each of which receives an internal jugular and subclavian vein. Persistence of the left

Fig. J4t.-The Thansformation of tile Postcardinal System of Veins, C representing The ADduT. The Wolffian Body is Dotted. (Lewis.)

a.c., precardinal; as. l., ascencling lumbar; az., azygos; c., caudal; c.h., common hepatic; c. il., common iliae; c.s., coronary sinus; d.C., common cardinal; g., spermatic or ovarian; h., hepatic; h.-az., hemiazygos; h.-az. ac., accessory hemiazygos (here draining into the intercostalis supremi ); i. j., internal jugular; l.c.i., left common iliac; l. in., left innominate; m.s., middle sacral; p.e., posterior cardinal; r., renal; r.a., renal anastomosis; r.c.i., right common iliac; l. in., right innominate; s., suprarenal; s-c., subcardinal; s-cl., subclavian; s.l., sinusoids; v.c.i., rena cava inferior; v.c.s., vena cava superior.

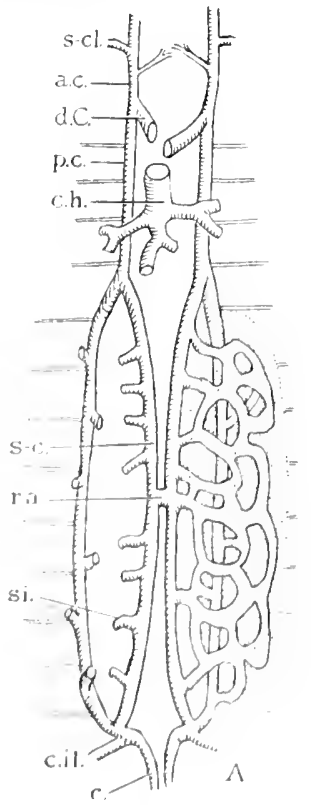

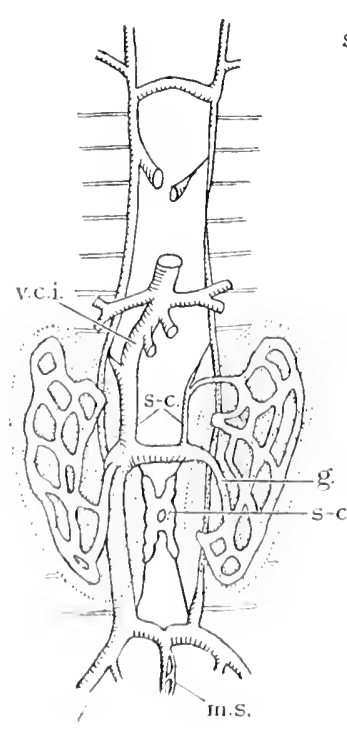

I3

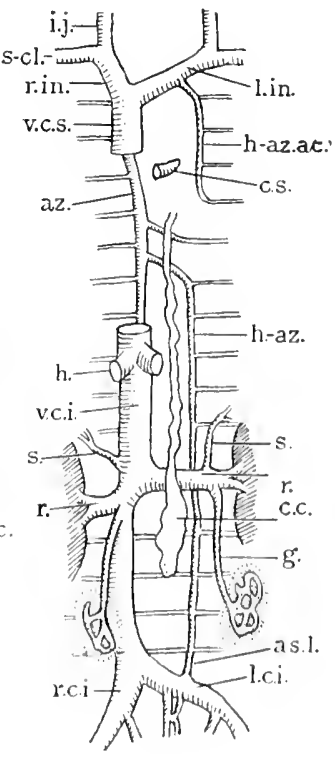

C

venat cava superior without failuse of the left imnominate may oecur in three classes of cases: (a) In which both cavin are present, equal in size or asymmetrical. (b) In which the left cava crify occurs, associated with situs inversus. (c) In which the left cava only is present, without situs imersus. The Inft vena cava superior, when present, erosses in front of the aortic arch and 
enters the right atrium by way of the coronary simus, collecting the coronary veins. Cases are on record of a left superior cava terminating in the left atrium.

The azygos veins. - Tariations of these veins and of the intercostal reins have been dealt with on pp. 663-664. For their morphogenesis, see under vena cara inferior.

The veins of the neck, face, and scalp.-These veins have so many variations in detail that it is difficult, in the case of some veins, to assign their nomal distribution. The external jugular, for instance, is usually described in English text-books as a tributary of the subclavian vein; it is assigned by the BNA to the internal jugular. It is frequently found to open into the angle between the two, or, forming a plexus with its tributaries, drain into both. The origin of the external jugular vein is also exceedingly variable. The external jugular may be smali, or absent, in which case the anterior jugular is large. The reverse may be the case since the external jugular frequently receives the posterior, and sometimes the common facial. Fortunately venous variations are not of prime surgical importance.

Veins of the cranium. - The venous sinuses of the dura mater are not subject to important variations. Variations in the relative size of the transverse simuses have been referred to on p. 651. The petro-squamous sinus, occasionally present, is described on p. 653. The occipital and inferior sagittal sinuses are frequently absent.

The cerebral veins are liable to great variation in detail: the great cerebral vein may be absent, as a single trunk, in which ease the internal cerebral reins open directly into the sinus rectus. The middle cerebral vein may open into the sphenoparietal, or superior petrosal sinus or into the basilar plexus.

Veins of the upper extremity.-The subclavian vein is occasionally posterior to the artery, or splits to enclose the latter and the anterior scalenus. Either case represents a partial retention of the early condition in which the vein passes behind the brachial plexus. Variations in the superficial veins have been referred to on p. 668 . The question of the most common distribution of these vessels has lately been fully reviewed by Berry and Newton. The cephalic vein occasionally opens into the external jugular by persistence of the embryonic jugulo-cephalic vein.

\section{B. THE VENA CATA INFERIOR AND ITS TRIBUTARIEN}

\section{MORPHOGENESIS}

The right and left post-cardinal veins (fig. 544) are at first symetrical in size and position. Early in development each posterior cardinal vein becomes involved in the growth of the corresponding mesonephros, and the original venous channel is converted into a system of sinusoids. In the sinusoidal circulation of each mesonephros two main longitudinal venous channels soon make their appearance. One lies ventro-medial to the mesonephros and is called the sub-cardinal vein. The other, which lies dorsal to the mesonephros, receives the segmental veins and is frequently called the post-cardinal. Since the mesonephric segment of the post-cardinal rein has obviously passed out of existence, the vein in question (unlabelled in fig. 544) will be here distinguished as the dorsal trunk. The sub-cardinals communicate freely between themselves and with the dorsal trunks, lie ventral to the mesonephric arteries, and are at first srmmetrical. The cephalic end of the right sub-cardinal now acquires a communication with the common hepatic vein, thus providing a new means of drainage for the sub-and post-cardinal systems (fig. 544). The rapidly enlarging main venous channel resulting from this alternative method of drainage follows the right dorsal trunk as far as the level of the permanent renal veins. It is then transferred, by means to an anastomosing channel, to the right sub-cardinal and, through this, to the common hepatic vein; it becomes the vena cava inferior. From now on the portions of the sub-cardinal veins not participating in the formation of the cava dwindle rapidly. A cross anastomosis between the right and left sub-cardinals persists as the portion of the adult left renal vein which crosses ventral to the aorta. By means of it the remainder of the left renal; the left internal spermatic and left suprarenal veins are connected with the rena cara. The left lumbar and left common iliac veins are also transferred to the vena cara, probably by direct anastomosis with the left post-cardinal vein. The vena cava inferior is at first lateral to the right ureter, its transference to the medial side occurs through anastomosis.

The portion of the right posterior cardinal vein above the mesonephric region, together with its continuation into the dorsal trunk, becomes the azygos vein (fig. 544). The corresponding vessel upon the left side is transformed into the accessory hemiazygos and hemiazygos reins. The hemiazygos vein is drained into the azygos by means of an anastomosing channel which may also drain the accessory hemiazygos. The variability of the means of drainage of the accessory hemiazygos vein, by means of anastomosing channels, is referred to on p. 663 . Thr ascending lumbar veins are anastomosing channels of new formation.

In the lower extremity, as in the upper, the original superficial plexus is gradually drained by a loop-like marginal vein. The fibular limb of this loop, the primitive fibular vein, becomes small saphenous; it follows the sciatic nerve and opens into the post-cardinal. The next vein to be developed is the great saphenous; the small saphenous is transferred to this by an anastomosing vein which is usually present in the adult-the femoropopliteal vein. The deep veins are of laterformation. The drainage of the small saphenous is usually taken over by the popliteal vein.

\section{VARIATIONS}

In determining the probable embryonic cause of variations of the vena cava inferior the possibility of abnormal persistence of the sub-cardinal veins must be remembered. 'The position of transverse anastomoses with regard to the aorta is often the key to diagnosis. Instruc- 
tive cases of abnormalities of the vena cava inferior have recently been published by $\mathrm{v}$. Alten and by Neuberger (see References). Both articles contain bibliographies. The chief yariations are as follows:-

(1) The inferior vena cava, in cases of transposition of the viscera, may lie on the left side of the aorta. (2) Without transposition it may also lie to the left of the aorta, crossing to the right to gain the caval opening immediately below the diaphragm, or after receiving the left renal vein. (3) It may be double, the left cava than usually passing across the aorta into the right after receiving the left renal vein. A communication between the right and left veins in the position of the normal left common iliac vein may or may not then exist. (4) The inferior vena cava may be absent, the blood from the lower extremities passing by a large vein in the position of the ascending lumbar and azygos veins through the diaphragm to open into the superior vena cava. The hepatic veins then open directly into the right atrium through the normal caval opening in the diaphragm. (5) The inferior vena eava may receive the left spermatic vein. (6) It may receive a left accessory renal vein passing behind the aorta, and into this the usual tributaries of the left renal vein may open. (7) It may receive several aceessory renal veins; as many as seven on each side have been met with. (8) The lumbar veins may enter it on one or both sides as a common trunk.

The variations in the veins of the lower extremity are for the most part unimportant. They have been mentioned in the deseription of the corresponding veins.

\section{THE PORTAL SYSTEM OF VEINS}

The portal system arises by transformations in the vitelline and umbilical veins. The proximal ends of the vitelline veins, where they lie between the umbilicals, are early enveloped in, and invaded by, the growing liver. 'The columns of liver cells, while not penetrating the end othelium, subject the vitelline veins to a process of fenestration by which the original ehannels are subdivided into innumerable smaller vessels or sinusoids. The sinusoids arising from the two vitelline veins intercommunicate to form one continuous network in which the vessels are larger in the afferent (portal) and efferent (hepatic) areas than in the intermediate zone.

Fig. 545.-Semidiagramiatic Reconstructions of the Veins of the Liver, Ventral Aspect (MalL). A, Embryo of 4.5 mm. Long; B, 4 m. (more advanced than A); C, 7 mm. d.v., ductus venosus; I., intestine; L., liver; m., superior mesenteric (continued as portal) vein; r.a., ramus angularis; r. a'., right branch of portal vein; r.h.d., right hepatic vein; r.h.s., left hepatic vein; r.u., recessus umbilicalis; u.v., left umbilical vein (the right umbilical vein is not labelled); v.o.m., vitelline veins.
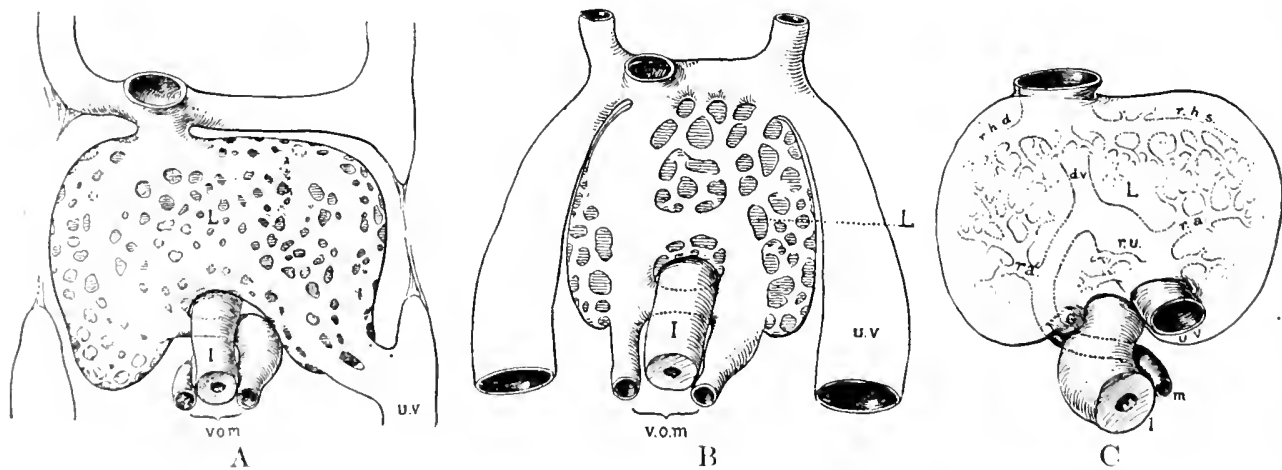

The two umbilical veins now form communications with the portal area of the sinusoidal network and eventually lose their original conncetions with the sinus venosus (fig. 545). 'The fate of the nmbilical veins differs on the two sides; the right degenerates, from the sinus venosus to the common unbilical vein, and leaves the left to receive all the blood flowing from the placenta. The left, having lost its connection with the sinus venosus, discharges its blood partly' into the portal sinusoilal zone, and partly, by means of the newly formed direct channel, the ductus venosus, into the right vitelline (fig. 545).

The hepatic (nd of the right vitelline vein enlarges considerably, for the left vitelline loses its original commection with the sinus venosus. It transmits blood both from the sinusoids and from the ductus venosus to the sinus venosus, and is called the common hepatic.

The vitelline veins are not only connected within the liver, but their distal ends become uniterl upon the yolk-stalk to form a single trunk. A third communication between them is effreted by a transverso vossel massing lorsal to the duodenum. The portion of the right vitelline lockw the transverse vessel lisapuears, as does the portion of the left between it and the liver. A tortums vitellime vein is thus produced which enters the liver by passing dorsal to the intestine from loft to risht. This vessel is joinerl, to the left of the intestine, by the sunerior mesenterir vein imb, dorsal to it, by the splenie. When the portion of the vitelline below the termination of the superion mesenterie finally disulporas the vessel extending from the splenis: vein to the liver beomes the portal vein of the arlult.

Inportant variations of the portal system are rarely found in the arhlt. The mechanism of anomalios fomml in the embryo have hien investigated hy Begg (Amer. Jour. Anat., Vol. 13). 


\section{FCETAL CIRCULATION}

The changes which accompany the transformation of the foetal type of circulation into that of the adult are initiated by the first inspiration. Prior to this act the functions of external respiration and digestion are performed by the

Fig. 546.-The Heart, with the Arch of the Aorta, the Pulionary Artery, the Ductus Arteriosus, and the Vessels concerned in the Fotal Circulation.

(From a preparation of a fotus in the Museum of St. Bartholomew's Hospital.)

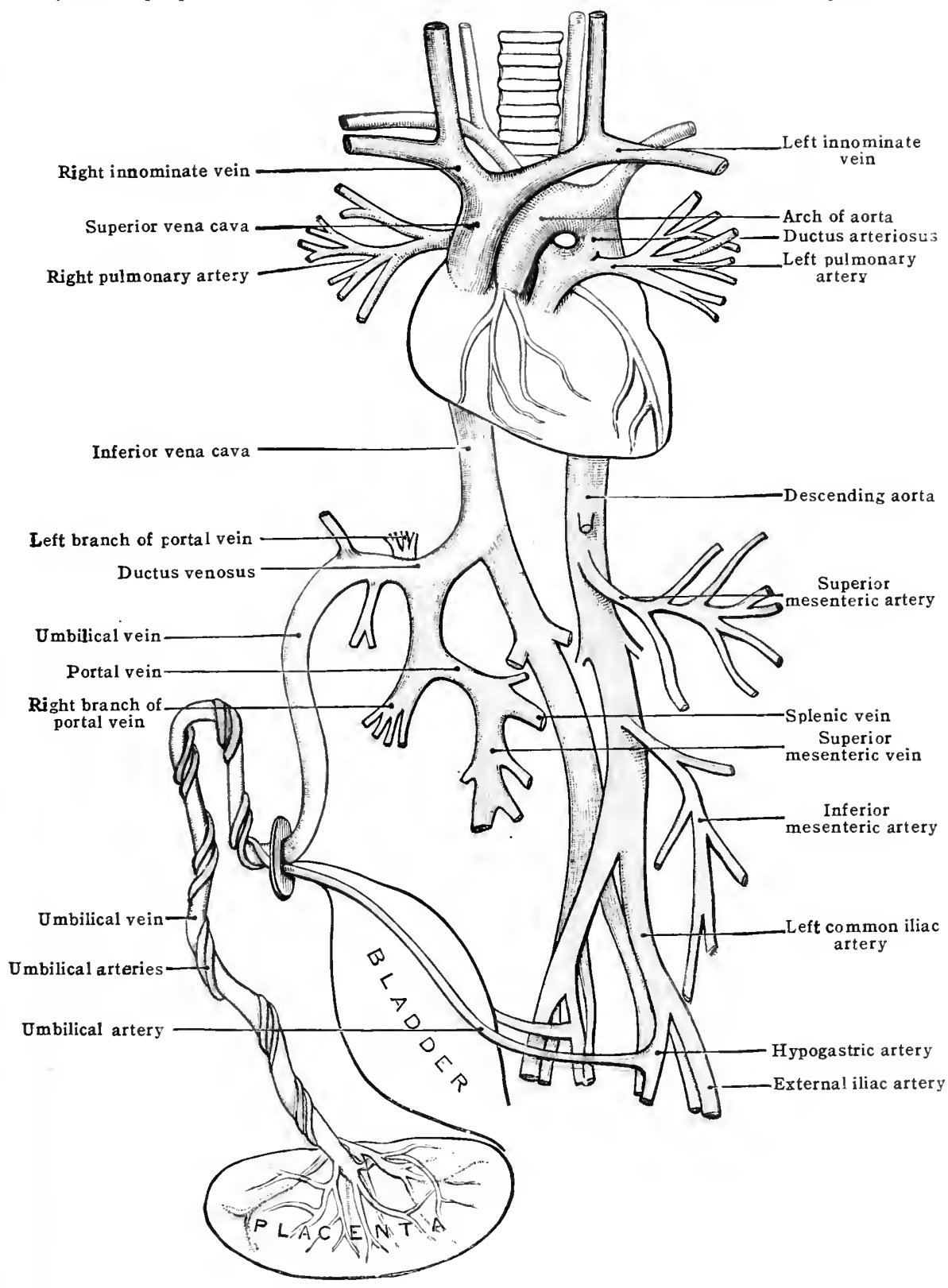

mother; the fotal venous blood passing to the placenta through the umbilical arteries and returning through the umbilical vein.

At the time of birth the right and left chambers of the heart communicate only by means of an oblique passage between the overlapping atrial septa (p. 511). The pulmonary artery and descending aorta communicate by means of the ductus arteriosus (p. 508). 
Arterial blood, transmitted from the placenta through the umbilieal vein, passes almost entirely by way of the ductus venosus to the vena eava inferior. From here it passes through the right atrium; then, obliquely between the atrial septa into the left atrium, from which it passes through the left ventriele and into the ascending aorta. Escaping largely through the branches of the aortie areh, it is distributed to the head and upper extremities, and returned to the vena eava superior. Having reached the right atrium it passes, to the right of the stream from the vena cava inferior (p. 513), through the atrio-ventrieular ostium into the right ventricle. The blood issuing from the right ventricle into the pulmonary artery goes almost entirely (the lungs being functionless) into the ductus arteriosus and so into the descending aorta. Having performed two cireuits, the blood returns to the placenta through the umbilical branches of the hypogastric arteries.

The two streams, arterial and semi-venous, cross one another in the right atrium. The degree of intermixture, if any, which oecurs in this eavity has been the subject of much discussion; for literature and experimental evidence on this point see Pohlmann, A. (Johns Hopkins Hosp. Bul., Vol. 18, 1907.)

When the lungs assume their function at birth the pressure in the left atrium is suddenly raised by an inrush of blood. The overlapping atrial septa (primum and sccundum) are brought into lateral apposition and thus the blood entering the right atrium finds but one exit-the atrio-ventricular ostium. Since the vessels of the expanded lungs now transmit a greatly increased volume of blood, the stream passing through the ductus venosus is diminished proportionately. The blood traversing the aortic areh, released from the eheek exerted by the lateral stream pouring from the ductus arteriosus, passes more readily into the deseending aorta; thus the adult equilibrium is established.

References for blood-vascular system.-A. Heart: (Development) Born, Archir f. mikr. Anat., Bd. 33, 1889; His, Anatomie menschl. Embryonen, 1880-85, Anatomie des mensehl. Herzens, 1886; Tandler, in Keibel and Mall's Human Embryology. (Morphology) MacCallum, Johns Hopkins Hospital Reports, vol. 9, 1900; Mall, Amer. Jour. Anat., vol. 11, 1911, vol. 13, 1912; (Atrio-ventricular bundle) Keith and Flack, Jour. Anat. and Physiol., vol. 41, 1907. B. Arteries. (Development) Evans, in Keibel and Mall's Human Embryology; (Pulmonary) Bremer, Anat. Ree., vol. 3, 1908; (Internal mammary) Mall, Johns Hopkins Hospital Bul., 1898; (Cephalic) Tandler, Morph. Jahrb., Bd. 30, 1902; (Coliac) 'Tandler, Anat. Hefte, Bd. 25, 1904; (Extremities) Müller, Anat. Hefte, Bd. 22, 1903; de Triese, Arch. de Biol., T. 18, 1902; (Tariations) Göppert, Morph. Jahrb., Bd. 40, 1909; C. Veins. (Development) Davis, Amer. Jour. Anat., vol. 10, 1910; (Brain) Mall, Amer. Jour. Anat., vol. 4, 1904; (Liver) Mall, Amer. Jour. Anat., vol. 5, 1905; (Cervical) Lewis, F. T., Amer. Jour. Anat., vol. 9, 1909; (Upper extremity) Berry and Newton, Anat. Anz., Bd. 33, 1908; (Vena cava inferior) Neuberger, Anat. Anz., Bd. 43, 1913; v. Alten (ibid): (Sinusoids) Minot, Proc. Boston Soc. Nat. Hist., vol. 29, 1900. 


\section{SECTION VI \\ THE LYMPIATIC SISTEM}

Revised for the Fifth Edition

BY ELIOT R. CLARK, A.B., M.D.

\section{GENERAL ANATOMY OF THE LYMIPHATIC SYSTEM}

$\mathrm{T}$

HE blood-vascular system has, as a part of its function, the collection of substances from the various tissues of the body which are to be conducted to the other tissues. In carrying on this function it is assisted by a second system of collecting vessels, the lymphatics.

This second system resembles the blood-vascular system in many ways, but differs markedly in others. Like the blood-vascular system, it is made up of minute endothelial-lined capillaries, where the absorption of substances occurs, and of larger conducting vessels. It differs from the blood-vascular system in two important particulars. While the blood-vascular system is provided with a pumping"mechanism by which its fluid content is driven through a complete circuit from the heart, through artery, capillary, vein and back to the heart, the lymphatics merely conduct fluid from the capillaries to the larger vessels, which eventually empty their contents into the large veins of the neck. The second important difference between the two systems is found in the presence, along the course of the lymphatic vessels, of glands or nodes (fig. 553) [lymphoglandulæ] in which the vessels branch out into lymph capillaries. These are lined, as are the absorbing capillaries, with a single layer of endothelial cells, thus permitting an interchange of substances between the contents of the lymph capillaries and the lymphoid tissue around them.

Our present knowledge does not permit an exact statement of the complete extent of the lymphatic system. While, in a general way, the lymphatics may be said to be present whereever blood-capillaries occur, there are certain tissues where lymphatics have not been definitely demonstrated.

The general constitution of the lymphatic system will be considered under three heads-(1) the capillaries, (2) the collecting vessels and (3) the lymphoid organs.

\section{THE LYMPHATIC CAPILLARIES}

The lymphatic capillary, like the blood-capillary, is the portion of the lymphatic system which is chiefly concerned in the specific function of this system. In the blood-capillaries, where the blood is separated from the outside tissues by a single layer of flat endothelial cells, there occurs the interchange of fluid substances and of cells, while the heart, arteries and veins serve to transport the blood, modified in the capillaries, to other parts of the body. Similarly in the lymphatic system, it is in the capillaries, both those most peripheral and those in the lymph nodes, where the absorption and interchange of fluid substances and of cells takes place. Consequently it becomes of prime importance to obtain a clear understanding of the structure of the lymphatic capillaries, their relation to the other tissues, and their mode of functioning. At the outset, however, it must be admitted that our knowledge on this subject is far from complete.

Historical.-Previous to the development of microscopic anatomy, in the middle thircl of the 19th century, there was no accurate knowledge of such small structures as the lymphatic capillary. In order to explain the absorption of substances by the lymphatics, as weill as the passage of substances from the blood-vessels through the tissues, various theories were invented. Prominent among such theories was that of the "vasa serosa," of $\mathrm{H}$. Boerhaave and other 1 sth century anatomists and physiologists, which was perhaps most elaborately developed by Bichat, 1S01-03. According to this theory there are two sets of minute vessels, too small for the passage of cellular elements. The one set leads from the blood-capillaries onto the various surfaces of the body and into the loose spaces in the tissues - the "exhalants." The other set leads from the body surfaces (including the serous cavities) and the loose spaces in the tissues to the lymphaticsthe "inhalants" or "absorbants," which take in fluids by a sucking action. 
This theory was somewhat shaken by the discovery of Magendie, in the first decade of the 19 th century, that absorption may take place by the veins, as well as the lymphatics, and by the criticism of early 19 th century anatomists who developed the technic of injection of lymphatics to a high point.

Our present conception of the lymphatic capillaries may be said to have started with Fölliker who, in 1S46, saw, with the aid of the microscope, the ly mphatic capillaries in the transparent tails of living frog larvae. He found them to be definite structures made up of a thin wall, from which projected fine-pointed processes, and in which were nuclei. Like Schwann who, in 1837, had studied the blood-capillaries in the tail of the frog larva, he erroneously supposed that the fine processes of the lymphatic capillaries were continuous with similar processes of the surrounding connective-tissue cells. Since, according to the conception current at the time, cells were thought to be hollow structures, with a membranous wall and fluid content, it was concluded that the mode of transmission of fluid from blood to lymphatic capillary took place through canaliculi inside these cells. This conception was elaborated by Virchow, in his Cellular-Pathologie.

In 1862 von Recklinghausen by means of the silver nitrate staining method discovered that the lymphatic vessels are lined with an endothelium made up of flattened cells whose outlines show as fine dark lines after this treatment. Again, however, as a result of the eagerness to find open passages through the tissues from blood to lymphatic capillary, an erroneous interpretation was made. von Recklinghausen held that the unstained parts outside the lymph vessels represent a system ofi irregularly shaped lymph-canaliculi ("Saftkanälchen") which are in open communication on the one hand with the blood-capillaries, and on the other with the lymphatics This conclusion has since been disproved by numerous investigators.

In a second series of observations, von Recklinghausen brought evidence in favor of open communications between the lymphatics and the peritoneal cavity. He watched, under the microscope, the passage into lymphatics, through minute openings, of milk, placed on a portion of the central tendon of the diaphragm. "These minute openings he termed "stomata." Cohnheim described similar though smaller openings in blood-capillaries, and His described them in other lymphatic capillaries. Arnold termed the openings in the vessels "stigmata," as distinguished from the openings into the peritoneal cavity, or "stomata."

With the advent into microscopical technic of the various dyes for staining cell-nuclei and protoplasm, and the more precise methods for making histological studies, the endothelial wall of the lymphatic capillary has been definitely established, although much remains to be learned concerning the differences between the lymphatics of the various tissues.

Moreover, recent investigators have failed to find open connections between the lumen of the lymphatic vessel and the tissue outside. Kolossow failed to find the "stomata" of von Recklinghausen and the "stigmata" of Cohnheim, His and Arnold. The "stomata" have been carefully studied by a number of other recent investigators. All agree in finding a complete endothelial lining for the lymphatic capillaries lying underneath the peritoneum and pleura, with no openings or "stomata." Careful studies of the lymphatic capillaries in the transparent tails of living frog larvae, which may be clearly seen with the higher magnifications of the microscope, show that the endothelial lining of these capillaries is complete, with no trace of an opening into the spaces in the tissue outside (E. R. Clark).

Form.- The shape of the lymphatic capillaries has been found to vary enormously in the different parts of the body, where they have been studied. In general they form richly anastomosing plexuses, from which may extend cul-de-sacs, which end blindly. Such cul-de-sacs are especially noticeable in the dermal papillæ, in the filiform papillæ of the tongue, and in the intestinal villi. The plexuses are of ten present in two layers-a superficial and a deep. The vessels of the superficial plexus are of smaller calibre than those of the deep. These two sets of plexuses are particularly well seen in the skin and the gastro-intestinal tract. In relation to the blood-capillaries, the lymphatic capillaries are generally the more deeply placed.

In calibre, unlike the comparatively uniform diameter of blood-capillaries, the lymphatics vary enormously. In the same capillary a very narrow part may be succeeded by a very wide one (figs. 547, 518). Teichmann found lymphatic capillaries varying in diameter from a few thousand ths of a millimetre to one inillimetre. In the capsule of the spleen of the cow some measured more than 1.5 mm.! The capillaries are without valves.

Activity.- That the lymphatic endothelium is not exclusively a passive membrane has been shown by Clark in studies on the lymphatics in the transparent tails of living frog larva. The lymphatics here are scen to send out protoplasmic processes which, somewhat like an amoba, actively take into the interior of the lymphatic red blood-cells accidentally forced from the blood-capillarieg into the tissue-spaces.

The mode of passage of leueorytes into or out of the lymphaties offers no such difficulties as that of the fluilds, for they are able, through their power of amoboid movement, to pass independently through the endothelinun-a process first directly observed by Cohnheim.

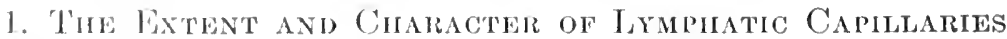

The skin over the entire surface of the body is richly provided with lymphatic capillaries. 'They form two sots of plexuses in the dermis, a superficial and a deep. Tlie superficial set sends (out blind cul-de-sacs into the dermal papillac. The richest skin plexuses are found in the serotum, the palms of the hami and palmar side of the fingers and in the soles of the feet and plintar side of the toes. In the loose subcutaneous fascia, according to Teichmann, there are present only the larerer colleeting vessels, with no lymphatie eapillaries. Lymphatic capillaries of the sorolum aro shown in lig. 547 .

The conjuntiva, both the selerotie and corneal, is supplied with a rich plexus of capillaries, which are narrower in the enrual than in the sclerotic portion. $\Lambda$ the corneal borter the 
capillaries form a fairly regular ring which has been called by Teichmann a circulus lymphaticus. At the various orifices of the body, the skin plexuses go over into the mucous plexuses, forming anastomoses with them. Throughout the entire alimentary tract, including the nasal cavities, the lymphatic capillaries form extensive plexuses which are in many places divided into a superficial plexus in the mucosa and a deeper plexus in the submucosa. In portions provided with a peritoneal covering, there is a third rich subserous plexus. In the tongue and the small intestine the plexus in the mucosa sends out blind cul-de-sacs; in the tongue into the filiform papillæ; in the small intestine into the villi. Where muscle is present along the alimentary tract, the lymphatics pass between the muscle bundles, but form no plexuses around them.

The lining of the tracheal and bronchial passages is supplied with a double plexus of lymphatic capillaries, a mucous and a submucous set, which vary in richness according to the looseness of the tissue. In the smaller bronchi but a single layer of capillaries is present, and, according to Miller, no capillaries are present around the air cells. Plexuses surround the pul-

Fig. 547.-The Lymphatics of the Scrotum. (After Teichmann.) Showing the transition of the capillaries to the vessels with valves $(a, a, a)$.

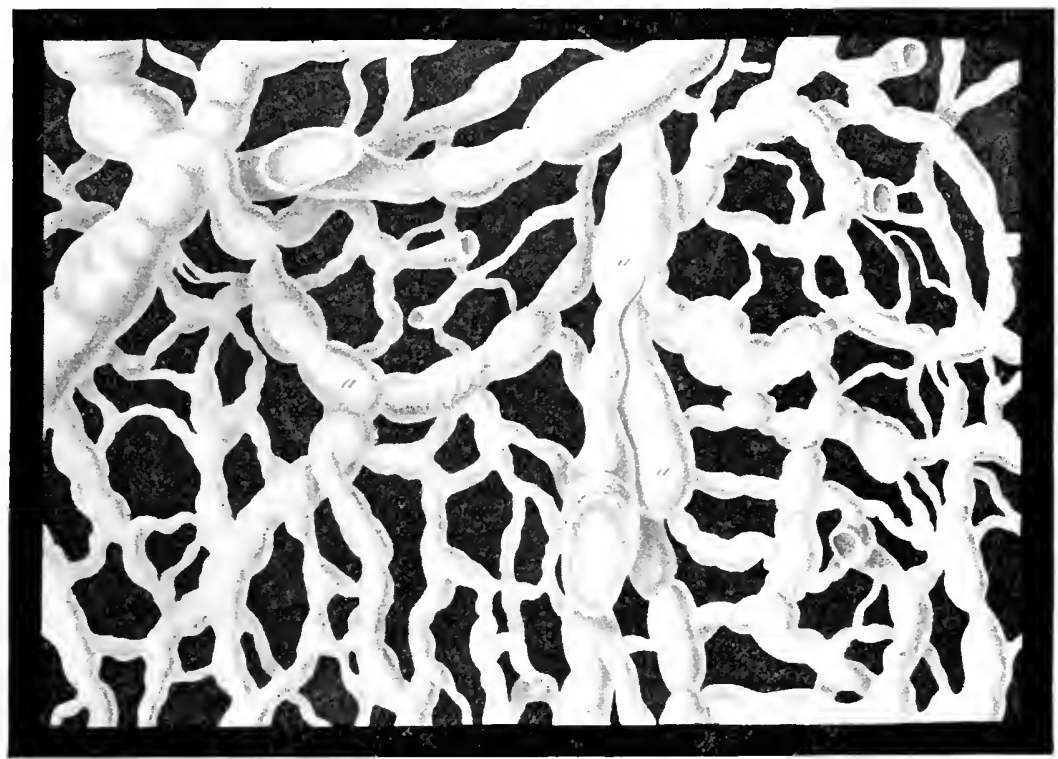

monary arteries and veins. Under the pleura lie rich plexuses which connect with the deeper lymphatics around the veins only in places where the veins reach the surface of the lung.

Concerning the arrangement of the lymphatic capillaries in the glands derived from the alimentary tract much remains to be learned.

The salivary glands have been recently studied anew by Aagaard, who has found lymphatic capillaries accompanying the blood-vessels into the interior of the lobules, and forming here irregular plexuses.

The thyreoid gland contains lymphatic plexuses which lie in relation to the colloid-containing alveoli. Direct connection between the lymphatics and the alveoli has lately been described by Matzunaga, but this observation needs verification. The lymphatics are apparently concerned in the absorption of the colloidal secretion, for traces of it have been found in the lymphaties draining the gland.

Concerning the lymphatics of the parathyreoids nothing is known.

The course of the lymphatics draining the thymus has been recently described, but the nature of the capillaries in this gland is unknown.

The lymphatic capillaries of the liver are of great importance, for the lymph which flows from this organ forms a very considerable part of the total lymph which is collected into the thoracic duct. And yet very little is definitely known about the nature and distribution of the lymphatic capillaries in the interior of the organ. In the capsule there is a rich plexus, lying under the peritoneum, in which very large widenings have been described (called by Teichmann "Lymphbehälter"). In the interior rich plexuses surround the branches of the hepatic artery" and portal vein (fig. 549), and plexuses have been described accompanying the branches of the portal vein into the lobules.

The linings of the large bile-ducts and the gall-bladder are provided with a submucous network of lymphatics (Sudler and Clermont). The gall-bladder has also a rich subserous plexus.

Concerning the lymphatic capillaries of the pancreas Bartels notes briefly that they form. richly branched plexuses in the interlobular connective tissues, which surround larger or smaller parts of whole lobules, not the single gland elements.

The mucous lining of the genito-urinary tract, wherever it has been carefully studied 
has been found provided with plexuses of lymphaties. In the blader they form a rich plexus of irregular eapillaries whieh lie immediately under the almost intraepithelial bloml-capillaries. They comnert, through the museular layer, with a subserous plexus. The lymphatic plexus of the urethra anastomoses with the capillaries of the base of the bladder. and in the male with those of the glans penis. The lymphatic eapilharies of the ductus deferens aud of the seminal vesicles have not been stulied. In the prostate (Camineti) the lymphatics form rich plexuses suroumbling the glands, which connect with a very wide mesherl subcapsular plexus, surrounding the entire gland.

In the testis there is a rich superficial plexus, lying directly beneath the tunica albuginea. Concerning the decp lrmphaties of the test is there has been much dispute. Ludwig and Thomsa

Fig, 5ts.--Serface View and Section of Lraphi-nodes of the Intestine. A. Solitary follicle. B. Peyer's pateh. (After Teichmann.)
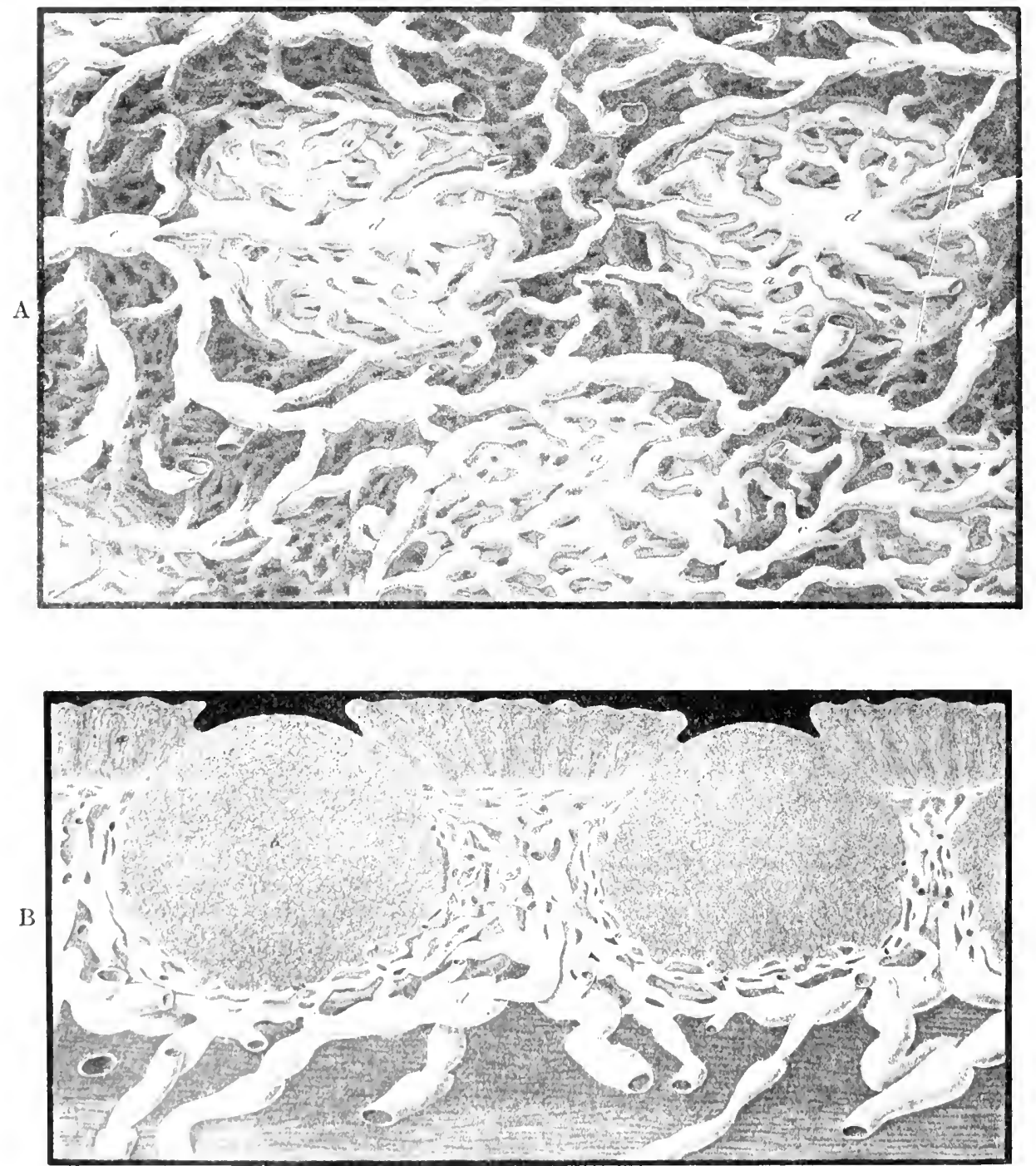

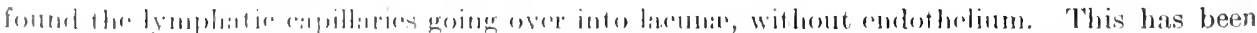

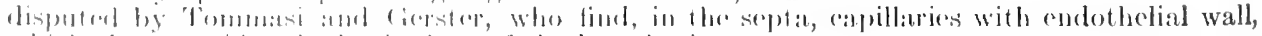

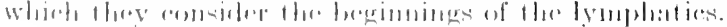

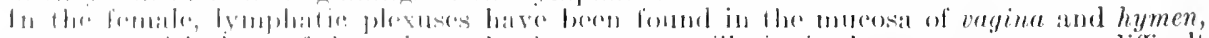

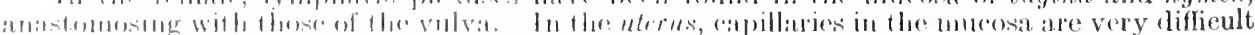

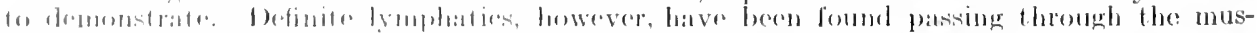

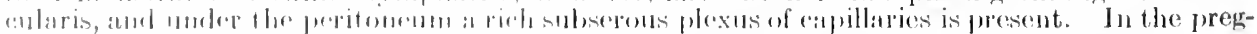

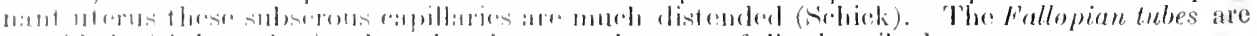

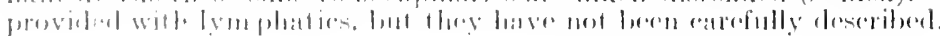


The ovary has a rich superficial lymphatic plexus. In the interior of the gland, according to His, the capillaries form networks in the connective tissue framework. In the tunica externa of the follicles there is a rich plexus.

The kidney has two sets of lymphatics, a superficial, capsular set, and a deep set. The capsular set is divided into two layers, one lying directly beneath the peritoneum made up oi a wide meshed plexus, and the otber in the fibrous capsule of the kidney, with finer capillaries and narrower meshes, which anastomose with the deeper capillaries. The lymphatic capillaries of the kidney parenchyma have recently been described by Lumita. He found rich plexuses in both cortex and medulla, surrounding the straight and convoluted tubules, the loops of Henle and the collecting tubules. He also found a plexus surrounding and accompanying the bloodvessels into the interior of the glomeruli.

The lymphatic capillaries of the adrenal have also been described recently by fumita. His results agree with those of Stilling, who studied the lymphatics of the adrenal of horse, cow and calf. Like the kidney, the adrenal possesses a superficial and a deep set. The superficial set

Fig. 549.-Lrmphatic Plexus around the Portal Vein in an Adult Man. (After Teichmann.) Showing the supporting relation of the vein.

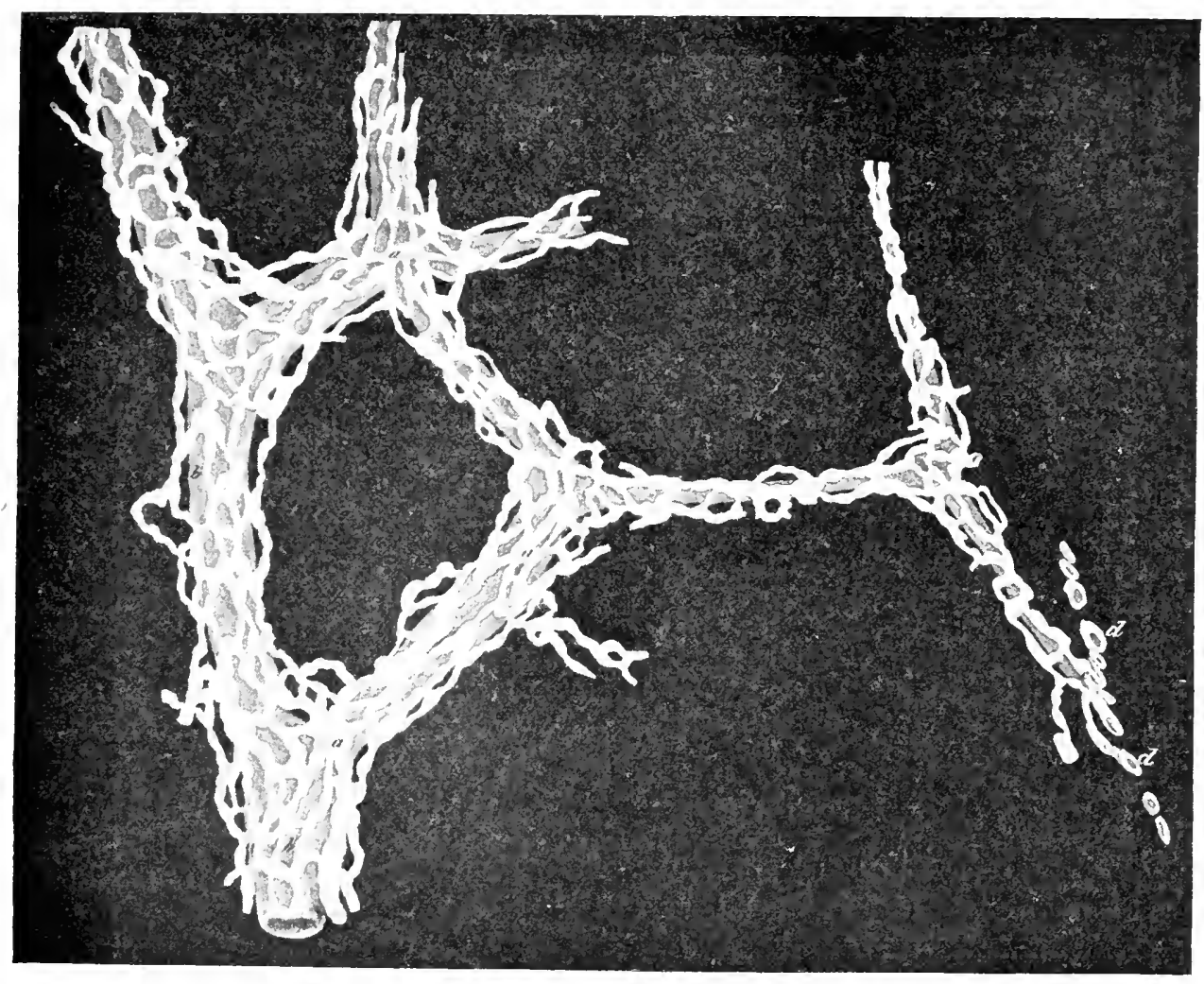

is in two layers, as in the kidney, the outer lying in the looser tissue around the adrenal and the inner lying within and just under the capsule. The latter is made up of a rich lymphatic plexus, which anastomoses with the capillaries of the parenchyma. The parenchymatous lymphatics are present in the form of plexuses which surround the groups of cells.

In spite of numerous investigations, endothelial-lined lymphatics have not been definitely. found in the central nervous system, or in the peripheral nerves. The subarachnoid and similar spaces, including the perineural spaces, do not form parts of the lymphatic system.

Rich plexuses of lymphatic capillaries are present in the tendons of miscles (AchweiggerSeidel and Ludwig). In muscles, themselves, the question of the presence of lymphatics bas long been disputed, sometimes answered in the affirmative, more of ten in the negative. A recent study by Aagaard, however, would seem to place beyond doubt the presence of lymphatic capillaries in striated muscles. By long continued injection, he was able to find lymphatics in the intramuscular portions of the tendons, which extended out among the muscle fibres themselves. He also found capillaries in the tongue musculature.

The heart is provided with a subpericardial plexus of lymphatic capillaries. A subendocardial plexus has also been described (Sappey, Rainer). Bock has recently found that there is an extremely rich lymphatic network throughout the substance of the heart. According to his description, the lymphatic capillaries are more numerous than the blood-capillaries.

The periosteum of bones is provided with a rich plexus of lymphatic capillaries. They are present in several layers, of which the outermost form the ricbest plexus. Lymphatic capiliaries 
have atso been described accompanying the blood-vessels in the Haversian canals in bones (Rauber, Schwalbe, Budge). Nothing is known concelning the lymphatics of the bone marrow. Cartilage lacks both blood and lymphatic capillaries.

The capsular membranes of joints are richly provided with lymphatic capillaries (Tillmanns). They are arranged in two layers-an inner layer made up of a rich plexus of wide capillaries, lying just outside the subendothelial blood-capillaries, and an outer layer, consisting of a rich plexus in the subsynovial tissue. The lymphatic capillaries have no open connection with the joint cavity.

The membranes surrounding the pleural, pericardial and peritoneal cavities are richly supplied with lymphatic capillaries, which form here thick plexuses outside the endothelium. These plexuses are usually described with the underlying organ, as the subserous lymphatic capillaries of the intestine, etc. In the central tendon of the diaphragm the subperitoneal lymphatics are extremely rich. They widen out here to form very large endothelial-lined cavities which, in the spaces betreen the connective-tissue bundles, lie directly in contact with the peritoneal epithelium. The existence of open connections between these capillaries and the peritoneal and pleural surfaces (the "stomata" of von Recklinghausen) has recently been disproven. The capillaries on the two surfaces of the central tendon communicate freely with one another.

\section{THE LYMPHATIC VESSELS}

The lymph which enters the lymphatic capillaries passes over into collecting vessels (ducts), which carry it through the lymph-glands (nodes) to the large veins at the base of the neck. The lymph-vessels course in the loose subcutaneous tissues, in the connective tissues between muscles and organs, often accompanying the arteries and veins, sometimes forming networks around them. An idea of their arrangement can be best obtained by glancing at the illustrations of the lymphatics of special regions. In general they are made up of numerous long, narrow vessels, rarely more than half or three-fourths of a millimetre in diameter, which occasionally communicate with one another, and which radiate toward groups of lymph-glands placed in certain definite regions. In the lymph-glands the afferent lymph-vessels break up into capillaries, which again collect into efferent vessels. Several of these efferents from each lymph-gland may pass to a second lymph-gland, where they undergo a second widening into capillaries. In this way the lymph, passing through one, two, three or more lymph-nodes in succession, eventually reaches the thoracic duct, or one of the short ducts, all of which empty into the large veins at the base of the neck. The thoracic duct, which receives, at its lower end, the lymph from the lower half of the body, is the only lymphatic vessel which attains any considerable size (four to six millimetres in diameter) and is usually the only one large enough to be seen readily without injection.

In structure the lymphatic vessels much resemble the veins. They possess an intima, a media and an adventitia, although the line of demarcation between the different layers is not sharp. In the thoracic duct, the endothelium of the intima is succeeded by a delicate layer of fibres, mainly elastic; outside of this is the media, made up mainly of cireular smooth muselecells, interspersed with elastic and connective-tissue fibres; then follows a layer of coarse elastie and connective-tissue fibres, which is succeeded by the adventitia, containing longitudinal and transverse bundles of smooth muscle-cells, as well as blood-vessels and nerves. The other lymphatic vessels possess the three layers, which, however, toward the capillaries, grow thinner, and eventually reach a stage is which, outside the endothelium, there are found only single musclecells, or muscle-cells in groujss of two or three.

The lymphatic vessels are characterised by their great richness in valves, which are present throughout their entire course, from their beginnings in the capillary region to their openings into the veins of the neck. The valves are bi- or tri-cuspid, and are always arranged so as to prevent the flow of lymph back to the capilliries. They thus aid indirectly in the movement of the lymph, in that any external pressure on the vessels inust always force the lymph onward.

Nerves of lymphatic vessels.- That the thoracic duct and the smaller lymphatic vessels are providerl with nerves has been shown by several observers. According to Kytmanoff (in dogs) the nerves to the lymphaties are mainily non-medullated, and are both motor and sensory. They form four sets of plexuses-adventitial, supramuscular, intermuseular and subendothelial. Sensory nerverendings (fig. 550) are found in adventitia and merlia, in the form of free-ending threads, and bush-like endings. Notor endings are present in connection with the smooth muscle cells of the merlia. In the intima there is a plexus of extremely fine varicose threads. The physiolngical action of the nerves supplying the receptaculum chyli has been tested by Camus and Giky who found in dogs a dilatation of the receptaculum as the result of electrical stimulation of the splanchuic nerve.

Homement of the lymph. - It hats been estimated (Julwig) that the amount of lymph which passes through the lymphatic ducts of a dog aggregates, during the twenty-four hours, one-third the broly-weight. In the theracise duct the lymph is momer : suffieient pressure to burst the duct behind at ligaturs. In the alsenee of any especial propulsive organ, such as the heart for the blowh-circulation, what are the foress which move the lymph? There must be recognised primary and areessory forces. As areessory forces there are the movement of the muscles and the 
general pressure of the organs on the lymph-ducts. Since these are provided with valves, all preventing the lymph from flowing backward, any such pressure causes the fymph to move onward. As accessory agents must atso be reckoned the smooth muscle and elastic tissue which is present in the walls of the lymph-vessels and in the lymph-gland. That these forces, however, are not primary is shown by numerous facts. There is an active circulation in the lymphatics of

Fig. 550.-A. The Adventitial and Supra-nuscular Nerte Plexuses, together with Sensory Endings in The Thoracic Duct of a Dog. (Methylene-blue method.) B. Nerve-fibres on the Endothelicil of a Limphatic Capillary of a Dog. After Kytmanoff.)

A

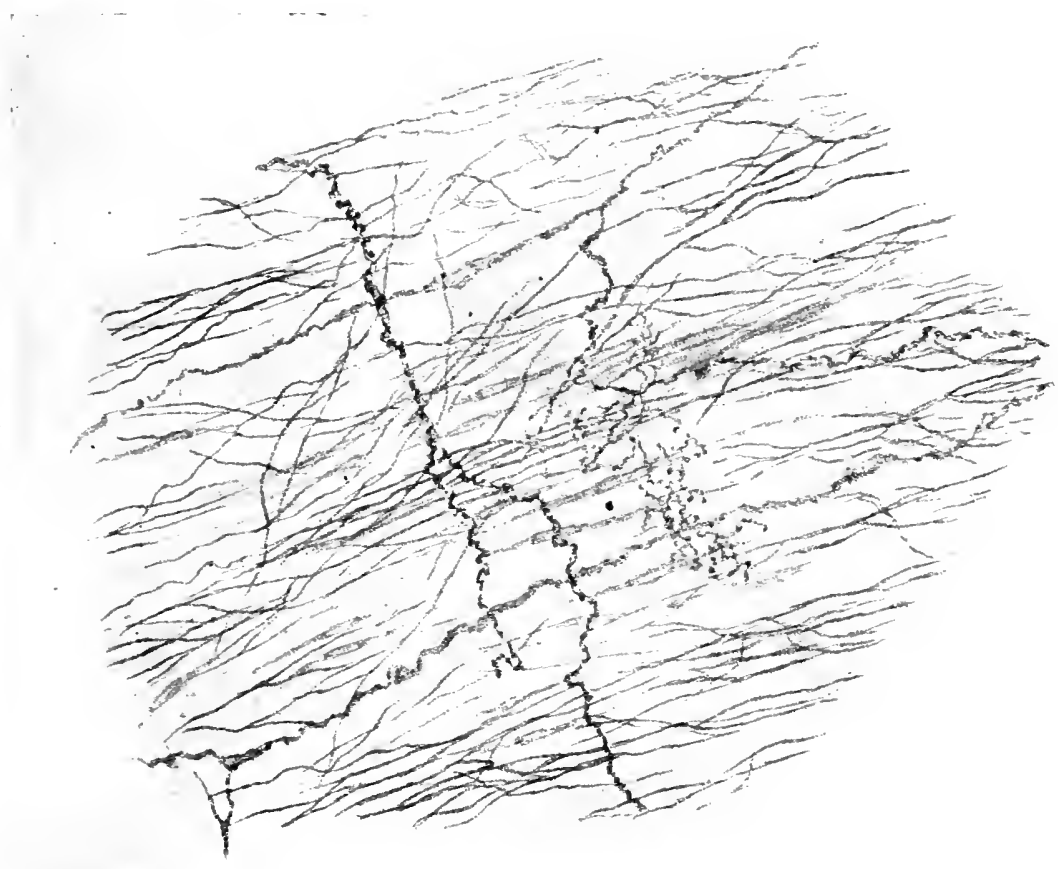

B

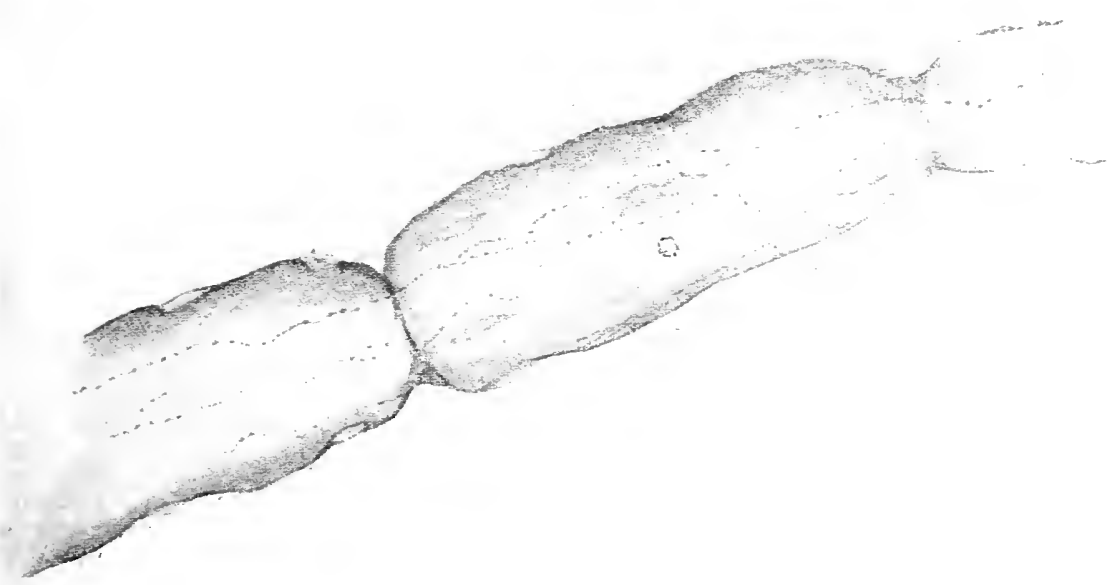

embryos long before valves develop. In many lower animals no valves derelop save at the entrance of the lymphatics to the veins. That neither valves nor muscular movements are essential is shown by the fact that, in the tails of frog larve, where no valves are present and where the muscle movements have been completely paralysed by an anesthetic, the circulation of lymph continues unclecked.

The primary cause, therefore, for the movement of lymph is to be sought in the capillary. region, in the force produced by the passage of lymph through the endothelial wall, whether this 
process be a filtration and diffusion-in which case the causes would lie in the pressure and molecular condition of the tissue fluid outside the lymphatic-or whether it be an active secretion by the endothelium-in which case the driving force would be this secretory power of the endothelium.

\section{THE LYMPHOID ORGANS}

Closely associated with the lymphatic capillaries and vessels is a group of glandular structures known as lymphoid organs. They consist, essentially, of groups of round lymphoid cells, lying in a meshwork of reticulum fibres, and having often a definite relationship to the blood or lymph vessels.

The group of lymphoid organs includes, in addition to the lymph-glands [lymphoglandulæ] or lymph-nodes, which are particularly related to the lymphatic vessels, the spleen, thymus and bone-marrow, which are also largely made up of lymphoid tissue. The spleen and thymus, however, are considered separately with the Ductless Glands.

Fig. 551.-Diagram of a Lymph-Node. (After Toldt, "Atlas of Human Anatomy, "Rebman, London and New York.)

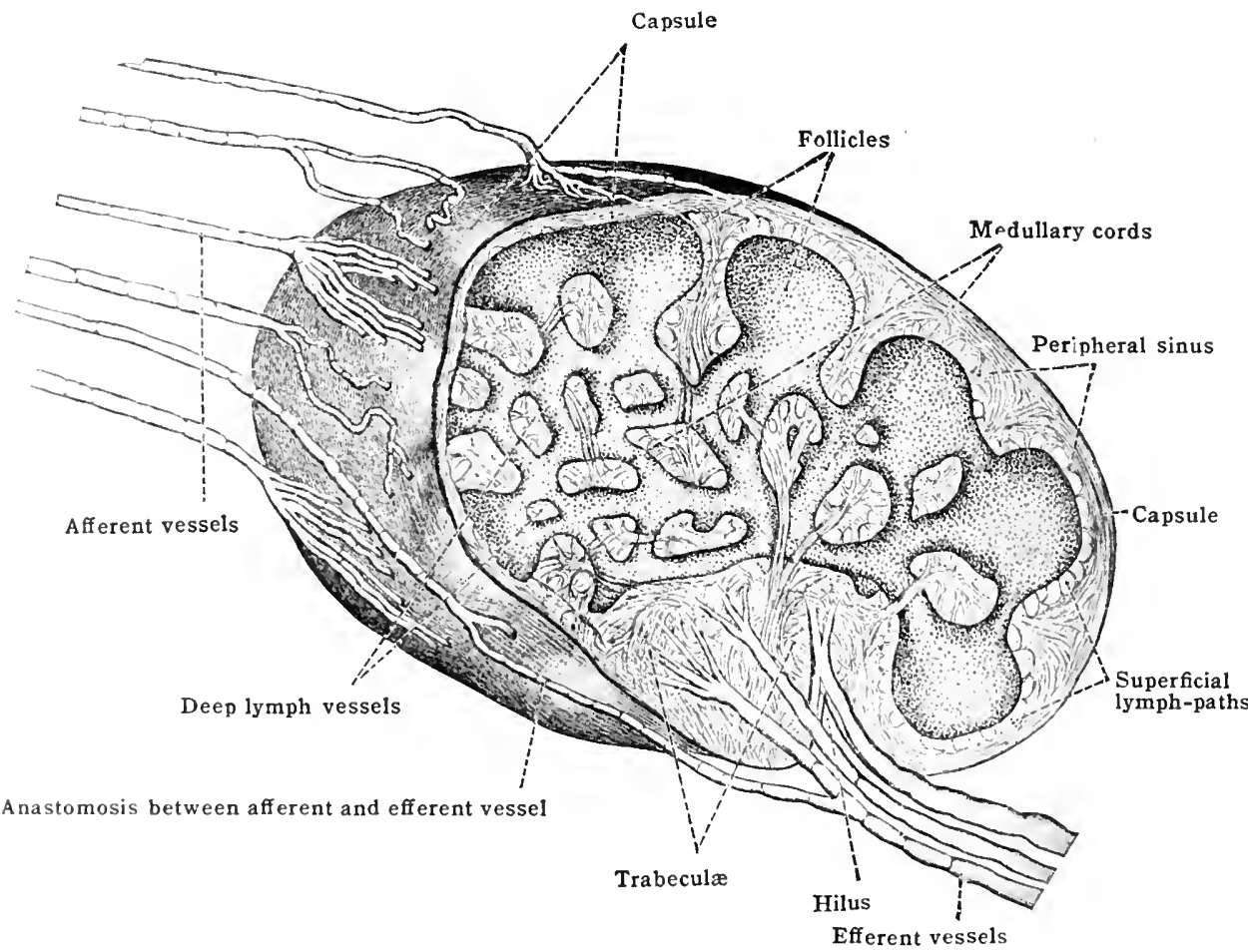

In the ir most simple form, the lymphoid organs form mere irregular aceumulations or patches of lymphoirl cells, which have heen termed lymphoid infiltrations. Such patehes are frequent in mucous membranes especially along the intestinal tract (fig. 549) and the air-passages in the lungs.

Larger accumulations of lymploid cells produce definite round nodules, which may oceur singly, as solilary follicles or in groups, as aggregated follicles (Peyer's patches) (fig. 548). In the solitary follicle the lymphoid eells are arranged concentrieally, with a region in the centre where the cells are less elosely packed together. This is called the germinal centre, and contains mmerous cells mndergoing mitotic division. 'The solitary follicle contains blood-capillaries. Jymph-capillaries, however, do not enter the follicle but form a rich plexus about it.

'The lymph-glands or norles (fig. 551) are litger lymphoid structures, which are developed alning the course of the lympl-vessels. They vary much in size, shape, and colour, and may oceur singly or in small or large groups. 'The size varies from the size of a pin-head to that of an olive, or larger. In shape they may be spherical, oval, or flattened on one or more sides, according to thesir relitjons to other organs. Each gland has an indentation or hilus, where the arteries entrer, and where the veins and efferent duets emerge. 'Their colour depends upon position and stale of function. The glands along the respiratory tract are black, due to the presenee of earbron grasules. The mesenterir ghands are milk-white during digestion, and other nodes are pale and transluent when their simuses are filled with fhuid, and pink or even red when red-blood 
cells are present in the sinuses. The lymph-gland is made up of four distinct plements: lymphoid elements, lymphatic capillaries, supporting structures, and blood-ressels.

The lymphoid elements (fig. 551) are arranged as follicles and as cell-strings. The follicles lie around the circumference of the gland, and form the cortex [substantia corticalis]. The cellstrings or medullary cords are irregular cords of cells which extend from the follicles through the central or medullary portion [substantia medullaris] of the gland. The follicles and meduthary cords are made up, as are the solitary follicles, of round lymphoid cells.

Fig. 552.-Surface View and Section of a Lymph-node showing the Peripheral axd CexTral Sinuses. (After Teichmann.)
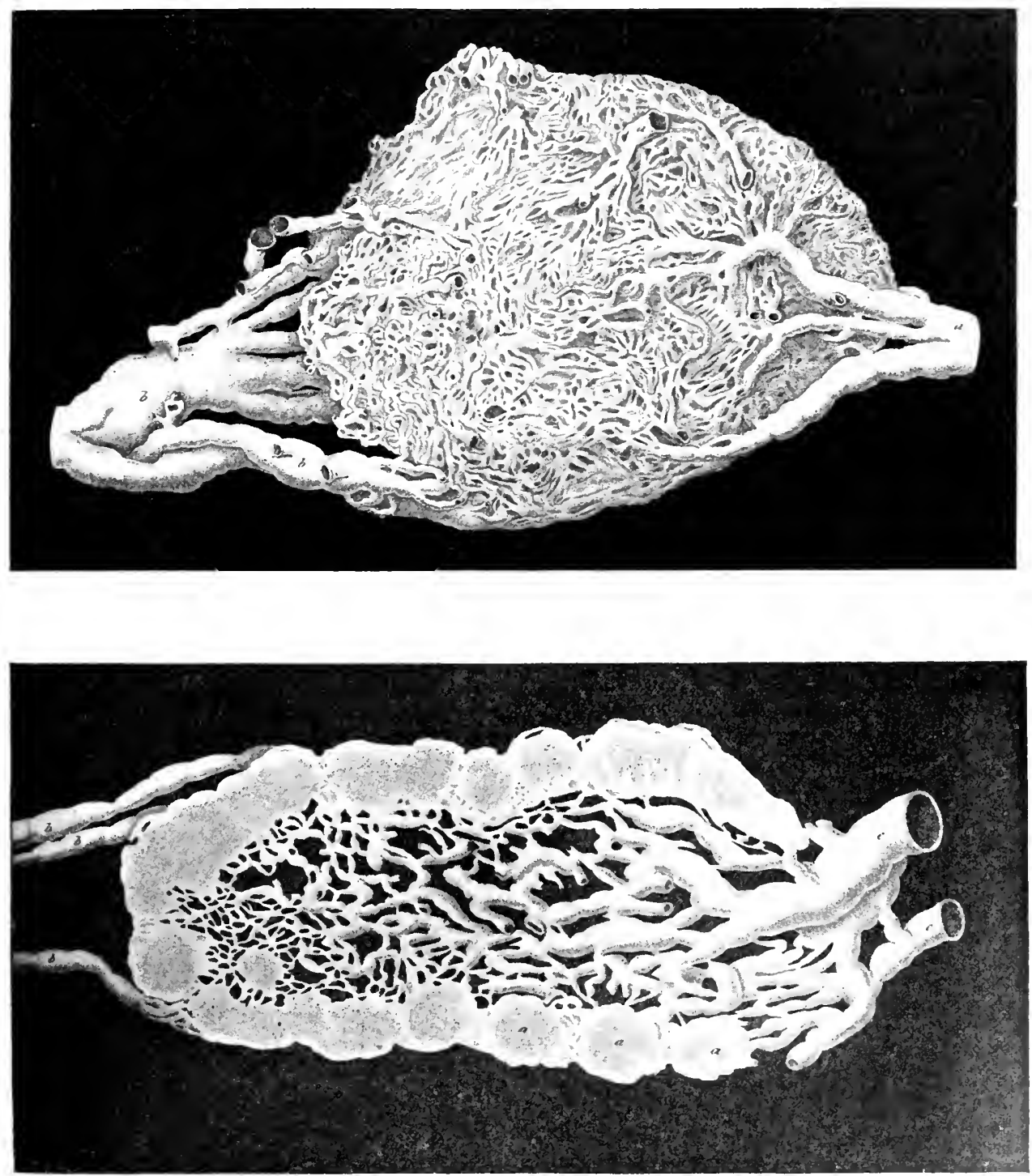

The lymphatic vessels (fig. 551) enter the lymph-gland as several rasa afferentia, and heave it, at the hilus, as the vasa efferentia. The vasa afferentia spread out in the eortical portion of the gland into an extremely rich plexus of wide capillaries which surround the follicles, forming the peripheral sinus. The eapillaries do not enter the follicle. This plexus continues, around the follicles, into the medullary portion where it forms again a rich plexus, the medulkary sinus, in the spaces around the medullary cords (fig. 552). At the hilus the methllary capillaries collect into larger vessels and emerge as the vasa efferentia.

The supporting structures consist of a fibrous capsule surrounding the gland, from which trabeculæe or septa pass in, around and between the follicles and cords. From the septa, a fine reticulum passes into the follicles and cords, where it forms a rich dense meshwork, in the interstices of which lie the lymphoid cells. The capsule and trabecule are made up of white fibres, elastic fihres and snooth muscle-fibres. 
The blood-vessels, which enter and leave at the hilus, send branches into the follieles and into the medullary cords.

The enormous widening of the lymph-stream in the lymph-node from the vasa afferentia to the capillaries-like a brook widening out into a pond-causes a very great diminution in the rate of flow of the lymph. Thus there is present in the gland a very slowly moving stream of lymph, which is separated from the lymphoid tissue outside by a single layer of flattened endothelial cells. There is thus possible an easy interehange of substances, and an opportunity for the passage, through the endothelium, of wandering cells. While the entire mode of funetioning of the lymph-gland is not clear, it is known that lymphocytes, formed here, enter the lymph-stream, and that substances such as, for instance, carbon granules, or leucoeytes laden with bacteria, are checked in their course by the lymph-gland.

Arrangement.-The lymph-glands are so arranged throughout the body that all the lymph which enters the lymphatic capillaries must pass through one or more lymph-glands on its way to the veins.

It is possible that this rule may have exceptions, although none have yet been definitely proved. Thus, some of the small lymphatics which join the thoracie duct may enter it without having passed through a gland. Moreover, there is often found (fig. 551) a direct anastomosis between an afferent and an efferent lymphatic vessel.

Most of the glands are collected in certain regions, where they form centers toward which the lymphatic vessels radiate. Such groups are termed regional glands. The glands forming such a group are connected with one another by numerous anastomoses, which are termed lymphatic plexuses [plexus lymphatici]. In addition to the regional glands there are many isolated glands which lie along the course of the lymph-vessels, and through which pass the vessels draining a much more limited capillary area. Such glands are termed intercalated glands.

\section{THE DEVELOPMENT OF THE LYMPHATIC SYSTEM}

Our knowledge of the lymphatic system has been very greatly increased during the past ten years by studies on its mode of development. Previous to 1902 nothing definite was known about the primary development or the mode of growth of the lymphatic system. It was concluded by some (Budge, Gullard and Saxer) that the lymphatics arise from undifferentiated mesenchyme cells; Ranvier believed that they arise from veins by budding of the endothelium; while Sala described them as arising partly from the mesenchyme and partly from venous endothelium.

Regarding the mode of growth and spreading of the ly mphatics, various theories were likewise held. Kölliker, His, Goethe and, later, Sala held that growth takes place by the successive addition of mesenchyme cells; Langer, Rouget, and Ranvier maintained that growth takes place by sprouting of the endothelium (fig. 553). S. Mayer thought that new lymphatics are derived from transformed blood-capillaries.

Miss Sabin in 1902 gave the first clear picture of the mode of origin and growth of the lymphatic system, and our present knowledge is largely based upon her discoveries. She showed by injections of embryo pigs that the lymphatics of the skin appear first in four regions of the body - two on eaeh side at the base of the neek, and two in the inguinal region-in the form of sacs which are connected with the veins. From these four regions the lymphatics spread out step by stcp over the skin of the entire body, in the form of a richly anastomosing capillary plexus. Since the publication of Miss Sabin's paper, numerous studies have been made on the mode of development of lymphatics in many different animals, including man. The results of these studies indicate that the lymphatic endothelium first appears in the form of buddings-out from the veins in certain well-defined regions of the embryo. As to the exaet manner of this primary origin views differ. Miss Sabin, in her first paper, held that it arises by buctding from the veins. F. T. Lewis held that it is formed by the transformation of plexuses of blood-capillaries. This vicw was aceepted by Miss Sabin, and verified by Huntington and McClure. Stromsten remid to Sala's view that the first lymphatic endothelium arises in part from venous endothelium, and in part from the mesenchyme cells. Hoyer and his pupils find that tloe first lymphatics arise as buds from the veins. This has also been found (1912) by E. R. and W. I. Clark in ehick cmbryos.

Tlms far six regions have been foumd, in which lymplaties develop from the veins-in the nock, on each side, at the angle formed liy the intermal jugular and subclavian veins; in the pelvis, on earli side, along the iliac veins; and two mpared sets in the region of the renal veins, one vental fo the antal, the nesenterie, and one dorsal to the aorta, retroperitoneal. In these six regions the lymplatios som enalesere to form large sacs, the jugular, iliae, mesenterie and retroprevitomeal. The sares are later broken up into the primary sets of lymph-nodes. The recoptarulum ehyli develops in the region of the retroperitomeal sale.

leon thes: primary anlages derived from the veins the lymplaties spread out into the

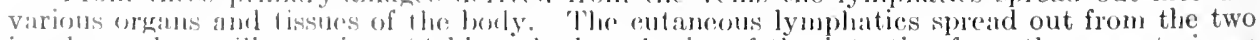
jugnlar abs two iliar jegions (Sabin), the lyuphaties of the intestine from the mesenteric sac (I)

The: method by which this extrusion of the primary lymphaties oceurs is still in dispute,

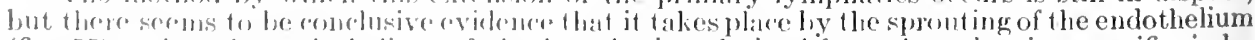

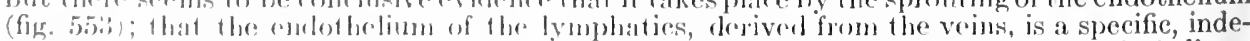

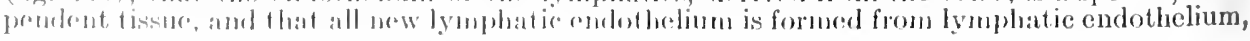


and not from blood-vessels or mesenchyme cells. This view is supported especially by the work of Sabin, MacCallum, Hoyer and his pupils and E. R. Clark.

On the other hand, F. T. Lewis has suggested that the spreading of lymphatics occurs by the transformation of blood-vessels into lymphatics; while Huntington and McClure and their pupils maintain that it occurs by the continued transformation of mesenchyme cells.

The lymphatics growing from the various primary centres meet and anastomose with one another, and gradually lose all connections with the veins save those at the base of the neck Sylvester has found, however, that in South American monkeys the connections with the veins in the region of the renal veins are maintained in the adult. Valves do not appear in the lymphatic vessels until quite late, in human embryos about 5 or $6 \mathrm{~cm}$. long. (Sabin.)

The lymphatic nodes do not make their appearance until the system of vessels is well established. They are at first represented by masses of lymphoid tissue in the meshes of a lymphatic network. Later the lymphoid mass breaks up into smaller portions, into which the blood-vessels and branches from the surrounding network penetrate; and each mass, together

Fig. 553.-The Sprouting of Lruphatic Capillailes in the Pig. (After MacCallum.) The lymphatics are injected and the sprouts are both single cells and clumps of cells.
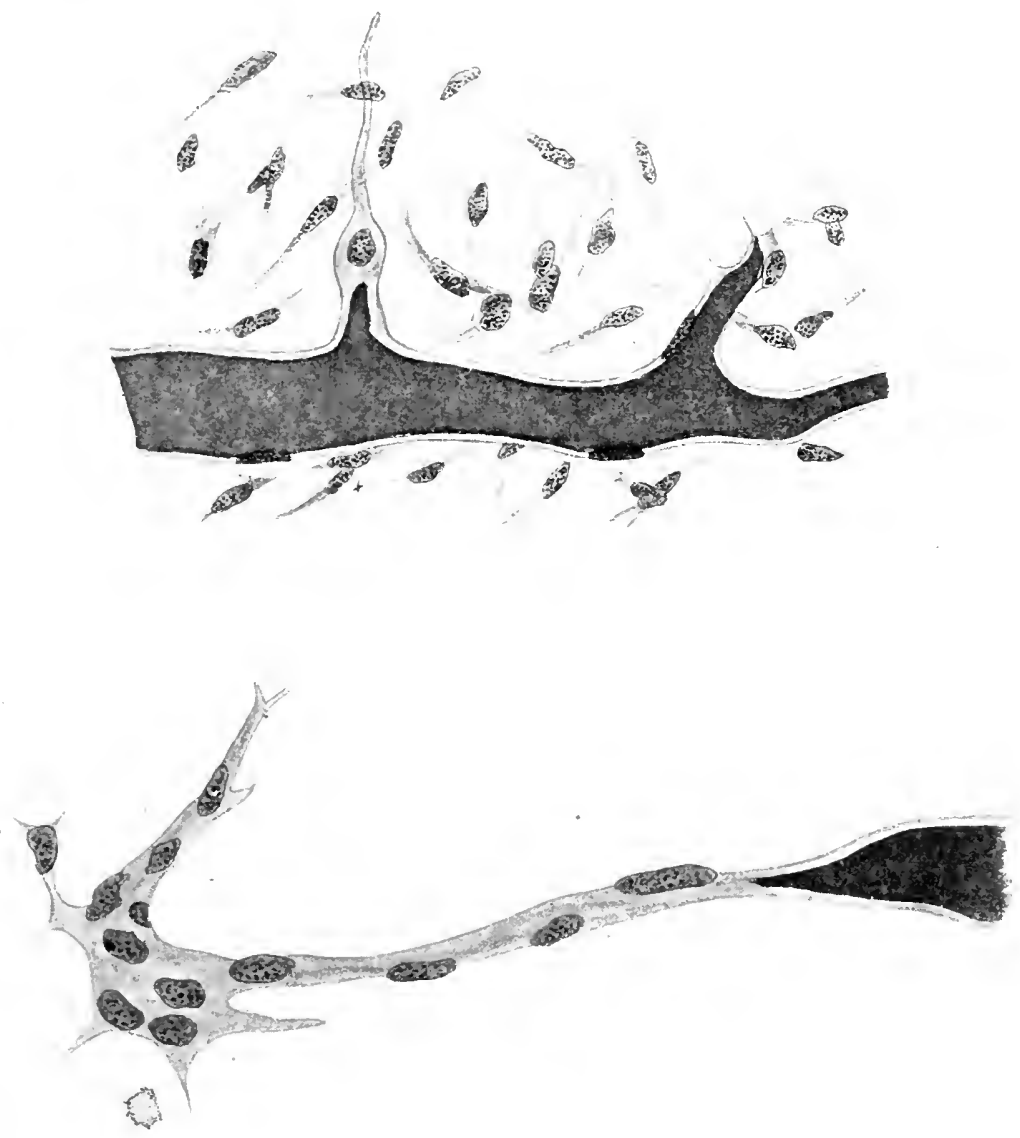

with the portions of the network surrounding it, becomes enclosed in a connective-tissue capsule. The original lymphoid tissue becomes transformed into the medullary cords and cortical nodules of the node, while the enclosing lymphatic capillaries form its peripheral lymph-sinus.

The earliest nodes appear in the places occupied by the primary lymphatic plexuses or sacs (Miss Sabin, F. T. Lewis, Jolly), and have been termed the "primary nodes" (Miss Sabin). Secondary and tertiary sets of nodes develop later at places of confluence of many lymphatics (cf. A. H. Clark.)

Regeneration and new growth of lymphatic vessels and glands.-While blood-ressels are known to possess throughout life the capacity for regeneration and new growth, this process in lymph-vessels has been very little studied. Yet enough has been learned from the work of Coffin and Evans to justify the statement that lymphatic vessels also possess the capacity for new growth. Evans made the interesting observation that lymphatic ressels grow into a timor of connective-tissue origin (a round-celled sarcoma), while they fail to grow into a tumor of epithelial origin (an experimentally-produced peritoneal carcinoma in mire). 
The question as to whether lymph-glands may form anew is not yet entirely settled. The study of the problem is extremely difficult, because very small lymph-nodes may be normally present in a certain region, yet they may escape observation until they become hypertrophied under cartain conditions. A. IV. Meyer in a careful experimental study found no evidence of new-formation of lymph glands. On the other hand, there is considerable evidence for the newformation of lymph-glands under pathological conditions.

The hæmolymph nodes. - In addition to the ordinary lymph-nodes, there occur along the course of certain veins small nodes which are either red or brown in colour, according to their state of functional activity. These have been termed hæmolymph nodes. The red nodes closely resemble in structure an ordinary lymph-node, except that the sinuses are filled with blood, while the brown nodes show not blood, but blood pigment, both free in the sinuses and in the phagocytic cells of the sinuses. In certain respects these nodes resemble the spleen, there being a reduction of the medullary cords and an increase in the amount of the sinuses, which resemble those of the spleen-pulp rather than the more open lymphatic sinuses; and their trabeculæ are also like those of the spleen in having numerous smooth muscle-cells. Some of these hæmolymph nodes have ly mphatic

Fig. 554.-A Developing Hemolymph Node.

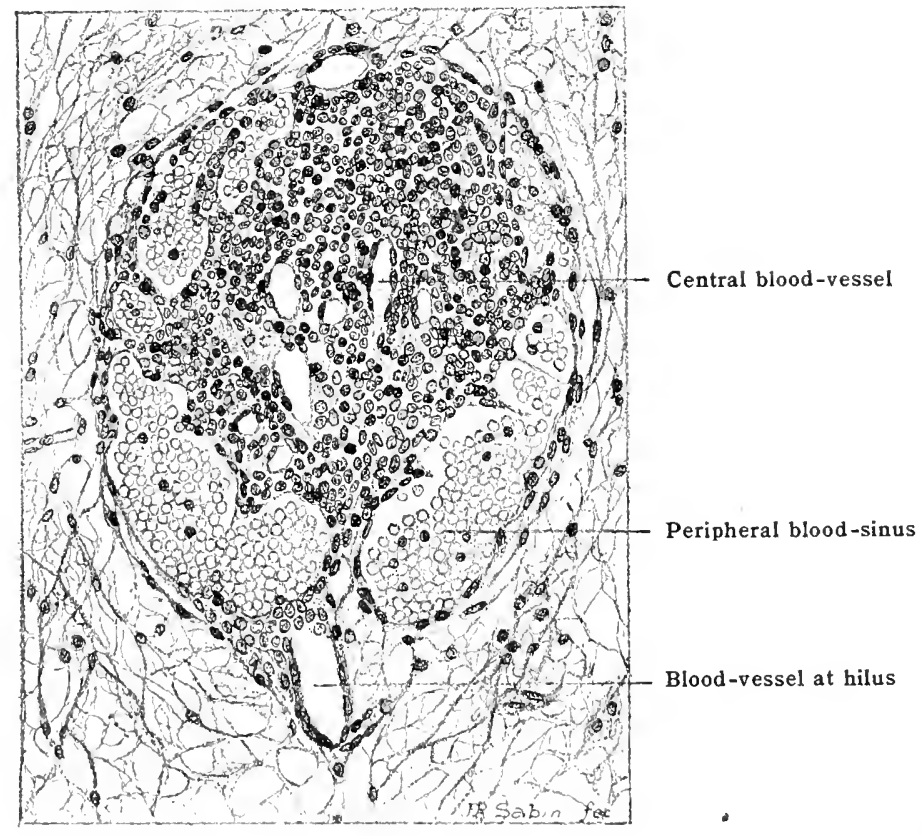

vessels, but whether, as in the spleen, these are limited to the capsule, or whether they open into the blood-sinuses, making true hæmolymph nodes, is not yet clear.

A difficult point in eonnection with the structure of the hamolymph nodes is the relation of the blood-sinuses to the blood-vessels. The greater weight of evidence seems to favour the view that the sinnses are connected with the veins rather than that the arteries open directly into them, atthough one ofserver fails to find any connection between the blood-vessels and the central sinus (Schumacher). In fig. 554 is shown a hamolymph node in the neck of a pig $24.5 \mathrm{~cm}$. long. This stage marks the first appearance of the hemal node in the neck, and shows the norle in its simplest form, the folliele and its peripheral blood-sinus (Miss Sabin).

There are wille variations in the distribution and number of the hamolymph nodes; indeed sufficient olservations have not yet been made to determine their complete distribution. They have been dividod into three gromps, the frevertebral, the renal, and the splenie. In one sulject, in which they were very numerons, they oecurred at the root of the lung, near the bronchi and bronchial vessels, a fow near the cesophagus, a continuous pravertebral chain in the ablomen extending from the diaphragm to the upper two or three siteral vertebra, as well as a few along the crothac axis and its branches, the superior mesenteric, renal, and iliac vessels (1, rowis).

Schumacher, from a study of lymph-glands and hemolymph glands of various stages, conchules that the banolymph glands anco not to be considered as olgans sui generis, but that they represcut rudimentary forms of ordinary lymph-ghums, which have lost their connections with the lymplantio vessols. Further investigations are needed to dear up this subjeet. 


\section{SPECIAL ANATOMY OF THE LY.MPHATIC SYSTEM}

The lymphatic system will be considered by regions as follows: A, head and neck; B, upper extremity; C, thorax; D, abdomen and pelvis; $\mathrm{E}$, lower extremity.

\section{A. THE LYMPHATICS OF THE HEAD AND NECK}

The lymphatics of the head and neck may be divided into two sets. One set is superficial, draining the entire skin surface, and has its nodes, for the most part, in the neck, the principal group lying along the external jugular vein. The other set is deeper and drains the mucous membrane of the upper part of the digestive and respiratory tracts, together with the deep organs, such as the thyreoid gland and the tendons of the muscles. The nodes of this set are deeply placed, being situated along the carotid arteries, with outlying retro-pharyngeal nodes.

\section{THE SUPERFICIAL NODES OF THE HEAD AND NECK}

Lymph-nodes appear first in the neck in the process of development. In the pig the first node to appear develops from the lymph heart, which is in the supraclavicular triangle behind the sterno-cleido-mastoid muscle. From here ducts grow across the muscle and give rise to a chain of nodes along the external jugular vein. This chain is to be considered as the main chain of superficial nodes in the neck. From it lymphatic vessels grow over the back of the head, the side of the head, the face, and the front of the neck, and in their course groups of secondary nodes develop. The nodes of the main chain are known as the superficial cervical nodes, and are from four to six in number. The secondary groups are-(1) the occipital; (2) the posterior auricular; (3) the anterior auricular; (4) the parotid; (5) the submaxillary, with the facial as a tertiary set, and (6) the submental.

1. The occipital nodes [lymphoglandulæ occipitales].--The lymphatics of the skin of the back of the head collect into a few trunks that either empty into from one to three small nodes near the occipital insertion of the semispinalis capitis muscle, or pass by the secondary group and empty clirectly into the upper nodes of the main superficial cervical chain (fig. 555).

2. The posterior auricular nodes [lgl. auriculares posteriores].-A portion of the temporal part of the scalp, together with the posterior surface of the ear, except the lobule, and the posterior surface of the external auditory meatus, drain into two small nodes on the insertion of the sterno-cleido-mastoid muscle. The efferent vessels of these nodes pass to the upper part of the superficial cervical chain.

3. The anterior auricular nodes [lgl. auriculares anteriores] are few in numberfrom one to three-and are situated immediately in front of the tragus of the ear. They receive vessels from the anterior surface of the auricle and the external auditory meatus, from the integument of the temporal region and the lateral portion of the eyelids. Their efferents pass to the parotid and superior deep cervical nodes.

4. The parotid nodes. - The parotid group of nodes is considerably larger than the two preceding, containing from ten to sixteen nodes, and the group drains a more complex area. It receives vessels from the adjacent surface of the external ear, the external auditory meatus, the skin of the temporal and frontal regions, and the eyelids and nose. The deeper nodes of this set receive vessels from the parotid gland.

In the embryo these nodes lie in the pathway of the lymph-vessels that grow to the scalp: many of these vessels, however, pass the parotid group and empty into the superficial cervical chain. The nodes of the parotid group lie embedded in the substance of the parotid gland, and their efferents pass to the submaxillary and the superior superficial and deep cervical nodes.

As "inferior auricular nodes" Bartels designates one or two small glands of the parotid group which lie below the ear, and receive afferent vessels from the lower part of the ear.

5. The submaxillary [lgl. submaxillares] and facial [lgl. faciales profundæ] nodes.-The submaxillary (perhaps better "mandibular") group consists of a 
chain of from three to six nodes, resting on the submaxillary (salivary) gland, along the inferior border of the mandible. They lie usually on the submaxillary gland, but may extend from the insertion of the anterior belly of the digastric to

Fis. 5.5.-The Lrmphatics of the Head and Neck. (After Toldt, "Atlas of Human Anatomy," Rebman, London and New York.

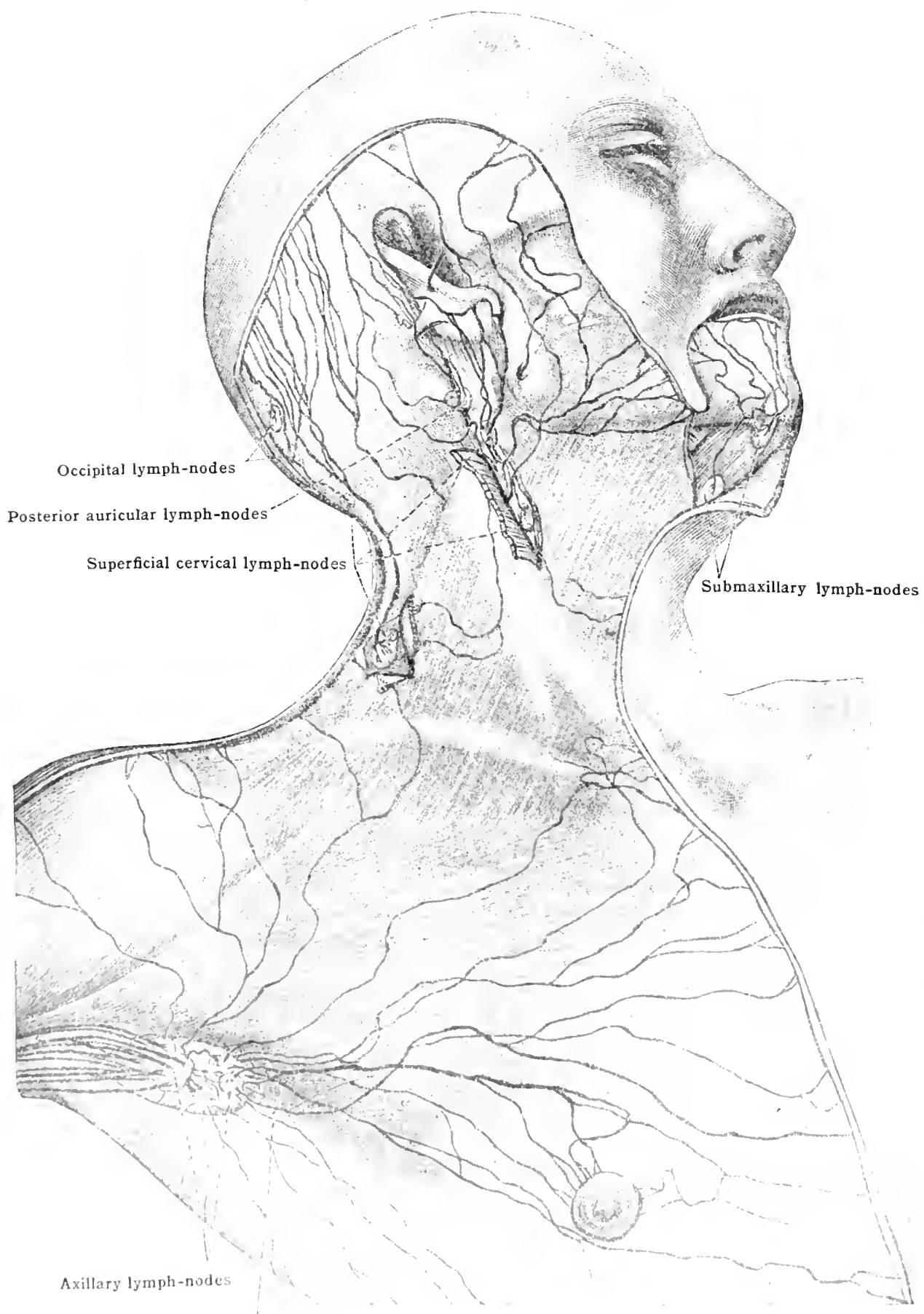

Axillary fascia

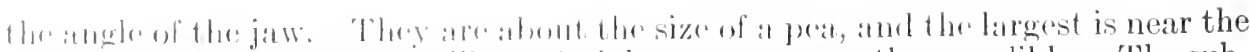

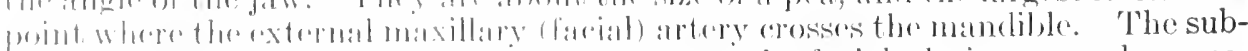

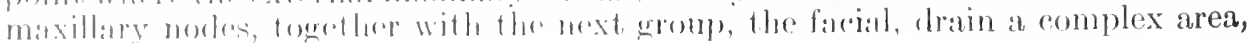


including not only skin, but mucous membrane. They receive lymph-vessels from the nose, cheek, upper lip, the external part of the lower lip, together with almost all those from the gums and teeth and from the anterior third of the lateral portions of the tongue. In agreement with the fact that these nodes, though lying superficially and draining the skin, drain also the mucous membrane, their vessels empty not only into the superficial cervical chain, but also into the deep carotid chain.

The facial nodes are evidently outlying nodes of the submaxillary group. They are in two main sets-(1) the supra-maxillary set, which consists of from one to thirteen nodes, resting on the mandible near the point where it is crossed by the external maxillary (facial) artery. (2) The buccinator set, lying on the

Fig. 5506.-Lymphatics of the Odter Nose and Face. (After Küttner.)

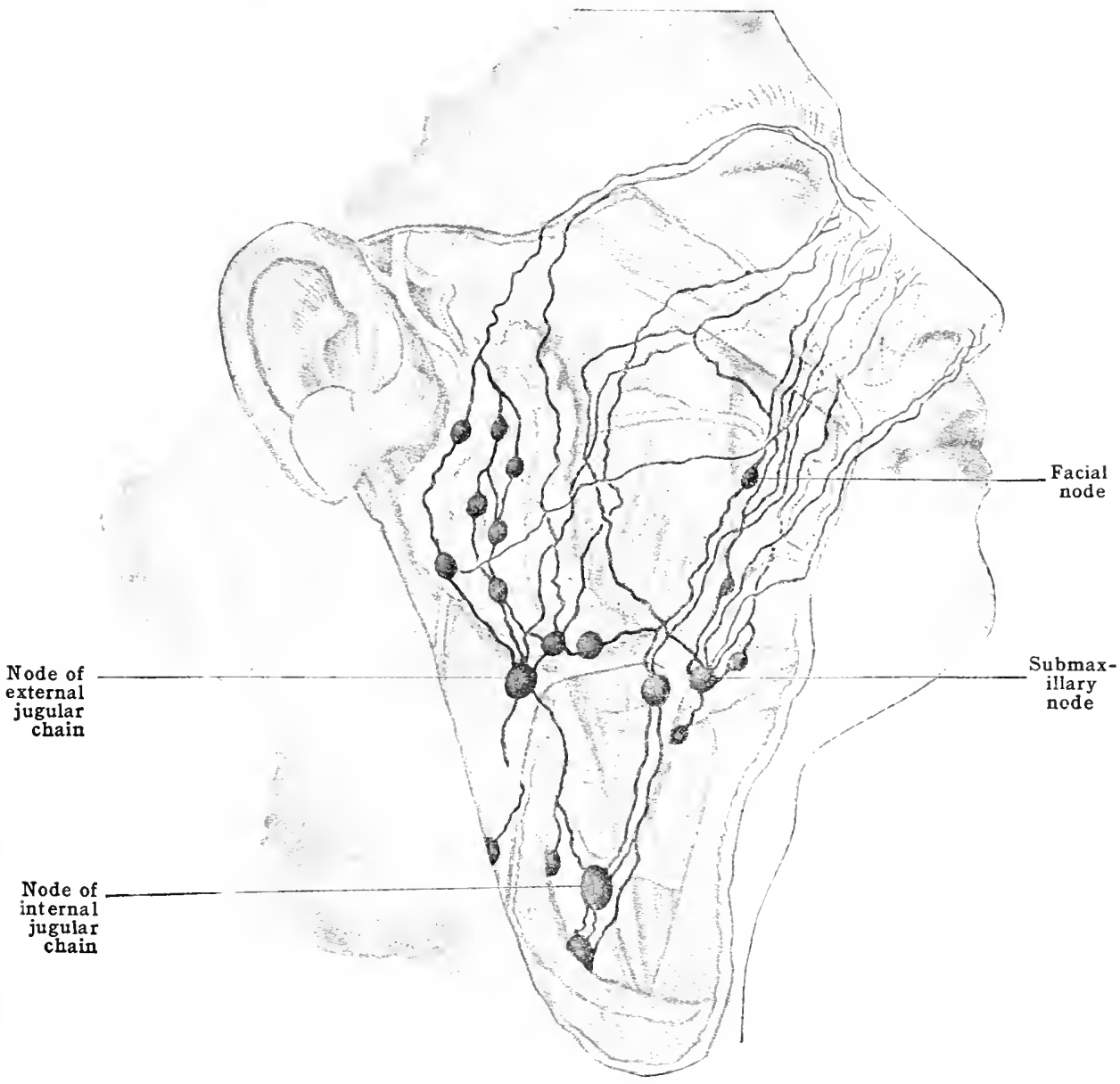

line connecting the lower margin of the ear and the angle of the jaw. Of these latter nodes, some lie near the point where the parotid duct perforates the buccinator muscle; the others are farther forward, between the external maxillary artery and the anterior facial vein. Additional nodes belonging to the group may occur near the nose and in the suborbital region. These facial nodes receive afferents from the outer surface of the nose, the lips, eyelids, cheek, temporal part of the face, the mucosa of the mouth, the teeth of the upper jaw, the gums, the tonsils, and the parotid gland. Their efferents pass to the submaxillary and parotid nodes.

6. The submental nodes [lgl. submentales], usually two in number, lie in the triangle bounded by the anterior bellies of the two digastric muscles and the hyoid bone (fig. 559). They are usually near the median line, and drain the skin of the chin, the skin and corresponding mucous membrane of the central part of the lower 
lip and jaw, the floor of the mouth, and the tip of the tonguc. The efferent ressels pass either to the submaxillary nodes or to the deep cervical chain.

\section{THE LYMPHATIC' IESSELS OF THE FACE}

The different parts of the face and their lymphatic relation to these groups of superficial nodes will now be considered.

The lymphatics of the scalp form a rich network in the neighbourhood of the vertex, from which vessels pass in various directions. From the frontal region a

Fig 557,-Lymphatic Nodes and Vessels of the Ear, Eyelids, Nose and Lips, Newborn child. P, parotid. M, submaxillary gland. B, buecal fat ("sucking pad"). Superolateral deep cervical lymph nodes are not labelled. (After Bartels.)

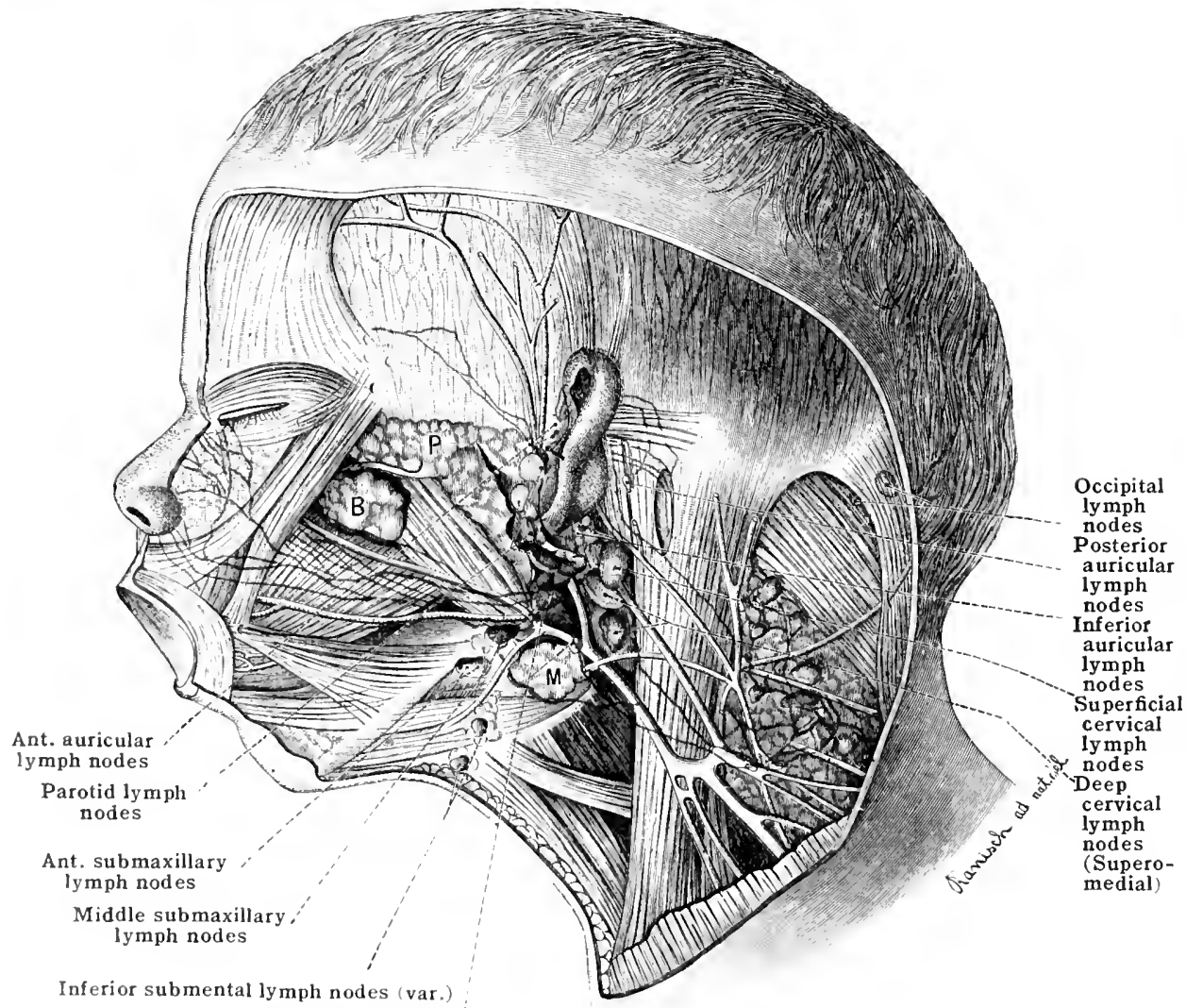

Posterior submaxillary lymph nodes

number of ducts pass downward and backward to the parotid nodes; those from the parictal and temporal regions pass to the anterior auricular, parotid, and posterior anrialalr nodes; and those from the occipital region pass partly to the occipital nodes and partly to the superior decp ecrvical group, while a single large vessed descends allong the posterior border of the sterno-mastoid muscle to terminate in one of the inferior clerp cervical nodes.

The lymphatics of the eyelids and conjunctiva.- The capillary plexus of the "Yolids and the conjumediva is an abumlant one, and at the free border of the

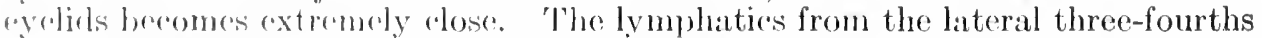
of the lids patse to the anterior amrienlar and parotid groups of nodes, while those from the medial ons-fomrth bass obliquely across the eheek with the facial vein to torminate in the facial and sulmaxillary motes (figs. 556, 557, 561).

The lymphatics of the nose. The lymphatic's of the nose (fig. 556) form a network which is contse at the root of the organ, hut dense over the alar region.

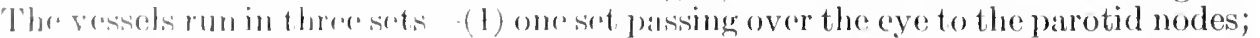
(2) a scet passing morke the "ye to the same noeles; and (3) the most important 
group, consisting of from six to ten trunks, passing to the facial and submaxillary nodes. There are some anastomoses between the capillaries of the shin and those of the mucous membrane of the nose.

Fig. 558.-The Facial Nodes. (After Buchbinder.)

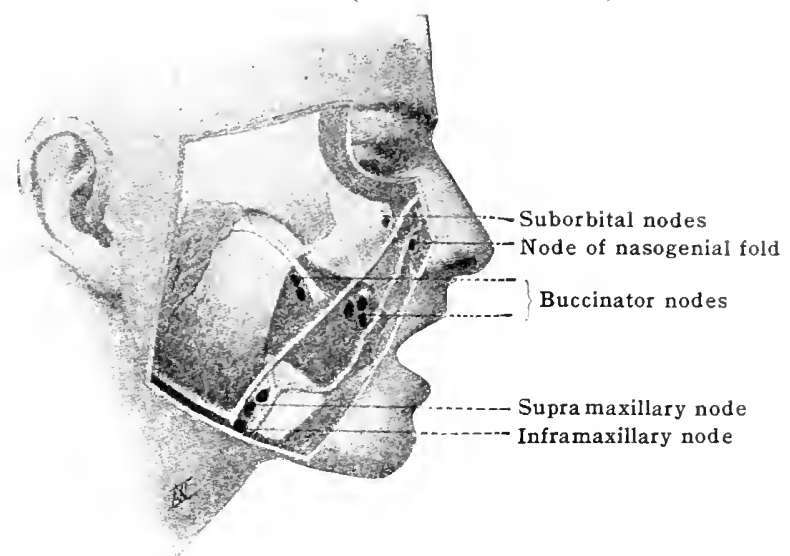

The lymphatics of the lips (fig. 559).-The capillary plexuses of the skin and mucous membrane are continuous at the free border of the lips. The vessels of the upper lip, of which there are about four on each side, pass to the submaxillary

Fig. 559.-The Limphatics of the Lips. Newborn child. (From Bartels after

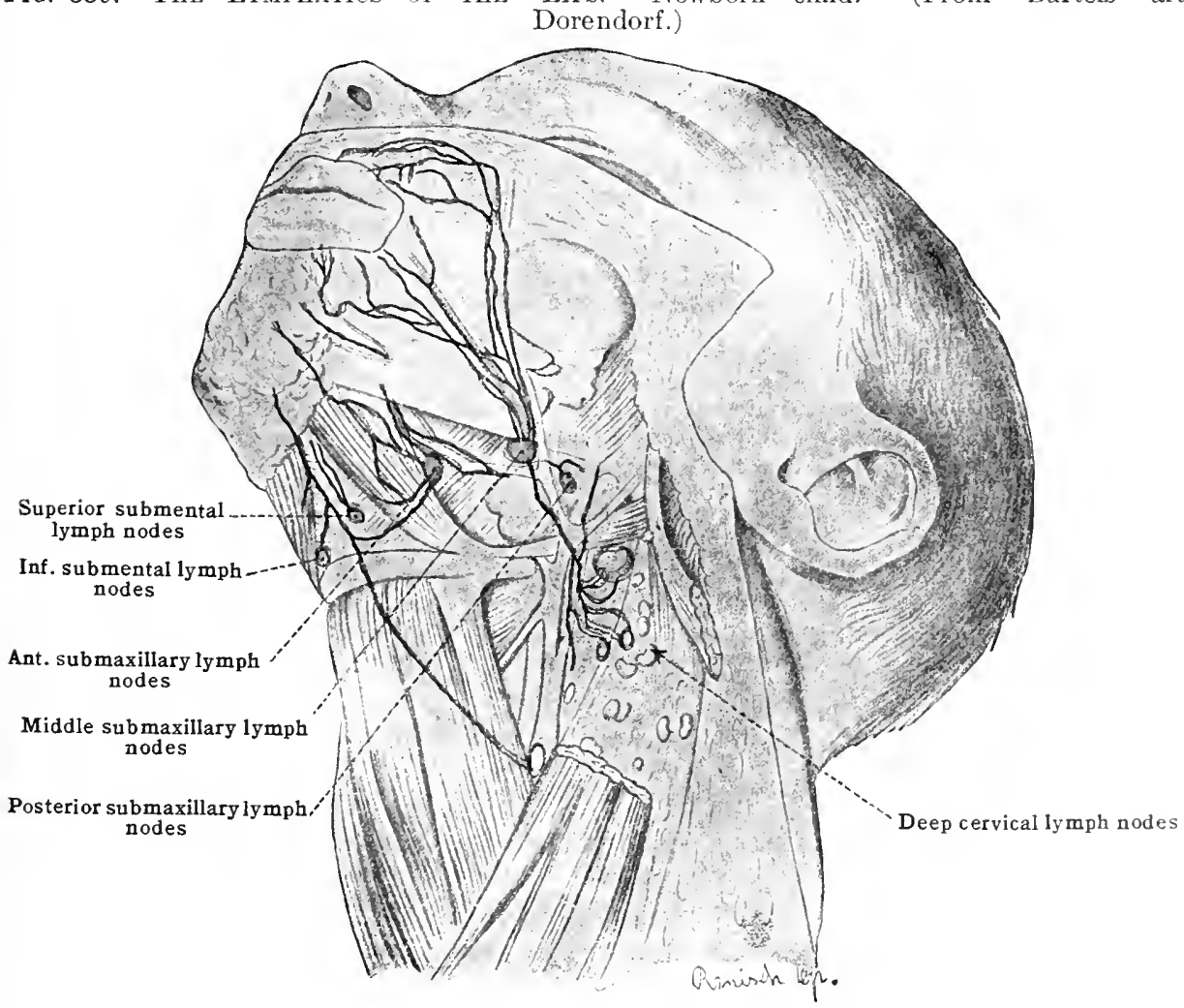

nodes. From the lower lip the trunks from near the angle of the moutl pass to the submaxillary nodes, while those from the centre of the lip pass to the submental nodes.

There are from two to foul subcutaneous vessels and from two to three submucous vessels on either side. The collecting trunks passing to the submaxillary nodes do not anastomose, and 
the same is true of the submucous ressels of the lower lip. The subcutaneous vessels, on the other hand, passing to the submental nodes, anastomose freely, an important fact in connection with the extension of cancer of the lower lip.

The lymphatics of the auricle and external auditory meatus.-The lymphatic plexus in the auricle, external auditory meatus, and the outer side of the tympanic membrane is an abundant one. An anastomosis has been described between a seanty plexus on the inner side of the tympanic membrane and the plexus on the outside. The collecting vessels pass to three sets of nodes:-(1) those from the external and internal surface of the auricle and the posterior part of the external auditory meatus pass to the posterior auricular nodes; (2) those from the lobule, the helix, a part of the concha and the outer portion of the external auditory meatus pass to the inferior auricular and superficial cervical chain; some of the vessels from the first and second areas also run to the deep cervical group; (3) an anterior group from the tragus and part of the external auditory meatus consisting of from four to six trunks, pass to the anterior auricular nodes, which are connected with the parotid nodes.

\section{THE DEEP LYMPHATIC NODES OF THE HEAD AND NECK}

The deep cervical chain is the largest mass of nodes in the neck. It consists of from fifteen to thirty nodes, which lie along the entire course of the carotid artery and internal jugular vein. This chain receives vessels from all the superficial nodes, also directly from the skin, as well as from the entire mucous membrane of the respiratory and alimentary tracts in the head and neck. Thus it drains both the superficial and the cleep structures.

For convenience of description this long chain, though usually continuous, is divided into two groups-(1) a superior group, lying above the level at which the omo-hyoid muscle crosses the carotid artery, and (2) an inferior or supra-clavicular group, lying below that level.

(1) The superior deep cervical nodes [lgl. cervicales profundæ superiores].This group of nodes extends from the tip of the mastoid process to the level at which the omo-hyoid muscle crosses the common carotid artery. The dorsal and smaller nodes of the chain lie on the splenius, levator scapulæ, and scalene muscles. They drain the skin of the back part of the head, both indirectly and directly, and receive (1) efferents from the occipital and posterior auricular nodes, (2) a large vessel from the skin of the occipital part of the scalp, (3) some trunks from the auricle, and (4) cutaneous and muscular vessels from the neck.

The ventral nodes of the chain lie on the internal jugular vein. They drain the face both directly and indirectly, as well as the deeper structures of the head and neck. They show especially well in fig. 563 in connection with the tongue.

(2) The inferior deep cervical [lgl. cervicales profundre inferiores] or supraclavicular nodes lie in the supra-clavicular triangle. In the upper part of the triangle the nodes rest on the splenius, the levator scapula, and the sealene muscles, while at the base of the triangle they are related to the subclavian artery and the nerves of the brachial plexus. They drain a wide area, receiving vessels from the hearl, neck, arm, and thoracic wall. They are connected with the superior deep cervical chain, and receive afferents from the axillary nodes, and, in addition, they rearive vessels clirectly from the back of the scalp, from the skin of the arm, and from the pecetoral region. Thus it will be seen that a large part of the lymph of the head and nerek, as woll as some from the arm and thorax, passes through these norles. 'Threir afferents unite to form the jugular trunk, which ends at the junction of the intermal jugular and subchavian veins.

In the descriptions of the deep lymphatic vessels certain additional groups of nodes will be considrend, which maty bo regarded as outlying groups from the deep rervical rhain.

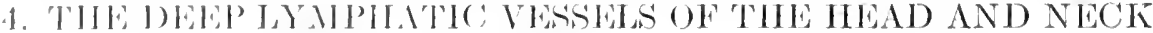

The lymphatics of the brain. - It is now recognised that there are no lymphaties in thro liain and cord, so that the function of absorption must be accomplishert hy means of the veins. There is an abundant exulation of lymph around thr norvous systrm into the subdural space, which is connected with the central 
canal of the nervous system, and which is to be considered as a zone in which the tissue-spaces are especially large. Along the arteries of the brain the adrentitia is loose and open, possessing tissue-spaces which have received the confusing name of perivascular lymphatics. It would be better to name them perivascular tissuespaces.

The lymphatics of the eye.- No lymphatic vessels have as yet been discovered either in the eyeball or in the orbit. In both, however, there are abundant tissuespaces, the most notewrorthy of the orbit being the interfascial space (space of Tenon), which communicates by a space between the optic nerve and its sheath with the subarachnoid spaces of the cranial cavity. In the eyeball the tissuespaces are abundant, even if the vitreous and aqueous chamber be omitted from the category. Numerous spaces exist in the chorioid coat, especially in the lamina supra-chorioidea, and in the sclerotic, both sets communicating by perivascular spaces surrounding the venæ vorticosæ with the interfascial space. In the cornea there are abundant lacunæ, united by their anastomosing canaliculi, to form a network of lymph-spaces which come into close relation with the conjunctival lymphatics at the corneal margin.

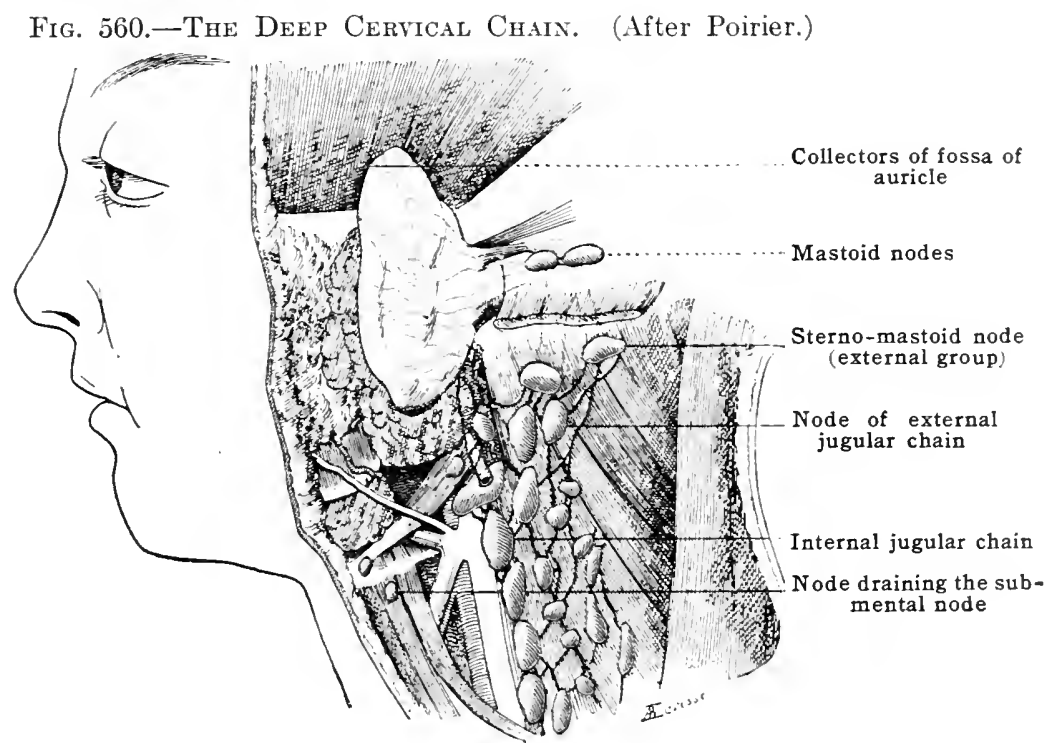

The conjunctiva, being a portion of the integument, does possess lymphatic vessels (fig. 562), arranged in a double network whose collecting vessels accompany those of the eyelids, and terminate with them in the submaxillary, anterior auricular, and parotid nodes.

\section{The Lymphatics of the Digestive Tract in the Head and Neck}

The lymphatics of the gums.- The lymphatics from the mucous membrane of the gums pass to the submaxillary nodes. The capillary plexus is abundant; the collecting vessels arise from it on the inner surface of the gum, and pass between the teeth to reach a common semicircular collecting vessel on the outer surface. Lymphatics have recently been demonstrated in the pulp of the tooth (Schweitzer).

The lymphatics of the tongue.--There is a rich lymphatic plexus throughout the entire extent of the submucosa of the tongue, but that portion lying in the basal part of the tongue seems to be more or less independent of the rest. According to Aagaard the tongue muscles are provided with lymphatics which are drained by the clucts of the submucosal plexuses. There are four groups of collecting vessels-(1) apical; (2) marginal; (3) basal; and (4) central.

(1) The apical vessels are usually four in number, two on each side. One pair perforates the mylo-hyoid muscle and ends in a supra-hyoid median node, while the other pair pass to the deep cervical chain. The latter are long, slender vessels, which run along the frenum of the tongue to the surface of the mylo-hyoid muscle, cross the hyoid bone just behind the pulley of the digastric, and then run downward in the neck to a node of the deep cervical chain, just 
above the omo-hroid. It will be noterl in fig. 563 that the most anterior vessels end in the lowest nodes, while those from the back of the tongue end in higher nodes.

(2) The marginal ressels are from eight to twelve in number. They all pass to the superior

Fig. 561.-Lruphatics of the Head, Neck, and Axilla. (After Toldt, "Atlas of Human Anatomy," Rebman, London and New York.)

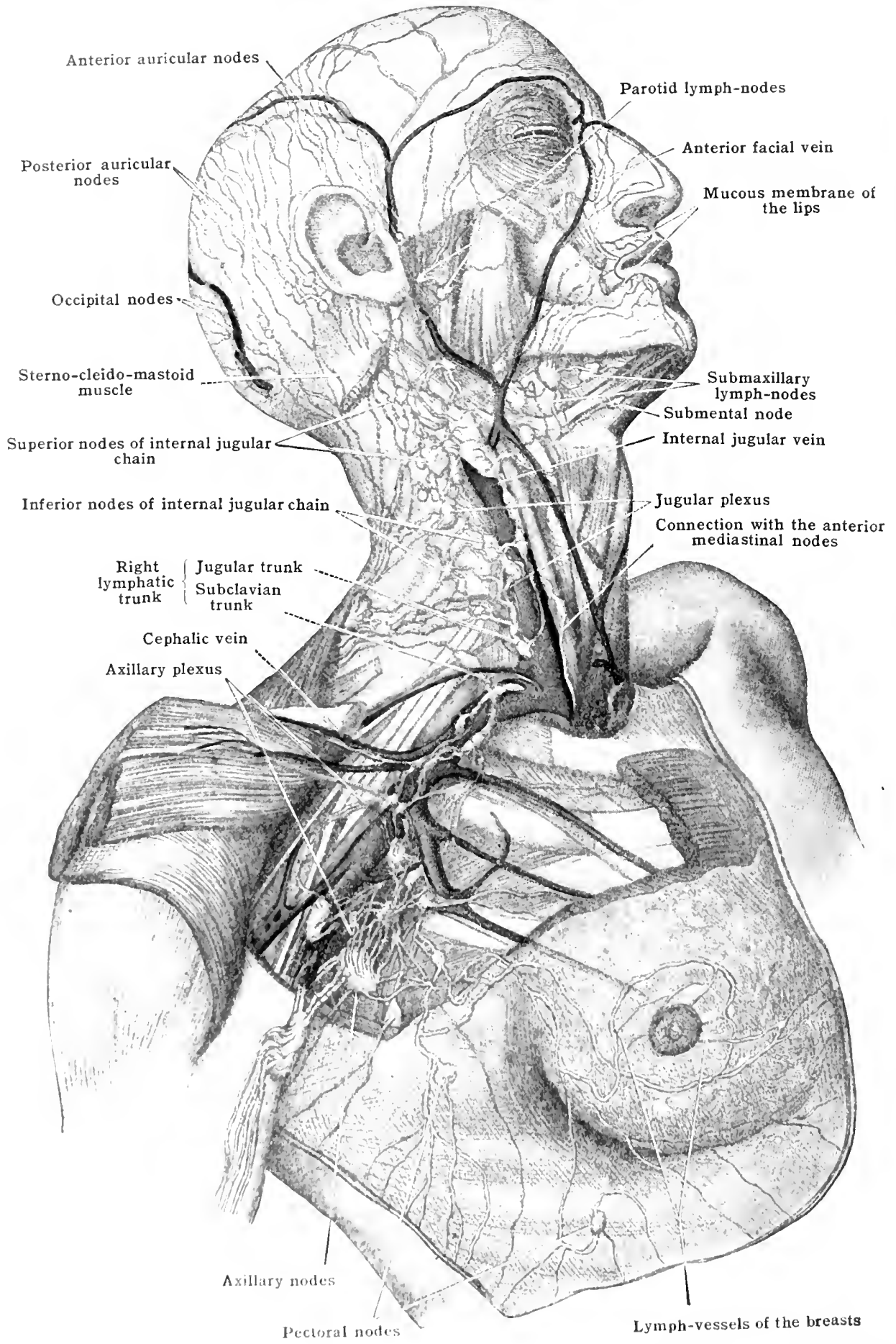

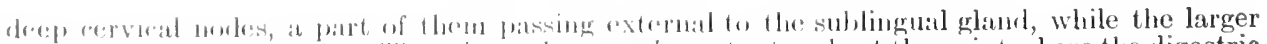
mumber pats intermal to it. There is onc barpe :mol comstant mole at the point where the digastric muscle crosses the jumblar vein, fo whirh a large mumber of the vessels converge. 
(3) The basal vessels are seven or eight in number, and drain the basal portion of the tongue. Some end in the large node just mentioned, while others run backward close to the median line, where they anastomose, as far as the glosso-epiglottidean fold, when they separate and join the tonsillar vessels to pass outward to the superior deep cervical nodes.

(4) The central vessels, arising from the central portion of the tongue, pass backward in the median line on the ventral surface of the tongue. They lie upon the mylo-hyoid muscle, cross the hyoid bone, and end in the superior deep cervical chain.

The lymphatics of the palate.-The lymphatics from the palate pass to the deep cervical chain. The trunks from the hard palate run in the submucosa as far as the last molar tooth, where they pass in front of the anterior pillars of the fauces and end in the superior deep cervical nodes beneath the digastric muscle In the soft palate the capillary plexus is very rich, reaching a maximum in the uvula. From the inferior surface of the soft palate and the pillars of the fauces vessels pass directly to the superior deep cervical chain, but some of the vessels

Fig. 562.-The Lrmphatics of the Conjunctiva. (After Teichmann.)

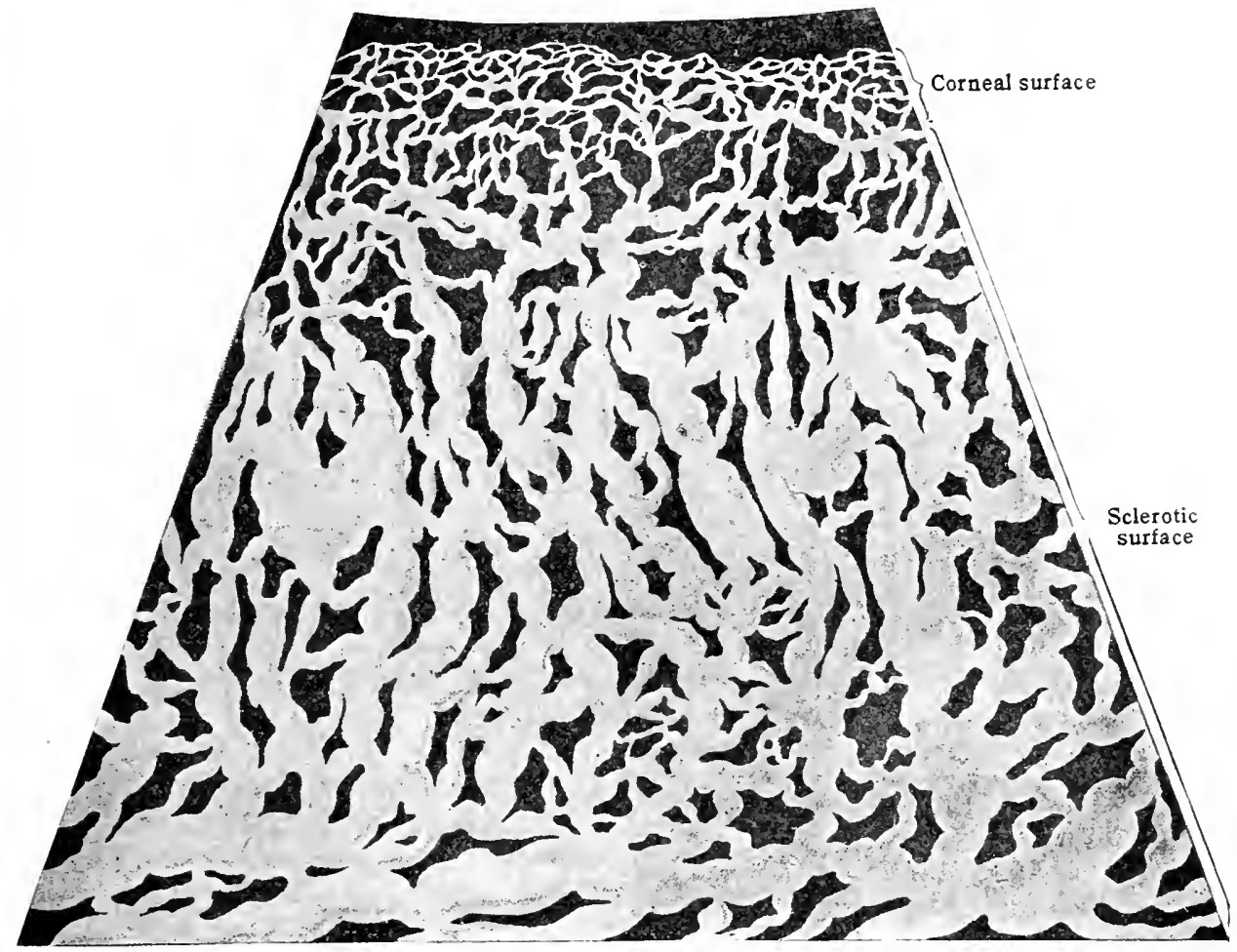

from the upper surface of the soft palate run forward with the pharyngeal vessels and end in the retro-pharyngeal nodes. It will be seen from fig. 564 that the retropharyngeal nodes are simply outlying nodes from the deep cervical chain.

The lymphatics of the pharynx. - As has just been stated, there are certain outlying nodes of the deep cervical chain which lie behind the pharynx. They receive some of the ducts from the submucosa of the roof of the pharynx, but many of the pharyngeal vessels pass by these nodes and end directly in the superior deep chain. The tonsil is especially rich in lymphatics, and its ducts, together with those from the middle and inferior portions of the pharynx, end in the superior deep cervical chain. The lymphatics of the Eustachian tube run to the lateral retro-pharyngeal lymph-nodes or, passing these, to the deep cervical nodes.

The lymphatics of the nasal cavities. - The mucous membrane of the nose contains a rich lymphatic plexus whose main ducts pass to the retro-pharyngeal nodes. An anterior set, however, anastomoses with the subcutaneous ressels, and through these their lymph is conveyed to the facial and submaxillary nodes. The posterior vessels run either to the deep cervical chain or to the retro-pharyngeal nodes. Key and Retzius have shown that an injection of the lymphatics of the nose may be made by injeeting the subarachnoid spaces at the base of the 
brain, although there is presumably no direct connection between the spaces and the lymphatic ressels. The lymphatics of the nasal sinuses end in the retropharyngeail nodes.

Fig. 563.-The Lrmphatics of the Tongue. (Poirier and Charpy.)

Basal trunks

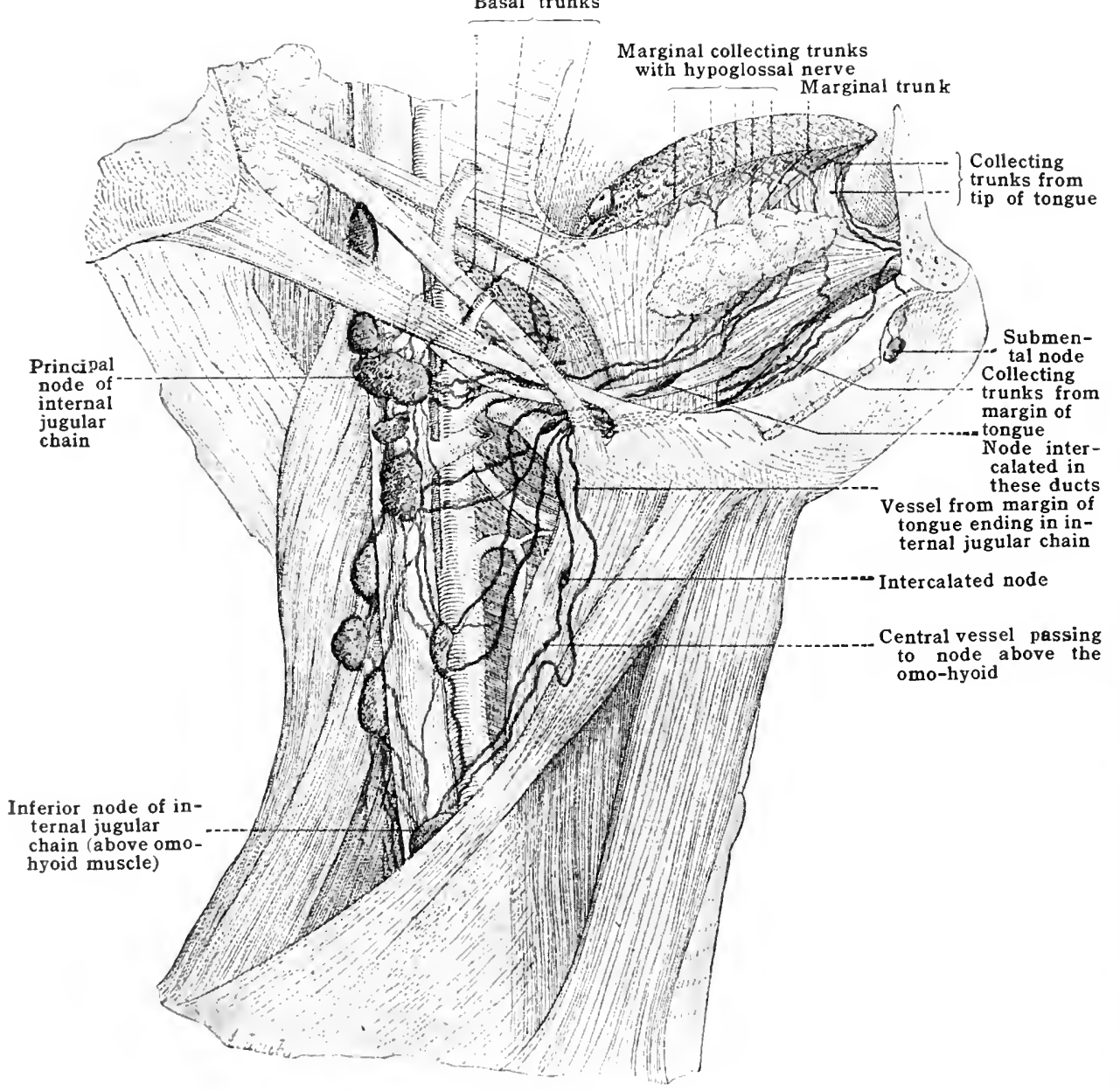

Fig. 561.-The Lymphatics of the Pharyax. (After Poirier and Cunéo.)

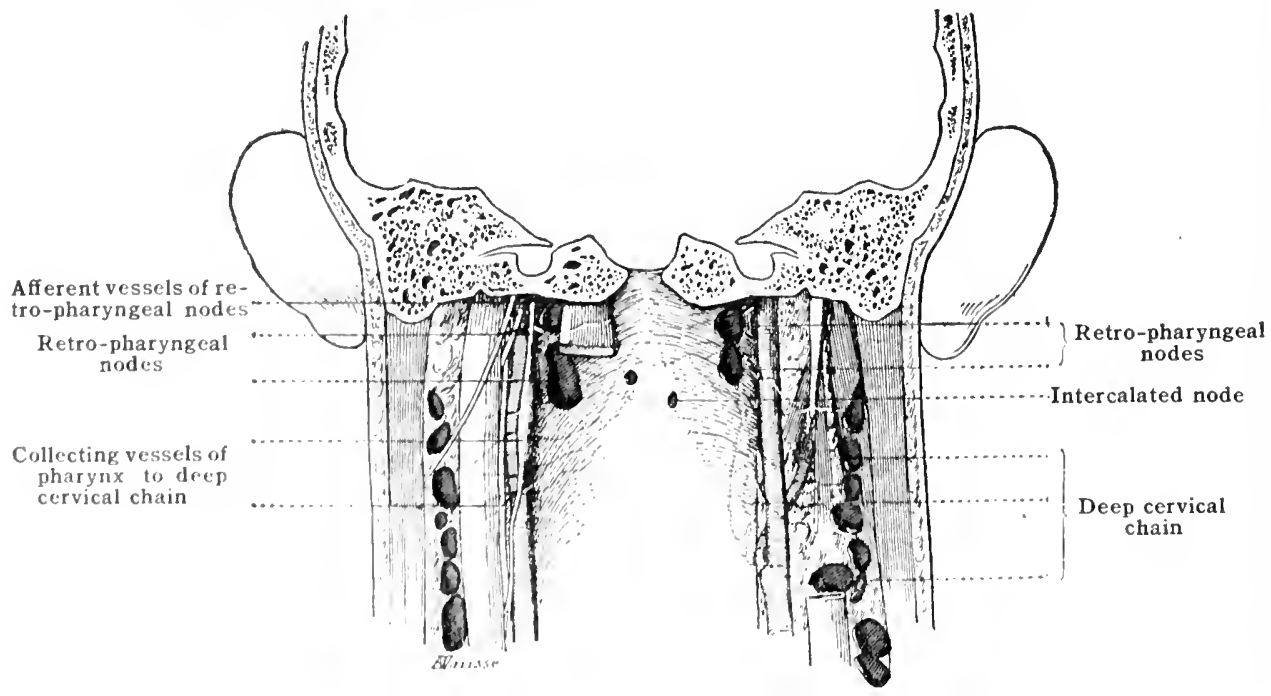


The lymphatics of the larynx.-The larynx is, for the most part, drained by the deep cervical nodes, although its lymph may also pass through certain outlying nodes situated upon its ventral surface. The mucous membrane is divided into two zones by the ventricular folds, the mucous membrane of these structures possessing but a scanty lymphatic plexus. The vessels from the upper part of the larynx, four or five in number, pass to the nodes of the superior cleep cervical chain, situated near the digastric muscle; those from the lower part pass to the lower nodes of the same chain, some even descending as far as the supra-clavicular nodes. The lymphatics of the trachea pass, on each side, to the paratracheal and inferior deep cervical nodes.

The lymphatics of the thyreoid body.--The lymphatics of the thyreoid body pass either to the small nodes situated in front of the larynx and trachea, or to nodes of the deep cervical chain, a part of them ascending and a part descending.

It will thus have been seen that the lymphatics of the mucous membrane of the head and neck all end in the deep cervical chain of nodes or in the outlying nodes from it. Some of the vessels pass by the outlying nodes, but since the nodes of the chain are so closely connected, the lymph must pass through several nodes before entering the veins. The main tonsils, the numerous lingual and pharyngeal tonsils, together with small lymph-follicles in the submucosa of the respiratory tract, represent lymph-nodes in the capillary zone.

\section{B. THE LYMPHATICS OF THE UPPER EXTREMITY}

\section{THE LYMPHATIC NODES OF THE UPPER EXTREMITY}

The lymph-nodes of the arm lie, for the most part, in the axilla, where there is a large group of nodes which receive almost the entire drainage of the arm and the thoracic wall. In addition, there is in the arm a set of outlying superficial nodes, the superficial cubital (supra-trochlear), while small isolated nodes are often intercalated along the course of the deep lymphatic vessels which accompany the radial, ulnar, anterior interosseus and brachial arteries, the cephalic vein, and the deep cubital vessels.

(1) The antibrachial nodes are very small, pin-head sized nodes which are intercalated along the deep lymphatics which accompany the radial, ulnar, anterior and posterior interosseus arteries.

(2) The deep cubital nodes [lgl. cubitales profundæ] are also very small nodes, one or two in number, intercalated along the ducts, near the deep vessels at the bend of the elbow.

(3) The superficial cubital node [lgl. cubitales superficiales] (or supratrochlear) is situated three or four centimetres above the medial epicondyle of the humerus. It lies in the superficial fascia on the medial side of the basilic vein near the place where it passes through the deep fascia. It is usually single, but may be absent or represented by a chain of from two to five nodes. Its efferents follow the basilic vein.

(4) The delto-pectoral nodes are very small intercalated nodes from one to three in number, and are situated in the groove between the deltoid and pectoral muscles. Their vessels follow the cephalic vein.

(5) The axillary nodes [lgl. axillares], from twelve to thirty-six in number, may be divided into groups according to the areas which they drain (fig. 566). In addition to the upper extremity, they receive lymphatic drainage from the thoracic walls, including dorsal, lateral and ventral (mammary) regions.

(1) The subclavian group consists of four or five nodes, situated in the apex of the axillary fossa. They receive the efferent vessels of all the other groups, and their efferent vessels in turn unite to form a single trunk, the subclaviar, which empties into the thoracic duct on the left side and on the right side either into the vein directly or else after uniting with the jugular trunk. (See pp. 726-728.)

(2) The centrol group. A little lower along the axillary artery is a group of three to five nodes, which makes a second centre for the vessels of the other groups, and sends its efferents to the subclavian group. It will be clear from the figure that the separation of groups 1 and 2 is arbitrary.

(3) The brachial group. - This consists of four or five nodes, and, as its position toward the junction of the axillary and brachial arteries indicates, is the main station for the lymphatics of the arm proper. It receives almost all the superficial and deep lymphatics of the arm, and its efferents pass to the central and subclavian groups, although a few pass directly to the 

suprascapular group. Small, outlying nodes of this group may be intercalated along the
vessels following the brachial artery throughout its course.

(4) The subscapular group [lgl. subscapulares].-In this group are six or seven nodes, which follow the subscapular artery and its branch, the circumflex (dorsal) scapular. Belonging

Fig. 565.-The Lrmphatics of the UPPer Extremity. (After Toldt, "Atlas of Human Anatomy," Rebman, London and New York.)

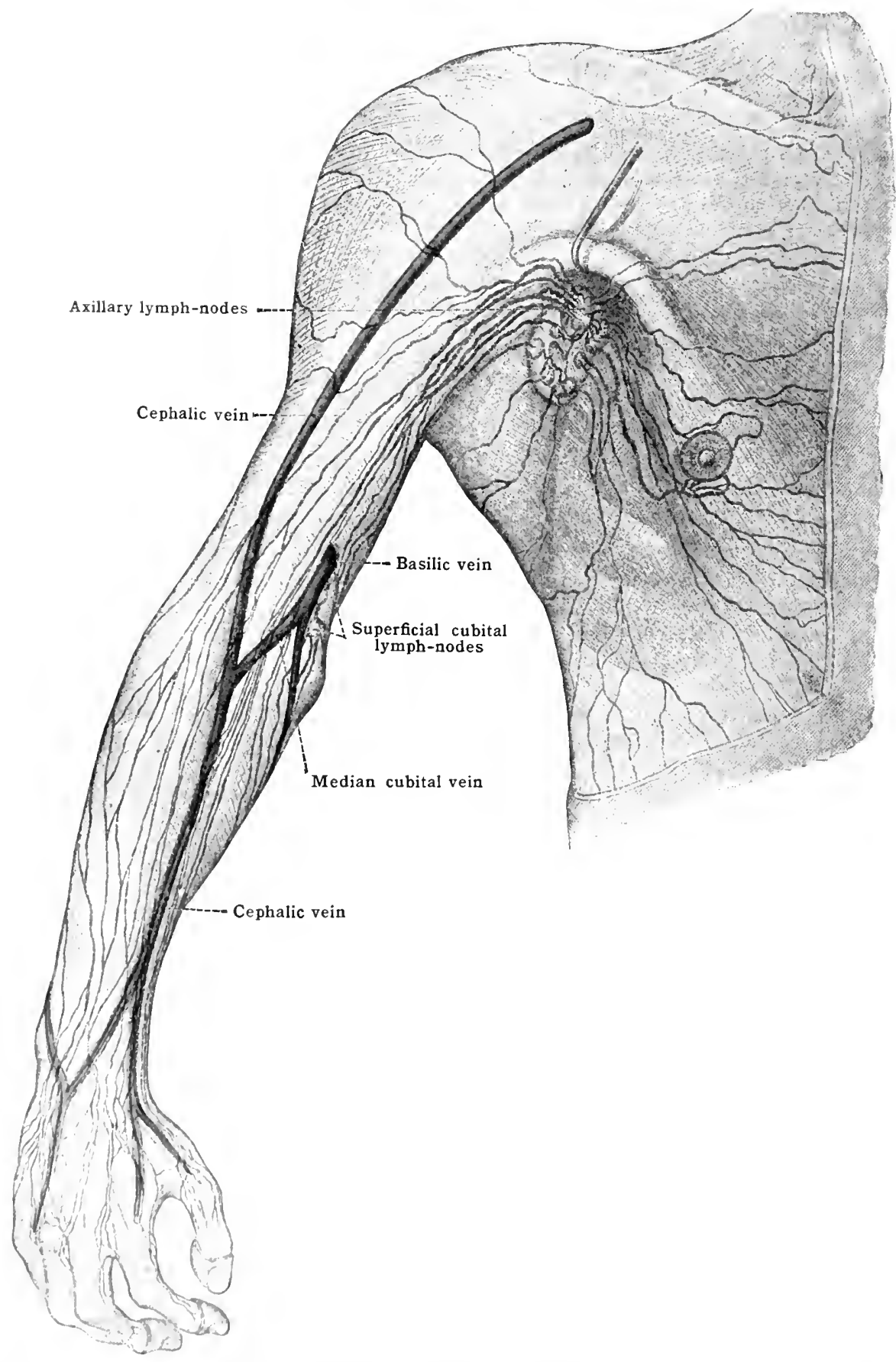

to it thror ate usually two or three small nodes on the dorsal surface of the seapula, in the gronve; which soparates the teres mijor and minor. This group receives vessels from the dorsal surfare of thr thorax, as well as from the arm, and its efferents pass to the brachial group.

(i) Thr anterioripcetoral.gronp [lgl. pectorales]. - This group consists of four or five nodes which lice along the lower border of the pectoralis major and Irain the mammary gland and front of the ehest. Their refferent vessede piss to the central and subclavian groups. 
(6) The posterior peetoral group [1gl. pectorales] consists of small nodes situated on the inner wall of the axilla, along the course of the long thoracic artery. They receive afferents from the lateral integument of the thorax and drain into the nodes of the central group.

\section{THE LYMPHATIC VESSELS OF THE UPPER EXTREMITY}

The lymphatic vessels of the upper extremity are divided into two sets - a superficial and a deep set.

The superficial vessels.-The superficial lymphatic vessels of the arm course in two layers, the one quite subeutaneous, the other next the deep fascia, with frequent anastomoses between the two sets. The majority of these vessels remain superficial throughout the arm, but some of them pass through the deep fascia in the upper arm especially where the basilie vein pierees the deep fascia,

Fig. 566.-The Axillary Lymph-Nodes. (After Poirier and Cunéo.)

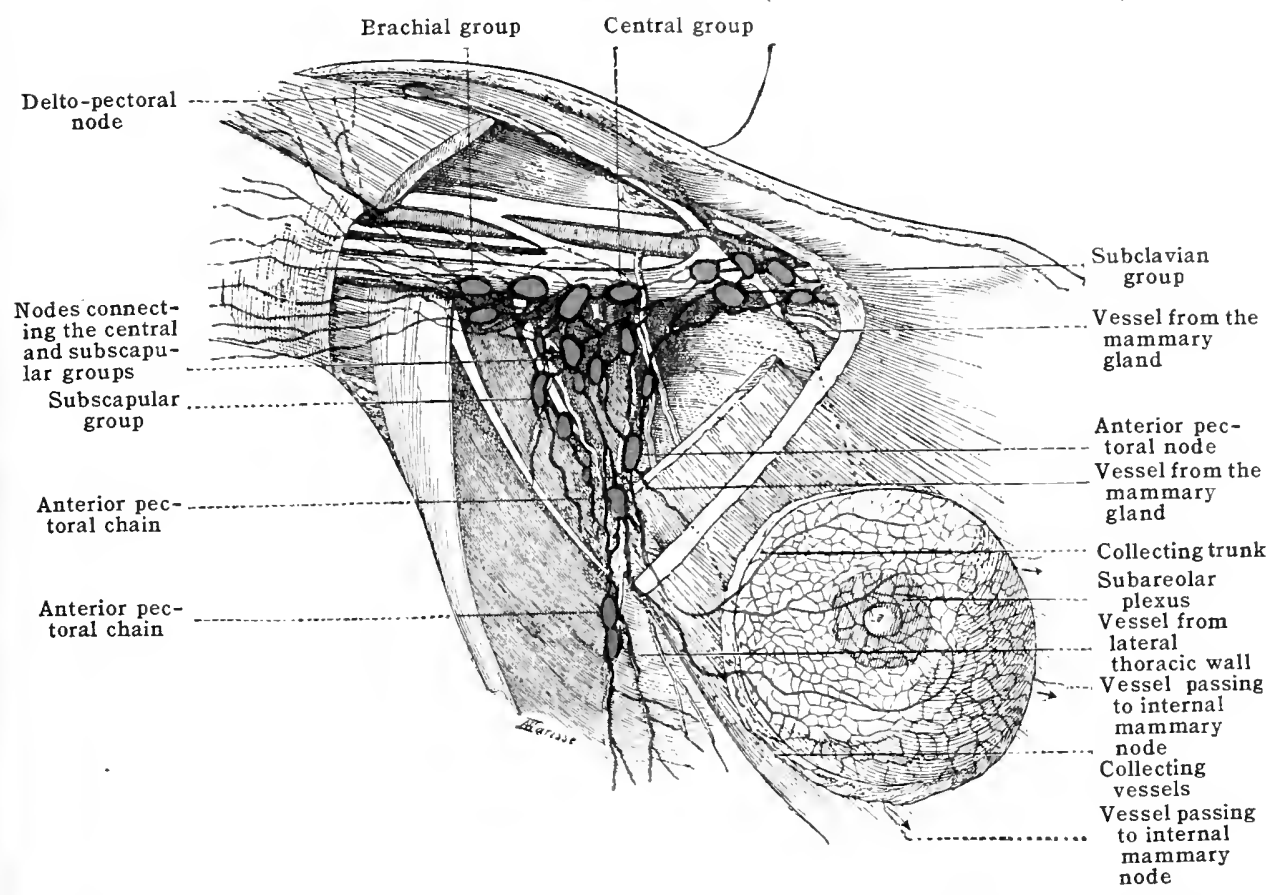

to join the deep lymphaties accompanying the brachial artery. The general distribution of the superficial lymphatics and their relations with the lymphnodes are shown in figs. 565 and 567.

The capillary plexus is most dense in the palmar surfaces of the fingers, where the meshes are so fine that they can only be seen with a lens. On the dorsal surface of the fingers and hand the plexus is less dense. From the plexus on the palmar side of the fingers vessels come together at the base of the fingers where they pass dorsally to be joined by the dorsal vessels of the inger. They now follow two rather distinct curves: (1) those from the thumb and index finger and a part of the middle finger pass upward along the radial side of the forearm, course medially over the lower part of the biceps muscle, and empty into the axillary lymph-nodes. One or two vessets follow the cephahic vein and, after traversing the delto-pectoral node, pierce the costo-coracoid membrane to enter the subclavian nodes, or pass over the clavicle into the inferior deep cervical nodes. (2) Those from the rest of the fingers course for a short stretch on the dorsum of the forearm, when they turn toward the ulnar side, wind around to the volar side and either continue superficially along the upper arm to the axillary nodes, or pass into the superficial cubital node, or, joining the efferents from these nodes, pass through the deep fascia to unite with the deep lymphatics. (3) A set of vessels from the palm of the hand passes upward along the volar side of the forearm. Anastomoses are frequent between these groups of lymphatic vessels, particularly in the cubital region.

It will thus be seen that the superficial cubital nodes receive lymph from the ulnar digits and from the palm of the hand, but not from the thumb and forefinger. levels.

The superficial lymphatics from the rest of the arm join these three main groups at various

The deep vessels.- The deep lymphatic vessels of the upper extremity drain the joint capsules, periosteum, tendons, and (if the recent work of Aagaard is 
correct) the muscles. They collect into vessels which, in general, accompany the arteries, in the forearm, the radial, ulnar, anterior and posterior interosseous, and in the arm the brachial. Above the elbow they are joined by numerous super-

Fig, 567.-The Lymphatics of the Forearm. (After Toldt, "Atlas of Human Anatomy," Rebman, London and New York.)

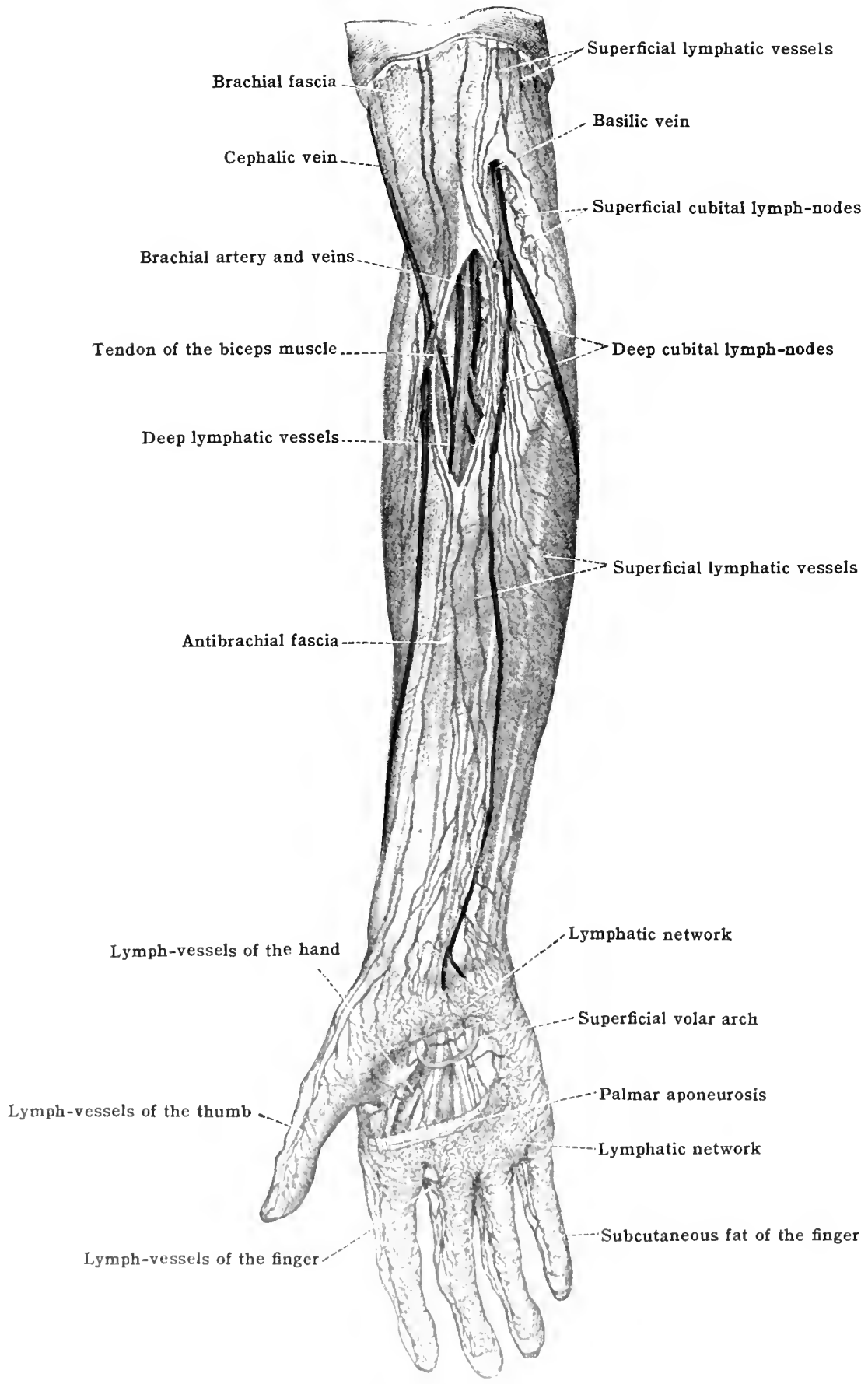

ficial bymohatic vessels including offerents from the superficial cubital nodes. Nong their rourse in the forrarm are intrealated small norles (pin-head size),

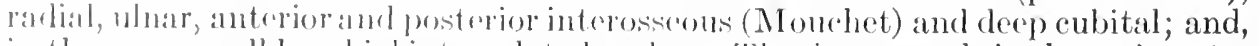

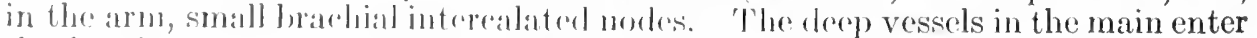
the brachial gromp of axillary lympli-glinds which lie behind the large vessels 
and nerves, the efferents from which nodes pass either into the lower deep eervical lymph-nodes or directly into the subelavian trunk.

The lymphatics of the shoulder-joint have recently been described by Tananesco. He finds a ring of lymphatics in the joint capsule, whose efferents, in the main, following the arteries, run to the central and subclavian groups of axillary nodes.

\section{THE LYMPHATICS OF THE THORAX}

The lymphatics of the thorax will be eonsidered under the following divisions: the superficial vessels, the deep nodes, and the deep vessels.

\section{THE SUPERFICIAL LYMPHATIC VESSELS OF THE THORAX}

The superficial lymphaties of the thorax pass almost exclusively to the axillary nodes, and may be regarded as forming three sets, a ventral, a lateral, and a dorsal. The ventral set drains the thoracie integument, which extends form the median line and the clavicle over to the lateral border of the chest, and includes the vessels of the mammary gland, which will, however, be described separately. The majority of the vessels from this area end in the anterior pectoral group of axillary nodes, a few, which arise beneath the claviele, passing to the supraclavicular nodes, and a few perforating the intercostal spaces and ending in the chain of nodes along the internal mammary artery.

It has been shown that an injection into the subcutaneous plexus near the median line passes to the opposite side, and that, in addition to the anastomosis between the networks of the two sides of the thorax which this result manifests, there may also be a few collecting trunks crossing the median line, and, furthermore, anastomoses occur between the superficial networks of the anterior thoracic and abdominal walls. Thus while the main channel of lymphatic drainage is through the axilla, there are minor accessory channels to (1) the supraclavicular nodes, (2) to the axilla of the opposite side, (3) to the internal mammary chain, and (4) in isolated cases even to the inguinal nodes. These accessory channels may become nore open in cases of obstruction to the main channel.

The lateral set of superficial thoracic lymphatics is much less extensive than the anterior, and its collecting vessels pass upward to open into the posterior pectoral group of axillary nodes.

The dorsal set, which occupies the subcutaneous tissue of the dorsal thoracic wall, sends its vessels to the subscapular group of axillary nodes.

\section{The Lymphatics of the Mammary Gland (Figs 566, 568)}

The lymphatic network over the peripheral portions of the mammary gland is like that of the rest of the thoracie wall. In the areola, however, the capillaries are far more abundant, forming a double subareolar plexus. The superficial plexus is so dense that its meshes can be seen only with a lens. The deeper plexus not only drains the superficial plexus, but receives the vessels from the mammary gland itself, and from it arise two large trunks, one from the inferior and one from the superior part of the plexus. These two vessels pass to one or two of the nodes belonging to the anterior pectoral group of axillary nodes. In addition there may be-(1) one or two vessels passing to the nodes along the axillary artery; (2) in rare cases a vessel passing directly to the subelavian nodes. There is also a definite channel from the medial margin of the gland to the internal mammary nodes, the ducts following the perforating branches of the internal mammary vessels, and it may be noted that the crossed anastomosis and that with the abdominal network, mentioned in connection with the superficial thoracic vessels, may, on occasions, serve as channels for the mammary drainage.

There is also clinical evidence indicating that lymphatic vessels from the lower and medial aspect of the mammiay gland may pass through the abdominal wall in the angle between the xiphoid process and the costal cartilages, establishing a communication with the lymphatics of the abdomen in the diaphragmatic region.

Lymphatics of the thoracic muscles. - The recent studies of Aagaard make it probable that muscles are provided with lymphatics. Whether his findings will be substantiated or not, however, it is unquestioned that lymphatic vessels course through the pectoral musclessome passing to the axillary, others to the subclavian, and still others to the internal mammary chain of nodes. This would suffice to explain the fact that cancer of the breast may extend into and through the pectoral muscles. 


\section{THE DEEP LIMPHATIC NODES OF THE THORAX}

The lymphatic nodes of the thoracic carity may be divided into the parietal and the risceral. The parietal nodes are arranged in two sets, the internal mammary chain and the intercostal nodes (fig. 570). Along the internal mammary artery are from four to six small nodes, [lgl. sternales] which receive ducts from the anterior thoracic and the upper part of the abdominal walls, from the anterior diaphragmatic nodes which drain the liver, and from the medial edge of the mammary gland. The efferent vessels usually unite with the vessels of the anterior mediastinal and bronchial nodes, to form the broncho-mediastinal trunk, which may join the thoracic duct on the left and the jugular or subclavian trunk on the right or may empty separately into the subclarian rein on both sides.

Fig. 568.-Limphatics of the Subareolar Plexus of the Breast. (After Sappey.) Vessels from network

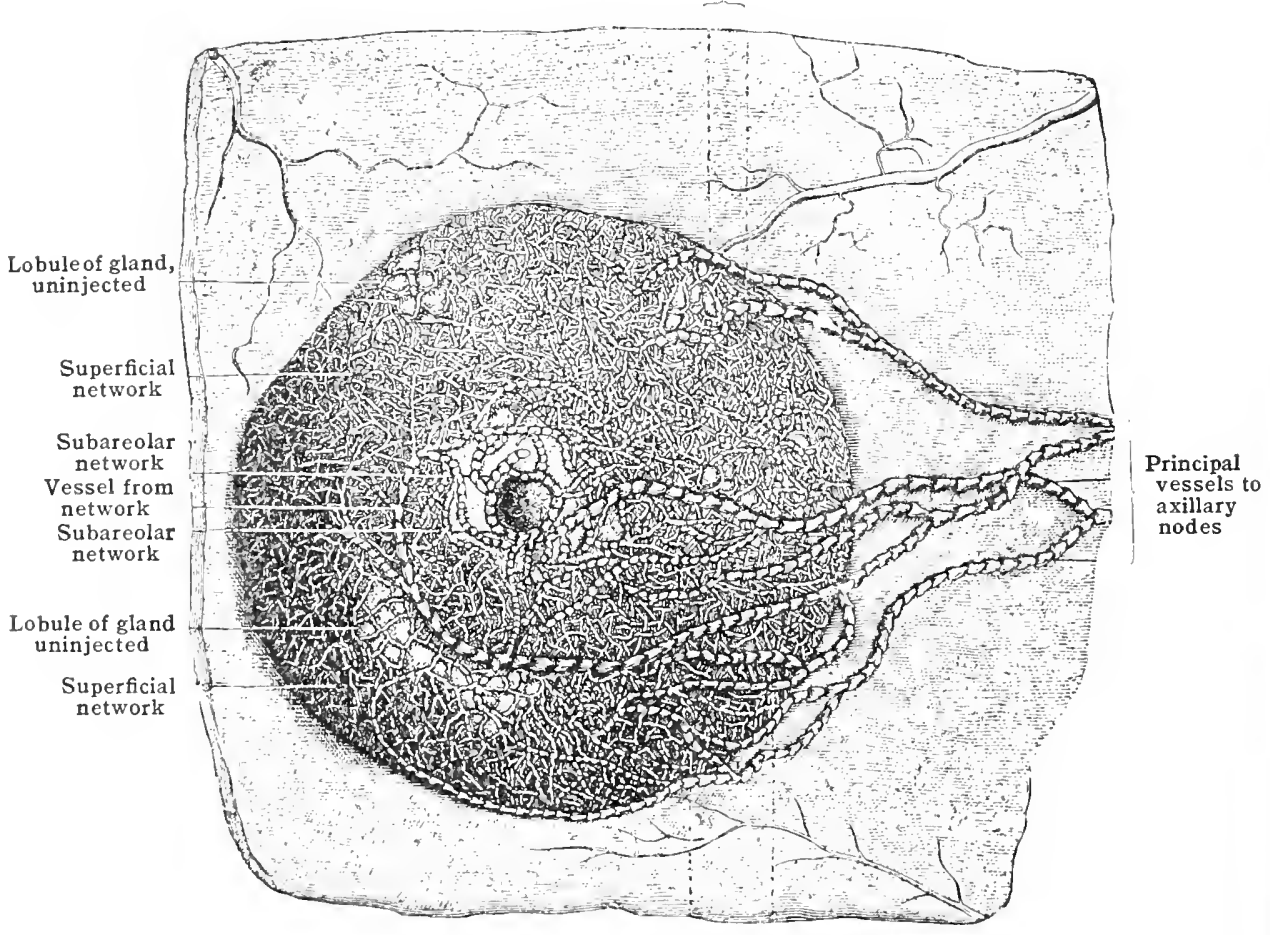

Vessels from network

The intercostal nodes [lol. intereostales] lie along the intercostal vessels, near the hrats of the ribs. There are usually one or two in rach space, and oceasionally a noxk is placed where the perforating lateral artery is given off. They receive alferents from the derper part of the thoracic wall and costal pleura. Their efferents enter the thoracice duet, those from the nodes of the lower four or five intersparess miting usually to form a common sluct on cach side, but more marked on the left sirle, which desienends to the reapentaculum ehyli.

The refferent lymph-vessels from the uppere intereostal nodes often unite into common trumks which drain soveral intersporess, and which nay pass through a large gland near the

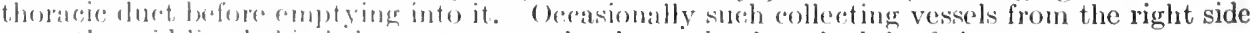
cross the mid-line behind the atortat to reach a latere ghand to the left of the aortat.

'The visceral nodes of the thorax alrearranged in three groups:-

I. 'T'he anterior mediastinal nodes [|gl. merliatstinales anteriores] are situated, as their nature indieater, in the anterior merliastinum, and are arranged in an upper

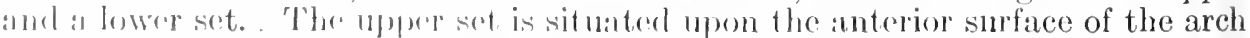
of the antal, and consistis of oight of tom nodes, which receive afferents from the periearelium and the remains of the thrmus ghand. 'Their efferent vessels pass

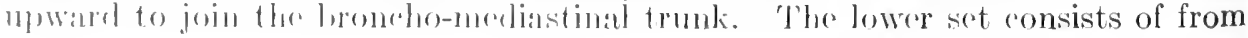


three to six nodes, situated in the lower part of the mediastinum. They receive afferent ducts from the diaphragm, hence they are sometimes termed the diaphragmatic nodes, and also from the upper surface of the liver. Their efferents pass upward to open into the upper anterior mediastinal nodes.

2. The posterior mediastinal nodes [lgl. mediastinales posteriores] eight or ten in number, are situated along the thoracic aorta, and receive vessels from the mediastinal tissue and from the thoracic portion of the oesophagus. Their efferents open directly into the thoracic duct.

3. The bronchial nodes [1gl. bronchiales] form an extensive group lying along the sides of the lower part of the trachea, and along the bronchi as far as the hilus

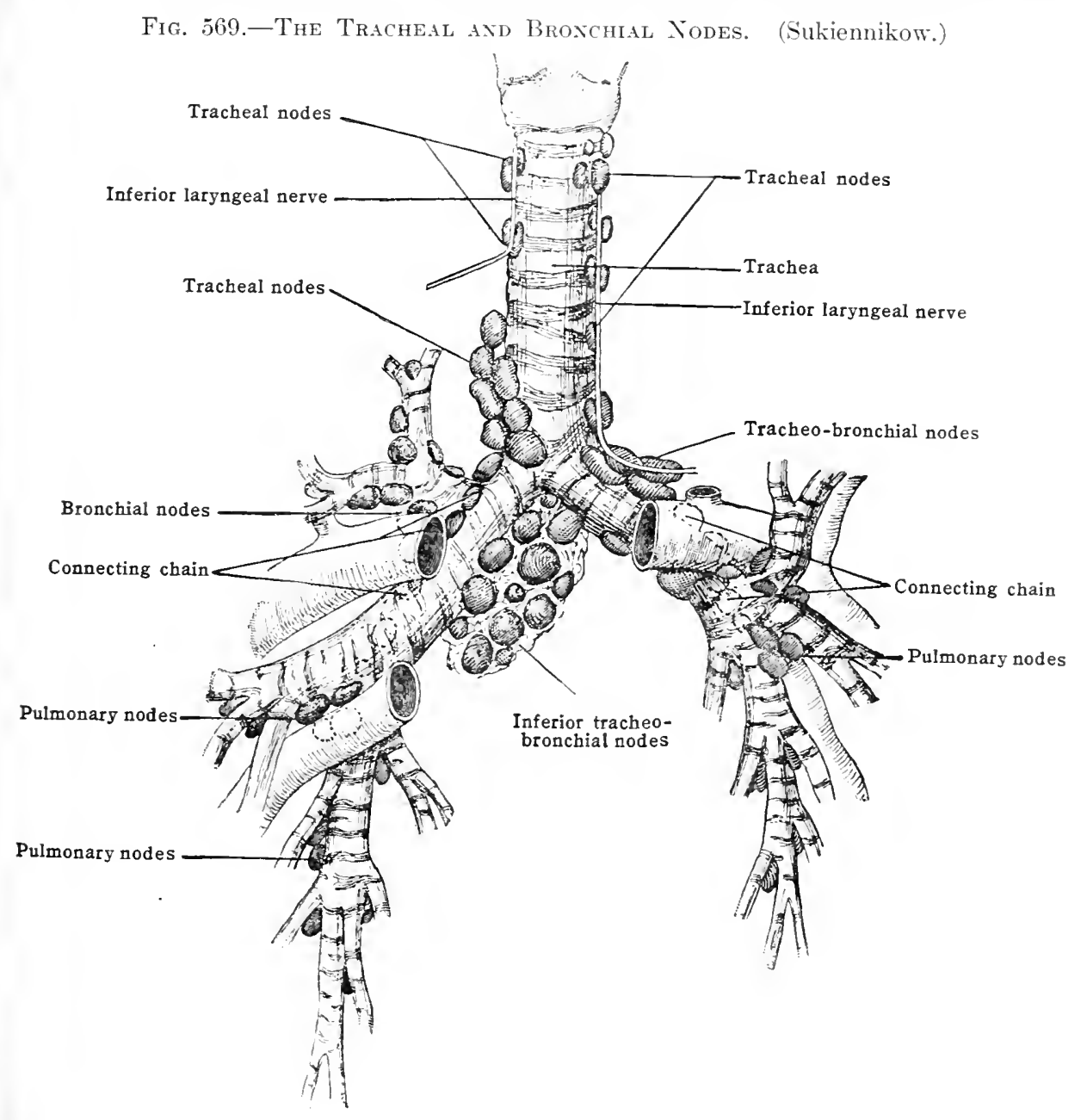

of each lung, those lying in the hilus being termed the pulmonary nodes, and others, according to their position, lateral tracheo-bronchial, inferior tracheobronchial (nodes of the bifurcation) and tracheal (paratracheal). They receive the drainage of the lower part of the trachea, the bronchi, the lungs, part of the cesophagus, and, to a small extent, the heart. Their efferent vessels unite with those from the upper anterior mediastinal and internal mammary nodes to form the broncho-mediastinal trunk.

\section{THE DEEP LYMPHATIC VESSELS OF THE THORAX}

In following the deep lymphatics of the thorax the course of development will be followed in describing first the thoracic duct and right lymphatic ducts, second the parietal vessels, and third the risceral ressels. 


\section{The Thoracic Duct}

The thoracic duct [ductus thoracicus] (fig. 570), which is the main eollecting duct of the lymphatic system, extends from the second lumbar vertebra along the spinal column and course of the aorta to the junetion of the left internal jugular and subclavian veins. It receives all the lymphatics below the diaphragm, and the deep lymphatics from the dorsal half of the ehest wall; and also, when joined, near its cephalic end, by the left broncho-mediastinal, subclavian and jugular trunks, from the remainder of the left half of the body, above the diaphragm. At the caudal end the duct is formed usually by the union of three collecting ducts, one from each of the lumbar groups of nodes, and an unpaired intestinal

Fig. 570.-The Thoracic Duct. (After Toldt, "Atlas of Human Anatomy," Rebman, London and New York.)

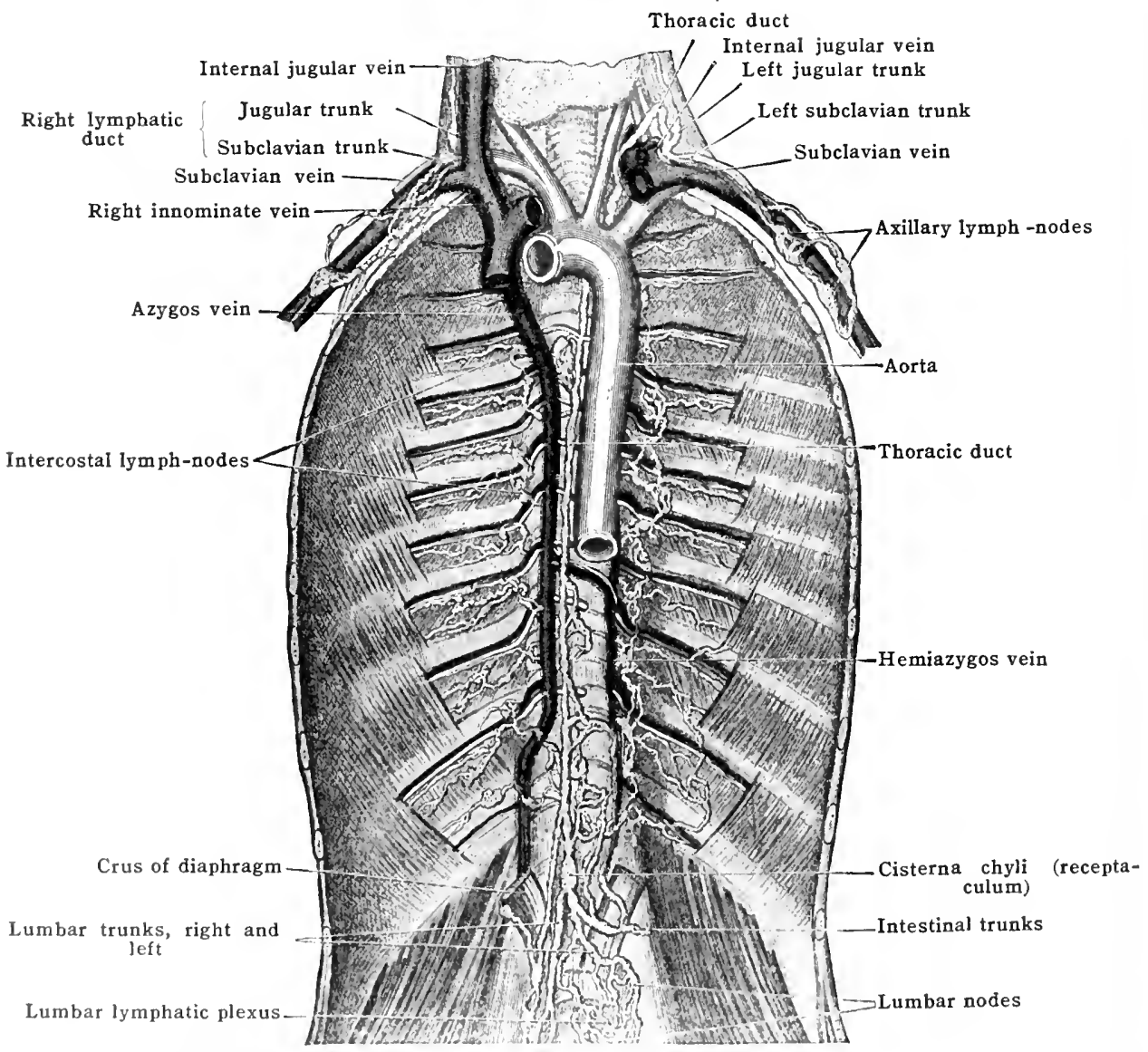

trunk. It itsorigin there is mstally a dilated portion known as the receptaculum [cisterna chyli]. This usually ('ndis opposite the borly of the eleventh thoracic vertebra, and from here on the duce is from 4 to 6 mm. in diameter, until near its termination, where it is again wider.

In its cardual part, the duct lies dorsal to the anota in the median line; it passes throngh the atortic openimg in the diaphratgm, and then inclines to the right and passe's mowarel to about the fomth, fifth, or sixth. thoracie vertebra, when it leenels to the loft and basses, continuing upward, over the apex of the left lung and the left subclavian artery, and in front of the root of the left vertebral artery and vein, and then surves downward to open into the left subclavian vein, elose to its junction with the left internal jugntar. The duet runs in the wall of the vein it short distanes brofore rneling.

Variations.- There is a wille range of variation from this msual course. The duet is frequently domble throughout a part of its rourse, the two branches being connected by cross anastrinoses, and finally uniting into: s sugle irmok before joining the veins. It may be 
multiple, or a single trunk may pass in front of the aorta instead'of behind. In a few instances it has been found emptying into the right instead of the left subclavian vein. There is also a wide range of variation in the height to which the duct ascends in the neck before curving downward to the vein. As regards the termination of the thoracic duct, variations are also frequent; it may bifurcate and end as two ducts. It often connects with the lowermost part of the internal jugular, or the beginning of the innominate. According to Henle, there is one undoubted case reported of a thoracic duct enting in the azygos vein near the sixth thoracic vertebra, the duct being obliterated above this point. At the terminal bend the thoracic duct receives the jugular trunk from the neck; it may also receive the subclavian and the bronchomediastinal trunks, but it is more usual for these last two to open either separately or together into the subclavian.

Variations are extremely numerous in the region of the receptaculum. Severa lobservers state that, in the majority of cases in man, no lefinite receptaculum exists. Bartels found one in only 25 per cent. of the cases studied. Instead, there is present a widening of each of the two lumbar trunks, with several anastomoses between them ( 55 per cent., Bartels), or a widening of these two stems without anastomosis ( 5 per cent.), or a much elongated widening arising

Fig. 571.-Abdominal Portion of the Thoracic Duct. (Poirier and Cunćo.)

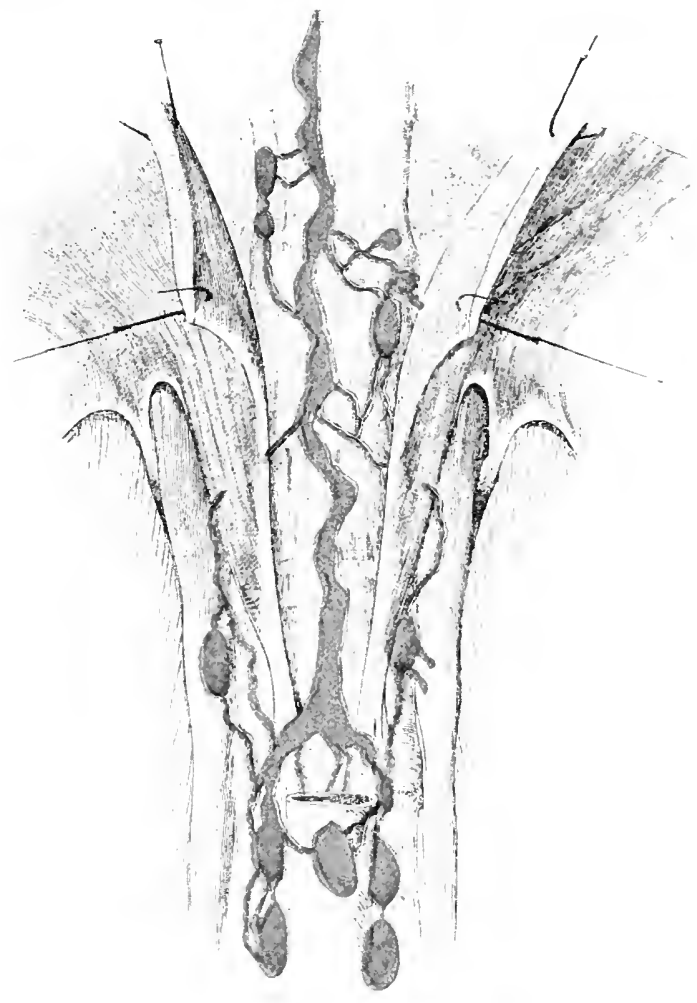

from the growing together of the two lumbar trunks (10 per cent.). In cases where the lumbar trunks remain separate, the intestinal trunk joins the left one.

Development. - While the exact mode of its development is still in dispute, enough is agreed upon by the various investigators to explain most of the variations in the thoracic duct. In brief, it is known that the lymphatics start in the neck as a variable number of outgrowths from the veins in the region of the junction between the kater internal jugular and subelavian veins. A variable number of these connections disappear, while the various combinations of one, two, three or four which are retained furnish the numerous variations in number and position of the ducts which enıpty into the vein in the adult. Thus the thoracic duct may have one, two or even three openings into the veins, while the jugular, subclavian and bronchomediastinal trunks may join the thoracic duct or may enter the veins separately or in various combinations.

It is also known that the upper part of the thoracie duct is at first bilateral, being formed by outgrowths from the primary plexus, which meet in a common plexus around the aorta. Normally the right portion of these connections disappears, so that the thoracic duct empties into the left subclavian vein. In exceptional cases, where it opens into the riglit subclavian vein, there have also bcen present rariations in the large right arterial trunk. These conditions in all probability at a certain stage in development produced a greater resistance to the lymph stream in the left than in the right vessel causing it to become obliterated so that the right instead of the left became the permanent ending of the duct. 
Most of the other variations - the frequent presence of longer or shorter doublings of the duct with anastomoses between the two parts, the numerous variations in the region of the receptaculum chyli-are easily explained by the fact that the duct and receptaculum pass through a stage in development in which they form richly anastomosing plexuses around the aorta.

\section{The Rigit Terminal Collecting Ducts}

On the right side the jugular, subclavian, and broncho-mediastinal trunks usually open separately into the subclavian vein, the orifices of the first two being near together. When the jugular and subclavian trunks unite, the common duct is termed the right lymphatic duct; this is a rare form, and it is still more rare for the three ducts to unite to form a common stem (fig. 572). These rariations have the same explanation, embryologically, as was given for the corresponding variations on the left side.

Fig. 572.-Terninal Collecting Ducts on the Right Side, (Poirier and Cunéo.)
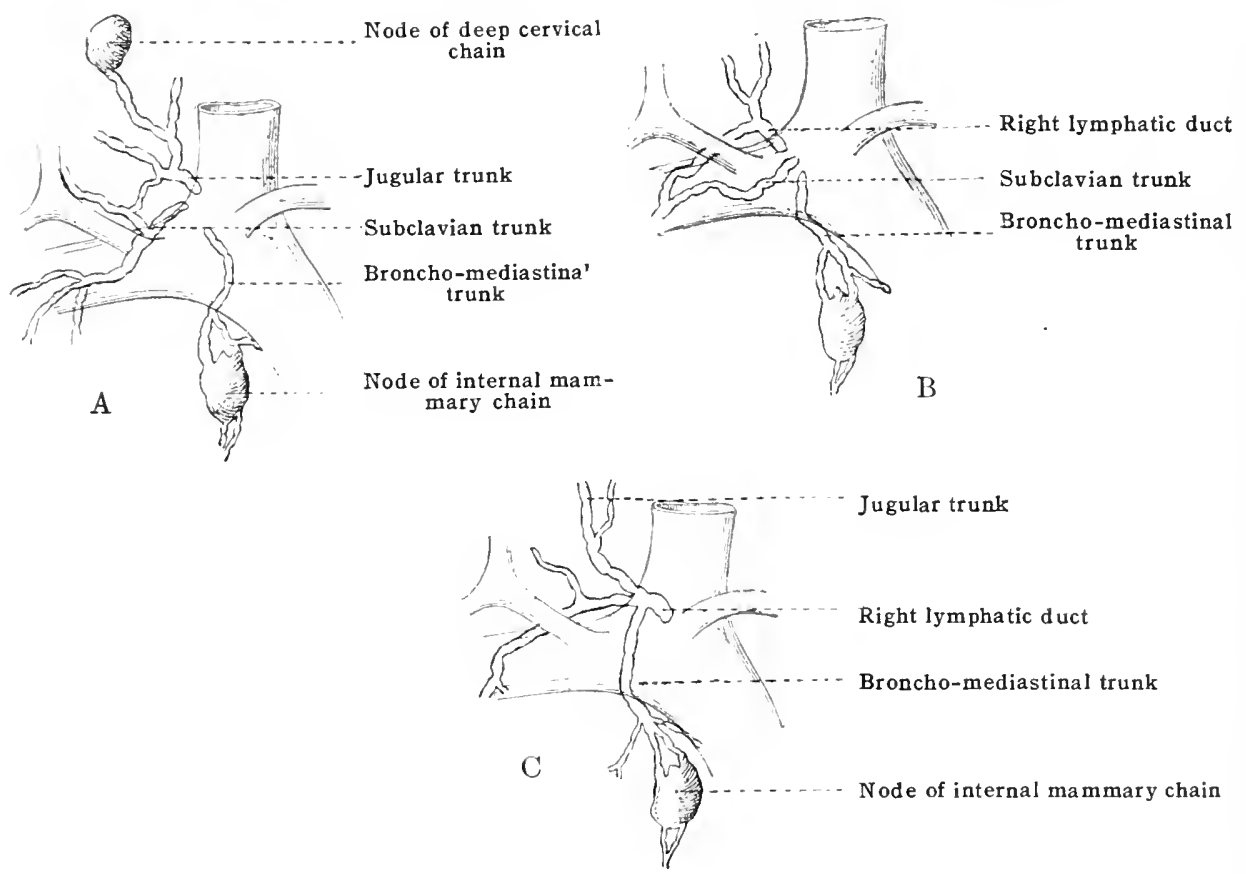

\section{The Deep Lymphatic Vessels}

As with the nodes, the deep lymphatic vessels of the thorax may be divided into a paridal and a visecral group. To the former group may be assigned the lymphatices of the interestal spaters and those of the diaphragm.

The intercostal lymphatics form plexuses in each intercostal space, which receive lymph from the poriostem of the ribs and from the parietal pleura, and from which the drainage is ather ventral or dorsal. From the dorsal half of ach spater the drainage is to the intereostal noles, while from the ventral half it is towarl the internal mammary modes.

The lymphatics of the diaphragm. There is an exceedingly rich plexus of capillaries hoth on the plemal and on the aldeminal surface of the diaphragm, esperiatly in the region of the rentral tendon, these plexuses lying in the subserous

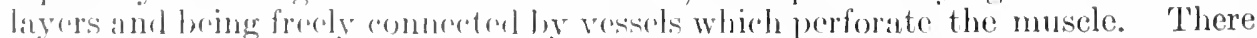
is, lowerer, only slight commmination betwern the plexuses of the right and left sides of the diaphragm. The vessets lie botweres the coarse muscle bundles, forming a rery charateristic: picture, in which the lymphaties stream outward radially, like the spokss of a where. The colloreting vessels empty into three uroups of small morles on the comvex surface. The ventral group lies ventral to the entral temlon. 'Two or thre nodes in the eentre of this group receive 
afferents from the liver and none from the diaphragm, but the rest receive vessels from the ventral surface of the diaphragm and the efferents of all pass to the lower set of anterior mediastinal nodes.

The middle group consists of from three to six nodes, which lie, on the left side, near the point where the phrenic nerve enters the diaphragm; on the right side, near the vena cava.

The dorsal group of four or five nodes is placed between the pillars of the diaphragm. The vessels from the lateral and dorsal groups pass to the posterior mediastinal nodes, and also to the upper coliac nodes, which likerrise receive the drainage from the dorsal part of the abdominal surface of the diaphragm.

Fig. 573.-The Lrmphatics of the CEsophages. (After Sakata.)

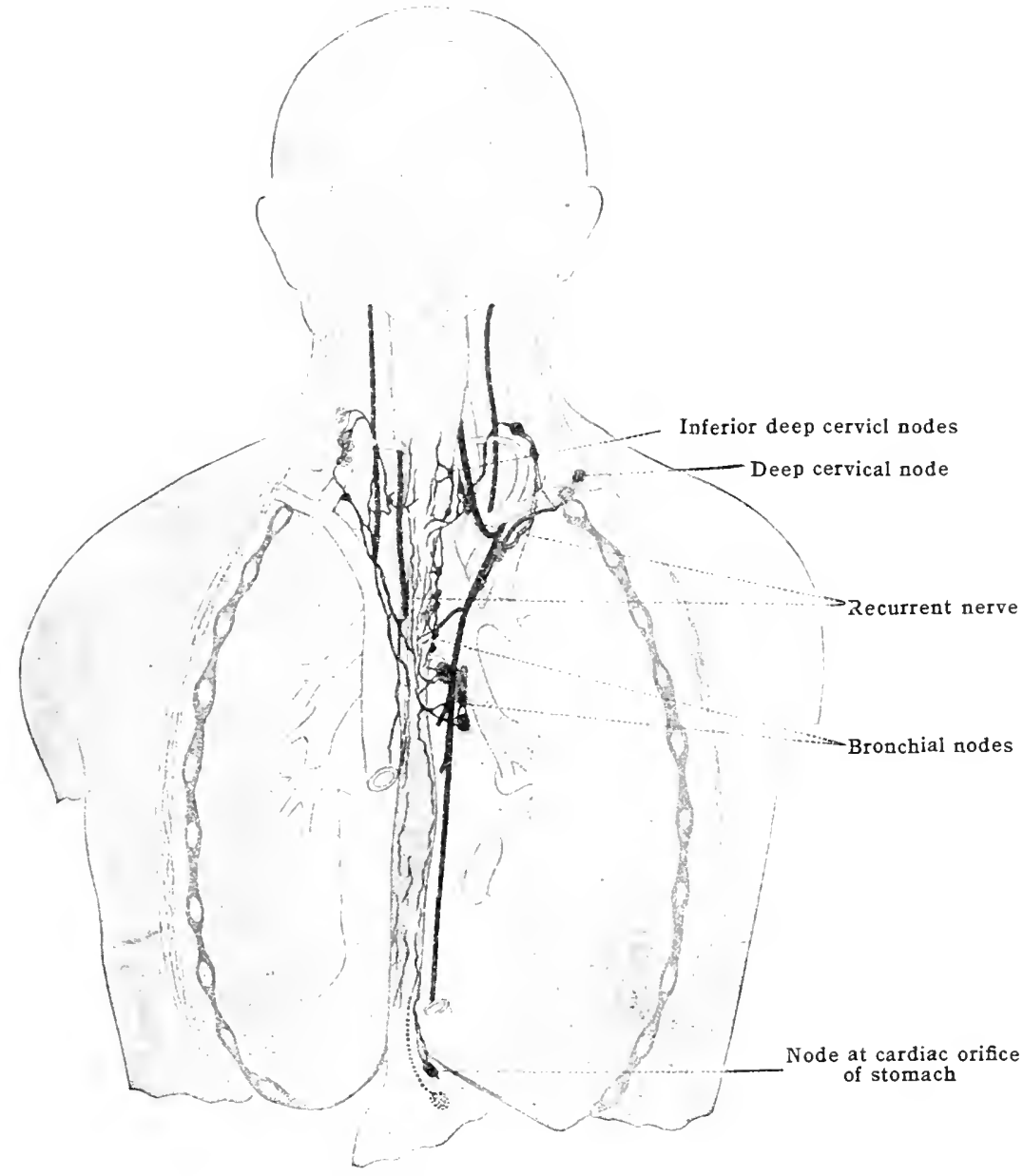

To the visceral group of thoracic lymphatics belong the ressels of the thymus, the lungs, the heart, and the osophagus.

The lymphatics of the thymus drain, according to severeanu, into three sets of glands, an anterior, a ventral and a dorsal group. The anterior set, one gland on each side, lies lateral to the cephaiic end of the thymus, and drains into the jugular or subclavian trunk. The ventral set includes $4-6$ of the anterior mediastinal lymph-glands. The dorsal set, 2 on each side, is made up of anterior mediastinal glands lying between the thymus and the pericardium.

The lymphatics of the lungs are arranged in two sets. A deep set takes its origin in plexuses which surround the terminal bronchi and follows the course of the bronchi, the pulmonary artery, and the pulmonary vein to the pulmonary nodes at the hilus, whence the stream passes to the main bronchial nodes (fig. 569), especially to those situated in the angle formed by the bifurcation of the trachea, 
and thence to the broncho-mediastinal trunk. A superficial set arises in a network situated upon the surface of the lung beneath the visceral layer of the pleura.

According to Miller, who has studied the lymphatics of lung and pleura most carefully in dog and man, the only communications between the lymphatics of the pleura and the deep lymphatics occur around the veins which reach the pleural surface. These vessels are provided with ralves so that the lymph stream passes, in them, toward the pleural surface. The collecting stems of the subpleural lymphaties pass independently to the pulmonary nodes.

Lymphatics of the heart.-The superficial (subepicardial) lymphatics of the heart collect to two main stems which accompany the main coronary vessels. The right stem accompanies the right coronary artery to its origin, passes on over the arch of the aorta and empties into one of the anterior mediastinal lymphnodes. The left stem, formed by two stems accompanying the circumflex and anterior descending branches of the coronary vein, passes behind the arch of the aorta to an anterior mediastinal lymph-gland. Two small subepicardial intercalated nodes have been described along these trunks.

Subendocardial lymphatics have been described in animals, which connect by vessels passing through the musculature with the superficial lymphatics.

Parenchymatous lymphatics have recently been demonstrated by Bock. The course of their efferent vessels has not yet been described.

The lymphatic vessels of the œsophagus, which will here be considered throughout its entire extent, cervical as well as thoracic, are arranged in two plexuses, one of which occurs in the mucosa and the other in the submucosa. The collecting vessels arising from the plexuses may be divided into three sets, of which the uppermost pass to outlying nodes belonging to the deep cervical chain, those from the thoracic portion of the tube pass to the bronchial and posterior mediastinal nodes, while those from its lowermost part pass to the superior gastric nodes (fig. 573).

\section{THE LYMPHATICS OF THE ABDOMEN AND PELVIS}

In the following section there will be described successively the lymphatic nodes of the abdomen and pelvis, the lymphatic vessels of the abdominal walls, and the visceral lymphatic vessels.

\section{The Lympinatic Nodes of the Abdomen and Pelvis}

The lymphatics which connect directly with the thoracic duct, though complicated, may be described bricfly by saying that they follow the aorta and its branches. In the abdomen there are four main chains along the aorta-(1) the left lumbar chain; (2) the right lumbar chain; (3) the pre-aortic chain; and (4) the post-aortic chain.

The right and left lumbar nodes [lgl. lumbales], form an almost continuous chain along the abdominal aorta, resting upon the psoas muscles, some of those on the right side being ventral and some dorsal to the inferior vena cava. They receive:-(1) the efferent lymphatics of the common iliae nodes, and hence drain the leg and external genitalia; (2) the efferent lymphaties that follow the lumbar arteries and hence drain the abdominal wall; (3) the efferents that follow the paired visceral aortic branches, namely, those from the kidneys, supra-renal, and internal reproductive organs. On the right side, the lymphaties from the reprorluetive organs pass to the nodes ventral to the vena cava-those of the abdominal walls pass to the dorsal set, while those from the kidney pass to both sets.

The efferent vressels of the lower lumbar nodes pass to higher ones and so on up the chain, the vessels from the uppermost nodes uniting to form a single lumbar trunk on each side. 'Thase trunks pass to the thoracic duct, forming two of the so-cealled trunks of origin of that vessel (fig. 571).

The pre-aortic nodes [lymphoglandulir eorliaex] are arranged in three groups at the root of each of the three unpaired visecral branches of the aorta-the creliac, the superior mosenterie, and the inforior mesenteric arteries. The cœliac nodes are from one to three in number, and are in reality parts of chains of nodes extending along the loranches of the artery and constituting the hepatic, gastric, and splenic nodes. 'They drain the stomach, duodenum, liver', pancreas, and spleen. 
The superior mesenteric group is larger, and is continuous with the mesenteric nodes lying in the root of the mesentery. 'This group drains the remainder of the small intestine, the cæcum and appendix, the ascending and transverse colons, and the pancreas.

The inferior mesenteric group usually has two nodes, one on either side of the artery. It drains the rectum and descending and sigmoid colons. All the nodes in the mesentery and intestinal walls may be considered as outlying nodes of the pre-aortic group. They will be studied in connection with the visceral lymphatics.

The inferior mesenteric nodes drain into the neighbouring lumbar nodes, and also directly upward to the superior mesenteric nodes, and then again to the cœliac nodes. From the last a single stem, the intestinal trunk, arises and passes either to the right lumbar trunk or directly to the thoracic duct, forming the third of the so-called trunks of origin of the duct.

Fig. 574.-Abdominal Aortic Nodes in the New-born. (Poirier and Charpy.)

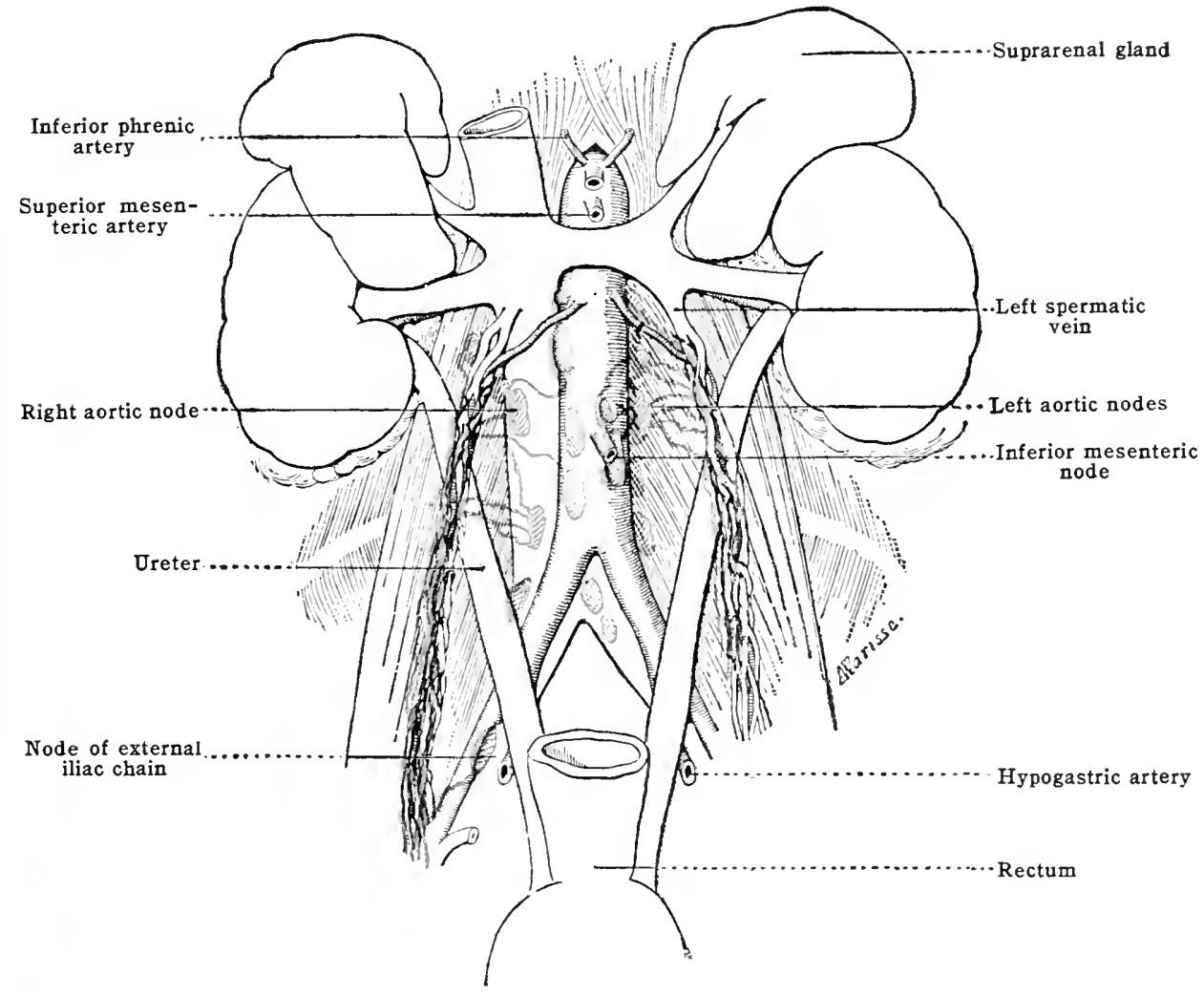

The post-aortic nodes are not true regional nodes, but receive vessels from the lumbar and pre-aortic chains.

Below the bifurcation of the aorta there are three large chains, the common iliac, the external iliac, and the hypogastric.

The common iliac nodes [lgl. iliacæ], are in three groups (fig. 575). The external set consists of about two nodes, which are in reality a part of a continuous chain extending along the side of the aorta, common iliac, and external iliac arteries. A second set of two to four posterior nodes lies behind the artery. These two groups receive the efferent vessels of the external iliac and hypogastric chains. The internal set usually consists of two nodes which rest upon the promontory of the sacrum. They receive vessels from the sacral nodes, together with most of those from the pelvic viscera, namely, from the prostate, neck of the bladder, neck of the uterus, the vagina, and part of the rectum. The efferent lymphatic vessels of the common iliac nodes pass to the lumbar chain. 
External iliac nodes.--These are likewise in three sets-external, middle, and internal. The external chain consists of three or four nodes, the lowest one being behind the crural arch. They receive:-(1) some of the vessels of the superficial and deep inguinal nodes; (2) ressels from the glans or clitoris, which come through the inguinal canal; (3) vessels from the part of the abdominal wall supplied by the deep epigastric and deep circumflex arteries, along which there may be a few outlying nodes-the epigastric nodes.

The middle chain consists of two or three nodes behind the artery. When there are three, the lowest is likewise near the crural areh. It receives vessels from the bladder, prostate, neek of the uterus, and upper portion of the vagina. The internal chain consists of three or four nodes, and is the continuation of the deep inguinal nodes. Its lowest nodes are likewise near the femoral ring, while the next node is large and constant, and usually lies within the pelvis. This chain

\section{Fig. 575.-Ilio-pelvic Nodes. (Cunéo andîarcille.)}

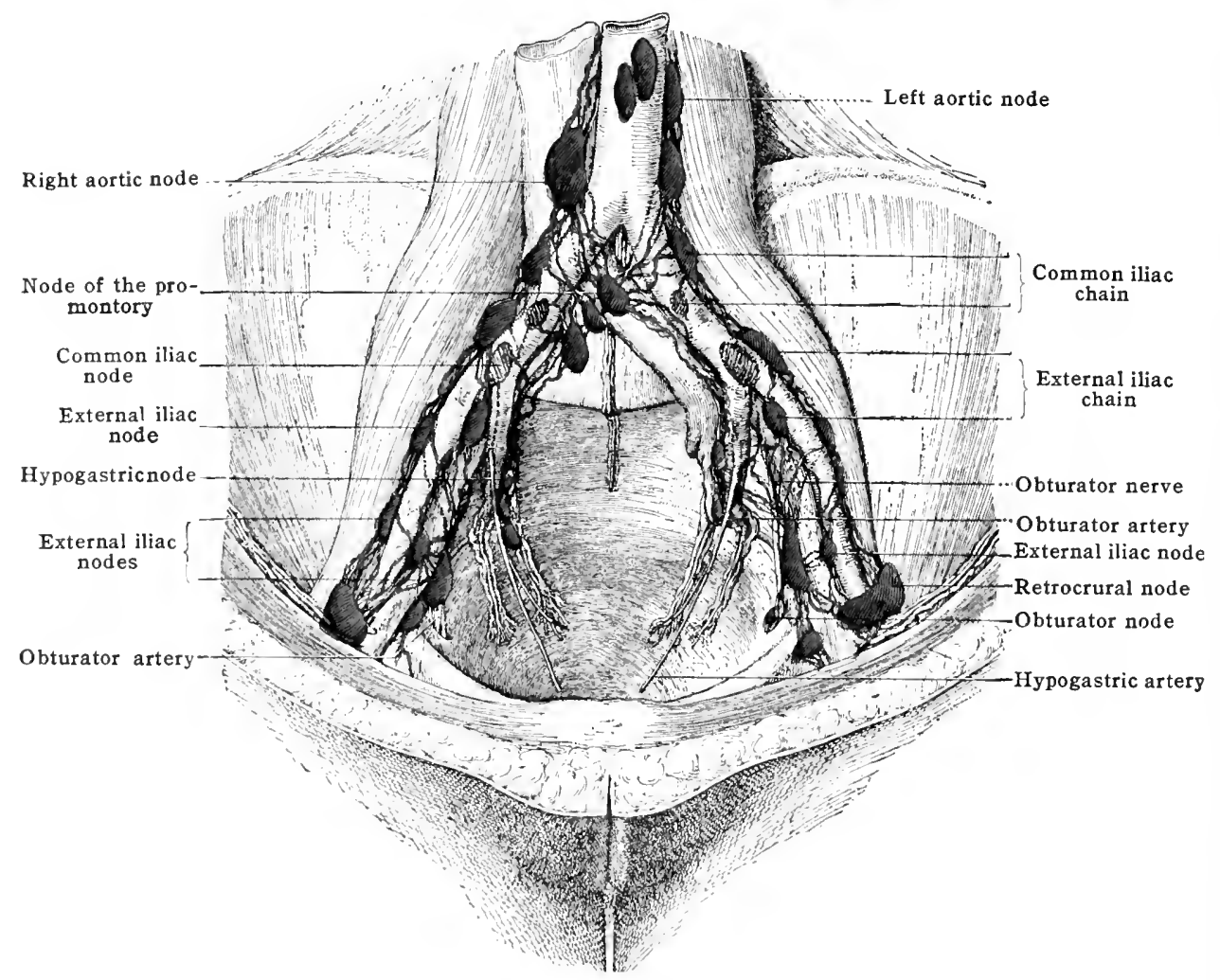

reecives many vrossels:-(1) from the superfedal and deep inguinal nodes; (2) from the glans and elitoris through the femoral eanal; (3) from the abdominal wall; (1) from the neighhourhoos of the olsturator vessels; (5) from the neck of the biadler, the prostatr, and membranous part of the urethra; (6) from the hypogastric: chain.

Thus, to smm un the nodes of the rextrmal iliae ehains:-they are a part of a rhain which includres the lumbar, ("ommon iliae, external iliar, and inguinal nodes. It will be netred that this rextensive (rhain stops, for the most part, with the deep inguinal group). 'T'he extemal iliac modes receive the efferents of the superficial and forp inguinal moles; the midlle and intermal groups receive vessels from the jerlvis. The efforent vessels of all the merles in the ehain pass to the higher nodes.

The hypogastric nodes [kgl. hypogustricar]. - Whese nodes are in groups near the origin of the branches of the hypegastric; (intemal iliac) artery. Thus they orene near the origin of the obturator, the nucrine, or prostatie, the trunk of the 
inferior gluteal (sciatic) and pudic, the middle hæmorrhoidal, and the lateral sacral arteries. All the nodes are beneath the pelvic fascia, and are connected by numerous anastomoses. They receive lymphatics from the structures supplied by the corresponding arteries, namely, from the pelvic viscera, the perineum, and the posterior surface of the thigh and gluteal region. Their efferent vessels pass partly to the middle group of the common iliac nodes, and partly to the posterior nodes of the same chain.

The sacral nodes [Igl. sacrales]. - These nodes, 5 or 6 in number, lie in the hollow of the sacrum, in or near the mid-line. They receive afferent vessels from rectum and prostate, and their efferents pass to the hypogastric and lumbar nodes.

\section{THE LYMPHATIC VESSELS OF THE ABDOMINAL WALLS}

The lymphatic vessels of the abdominal walls are arranged in two sets, one of which is subcutaneous and the other deep or aponeurotic. The subcutaneous vessels form a rich network through all the subcutaneous tissue of the abdomen, anastomosing above with the subcutaneous plexus of the thorax. The collecting vessels converge toward the inguinal region, those from the posterior wall curving forward along the crest of the ilium, and they all terminate in the superficial inguinal nodes.

The deep vessels drain along three principal lines. (1) A set of collecting vessels follows the line of the deep epigastric artery to terminate in the lower external iliac nodes; (2) a second set follows the deep circumflex iliac vessels to the same nodes; and (3) a third set follows the lumbar vessels to terminate in the nodes of the lumbar chain. A group of small epigastric nodes, which may be regarded as offsets from the iliac chain, occur on the lymph-vessels which accompany the deep epigastric vessels, not far from their termination, and a second less constant group of usually three small umbilical nodes occurs in the vicinity of the umbilicus in the network covering the posterior layer of the sheath of the rectus abdominis muscle.

\section{THE VISCERAL LYMPHATIC VESSELS OF THE ABDOMEN AND PELVIS}

The lymphatics to the viscera follow along the course of the arteries. At the point where the artery of an organ branches from the aorta there is a group of nodes which represents the main regional group, and a second chain of nodes extends along the artery. The final arrangement of nodes and ducts varies with each organ.

Though the lymphatics follow the blood-vessels, the lymphatic capillaries in the regions where their relations are known are separated from the vascular capillaries; in the intestinal villi, for example, the lymphatic capillaries are central, while the vascular capillary plexuses are peripheral. The relation of the lymphatic capillaries to the essential structures of each organ, that is to say, the arrangement of the lymphatics in the absorbing area, is not yet clear in many organs, and this is a point which can be worked out by tracing the development and gradual invasion of each organ by the lymphatics. The old theory of the origin of the lymphatics from the tissue-spaces made this problem most difficult of attack.

In almost all organs there is a peripheral or capsular lymphatic plexus, which anastomoses with the parietal lymphatics, these anastomoses being particularly well developed in the case of the liver. In addition there are one or two deep plexuses in the great majority of the organs which drain partly directly to their regional nodes and partly by way of the peripheral plexus.

\section{The Lymphatics of the Alimentary Tract}

The lymphatics of the mouth, pharynx, and cesophagus have already been described (pp. 715, 730). In general, throughout the abdominal part of the alimentary canal, the distribution of nodes is as follows:-(1) There are primary regional nodes situated at the roots of the arteries as they leave the aorta, that is to say, around the coliac and the superior and inferior mesenteric arteries; these 
drain large segments of the intestine; (2) groups of definite and constant nodes placed along the branches of the arteries in the root of the mesentery; these drain a definite smaller segment of the intestine; (3) chains of nodes along the anastomotic loops of the arteries, close to the intestinal wall; these are of the type called 'intercalated nodes'; (4) solitary or compound follicles, situated within the submueosa or capillary zone of the lymphaties.

What may be taken as the typical arrangement of the lymphatic vessels in the intestine may be seen in fig. 576. There are three zones in which the capillary plexuses are spread out, namely, in the subserosa, the submucosa, and the mucosa. There is an abundant plexus of large capillaries just beneath the serosa; in the submucosa the plexus is also formed by large capillaries, while the mucosal plexus is finer. The lymph-follieles lie in the zone of the mucosal plexus, and it is from this that the central chyle vessels of the villi arise. The collecting vessels are formed by the union of vessels from the submucous and subserous plexuses. They traverse the three sets of nodes just described.

The lymphatics of the stomach (fig. 577). - The stomach differs from the rest of the alimentary canal in its blood-supply in having a ventral anastomotic loop, namely, that along the lesser eurvature. Along this loop is the superior gastric chain [lgl. gastrieæ superiores] of nodes, lying between the folds of the lesser omentum, some of them being on the posterior surface of the stomach. This is the most important group of nodes draining the stomach, and it has been shown that the lymph-vessels from the pylorus run obliquely aeross the stomach to the main mass of nodes near the cardia, an important point in the surgery of the pylorus. The efferent vessels of the chain pass to the cœliac nodes. The vessels of the greater curvature pass to a group of inferior gastric nodes [lgl. gastricæ inferiores], situated along the right gastro-epiploic artery, while those of the fundus follow the short gastric and left gastro-epiploic vessels to the nodes which lie along the splenic artery, both these sets of nodes also draining to the cœliac group. There is a zone half-way between the lesser and greater curvatures, in which the lymphatics are scanty. The lymphaties of the cardia connect with those of the œesophagus, and the mucosal plexus of the pylorus is continuous with that of the duodenum.

The lymphatics of the duodenum.-The lymphatics of the duodenum depart somewhat from the type, owing to its relations with the panereas and the bileducts. The collecting vessels end:-(1) in nodes ventral to the pancreas, which follow the panereatico-duodenal artery to the hepatic chain; (2) in nodes dorsal to the pancreas, which follow the superior mesenteric artery to the superior mesenteric nodes. There are anastomoses between the lymphatics of the duodenum and those of the pylorus, of the pancreas, and of the chain along the common bile-duct.

The lymphatics of the jejuno-ileum (fig. 578) have already served as the type of the arrangement of the intestinal lymphatics (see above). The mass of mesenteric nodes [ [gl. mesenteriex] to which the lymphaties of the small intestine pass is the largest and one of the most important in the body, its individual nodes numbering anywhere from 130 to 150 .

The lymphatics of the ileo-cæcal region.--The surgical importance of the lymph-nodes in connection with the appendix warrants a detailed deseription of them in which the obscrvations of Brödel will be followed. The drainage of the cxecum and appendix is along the ilro-eolic artery, and is earried on by three sets of eollecting vessels-(1) an anterior cacal set, which generally pass through one or more outlying nodes before reaching the ileo-ceeal mesenteric nodes; (2) a similar posterior set; and (3) an appendicular set, three to six in number, whicb usually pass clirectly to the ileo-cecal nodes. The appendix thus has an independint drainage into one or two ileo-eacal nodes, albout $3 \mathrm{~cm}$. above the ileum. The iloo-cacal chain drains through the mesenteric nodes to the superior mesentrerie group (figs. 579, 580).

The lymphatics of the large intestine.-Along the ascending colon there are but fow nodes on the treminal vascular arches, but the number increases along the transverse colon, esperially at its two angles. These norles, together with those along tho drseconding and sinmoirl colons, are termed the meso-colic nodes [lgal. mesorolicare, and they drain partly to the superior mesenteric and partly to the inferior mesenteric nodes, their efferents following the eorresponding arteries. 
The lymphatics of the transverse colon connect with those of the omentum; those of the descending colon are more scanty.

The lymphatics of the rectum and anus.-There are three lymphatic zones of the rectum and anus. (1) An inferior zone, corresponding to the anal integument, in which the capillary networks, both superficial and deep, are extremely abundant, and from which from three to five collecting vessels on either side pass to the inguinal region and end in the medial superficial inguinal nodes. (2) A

Fig. 576.-The Lymphatic Vessels of the Intestine. (After Mall.)
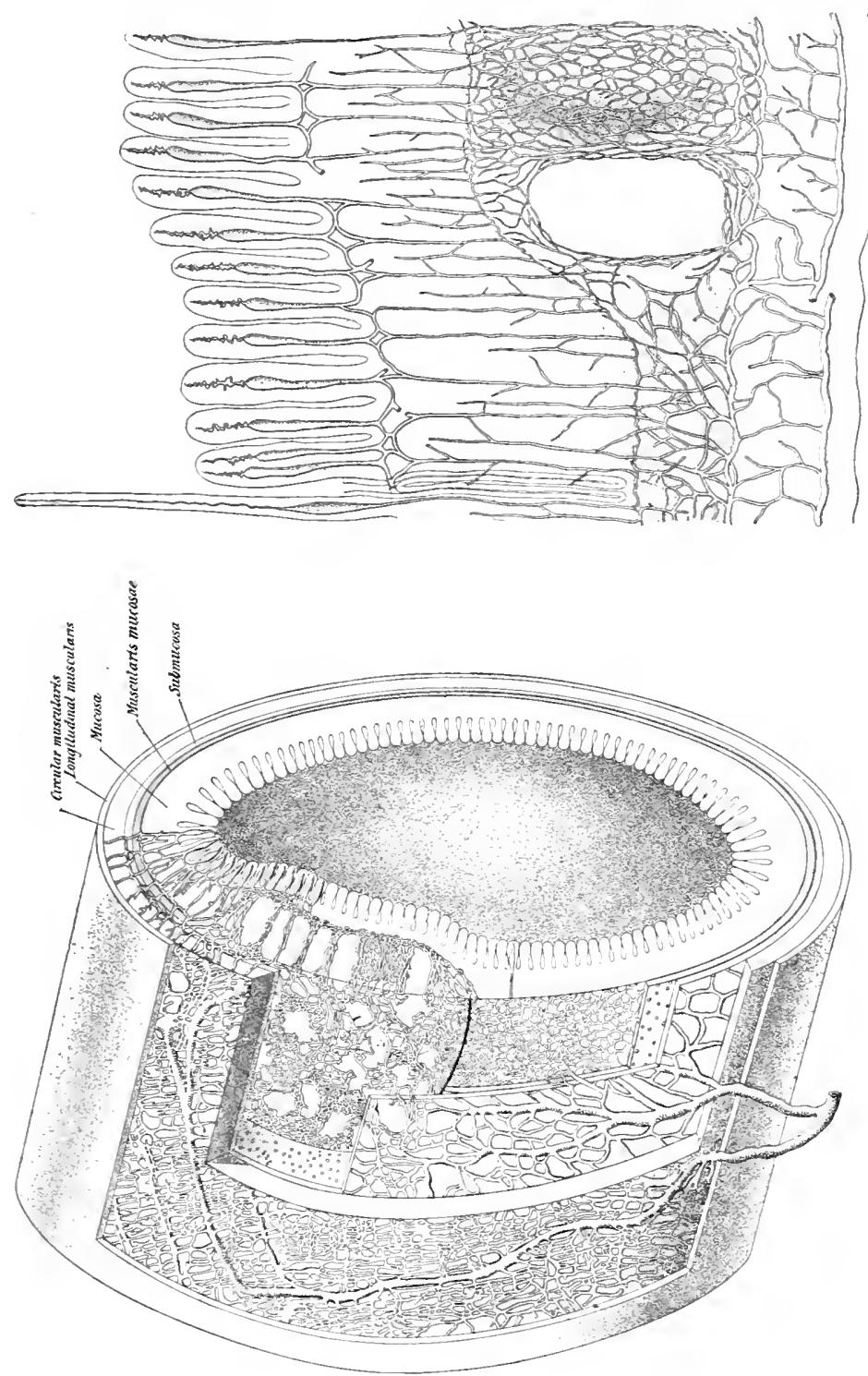

middle zone, corresponding with the transition zone of epithelium-that is, with the mucous membrane below the columns of Morgagni. Here the network is coarse, and has its meshes arranged vertically; its ducts drain partly into nodes situated along the inferior and middle hæmorrhoidal arteries, and partly pass to nodes in the meso-rectum, situated along the superior hæmorrhoidal artery and known as the ano-rectal nodes. (3) The superior zone corresponds to the remainder of the rectal mucous membrane, and contains a rich netrork whose collecting vessels pass to the ano-rectal glands, and thence along the superior hæmorrhoidal arteries to the inferior mesenteric nodes. 
Lymphatics of the liver.-The lymphatic drainage of the liver is complieated and has great need of being entirely restudied from the standpoint of development. Its course is mainly to the coliac nodes, but on the way it passes through a secondary group of three to six hepatic nodes [lgl. hepaticx], situated along the hepatic artery. Some of these nodes are along the horizontal part of the artery, parallel to the superior border of the pancreas, while the rest follow the artery in its rertical course along with the portal vein, and become continuous at the portal fissure with two distinct chains of nodes, one of which follows the hepatic artery and portal vein, and the other the cystic and common bile-ducts. These nodes are variable, but one constant node is at the junction of the cystic and hepatic ducts. A part of the drainage of the liver is also through the diaphragmatic nodes.

The superficial collecting lymph-vessels of the liver have been studied by sappey. Those from the superior surface include thrce sets. From the dorsal part vessels pass through the diaphragm with the vena cava, and end in the adjacent posterior mediastinal nodes. Some of these vessels from the right lobe pass in the coronary ligament to the coliac nodes, and some from the left lobe to the superior gastric nodes. The second set of vessels from the superior surface runs orer the ventral border to the hepatic nodes situated in the portal fissure. The third and most important set arises near the falciform ligament, and passes

Fig. 577.-The Limphatic Zones of the Stomach. (Cunéo.)

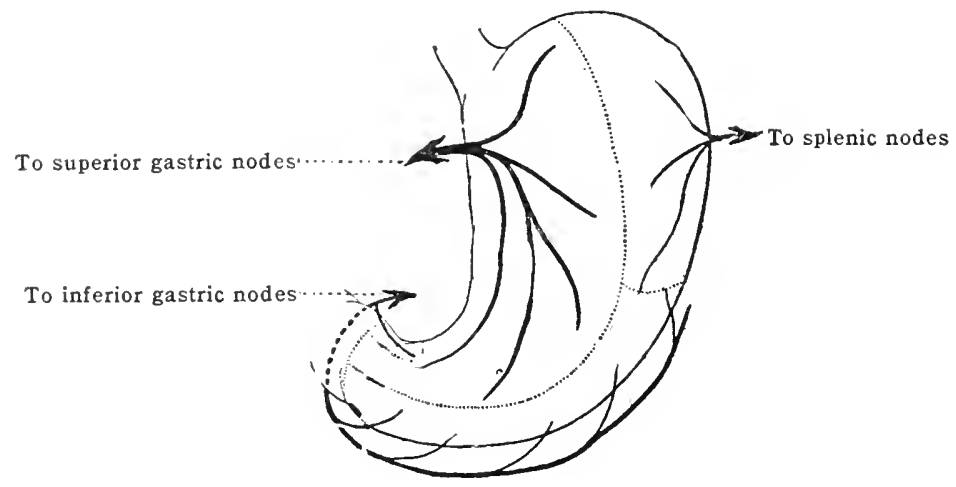

partly dorsalward to the anterior mediastinal group of nodes on the upper surface of the diaphragm, and to the nodes around the rena cava, and partly ventralward to the hepatic nodes of the portal fissure.

The collecting vessels of the inferior surface pass to the nodes situated in the portal fissure, either along the artery or the bile-ducts.

'The lymphaties of the gall-bladder join the hepatic nodes along the eystic and common bile-ducts, and also the superior pancreatic nodes.

Lymphatics of the pancreas. - The lymph-vessels which drain the pancreas fall, accorling to Bartels, into four groups: left, anterior (upper), right and posterior (10w(r). (1) 'The left group drain the tail of the pancreas and pass to the splenie lymph-nodes, at the hilus of the spleen. (2) Anteriorly lymphaties pass to "superior pancreatic lymph-nodes," superior gastric and hepatic nodes. (3) To the right, lymphaties pass to "pancreatico-duodenal lymph-nodes." (1) Posteriorly lymphatios pass to the andie, mesenteric, meso-colic, and inferior janereatic nodes. 'The sulenie, superior bancreatic, inferior pancreatic, and pancreatico-rluodenal norles are usually grouped together as "lymphoglandula francratico-licnales." Anistomose's exist betwern the lymphaties of the panereas and those of the diuorlemun.

The lymphatics of the spleen (fig. 582) are found only in the form of a sub(apsular plexus, there being uo derp notwork (Mall). 'They pass to the splenic nodes [Igl. mancreatico-lienales], which are variable in number and are situated 
along the course of the splenic ressels. In addition to the spleen they drain the fundus of the stomach and a part of the pancreas.

Fig. 575.-Lmaphatics of the Simal Ixtestine. (After Toldt, "Atlas of Human Anatomy," Rebman, London and New York.)

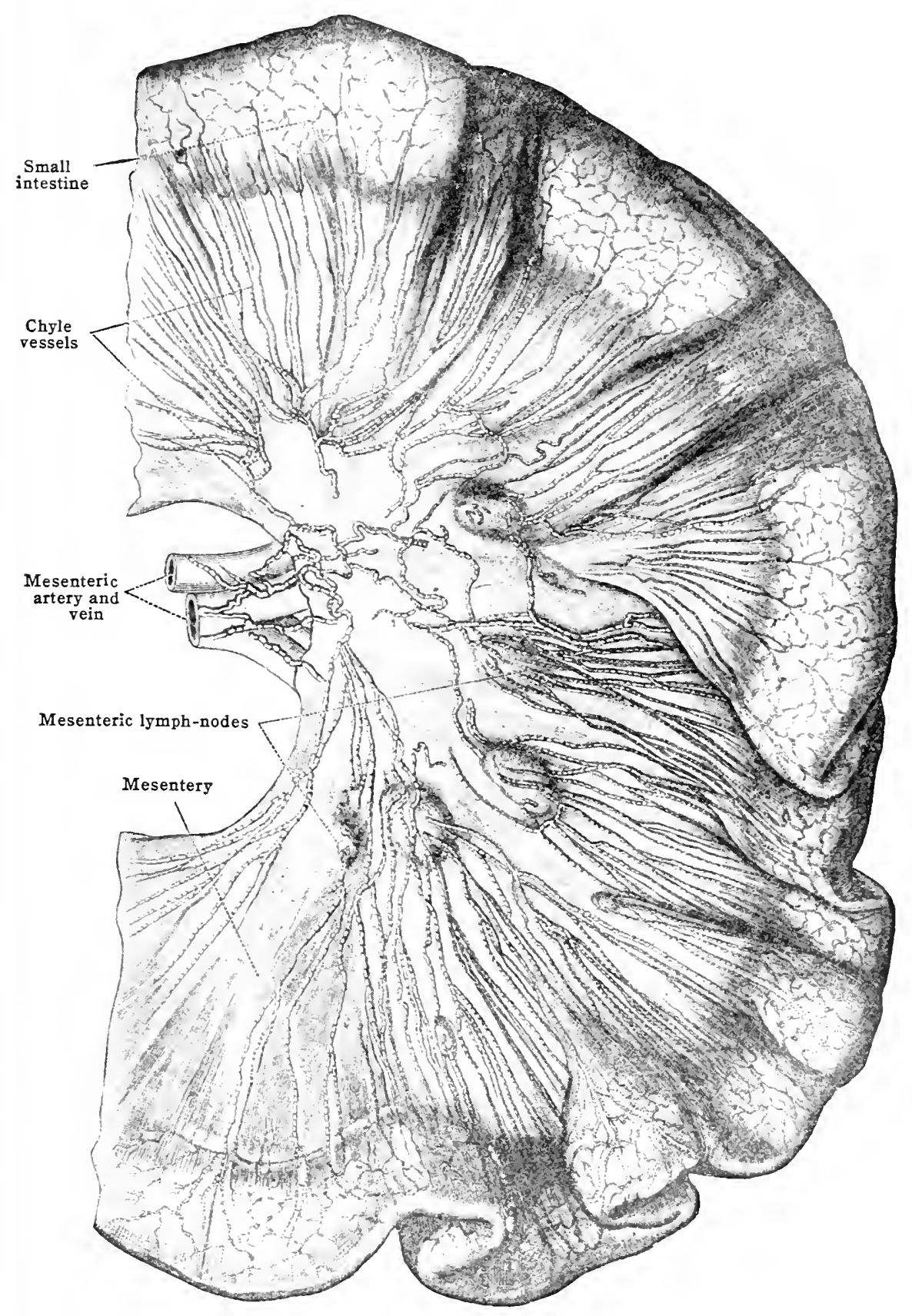

The Lmphatics of the Excretory OrGaxs axd of the SCPrarexal

The lymphatics of the kidney.--The lymphatic ressels from the leep capsular and parenchymatous lymphatics of the kidney run to the nodes of the lumbar chain (fig. 583). On the right side, part of the nodes concened lie ventral and 
part dorsal to the renal vein; one of the nodes lies as far caudalward as the bifurcation of the aorta; and one or two ressels may pass to pre-aortie nodes. On the left side the vessels end in four or frec nodes of the lumbar group. The efferents of these nodes pass through the diaphragm and end in the thoracie duet.

The lymphatics of the Suprarenal.-The lymphatic vessels coming from the capsular and parenchymatous plexuses pass, on the right side, into two or three anterior para-aortic nodes, and a small retro-venous gland, near the pillar of the diaphragm; on the left side, into para-aortic nodes, and, in part, through the diaphragm, in company with the splanchnic nerve, to a posterior mectiastinal

Fig. 579.-The Limphitic Circulation of the Ileo-C.ecal Region, Anterior View. (After Kelly.)

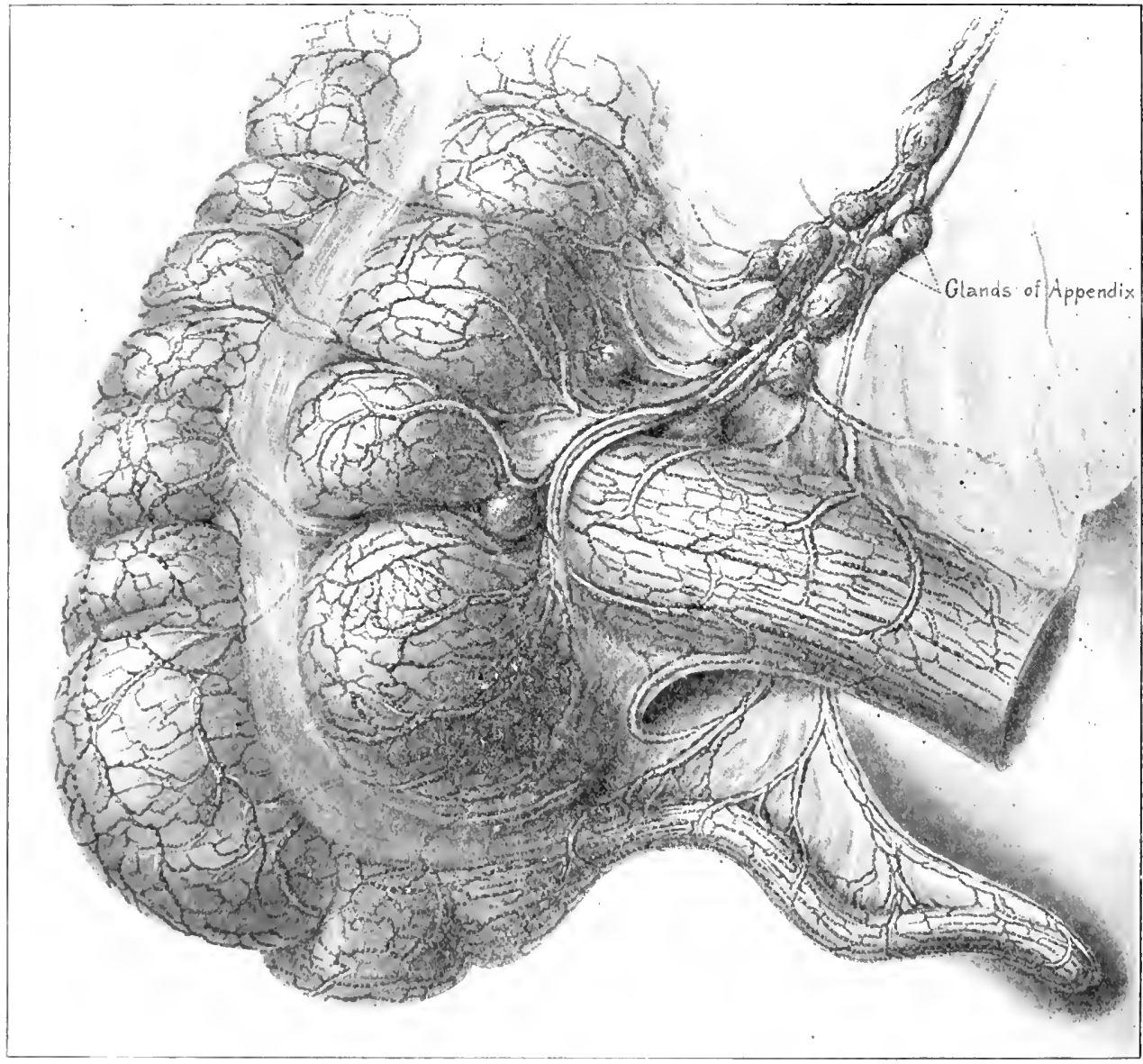

gland, lying betwern the ninth theracie vertebra and the arorta. Anastomoses ocente with the lymphaties of the kidney.

In audition to the aijesular lymphalies poper, Limnita deseribes a subserous plexus, which is presont over both kidney and allonal, which anastomoses with the lymphaties of the liver and diaphlagm. 'The efforents of this plexus collect,

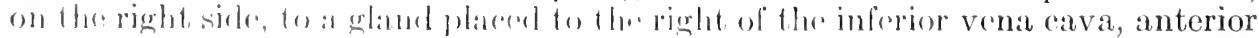

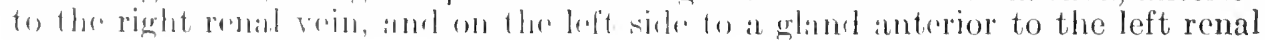
vin.

The lymphatics of the ureter. Salkata lats renenty studied the lymphaties of

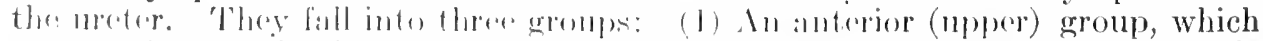
run to the antrion lumbar meles, or join the ronal lymphaties; (2) a middle

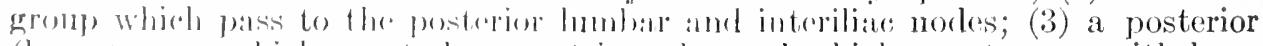

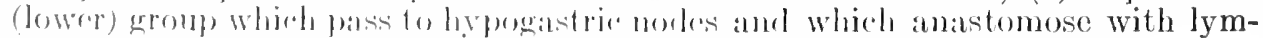
phaties of the bialler. 
The lymphatics of the bladder.-The collecting vessels from the lower part of the ventral surface pass to a node of the external iliat group, situaterl near the femoral ring and the obturator nerve; those from the upper part of the ventral and dorsal surfaces pass to the midclle node of the midlle gromp of the externat iliate chain, and from the rest of the dorsal surface they pass either to the hypugastric

Fig. 580.-The Lymphatic Circulation of the Ileo-cecal Region Posterior View. (After Kelly.)

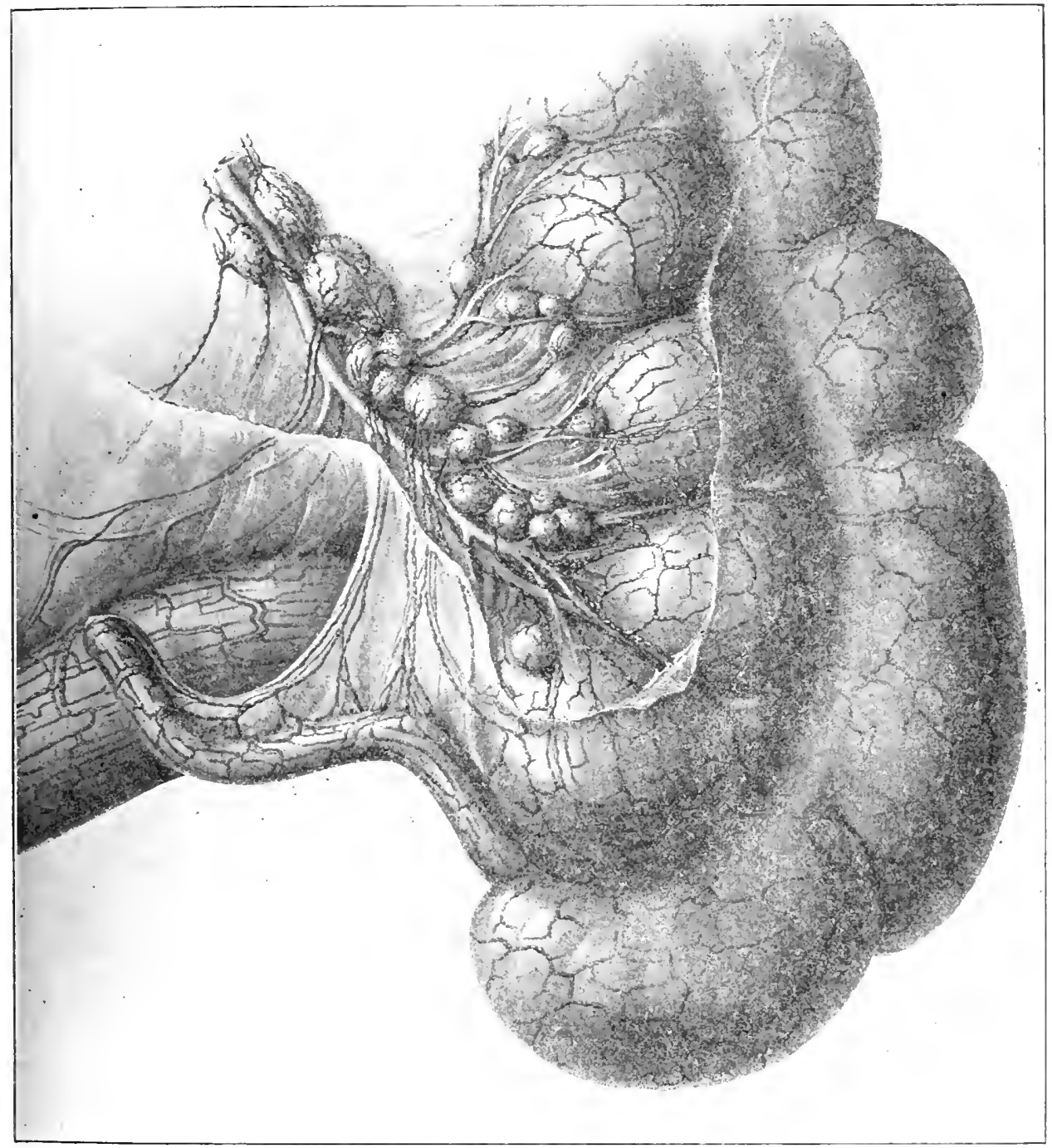

nodes or beyond these to the nodes at the bifurcation of the aorta (fig. 584). In this latter group end also the ressels from the neck of the bladder. Along some of the lymphatics of the bladder are intercalated lymph-notles, which have been termed anterior and lateral vesical nodes.

The lymphatics of the prostate.- The lymphatics of the prostate have been studied in the dog by Walker and in man by Bruhns. The collecting rescels, six to eight on each side, pass along the prostatic artery to the nodes along the external border of the hypogastric artery. These nodes are connected with those along the external and common iliac arteries, and it is possible, from an injection of the prostate, to fill the entire chain of nodes as far as the renal artery. A trunk from the posterior surface runs up over the bladder and curves ontward to 
the midule node of the midule group of the external iliac chain, and still other vessels from the posterior surface run first clownwarel, pass around the rectum, and then ascend to the lateral sileral nudes. From the anterior surface a desecnding duct may follow the deep artery of the penis, and the internat pudic to the hypogastric Fig. 5\$1.-The superfichl Limpinatic Network of the Liver. (After Teichmann).

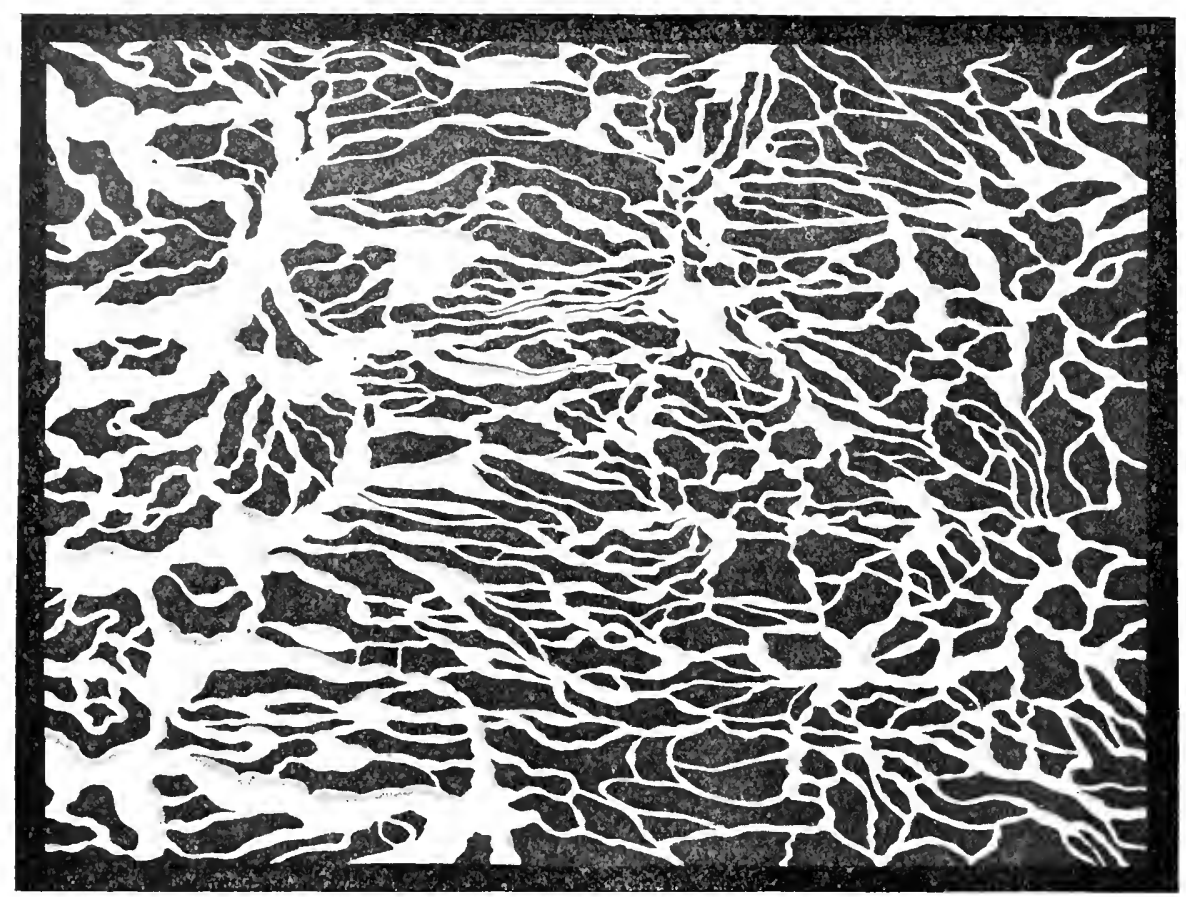

Fig. 5\$2.-Lrmphatics of the Periphery of a Pig's Sipleen. (After Teichmann.)

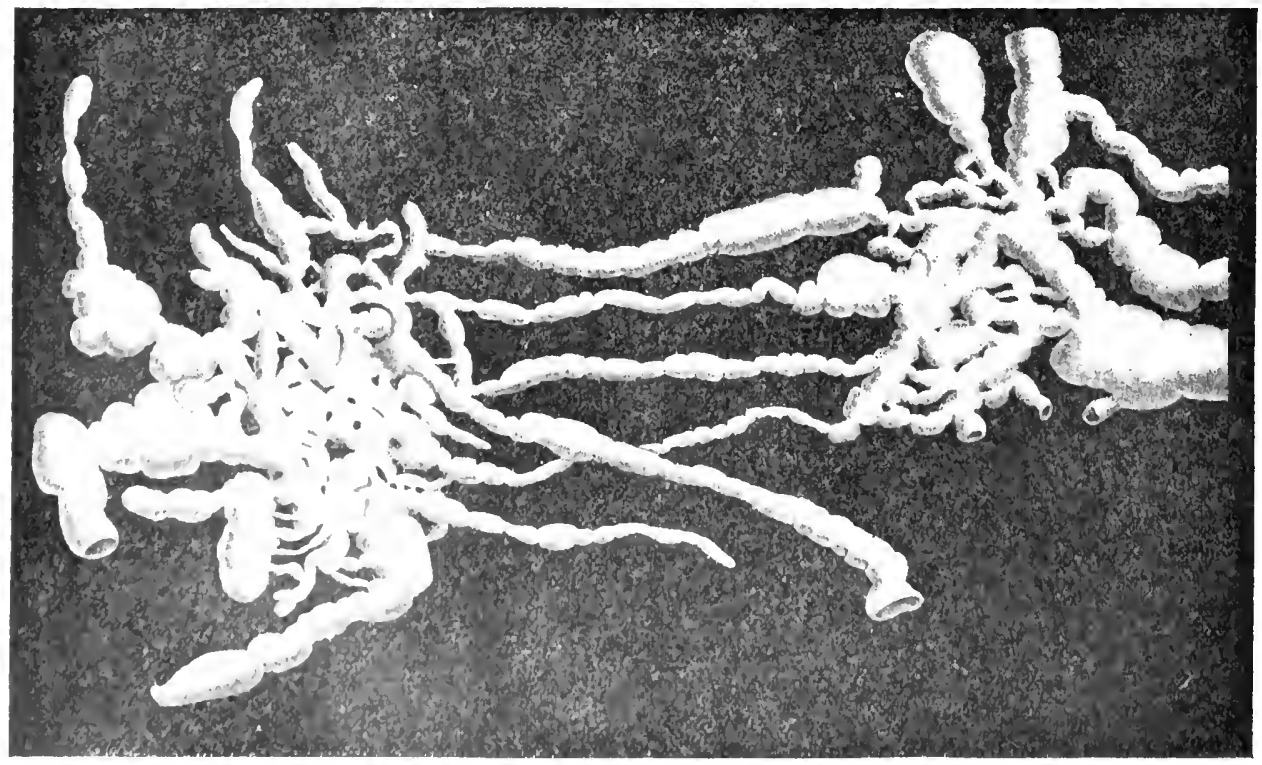

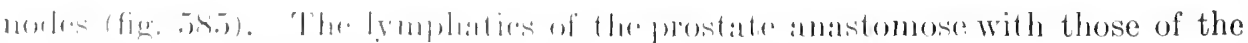

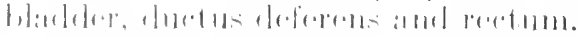

The lymphatics of the urethra. 1. In the Male. 'The "apillary plexus of the

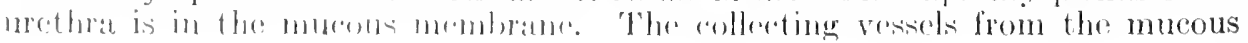


Fig. 583.-Lrmphatics of the Kindexey. (After Poirier and Cunéo.)

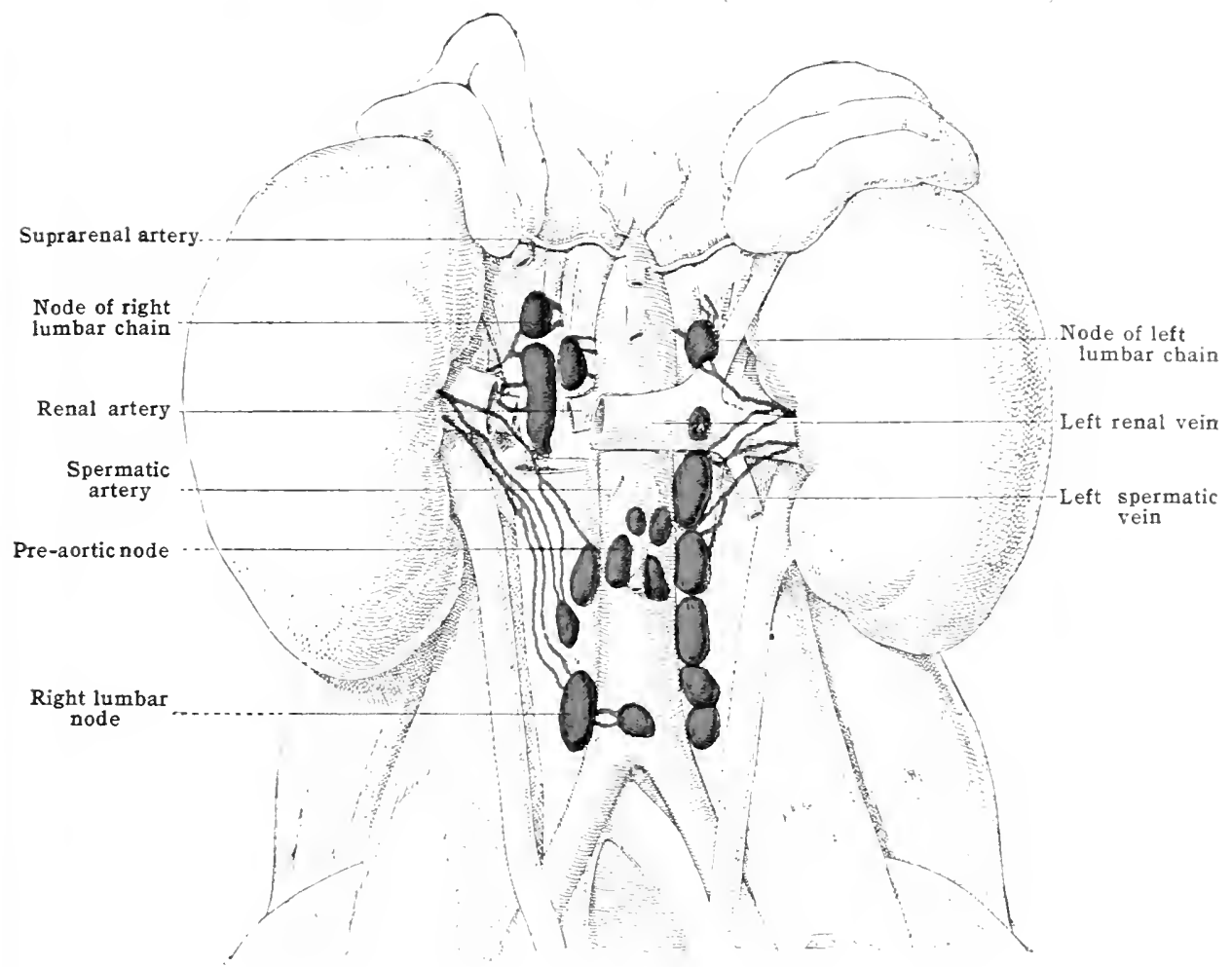

Fig. 5S4.-Lymphatics of the Bladder. (After Cunco and Marcille.

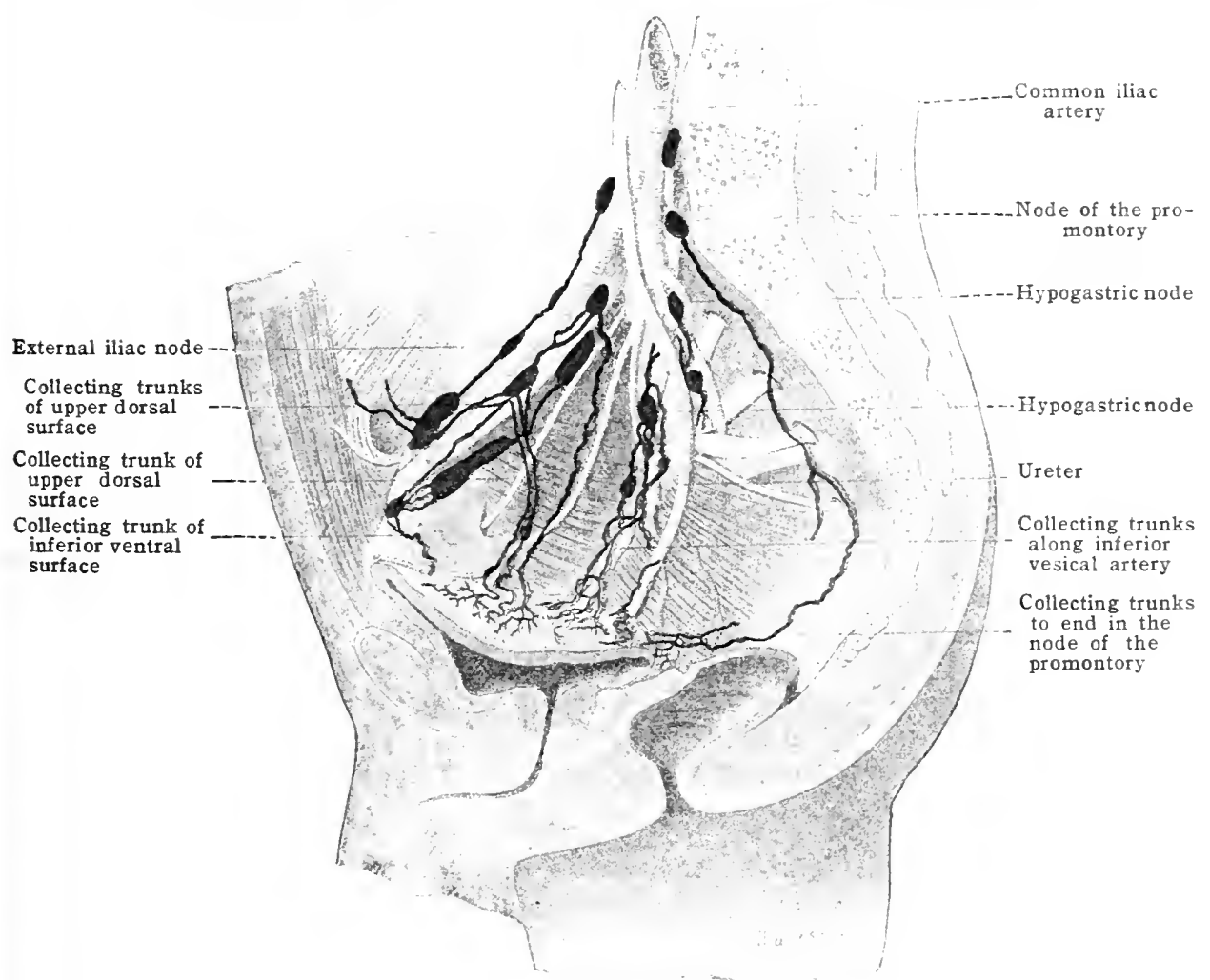


membrane of the glans follow the dorsal vein. Those from the penile and membranous portions of the urethra start from the inferior surface and curve around the corpora cavernosa, as seen in fig. 586 , to join the others along the clorsal vein. These vessels run with the vein to the symphysis, where they form a plexus in which there may be some small intercalated nodes. From this plexus vessels pass in two directions:- (1) Three or four vessels, the crural trunks, pass to the deep inguinal and external iliac nodes, and (2) one vessel enters the inguinal canal and ends in one of the external iliac nodes.

The ressels from the bulbar and membranous portions either follow the internal pudic artery, or pass to the symphysis and end in the external iliac nodes, or pass onto the surface of the bladder and thence to the external iliac chain. The

Fig. 585.-The Lmaphatics of the Prostate. (After Cunéo and Marcille.)

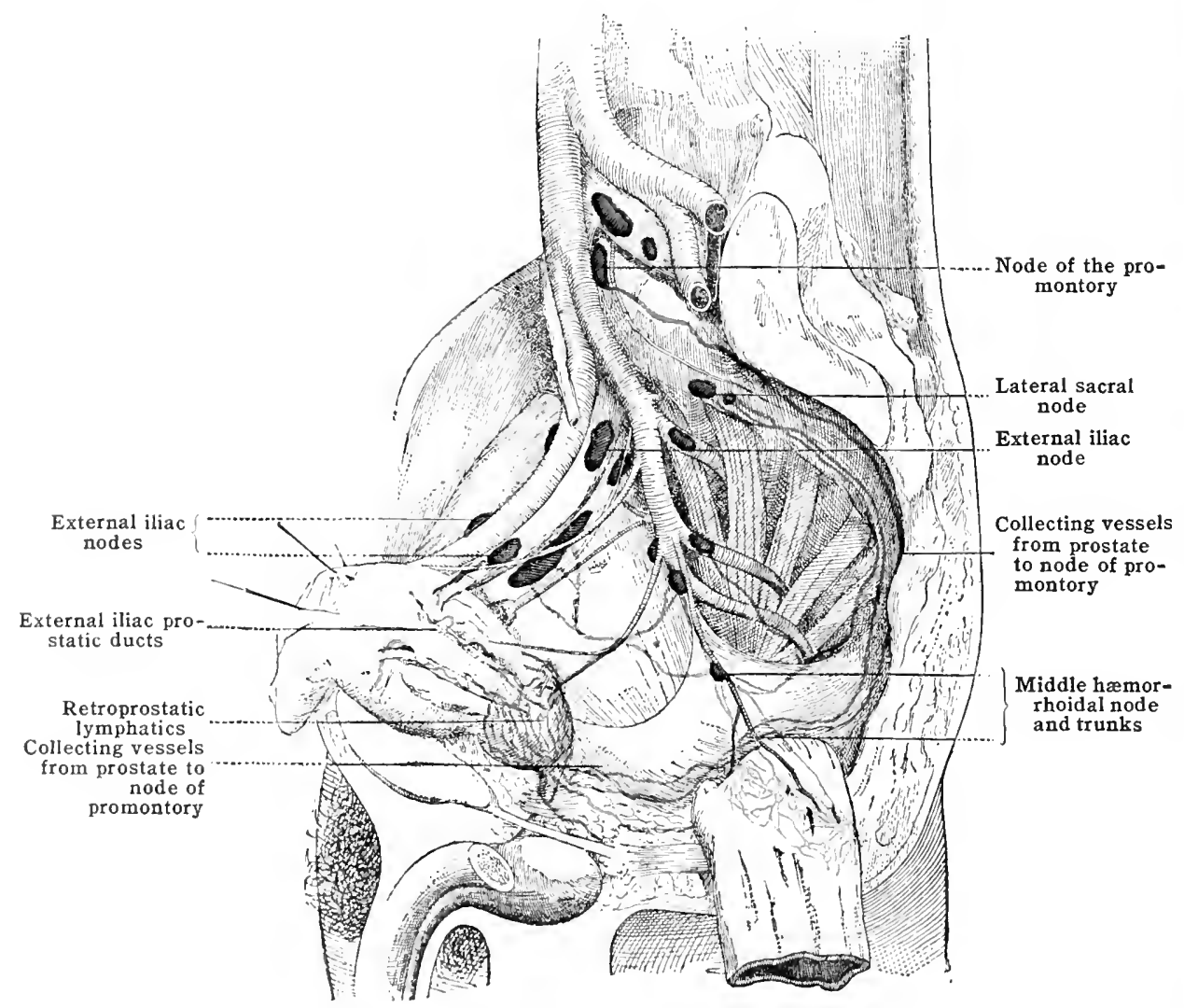

lymphaties of the prostatic portion run with the prostatic ducts. The lymphaties of the urethra anastomose with those of the bladder and those of the glans.

2. In the female the lymphatic vessels of the urethra end inthe external iliac and hypogastric nodes.

\section{Jampliates of the Reproductive Organs}

\section{In the Male (figs. 585, 586, 587)}

The lymphatios of the external genitalia will be first deseribed and then those of the internal orgatus (fig. 5s? ).

The lymphatics of the scrotum form a rich plexus which has been pictured by Trigehmann (fig. 547). The collecting vessels, ten to fiftern on either side, arise near the raphe and pass to the root of the penis, where some curve lateralward to the superior molial superficial inguinal nofles; white others, coming from the lateral surfate of the serotum, pass to the corresponding inferior nodes. 
Fig. 586.-Lymphatics of the Pfinle and Membranous Portions of the Urethra. (After Cunéo and Marcille.)

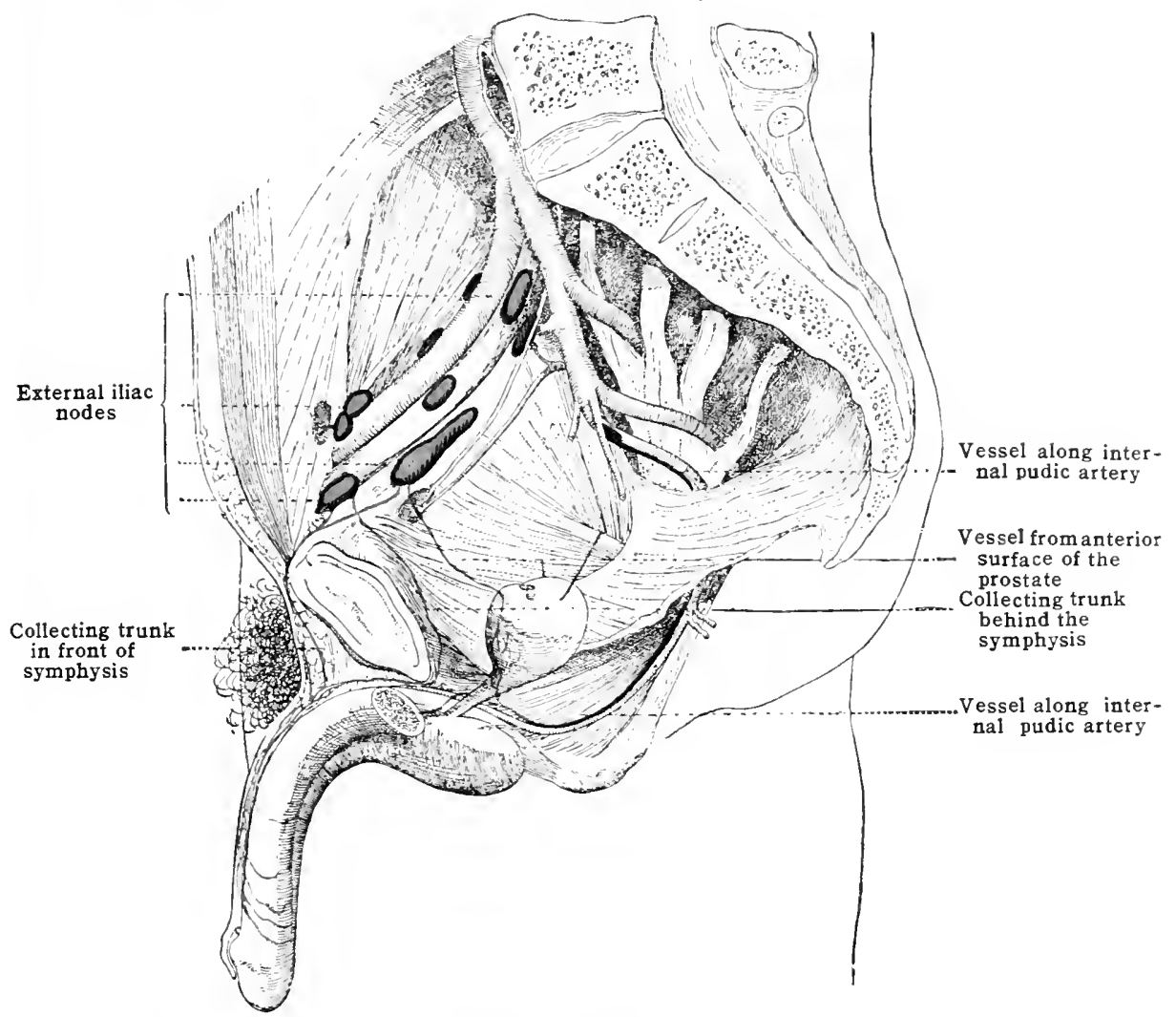

Fig. 587.-Lrmphatics of the Glaxs Pexis in a New-born Child. (Cunéo and Marcille.)

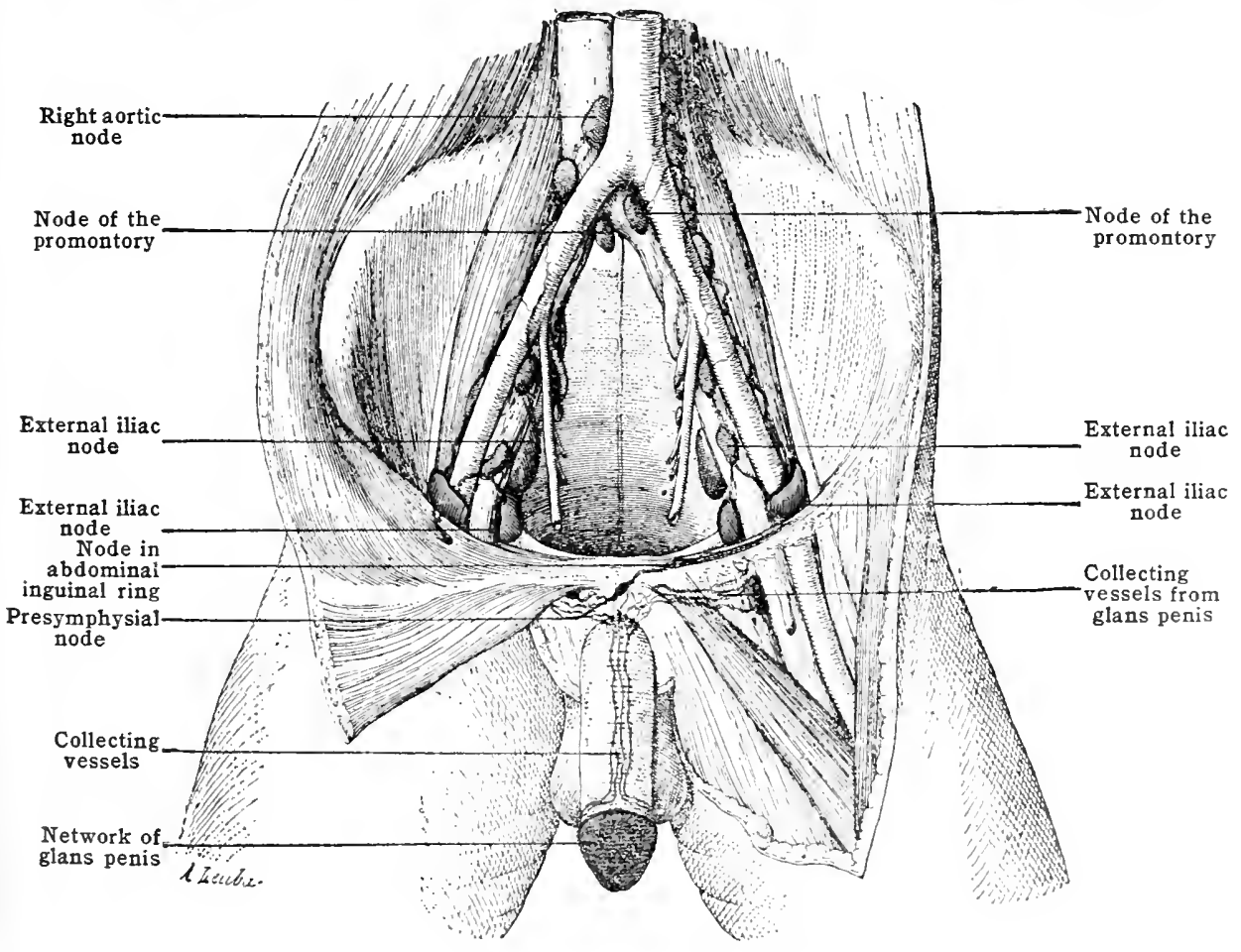


The lymphatics of the penis.-(1) The cutaneous lymphatics form a plexus from which collecting ressels follow the dorsal vein and end in the superficial inguinal nodes. (2) The lymphatics of the glans form an exccedingly rich plexus from which resscls follow the dorsal vein of the penis, as deseribed under the urethra, and end in the deep inguinal and external iliac nodes. (3) The lymphatics of the erectile structures are little known.

The lymphatics of the testis are both superficial and deep, the latter being exceedingly hard to inject. The collecting vessels follow the spermatic cord and artery and end in the lumbar nodes.

Fig. 5SS.-Limphatics of the Perneedr. (After Toldt, "Atlas of Human Anatomy," Rebman, London and New York.)

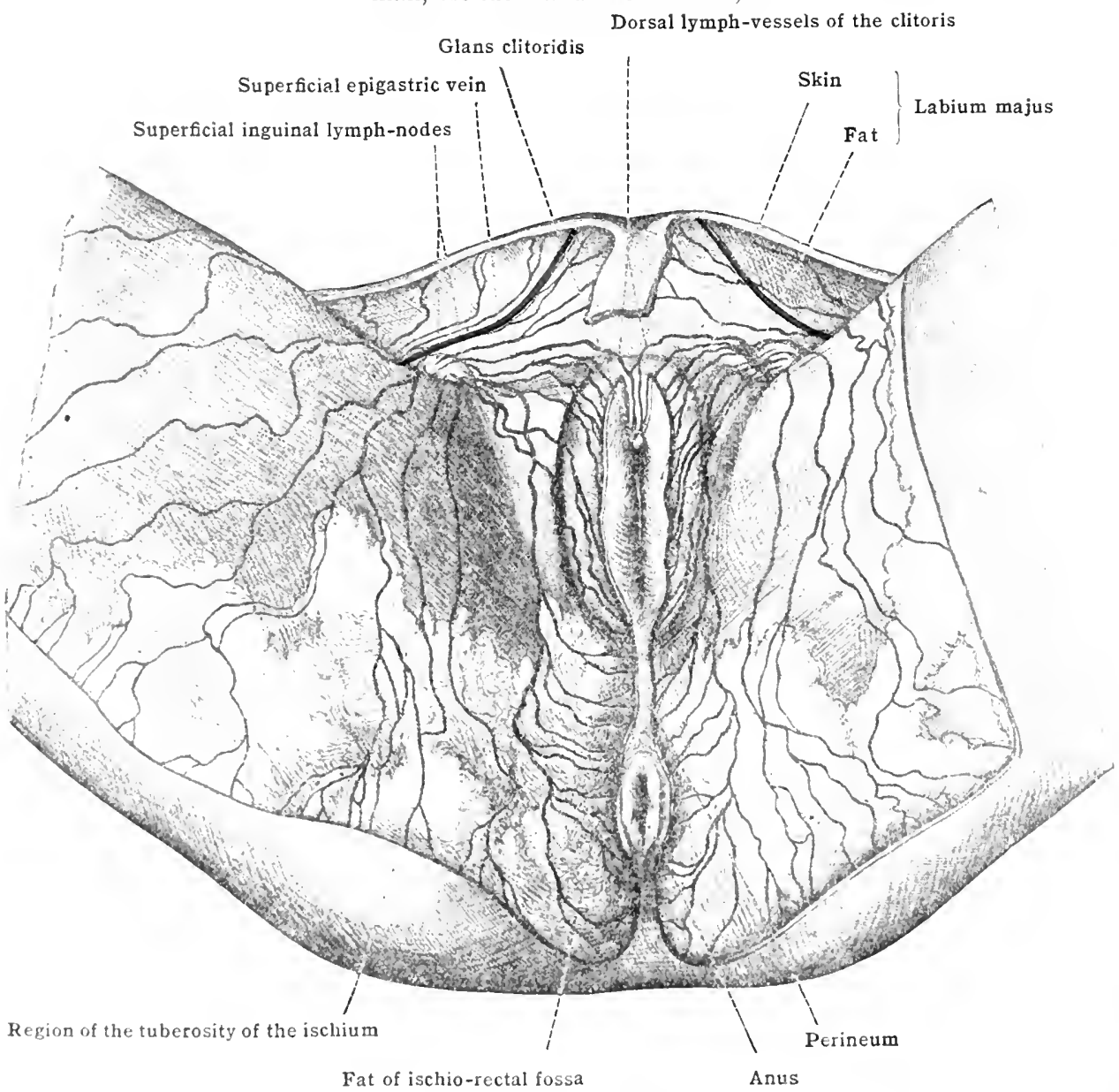

The lymphatics of the ductus deferens and vesiculæ seminales.-In the ductus forforous omly a superficial set has been injected, and its vessels pass to the rextronal iliar norles. The plexus of the vesieule seminales is double, superfirial and doep, and its vesseds pass to the external iliac and hypogastric nodes.

\section{In the Female}

(ligs. 588, 589, 590)

The lymphatics of the vulva. Throughont the vulva there is an execedingly rinh, suberficial lymphatic plexus, from which collecting vessels pass to the strmplysis and there tom lateralwated to the medial superficial inguinal nodes. The faret that thre apillary plexus is antinuons from side to side and that there is a plexus of the vessels in frout of the symphysis, makes the nodes of both sides liable fo inforetion from a milateral lessom. 
The lymphatics of the clitoris.-The lymphatics of the glans of the clitoris form an abundant network from which collecting vessels pass toward the symphysis pubis, and thence principally to the deeper inguinal nodes, one or two, however, passing through the inguinal canal to terminate in the lower external iliac nodes.

The lymphatics of the ovary.-The ovary has a remarkably rich lymphatic plexus, from which from four to six vessels leave the hilus and follow the orarian artery to the lumbar nodes. One ressel may run in the broad ligament to the internal iliac group.

The lymphatics of the Fallopian tube form three capillary networks from which collecting vessels run in part with those of the ovary, and in part with the uterine lymph-vessels.

The lymphatics of the uterus. -According to Poirier, the lymphatics of the uterus arise from three capillary plexuses, a mucous, a muscular, and a peritoneal. The collecting vessels from the body of the uterus are in three sets:- (1) Those from the fundus, consisting of four or five vessels, run lateralward in the suspen-

Fig. 589.-Lymphatics of the Internal Gexital Organs in the Female. (After Poirier.

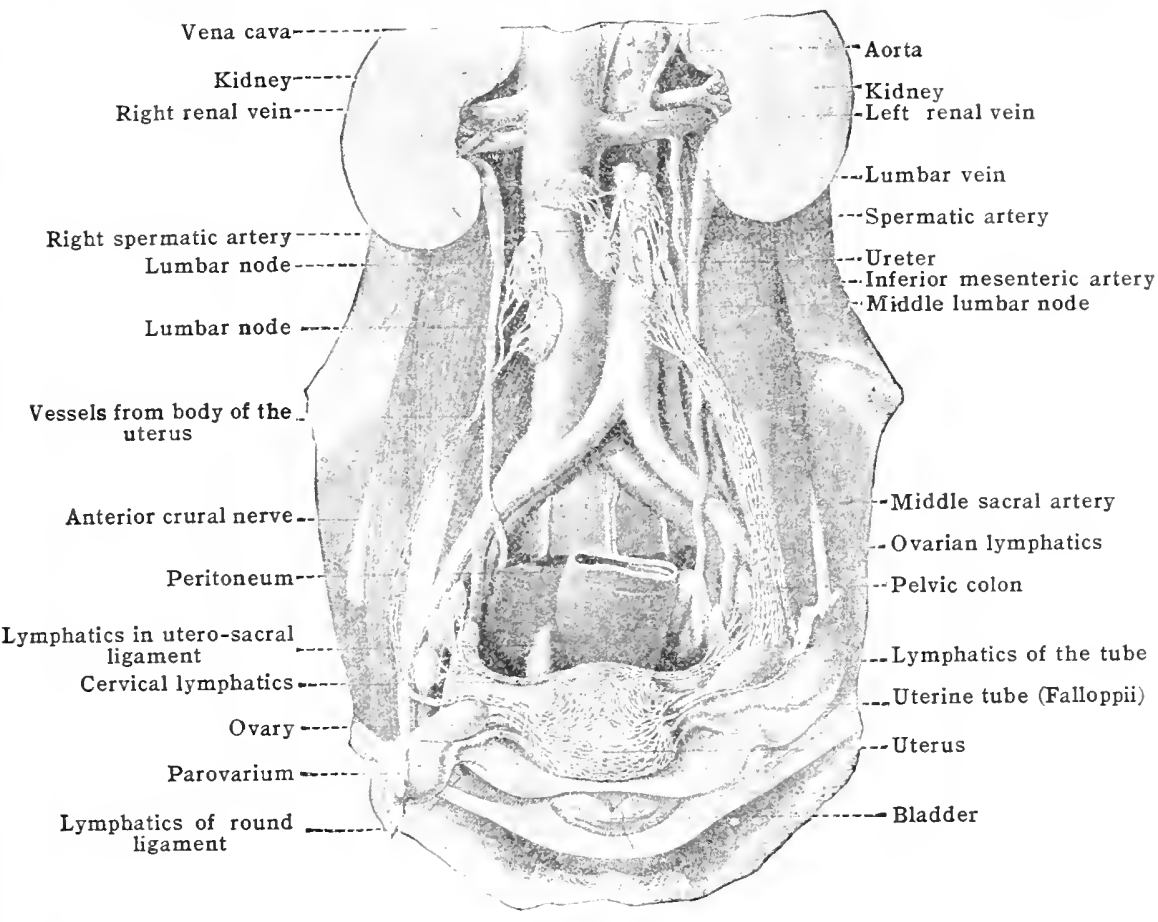

sory ligament of the ovary and follow the orarian vessels to the lumbar and preaortic nodes. They anastomose with the lymphatics from the ovary opposite the fifth lumbar vertebra; (2) some small vessels from the fundus follow the round ligament of the uterus and terminate in the inguinal nodes; and (3) others from the body of the uterus pass laterally with the uterine vessels and terminate in the iliac nodes.

The collecting vessels from the cervix, five to eight in number, form a large lymphatic plexus just after leaving the cervix. From this plexus run three sets of vessels. Two or three vessels pass lateralward with the uterine artery in front of the ureter, and end in the external iliac nodes; a second set passes behind the ureter and ends in a node of the hypogastric group, and a third set from the posterior surface runs downward over the vagina and then backward and upward to end in the lateral sacral nodes and node of the promontory of the sacrum.

The lymphatics of the vagina (fig. 590).- There are two lymphatic plexuses in the vagina, a superficial and deep-the latter, the mucosal plexus, being exceedingly rich. The collecting vessels are in three groups. The superior set drains the upper third of the vagina and takes the same course as those from the lower cervical portion of the uterus; the middle set follows the vaginal artery to 
the hypogastric nodes; and the inferior set runs to the lateral sacral nodes and to those of the promontory. The capillary network of the lower part of the vagina is continuous with the plexus of the vulva, which drains to the inguinal nodes.

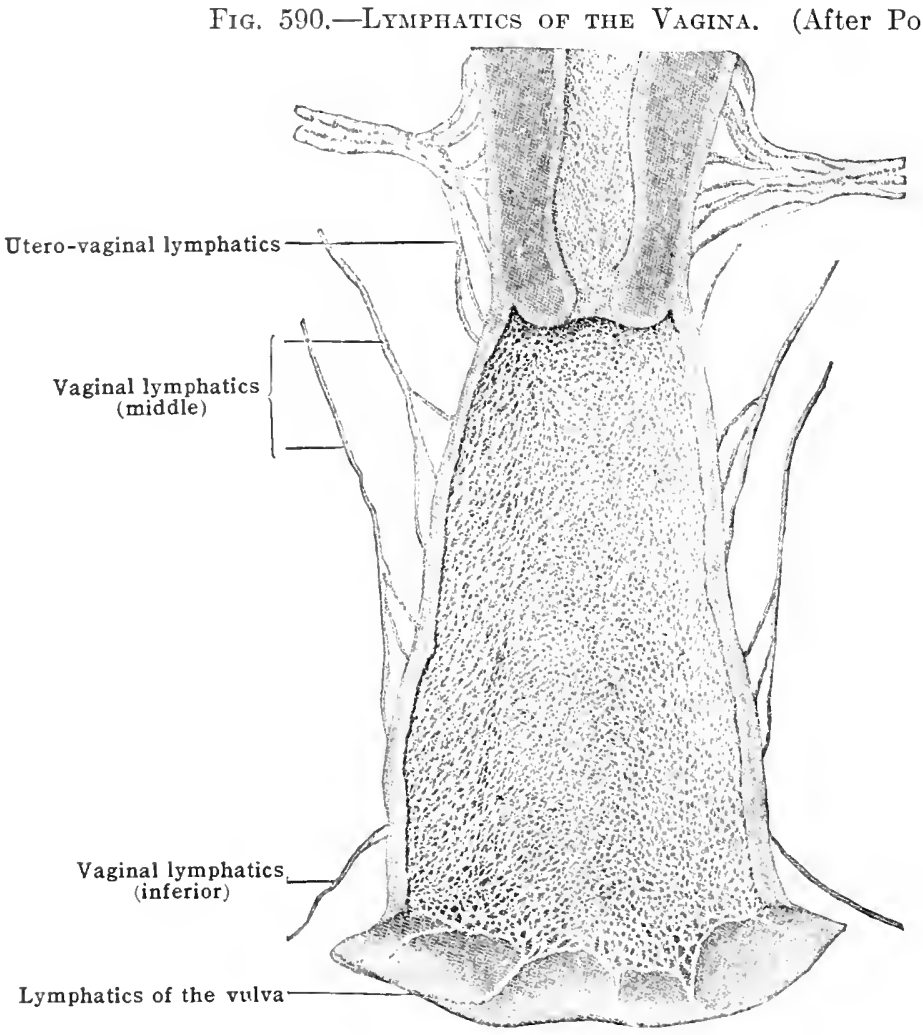

\section{E. THE LYMPHATICS OF THE LOWER EXTREMITY}

\section{THE LYMPHATIC NODES OF THE LOWER EXTREMITY}

The principal group of nodes of the lower extremity is situated in the inguinal region, and hence is known as the inguinal group. It is in many respects similar to the axillary group, although it is not quite equivalent to it developmentally. The nodes composing it are divisible into a superficial and a deep group, the former eontaining many more and larger nodes than the latter. Furthermore, it is convenient to divide each of these groups into an upper and a lower set, the dividing line being an arbitrary line drawn horizontally through the point where the simphenons vein pierces the fascia of the fossa ovalis. The nodes above this line are termed collectively the inguinal nodes, while those below it are known as the subinguinal nodes.

The superficial inguinal nodes [lgl. inguinales superficiales] (fig. 591), lie along the base of the femoral trigone immediately below Poupart's ligament, superficial to the fascia lata. 'Their number varies from ten to twenty. They receive the subcutaneous drainage of the abdominal walls, the gluteal region, and the perineal region, and their efferents descend to the fossa ovalis, which they perforate along with tho saphomous vein and terminate in the lower external iliar; norles.

The superficial subinguinal nodes [lgl. sulbinguinales superfieiales], occupy the lower part of the fromoral trigone and receive the entire superfieial drainage of the loge as woll as a fow vossols from the gluteal region and from the perineum. Their efferents piorce the fossa ovalis and pass partly to the deep subinguinal norles and partly directly to the lower external iliac nodes. 
The deep nodes. - The deep nodes are small, and vary from one to three. They lie medial to the femoral vein, the highest one (node of Cloquet or of Rosenmüller) being placed in the femoral ring and being of especial surgical

Fig. 591.-The Superficial Inguinal Nodes. (After Toldt, "Atlas of Human Anatomy," Rebman, London and New York.)

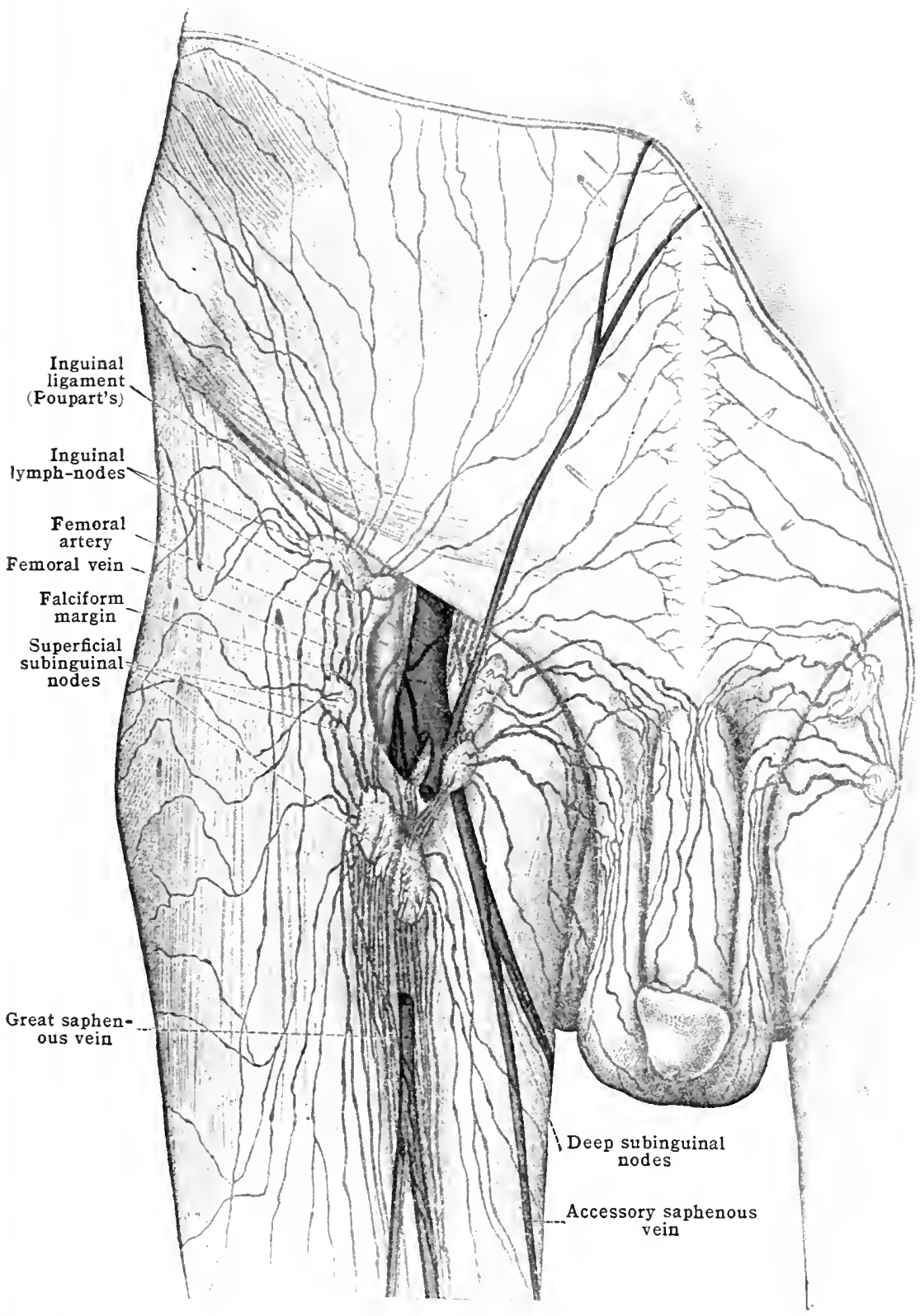

interest in that, when enlarged, it riay simulate a strangulated hernia. The lowest node is below the point where the lesser saphenous joins the femoral vein. These deep nodes receive the deep lymphatics of the leg, the vessels from the glans penis in the male, and the clitoris in the female, and some of the ressels from the superficial subinguinal nodes. Their efferent vessels enter the external iliac nodes.

In addition to the inguinal group of nodes there are some other nodes in the lower limb situated along the course of the deep vessels. Thus there is a node in the course of the anterior tibial vessels below the knee, and there is a small 
group of popliteal nodes [lgl. poplitece], in the popliteal space, which are in the course of the lesser saphenous vessels, and receive the vessels which accompany the posterior tibial and peroneal vessels and those which drain the knee-joint.

Fig. 592.-The Stperficial Lymphatics of the Lower Extremity. (After Toldt, "Atlas of Human Anatomy," Rebman, London and New York.)

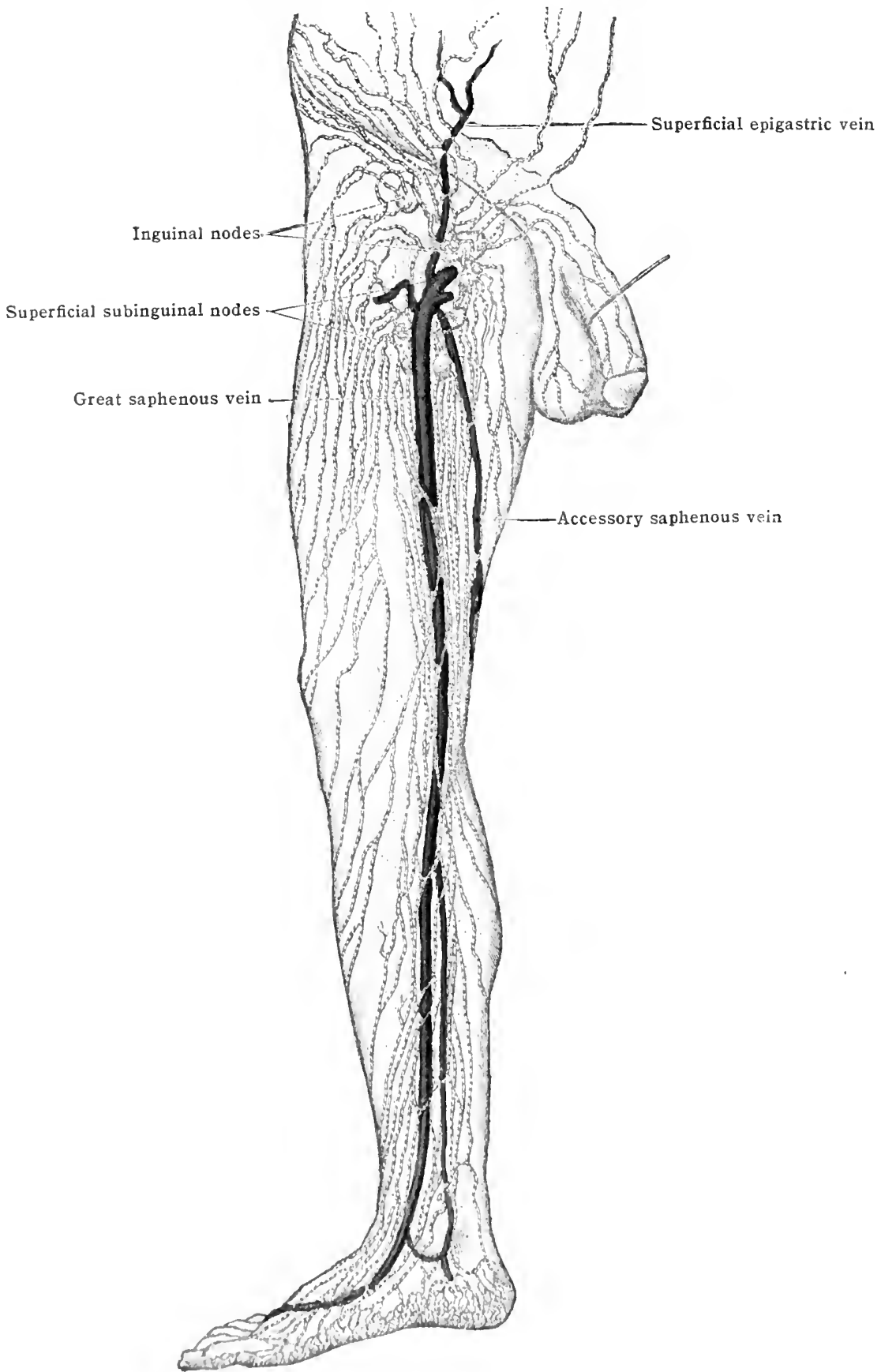

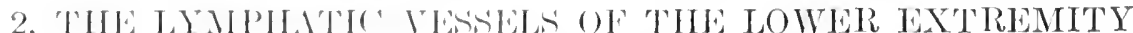

As in the mpper cxtermity, the suhentaneous capillary plexus of the lower varies grantly in complexity, fremg most abmulant in the soles of the fect. The collecting vessels form two main groups. 'The medial, larger group follows the saphenons voin, and ends in the suporficial subinguinal norles, while the lateral 
group curves around to join the medial, partly in the leg and partly in the thigh. Two or three vessels from the heel follow the lesser saphenous vein to the popliteal space. The vessels from the upper and dorsal part of the thigh curve around on both sides to reach the superficial inguinal nodes. The vessels of the anus and

Fig. 593.-The Lymphatics of the Back of the Lower Extremitr. (After Toldt, "Atlas of Human Anatomy," Rebman, London and New York.)

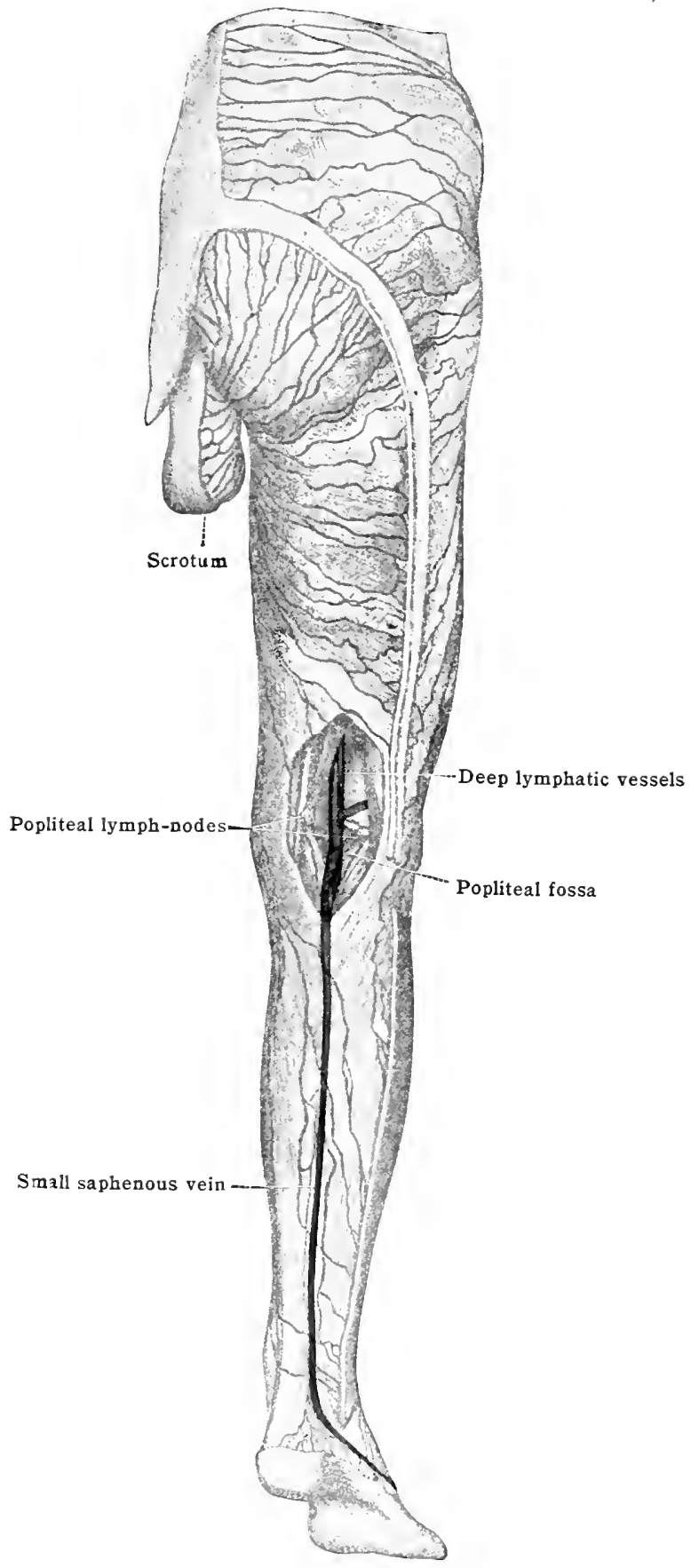

perineum, as well as those from the external genitalia, except from the glans penis or the clitoris, pass to the medial nodes of the superficial inguinal group.

The deep vessels follow the course of the arteries of the leg, those accompanying the dorsalis pedis and anterior tibial arteries coming into relation with the 
anterior tibial node, when it is present, and then passing backward to join the vessels which accompany the posterior tibial and peroneal arteries. These terminate in the popliteal nodes, from which efferents follow the course of the femoral artery and terminate in the deep inguinal nodes. The deep lymphatic vessels accompanying the gluteal and obturator arteries pass to the hypogastric nodes.

Lymphatics of the hip-joint.-According to Clermont, they accompany, in the main, the arteries about the joint. (1) Satellites of the anterior circumflex artery, draining almost the entire ventral surface, pass to the lateral inferior external iliac node. (2) Satellites of the posterior circumflex artery, draining the dorsal and medial surfaces, empty into the medial inferior external iliac node, occasionally into one of the deep inguinal nodes. (3) Satellites of the obturator vessel, draining the round ligament, empty into the obturator or hypogastric nodes. (4) Satellites of the inferior gluteal vessels, draining the dorsal surface, empty into three small nodes along the internal pudic and inferior gluteal arteries. Less important "accessory") vessels are: satellites of the superior gluteal artery leading to a gluteal node; vessels from the dorsal surface which cross the lateral border of the pectineus to reach the medial inferior external iliac node; and vessels from the ventral surface, crossing parallel to the cotyloid notch, passing under the psoas to the lateral inferior external iliac or one of the deep inguinal nodes.

Lymphatics of the knee-joint.-According to Tanasesco the lymphatics draining the structures around the knee-joint in the main follow the arteries about the joint and pass largely to the more deeply placed of the popliteal nodes. Some (superficial) follow the great saphenous vein to the subinguinal nodes, and sometimes deep vessels pass the popliteal nodes and, accompanying the femoral artery, run to the deep inguinal or inferior external iliac.

References for lymphatic system.-(Development): Sabin, Amer. Jour. Anat., vols. 1, 3, 4, 9, also in Keibel and Mall's Human Embryology; Lewis, Amer. Jour. Anat., vols. 5, 9; Huntington and McClure, Amer. Jour. Anat., vol. 10; Clark, E. L., Anat. Record, vol. 6; Clark, E. R., Amer. Jour. Anat., vol. 13. (Regeneration): Meyer, Johns Hopkins Hosp. Bul., vol. 17. (General): Bartels, in von Bardeleben's Handbuch d. Anatomie; Sappey, "Description et Iconographie des Vaisseaux Lymphatiques," Paris, 1885; 'Teichmann, "Das Saugadersystem," Leipzig, 1861. (Muscle, etc.): Aagaard, Anat. Hefte, Bd. 47. (Connective tissue): von Recklinghausen, "Die Lymphgefässe u. ihre Beziehung zum Bindegewebe," Berlin, 1862. (Stomata): Walter, Anat. Hefte, Bd. 46. (Lung): Miller, Anat. Rec., vol. 5. (Teeth): Schwcitzer, Arch. f. milir. Anat., Bd. 74. (Homolymph glands): von Schumacher, Arch. f. mikr. Anat., Bd. 81. Tumors): Evans, Beitr.z. klin. Chir., Bd. 78. 


\section{SECIION V I I \\ THE NERVOUS SYSTEM}

Revised for the Fifth Edition

By IRVING HaRdesty, A.B., Ph.D.

PROFESSOR OF ANATOMY, THE TULANE UNIVERSITY OF LOUISIANA

THE nervous system of man, both anatomically and functionally, is the most highly developed and definitely distributed of all the systems of the body.

It consists of an aggregation of peculiarly differentiated tissue-elements, so arranged that through them stimuli may be transmitted from and to all the other tissue systems or functional apparatuses. It is a mechanism with parts so adjusted that stimuli affecting one tissue may be conveyed, controlled, morlified, and distributed to other tissues so that the appropriate reactions result. While protoplasm will react without nerves, while musele will contract without the mediation of nerves, yet the nervous system is of the most vital importance to the higher organisms in that the stimuli required for the functioning of the organs are so distributed throughout their component elements that the necessary harmonious and coordinate activities are produced. For this purpose the nervous system permeates every organ of the body; nerve cell-bodies, accumulated into groups, receive impulses and give rise to the nerves whieh ramify and divide into smaller and smaller branches till the division attains the individual nerve-fibres of which the nerves are composed, and even the fibres bifurcate repeatedly before their final termination upon their allotted elements. So intimate and extensive is the distribution throughout that could all the other tissues of the body be dissolved away, still there would be left in gossamer its form and proportions - a phantom of the body composed entirely of nerves.

The parent portion or axis of the system extends along the dorsal mid-line of the body, surrounded by bone and, in addition, protected and supported by a series of especially constructed membranes or meninges, the outermost of which is the strongest. The cephalic end of the axis, the encephalon, is remarkably enlarged in man, and is enclosed within the largest portion of the bony cavity, the cranium, while the remainder of the central axis, the spinal cord, continues through the foramen magnum and lies in the vertebral canal.

The intimate connection of the axis with all the parts of the body is attained by means of forty-six pairs of nerves, which are attached to the axis at somerwat regular intervals along its extent. They course from their segments of attachment through the meninges and through their respective foramina in the bony cavity to the periphery. Of these cranio-spinal nerves, fifteen pairs pass through the cranium and are attached to the encephalon, and thirty-one pairs to the spinal cord. Some of the cranial nerves and all of the thirty-one pairs of spinal nerves contain both afferent fibres, which convey impulses from the peripheral tissues to the central axis, and efferent fibres, which convey impulses from the axis to the peripheral tissues. The different pairs of nerves possess the two types of fibres in varying proportions.

Upon approaching the spinal cord, each spinal nerve is separated into two roots -its posterior or dorsal root and its anterior or ventral root. The afferent fibres enter the axis by way of the dorsal roots, which are, therefore, the sensory loots, and the efferent fibres leave the axis by way of the rentral or motor roots.

As usually studied, the nervous system is referred to in two main divisions:-

(1) The central nervous system, composed of-(a) The spinal cord, or medulla spinalis, and $(b)$ the brain or encephalon. 
Fig. 594.-Showing the Ventral Aspect of the Central Nervous Systeir, with the Proxiial Portioxs of the Cranio-spinal Nerves attached and the Relation of the Proximal Portion (Gaxcliated Cord) of the Sympathetic Nervous System. The Encephalon or Brain is Straightened Dorsalward from its more Horizontal Position with Reference to the Spinal Cord. The Spinal Ganglia and the Dorsal and Tentral roots of the Spinal Nerves may be noted.

(Composite clrawing in part after Allen Thompson from Rauber-modified.)

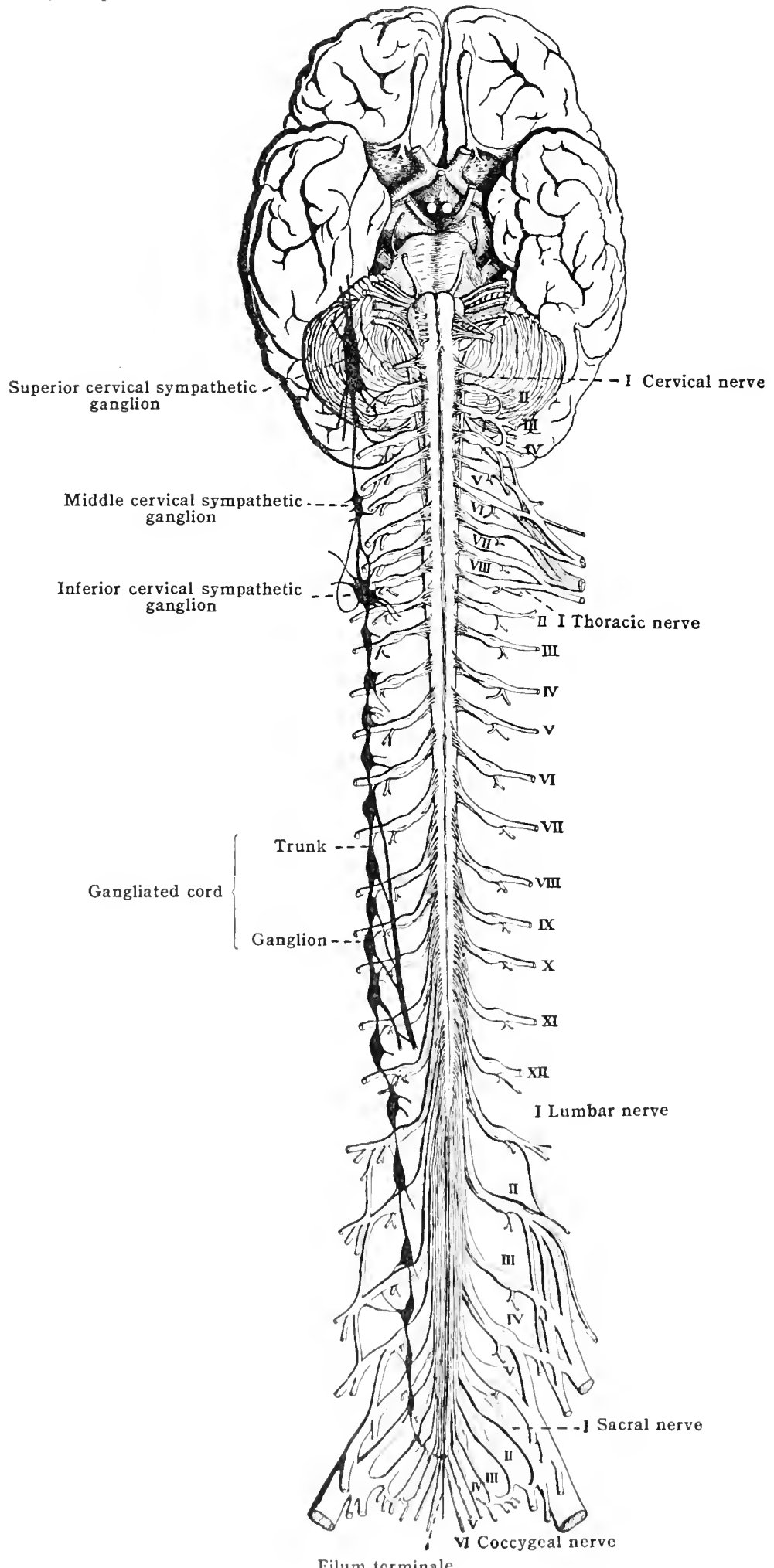



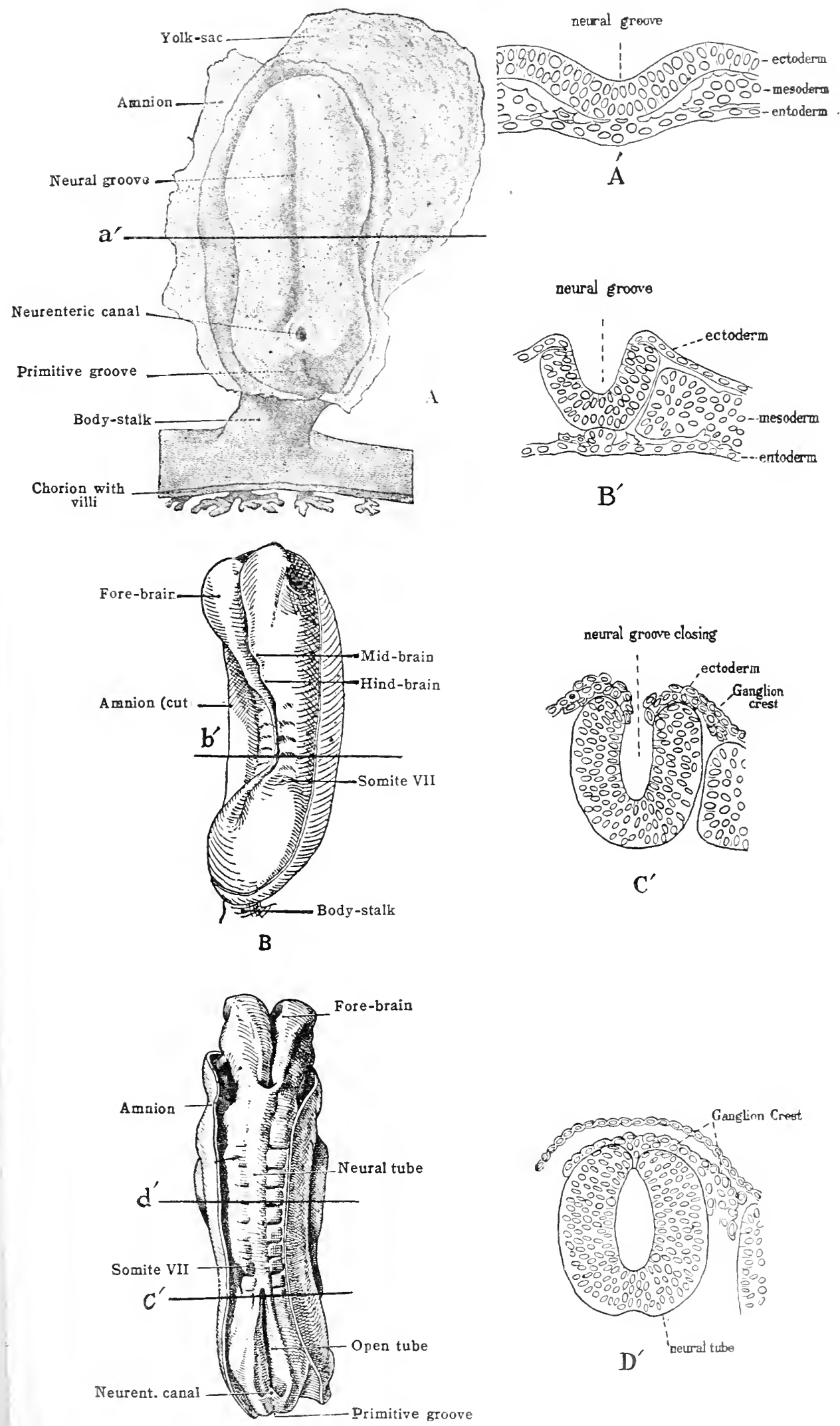
(2) The peripheral nervous system, composed of-(a) The cranio-spinal nerves, and $(b)$ the sympathetic nervous system.

All these parts are so intimately connected with each other that the division is purely arbitrary. The cranio-spinal nerves are anatomically continuous with the central system; their component fibres either arise within or terminate within the confines of the central system, and thus actually contribute to its bulk. The sympathetic system, however, may be more nearly considered as having a domain of its own. By communicating rami, it is intimately associated with the cranio-spinal nerves and thus with the central system, both receiving impulses from the central system and transmitting impulses which enter it. But, while its activities are largely under the control of the central system, it is possible that impulses may arise in the domain of the sympathetic system and, mediated by its nerves, produce reactions in the tissues it supplies without involving the central srstem at all. For this reason, as well as because of the structural peculiarities of the sympathetic system, the nervous system is sometimes divided into-(1) the cranio-spinal system, consisting of $(a)$ the central system and $(b)$ the cranio-spinal nerves; (2) the sympathetic nervous system, consisting of its various peripheral ganglia and their outgrowths forming its plexuses.

Within and elosely proximal to the central system or axis are grouped the parent cell-bodies whose processes comprise the nerve fibres of the eranio-spinal nerves. Other groups of nerve cell-bodies, distributed in the periphery without the bounds of the central system, give rise to the fibres of the sympathetic nerves and plexuses. Any group of such cell-bodies situated in the periphery, whether belonging to the cranio-spinal or sympathetic system, is known as a ganglion.

\section{THE DEVELOPMENT OF THE NERYOUS SYSTEM}

The essential elements of the nervous system, the nerve cell-bodies and the essential portion of all nerve fibres, central, cranio-spinal and sympathetic, develop from one of the embryonic germ layers, the ectoderm, and all arise from a given region of that germ layer. Further a small portion of the supporting tissue of the nervous system, the neuroglia, is of the same origin.

In its development the nervous system is precocious. It is the first of the functional apparatuses to begin differentiation and is the first to acquire its form. The first trace of the embryo appears on the developing ovum as the embryonic area, and the rapidiy proliferating cells of this area shortly become arranged into the three germinal layers:- the outer layer or cetoderm, the niddle layer or mesoderm, and the inner layer or entoderm. Early in the process of this arrangement there is formed along the axial line of the embryonic area a thickened plate of ectodermal cells, the nezral plate. In the further proliferation of these cells, the margins of the neural plate, which lie parallel with the long axis of the embryonic area, rise slightly above the general surface, forming the neural folds, and the floor of the plate between the folds undergoes a slight invagination, the process resulting in the neural groove (fig. $595, \mathrm{~A}^{\mathrm{A}} \mathrm{A}^{1}, \mathrm{~B}$ and $\mathrm{B}^{1}$ ). As levelopment proceeds and the embryonic area assumes the form of a distinet embryo, the neural folds or lips of the groove gradually converge, and beginning at the oral end, finally unite. Thus the groove is converted into the neural tube, extending along the dorsal mid-line and enclosed within the body of the embryo by the now continuous ectoderm above (fig 595, C, $\mathrm{D}$ and $\left.\mathrm{D}^{1}\right)$.

For a time the nemral tube remains connected with the inner surface of the general ectoderm along the line of fusion by a residual lamina of ectodermal cells. This lamina is known as the ganglion crest (nemral erest). It is a product of the proliferation of the ectoderm luring the proxess of fusion, consists of the aclk which composed the transition between the elosing lips if the original groove and the gencral ectoderm or skin, and whose fusion aided in the elosme of the tube. The eetoderm som beromes separated from the ganglion crest and the cells of the reset become distiuetly differentiated from the colls of the neural tube. The essential elements of the entire nervous system fogether with the neuroglia ate derived from the cells of the neural tube and the cells of the ganglien arest.

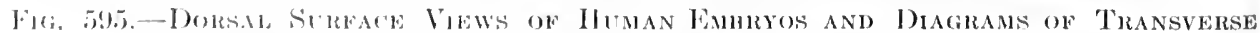

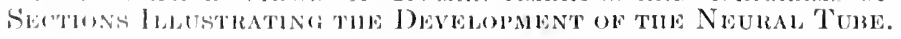

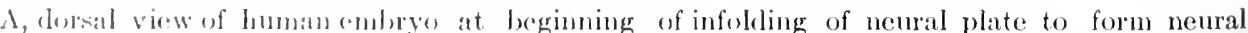

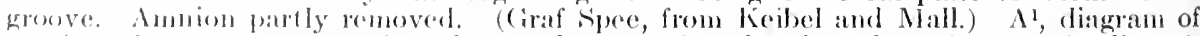

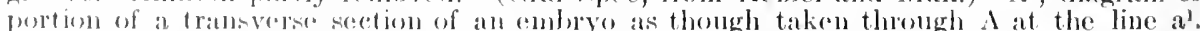

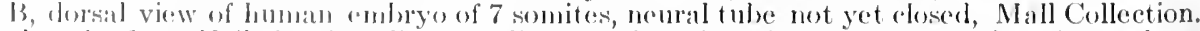
(1) andy, from kribaland Mall.) I31, diagram of portion of a transverse section of an embryo as fhongh takenthrough $b$ at the line $b$. (:" diagram of portion of a transverse section of

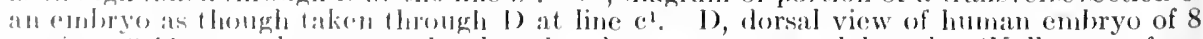
somites, 2.ll m.m, long, nenral tube chsed exerpt at candal ond. (liollmann, from

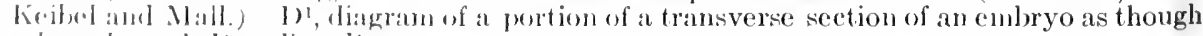
taken through I) at line: d!. 
Before the caudal extremity of the tube is entirely closed, its oral end undergoes marked enlargement and becomes distended into three vesicular dilations, the anterior, middle, and posterior primary brain vesieles. The anterior of these primary vesicles give off a series of secondary vesicles and by these, followed by further dilations, flexures of its axis, and by means of localized thickenings of its walls, the portion of the tube included in the three primary vesicles develops into the encephalon or brain of the adult. The remainder of the tube becomes the spinal cord. This latter portion retains the simpler form. By the proliferation and migration laterally of the cells lining this portion of the tube, there results a comparatively even bilateral thickening of its walls so that the mature spinal cord retains a cylindrical form throughout its length.

The proliferating and migrating cells of the wall of the neural tube are known as germinal cells. The products of their division are apparently indifferent at first, but later they become differentiated into two varieties: (1) spongioblasts, or those cells which will develop into neuroglia, and (2) neuroblasts, or those which will increase in size, develop processes and become nerve cell-bodies. As described below, the processes given off by a neuroblast are of two general characters: (1) a long process or axone which goes to form nerves, nerve roots, and nerve fasciculi, and $(2)$ dendritic processes which are numerous, branch much more frequently and extend but a short distance from the cell-body. An adult cell-body with all its processes is known as a neurone and the neuroblasts of the developing system become transformed into the neurones

Fig. 596.-Diagraus of Transverse Sections of Embryonic Spinal Cords showing the Migration of the Cells of the Ganglion Crest to form the Spinal and Sympathetic Ganglia and the Origin of the Dorsal and Ventral Roots of the Śpinal Nerves. A, a stage following $D^{1}$ of fig. 595 . B, a later stage in which the ganglia and the components of the nerve are assuming their form resulting from the further migration and from processes being given off by the neuroblasts.
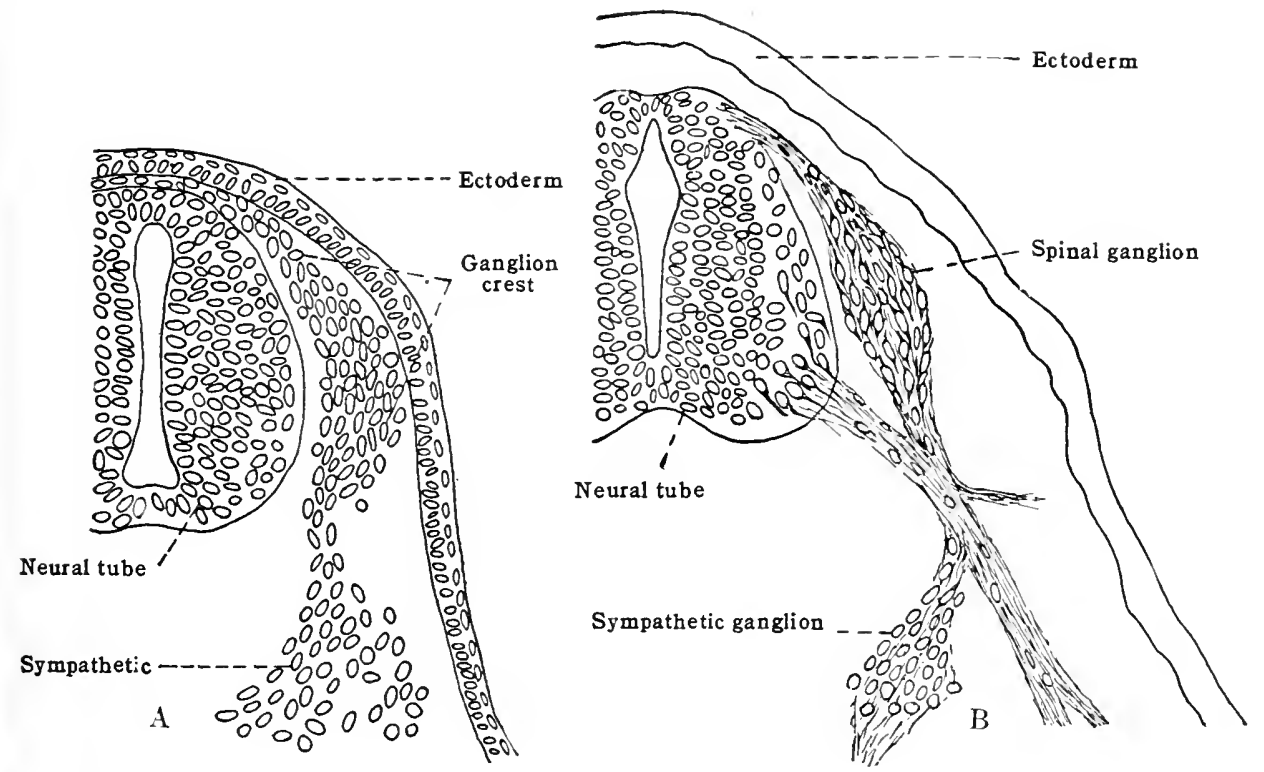

of the varying sizes, shapes, and arrangements of processes characteristic of different divisions and localities of the nervous system. Usually the first process to be noted is that which will become the axone or nerve fibre.

Neurones whose cell-bodies belong to the peripheral nervous system are not developed within the walls of the neural tube or central nervous system at all. These, comprising the spinal ganglion neurones and those of the sympathetic system, are derived from the cells of the ganglion crest. The wedge-shaped lamina of cells, comprising the ganglion crest, through rapid cell division, gradually extends outward and ventralward over the surface of the neural tube along either side. Soon the proliferation becomes most active in regions corresponding to the mesodermic somites or primitive body segments and this, together with the stress of the growing length of the body, results in the gar nglion crest (originally a lamina) becoming segmented also. The segments or localised cell masses thus formed are the beginning not only of the spinal ganglia, but also of the ganglia of the entire sympathetic system. The cells of the crest migrate to assume a more lateral position, and then occurs a separation of their ranks. A portion of them remain in a dorsolateral position near the wall of the neural tube and develop into the neurones of the spinal ganglia (the sensory neurones of the spinal nerves), hut others wander further out into the periphery and become the neurones of the sympathetic. Certain of those of this more nomadic group of cells settle within the vicinity of the vertebral column and by sending out their processes, form the gangliated eord or the proximal chain of sympathetic ganglia; others migrate further, but in more broken rank, and become the ganglia of the prevertebral plexuses (as the cardiac, coliac and hypogastric plexuses), or the scattered intermediate chain of ganglia; while still others wander into the very walls of the peripheral organs and 
Fig. 597.-Diagrair Showing the Chief Paths of Migration of the Cells from the Ganglia of the Spinal and Cranral Nerves to form the Adult Sympathetic Sistem (After Schwalbe, Modified.)

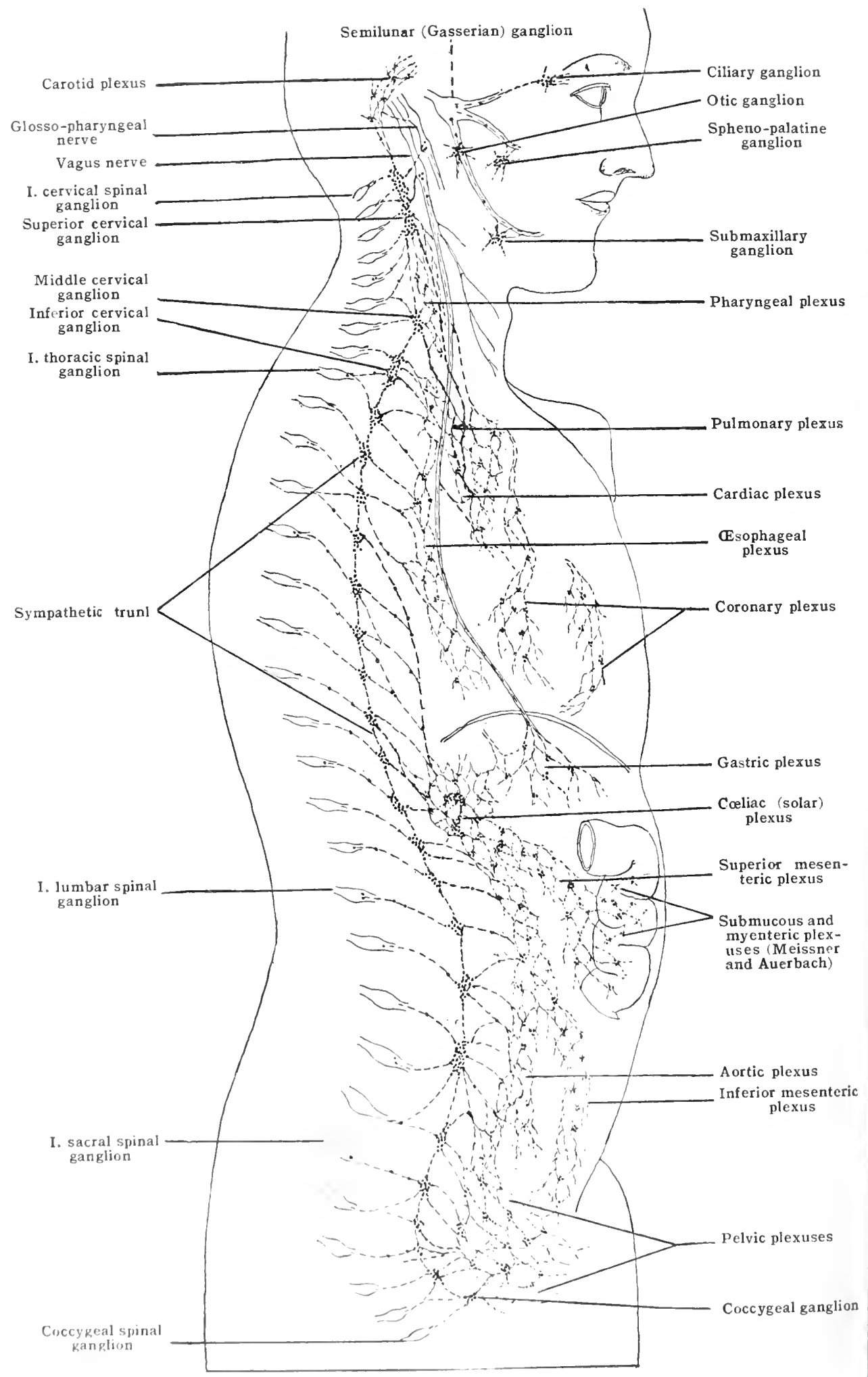


occur singly or in groups in such plexuses as those of Auerbach and Meissner, within the tunies of the walls of the alimentary canal. Scattered along between these proximal, intermediate, and distal groups there are to be found small straggling ganglia, many of which contain so few cell-bodies that they are indistinguishable with the unaided eye. All these sympathetic neurones, however, are always either directly or indirectly anatomically associated with and

Fig. 598.-Diagrams of Oral Portion of Human Neural Tube Showing the Three Primary Brain Vesicles and Some of the secondary Vesicles Derived from Them.

$A$, diagram of dorsal view of early stage. B, lateral view at about the third week. C. lateral view at about the eighth week. After $\mathrm{His}$, modified. $\mathrm{m}$, mamillary vesicle; $\mathrm{i}$, infundibular recess; o, olfactory vesicle.

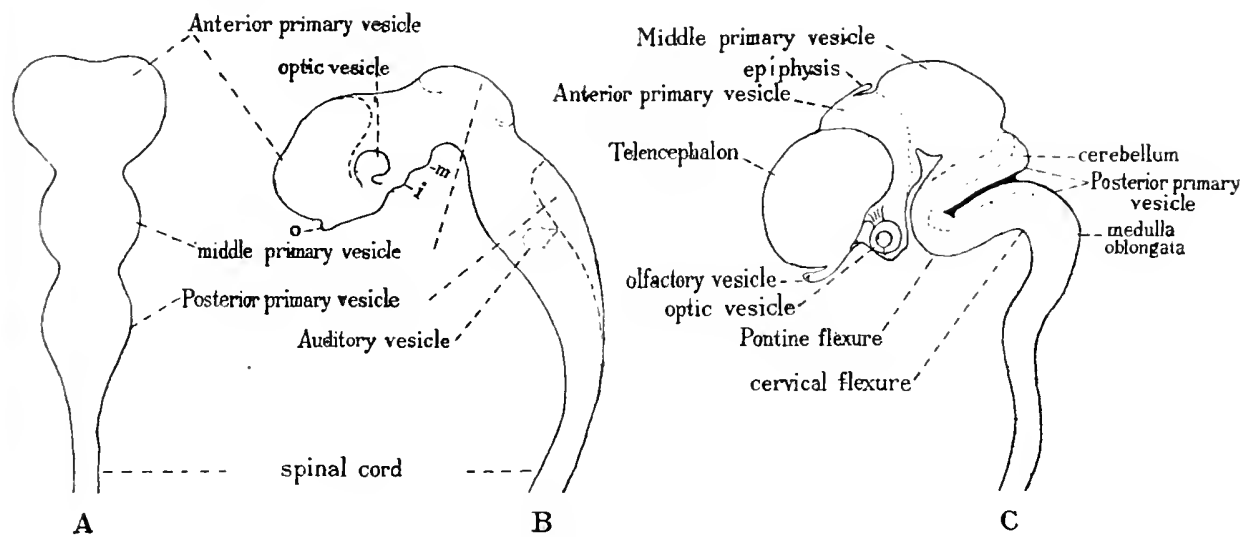

Fig. 599.-Diagramiatic Sagittal section of a Vertebrate Braix. (After Huxley.) 4 , fourth ventricle; $s$, cerebral aqueduct; 3 , third ventricle.

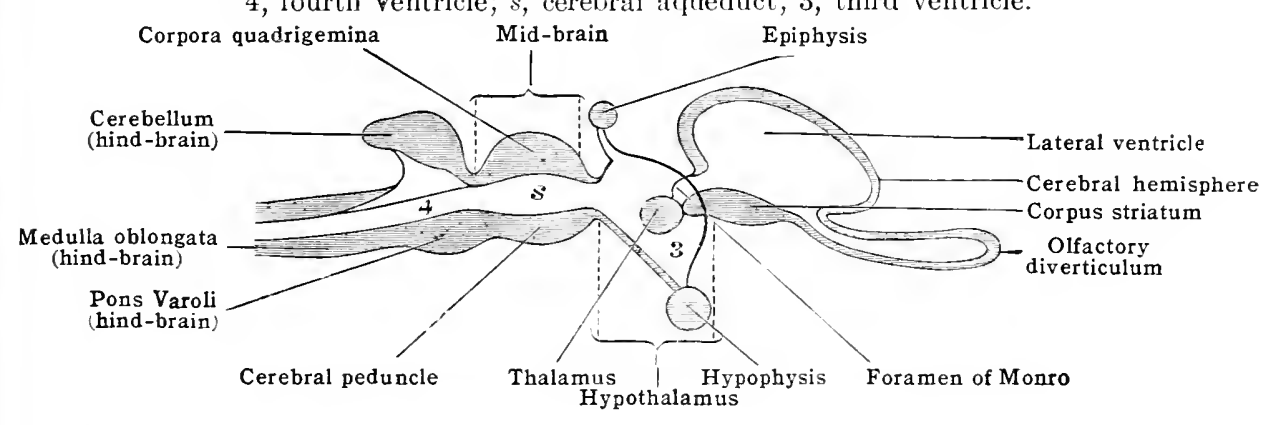

Fig. 600.-Diagramatic Horizontal, Section of a Vertebrate Brain. (Afte Huxley.) 4 , fourth ventricle; 3 , third ventricle.

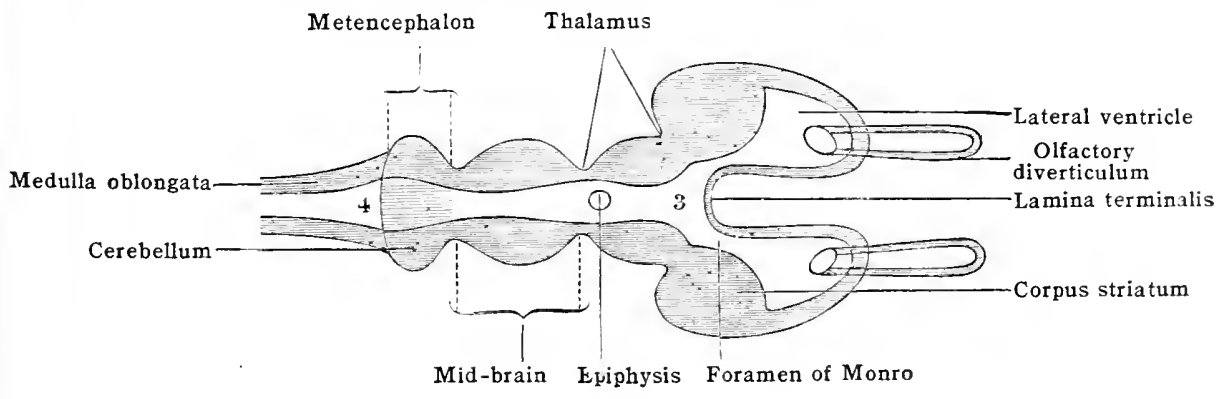

largely under the control of the neurones of the central system through central viscral iffent fibres passing to them by way of the rami communicantes or by way of the peripheral ilistribution of the spinal nerves.

The ganglia of the sensory portions of all those cranial nerves attached to the inferior of the main divisions of the brain and all the sympathetic ganglia of the head have an origin similar to that of the spinal and sympathetic ganglia in the remainder of the borly.

The behavior of the walls of the three primary vesicles, into which the oral end of the neural tube is converted, is much more complex than in case of the spinal cord. Their walls do not 
thicken uniformly and, to give rise to the form of the adult brain, the anterior and the posterior of the three vesicles give off secondary vesicles.

The walls of the posterior primary vesicle give rise to the posterior of the main divisions of the brain, the hind brain or rhombencephalon, the cerebellum developing from the anterior portion only of its dorsal wall, and the medulla oblongata and pons from its ventral wall. Its cavity persists and enlarges into the fourth ventricle of the adult, while the posterior portion of its dorsal wall does not develop functional nervous tissue at all but persists as a thin membrane known as the chorioid tela of the fourth ventricle. The cells which form the ganglia of the auditory and vestibular nerves arise from the dorsolateral regions of this vesicle.

From the middle primary vesicle comes the mid-brain or mesencephalon, the corprora quadrigemina [colliculi] developing from its entire dorsal wall and the cerebral peduncles occupying its ventral wall. The constriction between the middle and posterior vesicles becomes the isthmus of the rhombencephalon.

The anterior or first primary vesicle undergoes greater elaboration than either of the other two. At an early period it gives off a series of secondary vesieles or diverticula. First, two ventrolateral outpouchings oceur, the optic vesicles, which later become the optic stalks and optic cups of the embryo. A medial protuberance becomes evident in its antero-dorsal wall and from each side of this quickly starts a lateral diverticulum. The two lateral diverticula thus arising from the protuberance are the beginning of the two cerebral hemispheres or the telencephalon, and the vesicular cavities contained persist as the two lateral ventricles of the brain. Soon, each of these vesicular rudiments of the hemispheres gives off ventrally from its anterior part a narrow tube-like diverticulum, each continuous into the parent primary vesicle. These are the olfactory vesicles which are transformed into the olfactory bulbs and olfactory tracts of the adult encephalon. (See fig. 59S, B. and C.) As development proceeds, the eavities of the olfactory vesicles become occluded in man. However, in many of those animals

Fig. 601.-Diagran of Mesial Section of the Human Brain showing the Segments and the Flexures and the Expansion of the Cerebral Hemispheres over the Other Portions of the Brain. The Thalamus is not shown.

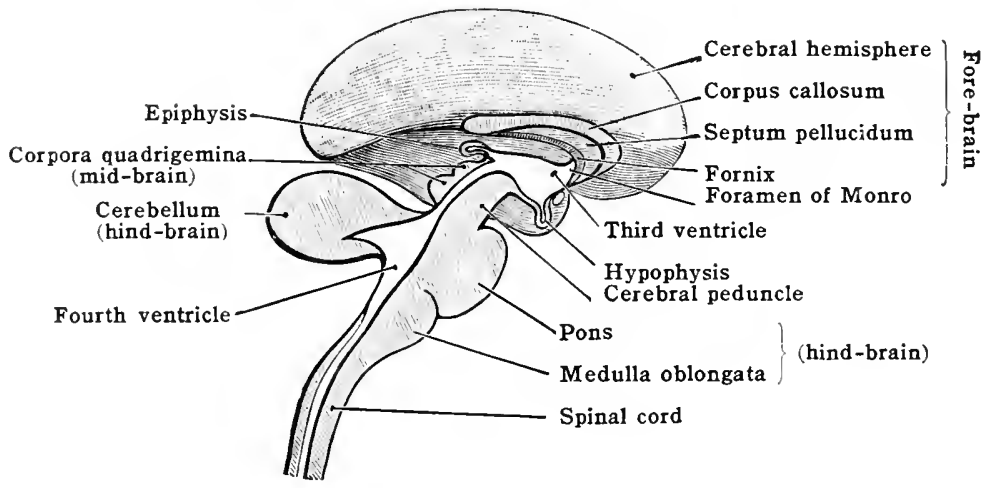

in which the olfactory apparatus attains greater relative development than in man, these cavities persist as the olfactory ventricles. The cavities of the optie vesicles never persist as ventricles in the alult. They form stalks which represent the future courses of the optic nerves, while from their extremities are developed the retine, portions of the ciliary bodies and portions of the iris of the ocular bullss.

In aldition to that which forms the cerebral hemispheres, the remaning portion of the anterior primary vesicle becomes the dincephalon or inter-brain. "The lateral walls of this part thicken to forn the thalami, the posterior end of its dorsal wall gives off a secondary vesicle wheh beromes the pineal body or epiphysis, and from its ventral wall projects the infundibular recess which beromes the posterior hobe of the hypophysis with its infundibulum and tuber (rineremin.

The adult human brain is eharacterised by the preponderant levelopment of the cerebral hemispheres. The secomblary vesicles forming these expand till, held within the eranial cavity, the hemispheres enue to extend postriorly completely over the thaldunemeephalon and the

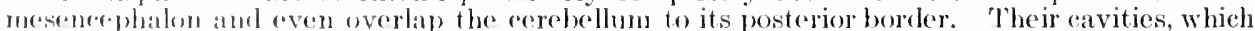
persist from their urigin from the anterior prinary vesicle, are correspondingly large (the lateral ventricles and anmprise two of the four erentricles of the atdult brain. The third ventricle berones a narrow avity situated between the two thalami. It represents the original eavity of the anterion primary vesicle from which the structures above mentioned arose as secondary vesiclos. It remains antinums with the lateral ventricles by the two inter-entricular foramina, known alos as the foraminn of momro, one into each cerebral hemisplere. The fourth rentricle of the alult represents the ravity of the posteriog primary vesiche and eomes to lie between

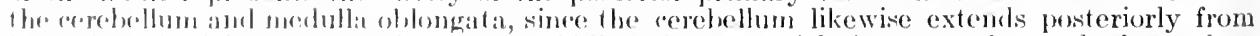
its region of origin. The "avity of the midhlle primary vesicle becomes the crebral aqueduct, or arfueluet of sylvius, bassing under the corpera qualrigemina and comnecting the fourth or pestriore ventricle with the thiril.

Development of the nerve fibres. - All axones begin as outgrowths or processes of the cytoHasm of neuroblasts. Most of such processes are sent out at a very early stage in the developmont of the norvous system and extejul to the tissues they are to innervate when these tissues are as yet guite near the neural tube. 'Then, as the structures of the bolly elaborate and assume 
their final forms and positions more remote from the central nervous system, the axones terminating in them must necessarily glow and be drawn out with the structures. At need, later axones are sent out by neurones developing later to supply the growth demands. Such axones follow the general paths made by those already extending to the tissues requiring them. Being processes of the cytoplasin of the cell-body, the growth and life of all axones (and dendrites) is under the control of the nucleus in the cell-body. They grow by absorbing nourishment, or having added to them substances, from the tissue stroma through which they pass, which stroma may be either ectodermal or mesodermal in origin.

The great majority of axones in the central nervous sytem and all in the peripheral system have sheaths about them. The sheath is an acquired structure and is not added till a relatively late period of development. These sheaths are of two general varieties, sheaths con-

Fig. 602.-Diagram illustrating the Gross Divisions of the Central Nervous System.

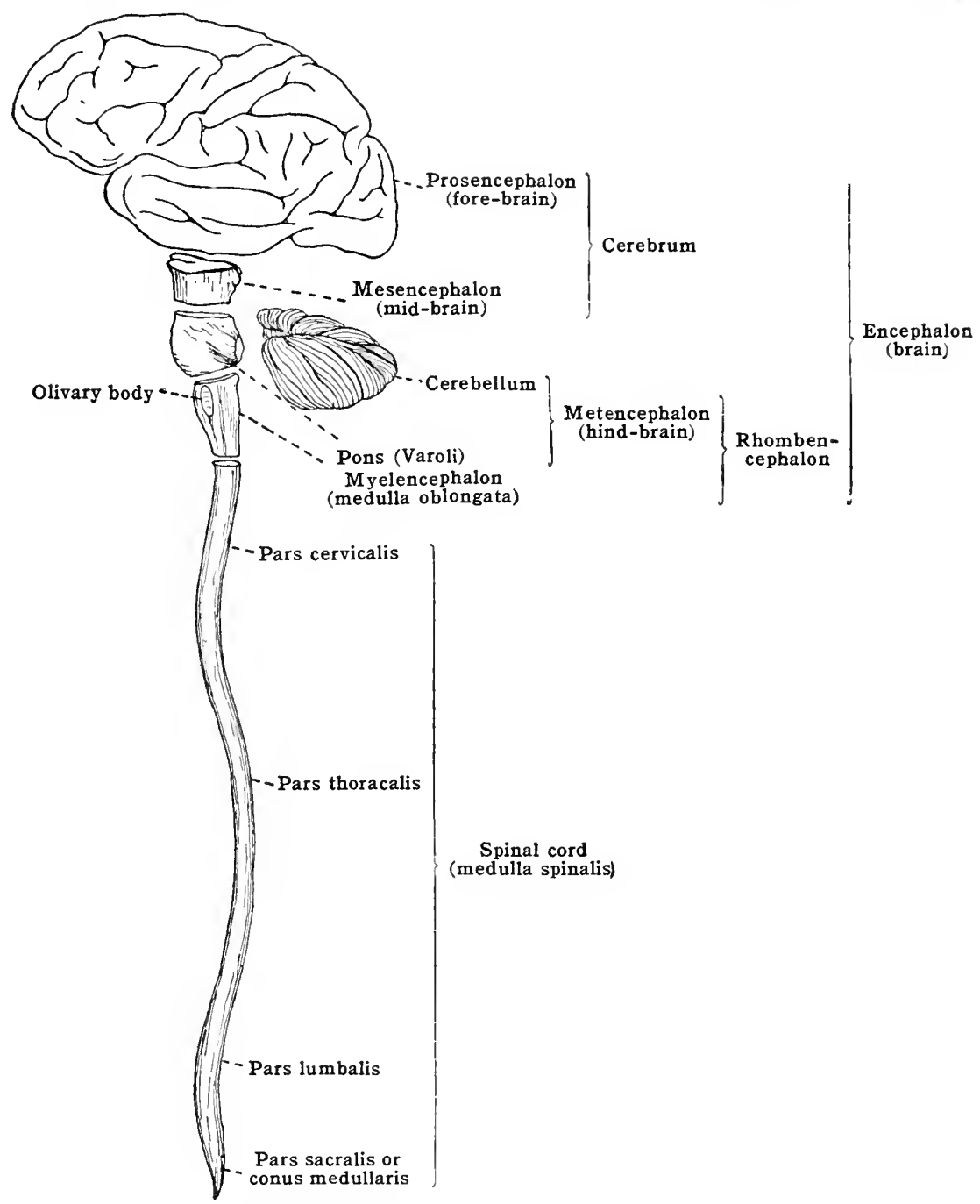

sisting merely of a fibrous coat with the nuclei belonging to it, and sheaths in which there has been added a coating of fat or myelin, medullary sheaths. A nerve fibre consists of an axone and its sheath whether medullated or non-medullated.

In the embryo, axones are given off flom the developing neurones at a time when the entire ectodermic neural tube and embryonic ganglia and the mesodermic tissue surrounding them are each void of definite cell boundaries, each being a continuous mass of nucleated protoplasm, a syncytium. From these syncytia are developed the fibrous connective tissues of the later framework supporting the nervous system. Of this, the fibrous tissue, neuroglia, is derived from the ectodermal syncytium, while the white and elastic fibrous tissues are derived from the mesodermal or mesenchymal syncytium. Before any connective tissue fibrils are developed in either syncytium, before and at the time of the ingrowth of blood-vessels into the developing ganglia and the neural tube from the mesenchyme about them, there occurs an invasion of the mesenchymal syncytium into the ectodermal syncytium. This invasion occurs both as independent ingrowths and fusions at the periphery of the neural tube and by 
the mesenchymal tissue being carried in by the ingrowing blood-vessels. After the mixture of the nuclei resulting from this fusion of the syncytia from the two sources, nuclei of mesodermal origin cannot be distinguished from those of ectodermal origin. Further, axones outgrowing from the embryonic ganglia and neural tube carry with them adhering portions of the ectodermal syncytium into the surrounding mesenchymal (fig. 603).

As development proceeds further, each syncytium becomes resolved into a reticulum of granular endoplasmic processes, containing the nuclei, with transparent exoplasm oecupying its meshes. Fibrils soon form in the exoplasm and from these develop the connective-tissue fibres, whether neuroglia in the central nervous system or mesenchymal fibrous tissue both without and within it. Certain of these fibrils of course surround the axones imbedded among them and from condensations of such fibrils are derived the fibrous sheaths of the axones, the sheath nuclei being acquired from the adjacent nuclei of the original syneytium. These sheaths become more dense or pronounced as the axones extend and the fibrous tissue increases with growth, but there are always present fine marginal fibrils by which the sheaths grade into the looser fibrous tissue about them. It is generally believed that the tissue giving rise to these

Fig. 603.-Drawixgs Illustrating the Origin of the Axone and the Development of the Medullary Sheaths.

A, rentral portion of transverse section of an embryonic spinal cord involving portion of periphery of future ventral horn and part of the mesenchymal (mesodermal) syneytium outside the external limiting membrane of the cord. B, later stage of ventral root (peripheral) axone with myelin droplets adhering to it and fibrillated stroma surrounding it. C, stage in which myelin droplets, supported by fibrils of stroma, have increased and accumulated to form a practically continuous myelin or medullary sheath. D, final stage with medullary sheath of even thickness, showing a node, and showing a neurilemma, sheath nucleus and fibrous framework of the myelin ("neurokeratin") derived from the fibrils of the original stroma.

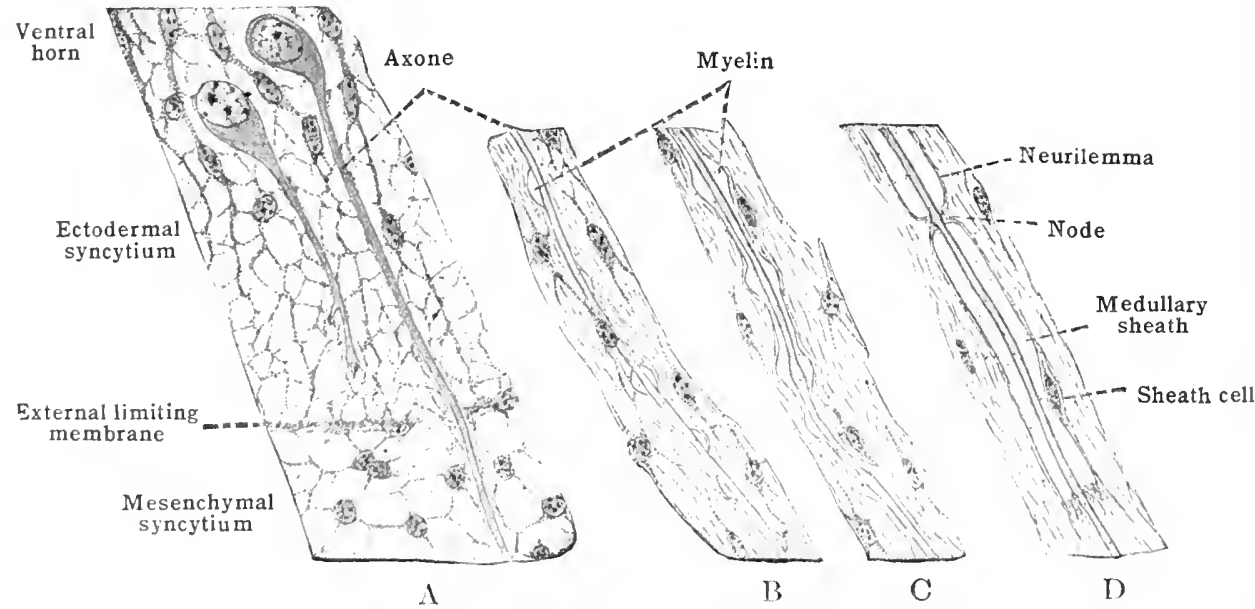

axone sheaths is of nesolermal origin. However, in amphibian larva, Harrison has shown that some sheath nuclei at least are derived from the nuclei of the ectodermal syneytium of the ganglion crest, and Veal has noled in elasmobranchs the fact that nuclei migrate from the ventral wall of the nemal tube along with the axones growing out to form the ventral roots of the spinal nerves. Whether all or any of these nuclei are originally ectodemal, and, if so, whether such cetorlerinal tissue gives rise to all axone sheaths, especially in the higher animals, are questionable contentions.

Axones fossessing only fijrous sheaths comprise the non-medullated nerve fibres. The majority of the srmplathetic fibres are of this varicty, and Ranson has found numerous nonmerlullated filmes jurent in the spinal nerves. The generally acepted form of non-medullated sympithetic fibros mat Je seen in fig. 609), C.

Medullalud filmes are those which possess an investing coat of fat or myelin in addition to the fibrous sheath. Most of the fiJ)res in the central nervous system and most of those belonging to the cranio-spinal nerves proper acpuire myeliu sheaths. Myelin begins to appear upon

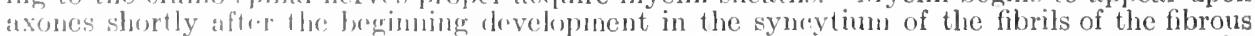
(n)mentive tiscure, and thas after the Jeginnings of what will becone the fibrous sheaths. The filpons jortions of the sheallis in the centrat nervous system devolop less rapilly and are far more scant than those of the merlullated filores of the peripheral nerves. Probably because of this, it has becen claines that myelin begins to ajpear on the axones of the central system before the apperarance of the fibrus sleath. In man, the first appearanee of myelin oceurs at abont the fourth month, fut myelinisation is not compleled lill after birth. The cranio-spinal

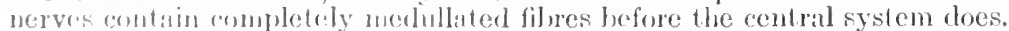

Myelin first appears as small droplets arbering to the axome at irrogular intervals. These droplets increace in size and number and gradually acemmbate to form a practieally continuous sheath of fat immerlialcly investing the axme. They probably result from the coaleseence of finer ironlets floating in the surmolnding filmrillated strona. However, collecting upon the axone, 
the myelin retains the form of an emulsion, and as it increases in amount it incloses the adjacent fibrils which serve as a framework supporting the droplets of the emulsion in its meshes. Thus supported, the increasing myelin does not inclose the adjacent nuclei and endoplasm of the original syncytium. Probably because of the fibrous support of the myelin thus obtained, medullating fibres may be often seen presenting the beaded appearance shown in fig. 603, C, instead of an even distribution of the emulsion after it has become continuous along the axone. The "beads" probably represent the uneven beginning of the accumulation indicated in B of this figure. Increasing further, the myelin becones a cylinder of even thickness, the adjacent nuclei being pressed away against its surface and the adjacent fibrils also condensed upon it.

There is good reason to believe that the fibrous portion of the sheath, the primitive sheath or neurilemma, of the medullated axone arises as a condensation of the fibrils of the surrounding stroma during development, that the sheath cells represent certain of the nearest nuclei incorporated from the original syncytium, and that the so-called neuro-keratin of the myelin represents the fibrous framemork of the myelin inclosed by it during its accumulation upon the

Fig. 604.- Showing Some of the Tarieties of the Cell-bodies of the Netrones of the Human Nervous System, including the Dendrites and Siall Portions of the Axones. Axone Sheaths rot 1 ncluded.

$A$. From spinal ganglion. B. From ventral horn of spinal cord. C. Prramidal cell from cerebral cortex. $D$. Purkinje cell from cerebellar cortex. $E$. Golgi cell of type II from spinal cord. E. Fusiform cell from cerebral cortex. G. Sympathetic. a, axone; d, dendrites; $c$, collateral branches; $a d$, apical dendrites; $b d$, basal dendrites; $c$, central process; $p$, peripheral process.

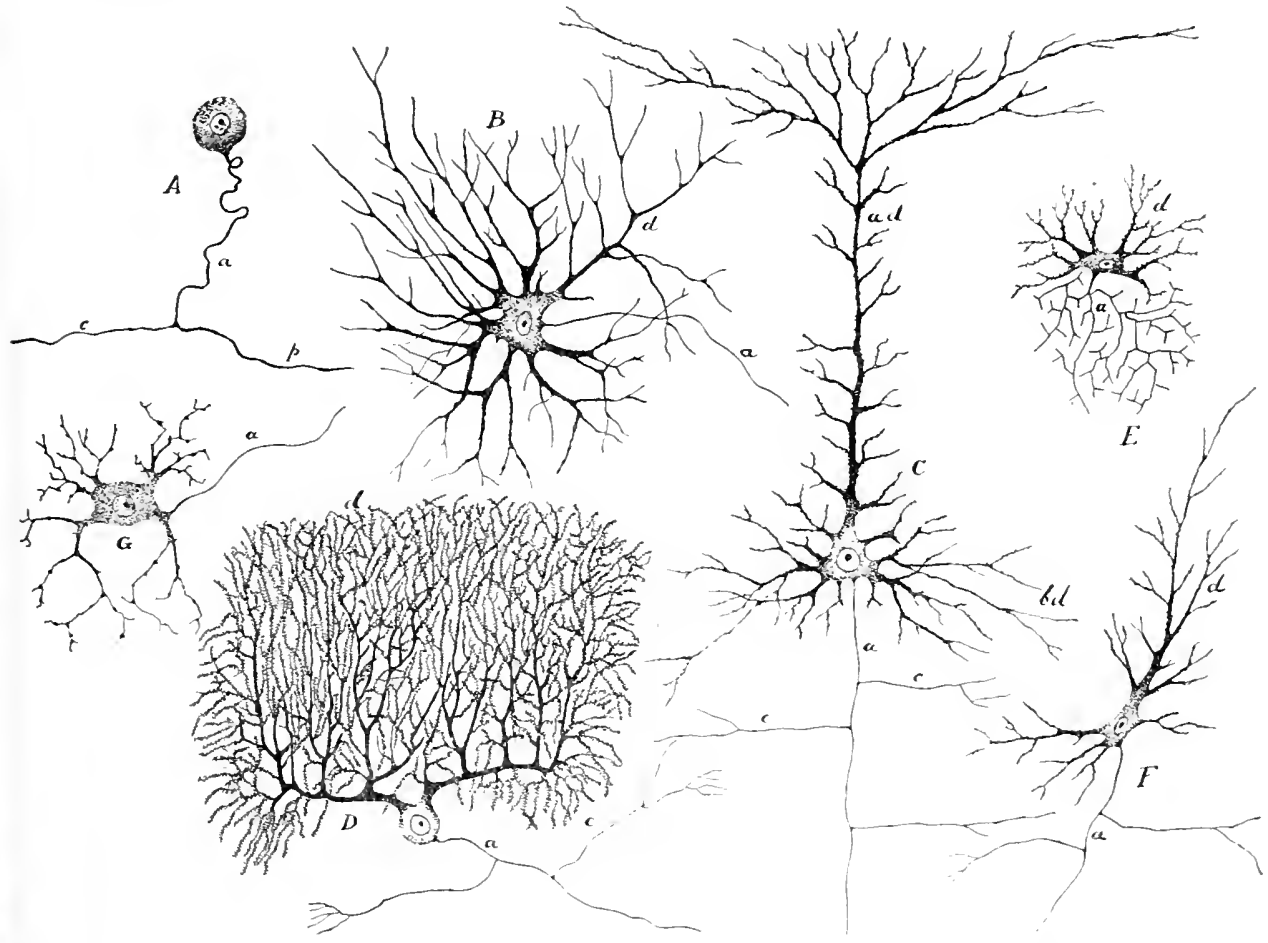

axone. The theory that the myelin arises as a differentiated portion of the axone and the theory that it is formed by the neurilemma have been advanced. That it is accumulated from the immediately surrounding fluid of the stroma and adheres to the axone, added clroplets coalescing there, in preference to other tissue elements because of some physical or chemical peculiarity of the axone, is more probably correct.

As the medullary sheath approaches completeness, constrictions may be observed at more or less regular intervals at which the myelin emulsion is absent. There are the nodes of Ravier. The process by which they arise is not clearly understood. While the fibre is growing in length, new myelin is added at the nodes. The internolal segments of the sheath increase in length with age, and each segnent may possess from one to several sheath nuclei.

In adolescence, fibres whose medullary sheaths are in various stages of completeness may be found both in nerve bundles in the central system and in the cranio-spinal nerves, and in both, the sheaths of some axones certainly never acquire myelin. Also, in the adult, fibres whose medullary sheaths present the beaded appearance may be observed, probably representing cases of arrested accumulation of myelin. According to Westphal there is a sliglit increase in the thickness of the sheath with age. Larger axones acquire thicker sheaths of myelin than smaller ones. Some fibres of the sympathetic system are medullated but in such the myelin sheath is relatively thinner than in the cranio-spinal system. Beaded sheaths are frequent in sympathetic rami, though non-medullated fibres are most abundant. 


\section{FUNDAMENTALS OF CONSTRUCTION}

The functionally mature nervous system consists of peculiarly differentiated essential cell elements held in place by two forms of supporting tissue and supplied with abundant blood-vessels.

The nervous element is distinguished from all other units of the structure of organs in that its cell-body gives off outgrowths or processes of peculiarly great length and characteristic form. Knowledge of the possible lengths and complexity of these processes is comparatively recent and, to include them together with their parent cell-body, which has long been known as the nerve cell, the term neurone is used. The neurone, therefore, may be defined as the nerve cellbody with all its processes, however numerous and far reaching they may be. As a class of tissue elements, all neurones possess characteristies distinguishing them from other tissue elements, but the varieties within this class vary greatly. They vary in form both according to function and according to their locality in the nervous system. They vary in different animals, those in the higher animals being more complex in form. Fig. 604 gives illustrations of the external form of the cell-body of a few of the types found in the human nervous system.

The cell-body of the neurone gives off two general types of processes, dendrites and axones:

(1) The dendritic processes or dendrites. These are the more numerous, the shorter, and the more frequent ly branching processes. They branch dichotomously and with rapid decrease in diameter as they branch. They serve to increase the absorbing surface of the cell-body for purposes of nutrition. Nerve impulses transmitted to the neurone are received by them and, therefore, they also serve to increase the recipient surface of the neurone. They never acquire medullary sheaths. Since they convey impulses toward the cell-body, they are known as cellipilal processes. Their absorbing and receptive surfaces are further inereased by the presence of thickly placed, very minute projections known as "pin-head processes" or gemmulcs.

(2) The axone (neuraxis). Each neurone possesses properly but one of these proeesses. It arises from the cell-body more abruptly and quickly becomes smaller in diameter than are most dendrites before the latter decrease by branching. It is the longest process, in most cases very much longer than dendrites. Computation shows that some axones may contain nearly 200 times the volume of the parent cell-body of the neurone. Occasionally the axone gives off a few small branches near the cell-body. These are known as collaterals and are given off at practically right angles instead of dichotomously. Regardless of its branching, the axone maintains a practically uniform diameter throughout its long course. Its usual nervous function is to convey the impulses away from the ecll-body, either to transmit them to other neurones by contact upon their ilendrites, etc., or to appropriate elements of the other tissue systems of the body. Thus the axones are the cellifugal processcs. There is one well-known partial exception to this, namely, a part of the axone of the spinal ganglion type of neurone, the peripheral sensory neurone. The axone of this bifurcates a short distance from the cellholly into a peripheral and a central branch. See fig. 604, A, and fig. 610 . The peripheral branch collects sensory impulses from the tissues of the body, the skin, ete., and, in conveying them to the central system, must necessarily convey them toward the cell-body as far as the point of bifureation. Thence the impulse goes on in the central branch, still toward the central system but now, in conformity, away from the cell-body of the neurone. While the continued vitality of the axone is dependent upon the cell-body, in the peculiar case of the spinal ganglion neurone the impulse does not necessarily pass through the cell-body. Experiments with the lower animals have shown that the impulses pass in the fibre from the peripheral tissues to the rentral system when the cell-bolly has been cut away.

Terminations of axones. - At its final temination, well beyond its collateral branches and nsinally a considerablo longth from its cell-hody, the axone practically always divides into two or morr terminal branches, and each of these breaks up, now dichotomonsly, into numerous terminal 1 wigs. These teminal twigs are known as tedodendrie. Telodendria vary in number and rharacter of form acoording to the tissues in and upon which they terminate. Functionally, they are of thres (lasses: Those terminating npon and in the other (peripheral) tissues of the borly are cither (1) sensory or (2) molor. In orler to transmit impulses from one neurone to another, tolodemlria of the axone of one neurone are placed in contact with the dendrites or (edl-body of another nomone forming (3) symapses. (Jpon approaching its termination, every axone loses its sheath, its telodendria being necessarily bare.

Sensory or afferent ixones, recriving impulses from the skin or other epithelial surfaces, break up into very mumbos tololendria each of which terminates directly upon the surface of the epithelial cell, stach as the cells of the germinative (Malpigin) layer of the skin or these of its basal or columnar layer. Surh telodemlria are known als free terminations. Free trrminations are also to be fommil in the eonnertive tissues of the body. $\Lambda$ seeond variety of pripheral tormination of alferent axones is the enerspsulatal form. These are known as end

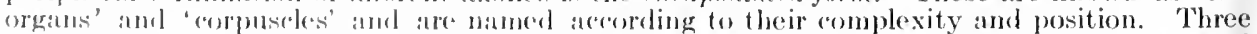
of tho difforent forms of them are shown in fig. 605, B, C, and D). These are always situated in litrons connective tissue from which their capsules are derived. Their most elaborate form is the lanellated or lacinian compusele. Besides the motor axomes terminating upon the fibres of voluntary or soletal muscle, sensory impulses are carried from this tissue and one of the forms of tolotemblat for this purpose terminates mpon the muscle fibre. 'This is known as 
Fig. 605. - Showing Some Varieties of Peripheral Terminations of Axo ves.

A. 'Free termination' in epithelium (after Retzius). B. Krause's corpuscle from conjunetiva (after Dogiel). C. Meissner's corpuscle from skin (after Dogiel). D. Pacinian corpuscle (after Dogiel). E. Termination upon tendon sheath (Huber and DeWitt). F. Neuro-muscular spindle (after Ruffini). G. Motor termination upon smooth muscle-cell. H. Motor 'end-plate' on skeletal muscle fibre (after Böhm and von Davidoff). a, axone; t, telodendria.

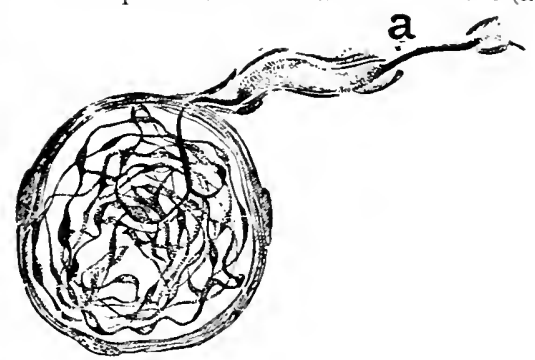

$\mathrm{B}$

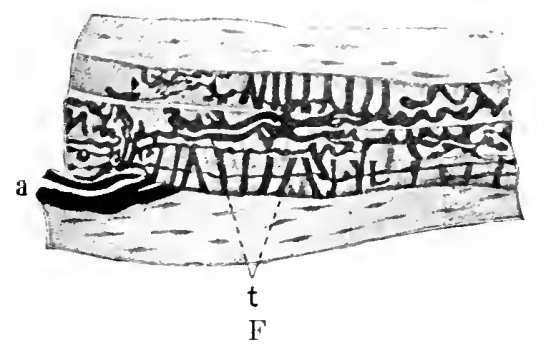

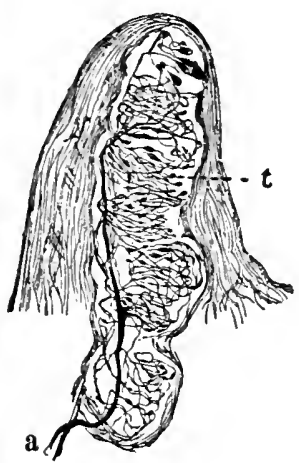

$\mathrm{C}$

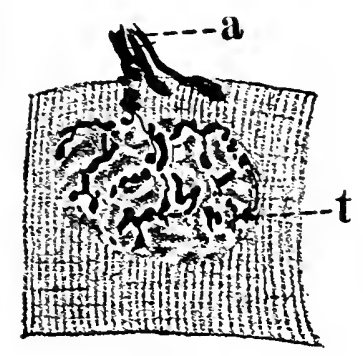

$\mathrm{H}$
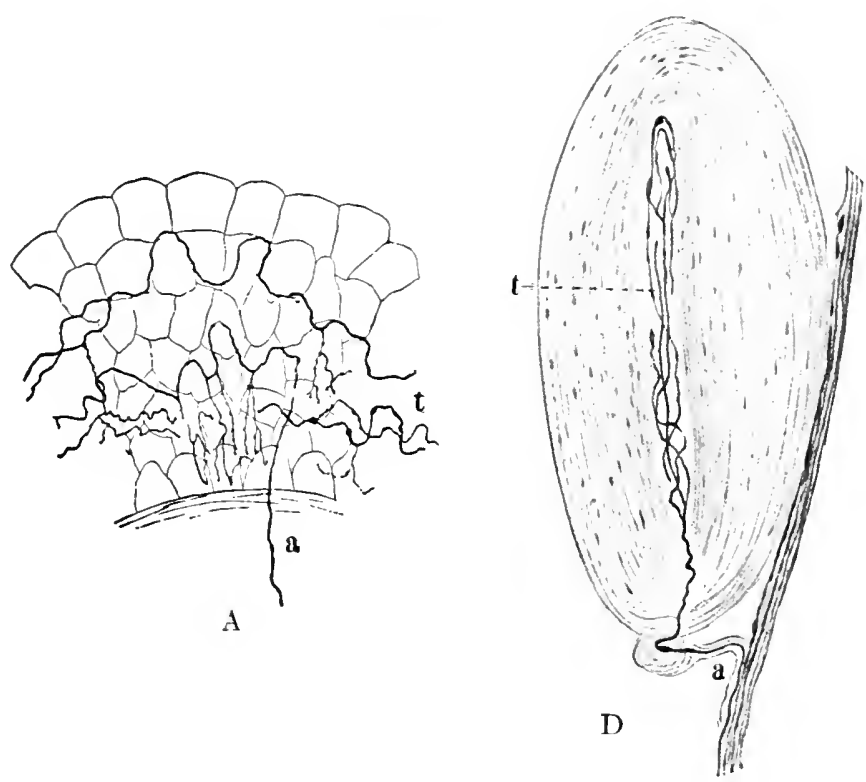

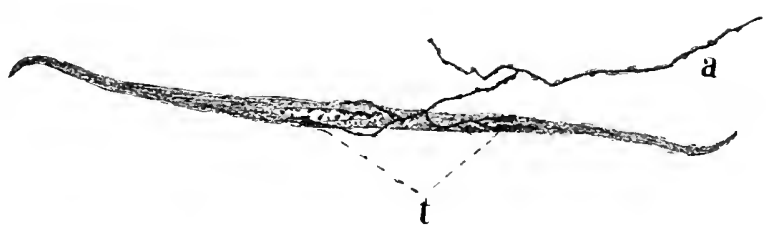

G

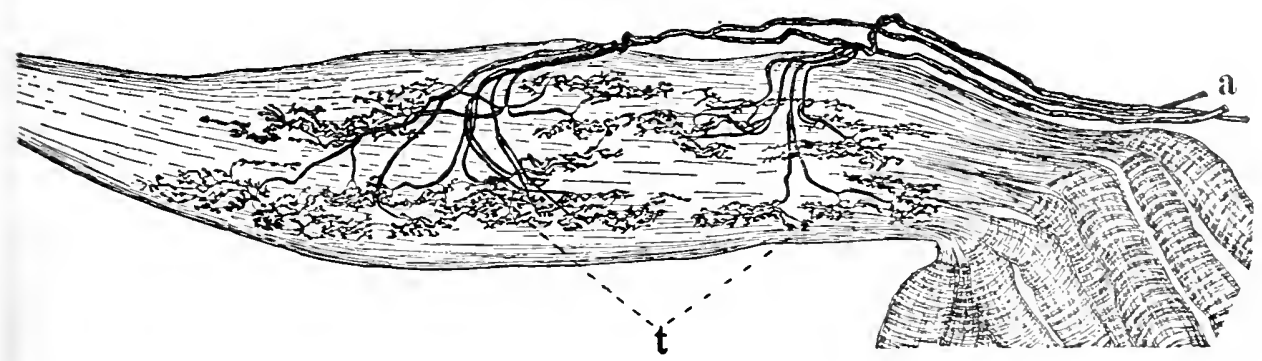


the 'neuromuscular spindle.' In it, the axone penetrates the sarcolemma and breaks into telodendria which coil spirally about the muscle fibre. The most extensive and elaborate form of sensory telodendria are those which spread out in plate-form upon tendons sheaths.

Fig. 606.--Schemes showing Two Forms of Synapses or the Termination of Axones upon Cell-bodies of other Neurones.

A. In ventral horn of spinal cord. B. In spinal ganglia.

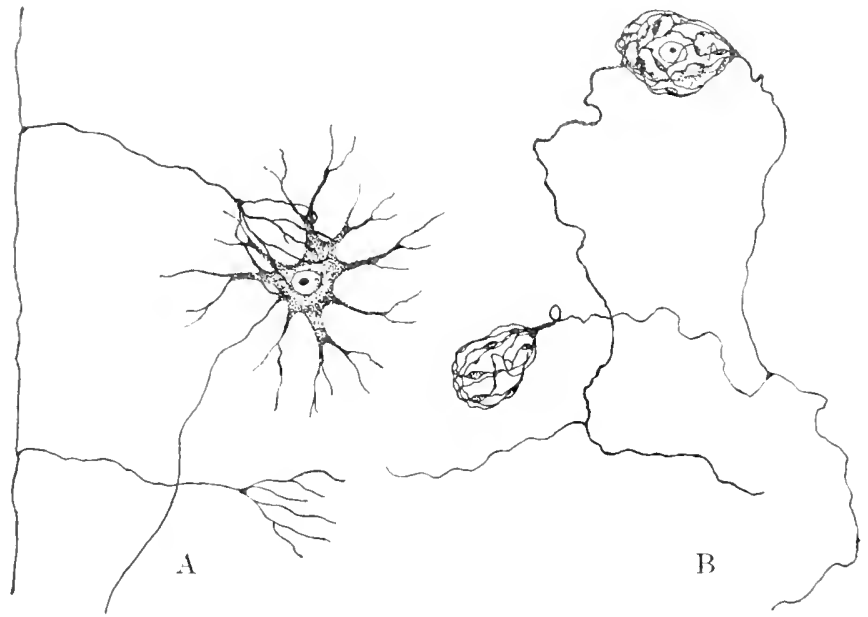

Fig. 607.-Drawings Illustrating two General Types of Arrangenent of NeuroFibrille in the Cell-bodies of Neurones.

A, cell-body of spinal-ganglion neurone. B, selected "giant pyramidal cell" from cerebral cortex, human. a, axone.

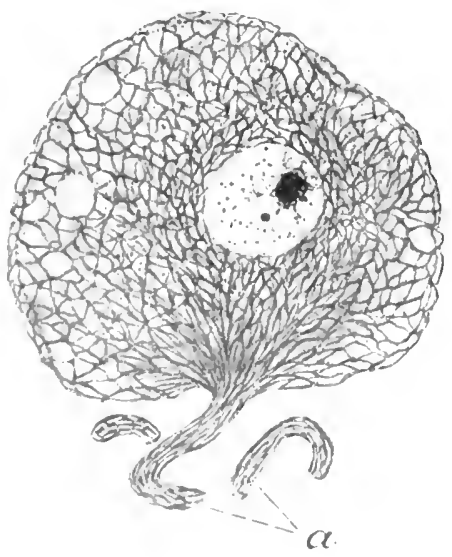

1

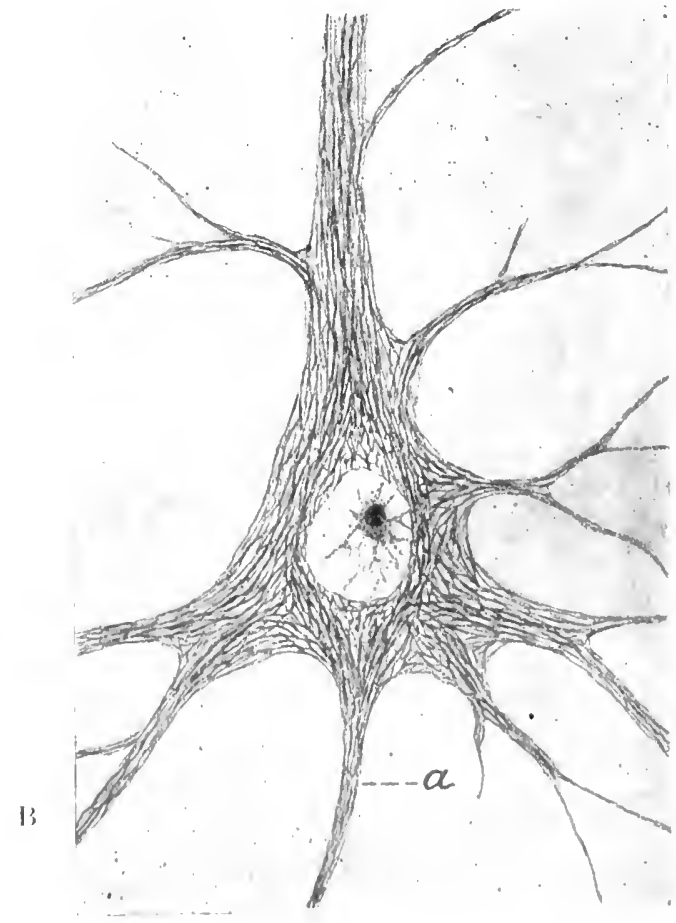

Motor periphoral axmes trmonate upon musele and upon the secretory cell of glands

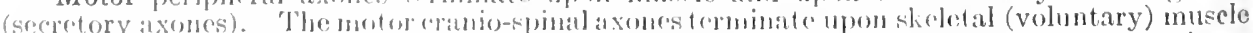
titeres and opon the reoll-bodies of sympathetice numbones, the axomes of which latter terminate

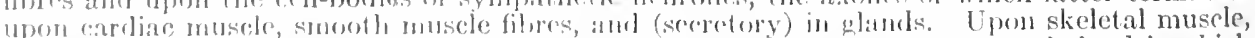

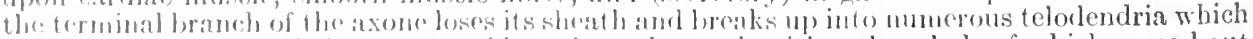
themolves hranch and show very evident, irregular variensities, the whole of which spread ont 
in plate-form, and lie in contact with the substance of the muscle fibre. In man and all mammals, the area covered is usually somewhat oval and is marked by a granular differentiation of the muscle substance. This with the telodendria is known as a motor end-plate. The telodendria of sympathetic axones ending upon cardiac and smooth muscle fibres are fewer and simpler than those of cranio-spinal axones upon skeletal muscle. They consist of a few fine fibrils, with rery small varicosities along them and at their ultimate terminations, which run longitudinally along the muscle fibre in close relation with its substance. Those upon gland cells are similar in character except that they often form a loose pericellular plexus about and upon the cell. The varicosities of telodendria are sometimes called end-feet and closer study of them has shown that they themselves consist of fine plexuses of the neuro-fibrils described below as contained in the cell-body of the neurone and extending throughout all its processes. Quite recently Boek has found that a sympathetic axone may sometimes accompany a cranio-spinal axone to an end plate on a skeletal muscle fibre.

Synapses.-Every functionally complete nerve pathway consists of two or more neurones arranged in series. Very often, the series consists of many more than two, the impulses being transmitted from neurone to neurone. The axone, bearing the impulse away from the cell-body of one neurone, gives off terminal branches, each of which loses its sheath and breaks up into telodendria which twine themselves upon the dendrites or cell-body of another neurone. The mpulse is transferred from one neurone to another by means of contact rather than by direct anatomical continuity of the parts of the two neurones. Such terminations of axones are known as synapses.

Fig. 608.-Drawings Illustrating the Abundance and General Arrangement of the Tigroid Masses in Cell-bodies of Neurones in Resting Condition.

A, cell-body from spinal ganglion. B, large cell-body from ventral horn of spinal cord. a, axone. d, dendrites.

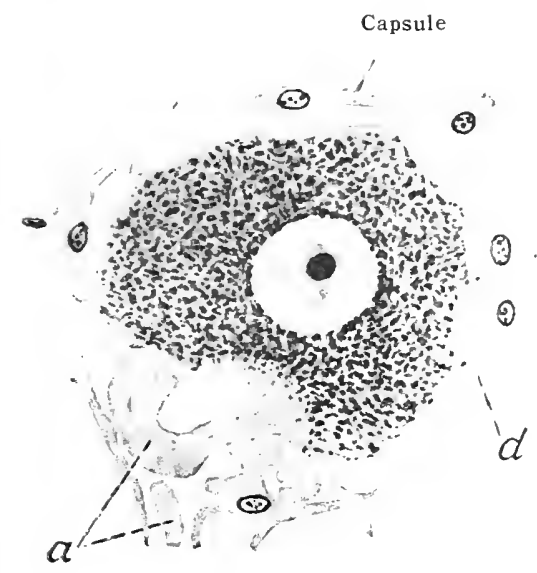

A

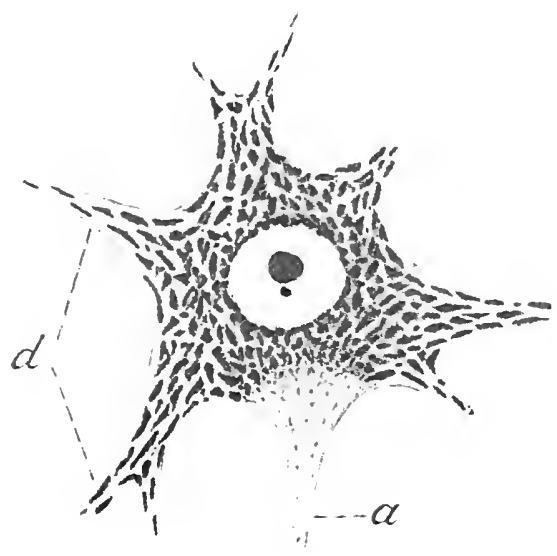

B

In the terminal arrangement of the telodendria, synapses assume forms varying from compact "pericellular baskets" and "climbing fibres" to the more open arborisations composed of fewer twigs in simpler arrangements, "end-brushes." In case of the spinal ganglion type of neurone, the cell-body of the majority of which has no dendritic processes, the telodendria of the visiting axone form an anastomosing pericellular plexus inclosing the entire cell-body. This and the simple end-brush form of synapses are illustrated in fig. 606 . It should be mentioned that, contrary to the general belief that impulses are transmitted by simple contact of the neurones in the series, it has been claimed that the ultimate twigs of the telodendria frequently penetrate the substance of the receiving cell-body and are fused in continuity. If during the processes of growth this becomes true, instead of being an appearance produced by the technique employed, it is better considered as merely an exception to the general rule.

Internal structure of the neurone.- The cell-body of the neurone consists of a large, spherical, vesicular nucleus and a cytoplasm continuous into its axone and dendritic outgrowths. Its nucleus is further characterized by having most usually but one nucleolus, large, spherical and densely staining, situated in a karyoplasm containing otherwise a remarkably small amount of chromatin. Of the cytoplasm, the two most interesting structures are its fibrillar and its granular components.

The fibrillar structure, known as the neuro-fibrilla, represents a growth and elaboration of the spongioplasmic reticulum of the original, embryonal cell. The filaments increase in thickness during the development of the neurone, and, in the sending out of its processes, the meshes of the original reticulum become so drawn out in the processes as to give the appearance of a more or less parallel arrangement of threads. The reticular or net-like arrangement is usually more nearly retained in the cytoplasm immediately about the nucleus, since here the stress of the outgrowing processes is less directly applied. In the cell-body of the spinal ganglion type of neurone, when no dendrites are given off, the net-like arrangement is apparent throughout the cytoplasm except in that region giving rise to the axone. On the other hand, in the typical so-called "pyramidal cell" of the cerebral cortex, from which two chief processes, the axone and the apical 
dendrite, are given off from opposite poles, the more reticular arrangement about the nucleus is of ten practically obliterated by the opposing growth stress.

So manifest does the parallel appearance of the neuro-fibrillæ in the processes often become that it has been interpreted as a series of individual and independent fibrils. In the application of gold chloride and similar methods to the neurones of lower forms, the reduced reagent is of ten precipitated upon the fibrils in parallel, seemingly independent lines. And, assuming the existence of independent fibrils, it has been contended that the neurone is not the functional unit of the nervous system but is itself composed of numerous functional units, individual fibrils, each for the conduction of nerve impulses. More recent and trustworthy methods, however, show that the neuro-fibrilla retain their original reticular form, the threads anastomosing in all planes, and that the meshes of the net may, in the processes, be so drawn in one direction that a parallel appearance predominates. Further, it is now held that the neuroplasm, or the more fluid substance in which the fibrils lie throughout, is capable, and probably fully as capable, of conducting impulses as the fibrils.

Of the granules in the cytoplasm, the most interesting are those first described in detail by Nissl. These are the most abundant of those in the cell-body and are known as tigroid masses or $N$ issl bodies. They consist of numerous basophilic granules collect ed into elumps or masses of varying size. They are known to disappear during fatigue of the nervous system and they are more abundant in animals after a period of rest. 'They are clistributed throughout the eytoplasm of the cell-body with the interesting exception that they are not found in the axone nor in the immediate vicinity of its place of origin from the cytoplasm, leaving a free region known as the axone hillock. As accumulated masses, they show characteristic shapes and arrangement

\section{Fig. 609.-Showing Pieces of Axones.}

A. From a cranio-spinal nerve. B. From the spinal cord. C. From the sympathetic. $a$, axones; $m$, medıllary sheath; $n$, node of Ranvier; $s$, neurilemna or sheath of Schwann with occasional sheath-nuclei.

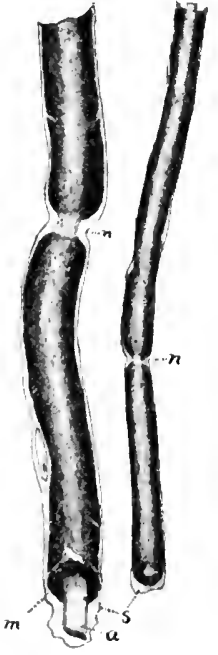

A

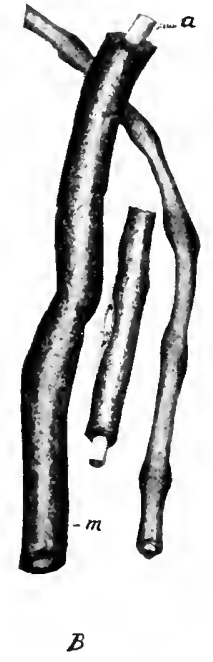

$B$

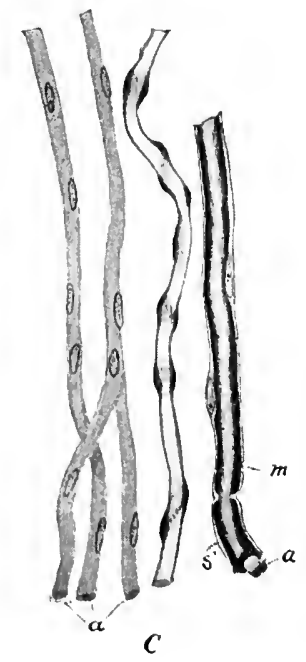

C

which are interpreted as signifying the shapes and arrangement of the spaces or meshes they occupy in the reticulum of the neuro-fibrillar. In coll-bodies of the varieties found in the ventra horns of the spinal cord or in the cerebral and cerebellar cortex, for example, the masses situated inmodiatcly about the nucleus are smaller, more numerous and of irregular shape. Nearer and in the beginnings of the dendrites, they are larger and mostly of fusiform or diamond shape. Farther ont in the dendrites, they heoome more and more thin and attenuated; and in the distant reaches of thre londrites they are invisible or absent. In the cell-borly of the spinal ganglion they are of irregular shape, smaller and more numerous throughout the eytoplasm, being slightly smitler and mone thickly placol in the immerliate vicinity of the mucleus. In all neurones sroveral homrs post-mertem, they appear in fower and larger masses and it was in this condition that Jisst originally described them in man. Choscly examined, the masses of all sizes are found to bre acommlations of fincr gramules. Functionally they are supposed to be of mutritive signi-

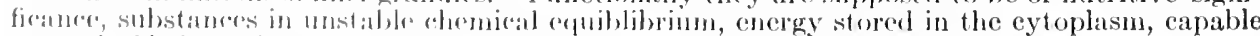
at ured of being split into simpler forms usable in the activitios of the neurone. The fact that tigroid masses are alsent font the axome hillork, the axome, and the distant reaches of the dendeitres maty signify that the sulstance is chichly present here only in the split and usable form. Also, in the axone especially, the neurofibrille are so closely arranged that the meshes of their net here are tor small to contain masses of appreviable size. ('Iose examination of the axone hillorek atul longituclinal sortions of tho axone in decply stained preparations usually show a few very minute biscophilic gramules.

Sheaths of the axone.- The graat majority of axones acquire sheaths about them which isolate and protect them in their conrse through other tissues or in company with other axones. 1 mere fibre is an axone together with its sheath. In transerse sections, the axone comprises 
the central portion of the nerve fibre or its so-called "axis-cylinder." It is of course the essential portion of the fibre. As noted above in describing their development, nerve fibres are classified according to the character of the sheaths. Those which possess sheaths of myelin, a peculiar form of fat, are known as medullated fibres, and those in which the sheaths are merely membranes of condensed fibrous tissue, void of myelin, are non-medullated fibres. A medullated fibre also possesses a fibrous membrane outside its myelin sheath, known as the neurilemma or sheath of Schwann. The neurilemma is of the same origin and general structure as the sheath of the non-medullated fibre, and both possess nuclei scattered along them. Medullated fibres, at more or less regular intervals, show constrictions at which the myelin sheath ceases, but over which the neurilemma continues. These constrictions are the nodes of Ramier. The myelin is in the form of an emulsion, whose fat droplets are supported in a fine fibrous reticulum (neurokeratin), while the neurilemma without serves to hold it in place. The neurilemma possesses from one to three or four sheath nuclei between adjacent nodes of Ranvier.

There is no sharp line of separation between medullated and non-medullated fibres, for in any locality there may be found axones in all degrees of medullation. Most of the fibres

Fig. 610.-Diagray of Transverse Section of Spinal Cord with Roots of Spinal Nerve and Neighbouring Ganglia Attached, Illustrating Simplest Foris of Neurone Chains.

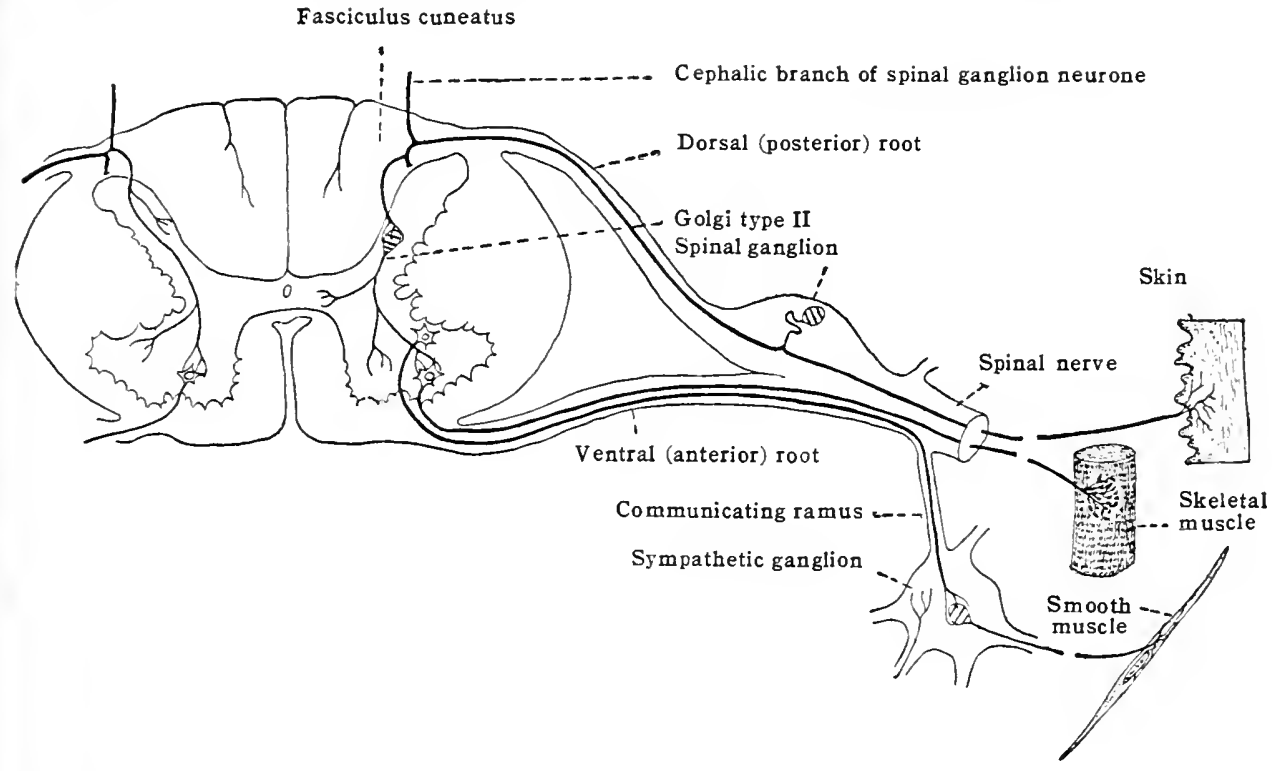

belonging to the sympathetic system (processes of sympathetic neurones) are non-medullated, but both partially medullated and completely medullated sympathetic fibres may be found. (See fig. 609.) The myelin sheaths of completely medullated sympathetic fibres are always thinner and less well developed than those of medullated cranio-spinal fibres. Most of the fibres belonging to the cranio-spinal nerves and to the central nervous system are medullated, but among the fibres belonging to either there are to be found numerous non-medullated fibres. As indicated in fig. 609, nodes of Ranvier are absent in the medullated fibres of the central system.

In all the higher vertebrates, the myelin sheath always begins on the axone a short distance from its parent cell-body. The neurilemma of the medullated and the fibrous membrane of the non-medullated fibre are each faintly continuous with the fibrous connective tissue surrounding it, and, in the cranio-spinal and sympathetic ganglia, in which each cell-body of the neurone has a fibrous capsule about it, the fibrous menbrane or the neurilemma, as the case may be, is directly continuous into the capsule of the cell-body. Cpon approaching its final termination, in other tissues or upon the dendrites or cell-body of other neurones, the nerve fibre always loses its sheath, the telodendria of the axone always being bare when placed in contact with the other element. In losing the sheath, the myelin sheath, if present, always ceases and the fibrous membrane becomes continuous with the tissue investing the receiving element, whether the capsule of the ganglion cell, the sarcolemma of the skeletal muscle fibre. the corium of the skin, or the connective-tissue capsule of the encapsulated terminal corpuscle,

The connective tissue of the nervous system is of two main varieties- white fibrons connective tissue and neuroglia. White fibrous tissue alone supports and binds together the peripheral system, and it is the chief supporting tissue of the central system. As connective tissues, these two varieties are quite similar in structure, each consisting of fine fibrillip, either dispersed or in bundles, among which are distributed the nuclei of the parent svncytium. In both tissues nuclei are frequently found possessing varying amounts of cytoplasm which has not yet been transformed into the essential fibrils.

In addition to its enveloping membranes, the three meninges, which are of white fibrous tissue, the white fibrous tissue supporting the central system within is quite abundant. It is all 
sent in from without, either as ingrowths of the developing pia mater, the most proximal of the membranes, or is carried in with the blood-vessels, of the walls of which it is an abundant component. Practically, the neuroglia as a connective tissue proper differs from white fibrous tissue only in origin and in its chemical or staining properties. Based upon the latter, there are methods of technique by which the two may be distinguished. White fibrous tissue is derived from the middle germ layer or the mesoderm, while neuroglia comes from the ectoderm. The epithelium lining the central canal of the spinal cord and the ventricles of the encephalon, with which the canal is continuous, is the remains of the mother tissue of the neuroglia, and in the adult is the only vestige representing its origin. The cells of this epithelium are known as ependymal cells, and they are usually classed as a variety of neuroglia.

Axones, with their medullated or non-medullated sheaths (nerve fibres) comprise all nerves in the periphery and all nerve tracts in the central system.

White substance [substantia alba] ("white matter") consists of a portion of nerrous tissue in which medullated fibres predominate. The myelin sheaths, being in the form of a fat emulsion, reflect the entire spectrum and thus appear white.

Grey substance [substantia grisea] ("grey matter") is a portion of nervous tissue in which medullated axones do not predominate. Thus sympathetic ganglia and sympathetic nerves may be grey, though the term is usually applied to grey portions of the central system, such as the cerebral cortex, the central grey column of the spinal cord, etc. Such grey regions contain more cell-bodies of neurones than other regions, though at least half of their volume may consist of neuroglia, white fibrous connective tissue, blood-vessels, and axones of both varieties.

Neurone chains.-As noted above, the numerous neurones comprising the nervous system are functionally and anatomically related to all the other tissues of the body and to each other. A functionally complete nerve pathway extends from the tissue in which the nerve impulse is aroused to the tissue in which a resultant reaction occurs. It is known that the simplest possible of such paths necessarily comprises at least two neurones. The great majority involve a greater number. The axone of one neurone bearing impulses from the peripheral tissue transfers the impulses to the dendrites or cell-body of another by synapsis, and the axone of this, in the same way, transfers them to another and so on till the final neurone receives the impulses and the telodendria of its axone transfer the impulse to the tissue element which reacts in response to the stimulus brought. Neurones are thus linked together in chains. A neurone chain may be defined, therefore, as a number of neurones associated with each other in series to form a functionally complete nerve pathway. Examples of the simplest forms of neurone chains as contained in the spinal cord are illustrated in fig. 610. An impulse aroused in the skin is borne by the spinal ganglion neurone to the spinal cord where, in the left half of the figure, telodendria of one of the terminal branches of its axone form synapses with a neurone in the ventral horn, and the axone of this bears the impulse out of the spinal cord to transmit it probably direct to skeletal muscle. This arrangement involves but two neurones and is supposed to be relatively rare. In the right half of the figure, a third neurone is seen interposed. This is a neurone, numerous in grey substance everywhere, whose axone is relatively short and branches frequently, making possible several synapses in the near neighbourhood of its parent cell-body. Its type is referred to as the Golgi neurone of type $I I$. This interposed, gives a chain of three neurones between the origin of the impulse in the periphery and the contraction of muscle in response. Simple chains like these can result only in reflex activities and such chains are often called reflex arcs. Another chain is indicated in the figure in which the reflex action involves involuntary or smooth musele. This must involve at least one sympathetic neurone, and, should the Golgi neurone of type II form synapses with the ventral horn neurone involved, a chain composed of four neurones results. In the more extensive and complex neurone chains, such as those in which the impulse from the skin, as above, ascends to the cerebral cortex and the resultant inuscular contraction is thrown under cerebral control, each of the several neurones or links in the series is not only referred to by name according to the position of its cell-body, but each is often called according to its order in the series, as "neurone of first order," "second order," "third orler," etc.

$\Lambda$ given axone inay break into a considerable number of branches each of which forms synapses with a different second neurone, or, if peripheral, the telodendria of each branch may terminate upon a separate pripheral tissue element. Thus, a given impulse aroused in a peripheral tissue eloment inay be transmitted to an ever increasing number of neurones, and the initial neurome may comprise the first link in a number of neurone chains. Such is quite goneral in the structural plan of the nervous system throughout. It is thought possible to consider cach nourome interposed in a chain as a separate source of energy, a sort of relay in the nerve path; that. the impulse passing through the axone is gradually weakened in overconing resistance, but, when transferred to another neurone, it incites a splitting into usable form of the substane: represented liy the tigroill masses and thus a liberation of energy or a reinforement of the impmlse. Further, thus is marle possible the economy of one neurone serving as a link in at number of nemrone chains.

The axonrs (nerve filores) laking part in the various neurone chains course in bundles of varying size, the larger of which have names. And there is a general tendency with axones of the same function and the same origin to eourse in company with each other. $\Lambda$ fibre bearing impunlsis from the peripheral tissines to the central systen is an afferent fibre or sensory fibre. A fibre luming impulses out of the contral system to peripheral tissues is an efferent fibre or motor 
fibre. Efferent fibres which bear impulses to skeletal muscle are known as somatic efferent fibres, while those which terminate upon the cell-bodies of sympathetic neurones and thus bear impulses destined for smooth muscle, cardiac muscle and glands (secretory) are visceral or splanchnic efferent fibres.

A nerve is a closely associated aggregation of parallel nerve fibres coursing in the periphery. It may be spinal, cranial or sympathetic according to its attachment or according to the origin of the majority of its fibres. It may contain several functional and structural varieties of fibres. The spinal nerves contain all structural varieties. Nerve roots are those bundles of fibres which join to form a nerve. Most of the cranial nerves have but one root of origin. Nerve roots, in their turn, are formed by the junction of smaller root-filaments. Nerve branches result from the division of the nerve, the separation of its component fibres into separate bundles. Some branches are of sufficient size and significance to be called nerves and given separate names. The smaller branches are called rami, twigs, etc.

In the central system, a given bundle of fibres is called a fasciculus, while two or more adja-

Fig. 611.-Diagam of Transverse Section of Medulla Oblongata, Illustrating Nuclei of Termination and Nuclei of Origin.

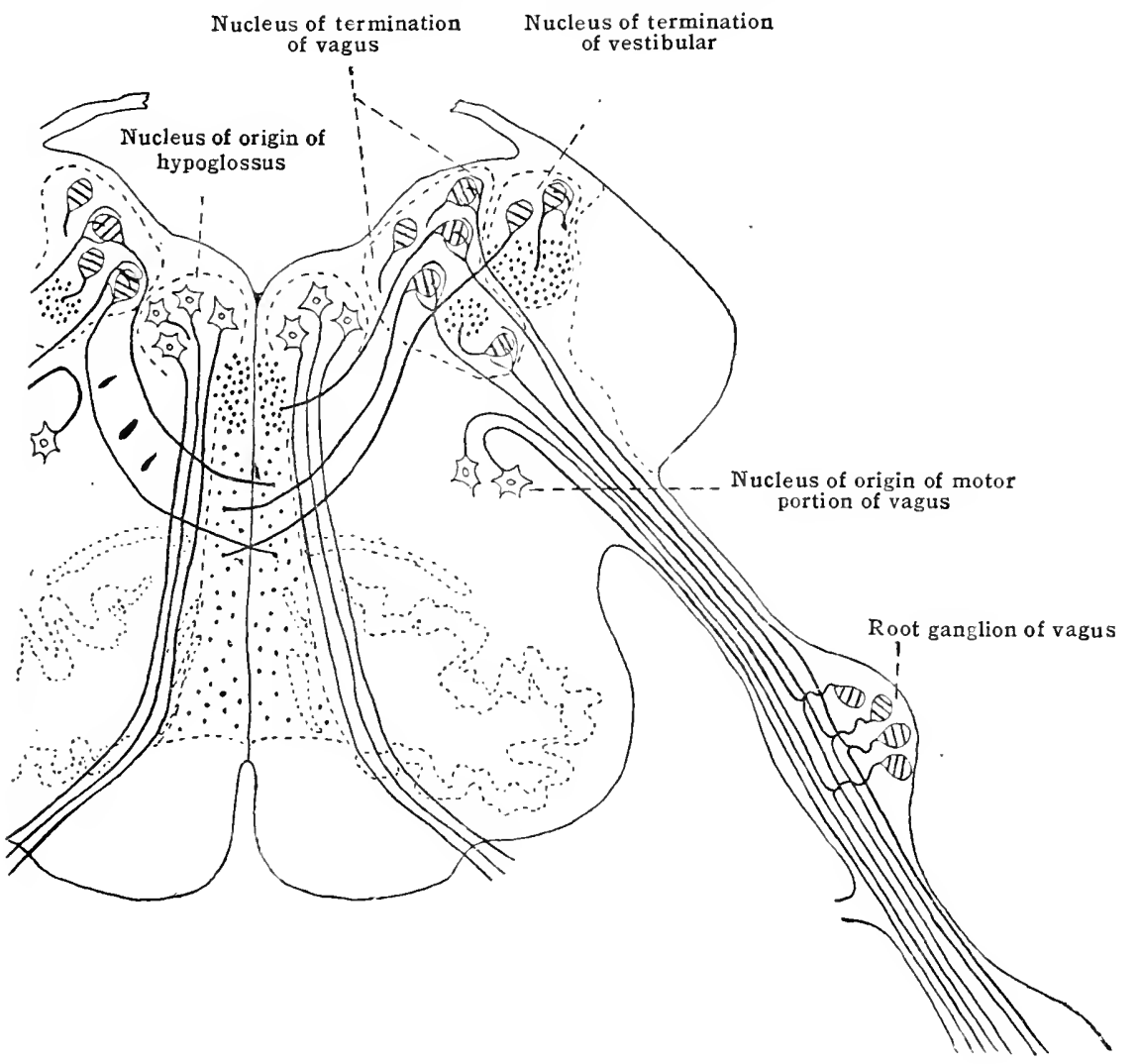

cent fasciculi coursing parallel to each other comprise a funiculus, a bundle of bundles. The central nervous system is bilaterally symmetrical throughout its length. A bundle of fibres arising from cell-bodies situated on one side and crossing the mid-line transversely to terminate in the opposite side is a commissure. The commissures vary greatly in size and contain fibres crossing in both directions. Scattered fibres which cross the mid-line are commissural fibres. Fibres of varying length, arising from cell-bodies situated in one locality of the central system, which do not cross the mid-line, but terminate in other localities of the same side, above and below the level of their origin or in a different region of the same level, form association fasciculi. The shortest association fasciculi, not extending beyond the bounds of a given division of the central system, are known as fasciculi proprii. When bundles of the same origin, functional direction and significance, running one on either side of the mid-line, cross the mid-line they' are said to decussate and the crossing is known as a decussation. In the decussations, the direction of the crossing is oblique rather than transverse.

The cell-bodies of neurones whose axones go to form certain nerve roots, fasciculi and certain commissures show a tendency to accumulation in localized masses. In the pcripheral system, such an accumulation of cell-bodies is known as a ganglion; in the central system such is distinguished as a nucleus. Thus, there are the sympathetic ganglia which give rise to sympathetic nerves and sympathetic roots of nerves; and on the beginning of each spinal nerve there is a spinal ganglion which gives rise to the afferent fibres of its dorsal root and in its nerve trunk. There are ganglia on the cranial nerves which give rise to the afferent or sensory axones in them and which are of the same significance as the spinal ganglia. Every ganglion, therefore, has 
connected with it bundles of nerve fibres. Some of these fibres bear impulses from neighboring ganglia or from the tissues of the neighboring organs and transmit them to the cell-bodies of the ganglion; others arise from the cell-bodies in the ganglion and bear impulses to the central system or, in case of the sympathetic, to other ganglia or to the tissues of the peripheral organs. Necessarily, the larger the ganglion, the larger will be the bundles of fibres connected with it.

Nuclei may be considered in two general classes: (1) Recipient nuclei or nuclei of termination, and (2) Nuclei of origin.

A nucleus of termination is an accumulation of cell-bodies in which the axones of a given fasciculus or of a nerve root terminate, that is, cell-bodies which, by synapses, receive the impulses borne by the terminating axones. In most cases the impulses transferred to a nucleus so named are sensory in character. The nucleus may be considered as a defined region in which neurones of the next order are interpolated in a given nerve pathway or system of neurone chains. Fasciculi in the spinal cord which bear impulses to the cerebrum have their nuclei of termination in the medulla oblongata, and the sensory or afferent axones of the cranial nerves find their nuclei of termination upon entering the central system.

A nucleus of origin is an accumulation of cell-bodies of neurones which give origin to the axones going to form a given nerve root or a fasciculus. Strictly speaking, a nucleus of termination for one nerve tract is the nucleus of origin for another, the next link in the neurone chain. However, the term is commonly used to distinguish a group of cell-bodies giving rise to a motor nerve tract. Thus each motor cranial nerve has its nucleus of origin within the central system. The central grey substance of the spinal cord is in the form of a column continuous throughout the length of the cord and so the cell-bodies in the ventral horns of this column which give rise to the motor or afferent roots of the spinal nerves are not considered as grouped into nuclei of origin, one for each of the motor roots.

The dorsal root of each spinal nerve is afferent or sensory in function and its axones arise as processes of cell-bodies comprising the spinal ganglion of the nerve. The afferent or sensory fibres of the cranial nerves arise as processes of cell-bodies comprising the ganglia of the cranial nerves, which ganglia are, in development and character, exactly homologous to the spinal ganglia.

The ventral root of each spinal nerve is efferent or motor in function and its fibres arise as processes of cell-bodies situated in the ventral horn of the grey substance of the spinal cord. The efferent or motor fibres of the cranial nerves arise as processes of cell-bodies accumulated as nuclei of origin in the grey substance of the encephalon, and homologous with those cell-bodies of the ventral horns of the spinal cord which give origin to the ventral-root fibres.

The general relation of the cerebrum (which includes the mesencephalon) to the remainder of the nevous system is a crossed relation. Neurone chains from the general body to the cerebrum, via the spinal nerves and cord and via the cranial nerves and medulla oblongata and pons of one side, cross the mid-line to terminate in the opposite side of the cerebrum. Axones, and neurone chains, arising in response in one side of the cerebrum, likewise usually decussate in descending to terminate in the respective regions of the opposite side.

Many of the names given nervous structures, prior to 1850 especially, instead of suggesting something of their functional or anatomical significance, indicate nothing more than active imaginations for accidental resemblances between the various structures of the nervous system and objects in ordinary domestic environment. Also, quite of ten the name given a structure is merely the name of some anatomist associated with it. The much needed elimination of these old non-descriptive names is proving a very slow process. Attempts have of ten increased the difficulty by making necessary the use of several names for a given structure instead of one. The most recent and concerted attempt, the nomenclature known as the BNA (anatomical names chosen by a commission appointed for the purpose which convened in Basle in 1895), has been adopted by modern text-books. It is here used in the form of the English equivalents of the Lat in terms, except in cases of those Latin terms which have becone so commonly used as to be considered words incorporated into the English language. The $3 \mathrm{NA}$ has retained many of the old names and, since a name should indicate something of the locality and significance of the structure to which it is applicd, it is not yet wholly satisfactory throughout. In applying the names of a few fasciculi, the BNA in the following pages is slightly modified by so compounding the name that the first word in the compound indicates the locality of origin of the fasciculus and the second, the locality of its termination. 'Thus, "Dorsal spino-cerebellar fasciculus" indicates the more dorsally coursing of the fasciculi which arise from cell-bodies in the spinal cord and terminate in the cercbellum. This principle applies to many of the BNA names without change, as "lateral cerebro-spinal fasciculus."

\section{TIIE CENTRAI, NERVOUS SYSTEM}

The contral nervous system [systema nervorum centrale] or organ is an aggrengation of nurlei, fasciculi and commissures-a large axis of grey and white substance situated in the dorsal midl-line of the body - and the bundles of fibres connecting it with the tissues of other systems and with the peripheral ganglia are of necessity correspondingly large. So mumerous are the axones connecting it and so intimately are its neirones associated that a disturbance affecting any one part of the system may extend to influence all other parts. The enlarged "whalic cxtremity of this central axis, the brain or encephalon, is a special aggregation of nuclei and masses of grey substance, many of which are much larger than any found in the periphery. 
In the study of the central nervous system its enveloping membranes or meninges are met with first, and logically should be considered first, but since a comprehensive description of these membranes involves a foreknowledge of the various structures with which they are related, it is more expedient to consider them after making a closer study of the entire system they envelop.

For convenience of study, the central nervous system is separated into the gross divisions, spinal cord and brain (encephalon) as illustrated in fig. 602 . Each of these divisions will be subdivided and considered with especial reference to its anatomical and functional relations to the other divisions and the interrelations of its component parts.

\section{THE SPINAI CORD}

The spinal cord [medulla spinalis] is the lower (caudal) and most attenuated portion of the central nervous system. It is approximately cylindrical in form and terminates conically. Its average length in the adult is $45 \mathrm{~cm}$. (18 in.) in the male and $42 \mathrm{~cm}$. in the female. It weighs from 26 to 28 grams or about 2 per cent. of the entire cerebro-spinal axis.

After birth it grows more rapidly and for a longer period than the encephalon, increasing in weight more than sevenfold, while the brain increases less than half that amount. Its specific gravity is given as 1.038 .

The line of division between the spinal cord and the medulla oblongata is arbitrary. The outer border of the foramen magnum is commonly given, or, better, a transverse line just below the decussation of the pyramids. Lying in the vertebral canal, the adult cord usually extends to the upper border of the body of the second lumbar vertebra. However, cases may be found among taller individuals in which it extends'no farther than the last thoracic vertebra. With increase in stature, its actual length increases, but the extent to which it may descend the vertebral canal decreases. Up to the third month of intra-uterine life it occupies the entire length of the vertebral canal, but owing to the fact that the vertebral column lengthens more rapidly and for a longer period than does the spinal cord, the latter, being attached to the brain above, soon ceases to occupy the entire canal. At birth its average extent is to the body of the third lumbar vertebra.

\section{External Morphology of the Spinal Cord}

In position in the body, the spinal cord conforms to the curvatures of the canal in which it lies. In addition to the bony wall of the vertebral canal, it is enveloped and protected by its three membranes or meninges, which are continuous with the like membranes of the encephalon: first, the pia mater, which closely invests the cord and sends ingrowths into its substance, contributing to its support; second, the arachnoid, a loosely constructed, thin membrane, separated from the pia mater by a considerable subarachnoid space; third, the dura mater, the outermost and thickest of the membranes, separated from the arachnoid by merely a slit-like space, the subdural space.

The intimate association of the central system with all the peripheral organs is attained chiefly through the spinal cord, and this is accomplished by means of thirty-one pairs of spinal nerves, which are attached along its lateral aspects. The nerves of each pair are attached opposite each other at more or less equal intervals along its entire length, and in passing to the periphery they penetrate the meninges, which contribute to and are continuous with the connective-tissue sheaths investing them. Each nerve is attached by two roots, an afferent or dorsal root, which enters the cord along its postero-lateral sulcus, and an efferent or ventral root, which makes its exit along the ventro-lateral aspect.

With its inequalities in thickness and its conical termination the spinal cord is subdivided into four parts or regions:--(1) The cervical portion, with eight pairs of cervical nerves; (2) the thoracic portion, with twelve pairs of thoracic nerves; (3) the lumbar portion, with five pairs of lumbar nerves; and (4) the conus medullaris, or sacral portion, with five pairs of sacral and one pair of coccygeal nerves. From the termination of the conus medullaris, the pia mater continues below in the subarachnoid space into the portion of the vertebral canal not occupied by the spinal cord, and forms the non-nervous, slender, thread-like terminus, the filum terminale. This becomes continuous with the dura mater at its lower extremity. 
In the early fotus the spinal nerves pass from their attachment to the spinal cord outward through the intervertebral foramina at right angles to the long axis of the cord, but, owing to the fact that the vertebral column increases considerably in length after the spinal cord has practically ceased growing, the nerve-roots become drawn caudad from their points of attachment, and, as is necessarily the case, their respective foramina are displaced progressively downward as the termination of the cord is approached, until finally the roots of the lumbar and sacral nerves extend downwird as a brush of parallel bundles considerably below the levels at which they are attached. This brush of nerve-roots is the cauda equine. The chura mater, being more closely related to the bony wall of the canal than to the spinal cord, extends with the vertebral column and thus envelops the cauda equina, undergoing a slightly bulbous, conical dilation which deereases rapidly and terminates in the attenuated canal of the coceyx as the coccygeal ligament.

The enlargements.--Wherever there is a greater mass of tissue to be innervated, the region of the nervous system supplying such must of neeessity possess a greater number of neurones. Therefore, the regions of the spinal cord associater with the slin and musculature of the regions of the superior and

Fig. 612.-Dorsal View of Portion of Sinal Cord in Position in Vertebral Canal

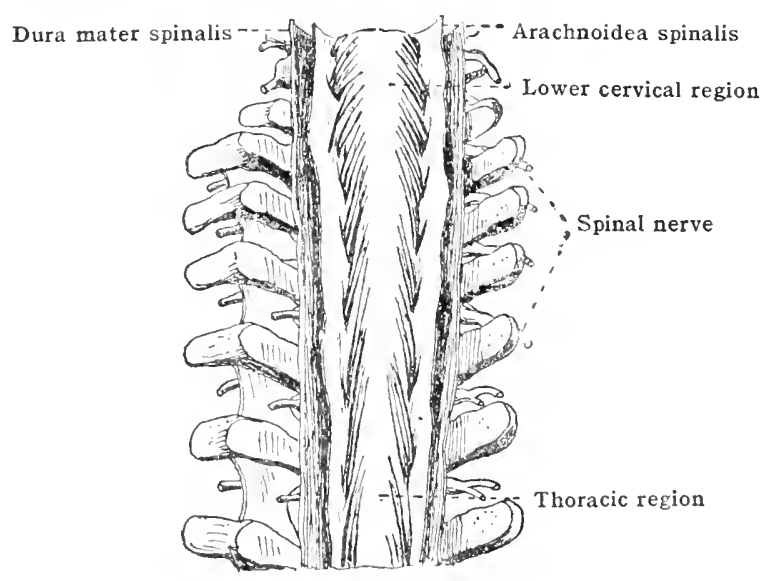

inferior limbs are thicker than the regions from which the neck or trunk alone are innervated. Thus in the lower cervical region the spinal cord becomes broadened into the cervical enlargement, and likervise in the lumbar region occurs the lumbar enlargement. The spinal nerves attached to these regions are of greater size than in other regions.

The cervical enlargement [intumescentia cervicalis] begins with the third cervical vertobra, accuires its greatest breadth (12 to $14 \mathrm{~mm}$.) opposite the lower part of the fifth cervical vertebra (origin of the sixth ecrvical nerves), and extends to opposite the second thoracic vertebra. Inlike the lumbar enlargement, its latrial is noticably greater than its clorso-ventral diameter.

The lumbar enlargement [intumeserntia lumbalis] begins gradually with the ninth or tonth thoracio vertolua, is most markerd at the twelfth thoracic vertebra (origin of the fonth lumbar norves), and rapielly aliminishes into the conus miminllaris.

both the lumbar and thoracie regions am pratet ally cipeular in transverse section. Neither diametor of the lumbat is (over so great as the lateril dianeter of the cervieal endargement. The thorate part attans ils smallest liameter opposite the lifth and sixth thoracio vertebre

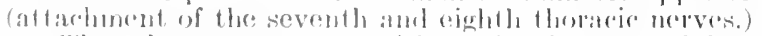

The culargenests ocenr with the development of the upper and lower limbs. In the embyro

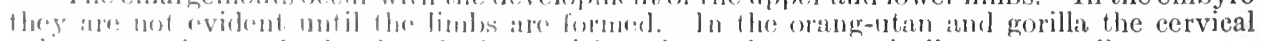

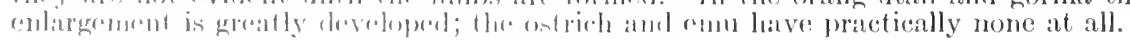

Surface of the spinal cord. 'Thre corrl is sepuruted into nearly symmetrical right and loft halyes by thr hrourl anterior median fissure into which the pia mater

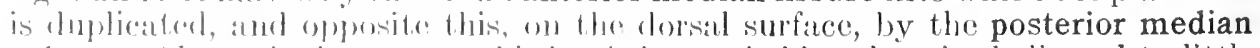

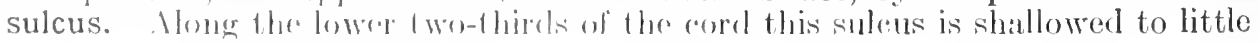


more than a line which marks the position of the posterior median septum; in the medulla oblongata it opens up and attains the character of a fissure. Each of the two lateral halves of the cord is marked off into a posterior, lateral, and anterior division by two other longitudinal sulci. Of these, the postero-lateral sulcus occurs as a slight groove 2 to $3 \frac{1}{2} \mathrm{~mm}$. lateral from the posterior median sulcus, and is the groove in which the root filaments of the dorsal roots enter the cord in regular linear series. The ventral division is separated from the lateral

Fig. 613.-Drawing from Specinen showing Cauda Equina, the Roots of Certain of the Spinal Nerves which form it, and its Accompanying Dura Mater. (Dorsal aspect.)

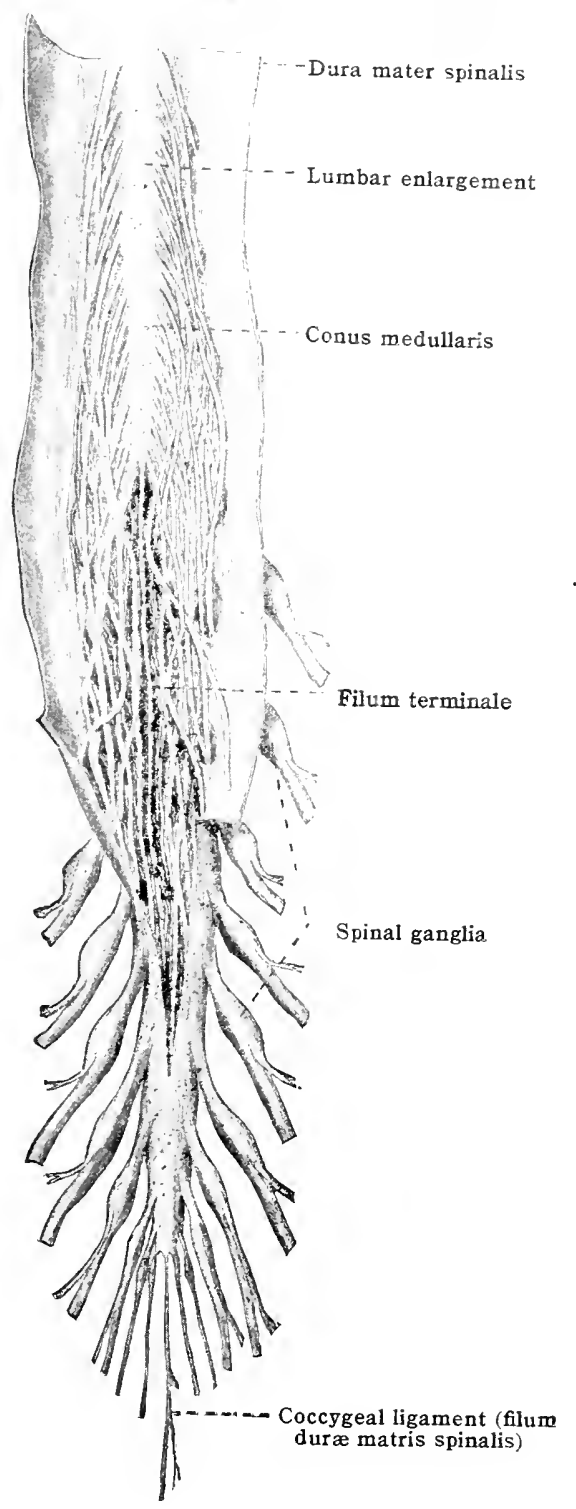

by the antero-lateral sulcus. This is rather an irregular, linear area than a sulcus. It is from 1 to $2 \mathrm{~mm}$. broad, and represents the area along which the efferent fibres make their exit from the cord to be assembled into the respective ventral roots. This area varies in width according to the size of the nerve-roots, and, like the postero-lateral sulcus, its distance from the mid-line varies according to locality, being greatest on the enlargements of the cord. In the cervical region, and along a part of the thoracic, the posterior division is subdivided by a delicate longitudinal groove, the postero-intermediate sulcus, which becomes more evident 
toward the medulla oblongata and represents the line of demarcation between the fasciculus gracilis and the fasciculus cuneatus. Occasionally in the upper cervical region a similar line may be seen along the ventral aspect close to the anterior

Fig. 614.-Posterior and Anterior Views of the Spinal Cord. (Modified from Quain.)
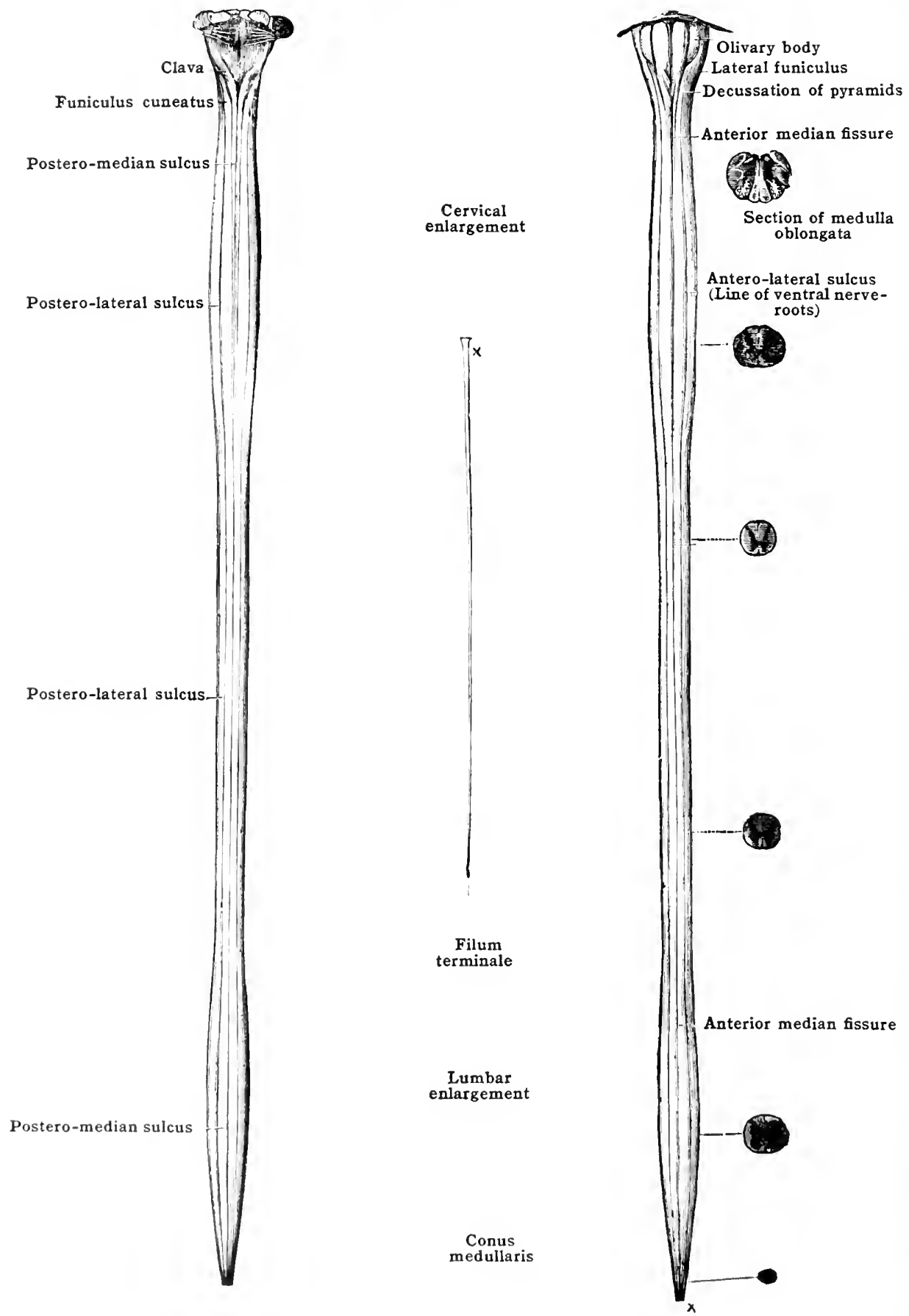

median fissure. This is the antero-intermediate sulcus, forming the lateral bounclary of the ventral cerebro-spinal fasciculus.

('ollectively, the entire space between the posterior median sulcus and the line of attarhment of the dorsal roots is oceupied by the posterior funiculus; the lateral space between the line of attachment of the dorsal and that of the ventral 
roots, by the lateral funiculus; and the space between the ventral roots and the anterior median fissure, by the anterior funiculus. Each of these funiculi is subdivided within into its component fasciculi.

The dorsal and ventral nerve-roots are not attached to the cord as such, but are first frayed out into numerous thread-like bundles of axones which are distributed along their lines of entrance and exit. These bundles are the root filaments [fila radicularia] of the respective roots. The fila of the larger spinal nerves are fanned out to the extent of forming almost continuous lines of attachment, while in the thoracic nerves there are appreciable intervals between those of adjacent roots. Throughout, the intervals are less between the fila of the ventral than between those of the dorsal roots.

\section{Internal Structure of the Spinal Cord}

By reflected light masses of medullated axones appear white in the fresh, and such masses are known as white substance. The spinaal cord consists of a continuous, centrally placed column of grey substance surrounded by a variously thickened tunic of white substance. The closely investing pia mater sends

Fig. 615.-A, Ventral, and B, Dorsal, Views of Portion of Spinal Cord showing Modes of Attachient of Dorsal and Ventral Roots.

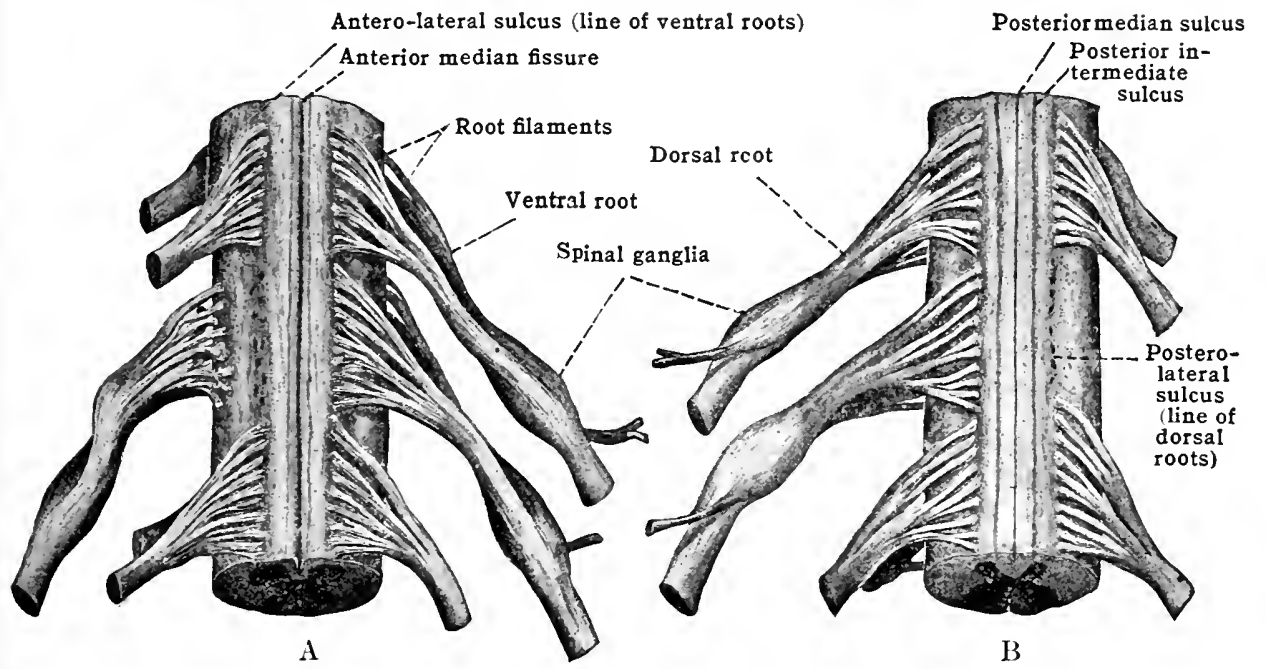

numerous ingrowths into the cord, bearing blood-vessels and contributing to its internal supporting tissue. The volume of white and of grey substance varies both absolutely and relatively at different levels of the cord. The absolute amount of grey substance increases with the enlargements. The absolute amount of white substance also increases with the enlargements coincident with the greater amount of grey substance in those regions. The relative amount of white substance increases in passing from the conus medullaris to the medulla oblongata, due to the fact that the ascending and descending axones associating the cord with the encephalon are the one contributed to the cord and the other gradually terminating in it at different levels along its entire descent.

The grey substance.- - In the embryo all the nerve-cells of the grey substance are derived from the cells lining the neural tube, and in the adult the column of grey substance, though greatly modified in shape, still retains its position about the central canal. In transverse section the column appears as a grey figure of two laterally developed halves, connected across the mid-line by a more attenuated portion, the whole roughly resembling the letter $H$. The cross-bar of the $H$ is known as the grey commissure. Naturally, it contains the central canal, which is quite small and is either rouncled or laterally or ventrally oval in section, according to the level of the cord in which it is examined. The canal continues upward, and in the medulla oblongata opens out into the fourth ventricle. Downward, in the extremity of the conus medullaris, it widens slightly and forms the rhomboidal sinus or terminal ventricle, then is suddenly constricted into an extremely small 
eanal extending a short distance into the filum terminale, and there ends blindly. The grey commissure always lies somewhat nearer the ventral than the dorsal surface of the cord, and itself contains a few medullated axones which vary in amount in the different regions of the cord. The medullated axones crossing the mid-line on the rentral side of the central canal form the ventral or anterior white commissure; those, usually much fewer in number, crossing on the dorsal side of the central canal, form the clorsal or posterior white commissure. These two commissures comprise fibres crossing in the grey substance as distinguished from others which cross in the white substance dorsal and ventral to them. The axones of these commissures serve in functionally associating the two lateral halves of the grey column.

Each lateral half of the grey column presents a somewhat erescentic or commashaped appearance in transverse section, which also varies at the different levels of the cord. At all levels each half presents two vertical, well-defined horns, themselves spoken of as columns of grey substance. The dorsal horn [columna posterior] extends posteriorly and somewhat laterally toward the surface of the cord along the line of the postero-lateral sulcus. It is composed of an apex and a neck [cervix columnæ posterioris].

In structure the apex is peculiar. The greater portion of it consists of a mass of small nerve-cells and neuroglia tissue, among which a gelatinous substance of questionable origin predominates, giving the horn a semi-translucent appearance. This is termed the gelatinous substance of Rolando, to distinguish it from a similar appearance immediately about the central canal, the central gelatinous substance. The apex of the dorsal horn is widest in the regions of the enlargements, especially the lumbar, and the gelatinous substance of Rolando is most marked in the cervical region. In these regions the cervix consists of a slight constriction of the dorsal horn between the apex and the line of the grey commissure. In the thoracic region, however, the base of the cervix is the thickest part of the dorsal horn. This thickness is due to the presence there of the nucleus dorsalis, or Clarke's column-a column of grey substance containing numerous nerve-cells of larger size than elsewhere in the dorsal horn, and extending betreen the seventh cervical and third lumbar segments of the cord. Tapering finely at its ends, this nucleus attains its height in the lower thoracic or first lumbar segment. About the ventro-lateral periphery of the nucleus dorsalis are scattered nerve-cells of the same type as contained in it. These cells are sometimes distinguished as Stilling's nucleus, though Clarke's column was also described by Stilling. They are more numerous about the lower extremity of the nucleus dorsalis, and they continue to appear below its termination in the lumbar region.

The ventral horn [columna anterior] of each lateral half of the grey figure is directed ventrally toward the surface of the spinal cord, pointing toward the antero-lateral sulcus. It contains the cell-bodies which give origin to the efferent or ventral root axones, and these axones make their emergence from the spinal cord along the antero-lateral suleus. The ventral horns vary markedly in shape in the different regions. In certain segments each ventral horn is thickened laterally and thus presents its two component columns of grey substance: the lateral horn [columna lateralis], a triangular projection of grey substance into the surrounding white substance, in line with or a little ventral to the line of the grey commissure; and the ventral horn proper [columna anterior], projecting ventrally. In the micl-thoracic region the lateral horn is relatively insignificant, and the anterior horn is quite slender; in the eervical and lumbar enlargements both horns are considerably enlarged.

The grey substance is not sharply demarcated from the white. In the blending of the two there are often small fasciculi of white substance embedded in the grey, and likewise the grey substance sends fine proeesses among the axones (omprosing the white substance. Such processes or grey trabeculie are most marked along the lateral aspects of the grey figure and present there the appearande known as the reticular formation. The reticular formation of the spinal corel is most rvirlent in the arvical region (fige. 616).

Minute structure.- Tho large cell-borlies of the ventral horn as a whole are divisible into

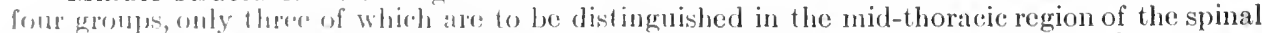
(w) l: - (1) A rintrul gromp of cells, sometimes separated into a ventro-lateral and a ventromorlial portion (sors figs. (illi, (i19), occupies the ventral horn proper, is constant throughout the ('ntigr Irogth of the (orel, and eontributes axones to the ventral root, most of which probably

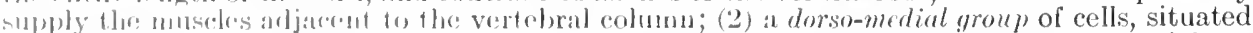
in the furedial part of the ventral horn, just below the level of the rentral canal, gives origin to axofers onec of which on to the ventral root of the same sicle, hut most of which cross the midline rif the anterios white (rommissure, cither to pass out in the ventral root of the opposite

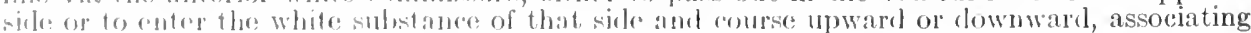
with other levets of tho (ort. Some of its axones terminate among the cells of the ventral horn 
in the same level of the opposite side; (3) a lateral group of cells, sometimes separated into a dorsolateral and a ventro-lateral portion, occupies the lateral column or horn, and is best differentiated in the cervical and lumbar enlargements. Most of the axones arising from its larger cells are contributed to the ventral root of the same side, and such axones probably supply the muscles of the extremities. Some of those from its ventral portion are distributed to the muscles of the body-wall; the dorso-lateral portion is that part of the lateral column which persists throughout the cord, and is considered as supplying the visceral efferent fibres in the ventral roots. (4) an intermediate group, occupying the mid-dorsal portion of the ventral horn. Axones arising from its cells are probably seldom contributed to the ventral root, but instead course wholly within the central nervous system. Some pass to the opposite side of the cord, chiefly viâ the anterior and possibly the posterior white commissure, to terminate either in the same or different levels of the grey column. Others of longer course pass to the periphery of the cord, join one of the spino-cerebellar fasciculi, and pass upward to the cerebellum.

Furthermore, there are scattered throughout the grey substance many smaller cell-bodies of neurones. These give rise to axones of shorter course, either commissural or associational proper. Of such axones many are quite short, coursing practically in the same level as that in which their cells of origin are located, and serve to associate the different parts of the grey substance of that level. Others course varying distances upward and downward for the association of different levels of the grey column.

It is evident from the above that in addition to the various nerve-cells it contains, there is also to be found a felt-work of axones in the grey substance. Many of these axones are medullated, though not in sufficient abundance to destroy the grey character of the substance. The felt-work is composed of three general varieties of fibres:-(1) The terminal branches of axones entering from the fasciculi of the white substance and forming end-brushes about the various cell-bodies in the grey substance (partly medullated); (2) axones given off from the cells of the grey substance and which pass into the surrounding white substance either to enter the ventral-roots or to join the ascending and descending fasciculi within the spinal cord (partly medullated); (3) axones of Golgi neurones of type II, which do not pass outside the confines of the grey substance (non-medullated). Some axones of any of these varieties nuay cross the mid-line and thus become commissural. In general all fibres of long course acquire medullary sheaths a short distance from their cells of origin, and lose them again just before termination.

The white substance of the spinal cord.-The great mass of the axones of the spinal cord course longitudinally and form the thick mantle surrounding the column of grey substance. This mantle is divided into right and left homolateral halves by the anterior median fissure along its ventral aspect, and along its dorsal aspect by the posterior median septum, which is for the most part a connective-tissue partition derived from the pia mater along the line of the posterior median sulcus. The mantle is supported internally by interwoven neuroglia and white fibrous connective tissue, the latter, derived chiefly from the pia mater, closely investing it without.

The axones of the white substance belong to three general neurone systems:(1) The spino-cerebral and cerebro-spinal system, which consists of axones of long course, one set ascending and another descending, forming links in the neurone chains between the cerebrum and the peripheral organs. The ascending axones of this system collect the general bodily sensations which are conveyed to the cerebrum, the cells of which in response contribute axones which descend the cord, conveying efferent or motor impulses. (2) The spino-cerebcllar and cerebello-spinal system consists of conduction paths, one set ascending and another descending, which are connections between cerebellar structures and the grey substance of the spinal cord. (3) The spinal association and commissural system of axones which serve to associate the different levels and the two sides of the spinal cord and which are proper to the spinal cord, i. e., they do not pass outside its confines.

Both the first and second systems increase in bulk as the cord is ascended. The ascending axones of each system are contributed to the white substance of the cord along its length, and therefore accumulate upward; the axones descending from the encephalon are clistributed to the different levels of the cord along its length, and therefore diminish downward.

The mass of the third system of axones varies according to locality. Wherever there is a greater mass of neurones to be associated, as there is in the enlargements of the cord, a greater number of these axones is required. Their cells of origin, being in the grey substance of the cord, contribute to its bulk and thus both the cells and the axones of this system serve to make the enlargements more marked. In the lumbar and sacral regions the greater mass of the entire white substance consists of axones belonging to this system. It forms a dense felt-work about the grey column throughout the cord. Necessarily this system contains axones of various lengths. Some merely associate different levels within a single segment 
Fig. 616.-Transterse Sections from Different Segments of the Spinal Cord, showing Shape and Relative Proportions of Grey and White Substance in the Various REgIONS.

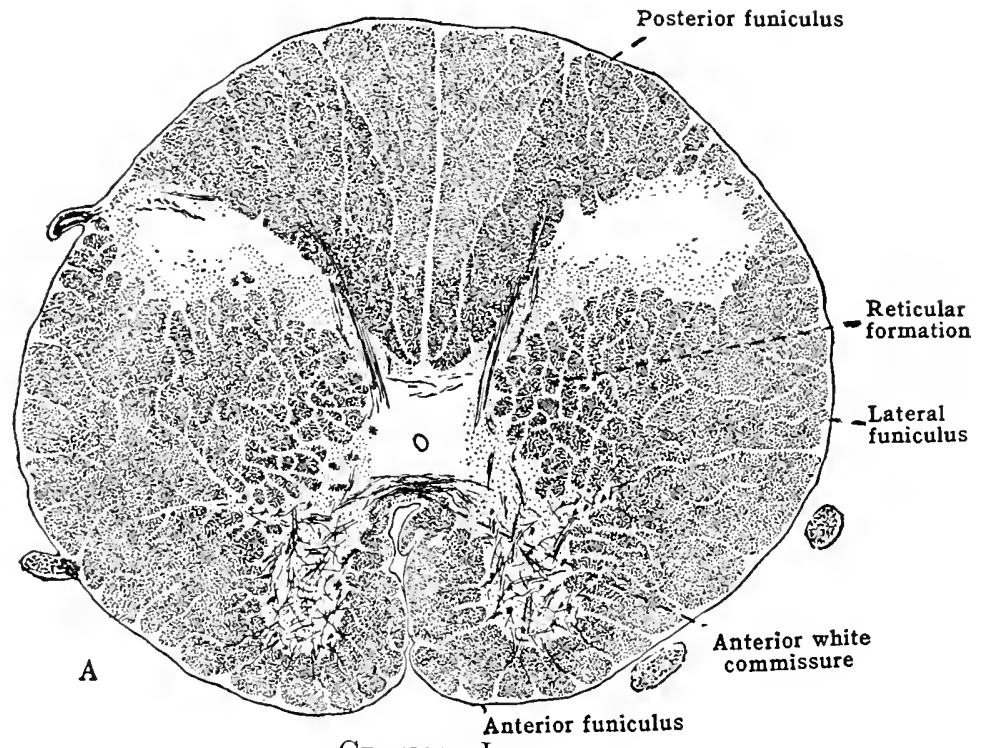

Cervical I

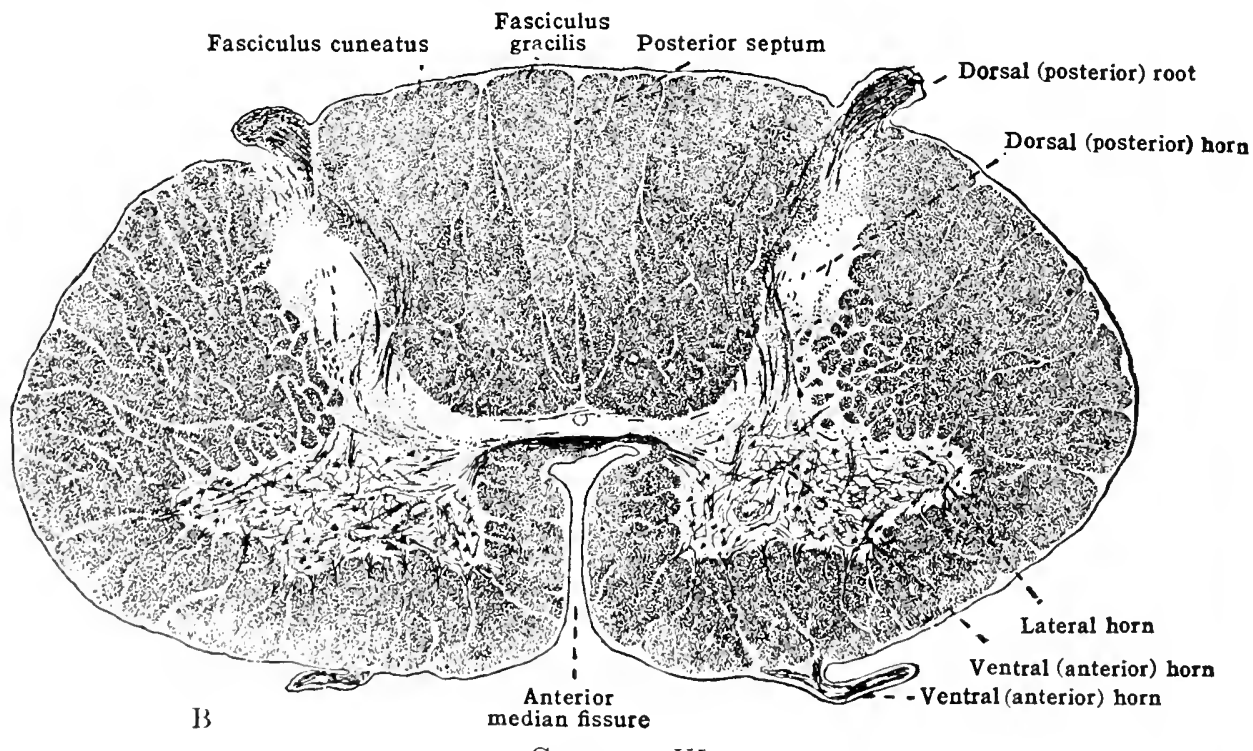

Cervical VI

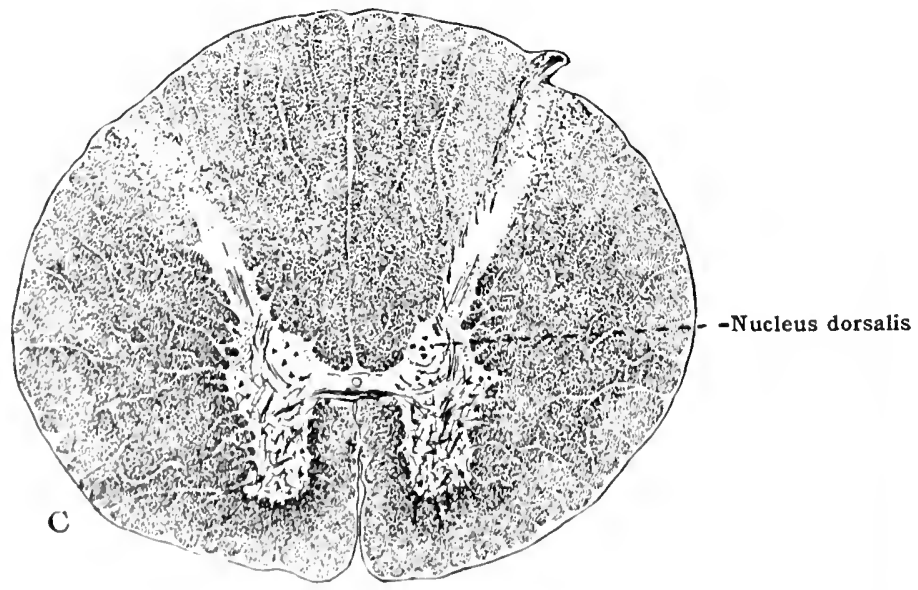

Timoracic VIII 
of the cord; others associate the different segments with each other. Axones which associate the structures of the spinal cord with those of the medulla oblongata may be included in this system. Many of these axones cross the midline both in the grey and in the white substance to associate the neurones of the two sides of the grey column. For purposes of distinction, such as cross the midline are called commissural fibres, while those which course upward and down-

FIG. 616-Continued.

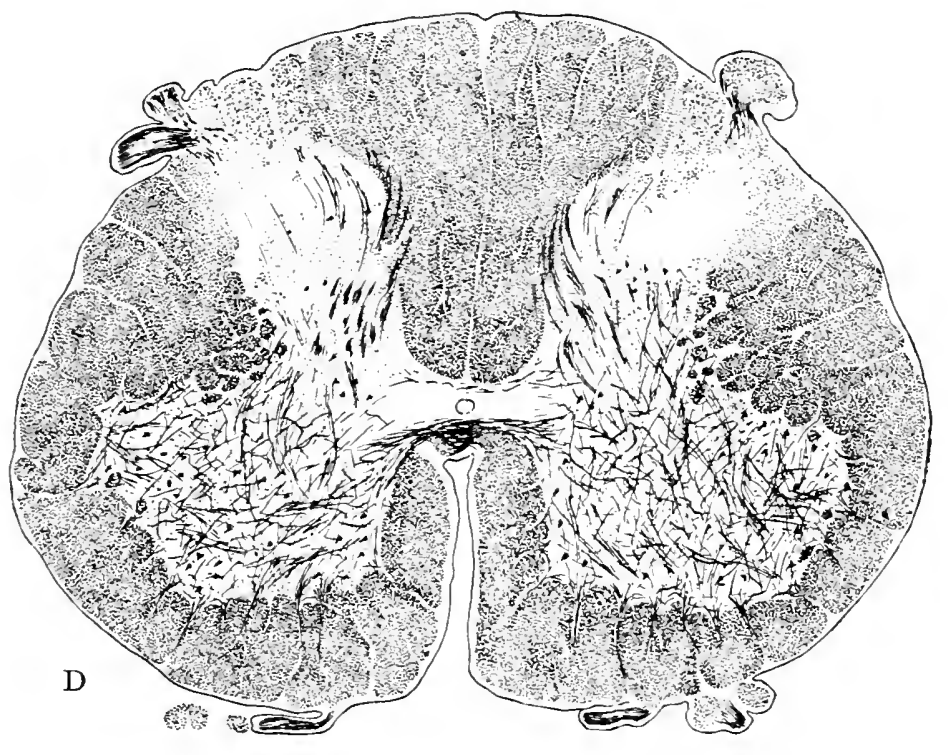

Lumbar III

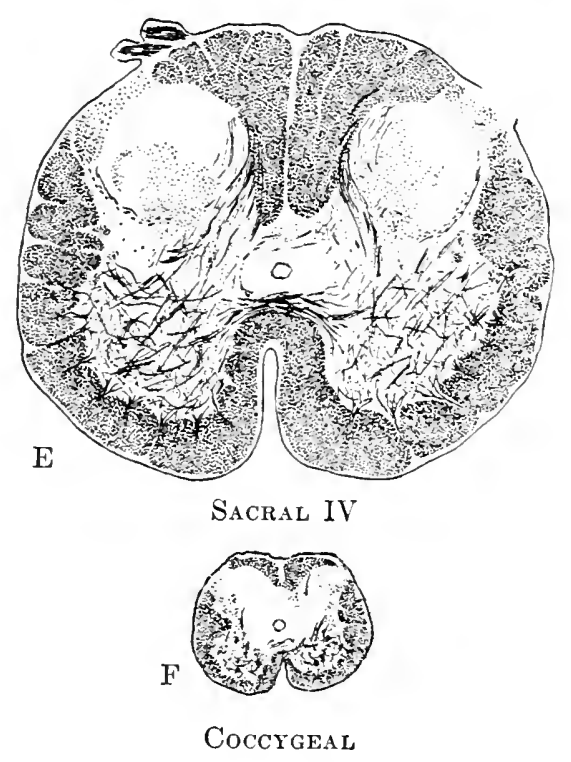

ward on the same side are association fibres. Coursing in longitudinal bundles about the grey figure, the latter compose the fasciculi proprii or 'ground bundles' of the spinal cord.

\section{METHODS BY WHICH THE CONDUCTION PATHS HAVE BEEN DETERMINED}

A purely anatomical examination of a normal adult cord, prepared by whatever means, gives no indication of the fact that the mass of longitudinally coursing fibres of the white sub- 
stance is composed of more or less definite bundles or fasciculi, each having a definite course, and whose axones form links (conduction paths) in a definite system of neurone chains.

Present information as to the size, position, and connections of the various fasciculi is based upon evidence obtained by three different lines of investigation:- -

(1) Physiological investigation.-(a) Direct stimulation of definite bundles or areas in section and carefully noting the resulting reactions which indicate the function and course of the axones stimulated. (b) 'Wallerian degeneration' and the application of such methods as that of Marchi. When an axone is severed, that portion of it which is separated from its parent cell-body degenerates. Likewise a bundle of axones severed from their cells of origin, whether by accident or design, will degenerate from the point of the lesion on to the locality of their termination in whichever direction this may be. This phenomenon was noted by Waller in 1852 and is known as Wallerian degeneration. By the application of a staining technique which is differential for degenerated or degenerating axones and a study of serial sections containing the axones in question, their course and distribution may be determined. The locality of their cells of origin, if unknown, may be determined by repeated experiment till a point of lesion is found not followed by degeneration of the axones under investigation. (c) The axonic reaction or 'reaction from a distance.' Cell-bodies whose axones have been severed undergo chemical change and stain differently from those whose axones are intact. Thus cell-bodies giving origin to a bundle of severed axones may. be located in correctly stained sections of the region containing them.

(2) Embryological evidence.-In the first stages of their development axones of the cerebro-spinal nervous system are non-medullated. They acquire their sheaths of myelin later. Axone pathways forming different chains become medullated at different periods. Based upon this fact a method of investigation originated by Flechsig is employed, by which the position and course of various pathways may be determined. A staining method differential for medullated axones alone is applied to the nervous systems of foetuses of different ages, and pathways medullated at given stages may be followed from the locality of their origin to their termination. In the later stages, when most of the pathways are medullated and therefore stain alike, the less precocious pathways may be followed by their absence of medullation.

(3) Direct anatomical evidence.- $(a)$ Stains differential for axones alone are applied to a given locality to determine the fact that the axones of a given bundle actually arise from the cell-bodies there, or that axones traced to a given locality actually terminate about the cellbodies of that locality. For example, it may be proved anatomically that the axones of a dorsal root arise from the cells of the corresponding spinal ganglion, and then these axones may be traced into the spinal cord and their terminations noted either by collateral or terminal twigs, or the fasciculus they join in their cephalic course may be determined. (b) The staining properties and the size and distribution of the tigroid masses in the cell-bodies of sensory neurones differ from those in the motor neurones, and recently Malone has claimed that, in the central system, the cell-bodies in the nuclei of sensory neurone chains, those ascending toward the cerebral cortex, may be distinguished from the cell-bodies of the motor or descending chains by the arrangement and size of their tigroid masses. He claims further that in the same way, the cellbodies of the somatic efferent neurones may be distinguished from those of the visceral efferent neurones. In this way the locality of origin of certain physiologically known paths may be determined.

(4) The so-called pathologico-anatomical method is based upon the same general principles as is the physiological (or experimental) method. A pathological lesion, a local infection or a tumor for example, may destroy a nucleus of cell-bodies or sever a bundle of axones, and the resulting degeneration of the axones may be followed through serial sections suitably prepared. The locality of the lesion known, the path may be followed to determine the locality of its termination; its locality of termination known from the symptoms resulting, the path may be followerl to its cells of origin, or to determine whatever be the locality of the lesion.

Funiculi.-In order that the various fascieuli may be referred to with greater case, the white substanee of the spinal cord in section is divided into three areas known as funiculi or columns and which eorrespond to the funiculi already mentioned as eviclent upon the surface of the cord when intact. The funieuli are ontlines wholly upon the basis of their position in the eord and with reference to the molian line and the contour of the column of grey substance; their eomponent fasciculi ars defined upon the basis of function. (i) The posterior funiculus or cohmm is bounderl by the posterior median septum and the line of the dorsal horn; (2) the lateral funiculus or column is bounded by the lateral concavity of the grey folumn and the lines of entrance and exit of the (lorsal and ventral roots; (3) the center funiculus or column is bounded by the line of exit of the ventral roots, and by the antrior morlian fissure.

The posterior funiculus or column [funiculus posterior].-This funieulus is compesed of two general varieties of axones arrangerl in five fasciculi. First, and constituting the frodominant type in all the higher segments of the cord, are the

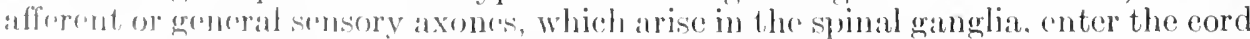
by the dorsal roots, assume their distribution to the neurones of the cord, and then

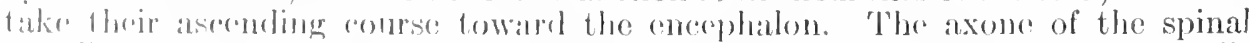
ganglion monronr mulergoes a T-shapert division a short distance from the eellforty, ons: limb of this division terminating in the peripheral organs and the other groing fo form the dorsal root. I poun entering the corel the dorsal root axones 
undergo a $Y$-shaped bifurcation in the neighbourhood of the dorsal horn, one branch ascending and the other descending. Their ascending branches form the fasciculus gracilis (Goll's column) and the fasciculus cuneatus (Burdach's column). These fasciculi are the chief ascending or sensory spino-cerebral connections, the direct sensory path to the brain. The neurones represented in them constitute the first link in the neurone chain between the periphery of the body and the cerebral cortex.

Fig. 617.-Showing Disposition of the Dorsal Root Fibres Upon Entering the Spinal Cond. (From Edinger, after Cajal.)

A, shows dorsal root axones DR, entering the spinal cord, bifurcating at B, and giving off collaterals $\mathrm{C}$ to the neurones of the cord. B shows the telodendria of these axones or of their collaterals displayed upon cell-bodies of the grey substance of the cord.

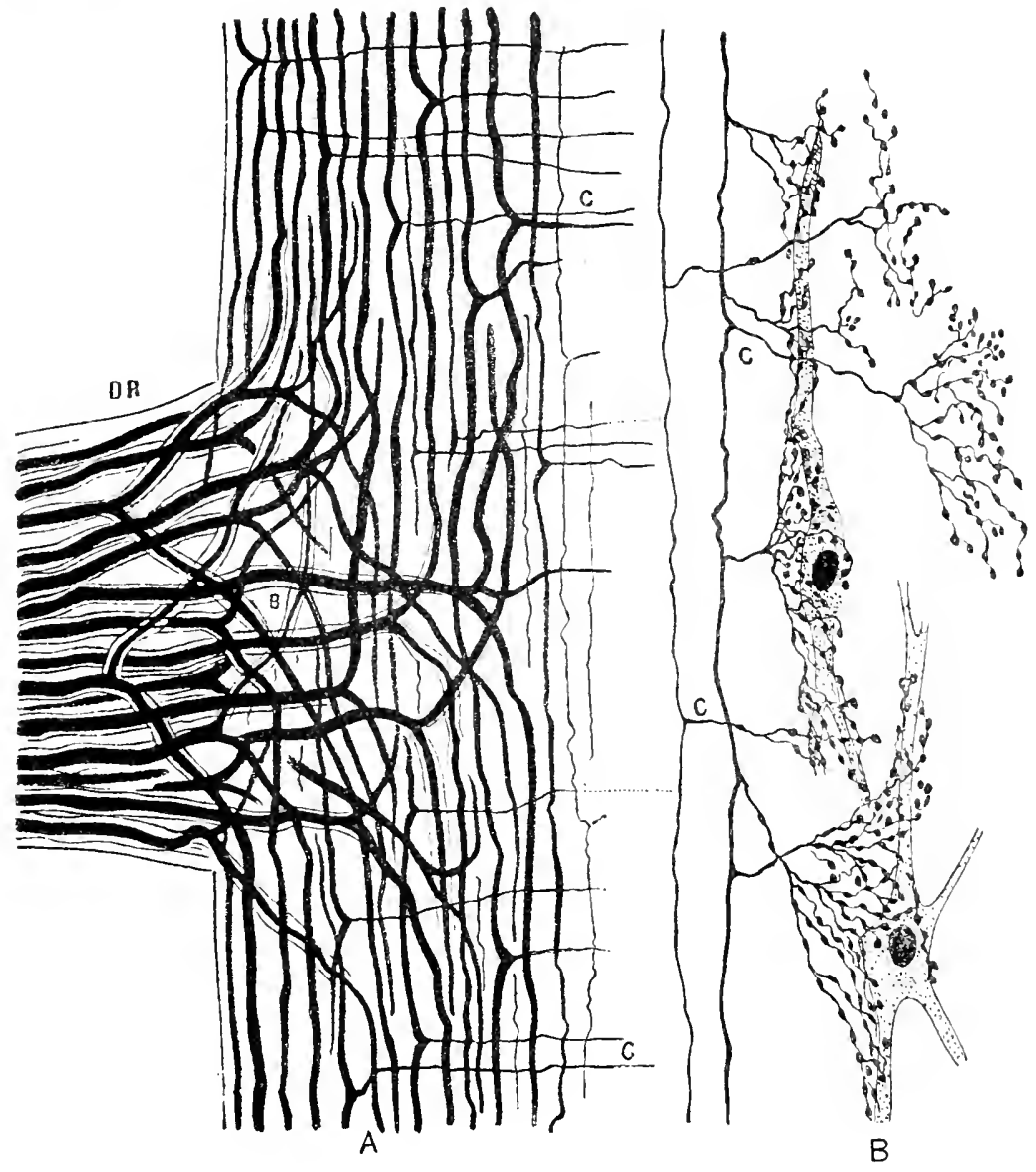

In threading their way toward the brain, these sensory axones tend to work toward the midline. Therefore those of longer course are to be found nearer the posterior septum, in the upper segments of the cord, than those axones which enter the cord by the dorsal roots of the upper segments. 'Thus it is that the fasciculus gracilis, the medial of the two fasciculi, contains the axones which arise in the spinal ganglia of the sacral and lumbar segments. In other words, it is the fasciculus bearing sensory impulses from the lower limbs to the brain, while the fasciculus cuneatus, the lateral of the two, is the corresponding pathway for the higher levels. Naturally, there is no fasciculus cuneatus as such in the lower segments of the spinal cord. The axones being much blended at first, it is only in the upper thoracic and cervical region that there is any anatomical demarcation between the two fasciculi. In this region the two become so distinct that there is in some cases an apparent connective-tissue septum between them, continuing inward from the postero-intermediate sulcus-the surface indication of the line of their junction (fig. 616).

Upon reaching the medulla oblongata the fibres of the fasciculus gracilis and the fasciculus cuneatus terminate about cells grouped to form the nuclei of these fasciculi. The nucleus of the fasciculus gracilis is situated medially and begins just below the point at which the central canal opens into the fourth ventricle; the nucleus of the fasciculus cuneatus is placed laterally and extends somewhat higher than the other nucleus. The neurones whose cell-bodies compose these 
nuclei constitute the second links in the neurone chains conveying sensory impulses from the periphery to the cerebral cortex.

The descending or caudal branches of the dorsal root axones are concerned wholly with the neurones of the spinal cord. They descend varying distances. some of them as much as four segments of the cord, and give off numerous collaterals on their way to the cells of the grey column. Those terminating about cell-bodies of the ventral horn which give rise to the ventral or motor root-fibres, are responsible for certain of the so-called 'reflex activities' and thus contribute to the simplest of the reflex arcs. In descending they serve to associate different levels of the grey substance of the cord with impulses entering by way of a single dorsal root. Some of their collaterals cross the mid-line in the posterior white commissure, and thus become connected with neurones of the opposite side. The caudal branches of longer course are scattered throughout the ventral portion of the fasciculus cuneatus (middle root zone), and the longest show a tendency to collect along the border-line between the fasciculus cuneatus and the fasciculus gracilis, and thus contribute largely to the comma-shaped fasciculus. Also some of the longest of them in the lower levels course in the oval bundle or septomarginal root zone.

The ascending branches of the dorsal root axones also give off collaterals to the grey substance of the cord, thus extending the area of distribution of a given dorsal nerve-root to levels of the cord above the region at which the root enters.

The greater number of the terminations of dorsal root axones within the spinal cord are concerned first with neurones other than those contributing ventral rootfibres. The greater mass of the neurones concerned are those of the Golgi type II and those contributing the fasciculi proprii or ground bundles of the spinal cord, or the second variety of axones composing the posterior funiculus. The latter fasciculi arise from the smaller cells of the grey column.

These axones pass from the grey substance to enter the surrounding white substance, bifurcate into ascending and descending branches, which in their turn give off numerous collaterals to the cells of the grcy substance of the levels through which they pass. The cell-bodies giving origin to such axones are so numerous that the entire column of grey substance is surrounded by a continuous felt-work of axones of this variety.

The dorsal fasciculus proprius (anterior root zone of posterior column) arises chiefly from cells situated in the dorsal horn (stratum zonale). Coincident with the ingrowth and arrangement of the fasciculi gracilis and cuneatus many fibres of the dorsal fasciculus proprius go to form both the oval bundle and the comma-shaped fasciculus. Thus these two bundles are mixed, being fasciculi proprii which contain caudal branches of dorsal root axones. The association fibres in the ovil bundle are the longest of any belonging to the dorsal fasciculus proprius. The cephalic and caudal branches combined of some are said to extend more than half the length of the cord and it has been claimed that some even associate the cervical region with the conus medullaris. Based upon this claim, Obersteiner has called the oval bundle, the "dorso-medial salcral ficld" and Edinger has referred to the most dorsal part of it as the "tractus cervico-lumbalis dorsalis." 'The 'median triangle' is formed by the continuation of the dorsal fasciculi proprii with the ovil or septo-marginal fasciculus. Some of the axones of the dorsal fasciculus proprius cross the midline to distribute impulses to the neurones of the opposite side. These commissural axones, together with certain collaterals of the dorsal root axones, which eross the mid-line outsicle the clorsal white commissure, compose the so-called cornu-commissural tract at the base of the posteriol septum.

The lateral funiculus or column [funiculus lateralis].- Not all the axones of the posterior or clorsal nerve-roots extend to the encephalon. Estimation shows that the sum of all the dorsal roots is greatly in excess of the sum contained in the fasciculi cunciatus and gracilis just before these enter their nuclei of termination. 'Therefore many of the ascending clorsal root axones are concerned with spinalcord relations wholly.

The marginal zone of Lissauer, situated along the lateral margin of the postero-lateral sulcus. is composed largely of clorsal root axones. Many of these finally work across the line of the sulcus inte the persterior funiculus. Many of the dorsal root-fibres which do not reach the brain orenr in Lissauce's zonc. Many others of course oceur throughout the posterior column. lissaner's zenc also eontains some fibres arising from the small cells of the dorsal horn, and to this cextent corresponds to a fascieulus proprius. Ranson has found that large numbers of the non-medullated dorsal rut axones which enter the cord are contributed to Lissaucr's zone.

The lateral fasciculus proprius (lateral ground bundle, lateral limiting layer) is situaterl in the lateral concavity of the grey column and is eontinuous with the other fasciruli proprii both dorsal and ventrai. Beyond that it probably contains 
fewer commissural axones, it is of the same general significance as the others. It is frequently divided into small bundles by the reticular formation (see fig. 616).

The lateral cerebro-spinal fasciculus (crossed pyramidal tract). In contrast to the sensory fibres passing through the spinal cord conveying impulses destined to reach the cerebral cortex, axones are given off from the pyramidal cells of the

Fig. 618.-Diagram Illostrating the Formation of the Fasciculi Proprii (association fascicoli) and the Comissural Fibres of the Spinal Cord, and the General Architecture of the Cord as a Mechanisis for Reflex Activities.

The ventral fasciculus proprius is omitted and the lateral is shown on one side only. The lower spinal ganglion neurone shown illustrates the type whose ascending branch is of much longer extent than that of the upper one.

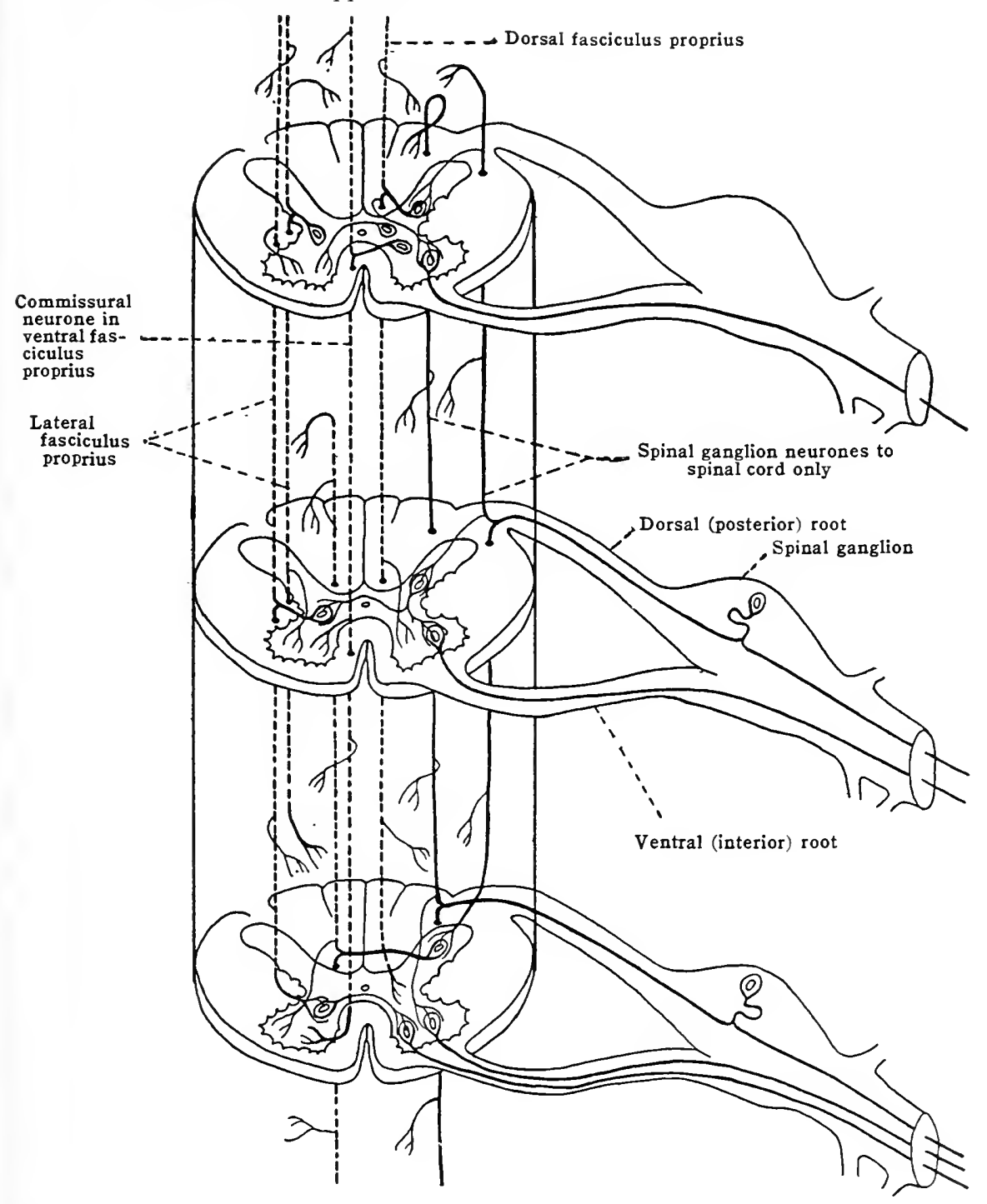

cortex, which descend to terminate about the cells of the grey substance of the spinal cord, chiefly the cells which give origin to the ventral root-fibers.

Upon reaching the medulla oblongata in their descent, these axones are accumulated into two well-defined, ventrally placed bundles, the pyramids, one from each cerebral hemisphere. In passing through the brain stem the pyramids contribute many fibres which cross the mid-line to terminate in the motor nuclei of the cranial nerves of the opposite side, and thus decrease appreciably in bulk. According to the estimate of Thompson, only about 160,000 of the pyramidal fibres are destined to enter the spinal cord.

Upon reaching the lower part of the medulla, the greater mass of the fibres of each pyramid, which are destined to enter the cord, suddenly cross the mid-line in the "decussation of the 
pyramids.' The remainder retain their ventral position in their descent decussating gradually in the cord itself. The pyramidal fibres which cross in the medulla course in the lateral column ventral to Lissauer's 'zone, and lateral to the lateral fasciculus proprius, and form the lateral cerebro-spinal fasciculus (crossed pyramidal tract). It is a large fasciculus, oval shaped in transection, and since its axones terminate in the grey column of the cord all along its length, it decreases in bulk as the cord is descended.

In addition to the three dispositions of the dorsal root axones given above, certain of them, either by collaterals or terminal twigs, form telodendria about the cells of the dorsal nucleus (Clarke's column), which nucleus extends from about the seventh cervical to the third lumbar segment of the cord. The axones given off by these cells pass to the dorso-lateral periphery of the lateral funiculus, and there collect to form the dorsal spino-cerebellar fasciculus (direct cerebellar tract of Flechsig). As such they ascend without interruption, and in the upper level of the medulla oblongata pass into the cerebellum by way of the inferior cerebellar peduncle or restiform body. Necessarily, this fasciculus is not evident in levels below the extent of the nucleus dorsalis.

Also situated superficially in the lateral funiculus is another ascending conduction path, and, like the dorsal spino-cerebellar fasciculus, to which it is adjacent, it is also in part at least a cerebellar connection. Its position suggests its name, superficial ventro-lateral spino-cerebellar fasciculus (Gowers' tract).

This tract at present does not include as great an area in transverse section as when originally deseribed. The more internal portion of the original Gowers' tract is now given a separate significance, and will be considered separately. While the exact location in the grey column of all the cell-bodies giving origin to the superficial ventro lateral spino-cerebellar fasciculus is uncertain, it is known that certain ventral horn cells contribute their axones to it. Many of its cells of origin are scattered in the area immediately ventral to the nucleus dorsalis, others in the intermediate and mesial portion of the lateral group of ventral horn cells. In the lumbar region these cells are quite numerous, and, therefore, the fasciculus begins at a lower level in the spinal cord than does the direet cerebellar tract. In degenerations it becomes visible in the upper segments of the lumbar region, and has been proved to inerease notably in volume as the cord is ascended. Its axones arise for the most part directly from cell-bodies of the same side of the cord, though it has been shown by several investigators that many of its axones come from the grey substance of the opposite side by way of the ventral white commissure. Terminal twigs and collaterals of the clorsal root-fibres, mostly of the same side, but oceasionally from the opposite side, terminate about its cells of origin. At one time Gowers' tract was considered an entity, but now, even in the more limited area it occupies, it must be considered a mixture of axones of several terminal destinations or distinct neurone systems. The destination of some of its axones has not been determined with certainty. A portion, the spino-cerebellar fasciculus proper, go to the cerebellum, and there have been traced to the cortex of the superior vermis. Most of these reach the cerebellum not by way of the restiform body, as does the dorsal spino-cerebellar tract, but pass on in the brain-stem to the level of the inferior corpora quadrigemina, and there turn back to join the brachium conjunctivum or superior cerebellar peduncle. (Auerbach, Mott, Hoche.) Only a few of its axones leave the fasciculus lower down in the medulla, to enter the cerebellum by way of the restiform body, in company with the dorsal spino-cerebellar tract. (Rossolimo, 'Tschermak.) Another portion of its axones are thought to reach the cercbrum, probally the nucleus lentiformis, thougl it has not been positively traced further than the superior corpora quadrigemina. Many axones in Gowers' tract of the cord correspond to those of the fasciculi proprii, and merely run varying distances in the cord, to turn again into its grey substance. Sichaeffer followed some of these from the lumbar region up to the level of the seroml cervical norve.

In the ventro-mesial border of Gowers' tract and immediately upon the periphery, near the antero-lateral sulcus (exit of ventral nerve-roots), there is found in the highere segments of the cord a small oval bundle, the spino-olivary fasciculus or Helweg's (Bechterew's) bundle. 'The functional direction of its fibres lias not bern settleil.

It is asserted to arise from coll-bodies of the olive in the medulla oblongata, and in the cord is believed to be associated with the ectls of the ventral column of grey substance, probably those of the lateral liorn. Nore recent chims assert that it arises fron cell bodies in the cord and thes is spino-oliviry. Jyy some observers it has freen traced as far down as the mid-thoracic region; by others, however, only as fiur as the third cervical segment. 'The olives being nuelei

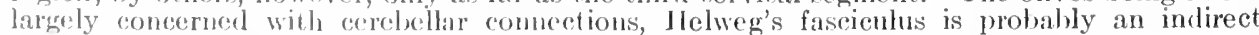
cerehellar association with the spinal eord neurones. It is composed of axones of relatively very small tlinneter, and it is one of the list fisciculi of the spinal cord to becone medullated.

Situaterl between the superficial ventro-lateral spino-cerebellar fascieulus and the lateral fasciculus proprius is an area which, in transverse sections, may be, by position, reforred to collectivaly ats the intermediate fasciculus. So intermingled are the axones comprising it that it has been rallow the mixed lateral zone. It contains filmres of at least five functional varieties: 


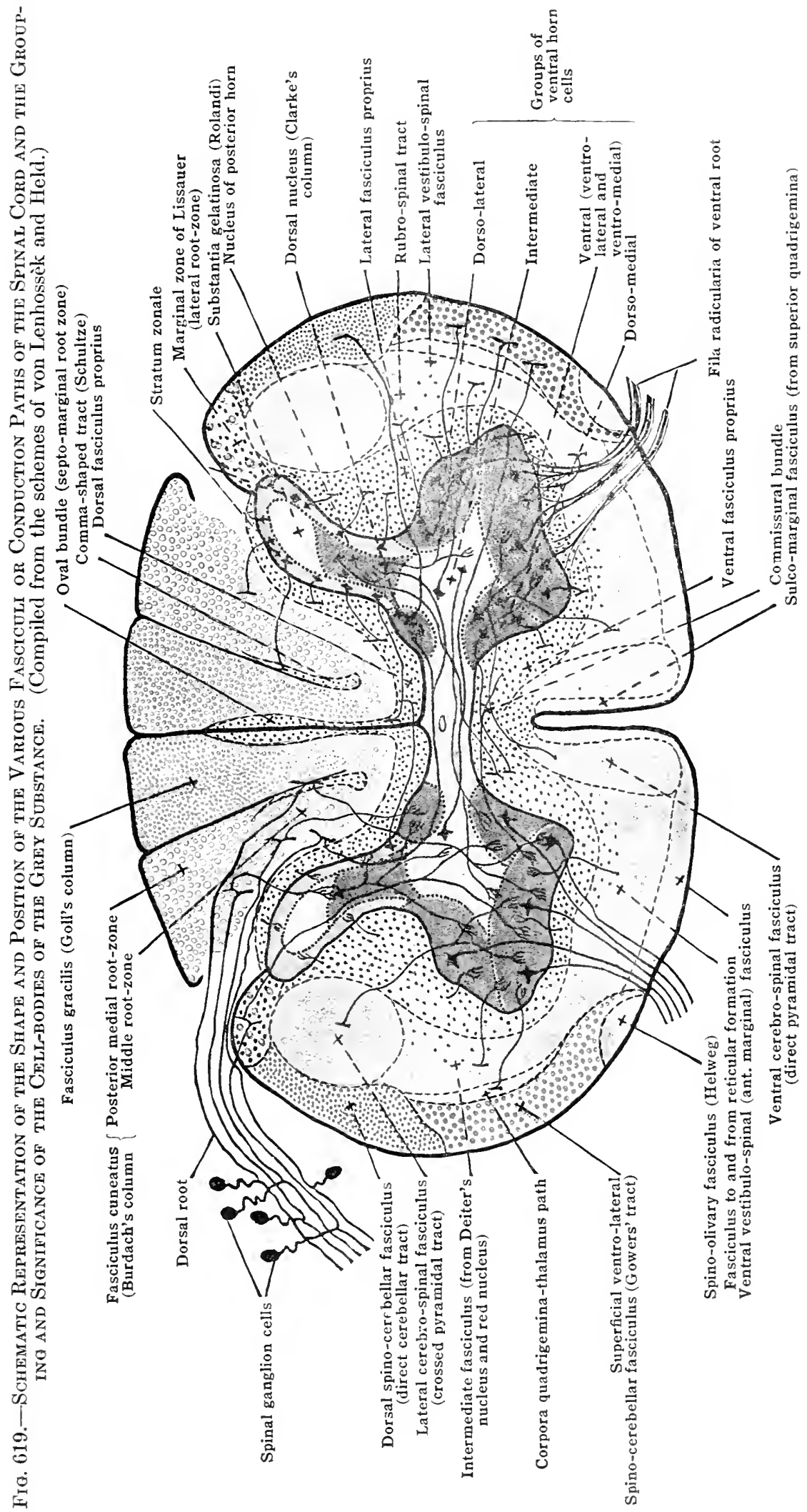


(1) Fibres belonging to the hateral fasciculus proprius which are of longer extent gradually course farther away from the grey substance of the cord and such mix into the intermediate fasciculus.

(2) It is said to contain fibres descencling from the cerebellum to associate with the neurones of spinal cord, probably directly with the ventral root or motor neurones.

(3) The rubro-spinal fasciculus. - This arises from cell-bodies in the red nucleus of the tegmentum (in the mesencephaton) and is a crossed fasciculus. Axones arising from the red nucleus of one side cross the mid-line while yet in the mesencephalon and descend in the lateral funiculus of the cord to terminate gradually about cell-bodies of the ventral horn, both those which give rise of ventral root fibres and those which contribute to the fasciculi proprii. Its fibres are more thickly bundled in a crescentic area fitting onto the ventral side of the lateral cerebro-spinal fasciculus, and some are said to mix into the area of this latter.

(4) The vestibulo-spinal fasciculus. - This is sometimes called the lateral vestibulo-spinal fasciculus from the fact that there is a tract of similar significance in the ventral funiculus of the cord. It arises from some of the cell-bodies comprising Deiter's nucleus, the lateral nucleus of termination of the vestibular nerve, and from some of those of the spinal nucleus (nucleus of the descending root) of this nerve, all of which is in the medulla. It descends the cord, uncrossed, to terminate gradually about ventral horn cells, thus comprising a part of the apparatus for the equilibration of the body. Its fibres are thought to be more closely collected in the area immediately ventral to the rubro-spinal fasciculus, but of course commingle with the latter.

(5) The corpora-quadrigemina-thalamus path. The most lateral portion of the intermediate fasciculus, a small area once included in Gower's tract, contains fibres both ascending and descending, connecting the spinal cord with the thalamus (diencephalon) and the quadrigeminate bodies of the mesencephalon. These are crossed paths. The ascending fibres arise from cellbodies in the ventral horn of one side, cross in the ventral white commissure (commissural neurones) and course upward in the intermediate fasciculus to their termination in the opposite side. Those terminating about ccll-bodies in the thalamus form what is known as the spinothalamic tract, while those terminating in the nuclei of the quadrigeminate bodies are called the spino-mesencephalic or spino-tectal tract (tractus spino-tectalis). It is not known in which l'egion of the cord most of these fibres arise but it is quite probably the cervical region. The fibres which arise from cell-bodies of the thalamus and nuclei of the quadrigeminate bodies cross the mid-line in the mesencephalon and descend the cord to terminate gradually about cellbodies in the ventral horn of the opposite side. Those from the thalamus are known as the thalamo-spinal tract and those from the quadrigemina, as the mesencephalo- or tecto-spinal tract. The latter is thought to be the larger.

By the fibres of the above tracts general sensory impulses from the body (skin, etc.) are carried to the central portion of the optic apparatus, and the descending fibres give a simple anatomical possibility for the movements of the body in response to visual and auditory impulses. The descending fibres are thought to terminate chiefly in contact with association neurones of the fasciculi proprii, these transferring the impulses to the neurones giving origin to the ventral or motor root fibres, but some are thought to terminate directly about the cellbodies of ventral-root neurones. A portion of the intermediate fasciculus, most adjacent to Gower's tract, has been designated as Loeventhal's tract.

The anterior funiculus or column [funiculus anterior].-The intermediate fasciculus is continued ventrally and mesially across the line of exit of the ventral root axones, and thus into the anterior funiculus. This portion is also mixed, but its axones of long course associate somewhat different portions of the nerve axis from those comnected by the more lateral portion.

Acrorling to the studies of Flechsig, von Bechterew, and Held, this mesial portion contains fibres, both ascending and descending, which associate the various levels of the grey substance of the spinal cord with the neurones in the reticular formation of the medulla oblongata. The levels to which they have been tracel comprise the olivary suclei, which are largely (encermenl in cerebellatr connections, and the nuclei of the vagus, glosso-pharyngeal, auditory, fiscial and the spinal tract of the trigeminus. Also some of the ascending fibres are probably anseciatel with thre murlo of the eve-moving nerves. This portion of the intermediate fascicullus also grades into and is mixed with the axomes of the ventral fasciculus proprius, as is its lateral portion with the lateral fascienlus proprius. In other words, the fascieuli proprii froper, the axones learest the grey substance, serve for the intersegmental association of the dilferent levels ol the grey substane of the eord, while the intermediate fasciculus contains ixones of longer conrse which serve to associate more distant levels of the grey substance of the nerve axis that of the spinal cord with its upward continuation into the medulla b) longata, pons and mosencephalon.

'J'ho anterior marginal fasciculus, ventral vestibulo-spinal tract (Loewenthal's trant) forms the superficial loumblary of the mesial portion of the intermediate fascionlus. It is a narrow hambl, parallel with the surfare of the cord, and extends mesially from the merial extremity of (iower's tract (from Helweg's bundle) to the lecginniug of the anterior merlian fissure.

The axones loconging to it proper are deseconding from the recipient nuche of the vestibular

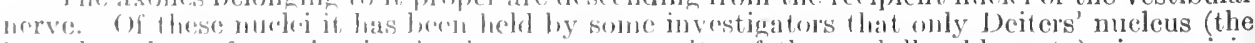
lateral nucleos of tomination in the upper extronity of the medulla oblongata) gives origin

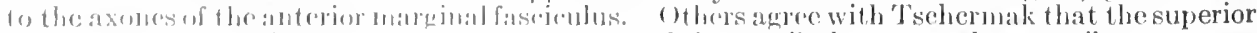

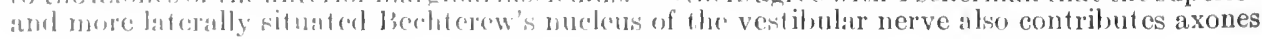


to it, and quite probably the nucleus of the spinal root of the vestibular adds further axones. Still other investigations have shown that a part at least of the fasciculus comes from the nucleus fastigius (roof nucleus) of the cerebellum. Since many axones from both Deiters' and Bechterew's nucleus terminate in the nucleus fastigius, the ventral vestibulo-spinal fasciculus

Fig. 620.-Diagram of Spinal Cord Illustrating the Two Chief Varieties of Spinocerebral and Cerebro-spinal Nedrone Chains. The ventral tecto-spinal (sulcomarginal) fasciculus, fibres descending from the superior quadrigeminate bodies, is not

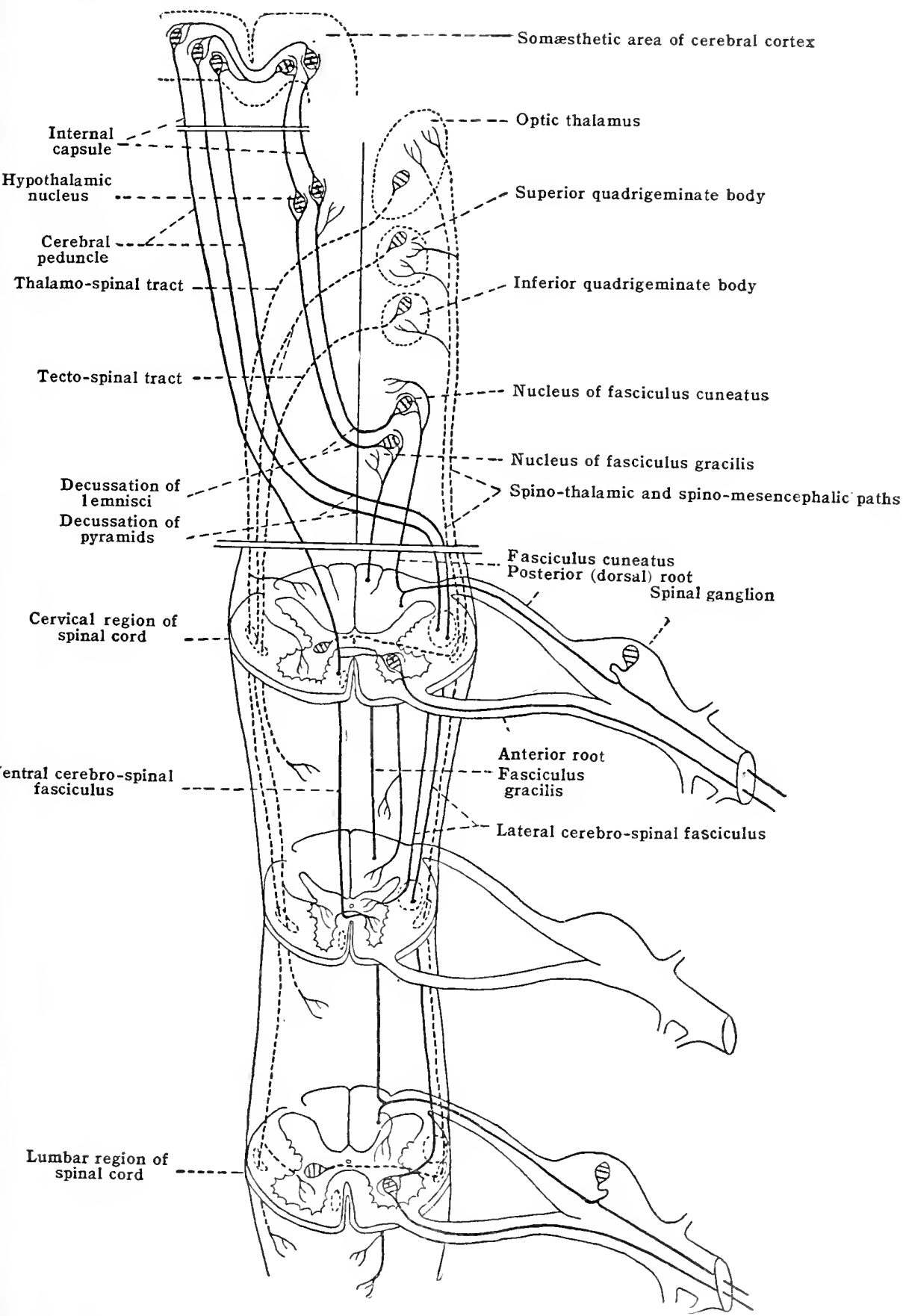

is, in any case, a conduction path from the nerve connections for cquilibration to the grey sulstance of the spinal cord. The fasciculus is said to extend as far as the sacral region of the added to its name to disting about the cclls of the ventral horns. The term "ventral "is in the lateral funito distinguish it from the vestibulo-spinal tract described above as coursing in the lateral funiculus. It is considered an uncrossed pathway. 
The ventral cerebro-spinal fasciculus (anterior or direct pyramidal tract), as stated above, is the uncrossed portion of the descending cerebro-spinal system of neurones. It is a small, oblong bundle, situated mesially in the anterior funiculus, parallel with the anterior median fissure. Like the lateral cerebro-spinal fasciculus (crossed pyramidal tract), its axones arise from the large pyramidal cells of the motor area of the cerebral cortex, and transmit their impulses to the neurones of the ventral horns of the grey substance of the spinal cord, and almost entirely to those neurones which give origin to the ventral or motor root fibres.

It represents merely a delayed decussation of the pyramidal fibres, for instead of crossing to the opposite side in the lower portion of the medulla oblongata, as do the fibres of the lateral fasciculus, its fibres decussate all along its course, crossing in the ventral white commissure and in the commissural bundle of the cord to terminate about the ventral horn cells of the opposite side. Hoche, employing Marchi's method, found that a few of its fibres terminate in the ventral horn of the same side. This conforms to the pathological and experimental evidence that there are homolateral or uncrossed fibres in the crossed pyramidal tracts also. Like the crossed tract, the ventral pyramidal tract diminishes rapidly in volume as it descends the cord. Its loss is greatest in the cervical enlargement, and it is entirely exhausted in the thoracic cord. With the exception of the anthropoid apes and certain monkeys, none of the mammalia below man, which have been investigated, possess this ventral pyramidal tract

Lying between the ventral cerebro-spinal fasciculus and the pia mater of the anterior median fissure is a thin tract of descending axones continuous ventrally with the anterior marginal fasciculus. From its position it is known as the sulcomarginal fasciculus; functionally it is the ventral mesencephalo-spinal (tectospinal) tract.

The extent of its course in the spinal cord is uncertain. It arises from the cells of the grey substance of the superior pair of the quadrigeminate bodies, and there, in largest part at least, it crosses the mid-line, and in the so-called 'optic acoustic reflex path' descends through the medulla oblongata into the spinal cord of the opposite side. The superior quadrigeminate bodies having to do with sight, this tract forms a second path conveying visual impulses to the neurones of the spinal cord.

The commissural bundle is situated about the floor of the anterior median fissure, and is the most dorsal tract of the anterior funiculus. It eontains decussating or commissural axones of three varieties.

(1) It contains the decussating axones of the ventral cerebro-spinal fasciculus throughout the extent of that fasciculus; (2) it is chiefly composed of the axones of the ventral fasciculus proprius which arise in the grey substance (ventral horn) of one side, cross the mid-line as commissural fibres, and course both upward and downward to be distributed to the neurones of different levels of the grey substance of the opposite side; (3) it contains decussating axones which arise from cell-bodies in the grey substance of one side and cross the mid-line to terminate about cell-bodies in practically the same level of the opposite side. The latter are merely axones belonging to the ventral white commissure which course without the confines of the grey figure. The commissural bundle is present throughout the length of the spinal cord, and is largest in the enlargements, i. e., where the association and commissural neurones occur in greater number generally. In its two last-mentioned varieties of axones it corresponds to the commissural portion of the clorsal fasciculus proprius (the cornu-commissural bundle).

The ventral fasciculus proprius is but a continuation of the lateral fasciculus proprius, and is composed of ascending and descending association fibres of the same general significance.

\section{SUMMARY OF THE SPINAL CORI)}

The spinal cord contains two general classes of axones arranged into three general systcms. It contains axones which-(a) enter it from cell-bodies situated outside its boundaries, i. e., in the spinal ganglia and in the encephalon, and (b) axones which arise from cell-bodies situated within its own grey substance, some of which axones pass outside its boundaries both to the periphery and into the (necephalon; some of which remain wholly within it. Its axones comprise-(1) a system for the intressegmental association of its grey substanee, both ascending and descending, association proper and commissural; (2) a spino-cerebral and corebro-spinal systrm, ascending and descending; and (3) a spino-cerebellar and rerebello-spinal system, ascending and descending.

For these relations the grey substance of the cord contains three general elasses of nerve-cells:- those which give rise to the peripheral efferent or motor axones of the ventral roots; these which give rise to central axones of long course, going to the cucephalon; and those which supply its contral axones of shorter course, thre assoriation and commissural systems. 
The three systems: (1) Association and commissural.-Axones of spinal ganglion (afferent) neurones bifurcate within the cord into cephalic and caudal branches which extend varying distances upward and downward and terminate, $(a)$ about cell-bodies whose axones are short and terminate within the grey substance of the same side and in the same level as their cellbodies (Golgi neurones of type II); (b) about cell-bodies whose axones pass without the grey substance, bifurcate into cephalic and caudal branches to terminate in the grey substance of the same side but in various levels above and below (association fibres in the dorsal, lateral and ventral fasciculi proprii); (c) about cell-bodies whose axones cross the mid-line to terminate either in the sanie level of the grey substance of the opposite side, or bifurcate and the cephalic and caudal branches pass in the fasciculi proprii to terminate in various levels of the grey substance of the opposite side. The longer cephalic branches of $(b)$ and $(c)$ may terminate in the medulla oblongata. All, associated with rentral root (efferent) neurones, belong to the neurone chains for the so-called reflex activities.

(2) The cerebral system.-(a) The cephalic branches of certain spinal gancrion neurones ascend beyond the bounds of the spinal cord to terminate within the medulla. Those ascending from the spinal ganglia of lower thoracic and lumbo-sacral segments accunulate mesially to form the fasciculus gracilis which terminates in the nucleus of this fasciculus; those arising from the upper thoracic and cervical segments accumulate more laterally in the posterior funiculus to form the fasciculus cuneatus which terminates in the nucleus of the fasciculus cuneatus. (b) The impulses transferred to the neurones of these nuclei are borne across the mid-line and finally reach the sensory-motor area of the cerebral cortex, and cell-bodies here give rise to axones which descend, some decussating in the medulla to form the lateral cerebro-spinal fasciculus, others form the uncrossed ventral cerebro-spinal fasciculus which crosses the mid-line as it descends the cord. Both of these fasciculi transfer their impulses either directly to efferent ventral horn neurones, or to association neurones and these to the efferent neurones. $(c)$ The cephalic and caudal branches of spinal ganglion neurones terminate about cell-bodies in the grey substance of the cord whose axones cross the mid-line and ascend laterally to terminate either in the quadrigeminate bodies (spino-mesencephalic tract), or in the thalamus (spino-thalamic tract). (d) Cell-bodies in thalamus and superior quadrigeminate bodies (receiving optic impulses) and in the inferior quadrigeminate bodies (probably mediating auditory impulses), give axones which cross the mid-line in the mesencephalon and descend, forming the thalamospinal and mesencephalo-spinal tracts, to terminate in contact with the efferent neurones of the cord. Axones from both sources descend in the lateral funiculus, while from the superior quadrigeminate body, a separate bundle descends in the ventral funiculus as the sulco-marginal (ventral mesencephalo-spinal) fasciculus. (e) The rubro-spinal tract arises from cell-bodies in the red nucleus (in the mesencephalon), crosses the mid-line and descends in the lateral funiculus to transfer (probably cerebellar) impulses to the efferent neurones of the spinal cord.

(3) The cerebellar system.-(a) The cephalic and caudal branches of spinal ganglion neurones give telodendria about the cell-bodies forming the dorsal nucleus of the cord (Clarke's column) and about cell-bodies situated in grey substances ventral to the dorsal nucleus ("Stilling's nucleus") and in the lateral horn. Axones arising from the cells of the dorsal nucleus pass laterally to form the dorsal spino-cerebellar fasciculus which ascends into the cerebellum by way of its inferior peduncle of the same side and terminates about cell-bodies of its cortex. Axones arising from Stilling's nucleus and the lateral horn cells, of both the same and opposite sides of the cord, accumulate to form the superficial ventro-latcral spino-cerebellar fasciculus, which ascends to enter the cerebellum by way of its superior peduncle and terminate about the cells of the cerebellar cortex. (b) A few axones arising in the roof nucleus of the cerebellum probably descend in the anterior marginal fasciculus in company with the ventral vestibulo-spinal tract to terminate upon the efferent neurones of the cord. (c) The inferior olivary nucleus, in the medulla, is a cerebellar relay and its cell-bodies are associated with the neurones of the upper portion of the same side of the spinal cord. Whether the axones arise in the olivary nucleus or in the grey substance of the cord is uncertain, but the more usual supposition favours the cord and thus the name, spino-olizary fasciculus is given them. (d) Among its other functions, the cerebellum is concerned with equilibration. The vestibular nerve is the afferent nerve of equilibration and a large mass of the axones arising from its nuclei of termination terminate in the cerebellum, in the roof nuclei especially. Axones arising from cell-bodies in Deiters' nucleus (its lateral nucleus of termination) and in the nucleus of its descending root descend the cord in the lateral funiculus to form the (lateral) vestibulo-spinal tract, and also in the anterior marginal fasciculus to form ventral vestibulo-spinal tract. Impulses borne by these axones reach the efferent or motor root neurones. The rubro-spinal fasciculus, mentioned above also may be possibly considered as belonging to the cerebellar system.

Sympathetic relations. - The cell-bodies of the efferent neurones in the ventral horns are of two general varieties: (a) those whose axones terminate upon skeletal muscle (somatic efferent), and (b) those whose axones terminate in contact with cell-bodies of sympathetic neurones, the splanchnic or visceral efferent neurones. The axones of the sympathetic neurones, in their turn, terminate upon cardiac and smooth muscle (motor) and in glands (secretory Like the somatic, the visceral efferent neurones receive impulses within the ventral hoins (a) from the cephalic and caudal branches of spinal ganglion neurones, $(b)$ the descending cerebro-spinal fasciculi, and $(c)$ from either, by way of the fasciculi proprii and Golgi neurones of type II. Their cell-bodies are situated for the most part in the dorsal portion of the lateral horn (dorso-lateral group of cells), which is the only portion of the lateral horn present in the thoracic region of the cord. Many of the visceral efferent fibres leave the spinal nerves distal to the spinal ganglia and make the white communicating rami, thus going to the nearest sympathetic ganglia; others pass on in the spinal nerve and its branches to terminate in more distal sympathetic ganglia. Dogiel has described axones which arise in sympathetic ganglia and terninate upon the cell-bodies of the spinal ganglia. Such convev sensory impulses which, however, enter the spinal cord by way of the dorsal root branch of the spinal ganglion neurone. Such afferent sympathetic neurones are relatively rare, the peripheral distribution of the ordinary 
Fig. 621.-Schematic Representation of the More Important Architectural Relations of Netrones in the Spinal Cord, Omiting those Involving the Mesencephalon and Thalamus.

a, afferent (spinal ganglion) axone of spino-cerebral chain with bifurcation and caudal branch; $b$, afferent axone coursing in Lissauer's zone and distributed wholly within the cord; c, collaterals of a and b disposed in three ways; p, pyraniclal axone in lateral (crossed) cerebro-spinal fasciculus distributed to levels of grey substance; pa, axone in ventral cerebrospinal fasciculus decussating before termination; $v$, ventral root or motor neurones; $n$, nucleus dorsalis giving axone to dorsal spino-cerebellar fasciculus; $\mathrm{g}$, ascending neurones of Gowers' tract; d, descending axone from cerebellum (probable); fp, neurones of fasciculi proprii, association proper; $h$, commissural neurones; e, Golgi cell of type II.

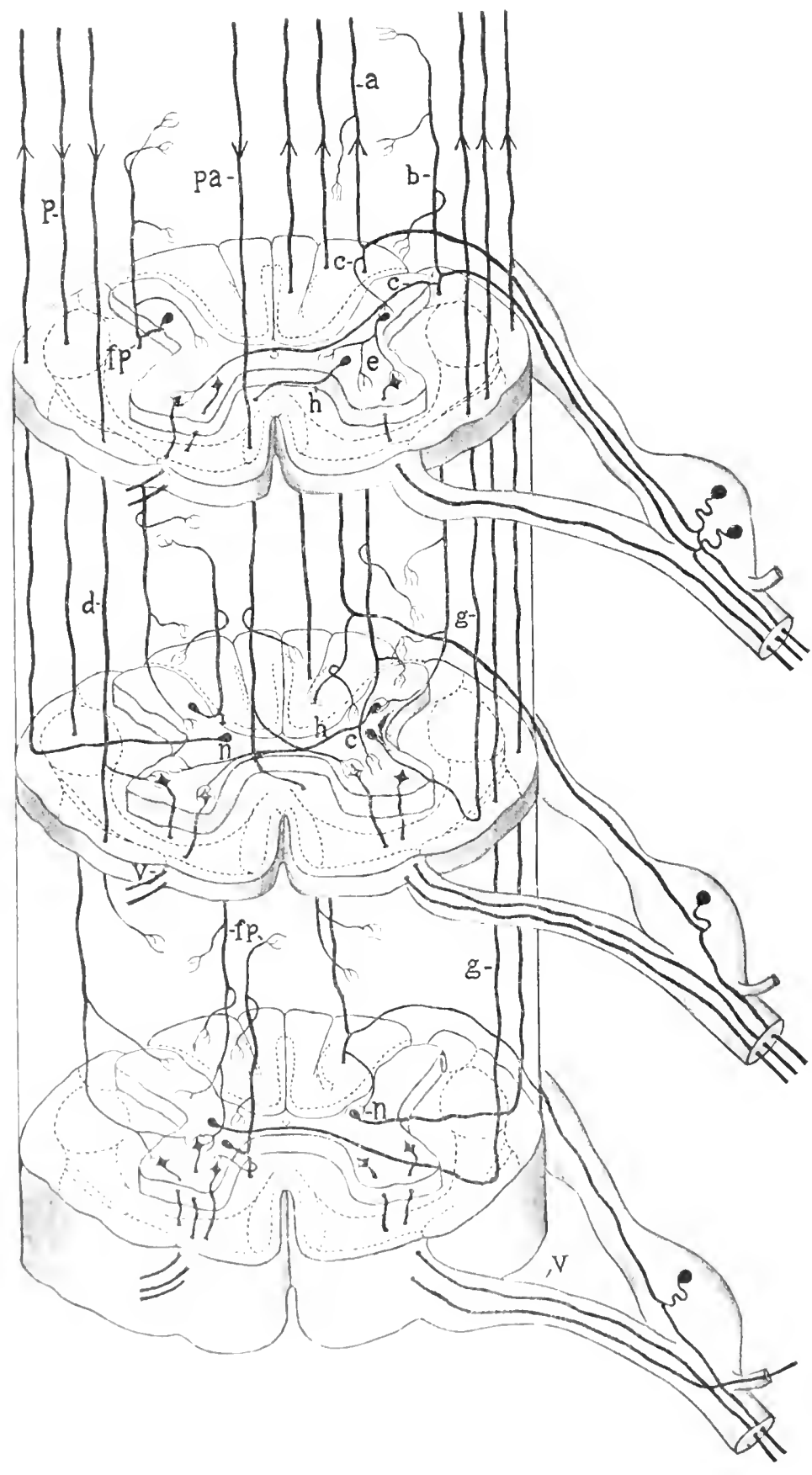


spinal ganglion neurone in the domain of the sympathetic supplying the needs for sensory axones.

In transverse sections of the spinal cord, the relative area of white substance as compared with that of grey increases as the cord is ascended. The absolute area of each varies with the locality, both being greatest in the enlargements. The grey substance predominates in the conus medullaris and lower lumbar segments. The white substance begins to predominate in the upper lumbar segments, not because of the increased presence of ascending and descending cerebral and cerebellar axones, but because of the increased volume of the fasciculi proprii coincident with the greater mass of grey substance to be intersegmentally associated in this region. In the thoracic region the greatly predominating white substance

Fig. 622.-Graphic Representation of the Varying Auounts of Grey and White Substance and of the Variations in Area of Entire Sections of the Different Seguents of the Spinal Cord. (From Donaldson and Davis.)

(Based upon measurements from several adult human spinal cords.)

\section{Curves showing area of cross seclion of hunan spinal cord.}

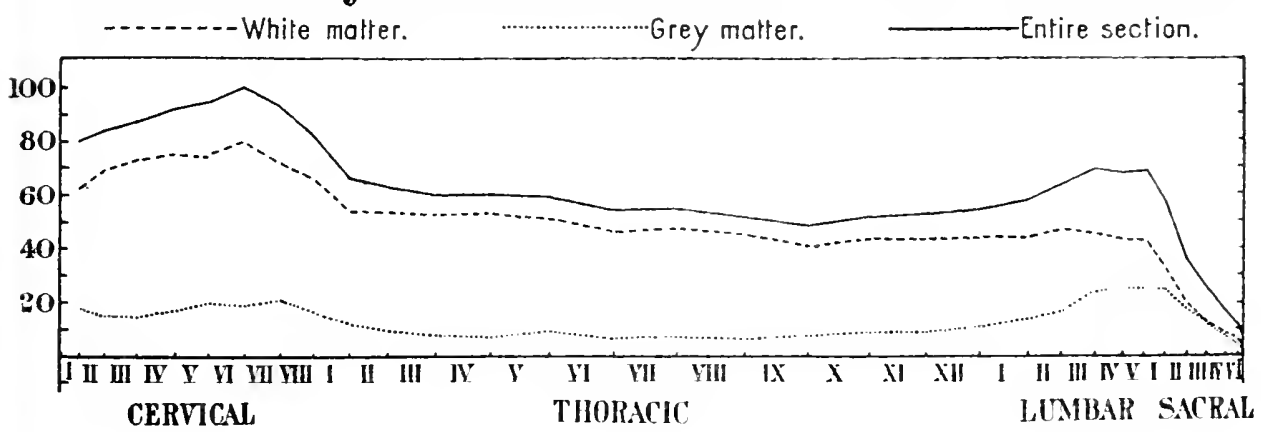

is composed mostly of the axones of long course. The greatly increased absolute amount of white substance in the cervical region is due both to the greater accumulation of cerebral and cerebellar axones in this region and to the increased volume of the fasciculi proprii of the cervical enlargement.

\section{ORDER OF MEDULLATION OF THE FASCICULI OF THE CORD}

The axones of the spinal cord begin to acquire their myelin sheaths during the fifth month of intra-uterine life and myelinization is not fully completed till between the fifteenth and twentieth years. In general, axones which have the same origin and the same locality of terminationthe same function-acquire their sheaths at the same time. While it has been proved that the medullary sheath does not necessarily precede the functioning of an axone, it may be said that those fasciculi which first attain complete and definite functional ability are the first to become medullated. At birth all the fasciculi of the spinal cord are medullated except Helweg's fasciculus, and occasionally the lateral and ventral cerebro-spinal tracts. The latter tracts vary considerably and in general may be said to become medullated between the ninth month (before birth) and the second year. As indicated by their medullation, those axones by which the cord is enabled to function as an organ per se, that is, the axones making possible the simpler reflex activities, complete their development before those axones which involve the brain with the activities of the cord.

According to Flechsig and van Gehuchten, and investigators succeeding them, the following is the order in which the axones of the cord become medullated:-

(1) The afferent and efferent nerve-roots and commissural fibres of the grey substance.

(2) The fasciculi proprii, first the ventrial, then the lateral, and last the dorsal, fasciculus proprius.

(3) The fasciculus cuneatus (Burdach's column) and Lissauer's zone-the area of those ascending spino-cerebral fibres which ruu the shorter course and which convey impulses from the upper limbs, thorax and neck.

(4) Fasciculus gracilis (Goll's column).

(5) The dorsal spino-cerebellar fasciculus (direct cerebellar tract).

(6) The superficial antero-lateral spino-cerebellar fasciculus (Gowers' tract).

I(7) The lateral cerebro-spinal fasciculus (crossed pyramidal) and the ventral cerebrospinal fasciculus (direct pyramidal tract).

(8) The spino-olivary or Helweg's (Bechterew's) fasciculus. 
The axones descending from the cerebellum and the brain-stem are so mixed with other axones that it is difficult to determine the sequence of their medullation. The fasciculi containing them also contain axones of the variety in the fasciculi proprii and so show medullation early. It is probable that the ascending, spino-cerebellar, fibres acquire their myelin earlier than the descending, if descending exist.

\section{Blood Supply of the Spinal Cord}

The spinal rami of the sacral, lumbar, intercostal, or vertebral arteries, as the case may be, accompany the spinal nerves through the intervertebral foramina, traverse the dura mater and arachnoid, and each divides into a dorsal and a ventral radicular artery. These accompany the nerve-roots to the surface of the cord, and there break up into an anastomosing plexus in the pia mater. From this plexus are derived three tortuously coursing longitudinal arteries and numerous independent central branches, which latter penetrate the cord direct. Of the longitudinal arteries, the anterior spinal artery zigzags along the anterior median fissure and gives off the anterior central branches, which pass into the fissure and penetrate the cord. These branches give off a few twigs to the white substance in passing, but their most partial distribution is to the ventral portion of the grey substance. The two posterior spinal arteries, one on each side, course near the lines of entrance of the dorsal root-fibres. They each branch and anastomose, so that of ten two or more posterior arteries may appear in section upon either side

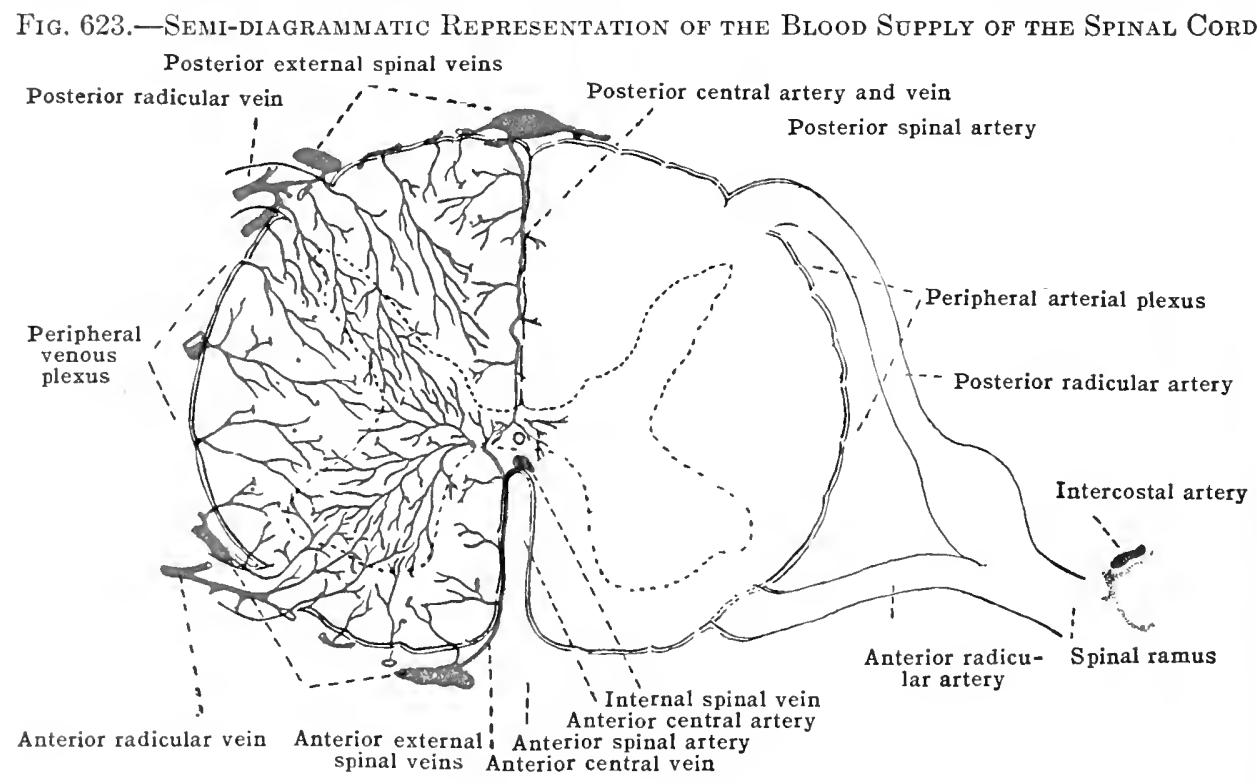

of the dorsal root. These give off transverse or central twigs to the white substance, but especially to the grey substance of the dorsal horns. Of the remaining central branches many enter the cord along the efferent fibres of the ventral roots, and are distributed chiefly to the grey substance; others from the peripheral plexus throughout penetrate the cord and break up into capillaries within the white substance. Some of the terminal twigs of these also enter the grey substance. The blood supply of the grey substance is so much more abundant than that of the white sulstance that in injected preparations the outline of the grey figure may be easily distinguished by its abundance of eapillaries alone. The central branches are of the terminal variety. In the white substance the capillaries run for the most part longitudinally, or parallel with the axones.

The venous system is quite similar to the arterial. The blood of the central arteries is colleeted into corresponding central venous branches which converge into a superficial venous plexus in which are six main longitudinal channels, one along the posterior median sulens, one along the anterior median fissure, and one along each of the four lines of the nerve-roots. These comprise the posterior and anterior external spinal veins (fig. 623).

The internal spinal veins course along the ventral surface of the grey commissure, and arise from the convergence of certain of the twigs of the antrior central vein. The posterior central vin courses along the posterior nedian septum in company with the posterior central artery, and cumpties intro the melian dorsal vin. The venous system communicates with the coarser extra-tural or internal vertebral plexus chiefly by way of the radicular veins.

\section{THH' IBRAIN OR ENCEPHALON}

'Tlue brain is that greatly modified and enlarged portion of the central nervous systrm which is renclosed within the cranial cavity. It is surromded and supported by the same three membrames (meninges) that envelop the spinal cord. 
While there is a considerable subarachnoid space, the brain more nearly fills its cavity than does the spinal cord.

The average length of the brain is about $165 \mathrm{~mm}$. and its greatest transverse diameter about $140 \mathrm{~mm}$. It averages longer in the nale than in the female. Exclusive of its dura mater, the normal brain weighs from 1100 to $1700 \mathrm{gm}$. (40-60 oz.), varying in weight with the stature of the individual or with the bulk of the tissues to be innervated. Its average weight is 1360 $\mathrm{gm}$. (4S oz.) in males and $1250 \mathrm{gm}$. ( $44 \mathrm{oz}$.) in females. It averages about fifty times heavier than the spinal cord, or about 98 per cent. of the entire cerebro-spinal axis. In its precocious growth it is at birth relatively much larger than at maturity. At birth it comprises about 13 per cent. of the total body-weight, while at maturity it averages only about 2 per cent of the weight of the body. Its specific gravity averages 1.036. In proportion to the bodyweight the brain-weight averages somewhat higher in smaller men and momen. Some very small dogs and monkeys and some mice have brains heavier in proportion to body-weight than man.

The minimal weight of the adult brain compatible with human intelligence may be placed at from 950 to 1000 grams. Above the minimal, there is only a general relation between the degree of intelligence and the weight of the brain, owing to the fact that several factors may be coincident with large brains. It may be said in general, however, that the average brain weight of eminent men is above the general average. Some men judged eminent have had brains weighing less than the general average. Of the records generally accepted, the greatest brain weight

Fig. 624.-Mesial Section of the Head of a Female Thirty-five Years Old.

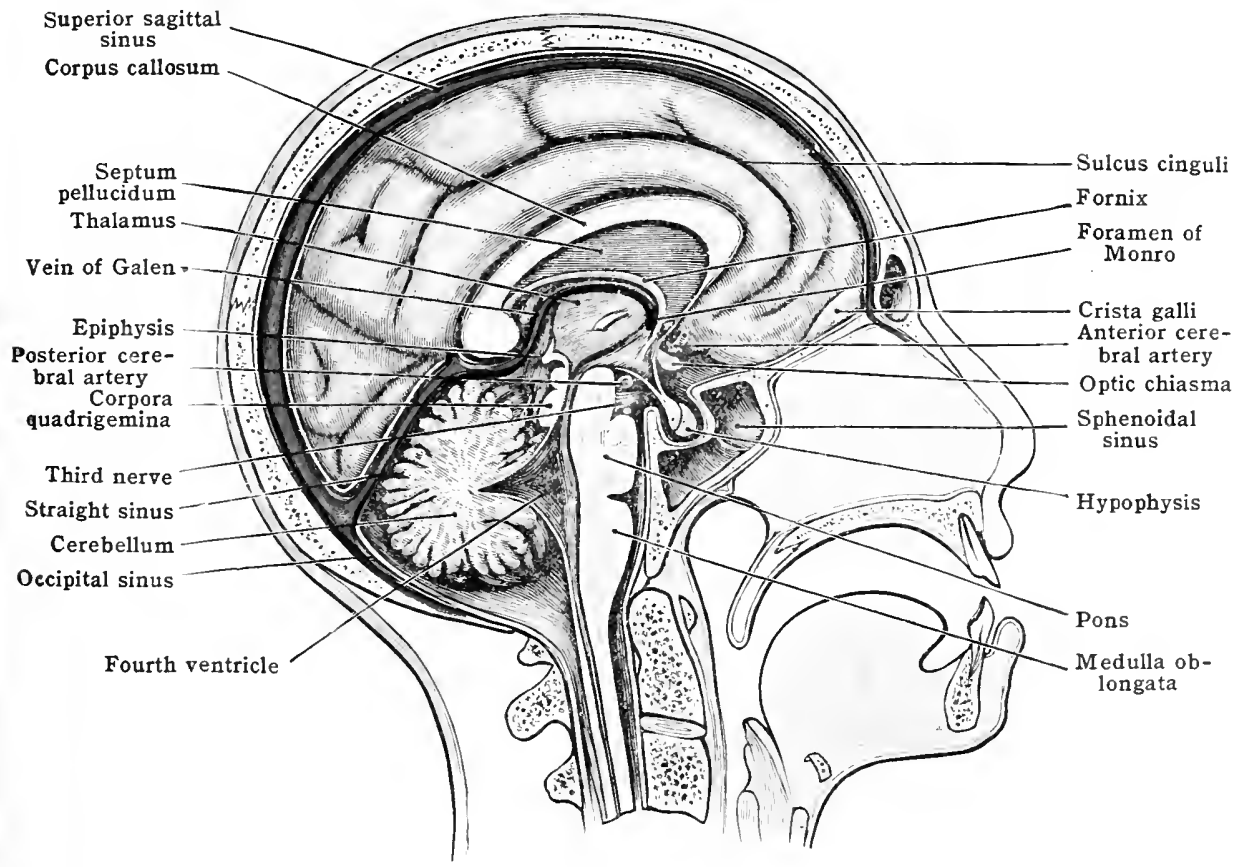

for eminent men is 2012 grams, recorded for the poet and novelist, Ivan Tourgenieff. The trustworthiness of this weighing is doubted by some authorities. From the undisputed records the following may be taken: Cuvier, 1830 grams; John Abercrombie, 1786 grams; Thackery, 1658 grams; Kant, 1600 grams; Spurzheim, 1559 grams; Daniel Webster, 1518 grams; Louis Agassiz, 1495 grams; Dante, 1420 grams; Helmholtz, 1440 grams; Goltz, 1395 grams; Liebig, 1352 grams; Walt Whitman, 1282 grams; Gall, 1198 grams. In the average brain weights for the races that for the Caucasian stands highest, the Chinese standing next, then the Malay, followed by the Negro, with the Australian lowest.

The differences between the meninges of the brain and those of the spinal cord occur chiefly in the dura mater. (1) The dura mater is about double the thickness of that of the spinal cord, and consists of two closely adhering layers, the outermost of which serves as the internal periosteum of the cranial bones, while that of ine cord is entirely separate from the periosteum lining the vertebral canal. (2) The inner layer is duplicated in places into strong partitions which extend between the great natural divisions of the encephalon. Of these, the sickleshaped falx cerebri extends between the hemispheres of the cerebrum, the crescentic tentorium cerebelli extends between the cerebellum and the overlapping posterior portion of the cerebrum, and the smaller falx cerebelli occupies the notch between the hemispheres of the cerebellum. Contained within these partitions of the dura mater are the great collecting venous sinuses of the brain. These will be considered in the more detailed description of the cranial meninges.

General topography.-In its superior aspect or convex surface the encephalon is oval in contour, with its frontal pole usually narrower than its occipital pole. 
Viewed from above, the cerebrum comprises almost the entire dorsal aspect, the occipital lobes overlapping the cerebellum to such an extent that only the lateral and lower margins of the cerebellar hemispheres are visible. The great longitudinal fissure of the cerebrum separates the cerebral hemispheres.

Laterally the temporal lobes, with their rounded anterior extremities, the temporal poles, are each separated from the frontal and parietal lobes above by the lateral cerebral fissure (fissure of Sylvius). In the depths of this fissure and overlapped by the temporal lobe is situated the insula, or island of Reil (central lobe).

The surface of each cerebral hemisphere is thrown into numerous folds or curved elevations, the gyri cerebri or convolutions, which are separated from each other by slit-like fissures, the sulci cerebri. The gyri (and sulci) vary greatly in length, in depth, and in their degrees of curvature. The larger and deeper of them are similar in the two hemispheres; most of them are individually variable, but each gyrus of one hemisphere is homologous with that of the like region of the other hemisphere. By gently pressing open the great longitudinal fissure, the corpus callosum, the chicf commissural pathway between the cerebral hemispheres, may be seen. The oceipital margin of this large transverse band of white substance is rounded and thickened into the splenium of the corpus callosum, while its frontal margin is curved ventrally into its genu and rostrum.

The base of the encephalon (fig. 625) is more irregular than the convex surface, and consists of a greater variety of structures. In the mid-line between the frontal lobes appears the anterior and inferior extension of the great longitudinal fissure. When the margins of this are separated, the outer aspect of the rostrum of the corpus callosum, the downward continuation of the curve of the genu, is exposed.

The inferior surface of each frontal lobe is concave, due to its compression upon the superior wall of the orbit. The orbital gyri with their respective orbital sulci occupy this concave area.

The cranial nerves [nervi cerebrales].-Along the mesial border of each orbital area, and parallel with the great longitudinal fissure, lie the olfactory bulbs continued into the olfactory tracts. Each olfactory bulb is the first central connection or the 'nucleus of reception' of the olfactory nerve, the first of the cranial nerves. A few fine filaments of this nerve may often be discerned penetrating the ventral surface of the bulb. The olfactory bulb and tract lies in the olfactory sulcus, which forms the lateral boundary of the gyrus rectus, the most mesial gyrus of the inferior surface of the frontal lobe. Upon reaching the area of Broca (area parolfactoria), or the region about the medial extremity of the gyrus rectus, each olfactory tract undergoes a slight expansion, the olfactory tubercle, and then divides into three roots or olfactory striæ - a medial, an intermediate, and a lateral, which comprise the olfactory trigone. The strix begin their respective courses upon the anterior perforated substance, an area which eontains numerous small foramina through which the antero-lateral group of central cerebral arteries enters the brain. 'This region forms the anterior boundary of that area of the base of the enceptalon in which the substance of the brain becomes continuous across the miel-line.

At the medial boundary of the anterior perforated substance the optic nerves come together and fusc to form the optic chiasma. Thence the optic tracts disappear under the poles of the temporal lobes in their backward eourse to the thalamiand the geniculate borlies or metathalami.

Immrdiately bebind the optic chisisma oecurs that diverticulum from the floor of the thirl ventricle known ats the tuber cinereum. It is connected by its tubular stalk, the infundibulum, with the hypophysis or pituitary body, which oceupies its special (tepression (sella tureica) in the floor of the eranium and is usually torn from the cocephalon in the process of its removal. Behind the tuber einereum are the two mamnillary bodies (corpora allicantia), each of which is connected with the fornix, one of the linger association fisciculi of the ecrebrum. The peduncles of the cerebrum (crura cerch)ri) are the two great funiculi which assoriate the corchoral hemispheres with all the structures below them. They diverge from the anterior border of the pons (Varoli) and, one for each hemisphere, disappear under the poles of the temporal lobes. The pons (brachium pontis or midhle corebellar pedunele) is (dicefly a hridge of white substance or a commissure between the arodedlar hemispheres. 
The oculomotor or third pair of cranial nerves make their exit from the posterior perforated substance in the interpeduncular fossa just behind the corpora mammillaria.

i The trochlear nerves emerge around the lateral aspects of the pedunculi cerebri along the anterior border of the pons. The trochlear is the smallest of the cranial nerves, and the only pair arising from the dorsal aspect of the brain.

The trigeminus, or fifth cranial nerve, is the largest. It penetrates the pons to find its recipient nuclei in the depths of the brain-stem. It is a purely sensory nerve, but it is accompanied by the much smaller masticator nerve which is motor and is usually referred to as the motor root of the trigeminus.

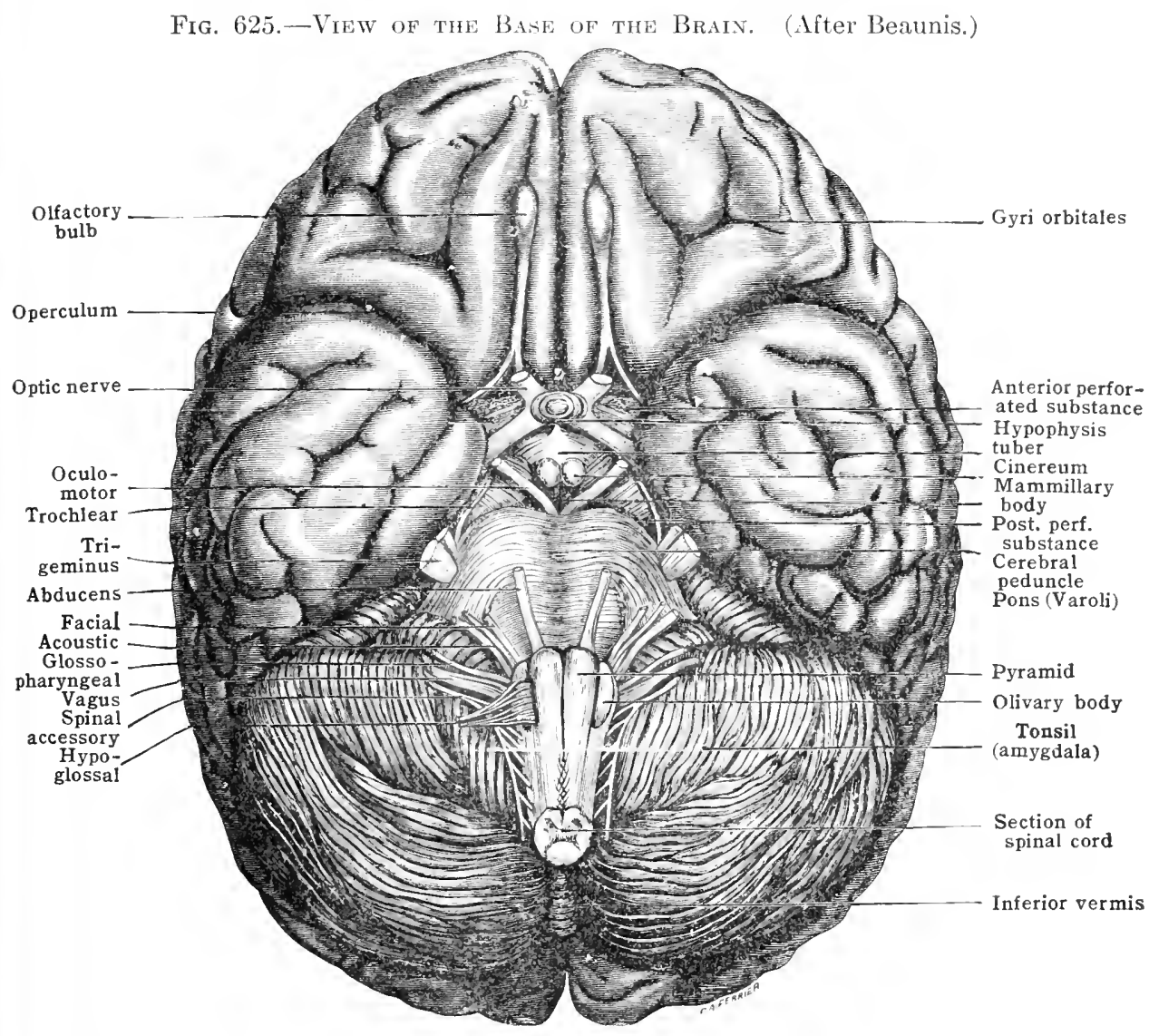

Five pairs of cranial nerves are attached to the brain-stem along the inferior border of the pons:- the abducens nerve, which is motor, emerges near the mid-line; the facial, motor, emerges from the more lateral aspect of the brainstem; the glosso-palatine or the intermediate nerve of Wrisberg, largely sensory, is attached in company with the facial: and, entering the extreme lateral aspect of the stem are the cochlear and vestibular nerves. These latter two, when taken together as one, are known as the acoustic (auditory) or eighth cranial nerve. They are both purely sensory. The cochlear courses for the most part laterally and dorsally around the inferior cerebellar peduncle, giving it the appearance from which it derives its name, 'restiform body.'

The remaining four pairs of the cranial nerves are attached directly to the medulla oblongata. This comprises that portion of the brain-stem beginning at the inferior border of the pons above, and continuous with the first segment of the spinal cord below. On its ventral surface the pyramids and the olives (olivary bodies) are the two most prominent structures. The pyramich, which are continuous below into the pyramidal (cerebro-spinal) tracts of the spinal cord, form the two tapering prominences along either side of the anterior median fissure; the olives are the oblong oval elevations situaterl between the prramids and the resti- 
form bodies, and each is the superficial indication of the inferior olivary nueleus.

The glosso-pharyngeal, the vagus (pneumogastrie), and the spinal accessory eranial nerves are attached along the lateral aspect of the medulla oblongata in line with the facial nerve and between the olive and the restiform body. The spinal aceessory, purely motor, is assembled from a series of rootlets which emerge from the lateral aspect of the first three or four cervieal segments of the spinal cord, as well as from the medulla. It beeomes fully formed before reaching the level of the olive, and passes lateralward in company with the vagus and further on joins the latter in part. The root filaments of the vagus and glossopharyngeal are arranged in a continuous series, and, if severed near the surface of the inedulla, those belonging to the one nerve are difficult to distinguish from those belonging to the other. Both of these are mixed motor and sensory.

The hypoglossal, purely motor, emerges as a series of rootlets between the pyramid and the olive. Thus it arises nearer the mid-line, and in line with the abducens, trochlear, and oculomotor.

If the oceipital lobes be lifted from the superior surface of the eerebellum and the tentorium cerebelli removed, the quadrigeminate bodies of the mid-brain or meseneephalon may be observed. These are situated above the cerebral peduncles, in the region of the ventral appearance of the oculomotor and trochlear nerves. Resting upon the superior pair of the quadrigeminate bodies [colliculi superiores] is the epiphysis or pineal body, and just anterior to this is the eavity of the third ventricle, bounded laterally by the thalami and roofed over by the tela chorioidea of the third ventricle (velum interpositum).

By separating the inferior margin of the cerebellum from the dorsal surface of the medulla oblongata the lower portion of the fourth ventricle (rhomboid fossa) may be seen. The cisterna cerebello-medullaris, the subarachnoid space in this region, is oceupied in part by a thickening of the arachnoid. This is continuous with the tela ehorioidea (ligula) and ehorioid plexus of the fourth ventriele. The former roofs over the lower portion of the fourth ventricle, and, passing through it in the medial line, is the lymph passage, the foramen of Magendie, by which the eavity of the fourth ventriele communieates with the subarachnoid space. The fourth ventricle, as it becomes continuous with the central eanal of the spinal eord, terminates in a point, the calamis scriptorius. From the inferior surface, the cerebellar hemispheres are more definitely demareated, and between them is the vermis or eentral lobe of the cerebellum.

Divisions of the encephalon.-The encephalon as a whole is developed from a series of expansions, flexures, and thiekenings of the wall of the cephalie portion of the primitive neural tube, the three primary brain vesicles. Being continuous with the spinal cord, it is arbitrarily considered as beginning just below the level of the deeussation of the pyramids, or at a line drawn transversely between the decussation of the pyramids and the level of the first pair of cervical nerves.

In its general conformation four natural divisions of the brain are apparent: the two most enlarged portions--(1) the eerebral hemispheres and (2) the eerebellum; (3) the mid-brain (neseneephalon) between the eerebral hemispheres and the cercbellum, and (4) the medullat oblongata, the portion below the pons and above the spinal cord (fig. 602). However, the most logical and advantageous arrangement of the divisions and subdivisions of the eneephalon is on the basis of their development from the walls of the embryomie brain vesieles. (See fig. 598.) On this basis, for example, both the medilla oblongata and the eerebellum with its pons are derived from the posterior of the primary vesicles, and are, therefore, included in a single gross division of the encephaton, viz., the rhombencephaton. In the following outline the anatomical eomponents of the eneephalon are arranged with reforence to the three primary vesicles from the walls of which they are derived, and the primary flexures and thickenings of the walls of which they are claborations.

Juring the early growth of the neural fulc its basal or ventral portion and the lateral portions acepuire a greater thickness than the roof of the tube, and thus the tube is longitudinally divicled into a basal or ventral zone and an alar or dorsal zone. This is especially marked in the brain vesicles. Structures arising from the dorsal zone begin as localised thickenings of the roof. for example, in the rhombencephalon the greater part of the medulla oblongata and of the pons region is derivel from thr ventral zome, while the cerebellum is derived from the dorsal zone. 'The first of the flexures oceurs in the region of the future mesencephalon, and is known as the cephalic flexure; next occurs lhe cervical flexure, at the junction with the spinal cord; 


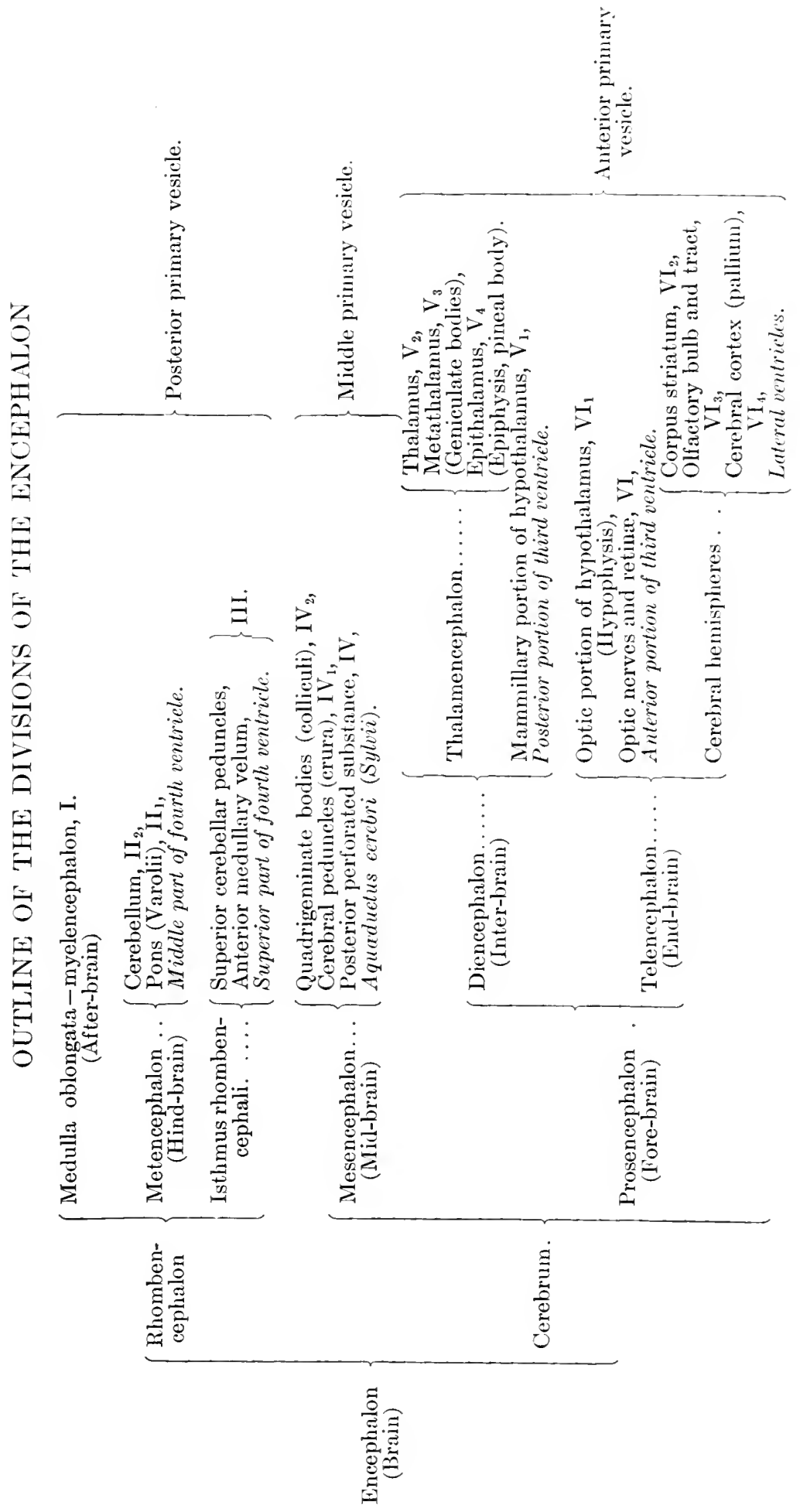


Fig. 626.-Median Sagittal Section turough Embryonic Human Brain at End of First MonTh. (After His.)

(Showing the localities of origin of the derivatives of the three primary vesicles named in outline on p. 797.)

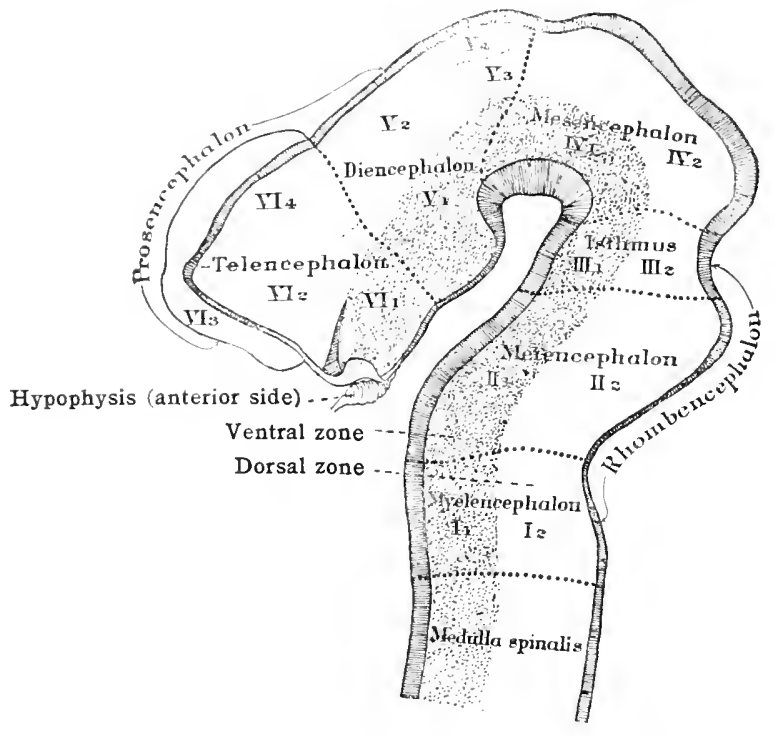

Fig. 627.-Sagittal Section of Brain of Human Embryo of the Third Month. (After His) (Reference numerals correspond with those of fig. 626 and those after names of parts in outline on p. 797.)

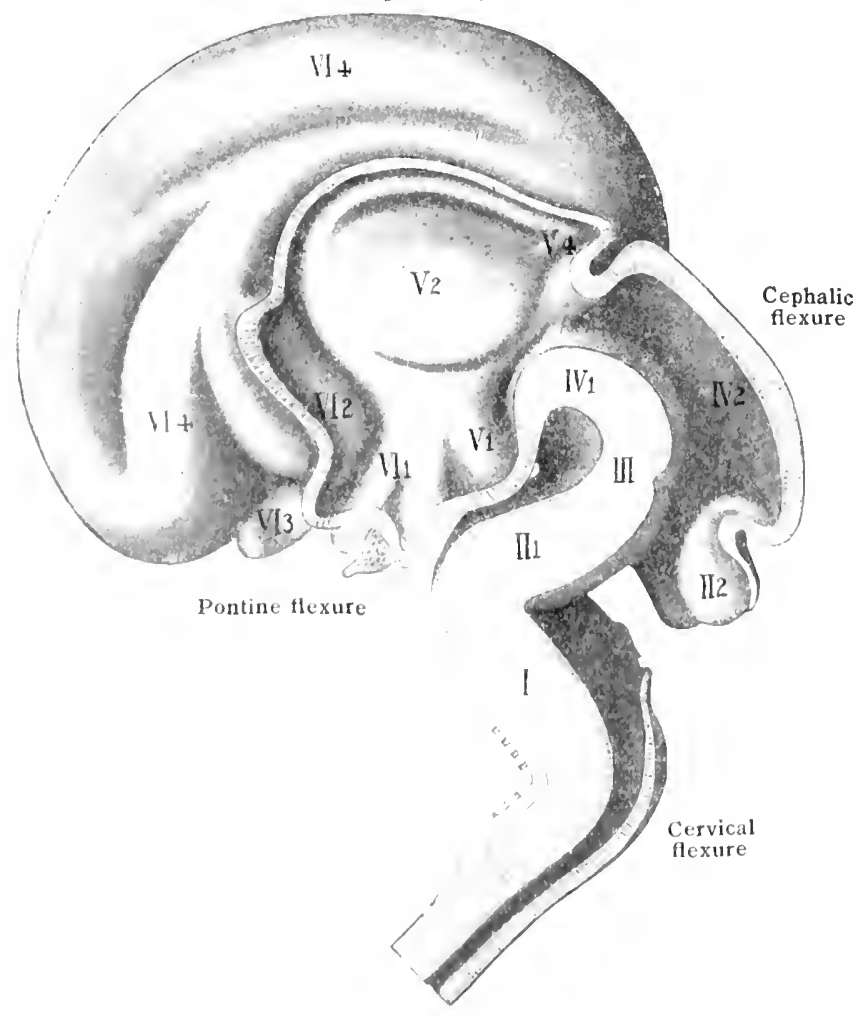


third, the pontine flexure, in the region of the future fourth ventricle. Both the cervical and pontine flexures, while having a significance in the growth processes, are almost entirely obliterated in the later growth of the encephalon.

The location of the development of the various parts of the encephalon may be determined, and their elaboration and changes in shape and position may betraced by comparing the accompanying figs. $626,627,628$. The reference numbers in

Fig. 628.-Median Sagittal Section of Adult Human Brain. (Drawing of model by His.) (Reference numerals same as in figs. 626 and 627. )

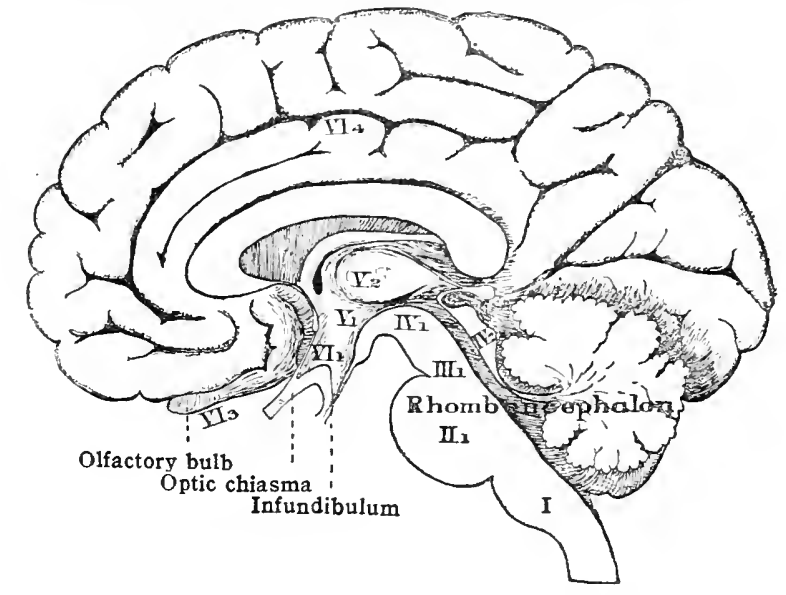

the last three figures correspond with the like numerals after the names of the parts on p. 797 in the outline of the divisions of the encephalon. The more detailed subdivisions of the parts will be met with in their individual descriptions.

\section{THE RHOMBENCEPHALON}

\section{THE MEDULLA OBLONGATA}

The medulla oblongata [myelencephalon] is the upward continuation of the spinal cord. It is only about $25 \mathrm{~mm}$. long, extending from just above the first cervical nerve (beginning of the first cervical segment of the spinal cord) to the inferior border of the pons. It lies almost wholly within the cranial cavity, resting upon the superior surface of the basal portion of the oceipital bone, with its lower extremity in the foramen magnum. Its weight is from 6 to $7 \mathrm{gm}$. or about onehalf of one per cent of the whole cerebro-spinal axis. It is a continuation of the spinal cord, and more. It contains structures continuous with and homologous to the structures of the spinal cord, and in addition it contains struetures which have no homologues in the spinal cord. Due in part to these additional structures, the medulla, as it approaches the pons, rapidly expands in both its dorsoventral and especially in its lateral diameters. With it are associated nine of the pairs of cranial nerves.

On its anterior or ventral aspect the anterior median fissure of the spinal cord becomes broader and deeper because of the great height attained by the pyramids. At the level at which the pyramids emerge from the pons, the region in which they are largest, the fissure terminates in a triangular recess so deep as to merit the name foramen cæcum. The pyramids are the great deseending cerebral or motor funiculi. In the medulla oblongata they decrease in bulk in passing toward the spinal cord, for the reason that many of the pyramidal axones are contributed to structures of the medulla, chiefly after crossing the mid-line. At the lower end of the medulla occurs the decussation of the pyramids, by which the anterior median fissure is almost obliterated for about $6 \mathrm{~mm}$., and which, upon removal of the pia mater, may be easily observed as bundles of fibres interdigitating obliquely across the mid-line.

Not all the pyramidal fibres cross to the opposite side at this level in man, but a portion of those coursing in the lateral portion of the pyramid maintain their ventro-mesial position 
and continue directly into the spinal cord, to form there the ventral cerebro-spinal fasciculus or direct pyramidal tract. However, most of such fibres finally cross the mid-line during their course in the spinal cord. The exact proportion of the direct fibres is variable, but always the greater mass of each pyramid crosses to the opposite side at the level of the decussation of the pyramids, and descends the cord as the lateral cerebro-spinal fasciculus or crossed pyramidal tract. Both of these pyramidal tracts are described in the discussion of the fasciculi of the cord.

Fig. 629.-Semi-diagamatic Representation of the Ventral Aspect of the Rhombencephalon and Adjacent Portions of the Cerebrum.

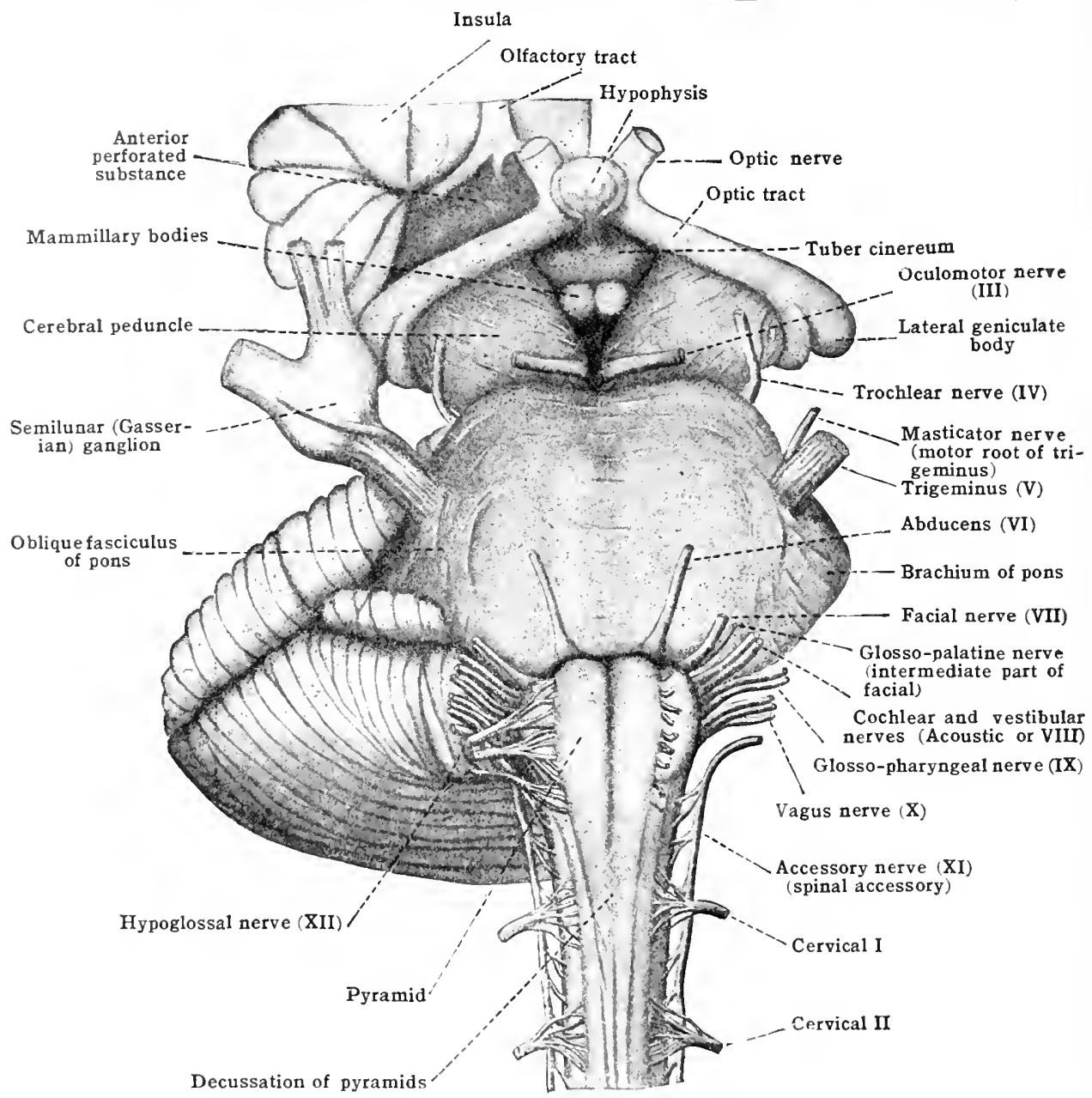

Each pyramid is bounded laterally by the antero-lateral sulcus, also continuous with that of the same name in the spinal cord. Toward the pons this sulcus separates the pyramid from the olive [oliva] (inferior olivary nueleus), and in the region of the olive there emerge along this suleus the root filaments of the hypoglossal nerve. These are in line with the filaments of the ventral roots of the spinal nerves. The olives, as their name implies, are oblong oval eminences about 1.2 $\mathrm{cm}$. in length. They 'xtend to the border' of the pons, and are somewhat thicker at their upper 'nels. Their surfaces : re usually smooth, except at their lower ends, where they frequently appear ribberl, owing to bundles of the external arcuate fibres passing across them to and from the restiform body, which occupies the extreme lateral portion of the inedullat. Along the line between the restiform body and the olive are attached the root filaments of the vagus, glosso-pharyngeal, and spinal accessory nerves. Both the abducens and the facial nerve emerge along the inferior horder of the pons, the facial in line with the glosso-pharyngeal, but the alulucens in line with the hispoglossus.

Dorsal aspect. - The increised linteral cliameter of the medulla oblongata is contributenl to a grat extent by the restiform bodies. These are the inferior cere- 
bellar peduncles (crura cerebelli ad medullam oblongatam) and contain the majority of the ascending fibres, which associate the cerebellum with the structures below it.

In toto, the restiform bodies are much larger than could be formed by the combined cerebellar fasciculi of the spinal cord, their great size being due to their receiving numerous axones coursing in both directions, which connect the cerebellum with structures contained in the medulla oblongata alone, so that in the medulla they increase as they approach the cerebellum. Their mesial borders form the lateral boundaries of the fourth ventricle. Their name (restiform, meaning rope-like) was suggested from the appearance frequently given them by the fibres of the cochlear (acoustic division of the eighth) nerve, which course around their lateral periphery to become the strice medullares in the floor of the fourth ventricle.

Fig. 630.-Diagram Showing the Decussation of the Prramids.

The uppermost level represented is near the inferior border of the pons.

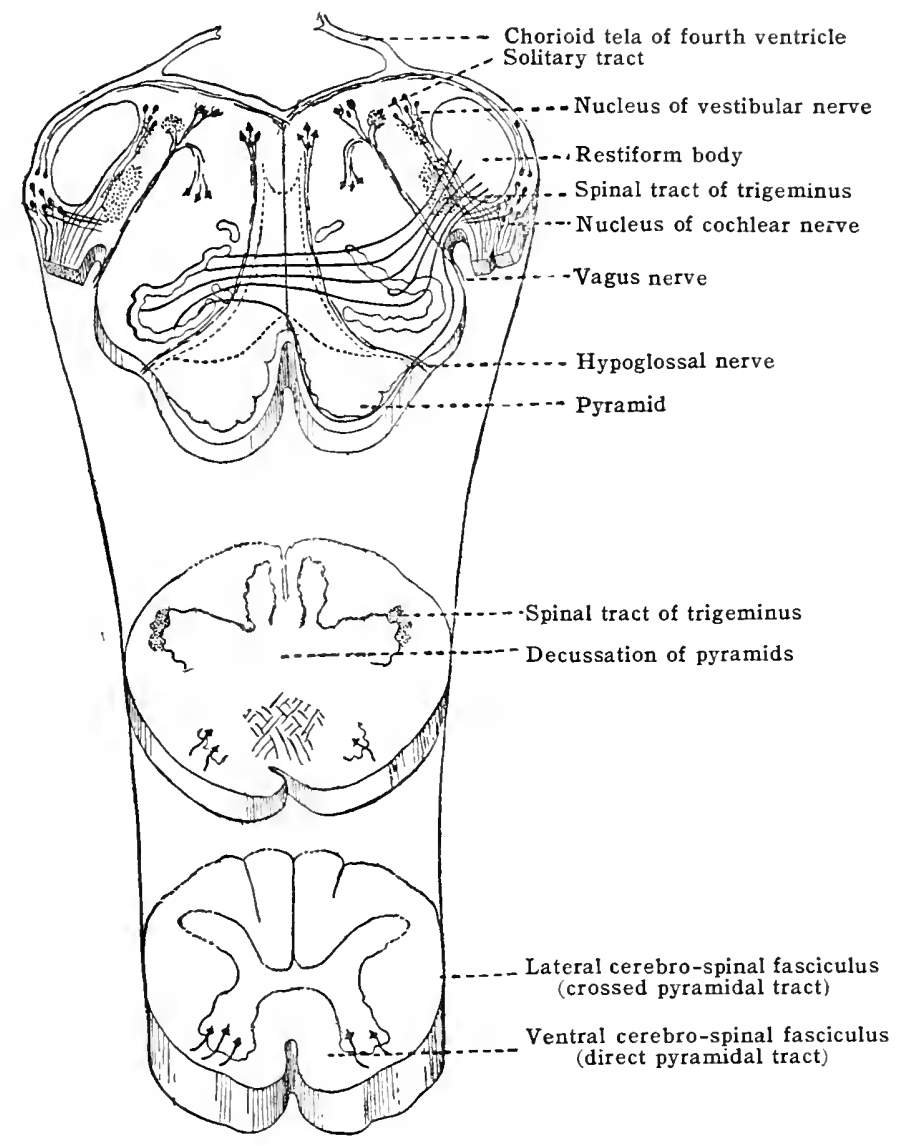

Upon removal of the cerebellum it may be seen that below the calamus scriptorius (inferior terminus of the fourth ventricle) the structures manifest in the dorsal surface of the medulla are directly continuous with those of the spinal cord. The fasciculus gracilis (Goll's column) of the spinal cord acquires a greater height and volume and becomes the funiculus gracilis of the medulla, and because of this increased height the posterior median sulcus of the cord becomes deepened in to the posterior median fissure. The posterior intermediate sulcus is also accentuated by the fasciculus cuneatus (Burdach's column) likewise now enlarged into the funiculus cuneatus of the medulla. The lateral funiculus of the medulla, of course, does not contain the lateral or crossed pyramidal tract present in the spinal cord.

At the border of the calamus scriptorius the funiculus gracilis terminates in a slight elevation, the clava, which is the superficial indication of the nucleus of the fasciculus gracilis. Beginning somewhat more anteriorly, and having a somewhat greater length, is a similar enlargement of the funiculus cuneatus, the tuberculum cuneatum or nucleus of the fasciculus cuneatus. 
These nuclei are the groups of nerve cell-bodies about which the ascending or sensory axones of the respective fasciculi terminate or where the sensory impulses are transferred to a second neurone in their course to the structures of the encephalon. These cell-bodies in their turn give off axones which immediately cross the mid-hine and assume a more ventral position, contributing largely to the lemniscus or fillet of the opposite side, and thus such axones are the encephalic continuation of the central sensory pathway conveying impulses from the periphery of one side of the body to the opposite side of the cerebrum. The crossing of these axones is knomn as the decussation of the lemnisci.

Fig. 631.-Dorsal Aspect of Medulla Oblongata and Mesencephalon, Showing the

Floor of the Fourth Ventricle (Rhombord Fossa). (Modified fiom Spalteholz.) Stria medullaris of thalamus
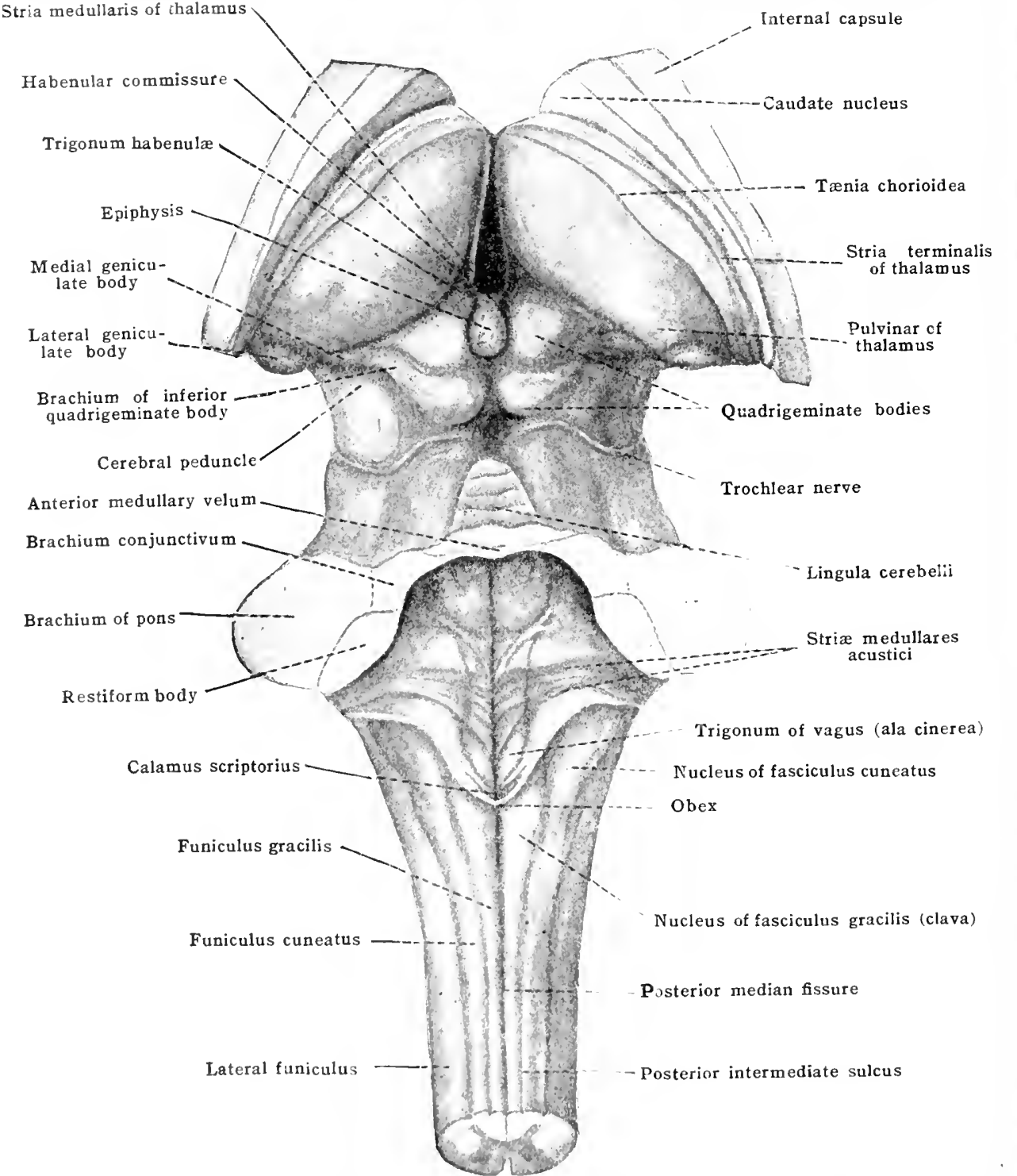

With the trinination of the dorsal funiculi and the ventral course of the fibres of the lemnised in their decossation, the ecutral canal of the spinal cord loses its reof of mervous tissuse in the malullat and comes to the surface as the fourth ventriele. 'The Hoor of the fourth ventriele, which comresponds to the floor of the central anal, is consicledilly widened into 1 wo lateral recesses opposite the junc-

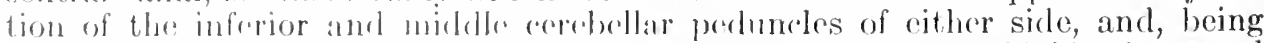
pointrel at both its smpuriol and inforior cxtrentics, it is rhomboidal in shape and thus is the rhomboid fossa. 'fler pia mater of the spinal cord is maintained across the fip of the alamus seriptorius to form the obex, at small, semilunar lamina roofing over the immerliats opening of the contral camal. 'The obex earries a few

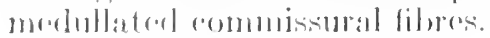


Fig. 632.-Diagran of the Spino-cerebellar Fasciculi and the Origin and DecussaTION OF THE LEMNISCI.

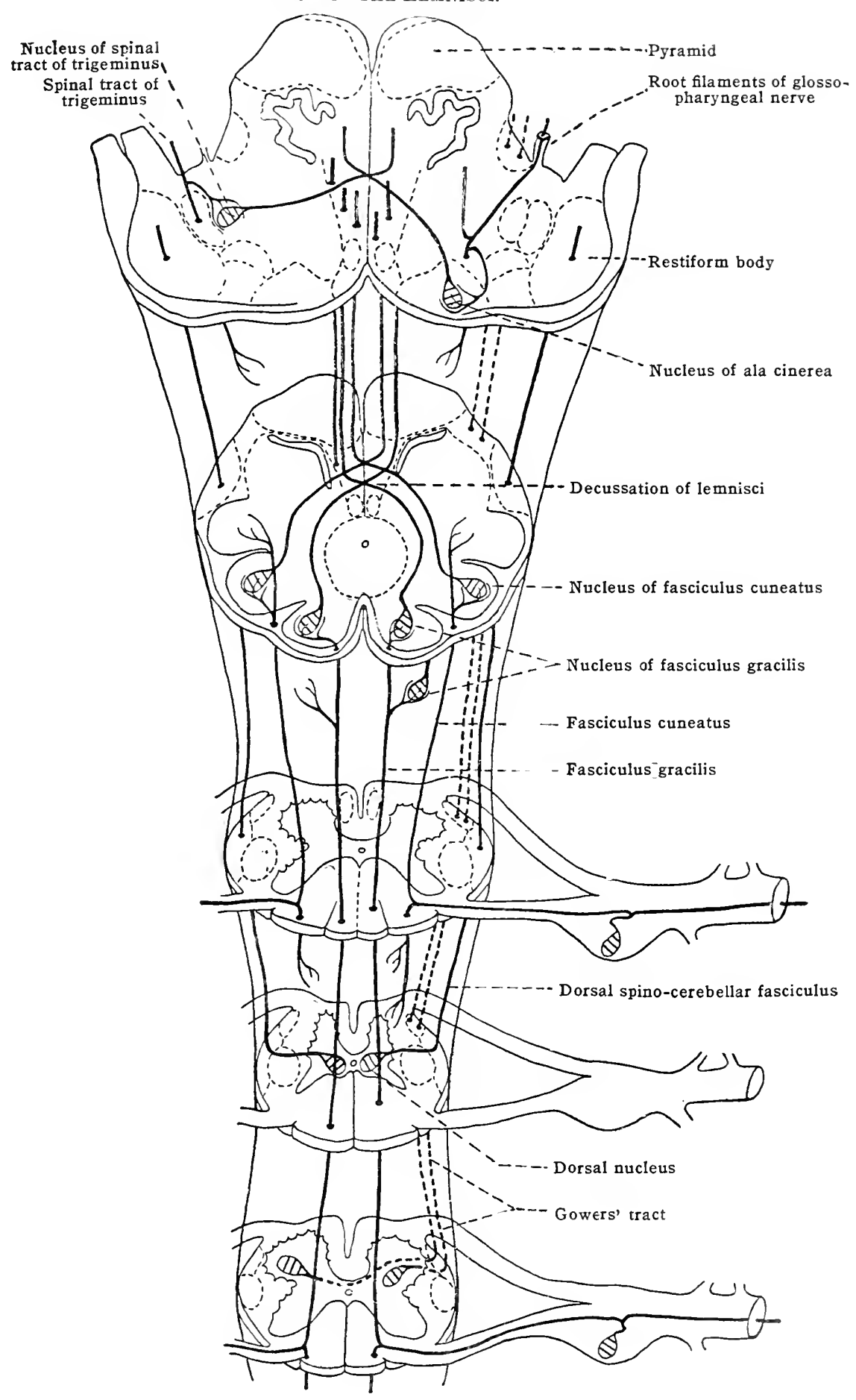




\section{THE PONS}

The pons (Varoli) is, for the most part, a great commissure or 'bridge' of white substance coursing about the ventral aspect of the brain-stem, and connecting the cerebellar hemisphere of one side with that of the other. In addition it contains fibres passing both to and from the structures of the brain-stem and the grey substance of the cerebellum, and fibres descending from the cercbral cortex. Each of its lateral halves forms the middle of the three cerebellar peduncles, the brachium pontis of either side.

In size it naturally varies directly with the development of the cerebellum, both in a given animal and relatively throughout the animal series. In man it attains its greatest relative size, and possesses a median or basilar sulcus in which lies the basilar artery. Its sagittal dimension varies from 25 to $30 \mathrm{~mm}$., while its transverse dimension (longitudinal with the course of its fibres) is somewhat greater. It is a rounded white prominence interposed between the visible portion of the cerebral peduncles (crura) above and the medulla oblongata below. Its inferior margin is rounded to form the inferior pontine sulcus, which, between the points of the emergence of the pyramids, is continuous with and transverse to the foramen cxeum. Its superior margin is thicker and is rounded to form the superior pontine sulcus, which, between the cerebral peduncles, is continuous with and transverse to the interpeduncular fossa. (See fig. 629.) It is bilaterally symmetrical. The ventro-lateral bulgings of its sides (and, therefore, the basilar sulcus) are produced by the passage through it of the fibres of the cerebral peduncles from above, to reappear as the pyramids below. Its ventral surface rests upon the basilar process of the occipital bone and the dorsum sellæ of the sphenoid, while its lateral surfaces are adjacent to the postcrior parts of the petrous portions of the temporal bones.

The fibres of the thicker superior portion of the pons (fasciculus superior pontis) course obliquely downward to their entrance into the brachium of the pons and the cerebellar hemisphere; those of the lower and mid-portions (fasciculus mcdius pontis) course more transversely, naturally converging upon approaching the cerebellum. Certain fibres of the upper midportion course at first transversely and then turn abruptly downward across the fibres above them, to join the inferior portion of the brachium pontis. This bundle is termed the oblique fasciculus (fig. 629). The trigeminus or fifth cranial nerve penetrates the superior lateral portion of each brachium pontis near the point of the downward turn of the oblique fasciculus; its large afferent root and the masticator nerve (its small efferent root) accompany each other quite closely. On either side of the basal surface of the pons usually may be seen a small bundle of fibres which begins in the interpeduncular fossa, near or in the sulcus of the oculomotor nerve. It passes laterally along or under the superior border of the pons, loses some of its fibres in the lateral sulcus of the mesencephalon, then runs inferiorly between the superior cerebellar perduncle and the brachium of the pons to disappear in the junction of these. Being sometimes double, it is known as the lateral filaments of the pons (fila lateralia pontis or tania pontis). The location of the cell-bodies giving origin to it is uncertain.

That portion of the rhombencephalon overlying the pons and forming the floor of the fourth ventricle is not really a part of the pons at all. It is nerely a continuation of the brainstem from the medulla below to the structures above. Therefore on the dorsal surface there is uo line of demareation between the pons and medulla below or between the pons and isthmus above. The fibres of the trigenimus and masticator nerve pass through the pontine fibres to and from the ir nuclei in the brain-stem.

\section{THE CEREBELLUM}

The cerebellum or hind brain is the largest portion of the rhombencephalon. It lies in the prostrior or cerebellar fossa of the cranium, and dorsal to the pons and medulla oblongata, overhanging the latter. It fits under the occipital lobes of the cerebral hemispheres, from which it is separated by a strong duplieation of the inder latyore of the durat mater, the tentorium cerebelli.

Its greatent diameter fies transersely, and its average weight, exclusive of the dura mater,

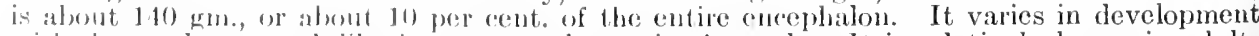
with the cerchermm, and, like it, atverages larger in the male. It is relatively larger in adults than in children. Its develeprnent legins as at thickening of the anterior portion of the roof (dersal zone of the posterior of the three primary brain vesieles. Resting upon the brainstem, it poffs over the fonth ventricle and is connected with the structures anterior, below, and pusterior to it by its three pars of peduncles.

'Thr surfare of the enewellum is thrown into numerous narrow folia or gyri, which in the given loralities run more or less parallel with each other. They are 
separated by narrow but relatively deep sulci. Unlike the spinal cord and medulla, in which the grey substance is centrally placed and surrounded by a mantle of white substance, the surface of the cerebellum is itself a cortex of grey substance, the corticul substance [substantia corticalis], enclosing a core of white substance, the medullary body [corpus medullare]. However, within this central core of white substance are situated definite grey masses, the nuclei of the cre bellum.

The gross divisions of the cerebellum are three: the two larger lateral portions, the hemispheres, and between these the smaller central portion, the vermis. The demarcation between these gross divisions is not very evident from the dorsal surface, because the hemispheres in their extraordinary development in man encroach upon the vermis, and, being pressed under the overlapping occipital ends of the cerebral hemispheres, they become partially fused upon the vermis

Frg. 633.-Section of Head Passing Through the Mastoid Processes of the Temporal Bones and Behind the Medulla Oblongata. Showing the Position of the CereBELLUM.

(From a mounted specimen in the Anatomical Department of Trinity College, Dublin.)

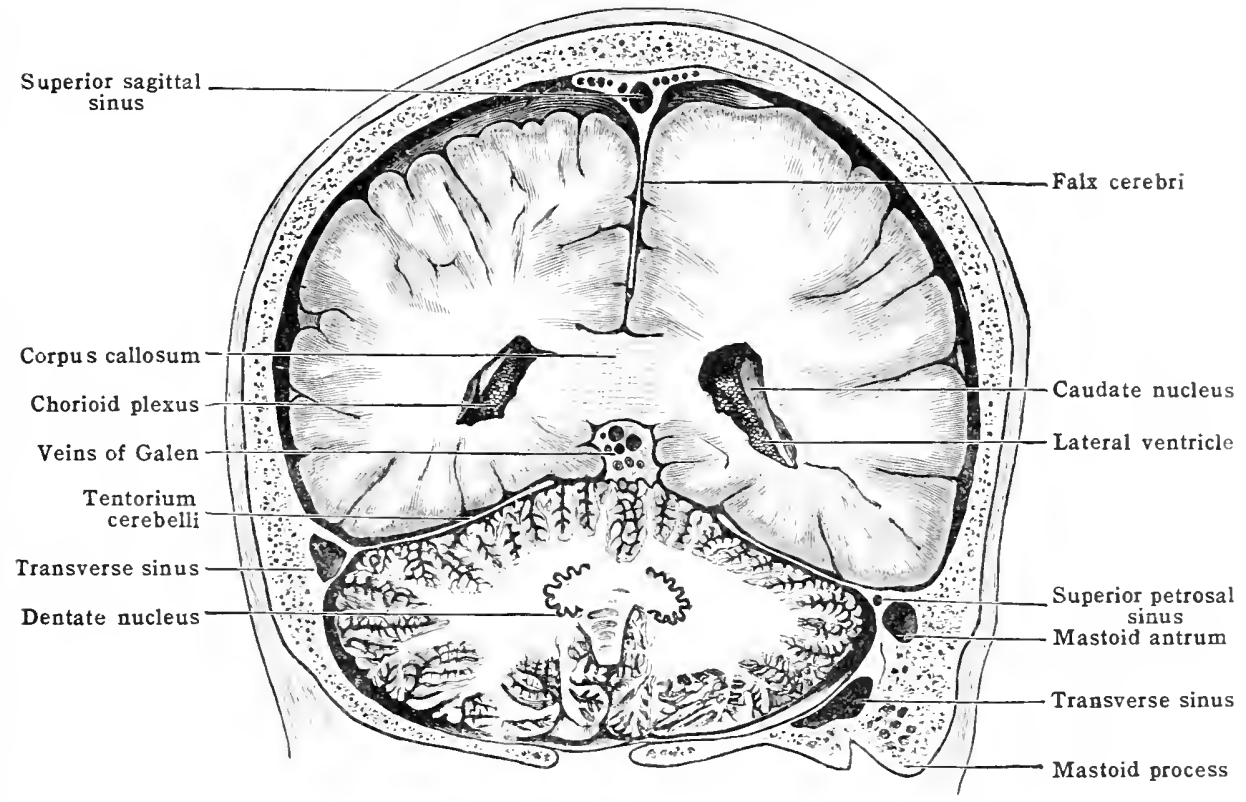

along the dorsal mid-line. Though differentiated simultaneously with the cerebellar hemispheres in the human fœetus, in most of the mammalia the vermis is the largest and most evident of the parts, and it is practically the only part which exists in the fishes, reptiles, and birds. In man, owing to the fact that the vermis does not keep pace in development with the hemispheres, there results a very decided notch between the two hemispheres along the line of the entire ventral and inferior aspect of the cerebellum, the floor of this notch being the surface of the vermis. The inferior portion of the notch is the posterior cerebellar notch (incisura marsupialis); its prolongation above is wider than below, and is termed the superior cerebellar notch. It is occupied by a fold of the dura mater, the falx cerebelli. With the variations in contour of the cerebellum, certain of its sulci are broader and deeper, and merit the name fissures. These are more or less definitely placed, and subdivide the hemispheres into lobes and the vermis (the median lobe) into lobules.

Superior surface.-The superior surface is bounded from the inferior surface by the horizontal fissure (fig. 635) which extends ventrolaterally, to the entrance of the brachium of the pons. Between this and the extreme anterior border of the dorsal surface are two other fissures, the posterior and anterior semilunar fissures. These, like the horizontal fissure, may be traced, with slight interruptions, across the mid-line, and consequently mark off not only the two hemispheres but also the vermis into corresponding divisions. 
The superior semilunar lobe [lobulus semilunaris superior] (postero-superior lobe) of each hemisphere lies between the horizontal and the posterior semilunar fissures. It largely composes the outer border of the cerebellum, and, therefore, is the longest of the lobes.

The adjacent surface of the hemispheres, because of the frequently less complete development of the anterior semilunar fissure, is sometimes referred to as the quadrangular lobe, with its posterior and its anterior portions. On the other hand, especially when the anterior semilunar fissure is well marked, this area may be divided into-(1) the posterior semilunar lobe, between the posterior and anterior semilunar fissures, and (2) the anterior semilunar lobe, anterior to the anterior semilunar fissure (fig. 635).

Anterior to the quadrangular lobe on each hemisphere is the ala of the central lobule, bounded by the postcentral and the precentral sulcus. Anterior to this, on the anterior margin of the hemisphere, is the vinculum lingulae, a slender process continuous with the lingula of the vermis (fig. 658).

Fig. 634.-Median Section Through Cerebellum and Brain-stem. (Allen Thompson, after Reichert.)

1. culmen monticuli; 2 , superior semilunar lobe; 3 , inferior semilunar lobe; 4 , slender lobe; 5 , biventral lobe; 6 , tonsil.

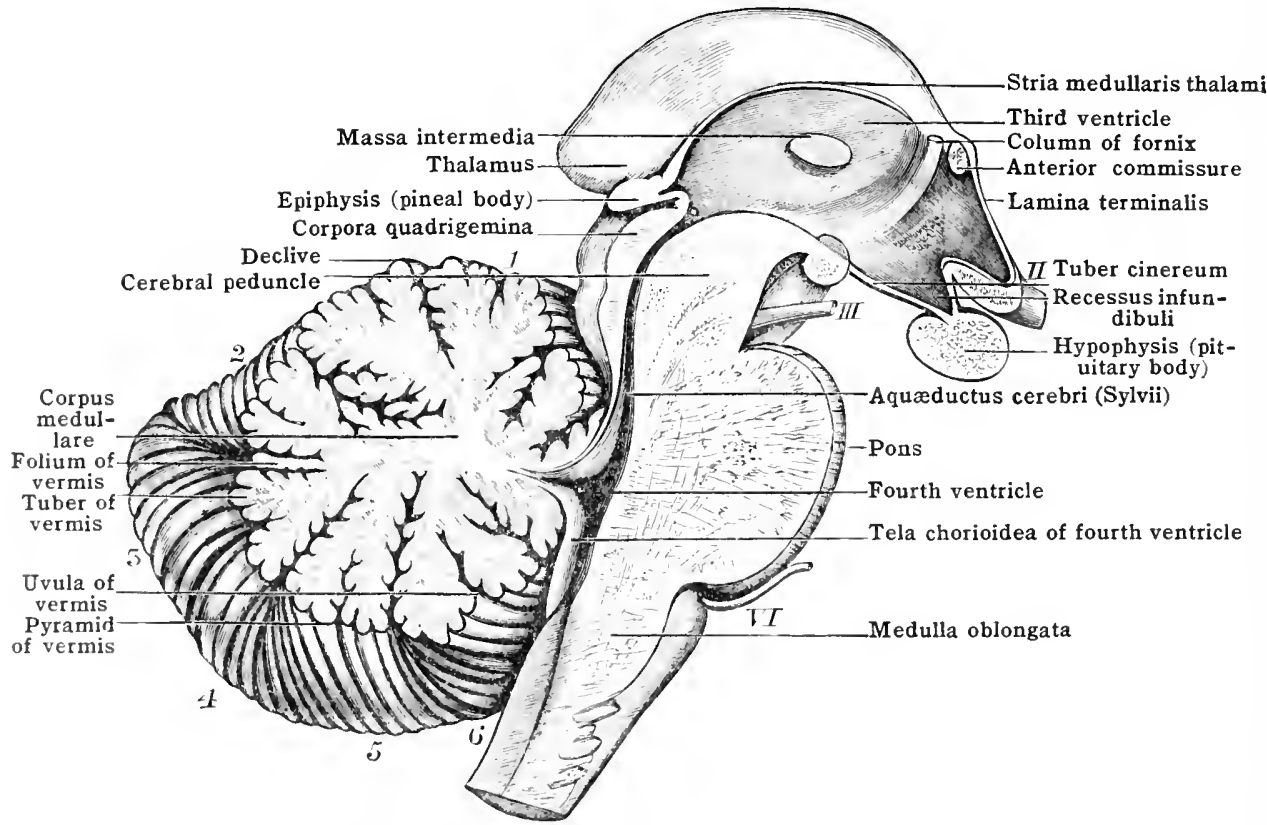

The superior aspect of the vermis, the superior vermis, because of the fusion of the hicmispheres, is, for the most part, a slight ridge, the monticulus (fig. 635), instead of a depression. However, in the posterior portion of the dorsal surface the depression of the posterior notch begins, and here the horizontal and the posterior semilunar fissures approach each other so closely that the corresponding subdivision of the vermis is seldom more than a single folium, the folium vermis (cacuminis).

The monticulus proper is divided into an inferior lobule, the declive, and a superior lobule, the culmen. These appear as continuations across the midline of the posterior and anterior semilunar lobes of the hemispheres, and are separated by the corresponding fissures (fig. (i35).

At the cxtreme anterior part of the superior surface and in the bottom of the antrerior ererellar noteh lies a more definitely defined portion of the vermis. This is the central lobule (fig. (53,5). It is broatched laterally into two pointed wings, the alo of the ecentral lolule, the folia of which, if present, are parallel with those of the anterior scmilunar lobes and separated from them by the postcentral sulcus.

If the anterior margin of the contral lobule be lifted, the lingula cerebelli 
(lingula vermis) will appear separated from the central lobule by the pre-central sulcus. It is a thin, tongue-like anterior projection of the cortical substance comprising four to eight folia adhering upon the anterior medullary velum, the roof of the superior portion of the fourth rentricle.

Inferior surface.-The three cerebellar peduncles of each side join to form a. single mass of white substance, and enter the ventral aspect of each hemisphere at the medial and ventral extremity of the horizontal fissure. The inferior surface of the cerebellum is less convex than the superior surface. The hemispheres are decidedly separated by a continuation of the posterior cerebellar notch, which becomes broader, the vallecula of the cerebellum, which contains the inferior portion of the vermis, vermis inferior, and whose margins embrace the medulla oblongata. The inferior surfaces of the hemispheres are each divided by the intervening fissures into four lobes (fig. 636).

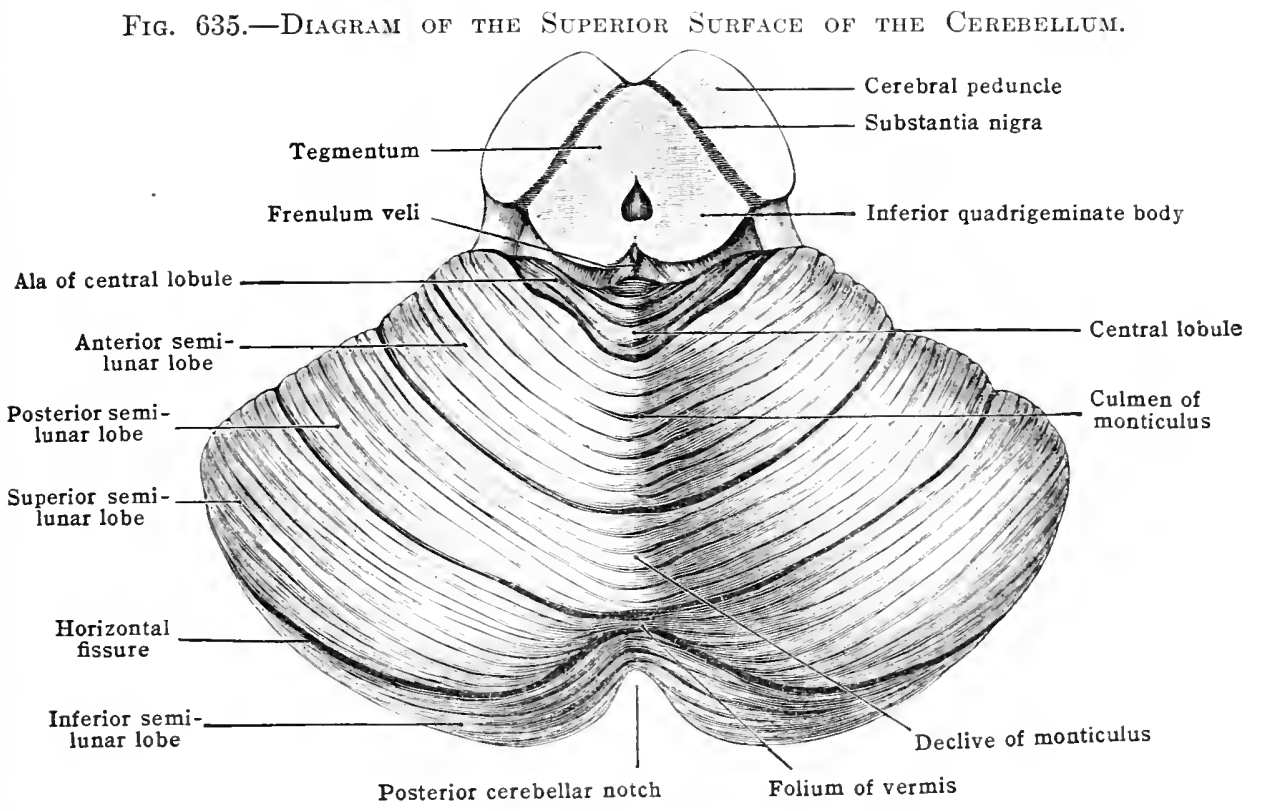

Below, the inferior semilunar lobe (postero-inferior lobe) is separated from the superior semilunar lobe of the superior surface by the horizontal fissure. It is the largest of the inferior lobes, and is broader at its medial extremity. Frequently two and sometimes three of its curved sulci appear deeper than others, and separate it into two or three slender lobules [lobuli graciles]. More commonly there are two of these, the lobulus gracitis posterior and lobulus gracilis unterior, separated by the postero-inferior sulcus.

The biventral lobe is smaller and more curved than the inferior semilunar lobe, from the anterior margin of which it is separated by the curved antero-inferior sulcus. Its medial extremity is pointed and does not extend to the rermis; its lateral extremity is broader and curves anteriorly to the ventral extremity of the horizontal fissure-the line of outer termination of the inferior semilunar lobe.

The tonsil [tonsilla cerebelli] (amygdala) is a rounded, triangular mass, placed mesially within the inner curvature of the biventral lobe, and separated from it by the retrotonsillar fissure. Its inferior mesial border slightly orerlaps the vermis.

The smallest of the lobes is the flocculus. It lies adjacent to the inferior and lateral surface of the mass of white substance produced by the confluence of the three cerebellar peduncles, and extends into the mesial extremity of the horizontal fissure. It is so flattened that it short folia give it the appearance suggesting its name. Occasionally there is added a second, less perfectly formed portion, the secondary flocculus. From each floccular lobe there passes toward the midline a thin band of white substance, the peduncle of the flocculus; these extend 
to meet each other at the most anterior portion of the inferior vermis, and thus form the narrow posterior medullary velum.

The inferior vermis (figs. 634,636) is more definitely demarcated than the superior. Lying in the floor of the vallecula cerebelli, it is separated on each side from the adjacent lobes of the hemispheres by a well-marked sulcus about it, the nidus avis. By contour and by deeper transverse fissures (sulci) occurring at intervals across it, four divisions or lobules of the inferior vermis are recognised. These lobules, like those of the superior vermis, are each in intimate relation with the pair of lobes of the hemispheres adjacent to it on either side.

1. The tuber vermis is adjacent to the folium vermis of the superior aspect, and thus is the most inferior lobule of the inferior vermis. It is a short, somewhat pyramidal-shaped division, whose four or five transversely arranged folia are continuous with the folia of the inferior semilunar lobes on either side.

2. The pyramid is separated from the tuber vermis by the post-pyramidal sulcus. Its several folia cross the vallecula cerebelli and curve to connect with the biventral lobes on either side.

3. The uvulva is separated from the pyramid by the prepyramidal sulcus. It is triangular in shape. Its base or broader inferior portion appears as two laterally projecting ridges of grey substance, the furrowed bands or alce uvulo, which extend across the floor of the nidus avis and under the mesial margins of the tonsils on either side. In these bands its folia curve and become continuous with the tonsils. The uvula and the two tonsils are sometimes referred to collectively as the uvular lobe.

4. The nodule is the smallest and most anterior division of the inferior vermis. It is separated from the uvula by the post-nodular sulcus, and is closely associated anteriorly with the posterior medullary velum, the transverse continuation of the peduncles of the floceular lobes.

\section{Summary of External Features of Cerebellum}

Superior Surface.

Henisphere

VERMIS

Anterior border-Anterior medullary velum-Anterior border

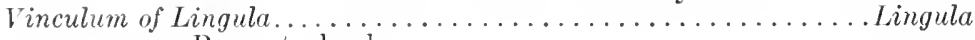

Precentral sulcus

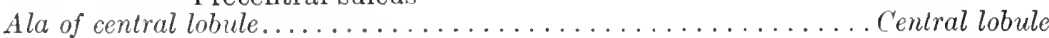

Post-central suleus

\begin{tabular}{|c|c|c|}
\hline $\begin{array}{l}\text { Quadran- } \\
\text { gular lobe }\end{array}$ & $\begin{array}{l}\text { Anterior semilunar lobule.................. Culmen } \\
\quad \text { Anterior semilunar fissure } \\
\text { Posterior semilunar lobule .................... Declive } \\
\text { Posterior semilunar fissure }\end{array}$ & Monticulus \\
\hline
\end{tabular}

Horizontal Fissure

Inferior Surfuce

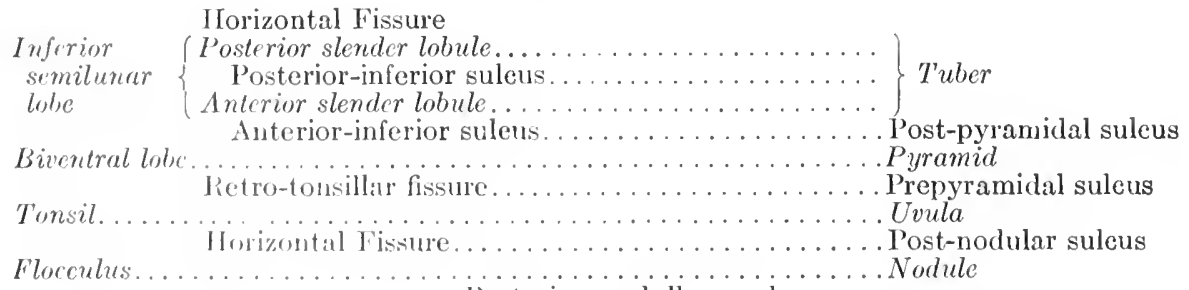

Posterior medullary velum

Internal structure of the cerebellum (fig. 637). - The white substance of the cerchellum is continuous with its perluncles and forms a compact central mass. Over the surface of this thre grey substance or cortex is spread in at thin but uniform and much folderl linyer. [Fon section of the ecrebellum certain of the sulci as well as the fissures are shown to be mucle deeper than is apparent from the surface. The decener sulci separate the lobes into divisions, the medullary laminæ, each of which is comprosed of a mumber of foliat and each of which has its own core of white sulsstaner. 'The folia of the limina line the sulci (and fissures), and also comprise thrir surface aspect, and are sc'parated by the shallow, secondary sulci. The larger 
laminæ are subdivided into from two to four secondary laminæ of varying size. Such subdivision is especially marked in the vermis. Here each lamina comprises a lobule and is, therefore, separated by a fissure, and each lobule is usually subdivided with the exception of the nodule, the folium, and the lingula. In sagittal sections, or sections transverse to the general direction of the sulci, this arrangement of the laminæ gives a foliate appearance, which, especially in sagittal sections of the vermis, is termed the arbor vitæ (see fig. 634).

iThe cerebellar cortex consists of three layers and contains four general types of cell-bodies of neurones, all of which possess features peculiar to the cerebellum.

The outermost or molecular layer contains small stellate cells, "basket cells," with relatively long dendrites. These serve to associate the different portions of a given folium. The axones of the largest of them give off branches which form pericellular baskets about the bodies of the cells of Purkinje, each axone contributing to several baskets. The layer of Purkinje cells, or the middle layer, is quite thin. The bodies of the cells of Purkinje are arranged in a single layer, and their elaborate systems of dendrites extend throughout and largely compose the molecular layer. The dendrites of these, the most essential cells of the cortex, are displayed in the form of arborescent fans (see fig. 604), arranged parallel with each other and transverse

Fig. 636.-Diagram of the Inferior Surface of the Cerebellum after the Removal of the Medulla Oblongata, Pons, and Mesencephalon.

The tonsil of the right side is omitted in order to display the connection of the pyramid with the biventral lobe, the furrowed band of the uvula, and more fully the posterior medullary velum. The anterior notch is less evident than in the actual specimen.

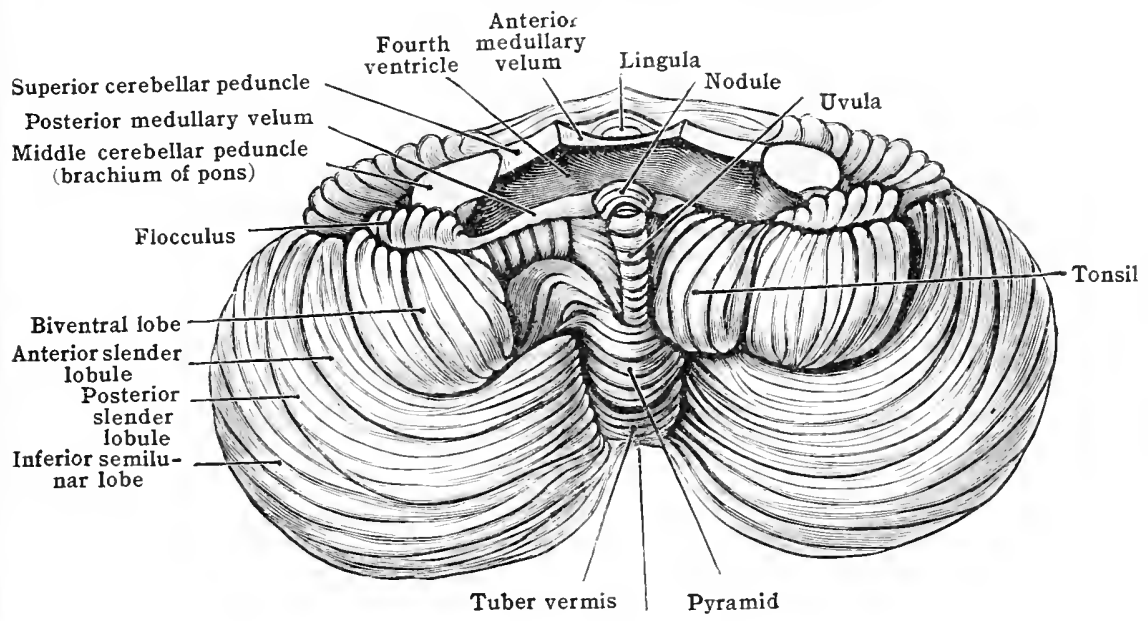

Posterior cerebellar notch

to the long axis of the folium containing them. Their axones are given off from the base of the cell-body and acquire their medullary sheaths quite close to the cell-body, and, after giving off several collaterals in the inner layer, pass into the general white substance and thence to other laminæ or lobes. Certain of them go to structures outside the cerebellum. The inner layer is the granular layer. It contains numerous small nerve-cells or "granule-cells" which possess from two to five radiating dendrites, unbranched except at their termination, which occurs suddenly in the form of three to six claw-like twigs. Their axones are given off either from the cell-body direct or more of ten from the base of one of the dendrites, and pass outward into the molecular layer, where they bifurcate and course in both directions parallel to the long axis of the folium, to become associated with the dendrites of the cells of Purkinje. In the layer of the cells of Purkinje there is situated at intervals a neurone of the Golgi type II (see fig. 604). The short, elaborately branched axone of this neurone is distributed among the cells of the granular layer. Axones conveying impulses to the cerebellar cortex terminate in the granular layer as 'moss fibres,' or directly upon the cells of Purkinje as 'climbing fibres,' and probably upon the cells of the Golgi type II.

Thus the neurones which receive impulses coming to the cortex are the cells of Purkinje, probably the Golgi cells of type II, and the granule-cells; those which distribute these impulses to other neurones of the folium are the Golgi cells of type II, the granule-cells, and the basketcells (association neurones), and the collaterals of the cells of Purkinje. Impulses are conveyed from the cortex of a folium to that of other folia, lamina, lobules or lobes, or to the nuclei of the cerebellum, or to structures outside the cerebellum by the axones of the cells of Purkinje.

The nuclei of the cerebellum (fig. 637) are in its central core of white substance. They are four in number, and all are paired, those of each pair being situated opposite each other on either side of the mid-line. 
1. The largest of them is the dentate nucleus. This is an isolated mass of grey substance situated in the core of white substance of each hemisphere. It is in the form of a folded or corrugated cup-shaped lamina, with the opening of the cup (hilus) directed anteriorly and obliquely toward the mid-line. It contains a miss of white substance and possesses a capsule. Its cell-bodies give rise to most of the fibres forming the superior cerebellar peduncles.

2. The nucleus emboliformis is an oblong and much smaller mass of grey substance, which lies immediately medial to the hilus of the dentate nucleus. It is probably of the same significance as the dentate nucleus, being merely a portion separated from it.

3. The nucleus globosus, the smallest of the cerebellar nuclei, is an irregular horizontal mass of grey substance with its larger end placed in front. It lies close to the medial side of the nucleus emboliformis, and often appears separated into two or more rounded or globular masses.

4. The roof nucleus [nucleus fastigii] is the sccond largest of the cerebellar nuclei, and is the most mesially placed. The pair is situated in the roof of the

Fig. 637.-Section of Cerebellum and Brain-stem Passing Obliquely Through Inferior Portion of Cerebellum to Superior Margin of Pons. (After Toldt, "Atlas of Human Anatomy," Rebman, London and New York.)

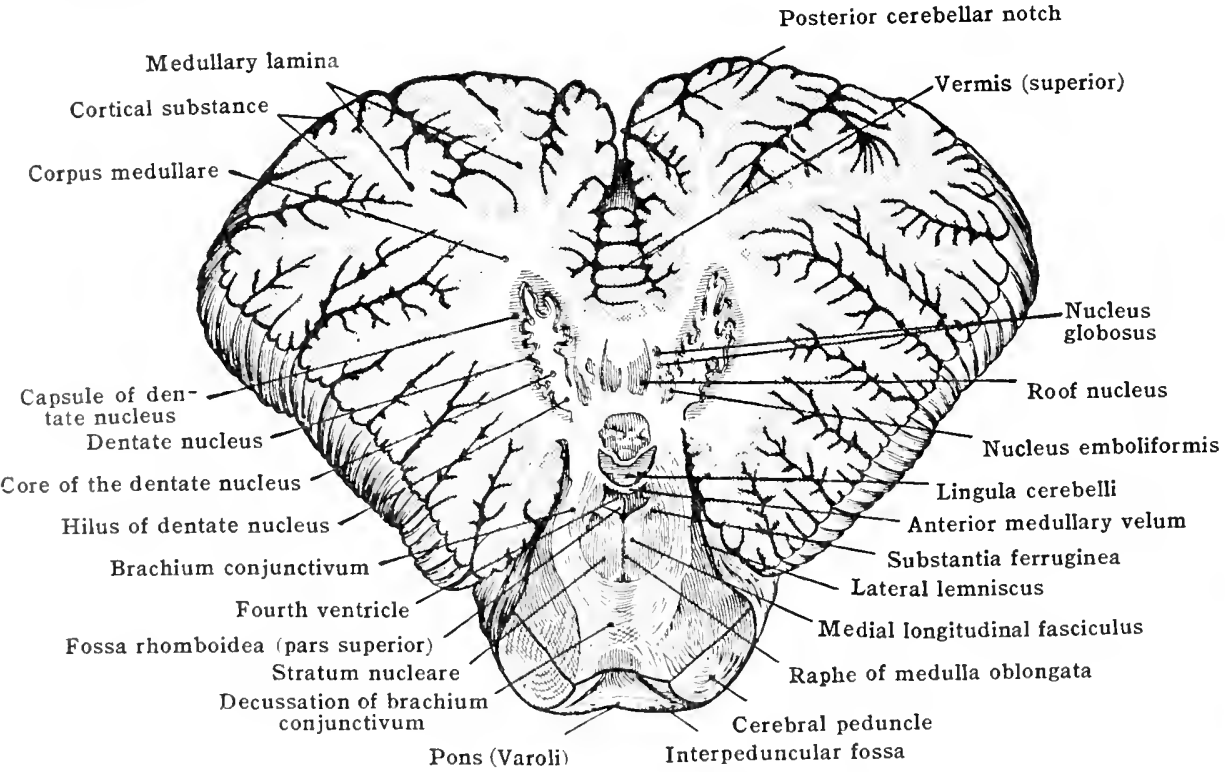

fourth ventricle, and so near the mid-line that both nuclei are in the white substance of the vermis. They are ovoid in shape, and the nucleus of one side receives ixones from the nucleus of the vestibular nerve chicfly of the opposite side, the derissation of these axones taking place in the vermis. Its cells are larger than those of the two first-mentioned unclei.

The peduncles of the cerebellum.-The perluncles consist of three pairs-the infrrior, midlll', and sirperior. The three perluncles of each side come together at the level of the lower borter of the pons, and the entering and emerging fibres of which they are composed berome continuous with the eentral core of white substanes of the cereobrilar hemispheres. (Fig. 631, 638, 639.)

'The restiform body of the merlullit oblongata is the inferior peduncle. It forms the lateral bemelary of the inferior port ion of the fourth ventricle, and upon ratehing the level of the pons tums sharply backward into the ecrebellum. In the region of the furn it is cureirelorl externally by fibres of the cochlear nerve. It rentains fitmes, loth assonding and descending, between the cercbellar cortex and

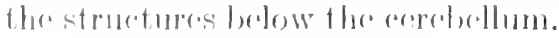

Its fiture include: (1) filmes from the spinal cord ineluding the dorsal spino-cerebellar

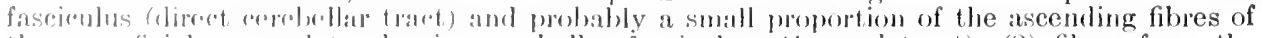
the superficial ventro-lateral spino-cerchellar fascioulus (Cowers' tract); (2) fibres from the 
olive of the same and opposite side of the medulla oblongata; (3) fibres from the nuclei of the funiculus gracilis and cuneatus of the same and opposite sides; (4) fibres to and from the olive of the opposite side; (5) fibres to the nuclei of the motor cranial nerves; (6) fibres descending to the ventral horn cells of the spinal cord. The ascending or afferent fibres of the spino-cerebellar and cerebello-olivary fasciculi are the principal components of the inferior peduncle; the existence of fibres (5) and (6) is not well established. Of these, the fibres of the direct cerebellar tract terminate in the cortex of the superior vermis of both sides of the mid-line, but, for the most part, in that of the same side. The olivary fibres end in the cortex of both the superior vermis and the adjacent cortex of the hemispheres, and some of them terminate in the nucleus dentatus.

The brachium pontis or the middle peduncle is the largest of the three cerebellar peduncles. In it the pons fibres pass slightly downward and into the cerebellar hemisphere, between the lips of the anterior part of the horizontal fissure, entering lateral to the inferior peduncle.

Fig. 638.- Transparency Drawing Showlyg the Origin, Course, and Connections of the Superior Cerebellar Peduncles (Brachia Conjenctia) in the Foriation op 'Stilling's Scissors.'

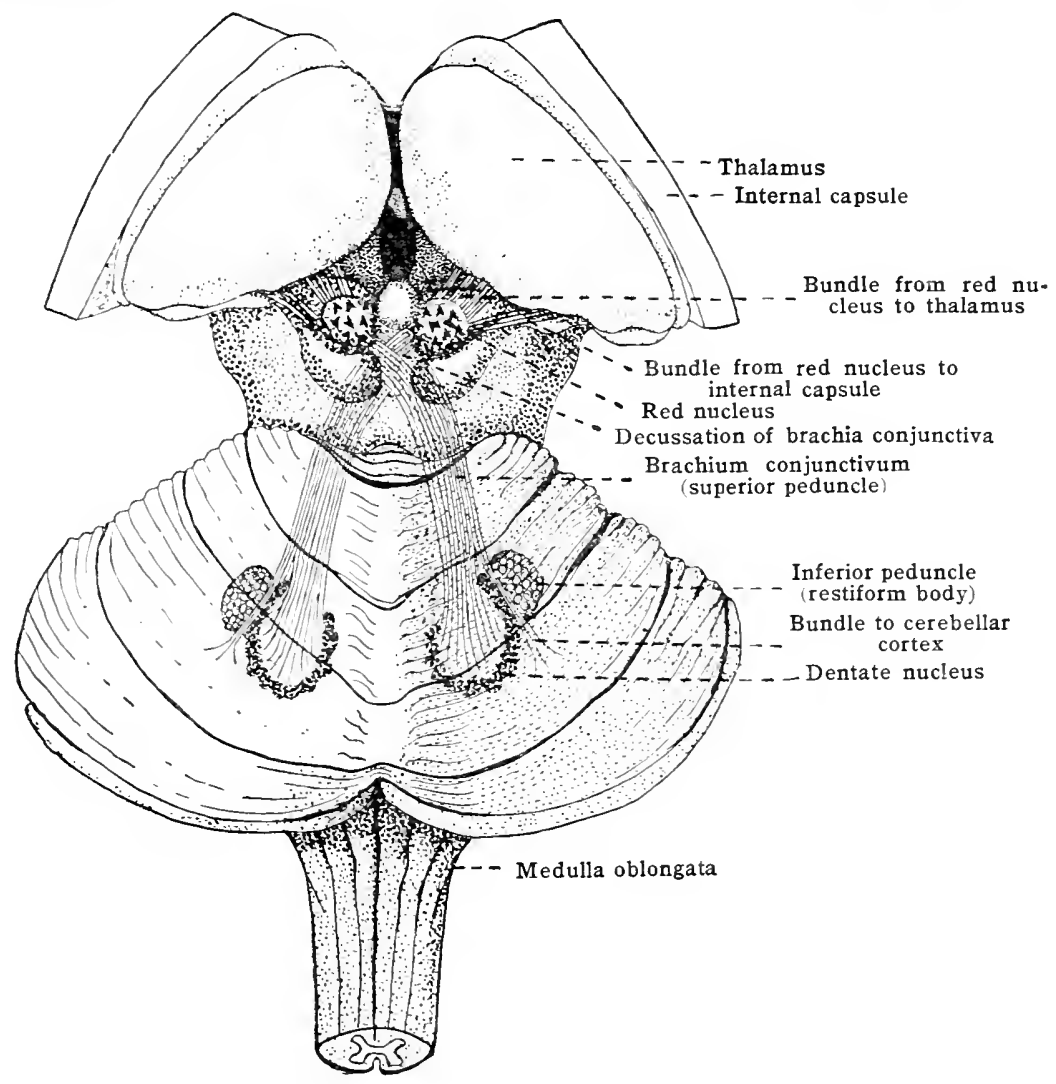

It consists of the transverse fibres of the pons, and within the cerebellum its fibres are distributed in two main groups - the upper transverse fibres of the pons apparently pass downward to radiate in the lower portion of the hemisphere, while the lower transverse fibres pass upward and medialward to radiate in the superior part of the hemisphere and vermis. For the most part the fibres of the middle peduncle mav be considered as commissural fibres, passing from one side of the cerebellum to the other. Each peduncle contains fibres coursing in opposite directions. Many of these fibres are interrupted in their course to the opposite side by cells scattered throughout the pons, nuclei of the pons, and, therefore, in each brachium pontis some of the fibres are processes of the cells of the cerebellum and course toward the opposite side, while others are processes of the cells of the pontine nuclei and course to the cerebellar hemisphere of the same side. Many cell-bodies of the nuclei of the pons whose axones terminate in the cerebellum receive impulses from fibres descending from the cerebral cortex of the opposite side-cortico-pontine fibres. Furthermore, there are evidences after degeneration that the brachium pontis also contains a few fibres from the cerebellum to the structures of the brainstem and spinal cord. 
The brachium conjunctivum or superior eerebellar peduncle emerges from the cerebellum on the medial side of the brachium pontis and also on the superior and medial side of the course of the restiform body. It forms the lateral boundary of the superior portion of the fourth ventricle and is the cerebello-cerebral peduncle. Its transverse section appears semilunar in shape, with the concave side next to the cavity of the ventricle. The medial border, which inclines toward the mid-line, is connected with that of the corresponding peduncle of the opposite side by the anterior medullary velum, which thus roofs over the superior part of the fourth ventricle. The lateral border is distinguished from the pons by an open furrow or lateral sulcus.

The superior cerebellar peduncles are almost entirely efferent pathways as to the cerebellum and form the chief connections between the cerebellum and the cerebrum. They arise almost wholly from the dentate nuclei. As they course forward they slightly converge and disappear under the inferior quadrigeminate bodies. Here, in the tegmentum of the mesencephalon, they undergo an almost total decussation, and then the majority of the fibres of each peduncle, having thus crossed the mid-line, terminate in the red nucleus of the opposite side. The red, nucleus lies in the tegmentum of the mesencephalon, below the superior quadrigeminate bodies, and therefore quite close to the decussation. The cells of the red nucleus, about which the fibres of the peduncle terminate, in their turn send processes (axones) into (1) the rubro-spinal tract of the spinal cord and (2) into the prosencephalon, most of which latter terminate in the thalamus whose cell-bodies give fibres to the cerebral cortex by way of the internal capsule; but some pass from the red nucleus under the thalamus to join the internal capsule.

In addition to the fibres having the origin and course described above, and which constitute the greater mass of the superior cerebellar peduncle, each peduncle is said to contain fibres which-(1) arise in the cerebellar cortex of the same and opposite sides of the mid-line, instead of from the dentate nucleus, and which join the peduncle at the side of the dentate nucleus, between it and the restiform body; (2) fibres which do not cross the mid-line in the decussation, but terminate in the red nucleus of the same side; (3) some fibres are not interrupted in the red nucleus, but pass directly into the thalamus; (4) a small proportion of fibres afferent as to the cerebellum, which arise in the structures of the cerebrum and pass in to the cerebellum; and (5) the greater part, if not all, of the ascending fibres of the superficial ventro-lateral spinocerebellar fasciculus (Gowers' tract) of the spinal cord. The latter, instead of entering the cerebellum by way of the restiform body, are deflected in the upper medulla and pass in the lateral tegmentum of the pons to the anterior medullary velum, where they turn backward to enter the cerebellum in its superior peduncle and pass to its cortex, probably from the lateral side of the dentate nucleus (see fig. 656).

The anatomy of the fourth ventricle.-The fourth ventricle is rhomboidal in shape, being considerably widened at the level of the brachia pontis and pointed at each end. Its floor consists of a slight depression in the brain-stem, the fossa rhomboidea, and corresponds to the floor of the central canal. Its pointed inferior end, the calamus scriptorius, is direetly continuous with the central canal, and its narrowed superior end is continued into the aqueductus cerebri (Sylvii) of the mesencephalon, which is nothing more than a resumption of the tubular form of the canal.

The entire cavity of the ventricle is lined with an cpithelium which is continuous with the epithelium, or epentyma, of the central canal below and the aqueduct above. 'The entire ventricle involves the isthmus of the rhombencephalon, the metencephalon and a portion of the medulla oblongata. It is divided for study into an inferior, an intermediate and a superior part.

The roof of the superior portion of the fourth ventricle is nervous, eonsisting of a thin lamina of white substance, the anterior (superior) medullary velum, thickened at the sides by the brachia conjunctiva. At its extreme mesencephalic end (in the isthmus of the rhombercephalon) the anterior medullary velum is slightly thickened by a continuation of the white substanee of the inferior quadrigeminate bodies, forming the frenulum veli. The inferior portion of the velum is continuous with the white substance of the cerebellum, and is eovered by the lingula corebelli, an extension of the eortical substance of the superior vermis (fig. 631).

The roof of the intermediate portion of the fourth ventricle is formed by the cerebellum proper, the vermis and the mesial portions of the hemispheres. The nervous portion of the roof terminates with the posterior (inferior) medullary velum, a thin, narrow band of white substance which is the continuation of the pedinncles of the floceular lobess, and which connects them at the mid-line with the nodule of the inferior vermis.

The ron of the inferiom protiom of the fourth ventricle is non-nervous. It is the chorioid tela of the fourth ventriele, a semilunar lamina consisting of the epithelial lining of the ventricle, reinforecol by a continuation of the connective tissue of the pia mater and the arliacent portion of the arachoid. Along the line of its 
attachment to the surface of the medulla it is thickened, and in sections this portion bears the name ligula (tonia ventriculi quarti). The thickest portion spans the tip of the calamus scriptorius and is termed the obex. The width of the rentricular cavity is extended laterally from its widest part into the lateral recesses: narrow pockets on each side and around the upper parts of the restiform bodies. In the mid-line of the lower part of the chorioid tela there is a more or less wellmarked opening, the foramen of Magendie (medial aperture of the fourth ventricle), which is a lymph-channel connecting the cavity of the ventricle with the subarachnoid space. There is a similar opening from each lateral recess (lateral apertures of Key and Retzius).

The chorioid plexuses of the fourth ventricle consist of highly vascular, lobular, villus-like processes of the ventricular lining (and pia-mater) of the chorioid tela. They are reddish in the fresh specimen, and the epithelial lining of the ventricle is closely adapted to the unevennesses of their surfaces. From below they run as

Fig. 639.-Diagram of the Roof and Lateral Bodndaries of the Fourth Ventricle. The trochlear nerve should be shown emerging from the lateral boundary of the frenulum veli.

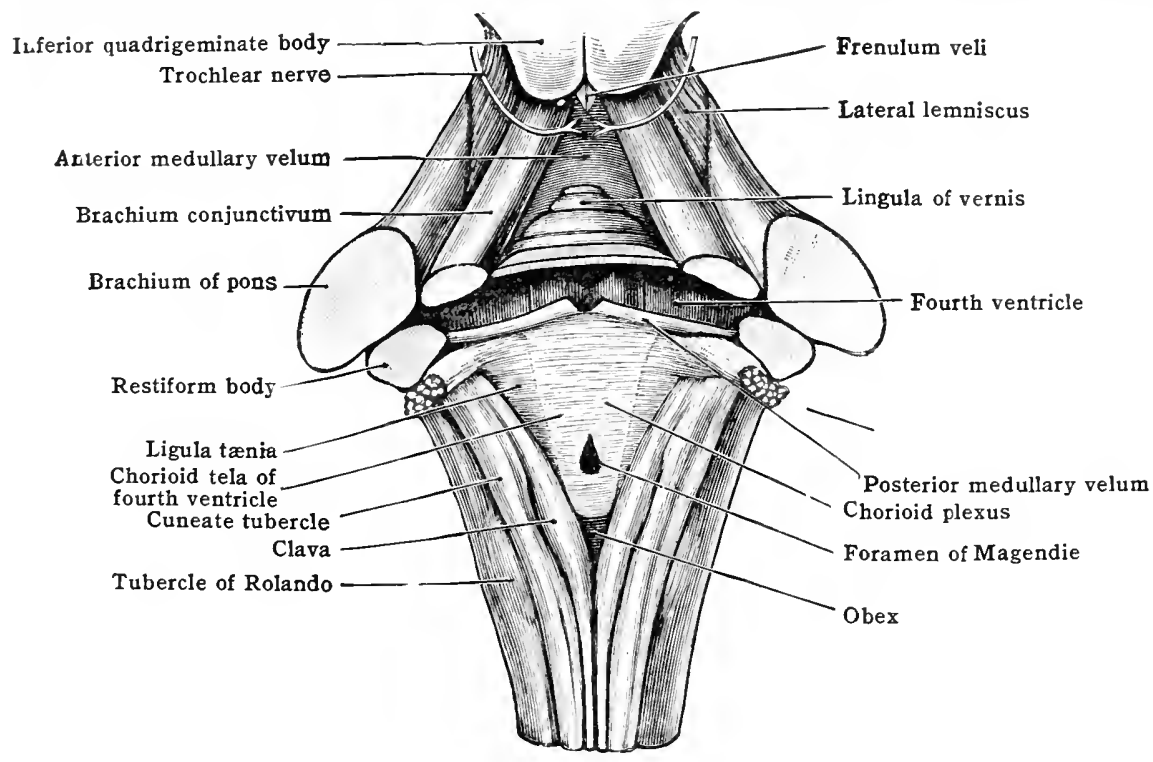

two parallel masses on either side of the mid-line, which become united above, and then are separated again into two lateral processes which bend at right angles and project into the lateral recesses. Portions frequently protrude through the three openings of the ventricle into the subarachnoid space.

The floor of the fourth ventricle [fossa rhomboidea] (fig. 640).-This is thrown into eminences and depressions indicative of the internal structures of the brain-stem subjacent to it. Its inferior portion is the dorsal surface of the upper portion of the medulla oblongata; its intermediate portion is the dorsal surface of the pons region, while its superior portion belongs to the isthmus of the rhombencephalon. Its triangular lower extremity terminates as the opening of the central canal of the spinal cord. This portion is deepened at the obex and shows furrows which point downward and converge medialward, giving the appearance known as the calamus scriptorius. The mid-line of the floor is sharply distinguished by the well-marked median sulcus, which becomes shallower above than below. In the tip of the calamus scriptorius, immediately anterior to the obex, the median sulcus deepens to become continuous into the central canal. This terminal depression is known as the ventricle of Arantius. Throughout the length of the floor on either side of the median sulcus is a continuous ridge, the medial eminence, which is bounded laterally by the limiting sulcus. Underlying the floor of the ventricle is a layer of grey substance of varying thickness, which is continuous with that surrounding the central canal of the cord. The medial eminence is subdivided into portions of unequal width and elevation, and the limiting sulcus accordingly shows foveæ of different depths. 
Beginning at the calamus scriptorius, the following areas of the floor of the fourth ventricle are usually distinguished (fig. 640):-

The area postrema of Retzius is a superficial vascular structure bounded inferiorly by the twnia and overlying the terminal portion of the nucleus of the fasciculus gracilis (clava) and a portion of the nucleus of termination of the vagus nerve. The funiculus separans, a short oblique fold of the floor, composed chiefly of neuroglia, separates the area postrema from the ala cinerea (trigonum ragi), which is an oblique, grey-coloured, wing-shaped eminence indicating the middle third of the nucleus of termination (recipient nucleus) of the vagus and glossopharyngeal nerves. At the superior extremity of the ala cinerea is a well-marked triangular depression of the limiting sulcus known as the inferior fovea. Mesial to and extending above the ala cinerea is a narrow triangular eminence lying close to the median sulcus, which represents the nucleus of origin of the hypoglossal nerve, the hypoglossal eminence [trigonum n. hypoglossi]. The lateral field of this eminence shows small oblique rugæ, giving it a "feathery" appearance, the area plumiformis of Retzius. The nucleus intercalatus of Van Gehuchten is a wedgeshaped portion very slightly demarcated from the hypoglossal eminence, and intercalated between it and the inferior fovea. This nucleus is considered by some observers as an inferior

Fig. 610.-Dorsal Surface of the Brain-stem Showing the Anatomy of the Floor of the Fourth Ventricle. (Modified from Spalteholz.)

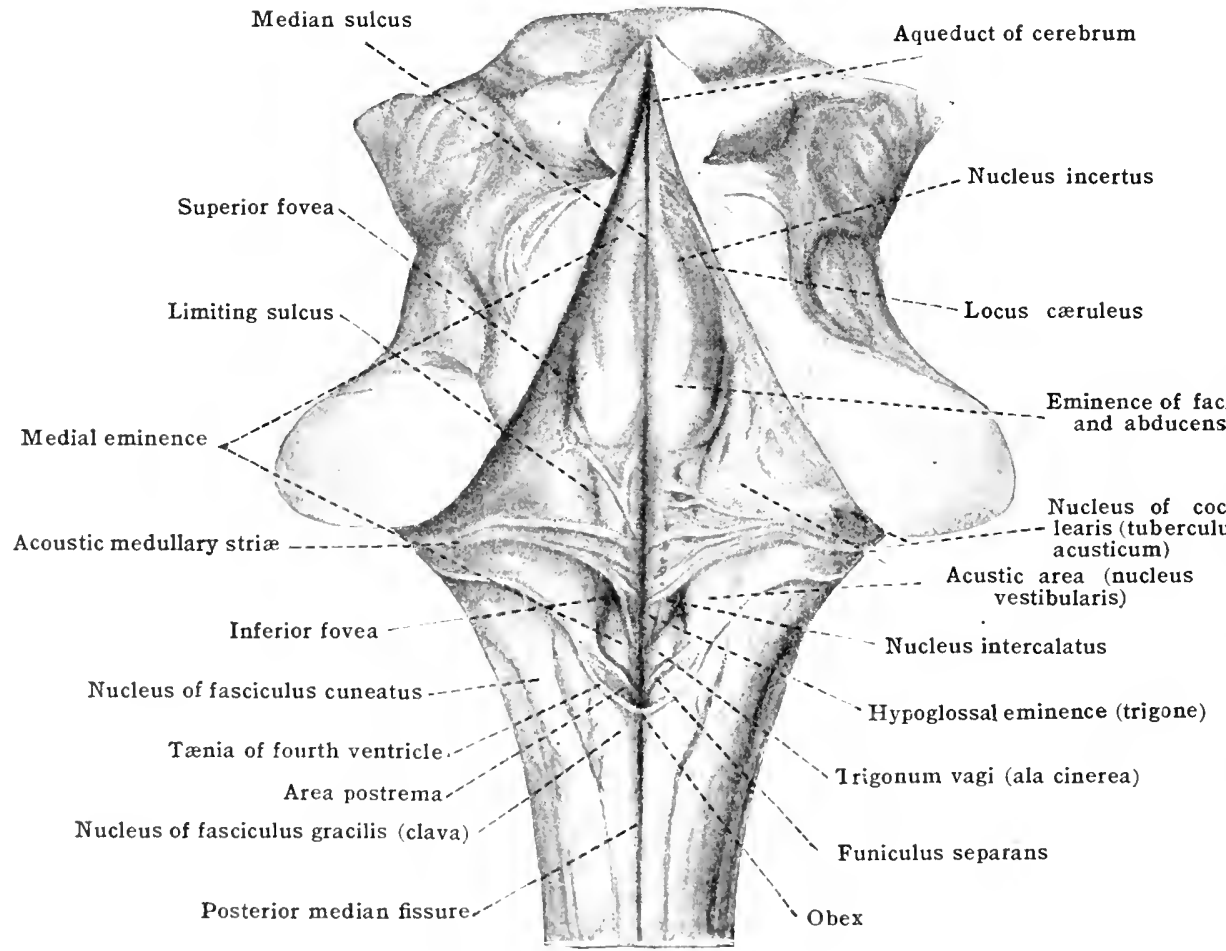

medial extension of the nuclens of termination of the vestibular nerve (area acustica), but Streeter, who has make a fetailed sturly of the floor of the fourth ventriele by means of serial sections, doubts that it is a part of this nucleus. It is much more probable that it supplies viscoral cofierent fibres to the vagus and is thus a continuation of the dorsal efferent nucleus of the vagus.

Siuperior to the inferior fovea, and crossing each half of the lloor of the fourth ventricle, are the acoustic strix. Therse are bumbles of axomes arising in the dorsal nucle of termination of the rochlear or atulitory nerve, which an situated in the lateral periphery of each restiform body. The bundles conses aromind the dorsal periphery of the upper portion of the restiform borly, then across catch hatf of the floor of the ventride to the nedian suleus, in which they sudilenty furn ventrally info the substine of the medulla oblongata, and in domg so they cross

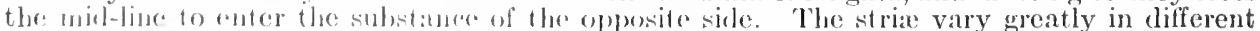

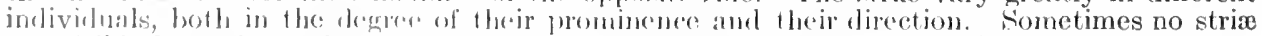
are visible from the surfar. Frefuntly a humble mat be disecrued which courses obliquely upward and lateralwarl from the neolian suldus to disappear in the floor further away from the mid-line and again, a humlle mat depart fom the transverse course before reaching the

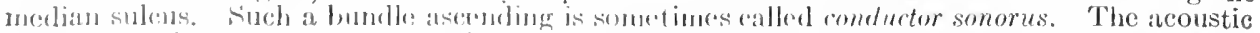
stria coss the acoustic area. This is the Hatfound clevation which ocempies the whole lateral portion of the intermerliatr portion of the lloos of the ventricle, lateral to the limiting suleus, and extends into the inforior poution lateral lo lhe inforion foveat. Jt represents the subjacent 
nucleus of termination of the vestibular nerve. The dorsal and ventral nuclei of the cochlear nerve (tuberculum acusticum) are indicated by the ventro-lateral fullness in the contour of the restiform body. In many of the mammals they produce a well-marked protuberance.

In its superior portion the medial eminence occupies the greater part of the floor of the fourth ventricle, and in the upper part of the intermediate portion of the floor it presents a broader, well-marked, elongated elevation, the eminence of the facial and abducens or the colliculus facialis. This represents the mesially placed nucleus of origin of the abducens and the genu of the root of the facial nerve, which root courses around and above the nucleus of the abducens. The nucleus of the facial is too deeply situated to produce an eminence. Lateral to this eminence is a depression of the limiting sulcus, which overlies the mesial part of the region of the larger portion of the nucleus of termination of the trigeminus, and is the fovea trigemini or superior fovea. The strip of the floor above the superior fovea and lateral to the inedial eminence often appears greyish blue or dark brown, owing to pigmented cells subjacent to it, and is known as the locus cæruleus. It also represents a portion of the nucleus of the trigeminus. The most superior portion of the medial eminence becomes narrow and lies close to the mid-line. The function of the underlying grey substance producing it is uncertain, and for this reason Streeter has named the elevation nucleus incertus, noting that by position it is closely related to the upper portion of the nucleus of the trigeminus.

\section{Internal Structure of the Medulla Oblongata and Pons}

The finer detail of the internal structure lies within the scope of microscopic rather than of gross anatomy. However, the significance and relations of certain of the more important and larger of the internal structures of the medulla and pons as observed in sections may be considered.

The entire brain-stem may be regarded as an upward continuation of the spinal cord, to which structures are added giving each part its peculiar character and conformation, and in which the structures characteristic of the spinal cord are modified in varying degrees.

The pyramids, the great descending or motor cerebro-spinal fasciculi, are directly continuous into the pyramidal fasciculi of the spinal cord. They form the extreme ventro-medial portion of the medulla, and from the fact that they contribute numerous fibres to the efferent nuclei (nuclei of origin) of the cranial nerves and to other portions of the grey substance of the brain-stem, they decrease appreciably in bulk in descending toward the spinal cord. Most of the fibres contributed to the medulla, as well as to other divisions of the brain-stem, decussate as they leave the pyramids, and terminate in the grey substance of the opposite side. However, the chief decussation of the pyramids occurs in the lower end of the medulla. Here usually about three-fourths of the fibres then comprising the pyramids cross the midline to form the lateral cerebro-spinal fasciculus (crossed pyramidal tract) of the spinal cord immediately below. The remaining fourth, comprising the more lateral fibres or those furthest away from the mid-line, continues uncrossed into the spinal cord as the ventral cerebro-spinal fasciculus or direct pyramidal tract. The majority of the latter fibres decussate gradually in the commissural bundle and in the ventral white commissure of the cord as they approach the levels of their termination. In practically all vertebrates except man and the apes there are no ventral pyramidal fasciculi, the decussation in the medulla being a total one. In man, the proportion of fibres crossing in the chief decussation varies. Cases have been noted in which apparently the entire pyramids decussate at this level. In other cases the direct or ventral pyramidal tract may be much larger than usual, at the expense of the lateral. The decussation usually appears to be symmetrical and it occurs so suddenly that the fibres, in coursing from the ventral to the lateral positions, detach the tips of the ventral horns of the spinal cord from the remainder of the grey figure, and these appear as isolated, irregularly shaped masses of grey substance in transverse sections of the medulla. From this level upward the outline of the grey figure of the cord is lost, and the cell-columns of the ventral horns occur in more or less detached groups as the motor nuclei of the cranial nerves.

The origin and decussation of the lemnisci (fillet) begins immediately above the decussation. of the pyramids, and here the arrangements characteristic of the spinal cord are further modified. The dorsal portion of the grey figure of the cord is manifest up to this level, but here, after a considerable increase in its thickness, the grey commissure gives rise to two thick dorsal outgrowths on each side of the mid-line. These dorsal projections of grey substance comprise the nuclei of termination (relays) of the chief ascending or sensory spino-cerebral fasciculi of the spinal cord. The nucleus of the fasciculus gracilis (nucleus of Goll's column) arises a little before the nucleus of the fasciculus cuneatus (nucleus of Burdach's column). The former extends slightly downward from its point of origin, so that its inferior extremity is included in sections through the decussation of the pyramids (fig. 611). It produces a slight bulbous enlargement (the clana) of the end of the fumculus gracilis, while the nucleus of the fasciculus cineatus corresponds to the cuncate tubercle of the external contour of the medulla (figs. 632, 640). From the cells of these nuclei arise the lemniscus-the cephalic continuation of the spino-cerebral pathway which conveys the general bodily sensations to the cerebrum. In passing out of the nuclei the fibres of the lemniscus course in a ventro-medial direction. Curving around the region of the central canal, they contribute largely to the internal arcuate fibres, then, sweeping across the mid-line, they convert it into the raphe, and immediately after crossing (decussating) they turn cephalad and collect to form the bundle known as the lemniscus.

In the medulla, the lemnisci are two thin bands of fibres spread vertically on each side of the raphe, with their lower or ventral edges thicker than their dorsal edges. In their course toward the cerebrum they increase in bulk, owing chiefly to fibres being added to them from the nuclei of termination of the afferent roots of the cranial nerves, which fibres likewise cross the mid-line as internal arcuate fibres to join the lemniscus of the opposite side. In passing 
through the pons, the lemnisei gradually become spread horizontally, and beyond the pons their then more lateral portions are further displaced and eome to eourse in the lateral borders of the isthmus rhombeneephali and meseneephalon, while the medial portions remain nearer the mid-line. This lateral sprearling of each lemniseus produces the lateral lemniscus and the medial lemniscus, distinguished in transverse seetions of the superior pons and mesencephalic

Fig. 641.-Transterse Section of Medulla Oblongata at the Level of the Decussation oF THE Pyramids.

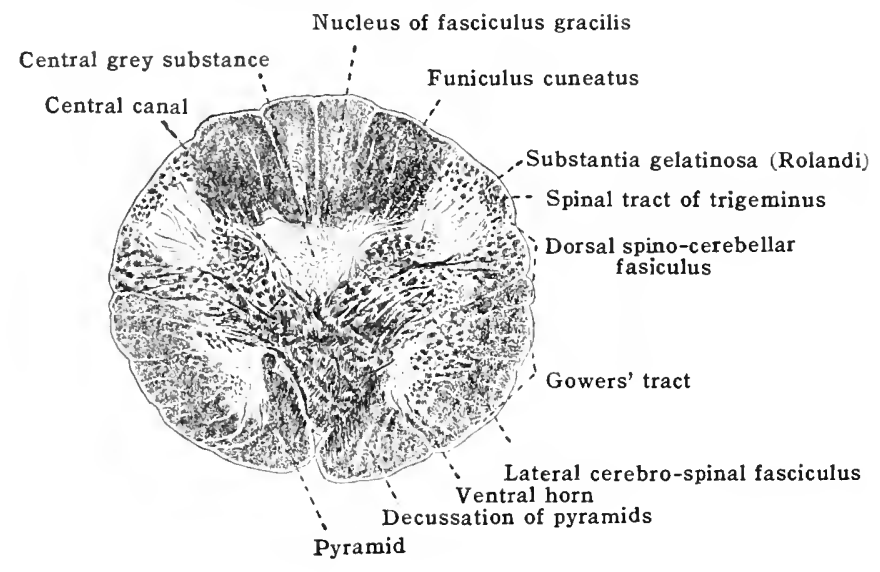

regions of the brain stem (fig. 660). The lateral lemniscus is contributed very largely by the eell-bodies of the nuclei of termination of the cochlear nerve of the opposite side.

The reticular formation of the medulla and pons region is considerably more abundant than in the spinal cord. As in the spinal cord, it consists of grey substance through which nerve-fibres, singly and in small bundles, eourse in all direetions, and more sparsely than in other regions. In the medulla it is traversed by the internal areuate fibres. It may be con-

Fig. 642.-Transterse Section of Medulla Oblongata at level of the Decussation of THE LENINISCI.

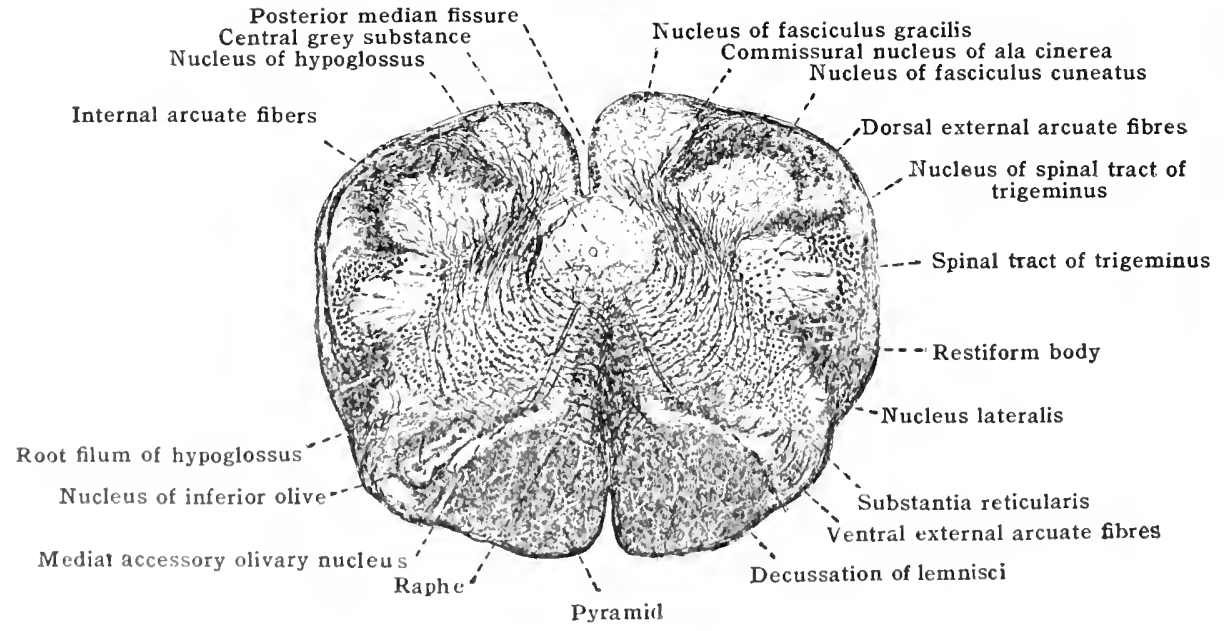

silleren an enlargerl contimution of the midnle portion of the grey column of the cord, dispersed by munerous fibres, giving it the reticulated appearance which suggests its name. Its numerous nervo-cells belong, for the most part, to the association and commissural systems of the brain stem, and, therefore, the filmes arising in it correspont latery to the fascienli proprii of the spinal corr. As in the corrl, most of the filmes are of short comse, serving to assoeiate different portions of the sane level and aljancrit. levels with each other. Tlhose of long course show a

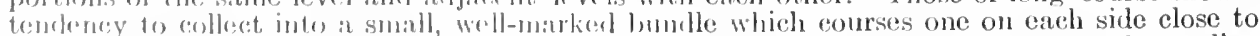

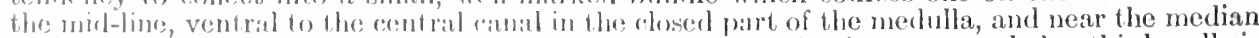

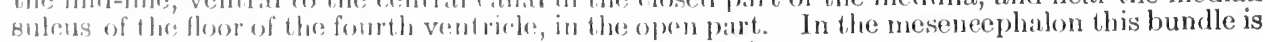

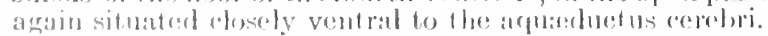


This bundle is known as the medial longitudinal fasciculus (posterior longitudinal bundle). It corresponds more nearly to the ventral fasciculus proprius of the spinal cord than to others of the fasciculi proprii. In the medulla it appears as the dorsal edge of the lemniscus, but in the shifting of the position of the lemniscus in the pous region, it retains itsmedial position and thus becomes isolated. By position it is especially adapted for the association of the nuclei of the cranial nerves. Evidence has been found that those fibres which arise in the corpora quadrigemina and descend the spinal cord in its sulco-marginal or ventral mesencephalo-spinal fasciculus, pass through the medulla in the medial longitudinal fasciculus. The nuclei of termination of the vestibular nerve are said also to contribute many fibres to it.

The inferior olivary nucleus is an added structure in the medulla oblongata, i. e., it has no homologue in the spinal cord. The two of them occupy the olivary prominences, the olives of the exterior, and constitute the most conspicuous and striking isolated masses of gley substance in sections of the medulla. They appear as crenated lamine of grey substance folded so as to encup a dense mass of white substance, and in actual shape the entire nucleus has the form of an irregular corrugated cup with the opening or hilus on the side toward the midline. The mass is so crumpled that the diameter of the hilus is appreciably less than the length of the nucleus, and thus transverse sections of either extremity of it appear as closed capsules.

Fig. 643.-Traxsverse Section of Medulla Obloxgata Throdgh Nuclei of Tagus axd Hrpoglosses and Throdgh the Midde of the Olives.

Medial longitudinal fasciculus

Chorioid tela of fourth ventricle Nucleus of ala cinerea (trigonum vagi

Nucleus of hypoglossus $\quad ; \quad ;$ Dorsal efferent nucleus of vagus

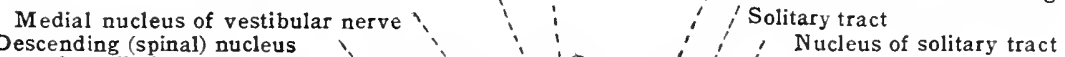
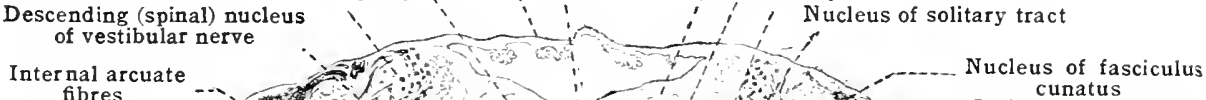
fibres

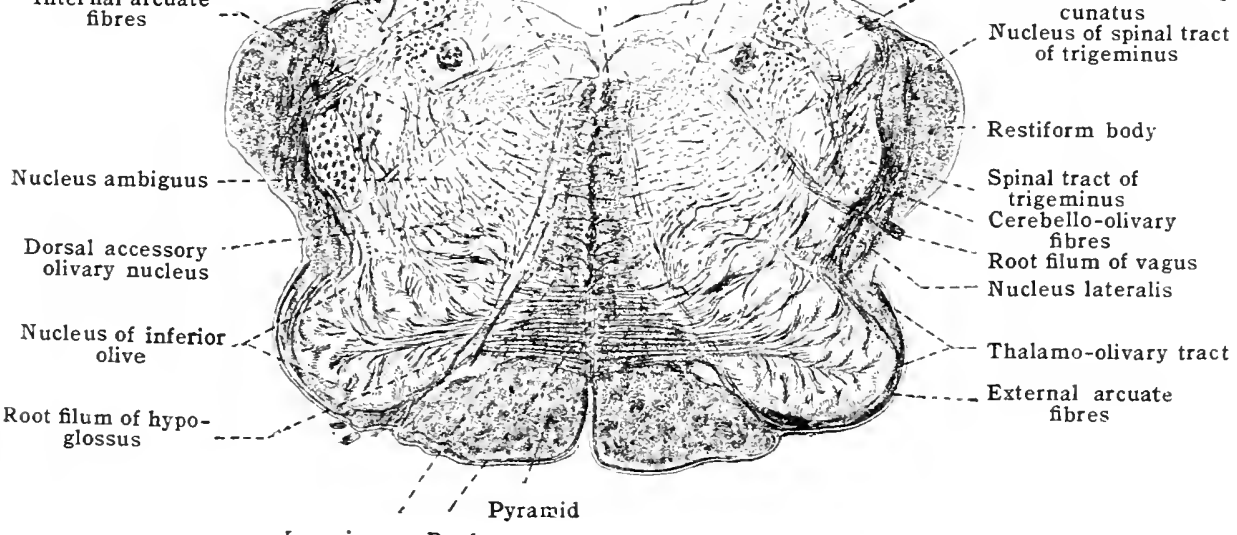

Lemniscus Raphe

There are several small detached portions of the olivary nucleus known as the accessory olivary nuclei. These are named according to their position with reference to the chief portion or olive proper. They are plates less corrugated than the chief nucleus, and appear rod-like in sections. The largest is the dorsal accessory olivary nucleus. The medial accessory olivary nucleus is widest at its inferior end, which extends a little below the inferior extremity of the chief nucleus. The lateral accessory olivary nucleus is the smallest. In serial sections the accessory nuclei are found to be plates of grey substance usually continuous with one another.

The olivary nuclei are mainly cerebellar connections. By both ascending and descending fibres each cerebellar hemisphere is connected with the olivary nucleus of the same and opposite sides. Serial sections of a human brain with congenital absence of one cerebellir hemisphere, described by Strong, show that the chief comnection of a hemisphere is with the olive of the opposite-side. These fibres necessarily pass between the cerebellum and the olives by may of the restiform body, and, in so doing, form an obliquely coursing bundle in the lateral borler of the medulla known as the cerebello-olivary fibres (fig, 613). The olivary nuclei also comprise a secondary relay between the spinal cord and the cerebellum by way of the spino-olivary fasciculus of the cervical cord, and it will be noted that they receive fibres from the thalami. The latter fibres, the thalamo-olivary tract, approach the olive at its lateral periphery, while upward through the brain-stem the tract courses in a more medial position. This tract comprises one of the cerebro-cerebellar paths. Arising in the thatamus and terminating in the olive, its impulses reach the opposite cerebellar hemisphere by way of the cerebello-olivary fibres.

The arcuate fibres are referred to as internal and external, according as they course dorsal or ventral to the inferior olivary nucleus.

The internal arcuate fibres comprise fibres destined for both the cerebellum and cerebrum, and also for the association of the tegmental grey substance of the two sides in which they course. Certain of the fibres passing between one restiform body (cerebellar hemisplrere) and the olive of the opposite side course internal to the olive of the sume side, and thus form the ventral portion of the internal arcuate fibres. As noted above, the internal arcuate fibres consist in 
greatest part of fibres being contributed to the lemnisci, arising from the eells of the nucleus of the fasciculus gracilis and fasciculus cuneatus and sweeping downward and decussating to form the lemniseus of the opposite side. However, all the fibres arising in these nuelei do not enter the lemniscus. A few of them cross the mid-line with the internal arcuates, but pass on to enter the restiform body (cerebellar hemisphere) of the opposite side. Some of these course ventrally and, upon approaching the olive of the opposite side, are deflected around the ventral side of both the olive and the pyramid, and thus pass to the restiform body as external arcuate fibres also. Certain of the internal arcuate fibres arise from the cells of the nuclei of termination of the cranial nerves and from small cells situated in the grey substance of the reticular formation. These, in crossing the mid-line, correspond to the white commissures of the spinal cord. Some of them terminate in the medulla; others, especially those from the nuclei of termination of the cranial nerves, join the lemniscus and pass toward the cerebrum; others reach the cerebellar hemisphere of the opposite side.

The external arcuate fibres, in addition to those mentioned above, comprise certain fibres which arise in the nuclei of the fasciculus gracilis and euneatus and pursue a dorso-lateral course to enter the restiform body (cerebellar hemisphere) of the same side. These form the dorsal segment of the external areuates. The greater mass of the external arcuates are cerebelloolivary fibres. Certain of those passing from one olive to the restiform body of the opposite side are defleeted at the raphe, and course on the ventral side of both the other olive and the pyramid in order to reach the opposite cerebello-olivary bundle. Likewise, those passing from the restiform body to the opposite olive are deflected by the olive of the same side and pursue a similar course to the raphe. While out of the hilus of each olive streams a dense mass of white substanee, yet many of the fibres concerned with the olive pieree its walls from all sides.

Many of the external arcuate fibres are said to be interrupted in the nucleus arcuatus. This is a thin sheet of grey substance, variabie in amount, which lies on the ventral aspect of

Fig. 641.-Reconstruction of the Inferior Olivary Nucleus, Dorso-lateral Surface. (After Sabin.)

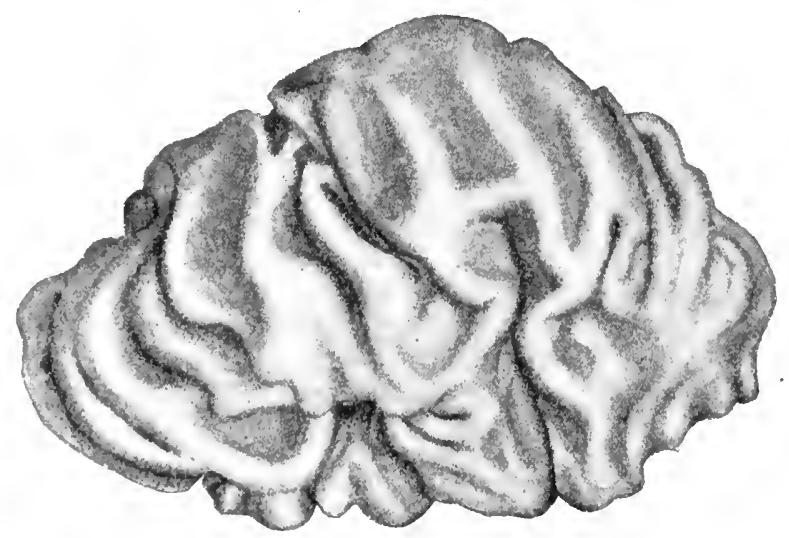

each pyramid, and, though it decreases inferiorly, it may be evident down to the decussation of the pyramids. The nucleus receives its name from the fact that its larger portion is interpolated in the course of the external arcuates. It is continuous anteriorly with the grey substance or nuclei of the pons.

The external arcuate fibres of longer course, like the olives with which they are largely concerned, have no homologues in the spinal cord.

The certral canal of the closed portion of the medulla is surrounded by a greater amount of central grey substance, substantia grisea centralis, than is the canal in the spinal cord. This is largely gelatinous substance, the central gelalinous substance, and the nerve-fibres in coursing through the grey sulstance are partially deflected by it, leaving it as a cylindrical, more evident area of grey substance thin in other regions. In the open portion of the medulla the central grey substance naturally forms a more transparent lamina just under the floor of the fourth ventricle. In the mesencephalon it again surrounds the reformed eanal or aqueduct of the cerelinum.

The central connections of the cranial nerves are most easily homologised with spinal-cord structures. Functionally the cranial nerves are of three varietires:- (1) thremotor or offerent norves, comprising the oculomotor, the trochlear, masticator, the afullorns, thr farcial, the spinal accessory, and the hypoglossus; (2) thro sensory or afforont, comprising the olfactory, the optic, the trigeminus, the vestibular, and the cochlrar and (3) the mixed, motor and sensory nerves, (omprising the glosso-patiatior, the glosso-pharyngeal, and the vagus. The nuclei of origin of 1 hremotor or afforent ranial nerves and the efferent portions of the mixel norves are diresty antimuous with the aell columns of the ventral horms of the sponal arol, while thr amorging root filaments and roots of these nerves eorrespond to the voutral roots of the spinal nerves. The nuclei of ter- 
mination of the afferent or sensory cranial nerves and of the sensory portions of the mixed nerves correspond directly to the nuclei of the fasciculus gracilis and fasciculus cuneatus, and to the cell-bodies of association and commissural neurones of the medulla and cord and, functionally, are merely anterior continuations of these.

The nuclei of the efferent or motor cranial nerves lie in two parallel lines, one near the mid-line and the other more laterally placed. The nuclei giving origin to the oculomotor, the trochlear, the abducens, and the hypoglossus are near the mid-line, and correspond to the ventro-medial and dorso-medial cell groups of the ventral horns of the spinal cord; the nuclei of origin of the masticator (motor

Figs. 645 and 646.-Diagrams showing the Composition of the Cerebellar Portions of the Internal and External Arcuate Fibres.

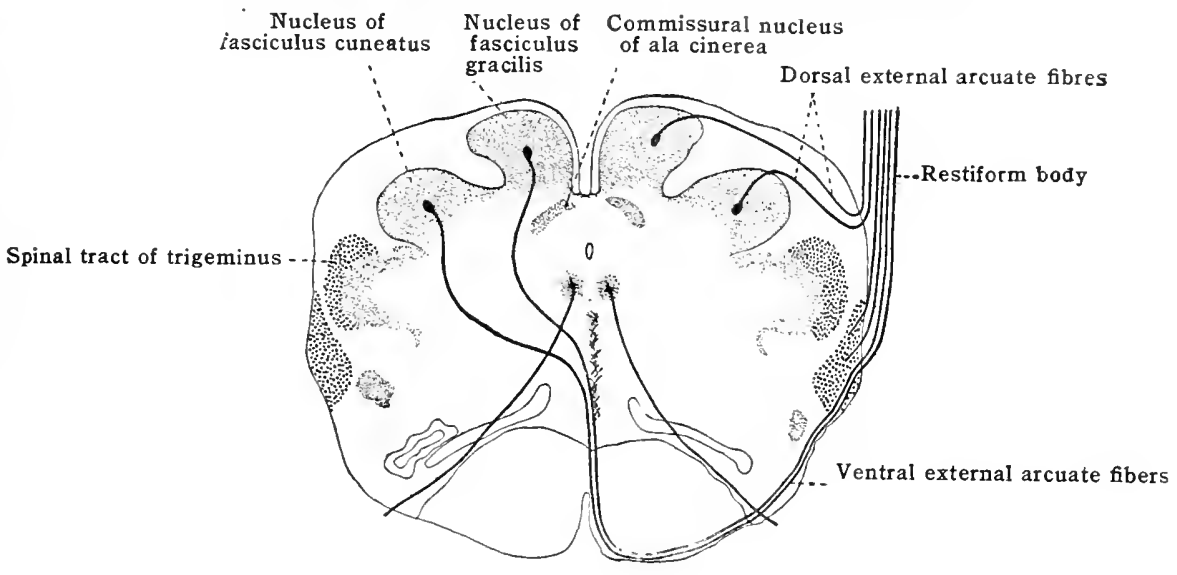

Nucleus of tractus solitarius

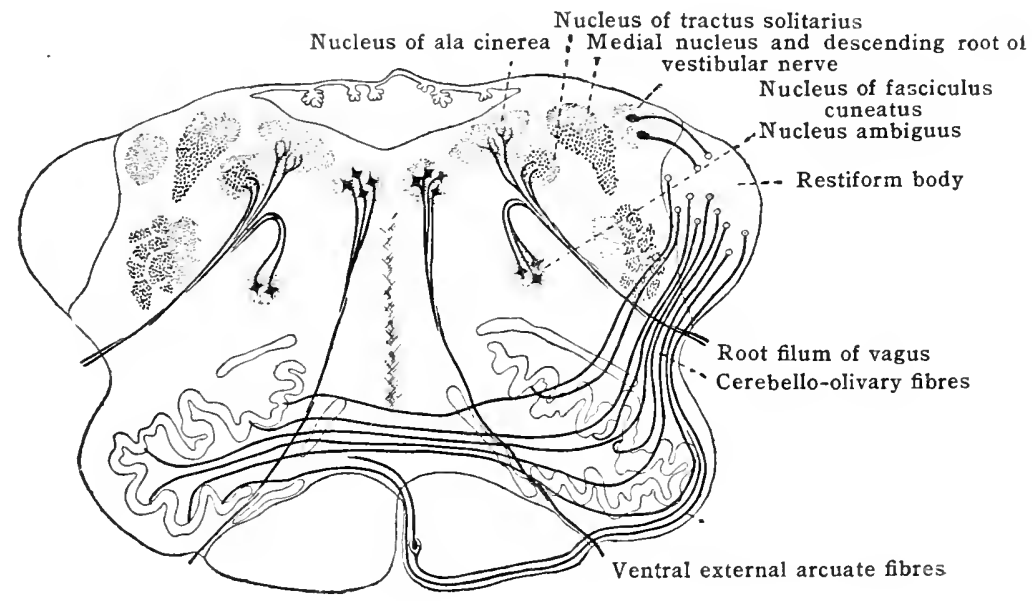

root of the trigeminus) of the facial, and the nucleus ambiguus giving origin to the motor portions of the glosso-pharyngeal and vagus nerves, together with the nucleus of the spinal accessory, correspond to the ventro-lateral and dorso-lateral cell-groups of the ventral horns of the spinal cord. The nerve-roots haring medial nuclei of origin are those which make their exit from the brain-stem along the more medial superficial line, while those having the more lateral nuclei comprise the more lateral line of roots apparent on the surface of the stem. Some of the efferent fibres of the vagus, supposedly visceral efferent, arise from a small nucleus dorso-medial to the nucleus ambiguus, the dorsal efferent nucleus of the vagus. The first two pairs of cranial nerves, the olfactory and optic, are attached to the 
prosencephalon. These are purely sensory, and make their entrance near the mid-line of the brain, both having superficially placed nuclei of termination. Of the other nerves, all having sensory or afferent functions enter the brain along the lateral or more dorsal line, and the ganglia giving origin to their afferent axones correspond directly to the spinal ganglia of the dorsal or afferent roots of the spinal nerves.

Commissural and associational neurones are much more numerous in the brain-stem than in the spinal cord. Their axones serve to connect the structures on the two sides of the mid-line and to associate the different levels of the same sicle. Just as in the spinal cord, those of longer course correspond to the fasciculi proprii. Many of their axones descend into the spinal cortl.

Of the fifteen pairs of cranial nerves, eleven pairs are attached to the medulla oblongata and pons, viz., the trigeminus, the masticator, abducens, facial, glosso-palatine, vestibular, cochlear, glosso-pharyngeal, vagus,. spinal accessory, and hypoglossus.

The hypoglossus, the motor nerve of the tongue, has its nueleus of origin beginning in the lower portion of the floor of the fourth ventricle at the level of the acustic striæ. It is a long nucleus, lying close to the mid-line and just under the floor of the ventricle (hypoglossal eminence) and extending down to the region of the funieulus separans. Here it curves ventrally to a slight degree, and below the obex assumes a position ventro-lateral to the central canal, and thus extends a short distance below the level of the inferior tip of the olive. The nerve arises as a series of rootlets which traverse the entire thickness of the medulla (fig. 643), to emerge in line in the furrow between the olive and the pyramid and fuse to form the trunk of the nerve. The lowermost of the rootlets usually cmerge below the olive. The nucleus reeeives impulses-(1) from the cerebrum by way of divergent fibres from the pyramid of the opposite side (voluntary); (2) impulses brought in by the sensory fibres of the cranial nerves (reflex); and (3) by axones from other levels of the medulla (associational). None of its axones are supposed to decussate, though numerous commissural fibres are known to pass between the nuclei of the two sides,

The spinal accessory is likewise a purely motor nerve, and has a laterally placed, long, and much attenuated nucleus of origin. Above, its nucleus is in line with and practically continuous with the nueleus giving motor fibres to the vagus and glosso-pharyngeus (nucleus ambiguus). Below, it consists of the lateral and dorso-lateral groups of eells of the ventral horn of the first five or six segments of the spinal cord. The nerve arises as a series of rootlets which emerge laterally and join a common trunk, which passes upward between the dorsal and ventral roots of the upper cervieal nerves and parallel with the medulla to turn lateralward in company with the vagus. (See fig. 629). The upper rootlets arise from that part of the nueleus contiguous to the inferior end of the nucleus ambiguus, and are described as comprising the medullary or accessory part of the nerve; those which arise from the ventral horn cells below are described as the spinal parl. The trunk of the spinal aceessory fuses with the vagus in the region between its two ganglia, and, lefore scparation, contributes fibres (the aeccssory part) to the trunk of the vagus. Some of the accessory fibres are distributed as motor fibres to the inuscles of the larymx and some of them are visceral efferent fibres. The latter probably terminate (hiefly in sympathetic ganglia which send axones to the heart. The spinal part is distributed to the sterno-mistoid ani trapezius muscles. The nucleus of the spinal accessory receives terminal twigs of pyramidal fibres from the opposite side and is otherwise subjected to influences similar to those alfecting the cells giving origin to the motor roots of the spinal nerves.

The vagus or pneumogastric and the glosso-pharyngeus, though they have widely different veripheral distributions, are so similar in origin and central connections that they may be described together. Both contain efferent fibres, though hoth are in greater part sensory. They arr sinfilar as to the origin of both their efferent and afferent components. The afferent fibres of the vagus arise in its jugular ganglion and its nodosal ganglion (ganglion of the trunk); the afferent fibres of the glosso-pharyngeus arise in its superior ganglion and its petrosal ganglion. In both nerves these fibres enter the lateral aspect of the modullat and bifureate into ascending and descrobling branches, similar to those of the dorsal root-fibres in the spinal cord. Some of these branches terminate in practically the same level of the medulla about cell-bodies sifnated on the same and the opposite sides. Such branches end chiefly in the nuelei of the loypoglosial aml spinal acessory, and about the cells giving urigin to the elferent components of the vagus and glosis-pharyngeus themselves - short reflex ares. llowever, most of the afferent difnes triminte in the nuclens of termination of the vingus and glosso-pharyngeus:-(1) the nucleus of the ala cinerea, the midlle portion of which is indicated in the floor of the fourth ventricle by the ala cinerea; (2) in the closed portion of the medulla, the lower end of the maleus of the ala cinerea comes to lie in the dorso-lateral proximity of the central canal, and this portion is known as the commissural nuches of the alu cinera (figs. 642 and 645 ) from the fatet llat fibres maly les sorn which pass directly from it across the mid-line; (3) the longer of the descenting branches of the lifureaterl fibres collect to form the solitary tract, a compact lumble situated forsally just vento-lateral to the mucleus of the ala cincrea and quite conspicurns in sections of the merhulla. The fibres of this bumlle terminate in the nucleus of the solitary tract, which is but a vontro-lateral and downward continution of the nucleus of the ala cincrea enelosing the lumbles forming the tract. It is most pobalole that the fibres of the solitary tract are chicfly form the vagus (pnemogastrie), though Brued has found evidence

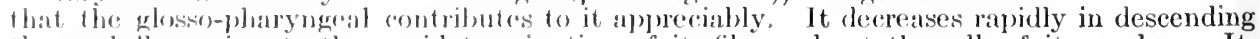
the modulla, owing to the rapjel termination of its fibres about the eells of its nucleus. It, 
with the axones given by the cels of its nucleus, is believer to extend as far downward as the level of the fourth cervical segment of the spinal cord. This being in the level of origin of the phrenic nerve, the tract forms a link in the respiratory apparatus which aids in the coordinated respiratory movements. The axones given off by the cells of the nucleus of the ala cinerea (terminal nuclei of the vagus and glosso-pharyngeus) course on both sides of the

Fig. 647.-Schene showing the Pelative Size and Position of the Nuclei of Origin (Red) of the Motor And the Nuclei of Termination (Blue) of the sexsory Cranial Nerves.

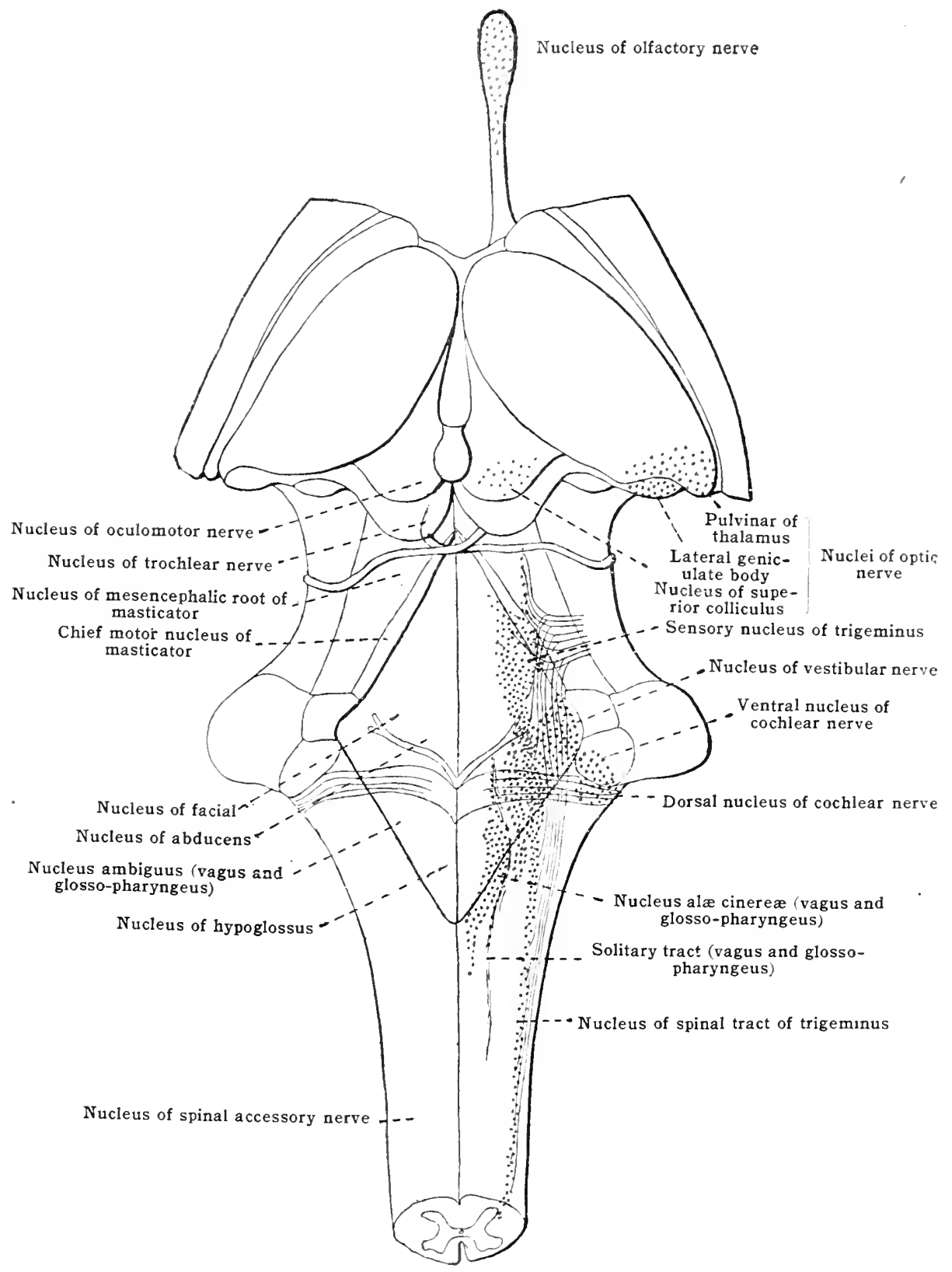

mid-line, associating nuclei of other cranial nerves with vagus and glosso-pharyngeal impulses, many decussating to be distributed to the structures of the opposite side. Many join the lemniscus of the opposite side and pass into the cerebrum; others are distributed to the motor nevrones of the cervical cord of the same and opposite sides (reflex axones), and no doubt others form central connections with the cells of the reticular formation of the medulla, though their precise relations have not been determined. 
Cell-bodies in the nucleus of the ala cinerea, the nucleus of the solitary tract and in the commissural nucleus of the ala cinerea comprise the so-called respiratory and vaso-motor nuclei ("centres") of the medulla. Some of the caudal branches of the axones given off by the cells of these nuclei descend the spinal cord, not only to the segments giving origin to the phrenic nerve, but also to those supplying the intercostal and levatores costarum muscles. Some of these augment the solitary tract; most of them descend in the reticular formation of the medulla and cord. Further, axones given off by these cells convey vaso-motor impulses which are distributed to visceral efferent neurones throughout the cord.

Fig. 64S.-Diagran illustrating Principal Central Relations of the Vagus Nerve, exclusibe of Relations to Descending Cerebral or Pyramidal Fibres.

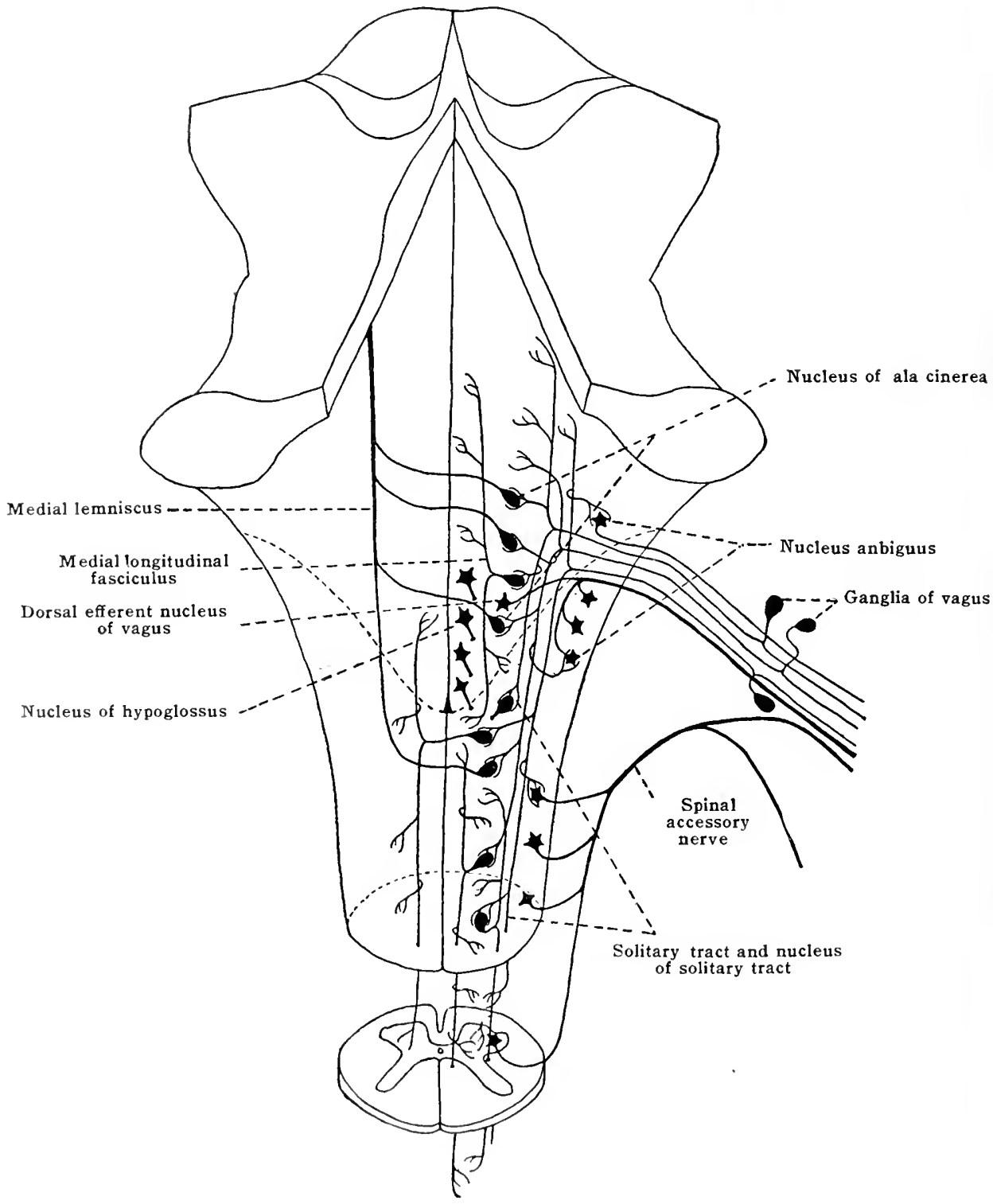

The nuclei of origin of the motor filores of the vagus and glosso-pharyngeus are the dorsal efferent nucleus of the vagus and the nucleus ambiguus. The cells of the dorsal nucleus of the vagus lie somewhat clusteren in the ventro-mesial side of the nucleus of the ala cinerea and lateral to the nucleus of the hypoglossus. Their axones pass outward among the entering or afferent vagus fibres, and it is suggested that most of them are visceral efferent fibres of the vagus, i. e., they terminate about sympathetic neurones. The nucleus ambiguus or ventral efferent nucleus of both nerves lies in the lateral half of the reticular formation, about mid-way betwen the olive and the line traversed by the rootlets of the two nerves. Its upper end is larger. Its cells are considerably dispersed by the fibres of the reticular formation. The axones arising from its cells conrse at first dorsalward and then turn abruptly outward to join 
the rootlets of the vagus or glosso-pharyngeus, as the case may be. The vagus is thought to receive more efferent fibres from the nucleus ambiguus than does the glosso-pharyngeus, and Cunningham notes that it may be questioned whether the latter nerve contains any motor fibres at all, there being paths by which the fibres of its motor branch (to the stylo-pharyngeus muscle) might enter it other than direct from motor uuclei.

The vescibular and cochlear nerves are usually considered as one nerve and together are designated as the acoustic or eighth cranial nerve. While both are purely sensory, are similar in development and course together, they are distinct as to function and their nuclei of termination differ. They are here described as separate cranial nerves. The two nerves approach the brain stem together and enter it at the lateral aspect of the junction of medulla oblongata and pons.

The vestibular nerve arises as the central processes of the bipolar cells of the vestibular ganglion, and passes into the brain-stem on the ventro-mesial side of the restiform body to find its nucleus of termination (nucleus vestibularis) in the floor of the fourth ventricle. 'This nucleus occupies a triangular area of considerable extent (area acustica, fig. 640), and is usually subdivided into a lateral nucleus (Deiters'), a medial nucleus (Schwalbe's), a supcrior nucleus (Bechterew's), and an inferior nuclcus (nucleus spinalis). The latter is a downward prolongation of the general nucleus vestibularis which accompanies the descending or spinal root of the nerve.

Fig. 649.-Transverse Segtion of Medulla at Inferior Border of Pons.

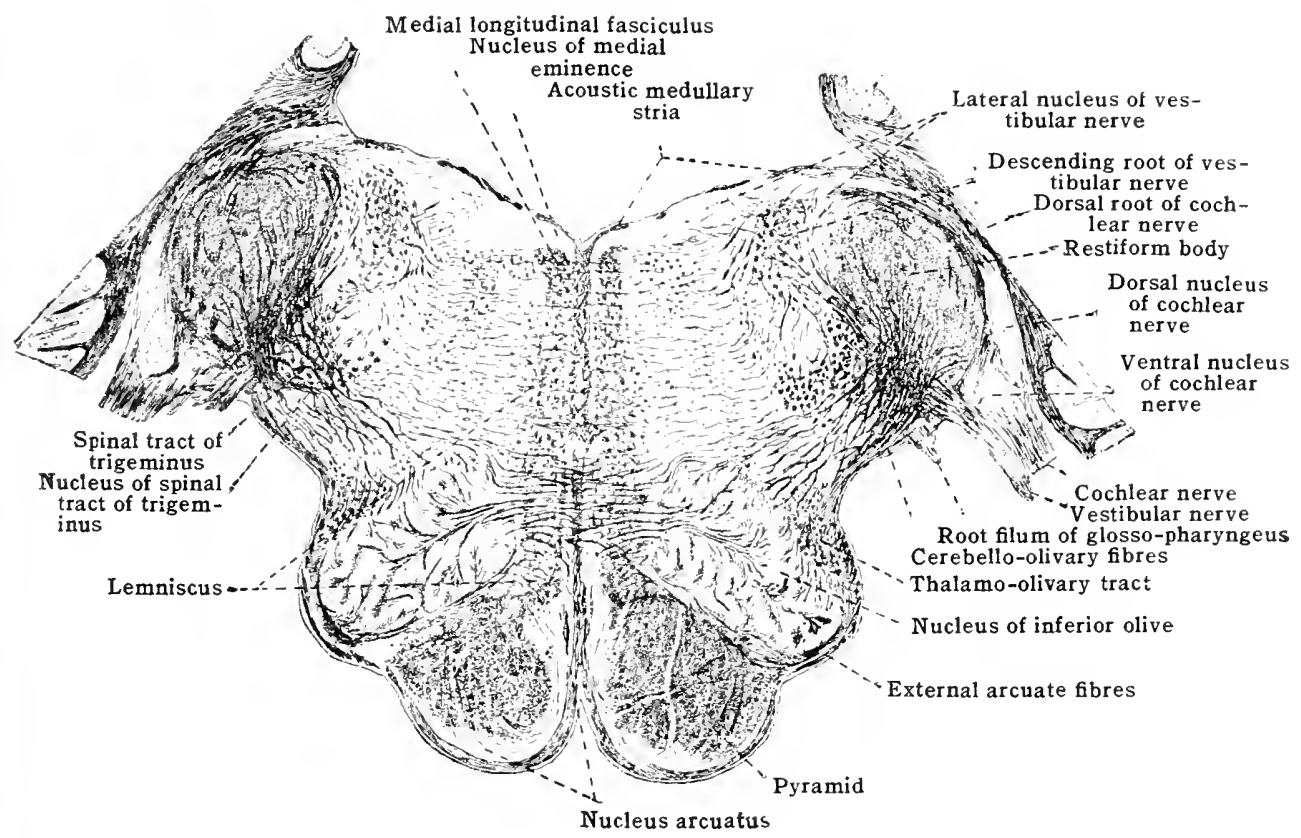

From the cells of the lateral and inferior nuclei axones are given off which form paths to the lateral funiculus of the spinal cord (vestibulo-spinal fasciculus, fig. 619) and to its anterior marginal fasciculus (ventral vestibulo-spinal tract). From both the lateral nucleus and the superior nucleus a special path is given off which passes upward and terminates in the roof nucleus of the cerebellum (nucleus fastigii) of the opposite side and in the nucleus dentatus and the cortex of the vermis. Also, fibres arising in the nuclei fastigii are said to terminate in the lateral (Deiter's') nucleus in addition to those which probably descend into the anterior marginal fasciculus of the spinal cord. From the medial and also from the superior nucleus fibres pass to the medial longitudinal fasciculus of both sides, and are distributed to the nucleus of the abducens of the same side and to the nuclei of the trochlear and oculomotor nerves of the opposite side and of the masticator nerve of the same and opposite sides. From the lateral and medial nuclei, and probably from all, fibres arise which cross the midline to enter the lemniscus and ascend to the cerebrum (lateral portion of the thalamus) on the opposite side. The lateral (Deiters') nucleus is said to contribute more fibres to the medial longitudinal fasciculus than does a uncleus of any other cranial nerve. If any of these fibres descend the cord, they must do so in its anterior marginal fasciculus.

The inferior nucleus is a ccompanied by the descending or spinal root of the vestibular nerve, which begins to assemble in the nuclei above. This root is composed of both caudal branches of the entering fibres of the nerve and chiefly of fibres arising from the cells of its nuclei. Thus for the vestibular nerve it corresponds in every way to the solitary tract for the vagus, and to the spinal tract of the trigeminus. Such of its fibres as descend into the spinal cord most probably do so in the lateral vestibulo-spinal fasciculus.

Many of the anatomical details of the central connections of the vestibular nerve have not yet been determined with exactness. In addition to whatever other functions it may have, 
it is considered to be the nerve of equilibration, and the connections noted above may be considered the pathways by which it exercises this function. The fibres of the apparatus which are represented in the spinal cord are supposed to convey impulses to the ventral horn (motor) cells of the cord as far down as the lumbar region.

The cochlear nerve, the auditory nerve proper, arises as the central processes of the bipolar cells of the spiral ganglion of the cochlea. In the lateral periphery of the restiform body, just before the latter enters the cerebellum, the nerve finds its two nuclei of termination, the ventral nucleus and the dorsal nucleus (tuberculum acusticum, fig. 640).

From the dorsal nucleus arise the acoustic medullary stria. These bundles pass around the dorsal aspect of the restiform body and course just under the ependyma of the floor of the fourth ventricle to the mid-line, where they suddenly turn downward into the substance of the medullsa and in doing so, cross to the opposite side and join the lemniscus. As the lemniscus becomes separated higher up into a medial and lateral portion, these fibres course in the lateral lemniscul and are distributed chiefly to the grey substance of the inferior quadrigeminate and media,

Fig. 6j0.--Schene showing Some of the Central Connections of the Acoustic Nerve. (In part after Edinger.)

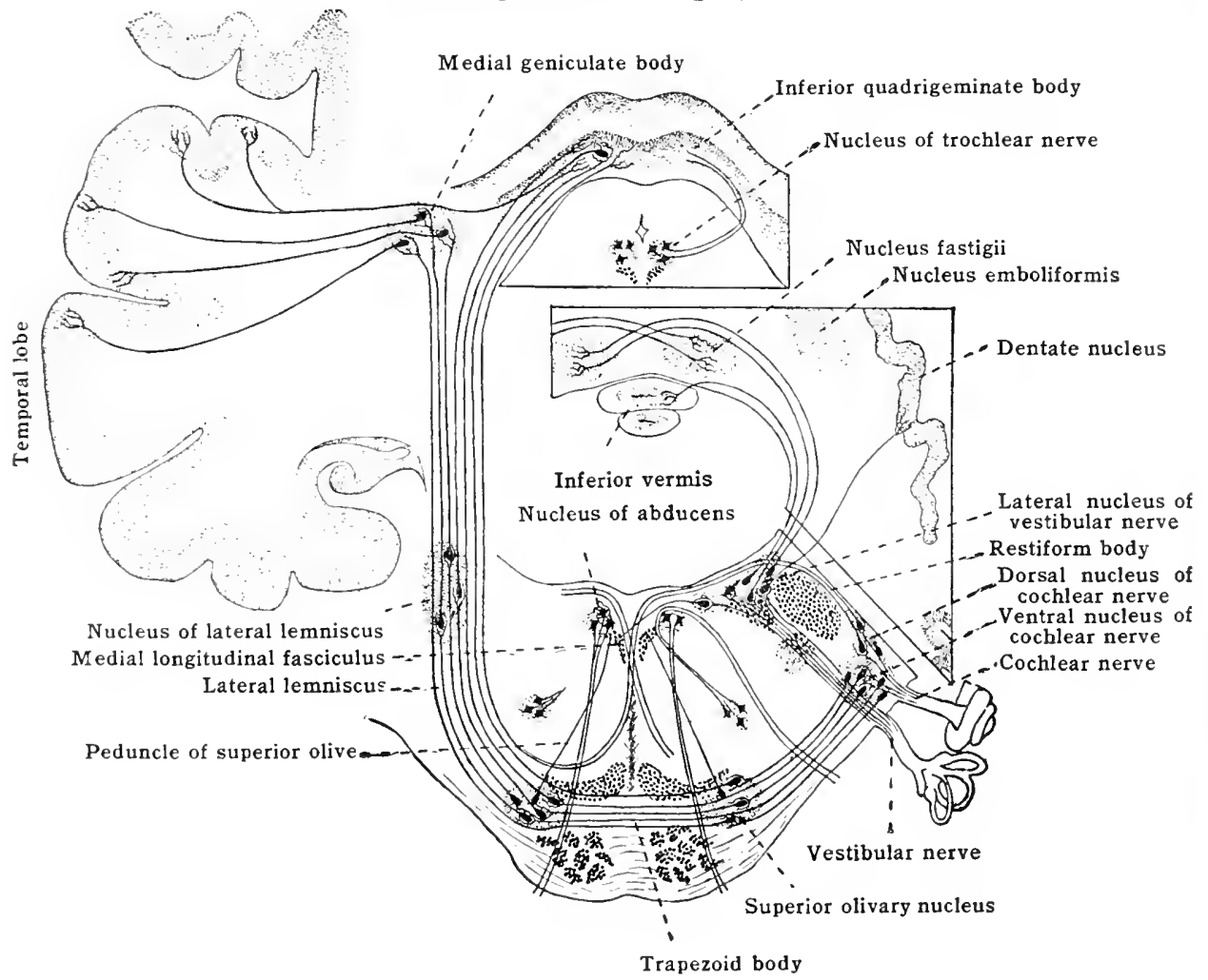

geniculate body of that sirle. At the mid-line some of their fibres join the median longitudinal fasciculus and by way of it are distributed to the nuelei of origin of other cranial nerves. In frequent cases, the acoustic strice course so decply bencath the ependyma as not to be superficially visible in the floor of the fourth ventricle.

From the ventral nucleus of termination fibres arise which terminate about the cells of the superior olivary nucleus of the same and opposite sides. The superior olive is a small accumulation of grey substance which lies in the level of the inferior portion of the pons, and in lime with the intuch larger inferior olivary nucleus of the medullit. However, it is not analogous to the latter in any sense. 'The two superior olives form links in the ecntral acoustic chain. From rells of the supreior olivary nureus of the same and opposite sides, fibres arise which pass by way of the lateral lomniscus and torminale in the grey sulstance of the inferior quadrigrominte lody and in the mertial geniculate borly, thus assoeinting theso bodies with the ventral mirelens of exchlear frmmination of the opposite side. from the medial geniculate body fibres arise which pass to the cortex of the superior comporal gyrus. 'This path is supplemented by filses arising in the inferior frumlrigeminate body, which likewise go to the temporal lobe. In

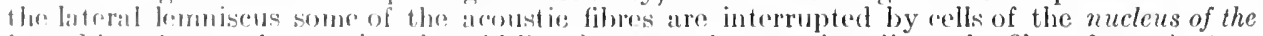
lat ral lommiscus. In erossing the mirl-line, hetworn the superior olives, the fibres from the two somrere form a more or less cemplat bundle, the corpus trapezoideum (traperium). To this arradral fibres arossing botwern thr nuclei trapeozidei, smaller masses of grey substance juse ventral to thes superior olives and probahly of the same significance.

Also, some filmes arising in the muclei of termination of the cochlear nerve pass to the inferior cpatelrigeminate borty of the same side. ()n the ofher hand, the connection with the medial 
geniculate body is thought to be wholly a crossed one. Further, some fibres are described as terminating in the superior quadrigeminate body of both the same and the opposite side. These, forming the stratum lemnisci of this body, are especially suggestive of associating auditory impulses with eye movements.

All the fibres arising in the superior olivary nucleus do not enter the corpus trapezoideum and the lateral lemniscus. A small bundle, the peduncle of the superior olive, arises in each nucleus and courses dorsally to the region of the nucleus of the abducens. Here certain of its fibres terminate about the cells of the nucleus of the abducens, while others enter the medial longitudinal fasciculus and pass to the nuclei of the trochlear and oculomotor nerves, thus further establishing connections between auditory impulses and eye novements.

The facial nerve is commonly described as consisting of the "facial proper" and its so-called sensory root or pars intermedia, the two together being designated as the seventh cranial nerve. However, the pars intermedia neither serves as a sensory root for the facial nor is it purely sensory. Many vears ago Sapolini considered it a separate nerve and later it was called the intermediate nerve of Wrisberg. More recent investigations of its development and distribution, especially those of Streeter and sheldon, further indicate that it merits a separate description

Frg. 651.-Transterse Section throdgh Inferior Border of Pons and Portiox of Overliting Cerebellum. (From Villiger.)

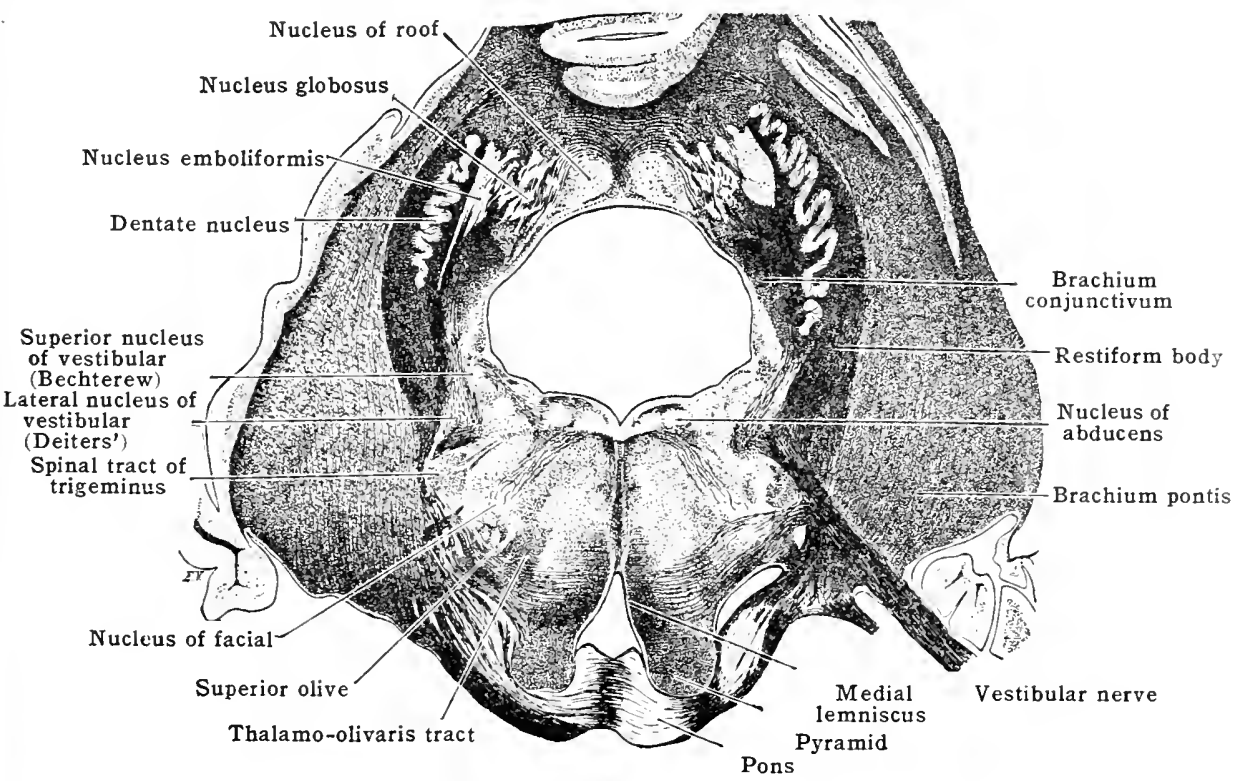

and a separate name, and, indicative of its distribution, it is here described as the glosso-palatine nerve. The facial, the glosso-palatine and the abducens all have their nuclei within the level of the pons though the roots of all appear from under its inferior border.

The facial [nervus facialis] has its nucleus (of origin) in the ventro-lateral region of the reticular formation, supe rior to and in line with the nucleus ambiguus. The axones given off by the cell-bodies of the nucleus collect into a bundle which, instead of passing ventrally and directly to the exterior of the pons, courses at first dorso-mesially to the mesial side of the nucleus of the abducens (ascending root of the facial); then it turns and courses superiorly for a few millimetres, parallel with the nucleus of the abducens and immediately beneath the floor of the fourth ventricle (genu internum); then it turns abruptly and pursues a ventro-lateral and inferior direction to its point of exit at the inferior border of the pons, just lateral to the olive and mesial to the entrance of the vestibular nerve. Its exit usually involves a few pons fibres. In transverse sections through the middle of the nucleus of the abducens the genu of the facial appears as a compact transversely cut bundle at the dorso-medial side of this nucleus.

The nucleus of the facial is described as consisting of two chief groups of cells, an anterior and a posterior group which give rise respectively to the axones of the superior and inferior branches of the facial nerve. It receives cortical impulses from the lower portion of the anter ior central gyrus of the cerebral cortex, from the root fibres of the trigeminus of the same side, which serves as its sensory root, and (chiefly) fibles arising from the nuclei of termination of the trigeminus. The nuclei of cermination of the optic and the auditory nerves of the same and opposite sides give rise to fibres which terminate about its cells. The fibres from the cerebral cortex descend in the pyramidal fasciculi and cross by way of the raphe and arcuate fibres to terminate in the nucleus of the opposite side. The anterior group of the cells of the facial nucleus must receive cortical fibres not only from the cerebral hemisphere of the opposite but also from that of the same side, evidenced by the fact that the strperior branch of the nerve is but little affected in facial paralysis resulting from a lesion in the cerebral cortex of one side. A lesion destroying the root of the nerve or its nucleus of origin will of course give total facial paralysis in the side of the lesion. 
The glosso-palatine nerve (nervus intermedius, sensory root of facial, etc.) is a mixed nerve but largely sensory. It accompanies the facial from a short distance beyond the geniculum (genu externum) of the facial to its attachment to the brain stem. Its sensory fibres arise as T-fibres of the cells of the genieulate ganglion (at the geniculum of the facial). The peripheral processes go as the chorda tympani to supply the epithelium of the anterior part of the tongue and that of the palate, especially of the palatine arches. The central processes enter the brain stem, bifurcate into candal and cephalic branches, and find their nucleus of termination in a superior extension of the nucleus of the solitary tract (the ventral portion of the nucleus of the ala cinerea). The geniculate ganglion contains some cell-bodies of sympathetic neuroues, left over in it during the period of migration for'm its homologue of the ganglion crest.

The efferent fibres of the glosso-palatine arise from cell-bodies lying dorso-medial to the nucleus of the facial and in the level between this and the nuclens of the masticator nerve superior to it. Its cells are usually scattered in the reticular formation in line with the dorsal efferent nucleus of the vagus. Since most of its fibres, at least, are concerned with sympathetic neurones (terminate in sympathetic ganglia) and convey secretory impulses destined for the salivary glands, it has been called the nucleus salivatorius.

Fig. 652.-Transverse Section throdgh Pons and Portion of Cerebellum at Level of Niclei and Root Filaments of Abducens and Facial Nerves. (From Villiger.)

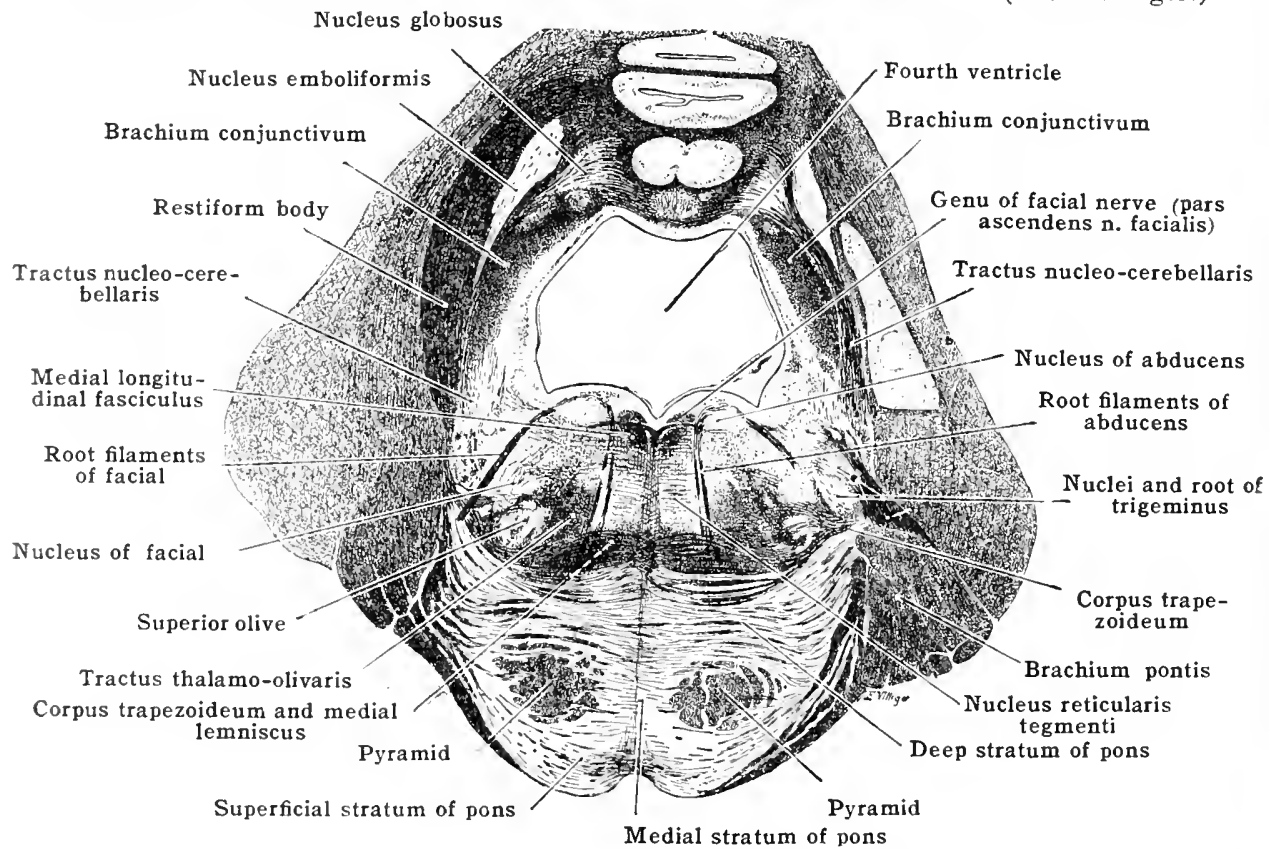

The abducens is a small, purely motor nerve, which supplies the lateral rectus musele of the eye. Its nucleus of origin lies close to the mid-line in the medial eminence of the floor of the fourth ventriele, and in line with that of the hypoglossus. Its root-fibres, unerossed, pursue a ventrul course, inclining a little laterally and curving inferiorly to cmerge from under the inferior border of the pons. They pass lateral to the pyramill, and often between some of its fisciculi. The nucleus receives cortical or voluntary impulses by way of the pyramidal fasciculi chietly of the opposite side. Its connection with the auditory apparatus and the medial longiturlinal fasciculus has already been noted. It probably receives afferent impulses throlegh the fibres of the trigeminus as well as by fibres descending from the nuclei of termination of the optic nerve. It is also associated, by way of the medial longitudinal fasciculus, with the nucleus of the oenlomotor nerve of the same and opposite sides.

The trigeminus is considerably larger than any of the nerves inferior to it, and has the most extensive central commections of any of the cranial nerves. It is a purely sensory nerve which enters through the brachiun pont is in line with the facial nerve. It serves as the nerve of general sensibility for the face from the vertex of the sealp clownward, and thus it corresponds to the afferent filires (clorsal root) for all the nerves giving motor supply to structures underlying its donsin. Its fibres arise from its harge, tribobed, semilunar (iasscrian) ganglion, situated c)itsicle the brain. 'This corresponds to the dorsal root ganglion of a spinal nerve, and its cells give off the charactoristic T-fibes with peripheral and central branches. The central or afferent. branches upon entering the brain-stem bifurcate into ascending and descending divisirms, just as the rotering dorsil root-filores of the spinal nerves, and find their nucleus of termination in a dorso-litteral colum of grey substance, lying deeply and extending longitudinally thromgh the lorain stom, and consisting of the njward continuation of the gelatinous substance of folando of thr spinal corl. Opposite the culrance of the norve is a considerably thickened protion of this rolumn of grey substance, known as the sensory nucleus of the trigeminus, and the remainder below is calforl the morlens of the spimal tract (fig. 6.17). Both parts are equally "scmsery." Aftor bifureation the branches of the entering fibres of the trigeminus terminate aloult the anls of these nuelei. The desending branches are much longer than the ascending, 
Fig. 653.-Drawing of Model of Bran-sted showing the Nuclei of Origin of the ilotor ('ravial Nerves. (After siabin.)

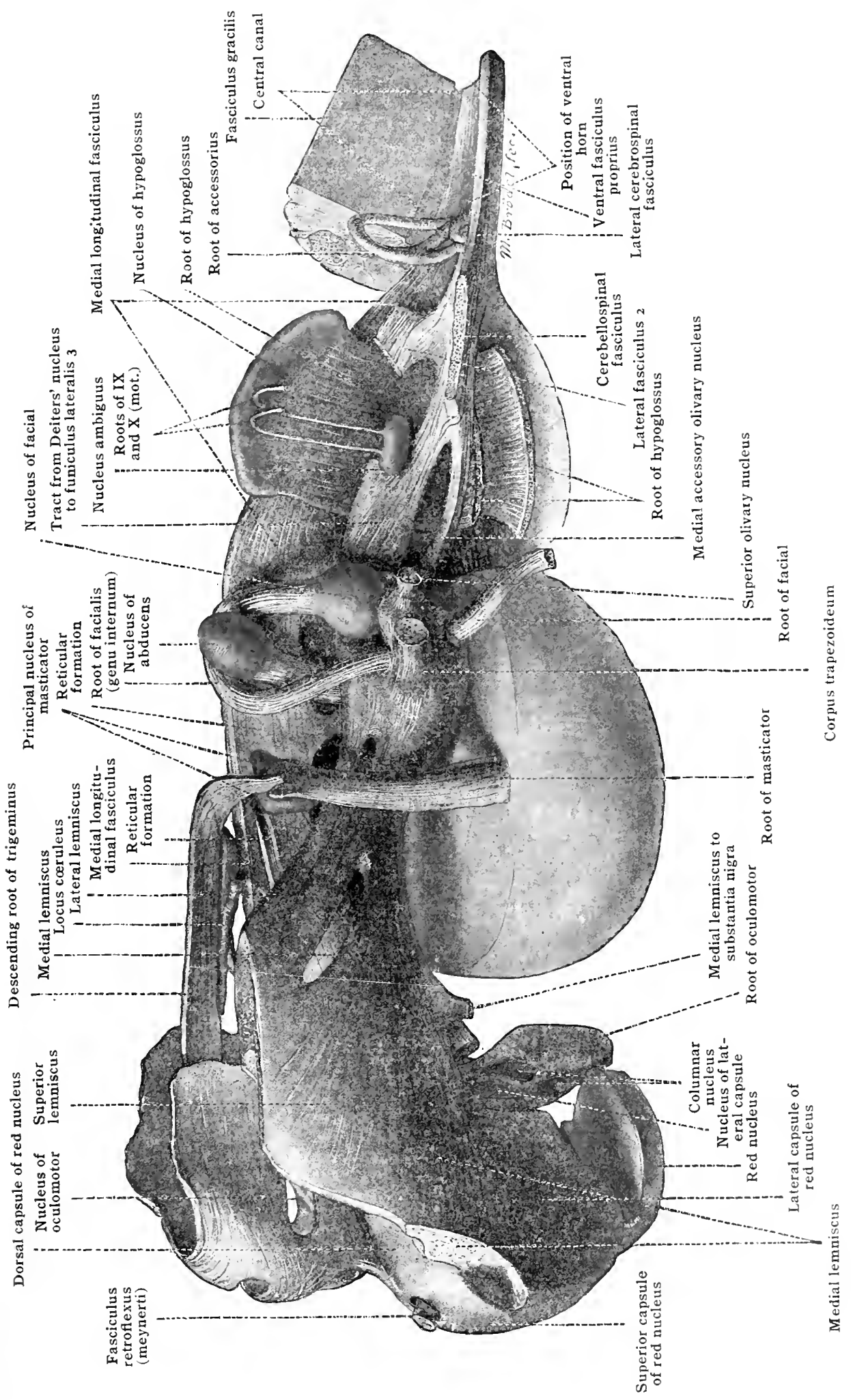


and in passing downward form the spinal tract of the trigeminus, well marked in all transverse sections of the medulla oblongata (figs. 641,642, 643, 649). The spinal tract decreases rapidly in descending the medulla, owing to the rapid termination of its fibres in the nueleus of the tract.

Fig. 654.-Diagrair Illustrating the Principal Central Connections of the Trigeminus and Masticator Nerves, Exclusive of Their Relations to Descending Cerebrat or Pyramidal Fibres.

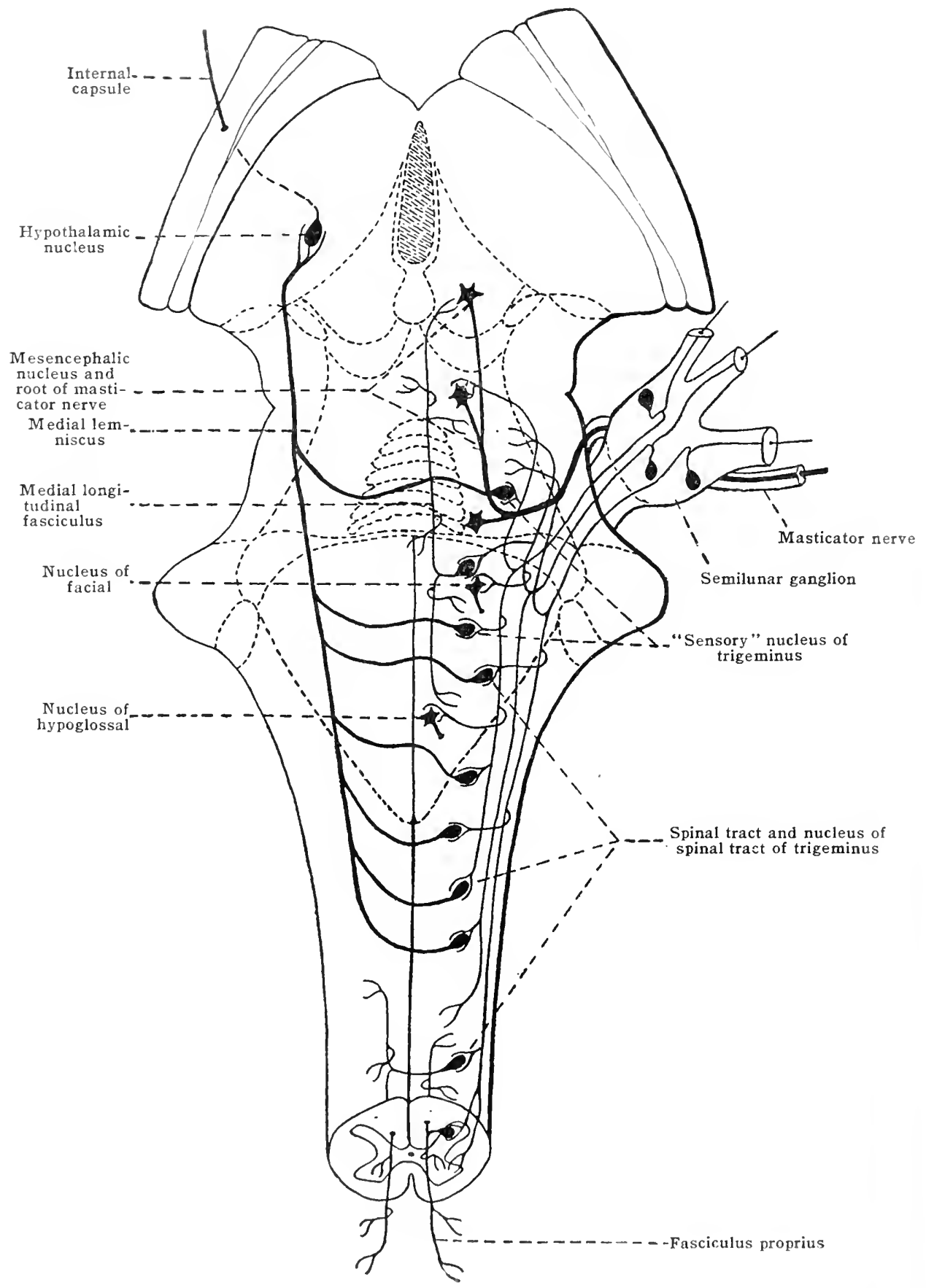

It las luen traced as far down as the second rervical segment of the spinal cord. The aseending branches being short, most of then terminate in the 'sensory nucless' and, therefore, the

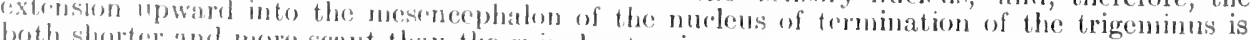
both shorter and more seant than the spinal rexemsion.

Axomes from the nuclems of formination of the trigeminus are distributed - (1) to the nuelei

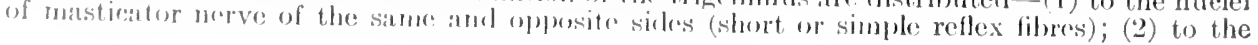


nuclei of the other motor cranial nerves, especially of the facial; (3) to the thalamus of the same and chiefly the opposite side, and thus, through interpolation of thalanic neurones, their impulses reach the somæsthetic area of the cerebral cortex. These fibres ascend in the recticular formation of the opposite side, most of them finally coursing strictly within the medial lemniscus. In crossing the mid-line they contribute to the internal arcuates. (4) Some fibres of both the trigeminus direct and from its nucleus pass laterally into the cerebellum. The longer of the reflex or association axones arising in the nucleus of termination may contribute to the medial longitudinal fasciculus; many of them descend to terminate in the grey substance of the spinal cord below the levels in which the fibres of the spinal tract proper terminate. The nucleus of termination is directly homologous to the nuclei of the fasciculus gracilis and fasciculus cuneatus, and, like the nuclei of termination of all sensory eranial nerves, it contains cell-bodies homologous to those which give rise to the fasciculi proprii and commissural fibres of the spinal cord.

The masticator nerve [portio minor n.trigcmini] is a purely motor nerve, usually called the motor root of the trigeminus from the fact only that it makes its exit from the pons by the side of the entering fibres of the trigeninus, passes outward over the ventro-mesial side of the semilunar ganglion and accompanies the inferior maxillary division (mandibular nerve) of the trigeminus till it divides totally into its branches for the motor supply of the muscles of mastication. It serves, therefore, as but a relatively small part of the "motor root" of the trigeminus.

The nucleus of origin of the masticator nerve is attenuated into two parts: (1) The chief nucleus (nucleus princeps) lies on the dorso-medial side of the larger portion (sensory nucleus) of the nucleus of termination of the trigeminus. It is the larger of the two parts and gives origin to much the greater part of the masticator. (2) Scattered anteriorly and continuous

Fig. 655.-Transverse Section Through Upper Part of Pons at the Leyel of the Entrance of the Trigeminus. (From Villiger.)

Anterior medullary velum

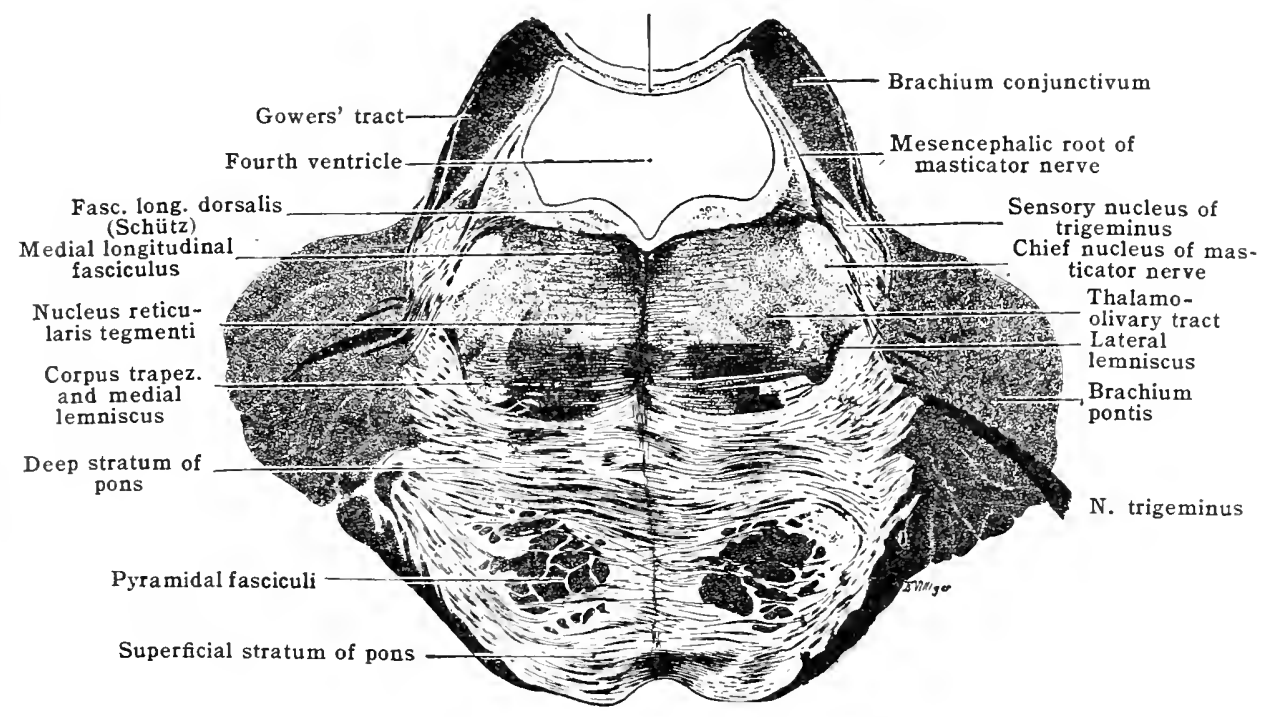

with the chief nucleus, in line with the locus caruleus, are the cell-bodies usually described as the nucleus of the mesencephalic (descending) root. These cells lie in decreasing linear distribution, through the mesencephalon, as far anterior as the posterior commissure of the cerebrum, and the mesencephalic root of the nerve accumulates as it descends to join the exit of the fibres arising from the chief nucleus. The average diameter of its cells is somewhat less than for the chief nucleus.

It is not clearly settled that the fibres arising from the mesencephalic nuclens of the masticator nerve go to the muscles of mastication. As suggested by Kölliker, some of these may supply the tensor veli palatini and tensor tympani muscles. Recent investigations of lower animals by Johnston and Willems indicate that the mesencephalic root may contain no motor fibres at all, representing instead a portion of the sensory trigeminus fibres. It is claimed that some fibres in descending give off collaterals which terminate about cells in the chief nucleus, and thus an impulse descending by them is given a wider distribution and also reinforced by the interpolation of another neurone. Such fibres, however, may be the sensory fibres just mentioned terminating upon the cells of the nucleus to form simple reflex arcs.

It is claimed that each masticator nerve receives a few fibres arising from the cells of the nucleus of that of the opposite side.

Both parts of the nucleus of the masticator receive afferent impulses brought in by the trigeminus of the same (chiefly) and of the opposite side, and both receive cortical impulses by fibres from the inferior portion of the precentral gyrus which descend in the cerebral peduncles and cross to terminate in the nucleus of the opposite side.

The internal structure of the pons.- The nuclei and roots of the trigeminus, masticator, abducens, facial, glosso-palatine, cochlear and vestibular nerves are extended within the level 
of the pons, and their position and course have been described above. The pons proper (the bridge) consists of a mass of transversely running fibres continuous on either side into the brachia pontis or middle cerebellar peduncles. In the animal series the relative amount of these fibres varies with the size of the cerebellum upon which they are dependent. They are relatively more abundant in man than in other animals.

In transverse sections the pons fibres are seen to course ventrally about the main axis of the brain-stem, making it possible to divide the section into a basilar or ventral part and a dorsal part (tegmentum). The fibres in their transverse and ventral course around the medulla oblongata involve the pyramids. At the inferior border of the pons the fibres little more than separate the pyramids as such from the main axis of the brain-stem, but more superiorly the pons fibres pass through the pyramids, splitting them into the pyramidal fasciculi. These pyramidal or chief longitudinal fibres of the pons are the continuation of the basal portion of the cerebral peduncles through the pons, to emerge as the pyramids proper at its inferior border. They occupy an intermediate or central area among the pons fibres of either side, leaving the periphery of the pons uninvaded. The superficial pons fibres form the solid bundle of its ventral and lateral periphery and the deep pons fibres form similar bundles dorsally enclosing the area of pyramidal fasciculi (fig. 655).

In transverse sections through the inferior portion of the pons, the dorsal or tegmental part consists of structures continuous with and analogous to the structures of the medulla oblongata immediately below, exclusive of the pyramids. In addition, this region contains the superior olivary nucleus and the corpus trapezoideum. The significance of these structures and their relation to the nucleus of termination of the cochlear nerve is shown in figs. 650,651 and 652 . In this region the lemniscus (fillet) changes from the sagittal to the coronal plane, and its

Fig. 656.-Diagram showing the Rhombencephalic Course of Gowers' Tract and the Direct Cerebellar Tract.

Dorsal spino-cerebellar fasciculus (direct cerebellar tract)

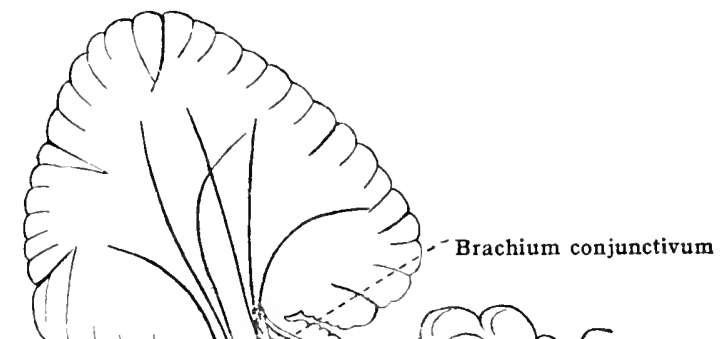

Superficial antero-lateral spino-cerebellar

fasciculus (Gowers' tract)

latera! edges are becoming drawn outward and carry the lateral lemniscus of the regions superior to this. The medial longitudinal fasciculus, left alone by the change in the arrangement of the leminscus, maintains its dorsal position throughout the pons and into the mesencephalon above. The thalamo-olivary tract appears loosely collected in the dorsal part of the pons, dorso-medial to the nueleus of the superior olive.

The restiform body acquires in this inferior region a more dorso-lateral position than in the medulla below. Its fibres are beginning to turn upward in their course to the cerebellum mesial to the brachium pontis. Here the restiform borly is nearing completion, and the fibres now container in it may be summarised as follows:side.

(1) The fibres of the dorsal spino-cerebellar faseiculus (direct cerebellar tract) of the same

(2) I ibres from the nuclei of the fasciculus gracilis and fasciculus cuneatus of the same and opposite side (externa! areuate fibres).

(3) Fibres to and from the inferior olives of the same and (chiefly) the opposite side (cerebello-roliviry filiress).

(4) Sensury cerebrllar filmes from the nuclei of termination of the vagus, glosso-pharyngeus, vestibular and trigeminus, vestibular especially, and from the cells of the reticular formation.

(5) I escending fibes to the motor nuelei of the vagus and glosso-pharyngeal, and fibres drescrurling into the anterior marginal fascienlus of the spinal cord, the latter, however, being in large part interupted by eells in the nuclei of the vestibular nerve.

(6) $\triangle$ fow fibres arising from the arcuate nuclei. 'These nuclei ase continuous superiorly with the nuclei of the pons and sone: of their fibres are described as entering the cerebellum by way of the restiform borly insteud of hy way of the brachium of the pons as in the levels above.

The asconding fibres of the resifoum lody are distribuled to the cortex of the vermis, the nurleus of the rouf (fastigii), the nuelens dontatus, nucleus emboliformis, and nueleus globosus

Vory fow if any of the fibres ascencling the corsl in Gowers' tract enter the cerebellum by way of the restiform borly. This lanet (the superficial antero-lateral spino-ecrebelar fasciculus) 
ascends the medulla, dispersed in the reticular formation, and therefore in a more ventral position than that of the direct cerebellar tract. In this position it becomes enclosed by the fibres of the pons, and so it passes upward, beyond the pons, around the lateral lemniscus to the brachium conjunctivum, and there turns back to enter the cerebellum by way of its superior peduncle. Certain clinical phenomena, probably purely psychological, have been alleged to indicate that some of the fibres of Gowers' tract pass on to the cerebrum instead of turning in the medullary velum to enter the cerebellum.

The dorsal part of a transverse section through the upper part of the pons contains the superior cerebellar peduncles [brachia conjunctiva] instead of the restiform bodies or inferior peduncles. Instead of the cerebellum forming the roof of the fourth ventricle, in this region the roof is formed by the anterior medullary velum bridging the space between the two brachia conjunctiva. Adhering upon the medullary velum is the lingula cerebelli-the superior and ventral extremity of the superior vermis. This is the only portion of the cerebellum attached to this region.

The lemniscus (fillet) is found more lateral than at the inferior border of the pons, and is divided into the medial lemniscus and lateral lemniseus proper. The lateral lemniscus has shifted dorsally until in this region it courses in the dorso-lateral margin of the section external to the brachium conjunctivum. The mesencephalic root of the masticator nerve occurs in the dorso-

Fig. 657.-Diagram showing Connections of the Fibres of the Pons.

The plane of the section is obliquely transverse or parallel with the direction of the brachia pontis

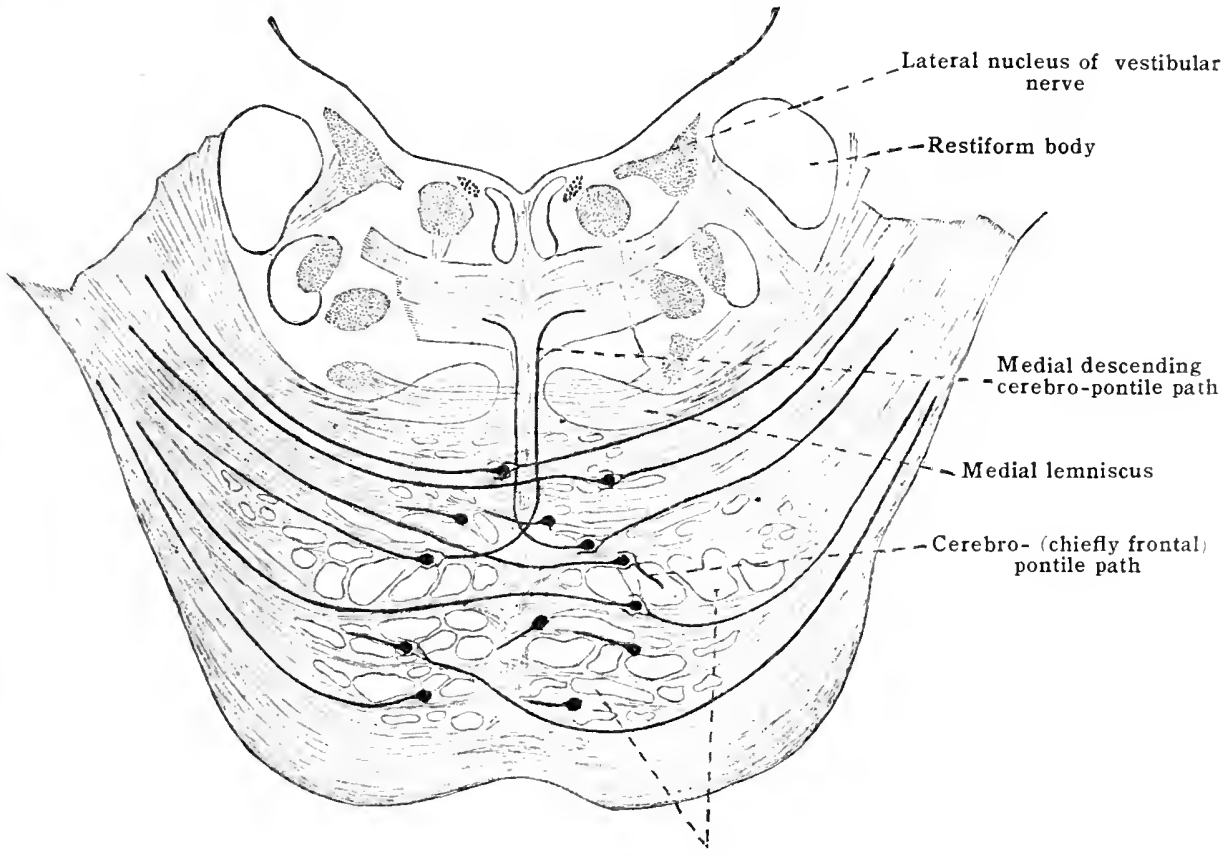

Longitudinal (pyramidal) fasciculi

lateral margin of transverse sections through this region, and this and the trigeminus are the only cranial nerves represented here.

The transverse fibres of the ventral part of the section (pons proper), and therefore the brachia pontis, consist of fibres coursing in opposite directions. Many are fibres which are outgrowths of the Purkinje cells of the cortex of the cerebellar hemispheres, and pass either directly to the cerebellar hemisphere of the opposite side or turn dorsalward in the raphe to course longitudinally in the brain-stem both toward the spinal cord and toward the mesencephalon. Others terminate in the grey substance (nuclei) of the pons. Others are fibres which arise in the grey substance of the pons and pass to the cerebellar hemispheres, and still others are the cerebro-pontile fibres, from the temporal, occipital and frontal lobes.

The grey substance of the pons [nuclei pontis\} occurs quite abundantly. At the inferior border of the pons it is found concentrated about the then more accumulated bundles of the emerging pyramids, and serial sections show it to be a direct upward continuation of the arcuate nuclei of the medulla oblongata below. Higher up it is dispersed throughout the central area in the interspaces between the transverse pontile and longitudinal pyramidal fasciculi. A large portion of the nerve-fibres passing through it are thought to be interrupted by its cells, which thus serve as links in some of the neurone chains represented by the fibres of the pons. of the more important of such relations, the following are said to exist:-

(1) Fibres which arise in the cortex of one cerebellar hemisphere and terminate about cells of the nucleus pontis of the same and opposite side of the mid-line. These cells give off axones which pass to the other cerebellar hemisphere. In this relation the nuclei of the pons are analogous to the arcuate nuclei, save that the cerebellar fibres interupted in the former are connected with the cerebellum by way of the brachia pontis instead of the restiform bodies. 
(2) Certain of the descending cerebro-pontile fibres terminate about cells of the nuclei of the pons. Such cells give off fibres which probably, for the most part, pass to the cerebellar hemispheres, the impulses from the cerebral hemisphere of one side being conveyed to the opposite cerebellar hemisphere. Most of the descending cerebro-pontile fibres are thought to cross the mid-line to terminate about cells of the nuelei of the pons of the opposite side, a relation not sufficiently emphasised in the aceompanying diagram (fig. 657).

Of the cercbro-pontile paths, the frontal pontile path (Amold's bundle) is deseribed as arising in the cortex of the frontal lobe (frontal operculum) passing in the anterior portion of the internal eapsule down into the medial part of the base of the cerebral peduncle, and terminating in the grey substance of the pons. The descending temporal pontile path, sometimes called Türk's bundle, arises in the cortex of the temporal lobe, traverses the posterior portion of the internal capsule, lies lateral in the pyramidal portion of the cerebral peduncle, and termi. nates in the grey substance of the pons. In the posterior part of the internal eapsule, the temporal pontile path is joined by a small bundle arising in the oecipital lobe and going to the pons nuclei. This, supposedly smaller than the other two, adds an occipito-pontile path.

The total area in eross section of the pyramidal fasciculi as they enter the pons above is considerably greater than that which they possess as they energe as the pyramids of the medulla below. The difference is considered very appreciably greater than can be explained as due to the loss of pyramidal fibres supplied to the nuelei of origin of the cranial nerves lying within the level of the pons, and the additional difference is explained as due to the termination within the pons of the cerebro-pontile paths.

\section{THE ISTHMUS OF THE RHOMBENCEPHALON}

The isthmus of the rhombencephalon is nothing more than the transition of the metencephalon into the mesencephalon above. It is quite short and comprised of only the structures which run through it, namely, the brachia conjunctive (superior peduncles of the cerebellum), the anterior medullary velum, the lateral sulcus of the mesencephalon, the cerebral peduncles, and the inferior end of the interpeduncular fossa. It surrounds the superior extremity of the fourth ventricle. The lateral and medial lemnisci, the superior extension of the nucleus of the trigeminus, the mesencephalic nucleus and root of the masticator nerve and Gowers' tract extend through it. At the mid-line, just inferior to the inferior quadrigeminate bodies is the frenulum of the anterior medullary velum and the trochlear nerves, emerging at the sides of this, course ventrally around the sides of the isthmus. In the lateral sulcus, the isthmus shows usually a small triangular clevation known as the trigonum lemnisci from the fact that the lateral lemniscus tends toward the surface in this region.

Functions of the cerebellum.-From the above descriptions involving the structures of the metenecphalon, it may be noted (1) that a given side of the eerebellum is associated chiefly with the same side of the general body and with the opposite side of the cerebrum. (2) That it receives afferent impulses from the spinal cord (brought in to the cord by the dorsal roots of the spinal nerves) by way of the direet cerebellar faseieulus of the same side, and by Gowers' tract and from the nuclei of the fasciculus gracilis and euneatus of the same and opposite sides. It further receives afferent impulses from the nuclei of termination of the trigeminus, glossotharyngeal and vagus of the same side chiefly, and especially does it receive afferent impulses from the muclei of the vestibular nerve of the opposite and same side. (3) That the cerebellum sents impulses to the red nucleus, the thalamus and the cerebral cortex of the opposite side, and some of its fibres terminate in the nuelei of termination of the vestibular nerve and probably sone fibres arising in its roof nuclei descend into the spinal cord direct. (1) That the cerebellun receives impulses from the thalimus of the opposite side by way of the thalamo-olivary tract and the infrerior olive, and especially from the cerebral cortex of the opposite side by way of the frontal, temporal and oecipital pontile paths and the nuelei of the pons. Further, fibres from the goneral pyramiclal fasciculi are deseribed as terminating about cells of the nuclei of the pens.

Tilking into ronsileration these known associations of the cerebellum, the anatomically possible paths which in part ma distribute corelollar impulses to the grey substance sending elferent filmes to the peripheral tissues aro (1) the general pyramidal fasciculi whose eortex of oligin may ropeive impulses by fibre proprio from the cortical areas recoiving impulses from the rerebellum. The rytamidal fisciculi, decussating, distribute impulses to the grey substance of the morlulla and rent of the same side as that from which the ecrebello-cerebral impulses pissoel to the cortex. (2) The lateral vestibule-spinal and the anterior marginal faseiculi to the ventral hern of the spinal eorl of the sane side, probably carrying impulses deseending from the cerobellum as woll as impulses brought in by the vestibular nerve and descending lieret from its nuelei of termination into the spinal corel. (3) 'The ruluo-spinal tract of the ford and probably some of the thalano-spinal fibres (eorpora-quadrigemina-thalamus path), flur red nuclei and thalami bring associated abundantly with the cerebellum. These traets likewise clecussate in desconfling but likewise do the corebellor impulses aseending to their cells of origin.

Whatrever other functions it may yossess, developmental defects and pathologic lesions show that the corebellum has to do with the coutulibration of the body and the finer coördinations, andjustive control of the eontractions of functionally correlated groups of muscles. Making this 
possible, in part at least, it is seen above that is it associated (1) directly with the special nerve of equilibration, the vestibular; (2) with the optic apparatus by way of the thalamus, and (3) with the afferent impulses from the general body, by way of the direct cerebellar and Gowers' tracts, by way of the nuclei of the fasciculus gracilis and cuneatus, and the nuclei of termination of the trigeminus, glosso-pharyngeal and vagus. It has been suggested that by way of these latter paths the cerebellum deals especially with those general afferent impulses which arise within the muscles of the body (neuro-muscular spindles, etc.) and which are grouped under the name "muscular sense." The cerebellum can be considered as an enlarged and modified portion of the grey substance of the spinal cord, receiving a greater number and variety of afferent impulses and with them mediating more compreliensive and complicated reflex activities than is possible with the less abundant grey substance of a given portion of the cord proper.

\section{SUMMARY OF PRINCIPAL STRUCTURES IN RHOMBENCEPHALON}

A. Gross Exterior.

1. Medulla Oblongata (Myelencephalon).

2. Netencephalon $\left\{\begin{array}{l}\text { Cerebellum }\left\{\begin{array}{l}\text { Hemispheres-lobes and lobules. } \\ \text { Vermis-lobules and lingula. }\end{array}\right. \\ \text { Pons }\left\{\begin{array}{l}\text { Dorsal part (preoblongata). } \\ \text { Ventral part (pons proper). }\end{array}\right. \\ \text { Cerebellar peduncles }\left\{\begin{array}{l}\text { superior-brachium conjunctivum. } \\ \text { middle-brachium of pons. } \\ \text { inferior-restiform body. }\end{array}\right.\end{array}\right.$

3. Isthmus of Rhombencephalon.

4. Fourth Ventricle and its Chorioid tela.

5. Anterior and Posterior Medullary Vela.

B. Grey and White Substance.

1. Funiculus gracilis, nucleus of fasciculus gracilis, funiculus cuneatus, nucleus of fasciculus cuneatus.

2. Internal and external arcuate fibres, decussation of lemnisci, lemniscus, medial lemniscus, lateral lemniscus.

3. Cerebral peduncles, pyramidal fasciculi, pyramids, decussation of pyramids, arcuate nuclei.

4. Superficial and deep strata of pons, nuclei of pons, branchia of pons.

5. Inferior olivary nuclei, cerebello-olivary fibres, thalamo-olivary tract, spino-olivary tract.

6. Nuclei emboliformis, globosus and fastigii (of the roof), and nucleus dentatus with brachium conjunctivum of cerebellum.

7. Central gelatinous substance and gelatinous substance of Rolando.

8. Reticular formation.

9. Hypoglossal nerve and nucleus of hypoglossal.

10. Spinal accessory nerve and lateral nucleus.

11. Vagus and glossopharyngeal nerves, nucleus of ala cinerea, solitary tract and nucleus of solitary tract, commissural nucleus of ala cinerea, nucleus ambiguus, dorsal efferent nucleus of vagus.

12. Vestibular nerve-its superior nucleus (Bechterew), its medial nucleus (Schwalbe), its lateral nucleus (Deiters), and the nucleus of its descending (spinal) root.

13. Cochlear nerve, dorsal nucleus and ventral nucleus of cochlear, acoustic medullary striæ, nucleus of superior olive, trapezoid body, nucleus trapezoidei, lateral lemniscus, nucleus of lateral lemniscus.

14. Facial nerve and nucleus of facial nerve.

15. Glosso-palatine nerve, nucleus of glosso-palatine and nucleus salivatorius.

16. Abducens and nucleus of abducens.

17. Trigeminus, "sensory nucleus" of trigeminus, spinal tract and nucleus of spinal tract of trigeminus.

18. Masticator nerve, chief nucleus and (so-called) mesencephalic nucleus and root of masticator.

19. Medial longitudinal fasciculus.

20. Nucleus intercalatus, nucleus of median eminence, nucleus incertus.

\section{THE CEREBRUM}

\section{THE MESENCEPHALON}

The mesencephalon or mid-brain is that small portion of the encephalon which is situated between and connects the rhombencephalon below with the prosencephalon above. It is continuous with the isthmus rhombencephali, and occupies the tentorial notch, the aperture of the dura mater which connects the meningeal cavity containing the cerebellum with that occupied by the prosencephalon. Its greatest length is about $18 \mathrm{~mm}$., and it is broader ventrally than dorsally. Its dorsal surface is hidden by the overlapping occipital lobes of the cerebral hemispheres. It consists of-(1) the lamina quadrigemina, a plate of mixed grey and white substance which goes over lateralward and below into (2), the cerebral 
peduncles (crura) and their tegmental structures, and it contains (3), the nuclei of origin of the trochlear and oculomotor nerves. It arises from thickenings of the walls of the middle cerebral vesicle of the embryo, the lamina quadrigemina arising from the dorsal or alar lamina of this portion of the neural tube, while the basal lamina thickens to form the nuclei of the nerves, the substantia nigra, etc., and by the ingrowing of the ccrebral peduncles. By means of the lamina quadrigemina roofing it over, the neural canal throughout the mesencephalon retains its tubular form and is known as the aquæductus cerebri (Sylvii), connecting the cavity of the fourth ventricle below with that of the third ventricle above.

External features.-Dorsal surface.-The lamina quadrigemina shows four well-rounded elevations, the quadrigeminate bodies [corpora quadrigemina], divided by a flat median groove crossed at right angles by a transverse groove. The anterior pair of these, the superior quadrigeminate bodics [colliculi], are

Fig. 658.-Dorsal Surface of Mesencepualon and Adjacent Parts. (After Spalteholz.)

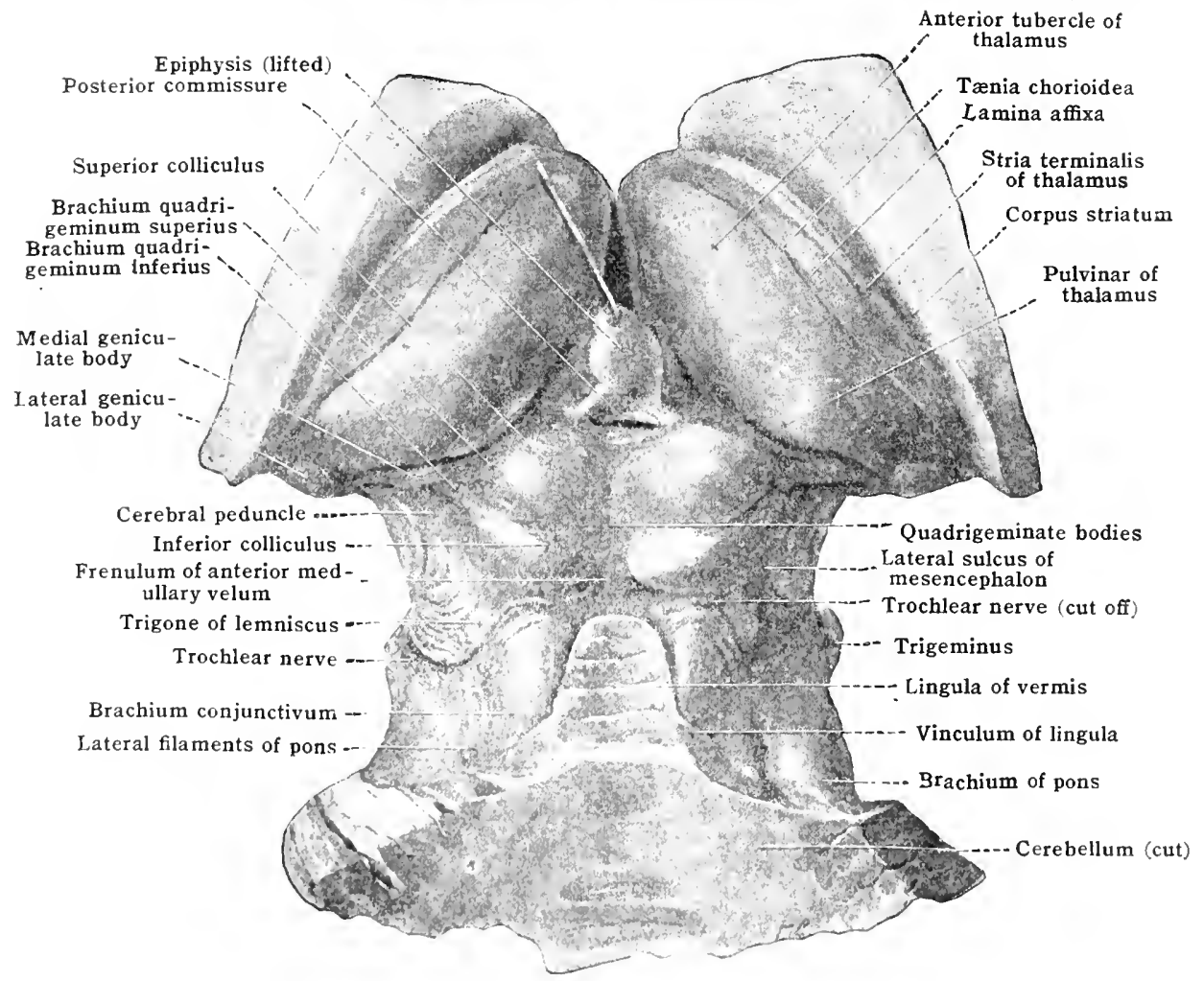

larger though less prominent than the inferior pair or inferior colliculi. Each colliculus is continuerl laterally and upward into its arm or brachium. The inferior brachium proceeds from the inferior colliculus, disappears beneath and is continuous into the medial geniculate body, and enters the thalamus. The superior brachium procereds from the superior colliculus, disappears between the medial genieulate borly and the overlapping pulvinar of the thalamus, and becomes continuous with the lateral geniculate body and thus with the lateral root of the optic tract.

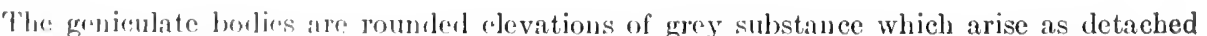
portions of the thalimi, and therefore loblong to the this lamencephalon rather than to the mesencephalon. The superior quitrigeminate bouly or superior colliculus and the lateral geniculate losly are a part of the optio apparatus, while the inferior colliculus and the medial genieuJate burly belong thiefly to the auditomy apporatus (see Cen'rua Connections of Cocmenar NERVE). Just as the forminal corliteap nuclei are connected by a few fibres with the superior colliculus, so do some fibres from the optic tract pass into the inferior collieulus. Also some fibres form thr optic tract (unsial rowt) are said to termimate in the medial geniculate body. Resting in the brostened medial gronve between the smperior fuadrigeminate bodies lies the non-nervous epiphysis or pineal broly. This also betongs to the thalamencephalon. Under the strm of the epiphysis is a strong transverse band of white substance crossing the 
mid-line as a bridge over the opening of the cerebral aqueduct into the third ventricle. This is the posterior commissure of the cerebrum, and contains commissural fibres arising in both the thalamencephalon and mesencephalon. The triangular area bounded by the stem of the epiphysis, the thalamus, and the superior colliculus with its brachium, is known as the habenular trigone.

Inferiorly, the lamina quadrigemina is continuous with the isthmus of the rhombencephalon by way of the brachia conjunctiva or superior cerebellar peduncles, and the anterior medullary velum which bridges between the mesial margins of these peduncles. The narrowed upper end of the velum, the part directly below the inferior quadrigeminate bodies, is thickened into a well-defined white band known as the frenulum veli. From the lateral margins of this band on each side and just below the inferior quadrigeminate bodies emerge the trochlear nerves (the fourth pair of cranial nerves), and the increased thickness of the band is largely due to the decussation of this pair of nerves taking place within it.

The brachium conjunctivum, together with the inferior and superior colliculi of each side, form a marked ridge which results in the lateral sulcus of the mesencephalon, a lateral depression between the base of this ridge and the cerebral peduncle below and continuous into the transverse sulcus at the superior border

Fig. 659.-Diagram of Lateral View of Mesencephalon and Adjacent Strdctures. (After Gegenbaur, modified.)

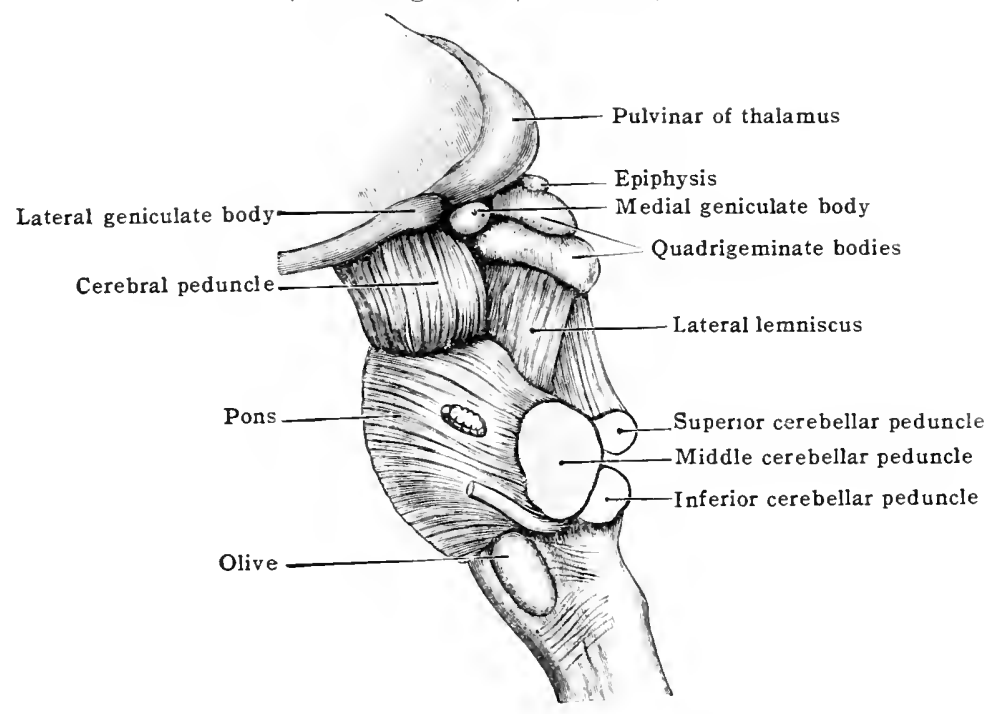

of the pons. The ridge is thickened laterally by the lateral lemniscus, which is disposed as a band of white substance passing obliquely upward from under the brachium pontis, applied to the lateral surface of the brachium conjunctivum and which enters the lateral margin of the mesencephalon. The region at which the lateral lemniscus approaches nearest the surface and in which the largest portion of its nucleus lies is the slightly elevated trigone of the lemniscus.

The ventral surface of the mesencephalon is formed by the cerebral peduncles (crura), two large bundles of white substance which are close to one another at the superior margin of the pons, but immediately diverge somewhat, producing the interpeduncular fossa, and in so doing pass upward and lateralward to disappear beneath the optic tracts (fig. 629). The posterior recess of the interpeduncular fossa extends slightly under the superior margin of the pons, while its anterior recess is occupied by the corpora mammillaria of the prosencephalon. The triangular floor of the fossa is the posterior perforated substance, a greyish area presenting numerous openings for the passage of blood-vessels. It is divided by a shallow median groove and is marked off from the medial surface of each peduncle by the oculomotor sulcus, out of which emerge the roots of the oculomotor nerves. The ventral surface of each peduncle is rounded and has a somewhat twisted appearance, indicating that its fibres curve from above medialward and downward. Sometimes two small, more or less transverse bands of fibres may be noted crossing the peduncle-an inferior, the tonia pontis, and a superior, the transverse pedun- 
cular tract. The inferior represents detached fibres of the pons; the superior, running from the brachium of the inferior quadrigeminate body and disappearing in the oculomotor sulcus, appears to be derived from the quadrigeminate bodies. Since it is well developed in the cat, dog, sheep, and rabbit, but is absent or little marked in the mole, it is supposed to be concerned with the optic apparatus.

Internal structure.-Transverse sections of the mesencephalon throughout are composed of-(1) a dorsal part, consisting of the lamina quadrigemina or the grey substance of the corpora quadrigemina, with the strata and bundles of nerve-fibres connected with them, and the abundant central grey substance surrounding the aqueduct; (2) a tegmental part, consisting of the upward continuation of the reticular formation of the medulla oblongata and that of the

Fig. 660.-Transterse Section Through the Inferior Quadrigeminate Bodies.

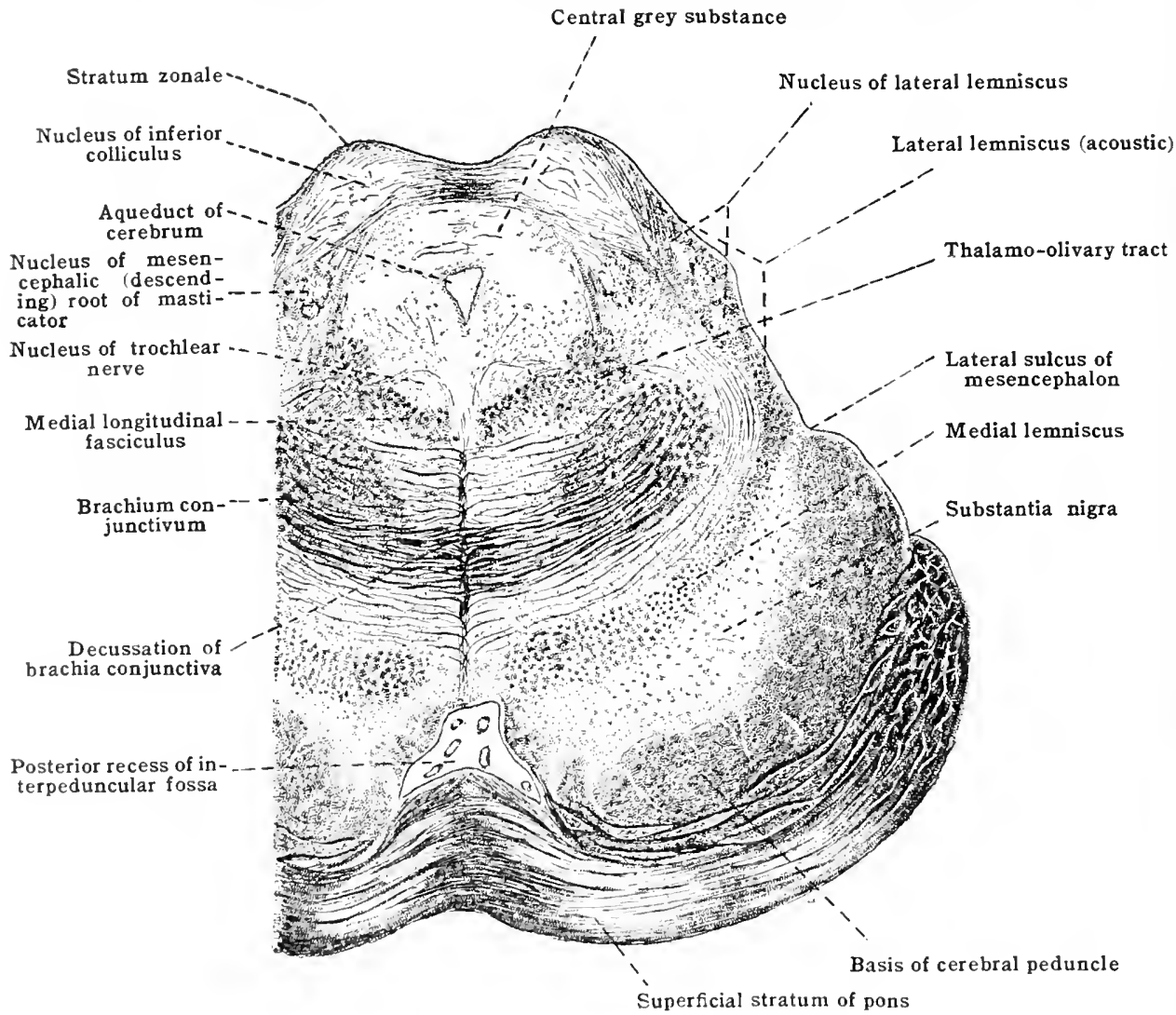

(lor:al (tegmental) portion of the pons region, to which are added the superior rerebellir perduncles and the red nuclei of the tegmentum in which these peduncles terminate; (3) a paired ventral part, the cerebral peduncles, each of which consists of a thick, pigmented stratum of grey substance, the substantia nigra, spread upon the large, superficial, and somewhat crescentic tract of white substance known as the basis of the peduncle. The eerebral perluncles eorrespond to the longitudinal or jyramickal fasciculi of the pons and medulka Likewise the lemuisens and the medial longiturlinal fasciculus of the medulla and pons continue throngh all secotions of the mesencephatom.

The central grey substance is a continuation of the central gelatinous substance of the spinal corrl and the similar stratum of the medulla and that which immodiately underlies the ependyma of the fourth ventricle. As in the spinat rorel and medulla, it is largely composed of gelatinous substance. It is mure more abuntant, in the meseneephalon, and in sections appears as a circommseribed area commatativaly void of nerve-fibres.

The muclens of the mesemer phatic root of the masticator nerve may likewise be traced throughont the moscocenhalom. It cousists of a fow small hundles of fibres surroumling a thin strand 
of nerve-cells which give origin to its fibres. It courses caudalward close to the lateral margin of the central grey substance, and is quite small at its beginning in the extreme superior part of the mesencephalon, but as it descends toward the exit of its fibres from the pons, it increases slightly in size, due to the progressive addition of fibres. Its nucleus also increases slightly in bulk in approaching the region of the ehief motor nucleus of the nerve. As mentioned above, the investigations of Johnston and Willems in lower animals suggest that the cells of the mesencephalic nucleus may be sensory instead of motor in character. The sensory nucleus (nucleus of termination) of the trigeminus tapers rapidly and probably does not extend throughout the mesencephalon.

The nuclei of the trochlear and oculomotor nerves form a practically continuous column of nerve-cells extending close to the mid-line and ventral to the aqueduct of the cerebrum. They are in line with the nuclei of origin of the abducens and hypoglossus, and, like them, may be regarded as an upward continuation of the ventral group of the cells of the ventral horn of the spinal cord. The portion of the column giving origin to the oculomotor nerve is considerably larger than that for the trochlear.

Fig. 661.-Diagrans showing the Course of Origin of the Trochlear Nerves. (Stilling. The upper figure shows roughly the entire central course of the trochlear nerves; the lower represents their region of exit in transverse section.
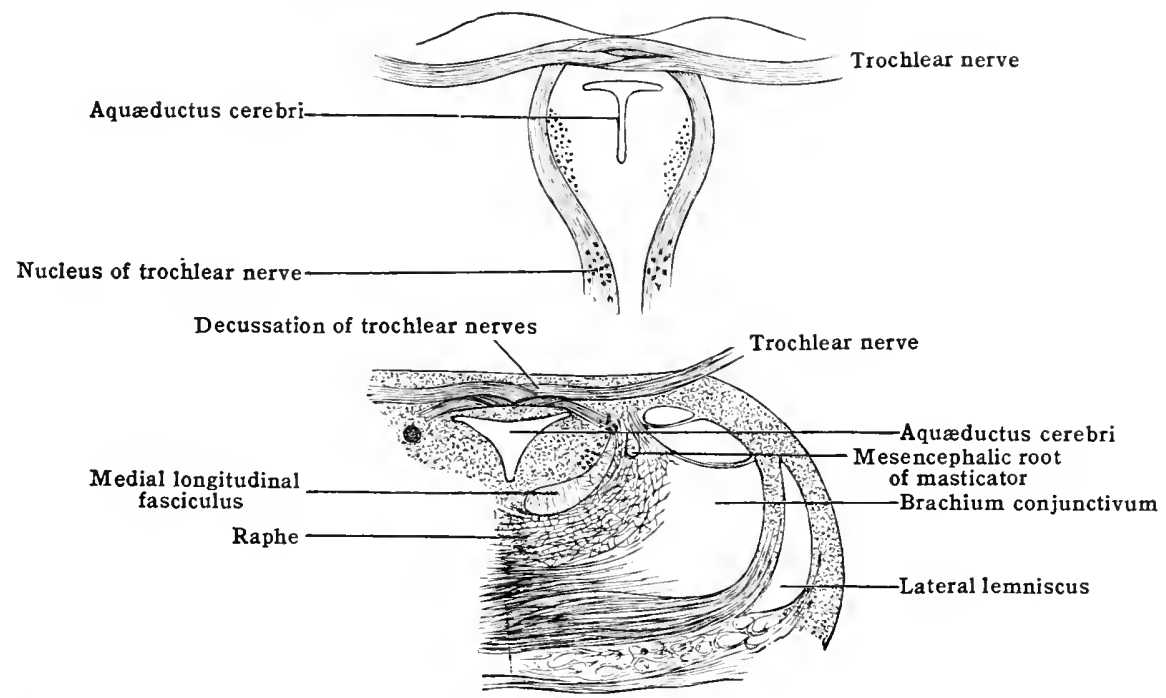

A transverse section through the inferior quadrigeminate bodies involves a portion of the decussation of the brachia conjunctiva and the nuclei of origin of the trochlear nerves, while a transverse section through the superior quadrigeminate bodies passes through the red nuclei of the tegmentum and the nuclei of origin of the oculomotor nerves. The latter section will also involve the brachia of the inferior quadrigeminate bodies and the medial geniculate bodies connected with them, and, if slanting slightly forward it will involve the pulvinars of the thalami and the lateral geniculate bodies.

The trochlear or fourth nerve is the smallest of the cranial nerves, and is the only one which makes its exit from the dorsal surface of the brain, as well as the only one whose fibres undergo a total decussation.

Its nucleus of origin is situated beneath the inferior quadrigeminate bodies in the ventral margin of the central grey substance, quite close to the mid-line and to its fellow nucleus of the opposite side, and it is closely associated with the dorso-mesial margin of the medial longitudinal fasciculus. Its root-fibres pass lateralward and dorsalward, curving around the margin of the central grey substance, mesial to the mesencephalic root of the masticator nerve. As the root curves toward the mid-line in the dorsal region just beneath the inferior quadrigeminate bodies, it turns sharply and courses inferiorly to approach the surface in the superior portion of the anterior medullary velum, the frenulum veli. In this it meets and undergoes a total decussation with the root of its fellow nerve, and then emerges at the medial margin of the superior cerebellar peduncle of the opposite side. Having emerger, it then passes ventrally around the cerebral peduncle, and thence pursues its course to the superior oblique muscle of the eye. It receives optic impulses from the superior quadrigeminate bodies and impulses from the cerebral cortex of chiefly the same side, and it is associated with the nuclei of other cranial nerves by way of the medial longitudinal fasciculus. 
The oculomotor or third nerve, like the trochlear, is purely motor. It is the largest of the eye-muscle nerves. It supplies in all seven muscles of the optic apparatus:-two intrinsic, the sphincter iridis and the ciliary muscle, and five extrinsic. Of the latter, the levator palpebræ superioris is of the upper eyelid, while the remaining four, the superior, medial, and inferior recti and the obliquus inferior, are attached to the bulb of the eye. As is to be expected, its nucleus of origin is larger and much more complicated than that of the trochlear nerve.

Practically continuous with that of the trochlear below, the nucleus is 5 or $6 \mathrm{~mm}$. in length and extends anteriorly a short distance beyond the bounds of the mesencephalon into the grey substance by the side of the third ventricle. It lies in the ventral part of the central grey substance, and is very intimately associated with the medial longitudinal fasciculus. Its thickest

Fig. 662,-Transverse Section Through Level of Superior Quadrigeminate Bodies. Stratum zonale of thalamus

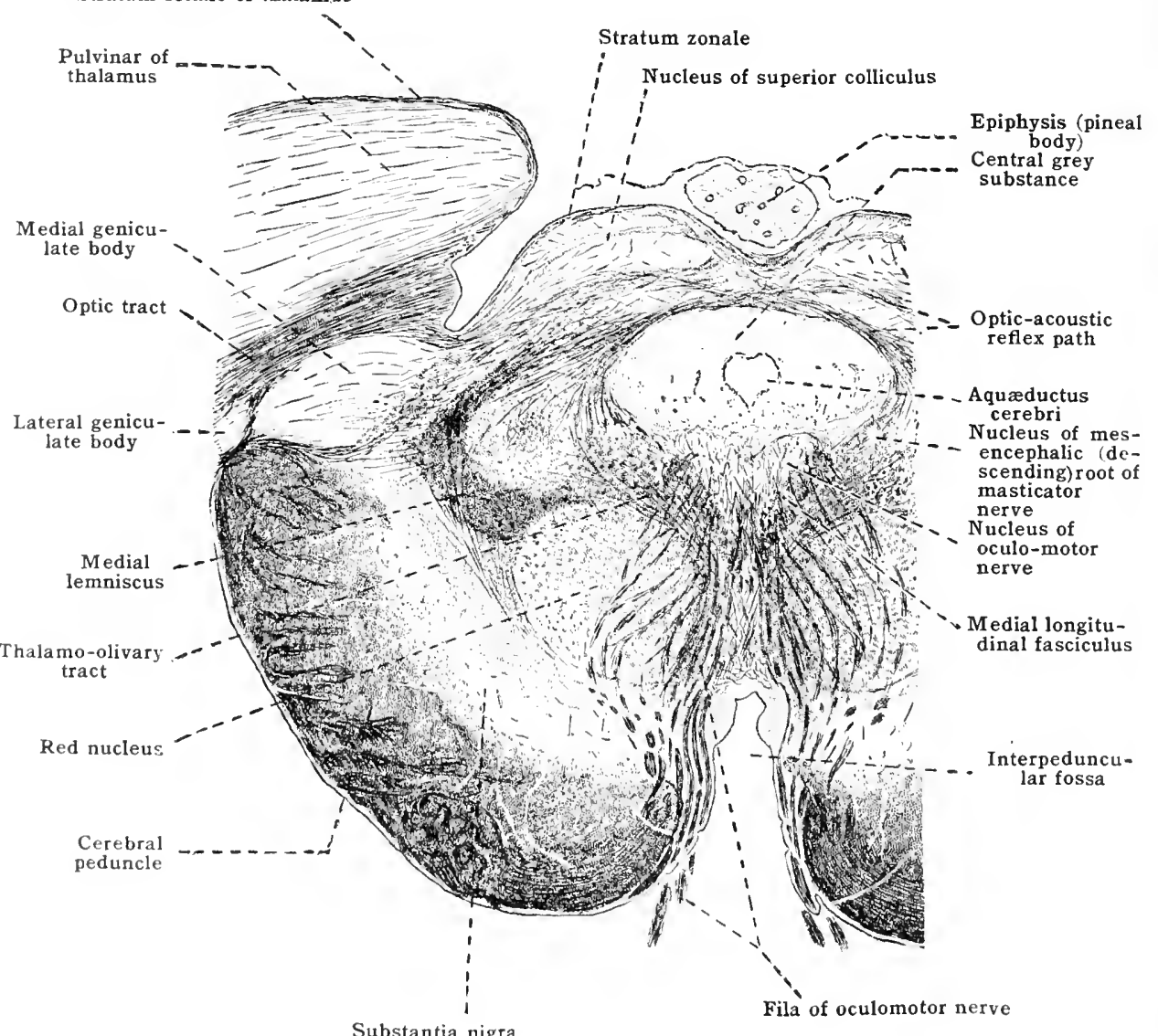

Substantia nigra

portion is bencath the summit of the superior (puadrigeminate body. The root-fibres leave the nucleus from its ventral side and collect into bundles which pass through the medial longitudinal fasciculus and course vontrally to the mesial portion of the substantia nigra, where they emerge in from six to fiftera rouflets which blend to form the trunk of the nerve in the oculomotor sulcus of the cerrebral pedundes. Those bundles which arise from the more lateral portion of the nucleus course in in series of eurves through and aromnd the substance of the red nucleus below and, in the substantia nigra, join those which pursue the nore direct course. The trunk thus assmbled passes lateralward anound the nesial border of the eerebral pedunele.

$\Lambda$ portion of the fibres of the oculomotor nerve upon leaving the nucleus decussate in the tegmentum immediately bolow and pass into the nerve of the opposite side, in which they are helieved to be distributer to the opposite medial rectus muscle. The cells of the nucleus have ban variously grouped and subdivided with reference to the different museles supplied by the nerve. Perlia has divided them into eight cell-groujs. The nucleus may be more easily considered as composed of an inferior and a superior medial group. The inferior group consists of a long latcral portion eontinums with the nucleus of the trochtear nerve below, and a smaller medial portion, sitnated in the modial planrame continuons across the mid-line with its fellow of the oppesite side. The superior morlial group consists of cells of smaller size than the

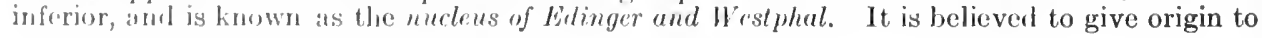


the fibres (visceral efferent fibres) which terminate in the ciliary ganglion, axones from which supply the two intrinsic muscles concerned, viz., the ciliary muscle and the sphincter iridis.

The nucleus of the oculomotor is associated with the remainder of the optic apparatus-(1) by way of the neurones of the superior quadrigeminate body with the optic tract (retina) and it receives impulses from the occipital part of the cerebral cortex of the same and the opposite sides, and probably from the motor cortex of the frontal lobe; (2) by way of the medial longitudinal fasciculus with the nuclei of the trochlear and abducens (the latter making possible the coordinate action of the lateral and medial recti for the conjugate eye movements produced by these muscles), and with the nucleus of the facial (associating the innervation of the levator palpebræ with that of the orbicularis oculi); (3) with the nuclei of termination of the sensory nerves, especially the auditory, by way of the lateral lemniscus and medial longitudinal fasciculus. It is probably connected with the cerebellum by way of the brachia conjunctiva and red nuclei.

Fig. 663.-Diagrail of Longitudinal Section of Nucleus of Oculonotor Nerve. (After Edinger.)

Nucleus of posterior commissure and med. longit. fasc.

$$
\begin{aligned}
& \text { Medial longitudinal } \\
& \text { fasciculus } \\
& \text { Ciliary muscles (a) and } \\
& \text { sphincter of iris (b) } \\
& \text { Levator palpebræ }
\end{aligned}
$$
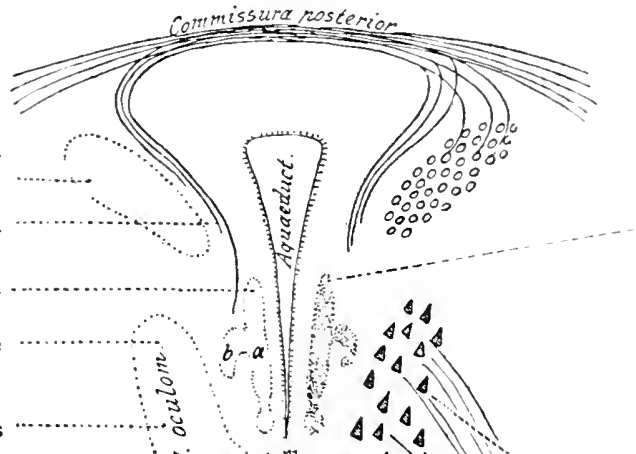

Superiorgroup nucleus of Edinger and Westphal)

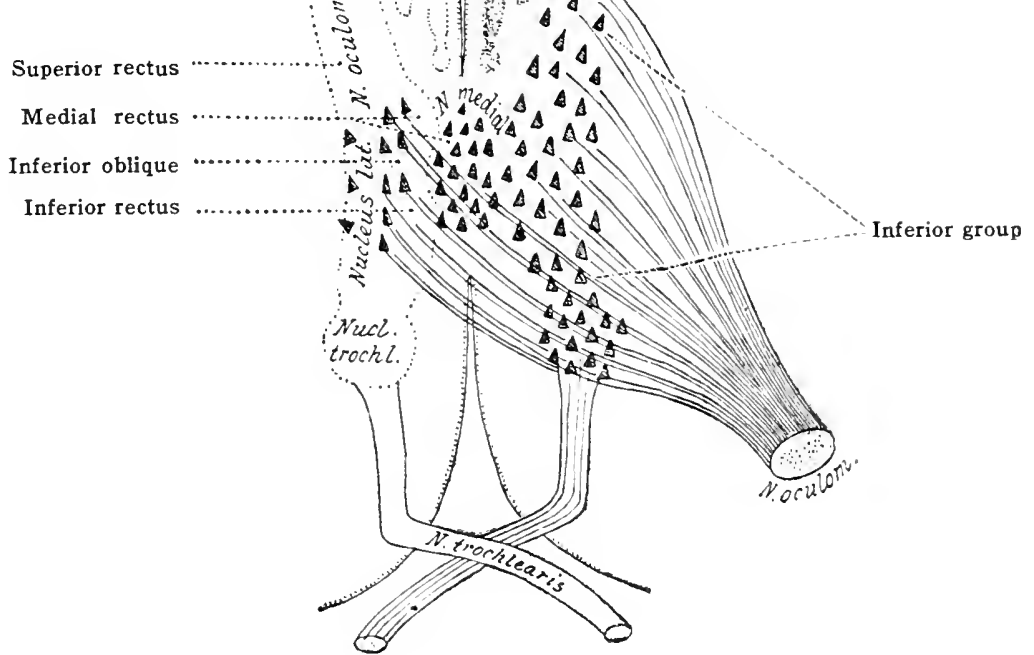

The eminence representing the inferior quadrigeminate body proper consists of an oval mass of grey substance, the nucleus of the inferior colliculus, containing numerous nerve-cells, most of which are of small size. A thin superficial lamina of white substance, the stratum zonale, forms its outermost boundary, and fibres from the lateral lemniscus enter it laterally and from below stratum lemnisci). Near the lateral margin of the central grey substance occurs the beginning of the inferior brachium, a bundle containing fibres to and from the medial geniculate body and the inferior quadrigeminate body.

The lemniscus in the mesencephalon is considered in two parts. The more lateral portion of the lemniscal plate occuring in the pons has here spread dorso-laterally, and occupies a position in the lateral margin of the section, and is known as the lateral lemniscus, while the medial portion which remains practically unchanged in the tegmentum is distinguished as the medial lemniscus. (See fig. 660). In the upper portion of the lateral lemniscus occurs a small, scattered mass of grey substance, the nucleus of the lateral lemniscus, in which many of its fibres are interrupted.

The upper and greater portion of the lateral lemniscus with its nucleus belongs to the auditory apparatus, being connected with the nucleus of termination of the cochlear nerve, chiefly of the opposite side. (See fig. 650.) A large part of the fibres of this portion terminate in the inferior quadrigeminate bodies. Many of the latter enter at once the nucleus of the body 
(nucleus of inferior colliculus) of the same side, and disappear among its cells; others cross the mid-line to the quadrigeminate body of the opposite side. In crossing, some pass superficially and thus contribute to the stratum zonale, while others pass either through the nucleus or below it and cross beneath the floor of the median groove between the stratum zonale and the dorsal surface of the central grey substance, forming there an evident decussation with similar fibres crossing from the opposite side. Most of the fibres arising from the cells of the nucleus of the inferior quadrigeminate body pass by way of the inferior brachium to the medial geniculate body and the thalamus; some pass ventrally to terminate in the nucleus of origin of the trochlear nerve and some pass forward and laterally to terminate in the cortex of the superior gyrus of the temporal lobe, the cortical area of hearing. Another portion of the lateral lemniscus passes obliquely forward in company with the inferior brachium, and terminates in the medial geniculate body. Thus a large portion of the lateral lemniscus, the inferior quadrigeminate bodies with their brachia and the medial geniculate bodies are concerned with the sense of hearing. The nucleus of the inferior quadrigeminate body receives fibres which arise in the cortex of the superior temporal grrus of chiefly the same side.

Practically all the remainder of the lateral lemniscus terminates in the nucleus, or stratum cinereum, of the superior quadrigeminate body of the sa me and opposite sides. They approach the nucleus from below, and contribute to the well-marked band of fibres coursing on the dorsolateral margin of the central grey substance, and known as the 'optic-acoustic reflex path' or' stratum leminisci (fig. 662).

The medial lemniscus arises in the medulla oblongata from the nuclei (of termination) of the funiculus gracilis and funiculus cuneatus of the opposite side, and likewise from the nuclei of termination of the sensory roots of the cranial nerves of the opposite side. It is, therefore, a continuation of the central sensory pathway conveying the general bodily (including the head) sensations into the prosencephalon. Coursing still more laterally than in the pons below, it passes in to the hypothalamic grey substance, in the lateral portion of which most of its fibres terminate. By axones given off from the cells of the hypothalamic nucleus the impulses borne thither by the lemniscus are conveyed by way of the internal capsule and corona radiata to the gyri of the somasthetic area of the cerebral cortex.

The basis (pes) pedunculi comprises the great descending pathway from the cerebral cortex, and thus is continuous with the internal capsule of the telencephalon.

The principal components of each basis pedunculi are as follows:-(1) The pyramidal fibres, which occupy the middle portion of the peduncle and comprise three-fifths of its bulk, and which are outgrowths of the giant pyramidal cells of the somesthetic area of the cerebral cortex. chiefly the anterior central gyrus. These supply 'voluntary' impulses to the motor nuclei of the cranial nerves on the opposite side, form the pyramids of the medulla, and are distributed to the ventral horn cells of the spinal cord of the opposite side. (2) The frontal pontile fibres, which course in the mesial part of the peduncle from the cortex of the frontal lobe to their termination in the grey substance of the pons. (3) The occipital and temporal pontile fibres. which run in the ventral and lateral portion of the peduncle from their origin in the occipital and temporal lobes to their termination in the grey substance of the pons.

The substantia nigra is continuous with the grey substance of the pons and that of the reticular formation below, and with that of the hypothalamic region above. Its remarkable abundance begins at the superior border of the pons, and it conforms to the crescentic inner contour of the cerebral peduncle, sending numerous processes which occupy the inter-fascicular spaces of the latter. It contains numerous deeply pigmented nerve-cells, which in the fresh specimen give the appearance suggesting its name.

Its anatomical significance is not well understood. It is known that some fibres of the medial lemniseus terminate about its cells instead of in the hypothalamus higher up, and Mellus has found in the monkey that a large portion of the pyramidal fibres arising in the thumb area of the cerebral cortex are interrupted in the substantia nigra. It is probable that other fibres of the peduncle also terminate here.

The brachia conjunctiva or superior cerebellar perluncles, in passing from their origin in the dentate nuclei, lose their flattened form and enter the mesencephalon as rounderl bundles. In the tegmentum, under the inferior colliculi, the two brachia come together and undergo a sudden and complete decussation. Through this derossation the fibres of the brachinm of one side pass forward to terminate, most of them, in the red nueleus [mucleus ruber] of the tegmentum of the opposite side (fig. 589). Some fibres are satid to pass the red nucleus and terminate in the vontroliateral part of the thalamus.

The red nuclei are two large, globular masses of nerve-cells situated in the

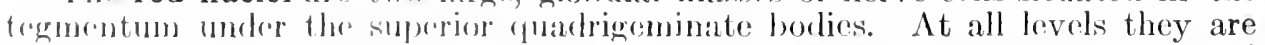
considerably mixed with the entring bundles of the brachia conjunctiva, and they rontain a pigment, whieh in the fresh condition gives them a reddish colour, suggesting their namer.

Thery recerve in andition desconding fibres from the crebral cortex (frontal operculum) and from the musloi of the corpus striatum. From the cells of each red nucleus arise fibres 
which pass-(1) into the thalamus and to the telencephalon (prosencephalic continuation of the cerebellar path), and (2) fibres which descend into the spinal cord, the 'rubro-spinal tract,' in the lateral funiculus (fig. 619). The latter cross from the red nucleus of the opposite side and descend in the tegmentum. The red nuclei are also in relation with the fasciculus retroflexus of Meynert, which belongs to the inter-brain.

Fig. 664.-Scheme to Illustrate the Principal or Crossed Relations of the Descending Cortical. (Pyranidal) Fibres to the Nuclei of Origin of the Cranial Nerves.

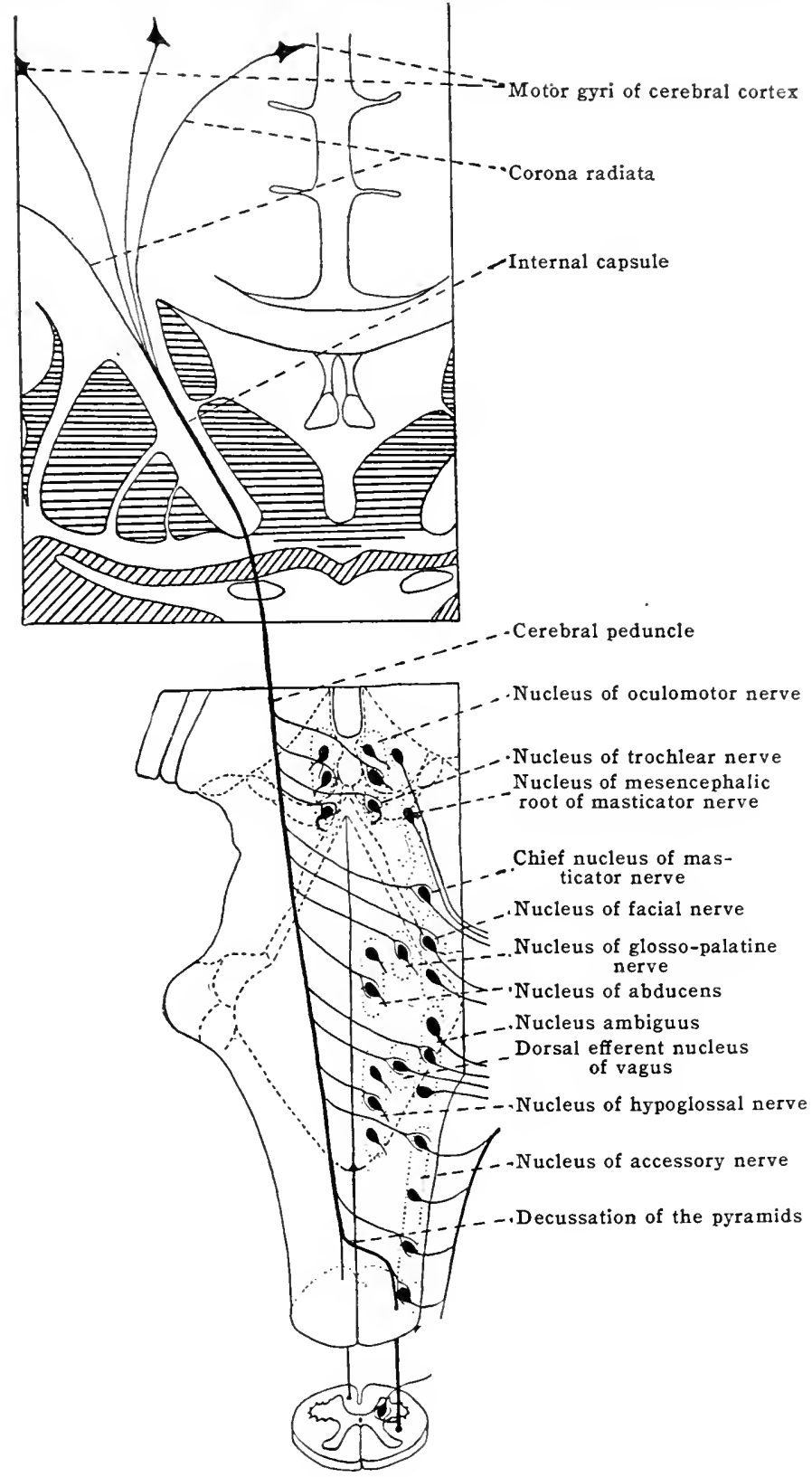

The thalamo-olivary tract courses in the mesencephalon more dorsally than in the pons region. It runs in the ventro-lateral boundary of central grey substance just lateral to the nuclei of the trochlear and oculomotor nerves.

A small quadrigemino-pontile strand of fibres has been described as arising in the quadrigemina, especially the inferior pair, and terminating in the nuclei of the pons. Impulses carried by these fibres are probably destined for the cerebellar hemisphere of the opposite side.

The superior quadrigeminate bodies (superior colliculi) are phylogenetically more important than the inferior. In certain of the lower vertebrates they are 
enormously developed and in most of the mammals they are relatively larger and appear more complicated in structure than in man. They are concerned almost wholly with the visual apparatus, mediating most of the reflexes with which it is concerned.

The nucleus of the superior colliculus is of somewhat greater bulk than that of the inferior. It is capped by a strong stratum zonale (fig. 662), which has been described as composed chiefly of retinal fibres, passing to it from the optic tract by way of the superior brachium, but, since Cajal found in the rabbit that extirpation of the eye is followed by very slight degeneration of the stratum zonale, it is probable that it is composed of other than retinal fibres-possibly fibres from the occipital cortex and fibres arising within the nucleus itself. The nucleus is separated from the central grey substance by a well-marked band of fibres, the stratum album profundum. This contains fibres from two sources:-(1) fibres from the lateral lemniscus which approach the nucleus from the under side, some to terminate within it, others to cross to the nucleus of the opposite side; (2) fibres which arise within the nucleus and course ventrally around the central grey substance, both to terminate in the nucleus of the oculomotor nerve and to join the medial longitudinal fasciculus and pass probably to the nuclei of the trochlear and abducens. The lemniscus fibres often course less deeply than (2) and give the stratum lemnisci. The optic fibres proper approach the nucleus by way of the superior brachium, and are dispersed directly among its cells; only a small proportion of them cross over to terminate in the nucleus of the opposite side. They consist of two varieties:-(1) retinal fibres which arise in the ganglion-cell layer of the retina and enter the superior brachium at its junction with the lateral root of the optic tract, and (2) fibres from the visual area of the occipital lobe of the cerebral hemisphere. Sometimes the optic fibres in their course within the nucleus of the superior colliculus form a more or less evident stratum near the stratum album profundum. This is known as the stratum opticum (stratum album medium). The portion of the nucleus between this stratuin and the stratum zonale is called the stratum cinercum.

The fibres entering the nucleus from the lateral lemniscus probably all represent auditory connections. The stratum album profundum, composed of the lemniscus fibres and fibres from cells of the nucleus, and the stratum opticum together, form the so-called 'optic-acoustic reflex path' (fig. 662).

The mesencephalo-spinal amd the spino-mesencephalic (spino-tectal) paths course together ventro-lateral to the nuclei of the colliculi. In the superior quadrigeminate bodies they course in the dorsal edge of the median lemniscus, between the stratum opticum and stratum album profundum.

From the various studies that have been made it appears that the superior colliculus of the corpora quadrigemina is mercly the central reflex organ concerned in the control of the eye muscles-eye muscle reflexes which result from retinal and cochlear stimulation, and from some general body sensations by way of the spinal cord. Fibres from its nucleus to the visual area of the occipital cortex have been claimed for certain mammals, but in man the superior colliculus may be entirely destroyed without disturbance of the perception of light or color and fibres arising from its nucleus to terminate in the cerebral cortex are denied.

In the level of the anterior part of the superior colliculus the fibres which arise from the cells of its nucleus and course ventrally in the stratum album profundum collect into a strong bundle. This bundle passes ventral to the medial longitudinal fasciculus and, in the space between the $t$ wo red nuclei, it forms a dense decussation with the similar bundle from the opposite side. In lecussating the fibres turn in spray-like curves downward and soon join the medial longitudinal fasciculus. This is the 'fountain decussation' of Forel. It is said to be augmented by decussating fibres from the two red nuclei.

There is abundant evidence that fibres arising in the corpora quadrigemina descend into the spinal cord. Various studies make it appear that at least part of these are fibres from the fountain rlecussation, and that these course through the medulla oblongata in the ventral part of the medial longitudinal fasciculus, and thence descend into the cord in the 'quadrigeminothalamus path' (lateral mesencephalo-spinal tract) (fig. 619). The medial longitudinal fasciculus is continuous with the ventral fasciculus proprius of the spinal cord and most of these fibres arising in the superior quadrigeminate borlies retain their ventral position in the cord as the sulco-marginal fasciculus of the opposite side. Their termination about those ventral horn cells of the cervical corl which send fibres through the rami communicantes probably establishes the pathway by which the superior fuadrigeminate bodies are connected with the cervical sympathetic ganglia, and by which may be explained the disturbances in pupillary contration indued by lesions of the lower cervical cord.

The medial graicitate body and the medial root of the optic tract, which runs into the former, probably have nothing to rlo with the functions of the optic apparatus. Both remain intact after extirpation of the eyes. The medial root of the optic tract is apparently nothing more than the fergimning of the inferior cercbral (Giudden's) commissure, a bundle passing by way of the optic tract, connerting the inedial geniculate body of one side with that of the other side, amel probably with the inferior colliculus.

The medial longitudinal fasciculus (posterior longitudinal faseiculus), continuons into the ventral fasciculus proprius and the sulco-marginal faseiculus of the spinal eorl, extends throughout the rhombencephalon and mesencephalon, and is represented in the hypothalamic region of the prosencephalon. Deserted hy the lemniscus at the inferior border of the pons, it maintains its closely medial position and courses throughout in the inmediate ventral margin of the central grey substance of the medulla and floor of the fourth ventricle, and likewise in the ventral margin of the central grey substance of the mesencephalon. 
The two fasciculi constitute the principal association pathways of the brain-stem, and, true to their nature as such, they are among the first of its pathways to acquire medullation. In the mesencephalon they become two of its most conspicuous tracts, and their course, in most intimate association with the nuclei of origin of the nerves supplying the eye muscles, suggests what is probably one of their most important functions, viz., that of associating these nuclei with each other and of bearing to them fibres from the nuclei of the other cranial nerves necessary for the co-ordinate action of the muscles of the optic apparatus associated with the functions of these other nerves.

Fibres from each medial longitudinal fasciculus terminate either by collaterals or terminal arborisations about the cells of the motor nuclei of all the cranial nerves, and each nucleus probably contributes fibres to it. It also receives fibres from the nuclei of termination of the sensory nerves especially the vestibular. Thus it contains fibres coursing in both directions, and, while it is continually losing fibres by termination, it is being continually recruited and so maintains a practically uniform bulk. Thus, a given lesion never results in its total degeneration. Many of the fibres coursing in it arise from the opposite side of the mid-line. A special contribution of fibres of this kind is received by way of the fountain decussation from the nucleus of the superior colliculus of the opposite side. As noted above, it is in part continuous into the spinal cord as the ventral fasciculus proprius. It receives some fibres by way of the posterior commissure of the prosencephalon from a small nucleus common to it and the posterior commissure situated in the superior extension of the central grey substance of the mesencephalon. Van Gehuchten and Edinger describe for it a special nucleus of the medial longitudinal fasciculus situated beyond this commissure in the hypothalamic rsgion. This nucleus may be explained as an accumulation of the gray substance of the reticular formation below and as receiving impulses from the structures of the prosencephalon which are distributed by its axones to the structures below by way of the medial longitudinal fasciculus.

Scattered in the posterior part of the posterior perforated substance, near the superior border of the pons, is a small group of cell-bodies forming the inter-peduncular nucleus (interpeduncular ganglion of von Gudden). Fibres arising in the habenular nucleus of the diencephalon curve posteriorly, forming the fasciculus retroflexus of Meynert, and terminate about its cells. Fibres arising from its cells course dorsalward and terminate about association neurones in the ventral periphery of the central grey substance. It is concerned with olfactory impulses.

\section{SUMMARY OF THE MESENCEPHALON}

1. Quadrigeminate bodies:

(a) Inferior colliculi, their nuclei and brachia.

(b) Superior colliculi, their nuclei and brachia.

2. Peduncles of the cerebrum

3 . Aqueduct of the cerebrum.

4. Central grey substance.

5. Substantia nigra.

6. Decussation of superior cerebellar peduncles and the red nuclei.

7. Medial lemniscus, lateral lemniscus and nucleus of lateral lemniscus

8. Mesencephalic nucleus and root of masticator nerve.

9. Trochlear nerve and its nucleus.

10. Oculomotor nerve and its nucleus.

11. Mesencephalo-spinal and rubro-spinal tracts.

12. Medial longitudinal fasciculus, its nucleus, the nucleus of the posterior commissure.

13. The fountain decussation.

14. Interpeduncular nucleus.

As frequently realized in the above, the structures of the mesencephalon are both overlapped by, and are of necessity functionally continuous with, the structures of the next and most anterior division of the encephalon, the prosencephalon.

\section{THE PROSENCEPHALON}

The prosencephalon or fore-brain includes those portions of the encephalon derived from the walls of the anterior of the three embryonic brain-vesicles. In its adult architecture it consists of -(1) the diencephalon (interbrain), comprising the thalamencephalon or the thalami and the structures derived from and immediately adjacent to them, and, in addition, the mammillary portion of the hypothalamic region; (2) the telencephalon (end-brain), comprising the optic portion of the hypothalamic region and the cerebral hemispheres proper. The last mentioned consist of the entire cerebral cortex or superficial mantle of grey substance, including the rhinencephalon, and also the basal ganglia or buried nuclei (corpus striatum), together with the tracts of white substance connecting and associating the different regions of the hemispheres with each other and with the structures of the other divisions of the central nervous system.

\section{EXTERNAL FEATURES OF THE PROSENCEPHALON}

A. THE DIENCEPHALON.-The basal surface of this division of the brain consists of only the mammillary portion of the hypothalamic region (fig. 668). 
This comprises-(1) the mammillary bodies [corpora mammillaria] (albicantia), the two rounded projections situated in the anterior part of the interpeduncular fossa, and (2) the anterior portion of the posterior perforated substance or the small triangle of grey substance forming the floor of the posterior part of the third rentricle, and which represents numerous openings for the passage of branches of the posterior cerebral arteries (fig. 668). The hypothalamie portions of the cerebral peduncles might be included. The structures of the optic or remaining portion of the hypothalamus belong to the telencephalon.

The upper or dorsal surface of the diencephalon is completely overlapped and hidden by the telencephalon, and covered by the intervening ingrowth of the

Fig. 665.-Dorsal Surface of Diencephalon with Adjacent Structures. (After Ober'steiner.)

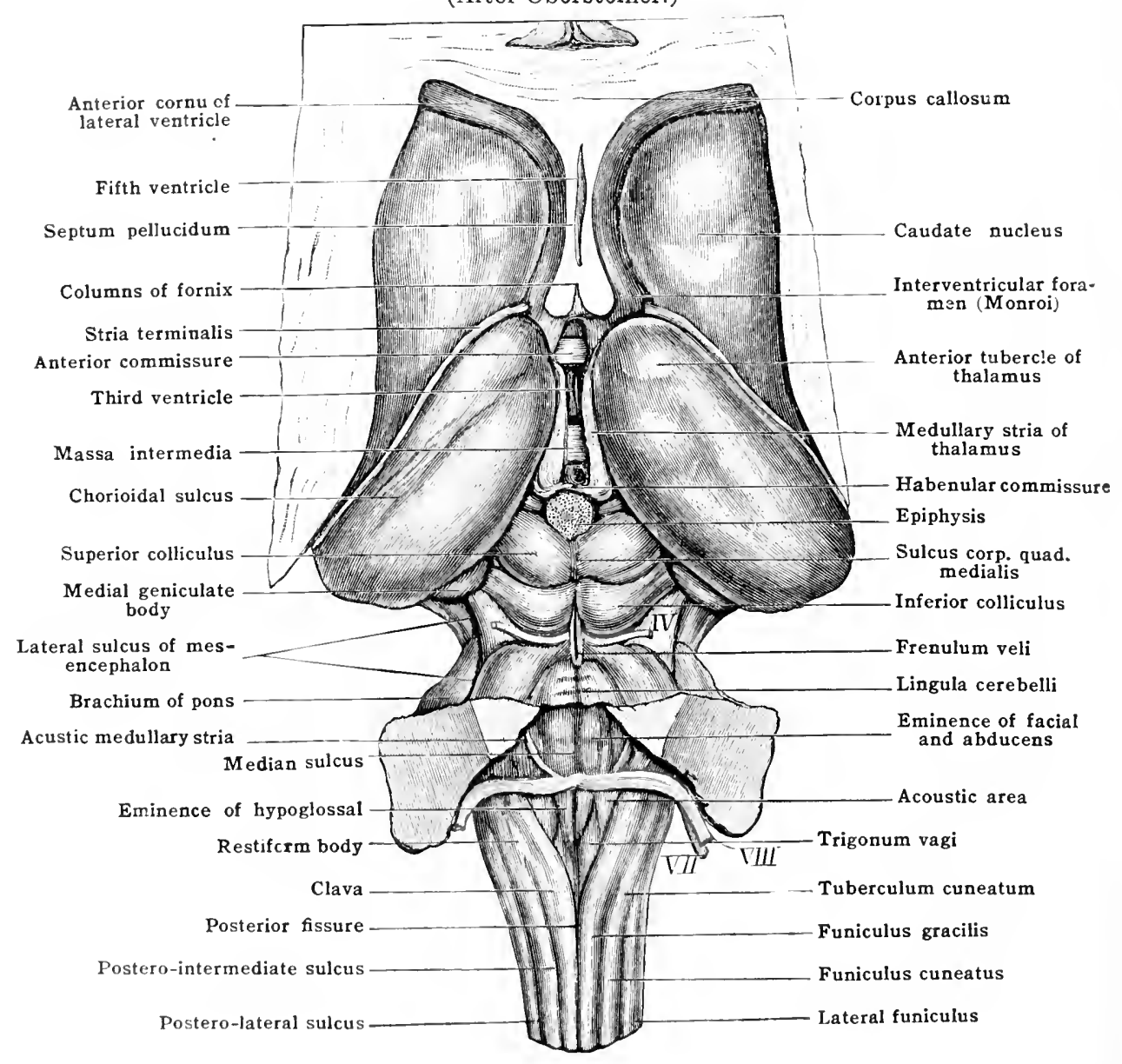

cerebral meninges, the tela chorioidea of the third ventricle (velum interpositum). These removerl (fig. 665 ), it is seen that the thalami on either side are by far the most conspicuons oljects of the diencephalon. They, together with the parts developed in commertion with them, are clistinguished as the thalamencpehalon. The thatamenecphaton consists of-(1) the thalami; (2) the metathalamus or gonienlate borlies; and (3) the epithalemus, comprising the epiphysis with the postrepor commissure below it and the habenular trigone on either side.

'Thr' thalami are two ovoicl, couch-like masses of grey substance which form the listraral watls of the third vontricle. The eavity of the ventricle is narrow, and quite frofuently the thatami are contimunes through it across the mid-line by a small but variable neek of grey sulstance, the massa intermedia ("middle commisstro"). "The upper surfaren of thre thalami are free. 'The edges of the tela "horicidea of the third sentriels are attached to the lateral part of the surface of

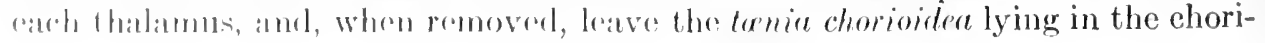


oidal sulcus. Each thalamus is separated laterally from the caudate nucleus of the telencephalon, by a linear continuation of the white substance below, known as the stria terminalis thalami (tænia semicircularis). Like the quadrigemina, each thalamus is covered by a thin capsule of white substance, the stratum zonale. The average length of the thalamus is about $38 \mathrm{~mm}$., and its width about $14 \mathrm{~mm}$; its inferior extremity is directed obliquely lateralward. The dorsal surface usually shows four eminences, indicating the position of the so-called nuclei of the thalamus within. These are the anterior nucleus or anterior tubercle, the medial nucleus or tubercle, the latcral nucleus, and the pulvinar, the tubercle of the posterior extremity. The pulvinar of the human brain is peculiar in the fact that it is so developed as to project inferiorly and slightly overhang the level of the quadrigeminate bodies. The projecting portion assumes relations with the optic tract and the metathalamus.

Fig. 666.-Dissection of Brain showing Metathalamus and Pulvinar with Adjacent STRUCTURES.

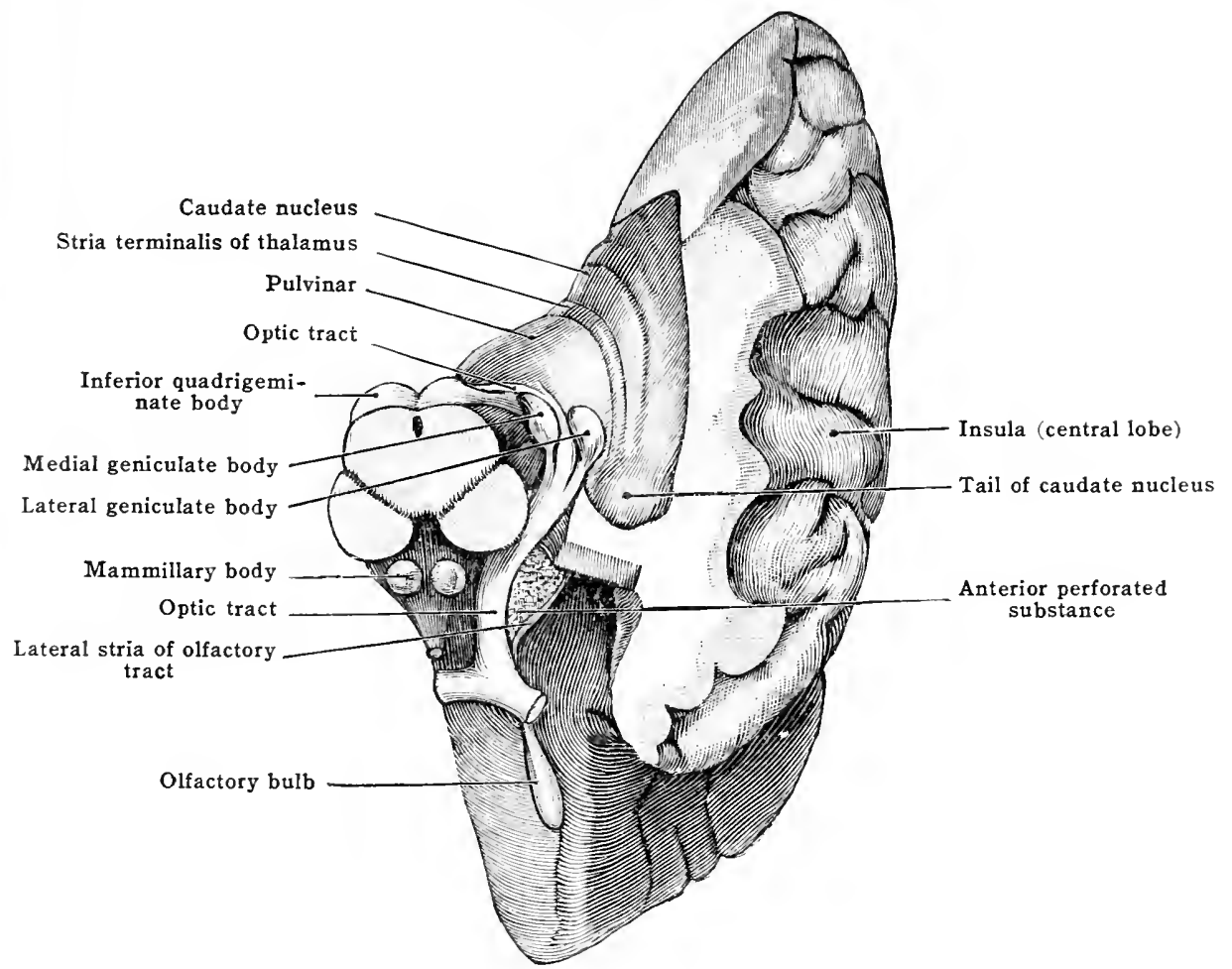

Both the structures of the metathalamus, the lateral and medial geniculate bodies, are connected with the optic tract, but it is thought that actual visual axones terminate only in the lateral genticulate body. As the optic tract curves around the cerebral peduncle it divides into two main roots. The lateral geniculate body receives a small portion of the fibres of the lateral root of the optic tract; the remainder pass under this body and enter the pulvinar of the thalamus. The medial geniculate body is connected with the medial root of the optic tract, which root consists largely, not of retinal fibres, as does the lateral root, but of the fibres forming Gudden's commissure (the inferior cerebral commissure). The retinal fibres contained in the medial root pass to terminate in the superior quadrigeminate bodies.

Of the epithalamus, the epiphysis (pineal body, conarium) is the most conspicuous external feature. This is an unpaired, cone-shaped structure, about 7 $\mathrm{mm}$. long and $4 \mathrm{~mm}$. broad, which also projects upon the mesencephalon so that its body rests in the groove between the superior quadrigeminate bodies. Its stem is attached in the mid-line at the posterior extremity of the third ventricle, and therefore just above the posterior commissure of the cerebrum (fig. 658). It is covered by pia mater, and is involved in a continuation of the tela chorioidea 
of the third ventricle. Though it develops as a diverticulum of that portion of the anterior primary vesicle which gives origin to the thalamencephalon, it is wholly a non-nervous structure, other than the sympathetic fibres which enter it for the supply of its blood-vessels.

It consists of a dense capsule of fibrous tissue (pia mater) from which numerous septa pass inward, dividing the interiol into a number of intercommunicating compartments filled with epithelial (ependymal) cells of the same origin as the ependyma lining the ventricles and aqueduct below. Among these cells are frequently found small accretions (brain-sand, acervulus cerebri), consisting of mixed phosphates of lime, magnesia, and ammonia and carbonates of lime. The compartments form a closed system. In function the epiphysis ranks as one of the glands of internal secretion of the body, and it is often referred to as the 'pineal gland.' However, it is perhaps functionless in man.

Fig. 667.-Mesial Section of Entire Brain, showing Mesial Surface of Diencephalon and Telencephalon. (After Henle.)

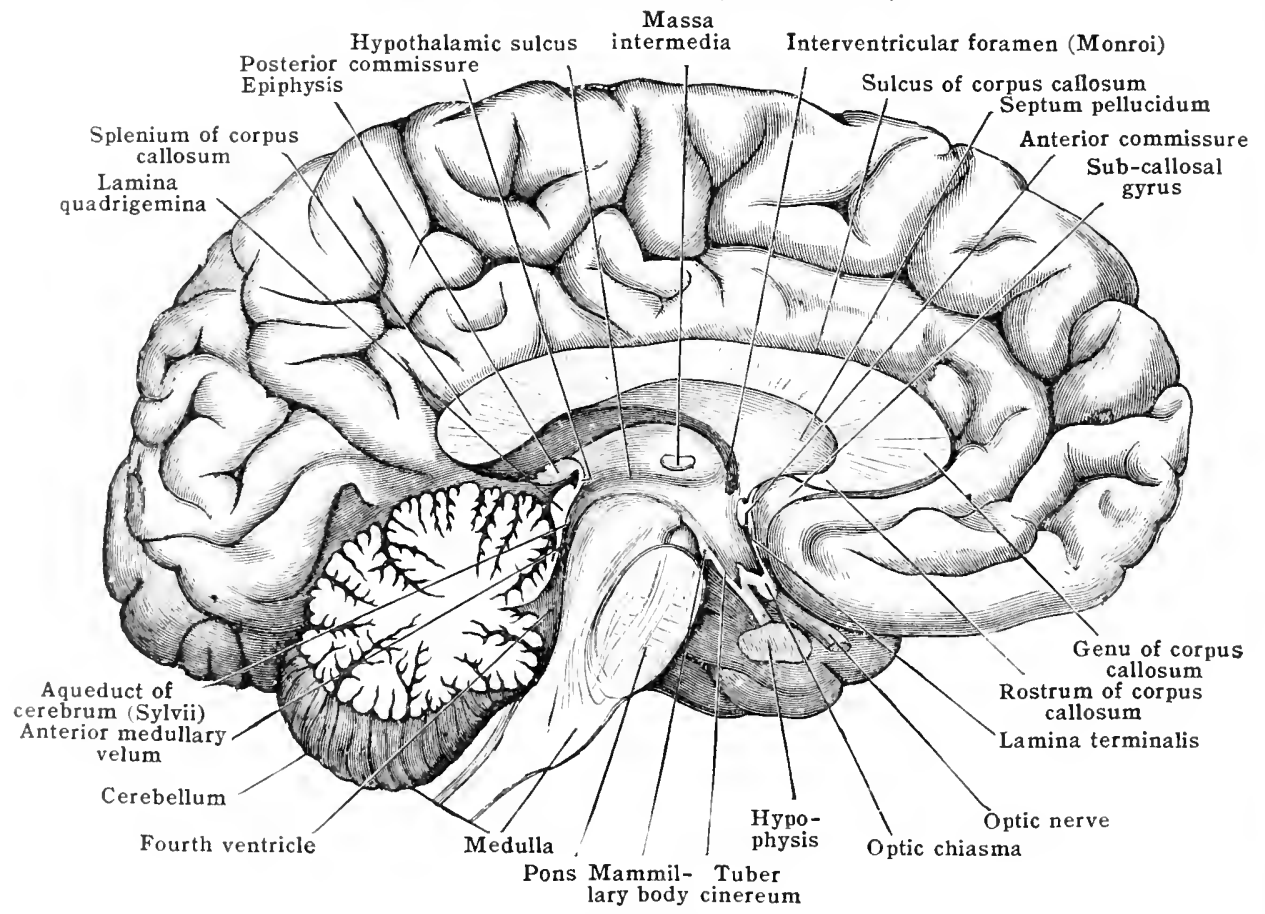

Apparently arising from the base of the epiphysis, but having practically nothing to do with it, are the striæ medullares of the thalamus (striæ pineales, pedunculi conarii, tænia thalami, habenulæ). These are two thin bands of white substance which extend from under the epiphysis anteriorly upon the thalamus, along the superior border of each lateral wath of the third ventricle, and thus form the boundaries between the superior and mesial surfaces of each thalamus.

They have been ealled the habemule, from their relation to the habenular nueleus, situated in the mesial grey substance at their inferior ends. They are continuous across the mid-line in the habruular commissure, just below the neek of the opiphysis, and between it and the posterior cerobral emmissiure, or, rather the superior part of the latter (figs. 631,665 ). It will be seen betow that earle habemula contains olfactory fibers from the formix, the anterior perforaterl substance and the septum pellucidum, as well as fibres out of the thalamus, and that most of its fibres terminate in the habenular nueleus.

The ventro-kateral surfare of the thalamencephalon is continuous into the hypothalanic tegnental region, the upward continuation of the tegmental grey substance of the mesemerphialon. It is also adjacent to a portion of the internal capsule. Both these relationships, as woll as the fibre comnections of the diencephalon with the struetures above and below it, are deferred until the discussion of the internal strueture of the prosencephalon.

The mesial surface of the climerphialon (fig. (ifi7), allows a better view of the shape and rolations of the third ventricle. Prelow the line of the massa intermodia the ventricle is nsually somewhat wider than it is along the upper margins of 
the thalami. This greater width is occasioned by a groove in the ventromesial surface of each thalamus, known as the hypothalamic sulcus (sulcus of Monro). It is along the line of this sulcus that the third ventricle is continuous with the aqueduct of the cerebrum, and thus with the fourth ventricle below, and, likewise, with the two lateral ventricles of the cerebral hemispheres at its anterior end. The latter junction occurs through a small oblique aperture, the interventricular foramen (foramen of Monro), one into each lateral ventricle. The dorsal or upper portion of the third ventricle extends posteriorly beneath its chorioid tela

Fig. 668.-Ventral Aspect of Brain-stem Ixcluding Mammllary and Optic Portions OF THE HYPOTHALAMUS.

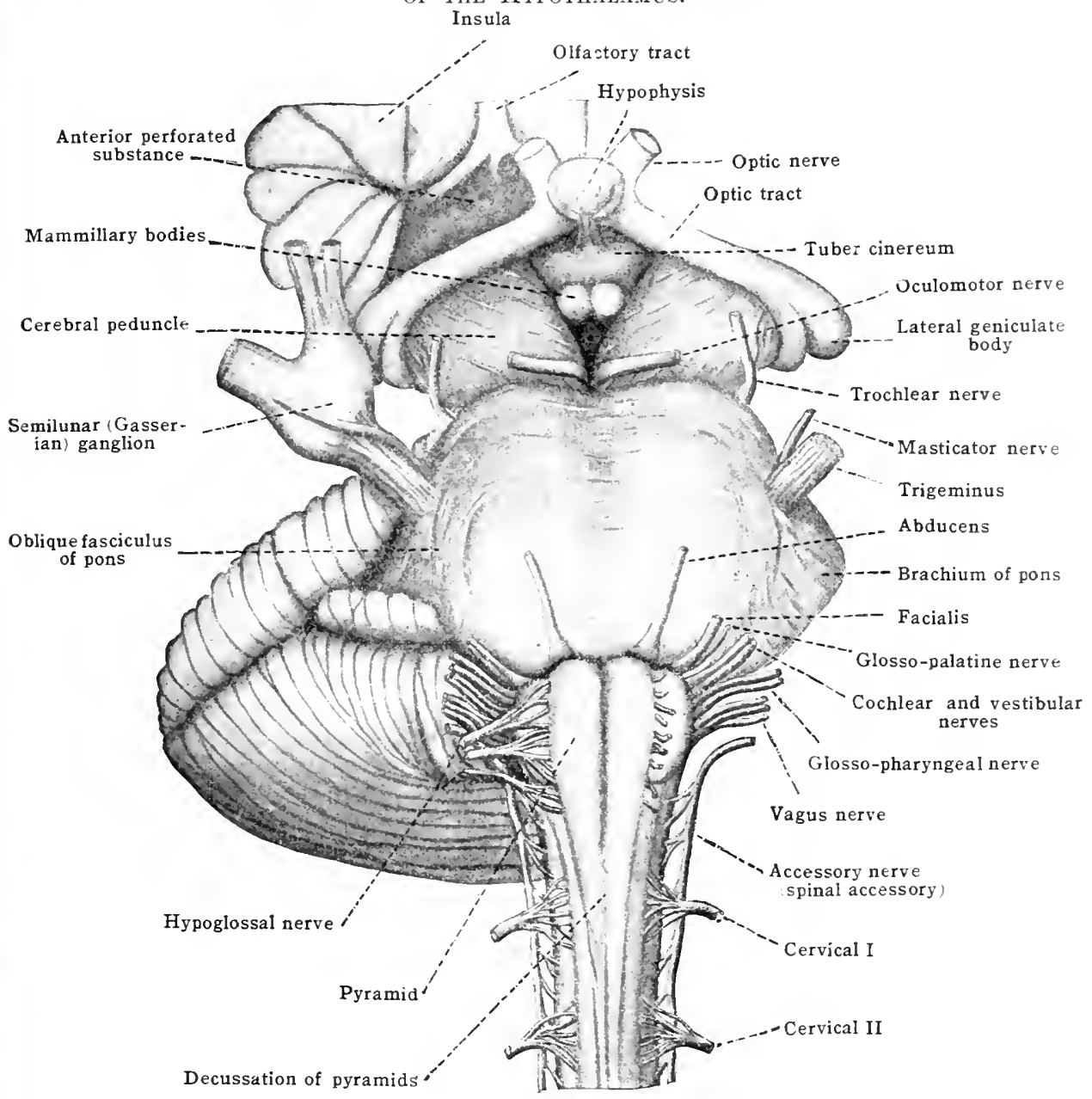

(velum interpositum) to form a small posterior recess about the epiphysis. This is known as the supra-pineal recess. The anterior and ventral extremity of the third ventricle involves the pars optica hypothalami, which belongs to the telencephalon.

B. THE TELENCEPHALON.-External features.-The optic portion of the hypothalamus consists of that small central area of the basal surface of the telencephalon which includes and surrourds the optic chiasma, and comprises the structures of the floor of the anterior and ventral portion of the third rentricle. The area extends anteriorly from the mammillary boclies in the interpeduncular fossa, and includes the tuber cinereum and hypophysis behind the optic chiasma, and some of the anterior perforated substance in front of it.

The most anterior portion of the third ventricle is in the form of a rentral extension. The wall of this portion is almost wholly non-nervous and quite thin, and thus the cavity of the ventricle is but thinly separated from the exterior of 
the brain. The front portion of this wall is the lamina terminalis and in the ventricular side of the upper part of this lamina the anterior commissure of the cerebrum is apparent.

The optic chiasma lies across and presses into the lower portion of the lamina terminalis, and in so doing produces an anterior recess in the cavity of the ventricle known as the optic recess. Behind the optic chiasma the floor of the third ventricle bulges slightly, giving the outward appearance known as the tuber cinereum, and the cavity bounded by this terminates in the infundibular recess.

The tuber cinereum then is a hollow, conical projection of the floor of the third ventricle, between the corpora mammillaria and the optic chiasma. Its wall is continuous anteriorly with the lamina terminalis and laterally with the anterior perforated substance.

The infundibulum is but the attenuated apex of the conical tuber cinereum, and forms the neck connecting it with the hypophysis. It is so drawn out that it is referred to as the stalk of the hypophysis. The cavity of the tuber cinereum (infundibular recess) is sometimes maintained throughout the greater part of the length of the infundibulum, giving it the form of a long-necked funnel. Near the hypophysis the cavity is always occluded.

\section{Fig. 669.-Diagrams of the Hypophysis Cerebri. (After Testut.)}

A, posterior surface; B. transverse section; C, sagittal section; 1, anterior lobe; 2, posterior lobe; 3 , infundibulum; 4 , optic chiasma; 5 , infundibular recess; 6 , optie recess. In $\mathrm{C}$ the infundibulum is relatively much shorter than in the actual specimen.
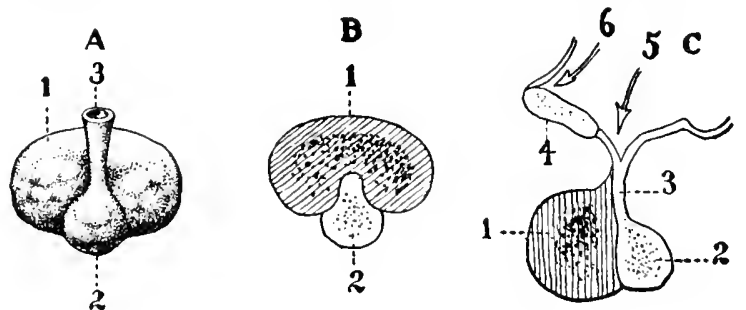

The hypophysis cerebri (pituitary body or gland) is an ovoid mass terminating the infundibulum. It lies in the sella turcica of the sphenoid bone, where it is held down and roofed in by the diaphragma sella, a spheroid pocket of the dura mater. It consists of two lobes, a large anterior lobe, the glandular or buccal lobe, and a smaller posterior or cerebral lobe. The posterior lobe is usually enclasped in a concavity of the anterior lobe.

Development. - The posterior or cerebral tobe alone is originally continuous with and a part of the infundibulum. It alone represents the termination of the hollow diverticulum which, in the embryo, grows downward from that part of the anterior cerebral vesicle which later becomes the third ventricle. The original eavity afterward becomes obliterated except in the upper part of the infundibulum. It is, therefore, of cerebral origin. The anterior or buccal lobe arises quite differently. It is developed from an upward tubular diverticulum (Rathke's pouch) of the primitive buceal cavity. In the higher vertebrates, inchuling man, its connection with the buecal cavity becomes obliterated as the cartilaginous base of the cranium is consolidaterl, but in the myxinoid fishes the connection remains patent in the adult. Cut off within the oranial cavity, the embryonic buceal lobe assumes its intinate association with the cerebral lobe. In alwut the second month of fetal life it begins to develop numerous secondary divertirula which become the epitheliat stuctures evident in the adult human subject.

Structure.- The posterior or cerebral lobe retains no organized structure. It may be said to eonsist of it mass of neuroglia and other fibrous connective tissue with the cells belonging to these and it molerate supply of blook-vessels, with some sympathetic ecll-hodies and fibres for the blocel-vessels. The anterior or glandular lobe is probably the functional part of the organ. In arlelition to its alumblant supporting tissue, it consists of compartments lined with two kinds of ruloidal rells-cells of difforent size and different staining yroporties. The principal or more mmmerous colls are smaller, with thickly gramular eytoplasm. In mixtures containing orange $G$ and fuchsin these colls stain orange, while the chromophile cells, the larger and hess numerous varicty, take the fuchsin alengly. The compartments have an abundant blood supply. Near the introlobar septum, the erolls frepuently aro arranged to form small vesicles which eontain

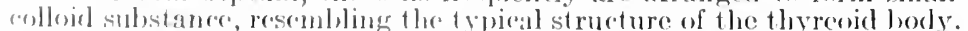

Jike the cpiphysis, the hypopliysis most he regarded as glandular-a gland with internal recretion. In the cuse of giants and in acromegaly it is usually greatly enlarged. The prineipal rells increase greatly in number after lemoval of the thyreodi borly.

The fundaments of the optic nerve are derived from this portion of the telencophaton, thomgh the mucles of temination of its fibres are located in the thalam- 
encephalon and mesencephalon. The optic apparatus consists of the retinæ and optic nerves, the optic chiasma, the optic tracts, the superior quadrigeminate bodies with their relations with the nuclei of the eye-moving nerves, the metathalamus, the pulvinar of the thalamus, and the visual area of the cerebral cortex of the occipital lobe. The fibres of the optic nerves arise from the cells of the ganglion-cell layer of the retinæ. The fibres which arise in the mesial or nasal halves of each retina cross the mid-line to find their nuclei of termination in the central grey substance of the opposite side, while those from the outer or lateral halves terminate on the same side (fig. 670.)

The optic chiasma (optic commissure) is functionally independent of the structures of the optic portion of the hypothalamus adjacent to it. It is formed by the

Fig. 670.-Diagram of the Principal Conponents of the Optic Apparatus. (After Cunningham.)

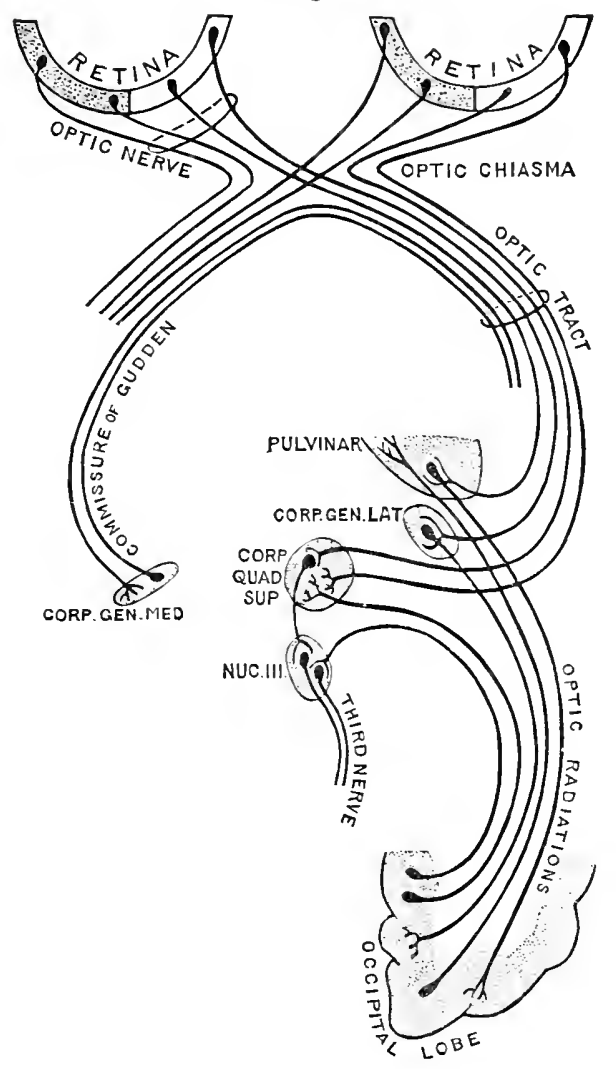

approach and fusion of the two optic nerves, and is knit together by the decussating fibres from the nasal halves of each retina, and, in addition, by the fibres of Gudden's commissure which is contained in it.

Beyond the chiasma the optic fibres continue as the optic tracts which course posteriorly around the cerebral peduncles to attain their entrance into the thalamenchephalon and mesencephalon. Upon reaching the pulvinar of the thalamus each optic tract divides into two roots, a lateral and mesial.

The lateral root contains practically all of the true visual fibres-fibres arising from the latera half of the retina of the same side and the nasal half of the retina of the opposite side. These fibres are distributed to three localities:-(1) part of them terminate in the lateral geniculate body; $(2)$ the greater portion pass over and around the lateral geniculate body and enter the pulvinar; (3) a considerable portion enter the superior quadrigeminal brachium and course in it to terminate in the nucleus of the superior quadrigeminate body. The most evident function of this latter portion is to bear impulses which, by way of the neurones of the quadrigeminate body, are distributed to the nuclei of the oculomotor, trochlear, and abducent nerves, and thus mediate eye-moving reflexes. The cells of the lateral geniculate body and the pulvinar, about which the retinal fibres terminate, give off axones which terminate in the cortex of the visual area, chiefly the gyri about the calcarine fissure of the occipital lobe. In reaching this area they curve upward and backward, coursing in a compact band of white substance known as the optic 
radiation (radiatio occipito-thalamica, fig. 699). Whether any fibres of the optic radiation arise in the superor quadrigeminate body is doubtful. It also is in large part composed of fibres arising from the cells of the visual area, which pass from the cortex to the pulvinar, superior quadrigeminate bodies, and possibly some to the medulla oblongata and spinal cord.

The mesial root of the optic tract contains few true visual fibres. It runs into the medial geniculate body, and neither it nor this body are appreciably affected after extirpation of both eyes. It may be considered as largely representing the fibres of Gudden's commissure (inferior cerebral commissure). This commissure consists of fibres which connect the medial geniculate bodies of the two sides with each other, and which, instead of crossing the mid-line through the mesencephalon, course in the optic tracts and cross by way of the posterior portion of the optic chiasma. It consists of fibres which beth arise and terminate in each of the bodies, and, therefore, of fibres coursing in both directions. It is also claimed that the fibres of Gudden's commissure connect the medial geniculate body of each side with the inferior colliculus of the opposite side.

\section{THE CEREBRAL HEMISPHERES}

The cerebral hemispheres in man form by far the largest part of the central nervous system. Together, when viewed from above, they present an ovoid surface, markedly convex upward, which corresponds to the inner surface of the vault of the cranium. The greater transverse diameter of this surface lies posteriorly in the vicinity of the parietal eminences of the cranium. The outline of the superior aspect varies according to the form of the eranium, being more spheroidal in the brachycephalic and more ellipsoidal in the dolichocephalic forms. The hemispheres are separated from each other superiorly by a deep median slit, the longitudinal fissure, into which fits a duplication of the inner layer of the dura mater known as the falx eerebri. The posterior or occipital extremities of the hemispheres overlap the cerebellum, and thus entirely conceal the mesencephalon and thalamencephalon. They are separated from the superior surface of the cerebellum and the corpora quadrigemina by the deep transverse fissure. This is occupied by the tentorium cerebelli, which is similar to and continuous with the falx cerebri and is connected with the tela chorioidea of the third ventricle below.

Each of the hemispheres is usually deseribed as having three poles or projecting extremities, and three surfaces bounded by intervening borders. The most anterior projection is the frontal pole. This is near the mid-line, and with its fellow of the other hemisphere, forms the frontal end of the ovoid contour of the cerebrum. The occipital pole is the most projecting portion of the posterior and inferior end, and is more pointed than the frontal pole. The infero-lateral portion of the hemisphere is separated anteriorly by the deep lateral fissure (fissure of sylvius) into at distinct division, the temporal lobe, and the anterior portion of this lobe projects prominently forward and is known as the temporal pole.

The surfaces of the hemisphere are-(1) the lateral or convex surface; (2) the medial surface; and (3) the basal surface. The convex surface comprises the entire rounded aspeet of the hemisphere visible previous to manipulation or dissection, and is the surface subjacent to the vault of the cranium. The mesial surface is perpendicular, flat, and parallel with that of the other hemisphere, the two bounding the longitudinal fissure and for the most part in contact with the falx ecrebri. The superomesial border intervenes between the convex and medial surfaces, and is thus convex and extends from the frontal to the occipital pole.

The mere complex basal surface fits into the anterior and middle cranial fossie, and posteriorly rests upon the tentorium cerebelli. Thus it is subdivided into-(a) an orbitul area, which is slightly eoncave, since it is adapted to the orbital plate of the frontal bone, and is separated from the convex surface by the ne'essarily areherl superciliary border and from the mesial surface by the medial orbital border, the latter being straight and extending from the frontal pole mesial to the olfaetory bulb and traet; (b) a tentorial area or surface, which is arched in conformity with the dorsal surface of the cerebellum. This is separated from the convex surface by the infero-lateral border, which runs from the oceipital to the temporal pole; and from the mesial surface by the medial occipital border, which is a more or less roumded ridge extending from the oecipital pole obliquely upward in the angle formed ly the junction of the perpendicular falx cerebri and the horizontal tentorium eerebelli. This border is best seen in brains which have beren hardened with the membranes in situ. The remainder of the basal surface includes the optie portion of the hypothalamus already considered, and the small 
depressed and punctate area, the anterior perforated substance, which is penetrated by the antero-lateral group of the central branches of the anterior and middle cerebral arteries and into which the strixe of the olfactory trigone disappear. In addition to the orbital area the basal surface of the hemisphere shows signs of the impress of the petrous portion of the temporal bone and of the great wing of the sphenoid.

The corpus callosum.- In their early development as lateral dilations of the anterior primary brain-vesicles, the hemispheres are connected with each other only at the anterior end of the thalamencephalon, where they are both continuous with the lamina terminalis. As development proceeds and the hemispheres extend upward, backward, forward, and laterally to completely conceal the base, and as the pallium, or cortex, thickens and its folds begin to appear, the two hemispheres become united across the micl-line above the thalamencephalon and the third ventricle by the inter-growth of the great cerebral commissure, the corpus callosum. After removal of the falx cerebri from the longitudinal fissure, the

Fig. 671.-Mesial and Tentorial Surfaces of Right Cerebral Hemisphere, Viewed from the Left. (After 'Toldt, "Atlas of Human Anatomy," Rebman, London and New York.)

Sulcus of corpus callosum

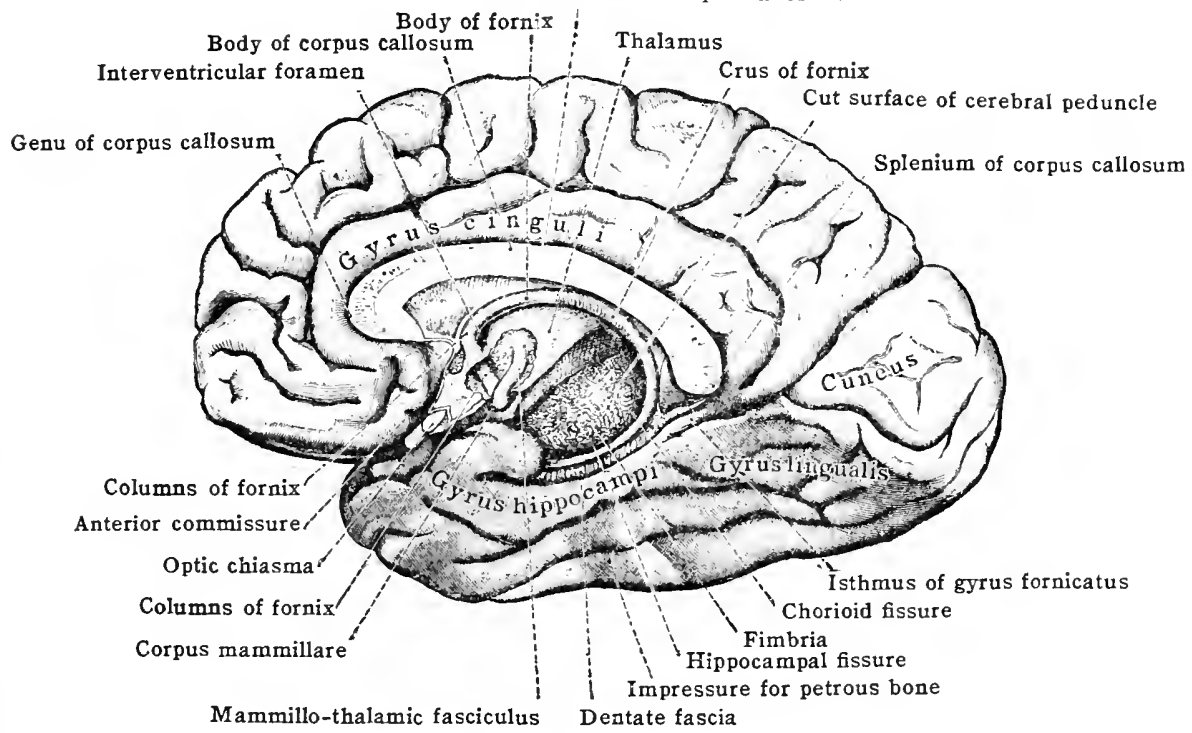

dorsal surface of the corpus callosum may be exposed by drawing apart the contiguous mesial surfaces of the hemispheres. It consists of a dense mass of pure white substance coursing transversely, and arises as out-growths from the cortical cells of both hemispheres. Thus it is the great pathway which associates the cortex of the two sides of the telencephalon. Only the smaller medial portion of the body lies free in the floor of the longitudinal fissure, by far the greater part being concealed in the substance of the hemispheres, where its fibres radiate to and from different localities of the pallium, forming the radiation of the corpus callosum. Its surface shows numerous transverse markings, the transverse strice, which indicate the course of its component bundles of fibres. In addition there may be seen two delicate, variable longitudinal bands running over its surface on each side of the mid-line. The medial longitudinal stria (stria Lancisii) runs close to the median plane, around the anterior end from the gyrus subcallosus (fig. 672), and over the posterior end downward and lateralward to disappear in the hippocampal gyrus of the base of the telencephalon. The lateral longitudinal stria is more delicate than the mesial stria, courses lateral to the medial stria, and can be seen only within the sulcus of the corpus callosum (fig. 672). Both striæ are composed largely of axones having to do with the olfactory apparatus.

When severed along the median plane, it may be seen that the anterior margin of the corpus callosum is turned abruptly downward, forming the genu, and that this turn continues, so that the tapering edge of the body points posteriorly and 
constitutes the rostrum (figs. 667,671). The rostrum is in contact with the lamina terminalis of the third ventricle below by a short, thin, dorso-frontal continuation of this lamina, known as the rostral lamina. The rostral lamina may be considered as beginning at the anterior cerebral commissure with the anterior aspect of which it is in contact, and extending to the rostrum. Beginning with the rostrum and genu, the corpus callosum arches backward as the body of the corpus callosum, and ends over the quadrigeminate region in its rounded, thickened posterior margin, the splenium. It is bounded above by the sulcus of the corpus callosum, and, attached to its concave inferior surface, are the chorioid tela of the third rentricle, the fornix, the septum pellucidum, and the medial walls of the lateral ventricles.

Each cerebral hemisphere includes-(1) a superficial and much folded mantle or pallium, divided into lobes and gyri, and consisting of grey substance, the cortex, covering an abundant mass of white substance; (2) a modified portion, the

Fig. 672.-Diagram of Convex Surface of Right Cerebral Hemisphere and Part of Upper surface of Corpus Callosum.

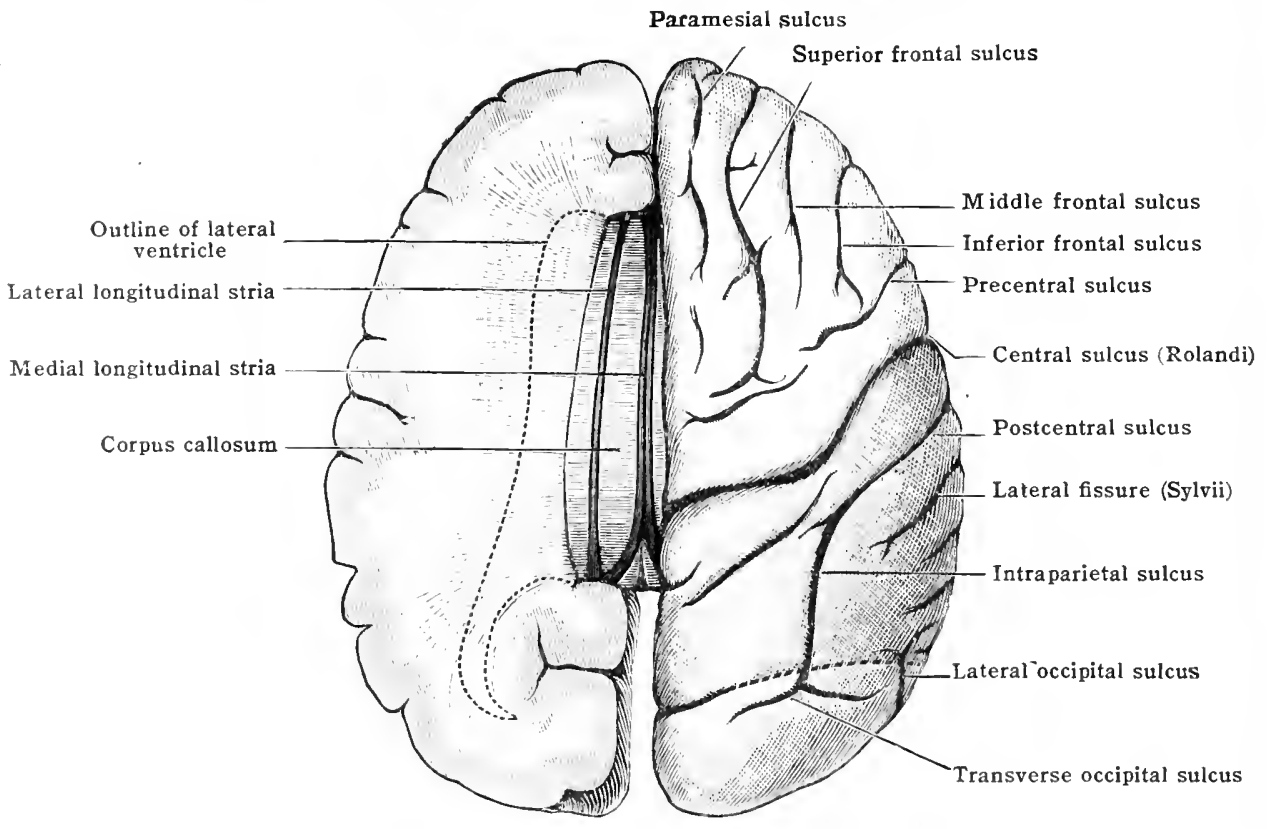

rhinencephulon, having especially to do with the impulses brought in by the olfactory nerve; (3) a cavity, the lateral rentricle; and (4) a buried mass of grey substance, the cuudate and lenticular muclei, which together with the internal capsule of white substance, are known as the corpus striatum.

Gyri, fissures, and sulci.-The eerebral pallium is thrown into numerous and varialle folds or gyri (convolutions). These are separated from each other by corresponding furrows, the deeper and most constant of which are called fissures; the remainder, sulci. All the fissures and the main sulei are named. There are, however, numbrons small and shallow sulei to which names are seldom given. 'These oceur ats short branches of main sulei or as short, isolated furrows bounding small gyri which connert adjacent gyri. 'T'hese small gyri are likewise seldom given individual names. They are very variable both in iliferent specimens and in the two hemisplueres of the same specimen. Collectively, they are the so-called transitory grri (gyri transitivi). ("ertain groups of them are named aceording to

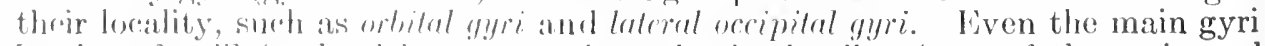
[gyri profundi] (and sulei) ar very irregular in detail. Some of the main and

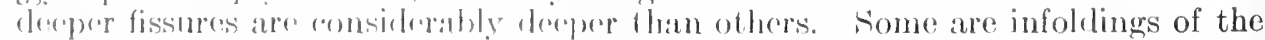

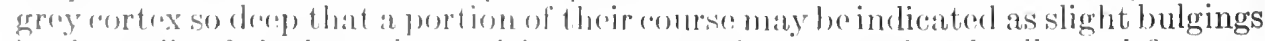
in the walls of the lateral vertereles, e. g., tho hippocampal and collateral fissures. While the general surface pattern is similar for all normal human brains, yet when a detailed compirison is made, the given gyri of different specimens are found to 
vary greatly. The main gyri of the two hemispheres of the simne brain, however, are nearly alike.

Origin of the gyri.-The gyri (and sulci) are the result of processes of unequal growthfolds necessarily resulting from the surface portion of the hemispheres increasing much more rapidly than the central core. In the early periods of fetal life the surfaces of the hemispheres are quite smooth. In many of the smaller mammals this condition is retained throughout life, but in the larger mammals, including man, as development proceeds the cerebral cortex becomes thrown into folds. The absolute amount of the grey substance of the hemispheres varies with the bulk of the animal, and apparently with its mental capabilities. 'This is especially true of the cortex, for in the larger brains, and that of man especially, by far the greater amount of the cerebral grey substance lies on the surface. Therefore, in either the growth or evolution of a small animal into a large one the amount of cerebral grey substance is increased, and in this increase the surface area of the brain is necessarily enlarged. It is a geometrical law that in the growth of a body the surface increases with the square, while the volume increases with the cube of the diameter. The cerebral hemisphere is a mass the increase of whose volume does not keep the required pace with the increase of its surface area or cortical layer. The white substance which forms the pallium arises in large measure as outgrowths from the cells of the cortical layer, and thus it can only increase in a certain proportion to the grey substance. Therefore, the surface mantle of grey substance of a hemisphere, enlarged in accordance with an increased bulk of body, is greater than is necessary to cover the surface of the geometrical figure formed by the combined white and grey substance. Consequently, in order to possess the preponderant amount of grey substance, the surface of the hemisphere is of necessity thrown into folds. It follows also that the thinner the cortical layer in proportion to the volume of the hemisphere, the greater and more folded will be the surface area. In accordance with this theory small animals have smooth or relatively smooth hemispheres, and that independently of their position in the animal scale or the amount of their intelligence, while large animals have convoluted brains.

The sulci in general begin to appear with the fifth month of fetal life, the larger of them, the fissures, appearing first and in a more or less regular order. Lp to the fifth month the encephalon, due to its rapid growth, closely occupies the cranial capsule. During the fifth month the cranium begins to grow more rapidly than the encephalon, and a space is formed between the cerebrum and the inner surface of the cranium. This space allows further expansion of the pallium, and at the time the space is relatively greatest (during the sixtl month) the form and direction of the principal gyri and sulci begin to be indicated. As growth proceeds the unrestricted expansion of the pallium results in the gyri again approaching the wall of the cranium, and during the eighth month of fetal life they again come in contact with it. Finally, the later relative growth of the cranium results in the space found between it and the cortex in the adult. It is obvious that the relation of the cranium may be a factor in the causation of the gyri, for the increase of surface area necessitated by the increased amount of cortical grey substance might be limited by a cranial cavity of small size. It is probable that the second contact of the cortex with the cranium (during the eighth month) may at least cause a deepening and accentuation of the gyri already begun. Evidently the form of the cranium modifies the gyri, and to a certain extent probably determines their direction, for in long, dolichocephalic crania the antero-posterior gyri are most accentuated, and in the wide, brachycephalic crania the transverse gyri are most marked. At birth all the main fissures and sulci are present, but some of the smaller sulci appear later. In the growing pallium both the bottoms of the sulci as well as the summits of the gyri move away from the geometrical center of the hemisphere, the summits more rapidly, and hence the sulci or fissures first formed grow gradually deeper as long as growth continues.

The mechanical factors in the growth processes which result in the more or less regular arrangement of the gyri of the hemispheres of a given group of animals have not been satisfactorily determined. It has been suggested that the differences in arrangement of the gyri in different groups of animals may be in part dependent upon the functional importance of the various regions- the amount of grey substance of a region varying with the functional importance, and the consequent local increases being accompanied by resultant local foldings. This idea is supported by the fact that while the somesthetic (sensory-motor) area of the cortex varies with the bulk of the body, the frontal gyri, so much developed in man and which are one of the chief regions of the associational phenomena, are relatively independent of and do not vary with the weight of either the body or the brain.

Surface area.- The total surface area of the adult human telencephalon is about $2300 \mathrm{sq}$. $\mathrm{cm}$. Of this area almost exactly one-third is contained on the outer or exposed surfaces of the gyri, while the other two-thirds is found in the walls of the sulci and fissures.

\section{Lobes of the Telencephalon and the Grri and Sulci}

The folded pallium of each hemisphere is arbitrarily divided into lobes, partly by the use of certain of the main fissures and sulci as boundaries and partly by the use of imaginary lines (figs. 672, 673). These divisions are six in number, themselves subdivided into their component gyri:-

(1). Temporal lobe.

(2) Insula (Central lobe or Island of Reil).

(3) Frontal lobe.

(4) Parietal lobe.

(5) Occipital lobe. 
(6) Olfactory brain or rhinencephalon (including structures comprised in the other lobes and often grouped under the two names olfactory lobe and limbic lobe).

This division of the cortex of the hemisphere is largely a merely topographical one. With the exception of the temporal lobe and the rhinencephalon, it has little of either morphological or functional value. The oceipital lobe contains the recognised visual area of the eortex, but this area, as such, does not involve all of the lobe. In their functional significanee, the frontal and parietal lobes, especially, overlap each other.

The temporal lobe.-This is the first lobe whose demarcation is indicated. During the second month of intra-uterine life there appears a slight depression on the lateral aspect of the then smooth hemisphere. As the pallium further grows, this depression deepens into a well-marked fossa with a relatively broad floor. This fossa marks the beginning of the lateral cerebral fissure or fissure of Sylvius, and is, therefore, known as the Sylvian fossa. As the pallium continues to project outward, the folds which form the margins of the sylvian fossa increase in size and height and begin to overlap and eonceal its broad floor, which is the beginning

Fig. 673.-Diagram of the Convex Surface of the Left Cerebral Hemisphere showing the Five Principal Lobes of the Pallium.

The opercular regions of the frontal, parietal, and temporal lobes are removed to show the central lobe or island of Reil.

Central sulcus (Rolandi)

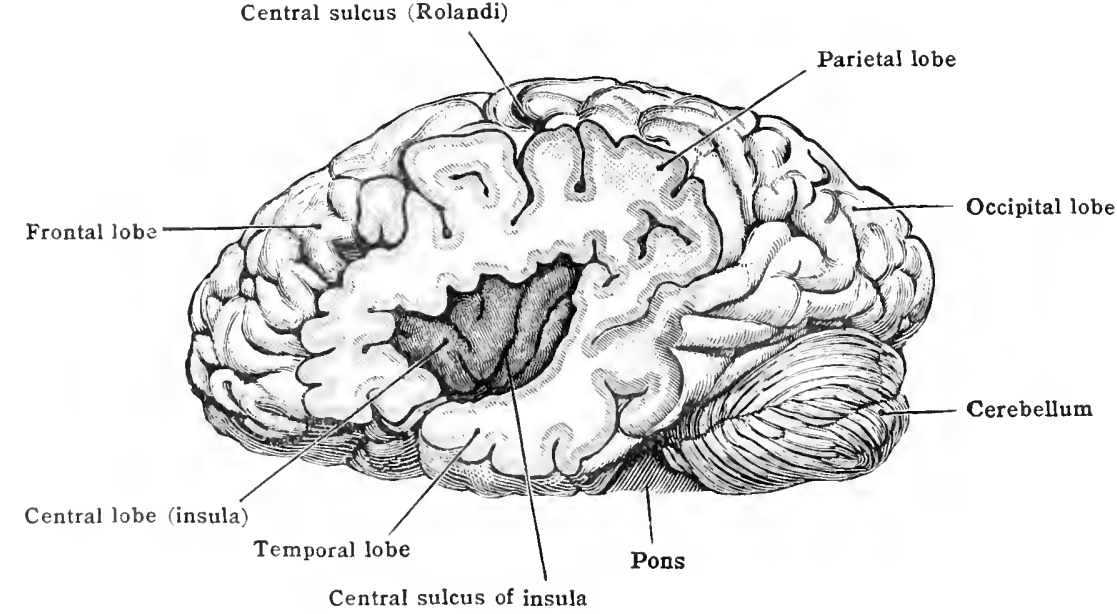

of the insula. The overlapping folds thus become the opercula, and as their lips approach each other, there results the deep fissure of sylvius, which marks off anteriorly an infero-lateral limb of the pallium, termed by position the temporal lobe. As growth proceeds further, the temporal lobe thickens, the temporal pole oxtends further forward and becomes a free projection, thus lengthening the fissure of hylvius and resulting in the inferior extension or stem of this fissure, which runs between the temporal pole and the frontal lobe and curves under so as to appear on the bisal surface of the hemisphere. Finally the cortex of the lobe itself is thrown into folds or gyri. Its posterior end is never marked off from the lobes aboveand behind, exeept by arbitrary lines which will be mentioned in connoction with those lolues.

The temporal lobe forms part of the lateral convex and tentorial surfaces of the hemisphere, and its anterior portion is adapted to the surface of the middle cranial fossit. It thus has at superior and lateral surface and a basal and tentorial surface. In these surfaces are the lollowing gyri with their intervening and bonnding sulei (fige. (67.6):

'The: superior temporal gyrus is bounded by the posterior ramus of the lateral fissure, anel extends from the temproral pole backwat into the supra-marginal region of the parictal lote: allove. Tho upper margin of this gyrus constitutes the temporal operculum, in that it aids in overlappling and conclosing the insula in the floor of the latranl fissure. 'This matrein is fol the most part smooth, being 
occasionally interrupted by a few weak twigs of the lateral fissure. It is separated from the gyrus below by the superior temporal sulcus, which is parallel with the posterior ramus of the lateral fissure and is frequently called the parallel sulcus. The posterior extremity of this sulcus divides the angular gyrus of the parietal lobe, and its anterior end disappears in the temporal pole, sometimes as a continuous groove, sometimes in isolated pieces.

The middle temporal gyrus likewise begins in the temporal pole and is continuous backward into the angular gyrus of the parietal lobe.

The inferior temporal gyrus forms the infero-lateral border of the temporal lobe, and is usually more broken up than the two gyri above it. It begins continuous with them in the frontal pole, and extends horizontally backward into the lateral gyri of the occipital lobe. It is separated from the middle gyrus by the middle temporal sulcus, which likewise is never so continuous a furrow as the superior temporal sulcus. Frequently this sulcus occurs in detached portions and often terminates within the temporal lobe.

Fig. 674.-Outhine Drawing of Convex Surface of Left Cerebral Hemisphere. (After Toldt, "Atlas of Human Anatomy," Rebrian, London and New York.)

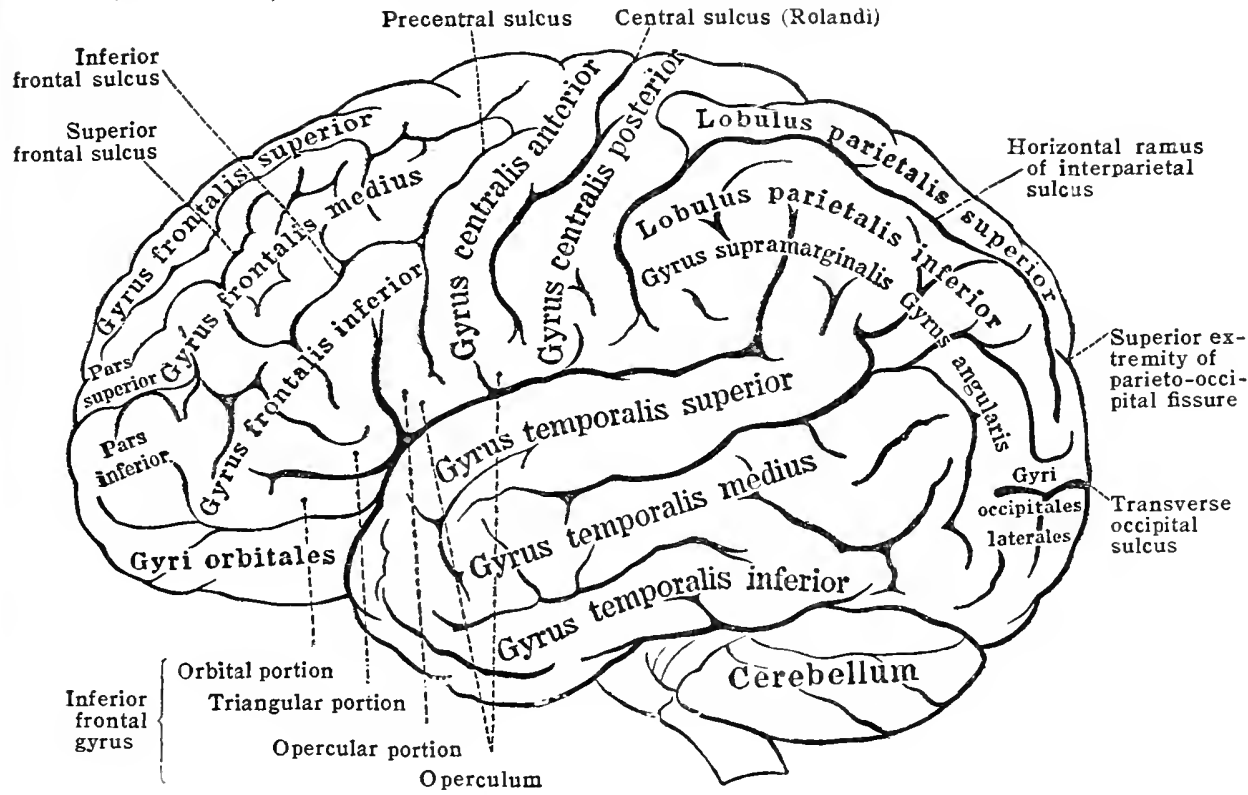

The fusiform gyrus is in the basal and tentorial surface of the temporal lobe (fig. 676). Its usual somewhat spindle shape suggests its name, and it is continuous backward into the occipital gyri, or its posterior end may be completely isolated by a union of the inferior temporal sulcus and the collateral fissure, which two furrows separate it from its neighbours on either side. Anteriorly the fusiform gyrus runs into the common substance of the other three gyri at the temporal pole.

The lingual gyrus is usually included in the tentorial surface of the temporal lobe, though in some texts it is regarded as a part of the occipital lobe. Its larger, posterior portion lies within the boundaries of the occipital lobe. Bounded laterally by the collateral fissure, it is continuous anteriorly into the hippocampai gyrus of the rhinencephalon (fig. 676).

All of the sulci give off occasional literal twigs (transverse temporal sulci) which themselves may or may not branch, and which tend to divide the main gyri into transverse temporal gyri.

The lateral fissure (fissure of Sylvius).-As promised in its origin by the overlapping and enclosing of the broad floor of the Sylvian fossa by the adjacentfolds of the pallium, the lateral fissure is the deepest and most conspicuous fissure of the cerebral hemisphere. Its main divisions are a short stem and three main branches. The stem lies in the basal surface of the hemisphere, where it begins 
in a depression in the anterior perforated substance, the vallecula Sylvii, and passes forward and upward between and separating the temporal pole and the superciliary border of the frontal lobe. It corresponds in direction with the posterior border of the lesser wing of the sphenoid bone, which projects backward into it, and it contains the middle cerebral artery, the Sylvian vein, and the sinus alæ parvæ. It appears on the upper surface at a point known in cranial topography as the Sylvian point, where it divides into its three main branches:-

(1) The posterior ramus is the linear continuation of the fissure, and runs horizontally backward and upward to telminate in the supra-marginal gyrus of the parietal lobe.

(2) The anterior ascending ramus passes upward for about $10 \mathrm{~mm}$., subdividing the inferior gyrus of the frontal lobe.

(3) The anterior horizontal ramus passes forward from the stem of the fissure about $10 \mathrm{~mm}$., and likewise into the inferior frontal gyrus, but parallel with the superciliary border.

Fig. 675,-The Insula with its Grri and Sulci. (Shown by widely separating the opercula.)

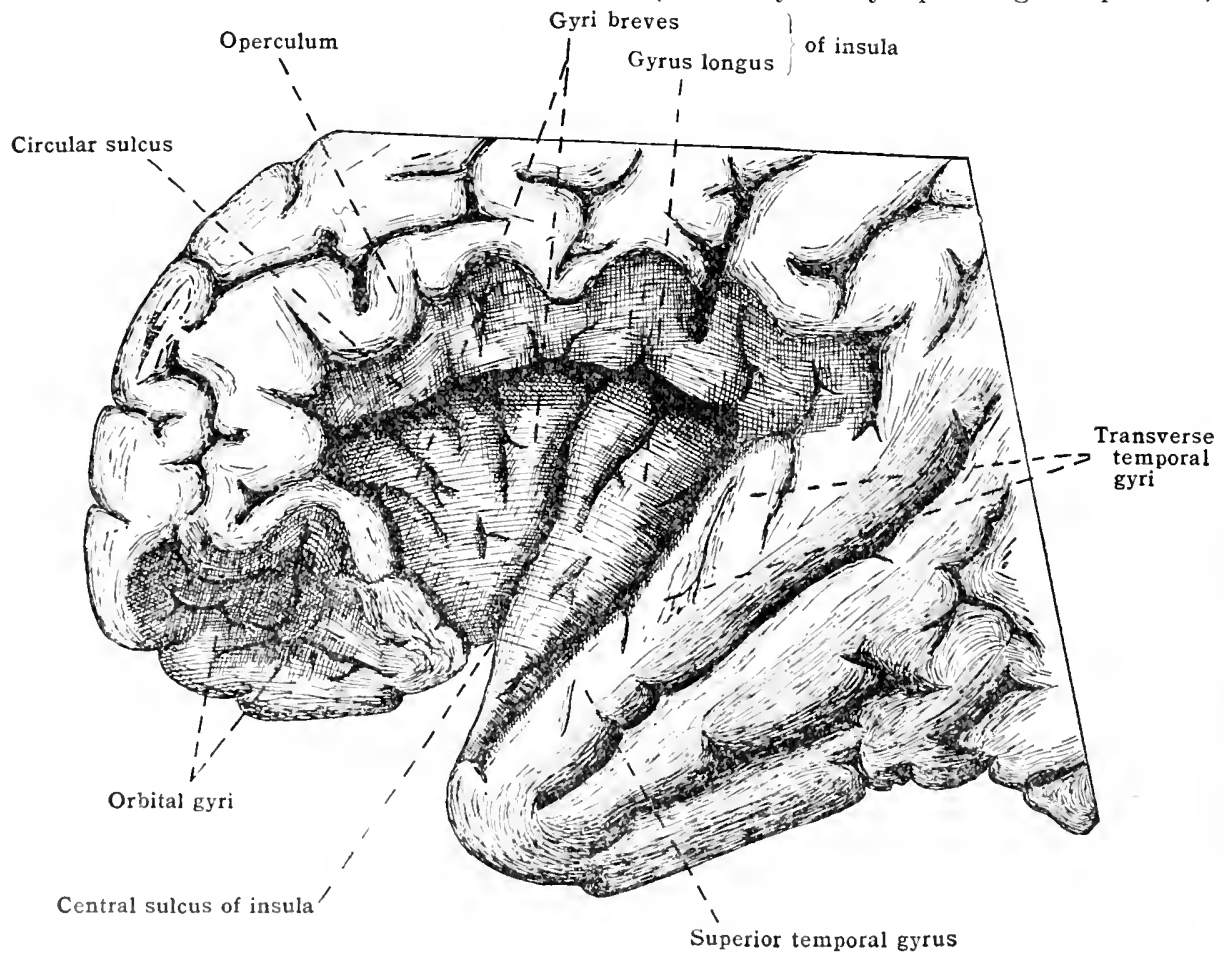

These branches, together with eertain smaller collateral twigs, divide the overlapping or opereulat portions of the adjacent pallium into $(a)$ the temporal operculum, whinh lins below the posterior ramus; (b) the fronto-parietal opereulum, or operentum froper, which hes albove and behind the anterior ascending ramus; $(c)$ thre fromlal "uprolum, between the latter and the anterior horizontal ramus; $(d)$ and the ombilal operenlum, below the anterior horizontal ramus. Collectively the operenta are kuwom as the operenla of the imsule.

The insula (central lobe).- The insula or islind of Ruil is a triangular area of the aremeral cortex lying in the floon of the lateral fissure, and conceated by the

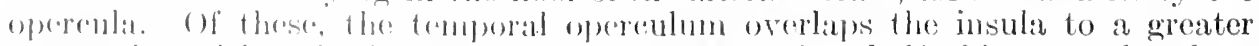
rextrot than wither the fromtal of parietal. Nore than half of it may, therefore, be exposed, ly gently prosing away the temporal lobe. The insula corresponds to the broad floor of the sylyian fositia of the ombryonie brain. In the developed

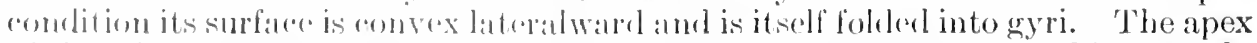
of the triangle: appears upon the hasial surfice of the hemisphere, and is the only

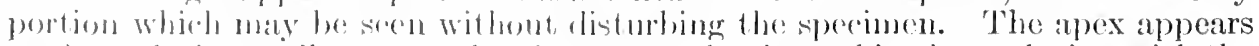
as the rom of a small gyrus muler the temperal pole, and in close relation with the 
anterior perforated substance and the vallecula Srlvii, and is known as the limen of the insula. In the folding process by which the opercula accomplish the overlapping and enclosing of the island, there results a deep sulcus which surrounds its entire area except at the limen insulæ. This is linown as the circular sulcus, or limiting sulcus of Reil. The gyri (and sulci) of the insula radiate from the apex of the triangle. The central sulcus of the insula is the leepest. It runs from below backward and upward, parallel with the central sulcus of Rolando above and divides the insula into a larger anterior and a smaller posterior portion. The anterior portion consists of from three to five short irregular gyri breves or precentral gyri, separated by sulci brevis; the posterior portion consists of a single, slightly furrowed gyrus, which is long and arched and extends from the apex to the base of the triangle, the gyrus longus.

In a recent study of the insula of more than 200 human braius, including a few of idiots and paralytics and a series of young foetuses, Nelidoff finds that the left island is more deeply marked by sulci and a verages $11 \mathrm{~mm}$. longer than the right; that, of the sulci in the island, the central sulcus is the first to appear, is the most persistent sulcus in defective brains, though occasionally absent in microcephalic idiots, and that in the average it is more pronounced in males than in females.

The frontal lobe.-This is the most anterior of the lobes of the hemisphere, and like the two lobes behind, it has a convex or lateral, a basal, and a mesial surface. The convex surface begins with the frontal pole, and is bounded posteriorly by the central sulcus (Rolandi). The basal surface extends backward to the stem of the lateral fissure, covered by the frontal pole. The mesial surface is separated from the gyrus cinguli of the rhinencephalon (limbic lobe) by the subfrontal part of the sulcus cinguli (calloso-marginal fissure), and from the parietal lobe by a line drawn perpendicularly from the upper extremity of the central sulcus (Rolandi) to the sulcus cinguli. These surfaces include the following gyri and sulci:-

GrRI.

Anterior central gyrus. Superior frontal gyrus.

Convex Middle frontal gyrus

surface Inferior frontal gyrus
Superior portion.

Inferior portion.

Opercular portion.

Triangular portion. Orbital portion.

Sulcr.

\author{
Precentral sulcus $\{$ Superior. \\ Superior frontal suleus. \\ Middle frontal suleus. \\ Inferior frontal suleus. \\ Anterior ascending ramus of lateral \\ fissure. \\ Anterior horizontal ramus of lat- \\ eral fissure. \\ Orbital sulei $\left\{\begin{array}{l}\text { Iateral. } \\ \text { Wedial. } \\ \text { Transverse. }\end{array}\right.$
}

Olfactory sulcus.

Postral sulci.

Basal
surface
Mesial
surface $\left\{\begin{array}{l}\text { Orbital gyri }\left\{\begin{array}{l}\text { Anterior. } \\ \text { Posterior. } \\ \text { Medial. }\end{array}\right. \\ \text { Gyrus rectus. } \\ \begin{array}{l}\text { Superior frontal gyrus. } \\ \text { Marginal gyrus. } \\ \text { Paracentral lobule (anterio }\end{array}\end{array}\right.$

Basal
surface
Mesial
surface $\left\{\begin{array}{l}\text { Orbital gyri }\left\{\begin{array}{l}\text { Anterior. } \\ \text { Posterior. } \\ \text { Medial. }\end{array}\right. \\ \text { Gyrus rectus. } \\ \begin{array}{l}\text { Superior frontal gyrus. } \\ \text { Marginal gyrus. } \\ \text { Paracentral lobule (anterio }\end{array}\end{array}\right.$

Lateral.

Paracentral lobule (anterior part).

Many of the sulci, especially the superior frontal and the rostral sulci, often give off twigs or are broken up into short furrows which give rise to small folds [gyri transitivi], too inconstant to be given special names.

The anterior central gyrus (ascending frontal convolution) is the only gyrus of the frontal lobe having a vertical direction. It lies parallel to the central sulcus (Rolandi), and thus extends obliquely across the convex surface from the posterior ramus of the lateral fissure (frontal operculum) to the supero-mesial border, and is continuous on the mesial surface with the anterior portion of the para-central lobule. It comprises the larger part of the motor portion of the somesthetic (sensory-motor) area of the cerebral cortex. It is separated from the horizontal frontal gyri in front of it by the precentral sulcus.

This sulcus is developed in three parts, but the upper and middle parts in the fortal brain usually fuse together, so that in the later condition it consists of a superior and an inferior' segment. The superior cuts the supero-mesial border of the hemispliere and appears on the mesial surface in the paracentral lobule. On the convex surface it is usually connected with the posterior end of the superior frontal sulcus (fig. 674).

The superior frontal gyrus is a relatively broad, uneven convolution, comprising the anterior portion of the supero-mesial border of the hemisphere, and therefore extends horizontally from the precentral sulcus to the frontal pole. It is sometimes inperfectly divided into a superior and an inferior part by a series of 
detached, irregular furrows, spoken of collectively as the para-medial sulcus. The resulting transitory gyri are of considerable interest in that they are peculiar to the human brain, and are said to be more marked in the higher than in the lower types.

The middle frontal gyrus is likewise a broad strip of pallium extending from the precentral sulcus to the temporal pole. It is separated from the superior frontal gyrus by the superior frontal sulcus, which is usually continuous into the superior section of the precentral sulcus and thence extends horizontally to the frontal pole. The middle frontal gyrus is in most cases subdivided anteriorly into a superior and an inferior portion by a middle frontal sulcus. This sulcus begins above and runs into the frontal pole, where, upon reaching the superciliary border, it frequently bifurcates into a transverse furrow, known as the fronto-marginal sulcus.

The inferior frontal gyrus forms the superior wall of the lateral fissure, and is separated from the middle frontal gyrus by the inferior frontal sulcus. This sulcus usually begins continuous with the inferior section of the precentral sulcus, and extends, very irregularly and frequently interrupted, toward the frontal pole. The gyrus abuts upon the anterior central gyrus, and its posterior portion is divicled into three parts (the frontal opercula) by the anterior ascending and horizontal rami of the lateral fissure. The part behind the anterior ascending ramus is the opercular portion (a part of the fronto-parietal operculum or operculum proper), sometimes referred to as the basilar portion. In most brains this part is traversed by a short oblique furrow, the diagonal sulcus. The part between the two anterior rami of the lateral fissure is the cap-shaped triangular portion. This portion frequently involves one and sometimes two descending twigs of the inferior frontal sulcus. The part below the anterior horizontal ramus is by position the orbital portion.

It is seen that the inferior frontal gyrus gives rise to the whole of the frontal operculum and the anterior half of the fronto-parietal operculum. The opercular portion is of special interest in that in the left hemisphere it constitutes the celebrated convolution of Broca, the motor area for the function of speech. The area controlling speech, however, involves that part of the triangular portion bounding the anterior ascending ramus of the lateral fissure as well, and both these parts often appear more developed on the left hemisphere. The development of the opereula of the inferior frontal gyrus is a distinctive characteristic of the human brain. This gyrus does not develop opercula even in the highest varieties of apes. The development of the function of speech in man no doubt infliences the development of the frontal opercula.

On the basal surface (fig. 676) of the frontal lobe is the orbital area and the gyrus rectus. The more pronounced of the orbital sulci are often so joined with aach other as to form an $\mathrm{H}$-shaped figure standing parallel to the mesial plane, and thus they comprise a medeal, a lateral and a transverse orbtial sulcus. This figure naturally diviles the orbital area into four gyri:-(1) The lateral orbital gyrus is the basal continuation of the inferior frontal gyrus, and is thus related to the orbital portion of the frontal opereulum; (2) the anterior orbital gyrus is continuous at the pole with the middle frontal gyrus; (3) the posterior orbital gyrus is closely related to the limen insula and the stem of the lateral fissure, and its outcre part is in relation with the orbital portion of the opereulum; (4) the medial orbital gyrus is continuous over the superciliary border with the superior frontal gyrus. It frequently contains one or two short, isolated sulci. Its meial bomblary is the straight olfactory sulcus, in which lies the olfactory bull, and tract of the rhinencephalon. This suleus marks off a narrow straight strip of cortex hetween it and the mesial horder of the lobe known as the gyrus rectus. 'The prosterior portion of the gyrus reetus comprises a part of the parolfactory area or Brora's arra, which functionally belongs to the rhinencephalon. Is an allea or ficlu, this alpuear's mesially lying between the anterior and posterior parrolfarchory sulci.

()n the mrsiol surface (fig. 679), of the frontal lobe the superior frontal gyrus is separated from the groms cinguli of the rlinencephaton (limbic lobe) by the wellmarlinl sulcus cinguli. Anteriorly tho suprerior frontal gyrus is subdivided by the main strin of the rostral sulci inte a marginal gyrus, and what may be termed a submarginal gyrus. The matrinal gryms is ustually broken into smaller parts by twigs of the rostral sulci, most of which are perpendicular to the main stem, while the sulmatrinal grems is less freguently interrmuterl. Posteriorly the superior fromtal eyrus anstitutes the anterios portion of the paracentral lobule, a part of 
the somæsthetic area of the mesial surface of the hemisphere. This lobule is usually marked off anteriorly by a vertical twig from the sulcus cinguli.

The sulcus cinguli (calloso-marginal fissure) is the longest and one of the most prominent sulci on the mesial surface of the hemisphere. It divides the anterior portion of the mesial surface into a marginal part above and a callosal part below -in other words, it separates the superior frontal gyrus from the gyrus cinguli. Its subfrontal portion begins below the rostrum of the corpus callosum and curves forward and upward around the genu, and then turns backward above the body of the corpus callosum. Before it reaches the level of the splenium, it turns upward and cuts and terminates in the supero-mesial border of the hemisphere, as the next sulcus behind the upper termination of the central sulcus. This upward

Fig. 676.-Basal Surface of the Cerebral Hemispheres. (After Toldt, "Atlas of Human Anatomy," Rebman, London and New York.)

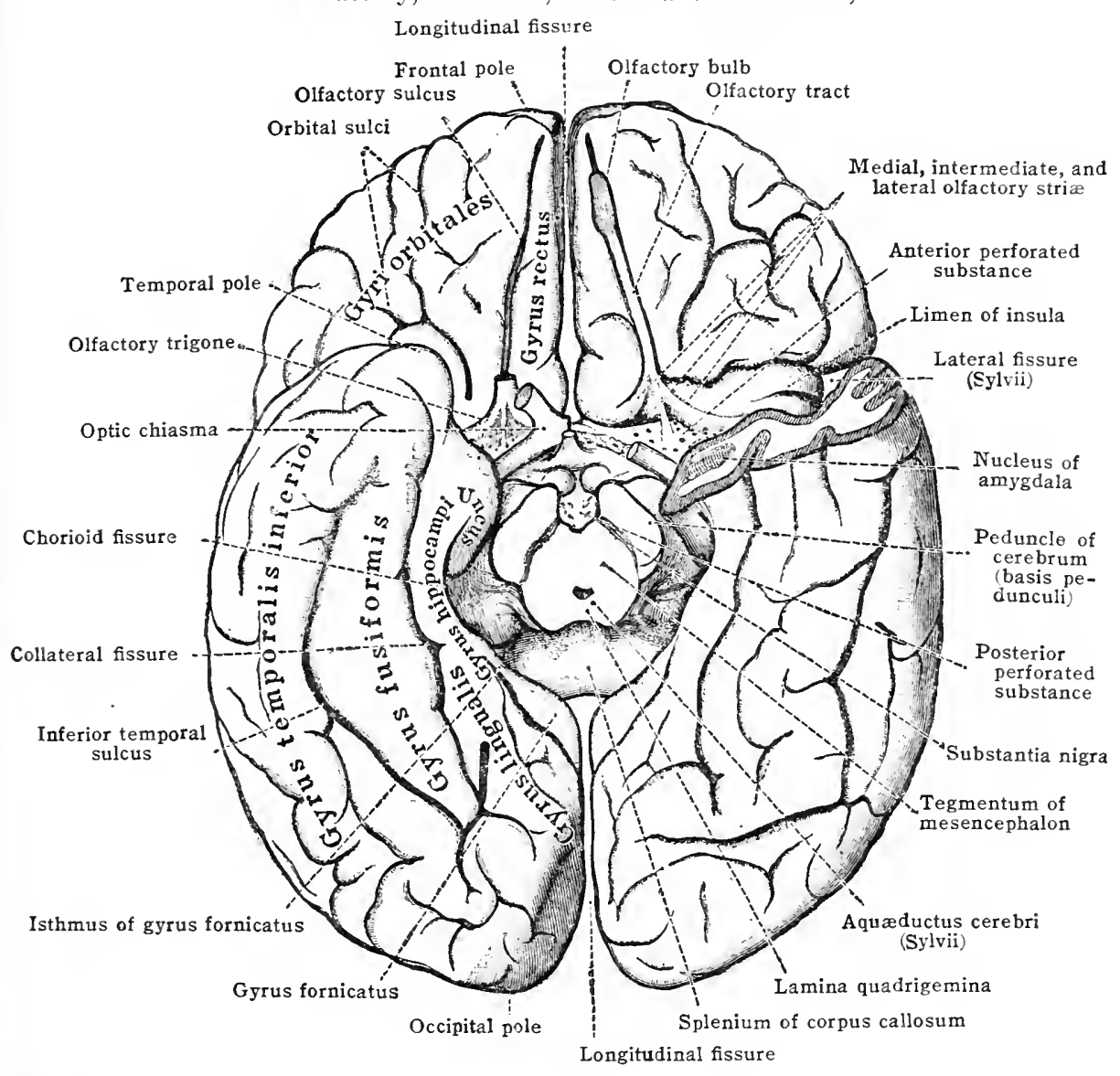

turn is the marginal portion of the sulcus cinguli. It is sometimes an abrupt curve and sometimes curves gradually, but its marginal relation to the upper end of the central sulcus is so constant that it serves as a means by which either of the sulci may be identified. The marginal portion separates the paracentral lobule from the precuneus (quadrate lobule), and is wholly within the parietal lobe. One of the most constant twigs of the sulcus cinguli is that which marks off the paracentral lobule from the superior frontal gyrus. Another sometimes diricles the paracentral lobule into its frontal and parietal portions.

The sulcus cinguli is developed from two and sometimes three (anterior, middle, and posterior) separate furrows, which later extend and fuse into continuity. This method of its development may explain the irregularities frequently met with and the fact that sometimes in the adult the sulcus occurs in separate pieces.

The central sulcus (fissure of Rolando) (figs. 674, 678) is one of the principal landmarks of the convex surface of the hemisphere. It separates the frontal from the parietal lobe, and likewise divides the somæsthetic area of the pallium. Its 
upper end terminates in and usually cuts the supero-mesial border of the hemisphere immediately in front of the termination of the marginal portion of the sulcus cinguli. Thence it pursues an oblique though sinuous course forward across the convex surface of the hemisphere, forming on the average an angle of about $72^{\circ}$ with the supero-mesial border (Rolandic angle), and terminates in the frontoparietal opereulum immediately above the posterior ramus, and about $2.5 \mathrm{~cm}$. behind the point of origin of the anterior rami of the lateral fissure. It rarely cuts through the fronto-parietal operculum. In its sinuous course, varying from the line of its supero-mesial end, two bends are marked (fig. 677):-(1) The superior genu occurs at about the junction of the upper and middle thirds of the sulcus and is concave forward. It accommodates the greater part of that portion of the cortex which is the motor area for the muscles of the leg and trunk, and the development of this area in man probably aids in producing it. (2) The inferior genu occurs below, is concave forward and is commonly a little more marked than the superior genu. It is probably in part a result of the superior genu - the turn of the sulcus in resuming its general course, but it may further result from the development of the shoulder and arm area of the cortex which occupies its concavity.

Fig. 677.-Diagram Representing the Most Common Form of the Central Sulcus and Indicating the Regions of Junction upon it of the Areas of the Precentral Gyrus Devoted to the Different Regions of the Body, as Estimated by Symington and Crymele.

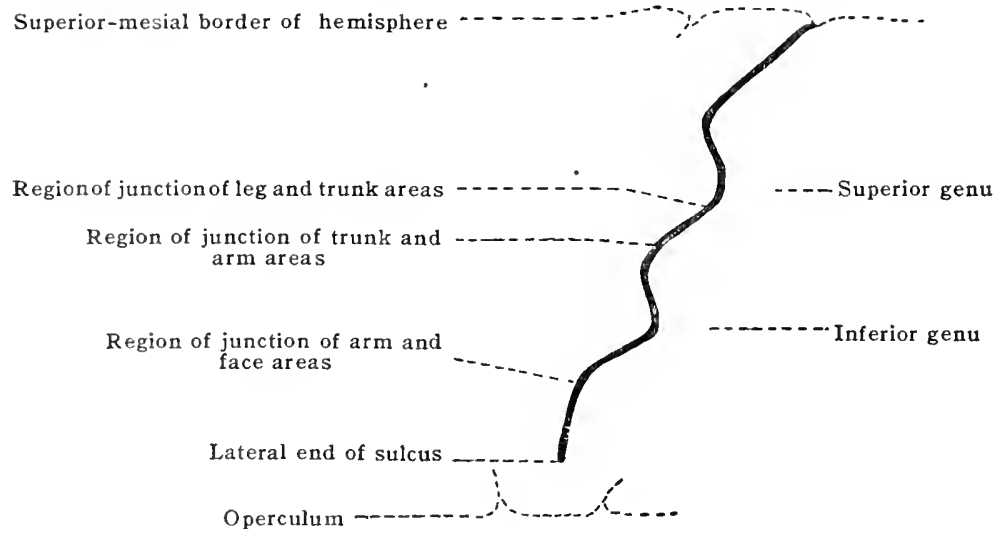

The central sulcus (Rolandi) appears in the pallium of the foctus during the latter part of the fifth month. It then consists of a lower longer and an upper shorter part. Usually these two parts become continuous before birth; vely rarely do they remain separate in the adult. The print of their fusion is sometinces manifest within the depth of the suleus. If the lips of the suleus be pressed widely apart at about the region of the junction of its middle and upper thires, it will he found that the opposing walls give off a number of protuberanees or lateral gyri, which dovetail into each other when the suleus is closed. Sometimes two of these lateral gyri appear fused across the flowe of the sulcus, so as to form a bridge of grey substance known as the deep annectant gyrus. This interruption of the continuity of the suleus, when present, represents the print at whinh the two parts of the sulcus in the fortal hrain joined each other without the continnity becoming wholly completed in the adult. The genta of the adult sulcus may often be due in the prenedent parts not being in line at the time of their fusion.

From a sproial stuly of the central sulats of $2: 3$ normal andult hemispheres, Symington and ('rvmble (191:3) give the following details: (1) that the most common eomrse of the suleus is that illustratul in lig. 675 , aluwe; (2) that it varies in denth both in a given specimen and in

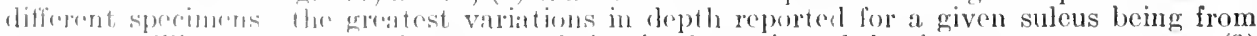

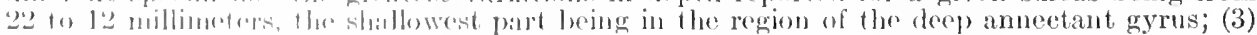

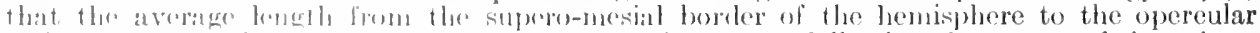

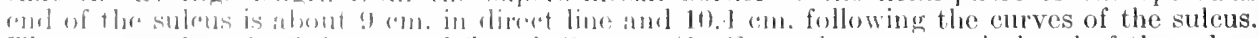

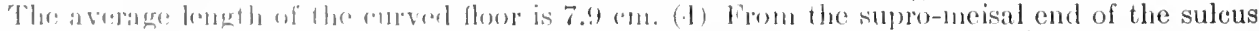

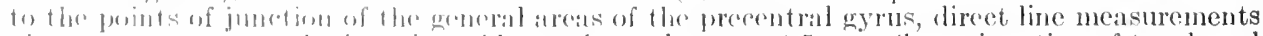

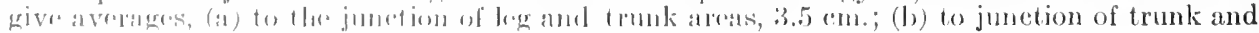

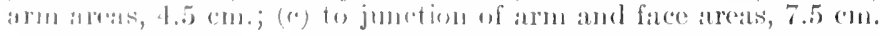

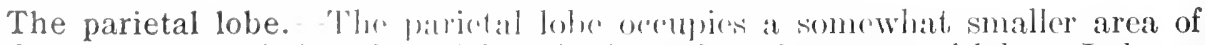

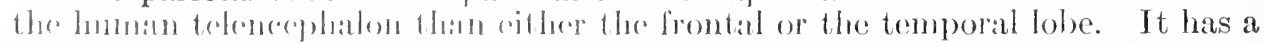

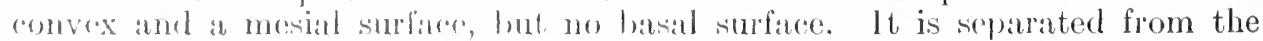

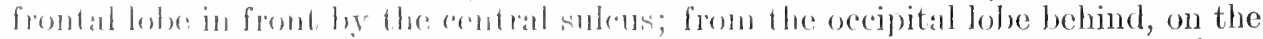

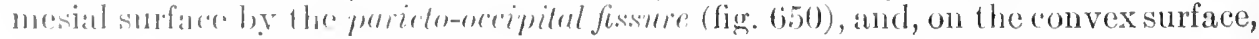


by an arbitrary line drawn transversely around the convex surface of the hemisphere from the superior extremity of this fissure to the infero-lateral border; and it is separated from the temporal lobe below by the horizontal part of the posterior ramus of the lateral fissure, and by a line drawn in continuity with this horizontal part to intersect the transverse line drawn to limit it from the occipital lobe.

The preoccipital notch. - In situ, the infero-lateral border of the posterior portion of the hemisphere rests over a small portion of the parieto-mastoid suture of the cranium, and upon this structure occurs a fold or vertical thickening of the dura mater, which slightly indents the infero-lateral border. This indentation occur's about $4 \mathrm{~cm}$. from the occipital pole, and is considered one of the points of limitation of the parietal from the occipital lobe, and is therefore called the preoccipital notch. While during late fœtal life and early childhood it is well marked, it is usually very slight in the adult brain, and is, as a rule, evident only in brains hardened

Fig. 678.-Convex Surface of the Cerebral Hemispheres as Viened from Above. (After Toldt, "Atlas of Human Anatomy," Rebman, London and New York.) Frontal pole

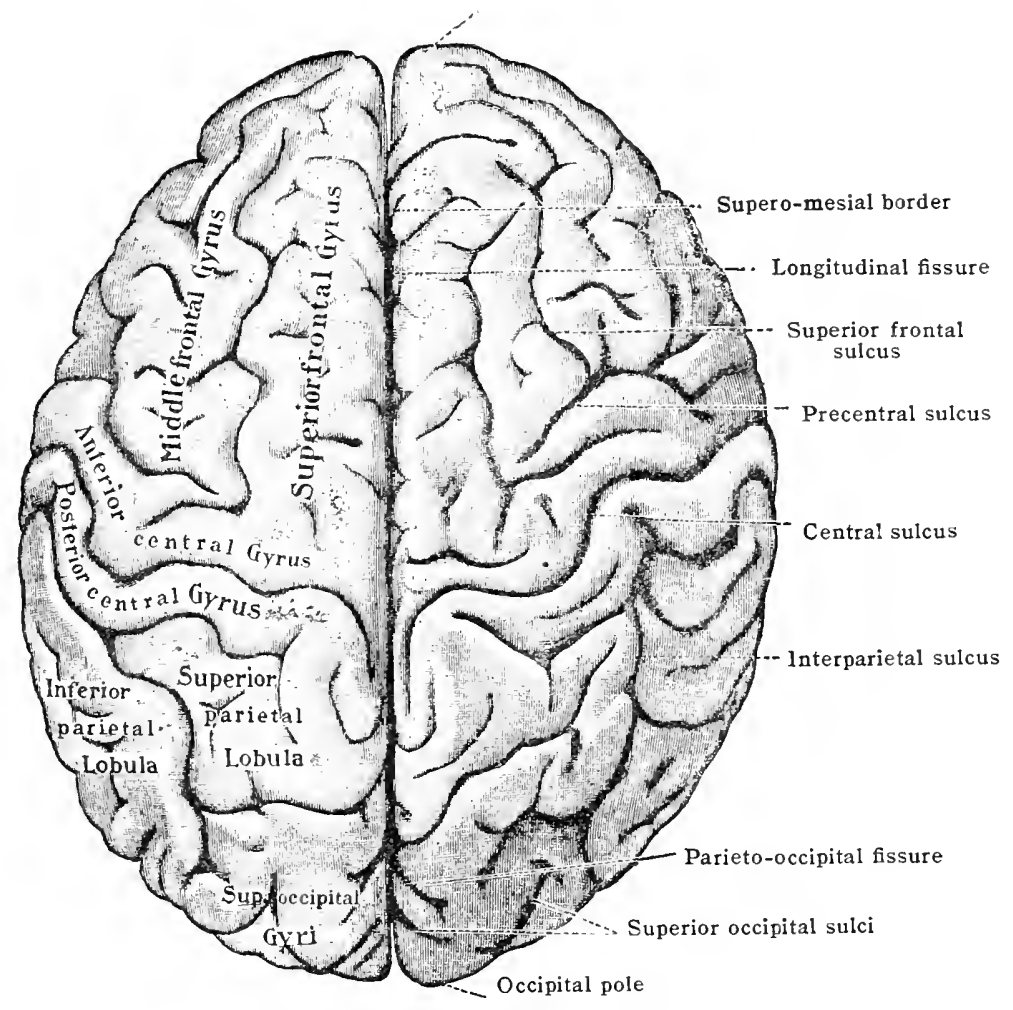

in situ. When it is visible, the arbitrary transverse line from the superior extremity of the parieto-occipital fissure, used as a boundary between the convex surfaces of the parietal and occipital lobes, should be so drawn as to bisect the preoccipital notch.

The convex surface of the parietal lobe comprises the following gyri and sulci:-

The posterior central gyrus (ascending parietal) extends obliquely across the hemisphere parallel with the anterior central gyrus of the frontal lobe, from which it is separated by the central sulcus. Its inferior end is bounded by the posterior ramus of the lateral fissure, and constitutes the posterior or parietal portion of the fronto-parietal operculum. Its upper end takes part in the supero-mesial border of the hemisphere, and is bounded posteriorly by the tip end of the marginal portion of the sulcus cinguli. Its postero-lateral boundary consists of the two more or less vertical rami or factors of the interparietal sulcus, viz., the inferior and superior portions of the postcentral sulcus, either continuous with each other or detached.

The interparietal sulcus (intraparietal) is often the most complicated sulcus of the pallium. Its development usually begins as four different furrows in the foetal brain, and the difficulty with which it is traced in the adult brain depends 
upon the extent to which these four factors become continuous in the later development. When continuity of the furrows is well established, the entire sulcus may be described as consisting of a convex horizontal ramus, which gives off a few short collateral twigs and whose either end is in the form of an irregular, reclining $\dashv$. The transverse bar of the anterior end arises fron two of the four factors of the entire sulcus:-(1) an inferior furrow, the inferior postcentral sulcus, commencing above the posterior ramus of the lateral fissure and ascending as the boundary of the lower half of the posterior central gyrus, and (2) a superior furrow, the superior postcentral sulcus, lying behind the upper portion of the posterior central gyrus, and which, upon approaching the supero-mesial border, may turn backward a short distance parallel with the horizontal ramus, as in fig. 674 . When confluent, these two factors form together a continuous postcentral sulcus. In the adult the inferior of the two is always continuous with the horizontal ramus; when confluent, the two figures join so as to form the transverse bar of the anterior end of this ramus. The horizontal ramus, which represents the

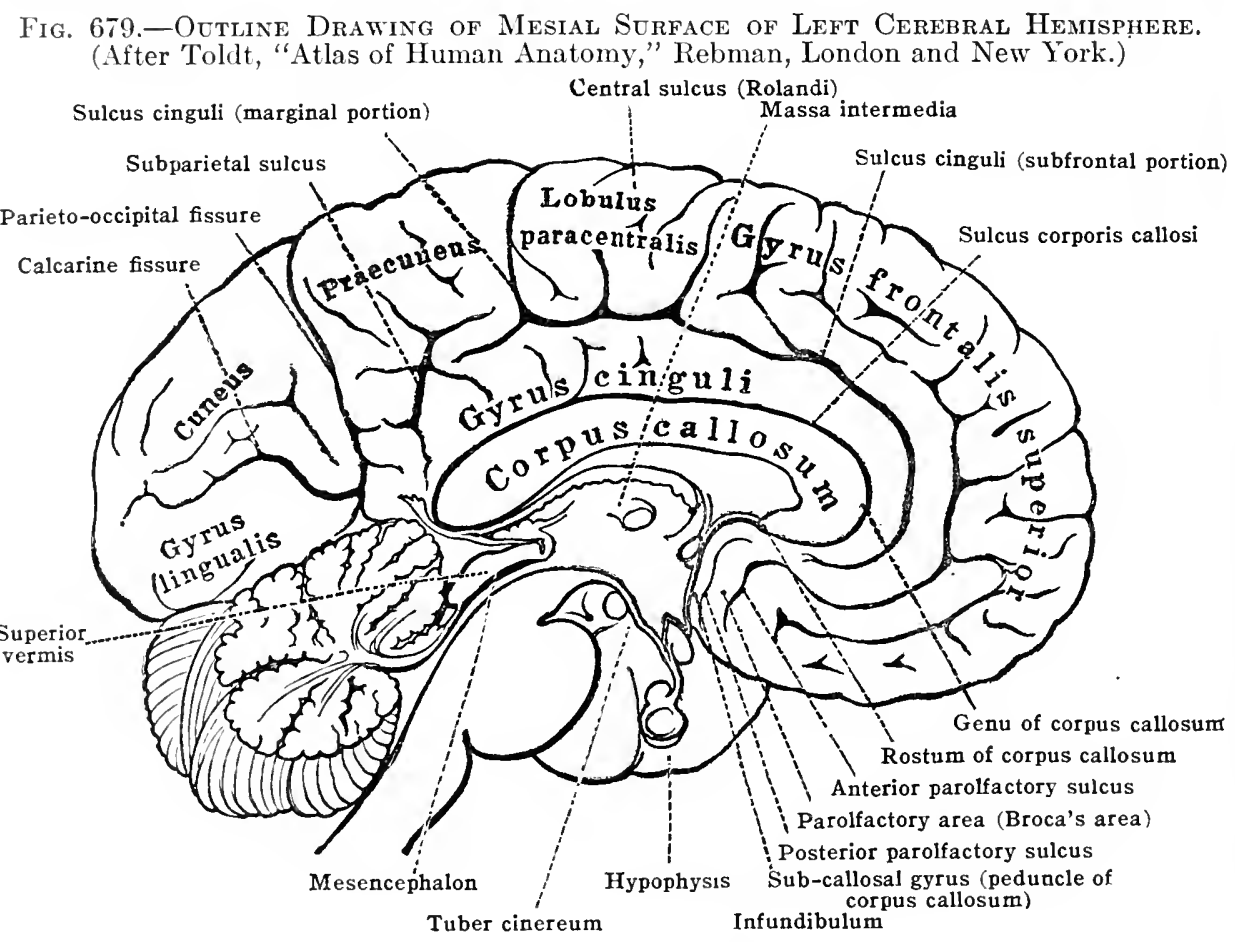

third of the primary furrows, is continued backward past the superior extremity of the parieto-occipital fissure into the occipital lobe, where it usually joins the occipital ramus, the fourth of the primary furrows. This ramus divides shortly into two branches which run at right angles to the stem, forming the transverse occipital sulcus, and thus arises the transverse bar of the posterior end of the interparictal sulcus. The occipital ramus may, however, consist of little more than the transverse bar, which may or may not be joined by the horizontal ramus. The occipital ramus is more frequently separate from the horizontal than is the postcentral suleis. In their clevelopment the inferior posteentral suleus appears first (luring the latter part of the sixth month), the oecipital ramus second, the horizontal ramus thirel, and last, the superior postcentral suleus.

The superior parietal lobule (gyrus) is the area of the supero-mesial border of the parictal lotee. It is limited in front by the superior postcentral sulcus, ledow ly the horizontal ramms of the interparictal suleus, and posteriorly it is continuous around the superior and of the paricto-oceipital fissure into the cortex of the occipital lobe. It is a relatively wicle area (lobule), always invaded by collateral twigs of its limiting sulci, and usually contains a few short, isolated furrows. When the parieto-occipital fissure is considerably prolonged over the supero-mesial border (external parieto-occipital fissure), the continuation of the 
lobule about the end of this fissure presents the appearance described as the parieto-occipital arch.

The inferior parietal lobule is limited in front by the inferior postcentral sulcus, and above by the horizontal ramus of the interparietal sulcus. It is continuous with the cortex of the temporal lobe below, and with that of the occipital lobe behind, and is therefore invaded by the ends of the sulci belonging to these lobes. Its anterior portion is separated from the temporal lobe by the horizontal portion of the posterior ramus of the lateral fissure. The upturned end of this ramus invades the anterior portion of the lobule and the broad fold, arched around this end and continuous behind it into the superior temporal gyrus, is known as the supramarginal gryus - the area to which auditory word- and tone-images are attributed. The angular gyrus is the portion which embraces the posterior end of the superior temporal sulcus, and is continuous behind this into the middle temporal gyrus and in front with the superior temporal gyrus. It is the area for visual word images. Its shape is usually such as to suggest its name. The most posterior part of the inferior parietal lobule, when arching in a similar way about the end of the middle temporal sulcus and continuous with the temporal gyri on its either side, is known as the post-parietal gyrus. This is a smaller area than either of the other two, and, owing to the variability of the end of the middle temporal sulcus, is not always evident.

The mesial surface of the parietal lobe is divided into two parts by the marginal portion of the sulcus cinguli. The anterior and smaller part is the mesial continuation of the posterior central grrus, and comprises the posterior portion of the paracentral lobule. It is limited from the part of this lobule belonging to the frontal lobe by a vertical line drawn from the marginal extremity of the central sulcus. 'The præcuneus (quadrate lobule) is the posterior and larger part of the mesial surface of the parietal lobe. It is separatd from the cuneus of the occipital lobe by the parieto-occipital fissure, and is imperfectly separated from the gyrus cinguli (limbic lobe) below by the subparietal sulcus (postlimbic fissure), branches of which invade it extensively.

The occipital lobe.-This is a relatively small, trifacial, pyramidal segment, comprising the posterior extremity of the hemisphere, its apex being the occipital pole. Though one of the natural divisions of the cerebral hemisphere, it is very indefinitely marked off from the lobes anterior to it. Though it contains the cortical area of the visual apparatus, only in the brains of man and the apes does it occur as a well-defined posterior projection. In most of the mammalia it is not differentiated at all. Its three surfaces comprise a convex, a mesial, and a tentorial surface.

Its convex surface is separated from that of the parietal and temporal lobes by the superior and external extremity of the parieto-occipital fissure, and by an arbitrary line drawn transversely from this extremity to the infero-lateral border of the hemisphere, or so drawn as to bisect the pre-occipital notch when this is evident. The sulci which occur on the convex surface may be described as two, though both of these are very variable in their extent and shape, and their branches are inconstant both as to number and length. (1) the transverse occipital sulcus is the most constant in shape. It extends a variable distance transversely across the superior portion of the lobe, and, as noted above, it is frequently continuous with the interparietal sulcus through its occipital ramus, and when so, it appears as the posterior terminal bifurcation of this sulcus (fig. 674). When detached, it often occurs merely as a definite furrow with few rami, and sometimes the ramus by which it otherwise would join the interparietal sulcus is entirely absent. (2) The lateral occipital sulcus is always short, and has its deepest portion below the transverse sulcus. It usually has a somewhat oblique course toward the supero-mesial border. Sometimes it occurs in several detached pieces, then knom n collectively as the lateral occipital sulci.

Therefore, the gyri of the convex surface of the lobe are also variable. They are not sufficiently constant to merit individual names. The lateral occipital sulcus or sulci roughly divide them into an inferior and lateral area, known as the lateral occipital gyri, and into a uperior larea, the superior occipital gyri. The lateral area is continuous into the gyri of the temporal lobe, while the superior area is continuous into the gyri of the parietal lobe.

The mesial surface of the occipital lobe is separated from that of the parietal lobe (precuneus) and from the gyrus cinguli of the limbic lobe by the well- 
marked parieto-occipital fissure. It comprises the constantly defined, wedgeshaped lobule known as the cuneus, and the posterior and mesial extremity of the lingual gyrus. Since the greater portion of the length of the lingual gyrus is involved in the basal surface of the temporal lobe, this gyrus as a whole has been considered as belonging to the temporal lobe (see figs. 671, 676). The cuneus is separated from the lingual gyrus by the posterior portion of the calcarine fissure, which always terminates in a bifurcation, one limb of which invades the cuneus near the superomesial border. In addition the cuneus may contain other twigs from both the fissures bounding it, and also, when wide, may eontain one or more short, detached sulci cunei.

The calcarine fissure and the parieto-occipital fissure are almost invariably joined in the human brain, forming a Y-shaped figure, the prongs of which give the cuneus its shape. The calcarine fissure begins on the tentorial surface in the posterior portion of the hippocampal gyrus of the limbic lobe, below the splenium of the corpus callosum, and extends backward across the internal occipital border of the hemisphere. It then bends downward and proceeds to its terminal bifurcation in the polar portion of the occipital lobe. The stem or hippocampal portion of the fissure is deeper than the posterior or occipital portion. It produces a wellmarked eminence in the medial wall of the posterior cornu of the lateral ventricle, known as the calcar avis or hippocampus minor. It is developed separately from the posterior portion, which itself first appears as two grooves. All three parts are usually continuous with each other before birth.

The parieto-occipital fissure usually appears from the first as a continuous groove. It begins in the supero-mesial border of the hemisphere, rarely extending into the convex surface more than $10 \mathrm{~mm}$. (external paricto-occipital fissure), thence it extends vertically downward across the mesial surface (internal parieto-occipital fissure), and terminates by joining the calcarine fissure at the region of the downward bend of the latter, or at about the junction of its anterior and middle thirds. In certain of the lower apes and in the brain of the chimpanzee there is no junction between the two fissures, they being kept apart by a narrow neck of cortex, the gyrus cunei. Neither are they joined in the human fotus. If in the adult human brain the region of their junction be opened widely, there will be found a submerged transitory gyrus (deep annectant gyrus), which is the gyrus cunei, superficial in the fotus. In the higher apes and in micro-cephalic idiots this gyrus may be on the surface or partially submerged. Two other transitory gyri (annectant gyri) are to be found by pressing open the calcarine fissure, and they mark the points at which its three original grooves became continuous during its development into a boundary between the cuneus and the lingual gyrus. Of these, the anterior cuneo-lingual gyrus crosses the floor of the calcarine fissure on the posterior side of its junction with the parieto-occipital fissure, and therefore near the gyrus cunei. The posterior cuneolingual gyrus occurs near the region of the terminal bifurcation of the fissure.

The tentorial surface of the occipital lobe is blended intimately with that of the temporal lobe, from which it is scparated only by an arbitrary line clrawn to join the line of demareation for the convex surface, at the region of the preoccipital noteh, and thenee to the isthmus of the gyrus fornicatus-the narrow neck of cortex connecting the gyrus cinguli with the hippocampal gyrus, just below the splenium of the corpus callosum (see fig. 671). The gyri blending the occipital and temporal lobes across this line are the lingual gyrus, already mentioned, and the fusiform gyrus (oceipito-temporal convolution). In fact, the tentorial surface of the lobe may be considered as nothing more than the posterior extremity of the fusiform gyrus, and the inferior portion of the same extremity of the lingual gyrus. The former is of ten somewhat broken up and is then eontinuous into the lateral oecipital gyri. The two gyri are separated by the collateral fissure the posterior cud of which extends into the oceipital lobe. The fusiform gyrus is bounded laterally by the inferior temporal suleus, which sometimes is eontinuous by a lateral twig, across the posterior end of this gyrus, with the eollateral fissure.

\section{The Rijinencepilalon}

The rhincurephaton or olfactory brain includes those portions of the eerebral hemisphere which are chiefly eonecrumed as the central components of the olfactory apparistis. ()wing to the prepond lolant devolopment of the other divisions of the homisphere, the parts anmprising this division appear relatively but feebly developerl in the himan brain. In most of the mammals the sense of smell is redatively much more highly deroloperl, and in many of the larger mammals the parts comprising the rhinenerphalon are of greater absolute size than in man,

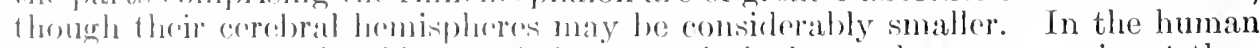
fortus the parts of the rhinencephalon are relatively much more prominent than after thr comploterl differentiations into the arluit condition. In the broader 
sense of the term the rhinencephalon includes those parts of the hemisphere usually classed as comprising two lobes, viz., the olfactory lobe and the limbic lobe. Neither of these is a 'lobe' in the sense of comprising a definite segment of the hemisphere, as do the other lobes, and therefore the rhinencephalon cannot be called a distinct lobe. It is so strung out that by one or the other of its parts it is either in contact or continuity with each of the other lobes of the hemisphere.

Morphologically, the rhinencephalon may be divided into an anterior and a posterior division.

The anterior division.--the olfactory lobe proper, belongs almost wholly to the base of the encephalon, and consists of the following parts:-

(1) The olfactory bulb is an elongated, oval enlargement of grey substance which lies upon the lamina cribrosa of the ethmoid bone, and, practically free, it presses under the anterior end of the olfactory sulcus in the basal surface of the frontal lobe. The numerous thin filaments of nonmedullated axones of the olfactory nerve enter the cranium through the foramina of the lamina cribrosa and pass into the ventral surface of the bulb.

Fig. 680.-Brain of Human Fetes of 22.5 Ch. (Begrnning of Fifth Month), showing the Parts of the Developing Rhinencephalon Apparent on the Basal surface. (After Retzius.)

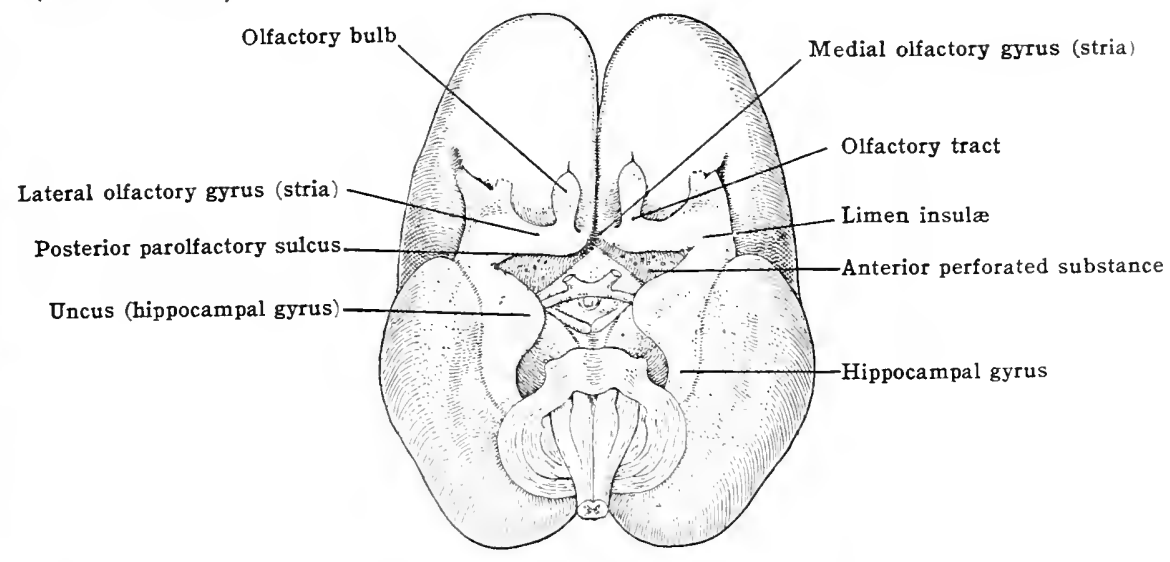

(2) The olfactory tract is a triangular band of white substance which arises in the olfactory bulb, and continues backward about $20 \mathrm{~mm}$. to the region of the anterior perforated substance. It appears triangular in transverse section from the fact that its upper side fits into the olfactory sulcus. It becomes somewhat broader at its posterior end.

(3) The olfactory trigone (olfactory tubercle) is the small triangular ridge, the posterior continuation of the olfactory tract joining the anterior perforated substance. In it the olfactory tract breaks up into three roots, the lateral, intermediate, and medial olfactory strice (gyri). The lateral olfactory stria emphasizes the lateral portion of the trigone into the lateral olfactory gyrus, a portion of which is directly continuous into the limen insula (figs. 676, 680).

While a few of the fibres of the lateral stria penetrate this region, the greater mass of them pass obliquely lateralward over it and gradually disappear in the antero-lateral portion of the anterior perforated substance, in which some of them terminate, but through which most of them pass to curve into the anterior end of the hippocampal gyrus and terminate there, chiefly in the uncus. In most of the mammals the lateral stria is so strong that it appears as a superficial white band passing directly into the uncus. In the early foetus it is seen to enter the uncus in two branches, forming the medial semilunar gyrus and the lateral gyrus ambiens upon the uncus. A portion of the limen insula belongs to the rhmencephalon.

(4) The parolfactory area (Broca's area) involves the mesial extension of the olfactory trigone, and is concerned with the medial olfactory stria. On the basal surface of the hemisphere this area involves the posterior extrenity of the gyrus rectus-a portion of which is sometimes separated from the remainder of the gyrus by a ventral prolongation of the anterior parolfactory sulcus of the medial surface (see figs. 679, 706). This prolongation when present has been called the fissura serotina. On the medial surface the parolfactory area appears as a 
definite gyrus. In front this is separated from the superior frontal gyrus by the anterior parolfactory sulcus, and from the subcallosal gyrus behind by the deeper posterior parolfactory sulcus (fig. 679). It is continuous above into the gyrus cinguli of the limbic lobe, a portion of the posterior part of the rhinencephaton.

A large portion of the fibres of the medial stria are lost in the parolfactory area, and are known to terminate about the cells there. This stria or root of the olfactory tract forms a slight ridge on the ventral surface of the area, which is frequently prominent enough to retain the name medial olfactory gyrus applied to it in the foetal brain (fig. 680).

(5) The subcallosal gyrus (peduncle of the corpus callosum) is the narrow fold of the pallium which lies between the posterior parolfactory suleus and the rostral lamina and the ventral continuation of the latter into the lamina terminalis. It begins above, in part fused to the rostrum of the corpus callosum, and in part continuous with the gyrus cinguli, and ventrally it goes over lateralward and posteriorly into that portion of the anterior perforated substance known as the diagonal band of Broca, and in this way it extends into the uncus. Mesially, it approaches its fellow of the opposite side so closely that the groove separating the two is known as the median subcallosal sulcus of Retzius. Some fibres of the medial olfactory stria disappear in the substance of the subcallosal gyrus.

(6) The anterior perforated substance must be considered with the rhinencephalon, but, like the limen insulæ, it can only be considered as belonging in part to this division of the brain. It comprises the basal region between the optic chiasma and tract and the olfactory trigone. Usually the posterior parolfactory sulcus (fissura prima of the embryo) is sufficiently evident to more or less distinctly separate it from the latter. Its postero-lateral area is occupied by the diagonal band of Broca. A few fibres from the medial stria are known to disappear within its depths, and, as mentioned above, many fibres from the lateral stria also pass into it. The intermediate olfactory stria is always much the weakest of the three strix, and in many specimens is apparently absent. The fibres of this stria run almost straight backward and plunge directly into the anterior area of the anterior perforated substance, where some of them are known to terminate, while others continue into the uncus.

On embryologieal grounds, the subcallosal gyrus and the anterior perforated substance are classed with the posterior division of the 'olfactory' lobe or anterior division of the rhinencephalon.

The olfactory bulb and tract arise as a hollow outgrowth from the lower and anterior part of the anterior of the three primary vesicles. It is a tubular structure at first, and in many of the mammals the cavity maintains throughout life as the olfactory centricle. In man the eavity becomes occluded and the cpendyma and gelatinous substance which surround it become the grey core of the bulb and traet of the adult.

The grey substance persists and develops ehiefly in the bulb, and in fact produces it as such. It is much thicker on the inferior surface of the bulb than on the superior surface, and in section shows definite layers. From within outward, the principal of these layers are-(1) the layer of large cells whose shape suggests their name, mitral cells; (2) large dendrites of the mitral cells projert towart the inferior surface of the bulh and there break up into numerous telodendria whirh (opionsly form synapses with like telodendria of the entering fibres of the olfactory nerve, thus forming rounded, much tangled glomeruli and the layer containing these, the glomerular layer; (3) the superfieial layer, or olfactory layer, consists of the fibres of the olfactory nerve which form a dense interlacenent with each other on the inferior surface of the bulb before they pass into its interior. 'Tle superior surface of the bulb becomes formed almost wholly of the fibres which arise as axomes of the mitral cells and pass backward to form the olfactory tract, and thence to their loralitios of termination, ehiefly by way of the three strix. Along the dorsal, covered, aspect of the offactory tract the gelatinous substance of the core may show through as a grey ridge.

The posterior division of the rhinencephalon or the so-called limbic lobe (a name introluced by Prora in 1878) takes part in both the medial and tentorial surfaces of the hemisphere (fig. 681). Seen from the medial surface, it forms an irregular alliptioal figure which encloses the corpus aallosum and the extrentities of which alpuroseh cach other at the anterior perforated substance, where they are continuons with the struetures of the anterior division of the rhinencephalon. The figmo is bommed externally hy the sulcus einguli above, by the subparietal sulcus (postlimbic suleus) and the anterior limb of the calcarine fissure behind, and by the collatral fissure bolow. These respectively separate it from the frontal, parictal, oceipital, and temporal lobes. It comprises the following 
structures which are either wholly or in part deroted to the functions of the olfactory apparatus:-

1. Gyrus fornicatus

Part of gyrus cinguli and cingulum.

Isthmus of the gyrus fornicatus.

Hippocampus $\left\{\begin{array}{l}\text { hippocampal gyrus. } \\ \text { uncus. } \\ \text { dentate gyrus (fascia). }\end{array}\right.$

fimbria.

2. The medial and lateral longitudinal striæ upon the corpus callosum.

3. The fornix.

4. The mammillary body, the mammillo-thalamic fasciculus to the anterior nucleus of the thalamus and the mammillo-peduncular fasciculus.

5. Part of anterior cerebral commissure.

6. Part of septum pellucidum.

7. Most of medullary stria of thalamus.

8. Most of habenular nucleus.

The gyrus fornicatus comprises the greater mass of the limbic lobe. As seen above, it is a term used to collectively represent a number of conjoined structures.

Fig. 681.-Diagram showing Position of Structures Conprising the Linibic Lobe as Seen from the Mesial Aspect of the Cerebral Hemisphere.

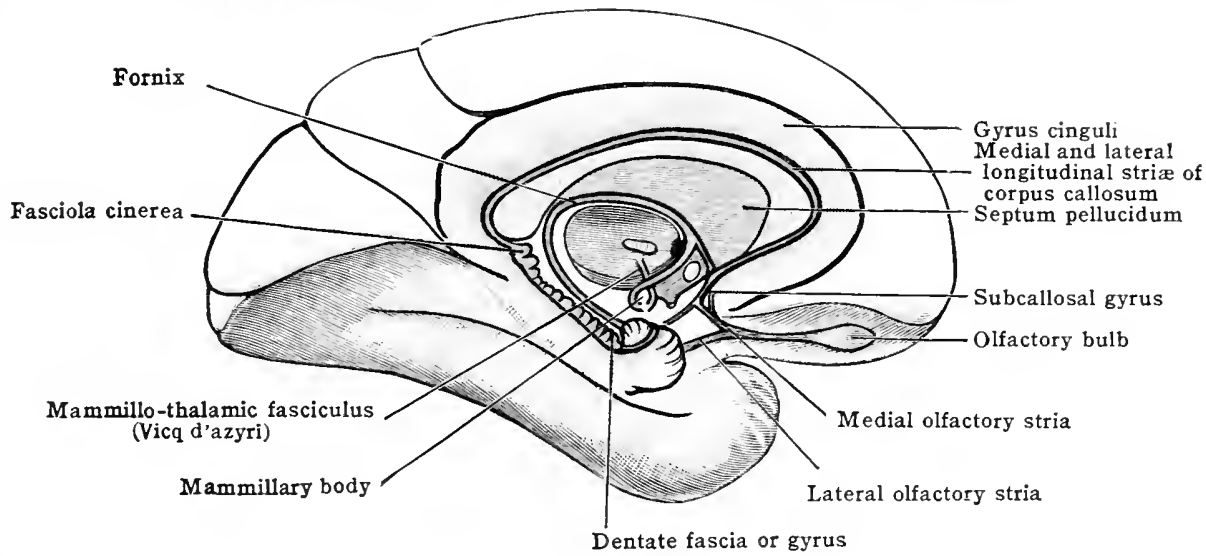

Being an incomplete ellipse in form, its two ends are united to form a closed ring by means of the connection of the parolfactory area with the gyrus cinguli and the connection of the anterior perforated substance with the uncus of the hippocampal gyrus. It is best described in terms of its three component parts indicated above:

The gyrus cinguli begins in junction with the area parolfactoria below the anterior end of the corpus callosum, and curves above so as to entirely embrace the upper surface of the latter. It is separated from the frontal lobe by the sulcus cinguli (calloso-marginal fissure), from the parietal lobe by the subparietal sulcus, and from the corpus callosum below by the sulcus of the corpus callosum. By the latter it is separated from the longitudinal strix of the upper surface of the corpus callosum.

The gyrus cinguli covers over, and its cells are closely associated with, the cingulum, a wellmarked arcuate band of white substance, which follows the gyrus in its bend around the rostrum and backward to turn around the splenium of the corpus callosum in the isthmus of the grrus fornicatus, and then to course forward into the hippocampal gyrus and the uncus. The cingulum is largely an association fasciculus between the gyri of the temporal lobe and those gyri on the mesial surface of the cerebral hemisphere, its fibres for the most part running short courses, being continually added to it and continually leaving it. However, it contains olfactory axones running in two directions: (1) fibres from the medial olfactory stria and fibres arising in the parolfactory area, the gyrus subcallosus and the anterior perforated substance which course posteriorly for distribution in the cortex of the gyrus cinguli and hippocampal gyrus; (2) fibres arising in the hippocampal gyrus, especially the uncus, to course dorsalward through the isthmus and then forward as association fibres. Some fibres arising from the cortical cells of the gyrus cinguli pass inferiorly through the cingulum, through the corpus callosum and, anteriorly, through the septum pellucidum to join the fornix below (perforating fibres of the formix).

The isthmus of the gyrus fornicatus is the constricted portion connecting the posterior end of the gyrus cinguli with that of the hippocampal gyrus (fig. 619 
and 671). It is bounded externally by the anterior end of the calcarine fissure, and incloses the posterior turn of the cingulum.

- The hippocampus is the name applied to the curved appearances produced in the floor of the lateral ventricle by the peculiar foldings of this part of the cerebral cortex. The hippocampal gyrus (gyrus of the hippocampus) is the main gyrus of the tentorial surface of the limbic lobe. Externally it is separated from the fusiform grrus by the collateral fissure, and it is bounded internally by the hippocampal or, more inclusive, the chorioid fissure. Posteriorly it is partially divided by the calcarine fissure into the lingual gyrus (of the temporal lobe) and the isthmus of the gyrus fornicatus. Its anterior extremity is hooked backward and is known as the uncus (gyrus uncinatus). This is almost entirely separated from the temporal lobe by a groove, the temporal notch. If the hippocampal fissure be opened up, the dentate gyrus or fascia and the fimbria will be seen. These lie side by side, separated by the shallow fimbrio-dentate sulcus (fig. 690.)

The free edge of the dentate gyrus presents a peculiarly notched appearance, produced by numerous parallel grooves cutting it transversely. Its posterior end, sometimes called the fasciola cinerea, continues backward over the splenium of the corpus callosum, and upon the upper surface of the corpus callosum appears as a thin strip of grey substance which contains embedded in it the medial and lateral longitudinal strio. This thin strip is sometimes called the supracallosal gyrus (gyrus epicallosus, induseum griseum), and is thought to represent a vestigial part of the hippocampal gyrus. Closely beneath the splenium of the corpus callosum, on the supero-mesial side of the hippocampal gyrus and mesial to the dentate gyrus, there sometimes occur suggestions of round or oval elevations of the grey substance which have been called the "callosal convolutions" or gyri Andrea Retzii. Rarely are they strongly developed, but when so they often produce a spiral appearance.

The fimbria is but the fimbriated, free border of the posterior end or origin of the fornix, so folded as to project in to the hippocampal fissure, parallel with the dentate gyrus (fig. 690). It is a conspicuous band composed almost entirely of white substance, continuous laterally with the thick stratum eovering the ventricular surface of the hippocampus. It begins anteriorly in the hook or recurved extremity of the uncus. Traced backward, it is seen so curve upward, and within the ventricle it becomes part of the general accumulation of the white substance (alvens) of the surface of the hippocampus, which accumulation is the beginning of the fornix. The free border of the fimbria (seen in section) is known as the tarnia fimbria. The fimbria is separated from the cerebral peduncles by the chorioid fissure, the thin, non-nervous floor of which alone intervenes between the exterior of the brain and the cavity of the lateral ventricle within.

The hippocampal fissure attains its greatest depth between the dentate gyrus and the hippocampal gyrus, and the resulting eminence produced in the floor of the lateral ventricle is known as the hippocampus major, as distinguished from the lesser eminence produced posteriorly by the end of the calcarine fissure and known as the hippocampus minor [calcar avis]. The collateral fissure may likewise produce a bulging in the wall of the ventricle, the collateral eminence. In transverse suetions of the hippocampus major, the layers of grey and white substance present a coiled appearance known as the cornu ammonis. Externally the merlial surface of the hippocampal gyrus adjoining the dentate gyrus has reflented ower it a delicate reticular layer of white substance known as the substantin reticularis alba (Arnoldi).

The fornix is the great association pathway of the limbic lobe, and appears to be wholly concerned in the apparatus of the rhineneephalon. It is a bilateral strueture arehed beneath the corpus callosim, with which it is eonnected anteriorly by the septum pellucielum. Posteriorly it passes in contact with the splenimm. It amsists of two prominent strips of white substance, one for each hemisphere, the ants of which are separate from each other, while their intermediate parts are fuserl across the midl-line. 'These rum above the chorioid tela of

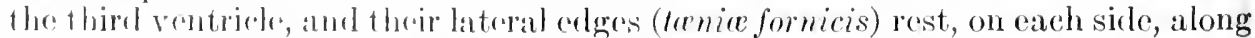
the line of the tania cherioblea. The posterior, separate conds are known as the posterior pillars or erura of the fornix; the fused, intermediate portion is the body, and the separate, anterior curls are the anterior pillars or colunms of the fornix.

The posterior pillars /crura| of the fornix. - When seen from the medial asperet of the hemisphere, the fused portion of the fornix, in the separation of the hrmispheres, is split along the mirl-line (fig. 671). The half under examination 
may be seen to course obliquely lateralward under the splenium of the corpus callosum, and then, continuous into the fimbria, to curve forward and rentratward toward the uncus. The greater mass of the fibres coursing in the fornix arise as outgrowths of the cells of the uncus, hippocampal gyrus, and dentate grrus. They accumulate as a dense stratum on the ventricular surface of these grri, termed the alveus, which crops outward as the fimbria and which passes backward and upward; upon reaching the region of the splenium it turns obliquely forward under

Fig. 682.-Diagram Showing Forntx and its Connections as seen from Above.

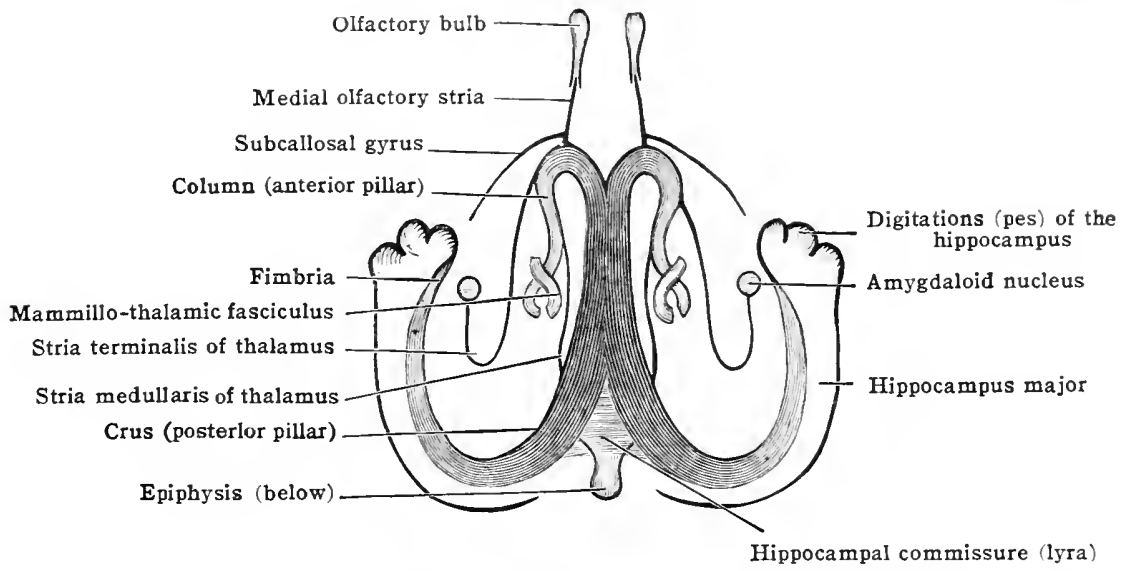

it and approaches the mid-line, to fuse with the like bundle from the gyri of the hippocampus of the opposite side. The bundles thus arising from the two sides are the pillars or crura of the fornix. They appear as two flattened bands of white substance which come in close contact with and even adhere to the splenium.

The angle formed by the mutual approach of the posterior pillars of the fornix is crossed by a lamina of commissural fibres connecting the hippocampal gyri of the two hemispheres (fig. 681). This lamina is the hippocampal commissure or transverse fornix. Like those of the fornix, its fibres arise from the cortex of the hippocampal gyri, but they serve as commissural fibres between the hippocampal gyri of the two hemispheres. Being of a different functional direction, it should not be considered a part of the fornix. The angle formed by the two pos-

Fig. 683.-Diagram Illustrating the Origin and Course of Fornix as viewed from the SIDE.

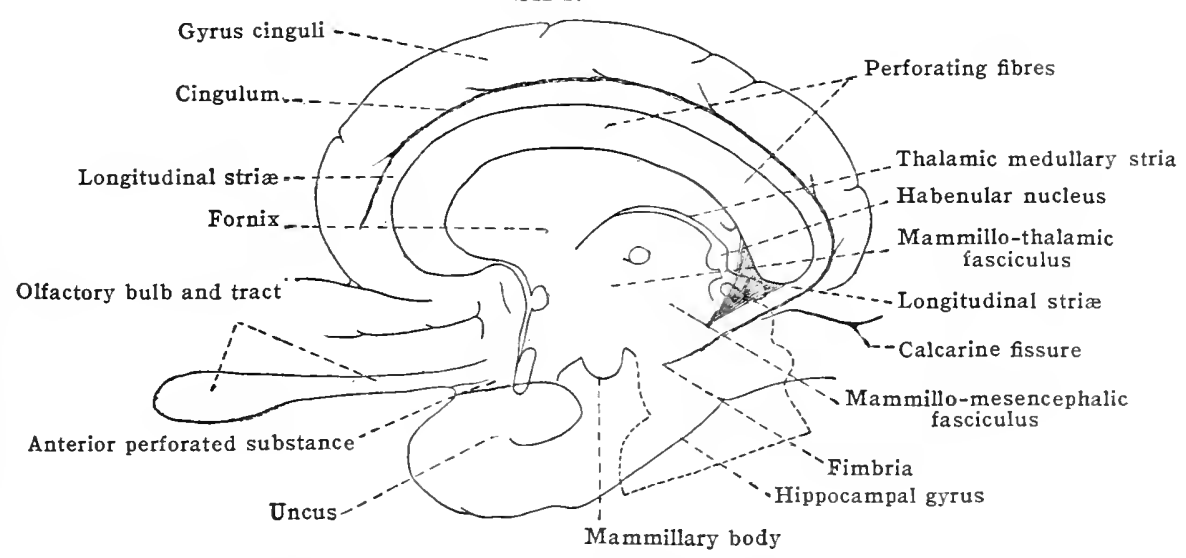

terior pillars of the fornix as trarersed by the hippocampal commissure gives a picture named the psalterium or lyra. Esually the hippocampal commissure and the posterior pillars (crura) are in close contact with the under surface of the splenium. When occasionally they do not adhere, the space between is known as Verga's ventricle. According to recent studies of brains with degenerated corpus callosum, further commissural fibres between the limbic lobes course in the posterior angle of the septum pellucidum, and all along, transverse to the body of the fornix.

The body of the fornix appears as a triangular plate of wlite substance produced by the fusion of the pillars. Its base or widest portion is behind. It is not always bilaterally symmetrical. Its upper surface is attached by the septum 
pellucidum to the lower surface of the corpus callosum. Below, it lies over the chorioid tela of the third ventricle, which separates it mesially from the cavity of the third ventricle and laterally from the upper surfaces of the thalami. Its sharp lateral edge or margin (tænia fornicis) projects into the lateral ventricle of either side in relation with the chorioid plexus of that ventricle, and thus the lateral portion of its upper surface forms part of the floor of the lateral ventriclean arrangement to be expected, since the posterior pillars arise from the floor of

Fig. 684.-Horizontal Section of Telencephalon showing Body of Fornix and Hippocampal Commissure as seen from Below and the Anterior Commissure in Section. (After Toldt, "Atlas of Human Anatomy," Rebman, London and New York.)

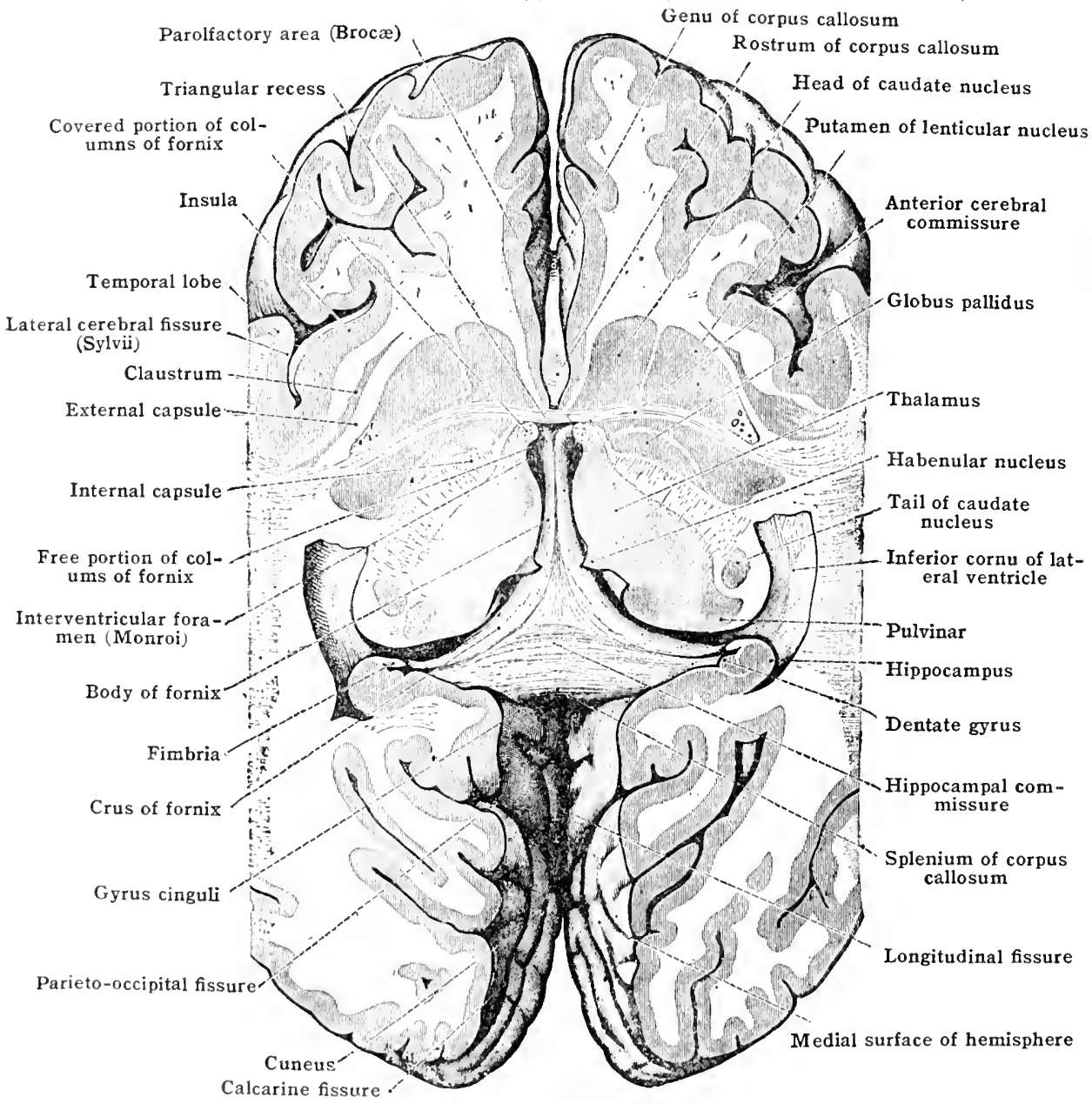

the ventricle, viz, the lippocampus. The ventricular portion is covered by a layer of cpentlynia in common with that lining the rest of the ventricle.

Along its berly the fornix recrives fibres arising from the cells of the cortex of the gyrus cinguli and fibres from the longitulinal striat nen the dorsal surface of the corpus callosum. These are known as the perforating fibres of the fornix. In the ir ventral course, they pass obligumely forward through the corpus callosum and, interiorly, through the posterior angle of the septum pellucidum to join the fornix and course in its fumctional direction. The fibres arising in the cortex of the gyrus einguli may conrse short distances in the cingulum before perforating the worpus callosimn.

The columns or anterior pillars of the fornix [columne fornicis], are two separate, eylindrical hundles which pass forward from the alpex of the besty of the fornix and then turn sharply downward along the anterior boundary of the third ven-

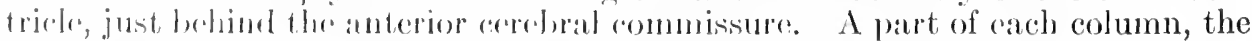
fres purfirm |uats liberal, forms the anterior houndary of the interventricular

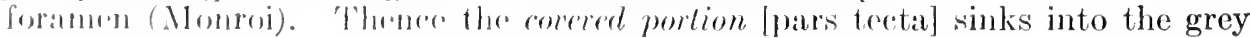


substance of the lateral wall of the third ventricle, and passes downward to the base of the brain, where it appears on the exterior as the mammillary body [corpus mammillare] (fig. 671).

Some of its fibres are interrupted in the nuclei of the mammillary body, chiefly in its lateral nucleus; probably most of them merely double back, forming a genu. From the mammillary body the fibres are disposed in at least three ways:-(1) The greater part perhaps pass directly upward and are lost in the anterior nucleus of the thalamus, where they ramify freely and terminate about its cells. These fibres form the bundle known as the mammillo-thalamic fasciculus, or bundle of Vicq d'Azyr; (2) A portion of the fibres go to form a mammillo-mesencephalic fasciculus (tegmento-mammillary fasciculus, mammillo-pcduncular fasciculus. This begins in the mammillary body and passes caudalward into the mesen cephalon to terminate about cell-bodies in or in the region of, the so-called nucleus of the medial longitudinal fasciculus and posterior commissure. Fibres given by these cell-bodies may convey impulses by way of the medial longitudinal fasciculus or the general reticular formation to the nuclei in the mesencephalon, rhombencephalon and perhaps into the spinal cord. Some of this portion of the fibres from the mainmillary body are said to pass caudalward through the mesencephalon without interruption there. (3) A portion of the fibres decussate in the superior parts of the mamillary bodies and are distributed to both the thalamus and the mesencephalon of the opposite side. This decussation is the supramamillary commissure.

As seen above, the fornix as a whole is composed of longitudinally directed fibres, some of which, however, cross the mid-line in the region of its body and course in the columns of the opposite side. For the greater part, its fibres rise from the cells of the hippocampal gyri, but it is knomn to contain some fibres which arise in the anterior perforated substance and subcallosal gyrus and course through the fornix to the hippocampal gyri.

The medial and lateral longitudinal striæ upon the corpus callosum consist of olfactory fibres coursing in both directions: (1) fibres arising in the parolfactory area, the subeallosil gyrus and the anterior perforated substance (diagonal band of Broca) course posteriorly and then inferiorly in then to the grey substance of the grvi of the hippocampus; (2) and chiefly, fibres from the hippocampal grri course in them anteriorly and inferiorly around the rostrum of the corpus callosum, through the ventral part of the septum pellucidum, to join the fornix. It is suggested that the strix, especially the medial, may be considered as a part of the fornix detached upon the dorsal surface of the corpus callosum during the projection of the latter between the cerebral hemispheres. The medial stria is often called the stria Lancisii.

The anterior cerebral commissure is only in part concerned in the rhinencephalon; it consists in greater part of commissural fibres connecting the two temporal lobes. It forms one of the four commissures of the telencephalon, the other three being the corpus callosum, the hippocampal commissure and the inferior cerebral commissure. It is a bundle of white substance with a slightly twisted appearance, which crosses the mid-line in the anterior boundary of the third rentricle between the lamina terminalis and the columns of the fornix (figs. 671 and 684 ), just below the interventricular foramen (foramen of Monro). In each hemisphere its main or temporal portion passes lateralward and slightly backward beneath the head of the caudate nucleus and through the anterior end of the lenticular nucleus, and thence is dispersed to the grey substance of the temporal lobe.

It contains fibres both to and from the temporal lobe of each side. In addition to these fibres the anterior commissure carries in its frontal side two sets of fibres belonging to the olfactory apparatus:-(1) fibres arising in the olfactory bulb of one side, which pass by way of the medial olfactory strix through it to the olfactory bulb of the opposite side; (2) fibres which pass through it from the medial stria (olfactory bulb) of one side to the uncus of the opposite side.

The anterior commissure is a more primitive commissure than the corpus callosum, in that it is present in the lower forms when the latter is absent, and diminishes in relative size and importance as the corpus callosum appears and increases in size. In man the appearance of the anterior commissure precedes but little that of the corpus callosum. During the fifth month the lamina terminalis, which then alone unites the anterior ends of the two hemispheres, develops a thickening of its dorsal portion. In a part of this thickening, transverse fibres begin to appear and their increase in number results in the partial separation posteriorly of the part containing them from the rest of the lamina, and then follows the differentiation of this part in to the anterior commissure. The remainder of the thickening of the lamina continues to increase in size with the increase of the hemispheres; its upper edge is directed posteriorly, and fibres begin to appear in it which arise in the cortex of one side and cross over to that of the other side. These fibres form the corpus callosum.

The corpus callosum, a development of fibres in the upper, expanded portion of the lamina terminalis, thus bridges over a portion of the longitudinal fissure between the hemispheres. In the mean time, the fornix arises as two bundles of fibres, one from the hippoeampus of each side. In the complex mechanics of the development of the cerebrum these two bundles approach cach other under the corpus callosum, fuse for a certain distance, and together areh the cavity of the third ventricle and come to acquire their adult position. There results from these processes of growth a completely enclosed space, a portion of the longitudinal fissure, the roof of which is the corpus callosum. its floor, the body of the fornix, and its lateral walls, portions of the mesial surfaces of the two cerebral hemispheres. The lateral walls of this space do not thicken 
as do the other regions of the pallium, but remain thin and constitute the septum pellucidum of the adult, the space itself being the so-called fifth ventricle or cavity of the septum pellucidum.

The septum pellucidum is a thin, approximately triangular, vertically placed partition which separates the anterior portions of the two lateral ventricles from each other. Its widest portion lies in front, bounded by the genu and rostrum of the corpus callosum, the rostral lamina, and the anterior pilars of the fornix, to all of which it is attached. Prolonged backward under the body of the corpus callosum, it narrows rapidly and terminates at the line of adherence between the posterior portion of the fornix and the splenium of the corpus callosum. It consists of two thin layers, the laminæ of the septum pellucidum, arrested developments of portions of the pallium of the hemispheres. The laminæ enclose a narrow median cavity known as the fifth ventricle [cavum septi pellucidi]. This cavity is of very variable size, is completely closed, and does not merit the term 'ventricle,' as applied to the other cavities of the brain, in that it has no communication with the ventricular system and has a different lining from the other ventricles.

Fig. 685.-Diagram showing Some of the Principal Tracts and Synapses of the OlFACTORY APPaRATUs.

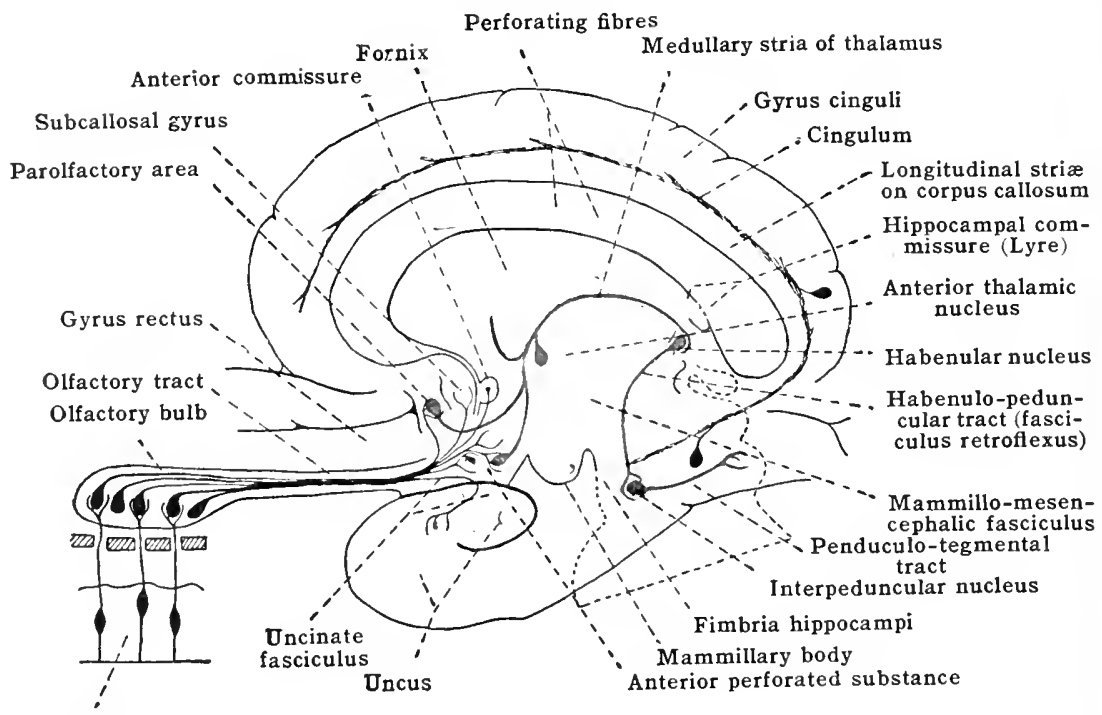

Olfactory epithelium

Each lamina of the septum pellucidum consists of a layer of degenerated grey substance next to the fifth ventricle and a layer of white substance next to the lateral ventricle, the latter covered by a layer of ependyma common to that ventricle. The white substance consists in part of fibres betonging to the general association systems of the hemispheres, and in part of four varieties of fibres coneerued with the rhinencephalon:--(1) fibres from each medial olfactory stria are known to reash the septum pellucidum and thence go by way of the fornix to the hippocampus inajor; (2) fibres are thought to be contributed by the fornix to the septum pellucidum, and through it reach the subeallosal gyrus and perhaps the parolfactory area and even the olfactory bulb; (3) the posterior angle of the septum pollueidum is preforated by some commissural fil,res passing from the hody of the fornix and by some perforating fibres of the fornix, passing from above thromgh it to the fornix below; (4) anteriorly, some fibres from the longitudinal stria upon the corpus eallosum pass through its inforior portion to join the fornix.

The medullary stria of the thalamus [stria medullaris thalami] (strie pincalis, tomia lhalami), already describer as to pusition, receives filmes from three sourees, the majority at least of which belong to the rhinenerphalon: (1) fibres from the fornix near-hy and thus from the cortex of hippocampal grasume aryus cinguli (a cortion-halomular tract); (2) filmes from the parolfactory area ind the anterior perforated sulstance, through the septum pellucidum and lamina

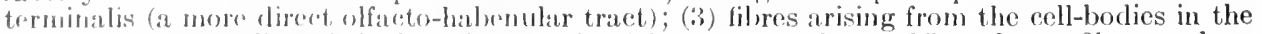
thalamus, supposedly chicolly from its anterior (olfactory) nucleus. 'l'hese later fibres make a thalame-lateroular tract.

Tho ma jority of the filmes of the mednllary strim torminate in the habenular nuclei, situated at the two sides of the stalk of the epriphysis. Most temninate in the habenular nucleus of the same side. Sinne cross in the habenular commissure (dorsal part of the posterior cerebral commissme) and trominate in the mustens of thr opposite side. $\Lambda$ few are clamed to pass to the

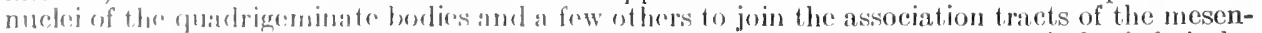

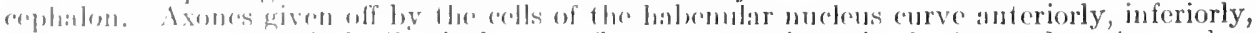
and then conrse pusteriorly (fiscienlus retroflexus) to teminate in the interpeduncular nucleus 
(a habenulo-peduncular tract), and fibres arising in this latter nucleus pass to the cells about the central grey substance of the mesenecphalon (an inter-pedunculo-tegmental tract). The two mesencephalic paths here noted and the mammillo-mesencephalic fasciculus noted above give three anatomical possibilities for olfactory reflex activities, visceral (or sympathetic) and somatic, involving the motor cranial nerves and possibly the spinal nerves. Fibres arising in the cortex of the hippocampal gyrus, uncus especially, may pass by way of the cingulum and thence by any suitable association fasciculus of the cerebral hemisphere to the motor area of the cerebral cortex; also fibres may arise from the anterior nucleus of the thalamus and pass to the motor cortex by way of the internal capsule. From the motor cortex, the descending pyramidal fibres give the possibilities for any higher cortical activities induced by smell.

A more direct mesencephalic path has been suggested by Wallenberg, namely, that cells in the olfactory trigone and anterior perforated substance, about which terminates fibres of the olfactory tract, send axones directly posteriorly, around the tuber cinereum, to terminate in the mammillary body and thence the impulses may go to the mesencephalon. Such fibres, if they exist, would form an olfacto-mammillary tract. A path is described in the hedge-hog which arises from cells in the olfactory trigone and passes directly posteriorly to terminate in the grey substance of the mesencephalon-an olfacto-mesencephalic tract.

To the complicated central connections of the sense of smell, Dejerine adds yet another path, namely, a portion at least of the terminal stria [stria terminalis] of the thalamus (trenia semicircularis). This contains fibres arising from cells in the anterior perforated substance and in the septum pellucidum and fibres from the opposite side by way of the anterior commissure. It runs a crescentic course posteriorly, bounding the thalamus from the caudate nucleus, turning downward and then anteriorly in the wall of the inferior cornu of the lateral ventricle to terminate in the amygdaloid nucleus, which latter is a more or less detached bit of the cortex of the extreme anterior portion of the hippocampal gyrus (uncus). The stria is said also to contain fibres which arise in the amygdaloid nucleus and course in it forward to be given off to the thalamus and probably to the internal capsule and thence to the cerebral cortex above.

\section{SUMMARY OF THE OLFACTORY APPARATUS}

\section{Peripheral part.}

(1) Olfactory area of nasal epithelium containing the cell-bodies and peripheral processes of olfactory neurones (olfactory ganglion).

(2) Non-medullated central processes of olfactory neurones, the olfactory nerve, passing as numerous filaments through the cribriform plate of the ethmoid, to terminate in contact with the dendrites of the "mitral cells" (stratum glomerulosum) in the olfactory bulb.

II. The Rhinencephalon.

A. The anterior division.

(1) Olfactory bulb, olfactory tract, olfactory trigone (tubercle), lateral olfactory stria (gyrus), medial and intermediate olfactory striæ.

(2) The parolfactory area, subcallosal gyrus, anterior perforated substance including the diagonal band of Broca.

B. The posterior division.

(1) Part of anterior commissure, septum pellucidum, uncinate fasciculus, hippocampal gyrus (uncus especially), dentate gyrus, gyrus cinguli and cingulum.

(2) Fimbria, hippocampal commissure, fornix, longitudinal striæ upon corpus callosum, mammillary body, mammillo-thalamic fasciculus, mammillo-mesencephalic fasciculus.

(3) The anterior nucleus of the thalamus.

(4) The medullary stria of the thalamus, habenular nucleus, fasciculus retroflexus, interpeduncular nucleus, and interpedunculo-tegmental tract.

(5) Probably an olfacto-mammillary and an olfacto-mesencephalic tract, and a part of the terminal stria of the thalamus with the amygdaloid nucleus.

\section{THE LATERAL VENTRICLES}

Two of the four cavities of the ventricular system of the brain are in the telencephalon. From their position, one in each cerebral hemisphere, they are known as the lateral ventricles. They arise as lateral dilations of the cavity of the anterior of the primary vesicles, and, just as the fourth ventricle remains in communication with the third by way of the aqueduct of the cerebrum, so the lateral are connected with the third by the two interventricular foramina (Monroi). The whole ventricular system, including the central canal of the spinal cord, is lined by a continuous layer of ependyma and contains a small quantity of liquid known as the cerebro-spinal fluid.

Each lateral ventricle is of an irregular, horseshoe shape. It consists of a central portion or body and three cornua, which correspond to the three poles of the hemisphere. The portion projecting into the frontal lobe is known as the anterior cornu, that projecting into the occipital lobe is the posterior cormu, and the portion which sweeps anteriorly downward into the temporal lobe is the inferior cornu. The ventricles of different individuals vary considerably in capacity, and the carity of a given ventricle is not uniform throughout. In some 
localities the space may be quite appreciable, while in other places the walls may be approximate or even in apposition. Each lateral ventricle is a completely closed cavity except at the interventricular foramen. However, a strip of the floor of the inferior colmu is separated from the exterior of the brain by only the thin, non-nervous lamina forming the floor of the chorioid fissure.

The interventricular foramen (foramen of Monro), by which the lateral ventricle is continuous with the cavity of the third ventricle, is a small, roundish chan-

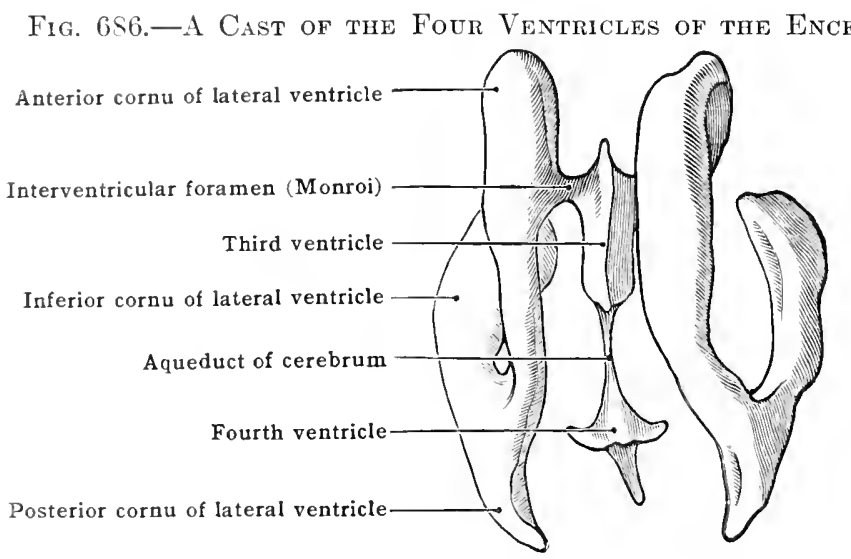

nel, 2 to $4 \mathrm{~mm}$. wide, which opens into the mesial side of the posterior end of the anterior cornu. It is bounded in front hy the free portion of the anterior pillars of the fornix, and behind by the anterior tubercle of the thalamus. That the greater part of the lateral ventricle is posterior to it is due to the backward extension of

Fig. 687.-Diagram of Sagittal Section tirrough Lateral Part of Right Heaisphere showing Lateral Ventricle from the Mesial Side of the section.

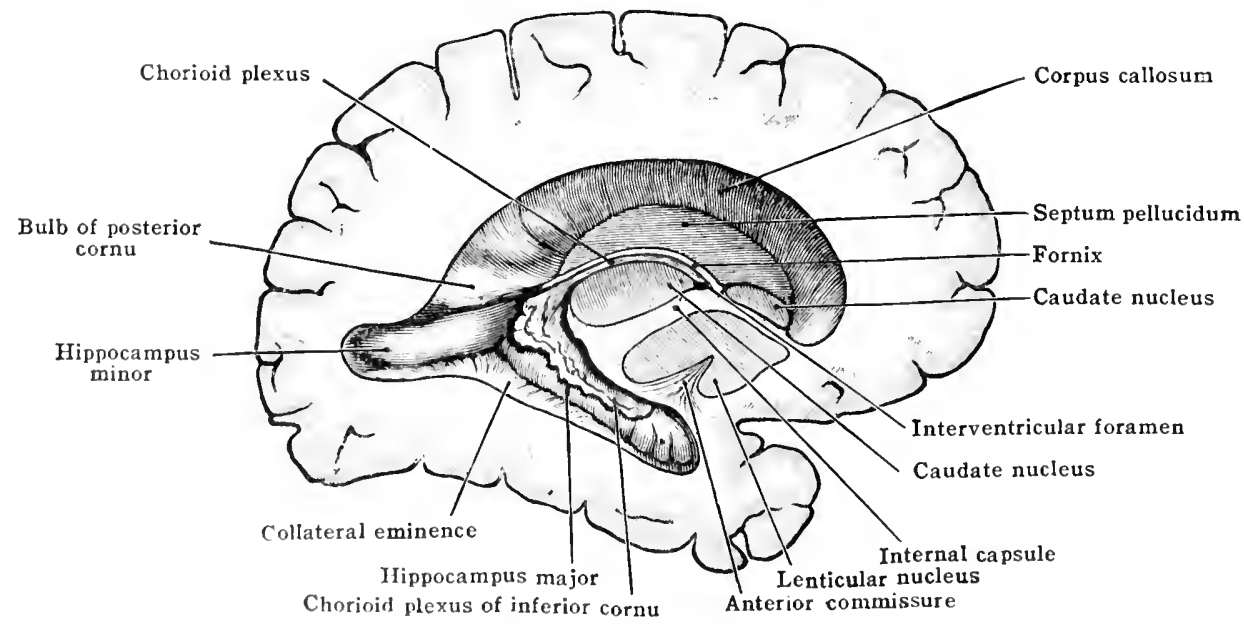

the hemispheres during their growth and claboration. Through the two foramina indirectly, the cavities of the two lateral ventricles are in communication with calch other.

The walls of the lateral ventricle. The anterior cornu is a bowl-like cavity, convex forward and rextending downward and nodialward into the frontal lobe. Alove and anteriorly it is bommled by the under surface of the corpus callosum and the ratliations of its genu into the substance of the frontal lobe. Its median boundary is the septun pellueidum; the heal of the eadade nucleus (part of the corpus striatum) gives it a bulging, infore-lateral wall, and the balance of its floor is formed liv the white substane of the orbitat part of the frontal lobe. 
The central portion or body is more nearly horizontal. It lies within the parietal lobe and extends from the interventricular foramen to the level of the splenium of the corpus callosum. Its roof is formed by the inferior surface of the body of the corpus callosum, and its mesial wall consists of the posterior part of the septum pellucidum, attaching the fornix to the under surface of the corpus callosum. Like the anterior horn, it is given an oblique, infero-lateral wall by the narrower, middle part of the caudate nucleus. Several structures contribute to its floor:-(1) the stria terminalis of the thalamus, a line of white substance conforming to the genu of the internal capsule without, and constituting the

Fig. 68s.-Horizontal Dissection of the Cerebral Hemispheres.

The fornix has been removed to show the relation of the tela chorioidea of the third ventricle to the chorioid plexus of the lateral ventricles. (From a mounted specimen in the Anatomical Department of Trinity College, Dublin.)

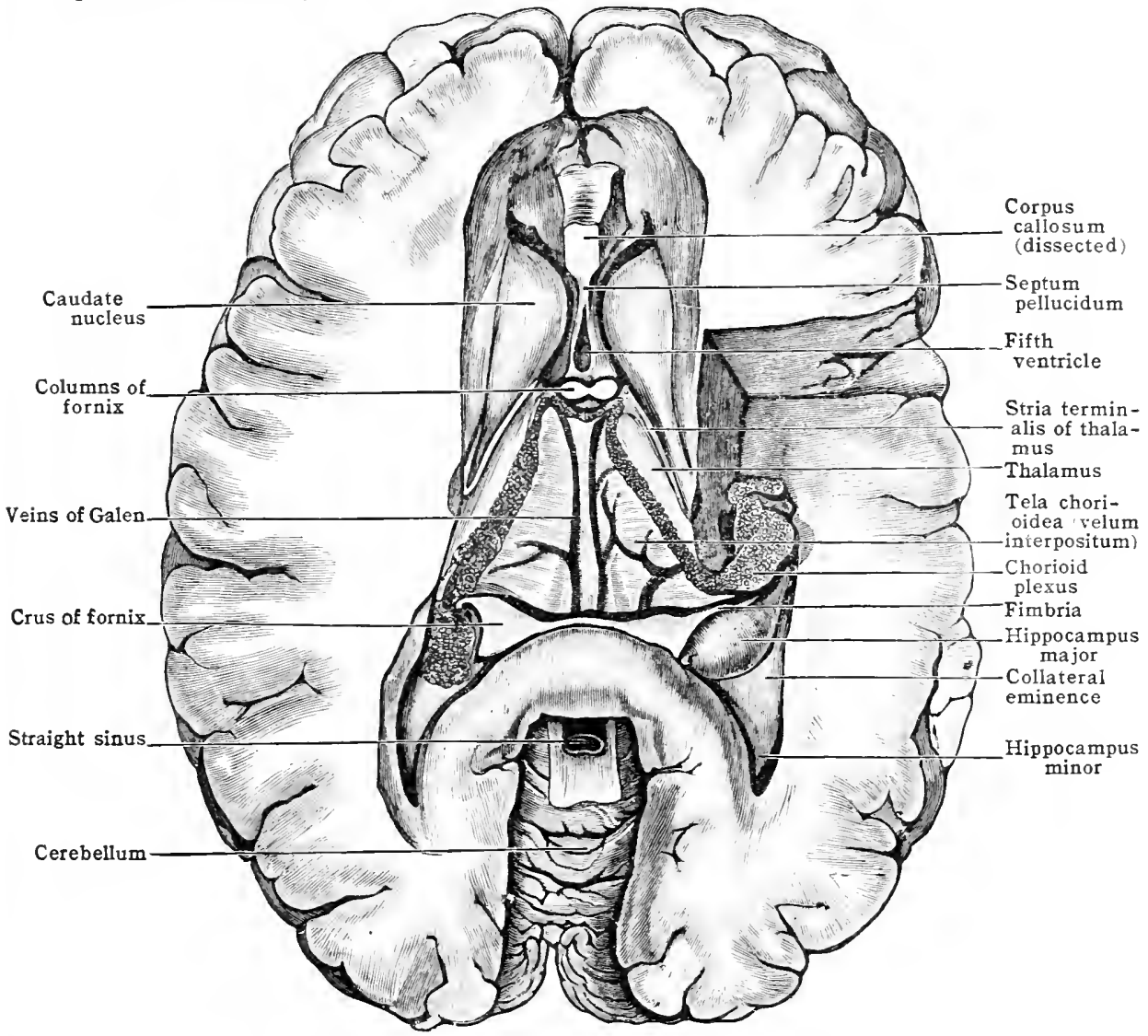

boundary between the caudate nucleus and the thalamus, and containing (2) the vena terminalis (vein of the corpus striatum); (3) the lamina affixa, a mesial continuation of the stria terminalis upon the surface of (4) the lateral part of the thalamus; (5) the medial edge of the lamina affixa, the tænia chorioidea, and the chorioid plexus continuing under (6) the edge (tænia) of the body and the beginning crura (posterior pillars) of the fornix (fig. 6SS).

The chorioid plexus of the lateral ventricle is continuous with that of the third ventricle. The chorioid tela of the third ventricle (velum interpositum) continues under the tænia of the fornix into the lateral ventricle, and there, along the line of the tænia chorioidea, becomes elaborated into a raricose, convoluted, villus-like fringe, rich in venous capillaries and lymphatics. This fringe is the chorioid plexus. It is continuous anteriorly, at the int rventricular foramen, with the corresponding plexus of the opposite lateral ventricle and with the chorioid plexus of the third rentricle. The latter consists of two similar but smaller fringes, which project close together into the cavity of the third rentricle from the median portion of the ventral surface of the chorioid tela. Behind, the chorioid 
plexus of the lateral ventricle curves posteriorly and inferiorly into the inferior cornu, being especially well developed at the region of its entrance into the latter, into what is called the chorioid glomus.

Though apparently lying free in the ventricle, the chorioid plexus is invested throughout by a layer of epithelium, the epithelial chorioid lamina, which is adapted to all its unevennesses of surface and which is a continuation of the ependymal lining of the remainder of the ventricle - continuous, on the one hand, with that of the lamina affixa and thalamus, and, on the other, with the epithelial covering upon the upper surface of the tænia of the fornix and fimbria.

The posterior cornu of the lateral ventricle is a crescentic cleft of variable length, convex latcralward, which is carricd backward from the posterior end of the body of the ventricle and, curving medialward, comes to a point in the oecipital lobe. Its roof and lateral wall are formed by a portion of the posterior radiation of the corpus callosum, which forms a layer, from its appcarance known as the tapetum. In transverse sections of the occipital lobe (fig. 699) the tapetum appears as a

Fig, 689.-Diagramatic Transverse Section of Prosencephalon throdgh Bodies of Lateral Ventricles and Middle of Thalamencephalon.

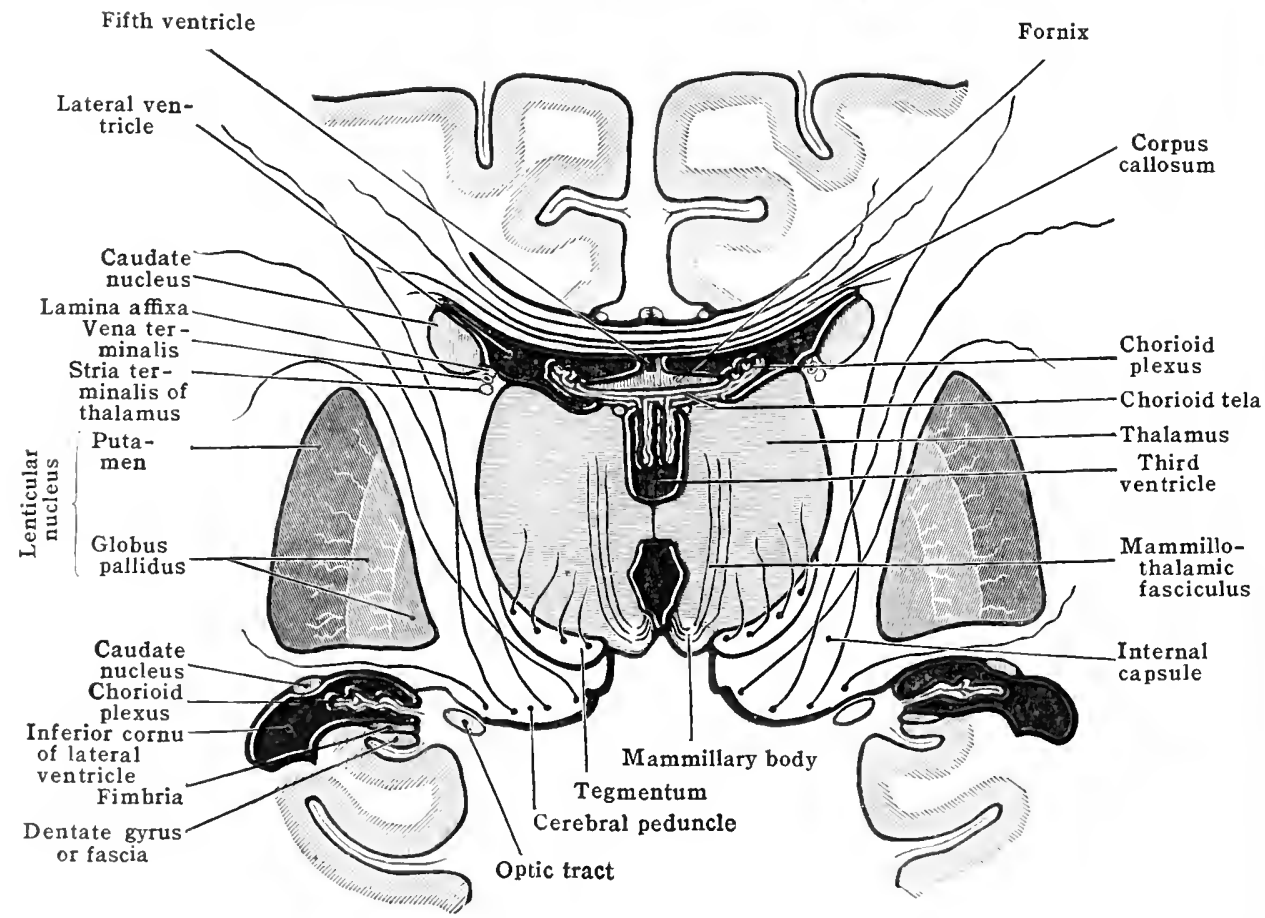

thin laminat of obliquely ent white substance immediately bounding the eavity, while ontside the tapetum occurs a thicker layer of more transversely eut fibres, the occipito-thalamic radiation. In the medial or inner wall of the posterior horn run two variable longitudinal eminences:-(1) The superior of these is the bulb of the posterior cornu, and is formed by the occipital portion of the radiation of the corpus callosum (splenium), which bends around the impression of the deep parieto-occipital fissure, and, hook-like, sweeps into the oceipital lobe. In horizontal sections these filmes, together with the splenium and the similar fibres into the opposite oreipital lobe, form the figure known as the forceps major. (2) The inferior and thicker of the eninences is the hippocampus minor [calcar avis] (cocks's spur), and is due to the anterior part of the ealcarine fissure, by which the wall of the lemisphere is projected into the ventricle. The posterior horn, like the antrior, is not antered thy the choriogel plexis.

The inferior cornu.- In its inforior and slightly lateral origin from the region of junetion betweesn the borly of the ventricle and the posterior eormu, the inferior form aids in producing a somewhat triangular dilation of the cavity known as the collateral trigone. Jinginning as a part of the trigone, the cavity of this hom at first pasces posteriorly and lateralward, but then suddenly eurves anteriorly and 
inferiorly into the medial part of the temporal lobe nearly parallel with the superior temporal sulcus. Above, it follows the curved crura (posterior pillars) of the fornix and fimbria; below, it does not extend to the temporal pole by from 2 to 3 $\mathrm{cm}$. The roof and lateral wall are, for the most part, like those of the posterior horn, being formed by the tapetum, but medialward a strip of the roof is formed by the attenuated, inferior prolongation, or tail, of the caudate nucleus, together with the inferior extension of the stria terminalis of the thalamus. At the end of the inferior horn the roof shows a bulging, the amygdaloid tubercle, situated at the termination of the tail of the caudate nucleus. This bulging is produced by the amygdaloid nucleus, an accumulation of grey substance continuous with that of the cortex of the hippocampal gyrus, and which gives origin to part of the longitudinal fibres coursing in the stria terminalis of the thalamus.

In the medial wall and floor of the inferior horn the following structures are shown:-(1) In the posterior or trigonal part of the floor is the longitudinal collateral eminence, a bulging, very variable in development in different specimens, produced by the collateral fissure. This is often pronouncedly in two parts, a posterior prominence corresponding to the middle portion of the collateral fissure and an anterior prominence (less frequent) produced by the anterior part of the

Fig. 690.-Dissection of Right Temporal Lobe showing the Medial Wall of the Exd of the INFerior Horn of the Lateral Ventricle. (From Spalteholz.)

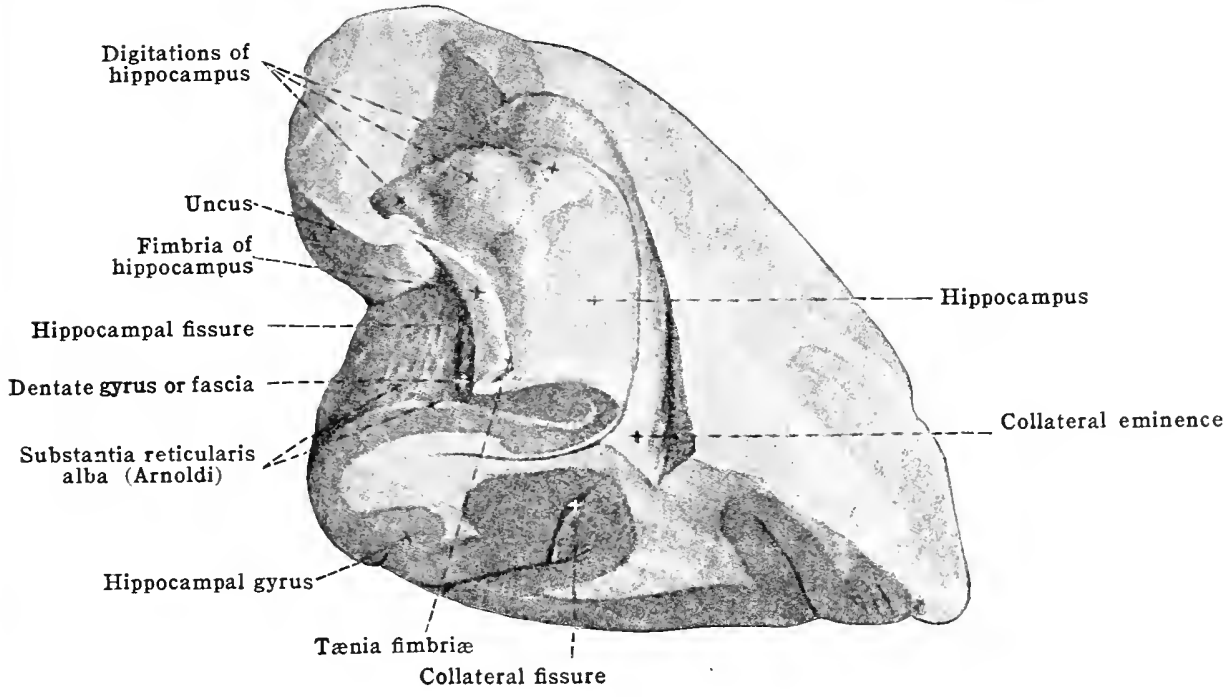

fissure. (2) Medial to this eminence lies the inferior extension of the chorioid plexus, usually more voluminous than the part in the body of the ventricle. (3) Partly covered by the chorioid plexus is the hippocampus major, a prominent, sickle-like ridge corresponding to the indentation of the hippocampal fissure. It begins as a narrow ridge posteriorly, at the end of the body of the ventricle, as the extension of the posterior pillar of the fornix, and expands anteriorly as the ventricular surface of the uncus. Its surface is not regular, but shows a concare medial margin as distinguished from a wider, convex, lateral surface. Its termination in front (pes hippocampi) is divided by two or three flat, radial grooves into a corresponding number of short elevations known as the hippocampal digitatrons. It is covered by a thick stratum of white substance, the alceus, arising from its depths and continued mesially into the fimbria. (4) The fimbria is so folded that its margin, tomia fimbrice, lies in the cavity of the inferior born attached to the chorioid plexus and the thin, non-nervous floor of the chorioid fissure.

The caudate nucleus (fig. 691).- As realised in the study of the lateral ventricle, the caudate nucleus is a comma-shaped mass of grey substance with a long, much-curved, and attenuated tail. Its head forms the bulging lateral wall of the anterior horn; thence it proceeds posteriorly in the lateral wall of the body of the ventricle and, at the collateral trigone, curves downward and its tail becomes 
a medial portion of the roof of the inferior horn. It is separated from the thalamus adjacent to it by the stria terminalis of the thalamus (tænia semicircularis). The end of its tail extends anteriorly below to the level of the anterior horn of the ventricle above. Owing to its much curved shape, both horizontal and vertical sections of the hemisphere passing through the inferior horn may contain the nucleus cut at two places (see figs. 694 and 698.)

The caudate nucleus is the intraventricular of the two masses of grey substance which together are sometimes referred to as the basal ganglia. The extraventricular of these masses is the lenticular nucleus, which is buried in the substance of the hemisphere, laterally and inferior to the caudate nucleus. The two masses

Fig. 691.-Diagrans of Lateral View and Sections of the Nuclei of xhe Corpus Striatum with the Internal Capsule Onitted.

$\mathrm{A}$ and $\mathrm{B}$ below represent horizontal sections along the lines $\mathrm{A}$ and $\mathrm{B}$ in the figure above. The figure also shows the relative position of the thalamus and the amygdaloid nucleus.
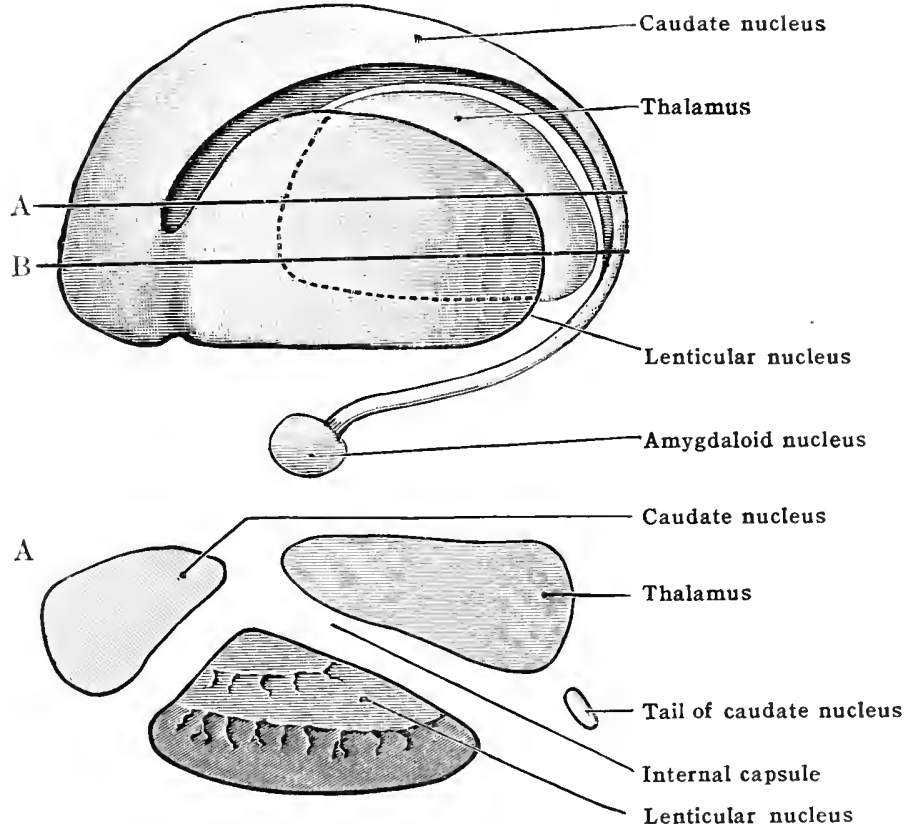

$\mathrm{B}$

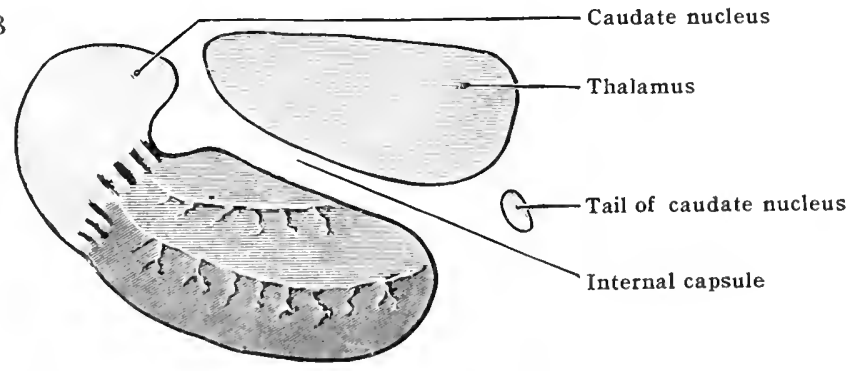

are separated be lle internal capsule, a thick band of nerve-fibres eontinuous into the cerebral primeles, and connecting the grey cortex of the hemisphere with the structures inferior to it. Anteriorly and bedow, the two muclei become continuous and the white substane of the internal capsule, in separating them posteriorly, contributes to the striatrel al] nearanee in sections, known collectively as the corpus strulum (figs. 692, 695). Thle corpus striatum as such is described below.

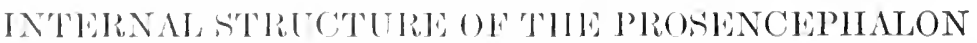

From the above examinations of their external and ventricular surfaces, it is afpharent that the (ereberal hemispheres consist of a folded, external mantle of

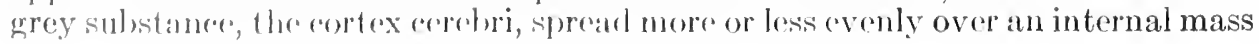


of white substance which contains embedded within it certain masses of grey substance, the chief of which are known as the caudate and lenticular nuclei of the corpus striatum. In addition, the hemispheres of the telencephalon overlie and are in functional connection with the structures of the diencephalon below, the chief of which are the thalamencephalon and the bases of the cerebral peduncles.

The grey substance of the telencephalon.- The grey substance is in intimate relation with the white substance, and in fact its cells give origin to the greater part of the fibres composing the white substance. The accumulations of grey substance to be considered are the cerebral cortex, with its variations in thickness and arrangement, the corpus striatum, the claustrum, and the amygdaloid nucleus.

The cerebral cortex [substantia corticalis] is distributed over the entire surface of each hemisphere except the peduncular region of the base and the region of the corpus callosum and fornix of the medial surface. Numerous measurements have been made to determine its average thickness. These have shown that the mantle is not uniformly distributed:-(1) that it is thicker on the convex surface than on the basal and medial surfaces; (2) that on the convex surface it is thicker on the central region of the hemisphere, somæsthetic area, than at the poles; (3) that in the average normal specimen it averages somewhat thicker on the left than on the right hemisphere; (4) that its average thickness varies greatly in different individuals, and that the thickness decreases with old age; $(5)$ that it is probably somewhat thicker in males than in females, and (6) that in a given specimen it averages thicker on the summits of the gyri than in the floor of the corresponding sulci. In the normal adult conditions it averages about $4 \mathrm{~mm}$. thick on the anterior and posterior central gyri, in the somæsthetic area, while it attains its mimimum thickness of about $2.5 \mathrm{~mm}$. on the basal surface of the occipital and frontal lobes. Its total average thickness is about $2.9 \mathrm{~mm}$. The practically nonnervous floor of the third ventricle and that of the chorioid fissure are very much thinner but are not considered in these measurements.

The cerebral cortex consists of layers of the cell-bodies of neurones, chiefly of the pyramidal type (fig. 604), which receive impulses from the structures below and from other regions of the cortex by way of fibres reaching them through the internal mass of white substance, and which in turn contribute fibres to the white substance. Certain fibres of shorter course and numerous collateral branches of fibres passing out of the cortex are devoted to the association of the region of their origin with the cortex of the immediate vicinity of their origin, and most of these course within the grey cortex itself. In certain gyri, such as the anterior central gyri and those of the medial surface of the occipital lobe, these short association fibres accumulate into strata, and in vertical sections give the cortex a stratified appearance. Two such strata of white substance may be noted in the above localities, one lying about midway in the thickness of the cortex and one slightly internal to this. They are known as the inner and outer stripes of Baillarger. In addition, a thin, superficial or tangential layer of fibres may often be distinguished lying in the surface of the cortex. Transverse sections through the anterior end of the hippocampus show a coiled arrangement of the layers of white substance, to which has been given the name cornu ammonis. The peculiar structure and appearance of the olfactory bulb and tract, parts of the cortex, have already been mentioned.

The corpus striatum is so called on account of the appearance in section of its component parts, the caudate and lenticular nuclei (basal ganglia) and the internal capsule between them. The two nuclei are directly continuous with each other at their anterior ends (fig. 691), and in addition they are connected by numerous small bands of grey substance which pass from one to the other through the internal capsule, especially its anterior part. Also each nucleus contributes numerous fibres to, and receives fibres from, the internal capsule. These bundles of fibres both arising and terminating within the nuclei, together with the grey substance among the fibres of the capsule, produce the ribbed and striped appearance suggesting the name, corpus striatum. The caudate nucleus - the intritventricular part of the corpus striatum-lies with its thicker anterior part (hear) closely related to the internal capsule, but its tail passes posteriorly around the posterior border of the capsule and curves downward and anteriorly in to the roof of the inferior cornu of the lateral ventricle.

The lenticular nucleus [nucleus lentiformis]-the extraventricular part of the corpus striatum-is embedded in the white substance of the cerebral hemisphere. It is somewhat pyriform in shape, not being so long as the caudate nucleus, and neither having a tail nor extending so far anteriorly. Its lower surface is separated from the inferior cornu of the lateral ventricle by the white substance of the roof of that cornu, and by the tail of the caudate nucleus, and, fur- 
ther forward, the anterior commissure passes through its base. Its lateral surface is rounded and conforms both in extent and curvature with the surface of the insula, from which it is separated by the fibres of the external eapsule and the intervening claustrum. Its oblique superior and mesial surface is adapted to the lateral surface of the internal eapsule, and it comes to a rounded apex in the angle formed by the internal capsule and a plane parallel with the base of the hemisphere. In both horizontal and coronal (transverse) sections through its middle it resembles a compound biconvex lens. Internally this appearance is produced by two vertically curving laminæ of white substance, an external and an internal medullary lamina, which divide its substance into three zones:- the two medial zones together form an area, triangular in section, known as the globus pallidus; the litteral, larger and more grey, concavo-convex zone is the putamen. Radiating fibres from the medullary lamina extend into the zones, especially those of the globus pallidus. These zones disappear in transverse sections of the anterior

Fig. 692.-Coronal Section of Telencephalon Passing Through Frontal Lobes and Anterior Portion of Corpus Striatum.

(From mounted specimen in the Anatomical Department of Trinity College, Dublin.)

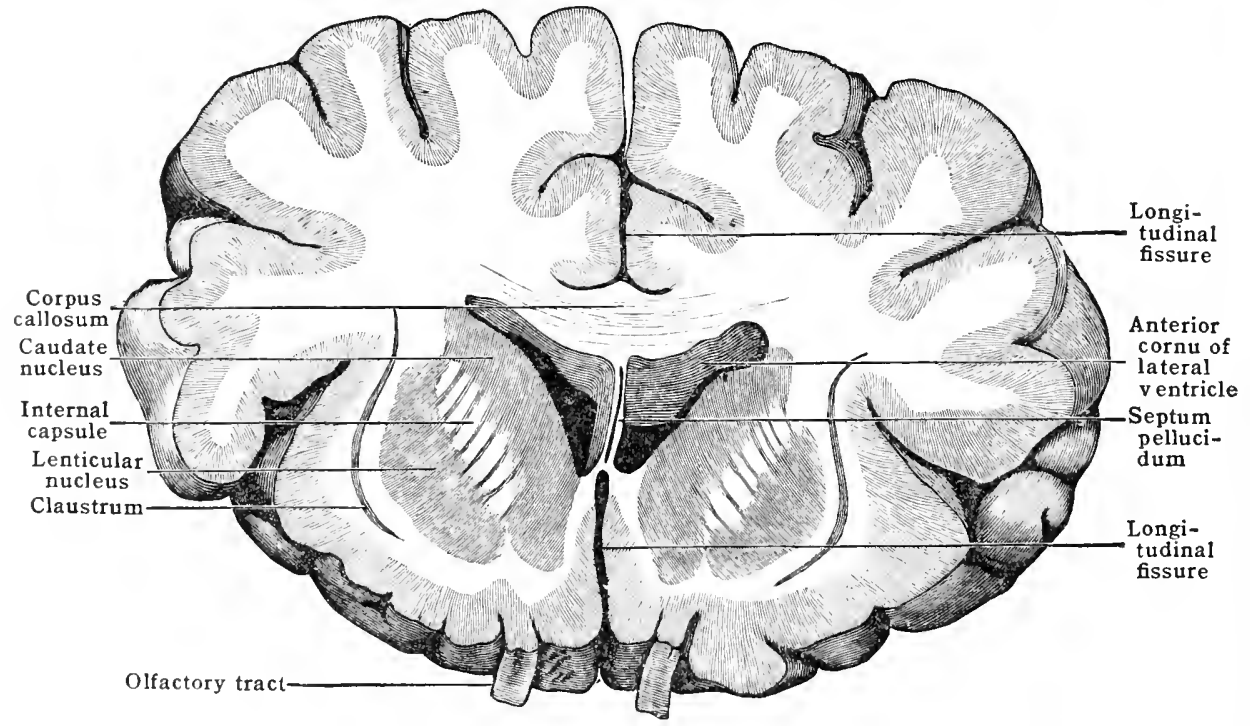

portion of the lenticular nucleus (fig. 692), due to the fact that the larger putamen alone comprises this portion and alone becomes continuous with the caudate

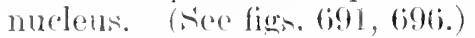

Connections.-Both nuclei of the corpus striatum become continuous with the cortex in the region of the anterior perforated substance, and the putamen of the lenticular nucleus may b) lend with the anterior part of the base of the daustrum. The following are the principal fibre connections:- (1) Fibres arising in the nuelei which join the internal capsule to reach the corebral cortex, and fibres arising in the cortex which deseend by the same course to the cells of Her unelei. (2) Jilures which pass in both directions between the thalamus and the corpus striatum (eatulate nucleus especially). 'Jhese are more al)undant anteriorly, and necessarily pass through the internal capsule. (3) The ansa lenticularis, or strio-subthalamie radiation, at usually distinet linnima, eomposed largely of fibres passing inferiorly between the thalamus and lentivular moldous. It passes from the basil aspect of the anterior tuberele of the thalamus and rurves beluw throngle the internal callsule to the basal surface of the lenticular nucleus,

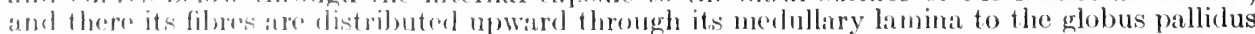
and putanen. Foms anter the internal capsule and reach the eortex, ehiefly that of the tem-

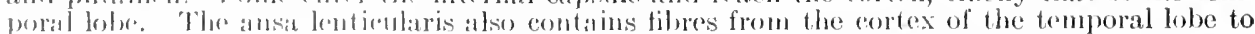
terminate in the inferior and nesial parts of the thalames. The fibres associating the thalamus

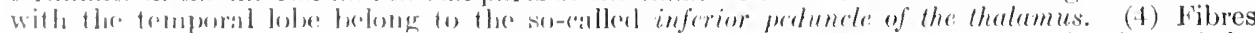

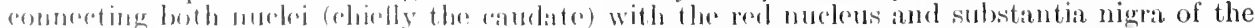

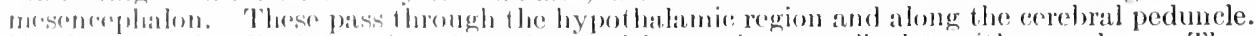

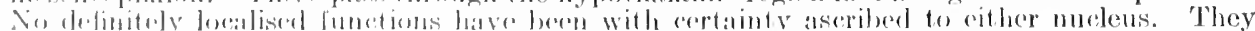

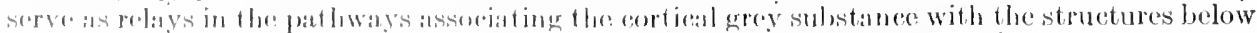

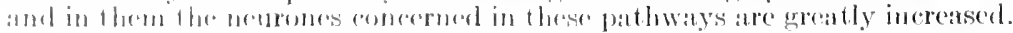

The claustrum is a triangular plito of grey substaner which is embedded in

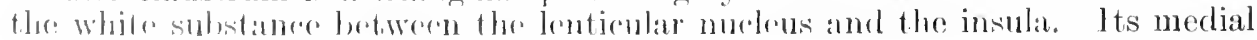


surface is concave, conforming to the convexity of the putamen. The sheet of white substance intervening between it and the putamen is known as the external capsule. Its lateral surface shows ridges or projections in section which conform to the neighbouring gyri of the insula, and it is spread through an area which quite closely coincides with that of the inusla. Below and anteriorly it becomes continuous with the cortex of the anterior perforated substance and with the lenticular nucleus at the region of the junction of these. Above and posteriorly it gradually becomes thinner, and finally disappears in the white substance about it. In origin it is thought to be a detached portion of the cortical grey substance of the insula.

The amygdaloid nucleus [nucleus amygdalæ] is represented by the amygdaloid tubercle, which has already been described in the extremity of the inferior cornu of the lateral ventricle (figs. 666 and 691). It is an almond-shaped mass of cells joined to the tail of the caudate nucleus, continuous above with the putamen and anteriorly continuous with the cortex of the hippocampal gyrus.

Fig. 693.-Coronal Section of Telencephalon througli the Anterior Commissure, Optic Chiasia, and Trunk of Corpus Callosum. (After Toldt, "Atlas of Human Anatomy," Rebman, London and New York.)

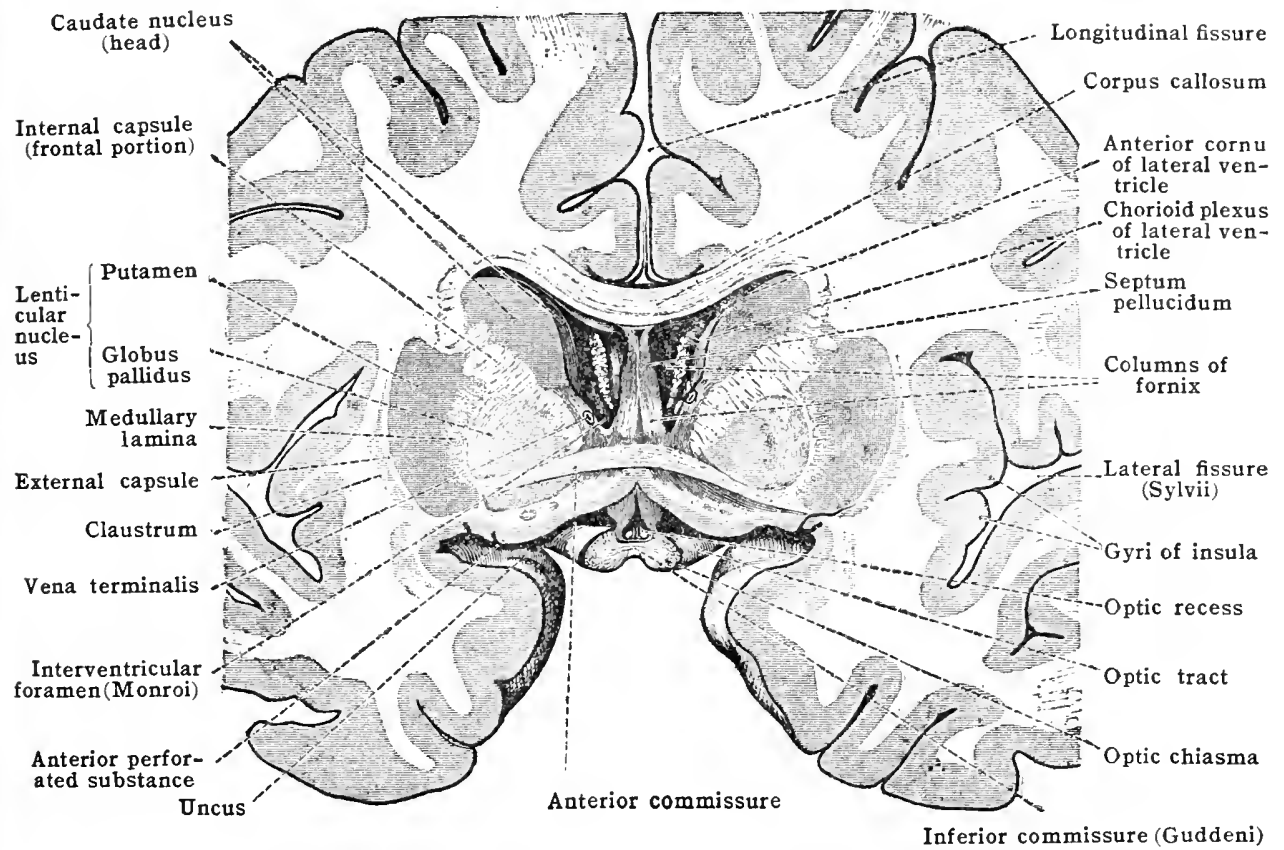

The chief connections of the amygdaloid nucleus by way of the stria terminalis of the thalamus are noted above under the description of the posterior division of the rhinencephalon. The amygdaloid nucleus, like the claustrum, is thought to represent a detached portion of the cortex, it being detached from the uncus. Considering this and its chief comnections, it, with the stria terminalis of the thalamus, are concemed in the central portion of the olfactory apparatus.

The thalamus and hypothalamus. - The external features of these portions of the prosencephalon have been described in their natural place, but inasmuch as they contain the chief relays between the telencephalon and the divisions of the nervous system caudal to the prosencephalon, the consideration of their internal structure has been deferred till now. The principal grey masses to be considered are the thalamus and the hypothalamic nucleus. The structures comprising the metathalamus and epithalamus have already been mentioned in their relations with the mesencephalon and the optic and auditory apparatus.

The thalamus has upon its upper surface, under its ependyma, a thin stratum zonale of white substance, derived in part from the incoming fibres and in part from its own cells. Its oblique lateral surface conforms to the medial surface of the internal capsule; its vertical medial surface forms the lateral wall of the third ventricle, and below it is continuous into the hypothalamic (tegmental) region. 
Its upper surface shows a middle, an anterior, and a posterior prominence or tubercle. The anterior tubercle (nucleus) forms the posterior boundary of the interventricular foramen; the posterior tubercle is the cushion-like pulvinar which projects backward over the lateral geniculate body and the brachium of the superior quadrigeminate body.

A horizontal section through the supero-medial edge, splitting the stria medullaris of the thalamus and thus passing above the massa intermedia, shows the grey mass of the thalamus divided into segments or nuclei by a more or less distinct internal medullary lamina. This extends the whole length of the thalamus, dividing its middle and posterior portion into the medial and the lateral nucleus.

Fig. 694.-Horizontal Dissection showing the Grey and White Substance of the Telencephalon Below the Corpus Callosum and the Relative Position of the Thalamencephalon. (After Landois and Stirling.)

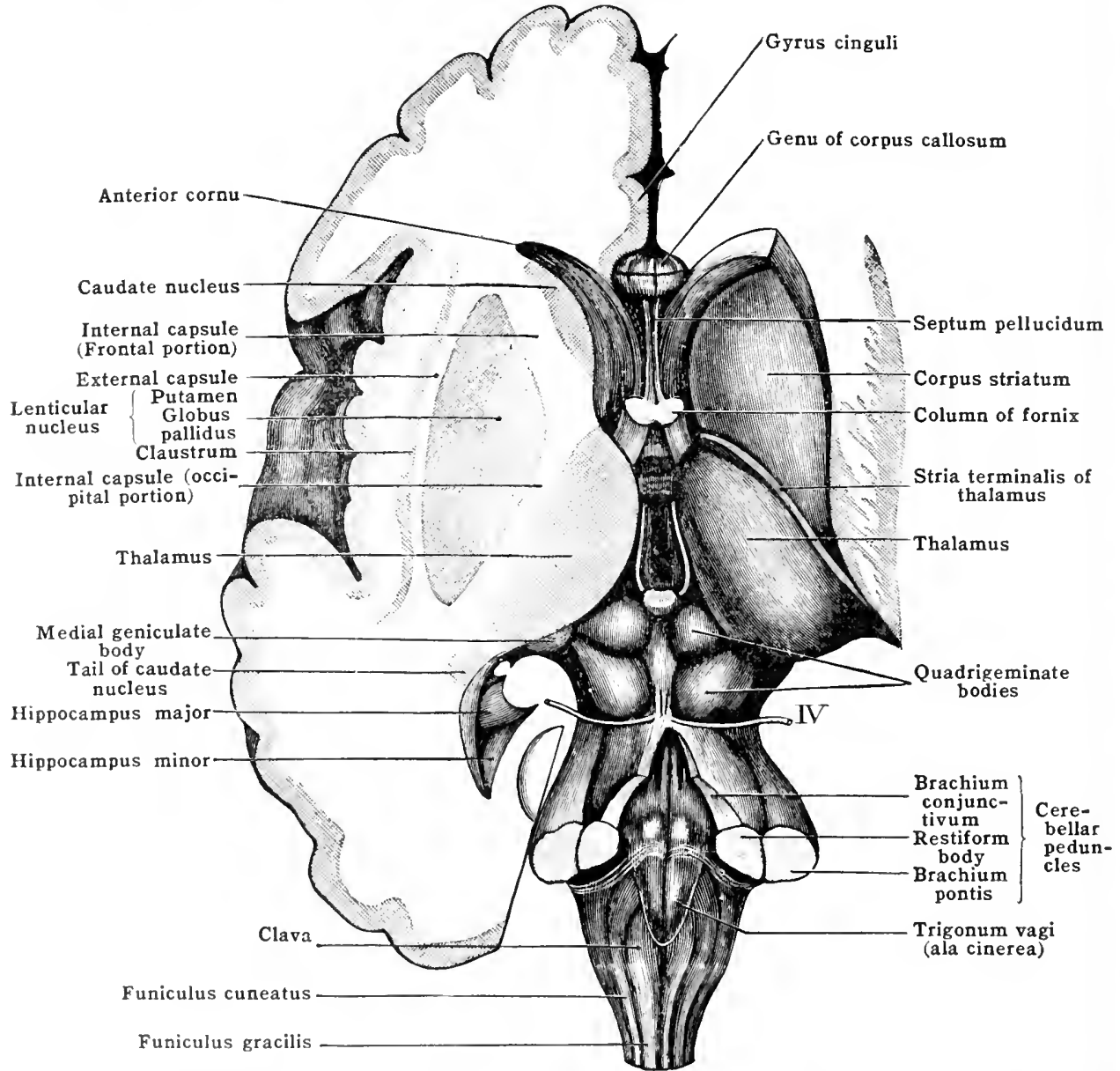

Anteriorly the lamina bifurcates into a medial limb, extending to the medial surface of the thalamus, and a lateral limb, extending forward to join the genu of the internal capsule (figs. 695, 700). This bifurcation results in a cup-like sheet of white substance which encloses the anterior nucleus. On the lateral surface of the section, next to the internal capsule, there may usually be distinguished an external medullary lamina, separated from the white substance of the capsule by a relicular layer of mixed white and grey substance.

The anterior nucleus, lying partially encapsulated in the bifurcation of the internal inedullary lamina, is somewhat wedge-shaped and points backward between the anterior portions of the lateral and medial nuclei.

It is composed chiefly of large cells, and constitutes the anterior tuberele of the superior aspect. Its principal connection from below is with the nuclei of the mammilary body of the same and opposite sides, and with uninterrupted fibres derived from the columns of the fornix. 
The fibres from both sources enter it by way of the mammillo-thalamic fasciculus (figs. 671 and 695). The significance of this connection is mentioned in the description of the limbic lobe.

The lateral nucleus, lying between the external and internal medullary laminæ, extends posteriorly to include the entire pulvinar.

The pulvinar, as already noted, together with the lateral geniculate body, constitutes the prosencephalic nucleus of termination of the optic tract, and the stratum zonale upon the surface of this nucleus might be called the stratum opticum. The anterior portion of the lateral nucleus receives fibres inferiorly from the red nucleus, from the brachium conjunctivum (cerebellum direct), and some fibres of the medial lemniscus terminate about its cells.

The medial nucleus lies medial to the internal medullary lamina and forms the posterior portion of the lateral wall of the third ventricle. It is shorter than the lateral nucleus, and is less extensively pervaded by fibres.

Fig. 695.-Coronal Section of Prosencephalon throdgh Thalamencephalon at Region of Corpora Mammillaria. (Seen from in front.) (After Toldt, "Atlas of Iluman Anatomy," Rebman, London and New York.)

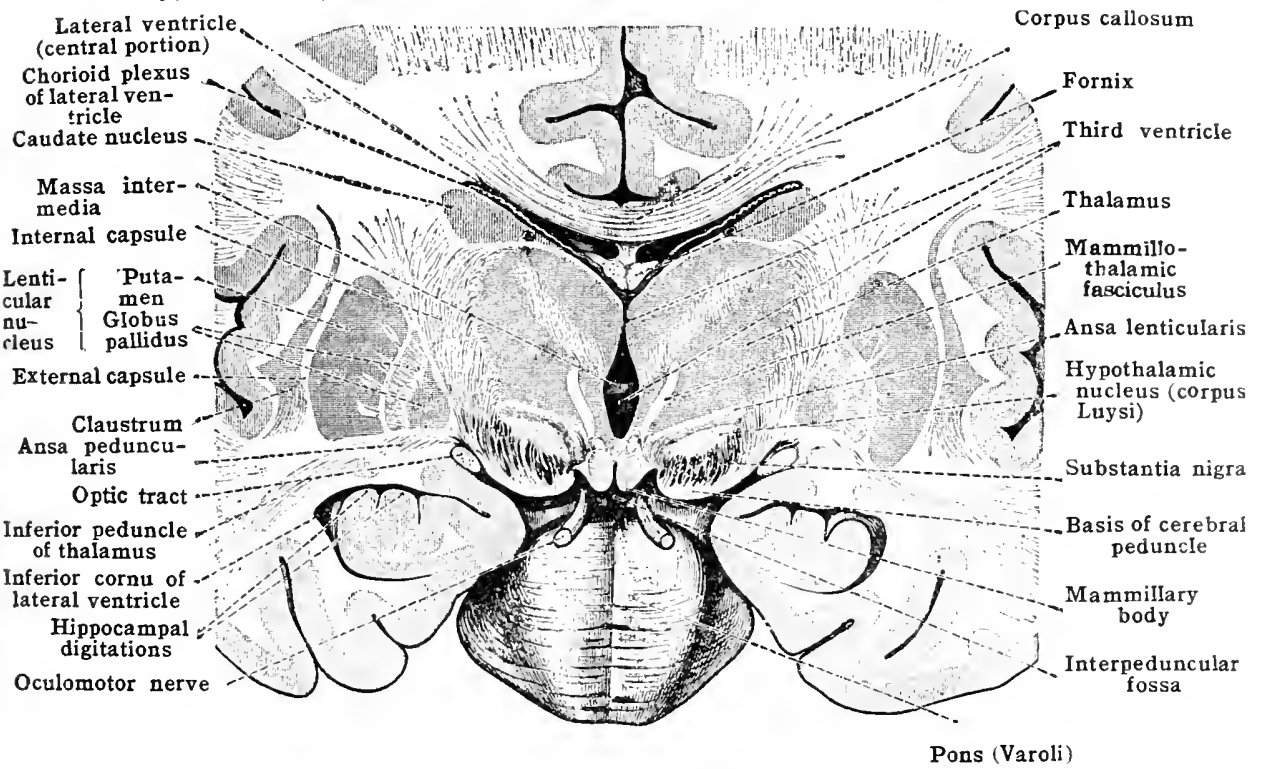

It is thought to receive fibres from the red nucleus, and perhaps some from the lemniscus, and is usually continuous across the third ventricle with the opposite medial nucleus by the massa intermedia.

In comparative anatomy, the nuclei of the thalamus have been variously subdivided by the different investigators. All the nuclei are connected with the lenticular nucleus by fibres passing between the two through the internal capsule directly, and by fibres curving from below, chiefly from the anterior, lateral and medial nuclei, and passing in the ansa lenticularis.

The cortical connections of the thalamus are abundant. They consist of fibres both to and from the cortex of the different lobes of the hemisphere, the greater part arising in the thalamus and terminating in the cortex. These fibres collect in the internal and external medullary laminæ and the stratum zonale; most of them enter the internal capsule and thence radiate to the different parts of the cortex.

They form the so-called peduncles of the thalamus, which have been distinguished both by the Flechsig method of investigation and by the degeneration method. The anterior or frontal peduncle passes from the lateral and anterior part of the thalamus through the frontal portion of the internal capsule, and radiates to the cortex of the frontal lobe. (See fig. 700.) The middle or parietal peduncle passes from the lateral surface of the thalamus through the intermediate part of the internal capsule, and upward to the cortex of the parietal lobe. The posterior or occipital peduncle passes chiefly from the pulvinar, through the occipital portion of the internal capsule, and radiates backward to the occipital lobe by way of the occipito-thalamic (optic) radiation (fig. 699). The inferior peduncle passes from the medial and basal surface of the thalamus (from the anterior and medial nuclei chiefly), turns outward to course beneath the lenticular nucleus, and radiates to the cortex of the temporal lobe and insula. The fibres of this peduncle course chiefly in the ansa lenticularis (fig. 695). Some turn upward in the external capsule to reach the cortex above the insula; others pass upward through the medullary laminæ of the lenticular nucleus. 
The hypothalamic nuclues (fig. 698), or body of Luys, is the principal nucleus of termination of the medial lemniscus, the great sensory spino-cerebral pathwayl It is a biconvex plate of grey substance situated on the basal aspect of the latera. and anterior nuclei of the thalamus, and between these and the basis of the cerebral

Fig. 696.-Horizontal Sections of the Prosencephalon through the Thalamus and Corpus Striatum.

The plane of the section of the left hemisphere splits the medullary stria of the thalamus and is about 15 millimeters superior to the plane through which the right hemisphere is cut. (After Toldt.)

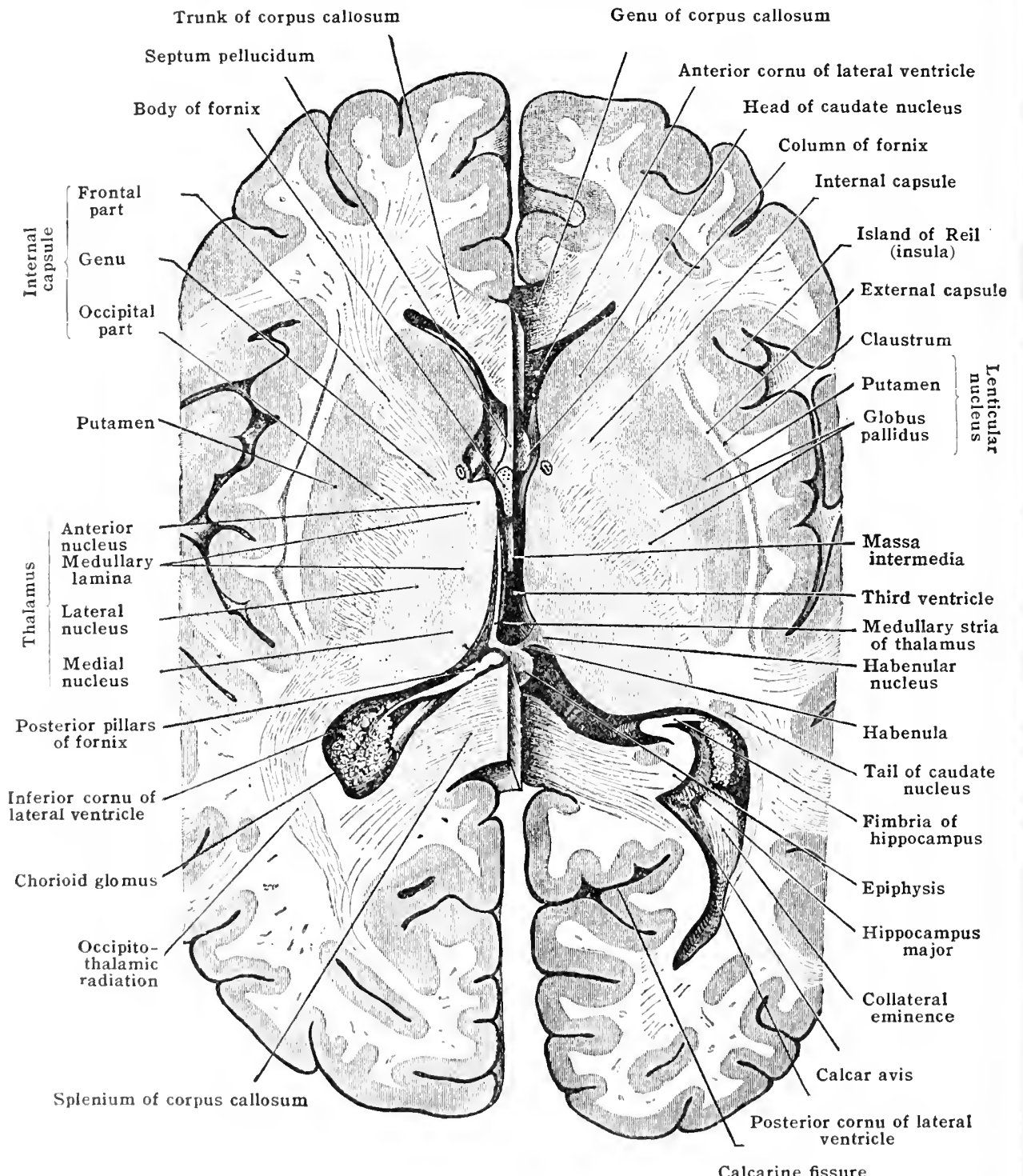

peduncle, or rather the substantia nigra, which is spread upon the dorsal surface of the peduncle, and which, though greatly diminished, extends in to the hypothalanic region. 'The hypothalanic: murelous presents a brownish-pink colour in fresh matrial, dure to prignent in its cells and to its abmentant blood capillaries.

It contains the cell-borlios of the nomrones of the third order in this bathway, those of the first eserler being situater] in the spinal ganglia, and fluse of the second order in the nuelei of the

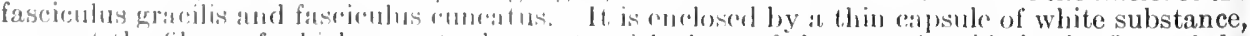

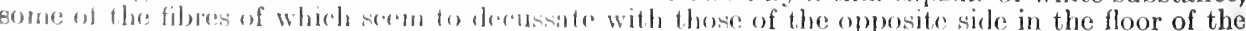

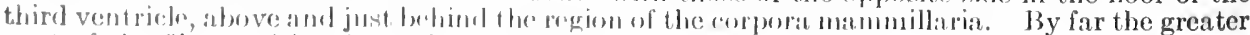

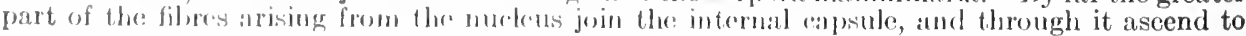


radiate to the cortex of the pre- and post-central gyri, the sensory-motor or somæsthetic area of the hemisphere. The majority terminate in the post-central gyrus.

All the fibres connecting the cerebral cortex with both the thalamus and the hypothalamic nucleus belong to the so-called projection fibres of the cerebral hemisphere.

The habenular nucleus and the fasciculus retroflexus of Meynert have been noted in the description of the rhinencephalon. The habenular nucleus, a part of the epithalamus, is a small group of nerve cells situated in the habenular trigone just infero-lateral to the epiphysis. The fibres of the medullary stria of the thalamus (habenula) terminate about its cells. A small bundle of fibres crossing the mid-line under the epiphysis in the superior aspect of the posterior cerebral commissure is called the commissure of the habenulc, from the fact that it connects the habenular nuclei of the two sides.

Fig. 697.-Oblique Frontal Section throdgh the Brain in the Direction of the Cerebral Peduncles and the Prraiids. (Seen from in front.) (After Toldt, "Atlas of Human Anatomy," Rebman, London and New York.)

Superior frontal gyrus

Longitudinal fissure Body of corpus callosum

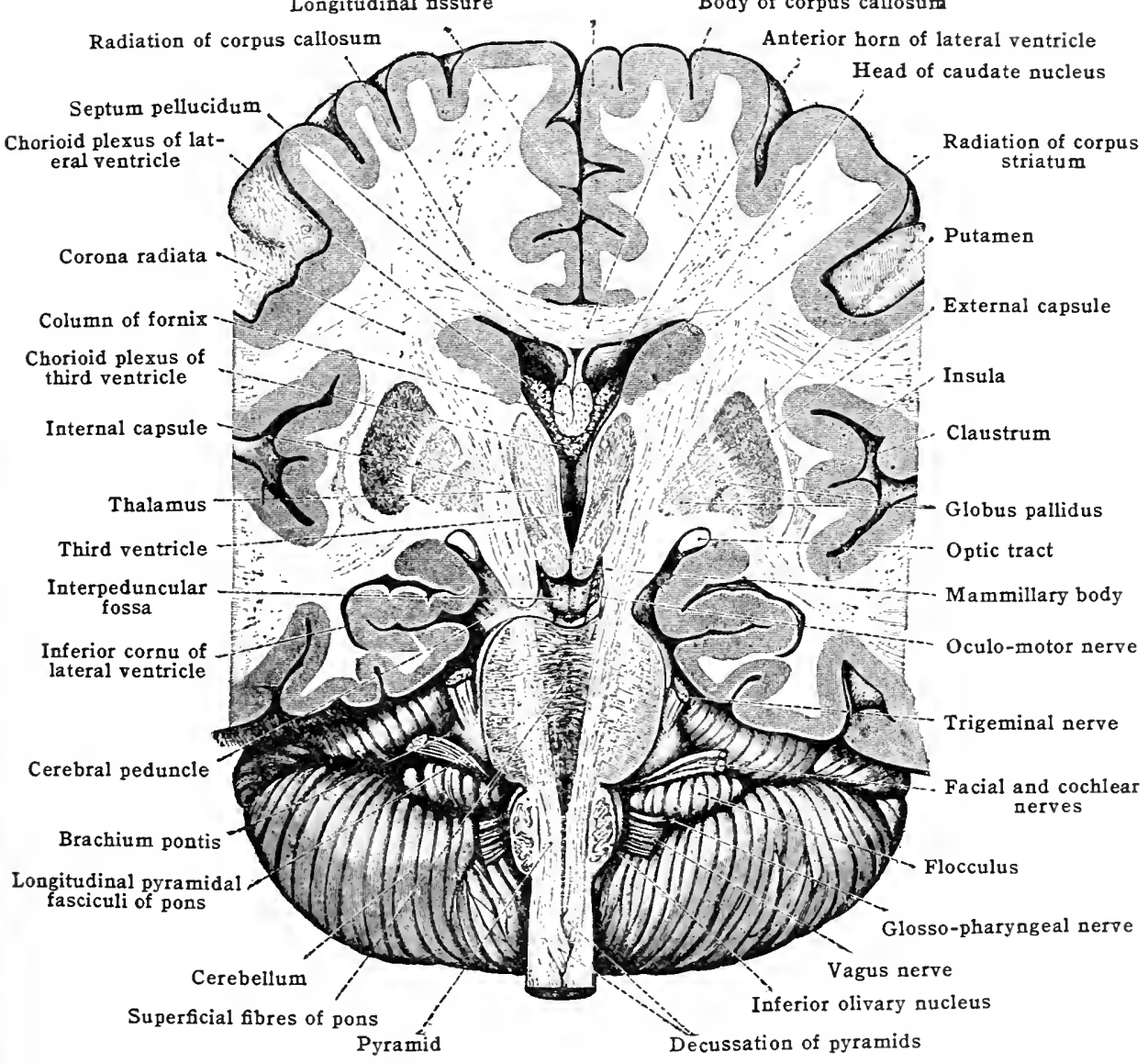

The fasciculus retroflexus (Meynerti) is a relatively strong bundle of medullated fibres which runs downward and then turns caudalward from the habenular nucleus toward the inferior portion of the interpeduncular fossa. It has been shown that many, at least, of the fibres of this bundle arise from the cells of the habenular nucleus. In its slightly caudad course, the bundle passes obliquely through the red nucleus, entering the medial superior aspect and making its exit from the ventro-mesial side of the inferior extrenity of this nucleus. In the animals in which it has been studied, the bundle ends in the interpeduncular nucle'ts (ganglion), a group of nerve cells lying in the floor of the interpeduncular fossa at the level of the inferior quadrigemina. In man, the interpeduncular nucleus is not definitely assembled and the bundle seems to disappear in the posterior perforated substance. However, the microscope shows cells dispersed among the fibres of the bundle and these cells probably represent the nucleus.

The white substance of the telencephalon.-A horizontal section through the upper part of the trunk of the corpus callosum will pass above the basal grey substance of the corpus striatum, and, aicled by the corpus callosum, each hemisphere in such a section will appear as if consisting of a solicl, half-oral mass of white substance, bounded without by the grey layer of the cortex (fig. 672). As 
seen at this level, the white substance of each hemisphere is known as the centrum semiovale. Horizontal sections passing below the body of the corpus callosum involve the corpus striatum and thalamus, and the appearance of the white substance is modified accordingly (fig. 694).

In the white substance of the cerebral hemispheres as a whole three main systems of fibres are recognised:- projection fibres, commissural fibres, and association fibres. The projection fibres are those of a more or less vertical course, which pass to and from the cortex of the hemisphere, associating it with the structures below the confines of the hemisphere. The commissural fibres are those of a transverse or horizontal course, which cross the mid-line and functionally connect the two hemispheres with each other. The association fibres are those which neither cross the mid-line nor pass beyond the bounds of the hemisphere in which they arise, but instead associate the different parts of the same hemisphere-lobes with lobes and gyri with gyri. The fibres which associate the cortex with the

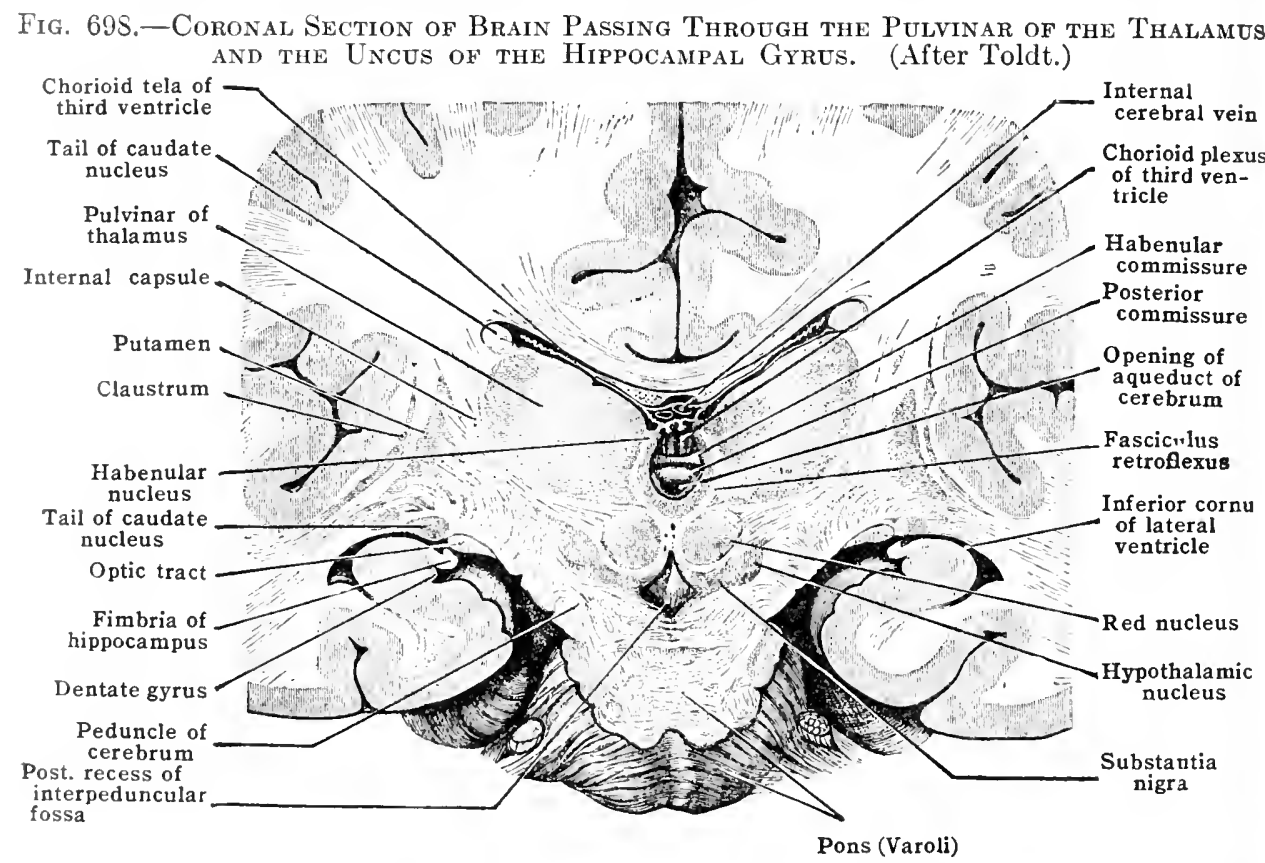

nuclei of the corpus striatum must also be classed as association fibres, since these masses of grey substance are a part of the telencephalon, while by definition those which associate the thalamus and hypothalamus with the cortex belong to the projection system. Some of the fibre bundles of the above systems have already ber'n deseribed in connection with the parts with which they are concerned.

The projection fibres of the hemisphere comprise both aseending and descending fibres between the corebral cortex and structures below the bounds of the hemisphere, i.e., some arise in the structures below and terminate in the cortex; others arise from the cortical cells and terminate in the structures below, including the grey substance of the thalamencephalon, mesencephalon, rhombencephalon, and spinal cord. The projection fibres are given different names in the hemisphere accorling to their arrangement and the appearances to which they contribute in the dissections. Beginning with the pyrimiclal fascieuli and the basis of the poduncle, they contribute-(1) to the internal capsule and some to the external capsule and (2) to the corona radiala.

The internal capsule [capsula interna] is a band of white substance, consisting of the ascending fibres from the nuelei of the thalamus, hypothalamus, and corpus striatum, reinforeed by the descending fibres from the cortex to these nuclei and by those desernding in the corebral peduncle to terminate in the mesencephalon, rhomberncephalon and spinal cord. It is a broad, fan-like mass of fibres, which increases in wielth from the base? of the hemisphere up ward, and which is spread betwern the lentirular nucleus on its lateral aspect and the eaudate nucleus and 
thalamus on its medial side. To reach the cortex above, the course of its fibres necessarily intersects that of the radiations of the corpus callosum, and thus, together with the corpus callosum, the fan-like bands of the two hemispheres form a capsule containing the thalami, the third ventricle, the caudate nuclei, and the anterior and central portions of the lateral ventricles. In horizontal sections, each internal capsule appears bent at an angle, the genu, which approaches the cavity of the lateral ventricle along the line of the boundary between the thalamus and the caudate nucleus. Along the genu runs the stria terminalis of the thalamus, and through the genu the capsule receives fibres from the internal medullary lamina of the thalamus, from the stratum zonale of the thalamus and from that of the caudate nucleus. At the genu each capsule is separable into two parts:(1) the anterior (frontal) portion, spreading between the caudate and lenticular nuclei; (2) the posterior (occipital) portion, between the lenticular nucleus and the thalamus (fig. 700.)

Fig. 699.-Coronal Section throdgh the Splenium of the Corpus Callosum and the Posterior Cornua of the Lateral Ventricles. (Viewed from bebind.) (After Toldt, "Atlas of Human Anatomy," Rebman, London and New York.)

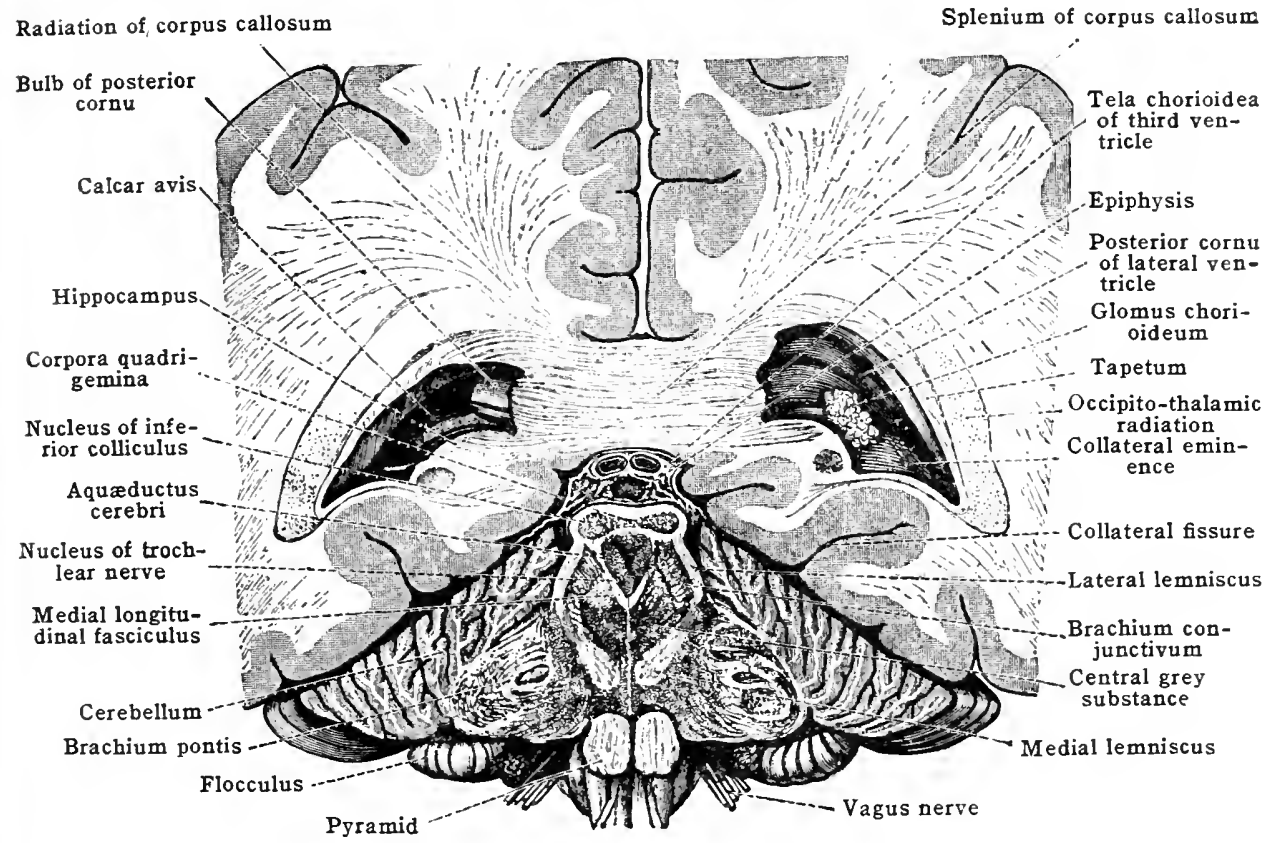

Functionally, the internal capsule may be divided into a frontal, a fronto-parietal and an occipital part. The frontal part consists of (1) an anterior segment, carrying chiefly fibres coursing in both directions between the thalamus and the cortex of the frontal lobe, and (2) a posterior segment carrying the frontol-pontile tract.

The fronto-parietal part may be considered in four segments:--(1) An anterior segment, the gen $u$, carrying fibres from the cortex to the nuclei of the motor cranial nerves; (2) posterior to this is the cortico-spinal segment for the arm and thorax, descending cortical fibres to the regions of the spinal cord supplying these; (3) next is the cortico-spinal segment for the lower extremity; (4) a posterior segment carrying the general sensory path ascending from the hypothalamic nucleus, the infero-lateral part of the thalamus and the red nucleus to the cortex. All the segments of the fronto-parietal part carry in addition, fibres in both directions between the cortex above and the thalamus and the nuclei of the striate body.

The occipital part consists (1) of an anterior segment which carries the temporal and cccipital portile paths, and (2) a posterior segment carrying the visual fibres between the occipital cortex and the nuclei of termination of the optic narve. This segment also carries the auditory fibres passing between the cortex of the superior temporal gyrus and the regions of termination of the lateral lemniscus. Thus it carries a visual and an auditory path.

The corona radiata.-Above the corpus callosum and laterally joining its radiations, the fibres of the internal capsule are dispersed in all directions. The appearance known in coronal sections of the hemispheres as the corona radiata is produced by the ascending and descending fibres of the internal capsule combined with the radiations of the corpus callosum. The radiations related to the internal 
capsule may be divided into a frontal, a parietal and an occipital part, corresponding to the frontal, parietal and occipital peduncles of the thalamus, or to the parts of the internal capsule.

The radiation derived from the posterior segment of the occipital part of the internal capsule, the risual path, accumulates into a well-defined band of fibres which passes posteriorly into the occipital lobe, spreading in the lateral wall of the posterior cornu of the lateral ventricle immediately lateral to the tapetum. This band consists for the most part of fibres arising in the pulvinar of the thalamus and

Fig. 700.-Diagram to Indicate the Relative positions of the Projection Fibres in the Internal Capsule. (In part after Villiger.)

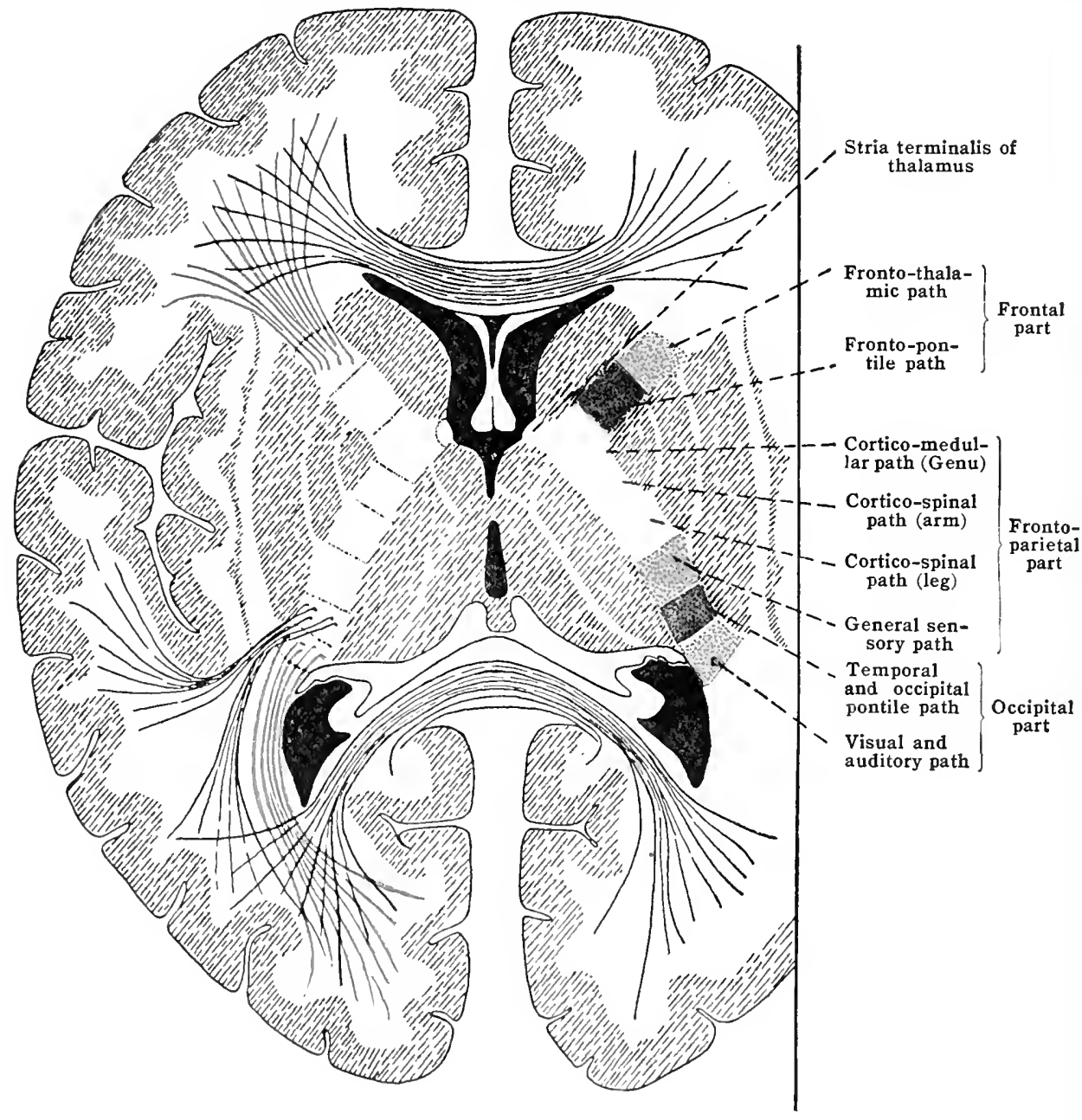

in the lateral geniculate body and going to the visual area of the occipital cortex, and of fibres arising in this cortex to terminate in the thalamus and mesencephalon. Bscing thus concerned with the optic apparatus, it is known as the occipitothalamic radiation or optic radiation (fig. 699).

The external capsule is, as alrearly noted, a thin sheet of white substance spreat betwern the chanstrmand the lenticular nueleus.

It wwes its apperance as such to the presence of the elanstrum. It joins the internal capsule at the mpere, prosterion, and anforior borders of the putamen, and bolow the elaustrum it is continums with the groncrit whife substance of the teuporal hobe. Thus it contributes to an encaponlation of the lantienlar nuclens by white substance. Most of the fibres contained in it betong to the association system. Its projection fibres eonsist of these of the inferior perbuele of the that:anus, which pass from the basnd surface of the thalamus and, instead of eontinuing betow to the cortex of the temporal lobe and insula, tum upward, aromed the lenticular nuelens to the cortex aboves the insuliz. Some of these thalimus fibres are known to pass

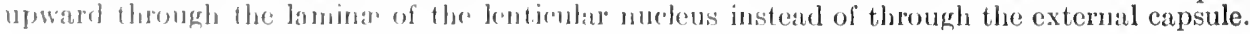


The ascending projection fibres arise mostly from the cells of the nuclei of the thalamus and hypothalamic nucleus; some arise from nuclei in the mesencephalon and from the red nucleus.

They may be summarised as follows:-

(1) The terminal part of the general sensory pathway of the body. The portion of the medial lemniscus which arises in the nuclei of the fasciculus gracilis and cuneatus, of the opposite side, terminates in the hypothalamic nucleus and the inferior portion of the lateral nucleus of the thalamus. The projection fibres given off by the latter nuclei pass chiefly through the posterior segment of the fronto-parietal part of the internal capsule and radiate to and terminate in the somæsthetic area of the cortex, chiefly in the posterior central gyrus. Some few pass outside around the lenticular nucleus, and ascend by way of the external capsule.

(2) The terminal part of the general sensory pathway of the head and neck. The nuclei of termination of the sensory portions of the cranial nerves of the rhombencephalon (except the nuclei of the cochlear nerve) give fibres which course upward in the medial lemniscus (fillet) and reticular substance of the opposite side and terminate in the infero-lateral portions of the thalamus and in the hypothalamic nucleus. Thence arise projection fibres which ascend to the somæsthetic area by practically the same route as those of the general sensory system for the body.

(3) The terminal part of the auditory pathway. The ventral and dorsal nuclei of termination of the cochlear nerve send impulses which, by way of the lateral lemniscus, are distributed to the inferior quadrigeminate body, the medial geniculate body, and the nucleus of the lateral lemniscus of the opposite side. These nuclei send projection fibres through the posterior segment of the fronto-parietal part of the internal capsule, and thence by the temporal portion of the corona radiata to the cortex of the superior temporal gyrus (auditory area). Probably some of these fibres pass by way of the inferior peduncle of the thalamus. Some of the fibres arising in the nuclei of termination of the vestibular nerve convey impulses which reach the somæsthetic area, but the origin of the terminal portion of this system is uncertain.

(4) The terminal part of the visual pathway. The cells of the pulvinar and the lateral geniculate body, serving as nuclei of termination of the optic tract, give off projection fibres which pass by way of the posterior segment of the occipital portion of the internal capsule and the occipito-thalamic radiation to the cortex of the occipital lobe, chiefly the region about the posterior end of the calcarine fissure-the visual area.

(5) The terminal ascending cerebellar pathway. The fibres of the brachium conjunctivum, after decussating, terminate both in the red nucleus and in the lateral nucleus of the thalamus. Some fibres from the red nucleus become projection fibres direct, others terminate in the medial and anterior portion of the lateral nucleus of the thalamus. From the thalamus the projection fibres of this system pass in the parietal peduncle of the thalamus to the somæsthetic area.

The descending projection fibres arise as outgrowths of the pyramidal cells of the cerebral cortex. Practically all of them cross to the opposite side in their descent to the structures of the brain stem and spinal cord. The majority of them arise near and within the gyri in which the respective ascending fibres terminate. Those transmitting cortical impulses to the cells giving origin to the motor fibres of the cranial and spinal nerves arise chiefly from the giant pyramidal cells of the precentral (anterior central) gyrus, the paracentral lobule and the posterior ends of the superior, middle, and inferior frontal gyri. These latter occupy nearly three-fourths (the anterior three segments) of the fronto-parietal part of the internal capsule and the middle three-fifths of the basis of the cerebral peduncle, and are usually called pyramidal fibres (fig. 700).

The principal descending projection fibres may be grouped as follows:

(1) The pyramidal fibres to the spinal cord (cortico-spinal or pyramidal fasciculi proper). These arise from the giant pyramidal cells of the upper two-thirds of the precentral gyrus, the anterior portion of the paracentral lobule and the posterior third of the superior frontal gyrus. Those for the lumbo-sacral region of the spinal cord arise nearest the supero-mesial border of the cerebral hemisphere. The tract descends through the two middle segments of the fronto-parietal part of the internal capsule. Those carrying cortical impulses for the muscles of the arm and shoulder course in the segment anterior to the course of those for the muscles of the leg. Both continue through the cerebral peduncles and the pons and through the pyramids of the medulla, and then decussate, passing down the spinal cord to terminate about the ventral horn cells (the origin of the motor nerve roots) of the opposite side.

(2) The pyramidal fibres to the nuclei of origin of the motor cranial nerves arise from the pyramidal cells in the inferior third of tre precentral gyrus, the posterior end of the inferior frontal gyrus, the opercular margin of the posterior central gyrus, and probably some (for eye movements) in the posterior end of the middle frontal gyrus. The locality of the origin of the pyramidal fibres terminating in the nuclei of the facial and hypoglossal nerves only has been determined with certainty. The general tract passes in the gernu of the internal capsule, through the cerebral peduncle, and, gradually decussating along the brain stem, terminates in the nuclei of the motor cranial nerves of the opposite side.

(3) The frontal pontile path (Arnoll's bundle) arises in the cortex of the frontal lobe. anterior to the precentral gyrus, descends through the frontal part of the corona radiata and posterior segment of the frontal portion of the internal capsule into the fronto-mesial portion of the cerebral peduncle, and terminates in the nuclei of the pons. 
(4) The temporal pontile path (Türk's bundle) arises in the cortex of the superior and middle temporal gyri, passes through the posterior segment of the occipital part of the internal capsule, enters the cerebral peduncle postero-lateral to its pyramidal portion, and terminates in the nuclei of the pons. An occipito-pontile path is described as arising in the occipital cortex and joining the temporal pontile path in the internal capsule to pass to the nuclei of the pons.

(5) The occipito-mesencephalic path (Flechsig's secondary optic radiation) arises in the cortex of the visual area of the occipital lobe (cuneus and about the calcarine fissure), passes forward through the occipito-thalamic radiation, downward in the posterior segment of the occipital portion of the internal capsule, and terminates in the nucleus of the superior quadrigeminate body and the lateral geniculate body. It is probable that some of its fibres terminate directly in the nuclei of the eye-moving nerves.

(6) Those fibres of the fornix which arise in the hippocampus and terminate in the corpus mammillare or pass through it to the anterior nucleus of the thalamus of the same and opposite side (mammillo-thalamic fasciculus) or pass in to the mescencephalon and probably to structures lower down.

The commissural system of fibres.-The commissural fibres of the telencephalon serve to connect or associate the functional activities of one hemisphere with those of the other. They consist of three groups:- The corpus callosum, the anterior commissure and the hippocampal commissure.

(1) The corpus callosum, the great commissure of the brain. A general description of this with the medial and lateral striæ running over it has already been given. It is a thick band of white substance, about $10 \mathrm{~cm}$. wide, which crosses between the two hemispheres at the bottom of the longitudinal fissure. Its shape is such that in its medial transverse section its parts are given the names splenium, body, genu, and rostrum (figs. 667 and 679). Its lower surface is medially joined to the fornix, in part by the septum pellucidum and in part directly. Laterally it is the tapetum of the roof of the lateral ventricle of either side. The majority of its fibres arise from the cortical cells of the two hemispheres, and terminate in the cortex of the side opposite that of their origin. In dissections, its fibres are seen to radiate toward all parts of the cortex-the radiation of the corpus callosum. These radiations may be divided into frontal, parietal, temporal and occipital parts. The occipital parts curve posteriorly in two strong bands from the splenium into the occipital lobes, producing the figure known as the forceps major. Anteriorly, the frontal parts are two similar but lesser bands which curve from the genu forward into the frontal lobe, producing the forceps minor.

(2) The anterior commissure has been described in connection with the rhinencephalon. In addition to the olfactory fibres coursing through it from the olfactory bulb and parolfactory area of one hemisphere to the uncus of the opposite hemisphere, its greater part consists of fibres which arise in the cortex of the temporal lobe, the uncus chiefly, of one side and terminate in that of the opposite side. It crosses in the substance of the anterior boundary of the third ventricle, and through the inferior portions of the lenticular nuclei, and can be seen only in dissections (figs. 684, 693). It is a relatively small, round bundle, and its mid-portion between its terminal radiations presents a somewhat twisted appearance.

(3) The hippocampal commissure (transverse fornix) belongs wholly to the limbic lobe (rhinencephalon), and has bcen described there. It connects the hippocampal gyri of the two sides, and crosses the mid-line under and usually adhering to the under surface of the splenium of the corpus callosum. Crossing the body of the fornix, it thins anteriorly and ceases in the posterior angle of the septum pellucidum.

With these three commissurcs of the telencephalon, the three other commissures of the prosencephalon should be called to mind. The inferior cerebral commissure (Gudden's commissure), while occurring in the optic chiasma and allotted by position to the telencephalon, really belongs to the diencephalon since it connects with each other the medial geniculate bodies of the two sides. The supra-mammillary commissure, connecting the nuclei of the maminillary bodies of the two sides, is allotted to the diencephalon. The posterior cerebral commissure, situated just below the stalk of the epiphysis, belongs to both the diencephalon and meseneephalon. Its superior part, the habenular commissure, connecting the two nuclei of the habenulie, belongs wholly to the diencephalon. In its inferior part, the fibres arising in the thalamus of one side and terminating in that of the other side belong likewise to the diencephalon, but those passing between the superior quadrigeminate bodies of the two sides and between the so-called nuclei of the medial longitudinal fasciculi belong to the mesencephalon.

The association system of the hemisphere.-The possibilities for association bundles connecting the different parts of the same hemisphere with each other are innmerable, and a large number are recognised. They serve for the distribution or cliffusion of impulses brought in from the exterior by the ascending projection system, and it is by means of them that the different areas of the cortex may function in harmony and coördination. Most of the association bundles are supposed to contain fibres coursing in both direetions. Several of them have already been described in company with the grey masses with which they are crneerned. They may be summarised as follows (see figs. 683, 701 and 702):-

(1) 'Tlese: of short course, the fibræ propriæ, which associate contiguous gyri with each other. 'These arise from the cells of a gyrus and loop around the bottoms of the sulci, continually recoiving and hosing fibres in the cortex they associate. The stripes of Baillarger within the cortical layer might be included among the short association bundles.

(2) 'l'he cingulum (girlle) lies in the gyrus cinguli and is shaped correspondingly. 
extends from the anterior perforated substance and the subcallosal gyrus around the genu of the corpus callosum, then, under cover of the gyrus cinguli and around the splenium, and thence downward and forward in the hippocampal gyrus to the uncus. It is chiefly an aggregation of fibres of short course-fibres which associate neighbouring portions of the cortical substance

Fig. 701.-Photograph of "Torn Preparation" of Cerebral Hemisphere showing some of the Association Fasciculi. (After R. B. Bean.)

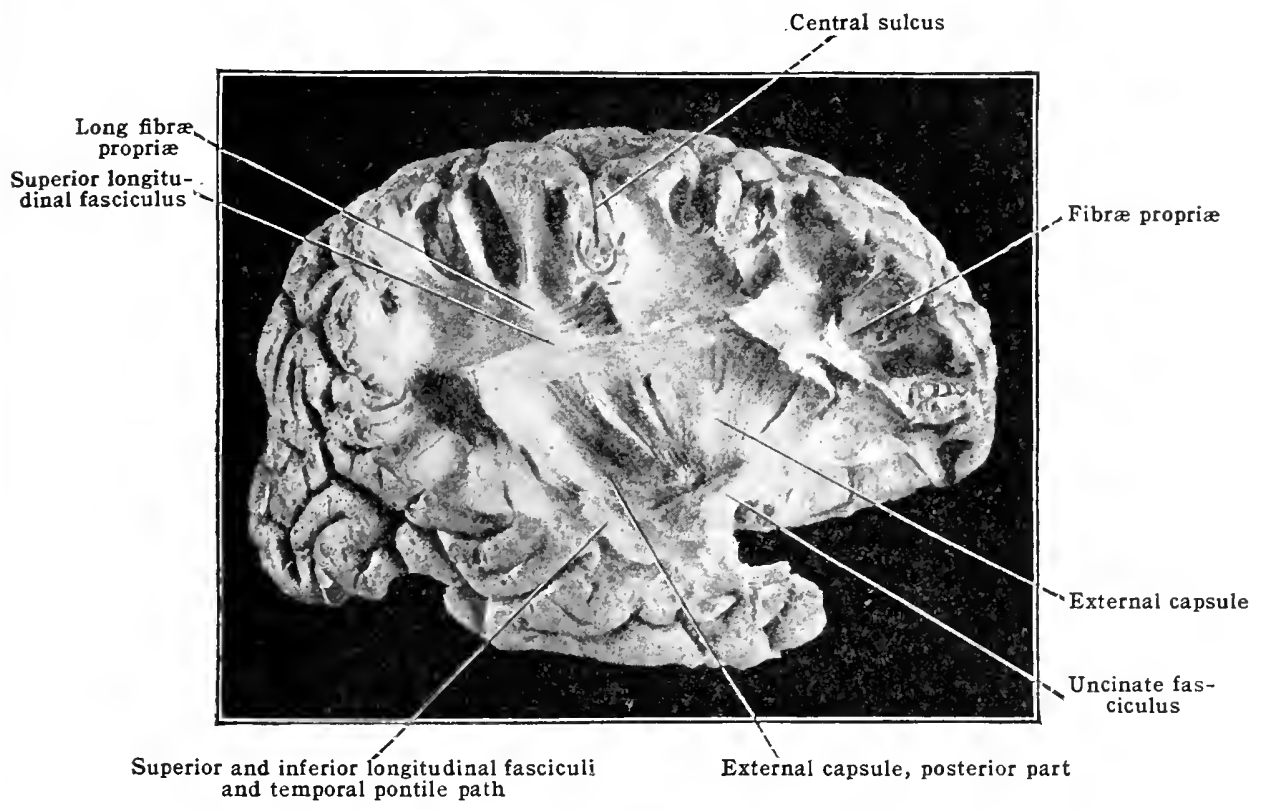

Fig. 702.-Schenatic Representation of Certain of the Association Pathways of the Cerebral Heuisphere.

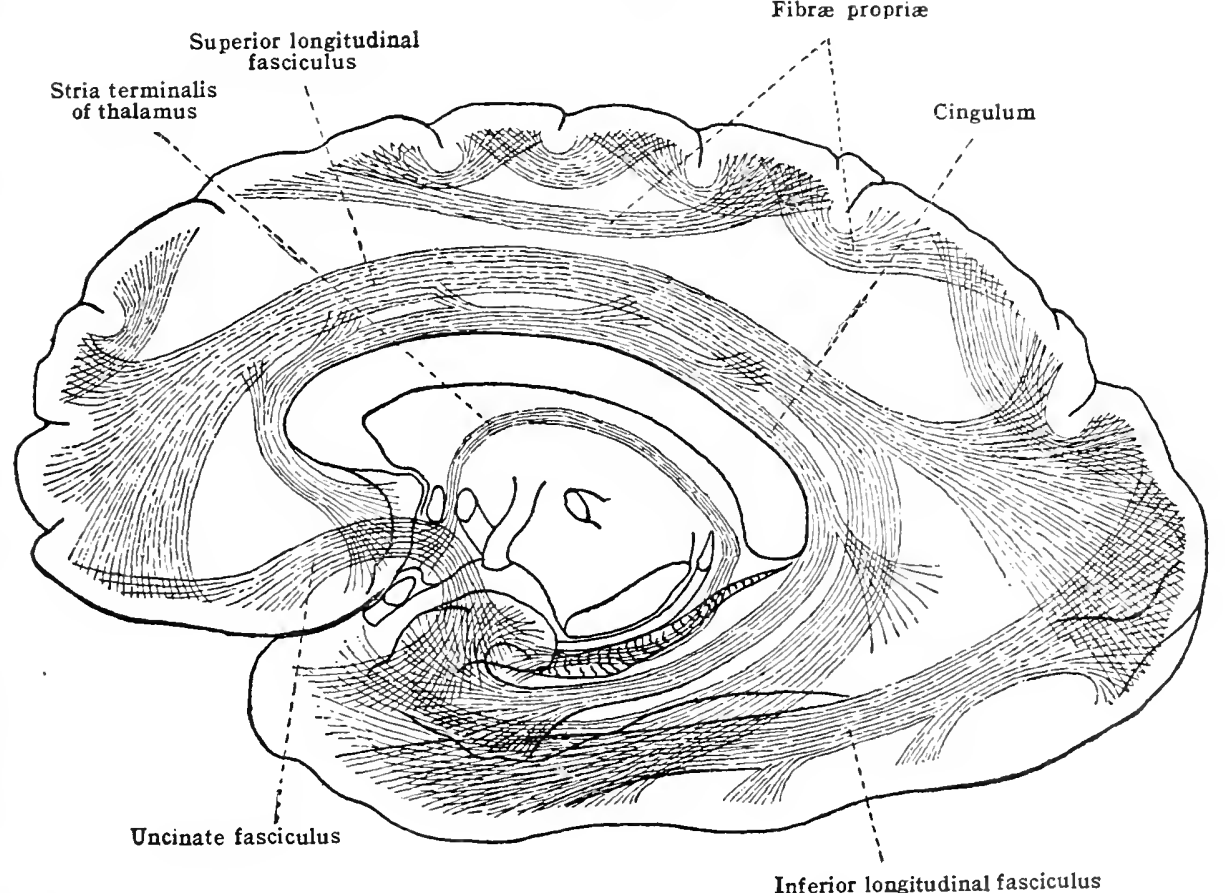

beneath which they course, and which, by continually overlapping each other, form the bundle.

(3) The uncinate fasciculus is a hook-shaped bundle which associates the uncus and anterior portion of the temporal lobe with the olfactory bulb, parolfactory area and anterior perforated substance and perhaps the frontal pole with the orbital gyri. Its shape is due to its having to curve medialward around the stem of the lateral cerebral fissure. 
(1) The superior longitudinal fasciculus is the longest of the association paths, and associates the frontal, occipital, and temporal lobes. From the frontal lobe it passes laterally in the frontal and parietal opereulum, transverse to the radiations of the corpus callosum and the lower part of the corona radiata, and above the insula to the region of the posterior end of the lateral fissure, and thence it curves downward and forward to the cortex of the temporal lobe. Some of its fibres extend to the cortex of the temporal pole. The occipital portion consists of a loose bundle given off from the region of the downward curve, which radiates thence to the oceipital cortex.

(5) The inferior longitudinal fasciculus associates the temporal and occipital lobes and extends along the whole length of these lobes parallel with their tentorial surfaces. Posteriorly it courses lateral to the lower part of the oceipito-thalamic radiation, from which it differs by

Fig. 703.-Diagrams Suggesting the General Motor, General and Special Sensory and the Association Areas of the Convex and Mesial Surfaces of the Cerebral HeMISPHERE.
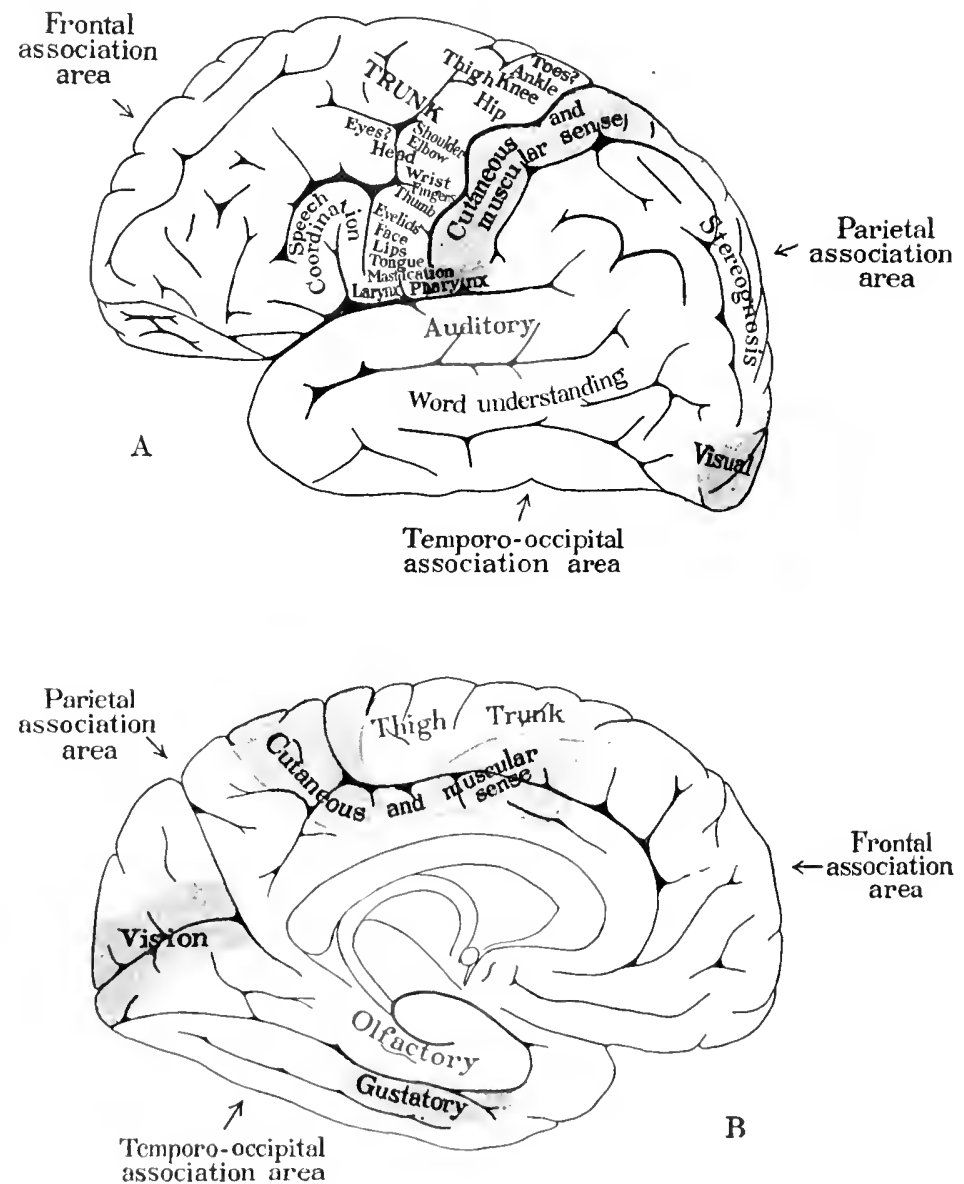

the fact that its fibres are less compactly arranged. It assoeiates the lingual and fusiform gyri and the cuncess with the temporal pole.

(ij) The inedial amel lateral longitudinal striæ of the upper surface of the corpus callosum may le considered among the association pat hways, since most of their filmes associate the grey substance of the hippocalnpil gyrus with tho subcallosal gyrus and the anterior perforated

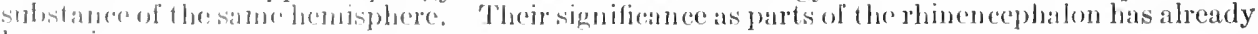
barn givent.

(7) Jikewise the longitulinal fibes in the stria terminalis of the thalamus (tienia semicircularis) may be consielored among the association pathwas, since these comnect the amyg-

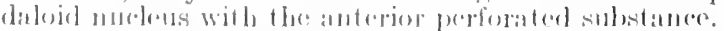

(8) The mumerous dilmes pascing in both directions between the cerebral cortex and the

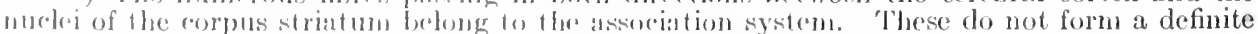
bundle, but, instead, contribute apporecinbly to the corona radiata. However, a pathway lescribed as the occipito-frontal fasciculus probubly comsists largely of the more sigitally running libres of this nature. 'The existence of this fasciculus bas been noted in degenerations and in cases of arrestrol development of the corpus allosum. Its fibres are deseribed as contributing greatly to the tapetum, and as ansing benoth the eorpus callosm immediately 
next to the ependyma of the lateral ventricle. As a mass, they appear in intimate connection with the caudate nucleus, and are spread toward both the frontal and the occipital lobes (chiefly the latter), in the mesial part of the corona radiata of those lobes. It is described as also containing fibres in both directions associating the occipital with the temporal lobe. Tertical association fibres pass through the caudate and lenticular nuclei between the cortex above and that of the temporal lobe below.

(9) Since the olfactory bulb is a part of the hemisphere proper, the olfactory tract may be considered an association pathway connecting the olfactory bulb with the parolfactory area, the subcallosal gyrus, the anterior perforated substance, and the uncus. As already shown, a portion of the fibres of the tract belongs to the commissural system.

\section{THE FUNCTIONAL AREAS OF THE CEREBRAL CORTEX}

The definitely known areas of specific function of the human cerebral cortex are relatively small. They comprise but little more than a third of the area of the entire hemisphere. They are-(1) the general sensory-motor or somæsthetic area, and (2) the areas for the organs of special sense. They represent portions of the cortex in which terminate sensory or ascending projection fibres bearing impulses from the given peripheral structures, and in which arise motor or descending projection fibres bearing impulses in response.

Knowledge of the location of the areas has been obtained-(1) by the Flechsig method of investigation, and to a considerable extent by Flechsig himself; (2) from clinico-pathological observations, largely studies of the phenomena resulting from brain tumors and traumatic lesions; (3) by experimental excitation of the cortex of monkeys and apes, the resulting phenomena being correlated with the anatomical findings and compared with the observations upon the human brain. The remaining larger and less known areas of the cortex are referred to as 'association centres' or areas of the 'higher psychic activities.'

In development, the sensory fibres to the specific areas acquire their medullary sheaths first, before birth, and then the respective motor fibres from each become medullated. It is not till a month after birth that the association centres show medullation and therefore acquire active functional connection with the specific areas.

In defining an area it is not claimed that all the fibres bearing a given type of impulse terminate in that area, nor that all the motor fibres leading to the given reaction originate in the area. It can only be said that of the fibres concerned in a given group of reactions, more terminate and arise in the areas cited than in any other areas of the cortex. The corresponding motor fibres arise both in the region of the termination of the sensory fibres (sensory area) and also in a zone (motor area) either partially surrounding or bordering upon a part of the region of termination.

The different areas are as follows:-

(1) The somæsthetic (sensory-motor) area, the area of general sensibility, and the area in which arise the larger part of the cerebral motor or pyramidal fibres for the cortical control of the general muscular system. As is to be expected, it is the largest of the specific areas. It includes the anterior central gyrus, posterior central gyrus, the posterior ends of the superior, middle, and inferior frontal gyri, the paracentral lobules, and the immediately adjacent part of the gyrus cinguli. The ascending or sensory fibres are found to terminate most abundantly. in the part posterior to the central sulcus (Rolandi), the posterior central gyrus being the special area of cutaneous sensibility, and the adjacent anterior ends of the horizontal parietal gyri have been designated as the area of 'muscular sense.' Both these areas are carried over upon the medial surface to involve the lower part of the paracentral lobule and a part of the gyrus cinguli. The anterior central gyrus gives origin to relatively more motor fibres than the other portions of the somæsthetic area. In distribution, the muscles furthest away from the cortex are innervated from the most superior part of the area, the leg area being in the supero-mesial border of the hemisphere, while that from the head is in the anterior and inferior part of the area (fig. 703). The muscles of mastication and the laryngeal muscles are controlled from the fronto-parietal operculum. Broca's convolution, the opercular portion and part of the triangular portion of the inferior frontal gyrus, of the left hemisphere, constitutes the especial motor area of speech, and Mills has extended this area to include the supero-anterior portion of the insula below. The various authorities differ considerably as to the exact locations of many of the areas for the cortical control of given sets of muscles. Further observations must be skillfully made for localisation of areas of the human cortex in detail and further correlations must be determined between the experiments upon the cortex of anthropoid apes and the functions of that of man. The accompanying diagrams are compiled from several of the diagrans more usually given and must be considered as only approximately correct.

(2) The visual area.- The especial sensory portion of this area is that immediately bordering upon either side of the posterior part of the calcarine fissure. The entire area, motor and sensory overlapping each other, includes the whole of the cuneus. The motor visual area proper is described as the more peripheral portion of the entire area. In addition, an area producing eye movements is described as situated in the posterior end of the middle frontal gyrus.

(3) The auditory (cochlear) area comprises the middle third of the superior temporal gyrus and the transverse temporal gyri of the temporal operculum. The motor portion of this area lies in its inferior border. The fibres arising in the area course downward in the temporal pontile path to the motor nuclei of the medulla.

(4) The olfactory area consists of the olfactory trigone, the parolfactory area, the subcallosal gyrus, part of the anterior perforated substance, the hippocampal gyrus (especially the uncus), and the callosal half of the gyrus cinguli. Its motor or efferent area lies chiefly in the hippocampal gyrus, the fibres from which pass out from the telencephalon by way of the fornix and cingulum. 
(5) The gustatory area is supposed to comprise the anterior portion of the fusiform gyrus and the zone (motor portion) about the anterior extrenity of the inferior temporal sulcus.

(6) The assocaition areas.-The relatively large areas allotted at present to the so-called higher psychic activities are indicated in fig. 703. The great relative extent of these is one of the characteristics of the human brain. They probably merely represent the portions of the cortex of which little is known, and may eventually be subdivided into more specific areas. They are considered to be connected with the structures below by fewer projection fibres than are the recognised areas named above, while, on the other hand, they are rich in association fibres. By means of the latter they are in intimate connection with the specific areas and have abundant means of correlating and exercising a controlling influence upon the functions of these areas. According to Flechsig, they consist of-(1) a parietal association area, comprising that part of the parietal cortex between the somæsthetic area and the visual area; (2) an occipitotemporal association area, including the unspecified portions of the temporal lobe and the adjoining portion of the occipital lobe not included in the visual area; (3) a frontal association area, including all the frontal lobe anterior to the somesthetic and olfactory area. In the folds of the inferior parietal lobule of the parietal association area such intellectual activities as the optic discrimination of words, letters, numbers, and objects generally are supposed to

Fig. 704.-Convex Surface of left Cerebral Hemisphere with Diagrammatic Presentation of the Areas Suggested as Concerned with Speech.

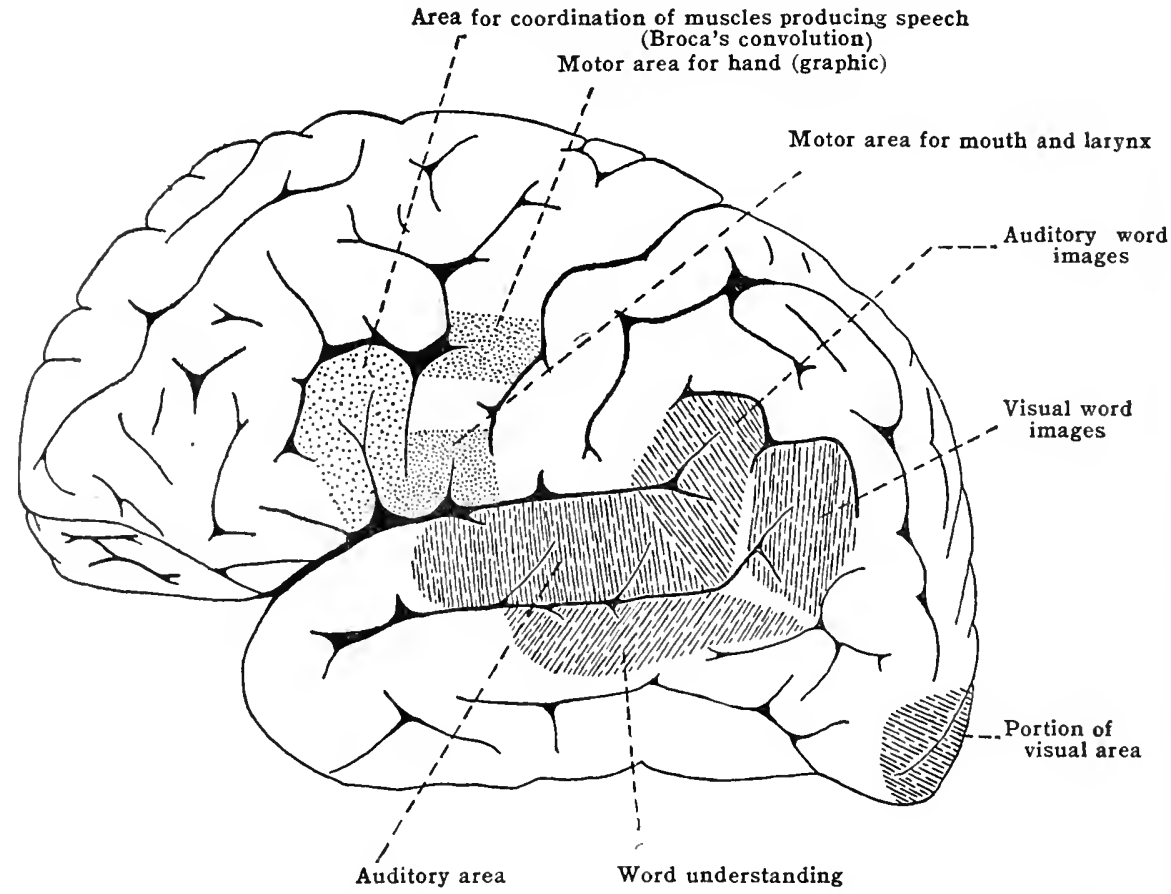

take place, while the superior parictal lobule continued into the posterior part of the pracuneus is the general region for the perception of form and soliclity of objects- the stereognostic centre.

The insula is suggested as the area in which auditory, olfactory and gustatory impulses are associated with the motor areas beginning in the operculum dorso-laterally adjacent to it.

Observations of symptoms and the position of lesions accompanying them have made it possible to arrive at some trustworthy conclusions regarding the cortical areas controlling speech. Broca announced in 1861 that the inferior frontal gyrus of the left hemisphere was peculiarly concerned with speech. This area was later confined to the posterior end or opercular portion of this gyrus and the name "Broca's Convolution" was given it. It is now known that Broca's convolution and the arljacent portion of the triangular part of the inferior frontal gyrus as well comprise thr motor area or emissive speech area-the area especially devoted to the control of that coordinated action of the museles concerned which makes possible articulate speech. Patients in whom this area is impaired are unable to give utterance to words though they may understand them both written and spoken, and though they may give utterance to sound. This inability is known as motor aphasia. Results of observed lesions have further shown that the area in which the anditory images of words are retained (word memories) comprises the posterior end of the superior temporal gyrus and the adjoining portion of the supramarginal gyrus. Injury to this area is accompanied by inability to recognise spoken words although the patient hears them and may recognise and understand written words, a phenounenon known as "worl-deafness" or sensory aphasia. This area may be considered as continuons with the superior portion of the posterior end of the iniddle temporal gyrus whieh has been suggested as the area of "word-understanding," or "lalognosis." On the other hand, the area in which visual images of words are retained is located as the angular gyrus. Injury to this results in an inability to recognise printed or written words although the patient 
may hear, understand and speak them. This is called "word-blindness." This area is nearest the special area of vision on the one hand and on the other hand, is continuous into the area to which word-understanding is attributed. For purposes of writing, it must be associated with the motor area for the muscles of the hand in the precentral gyrus.

While the motor area for speech is most functional in the left hemisphere, the remaining areas concerned are probably equally developed in the two hemispheres.

\section{GENERAL SUMMARY OF SOME OF THE PRINCIPAL CONDUCTION PATHS OF THE NERVOUS SYSTEM}

In the following summary the arabic numerals indicate paragraphs in which are mentioned the nuclei or ganglia containing the cell-bodies of the neurones interposed in the chains; the small letters indicate the different names given to the different levels of the pathways through which their fibres run. For detailed descriptions of either nuclei or pathways see pages describing them. Only the more common neurone chains are followed here.

\section{The Spino-cerebral and Cerebro-spinal Path}

A. The ascending system of neurones. (fig. 705)

1. Spinal ganglion-neurone of first order.

(a) Terminal corpuscles and peripheral process of T-fibre.

(b) Dorsal or afferent root of spinal nerve.

(c) Ascending branch of bifurcation of dorsal root fibre in fasciculus gracilis, or fasciculus cuneatus of spinal cord.

2. Nucleus of fasciculus gracilis or nucleus of fasciculus cuneatus in medulla oblongataneurone of second order.

(a) Internal arcuate fibres.

(b) Decussation of lemniscus.

(c) Interolivary stratum of lemniscus of opposite side.

(d) Medial lemniscus.

3. Hypothalamic nucleus and lateral nucleus of thalamus-neurone of third order.

(a) Internal capsule, posterior segment of fronto-parietal portion.

(b) Corona radiata, fronto-parietal part.

(c) Posterior central gyrus of somæsthetic area of cerebral cortex.

B. Descending system of neurones (fig. 706).

1. Giant pyramidal cells of precentral gyrus of somæsthetic area.

(a) Corona radiata, fronto-parietal part.

(b) Internal capsule, middle segments of fronto-parietal portion.

(c) Basis of the cerebral peduncle and the peduncle.

(d) Pyramid of medulla oblongata.

$\left(e^{1}\right)$ Decussation of pyramids.

$\left(f^{1}\right)$ Lateral cerebro-spinal fasciculus (crossed pyramidal tract).

$\left(e^{2}\right)$ Ventral cerebro-spinal fasciculus (direct or uncrossed pyramidal tract).

$\left(f^{2}\right)$ Gradual decussation of latter in cervical and upper thoracic regions of spinal cord.

2. Cells of ventral horn of spinal cord of opposite side.

(a) Ventral or efferent roots of spinal nerves.

(b) Peripheral nerve-trunks directly to skeletal muscles or indirectly to smooth muscle or glands by way of sympathetic neurones.

\section{Short 'Reflex' Paths of Spinal Cord}

1. Spinal ganglia.

(a) Terminal corpuscles and peripheral process of T-fibres.

(b) Dorsal root of spinal nerve.

(c) Collaterals and descending branches of bifurcation of dorsal root fibres in spinal cord

(d) Directly to ventral horn cells of same level of spinal cord.

(e) Or, more commonly, to same through intermediation of Golgi cell of type II.

$(f)$ Or to neurones of fasciculi proprii to ventral horn cells of other levels of spinal cord.

2. Ventral horn cells of same (chiefly) and opposite side and thence by way of ventral roots and peripheral nerve trunks directly to muscles.

3. Dorso-lateral group of ventral horn cells of same (chiefly) and opposite sides and thence by ventral root fibres to cell-bodies in sympathetic ganglia.

4. Sympathetic axones to smooth muscle or glands.

III. Cerebral Path for the Cranial Nerves, Exclusive of Those of Special Sense

\section{A. Ascending system of neurones.}

1. Ganglia of origin of sensory components of vagus, glossopharyngeus, glosso-palatine and trigeminus.

(a) Peripheral arborisations and afferent peripheral branches of T-fibres of same.

(b) Central branches of T-fibres of same (sensory nerve roots).

2. Nuclei of termination of central branches (bifurcated and unbifurcated) in medulla oblongata.

(a) Reticular formation, internal arcuate fibres and medial lemniscus of the opposite side. 
3. Hypothalamic nucleus and lateral nucleus of thalamus.

(a) Internal capsule, posterior segment of fronto-parietal portion.

(b) Corona radiata, fronto-parietal part.

(c) Cerebral cortex-chiefly lower third of posterior central gyrus.

Fig. 705.-Scheme of Ascending or Spino-cerebral Conduction Pathways.

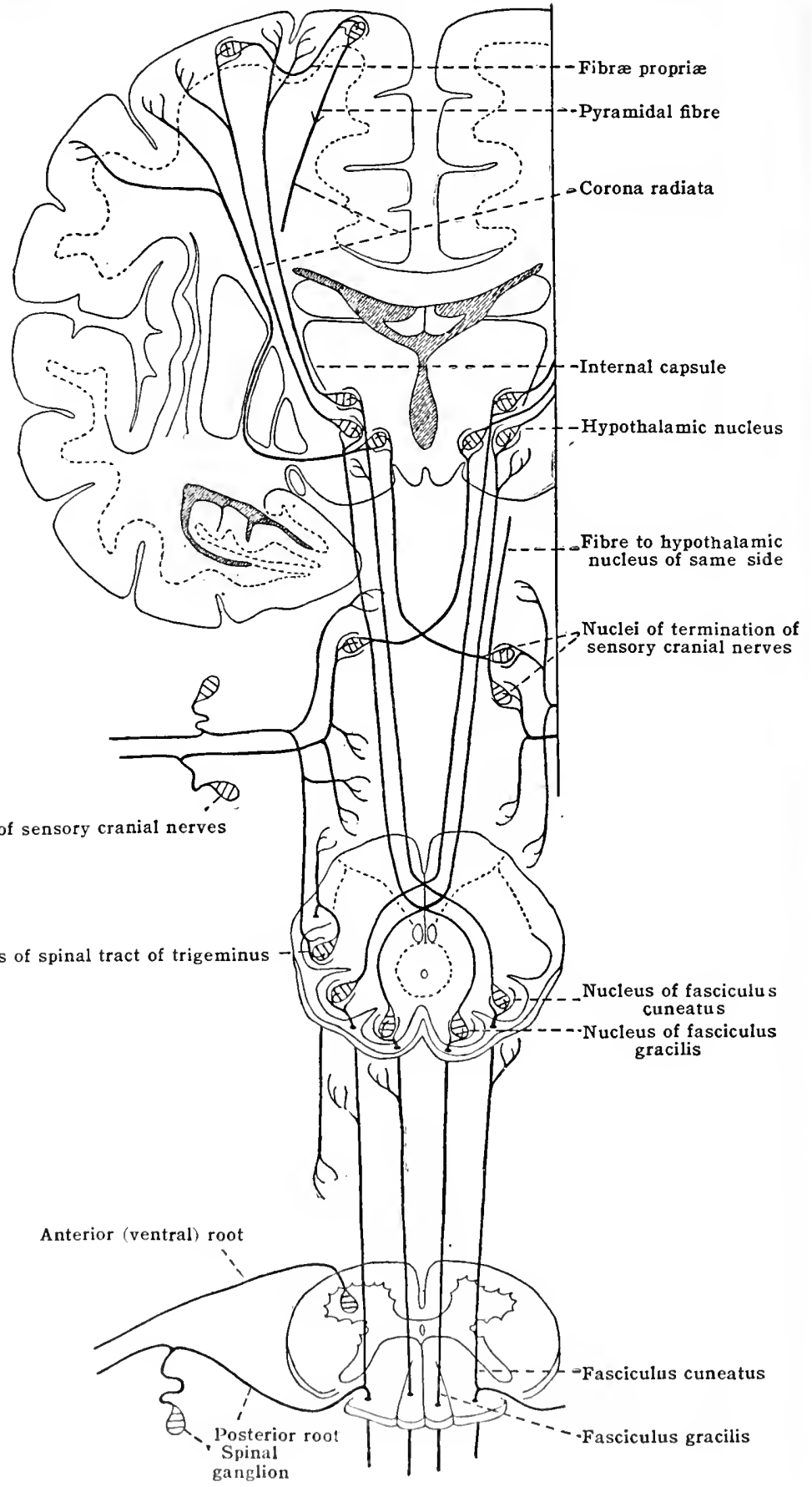

B. Descending system of nerurones.

1. I'yramindal ectls of opereular region of somasthetic areat.

(a) Corona radiatat, fronte-parietal.

(b) Intronal capsule, gentl chicefly.

(c) Ibasis of corolmal podumcle and peolunele.

(d) Jocussation in brain stem. 
2. Nuclei of origin of motor cranial nerves and motor components of mixed cranial nerves, of opposite side chiefly and thence by way of these nerves to the respective muscles supplied.

Notes: (1) Most of the descending cortical fibres to the nucleus of origin of the trochlear

Fig. 706.-Scheme of Descending Cerebro-spinal Conduction Pathways.

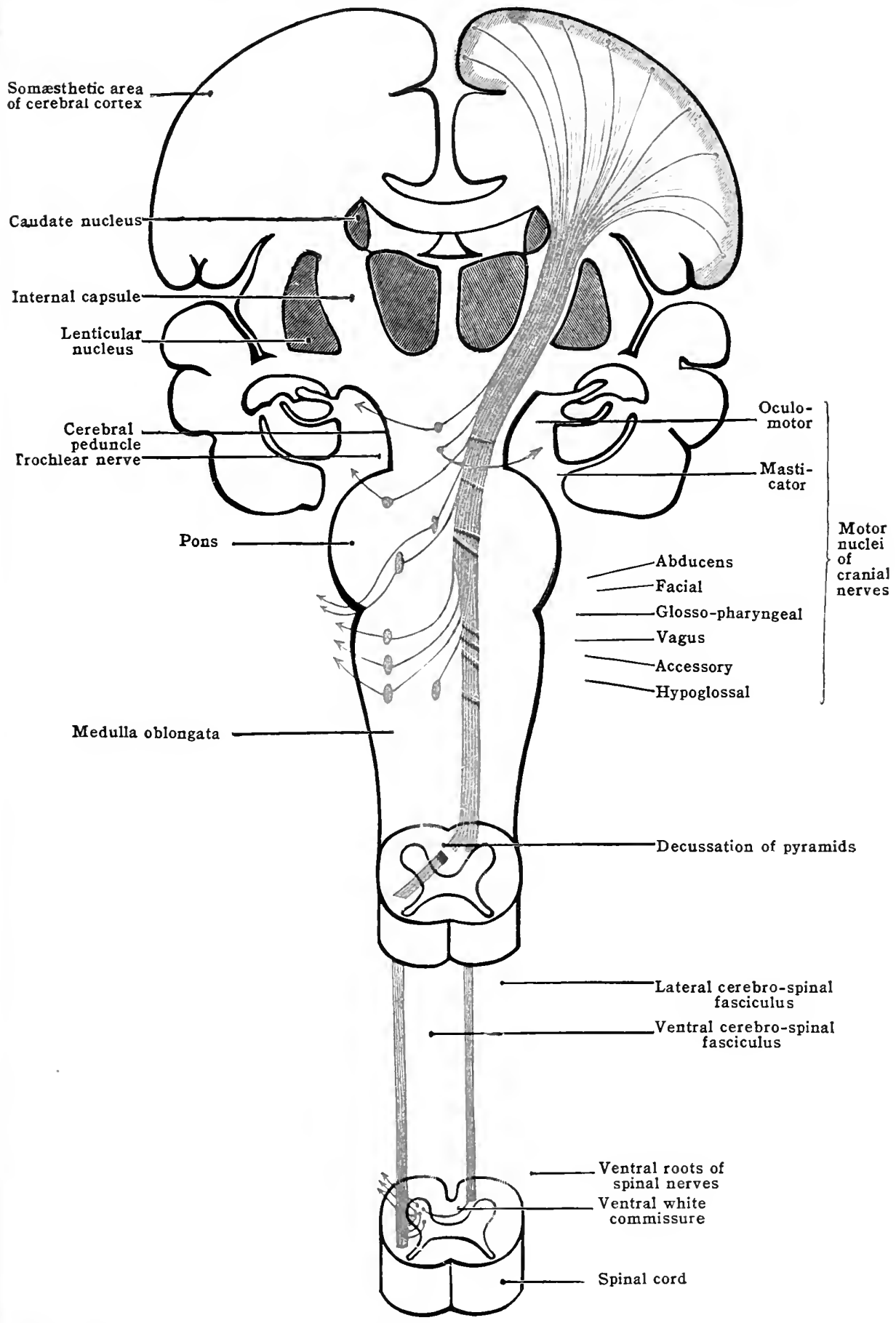

nerve and that portion of the nucleus of the oculomotor which supplies the internal rectus muscle apparently do not decussate but terminate in the nuclei of the same side.

(2) The efferent nucleus of the glosso-palatine (salivatory nucleus) and the dorsal efferent nucleus of the vagus give rise to visceral efferent fibres, i. e., carry impulses destined for smooth muscle and glands by way of sympathetic neurones. The same is true for the supero-median part of the nucleus of the oculomotor. 
(3) The nuclei of termination of the cranial nerves, especially those of the vestibular and trigeminus, send fibres also into the cerebellum.

\section{IT. The Sholt 'Reflex' Paths of the Cranial Nerves}

These consist of the central branches of their afferent or sensory fibres, bearing impulses to the nuclei of origin of both their own motor components and to the muclei of origin of other

Fig. Tut.-Scheme of Principal Ascending Cerebellar Conduction Paths.
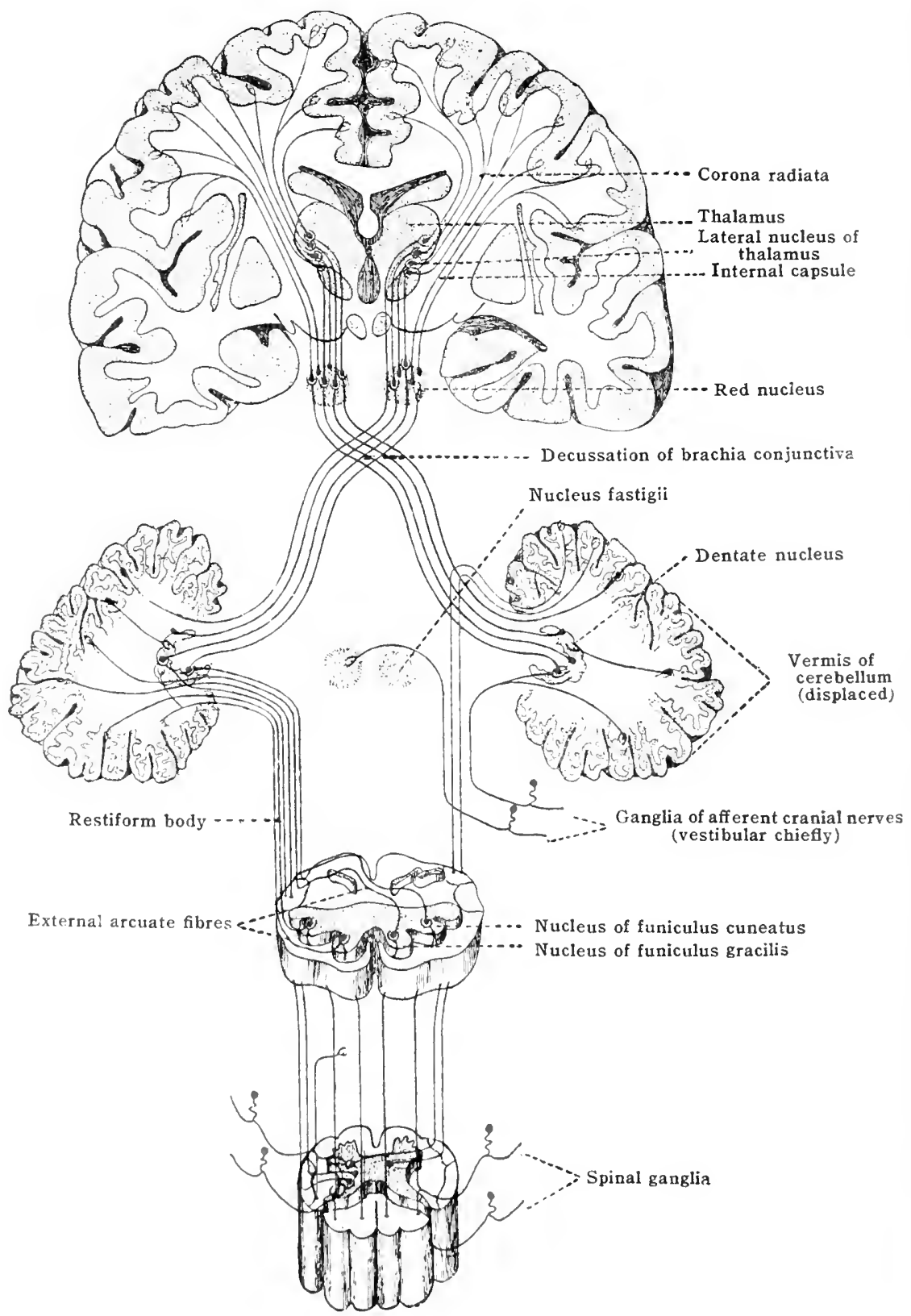

motor nerves. Fibres to the more distant nuclei pass (1) them by way of the medial longitudinal fascimbls. Instoud of frminating in the motor nuclei directly, the sensory fibres are usually interrupted by a third or intermodiate neurone interposed in the ehain. 'The vagus and glosso-pharyngeus are connected by way of the solitary fasciculus and its nucleus with the structures below their level of entrance, "ven with the ventral horn cells of the upper segments of the cervical cord, and through these with the museles of respiration. 


\section{Conduction Paths Intoltixg the Cerebellum}

A. Ascending cerebellar pathways.

1. Spinal ganglia.

(a) Dorsal roots of spinal nerves.

(b) Collaterals and descending branches of bifurcation of dorsal root fibres in spinal cord, chiefly those conveying impulses of muscle-sense.

2x. Dorsal nucleus (Clarke's column).

(a) Dorsal spino-cerebellar fasciculus (direct cerebellar tract).

(b) Restiform body (inferior cerebellar peduncle)-

(c) Joined in medulla by external arcuate fibres (crossed and uncrossed fibres arising in nuclei of funiculus gracilis and cuneatus);

(d) Joined in medulla by fibres arising in nuclei of termination of afferent vagus, glosso-pharyngeal, vestibular, and trigeminal nerves;

(e) Joined by fibres both to and from (ascending and descending) the inferior olivary nucleus of the same and opposite sides (cerebello-olivary fibres).

$2 y$. Nerve-cells in base of ventral horn of same and opposite side.

(a) Superficial antero-lateral spino-cerebellar fasciculus (Gowers' tract), ascending through spinal cord and reticular formation of medulla and pons.

(b) Anterior medullary velum and brachium conjunctivum to cerebellin cortex (vermis).

3. Cerebellar cortex (vermis), dentate nucleus, nucleus fastigii, nucleus emboliformis, and nucleus globosus.

(a) White substance (corpus medullare) of cerebellum, associating various regions of its cortex and its nuclei with each other.

(b) Brachium conjunctivum (superior cerebellar peduncle) arising chiefly from dentate nucleus.

(c) Decussation of brachiun conjunctivum.

4. Red nucleus and ventral portion of lateral nucleus of thalamus. Most fibres of the brachium conjunctivum terminate in the red nucleus; many merely give off collaterals to it in passing to their termination in the thalamus. Mlost of the ascending fibres arising in the red nucleus also terminate in the ventral part of the thalamus; some ascend to the cerebral cortex direct.

(a) Internal capsule, middle third, and fronto-parietal part of corona radiata.

(b) Somæsthetic area of cerebral cortex and cortex of frontal lobe anterior to it.

(c) Inferior peduncle of thalamus to cortex of temporal lobe.

B. Descending cerebrocerebellar paths.

1. Pyramdial cells of somæsthetic area send fibres through corona radiata, internal capsule, and cerebral peduncle to nuclei of pons and arcuate nucleus of same and opposite side.

2. Cells of cortex of posterior part of frontal lobe give fibres to form frontal pontile path through frontal parts of corona radiata and internal capsule and through medial part of cerebral peduncle to nuclei of pons of opposite side.

3. Cells of cortex of temporal lobe (superior and middle gyri) give fibres to form temporal pontile path which passes under the lenticular nucleus into anterior segment of occipital portion of internal capsule and lateral part of cerebral peduncle to nuclei of pons of opposite side. This path is joined in the in ternal capsule by a small occipitopontile path.

4. Cells of nuclei of pons send fibres by way of brachium pontis (middle cerebellar peduncle) to cortex of cerebellar hemisphere, of side opposite to that of the origin of the cerebral fibres making synapses with the cells of the pons.

C. Descending cerebello-spinal paths.

1. From cells of nucleus fastigii of same and opposite sides and probably from other nuclei of cerebellum arise fibres which terminate in the nuclei of termination of the vestibular nerve and these send fibres in to the intermediate and anterior marginal fasciculi of spinal cord (fig. 619), and thence to the cells of the anterior horn.

2. Probably connected with the cerebellum is the pathway arising in the red nucleus of the opposite side and descending in the rubro-spinal tract of the lateral funiculis of the spinal cord (fig. 619). The rubro-spinal tract decussates in the ventral portion of the tegmentum of the mesencephalon and is said to pass through the medulla oblongata in the medial longitudinal fasciculus. It must be noted here that some fibres arising in the cortex of the frontal lobe terminate in the red nucleus.

\section{The Vestibular Conduction Paths (Equilibration)}

1. Vestibular ganghion gives origin to the peripheral utricular and three ampullar branches and to the combined and centrally directed vestibular nerve.

2. Lateral vestibular nucleus (Deiters'), medial nucleus, superior nucleus, and nucleus of descending or spinal root (nuclei of termination) give origin to fibres as follows:(a) From lateral and superior nuclei to nucleus fastigii of opposite side and to cortex of vermis and to dentate nucleus (cerebellar connection).

(b) From medial and superior nuclei to nuclei of origin of eye-muscle nerves of same and opposite sides, by way of medial longitudinal fasciculi.

(c) From lateral nucleus and nucleus of descending root through reticular formation into_lateral and ventral vestibulo-spinal tracts of spinal cord. 
(d) The nuclei receive fibres from the grey substance of the vermis. It is probable that all the nuclei of termination give off fibres bearing ascending impulses which ultimately reach the somsesthetic area, but the course pursucd and neurones involved in such a chain are uncertain.

\section{vil. The Auditory Condection Path (Cochlear Nerve)}

1. Spiral ganglion of the cochlea gives origin to short peripheral fibres to organ of Corti, and to the centrally directed cochlear nerve.

2. Dorsal and ventral nuclei of the cochlear nerve (nuclei of termination).

(a) Striæ medullares arise from dorsal nueleus and pass around outer side of restiform body (acoustic tubercle), then medianward under ependyma of floor of fourth ventricle to mid-line, then ventralward into tegmentum, where they decussate and join trapezoid body and lateral lemniscus of opposite side.

Fig. 708.-Diagram Showing Some of the Connections of the Vestibular and Cochlear Nerves.

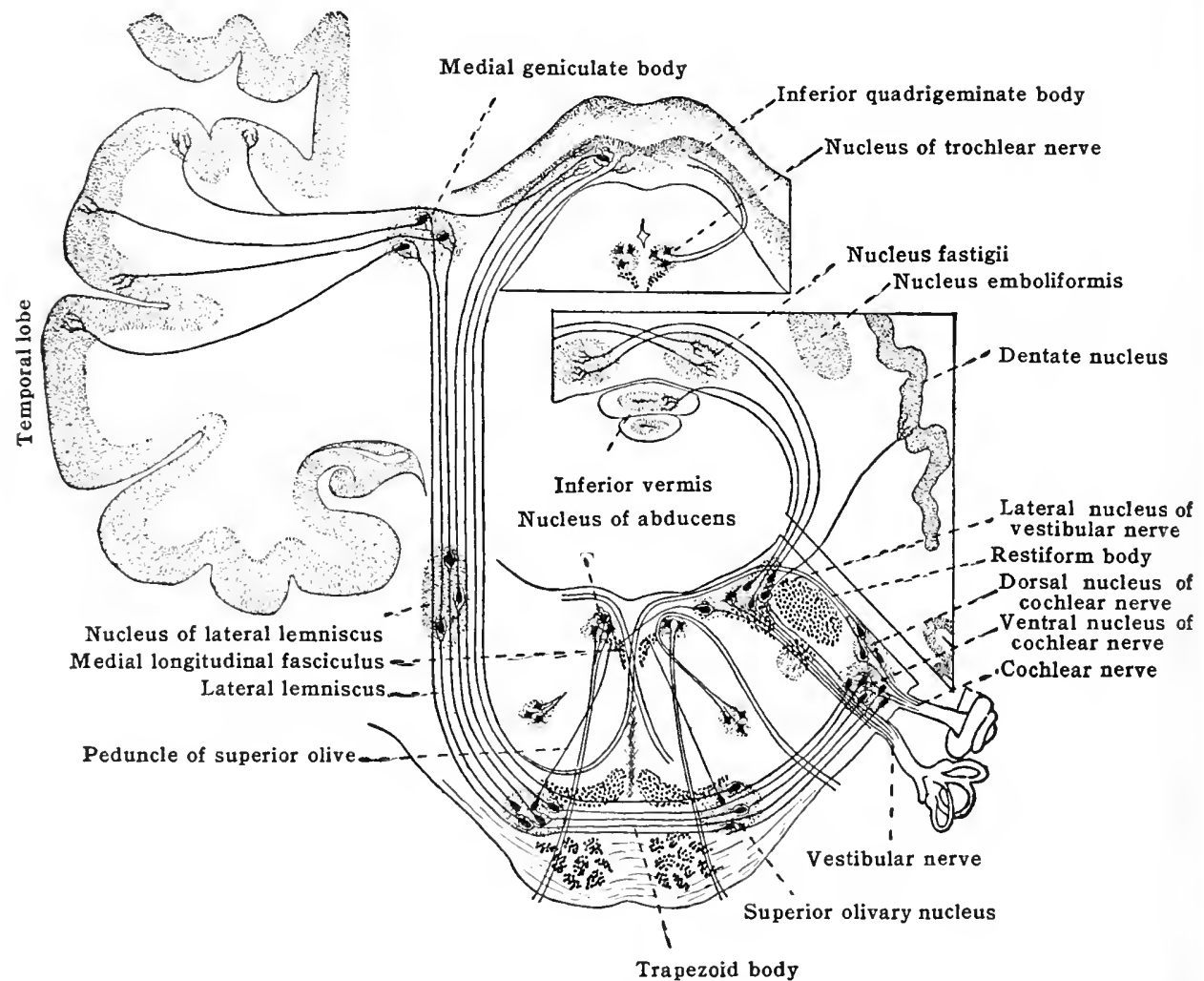

(b) Fibres arising in ventral nucleus pass ventrally medianward and some terminate in the superior olivary nucleus of same side; others pass by way of trapezoid body and lateral lenmiscus to terminate in superior olivary nueleus, nucleus of lateral lemniscus, medial genieulate body and nucleus of inferior quadrigeminate body of the opposite side.

3. Nuclei of superior olives of both sides and nucleus of lateral lemniscus send fibres by way of lateral lemniscus to inferior quadrigeminate body and through inferior hrachium to medial genieulate body, and some may pass uninterrupted to the cortex of the temporal lobe.

4. Fibres from medial genieulate body and probably from nucleus of inferior quadrigeminate lody pass into internal capsule and through temporal part of colona radiata to middle third of superior temporal gyrus and adjacent portions (auditory area).

5. From strice medullires and fron superior olivary nueleus (peduncle of superior olive) arise fibres which terminate in nueleus of ablucens or pass hy way of the inedial longitudinal fasciculus to other notor nuclei of cranial nerves. It is probable that filores from the auditory area of the cerebral eortex are also distributed to nuelei of the cranial nerves.

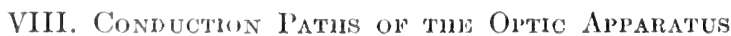

A. Optic impulses.

1. 'IBipolar' cells of retina with short (peripheral) processes to layer of rods and cones (neuro-epithelium) and short contrally directed processes to ganglion-coll layer of retina (nucleus of temination). 
2. Ganglion-cells of retina give origin to-

(a) Optic stratum of retina.

(b) Optic nerve.

(c) Optic chiasma; fibres from nasal side of retina cross in chiasma to opposite side; fibres from lateral side of retina continue on same side in-

(d) Optic tract to-

3. Pulvinar of thalamus, lateral geniculate body, and nucleus of superior quadrigeminate body.

(a) Fibres from nucleus of superior quadrigeminate body pass ventrally, to nuclei of origin of oculomotor and trochlear nerves and to medial longitudinal fasciculus of same and opposite sides, and from it are distributed to nucleus of origin of abducens.

(b) Fibres from lateral geniculate body and pulvinar pass through occipital"portion of internal capsule and occipito-thalamic radiation (optic radiation) to cortex of occipital lobe (visual area).

Fig. 709,-Diagram of Principal Pathways of Optic Apparatus. (After Cunningham.)

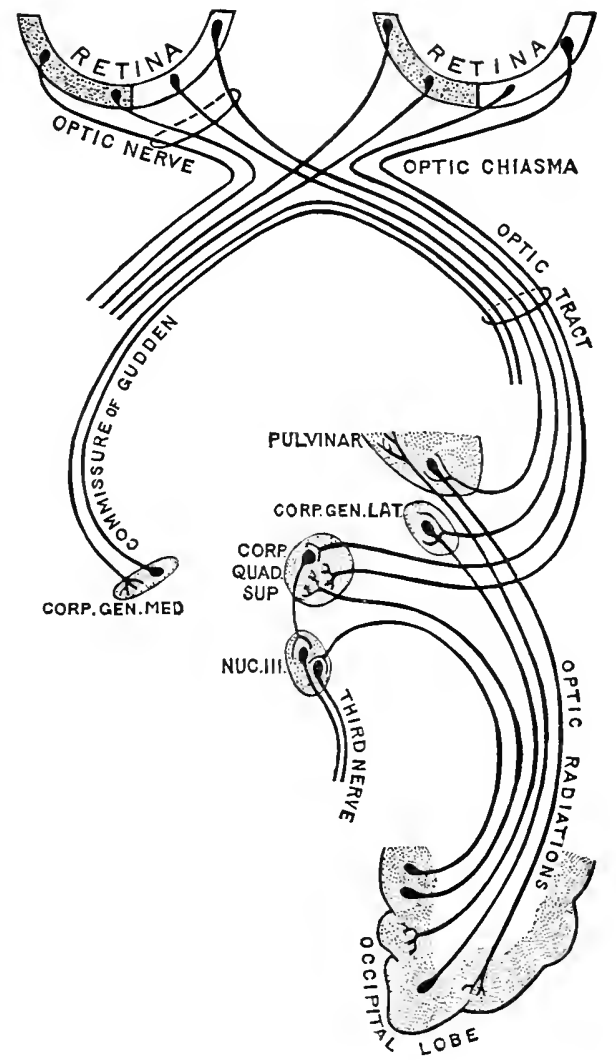

4. Cells of visual area of cortex send fibres through occipito-thalamic radiation and occipital portion of internal capsule to nucleus of superior quadrigeminate body (occipito-mesencephalic fasciculus), and thence, probably interrupted by cells of this nucleus, to nuclei of eye-muscle nerves.

5. Cells of nucleus of superior quadrigeminate body and pulvinar send fibres by way of medial longitudinal fasciculus into lateral and ventral funiculi of spinal cord (see fig. 619), chiefly of the opposite side. Fibres from the quadrigeminate body cross mid-line chiefly in decussation of 'optic-acoustic reflex path' (fig. 662).

6. The smaller cells of the supero-mesial group of the nucleus of the oculomotor nerve (nucleus of Edinger and Westphal) send axones, by way of the trunk of the nerve and the short root of the ciliary ganglion, which terminate about cells in-

7. The ciliary ganglion, whose cells send axones to enter the ocular bulb and terminate upon the smooth muscle fibres of the ciliary body and iris.

B. Skin-pupillary reflexes.

1. Peripheral processes of spinal ganglion cells terminating in the skin and central processes of same entering by way of dorsal roots of cervical nerves to bifurcate in spinal cord and give terminal twigs about-

2. Cells of the dorso-lateral group of the ventral horn of the same and opposite sides. These cells send (visceral efferent) axones to terminate about cells in- 
3. The superior cervical sympathetic ganglion, which cells send axones chiefly by way of the carotid plexus and the sympathetic roots of the ciliary ganglion to terminat about cells in--

4. The ciliary ganglion. Such cells send axones into the ocular bulb to terminate in the ciliary body and radial muscle fibres of the iris, producing dilation of the pupil.

C. Auditory-eye reflexes:

1. Cells of the nuclei of termination of the cochlear nerve and superior olive send fibres by way of the medial longitudinal fasciculus (some to this by way of the peduncle of the superior olive) to the nuclei of origin of the eye-moving nerves.

2. The same nuclei of the cochlear nerve send axones by way of the lateral lemniscus to terminate in the superior quadrigeminate body and thence may be sent impulses which are distributed to the nuclei of the eye-moving nerves

\section{Principal Conduction Paths of Olfactory Apparatus}

1. Bipolar cells of olfactory region of nasal epithelium send short (peripheral) processes toward surface of nasal cavity and centrally directed processes, the olfactory nerve, through lamina cribrosa of ethmoid bone into olfactory bulb (glomerular layer).

2. 'Mitral cells' of olfactory bulb give fibres which form-

(a) The olfactory tract which divides into-

Fig. 710. - Diagran Showteg Some of the Principal Tracts and Sinapses of the OlfacTORY Apparatus.

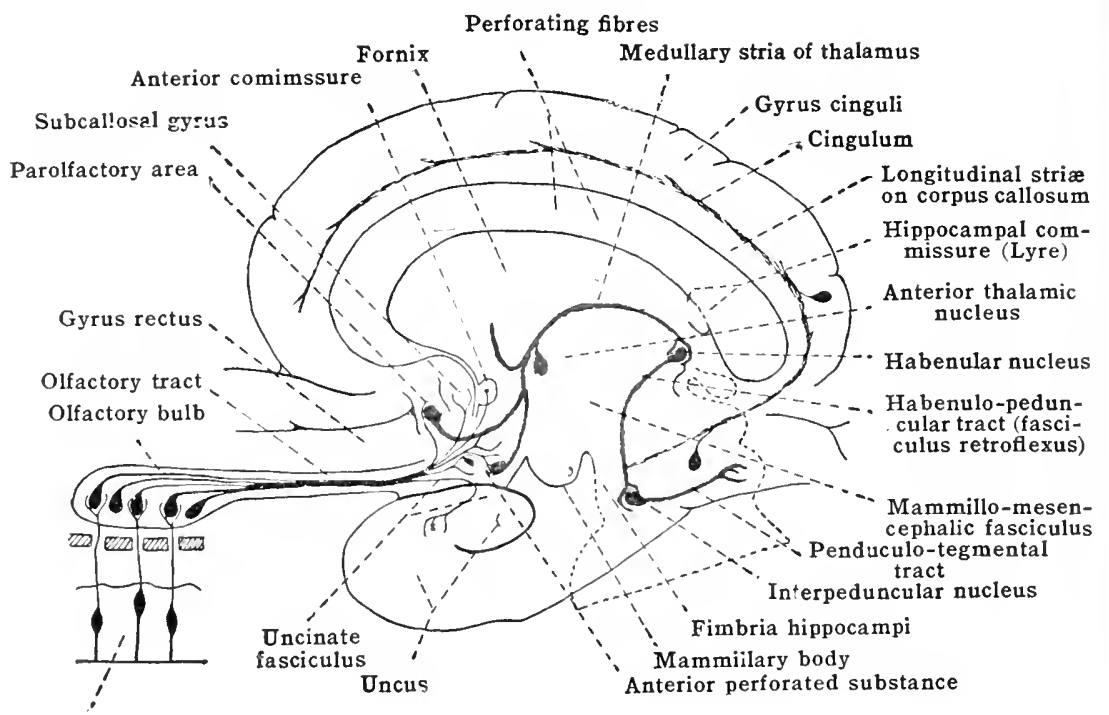

Olfactory epithelium

(b) Medial olfactory stria through which fibres pass-(1) into parolfactory area (Broca's area); (2) into subcallosal gyrus; and (3) ly way of anterior cerebral commissure to olfactory bulb and uncus of hippocampal gyrus of opposite side.

(c) Intermediate olfactory stria to anterior perforated substance.

(d) Literal olfactory stria, which terminates to some extent in anterior perforated sulstance, but chiefly in uncus, hippocarupal gyrus, and gyrus cinguli (olfactory inces) of same side.

3. C'ells of uncus and hippocampal gyrus give fibres which form-

(a) The cingulum (in part), by which they are associated with the cortex of the gyrus (inguli and ot lier areas of the cerebral eortex.

(b) The hipporampal commissure (in patt), by which they are connected with the grey substance of the opposite side.

(c) The fornix, which, intermpted in part in the nuclei of the corpus mammillare, conveys inpulses-(1) to the anterior nucleus of thalamus of the same (chiefly) and opposite sides (mammillo-thalamic fasciculus), and (2) into the mesencephalon and substintiat nigra (mammillo-mesencephalic fasciculus), and by way of this tract probably to the nuclei of the mesencephaton and medulla oblongata.

4. The parolfactory area, anterior perforated substance, anterior portion of thalamus and formix give filses which form the medullary stria of the thalamus and which terminate in the habenular nuclens.

5. Ilatemular nuclens sends filores in fascieulus retroflexus to terminate in interpeduneular nuclens.

6. Interperluncular mucheus sends fibres to nuclei of mesencephalon and probably to structures below it. 


\section{The Relations of the Brain to the Walls of the Cranial Cavity}

The precise methods by which the exact positions of the most important fissures, sulci, gyri, and areas can be ascertained and mapped out on the surface of the head in the living subject are fully described in Section XIII. Here, only a very general survey of the relations of the brain to the cranial bones is given and from a purely anatomical standpoint.

The parts of the brain which lie in closest relation with the walls of the cranial cavity are the olfactory bulb and tract, the basal and lateral surfaces of the cerebral hemispheres, the inferior surfaces of the lateral lobes of the cerebellum, the ventral surfaces of the medulla_and pons, and the hypophysis.

Certain of these portions of the brain lie in relation with the basi-cranial axis, that is, with the basi-occipital, the basi-sphenoid, and the ethmoid bones, while others are associated with the sides and vault of the eranial cavity. Considering the former portions first, the ventral surface of the medulla oblongata, which is formed by the pyramicls, lies upon the upper surface of the basi-occipital bone. More superiorly the ventral surface of the pons rests upon the basi-

Fig. 711.-Drawing of a Cast of the Head of an Adult Male.

(Prepared by Professor Cunningham to illustrate cranio-cerebral topography.)

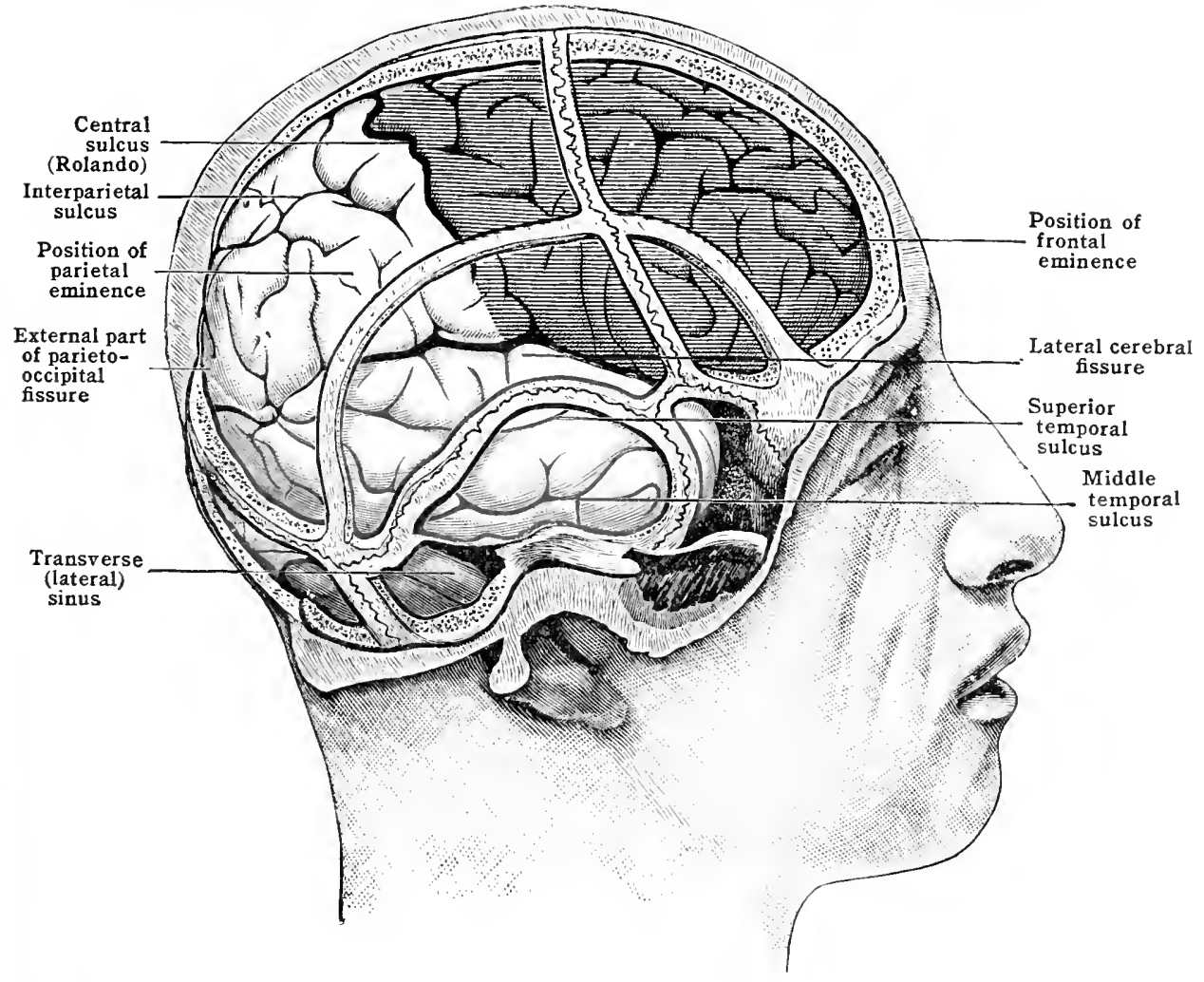

sphenoid, from which it is partly separated by the basilar artery and the pair of abducens nerves. In front of the dorsum sellæ the hypophysis (pituitary body) is lodged in the hypophyseal fossa. Still further forward the olfactory tracts lie in grooves on the upper surface of the presphenoid section of the sphenoid bone; and in front of the sphenoid the olfactory bulbs rest upon the cribriform plates of the ethmoid.

Posterior and lateral to the posterior part of the foramen magnum the lateral lobes of the cerebellum are in relation with the crania! wall, resting upon the lower parts of the supraoccipital and the posterior parts of the ex-occipital portions of the occipital bone, while anteriorly each lobe is in relation with the inner surface of the mastoid process and the posterior surface of the petrous portion of the temporal bone. The area of the skull wall which is in close relationship with the cerebellar hemispheres mi be indicated, on the external surface of the skull, by a line which commences at the inferior part of the external occipital protuberance and thence runs upward and lateralward. It crosses the superior nuchal line a little beyond its centre, and, continuing in the same direction, crosses the inferior part of the lambdoid suture and reaches a point directly above the asterion (the meeting-point of the occipital, temporal, and parietal bones); thence it descends, just in front of the occipito-mastoid suture, to the tip of the mastoid process, and there turns medialward to its termination at the margin of the foramen magnum, immediately behind the posterior end of the occiptal condyle.

The basal surface of each cerebral hemisphere may be said to consist of two parts, an anterior and a posterior, separated by the stem of the lateral cerebral fissure. The anterior part, formed 
by the orbital surface of the frontal lobe, rests upon the upper surfaces of the orbital plate of the frontal bone and the lesser wing of the sphenoid. It is, therefore, in close relation with the upper wall of the orbital cavity. The posterior part, behind the stem of the lateral fissure, begins with the anterior portion of the temporal lobe, including its pole. The pole itself projects against the orbital plate of the great wing of the sphenoid bone, and it is in relationship with the posterior part of the lateral wall of the orbit. The basal surface of the hemisphere, behind the pole of the temporal lobe is in contact with the upper surfaces of the great wing of the sphenoid and the petrous part of the temporal bone.

The convex surfaces of the cerebral hemispheres have the most extensive relationships with the cranial wall, and it is more especially to these surfaces that the surgeon turns his attention. The general area in which the convex surface of each cerebral hemisphere is in relation with the skull bones is readily indicated by a series of lines which correspond with the positions of its superciliary, infero-lateral, and supero-mesial borders.

The line marking the superciliary margin of the hemisphere commences at the nasion (the mid-point of the fronto-nasal suture); it passes lateralward above the superciliary ridge, crosses the temporal ridge, then, turning posteriorly in the temporal fossa, it reaches the parietosphenoidal suture, and continues backward along it to its posterior extremity.

Fig. 712.-Drawing of a Cast of the Head of a Newly Born Male Infant. (Prepared by Professor Cunningham to illustrate cranio-cerebral topography.)

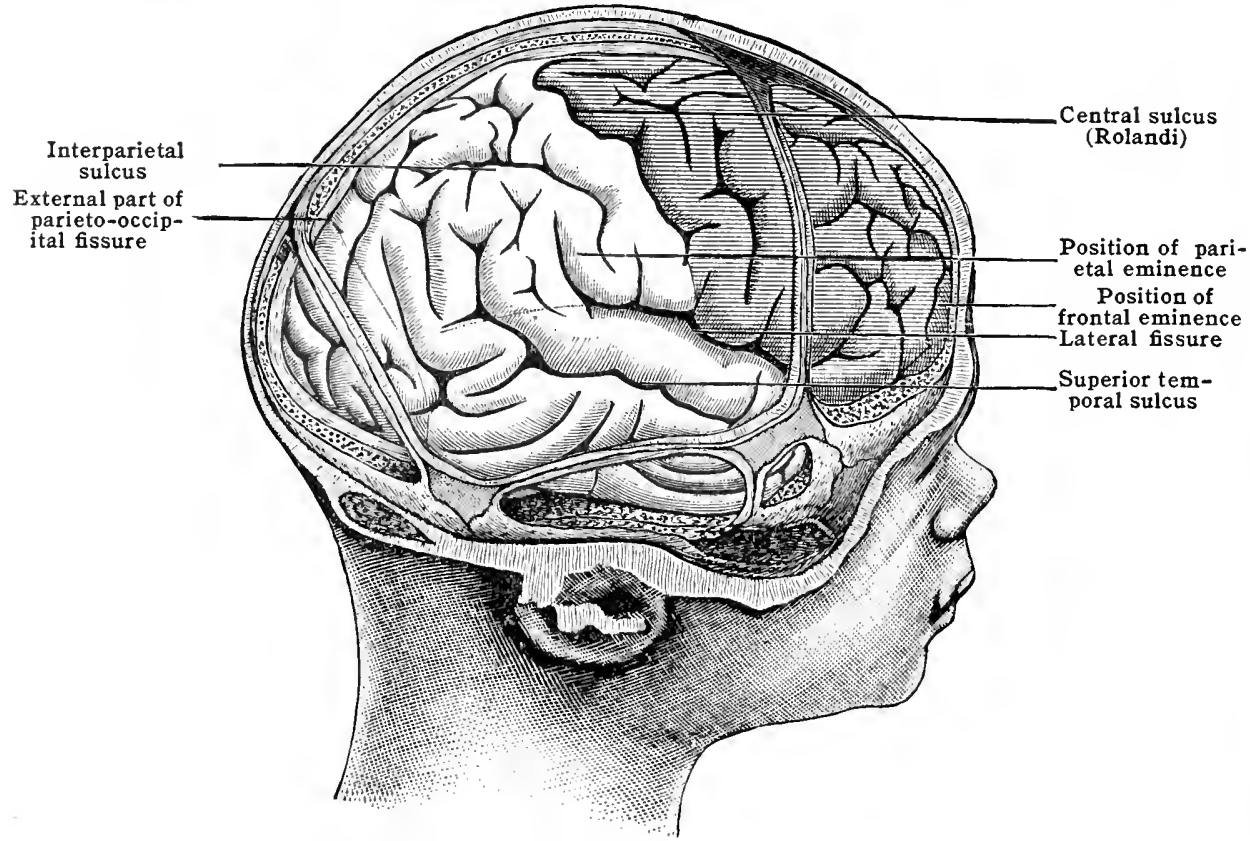

The line marking out the infero-lateral border commences at the posterior end of the parietosphenoidal suture, whence it passes downward, in front of the spheno-squamous suture, to the infra-temporal crest (pterygoid ridge); there it turns posteriorly and, running parallel with and mesial to the zygomatic arch, it crosses the root of the zygoma, and, ascending slightly, it passes above the external auditory meatus. Continuing backward with an inclination upward it reaches a point immediately above the asterion; thence it descends, and, crossing the inferior part of the lambrloid suture and the superior nuchal line, it passes medialward to the inferior part of the external oceipital protuberance.

The supero-mesial border of the bemisphere is defined by a line which runs from the nasion to the inion. This line should be drawn about $5 \mathrm{~mm}$. lateral to the sagittal suture, because the mesial area is oceupiel by the superior sagittal sinus, and it should be further away from the middle line on the right than on the left side, beeause the sinus tends to lie more to the right side.

The area of the skull wall enelosed by the three lines which mark the positions of the superciliary, infero-lateral, and the supero-mesial horders of the cerebral hemisphere is formed by the vertical plate of the frontal bone, the parietal bome, the great wing of the sphenoid, the squainous part of the temporal, and the upper scetion of the supra-oceipital segment of the occipital bone. It eovers theonter surfaces of the fromtal, parintal, temporal, and occipital lobes of the cerebrum and the fistures and suldei which hound and mark theme

In every consideration of the topogruphieal relations of the cerebral gyri to the walls of the cranial envity it must he horne in mind that the conditions are not eonstant, and that, therefore, the rations are? variable. "The three man factors upon which this variability depends are age, sex, and the shape of the skull. As examples of the variations which oceur it may be mentioned that the lateral cerobral fissure is relativaly highere in the child than in the adult (compare fies. 7 ] and 7]2). 'The supero-mesial cont of the central suleus is further away from the coronal suture in the female and in the child than in the arhlt male, and in dolichocephalic than in 
brachycephalic heads. The angle formed between the line of the central fissure and the midsagittal plane, which averages about $68^{\circ}$ in the adult, is more acute in dolichocephalic heads, and the external part of the parieto-occipital fissure is further forward in the child, and possibly in the female, than it is in the adult male.

The position of the posterior horizontal limb of the lateral fissure varies even in the adult. Its posterior part is always under cover of the parietal bone, and it terminates either in front of or inferior to the parietal eminence, but the anterior part may be above, parallel with, or inferior to the squamo-parietal suture. In the adult the anterior part of the fissure runs upward and backward from the posterior end of the spheno-parietal suture along the anterior part of the squamo-parietal suture to its highest point; thence it continues in the same direction beneath the parietal bone toward the lambda, terminating either in front of or below the parietal eminence. In the child, however, the fissure is considerably above the line of the squamo-parietal suture (fig. 712), which it gradually approaches, attaining its adult position about the ninth year. This change of position, which occurs during the first nine years, is due partly to the ascent of the sutural line and partly to the descent of the fissure on the surface of the brain.

The frontal bone always covers the superior, middle, and inferior frontal gyri, except their posterior extremities, which are beneath the parietal bone (fig. 711). The ascending limb (ramus anterior ascendens) of the lateral fissure, which cuts into the posterior part of the inferior frontal gyrus, runs parallel with and under cover of the lower part of the coronal suture, or immediately in front of it, and the anterior horizontal limb is parallel with and beneath the upper margin of the great wing of the sphenoid.

The parietal bone is in relation with the convex surfaces of four lobes of the brain. Speaking very generally, it may be said that the anterior third covers the posterior part of the frontal lobe, including the anterior central gyrus, and the posterior ends of the superior, middle, and inferior frontal gyri and the precentral sulcus. The posterior two-thirds of the bone are superficial to the perietal lobe, the posterior part of the temporal lobe, the anterior part of the occipital lobe, the posterior part of the horizontal limb of the lateral fissure, the superior and inferior parts of the post-central sulcus, the interparietal sulcus, the posterior sections of the superior and middle temporal sulci, and the external part of the parieto-occipital fissure. The central sulcus is beneath the parietal bone at the junction of its middle and anterior thirds (fig. 711).

In the adult, the upper end of the central sulcus is situated at about 55 per cent. of the whole length of the naso-inionic line posterior to the nasion. It is about 4 or $5 \mathrm{~cm}$. from the coronal suture. The inferior end of the sulcus, which extends to near the posterior horizontal limb of the lateral fissure, lies beneath the point of intersection of the auriculo-bregmatic line with a line drawn from the stephanion (the point where the temporal ridge cuts the coronal suture) to the asterion. This point is about 46 per cent. of the horizontal arc measured from the glabella to the inion.

The superior end of the parieto-occipital fissure usually lies about $5 \mathrm{~mm}$. in front of the lambda, and the course of the fissure may be indicated by a line drawn from $5 \mathrm{~mm}$. in front of the lambda to a point immediately above the asterion, and, as the latter point corresponds with the pre-occipital notch on the infero-lateral border of the hemisphere, the line in question will indicate the adjacent margins of the parietal, temporal, and occipital lobes.

The occipital bone is in close relation with the cerebellum, as already pointed out, but it also covers the posterior part of the lateral surface of the occipital lobe of the cerebral hemisphere. ' The great wing of the sphenoid covers the outer surface of the pole of the temporal lobe, and the squamous part of the temporal bone covers the anterior parts of the superior, middle, and inferior temporal gyri and the sulci which separate them.

\section{The Blood Supply of the Encephalon}

The double origin of the continuous arterial system of the brain given by the confluence of the two vertebral arteries and the two internal carotid arteries, together with the description of the general distribution of the different cerebral, mesencephalic, and cerebellar arteries into which the system is divided, and the origin and course of the corresponding veins, are fully dealt with in Section V. Here attention may be called briefly to the abundant and systematic internal distribution of the terminal branches of the system and their intimate arrangement for the actual nourishment of the nervous tissues within.

The general plan of the blood supply for the entire encephalon may be summarised as follows:-(1) At their origin the different arteries are so connected, directly or indirectly, on the base of the encephalon, that the blood approaching the brain by way of the vertebral and internal carotid arteries is practically a common supply for all the arteries of the encephalon, 1 and a given part of it may possibly pass into any one of them. (2) In the pia mater of each gross division of the encephalon the different arteries again become connected with each other in a superficial, freely anastomosing plexus, continuous throughout. (3) From this plexus of the surface, naturally composed in part of the trunks of the different arteries themselves, arise branches which enter directly into the nervous substance and which break i up into twigs that are terminal; i. e., twigs that do not anastomose with each other. (4) The arterial capillary system arising from the terminal twigs passes over into venous capillaries which converge to form corresponding venous twigs which in their turn pass to the surface and join in forming a peripheral, anastomosing venous plexus superimposed upon the similar arterial plexus. (5) From this venous plexus arise the different veins of the encephalon which may or may not accompany the arteries for a short distance, and which finally empty in to the sinuses in the cranial dura mater. These, likewise confluent, empty into the internal jugular veins. The chorioid plexuses of the ventricles of the brain are modifications of the general anastomosing peripheral plexuses. The chorioid plexuses of the lateral and third ventricles are derived largely from branches of the chorioid arteries, which arises separately from the internal carotid artery. 
The blood supply of the cerebrum may best be taken as an illustration of the general plan of the blood-vaseular system of the encephalon. The terminal or internal branches of the surface plexus, derived from the posterior, middle, and anterior cerebral arteries, are arranged into two groups, a central or ganglionic and a cortical group. The central branches themselves form four groups in each hemisphere:-

(1) The antero-mesial group consists of terminal branches from the plexus of the domain of the anterior cerebral artery, which pass through the medial part of the anterior perforated substance and supply the head of the caudate nucleus, the septum pellucidum, the columns of the fornix, and the lamina terminalis.

(2) The antero-lateral group consists of terminal branches from the domain of the middle cerebral artery. These pierce the anterior perforated substance in two sub-groups- $(a)$ the internal and $(b)$ the external striate arteries (fig. 713). The internal striate arteries pass through the segments of the globus pallidus of the lenticular nucleus and through the internal capsule, to both of which they give branches, and they terminate in the caudate nucleus and thalamus. The external striate arteries are larger and more numerous. They pass upward between the external capsule and the putamen, and then through or around the upper part of the putamen into the internal capsule, where they form two groups, the lenticulo-thalamic and the lenticulo-caudate groups. The former terminate in the thalamus and the latter in the caudate nucleus. On account of its larger size at its origin and its direct linear continuation with the internal carotid, emboli (thrombi) pass more frequently in to the middle cerebral artery

Fig. 713.-Diagram Showing the Manner of Distribution of the Cortical and Central Branches of the Cerebral Arteries.

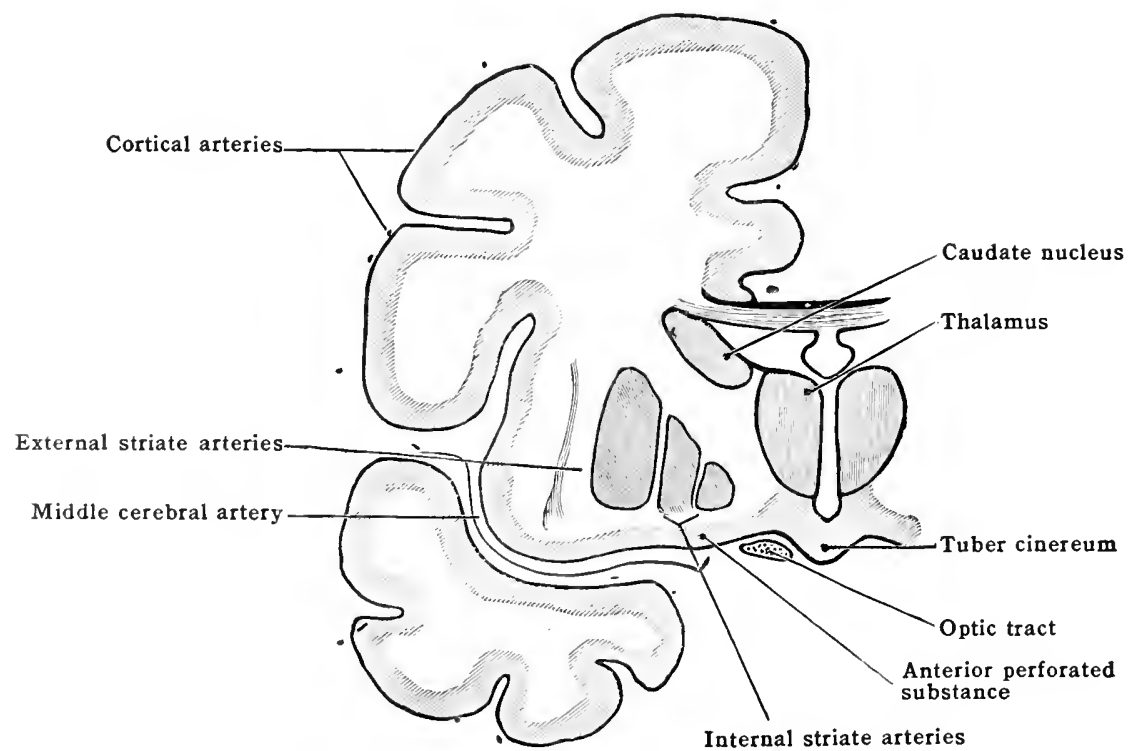

than into the anterior cerebral artery. One of the lenticulo-caudate arteries which is larger and longer than the others and which is a direct branch from the middle cerebral artery has been called the 'artery of cerebral hemorrhage' (Charcot), on account of the greater frequency with which it is ruptured.

(3) The posteromedial central arteries are terminal branches of the posterior cerebral artery. 'They also enter the anterior perforated substance, but supply the floor of the third ventriele, the posterior part of the thalimus, and the hypothalanie region.

(4) The postero-lateral group are also terminal branches of the posterior cerebral artery. They supply tho posterior part of the internal eapsule, the pulvinir of the thalamus, the genjeulate bodies, the corpora quadrigemina and their brachia, the epiphysis, and the cercbral peduners.

The corlical gromp of the eecestral arteries arise from the anastomosing plexus in the pia mater of the eortical surfaces of the hemisphere. They pass into the eortieal substance both from the summits of the gyri and from the walls of the sulei. They eonsist of short, medium, and long branches, and pass at right angles into the gyri. The shortbranches terminate in the eortical substance; the medium brinches supply the more itjacent white substance, and the longer branches pass more deeply into the goneril medulary centre of the hemisphere.

All of both the central or ganglionic ancl the cortical arteries are terminal in the sense that they fo not anastomose in the substance of the cerebrum.

The blood-vasculitr system of the other divisions of the encephaton is in accordance with the same general plan of that of the ecrebrum. Slight individual modifications of the general plan sue to be expreted. 
The blood-vessels of the mesencephalon, in addition to the supply derived from the posterolateral group of central arteries, include the vessels of the quadrigeminate bodies and those of the cerebral peduncles. The arteries of the quadrigeminate bodies are usually six in number, three for each side-the superior, middle, and inferior quadrigeminate arteries. The superior and middle are branches of the posterior cerebral arteries, and the inferior are branches of the superior cerebellar arteries. The superior supply the superior quadrigeminate bodies and the epiphysis; the middle supply both the superior and inferior quadrigeminate bodies, and the inferior the inferior quadrigeminate bodies. They all anastomose in the pia on the surface of the stratum zonale, forming a fine-meshed plexus, and from this superficial plexus the terminal branches pass into the substance of the bodies. The veins terminate in the vein of Galen ( $v$. cerebri magna.)

The arteries of the cerebral peduncles form two groups, mesial and lateral. The mesial peduncular arteries are branches of the basilar and the posterior cerebral arteries. They pass to the medial sides of the penduncles and supply the superior and medial part of the tegmentum. The ressels of this group which accompany the fibres of the oculomotor nerves are known as the radicular arteries; they supply the root-fibres and the nuclei of the nerves, which receive no other branches. The lateral peduncular arteries are branches of the posterior cerebral and

Fig. 714.-Showing the Capillary Supply of the Cerebeliar Cortex. (After Aby, "Journal of Comparative Neurology," Vol. IX.)

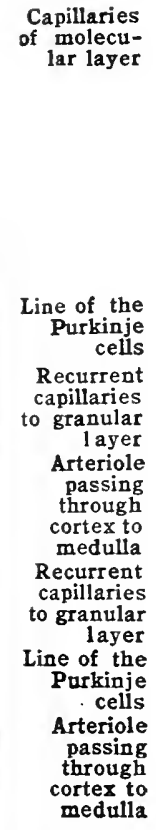

superior cerebellar arteries. They supply the lateral portions of the peduncles and the lateral part of the tegmentum. The veins of the mid-brain terminate in the basilar veins and the vein of Galen.

The blood-vessels of the cerebellum.-Six arteries supply the cerebellum; two, the posterior inferior cerebellar, are derived from the vertebral arteries, and the remaining tour, two anterior inferior and two superior cerebellar, from the basilar artery. The course and general distribution of the arteries are described in Section $V$, but here it must be noted that the branches of these six vessels form a rich network in the pia mater on the surfaces of the cerebellar lobes, and that extensions of the plexus pass with the folds of the pia mater into the sulci and fissures. From the superficial plexus terminal branches pass into the interior of the cerebellum and their collaterals form capillary plexuses $i_{r_{2}}$ the white and grey substance. The extensions of the surface plexus are of three lengths:--(1) a longer set, which pass through the cortex of the cerebellum and supply the white substance of the corpus medullare; (2) a set of shorter arterioles which pass through the molecular layer of the cortex and break up in its granular layer; (3) the shortest set pass into the cortex and immediately break up in its molecular layer. The meshes of the capillary plexuses in the grey susbtance are ovoidal and their axes run radially. The meshes of the plexuses in the white substance are parallel with the nerve-fibres. In addition to the vessels mentioned, a distinct branch is distributed to each dentate nucleus. This springs either from the superior cerebellar or from the anterior inferior cerebellar artery of the corresponding side. 
The efferent veins of the cerebellum do not accompany the arteries; they spring from a plexus in the pia mater which receives tributaries from the interior, and they form three groups on each cerebellar surface, the vermian veins and the lateral veins. The superior vermian vein runs forward on the superior surface of the vermis and terminates in the vein of Galen. The inferior vermian vein runs posteriorly and ends in one of the transverse sinuses. The superior lateral veins open into the superior petrosal or transverse sinuses, and the inferior lateral veins into the inferior petrosal and transverse sinuses. The vein from the dentate nucleus usually joins the inferior lateral veins.

The blood-vessels of the pons.-The arteries to the pons are branches of the basilar artery, and of its anterior inferior and superior cerebellar branches. The plexus in the pia mater is comparatively unimportant, and the branches which enter the substance of the pons form two main groups, the central and the peripheral. The central arteries spring directly from the basilar. They pass backward along the raphe, giving branches to the adjacent parts, and they terminate in the nuclei of the pons and those in the floor of the fourth ventricle. The peripheral arteries are radicular and intermediate. The radicular branches spring from the peripheral plexus and from the anterior inferior cerebellar arteries; they accompany the roots of the trigeminus, abducens, facial, vestibular, and cochlear nerves, supply their fibres and the adjacent parts, and they end in the grey nuclei with which the nerve-fibres are connected. The intermediate artcries enter the surfaces of the pons irregularly and break up into capillaries in its substance. The veins form a plexus on the surface. The dorsal and lateral part of this plexuis drained into the basilar vein on each side, and the inferior part is connected by efferent channels with the inferior petrosal sinus and the cerebellar veins.

The blood-vessels of the medulla oblongata.-The arteries of the medulla are derived directly from the vertebral arteries, from their anterior and posterior spinal and posterior inferior cerebellar branches, and from the basilar artery. The branches of these vessels form a plexus in the pia mater from which, and from the arteries themselves, three main groups of vessels pass into the medulla - the chorioidal, the central, and the peripheral. The chorioidal arteries are derived chiefly from the posterior inferior cerebellar arteries. They supply the chorioid plexus of the fourth ventricle. The anterior central arteries rise from the anterior spinal artery, from the basilar artery, and from the peripheral plexus; they pass eaudalward along the raphe, supplying the adjacent parts of the ventral funiculi and the olivary bodies, and they break up in to fine terminals in the grey substance of the floor of the fourth ventricle around the nuclei of the cranial nerves. The posterior central arteries spring from the posterior spinal arteries; they pass down the median septum of the inferior part of the medulla and supply the adjacent nervous substance. The peripheral arteries, like those of the spinal cord, are separable into radicular and intermediate groups. The radicular arteries pass from the anterior and posterior spinal branches and from the trunks of the vertebral arteries and accompany the fibres of the last six cranial nerves into the substance of the medulla. They supply the nerve-roots and adjacent white substance and they terminate in eapillaries in the grey substance of the lateral part of the floor of the ventricle. The intermediate peripheral arteries spring from the arteries previously named and from the peripheral plexus, and they pass direetly into the funiculi of the medulla, where they terminate in a capillary plexus which supplies the white substance and the grey nuclei; some of these arteries, more especially those derived from the posterior inferior cerebellar and the posterior spinal arteries, extend in ward to the lateral part of the floor of the fourth ventricle.

The veins which issue from the medulla form a peripheral plexus in the pia mater in which there are two main longitudinal channels, an anterior median and a posterior median vein. The former communicates posteriorly with the anterior median vein of the cord, and anteriorly with the veins of the pons and with the veins which accompany the hypoglossal nerves. The latter veins empty into the internal jugular veins. The posterior median vein is continuous caudally with the corresponding vein of the cord, and anteriorly, in the region of the calamus scriptorius, it divides into branches which join the radicular veins. The blood is carried away from the peripheral plexus mainly by the radicular veins, which pass along the roots of the last six cranial nerves. Those which accompany the hypoglossal nerves have already been referred to. The others end in the terminal parts of the transverse sinuses, the inferior petrosal sinuses, or the inferior part of the occipital sinuses.

The nerve supply of the blood-vessels of the brain consists of a perivascular plexus of sympathetic nerve-fibres upon the walls of the vessels and inedullated fibres which accompany the vessels and apparently terminate, for the most part, in the connective tissue about them. The former are thought to be vaso-motor in function; the latter probably sensory fibres of the cranio-spinal type. Nerves have been described only for the larger vessels.

\section{THE MENINGES}

Three membranes, collectivoly called the meninges, envelope the entire central norvous system, separate it from the walls of the bony eavities in which it lies, and aid in its protection and support. They consist of feltworks in which white fibrous connective tissur predominates, and through them jass the blood-vessels which supply the central nerve-axis and the nerves by which the axis is eonnected with the poriphery. Though there are definite spaces or eavities between them, the uncmbranes are not wholly separaterl from each other, and they are both rontinuous with and contribute to the walls of the blood-vessels and the sheaths (epineurium) of the nerves passing through them. Beginning with the outermost, they art- (1) the dura maler, the thickest, most dense and resistant of the mem- 
Fig. 715.-Shoning the Spinal Dera Mater Exposed in situ. (Dorsal aspect.) (After Toldt, "Atlas of Human Anatomy," Rebman, London and New York.)

Foramen magnum

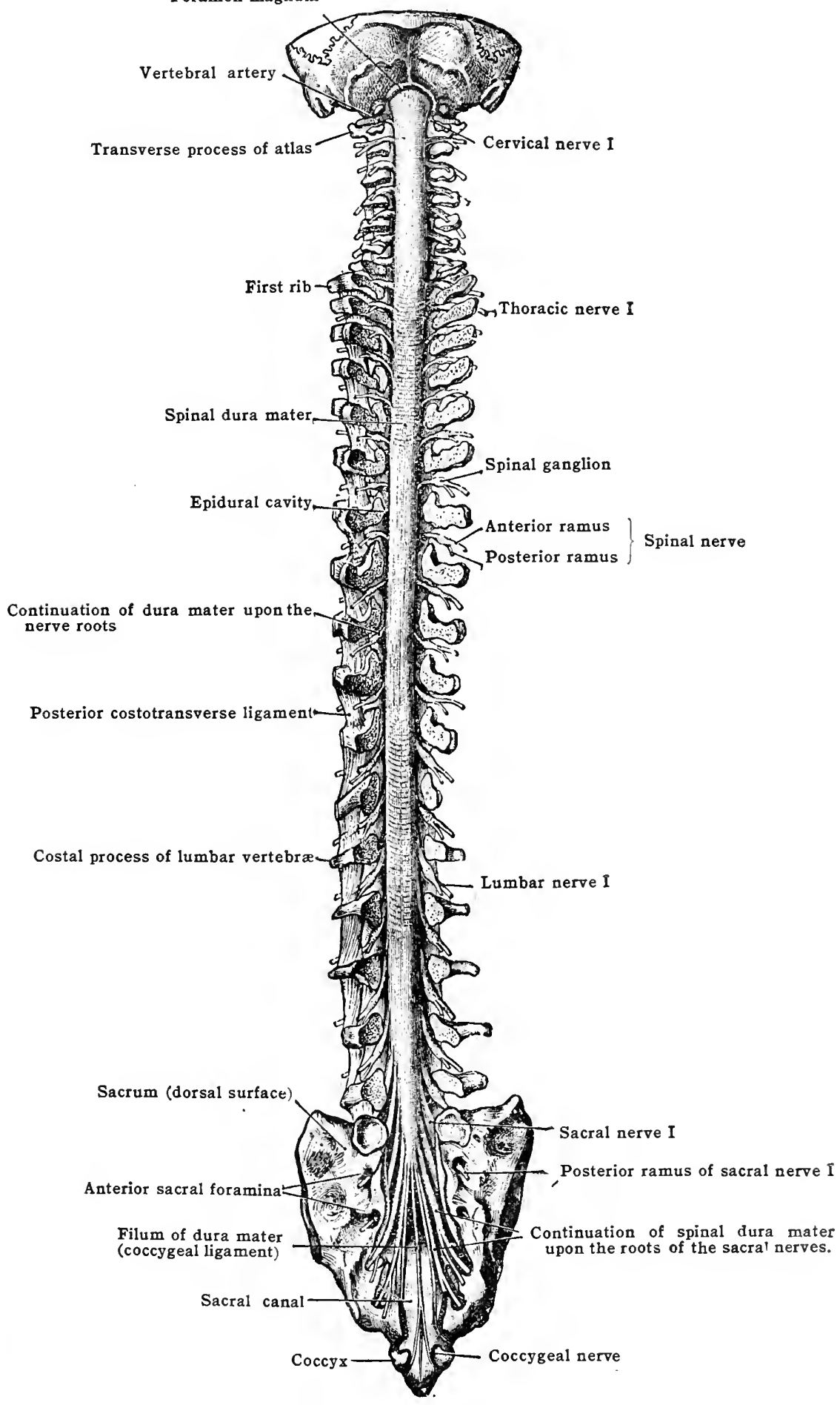


branes; (2) the arachnoid, the much less dense, web-like middle membrane; and (3) the pia mater, a thin, compact membrane, closely adapted to the surface of the central system, into which it sends numerous connective-tissue processes. It is highly vascular in that it contains the rich superficial plexuses of bloodvessels from which the intrinsic blood supply of the central system is derived. The space between the dura mater and the arachnoid is known as the sub-dural

Fig. 1716.-Dorsal Aspect of the Medulla Oblongata and Spinal Cord with the Dura Mater Partially Removed. (Hirschfeld and Leveillé.)
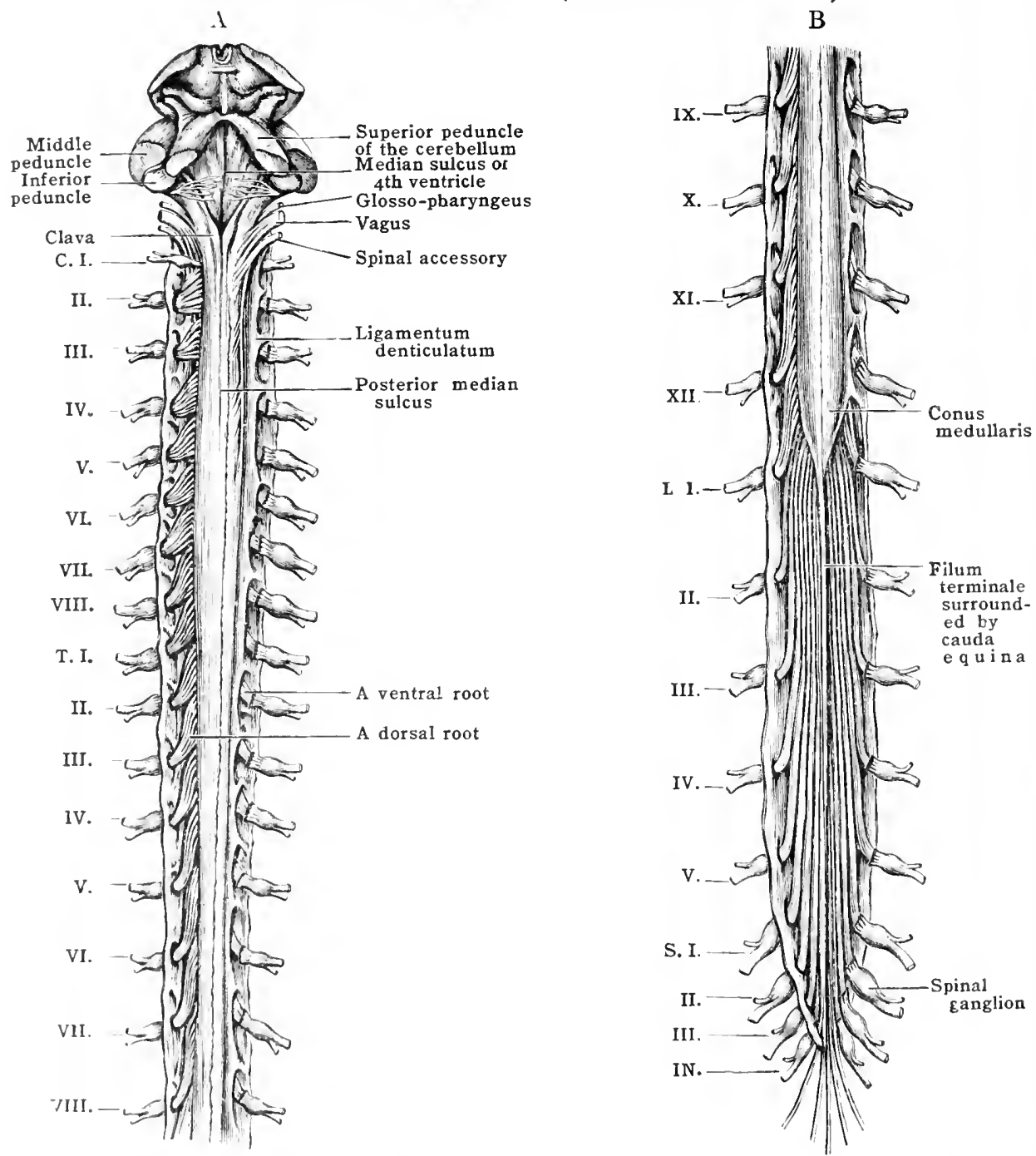

cavity, and that between the arachnoid and the pia mater is the sub-arachnoid cavity.

\section{The Dura Mateli}

In the fresh condition the dura mater appears as at hluish-white, exceedingly resistant mombrane, forming the outermost envelope of the entire ecntral nervous system. Its external surface or that next to the bony wall is rough, while its internal surface ajprars smooth, lue to the fact that the subdural cavity partakes of the nature and has the lining of a lymph-space. The cranial dura mater (onsists of two distinet, (dosely associated layers, the outermost of which serves as the internal periosteum of the cranial bones. The spinal dura mater is deseribed as "onsisting of hut one layer. 'The internal periosteum of the spinal 
canal, though continuous at the foramen magnum with the outer layer of the cranial dura mater, is not considered a part of the spinal dura mater, from the fact that it is so widely separated from the layer actually investing the spinal cord. Thus, since the cranial and spinal portions of the dura mater differ, they are described separately.

The spinal dura mater is a fibrous tube with funnel-shaped caudal end which encloses and forms the outermost support of the spinal cord. It consists of but one layer and this corresponds to the inner layer of the cranial dura mater. It begins at the foramen magnum and terminates in the spinal canal at about the level of the second piece of the os sacrum. It is firmly attached to the periosteum of the surrounding bones only in certain localities:-

(1) The upper end of the tube blends intimately with the periosteum of the margin of the foramen magnum, and thus in this locality it becomes continuous with the outer layer of the cranial dura mater. Also in this locality it is attached firmly, though less intimately, to the periosteum of the posterior surfaces of the second and third cervical vertebræ. This locality may be considered the upper fixation-point of the spinal dura mater. (2) It extends laterally and contributes to the connective tissue investments of each pair of spinal nerves, and as such it passes into the intervertebral foramina and becomes continuous with the periosteum lining each. (3) Along its ventral aspect the spinal dura mater is attached by numerous proc-

Fig. 717.-View of Membranes of Spinal Cord from Ventral Aspect. (Ellis.)

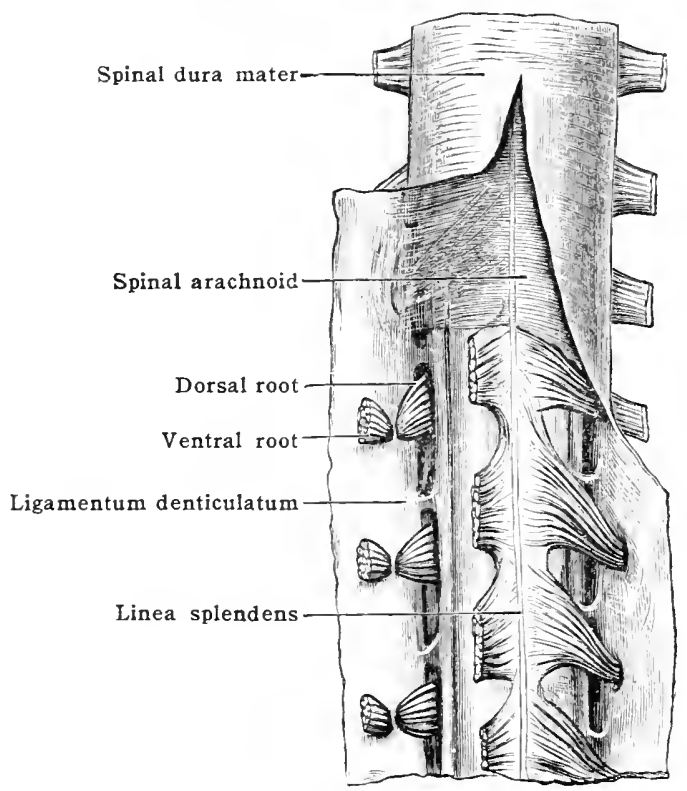

esses to the posterior longitudinal ligament of the vertebral canal. These attachments are more or less delicate, loose, and irregular, and are easily torn or cut in removing the specimen. They are stronger and more numerous in the cervical and lumbar regions than in the thoracic. (4) In the space between the dura and the walls of the vertebral canal (epidural cavity) lies the rich internal vertebral venous plexus, and along the lateral aspect the dura is occasionally connected with the periosteum through the tissue of the walls of the vessels of this plexus, especially in case of the vessels which penetrate the dura. Along its dorsal aspect the spinal dura mater is practically free from the wall of the vertebral canal. (5) At its lower and funnel-shaped extremity, opposite the second sacral vertebra, the tube suddenly contracts into a filament extending into the coccyx and breaking up into a number of processes which become continuous with the periosteum of the dorsal surface of the coccyx. This filament is the coccygeal ligament or filum of the dura mater, and its attachment may be considered the lower fixation-point of the spinal dura mater. (See figs. 613 and 715). The extent of the tube is maintained chiefly by means of the two fixation-points, for all the_other attachments are sufficiently loose to permit of the movements of the vertebral column.

The inner surface of the spinal dura mater appears smooth, but upon eloser examination it is found to be connected with the arachnoid by a few delicate subdural trabeculæ-occasional fine strands of connective tissue bridging the subdural space (fig. 725). Along its lateral aspects the inner surface is at intervals quite firmly attached to the pia mater by the dentations of the ligamenta denticulata, which are prolonged through the arachnoid. 
Further, it is continuous at intervals with both the pia mater and arachnoid by way of the connective-tissue sheaths of the nerve-roots which are prolonged from the pia and blend with the dura mater in the passage of the nerve-roots through it. The dura is also pierced by the spinal rami of the vertebral arteries, and the connective tissue of the outer walls of these vessels blends with all three of the meninges. The filum terminale of the pia mater extends below the termination of the spinal cord into the point of the funnel-shaped end of the dura mater, and there blends with it in line with the coccygeal ligament of the outer surface.

The tube of the spinal dura mater varies in calibre with the variations in the diameter of the spinal cord. However, the termination of its cavity occurs about seven segments below the termination of the spinal cord. This extension contains the long intra-dural nerve-roots forming the cauda equina, and the calibre of this part, before its sudden contraction, is about as great as that found in any

Fig. 718.-The Dura Mater Encephali of the Base of the Cranium. (After Toldt, "Atlas of Human Anatomy," Rebman, London and New York.)

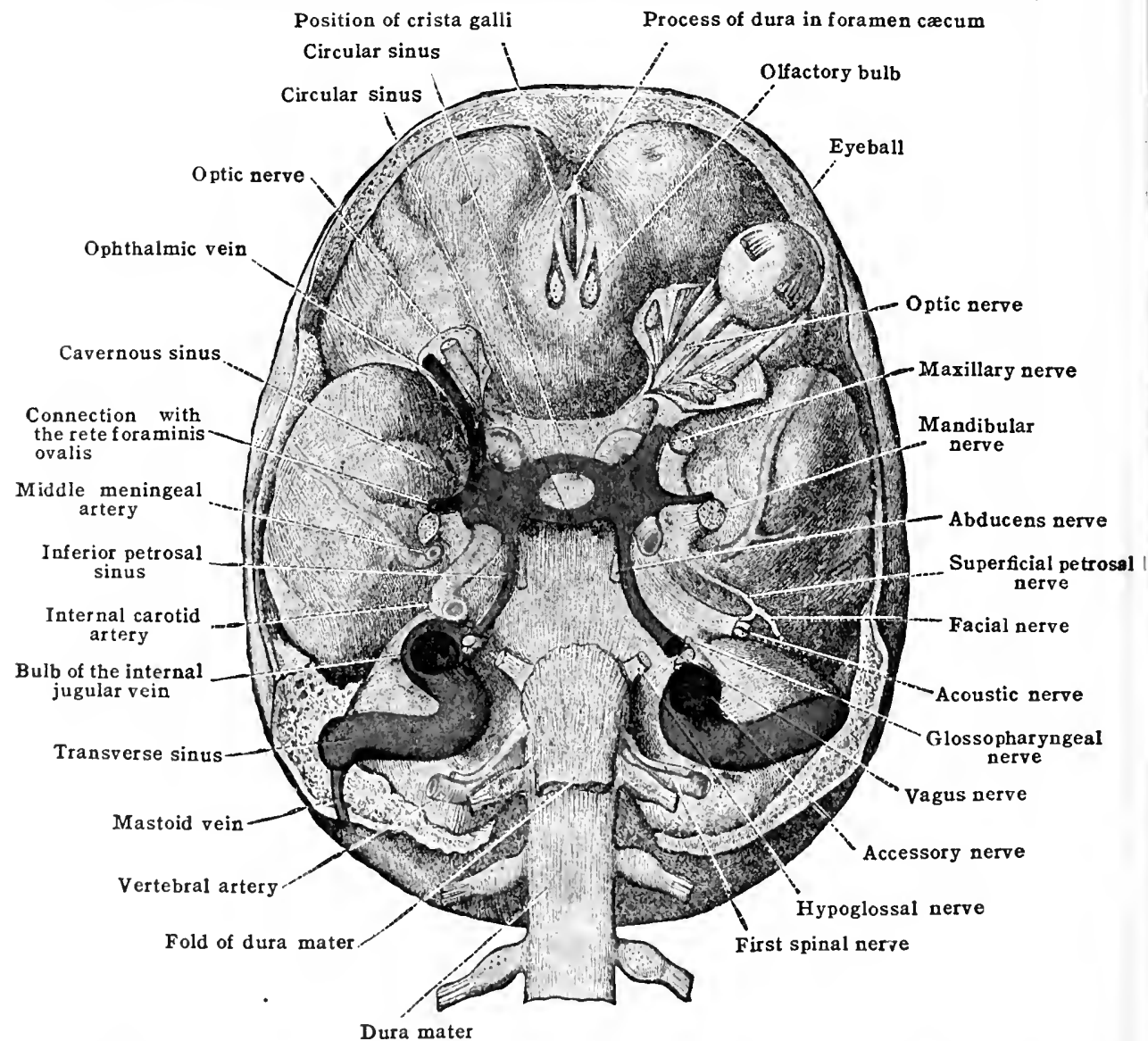

other region. As each pair of nerve-roots of the eauda equina passes outward, they lie free for a variable distance in a tubular extension of the dura before the latter blends with and contributes to the thickness of their sheath.

The subdural cavity, the space between the dura mater and the arachnoid, is the thinnest of the ineningeal spaces. Along the ventral aspect especially, the spinal arachnoid is quite closely applied to the inner surface of the dura mater. It contains a small amount of eerebro-spinal fluid (lymph) which prevents friction between the opposing surfaces, and is continuous with the fluid in the like space of the eranial meninges.

The space communicates with the venous sinuses of the cranium in the region of the Pacchionian bodies, and its fluid is likewise in contact with the blood-vessels passing through it. It is probably continuous with the lymph-spaces of the nerve-roots passing through it, for colored fluids injected into it pass into the nerve-roots. The arachnoiel is so thin and gauzelike that a realy interchange of fluils between this space and the subarachnoid space is possible by simple filtration. 
The cranial dura mater [dura mater encephali].-The dura mater investing the brain performs a double function-it serves as an internal periosteum for the cranial bones and gives support and protection to the brain. In conformity with its double function it consists of two layers, easily separable in the child, but closely adhering to each other in the aduit, except in occasional localities, where there exist small clefts lined with endothelium. The large blood sinuses and venous lacuna, corresponding to the internal vertebral venous plexus of the vertebral canal, are placed between the two lavers and the semilunar ganglia of the trigemini also lie between them. The cranial dura begins with the adhesion of the spinal dura mater to the periosteum at the foramen magnum, and it forms a saclike envelope about the entire encephalon. Consisting of two layers, it is a much thicker membrane than that of the spinal cord.

The outer surface of the cranial dura mater when torn away from the cranial bones appears very uneven, and when placed in water presents a flocculent appearance.

Fig. 719.-Coronal Section of the Head, Passing throdgh the Posterior Horns of the Lateral Ventricles.

From a mounted specimen in the Anatomical Department of Trinity College, Dublin.

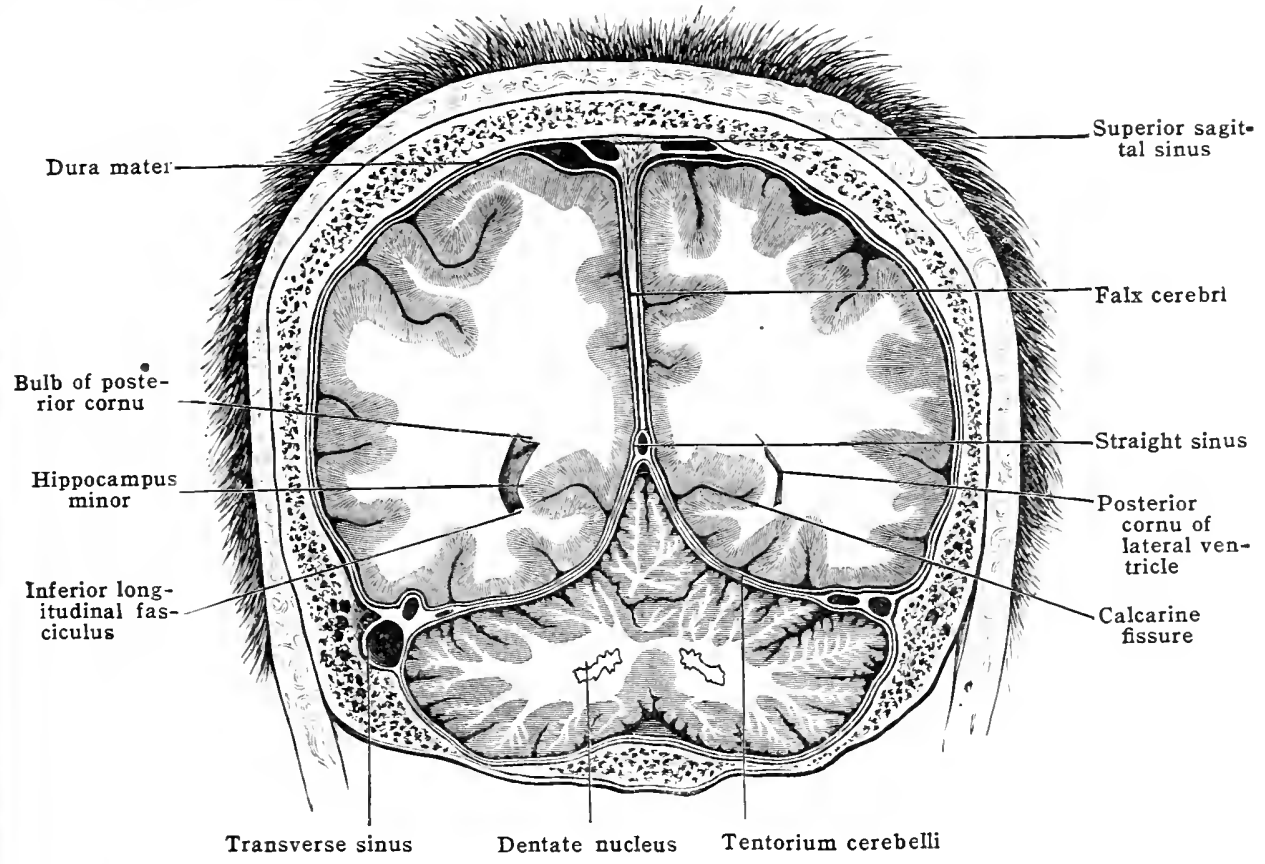

This is due to the many fine bundles of connective tissue and the blood-vessels which pass between the dura and the cranial bones and which are partially pulled out of their openings in the latter in the process of separation. The abundance of these connections, and, therefore, the degree of adhesion to the bones, varies in different localities. The separation is much less difficult from the inner table of the bones of the vault of the cranium than from the bones of the base of the cavity. The adhesions to the vault of the cranium are most firm along the lines of the sutures. This is due to the fact that during the period before the sutures are closed the outer layer of the dura mater is directly continuous with the external periosteum, and, in consequence of this condition during development, the connective-tissue connection is more abundant along these lines and some is even caught in the closure of the sutures. Along the vault there are occasionally noticed small lymph-spaces between the bone and the dura mater. The stronger adherence to the base of the cranial cavity is due to the numerous foramina in the floor, through which all the larger cranial blood-vessels and the cranial nerves pass, and the dura mater is continuous with the connective-tissue investments of these as well as with the periosteum lining the foramina. Also the floor of the cavity is more uneven than the vault, and the projections of the bones here tend to increase the firmness of attachment. The weight of the brain upon the floor probably contributes to the result.

The inner surface of the inner layer of the cranial dura mater forms the outer boundary of the subdural cavity. Except for the occasional delicate subdural trabeculæ and the passage of blood-vessels and nerve-roots, this surface appears 
smooth and glistening, being lined by a layer of endothelium and containing a small amount of the cerebro-spinal lymph.

The subdural cavity of the base of the brain is prolonged a short distance outward along the roots of the rarious cranial nerves before it is obliterated by the blending of the dura mater with the sheaths of the nerves. This outward extension of the space is most marked about the optic and auditory nerves. In the optic especially, the dura mater remains separate from the nerve throughout its length, only fusing with its sheath upon the posterior surface of the ocular bulb (fig. 718 ).

One of the most striking differences between the cranial dura mater and that of the spinal cord is that the inner layer of the former undergoes striking septa-like duplieations or folds, forming exceedingly strong partitions which project between the larger subdivisions of the encephalon. These are four in number, two large and two small-the falx cerebri and the tentorium cerebelli; the falx cerebelli and the diaphragma sellæ. The larger enclose within their folds the great venous sinuses, into which most of the spent blood of the encephalon collects to pass outward by way of the internal jugular veins (figs. 720, 721).

Fig. 720.- The Cranium with Encephalon Removed to show the Falx Cerebri, the

Tentorium Cerebelli, and the Places where the Cranial Nerves pierce the Dura Mater. (Sappey.)

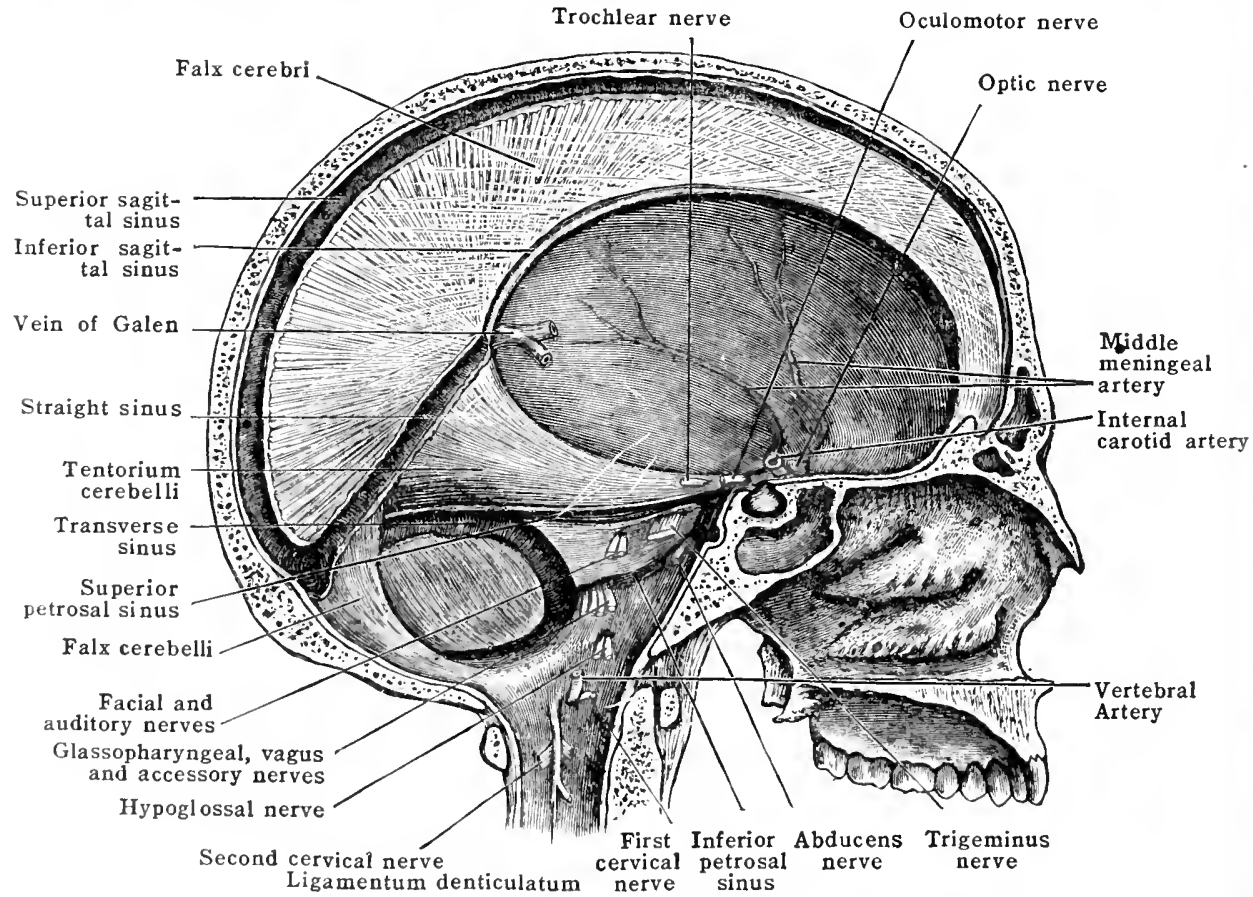

The falx cerebri is the most striking of these partitions. It is a sickle-shaped fold which projects vertically from the vault into the longitudinal fissure between the cercbral hemispheres. It begins attached to the crista galli in front, and arches to terminate by blending with the superior surface of the hirozontally placed tentorium cerelicli. Its convex, superior border joins the outer layer of the dura along the medial plane of the vault, and encloses the superior sagittal sinus. Its concave border is free and contains in its posterior two-thirds the smaller inferior sagittal sinus. The anterior and narrower end is often perforated and ocensionally so murh so as to appear as a coarse, fibrous reticulum. The posteriol part of the concave border touches the upler surface of the corpus callosum, but the anteriog part, which does not descend so low, is separated from the eorpus (a)lostun by a bate of the subarachoid space. The base of the fold which slopes downwal and blends with the upper sulfare of the tentorium cerebelli, contains the straight sinus running along the line of junction.

The tentorium cerebelli is a large transverse, scmilunar fold, concave forward. It descends from its central part which is elevated, and consequently it forms a 
tent-shaped covering. Its superior surface is in relation with the tentorial surfaces of the hemispheres, and its inferior surface conforms accurately to the superior surface of the cerebellum. The outer or convex border of the fold is attached on each side to the posterior clinoid process, the superior border of the petrous portion of the temporal bone, the mastoid portion of the temporal bone, the posterior inferior angle of the parietal bone, and the horizontal ridge of the occipital bone. The transverse sinus lies in this border. From the internal occipital protuberance to the mastoid portion of the temporal bone and along the petrous part of the temporal bone it encloses the superior petrosal sinus.

The greater part of the inner or anterior border of the tentorium is free, and it forms the superior and lateral boundaries of an arched cavity, the tentorial notch or foramen ovale of Pacchioni, which encloses the mesencephalon, and through which ascend the cerebral peduncles and the posterior cerebral arteries. The anterior extremities of the inner border cross the outer border, and they are attached to the anterior clinoid processes. A depressed angle is formed between

Fig. 721.-Shoting the Upper Strface of the Tentoriom Cerebelli and the Tentorial Notch throdgh which the Mid-Brain and Posterior Cerebral Arteries enter the Midde fossa of the Craniui.

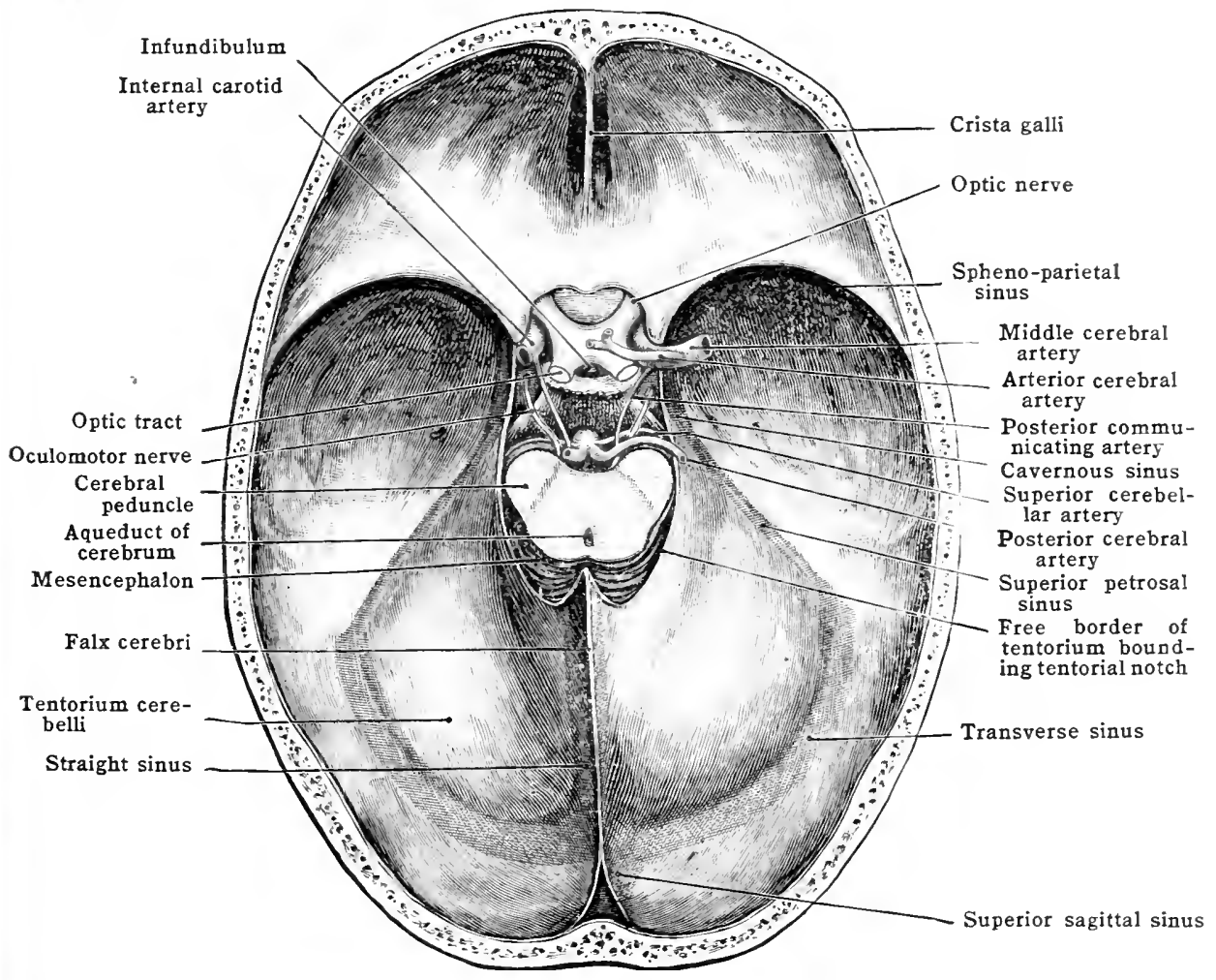

the inner and outer borders of the tentorium in the midlle fossa of the skull at the lateral portion of the posterior clinoid process, and in this angle the root of the oculo-motor nerve pierces the inner laver of the dura mater.

The falx cerebelli is a small, sickle-shaped, triangular fold which projects forward into the small groove (posterior cerebellar notch), between the hemispheres of the cerebellum. Its base is attached to the tentorium; its postero-inferior border, along which runs the occipital sinus, is attached to the internal occipital crest. Its anterior border is free, and its apex, which lies immediately above the foramen magnum, usually bifurcates as it disappears anteriorly, grasping the foramen magnum from behind. Bifurcation is always the case when the internal occipital crest splits below to enclose a vermiform fossa.

The diaphragma sellæ is a small circular fold, deficient in the centre, which projects horizontally from the margins of the hypophyseal fossa or sella turcica. Its lateral border is attached to the clinoid processes and the limbus of the sphe- 
noid, and its medial border forms the boundary of the foramen of the diaphragma sellce and surrounds the inf undibulum. Its superior surface is in relation with the base of the brain, and its inferior surface is in relation with the hypophysis, which it binds lown in the hypophyseal fossa.

The spaces which lie between the layers of the eranial dura mater are Meckel's caves, the spaces which lodge the endolymphatie sacs, and the blood sinuses and lacunie.

Meckel's caves are two cleft-like spaces or niches which lie, one on each side, in the trigeminal impression on the apex of the petrous portion of the temporal bone. Each space lodges the semilunar (Gasserian) ganglion and the trigeminus and masticator nerves of the corresponding side, and it communicates with the subdural space in the posterior fossa of the cranium by an oval opening, which lies above the superior border of the petrous portion of the temporal bone and inferior to the superior petrosal sinus.

Fig. 722.-Showing Blood-vessels of Cranial Dura Mater and Cranial Nerves in the BASE OF THE SKULL.

(On the left side the dura mater has been removed from the middle fossa.)

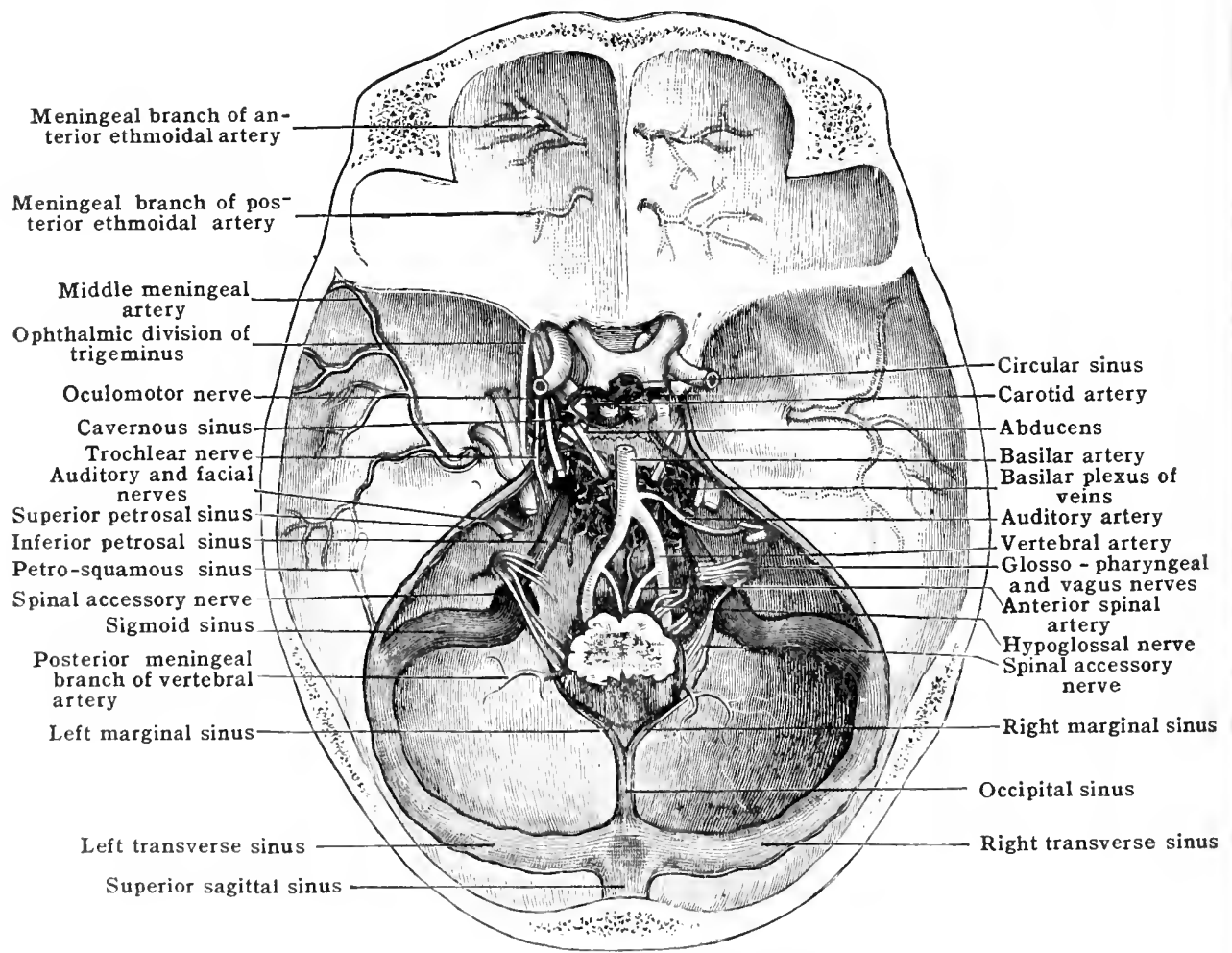

The spare which contains the endolymphatic sac on each side lies behind the petrous portion of the temporal bone and communicates with the aquaductus vestihuli.

The venous sinuses and lacunæ. - The cranial blood sinuses have alrealy been fully deseribod in the areonnt of the vaseulats system, and it is suflicient to note bere that they are rontinums, on the one hand, with the noningeal veins, and, on the other, with the veins ontside the cranial walls. 'The vessols which establish rommunieation between the blood sinuses and the rextraranial veins are loferred to collortivoly as emissary veins. They possibly help to maintain the regularity of the rranial circulation, and they bave therefore a certain amount of mactical importance.

The sinmses which are connectol with the extucranial veins by emissary veins are the superior sagittal, the transverse (latomb), and the eavernous. Three or four omissary veins b.2s from the superior sagit tal simus:- ome passes thromgh the foramen cacam and eommunicates with the veins of the roof of the mose, or, through the natsal bones, with the angular veins. "Two pass throngh the parjotal foramina and establish communieations with the occipital veins, and a fourth, which is very incoustint, pieress the oreipital protuberance aud joins the trihmtarios of thr: encipital veins. Comnecting ralch lateral sints with the extrateranial veins 
there are, as a rule, two emissary veins:- one, the mastoid emissary rein, which passes through the mastoid foramen to the occipital or posterior auricular vein; and the other, the post-condyloid vein, which traverses the condvloid (posterior condyloid) foramen and joins the suboccipital plexus. The cavernous sinus is in communication anteriorly with the superior ophthalmic vein, and through the latter with the angular vein; it is connected with the pterygoid plexus by emissary veins which pass either through the foramen ovale or the foramen Vesalii, and with the pharyngeal plexus by small venous channels which accompany the internal carotid artery through the carotid canal.

The venous lacunæ or spaces are small clefts lined by endothelium which communicate with the meningeal veins and with the blood simuses. They also have communications with the emissary veins and the diploic veins. They lie between the outer and inner layers of the dura mater, the majority of them at the sides of the superior sagittal sinus, but others are found in the tentorium associated with the transverse sinuses and the straight sinus.

Blood-vessels. - The blood supply of the cranial dura mater is derived from the meningeal arteries, which ramify in its outer layer. The more important of these arteries have already been described in the account of the vascular system, and it is only necessary here to recall the fact that the greater part of the dura mater above the tentorium cerebelli is supplied by branches of the middle meningeal arteries. These are reinforced-(1) at the vertex by branches of the occipital arteries which enter through the parietal foramina; $(2)$ in the middle fossa by the small meningeal arteries and by meningeal branches of the internal carotid, lacrimal, and ascending pharyngeal arteries; and (3) in the anterior fossa by meningeal branches of the anterior and posterior ethmoidal arteries.

The dura mater in the posterior fossa of the skull, below the tentorium cerebelli, also receives branches from the middle meningeal arteries, but its blood supply is derived mainly-(1) from the meningeal branches of the vertebral arteries which enter the fossa through the foramen magnum, (2) from meningeal branches of the occipital arteries which enter through the mastoid and hypoglossal foramina, and (3) from meringeal branches of the occipital and ascending pharyngeal arteries which enter through the jugular and hypoglossal (anterior condyloid) foramina.

The meningeal veins accompany the arteries as venc comitantes, usually one vein with each artery. The middle meningeal artery usually has two venæ comitantes. The meningeal veins communicate with the venous sinuses and with the diploic veins, and, unlike ordinary veins, they do not increase much in calibre as they approach their terminations.

The nerves of the dura mater are partly derived from the sympathetic filaments which accompany the arteries and partly from the cranial nerves. The nerves, other than sympathetic filaments, which supply the cranial dura mater are sensory fibres derived from the trigeminus and vagus nerves, and possibly from the first cervical nerves. The branches from the trigeminus are derived from the three divisions of that nerve on each side, and it has been stated that branches are given from the nasal branch of the ophthalmic division to the dura mater in the anterior fossa.

The meningeal branch of the ophthalmic division of the trigeminus supplies the tentorium; that from the maxillary division accompanies the branches of the middle meningeal artery. The meningeal branch of the mandibular division (nervus spinosus) passes in to the skull through the foramen spinosum and is distributed to the dura mater over the great wing of the sphenoid and to the mastoid cells. The "recurrent branch of the hypoglossal nerve" passes to the dura mater of the posterior fossa of the cranium. This recurrent or meningeal branch of the hypoglossal nerve really consists of fibres derived from the superior cervical ganglion of the sympathetic, and contains sensory fibres from the first and second cervical nerves. The meningeal branch of the vagus springs from the ganglion of the root of that nerve, and is distributed in the posterior cranial fossa. The sympathetic filaments are distributed to the smooth muscle of the walls of the blood-vessels.

The cranial subdural cavity is not of uniform thickness throughout, being thinner along the basal aspect of the encephalon. The lymph contained in it is usually but little more than is sufficient to keep moist its bounding surfaces. It is continuous with the lymph capillaries of the nerves and those of all the tissues it bathes, and it is continuous with the similar cavity of the spinal canal. Its lymph is in free contact with the blood-ressels pasing through it and with those in the tissues it bathes, and it is replenished by filtration through their walls. Though extensive, the subdural space is thin at best, for the dura mater is quite closely applied to the second of the three meninges.

\section{The Arachnoid}

The arachnoid or 'serous' membrane is the middle of the three meninges of the c central nervous system. As in the case of the other two, an attempt is made to give this membrane a name descriptive of its texture. It is a gauzy reticulum of almost web-like delicacy, which in reality pervades the space it occupies.

Its outer surface, or that closely related to the dura mater and bounding the subdural cavity alone shows a sufficiently organized structure to merit the name of membrane. This surface is covered by a layer of endothelium which is identical with that lining the inner surface of the dura mater and is continuous with it by way of the endothelial cells covering the blood-vessels, 
the nerve-roots, the ligamenta denticulata of the spinal cord, and the occasional delicate tra. beculæ passing between the dura mater and the arachnoid. Immediately under the endothelium, the connective-tissue fibres of the arachnoid are woven into a very thin, more or less compact web. This, however, quickly grades into a loose, spongy reticulum which pervades the thick subarachnoid cavity throughout, and the strands of which are directly continuous into the more compact tissue of the pia mater. Thus an inner surface can hardly be claimed. This loose, sponge-like arachnoid tissue holds the cerebro-spinal fluid of the subarachnoid cavity, the meshes of the sponge constituting a reticular web of intercommunicating spaces lined by endothelioidal cells covering the strands of the web. The cranial subarachnoid cavity is larger, and the strands of the web are relatively more abundant than in that of the spinal canal. In addition, the cavity is traversed by the spinal and cranial nerves, by the blood-vessels passing to and from the pia, and, in the spinal canal distinctively, it is traversed by the ligamenta denticulata and the filum terminale. Through these the arachnoid is further continuous with the pia mater.

The cranial arachnoid is directly continuous into that of the spinal cord, and in the two localities does not differ as much as does the dura mater. Within the cranium, the arachnoid does not closely follow the surface of the encephalon. It is folded in between the cerebellum and cerebral hemispheres, following the contour of the tentorium cerebelli, but it does not dip into the fissures and sulci except the anterior part of the longitudinal fissure and slightly into the lateral (Sylvian) fissure. Otherwise it fills in the inequalities of surface of the encephalon, its outer surface forming a sheet enveloping the whole and bridging over the sulci and the deeper grooves between the gross divisions. Upon the summits of the gyri it is more closely applied to the pia mater, and there its reticulum becomes so dense

Fig. 723.-Diagram showing the Relations of the Pia Mater, the Arachnoid, and the Subarachnoid Cavity to the Brain.

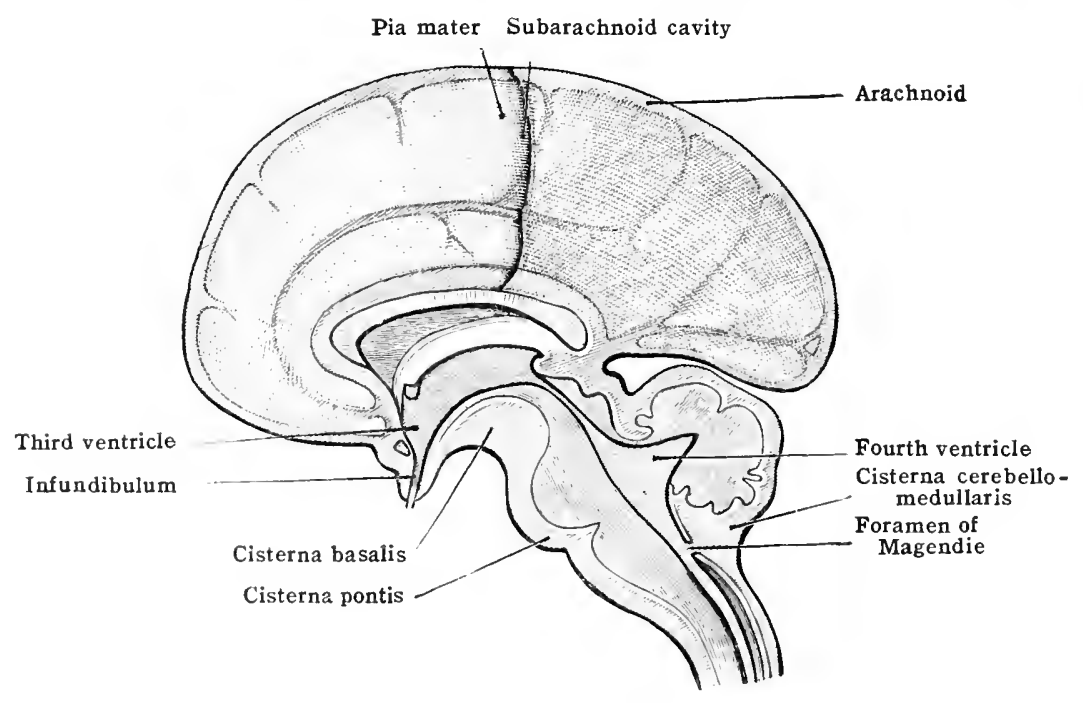

that the two membrands almost appear as one. The sulei, oceupied by looser roticulnm, form a continuous system of chamnels filled more abundantly by the cerebro-spinal fluid.

The arachnoirl folds in between the cerebellum and medulla oblongata, and at the base of the brain it ensheathes the olfactory bulbs and tracts, and its outer surface forms a continnous sheet stretehing from one temporal lobe to the other and lirilging over the interpeduncular fossa and the inequalities of surface in the region of the optic chiasma and the stems of the lateral fissures. Obviously, therefore, the subarachnoid cavity between its outer surface and the pia mater is of considerable depth in eretain loealities. These localities comprise the subarachmoirl cistemes. 'These orenr where the eavity at the hase of the brain is especially larere, and make posibible : 'water-bed' which serves to protect the brain from injmious contact with the lones.

"The following cisternar are distinguished (fig. 72:3):-

(1) The cisterna basalis lies at thr base of the cerebrum and is divided by the optic chiasma into, wo parts-(a) the cisterna rhinsmalis and (b) the cisterna interpeduncularis.

(2) The cisterna pontis is siluated about the pons, especially in its basilar sulcus and the 
transverse fissures of either border, and is continuous anteriorly with the cisterna basalis and posteriorly with the subarachnoid cavity about the medulla.

(3) The cisterna superior lies in the angle between the splenium of the corpus callosum and the superior surfaces of the cerebellum and the mesencephalon, and is connected ventrally, around the cerebral peduncles, with the cisterna basalis.

(4) The cisterna cerebello-medullaris (cisterna magna) is the cavity between the inferior surface of the cerebellum and the dorsal surface of the medulla oblongata. It is continuous below into the spinal subarachnoid space. The fluid in this cavity is directly continuous with that in the fourth ventricle by way of the foramen of Magendie (median aperture of the fourth ventricle).

Pacchionian bodies [granulationes arachnoideales] (fig. 724.) - In certain situations, more particularly along the margins of the longitudinal fissure, particularly in the frontal region, and to a much less extent upon the superior surface of the vermis of the cerebellum, the subarachnoid tissue elaborates numerous small, ovoid or spherical nodules, the Pacchionian bodies. Each body or arachnoid villus consists of a retiform network of subarachnoid substance and its meshes are filled with cerebro-spinal fluid. The Pacchionian bodies on the vertex of the brain project through the inner layer of the dura mater, both into the superior sagittal sinus and into the venous spaces or parasinoidal sinuses which lie at the sides of that sinus, and, as they become larger, they press against the outer layer of the dura mater and produce ovoid depressions in the inner plate of the cranium.

Fig. 724.-Coronal Section transverse to the Great Longitudinal Fissure, Showing THE Meninges. (Key and Retzius.)

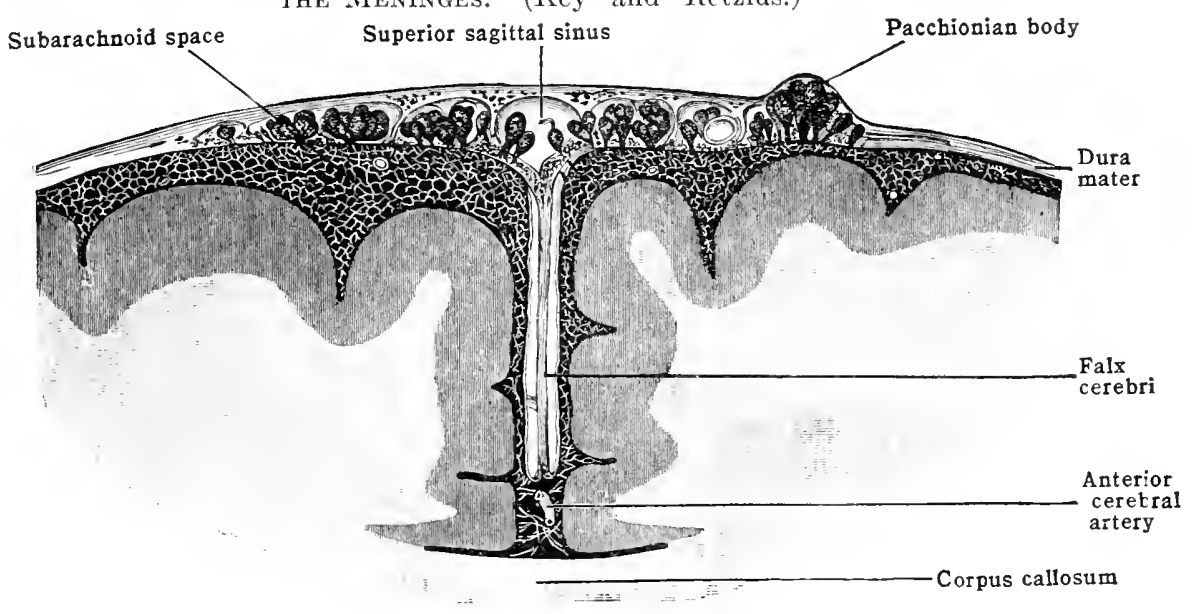

They probably facilitate the passage of lymph from the subarachnoid cavity into the blood sinuses, and thus may aid in relieving pressure within. On the other hand, through them the cerebro-spinal fluid is replenished at need from the blood plasma. They are not present at birth, but they appear at the tenth year and increase in number and size with advancing age. They are less marked in the female than in the male.

The spinal arachnoid (figs. 725, 726) is a loose, reticular sac which is most capacious about the lumbar enlargement of the spinal cord and about the cauda equina. Like that of the encephalon, the portion next to the dura mater alone resembles a membrane, being a loosely organized feltwork, covered on the side of the subdural cavity by a layer of endothelium common to that cavity. Throughout its length the spinal subarachnoid cavity is relatively wide, and, as in the cranium, contains a fine, spongy, web-like reticulum, numerous threads of which are continuous with the pia mater. This spongy tissue is the inner modification of the arachnoid, and its meshes are ocsupied by the cerebro-spinal fluid. It is not so abundant as in the cranial subarachnoid cavity.

In addition to the delicate threads, the arachnoid is more firmly attached to the pia mater by three incomplete partitions. The most continuous of these is arranged along the dorsal mid-line and is known as the septum posticum of Schwalbe (subarachnoid septum). This may be described as a linear accumulation of the spongy tissue which pervades the subarachnoid space. It is most incomplete in the upper cervical region, where it becomes merely a line of threads connecting with the pia. It is most complete as a septum in the lower cervical and in the thoracic region, but at best it maintains a spongy character. The other two partitions are 
formed by the denticulate ligaments, which extend laterally from either side of the spinal cord, connecting the pia and dura mater and involving the arachnoid in passing through it. Within the subarachnoid cavity these form more or less complete septa, though outside the arachnoid they are attached to the dura only at the intervals of their pointed dentations. 'They belong to the pia mater and will be described with it. The arachnoid is further continuous with the pia by way of the connective-tissue sheaths of the roots of the spinal nerves and the bloodvessels passing through the subarachnoid cavity.

Vessels and nerves.--The arachnoid has no special blood supply and probably no special nerves other than those supplying the walls of the blood-vessels passing through it.

The cerebro-spinal fluid. - The subarachnoid cavity is the great lymph-space of the central nervous system. That of the spinal region is directly continuous into that of the cranium, and the fluid contained communicates freely with that in the ventricles of the brain and the central canal of the medulla and spinal cord by way of the foramen of Magendie or medial aperture into the fourth ventricle. In addition, there are the lateral apertures in to the fourth ventricle and there is possible an interchange of fluid between the lateral ventricle and the subarachnoid cavity of the base of the brain by diffusion through the thin floor of the chorioid fissure. The arachnoid throughout is not a membrane sufficiently compact to seriously oppose diffusion between the fluid contained in its cavity and that contained in the subdural cavity, and the endothelium covering it probably even facilitates such activities. The cerebro-spinal fluid occupying the cavities is a transparent fluid of a slight yellow tinge, characteristic of the

Fig. 725.-Diagrai of Transverse Section of Upper Thoracic Region of the Spinal Cord showing the Relations of the Spinal Meninges and their Cavities.

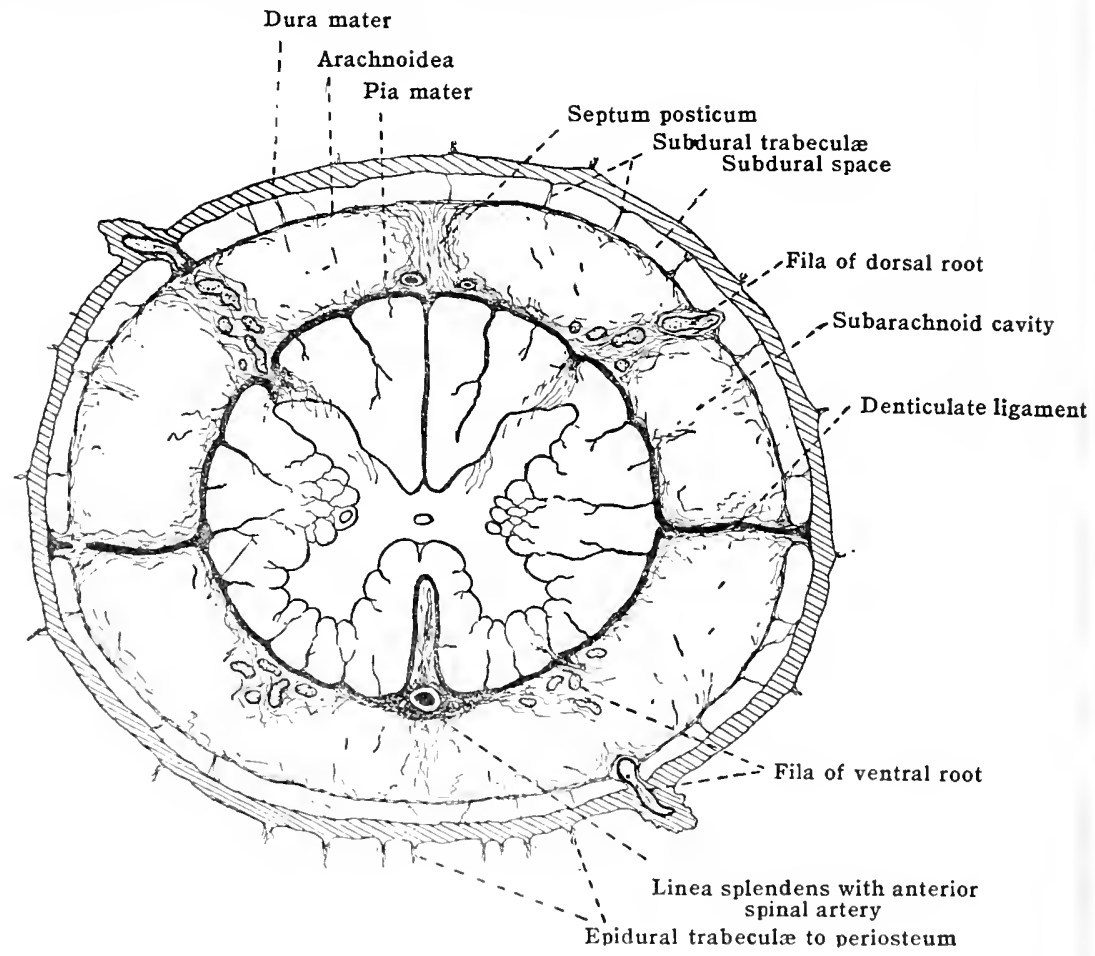

Iymph in oflure lymph-spaces of the boly. It is not very great in amount, probably never 'xroesling 200$)(\%$. in mormal conditions. It is greatest in amomnt in old age, when the cavities are larger, dur to atrophy and slorinkage of the nervous tissues. It collects from the lymph spaces in the meningest and from exulation through the walls of the vasenlar chorioid plexuses and sinteses of lha system it hathes. Its amomit nay be temporarily inereased by a period of incerasol blood-pressure in the eranial vessels. Fressure due to its abundance may be

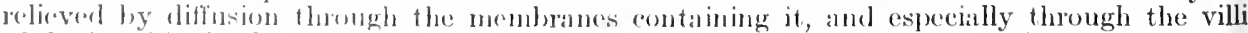

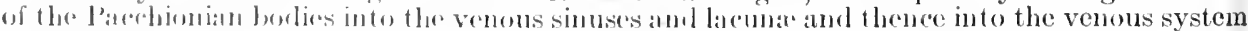
through the intrinal jugulat grins.

\section{THE PA MATER}

The pia mater, the third of the meninges, is at thin memblane which envelopes

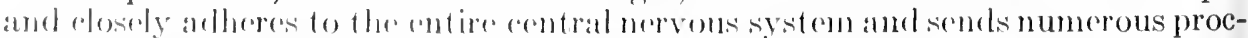
asses into its substanee. It likewise combihutes the most proxinal and compact portion of the sheaths worm hy the nerveroots in their passage through the meningral sparens. It is very vaserilar in that the superficial plexuses of blood-vessels of 
both the brain and spinal cord ramify in it as ther give off the central branches into the nervous substance. The structure and arrangement of the membrane vary somewhat in the cranial and spinal regions.

The spinal pia mater consists of two layers, an inner and an outer. It is thicker and more compact than that of the encephalon, due to the extra development of its outer layer, which is in the form of a strong, fibrous layer with the fibres arranged for the most part longitudinally.

The spinal pia mater also appears less vascular than the cranial from the fact that the blood-vessels composing the plexus lying in it are obviously much smaller than those of the encephalon. Its inner layer is a thin feltwork of fibres which is closely adherent to the surface of the spinal cord throughout, sending numerous connective-tissue processes into it which contributes to the support of the nervous tissues. The larger of these processes carry with them the numerous intrinsic blood-vessels from the superficial plexus. The two layer's are closely connected with each other, and are distinguished by the difference in the arrangement of their fibres.

The membrane dips into the anterior median fissure and bridges it over by forming an extra thickening along it. This thickening appears as a band along the mid-line of the ventral surface of the cord, the linea splendens (fig. 717). It carries, or ensheathes, the anterior spinal artery, the largest of the arterial trunks of the superficial plexus (fig. 725).

Fig. 726.-Diagram showing Relations of Meninges to spinal Nerte-roots. Denticulate ligament

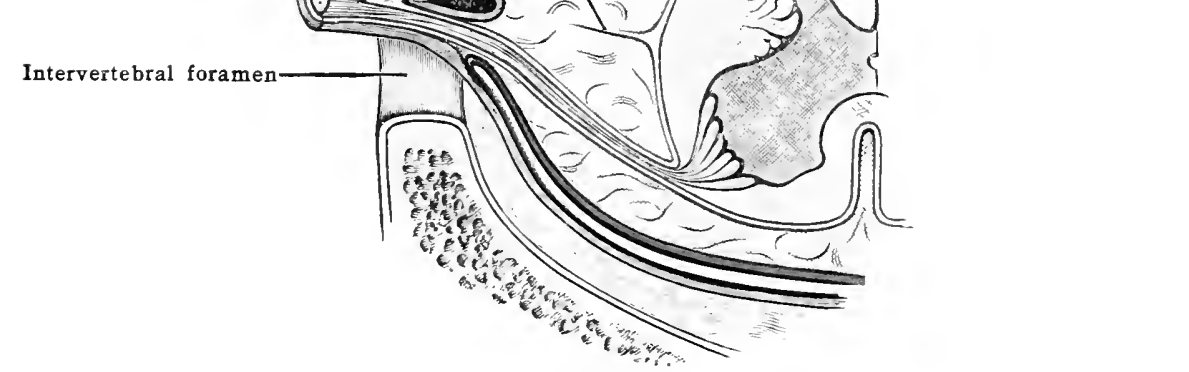

The pia mater contributes the innermost and most compact portion of the epineurium of each of the nerve-roots, and thus, upon the roots, it is prolonged laterally into the intervertebral foramina, where the dura mater blends with it in producing the increased thickness of the epineurium.

From each side of the cord the pia mater gives off a leaf-like fold, the denticulate ligament, which spreads laterally toward the dura mater midway between the lines of attachment of the dorsal and ventral nerve-roots. The outer border of this fold is dentate or scalloped into about twenty-one pointed processes, which extend through the arachnoid and are attached to the inner surface of the dura mater. The dentations are usually inserted between the levels of exit of the roots of the spinal nerves, the uppermost one a little cephalad to the first cervical nerve and the region where the vertebral artery perforates the dura mater; the most caudal one between the last thoracic and first lumbar nerves, or, between the last two thoracic nerves. The ligaments, aided slightly by the septum posticum, serve to hold the spinal cord more or less suspended in the subarachnoid cavity.

Below, at the sudden, conical termination of the spinal cord in the lumbar portion of the spinal canal, the pia mater is spun out into a thin, tubular filament, the filum terminale, which continues caudalward into the sac formed by the dura mater about the cauda equina, and at the end fuses with the dura mater in line with the filum of the spinal dura mater (coccygeal ligament) of the outside (figs. $613,715)$. 
The cranial pia mater is closely applied to the external surface of the brain, dipping into all the fissures, furrows, and sulci. It is connected with the arachnoid by numerous filaments of the spongy subarachnoid tissue and by the bloodressels traversing the subarachnoid cavity. It is also pierced by the cranial nerves, and furnishes them their sheaths, which become continuous with the arachnoid and dura mater.

Its outer surface bounds the subarachnoid cavity. It is with difficulty separable into two layers of mixed white fibrous and elastic connective tissue, with slightly pigmented connectire-tissue cells enmeshed between them. Its inner surface sends a large number of fibrous processes into the nervous substance, which blend with the neuroglia and aid in the support of the nervous elements. The larger of these processes accompany the central arterial and renous branches of the rich superficial plexuses of blood-vessels contained in the pia on the surface of the brain. Pieces of the pia when pulled off and placed in water present a flocculent appearance as to their inner surfaces, due to these processes having been pulled out.

The cranial pia mater sends strong, vascular duplications into two of the great fissures of the encephalon; viz., the transverse cerebellar fissure, between the cerebellum and the medulla oblongata, and the transverse cerebral fissure, between the cerebellum, mesencephalon, and thalamencephalon, and the overhanging cerebral hemispheres. These duplications are spread over the cavities of the fourth and third ventricles, and are known as the chorioid telae of these ventricles respectively.

Fig. 727.-Diagram showing Chorioid Tela of Fourth Ventricle after Removal of Cerebellum.

(The trochlear nerve should be shown emerging from the frenulum veli.)

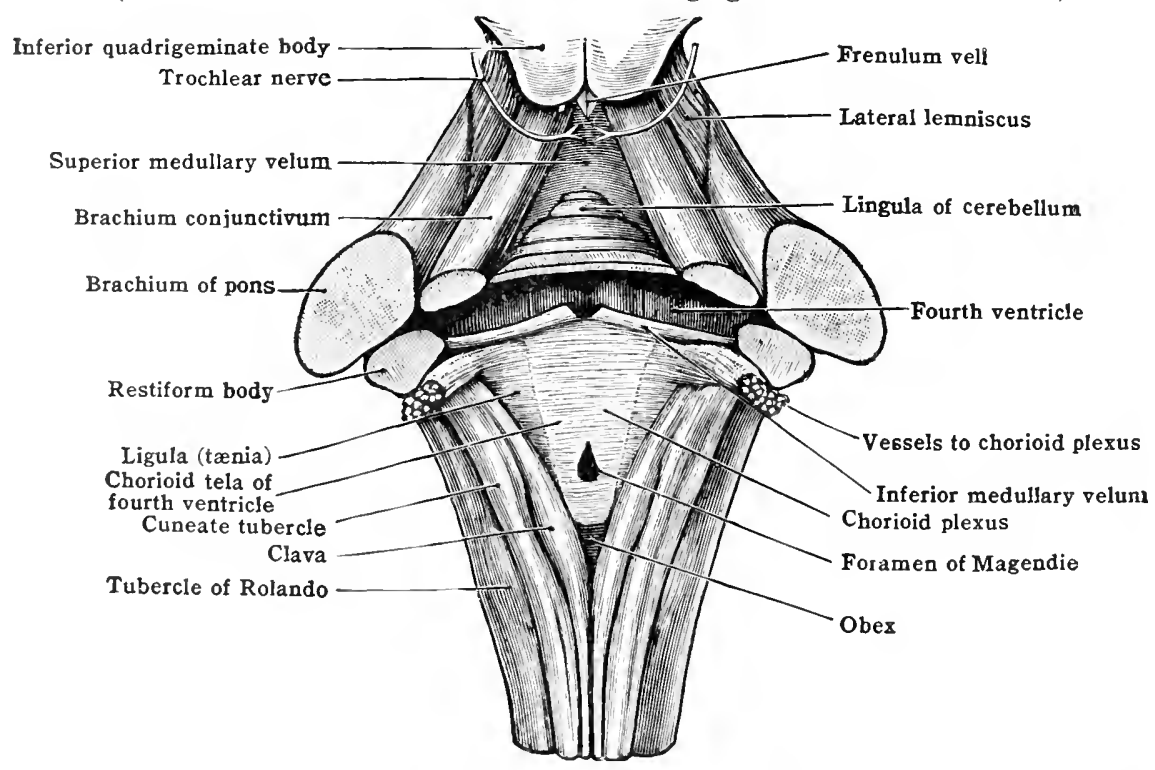

The tela chorioidea of the fourth ventricle lies in the transverse cerebellar fissure, betwen the inferior surface of the cercbellum (vermis chicfly) and the dorsal surface of the medulla (fourth ventricle). The two layers of this fold of the pia remain seaparate and a portion of the cisterna posterior of the subarachnoid "avity lies between them. The inferior of the layers is the tela chorioidea (fig. 727.) It is triangular in shape, with its base cephalad at the nodule of the vermin and itsapex below at the level of the tuber vermis. The superior layer of the fold is the pria mater of the vermis. The tela chorioidea is strengthened by the (p) bithelial roof (ependymat) of the fourth ventricle and is continuous with the pia mater of the medulla oflongata and spinal eord. In roofing over the fourth ventricle the tela rhorioflea of the fourth ventricle constitutes the ligula and the obex. A little almove the calamus seriptorius it is piereed by the foramen of Magendic and the two lateral anertures into the fourth ventriele.

In front of the forancen of Magendie the vessels of the ehorioid tela, which are deriver from the posterior inforior ecrebellar arteries, form two longitudinal, lobulated strands which invaginate the epithelial roof of the ventricle, one on wither sidfe of the midline, and project into its eavity. These form the chorioid 
plexus of the fourth ventricle. At the base of the tela the two chorioid plexuses join each other and then turn transversely lateralward into the lateral recesses of the ventricle, where they pass behind the restiform bodies and form the 'cornucopia.'

The chorioid tela of the third ventricle, or velum interpositum, is a triangular duplication of the pia mater which extends between the fornix above and the thalami and third ventricle below, and in front fuses with the brain substance at the interventricular foramina.

In the transverse cerebral fissure the layers of pia forming this tela are separate, the upper being the pia of the under surface of the corpus callosum and continuous with that of the tentorial surfaces of the occipital lobes; the lower being continuous into the pia enfolding the epiphysis, and covering the mesencephalon, anterior medullary velum, and cerebellum. The

Fig. 72S.-Horizontal Dissectiox of the Cerebrum showing the Tela Chorioddea of the Third Ventricle.

(From a mounted specimen in the Anatomical Department of Trinity College, Dublin.)

The fornix has been removed to show the chorioid tela of the third ventricle.

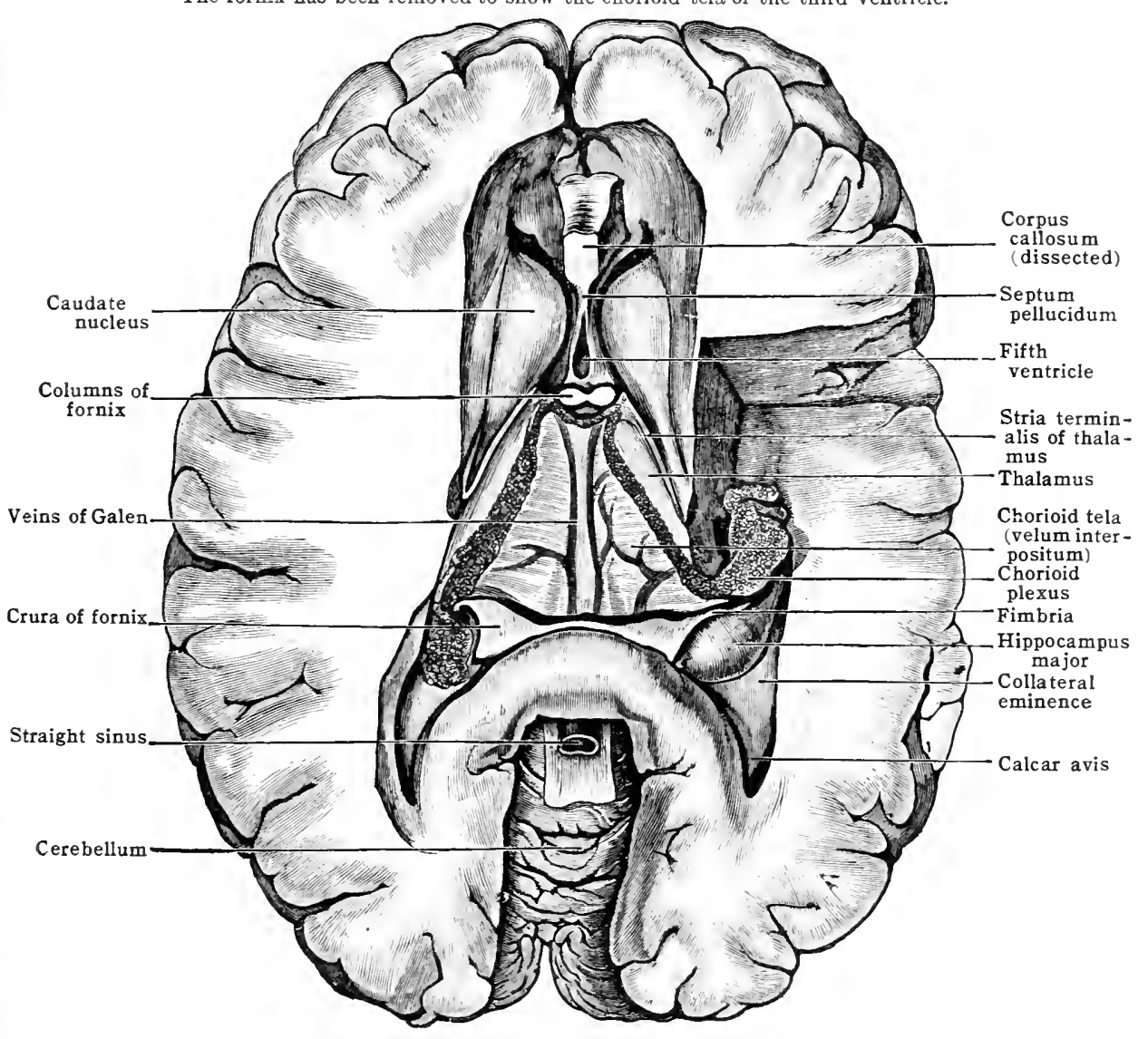

layers forming the portion of the duplication which roofs over the third ventricle are loosely adherent to each other and form the tela chorioidea proper of that ventricle. The upper surface of this portion is in relation with the fornix and its lower surface, covered by the epithelial chorioid lamina, lies laterally over the superior surfaces of both thalami, and mesially forms the roof of the third ventricle between them. The epithelium or ependyma is continuous with that covering the thalami and lining the ventricles. Between the two layers of this portion, and embedded in a small amount of the spongy subarachnoid tissue retained between them, are the two veins of Galen, the internal cerebral veins. Posteriorly these veins unite in the region of the epiphysis to form the single great cerebral vein (vena cerebri magna) which empties into the straight sinus. Anteriorly the veins of Galen receive the veins of the septum pellucidum from each lamina of the septum pellucidum above, and also the terminal vein (vein of corpus striatum), lying in the stria terminalis of the thalamus, empties into them from each side.

The chorioid tela of the third ventricle or velum interpositum extends laterally between the fornix and fimbria above and the stria terminalis of the thalamus be- 
low into each lateral ventricle. The blood-ressels of the border projecting into the lateral ventricle are amplified into a plexus which appears as a strip of reddish, lobulated, villus-like processes known as the chorioid plexus of the lateral ventricle. The plexus, being in the border of the tela, begins at the interventricular foramen, extends through the body or central portion of the ventricle, and downward into its inferior cornu. It is most cleveloped at the junction of the body with the inferior cornu, and is there known as the glomus chorioideum.

From the under surface of the chorioid tela of the third ventricle, hanging down on either side of the mid-line into the cavity of the ventricle, are two other longitudinal, lobulated strands of blood-vessels which are the chorioid plexuses of the third ventricle. At the anterior end of the third ventricle these two plexuses join with each other and also with the plexus of the lateral ventricle of each side through the interventricular foramina.

The chorioid plexuses of both the ventricles are covered by a layer of ependyma, epithelial chorioid lamina, which is but a reflexion of the ependyma lining the eavities throughout and represents the remains of the germinal layer of the embryonic brain vesicles. The blood-vessels

Fig. 729.-Diagram of Coronal Section of Cerebrum through Middee of Thalamencephalon showing Relations of Pia Mater Encepilali and Chorioid Plexuses of Third aNd LATERAL Ventricles.

Fifth ventricle

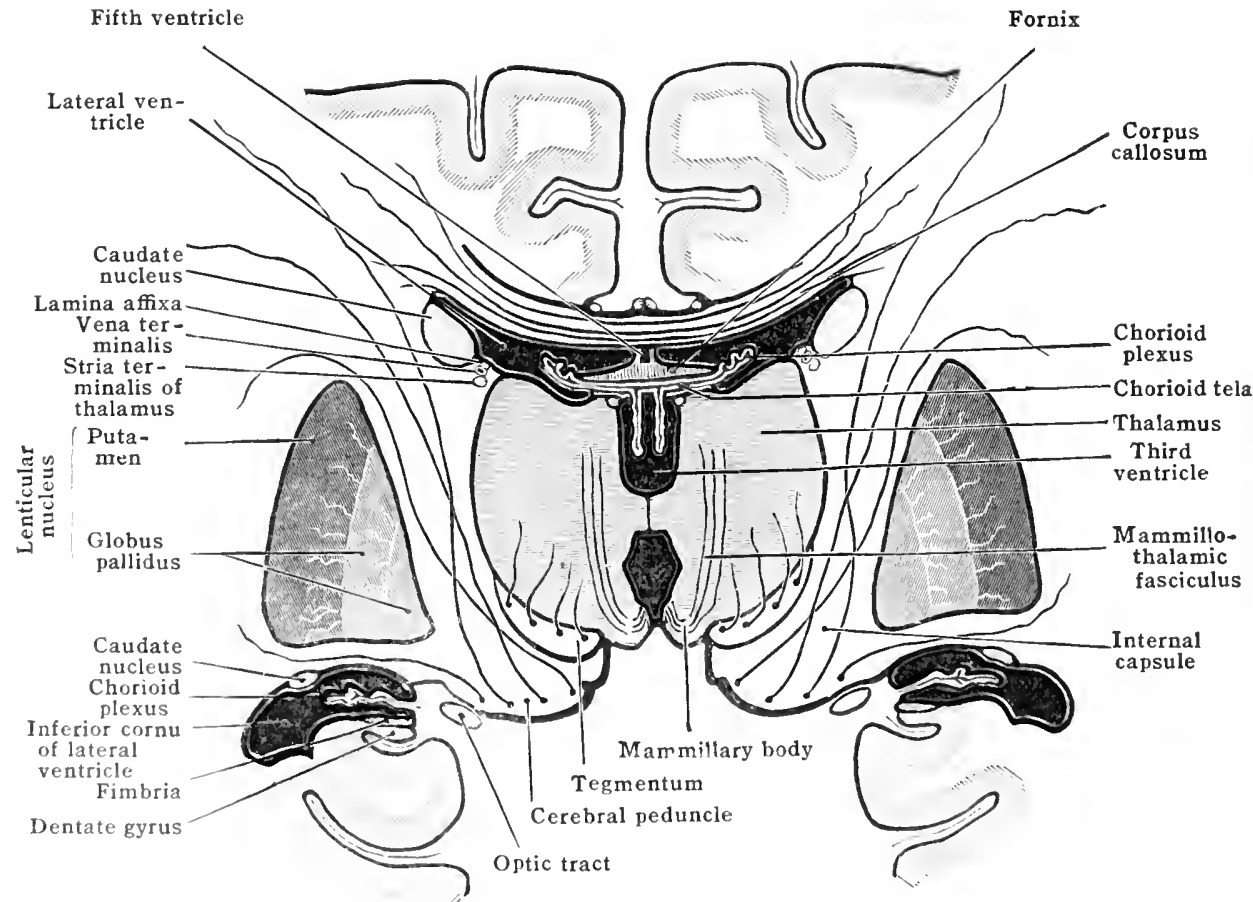

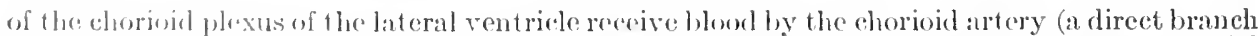
of the intornal carotid), which onters the plexus thromeh the chorioid fissure inmediately mesial to the uncus, and also liv the chorioidal branches of the pesterion cerebral artery, which supply the plexus of the buly of the ventricle. The chorioid plexuses of the third ventriche receive blood chiefly by branches from fles superior eerebellar arteries. The greater part of the blood of both

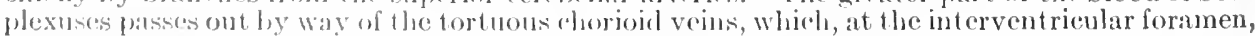

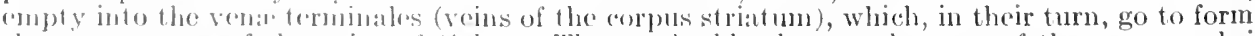

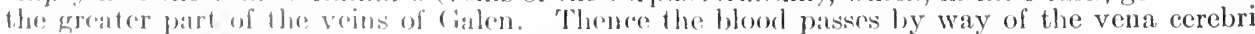
magna into the strabht sinus. It is probulde that a large part of the ecrebro-spinal fluid of the third and lateral ventricles is driverl hy diffusion through the walls of the vesseds of the chorioid plexuses.

\section{TIIE PERIPHER.M, NERVOL SYSTEM}

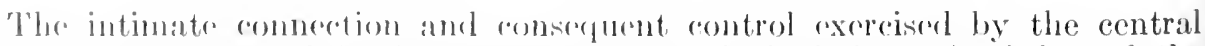
nervols systron overall the tissues and ormans of the body is attained through the 
Fig. 730.-Showing the Relation between the Central and the Peripheral Nervous SYSTEMS.

(Combination drawing, spinal part after Allen Thompson, from Rauber.)

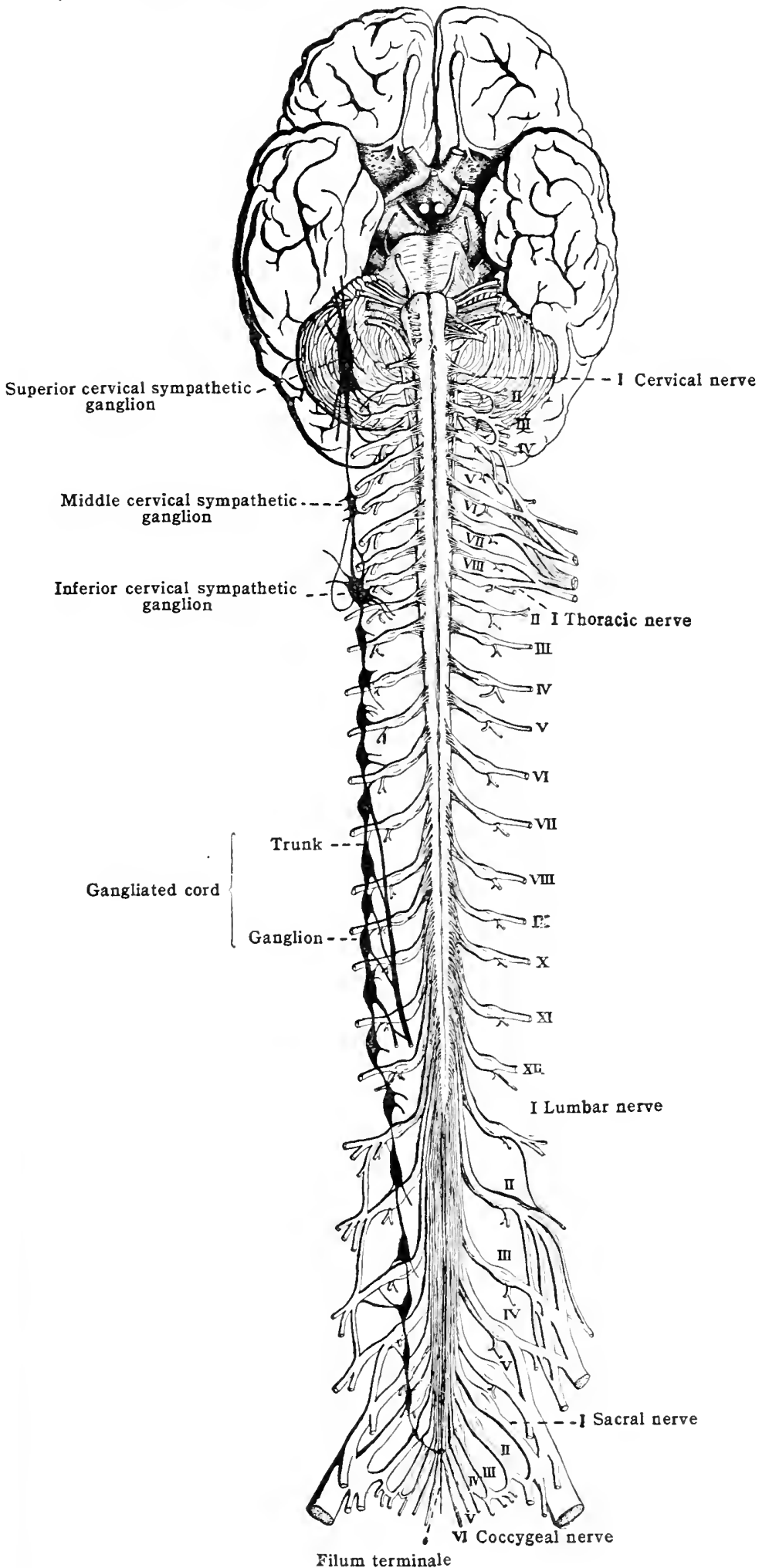


peripheral nervous system. This system, abundantly attached to the central system, consists of numerous bundles of nerve-fibres which divide and ramify throughout the body, anastomosing with each other and forming various plexuses, large and small. The terminal rami divide and subdivide until the divisions attain the inclividual nerve-fibres of which they are composed, and finally the nervefibres themselves divide and terminate in relations with their allotted peripheral elements. It is by means of this system that stimuli arising in the peripheral tissues are conveyed to the central system, and that impulses in response are borne from the central system to the peripheral organs. For purposes of description, as well as upon the basis of certain differences in structure, arrangement, and distribution, the peripheral nervous system is separated into two main divisions:(1) the cranio-spinal and (2) the sympathetic system.

Both of these divisions include numerous ganglia or peripheral groups of nervecells from which arise a considerable proportion of the fibres forming their nervetrunks, but neither of the divisions may be considered wholly apart from the central system nor are they independent or separate from each other. The sensory or afferent fibres of the cranio-spinal nerves pass by way of the afferent nerveroots into the central system and contribute appreciably to its bulk, and the motor or efferent fibres of these nerves have their cells of origin (nuclei) situated within the confines of the central system. The sympathetic system is intimately associated with the cranio-spinal, and consequently with the central system-(1) by means of fibres which enter and terminate in the cranio-spinal ganglia and transfer impulses which enter the central system; (2) by efferent fibres of central origin which course in the nerve-trunks and terminate in the ganglia of the sympathetic system; (3) also, the sympathetic trunks usually contain numerous afferent cranio-spinal fibres which thus course to their peripheral termination, usually in the so-called 'splanchnic area,' or domain of the sympathetic, in company with the sympathetic fibres. Likewise the peripheral branches of the cranio-spinal nerves of ten carry for varying distances numerous sympathetic fibres which are on their way to terminate either in other sympathetic ganglia or upon their allotted peripheral tissue-elements.

The following differences between the cranio-spinal and sympathetic systems of nerves may be cited:- (1) The cranio-spinal nerves are anatomically continuous with the brain and spinalcord; probably no fibres arising in the sympathetic ganglia actually enter the central system other than for the innervation of its blood-vessels. (2) The ganglia of the cranio-spinal nerves all lie quite near the central axis, in line on either side of it, and at more or less regular intervals; the sympathetic ganglia are scattered throughout the body tissues, are far more numerous and more variable in size, and probably only the larger of them are symmetrical for the two sides of the body. (3) The cranio-spinal nerves are paired throughout, and the nerves of each pair are symmetrical as to their origin and also, with certain exceptions (notably the vagus), in their course and distribution; most of the larger and more proximal of the sympathetic nerve-trunks are symmetrical for the two sides of the body; many of them are not, and many of the smaller and most of the more peripheral nerves and ganglia, large and small, are not pirired at all. (4) Even in their finer twigs, the cranio-spinal nerves of the two sides probably do not anastomose with eacl other across the mid-line of the body; the sympathetic nerves do so abundantly, especially within the body cavity. (5) The cranio-spinal nerves are distributed to the ordinary sensory surfaces of the body and the organs of special sense and to the somatic, striated or 'voluntary' museles of the body; the sympathetic fibres are devoted chiefly to the supply of the so-called involuntary muscles of the body, including the smooth muscle in the walls of the viscera and in the walls of the blood and lymph vascular-systems, while others serve as secretory fibres to the glands. (6) Cranio-spinal nerve-fibres are characterized in general by well-cleveloped medullary sheaths, maling the nerves appear as white strands; most of the sympathetic fibres are non-medullated, some are completely and some partially medullated, but none possess as thick medullary sheaths as those of the eranio-spinal nerves. Thus sympathetic nerves appear as grey strands.

The cranio-spinal nerves.- There are forty-six pairs of cranio-spinal nerves, of which thirty-onc pairs are attached to the spinal cord (spinal nerves) and fifteen pairs to the concephaton (ranial nerves). The spinal nerves are the more primitive and retain the typical character, i. e, each is attached to the spinal cord by two roots, a dorsal or semsory ganglionated root, and a ventral, which is motor, and thus not ganglionated. Most of the cranial nerves have only one root, which in come cases corresponds to a dorsal root and therefore has a ganglion, and in other casces corresponds, physiologically at least, to a ventral root of a spinal nerve. Among other differences, the fibres of the first cranial nerve, for example, do not collect to form a distinct nerve-trunk. 


\section{THE CRANIAL NERVES}

Customarily, the cranial nerves are described as comprising twelve pairs and each is referred to by number. However, present knowledge of their origin, central connections and peripheral distribution suggests that those enumerated as the fifth, seventh, and eighth pairs under the old nomenclature are better each separated into its two component nerves, each of which merits a separate description and a separate name. None of the cranial nerves corresponds closely to a typical spinal nerve with its motor and sensory root. The so-called motor portion of the fifth is no more its motor root than is the seventh nerve. The sensory portion of the seventh is not wholly sensory and rather resembles the ninth pair in distribution, and it has long been commonly referred to as a separate nerve. The two parts of the eighth nerve, both sensory, are known to be wholly different in functional character and are so named. Further, the names of the nerves, descriptive of their function, are pedagogically much more efficient than the use of numbers in referring to them.

Separating the three pairs mentioned, each into its two nerves, gives fifteen pairs instead of twelve. Their names and functional nature are given in the following table. The Roman numerals given in parentheses correspond to the serial numbers given when twelve pairs only are considered. It is also customary to enumerate the cranial nerves from in front backward and caudalward, and this custom is followed here, but again it would be pedagogically better to take them in the reverse order. Then each in its turn could be directly considered as in continuous series with the spinal nerves below and the similarities to and progressive modifications from the spinal type could be better realized. It will be remembered that somatic motor or efferent fibres are those which terminate directly upon the fibres of skeletal muscle while visceral motor fibres transfer their impulses to sympathetic neurones, and the axones of the latter terminate upon gland cells and upon the fibres of cardiac and smooth muscle.

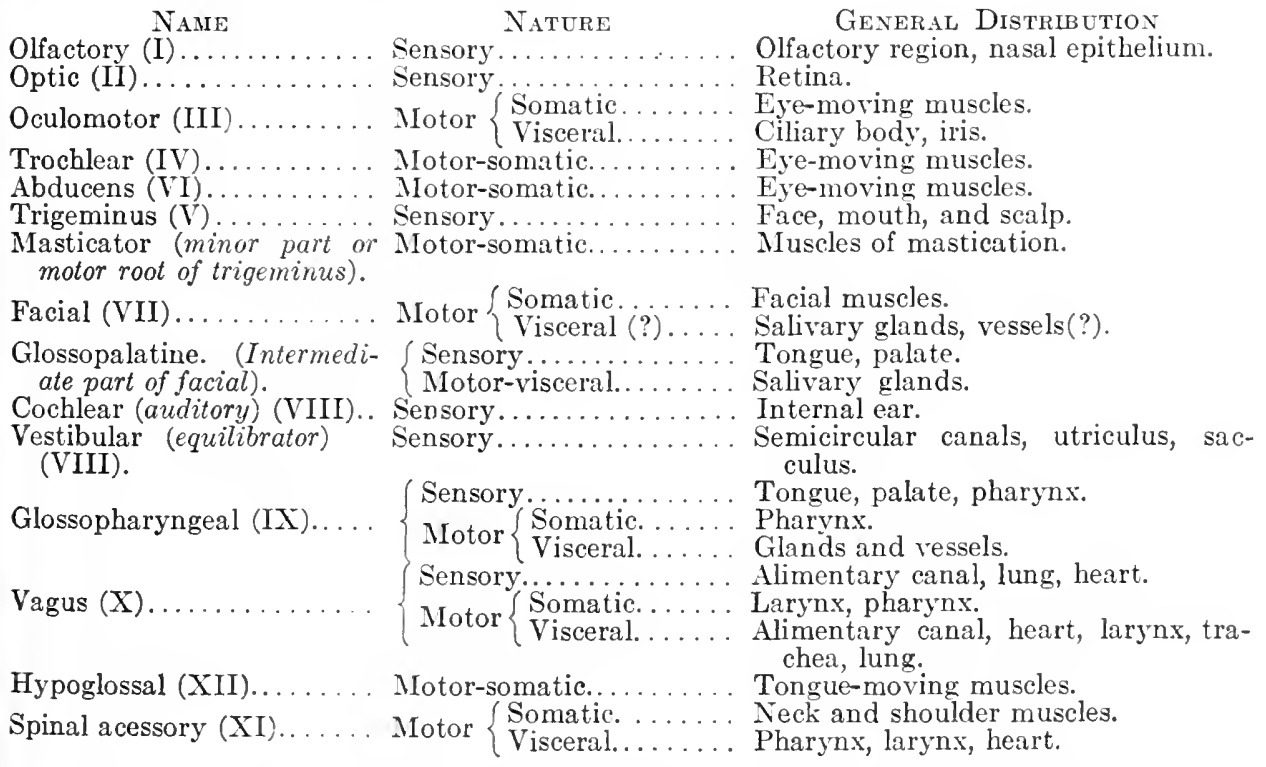

The cranial nerves, like the spinal nerves, are developed from cells of the primitive neural tube and, beginning with the fifth pair downward, all the sensory nerves are developed from the cells corresponding to those of the ganglion crest which give origin to the spinal ganglia with the sensory components or dorsal roots of the spinal nerves. Otherwise between the cranial nerves and the spinal nerves there are many important differences. Each spinal nerve has a dorsal or sensory root, which springs from the cells of a spinal ganglion; a ventral or motor root, whose fibres are processes of the nerve-cells which are situated in the walls of the central system, and at their attachment to the surface of the cord the two roots are some distance apart. Only one of the (usually considered) twelve pairs of cranial 
nerves corresponds at all closely with typical spinal nerves. This one is the trigeminus which possesses a sensory ganglionated root and near its attachment is accompanied by a small motor nerve, the masticator, which serves in very small par' as a corresponding motor root of the trigeminus. But even in this case where the similarity between the cranial and spinal nerves is greatest, there are still points of anatomical difference, which if not essential are very obvious, for the so-called motor root joins not the whole but only with one branch of the sensory portion. The two are only slightly separated from each other at their attachment to the surface of the brain. All the other cranial nerves differ in a still more marked manner from typical spinal nerves. The first nerve is an afferent nerve whose cells of origin (olfactory ganglion) are scattered in the mueous membrane

Fig. 731.-Surface Attachuent of the Cranial Nerves.

(After Allen Thomson, modified.)

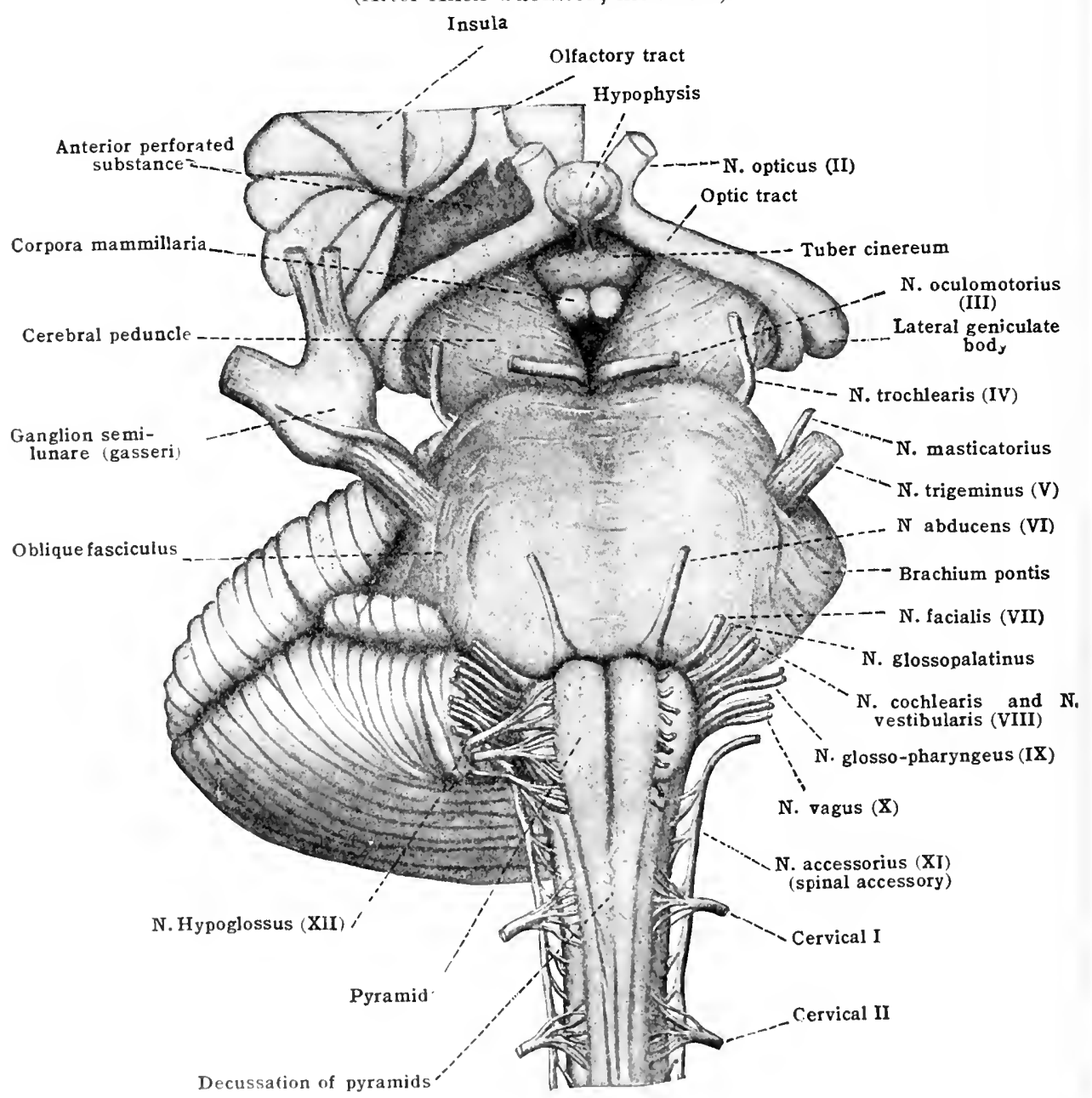

of the nose, an organ of special sense, and its fibres are not eollected together into a norve-trunk, but pass, as a number of small bundles, through the lamina eribrosa of the rethond bene directly into the olfactory bulb. The optie nerve is also a nerve of speecial sense. It fibres form a very distinct bundle, similar in appearance to all ordinary norve, from which, however, it differs essentially, both with regard testructure and development; for, unlike an ordinary nerve, its eonnective tissue consists to a large extent of neuroglia instead of ordinary connective tissue, and its component nerve-fibres are of much smaller ealibre than those of an ordiniry norve. It represents the location of the original optie stalk, a diverticulum from the noural tulke and it assoniates the retina (optic cup), a bit of modified cor- 
tex, with the encephalon. The optic nerve, therefore, corresponds more closely with an association tract of the central system than with an ordinary nerve.

The oculomotor, trochlear, abducens and hypoglossal nerves are purely motor nerves, and thus correspond only with the ventral roots of spinal nerves. The spinal accessory is also purely motor. Its fibres arise from the cells of the anterior horn of the spinal cord and from a nucleus of the medulla which represents a displaced portion of that horn, but they do not leave the surface of the spinal cord and brain in the usual situation of ventral roots. On the contrary, they cmerge in a series of rootlets from the lateral funiculus of the cord on the dorsal side of the ligamentum denticulatum, and from the upward prolongation of this funiculus.

The cochlear and vestibular are nerves of special sense, and in some respects both correspond closely with the dorsal root of a typical spinal nerve, and the ganglia of both represent spinal ganglia, but their distribution is limited to the membranous labyrinth.

The vagus and glosso-pharyngeal nerves contain both motor and sensory fibres, but they differ from typical spinal nerves in that the motor fibres, in company with the sensory, issue from the postero-lateral sulcus of the medulla, and they are intimately intermingled, from their origin, with the sensory fibres, which latter arise from ganglia interposed in the trunks of the nerves and otherwise correspond with the fibres of the dorsal root of a typical spinal nerve.

Superficial attachments and origins. - It is customary to speak of the area where the nerve-fibres leave or enter the brain substance as the superficial attachments of the cranial nerves, and the groups of cells from which the fibres spring, and about which they terminate, as their nuclei of origin or termination, respectively.

\section{THE OLFACTORY NERVES}

The olfactory nerve-fibres are the central processes of the bipolar olfactory nerve cell-bodies situated in the olfactory region of the nasal mucous membrane. In man, the olfactory region comprises the epithelium upon the superior third of the nasal septum and that upon practically the whole of the superior nasal concha. The area is relatively small as compared with that of other mammals and, as in other mammals, is characterized by an increased thickness of the epithelium and a yellowish brown colour in the fresh. The peripheral processes of the olfactory cell-bodies (the olfactory ganglion) are short and extend only to the surface of the olfactory epithelium. As the central processes pass upward from their cells of origin they form plexuses in the mucous membrane, and from the upper parts of these plexuses, immediately below the lamina cribrosa of the ethmoid, about twenty filaments issue on each side. These filaments comprise the olfactory nerve. They are non-medullated. They pass upward, through the foramina in the lamina cribrosa, into the anterior fosia of the cranium in two rows, and after piercing the dura mater, the arachnoid, and the pia mater, they enter the inferior surface of the olfactory bulb. They contribute to the superficial stratum of nervefibres on the inferior surface of the olfactory bulb and end in the glomeruli, which are formed by the terminal ramifications of the olfactory nerve-fibres intermingled with the similar ramifications of the main dendrites of the large mitral cells which lie in the deeper part of the grey substance of the olfactory bulb.

The olfactory nerve-fibres are grey fibres, since they do not possess medullary sheaths, and they are bound together into nerves by connective-tissue sheaths derived from the pia mater, from the subarachnoid tissue, and from the dura mater. Prolongations of the subarachnoid space pass outward along the nerves for a short distance.

Central connections. - The olfactory impulses are transmitted by way of the peripheral processes of the olfactory neurones through the cell-bodies and the olfactory nerve-fibres and through the glomeruli to the mitral cells. Thence they are carried by the central processes (axones) of the mitral cells, which pass backward along each olfactory tract and its three olfactory striæ (see Rhinencephalon, p. 864).

\section{THE TERMLNAL NERVE (Nervus Terminalis)}

In lower vertebrates and recently in those mammals whose sense of smell is relatively much more developed than in man, three nerves have been found concerned with the olfactory ipparatus:-(1) The olfactory nerve proper whose fibres, as noted above, are the central processes of 
the nerve cell-bodies situated in the epithelium of the olfactory region of the nasal mueosa, and which terminate in the olfactory bulb; (2) The vomero-nasal nerve, whose fibres are the eentral processes of nerve cell-bodies situated in the epithelium of the vomero-nasal (Jacobson's) organ and which pass caudalward in the submueosa and upward to join the filaments of the olfaetory nerve proper and which, in the $\log$, eat, rabbit, rat, etc., terminate in the accessory olfactory bulb-a small protuberance possessed by these animals on the postero-median aspeet of the olfactory bulb proper; (3) The terminal nerve, a small plexiform nerve, which unlike the other two, is ganglionated.

In man, the romero-nasal (Jacobson's) organ is rudimentary after birth and, therefore, the vomero-nasal nerve is not present, the only fibres for the vomero-nasal region being those of general sensibility from the trigeminus and sympathetic fibres common to the epithelium of the entire nasal fossa.

The terminal nerve has been recently deseribed as present in the human fœetus and it is mentioned here because of the expressed belief that it is present in the adult. From the observations recorded for human and rabbit fotuses and the adult dog and eat, the following description may be given: It is variably plexiform throughout its course. Its peripheral twigs are distributed to the mucosa of the nasal septum, some to the mucosa joining the olfactory region while other and larger twigs extend further forward and are distributed to mueosa of the vomero-nasal organ, accompanying and sharing in the distribution of the vomero-nasal nerve when this is present. Its central conneetions are in the form of two or three small roots which pass through the eribriform plate of the ethmoid bone in company with and mesial to the vomero-nasal nerve and then, still plexiform, extend eaudalward over the infero-mesial aspeet of the olfactory bulb and upon the olfactory peduncle or stalk (olfactory traet) beyond, a root of ten extending to near the lamina terminalis and optic ehiasma. The roots disappear in the mesial and infero-mesial aspect of the frontal portion of the brain at different localities eaudal to the olfactory bulb and usually near the olfactory pedunele, but often one may disappear in the region corresponding to the anterior perforated substance of the adult human brain.

Numerous small groups of ganglion cells are found interposed along both the peripheral and intracranial course of the terminal nerve. A group, larger in size than the others and situated in the intracranial course of the nerve, is ealled the ganglion terminale. The fibres of the nerve are non-medullated. Both the ganglion cells and the fibres of the nerve are described as having more the appearanees eharaeteristic of sympathetic neurones than of cranio-spinal. On the other hand, our con eeptions of sympathetic neurones do not permit of their terminating within the eentralsystem except for the innervation of its blood vessels. It may result that, instead of being an independent nerve as now claimed, the nervus terminalis is a part of the forward extension of the cephalic sympathetic, the larger ganglia and plexuses of which latter are well known, and that its neurones receive and convey impulses to the gland cells of the nasal mueosa and to the musele of the blood-vessels of the mucosa and those supplying the infero-mesial part of the frontal end of the cerebrum.

\section{THE OPTIC NERVES}

The fibres of the optic nerve are the eentral processes of the ganglion cells of the retina. Within the ocular bulb they converge to the optic papilla, where they are aceumulated into a rounded bundle, the optic nerve. The nerve thus formed pierces the chorioid and the selerotic coats, and, at the back of the bulb, enters the orbital fat, in which it passes backward and medialward to the optic foramen. After traversing the foramen it enters the middle fossa of the eranium, and anastomoses with its fellow from the opposite side, forming the optie ehiasma. It may, therefore, for deseriptive purposes, be divided into four portions- the intra-ocular, the intra-orbital, the intra-osseous, and the intra-cranial. The total length of the nerve varies from forty-five to fifty millimetres.

The intra-ocular part is rather less than one millimetre in length. It passes backward from the optie papilla through the ehorioid and through the selerotic coats of the bulb. As it passes through the latter coat of the bulb in many separate hundles, the area it traverses has a cribriform appearance when the nerve is removed, and conseguently is lnown as the lamina cribrosa sclere.

The intra-orbital part of the nerve emerges from the selerotie about three millimetres below and to the meelian side of the posterior pole of the bulbus, and it is about thirty millimetres long. It passes backward and medialward, surrounded by the posterior part of the fascia bulbi ('Tenon's capsule) and by the orbital fat, to the optic foramen.

As it runs hackwarl in the orlut it is in relation above with the naso-eiliary (nasal) nerve and the ophthalnic artery which pass ohliquely from behind and laterally, forward and medialward aresoss the junction of its posterior and middle thirds, and also in relation with the superior ophthatmic vein, the superior rectus musele, and the upper branch of the oculo-motor nerve. Below it are the inferior rectus muscle, and the inferior division of the oculo-motor nerve. 'To its lateral sic] e, near the posterior part of the orbit, are the ophthalmic artery, the ciliary ganglion, the ahdiecons nerve, and the external rectus muscle. The anterior two-thirds of this portion of the opticuserve are surrounded hy the ciliary arteries and the eiliary nerves and it is penetrated on, its 
medial and lower aspect by the central artery of the retina. As it enters the optic foramen to become continuous with the intra-osseous part, it is in close relation with the ligaments of Lockwood and Zinn (annulus tendineus communis) and with the four recti muscles which arise from them.

The intra-osseous portion is from six to seven millimetres long. It lies between the roots of the small wing of the sphenoid and the body of that bone, and it is in relation below and laterally with the ophthalmic artery.

The intra-cranial portion, which is from ten to twelve millimetres long, runs backward and medialward, beneath the posterior end of the olfactory tract, and above the ophthalmic artery, the medial border of the internal carotid artery and the diaphragma sellæ to the chiasma. From the chiasma to the central connections of the nerve, the path is known as the optic tract.

Central connections. - The central connections of the fibres of the optic nerve have been considered with the optic chiasma and the optic tract (see p. 819).

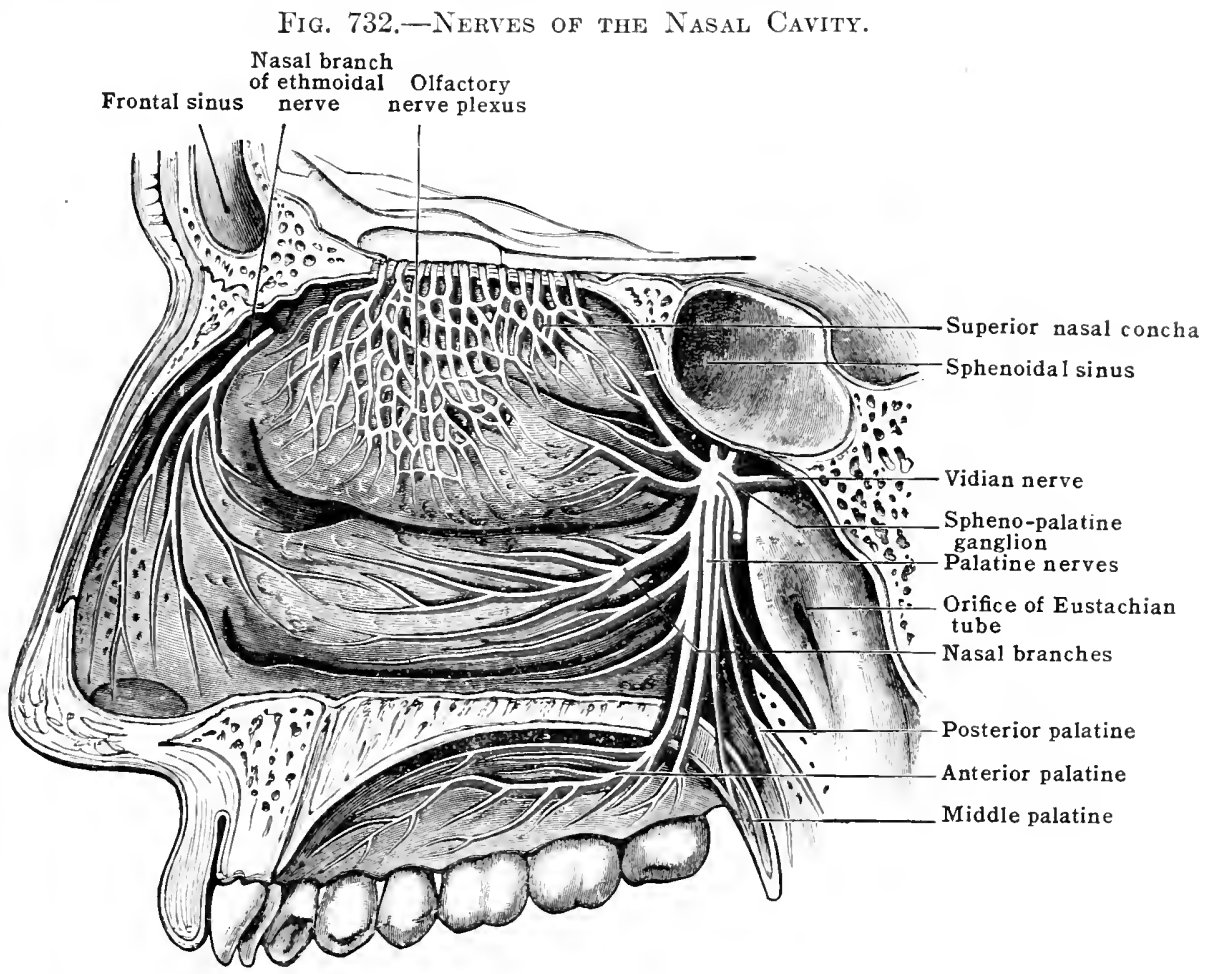

The sheaths of the optic nerve.-The optic nerve receives a sheath from each of the membranes of the brain, and prolongations of the subdural and subarachnoid cavities also pass outward along it to the posterior part of the sclera.

\section{THE OCULO-MOTOR NERVES}

The oculo-motor or third cranial nerve is a purely motor nerve. Each supplies seven muscles connected with the eye, two of which, the sphincter of the iris and ciliary muscle, are within the ocular bulb. The remaining five are in the orbital cavity, and four of them-the superior, inferior, and medial recti and the inferior oblique-are attached to the bulb, while the fifth, the levator palpebræ superioris, is inserted into the upper eyelid.

The fibres of the oculo-motor nerve spring from their nucleus of origin situated in the grey substance of the floor of the cerebral aquæduct in the region of the superior quadrigeminate body (fig. 662). The cells of this nucleus are divided into two main groups, a superior and an inferior (fig. 663). The superior group includes two nuclei, a medial and a lateral. The latter, besides being lateral, is also somewhat dorsal to the former. The inferior group has been divided into five secondary nuclei, according to the eye-muscles the cells of each group innervate. Three of the five lie lateral to the others and somewhat dorsally, and of the remaining two, which are placed more medially, one encroaches upon the mid-line (nucleus medialis) and is con- 
tinuous with the corresponding group of the opposite side and is common to the oculo-motor nerves of botll sides.

It has been found, by the study of diseased conditions and by experiments with animals, that the centres of innervation of the eye-muscles supplied by the nerve correspond to the above divisions of both the superior and inferior group of cells into a medial and lateral series. The relative position of the divisions of each group and the muscles they are thought to innervate are shown in the following diagram devised by starr:-

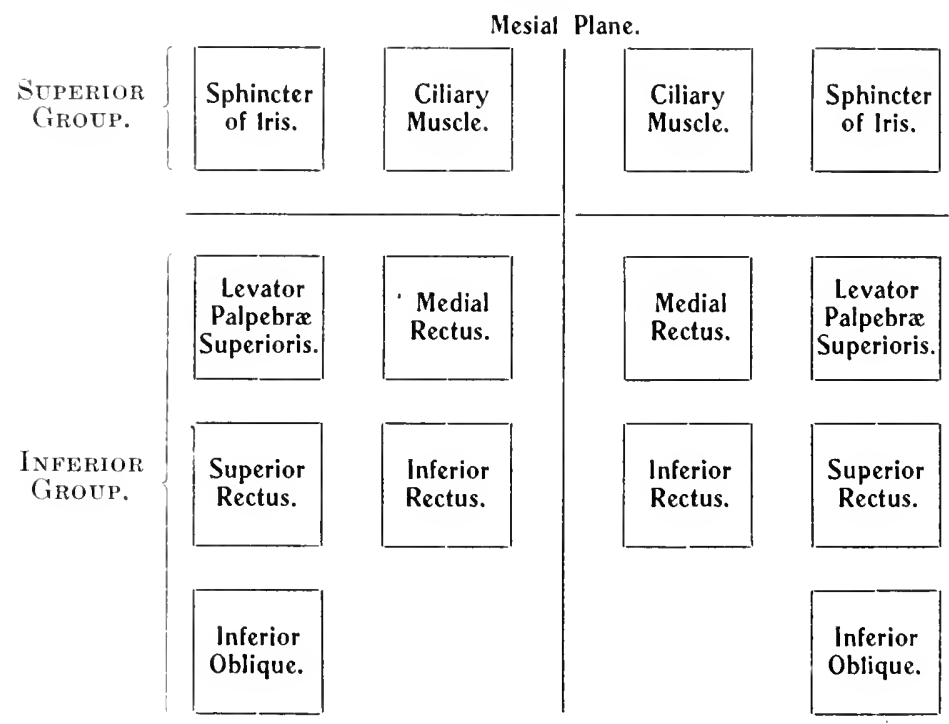

As they leave their nucleus of origin in the mid-brain, the fibres of the oculomotor nerve form a series of fasciculi, which eurve ventrally around and through the red nucleus and the medial part of the substantia nigra, to the oculo-motor sulcus on the medial surface of the cerebral peduncle, where they emerge in from six to fifteen small bundles which pierce the pia mater and collect into the trunk of the nerve. Immediately after its formation along the oculo-motor suleus, the trunk of the nerve passes between the posterior corebral and the superior cerebrllar arteries, and, ruming downward, forward, and laterally in the posterior part of the cisterna basalis, it erosses the anterior part of the attached border of the trntorium cerebelli at the side of the dorsum scllw, and, piercing the arachnoid and the innor layor of the dura mater, it enters the wall of the cavernous sinus alont midway betwen the anterior and posterior elinoid processes. Immediately after its entry into the wall of the sinus it lies at a higher level than the trochlear nerve, but the latter som crosines on its lateral side and gets above it, and directly afterward the oculo-notor nerve divides into a smaller superior and a larger inferior branch (fig. 734). Before its division communications join it from the "avernous plexus of the sympathetic about the internal carotid artery, and from the ophthalnice division of the 1 rigeminus. Both branches proceed forward, and the malsal bratnch of the trigeminus, which has passed upward, on the lateral side of the inferior branch of the oculomotor lies between them. At the anterior end of the "avernous sinns the two branches pass through the superior orbital (sphemoidal) fissure, between the heads of the lateral rectus muscle, and enter the orbital arvity. In theorbit, the superior branch lies between the superior reetus and the ontice nerve; it supplies the superior rectus and then turns round the medial horder of that musele and terminates in the levator palpobra superioris. The inferior branch runs forward, bencith the optic nopve, and divides into three hranches which smpply the inforior and modial recti and the inferior oblicue.

The branch to the inforior ohligue muscle is eonnected with the ciliary ganglion by a short thick oflsed, the short root of the ciliary ganglion, by mediation of the sympathetic nemrones of which the oculo-motor nerve sends impulses to the eiliary musele and the sphincter muscle of the iris. The inferior branch also gives some small twigs to the inferior redus. The branches of the oculo-motor nerve, which supply the reet i musclese, anter the muscles on their ocular surfaces, but the branch

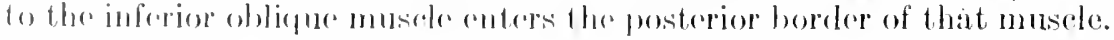


Some of the fibres which spring from the medial portion of the oculo-motor nucleus do not pass into the nerve of the same side, but into that of the opposite side, and it is believed that they are distributed to the opposite medial rectus muscle. Other fibres which arise from the nucleus descend in the medial longitudinal fasciculus and either terminate about the cells of the nucleus of the facial or join the facial nerve, in which they pass to the upper part of the orbicularis palpebrarum. The eye is opened by the oculo-motor and closed by the facial nerve.

Central connections. - The nucleus of the oculo-motor is associated with the middle portion of the anterior central gyrus, the posterior end of the middle frontal gyrus and with the cortex about the visual area of the occipital lobe of the opposite side of the brain by the pyramidal fibres. It is probably associated with the cerebellum by the fibres in the superior cerebellar peduncles, with the superior calliculus, and with the sensory nuclei of the other cranial nerves by the medial longitudinal fasciculus. To produce the coordmated activities of the eye-moving muscles, it must be associated with the nuclei of the trochlear and abducens.

\section{THE TROCHLEAR NERIES}

The fibres of each trochlear or fourth nerve (or patheticus) spring from the cells of a nucleus which lies in the grey substance of the floor of the cerebral aquæduct in line with the oculo-motor nucleus, but in the region of the inferior quadrigeminate bodies. As the fibres pass from their origins they run ventrally and laterally in the substance of the tegmentum for a short distance, then they curve medianward and dorsalward, and, in passing through the anterior end of the superior medullary velum they decussate totally with the fibres of the trochlear nerve

Fig. 733.-Diagrans of Sections throvgh the Origin of the Trochlear Nerie. (Stilling.) (The upper figure is an oblique section, the lower is a coronal section.)

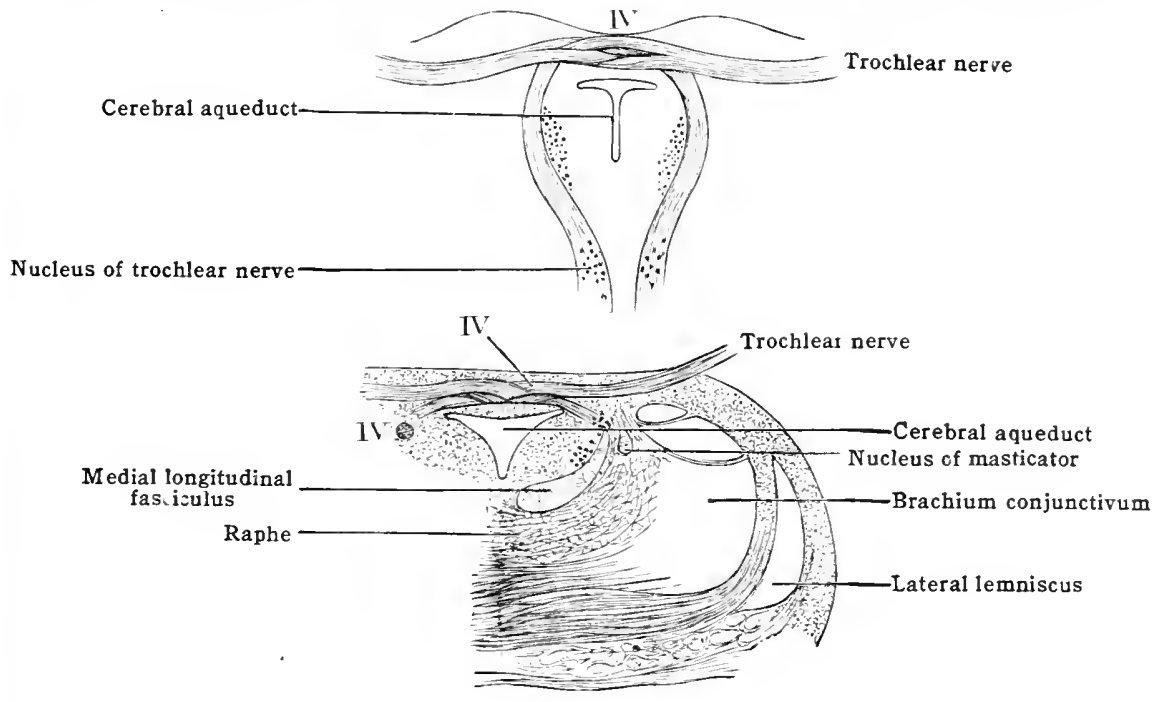

of the opposite side. After the decussation the fibres emerge from the surface of the superior medullary velum, at the side of the frenulum veli, usually in two small bundles, which pierce the pia mater and join together to form the slender trunk of the nerve. This trunk curves forward and ventralward to the base of the brain around the sides of the superior peduncle of the cerebellum and cerebral peduncle of the side opposite to that in which the nerve originates, running parallel with and between the superior cerebellar and posterior cerebral arteries. As it reaches the base of the brain behind the optic tract the nerve enters the cisterna basalis, in which it runs forward, immediately beneath or piereing the frec border of the tentorium cerebelli, to the superior border of the petrous portion of the temporal bone, where it pierces the arachnoid and the dura mater and enters the posterior end of the lateral wall of the cavernous sinus. In the wall of the cavernous sinus it receives communications from the cavernous plexus of the sympathetic and by a small filament from the ophthalmic division of the trigeminus. It gradually ascends, as it passes forward in the lateral wall of the sinus, and, beyond the middle of the sinus, it crosses the lateral side of the trunk of the oculo-motor nerve and gains a higher position. At the anterior end of the sinus the nerve 
enter's the orbit above the lateral rectus and immediately turns medialward between the periosteum of the roof of the orbit and the levator palpebræ superioris. At the medial border of the roof it turns forward to its termination, and enters the orbital or superior surface of the superior oblique muscle to which its fibres are distributed.

The central connections of the nucleus of the trochlear nerve are similar to those of the oculo-notor save that its cells probably do not send fibres whieh eonneet with the faeial nerve.

The trochlear is peculiar in that-(1) it is the smallest of the eranial nerves; (2) it is the only nerve having its superficial attaehment upon the dorsal aspect of the encephalon; (3) it is the only cranial nerve whose fibres undergo a total decussation, and (4) in that it terminates in a muscle of the side of the body opposite that in which it has its origin. Gaskell has suggested that this latter condition has probably been brought about, phylogenetically, by the transference of the muscles which have carried their nerves with them. It should be remembered that most of the fibres arising from the medial group of the cells of the nueleus of the oculo-motor, cross the opposite side. This is thought to be especially true for those supplying the medial rectus muscle.

\section{THE ABDUCENS}

The abducens (or sixth nerve) on each side arises from the cells of a nucleus which lies in the grey substance of the floor of the fourth ventricle in the region of the inferior part of the pons. The nucleus is situated close to the middle line, ventral to the acoustic medullary striæ and beneath the colliculus facialis and it is in direct linear series with the nuclei of the oculo-motor, trochlear and hypoglossal nerves. It is the third of the eye-moving nerves. The fibres which pass from the nucleus into the nerve run inferiorly and ventralward through the reticular formation, the trapezium, and the pyramidal fasciculi, and they emerge from the ventral surface of the medulla in the sulcus at the inferior border of the pons and the upper end of the pyramid of the medulla. From this superficial attachment the nerve runs upward and forward in the subarachnoid space between the pons and the basisphenoid and at the side of the basilar artery. A little below the level of the upper border of the petrous portion of the temporal bone it pierces the dura mater, passes beneath the petro-sphenoidal ligament, at the side of the dorsum sellæ, and enters the cavernous sinus, in which it runs forward along the lateral side of the internal carotid artery. At the anterior end of the sinus it passes through the superior orbital (sphenoidal) fissure between the heads of the rectus lateralis, below the inferior branch of the oculo-motor nerve, and above the ophthalmic vein. In the orbit it runs forward on the inner or ocular surface of the rectus lateralis, and finally it pierces this muscle and terminates upon its fibres.

While it is in the cavernous sinus it receives communications from the carotid plexus of the sympathetic and from the ophthalmic nerve.

All the fibres arising in the nueleus of the sixth nerve do not pass into the sixth nerve. Some of them ascend in the medial longitudinal fasciculus of the same and opposite sides, and terminate aljout cells of the medial group of the nucleus of the oculo-motor nerve, by which the impulses are conveyed to the opposite inedial reetus muscle. Thus impulses reaching the abducens nucleus can throw into simultancous action the hateral rectus of the same side and the medial rectus of the opposite side, and thus turn both eyes in the same direction.

Central connections. - The nucleus of the abdueens receives impulses from the anterior entral gyrus of the opposite side by the pyramidal fibres, and it is associated with the sensory nuelei of other nerves by way of the modial longitudinal fascieulus, and that of the trigeminus especially through the reticular formation.

\section{THE TRIGENINUS}

The trigeminus is the largest of the cranial nerves with the exception of the optic. It is usually describerl as the fifth cranial nerve and as possessing both a sensory and a motor root. For loasons alpeady given, the "motor root" is here described separately and given the separate name, masticator nerve. The filmes of the trigeminus, which are all sensory, spring from the cells of the semilunar (Ciasserian) ganglion, which corresponds with the ganglion of the dorsal root of a spinal nerve, and thry enter the brain stem through the side of the anterior thirel of the pons. 
The semilunar (Gasserian) ganglion is a semilunar mass which lies in Meckel's cave, a cleft in the dura mater above a depression in the medial part of the upper surface of the petrous portion of the temporal bone. The convexity of the ganglion is turned forward, and from it three large nerves, the ophthalmic, the maxillary, and the mandibular, are given off. From the concavity, which is directed backward, springs the root of the nerve. The medial end of the ganglion is in close relation with the cavernous sinus and the internal carotid artery at the foramen lacerum, and the lateral end lies to the medial side of the foramen ovale. The surfaces of the ganglion are striated, due to bundles of fibres traversing them. The upper surface is separated by the dura mater from the temporal lobe of the brain, and the lower rests upon the masticator nerve and the outer layer of dura mater upon the petrous portion of the temporal bone.

The fibres of the trigeminus root as they leave the semilunar (Gasserian) ganglion, form from thirty to forty fasciculi which are bound together into a flat band, from six to seven millimetres broad, which passes backward over the upper border of the petrous portion of the temporal bone and below the superior petrosal sinus into the posterior fossa of the cranium. In the posterior fossa it runs backward, medialward, and downward, and passes into the pons through its continuation into the middle peduncle of the cerebellum. In the tegmentum of the pons region, the fibres bifurcate into ascending and descending branches which terminate about the cells of the nucleus of termination of the trigeminus. This nucleus, large at the level of the entrance of the root, has tapering superior and inferior extremities. The inferior extremity of the nucleus, which is much the longer, descends as low as the upper portion of the spinal cord and the fibres of the root terminating about the cells of this extremity are known as the spinal tract of the trigeminus.

Central connections. - The nuclei of termination of the trigeminus send impulses to the somæsthetic area of the cortex of the opposite side by the fibres of the medial lemniscus (fillet) and, for reflex actions, to the motor nuclei of other cranial nerves by the medial longitudinal fasciculus and by fasciculi propri in the reticular formation of the same, and opposite sides.

\section{THE BRANCHES OF THE TRIGEMINUS}

The main branches of the trigeminus, given off by the front side of the semilunar ganglion, are three in number (ophthalmic, maxillary, and mandibular), each of which is referred to as a nerve and each of which is purely sensory, though the third branch, or mandibular nerve, is joined by the fibres of the masticator nerve which is motor.

\section{(1) The Ophthalmic Nerve or First Division}

The ophthalmic nerve, the first division of the trigeminus, is the smallest of the three branches which arise from the semilunar (Gasserian) ganglion. It springs from the medial part of the front of the ganglion and passes forward, in the lateral wall of the cavernous sinus, where it lies below the trochlear nerve and lateral to the abducens nerve and the internal carotid artery (fig. 734). A short distance behind the superior orbital (sphenoidal) fissure the nerve divides into three terminal branches-the frontal, lacrimal, and naso-ciliary (nasal) nerves. They pierce the dura mater, which closes the fissure, and pass forward into the orbit. Before its division the ophthalmic nerve receives filaments from the cavernous plexus of the sympathetic and it gives off, soon after its origin, a tentorial (recurrent meningeal) branch which runs backward, in close association with the trochlear nerve, and ramifies between the layers of the tentorium cerebelli. Further forward three branches spring from the ophthalmic nerve which contribute sensory fibres to the oculo-motor, trochlear, and abducens nerves.

The terminal branches.- $(a)$ The frontal nerve is the largest terminal branch. It pierces the dura mater and passes into the orbit through the superior orbital (sphenoidal) fissure, above the rectus lateralis and a little below and to the lateral side of the trochlear nerve. In the orbit it runs forward, between the levator palpebræ superioris and the periosteum, and breaks up in to three branches, the supra-orbital, frontal proper, and supratrochlear.

The supra-orbital nerve, the largest of the three branches, leaves the orbit at the supra. orbital notch (fig. 734). As it passes through the notch it gives off a small branch which enters the bone and supplies the diploë and the mucous membrane of the frontal sinus. Its terminal branches give twigs to the pericranium and to the skin of the scalp, the upper eyelid, the frontal 
region, and the parietal region almost as far as the lambdoid suture (fig. 740). One branch running at the upper margin of the orbital cavity unites with a branch of the facial nerve.

The frontal branch, given off at a variable point, lies medial to the supra-orbital, passes through the frontal foramen, and is distributed to the skin of the forehead and upper eyelid (fig. 734).

The supratrochlear branch runs forward and medialward toward the upper and medial angle of the orbit. Where it passes above the pulley of the superior oblique muscle, pierces the palpebral fascia, and ascends to the lower and middle part of the forehead, accompanied by the frontal artery (fig. 734), Before it leaves the orbit it sends a branch downward behind or in front of the pulley of the obliquus superior which joins with the infratrochlear nerve, and as it leaves the orbit it gives off filaments to supply the skin and conjunetiva of the medial third of the upper eyelid. Its terminal branches pierce the orbicularis and frontalis, and, as they pass to the skin of the forehead, they communicate with branches of the facial nerve.

(b) The lacrimal nerve [n. lacrimalis] is the smallest of the three branches of the ophthalmic division. It passes through the superior orbital (sphenoidal) fissure lateral to and slightly below the frontal nerve, and is directed forward and lateral-

Fig. 734.-Nerves of the Orbit from Above and Benind. (Schematic.)

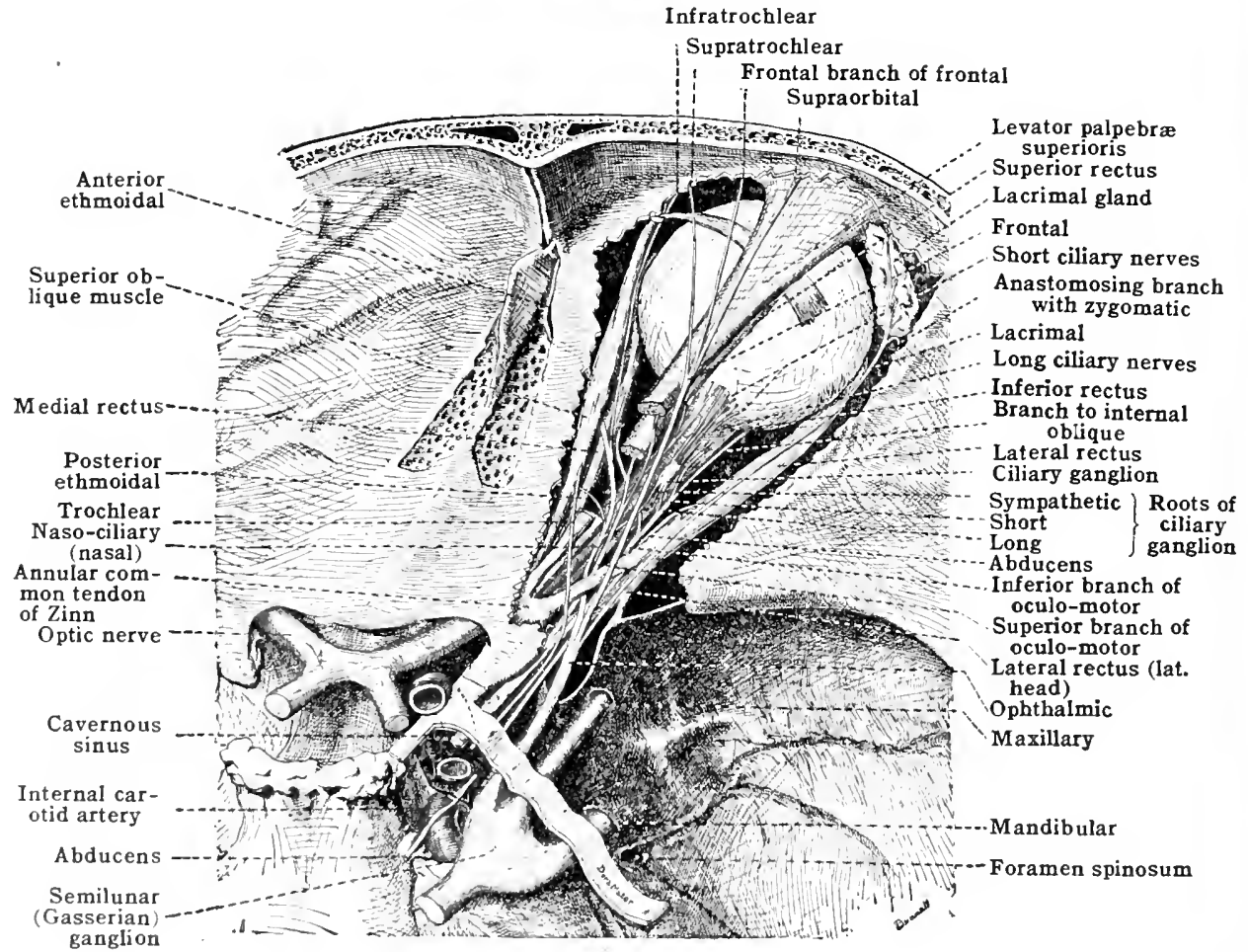

Dura mater

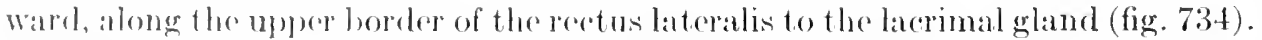
()n the latral wall of the orlit it recoives a small braneh from the zygomatic norre (the oflital Juanch of the maxillary nore). This branch brings to the

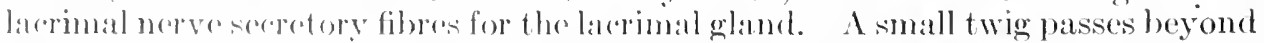

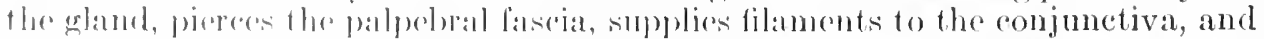
is then distrihuterl to tho integument at the lateral angle of the rye and to the skin

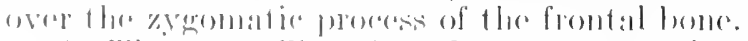

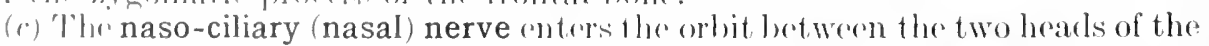

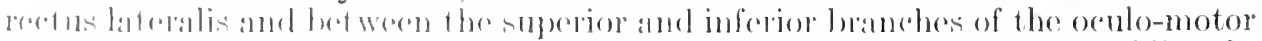

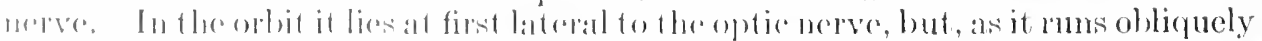

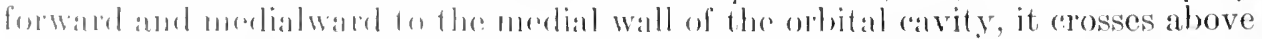

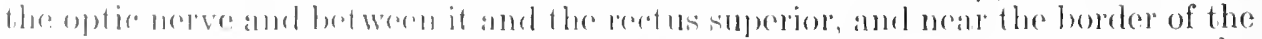

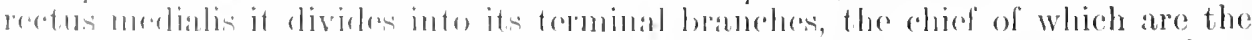

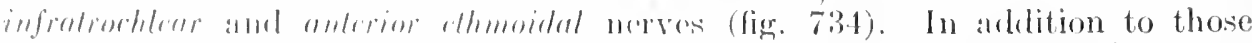

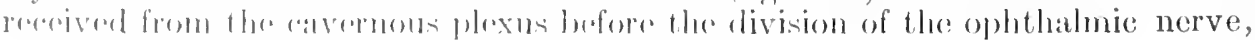


the naso-ciliary nerve itself receives numerous sympathetic (secretory and vasomotor) fibres.

Its several branches are: (i) The long root of the ciliary ganglion whieh is given off at the superior orbital (sphenoidal) fissure. It is a slender filament which runs forward on the lateral side of the optic nerve to the superior and posterior part of the eiliary ganglion (fig. 734).

(ii) The long ciliary nerves, usually two in number, which arise from the naso-ciliary nerve as the latter is crossing above the optic nerve. 'They run forward, on the medial side of the optic nerve, pierce the sclerotic, and are distributed with the lower set of short ciliary nerves (fig. 734). The long root of the ciliary ganglion and the long ciliary nerves carry sensory fibres which belong to the naso-ciliary nerve proper, most of which nerely pass through the ganglion, and it carries sympathetic fibres, added to it, most of which may terminate about the cell-bodies of the ganglion.

(iii) The posterior ethmoidal (spheno-ethmoidal) branch springs from the posterior border of the naso-ciliary nerve near the upper border of the rectus medialis. It passes through the posterior ethmoidal can al and is distributed to the mucous membrane of the posterior ethmoidal cells and the sphenoidal sinus.

(iv) The infratrochlear nerve passes forward between the obliquus superior and the rectus medialis, and under the pulley of the former muscle divides into two branches:- The superior I palpebral branch helps to supply the eyelids with sensory fibres and usually anastomoses with the supratrochlear nerve. The inferior palpebral branch is distributed to the lacrimal sac, the conjunctiva and skin of the medial part of the upper eyelid, the caruncle, and the skin of the upper part of the side of the nose.

(v) The anterior ethmoidal (distal part of the nasal) nerve, passing forward and medialward between the obliquus superior and the rectus medialis, leaves the orbit through the interior ethmoidal foramen, accompanied by the anterior ethmoidal vessels, and enters in to the anterior I fossa of the cranium (fig. 734). It then crosses the lamina eribrosa of the ethmoid, lying out side the dura mater, which separates it from the olfactory bulb, and descends into the nasal fossa through the ethmoidal fissure, a slit-like aperture at the side of the crista galli. In the submucosa of the nasal fossa it terminates by dividing into two sets of anterior nasal branches: the internal nasal branches and the external nasal branch (fig. 732).

The internal nasal branches divide into the medial nasal branches (the septal branches of the nasal nerve), which run downward and forward on the upper and front part of the septum, and the lateral nasal branches (the external terminal branch of the nasal nerve), which give twigs to the anterior extremities of the superior and middle nasal conche (turbinated bones), and to the mucous membrane of the lateral wall of the nose (fig. 732).

The external nasal branch (the anterior terminal branch of the nasal nerve) runs downward $t$ in a groove on the inner surface of the nasal bone. It pierces the wall of the nose between the inasal bone and the upper lateral cartilage, and supplies the integument of the lower part of the dorsum of the nose as far as the tip.

\section{(2) The Maxillary Nerye or Second Division of the Trigeminus}

The maxillary nerve is entirely sensory in function and it is intermediate in size between the ophthalmic and mandibular nerves.

It springs from the middle of the anterior border of the semilunar (Crasserian) ganglion and runs forward in the lower and outer part of the lateral wall of the cavernous sinus (fig. 735). Leaving the middle fossa of the cranium, by passing through the foramen rotundum, it enters the pterygo-palatine (spheno-maxillary) fossa (fig. 734), where it is joined by twigs with the spheno-palatine ganglion; then, changing its name, it passes forward, as the infra-orbital nerve, through the inferior orbital (spheno-maxillary) fissure into the infra-orbital sulcus in the floor of the orbit; continuing forward it traverses the infra-orbital canal accompanied by the infra-orbital artery, and appears in the face, beneath the levator labii superioris (quadratus) and above the levator anguli oris (caninus) where it divides into four sets of terminal branches which anastomose more or less freely with branches of the facial nerve to form the infra-orbital plexus.

Branches.- The branches of the maxillary nerve are- $(a)$ branches given off in the middle fossa of the cranium; (b) branches given off in the pterrgo-palatine (spheno-maxillary) fossa: (c) branches given off in the infra-orbital suleus and canal; and $(d)$ terminal branches.

(a) The middle (recurrent) meningeal branch, given off in the middle fossa. of the cranium, breaks up into numerous branches which supply the dura mater with sensory fibres, reinforce the sympathetic plexus on the midlle meningeal artery, and anastomose with the spinous nerve (the recurrent branch of the mandibular nerve).

(b) The branches given off in the pterygo-palatine (spheno-maxillary) fossa are the spheno-palatine nerves, the zygomatic branch of the maxillary nerve, and the posterior superior alveolar nerves. 
The spheno-palatine nerve has two or three branches which descend in the pterygopalatine fossa and give a small part of their fibres to the spheno-palatine (Meckel's) ganglion (fig. 735), the larger part of their fibres passing through the ganglion into its orbital, nasal, and palatine branches. (See Spheno-Palatine Ganglion, p. 962.)

The zygomatic (orbital or temporo-malar) branch, given off from the upper surface of the maxillary nerve, passes forward and lateralward, and, at the end of the inferior orbital (sphenomaxillary) fissure, passes through it into the orbit and divides into two branches, facial and temporal.

The zygomatico-facial (malar) branch runs forward, passes through a zygomatico-orbital foramen, then through the zygomatico-facial (malar) foramen, pierces the orbicularis palpebrarum, communicates with the zygomatic (malar) branch of the facial nerve, and supplies the skin of the prominence of the cheek. The zygomatico-temporal (temporal) branch runs upward in a groove in the lateral wall of the orbit, passes through a zygomatico-orbital foramen, then through the zygomatico-temporal (spheno-malar) foramen, and enters the temporal fossa. It turns around the anterior border of the temporal muscle, pierces the deep layer of the temporal fascia, and runs backward for a short distance in the fat between the superficial and deep lamellæ, then, turning lateralward, it pierces the superficial lamellæ about an inch above the zygoma, anastomoses with the temporal branch of the facial nerve, and supplies the skin of the anterior part of the temporal region.

The infra-orbital nerve, that part of the maxillary nerve lying distal to the sphenopalatine ganglion, enters the orbit through the inferior orbital (spheno-maxillary) fissure, accompanied by the infra-orbital artery, and with it passes through the infra-orbital canal (fig. 735) to the face, where it divides into fous sets of terminal branches, some of which, by anastomoses with the branches of the facial nerve, form the infra-orbital plexus.

Three sets of superior alveolar nerves arise from the maxillary and the infra-orbital nerves, namely, the posterior superior alveolar branches, the middle superior alveolar branch, and the anterior superior alveolar branches.

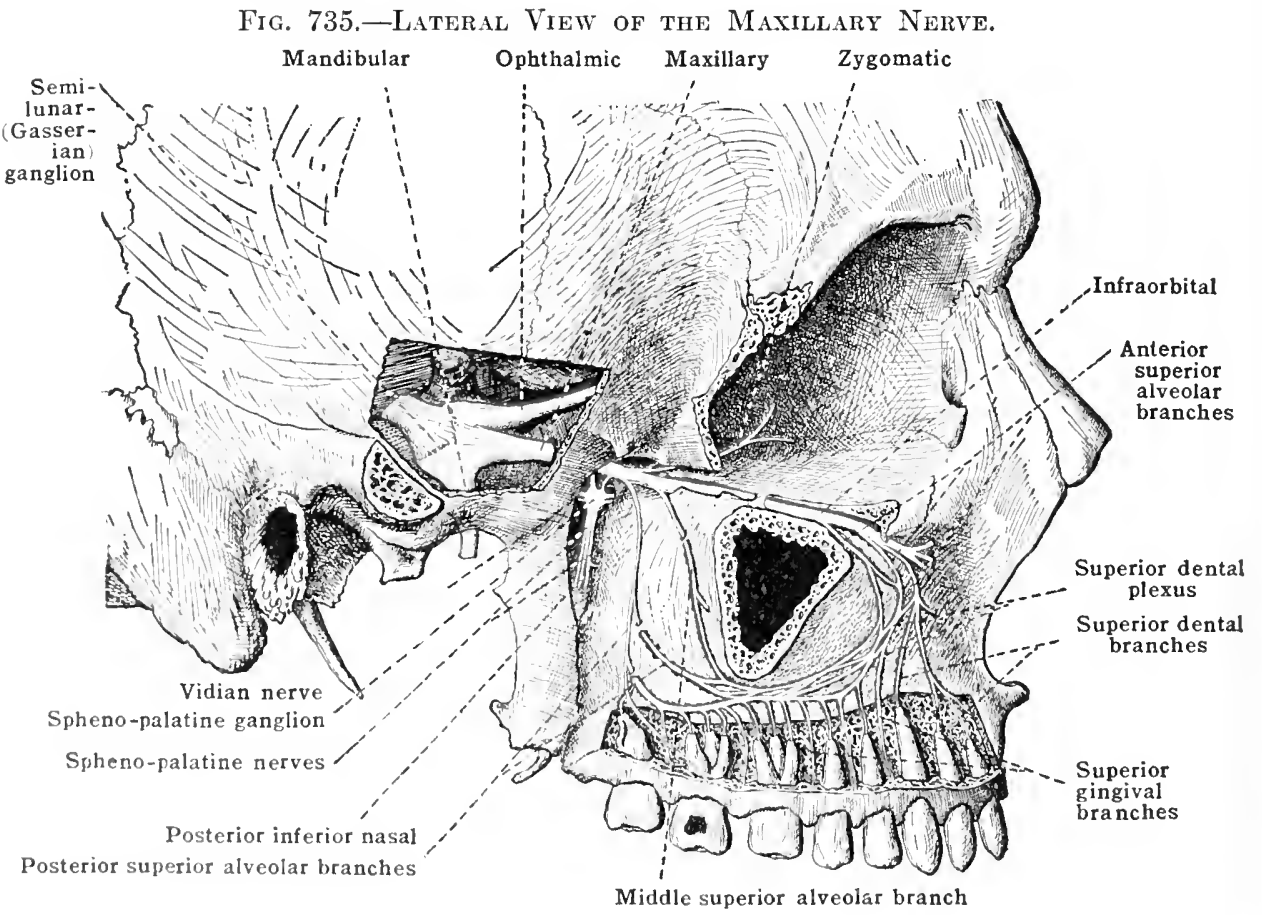

The posterior superior alveolar (dental) nerves are usually two in number, but sometimes arise by a single irunk. 'They piss downward and lateralward through the pterygo-maxillary fissure into the zygomatie frossa, where they give branches to the mucous membrane of the gums and the posterior part of the mouth; then they enter the posterior alveolar (dental) canals and unite with the other alveolar bianches to form the superior dental plexus, through which they give branches to the rorts and pulp eavities of the molar teeth and to the mucous membrane of the maxillary sinus (fig. 7:35).

(c) 'The branches griven off in the infra-orbital sulcus and canal are the middle and anterior superior alveolar (dental) nerves.

(i) The middle superior alveolar (dental) nerve kaves the infra-orbital nerve in the pos" terior pert of the infre-orbital sulcus, and, bassing downward and forward in a canal in the maxillit, it divides info derminal branches that anastomose with the other alveohar branches to form Hor superior dental plorus. Through the plexus it supplies the bieuspid tecth and gives branches (1) the murous membrane of the maxillary sinus and alko to the gums (fig. 735). 
(ii) The anterior superior alveolar (dental) nerve is the largest of the superior alveolar nerves. It is given off by the infra-orbital nerve in the anterior part of the infra-orbital canal, and passes downward in a bony canal in the anterior wall of the maxilla. After uniting with the other alveolar nerves to form the superior dental plexus, it supplies the canines and the incisors and gives branches to the mucous membrane of the maxillary sinus and the gums (fig. 735). It also gives off a nasal branch which enters the nasal fossa through a small foramen, and supplies the mucous membrane of the anterior part of the inferior meatus and the adjacent part of the floor of the nasal cavity.

(iii) The superior dental plexus is formed in the bony alveolar canals by the three superior alveolar nerves. It is convex downward and anastomoses across the mid-line with the corresponding plexus of the other side (fig. 735). From it arise the superior dental branches supplying the superior canines and incisors, superior gingival branches supplying the gums, and also branches to the mucous membrane of the maxillary sinus and to the bone. On the plexus are two gangliform enlargements, one, called the ganglion of Valentine, situated at the junction of the middle and the posterior branches, and the other, called the ganglion of Bochdalek, at the junction of the middle and anterior branches.

(d) The terminal branches of the maxillary nerve are the inferior palpebral, the external and internal nasal (nasal), and the superior labial.

The inferior palpebral branches, usually two, pass upward and supply sensory fibres to all the skin and conjunctiva of the lower eyelid (fig. 740).

The external nasal branches pass medialward under cover of the levator labii superioris (quadratus), and supply the skin of the posterior part of the lateral aspect of the nose.

The internal nasal branches pass downward and medialward under the lateral wall of the nose, and then turn upward to supply the skin of the vestibule of the nose.

The superior labial branches, three or four in number, as a rule are larger than the palpebral and nasal branches. They pass downward to supply the skin and mucous membrane of the upper lip and the neighbouring part of the cheek.

\section{(3) The Mandibular Nerve or Third Division of the Trigeminus}

The mandibular division is the largest of the three divisions of the trigeminus (figs. 736 and 740). As a nerve, it is usually described as formed by the union of two distinct nerves, namely, the entire masticator nerve and the large bundle of sensory fibres derived from the semilunar (Gasserian) ganglion which pass peripherally as the third division of the trigeminus. These two nerves remain separate until they pass through the foramen ovale and then unite immediately outside the skull to form a large trunk which almost directly after its formation divides into a small anterior and a larger posterior portion. The trunk is situated between the pterygoideus externus, laterally, and the otic ganglion and the tensor palati medially. In front of it is the posterior border of the pterygoideus internus, and behind it, the middle meningeal artery. Two branches arise from the trunk of the nerve before its division, namely, the spinous (recurrent) nerve and the nerve to the pterygoideus internus.

The spinous (recurrent) nerve, after receiving a vasomotor filament from the otic ganglion, enters the cranium through the foramen spinosum, a ccompanying the middle meningeal artery, and divides into an anterior and a posterior branch. The anterior branch communicates with the meningeal branch of the maxillary division of the trigeminus, furnishes filaments to the dura mater, and ends in the osseous substance of the great wing of the sphenoid. The posterior branch traverses the petrosquamous suture and ends in the lining membrane of the mastoid cells.

The fibres going to form the nerve to the internal pterygoid muscle are almost wholly motor fibres and therefore comprise a branch of the masticator nerve and are described as such under the description of the masticator (fig. 737).

The anterior portion of the mendibular nerve is smaller than the posterior and is chiefly composed of motor fibres which form branches of the masticator nerve and supply the muscles of mastication, the temporalis, masseter, and pterygoideus externus. Practically all of the sensory fibres of the anterior portion (fibres of the mandibular nerve proper) form the buccinator (long buccal) nerve. The latter is accompanied, in the first part of its course, by a small strand of motor or masticator fibres which leaves it to end in the anterior part of the temporal muscle.

The buccinator (long buccal) nerve, entirely sensory, passes between the two heads of the external pterygoid muscle and runs downward and forward under cover of or through the anterior fibres of the temporalis to the cheek (fig. 736). As it passes forward it emerges from under cover of the anterior border of the masseter and lies on the superficial surface of the buccinator, where it interlaces with the buccal branches of the facial nerve and gives off filaments to supply the superjacent skin; finally it pierces the buccinator and supplies the mucous membrane on its 
inner surface as far forward as the angle of the mouth. The fibres of the anterior deep temporal nerve, a branch of the masticator, are frequently associated with the buccinator until the latter has passed between the heads of the external pterygoid; then the anterior deep temporal nerve separates from the buccinator and passes upward on the lateral surface of the upper head of the external prerygoid.

The posterior portion of the mandibular nerve divides in to three large branches. Two of these, the lingual and the auriculo-temporal nerves, are exclusively sensory; the third, the inferior alveolar (dental) nerve, contains a strand of motor fibres, the mylo-hyoid nerve, which comprise a branch of the masticator nerve.

The lingual nerve is the most anterior branch of the mandibular nerve (figs. $736,743)$. It lies in front and to the medial side of the inferior alveolar (dental) nerve and descends at first on the medial side of the pterygoideus externus, then between the pterygoideus internus and the ramus of the mandible to the posterior part of the mylohyoid ridge, where it passes off the anterior border of the pterygoideus internus; at this point it is situated a short distanee behind the last

Fig. 736.-Distribution of the Mandibular Division of the Trigeninus combined with Branches of the Masticator Nerve. (Henle.)

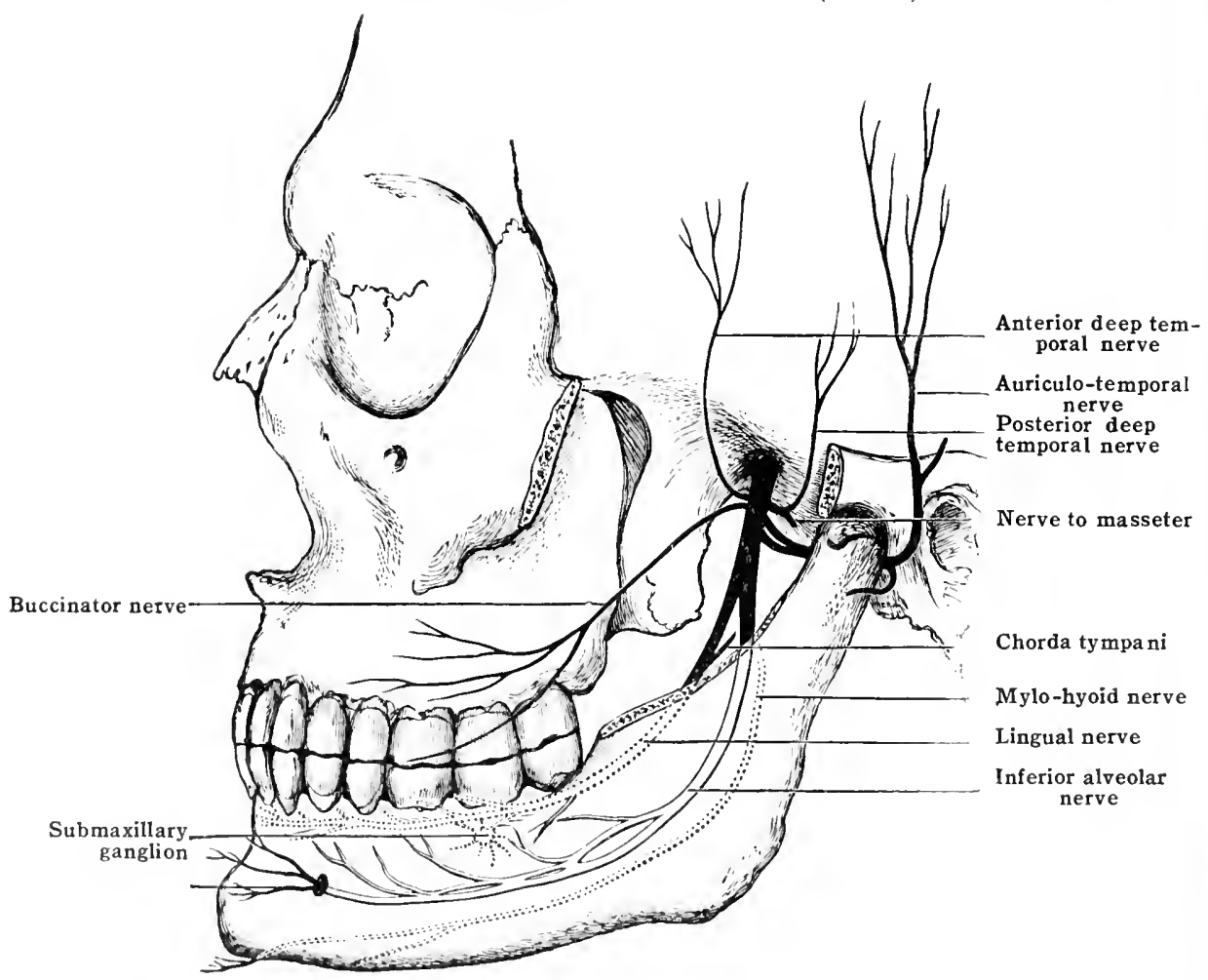

molar tooth and is avered in front by the mucous membrane of the posterior part of the mouth mavity. After leaving the pteryoideus internus it crosses the fibres of the superior constrictor, which are attached to the mandible, and turns forward towarl the tip of the tongue, crossing the lateral surfaces of the styloglossus, hyoglositu, and genioglossus. In its course across the hyoglossus it lies first above, then to the lateral sille of, and finally below Wharton's duet, and ats it asernels on the genioglossus it lies on the merlial sirle of the duct.

Communications and branches. While it is on the merlal side of the pterygoideus externus

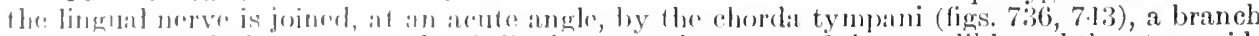

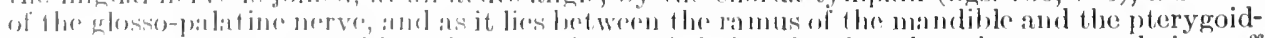

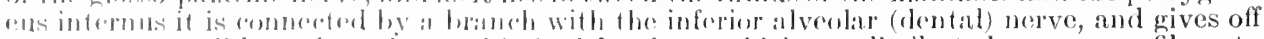
(ne or 1 wo suall branches, the rami isthmi faucium, which are ditributed as sensory fibres to

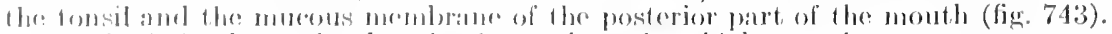

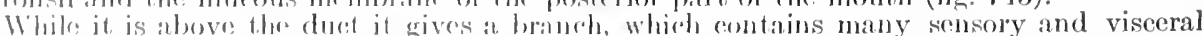

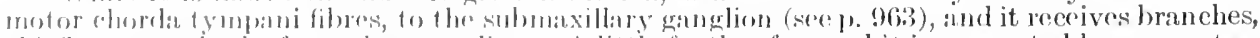
chicfly sympat hetice, from that ganglion. A lit, li further forward it is connected by one or two branches, which run aleng the anteriog boneler of the hyoglossus, with the hypogtossibl nerve 
(fig. 743). It then gives off the sublingual nerve, which runs forward to supply the sublingual gland and the neighbouring mucous membrane (fig. 743). Its terminal (lingual) branches are derived chiefly from the glosso-palatine nerve. They pierce the muscular substance of the tongue and are distributed to the mucous membrane of its anterior two-thircts. They interlace with similar branches of the other side and with branches of the glosso-pharyngeal nerve.

The inferior alveolar (dental) nerve is the largest branch of the posterior portion of the mandibular nerve. It commences on the medial side of the external pterygoid muscle and descends to the interval between the spheno-mandibular ligament and the ramus of the mandible, where it receives one or two communicating branches from the lingual nerve. Opposite the midclle of the medial surface of the ramus it enters the mandibular (inferior dental) canal, accompanied by the inferior alveolar (dental) artery, which lies in front of the nerve, and it runs downward and forward through the ramus and the body of the mandible (fig. 736). At the mental foramen it divides into two parts, one of which, the mental nerve, passes out through the mental foramen, the other, commonly called the incisive branch, continues forward in the canal, and supplies, through the inferior dental plexus, the inferior canine and incisor teeth and the corresponding regions of the gums.

Branches.-The branches of the inferior alveolar (dental) nerve are branches forming the inferior dental plexus, and the mental branch. A bundle of motor fibres, the mylohyoid nerve, a branch of the masticator nerve, is given off just before the inferior alevolar nerve enters the mandibular canal.

The inferior dental plexus is formed by a series of branches which communicate with one another within the bone, giving rise to a fine network. From this plexus two sets of branches are given off:- the inferior dental branches, corresponding in number to the roots of the teeth, enter the minute foramina of the apices of the roots and end in the pulp; the second set, the inferior gingival branches, supply the gums.

The mental nerve is a nerve of considerable size which emerges through the mental foramen (fig. 736). It communicates, near its exit from the bone, with branches of the facial nerve, and then divides into three branches. The smallest branch, turning down ward, divides into several twigs, the mental branches, which supply the integument of the chin. The other two, inferior labial branches, pass upward, diverging as they ascend, and divide into a number of twigs. The stoutest twigs ramify to the mucous membrane which lines the lower lip. Other twigs are distributed to the integument and fascia of the lip and chin.

The auriculo-temporal nerve usually arises from the posterior portion of the mandibular nerve by two roots which embrace the middle meningeal artery and unite behind it to form the trunk of the nerve. The trunk passes backward on the medial aspect of the pterygoideus externus, and between the spheno-mandibular ligament and the temporo-mandibular articulation, lying in close relation with the capsule of the joint. Behind the joint it enters the upper part of the parotid gland, through which it turns upward and lateralward. It emerges from the upper end of the gland, crosses the root of the zygoma close to the posterior border of the superficial temporal artery, and divides into auricular and temporal terminal branches at the level of the tragus of the pinna (fig. 736).

Communications. - (a) Each of the two roots of the nerve receives a communication from the otic ganglion containing fibres derived from the glosso-pharyngeal nerve. These fibres have passed from the glosso-pharyngeal through the tympanic plexus and the small superficial petrosal nerve and through the otic gangtion.

(b) Sensory filaments pass from the auriculo-temporal nerve to the temporo-facial branch of the facial nerve.

(c) Filaments of connection with the sympathetic plexus on the internal maxillary artery.

(d) A communication to the inferior alveolar (dental) nerve.

Branches of the auriculo-temporal nerve.- (a) An articular branch to the temporo-mandibular joint, given off as the nerve lies on the medial side of the capsule.

(b) Branches to the external auditory meatus. Two branches, as a rule, are given off in the parotid gland. They enter the meatus by passing between the cartilage and the bone and supply the upper part of the meatus, the membrana tympani by a fine branch, and occasionally the lower branch gives twigs to the skin of the lobule of the pinna.

(c) Parotid branches are distributed to the substance of the parotid gland. Sensory or trigeminal fibres for the gland spring either directly from the nerve or from the communicating branches previously given by it to the glosso-palatine nerve. The parotid branches also contain fibres derived from the glosso-pharyngeal nerve which pass successively through its tympanic branch, the tympanic plexus, the small superficial petrosal nerve, the otic ganglion, and the communicating twigs from the otic ganglion to the roots of the auriculo-temporal nerve. The parotid branches are later again mentioned as concerned chiefly with the gangliated cephalic plexus.

$(d)$ The anterior auricular branches, usually two in number, are distributed to the skin of the tragus and the upper and outer part of the pinna. 
(e) The superficial temporal branches supply the integument of the greater part of the temporal region, and anastomose with the temporal branch of the facial nerve.

THE MASTICATOR NERVE (Fig. 737)

The masticator nerve (motor root or portio minor of trigeminus). The fibres of the masticator nerve spring from two nuclei, a slencler upper or mesencephalic nucleus and a clustered lower or chief nucleus. The fibres arising in the mesencephalic nucleus descend along the lateral aspect of the nucleus to the pons as the descending or mesencephalic root; ${ }^{*}$ here they join the fibres from the chief motor nucleus and issue with them from the side of the pons in from six to ten root filaments. These blend to form the nerve, which is from one and a half to two millimetres broad. At the point where it emerges from the pons the nerve is in front of and ventral to the root of the trigeminus and it is separated from the latter by a few of the transverse fibres of the pons which constitute the lingula of Wrisberg. From its superficial exit from the pons, the masticator nerve passes upward, lateralward, and forward in the posterior fossa of the cranum, and along the medial and anterior aspect of the trigeminus, to the mouth of Meckel's cave. In this cavity it runs lateralward below the semilunar (Gasserian) ganglion to the foramen ovale, through which it passes to join the mandibular division of the

Fig. 737.-Schematic Representation of the Masticator Nerve and its Branches (IN BLACK). Lateral view. Modified from Spalteholz.

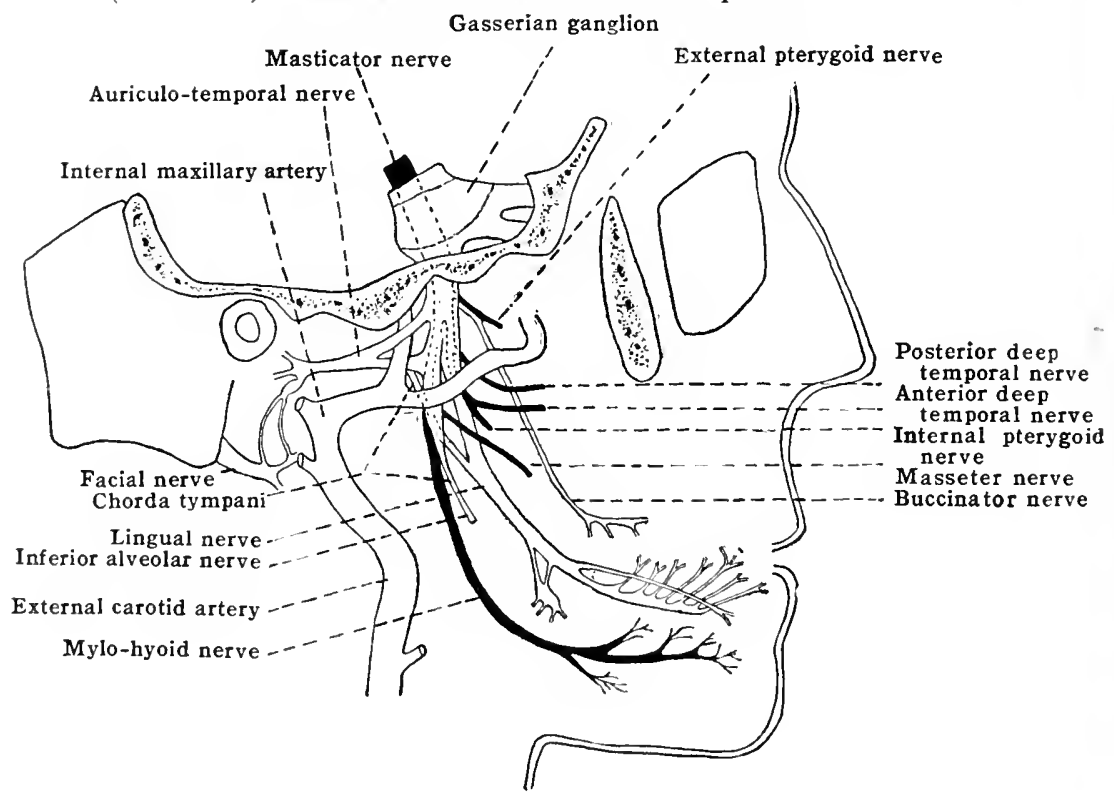

trigeminus immerliately outside and below the base of the skull. The nerve is purcly motor and its fibres are devoted almost wholly to the muscles having to do with mastication.

Central connections.- The nuclei of origin of the inasticator nerve are connected with the lower part of the somsesthetic area of the cerebral cortex of the opposite side by the pyramidal fibres clescending in the genu of the internal capsule, and they are associated with the sensory nuclei of other cranial nerves through the reticular formation and by the medial longitudinal fasciculns.

Branches.-Almost inmodiately after joining the trunk of the mandibular nerve, most of the filsres of the mastieator leave it to form the greater part of the so-called anterior portion of the inandibular. However, one branch of masticator fibres, the nerve to the internal pterygoid musele, is given off from the mandibular just before its division into anterior and posterior portions. 'The masticator

* Recent investigations imlieate that the mesencphalic root is not wholly motor but at least in part sensory in character, and thus lelongs partly to the trigeminal nerve. (See vage 829.$)^{\circ}$ 
branches derived from the anterior portion are the deep temporal nerves, the masseteric nerve, and the nerve to the external pterygoid. One branch, the mylo-hyoid nerve, is carried in the posterior portion of the mandibular and is given off from its inferior alveolar branch.

The nerve to the internal pterygoid passes under cover of a dense layer of fascia derived from an expansion of the ligamentum pterygo-spinosum, and enters the deep surface of the muscle. Near its commencement this nerve furnishes a visceral motor root to the otic ganglion, and small twigs to the tensor tympani and tensor palati.

The deep temporal nerves, usually two in number, posterior and anterior, pass between the bone and the upper border of the external pterygoid muscle, and turn upward around the infratemporal crest of the sphenoid bone to end in the deep surface of the temporalis (fig. 736). The posterior of the two often arises in common with the masseterie nerve. The anterior is frequently associated with the buccinator (long buccal) nerve till the latter lias passed between the two heads of the pterygoideus externus. There is frequently a third branch, the medius, which passes lateralward above the pterygoideus externus, and turns upward close to the bone to enter the deep surface of that muscle. A small strand of masticator fibres accompanies the buccinator nerve to enter and end in the anterior part of the temporal muscle.

The masseteric nerve, which frequently arises in common with the posterior deep temporal nerve, passes between the bone and the pterygoideus externus, and accompanies the masseteric artery through the notch of the mandible to be distributed to the masseter (fig. 736). It is easily traced through the deeper fibres nearly to the anterior border of the masseter. As it emerges above the pterygoideus externus it gives off a twig to the temporo-mandibular articulation.

The nerve to the external pterygoid, after a course of about $3 \mathrm{~mm}$. (an eighth of an inch), divides into twigs which enter the deep surface of the two heads of the nuscle. It is usually adherent at its origin to the buccinator nerve.

The mylo-hyoid branch, carried in the posterior portion of the mandibular nerve, is given off immediately before the inferior alveolar (dental) nerve enters the mandibular (inferior dental) canal. It pierces the lower and back part of the spheno-mandibular ligament and runs downward and forward in the mylo-hyoid groove between the mandible on the lateral side, and the internal pterygoid muscle and the lateral surface of the submaxillary gland on the medial side. In the anterior part of the digastric triangle it is continued forward between the anterior part of the submaxillary gland and the mylo-hyoideus, and it breaks up into branches which supply the mylo-hyoideus and the anterior belly of the digastric (fig. 736).

\section{THE FACIAL NERVE}

The facial or seventh nerve is purely motor. It is accompanied a short distance by a bundle usually called its sensory root or the intermediate nerve. This latter, however, on the basis of its origin, distribution, and mixed instead of sensory character, is described separately below as the glosso-palatine nerve. It is smaller than the facial, is fused to the trunk of the facial and the ganglion giving rise to its sensory fibres is situated upon the external genu of the facial (figs. 738 and 741).

The fibres of the facial nerve (fig. 738) spring from a nucleus of cells situated laterally in the reticular formation at the level of the lower pons, dorsal to the superior olive, and between the root fibres of the abducens nerve and the laterally placed spinal tract of the trigeminus. From this nucleus the fibres of the nerve pass medially and dorsalward to the floor of the fourth ventricle and, just under the floor, they turn anteriorly, passing dorsal to the nucleus of the abducens (fig. 653, p. 827). At the anterior end of this nucleus they turn sharply ventralward and lateralward, and at this point it is claimed that fibres descending in the near-by medial longitudinal fasciculus from the nucleus of the oculo-motor nerve of the same side become intermingled with the fibres of the facial nerve and pass outward with them. This, however, is uncertain. Continuing ventralward through the reticular formation the fibres of the facial emerge from the brain-stem at the inferior border of the pons, lateral to the superficial attachment of the abducens. At the point of its emergence, the facial nerve pierces the pia mater, from which it receives a sheath, and then proceeds forward and lateralward in the posterior fossa of the cranium to the internal auditory meatus, which it enters in company with the glosso-palatine nerve and with the cochlear and vestibular nerves. As it lies in the meatus it is situated above and in front of the latter nerves, from which it is separated by the glosso-palatine, and it is surrounded, together with these three nerves, by sheaths of both the arachnoid and the dura mater and by prolongations of the subarachnoid and sub-dural spaces. While it is still in the meatus it blends with the glosso-palatine and thus the combined trunk is formed. At the outer end of the meatus the trunk pierces 
the arachnoid and the dura mater and enters the facial canal (aqueduct of Fallopius), in which it runs forward and slightly lateralward to the hiatus Fallopii, where it makes an angular bend, the external genu [geniculum], around the anterior boundary of the restibule of the inner ear; this bend is enlarged by the adhesion of the geniculate ganglion (of the glosso-palatine) upon its anterior border. From the geniculum the facial nerve runs backward in the facial canal along the lateral wall of the vestibule and the medial wall of the tympanum, above the fenestra restibuli (ovalis), to the junction of the medial and posterior walls of the tympanic carity; then, bending downward, it descends in the posterior wall to the stylo-mastoid foramen. As soon as it emerges from the stylo-mastoid foramen it turns forward around the lateral side of the base of the styloid process,

Fig. 73S.-Diagram of the Facial (Yellow) and Glosso-palatine Nerve (Blue).

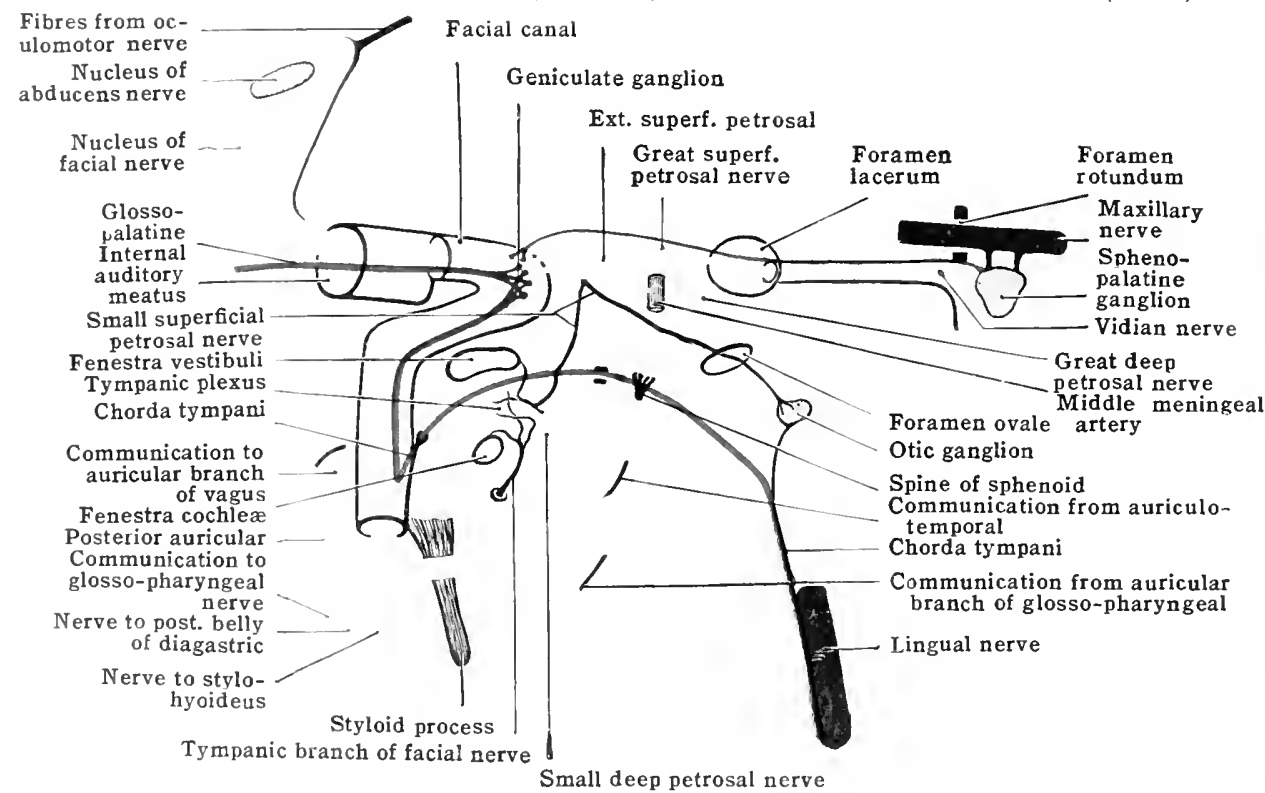

and plunges into the substance of the parotid gland, where it divides into its cervico-facial and temporo-facial terminal divisions. Before its terminal divisions, the nerve gives off three, and sometimes four, small branches: one, the nerve to the stapedius muscle, before it leave's the skull, the others after it leaves the skull.

The nerve to the stapedius is given off from the facial nerve as it iescends in the posterior wall of the tympanum behind the pyramidal eminence. It is stated that filaments are also given off from the laceial to the auditory artery (probably visceral notor from the glosso-palatine) While the noreve is passing through the intornal auditory meatus.

After it leaves the skull the facial nerve gives off two or three collateral branches and its two terminal divisions, the temporo-facial and eervico-facial. T'he collateral hranches arre the posterior auricular nerve, a branch to the posterior berlly of the digatstrie, and sometimes a lingual branch.

(1) The posterior auricular nerve is the lirst branch of the extracranial portion of the facial nerve. It passes butwen the parotid ghand and the anterior border of the stemo-mastoid muscle and runs mpwall in the decp inferval betwern the external auditory meatus and the mastoid poserse. In this sifuation it anmmunicates with the aurieular branch of the vagus. It supplies the anricularis posterior, sonels a slender twig npward to the anricularis superior, and conds in a long solnder lnatuch, the occipital branch, which passes backward to supply the

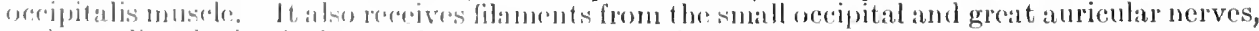
and supplies the intrincire museles of the andricle (pintua).

(2) The nerve to the posterior belly of the digastric arises from the facial nerve ctose to

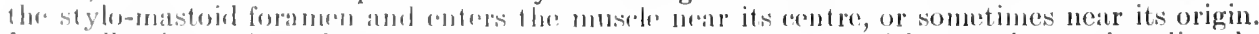
It ustially gives off 1 wo lormehes: the nerve to the stylo-hyoid, which smmetimes arises directly from the farial merve murl passes to the uppere part of the muscle that it supplies, and the anastomotic branch, which joins 1 ho glosso-pharyngeal norve betow its petrons ganglion.

(3) 'Thro lingual branch, first descrihed liy cruvoilhier, is not commonly present. It arises

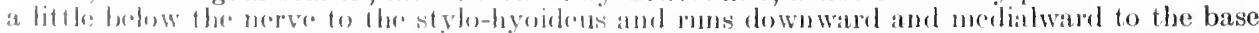

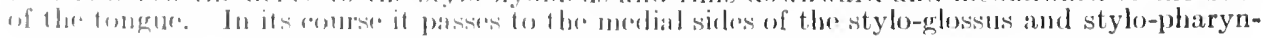


geus, and runs downward along the anterior border of the latter muscle to the wall of the pharynx. It pierces the superior constrictor, insinuates itself between the tonsil and the anterior pillar of the fauces, and it is stated that it gives filaments to the base of the tongue and to the stylo-glossus and glosso-palatinus (palato-glossus) muscles.

The terminal divisions.--In the substance of the parotid gland the two terminal divisions of the facial merve lie superficial to the external carotid artery and to the posterior facial (temporo-maxillary) vein. The way in which these terminal divisions give off their branches varies much in different subjects and often on the opposite sides of the same subject. One of the more common forms is here described.

The temporo-facial or upper division runs upward and forward, and, after receiving communicating twigs from the auriculo-temporal nerve, gives off temporal and zygomatic (malar) branches. The cervico-facial or lower division runs downward and forward, receives branches from the great auricular nerve, and

Fig. 739.-The Right Facial Nerve, Within the Skull, axd the Relatioxs of the Glosso-palatine and Glosso-pharycigal Nerves mith the Trupanic and Ixterial Carotid Plextses. (From Sobotta's Atlas, modified.)

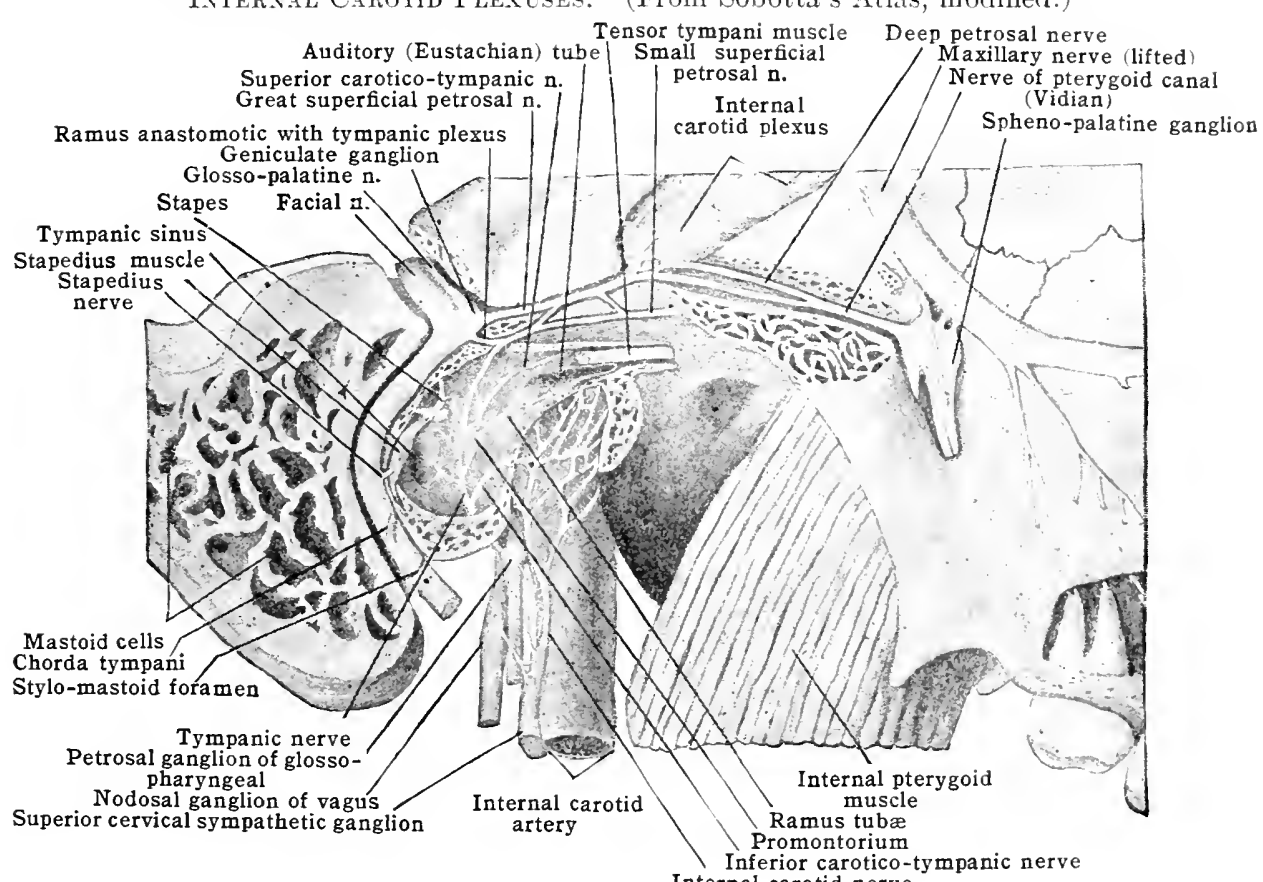

Internal carotid nerve

gives off-(1) buccal branches, comprising what have been called infraorbital and buccal branches; (2) the marginal mandibular (supra-mandibular) branch; and (3) the ramus colli (infra-mandibular branch). These branches from the two terminal divisions anastomose freely to form the parotid plexus (pes anserinus).

The temporal branches passing upward communicate freely with each other and with the zygomatic branches. They also communicate with the zygomatico-temporal branch of the zygomatic nerve (the orbital branch of the maxillary nerve) and with the supra-orbital nerve. They supply the frontalis, orbicularis oculi, corrugator supercilii, and auricularis anterior and superior (fig. 740).

The zygomatic (malar) branches passing upward and forward, communicate with the buccal branches of the facial nerve; with the zygomatico-facial branch of the zygomatic nerve (the orbital branch of the maxillary nerve); with the supraorbital and lacrimal branches of the ophthalmic nerve, and with the palpebral twigs of the maxillary. They supply both eyelids, the orbicularis oculi, and the zygomaticus (fig. 740 ).

The buccal (infra-orbital and buccal) branches arise sometimes from the lower terminal division and sometimes from both the upper and the lower terminal divisions. The buccal branches, passing forward upon the masseter and underneath the zygomaticus and quarratus labii superioris, interlace with the zygomatic and marginal mandibular (supra-mandibular) branches of the facial nerve, with the buccinator (long buccal) branch of the trigeminus, and with the terminal branches of the maxillary nerve, forming with the last-named nerve the infraorbital plexus. They supply the zygomaticus, risorius, quadratus labii superioris, caninus, 
buccinator, incisivi, orbicularis oris, triangularis, quadratus labii inferioris, and the muscles of the nose (fig. 740).

The marginal mandibular (supra-mandibular) branch, passing downward and forward under cover of the risorius and the depressors of the lower lip, communicates with the buccal branches and with the ramus colli of the facial nerve, and with the nental branch of the mandibular nerve. It supplies the quadratus labii inferioris and mentalis.

The ramus colli (infra-mandibular branch) runs downward and forward under cover of the platysma, which muscle it innervates (fig. 740). Beneath the platysma it forms one or more communicating loops, near its commencement, with the great auricular nerve, and longer loops, lower down, with the superficial cervical nerve.

Central connections.- The nucleus of origin of the facial in the rhombencephalon includes an anterior and a posterior group of cells which give rise respectively to its upper and lower terminal divisions. They are associated with the somæsthetic area (lower third of the anterior central gyrus) by way of the pyramidal fasciculi of the opposite and same sides, and with the nuclei of the other cranial nerves, including the nucleus of termination of the glosso-palatine, by way of the reticular formation and the medial longitudinal fisciculus.

Fig. 740.-Superficial_Distribution of the Facial and other Nerves of the Head, (After Hirschfield and Leveillé.)

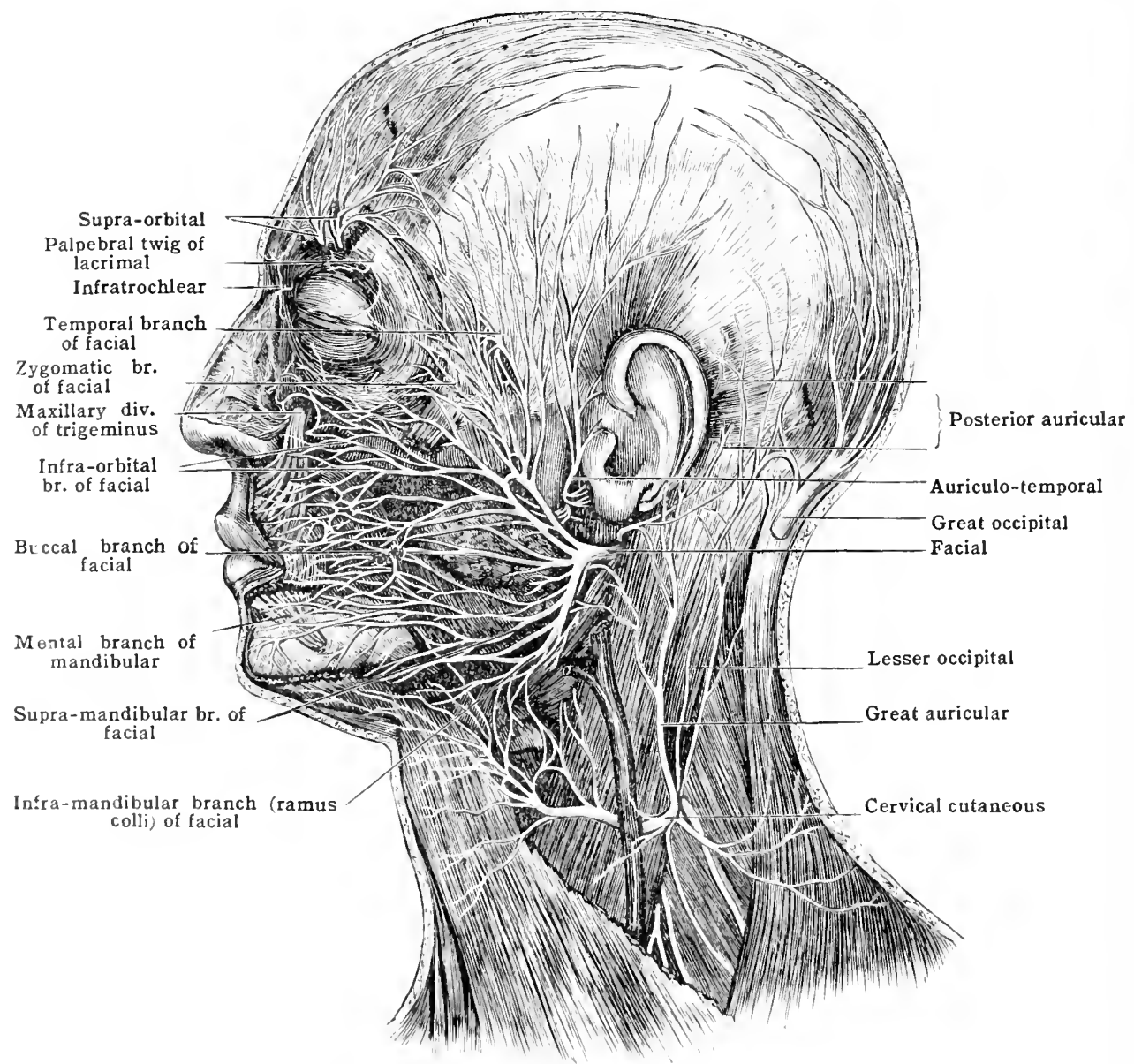

GLOSSO-PALATINE NERVE

'T'he glosso-palatine nerve (sensory cout or pars intrmedin of facial, nerve of Wrisberg) contains boll seneory and notor fibres. While it has a separate altaclument to the medulla, it comrses in close company with the facial and, in the intermal anditory moatcs, it is involved in the same sheath with the facial, whech relation is maintained ly its larger part thence through the facial canal till

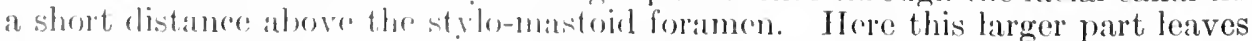
the tronk of the fariat as the chorde tympani nowe. The origin, central connections and peripheral distribution of the glosion-palatine are similar to those of the 
glosso-pharyngeal nerve and suggest that it may be considered an aberrant portion of that nerve.

The sensory portion is much greater than the motor. Its fibres arise from cells situated in the geniculate ganglion which thus corresponds to a spinal ganglion. The central processes from these cells pass medialward in the facial canal (aqueduct of Fallopius) enclosed in the sheath of the facial nerve, which they leave in passing through the internal auditory meatus, to turn slightly downward in the posterior fossa of the cranium and enter the medulla at the inferior border of the pons, between the attachments of the facial and vestibular nerves. They course through the reticular formation of the medulla, medianward and dorsalward to terminate about cells which comprise a superior extension of the nucleus of termination of the glosso-pharyngeal nerve (nucleus of ala cinerea). The peripheral processes from the geniculate ganglion are distributed chiefly to the epithelium covering the soft palate, portions of the glosso-palatine arches, and the anterior two thirds of the tongue.

The geniculate ganglion is so named from the fact that it is embedded upon the anterior border of the external genu (geniculum, great bend) of the facial nerve, behind the hiatus Fallopii. It is somewhat triangular in form. From its superomedial angle leave the central processes of its cells, the root of the nerve; from its infero-lateral angle leave the fibres which later leave the sheath of the facial as the chorda tympani, and its anterior angle is connected with the great superficial petrosal nerve (figs. 738 and 741). The geniculate ganglion contains a relatively large number of cell-bodies of sympathetic neurones many of whose processes run in this latter nerve, a relation mentioned below with the gangliated cephalic plexus.

The motor portion of the glosso-palatine consists for the most part of visceral efferent fibres, chiefly secretory. These arise in the medulla oblongata from a small group of cells scattered in the reticular formation dorso-medial to the nucleus of the facial and in line with the dorsal efferent nucleus of the vagus below. It is called the salivatory nucleus. The fibres course ventralward and lateralward to their exit, mingle with the entering sensory fibres of the glossopalatine in the sheath of the facial and, through the branches of the glossopalatine, pass to terminate in sympathetic ganglia of the head, large and smali. These ganglia send axones which terminate in the smooth muscle of vessels and about the cells of the glands of the lingual and palatine mucous membrane and of the salivary glands proper. Some of the motor fibres of the nerve terminate in contact with the sympathetic cells remaining in the geniculate ganglion and which give rise to sympathetic fibres issuing from it. Most of the motor fibres pass into the great superficial petrosal nerve and the chorda tympani to terminate in (chiefly) or pass through the spheno-palatine and submaxillary ganglia respectively. Some may pass by the geniculo-tympanic branch and tympanic plexus to end in the otic ganglion. Many no doubt end in the smaller ganglia involved in the various sympathetic plexuses. It is suggested that the motor part carries secretory impulses destined chiefly for the sub-maxillary and sublingual glands. A small gangliated plexus on the capsule of the medial side of the parotid gland has been frequently dissected and found to communicate freely with twigs from the facial nerve and twigs concerned with the trigeminus. It is possible that some glosso-palatine visceral motor fibres terminate in these ganglia for secretory impulses to the parotid gland as well.

Central connections.- The nucleus of termination of the glosso-palatine nerve (superior extension of the nucleus of termination of the sensory portion of the glosso-pharyngeal) is associated with the somesthetic area of the cerebral cortex of the opposite and same sides by way of the medial lemniscus, and with the salivatory nucleus and motor nuclei of other cranial nerves by way of the reticular formation and medial longitudinal fasciculus. The nucleus of origin of the motor portion (salivatory nucleus) may be associated not only with the nucleus of termination of the sensory part, but wit. the nuclei of termination of other cranial nerves, and perhaps with the motor area of the cortex of the opposite side by way of the pyramidal fasciculi.

Branches and communications.- Aside from its two or three small collateral twigs of communication, the fibres of the glosso-palatine course in two main branches or nerves: (1) the great superficial petrosal nerve, continued through the Vidian nerve, and extended through and beyond the spheno-palatine ganglion as the palatine portion of the glosso-palatine (palatine nerve); (2) the chorda tym- 
pani, the larger branch, which extends to join and contribute its quota of fibres to the lingual nerve, a branch of the trigeminus.

In the internal auditory meatus, the glosso-palatine gives two delicate collaterals to the restibular nerve, and some filaments (visceral motor probably) are described as given to the auditory artery and to the temporal bone.

A small geniculo-tympanic branch is given, in the facial canal, from the geniculate ganglion to the small superficial petrosal nerve. This is probably all visceral motor and sympathetic fibres (fig. $7+1$ ).

There may occur a twig arising from or near the beginning of the chorda tympani and forming a communication with the auricular branch of the vagus.

A large part of the great superficial petrosal nerve is formed of glosso-palatine fibres. This nerve is further described below in its relation to the spheno-palatine ganglion. It arises from the anterior angle of the geniculate ganglion, enters the middle fossa of the cranium through

Fig. 741.-Diagram of tile Glosso-palatine Nerve (Black) and the Relations of the Gajgliated Cephalic Plexus to other Cranial Nerves. (After Bean.) Broken lines, notor; continuous lines, sympathetic; glosso-palatine in solid black. Medial view. Left side.

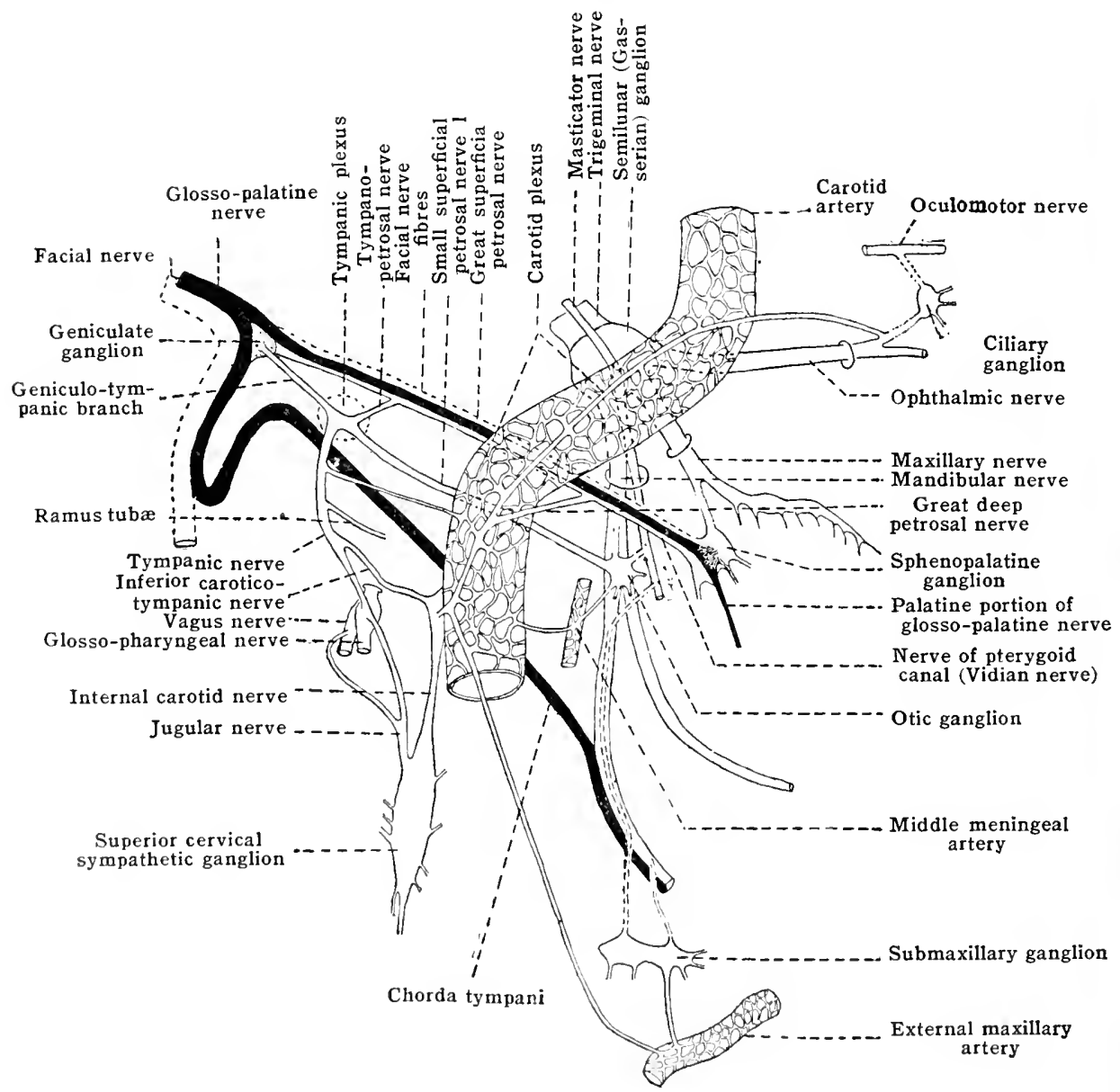

the hiatus fallopii, and patsses beneath the semilunar ganglion in to the forancn lacerum, where it joins with the great drap petrosal nerve to form the Vidian nerve. Thence the glossopalatine portion passes over of through the spheno-palatine ganglion to form the greater part of the small and middle palatine nerves which are distributed to the epithelium and glands of the soft patate, sone of the sensery libres probably terminating in the taste organs found there; the rematurler serving as filmes of genoral sensilility. It is probable that most of the motor glosio-palatine fibres in the great stuperficial petrosal nerve terminate in the spheno-palatine ganghim; some may pass to the arotid plexus ant to small ganglia elsewhere.

The chorda tympani consists to a very large extent of sensory filores (peripheral processes of the ("ells of the geniculate gangliwe), but it also conting motor fibres and is thus also a mixed urive. It leaves the trunk of the facial ueve a short distance above the stylo-mastoid foramen,

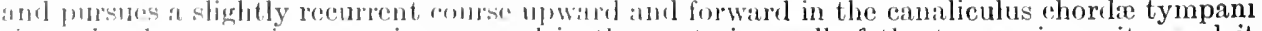
(itor chordes [ostorius), a minate camal in the postorior wall of the tympanic eavity, and it 
enters that cavity close to the posterior border of the membrana tympani. It crosses the cavity, running on the medial surface of the tympanic membrane at the junction of its upper and middle thirds, covered by the mucous membrane lining the tympanic cavity, and passes to the medial side of the manubrium of the malleus above the tendon of the tensor tympani. It leaves the tympanic cavity and passes to the base of the skull through a small foramen (the iter chorda anterius) at the medial end of the petro-tympanic (Glaserian) fissure. At the base of the skull it inclines downward and forward on the medial side of the spine of the sphenoid, which it frequently grooves, and, on the medial side of the pterygoideus externus, it joins the posterior border of the lingual nerve at an acute angle. Some of its fibres (motor chiefly) leave the lingual nerve and pass to the sub-maxillary ganglion, and others (sensory) continue forward to the tongue, where, in company with fibres of the lingual nerve, they terminate in the epithelium covering the anterior two-thirds of the tongue. Some probably serve to convey sensations of taste, most of them are fibres of general sensibility. Before it joins the lingual nerve the chorda tympani receives a communicating twig from the otic ganglion (figs. 738, 741).

\section{THE VESTIBULAR NERVE}

The vestibular nerve is purely sensory. With the peripheral processes of its cells of origin terminating in the neuro-epithelium of the semicircular canals and

Fig. 742.-The Left Membranous Labyrinth of a Human Foetus-of 10 Weeks (30 mar.), Lateral Aspect. Vestibular ganglion and nerve, red; cochlear nerve, yellow. (Streeter, American Journal of Anatomy.)

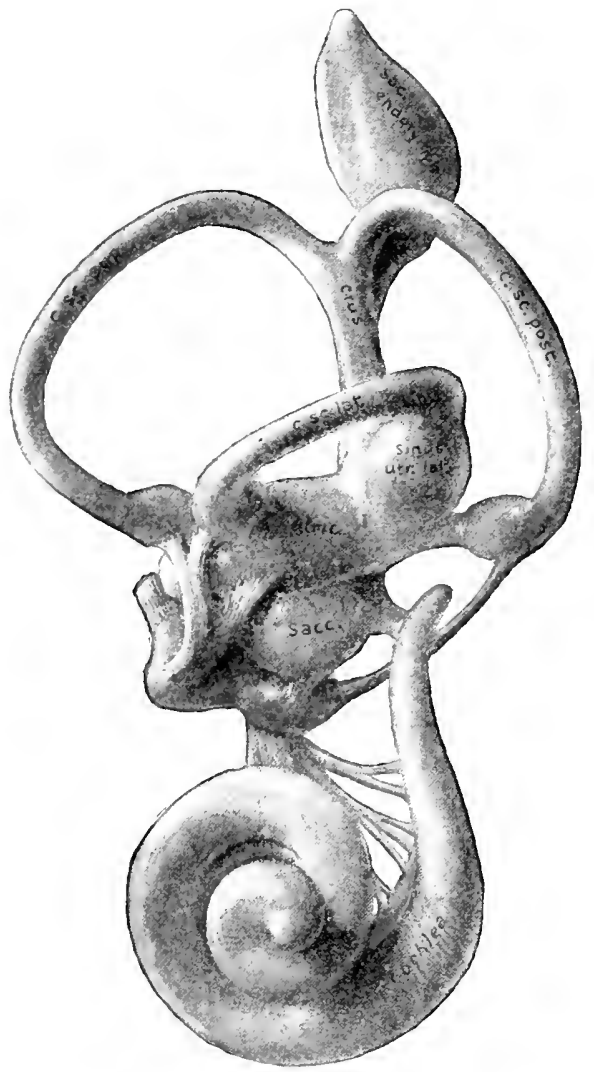

a. $30 \mathrm{~mm}$. lateral.

the vestibule, and their central processes conveying impulses which are listributed to the gray substance of the cerebellum and spinal cord, the nerve comprises a most important part of the apparatus for the equilibration of the body. It has been customary to describe the vestibular [radix vestibularis] and the cochlear [radix cochlearis] nerves combined as the acoustic (auditory) or eighth cranial nerve. While the two are blended in a common sheath from near the medulla to the bottom of the internal auditory meatus, they are likewise partly enclosed in the same sheath with the facial and glosso-palatine nerves and the internal auditory artery which accompany them in this meatus. At the bottom of the meatus 
the vestibular and the eochlear are separate; they are separate at their entrance into the lateral aspect of the medulla oblongata; and their central connections, peripheral distributions and functions are different.

The vestibular nerve arises as processes of the cells of the vestibular ganglion (ganglion of searpa), situated upon and blended within the nerve at the bottom of the internal auditory meatus. Unlike the ordinary spinal ganglion, to which it corresponds, the cells of the vestibular ganglion retain an embryonal, "bipolar," form. The central processes eourse with the cochlear nerve in the internal auditory meatus medialward, eaudad and slightly downward, inferior to the accompanying facial and glosso-palatine nerves, and, arching ventrally around the restiform body, they enter the medulla at the inferior border of the pons, lateral to the glosso-palatine and facial and medial to the entrance of the eochlear nerve. They find their nueleus of termination spread in the floor of the fourth ventricle and grouped as the median, the lateral (Deiters'), the superior, and the nucleus of the spinal root of the vestibular nerve. In the internal auditory meatus, the vestibular nerve is comnected by two small filaments of fibres with the glosso-palatine nerve. These are either visceral motor fibres for the vessels of the domain of the vestibular or are aberrant fibres which eourse only temporarily with the vestibular and return to the glosso-palatine.

The peripheral processes of the cells of the vestibular ganglion terminate in the specialised or neuro-epithelium comprising the maculce in the saceulus and the utriculus and the cristoe in the ampulle of the three semicircular canals. Thus there are five terminal branches of the nerve. None of its fibres terminates in the coclulea. The vestibular ganglion has a lobar form, one lobe giving rise to a superior utriculo-ampullar division which divides into three terminal branches; the other giving a sacculo-ampullar division which gives two terminals.

The superior or utriculo-ampullar branch divides into the following terminal branches:-

(1) The utricular branch passes through the superior macula cribrosa of the vestibule and terminates in the macula acustica of the utriculus.

(2) Accompanying the utricular branch through the superior macula cribrosa is a branch, the superior ampullar, to the crista acustica of the ampulla of the superior semicircular canal, and-

(3) A similar branch, the lateral ampullar, to the ampulla of the lateral semicircular canal.

The inferior or sacculo-ampullar branch accompanies the cochlear nerve a short distance further than the superior, and divides into-

(4) A branch, the posterior ampullar, which passes through the foramen singulare and the inferior macula cribrosa and terminates in the ampulla of the posterior semicircular canal, and-

(5) A branch, the saccular, which passes through the middle macula cribrosa and terminates in the macula acustica of the sacculus.

The central connections of the vestibular nerve are described in detail on pages 823,824 . Its large nucleus of termination, spread through the area acustica in the floor of the fourth ventricle, and divided into four sub-nuclei, is associated with the nuclei fastigii, globosus, and emboliformis of the cerebellum, with the nuclei of the eye-moving nerves, with the spinal cord, and probably with the cercbral cortex.

\section{THE ('OC'HLEAR OR AUDITORY NERVE}

The fitmes of the aodulear norve are distributed to the organ of Corti in the cochleal, and iso arre considered as comprising the auditory nerve proper. They arise from the lomg, coiled spiral ganglion of the cochlea, the cells of which, like those of the vestilsular wanglion, are bipolar. The peripheral processes of these cells are shorter than those of the vestibular ganglion. They terminate about the auditory of hatirecells of the organ of corti and thus collect impulses aroused by stimuli affecting these cells. The central processes of the ganglion cells continue through the modiolar canal and the tractus spiralis forminosus of the cochlea, and thence, joining the vestihnlar nerve through the internal anditory meatus, areompanying the farial norre and internal anditory antery, they course medialwarl and downward, alprosteh and enclasp the restiform body (fig. 665) and enter the lateral aspeet of brain-stente to terminate in their dorsil and ventral nuclei. A description of these moldei and the further central connections of the rochlen with the superior olive, the matei of the eye-moving nerves, the inferior guarlrigeminate bodies, the modial geniculate bodio's, and with the eerebellum and temporal lobes of the coredral hemispheres is given on pages 824, 839. 
The cochlear nerve is separate from the vestibular at the bottom of the internal auditory meatus and at its entrance into the medulla.

THE GLOSSO-PHARYYGEAL NERVE

The glosso-pharyngeal or ninth cranial nerves are mixed nerves and each is attached to the medulla by several roots which enter the postero-lateral sulcus. dorsal to the anterior end of the olivary body and in direct line with the facial nerve.

The filaments, when traced lateralward, are seen to blend, in front of the flocculus, into a trunk which lies in front of the vagus nerve, but which passes through a separate opening through the arachnoid and the dura mater and through the jugular foramen. In the foramen this trunk lies in front, and lateral to the vagus nerve in a groove on the petrous portion of the temporal bone; and in this situation two ganglia are interposed in it, a superior or jugular, and an inferior or petrosal. After it emerges from the jugular foramen the glosso-pharyngeal nerve descends at first between the internal carotid artery and the internal jugular vein and to the lateral side of the vagus; then, bending forward and medialward, it descends medial to the styloid process and the muscles arising from it, and turning around the lower border of the stylo-pharyngeus it passes between the internal and the external carotid arteries, crosses the superficial surface of the stylo-pharyngeus, and runs forward and upward medial to the hyoglossus muscle and across the middle constrictor and the stylo-hyoid ligament, to the base of the tongue (fig. 743).

Ganglia.- The superior or jugular ganglion (ganglion of Ehrenritter), is a small, ovoid, reddish-grey body which lies on the back part of the nerve-trunk in the upper part of the jugular foramen. No branches arise from it. It is sometimes continuous with the petrosal ganglion or it may be absent.

The inferior or petrosal ganglion, (ganglion of Andersch), is an ovoid grey body which lies in the lower part of the jugular foramen, and appears to include all the fibres of the nerve.

Branches and communications.-(1) The petrosal ganglion is connected with the superior cervical ganghion of the sympathetic by a fine filament.

(2) It also has a filament of communication with the auricular branch of the vagus which varies inversely in size with the latter branch and sometimes entirely replaces it. This filament may be absent.

(3) An inconstant communication with the ganglion of the root of the vagus.

(4) A short distance below the petrous ganglion the trunk of the nerve is connected by a twig with that branch of the facial nerve which supplies the posterior belly of the digastric muscle. There is also a small twig (probably sensory') to the stylo-hyoid.

(5) From the petrosal ganglion: The tympanic branch (nerve of Jacobson) arises from the petrosal ganghion and passes through a foramen, which lies in the ridge of bone between the carotid canal and the jugular fossa, into the tympanic canaliculus (Jacobson's canal), where it is surrounded by a small, fusiform mass of vascular tissue, the intumescentia tympanica. After traversing the tympanic canaliculus it enters the tympanum at the junction of its lower and medial walls, and, ascending on the medial wall, breaks up into a number of branches which take part in the formation of the tympanic plexus on the surface of the promontory (fig. 739). The continuation of the nerve emerges from this plexus as the small superficial petrosal nerve, which runs through a small canal in the petrous portion of the temporal bone, beneath the canal for the tensor tympani, and appears in the middle fossa of the cranium through a foramen which lies in front of the hiatus Fallopii. From this foramen it runs forward and passes through the foramen ovale, the canaliculus innominatus, or the spheno-petrosal suture, and enters the zygomatio fossa, where it joins the otic ganglion. While it is in the canal in the temporal bone the small superficial petrosal nerve is joined by a geniculo-tympanic branch from the geniculate ganglion of the glosso-palatine nerve.

(6) Branches from the tympanic plexus:-(a) The tubal branch (ramus tubre), a delicate branch, which runs forward to the nucous membrane of the tuba auditiva (Eustachian tube) and sends filaments backward to the region of the fenestra vestibuli (ovalis) and the fenestra cochleæ (rotunda).

(b) The superior and inferior caroticu-tympanic (carotid) branches pass medianward to the internal carotid plexus (fig. 741).

The above communications carry fibres almost entirely concerned with the sympathetic plexuses of the head and they will be again mentioned below with the gangliated cephalic plexus.

Branches from the trunk of the nerve:-(1) Pharyngeal branches, which may be two or three in number, arise from the nerve a short distance below the petrosal ganglion. The principal and most constant of these passes on the lateral side of the internal carotid artery, and after a very short independent course joins with the pharyngeal branch of the vagus and with branches of the superior cervical ganglion to form the pharyngeal plexus (fig. 743). 
(2) A muscular branch is distributed to the stylo-pharyngeus muscle. This branch receives a communication from the facial nerve (fig. 743 ).

(3) The tonsillar branches are a number of snall twigs which arise under cover of the hyoglossus muscle; they proceed to the tonsil, around which they form a plexus, the circulus tonsillaris. From this plexus fine twigs proceed to the glosso-palatine arches (pillars of the fauces) and to the soft palate.

(4) The lingual branches are the terminal branches of the nerve and supply the mucous membrane of the posterior lialf of the dorsum of the tongue, where, chiefly as taste-fibres, they are distributed to the vallate papille. Some small twigs pass backward to the follicular glands of the tongue, and to the anterior surface of the epiglottis. Other twigs are distributed around the foramen crecum, where they communicate with the corresponding twigs of the opposite side.

The sensory fibres.- The sensory fibres of the glosso-pharyngeal nerve spring from the superior and petrosal ganglia and pass peripherally and centrally. The peripheral processes of the ganglion cells are those which are distributed to the mucous nembrane (taste-buds) of the tongue and pharynx, and the central processes pass medialward to the medulla. In the medulla they pass dorsalward and medianward through the reticular formation and, bifurcating into ascending and descending branches, they end in the nucleus of termination of the glosso-pharyngeal nerve, that is, in the superior part of the nucleus alæ cinerex and in the nucleus of the tractus solitarius.

The motor fibres arise from the mucleus ambiguus in the lateral funiculus of the medulla, in line with the nucleus of origin of the facial nerve. From this nucleus they pass at first dorsalward and then, turning lateralward, they emerge and join the sensory fibres and run with them in the trunk of the nerve (fig. 646).

Van Gehuchten's observations point to the conclusion that one motor nucleus of the glossopharyngeal nerve is separate from and lies above and to the medial side of the nucleus ambiguus, and that a portion of the nucleus of the ala cinerea is also a motor nucleus common to the glosso-pharyngeal and vagus nerves. It is quite probable that the former motor nucleus is that now considered as the dorsal motor nucleus of the vagus. An unknown proportion of the motor fibres are visceral motor and course in the various communications of the glossopharyngeal nerve with cephalic plexus.

Central connections. - The nuclei of termination of the glosso-pharyngeal nerve are associated with the motor nuclei of other cranial nerves by the medial longitudinal fasciculus, and with the somæsthetic area of the cortex cerebri of the opposite side by the medial lemniscus (fillet). The motor nucleus of the nerve is associated with the somæsthetic area by the pyramidal fibres.

\section{THE HYPOGLOSSAL NERVE}

The hypoglossal nerves are exclusively motor; they supply the genio-hyoidei and the extrinsic and intrinsic muscles of the tongue except the glosso-palatini. They are usually designated as the twelfth pair of cranial nerves. The fibres of each nerve issue from the cells of an elongated nucleus which lies in the floor of the central canal in the lower half of the medulla and in the floor of the fourth ventricle in the upper half beneath the trigonum hypoglossi. This nucleus is the upward continuation of the ventro-medial group of cells of the ventral horn of the spinal cord. From their origin the fibres run ventralward and somewhat lateralward, probably joined in the medulla by a few fibres from the nucleus ambiguus which is a segment of the upward prolongation of the lateral group of cells of the ventral horn. The conjoined fibres issue from the medulla in the sulcus between the pyramid and the olivary body, in a series of from ten to sixteen root filaments, which pierce the pia mater and unite with each other to form two bundles (fig. 731). These bundles pass forward and lateralward to the hypoglossal (anterior condyloid) foramen, where they pieree the arachnoid and dura mater. In the outer part of the foramen the two bundles unite to form the trunk of the nerve. At its commencement, at the base of the skull, the trunk of the hypoglossus lies on the medial side of the vagus, but as it deseends in the neck it turns gradually around the clorsal and the lateral side of the latter nerve, lying between it and the internal jugular vein, and a little above the level of the hyoid bone it bends forward, and crosses lateral to the internal carotid artery, the root of origin of the occipital artery, the external earotid, and the loop formed by the first part of the lingual artery (fig. 743). After crossing the lingual artery it proceeds forward on the lat cral surface of the hyo-glossus, crossing to the medial side of the posterior berly of the digastric, and the strlo-hyoid muscles. It disappears in the anterior part of the submaxillary region between the mylo-hyoid and the hyo-glossus, and diviles into its terminal Jranches between the latter musele and the genio-glossus.

As it descends in the neck the trunk lies areply between the intermal jugular vein and

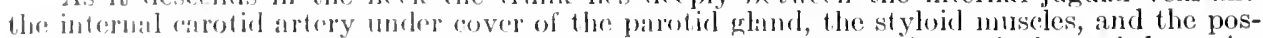
terios telly of the digastric, and it is crossed superficially by the posterior aurieular and the occip-

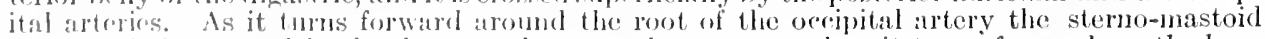
branch of that vesed hooks downwalel aeross the nerve, and as it turns forward on the hyo- 
nerve within the thorax. The nerve to the posterior belly of the omo-hyoid runs in a loop of the cervieal fascia below the central tendon of the musele.

(b) The nerve to the thyreo-hyoid leaves the hypoglossus near the tip of the great cornu of the hyoid bone, and runs obliquely downward and medialward to reach the musele. All the fibres in (a) and (b) are derived from the first, second and third cervieal nerves.

(c) The nerve to the genio-hyoid arises under cover of the mylo-hyoid, where loops are formed with the lingual nerve from which loops branches pass into the musele. It probably contains some true hypoglossal fibres.

(3) The branches of the hypoglossus proper, the rami linguales, supply the stylo-glossus, hyo-glossus, genio-glossus, and the intrinsic muscular fibres of the tongue.

The nerve to the stylo-glossus is given off near the posterior border of the hyo-glossus. It pierces the stylo-glossus, and its fibres pursue a more or less recurrent eourse within the muscle.

The nerves to the hyo-glossus are several twigs which are supplied to the muscle as the hypoglossal nerve crosses it.

The nerve to the genio-glossus arises under cover of the mylo-hyoid in common with the terminal branehes to the intrinsic museles of the tongue. It communicates freely with branches of the lingual, forming long loops which lie on the genio-glossus. From these loops twigs pass into the genio-glossus and into the museular substance of the tongue.

Central connections.--The nucleus of origin of the hypoglossus is associated with the somrsthetic area (operculum) of the cortex cerebri of the opposite side by the pyramidal fibres, and it is connected with the sensory nuelei (nuelei of termination) of other cranial nerves by way of the reticular formation and the medial longitudinal faseiculus.

\section{THE VAGUS OR PNEUMOGASTRIC NERVE}

The vagus or pneumogastric nerves are the longest of the cranial nerves, and they are remarkable for their almost vertical course, their asymmetry, and their extensive distribution, for, in addition to supplying the lung and stomach, as the name 'pneumo-gastric' indicates, each nerve gives branches to the external ear, the pharynx, the larynx, the trachea, the œesophagus, the heart, and the abdominal viscera. They are commonly referred to as the tenth pair of cranial nerves.

Each nerve is attached to the side of the medulla, in the postero-lateral sulcus, dorsal to the olivary body, by from twelve to fifteen root filaments which are in linear series with the filaments of the glosso-pharyngeal nerve. The filaments contain both sensory and motor fibres. They pierce the pia mater, from which they receive sheaths, and, traced outward, they pass into the posterior fossa of the cranium toward the jugular foramen and unite to form the trunk of the nerve, which passes through openings in the arachnoid and the dura mater which are common to it and to the spinal accessory nerve. In the jugular foramen a small spherical ganglion, the jugular ganglion (ganglion of the root), is interposed in the trunk which here turns at right angles to its former course and descends through the neck. As it leaves the jugular foramen it is joined by the internal or accessory portion of the spinal accessory nerve, and immediately below this junction it enters a large ovoid ganglion, the ganglion nodosum or ganglion of the trunk (fig. 743). As it descends through the neek the nerve passes ventral and somewhat lateral to the superior eervical sympathetic ganglion, and in front of the longus capitis and longus colli, from which it is separated by the prevertebral fascia. In the upper part of the neck it is placed between the internal earotid artery and the internal jugular vein, and on a plane dorsal to them, the artery being ventral and mesial, and the vein ventral and lateral. In the lower part of the neck it occupies a similar position in regard to the eommon carotid artery and the internal jugular vein, and the thres structures are enclosed in a common sheath derived from the (erep rervial fascia, hut within thr sheath each structure oceupies a separate (compartment (fig. 7.33). In the root of the need and in the thorax the relations of the nerves of the two sickes of the body diffor somewhat, and they must, therefore, he romsidered separaterly.

The right vagus pasises in frout of the first part of the right subelavian artery in the root of the neck and then deserme in the thorax, passing oblicuely downward and backward on the right of the trachea, ancl behind the right imnominate voin and the superior vena eava, to the back of the rent of the right hang. Just before it reaches the right bronehus it lies elose to the medial

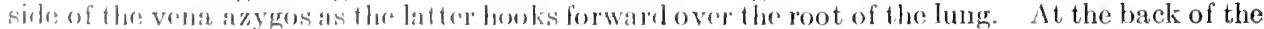
right henelus the right vagus herels mp into a mumber of hranches which join with the branehes of the sympluthefir: to form the right posterior pulmonary plexus, and from this plexus it issues in the form of one or morre cords, combined sensory, viscral motor and sympathetic, which de-

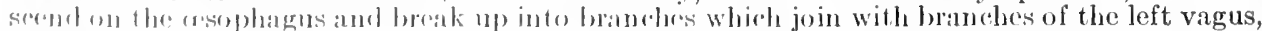
forming the posterior osophageal plexus. It thr hower part of the thorax filores of this plexus

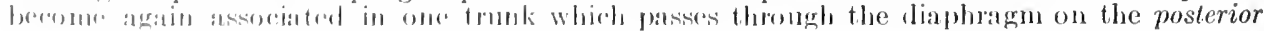


surface of the cesophagus, and is distributed to the posterior surface of the stomach and to the cœliac (solar) plexus and its offsets.

The left vagus descends through the root of the neck between the carotid and subclavian arteries and in front of the thoracic duct. In the upper part of the superior mediastinum it is crossed in front by the left phrenic nerve, and in the lower part of the same region it crosses in

Fig. 74t.-Diaram of the Branches of the Vagus Nerves.

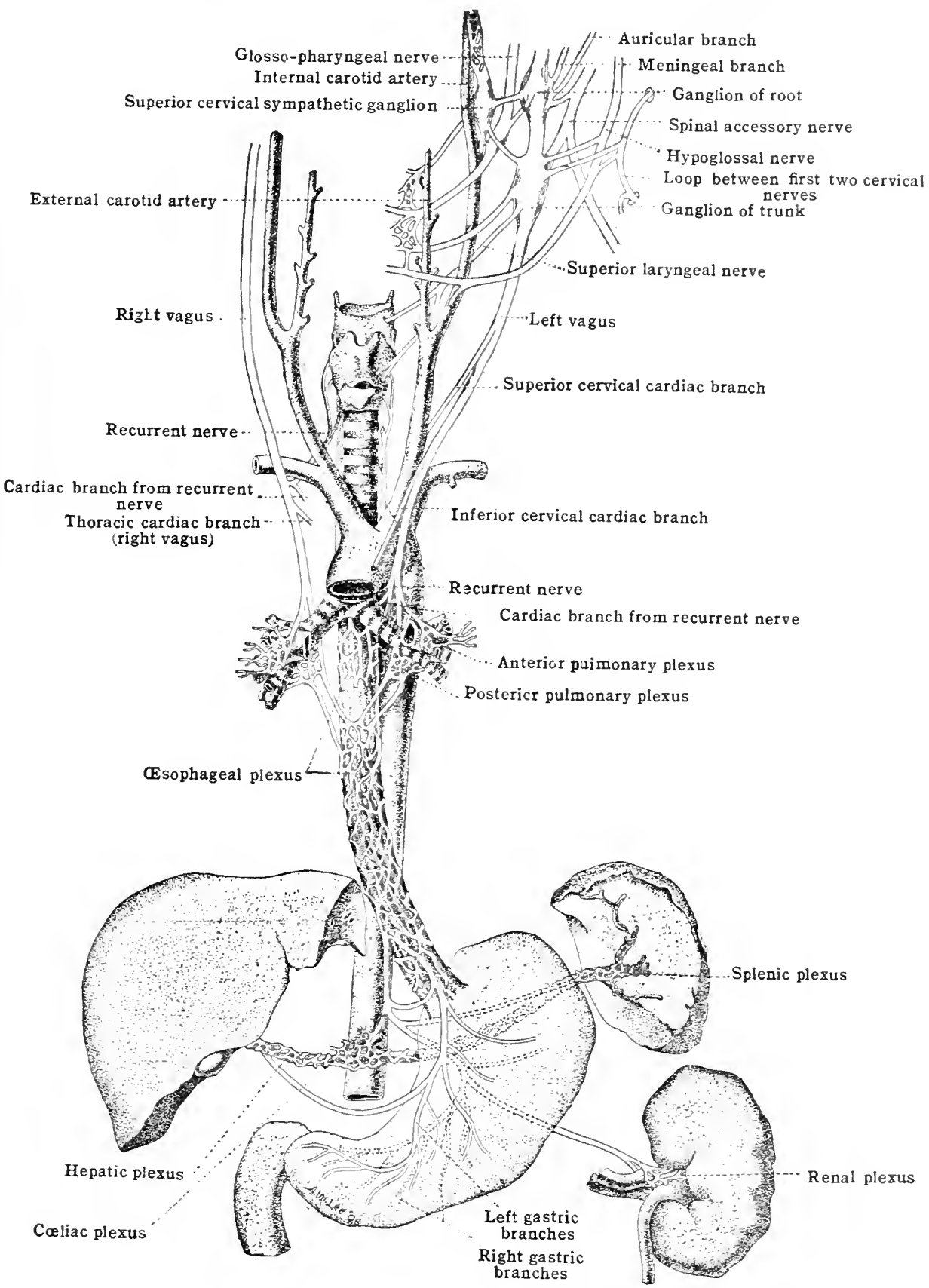

front of the root of the subclavian artery and the arch of the aorta and behind the left superior intercostal vein. Below the aortic arch it passes behind the left bronchus and divides into branches which unite with twigs of the sympathetic to form the left posterior pulmonary plexus. From this plexus the fibres of the left vagus issue as one or more cords that break up into anastomosing branches to form the anterior œsophageal plexus. At the lower part of the thorax this plexus becomes a single trunk, which passes through the diaphragm on the anterior surface of, the cesophagus, and it is distributed to the anterior surface of the stomach and to the liver. 
The jugular ganglion (ganglion of the root) is a spherical grey mass about five millimetres in diameter which lies in the jugular foramen (fig. 744). It is connected with the spinal accessory nerve and with the superior corvical sympathetic ganglion, and it gives off an auricular branch, by means of which it becomes associated with the facial and glosso-pharyngeal nerves, and a recurrent meningeal branch.

The ganglion nodosum (ganglion of the trunk) lies below the base of the skull and in front of the upper part of the internal jugular vein. It is of flattened ovoid form and about seventeen millimetres long and four millimetres broad (figs. 744 and 743 ). It is joined by the accessory part of the spinal accessory nerve, and is associated with the hypoglossal nerve, with the superior cervical ganglion of the sympathetic, and with the loop between the first two cervical nerves, and it gives off a pharyngeal, a superior laryngeal, and a superior cardiac branch. Both ganglia and especially the nodosal retain numerous cell-bodies of sympathetic neurones and the twigs issuing from the ganglia thus contain sympathetic fibres. The greater part of the cell-bodies are of sensory neurones.

Communications.-The vagus nerve is connected with the glosso-pharyngeal, spinal accessory and hypoglossal nerves, with the sympathetic, and with the loop between the first and second cervical nerves.

(1) Two communications exist between the vagus and glosso-pharyngeal nerves: one between their trunks, just below the base of the skull, and one, in the region of their ganglia, consisting of one or two filaments. When two filaments are present one passes from the jugular ganglion and the other from the auricular nerve to the petrosal ganglion of the glosso-pharyngeal nerve. Either or both of these filaments may be absent.

(2) Two twigs pass from the spinal accessory nerve to the ganglion nodosum, and at a lower level the accessory part of the spinal accessory nerve also joins the same ganglion (fig. 744). The majority of the fibres of the accessory part of the spinal accessory nerve merely pass across the surface of the ganglion and are continued into the pharyngeal and superior laryngeal branches of the vagus, but a certain number blend with the trunk of the vagus and are continued into its recurrent laryngeal and cardiac branches.

(3) Two or three fine filaments connect the ganglion nodosum with the hypoglossal nerve as the latter turns around the lower part of the ganglion (fig. 744).

(4) Fibres pass from the superior cervical ganglion of the sympathetic to both ganglia of the vagus (fig. 744).

(5) A twig sometimes passes from the loop between the first two cervical nerves to the ganglion nodosum (fig. 744 ).

Terminal branches.-These are the meningeal, auricular, pharyngeal, superior laryngeal, recurrent (inferior laryngeal), cardiac, bronchial, pericardial, osophageal, and the abdominal branches.

(1) The meningeal or recurrent branch is a slender filament which is given off from the jugular ganglion. It takes a recurrent course through the jugular foramen, and is distributed to the (lura mater around the transverse (lateral) sinus.

(2) The auricular branch, or nerve of Arnold, arises from the jugular ganglion in the jugular foramen. It receives a branch from the petrosal ganglion of the glosso-pharyngeal, enters the petrous part of the temporal bone through a foramen in the lateral wall of the jugular fossa, and communicates with the facial nerve or mercly lies in contact with it as far as the stylomastoid foramen. It usually leaves the temporal bone by the stylo-mastoid foramen, but it may pass through the tympano-mastoid fissure, and it divides, behind the pinna, into two branches, onc of which joms the posterior auricular branch of the facial while the other supplies sensory fibres to the posterior and inferior part of the external auditory meatus and the back of the pima. It also supplies twigs to the osseous part of the external auditory meatus and to the lower part of the outer surface of the tympanic membrane.

(3) The pharyngeal branches may be two or thrce in number. The principal of these joins the pharyngral branch of the glosso-pharyngeal on the lateral surface of the internal earotid artery, and aftor passing with the latter medial to the cxtemal carotid artery it turns rlownwal and nodialward to reach the posterior aspeet of the pharynx. Here the two nerves are joined hy branches from the superior corvionl ganglion of the sympathetic, with which they form the pharyngeal plexus (figs. 74:, 744). Jlanches from this plexus supply sensory fibres to the mucous membrane of the pharynx and motor fihes to the const rictores pharyngis, levator palatini, uvular, glosos-palatimus, and pharyongo-palatimus.

(1) 'The superior laryngeal nerve arises from the lower part of the ganglion

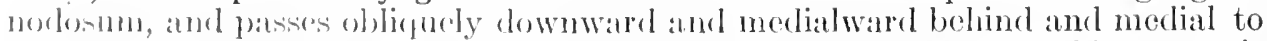
hoth internal and rextermal earotid arteries toward the larynx. In this course it dereriles a curve with the convexiby downward and lateralward and divides into

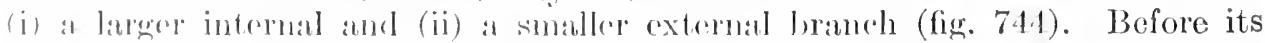
divison it is joinorl hy twigs with the smmpathet ic and with the pharyngeal plexus, and it gives a small himele to the internal camotiel artery. 
(a) The internal branch accompanies the superior laryngeal artery to the interval between the upper border of the thyreoid cartilage and the great cornu of the hyoid bone. It passes under cover of the thyreo-hyoid muscle and pierces the hyo-thyreoid membrane to gain the interior of the pharynx, where it lies in the lateral wall of the sinus piriformis and divides into a number of diverging branches. The ascending branches supply the mucous membrane on both surfaces of the epiglottis, and probably that of a small part of the root of the tongue. The descending branches ramify in the mucous membrane lining the larynx, and supply the mucous membrane which covers the back of the cricoid cartilage. One of the descending branches passes downward on the internal muscles of the larynx to anastomose with the terminal part of the inferior (recurrent) laryngeal nerve.

(b) The external branch runs downward on the inferior constrictor to the lower border of the thyreoid cartilage, where it ends, for the most part, in the crico-thyreoid muscle. A few filaments pierce the crico-thyreoid membrane and are distributed to the membrane lining the larynx. It occasionally gives off a cardiac branch which joins one of the cardiac branches of the sympathetic; it also furnishes twigs to the inferior constrictor, and communicating twigs to the pharyngeal plexus, and it receives a communication from the superior cervical ganglion of the sympathetic.

(5) The recurrent (inferior or recurrent laryngeal) nerve of the right side arises from the vagus at the root of the neck in front of the right subclavian artery. It hooks around the artery, passing below and then behind that vessel, and runs upward and slightly medialward, crossing obliquely behind the common carotid artery (fig. 744). Having gained the side of the trachea, it runs upward in the groove between the trachea and the osophagus, accompanying branches of the inferior thyreoid artery, and, near the level of the lower border of the cricoid cartilage, becomes the inferior laryngeal nerve.

In its course the right recurrent nerve gives off branches to the trachea, cesophageal branches to the csophagus and pharynx, and, near its commencement, one or more inferior cardiac branches. It communicates with the inferior cervical sympathetic ganglion and with the superior laryngeal nerve.

The inferior laryngeal nerve, the continuation of the recurrent, ascends between the trachea and cesophagus, enters the larynx under cover of the inferior constrictor of the pharynx, and divides into two branches, anterior and posterior. The anterior branch passes upward and forward on the crico-arytænoideus lateralis and thyreo-arytænoicleus, and supplies these muscles and also the vocalis, arytænoideus obliquus, ary-epiglotticus, and thyreo-epiglotticus. The posterior branch, passing upward, supplies the crico-arytænoideus posterior and arytænoideus obliquus, and anastomoses with the medial branch of the superior laryngeal nerve.

On the left side the recurrent nerve arises in front of the aortic arch and winds around the concavity of the arch lateral to the ligamentum arteriosum. It crosses obliquely behind the root of the left common carotid artery, gains the angular interval between the œsophagus and trachea, and corresponds with the nerve of the right side in the remainder of its course and clistribution (fig. 744).

(6) Cardiac branches.-Of these branches of the vagus, there are two sets, the superior and inferior. All the branches of both sets pass to the deep part of the cardiac plexus except a superior branch on the left side that passes to the superficial part of the cardiac plexus. All contain visceral motor, sympathetic and sensory fibres.

(a) The superior (superior and inferior cervical) cardiac nerves arise from the vagus and its branches in the neck (figs. 744,786 ). Some of these branches on both sides join with the cardiac branches of the sympathetic in the neck and pass with them to the cardiac plexus. Some on the right side pass independently through the thorax to the deep part of the cardiac plexus, and a branch on the left side passes through the thorax to the superficial part of the cardiac plexus.

(b) The inferior (thoracic) cardiac branches.-These branches on the right side arise in part from the recurrent nerve and in part from the main trunk of the vagus, while on the left side they usually arise entirely from the recurrent. All these branches pass to the deep part of the cardiac plexus (figs. 744, 786).

(7) The bronchial (pulmonary) branches are anterior and posterior (fig. 744).

(a) The anterior bronchial (pulmonary) branches consist of a few small branches which arise at the upper border of the root of the lung. They pass forward to gain the anterior aspect of the bronchus, where they communicate with the sympathetic and form the anterior pulmonary plexus, from which fine twigs pass along the bronchus.

(b) The posterior bronchial (pulmonary) branches.-Almost the entire remaining trunk of the vagus usually divides into these branches, which join with branches from the second, third, and fourth thoracic ganglia of the sympathetic to form the posterior pulmonary plexus (fig. 744). The plexuses of the two sides join freely behind the bifurcation of the trachea, and branches from the plexus pass along each bronchus in to the lung.

(8) The pericardial branches pass from the trunk of the vagus or from the bronchial or csophageal plexuses to the anterior and posterior surfaces of the pericardium. They are chiefly sensory. 
(9) Esophageal branches, given off by the trunk of the nerve above the bronchial plexuses and from the osophageal plexuses lower down, pass to the wall of the osophagus.

(10) Abdominal branches.- The terminal part of the left vagus divides into many branches, some of which communicate freely along the lesser curvature of the stomach with filaments from the gastric plexus of the sympathetic, and to some extent with branches of the right vagus, to form the elongated anterior gastric plexus (fig. 744). From this plexus as well as from the nerve-trunk, gastric branches are given to the anterior surface of the stomach. Hepatic branches from the trunk or from this plexus pass in the lesser omentum to the hepatic plexus (fig. 744). The terminal part of the right vagus divides into many branches, and forms along the lesser curvature of the stomach an elongated posterior gastric plexus by communications with branches from the gastric plexus of the sympathetic and with branches from the right vagus. Gastric branches are given off by the trunk of the nerve and from this plexus. Cœliac branches are given by the trunk to the coliac (solar) plexus, and splenic and renal branches, either directly or through the cœliac (solar) plexus, are given to the splenic and renal plexuses (fig. 744).

Central connections. - The sensory fibres of the vagus are processes of the cells of the jugular ganglion and the ganglion nodosum. The peripheral fibres from these cells bring in sensory impulses from the peripherv, and their central fibres convey the impulses to the brain. The latter fibres enter the medulla in the filaments of attachment in the postero-lateral sulcus, and, in the reticular formation, they bifurcate into ascending and descending branches which end in the nuclei of termination of the vagus, namely, in the nucleus alæ cinereæ in the floor of the fourth rentricle and in the nucleus tractus solitarii. The tractus solitarius consists largely of the descending branches. These and the axones arising from the nuclei of termination of the vagus descend the spinal cord to terminate about ventral horn cells which give origin to the phrenic nerve and to motor fibres supplying other muscles of respiration, and they also convey impulses which are distributed to visceral motor neurones along the spinal cord.

The motor fibres spring from the nucleus ambiguus and from the dorsal efferent (motor) nucleus of the vagus, described on page 820 . They join the sensory fibres in the reticular formation. Some of the motor fibres, especially those from the dorsal efferent nucleus, are visceral motor fibres.

The central connections of the vagus are similar to those of the glosso-pharyngeal nerve (fig. 647). Van Gehuchten's observations point to the conclusion that the chief nucleus of termination of the vagus nerve is that of the tractus solitarius.

\section{THE SPINAL ACCESSORY NERVE}

The spinal accessory nerve [n. accessorius] is exclusively motor. It consists of two parts, the accessory or superior, and the spinal or inferior part.

The fibres of the accessory or superior portion [ramus internus] ("accessory vagus") spring chiefly from the inferior continuation of the nucleus ambiguus, in common with the motor fibres of the vagus above, and they pass through the reticular formation to the postero-lateral sulcus of the medulla, where they emerge as a scries of filaments, below those of the vagus. The filaments pieree the pia mater and unite, as they pass outward in the posterior fossa of the cranium, to form a part of the nerve which enters the aperture in the dura mater common to the vagus and spinal accessory nerves. In the aperture this trunk is joined by the spinal portion of the nerve.

The spinal or inferior portion [ramus externus] arises from the ventro-lateral cells of the ventral horn of the cord as low as the fifth, and rarely the seventh, cervical nerve. The fibres pass dorsalward and lateralward from their origins through the lateral part of the ventral horn and through the lateral funiculus of white substanee, and they emerge from the lateral aspect of the cord behind the ligancntum dentieulatum, along an oblique line, the lower fibres passing out inmediately dorsal to the ligament, and the upper elose to and sometimes in association with the dorsal roots of the upper two spinal nerves. As the spinal fibres pass out of the surface of the cord they unite to form an aseending strand which enter's the posterior fossa of the cranium, through the foramen magnum, and, turning lateralward, blends more or less intiuately with the aceessory portion. 'Thus combined, the nerve enters the jugular foramen in company with the vagus, but here it is again separated into its two branches, which contain chiefly the same filners as the original superior and inferior parts.

The superior branch, or accessury portion of the nerve, gives one or more filaments to the jugular ganglion (ganglion of the root of the vagus), anel then joins either the trunk of the vagus directly or its ganglion nodosnm, the fibres of the lisuch being contributed to the pharyngeal, laryngral, and cardiac branches of the vagus. Fibres corresponeling to the white rami communicantes, absent in the cervical noves, pobably enter the covical sympathetic ganglion through this ramms of the spinal areesiory nerve. The fildes from the aceessory to the vagus therefore

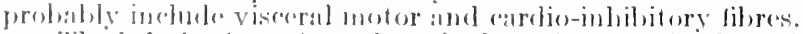

'l'he inferior branch or the spinal portion runs bickward and downward under cover of the pesterier lenty of the digistric and the strmo-mastoid. It usually crosses in front of and to the lateral side of the intemal jugnlar vein and between it and the oecipital artery; then it 
pierces the sterno-mastoid, supplies filaments to it, and interldces in its substance with branches of the second cervical nerve. It emerges from the posterior border of the sterno-mastoid slightly above the level of the upper border of the thyreoid cartilage, passes obliquely downward and backward across the occipital portion of the posterior triangle, and disappears beneath the trapezius about the junction of the middle and lower thirds of the anterior border of that muscle (fig. 743). In the posterior triangle it receives communications from the third and fourth cervical nerves, and beneath the trapezius its fibres form a plexus with other branches of the same nerves. Its terminal filaments are distributed to the trapezius and they can be traced almost to the lower extremity of that muscle.

Central connections.-The nuclei of origin, like other motor nuclei, are connected with the somæsthetic area of the cerebral cortex of the opposite side by the pyramidal fibres, and they are associated with the sensory nuclei of other cranial nerves br the medial longitudinal fasciculus, and with sensations brought in by the spinal nerves by the fibres of the fasciculi proprii.

\section{THE GANGLIATED CEPHALIC PLEXLS}

\section{The Sympathetic Ganglia of the Head and Their Associations with the Cranial Nerves}

The sympathetic system of the head, like that of the remainder of the body described below, is arranged in the form of a continuous gangliated plexus subdivided into sub-plexuses. Unlike the great unpaired prevertebral plexuses in the thoracic and abdominal cavities, all the larger sympathetic ganglia of the head are paired, ganglia corresponding to each other being found on either side. Thus they may be considered as an upward extension of the series of paired lumbar, thoracic and cervical ganglia belonging to the sympathetic trunks lying along either side of the vertebral column. Numerous small ganglia, many of them microscopic, occur in the sub-plexuses throughout the head. These are irregular in size and position and those in the region of the median line are no doubt unpaired.

In origin, the ganglia of the cephalic plexus consist of cell-bodies which, in the early stages of development, migrated from the fundaments of the ganglia of the vagus, glosso-pharyngeal and glosso-palatine nerves, and most especially from that of the semilunar (Crasserian) ganglion of the trigeminus-a developmental relation identical with that of the remainder of the sympathetic system to the ganglia of the spinal nerves. Just as is known for the spina! ganglia, some cell-bodies destined to develop into sympathetic neurones, instead of migrating, remained within the confines of the ganglia of the above nerves, in company with the cell-bodies of their sensory neurones. This is thought to be especially true for the geniculate, the petrosal and the jugular ganglion. Therefore these ganglia must be considered as in small part sympathetic ganglia.

The gangliated cephalic plexus could properly be included as a division of the general sympathetic system described later. However, because its larger ganglia are so intimately associated with branches of the oculomotor, trigeminal, masticator, glosso-palatine, glosso-pharyngeal and vagus nerves, it is customary to describe it in connexion with the cranial nerves.

The larger ganglia, one on either side of the head, comprise the ciliary ganglion, the spheno-palatine (Meckel's) ganglion, the otic and the submaxillary ganglion. To these must be added portions of the geniculate, petrosal, jugular and the ganglion nodosum, and a part of the superior cervical sympathetic ganglion. The chief relations of the gangliated cephalic plexus to the cranial nerves are shown in fig. 741 .

The so-called roots and branches of the ganglia carry three varieties of fibres: (1) Sensory, (2) Motor (visceral motor or preganglionic), and (3) Sympathetic. Most roots and branches are mixed, the name of a root being determined only by the variety of fibres predominating in it.

A bundle of sensory fibres going to a ganglion is called its sensory root. Such, however, cannot comprise a true root since none of its fibres arises in the ganglion and very few or none may terminate in it. The only sensory fibres terminating in a ganglion are the few which may approach it in any of the roots to terminate in its capsule or the capsules of its cells and convey impulses of general sensibility from the ganglion to the central nervous system. Almost all of the fibres of a "sensory root" merely pass a round or through a ganghion and into its branches beyond, which they borrow as paths for reaching their allotted fields of distribution. In this relation it should be realized that while the ciliary, spheno-palatine, otic and submaxillary ganglia are customarily described under the discussion of the trigeminus, this nerve has funetionally less to do with them than any of the other eranial nerves with which they are associated. Bundles of trigeminal (sensory) fibres, traceable in gross anatomy because medullated and of appreciable size, pass to the ganglia, but only to pass through them as continuations of the terminal branches of the trigeminus.

The so-called motor root of a ganglion may carry two kinds of fibres: (a) visceral motor (preganglionic) fibres, arising in the nuclei of origin in the central system and passing in the trunk 
and branches of a cranial nerve (oculomotor, masticator, ctc.) to enter and terminate in contact with the cell-bodies of the ganglion, which, in their turn, give fibres to the branches of the ganglion; (b) fibres of the same origin, name and course but which may pass through the ganglion to terminate in contact with the cells of a more distant ganglion. Any root, the motor especially, may contain somatic motor fibres, that is, fibres of central origin which pass through the ganglion uninterrupted and into its branches to tcrminate upon the fibres of skeletal (voluntary) muscle.

A sympathetic root likewise may carry two and perhaps three varieties of fibres conforming to the nane: (a) fibres arising from the cells of other sympathetic ganglia and terminating in the ganglion in question; (b) fibres arising in other ganglia which pass through the ganglion in question to enter its branches and terminate either in other ganglia or upon their allotted muscular or glandular elements. A third is the fibre of the sensory sympathetic neurone, probably quite rare, which may arise from a cell-body in the ganglion and pass centralward in its root and in the appropriate cranial nerve to terminate about a cell-body of the dorsal-root or spinal ganglion type, the central process of which latter conveys this sensory impulse of sympathetic origin into the central system just as sensory cranio-spinal impulses are conveyed.

Fig. 745.-Diagrall to Illustrate the Structural Relations of the Roots and Branciles of a Cephalic sympathetic Ganglion. Sensory fibres, blue; motor, red; sympathetic, black.

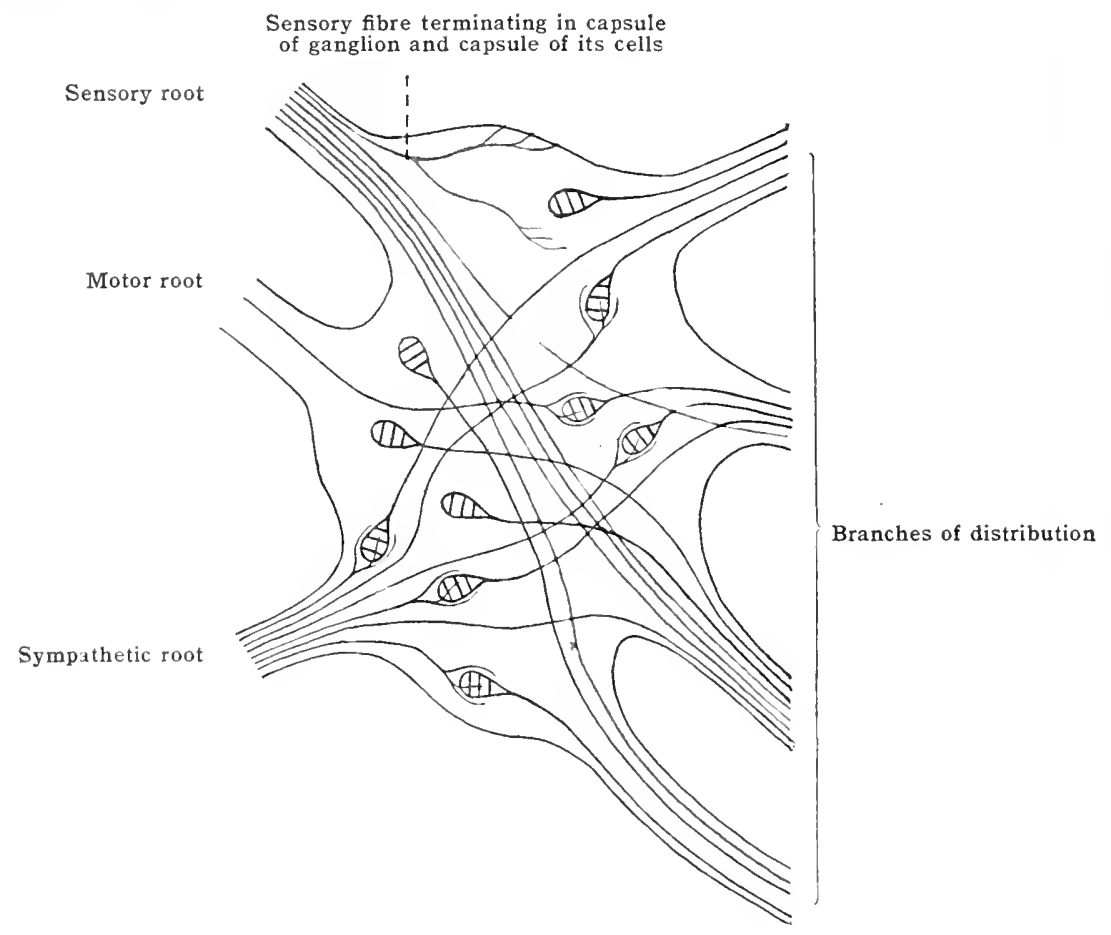

'The branches of distribution of the ganglia, the larger of them often called nerves, are those bunclles in which the fibres, both arising in or passing through the ganglia, course toward their terminations upon their allotted tissue elements of the head. The larger ganglia of the head are driscribul at eads pussessing the three roots above nentioned. In the branches pass fibres motor to the veswols of the head, to the intrinsic muscles of the eye bulb, to the lacrimal glands, the mucons nemblanes (gland cells) of the nasal and oral cavities and the salivary glands, and sensory fibres conveying inpulses from these structures.

Thic plexuses into which the gangliated cephalic plexus is divided and which connect the ganglia to form it, are muncrous and vary greatly in size. 'They underlie the inucous membranes ind they surround all the vessels and glands. They are named aceording to their locality. The largest of thent are the tympanie plexus and the carotid and cavernous plexuses. They

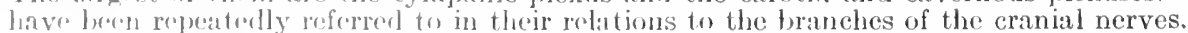

()f the numbrus hranches described from the superior cervical sympathetic ganglion, the two linge ones which pass unwarl associate it especially with the gangliated cephalic plexus.

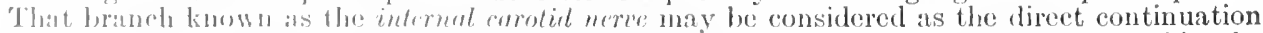
upward of the gangliater] sympithetio trunk of the fondy. 'Through the branches of this, the

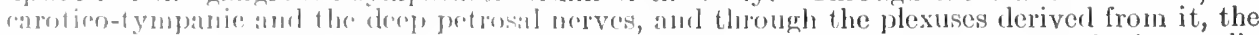
superior cervical ganglion may be assomiated with practically all the other sympathetic ganglia of the heard (figes. Fis!) arul 7.11). The other branch from the superior cervieal ganglion, the jughlur mow, asoreiates it with the ganglia of the glosso-pharyngeal and vagus nerves, with the

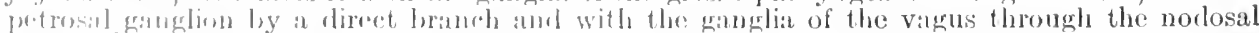

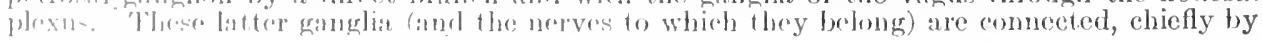


way of the tympanic nerve, which is from the petrosal ganglion, with the tympanic plexus fig. $741)$.

The tympanic plexus serves as a common point of distribution of fibres from the superior cervical sympathetic ganglion, the ganglia of the vagus, the petrosal ganglion, and the geniculate ganglion, to the cavernous and carotid plexuses and to the spheno-palatine and otic ganglia. The superior cervical ganglion is associated with the cavernous and carotid plexuses direct by the internal carotid nerve and with the tympanic plexus by the inferior and superior caroticotympanic nerves. The tympanic plexus receives fibres from the geniculate ganglion by a small geniculo-tympanic branch and it is connected with the spheno-palatine ganglion by a small anastomotic or tympano-petrosal branch to the great superficial petrosal nerve, and with the otic ganglion by the small superficial petrosal nerve. It is not directly connected with either the ciliary or the submaxillary ganglion. However, these ganglia, as well as the sphenopalatine and otic, are connected with the carotid plexus either directly by named branches or indirectly by way of plexuses derived from the carotid. The geniculo-tympanic branch, the tympanic nerve and twigs of the nodosal plexus may be considered as analogous to the rami communicantes of the spinal nerves.

The parotid branches, described above as branches of the auriculo-temporal nerve (from the trigeminus) and as containing fibres from the glossopharyngeal, should be mentioned here as belonging to the gangliated cephalic plexus. These branches are sympathetic fibres arising in the otic ganglion and passing as branches of the ganglion to the auriculo-temporal in which they remain till this nerve enters the parotid gland and then they are distributed to the gland. The visceral motor or preganglionic fibres which terminate about their cells of origin in the otic ganglion are derived from the glosso-pharyngeal nerve and pass successively through the tympanic nerve, the tympanic plexus, and the small superficial petrosal nerve to the otic ganglion.

The tympanic nerve (tympanic branch of the glosso-pharyngeal, or nerve of Jacolson), the branch to the Eustachian tube (ramus tuba), and the superior and inferior carotico-tympanic branches are also described as branches of the glosso-pharyngeal nerve. These must likewise be considered as belonging to the gangliated cephalic plexus.

For purposes of dissection, it may be more expedient to consider separately, with its roots and branches, each of the larger ganglia of the gangliated cephalic plexus. Under this heading belong in part the geniculate ganglion of the glossopalatine nerve, and the ganglia of the glosso-pharyngeal and vagus, especially the petrosal ganglion of the former and the jugular ganglion of the latter, from the fact that these ganglia contain numerous cell-bodies of sympathetic neurones as well as those of the sensory neurones of their nerves.

These ganglia, however, have been described with their corresponding cranial nerves. The sensory and motor roots of their sympathetic portions are contained in the roots of their nerves. The geniculate probably has no sympathetic root. The sympathetic roots of the petrosal and jugular ganglia are contained in the branches of the jugular nerve. The chief branches of distribution of the geniculate are the geniculo-tympanic branch, the great superficial petrosal nerve, and the external superficial petrosal nerve. The branches of the petrosal ganglion are the tympanic nerve and its branches of the tympanic plexus. The chief branch of distribution from the jugular ganglion is contamed in the auricular branch of the vagus, or nerve of Arnold, supplemented by sympathetic fibres in the trunk of the vagus itself.

The principal cephalic sympathetic ganglia are the ciliary, the spheno-palatine (Meckel's), the otic and the submaxillary.

\section{The Ciliary Ganglion}

The ciliary, lenticular, or ophthalmic ganglion lies in the posterior part of the orbital cavity, about $6 \mathrm{~mm}$. in front of the superior orbital (sphenoidal) fissure, to the lateral side of the optic nerve, and between the optic nerve and the external rectus muscle. It is a small, reddish, quadrangular body, compressed laterally, and it measures about two millimetres from before backward (fig. 731).

Roots.- (a) Its motor or short root enters its lower and posterior angle and is a visceral motor branch derived from the branch of the inferior division of the oculomotor nerve which supplies the inferior oblique muscle. The fibres of the motor root probably all terminate in the ciliary ganglion in connection with motor sympathetic neurones.

(b) The sensory or long root passes through the upper and back part of the ganglion. It is a branch of the naso-ciliary (nasal) nerve and is, therefore, composed of fibres from the trigeminus passing through the ganglion.

(c) The sympathetic root consists of fibres derived from the cavernous plexus of the sympathetic; it passes to the ganglion with the long root.

Branches.-From three to six short ciliary nerves emerge from the anterior border of the ganglion; they divide as they pass forward and eventually form about twenty nerves which are arranged in an upper and a lower group, and the latter group is joined by the long ciliary branches of the naso-ciliary (nasal) nerve, now sensory and sympathetic (fig. 734). When they reach the eyeball, the ciliary nerves pierce the sclerotic around the optic nerve, and pass forward in grooves on the inner surface of the sclera. The sympathetic fibres contained are distributed as motor fibres to the ciliary muscle, the sphincter of the iris, and to the vessels of these and of the cornea.

61 


\section{The Spheno-palatine or Meckel's Ganglion}

This ganglion is associated with the maxillary nerve (fig. 743). It is a small reddish-grey body of triangular form, which is flattened at the sides, and measures about five millimetres from before backward. It lies deeply in the pterygopalatine (spheno-maxillary) fossa at the lateral side of the spheno-palatine foramen and in front of the anterior end of the pterygoid (Vidian) canal. It is attached to the maxillary nerve, from which it receives its sensory root, and it is connected with the Vidian nerve, which furnishes it with motor and sympathetic filaments (fig. 739).

The exact position of the ganglion depends upon the size and shape of the sphenoidal air cells. When these are small, or high and narrow, the ganglion lies lateral to them; when they are large, or broad and flat, the ganglion lies inferior to them. Sometimes it may lie anterior to them if the cells are short from in front backward. The ganglion may be reached with ease by chipping amay the bone around the sphenoidal air cells after the skull is divided sagitally.

Roots.- (a) Its motor root, consisting of visceral motor fibres of the glosso-palatine nerve, is contained in the great superficial petrosal nerve which is incorporated in the Vidian nerve. It springs from the anterior angle of the genienlate ganglion and passes through the hiatus of the facial canal (hiatus Fallopii) into the middle fossa of the cranium, where it runs forward and medialward, in a groove on the upper surface of the petrous part of the temporal bone, to the foramen lacerum, and in this part of its course it passes beneath the semilunar (Gasserian) ganglion and the masticator nerve. In the foramen lacerum it joins with the great deep petrosal nerve to form the Vidian nerve (nerve of the pterygoid canal), which passes forward through the pterygoid (Vidian) canal and its motor and sympathetic fibres terminate in the spheno-palatine ganglion in the pterygo-palatine (spheno-maxillary) fossa. The great superficial petrosal nerve contains sensory as well as sympathetic and motor fibres. The sensory fibres pass through the ganglion and, in the small palatine nerve, descend to the soft palate, where they terminate in the epithelium covering it and some are probably concernet with peripheral taste organs found there. They arise from the cells of the geniculate ganglion and therefore belong to the glosso-palatine nerve.

(b) The sympathetic root is the great deep petrosal portion of the Vidian nerve. This root, which is of reddish colour and of soft texture, springs from the carotid plexus which lies on the outer side of the internal carotid artery in the carotid canal. It enters the foramen lacerum through the apex of the petrous portion of the temporal bone, and unites with the great superficial petrosal branch of the facial nerve to form the Vidian nerve. The great superficial petrosal nerve also carries sympathetic fibres to the spheno-palatine ganglion, derived from the geniculate ganglion and from the tympanic plexus.

The Vidian nerve [n. canalis pterygoidei] commences by the union of the great superficial and deep petrosal nerves in the foramen lacerum, and runs forward through the pterygoid (Vidian) canal to the pterygo-palatine (spheno-maxillary) fossa to the spheno-palatine ganglion. The Vidian nerve often may be seen in a rilge of bone along the floor of the sphenoidal cells and its direction there depends upon the position of the spheno-palatine ganglion. While it is in the pteryoid canal the Vidlian nerve is joined by a sphenoidal filament from the otic ganglion, and it gives branches to the upper and back part of the roof and septum of the nose, and to the lower end of the Eustachin tube.

(c) The sensory roots consist of the sensory fibres mentioned above in the great supcrficial petrosal nerve and of usually two spheno-palatine branches from the maxillary nerve. The majority of the fibres of these roots to not join the ganglion, hut pass by its medial side and enter the palatine branches.

Branches.- The branches of the ganglion, containing sensory, vaso-motor and secretory fibres, are orbital or ascending, internal or nasil, descending or palatine, and posterior or pharyngeal.

Ascending branches. - The orbital or ascending branches are two or threc small twigs which enter the orbit through the inferior orbital (spheno-maxillary) fissure and proceed, within the periostem, to the inuer wall of the orbit, where they pass through the posterior ethmoidal foramen and through the formmina in the suture hehind that foramen to be distributed to the mucous menbrane which lines the posterior ethmoidal cells and the sphenoidal sinus.

Internal branches.- The internal or masal branches are terived in part from the medial side of the ganglion, but are also largely mate up of fibres which pass from the spheno-palatine branches of the maxillary neve without traversing the ganglionic substance. They are disposer in two sets, the lateral and the medial (septat) posterior superior nasal branches.

The lateral posterior superior nasal branches are six or seven small twigs which pass through the spheno-palintine foramen, and are distributed to the mueous unembane covering the posterin parts of the superion and wildle natsal conchar (turbinated bones) (fig. 732). They also fornish twigs to the linimg mombine of the posterior ethmoinal cells.

'The medial posterior superior nasal (septal) branches, two or thre in number, pass medialwarl through the spheme-palatine foramen. They aros the rouf of the nasial fossa to reach the back bart of the nasal septum, where the smaller twigs teminate. The largest nerve of the set, the naso-palatine nerve, of nerve of Cotunnius, runs downwal and forward in at groove in the vener betwern the periostenus and the mucous membane to the incisive (anterior palatime) canal, where it commungutes wh the nasal branch of the anterior superior alveolar nerve.

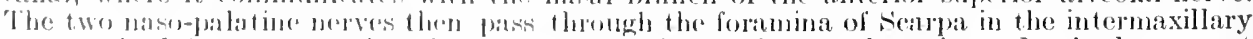

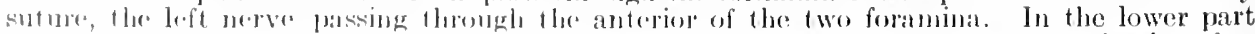

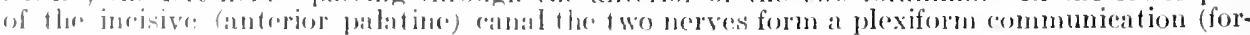


merly described as Cloquet's ganglion) and they furnish twigs to the anterior or premaxillary part of the hard palate behind the incisor teeth. In this situation they communicate with the anterior palatine nerves.

Descending branches.-The descending branches are the great or anterior, the posterior, and the middle (external) palatine nerves. Like the internal set of branches, they are in part derived from the ganglion and in part are directly continuous with the spheno-palatine nerves (fig. 732).

The great or anterior palatine nerve, its sensory fibres derived from the maxillary nerve, arises from the inferior angle of Meckel's ganglion, and passes downward through the pterygopalatine canal, aceompanied by the descending palatine artery. Emerging from the canal at the greater (posterior) palatine foramen it divides into two or three branches, which pass forward in grooves in the hard palate and supply the glands and mucous membrane of the hard palate and the gums on the inner aspect of the alveolar border of the upper jaw. During its course through the pterygo-palatine canal the anterior palatine nerve gives off the posterior inferior nasal nerves. These nerves pass through small openings in the perpendicular plate of the palate bone to supply the mucous membrane covering the posterior part of the inferior nasal concha (turbinated bone) and the adjacent portions of the middle and inferior meatuses of the nose.

The posterior or small palatine nerve passes downmard through a lesser palatine foramen (aceessory palatine canal), and enters the soft palate, distributing branches to that organ, to the uvula, and to the tonsil. Its sensory fibres are derived from the glosso-palatine nerve, through the great superficial petrosal nerve and through the splseno-palatine ganglion. It was formerly believed to convey motor fibres from the facial nerve to the levator palati and azygos uvulæ, but it is now believed that these muscles are supplied by the spinal accessory. nerve through the pharyngeal plexus (fig. 732).

The middle (external) palatine nerve, the smallest of the three, in part, likewise from the glosso-palatine nerve, traverses a lesser palatine foramen and supplies twigs to the tonsil and to the adjacent part of the soft palate (fig. 732 ).

Posterior branch.-The pharyngeal branch, which is of small size, passes backward and somewhat medialward through the pharyngeal canal accompanied by a pharyngeal branch of the spheno-palatine artery. It is distriluted to the mucous membrane of the uppermost part of the pharynx, to the upper part of the posterior nares, to the opening of the Eustachian tube, and to the lining of the sphenoidal sinus. Its sensory fibres are derived from the maxillary nerve.

\section{The Otic Ganglion}

The otic or Arnold's ganglion is a small reddish-grey body which is associated with the mandibular nerve. It lies deeply in the zygomatic fossa, immediately below the foramen orale, on the inner side of the trunk of the mandibular nerve. It is in relation internally with the tensor palati, which separates it from the Eustachian tube. In front of it is the posterior border of the pterygoideus internus, and behind it lie the middle and small meningeal arteries. It is compressed laterally, and its greatest diameter, which lies antero-posteriorly, is about three millimetres.

Roots. - The ganglion is closely connected with the nerve to the pterygoideus internus, through which it may reeeive a motor root from the masticator nerve. Through the small superficial petrosal nerve, which joins the upper and back part of the ganglion, it receives a motor root from the glosso-palatine nerve and sensory and motor fibres from the glossopharyngeal nerve. It receives also a slender sphenoidal filament from the Vidian nerve. The sympathetic roots are derived from the small superficial petrosal nerve and from the sympathetic plexus on the middle meningeal artery.

Branches.-The communicating branches which pass from the ganglion are:-(1) The filaments to the chorda tympani; some of whose fibres probably terminate in the submaxillary ganglion; (2) filaments to the auriculo-temporal nerve; (3) filaments to the spinous nerve (the recurrent branch of the mandibular nerve). The branches of distribution are sympathetic to the vessels and somatic motor branches to the tensor tympani, and tensor veli palatini.

\section{The Stbuatillary Ganglion}

The submaxillary ganglion is suspended from the lingual division of the mandibular nerve by anterior and posterior branches. It is a small reddish body, of triangular or fusiform shape, which lies between the mylo-hyoideus and hyoglossus and above the duct of the submaxillary gland.

Roots.-The sensory root is received frum the lingual nerve. The motor root is from both the masticator nerve by way of the lingual nerve, and from the glosso-palatine nerve by way of the chorda tympani. The motor fibres pass from the chorda tympani after it has joined the lingual, and the sensory fibres come directly from the lingual nerve. The sympathetic root is formed by filaments from the sympathetic plexus on the facial artery.

Branches.- (a) Five or six glandular branches are given to the submaxillary gland and to Wharton's duet

(b) Branches to the lingual nerve and the sublingual gland.

(c) To the mucous membrane of the floor of the mouth. 


\section{THE SPINAL NERVES}

The spinal nerves are arranged in pairs, the nerves of each pair being symmetrical in their attachment to either side of their respective segment of the spinal cord, and, in general, symmetrical in their course and distribution. There are usually thirty-one pairs of functional spinal nerves. For purposes of description these are topographically separated into eight pairs of cervical nerves, twelve pairs of thoracic nerves, fue pairs of lumbar, five pairs of sacral, and one pair of coccygeal nerves. Occasionally the coccygeal or thirty-first pair is practically wanting, while, on the other hand, there may be frequently found small filaments representing one or even two additional pairs of coccygeal nerves below the thirty-first pair. These rudimentary coccygeal nerves are probably not functional. They never pass outside the vertebrai canal, and often even remain within the tubular portion of the filum terminale. There sometimes occurs an increase in the number of vertebra in the vertebral column and in such cases there is always a corresponding increase in the number of the spinal nerves.

Origin and attachment.-Each spinal nerve (unlike the cranial nerves) is attached to the spinal cord by two roots:- - a sensory or afferent dorsal root [radix posterior] and a motor or efferent ventral root [radix anterior]. Each dorsal root has interposed in its course an ovoid mass of nerve-cells, the spinal ganglion, and the nerve-fibres forming the root arise from the cells of this ganglion and are thus of peripheral origin. The fibres composing the ventral root, on the other hand, are of central origin; they arise from the large motor cells of the ventral horn of the grey column within the spinal cord.

Each dorsal root-fibre upon leaving its cell of origin pursues a short tortuous course within the spinal ganglion and then undergoes a T-shaped bifurcation, one product of which passes toward the periphery, where it terminates for the eollection of sensations and is known as the peripheral branch, or, since it conveys impulses toward the cell-body, the dendrite of the spinal

Fig. 746.-Ventral and Dorsal Views of Spinal Cord showing Manner of Attachment of Dorsal and Ventral Roots.

Antero-lateral sulcus (line of ventral roots)

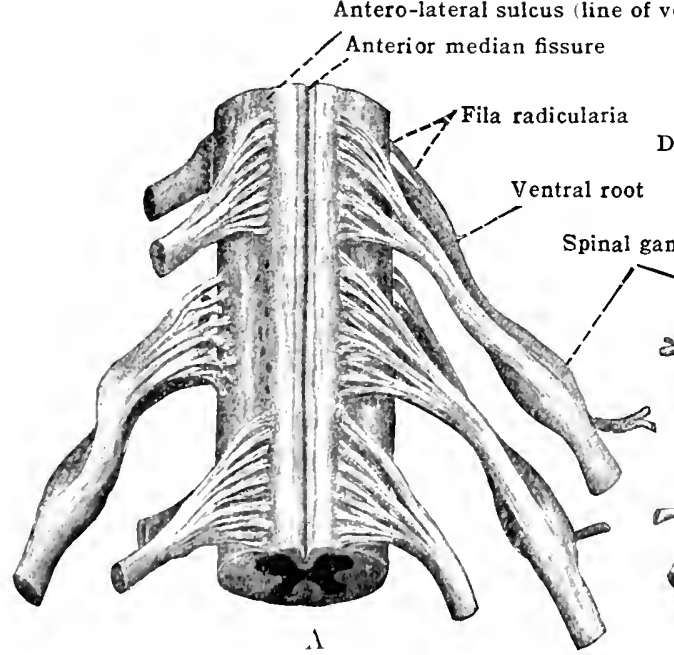

Posterior median sulcus

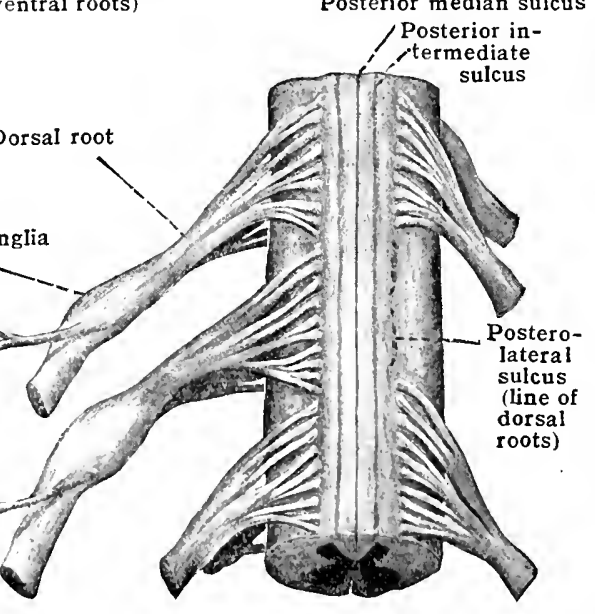

13

ganglion neirone. It is more correct, however, to consider the T-fibre as a bifurcated axone. The uther product of the bifurcation, the ccntral branch, passes in to the spinal cord and in its contse towart the cord contributes to form the dorsal root proper.

The rentral branches, upon emerging from the spinal ganglia, form a single compaet bundle at first, which passes through the rlura mater of the spinal cord and then breaks up into a series. of root-filaments [lilic molicularia]. These thread-like bundles of fibres spread out vertically in at fin-like manner and enter the cord in a direct linear series along its postero-lateral suleus. The fibres of the vent mil root emerge from the cord in a series of more finely divided root filanents, which, unlike the antering filaments of the dorsal root, are not arranged in direet linear series, fut make their exit ower in strip of the ventro-lateral aspeet of the cord in some places as much as two millinulires wide.

As they enter the spinal eorl the fildes of the torsal roots undergo a Y-shaped division,

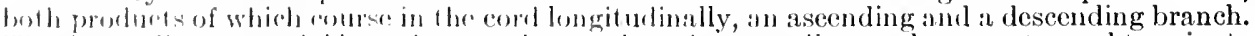

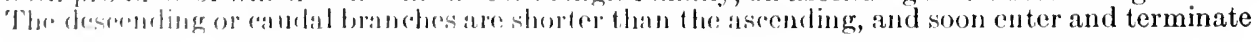


about the cells within the grey column of the cord, forming either associational, commissural, or reflex connections, or about cells whose fibres form cerebellar connections. The ascending or cephalic branches are either short, intermediate, or long. The short and internerliate branches are similar in function to the descending branches, save that they become associated with the grey substance of segments of the cord above rather than below the level of their entrance. The long branches convey impulses destined for the structures of the brain, and pass upward in the fasciculus gracilis or fasciculus cuneatus of the cord, and terminate in the nuclei of these fasciculi in the medulla oblongata (figs. 618 and 620).

Aberrant spinal ganglia.- In serial sections on either side of the spinal ganglion of a nerve there may often be found outlying cells either scattered or in groups of sufficient size to be called small ganglia. Such are more often found in the dorsal roots of the lumbar and sacral nerves. These cells are nothing more than spinal ganglion-cells displaced in the growth processes, and have the same nature and function as those in the ganglion. In some animals occasional cells very rarely have been found in the outer portion of the ventral root. These probably represent afferent fibres which enter the cord by way of the ventral root. Likewise, especially in the birds and amphibia, it has been shown that occasional efferent fibres may pass from the grey substance of the cord to the periphery by way of the dorsal instead of the ventral root.

Relative size of the roots.-The sensory or dorsal root is larger than the ventral root, indicating that the sensory area to be supplied is greater and perhaps more abundantly innervated than the area requiring motor fibres.

It has been shown that in the entire thirty-one spinal nerves of one side of the body of man the dorsal root-fibres number 653,627 , while all the corresponding ventral roots contain but 233,700 fibres, a ratio of $3.2: 1$. (Ingbert.) In the increase in the size of the nerves for the supply of the limbs the gain of dorsal root or sensory fibres is far greater than the gain of ventral root-fibres. The first cervical or the sub-occipital nerve is always an exception to the rule; its dorsal root is always smaller than its ventral, and in rare cases may be rudimentary or entirely absent. The spinal ganglion and, therefore, the sensory root of the coccygeal nerve, is also quite frequently absent.

The dorsal and ventral root-fibres of each spinal nerve proceed outward from their segment of attachment to the spinal cord, pierce the pia mater and arachnoid, collect to form their respective roots, and pass into their respective intervertebral foramina. On the immediate peripheral side of the spinal ganglion the two roots blend, giving origin to the thus mixed nerve-trunk. As the trunk, the sensory and motor fibres make their exit from the vertebral canal through the intervertebral foramen.

Relation to the meninges.- The root filaments of each nerve receive connective-tissue support from the pia mater and arachnoid in passing through them. In the sub-arachnoid cavity they become assembled into their respective nerve-roots; and the roots, closely approaching each other, pass into the dura mater, from which they receive separate sheaths at first, but at the peripheral sicle of the ganglion these sheaths blend into one, which, with the subsequent blending of the roots, becomes the sheath or epineurium of the nerve trunk. By means of the sheaths derived from the meninges, especially the dura, the nerve-roots and the trunk are attached to the periosteum of the margins of the intervertebral foramina and thus are enabled to give some lateral support to the spinal cord in the upper portion of the canal.

The majority of the spinal ganglia lie in the intervertebral foramina, closely ensheathed, and thus outside the actual sac or cavity of the dura mater. The ganglia of the last lumbar and first four sacral nerves lie inside the vertebral canal, but since the sheath derived from the dura mater closely adheres to them, they are still outsicle the sac of the dura mater. The ganglia of the last sacral and of the coccygeal nerves (when present) lie in tubular extensions of the sub-dural cavity, and thus not only within the vertebral canal, but actually withini, the sac of the dura mater. The trunk of the first cervical nerve is assembled within the sac of the dura mater, and, therefore, the spinal ganglion of this nerve, when present, may lie within the sac.

Course and direction of emergence.-Invested with the connective-tissue sheath derived from the meninges, each thoracic, lumbar and sacral nerve energes from the vertebral canal through the intervertebral foramen below the corresponding vertebra, and all the nerves are in relation with the spinal rami of the arteries and veins associated with the blood supply of the given localities of the spinal cord.

The first cervical nerve does not pass outward in an intervertebral foramen proper, but between the occipital bone and the posterior arch of the atlas and beneath the vertebral artery. Thus the eighth or last cervical nerve emerges between the seventh cervical and the first thoracic vertebra.

The first and second pairs of cervical nerves pass out of the vertebral canal almost at right angles to the levels of their attachment to the spinal cord. During the early periods of development the level of exit of each pair of spinal nerves is opposite the level of its attachment to the 
cord, but, owing to the fact that in the later periods the vertebral column grows more rapidly than the cord and increases considerably in length after the cord has practically ceased growing, all the spinal nerves, with the exception of the first two, pass downward as well as outward. The obliquity of their course from the level of attachment to the level of exit increases progressively from above downward, and, as the cord ends at the level of the first or second lumbar vertebra, the roots of the lower lumbar and of the sacral nerves pass at first vertically downward within the dura mater, and form around the filum terminale a tapering sheaf of nerve-roots, the cauda equina (horse's tail) (fig. 613, p. 773).

Topography of attachment.-The relations between the levels of attachment of the spinal nerves to the cord and the spinous processes of the vertebræ situated opposite these levels have been investigated by Nuhn and by Reid. The following table compiled by Reid gives the extreme limits of attachment as observed in six subjects.

\section{Table of Topography of Attachment of Spinal Nerves to the Spinal Cord.}

(Reid.)

(A) signifies the highest level at which the root filaments of a given nerve are attached to the cord, and (B) the lowest level observed. For example, the root filaments of the sixth thoracic nerve may be attached as high as the lower border of the spinous process of the second thoracic vertebra, or some may be attached as low as the upper border of the spinous process of the fifth thoracie vertebra, but in a given subject they do not necessarily extend either as high or as low as either of the levels indicated.

\section{Terves}

Second cervical (A) A little above the posterior arch of atlas.

Thirl " (A) Aidway between posterior arch of atlas

(B) Junction of upper two-thirds and lower third of spine of epistropheus.

Fourth " (A) Just below upper border of spine of epistropheus.

Fifth “ (B) Middle of spine of third cervical vertebra.

. (B) Just below lower border of spine of fourth cervical vertebra.

Sixth " (A) Lower border of spine of third cervical vertebra.

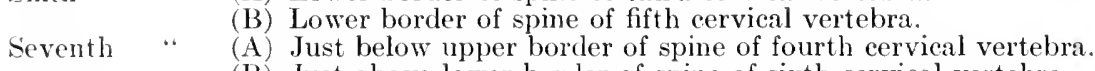

(B) Just above lower border of spine of sixth cervical vertebra.

Eighth " (A) Upper border of spine of fifth cervical vertebra.

(B) Upper borler of spine of seventh cervical vertebra.

First thoracic (A) Midway between spines of fifth cervical and sixth cervical vertebra.

(1) Junetion of upper two-thirds and lower third of interval between seventh cervical and first thoracic vertebra.

Second " (A) Lower border of spine of sixtly cervical vertebra.

(B) Just above lower border of spine of first thoracic vertebra.

Thirl thoracic (A) Just above middle of spine of seventh cervical vertebra.

(B) Lower border of spine of second thoracic vertebra.

Fonrth “ (A) Just below upper border of spine of first thoracie vertebra.

(B) Junction of upper third and lower two-thirds of spine of third thoracic

Fifth “ (A) Upper border of spine of second thoracic vertebra.

(B) Junction of upper quarter and lower three-quarters of spine of fourth thoracic vertabra.

sixth " (A) Lower border of spine of second thoracie vertebra,

(13) Just below upper border of spine of fifth thoracie vertebra.

seventh " (A) Junction of upper third and lower two-thirds of spine of fourth thoracie vertebria.

Eighth " (A) Jumptien of upper two-thirds and lower third of interval between spines of fourth thoracie and fifth thoracie vertebrat

(13) Junction of upper quarter and lower thres-quarters of spine of sixth thoriaric vertebria.

Ninth " (A) Mlidwaly botweren spines of fifth thoracie and sixth thoracie vertebra.

(B) loper borker of spine of seventh thoracic vertebra.

Trenth " (1) Midway betwern spines of sisth thoracic and seventh thoracie vertebra.

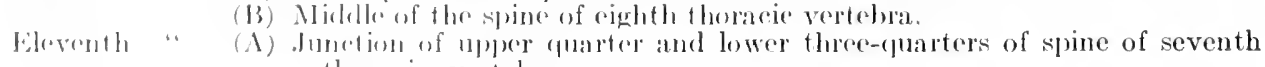

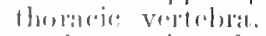

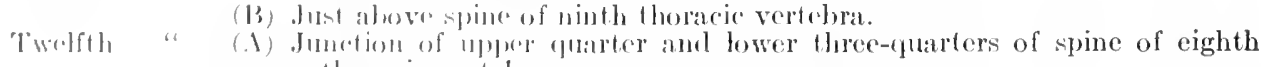

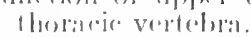

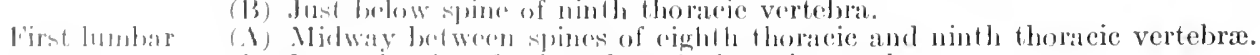

(1) Midway betwern spines of cighth thoracie and 1 ing

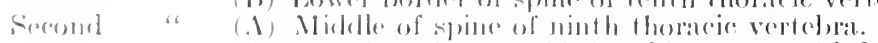

(i) Junction of ulpere third and hower two-thirds of spine of eleventh thoracie verterin:i. 
Nerves

Third " (A) Middle of spine of tenth thoracic vertebra.

(B) Just below spine of eleventh thoracic vertebra.

Fourth " (A) Just below spine of tenth thoracic vertebra.

(B) Junction of upper quarter and lower three-quarters of spine of twelfth thoracic vertebra.

Fifth " (A) Junction of upper third and lower two-thirds of spine of eleventh thoracic vertebra.

First sacral (A) Just above lower border of spine of eleventh thoracic vertebra.

Fifth " (B) Lower border of spine of first lumbar vertebra.

Coccygeal (A) Lower border of spine of first lumbar vertebra.

(B) Just below upper border of spine of second lumbar vertebra.

Relative size of the nerves.--The size of the different spinal nerves varies greatly. Just as the spinal cord shows marked enlargements in the cervical and lumbar regions necessitated by the greater amount of innervation required of these regions for the structures of the upper and lower limbs, so the nerves attached to these regions are considerably larger than elsewhere.

The smaller nerves are found at the two extremities of the cord and in the mid-thoracic region. The smallest nerve is the coccygeal, and the next in order of size are the lower sacral and the first two or three cervical nerves. The largest nerves are those which contribute most to the great nerve trunks for the innervation of the skin and muscles of the limbs:- the lower cervical and first thoracic for the upper limbs and the lower lumbar and first sacral for the lower limbs. The nerves gradually increase in the series in passing from the smaller toward the larger.

Fig. 747.-Diagrams Illustrating the Origin and Distribution of a Typical Spinal NERTE.

$A$, in thoracic region; $B$, in region of a limb (highly schematic).

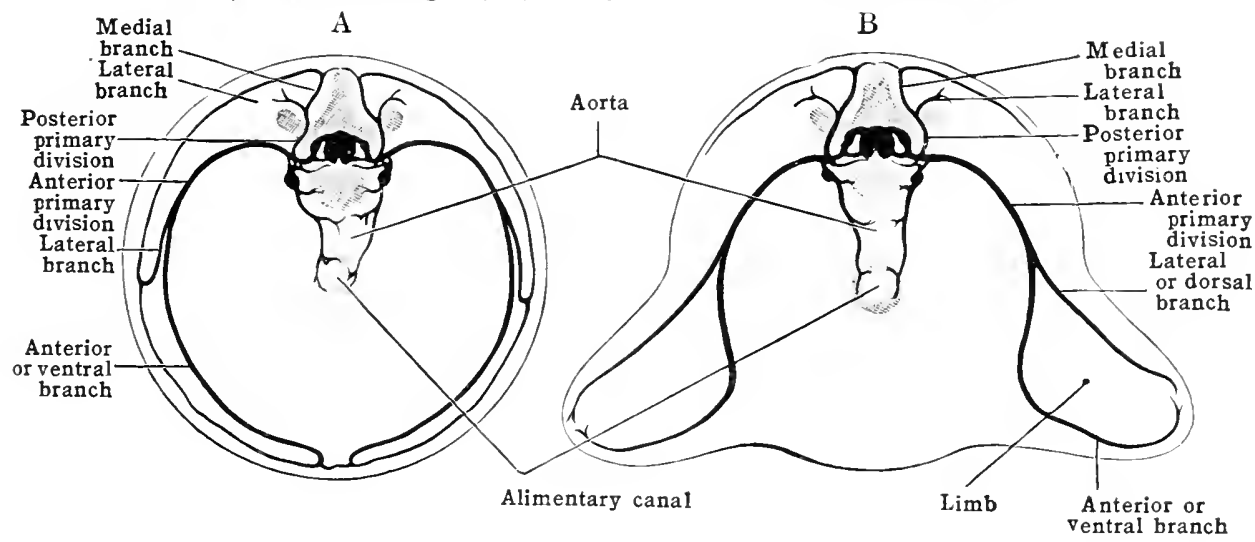

The primary divisions of the nerve-trunk. - A typical spinal nerve (middle thoracic, for example), just as it emerges from the intervertebral foramen, divides into four branches:-- the two large primary divisions; viz., the posterior primary division [ramus posterior] and the anterior primary division [ramus anterior]; third, the small ramus communicans, by which it is connected with the sympathetic; and fourth, the smaller, ramus meningeus (recurrent branch), which immediately turns centralward for the innervation of the membranes and ressels of the spinal cord.

In general, the posterior primary division passes dorsalward between the arches or transverse processes of the two adjacent vertebræ in relation with the anterior costo-transverse ligament, and then divides (with the exception of the first cervical, the fourth and fifth thoracic, and the coccygeal nerves) into a medial (internal) branch and a lateral (external) branch. The medial branch turns toward the spinous processes of the vertebræ, and supplies the bones and joints and the muscles about them, and may or may not supply the skin overlying them. The lateral branch turns dorsalward and also supplies the adjacent muscles and bones, and, if the medial branch has not supplied the overlying skin, it also terminates in cutaneous twigs. 
In the upper half of the spinal nerves the medial branches supply the skin; in the lower half, it is the lateral branches which do so. Both branches of almost all the posterior divisions, especially those of the lower nerves, show a tendency to run caudalward and thus are distributed to muscles and skin below the levels of their respective intervertebral foramina. They never supply the muscles of the limbs, though their cutaneous distribution extends upon the buttock, the shoulder, and the skin of the back of the head as far upward as the vertex. The posterior primary divisions, with the exception of those of the first three cervical nerves, are much smaller than the anterior primary divisions.

As their mixed function suggests, the posterior primary divisions contain both nerve-fibres from the ventral roots and peripheral processes of the spinal ganglion-cells. If the nerve-trunk on the immediate peripheral side of the spinal ganglion be teased, bundles of ventral root-fibres may be seen crossing the trunk obliquely to enter the posterior division, and fibres from the spinal ganglion may be also traced into it. Also a few sympathetic fibres, derived chiefly by way of the ramus communicans, are known to course in it for distribution in the walls of the blood-ressels, etc., of the area it supplies.

The anterior primary divisions run lateralward and ventralward. With the exception of the first two cervieal nerves, which contribute the hypoglossal loop, they are larger than the posterior primary divisions, and appear as direct continuations of the nerve-trunks. Only in case of most of the thoracic nerves do they remain independent in their course. In these they run lateralward and ventralward in the body-wall. In general, these clivisions supply the lateral and ventral

Fig. 748.-Diagram Illustrating the Origin of the Component Nerve-fibres of the Primary Divisions of a Trpical Spinal Nerve.

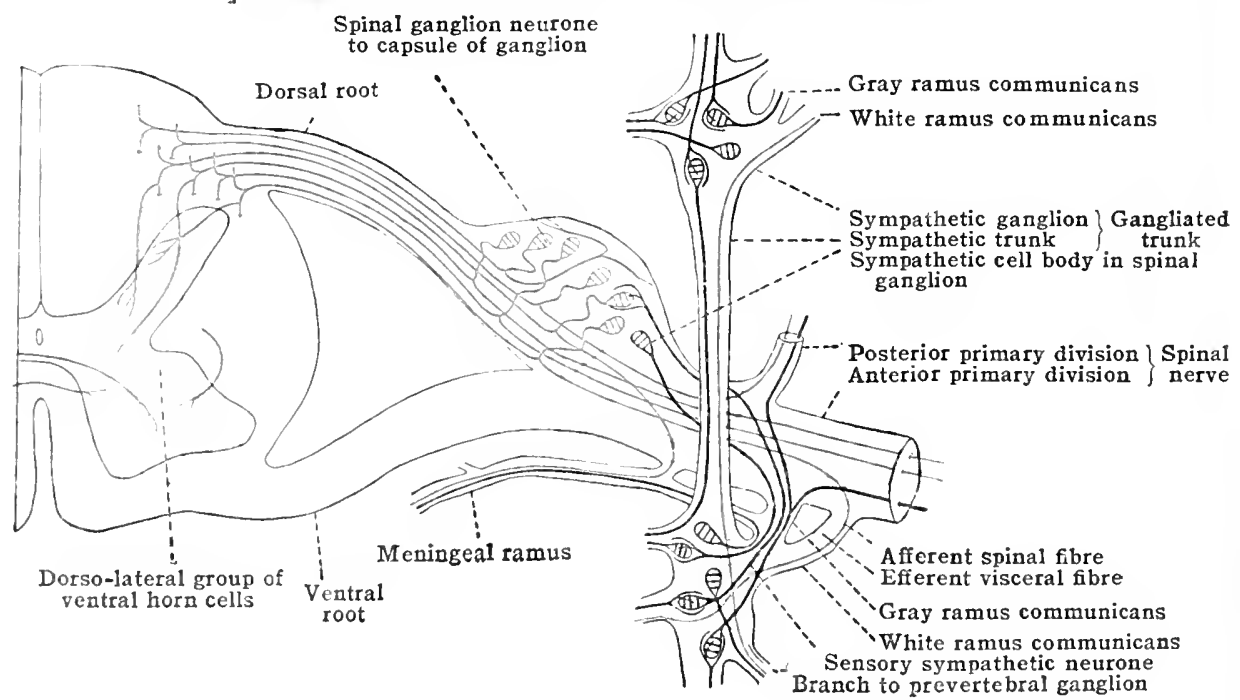

parts of the body, the limbs, and the perineum. In the eervieal, lumbar, and sacral regions the'y lose their anatomieal identity by dividing, subdividing, and anastomosing with cach other so as to give rise to the three great spinal plexuses of the borly- the cervical, the brachial, and the lumbo-sacral plexuses. 'The majority of the thoracice nerves retain the typical or primitive charaeter in hoth their anterion and josterior jrimary divisions. In them the anterior division (intercostal nerve divisles into a lateral or dorsal and an anterior or ventral braneh, both of which siblivide. The lateral branch is ehiefly eutaneous; it pierees the suprerficial muscles and, in the subeutaneous connertive tissue, divides into a smallor posterior and a larerer anterior ramus, which respetively supply the skin of the sides and the latoral part of the ventral surface of the body. 'The anterior branch eontinnes vontralward in the body-wall, giving off twigs along its eourse to thro aljacent muscles and lumes, and, as it approarehes the ventral mid-line of the hoely, it forms sharphy lateralward and sends rami unedialward and lateralward to supiply the skin of the ventsil aspect of the horly. In the region of the limbs the tyjural anrangrment is interfored with in that what corresponds to the lateral and antreror lianders of the division are rarried out into the limbs for the skin and

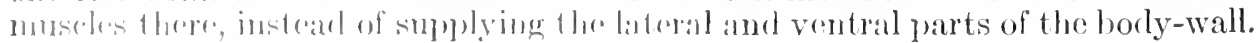


Nerve-fibres arising in the spinal ganglion and fibres from the ventral root pass directly from the nerve-trunk into the anterior primary division of the spinal nerve. This division also receives sympathetic nerve-fibres by way of the ramus communicans. These latter accompany the division and are distributed to their allotted elements in the territory it supplies.

Fig. 749.-Table Giving the Approximate Areas of Distribution of the Different Spinal Nerves with a Diagram showing Their Respective Levels of Exit frou the Vertebral Colums. (Arranged by Dr. Gowers.)

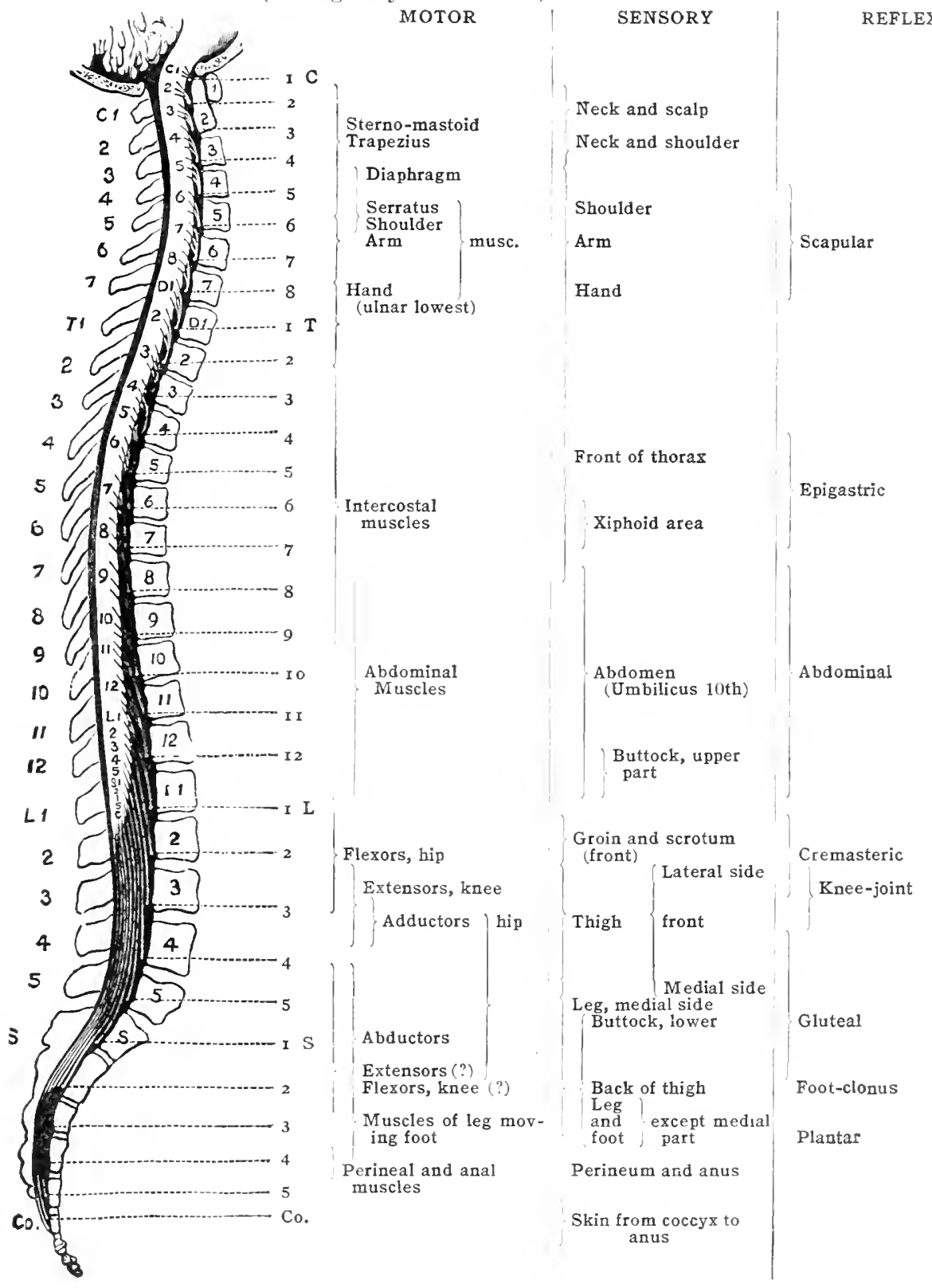

The rami communicantes are small, short, thread-like branches by which the nerve-trunks are connected with the nearest ganglion of the vertically running gangliated cord of the sympathetic (sympathetic trunk). The trunk or anterior primary division of every spinal nerve has at least one of these; most of the nerves have two, and sometimes there are three. The nerves of the cervical region usually have but one, and this is composed largely of sympathetic fibres (grey 
ramus). Where there are two, one usually contains medullated fibres, chiefly from the ventral root, sufficient to give it a whiter appearance (white ramus).

In the upper cervical and in the sacral regions one sympathetic ganglion may be connected with two or more spinal nerves, and sometimes one nerve is connected with two ganglia. The rami communicantes of the spinal nerves are equivalent to the communicating rami connecting certain of the cranial nerves with the sympathetic system (trigeminus, glosso-pharyngeus, vagus). The medullated fibres of the rami and, therefore, the white rami consist chiefly of fibres from the spinal nerves, viz., fibres from the spinal ganglion-cells which enter and course to their distribution through branches of the sympathetic nerves, visceral afferent fibres, and fibres from the ventral roots of the spinal nerves which terminate in the sympathetic ganglia, visceral efferent(preganglionic) fibres. Thus the white rami have been termed the visceral divisions of the spinal nerves. The grey rami consist chiefly of sympathetic fibres, most of which are non-medullated or partially medullated, and which course to their distribution by way of the spinal nerves. Some of the sympathetic fibres terminate in the spinal ganglion, afferent sympathetic fibres (fig. 748). The usual absence of white rami communicantes from the cervical nerves is explained on the grounds-(1) that probably relatively few efferent visceral fibres are given to the sympathetic from this region of the cord; (2) that many of the visceral efferent fibres which do arise from this region of the cord probably join the rootlets of the spinal accessory nerve and pass to the sympathetic system through the trunk of this nerve, and through the vagus with which it anastomoses; and (3) that such of these fibres as are given off from the lower segments of the cervical region, descend the cord and pass out by way of the upper thoracic nerves which give very evident white rami to the sympathetic.

The meningeal or recurrent branch (figs. $747,74 S$, and 762 ) is very small and variable, and is often difficult to find in ordinary dissections. It is given off from the nerve-trunk just before its anterior and posterior primary divisions are formed. It consists of a few peripheral branches of spinal ganglion-cells (sensory fibres) which leave the nerve-trunk and re-enter the vertebral canal for the sensory innervation of the meninges, and which are joined by a twig from the grey ramus or directly from the nearest sympathetic ganglion (vaso-motor fibres). There is considerable evidence, both physiological and anatomical, obtained chiefly from the animals, which shows that at times certain of the peripheral spinal ganglion or sensory fibres Inay turn backward in the nerve-trunk ancl pass to the meninges within the ventral root instead of contributing to a recurrent branch. The occurrence of such fibres in the ventral root explains the physiological phenomenon known as 'recurrent sensibility.' Likewise, sympathetic fibres entering the trunk through the grey ramus may pass to the meninges by way of the ventral root, and at times the recurrent branch is probably absent altogether, its place being taken entirely by the meningeal fibres passing in the ventral root.

Areas of distribution of the spinal nerves.-Both the posterior and anterior primary divisions divide and subdivide repeatedly, and their component fibres are distributed to areas of the body more or less constant for the nerves of each pair, but the distribution of the different nerves is very variable. Corresponding to their attachment, each to a given segment of the spinal cord, the nerves have primarily a segmental clistribution, but, owing to the developmental changes and displacement of parts during the growth of the body, the segmental distribution becomes greatly obscured and in some nerves practically obliterated. Naturally it is more retained by the nerves supplying the trunk than by those contributing to the innervation of the limbs and head, and the areas supplied by the posterior primary divisions are less disturbed than those supplied by the anterior. The segnental areas of cutancous distribution of the posterior divisions are more evident than the areas of muscle supplied by these divisions, from the fact that the segmental myotomes from which the dorsal muscles arise fuse together and overlap cach othrer considerably during devolopment. No nerve has a definitely prescriberlarea of rlistribution, cutaneous or muscular, for its area is always considerably overlalpled hy the areas of the norves adjacent to it. The mid-thoracic nerves more nearly smply a definitely prescribed belt of the body.

\section{POSTERIOR PRIMARY DIVISIONS}

The posterior primary livisions of the spinal nerves spring from the trunks immorliately ontside the interverteblat foriminat and they pass dorsalward bretwen the arljanent transverse processess. With the exeeptions of the first and secome cervial nerves they arre smaller than the corresponding anterior primary rlivisions, which in these berves is smaller from the fact that a large portion of throm go over into the hypoglossil or cervical loop. The posterior primary divisims, affer pasing betwern the transwerse processes into the region of the back, divide into merbial and lateral branches. This division, however, does not oceur in the cates of the first erevical, the last two sacral, and the coecygeal nerves. 


\section{Cervical Nerves}

The posterior primary division of the first cervical or sub-occipital nerve springs from the trunk, between the vertebral artery and the posterior arch of the atlas, passes dorsalward into the sub-oecipital triangle, and breaks up into branches which supply the superior oblique, the inferior oblique, and the major rectus eapitis posterior museles, which form the lateral boundaries of the triangle. It also gives a branch across the posterior surface of the major rectus capitis posterior to the minor rectus capitis posterior, and a branch to the semispinalis capitis (complexus) in the roof of the triangle.

It communicates with the medial branch of the posterior primary division of the second cervical nerve, either through or over the inferior oblique muscle, and it occasionally gives a cutaneous branch to the skin of the upper part of the back of the neck and the lower part of the scalp.

The posterior primary division of the second cervical nerve is the largest posterior division of all the cervical nerves. It divides into a small lateral branch and a very large medial branch. The lateral branch gives a twig to the inferior oblique and terminates in branches which supply the splenius and longissimus capitis (trachelo-mastoid) museles. The medial branch is the greater occipital nerve. It turns around the lower border of the inferior oblique, erosses the sub-oceipital triangle obliquely, pierces the semispinalis capitis (complexus), the tendon of the trapezius, and the deep cervical fascia, passing through the latter immediately below the superior nuchal line of the occipital bone, and it divides into several terminal sensory branches which ramify in the superficial faseia of the scalp.

It gives one or two motor twigs to the semispinalis capitis (complexus), and its terminal branches which are accompanied by branches of the occipital artery supply the skin of the scalp, above the superior nuchal line, as far forward as the vertex. Occasionally one branch reaches the pinna and supplies the skin on the upper part of its medial aspect. As it turns around the inferior oblique it gives branches which join with the medial branches of the posterior primary divisions of the first and third cervical nerves, and in this manner a small looped plexus is formed beneath the semispinalis capitis (complexus) muscle, the posterior cervical plexus of Cruveilhier.

The posterior primary branches of the third, fourth, and fifth cervical nerves divide at the lateral border of the semispinalis colli into medial and lateral branches. The medial branches of the third, fourth, and fifth nerves run backward between the semispinalis colli and capitis (complexus), supplying both muscles. Then, after passing backward between the semispinalis eapitis and the ligamentum nuchæ, they pierce the origin of the trapezius and supply the skin of the back of the neck. The greater part of the medial branch of the third nerve, which runs upward in the superficial fascia to the sealp, is called the third or smallest occipital nerve; it interlaces with the greater oceipital nerve, and it supplies the skin of the upper part of the back of the neck, near the middle line, and the skin of the scalp in the region of the external oceipital protuberance.

The medial branches of the posterior primary divisions of the sixth, seventh, and eighth cervical nerves pass to the median side of the semispinalis colli, between it and the subjacent multifidus spinæ, and they end in the neighbouring muscles. The lateral branches of the posterior primary divisions of the last five cervical nerves are small and they are distributed to the longissimus capitis (trachelomastoid), the iljo-costalis cervicis (cervicalis ascendens), the longissimus cervicis (transversalis cervicis), the semispinalis capitis (complexus), and the splenius muscles.

\section{Thoracic Nerves}

The posterior primary divisions of all the thoracic nerves divide into medial and lateral branches while in the vertebral groove. The medial branches of the upper six thoracic nerves pass dorsalward between the semispinalis dorsi and the multifidus spinæ; they supply the spinalis dorsi, the semispinalis dorsi, the multifidus spinæ, the rotatores spinæ, the intertransversales, and the interspinales museles; and they end in cutaneous branches which, after piercing the trapezius, turn lateralward in the superficial faseia of the back, and supply the skin as far as the middle of the scapula. The cutaneous branch of the second nerve is the largest; it can be traced lateralward as far as the acromion process. The medial branches of the lower six thoracic nerves run dorsalward, between the longissi- 
mus dorsi and the multifidus spinæ; they ehiefly end in twigs to the adjacent muscles, but not uncommonly they give small cutaneous twigs which pierce the latissimus dorsi and the trapezius and end in the skin near the mid-line of the back.

The lateral branches of the upper six thoracic nerves pass between the longis-

Fig. 750.-Distribution of the Posterior Primary Divisions of thenspinal Nertes. (Henle.)

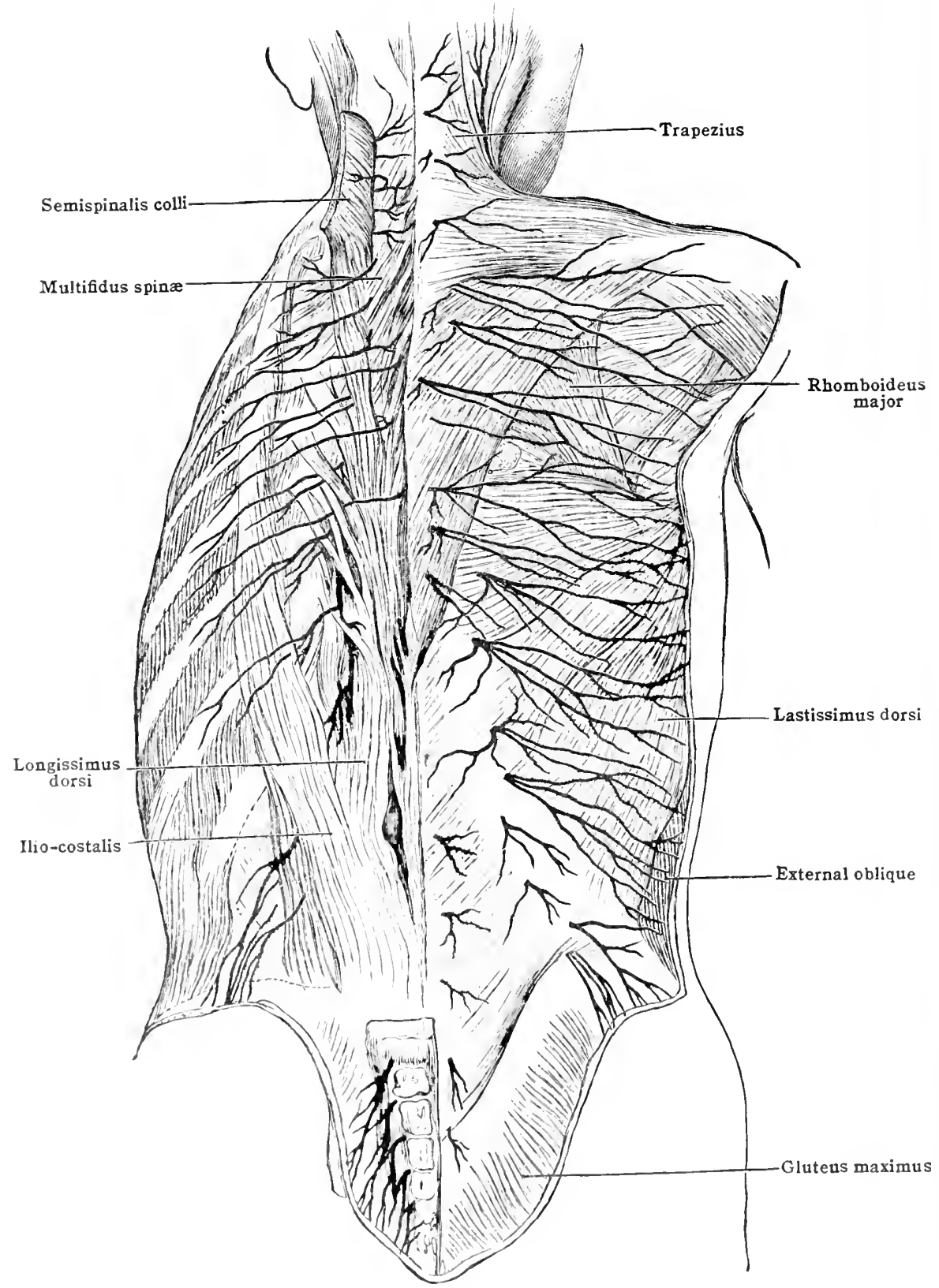

sinus dorsi and the ilio-costalis dorsi (accessorius) and end in those muscles, but the lateral branches of the six lower nerves are longer; they pass into the interval betwern the longrissimus dorsi and the iljo-costalis forsi and give branches to them, and then thery fireree the latiscimms dorsi and are distributed to the skin of the lower and latrial part of the bark. 


\section{Lumbar Nertes}

The medial branches of the posterior primary divisions of all the lumbar nerves end in the multifidus spinæ and those of the three lower nerves send very small branches to the skin of the sacral region.

The lateral branches of the upper three nerves pass obliquely lateralward, supplying twigs to the adjacent muscles, pierce the posterior layer of the lumbar aponeurosis at the lateral border of the sacro-spinalis (erector spinæ) and enter the subcutaneous tissue. They are, for the most part, cutaneous, forming the superior clunial nerves, which cross the crest of the ilium and pass downward to occupy different planes in the thick superficial fascia which covers the upper part of the gluteus medius.

The branch from the first lumbar nerve is comparatively small, and occupies the most superficial plane. The second occupies an intermediate position. The lateral branch from the third nerve is the largest of the three, and occupies the lowest position; it distributes branches over the gluteus maximus as far as the great trochanter. The three nerves anastomose with one another and also with the cutaneous branches from the posterior primary divisions of the two upper sacral nerves.

The lateral branch of the fourth lumbar nerve is of small size and ends in the lower part of the sacro-spinalis (erector spinæ). That of the fifth lumbar is distributed to the sacro-spinalis and communicates with the first sacral nerve.

\section{Sacral Nerves}

The posterior primary divisions of the upper four sacral nerves escape from the vertebral canal by passing through the posterior sacral foramina; those of the fifth sacral nerve pass out through the hiatus sacralis between the posterior sacrococcygeal ligaments. Those of the upper three sacral nerves divide in the ordinary manner into medial and lateral branches. Those of the lower two sacral nerves remain undivided.

The medial branches of the upper three sacral nerves are of small size, and are distributed to the multifidus spinæ. The lateral branches anastomose with one another and with the lateral branch of the last lumbar nerve, forming loops on the posterior surface of the sacrum from which branches proceed to the posterior surface of the sacro-tuberous (great sacro-sciatic) ligament, where they anastomose and form a second series of loops, from which loops two or three branches are given off. These branches pierce the gluteus maximus and come to the surface of that muscle in a line between the posterior superior spine of the ilium and the tip of the coccyx. Then, as the middle clunial nerves, they are distributed to the integument over the medial part of the gluteus maximus, and communicate, in their course through the superficial fascia, with the posterior branches of the lumbar nerves.

The posterior divisions of the lower two sacral nerves unite with one another, with the posterior branch of the third sacral, and with the coccygeal nerve, forming loops from which twigs pass to the integument over the lower end of the coccyx.

The posterior primary division of the coccygeal nerve is also undivided. It separates from the anterior division in the sacral canal and emerges through the hiatus sacralis, pierces the ligaments which close the lower part of that canal, receives a communication from the posterior division of the last sacral nerve, and ends in the skin over the dorsal aspect of the coccyx.

\section{B. ANTERIOR PRIMARY DIVISIONS}

The anterior primary divisions of the spinal nerves are larger than the posterior primary divisions, and each is joined near its origin by a grey ramus communicans from the sympathetic gangliated cord (figs. 751, 752, 762). Beginning with the first or second thoracic nerve and ending with the second or third lumber nerve, each anterior division sends to the gangliated cord a white ramus communicans. The same is true of the second and third or of the third and fourth sacral nerves. These white rami are appropriately designated the visceral branches of 
the spinal nerves. The anterior primary divisions of the cervical, lumbar, sacral, and coccygeal nerves unite with one another to form plexuses, but the anterior primary dirisions of the thoracic nerves, except the first and last, remain separate, pursue independent courses, and each divides, in a typical manner, into a lateral and an anterior or ventral branch. The separation of the anterior primary division into lateral and anterior branches is not eonfined to the thoracic nerves; it occurs also in the lower cervical, the lumbar, and the sacral nerves, but such a division cannot be clearly distinguished either in the upper cervical nerves, or in the cocergeal nerve.

\section{CERVICAL NERVES}

The anterior primary divisions of the upper four cervical nerves unite to form the cervical plexus, and each receives a communicating branch from the superior cervical srmpathetic ganglion. The anterior divisions of the lower four cervical nerves are joined by the greater part of the first thoracic nerve and they unite to form the brachial plexus (figs. 751, 754, 755). The fifth and sixth cervical nerves receive communicating branches from the middle cervical sympathetic ganglion, and the seventh and eighth from the inferior cervical ganglion, while the first thoracic nerve is always connected with the first thoracic sympathetic ganglion by a grey ramus (figs. 751, 786) and in most cases also by a white ramus communicans.

\section{THE CERVICAJ PLEXUS}

The cervical plexus (figs. 751, 752) is formed by the anterior primary divisions of the upper four cervical nerves which constitute the roots of the plexus. It lies in the upper part of the side of the neck, under cover of the sterno-mastoid, and upon the levator scapulx and the scalenus medius. It is a looped plexus, consisting of three loops.

A large part of the anterior primary division of the first cervical nerve is given to the hypoglossal or cervical loop; the remainder passes to the cervical plexus and in doing so it runs lateralward on the posterior arch of the atlas beneath the vertebral artery, then it turns forward, between the vertebral artery and the outer side of the upper articular process of the atlas, and finally it descends, in front of the transverse process of the atlas, and unites with the upper branch of the second nerve, forming with it the first loop of the plexus. It gives branches to the rectus capitis lateralis, longus capitis (major rectus capitis anterior), and to the rectus capitis anterior (minor). The division communicates with the ganglion of the trunk of the vagus and with the superior eervical ganglion of the sympathetic srstem (fig. 752). From the first loop of the plexus, two branches of the division pass over into the sheath of the hypoglossal nerve and deseend with it to contribute to the hypoglossal loop [ansa hypoglossi] or better, the cervical loop. The fibres entering the sheath of the hypoglossus, after giving a few twigs to the genio-hyoid and thyreo-hyoid muscles, lave the shoath as the descendens cervicalis (hypoglossi) and this latter joins the communicans cervicalis, (the portion of thr loop from the second and third cervical nerves) and thus completes the arrical or hypoglossal loop.

This lon, usmally mat be found between the sheaths of the stemo-mastoid muscle and the comotid artary, superficial to the internal jugular voin; sometimes it may lie in the carotid shrath hetwen the ranotid artery and the intronal jugular vein; rarely it may lie dorsal to both

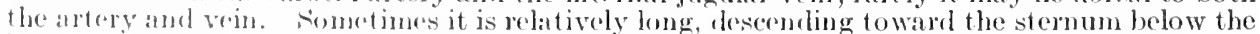

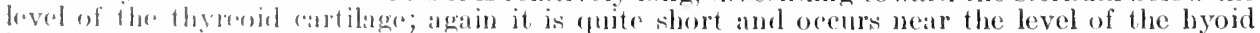

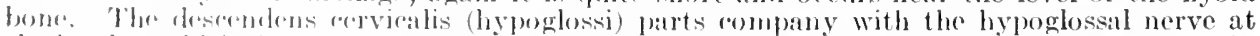

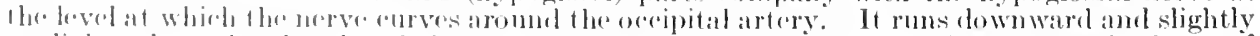

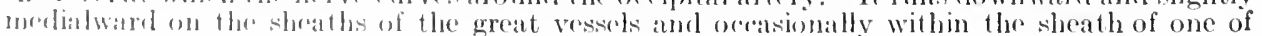
thrin.

'The second cervical nerve (anterior primary division) passes behind the upper articular proeses of the axis and the vertobral artery, and between the intertransverse mosedes extending from the first to the serend eervieal vertebra, to the interval betwern the sealenus medius and the longus apditis (rectus eapitis anteriol natjor), where it diviles into two parts. 'The upper part ascends and muites with the first nerve to form the first loop of the plexus, and the lower branch

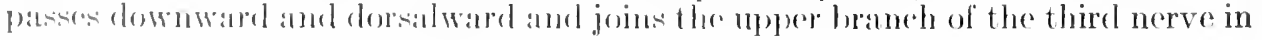


the second loop of the plexus (figs. 751, 752). This branch gives off the small occipital nerve and a filament to the sterno-mastoid, which communicates with the spinal accessory nerve in the substance of the muscle, and it gives branches which assist in forming the hypoglossal or cervical loop (ansa hypoglossi) the cervical cutaneous and the great auricular nerves (fig. 752).

Fig. 751.-Origin of the Cervical and Brachin Plexus. (After Toldt, "Atlas of Human Anatomy," Rebman, London and New York.)

Muscular branch to rectus capitis anterior and Internal carotid artery lateralis and longus capitis Rectus capitis anterior Rectus capitis lateralisFirst cervical nerve

Ramus communicans

Second cervical nerve

Muscular branch to longus capitis and longus colli .

Communicating branch to descendens cervicalis (hypoglossi)

Small occipital

Communicating branch to spinal accessory

Great auricular

Cervical cutaneous

Muscular branch

ר:

Supra-clavicularis Dorsal scapular --

Supra-scapular
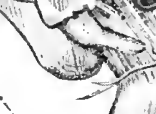

Superior cervical ganglion

Third and fourth cervical nerves

Ramus communicans

Vertebral artery

Gangliated trunk

Fifth, sixth and seventh cervical nerves

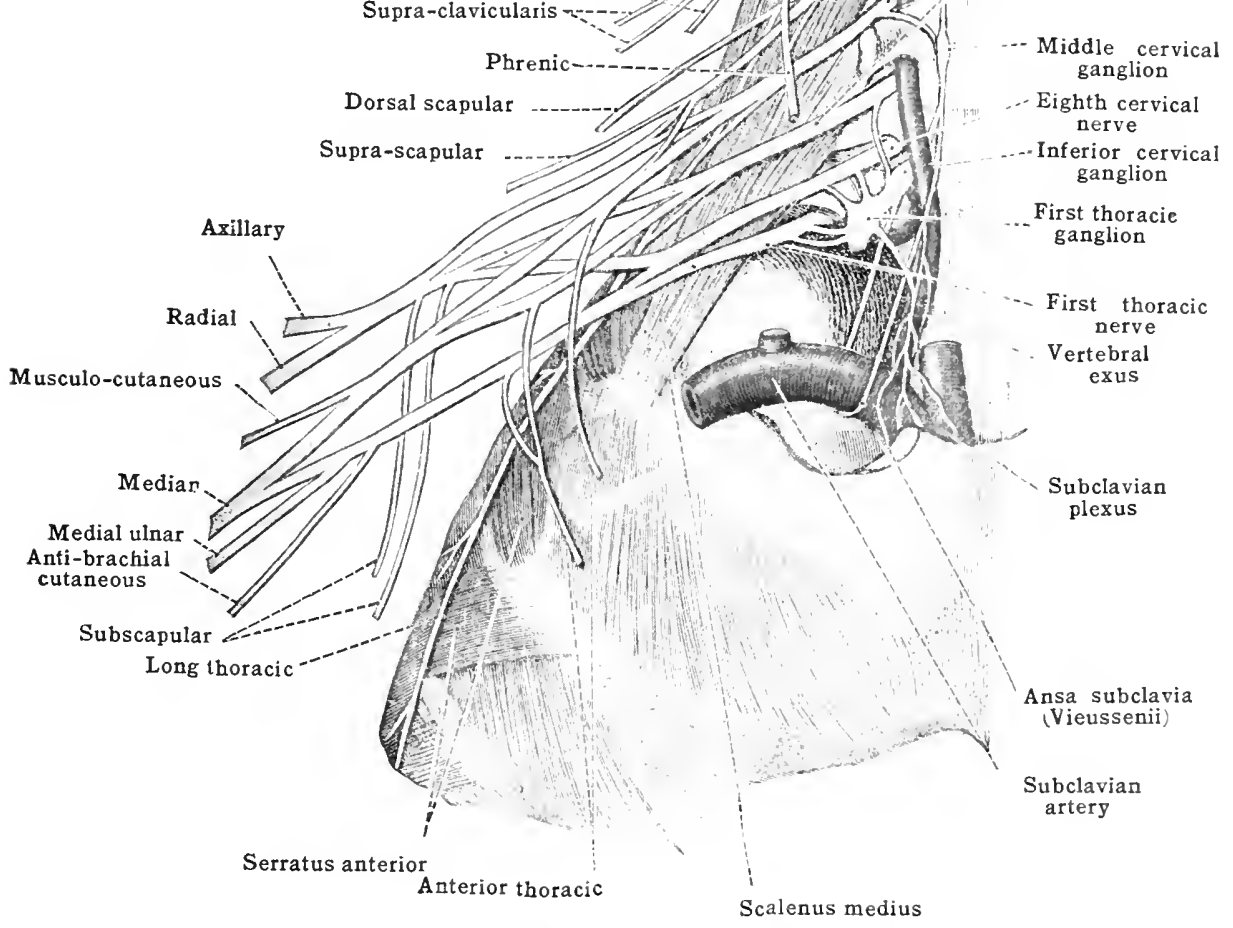

The third and fourth cervical nerves pass behind the vertebral artery (fig. 751) and between the intertransverse muscles to the interval between the sealenus medius and the longus capitis (rectus capitis anterior major), where the third unites with the second and fourth nerves and completes the lower two loops of the plexus. The anterior primary divisions of these nerves are about double the size of the preceding. The third gives off branches to the hypoglosisal loop, to the 
larger part of the great auricular and cervical cutaneous nerves, a branch to the phrenic, a branch to the supra-clavicular nerves, and muscular branches to the scalenus medius, levator scapulæ, longus capitis, and trapezius (fig. 752). The trapezius branch joins the spinal accessory nerve beneath the muscle. The fourth neive gives a branch to the phrenic, a branch to the supra-clavicular nerves, and muscular branches to the scalenus medius, levator scapulæ, longus colli, and trapezius (fig. 752). The branch to the trapezius unites with the one from the third nerve and joins the spinal accessory nerve beneath the muscle.

The fibres forming the cervical (hypoglossal) loop innervate all the muscles of the infra-hyoid group, though twigs to the genio-hyoid and thyreohyoid seemingly enter these muscles from the trunk of the hypoglossus (fig. 752).

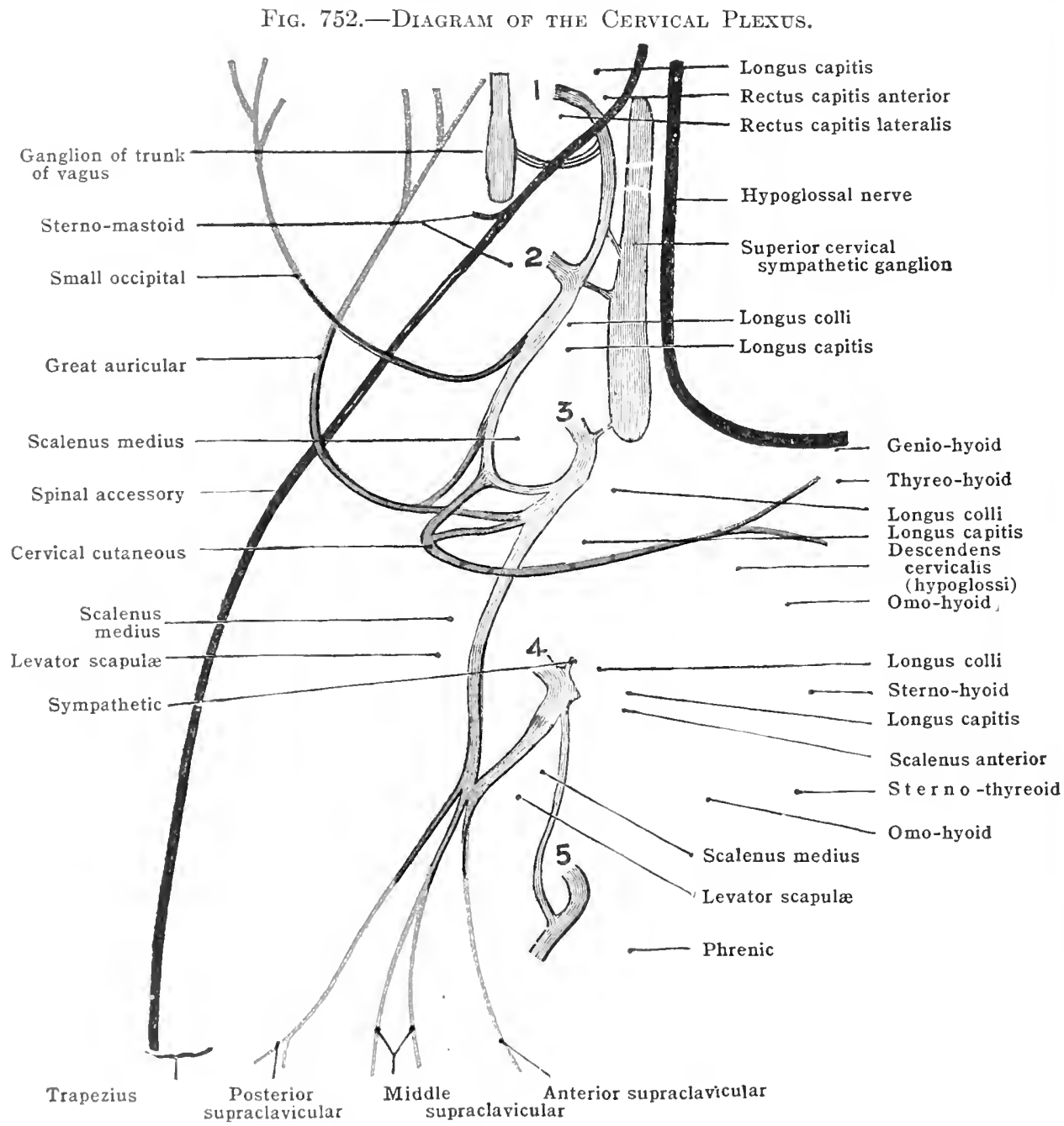

The nerve to genio-hyoid is given off from the trunk under cover of the mylo-hyoid in common with the terminal branches of the hypoglossal proper going to the intrinsic muscles of the tongue. The nerve to the thyreo-hyoid muscles leaves the trunk of the hypoglossal near the tip of the great cormu of the lyyoid bone, running obliquely downward and medianward to reach its muscle. I twig to the anterior belly of the omo-hyoid is given from the upper part of the descendens corvicalis and the nerves for the sterno-hyoid, the sterno-thyreoid and the posterior belly of the omo-hyoid are supplied from the turn of the loop (fig. 752). The nerves to thes stemo-hyoid and sterno-thy reosd send twigs lownward in the muscles behind the manubrium strorni and fibres from these in rare astses join the phrenie nerve in the thorax. The nerve to the posterior belly of the omo-hyoid courses as a loop in the cervical fascia below the central temolon of its muscele.

Warch root of the cervieal plexus receives a communicating erey ramus from the superion cervical ganglion of the sympathetic, and from the roots and loops of 
the plexus a number of branches arise which form two main groups, the superficial and the deep.

\section{Superficial Branches of the Cervical Plexus}

The superficial branches are described, according to the direction in which they run, as ascending, transverse, and descending branches. The ascending branches are the small occipital and the great auricular nerves. There is only one transverse branch, the cervical cutaneous (transverse cervical), and the descending branches are distinguished as the supractavicular nerves and the cervical (hypoglossal) loop.

The ascending branches.-(1) The small occipital nerve (fig. 751) arises from the second and third cervical nerves, or from the loop between them, and runs

Fig. 753.-Superficial Branches of the Certical Plexus. (After Hirschfeld and Leveillé.)

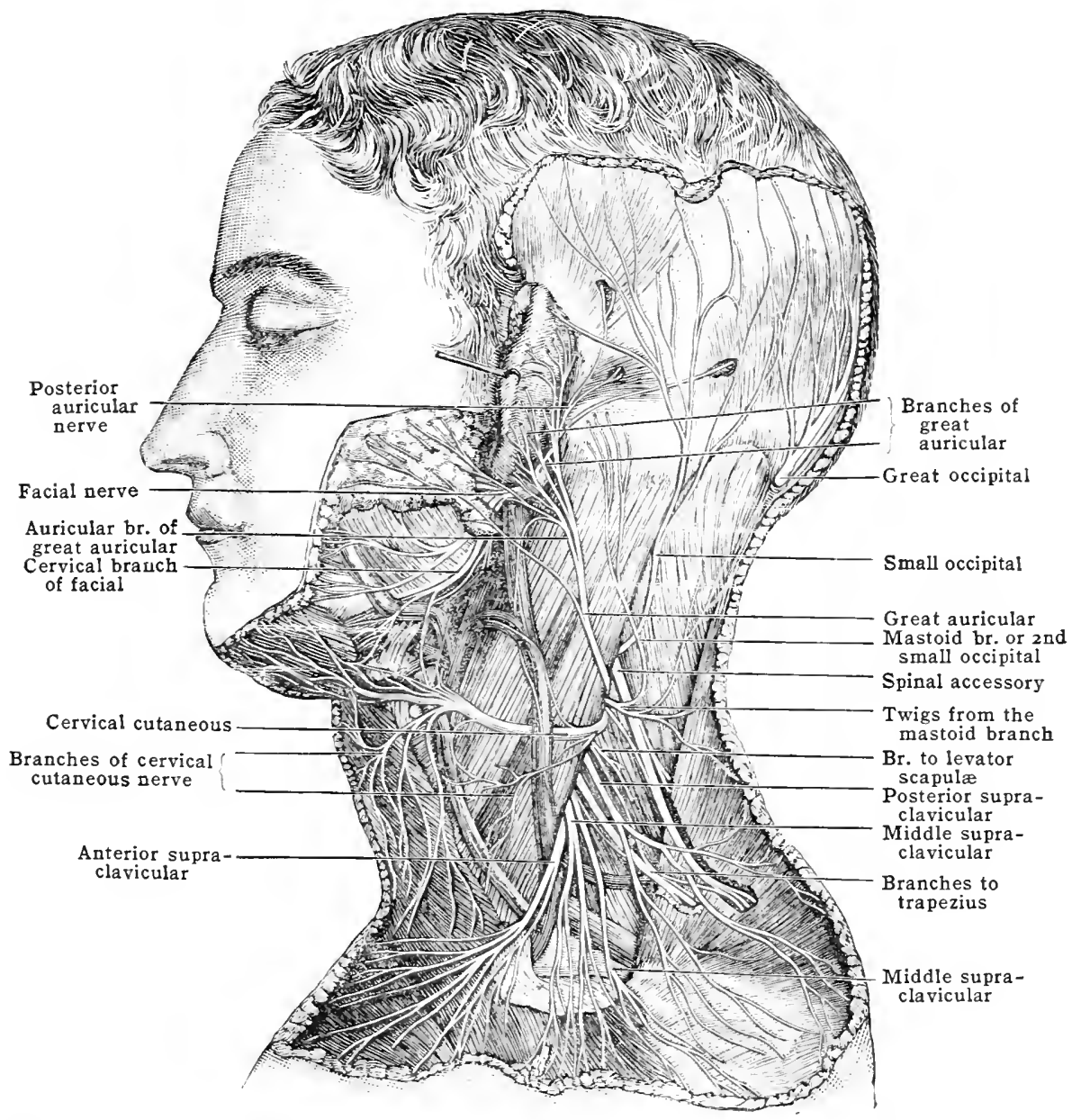

upward and dorsalward to the posterior border of the sterno-mastoid, where it hooks around the lower border of the spinal accessory nerve and then ascends along the posterior border of the muscle to the mastoid process. It pierces the deep cervical fascia and passes across the posterior part of the insertion of the sterno-mastoid into the superficial fascia of the scalp, in which it breaks up into auricular, mastoid, and occipital terminal branches.

(a) The auricular branch runs upward and slighly forward to reach the integument on the upper median part of the auricle(pinna), which it supplies. (b) The mastoid branch is distributed to the skin covering the base of the mastoid process. (c) The occipital branches ramify over the occipitalis muscle and are distributed to the skin of the scalp they communicate with one another and with the great occipital nerve. The branches of the small occipital nerve 
anastomose with twigs of the posterior auricular, great auricular, and great occipital nerves (fig. 753).

(2) The great auricular nerve arises from the second and third cervical nerves (figs. 751, 752). It accompanies the small occipital to the posterior border of the sterno-mastoid, but at that point it diverges from the small occipital (fig. 753) and runs upward and forward across the sterno-mastoid toward the angle of the mandible. When it is about half-way across the muscle it begins to break up into its terminal branches, which are named, according to the area of their distribution, mastoid, auricular, and facial.

As the nerve ascends obliquely across the sterno-mastoid it is embedded in the deep cervical fascia, is covered by superficial fascia and the platysma, and it lies parallel with and slightly dorsal to the external jugular vein. (a) The mastoid branch is small, and is distributed to the integument eovering the mastoid process. It anastomoses with the posterior auricular and small occipital nerves. $(b)$ The auricular branches are three or four stout twigs which interlace with the branches of the posterior auricular nerve; they eross the superficial surface of the posterior auricular branch of the facial, and are distributed to the skin on the back of the auricle with the exception of its uppermost part. One or two twigs pass through fissures in the cartilage of the auricle, and are distributed to the integument on the lateral surface of the lobule and the lateral surface of the lower part of the helix and anthelix. (c) The facial branches pass upward and forward among the superficial lobules of the parotid gland, and supply the skin over that gland and immediately in front of it, and they anastomose in the substance of the gland with the cervico-facial division of the facial nerve. In some cases fine twigs may be traced forward nearly to the angle of the mouth.

Transverse branch of the plexus.-The superficial cervical cutaneous nerve (transverse cervical) arises from the second and third cervieal nerves (figs. 751, 752), and appears at the posterior border of the sterno-mastoid, a little below the great auricular nerve. It passes transversely across the sterno-mastoid under cover of the integument, platysma, and external jugular vein, and clivides into a number of twigs which spread out after the manner of a fan, and, as they approach the middle line, extend from the chin to the sternum (fig. 753).

The upper two or three of these twigs unite, beneath the platysma, with the cervical (inframandibular) branch of the facial and thus form loops. From the terminal branches of the nerve numerous twigs arise which pierce the platysma and end in the skin of the front part of the neck.

The descending or supra-clavicular branches.- These are derived from the third and fourth cervical nerves (figs. 751, 752), and arise under cover of the sterno-mastoid. At their commencements they are usually united with the muscular branches destined for the trapezius. They become superficial at the middle of the posterior border of the sterno-mastoid, and as they pass downward they pierce the deep cervical fascia. They include the following:

(1) The anterior supra-clavicular (suprasternal) branches (fig. 753) are small, and cross over the elavieular attachment of the sterno-mastoid to reach the integument over the upper part of the manubrium sterni. They also supply the sterno-clavicular joint. (2) The middle supra-clavicular (supra-clavicular) nerves are of considerable size. They cross in front of the middle third of the elavicle under cover of the platysma, and are distributed to the skin covering the upper part of the peetoralis major as low as the third rib. (3) The posterior supraclavicular (supra-acromial) branches (fig. 753) cross the clavieular insertion of the trapezius and the acromion process. They are distributed to the skin which covers the upper two-thirls of the deloid muscle and they supply the aeromio-clavicular joint.

\section{Deep Branches of the Cervical Plexus}

The deep branches of the plexus pass lateralward and dorsalward, or ventralward and nedialward; therefore they form two series, the lateral and the medial.

The lateral branches of the deep series inchule communieating branches from the secoml, third, and fourth cervical nerves to the spinal accessory nerve, and museular branches to the sterno-mastoid and the scalenus medius, levator seapula, and traperius.

The communicating branches.-The communieating branch from the second cervical nerve is ultimat ly distributed to the sterno-mastoid, and those from the third and fourth nerves end in the traperius.

I. 'The nerve to the sterno-mastoid arises from the second celvieal nerve (fig. 753). It pierces the rece surface of the sterno-mastoid, and communieates within the muscle with the kpinal aceessory nerve.

2. The nerves to the scalenus medius (fig. 752) are derived from the third or fourth to the eighth cervical nerves close to their exit from the intervertebral foramina. 
3. The nerves to the levator scapulæ (fig. 752) are derived from the third and fourth cervical nerves, and occasionally from the second or fifth. They pierce the superficial surface of" the levator scapulæ, and supply the upper three divisions of that muscle.

4. The branches to the trapezius (fig. 752) are usually in the form of two stout twigs which are given off by the third and fourth cervical nerves. 'They emerge from under cover of the sterno-mastoid at its posterior border and cross the posterior superior triangle of the neck at a lower level than the spinal accessory nerve (fig. 753). They pass under cover of the trapezius in company with the last-named nerve, and communicate with it to form the subtrapezial plexus, from which the trapezius is supplied.

The medial branches of the deep series also comprise communicating and muscular branches.

The communicating branches (figs. 751, 752) include (1) branches which connect each of the first four cervical nerves with the superior cervical ganglion of the sympathetic; (2) a branch to the vagus; (3) a branch to the hypoglossal; and (4) branches which pass from the second and third cervical nerves to the descendens cervicalis (hypoglossi). The ultimate distribution of the twigs connected with the sympathetic and the vagus nerves is not known, but the fibres which pass to the hypoglossal nerve pass from it to the thyreo-hyoideus muscle, and to the descendens cervicalis and the latter joins with the branches from the second and third cervical nerves, forming with them the cervical or hypoglossal loop [ansa hypoglossi] which lies on the carotid sheath. From this loop the two bellies of the omo-hyoid muscle and the sterno-hyoid and sterno-thyreoid muscles are supplied as described above.

The muscular branches supply the rectus capitis lateralis, the longus capitis (rectus capitis anterior major), the rectus capitis anterior (minor), the scalenus anterior, and the diaphragm. The nerve to the latter muscle is the phrenic.

1. The branch to the rectus capitis lateralis is furnished to that muscle by the first cervical nerve as it crosses the deep surface of the muscle.

2. The nerve to the rectus capitis anterior (minor) is given off by the first nerve at the upper part of the loop in front of the transverse process of the atlas.

3. The longus capitis (rectus capitis anterior major) receives twigs from the upper four cervical nerves.

4. The longus colli receives branches from the second, third, and fourth cervical nerves, and additional branches also from the fifth and sixth nerves.

5. The phrenic nerve (fig. 752) springs chiefly from the fourth cervical nerve, but it usually receives a twig from the third and another from the fifth cervical nerve, a small communicating branch from the sympathetic, and, rarely, a branch from the vagus. The twig from the fifth cervical nerve is frequently connected with the nerve to the subclavius. After the union of its roots the phrenic nerve passes downward and medialward on the scalenus anterior (fig. 755). In this part of its course it is crossed by the tendon of the omo-hyoid and by the transverse cervical and transverse scapular (suprascapular) arteries. It is overlapped by the internal jugular vein, and it is covered by the sterno-mastoid muscle. At the root of the neck the left phrenic nerve lies behind the terminal portion of the thoracic duct, and each nerve passes off the anterior border of the scalenus anterior and descends in front of the first part of the subclavian artery and the pleura immediately below that artery; each nerve passes dorsal to the terminus of the subclavian vein, crosses either in front of or dorsal to the internal mammary artery and gains the medial surface of the pleural sac. From the root of the neck the relations of the phrenic nerves differ. The right phrenic nerve descends along the medial surface of the right pleural sac and crosses in front of the root of the lung. It is accompanied by the pericardiaco-phrenic artery (comes nervi phrenici), and it is in relation medially, and from above downward, with the right innominate vein, the superior vena cava, and the pericardium, the latter membrane separating it from the wall of the right atrium (auricle). The left phrenic nerve clescends along the medial surface of the left pleural sac accompanied by the pericardiaco-phrenic (comes nervi phrenici) artery. In the superior mediastinum it lies between the left common carotid and the left subclavian arteries, and it crosses in front of the left vagus, the left superior intercostal vein, and the arch of the aorta. Below the arch of the aorta it crosses in front of the root of the left lung, and then lies along the left lateral surface of the pericardium, which separates it from the wall of the left ventricle.

Branches.-Both phrenic nerves distribute branches to the pericardium and to the pleura. The right nerve gives off a branch, pericardiac, which accompanies the superior vena cava and supplies the pericardium. Each phrenic nerve divides into numerous terminal phrenicoabdominal branches. As a rule, the right phrenic nerve divides in to two main terminal branches, an anterior and a posterior. The anterior branch runs forward and one of its terminal filaments 
anastomoses with the phrenic of the opposite sicle in front of the pericardium; others descend between the sternal and costal attachments of the diaphragm in to the abdomen, where some of them supply the diaphragm and others descend in the falciform ligament to the peritoneum on the upper surface of the liver. The posterior branch passes through the vena caval opening and ramifies upon the lower surface of the diaphragm, anastomosing with the diaphragmatic plexus of the sympathetic, and its terminal branches supply the muscular fibres of the right half of the diaphragm, the inferior vena cava, and the right suprarenal gland.

The left phrenic nerve divides into several branches. One of the most anterior branches anastomoses with the right phrenic nerve; the others pierce the diaphragm and ramify on its under surface, where they anastomose with filaments of the left diaphragmatic plexus of the sympathetic and supply the left half of the diaphragm and the left suprarenal gland. The left phrenic nerve is considerably longer than the right nerve, partly on account of the lower level of the diaphragm on the left side, and partly on account of the greater convexity of the left side of the pericardium.

\section{THE BRACHIAL PLEXUS}

The brachial plexus (figs. $751,754,755$ ) is formed by the anterior primary divisions of the four lower cervical nerves and the greater part of that of the

Fig. 754.-Diagram of a Comnon Form of Brachial Plexus.

The posterior cord of the plexus is darkly shaded.

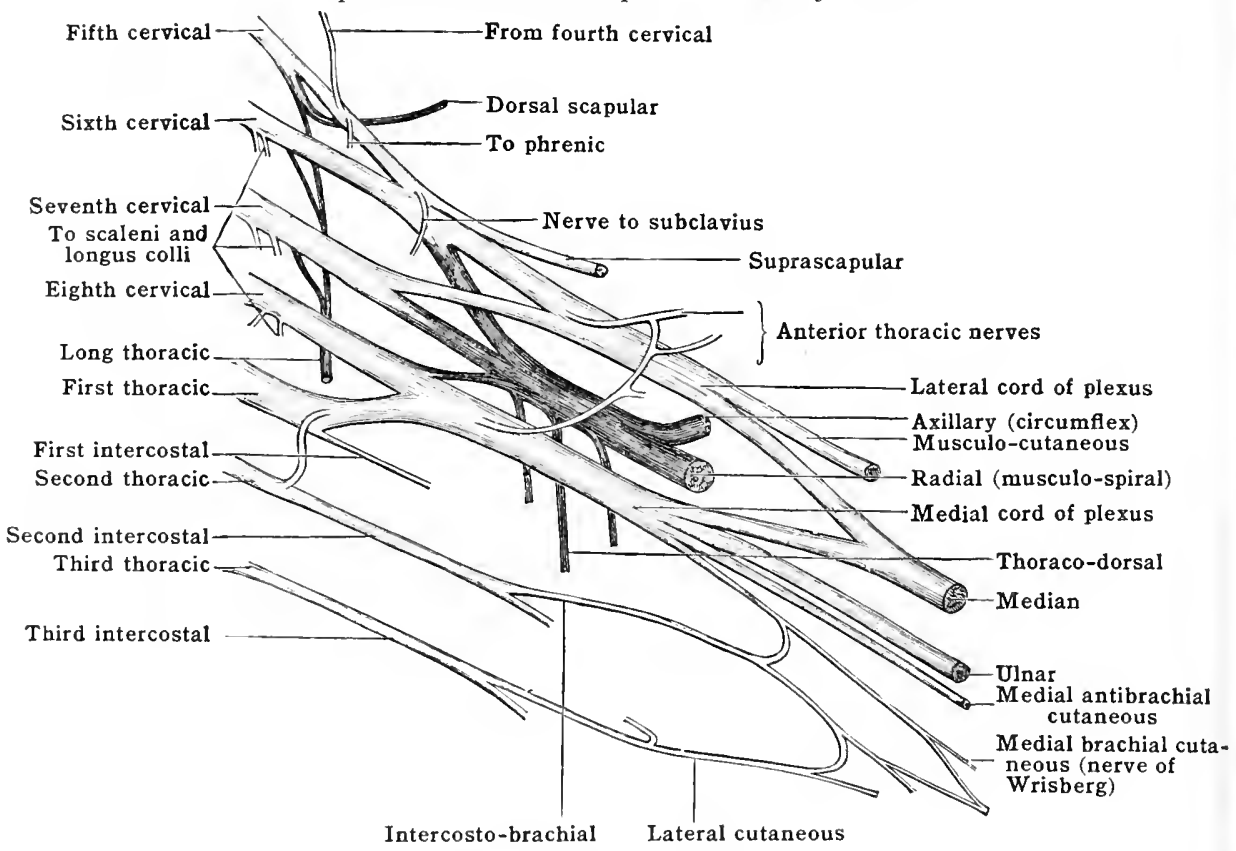

first thoracic nerve. It is usually joined by small twigs from the fourth cervical and second thoracic nerves.

'The anterior printury divisions of the lower four cervieal nerves, after passing dorsal to the vorterbral artery and betwoen the anterior and posterior parts of the intertransverse museles, pass into the posterior triangle in the interval between the adjacent borders of the anterior and middle scalene muscles, where the fifth and sixth nerves reerive a grey ramus communicans each from the middle eervieal sympathetic ganglion, and the seventh and righth nerves each receive a grey ramus from the inforior envieal sympathetic ganglion. The first thoracie is connected by two rami communicantes with the first thoracie sympathetie ganglion, and it divides into a smaller and a larger braneh. The smaller branch passes along the intereostal suare as the first intercostal nerve, and the larger braneh, after being joined by a twig from the serond thoracic nerve, passes upward and lateralward, in front of the norek of the first rib and behind the apex of the pleural sace, into the lower part of the posterior triangle of the neck, where it takes part in the formation of the plexus.

'The anterior primary divisions of those cervical nerves that form the brachial plexus may be considered as typieally giving off anterior and posterior branches, 
except that the fifth and sixth nerves often unite before branching and give off their posterior branches as a common trunk, and the eighth nerve often receives its branch from the first thoracic nerve before giving off its posterior branch.

It is on account of this variation in the point of union of the fifth and sixth cervical nerves and of the eighth cervical and first thoracic nerves that so many different forms of the plexus have been pictured and described. But if the differences in primary branching be borne in mind, the formation of the plexus is always uniform and simple, notwithstanding its different appearances.

Fig. 755.-The Brachial Plexes and its Branches of the Region of the Neck and Shoulder. (After Toldt, "Atlas of Human Anatomy," Rebman, London and New York.)

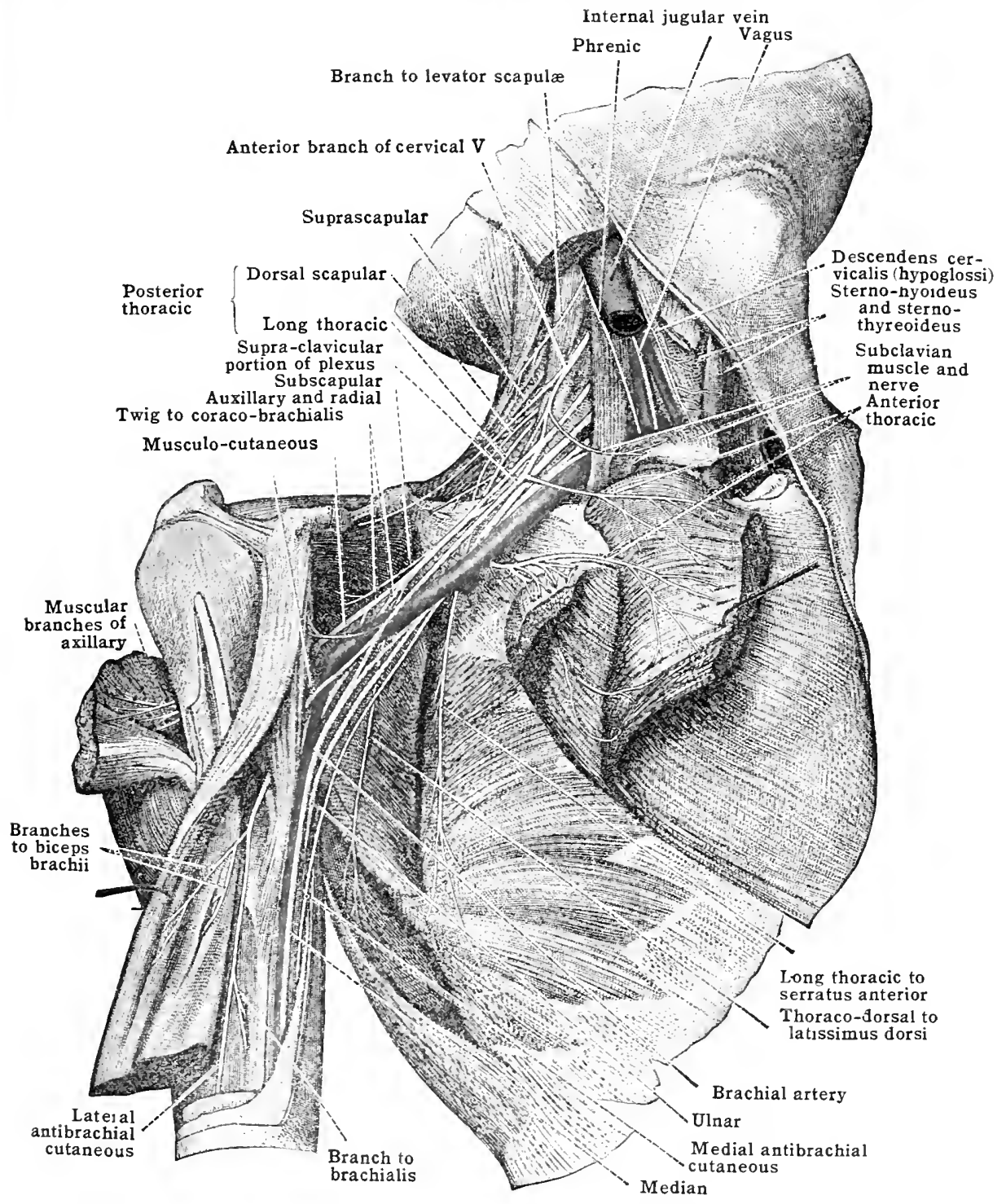

Three cords are formed from these branches in the following manner:-(1) The lateral (outer) cord [fasciculus lateralis] is formed by the anterior branches of the fifth, sixth, and seventh nerves; (2) the medial (imer) cord [fasciculus medialis], by the anterior branches of the eighth cervical and first thoracic nerves; and (3) the posterior cord [fasciculus posterior], by the posterior branches of all of these cervical nerves.

Relations.-The plexus extends from the lateral border of the scalenus anterior, where the roots of its constituent nerves appear, to the lower border of the pectoralis minor, where each 
of its three cords divides into two terminal branches, and it lies in the posterior triangle, in the root of the neck, and in the axillary fossa. In the posterior triangle and in the root of the neck it is in relation behind with the scalenus medius (figs. 751, 755). In the posterior triangle it is covered superfieially by the skin and superficial fascia, the platysma, the supra-clavicular branches of the cervical plexus, and the deep fascia, and it is crossed by the lower part of the external jugular vein, by the nerve to the subclavius, the transverse cervical vein and the transverse scapular (supra-scapular) vein, the posterior belly of the omo-hyoid muscle, and by the transverse cervical artery. At the root of the neck it lies behind the clavicle and the subclavius muscle, and the transverse scapular (suprascapular) artery crosses in front of it. In the axillary fossa the cords are arranged around the axillary artery, the lateral (outer) cord lying lateral to the artery, the medial (inner) cord medial to it, and the posterior cord dorsal to the artery. In this region the posterior relations of the plexus are the fat in the upper part of the fossa and the subscapularis muscle, and it is covered in front by the pectoral muscles and the coraco-clavicular fascia. The lower border of the plexus is in relation in the posterior triangle and at the root of the neek with the pleura and the first rib, and it is overlapped in front by the third part of the subelavian artery. In the axillary fossa the medial cord which forms the lower bordes' of the plexus is overlapped anteriorly by the axillary vein. The upper and lateral border of the plexus has no very important relations.

In gross, the brachial plexus may be formulated as beginning with five nerves and terminating in five nerves, with its intermediate portions displayed in sets of threes. It begins with the fifth, sixth, seventh and eighth cervical and first thoracic nerves; it terminates as a plexus with the formation of the musculocutaneous, radial, axillary, median, and ulnar nerves; in its intermediate portions, first main trunks are formed and these divide into two sets of threes which, by union, give rise to three cords. The branches from the cords are three main lateral branches from each and the terminal branches of the plexus. The lateral branches, according as they are given off above, below, and dorsal to the clavicle, are grouped as the supra-clavicular, the infra-clavicular and the subscapular portions of the plexus.

The branches of the supra-clavicular portion.-After the roots of the plexus have received communications from the sympathetic, which have already been referred to, they give off a series of muscular branches, viz.- the posterior thoracic nerves (the dorsal scapular and the long thoracic nerve), the suprascapular nerve, a twig to the phrenic, the nerve to the subclavius, and small twigs to the scalene muscles and the longus colli muscle.

The posterior thoracic nerves are two in number:- $(a)$ the dorsal scapular (nerve to the rhomboids) arises principally from the fifth cervical nerve, but it frequently receives a twig from the fourth nerve (fig. 751).

It passes downward and dorsalward, across the middle sealene, parallel with and below the spinal accessory nerve to the anterior border of the levator scapula, under which it disappears. It continues its descent under cover of the levator scapula and the rhomboids almost to the lower angle of the seapula, lying a little medial to the posterior border of the bone, and it supplies the lower fibres of the levator and the smaller and larger rhomboid museles.

(b) The long thoracic nerve (external respiratory nerve of Bell) supplies the serratus anterior.

It usualiy arises, by three roots, from the fifth, sixth, and scventh cervical nerves. The lizst is sometimes absent (figs. 751 and 754). The upper two ronts traverse the substance of the scallonis medius; the root from the seventh passes in front of that musele. Twigs are furnished to the superior portion of the serratus anterior by the upper two roots; lower down they unite and are subsequently joined by the root from the seventh when present. The trunk of the norve jasses downward behind the brachial plexus and the first stage of the axillary artery, and runs along the axillary surface of the serratus anterior (magnus), supplying twigs to each of the digitations of that muscle (fig. 755).

The suprascapular nerve (fig. 751) supplies the supraspinatus and infraspinatus muscless.

It recrejves fibres from the fifth and sixth cervieal nerves, and oceasionally also a twig from the fourth nerve. It is a nerve of considerable size, and it passes downwat and dorsalward famallel with the dorsal scapular nerve, at first along the upper border of the posterior belly of the omo-hyoil musc:le, then internal to the litfer musele and under cover of the anterior borker of the trinezing to the supmatseapular notel (fig. 755), where it eomes in to relation with the transverse scapular (suprascapular) artery. It is separated from the artery at ihe noteh by the superior trussverse ligiment, the nerve passing through the notel and the artery above the ligament. After entering the supraspinous fossa the nerve supplies branches to the supraspinatiss and a branch to the shoulder-joint; then it desecends through the great seapular noteh betwen thr bone and the inferior transverse limanent to the infraspinous fossa, where it terminates in the infraspinatus musele.

Thr: twig to the phrenic (fig. 751 ) arises from the fifth cervical nerve elose to the point where the lafter norve ronerives its twig from the cervical plexus. 
The nerve to the subclavius (fig. 755) is a small twig which arises from the fifth nerve or from the upper trunk of the plexus, but occasionally it receives additional fibres from the fourth and sixth nerves. It runs downward in front of the lower part of the plexus and the third stage of the subclavian artery and, after giving off sometimes a branch to the phrenic, pierces the posterior layer of the coraco-clavicular fascia, and enters the subclavius at its lower border.

Variety.-In rare cases the entire phrenic nerve may pass via the nerve to the subclavius in front of the third stage of the subclavian artery.

The scaleni and longus colli (figs. 751,754) are supplied by twigs which arise from the lower three or four cervical nerves immediately after their exit from the intervertebral foramina.

The lateral branches of the infra-clavicular portion of the brachial plexus are the anterior thoracic nerves, from the lateral and medial cords respectively, the medial antibrachial (internal) cutaneous and the medial brachial (lesser internal) cutaneous nerves, from the medial cord, and the subscapular nerves and thoraco-dorsal from the posterior cord.

The lateral anterior thoracic nerve joins with the medial to form a loop which supplies the pectoralis major and minor.

Fig. 756.-Distribution of Cutaneous Nerves on the Anterior and Posterior Aspects of the Superior Extremity.
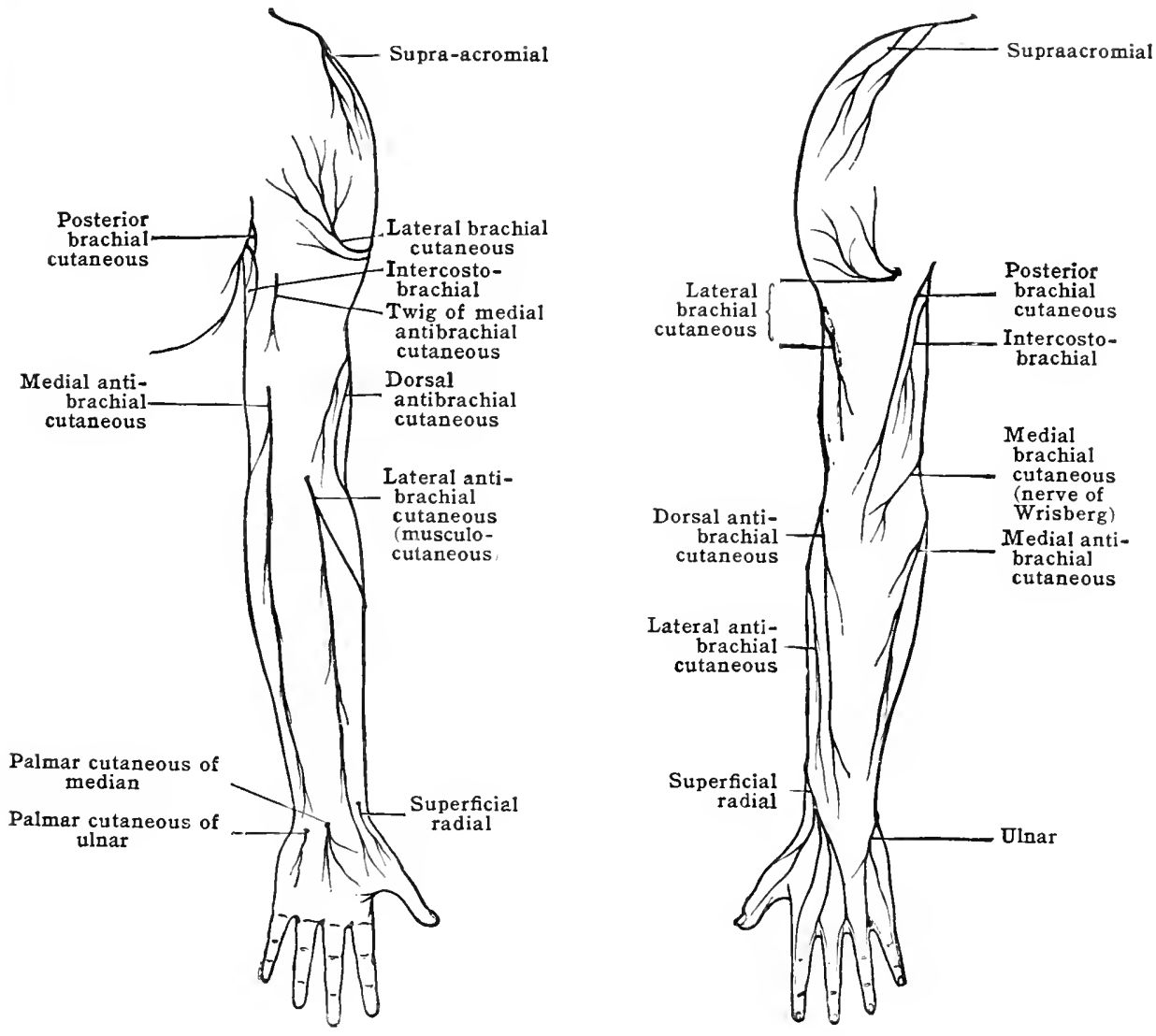

It arises from the lateral cord of the plexus and contains fibres from the fifth, sixth, and seventh cervical nerves (figs. 751, 754, 755). After joining the medial anterior thoracic it pierces the coraco-clavicular fascia and ends in branches that supply the pectoralis major muscle. The medial anterior thoracic nerve arises from the medial cord (figs. 751, 754, 755), contains fibres from the eighth cervical and first thoracic nerves, and passes forward between the first stage of the axillary artery and the axillary vein. It unites with a branch from the lateral anterior thoracic, to form a loop which is placed in front of the first stage of the axillary artery; it gives branches to the pectoralis minor, and branches which pass through the latter muscle and end in the pectoralis major. From the loop additional branches are furnished to the pectoralis major.

The medial brachial (lesser internal) cutaneous nerve, or nerve of Wrisberg (fig. 754), arises from the medial cord of the brachial plexus and sometimes contains fibres from the eighth cervical and first thoracic nerves, but usually fibres 
from the first thoracic nerve alone. It runs downward on the medial side of the axillary vein, being separated by that vessel from the ulnar nerve, and it continues downward with a slight inclination clorsalward under cover of the deep fascia on the inner side of the arm. At the middle of the arm it pierces the deep fascia, and near the bend of the elbow it turns somewhat sharply dorsalward to supply the integument which covers the olecranon process (fig. 756).

As it traverses the axilla the nerve of Wrisberg communicates with the intereosto-brachial nerve, forming one, or sometimes two loops (fig. 754). In its course down the arm it gives a few fine twigs to the integument. This nerve may be absent, its place being taken by the intercosto-brachial or by part of the posterior brachial (internal) cutaneous branch of the radial (musculo-spiral) or, rarely, by a branch from the first intercostal nerve.

The medial antibrachial (internal) cutaneous nerve (figs. 751 and 754) arises from the medial cord in elose relation with the ulnar nerve. It contains fibres from the eighth cervical and first thoracic nerves. At its origin it lies directly on the medial side of the axillary artery (fig. 755), but it soon becomes more superficial and then lies in the groove between the artery and the vein. In the upper two-thirds of the arm it lies in front and to the medial side of the brachial artery. It divides into two branches (volar and ulnar) which supply the medial aspect of the forearm.

At the junction of the middle and lower thirds of the arm this nerve pierces the deep fascia, in company with the basilic vein, and divides into an anterior and a posterior branch. Previous to its division it gives off trigs which pierce the deep faseia and supply the integument of the upper and medial part of the arm. The volar (anterior) branch is larger than the ulnar (posterior); it passes in front of or dorsal to the median basilic vein, and divides into several twigs which run down the forearm, supplying the integument covering its anterior and medial aspect as far as the wrist, and anastomosing with the branches of the ulnar nerve. The ulnar (posterior) branch passes downward and dorsalward in front of the medial condyle of the humerus, and divides into branches which supply the skin on the postero-medial aspect of the forearm. It anastomoses with the dorsal antibrachial (inferior external) cutaneous branch of the radial (museulo-spiral) nerve and the dorsal branch of the ulnar nerve).

The subscapular nerves are branches of the posterior cord (fig. 754). They are three in number, are distinguished as upper, thoraco-dorsal or middle, and lower, and are distributed to the subscapularis, latissimus dorsi, and teres major muscles.

The upper or short subscapular nerve is derived from the fifth and sixth cervical nerves. It lies in the upper and posterior part of the axillary fossa, and it is distributed exclusively to the subscapularis muscle. It is occasionally double.

The thoraco-dorsal, middle, or long subscapular nerve consists mainly of fibres from the seventh and eighth cervical nerves, but it may contain fibres from the fifth or the sixth nerve. It passes behind the axillary artery, a ceompanies the subscapular artery along the axillary margin of the subscapularis muscle, and ends in the latissimus dorsi (fig. 755).

The lower subscapular nerve, carrying fibres from the fifth and sixth cervical nerves, passes behind the subscapular artery, below the cireumflex branch (dorsalis seapula), and is distriluted to the teres major, and furnishes to the subscapularis one or two twigs which enter that muscle near its axillary margin.

The terminal branches of the plexus are two from each cord. The posterior cord divides into the axillary (circumflex) and the radial (musculo-spiral) nerves. The lat real cord divides into the musculo-cutaneous nerve, and the lateral root of the median nerve; the medial cord divides into the uhar nerve, and the medial root of the median nerve, the median nerve as a whole being one of the five terminal branches of the plexus.

The axillary (circumfiex) nerve is the smaller of the two terminal branches of the posterior corel, and contains fibres from the fifth and sixth cervical nerves (figs. 751 and 751). At the lower border of the subseapularis it passes dorsalward and ancompanies the postcrior eireumflex artery through the quadrilateral space, which is bounderl by the teres major, long head of trieeps, and subseapularis musrles, and the surgicat neek of the lumerus, and it divides into a smaller superior and at larger inferiol division. Previous to its division it furnishes an artieular twig to the shonleler-joint. This twig pierees the inferior part of the articular capsisle.

The superior division anemuntes the posterior eirenmflex artery around the neok of the humerus, and gives off a number of stont twigs which enter the deltoid muscho(fig. 755). A few fincefilaments pieree the deltoid and end in the integnunent which covers the middle third of that musele. 
The inferior division divides into cutaneous and muscular branches. The cutaneous branch (the lateral brachial cutaneous nerve) turns around the posterior border of the deltoid, pierces the deep fascia, and supplies the skin covering the lower third of the deltoid and a small area of integument below the insertion of the muscle (fig. 756). One muscular branch is distributed to the teres minor; it swells out into an ovoid or fusiform, reddish, gangliform enlargement before entering the muscle. Other branches supply the lower and posterior part of the deltoid.

The radial (musculo-spiral) nerve is the largest branch of the brachial plexus. It contains fibres from the sixth, seventh, and eighth cervical and sometimes from the fifth cervical and first thoracic nerves (figs. 751, 754). It commences at the lower border of the pectoralis minor, as the direct continuation of the posterior cord of the brachial plexus, and passes downward and lateralward in the axillary fossa behind the third part of the axillary artery (fig. 755) and in front of the subscapularjs, latissimus dorsi, and teres major muscles. From the lower border of the axillary fossa it descends into the arm, where it lies, at first, on the medial side of the upper third of the humerus, behind the brachial artery and in front of the long head of the triceps; then it runs obliquely downward and lateralward behind the middle third of the humerus, in the groove for the radial nerve (musculo-spiral groove), and between the lateral and medial heads of the triceps. It is accompanied, in this part of its course, by the profunda artery. At the junction of the middle and lower thirds of the humerus it reaches the lateral side of the arm, pierces the external intermuscular septum, and runs downward and forward between the brachio-radialis and extensor carpi radialis longus externally, and the brachialis internally (fig. 758), and it terminates, a short distance above the capitulum, by dividing into deep and superficial terminal branches. In the last part of its course it is accompanied by the anterior terminal branch of the profunda artery.

Branches.-The branches of the radial or musculo-spiral nerve are cutancous, muscular, articular, and terminal, but for practical purposes it is best to consider them in association with the situations of their origins. While it is in the axillary fossa the radial (musculo-spiral) nerve gives branches to the medial and long heads of the triceps (fig. 758), and a medial cutaneous branch. The branch to the long head of the triceps at once enters the substance of the muscle, that to the medial head breaks into branches which terminate in the muscle at different levels, and one of them, the ulnar collateral nerve, accompanies the ulnar nerve to the lower part of the arm. The posterior brachial (internal) cutaneous branch crosses the tendon of the latissimus dorsi, passes dorsal to the intercosto-brachial (intercosto-humeral) nerve, pierces the deep fascia, and is distributed to the skin of the middle of the back of the arm below the deltoid.

While it lies behind the middle third of the humerus, the radial nerve gives branches to the lateral and medial heads of the triceps and to the anconeus. The latter branch descends in the substance of the median head of the triceps, close to the bone, and it is accompanied by a small branch of the profunda artery. The dorsal antibrachial (external) cutaneous branch, passing down between the lateral and median heads of the triceps, divides near the elbow into its upper and lower branches (fig. 756), each of which perforates either the lateral head of the triceps muscle near its attachment to the humerus or the external intermuscular septum.

The upper branch, much the smaller, pierces the deep fascia in the line of the external intermuscular septum; it accompanies the lower part of the cephalic vein, and supplies the skin over the lower half of the lateral and anterior aspect of the arm. The lower branch is of considerable size. It pierces the deep fascia a little below the upper branch, runs behind the external condyle, and supplies the skin of the middle of the back of the forearm as far as the wrist, anastomosing with the medial antibrachial (internal) cutaneous and musculo-cutaneous nerves (fig. 759).

After the radial nerve has pierced the external intermuscular septum it gives branches to the brachio-radialis, extensor carpi radialis longus, and to the lateral portion of the brachialis (fig. 759). From one of these branches an articular filament is distributed to the elbow-joint.

The terminal branches of the radial nerve are:-a motor branch, the deep radial, to the supinator and extensor muscles of the forearm, and a sensory 
branch, the superficial radial, which supplies the dorsal aspect of the radial half of the hand.

The deep radial [ramus profundus] (posterior interosseous) nerve runs downward in the interval between the brachialis and extensor earpi radialis longus. It passes in front of the lateral part of the elbow-joint, and after giving off branches to supply the extensor carpi radialis brevis and supinator, it is crossed in front by the radial recurrent artery (fig. 759). It then runs downward and dorsalward through the substance of the supinator, and enters the interval between the superficial and deep layers of muscles at the back of the forearm, where it comes into relation with the posterior interosseous artery, and accompanies it aeross

Fig. 757.-A Dissection of the Cutaneous Nerves on the Dorsal Aspect of the Hand AND Fingers. (H. St. J. B.)

The branches of the median nerve are shown in black.

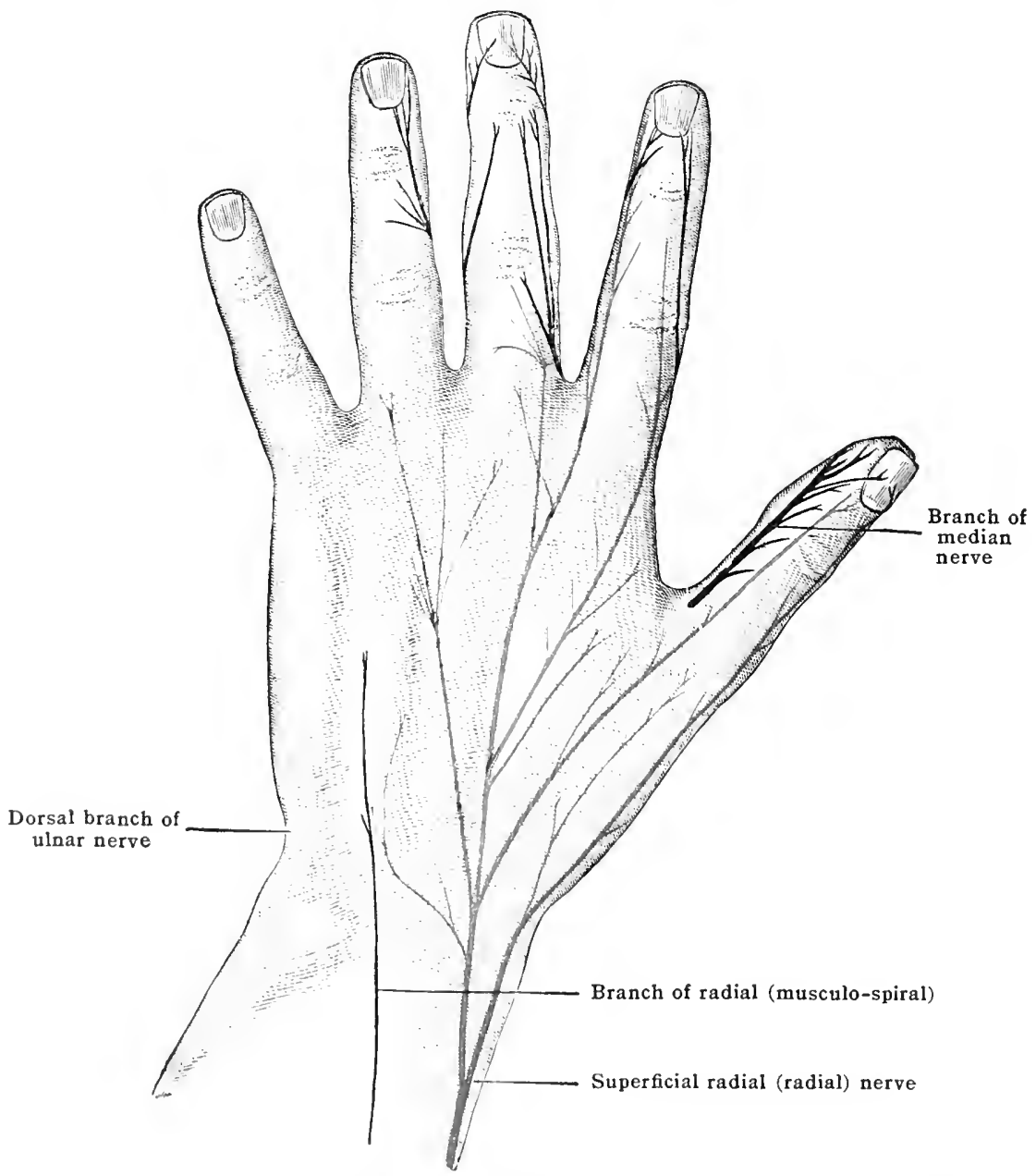

the abrluntor pollicis longus. At the lower border of the latter muscle it gives off a branch to the extrosor jolliris longus, and another which erosses this musele to there extensor inclicis proprius.

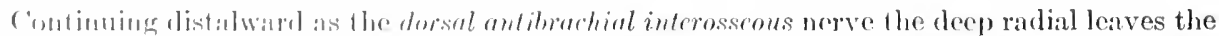

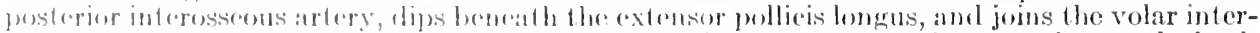

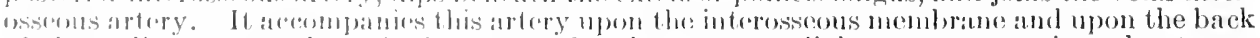

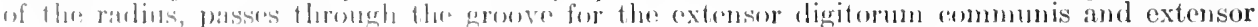

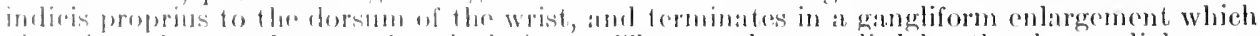

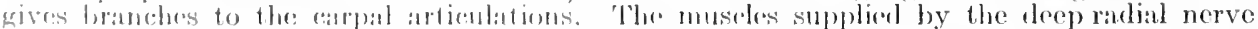

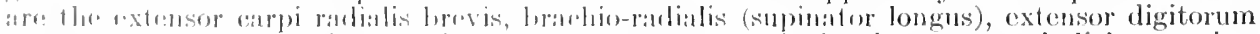

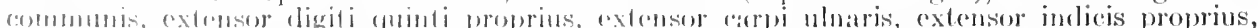

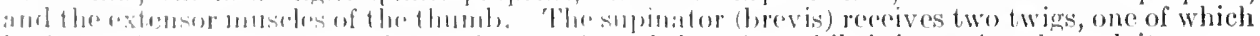

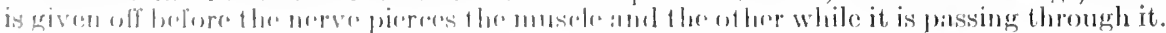


The superficial radial (radial) nerve [ramus superfieialis n. radialis] is somewhat smaller than the dcep radial (posterior interosseous), and is a purely cutaneous nerve. It runs downward under cover of the brachio-radialis, passing in front of the elbow-joint, the radial recurrent artery, and the supinator (brevis). At the lower border of the supinator it approaches the radial artery at an acute angle, and runs parallel to the lateral side of that vessel in the middle third of the forearm, across the pronator teres. At the lower border of the pronator teres it bends dorsalward on the deep surface of the tendon of the brachio-radialis, and appears on the back of the forearm. It pierces the deep faseia and is directed across the dorsal carpal (posterior annular) ligament toward the dorsum of the wrist, where it divides into its terminal branches (fig. 759).

The most lateral of these branches supplies the skin on the radial part of the thenar eminence; the most medial, designated the ulnar anastomotic branch, communicates with the dorsal branch of the ulnar nerve. The other terminal branches, the dorsal digital nerves, supply to a variable extent the skin on the dorsum of the first digit, both sides of the second and the radial side of the third digit. These branches usually extend to the base of the nail of the first digit, to the distal interphalangeal joint of the second, not quite to the proximal interphalangeal joint of the third, and to the metacarpo-phalangeal joint of the fourth digit.

The terminal branches of the lateral cord of the brachial plexus are the musculo-cutaneous and the lateral component of the median nerve. The latter nerve will be described with the medial cord.

The musculo-cutaneous nerve is composed of fibres derived chiefly from the anterior divisions of the fifth and sixth cervical nerves, together usually with some fibres from that of the seventh (figs. 751 and 754). The nerve to the coracobrachialis usually consists of two or three twigs given off from the nerve close to its origin before it enters the muscle (fig. 755). Sometimes, however, the fibres from the seventh cervical nerve pass directly to this musele without joining the main trunk. The musculo-cutaneous nerve is placed at first close to the lateral side of the axillary artery (fig. 755), but soon it leaves that vessel and, piercing the coraco-brachialis muscle, it passes obliquely downward and lateralward between the biceps and brachialis muscles. Soon after piereing the eoraco-brachialis it gives off muscular branches to each head of the biceps and to the brachialis (fig. 758). It also gives twigs to the humerus, to the nutrient artery, and gives the chief supply to the elbow-joint. Below the branch to the brachialis the cutaneous portion of the nerve forms the lateral antibrachial cutaneous nerve (figs. 756, 758). This portion continues downward between the biceps and brachialis, pierces the deep fascia at the lateral border of the former muscle a little above the bend of the elbow, receives a communication from the upper branch of the dorsal antibrachial (upper external) cutaneous branch of the radial (musculo-spiral) nerve, passes dorsal to the median cephalic vein, and divides into an anterior and a posterior branch.

The anterior branch runs downward on the lateral and anterior part of the forearm, supplying the integument of that region, and it terminates in the skin covering the middle part of the thenar eminence (fig. 759). A short distance above the wrist, after it has received a communicating twig from the superficial radial nerve, it gives off an articular branch to the carpal joints. This branch pierces the deep fascia and accompanies the radial artery to the dorsum of the wrist. The posterior terminal branch is small, and is directed downward and backward in front of the external condyle of the humerus, to be distributed to the skin on the lateral and posterior aspect of the forearm as low as the wrist (fig. 756). It anastomoses with the superficial radial and with the lower branch of the dorsal antibrachial (lower external) eutaneous branch of the radial nerve.

The terminal branches of the medial cord of the brachial plexus are the ulnar nerve and the medial component of the median nerve. Neither of these gives any branches in the upper arm, and thus they differ from the other terminal branches of the plexus. They both supply the muscles and joints of the forearm, and the museles, joints, and integument of the hand.

The ulnar nerve, which is the largest branch of the medial cord of the brachial plexus, contains fibres from the anterior divisions of the eighth cervical and first thoracic nerves (figs. 752 and 762). It commences at the lower border of the pectoralis minor and runs downward in the axillary fossa in the posterior angle between the axillary artery and vein. In the upper half of the arm it lies on the medial side of the brachial artery (fig. 755), but at the level of the insertion of the 
coraco-brachialis it passes backward at an acute angle, and, accompanied by the superior ulnar collateral (inferior profunda) artery, it pierces the internal intermuscular septum. After passing through the septum it runs downward, in a groove in the medial head of the triceps (fig. 758), to the interval between the olec-

Fig. 758.-Nerves of the Right Upper Arm viewed from in Front. (Spalteholz.)

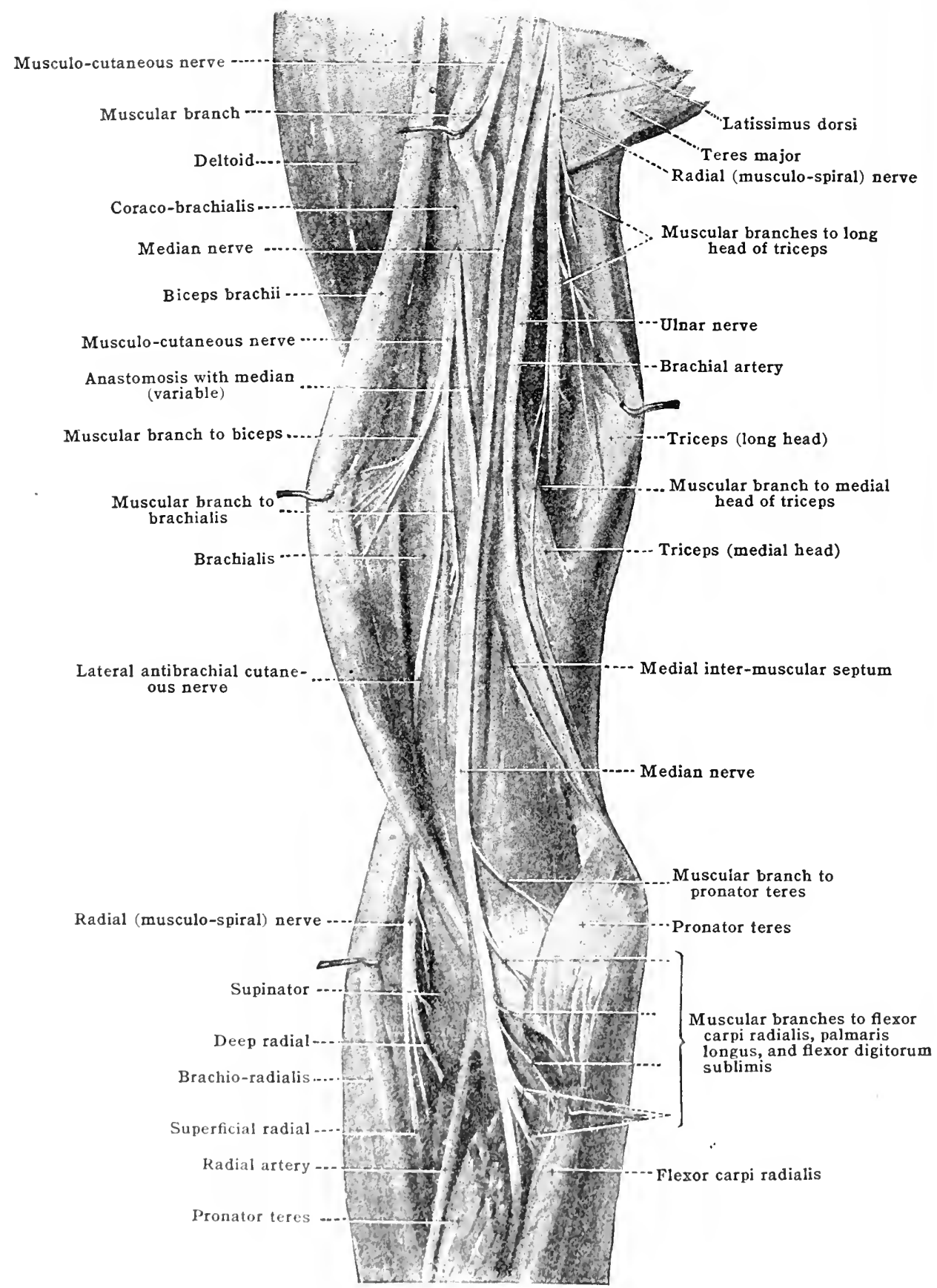

ranon process and the medial eomelyle of the humerus, and in this part of its course it is closely bound to the muselo by the dere fascia. Immediately below the merlial eonelyle it passes between the two heads of the flexor carpi ulnaris, along the medial side of the medial collateral liganent of the elbow, and it comes into relation with the dorsal ulnar recurrent artery. 
In the upper forearm the ulnar nerve lies on the flexor digitorum profundus, covered by the flexor carpi ulnaris. Near the junction of the upper and middle thirds of the forearm it is joined by the ulnar artery, which accompanies it to its termination, lying throughout on its radial side (fig. 759). In the lower part of the forearm it still rests on the flexor digitorum profundus, but

Fig. 759.-Deep Nerves of the Tolar Serface of the Forearm. (After Toldt, "Atlas of Human Anatomy," Rebman, London and New York.)

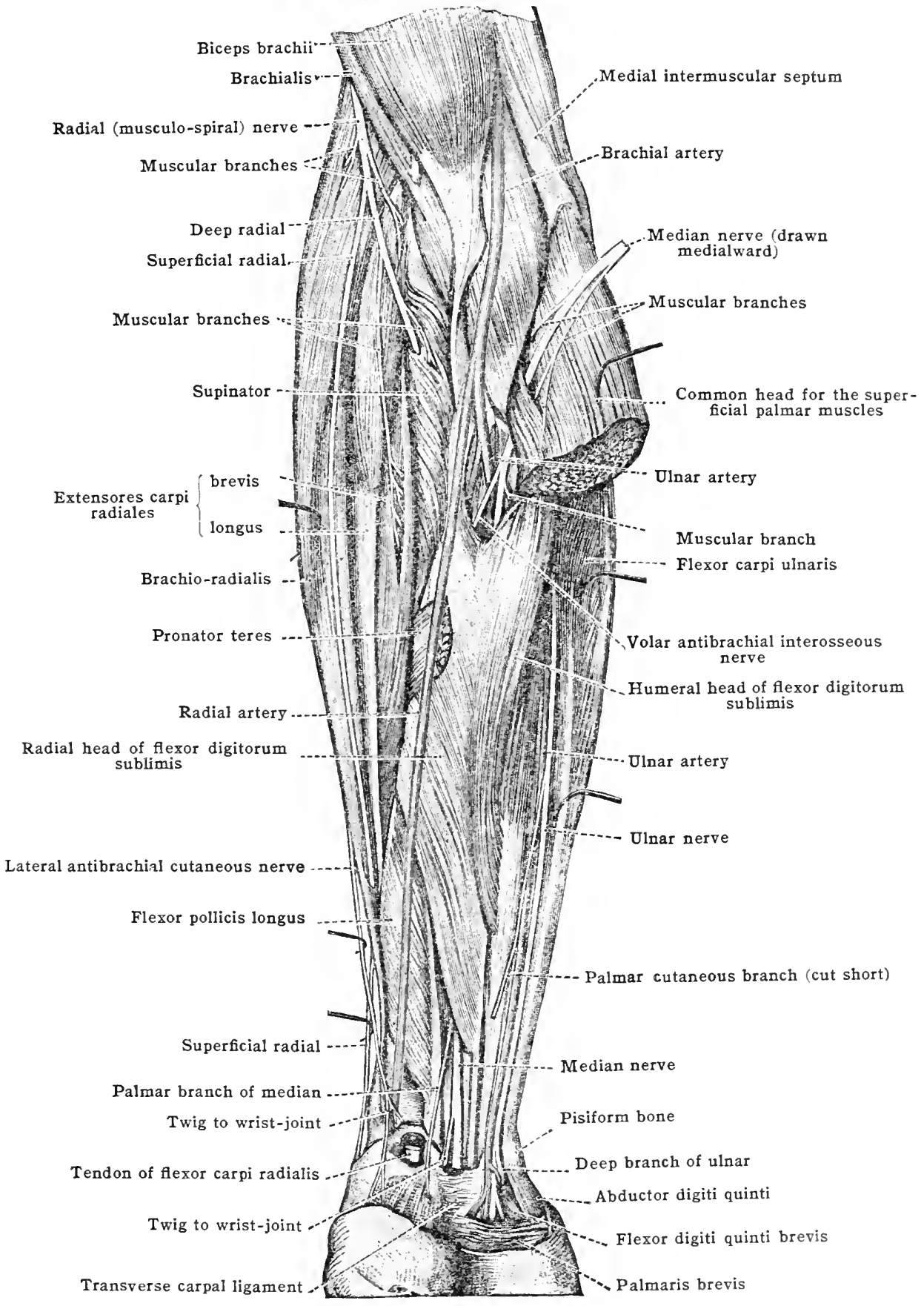

between the flexor carpi ulnaris and flexor digitorum sublimis, and is covered only by skin and fascia. At a variable point in this part of the forearm, usually about 5 to $8 \mathrm{~cm}$. (2 to 3 in.) from the carpus, the nerve divides into its two terminal branches, a dorsal branch to the dorsal aspect of the hand, and a volar branch to the volar aspect. 
Branches.-The ulnar resembles the median nerve in not furnishing any branches to the upper arm. As it passes between the olecranon process and the medial condyle it gives off two or three fine filaments to the elbow-joint. In the upper part of the forearm it supplies the flexor carpi ulnaris and the medial portion of the flexor digitorum profundus, and in the lower half it gives off the three cutaneous branches. In the palm of the hand it supplies the integument of the hypothenar eminence, the fifth digit, and half of the fourth digit, and part of the skin of the dorsum. It also supplies the short intrinsic muscles of the hand with the exception of the abductor pollicis, the opponens, the lateral head of the flexor pollicis brevis, and the two lateral lumbricales.

The nerves to the flexor carpi ulnaris and to the medial two divisions of the flexor digitorum profundus arise from the ulnar nerve in the upper third of the forearm.

Cutaneous branches. - About the middle of the forearm the ulnar nerve gives off two cutaneous branches:- one pierces the fascia and anastomoses with the volar branch of the medial antibrachial (internal) cutaneous nerve, and the other, the palmar cutaneous branch, runs downward in front of the ulnar artery (fig. 759) and is condueted by this vessel into the palm

Fig. 760.-Diagrams Illustrating a Common Distribution of Cutaneods Nerves of Forearm. A, dorsum; B, volar aspect.

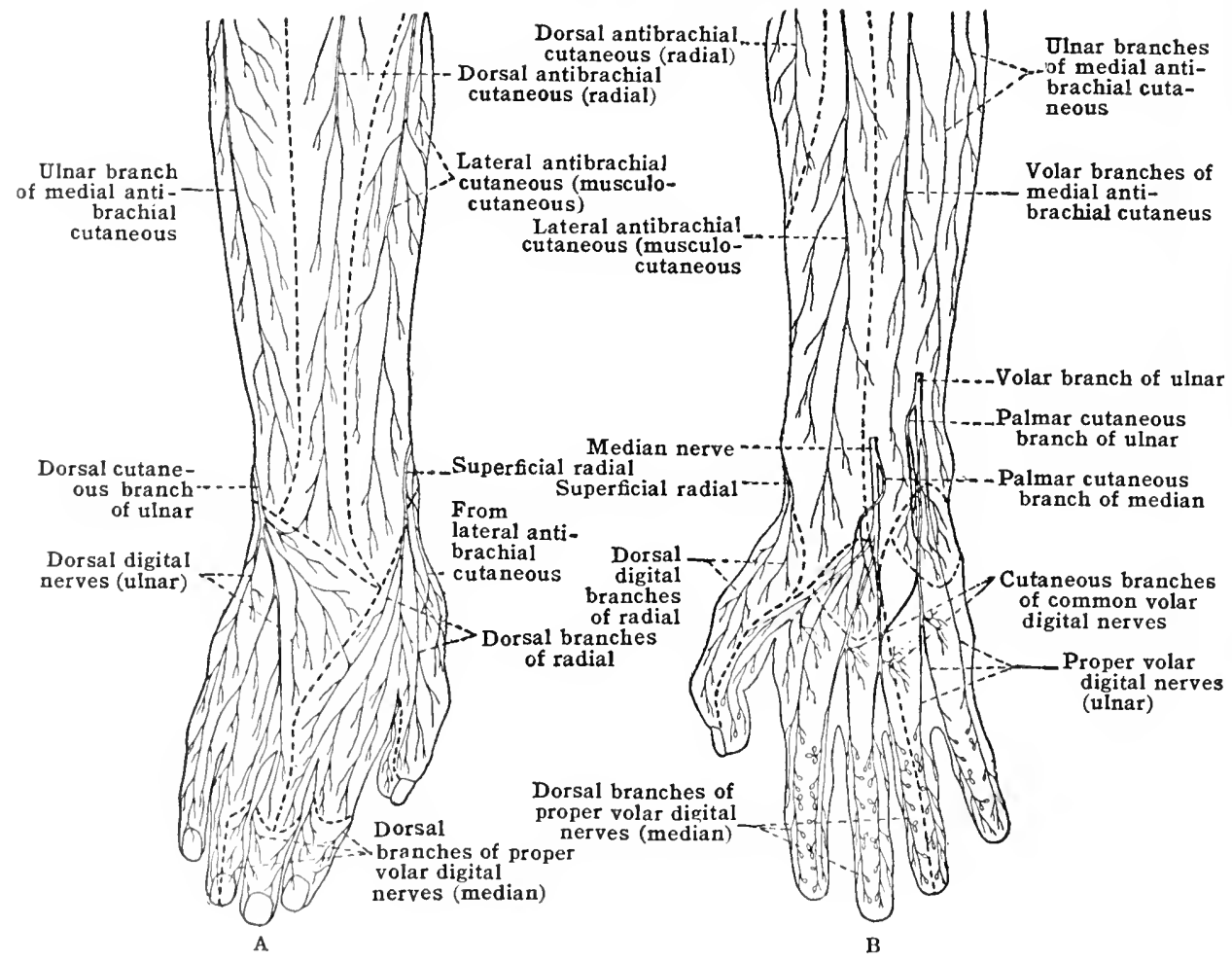

(fig. 756). It furnishes some filaments to the vessel, supplies a few twigs to the skin of the hypothenar emincmec, and ends in the integument covering the central depressed surface of the palm.

'The dorsal or posterior cutaneous branch, usually the smaller of the terminal branches, arises about 5 ( $\mathrm{cm}$. (' $2 \mathrm{in}$.) above the wrist-joint, and passes backward under cover of the flexor carpi ulnaris to raneh the rlorsal aspect of the wrist (fig. 761), where it gives off delicate branches to anastomese: with branches of the medial antibrachial (internal) cutaneous, the dorsal antibrachial (extronal) cutancous branch of the radial (museulo-spiral), the lateral antibrachial mutanesus of the museulo-coltaneous nerve, and with branches of the superfieial radial, and then divides into five branches, the dorsal digitals (fig. 757), which are distributed to the uhnar sirles of the third, fourth, and lifth cligits and the radial sides of the fourth and fiftl digits. 'These branehes usually extronl on the fifth digit only as far as the base of the terminal phalanx, and on the fourth ligit as far as the hase of the second phalanx. The more distal parts of these digits arr: supplieal by falmar digital branches of the uluar nerve.

'Thr: volar branch, the other ferminal branch of the ulnar nerve, eontinues its course between the flexor carpi mlateris and flexor cligitormu sublimis, on the medial side of the ulnar artery, to the wrist, whore, on the lateral side of the pisiform hone, it elivides into a superficial and a deep branch (figs. 759 and 76,1 ). The later accompanies the derp branch of the ulnar artery into the intrerval between the abductor digiti quinti and flexor digiti quinti brevis, and then 
passes through the fibres of the opponens digiti quinti to reach the deep surface of the flexor tendons and their synovial sheaths. It supplies the abductor and opponens digiti quinti, the flexor digiti quinti brevis, the third and fourth lumbricales, all the interossei, the adductors of the thumb, and the medial head, and occasionally the lateral head, of the flexor pollicis breris. The superficial branch gives off a branch to supply the palmaris brevis muscle, an anastomosing branch to the median nerve, and then divides in to two branches, the proper volar digital branch, which is distributed to the medial side of the fifth digit on its volar aspect, and the common volar digital branch, which passes underneath the palmar aponeurosis and divides into two branches, which supply the contiguous margins of the fourth and fifth digits. These branches usually supply also the dorsal surface of the second and third phalanges of the same digits.

The median nerve contains fibres of the sixth, seventh, and eighth cervical nerves and of the first thoracic, and sometimes of the fifth cervical nerve. The trunk is formed a little below the lower margin of the pectoralis minor, by the

Fig. 761.-Nerves of the Palmar Surface of the Hand. (Testut.)

The transverse carpal (anterior annular) ligament, superficial palmar arch, the flexor tendons of the digits, and the proximal portions of the lumbrical muscles have been removed.

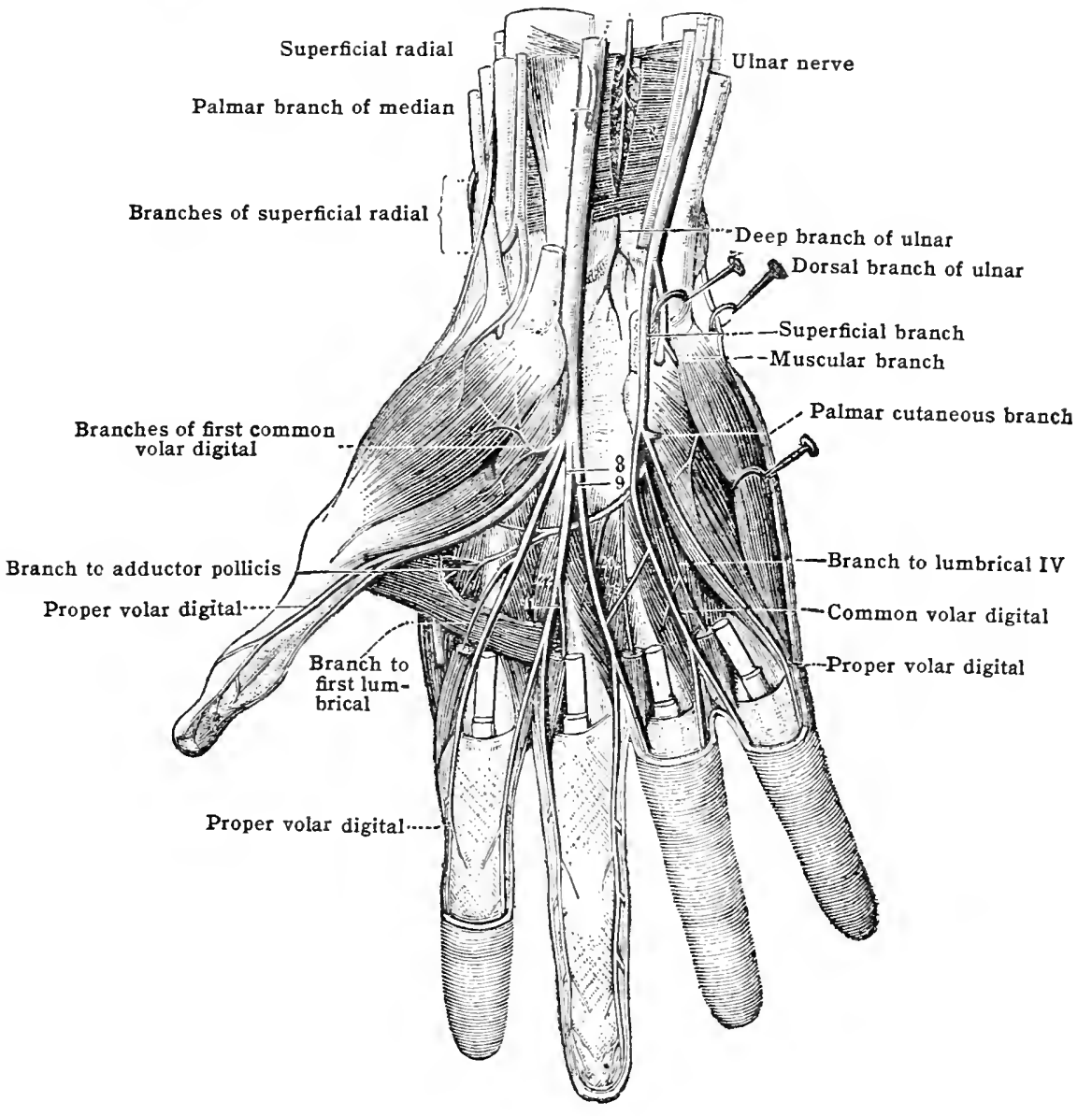

union of two components, one from the medial and one from the lateral cord of the brachial plexus (fig. 755). The medial component passes obliquely across the third part of the axillary artery, and in the upper part of the trunk the fibres of the two components are felted together. From its commencement the median nerve runs almost vertically through the lower part of the axillary fossa and through the arm and forearm to the hand.

In the fossa it lies lateral to the axillary artery and it is overlapped, on its lateral side, by the coraco-brachialis muscle. In the upper half of the arm it lies along the lateral side of the brachial artery, and it is overlapped by the medial border of the biceps. At the middle of the arm it passes in front of the brachial artery, and then it descends, on the medial side of the artery, to the elbow. In the upper part of the antecubital fossa it is still at the medial side of the brachial artery, but separated from it by a small interval, and in the lower part of the fossa it lies 
along the medial side of the ulnar artery. In ease of the high division of the brachial artery, when the radial and the ulnar arteries lie together in the upper arm, the median nerve may pass between them and then one or the other of the arteries will be superficial to the nerve. As it leaves the antecubital fossa it passes between the two heads of the pronator teres, and it crosses in front of the ulnar artery (fig. 759), from which it is separated by the deep head of the pronator. In the forearm it passes vertically downward, accompanied by the median (comes nervi mediani) artery. In the upper two-thirds of this region it hies deeply, between the flexor digitorum sublimis and the flexor digitorum profundus, but in the lower third it becomes more superficial, and is placed beneath the deep fascia, between the flexor carpi radialis on the radial side and the palmaris longus and flexor digitorum sublimis tendons on the ulnar side. It crosses beneath the transverse carpal (anterior ammular) ligament, in front of the flexor tendons, and in the palm at the lower border of the ligament it enlarges and divides into three branches, the common volar digital nerves (fig. 760).

Branches.--The median nerve does not supply any part of the upper arm. In front of the elbow-joint it furnishes one or two filaments to that articulation. In the forearm it supplies all the superficial anterior muscles (with the exception of the flexor carpi ulnaris) directly from its trunk, and it supplies the deep muscles (with the exception of the ulnar half of the flexor digitorum profundus) by its volar (anterior) interosseous branch. Thus in general it supplies the pronator and flexor muscles of the forearm (radial side). In the hand it supplies the group of short muscles of the thumb, which are placed on the radial side of the tendon of the flexor pollicis longus, the two lateral lumbricales, the integument covering the central part of the palm and ulnar aspect of the thenar eminence, and the palmar aspect of the first, second, third, and radial half of the fourth digits. It also sends twigs to the dorsal aspect of these digits.

The nerve to the pronator teres usually arises a little above the bend of the elbow, and pierces the lateral border of the muscle (figs. 759 and 761 ). It may arise in a common trunk with the following norves:-

The nerves to the flexor carpi radialis, palmaris longus, and flexor digitorum sublimis arise a little lower down, and pierce the pronator-flexor mass of muscles to end in the respective members of the group for which they are destined (fig. 758 ).

The volar (anterior) interosseous nerve arises from the median at the level of the bieipital tubercle of the radius (fig. 759), and runs downward, on the in terosseous membrane, aceompanied by the volar (anterior) interosseous artery. It passes under cover of the pronator quadratus, and pierces the deep surface of that nuscle, which it supplies. The volar interosseous nerve also furnishes a twig to the front of the wrist-joint, and supplies the flexor digitorum profundus and the flexol pollicis longus. 'The nerve to the former musele arises from the volar interosseous near its commencement; it supplies the outer two divisions of the muscle, and it communicates within the substance of the muscle with twigs derived from the ulnar nerve.

It also supplies a branch to the interosseous membrane which runs downward upon, or in, the nembrine, supplying it and giving branches to the volar (anterior) interosseous and nutrient arteries and to the periosteum of the radius, the ulna, and the earpus.

The palmar cutaneous branch arises immediately above the transverse carpal (anterior annular) ligament and passes between the tendons of the flexor carpi radialis and the palmaris longus (fig. 759). It then erosses the superficial surface of the transverse carpal ligament, and is distributed to the integument and fascia on the central, depressed surface of the palm. It also supplies a few twigs to the medial border of the thenar eminence; these twigs communicate with the musculo-cutaneous and superficial radial nerves.

The three common volar digital nerves pass in the palm of the hand dorsal to the superficial palnar arch and its ligital branches, while the proper volar digitals, branches of these nerves, he on the volar side of the digital arteries.

The first of the common volar digital nerves gives off a branch to supply the abduetor pollicis, the opponens, and the superficial head of the flexor pollicis brevis, and joins by a delieate branch with the de(p) hranch of the ulnar nerve. It then divides into three proper volar digitals (fig. 761). The literal of these passes obliquely acress the long flexor tendon of the thumb and runs along the raclial borkep of the thumb to its extremity. It gives numerous branehes to the pulp of the thuml, and a strong twig which passes to the dorsmm to supply the matrix of the nail. 'The secont of these propere volar digitals supplies the medial side of the volar aspeet of the thumb and gives off a twig to the matrix of the thumb nail. The third supplies the radial side of the sceoml digit and gives a twig to the first lumbrical muscle.

The second "onmon volin digital scuds a twig to the second lumbrical musele, and divides a little abeve the medacaposphalangeal articulition into two proper volar digitals, which respectivety supply the adjatent sicles of the second and thind digits.

The third common volia cligital commmioates with the ulnar nerve, often gives a branch to the thirel lumbrical muscle, and divirles into two proper volar digitals which supply the adjacent sides of the third and fouldh digits.

Is the proper volar digitats pass along the margins of the fingers they give off twigs for the inmervation of the skin on the dersme of the second and third phalanges and the matrix of their nails. Sarch of the nerves terminates in filaments to the pulp of the finger. 
Table Showing Relation of Cervical and Thoracic Nertes to Branches of Brachial Plexus

Nerves Contributing.

Nertes, Branches of Plexus.
5 C........... Dorsal scapular (nerve to rhomboids)
Nerve to subclavius
Suprascapular
5 and $6 \mathrm{C} \ldots \ldots \ldots$ Nerve to subclavius
Upper subscapular
Lower subscapular
Axillary (circumflex)
5,6 , and $7 \mathrm{C} \quad$ Long (posterior) thoracic
- Lateral anterior thoracic
5,6 , and (7) C....... Musculo-cutaneous
(5), 6, 7, 8 C ...... Radial (musculo-spiral)
(5), $6,7,8 \mathrm{C}$. and $1 \mathrm{~T}$ Median
7 and 8 C........... Thoraco-dorsal (middle or long subscapular)
$8 \mathrm{C}$. and $1 \mathrm{~T}$.
Medial anterior thoracic
$1 \mathrm{~T}$ Ulnar
Medial antibrachial (internal) cutaneous
Medial brachial (lesser internal) cutaneous

\section{Table Showing the Relations of the Cervical Nerves to the Muscles OF THE UPPER Extremity}

\section{Nerves Contributing.}

Accessory, 2 C...... Sterno-mastoid $3,4 \mathrm{C} \ldots$ Trapezius

3 and 4 C......... Levator scapulie

Subclavius

Supraspinatus

Infraspinatus

Subscapularis

Teres major

Teres minor

Deltoid

Brachialis

Biceps

Brachioradialis

Supinator

Pronator teres

Flexor carpi radialis

Palmaris longus

Ext. carpi radialis longus

6 and $7 \mathrm{C}$

5,
7

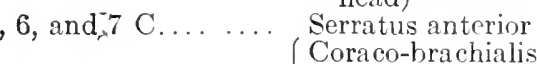

Coraco-brachialis
Ext. digitorum comm

" digiti quinti proprius

" carpi ulnaris

Abductor pollicis longus

Extensor pollicis brevis

Extensor pollicis longus

Ext. indicus proprius

Latissimus dorsi

Triceps

Anconeus

7 and $8 \mathrm{C} \ldots$
$5,6,7$, and $8 \mathrm{C}$

Pectoralis major

Dorsal inteross.

Palmar

Add. pollicis

" pollicis trans.

Flex. pollicis brev. (deep)

Pectoralis minor

Flex. digit. subl.

Lumbricalis

Flex. carpi ulnaris

" digit. prof.

" pollicis long.

Pronator quadratus
Neries to Muscles.

Spinal accessory

3 and $4 \mathrm{C}$

Nerve to subclavius

Suprascapular

Upper and lower subscapular

Lower subseapular

Axillary (circumflex)

Musculo-cutaneous

Radial (musculo-spiral)

Deep radial (posterior interosseous)

Median

"6

Radial (musculo-spiral)

Deep radial (posterior interosseous)

Median

"6

Long (posterior) thoracic

Misculo-cutaneous

Deep radial (posterior interosseous)

" 6 "6 "6

"6 "6 6

$\begin{array}{lll}6406 & 66\end{array}$

6 6406

6 6 " 6

Thoraco-dorsal (long- subscapular)

Radial (musculo-spiral)

Lat. and med. ant. thoracic

Ulnar

"6

66

6

Med. ant. thoracic

Median

" and ulnar

Ulnar

" and median

Median 


\section{THE THORACIC NERVES}

The anterior primary divisions of the thoracic nerves, with the exception of the first, retain, in the simplest form, the characters of anterior primary divisions of the typical spinal nerve. They do not form plexuses, but remain distinet from each other. Each divides into an easily recognisable lateral or clorsal and anterior or ventral branch (figs. 762 and 763), and they are not distributed to the limbs. The first, second, and last thoracic nerves, on account of their peculiarities, require separate description. The remainder are separable in to two groups, an upper and a lower. The upper group consists of four nerves, the third to the sixth inclusive. which are distributed entirely to the thoracic wall. The lower group contains five nerves, the seventh to the eleventh inclusive, which are distributed partly

Fig. 762.-Diagrail of the Distribution of a Typical Thoracic Nerve.

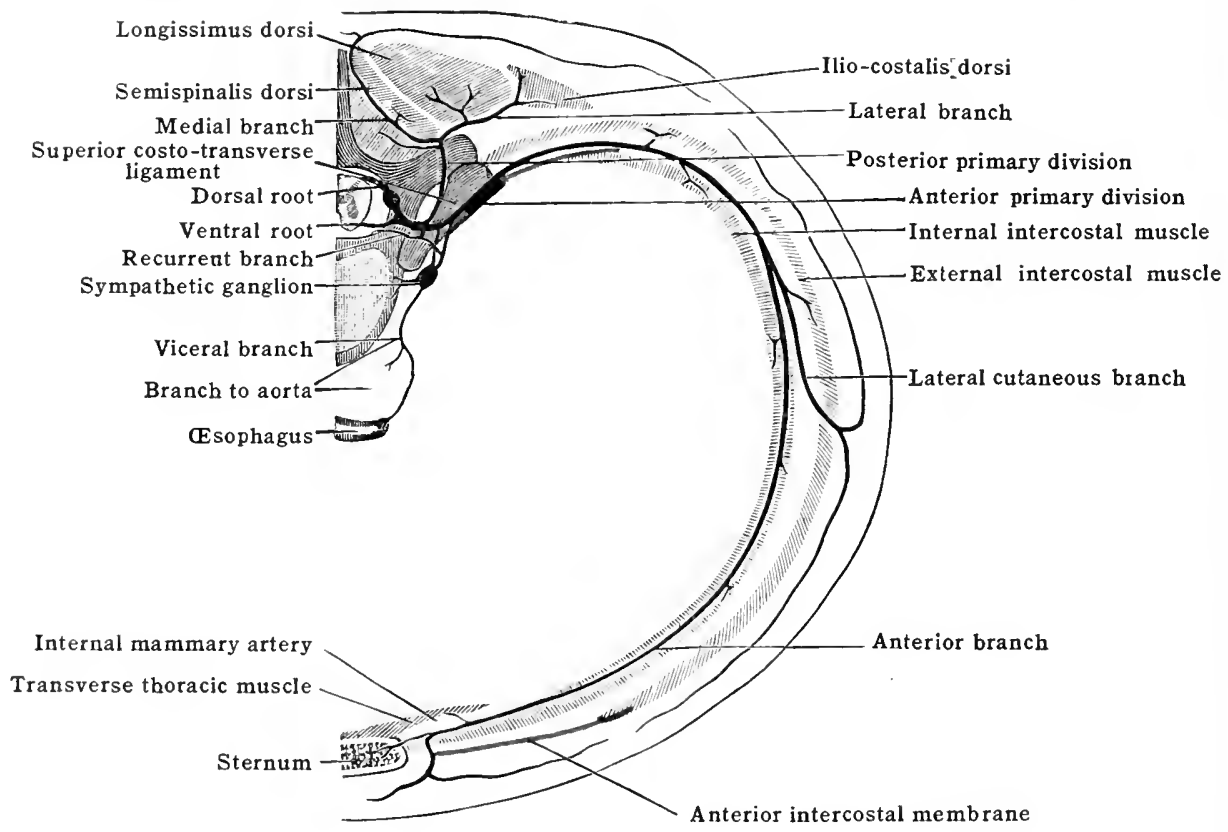

to the thoracic and partly to the abdominal wall. The upper group is therefore purely thoracic in distribution, and the lower thoraco-abdominal.

The first thoracic nerve is connected with the first thoracic sympathetic ganglion, and it frequently is joined by a small branch with the second nerve. It is distributed chiefly to the upper limb. Opposite the superior costo-transverse ligiment of the second rib it divides into a larger and a smaller branch; the larger passes upward and lateralward, between the apex of the pleura and the neck ol the first rit, and on the lateral side of the superior intercostal artery, to the root of the nerek, where it joins the brachial plexus. The sualler branch continues along the intereostal space, below the first rib and between the intercostal muscles in which, as a rule, all its fibres terminate.

IJowever, thr smaller brand may give off a lateral cutaneous branch which connects with the molial brachial (lesser intronal) cutaneous nerve and with the intercosto-frachial nerve in the axillary fossa; and ocosionally it terminates in an anterior cutaneous branch at the anterior extremity of the first intereostal spatere.

The second thoracic nerve, as it lies botween the pleura and the superior costo-transverse ligament of the third rib, gives a branch to the first nerve, then if pireres the posterior interestal membrame and passes between the external and internal intererestal museles in the serond intereostal space. In the dorsal part of the spater it semels branches batek ward, through the external in tereostal muscle, 
to supply the second levator costæe and the serratus posterior superior, and then it divides into a lateral and an anterior branch. The two branches run forward together to the mid-axillary line, where the lateral branch pierces the external intercostal muscle and passes between two digitations of the serratus anterior (magnus) into the axillary fossa; the anterior branch enters the substance of the internal intercostal muscle.

The lateral branch, the intercosto-brachial (intercosto-humeral), may divide into a small anterior and a large posterior division, or the anterior division may be absent. In either case the lateral branch anastomoses with the medial brachial (lesser internal) cutaneous nerve, and usually with the lateral branch of the third intercostal nerve; it also anastomoses with the lateral branch of the first nerve, if the latter is present. After forming these junctions it passes out of the axillary fossa, pierces the deep fascia, and supplies the integument in the upper and posterior half of the arm. It also gives off a few filaments which terminate in the skin over the axillary border of the scapula. The size of the intercosto-brachial nerve and the extent of its distribution are usually in inverse proportion to the size of the other cutaneous nerves of the upper arm, especially the middle brachial (lesser internal) cutaneous. When the latter nerve is absent, the inter costo-brachial usually takes its place.

The course and distribution of the anterior branch, when it is present, being similar to the course and distribution of the anterior branches of the next four nerves, do not require a separate description.

The thoracic intercostal nerves (upper group).-The third, fourth, fifth, and sixth thoracic nerves, in the posterior parts of the intercostal spaces, give muscular branches to the levatores costarum, the first to the fourth also giving branches to the serratus posterior superior. They pass forward a short distance between the external and internal intercostals, giving twigs to these muscles, and divide into two branches, lateral and anterior.

The lateral cutaneous branches continue forward between the intercostal muscles, and, near the mid-axillary line, pierce the external intercostals and serratus anterior (magnus) and divide into two branches, posterior and anterior. The posterior branches pass backward over the latissimus dorsi to supply the skin in the lower part of the scapular region. The anterior branches, in the four nerves, increase in size from above downward. They pass around the lateral border of the great pectoral muscle and are distributed to the integument over the front of the thorax and manma, sending filaments, the lateral mammary branches, into the latter organ. The lowest two nerves also supply twigs to the upper digitations of the external oblique muscle.

The anterior branches run obliquely forward and medialward through the substance of the internal intercostal muscles, reaching the deep surface of these muscles at the extremity of the costal cartilages (fig. 762). They continue forward between these muscles and the pleura, pass in front of the internal mammary artery, turn abruptly ventralward a short distance from the sternum, pierce the internal intercostals, the anterior intercostal membrane, and the pectoralis major, and give off three sets of terminal branches. One set supplies the transverse thoracic muscle and the back of the sternum. A second set, cutaneous, runs mesially. The third set passes laterally over the pectoralis major, supplying the skin in that region, and, in the female, the mammary gland through the medial mammary branches. The anterior branches in their course supply the intercostal and subcostal muscles and give filaments that supply the ribs, the periosteum, and the pleura.

The thoraco-abdominal nerves (lower group).--The relations of the posterior portions of the seventh, eighth, ninth, tenth, and eleventh thoracic nerves to the thoracic wall are similar to those of the upper thoracic intercostal nerves. Each divides in a similar manner into a lateral and an anterior branch, but these branches are distributed partly to the abdominal and partly to the thoracic wall, and the smaller muscular branches have also different distributions.

The lateral branches, lateral cutaneous nerves of the abdomen, pierce the external intercostal muscles and pass through or between the digitations of the external oblique into the subcutaneous tissue, where they divide in the typical way into anterior and posterior branches. The posterior branches pass backward over the latissimus dorsi. The anterior branches give filaments to the digitations of the external oblique and extend forward, medialward and downward to the outer border of the sheath of the rectus.

The anterior branches pass forward between the external and internal intercostal muscles, to the ends of the intercostal spaces; there they insinuate 
themselves between the interdigitating slips of the diaphragm and the transversus abdominis and enter the abdominal wall. The seventh, eighth, and ninth nerves, in their transit from the thoracic to the abdominal wall, pass behind the upturned ends of the eighth, ninth, and tenth rib-cartilages respectively. Having entered the abdominal wall the nerves rum forward between the transversus abdominis and the internal oblique muscles to the outer border of the rectus abdominis, where they pierce the posterior lamella of the internal oblique aponeurosis and enter the sheath of the rectus. In the sheath they pass through the substance of the rectus. Finally they turn directly forward, pierce the anterior part of the sheath, and become anterior cutaneous nerves of the abdomen.

The muscular branches.-Muscular branches from all the thoraco-abdominal nerves are distributed to the levatores costarum, the intercostal muscles, the transversus abdominis, the internal oblique, and to the rectus abdominis, and the ninth, tenth, and eleventh nerves gives branches also to the serratus posterior inferior. Branches are also distributed from a variable number of the lower nerves to the costal portions of the diaphragm.

The last thoracic nerve.- The anterior primary division of the last thoracic nerve is distributed to the wall of the abdomen and to the slin of the upper and front part of the buttock. It appears in the thoracic wall immediately below the last rib, where it communicates with the sympathetic cord and gives off a communicating branch to the first lumbar nerve. It passes from the thorax into the abdomen beneath the lateral lumbo-costal arch (external arcuate ligament), accompanied by the subcostal artery, and it runs across the upper part of the quadratus lumborum dorsal to the kidney and to the ascending or the descending colon according to the side considered. At the lateral border of the quadratus lumborum it pierces the aponeurosis of attachment of the transversus abdominis muscle and divides, between the transversus and the internal oblique muscle, into a lateral and an anterior branch. It gives branches to the transversus abdominis, the quadratus lumborum, and the internal oblique muscles.

The anterior branch passes forward, between the internal oblique and the transversus abdominis, to which it supplies twigs. It enters the sheath of the rectus, turns forward through that muscle, and terminates in branches which become cutaneous midway between the umbilicus and the symphysis. Before it becomes cutaneous it supplies twigs to the transversus abdominis, the internal oblique, the rectus abdominis, and the pyramidalis muscles.

The lateral branch pierces the internal oblique; it supplies the lowest digitation of the external oblique, and then pierces the latter muscle from 2.5 to $8 \mathrm{~cm}$. (1 to $3 \mathrm{in}$.) above the iliac crest, and descends in the superficial fascia of the anterior part of the gluteal region, crossing the iliac crest about $2.5 \mathrm{~cm}$. (1 in.) behind its anterior extremity and reaching as far down as the level of the great trochanter. Occasionally this branch is absent and its place is taken by the iliac brinch of the ilio-hypogastric. In such cases, however, the branch from the last thoracic to the first lumbar nerve is larger than usual.

\section{THE LUMBO-SACRAL PLEXUS}

Tho lumbo-sacral plexus is formed by the union of the anterior primary divicions of the lumbar, sacral, anel coceygeal nerves. In about 50 per cent. of catses it receives a branch from the twelfth thoracic nerve. Its components are distributerd to the lower extremity in a manner homologous and similar to the distrilution of the parts of the brachial plexus to the upper extremity; the lumbir nerves alde distributer similarly to the nerves formed from the anterior (medial and liatcral) cords of the brachial plexus, and the sacral nerves are distributer in a manner similar to the distribution of the nerves from the posterior corel of the hrielial plexus.

P'artly for comvenione of deseription and partly on alecount of the differences in position and arourse of some of the nerves arising from it, this plexus is subdivided into four parts the lomhar, sateral, pudendal, and coceygeal plexuses. These plexuses overlap so that there is no definite line of demareation between theon. IJowerer, they will be enensidered separately.

\section{THE LUMBAR NERTES}

The ant reror primary divisions of the five lumbar nerves increase in size from the first to the last. Fiach humbur nerve is comnected by one or two long, slender 
rami with a lumbar sympathetic ganglion. The first three nerves and the greater part of the fourth enter into the formation of the lumbar plexus, and the smaller

Fig. 763.-Cutaneous Nerves of the Thorax and Abdonen, viewed from the Side. (After Henle.)

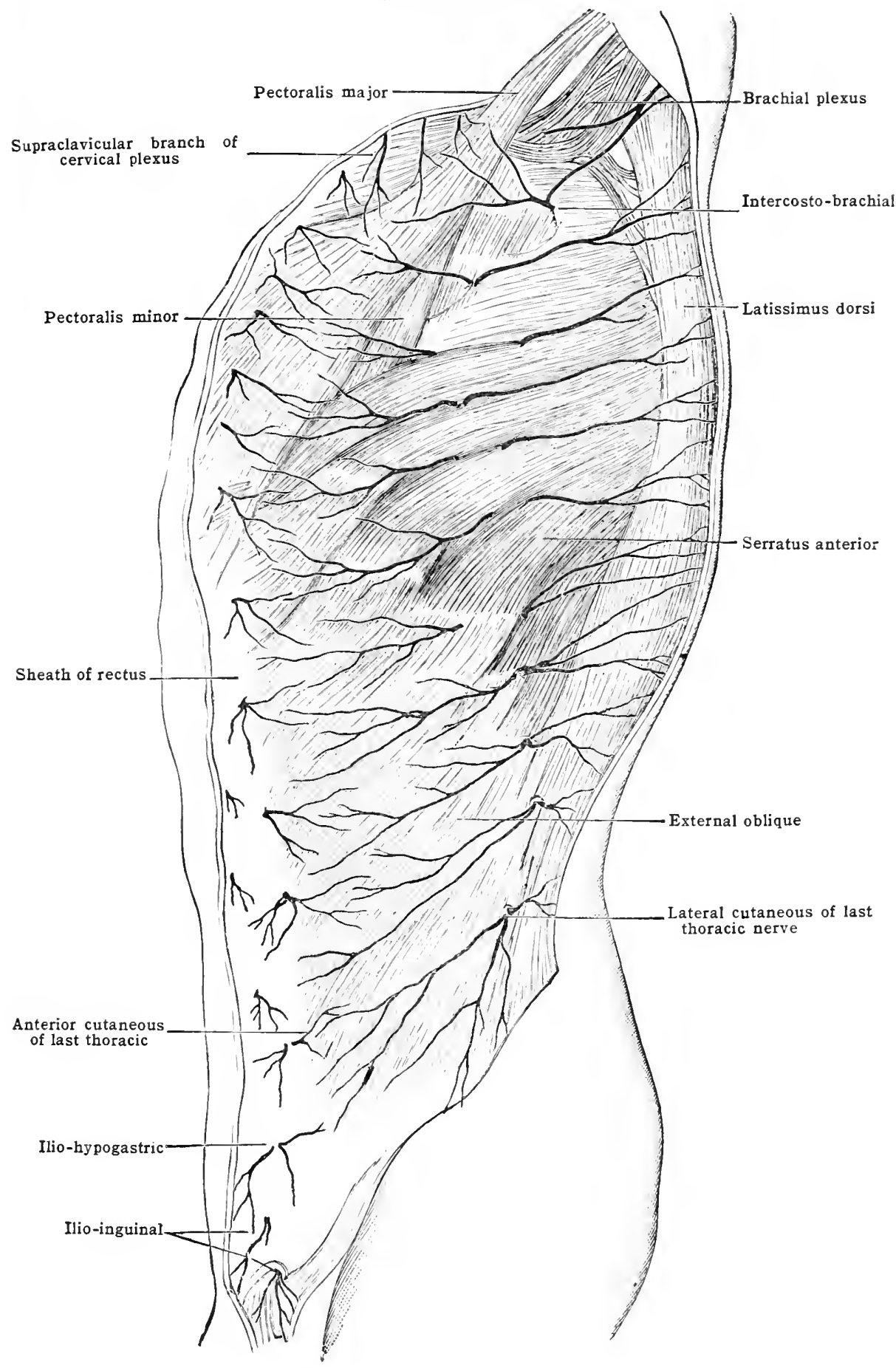

part of the fourth and the fifth nerve commonly unite to form the lumbo-sacral cord which takes part in the formation of the sacral plexus (figs. 764, 765). When the fourth nerve enters into the formation of both lumbar and sacral plexuses, 
it may be called the furcal nerve, but this name is also applied to any of the nerves that enter into the formation of both plexuses, so there may be one or more furcal nerves.

\section{THE LUMBAR PLEXUS}

Although the lumbar plexus is ordinarily formed by the first three lumbar nerves and a part of the fourth, yet it is subject to considerable variation in the manner of its formation.

Owing to this variation three general classes of plexuses may be found, proximal or prefixed, ordinary, and distal or post-fixed. The basis of classification is the relation of the nerves of the limb to the spinal nerves which enter into their formation. The intermediate or slighter degrees of variation may consist only of changes in the size of the portions contributed by the different spinal nerves to a given peripheral nerve, for a given nerve may receive a larger share of its fibres from a more proximal spinal nerve, and a smaller share from a more distal nerve, or vice versâ. However, in the more marked degrees of variation the origin of a given peripheral nerve may vary in either direction to the extent of one spinal nerve. The more extreme types of the plexuses are sometimes associated with abnormal conditions of the vertebral column. It has been suggested that when the prefixed or proximal condition occurs, it indicates that the lower limb is placed a segment more proximal than in the ordinary cases, and when the distal condition is present, that the limb is arranged a segment more distal. Three types each of the proximal and the distal classes and one type of the ordinary class have been described by Bardeen. His statistics are made use of in the compilation of the following tables, in which are shown the range of variation and the common composition of each class of plexus:-

\section{Composition of the Nerves of the Lumbar Plexus Range of Variation}

\section{Nerve.}

Lateral (external) cutaneous Femoral (anterior crural) ... Obturator...............

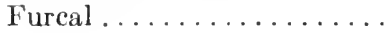

Nerve.

Lateral (external) cutaneous Femoral (anterior crural). . Obturator. Furcal.

\section{Proximal.}

$12 \mathrm{~T}, 1,2,3 \mathrm{~L}$.

$12 \mathrm{~T}, 1,2,3,4 \mathrm{~L}$.

$1,2,3,4 \mathrm{~L}$.

3 or $3,4 \mathrm{~L}$.
ORDINARY.

$1,2,3,4 \mathrm{~L}$.

1, 2, 3, 4 L.

$1,2,3,4 \mathrm{~L}$.

$4 \mathrm{I}$.
Distal.

1, 2, 3, $4 \mathrm{~L}$.

$1,2,3,4,5 \mathrm{~L}$

$2,3,4,5 \mathrm{~L}$

4,5 or $5 \mathrm{I}$.

\section{Common Composition}

\section{Proximal.}

$1,2 \mathrm{~L}$

$1,2,3,4 \mathrm{~L}$.

$1,2,3,4 \mathrm{~L}$.

$4 \mathrm{~L}$.
Ordinary.

$1,2,3 \mathrm{~L}$.

$2,3,4 \mathrm{~L}$.

$2,3,4 \mathrm{~L}$

$4 \mathrm{~L}$.
Distal.

$2,3 \mathrm{I}$.

$2,3,4,5$, L. $2,3,4 \mathrm{I}$

$4 \mathrm{~L}$.

The lumbar plexus lies in the posterior part of the psoas muscle (fig. 765), in front of the transverse processes of the lumbar vertebræ and the medial border of the quadratus lumborum, and its terminal branches are distributed to the lower part of the abdominal wall, the front and medial part of the thigh, the external genital organs, the front of the knee, the medial side of the leg, and the merlial sirle of the foot.

The first and second of the lumbar nerves give collateral muscular branches to the quarlratus lumborum muscle, and the second and third nerves give similar branches to the psoas. The remaining branches of the plexus are terminal branches. The first lumbar nerve, after it has been joined by the branch from the last thoracic nerve, divides into three terminal branches, the ilio-hypogastric nerve, the ilio-inguinal nerve, and a branch which joins the second nerve. The fibres of this latter brinch pass mainly into the genito-femoral (genito-crural) nerve, but occisionally some of them enter the femoral (anterior crual) and obturator nerves. The remaining nerves divide into anterior or ventral and posterior or dorsal divisions. The anterior divisions form at portion of the genitofemoral (genito-crural) nerve and the obturator nerve, and the posterior divisions enter the lateral (external) eutaneous and femoral (anterior crural) nerves.

All the terminal branches of the plexus are formed in the substance of the psoas inusele; four of them, the ilio-hypogastrie, the ilio-inguinal, the lateral (external) cutancous, and the fanoral (anterior crural), leave the muscle at its lateral border. The genito-femoral (genito-crural) passes through its anterior surface, and the olburator through its modial borter.

Terminal branches. - Tho ilio-hypogastric nerve springs from the first lumbar nerve, after the latter has been joined by the communicating branch 
from the last thoracic nerve, as it is in about 50 per cent. of the cases, and it thus contains fibres of both the last thoracic and the first lumbar nerves. It pierces the lateral border of the psoas and crosses in front of the quadratus lumborum (fig. 765), and behind the kidney and the colon. At the lateral border of the quadratus it pierces the aponeurosis of origin of the transversus abdominis and enters the areolar tissue between the transversus and the internal oblique, where it frequently communicates with the last thoracic and with the ilio-inguinal

Fig. 764.-Diagram of a Common Form of Lumbo-sacral Plexus. (Modified from Paterson.)

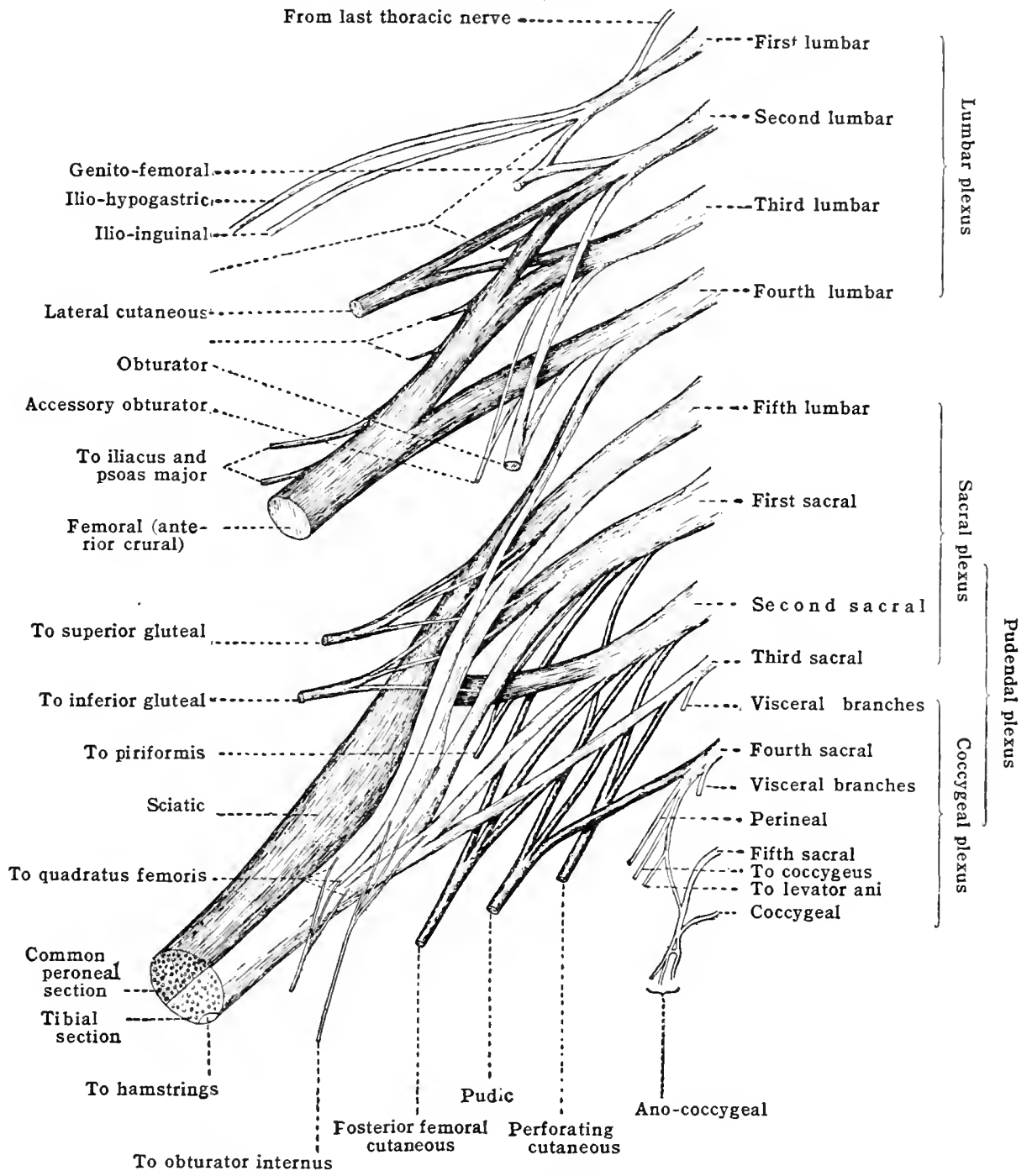

nerve, and it divides into an iliac and a hypogastric branch, which correspond, respectively, with the lateral and anterior branches of a typical spinal nerve.

The anterior cutaneous (hypogastric) branch passes forward and downward, between the transversus abdomin is and the internal oblique muscles, giving branches to both; it communicates with the ilio-inguinal nerve, and, near the anterior superior spine of the ilium, it pierces the internal oblique muscle and continues forward beneath the external oblique aponeurosis toward the middle line. About $2.5 \mathrm{~cm}$. (1 in.) above the subcutaneous inguinal ring it pierces the aponeurosis of the external oblique, becomes subcutaneous, and supplies the skin above the symphysis.

The lateral cutaneous (iliac) branch pierces the internal and external oblique muscles, emerging through the latter above the iliac crest at the junction of its anterior and middle thirds (fig. 769). It is distributed to the integument of the upper and lateral part of the thigh, in the neighborhood of the gluteus medius and tensor fasciæ latæ muscles (fig. 768 ). 
The ilio-inguinal nerve arises principally from the first lumbar nerve, but it frequently contains fibres of the last thoracie nerve. It emerges from the lateral border of the psoas, at a lower level than the ilio-hypogastric nerve, and passes aeross the quadratus lumborum (figs. 765,766 ). As a rule, it is below the level of the inferior end of the kidney, but it passes dorsal to the ascending or the descending colon according to the side considered, and erosses the posterior part of the inner lip of the iliac crest; it then runs forward on the upper part of the iliacus, pierees the transverus abdominis near the anterior part of the crest, and communieates with the anterior cutaneous (hypogastric) branch of the iliohypogastric nerve. A short distance below the anterior superior spine it passes through the internal oblique musele, and then descends in the inguinal eanal to the subeutaneous inguinal (external abdominal) ring, through which it emerges into the thigh on the lateral side of the spermatic eord (fig. 763). It is distributed to the skin of the upper and medial part of the thigh, in the male to the root of the penis and to the skin of the root of the scrotum through the anterior scrotal nerves (fig. 768 ), and in the female to the mons veneris and labium majus through the anterior labial nerves.

Not uncommonly the ilio-inguinal nerve is blended with the ilio-hypogastrie nerve and separates from the latter between the transversus abdominis and the internal oblique museles. It may be replaced by branches of the genito-femoral (genito-crural) nerve, or it may replace that nerve or the lateral eutaneous nerve.

The genito-femoral (genito-crural) nerve is connected with the first and second lumbar nerves, but the majority of its fibres are derived from the second nerve. It passes obliquely forward and downward through the psoas and emerges from the anterior surface of that musele, close to its medial border, at the level of the lower border of the third lumbar vertebra. After emerging from the substance of the psoas it runs downward on the anterior surface of the muscle (fig. 765 ), to the lateral side of the aorta and the common iliac artery, passes behind the ureter and divides into two branches, an external spermatic or genital, and a lumbo-inguinal or erural (fig. 766). Oceasionally it divides in the substance of the psoas, and then the two branches issue separately through the anterior surface of the musele.

The external spermatic (genital) branch runs downward on the psoas musele, external to the external iliac artery; it gives a branch to the psoas, and at Poupart's ligament it turns around the inferior epigastric artery and enters the inguinal canal, accompanying the spernatic cord in the male or the round ligament in the female. It supplies the cremaster musele, and gives twigs to the integument of the serotum (fig. 766) or the labium majus.

The lumbo-inguinal (crural) branch passes downward along the external iliac artery and beneath l'oupart's ligament into the thigh, which it enters to the lateral side of the femoral artery. A short distance below Poupart's ligament it picrces the fascia lata or passes through the fossa ovalis (saphenous opening) and supplies the skin in the middle of the upper part of the thigh. A short distance below Potpart's liganent it sometimes sends branches to the anterior branch of the latera] cutancous nerve, and about the middle of the thigh it of ten joins with the cutineous branches of the femoral (anterior crural) nerve.

The lateral cutaneous nerve receives fibres from the dorsal branches of the anterior prinary divisions of the second and third lumbar nerves, and frequently some fibres from the first lumbar (fig. 769). It emerges from the lateral border of the peots and passes obliquely across the iliacus dorsal to the iliae faseia, and dorsal to the caromm on the right side and the sigmoid colon on the left side, to a point immediately below the anterior superior spine of the ilium, where it passes below Poupart's ligament into the lateral angle of the femoral trigone (Scarpa's triangle). Letiving the trigone at once it passes through, behind, or in front of the sartorins and divides into two branches, anterior and posterior, which enter the derep fascial (fig. T(66).

The posterior branch of the lateral cutancous nerve breaks up into several secondary branches which becone subeutancous, and they supply the integument of the lateral part of the thigh, from the great trochanter to the level of the middle of the fonur. The anterior branch runs downward in a canal in the derp laseia, for three or four inches, Jefore it becomes subcutaneons. I1 usually divides info two branches, a lateral and a medial. The lateral branch supplies the slin of the lower half of the lateral side of the thigh, and the medial branch is distributed to the skin of the litceral side of the front of the thigh as far as the knee (fig. 766). Its lower filunents frequently unite with the cutaneous branches of the femoral (anterior 
crural), and with the patellar branch of the saphenous nerve in front of the patella, forming with them the patellar plexus.

The femoral (anterior crural) nerve is the largest terminal branch of the lumbar plexus. It is formed chiefly by fibres of the dorsal branches of the anterior primary divisions of the second, third, and fourth lumbar nerves, but it sometimes receives fibres from the first nerve also (figs. 765 and 769 ). It emerges from the lateral border of the psoas a short distance above Poupart's ligament, and descends in the groove between the psoas and the iliacus, behindPoupart's ligment, into

Fig. 765.-Lumbo-Sacral Plexus. (After Toldt, 'Atlas of Human Anatomy,' Rebinan, London and New York.)

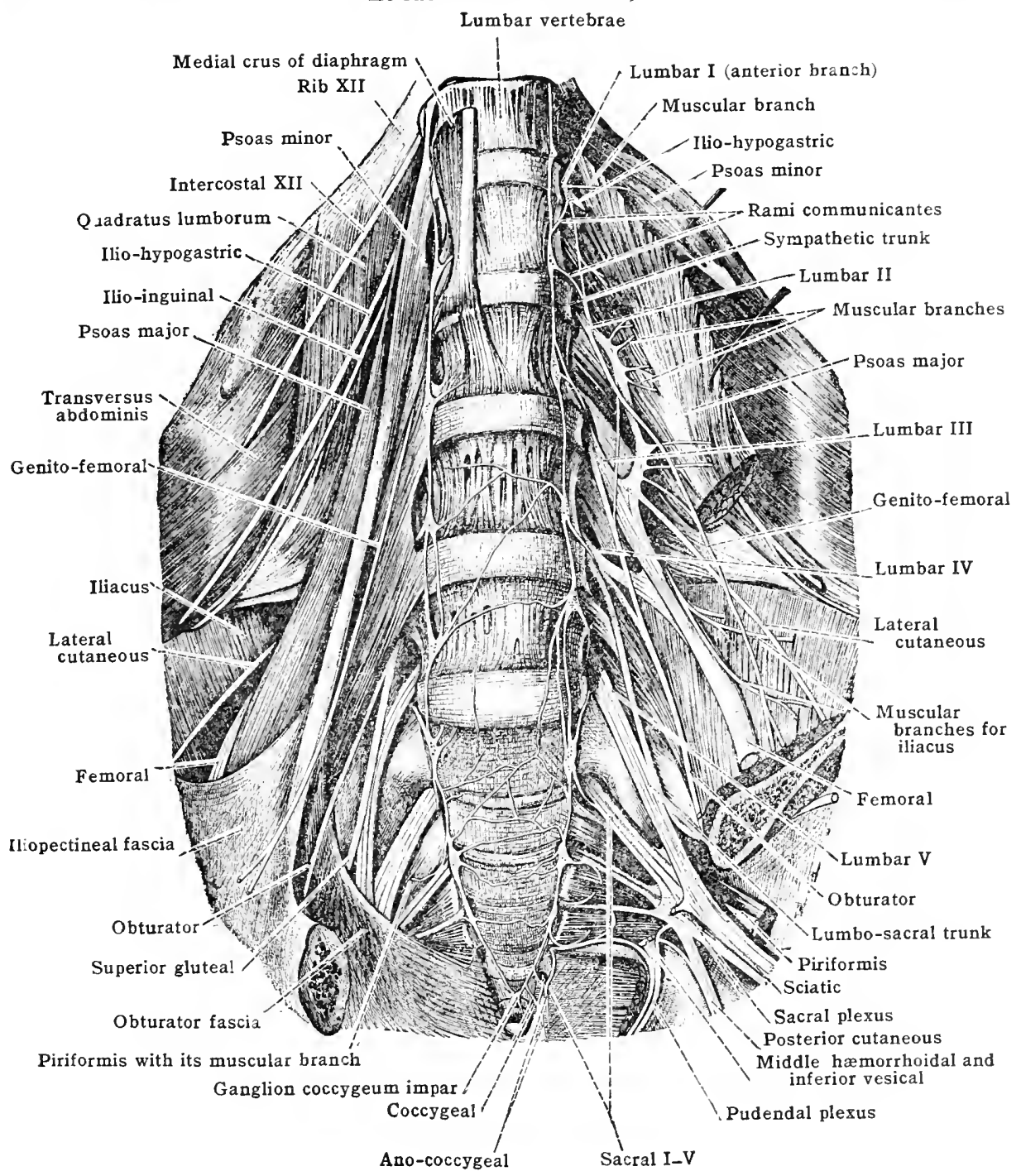

the femoral trigone (Scarpa's triangle), where it lies to the lateral side of the femoral artery (fig. 767), from which it is separated by some of the fibres of the psoas. In this situation it is flattened out and it divides into two series of terminal branches, the superficial and the deep. In general, they supply the muscles and skin on the anterior aspect of the thigh.

Branches.- The branches of the femoral nerve are collateral and terminal.

The collateral branches are twigs of supply to the iliacus, and a branch to the femoral artery; they are given off before the nerve enters the femoral trigone. 
The terminal branches form two groups, the superficial and the deep.

The superficial terminal branches are two muscular branches, the nerve to the pectineus, and the nerve to the sartorius, and two anterior cutaneous branches.

Fig. 766.-Cutaneous Nerves of the Rigit Thigh. (Spalteholz.) (The iliac fascia has been removed, the fascia lata retained.)

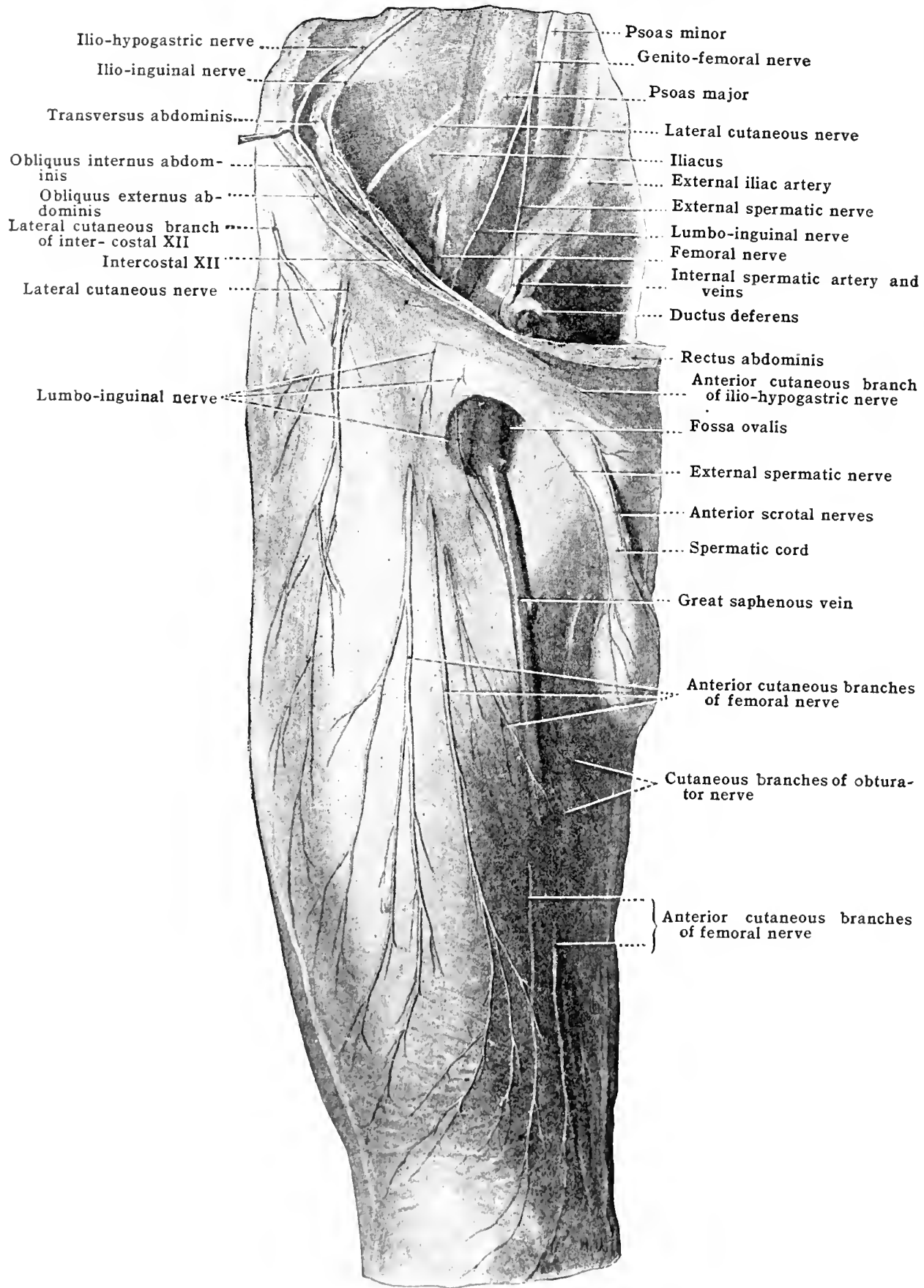

The nerve to the pectineus passes medially and dww ward behind the femoral sheath and in fromt of the psoas to the anterior surfuce of the pectineus, in which it terminates.

Thro nerve to the sartorius acompanies the midlle cutaneous nerve; it leaves the latter nerve abuve the sartorius and couls in the npper part of the musele. 
The anterior (middle and internal) cutaneous nerves are best described separately. The middle cutaneous nerve soon divides in to two branches, medial and lateral. The lateral branch pierces the sartorius and both branches become cutaneous about the junction of the upper and middle thirds of the thigh (figs. 766, 768). They descend along the medial part of the front of the thigh to the knee, supplying the skin in the lower two-thirds of the medial part of the front of the thigh, and their terminal filaments take part in the formation of the patellar plexus. About the middle of the thigh the middle cutaneous is often joined by a twig with the lumboinguinal nerve (crural branch of the genito-crural nerve). The medial or internal cutaneous nerve runs downward and medialward along the lateral side of the femoral artery, to the apex of the femoral trigone (Scarpa's triangle), where it crosses in front of the artery and divides into an anterior and a posterior terminal branch. Before this division takes place, however, two or three collateral branches are given off from the trunk. The highest of these passes through the fossa ovalis (saphenous opening), or it pierces the deep fascia immediately below the opening, and supplies the skin as low as the middle of the thigh. The lowest pierces the deep fascia at the middle of the thigh and it descends in the subcutaneous tissue, supplying the skin on the medial side of the thigh from the middle of the thigh to the knee (figs. 768, 769). This nerve frequently varies in size inversely with the cutaneous branches of the obturator and saphenous nerves. The anterior branch of the internal cutaneous nerve passes vertically downward to the junction of the middle and lower thirds of the thigh, where it pierces the deep fascia. It still continues downward for a short distance, then it turns lateralward and passes to the front of the knee, where it enters in to the patellar plexus.

The posterior branch descends along the dorsal border of the sartorius, and it gives off a branch which passes beneath that muscle to unite with twigs from the saphenous and from the superficial division of the obturator nerve, forming with them the subsartorial plexus which lies on the roof of the adductor (Hunter's) canal. At the medial side of the knee the nerve pierces the deep fascia and it descends to the middle of the calf (figs. 766,768 ).

The deep terminal branches of the femoral nerve are six in number, one cutaneous branch, the saphenous, and five muscular branches. The branches radiate from the termination of the trunk of the femoral nerve, and they are arranged in the following order from medial to lateral:- the saphenous nerve, the nerve to the vastus medialis, the nerve to the articularis genu (subcrureus), the nerve to the vastus intermedius (crureus), the nerve to the vastus lateralis, and the nerve to the rectus femoris.

The saphenous nerve passes down through Scarpa's triangle along the lateral side of the femoral artery. At the apex of the triangle it enters the adductor (Hunter's) canal and descends through it, lying first to the lateral side, then in front, and finally to the medial side of the artery (fig. 767). After emerging from the lower end of the canal, accompanied by the superficial branch of the genu suprema (anastomotic) artery, it passes between the dorsal border of the sartorius and the anterior border of the tendon of the gracilis, and, becoming superficial, it enters into relationship with the great saphenous vein and descends with it along the inner border of the upper two-thirds of the tibia (fig. 768). It crosses the medial surface of the lower third of the tibia, passes in front of the internal malleolus, and runs forward along the medial border of the foot to the ball of the great toe.

While it is in the adductor (Hunter's) canal it gives off a twig to the subsartorial plexus. Before it passes from under cover of the sartorius it gives off an infra-patellar branch, which pierces the sartorius just above the knee and passes outward to the patellar plexus. After it becomes superficial it supplies the integument on the medial side of the leg and foot, and it anastomoses, in the foot, with the medial dorsal cutaneous branch of the superficial peroneal (musculo-cutaneous) nerve.

The nerve to the vastus medialis accompanies the saphenous nerve in the femoral trigone (Scarpa's triangle), lying to its outer side. At the upper end of the adductor canal it passes beneath the sartorius, external to the roof of the canal, and enters the medial surface of the vastus medialis. It sends a twig down to the knee-joint.

The nerve to the articularis genu (subcrureus), usually a terminal branch of the femoral, frequently arises from the nerve to the vastus intermedius. It passes between the vastus medialis and the vastus intermedius to the lower third of the thigh, where it supplies the articularis genu and sends a branch to the knee-joint.

The nerve to the vastus intermedius (crureus) is represented by two or three branches which enter the upper part of the muscle. One of them frequently sends a twig to the knee-joint.

The nerve to the vastus lateralis passes downward behind the rectus and along the anterior border of the vastus lateralis accompanied by the descending branch of the lateral circumtlex artery. It also sends a branch to the knee-joint.

The nerve to the rectus femoris (fig. 767) enters the deep surface of that muscle, having previously given off a twig to the hip-joint which accompanies the ascending branch of the external circumflex artery.

The obturator nerve contains fibres from the anterior primary divisions of the second, third, and fourth lumbar nerves, but its largest root is derived from the third nerve (figs. 765, 769). It sometimes receives fibres from the first and third lumbar nerves. It emerges from the medial border of the psoas at the dorsal part of the brim of the pelvis, where it lies in close relation with the lumbo-sacral trunk of the plexus, from which it is separated by the ilio-lumbar artery. Immediately after its exit from the psoas it pierces the pelvic fascia, crosses the 
lateral side of the internal iliae vessels and the ureter, and runs forward in the extraperitoneal fat, below the obliterated hypogastric artery and along the upper part of the medial surface of the obturator internus to the upper part of the obturator foramen, where it passes through the obturator canal below the soealled horizontal ramus of the pubis and above the obturator membrane, into the upper part of the thigh. It is accompanied in the pelvis and the obturator canal by the obturator artery, which lies at a lower level than the nerve, and it divides

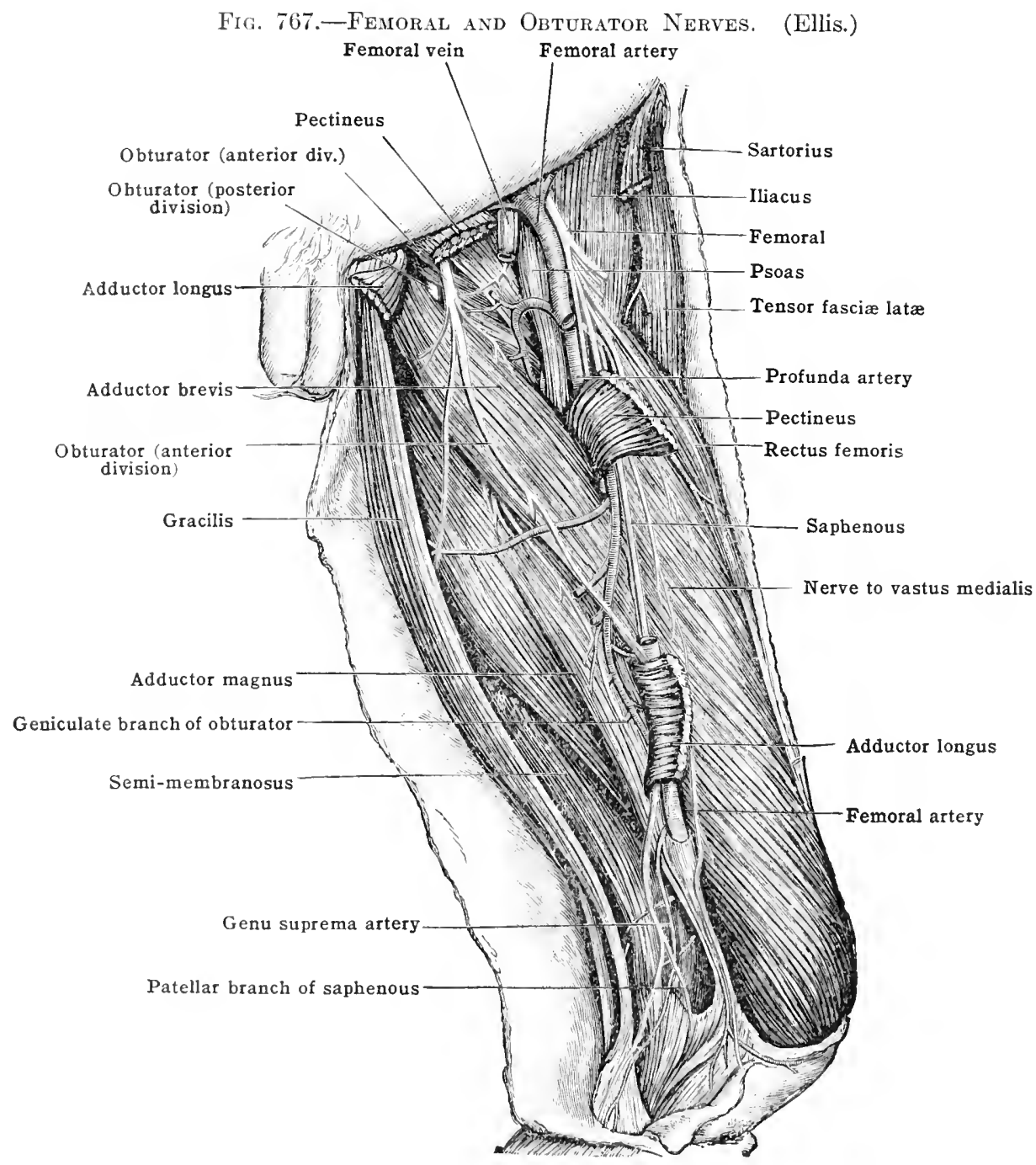

11 the obturator canal into two branches, an anterior and a posterior, which supply the addinctor group of muscles, the hip and kner-joints, and the skin on the incdial aspect of the leg.

The anterior branch of the obturator has a twig joining it with the accessory ohturator nerve, if that nerve is present, and then descends behind the pectineus and adductor longus and in front of the obturator extermus and adductor magnus nunscles (fig. 767). Its linanches are:-

1. A twig to the acessory obturator norve if the litter is present.

2. In articular branch to the hip-joint.

3. Muscular branches to the gracilis, adductor longus, and, usually, to the adduetor brevis.

1. T'wo terminal branches, of which one is distributed to the femoral artery and the other communicates with the subsartorial ploxus. The subsarorial branch is occasionally longer 
than usual, and it then descends, along the dorsal border of the sartorius, to the medial side of the knee, where it enters the subcutaneous tissue, and, proceeding downward, supplies the skin on the medial side of the leg as far as the middle of the calf. Twigs join it with the saphenous.

The posterior branch of the obturator (fig. 767 ) pierces the upper part of the obturator externus and passes downward between the adductor brevis and adductor magnus. Its branches are:-

1. Muscular branches to the obturator externus, to the oblique fibres of the adductor magnus and to the adductor brevis when the latter is not entirely supplied by the anterior branch. The branch to the obturator externus is given off in the obturator canal.

2. An articular branch to the knee-joint which appears in some cases to be the continuation of the trunk of the posterior branch (fig. 767 ). It either pierces the lower part of the adductor

Fig. 768.-Distribution of Cutaneous Nerves ox the Posterior and Aiterior Aspects of THE INFERIOR Fixtrearty.
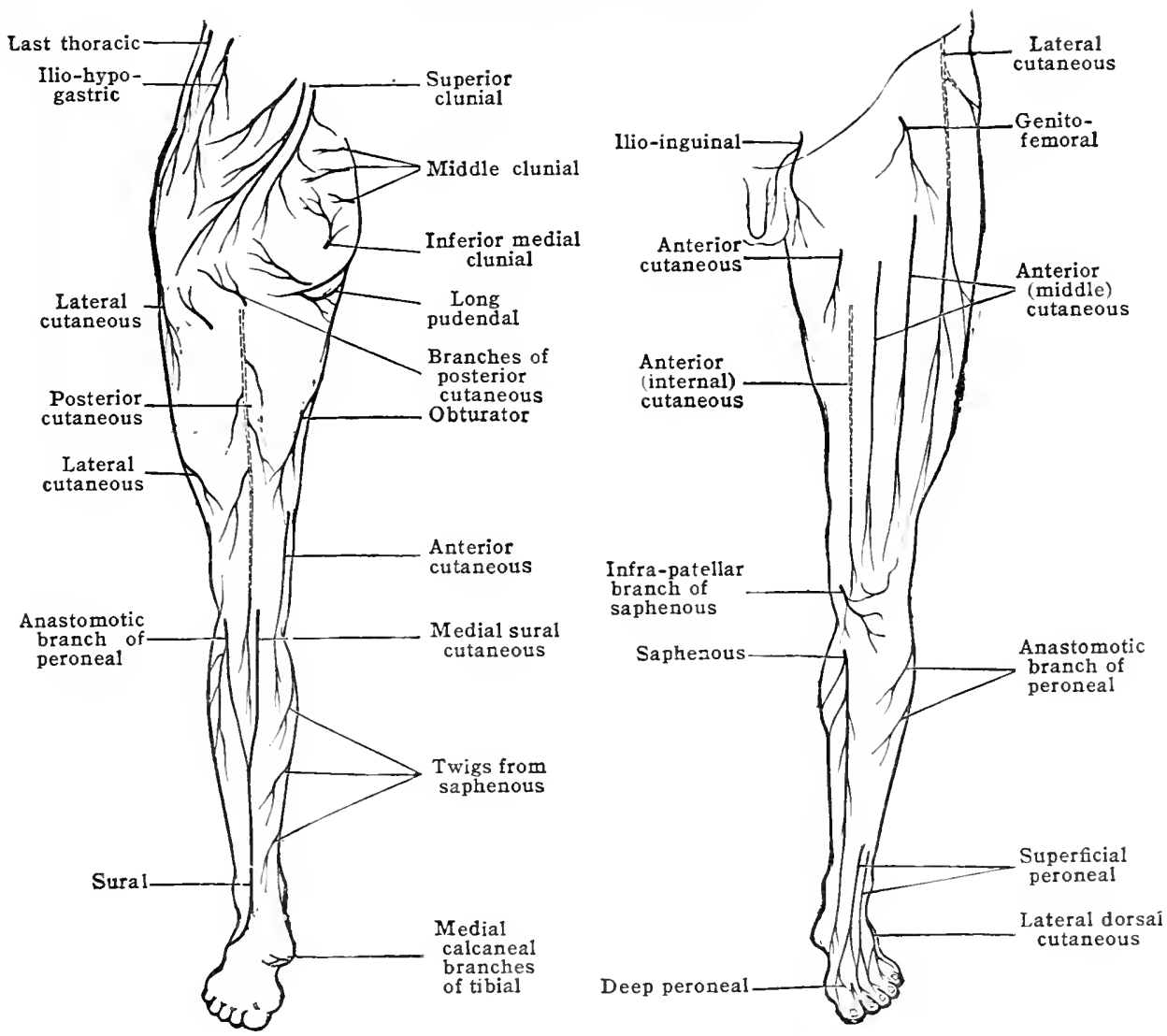

magnus, or it passes through the opening for the femoral artery. In the popliteal space it descends on the popliteal artery to the back of the joint, where it pierces the posterior ligament, and its terminal filaments are distributed to the crucial ligaments and the structures in their immediate neighbourhood. This branch is not uncommonly absent. Oceasionally the posterior branch of the obturator nerve also supples a twig to the hip-joint.

The accessory obturator nerve arises from the third or fourth or from the third and fourth lumbar nerves, in the angles between the roots of the femoral (anterior crural) and obturator nerves. It is present in about twenty-nine per cent. of all cases (Eisler). It is often closely associated with the obturator nerve to the level of the brim of the pelvis, but instead of passing through the obturator foramen, it descends along the medial border of the psoas, crosses the anterior part of the brim of the pelvis, nasses beneath the pectineus, and terminates in three main branches. One of these branches joins the anterior division of the obturator nerve, another supplies the pectineus, and the third is distributed to the hip-joint.

\section{The Lumbo-sacral Trunk}

The trunk of the plexus usually formed by the union of the smaller part of the fourth and the entire fifth lumbar nerves is called the lumbo-sacral trunk 
(figs. 765, 769). Sometimes the larger part of the fourth nerve may help to form the trunk. It may receive fibres from the third lumbar nerve or be formed entirely from the fifth. At its formation it is situated on the ala of the sacrum under cover of the psoas. It descends into the pelvis, and, as it crosses the anterior border of the ala of the sacrum, it emerges from beneath the psoas at the medial side of the obturator nerve, from which it is separated by the ilio-lumbar artery. It passes behind the eommon iliac vessels and unites with the first and second sacral nerves, forming with them the upper trunk of the sacral plexus.

\section{SACRAL NERVES}

The anterior primary divisions of the upper four sacral nerves enter the pelvis through the anterior sacral foramina and they diminish in size progressively from above downward. The first sacral is the largest of the spinal nerves, the second is slightly smaller than the first, while the third and fourth are relatively small. The fifth saeral nerve is still smaller than the fourth; it enters the pelvis between the sacrum and the coceyx. The anterior divisions of these nerves enter into the formation of three parts of the lumbo-sacral plexus, the sacral, pudendal, and cocergeal.

\section{Sacral Plexus}

The sacral plexus shows in its formation variations similar to those of the lumbar plexus; hence there are also seven types of this plexus, three of them belonging to the prefixed or proximal class, three to the postfixed or distal class, and one to the ordinary class. The following tables show the range of variation and the eommon arrangement in these classes:-

\section{Composition of the Nerves of the Sacral Plexus RANGE OF VARIATION}

\begin{tabular}{|c|c|c|c|}
\hline Nerie. & $\begin{array}{l}\text { Proximal. } \\
3 \text { or } 3,4 \mathrm{~L} .\end{array}$ & $\begin{array}{l}\text { ORDINARY. } \\
4 \mathrm{~L} .\end{array}$ & $\begin{array}{l}\text { Distal. } \\
4,5 \text { or } 5 \mathrm{~L} \text {. }\end{array}$ \\
\hline $\begin{array}{l}\text { Common peroneal (exter- } \\
\text { nal popliteal)............ }\end{array}$ & & & $4,5 \mathrm{~L}$. \\
\hline $\begin{array}{l}\text { Tibial (internal popliteal) } \\
\text { osterior femoral cutane- } \\
\text { ous (small seiatic). }\end{array}$ & $1,2,3 \mathrm{~S}$ & $\begin{array}{l}4,5, \mathrm{~L} . \quad 1,2,3 \mathrm{~S} . \\
5 \mathrm{~L} .1,2, \quad 3,4 \mathrm{~S} .\end{array}$ & $\begin{array}{ll}5 \mathrm{~L} . & 1,2,3,4, \mathrm{~S} . \\
5 \mathrm{~L} . & 1,2,3,4 \mathrm{~S} .\end{array}$ \\
\hline
\end{tabular}

\section{Common Composition}

\section{NERVE.}

Furcal.

Comnon peroneal external poprliteil.

Thibial (intermal popliteal).

losterior fomoral cutane-

olls (small sciatic).....
Proximal.

$4 \mathrm{I}$.
Ordinary.

$4 \mathrm{~L}$.

\section{Distal.}

4L.

4, 5 L. $1,2 \mathrm{~S}$.

4, 5 I. $1,2 \mathrm{~S}$

4, 5 L. $1,2,3$ s.

1, 2, $3 \mathrm{~s}$.
4. L. $1,2,3,4 \mathrm{~S}$.

2, $3 \mathrm{~S}$.

The ordinary type of sacral plexus is commonly formed by the smaller part of thr anterior livision of the fourth lumbar nerve and the entire anterior division of the fifth hmbar norve, together with the first and parts of the second and third sacril nerves.

The plexus lies in the pelvis on the anterior surface of the piriformis (fig. 765) and behind the pelvir fasciat and the branches of the hypogastric (internal iliae) artery. It is also dorsal to the coils of intestine, the lower part of the ilio-pelvie colon lying in front of the left plexus, and the lower part of the ileum in front of the right plexus.

'The branches given off by this plexus are:-visceral, cutaneous, and muscular.

Visceral branches are given off from the second, third, and fourth sacral norves to the prolvir: visererit.

'Phre viseral branches correspond to white rami communicantes, through not joining the sympathetio trunk. The hranches from thr seomel and fourth sacral nerves are incoustant. 
Cutaneous branches.- (a) The posterior femoral cutaneous (small sciatic) nerve arises partly from the anterior and partly from the posterior branches of the anterior primary divisions of the first, second, and third sacral nerves. It lies on the back of the plexus (figs. 765, 769), leaves the pelvis at the lower border of the piriformis, and descends in the buttock between the gluteus maximus and the posterior surface of the sciatic nerve (fig. 770). At the lower border of the gluteus maximus it passes behind the long head of the biceps femoris, and descends, immediately beneath the deep fascia, through the thigh and the upper part of the popliteal space (fig. 740 ). At the lower part of the popliteal region it perforates the deep fascia, and it terminates in branches which are distributed to the skin of the calf.

Branches of the small sciatic.-1. Perineal branches are distributed in part to the skin of the upper and medial sides of the thigh on its dorsal aspect. One of the branches, known as the long pudendal nerve, runs forward and medialward in front of the tuberosity of the ischium to the lateral margin of the anterior part of the perineum, where it perforates the fascia lata and Colles' fascia and enters the anterior compartment of the perineum. In the perineum twigs join it with the superficial perineal nerves, and its terminal filaments are distributed to the skin of the scrotum in the male. and to the labium najus in the female.

2. Inferior clunial (ghuteal) branches, two or three in number, are given off beneath the gluteus maximus; they turn around the lower border of this muscle and are distributed to the skin of the lower and lateral part of the gluteal region.

3. Femoral cutaneous branches are given off as the nerve descends through the thigh. They perforate the deep fascia and are distributed to the skin of the back of the thigh, especially on the medial side.

In case of the separate origin of the tibial (internal popliteal) and common peroneal (external popliteal) nerves, the posterior femoral cutaneous (small sciatic) also arises from the sacral plexus in two parts. The ventral portion descends with the tibial nerve below the piriformis and gives off the perineal branches and medial femoral branches, while the dorsal portion passes through that muscle with the common peroneal nerve, and furnishes the gluteal and lateral femoral branches.

(b) The inferior medial clunial (perforating cutaneous) nerve arises from the posterior portion of the second and third sacral nerves (figs. 765, 769). It perforates the lower part of the sacro-tuberous (great sciatic) ligament, turns around the inferior border of the gluteus maximus, and is distribtued to the skin over the lower and medial part of that muscle. It is sometimes associated at its origin with the pudic nerve. It is not always present. Its place is sometimes taken by a small nerve (the greater coccygeal perforating nerve of Eisler), arising from the third and fourth or fourth and fifth sacral nerves, and sometimes it is represented by a branch of the posterior femoral cutaneous.

Muscular branches of the sacral plexus.-- (a) One or two small nerves to the piriformis pass from the posterior divisions of the first and second sacral nerves.

(b) The superior gluteal nerve receives fibres from the posterior branches of the fourth and fifth lumbar, and the first sacral nerves. It passes out of the pelvis through the great sciatic foramen, above the upper border of the piriformis, and it is accompanied by the superior gluteal artery. As soon as it enters the buttock it divides into two branches, an upper and a lower.

1. The upper branch is the smaller. It accompanies the upper branch of the deep division of the superior gluteal artery below the middle curved line of the ilium, and it ends entirely in the gluteus medius (fig. 770 ).

2. The lower branch, larger than the upper, passes forward across the middle of the gluteus minimus, with the lower branch of the gluteal artery; it supplies the gluteus medius and the gluteus minimus, and it ends in the medial and posterior part of the tensor fasciæ latæ.

(c) The inferior gluteal nerve is formed by fibres from the posterior branches of the fifth lumbar, and the first and second sacral nerves. It passes through the great sciatic foramen, below the piriformis, and divides into a number of branches which end in the gluteus maximus (figs. 765, 769).

(d) The nerve of the quadratus femoris is formed by the anterior branches of the fourth and fifth lumbar and the first and second sacral nerves. It lies on the front of the plexus and issues from the pelvis below the piriformis. In the buttock it lies at first between the sciatic nerve and the back of the ischium, and, at a lower level, between the obturator internus with the gemelli and the ischium. It terminates in the anterior surface of the quadratus femoris, having previously given off a branch to the hip-joint and another to the inferior gemellus.

(e) The nerve of the obturator internus is formed by the anterior branches of the fifth lumbar, and the first and second sacral nerves (figs. 765, 769). It leaves the pelvis below the piriformis, and crosses the spine of the ischium on the 
lateral side of the internal pudie artery and on the medial side of the sciatic nerve. It gives a branch to the gemellus superior, and turns forward through the small seiatic foramen into the perineum, where it terminates in the inner surface of the obturator internus.

The sciatic nerve [n. ischiadicus].-The sciatic is not only the largest nerve of the sacral plexus, but it is also the largest nerve in the body. Its terminal branches are chiefly museular, though some of its fibres are eutaneous. Although it is referred to as one trunk, it consists in reality of peroneal (lateral) and tibial (medial popliteal) portions, which are bound together by a sheath of fibrous tissue as far as the upper end of the popliteal space. In about 10 per cent. of the cases the two parts remain separate, and in such eases the peroneal (lateral popliteal)

Fig. 769.-A Dissection of the Lumbar and Sacral Plexuses, from Behind. (The anterior crural nerve is placed between the external cutaneous and obturator nerves.)

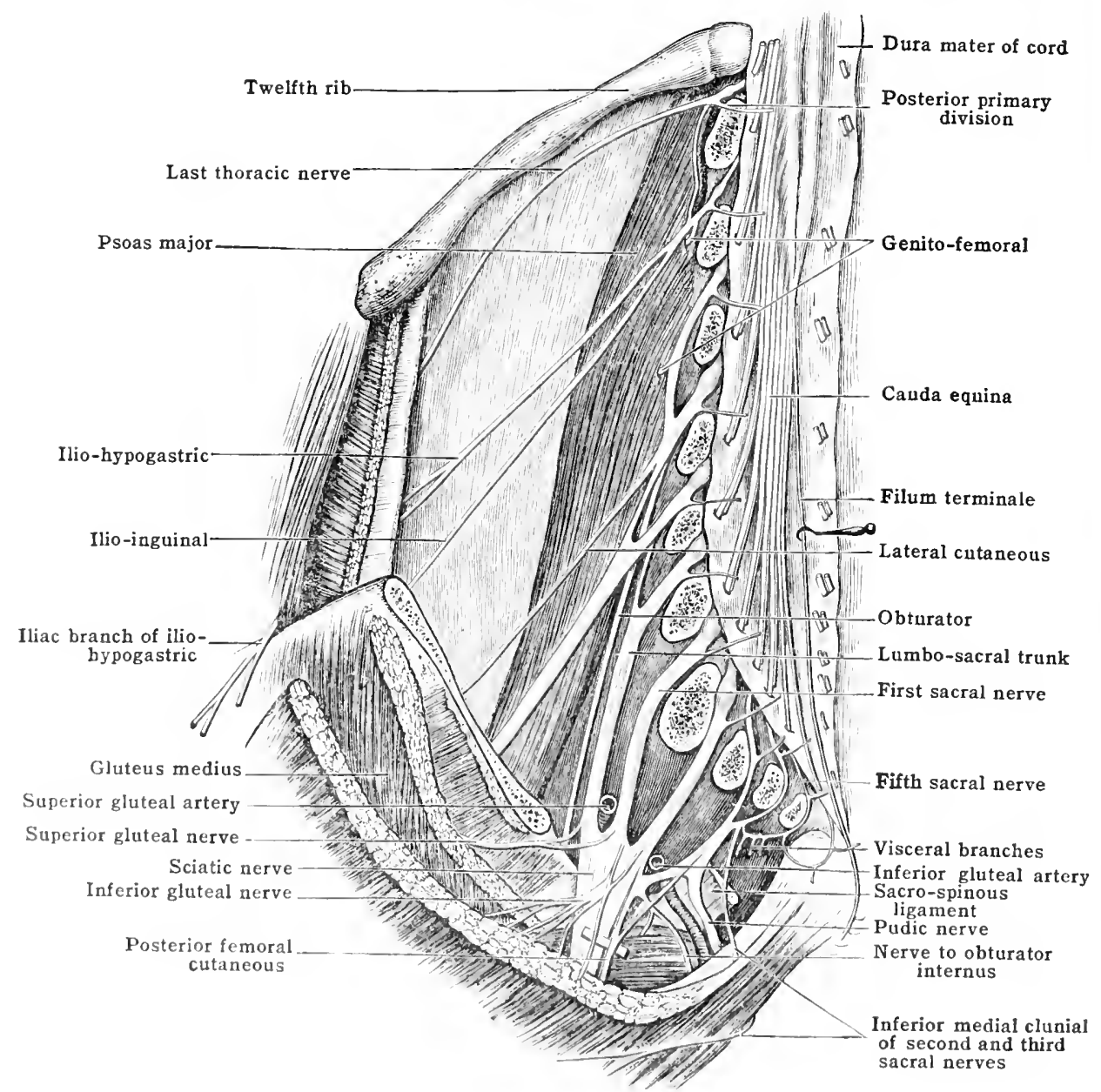

part usually pieres the piriformis. The peroncal portion of the nerve consists of fibers derived from the dorsal branches of the anterior primary divisions of the fometh amel fifth hunbar and the first and secomel sineral nerves, while the tibial part is lomened by the filmes from the anterior branches of the fourth and fifth lumbar, and threfirst, seromel, and third satcral norves (figs. 76.5, 769). The common lrumk baves the pelvis hy basing thromgh the great sacro-sciatie foramen, usually baldow the piriformis, and desernds through the buttock, running midway betweren the tuber ischii and the grate trochanter (fig. 770). Passing down the thigh, the trunk torminates at the uppere angle of the popliteal space by dividing 
into the common peroneal (external politeal) and the tibial (internal popliteal) nerves (fig. 771).

The relation of the trunk to the piriformis muscle is more or less unique. It may pass either above or below the muscle, it may split and pass around the muscle, or the muscle may be split and surround the nerve. Again, there may be a splitting of both the muscle and the nerve, in which case any possible combination of the four parts may occur; a portion of the nerve may be above and a portion between the parts of the muscle, or a portion may be below and a portion between. The trunk of the nerve lies deeply in the thigh, and it is covered posteriorly by the skin and fascia, the gluteus maximus and the long head of the biceps femoris. Anteriorly it is in relation, from above downward, with the following structures:- the posterior surface of the ischium and the nerve to the quadratus femoris, the gemellus superior, obturator internus, gemellus inferior, quadratus femoris, and adductor magnus muscles.

Muscular branches of the sciatic are given off at the upper part of the thigh to the semitendinosus, to the long head of the biceps femoris, to the semimembranosus,

Fig. 770.-A Dissection of the Nerves in the Gluteal Region.

(The gluteus maximus and gluteus medius bave been divided near their insertions, and thrown upward.)

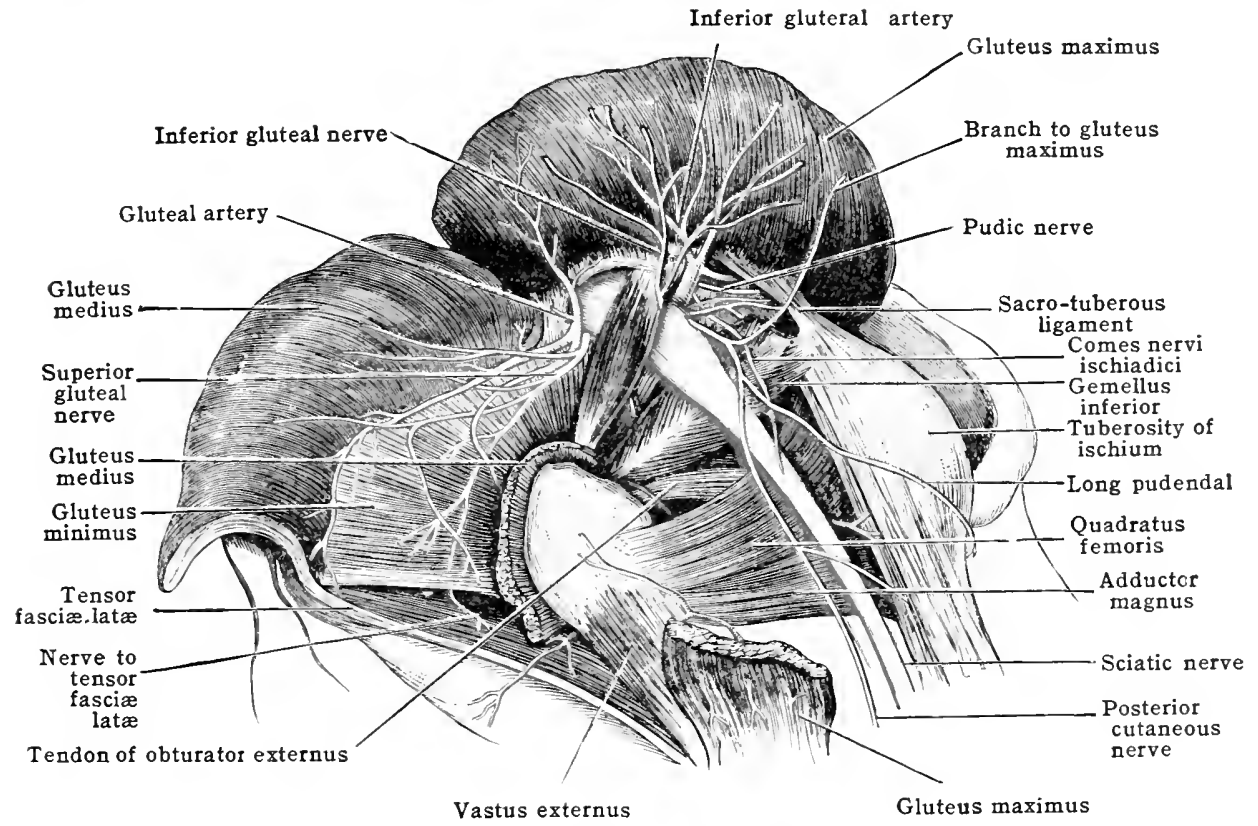

and to the adductor magnus, and, about the middle of the thigh, a branch is furnished to the short head of the biceps.

The branch to the short head of the biceps femoris is derived from the peroneal (lateral popliteal) portion of the nerve, while all the other muscular branches are given off by the tibial (medial popliteal) part. The semitendinosus receives two branches, one which enters it above and another which passes into it below its tendinous intersection. The nerve to the long head of the biceps descends along the sciatic trunk and enters the middle of the deep surface of the muscle. The nerves to the semimembranosus and adductor magnus arise by a common trunk which divides into three or four branches. One branch ends in the adductor, and the others are distributed to the semimembranosus. The branch to the adductor magnus supplies only those fibres of the muscle which begin from the tuberosity of the ischium and descend vertically to the medial condyle of the femur.

At the apex of the popliteal space the two component parts of the common trunk of the sciatic become distinct. The tibial nerve (internal popliteal), formed by fibres from the anterior branches of the fourth and fifth lumbar and first, second, and third sacral nerves, passes vertically through the popliteal space, descends through the leg to a point midway between the medial malleolus and the most prominent part of the medial tubercle of the os calcis, where it divides into its terminal branches, the lateral plantar and the medial plantar nerves. The part of the nerve from the point of bifurcation to the lower border of the popliteus muscle is sometimes called the internal popliteal; the part of the nerve in the dorsum of the leg being then designated the posterior tibial nerve. 
In the upper part of the popliteal space the tibial nerve lies relatively superficially, being covered dorsally by the skin and fascia, while in the lower part of the space it is overlapped by the heads of the gastrocnemius and is crossed by the plantaris. In the upper part of the space it lies in front of the posterior femoral cutaneous (small sciatic) nerve and to the lateral side of the vein and artery; at the middle of the space it is dorsal and in the lower part of the space it is medial to both of them.

The branches given off by the tibial nerve in the popliteal space are articular, cutaneous, and muscular.

The articular branches are usually three in number, a superior and an inferior internal articular and an azygos articular. They accompany the corresponding arteries, and, after piercing the ligaments, are distributed in the interior of the joint. The superior branch is often wanting.

The cutaneous branch, the medial sural cutaneous (tibial communicating) nerve, descends between the heads of the gastrocnemius, beneath the deep fascia, to the middle of the calf, where it pierces the fascia and unites with the peroneal anastomotic branch of the lateral sural cutaneous to form the sural (external saphenous) nerve, through which its fibres are distributed to the skin of the lower and dorsal part of the leg and the lateral side of the foot.

The muscular branches are distributed to both heads of the gastrocnemius, to the plantaris, soleus, and popliteus.

The nerve to the soleus is relatively large, and passes between the lateral head of the gastrocnemius and the plantaris before it reaches its termination (fig. 771). The nerve to the popliteus descends on the posterior surface of the muscle, turns around its lower border, and is distributed on its anterior aspect. In addition to supplying the popliteus, it gives articular branches to the knee and superior tibio-fibular joints, a branch to the tibia which accompanies the medullary artery, and a long, slender twig which gives filaments to the anterior and posterior tibial arteries, and it descends as the interosseous crural nerve on the interosscous membrane to the inferior tibio-fibular joint. It also gives branches to the interosseous membrane and to the periosteum of the lower part of the tibia.

Relations.- In the upper part of the leg the tibial nerve is placed deeply, under the gastrocnemius and soleus, but in the lower half it is merely covered by the decp fascia, which is thickened between the medial maleolus and the calcaneus to form the lacinate (internal annular) ligament, and the termination of the nerve lies either under cover of this ligament, or under the attachment of the abductor hallucis. The anterior relations of the nerve are, from above downward, the tibialis posterior, the flexor digitorum longus, the lower part of the tibia, and the posterior ligament of the ankle-joint. For a short distance after its commencement the nerve lies to the medial side of the posterior tibial artery; then it crosses behind the artery and runs down. ward along its lateral aspect.

The branches of the lower part of the tibial nerve (below the popliteal space) are likewise muscular, cutaneous, and articular. They are supplied to the deep muscles of the clorsum of the leg, to the fibula, to the skin of the heel and foot, and to the ankle-joint. Several of the terminal branches are important enough to receive special names and special treatment.

The muscular branches pass from the upper part of the nerve to the tibialis posterior, flexor digitorum longus, soleus, and flexor hallucis longus. The fibular branch arises with the nerve to the flexor hallucis longus, and accompanies the peroneal artery. It supplies the periosteum and gives filanents which accompany the medullary artery.

The articular branches arise from the lower part of the nerve, immediately above its terminal branches, and they pass into the ankle-joint through the deltoid ligament.

The medial calcaneal (calcaneo-plantar cutaneous) nerves arise from the trunk of the tibial nerve in the lower part of the leg. They pierce the laciniate (internal ammular) ligament, and are distributerl to the integument of the medial side and plantar surface of the heel and the adjoining part of the sole of the foot (fig. 771).

Terminal branches of tibial nerve.-The medial plantar nerve is the larger of the two terminal branches of the tihial nerve. It commonees under cover of the lower bordre of the lireiniate (intrmal annular) ligament, or under the posterior border of the atheluctor hallucis, and passes forwart, accompanied by the small internal plantar artory, in the inter-muscular septum between the abductor halluris and the fluxor digitorum brevis. At the midrlle of the length of the foot it heconnes superficial, in the intrrval between the two muscles, and divides into four sots of trominal hranchos (fig. 772):-

(a) Muscular branches pass from the trunk of the nerve to the abductor hallucis and the floxor digitorum brevis.

(b) Articular branches are distributed to the talo-mavieular (astragalosicephoil) aud the naviculari-comeiform joint.

(c) Plantar cutaneous branches are supplied to the skin of the medial part of thro sole. 
(d) The digital branches are four in number, the first, a proper plantar digital, the second, third, and fourth, the common plantar digitals. Near the bases of the

Fig. 771.-Muscle Nerves of the Right Leg, viewed from Behind. (Spalteholz.) The semitendinosus, semimembranosus, biceps femoris, gastrocnemius, plantaris, soleus, and flexor hallucis longus have been wholly or in part removed.

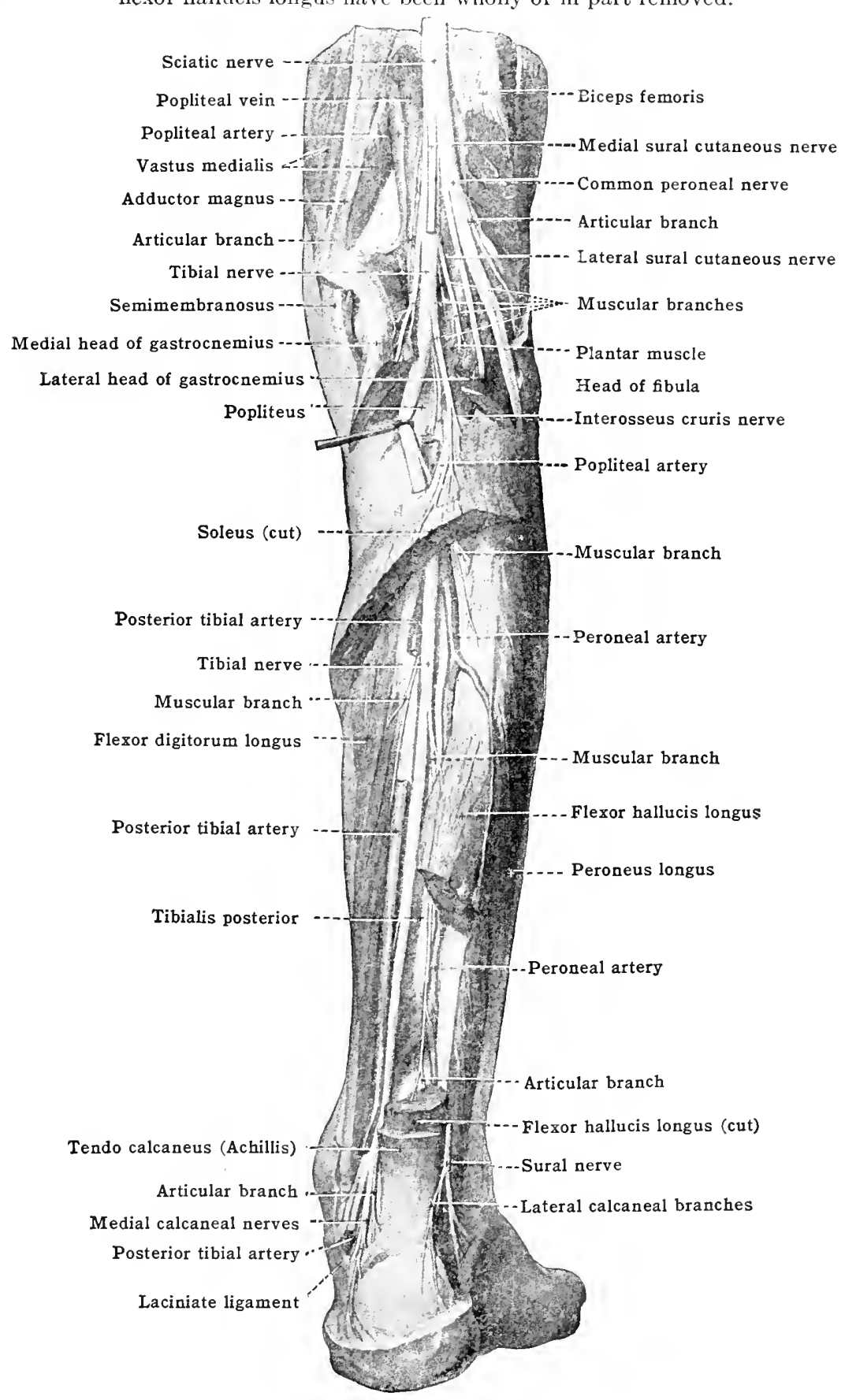

metatarsal bones, the second, third and fourth common plantar digital divide into proper plantar digital nerves.

The first proper plantar digital nerve becomes subcutaneous farther back than the others, and, after sending a branch to the flexor hallucis brevis, passes to the medial side of the great 
toe. The second (common digital) nerve gives a twig to the first lumbrical and bifurcates to supply the adjacent sides of the first and second toes. The third supplies the adjacent sides of the second and third toes, and the fourth, after connecting with the superficial branch of the lateral plantar nerve, divides to supply the adjacent sides of the third and fourth toes. All the proper digital nerves run along the sides of the toes and lie below the corresponding arteries: they supply the joints of the toes, and each gives off a dorsal branch to the skin over the second and terminal phalanges and to the bed of the nail. All of them give fibres terminating in numerous Pacinian corpuscles.

The lateral plantar nerve is the smaller of the two terminal branches of the tibial nerve. It commences at the lower border of the laciniate (internal annular)

Fig. 772.-Superficial Nerves in the Sole of the Foot. (Ellis.)

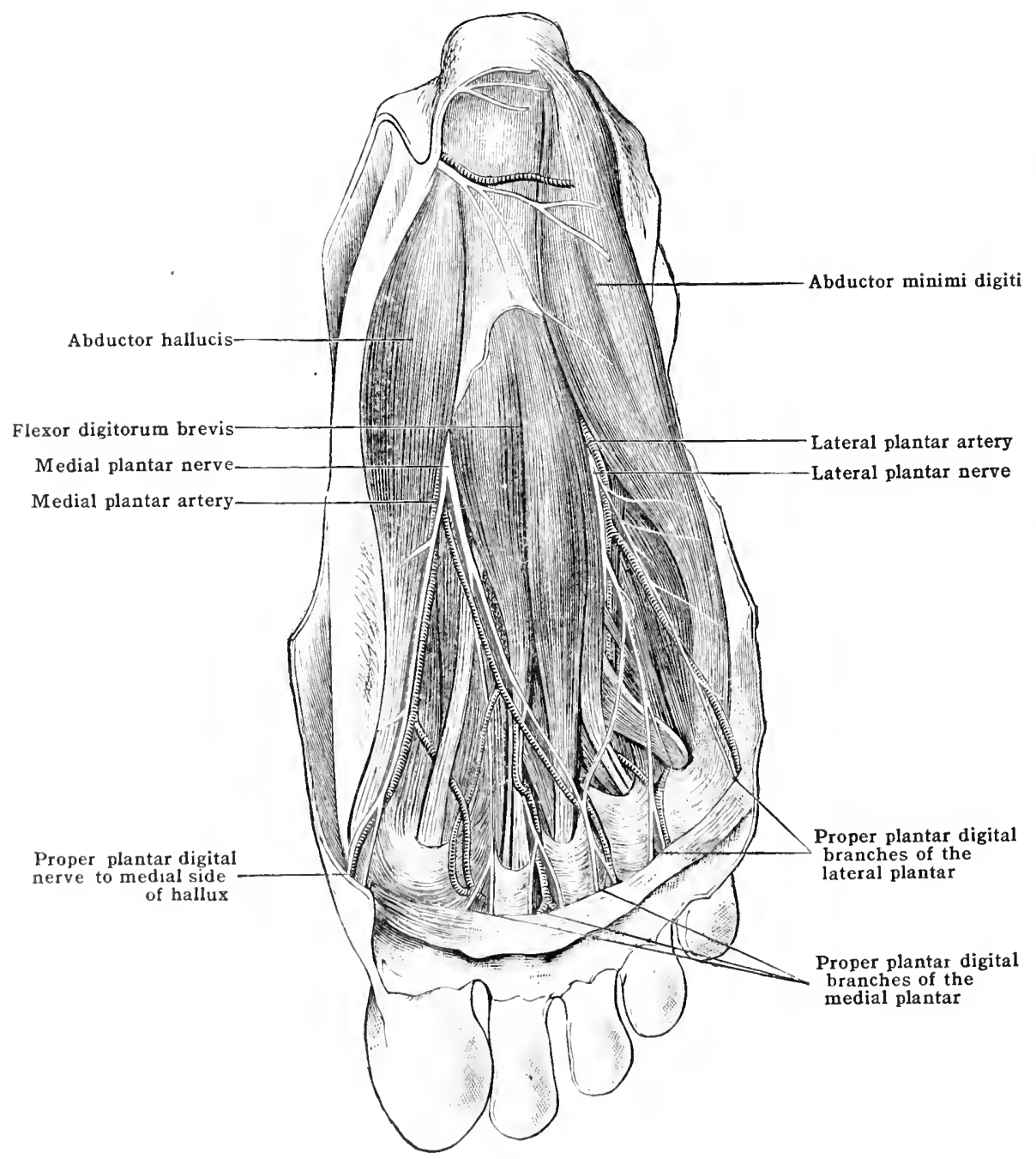

ligament, or under cover of the origin of the ahductor hallueis, and passes forward and lateralward to the base of the fifth metatarsal bone, where it divides into a superficial and a deep branch (fig. 772). As it runs forward and lateralward it it is superfieial to the truelon of the flexor hallueis longus and to the quadratus plantie (flexor accessorius), and loep to the flexor ligitorum brevis. At its termination it lies in the interval between the flexor digitorum brevis and abductor digiti quinti.

Branches.-From the trunk of the lateral plantar nerve muscular, superficial and deep, and articular branches are given off. 
The muscular branches arise from the commencement of the nerve and are distributed to the abductor digiti quinti and quadratus plantr.

The articular branches supply the calcaneo-cuboid joint.

The superficial branch supplies muscular filaments to the flexor digiti quinti brevis, the opponens, the third plantar and fourth dorsal interosseous muscles, and divides into two common plantar digital nerves, each of which subdivides to form proper plantar digital nerves.

The lateral of the two common branches supplies the lateral side of the fifth digit; the medial connects with the lateral digital branch of the medial plantar nerve (fig. 772) and divides into proper plantar digital nerves for the adjacent sides of the fourth and fifth digits. The digital branches of the superficial division of the lateral plantar, like those of the medial plantar, supply the skin of the toes and the beds of the nails, and their fibres terminate in numerouos Pacinian corpuscles.

The deep branch passes forward and medialward into the deep part of the sole with the plantar arterial arch. It runs deep to the quadratus plantie, the long flexor tendons and the lumbricals, and the oblique adductor of the great toe. It lies, therefore, immediately beneath the bases of the metatarsal bones and it supplies the following muscular and articular branches:-

Muscular branches to the lateral three lumbricals, the interossei of the medial three intermetatarsal spaces, and the transverse and oblique adductor muscles of the great toe.

Articular branches to the intertarsal and to the tarso-metatarsal joints and not uncommonly to the metatarso-phalangeal joints also. Filaments from the deep branch frequently pass through the interosseous spaces and join with the interosseous branches of the deep peroneal (anterior tibial) nerve.

The common peroneal (external popliteal) nerve.-At the apex of the popliteal space, where the two component parts of the sciatic trunk usually become distinct, the lateral portion receives the name common peroneal nerve. It descends along the posterior border of the biceps fenoris, which forms the upper part of the lateral boundary of the space (fig. 771). It leaves the space at the lateral angle, crosses the plantaris, the lateral head of the gastrocnemius, the popliteus, and the inferior external artery, and descends behind the upper part of the soleus, to the neck of the fibula, where it turns forward between the peroneus longus and the bone, and breaks up into its three terminal branches, the recurrent articular, the superficial peroneal (musculo-cutaneous), and the deep peroneal (anterior tibial) nerves (fig. 773).

Upper branches.- While it is in the popliteal space the common peroneal (external popliteal) nerve gives off two articular branches and a cutaneous branch.

The superior articular branch accompanies the superior external articular artery. The lateral head of the gastrocnemius, and it joins the inferior external articular artery behind the tendon of the biceps femoris. Both the upper and lower articular branches pierce the ligaments and are distributed in the interior of the knee joint.

The cutaneous branch (communicans fibularis), lateral sural cutaneous, is extremely variable both as to the number of its branches and as to the place of its anastomosis with the medial sural cutaneous. Leaving the common peroneal (external popliteal) in the popliteal space, it descends between the deep fascia and the lateral head of the gastrocnemius to the middle of the calf, where it pierces the fascia and unites with the medial sural cutaneous to form the sural (external saphenous) nerve. In its course it may give off no branches; or it may give off several, some of which supply the skin of the dorsum of the leg, while one of them, the peroneal anastomotic branch, unites with the medial sural cutaneous to form the sural (short saphenous) nerve. The junction of the peroneal anastomotic branch with the medial sural cutaneous may take place at any point between the popliteal space and the lower third of the leg.

The sural (external or short saphenous) nerve is formed by the union of the lateral sural cutaneous nerve either directly, or through a connecting branch, the peroneal anastomotic, with the medial sural cutaneous (fig. 771). It descends along the lateral border of the tendo Achillis, giving branches to the lower and lateral part of the leg, and lateral calcaneal branches to the lateral sicle of the heel. It passes dorsal to the lateral malleolus, turns forward across the lateral surface of the cruciate (external annular) ligament, and becomes the lateral dorsal cutaneous nerve. Continuing along the lateral side of the foot it divides into two branches, the dorsal digitals, one of which supplies the lateral side of the fifth digit, while the other anastomoses with or takes the place of a branch of the superficial peroneal (musculo-cutaneous) nerve, which is distributed to the adjacent sides of the fourth and fifth digits (fig. 773 ).

The terminal branches of the common peroneal.-(1) The recurrent articular nerve passes medialward, around the neck of the fibula, and through the upper 
part of the attachment of the extensor digitorum longus. At the medial border of the fibula it becomes associated with the anterior tibial recurrent artery, with which it ascends through the upper part of the tibialis anterior to the head of the

Fig. 773.-Distribution of the Superficial and Deep Peroneal Nerves on the Anterior Aspect of the Leg and on the Dorsun of the Foot. (Hirschfeld and Leveillé.)

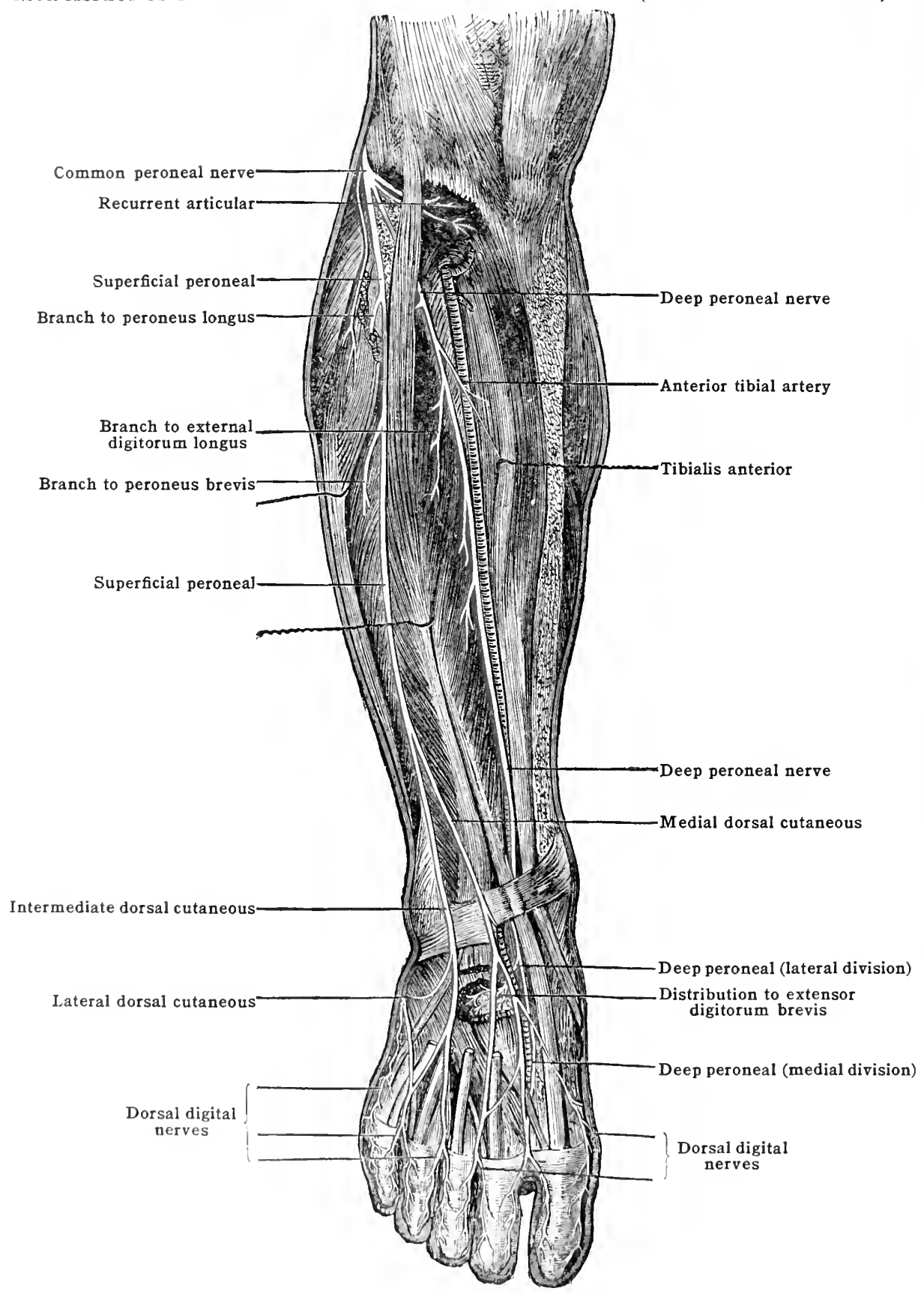

tibia and the knee-joint. It supplies the tibialis anterior, the superior tibiofibular joint, and the knee-joint.

(2) 'Th: superficial peroneal (musculo-cutaneous) nerve arises from the common peroneal betwern the peronems longus and the neek of the fibula and desecends in the intermuscular septum between the long and short peronei on the 
lateral side, and the extensor digitorum longus on the medial side. It gives off muscular and cutaneous branches in its descent, and at the junction of the middle and lower thirds of the leg it pierces the deep fascia and divides into a medial and a lateral branch (fig. 773).

Muscular branches are given off from the superficial peroneal to the peroneus longus and peroneus brevis before the nerve pierces the deep fascia.

Cutaneous branches pass from the trunk of the superficial peroneal to the skin of the lower part of the front of the leg.

The medial dorsal cutaneous (internal cruciate branch of the superficial peroneal), passes downward and medialward across the transverse and the cruciate (anterior annular) ligament of the ankle and subdivides into two branches. The medial branch passes to the medial side of the great toe; it also supplies twigs to the skin of the medial side of the foot, and it anastomoses with the deep saphenous nerve and with the medial terminal branch of the deep peroneal (anterior tibial) nerve. The lateral branch passes to the base of the cleft between the second and third toes and divides into two dorsal digital branches which supply the adjacent sides of the cleft.

The lateral branch (intermediate dorsal cutaneous) of the superficial peroneal, in separating from the medial, crosses in front of the cruciate ligament and divides into two dorsal digital branches, which pass beneath the dorsal venous arch. The medial of these branches supplies the adjacent sides of the third and fourth toes (fig. 773). The lateral branch communicates with the sural (external saphenous) nerve and is distributed to the adjacent sides of the fourth and fifth toes. This latter branch is frequently replaced by the sural nerve.

(3) The deep peroneal (anterior tibial) nerve springs from the end of the common peroneal (external popliteal) nerve between the peroneus longus muscle and the neck of the fibula. It passes forward and medialward through the upper part of the origin of the extensor digitorum longus, to the interval between that muscle and the tibialis anterior; then it descends, in the anterior compartment of the leg, to the ankle, where it divides into a medial and a lateral terminal branch (fig. 773).

In the upper part of the leg the deep peroneal nerve lies between the extensor digitorum longus and tibialis anterior and lateral to the anterior tibial artery. In the middle of the leg it is in front of the artery and between the extensor hallucis longus and tibialis anterior; then it crosses beneath the extensor hallucis, and in the lower third of the leg it is again to the lateral side of the artery, but between the extensor hallucis longus and the extensor digitorum longus.

Branches furnished from the trunk of the deep peroneal are muscular, articular, and terminal.

The muscular branches supply the tibialis anterior, extensor digitorum longus, extensor hallucis longus, and peroneus tertius.

Articular filaments are given to the ankle-joint and the inferior tibio-fibular articulation.

Terminal branches.-The medial terminal branch passes downward along the side of the dorsalis pedis artery and divides into two dorsal digital branches which supply the adjacent sides of the first and second toes. It also gives filaments to the periosteum of the adjacent bones, to the metatarso-phalangeal and interphalangeal articulations, a twig to the dorsal interosseous muscle of the first space, and a perforating twig which connects with the lateral plantar nerve. The lateral terminal branch passes lateralward, beneath the extensor digitorum brevis, and it ends in a gangliform enlargement from which branches are distributed to the extensor digitorum brevis, the tarsal joints, and to the three lateral intermetatarsal spaces. The latter branches supply the neighbouring bones, periosteum, and joints. They give off perforating twigs, which pass through the spaces and anastomose with branches of the lateral plantar nerve, and the most medial also gives a twig to the second dorsal interosseous muscle. 
Table Showing Ordinary Relations of Lumbar and Sacral Nerves to Branches of the Lumbar and Sacral Plexuses and to the Pudic Nerve

Nerves Contributing.

$1 \mathrm{~L}$.

1 and $2 \mathrm{~L}$.

1,2 , and $3 \mathrm{I}$

2,3 , and $4 \mathrm{~L}$.

4, $5 \mathrm{~L}$., and $1 \mathrm{~S}$.

$4,5 \mathrm{~L} ., 1$ and $2 \mathrm{~S}$.

4,5 L., 1,2 , and $3 \mathrm{~s}$

5 L., 1 and $2 \mathrm{~S}$.

1 and $2 \mathrm{~s}$.

2 and $3 \mathrm{~S}$

1,2 , and $3 \mathrm{~S}$

2,3 , and $4 \mathrm{~S}$
Nerves.

Sllio-hypogastrie

Ilio-inguina

Genito-femoral

Lateral cutaneous

Femoral

Obturator

Superior gluteal

Nerve to quadratus femoris

Sciatic (peroneal part)

Sciatic (tibial part)

Inferior gluteal

Nerve to obturator internus

Nerve to piriformis

Medial inferior clunial

Posterior femoral cutaneous

Pudic

Table Showing Relations of Muscles of Lower Extremity to Nerves of Lumbar and Sacral Plexuses

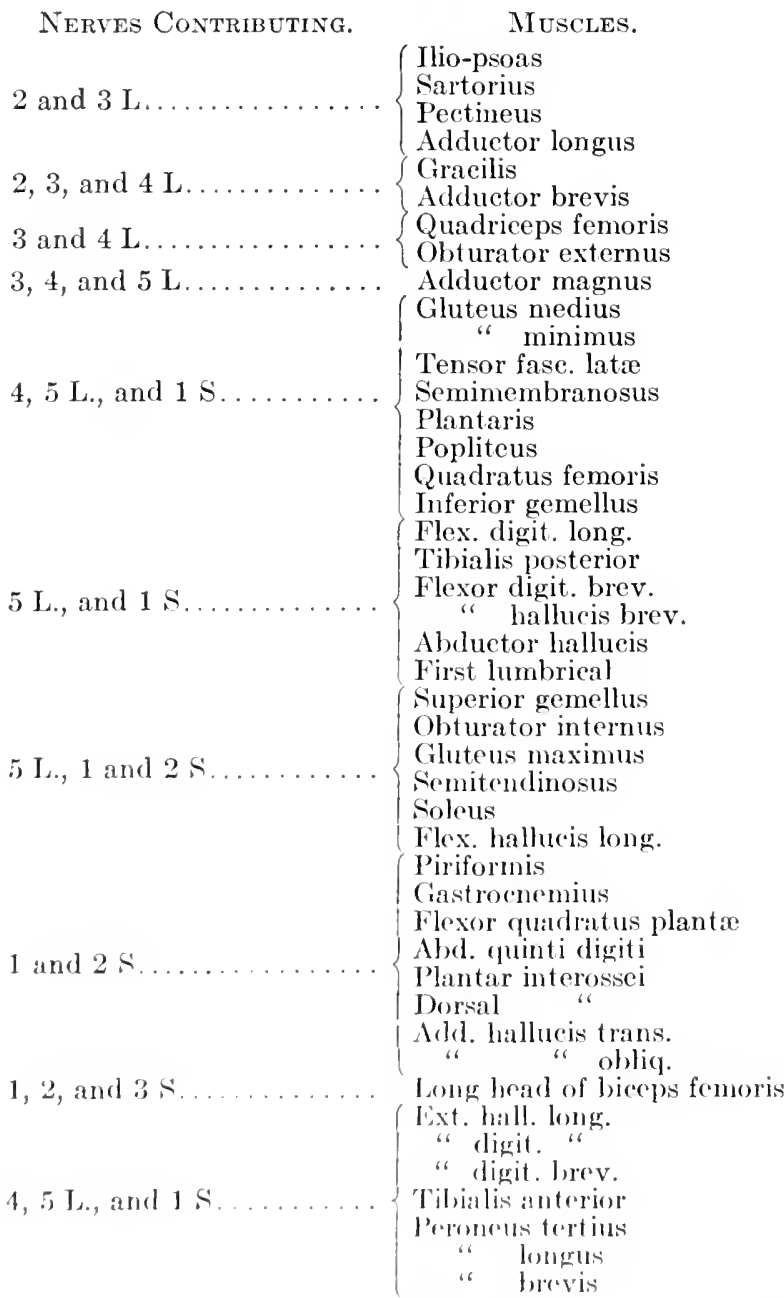

\author{
Nerves. \\ Femoral \\ (4) \\ Obturator \\ " \\ Femoral \\ Obturator \\ Obturator and sciatic \\ Superior gluteal \\ Sciatic \\ Tibial
}

Nerve to quad. fem.

Tibial

Posterior medial

Plantar

6

Nerve to obt. int.

Inferior gluteal

Sciatic

Tibial

“

Tibial

Lateral plantar

$\begin{array}{ll}" 6 & " 6 \\ " 6 & 6 \\ " 6 & 6 \\ " 6 & 6\end{array}$

Seiatic

Deep peroneal

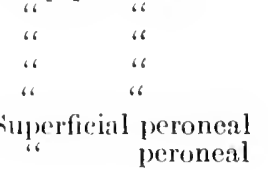

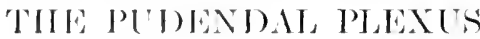

The pudendal plexus, like the parts of the lumbo-sacral plexus already described, varies in its formation. The accompanying tables show the extreme 
range of variation and the common method of formation of the large nerve of this plexus in each of the three classes.

\section{COMPOSITION OF THE NERVES OF THE PUDENDAL PLEXCS}

\section{RaNGe OF VARIATION}

Nerve.

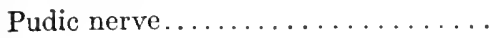

\author{
Proximal.
}

$1,2,3,4,5 \mathrm{~s}$.
ORdinary.

$1,2,3,4 x$.
DISTAL.

$2,3,4,5 \mathrm{~s}$.

\section{Common Composition}

Nerve.

\section{Proxinal.}

$2,3 \mathrm{~S}$.
Ordinary.

$2,3,4 \mathrm{~S}$.
Distal.

3,45 .

Pudic nerve...

The pudendal plexus is commonly formed by parts of the anterior divisions of the second, third, and fourth sacral nerves. It lies in the lower part of the back of the pelvis, and gives off visceral, muscular, and terminal branches.

Visceral branches (pelvic splanchnics) arise from the third and fourth sacral nerves especially, and enter branches of the sympathetic plexus. They are distributed both directly (their afferent or sensory fibres terminating in the pelvic viscera) and by their visceral efferent fibres terminating in the ganglia of the sympathetic plexus to the pelvic viscera (figs. 765, 791). The middle hæmorrhoidal nerves pass to the rectum, the inferior vesical nerves to the bladder, and, in the female, the vaginal nerves to the vagina (see Sympathetic Srstem).

Muscular branches are given by the fourth sacral nerve to the coccygeus, levator ani, and sphincter ani externus (fig. 765).

The nerves to the two former muscles pass into the pelvic surfaces of the muscles, but that to the last-named muscle, called the perineal branch, passes backward between the levator ani and the coccygeus, or through the posterior fibres of the latter muscle, into the posterior part of the ischio-rectal fossa, and, in addition to supplying the sphincter ani, it gives cutaneous filaments to the skin between the anus and the coccyx.

Terminal branches.-The pudic nerve [n. pudendus] rises usually from the anterior primary divisions of the second, third, and fourth sacral nerves (fig. 765). It emerges from the pelvis below the piriformis, crosses the spine of the ischium, lying to the medial side of the internal pudic artery (fig. 769), and accompanies the artery, through the small sciatic foramen, into Alcock's canal in the obturator fascia on the lateral wall of the ischio-rectal fossa, where it terminates by dividing into three branches, the inferior hæmorrhoidal, the perineal, and the dorsal nerve of the penis.

The inferior hæmorrhoidal nerves frequently arise independently from the third and fourth sacral nerves, pierce the medial wall of Alcock's canal, and pass forward and medialward through the ischio-rectal fat to supply the sphincter ani externus and adjacent skin. They anastomose with branches of the perineal nerve.

The perineal nerve runs forward for a short distance in Alcock's canal and divides into a deep and a superficial branch. The deep branch breaks up into filaments, one or two of which pierce the medial wall of the canal and pass medialward to the anterior fibres of the sphincter and levator ani. The remaining part of the nerve pierces the base of the uro-genital trigone (triangular ligament), and enters the superficial pouch of the urethral triangle, where it is distributed to the bulb of the urethra, and to the transversus perinei, bulbocavernosus, and ischiocavernosus. It also sends some sensory filaments to the mucous membrane of the urethra. The superficial branch almost at once divides into medial and lateral branches, the posterior scrotal (labial) nerves.

Both branches pass through the wall of Alcock's canal into the anterior part of the ischiorectal fossa, then they pierce the base of the uro-genital trigone, and enter the superficial pouch of the urethral triangle. The lateral branch usually passes below the transversus perinei, and the medial branch above the muscle or through its fibres. The lateral branch connects with the long pudendal nerve, and with the inferior hæmorrhoidal nerve, and both branches end in terminal filaments which anastomose and which are distributed to the skin of the scrotum and the anterior part of the perineum in the male, and to the labium majus in the female. 
The dorsal nerve of the penis runs forward in Alcock's canal above the internal pudic artery. It pierces the base of the uro-genital trigone, continues forward between the layers of the trigone, embedded in the fibres of the constrictor urethræ, and it gradually passes to the lateral sicle of the internal pudic artery. A short distance below the pudic arch it pierces the anterior layer of the uro-genital trigone, gives a branch to the corpus cavernosum penis, passes forward between that structure and the bone, and turns downward on the dorsum of the penis, passing between the layers of the fundiform (suspensory) ligament and along the outer side of the dorsal artery of the penis. It supplies the skin of the dorsum of the penis, and, having given branches to the prepuce, it breaks up into terminal filaments which are distributed to the glans penis.

The dorsal nerve of the clitoris is much smaller than the dorsal nerve of the penis to which it corresponds. Is is distributed to the clitories.

\section{THE COCCYGEAL PLEXUS}

This plexus is frequently, and with some reason, considered as a subdivision of the pudendal plexus, and sometimes it is described with the coccygeal nerves. It is formed chiefly by the anterior division of the fifth sacral nerve and the coccygeal nerve, but it receives a small filament from the anterior division of the fourth sacral nerve (figs. 765, 769). These constituents unite to form plexiform cords lying on either side of the coccyx. From these cords arise the ano-coccygeal nerves, which pierce the sacro-tuberous (great sacro-sciatic) ligament and supply the skin in the neighbourhood of the coccyx.

\section{THE DISTRIBUTION OF THE CUTANEOUS BRANCHES OF THE SENSORY AND MIXED CRANIAL AND SPINAL NERVES}

The cutaneous filaments of the sensory and mixed nerves are distributed to definite regions of the surface of the body which are known as 'cutaneous areas.' Each cutaneous area has one special nerve of supply and the central part of the area receives that nerve alone, but wherever the borders of two areas meet they reciprocally overlap, therefore each margin of every cutaneous area has two nerves of supply, its own nerve and that of an adjacent area, and of these, sometimes one and sometimes the other preponderates.

\section{The Cutaneous Areas of the Scalp}

The limits of the cutaneous areas in the scalp region are indieated in figs. 774,776 , but in general terms it may be said that the skin of the scalp in front of the pinna is supplied by four cutaneous nerves, viz, the mesial part by the suprat rochlear and the supra-orbital branehes of the ophthalmic division of the trigeminus, and the lateral part by the temporal branch of the maxillary division, and the auriculo-temporal branch of the mandibular division of the same nerve.

The portion of the scalp behind the pinna also receives four cutaneous nerves; laterally it is supplied by the great auricular and sinall oceipital branches of the eervical plexus whieh contain filaments from the second and thirl cervical nerves, and medially it receives the great and smallest oreipital nerves which are lerived from the internal branches of the posterior prinary divisions of the second and third cervieal nerves respeetively.

\section{Time Cutaneous Areas of the Face}

With the exeeption of the skin over the posterior part of the masseter musele, the whole of the skin of the face is supplied by the branches of the trigeminus. The nose is supplied morlially by the supratrochloar, the infratrochlear, and the nasal branches of the ophthalmie division, and batrally by the infratorbital branch of the maxilary division. The upper eyelid is supplied by the supratrochloar, the supra-orlsital, and the laerimal branches of the ophthalmin: llivision; the lower ryelis by the infratrochlear branch of the ophthalmic division and lyy the infra-orbital and the zygomatico-facial (malar) branches of the maxillary division. The skin over the upper jaw ant the zyentatic (malar) bone is supplied by the infra-orbital and zygonatico-facial branches of the maxillary division, that over the buccinator by the buecal branch of the mandibular division, and that iver the lower jaw, from in front baekward, by the mental, bucral, and anriculo-temporal branches of the mambibular division, except a small

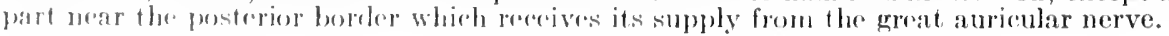




\section{The Cutaneous Areas of the Auricle (Pinna)}

The upper two-thirds of the outer surface of the pinna are supplied by the auriculo-temporal branch of the mandibular division of the trigeminus, and the lower third by twigs of the great

Fig. 774.-Diagran of the Cutaneous Nerve Areas of the Head and Nech.

Red-ophthalmic division of trigeminus. White-maxillary division of trigeminus. Blue-mandibular division of trigeminus.

Dotted shading-Posterior primary divisions of cervical nerves.

Oblique shading-Ascending and transverse superficial branches of cervical plexus.

Transverse shading-Descending superficial branches of cervical plexus.

It must be remembered that the boundaries of each area are not distinct; wherever two areas meet they overlap.

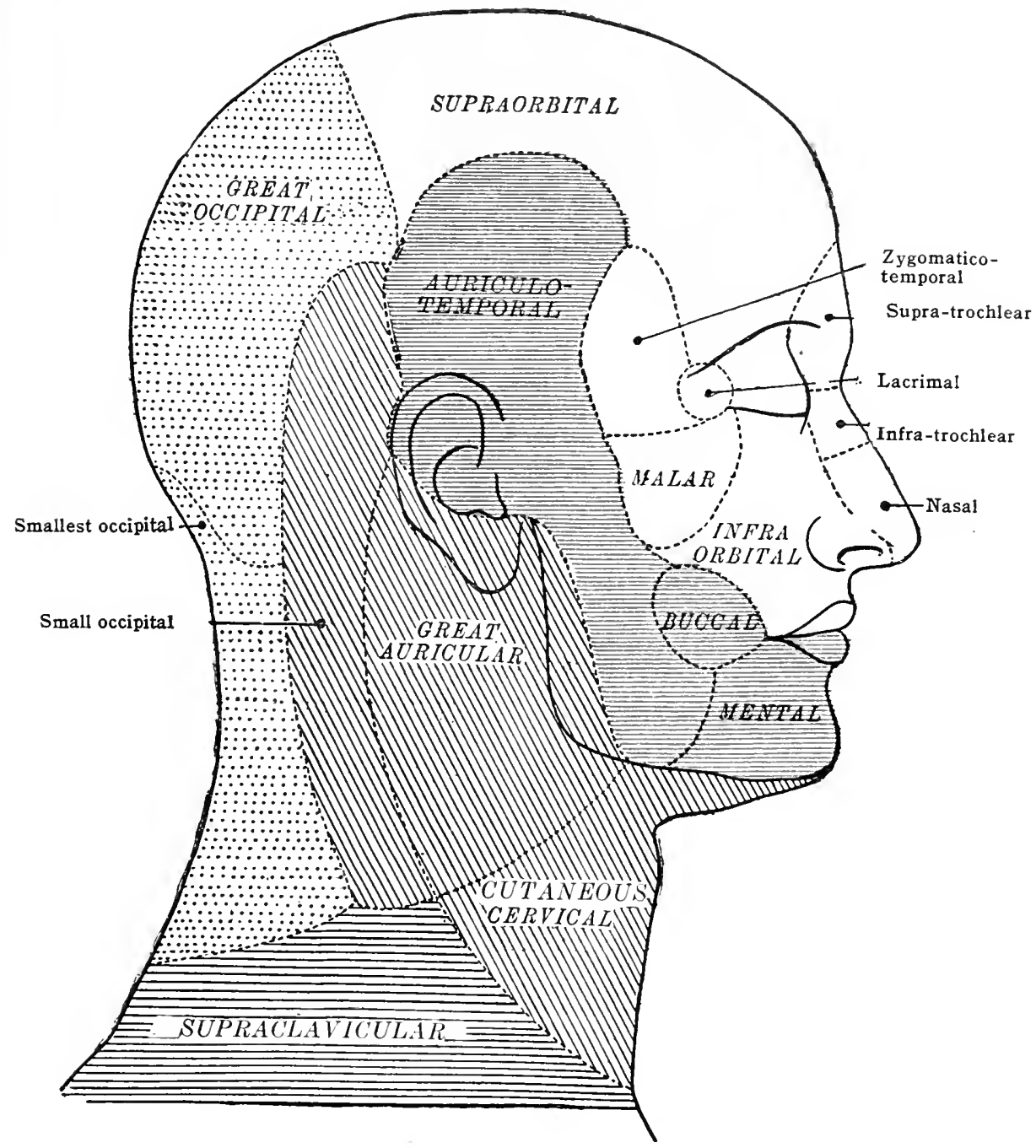

auricular nerve. The lower three-fourths of the cranial surface of the pinna are supplied by the great auricular nerve, and the upper fourth by the small occipital nerve. The posterior surface of the external auditory meatus receives filaments from the auricular branch of the vagus.

\section{The Cutaneous Areas of the Nech}

The skin over the anterior part of the neck is supplied by the superficial cervical branch of the cervical plexus, which contains fibres from the second and third cervical nerves, and in the lower part of its extent, by the anterior supra-clavicular nerves (suprasternal branches), 
which convey twigs of the third and fourth cervical nerves (fig. 774). The lateral part of the neck receives filaments from the second, third, and fourth cervical nerves by way of the great auricular, small occipital, and middle supraclavicular (supra-clavicular) branches of the cervical plexus, and posteriorly the skin of the neck is supplied by the small occipital nerve and by the medial branches of the posterior primary divisions of the cervical nerves from the second to the sixth inclusive (fig. 766 ).

\section{The Cutaneous Areas of the Trunk}

The skin over the ventral aspect of the trunk as far down as the third rib is supplied by the anterior supra-clavicular (suprasternal) and middle supra-clavicular (supra-clavicular) branches of the cervical plexus, which contain filaments from the third and fourth cervical nerves (fig. 776). From the third rib to the lower part of the abdominal wall the skin receives the anterior cutaneous branches, and the anterior divisions of the lateral cutaneous branches of

Fig. 775.-Diagrai of the Cutaneous Areas of the Side of the Body and Part of the Limb. (After Head.)

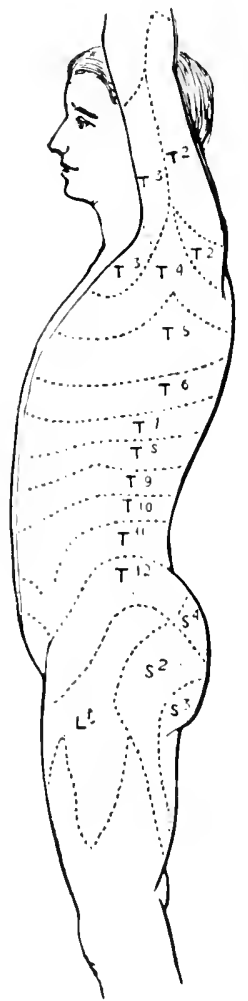

the thoracic nerves except the first, secoml, and twelfth (fig. 776). The skin over the lower and anterior fart of the abelominal wall is supplied by the ilio-hypogastric branch of the first lumbar nerve.

The cutaneous suppty of the lateral aspects of the body is derived from the lateral branches of the anterior primary divisions of the thoracie nerves from the second to the eleventh, and the skin over the dorsill aspect of the body is supplied laterally by the posterior divisions of the hateral branches of the thoracie nerves from the third to the eleventh, and medially by the posterior primary divisions of the thoracie nerves, in the uper half by their medial branches and in the lower hat principally by their lateral branches.

\section{'THE ('UTANEOIT' AREAS OF' THE IIMIBS'}

The: areas of skin of the upper and lower limbs which are supplied by the branches of the lomalabl, lumbar, and sacral plexuses atre indicated in fig. 776, and the spinal nerves which con-

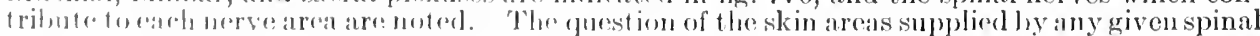
norve is ono: of groat elinieal jumprtanes, in comneation with the diagnosis of injuries of nerves and of palloluginal conditions affocting them. Therefore, considerable attention has been firected to the matter and it has been foumd that the areas which become hypersensitive when cretain spinal nerve-roots are irritated, or andesthetic when the roots are destroyed, do 
Fig. 776.-Diagram showing Areas of Distridtion of Cutaneous Nerves.

RED-Ophthalmic division of trigeminus. White-maxillary division of trigeminus. Blue-mandibular division of trigeminus. Dotted area-Posterior primary divisions of cervical nerves. Oblique and transverse shading-Branches of cervical plexus.

Body AND LinBs:-

RED-Anterior branches of anterior primary divisions. Blue-Posterior branches of anterior primary divisions. Two colours in one area indicate that the area is supplied by two sets of nerves, and it should be remembered that wherever two nerve areas approach each other they overlap. The dotted blue area of the posterior femoral cutaneous (small sciatic) indicates that the nerve comes from the posterior as well as from the anterior parts of the anterior primary divisions of the sacral nerves, but it supplies a flexor area. The area of the inferior medial cluneal nerve is left uncoloured, because its true nature is uncertain. Dotted shading-posterior primary divisions. The numbers and initial letters refer to the respective spinal nerves from which the nerves are derived.

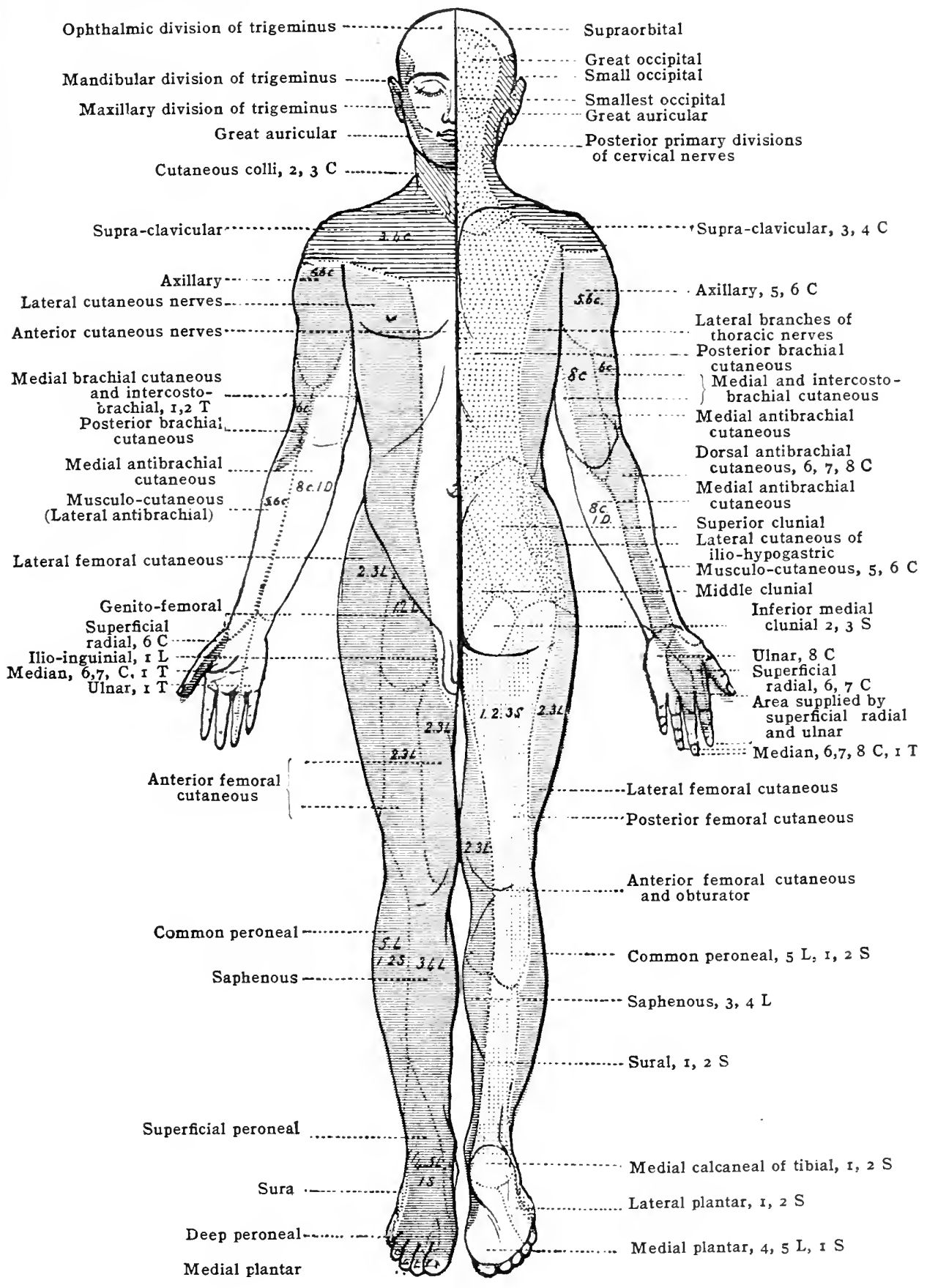


not correspond exactly with the regions to which the fibres of the roots can apparently be traced by dissection. Moreover, it has been discovered, partly by clinical observations on the human subject and partly by experiment on monkeys, that the nerves of the limbs have a more or less definite segmental distribution. To understand clearly this segmental arrangement the reader must remember that in the embryonic stage when no limbs are present the body is formed of a series of similar segments, each of which is provided with its own nerve. At a later stage when the limbs grow outward, each limb is formed by portions of a definite number of segments which fuse together into a common mass of somewhat wedge-like outline. Each rudimentary limb possesses a dorsal and a ventral surface. The dorsal surfaces of both the upper and the lower limbs are originally the extensor surfaces, and the ventral surfaces the flexor surfaces, but, as the upper limb rotates lateralward and the lower limb rotates medianward as development procecds, in the adult, the extensor surface of the upper limb becomes the posterior surface, and the extensor surface of the lower limb, the anterior surface. The preaxial border of the upper limb is the radial or thumb border, and the postaxial border, the ulnar or little finger border. The preaxial border of the lower limb is the tibial or great toe border, and the postaxial border, the fibular or little toe border. As projections of the segments of the body grow out to form the limb-buds and limbs each projection carries with it the whole or part of the nerve of the segment to which it belongs, and therefore the number of body segments which take part in a limb is indicated by the number of spinal nerves which pass into it. If these facts are remembered it will naturally be expected (1) that the highest spinal nerves passing into a limb will be associated with its preaxial portion and the lowest with its post-

Fig. 777.-Diagrams A, B, and C, Illustrating Stages in the Projection of the LimbBUds for the Upper Extremty, and the Drawing out of the Nerves of the Corresponding Body Seguents for the Cutaneous Areas of the Preaxial and Postaxial Border of THE LIMB.

Postaxial border shaded.
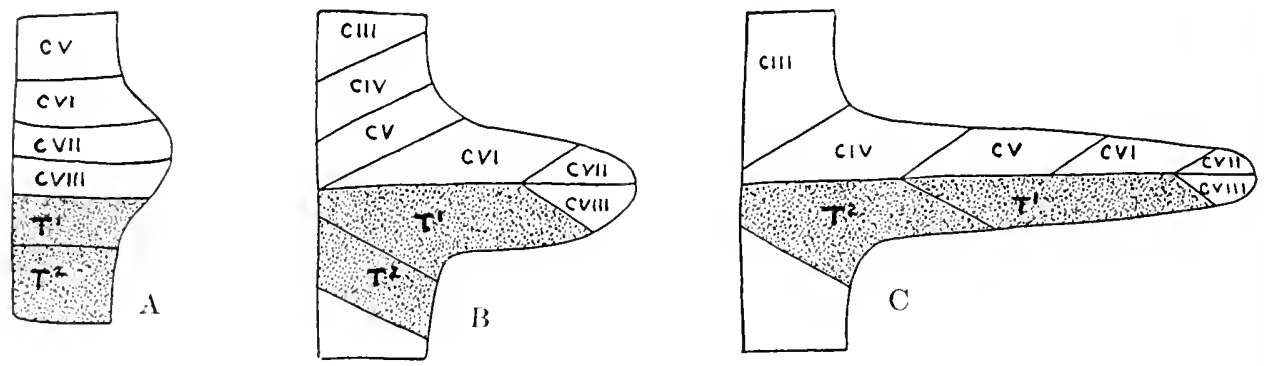

axial portion; (2) that only the nerves of those segments forming middle or central portions of the limbs will extend to the tips of the linbs; (3) that the highest and lowest segments in each limb area will take a smaller part in the formation of the limb that the middle segments; and (4) that, consequently, the highest and lowest nerves will pass outward into the limb for a shorter distance than the middle nerves. Observers are not yet in perfect agreement as to the exact distribution of each nerve, but the diagrams in figs. 775 to 781 show the embryonic lerivation of the cutaneous areas and the adult dorso-ventral segmental arrangement in the projected portions of both the upper and lower limbs as assumed from clinical observations. In the upper parts of the lower limbs, the original segmental distributuion appears to be masked. This may be due (1) partly to the fact that the areas recognisable by clinical phenomena do not correspond exactly with the areas to which definite dorsal root-fibres are distributed, but rather to definite segments of the grey sulstance of the spinal cord with which the root-fibres are connected; (2) partly to the overlapping of segments and the acquired preponderance of one nerve over another in the overlapping areas, and (3) partly to the fact that in the lower limb there has been a greater amount of shifting of parts to result in the fixed flat position of the sole of the foot; (4) and partly to the incompleteness of the data which are at our disposal in the case of the human subject. Sherrington has proved that in the monkey the sensory arcas of the limbs are arranged in serial correspondence with the spinal nerves, the niddle nerves of rach limb series passing to the clistal extremity while the higher and lower nerves are limited to the proximal regions. 'Thorburn's observations, which differ from Head's, are, especially as regaris the upper limb, in close conformity with the results obtained by Sherrington's experiments on monkeys.

bach limb nay be divided into its preaxial and postaxial borders by a line drawn longitudinally along the midelle of hoth its anterior and posterior surfaces (compare figs. 777 and 779 ) The rataneens nerves to the preaxial borkler are from the eephalic portion of the limb plexus. and these to the postaxial are from the caudal eomponents of the plexus. Thus the thumb and index finger are ceplatad.

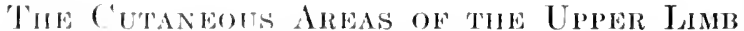

$\Lambda$ line passing along the midelle of both the anterior and posterior surfaces of the upper extrentey to the tip of the middle finger (fig. 779) separates the preaxial from the postaxial forder and passes longitudinally along the area of the cutancous fibres derived from the seventh cervical norve. 
The skin over the upper third of the deltoid muscle is supplied by the posterior supraclavicular (supra-acromial) and middle supra-clavicular (supra-clavicular) nerves, which are branches of the cervical plexus containing fibres of the third and fourth cervical nerves, and that over the lower two-thirds by the axillary (circumflex) nerve which conveys fibres of the fifth and sixth cervical nerves (fig. 776).

The skin over the lateral surface of the upper arm is supplied externally by the axillary (circumflex) nerve above, and below by the superior branch of the dorsal antibrachial cutaneous,

Fig. 778.-Diagram of the Cetaneous Areas of the Upper Extrenity.

(Modified from Head.)
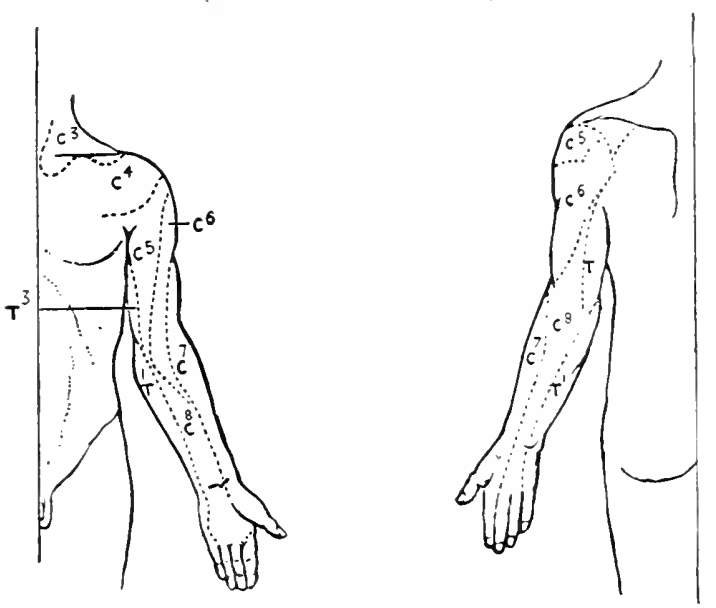

the external cutaneous branch of the radial (musculo-spiral) nerve. The former contains filaments of both the fifth and sixth cervical nerves, and the latter filaments of the sixth alone. The skin of the medial side of the upper arm is supplied by the medial antibrachial cutaneous (internal cutaneous) nerve with fibres of the eighth cervical and first thoracic nerves, and by the medial brachial cutaneous (lesser internal cutaneous) and intercosto-brachial (intercostohumeral) nerves which are derived from the first and second thoracic nerves. The dorsal side of the upper arm is supplied, laterally, by the fifth and sixth cervical nerves through the axillary

Fig. 779.-Diagram of the Cutaneous Areas of the Upper Extrenity. The solid middle lines are drawn to separate preaxial (radial) borders from postaxial borders. (After Thorburn, modified.)

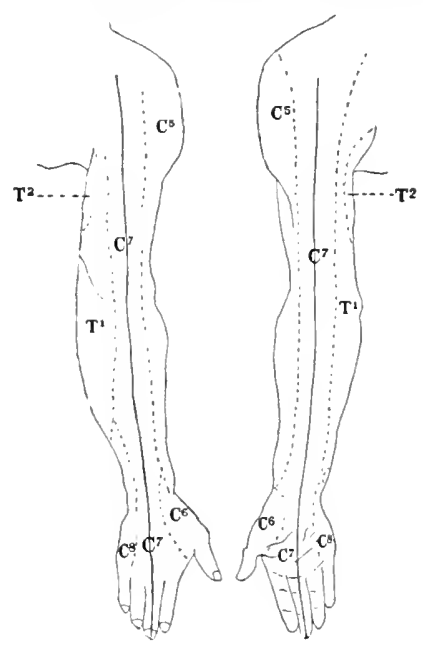

(circumflex) nerve and by the dorsal antibrachial cutaneous; the middle portion, by the seventh cervical nerve through the posterior brachial cutaneous, the internal cutaneous branch of the radial (musculo-spiral) nerve; and the medial portion by the first and second thoracic nerves through the medial brachial cutaneous (lesser internal cutaneous) nerve, and the intercostobrachial (intercosto-humeral) nerve (fig. 776).

The front of the forearm is divided into three areas, a lateral which is supplied by the fifth, sixth, and possibly the seventh cervical nerves, through the musculo-cutaneous branch of the 
brachial plexus; a middle which is supplied by the seventh cervical nerve as above, and a medial area supplied by the eighth cervical and first thoracic nerve through the medial antibrachial cutaneous (internal cutaneous) nerve. On the dorsal side of the forearm there are three areas: -(1) a lateral supplied by fibres of the fifth and sixth cervical nerves through the musculocutaneous nerve; (2) a middle, which receives fibres of the seventh, and probably some from the sixth and eighth cervical nerves through the lower branch of the dorsal antibrachial cutaneous of the radial (inferior external cutaneous branch of the musculo-spiral nerve), and (3) a medial which receives the eighth cervical and first thoracie nerves through the medial antibrachial cutaneous (figs. 776,779 ).

The palm of the hand is supplied by the sixth, seventh, and eighth cervical nerves through the superficial radial (radial) nerve, and through the median and ulnar nerves. The superficial radial supplies the radial side of the thumb by its palmar eutaneous branch. The remainder of the palm and the palmar aspects of the fingers are supplied by the median and ulnar nerves through their palmar cutaneous and digital branches, the median supplying three and a half digits and the ulnar the remaining one and a half (figs. 776 and 779).

The dorsal aspect of the hand is supplied by the sixth, seventh, and eighth cervical nerves, which reach it through the superficial radial( radial) and through the median and ulnar nerves. The superficial radial supplies the lateral part of the dorsum and the lateral three and a half digits, except the lower portions of the second, third, and half of the fourth digits, which receive twigs from the median nerve; the ulnar nerve supplies the ulnar half of the dorsum of

Fig. 780.-Diagrair of the Cutaneous Areas of the Lower Extremity. (After Head.)

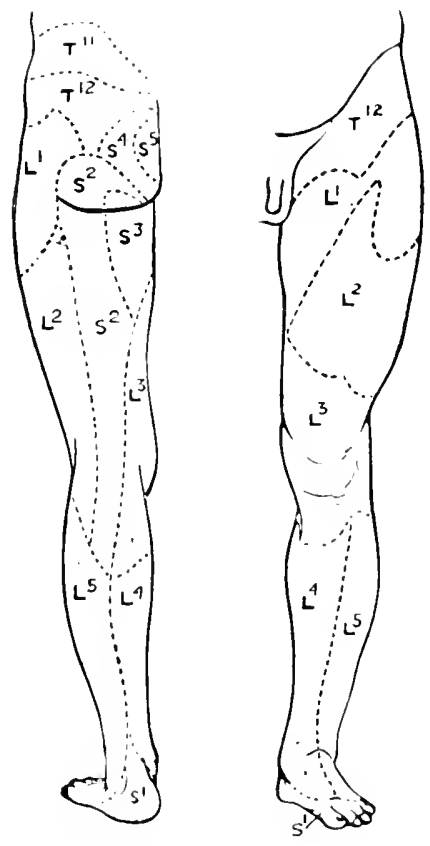

the hand, inchuling the medial one and a half digits. The areas supplied by definite spinal nerves, according to the observations of Head and Thorburn, are shown in figures 778 and 779 respectively.

\section{The Cutaneous Areas of the Lower Extremity}

The seginental arrangement of the cutaneous areas of the lower extremity is not so well retained as in the upper, due largely to a greater amount of developmental shifting of the parts. Both of the lincs separating the areas of the lumbar (cephalic) and the sacral (caudal) parts of the limbo-sacrat plexis lie on the dorsal aspect of the limb. The nerves from the lumbar part of the plexus are distributed to the entire anterior and the medial and lateral surfaces of the limb and to the muscles of the anterior and medial portions of the thigh and the anterior wortion of the leg, whereas the culaneous nerves from the sacral part of the plexus are confined to a narrow strip along the dorsal aspect of the limb (fig. 78I). However, the muscular distribution of the sacral part is as much cxpanded as its eutaneous area is eontracted; it supplies the muscles in the dorsal portions of the hip, thigh and knee, the whole of the dorsal part of the leg and ankle and the plantar museles of the foot.

There are six cutaneous areas in the region of the buttock, three upper and three lower. ()f the upper areas the lateral is supplied by the anterior primary divisions of the last thoracic and first lumbar nerves though the iliae branches of the last thoracie and the ilio-liypogastric nerves; the midlls: upper area recrives the lateral divisions of the posterior primary branches of the upper three lumbar nerves, and the medial upper area is supplied by twigs from the lateral branches of the posterior primary divisions of the upper two or three sacral nerves (figs. 776, $78(1)$. 
Of the lower three areas, the lateral receives filaments from the second and third lumbar nerves through the lateral femoral eutaneous (external cutaneous) branch of the lumbar plexus; the middle area is supplied by the first, second, and third sacral nerves through the posterior femoral cutaneous (small sciatic) nerve; and the medial area by the second and third sacral nerves through the medial inferior clunial (perforating cutaneous) branch of the sacral plexus (fig. 776 ).

On the back of the thigh there are three areas. According to Head, the medial and lateral areas are supplied by the second and third lumbar nerves, the former through the lateral femoral cutaneous (external cutaneous) branch of the lumbar plexus, and the latter througli the anterior cutaneous branches of the femoral (internal cutaneous branch of the anterior crural) nerve. The middle area receives twigs from the first, second, and third sacral nerves through the posterior femoral cutaneous (small sciatic), a branch of the sacral plexus.

The front of the thigh is supplied by the first, second, and third lumbar nerves, and, according to Head, there are five cutaneous areas. The lateral area receives twigs of the second and third lumbar nerves through the lateral (external) cutaneous nerves. There are two medial areas, an upper and a lower. The former is supplied by the lumbo-inguinal (crural) branch of the genito-femoral (genito- crural), which conveys twigs of the first and second lumbar nerves; the latter receives fibres of the second and third lumbar nerves through one of the an-

Fig. 781.-Diagrair of the Cutaneous Areas of the Lower Extremity (After Thorburn, modified.)

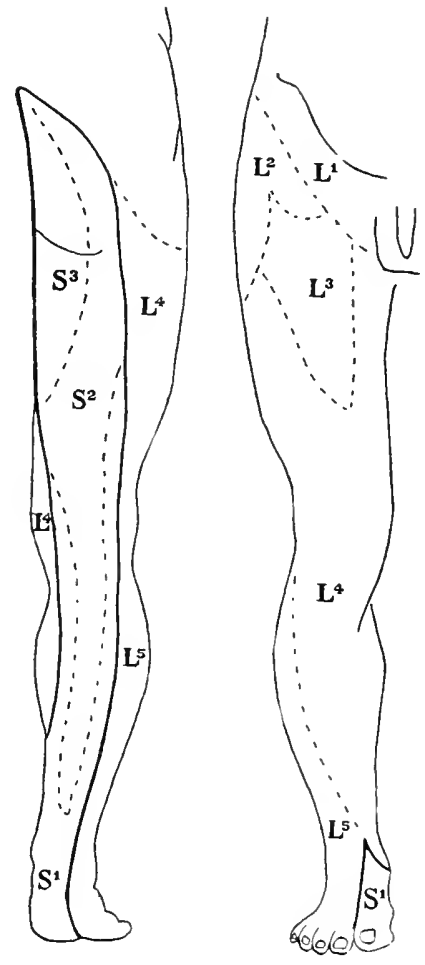

terior (middle) cutaneous branches of the femoral (anterior erural) nerve. The small upper and medial area is supplied by the first lumbar nerve through the ilio-inguinal, and the lower medial area receives twigs of the second and third lumbar nerves through one of the anterior cutaneous branches (internal cutaneous) of the femoral (anterior crural) nerve (fig. 776).

The front of the knee is supplied by the second, third, and fourth lumbar nerves through the anterior (middle and internal) cutaneous and saphenous (long saphenous) branches of the femoral (fig. 776).

Of the skin over the region of the popliteal space, the medial portion receives fibres from the second, third, and fourth lumbar nerves through the anterior (internal) cutaneous branch of the femoral (anterior crural) nerve and through the superficial division of the obturator nerve; the middle and lateral portion receives twigs of the first three sacral nerves through the posterior cutaneous (small sciatic) nerve (fig. 776).

The skin over the front and medial side of the leg is supplied by the fourth lumbar nerve through the saphenous nerve, and the skin of the front and lateral side receives nerve-fibres from the fifth lumbar nerves through the sural cutaneous (fibular communicating) branch of the common peroneal (external popliteal) nerve.

In the skin of the back of the leg four areas can be distinguished, a medial, two middle, upper and lower, and a lateral area. The medial area is supplied by the fourth lumbar nerves through an anterior cutaneous branch (internal cutaneous) of the femoral (anterior crural) 
nerre and the superficial branch of the obturator nerve. The upper middle area is supplied by the second, and third sacral nerves through the posterior femoral cutaneous (small sciatic) nerve, and the lower middle area by the first sacral nerve through the sural (external saphenous) nerve. The lateral area is supplied by the fif th lumbar nerve through the lateral sural cutaneous (fibular communicating) branch of the common peroneal (external popliteal) nerve (fig. 776, 780, 781 ).

The skin of the dorsum of the foot is supplied principally by the fifth lumbar and by the first sacral nerves; the majority of the nerve-fibres travel by the superficial peroneal(musculocutaneous) nerve, but the adjacent sides of the first and second toes are supplied by the femoral (anterior crural) nerve and the side of the dorsum of the little toe is supplied through the sural (external saphenous).

The skin of the region of the heel is supplied by the first sacral nerve, the medial surface and medial part of the under surface by the medial calcaneal branches of the tibial (calcaneoplantar) nerve and the posterior, external, and lower aspects by the sural (external saphenous) nerve (fig. 776 ).

The sole of the foot in front of the heel receives cutaneous fibres from the fifth lumbar and the first sacral nerves; the medial area, which includes the medial three and a half digits, being supplied by the medial plantar nerve which conveys fibres of the fifth lumbar and the first sacral nerves; and the lateral area by the fifth lumbar nerve through the lateral plantar nerve.

The medial side of the foot is supplied by the first sacral and fourth lumbar nerves through the saphenous nerve and the lateral side by the fifth lumbar nerve through the sural (external saphenous) nerve.

The skin of the scrotum and penis is supplied by the first lumbar nerve through the ilioinguinal nerves, and by the second and third sacral nerves through the perineal and dorsal penile branches of the pudendal (pudic) nerve.

The cutaneous areas of the lower extremity which have been demarcated by Head and Thorburn are shown in fig. 780. These do not conform wholly with each other nor with the areas given in more detail in fig. 776, due probably to individual differences in subject and observer and to the difficulties coincident with the overlapping of the areas. Fig. 781 is more general in character and is considered more approximately correct.

The homology of the parts of the plexuses of the upper and lower extremities is not well carried out in the distribution of the ncrves. The radial and great sciatic nerves are similar to the extent that the one arises from the posterior cord of the brachial plexus and the other from the sacral plexus, and that the one is distributed to the dorsal aspect of the arm and the other to the dorsal surface of the lower extremity, but the great sciatic supplies the sole of the foot, and the plantar muscles, whereas the radial does not supply the palm of the hand and the palmar muscles:

\section{THE SYMPATHETIC SYSTEM}

The so-called sympathetic system is that portion of the peripheral nervous system which is especially concerned in the distribution of impulses to the

Fig. 782,-Diagam showing two stages of the Migration of the Primitive Gangla from the Ganglion Crest; A. tile Division of the Primitive Ganglia into Spinal and Sympathetic Portions, and B. the Formation of tie Nerves.
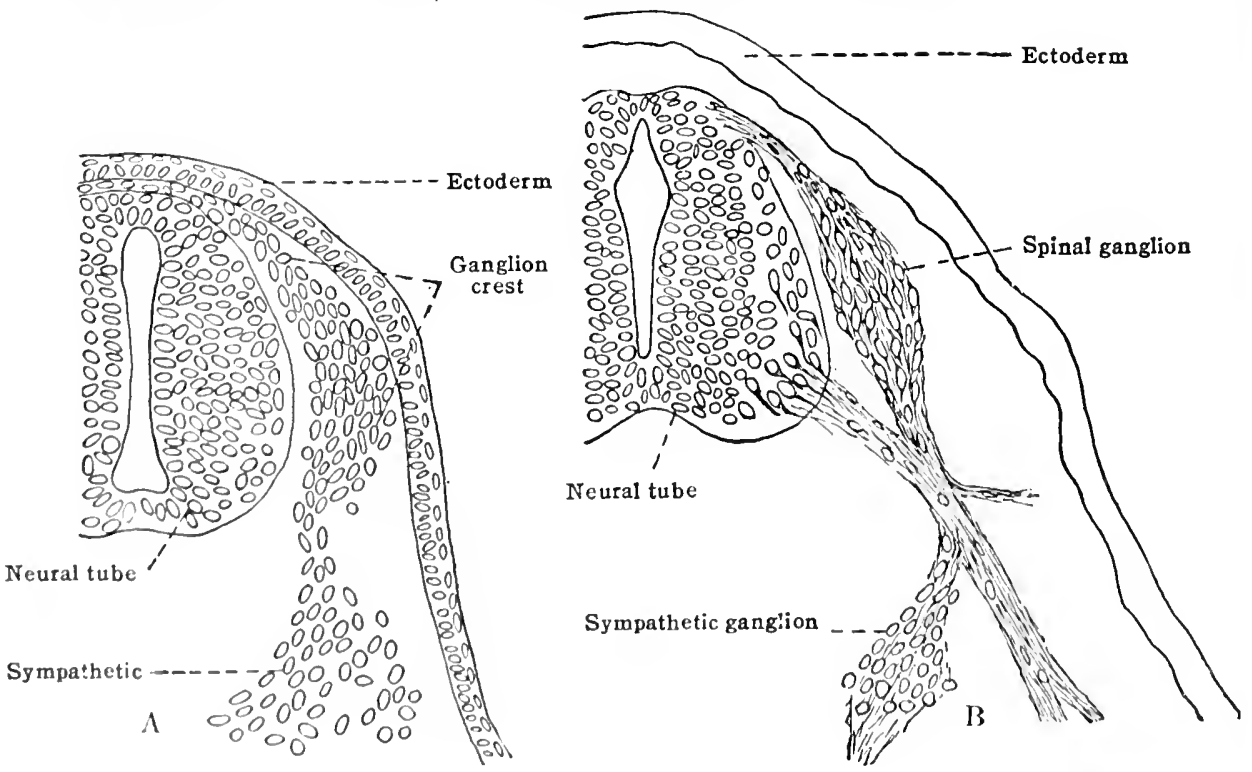

glandular tissues, to the muscle of the heart and blood-vessels, and to the nonstriated muscular tissue of the borly wherever found. Since these tissues are most 
Fig. 783.-Diagrai Showing the Chief Paths of Migration of the Cells from the Ganglia of the Spinal and Cranial Nerves to form the Adult Sympathetic System (After Schwalbe, modified.)

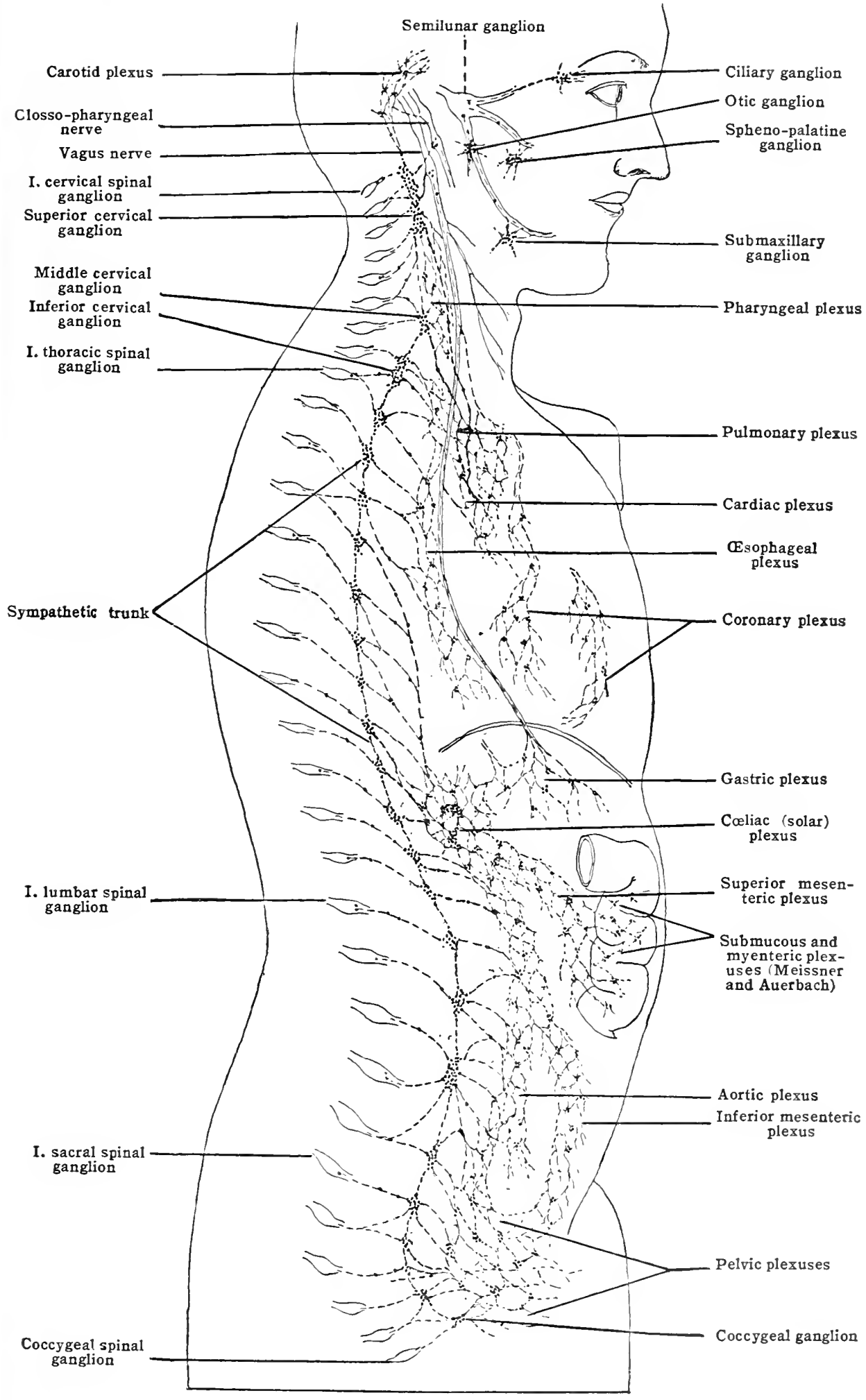


abundant in and largely comprise the viscera or splanchnic organs of the body, the largest and most evident of the structures comprising the sympathetic system are found either in or near the cavities containing the viscera. However, the

Fig. 784.-Scheme showing General Plan of the Coarser Portions of the Sympathetic Nervous Systea and its Principal Communications with the Cerebro-spinal System. (After Flower, modified.)

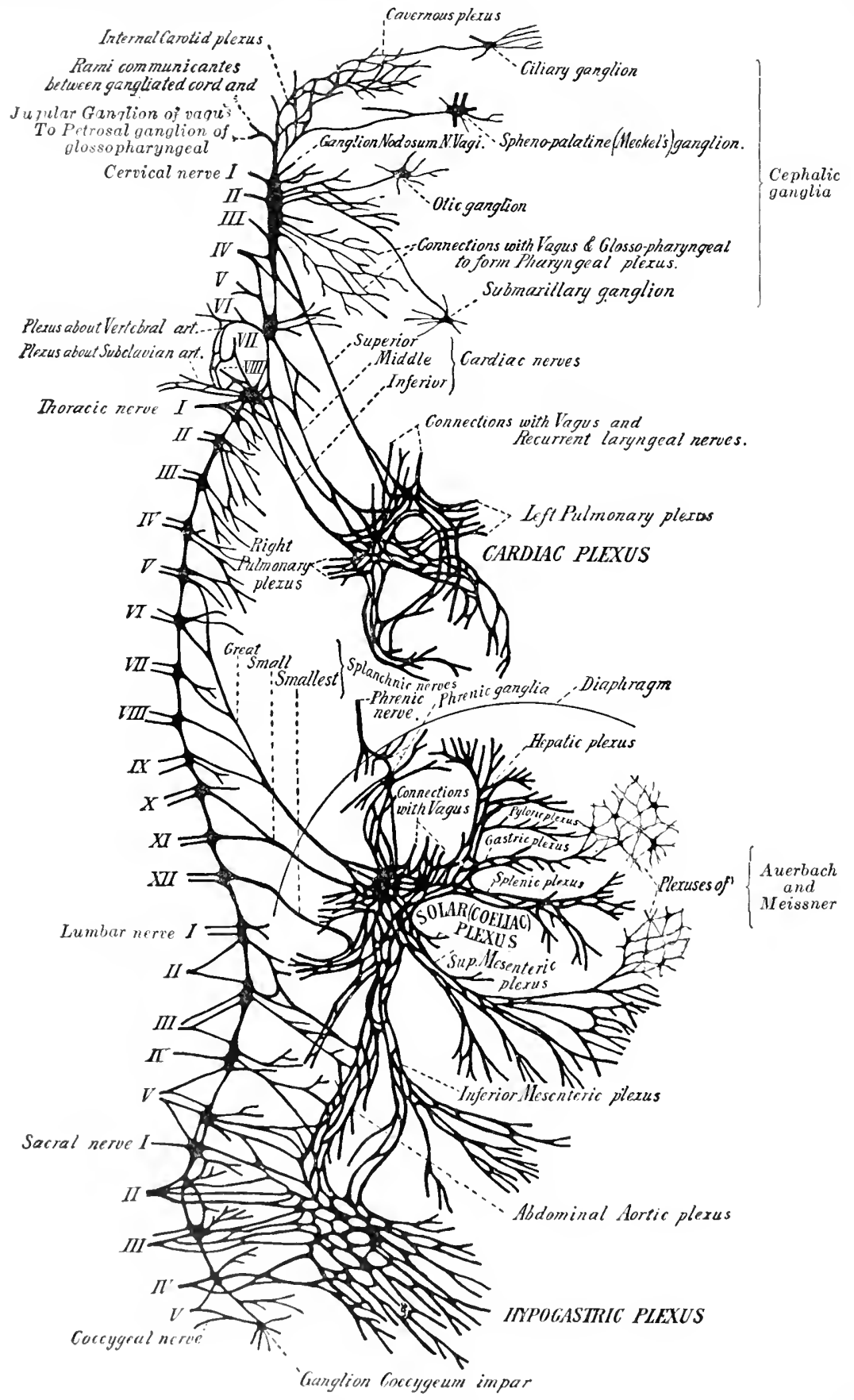

finer divisions of the system ramify throughout the whole body, supplying vasoinotor fibres to the blool-vessols throughout their course, controlling the glands of the skin, and supplying pilo-motor fibres for the hairs, forming intrinsic plexuses within the walls of the viseerat, and it is clamed that a few of its neurones 
convey inpulses toward the central systen (sensory sympathetic neurones). While it is very probable that certain of the simpler reflexes of the splanchnic organs may be mediated by the sympathetic system alone, yet the sympathetic is by no means independent of the cranio-spinal system, but is rather, both anatomically and functionally merely a part of one continuous whole. Throughout, it shares its domain of termination with cranio-spinal fibres, chiefly of the sensory variety, and most of its rami and terminal branches carry a few cranio-spinal fibres toward their areas of distribution. Likewise the cranio-spinal nerves carry numerous sympathetic fibres gained by way of rami connecting the two systems.

Like the cranio-spinal system, the sympathetic consists of cell-bodies, each of which gives off one axone. In addition, the cell-bodies give off numerous dichotomously branched dendrites by which their receptive surfaces are increased, and they are accumulated into ganglia, large and small. The larger ganglia have more or less constant positions, shapes, and arrangements, while the smaller, some of which are microscopic, are scattered throughout the body in a seemingly more indefinite manner. The axones or fibres arising in these ganglia are given off in trunks and rami which associate the ganglia with each other or with the cranio-spinal system, or which pass from the ganglia to be distributed directly upon their allotted elements.

The sympathetic fibres arising from the ganglia are, for the most part, either totally nonmedullated or partially medullated. Some fibres are completely medullated near their cells of origin, but lose their medullary sheaths before reaching their terminations. Some of them possess complete medullary sheaths throughout, but in no cases are the sheaths as thick or well developed as is the rule with the cranio-spinal fibres. Thus, nerve-trunks and rami in which sympathetic fibres predominate appear greyish in colour and more indefinite, as distinguished from those of the cranio-spinal nerves, which always appear a glistening white, due to light being reflected from the emulsified myelin of the sheaths of their fibres.

Origin of the sympathetic system.-Not only must the cranio-spinal and sympathetic systems be considered anatomically continuous and dependent, but also the neurones of the two systems have a common origin, namely, the ectoderm of the dorsal mid-line of the embryo. The cells of the ganglion crest (see p. 754) become arranged in segmental groups and soon separate into two varieties:- those which will remain near the spinal cord and develop into the spinal ganglia, and those which, during the growth processes, migrate and become displaced further into the periphery and form the sympathetic ganglia.

Fig. 785.-Scheme showing the Connection between the Simpathetic and the Cranio-

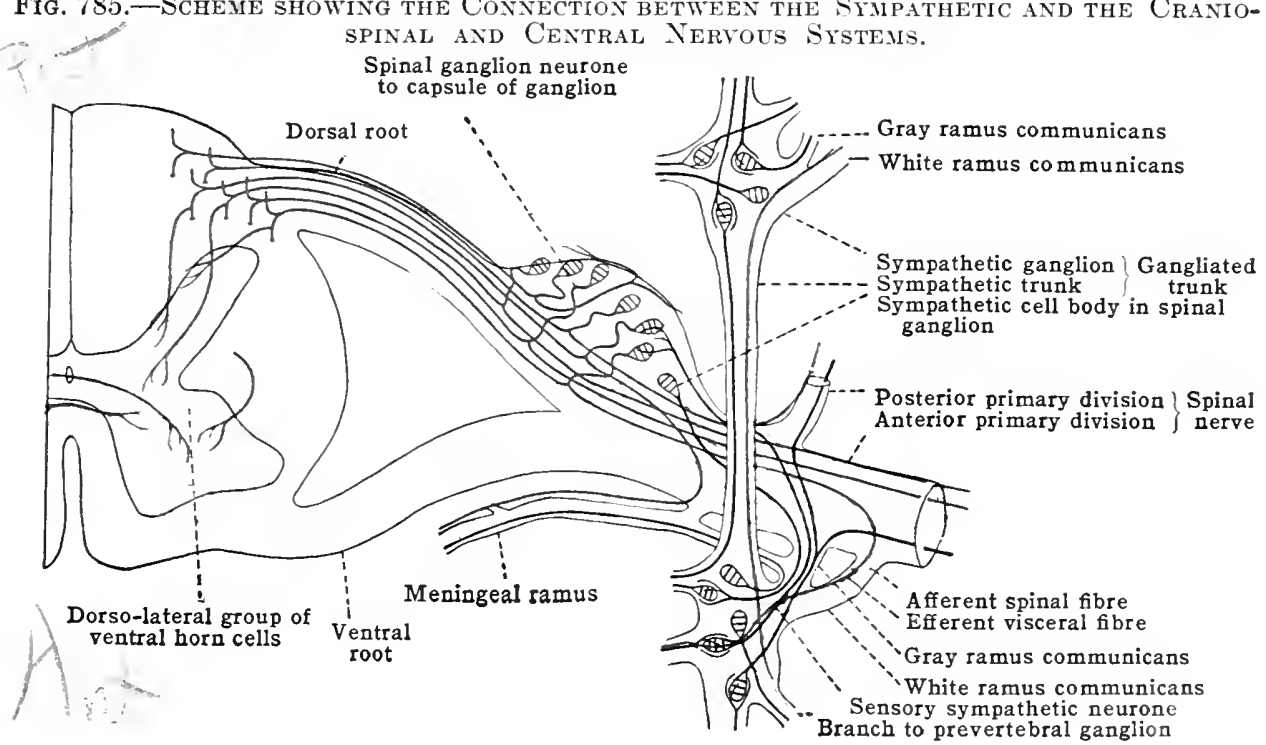

In the development of the sympathetic system the migration from the vicinity of the central system occurs to varying extents, so that in the adult the cells comprise three general groups of ganglia situated different distances a way from the central nerve axis.-(1) A large portion of the cells remain near the central system and form a linear series of ganglia which, with the trunks connecting them, become two gangliated nerve trunks extending along each side, proximal to and parallel with the vertebral column; (2) a still larger portion of the cells migrate further toward the periphery and are accumulated into ganglia which assume an intermediate position and which, with the rami associating them with each other and with other structures, form a series of great prevertebral 
plexuses; (3) still other cells wander even further away from the locality of their origin and invade the very walls of the organs innervated by the sympathetic system. The latter cells occur as numerous small terminal ganglia, most of which are microscopic and which, with the twigs connecting them, form the most peripheral of the sympathetic plexuses. Examples of these are the intrinsic ganglia of the heart and pancreas and the plexuses of Auerbach and Meissner in the walls of the digestive canal. Small, straggling ganglia may be found scattered between these three general groups. In the head, the gangliated trunks and great prevertebral plexuses are represented by the eiliary, sphenopalatine, otic and submaxillary ganglia and the plexuses associated with these. The supporting tissue of the sympathetic system accumulates early and is probably all of mesodermic origin.

Construction of the sympathetic system.-The sympathetic ganglia may be considered as relays in the pathways for the transmission of impulses from the region in which they arise to the tissues in which they are distributed; the cells composing the ganglia are the cell-bodies of the neurones interposed in the various neurone chains performing this function. A fibre arising from a cell-body in a given ganglion may pass out of the ganglion and proceed directly to its termination upon a smooth muscle-fibre or gland-cell, or it may pass through a connecting trunk to another ganglion and there terminate about and thus transmit the impulse to another cell, which, in its turn, may give off the fibre which bears the impulse to the appropriate tissue-element. Fibres arising in given ganglia may pass uninterrupted through other ganglia and proceed to their respective destinations. On the other hand, several neurones may be involved in the transmission of a given impulse when sent from a region distant from the tissue to which it is distributed.

Communication between the central nervous system and the sympathetic is established through both efferent and afferent fibres. In the region of the spinal cord both varieties of fibres pass from one system to the other by way of the rami communicantes, delicate bundles of fibres comnecting the nearby sympathetic trunk with the respective spinal nerves (fig. 785).

The efferent fibres of the rami arise in the ventral horn (dorso-lateral cell-group chiefly) of the spinal cord, emerge through the ventral roots, enter the rami, and terminate chiefly about the cells of the nearest sympathetic ganglion; some, however, may pass through or over the ganglion of the sympathetic eord and terminate about cells in more distant ganglia. Since these fibres transmit impulses from the central to the sympathetic system, they are known as visceral efferent fibres. They are of smaller size than is the average for the cranio-spinal efferent or motor fibres of the ventral root. The visceral afferent fibres are of two varieties:-(1) Peripheral processes of the spinal ganglion-cells which run outward in the nerve-trunk, enter the rami communicantes, pass through the various connecting trunks and terminal rami of the sympathetic and terminate in the tissues supplied by these rami. Such are merely sensory fibres of the cranio-spinal type which collect impulses in the domain of the sympathetic and convey them to the central system by way of the sympathetie nerves and the dorsal roots of the spinal nerves. (2) Afferent sympathetic fibres proper. The actual existence of these has not been long established, and their relative abundance is as yet uncertain. They consist of fibres arising in the sympathetic ganglia which enter the spinal gang? ia by way of the rami commnicantes and the cranio-spinal nerve-trunk and terminate in arborisations about the spinal ganglion-cells (fig. 785). The afferent impulses transmitted by these sympatletic fibres are borne into the spinal cord or brain by way of the cranio-spinal fibres of the dorsal roots. These sensory synipathetic fibres must necessarily either receive the impulses they bear from sympathetic neurones having both peripheral and central processes or they themselves must be axones or central processes of neurones having also processes terminating in the peripheral tissues. Dombtless the variety of visceral afferent fibres first mentioned greatly predominates.

The thoracie and the lumbar spinal nerves are eonnected with the sympathetic trunk (gangliated cord) by two rami communicantes. Most of both the visceral efferent and also the visceral afferent fibres (which arise in the spinal ganglia) pass by way of a separate ramus. Both these varieties being of the eranio-spinal type, and, therefore, merlullated, they give the ramus a white appearance meriting the name white ramus communicans. Fibres of the sympathetic type predominate in the second ramus and thus it is the grey ramus communicans. The latter consists of:-(1) afferent sympathetic fibres and (2) of sympathetic fibres which join the primary divisions of the spinal nerves and comese in them to their allotted tissues (fig. 785)

In the sacral region, most of the viseral efferent fibros pass over the ganglia of the sympathetictrunkand terminate in themoremeripheral ganglia of the plexuses of this region. This is 
especially true for the fibres passing from the second, third, and fourth sacral nerves. In the cervical region white rami are not in evidence, a fact probably explicable as due to an arrangement by which at least most of the visceral efferent fibres arising in the cervical segments of the spinal cord pass downward in these segments and join the sympathetic through the white rami of the upper thoracic nerves; others may enter the cervical portion of the gangliated cord through the spinal accessory or eleventh cranial nerve, rather than through individual white rami, while others pass into the nerves of the brachial plexus to terminate in the minute ganglia of the plexuses upon the blood-vessels of the limb. All the spinal nerves are joined by grey rami communicantes from the sympathetic trunk.

Vaso-motor fibres to the meninges and intrinsic blood-vessels of the spinal cord pass to the spinal nerves by way of the grey rami. Thence they may reach the meninges by one of three ways:-(1) through the delicate recurrent or meningeal branch of the spinal nerve (fig. 785); (2) through the trunk and ventral

Fig. 786.-Diagram suggesting the Origin, Course and Connections of SyMPathetic Nerve-Fibres.

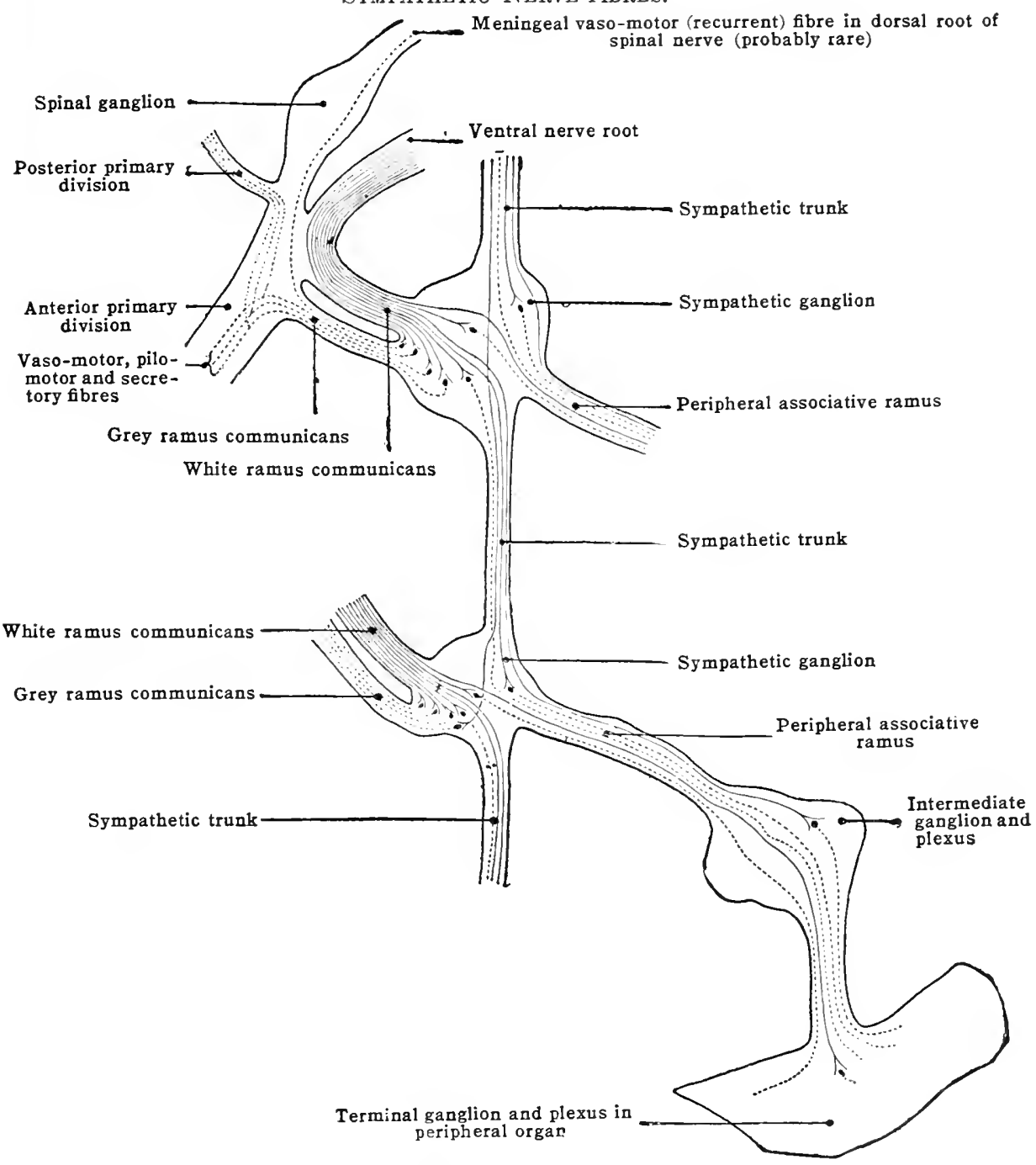

root of the spinal nerve; (3) probably more rarely, through the trunk and dorsal root of the spinal nerve (fig. 786).

Corresponding communications exist between the cranial nerves and the sympathetic, but the corresponding rami usually extend further toward the periphery and in not so regular a manner as the communications between the spinal nerves and the sympathetic system. The mesencephalon, for example, is chiefly connected with the ciliary ganglion of the sympathetic by fibres which are sent through the oculo-motor nerve and which enter this ganglion by way of its short root and terminate about its cells. Visceral efferent fibres from the rhombencephalon pass outward to the sympathetic in the roots of the facial, glosso-palatine, glosso-pharyngeal, 
vagus, and spinal accessory nerves, all of which have more or less irregularly disposed communicating rami. The ganglia of origin of the vagus, more than perhaps any other nerve, both receive impulses from visceral efferent fibres and give origin to sympathetic fibres. Likewise twigs of other cranial nerves, especially of the trigeminus, connect with (pass through) the small sympathetic ganglia of the head. The meningeal branches given by certain of the cranial nerves contain vaso-motor fibres, and these correspond to the sympathetic fibres in the recurrent branches and in the roots of the spinal nerves.

It is known that spinal ganglia and certain of the ganglia of the cranial nerves contain cell-bodies of sympathetic neurones-cell-bodies which, during the period of the migration peripheralward, remained within the confines of these ganglia (fig. 785). These cell bodies receive efferent impulses from ventral root fibres and send their axones further into the periphery just as if in the sympathetie ganglion. Their relative abundance is not known. It is supposed that the ganglia of the vagus, glosso-pharyngeus, trigeminus and the geniculate ganglion contain a considerable proportion of such sympathetic cell-bodies.

From the above it may be seen that the ganglia and conneeting trunks and rami of the sympathetie system may be divided as follows:-(1) The two sympathetic gangliated trunks lying proximal to and parallel with the vertebral column; (2) the great prevertebral plexuses, of which there are roughly four, one in the head, one in the thorax, one in the abdomen, and one in the pelvic eavity (fig. 784), each of which is subdivided; (3) the numerous terminal ganglia and plexuses situated either within or close to the walls of the various organs; (4) the trunks and rami associating the ganglia with each other and thus contributing to the plexuses, or connecting the ganglia with other nerves or with the crgans with whose innervation they are concerned. The trunks and rami may be divided into- $(a)$ the rami communicantes, or central branches, conneeting the sympathetic with the cranio-spinal and central systems; (b) associative trunks, best considered as those which associate sympathetic ganglia situated on the same side of the body; (c) commissural branches, or those which associate ganglia situated on opposite sides of the mid-line of the body, such as the transverse connecting branches between the sympathetic trunk in the lumbo-sacral region (fig. 787), or all the associating trunks between the ganglia of plexuses oceupying the mid-region of the body; (d) terminal or peripheral branches, or those which pass from the ganglia to their final distribution apparently uninterrupted by other ganglia.

\section{THE SYMPATHETIC TRUNKS}

The sympathetic gangliated trunks, or gangliated cords, of the sympathetic system are two symmetrical trunks with ganglia interposed in them at intervals of varying regularity, and extending vertically, one on each side of the ventral aspect of the vertebral column, from the second cervical vertebra to the first piece of the eoccyx. Upon the coceyx the two trunks unite and terminate in a single medial ganglion, the ganglion coccygeum impar. The various ganglia are connected with the eranio-spinal nerves by the rami eommunieantes. Morphologirally, each trunk might be expected to possess thirty-one ganglia, one for earh spinal nerve, but, owing to the fusion of adjacent ganglia in certain regions, especially in the cervical, there are in the adult only twenty-one or twenty-two ganglia in each trunk. These occur as three cervical ganglia, ten or eleven thoracic ganglia, four lumbar and four sacral ganglia, and the ganglion coceygeum impar, which is common to both trunks.

In the corvical region the sympathetie trunks lie in front of the transverse processes of the vertebra, from which they are separated by the longus capitis (rectus eapitis antieus major) and longus colli; in the thoracic region they tie at the sides of the bodies of the vertebre and on the heads of the ribs; in the lumbir region they are placed more ventally with reference to the spinal nerves and nuore in front of the bodies of the vertebra and along the anterior borders of the pons nuscles; in the pelvis the ganglia lie between and vent ral to the openings of the sucral foramina. In the lower humbar and sacral region one ganglion may send rani communirantes to two spinal nerves and one spinal nerve nna be connected with two ganglia. The ganglia of thro trumks throughout givo off associative bumeses to the ganglia of the prevertebral plexuses and branches to the neirhy viserat and blood-vessels. These branches may appear cither white or grey aceording to the predoninance of medullated or non-medullated fibres in

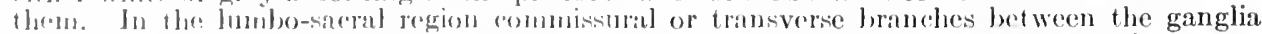
of thr two trunks arr ospecially alumblant. In trunks having a whiter appearance, the greater part of the medullated fibres profuring it are semsory and visceral motor filores from the spinal lorves which bave passol thromgl the sympathetic ganglia without termination. The nerve trunks connecting the ganglia of the sympinthetice trumks all contain three varieties of fibres:-(1) 
visceral motor fibres which have entered them in the white rami communicantes from the spinal nerves of higher or lower levels, and which are coursing in them to terminate in other ganglia, either in the trunks above or below or in ganglia not belonging to the trunks; $(2)$ fibres arising in sympathetic ganghia of a higher or lower level and passing upward or downward to terminate in other ganglia of the trunk or to issue from the trunk and proceed to more peripheral ganglia or to ganglia of the opposite trunk (both associative and commissural fibres); (3) afferent fibres or sensory fibres arising either in the spinal ganglia, or sensory sympathetic fibres arising in sympathetic ganglia and coursing in the trunk to pass into spinal ganglia above or below by way of the grey rami communicantes.

\section{THE CEPHALIC AND CERVICAL PORTIONS OF THE SYMPATHETIC TRUNK}

The cephalic portion of the sympathetic system consists of numerous small ganglia and of numerous plexuses connected with the internal carotid nerve, the ascending branch given off by the superior cervical sympathetic ganglion. The cephalic ganglia are all relatively small. There are four considered in the ordinary macroscopic dissections, namely, the ciliary or ophthalmic, the sphenopalatine or Meckel's ganglion, the otic, and the submaxillary. To these may be added a portion of the superior cervical sympathetic ganglion, the sympathetic portions of the nodosal, petrous, geniculate and semilunar ganglia, and the various small ganglia dispersed in the plexuses. These ganglia with their roots or communicating branches have been described in their relations with the divisions of the trigeminus and with the oculo-motor, glosso-palatine, vagus and facial nerves.

The internal carotid nerve, the ascending branch from the superior cervical sympathetic ganglion, may be regarded as an upward prolongation of the primitive sympathetic trunk.

It arises from the upper end of the superior cervical ganglion and passes through the carotid canal into the cranial cavity. It divides into two branches which subdivide to form a coarse plexus, the internal carotid plexus, which partly surrounds the internal carotid artery before the latter enters the cavernous sinus (fig. 787 and 788). It passes with the artery to the cavernous sinus, where it forms the finer meshed cavernous plexus.

The internal carotid plexus supplies offsets to the artery and receives branches from the tympanic plexus through the inferior carotico-tympanic nerve and from the spheno-palatine ganglion through the great deep petrosal nerve. It also communicates by fine branches with the semilunar (Gasserian) ganglion and with the abducens nerve.

The cavernous plexus gives branches of communication to the oculo-motor and trochlear nerves and to the opthalmic division of the trigeminus. According to Toldt and Spalteholz, it communicates with the tympanic plexus through the superior carotico-tympanic (small deep petrosal) nerve. It also communicates with the ciliary ganglion through the long root of the ciliary ganglion and usually through a separate sympathetic root of this ganglion. These branches may pass through the superior orbital (sphenoidal) fissure either separately or with the nasociliary (nasal) nerve.

The cavernous plexus also gives branches to the carotid artery and filaments of the plexus accompany small branches of the artery to the hypophysis (pituitary body) and to the dura mater on the sphenoid bone.

The terminal branches of the cavernous plexus consist of delicate filaments that anastomose freely, forming fine plexuses, and pass from the cavernous plexus along the terminal divisions of the internal carotid artery and their branches. These fine plexuses take the name of the artery on which they lie. The four larger of them are the plexuses of the anterior and middle cerebral arteries, the plexus of the chorioid artery, and the ophthalmic plexus.

The cervical portion of the sympathetic cord extends upward along the great vessels of the neck. No white rami communicantes connect it directly with the spinal cord, but instead it receives risceral efferent fibres from the upper thoracic spinal nerves through the sympathetic trunk, and probably also from the cerrical spinal cord through the spinal acessory nerve and the connections with the ragus. It sends grey rami communicantes to each of the cervical nerves. It extends from the subclavian artery to the base of the skull, lying dorsal to the sheath of the great vessels and in front of the longus capitis and longus colli, which separate is from the transverse processes of the cervical vertebræ (fig. 787). It usually 
Fig. 787.-Showing the Sympathetic Trunks in their Relation to the Vertebral Column, to the Spinal Nerves, and to each Other. (Modified from, Toldt, "Atlas of Human Anatomy," Rebman, London and New York.)

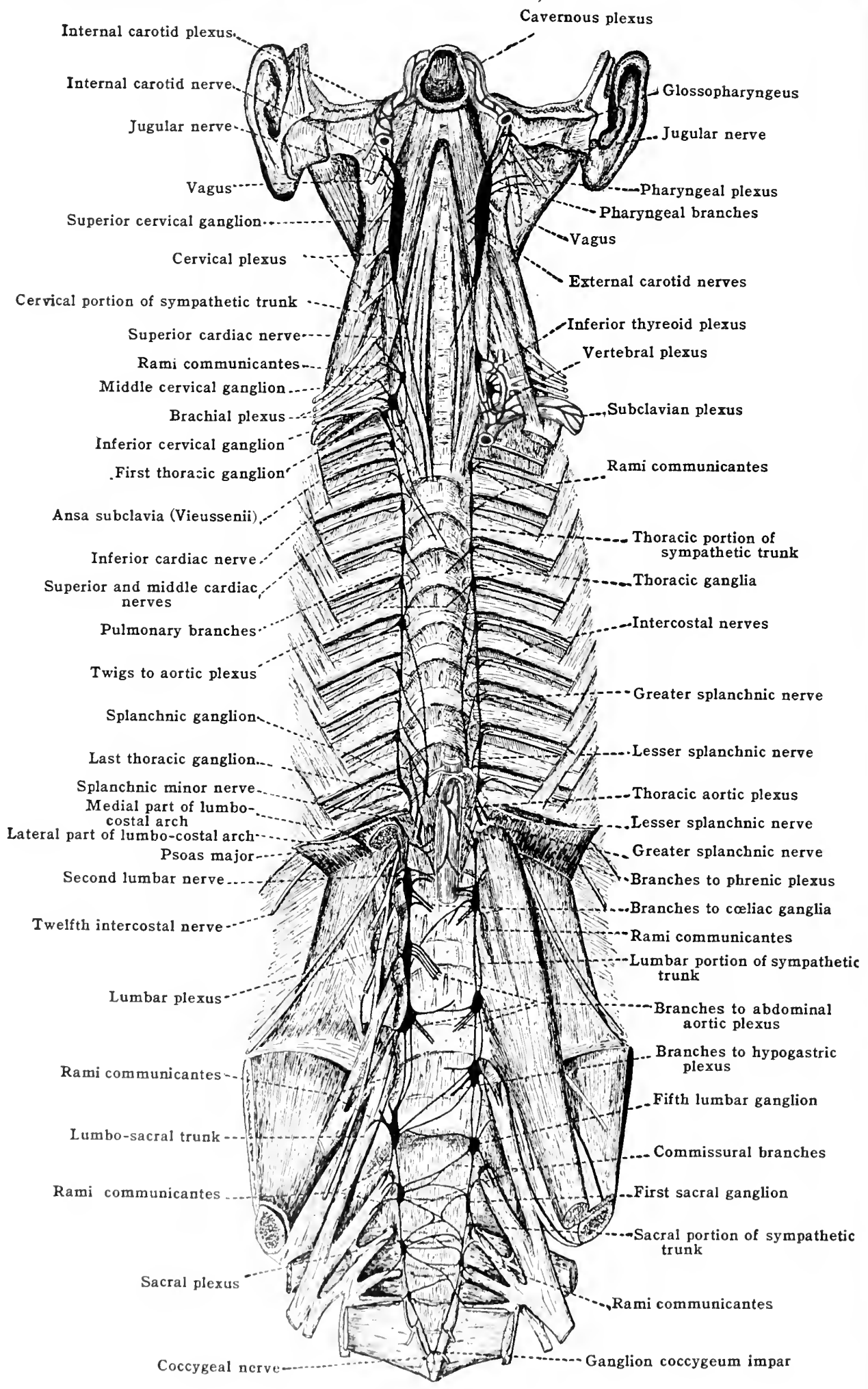


has but three ganglia, one at each end, the superior and inferior, and one between these two, called the middle ganglion. The latter varies somewhat in position and is sometimes absent.

\section{Superior Cervical Ganglion}

The superior cervical ganglion is usually fusiform in shape and is sometimes marked by one or more constrictions. There is ground for the belief that it is formed by the coalescence of four ganglia corresponding to the first four cervical nerves. It varies from an inch to one and one-half inches $(2.5$ to $3.7 \mathrm{~cm}$.) in length, lying dorsal to the upper part of the sheath of the great vessels of the neck and in front of the transverse processes of the second and third cervical vertebræ.

Fig. 788.-Diagram of the Glosso-palatine Nerve and the Relations of the Gangliated Cephalic Plexus to other Cranial Nerves. (After Bean.)

Broken lines, motor; continuous lines, sympathetic; glosso-palatine in solid black. Medial view. Left side.

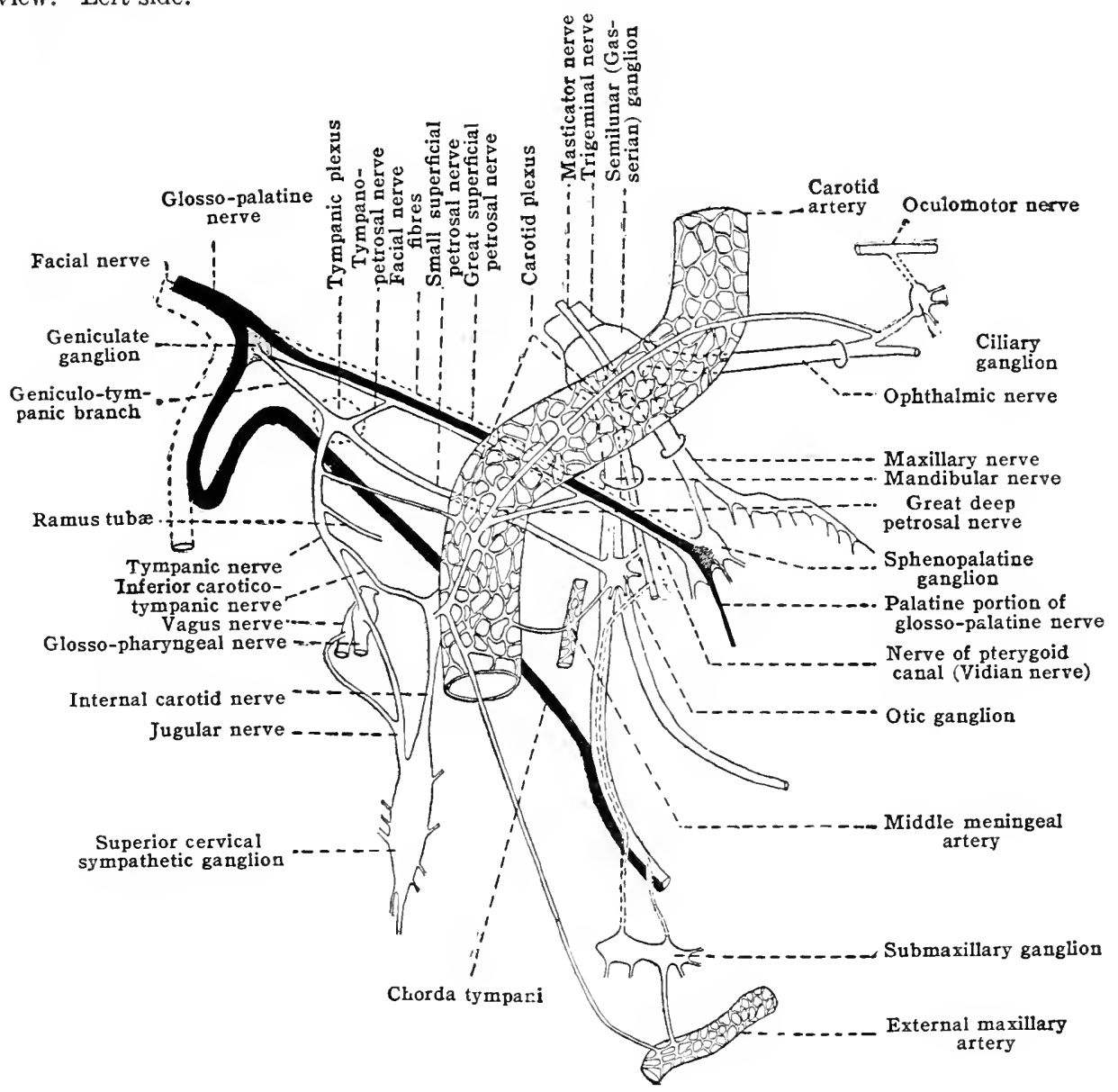

It occasionally extends upward as high as the transverse process of the first vertebra (fig. 787). It is connected with the middle cervical ganglion by the intervening trunk, and it gives off a large number of communicating branches.

Rarely, the ganglion may be double or split with a ventral portion lying superficial to the carotid sheath and a dorsal portion dorsal to the sheath, connected by sympathetic filaments near the superior and inferior extremities of the ganglion.

Communications:-(1) Four grey rami communicantes associate the ganglion with the anterior primary divisions of the first four cervical nerves.

(2) Communicating branches to the cranial nerves.- An irregular number of small twigs pass between the superior cervical ganglion and the hypoglossal nerve and to the ganglion nodosum of the vagus. A named branch, the jugular nerve, runs upward to the base of the skull and divides into two branches, one of which enters the jugular foramen and terminates in the jugular ganglion of the vagus, and the other ends in the petrous ganglion of the glossopharyngeus. (See fig. 788). 
(3) Four or five laryngo-pharyngeal branches come from the superior ganglion and the plexus extending downward from it, and pass forward and medialward, lateral to the carotid vessels, to the wall of the pharynx, where they unite on the middle constrictor with the pharyngeal branches of the glosso-pharyngeus and vagus, forming with them the pharyngeal plexus, from which branches are distributed to the walls of the pharynx and to the superior and external laryngeal nerves (fig. 787 ).

(4) The superior cervical cardiac nerve springs from the lower part of the ganglion or from the trunk immediately below it. It passes downward behind the earotid sheath, either in front of or dorsal to the inferior thyreoid artery, and in front of the longus colli, and establishes communications with the upper eervical cardiac branch of the vagus, the middle cervical eardiac branch of the sympathetic, and with the inferior and external laryngeal nerves. At the root of the neck the nerve of the right side passes in front of or behind the first part of the right subclavian artery, and is continued along the innominate artery to the front of the bifurcation of the trachea, where it ends in the deep part of the cardiac plexus. The left nerve passes in to the thorax along the front of the left common carotid artery, crosses the front of the arch of the aorta immediately anterior to the vagus, and terminates in the superficial part of the cardiac plexus (fig. 789). Filaments from both the right and left nerves pass to the inferior thyreoid plexus.

(5) The external carotid nerves (fig. 787) pass forward from the superior cervical ganglion to the external carotid artery, where they divide in to branches which anastomose freely to form around the artery the external carotid plexus. This plexus extends to the beginning of the artery, and is continued upon the common carotid artery as the common carotid plexus. From the external carotid plexus, filaments pass to form secondary plexuses around each of the branches of the external carotid artery. These plexuses take the names of the arteries which they follow, namely, the superior thyreoid plexus, lingual plexus, ete. Filaments pass from the external carotid plexus to the glomus caroticum (the carotid gland), and from the superior thyreoid plexus to the thyreoid gland.

From the external maxillary (facial) plexus passes the sympathetic root of the submaxillary ganglion.

A part of the internal maxillary plexus is continued upon the middle meningeal artery as the meningeal plexus. From this plexus filaments pass to the otic ganglion, and sometimes a branch, ealled by English anatomists the external superficial petrossal nerve, passes to the genieulate ganglion.

(6) Small branches to the ligaments and bones of the upper part of the vertebral column.

(7) The internal carotid nerve (ascending branch) and plexus have been deseribed with the cephalie portion of the sympathetic system.

\section{The Middle Cervical Ganglion}

The middle cervical ganglion is small and somewhat triangular in outline. It is sometimes absent. Its position is variable, but it commonly lies about the level of the cricoid cartilage, in front of the bend of the inferior thyreoid artery (fig. 787), and it is associated with the superior cervical ganglion and with the inferior cervical ganglion by the trunk of the gangliated cord. From the lower part of the middle ganglion some filaments pass dorsal to the subclavian artery, while others pass in front of and beneath that artery and anastomose with the first-mentioned filaments to form a loop, the ansa subclavia (ansa Vieussenii) (figs. 751, 787). Filaments from this loop to the inferior cervical ganglion thus form another communication between the middle and inferior cervical ganglia.

Connections.-The middle eervical ganglion gives off four or more rami.

"Two $(a$ and $b$ ) are grey rami communieantes which connect the middle ganglion with the anterior primary branches of the fifth and sixth cervical nerves.

(c) One or more peripheral branches pass along the inferior thyreoid artery and anastomose with branches from the superior and middle eardiac nerves and from the inferior cervical ganglion, thus taking part in the formation of the inferior thyreoid plexus, from which branches pass to the thyrooill gland.

(d) The middle cardiac nerve arises by one or more branches from the ganglion, or from the trunk of the cord, and passes downward dorsal to the common carotid artery and, on the right side, rither in front of or dorsal to the subclavian artery, and then along the immominate artery to the derep part of the carliac plexus (figs. 787 and 789 ). It is frequently larger than the sipgerior cardiac norve. On the left side the nerve runs between the subelavian and common carntid arteries. (In hoth sides the nerve communicates with the inferior laryngeal nerve and extranal laryngeal norve.

The middle cervical ganglion also gives branches to the common arotid plexus.

\section{3. 'The Inlerhor ('envical, Gangliton}

The inferior cervical ganglion is irregular in form. It is larger than the mirldle crevical ganglion, and it lies deeply in the root of the neek dorsal to the vertemal altery or the first part, of the subelavian artery, and ventral to the interval betwon the transverse processes of the last cervical and the first thoraeic vertubro (figs. 759, 761). It is connected with the midelle eervical ganglion by 
the sympathetic trunk, and by filaments passing to the ansa subclavia (Vieussenii), and it is either blended directly with the first thoracic ganglion or connected with it by a short stout portion of the trunk. It gives rami to the last two cervical nerves and peripheral branches to the vertebral and internal mammary arteries, to the heart, and to the inferior thyreoid plexus.

Connections.-(1) The rami to the seventh and eighth cervical nerves are grey rami communicantes.

(2) The branches to the vertebral artery are large and they unite with similar branches from the first thoracic ganglion to form a plexus, the vertebral plexus (fig. 787), which accompanies the artery into the posterior fossa of the cranium, where it is continued on the basilar artery. The plexus communicates in the neck by delicate threads with the cervical spinal nerves. These are probably meningeal rami.

(3) The branches to the internal mammary artery form the internal mammary plexus.

(4) The inferior cardiac nerve may arise from the inferior cervical ganglion, from the first thoracic ganglion, or by filaments from both these ganglia (figs. 7S7 and 759). It communicates with the recurrent laryngeal nerve and with the middle cardiac nerve, and passes to the deep part of the cardiac plexus. On the left side it frequently joins the middle cardiac nerve to form a common trunk.

Construction of the cervical portion of the sympathetic trunk.--This portion of the trunk contains both medullated and non-medullated fibres, and a large part of the former are of cranio-spinal origin. In the absence of white rami communicantes to this portion of the sympathetic trunk, it is evident that few if any of the cranio-spinal or efferent visceral fibres are contributed to it below the superior ganglion by the cervical region of the spinal cord. Instead, such fibres are known to enter by way of the white rami from the upper thoracic nerves, and to ascend to this portion of the sympathetic trunk. Most of these fibres terminate about the cells of the superior, middle, and inferior cervical ganglia, and these cells in their turn give off sympathetic fibres which pass by way of the branches mentioned above for the cephalic and cervical portions, to their distribution in the structures of the head, neck, and thorax. The efferent visceral fibres which terminate in the superior ganglion especially are among those which mediate-(1) vaso-motor impulses for the head; (2) secretory impulses for the submaxillary gland; (3) pilo-motor impulses for the hairs of the face and neck; (t) motor impulses for the smooth muscle of the eyelids and orbit, and (5) dilator impulses for the pupil. The sympathetic or grey fibres in the cervical portion of the sympathetic trunk arise from the cells of the upper thoracic and the cervical ganglia, and are passing either to connect the ganglia with each other or to enter the peripheral branches and proceed to their terminal distribution.

\section{THE THORACIC PORTION OF THE SYMPATHETIC TRUNK}

The thoracic part of the gangliated trunk runs downward on the heads of the ribs from the first to the tenth, and then passes a little ventralward on the sides of the bodies of the lower two thoracic vertebræ. Above it is continuous with the cervical portion at the root of the neck, dorsal to the vertebral artery. Below it leaves the thorax dorsal to the medial lumbo-costal arch (arcuate ligament), or sometimes dorsal to the lateral lumbo-costal arch, and continues into the lumbar portion of the trunk. It lies behind the costal pleura and crosses over the aortic intercostal arteries.

The number of ganglia in this part of the trunk is variable. There are usually ten or eleven, but the first is sometimes fused with the inferior cervical ganglion and occasionally other ganglia fuse. The ganglia are irregularly angular or fusiform in shape, and lie on the head of the ribs, on the costo-vertebral articulations, or on the bodies of the vertebra. The portions of the trunk connecting the ganglia usually are single, but sometimes they are composed of two or three small cords in juxtaposition. Each ganglion, with the possible exception of the first, receives a white ramus communicans from a thoracic nerve and all give off grey rami communicantes to these nerves.

The white rami communicantes, as they approach the sympathetic trunk, quite often appear double, clue to the separation of a large portion of their fibres into two main streams, one passing upward in the sympathetic trunk, and one passing downward. Of the white rami from the upper five thoracic nerves, the upward stream of fibres is much larger than the downward, due to the fact that a greater part of the efferent visceral fibers from these nerves are distributed through the cervical portion of the sympathetic trunk, as noted above in the construction of that portion. Usually the white rami from the spinal nerves pass directly to the corresponding ganglia of the trunk, and thus lie in company with the corresponding grey rami. Sometimes, however, they may join the intermediate portions of the trunk, and in the lower thoracic region especially, a ramus may pass from a nerve to the ganglion corresponding to the nerve above or below. The 
fibres of the white rami from the lower thoracie nerves are in greater part directed downward in the sympathetie trunk, and also downward in its peripheral branches, to be chistributed to the abdominal viscera. In all cases, however, some of the fibres of the thoracic white rami terminate in the ganglia nearest their junction with the trunk, while others pass into the nearest peripheral branches. In this way the white rami from all the thoracic spinal nerves, especially those of the mid-region, are directly concerned in the innervation of the thoracic viscera, lungs, oesophagus, aorta, ete.

The first thoracic ganglion is larger than the other ganglia of this region and is irregular in form. It may be narrowly ovoid or semilunar. It lies in front of the neck of the first rib, behind the pleura, and on the medial side of the costocerrical trunk (superior intereostal artery), which vessel separates it from the prolongation of the portion of the first thoracic nerve which passes to the brachial plexus. It sometimes fuses with the inferior cervical ganglion, and, on the other hand, sometimes extends to the upper part of the second rib to fuse with the second thoracie ganglion. The result of the latter fusion resembles the stellate ganglion of the earnivora, and when it oceurs, is sometimes referrech to as the ganglion stellatum. When well developed, the first ganglion sends a branch to the cardiac plexus, forming the fourth eardiae nerve of Valentin.

The second thoracic ganglion, triangular in shape and almost as large as the preceding, is sometimes placed on the costo-vertebral articulation, and is sometimes partly eoncealed by the first rib.

The third to the ninth thoracic ganglia are usually placect opposite the heads of the corresponding ribs, but the tenth and eleventh may lie on the bodies of the vertebræ.

The fibres passing from the ganglia form two groups of branches, the central and the peripheral.

The central branches are the grey rami communicantes, which pass from the ganglia to the corresponding spinal nerves. After they have joined with the anterior primary divisions of the nerves, the fibres of these rami divide into four groups:-(1) Fibres which pass medialward along the roots of the nerves to supply vessels of the membranes of the spinal cord, or enter a meningeal or recurrent branch for the same purpose; (2) fibres which enter the spinal ganglion and terminate there (sensory sympathetic fibres); (3) fibres which pass dorsalward into the posterior primary divisions of the nerves; 4 ) fibres which pass lateralward in the anterior primary divisions of the nerves. The last two groups of fibres are distributed to the muscle of the blood-vessels of the body-walls, to the skin-glands, and to the muscles of the hairs of the body.

The peripheral branches of the ganglia form two series, an upper and a lower.

Those of the upper series pass from the upper four or five ganglia ventralward to be ristributed as follows:-

(1) Pulmonary branches which accompany the intercostal arteries toward their aortic origin without forming plexuses around them, and pass to the posterior pulmonary plexus (fig. 789 ).

(2) Aortic branches, some of which arise directly from the ganglia and some from the pulmonary branches, and unite with branches from the cardiac plexus and from the splanchnic nerves 10 sulround the aorta as the thoracic aortic plexus (fig. 789). This plexus accompanies the anrta into the aledomen and there joins with the ealiae (solar) plexus.

(3) Esophageal branches join with the crsophageal plexus of the vagus.

(1) Vertebral branches, some of which pass with the nutrient arteries into the bodies of the vertebrat and enme of which pass to the median line and there anastomose with similar branches from the opposite sile (commissural branches).

The peripheral ganglionic branches forming the lower series consist largely of offerent amel afferent fibues from the spinal nerves, whieh pass through the ganglia and roinfore the sympathetie filaments proper. Thus composed, these branches lom vontralward and medialward on the sides of the bodies of the vertebre and Imite: to form the splanchunc nerves which supply the aldominal organs, the afferent filmes serving to collect sensory impulses in this domain of the sympathrotic.

(1) The great splanchnic nerve mat be formel by lianches from all the thoracic ganglia from the fifth to the truth inclusive, of it may receive fibres from only two or three of these 
ganglia (fig. 787). It is usually formed by branches from the fifth to the tenth. The superior branch, usually the largest, receives smaller inferior branches from the lower ganglia as it passes downward on the sides of the bodies of the vertebra in the posterior mediastinum. The nerve enters the abdominal cavity by passing through the crus of the diaphragm, and joins the upper end of the coeliac (semilunar) ganglion of the coliac (solar) plexus. Near the disk between the eleventh and the twelfth thoracic vertebra there is formed on the nerve the splanchnic ganglion. Filaments from the nerve and from this ganglion pass along the intercostal arteries to the aorta, œsophagus, and the thoracic duct, and some fibres from the right side pass to the vena azygos (major). Sometimes this nerve divides into two cords, giving off numerous branches which anastomose with each other and with the lesser splanchnic nerve to form a plexus, in the meshes of which are found some small ganglia.

(2) The lesser splanchnic nerve receives fibres from the ninth and tenth ganglia. Its course is similar to that of the great splanchnic nerve (fig. 787 ), but on a more dorsal plane, and it terminates in the coliac (solar) and renal plexuses.

(3) The least splanchnic nerve, not always present, arises from the last thoracic ganglion or sometimes from the small splanchnic nerve. It passes through the crus of the diaphragm and ends in the renal plexus.

Construction of the thoracic portion of the cord.-The majority of the visceral efferent fibres which pass from the central nervous system enter the thoracic portion of the sympathetic trunk; some end there in ramifications around the cells of its ganglia, while others merely pass through on their way to more distant terminations. With regard to those which terminate in the ganglia, it has been shown that in the dog and cat many end in the ganglion stellatum which corresponds with the last cervical and the upper three or four thoracic ganglia in man. Among these are the fibres conveying secretory impulses to the sweat-glands of the upper limb, which emerge from the spinal cord in the thoracic nerves from the sixth to the ninth, and, in the dog, those which convey and transfer vaso-constrictor impulses to the sympathetic neurones supplying the pulmonary blood-vessels. These visceral efterent fibres leave the spinal cord in the second to the seventh thoracic nerves. Other fibres which terminate around the thoracic sympathetic ganglion-cells in the dog and cat are the vaso-constrictor fibres for the upper limbs and some of the vaso-constrictor fibres for the lower limbs.

Of the fibres which traverse the thoracic portion of the sympathetic trunk to gain more distant terminations, some ascend to the cervical region (p. 1033), others descend to the lumbar region, and many pass by the immediate peripheral branches to the splanchnic nerves.

Among those which descend to the lumbar region are pilo-motor fibres, vaso-motor fibres, and secretory fibres to the lower limb, some vaso-constrictor fibres to the abdominal bloodvessels, motor fibres to the circular, and inhibitory fibres to the longitudinal muscle of the rectum. The latter enter the sympathetic trunk by the lower thoracic nerves and pass in the lumbar peripheral branches to the aortic plexus, and terminate around the cells of the inferior mesenteric ganglion.

The visceral efferent fibres which pass through the thoracic ganglia to the splanchnic nerves are mainly vaso-motor fibres to the abdominal blood-vessels; the majority of then probably terminate around the cells of the ganglia in the coelic (solar) plexus, but those for the renal bloodvessels no doubt end in the renal ganglia. In addition to all the above-mentioned fibres there are in the thoracic part of the sympathetic trunk afferent fibres of both sympathetic and cerebro-spinal type, passing toward the spinal ganglia and the latter, greatly predominating, pass into the dorsal roots of the thoracic spinal nerves.

\section{THE LUMBAR PORTION OF THE SYMPATHETIC TRUNK}

The lumbar portion of each trunk lies on the fronts of the bodies of the vertebræ along the anterior border of the psoas muscle, and nearer to the median line than the thoracic portion. It is comnected with the thoracic portion of the sympathetic trunk by a slender intermediate portion of the trunk that may pass through the diaphragm or dorsal to it (fig. 787). The continuation of the lumbar into the sacral portion is also slender, and descends dorsal to the common iliac artery. The right trunk is partly covered by the vena cava inferior and the left by the aorta.

The ganglia, which are small and oval, vary in number from three to eight, but are usually four. Rarely they are so fused as to form one continuous ganglion.

White rami communicantes pass to the ganglia from the first two or three lumbar nerves only. This portion of the sympathetic trunk also receives visceral efierent and afferent fibres which are derived from the white rani communicantes of the lower thoracic nerves and continue downward in the trunk.

Branches.-As in the thoracic region, the branches from the ganglia are central and peripheral. The central are grey rami communicantes. There may be two branches to a nerve or one ramus may divide so as to join two adjacent spinal nerves. Sometimes a spinal nerve may receive as many as five grey rami from the sympathetic trunk.

The peripheral branches include:- (a) Branches passing to the aorta and taking part in the formation of the aortic plexus; $(b)$ branches which descend in front of the common ihac artery to the hypogastric plexus; and $(c)$ branches to the vertebræ and ligaments. 


\section{THE SACRAL PORTION OF THE SYMPATHETIC TRUNK}

The sacral part of each trunk passes downward in front of the sacrum, immediately lateral to the medial borders of the anterior sacral foramina. It is continuous above with the lumbar portion of the trunk, and below it anastomoses freely in front of the coccyx with the trunk of the other side to form a plexus in the terminus of which is the coccygeal ganglion (ganglion coccygeum impar) (fig. 7S7). Like the cervical and lower lumbar portions of the sympathetic trunk, the sacral part receives no white rami communicantes from the spinal nerves.

The sacral ganglia are small in size, and usually four in number. The variation both in size and number is more marked in this portion of the trunk than in the two parts above.

Branches.-The branches of the sacral ganglia include:-

(1) Grey rami communicantes to the sacral nerves.

(2) Branches to the front of the sacrum which anastomose with their fellows of the opposite side (commissural branches).

(3) Branches which enter into the formation of the plexus on the middle sacral artery.

(4) Branches which join the pelvic plexuses.

(5) Branches given off by the ganglion coccygeum impar to the coccyx and its ligaments and to the glomus coccygeum (coccygeal gland).

Construction of the lumbar and sacral portions of the gangliated trunk. - The ganglia of both these portions of the trunk are very variable in shape, size, position, and number. There are usually four ganglia belonging to each portion, but sometimes as many as eight may be distinguished in the lumbar and at other times there may be as many as six in the sacral portion. In the majority of cases, especially in the sacral region, these masses of cells are so fused that their number is less than the number of the spinal nerves with which they are associated. As noted above, only the first two or three lumbar spinal nerves send white rami which enter these ganglia directly as such. However, visceral efferent fibres descend this entire stretch of the trunk, through both the lumbar and sacral portions, from the white rami of the lower thoracic and the upper lumbar nerves above. These fibres either terminate in the various ganglia or pass uninterrupted to the more distant sympathetic cell-bodies which are concerned in impulses that are vaso-motor to the genital organs, motor for the uterus, the vas deferens, and the muscular coats (circular coat especially) of the bladder. Also, some of them convey secretory, pilomotor, and vaso-motor impulses for the glands, skin, and vessels of the lower extremity in addition to the similar impulses conveyed in the peripheral branches from the lower part of the thoracic portion of the sympathetic trunk. The motor impulses for the uterus or vas deferens and for the bladder pass, in most part probably, by way of the peripheral branches from the lumbar portion of the cord, through the aortic plexus to the inferior mesenteric ganglion; others, the vaso-motor impulses to the genital organs especially, pass by way of the sacral ganglia and the peripheral branches from them to the hypogastric or pelvie plexus and the appropriate subplexuses of this region. Of the vaso-motor fibres for the penis, some of the constrictor filores pass down the sacral portion of the sympathetic trunk and terminate about the cells of the silcril ganglia, and these cells send out sympathetic fibres which join and course in the pudic nerve (n. pudendus).

All of Joth the lumbar and sacral spinal nerves receive grey rami from the gangliated trunk. These, just as those from the other portions of the trunk, consist of-(1) vaso-motor fibres to vessels of the meninges and the vertebral canal; (2) sympathetic fibres which join the divisions of the spinal nerves and course in them to their distribution, and (3) afferent sympathetic fibres terninating in the spinal ganglia.

In aldition to the viseeral efferent fibres, the branches of the lumbo-sacral portion of the sympathetic trunk carry cerebro-spinal fibres of general sensibility-sensory fibres arising in the spinal gangtia of this and the lower thoracie region.

There are no white rami proper passimg from the sacral spinal nerves to course or terminate in the sympathetic trunk. Visceral efferent fibres are given off by these nerves in abundance, but, insteal of entering the trunk and its ganglia, they form bundles which pass over the trunk and directly into its peripheral branches and to the nore distant ganglia. 'The bundles passing from the second, third, and fourtl satral nerves are large and especially definite. While hounlogens to white rami, snch hundles are better known as the visceral branches of the sacral nerves or the plevic splanchnics. They contain some spinal sensory fibres, but consist for the most part of visceral efferent, convering impulses, vaso-motor (vaso-rlilator, chicfly) to the genital organs, both motor and inhilitory for the rectum, uterus, and bladeler (longitudinal coat (apresialty), and socrotory for the prostate rand. These filores contribute to the hypogastric plexus and are intermpted in the small ganglia of its sub-plexuses, named according to the varions urino-genital orguns concorued.

\section{TIIE GREAT PREVER'TEBRAL PLEXUSES}

The ureat prevertebral plexuses, in the hody eavities, are three in numberthe "ardiar, the axdiac (solitr or" (p)igastric), and the hypogastric or pelvic. The "arcliace plexus lims behind and betow the arch of the aorta, and the corliac and 
hypogastric plexuses are situated in front of the lumbar vertebræ. Each plexus receives not only sympathetic fibres which have passed from or through the ganglia of the sympathetic trunks of either side, but also both afferent and efferent cranio-spinal nerve-fibres derived directly from the cranio-spinal nerves. In addition the cardiac and coliac plexuses receive both efferent visceral and craniospinal sensory or afferent visceral fibres from both vagus nerves. It shoukd be clearly understood that the branches which run from the sympathetic gangliated trunks to the prevertebral plexuses contain medullated fibres which are passing, like the fibres from the sacral nerves, directly from the spinal cord to terminate about the cells of the plexuses.

\section{The Cardiac Plexus}

The cardiac plexus is formed by the cardiac branches from both vagus nerves and from both sympathetic trunks. It lies beneath and dorsal to the arch of the aorta, in front of the bifurcation of the trachea, and extends a short distance upward on the sides of the trachea. It is composed of a superficial and a deep part (fig. 789).

The superficial part of the cardiac plexus is much smaller than the deep part, and lies beneath the arch of the aorta in front of the right pulmonary artery. It is formed chiefly by the cardiac branches of the left vagus and by the left superior cardiac nerve, but sometimes receives filaments from the deep cardiac plexus. The cardiac ganglion (ganglion of Wrisberg, ) usually found connected with this plexus, lies on the right side of the ligamentum arteriosum.

Branches.-From this plexus some branches pass to the left half of the deep cardiac plexus, and others accompany the left pulmonary artery to the left anterior pulmonary plexus. It also sends branches to the right anterior coronary plexus.

The deep portion of the cardiac plexus lies dorsal to the arch of the aorta at the sides of the lower part of the trachea and in front of its bifurcation. It consists of two lateral parts, more or less distinct, connected by numerous branches, which pass around the lower part of the trachea. It is formed by the superior, middle, and inferior cervical cardiac branches from the right sympathetic trunk, the middle and inferior cervical cardiac branches from the left trunk, and all the cervical and thoracic cardiac branches of the vagus except the superior cervical cardiac branch of the left vagus. It also receives branches from the superficial cardiac plexus.

The left part of the deep cardiac plexus gives branches to the left atrium (auricle) of the heart, to the left anterior pulmonary plexus, to the left coronary plexus, and sometimes to the superficial part of the cardiac plexus.

The right part of the deep cardiac plexus gives branches to the right atrium, to the right anterior pulmonary plexus, and to the right and the left coronary plexuses (fig. 789). The branches to the left coronary plexus pass behind the pulmonary artery. Some of those to the right coronary. plexus pass anterior and some posterior to the right pulmonary artery.

The coronary plexuses are formed by branches given off by the cardiac plexus. They accompany the coronary arteries and are right and left.

The right (anterior) coronary plexus receives filaments from the superficial part of the cardiac plexus, but is formed chiefly by filaments from the right portion of the deep cardiac plexus (fig. 789). Its distribution to the heart follows that of the right coronary artery.

The left (posterior) coronary plexus is larger than the right plexus, and is formed for the most part by filaments from the left portion of the deep cardiac plexus, but it receives some filaments from the right portion of the deep cardiac plexus (fig. 789). Its distribution to the hoart follows that of the left coronary artery.

The cardiac plexus and the network of nervous structures in the walls of the atria are the remains of the primitive plexuses found in the embryo, which are called the bulbar, the intermediate, and the atrial plexuses, terms which sufficiently indicate their relative positions. The bulbar plexus gives off the coronary nerves and is transformed into the superficial part of the deep cardiac plexus; the remainder of the deep cardiac plexus is formed by the intermediate plexus, and the atrial plexus becomes the network of the atrium.

The fibres which pass to the cardiac plexus are medullated and non-medullated; the former 
Fig. 759. Cardiac, Pulmonary, and Coronary Plexuses. (Schematic.)

(Modified from Cunningham.)

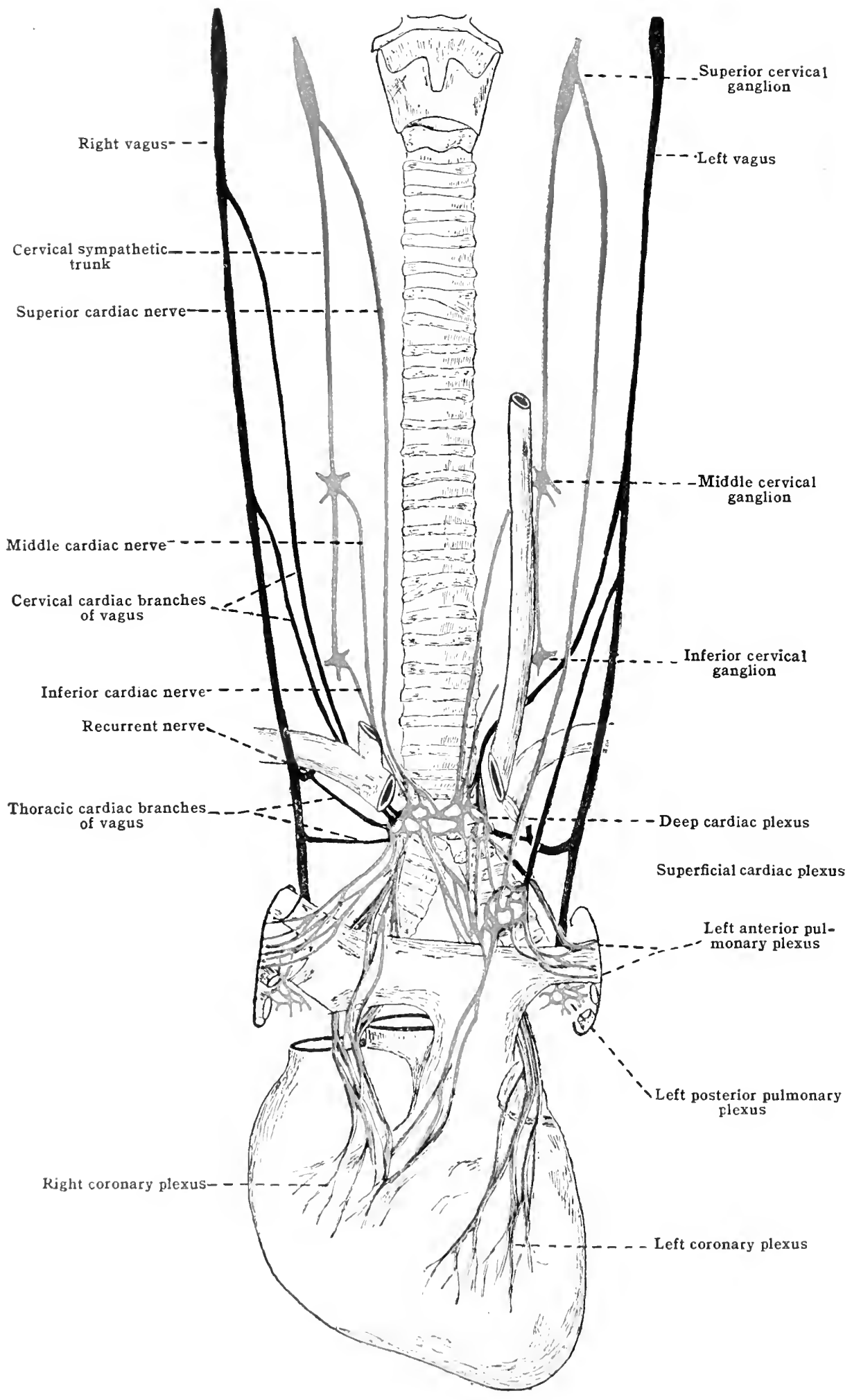


are the so-called inhibitory, the latter motor. The inhibitory impulses leare the central nervous system by the spinal accessory and vagus nerves. The motor fibres leave the spinal cord by the ventral roots and white rami communicantes of the thoracic nerves and terminate about the cells of the intervening sympathetic ganglia. From the cells of these ganglia arise the non-medullated (grey) fibres of the plexus. These fibres terminate dircetly upon the fibres of cardiac muscle or about the cells of the minute intrinsic cardiac ganglia which in their turn give axones to the muscle.

\section{The Pulionary Plexuses}

The pulmonary plexuses are a continuation of the cardiac plexuses. The two are so intimately joined that it is difficult to distinguish them as separate plexuses. The pulmonary are formed by fibres from both the vagus and sympathetic nerves. The anterior and posterior pulmonary branches of the vagus unite, dorsal to the bifurcation of the trachea, with fibres from the second, third and fourth ganglia of the thoracic portion of the sympathetic trunk to form the anterior and posterior pulmonary plexuses that lie ventral and dorsal to the bifurcation of the trachea. Here the pulmonary plexuses of both sides connect with each other freely. Leaving the trachea, the plexuses pass into the lungs along the pulmonary arteries (figs. 744, 789). The parts of the plexus of each side are named according to their position anterior or posterior to the right and left pulmonary arteries; thus, there is a right anterior and a right posterior, a left anterior and a left posterior pulmonary plexus.

\section{The Coliac Plexus}

The coliac (solar or epigastric) plexus is the largest of the prevertebral plexuses. It is unpaired, and is continuous above with the aortic plexus of the thorax and below with the abdominal aortic and superior mesenteric plexuses. It lies in the epigastric region of the abdomen behind the bursa omentalis (lesser sac of the peritoneum) and the pancreas, upon the crura of the diaphragm and over the abdominal aorta, and around the origin of the coliac and the superior mesenteric arteries. It occupies the interval between the suprarenal bodies and extends downward as far as the renal arteries. It is formed by the great and the lesser splanchnic nerves of both sides, by coeliac branches of the right vagus, and by filaments from the upper lumbar ganglia of the sympathetic trunk. It sometimes receives cœliac branches from the left vagus. It contains two large ganglia, the right and left coliac (semilunar) ganglia (fig. 790).

The cœliac (semilunar) ganglia are two large, flat, irregularly shaped masses, separable into a varying number of ganglia. These two masses, or rather the smaller ganglia which compose them, are associated by a varying number of communicating branches. Each mass, right and left, lies upon the corresponding crus of the diaphragm, at the medial border of the corresponding suprarenal body, being sometimes overlapped by this body. The right mass lies behind the inferior vena cava. Each coeliac ganglion receives at its upper border the greater splanchnic nerve, and, near its lower border, lying over the origin of the renal artery, is a more or less detached part, known as the aortico-renal ganglion. This ganglion receives the lesser splanchnic nerve and may seemingly give origin to the greater part of the renal plexus. Another part of the coliac ganglion, of ten found dorsal to the origin of the superior mesenteric artery, is known as the superior mesenteric ganglion (fig. 790).

From the coeliac plexus and its ganglia subordinate plexuses are continued upon the aorta and its branches. These comprise both paired and unpaired plexuses. The paired plexuses are the phrenic, suprarenal and renal, the spermatic in the male, and, in the female, the ovarian plexuses. The unpaired plexuses are the aortic, hepatic, splenic, superior gastric, inferior gastric, superior mesenteric, and inferior mesenteric.

That part of the coliac plexus surrounding the celiac artery was formerly described as the coliac plexus. It is better considered as an unnamed part of the larger coliac (solar) plexus. This part of the plexus receives fibres from both vagus nerves, and gives filaments that form plexuses around the branches of the coliac artery and their ramifications. 
The paired subordinate plexuses of the cœliac.-(1) The phrenic (diaphragmatic) plexuses consist of fibres from the upper part of the coeliac ganglia, which follow the inferior phrenic arteries and their branches on the under surface of the diaphragm (fig. 790). Filaments are given off by the roots of the plexuses to the suprarenal bodies, and others unite with the terminal branches of the phrenic nerves. The point of junction with the right phrenic nerve is marked by the phrenic ganglion, from which branches are distributed to the inferior vena eava; to the right suprarenal body, and to the hepatic plexus.

(2) The suprarenal plexuses are comparatively large plexuses, formed mainly by branehes from the coliac (semilunar) ganglia. However, fibres come to them from the coliac plexus

Frg. 790.-Abdominal Plexuses of the Srmpathetrc. (After Tolde, "Atlas of Human Anatomy," Rebman, London and New York.)

$$
\text { Cœliac plexus Left vagus nerve }
$$

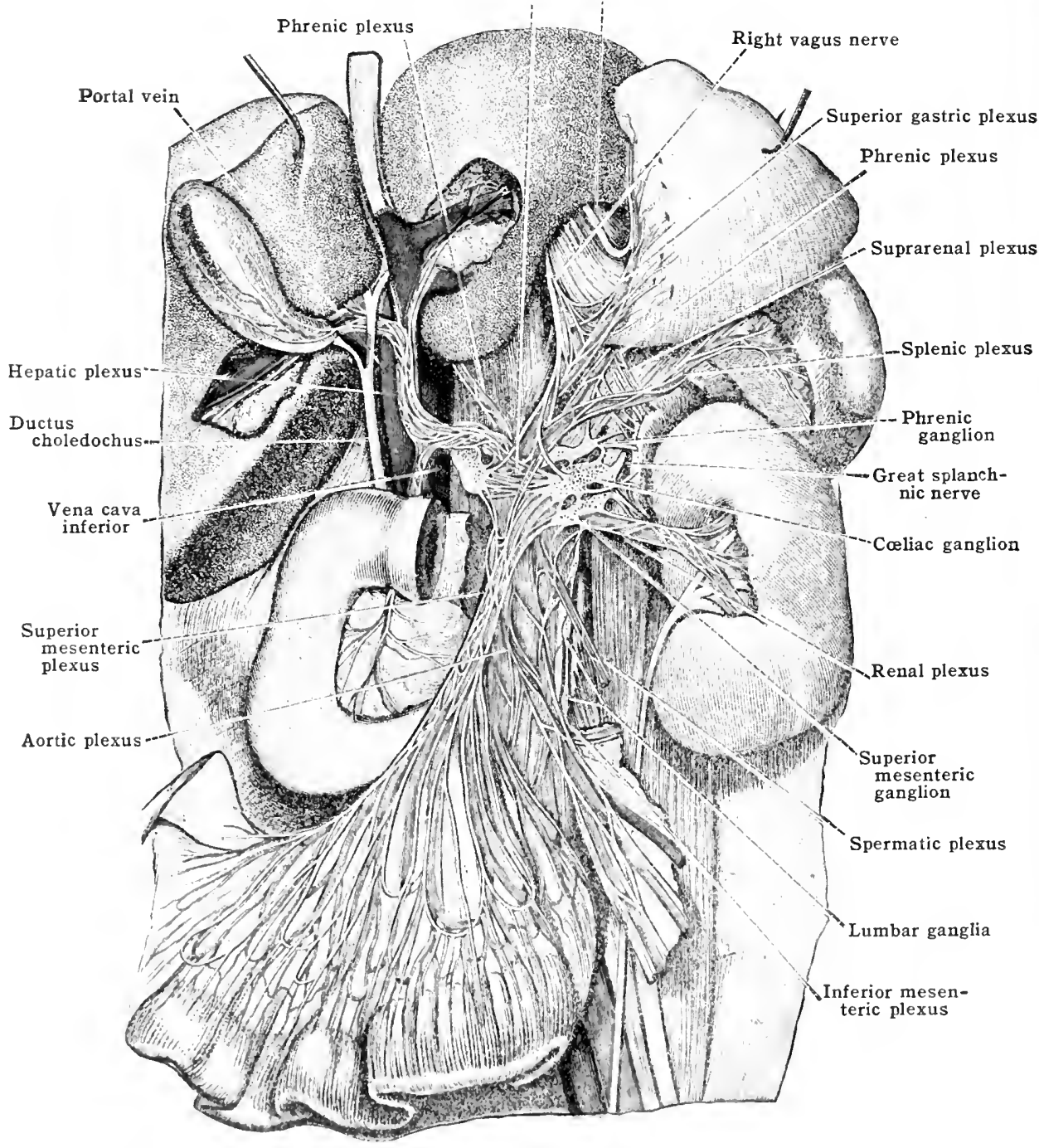

along the suprapenal arteries, from the phrenic plexus along the inferior phrenic arteries, and from the rentel plexus alomg the inforior suprarenal arteries. They are distributed to the

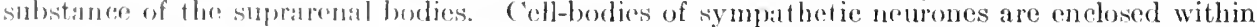
the suprarenal bodies forming intrinsie ganglia. 'The medulla of the suprarenal is of ectodernal origin and comsidered as derived from muleveloped components of the sympathetic norvous system.

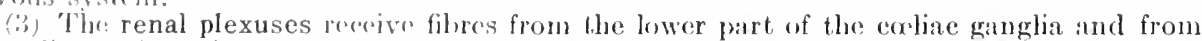

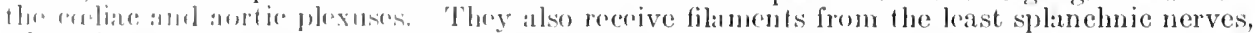
when these noves are presint, and sometimes filaments from the small splanchnic nerves and from the lirst lumbar ganglion of the svmpathetic trunk. These plexuses pass along the renal arteries into the substaneo of the kirlueys. Most of the tibes of caeb renal plexus are grey fibres,

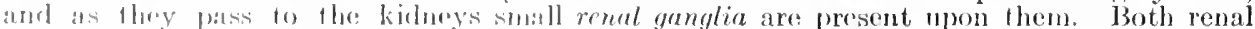
phexuses give hanches to the corresponding spermatic plexuses and to the meter, and the

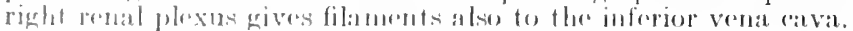


(4a) The spermatic plexuses (fig. 790) are formed by fibres from the renal and aortic plexuses. They accompany the spermatic arteries and are joined at the abdominal inguinal (internal abdominal) ring by fibres that have passed along the vas deferens from the pelvic plexuses. Their terminal filaments are distributed to the testis and the epirlidymis.

(4b) The ovarian plexuses are formed in the female like the spermatic plexuses in the male. They accompany the ovarian arteries and, in the broad ligament, receive fibres from the utero-vaginal plexus. They supply the ovaries, the broad ligaments, and the Fallopian tubes, and send some fibres to the fundus of the uterus, where they become continuous with the utero-vaginal plexus.

The unpaired subordinate plexuses:-(1) The abdominal aortic plexus is formed by two strands of fibres which descend along the sides of the aorta and communicate with each other across its ventral aspect. It is connected above with the renal plexuses, and it receives peripheral branches from some of the lumbar ganglia of the sympathetic trunk on each side. It often contains a number of ganglia, which are situated at the points where the peripheral branches join the plexus, and it terminates below, chiefly by anastomoses with the hypogastric plexus (figs. 790 and 791). Besides giving filaments to the inferior vena cava, it also gives fibres that form plexuses along each of the branches of the aorta. The fibres that pass from the lower end of the aortic plexus upon the common iliac artery form the iliac plexus, which is continued along the femoral artery as the femoral plexus, and still further along the popliteal artery as the popliteal plexus.

(2) The superior gastric (coronary) plexus, receiving filaments from the coliac plexus, accompanies the left gastric (coronary) artery along the lesser curvature of the stomach. Its filaments anastomose with filaments of the vagus nerves and with the plexus that accompanies the right gastric (pyloric) artery (fig. 790), and it gives fibres to the walls of the stomach which terminate within the walls, about the cell bodies of the delicate gangliated plexus myentericus and plexus submucosus (plexuses of Auerbach and Meissner). The axones of these supply the smooth muscle of the stomach walls and its vessels.

(3) The inferior gastric plexus receives from the splenic plexus filaments that accompany the left gastro-epiploic artery. It gives filaments to the walls of the stomach, which terminate as in the superior gastric plexus, and it receives filaments from the vagus nerves and from the plexus that accompanies the right gastro-epiploic artery.

(4) The hepatic plexus receives filaments from the coliac plexus and from the left vagus. It accompanies the hepatic artery and gives fibres that form plexuses on the branches of the artery and on their ramifications within the liver and gives secretory fibres to the liver cells. It also gives filaments to the portal vein (fig. 790 ).

The splenic or lienal plexus is formed by filaments from the coliac plexus, the left cceliac (semilunar) ganglion, and from the right vagus. It accompanies the splenic artery and gives filaments which form plexuses on the branches of this artery, and which pass with the branches to supply fibres to the stomach and the pancreas (fig. 790).

(5) The superior mesenteric plexus is formed chiefly by filaments from the lower part of the coliac plexus, but it also receives fibres from the right vagus and fibres direct from the coliac (semilunar) ganglia. At the origin of this plexus, dorsal to the superior mesenteric artery, lies the superior mesenteric ganglion (fig. 790). The filaments of the plexus, which are white and firm, accompany the superior mesenteric artery and, following its branches and their ramifications, are distributed to the walls of the small intestine, the cocum, and the ascending and transverse colon. From the secondary plexuses that accompany the branches of the artery fibres pass to form still other plexuses that lie near the wall of the in testine, between the branches of the artery and between the layers of the mesentery. Filaments pass with the branches of the arteries and from plexuses between them into the intestinal wall, and there form between the longitudinal and circular muscle layers of the intestine the fine gangliated plexus myentericus (plexus of Auerbach), and filaments from this plexus form in the submucosa the delicate plexus submucosus or plexus of Meissner. From these latter plexuses fibres arise which terminate upon the gland cells and smooth muscle fibres of the intestinal wall and its vessels. The white appearance of the filaments of the superior mesenteric plexus is due to the large number of cranio-spinal sensory and visceral motor fibres (vagus especially) in it.

(6) The inferior mesenteric plexus is derived chiefly from the left side of the aortic plexus. It descends upon the inferior mesenteric artery and gives off filaments which accompany the branches of the artery and are distributed to the descending colon and to the ilio-pelvic colon (figs. 790 and 791). The filaments which accompany the left colic branch of the inferior mesenteric artery anastomose with the filaments of the superior mesenteric plexus which areompany the middle colic artery. The filaments which accompany the superior hæmorrhoidal artery form the superior hæmorrhoidal plexus. This plexus gives off the superior hamorrhoidal nerves (fig. 791) which supply the upper part of the rectum and anastomose with the midcle hamorrhoidal plexus.

\section{The Hypogastric Plexus}

The hypogastric plexus lies partiy in the abdominal cavity and partly in the pelvic cavity. It is formed chiefly by filaments continued downward from the aortic plexus, and by the pelvic splanchnics and peripheral branches from the lumbo-sacral nerves and sympathetic trunk (fig. 784). The abdominal part of this plexus consists of plexiform bundles of fibres descending between the common iliac arteries and interlacing in front of the fifth lumbar vertebra to form a broad, flattened, plexiform mass. In its extent it receives branches from the lumbar ganglia of the sympathetic trunk. This plexiform mass then divides into two 
parts, right and left, which descend into the pelvic cavity and which, by English authors, are frequently designated as the pelvic plexuses.

The pelic parts of the hypogastric plexus (pelvic plexuses) lie at the sides of the rectum in the male, and at the siles of the rectum and the vagina in the female. They receive peripheral branches from the sacral ganglia of the sympathetic trunk and visceral efferent fibres by way of the pelvic splanchnics from the second and Fig. 791.-The Hypogastric and Sub-plexuses of the Pelyic Cavity. (After Spalteholz.)

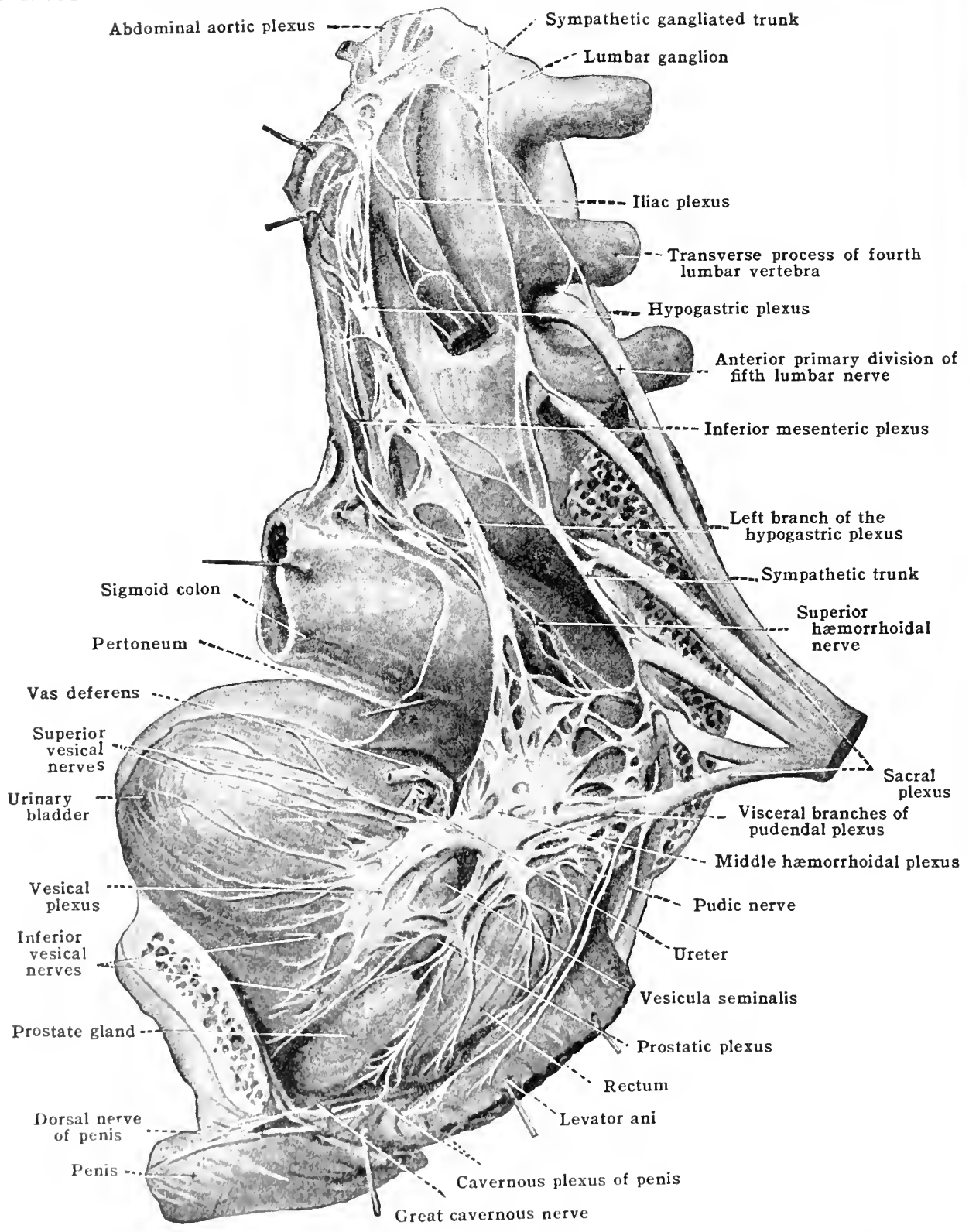

third or thirl and fourth saleral spinal nerves. Warh pelvie part of the plexus aterompanies the correspomeling hypogastric (internal iliac) antery, and gives off

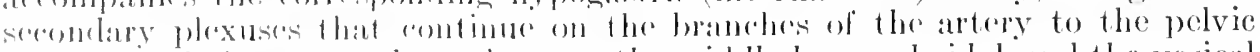

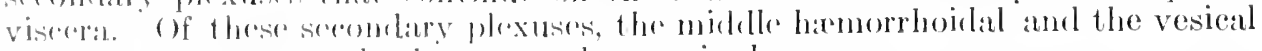

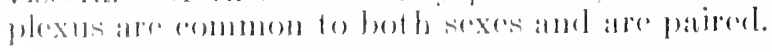

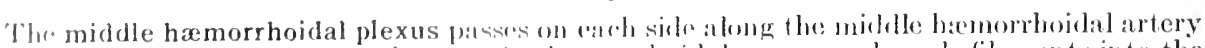

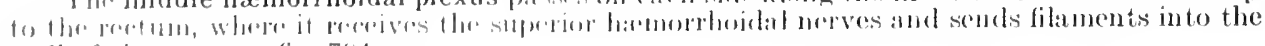
wall of the rectom (fig. Tol). 
The vesical plexus receives some branches from the pelvic parts of the hypogastric plexus, but is largely reinforeed by way of the pelvie splanchnics, from the third and fourth sieral nerves. Each part passes along the corresponding vesieal arteries to the bladder, and gives off two sets of brinehes, namely, the superior vesical neres (fig. 791), which supply the upper part of the bladder-wall and send some branches to the ureter, and the inferior vesical neres, which supply the lower part of the bladder and, in the male, give secondary deferential plexuses to the vas deferens. These plexuses surround the vasa deferentia and the vesieule seminales and anastomose with the spermatic plexuses.

The prostatic plexus, found only in the male, is formed in two parts by nerves of considerable size, and lies chiefly on the sides of the prostate gland between it and the levator ani (fig. 791). Each of these parts supplies the gland and the prostatie part of the urethra, and sends offsets to the neck of the bladder and the vesieular seminales. This plexus is continued forward on either side to form the cavernous plexus of the penis (fig. 791), which anastomoses with branches of the dorsal nerve of the penis, gives off branches to the membranous part of the urethra, and also gives origin to two sets of nerves, namely, the large and the small eavernous nerves of the penis.

The large cavernous nerve, one on each side, runs forward to the middle of the dorsum of the penis, where it anastomoses with the clorsal nerve of the penis on the corresponding side, and ends in twigs which are distributed ehiefly to the walls of the simuses of the corpus cavernosum penis, but some of the terminal filaments supply the corpus cavernosum urethrip (corpus spongiosum) (fig. 791).

The small cavernous nerves are small filaments which pieree the uro-genital trigone (triangular ligament) and the compressor urethræ, and enter the posterior part of the corpus cavernosum.

The utero-vaginal plexus, found in the female, is formed in its upper part on cach side largely by fibres derived from the pelvie part of the hypogastrie plexus, hut it receives some fibres from the pelvie splanchnies of the third and fourth sacral nerves. The nerves from this part of the plexus accompany the uterine arteries as they pass between the layers of the broad ligament. Some aceompany each uterine artery and its branches to their termination, but a considerable number of fibres leave the artery and pass into the body of the uterus to supply its lower part and eervix. Between the lavers of the broad ligament this plexus anastomoses with the ovarian plexus and sends some filaments to the uterine tube (Fallopian tube). The lower part of the plexus utero-vaginalis receives some fibres on each side from the pelvic part of the hypogastrie plexus, but it is formed chiefly by efferent visceral fibres from the second, third, and fourth sacral nerves. These fibres terminate in contaet with intrinsie cell-borlies whose axones supply the wall and mueous membrane of the vagina and urethra. From the plexus on the anterior surface of the vagina fibres pass to form the cavernous plexus of the clitoris, which gives off the great and lesser cavernous nerves of the clitoris for the supply of the clitoris. The utero-vaginal plexus of the female corresponds to the prostatie plexus of the male.

References for the Nervous System. A. General. Barker, Nervous System, 1899; Edinger, Vorlesungen, 1908; Johnston, Nervous System, 1906; (phylogeny) Parker, Anat. Rec., vol. 4; (development) Streeter, in Keibel and Mall's Human Embryology. B. Brain and Spinal Cord. Bechterew, Funktionen der Nervencentra, 3 vols., 1908; (cell-structure) Malone, Anat. Ree., vol. 7; (axone-sheaths) Hardesty, Amer. Jour. Anat., vol. 4; (cortical localization) Donaldson, Jour. Nerv. and Mental Dis., vol. 13; Smith, Jour. Anat. and Physiol., vol. 41; Israelsohn Arb. Wien. neurol. Inst., vol. 20; (central fissure) Symington and Crymble, Jour. Anat. and Physiol., vol. 47; (biain-weight) Pearl, Jour. Comp. Neurol., vol. 25; Spitzka, Phila. Med. Jour., 1903; (centrieles Harvey, Anat. Ree., vol. 4; (mid-brain and medulla) Sabin, Atlas, 1901; (trigeminal nuclei) Willems, Nevraxe, T. 12; (spinal cord, comparative) Bullard, Amer. Jour. Anat., vol. 14. C. Peripheral. (Histogenesis) Barreen, Amer. Jour. Anat., vol. 2; (experimental) Harrison, Amer. Jour. Anat., vol. 5; Jour. Exper. Zool., vol. 9; (phylogeny of facial) Sheldon, Anat. Rec., vol. 3; (trigeminus) Symington, Jour. Anat. and Physiol., vol. 45; (nerws termualis) Johnston, Anat. Rec., vol. 8. (afferent spinal neurones) Ranson, Jour. Comp. Neurol., vol. 18; (structure) Ranson, Anat. Rec., vol. 3; (brachial plexus) Todd, Anat. Anz., Brl. 42; (abdominal, statistical) Bardeen, Amer. Jour. Anat., vol. 1 (sympathetic terminations) Boeke, Anat. Anz., vol. 44. 


\section{SECTION TIII \\ SPECIAL SENSE ORGANS}

Revised for the Fifth Edition

Br DAVID WATERston, M.A.,M.D., F.R.C.S.E., King's College, London

PROFESSOR OF ANATOMY IN THE UNIVERSTY OF LONDON

\section{GENERAL CONSIDERATIONS}

$\mathrm{T}$ THE term "special sense organs" indicates those structures situated on or near the surface of the body which receive the impressions of sound, light taste and smell, and transmit them to the brain in the form of nerve impulses.

The essential difference between what is termed general sensibility and the special senses lies in the fact that the organs of special sense are each sensitive to a specific stimulus which does not affect the general sensory apparatus of the body surface to an appreciable degree.

Thus, the waves of light or of sound, flavoured substances which have a taste, and the minute particles which stimulate the sensory organ for smell-all these varied stimuli create no impression when they come into contact with the sensitive general surface of the botly.

The vibration of sound waves present in an organ pipe may indeed be felt by the hand, but the sensation is that of vibration and not of sound.

This difference in function between the ordinary and the special senses as well as the difference between the individual organs of special sense, is associated with a difference in structure; for each special sense organ has a characteristic receptive mechanism of cells highly specialised in form and structure, which receive the stimuli coming from without, and transmit them to the brain in the form of a nerve-current. These cells may be derived by the specialisation of certain cells coming directly from the surface of the body, or they may be cells derived from the central nervous system-as in the case of the eye. In this case, the cells are placed in close relation to the terminals of a special cranial nerve.

Many of the sense organs, and especially the eye and ear, are highly complex in structure. The complexity is due largely to the elaborate mechanical arrangement for receiving the external stimulus, and for conveying it to, or focussing it upon, the sensory cells proper.

It must always be borne in mind that sensation itself is a function of the brain-it is the response in consciousness to the afferent impressions transmitted to the brain by the sensory nerves. Further, the quality of the sensation does not arise in the sense organ, but in the brain itself. Thus, stimulation of the trunk of the optic nerve by mechanical means produces sensations of light, apart from stimulation of the retina.

In the following account, the organs of smell, taste, vision and hearing will be successively considered.

\section{THE OLFACTORY ORGAN}

The olfactory apparatus [organon olfactus] in man does not reach the high development which is found in many of the lower animals. In them, not only is the sensory apparatus found distributed over a large area of the nasal mucous membrane, but the central connections of the olfactory nerves make up a considerable portion of the brain, including all those structures known under the name of rhinencephalon. In man, sensibility to smell is localised to a comparatively limited area in the upper part of the nasal cavity, known as the olfactory area.

The structure of the nose in all its parts has been fully dealt with in the 1049 
section on the Respiratory Srsten-and hence it is not necessary to describe the whole nasal carity.

The olfactory area of the nose includes the uppermost part of the nasal fossa on the lateral wall above the superior concha, and a shightly larger area of the septum.

Fig. 792 shows the size of this area, and it will be noticed that the area on the lateral wall of the nose does not coincide with the area of the superior concha, but is rather smaller. It should be added that the olfactory nerves can be traced to a somewhat larger area of the mucous membrane, to the middle concha; it is, therefore, possible that the area indicated is too small.

The mucous membrane in the olfactory area has special characters, both naked eye and microscopie, which distinguish it from the rest of the nasal mueous

Fig. 792.-Dlagral of the Distribution of the Nerves in the Nasal Cavitr. (Poirier and Charpy.) The olfactory area is represented by dots. A, septum. B, lateral wall.

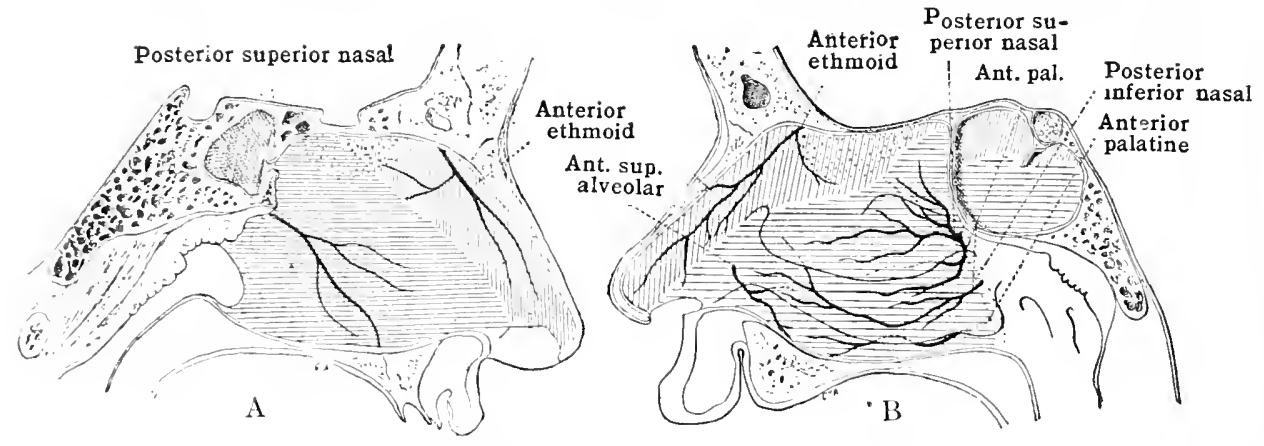

membrane. It is usually of a yellowish colour, and is soft and pulpy in consistence It is covered by a columnar eiliated epithelium and contains numerous glands (glands of Bowman).

The olfactory apparatus within it consists of the olfactory cells. These cells are elongated spindle-shaped structures, lying between the deeper parts of the investing columnar cells. From carh a slender process passes to the surface of the mucosa, and terminates in a group of short hair-like processes, the olfactory hairs ( $\mathrm{v}$. Bumm), while from the deep portion of the cell a long slender process passes deeply into the mucosa. These processes resemble nerve filaments, with no medullary sheath, and they pass in the olfactory nerves to the olfactory bulb, in which they terminate in arborisation around the dendritic enlargements of the mitral cells of the olfactory buhl) (see fig. 795; also (Offactory Nerve, p. 929).

fig. 793.- Shetion showing tie Develophent of the Olfactory Pit.

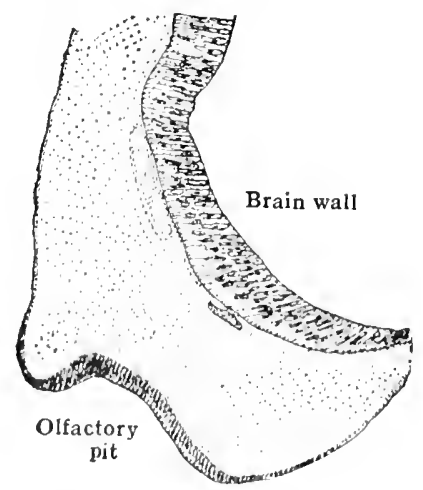

The connections of the olfactory hundle and tract with the brain are fully dealt with in the seetion on the Neivous sixstese.

The development of the olfactory organ is connerted with the development of the nose,

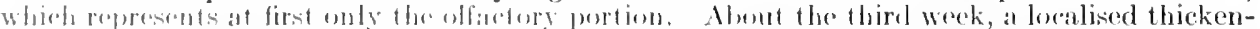

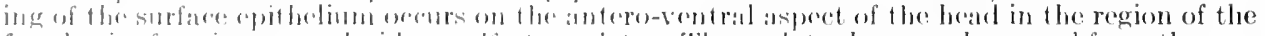

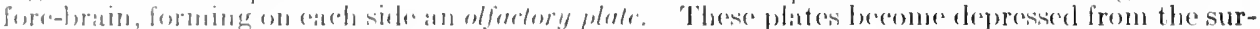
fane ley the growth of the margins, giving rise to the olfactory pits. The lurther changes are 
associated with the formation of the face and nose (see Morphogenesis). The cells of the surface epithelium on the olfactory pits in part form olfactory cells, and send processes inward which pass to the olfactory lobe of the brain, and form the olfactory nerve.

The organ of Jacobson is a small rudimentary structure in man. It is represented by a minute canal, 2 to $9 \mathrm{~mm}$. long, placed on each side in the lower portion of the nasal septim, opening on the surface slightly above the orifice of the naso-palatine canal. Below it lies a small piece of cartilage, lying below the eartilage of the septum, and known as Jacobson's cartilage. The canal is lined by epithelium, but contains no olfactory cells. It is developed from a small portion of the olfactory plate which becomes separated from the area which gives rise to epithelium of the olfactory region.

\section{ORGAN OF TASTE}

The taste organs [organon gustus] consist of minute epithelial structures, the taste buds [calyculi gustatorii], situated mainly in the epithelial covering of the tongue and also in the epiglottis.

In the tongue, the taste buds are found mainly on the walls of the vallate papillæ (see p. 1106), but they are found to a slight extent scattered over the whole area of distribution of the glosso-pharyngeal nerve, on the surface of the foliate and fungifor $m$ papillæ, and on the plic fimbriatæ on the lower surface of the tongue.

Figs. 794 and 795.-Diagrans Illustrativg the Strudeture of the Taste Buds aNd The OlFactory IIUcosa.
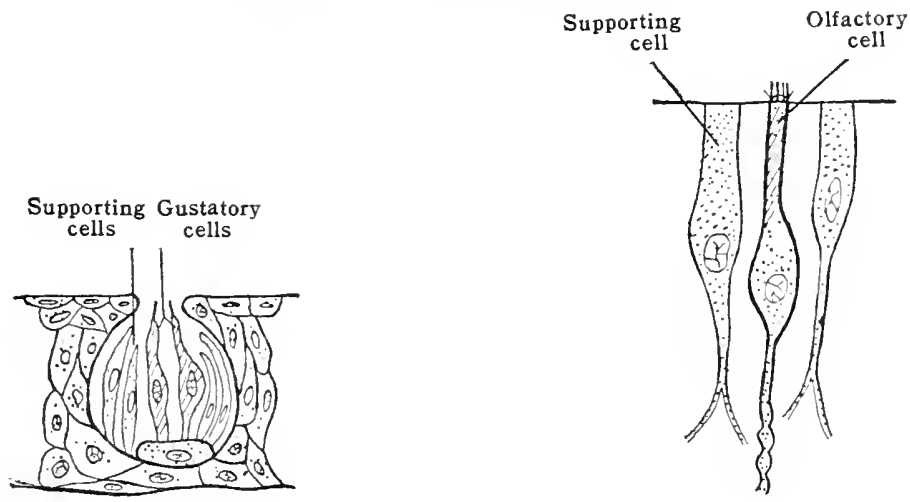

In the fœtus, the distribution is even wider, and they have been described as occurring on the soft palate, palatine arches, uvila, and in the mucous membrane covering the medial surfaces of the arytenoid cartilages. It is possible that such structures, though found in these regions in the fotus, usually disappear in the adult.

Each taste bud is a hollow conical or oval structure, measuring .07-.08 mm. in length. At one end it opens by a small channel, termed the pore canal, which passes to the surface between adjacent epithelial cells. The surface opening is termed the outer pore and the opening at the taste bud the inner taste pore.

The taste bud consists of epithelial supporting, of gustatory and of basal cells, arranged as seen in figure 794 . The gustatory cells are long slender fusiform cells. The free end of each passes to the inner taste pore, and terminates in stiff hair-like processes, which project toward the pore canal. The deep end of each is connected with a basal cell. Terminal branches of the glosso-pharyngeal nerve ramify around the gustatory celts, and convey to the brain the impulses generated by contact of the ends of these cells with sapid particles. The epithelial supporting cells line the taste buds, and also project into the interior between the olfactory cells.

Development. - The taste buds appear comparatively late in embryonic life - about the third month. They arisc mainly from the entodermal portion of the tonguc, by differentiation of the deeper cells of the epithelial covering over localised areas. Around these cells terminations of the glosso-pharyngeal nerve are found. These cells assume the characteristic shape and arrangement of the adult to form a taste bud. At first the opening of the bud lics upon the surface, but as the surrounding epithelial cells increase in size and thickness, the pore-canal is formed as a space between adjacent epithelial cells on the summit of the bud.

\section{THE EYE}

The sensory portion of the eye is the retina, a cup-shaped membrane, which lines the posterior half of the eyeball. It is formed of layers of nerve cells, from 
which processes pass to the brain in the optic nerve. The eyeball is a hollow spherical structure, whose wall is formed externally by a fibrous tunic including the sclera (the white of the eye), and the cornea (the transparent area in the anterior aspect of the eyeball). Internal to the tunic formed by these membranes is a pigmented rascular membrane, the chorioidal membrane, of which the anterior part forms the iris, or the coloured part of the eye.

Within these tunics is formed a cavity, in which lies the crystalline lens of the eye. In front and behind the lens are two chambers; that in front of the lens contains the aqueous humour and that behind it the vitreous.

The study of the eve is best undertaken by examining the eye in the living, and subsequently by the dissection of specimens, and that order is followed in this account.

\section{General Surface View}

The two eyes are situated nearly in the line where the upper and middle thirds of the face meet; they lie right and left of the root of the nose, the most prominent part of the front of each globe being about $3 \mathrm{~cm}$. ( $1 \frac{1}{4} \mathrm{in}$.) from the mid-line of the face. Each eye is overshadowed by the corresponding eyebrow, and is eapable of being concealed by its eyelids, upper and lower.

The orbital margin may be traced all round with the finger. At the junction of the medial and intermediate thirds of the upper margin the supraorbital notch (incisura supraorbitalis) can usually be felt, and the supraorbital nerve passing through it can sometimes be made to roll from side to side under the finger. The medial margin is the most difficult to trace in this way, partly because it is more rounded off than the others, partly because it is bridged over by a firm band (medial palpebral ligament), passing medially from the merlial angle of the eyelids; below this band, however, a sharp bony crest is felt, which lies anterior to the lacrimal sac. Note how the eye is protected by the rim of the orbit, above and below; if we lay a hard flat

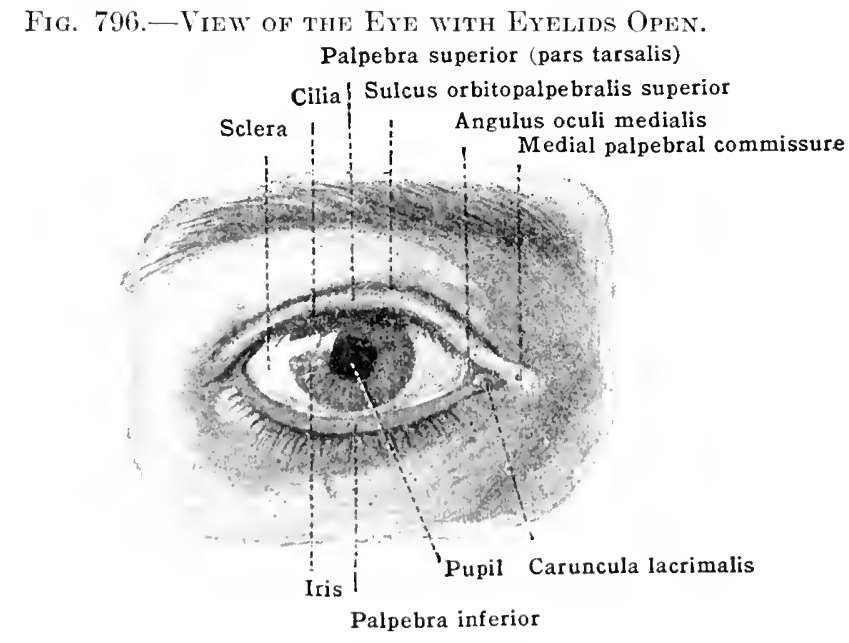

borly over the orthit opening, it will rest upon the upper and lower bony prominenees, and will not touch the surface of the globe. Medially, the eye is protected from injury mainly by the hrielge of the nose; laterally it is most readily vulnerable, as liere the orbital rim is comparatively low. With one finger plared over the elosed upper hid, press the eyeball gently backward into the orlit, and observe the elastic resistance met with, flue to the fact that the globe rests posteriorly on a pard of fatt.

The spate between the free edges of the upper and lower lids is known as the palpebral aperture [rima palpebrarmu]: it is a nere slit when the licls are closed; but when they are open ifs shape is, ronghly, that of an ahmond lying with its long axis horizontal, and about thirty millinretres in length.

When the eyes are limected to an object straight in front of them, this aperture is about twolve millimetres wide, hut is width varies with upward and downward movenents of the eyoball, boing greatest on hoking strongly upward, diminishing gradually as the eye looks progressively lower. 'The angles formorl by the morting of the lids at each end of the palpebral aperture are named respectively the literal and medial angles (or annthi) angulus oeuli lateralis, modialis], of which the latival is shate, while the merlial is romeded off. On a closer in-

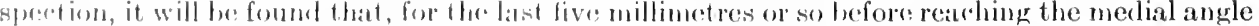
the oflgres of the lifls rum an almost parallel comrse, and are lere devoid of lashes. 'Through the

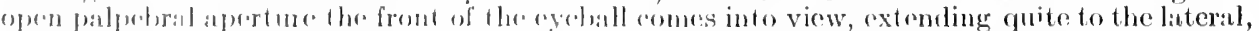
but not reaching as far as the medial, aluglo; just within the latter wo find a snall reddish promi-

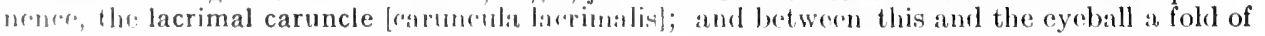


conjunctiva known as the plica semilunaris. While the eye is open, press one finger on the skin, a little beyond the lateral angle, and draw it firmly away from the middle line; observe that the upper lid then falls over the eyeball, and that the outline of a firm band already leferrerl to (the medial palpebral ligament) becomes evident, passing between the medial angle and the nose. The falling of the lid is caused by our dragging upon a ligament (the lateral palpebral raphé) to which the lateral end of its tarsus is attached, and so putting the lid itself upon the stretch. If, while the eyeball is directed downward, we place one finger on the lateral end of the upper eyelid and draw it forcibly upward and laterally, we can usually cause the lower division of the lacrimal gland to present just above the lateral angle.

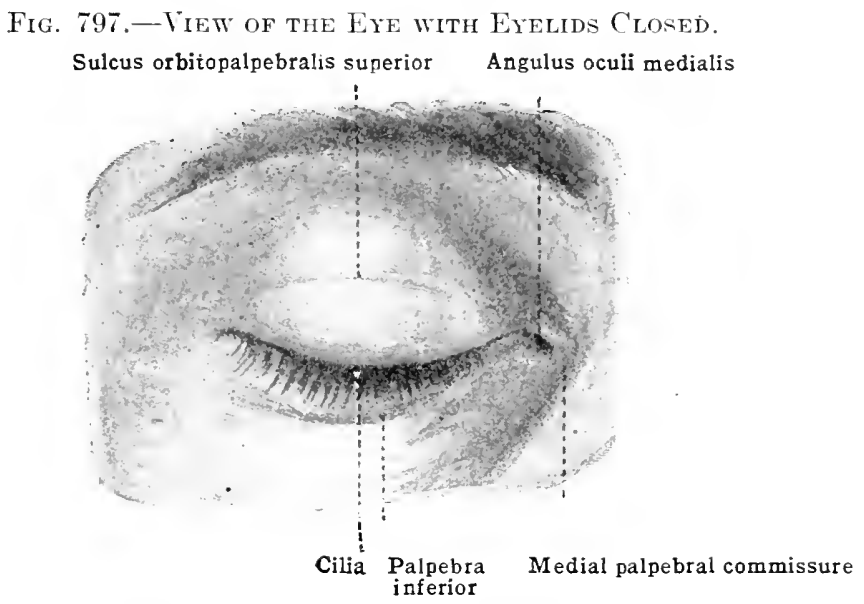

The upper eyelid [palpebra superior] is much broarler than the lower, extending upward as far as the eyebrow. The skin covering it is loosely attached to the subjacent tissues above, but more firmly below, nearer the free margin, where it overlies a firm fibrous tissue called the tarsus superior. When the eye is open, a fold is present at the upper border of this lower more tightly applied portion of skin, called the superior palpebral fold, and by it the lid is marked off into an upper or orbital, and a lower or tarsal, division. The presence of the tarsus can be readily appreciated on our pinching horizontally the entire thickness of the eyelid below the palpebral fold. The lower eyelid [palpebra inferior] is similarly divided anatomically into a tarsal and an orbital part, but the demarcation is sometimes unrecognisable on the surface,

Fig. 798.- View of Medial Region of the Eye, with the Erelids Widely Separated and the Eveball Turned Laterally.

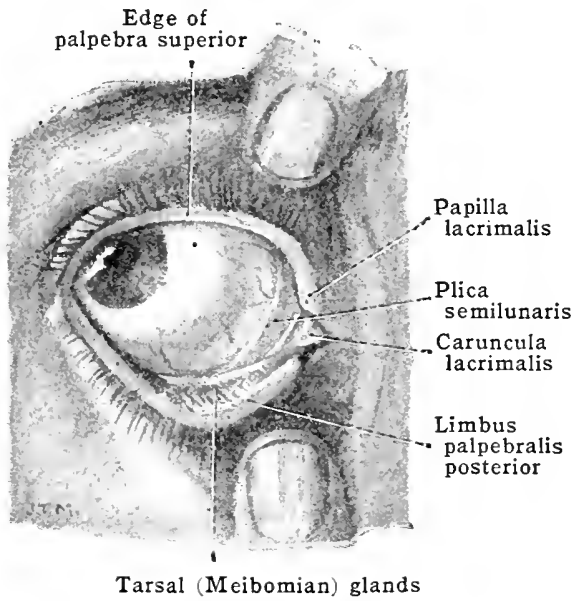

though a fold or groove (the inferior palpobral) is usually visible when the eye is widely opened. There is no precise limit of this lid below, but it may be regarded as extenting to the level of the lower margin of the orbit. Numerous very fine short hairs are seen on the anterior surface of both eyelids. Each eyelid presents an anterior and a posterior surface, separated by a free margin with two edges:- (a) An anterior, rounded edge [limbus palpebralis anterior] along which the stiff cilia, or eyelashes, are closely placed in a triple row; and $(b)$ a sharp posterior edge [limbus palpebralis posterior] which is applied to the surface of the globe (see fig. \$13). The cilia of both eyelids have their points turned away from the palpebral aperture, so that the upper ones curve upward, and the lower downward; the cilia of the upper lid are the stronger, 
and those in the middle of each row are longer than those at each end. Between the two erlges just described, the lid-margin has a smooth surface, on which is a single row of minute apertures, the openings of large modified sebaceous glands, the tarsal or Meibomian glands. It is by these glistening, well-lubricated surfaces that the opposite lids come into apposition when they are closed. The secretion of these glands is known as the sebum palpebrale. The sharp posterior edge of the lid-margin marks the situation of the transition of skin into mucous membrane. Near the medial end of the margin of the lids we find a prominence, the lacrimal papilla, on the summit of which is a small hole [punctum lacrimale], the opening of the lacrimal duet (ductus lacrimalis) for the passage of tear's into the lacrimal sac. The lower punctum is rather larger than the upper, and is placed further from the medial angle of the eye.

If we now examine the posterior surface of the eyelids-e. g., of the lower-we observe that it is lined by a soft mucous membrane, the palpebral conjunctiva [tunica conjunctiva palpebrarum]. Uver the tarsal part of the lic the conjunctiva is closely adherent, but beyond this it is freely movable along with the loose submucous tissue here present. On tracing it backward, we find that it covers the whole posterior surface of the lids, and is then continued forward over the front of the eyeball, forming the conjunctival tunic of the globe [tunica conjunctiva bulbi]. The bend it makes as it changes its direction here is called the conjunctival fornix [fornix conjunctive superior or inferior]. Numerous underlying blood-vessels are visible through the palpebral conjunctiva, and under cover of its tarsal part we can see a series of nearly straight, paralled, light yellow lines, arranged perpendicularly to the free margin of the lidthe tarsal glands. The conjunctiva over the medial and lateral fourths of each lid is not quite so smooth as elsewhere, and is normally of a deeper red colour; we shall find later that there are glands well developed in these positions.

When the eyelids are opened naturally, we see through the palpebral aperture the following: the greater part of the transparent cornea, and behind it the coloured iris with the pupil in its centre; white sclera to the medial and lateral sides of the cormea; the semilunar fold and lacrimal caruncle at the medial angle. The extent of the eyeball visible in this way varies according to its position. Thus, with the eyes looking straight forward, the lower margin of the upper lid is nearly opposite to the top of the cornea, or, more strictly, to a line midway between the top of the cornea and the upper border of the pupil, while the lower hid corresponds with the lower margin of the cornea. When the eyes are directed strongly upward, the upper lid is relatively on a slightly higher level, as it is simultaneously raised, but the lower lid now leaves a strip of sctera exposed below the cornea. On looking downward the upper lid covers the upper part of the cornea as low down as the level of the fop of the pupil, while the lower lid is about midway between the pupil and the lower margin of the cornea.

If we draw the evelicls forcibly apart, we expose the whole cornea, and a zone of sclera about eight and a half millimetres in breadth above and below, and ten millimetres in breadth to the lateral and medial sides-altocether about one-third of the globe; all the eyeball thus exposed is covered by the ocular conjunctiva [tunical conjunctiva bulbi]. Over the selera the conjunctiva is freely movable, and through it we see superficial blood-vessels that can be made to slip from side to side along with it (episcleral vessels). Occasionally other deeper vessels may also be seen which do not move with the conjunctiva, but are attached to the sclera (anterior eiliary arteries and veins). Near the corneal border the conjunctiva ceases to be freely movable, and it is closely adherent to the whole anterior surface of the cornea, giving the latter its characteristic bright, reflecting appearance; no blood-vessels are visible through it here in health. When the licls are shut, the space encloserl between their posterior surfaces and the front of the eyeball is thus everywhere lined by conjunctiva, and is known as the conjunctival sac.

Not unfrequently the tendinous insertions of some or all of the recti muscles into the sclera may he seen through the conjunctiva, each insertion appearing as a series of whitish parallel lines luming toward, but terninating about seven millinetres from, the corresponding corneal border.

The cornea appears as a transparent dome, having a curvature greater than that of the sclerat; the junction of the two unequally curverl surfaces is marked by a shallow depression punning around the orornea, known as the scleral sulcus [sulcus selerex]. In outline the eornea is noarly circulas, but its horizontal diameter is slightly greater than its vertiral. Between it and the jris a suane exists, whose depth we an estimate roughly by looking at the eye from one

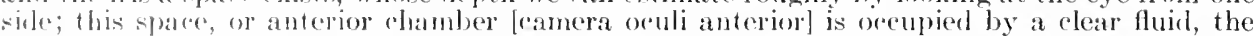
afueous hummur. Almost the whole anterior surface of the iris is visible, its extreme periphery only boring concealed by scleria.

In colour the iris varies mreatly in different individuals. Near its centre (really a little up and in) a round holn oxists in the iris, the black pupil [pupilla], whose size varies considerably in diffrent eyrs, and in the same eye acoording to temporary comditions, suld as exposure to light, etce

() 1 les surface of the iris we sere a number of ridges [plica iridis] rumbing more or less radially;

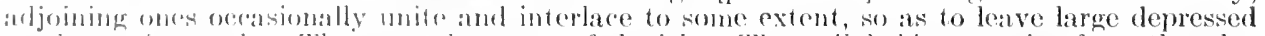

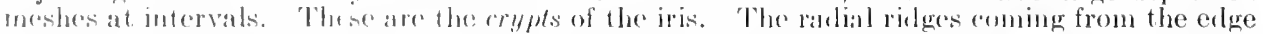
of the pupil, and those coming from the more peripheral part of the iris, meet in a zigzag ele-

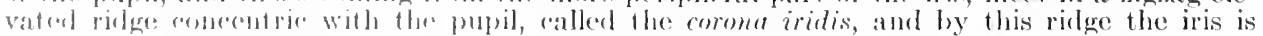

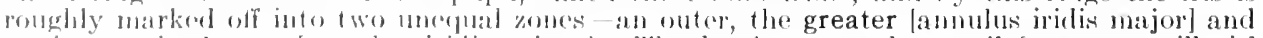
an immer, the lesser [anmbles irilis mimol. 'The bordes next the pupil [margo pupilaris]

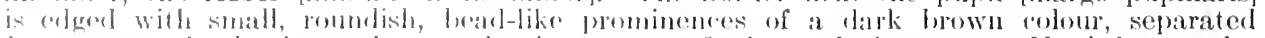

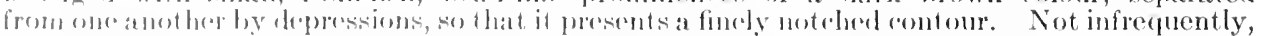

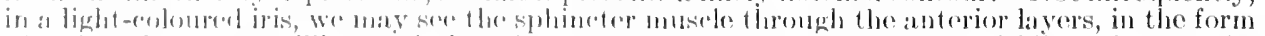

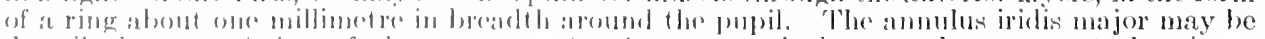

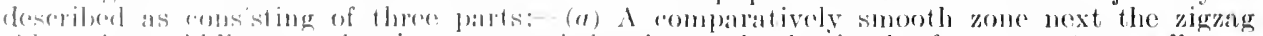

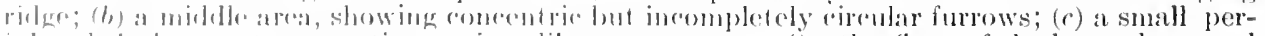

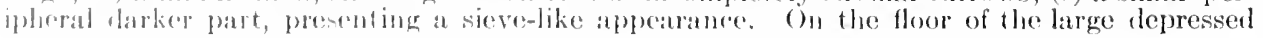


meshes, or crypts, parallel radial ressels can be traced, belonging to the iris-stroma. The zigzag line mentioned above corresponds to the position of the circulus arteriosus minor. Occasionally, especially in a light iris, superficial pigment spots of a rusty brown colour occur.

(In examining the living eye, the ophthalmoscope nay nom be used, so as to gain a view of the fundus, and to study the termination of the optic nerve, the distribution of the larger retinal ressels, etc.)

The general red reflex obtained from the fundus is due to the blood in a rapillary network (chorio-capillaris) situated in the inner part of the chorioid. To the nasal side of the centre of the fundus is a paler area of a disc shape corresponding to the intraocular end of the optic nerve, and known as the papilla of the optic nerve [papilla n. optici]. 'This papilla (or 'optic (tise') is nearly circular, but usually slightly oval vertically; it is of a light orange-pink colour, with a characteristic superficial transhcency; its lateral third segment is paler than the rest as nervefibres and capillaries here are fewer in number. About its centre we often observe a wellmarked whitish depression [excavatio papille n. optici], formed by the dispersion of the nervefibres as they spread out over the fundus; at the bottom of this depression a sieve-like appearance may be seen, due to the presence of the lamina cribrosa scleræ, which consists of a white fibrous tissue framework, with small, roundish, light-grey meshes in it, through which the nerve-fibre bundles pass. Also near the centre of the papilla, the retinal blood-ressels first come into view, the arteries narrower in size and lighter in colour than the veins; they divide dichotomously as they are distributed over the fundus. The retina proper is so transparent as to be ophthalmoscopically invisible, but its pigment-epithelium gives a very finely granular or darkly stippled appearance to the general red reflex. In the centre of the fundus, and therefore to the lateral side of the papilla, the ophthalmoscope often shows a shifting halo of light playing round a

Fig. 799.-The Normal Fundus of the Eyeball. (Parsons.)

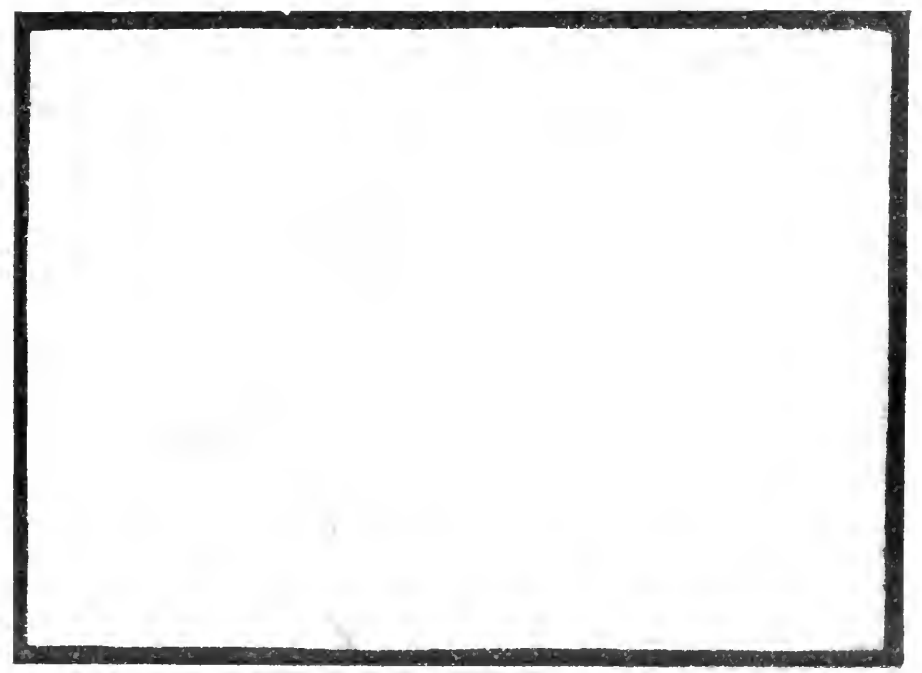

horizontally oval, comparatively dark enclosed area; this latter corresponds to the yellow spot [macula lutea] region, and about its centre a small pale spot usually marks the position of the fovea centralis.

Two structures visible at the nasal end of the palpebral aperture have been previously mentioned, and should now be examined more narrowly. The lacrimal caruncle is an island of modified skin, and fine hairs can commonly be detected on its surface, and it contains sebareous and sweat glands. Lateral to it and separated from it by a narrow groove, is the semilunar fold of conjunctiva; it rests on the eychall, and is a rudiment of the third eyelid or nictitating membrane, present in birds and well represented in many other vertebrates.

\section{Examination OF THE ETEBall}

(In the following account, the structure of the eyeball is described as it would appear upon dissection.)

The eyeball [bulbus oculi] is almost spherical, but not perfectly so, mainly because its anterior, clear, or corneal segment has a greater curvature than the rest of the eye. Considering it as a globe, it has an anterior pole [polus anterior] and a posterior pole [polus posterior]; the former corresponding to the centre of the front of the cornea, the latter to the center of the posterior curvature. In imaginary straight line joining the two poles is called the axis of the eyeball. The equator of the eye is that part of its surface which lies midway between the two poles. The various meridians are eircles which intersect the poles. The sagittal axis of the globe is the greatest (about $24.5 \mathrm{~mm}$.), the vertical equatorial the least 
(about $23.5 \mathrm{~mm}$.), and the transverse equatorial axis is intermediate in length (about 23.9), so that the eyeball is in reality an ellipsoid, flattened slightly from above downward. These figures refer to the adult male; in the female the ey eball is $.5 \mathrm{~mm}$. smaller in all axes. Again, if the globe is divided in its mid-sagittal plane, the nasal division will be found to be slightly smaller than the temporal. The optic nerve joins the globe three or four millimetres to the nasal side of the posterior pole.

The shape of the eye depends on, and is preserved by, the outermost tunic, formed conjointly by the cornea and sclera, the entire outer surfaces of which are now in riew. The anterior or corneal part has already been examined. All around the cornea there remains a little adherent conjunctiva; elsewhere, the sclera is directly exposed, except for some loose connective tissue which adheres to it, especially around the optic nerve entrance. In front of the equator we see the tendinous insertions of the four recti muscles. Behind the equator are the insertions of the two oblique museles - that of the superior oblique tendinous, and further forward; that of the inferior more fleshy, and placed between the optic nerve and the lateral rectus.

Fig. 800.-Diagramatic View of the Ingertions of the Ocular Muscles.
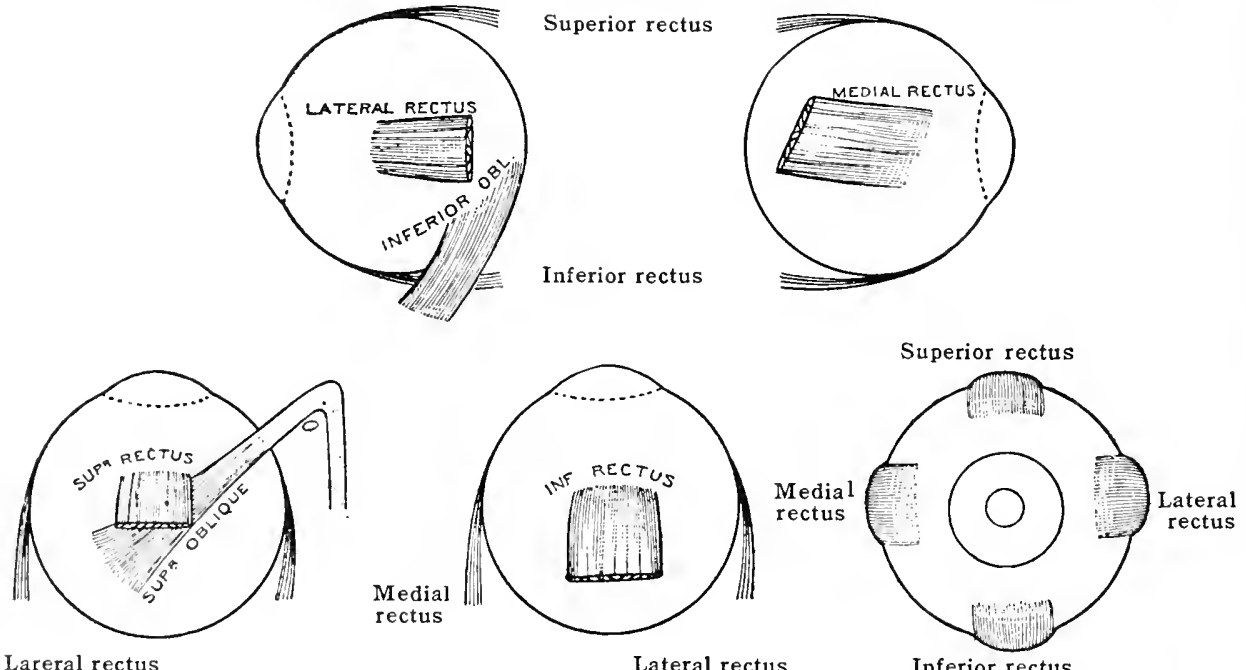

Lareral rectus

Lateral rectus

Inferior rectus

It is difficult to recognise the different recti muscles by their insertions if we do not know whether the eye examined is a right or a left one. To determine this we should hold the globe with the optic nerve toward us, and in the natural position with the superior oblique tendon uppermost. The inferior oblique tendon will now point to the side to which the eye belongs, and we can consequently determine the different reeti muscles.

The medial [m. rectus medialis] rectus is inserted nearest (5.5 to $7 \mathrm{~mm}$. from) the corneal border; the superior [m. rectus superior] rectus commonly, sometimes the lateral [m. rectus lateralis], is inserterl furthest from it $(7.7$ to $8 \mathrm{~mm}$.). Nll the recti tendons are broad and thin, Wut that of the medial is the broalest ( 8 to $10.3 \mathrm{~mm}$.); those of the lateral and inferior the narrowest ( $; 169.2$, or $9.8 \mathrm{~mm}$, respectively). The greatest interval between two neighbouring tadons is thit lontween the superior and medial reeti (about $12 \mathrm{~mm}$.); the least is between the superior and hatral ( $7 \mathrm{~mm}$.). The form of the lines of insertion of the different tendons varies comsiderably, the inferior being almost straight, the superior and lateral convex forward, the medial further removed from the colneal border helow than above.

The insertions of the ollique museles [mm. obliqui] are at more than double the average distance of the insertions of the recti from the corneal border. That of the superior oblique is formb on the superior surface of the sclera, about sixten millimetres from the corneal edge, in the form of a line $10.7 \mathrm{~mm}$. Iong sloping from before backward and mediatly. The inferior (b) licpe has a long fleshy insertion lying botween the lateral rectus and the optic nerve ent rance; the posterion end of the insertion, which is also the higher, is only about five to six millimetres from the optic norve, and from this point it slopes forward, laterally, and slightly downward.

Sieveral small nerves and two arteries may be seen running forward and ultimately perforating the selera not, far from the entrance of the optie nerve. The two arteries are the long posterior ciliary [aa. eiliares posteriores longi]; they both perforate the glohe in the horizontal meridian, 3.5 $\mathrm{mm}$. from the optie nerve, one on the lateral, the other on the medial, sicle. Theshort ciliary arteries [aa. eiliares 
posteriores breves] are too small to be seen in an ordinary examination. The nerves are the long and short ciliary [nn. ciliares longi, breves]. Nearer the equator large venous trunks emerge; they can be traced for some distance in front of their exit as dark lines, running antero-posteriorly internal to the sclera. The optic nerve is seen in section, surrounded loosely by a thick outer sheath; in the centre of the nerve-section a small red spot indicates the position of the central retinal blood-ressels [a. et v. centralis retince].

(The following struetures appear in an eveball divided into fore and hind halves by eutting through it in the equatorial plane.)

1. Posterior hemisphere seen from in front.-This is much the same view that the ophthalmoscope affords us. Unless the eye be very fresh, however, the retina will have lost its transparency, and will now present the appearance of a thin whitish membrane, detached in folds from the external coats, but still adlherent at the optic papilla. The vitreous jelly lying within the retinal eup may be torn away. In the human eye the retina next the posterior pole is stained yellow [macula lutea]. On turning the retina over, a little pigment may be seen adhering to its outer surface here and there. Cut through the retina close to the optic lisc all around and remove it: note how easily it is tom. We now see a dark brown surface, consisting of the retinal pigment layer [stratum pigmenti retine] adherent to the inner surface of the chorioid. Brush off the retinal pigment under water. The chorioid thus exposed ean for the most part be fairly easily torn away from the thick sclera, as a lymph-space exists between them, but the attachment is firm around the optie nerve entrance, and also where the arteries and nerves join the chorioid after penetrating the sclera. The ehorioid is darkly pigmented, of a brown colour, with markings on its surfaces corresponding to the distribution of its large veins. The inner

Fig. 801.-Axterior Hemisphere of Eyeball, Viewed from Behind.

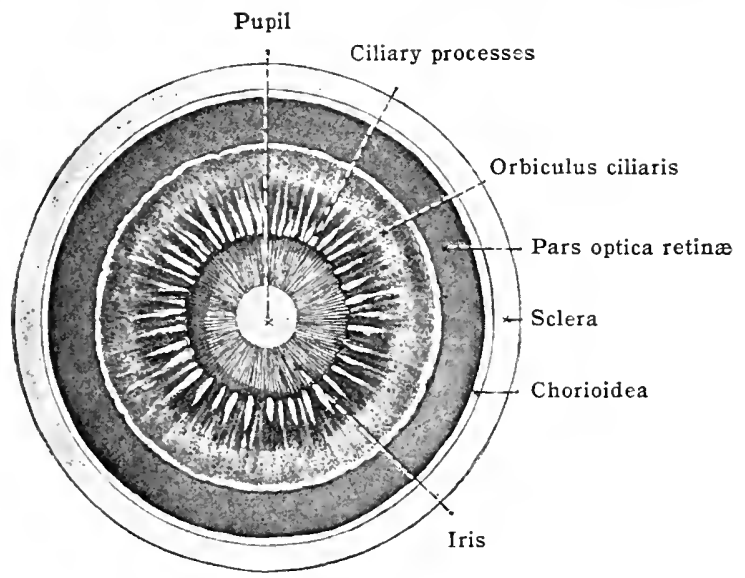

surface of the selera is of a light brownish colour, mainly from the presence of a delicate pigmented layer, the lamina suprachorioidea, which adheres partly to it, partly to the chorioid, giving to their adjacent surfaces a flocculent appearance when examined under water.

2. Anterior hemisphere viewed from behind.- The round opening of the pupil is visible in the middle, in front of the large elear crystalline lens. The retina proper extends forward a little way from the line of seetion, and then ends abruptly in a wavy line called the ora serrata, beyond which it is only represented by a very thin membrane [pars ciliaris retinæ]. Outside the periphery of the lens are a number of ciliary processes arranged elosely together in a circle concentric with the pupil, and each radially elongated; posteriorly they are eontinuous with $\mathrm{n}$ umerous fine folds, also radial, which soon get very indistinet as they pass baekward, but reach almost to the ora serrata [plicæ ciliares]. Between the front of the ciliary processes and the edge of the pupil hies the iris. On removal of the retina the inner surface of all this region is seen to be darkly pigmented, but espeeially dark in front of the position of the ora serrata. Vitreous probably still adheres to the back of the lens, and by pulling upon it the lens can be removed along with its capsule and suspensory ligament; some pigment will now he found adhering to the front of the vitreous, torn from the eiliary processes, which are consequently now lighter in colour than before. The lens-capsule is transparent, and has a smooth glistening outer surface; through it a greyish, star-shaped figure may be observed on the anterior and posterior surfaces of the lens. The suspensory ligament is a transparent membrane at tached to the capsule of the lens about its equator, and is best seen by floating the lens in water in a glass vessel placed on a dark ground. On opening the capsule we expose the lens itself, which is superfieially soft and ghutinous to the touch, but becomes firmer as we rub ofi its outer layers and approach its centre. Carefully tear the ehorioid and iris from the sclerotic as far as possible; a firm adhesion exists just behind the eorneal periphery. The outer surface of the chorioid thus exposed is found to be also rather darkly pigmented, but it shows a white ring corresponding to the adhesion just mentioned, and a pale area behind this ring indieates the position of the ciliary muscle [m. eiliaris]. On this surface numerous white nerve-cords are risible rumning 
forward. Observe that the iris, the ciliary processes, etc., and the chorioid are all different parts of the same ocular tunic-mere local modifications of it. Similarly the sclera and cornea are seen to blend together to form one outer coat.

An eyeball should now be placed for half an hour in a freezing mixture of crushed ice and salt. It will thus become quite hard, and should at once be divided into two parts by cutting it antero-posteriorly through the centre of the cornea and the optic nerve. We thus gain another view of the relations of parts, the position of the lens between the aqueous and vitreous chambers, etc. On removing the lens, vitreous, and retina, and brushing off its pigment, the light markings corresponding to the chorioidal veins (venæ vorticosæ) should be noted, and their distribution studied. Usually four vortices or fountain-like markings are found in the whole chorioid,

Fig. S02.-Horizontal Section of the Eyeball. $\times 4$.

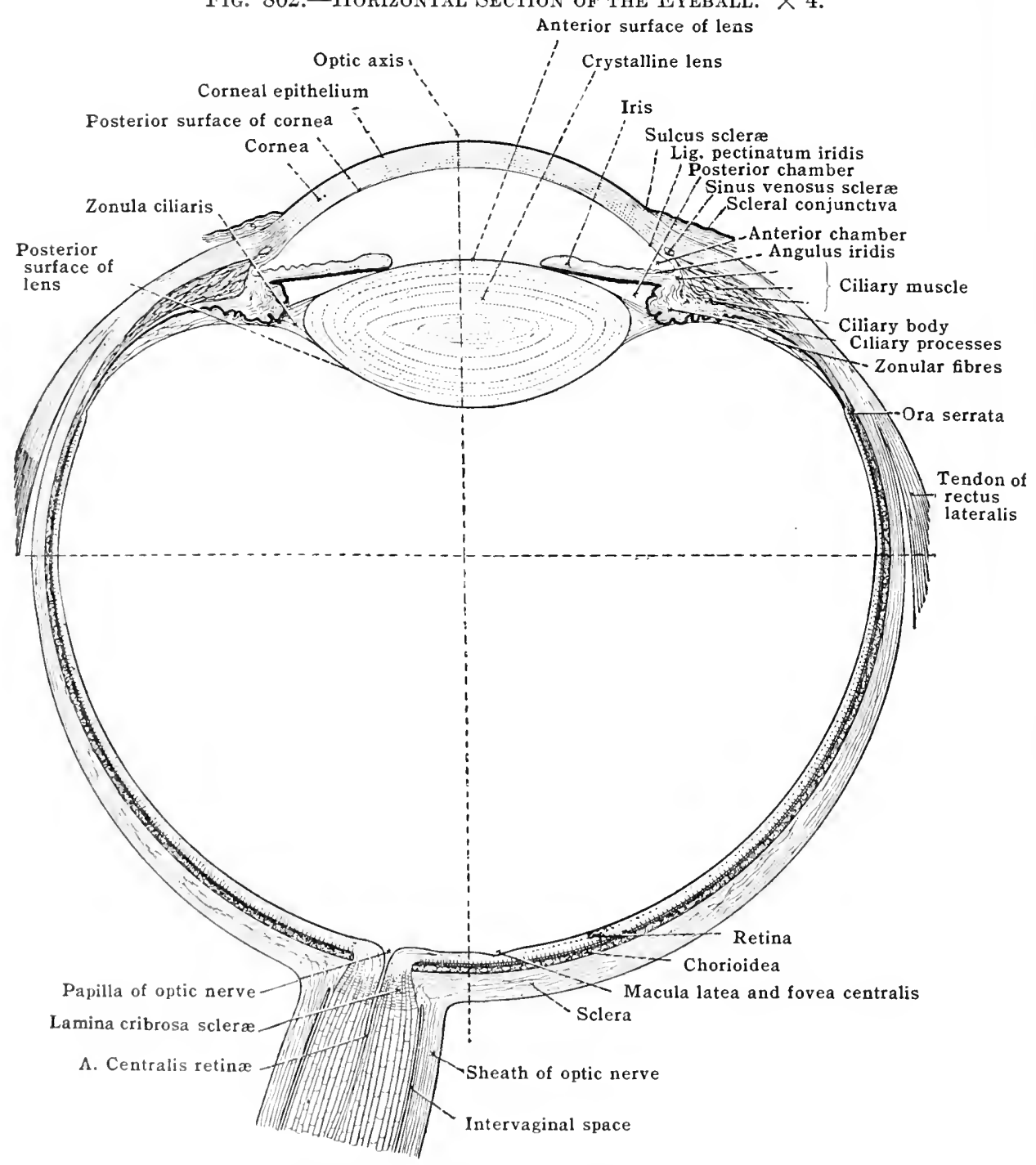

their points of junction situated at approximately erfual distances from one another at about the line where the posterior and middle thirds of the globe meet. These sections should be kept for reference while following the further lescription of the ocular tunies.

The coats of the eyeball.-1. The outer, fibrous coat of the eye [tunica fibrosi oculi] is formed by the sclera and cornea, which pass into one another at the scoleral sulcus. It consists throughont mainly of fine connective-tissuc fibres, arranged in interlacing bundles, with small lymph-spaces at intervals between then. The nakerl-eye appearanee of the two divisions of this fibrous coat is, however, quite different, the cornea being transparent, while the selera is white and oparule.

The sclera encloses the posterior five-sixths or so of the eyeball. It is perfo- 
rated by the entrance of the optic nerve, and the opening in the sclera, only partially bridged across by fibres from the inner layers, forms the lamina cribrosa.

The fibre-bundles composing the sclera are arranged more irregularly than in the cornea, and run mainly in two directions, viz., antero-posteriorly and circularly; the circular fibres are particularly well developed just behind the sulcus. It is thickest (about $1 \mathrm{~mm}$.) posteriorly, where it is strengthened chiefly by the outer sheath of the optic nerve, and partly also by the tissue surrounding the ciliary vessels and nerves. It becomes gradually thinner as it passes forward, up to the line of insertion of the recti muscles, where it is $.3 \mathrm{~mm}$. thick. In front of that line it is again reinforced by their tendinous fibres becoming incorporated with it and its thickness increases to $.6 \mathrm{~mm}$. In children the sclera is often so thin as to allow the underlying chorioidal pigment to show through, its colour then appearing bluish white. In the aged, again, it is sometimes yellowish. It always contains a few pigment cells, but these are in the deep layer termed the lamina fusca, and only become visible externally where the sclera is pierced by vessels and nerves going to the chorioid. It is almost non-vascular, but quite at its anterior end a large venous sinus [sinus venosus scleræ; canalis Schlemmi (Lauthi)], (canal of Schlemm) runs in its deeper layers circularly around the cornea. Just in front of this sinus, at the corneal limbus, the sclera merges into the cornea, its inner layers changing first, and finally the outer ones.

Fig. S03.-Portion of Fig. S02, Enlarged.

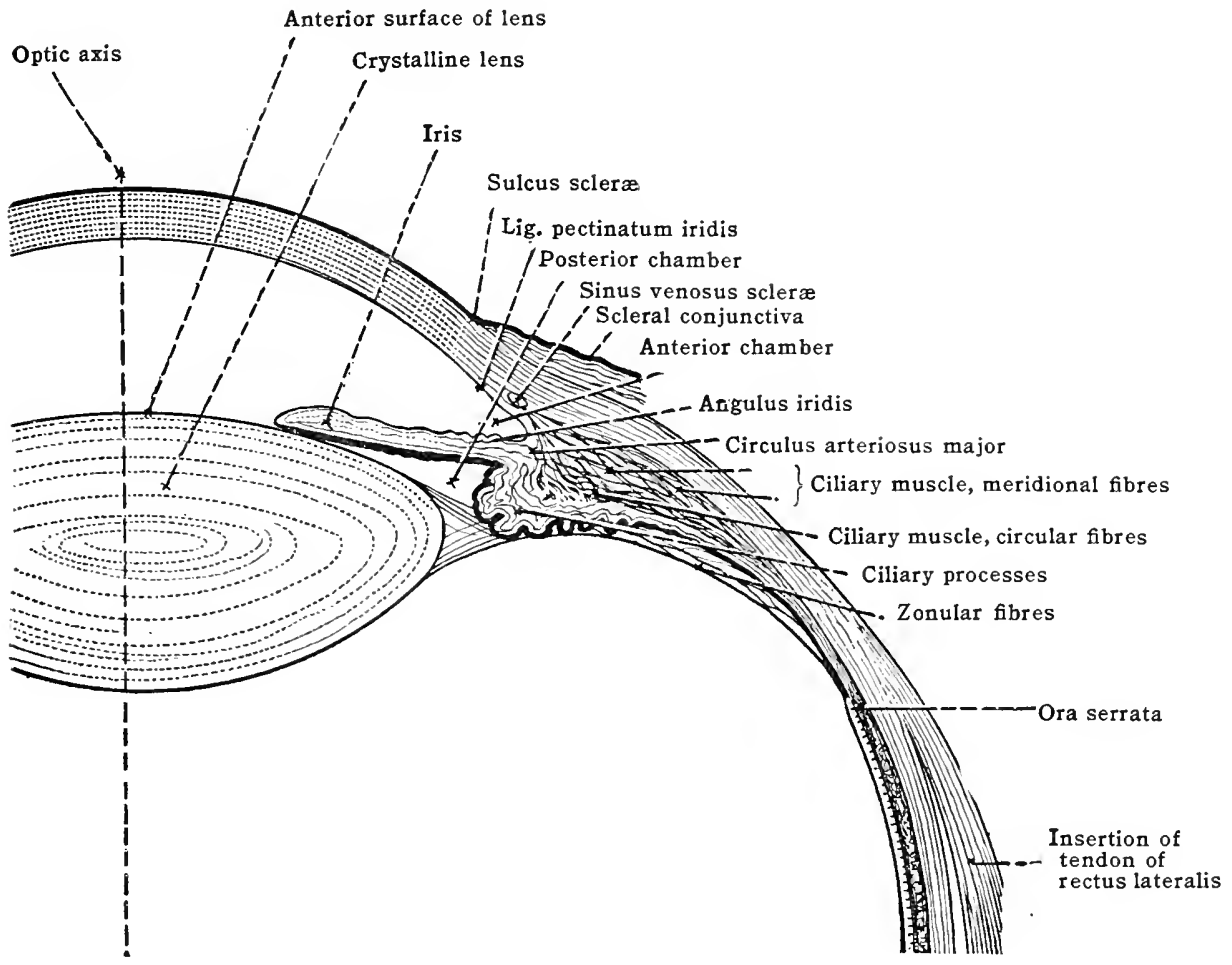

The cornea forms the anterior sixth of the eyeball. It is thickest "at its periphery $(1.1 \mathrm{~mm}$.$) and becomes gradually thinner toward its centre$ $(0.8 \mathrm{~mm}$.); the curvature of its posterior is consequently greater than that of its anterior surface, but even the latter is more curved than the surface of the sclera.

In the cornea proper, fibre-bundles are arranged so as to form a series of superposed lamellæ, each of which is connected here and there to the adjacent ones by fibres passing from one to the other, so that they ean only be torn apart with difficulty. The corneal lymph-spaces communicate with one another by very fine canals. and thus not only is a thorough lymph-circulation provided for, but the protoplasm with which these spaces are partially occupied may be also regarded as continuous throughout. It contains no blood-vessels, with the exception of a rich plexus at its extreme periphery, on which its nutrition is ultimately dependent. The sinus venosus of Schlemm is an important channel for the return of blood and also of fluid which transudes into it from the anterior chamber. It consists of a network of venous spaces, formed of a principal vessel accompanied by several smaller ones, which unite with it and with one another in a plexiform manner. They commence indirectly with the spaces of the angle of the iris and they are in direct communication with the anterior ciliary veins. 
The outer surface of the cornea is covered by an extension of the ocular conjunctiva, in the form of an epithelium several layers deep. The most external part of the true cornea appears homogeneous, even when highly magnifiel and constitutes the anterior elastic lamina, Bowman's membrane, though there is reason to believe that its structure only dilfers from that already described in the closeness of its fiblous texture; the two parts are certainly connected by fine fibres. Posteriorly, the comea is lined by a fim, thin, glass-like layer (posterior elastic lamina, membrane of Descemet), distinct from the corneal tissue both anatonically and ehemically. At the periphery this nembrane breaks up into a number of fibres, which mainly arch over to join the base of the iris and form part of the ligamentum pectinatum iridis. The pectinate ligament is an open network of interlacing fibres, directly continuous with the circular and longitudinal bundles of sclera suroumling the venous sinus of Schlemm (Henderson). The interstices between these fibres constitute spaces (spaces of Fontana) [spatia anguli iridis (Fontane ] freely communicating with the aqueous chamber on the one hand, and indirectly with the venous sinus of the sclera on the other. The posterior elastic lamina is in turn lined by a single lay or of flat cells, which are continuous peripherally with cells lining the spaces of the angle ancl the anterior surface of the iris which form the endothelium of the anterior chamber. The colnea is richly supplied with nerves, particularly in its most superficial layers.

2. The dark, middle, or vascular coat of the eye [tunica vasculosa oculi] is formed by the iris, ciliary body, and chorioid. It is closely applied to the sclera, but actually joins it only at the anterior and posterior limits of their course together, viz., at the scleral suleus, and around the optic nerve entrance. It is separated from the selera between these two points by a narrow slit-like lympspace [spatium perichorioideale]. In front of the sulcus, the middle coat is separated from the outer (i. e., the iris from the cornea) by a considerable space filled with fluid, called the anterior aqueous chamber. The vascular coat has two openings in it; a larger one in front, the pupil, and a smaller one behind, for the passage of the optic nerve. Its structure is that of a pigmented connective tissue, supporting numerous blood-ressels and containing many nerves and three deposits of smooth muscle-fibres.

'The chorioid ['horioidea] forms the posterior part of the vaseular coat, and extends, with slowh diminishing thickness, forward as far as the ora serrata. Its outer and inner surfaces are both formed by non-vascular layers; that covering the outer, the lamina suprachorioidea, is pigmented, arranged in several fine loose lamelat that covering the imner surface is a thin, transparent, homogeneous membrane, called the basal lamina of the chorioid. The interrening thorioidal stroma is very rich in blood-vessels, which are of largest size next its outer surfatce constituting the lamina vasculosa. These hecome progressively smaller toward the basal lamina, next to which is a layer of elosely placed widle eapillaries, called the lamina choriocapillaris. The pigment becomes less in amount as we pass inward, and finally ceases, being alsent entirely from the choriocapillary and basal laminae.

In front of the ora serrata the vascular eoat becomes considerably modified' and the part reaching from the ora serrata of the retina to the iris is termed the ciliary region of the tract, or ciliary body [corpus ciliare]. Its superficial aspects havo been alrealy briefly described. In front, the eiliary processes, about seventy in number, project towarel the interior of the eye, forming the corona ciliaris. Behind this part lies the orbiculus ciliaris, whose inner surface is almost smooth, faint ratial folds [plice ciliares] only being present, three or four of which join each riliary process.

The more minute strueture of this ciliary region resembles elosely that of the chorioid, except that the chorio-eapitharis is no longer present, that the stroma is thickes and richer in bloodressels, and that a moscoldar olement (ciliary musele) exists between the vascular layer and the lamina suprarborioiclea. On antero-posterior sertion the riliary boty is triangular; the shortest side look forwarl, and from abont its midelle the iris arises; the two long sides look respeetively inward and ontwal, the inner having the riliary processes upen it, while the onter is formed by the ciliary muscle. This muscle possesses smooth fibres and consists of an outer [libra me-

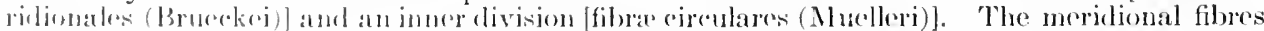
lake origin from the onter fibrous coat of the rye at the selero-corneal junetion in front, and pass-

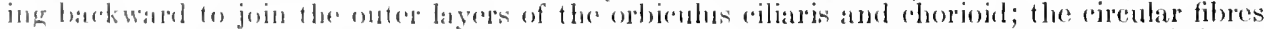
are situaterl next to the riliary provesses. The entire musele is destitute of pigment, and there-

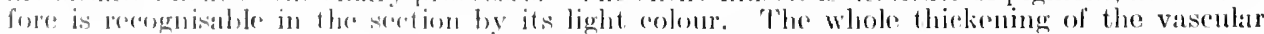
tunie in this region, muscle and folits and processes together, is mamed the ciliary body. It

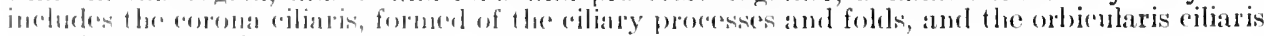
('onlationge the riliary muscle.

'The iris projects inte the interior of the front hatf of the aye in the form of a

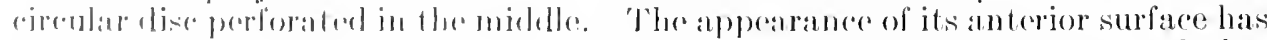

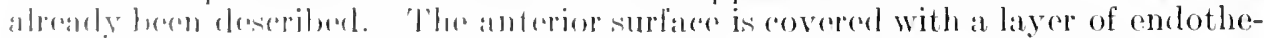

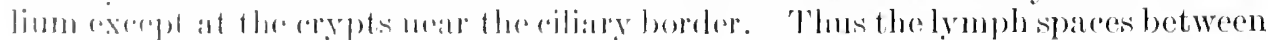

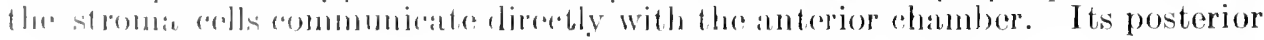


surface exhibits numerous radial folds running from the ciliary processes to near the pupillary margin; a thick layer of black pigment covers it and curls around this edge, so as to come into view all around the pupil as seen from in front. The ciliary border of the iris is continuous with the front of the ciliary body, and there it also receives fibres from the ligamentum pectinatum iridis; in other respects the iris is quite free, merely resting on the front of the lens-capsule near the pupil.

Its stroma [stroma iridis] is spongy in character, being made up of vessels covered by a thick adventitia, running from the periphery to the pupillary borler, with interspaces filled by branching pigment cells, which are particularly abundant near the front surface. Deep in the stroma, running around near the pupillary border, we find a broarl flat band of smooth muscle-fibres, constituting the m. sphincter pupillæ. Immediately behind the vascular tissue hies a thin membrane, consisting of fine, straight fibres running radially from the ciliary border to the stroma behind the sphincter. The nature of these fibres was long in dispute, but they are now accepted as being undoubtedly smooth muscular-and comprise the $\mathrm{m}$. dilatator pupillæ.

Fig. S04.-Diagramatic Horizontal Section of Ereball and Orbit.

(After Fuchs, much modified.)

Periorbita green; muscle-fascia red; Tenon's capsule yellow.

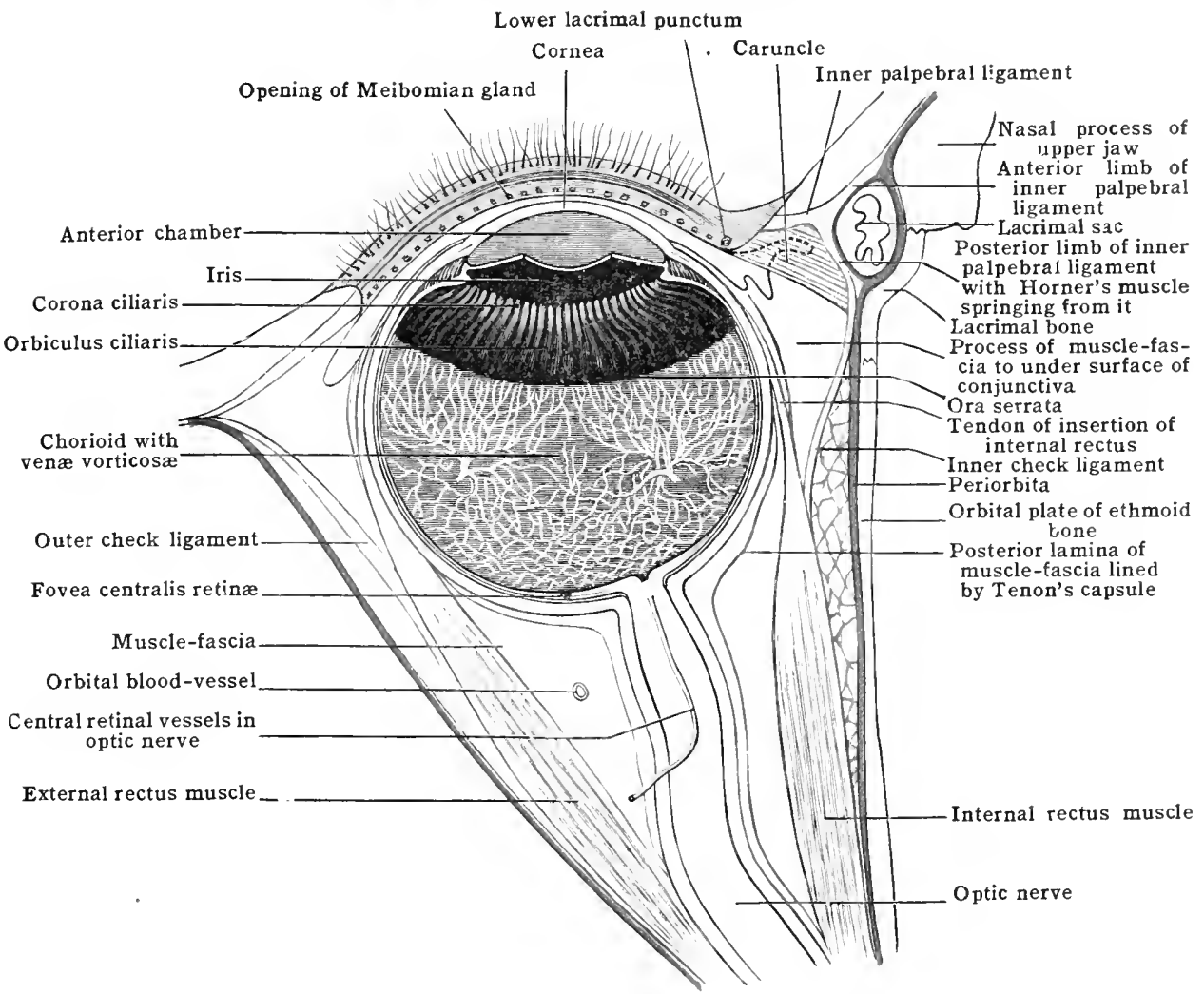

The m. sphincter mupilixe and the ciliary muscle are supplied indirectly by the oculomotor nerve through the ciliary ganglion. The dilatator pupille' is supplied by sympathetic fibre's, which have their origin from the cells of the superior cervical ganglion. Thence they ascend in the carotid and cavernous plexuses, and join the ophthalmic division of the trigeminal nerve, passing to the eyeball by way of the long ciliary nerves. The pre-ganglionic sympathetic fibres leave the spinal cord by the motor roots of the first two or three thoracic nerves, and ascend the sympathetic trunk to the superior cervical ganglion without interruption.

The posterior surface of the iris is lined by pigment already mentioned, consisting of two layers of pigmented cells, each layer representing the extension forward of one subdivision of the retina. The anterior surface of the iris is covered by a delicate epithelial layer, continuous with the cells of the posterior elastic lamina of the cornea. The colou of the iris in different individuals depends upon the amount of stromal pigment

3. The retina. - The inner surface of the vascular coat is every where lined by a layer of pigment of corresponding extent, which usually alheres to it closely on dissection. 
Developmentally this general pigment lining is quite distinct from the vascular coat, and represents the outer wall of the secondary optic vesicle or embryonic retina; it consists of a single layer of pigmented epithelial cells. It is known as the stratum pigmenti. The amount of pigment is greatest anteriorly, over the ciliary region and iris, and there is again a small local increase posteriorly, corresponding to the macula lutea and to the edge of the optic nerve entrance. In the eiliary region these cells have recently been described as lining numerous narrow tubular depressions in the inner part of the vascular tract, and they are said to have here a special function, viz., that of secreting the intraocular fluid.

From the manner in which the secondary optic vesicle, or optic cup, is formed, its two walls are necessarily continuous in front, at what may be termed the lip of the cup; we have just observed that the outer wall lines the vascular coat everywhere and corresponds in extent; consequently, the lip must be looked for at the edge of the pupil, i. e., at the termination of this coat anteriorly. The inner wall of the cup, consequently, reaches from the lip, or pupillary edge, in front to the optic stalk or nerve behind, and is in close apposition to the pigment-epithelium; unlike the outer, however, this wall is represented in the developed eye by tissues very dissimilar in structure in different parts of its extent. Tracing it backward from the pupillary edge, we find that over the whole posterior surface of the iris it exists as a single layer of pigmented epithelium, the two layers of the cup having here produced a double layer of pigment cells. At the root of the iris the single inner layer of cells still exists; but now they become destitute of pigment, and this condition obtains over the entire ciliary region, constituting what is known as the pars ciliaris retinæ. At the line of the ora serrata the tissue derived from the inner wall abruptly increases in thickness, and rapidly acquires that complexity of structure characteristic of the retina proper, which extends from here to the optic nerve and is termed the pars optica retince. It eonsists of several layers-nervefibres, nerve-cells, and nerve-epithelium-held together by a supporting framework of delicate connective tissue.

The nerve-epithelium is on the outer surface, immediately applied to the pigment-epithelium; at the posterior pole of the eye a small spot [fovea centralis] exists, where this is the only retinal layer represented, and where consequently the retina is extremely thin. The nervefibres run on the inner surface of the retina and are continuous with those of the optic nerve; they constitute the only retinal layer that is continued into the intraocular end of the nerve. The nerve-cells are found between these surface layers. The larger blood-vessels of the retina run in the inner layers, and none encroach on the layer of nerve-epithelium.

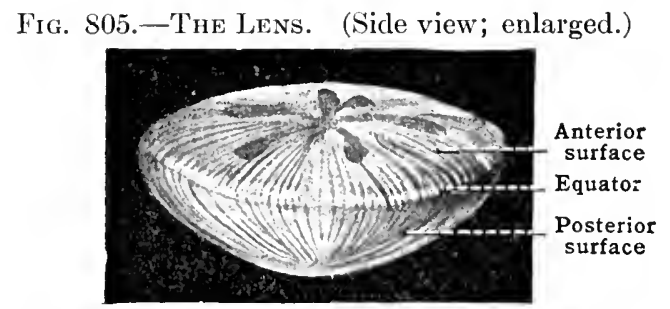

Within the coats mentioned, the interior of the eycball is fully occupied by concents, which are divided into three parts, which are named aceording to their consistence and anatomical form. They are all transparent, as through them the light has to pass so as to gain the retina. Of these, the only one that is sharply and independently outlined is the lens, which is situated in the anterior half of the globe at the level of the ciliary processes, where it is suspended between the other contents, which fill respectively the space in front of it and the space behind it. The space in front of the lens called the aqueous chamber; that behind the lens is the vitreous chamber.

'The lens [lens crystallinal is a biconvex dise, with its surfaces directed anteriorly and posteriorly; these surfaces meet at its rounded-off edge or equator [aefuator lentis] which is near. (but does not touch) the ardjacent eiliary processes. 'The posterior is considerably more convex than the anterior surface; the central part of aach surface is called its pole [polus anterior; polus posterior]. The lens is assoly encused in a hyaline clastic capsule [eapsula lentis] thicker over the anterior than over the posterior surfare. 'Thus enclosed, it is held in position in the globe by a suspensory liganent, attarched to the lens eapsule near the equator of the eye, and swung from the ciliary region. Posteriorly, the lens rests in a cup 
formed by the front part of the vitreous, while its anterior capsule is in contact with the aqueous fluid and lies close against the back of the pupillary margin of the iris. When in position the lens measures nine millimetres across, and about four millimetres between its poles.

On each surface a series of fine, sinuous, grey lines can be seen radiating from the pole toward the equator, called respectively the anterior and posterior stellate figures. The lines observable on the posterior are always so placed as to be intermediate with those on the anterior surface, so that on viewing them through the lens they occupy a position corresponding to the

Fig. 806.-Diagramatic Representation of the Blood-vessels of the Eyeball. (Parsons, after Leber.)

Arteries red; veins blue.

s.p., Short posterior ciliary arteries. l.p.c., Long posterior ciliary artery. a.c., Anterior ciliary vessels. $C$ of S., Canal of Schlemm. c.a.i.ma., Circulus arteriosus iridis major. v.v,. Venæ vorticosæ. a. conj., Anterior conjunctival vessels. p. conj., Posterior conjunctival vessels.

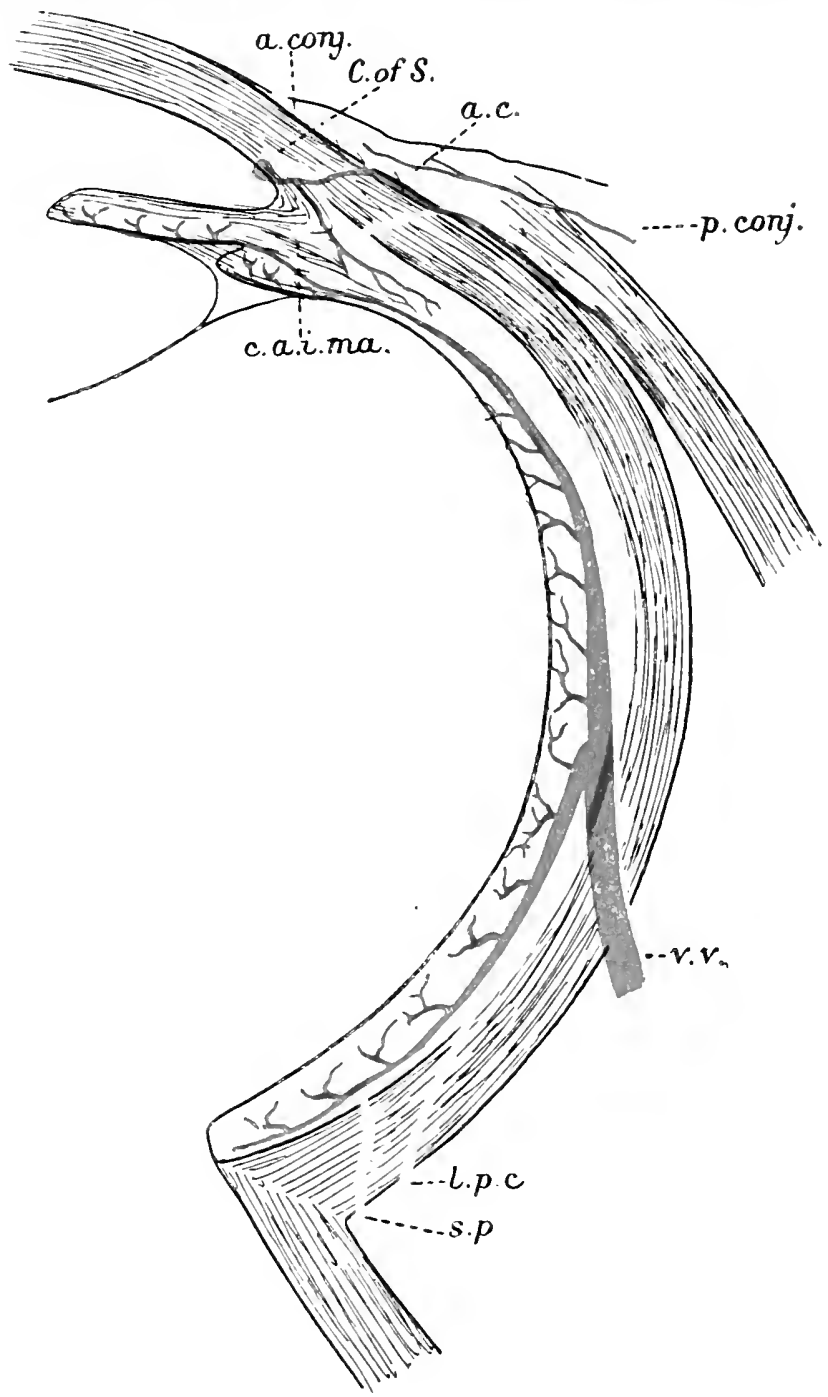

intervals between the lines on the anterior surface. The lens-capsule is comparatively brittle, and can be readily cut through when scraped with a sharp-pointed instrument; on doing so the divided edges curl outward, away from the lenticular substance. When removed from its capsule, the outer portion of the lens is found to be soft and glutinous, but its substance gets progressively firmer as we approach the centre. This harder central part is known as the nucleus [nucleus lentis], and the surrounding softer matter as cortex [substantia corticalis]. The cortical part shows a tendency to peel off in successive layers. It eonsists of long fibres, the ends of which meet in front and behind at the anterior and posterior stellate figures. 
Histologically the capsule is not in immediate contact with the cortex over the front surface of the lens, a single layer of cells intervening, called the epithelium lentis.

The zonula ciliaris or suspensory ligament of the lens is formed by a number of fine zonular fibres [fibra zonulares] passing from the ciliary body. They are attached to the lens-capsule a little in front of and behind the equator, and the spaces included between the fibres of the ligament are termed the zonular spaces [spatia zomularia]. A continuous space, which can be injected after death, round the margin of the lens is known as the canal of Petit. It is probably an artefact. This space is bridged across by fine intermediate suspensory fibres, and is occupied by fluicl.

The vitreous body [corpus vitreum] is a transparent, colourless, jelly-like mass, the vitreous humour, enclosed in a delicate, clear, structureless membrane, called the hyaloid membrane. This latter is closely applied to the back of the posterior lens-capsule and of the suspensory ligament, and to the inner surface of the pars ciliaris retinx, retina proper, and optic papilla. Although possessing some degree of firmness, the vitreous humour contains quite 98 per cent. of water, and has no definite structure.

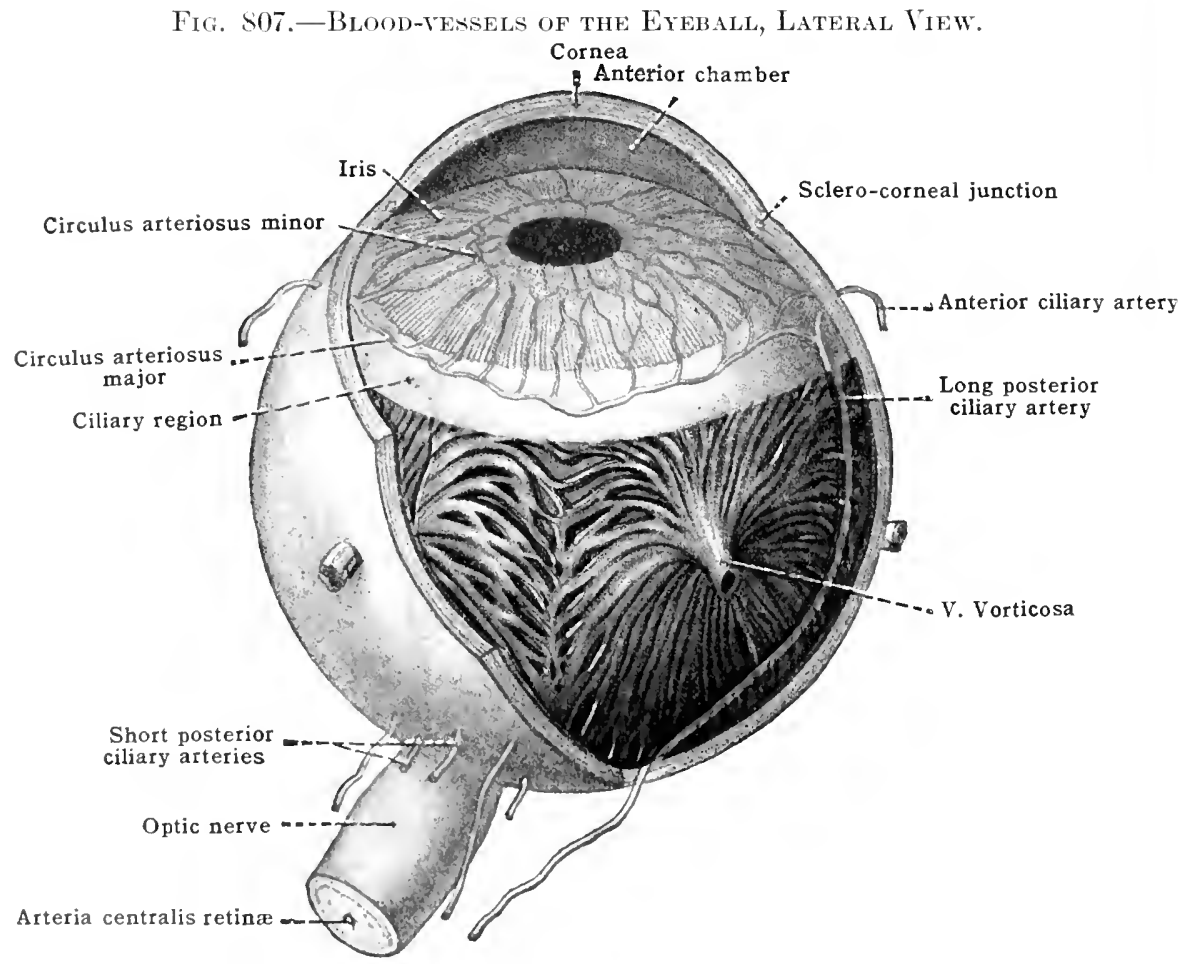

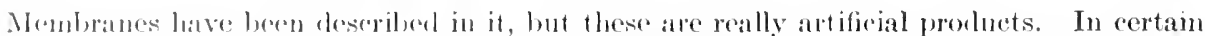

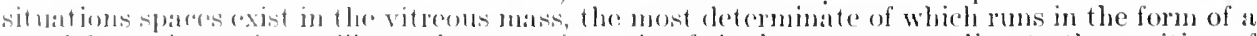
ranal from the ofitice papilla to the pestrorion pole of the lens, corresponding to the position of the fortal hyatuil antry (hyaloid canal or canalis hyaloidea). ()ther very time spaces are de-

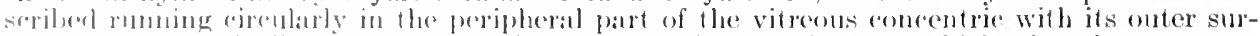

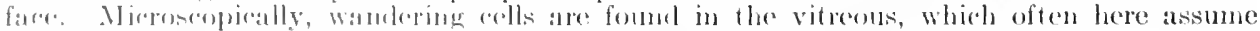

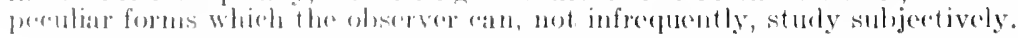

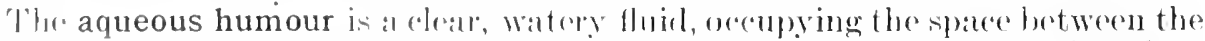

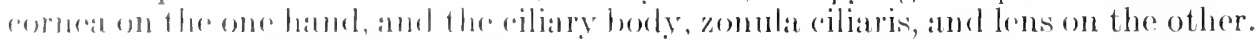
Ther iris, projereting into this sparer, has beth its surfares bathed in the aqueous;

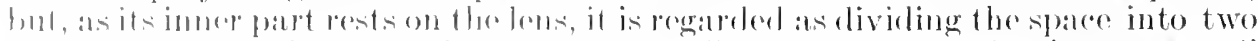
parls, an anterior larger, and a posterior smaller, aqueous chamber [camera oculi

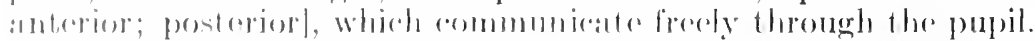

Ciliary nerves of the eyeball. Thro long ind short ciliary nerves, after per-

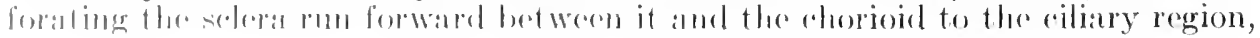


where they form a plexus, from which proceed branches for the ciliary muscle, the iris, and the cormea.

The nerves of the iris enter it at its eiliary border, and run toward it s pupillary edge, losing their medullary sheath sooner or later, and supplying especially the sphineter muscle. The corneal nerves form an annular plexus near the limbus, from which a few twigs proceed to the sclera and conjunctiva, while most of the offsets enter and run radially in the corneal stroma, branching and anastomosing so as to form a plexus. The nerves entering the cornea are about sixty in number, each containing from two to twelve non-medullated nerve-fibres.

Blood-vessels of the eyeball.-The eyeball receives blood from two sets of vessels, viz., the retinal and the ciliary arteries, as described in the section on the Blood-Vascular System.

1. The arteria centralis retinæ either comes direct from the ophthalmic artery, or from one of its branches near the apex of the orbit. Entering the optic nerve twenty millimetres or less behind the globe, it runs forward in its axis to the end of the nerve-trunk, and then divides into branches which run in the inner layers of the retina, and divide dichotomously as they radiate toward the equator. The smaller branches lie more deeply in the retina, but none penetrate into the nerve-epithelium, so that the fovea centralis is non-vaseular. In the retina, the branches of the central artery do not communieate with any other arteries, but while still in the optic nerve fine communications take place between this artery and neighbouring vessels. Thus (a) minute twigs from it, which help to nourish the axial part of the nerve, communicate with those running in the septa derived from the pial sheath. Again, as the nerve passes through the selera, it is surrounded by a vaseular ring [cireulus vaseulosus n. optici (Halleri)], former] of fine branches derived from the short posterior eiliary arteries; fine twigs passing inward from this ring to the optic nerve join the vessels of the pial sheath, and $(b)$ an indirect communieation is thus brought about between the retinal and eiliary vessels. Finally, as the nerve passes through the ehorioid, there is $(c)$ a direct conneetion between these two sets of vessels, the capillary network of the optic nerve being here continuous with the ehorio-capillaris. Not infrequently, a braneh from a short posterior eiliary artery pierces the optie papilla, and then courses over the adjoining retina (a eilio-retinal artery), supplying the latter in part in place of the central artery.

The branches of the a. centralis retina in the retina are: arteriola temporalis retina superior, arteriola temporalis retinæ inferior, arteriola nasalis retina superior, arteriola nasalis retinæ inferior, arteriola macularis superior, arteriola macularis inferior, arteriola retinx medialis.

The vena centralis retinæ returns the blood of the corresponding artery and has branches corresponding to those of the artery.

2. The ciliary system of blood-vessels (see Blood-Vaseular System).--There are three sets of arteries belonging to this system, all derived directly or indirectly from the ophthalmic artery

(1) Short posterior ciliary arteries twelve to twenty in number, pierce the sclera round the optic nerve entrance, and are distributed in the chorioid. Before entering the eyeball, small twigs are given off to the adjoining selera and to the dural sheath of the optic nerve.

(2) Two long posterior ciliary arteries, medial and lateral, piereing the sclera further from the nerve than the short ciliaries, run horizontally forward between the sclera and chorioid, one on each side of the globe. On arriving at the eiliary body, they join with the anterior ciliary arteries, forming the circulus arteriosus major, which sends off branches to the ciliary processes and the iris. The long eiliaries also give twigs to the ciliary muscle, and small recurrent branches run backward to anastomose with the short eiliary arteries. The arteries of the iris run radially toward the pupillary border, anastomosing with one another opposite the outer border of the sphincter and forming there the circulus arteriosus minor.

(3) The anterior ciliary arteries come from the arteries of the four recti muscles, one or two from each; they run forward, branching as they go, and finally pierce the selera near the corneal border. Externally to the globe they send twigs to the adjoining sclera, to the conjunctiva, and to the border of the cornea. After passing through the sclera the arteries enter the ciliary muscle, where they end in twigs to the muscle and to the cireulus arteriosus major, and in recurrent branches to the chorioid.

Veins.-The venous blood from almost the whole middle coat (chorioid, ciliary processes and iris, and part of the ciliary muscle) ultimately leaves the eveball by-(1) the venæ vorticosæ, which have been already noticed in deseribing an antero-posterior section through the globe. One large vein passes backward from each vortex, piereing the sclera obliquely; it is joined by small episeleral veins when outside the globe.

(2) The anterior ciliary veins commence by the junction of a few small veins of the ciliary musele; they pass outward through the sclera near the corneal border, receiving bloot from the veins in connection with the sinus venosus of the selera, and afterward from episcleral and conjunctival reins, and from the marginal corneal plexus. Finally they join the reins running in the recti muscles.

Lymphatic system of the eyeball.-Apart from those in the conjunctiva there are no lymphatic ressels in the eyeball, but the fluid is contained in spaces of various sizes. These are usually divided into an anterior and a posterior set.

1. Anteriorly, we have the anterior and posterior aqueous chambers (together composing the aqueous chamber of the eye), which communicate freely through the pupil. The arueous humour is formed in the posterior of these chambers by 
transudation from the vessels of the ciliary body and posterior surface of the iris (see also page 1076). The stream passes mainly forward through the pupil into the anterior aqueous chamber, whence it escapes slowly by passing through the spaces of the angle of the iris into the venous sinus of the sclera, and thence into the anterior ciliary veins. Part of the lymph-stream passes from the posterior aqueous chamber backward into the zonular spaces, out of which fluid can pass into the lens substance, or cliffuse itself in to the front of the vitreous body.

In the cornea the lymph travels in the spaces already mentioned as existing between the fibre-bundles, and in the nerve-channels and at the periphery of the cornea it flows off into the lymphatic vessels of the conjunctiva.

In the iris there is a system of lymphatic spaces opening anteriorly into the crypts of the surface, and communicating peripherally with the spaces of the angle of the iris.

Fig. S0S.-Lymphatic Spaces of the Eyeball (in green).

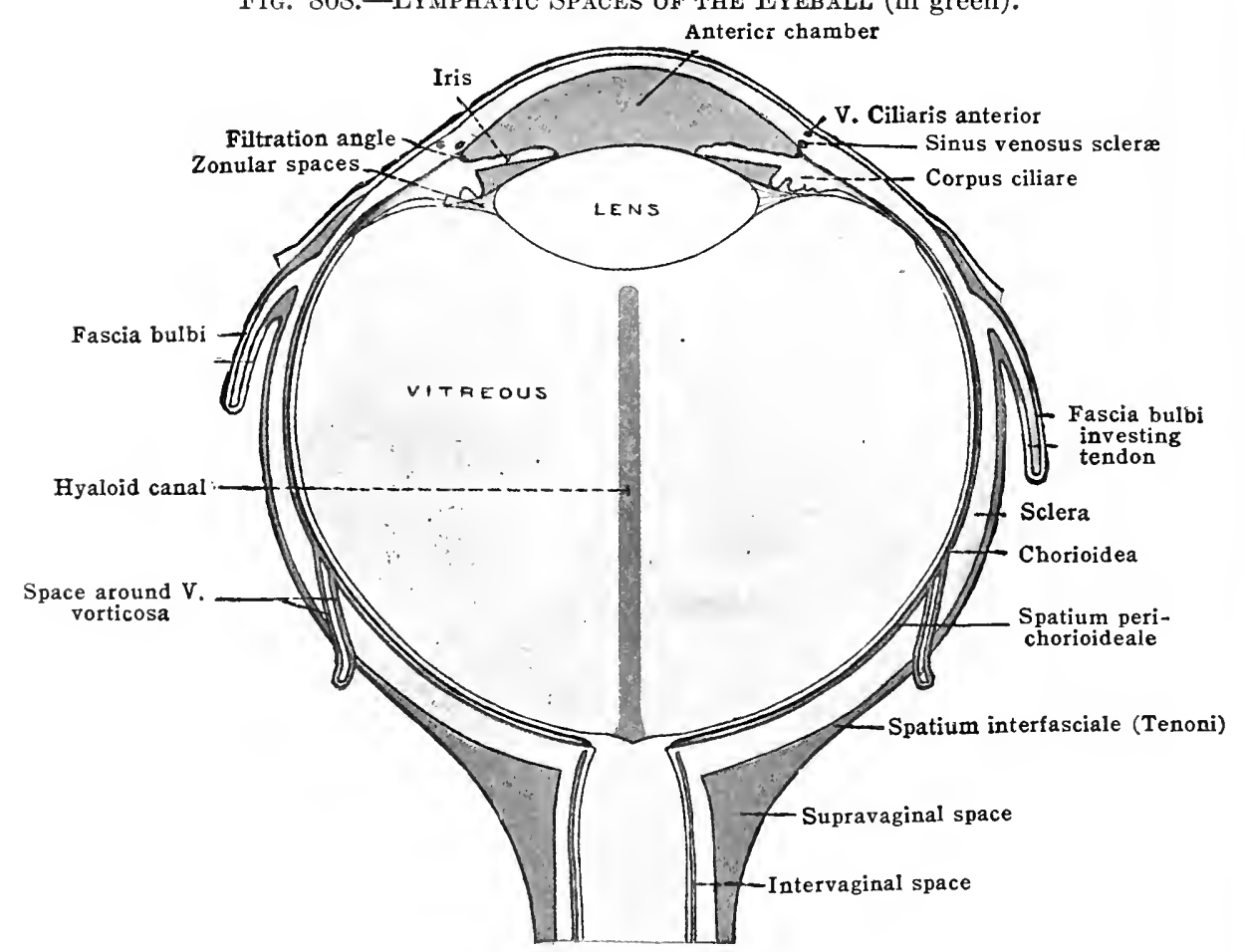

2. Posteriorly, we have $(a)$ the hyaloid canal, between the posterior pole of the lens and the optic nerve entrance, and $(b)$ the perivascular canals of the retina; the lymph from both of these situations flows into the spaces of the optic nerve, which communicate with the intervaginal spaces of the nerve, and thus with the great intracranial spaces. Further, between chorioid and sclera we have $(c)$ the perichorioidal space, which gets the lymph from the ehorioid, and communicates with the interfascial space (of T'enon) outside the selera by perforations corresponding to the vasa vorticosa and posterior ciliary arteries, and with the intervaginal spaces around the optic nerve cutrance. The interfascial space of Tenon, again, is continuous with the supravaginal space around the optic nerve, which communirates both with the intervaginal spaces, with the lymph-spaces of the orbit, and clirertly with the intracranial spaces at the apex of the orbit.

\section{(AVTTY OF THE ORBI'T}

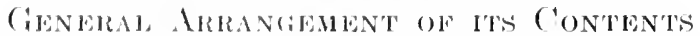

The anterior wider half of the cavity is mainly occupied by the eyeball, which lims almost axially, but is rather nearer to the upper and lateral than it is to the other walls. The posterior two-thirds of the glole are in relation with soft parts, 
chiefly muscles and fat, and its posterior pole is situated midway between the base (or opening) and the apex of the orbital cavity. The anterior third of the eyeball is naturally free, except for a thin covering of the conjunctiva, and projects slightly beyond the opening of the orbit, the degree of prominence varying with the amount of orbital fat, and also to some extent with the length of the globe. A straight line joining the medial and lateral orbital margins usually cuts the eye behind the cornea-laterally behind the ora serrata, medially further forward, at the junction of the ciliary body and iris. The globe is held in position by numerous bands of connective tissue. The lacrimal gland lies under the lateral part of the roof of the orbit anteriorly. The orbital fat occupies the spaces between the orbital muscles, and is in greatest amount immediately behind the eyeball; it also exists between the muscles and the orbital walls in the anterior half of the cavity. Six muscles, viz., the four recti, the superior oblique, and the levator palpebræ superioris, arise at the apex of the orbit, and diverge as they pass forward. The recti muscles-superior, inferior, lateral, and medial-run each near the corre-

Fig. 809.-Horizontal Section of the Orbital Region, Viewed From Above.

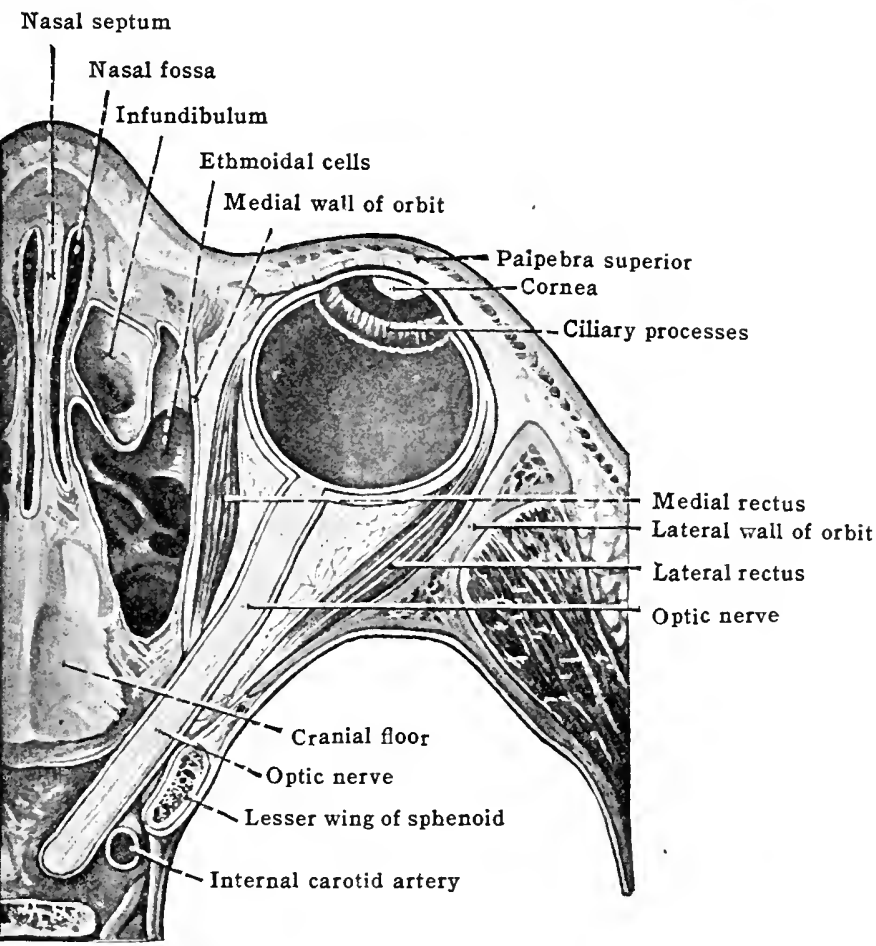

sponding orbital wall, but the superior is overlapped in part by the levator palpebræ. The superior oblique lies about midway between the superior and medial recti. A seventh muscle, the inferior oblique, has a short course entirely in the anterior part of the orbit, coming from its medial wall and passing below the globe between the termination of the inferior rectus and the orbital floor. The optic nerve with its sheaths passes from the optic foramen to the back of the eyeball, surrounded by the orbital fat, and more immediately by a loose connective tissue. Among the contents of the cavity are also to be enumerated many vessels and nerves and fibrous tissue septa, while its walls are clothed by periosteum (periorbita).

The muscles of the orbit are seven in number, of which six are ocular, i. e., are inserted into the eyeball and rotate it in different directions. These ocular muscles are arranged in opponent pairs, viz., superior and inferior recti, superior and inferior obliques, lateral and medial recti. With the exception of the short inferior oblique, they all arise from the back of the orbit along with the seventh orbital muscle, the levator palpebræ superioris. All these long muscles take their origin from the periosteum in the vicinity of the optic foramen. The four recti muscles arise from a fibrous ring, the annulus tendineus communis, which arches close over the upper 
and medial edge of the foramen, and extends down and out so as to embrace part of the opening of the superior orbital fissure. Their origins may be said at first to form a short, common, tendinous tube, from which the individual muscles soon separate, taking the positions indicated by their respective names. The lateral rectus has two origins from bone, one on either side of the superior orbital fissure. But in the fresh state the fissure is here bridged across by fibrous tissue, from which this rectus also springs, so that its origin is in reality continuous. The part of this fibrous ring neirest the foramen (corresponding to the origins of the superior and medial recti) is closely connected with the outer sheath of the optic nerve. The remaining two long museles arise just outside the upper and medial part of the above-mentioned ring, and are often partially united; the levator palpebra tendon is in close relation to the origin of the superior rectus, while the superior oblique arises from the periosteum of the body of the sphenoid bone one or two millimetres in front of the origin of the medial rectus.

The four recti muscles lie rather close to the corresponding orbital walls for the first half of their course, the superior rectus, however, being overlapped in part by the levator palpebra; they then turn toward the eyeball, running obliquely through the orbital fat, and are finally inserted by broad, thin tendons into the sclera in front of the equator. From their respective positions in the orbit, the axis of this cone of muscles is oblique to the antero-posterior axis of the eyeball. The thickest of these muscles is the medial rectus, next the lateral, then the infe-

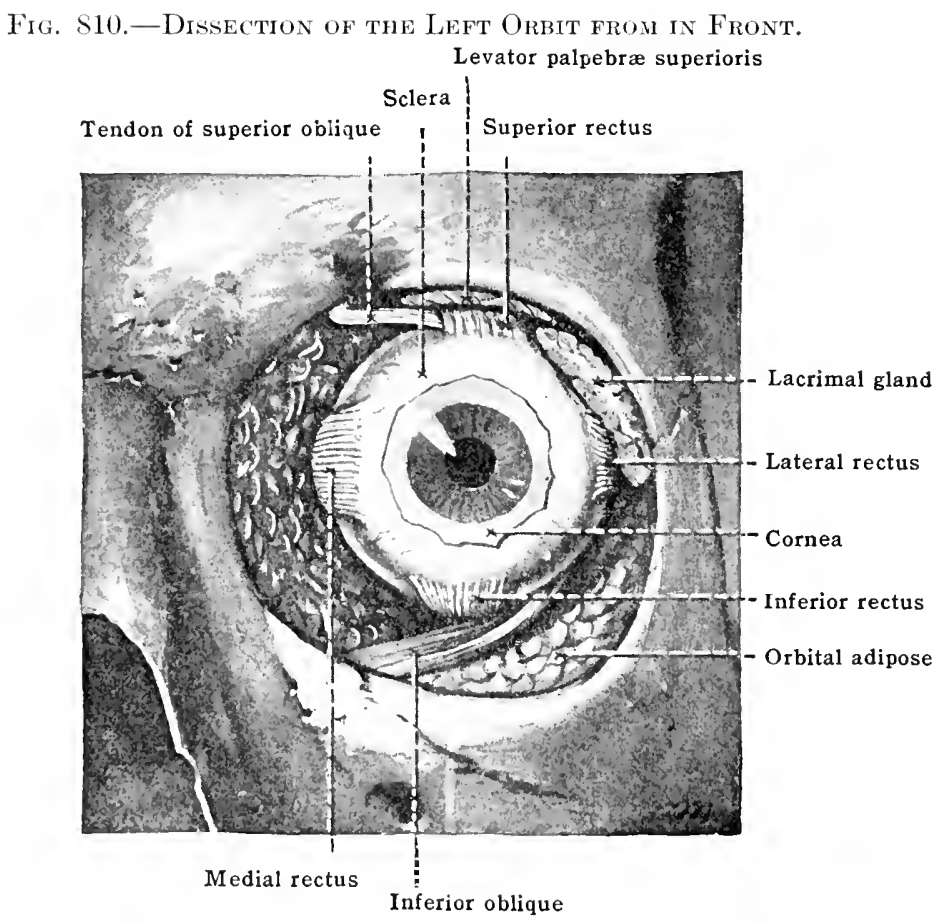

rior, and the superior rectus is the thimnest. As acgards length, the muscular belly of the superior rectus hat the longest comrse, and the others diminish in the order-medial, lateral, and inferiol' rectus. The lateral wertus is supplied by the aluluecus nerve. The other three recti muscles are all supplied ly the ocinlonotol nerve.

Tho levator palpebræ superioris courses along the roof of the orbit elose to the periostem, for 1 ho greater pall of its course, partially overlapping the superiol rectus; it finally descends through the ofl, ital fitt, and wilcos ont wo be inserted into the root of the upper lid. It may be brietly lescribed ats being inserted in two distinet layers separated hy a horizontal interval. The ifpere of anterion laver ef insertion is librons, and passes in front of the tarsus, where it comes into relation with fihres of the orhinularis. 'The lower layer consists of smootlo muscle (Müller's superior tarsal muscle), and is inserted alomg the upper horder of the tarsus. 'The levator has

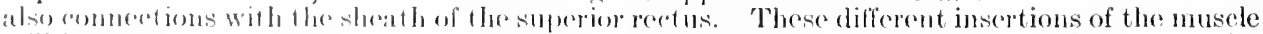
will lare refered to later alome with the description of the orbital fasciar and of the upper eyelid.

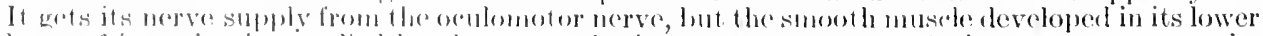

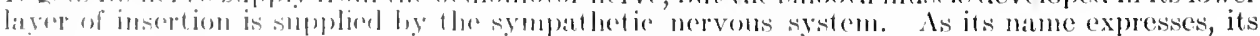

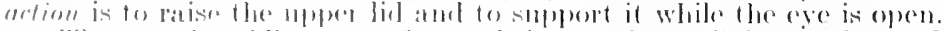

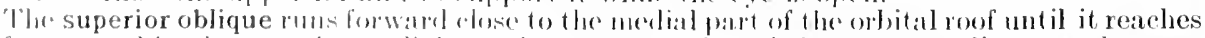

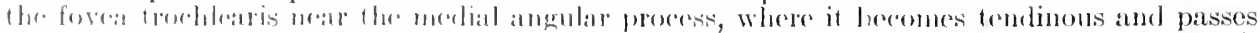

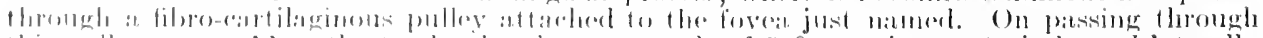

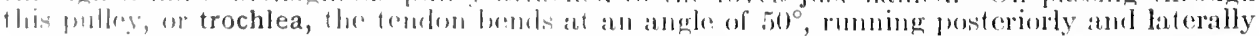

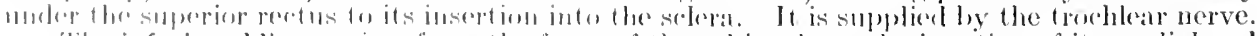

The inferior oblique arises form the from of the oflit, ahomt the jumetion of its medial and

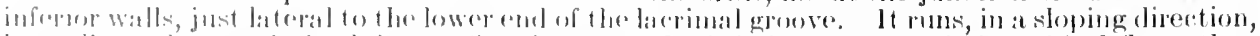

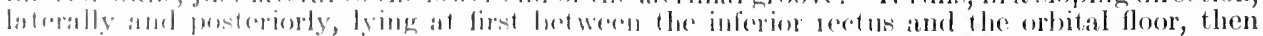

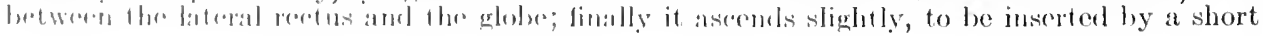


tendon into the sclera at the back of the eye. Its nervous supply is derived from the oculomotor nerve. The precise manner of insertion of the different ocular muscles has been rlescribed above (p. 1056). For muscles of the evelids and evebrows, see pp. 1077 and 107.

Action of the ocular muscles. - While rotating the globe so that the cornea is turned in different directions, the ocular muscles do not alter the position of the eyeball in the orbit either

Fig. S11.-Section throdgh Contents of Rigit Orbit 8-11 ma. Behind the Eyeball, VIEWED FROM BEIIND. (After Lange.)

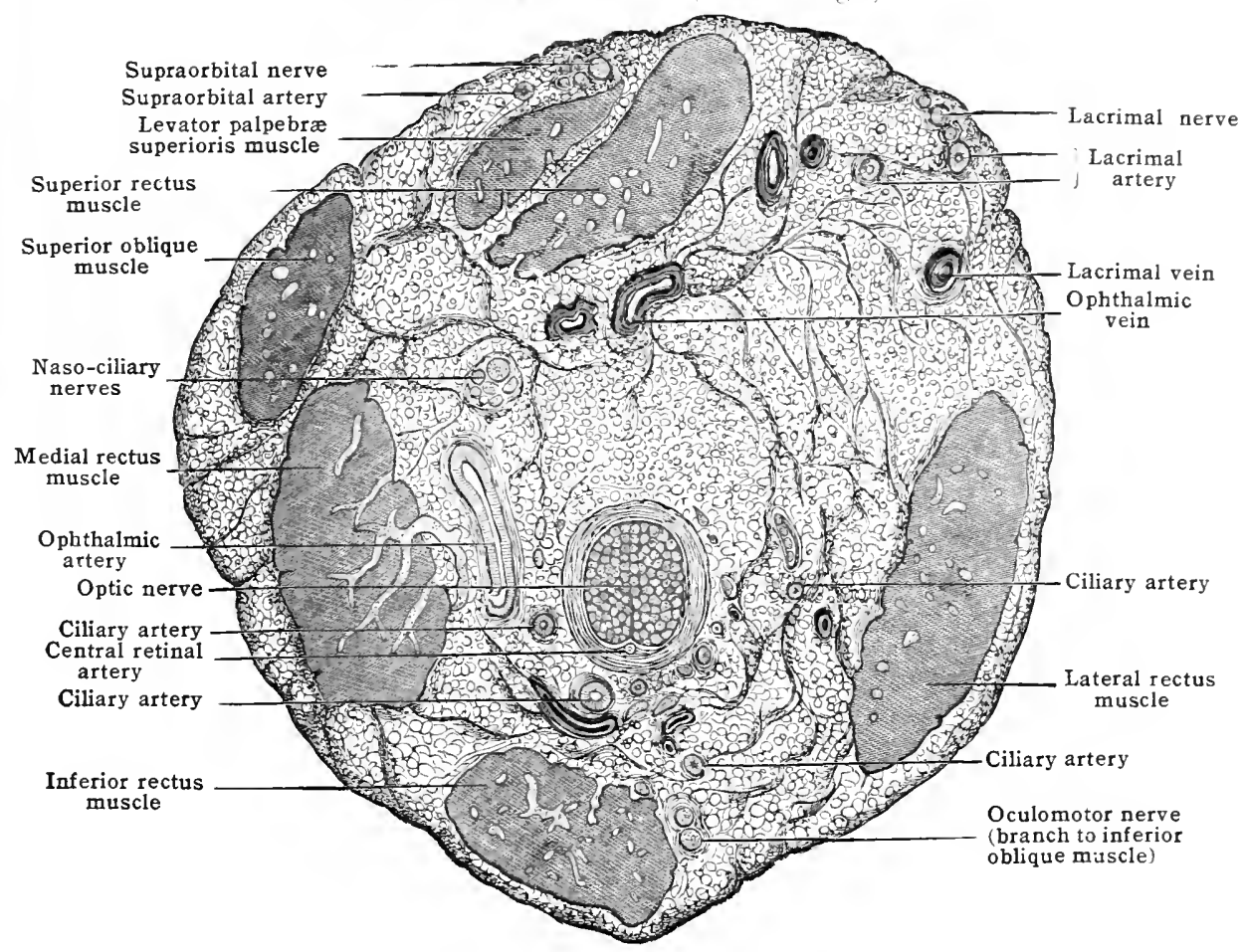

Fig. 812.-Diagram Representing the Origin of the Muscles at the Apex of the Right ORBit.

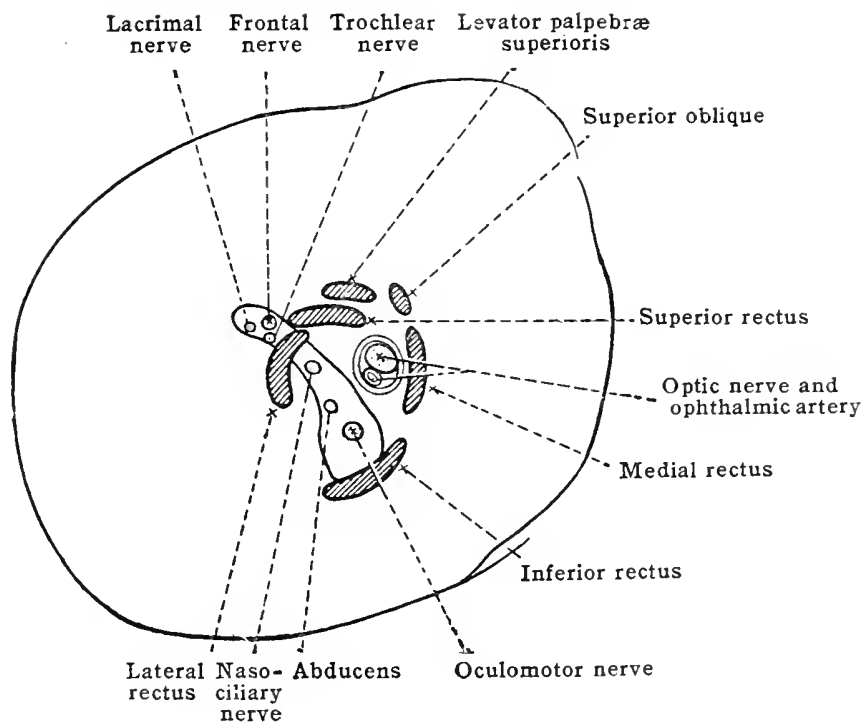

laterally, vertically, or antero-posteriorly. In speaking, therefore, of the eye being moved upward or laterally, etc., it is the altered position of the cornea or front of the eye that we mean to express; it is manifest that, if the cornea moves up, the back of the eyeball must sinultaneously be depressed, and similarly with other movements. All the movements of the globe take 
place by rotation, on axes passing through the centre. Though the possible axes are numerous in combined muscular action, there are three principal axes of rotation of the eycball, and in reference to these the action of individual muscles must be described. Two of these axes are horizontal and one rertical; they all pass through the centre of rotation at right angles to one another. By rotation of the eye on its vertical axis the cornea is moved laterally (toward the temple) and medially (toward the nose): movements called respectively abduction and adduc-

Fig. 813.-Dissection of the Muscles of the Right Orbit, Lateral View. Frontal sinus

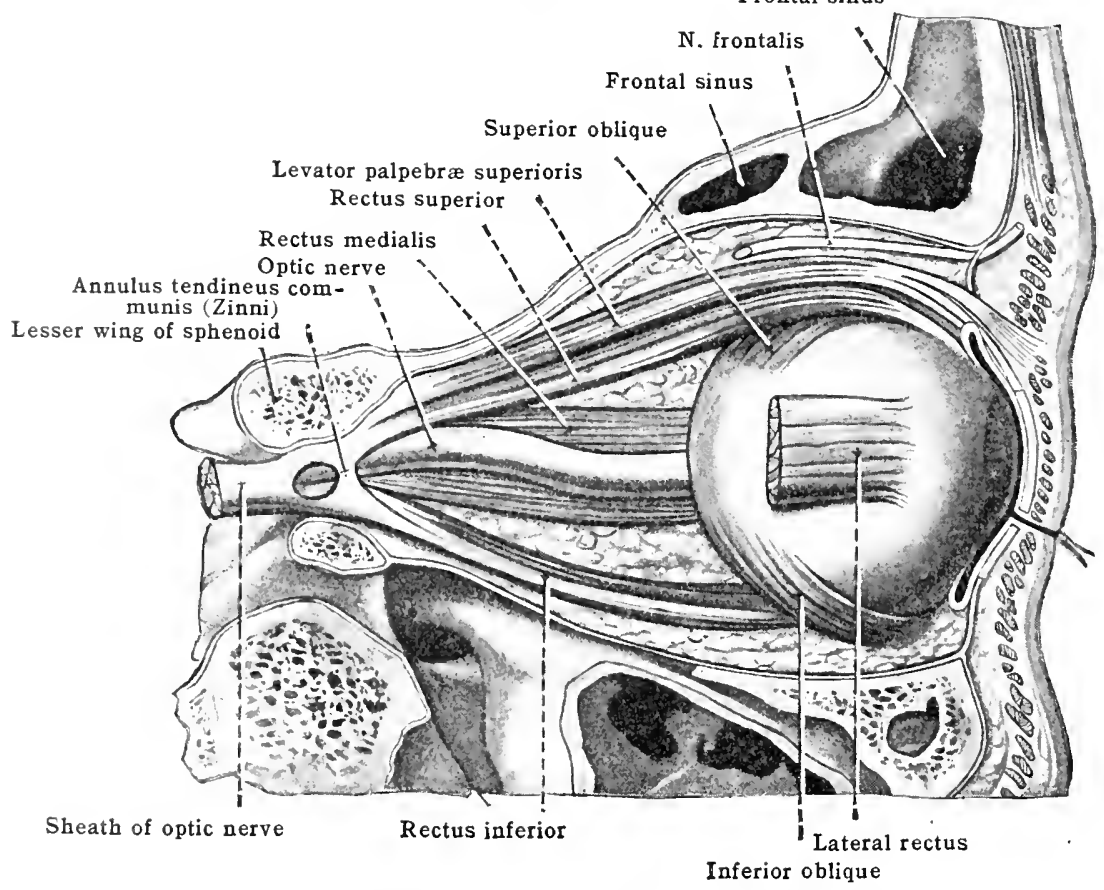

tion. In upward and downward movements of the cornea the eye rotates on its horizontal equatorial axis. The other principal axis of rotation is the sagittal, which we have previously described as corresponding to the line joining the anterior and posterior poles of the globe (page 1055). In rotation of the eve on its sagittal axis, therefore, the cornea may be said to move as a wheel on its axle, for its centre now corresponds to one end of the axis; in other words, this is a rotation of the cornea. Such movements may, consequently, be expressed with reference to their effect on an imaginary spoke of the corneal wheel-e. g., one rumning vertically

Fir. 814.-Dissertion of the Muscles of the Left Orbit, From Above.

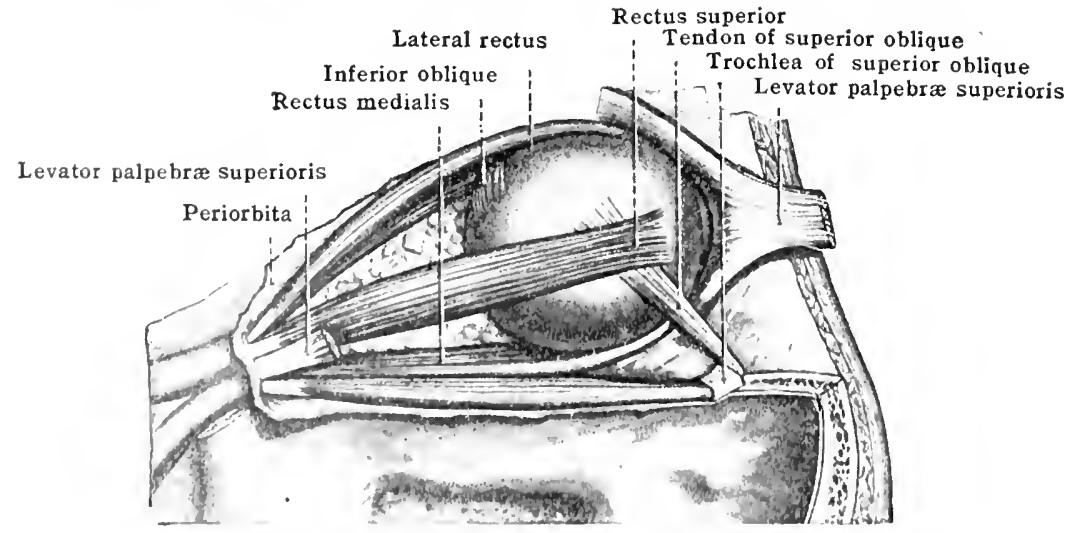

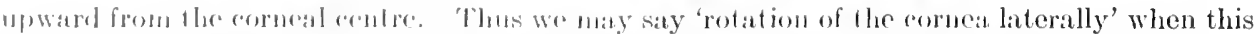
part of the wheol moves foward the lateral angle, or "morlially' when toward the nose.

The only two moseles that rotato the corbitl morely on one axis are the lateral rectus and the medial rectus; the former ablucting, atul the latter allowting, the cornea. 'The action of the supurior and inforion recti is complicated ly the oblinuity of the axes of muscles and globe previonsly mentioned. 
The chief action of the superior rectus is to draw the cornea upward, but at the same time it adducts and rotates the cornea medially.

The inferior rectus mainly draws the cornea downward, also adducting it and rotating it laterally.

The chief action of the superior oblique is to rotate the cornea medially, also drawing it downward and slightly abducting it.

The inferior oblique mainly rotates the cornea laterally, also drawing it upward and slightly abducting it.

The fasciæ of the orbit [fasciæ orbitales].- The orbital contents are bound together and supported by fibrous tissues, which are connected with each other, but which may conveniently be regarded as belonging to three systems. These are:(1) Those lining the bony walls; (2) those ensheathing the muscles; and (3) the tissue which partially encapsules the eyeball.

1. The orbital periosteum [periorbita], is closely applied to the bones forming the walls of the cavity, but may be stripped off with comparative ease. It presents openings for the passage of vessels and nerves entering and leaving the orbit.

Fig. 815.-Diagrair Representing the Orbital Fasciæ in Vertical Section. Periorbita black; muscular sheaths violet; Tenon's capsule green.

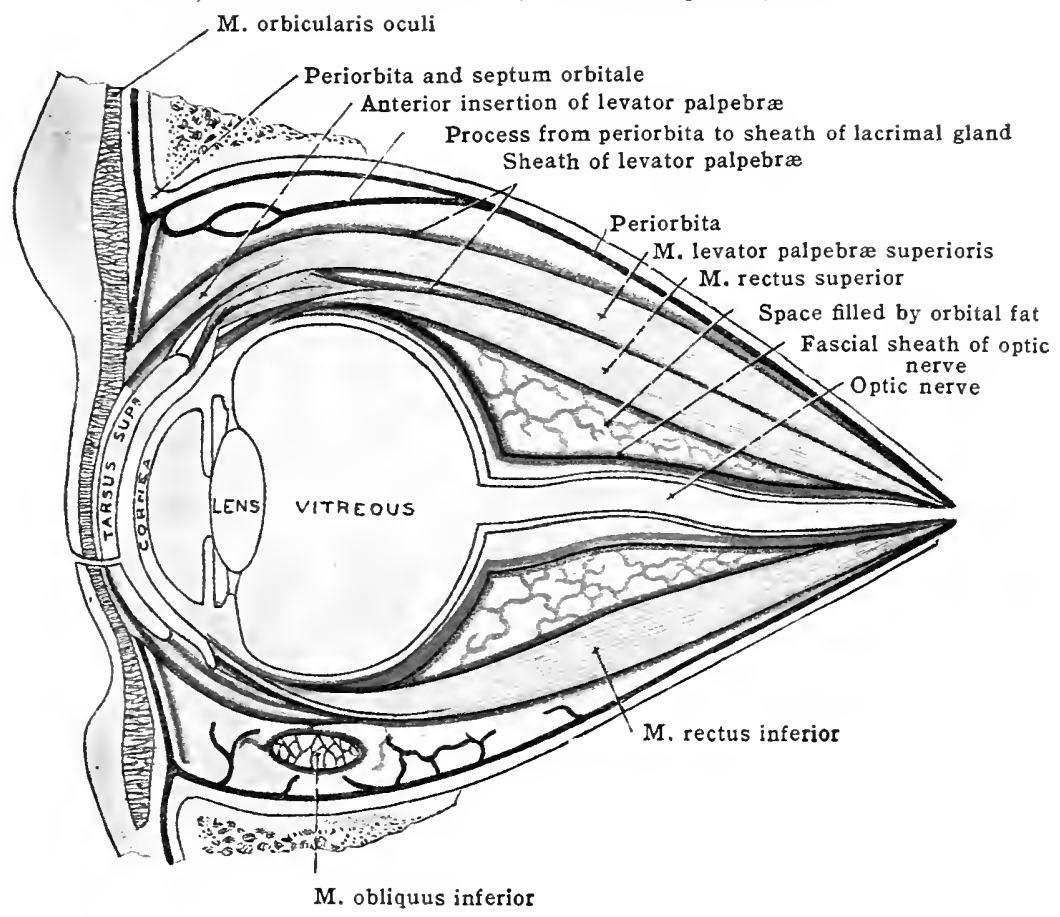

Posteriorly this tissue is very firm, being joined by processes of the dura mater at the optic foramen and superior orbital fissure; at the optic foramen it is also connected with the dura sheath of the optic nerve. As it covers the inferior orbital (spheno-maxillary) fissure its fibres are interwoven with smooth muscle, forming the orbital muscle of Müller. From its inner surface processes run into the orbital cavity, separating the fat lobules. One important process comes from the periorbita about midway along the roof of the orbit, runs forward to the back of the upper division of the lacrimal gland, and there splits, helping to form the gland-capsule: this capsule is joined at its medial border by other periorbital bands coming off near the upper orbital rim, and forming the suspensory ligament of the gland. On the side of the orbit the periorbita sends fibrous processes to the trochlea of the superior oblique, which keep it in position. On arriving at the lacrimal groove the periorbita divides into two layers, a thin posterior one continuing to line the bone forming the floor of the groove, whilst the thicker anterior layer bridges over the groove and the sac which lies in it, forming the limbs of the medial palpebral ligament (p. 1052).

Quite anteriorly, at the rim of the orbit, the periorbita sends off a membranous process which aids in forming the fibrous tissue of the eyelids (orbito-tarsal ligament, or palpebral fascia), and is itself continuous with the periosteum of the bones outside the orbital margin.

2. The orbital muscles are connected by a common fascia, which splits at their borders and furnishes a sheath to each. Processes of this fascia give membranous investments for the vessels and nerves (including the optic nerve), splitting simi- 
larly to enclose them: these membranous processes also assist in separating the fat lobules.

Posteriorly, this fascia is thin and loose, and blends with the periorbita at the origin of the muscles. Anteriorly, it becomes thicker and firmer, accompanies the muscles to near the equafor of the cyeball, and there divides into two lamina, an anterior and a posterior; the former continues a fortrar course, forming a complete funnel-shaped investment all around, passing ultimately to the evelich and orbital margin-whilst the latter turns backward, covering the hinder thirl of the globe.

The anterior lamina is a well-marked membrane everywere, but in certain situations it presents sperial lands of thickening, corresponding to the direct continuation forwarl of the sheath of each rectus muscle. Above and below, this lamina spreads out in the form of two large membranes, which are finally applied to the deep surface of the palpebral fascia; the lower membrane constitutes what has been described as the suspensory ligament of the eyeball.' The upper membrane requires a fuller description, as its distribution is modified by the presence of the levator palpebra muscle.

Fig. S16.-Horizontal Section Through Left Orbit, viewed from above. (After von Gerlach. To show check ligaments, etc.)

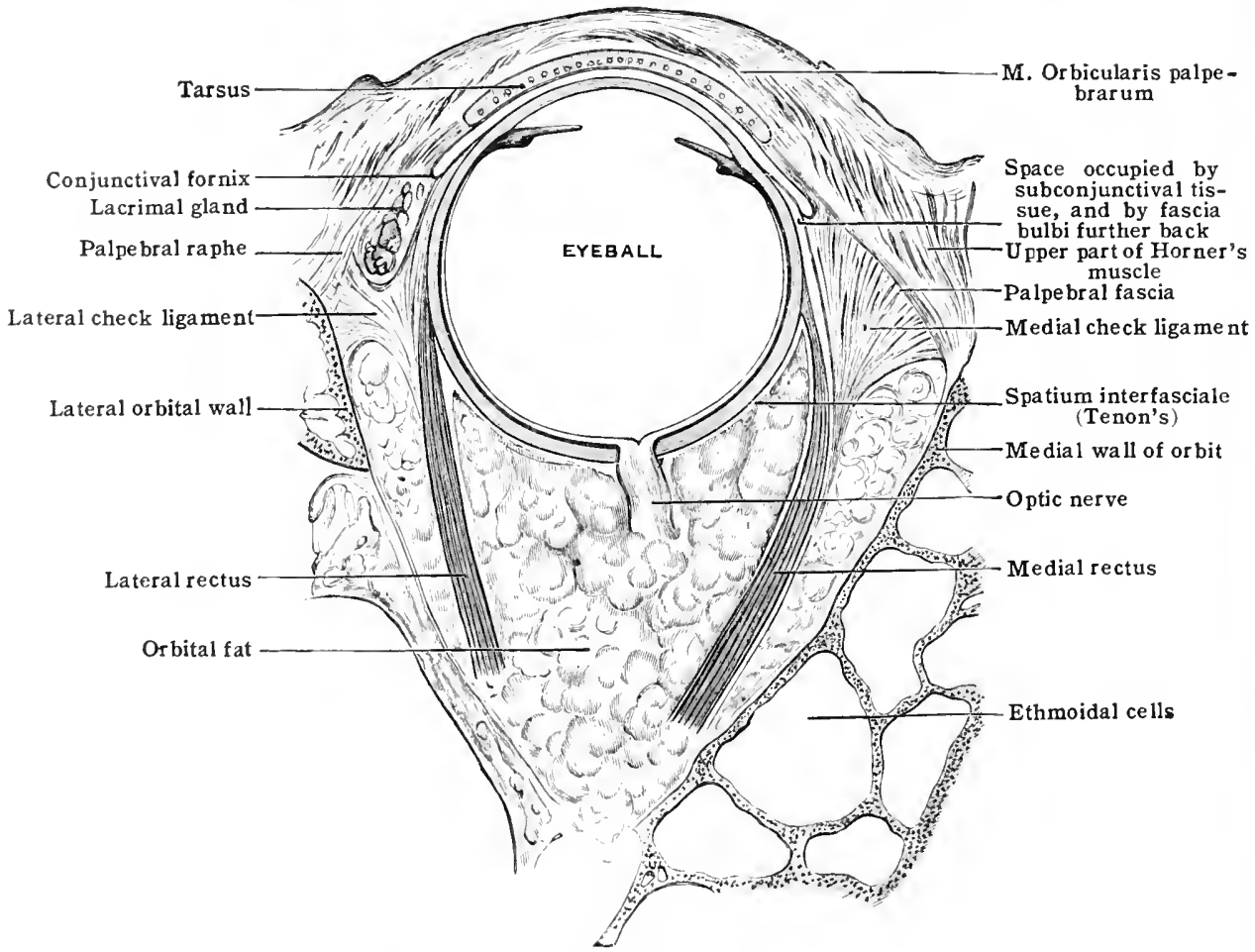

The nuper part of the sheath of the superior rectus (along with the arjoining membrane on (arch sirle of it passes to the elecp surface of the levator, to which it elosely adheres, and complede ensheath this tendon by extending round its borders to its mpper surface. The lower part if this levetor sheath is applied to the inferior surface of the decper of the two divisions of the levitor musele, suprow tarsal muscle, and is attached to the mpper border of the tarsus of the ulpere lid, robehing on each side to the lateral and medial angles of the orbit. The upper part of the shealt al the superior tarsal muscle reaches to the middle of the palpeloral fascia, and is manly continued forwal between the muscle and the fascia to the anterior surface of the litrsist.

The bowr uncmlarine (suspensory ligament of the eychall), joined by the sheath of the

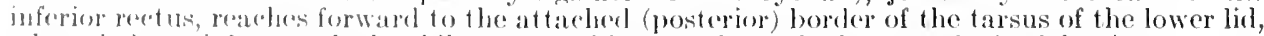
where it is maisly attached, white a part of it extesds to the lower palpebral faseia.

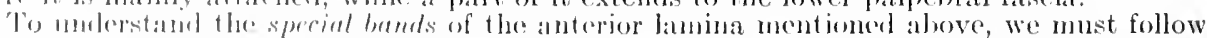
the sheath of anch rectus monedre forward, when we find that, while it is rather loesely applied

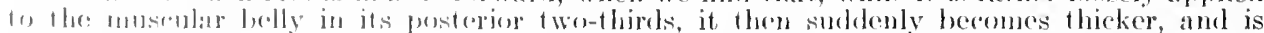
fimmly attanded to the musele for some distance before finally leaving it, and is thereafter of ten

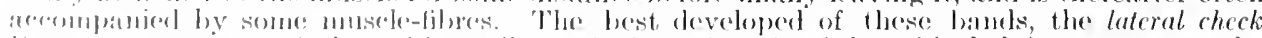

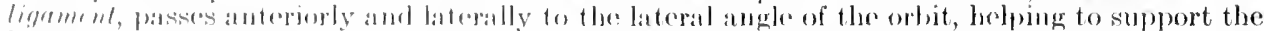

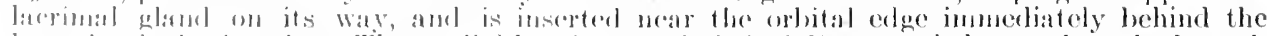

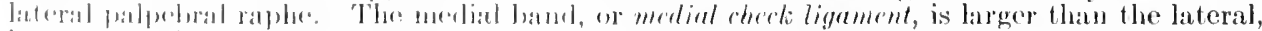

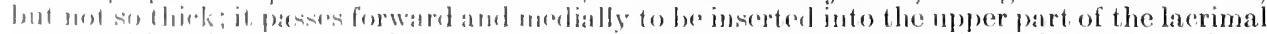

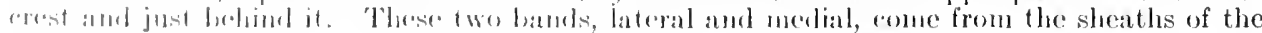


corresponding recti muscles. From the sheath of the superior rectus come two thin bands, one from each border. The medial joins the sheath of the tendon of the superior oblique; the lateral goes to the lateral angle of the orbit, assisting in the support of part of the lacrimal gland. The sheath of the inferior rectus is thickened in front, and, on leaving the muscle, goes to the middle of the inferior oblique, splitting to enclose it; it then passes to be inserted into the lower medial angle of the orbit close behind its margin, about midway between the medial check ligament and the orbital attachment of the inferior oblique.

3. In addition to its partial investment by the muscle-fascia, the eyeball has a special membrane enclosing its hinder two-thirds, the fascia bulbi ("Tenon's capsule").

This is a thin, transparent tissue, situated immediately internal to the posterior lamina of the muscle-fascia. It follows the curve of the sclera from the insertion of the recti to about 3 $\mathrm{mm}$. from the optic nerve entrance. There it leaves the eyeball and blends with the posterior lamina of the muscle-fascia; the combined membrane may be traced backward, enveloping the optic nerve-sheath loosely, approaching it as it nears the optic foramen, but never actually joining it. The interval between it and the nerve-sheath is called the supravaginal lymph-space. The fascia bulbi first comes into relation with the muscles at the point where they are left by their proper sheaths; it there invests their tendons, forms a small serous bursa on the anterior surface of each, and adheres to the sclera along a line running around the globe, just anterior to the insertions of the four recti muscles. Between this line and the corneal border, the conjunctiva is separated from the sclera by the subconjunctival tissue, strengthened by a fine expansion of the muscle-fascia.

The inner surface of the fascia is smooth, and is only connected with the sclera by a loose, wide-meshed areolar tissue. This interval between the sclera and fascia, known as the interfascial (Tenon's) space, is a lymph cavity, and permits free movements of the eyeball within the capsule.

Relation of the Fascia Bulbi to the Oblique Muscles.-The fascia surrounds the posterior third of the inferior oblique and its tendon, running along its ocular surface till it meets the fascial band coming from the inferio rectus (see above), and forming a serous bursa on the superficial surface of the oblique near its insertion. The tendon of the superior oblique for about its last five millimetres is invested solely by the fascia bulbi; in front of this, as far as the trochlea, the tendon lies in a membranous tube derived from the muscle fascia, the inner lining of which is smooth, and may be considered as a prolongation of the fascia bulbi.

\section{The Optic Nerve}

The part of this nerve with which we have here to do lies within the orbit, extending from the optic foramen to the eyeball (fig. 813). The length of this portion of the nerve is from 20 to $30 \mathrm{~mm}$. and its diameter about $5 \mathrm{~mm}$. Its course is somewhat S-shaped; thus, on entering the orbit, it describes a curve, with its convexity down and laterally, and then a second slighter curve, convex medially. Finally, it runs straight forward to the globe, which it enters 3 to $4 \mathrm{~mm}$. to the medial side of its posterior pole.

In its passage through the optic foramen the nerve is surrounded by a prolongation of the meninges. The dura mater splits at the optic foramen, part of it joining the periorbita, while the remainder continues to surround the nerve loosely as its outer or dural sheath. The nerve is closely enveloped by a vascular covering derived from the pia mater, named accordingly the pial sheath. The space between these two sheaths is subdivided by a fine prolongation of the arachnoid (the arachnoidal sheath) into two parts, termed the intervaginal spaces [spatia intervaginalia], viz., an outer, narrow, subdural, and an inner, wider, subarachnoid space, communicating with the corresponding intracranial spaces. The arachnoidal sheath is connected with the sheath on each side of it by numerous fine processes which bridge across the intervening spaces. The pial sheath sends processes inward, which form a framework separating the bundles of nerve-fibres; between the enclosed nerve-fibres and each mesh of this framework there is a narrow interval occupied by lymph. The nerve-fibres are medullated, but have no primitive sheath. About fifteen or twenty millimetres behind the globe the central vessels enter, piercing obliquely the lower lateral quadrant of the nerve, and then run forward in its axis. They are accompanied throughout by a special process of the pial sheath, which forms a fibrous cord in the centre of the nerve.

On reaching the eyeball, the dural sheath is joined by the arachnoid, and turns away from the nerve to be continued into the outer two-thirds of the sclera. Similarly the pial sheath also here leaves the nerve, its greater part running into the inner third of the sclera, while a few of its fibres join the chorioid; the intervaginal spaces consequently end abruptly in the sclera around the nerve-entrance. In this locality the connective-tissue framework of the nerve becomes thicker and closer in its meshwork, and has been already alluded to as the lamina cribrosa scleræ. It is formed by processes passing out from the central fibrous cord at its termination and by processes passing inward from the pial sheath, sclera, and chorioid. It does not pass straight across the nerve, but follows the curve of the surrounding sclera, being therefore slightly convex backward. The nerve-trunk here quickly becomes reduced to one-half its former diam- 
eter, the fibres losing their medullary sheath, and being continued henceforward as mere axiseylinders. Apart from the consequent loss of bulk, this histological change may be readily recognised macroscopically in a longitudinal section of the nerve, its aspect here ehanging from opaque white to semi-translucent grey. The part of the nerve within the lamina cribrosa has already been noted in the ophthalmoscopic examination of the living cye (p. 1055).

The optic nerve is mainly nourished by fine vessels derived from those of the pial sheath, which run into the substance of the nerve in the processes above mentioned. In front of the entrance of the central retinal artery this ressel aids to some extent in the blood-supply of the axial part of the nerve.

Fig. S17.-Transyerse Section throvgh Optic Nerve, showing the Relations of its Sheaths and Connective-tissue Frahework.

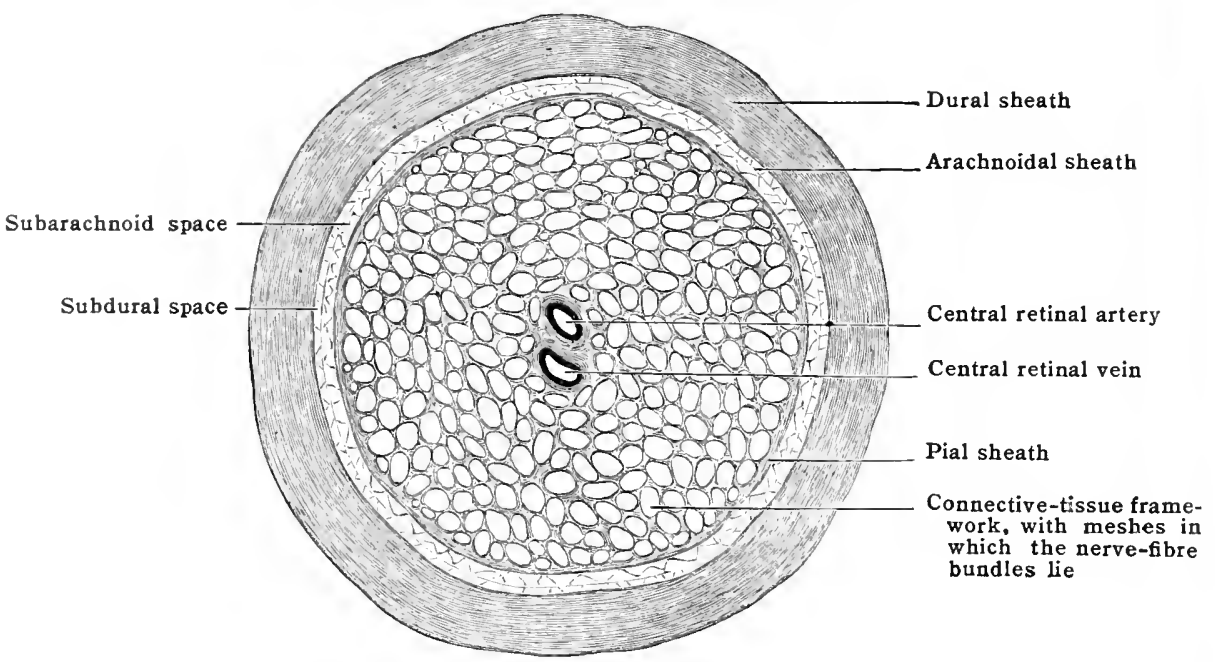

Fig. 81S.-Longitudinal Section through Termination of Optic Nerve.

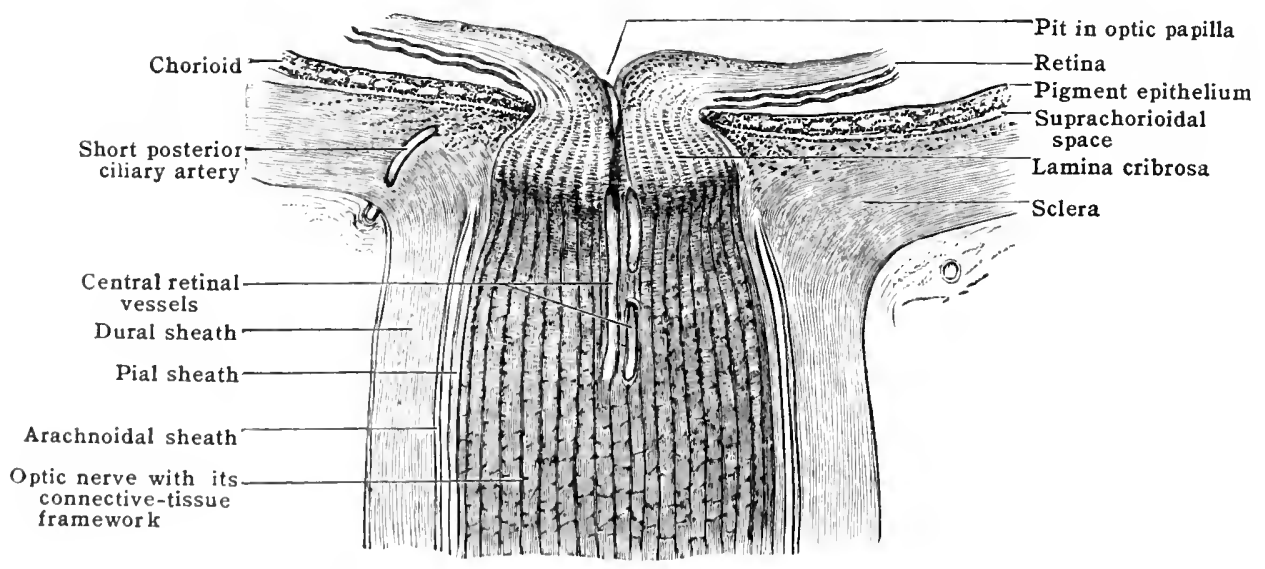

Tile Blogn-vessels and Nerves of the Orbit

As these structures will be more particularly deseribed in other sections of this work, a very short general aleount will suffice here.

Arteries.-The main blemel-supply is afforded by the ophthalmic artery, a branch of the internal carotid, which gains the orbit through the opt ic foramen, where it lies below and lateral to the nerve. On entering the orbit it ascemls, and passes obliquely over the optie nerve to the medial wall of the orhit; in this carly part of its course it gives of most of its branches, which vary murh in their mamme of origin and also in their course. The arteries of the orbit aro remarkablo for thrir tortmons comrse, for their delinate walls, and for their loose attachment to the surromaling tissurs. The ophthaluice artery gives off special branches in the orbit to the lacrimal gland, the muscles, the retina (through the optic nerve), and the eyelall, as well as fo the meninges, the othmoiclal colls, and the nasal mucous membrane. Tivigs from all the different branches go to supply thre fat, fasciar, and ordinary nerves of the orbit. Branches which leave the orlit anteriorly ramify on the forchead and iose, and also go to the supply of 
the eyelids and the tear-passages. The ophthalnic artery has many anastomoses with branches of the external carotid. The contents of the orbit are also supplied in part by the infraorbital artery, a branch of the internal maxillary; in particular this artery supplies part of the inferior rectus and inferior oblique muscles in the cavity, and also gives a branch to the lower eyelid.

Veins.-Branches, corresponding generally to those of the artery, unite to form the superior and inferior ophthalmic veins, which ultimately, either separately or united into one trunk, pass through the superior orbital fissure and empty into the cavernous sinus. The inferior vein is connected with the pterygoid plexus by a branch which leaves the orbit by the inferior orbital fissure.

Nerves of the orbit.-These are (A) motor, (B) sensory, and (C) sympathetic, and all enter the orbit by the superior orbital fissure, with the exception of one small sensory branch passing through the inferior orbital fissure. (The optic nerve has been already described, and is not included in this account.)

A. The motor nerves are the oculomotor, trochlear, and abducens.

1. The oculomotor nerve enters the orbit in two parts, an upper smaller, and a lower larger, division. The upper division [ramus superior] gives off two branches: one supplies the superior rectus, entering its lower surface far back; the other branch goes to the levator palpebræ, entering its lower surface in its posterior third. The lower division [ramus inferior] divides into three branches, of which one supplies the inferior rectus, entering its upper surface

Fig. 819.-The Blood-vessels of the Left Orbit, Viewed from above.

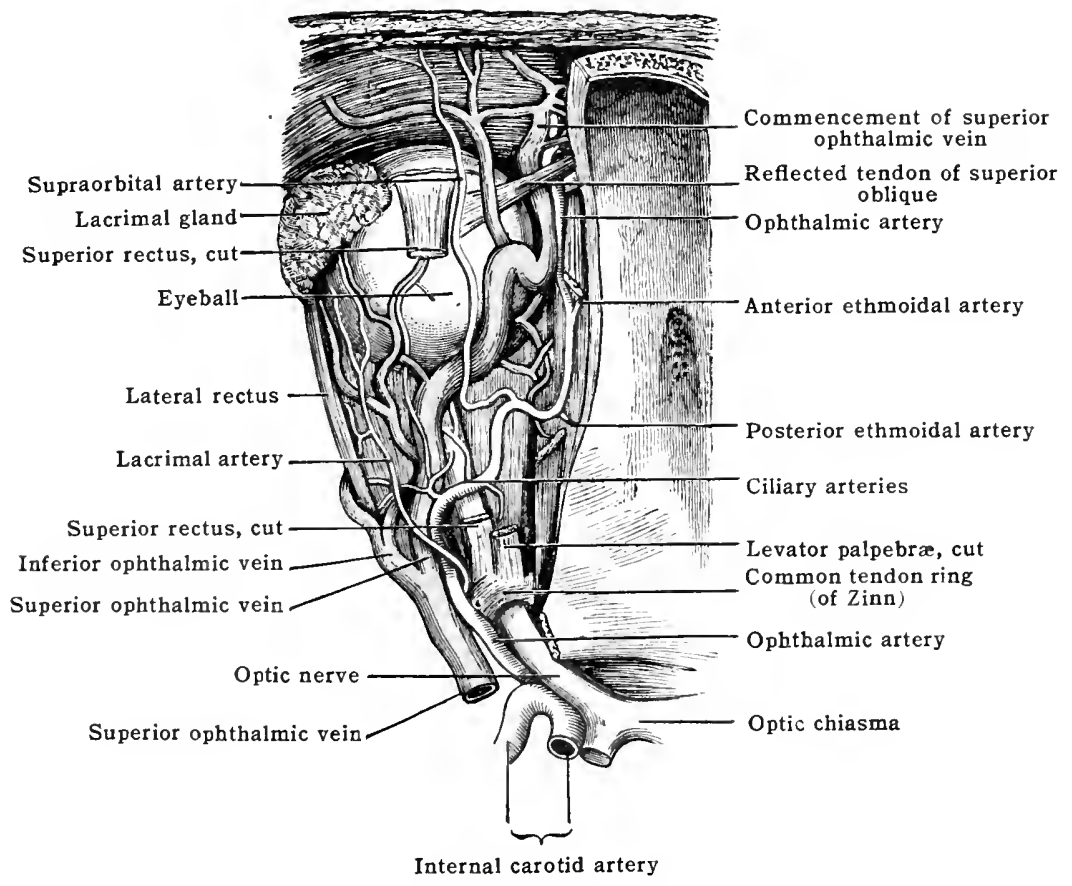

far back, and another supplies the medial rectus, entering its medial surface a little behind its middle. The third branch of the lower division gives (1) the short root to the ciliary ganglion, and (2) one or more twigs to the inferior rectus, and the remainder of this branch then enters the lower surface of the inferior oblique muscle about its middle.

2 . The trochlear nerve supplies the superior oblique muscle, entering its upper surface about midway in its course.

3. The abducens nerve supplies the lateral rectus, entering its medial surface about the junction of the posterior and middle thirds of the muscle.

As regards the manner of termination of these motor nerves, it is found that in all the ocular muscles the nerve on its entrance breaks up into numerous bundles of fibres, which form first coarse and then fine plexuses, the latter ultimately sending off fine twigs supplying the muscle throughout with nerve-endings. The posterior third of these muscles is, however, comparatively poorly supplied with both kinds of plexuses and with nerve-endings.

B. The sensory nerves are supplied by the ophthalmic and maxillary divisions of the trigeminal cranial nerve. The ophthalmic division is chiefly orbital; while the maxillary sends only a small branch to the orbit.

1. The ophthalmic division of the trigeminal nerve enters the orbit in three divisions, namely:-

(1) Frontal, splitting subsequently into supratrochlear and supraorbital, both passing out of the orbit. It is distributed to the corresponding upper eyelid, and the skin over the root of the nose, the foreheal, and the hairy scalp as far back as the coronal suture on the same side. It also gives branches to the periosteum in this region, and to the frontal sinus.

(2) Lacrimal, supplying the lacrimal gland, anastomosing with a branch of the maxillary 
in the orbit, and finally piercing the upper eyelid. Outside the orbit it is distributed to the lateral part of the upper lid, the conjunctiva at the lateral angle, and the skin between this and the temporal region.

(3) Naso-ciliary [n. naso-ciliaris] giving off- $(a)$ a branch to the ciliary ganglion, constituting its long root: $(b)$ two or three long ciliary nerves; and $(c)$ the infratrochlear, passing out of the orbit. The nerve then leaves the orbit as the anterior ethmoidal nerve [n. ethmoidalis anterior], reentering the cranial cavity before being finally distributed to the nose. The infratrochlear branch [n. infratrochlearis], supplies the eyelids and skin of the side of the nose near the medial angle of the eye, the lacrimal sac, caruncle, and plica semilunaris. The anterior ethmoidal nerve, after its course in the cranial cavity, passes through an aperture in the front of the lamina cribrosa of the ethmoid bone, and is ultimately distributed to the nasal mucous membrane, and to the skin of the side and ridge of the nose near its tip.

2. The maxillary division of the fifth nerve gives a branch, called the zygomatic nerve, which passes into the orbit through the inferior orbital fissure, anastomoses with the lacrimal, and leaves the orbit in two divisions. These are distributed to the skin of the temple and of the prominent part of the cheek.

A few minute twigs from the spheno-palatine ganghon, and sometimes from the maxillary division of the fifth nerve, also pass through the inferior orbital fissure to supply the periorbita in this neighbourhood.

C. The sympathetic nerves of the orbit are mainly derived from the plexus on the internal carotid artery. With the exception of branches accompanying the ophthalmic artery, and of the distinct sympathetic root of the ciliary ganglion, they enter the orbit in the substance of

Fig. 820.-Section throdgh Contents of Right Orbit, 1-2 min. in front of the Optic FORAMEN, VIEWED FROM BEHIND. (After Lange.)

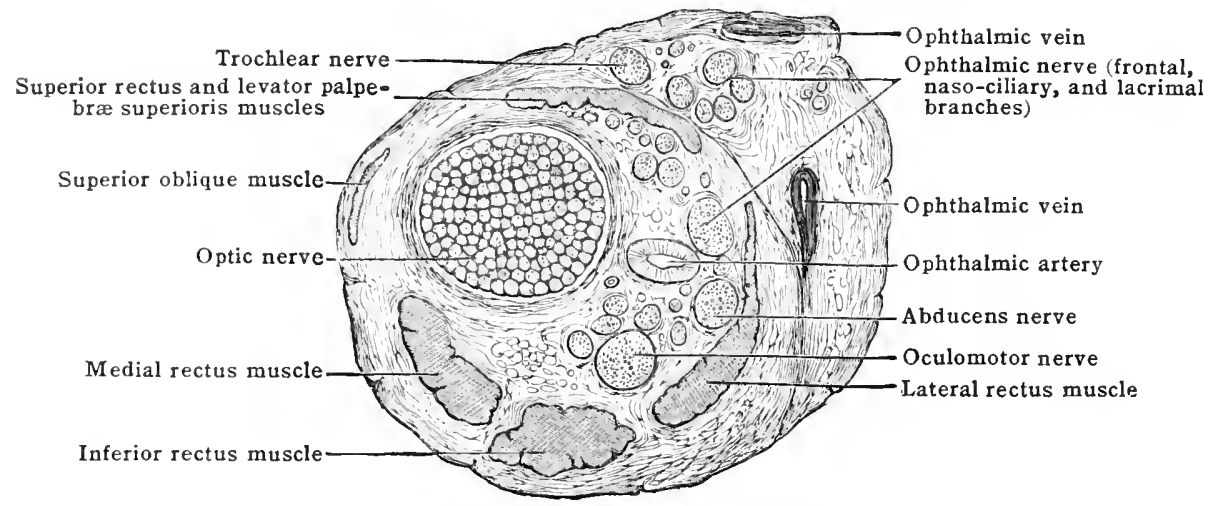

the other nerve-cords. The connections between the ocular nerves and the carotid plexus are recognisable as fibres going to the oculomotor, abducens, and ophthalmic nerves; as a rule, the comparatively large twigs going to the abducens join it furthest back, and those to the oculomotor furthest forward. Sympathetic connections with the trochlear nerve are very doubtful. The special courses of the motor fibres to the dilatator pupillæ muscle have already been described.

The ciliary ganglion is situated between the optic nerve and lateral rectus far back in the orbit. Its three roots-motor, sensory, and sympathetic-have been already mentioned. Anteriorly, it gives off three to six small trunks, which subdivide to form the short ciliary nerves [nn. ciliares breves] about twenty in number, piercing the sclera around the optic nerve entrance.

The lymphatic system of the orbit.-Although there are no lymphatic vessels or glands in the orbit, the passage of lymph is nevertheless well provided for. We have alrealy observed the lymph channels within, between, and outside the sheaths of the optic nerve, and have seen how these communicate anteriorly with the lymph channels of the eycball, and posteriorly with the intracranial meningeal spaces. In addition, there are lymph-spaces around the blood-vessels, situated between the outer coat and the loose investment furnished by the muscle fascia. The nerves of the orbit (apart from the optic) are probably similarly surrounded by lymph-spaces. In the absence of lymphatic vessels it is difficult to trace the circulation thoroughly; much of the lymph from the orbital eavity is said to pass into the parotid nodes.

\section{THE EYELIDS}

The cutaneous and conjunctival surfaces of the eyelids [palpebra] have alrealy been examined (p. 1053), and the position of the tarsus has been indicated. We have now to ascertain the nature and relations of the tarsus, and describe the other tissuess entering into the formation of the eyelids (fig. 821). 
The skin here is thin, bearing fine hairs, and having small sebaceous and numerous small sweat-glands. Immediately beneath it is a loose subcutaneous tissue, destitute of fat, separating the skin from the palpebral part of the orbicularis muscle. The lid-fibres of this muscle arise from the medial palpebral ligament, and course over the whole upper and lower eyelids in a succession of arches, so as to meet again beyond the lateral angle; there they in part join one another, in part are inserted into the lateral palpebral raphe. The muscular fibres are arranged in loose bundles, with spaces between them occupied by connective tissue; in the upper lid these connective-tissue fibres may be traced upward and backward into the fibrous expansion of the tendon of the levator palpebræ supe-

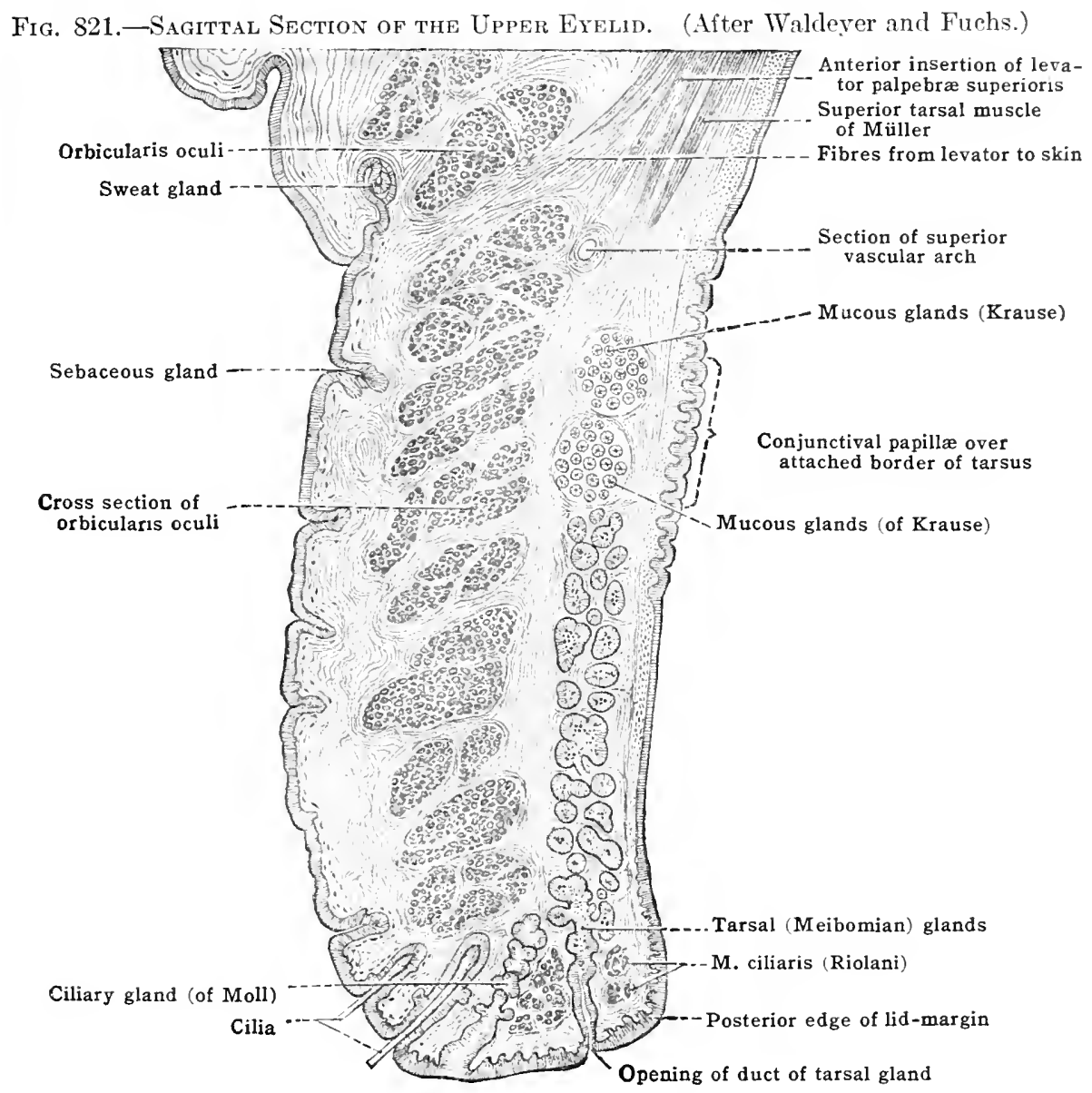

rioris. One strong bundle of orbicularis fibres, called the musculus ciliaris Riolani, is found near the edge of the lid, in front of and behind the efferent ducts of the tarsal glands (fig. 821).

A central connective tissue separates the orbicularis muscle from the tarsus in the tarsal division of the lids. In the upper lid this is to be regarded as mainly the anterior or fibrous expansion of the tendon of the levator palpebræ, which sends connective-tissue septa between the bundles of the overlying orbicularis (as just mentioned) going to the skiu. In the orbital part of this lid the central connective tissue includes also the palpebral fascia, lying here immediately beneath the orbicularis muscle; but this soon thins off and fades into the more deeply placed levator expansion. This latter is strengthened by an extension of the sheath of the superior rectus, by which this muscle is enabled to influence the elevation of the lid indirectly, In the lower lid the central connective tissue similarly consists of palpebral fascia, blended with a thin fibrous extension of the sheath of the inferior rectus. Immediately in front of each tarsus is a little loose connective tissue, which contains the large blood-vessels and nerves of the lids.

The tarsus of each lid is a stiff plate of close connective tissue, with its surfaces directed anteriorly and posteriorly; in its substance the tarsal glands are 
embedded. One tarsal border is free, viz., toward the edge of the lid, the other is attached; the former is straight, while the latter is eonvex, especially in the upper licl.

The length of each tarsus is about twenty millimetres. Its breadth is greatest in the middle of the lid, and becomes gradually smaller toward each angle, where the tarsi are joined to the lateral raphe and medial palpebral ligament. The breadth of the upper tarsus $(10 \mathrm{~mm}$.) is about twice that of the lower. The thickness of each is greatest, and its texture closest, at the middle of its length, thinning off toward the angles of the eve and toward both borders. Into the superior anterior border of the upper tarsus the lower layer of the levator expansion is attached, consisting of smooth muscle-fibres constituting the superior tarsal muscle of Müller. In like manner, at the inferior border of the lower tarsus, bundles of smooth muscle-fibre are inserted (the inferior tarsal muscle of Müller), developed in what has been regarded as part of the extension of the sheath of the inferior rectus.

The palpebral conjunctiva is firmly adherent to the posterior aspect of the tarsus; but in the orbital part of the lid loose subconjunctival tissue intervenes between it and Müller's tarsal muscle. Lymphoid tissue oceurs in the substance of the eonjunetiva, especially in its orbital division. Near the upper fornix, the conjunetiva receives expansions of the tendon of the levator palpebræ and of the sheath of the superior rectus, and, at the lower fornix, of the sheath of the inferior reetus. The surface of the tarsal conjunctiva shows small elevations or papillæ everywhere; but these are particularly well marked over the attached border of the tarsus.

Glands of the eyelids.-From its manner of formation the eyelid may be regarded as consisting of two thicknesses of skin, the posterior having been cloubled back upon the anterior at the edge of the lid; thus the epidermis and corium of the skin proper are represented respeetively by the eonjunetiva (epithelium) and tarsus of the inner thickness. At the free border of the lid, aceordingly, we find glands eorresponding to the sebaceous and sweat-glands of the skin, viz., large sebaceous glands of the cilia (Zeiss's glands) and the ciliary glands of Moll, which are modified sweat-glands. Again, in the imner skin-thiekness of. the lid, the tarsal (Meibomian) glands are sebaceous.

Acino-tubular mucous glands occur at the attached border of the tarsus (Kirause's or Waldever's glands), and similar glands also occur at the fornix, and are especially abundant near the outer angle of the upper lid, close to the efferent ducts of the lacrimal gland; from their structure and the character of their secretion, these acinous or acino-tubular glands have been termed by Henle 'accessory lacrimal glands.' Other simple tubular glands (Henle), formed merely by the depressions between the papillae, are best developed in the medial and lateral fourths of the tarsal conjunctiva of both lids.

Blood-vessels. - The arteries run in the central connective tissue of the lids, mainly in the form of arches near the borrlers of the tarsus, from which twigs go to the different palpebral tissues. They are supplied by the lacrimal and palpebral branches of the ophthalmic and by small branches derived from the temporal artery. The veins are more numerous and litrge than the arteries, and form a close plexus beneath earh fornix. They empty themselves into the vins of the face at the medial, and into the orbital veins at the lateral angle of the eye.

'The lymphatic vessels of the lids are numerous, and are principally situated in the conjunctiva. Lymph-spares also surround the follicles of the tarsal glands. The palpebral lymplantic vescels from the lateral three-fourths of the lid piss through the anterior auricular and parotid nonles; those from the medial fourth of the lower lid go to the facial and submaxillary lymplatic nomes.

Nerves.-(a) Sensory. The upper lid is ahiefly supplied by branches of the supraorbital and supratrochlear nerres, the lower lid by one or two branches of the infraorbital. At the unclial angle the infratrochlear nerve also aids in the supply, and, at the lateral angle, the lacrinal. (b) Motor. The palpobal part of the orbicularis is supplied by branches of the

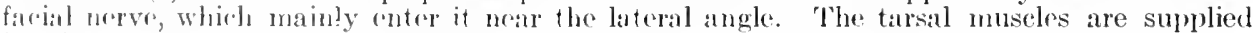
by tha sympathetir neprous system.

The medial palpebral ligament has been referred to previously. Arising from thre frontal proress of the maxillat, it extends laterally over the front wall of the latcrimal sate, bends roumel the latcral wall of the sae, and then passes backward to the pestoriog erest on the lacrinal hone. It is thus U-shaped, having its limbs

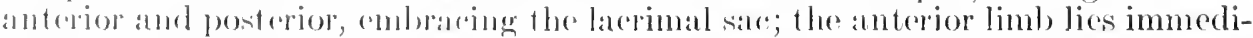
atoly honeath the skin, and is visible in the living. The palpeloral filores of the orbinularis ase inserted into the antrerior surface of both limbs, those attached to the posterion limb constituting the bat latedimalis of the orbicularis palpebrarum

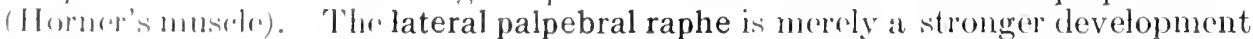

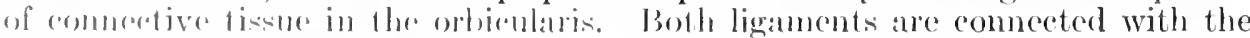

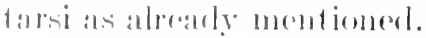




\section{The Lacrimal Apparatus}

The tears are secreted by an aeinous gland, and flow through fine ducts to the upper lateral part of the conjunctival sae, whence they pass over the eornea and are drained off through the puncta, pass along the canaliculi into the lacrimal sac, and ultimately down the naso-lacrimal duct to the inferior meatus of the nose.

The lacrimal gland is situated near the front of the lateral part of the roof of the orbit, lying in a depression in the orbital plate of the frontal bone. It consists of two very unequal parts, one placed above and the other beneath the tendinous expansion of the levator palpebræ superioris, but small gaps in the expansion permit of connections between these two parts of the gland. The upper and larger subdivision (superior lacrimal gland) is a firm elongated body, about the size of a small almond; it has a grevish-red colour, and is made up of closely aggregated lobules. The upper surface (next the orbital roof) is convex, and its lower surface is slightly concave.

Anteriorly, the gland almost reaches the upper orbital margin, and it extends backward for approximately one-fourth the depth of the orbit, measuring about twelve millimetres in this direction. The lateral border of the gland descends to near the insertion of the fascial expansion of the lateral rectus, while its medial border almost reaches the lateral edge of the superior rectus; its transverse measurement is about twenty millimetres. It is enveloped in a capsule, which is slung by strong fibrous bands passing to its medial borcler from the orbital margin (suspensory ligament of the gland).

Fig. 822.-Dissection of the Eye to Show the Lacrimal Apparatus, Anterior View.

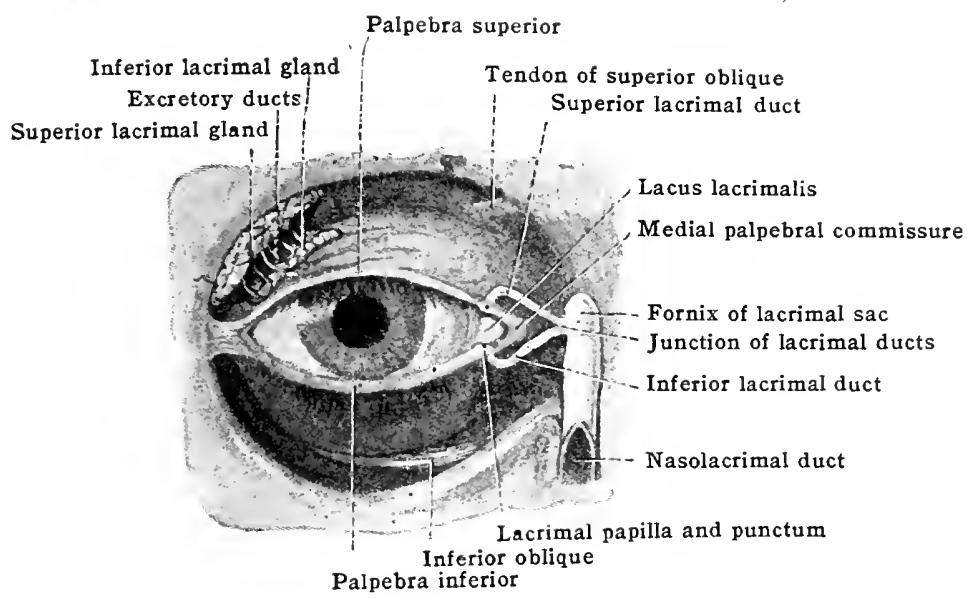

The lower subdivision of the gland (inferior lacrimal gland) is composed of loosely applied lobules, and lies immediately over the lateral third of the upper conjunctival fornix, reaching lateralward as far as the lateral angle.

Each subdivision of the gland possesses several excretory ducts, which all open on the lateral part of the upper fornix conjunctivæ, about four millimetres above the upper border of the tarsus. Those of the superior gland, three or four in number, pass between the lobules of the lower gland; the most lateral duct is the largest, and opens at the level of the lateral angle of the eye. The ducts of the inferior gland in part diseharge themselves into those of the upper, but there are also several fine ducts from this subdivision that run an independent course.

Near the medial angle are the two puncta lacrimalia, upper and lower, each situated at the summit of its papilla. The top of each papilla curves backward toward the conjunctival sac, so that the puncta are well adapted for their function of draining off any fluid collecting there.

The ductus (canaliculi) lacrimales extend from the puncta to the lacrimal sac. The lumen at the punctum is horizontally oval, from its lips being slightly compressed antero-posteriorly; the lumen of the lower punctum is somewhat larger than that of the upper. As the lower papilla is a little further from the medial angle of the eye than the upper, the corresponding canaliculus is longer.

On tracing either ductus from its origin, we find that at first it runs nearly vertically for a short distance, then bends sharply toward the nose, and finally 
courses more or less horizontally, converging slightly toward its fellow, and not infrequently joining it before opening into the sac. The calibre varies considerably in this course, being narrowest a short distance from the punctum, and widest at the bend, from which point it again narrows very gradually as it nears the sac.

The wall of the ductus consists mainly of elastic and white fibrous tissue, lined internally by epithelium, and covered externally by striated muscle (part of the orbicularis). The musclefibres run parallel to the ductus in the horizontal part of its course; but they are placed, some in front and some behind, around the vertical part, acting here as a kind of sphincter. Just before their termination, the ducts pierce the periosteal thickening that constitutes the posterior limb of the medial palpebral ligament.

The lacrimal sac [saccus lacrimalis] lies in a depression in the bone at the medial angle of the orbit (the lacrimal fossa). It is vertically elongated, and narrows at its upper and lower ends; the upper extremity or fundus is closed, while the lower is continuous with the naso-lacrimal duct. Laterally, the sac is somewhat compressed, so that its antero-posterior is greater than its transverse diameter. 'The ducts, either separately or by a short common tube, open into a bulging on the lateral surface of the sac near the fundus.

As has previously been mentioned, the sac is surrounded by periosteum, but between this and the mucous membrane forming the true sac-wall there is a loose connective tissue, so that the cavity is capable of considerable distention. The relations of the medial palpebral ligament have already been described; it is to be noted that the fundus of the sac extends above this ligament.

The naso-lacrimal duct [ductus naso-lacrimalis] reaches from the lower end of the sac to the top of the inferior meatus of the nose, opening into the latter just beneath the adherent border of the inferior nasal concha. Traced from above, its main direction is downward, but it has also a slight inclination backward and laterally. It lies in a bony canal, whose periosteum forms its outer covering. Between this and the mucous membrane of the duct there is a little intermediate tissue, in which run veins of considerable size connected with the plexus of the inferior concha. The duct does not usually open directly into the nasal cavity at the lower end of the bony canal, but pierces the nasal mucous membrane very obliquely, so that a flap [plica lacrimalis (Hasneri)] of mucous membrane covers the lower border of the opening in the bone, upon which flap the tears first trickle after escaping from the duct proper.

The sac and naso-lacrimal duct together constitute the lacrimal canal, lined throughout by a continuous mucous membrane. This membrane presents folds in some situations, especially near the opening of the canaliculi, at the junction of the sac and duct, and at the lower end of the duct. That at the top of the duct is the most important, as it sometimes interferes with the proper flow of tears out of the sac. 'The total length of the lacrimal canal is roughly twenty-four millimetres, half of this being sac, and half naso-lacrimal duct. If, however, we reckon as duct the oblique passage through the nasal mucous membrane, this measurement may occasionally be increased by eight or ten millimetres. The lacrimal sac, when distended, measures about six millimetres from before backward, by four millimetres transversely. The naso-lacrimal duct is practically circular, and has a diameter of about three millimetres, rather less at its junction with the sac', where we find the narrowest part of the whole lacrimal canal.

Development of the Exe

The eye is developed from the three sources involving two fundamental embryonic layersthe retina from a portion of the ectodermal wall of the forebrain on each side; the lens from the ectodermal surface epithelium; and the sclera, cornea (except epithelium) and chorioidal coat from the mesoderm which surrounds the former structures.

The process of development is, briefly, as follows:- The site of the eye is marked by a slight repression on the surface of the forchrain on either side. There later an outgrowth occurs from the ventro-lateral aspect on each side of the forebrain, in the form of a hollow vesicle, whose cavity is continuous with that of the forebrain. 'This outgrowth is termed the primary optic vesicle [vesicula ophthalnica]. The lateral surface of the vesicle comes into contact with the surface epithelium of the head and this cpithelium becomes thickened at the area of contact. The superficial portion of the vesicle expands, while its connection with the brain remains slender; becoming depressed on the surface, it forms a cup-shaped hollow, the secondary optic vesick or optic cup [caliculus ophthalnicus] whose wall is formed of two layers, an outer investing laver and an inner inverted onc.

The chorividal fissure is present almost from the first stages, as a cleft on the ventral aspect of both the alistal portion of the vesicle, or cup, and of the stalk; and it is formed by an infolding of the surfare into the eavity of the vesisele along a narrow linear area.

In this eloft arr found vossols which pass to the loblow of the optic cup. The margins of the cleft meet and fusc, and enclose the vessels in the interior-bence the enclosure of the a. ('nt ralis retinar within the opt ire nerve, and of the hyaloid artery in the interior of the vitreous. shomkl the margins of the cleft remain separate, the condition of coloboma results. 
From the optic cup is formed the whole of the retinal or nervous tunic. It will be noticed that this tunic is composed of two layers, with a narrow slit-like interval between them, but that the layers are continuous with one another at the margin of the cup. This margin is afterward found, in the fully developed eye, at the pupillary margin of the iris. The outer investing layer forms the pigment layer, and the inner inverted layer gives rise to the other parts of the retina, viz., the pars optica, over the bottom of the cup, the pars ciliaris, in the ciliary region, and the pars iridica, near the margin of the original cup, including the dilatator and sphincter pupillæ muscles of the iris.

The lens is formed as a hollow invagination from the surface epithelium, which sinks into the hollow of the optic cup. The margins meet and fuse, enclosing a cavity, and the lens mass sinking more deeply in, loses its connection with the surface, and a layer of mesoderm passes in between them.

The anlages of the lens and the primitive retina are at first in contact with one another. They gradually draw apart, and the intervening space is filled by the vitreous humour. The origin of the vitreous humour is not yet fully understood, but it appears to be developed from the adjacent ectoderm of the optic cup, and in part from the surrounding mesoderm.

Figs. 823, 824, 825 and 826.-Sections Representing Four Successive Stages in the Origin of the_Optic Vesicle and the Development of the Eyeball.
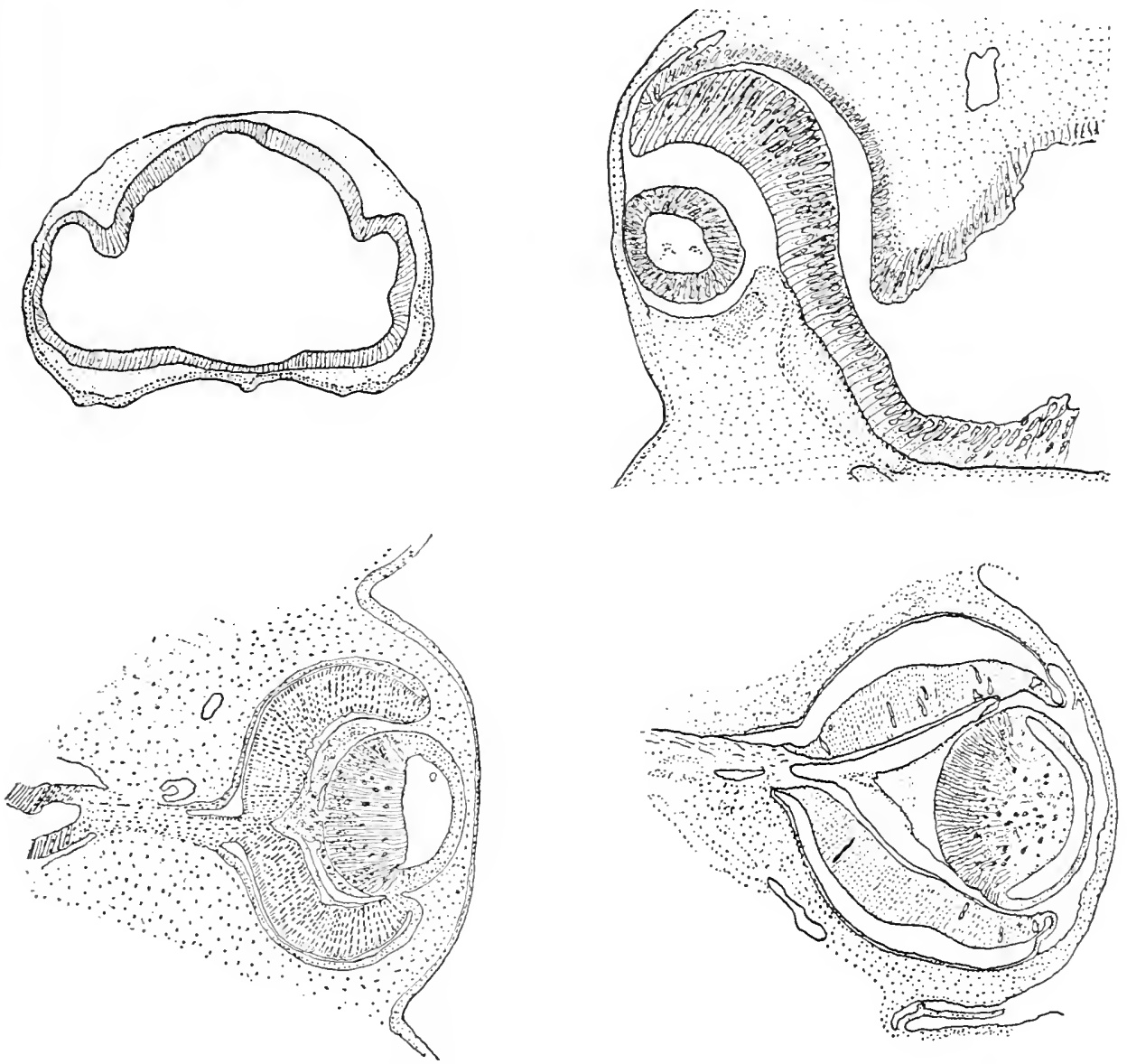

The optic cup and the lens are surrounded by mesoderm and from it are formed the structures of the tunica vasculosa (middle coat) in its different parts, viz., chorioid, ciliary body and iris, and also the sclera and cornea (fibrous portion).

The anterior chamber is formed by cleavage of the mesoderm, a space appearing in it, filled with fluid. The mesoderm surrounding this space forms the endothelium lining the anterior chamber. The mesoderm also forms a vascular covering for the front of the lens, termed the capsula vasculosa lentis, or pupillary membrane, which disappears from the surface of the lens in the later months of development.

The eyelids and conjunctiva are formed from the integumentary covering of the eye. The former are mostly skin folds, which, at first separate, meet and fuse with one another along their margin. Subsequently they become undermined by the ingrowth of epithelium from a central horizontal slit, the rima palpebrarum; the central part of the invading epithelium breaks down, and the free folds are formed.

The lacrimal gland is developed from a series of tubular outgrowths from the conjunctival sac. 
The lacrimal canals and naso-lacrimal duct are formed by the growth of an epithelial band which passes through the mesoderm to the nasal cavity along the naso-lacrimal groove. This band loses its primitive connection with the groove, and is reunited to the lid margins by secondary epithelial bands which grow from the naso-lacrimal duct to the lid margin. Similarly a secondary connection is later made with the nasal cavity at the lower end of the duct. The position of the naso-lacrimal duct corresponds to the line of union of the nasal and maxillary processes; but the duct does not represent a portion of the cleft between these processes, and is formed secondarily between them.

\section{THE EAR}

Ender the name of the ear [organon auditus] there is included a number of structures of which some, the ear proper, constitute the auditory mechanismthat is, an apparatus for the collection, transmission and reception of the waves of sound; while others-the semicircular ducts and associated structures-are concerned in receiving and transmitting impressions produced by movements of the head. These impressions constitute the basis of what may be termed the static or equilibratory sense, and afford data employed in estimating movements of the body in relation to surrounding objects.

The former of these, the ear proper, consists of three main parts, each possessing distinet structural and functional eharaeters. The first portion, of ten known as the external ear, consists of a receptive organ placed upon the surface of the head, the auricle or pinna, and of a short tube, the external auditory meatus, which leads into the interior, and is elosed at its deep end by the tympanic membrane.

The second portion, known as the middle ear, consists of the tympanic cavity, a small air-containing ehamber in the petrous portion of the temporal bone, connected with the nasal part of the pharynx by a tube, the auditory (or Eustachian) tube. From the tympanic chamber a recess passes posteriorly and leads to a cavity in the mastoid portion of the temporal bone, the mastoid or tympanic antrum. A chain of three small bones transmits the sounds across the middle ear.

The third part, or internal ear which contains the essential sensory apparatus, lies within the complex eavities in the interior of the petrous temporal bone known as the osseous labyrinth. It consists of (1) the utricle and saccule, two small vesicular struetures lying in the bony vestibule, and (2) the membranous semicircular ducts and (3) the membranous cochlea, which lie within the corresponding bony canals.

These structures are filled with fluid, the endoly mph, and communicate with one another. They are largely separated from the bony walls by fluid, perilymph, and they are lined by sensory epithelium. Closely related to the epithelial sensory cells are found the terminal branches of the cochlear and vestibular nerves.

The deseription of the three divisions of the ear is taken up in order from the surface in ward.

\section{THE EXTERNAL EAR}

The external ear consists of the auricle attached to the side of the head, and the extromal aurlitory meatus learling from it to the midelle ear (fig. 829).

\section{TIIE AURICLE}

Thr auricle, or pima, is an irregular oval plate-like strueture which lies upon the lateral surface of thro houl. It presents a lateral and a medial surface. The latcral surfatee is irrogularly roncave (fig. 827 ). The decpest part of its eoneavity situated noar the rentro, is tomed the concha, and it is partially divided by a prominemt oblicue rislge, the crus of the helix, into a superior part, the cymba conchæ, and a large inforior bat, the cavum conchæ. The "avmum coneha leads into 1 her axternal anditory meatus, and is bomded ventrally by a prominent process, the tragus, which projocts pesteriorly over the ontraner to the meatus. The tragus, is sepatratod from the arus of the helix by a well-marked depression, the anterior incisure and has a small fulerele on it superiorly, the supratragic tubercle. liomeling the "avum conchar pestoriorly and inforiorly is a projection, the antitragus, lying oplosite, but inferior, to the tragus, and hetween the two is a (lep) notrl, fla intertragic notch fincisura intertragical. A prominent semieircular 
ridge, the anthelix, bounds the concha posteriorly and superiorly. Inferiorly it is separated from the antitragus by a slight depression, the posterior auricular !sulcus. Superiorly the an thelix clivides into two ridges, the crura of the anthelix, and between these is a shallow depression, the triangular fossa. The superior and dorsal margin of the auricle is inverted and forms a prominent rim, the helix, which

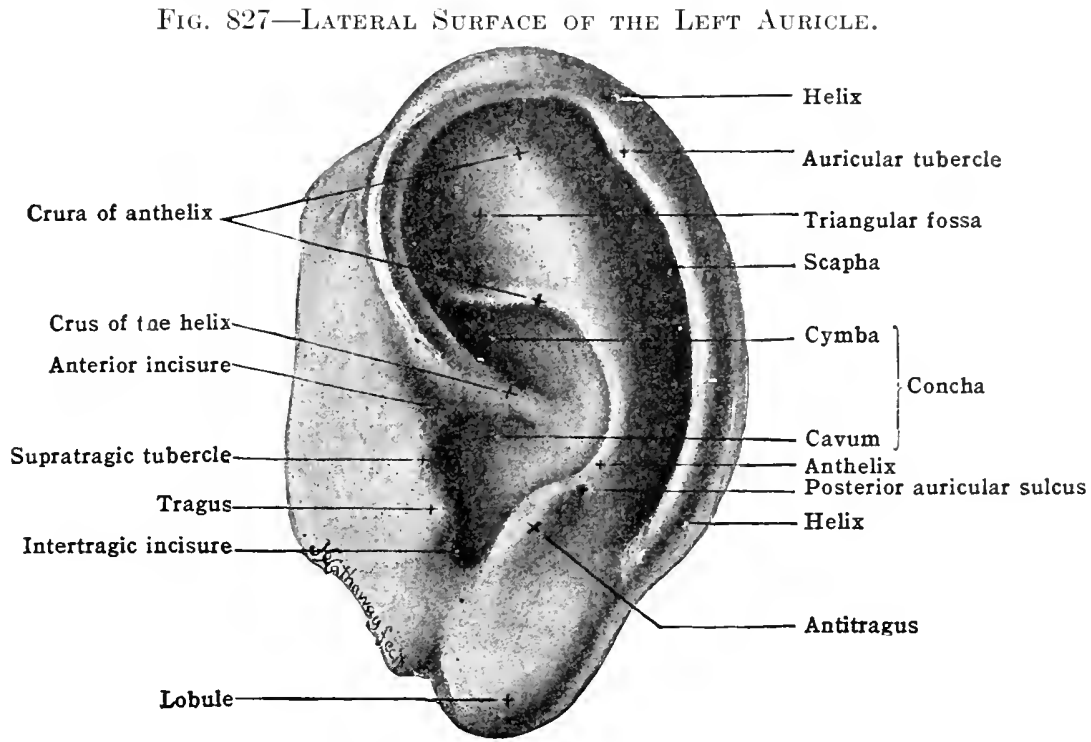

is continued anteriorly into the crus of the helix, and inferiorly into the lobule. An elongated depression, partly overlapped by the helix, termed the scapha (scaphoid fossa) separates the helix and the anthelix. Superiorly and dorsally the free margin of the helix frequently presents a slight projection, the auricular. tubercle (tubercle of Darwin).

Fig. 828.-Lateral and Medial Surface of the Cartilage of the Right Auricle and its Muscles, ETC.

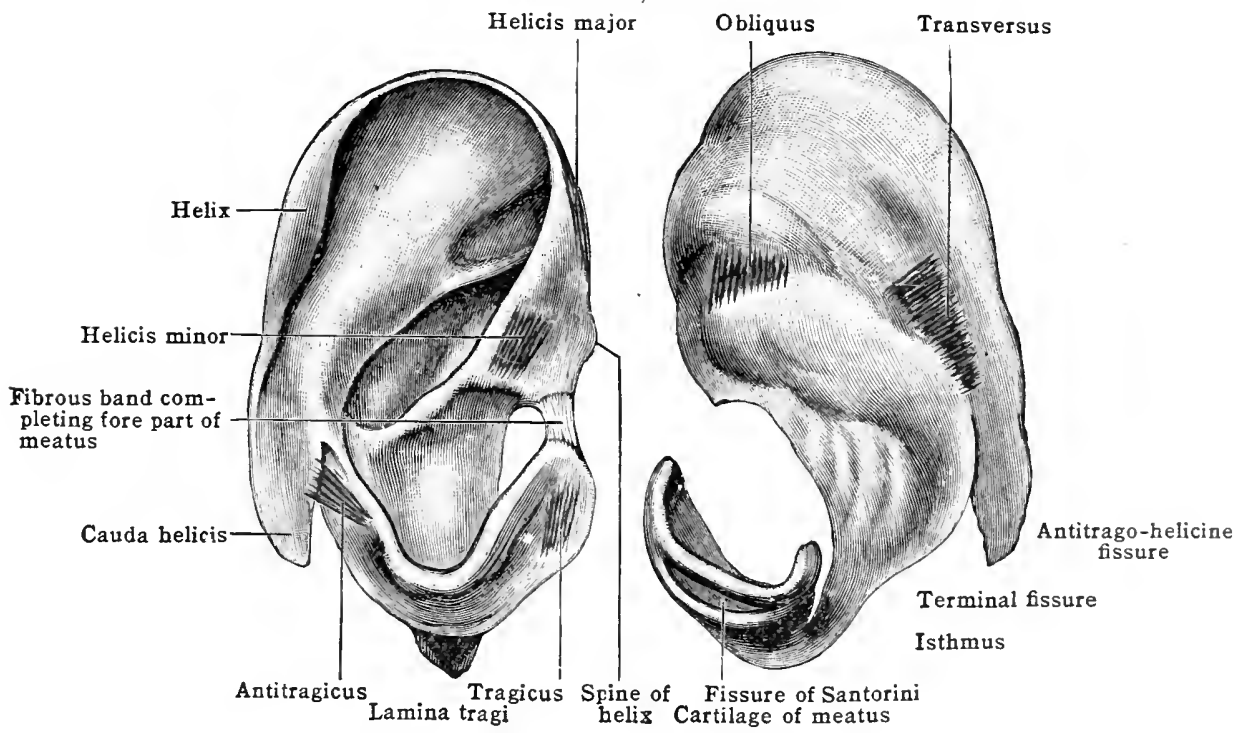

Upon the medial surface of the auricle the depressions of the lateral surface are represented by elevations, viz., the eminence of the concha, the eminence of the scapha, and the eminence of the triangular fossa, respectively; and the elevations by depressed areas, viz., the fossa of the anthelix, transverse sulcus of the anthelix, 
and the sulcus of the crus of the helix. The attachment of approximately onethird of the medial surface covers up the two latter depressions. The cephalo-auricular angle, between the dorsal free part of the auricle and the side of the head, averages 20 to 30 degrees.

\section{Structure of the Auricle}

The features of the auricle just described are mainly produced by a plate of yellow elastic cartilage, the auricular cartilage. In addition to the elevations and depressions already noted, it presents the following additional features. Projecting anteriorly from the helix, near the crus is a small tubercle, spine of the helix (fig 828); while the posterior margin of the helix terminates in a pointed tail-like process, the cauda helicis which is separated inferiorly from the antitragus by the deep antitrago-helicine fissure. Another deep fissure, the terminal notch [incisura terminalis auris], separates the cartilage of the auricle from that of the meatus, leaving only a narrow strip, the isthmus, connecting the two. The cartilage of the tragus, the lamina tragi, is separated from that of the auricle and is attached to the lateral margin of the cartilage of the meatus.

The auricle is covered on both its medial and lateral aspects by skin which closely follows the irregularities of the cartilage. Thus it is tightly bound to the perichondrium of the lateral surface by the subcutaneous areolar tissue, but much more loosely attached to the medial surface, and in the subcutaneous tissue there is little fat except in the lobule, which is made up almost entirely of fat and tough fibrous tissue. Hairs are abundant but rudimentary, except in the region of the tragus and antitragus, where they may be large and long, particularly in males and in the aged. Sebaceous glands are found on both surfaces, and are especially well developed in the concha and triangular fossa, but sudoriferous glands are few and scattered.

Ligaments and muscles. - The auricle is attached to the side of the head by the skin, by the continuity of its cartilage with that of the acoustic meatus, and by certain extrinsic ligamente and muscles. Three ligaments may be distinguished in the connective tissue:-The anterior ligament, stretching from the zygona to the helix and tragus; the superior ligament, from the superior margin of the bony external acoustic meatus to the spine of the helix; and the posterior ligament, from the mastoid process to the eminence of the concha. There are also three extrinsic muscles, the anterior, superior, and posterior auricular (see p. 337, fig. 341). Six intrinsic muscles are distinguished. These are poorly marked in man and vary much in development. Upon the lateral surface (fig. 828 ) the helicis major stretches from the spine of the helix to the ventral superior margin of the helix; the helicis minor overlies the crus helicis; the tragicus runs vertically upon the tragus; and the antitragicus stretches from the antitragus to the cauda helicis. Upon the medial surface (fig. 828) the transversus auriculæ stretches between the eminences of concha and scapha, and the obliquus between the eminences of the concha and the triangular fossa. Two small muscles occasionally present are the $\mathrm{m}$. pyramidalis auriculæ (Jungi) and the m. incisuræ helicis (Santorini).

\section{Vessels and Nerves of the Auricle}

The arteries are the auricular branch of the posterior auricular and the anterior auricular branches of the superficial temporal arteries. The veins are the anterior auricular vein of the posterior facial (temporal) and the auricular branches of the posterior auricular veins. The latter vessels sometimes join the transverse (lateral) sinus through the mastoid emissary vein. The lymphatics empty into the anterior, posterior and inferior auricular lymph-nodes. The sensory nerves of the auricle are the branches of the great auricular, small occipital (p.977, fig. 753), and anriculo-temporal (p. 941, fig. 740). The muscles are supplied by the posterior auricular branch of the facial (p. 944, fig. 740).

\section{VARIATIONS}

There are many variations in the size, shape, and conformation of the auricle and in the cephalo-auricular angle. These are associated not only with differences in sex, age, and race, but are also found in individuals of the same family.

\section{THE EXTERNAL AUDITORY MEATUS}

The external auditory (acoustic) meatus [meatus acusticus externus] extends medially and somewhat anteriorly and inferiorly from the concha to the tympanic monbrane (fig. 829). It is alout twenty-five mm. (1 in.) long, and, owing to the obliquity of the tympanic membrane, its anterior and inferior wall is $5-6 \mathrm{~mm}$. 
longer than the posterior and superior. It consists of a lateral cartilaginous and a medial osseous portion. The canal describes an S-shaped curve in both horizontal and vertical directions. Near the auricular end it is convex anteriorly and inferiorly, while at the tympanic end the curve is reversed, and is concave in the same direction. The lumen is irregularly elliptical in outline, the longer axis being vertical at the auricular, but nearly horizontal at its tympanic end. The meatus is constricted at about its centre, and also near the tympanum.

Fig. 829.-Vertical Section of the Middle and External Ear.

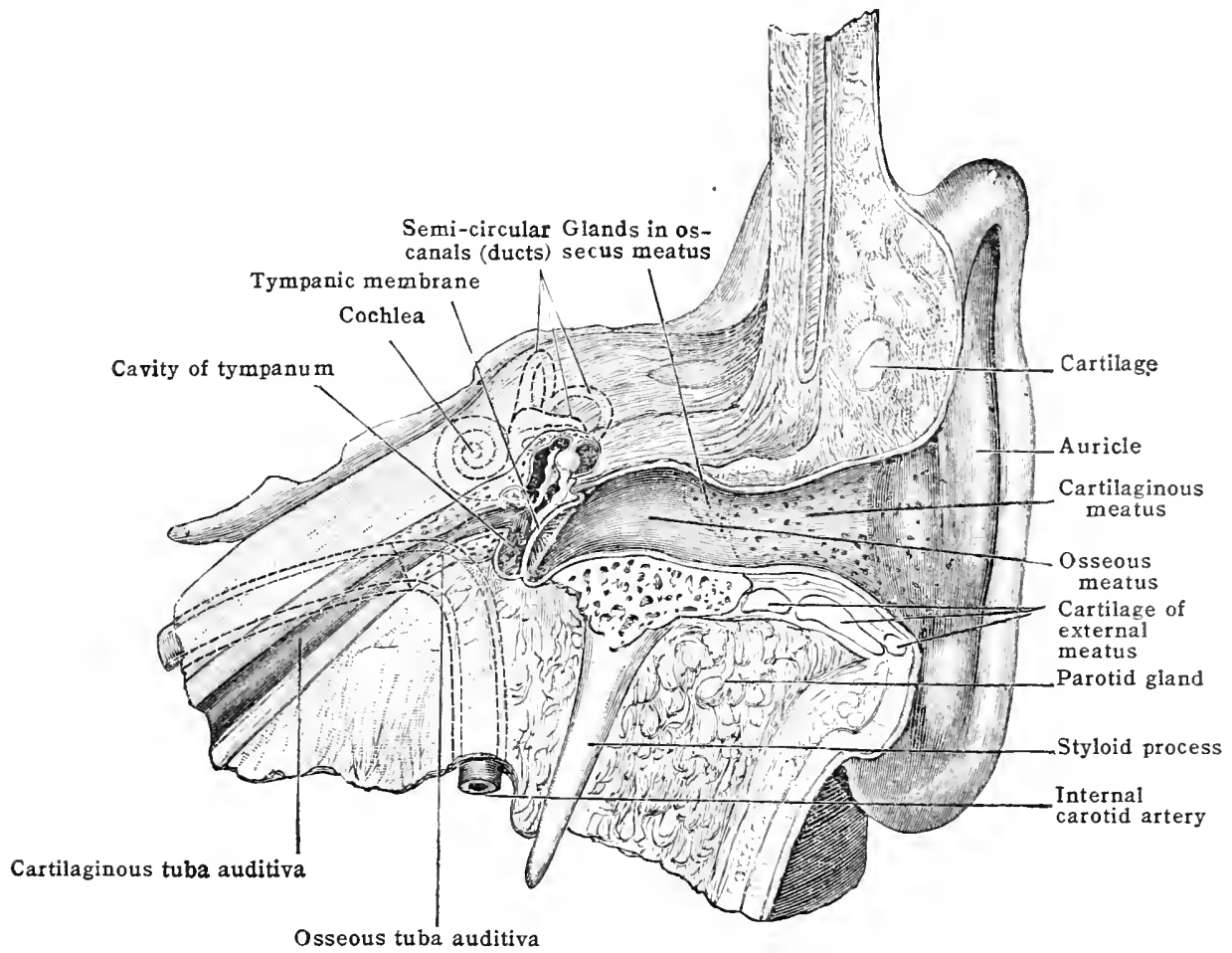

Relations.-The anterior wall is in relation with the condyle of the mandible medially, and with the parotid gland laterally; the inferior wall is closely bound to the parotid gland; and the posterior wall of the bony part is separated by only a thin plate of bone from the mastoid cells. The superior wall is separated at its medial end by a thin plate of bone from the epitympanic recess, and laterally a thicker layer of bone separates it from the cranial cavity.

Structure of the meatus. - The walls of the meatus are formed laterally of fibro-cartilage and medially of bone, lined internally by skin. The cartilage is folded upon itself to form a groove, deficient in its dorsal part, where the edges of the cartilage are united by dense connective tissue. The cartilaginous groove is thus converted into a canal. Medially, the cartilage forms about one-third of the circumference; laterally, two-thirds. Two fissures (incisures of Santorini) usually occur in its anterior wall (fig. 828). Laterally the cartilage is clirectly continuous with the cartilage of the auricle and medially it is firmly connected with the lateral lip of the osseous portion. The osseous portion, which forms slightly more than half the canal, is formed by the tympanic portion of the temporal bone; it is described in connection with that bone.

The skin of the meatus forms a continuous covering for the canal and tympanic membrane. It is thick in the cartilaginous, but very thin in the bony, part of the meatus, especially near the tympanic end, where it is tightly bound to the periosteum. In the cartilaginous meatus it contains numerous fine hairs and sebaceous glands, but neither hairs nor sebaceous glands are found in the bony meatus. Tubular ceruminous glands, which secrete the cerumen (ear wax), form a nearly continuous layer throughout the cartilaginous, but occur on only a small part of the posterior and superior wall of the bony, meatus. The openings of their ducts appear as dark points to the naked eye (fig. 829). 
The arteries are branches from the posterior auricular, superficial temporal, and deep auricular arteries (q. . .). The veins and lymphatics connect with those of the auricle and empty similarly. The nerves are branches from the auriculo-temporal and the auricular ramus of the ragus.

\section{THE MIDDLE EAR}

Under the term middle ear there are included the tympanic cavity (tympanum), the tympanic antrum and the auditory (Eustachian) tube. These form a continuous irregular passage, filled with air, and located within and upon the surface of the temporal bone. The tympanum is shut off from the external ear

Fig. S30.-Frozex Coronal Section of the Right Ear. (Somewhat Enlarged.)

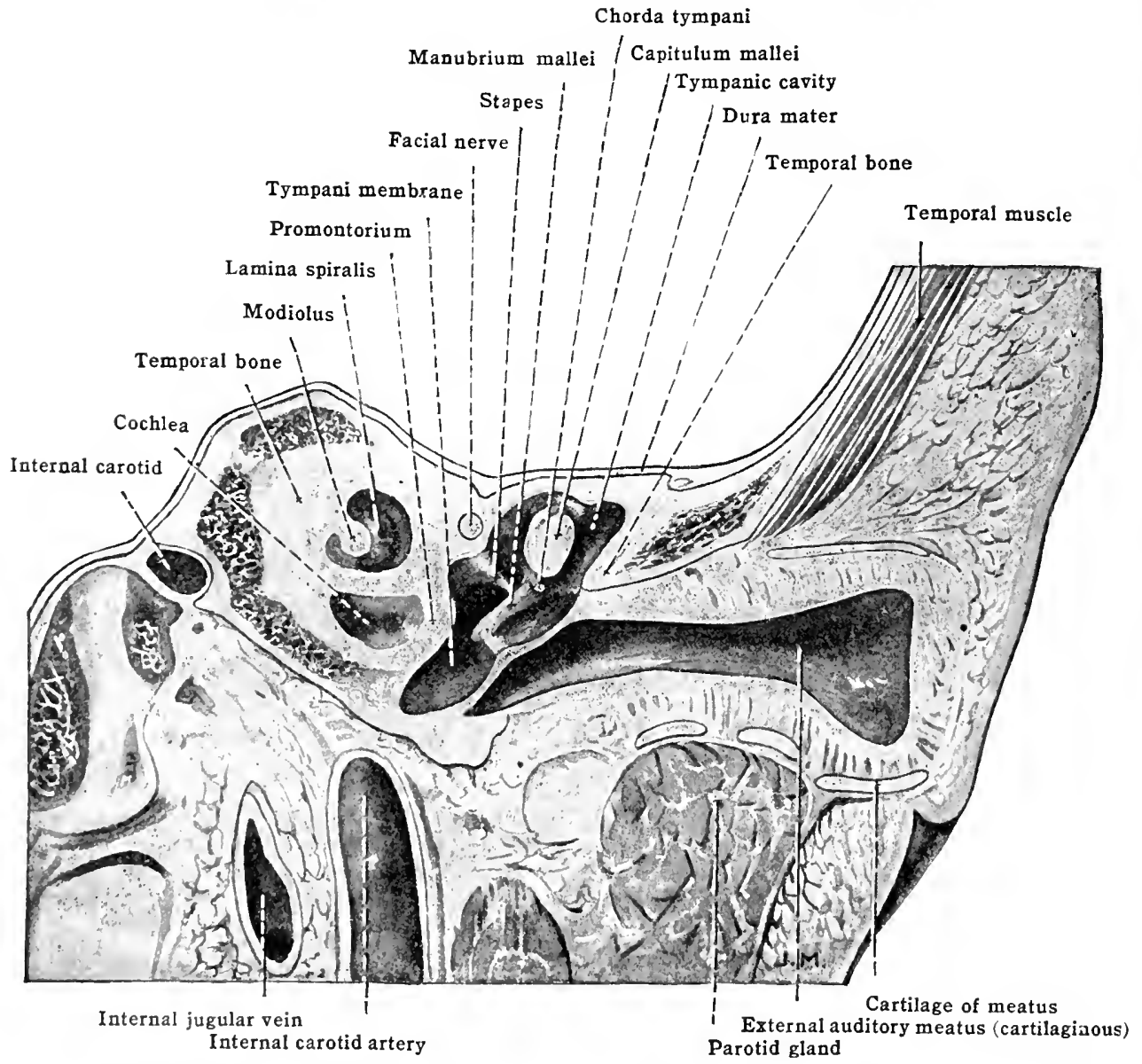

by the tympanic membrane; and from the chamber which forms the internal ear by the struetures which fill in the cochlear and vestibular fenestro. It communicates with the pharynx by the auditory (Enstachian) tube. The structures of the midelle ear are of importance, and the study is somewhat difficult, on account of the small size of the structures, the depth at which they lie, and the hard character of the surrounding home.

The jllustrations (figs. 829, $8330,831,833,834$ ) will help to explain the text and should be roristantly referred to). liges. 330 and s.31 are taken from frozen sections traversing the right ear in the coronal plines; while figs. 8333,831 represent dissections.

The parts to be considered in order are the tympanic membrane, the tympanic ravity, the tympanic antrum and the anditory (Eustachian) tube.

\section{The Trumane Memizane}

The: tympanic membrane [membrana tympani] (fig. 835) is clliptical in shape, its long axis noarly vortical, measuring 9 to $10 \mathrm{~mm}$., its short axis, 8 to $9 \mathrm{~mm}$. It sopes medially from the superior and posterior to the inferior and anterior 
wall of the meatus, forming, as a rule, with the superior wall, an angle of 140 degrees. It varies, however, greatly in form, size, and obliquity. Tiewed from the meatus, it appears as a semitransparent membrane, which sometimes has a reddish tinge. It is drawn medially and made funnel-shape by the manubrium of the malleus, but the walls of the funnel bulge toward the meatus (fig. 834). The most depressed point at its centre, the umbo, is slightly inferior and posterior to the centre of the membrane, and corresponds to the tip of the manubrium (fig. 832). From it a whitish streak, the malleolar stria, caused by the manubrium shining through, passes superiorly toward the circumference. At the superior end of the stria is a slight projection, the malleolar prominence, formed by the lateral process of the malleus. From it two folds, the anterior and posterior

Fig. 831.-Frozen Coronal Section of the Right Ear. (Somewhat Enlarged.)

Prominence of facial canal

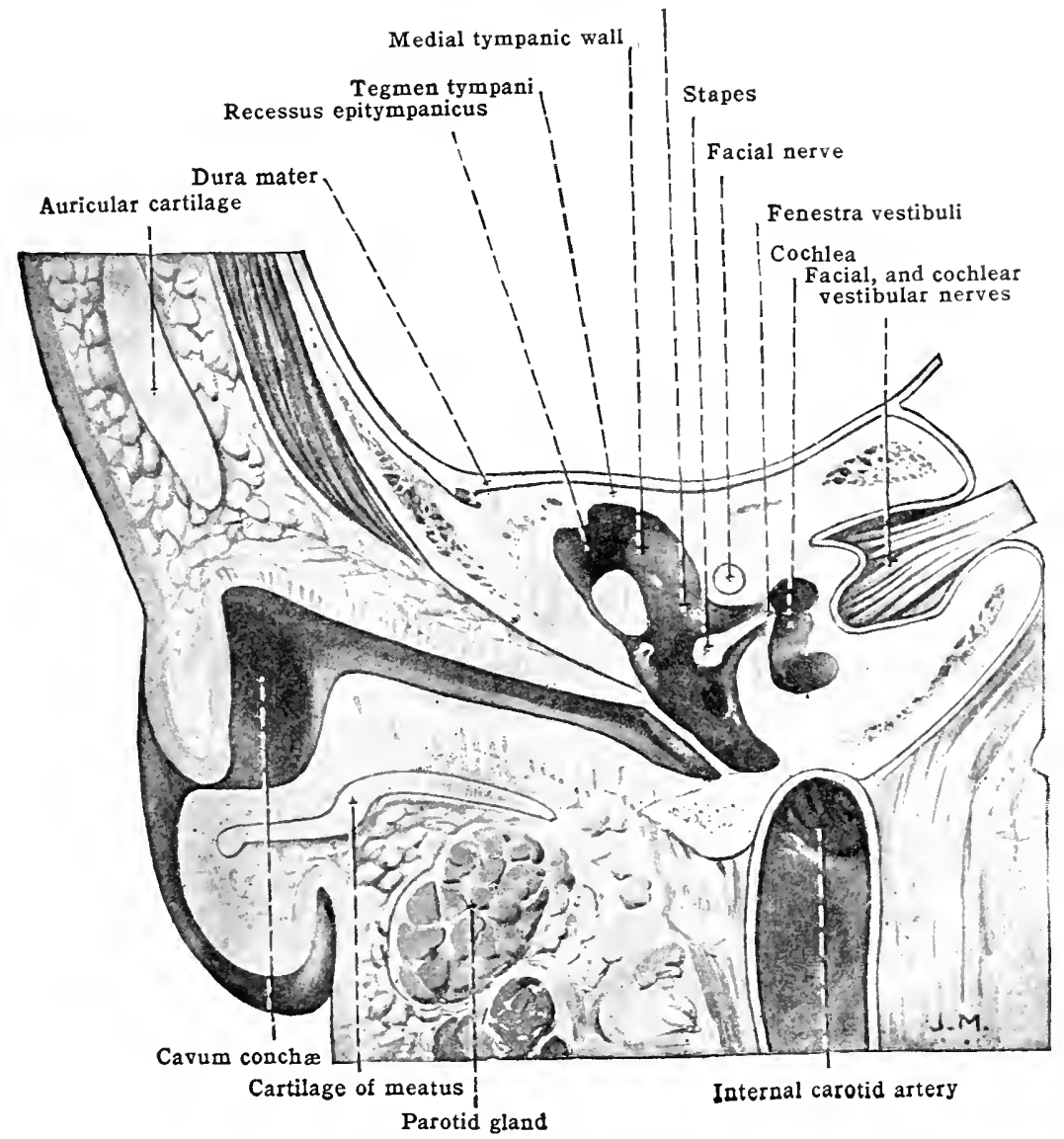

plicæ, stretch to the extremities of the tympanic sulcus (fig. 832). The small triangular area of the membrane bounded by the plicæ, is termed the pars flaccida (Shrapnell's membrane). It is thin and flaccid, and is attached directly to the petrous bone in the tympanic notch (notch of Rivinus). The larger part of the tympanic membrane, the pars tensa, is inferior to the plice and is tightly stretched. Its thickened margin, the limbus, is attached by a fibro-cartilaginous annulus to the tympanic sulcus, and at the spines of the tympanic ring is continuous with the plicæ.

Structure of the tympanic membrane.-The tympanic membrane is about $.1 \mathrm{~mm}$. thick, and consists of four layers. The lateral cutaneous layer, relatively thick, is a continuation of the skin lining the external auditory meatus. Next to it is a radiate fibrous layer, composed of connective tissue, the fibres of which are attached to the manubrium of the malleus and radiate from it. Medial to it is the circular fibrous layer, which has its fibres arranged concentrically and is especially thick at the circumference. It is closely bound to the radiate layer. The mucous layer, which is a continuation of the mucosa of the tympanic cavity, covers the medial surface of the membrane smoothly, except where the manubrium of the malleus causes a projection. The fibrous layers are attached to the fibro-cartilaginous ring and are not present in the pars flaceida. 


\section{The Trmpanic Cavity}

The tympanic cavity [cavum tympani], as has been stated, is an air-space, lined with mucous membrane, situated between the external and the internal ear. It is of irregular outline, but, roughly, it is a slit-like cavity, lying in an oblique antero-posterior plane. Its transverse diameter measures only from $2-4 \mathrm{~mm}$., while the vertical and antero-posterior diameters measure about $15 \mathrm{~mm}$. (fig. 834).

It is narrowest at the centre, and wider superiorly than inferiorly. The bony walls have already been partly described with the temporal bone, and hence the description given here will refer to the appearance found in the fresh, or unmacerated condition.

It will be noticed (see fig. 829) that the floor of the space is on very much the same horizontal plane as the floor of the external meatus, and the lower margin of the tympanic membrane. The roof, on the other hand, lies at a much

Fig. 832.-Lateral Surface of the Left Membrana Tympani. (Enlarged from life.)

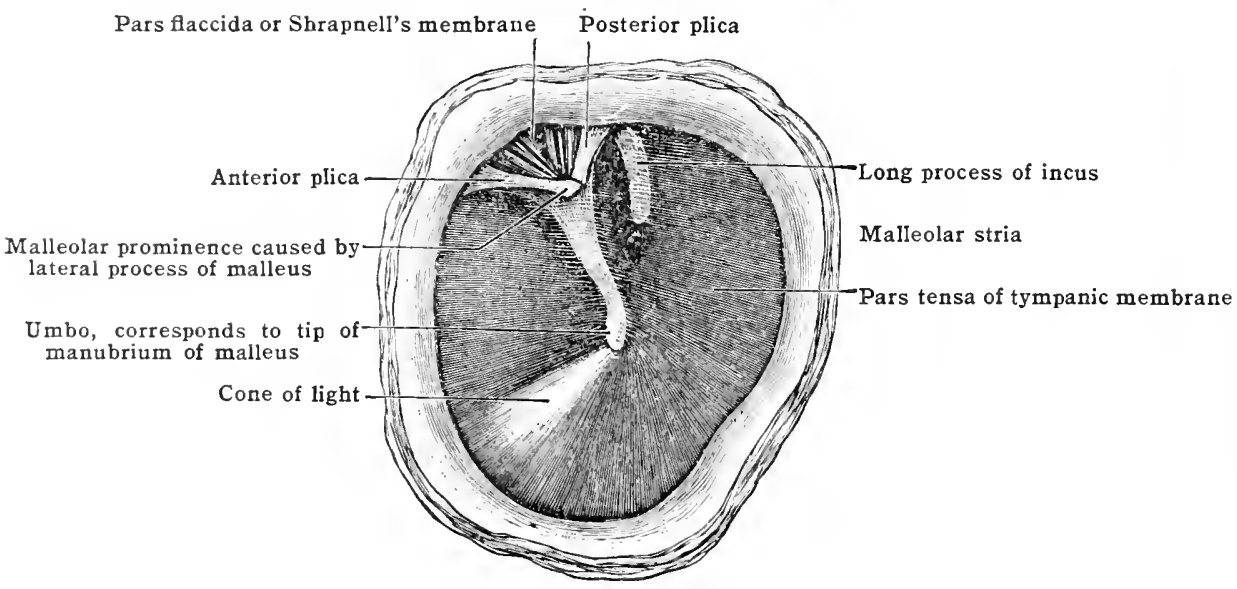

higher level than the upper margin of that membrane. Hence the cavity may be divided into two regions, a lower part, corresponding in extent to the tympanic membrane, and an upper, above the upper border of the membrane, known as the epitympanic recess. This division forms a definite chamber, and contains the head of the malleus and the body and short process of the incus. It is on the posterior part of this chamber that the communication with the tympanic antrum is found (fig. 835).

As the shape of the tympanum is irregular, its walls are not everywhere clearly marked off from one another, but there may be recognized (figs. 829 and 835 ) a roof, or tegmental wall, a floor, or jugular wall, a medial or labyrinthine wall and a lateral or membranous wall, an anterior or carotid, and a posterior or mastoid bounclary or wall.

The roof, or tegmental wall, is formed by a portion of the tegmen tympani, a thin plate of bone which is continued backward to form the roof of the tympanic antrum. This plate is formed by the petrous piut of the temporal bone, and at its lateral margin is the petro-squamous suture, where a slight defiriency in the roof may oecur.

The floor, or jugular wall is very narrow transversely, and is in intimate relation to the internal jugular vein (fig. 831 ). $\Lambda$ s shown in fig. 833 , the surface is frequently very irregular from stalactite-like projections between which are the tympanic cellula (air cells), while near the back there is occasionally a marked projection corresponding externally to the root of the styloid process.

'The posterior or mastoid wall presents at its lower part, many additional tympanie cellula, and higher up, an clevation, the pyramidal cminence, on whose apex is an aperture transmitting the tendon of the stapedius muscle. The fleshy belly of that muscle is contained in a cavity in the interior of the bony pyramid of the posterior wall. Lateral to this is an aperture, the apertura lympanica canalicule chorder, through which the chorda tympani nerve enters the tympannm, covered by a reflexion of the murous membrane. Between this opening and the pyraInil is a stight clevation; and above it is a fossa, termed the sinus posterior. Above this again is a recess, where the posterior liganent of the incus is attached, known as the fossa incudis. 'This portion of the posterior wall forms the boundary of the epitympanic recess. Here the cavity of the tympanm is continued with that of the antrum tympanicum, or mastoid antrum, 
a large irregular space into which open the mastoid cells (see p. 1092). The boundaries of the orifice are formed above by the tegmen tympani, medially by the prominences of the lateral semicircular canal and facial nerve, and laterally by a plate of bone termed the scutum.

The carotid (anterior) wall presents superiorly the tensor tympani muscle in its canal, and at a lower level the opening of the tuba auditiva (Eustachian tube) (fig. 835). Inferiorly, a thin, bony wall, covered with tympanic cellula and pierced by the carotico-tympanic nerves, separates the tympanic cavity from the carotid canal.

The membranous (lateral) wall is formed mainly by the tympanic membrane, with the small rim of bone to which it is attached, but superiorly the lateral wall of the epitympanic recess is formed by a plate of bone termed the scutum.

The labyrinth (medial) wall (fig. S33) presents inferiorly the promontory, produced by the first turn of the cochlea with the tympanic plexus (Jacobson's nerve) lorlged in grooves upon its surface. Inferior and posterior to the promontory is a depression or fossula at the bottom of

Fig. 833.-The Labirinth (Nedial) Wall of the Right Trupanun with the Tympaxic Ossicles in Position.

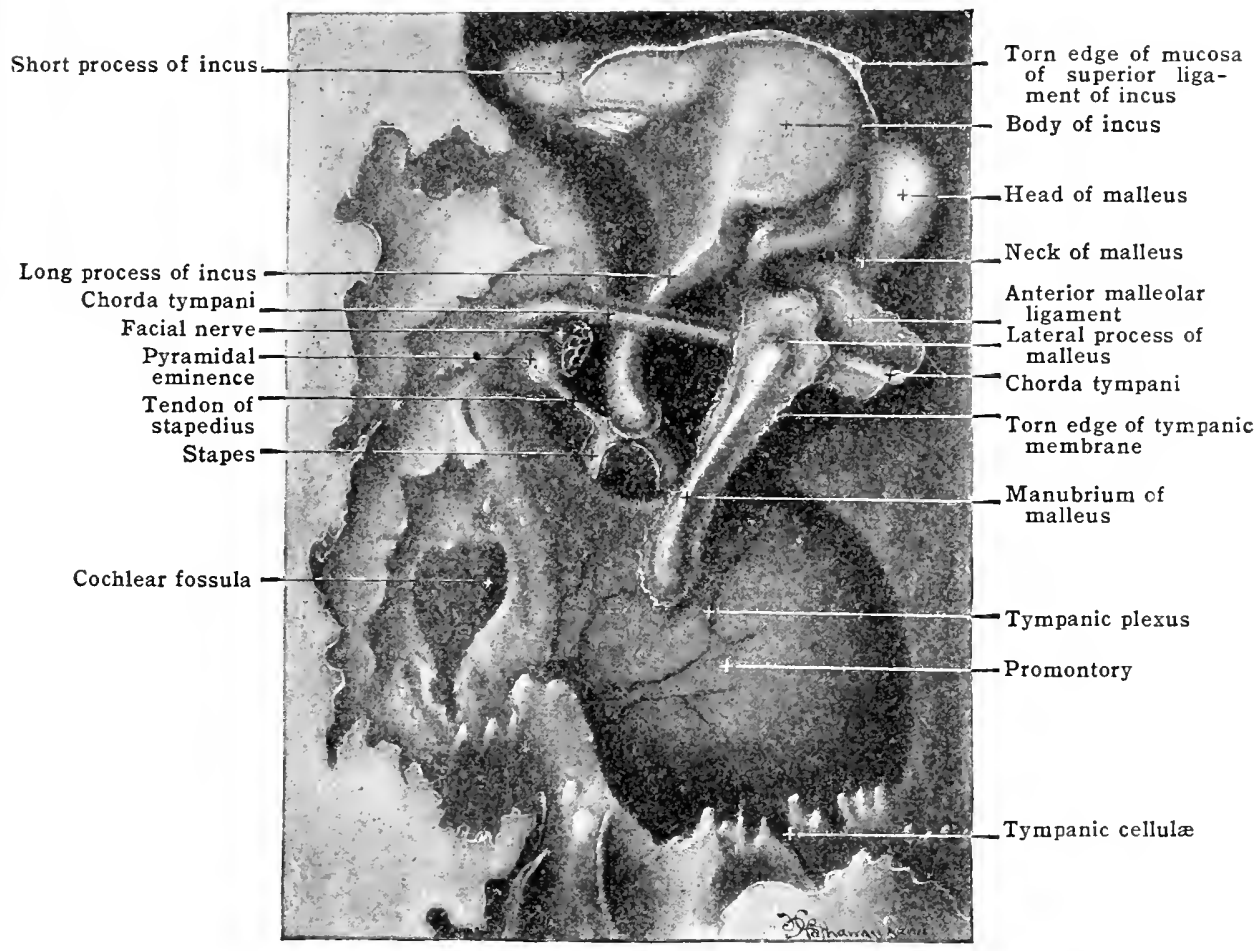

which is the cochlear fenestra (fenestra rotunda), closed by the secondary tympanic membrane, and posterior to the promontory is a smooth projection, the subiculum of the promontory, which forms the inferior border of a rather deep depression known as the tympanic sinus. Anteriorly and superiorly is the cochleariform process, and superiorly and posteriorly are a depression or fossula leading to the vestibular fenestra (fenestra ovalis), which is closed by the base of the stapes, the prominence of the facial (Fallopian) canal, and the prominence of the lateral semicircular canal, the two latter being formed in the medial wall of the entrance to the mastoid antrum.

The tympanic mucous membrane forms a complete covering for the walls and contents of the tympanic cavity. It is continuous anteriorly with the mucosa of the tuba auditiva (Eustachian tube) and posteriorly with that of the tympanic (mastoid) antrum and mastoid cells. It is a thin, transparent, vascular membrane intimately united to the periosteum. As it passes from the walls to the contents of the tympanic cavity, besides covering the ligaments of the malleus and the incus and the tendons of the tensor tympani and stapedius muscles, it forms a number of special folds and pouches.

The anterior malleolar fold is reflected from the tympanic membrane over the anterior process and ligament of the malleus and the adjacent part of the chorda tympani, and the posterior malleolar fold stretching between the manubrium and the posterior tympanic wall, surrounds the lateral ligament of the malleus and the posterior part of the chorda tympani. Each of these folds presents inferiorly a concave free border, and between them and the tympanic membrane are two blind pouches, the anterior and posterior malleolar recesses or pouches 
of Tröltsch. Connected with the posterior recess is a third cul-de-sac, the superior recess of the tympanic membrane, or pouch of Prussak, situated between the pars flaceida of the tympanic membrane and the neck of the malleus. The floor of this recess is formed by the lateral process of the malleus, and is lower than its outlet; therefore, the recess may serve as a pocket in which pus or other fluid may accumulate. A somewhat variable fold of mucosa, the plica incudis, passes from the roof of the tympanic cavity to the body and short process of the incus. The body and short process of the incus, the head of the malleus, and this fold incompletely separate off a lateral cupular portion of the epitympanic recess, and a stapedial fold stretches from the posterior wall of the tympanic cavity and surrounds the stapes, including the oburator membrane, which stretches between its crura. Other inconstant folds have been described. The mucosa of the typanic cavity, except over the tympanic membrane, promontory, and ossicles, is covered by a columnar ciliated epithelium.

Fig. 834.-The Trmpanic Cavity, Anterior Wall Removed.

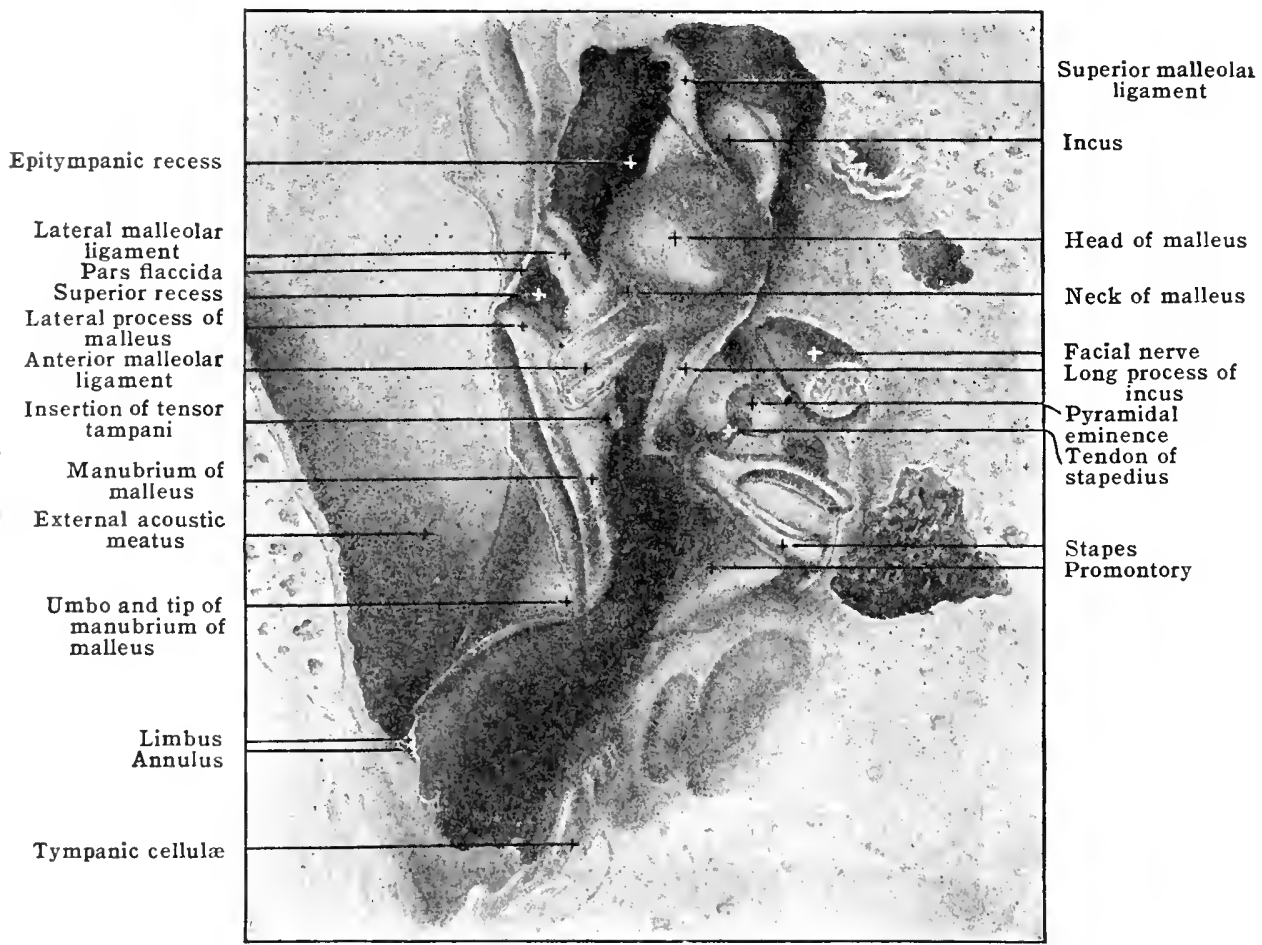

Bones.-The tympanic cavity contains three small movable bones, joined together and to the walls of the cavity, and having attached to them special muscles and ligaments. These auditory ossicles form a chain across the tympanic cavity connecting the tympanic membrane and the vestibular (oval) fenestra. They are the malleus, the incus, and the stapes, and are described in the section on OsTEOLOGY on P. 7 \%.

Articulations of the ossicles.-The manubrium and lateral process of the malleus are imoedderl in the tympanic nembrane. The margin of the irregularly elliptical articular surface bn the posterior sille of the head of the malleus is bound to the body of the incus by a thin eapsular ligament, forming a diarthrodial joint, the incudo-malleolar articulation. From the inner surface of the capsulan lipament, a wedge-shaped rim projects into the joint eavity and incompletely divides it. The long r'rus of the incus lies parallel to the manubrium of the malleus and on its superior and needial aspect (figs. 833 and 835). It ends in the lenticular process. 'The convex extremity of this fits into the concavity on the head of the stapes, to form a cliarthorodial joint, the incudo-stapedial articulation. From its articulation with the incen, the stapes passes almost herizontally aleross the tympanic cavity to its junction with the merdial wall. 'The cartilage-rovered crlac of the base is bound to the cartilage-covered rim of the vestibular (r)val) fenestra by the annular liganent of the base of the stapes, thus forming the tympano-stapedial syndesmosis.

Ligaments of the ossicles. - In addition to the attachment of the mamubrium of the mallems ancl the base of the statpes to the walls of the tympanic eavity, the bones have arditionat liganentons attachments. The superior malleolar liga- 
ment runs almost vertically from the superior wall of the epitympanic recess to the head of the malleus (fig. 834). The anterior malleolar ligament extends from the angular spine of the sphenoid bone through the petro-tympanic (Glaserian) fissure to the anterior or long process of the malleus, which it surrounds, and is inserted with it into the neck of the malleus. The lateral malleolar ligament is short and thick, and runs from the margins of the tympanic notch (notch of Rivinus) to the neck of the malleus (fig. 834). The posterior ligament of the incus passes from the fossa on the posterior tympanic wall to the crus brevis of the incus (fig. 835). 'The superior ligament of the incus is little more than mucous membrane; it runs from the tympanic roof to the body of the incus.

Muscles of the ossicles.-Each of the muscles of the ossicles is contained in a bony canal. The tensor tympani is a pinniform muscle about $2 \mathrm{~cm}$. long. It arises from the cartilaginous part of the tuba auditiva (Eustachian tube), from the

Fig. 835.-Medial Surface of Right Membrana Tympani. (Enlarged.)

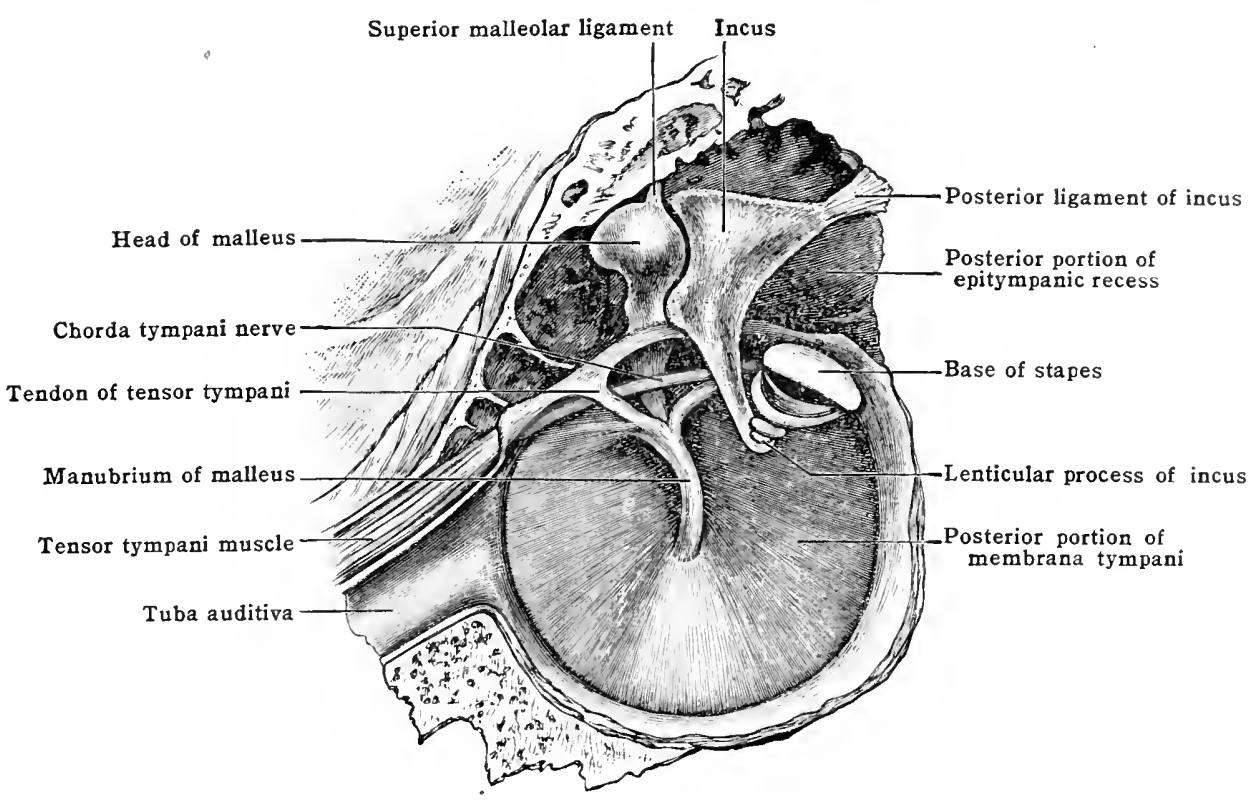

adjacent part of the great wing of the sphenoid, and from the bony walls of the semicanal which encloses it. It ends in a round tendon which turns almost at right angles over the cochleariform process and passes laterally across the tympanic cavity to be attached to the manubrium of the malleus near the neck. It draws the manubrium medially and tightens the tympanic membrane, and is supplied by the motor division of the trigeminal cranial nerve, through the tersor tympani branch from the otic ganglion. The stapedius arises in the interior of the hollow pyramidal eminence. The tendon escapes through the openings at the apex and then turns inferiorly and is inserted on the posterior surface of the neck of the stapes. It draws laterally the ventral border of the base of the stapes and is supplied by the facial nerve.

Vessels and nerves.-The arteries of the tympanic cavity are the anterior tympanic from the internal maxillary artery (fig. 451), the stylo-mastoid from the posterior auricular artery, the superficial petrosal from the middle meningeal artery, the inferior-tympanic from the ascending pharyngeal (fig. 446), and the carotio-tympanic branch from the internal carotid. The veins empty into the superior petrosal sinus and into the posterior facial (temporomaxillary vein). The nerves are the tympanic plexus formed by the tympanic branch of the glosso-pharyngeal (p. 951), and the inferior and superior carotico-trmpanic nerves which join the internal carotid plexus of the sympathetic (p.960). The small superficial petrosal nerve takes its origin from the tympanic plexus, and the chorda trmpani crosses the tympanic cavity from the posterior to the anterior wall (p. 948, figs. 738 and 835 ). 


\section{The Antrum Trmpanicum}

The aperture (aditus) in the upper part of the posterior wall of the tympanum leads into the chamber termed the antrum tympanicum. This is a comparatively large cavity, of irregular form, lying mainly behind but also somewhat above and lateral to the tympanum, and extends to the medial end of the external auditory meatus. It is lined by mucous membrane, continuous with that of the tympanic cavity, and into it open the mastoid cells (cellulæ mastoideæ). These cells are small, irregular cavities in the interior of the mastoid process and they communicate with one another freely. They vary exceedingly in their size and asrangement.

The antrum tympanicum has a roof, formed by the tegmen tympani, a posterior wall, separating it from the bend of the transverse sinus, a lateral wall, lying about $10 \mathrm{~mm}$. from the surface of the head, a medial wall, and an anterior wall (see also p. 78).

\section{The Auditory (Eustachian) Tube}

The auditory tube [tuba auditiva] (Eustachian tube) (fig. 829) extends from the carotid (anterior) wall of the tympanic cavity inferiorly, medially, and anteriorly to the pharynx. It is about $37 \mathrm{~mm}$. (1.5 in.) long. In the lateral one-third of its length it has a bony wall, while in the medial two-thirds this wall is cartilaginous. The osseous part (see p. 74) begins at the tympanic ostium on the anterior wall of the tympanic cavity. It is in relation medially and inferiorly with the carotid canal, and gradually contracts to its irregular medial extremity, which is the narrowest point in the tube, and is termed the isthmus. The cartilaginous part is firmly attached to the osseous and lies in a sulcus at the base of the angular spine of the sphenoid bone. It gradually dilates in its passage to the lateral wall of the pharynx, where its opening, pharyngeal sotium, is just posterior to the inferior nasal concha (turbinated bone). The walls of the cartilaginous part are formed by a cartilaginous plate which is folded so as to form a trough-like structure, consisting of a medial and a lateral lamina, completed inferiorly by a membranous lamina formed of connective tissue.

A small portion of the lumen in the superior part of the cartilaginous tube remains permanently open; elsewhere the walls are in contact, except during deglutition, when they are opened by the tensor veli palatini muscles. The mucosa of the osseous part is thin, and firmly attached to the bony wall, but in the cartilaginous part it becomes thicker, looser, and folded, and contains nucous glands, especially near the pharynx, where there is also some adenoid tissue.

\section{THE INTERNAL EAR}

The internal ear [auris interna] is the essential part of the organ of hearing. It consists of a cavity, the osseous labyrinth, contained within the petrous portion of the temporal bone, and enclosing a membranous labyrinth. The osseous labyrinth is (livided into cochlea, vestibule, and semicircular canals (see p. 80), and the accompanying figures (338-838) show their position and relations.

It will be noticed that the vestibule forms a central chamber, from which the semicircular canals and the cochlea branch off; the former from the superion and dorial portion, and the latter from the ventral and inferior.

It will furt her be noticed that the bony wall of this vestibule shows depressions and ridges on Its interior, whichareassoriated with parts of the membranous labyrinth, viz., an upper recess for the utricle (fovea lomielliptica) atnd a lower recess for the saceule (fovea hemispherica). There are openings in the bony wall for the entrance of nerves to the different parts of the mombranons labyrinth, and for the transmission of the duetus endolymphatiens, as well as the small openings of the semireireular canals (ducts) and the opening of the cochlear canal (or luct).

The membranous labyrinth, in which the auditory (acoustic) nerves (cochlear and vestibular) cond, lies within the osseous labyrinth, the form of which it more or lus closely resembles. Thus the membranous semicircular ducts lie within the bony semicircular canals, the membranous cochlear duet within the bony (o) hlea; while the vestibule contains two small membranous sacs, the utricle ancl sacenle, with their connections. The nombranous structures are much sulallar in climnot(re than the osseons, and are partially separated from the bone by an condothelial-hined space which is filled with a fluid, the perilymph. The 
membranes are in contact, however, with the bony wall along their convex margin, and the utricle, saccule and cochlear canals are in contact with the bony walls over the areas where the nerves enter them. The fluid which fills the membranous labyrinth is termed the endolymph.

Fig. S36.-The Osseous Labyrinth of the Right Side. (Modified from Soemmerring. Enlarged.)

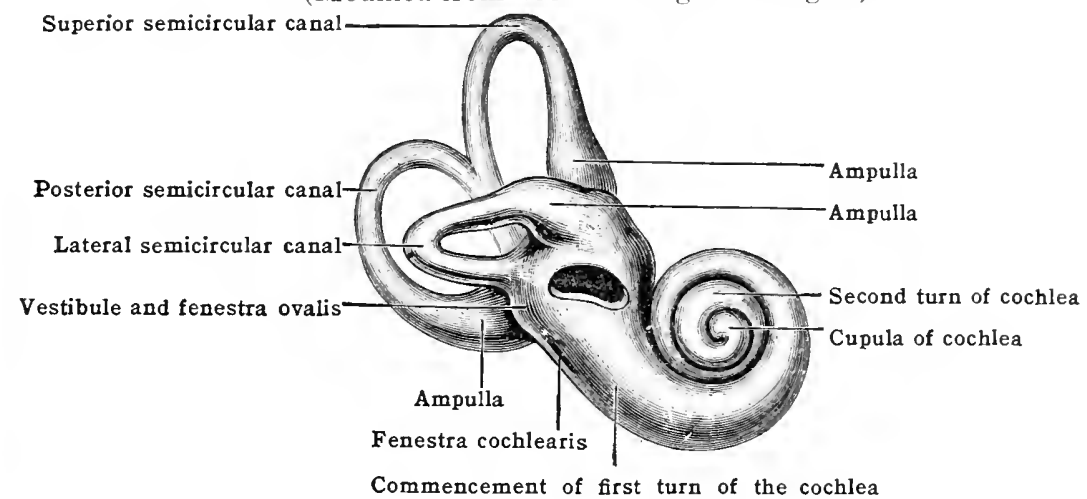

The utricle is an oval tubular sac, whose rounded end lies in the superior and dorsal portion of the vestibule. It is here tightly bound to the elliptic recess (fovea hemielliptica) by connective tissue and by the entrance of the filaments of the utricular division of the vestibular nerve as they pass from the superior

Fig. 837.-Interior of the Osseous Labyrinth of the Left Side. (Modified from Soemmerring. Enlarged.)

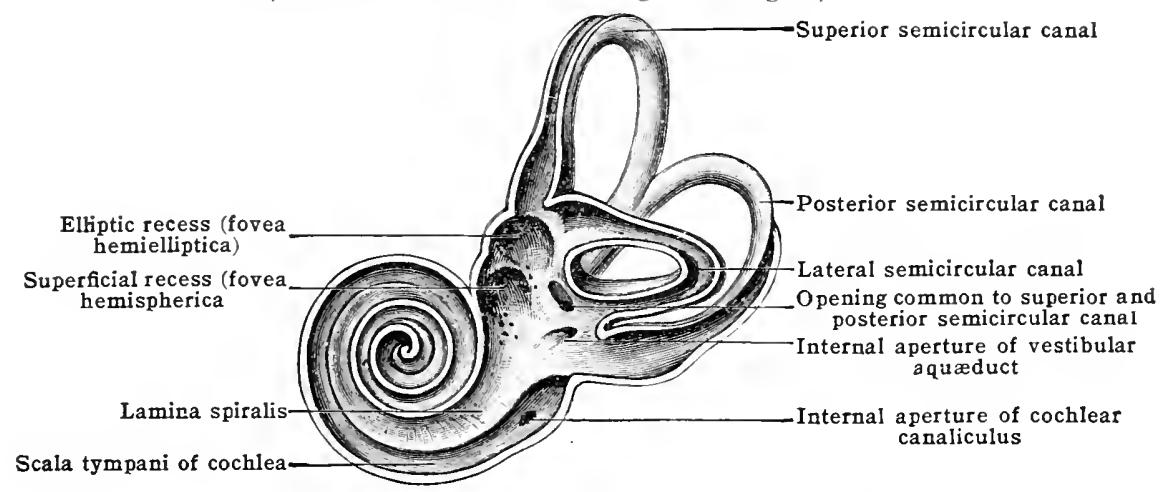

macula cribrosa to the wall of the utricle. In the anterior part of the interior of the utricle, an oval, whitish, thickened area, macula acustica utriculi, marks the terminal distribution of the nerve, and posteriorly the utricle is joined by the orifices of the semicircular ducts.

Fig. 838.- Interior of the Osseous Cochlea. (Enlarged.)

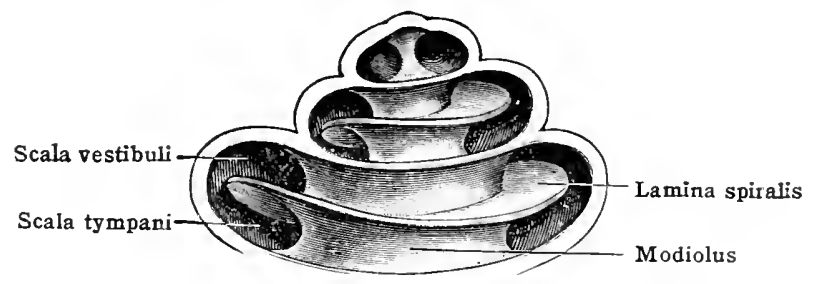

The saccule is a flattened, oval sac, smaller than the utricle, and situated in the anterior and inferior part of the vestibule. It is bound to the spherical recess (fovea hemisphærica) by connective tissue and by the saccular division of the 
vestibular nerve, filaments of which extend from the middle macula cribrosa to the anterior and medial wall of the saccule, to be distributed over a thickened area, macula acustica sacculi. Anteriorly and inferiorly the saccule gradually passes into a short canal, the ductus reuniens, which connects it with the cochlear duct, and posteriorly the very small endolymphatic duct is attached (fig. 839).

Fig. 839.-Diagram of the Left Membranous Labyrinth. (Deaver.)

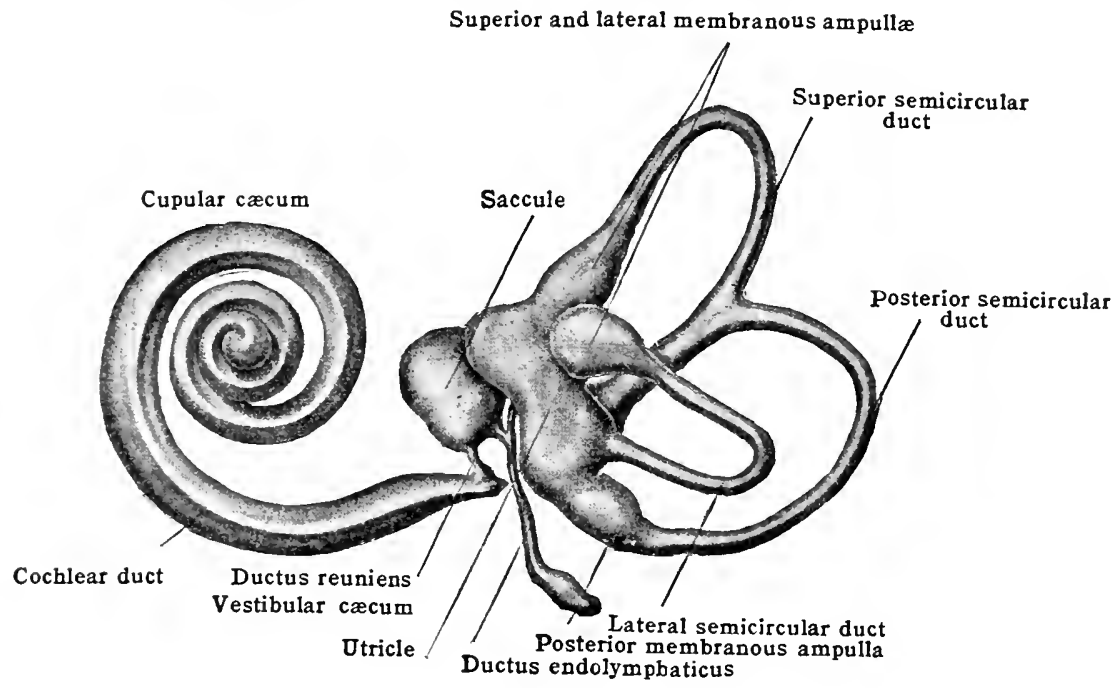

This extends through the aquæductus vestibuli to the posterior surface of the petrous portion of the temporal bone, where it ends in a dilated blind pouch, the endolymphatic sac, situated just beneath the dura. Just beyond the saccule, the endolymphatic duct is joined at an acute angle by a short canal of minute calibre, the utriculo-saccular duct, which opens in to the utricle through its anterior medial wall and, with the endolymphatic duct, connects it with the saccule.

Fig. 840.- Right Membranous Labyinth of a Newborn Child, Exposed by Partial Renoval of tile Bony Labyrinth. Dorsal view. (Toldt, "Atlas of Human Anatomy," Rebman, London and New York.)

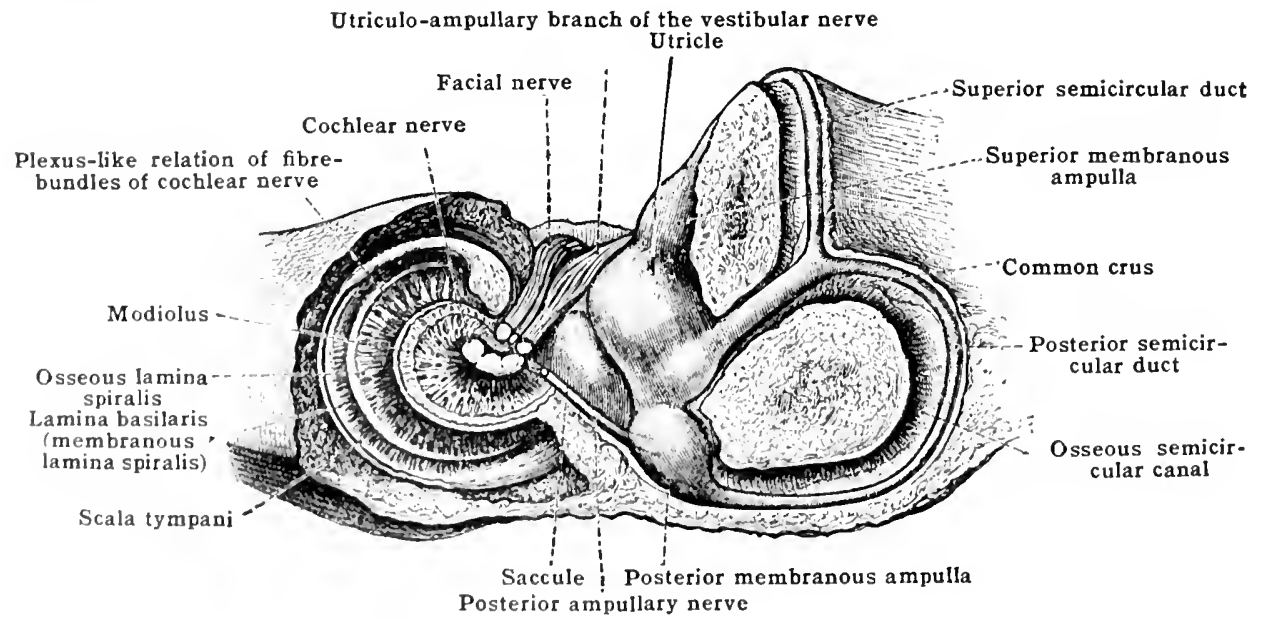

The semicircular ducts (mombranous semicircular canals) are situated within thro osseous semicircular canals and are, therefore, known as the lateral, superior, and postrorior semicircular ducts. They connect with the utricle by five openings, the posterior and superior ducts uniting to form a common crus before their 
termination. Each duct is less than a third of the diameter of the bony canal, from which it is separated by a large perilymphatic space, except along the greater curvature, where it is attached. The ducts are dilated in the bony

Fig. 841.-Schematic Representation of the Right Membranous Labirinth and the Drvisions of THE Acoustic Nerve. Dorsal view. (Toldt, "Atlas of Human Anatomy," Rebman, London and New York.)

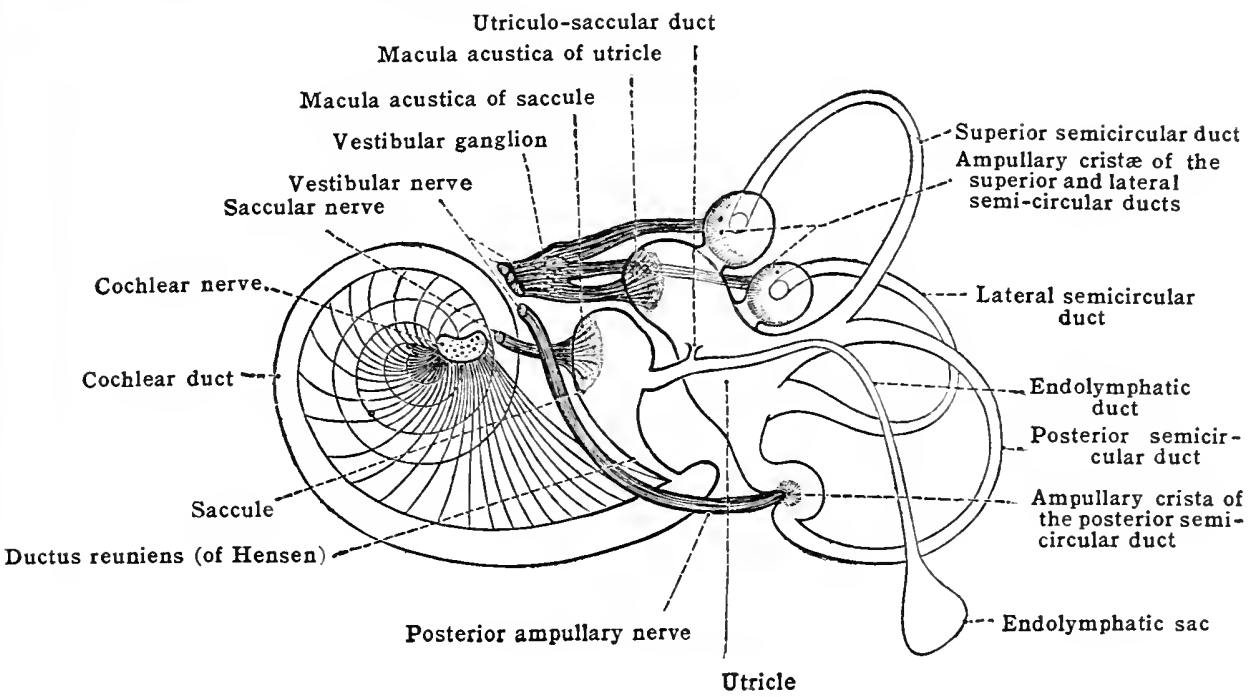

ampullæ, producing the lateral, superior, and posterior membranous ampullæ, and on the attached surface of each of these there is a transverse groove, the ampullary sulcus, for the ampullary division of the vestibular nerve, and corresponding to the sulcus a ridge, the ampullary crista, projects into the interior.

Fig. 842.-Axial Section Throdgh the Decalcified Cochlea of a Nemborn Child (Toldt, "Atlas of Human Anatomy," Rebman, London and New York.)

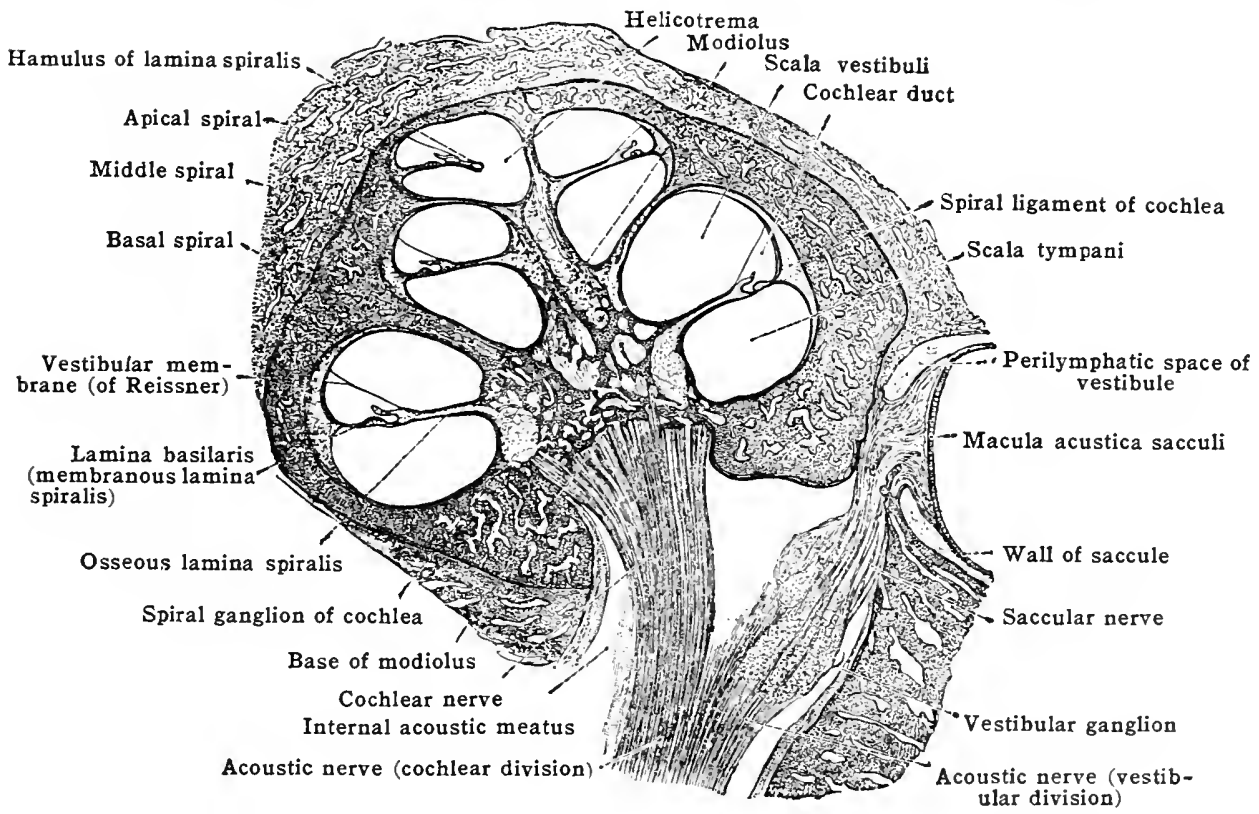

The cristæ in the ampullæ of the membranous semicircular ducts and the maculæ in the saccule and utricle are superficially covered with fine crystals of calcium carbonate, otoconia (otoliths). 
The cochlear duct (membranous cochlea or scala media) begins within the cochlear recess of the vestibule in a blind pouch, the vestibular cæcum, and traversing the spiral canal of the cochlea, ends just beyond the hamulus of the lamina spiralis in a second blind pouch, the cupular cæcum. Close to the vestibular cæcum it is joined to the saccule by the ductus reuniens. It is lined throughout by epithelium and is somewhat triangular in cross-section. Its floor is formed by thickened periosteum over part of the osseous lamina spiralis and by a fibrous membrane, the lamina basilaris, which stretches from the free border of the lamina spiralis to a thickening of the periosteum, the spiral ligament of the cochlea, on the peripheral wall.

The epithelium of this floor is greatly modified, forming the spiral organ (organ of Corti) in which the fibres of the cochlear nerve terminate. The peripheral wall is formed by the thickened periosteum upon the peripheral wall of the cochlear canal, while the third wall is

Figs. S43 and 844.-Siections Showing Early Stages in the Developaent of the Otic VESICLE.
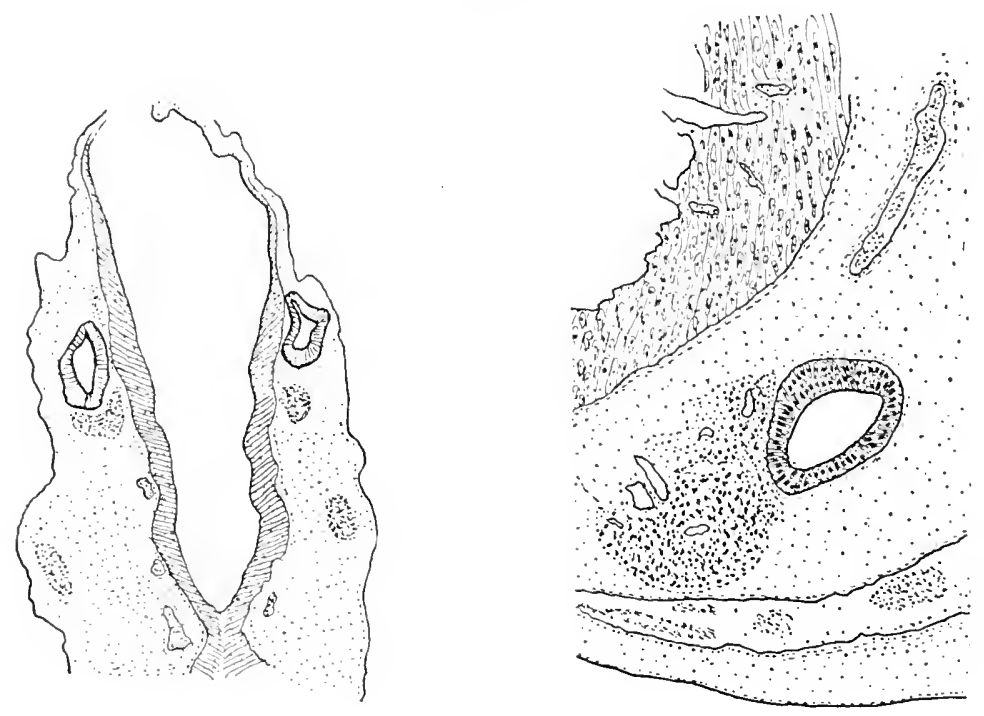

fomed by a thin vestibular membrane (membrane ot Reissner) which passes from the periphera wall to the osscous lamina spiralis near its free margin, forming with the lamina spiralis an angle If 45 degrees. The cochlear duct and the osseous spiral lamina divide the cochlear spiral canal into two parts, one next to the hasilar membrane, the scala tympani, and one next to the vestilunlar membrane, the scala vestibuli. The scala tympani unites with the seala vestibuli at the helicotrema, and from the scala tympani a minute canal, the perilymphatic duct, passes through the cochlear canaliculus and connects with the subarachnoid space. A thin fibrous layer, the secondary tympanic membrane, closes the cochlear fenestra (fenestra rotunda) and thus separates the scala tympani from the tympanic cavity, and the vestibular perilymphatic space (scala vestibuli) is separated from the tympanic cavity by the base of the stapes in the vestiluular fenestra (fenestra ovalis).

Vessels and nerves. - The internal auditory artery, fig. 514), a branch of the basilar artery, accompanies the rochlear and vestibular nerve. It supplies the vestibule, semicircular canals, and corlilea, and their membranous contents. The blood is returned by the internal auditory vein into the inferior petrosal sinus, and by small veins which pass through the cochlear and vestibular arperhuts to the inferior and superior petrosal simuses. The acoustic nerve (p. 949, figs. \$.t and \$.42) consists of a vestibular and a cochlear division. The membranous ampulla of the semirimenlar ruets and the acoustic macula of the utricle and sacerle are supplied by the vestibular norve. The spiral organ (organ of Corti) in the eochlear duct is supplied by the cochlear norve.

\section{1) HN LOPMENT OF THE FAR}

The extermal and midele ears have a common origin quite distinet from that which gives rise to the intornal rars, and are to lo regarded as portions of the branchial arch apparatus secombarily adapter to anditory purposes.

The sensory ejuthelium lining the internal car is derived from the otic vesicle, a structure formen from the surfare epithelimm of the heal, while the membrane and bones surrounding it are forment from the mesolerm which surrounds the vesicle. 
Internal ear.-The process of development is as follows (fig. 843-845):-

By invagination from the surface, an epithelial-lined vesicle, termed the primitive otocyst or otic vesicle, is formed dorsal to the extremity of the second branchial cleft. It is at first merely a pit on the surface, but eventually it loses its connection with the surface epithelium and sinks into the interior. It then undergoes the alterations in shape and form shown in the accompanying fig. 845 . The vesicle is at first somewhat oval, and a small hollow stalk arises from it, the recess of the labyrinth, which forms the ductus endolymphaticus in the adult. The ventral and dorsal portions of the cyst become enlarged. From the former two hollow plate-like projections arise, one placed vertically, the other horizontally, and along the free margins of these plates are formed the semicircular ducts, the superior and posterior from the vertical, and the lateral duct from the horizontal one. The central part of each plate becomes peforated, and the periphery is thus altered to the characteristic loop form of the adult semicircular ducts. The portion of the vesicle lying between the dorsal and ventral enlargements forms the primitive atrium. It becomes divided into two chambers, an upper dorsal connected with the semicircular ducts, forming the utricle, and an inferior ventral, the saccule, which is connected with that portion of the ventral expansion from which the cochlea is formed.

The recess of the labyrinth retains its connection with the cavity of the vesicle at the narrow stalk connecting utricle and saccule, (fig. 845). The cochlea is formed by an outgrowth from the saccule, at first straight, and later coiled in the fashion formed in the adult.

Fig. 845.-Diagrans Illustrating Successive Stages in the Developuent of the Membranotos Ear.

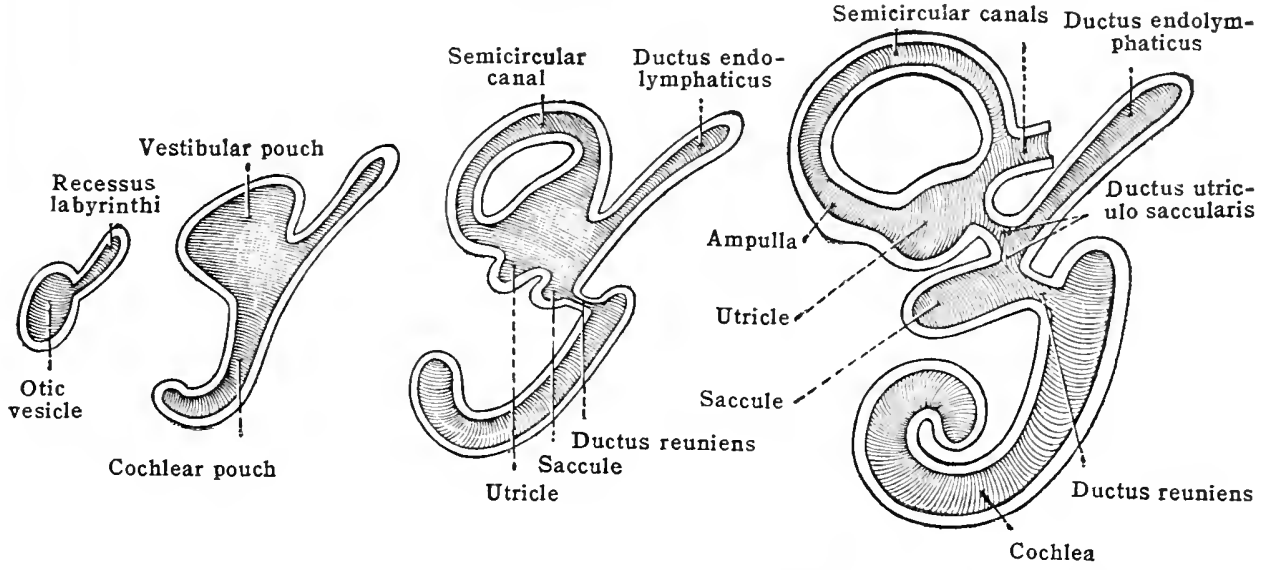

External and middle ear.-The external auditory meatus is formed from the dorsal part of the first (external branchial) pouch, and the tympanic membrane from the membrane which forms the floor of that pocket and separatcs it from the corresponding pharyngeal (internal) pouch. Its outer surface is thus formed from ectoderm and the inner from endoderm. The internal (pharyngeal) groove gives origin to the tympanic cavity and tuba auditiva, the margins of the groove uniting.

The auricle is formed from nodular thickening of the tissue bounding the outer end of the first branchial cleft. Three nodules are formed on the first (mandibular) and three on the second (hyoid) arch. Behind the latter, the free margin of the auricle is formed by a folding off of the integument. Later an additional tubercle is formed dorsally between the two sets of nodules. From the mandibular nodules are formed mainly the tragus and the crus of the helix-from the hyoid tubercles the scaphoid fossa, antitragus and the crus of the anthelix.

The auditory ossicles, and their muscles are formed from the neighbouring arches, the malleus and incus, together with the tensor tympani, being derived from the first arch, while the stapes and stapedius probably are derived from the second arch.

The tympanic cavity is at first quite small, but later increases greatly, partly by the condensation of the loose areolar tissue which underlies its mucous membrane, the auditory ossicles and their muscles being thus apparently brought within the cavity, and partly by the absorption of the neighbouring bone. By this latter process the antrum and the tympanic and mastoid cells are formed, all these depressions or cavities teing lined by mucous membrane continuous with that of the tympanic cavity.

The Ear in the Child.-The ear in the newborn child shows several marked differences from the adult ear.

Among the principal differences are the following:-

1. The external auditory meatus is very short, since the bony portion is undeveloped, and is represented only by the tympanic ring. As a result of this, the tympanic membrane is placed on a level with the surface of the head, and looks very much downward.

2. The mastoid or tympanic antrum is relatively very large, and lies above and behind the tympanum. Its lateral wall is only about $1 \mathrm{~mm}$. in thickness.

3. The mastoid process is not developed, and hence the stylomastoid foramen opens on the surface behind the lower part of the tympanic ring. The exit of the facial nerve is therefore much more upon the surface, and higher up than in the adult.

4. The auditory (Eustachian) tube is nearly horizontal in direction.

5. The ossicles are of nearly the same size as in the adult. 
References for the Special Sense Organs.-For the development of the various sense organs, see article by Keibel in Keibel and Mall's Human Embryology, vol. 2. A. Visual. Graefe-Saemisch, Handbuch d. ges. Augenheilkunde; Salzmann, Anat. u. Histol. d. Augapfels, 1912; various papers in Archiv f. Ophthalmologie; (Anterior chamber, etc.) Henderson, Ophthalmic Review, 1910-11; (Optic disc) Johnson, Phil. Trans. Royal Soc. B. vol. 194; B. Auditory. Gray, Labyrinth of Mammals, 1910; (Tectorial membrane, etc.) Hardesty, Amer. Jour. Anat., vol. 8; (Auditory nerve, comparative) Holmes, Trans. Royal Irish Acad., vol. 32, ser. B; (Experimental embryology) Lewis, Amer. Jour. Anat., vols. 3, 7; C. Olfactory, Read, Amer. Jour. Anat., vol. 8. D. Taste. Von Ebner, in Koelliker's Handbuch d. Gewebelehre; Graberg, Anat. Hefte, Bd. 12. 


\title{
SECTION I I
}

\section{DIGESTIVE SYSTEM}

\author{
Revised for the Fifth Edition
}

By C. M. JACKSON, M.S., M.D.,

PROFESSOR OF ANATOMY IN THE UNIVERSITY OF MINNESOTA

I $\mathrm{N}$ order to furnish the living protoplasm with the materials necessary for energy, growth and repair, a constant supply of food must be provided. Most foods must be rendered soluble, and must undergo certain preliminary chemical changes, in order to render them suitable for absorption and assimilation by the cells of the body. For this preparation of the food-supply, the digestive system [apparatus digestorius] is provided, which includes the alimentary canal and certain accessory glands (salivary glands, liver and pancreas). The alimentary canal is divided into a number of successive segments, varying in size and structure according to their function. These segments (fig. $8+6$ ) include the mouth, pharynx, œsophagus, stomach, small and large intestines.

Typical structure.-The most important layer of the tubular alimentary canal is the inner mucous membrane [tunica mucosa]. From its epithelial lining, the various digestive glands are derived, and through it the process of absorption takes place. The epithelium is supported by a fibrous tunic [lamina propria mucosæ] beneath which is a thin layer of smooth muscle [lamina muscularis mucosæ]. The layer next in importance is the muscular coat [tunica museularis] which propels the contents along the canal. It is typically composed of two layers of smooth (involuntary) muscle, the inner circular and the outer longitudinal in arrangement. Between the mucosa and the muscularis is a loose, fibrous submucous laver [tela submucosa], which allows the folds in the mucosa to spread out when the canal is distended. Finally, there is an outer fibrous coat [tunica fibrosa], which in the abdominal cavity becomes the smooth serous coat [tunica serosa], or visceral layer of the peritoneum, which eliminates friction during movements. The variations in the structure of the alimentary canal in different regions are due chiefly to differences in the mucosa.

Glands.- Since the glands form an important part of the digestive system, the classification of glands in general will be discussed briefly. A gland may be somewhat loosely defined as an organ which elaborates a definite substance which is either a waste product to be eliminated (excreted), or a secretion to be further utilized by the organism. Glands may be divided into (a) ductless glands (e. g., spleen, thyreoid gland), which pour their secretions directly into the blood or lymph; and (b) glands with ducts, which open upon an epithelial surface. Some organs, however, belong in both classes (e. g., liver, pancreas).

The glands with ducts (the so-called 'true' glands) are always derived from an epithelial surface and may be further subdivided upon the basis of either (1) form or (2) cell-structure. According to form, glands are classified as either tubular or saccular (alveolar, acinous). Each of these may be either simple or compound (branched). The compound saccular form is often called racemose. Moreover, intermediate forms (tubulo-racemose) occur.

According to cell-structure and character of secretion, glands are divided into mucous and serous types. In the mucous type, the cells appear larger and lighter (fig. 867 ) when swollen with mucus which is secreted for purposes of lubrication. The goblet-cells of the intestine represent unicellular glands of this type. In the serous (or albuminous) type of glands, the cells usually appear somewhat smaller and more deeply stained, with numerous zymogen granules (fig. 867). The secretion is a watery, albuminous fluid, which contains the digestive enzymes. There occurs also a mixcd type, with separate mucous and serous saccules, or both types of cells may occur in the same saccule (the serous cells as 'demilunes' or 'crescents' (fig. 867 ). In all cases, the epithelial gland cells are supported by a fibrous connective-tissue stroma, which provides a rich vascular and nerve-supply.

Morphology.- The alimentary canal in comparative anatomy is divided into the head-gut (mouth and pharynx), forc-gut (cesophagus and stomach), mid-gut (small intestine), and hindgut (large intestine). Embryologically, the mid-gut corresponds roughly to the portion of the archenteron attached to the yolk-sac, the portions of the archenteron anterior and posterior to the yolk-sac being designated as fore-gut and hind-gut respectively. (See Section I, MorpHoGENESIS.) The lining epithelium of the alimentary tract is endodermal, excepting the anal canal and the mouth cavity, which are lined by invaginations of the ectoderm.

In the region of the mouth and pharynx, the digestive and respiratory systems are closely related in position, structure, function and origin. Morphologically, the head-gut represents a primitive alimentary-respiratory apparatus. 


\section{THE MOUTH}

The oral cavity [cavum oris] represents the first segment of the alimentary canal. Its walls are exceedingly specialised in structure, corresponding to its manifold functions (mastication, insalivation, taste, speech, etc.).

Boundaries. - The oral cavity communicates anteriorly with the exterior through the transverse oral fissure [rima oris], and posteriorly with the pharynx through the isthmus of the fauces [isthmus faucium]. The anterolateral walls are formed by the flexible lips and cheeks. The roof is chiefly immovable and is

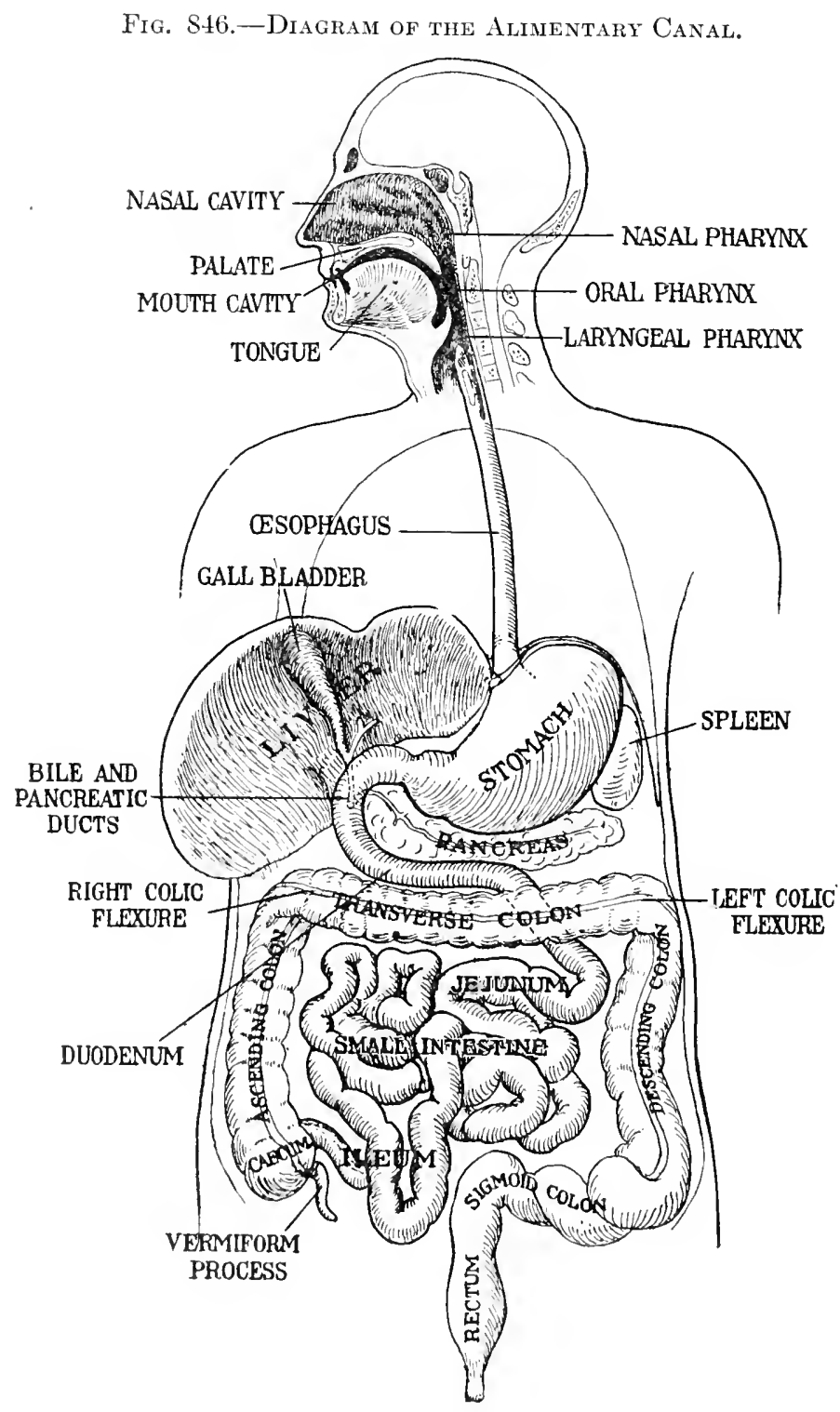

formed by the uppere jaw with the hard and soft palate. The movable floor is formed by the lower jaw and the temgne.

Subdivisions. - The oral civity is sublivided by the alveolar and dental arrehes inte an inner cavity, the oral cavity proper [avum oris proprium], and an outer erstibule [vest ibulum oris] adjacent to the lips and checess (fig. 848). When the mpler and the lower forth are in appesition, the vestibule communicates 
with the oral cavity proper (aside from the small interdental spaces) only through a space behind the last molar teeth on each side. Opening into the oral carity are certain accessory glands, the salivary glands.

Fig. 847.-Coronal Section throdgh Oral Region.

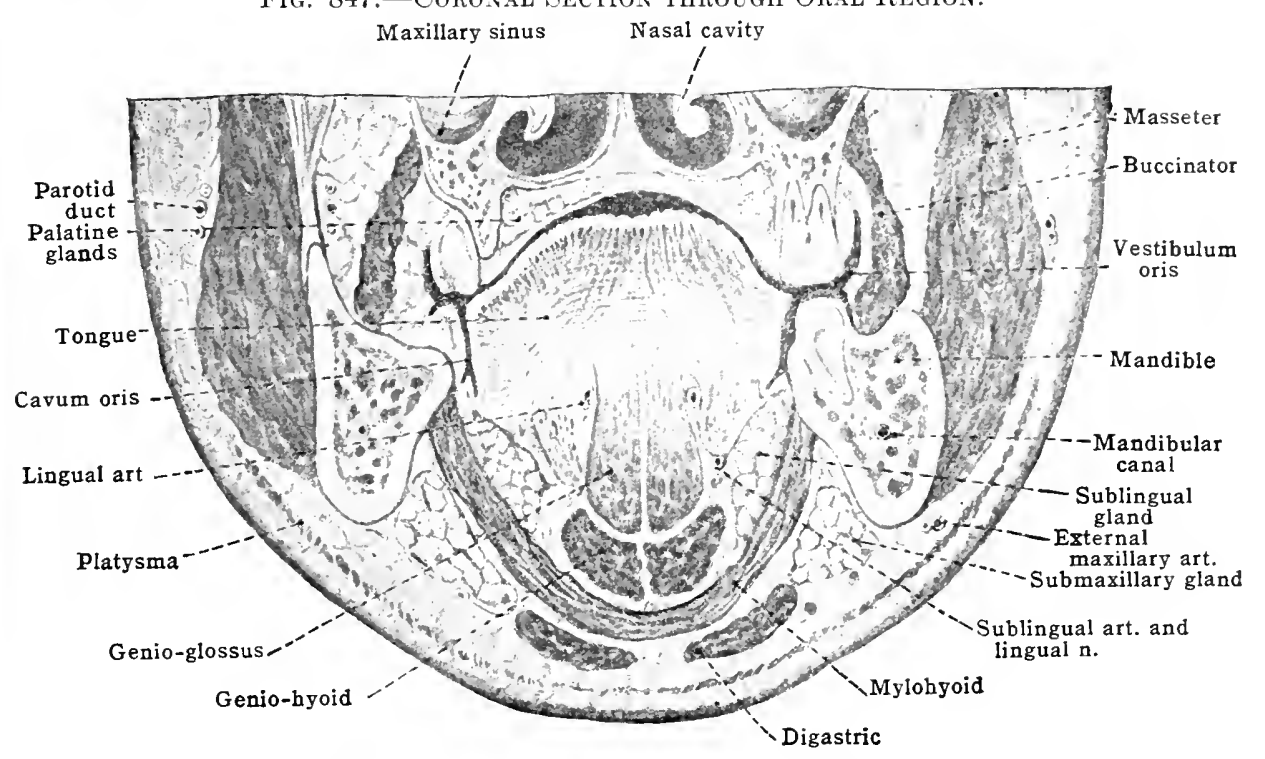

Structure.-Of the typical layers of the alimentary canal, only the mucous membrane can be recognised as a continuous layer in the mouth cavity. Even this is greatly modified and in structure somewhat resembles the skin, from which it is derived and with which it is continuous

Fig. 848.-Mid-sagittal Section of the Head, throvgh Oral and Nasal Regiods. (Rauber-Kopsch.)

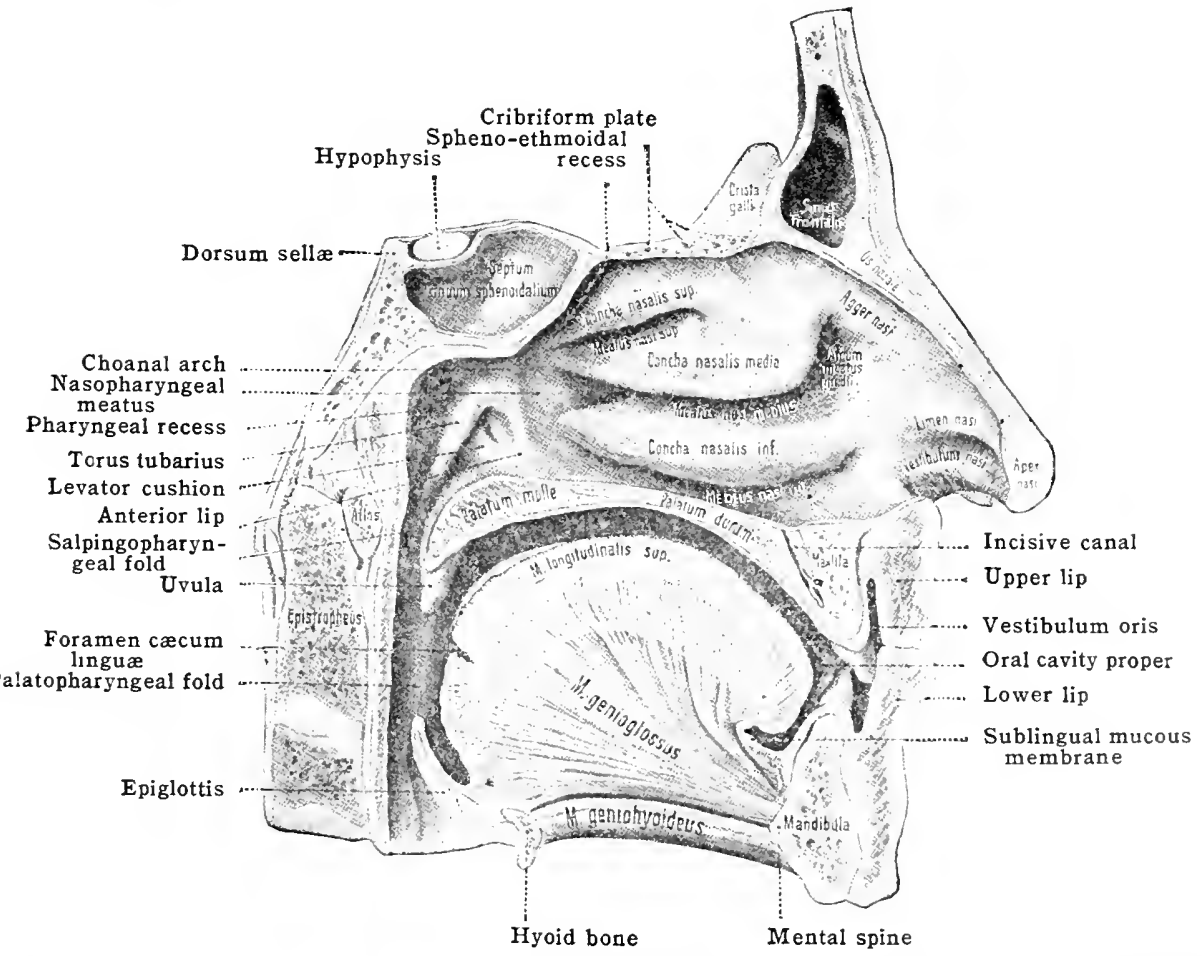

at the rima oris. The submucosa is a strong fibrous layer connecting the mucosa with adjacent structures, and lodging numerous racemose mucous glands. The muscles in the walls of the mouth cavity are not homologous with the typical muscularis of the alimentary canal. The outer fibrous tunic is also wanting. 
The development of the oral cavity.-As stated in the section on Morphogenesis, the oral carity has its origin in a depression, the oral fossa, situated between the ventrally bent, developing head and the region occupied by the developing heart. This fossa is bounded anteriorly by the fronto-nasal process, and laterally by the maxillary and mandibular processes, portions of the first branchial arches. The fossa is lined by ectoderm. Its floor is in apposition with the cephalir end of the archenteron, lined by entoderm, the ectoderm of the oral fossa and the entoderm of the archenteron being in immediate contact and forming the pharyngeal membrane. The oral fossa deepens with further development, and becomes the oral sinus. The pharyngeal membrane becomes perforated in embryos about $2 \mathrm{~mm}$. in length and disappears, leaving a free communication between the oral sinus and archenteron. On each side of the developing head and in a latero-ventral position there is early developed an area of thickened ectoderm, known as the nasal area. These areas soon develop into depressions, the nasal fossæ, and assume a position, one on either side of the fronto-nasal process; on each side of the frontonasal process there is developed a prominent protuberance, the globular process, each process forming the median wall of a nasal fossa. The lateral wall of each nasal fossa also thickens to form the lateral nasal process. With the further development, the ventral portion of each lateral nasal process fuses with the corresponding globular process, the maxillary processes also uniting with the globular processes, in this way separating the nasal fossæ from the oral sinus. With the further growth toward the median line of the maxillary processes the fronto-nasal process becomes narrower, ultimately forming the nasal septum and a small median portion of the upper jaw, the remainder of the upper jaw being formed by the maxillary processes, and the lower jaw having its origin in the mandibular processes.

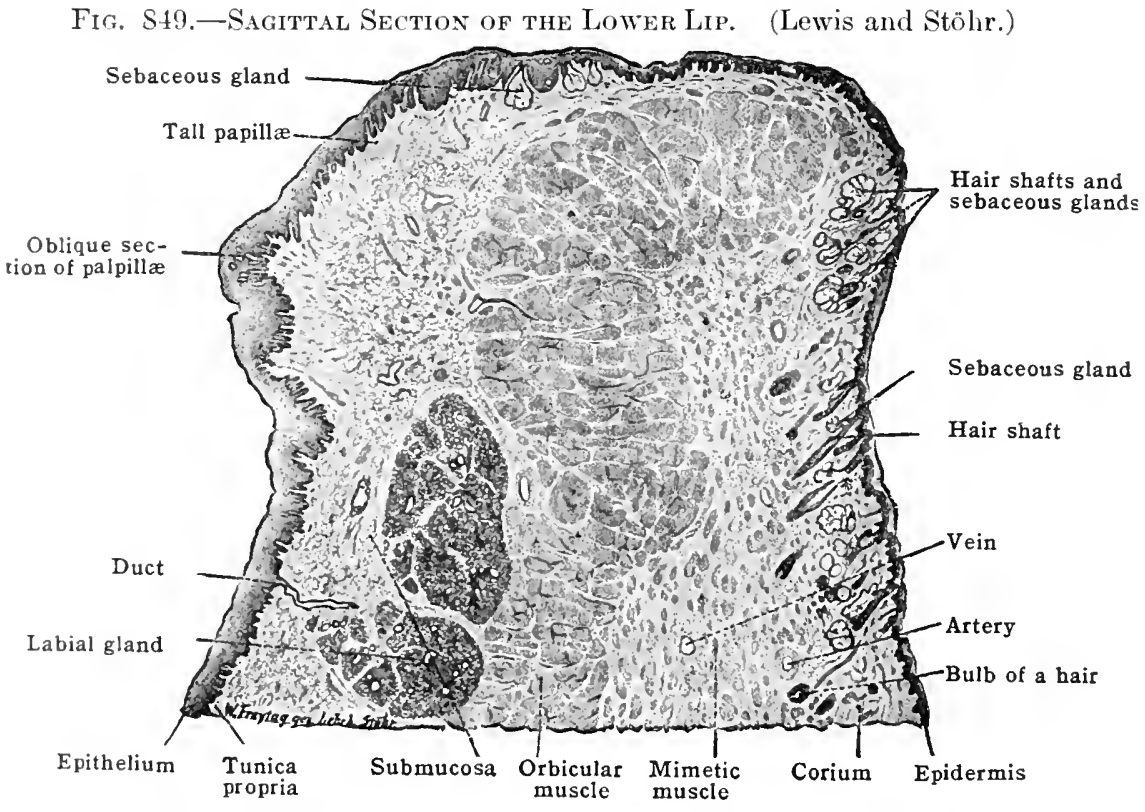

Variations.-The mouth is rarely absent, due to failure of the stomatodeal invagination, or imperforate, due to at resia of the pharyngeal membrame. Other variations will be mentioned in connection with the various mouth organs.

Comparative. - The phylogenetic origin of the mouth eavity from the integument is indieated uot only by the ectodermal origin of its lining epithelium, but by its general structure and its appendages. Among the latter may be noted the teeth (representing modified dermal

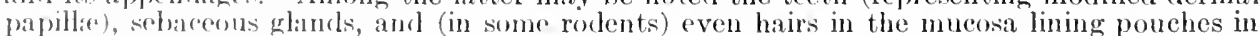
the cheeks.

\section{TIIE LIPS AND CHEEKS}

The lips [labia oris] form the anterior wall of the month avity. The lower lip) [latrimm inforinst is marked off from the chin by the sulens mentolabialis. The upper lip [lalsimn superius] extends upward to the nose medially and the sul("us masolathialis laterally. 'The phillrum is a moclian groove on the upper lip extenting from the septim of the nose al wove to the labial tubercle [tuberculum

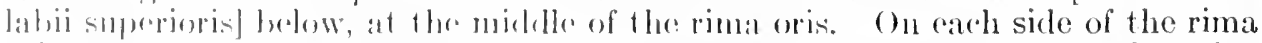
oris therpperam the lower lips are antiunous at the angle of the mouth [angulus oris], whine is matually opposite the first premolat teeth. Iaterally, the lips are 
continuous with the cheeks [buccæ], which form the lateral walls of the mouth cavity.

In structure, the lips (fig. 849) consist essentially in a middle layer of cross-striated muscle (orbicularis oris) covered externally by skin which is continuous through the rima oris with the mucosa forming the inner layer of the lips. The mucosa lines the vestibulum oris and is reflected upon the gums above and below. In the median line above and below, there extends from the lip to the gum a small fold of the mucosa [frenulum labii superioris vel inferioris]. 'The structure of the cheeks (figs. 847, 864) is similar to that of the lips but somewhat more complicated.

Fig. 850.-Labial and Buccal Glands Exposed bx Dissection of the Skin from in Front. (From Toldt's Atlas.)

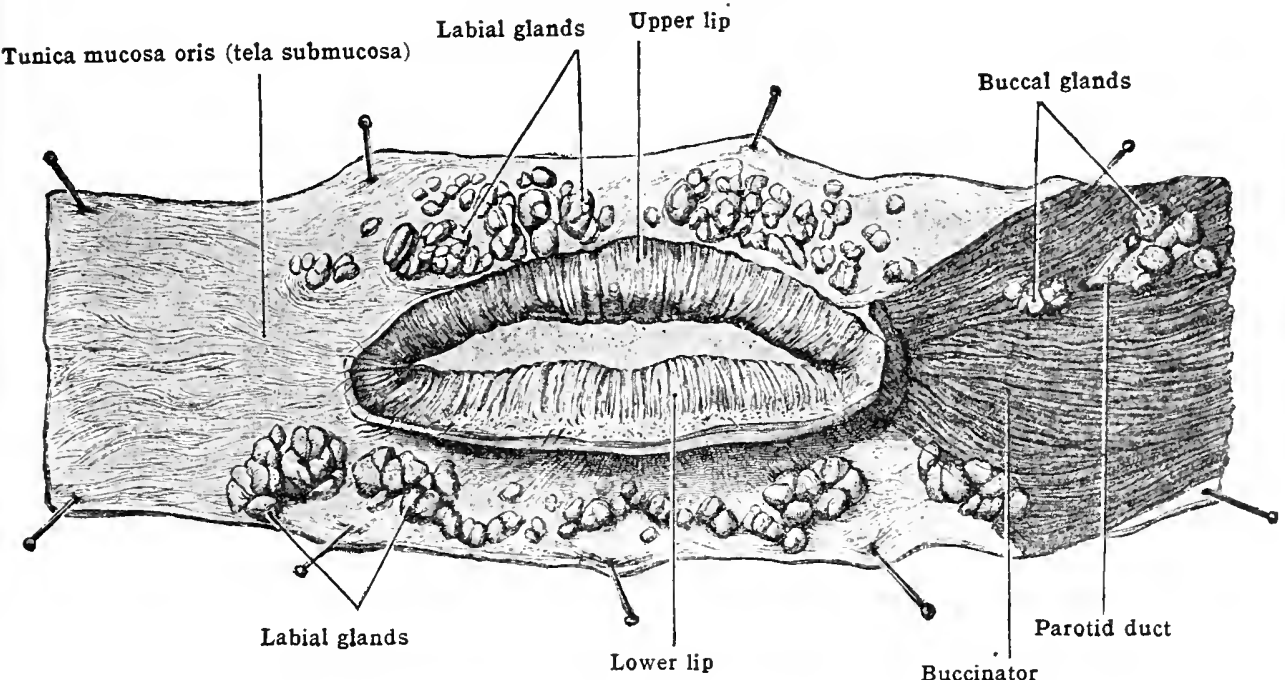

The muscular basis of the cheek is the buccinator muscle. External to this is a thick layer of fat [corpus adiposum buccæ] covered partly by the dermal muscles (platysma, zygomaticus, etc.) and lastly the skin. Internally the cheek is lined by the mucosa, continuous with that of the cheeks. The parotid duct opens into the vestibule opposite the second upper molar tooth.

Glands. - The skin of the lips and cheeks is well supplied with the usual sudoriparous and sebaceous glands. The mucosa likewise presents two kinds of glands, the sebaceous and the mucous glands. The sebaceous glands are relatively few in number and variable, being present in about 30 per cent. of cases in the adult (Stieda). They are similar in structure to those of

Fig. 851.-Section of Labial Mucosa, Showing Glands. $\quad \times 16 . \quad$ (From Toldt's Atlas.)

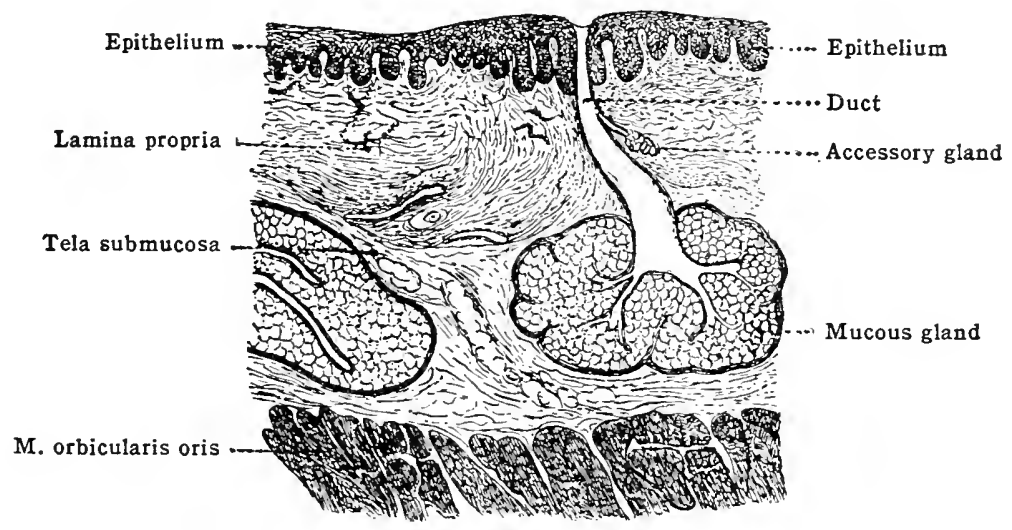

the skin (though not associated with hair follicles), and when present are visible as small yellowish bodies in the mucosa. They occur chiefly near the free margins of the lips and along the cheek opposite the teeth.

The mucous glands are much more numerous and constantly present (figs. 850, 851). They' are all of the racemose type. They are variable but small in size, and closely packed together in the submucosa of the lips [glandulæ labiales], where they may easily be felt. Those of the cheeks [gl. buccales] are less numerous. A few of them especially in the region of the molar 
teeth [gl. molares], are placed outside the buccinator. The ducts of the molar glands pierce this muscle near the parotid duct to open on the surface of the mucosa.

Vessels and nerves.- The mucosa of the lips and cheeks has a characteristic reddish hue, on account of the numerous blood-vessels which are visible through the thick but transparent stratified squamous epithelium (figs. 849,851 ) The numerous papillæ of the lamina propria are highly vascular. The blood-supply of the lips and cheeks is derived chiefly from the labial (coronary) and buccal arteries. The rich nerve-supply (sensory) is from the infra-orbital, mental and buccal branches of the fifth. The lips are especially sensitive near the rima oris.

Development.-During the second month in the human embryo, ledges of epithelium grow into the substance of the mandibular and the fused fronto-nasal and maxillary processes. These ledges develop into grooves which separate the upper and the lower lips from the upper and the lower jaws, the grooves forming the oral vestibule.

The philtrum and labial tubercle are said to correspond to the lower part of the frontonasal process. A failure of union between the globular and the maxillary processes presents an arrest of development resulting in the malformation known as "hare-lip."

In the late fotus and newborn, the red portion of the lips consists of an external smooth pars glabra, and an inner zone, pars villosa, which is covered with numerous villus-like projections. The largest of these reach a length of $1 \mathrm{~mm}$. They also extend backward in an irregular band along the mucosa of the cheek. They disappear during the first few weeks of postnatal life.

In the infant, the corpus adiposum is especially well developed. On account of its supposed aid as a support for the buccinator in sucking, it has been called the "sucking pad."

The scbaceous glands of the mucosa are said not to appear until about the age of puberty.

Variations.-As is well known, the lips and cheeks are exceedingly variable in shape, size and structure in different individuals. There are also characteristic differences according to race and sex in the form and structure of the lips, rima oris, beard, etc. The "hare-lip" malformation was mentioned above.

Comparative.-Typical lips are found only in mammals, and are probably organs phylogenetically developed in connection with the process of suckling.

\section{THE PALATE}

The palate forms the roof of the mouth eavity proper, and consists of two portions, the anterior or hard palate and the posterior or soft palate.

The hard palate [palatum durum] (figs. 848, 852) is continuous in front and laterally with the alveolar processes of the upper jaw, and gives attachment posteriorly to the soft palate. It separates the mouth from the nasal eavity. It is supported by the palatine process of the maxilla and the horizontal part of the palate bone. The oral surface is coneave from side to side, and also from before backward. It is eovered by a thick, somewhat pale mucosa, which is firmly adherent to the periosteum through the submucosa. The submucosa contains numerous mueous glands [gl. palatinæ] (fig. 852), similar to those of the lips.

In the median line of the hard palate is a line or ridge, the raphe (fig. 852) terminating anteriorly in the small incisive papilla, which eorresponds in position to the bony incisive foramen. Anteriorly there oeeur four to six more or less distinct transverse ridges [plicæ palatinæ transversæ]. Near the posterior margin of the hard palate there is on each side of the raphe a small pit (fig. 852), the foresta palatina, which is variable and ineonstant.

The soft palate [palatum molle] (figs. 848,892 ) separates the posterior portion of the mouth cavity from the nasal part of the pharynx. It is attached to the hard palate anteriorly and to the pharyngeal wall laterally. The posterior portion or edum projects backward and downward into the pharynx. Its free margin prescnts a median conieal projection, the uvula, and splits laterally on each side to form two folds, the palatine arehes, between which is located the palatine tonsil (fig. 8.52). The palatine arches and tonsil will be deseribed later in connection with the pharyn.

Structure. - The soft palate is a fold of mucous membrane enclosing a fibrous aponeurosis, muscles, vossels, and norves. It is marked in the midcle line by a raphe indicating the line of junction of the two halves from which it was formed.

The posterior liayer of the nucous fold which is directed toward the cavity of the pharynx is contimmus with the nasil muenus membrame; the anterior layer lies in the posterior boundary of the month and is continuols with the mucous membrane of the hard palate. The strueture of the muessit is very similar to that of the lips (fig. 8.19). Mucous glands are numerous in both layers, but more especially in the anterior, and nake up a litge portion of the mueosa and submunesia (figs. 651,652 ).

'The apromenrosis is at tueloed above to the pesterior margin of the hard palate; laterally it is entimusess with the aponenrotic latyer of the pharyngeal wall; below, toward the lower margin of the velum, it gradually disipueats. It gives attachnent to fibres of the levator veli palafini and the pharymg-palitinus (patato-pharyngens) and to the tendon of the tensor veli pralatini. 
Muscles.-The muscles of the soft palate are described later (p. 113t) with those of the pharynx, with which they are closely associated.

Vessels and nerves. - The arterial supply of the hard palate is derived chiefly from the major palatine branches of the internal maxillary. The arteries of the soft palate include:

Fig. 852.-Roof of Mouth, Showing Hard and Soft Palate Dissected ox One Side. (Rauber-Kopsch.)

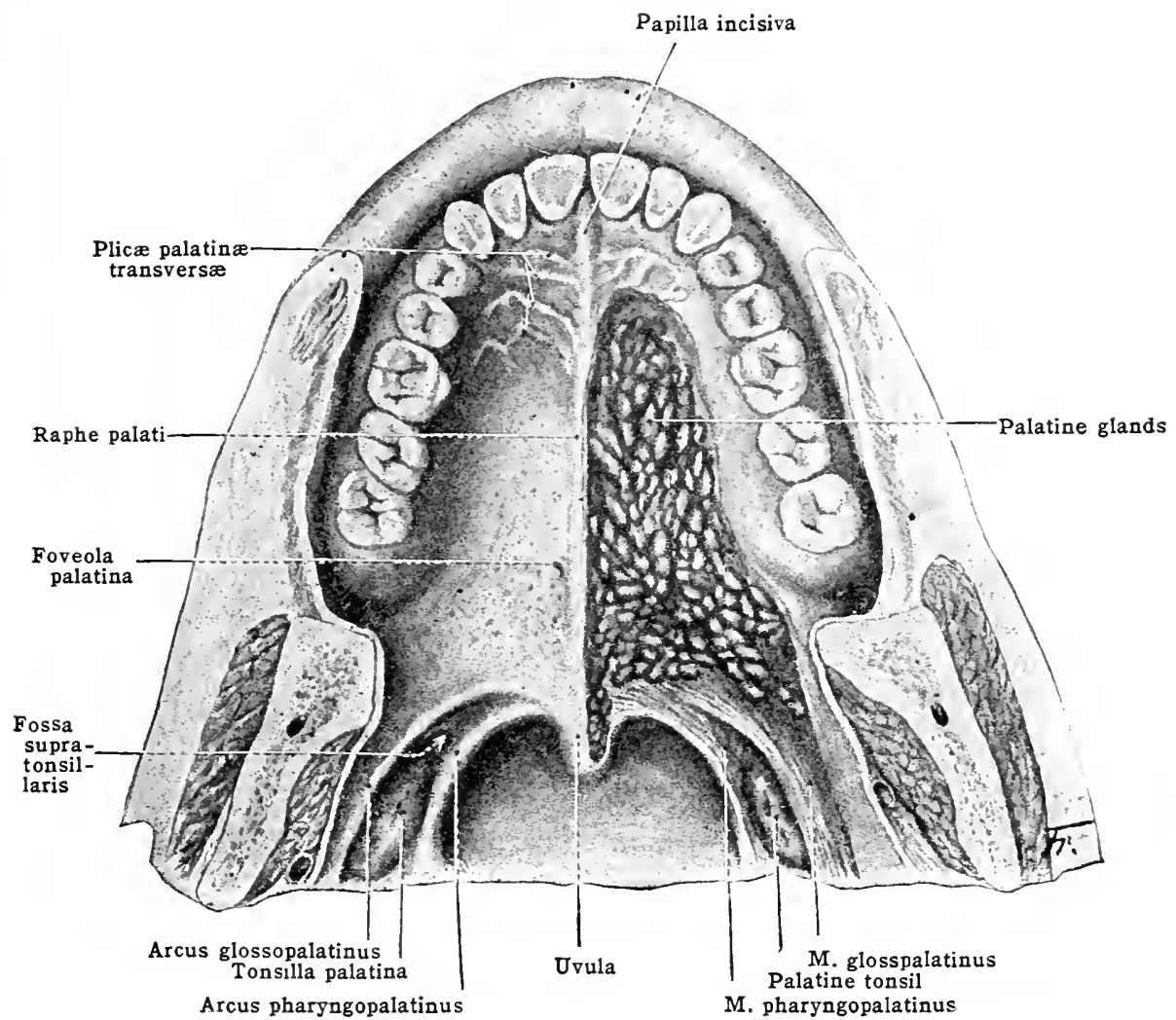

(1) Ascending palatine of external maxillary (facial); (2) pharyngeal branches of ascending pharyngeal; (3) twigs from descending palatine of internal maxillary, which enter the smaller palatine canals, are distributed to the soft palate and tonsils, and communicate with the ascending palatine of the external maxillary (facial) artery; $(4)$ lingual artery, by twigs from tbe dorsal branch.

Fig. S53.-Developing Palatine Shelves, Viened from Below. (MeMurrich, from His.)

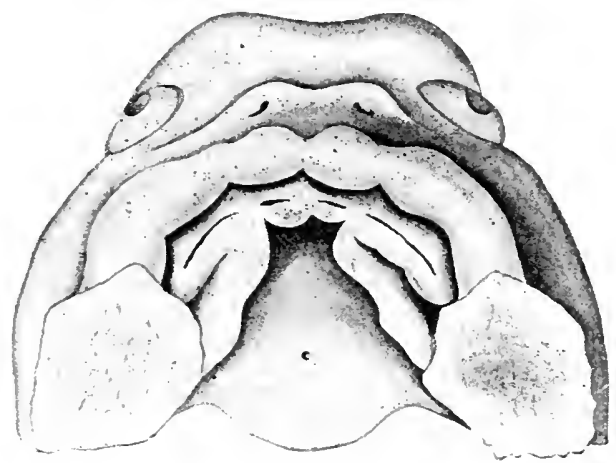

The sensory nerves to the palate are derived chiefly from the fifth through the sphenopalatine ganglion. The hard palate is supplied by the nasopalatine and anterior palatine branches; the soft palate chiefly by the median and posterior palatine branches. The motor nerves will be mentioned later in connection with the muscles. 
The development of the palate.-The hard and soft palates arise (fig. 853) in two ridges of tissue, designated the palate shelves, which develop on the inner surfaces of the maxillary processes. These shelves grow toward the median line, and at the beginning of the third month of fœtal life meet beneath the nasal septum, uniting with each other and with the nasal septum, the union taking place from before backward. The incisive foramen indicates the place of meeting of the premaxillary and palate shelves, which closes the primitive communication between the oral and the nasal cavity. A want of union of the palate shelves presents an arrest of development known as eleft-palate. The uvula is similarly formed by the union of the posterior ends of the lateral palate anlages, and a failure to unite may produce a bifid uvula. The transverse palatine ridges are better developed in the infant than in the adult, and may assist in holding the nipple in sucking.

Variations.-Cleft-palate and bifid uvula were mentioned above. The transverse palatine ridges are quite variable in number and prominence. On each side of the incisive papilla there is often found a small pit or shallow tube, a vestige of the embryonal incisive canal (Merkel). Sometimes there is instead a single median pit, representing the lower end of the incisive (Stenson's) canal. These pits are remnants of the primitive embryonic communication between mouth and nasal cavities.

Comparative.-The palate is absent in fishes and amphibia, the choanæ opening directly in to the primitive mouth cavity. In some birds, the palate shelves fail to unite, leaving a normal eleft-palate. The incisive (Stenson's) canal remains open permanently in some mammals (e. g., ruminants), bifurcating above and thus placing the mouth cavity in communication with the nasal cavity on each side in the vicinity of Jacobson's organ. The transverse palatine ridges are much better developed among many mammals, especially the carnivora.

\section{THE TONGUE}

The tongue [lingua] is a muscular organ covered with mucous membrane and located in the floor of the mouth. It is an important organ of mastication, deglutition, taste and speech. Upon its upper surface (figs. 854, 864) is a $\mathbf{V}$-shaped groove (sulcus terminalis) indicating the division of the tongue into two parts. The larger anterior part, or body [corpus linguæ] belongs to the floor of the mouth, while the smaller posterior part, or root [radix linguæ], forms the anterior wall of the oral pharynx. The inferior surface (facies inferior) of the tongue is chiefly attached to the muscles of the floor of the mouth, from the hyoid bone to the mandible (fig. 858). Anteriorly and laterally, however, the inferior surface of the body is free and covered with mucosa. The superior surface of the body is called the dorsum. It is separated from the inferior surface by the lateral margins, which meet anteriorly at the tip [apex linguæ].

The dorsum of the tongue usually presents a slight median groove [sulcus medianus linguæ]. Its posterior end corresponds to a small pit of variable depth, the foramen cæcum, which is placed at the apex of the $\mathbf{V}$-shaped terminal sulcus, The dorsum of the body has a characteristic rough appearance due to numerous small projections, the lingual papilloe.

Lingual papillæ.-Five or six varieties of papillæ are distinguished, between which intermediate forms occur. The conical [papillæ conices] and thread-like [papillæ filiformes] are most numerous, and are arranged more or less distinctly in rows parallel with the terminal sulcus (fig. 856). They arc best developed toward the mid-line of the dorsum in its posterior part. As shown in vertical section (fig. 856), each papilla consists of an axial core of vascular fibrous tissue (from the lamina propria) often beset with smaller secondary papillæ. The stratified squanous epithelial covering often presents numcrous thread-like prolongations from the apex of the papilla. The papillæ vary from 1 to $3 \mathrm{~mm}$. in length.

'I'le fungiform ("twad-stool shaped") papille are somewhat similar to the conical in structure, but larger and more prominent, with an expanded free portion and a slightly constricted stalk of attachment. They are relatively few in number and are seattered irregularly over the dorsum, being ruest numerous near the margins (fig. 864). 'They are easily distinguished in life by their larger size and reddish colour. A smaller, flattened variety of the fungiform is sometines ealled the tomticular ('lens-shaped') papille. ('This term, however, is applied by Toklt to certain sumll romeded elevations with underlying lymphatic nodules in the mucosa of the root of the tongue.)

The vallate (ciremuvallate) papilla', usually seven to eleven in number, are conspicuous and arrangerl in a $V$-shaped line parallel with and slightly anterior to the sulcus terminalis, (figs. $45.1,557$ ). 'They are, as a rule, shaped like short cylinders, 1 to 2 mm. in width, and somewhat loss in height. As is shown in sertion (fig. 857), each is surromeded by a trench or fossa, into the lontonn of which opren ducts of the serous glands of von bibner. On the sides of

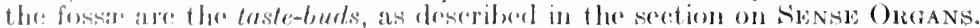

'The foliate pip pilla are represented by a fow (fivo to eight) parallel transverse or vertical folds of mueosa, along the margins of the fongue just anterior to the glosso-palatine areh on each side (fig. s6.1). They are variable in sime and sometimes rudimentary. In structure they somewhat resimble the vallate papillar (thomgh of different form), their walls being studded with taste-burls. 
The free inferior surface of the tongue (fig. 858) is covered by a thin smooth mucosa. In the median line is a prominent fold, the frenulum, which connects the tongue with the mandible and the floor of the mouth. On each side of the inferior surface, an irregular, variable, fringed fold, the plica fimbriata, extends from near the apex backward approximately parallel with the lateral margin of the tongue (fig. 858). Between the frenulum and the plicæ fimbriatæ, the lingual (ranine) veins are visible on each side beneath the mucosa.

The root (or base) of the tongue [radix lingux] belongs to the pharynx, but is here included with the mouth for convenience of description. Its free surface is directed posteriorly, and represents the continuation of the dorsum linguæ (fig. 854). Laterally it is continuous with the region of the palatine tonsils. Infe-

Fig. 854.-Dorsum and Root of the Toxgue. (Papillæ diagrammatic.)

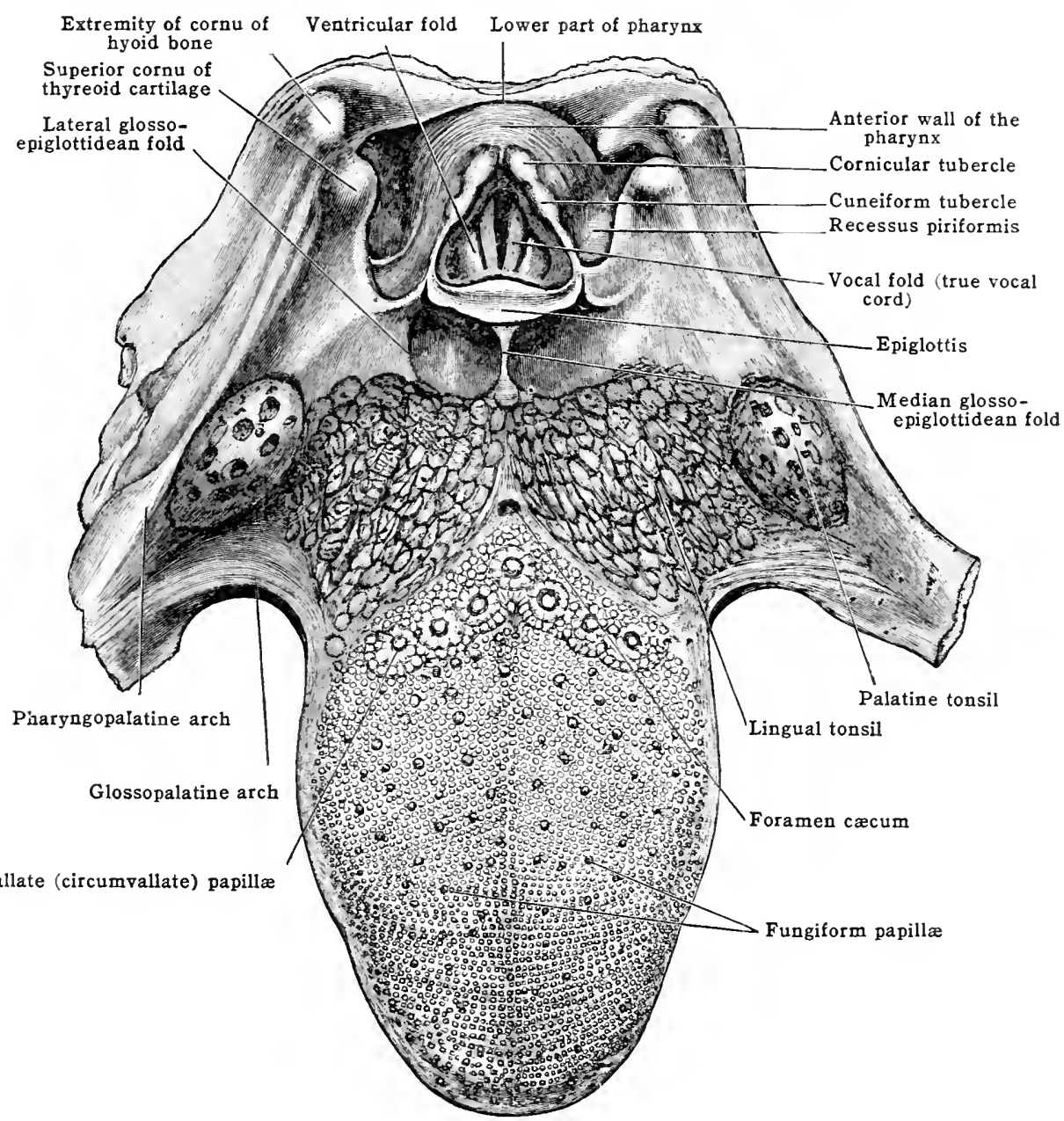

riorly it extends to the epiglottis, with which it is connected by a median and two lateral folds, between which are the depressions known as the valleculce. The mucosa over the root of the tongue is irregular and warty in appearance due to the projections of the underlying nodular masses of lymphoid tissue, the lingual follicles. A crypt or tubular pocket of surface epithelium usually dips down into each of these follicles, as seen in surface view (fig. 854), and shown in section (fig. 859). The follicles vary from 34 to 102 in number, the average being 66 (Ostman), and are somewhat irregular in size and form. They are often arranged in more or less distinct longitudinal rows, with corresponding folds of the mucosa (Jurisch). The lingual follicles are collectively designated as the lingual tonsil [tonsilla linguæ]. Between the lingual follicles and around the periphery of the lingual tonsil there are found smaller ordinary nodules (without crypts) and indefinite 
masses of lymphoid tissue. The sulcus terminalis forms a fairly sharp boundary between the lymphoid mucosa of the root and the papillated mucosa of the body of the tongue (fig. 854).

Fig. 855.-Left Side of the Tongue, with its Muscles, etc.

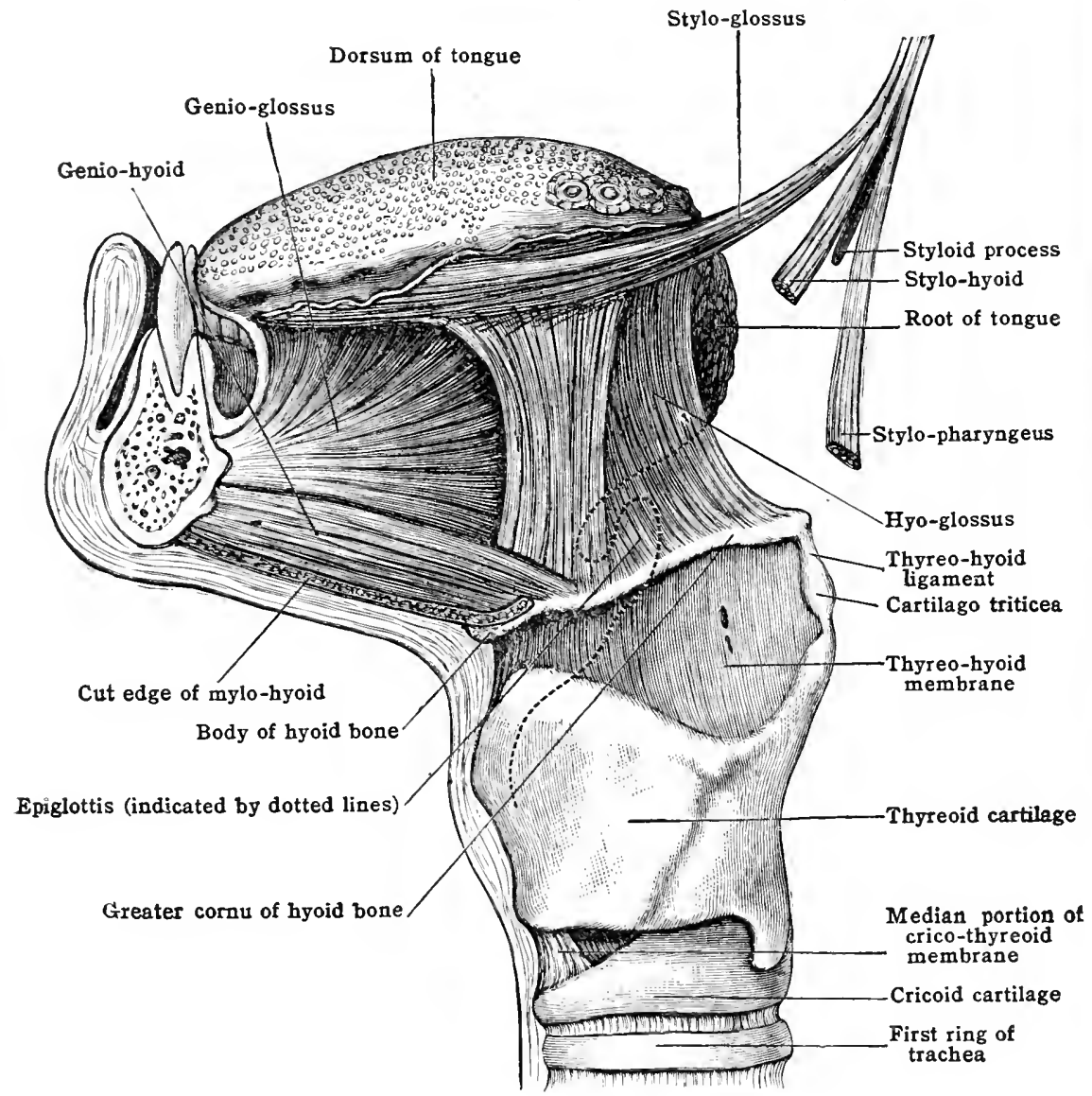

Glands. - The glands of the tongue are of three types-mucous, serous and mixed-and are distributed as shown in fig. 860 . The most numerous are those of the mucous type, which

Fig. S56.-Section of Lingual Papilla. $\times 20 . \quad$ (From Toldt's Atlas.)

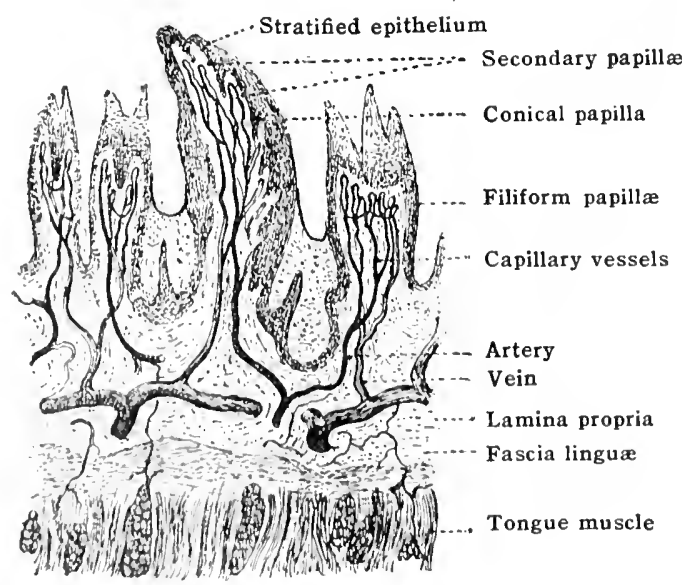

are typical for the mouth cavity in general and resemble those already deseribed in the lips, cherks and palate. They are spreal over the entire surface of the root of the tongue, in the 
spaces between the lingual follicles, usually opening upon the surface but in many cases into the crypts. Anteriorly, they extend a short distance along the posterior portion of the lateral

Fig. 857.-Vertical Section of a Human Vallate Papilla With Lingual Glands.

$$
\times 25 \text {. (Lewis and Stöhr.) }
$$

Secondary papillæ Taste bud

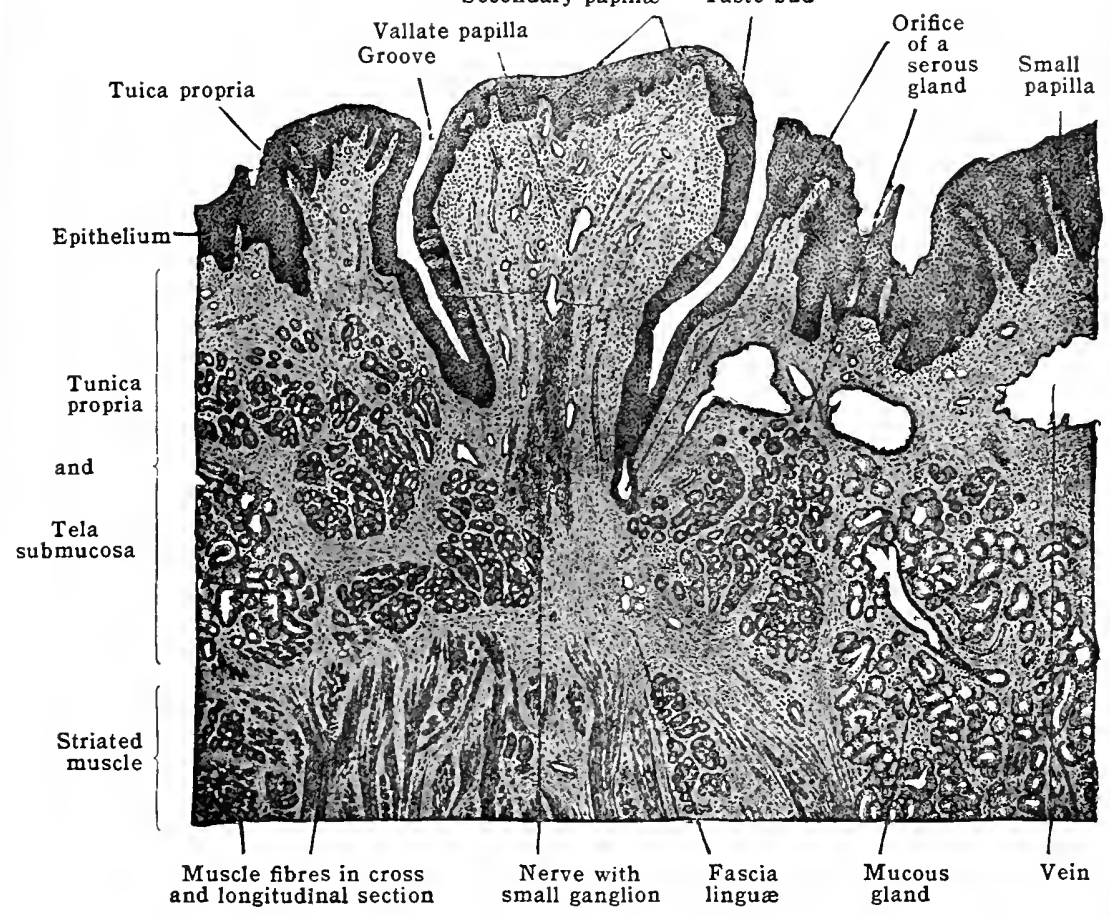

Fig. 858.-Inferior Surface of the Tongue. (Modified from Spaltholz.)

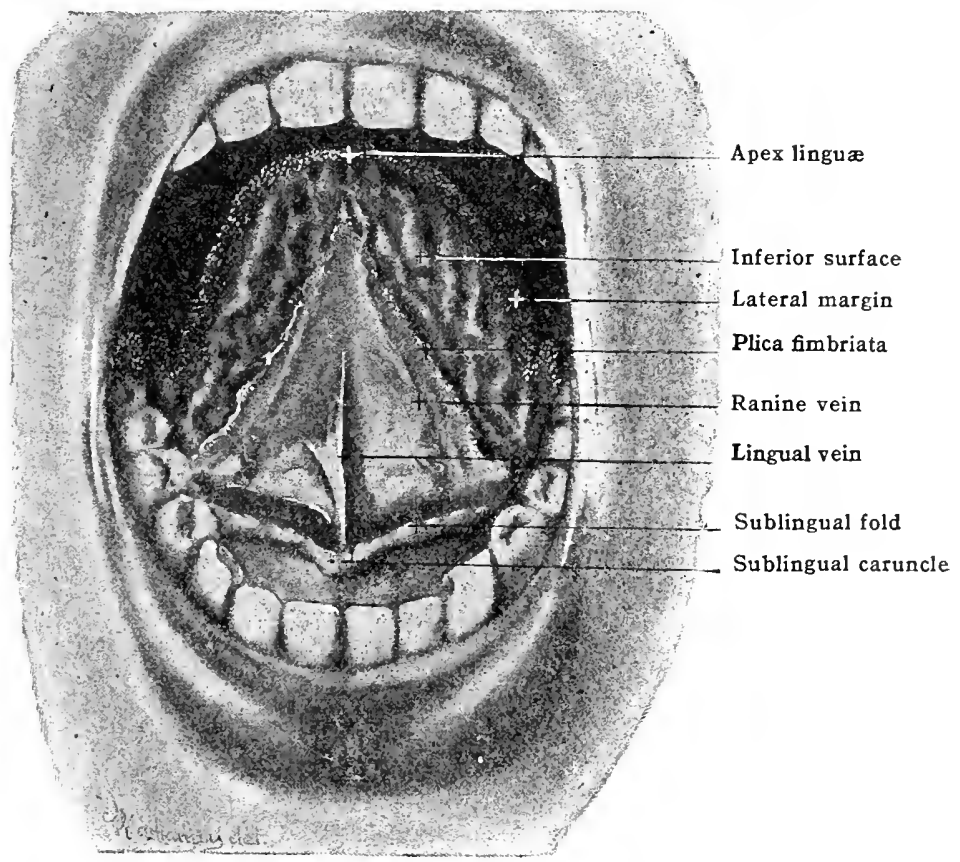

margin of the tongue, and also occupy small areas in and near the mid-line in front of the vallate papillæ.

In the immediate region of the vallate papillæ, and in the small lateral areas corresponding 
to the foliate papillæ (i. e., in the regions of the taste-buds), the mucous glands are displaced by the serous glands (of von Ebner), which have a watery secretion (fig. 860). Finally, on the inferior surface of the tongue, on either side of the frenulum near the apex, are the anterior lingual glands (glands of Nuhn or Blandin). Each is about $15 \mathrm{~mm}$. in length, and is composed of a group of racenose glands with three or four very small ducts opening on the surface of the tongue near the plica fimbriata. The anterior lingual glands are deeply placed and are covered not only by the mucosa, but also by some of the longitudinal muscle fibres (inferior longitudinal and styloglossus). This gland is of the mixed type, though chiefly mucous.

Fig. 859.-From a Section of the lingual Tonsil of an Adult Man. $\times 20.1$. Pit eontaining leucocytes which have infiltrated its epithelium on the lef side; that on the right is almost intact. (Lewis and Stöhr.)

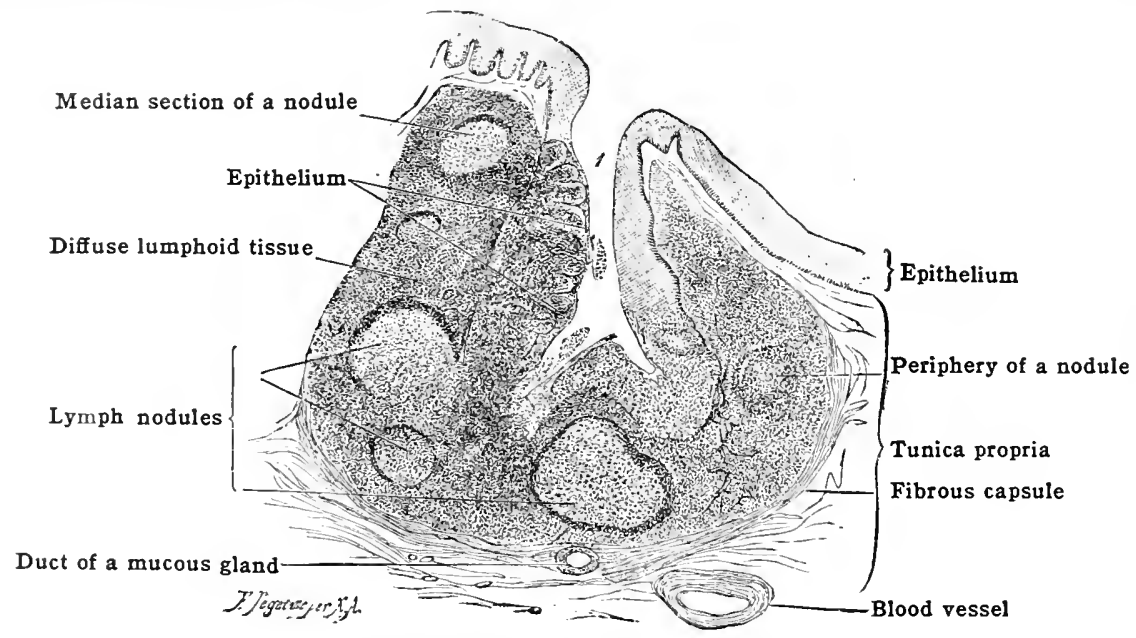

Muscles of the tongue.-A layer of fibrous connective tissue, the lingual'septum, separates the halves of the tongue, extending in the median plane from the apex to the root, where it is attached below to the hyoid bone. The muscles of the tongue are classified as extrinsic and intrinsic. The extrinsic muscles (fig. 855) extend into the tongue from without. They are the hyoglossus, chondroglossus, genioglossus, styloglossus, and glossopalatinus (palatoglossus), all of which are described elsewhere (see Section IV.)

Fig. 860.-Diagram of the Distribution of the Lingual Glands. Horizontal lines indicate the mucous type; cross-hatched, the mixed type; and dotted areas, the serous type. (After Oppel.)

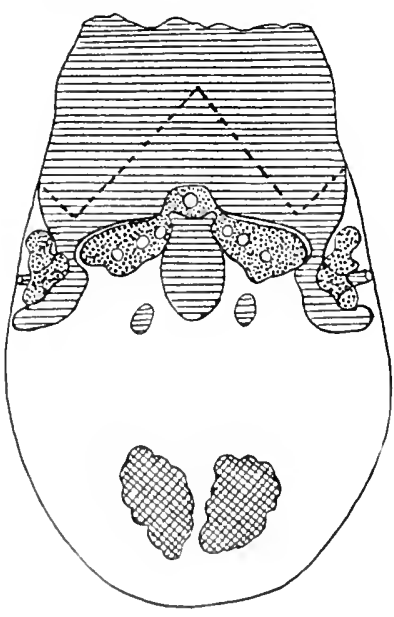

The intrinsic muscles.-The longitudinalis superior (fig. 861) is a superficial longitudinal stratun extending from the bise to the apex of the tongue, inmerliately beneath the mucosa of the rlorstim, to which many of its filmes are attached. The longitudinalis inferior (fig. 861) is composed of two musele-binds extemline from base to apex on the inferior surface of the tongue, and is situated between the lyyoglossus and the genioglossus, some of its fibres near the apex mixing with the styloglossus, while dorsally some atre attached to the hyoid bone. The transversus linguæ (fig. 861 ) consists of filores which pass transversely, and is situated between 
the superior and inferior longitudinal muscles. The fibres arise from, or pass through, the septum lingux, and are attached to the mucosa of the dorsum and lateral margins of the tongue. The verticalis linguz (fig. 861) is composed of fibres which pass from the mucosa of the dorsum to the mucosa of the inferior surface of the tongue, interlacing with those of the other intrinsic and extrinsic muscles.

Fig. 861.-Transverse Section throdgh the Left Half of the Tongue. (Magnified.) (From a preparation by Mr. J. Pollard, Middlesex Hospital Museum.)

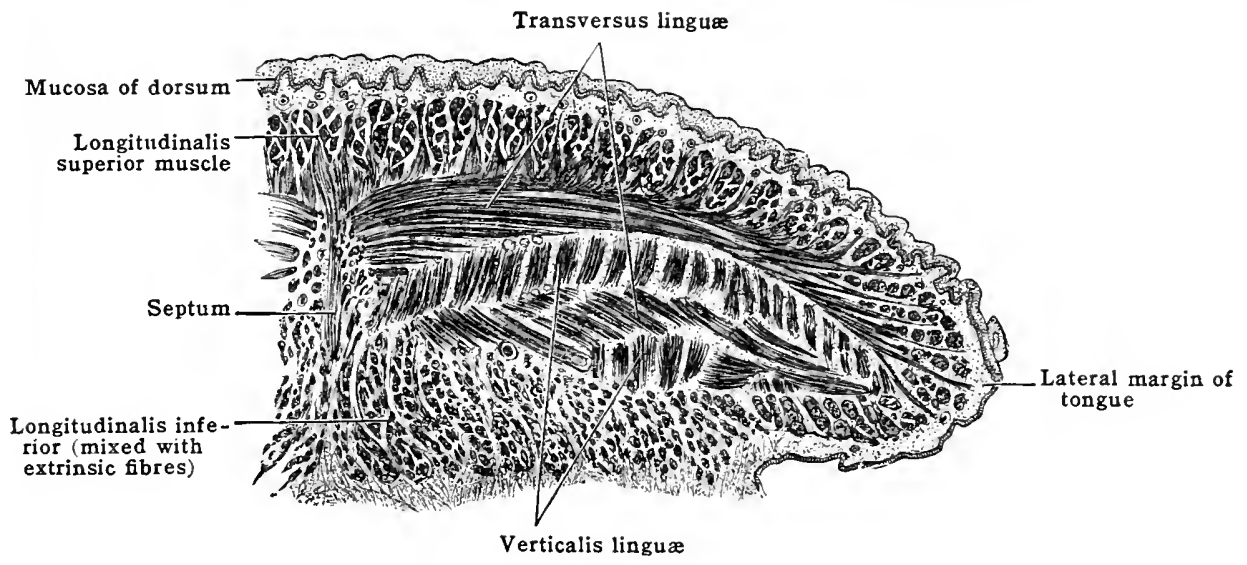

Vessels and nerves.-The lingual arteries furnish the prineipal blood-supply. The lingual veins carry the blood from the tongue to the internal jugular. The lymphatics form a network in the lamina propria, connected with a deeper network in the submucosa. The latter forms plexuses around the lingual follicles. The efferent lymph-vessels from the tongue empty chiefly into the superior deep cervical lymph-nodes. (For details concerning the blood-and lymphvessels, see Sections $V$ and VI.) The nerves are motor and sensory. The hypoglossal nerve

Fig. 862.-Schematic Representation of the Distribution of tee Sensory Nerves in'The Mucous Membrane of The Tongoe. (Areas of distribution according to R. Zander. White dotted area indicates vagus; oblique lines, glosso-pharyngeal; horizontal lines lingua nerves.)

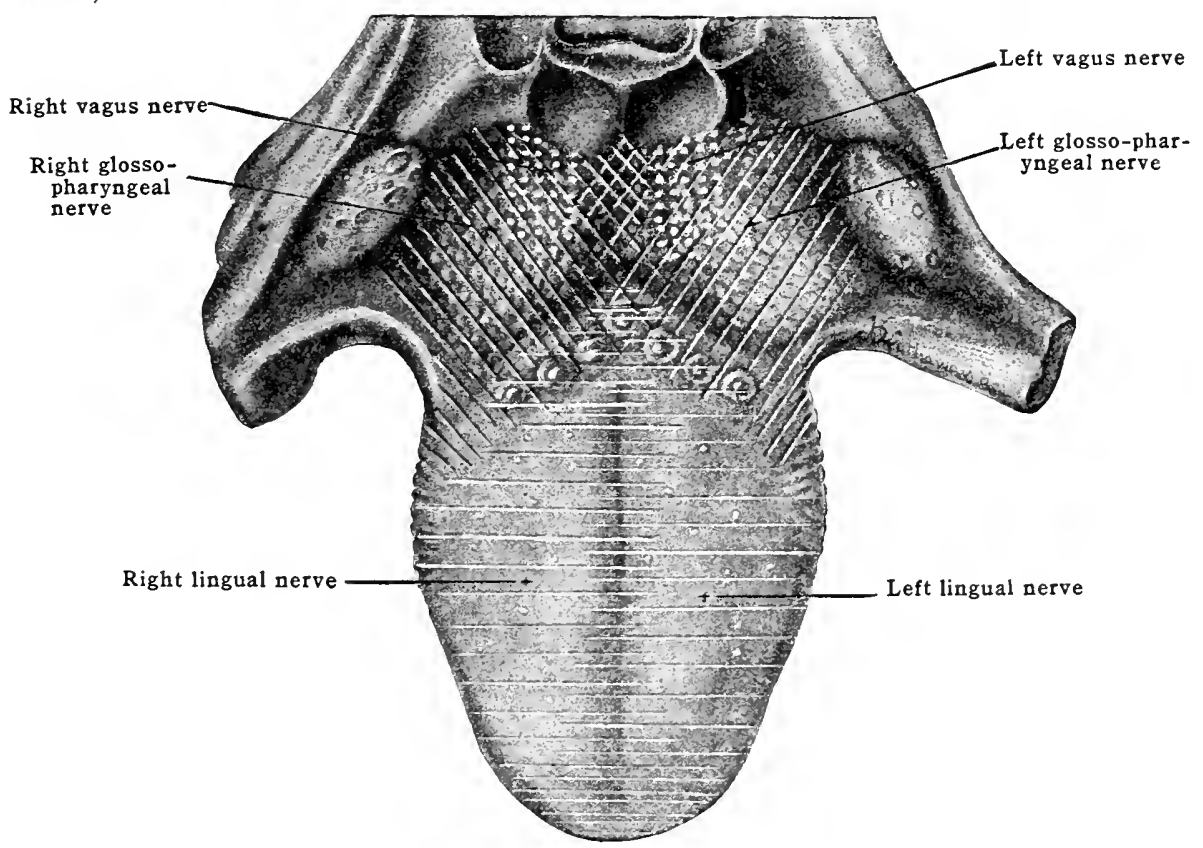

supplies the intrinsic and all the extrinsic muscles of the tongue except the glossopalatinus (palato-glossus), which is supplied from the pharyngeal plexus. The sensory nerves (fig. 862) are:-the lingual nerve, a branch of the mandibular division of the fifth, which, after joining with the chorda tympani from the seventh, is distributed to the anterior two-thirds of the tongue and represents the nerve of touch; the lingual branches of the glossopharyngeal, which are distrib- 
uted to the root of the tongue, including also the vallate and foliate papillæ (nerve of taste); and the superior laryngeal branch of the vagus, which supplies a small area near the epiglottis.

Development.- The development of the tongue is quite complicated. In general, the body of the tongue is derived from the region corresponding to the ventral portion of the first arch, just behind the mandible. It does not develop from the tuberculum impar, however, which is a transitory strueture (Hammar). The epithelium of the body of the tongue is probably of ectodermal origin. The root of the tongue develops from the corresponding lower portion of the second or hyoid arch, and its epithelium is endodermal in origin. The transverse groove between the two arches later becomes the sulcus terminalis. At the middle of this groove there is an ingrowth of the epithelium to form the anlage of the thyreoid gland. The foramen cocum and the occasional ductus lingualis represent persistent port ions of the thyreoid duct. The third arch does not appear to enter into the formation of the tongue, but forms the epiglottis (Hammar).

The musculature of the tongue appears to develop from the mesenchyme in situ although its innervation from the hypoglossal would indicate a derivation from the occipital myotomes. A pair of premuscle masses appears in the $9 \mathrm{~mm}$. embryo, the individual extrinsic muscles being distinguishable at $14 \mathrm{~mm}$, and the intrinsic at $20 \mathrm{~mm}$. (W. H. Lewis). The glands appear in the fourth foctal month as solid epithelial downgrowths which later acquire a lumen. The mucous glands appear first, the serous slightly later. Longitudinal folds in the mucosa of the

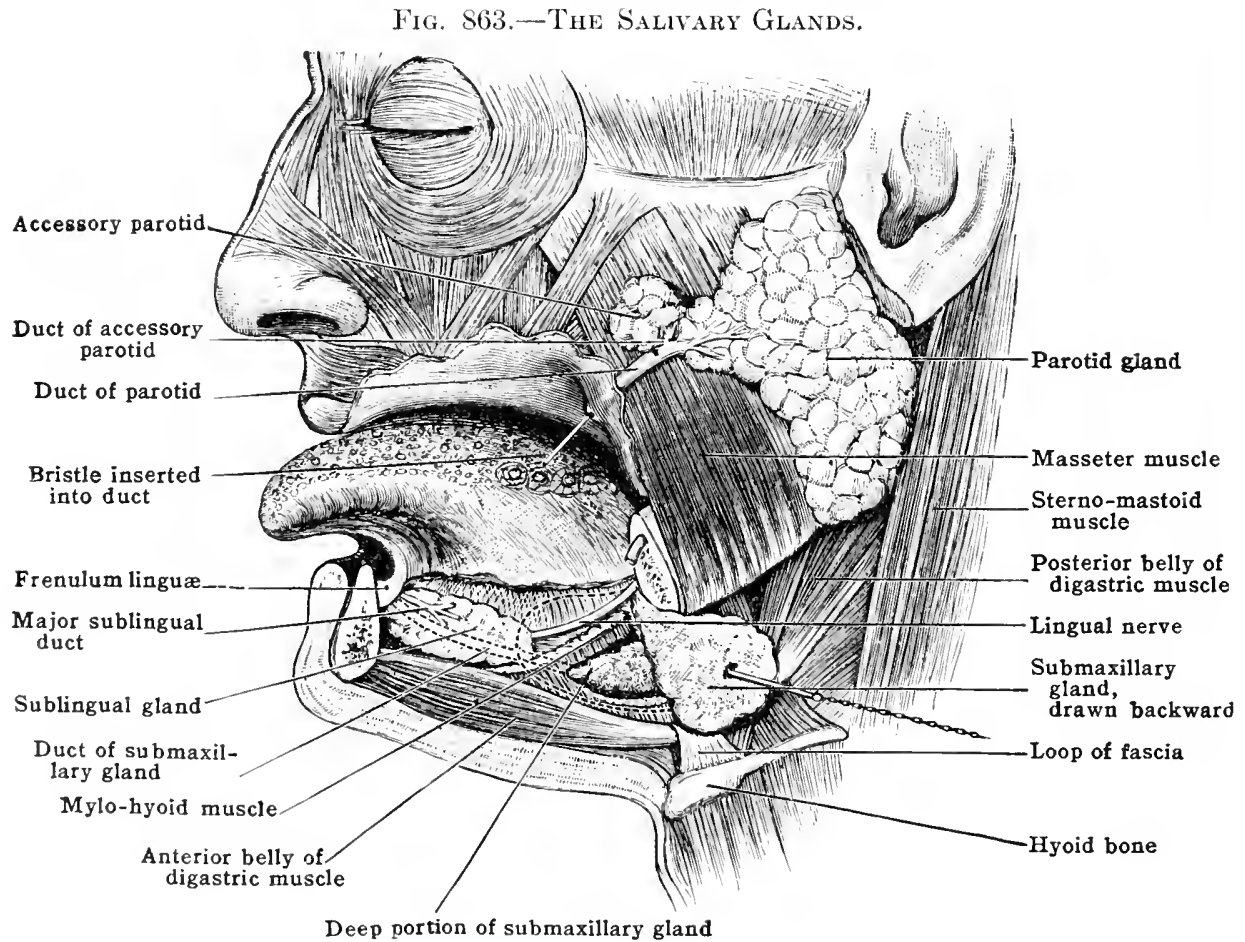

radix appear in the third or fourth fortal month (Jurisch). The lymphoid tissue appears somewhat later as aggregations in the lamina propria, chiefly around the gland-ducts. From the beginning, the lymplosid struetures are suljoet to marked individual variations. Characterist ir, Well-d(*Vreloperl lingual follicles do not a ppear until some time after birth, however (Juriseh). Of the lingual papille, the fungiform appear at the end of the third foctal month, followed stortly by the filiform and vallate. The formation of the papilla is not completed at birth, however, sine they later undorgo changes in number, form, size and arrangement. The foliate papillar aupear about the fifth fortal month. They are best developed in infants, undergoing retrogressive changes in the adult (Stahr). The same is true of the ptien fimbriatae.

Variations. - Of the manifold variations in the strueture of the tongue, some have already bern mentioned. Adelitional mucoms glands sometimes oredur along the margin of the tongue

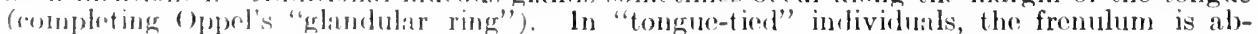
normally short. A forlest tongur (normal in some animals) is a rare congenital anomaly. Amother rare variation is the so-called "hairy" tongue, due to hypertrophy of the filiform

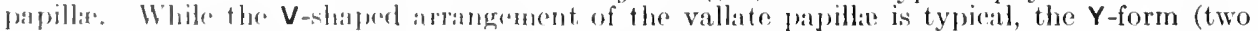
to form papillar in the molian line forming the stem of the $Y$ ) is nearly as frequent. Indeed, in some of the coloured rases the latter type seems to predominate. The sulens terminalis and forament casesum are often indistinct and sometimes absent.

Comparative. - The tongur of fishes and lower anphibia contains nejther glands nor intrinsir musculature. Anong higher verteblates, the tongue varies exreedingty in form and structure, lunt always contains intrinsir muscolature and mueous glands. The latter primitive!y form a ring aronnd the margin and rost of the tongue (Oppel). The serous glands occur only in mantmals, and are associated chesely with the papilla bearing taste-buds. 
The plica fimbriata in man is homologous with the 'sublingua' of lower mammals. According to Gegenbaur, the 'sublingua' represents the entire primitive vertebrate tongue, but this view is opposed by Oppel. Anong various mammals, the number of vallate papill:e varies from one to thirty, but the $\mathbf{V}$ - or $\mathbf{Y}$-arrangement is typical. The region of the foliate papilla ('marginal organ') is typical for mammals, and is much better developed in some (e. g., rabbit) than in man. The mucosa of the root of the tongue is always different from that of the body. The lingual papillæ are especially developed in the tongue of carnivora.

\section{THE SALIVARI GLANDS}

Numerous glands-labial, buccal, palatine and lingual-have alrealy been mentioned, which pour their secretions into the mouth cavity. In addition to these, there are three larger pairs, the salivary glands proper. They include the parotid, the submaxillary, and the sublingual (the latter really a group of glands).

\section{THE PAROTID GLAND}

The parotid gland [gl. parotis] is the largest of the salivary glands, varying from 15 to $30 \mathrm{gm}$. in weight. It is located below and in front of the ear in the

Fig. 864.-Horizontal Section through Head at Level of Rima Oris. (After Henle, modified.)

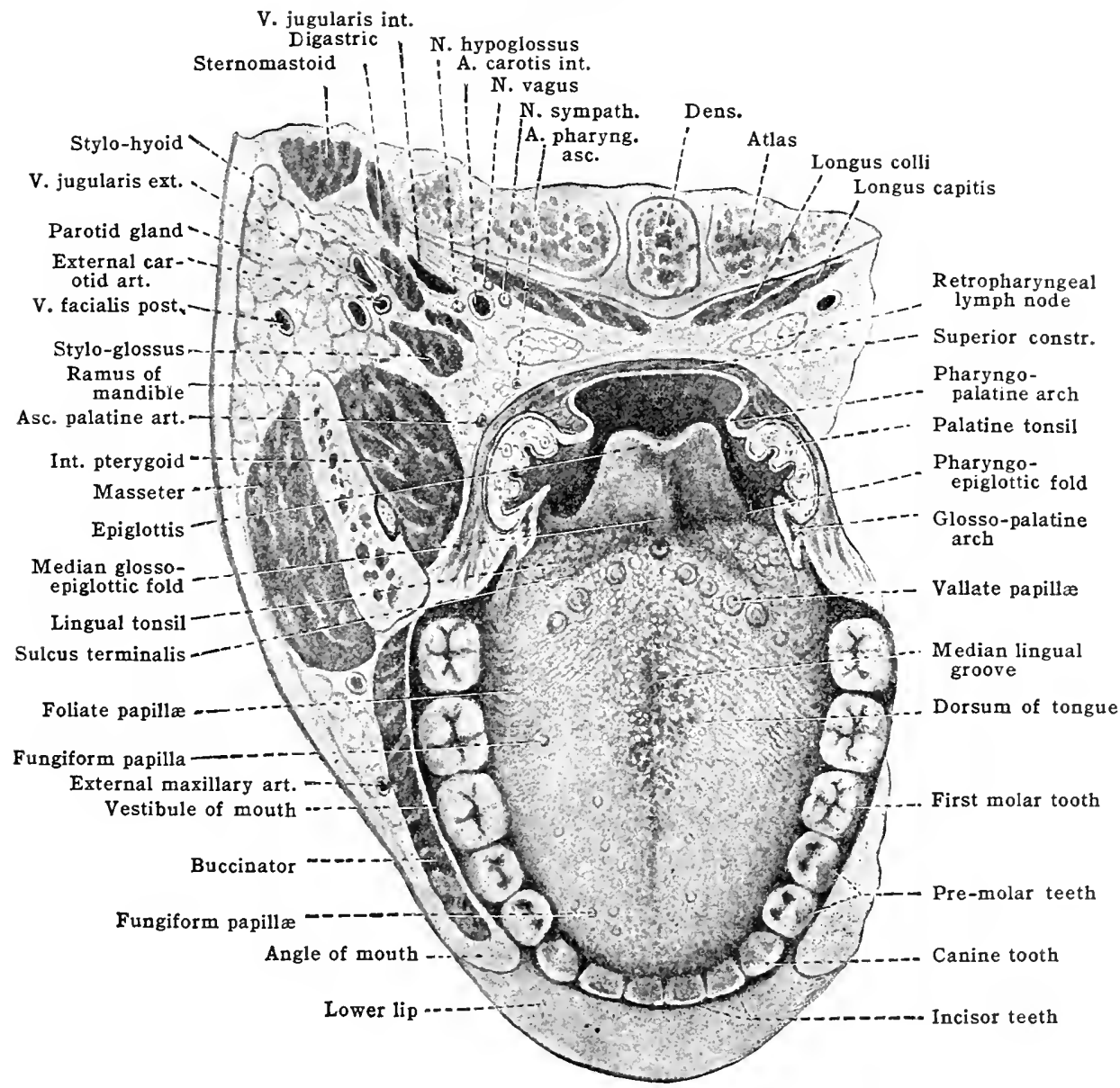

retromandibular fossa (fig. 863), extending from the zygomatic arch above to the angle of the mandible below.

Form and relations.-The parotid is somewhat prismatic or wedge-shaped (figs. 863, 864), with three surfaces and three borders or angles. The lateral surface is covered by skin and superficial fascia, and in its lower part by the platysma. The anterior surface overlaps the masseter and extends medialward in contact 
with the posterior border of the mandibular ramus and with the posterior aspect of the internal pterygoid muscle. An irregular "pterygoid lobe" may extend between the internal and the external pterygoid muscles. The posterior surface is in contact with the sternomastoid muscle laterally, and with the styloid process and associated muscles medially. Between the sternomastoid and styloid process it touches the posterior belly of the digastric, and is in relation with the internal carotid and jugular vessels. The various struetures in contact with the parotid gland often make more or less distinet grooves upon its posterior and anterior surfaces.

Borders.-The anterior border usually extends from below obliquely upward and forward so as to give the whole superficial surface a triangular appearance. Near the upper end of the anterior border, the parotid duct leaves the gland, and just above this there is usually a small separate accessory lobe [gl. parotis accessoria], of variable form and size. The branches of the facial nerve also emerge from the anterior border. The posterior border extends along the anterior aspect of the sterno-mastoid muscle up to the mastoid process. The medial border is deeply placed (at the junction of the anterior and posterior surfaces), and approaches the wall of the pharynx.

The upper extremity of the parotid sends a process into the posterior part of the manibular fossa, behind the condyle of the mandible, and is related with the

Fig. 865.-Diagram of Horizontal Section Showing the Parotid Compartant and Relations. Arrow indicates opening in sheath. (Modified from Woolsey after Testut.)

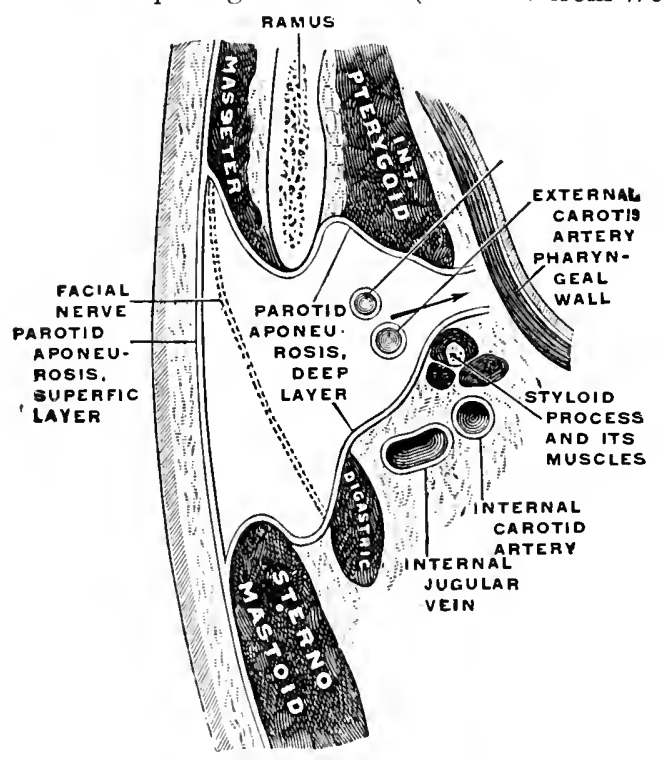

external auditory meatus. From the upper extremity emerge the superficial temporal vessels and the aurieulo-temporal nerve. The lower extremity is separated by the stylo-mandibular ligament from the posterior end of the submaxillary gland.

Fascia.-As shown in fig. 865, the parotid gland is enclosed in a sheath (called the parotid fascia or aponeurosis) derived from the deep fascia of the neighbourhood. The superficial layer of the sheath covers the lateral surface of the gland, while the deep layers correspond to the anterior and posterior surfaces of the gland. The sheath is very feeble or deficient at the medial angle. The superficial and deep layers of the varotid sheath unite below to form a thick fascial hand extending from the angle of the mandible to the sterno-mastoid muscle.

Contents. - Within the sheath, the parotid gland is in intimate relation with numerous important structures. Fxtending along the medial border, and partly embedded in the gland, is the external carotil artery, dividing above into the superficid temporal and internal maxillary (inchuling the origins of the drep auricular aud transerse facial); and the posterior facial (temporo-maxilary) vein and branches. The anrieulo-temporal nerve passes through the upper part of the gland, while the farial nerve passes somewhat horizontally through it, dividing into its temperofarial and ecrvico-farial divisions. Finally, there are emberded in the gland two or three drep lymphatic nodes, which reneive lymphatic vessels from the external auditory meatus, the soft palite and the posteriof part of the natsal fossa; and several superfieial nodes, which recerive lymphatic vossels from the templo, eyolorows and eyelids, cheek and auriele.

Structure. - The parotid is a racomose gland of the serous type. 
Duct, vessels and nerves.-The duct of the parotid (Stenson's) issues from the anterior border of the gland, crosses the misseter a finger"s brealth below the zygoma, and turns abruptly medialward round its anterior border. It penetrates the fat of the cheek and the fibres of the buceinator muscle, between which and the mucous membrane it runs for a short distance before it terminates, sometimes on the summit of a little papilla, by a minute orifice. This opening is placed opposite the crown of the second upper molar tooth. The duet commences by numerous branches, which eonverge toward the anterior border of the gland, and receives in its passage across the masseter the duet of the accessory parotid gland. The eanal is about the size of a crow-quill, length about 35 to $40 \mathrm{~mm}$., diameter $3 \mathrm{~mm}$. Its mucous membrane is covered for a short distance, beginning with its oral termination, by stratified pavement epithelium, for the remainder of the distance by columnar epithelium. The coat of the duet is thick and tough, and consists of fibrous tissue intermixed with nonstriated muscle-fibres.

The arteries are derived from those lying in the gland substance and from the posterior aurieular artery.

The veins terminate in the posterior facial (temporo-maxillary) trunk.

The nerves.-The parotid gland receives its secretory fibres from the otic ganglion, conveying impulses from the glosso-pharyngeal via the lesser petrosal and the auriculo-temporal; its sensory supply through branches of the fifth nerve; and its sympathetic supply from the earotid plexus. The lymphatics from the parotid gland terminate in the superficial and deep cervical glands, especially in the deeper group of parotid nodes embedded in the substance of the gland.

Variations.-The parotid is quite variable in size and in the form of its various processes, especially of the accessory lobe, as already mentioned. The lobulations are less distinct in infaney. Rarely the parotid is eonfined to the masseteric region, the retro-mandibular fossa being filled with a fatty tissue enelosing the vessels and nerves normally found with the gland.

\section{THE SUBMAXILLARY GLAND}

The submaxillary gland [gl. submaxillaris] weighs 7 to 10 grams, and is of about the form and size of a flattened walnut. It consists of a chief or superficial part, and a smaller deep process. The chief portion is located in the digastric triangle, and presents three surfaces-superficial, deep and lateral (figs. 847, 866).

Fig. 866.-Medial View of the Submaxillary and Sublingual Glands. (SobottaMe Murrich's Atlas.)

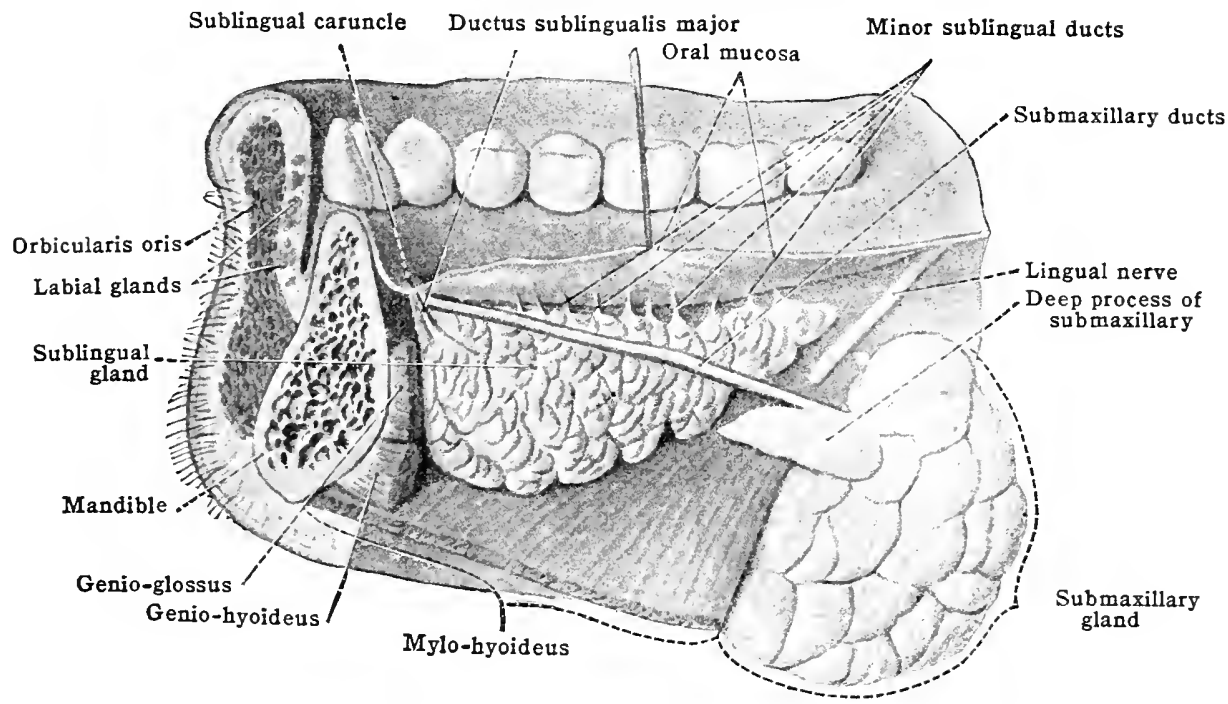

Surfaces.-The superficial or latero-inferior surface is covered by skin, superficial fascia, platysma and deep fascia (which forms an incomplete capsule around the gland). It is crossed by the facial vein and by cervical branches of the facial nerve. Several lymphatic glands, which receive vessels from the anterior facial region, lie upon or embedded in this surface.

The lateral surface is the smallest of the three. It is in contact with the submaxillary fossa of the medial surface of the mandible, and with the lower part of the internal pterygoid muscle. The posterior aspect of the gland is deeply grooved by the external maxillary (facial) artery and is separated from the parotid gland by the stylo-mandibular ligament. The deep or medio-superior surface is in contact with the lower surface of the mylohyoid, and behind this with the hyo- 
glossus, stylohyoid and posterior belly of the digastric. Between this surface and the mylohyoid muscle are the mylohyoid nerve and artery and the submental artery.

The deep portion is a tongue-like process which passes from the deep surface of the submaxillary gland around the posterior border of the mylohyoid muscle, and extends forward in company with the duct, under cover of (above) the mylohyoid, and in relation with the hyoglossus and genioglossus muscles. At its commencement, the deep process lies just below the submaxillary ganglion and anteriorly it gives off the submaxillary duct as it approaches the sublingual gland.

Structure.-The submaxillary is a racemose gland belonging to the mixed type, some of the acini being serous, others mucous (fig. 867 ).

The submaxillary (Wharton's) duct springs from the deep surface of the superficial part of the gland; it passes forward and inward, along the medial surface of the deep lobe, and opens by a small orifice on the sumnit of a papilla [earuneula sublingualis] by the side of the frenulum of the tongue. It is crossed superficially by the lingual nerve. It lies at first between the mylo-

Fig. 867.-Section of the Submaxillary Gland of an Adult Man. $\quad \times 252 . \quad$ (Lewis and Stöhr.)

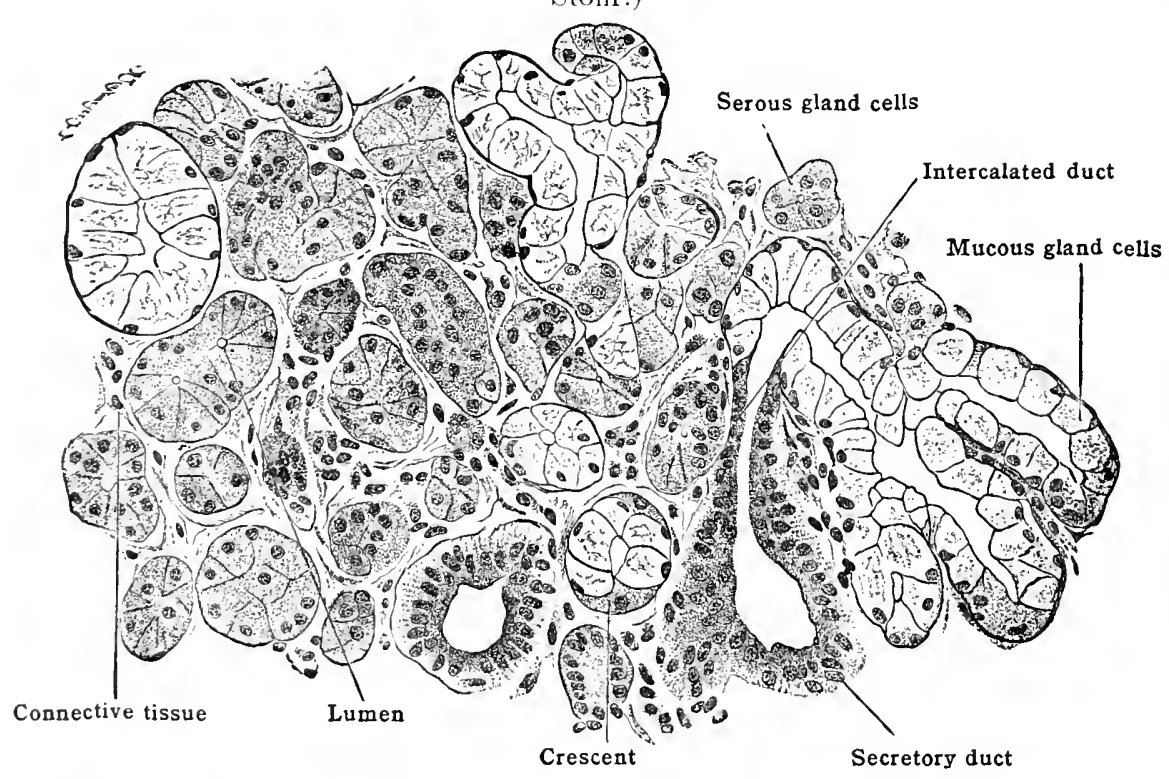

hyoid and hyoglossus; next, between the myloliyoid and genioglossus; and lastly, under cover of the mucous membrane of the mouth, between the genioglossus and the sublingual gland. The duct is about $5 \mathrm{~cm}$. in length, and has comparatively thin walls. It is lined by columnar epithelium.

Vessels and nerves. - The arteries to the gland are derived from the external maxillary (facial) and lingual, and they are accompanied by corresponding veins.

The nerves. - The submaxillary gland receives its seeretory fibres from numerous small sympathetic ganglia situated on the submaxillary duet and in the hilus of the gland, these conveying impulses from the chorda tympani its sensory branches probably come from the geniculate ganglion, and its sympathetic branches from the cervical sympathetic.

Variations. - Mbsence of the gland is a rare anomaly. $A$ ease is recorded (Turner) where the submaxilary was placed entirely under cover of the mylohyoid, being closely associated with the sublingual ghand.

\section{THE S'UBLINGUAL GLAND}

The sublingual gland [gl. sul,lingualis] — the smallest of the salivary glands (2 to 3 gm.) is in reality a group of glands forming an elongated mass in the floor of the month under the tongue (fig. \$.47). Above, it forms a distinet ridge, covered by a fold of mucosa (plicat sublingualis) upon which its ducts open (fig. 866). It is flattened from side to side, its lower border resting upon the upper surface of the mylohyod, its lateral surfare in contact with the sublingual fossia of the mandible, and its medial surface with the gentohyoid, geniolnyoglossus, lingual nerve, deep lingual artery and submaxillary duct (fig. S6i3). Anteriorly it touches its fellow of thre opposite side, while posteriorly it is often related with the deep process of the 
submaxillary gland. It has no distinct capsule, thus differing from the submaxillary and parotid glands. In structure, it is a racemose mixed gland, but predomiinantly mucous.

Ducts.- The minor sublingual ducts [ductus sublinguales minores], ducts of Rivinus, vary. from five to fifteen or more in number, and open on minute papillæ along the crest of the plica sublingualis (fig. S58). The anterior portion of the gland often forms a larger (Bartholin's) duct [ductus sublingualis major] which opens alongside the submaxillary duct on the caruncula sublingualis (figs. $85 \mathrm{~S}, 866$ ).

Vessels and nerves. - The arteries are derived from the sublingual and submental, with corresponding veins. The lymphatics are tributaries of the superior deep cervical nodes.

Nerves. - The sublingual glands receive their secretory fibres from the submaxillary and associated sympathetic ganglia, conveying impulses from the chorda tympani; sympathetic branches come from the cervical sympathetic and sensory fibres probably from the geniculate ganglion, although this question needs further investigation.

Development of the salivary glands. - The salivary glands appear early as buds from the ectodermal epithelium extending into the adjacent mesenchyme of the mouth cavity. The parotid appears first on the side of the mouth cavity in an embryo of $\mathrm{S} \mathrm{mm}$., as a groove which becomes tubular and pushes back over the masseter to the ear region, developing branches (at first solid). Around the gland and between the branches is mesenchyme which becomes condensed to form the peripheral capsule. The submaxillary gland appears in the $13 \mathrm{~mm}$. embryo as a ridge in the epithelium of the alveolo-lingual groove. The solid cord (lumen appearing later) grows forward to the region of its adult orifice. Its posterior end extends backward and gives off solid branches which later form the acini and duct system of the mature gland. The sublingual glands appear somewhat later $(24 \mathrm{~mm}$. embryo) as a series of separate anlages of variable number, budding off in the positions where the adult ducts empty. The major sublingual gland, if present, appears first. The histogenetic development of the salivary glands is not completed until some time after birth, probably about the time of weaning. However, mucin cells appear in the sublingual glands in the foetus of four months and serous cells in the parotid of five months.

Variations. - The duct of Bartholin is present in about half of the cases, and the corresponding anterior part of the gland may be more or less separate [gl. sublingualis major]. The number of ducts may reach thirty (Tillaux). Rarely processes from the gland may penetrate the mylohyoid, appearing on its lower surface in one or more places (Moustin). Nost of the variations in this and the other salivary glands are due to developmental irregularities.

Comparative.-Oral glands are not found in the lower aquatic vertebrates. Mucous glands occur in all terrestrial vertebrates, but true salivary (digestive) glands appear only in mammals. Although great variations occur in the different species of mammals, those in man (excepting the anterior lingual) are typical for the order. The sublingual gland, however, of ten occurs as two separate glands, corresponding to the sublingualis major and minor. The parotid gland apparently has no representative in forms below mammals. In some mammals (e. g., monkey) it has two main lobes-a larger superficial and a smaller deeper lobe between which lies the facial nerve (Gregoire). Other oral glands (e. g., orbital, zygomatic) appear in some mammals.

\section{THE TEETH}

The teeth [dentes] are highly specialized structures developed in the oral mucosa as organs of mastication and also (in man) of speech. The adult individual with perfect dentition has thirty-two teeth, arranged arch-like in the sockets (alveoli) of the maxilla and the mandible. Sixteen belong to the upper or maxillary arch; and sixteen to the lower or mandibular. The four central teeth in each dental arch are the incisors; the tooth next to these on each side is the canine; behind these are the two premolars (bicuspids); and lastly the three molars. This relation of teeth is expressed by the following dental formula:

$$
\mathrm{i} \frac{2}{2}, \mathrm{c} \frac{1}{1}, \mathrm{pm} \frac{2}{2}, \mathrm{~m} \frac{3}{3}=32 \text {. }
$$

Form.-Each tooth [dens] has a crown [corona dentis], the portion exposed beyond the gum, and covered with enamel (figs. 871, 872). The root [radix dentis] is the portion covered with cementum and embedded in the bony socket. At the line of union of crown and root is the slightly constricted neck [collum dentis]. The surface of the tooth directed toward the lip (or cheek) is termed the labial (or buccal) surface [facies labialis; f. buccalis]; while that toward the tongue is the lingual surface [f. lingualis]. The crowns of the opposite arches meet at the masticating surface [f. masticatoria]. The surfaces in contact with the adjacent teeth of the same arch [facies contactus] are, for the incisors and canines, termed medial and lateral, while those for the premolars and molars are termed anterior and posterior. 
Structure.-As shown in longitudinal section (fig. 873), each tooth has a central cavity [cavum dentis] or pulp cavity, which is filled with $p u l p$ [pulpa dentis]. The pulp is a soft fibrous tissue richly supplied with vessels and sensory nerves which enter the root canal through the apical foramen [foramen apicis dentis]. The body of the tooth, both crown and root, is composed of a dense modified variety of bone called dentine [substantia eburnea]. It is yellowish in colour. The striated appearance of the dentine is due to numerous fine canals, the dentinal

- Fig. 868.--Teteth of an Adult, External View.
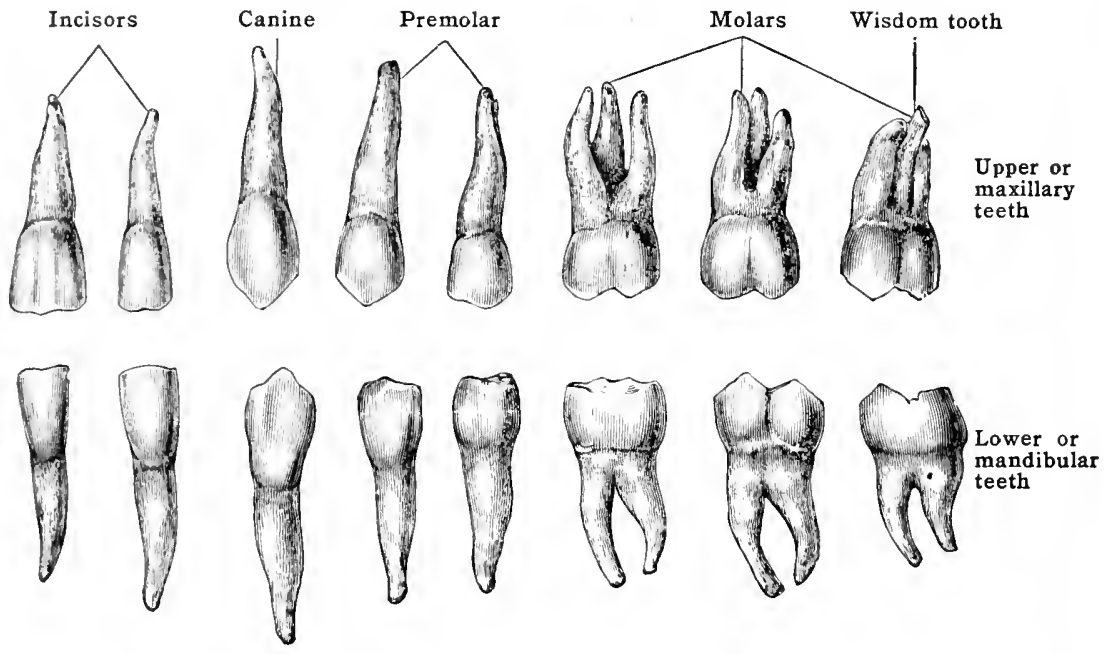

Fig. S69.-Teeth of Adult, Lingual Fig. 870.-Teeth of Adult, Labial and Surfaces. (Broomell and Fischelis.) Buccal Surfaces. (Broomell and Fischelis.)

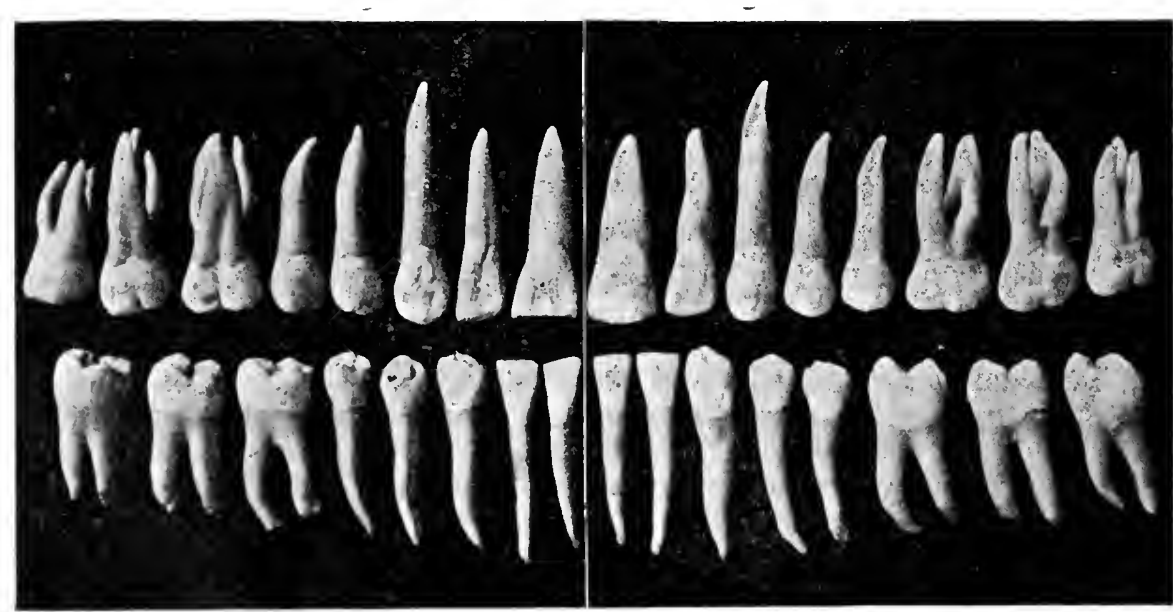

Fig. 871.-Canine Touti, Lingual Surface.

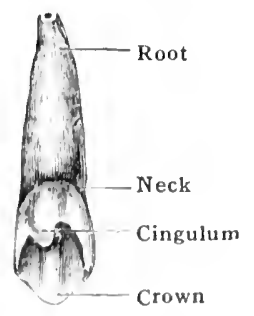

Fig. 872.-A Molar Tooth in Section.

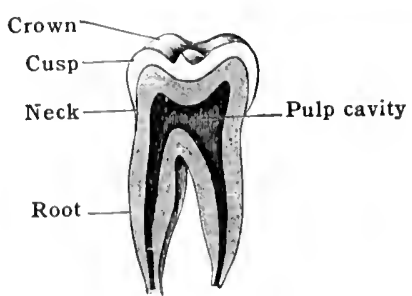

tubules. These entain 'Tomes' fibrils,' which are long protoplasmic branches of the odontoblasts, a layer of cells on the surface of the pulp. At the outer surface of the dentine are numer(ons sinatl, irregular interglobular speeces, corresponeling in the root to 'Tomes' 'granular sheath' (fig. 873). 'The dentine of the "rown is covereal with a latyor of white enamel [substantia atdanantina], which is the latelest substance in the borly. It is composed of numerous minute 
hexagonal prisms [prismata adamantina] which are arranged perpendicular to the surface and are of epithelial origin. In adult teeth, the enamel is of ten worn through in places, exposing the yellowish dentine. The dentine of the root is covered by a thin layer of cementum [substantia ossea], a layer of bone which is very thin at the neck, but becomes thicker toward the root apex (fig. 873). Surrounding the root is the alveolar periosteum, a fibrous membrane connecting the cementum firmly with the bony lining of the socket. For further details of the minute structure of teeth, works on histology may be consulted.

Gums.-Covering the alveolar portions of the maxilla and mandible are the gums [gingivæ]. They are continuous with the mucosa of the vestibule exter-

Fig. 873.-Vertical Section of an Inferior Canine Tooth, in Situ. $\times 4$. (From Toldt's Atlas.)

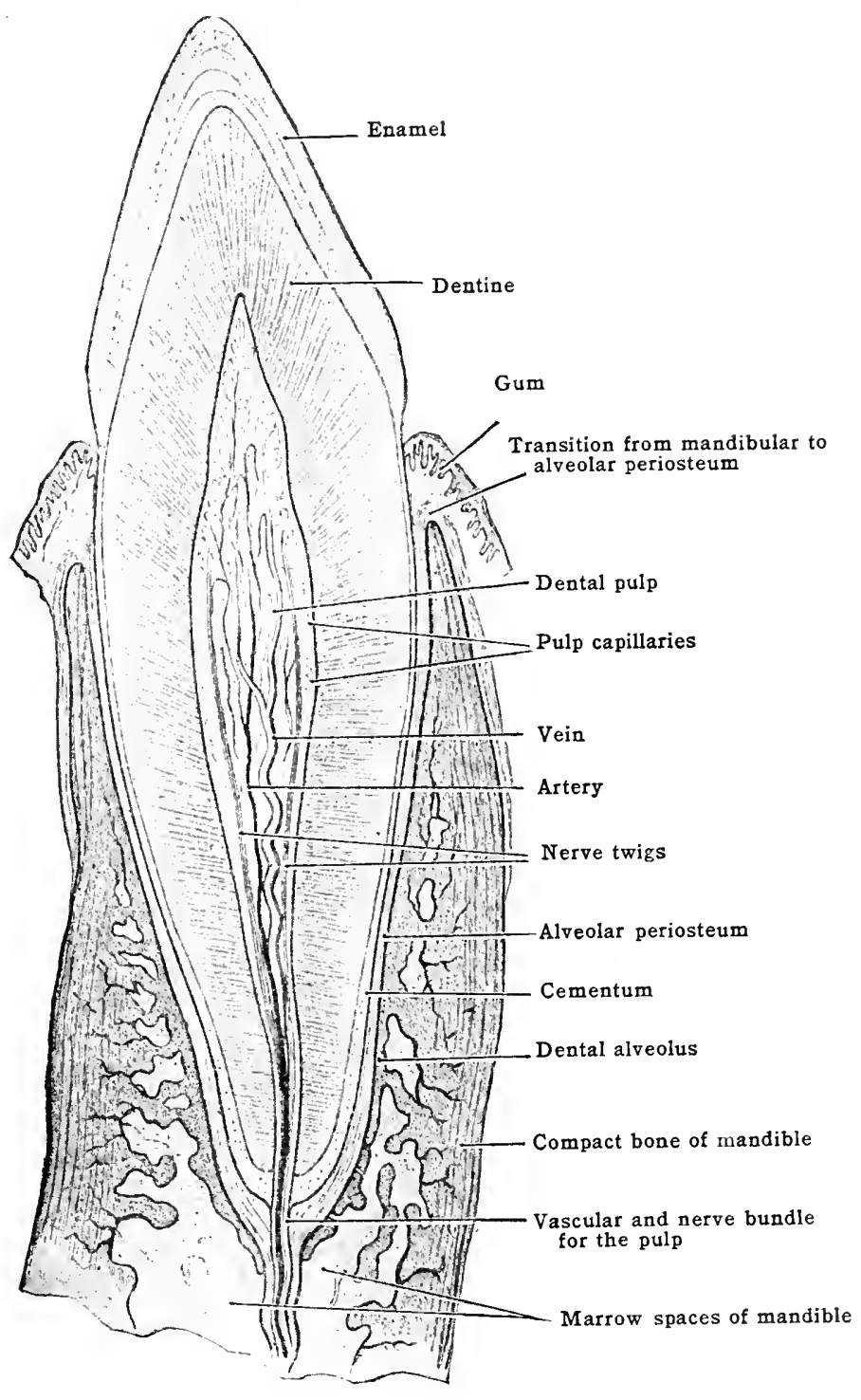

nally and of the palate or floor of the mouth internally. Like the mucosia of the mouth elsewhere, they are covered with stratified squamous epithelium. The lamina propria is especially thick and strong, and is firmly attached to the subjacent bone. Around the neck of each tooth, the epithelium of the gum forms an overlapping collar and the lamina propria is continuous with the alveolar periosteum (fig. 873).

The incisors.-(Figs. 868, 869, 870, 874.) The incisor teeth [dentes incisivi] are so named on account of their function in cutting the food. The crown has a 
characteristic chisel shape. The masticating surface is narrow and chisel-edged. In recently erupted teeth, the cutting edge is elevated into three small cusps, which soon wear down, leaving a straight edge. These cusps correspond to three inclistinct ridges on the labial surfaces. The lateral angle of the crown is usually more rounded than the medial. The labial surfaces are slightly convex, the lin-

Fig. 874.-Cross-Section of the Medial Upper Incisor, in Situ. $\times 4 . \quad$ (From Toldt's Atlas.)

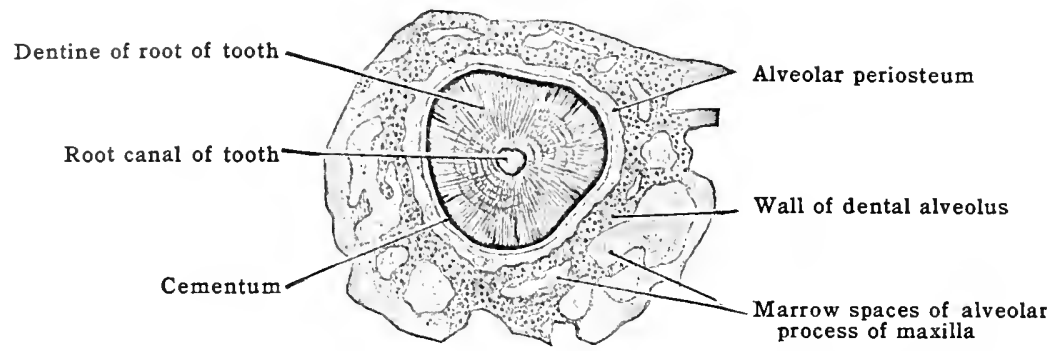

gual slightly concave. The contact surfaces are somewhat triangular. The roots of the incisors are single, though often longitudinally grooved, indicating traces of a division. They are somewhat conical, but flattened from side to side, expecially the lower set, and are slightly curved lateralward.

The upper or maxillary incisors are much larger than the lower. They are lodged in the premaxilla, and are inclined down ward and forward. They overlap the lower incisors in mastieation, hence the masticating surface is worn off and rounded at its posterior edge, while the anterior edge beeomes sharp and ehisel-like. The lingual surfaces of the erowns terminate near the gum in a low, inverted $\mathbf{V}$-shaped ridge, the basal ridge or cingulum. At the apex of

Fig. 875.-Variations in the Form of the Upper Third Molar. (Broomell and Fischelis.)

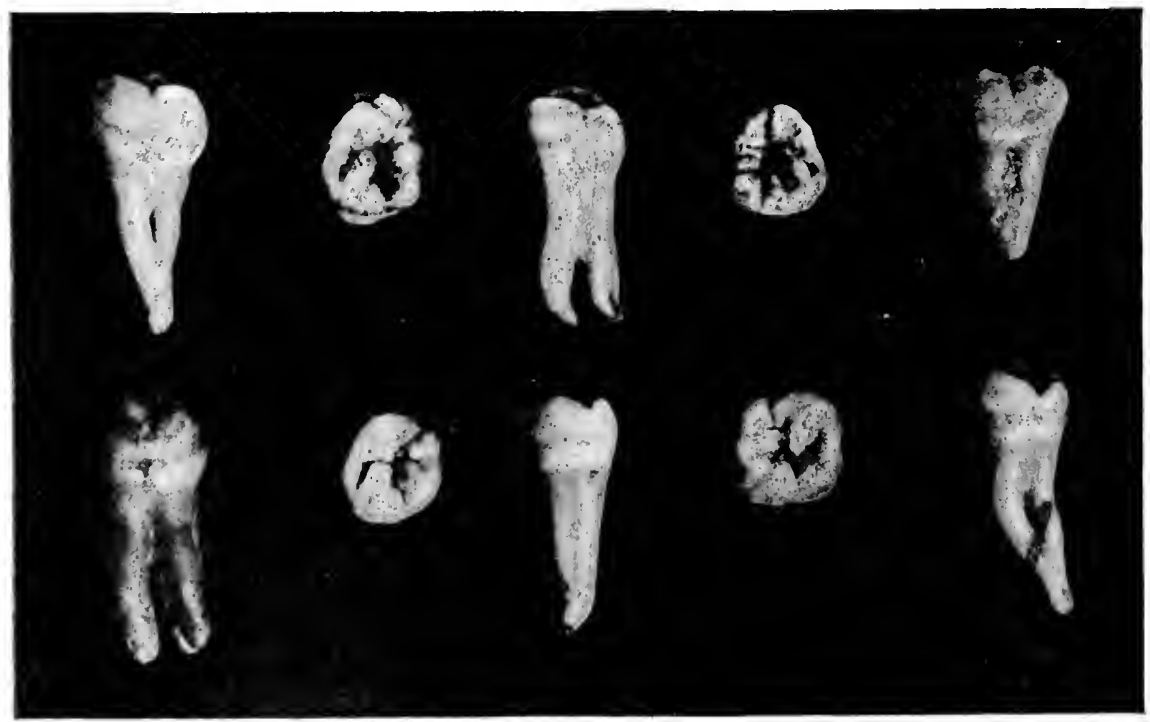

the $\mathrm{V}$, near the gum, there is often (especially on the lateral incisor) a small lingual cusp. The n.edial upper incisor is clistinguished from the lateral by its much larger size.

The lower or mandibular incisors are smaller than the upper, the entting elges leing only about half :L wide. Boing overlapped by the upper set, the lower incisors have the masti(at ing surface worn off anteriorly, leaving a sharp cutting edge posteriorly. The lower incisors are vortically placel, and the erown becomes narrower toward the neck. $A$ cingulum is rarely risible. The medial fower incisor, unlike the upper, is shightly smaller than the lateral.

The canines.-(ligs. 868, 869, 870, 871.) The canine teeth [dentes canini] so-called from their prominence in the dog-tribe, are the longest of all the teeth (fig. s68). 'The crown is thicker and more conjeal than in the incisors. The masticating surface forms a merlian angular point, on either side of which the cutting 
edge slopes to the lateral angle. The medial limb of the cutting edge is usually somewhat shorter than the lateral, rendering the crown asymmetrical. The labial surface is convex, the lingual somewhat concave. The root is single, long, flattened from side to side and grooved on the sides as in the incisors. The canine root is usually slightly curved lateralward. The bony alveolar protuberances [juga alveolaria] are more prominent than those of any other teeth.

The upper canine slants forward and overlaps the lower, as in the incisors. The upper canine also presents a well-marked cingulum, and usually a distinct lingual cusp (fig. S71) below which a slight median ridge extends along the lingual surface. On the lower canine, these structures are poorly marked or absent. The lower canine is somewhat smaller than the upper, and its root is occasionally bifid.

The premolars.-(Figs. 868, 869, 870, 876, 877.) The premolars [dentes premolares] are so named on account of their position in front of the molars. The

Fig. 876.-Dissection Showing the Roots of the Teeth. Teeth in Occlusion. $\times 1$ (From Toldt's Atlas.)

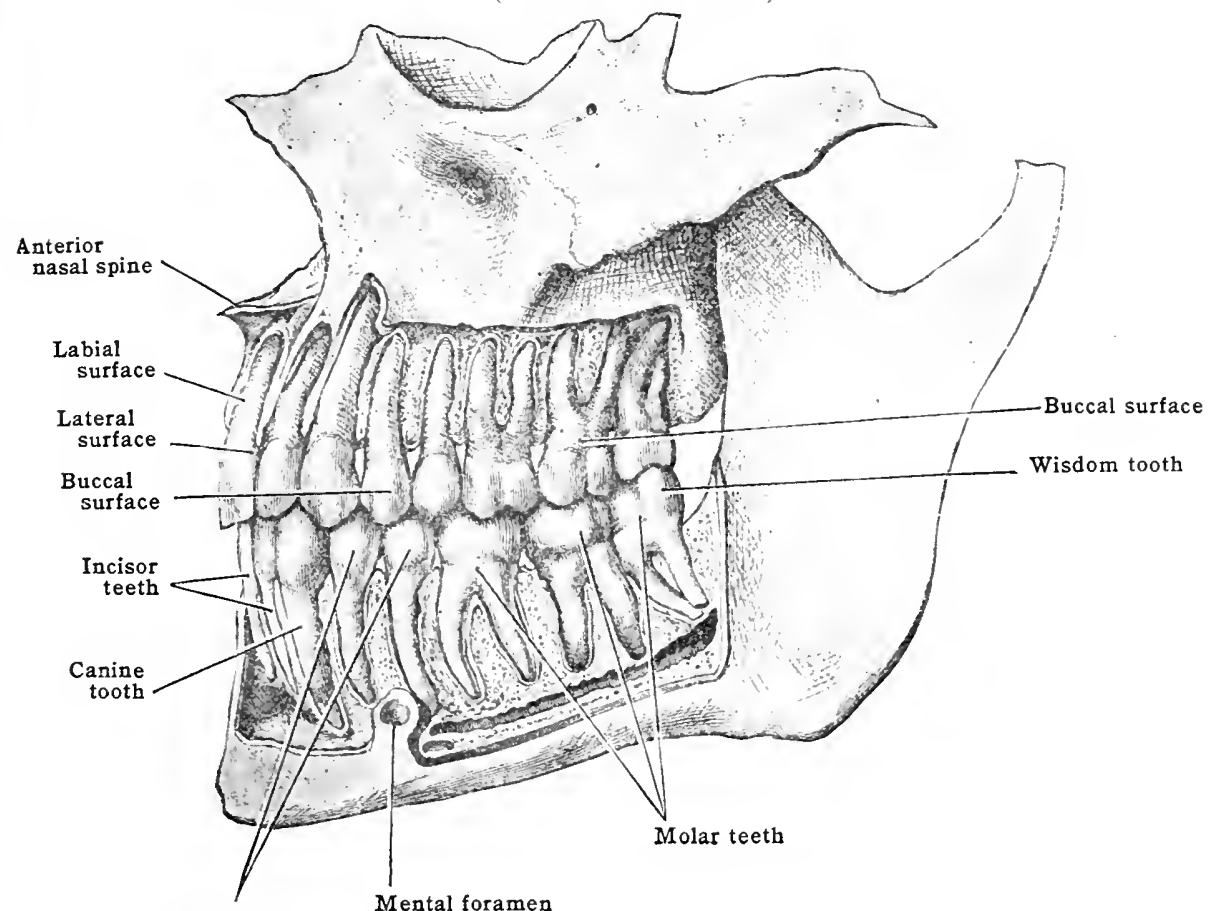

Premolar teeth

crown presents on the masticating surface two prominent cusps, on account of which the premolars are often called 'bicuspids.' The buccal and lingual surfaces are convex especially from side to side, so that the crown is somewhat cylindrical in form, with flattened, quadrilateral anterior and posterior contact surfaces. The root is (usually) single and more or less flattened antero-posteriorly, and usually somewhat curved backward.

The upper premolars are distinguished from the lower by a greater antero-posterior flattening of the crown and by a deep groove separating the cusps (excepting at their anterior and posterior margins) on the masticating surface. In the first upper premolar the lingual cusp and surface are decidedly smaller than the buccal; and the root is frequently bifid or double (occasionally even triple). In the second upper premolar the lingual cusp and surface are as large as the buccal; and the root, though deeply grooved, is rarely bificl.

In the lower premolars, the crowns are more cylindrical in form, and the cusps are united by a median ridge so that the masticating surface presents two small pits. The roots are more rounded and tapering, and rarely grooved. In the first lower premolar (like the corresponding upper) the lingual cusp and surface are much smaller than the buccal, the lingual eusp sometimes being rudimentary; while in the second they are more nearly equal. The second lower premolar is often slightly larger than the first, while in the upper premolars the converse is true. It should be noted, however, that the premolars are quite variable in all respects, and it is therefore often difficult to identify the individual isolated teeth.

The molars.-(Figs. 868, 869, 870, 872, 875, 876.) The molars [dentes molares] or 'grinders' are characterized by their large size, and by the presence of 
three to five masticating cusps (hence sometimes called 'multicuspids'). The crowns are massive, somewhat resembling rounded cubes, and the lingual and buccal surfaces present rertical grooves continuous with the fissures separating the cusps. The pulp cavity (fig. 872) has slight extensions corresponding to the cusps, and also communicates with the canals of the roots, which are usually two or three in number, and more or less curved.

Fig. 877.-Diagram Showing the Articulation of the Teeth. (Poirier-Charpy.)

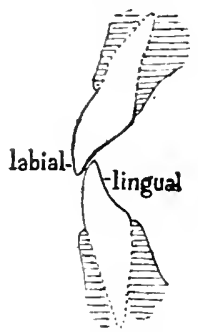

A

Incisors

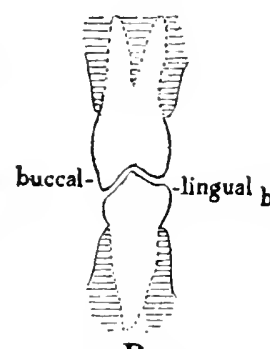

B

Premolarn

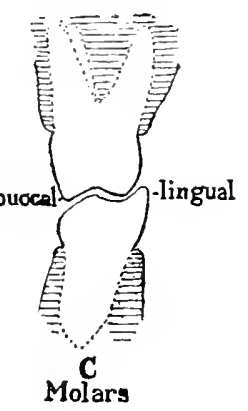

The upper molars are most easily distinguished from the lower by the presence of a triple root. The masticating surface is nearly square with rounded angles. They each have typically four cusps, separated by grooves resembling a diagonally placed H (fig. 852). The crowns of the upper molars are obliquely placed so as to slant downward and slightly lateralward.

Each upper molar has three roots, two buccal and one lingual or palatal. They are all (especially the buccal) in more or less close relation with the floor of the maxillary antrum (of Highmore) (fig. 876). The buccal roots are flattened antero-posteriorly, and longitudinally grooved, and bent backward. The palatal root is more rounded, with a groove on the lingual surface, and usually bent medialward. Either of the buccal roots may fuse with the palatal, or there may be an extra fourth root.

As to the individual upper molars, the first has almost invariably four typical cusps (rarely only three, or with an additional fifth rudimentary). The second upper molar has only three cusps in about half of the cases (in Europeans), and four in the remainder. The third, or wisdom tooth [dens serotinus] is exceedingly variable in size and form (fig. 875). It has three cusps much more frequently than four, and its three roots are often more or less fused into a conical mass. It is usually much smaller than the other molars, and is absent in nearly one-fifth of all eases.

Fig. 878.-Diagrams Showing the Early Development of Three Teeth, One of which is Shown in Vertical Section. (Lewis and Stöhr.)

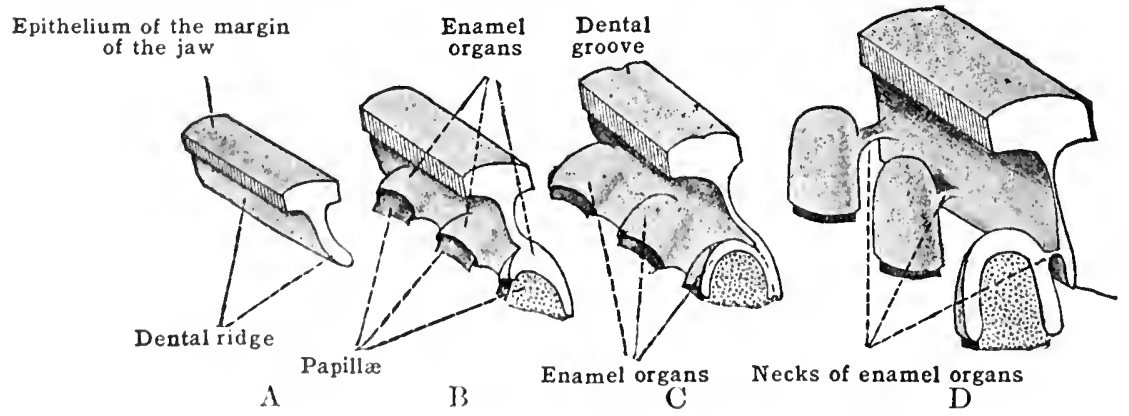

The lower molars have usially four or fove cusps (two lingual, and two or three buccal) the fissures separating them being eross-shaperl or stellate (fig. St5). 'The crowns incline upward and slightly medialward. 'Thry have each two roots, anterior and posterior, flattened antro-postcriorly, and ustally soncwhit curved hackwad. The roots, especially the anterior, may be longitulinally growven. 'The anterior has two rost-canals, the posterior usually only one. The apices of the roots of the lower molars, especially of the third, approach the mandibular (inforior dental) ranal (fig. 876 ).

()f the indindual lower moliry, the first is msully slightly the largest, and has five eusps in the great majority of rases (variously estimated at from 60 to 95 per cent.), otherwise four, The four man ('uspes (two buesal and two lingual) are separated by a crueiform fissure, which hifurcates postcriorly to cmbrace the small fifth cusp (which is placed slightly to the buccal 
side) when present. The second lower molar has usually four cusps (75 to 85 per cent. of cases), otherwise five, the fifth usually small or rudimentary. The roots are sometimes confluent. The lower third or wisdom tooth, like the upper, is usually small and exceedingly variable (fig. 875). It has usually four or five cusps; but the number may be increased to six or seven,

Fig. 879.-Model of Ectoderu of Jaw of Human EMbryo 40 mir. Long, Showtng Dental Ridge with Examel Organs for the First Teeth. (Kingsley, after Röse.).

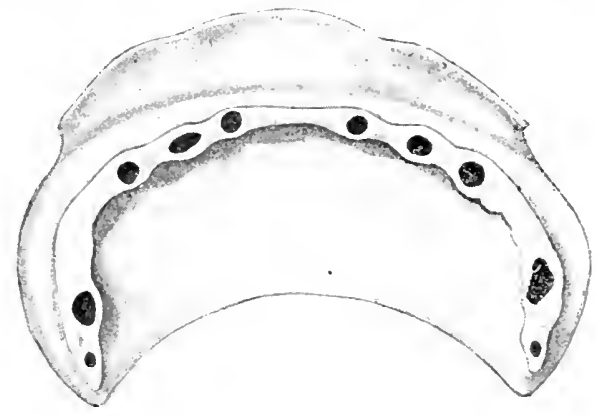

or reduced to three, two, or one. The roots are often short and fused into a conical mass in which sometimes only a single canal is present.

The dental arches.-On comparing the upper and the lower dental arches, it is seen that the upper (fig. 852) forms an elliptical curve, while the lower (fig. 864) resembles a parabola.

Fig. 880.-Section Showmg Later stages of Tooth Developaent. (Szymonowicz.)

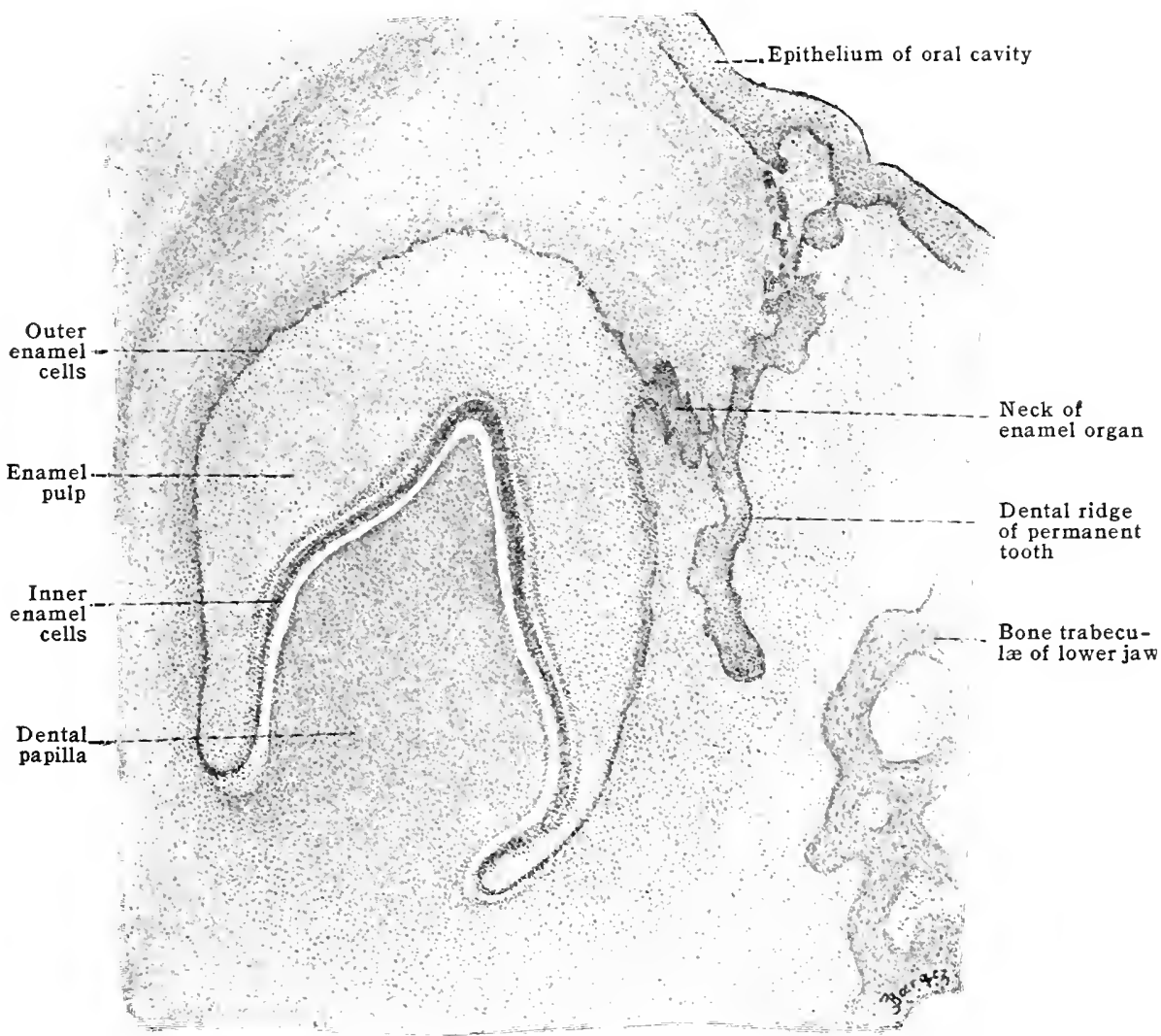

The upper arch is slightly larger (due chiefly to the slant of the teeth, as previously explained) so that it slightly overlaps the lower when the teeth are in occlusion. Thus, as shown in fig. 876, the upper incisors (and canines) overlap the lower. The buccal cusps of the lower premolars and molars fit into the groove between the upper buccal and hingual cusps; while the upper lingual cusps correspond to the groove between lower buceal and lingual cusps. This arrangement favors a more perfect mastication (see fig. 877 ).

Moreover, when viewed from the side (fig. 876), it is seen that in general, the corresponding teeth of the upper and the lower arches are not opposite, but alternate with each other. This is 
due chiefly to the great width of the upper central incisol. The lower molars, however, especially the third, are wider (antero-posteriorly) than the upper, so that the two arehes are nearly equal in length. The interdental line between the two arches is not straight, but slightly convex downward (fig. S76). In both arches, the crowns of the incisors and canines are taller than those of the premolars and molars.

Vessels and nerves.- The vessels and nerves of the teeth are distributed partly to the pulp and partly to the surrounding alveolar periosteum. The arteries are all derived from the internal maxillary. Those for the upper teeth are the posterior superior alveolar and the anterior superior alveolar (from the infraorbital). Similar branches to the lower jaw are given off by the inferior alveolar. They give off twigs to the gums (rami gingivales), the alveolar

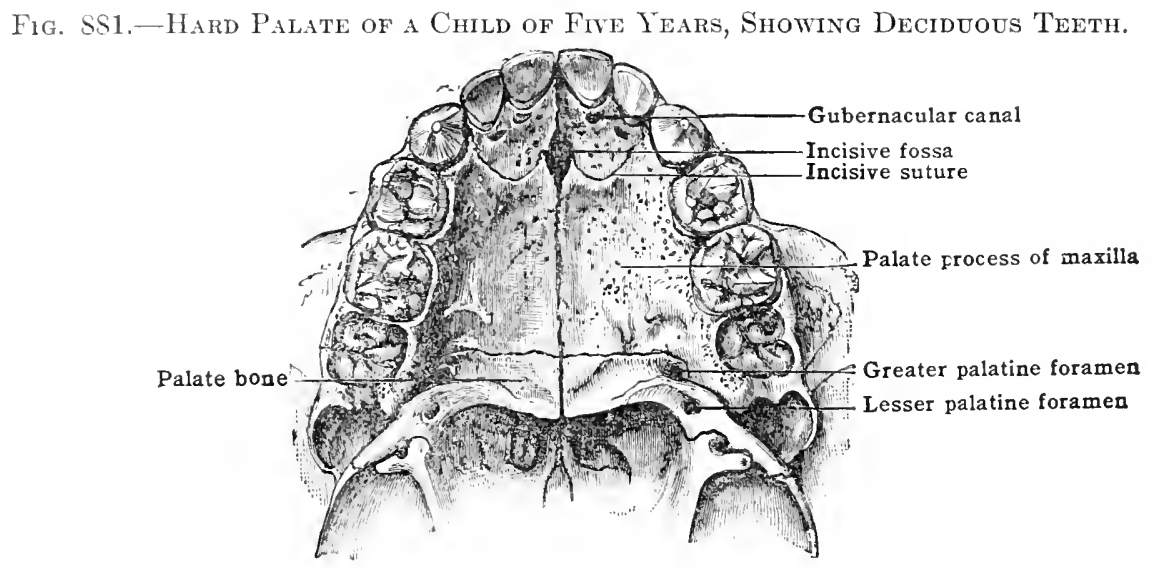

periosteum (rr. alveolares), and the pulp cavities (rr. dentales). A dental branch enters each root canal through the apical foramen, ancl breaks up into a rich peripheral capillary plexus under the odon toblast layer. From th is plexus, the corresponding veins arise. There is a plexus of peridental lymphatics, which anastomose with those of the surrounding gums, and drain chiefly into the submaxillary nodes. Lymphaties have also recently been demonstrated in the pulp of the tooth (Schweitzer).

The nerves are sensory branches derived from the trigeminus. Those for the upper teeth are from the anterior, middle, and posterior superior alveolar (fig. 735); while those for the lower teeth are from the inferior alveolar (fig. 736). These nerves give numerous branches to
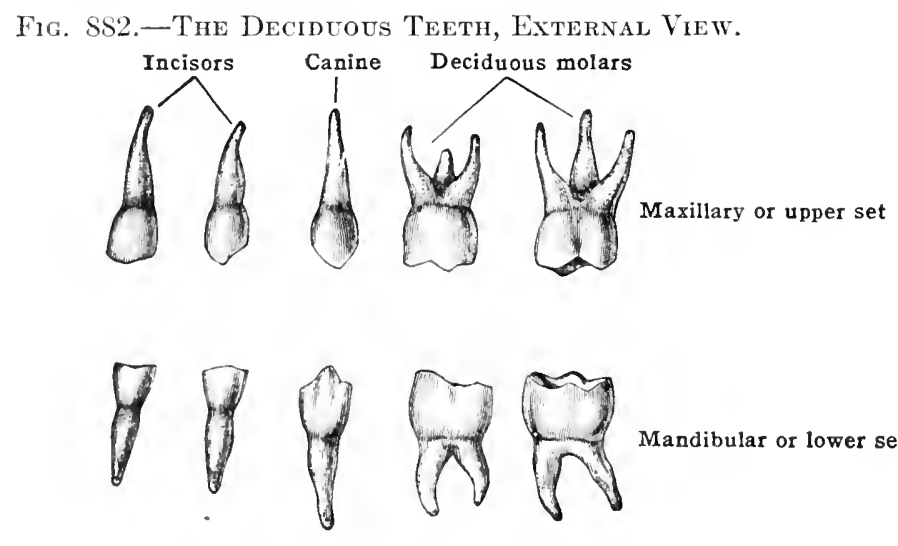

Mandibular or lower set

the gums, alvoolar poriosteum, and pulp cavities. The lattor conter with the rolresponding vacts, and their distribution within the tooth is a subject of controversy. They may be followed ansily to a plexus under the ondontoblasts; but whether they end freely, or in connection

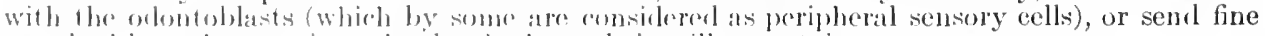

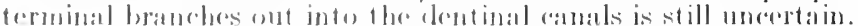

Development of the teeth. -Thr terth represent ealeifirl papillar of the oral mucosa, the

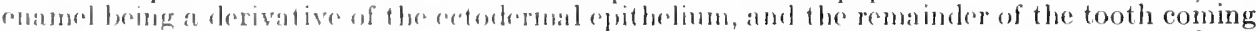
from the menlerlying mesenchyme. The first trace of the torth apuears in the human embryo of about It mus, in the form of an "pithelial shelf, the denlul ridge, extending into the mesenchyme corresponding to the future alvoular portions of the jaws (figs. 878, 879). From the

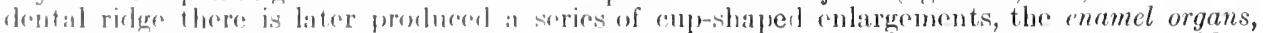

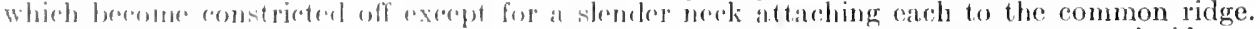
I3y the encl of the thirl fortal month, the twenty antmel orgats of the temporary or deciduous

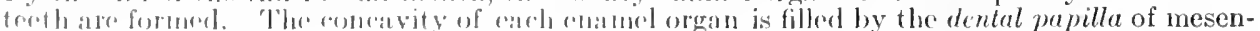
rliture. 
A somewhat later stage in the organogenesis of a tooth is shown in fig. 880 . The mesenchymal cells on the surface of the dental papilla, next to the enamel organ, form a single layer of columnar cells, the odontoblasts. These cells form the dentine upon their outer surfaces, gradually retreating toward the center of the tooth as the dentine increases in thickness. The first dentine formed is irregular, enclosing the spatia interglobularia. The odontoblasts remain through life just beneath the dentine on the surface of the pulp, sending stender processes: up into the dentinal tubules as previously noted in the structure of the adult tooth. The remainder of the dental papilla becomes the pulp, receiving its vascular and nerve supply at the point opposite the enamel organ, corresponding to the future root.

The enamel organ (fig. SSO) is differentiated into three layers: a thin outer layer attached by the neck to the dental ridge; a thick middle layer (forming the spongy "enamel pulp"); and a single inner layer of cylindrical enamel cells, the adamantoblusts. The latter form the enamel prisms, which are deposited gradually upon the outer surface of the dentine.

Fig. 883.-Dissection Showing the Teeth at about Six Years. (Broomell and Fischelis.)

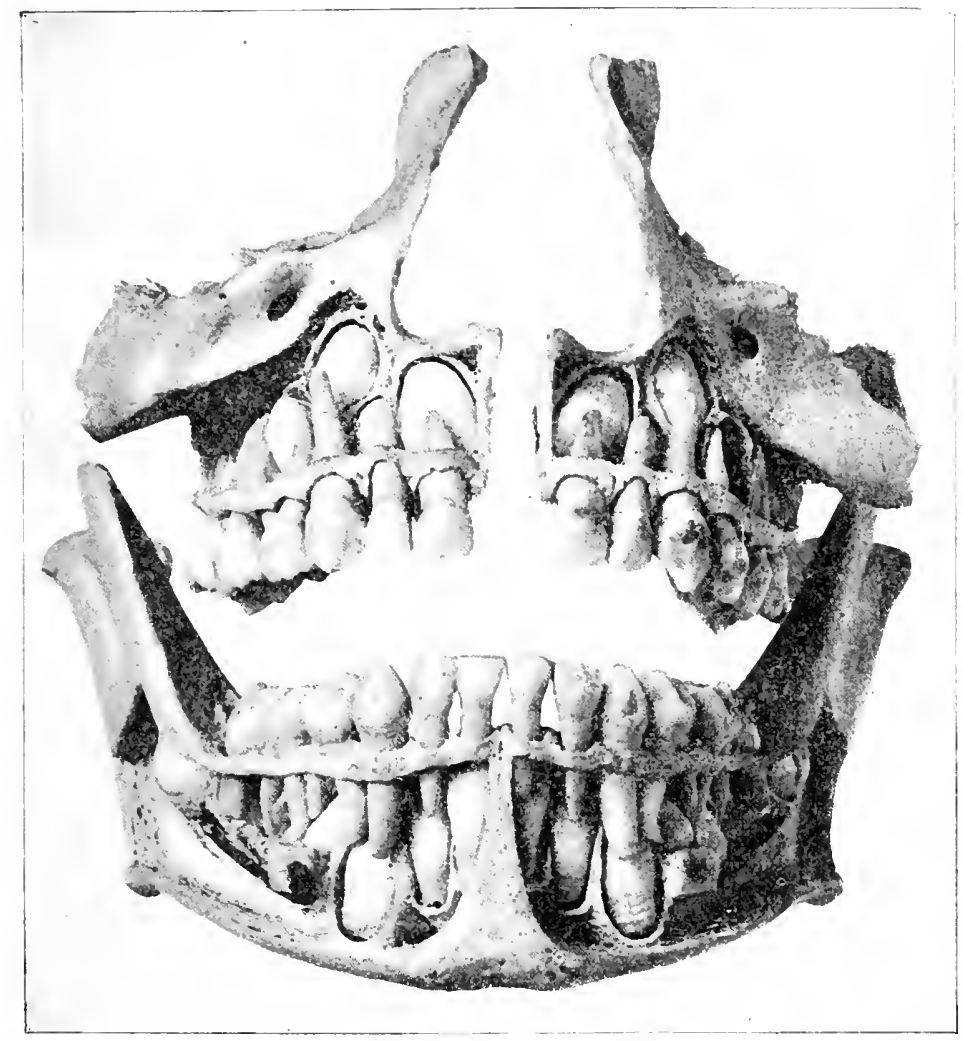

Surrounding the entire developing tooth there is formed a strong, fibrous connectivetissue membrane, the tooth-sac. The deeper part of this sac later becomes the alveolar periosteum around which the bony alveoli are formed. This bone may entirely surround the tooth-sac, excepting at the summit, where a foramen persists through which a process of connective tissue (gubernaculum dentis) connects the tooth-sac with the overlying gum (see figs. 114, SS1). Upon the inner surface of the tooth-sac, next to the root, the bony eementum is deposited upon the dentine. The root gradually elongates, and is usually not completed until long after the eruption. The remaining superficial portion of the tooth-sac undergoes pressure atrophy and absorption. The remnants of the enamel organ, however, persist and form a thin tough cuticle [cuticula dentis], Nasmyth's membrane, which is soon worn off when the crown is exposed at the surface.

From the remainder of the dental ridge, which lies on the lingual side of the deciduous teeth (fig. S7S), the permanent teeth are later derived in a very similar manner. (Rudimentary indications of a prelacteal dental ridge have also been described.) The anlages of the permanent teeth therefore lie to the lingual side of the deciduous (fig. 8S3). From the posterior end of the dental ridge a process extends into the jaw behind the deciduous teeth, and from this process the permanent molars (which have no deciduous predecessors) are formed. At birth, although no teeth have yet been cut, there are present in the gums the anlages of not only all of the deciduous teeth, but also all of the permanent teeth, with two exceptions. Those of the second molars do not appear until six weeks after birth, and of the third molars not until the fifth year. The remnants of the dental ridges become broken up into small masses of epithelial cells, which persist for a variable time. 
The deciduous teeth.-The deciduous [dentes decidui], temporary or milk teeth are twenty in number, corresponding to the following formula:

$$
\text { di } \frac{2}{2}, \mathrm{dc} \frac{1}{1}, \mathrm{dm} \frac{2}{2}=20 \text {. }
$$

The deciduous teeth (figs. 882, 883) are much smaller in size than the permanent teeth, and their necks are more constricted. The enamel of the crown cap is thicker. In general, their form and structure otherwise is very similar to that

Fig. 884.-Pulp-cavity of the Upper First Molar, From the Fifith to the Ninth Year (Broomell and Fischelis.)

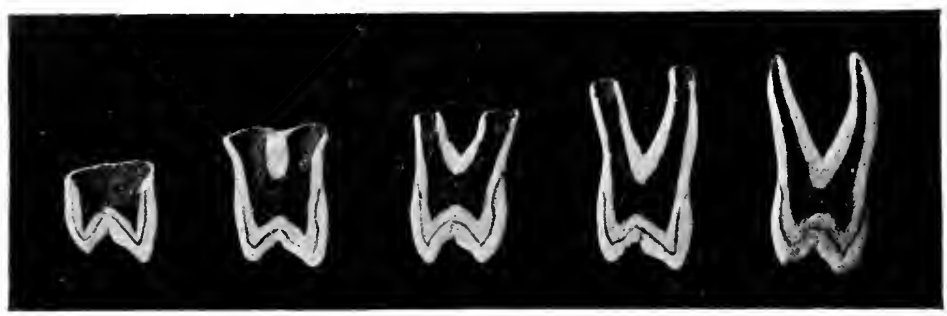

already described in the case of the permanent incisors and canines. The molars, however, are different. Their cusps on the masticating surface are very sharp and irregular. There are usually three cusps on the first upper molar and four on the second; four cusps on the first lower molar and five on the second. The roots

Fig. 885.-Showing the Extent of Calcification of Deciduous Teeth. (Peirce.)

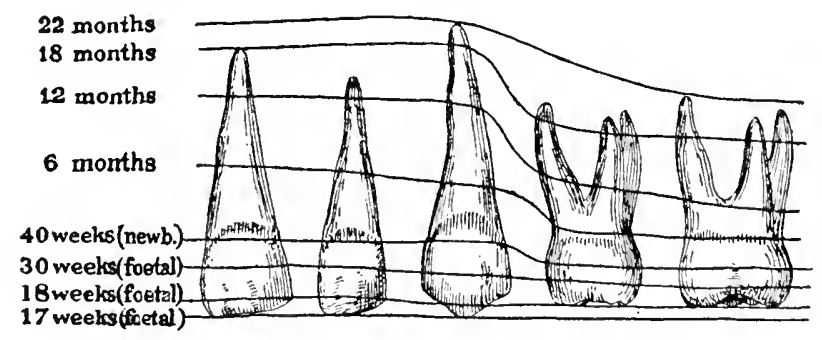

correspond to those of the permanent molars (three above and two below), but they are much more divergent, to allow room for the development of the corresponding subjacent permanent premolar teeth. The first molar is always considerably smaller than the second.

Fig." 886.-Showing the Extent of Calcification of the Permanent Teeth. (Peirce.)

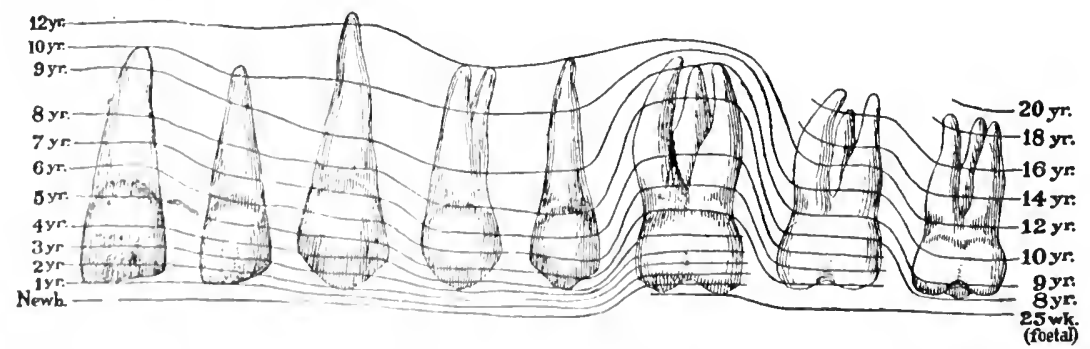

Calcification in the dentine and enanel of the teeth does not begin until the anlages of the crowns are well formed. The process of calcification follows that of the development of the tooth in general, beginning in the superfieial portion of the erown and gradually spreading toward the root. Calcification in the deciluous teeth begins during the fifth fretal month, and at birth the crowns are nearly completed (fig. 885). Of the permanent set of teeth, only the first molar has begun to calcify at birth (fir. 886). Calcification of the other permanent teeth begins during the second year; excepting the second molis, which begins during the fifth, and the third molar, which begins abont the eighth year. 'There are, however, great variations 
in the time at which the calcification of the various teeth begins. As a rule, the calcification of the roots is not completed at the apices until some time after the crowns are exposed in eruption.

Eruption of the teeth.-On account of pressure due to growth and expansion at the root of the tooth (and probably other obscure factors), the crowns are pushed toward the surface. The overlying portion of the tooth-sac, together with corresponding portions of the temporary alveolar bone, are absorbed, and the crown is "cut," i. e., breaks through the surface of the gum in eruption. In the case of the permanent teeth, this is normally preceded by a shedding of the deciduous teeth. The latter have been loosened by the absorption of their roots, which is perhaps due largely to the activity of certain odontoclasts (like the osteoclasts of bone) which are found in the region of absorption.

Time and order of eruption.-The time of the eruption of the various teeth is subject to great variation, so that no two investigators agree upon it. Aside from the wisdom teeth, the time of eruption is most variable in the canines and premolars, and least variable in the first permanent molars (Röse). The eruption averages four and one-half months earlier in the male, and is also earlier in well-to-do and city children (Röse). The order in which the teeth appear is less variable. The average time at which the various deciduous and permanent teeth appear is indicated approximately in the following table.

\section{A. Deciduous Teeth}

\section{Months AFTER Birth}

(Average)

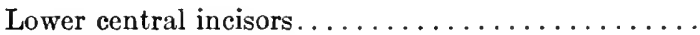

Upper central incisors. . . . . . . . . . . . . . . . .

$7(6-8)$

Upper lateral incisors. . . . . . . . . . . . .

Lower lateral incisors. . . . . . . . . . . . . . . .

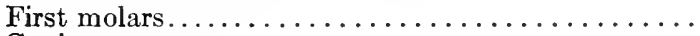

$9-10$
$12-14$

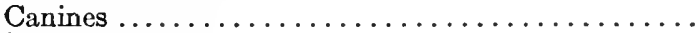

14

Second molars $\ldots \ldots \ldots \ldots \ldots \ldots \ldots \ldots \ldots \ldots \ldots$

18

$22-24$

\section{B. Permanent Teeth}

The average time at which the teeth in the lower jaw undergo eruption is shown in the table below. The corresponding teeth in the upper jaw appear a little later:-

$$
\text { YEARS }
$$

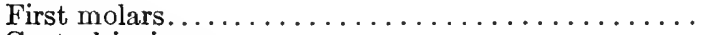

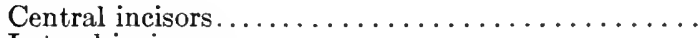

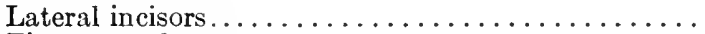

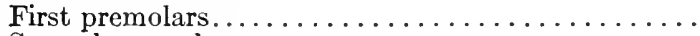

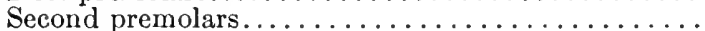

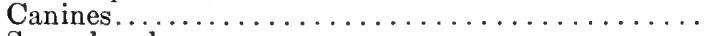

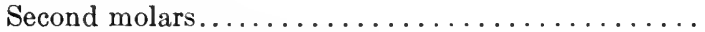

Third molars (wisdom teeth) .............

$6-7$
7
8
$9-10$
$9-10$
11
12
$17-25$

Variations.-The great variability of the teeth has already been emphasized, and numerous variations described in connection with the various individual teeth and their development. In number, the teeth may be reduced, due to absence (oftenest of the third molar) or incomplete development with failure of eruption. An increase in the normal number is less common ${ }^{1}$ It may be only apparent, due to the retention of a deciduous tooth. There may rarely, however, be a true extra third incisor or premolar, or a fourth molar. Aberrant teeth may occur either on the labial or palatal side of the dental arch. A third dentition appears rarely in old age. In form, there is much greater variation as before mentioned. All intermediate forms between rudimentary and fully developed teeth may occur. Fusion between neighbouring teeth is sometimes found, and deformities in the dental arches necessarily accompany palatal defects involving the alveolar arches.

Comparative.-As the oral mucosa represents an invagination of the integument, so the teeth are morphologically equivalent to dermal papillæ. The close relationship between the teeth and the dermal appendages is clearly shown among many of the lower vertebrates, but most clearly in the Selachians (which include sharks and allied forms). In fig. 887 , which illustrates a sagittal section through the lower jaw of a young dogfish, it is clearly evident that the external placoid scales or 'dermal teeth' are continuous with the equivalent oral teeth at the oral margin of the jaw. Both the dermal teeth and the oral teeth are composed of dentine which presents an enlarged base and a somewhat conical apex. The base is embedded in the fibrous lamina propria (often in bony plates) while the apex projects through the epithelium and is covered with a thin cuticular layer the "enamel membrane." True enamel is usually rudimentary or absent in the primitive teeth of lower vertebrates, and represents a secondary acquisition. The dentine is in all cases derived from the connective tissue, and the enamel from the epithelium.

The process of development of the primitive oral teeth is also illustrated in fig. 887 . Just within the oral margin there is a shelf-like downgrowth of the ectodermal epithelium, forming a primitive germinal ridge. Along this ridge may be seen the anlages of several rows of teeth in various stages of development. As fast as the mature teeth at the oral margin are worn off, new teeth pass up from below to replace them. Thus the primitive form of dentition is polyphyodont, with many sets of teeth developed successively throughout life. As we pass up the vertebrate scale there is a tendency to a reduction in the number of sets, although there is a 
wide variation among the various forms. In most mammals, as in man, the number of sets of teeth has been reduced to two, or diphyodont dentition, with only traces of an earlier (prelacteal) and also a later (post-permanent) set. In some mammals (monotremes, cetacea) the dentition has been redueed to a single set, monophyodont, while in birds all except rudimentary traces of dentition have been lost.

is may be further observed in fig. $\$ 87$, the primitive teeth are of a recurved conical form, and serve primarily for grasping and holding the food. The specialization of the teeth for purposes of mastication is in general a secondary acquisition anongst higher vertebrates.

It is also noteworthy that the primitive teeth, as found among nearly all forms below the mamnals, are practically alike in form, i. e., homodont. Among mammals, however, there is a marked specialization of the teeth, or heterodont dentition. The mammalian teeth are usually differentiated into four distinet classes, incisor's, canines, premolars and molars, similar to those found in man.

The typical or complete mammalian dentition, however, contains a larger number of teeth than found in man, and is represented by the formula

$$
\mathrm{i} \frac{3}{3}, \mathrm{c} \frac{1}{1}, \mathrm{pm} \frac{4}{4}, \mathrm{~m}_{3}^{3}=44 \text {. }
$$

Thus it is evident that there has been a reduction in the incisors and premolars in the human species, and there has been considerable discussion of the question as to which teeth of the

Fig. SSt.-Section throdgh Lower Jaw of Dog-fish, Showing the Development of the Oral Teeth, and the Transition to Derhal Teeth. M, mandible. (After Gegenbaur.)

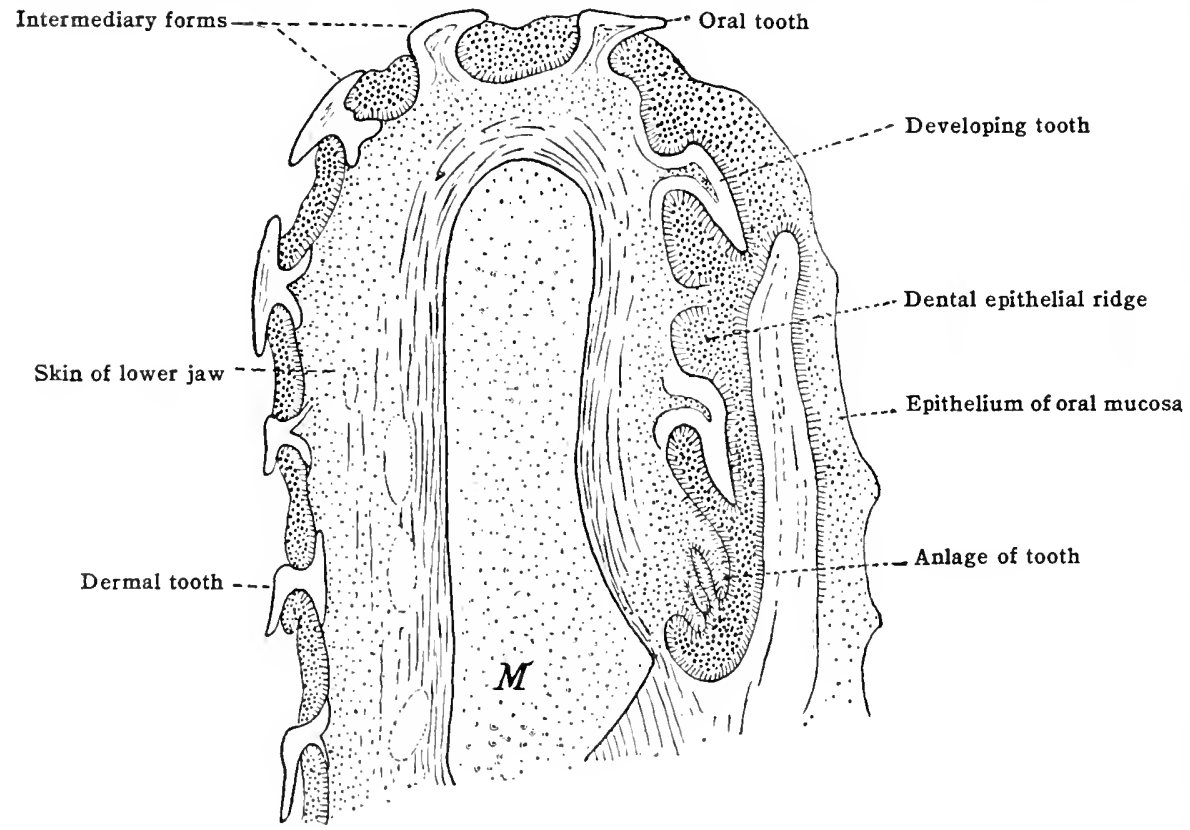

primitive series have been lost. This reduction in the number of teeth is probably correlated with the general reduetion in the jaws, which are relatively mueh larger and stronger in the savage races and lower animals. 'The third molar, or wisdom tooth, is probably now on the road to extinction, due to a continuation of the same evolutionary process.

Another interesting froblem, eonecrning which there has been much speculation, is the origin of the multicuspiclate mammalian molar. It has clearly been derived from the primitive conical type of the homolont dentition, but as to the method of evolution there is a differenee of opinion. Acerrling to one view (the 'concrescence' theory), the molat has been derived by a proesss of fusion, cach cusp representing a primitive eonical tooth. Another view (the 'difformtiation' theory) is that the noblar represents a single primitive tooth, upon the erown of whioh the varions insps have been differentiated. Aceording to a third view, whieh is a compromise, the trituberentar (trimspid) form of tooth, which is that found in the earliest fossil mammals, was deriverl hy a process of concresenee of three primitive teeth, while from this triaspirl form the multionspilate molar has been derived hy a process of differentiation.

\section{TIIE PIIARINA}

The pharynx is a vertical, tubular passage, flattened antero-posteriorly, and extonling from the base of the aranium above to the begiming of the cesophagus

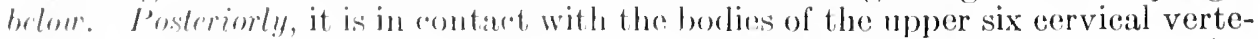
brar. Laterally, it is in relation with the intermal and common carotid arteries, 
the internal jugular rein, the sympathetic and the last four cranial nerves. Anteriorly, it communicates above with the nasal cavity, beneath this with the oral cavity, and below with the laryngeal cavity. The pharyn is correspondingly divided into three parts: the nasal pharynx [pars nasalis], which is exclusively respiratory in function; the oral pharynx [pars oralis], which is both respiratory and alimentary; and the laryngeal pharynx [pars laryngea], which is almost entirely alimentary.

Size and form.- The average length of the pharynx is about $12 \mathrm{~cm} .(5$ inches). It is widest at the nasal pharynx, with a constriction (isthmus) connect-

Fig. 888.-The Interior of the Pharyxx, Viewed from Behind. (Sobotta-MeMurrich.)

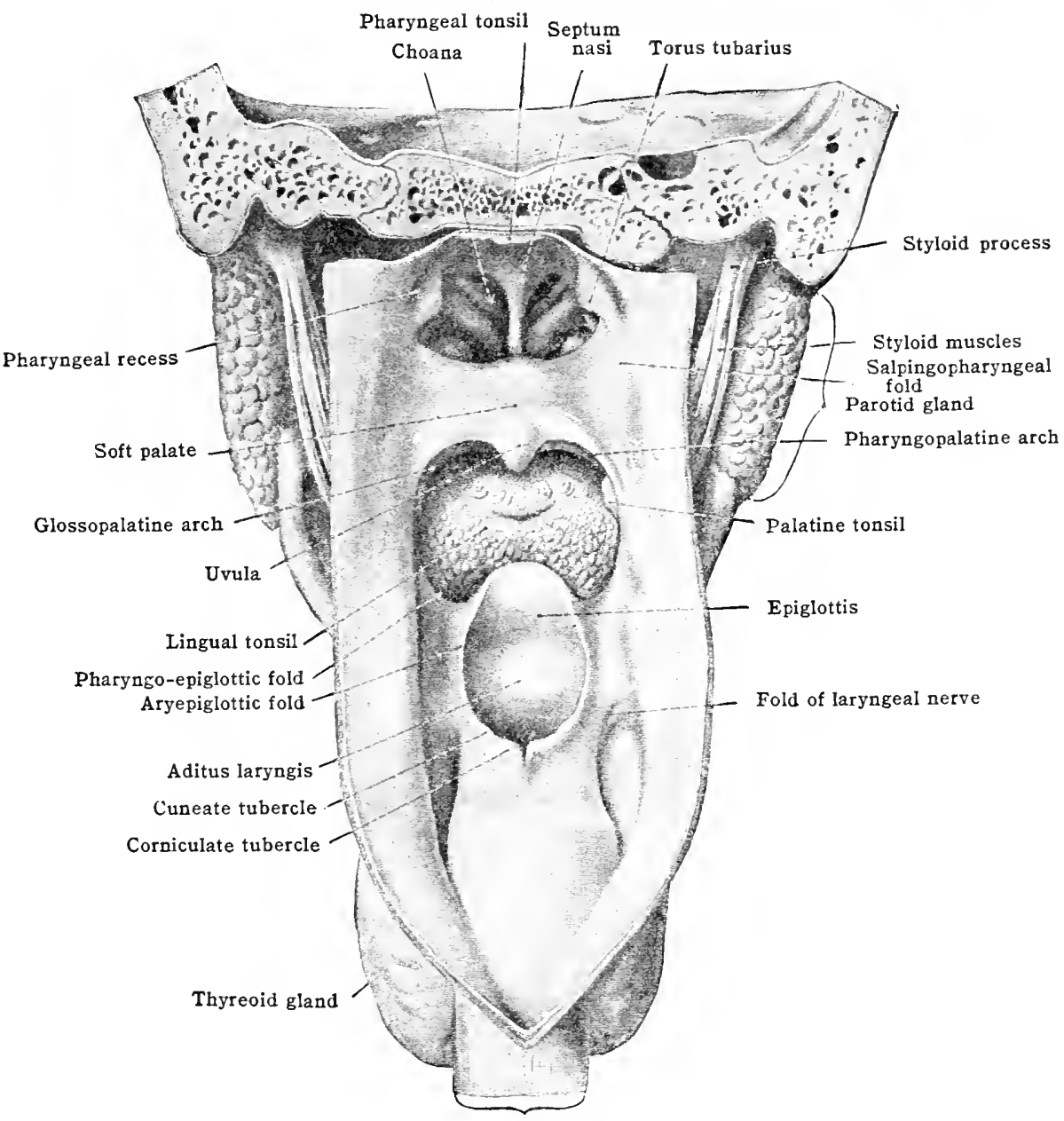

Esophagus

ing it with the widened oral pharynx, and is again somewhat narrowed at the junction of oral and laryngeal pharynx (fig. 888). It is narrowest at the point where it joins the œsophagus below. In sagittal section (fig. 848 ), it is evident that the anterior and posterior walls are closely approximated in the laryngeal pharynx, and have only a small space between them in the oral pharyn. The nasal pharynx, however, has a considerable antero-posterior depth, and by its bony walls is always kept open for respiratory purposes.

Structure.-The pharynx approaches the typical structure of the alimentary canal, yet differs from it in several important respects. The lining mucosa is continuous with that of the various cavities which open into the pharynx. Above, it is closely adherent to the base of the cranium, where it is thick and dark in colour. It becomes thinner where it approaches the openings of the auditory tubes and choanz; and below it is paler and thrown into longitudinal folds. The epithelium of the greater part of the nasal pharyx (from the orifice of the auditory tube upward) is stratified ciliated columnar, while that of the remainder of the pharymx is stratified squamous. 
External to the mucosa, there is a characteristic fibrous membrane, the pharyngeal aponeurosis [fascia pharyngobasilaris], which is well marked above, but below it loses its density and gradually disappears as a definite structure. Above, it is attached to the basilar portion of the occipital bone in front of the pharyngeal tubercle. Its attachment may be traced to the apex of the petrous portion of the temporal bone, and thence to the auditory (Eustachian) tube and medial lamina of the pterygoid process. It descends along the pterygo-mandibular ligament to the posterior end of the mylohyoid ridge of the lower jaw, and passes thence along the side of the tongue to the stylohyoid ligament, the hyoid bone, and thyreoid cartilage.

External to the pharyngeal aponeurosis is a thick muscular layer, made up of various crossstriated muscles, as will be described later. Outside of the muscular layer is a thin fibrous tunica adventitia, connected with the adjacent prevertebral fascia by a loose, areolar tissue. This loose tissue allows movement of the pharynx, and also favours the spreading of postpharyngeal abscesses.

The nasal pharynx (figs. 848,888 ) belongs, strictly speaking, with the nasal fossa as a part of the respiratory rather than the digestive system. Its anterior wall is oceupied by the two choance (posterior nares), with the nasal septum between them. The floor is formed by the upper surface of the soft palate and in a direct posterior continuation of the floor of the nasal fossæ. Posteriorly, however, the floor presents a more or less narrowed opening, the pharyngeul isthmus, which communicates with the oral pharynx below. The isthmus is formed anteriorly by the uvula, laterally by the posterior (pharyngo-palatine) arches. These stope backward and downward to the posterior wall of the pharynx, which forms the posterior boundary of the isthmus. The floor and isthmus change their form and position greatly during the action of the palatal muscles, as will be mentioned later.

The lateral wall of the nasal pharynx presents above and behind, corresponding to its widest point, a wide, slit-like lateral extension, the pharyngeal recess [recessus pharyngeus] or fossa of Rosenmueller (fig. 888). Below and in front of this recess, the greater part of the lateral wall is occupied by the aperture of the auditory (Eustachian) tube [ostium pharyngeum tubæ]. This is a somewhat triangular, funnel-shaped opening, with an inconspicuous anterior lip [labium anterius], a more distinct posterior lip [labium posterius], which presents posteriorly a rounded prominence (due to the projecting cartilage of the auditory tube), called the torus tubarius. The prominence of the posterior lip facilitates the introduction of the Eustachian catheter, in connection with which the location of the aperture in the mid-lateral wall just above the level of the floor of the nasal fossa should be carefully noted. On the lower aspect of the triangular aperture is a slightly rounded fold, the levator cushion, which is a prominence caused by the levator palati muscle. A fold of mucosa descending from the posterior lip of the aperture to the lateral pharyngeal wall is the plica salpingo-pharyngea (due to the m. salpingo-pharyngeus). An inconspicuous plica salpingo-palatina descends from the anterior lip to the soft palate.

The posterior wall (fig. 848) of the nasal pharynx slopes from below upward and forward, passing (at the level of the anterior arch of the atlas) into the roof [fornix pharyngis]. The roof is attached chiefly to the basi-occipital and basisphenoid bones, extending laterally to the carotid canal of the pyramid, and anteriorly to the base of the nasal septum. In the posterior wall of the nasal pharynx there is found in the mucosa a variable and inconstant blind sac, the pharyngeal bursa.

The mucosa of the roof, and to a certain extent also of the posterior wall, especially in children, is thrown into numerous folds, which may be irregular or radiate from the neighbourhood of the bursa. There is often a median longitudinal groove (or sometimes ridge) at the posterior (inferior) end of which is the bursa. These folds of the mucosa contain much lymphoid tissue, both diffuse and in the form of numerous characteristic lymphoid nodules, with crypt-like invaginations of the surface epithelium. This area constitutes the pharyngeal tonsil [tonsilla pharyngea] (fig. 890 ), which is well-developed in children (often ab) normally enlarged, producing 'adenoids'), but usually, though not always, "atrophied in the adult. According to Symington, the involution of the pharyngeal tonsils begins at 6 or 7 years, and is usually completed at 10 ycars. In the region of the pharyngeal tonsil and elsewhere, the mucosa presents numerous small racemose mucous glands, especially thick in the palatal floor of the nasal pharynx and similar to those of the oral cavity.

The oral pharynx (figs. $848,864,888$ ) is continuous above tlirough the pharyn- 
geal isthmus with the nasal pharynx and below with the laryngeal pharynx. Its posterior wall presents no special features. The anterior wall is deficient above, where there is a communication with the mouth cavity through the isthmus

Fig. 889.-Vertical Section of a Human Palatine Toxsil. a, Stratified epithelium; $b$, basement membrane; $c$, tunica propria $; d$, trabeculæ; $e$, diffuse lymphoid tissue; $f$, nodules; $h$, capsule; $i$, mucous glands; $k$, striated muscle; $l$, blood vessel; $q$, pits. (From Radasch.)

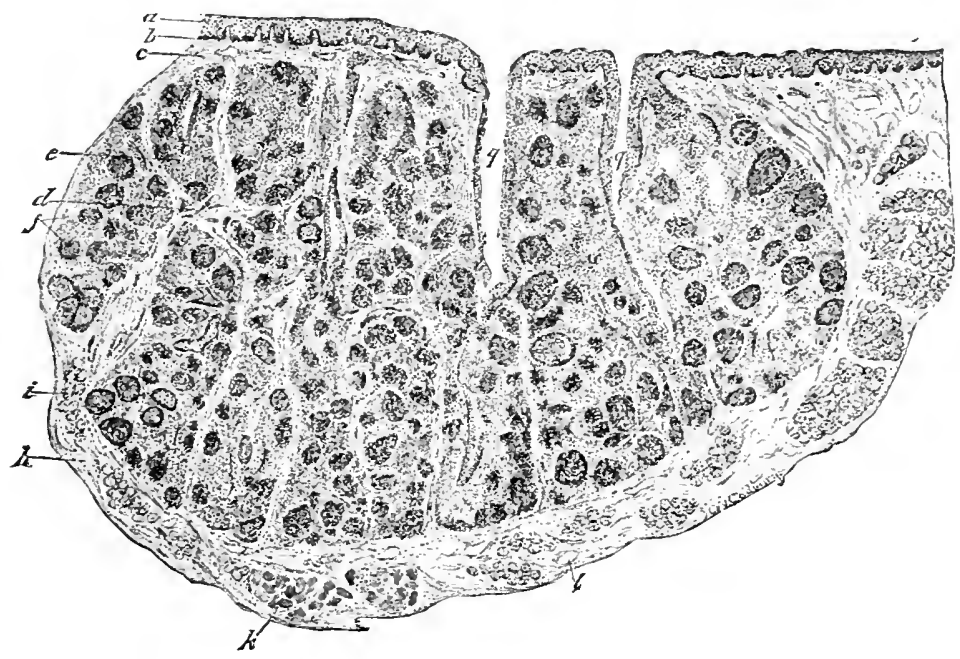

faucium. The faucial isthmus is bounded above by the uvula, laterally by the anterior (glosso-palatine) arches, and below by the clorsum of the tongue in the region of the sulcus terminalis. Below the faucial isthmus, the anterior wall of

Fig. 890.-Portion of a Coronal Section throdgh the Pharycagal Region, Showing Waldeyer's Tonsillar Ring. (Palatine tonsils hypertrophied.)

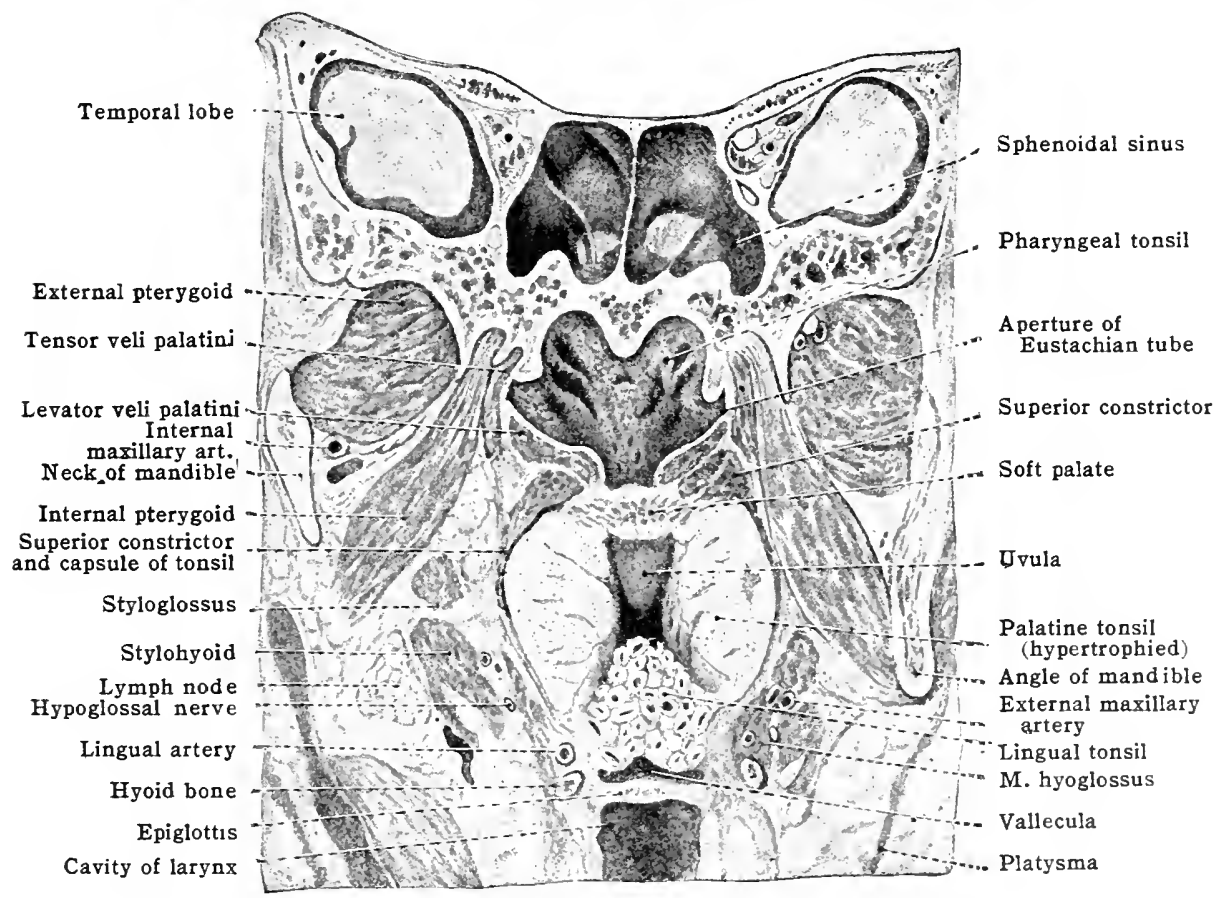

the oral pharynx is formed by the root of the tongue, which has been described previously. The lateral wall of the oral pharynx on each side presents the palatine tonsil, enclosed in a somewhat triangular tonsillar fossa [sinus tonsillaris] 
limited anteriorly and posteriorly by the anterior and posterior palatine arehes, and below by the root of the tongue.

The palatine arches are folds of the mucosa formed at the sides of the free posterior border of the soft palate, as already mentioned in connection with that organ. The anterior arch (or pillar) [arcus glossopalatinus] extends from the soft palate downward and forward to the lateral margin of the tongue, just behind the papillæ foliatæ. It is a fold of mucosa due to the underlying glosso-palatine muscle, and inconspicuous except when this muscle is in action, or when the tongue is depressed. It forms the lateral boundary of the faucial isthmus. The posterior arch [arcus pharyngopalatinus] is a more prominent fold which extends from the soft palate in the region of the uvula downward and backward to join the postero-lateral aspect of the pharyngeal wall. It forms the la teral boundary of the pharyngeal isthmus, and encloses the pharyngo-palatine muscle, whose actior will be explained later.

The palatine tonsil [tonsilla palatina] (figs. 864, 889, 890, 891) is a flattened ovoidal body, usually visible through the mouth cavity and faucial isthmus, and located on each side of the oral pharynx. The tonsil is extremely variable in size, but in the young adult averages about $20 \mathrm{~mm}$. in height, $15 \mathrm{~mm}$. in width (antero-posteriorly) and $12 \mathrm{~mm}$. in thickness.

The lateral or attached surface of the tonsil is covered by a thin but firm fibrous capsule, which is continuous with the pharyngeal aponeurosis, and in contact with the middle constrictor muscle of the pharynx (fig. 864). Just outside the constrictor, the tonsil is in relation with the ascending pharyngeal and ascending palatine arteries, but is separated by a considerable space from the external and internal carotids. Rarely, however, the lingual or external maxillary may extend up higher than usual, so as to be in close relation with the lower aspeet of the tonsil. Further lateralward, the palatine tonsil is in relation with the internal pterygoid muscle, and on the surface corresponds to a point somewhat above and in front of the angle of the mandibie. The posterior border of the tonsil is thicker than the anterior, and forms a somewhat flattened surface in contact with the pharyngo-palatine muscle (fig. 891).

The medial or free surface of the tonsil is covered with mucosa and presents a variable number (12 to 30 ) small pits which are the openings into the tubular or slit-like crypts [fossulæ tonsillares]. These crypts are somewhat more numerous in the upper part of the tonsil, and are sometimes branched or irregular in form. Usually they end blindly in the substanee of the tonsil, surrounded by lymphoid tissue in characteristic nodular masses (fig. 889). The lymphoeytes normally migrate through the stratified squamous epithelium lining the crypts (occasionally eroding passages of considerable size), and escape into the pharyngeal and mouth cavities, where they form the so-called salivary corpascles. Around the periphery of the palatine tonsil, within the capsule, are many mucous glands (fig. 889), similar to those described in connection with the lingual and pharyngeal tonsils. The ducts of the mucous glands sometimes enter the erypts, but usually pass to the surface chiefly around the margins of the palatine tonsil.

Tonsillar plicæ and fossæ.-Connected witl the tonsil are certain important folds and fossie. 'The plica triangularis (fig. 891) is a fold of variable extent and appearance, placed just behind the anterior arch, wider below and narrower above. Aceording to Fetterolf, it is a prolongation of the tonsillar eapsule, covered with mucosa. It may be adherent to the anterior part of the medial surface of the tonsil, or it may be free, in which case it covers a recess called the anterior tonsillar fosia. Ocrasionally there is a similar plie:a and fossa at the posterior border of the tonsil. Nhove the tonsil there is similarly a supratonsillar fossa [fosca supratonsillaris], which is also inconstant and exceedingly variable in size and shape. Killian found a sipmatonsillar fossia or canal in 41 of 105 carlavers.

Tonsillar vessels. - The arteries to the tonsil inclule the anterior tonsillar (from the dorsalis lingual); the inferior tomsillar (from the extermal maxillaty); the posterior tomsillar (from the

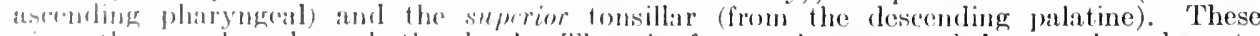
piere lhe atpsule and supply the gland. The rims form a plexus around the capsule and empty indo thr dingual win and the pharyngeal plexus. The lymphatie relations of the palatine

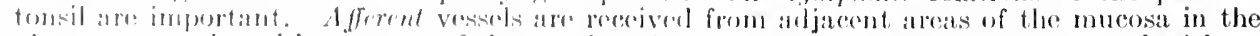
phargux, month and lower part of the masal eavity (v. Isnart). 'These are commected with an

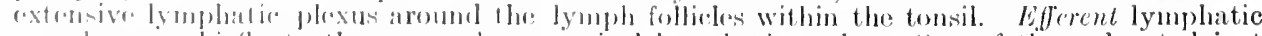

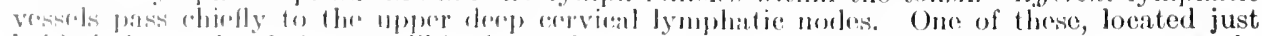

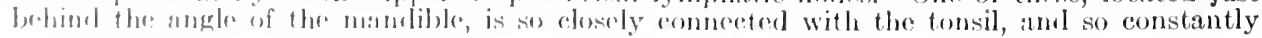


enlarged following tonsillar infection, that it has been called the tonsillar lymph gland (Wood). There are also communications with the submaxillary and superficial cervical lymphatic nodes. The tonsillar lymphatic vessels connect also with those of the lingual tonsil in the root of the tongue.

The tonsillar ring.--The two palatine tonsils, together with the lingual tonsil below and the pharyngeal tonsil above, form an almost complete ring of characteristic tonsillar tissue surrounding the pharynx and known as Waldeyer's 'tonsillar ring' (fig. 890). It is a highly specialized development of the diffuse lymphoid tissue which is found everywhere in the mucosa of the alimentary and respiratory tracts. It may be noted that the 'tonsillar ring' corresponds to the anterior linit of the embryonic foregut, hence the epithelium is of endodermic origin. The arrangement of the tonsils, together with their lymphatic connections, has suggested the widely accepted view that they are to be considered as protective mechanisms whose function is to intercept infectious material which has entered the mouth or nasal cavities. This theory is supported by the experiments of $v$. Lenart, who found that substances in jected into the nasal mucosa are intercepted partly in the tonsils, and partly in the cervical lymph

Fig. 891.-The Left Palatine Tonsil, Showixg the Arterial Supply.

1, Mesial aspect. 2, Postero-lateral aspect. E, lateral surface. B, posterior surface. $\mathrm{T}$, medial surface. $\mathrm{G}$, groove for pharyngo-palatine muscle. C, capsule. PT, plica triangularis. Arteries: AA, anterior tonsillar (from dorsal lingual); PA, posterior tonsillar (from ascending pharyngeal); SA, superior tonsillar (from descending palatine); IA, inferior tonsillar (anterior from dorsal lingual; posterior from tonsillar branch of internal maxillary). (Fetterolf: Amer. J. Med. Sc., 1912.)

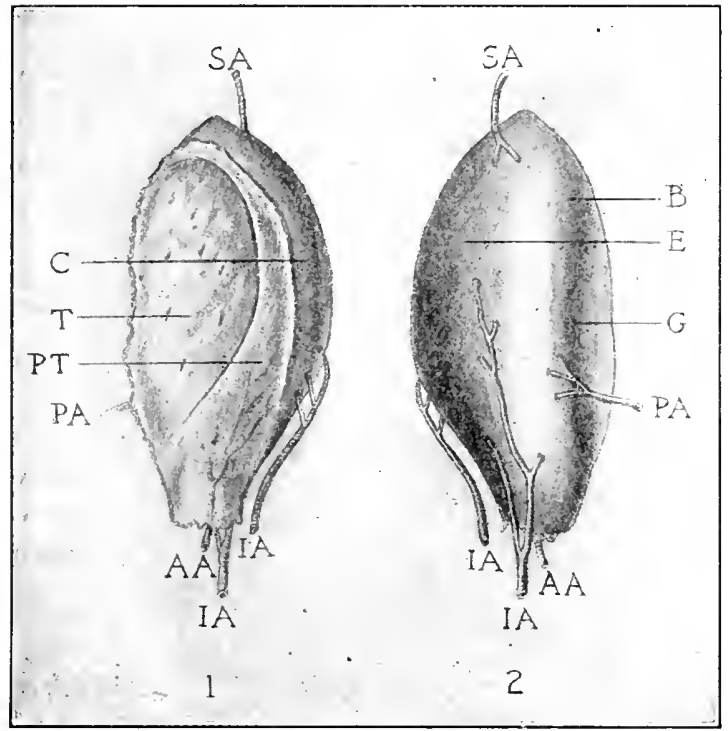

nodes. Oppel, however, opposes this view, holding that the function of the tonsils, as of lymphoid tissue elsewhere, is merely the production of lymphocytes.

Development of the tonsil.- According to Hammar, the palatine fossa (sinus tonsillaris) is a derivative of the second inner branchial groove and is visible in the human embryo of 17 $\mathrm{mm}$. There appears in the floor of the fossa a tubercle (tuberculum tonsillare) which later becomes atrophied, excepting a portion which is converted into the plica triangularis. The primitive tonsil becomes divided in to two lobes, upper and lower, by a fold (plica in tratonsillaris) which later usually disappears. In the foetus of about $100 \mathrm{~mm}$. (crown-rump length) the epithelium of the floor grows into the subjacent mesenchyme in the form of somewhat irregular solid sprouts of epithelium. These later become hollow and form the crypts. Around them, in about the sixth foetal month, the lymphoid tissue begins to accumulate, at first diffusely, later forming characteristic follicles. The lymphocytes arise in situ from the connectivetissue cells (Hammar) or by immigration from the blood-vessels (Stöhr). Retterer's claim that the tonsillar lymphoid cells are derived from the epithelial cells has not been confirmed.

The later foetal development of the tonsil is subject to considerable individual variation. The supratonsillar fossa is a remnant of the upper part of the primitive sinus tonsillaris, which may be transformed into a canal by growh of adenoid tissue around it. It is inconstant and quite variable in size and extent. A portion of the sinus may likewise persist anteriorly (anterior tonsillar fossa) between the tonsil and the plica triangularis, but this portion is usually obliterated by fusion of the plica with the tonsil. The occasional retro-tonsillar fold and fossa are said to arise secondarily (Hammar).

Variations in the tonsil. - The palatine tonsil, like the lingual and pharyngeal tonsils, is an exceedingly variable organ. Many of the variations are developmental in origin, as above indicated, and are therefore congenital. Furthermore, the tonsils, like all lymphoid structures, are subject to marked age variations. Though fairly well formed at birth, they are yet somewhat undeveloped. They rapilly increase in relative size and complexity, however, being 
best developed in childhood. After the age of puberty, they usually undergo certain retrogressive changes, become smaller in size, and in old age become almost entirely atrophied and lost. They are also markedly subject to inflammatory hypertrophy, especially in children. Variations in the relations of the blood-cessels were mentioned above.

The laryngeal pharynx (fig. 848) is the lower portion leading from the oral pharynx above into the osophagus below (at the level of the lower border of the cricoid cartilage, usually opposite the sixth cervical centrum). It is wide above

Fig. 892.-The Muscles of the Soft Palate and the Palatal Arches as Seen from in Froxt. (After Toldt, "Atlas of Human Anatomy," Rebman, London and New York.) Incisive papilla

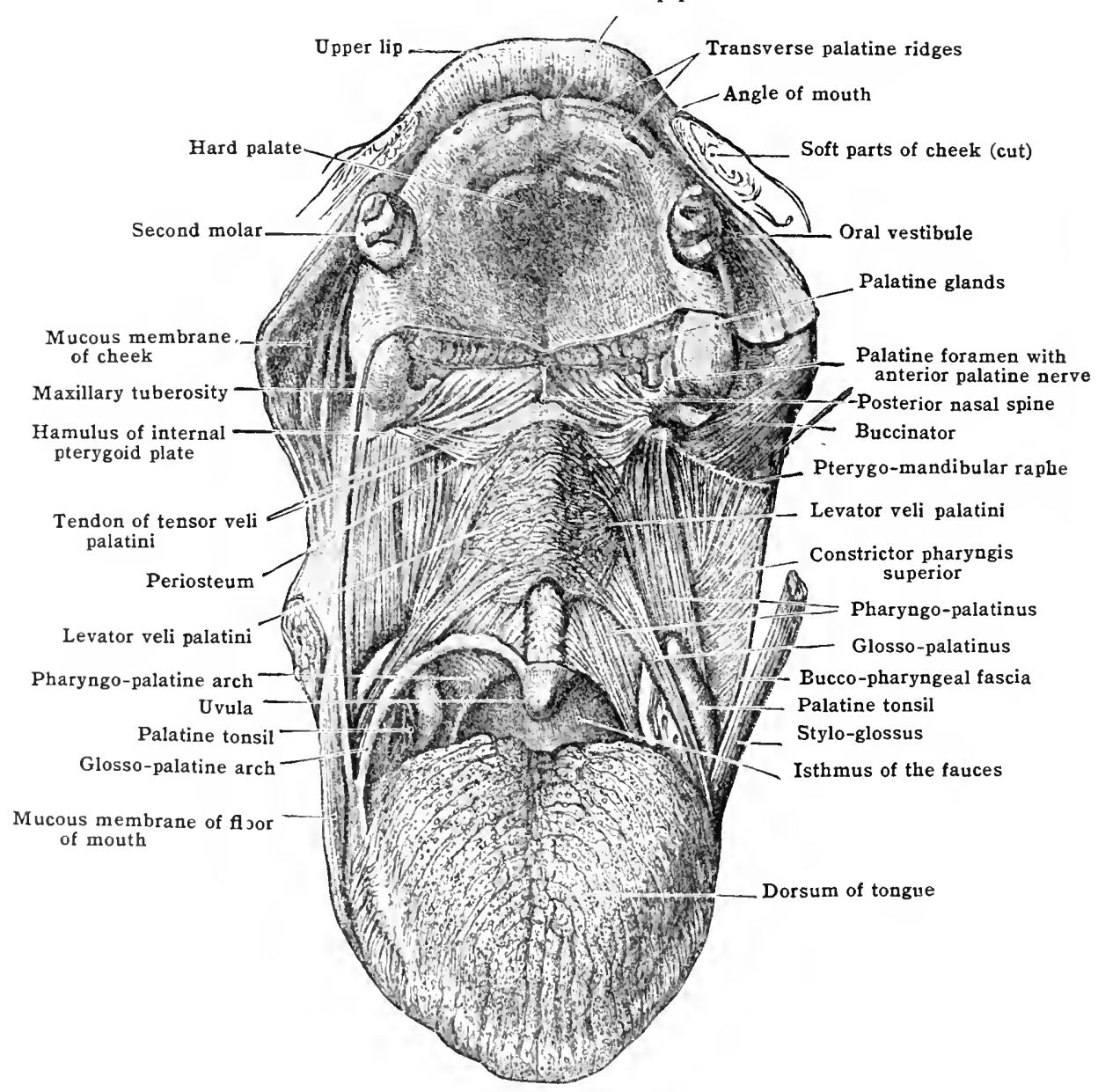

and narrow below (fig. S88). Its posterior walls are continuous with those of the oral pharynx and in relation with the vertebral centra. Its lateral walls are attached to the hyoid hone and the posterior part of the medial surface of the thyreoid cartilage. Anteriorly it is in reation with the larynx. In the median line above is the rpiglottis, below which is the superior aperture of the larynx. Still lower is the posterior wall of the larynx, containing the arytaenoid and lamina of the crieoid cartilage. Jaaterally, are the pharyngo-epiglottic folds, and below these on each side a derel), alongated fossia, the recessus piriformis, bounded laterally by the medial surface of the thyreoil cartilage. The mucosa of the laryngral pharynx is simikar to that of tho oral pharynx, and contains racemose mucous glands, which are especially numcrous in its anterior wall.

Muscles of the pharynx and soft palate.-These muscles (figs. 892, 893, 894), which are here grouped together for convenience of description, are ehiefly sphincter-like constrictors in function. They include the constrictors of the faucial isthmus (mm. glossopalatini), the eomstrictors of the pharyngeal isthmus 
(mm. pharyngopalatini), the three pharyngeal constrictors, and also the levator and the tensor veli palatini, the $\mathrm{m}$. uvulæ and the stylo-pharyngeus. The stylopharyngeus and pharyngo-palatine muscles form an incomplete longitudinal layer within the more eireularly arranged constrictors of the pharynx.

Fig. 893.-View of Muscles of Soft Palate, as Seen from Behind, Within the Pharyax.

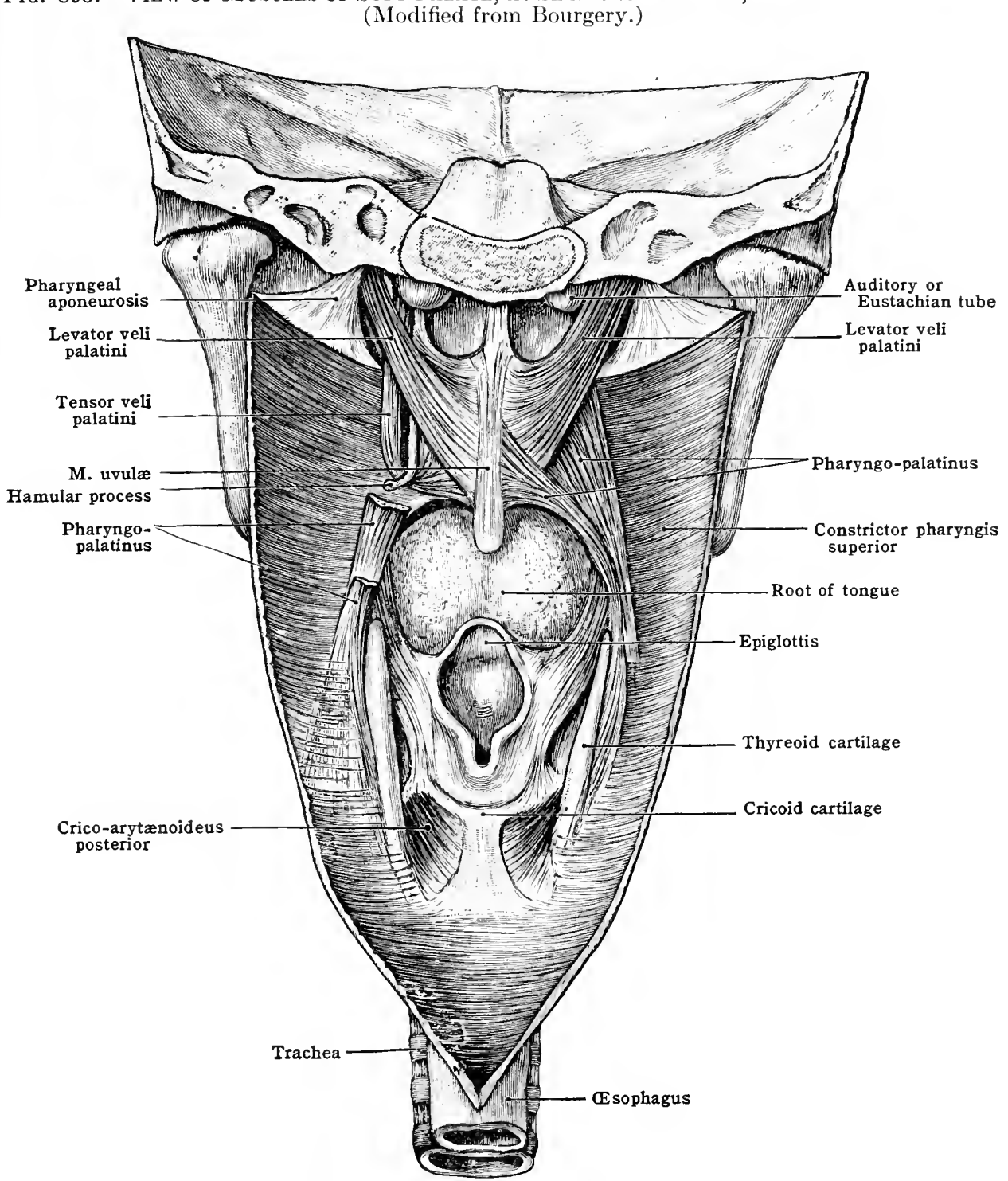

The muscles are arranged in layers either behind or in front of the apo neurosis, and in a horizontal section of the soft palate the following layers are met with from behind forward: (1) The mucous membrane on the pharyngeal surface; (2) the posterior layer of the pharyngo-palatinus (palato-pharyngeus); (3) the m. uvulæ; (4) the levator veli palatini; (5) the anterior layer of the pharyngo-palatinus; (6) the palatal aponeurosis with the iensor veli palatini; $(7)$ the glosso-palatinus palato-glossus); and (8) the mucous membrane on the oral aspect.

The glosso-palatinus (palato-glossus) is a cylindrical muscle extending between the soft palate and the lateral border of the tongue. Origin.-From the oral surface of the palatal aponeurosis. Insertion.-(1) The superficial layer of muscles which covers the side and adjacent part of the under surface of the tongue; (2) the transversus linguæ. Structure.-At its origin the muscle forms a thin sheet, but the fibres, passing lateralward, quickly concentrate to form a cylindrical bundle, which passes downward beneath the mucous membrane of the pharynx 
and in front of the tonsil, forming the glosso-palatine arch of the fauces. It reaches the side of the tongue at the junction of its middle and posterior thirds, and some of its fibres continue forward to join with those of the stylo-glossus and hyo-glossus, while the majority pass medially to become continuous with the transversus lingure. Neree-supply.-From the pharyngeal branches (plexus) of the vagus. Action.-(1) To draw the sides of the soft palate downward; (2) to draw the sides of the tongue upward and backward. The eombination of these actions tends to constrict the faucial isthmus. (The origin and insertion of the glosso-palatinus as given above are often deseribed as reversed.)

The pharyngo-palatinus (palato-pharyngeus)-named from its attachments-is a thin sheet. Origin.-(1) From the aponeurosis of the soft palate by two heads which are separated by the insertion of the levator veli palatini; (2) by one or two narrow bundles from the lower part of the cartilage of the auditory (Eustachian) tube (salpingo-pharyngeus). Insertion.-(1) By a narrow fasciculus into the posterior border of the thyreoid eartilage near the base of the superior cornu: (2) by a broad expansion into the fibrous layer of the pharynx at its lower part.

Fig. S94.-The Mugcles of the Pharynx, Lateral View.

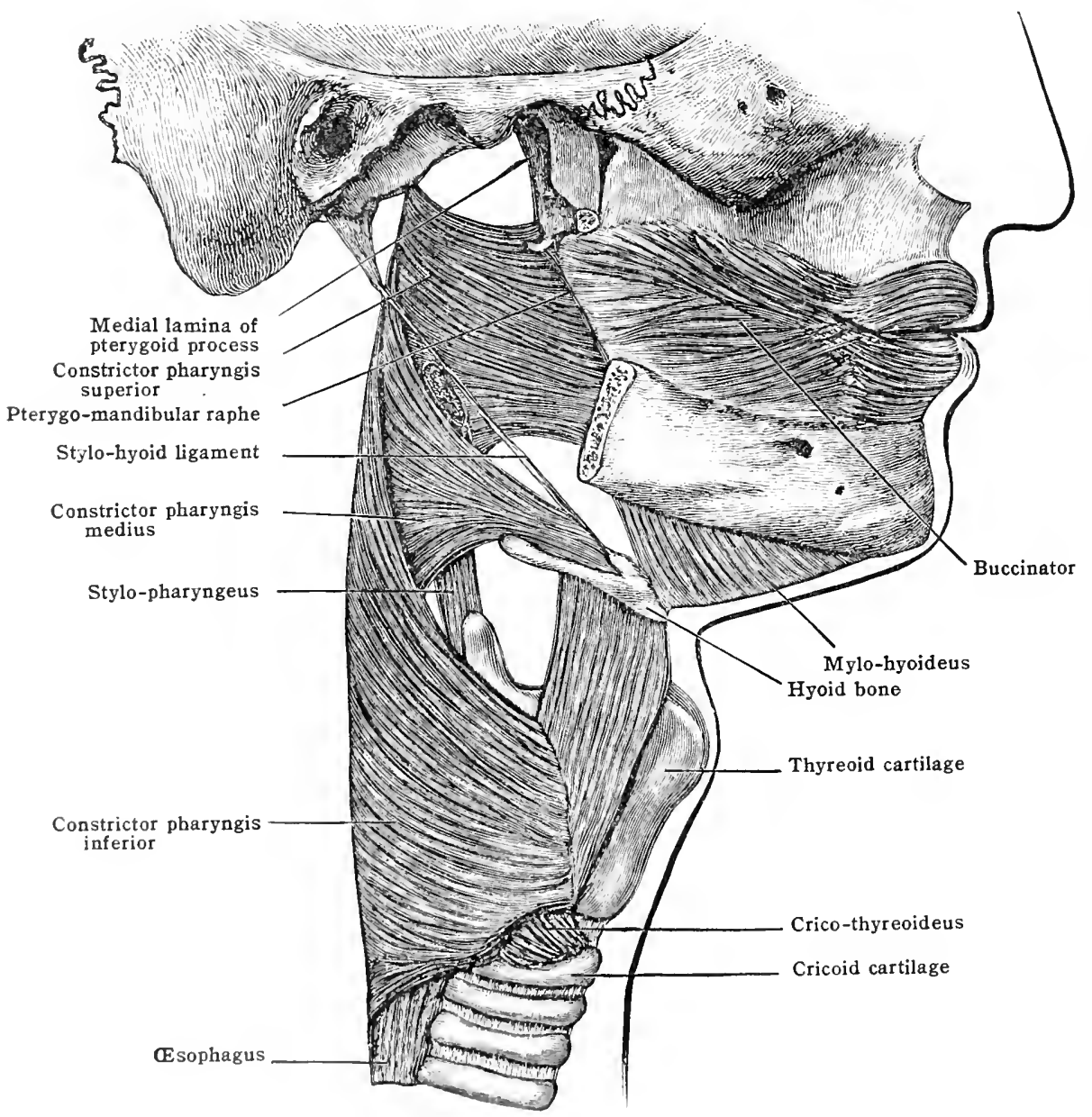

Sirurture- The upper hearl of the muscle consists of seattered fibres which blend with the oppo-

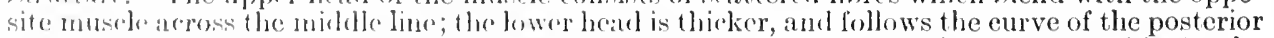
border of the palate. "The two hrads with the fascientus from the auditory (Eustachian) tube form a compact musenlar batel in the pesterior palatine areh; the fibres mingle with those of the style-pharyngens, at the lower forter of the suprerior constrictor, and then expand upon the lower part of the pharyax. Nome-supply.-From the pharyngeal hranch (plexus) of the vagus. Artion.-(1) Approximates the pesterior arehes of 1 he latures; (2) depresses the soft palate;

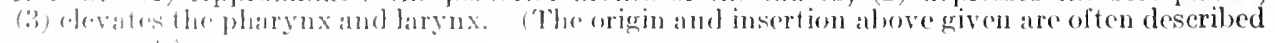

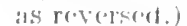

The inferior constrictor is lhick am strong. It arises from the thyreoid cartilage im-

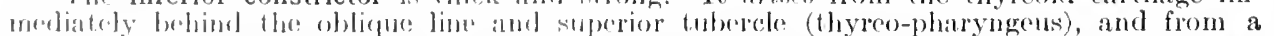

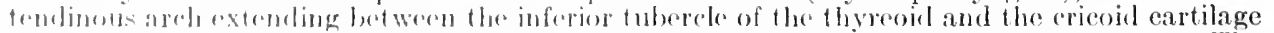

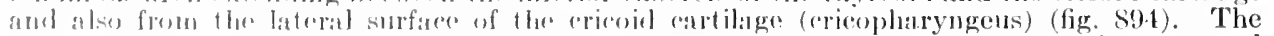
fibres spreal batekwarl and medialwalle the lowest horizontally, whilst those above ascend ruere and mere obliquely, and are imserted into the fibrous raphe of the pharynx. Some of 
the lowest fibres are continuous with the muscular fibres of the csophagus, and the upper overlap the middle constrictor (fig. 894). The nerve-supply of all three constrictors is from the pharyngeal nerve.

Near the upper border the superior laryngeal nerve and artery pierce the thyreo-hyoid membrane to reach the larynx. The inferior laryngeal nerve ascends beneath the lower border immediately behind the crico-thyreoid articulation.

The middle constrictor is a fan-shaped muscle which arises from the lesser cornu of the hyoid bone and from the stylo-hyoid ligament (chondro-pharyngeus), and from the whole length of the greater cornu (cerato-pharyngeus). The diverging fibres are inserted into the median raphé, and blend with those of the opposite side. The lower fibres of the muscle descend, beneath the inferior constrictor, to the lower part of the pharynx; the upper overlap the superior constrictor, and reach the basilar process of the occipital bone, whilst the middle fibres run transversely (fig. 894).

The glosso-pharyngeal nerve passes downward above its upper border, the stylo-pharyngeus passes between it and the superior constrictor, and near its origin it is overlapped by the hyoglossus and crossed by the lingual artery.

The superior constrictor is quadrilateral in shape, pale, and thin (fig. 894). It arises from the lower third of the hinder edge of the median lamina of the pterygoid process and its hamular process (pterygo-pharyngeus), from the pterygo-mandibular ligament (bucco-pharyngeus), from the posterior fifth of the mylo-hyoid ridge of the mandible (mylo-pharyngens), and from the side of the root of the tongue (glosso-pharyngeus). The fibres pass backward to be inserted into the median laphé, the highest reaching the pharyngeal tubercle. The Eustachian tube and the levator veli palatini are placed above the superior arched border, and the space (sinus of Morgagni) between this and the basilar process, devoid of muscular fibres, is strengthened by the pharyngeal aponeurosis, this portion of it being semilunar in shape.

The stylo-pharyngeus arises from the base of the styloid process internally. It passes downward and medialward to reach the pharynx between the superior and middle constrictors. Its fibres spread out as it descends beneath the nucous membrane. At the lower border of the superior constrictor some of its fibres join fibres of the pharyngo-palatinus (palato-pharyngeus), and are inserted into the posterior border of the thyreoid cartilage (fig. 894); the rest blend with the constrictors. The nerve-supply of the stylo-pharyngeus is from the glosso-pharyngeal nerve.

The levator veli palatini-named from its action on the velum of the soft palate-is somewhat rounded in its upper, but flattened in its lower, half. Origin.-(1) The inferior surface of the petrous portion of the temporal, anterior to the orifice of the carotid canal; (2) the lower margin of the cartilage of the auditory (Eustachian) tube. Insertion.-The aponeurosis of the soft palate; the terminal fibres of the muscles of each side meet in the middle line in front of the m. uvulæ. Structure.-Its origin is by a short tendon; the muscle then becomes fleshy, and continues so to its insertion. Nerve-supply.-From a pharyngeal branch (plexus) of the vagus. Action.-(1) To raise up the velum of the soft palate, and bring it in contact with the posterior wall of the pharynx; (2) to narrow the pharyngeal opening and to widen the isthmus of the auditory (Eustachian) tube. (According to Cleland, it closes the pharyngeal opening of this tube.)

The tensor veli palatini-named from its action on the velum of the soft palate-is a thin, flat, and narrow sheet. Origin.-(1) The scaphoid fossa of the sphenoid; (2) the angular spine of the sphenoid; $(3)$ the lateral side of the membranous and cartilaginous wall of the auditory (Eustachian) tube. Insertion.-(1) Into the transverse ridge on the under surface of the horizontal plate of the palate bone; $(2)$ the aponeurosis of the soft palate.

Structure.-Its belly as it descends between the pterygoideus internus and the internal pterygoid plate is muscular. On approaching the hamular process it becomes tendinous, and continues so to its insertion. A bursa is interposed between the hamular process and the tendon. The belly of the muscle is at nearly a right angle with its tendon. Nerve-supply.-From the mandibular division of the trigeminus through the tensor palati branch of the otic ganglion. Actions.- (1) Tightens the soft palate; (2) opens the auditory (Eustachian) tube during deglutition.

The m. uvulæ.- - so named by reason of its position in the uvula. Origin.-(1) From the aponeurosis of the soft palate and tendinous expansions of the two tensores veli palatini. Insertion.-Into the uvula. Structure.-The muscle consists of two narrow parallel strips lying on each side of the middle line of the palate. Nerve-supply.-From the pharyngeal branch of the vagus. Action.-To draw up the uvula.

Origin of the muscles. - According to W. H. Lewis, the tensor palati is a derivative of the mandibular arch (probably split off from the pterygoid mass); the levator palati and m. uvulæ come with the facial musculature from the hyoid arch; the glosso-palatine, stylo-pharyngeus and pharyngeal constrictors probably from the third visceral arch, in a pre-muscle mass visible in a $9 \mathrm{~mm}$. embryo. The adult innervation of the pharyngeal muscles does not agree entirely with this, however. The pharyngeal museles (as above stated) are innervated chiefly from the vagus, whereas if derived from the third arch their innervation from the glosso-pharyngeus would be expected.

Process of swallowing.- In the act of swallowing, practically all of the muscles of the mouth, tongue, palate and pharynx are involved. By compression of the lips and cheeks, together with elevation of the tongue, the food is forced backward through the faucial isthmus into the oral pharynx. Constriction of the faucial isthmus by the glosso-palatine muscles assists in preventing a return to the mouth. By the action of the levator palati, tensor palati, and pharyngo-palatime muscles, the soft palate is retracted and tightened, with constriction of the pharyngeal isthmus, so as to prevent the passage of the food upward into the nasal pharynx. The pharynx is drawn upward by the stylo-pharyngeus, and the pressure produced by the pharyngeal constrictors (the contraction beginning above and extending downward) forces the food downward through the laryngeal pharynx and into the cesophagus. Passage of the food into the larynx is prevented by constriction of the superior aperture of the larynx. 
Vessels and nerves. - The vessels of the tonsil and the motor nerves of the various muscles have already been mentioned. In general, the arteries to the pharynx are derived chiefly from the ascending pharyngeal, the ascending palatine branch of the external maxillary, and the descending palatine and pterygo-palatine branches of the internal maxillary. The veins form a venous plexus between the pharyngeal constrictors and the pharyngeal aponeurosis, and also an external plexus, communicating with the pterygoid plexus above and with the posterior facial or intermal jugular vein below. The lymphatic vessels pass chiefly to the deep cervical nodes, those from the upper portion (including the pharyngeal tonsil) ending partly in the retro-pharyngeal glands. The nerves of the pharynx, both motor and sensory, are derived chiefly from the glosso-pharyngeal and vagus, by way of the pharyngeal plexus.

The development of the pharynx. - The pharynx is developed chiefly (if not entirely) from the anterior end of the archenteron. In this portion of the archenteron, with the development of the branchial arches, there are formed on each side four entodermal pouches or grooves (with a rudimentary fifth), the branchial clefts (see p. 17). With further development the first pair of branchial clefts form the tympanic cavities and the auditory or Eustachian tubes; the lower portion of each second branchial cleft persists as a fossa in which a palatine tonsil is developed; the remains of the third and fourth pairs are found on each side in the vallecula and piriform sinus of the larynx. The origin of the pharyngeal tonsil may be observed in the third month of fotal life in the form of small folds of mucous membrane which, during the sixth month, become infiltrated with diffuse adenoid tissue, lymph-nodules differentiating in this toward the end of fœtal life. The pharyngeal bursa, which is not a constant structure (Killian), may be observed as a small diverticulum of the pharyngeal wall, closely connected with the anterior extremity of the notochord. The diverticulum develops independently of Rathke's pouch (which gives rise to the anterior portion of the hypophysis), and is also apparently distinct from seesel's pocket.

The entire pharynx, like the associated facial region, is relatively small and undeveloped in the fotus and newborn, but develops rapidly during infancy. The development of the muscles and of the palatine tonsils has already been considered.

Variations.- Variations in the palatine and pharyngeal tonsils and in the pharyngeal bursa have already been mentioned. Remnants of the visceral clefts may persist as aberrant diverticula or as 'branchial fistulæ' connected with the pharynx. Many additional muscles have been described, chiefly longitudinal muscles arising from the base of the cranium either by splitting of those normally present, or as separate slips. A detailed description of these may be found in Poirier-Charpy's work. Abnormally extensive fusion of the posterior arches of the palate with the walls of the pharynx may produce a congenital stenosis of the pharyngeal isthmus.

Comparative.- The pharynx is not distinctly separated from the mouth cavity in the lower vertebrates. It is the region containing the branchial or visceral clefts and is thus both respiratory and alimentary in function. The nasal pharynx, including the apertures of the auditory tubes, becomes clistinct along with the nasal cavity when the palate is formed (from the reptiles upward). In the air-breathing vertebrates, the laryngeal aperture appears in the ventral wall of the pharyux just anterior to the beginning of the cesophagus. Of the tonsils, the pharyrigeal are the most primitive, being present in the roof of the pharynx in amphibia, well-developed in reptiles, birds, and mammals (Killian). The palatine tonsils, on the other hand, are characteristic of mammals, being rarely absent, however (e. g., rat, guinea pig). From the embryological point of view, Hammar has classified the palatine tonsils in the various malnmals under (1) the primary type (including rabbit, cat, and $\log$ ), in which the tonsil is formed from the embryonic tonsillar tubercle (described above under development of tonsil); and (2) the secondary type (including pig, ox, sheep and man), in which the tonsillar tubercle disappears and the tonsil is developed from the wall of the surrounding tonsillar sinus. 'Typical epithelial crypts (highly branched in the ox) are found only in the secondary type. The tonsil may form a single (lymphoid) lobe (cat, pig, rabbit) or may develop typi("ally two lobes (ox, shcep, man), separated by the intratonsillar fold. There are great variations among different speeies as to relative size, number and character of folds, erypts, etc. The intimate relation of the epitheliun with the underlying lymphoid tissue is characteristic and constant.

\section{THE QESOPHAGLS}

The œsophagus (figs. 895,896 ) is that portion of the alimentary tract which exconds botween the pharynx and the stomach. It is more constricted than the rest of the canal, being narrowest at its commeneement opposite the lower border of the cricoid cartilage. It is again somewhat contracted behind the left bronchus, and at its jassige through the diaphragm, which is opposite the tenth or eleventh thoracie vertebra. It has an average length of 25 em. (varying from 20 to 35 ('m.). Thte average distanes from the rima oris to the beginning of the (x'sop)hagus is about 15 ) (mo. In its course downward the asophagus follows the curves of the vertebral columm until it finally pasises forward in front of and stightly to the left of the arotat to gain the cesoph hageal opening in the diaphragm. In addition to these rurves it presents two lateral curvatures, one convex toward the left side at the root of the neere and in the upper part of the thorax, and the othere andeave toward the left in the lower part of the thorax where it leaves the vertelusal colmmn. It lies in the midelle line at its eommeneement (usually opmosite the sixth rervical verternat), and again, at a lower level, opposite the fifth thoracice vertebrat. 
After death the œophagus is somewhat flattened from before backward, but it is more rounded during life. It is closed except during the passage of food, etc.

The peristaltic movements of the œsophagus can readily be observed by means of the Rœntgen-rays. Solids often lodge a short time at the level of the arch of the aorta, but pass quickly through the cardiac orifice. A swallow of liquid, on the other hand, is usually detained at the lower end of the œsophagus (probably by sphincteric action of the cardia) for about seven seconds before passing into the stomach (Pfahler).

Fig. 895.-The Cesophagus and Stomach. (Testut.)

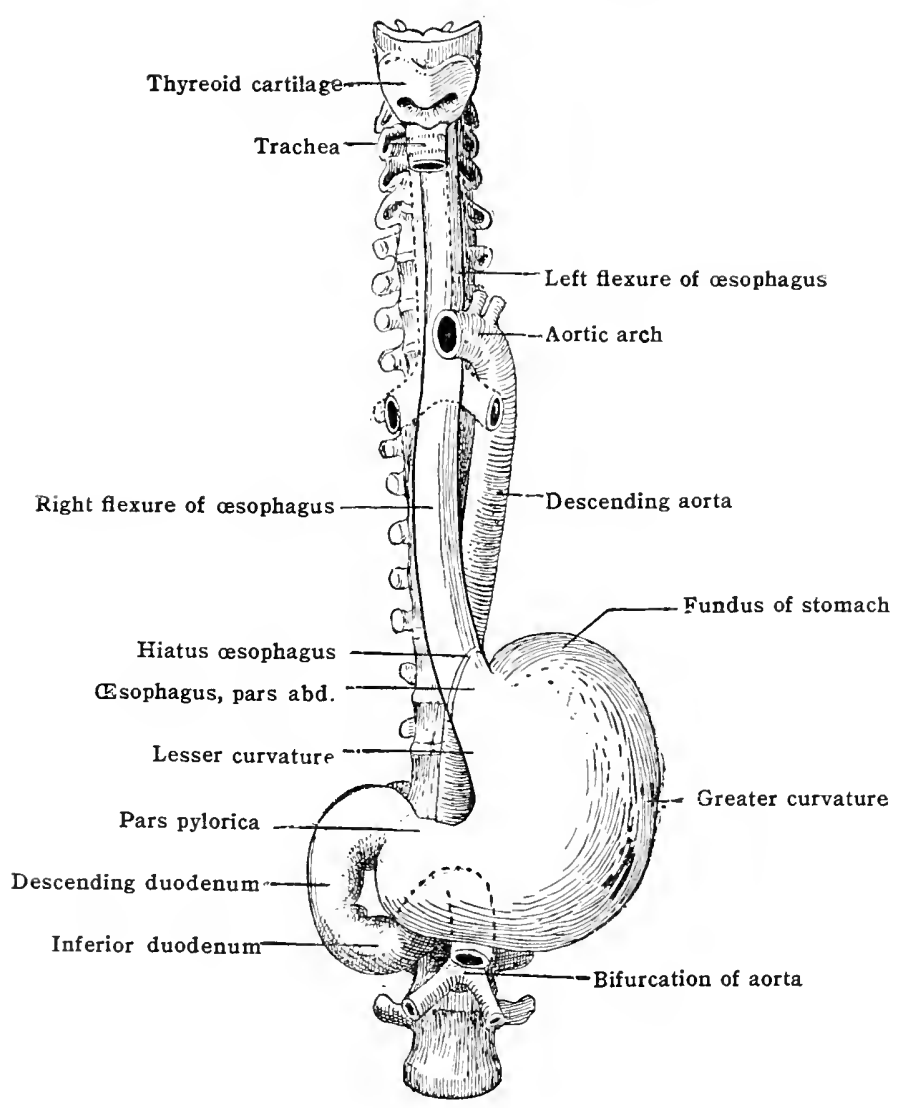

The œsophagus is divided into three parts: cervical, thoracic and abdominal.

Cervical portion.-The osophagus has anteriorly the trachea, the posterior portion of the left lateral lobe of the thyreoid gland, and the left recurrent nerve, branches of the inferior thyreoid artery, and the carotid sheath. Posteriorly, it rests upon the vertebral column, the longus colli muscles, and prevertebral fascia. On its right side are placed the right carotid and right recurrent nerve; and on the left side the left inferior thyreoid vessels, left carotid artery, left subelavian, and the thoracic duct. The recurrent nerves pass upward on each side to gain the interval between the trachea and œsophagus. The left nerve, as already described, lies in front of the tube, and the right along its right borcler.

Thoracic portion.- The csophagus descends in the thorax through the superior and the posterior mediastina. In the superior mediastimum its anterior relations are the trachea, with the deep cardiac plexus in front of its bifurcation, the left subclavian and carotid arteric s crossing its left border obliquely, the left recurrent nerve, and the arch of the aorta. To the left are the left carotid and subclavian arteries, the end of the arch of the aorta, and the left pleural sac. 'To the right it is in relation with the right vagus nerve and the right pleural sac. Posteriorly, it rests upon the vertebral column, the left longus colli muscle, and it overlaps the thoracic duct. As it enters the posterior mediastinum it passes behind the left bronchus (or bifurcation of the trachea) and the right pulmonary artery, resting posteriorly on the vertebral column and thoracic duct. In the posterior 
mediastinum it has anteriorly the pericardium, which separates it from the left atrium and a portion of the diaphragm; posteriorly it rests upon the vertebral column, accessory hemiazygos and hemiazygos veins, the right aortic intercostal arteries, the thoracic duct, and the descending aorta. To the right is the right pleural sac, the vena azygos, which it partly overlaps, and below, the thoracic duct. To the left in the upper part is the descending thoracic aorta, and, below, the left pleural sac is separated from it by a little loose areolar tissue. It is surrounded by the œsophageal plexus formed by the vagi nerves, and, as they emerge from the lower part of the plexus, the left vagus lies in front of the osophagus and the right vagus behind.

Fig. S96.-Cross-sections Illustrating the Relations of the Cesophagus at Various LEVELS.

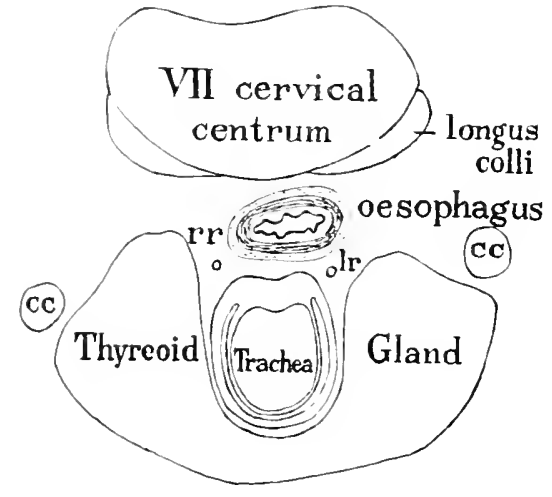

A

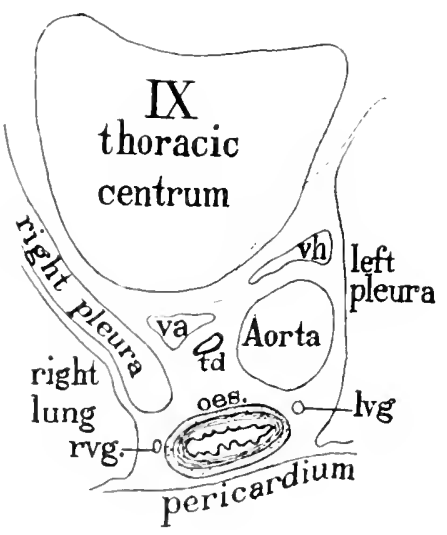

(;

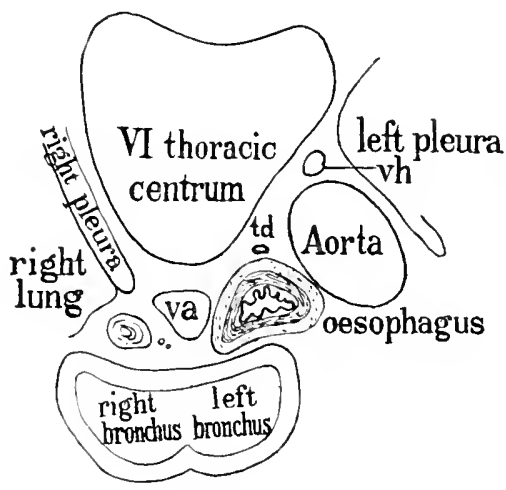

$\mathrm{B}$

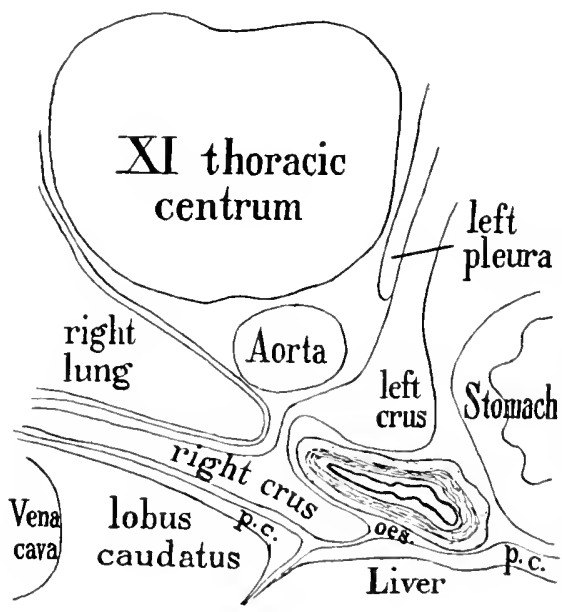

D)

Abdominal portion.- The cesophagus lies in the epigastric region of the abdomen. Anleriorly is the left lobe of the liver. To the left the left lobe of the liver and the fundus of the stomach. To the right the caudate (Spigelian) lobe of the liver, and posteriorly the decussating fibres of the crura of the diaphragm and the loft infrrior phrenic artery. The abdominal portion is very short, usually not more than 2 (1m. (4/5 inch) in length (see figs. $896 \mathrm{D}, 907$ ).

Structure. The thick-wallenl asophagus presents the four typical tunics of the alimentary canal (fig. .597 ). The murosa and the muscularis are the mest important, the submucosa and thre retermal arlventitia being arecessory lityers. The mucosa (fig. $\$ 97$ ) is thiek and strong, of roldish eolonr in its apper portion and more greyish below. It presents deep longitudinal folds to allow for distention, and when empty the lumen is therefore stellate in cross sections. The lining cpithrium is stritified squamous. The lamina propria presents mumerous papilloe, and is limitrel externally by a muscularis murose. This is a comparatively thick layer (except at the upper (ond) and is composed of smooth muscle fibres, longiturlinally arranged. 
The submucosa (fig. \$97) is a thick, very loose fibrous layer connecting the mucosa with the muscularis. It contains numerous vessels and nerves, and mucous glands. The latter [gl. cesophageæ] are of the racemose type, like those of the mouth, and are variable in number. There are also two sets of superficial glands, confined to the lamina propria, and resembling the fundus glands of the stomach. The upper set (Rüdinger-Schaffer glands) are found in 70 per cent. of cases, occurring above the level of the fifth tracheal ring. The lower set (cesophageal cardiac glands) form a ring around the csophagus just above the cardiac aperture. A few small lymph nodes also occur in the submucosa, of ten around the ducts of the mucous glands.

The muscularis (fig. S97) is a thick reddish tunic with two distinct layers, approximately equal in thickness. The fibres of the inner layer are arranged circularly and are continuous with the inferior constrictor above and with the oblique fibres of the stomach below. The fibres of the outer layer are longitudinal and commence above as three flattened bands: a strong anterior band arising from the ridge on the back of the cricoid cartilage, and two lateral bands blending with the fibres of the stylo-pharyngeus and the pharyngo-palatine. These all unite into a continuous layer which below passes in to the muscular coat of the stomach. The upper third or fourth of the asophagus contains exclusively cross-striated muscle fibres, like those of the pharynx. Below this, there is a zone of intermingled smooth and cross-striated fibres. The lower half of the asophagus muscle is usually composed exclusively of smooth fibres.

Around the muscular coat is a thin loose fibrous layer [tunica adventitia] connecting the œesophagus with neighbouring structures.

Vessels and nerves. - The arterial supply of the cesophagus is derived from the inferior thyreoid, the osophageal branches of the aorta, the intercostals, the inferior phrenic and the

Fig. 897.-Transverse Section of the Upper Third of the Humax Esophagus. $\times 5$. (Lewis and Stöhr.)

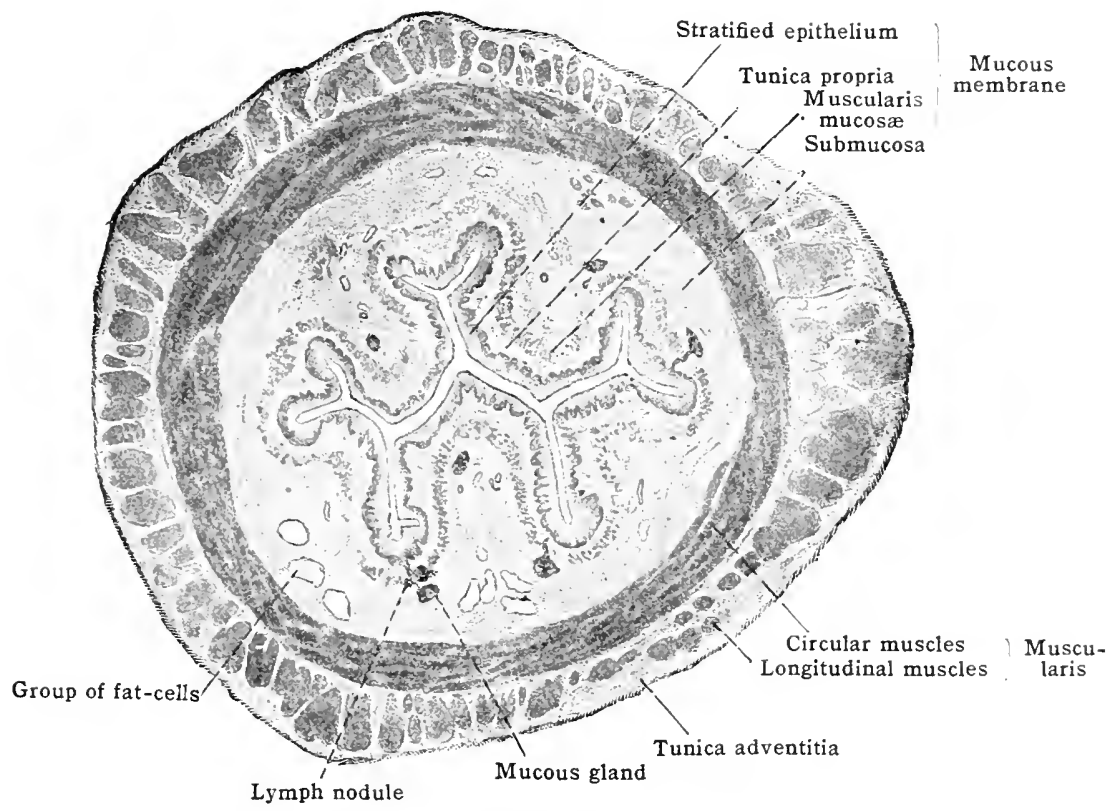

left gastric arteries. Branches pierce the wall and supply the rarious coats. The veins accompany the arteries. They form on the outer surface of the asophagus a venous plexus opening into the gastric coronary vein below and the azygos and thrreoid veins above (thus establishing a communication between portal and systenic veins). There are also numerous lymphatics in the osophagus arising chiefly in the mucosa and draining into the lower deep cervical, posterior mediastinal and superior gastric nodes. The nerves form two synpathetic plexuses, the submucous and the myenteric, from which the walls are supplied as will be described later for the stomach and intestine. Branches are received from the sympathetics, and from the vagus, including the recurrent nerve.

Development.-The embryonic osophagus is at first relatively very short, but lengthens rapidly in connection with the descent of the stomach. The upper end is still high in children, corresponding to the higher vertebral level of the larynx. The lining epithelial cells are primitively cylindrical in form, and irregular ciliated areas are found from the third fretal month up to birth (F. T. Lewis). In the embryo of about $20 \mathrm{~mm}$., there is a proliferation of the epithelium, associated with the formation of vacuoles, but the lumen does not appear to be normally occluded. The primary longitudinal folds of the mucosa appear early (third month) and at the lower end seem to participate in the rotation of the stomach (F. P. Johnson). The superficial cesophageal glands appear about the fourth month $(7 \mathrm{~s} \mathrm{~mm}$.), the deep glands at $240 \mathrm{~mm}$. (Johnson). Of the muscular layers, the circular appears first (at about $10 \mathrm{~mm}$.) the longitudinal slightly later $(17 \mathrm{~mm}$.)

Variations.-Usually a bundle of smooth muscle connects the cesophagus with the left bronchus [ $\mathrm{m}$. broncho-cesophageus], and another similarly with the left mediastinal pleura [m. pleuro-œsophageus]. More rarely there are similar bands connecting with the trachea, peri- 
cardium, etc. Pouch-like dilatations of the cesophagus may occur, especially in the upper part of its posterior wall or at the lower end. According to C. R. Robinson, the latter include (1) ampulla phrenica, just above the diaphragm, and (2) antrum cardiacum, in the abdominal portion of the asophagus. Dicerticula also occur, some of which may be derived from the embryonic vacuolization of the epithelium previously described, as may likewise the occasional congenital atresia. Abnormal strictures of the cesophagus may occur, of tenest at the upper end, at the left bronchus, and near the lower end. Finally, the cesophagus may be in part either double or absent, and may communicate by fistula with the trachea.

Comparative.--The length of the osophagus varies with the length of the neck, being shortest in fishes and amplibia where the osophagus is not well marked off from the stomach. The lining epithelium is stratified squamous in mammals and birds, but often ciliated in lower forms. I ucous glands are absent in fishes, but occur typically in all higher forms. They are found best developed toward the lower end of the oesophagus, except in mammals, where they are usually more numerous at the upper end. Dilatations may occur normally, as in the crop of birds, which is richly supplied with glands. The musculature of the osophagus is primitively entirely smooth (Oppel) as found in amphibia, reptiles and birds. A secondary replacement by cross-striated muscle is found to a variable extent in the majority of mammals and fishes.

\section{THE ABDOMEN}

The abdomen properly consists of that part of the body situated between the thorax and the pelvis. It is bounded above by the diaphragm; below, by the brim of the true pelvis; behind, by the vertebral column, diaphragm, quadratus lumborum and psoas muscles, and by the posterior portions of the ilia. At the sides it is limited by the anterior parts of the ilia and the hinder segments of the muscles which compose the anterior abdominal wall, viz., the transversus, internal oblique,

Fig. 898.-Diagram of the Abdominal Regions.

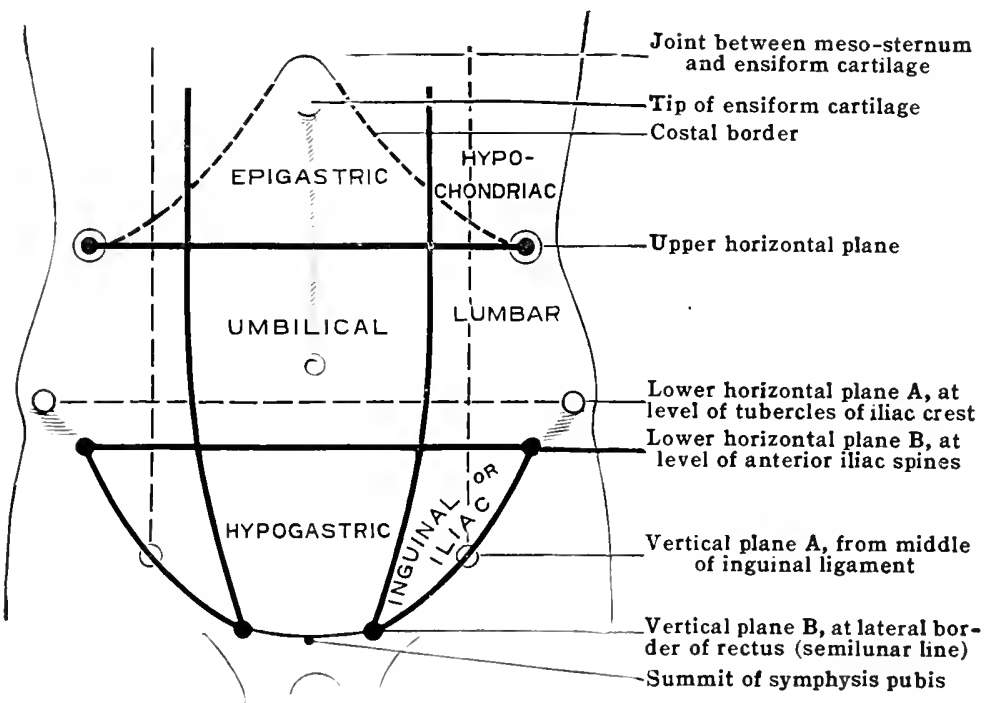

and extrual obligue. In front, besides these museles, there are the two reeti and pyramialales muscles. Extronat to the peritoneum the abdomen is tined by a spereial layer of falsciat.

It is colstomary for anatomists and physicians to divide, for purposes of deseription, the ventral surface of the abdomen, by means of two horizontal and two vertical lines, into nine regions (fig. 898). A complete uniformity in the use of the bommlary lines mating these regional subdivisions has not as yet been attained, althougli the variations in the sehemes used are not marked as coneerns the main fratures. It shonld be borne in mind that it is neeessary that the boundary lines userl should be enoverted into planes carricel through the whole depth of the abdomen and defined on the dorsal as well as the ventral surface, and that the relations defined an only be afproximate, owing to the wide range of the physiologieal variation in the pesition of the abdominal contents. The nine regions or subdivisions may he outlined as follows:- T'he upper horizontal line or plane passes through the howest point of the tenth costal cartilages, about $5 \mathrm{~cm}$. above the umbiliens, and dorsally through the second or third lumbar vertebra. The lower 
horizontal line and plane passes through the level of the anterior superior iliac spines, and dorsally about $2.5 \mathrm{~cm}$. below the promontory of the sacrum. Cunningham has proposed that this line be passed through the tuberculum eristie, therefore in a plane slightly higher than the interspinous plane. For the longitudinal lines and planes it has been customary to run vertical lines parallel with the mid-body line or mid-sagittal plane, and from the middle of the inguinal higaments. The outer border of ach rectus would seem, however, preferable as a guide for these longitudinal hines and planes, which may be easily localised above by the lateral infra-costal furrow and below by the pubic spines, leaving thus on each side an inguinal region which includes the whole of the inguinal canal. The boundary lines here indicated may be made intelligible by a reference to fig. 898. The regions thus outlined are known as the right and left hypochondriac and epigastrie regions, found above the upper horizontal line; the right and left lumbar and the umbilical regions, found between the two horizontal lines; the right and left

Fig. S99.-The Adbominal Viscera in Situ, after Remoral of the Axterior AbdomINAL Wall. (After Sarazin.)

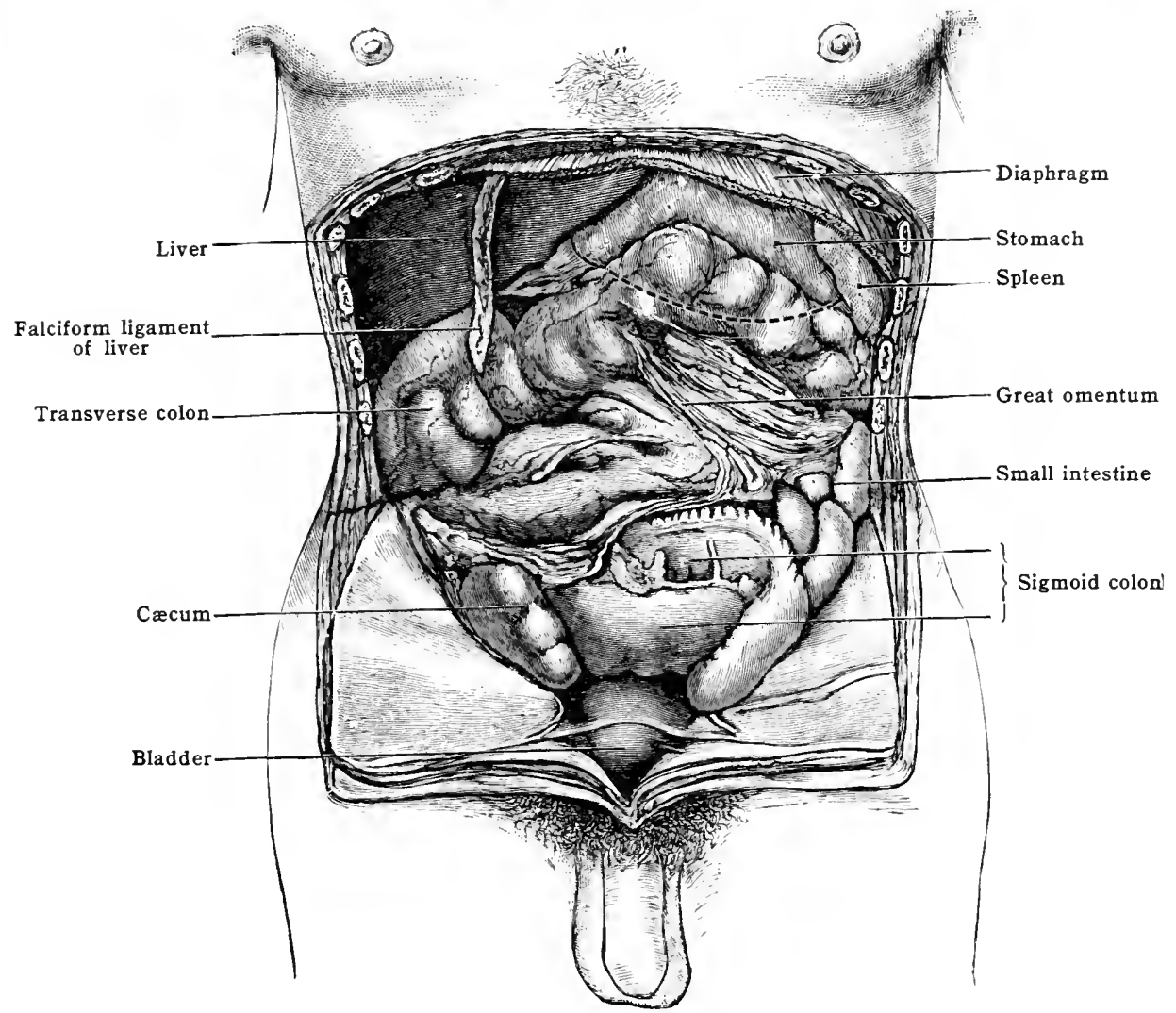

inguinal or iliac and the hypogastric regions, found below the lower horizontal lines. (According to the BNA, the lumbar regions are termed 'iateral abdominal'.)

On freely laying open an abdomen from the front, the general form of the space is seen to be an irregular hexagon, the sides of which are formed as follows:- The upper two by the margins of the costal eartilages with the ensiform cartilage between; the two lateral sides by the edges of the lateral boundary; and the two lower by the two inguinal ligament s which meet at the pubes.

In this irregular hexagon the following organs can be observed without disarranging their normal position (fig. 899). Above, on the right side, under the costal cartilages, can be seen the liver, which extends from the right across the median line to a point below the left costal cartilages. Below the liver, and lying to the left side, can be seen the anterior surface of the stomach; from the lower border of the stomach the omentum extends downward, and shining through it can be seen the middle part of the transverse colon. On each side and below the 
irregularly folded omentum are exposed the coils of the small intestine; in the right iliac fossa a part of the cæcum appears; and in the left iliac fossa the lower (iliac) part of the descending colon and the beginning of the sigmoid colon.

To the left of the stomach and under cover of the lower ribs of the left side the edge of the spleen may possibly be observed; and just below the edge of the liver, and about the level of the tip of the ninth rib, the gall-bladder may be seen. The dome of the urinary bladder may be noticed just behind the symphysis pubis and in the median line. The disposition of the viscera in the fœtus is shown in fig. 953.

General morphology-Before taking up the various individual organs included in the abdominal and pelvic portions of the alimentary canal, a brief consideration of their general morphology is desirable. The primitive canal, as already described in the embryo (in the

Fig. 900.--Digramuatic Representation of an Early Stage in the Development of the Alinentary Canal and the Peritoneum. (After Sobotta-MeMurrich.)

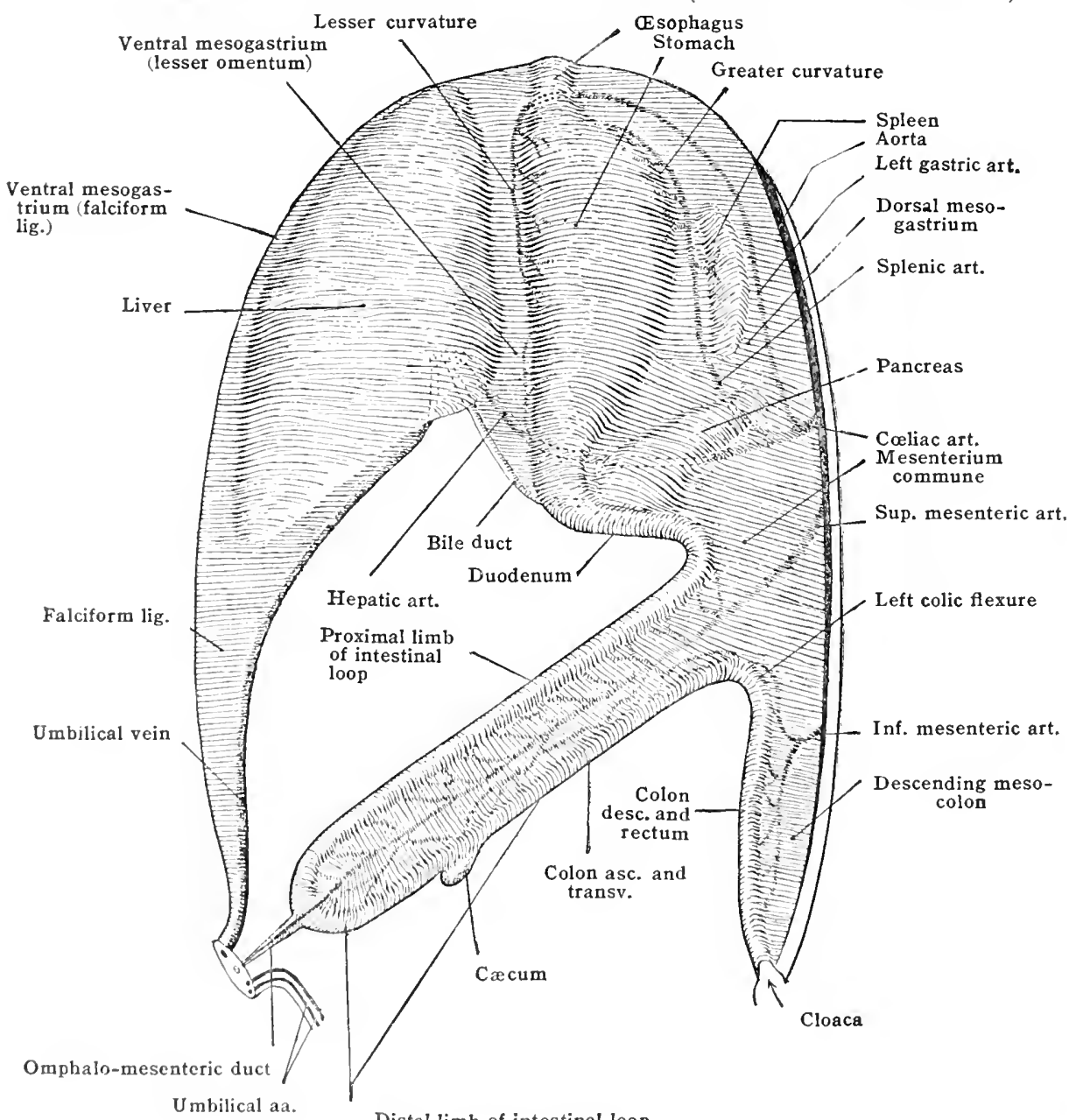

Distal limb of intestinal loop

section on Mompuogingsis), and as fommel in the lower vertobrates is a comparatively straight,

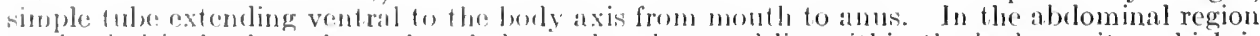
(and prinitively thromglout llowhole trunk), the anal lies within the borly eavity, which is lesed by parietal perjoneum. 'The viseral peritoneum is reflected from the mid-dorsal lime as it double latyer, the mimitime dorsol mesenlery, within which the vessels and nerves pass to the walls of the caual. Within the dorsal mesentery are also the spleen and pancreas. In the anterior (upg)er) regron of the abulomen there is also a similar primitive vontral mesentery, which contains the liver.

'The relations alowe mentioned are: indicated diagrammatically in fig. 900, which represents

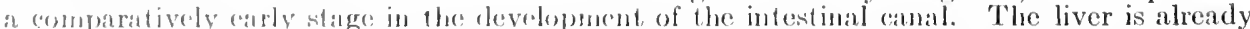

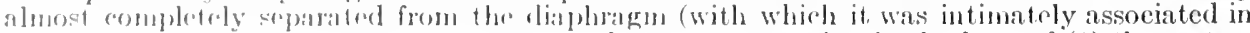
the earlier septum trunsversum). 'Tle: ventral mesentery persists in the form of (1) the gastro- 
hepatic or lesser omentum, connecting the stomach with the liver; and (2) the falciform ligament, connecting the liver with the ventral body wall.

The stomach undergoes a rotation on its longitudinal axis so that its anterior border (lesser curvature) is turned to the right, and its posterior border (greater curvature) to the left (fig. 901). Thus the posterior mesentery of the stomach [mesogastrium], bulges to the left and forward, carrying with it the spleen and pancreas. The portion of the mesentery corresponding to the pancreas, and that from the spleen to the root of the mesentery, become fused with the posterior body wall. The portion of the primitive mesogastrium between the stomach and spleen persists as the gastro-splenic omentum (or ligament), while the lower portion arches forward and downward as an extensive fold, the great omentum. The portion of the peritoneal cavity left behind the stomach is termed the bursa omentalis, or lesser sac, the remainder of the peritoneal cavity being the greater sac.

Along with the pancreas, the duodenum becomes adherent to the posterior wall. The remainder of the intestine forms a loop (fig. 901), the upper portion of which forms the jejunoileum, the lower portion the large intestine. The intestinal loop rotates counter-clockwise, so that the cæcum and ascending colon are carried over to the right side of the body cavity, where (with the corresponding portion of the primitive mesentery) they become adherent to the posterior body wall (fig. 901). The mesentery of the transverse colon persists (though fused partly with the great omentum, as explained later under development). The descending colon becomes displaced to the left side, and (together with its mesentery) becomes adherent to the posterior wall of the abdomen. The mesentery of the sigmoid colon usually persists (in part), while that of the rectum is obliterated. Through these modifications of the peri-

Fig. 901.-Diagrams Illustrating the Development of the Great Omentum, Mesentery, etc. A, Enrlier Stage; B, Later Stage.

bld, cæcum; dd, small intestine; dg, yolk-stalk; di, colon; du, duodenum; gc, greater curvature of the stomach; gg, bile duct; gn, mesogastrium; $\mathrm{k}$, point where the loops of the intestine cross; me, mesocolon; md, rectum; mes, mesentery; wf, vermiform appendix. (McMurrich after Hertwig.)
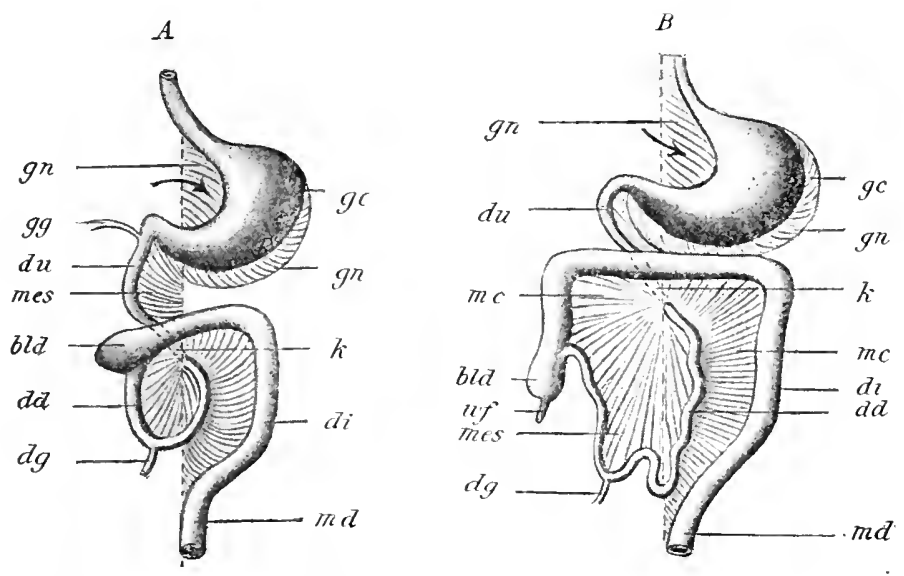

toneum, and through unequal growth in the different regions, the simple primitive intestinal tube is transformed into the complicated adult canal. The details of the transformation will be more fully discussed later.

Under certain rare conditions, the developmental process is modified so as to produce a situs inversus, which may be partial or complete, involving both thoracic and abdominal viscera. Under these circumstances, the viscera are transposed, the right and left sides being reversed.

\section{THE PERITONEUM}

The peritoneum, as has been shown, is a serous membrane which lines the carity of the abdomen from the diaphragm to the pelvic floor, and invests or covers to a varying extent the viscera which that cavity contains. Viewed in its very simplest condition, it may be regarded as a closed sac, the inner surface of which is smooth, while the outer surface is rough and is attached to the tissues which surround it.

In the male subject the peritoneum forms actually a closed sac; but in the female its wall exhibits two minute punctures, which correspond to the openings of the Fallopian tubes. That part which lines the walls of the abdomen is termed the parietul peritoneum; that which is reflected on to the viscera is the visceral peritoneum. The disposition of the peritoneum may first be studied by noting 
its arrangement as made evident in transverse sections of the abdomen at certain levels.

The first section to be described shows the peritoneum in its simplest condition. This is a transverse section through the body, at about the level of the upper surface of the fourth lumbar vertebra, and therefore about the site of the umbilicus (fig. 902).

Starting on the inner surface of the anterior abdominal wall, the peritoneum is seen to cover the transversalis fasera, and indireetly the anterior abdominal muscles; then, passing

Fig. 902.-Diagrair of Cross-section of the Abdonen, Showing the Peritoneal Relations at the Level of the Unibicus. AO, Aorta. AS. COL., Ascending colon. DES. COL., Descending colon. MES., Mesentery. M. COL., Deseending mesocolon. SI, Small intestine. T.C., Vena cava inferior.

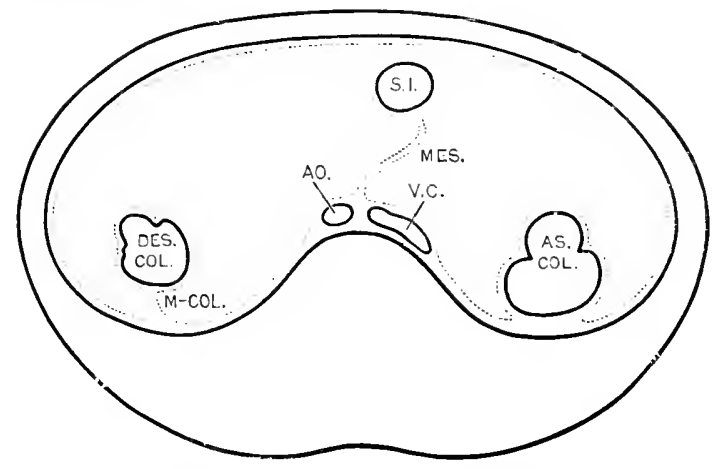

to the left, it lines the side of the abdomen, until it reaches the descending colon. This it covers, as a rule, in front and on the sides, though oceasionally it forms a mesocolon. Then it passes over the bodies of the vertebræ with the large vessels upon them, and leaves the baek of the abdomen to run forward and enclose the small intestine, returning again to the spine. The two layers thus form the mesentery, having between them a middle layer [lamma mesenterii propria] containing the terminal branches of the superior mesenterie vessels. It then passes over the right half of the posterior abdominal wall, covering the ascending colon in front and at the sides only (unless there be a mesocolon), and then passes on to the side and front of the abdomen to the point from which it was first traced.

Fig. 903.-Diagram of Cross-section of the Abdomen, Showing the Peritoneal Relations at the Level of the Foramen of Winslow. (F, of W.)

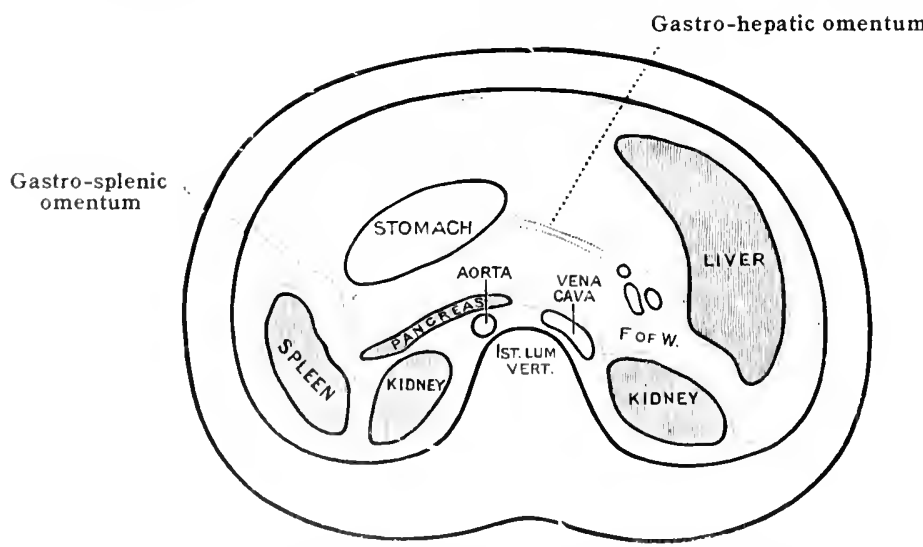

In tracing the peritoncum in a section of the bocly opposite the stomach (fig. 90.3), on a level with the first lumbar verteluri, its course becomes more complieraled and difficult to follow.

In the section aldeaty given the protomenum as a simple chosed sac can be readily con-

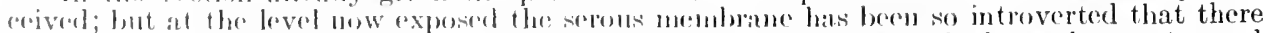
spupar to be two sates, one leating from the othere, and known respectively as the greater and

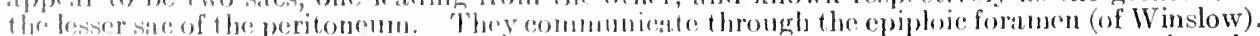

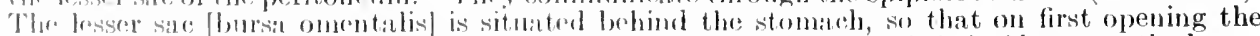

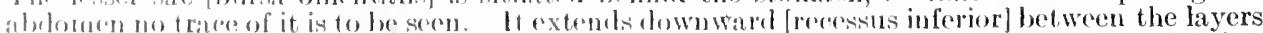
of the: grrat ormontmon (though this part of the lesser sac is largely obliterated by adhesion 
in the adult). It extends upward [recessus superior] behind the caudate lobe of the liver. The vestibule [vestibulum bursie omentalis] is the portion which lies just bebind the lesser omentum, and communicates with the greater sac through the epiploic foramen. In general, the lesser sac is limited anteriorly by the liver, stomach, and omenta; posteriorly by the posterior abdominal wall, and below, behind the great omentum, by the transverse meso-colon. Its disposition on vertical section is shown in fig. 904 .

The epiploic foramen (foramen of Winslow) (figs. 903, 906) is situated just below the liver; it looks toward the right, and will readily admit one or two fingers. It is bounded superiorly by the caudate lobe of the liver; inferiorly, by the duodenum (pars superior); posteriorly, by the vena cava; and anteriorly by the right margin of the gastro-hepatic or lesser omentum, containing the structures passing to and from the liver. Starting at the epiploic foramen, the lesser sac will be found to turn to the left.

Fig. 904.-Diagram of a Sagittal Section of the Trunk, Showing the Relations of the Peritoneum. (Allen Thompson.)

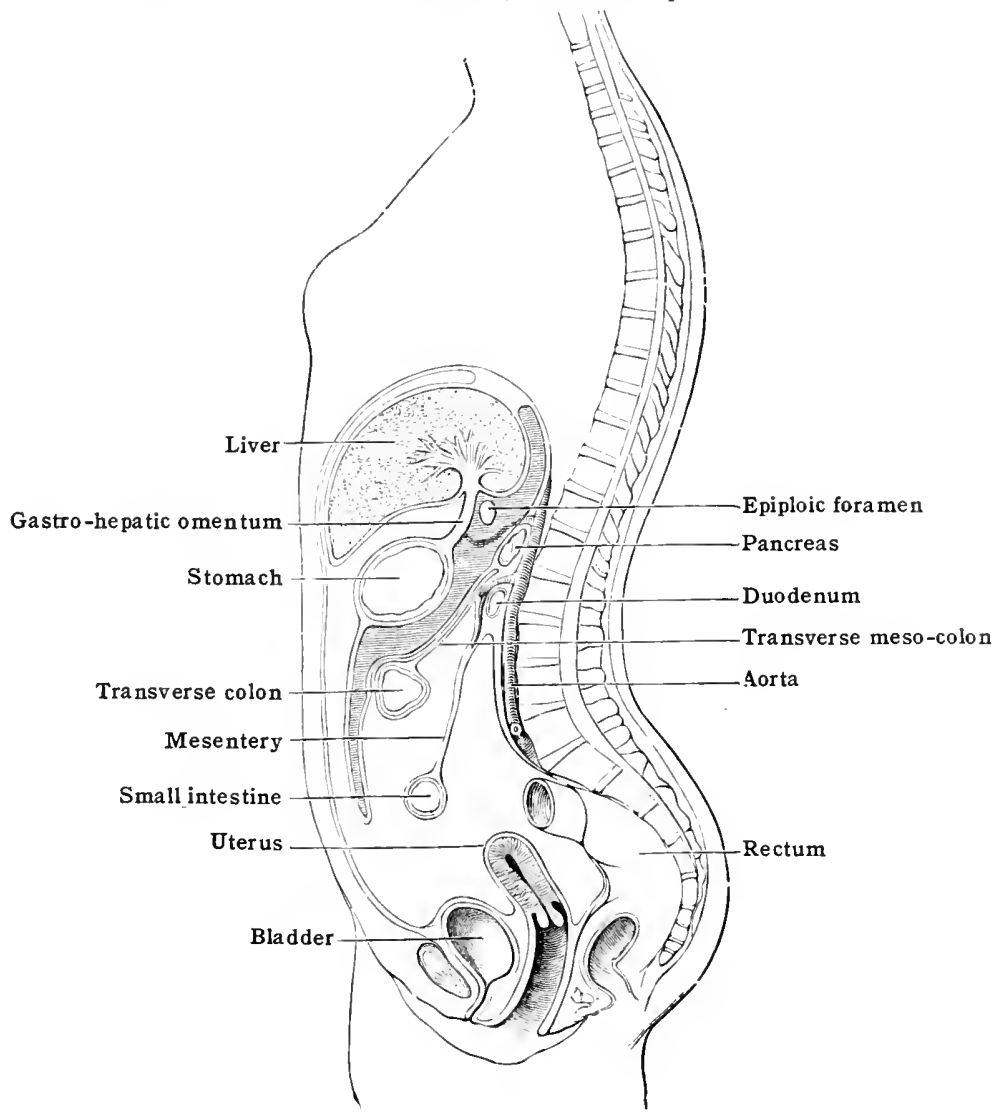

If, now, the peritoneum be viewed in a transverse section of the body at the level named, viz., through the first lumbar vertebra, it will be found that the section has probably passed through the epiploic foramen (fig. 903). Starting at the front of the abdomen and going to the right, the peritoneum is seen to line the anterior abdominal wall, to pass over the side of the abdomen, and to cover the front of the right kidney; it then extends on to the vena cava, when it becomes a part of the lesser sac; then along the back of the lesser sac, over the aorta and pancreas, which separate it from the vertebral column; next it reaches the anterior of the two internal surfaces of the spleen internal to the hilus. Here it meets with another layer of peritoneum, and helps to form the gastro-splenic ligament [lig. gastrolienale]. Leaving the spleen, it changes its direction forward and to the right, and runs to the stomach, forming the posterior, layer of the gastro-splenic ligament; it covers the posterior surface of the stomach, and leaves its mesial border (lesser curvature) to form the posterior layer of the lesser omentum, and then passes upward and to the right to the liver. In this transverse section it is only seen passing on the right margin of the lesser omentum, where it forms the anterior boundary of the epiploic foramen. Here it bends sharply around the omental margin enclosing the hepatic vessels continuing to the left as the anterior layer of the lesser omentum; and then passing to the left reaches the stomach, which it covers in front. It then forms the anterior layer of the gastro- 
splenic ligament, and once more reaches the spleen. It passes right around the spleen to the back of the hilus, where it is reflected on to the left kidney as the lieno-renal ligament (fig. 903). Hence the peritoncum passes along the side and front of the abdomen to the point from which it started. In this section the liver is so divided as to appear separated from all connection with the other viscera and the abdominal wall, and to be surrounded by peritoneum.

The course of the peritoneum in a longitudinal section of the body will now be considered (fig. 904). Starting at the umbilicus and passing downward, the peritoneum is seen to line the anterior abdominal wall. Before reaching the pelvis it covers also the urachus, the deep epigastric arteries, and obliterated hypogastric arteries, which form ridges beneath it. For some little way above the os pubis the peritoneum is loosely connected with the abdominal wall, a circumstance which is made use of in supra-pubic cystotomy. Moreover, as the distended bladder rises from the pelvis it can detach the serous membrane to some extent from the anterior abdominal wall. In extreme distension of the bladder the peritoneum may be lifted up for some $5 \mathrm{~cm}$. vertically above the symphysis. On reaching the os pubis it is refleeted on to the upper part of the bladder, covering it as far back as the base of the trigone; thence it is reflected on to the rectum, wihch it covers in front and at the sides on its upper part, rarely forming a distinct mesorectum. Between the bladder and rectum it forms in the male the recto-vesical pouch. The mouth of this pouch is bounded on either side by a crescentic fold, the plica semilunaris. In the female the peritoneum is reflected from the bladder on to the uterus, which it covers; it then extends so far down in the pelvis as to pass over the upper part of the vagina behind; thence it extends to the reetum. The peritoneum which invests the uterus is reflected laterally to form the broad ligaments. The fold between the vagina and reetum forms the recto-vaginal pouch, or pouch of Douglas. The membranc has now been traced back to the spine.

Following it upward, the sigmoid colon will be found to be completely covered by peritoneum, a mesocolon attaching the gut to the abdominal wall (shown in fig. 905). A little higher up in the median line the peritoneum passes forward, to enclose the small intestine, and, returning to the spine, forms the mesentery (fig. 904). It now passes over the third part of the duodenum to the pancreas, from which point it again passes forward to form the lower layer of the transverse mesocolon. It invests the transverse colon below and partly in front, and then leaves it to pass downward to take part in the great omentum. Running downward some distanee, it returns and forms the anterior layer of the omentum. On reaching the stomach it goes over the anterior surface, and at the upper border forms the anterior layer of the lesser or gastro-hepatic omentum, which extends between the stomach and the liver. It invests the inferior surface of the liver in front of the transverse fissure, and, turning over its anterior border, covers the upper surfare. At the posterior limit of the upper surface it leaves the liver and gor's to the diaphragm, forming the superior layer of the eoronary ligament. It covers the anterior part of the dome of the diaphragm, and, once more reaching the anterior abdominal wall, ean be followed to the umbilieus, where it was first describerl. This completes the boundary of the greater sae. On reference to the diagram (fig. 904) the student might be led to suppose that the two sacs are quite separate. This, of course, is not the case; but in a Iongitudinal seetion of the borly made any'whe to the left of the epiploie foramen (foramen of Winslow), it is impossible to show the direct connection between the two sacs. (See fig. 905.)

'The pritonem has only been traced in this longitudinal section so far as it concerns the greater sac. It now remains to follow upon the same section (fig. (304) such part of the nirmbranc as forms the lesser sac. The peritoneum here will be seen to cover the posterior surface of the stomach; thence from the lesser curvature it runs upward to the liver, forming the posterior layer of the lesser or gastro-hropatic omentum. It reaches the liver behind the transverse fissure. It "evers only a part of its postcrior surface: (caudate lobe), and is refleeted on to the diatphragm, forming the lower layer of the coronary ligament. It now goes downWarle erer the posterior part of the dome ol the diaphragm to the spine, separated from the latter by the great vessels. ()n reaching the anterior border of the panreas it pasces forward, and forms the upper layer of the transverse meso-eolon. It them covers the upper hall of the trinsverse colon, and, descending, forms the innermest layer of the great omentum. (l'he inner layers of the great omentum arrasully fuserl in the adult, however, thus olditerating this portion of the lesser sir.) It inow aseronds, and, arriving at the greater eurvature of the stomach, 
passes on to its posterior wall. At this point its description was commenced. The general relations of the greater and the lesser sac are also evident in fig. 905 showing the lines along which the parietal peritoneum is reflected from the posterior abdominal wall as the visceral peritoneum, forming the various mesenteries and covering the various abdominal organs.

Fig. 905.-Reflections of the Peritoneum on the Posterior Abdoninal Wall. (From Rauber-Kopsch, modified.)

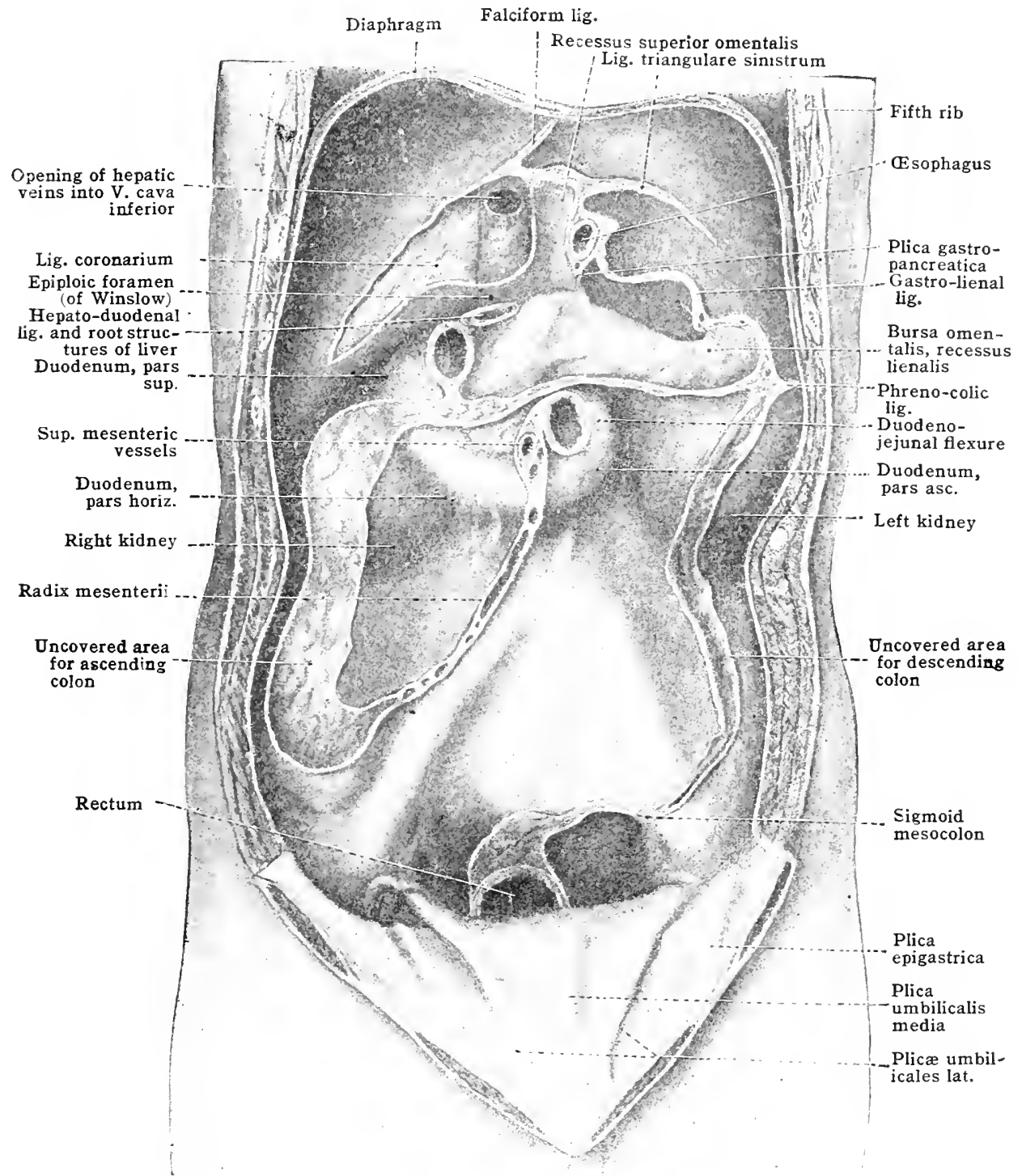

The precise manner in which certain organs-such as the liver, the crecum, the duodenum, and the kidneys-are invested by peritoneum is described in the accounts of those viscera. To such accounts the reader is referred for a description of the many 'ligaments' (such as those of the bladder and liver) which are formed by the peritoneum.

The great omentum.-As is evident from its development, the great omentum [omentum majus] is formed of four lavers of peritoneum, though this is quite impossible to demonstrate in an aduit, the individual lavers having become adherent.

The great omentum acts as an apron, protecting the intestines and providing 
them with a heat-economising covering of fat. It is nearly quadrilateral in shape, and is variable in extent. In fig. 904 the great omentum is shown to be connected with the greater curvature of the stomach, on the one hand, and the transverse colon, on the other. Originally it extended backward above the transverse colon and mesocolon to the posterior abdominal wall. The line along which it fuses with the transverse colon and mesocolon during development is shown in fig. 904.

Mr. Lockwood has made some investigations on the lengths of the transverse meso-colon and great omentum in thirty-three eases. In twenty, under the age of forty-five, only one subject had a great oment um long enough to be drawn beyond the pubic spine; in five, the omentum reached as far as the pubes. In the cases beyond forty-five years it was the exception rather than the rule to find an omentum which could not be pulled beyond the lower limits of the abdomen.

The lesser omentum [omentum minus] consists of a double layer of peritoneum extending between the stomach and the liver. If the two anterior layers of the great omentum are traced upward, they are seen to enclose the stomach, and then

Fig. 906.-Abdominal Viscera, Anterior View, after Renoval of a Part of the Liver And Intestines. (Rauber-Kiopseh.)

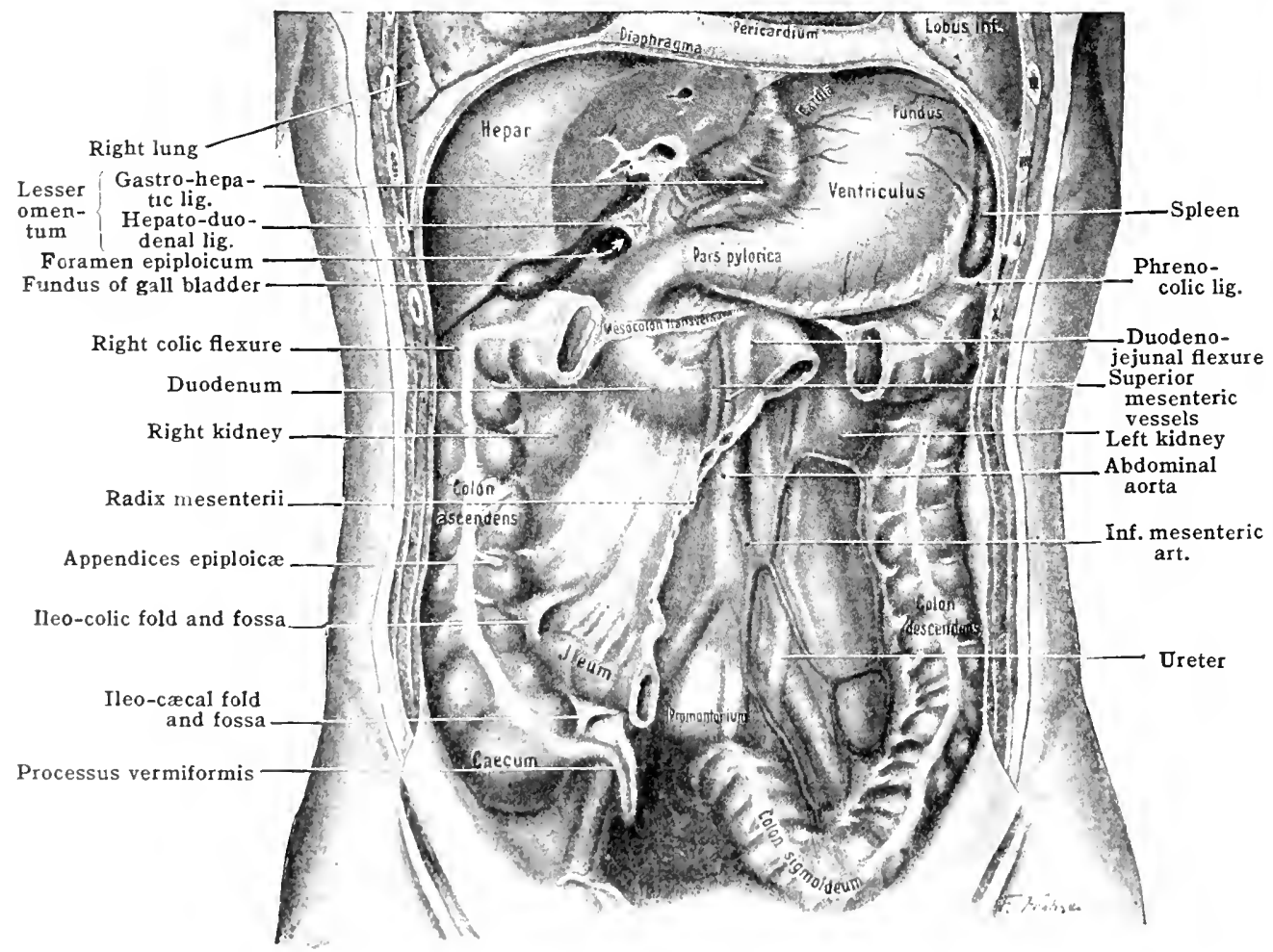

join together again at the lesser curvature to form the lesser omentum (fig. 904). It is connected above with the portal (transverse) fissure and the fissure for the duetus venosus; bolow, with the lesser curvature of the stomach; the left extremity encloses thre a sophlagus; the right border contains the hepatic vessels and is free, forming the anterior bountary of the epiploic foramen (see fig. 906).

The lesser omentum is divided into two parts. The portion connecting the portal fissure of the liver with the first part of the duodenum, and enelosing the root struetures of the liver, is callerd the he pato-fuordenal ligmment [lig. hepatoduodenale]. 'The portion of the lesser omentum comberting the Irsser corvatire of the stomith with the fissure of the ductus venosus is the

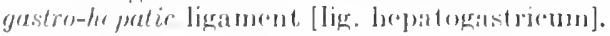

'Ther gastro-splenic ligament [lig. gitstrolienale] connects the loft extremity of the stomateh with the splene, rontinuing the bayers of peritoneum which enclose the stomiteh (fig. $9(0) 3)$.

The gastro-phrenic and phreno-colic ligaments. As the peritonemm passes from the diaghrigm to the stomach it forms a small fold just to the left of the 
œsophagus. This is the gastr o-phrenic ligament. A strong fold of the membrane also extends from the diaphragm (opposite the tenth and elerenth ribs) to the splenic flexure of the colon, and is known as the phreno-colic (costo-colic) ligament [lig. phrenicolienale]. (See figs. 905, 906.)

Minute anatomy.-The peritoneum, like all serous membranes, consists of two layers; a lining layer composed of simple squamous epithelium (mesothelium), and an underlying layer of fibrous connective tissue. The latter is highly elastie, and denser in the parietal than in the visceral layer. It often contains fat. In mesenteries and similar struetures, the eonnective tissue is usually very scanty, except surrounding the vessels and nerves. Ruptures often oceur in the omenta, which thus become fenestrated in structure. The visceral peritoneum is usually closely attaehed to the organs for which it forms the outer serous tunic, but the parietal peritoneum is often loosely attached to the adjacent wall by a fatty subserous layer [tela subserosa]. Smooth muscle oecurs frequently in the various peritoneal folds.

The peritoneal cavity contains normally a very slight amount of watery fluid, which serves to lubricate the smooth peritoneal surface and thus to eliminate friction between adjacent surfaces during the movements of the alimentary canal.

Vessels and nerves.-The peritoneum is in general somewhat sparsely supplied with bloodvessels from various adjacent trunks. Lymph-vessels also oceur, but they probably do not conneet directly with the peritoneal eavity by stomata (as is found in the frog and as elaimed by some to oceur in man). They communicate with the lymphaties of neighbouring regions. The nerves are also comparatively scaree. They are partly of sympathetic origin (vasomotor), and partly sensory nerves from the intereostal ( 7 th to 12 th), and lumbar nerves. The sensory nerves are more frequent in the parietal peritoneum and end in the conneetive tissue, either freely or in special end-organs (varying from simple end-bulbs to Pacinian corpuscles).

Development.-The principal features in the development of the peritoneum have already been mentioned in the section on MorphogenEsis and in the remarks on the general morphology of the intestinal canal (p. 19). Further details will be ineluded later under the development of the intestine, etc.

Variations. - Variations in the form and relations of the peritoneum are exceedingly common, and are most commonly of developmental origin. Variations in the form and relations of the various abdominal organs necessarily involve corresponding modifieations in the peritoneum. The diaphragm may be incompletely formed, leaving the peritoneal cavity in communication with the pleural, or more rarely the perieardial cavity. The primitive dorsal mesentery of the intestine [mesenterium commune] may persist unmodified (in about 2 per cent. of adults), or the various secondary changes may be inhibited at any stage. Thus the stomach or the intestinal loop may fail, either wholly or partly, to undergo their charaeteristie rotations. The adhesions of the various mesenteries may be incomplete, or they may be more extensive than usual. For example, the sigmoid mesocolon may be more or less completely obliterated by adhesion, and numerous unusual peritoneal pockets or ligamentous bands may be formed in this way in various loealities. Variations thus due to extensions of the normal developmental process are sometimes difficult to distinguish from pathological arlhesions caused by peritonitis.

Comparative.-As previously mentioned, the primitive body eavity in vertebrates extends throughout the trunk region. In the eyclostomata, this primitive relation persists, the perieardial eavity remaining in communication with the general body cavity. In all higher forms, however, the pericardial cavity becomes entirely separated. In amphibia the lungs lie in the general (pleuroperitoneal) body eavity; in the reptiles and birds, they are partially separated; but a complete separation of the pleural eavities oecurs only with the formation of the definite diaphragm in mammals.

The formation in the peritoneal cavity of a complete dorsal mesentery, and an ineomplete ventral mesentery (in the hepatie region) is typical for all classes of vertebrates. slight modifieations in the form of the mesenteries depend ehiefly upon the different degrees of complexity in the development of the various parts of the intestinal traet. The markerl changes associated with extensive secondary adhesions of the primitive peritoneal struetures are found only among the higher mammalia, especially in man.

\section{THE STOMACH}

The stomach [ventriculus; gaster] is a dilation of the alimentary canal succeeding the osophagus. In the stomach the food is mixed with the gastric juice and reduced to a viscid, pulpy liquid, the chyme [chymus], which undergoes a certain amount of digestion and absorption before passing into the duodenum.

The stomach (figs. 906, 907) is a somewhat pear-shaped organ located in the upper, left side of the abdominal cavity. It presents a body [corpus ventriculi], with an enlarged upper end or fundus, on the right side of which is the cardia, the aperture communicating with the osophagus. The body of the stomach is extremely variable in form, as will be explained later, but is in general divisible into a more expanded upper two-thirds, the cardiac portion [pars cardiaca], which is nearly vertical, and a more constricted lower third, the pyloric portion [pars pylorica], which turns horizontally toward the right. The pyloric portion often presents toward its lower end a slight, variable dilation, the antrum pylori, 
succeeded by a short constricted pyloric canal (Jonnesco). At the lower end of this canal the pylorus forms the aperture leading into the duodenum, and contains a thick sphineter derived from the circular fibres of the muscular layer. The stomach has two borders and two surfaces. The medial (or upper) border forms the lesser curvature [curvatura ventriculi minor], which is concave (except near the pylorus) and gives attachment to the lesser omentum. The lateral (or lower) border forms the greater curvature [curvatura ventriculi major], which is convex, and gives attachment to the great omentum. The curvatures separate the anterior surface [paries anterior], which faces forward and upward, from the posterior surface [paries posterior], which is placed backward and downward.

Dimensions. - The dimensions of the stomach are subject to great variation and therefore only a gross approximation can be given. The length of the lesser curvature averages about $10 \mathrm{~cm}$. $(7.5 \mathrm{~cm}$. to $15 \mathrm{~cm}$.), and that of the greater

Fig. 907.-Longitudinal Section of Stomach, Showing the Interior of the Posterior HALF. (Rauber-Kopsch.)

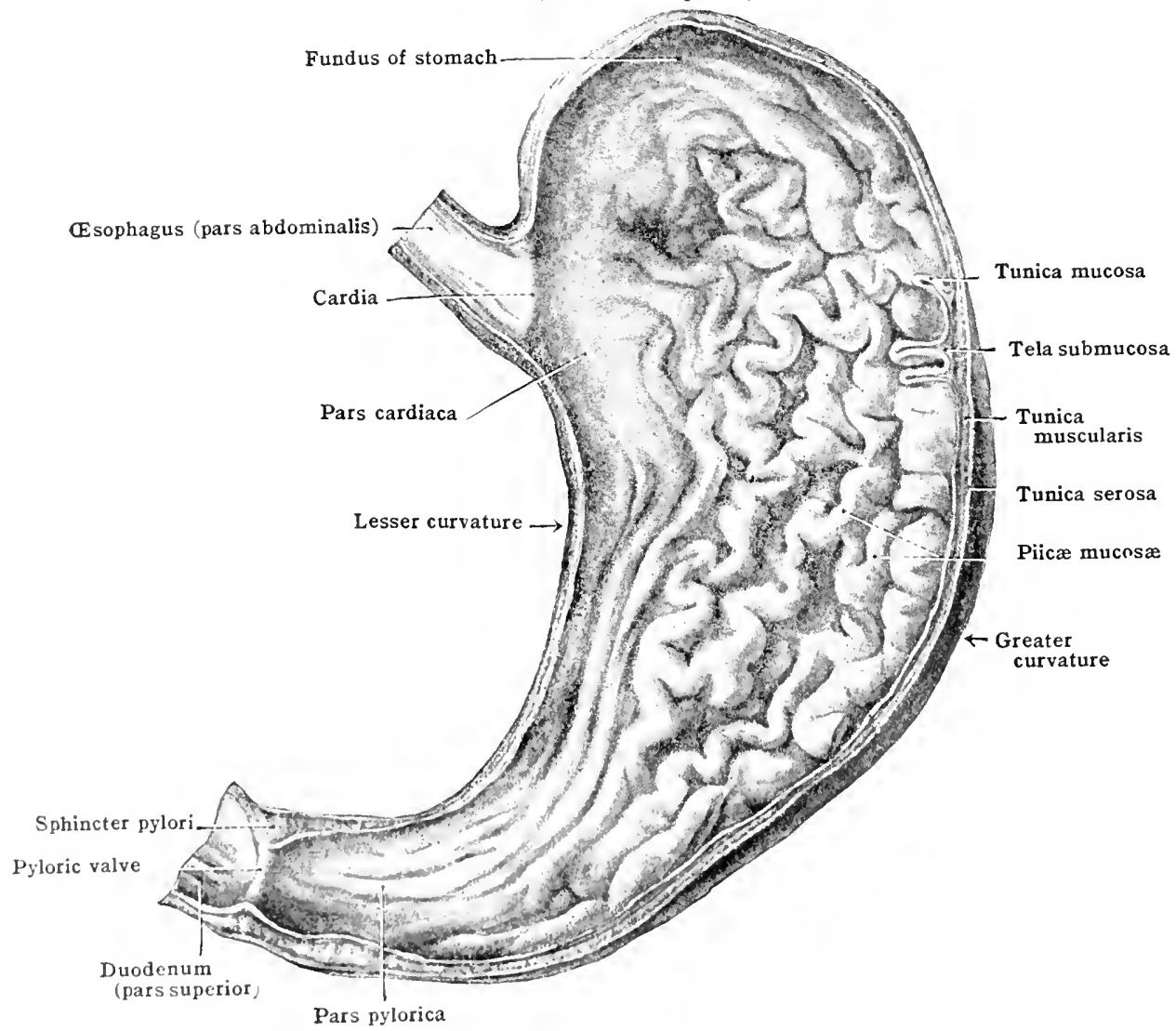

curvature is threr or four times as great. The diameter varies exceedingly aceording to the amount of contents. When nearly empty, it presents, especially in the pyloric portion, a narrow tubular form, with a diameter of about $4 \mathrm{~cm}$. or 5 cm. (fig. 1108, Section XIII). The liameter of the pylorus, which is the narrowcst point in the alimentary canal when constricted is only about $1.5 \mathrm{~cm}$. It is distensible, however, ats hard borlies with diameters of $2 \mathrm{~cm}$. or more may readily pass through.

The average capacity of the stomach is between one and two litres, being subject to extrene individual variations. In the newborn, it averages about 30 ce. (25) to 35 (c). , increasing very rapully in the early postnatal months and reaching an alverage of $270 \mathrm{ce}$ at one y'ar (Iissmenko). The average weight of the adult stomach is about $135 \mathrm{gm}$.

Position and relations of the stomach. - The position and relations of the stomarel, like its form and strueture, are subject to many variations in different indi- 
viduals, and in the same individual according to changes in physiological condition, posture, etc. It is therefore difficult to give a concise and accurate description.

The normal position of the stomach has long been disputed. It is generally recognised that the long axis is oblique, extending from above downward, forward and to the right. Some, however, especially among the older anatomists, have maintained that the gastric axis normally approaches more nearly to the horizontal type, with the pylorus but little below the cardia (approximately the position shown in figs. 915, 916). Others, especially among the more recent anatomists, have maintained that the axis of the stomach is normally more nearly vertical in position (see fig. 1125, Section XIII). The results of an extended and careful study, both in formalin-hardened bodies and by means of the Rœntgen-rays in the living body, demonstrate that there is much variability in the position of the stomach. Both the horizontal and the vertical types may occur as the extremes of normal variation, but the more usual type is the intermediate oblique position. The gastric axis, however, is not straight, but somewhat curved and bent in a reverse L-shape. The larger cardiac portion is approximately vertical (especially when the trunk is in the upright posture) the smaller pyloric portion more nearly horizontal (figs. 895, 906, 918,919). In the empty stomach, the pylorus opens into the duodenum from left to right. In distention, however, the pylorus is carried in front of the duodenum. In extreme distention, it is carried to the right and downward so as to open upward and to the left.

Fig. 908.-Longitudinal Section of the Pyloric Portion of the Stomach. (Cunningham, Trans. Royal Soc. Edinb., vol. 45.)

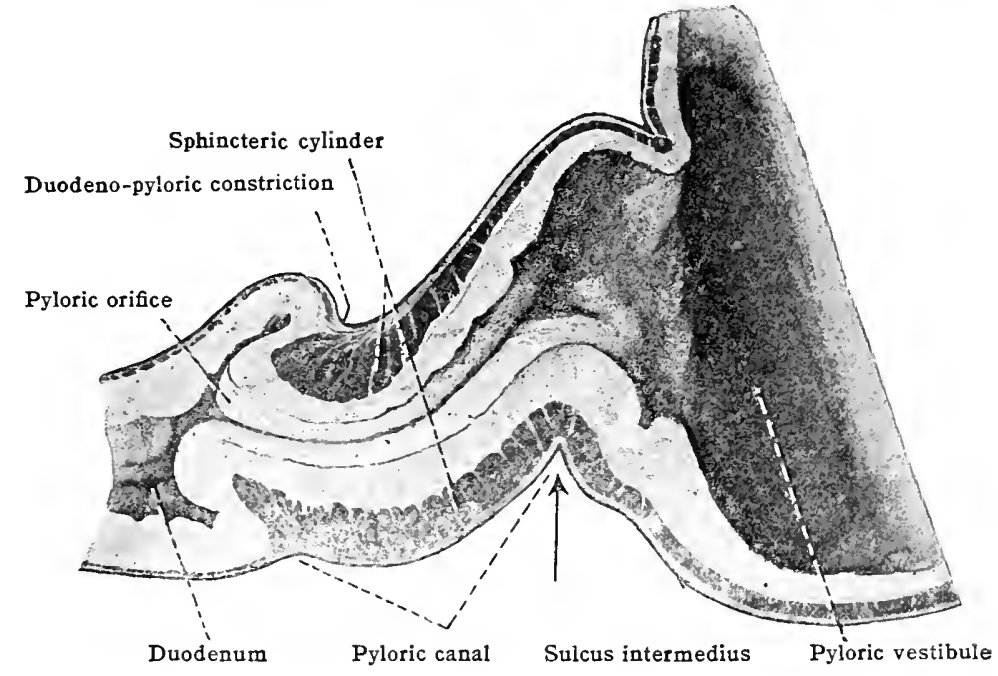

In surface relation (fig. 914), the stomach lies within the left hypochondriac and the epigastric regions. Often, however, especially when distended, it extends into the umbilical and even the right hypochondriac region. When empty, it usually lies almost entirely in the left half of the body, with the pylor'us not more than $1 \mathrm{~cm}$. or $2 \mathrm{~cm}$. to the right of the mid-sagittal plane. When distended, the long axis of the stomach is lengthened and the pylorus is displaced $5 \mathrm{~cm}$. or more to the right and downward. In distention, the stomach expands in all directions (except posteriorly), and cloes not appear to rotate as is sometimes stated. The position of the stomach, especially when distended, also varies appreciably according to the posture of the body. It sags downward when the body is in the upright position, and to the right or left when the body is placed on the corresponding side. The cardia lies on the left side of the 10 th or 11 th thoracic vertebra, and corresponds to a surface point behind the left 7 th costal cartilage about $2.5 \mathrm{~cm}$. from its sternal end. The pylorus usually lies opposite the right side of the 1st lumbar vertebra, about midway between ensiform cartilage and umbilicus, or in Addison's 'transpyloric line,' midway between the suprasternal notch and the symphysis pubis, when the body is recumbent; but descends to the $2 \mathrm{~d}$ or lower in upright posture. The fundus corresponds to the left dome of the 
diaphragm (which separates it from the lung and heart), opposite the sixth sternocostal junction. The fundus of course rises and falls with respiratory movements of the diaphragm, the excursion being from 2 to $6 \mathrm{~cm}$.

The relations of the stomach with surrounding organs are indieated diagrammatically in figs. 915 and 916 . The anterior surface is in contact on the right with the left lobe of the liver, the pylorus reaching the quadrate lobe; on the left it is in contact with the diaphragm (separating it from the heart and left lung); and below with the anterior body wall by a triangular area of variable size. The posterior surface is in relation (separated by the lesser sac) with the pancreas, above which are areas of contact with the diaphragm, spleen, left kidney and suprarenal body; below the pancreas, the stomach is in contact with the transverse mesocolon, and through this with the transverse colon and coils of small intestine. The relation with the cluodeno-jejunal angle is indicated in fig. 895 . Further details concerning topography of the stomach are given in section XIII on Clinical and Topographical Anatomy.

Peritoneal relations. - The stomach is covered by peritoneum in its whole extent, except immediately along the curvatures and upon a small triangular space at the back of the eardiac orifice, where the viseus lies in direct contact with the diaphragm and possibly with the upper part of the left suprarenal gland. It is enclosed between two layers. These two layers at its lesser curvature come together to form the gastro-hepatic portion of the lesser omentum, and at the greater curvature extend clownward to form the great omentum (figs. 903, 904). At the left of the osophagus the two layers pass to the diaphragm, form-

Fig. 909.-Surface View of Gastric Mocosa. $\times 4$. (Sobotta-MeMurrich.)

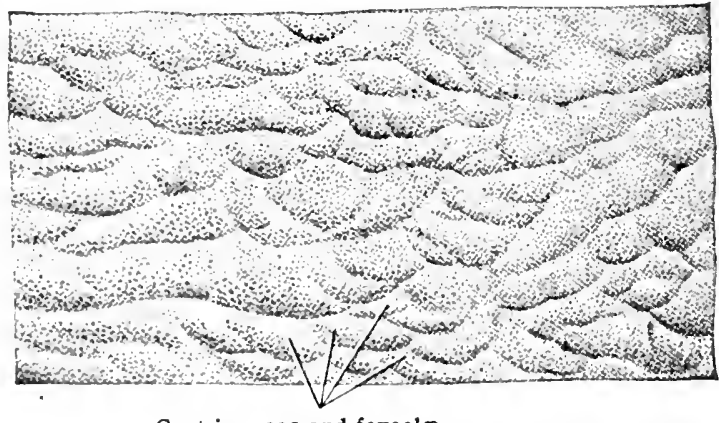

Gastric areas and foveolæ

ing the gastro-phrenic ligament; and at the fundus they pass on to the spleen, forming the gastro-splenic ligament.

The posterior surface of the stomach is in relation with the lesser sac (bursa omentalis), forming part of its anterior wall. The anterior surface of the stomach is in relation with the greater sac of the peritoneal eavity.

Minute anatomy. - The stomach is composed of the four typical layers of the alimentary canal-mucosil, submucosi, muscularis and serosia. 'The mucosa (figs. 907, 908, and 909) is thrown into a series of conirse folds (plica meosa), chicfly longitudinal, which disappear when the stomach is distended. Nlong the lesser eurvature, the ridges are more regular (eorresponding to Waldeyer's 'Mlagenstrasie') and form a longitudinal grooved channel from eardia to pytorts. Epon etoke rxamination (fig. 909) the inner surface of the mucosa presents a somewhat warty ('mammilatod') appearance, due to numerous small elevated areas [area gastrical, varying from 1 to $6 \mathrm{~mm}$. in dianetor. When examined with a lens, it is seen that rich areat is besel with nunurous small pits [foveote gastricie], separated by partitions which somnotimes (esperially in the pyloric region) boar villus-like prolongations [pliea villose]. The average number of fovestic is estimated at $87 \mathrm{per}$ sq. mm., or more than 6 millions for the contire stomach (Toldt). Into (ach pit or foveola opon 3 to 5 gastrie glands. The entire

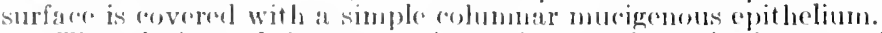

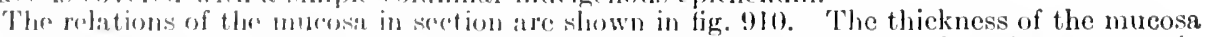
varies, lwing greatest (about '2 1mm.) in the pylorie regiom, dereasing to less than $.5 \mathrm{~mm}$. in the cardiac: region (Kiblliker). Ther lamina propria is erowed with glands, of which three variofies are distinguishorl. The rardiac glands are tubulo-racemose (chiefly mueous) glands ocenpying a narrow zonc a few millimetris in width adjacent to the cardiac orifice. The

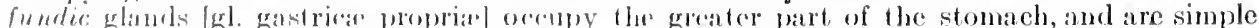
fortly brancherl) fubmlar glands (fig. 910). They eontain three varieties of cells-mucous

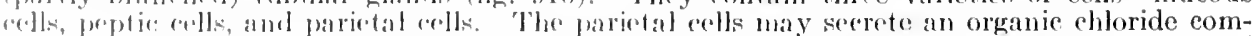
ponarl, hat the Jic' of the gastric juice is formed not in the gland tubules but at the surface of 
the mucosa (Harvey and Bensley). The pyloric glands [gl. pylorica] are branched tubular glands occupying the pyloric region. Whether they are merely mucous or also secrete pepsin is still in dispute.

The interstitial tissue of the lamina propria contains diffuse lymphoid tissue and a few small lymph nodules, especially in the pyloric region. The muscularis mucosa is a thin sheet of smooth muscle lying just below the fundus of the glands and is composed of an inner circular and an outer longitudinal layer.

The tela submucosa (fig. 910) is a very loose areolar, vascular layer which permits the wrinkling of the mucosa according to the degree of distention.

The tunica muscularis contains three layers of smooth muscle (figs. 911, 912, and 913). The outer or longitudinal layer [stratum longitudinale] is thickest along the lesser curvature, and is continuous with the longitudinal fibres of the oesophagus and the duodenum. On thes anterior and posterior walls of the antrum pylori, the longitudinal fibres form thickened bands,

Fig. 910.-Diagramiatic Section of the Stomach Wall Showing (A.) The Blood vessels, $(B)$ the Tunics, and $(C)$ the Lymphatics. $M$, Mucosa. $H_{1}$, Muscularis mucose. $S$, Submucosa. I, Circular, and O, longitudinal muscle layer. (Szymonowicz, after Mall.)

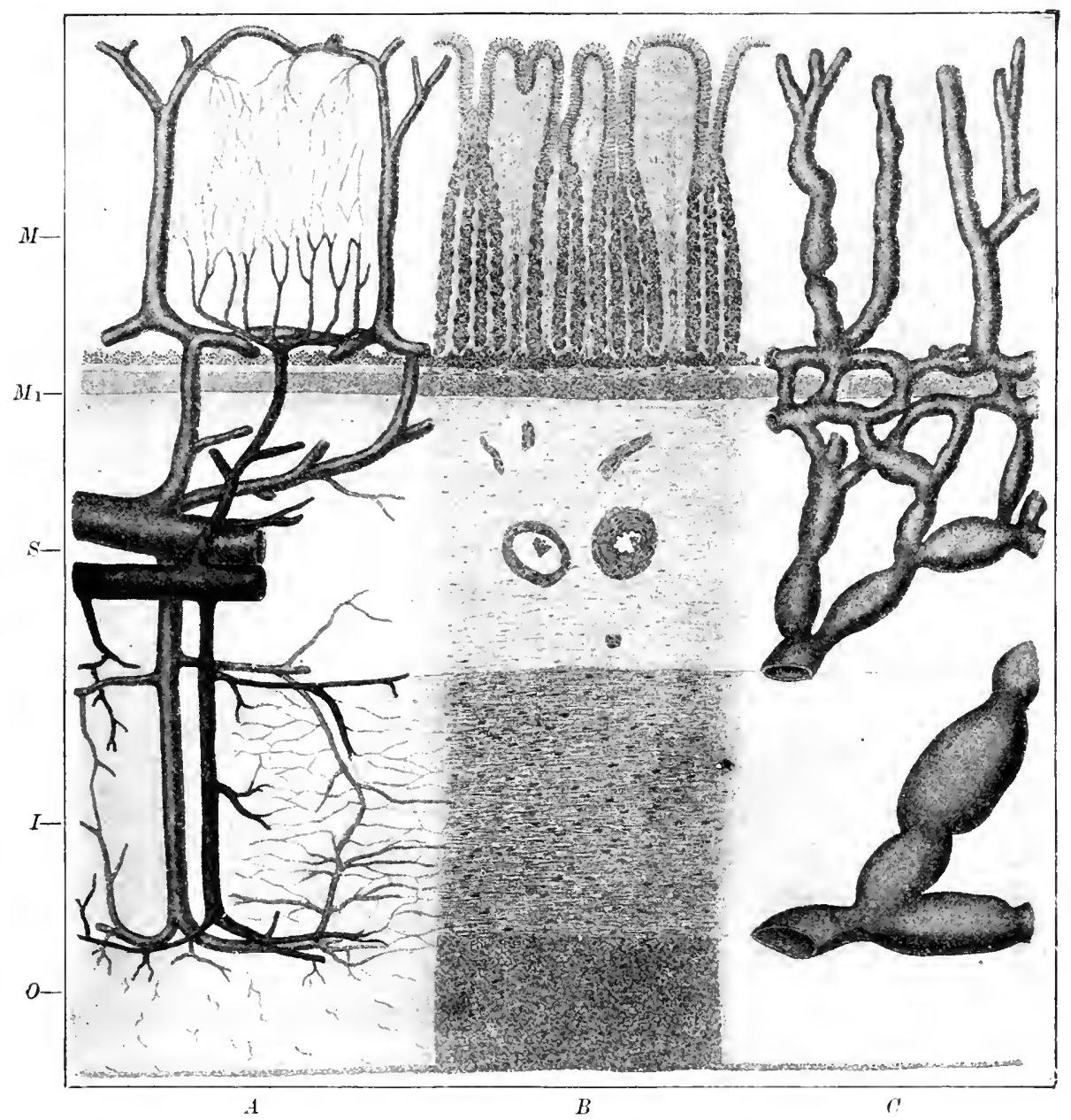

the ligamenta pylori. The middle or circular layer [stratum circulare] is continuous with the circular fibres of osophagus and duodenum and surrounds the entire stomach. It is especially thickened in the region of the pyloric canal, at the lower end of which it forms a thickened ring-like band, the pyloric sphincter [m. sphincter pylori]. The inner or oblique laver [fibræ obliquæl is composed of fibres continuous with the decpest circular fibres of the oesophagus. They form an incomplete layer which encircles the fundus and passes obliquely downward around the body of the stomach toward the greater curvature.

The external tunica serosa is formed by the peritoneum, and has the smooth shiny appearance and the structure typical for a serous membrane.

Blood-vessels. - The stomach receives its blood-supply from many branches. From the coliac axis there is the left gastric artery, which runs along the lesser curve from left to right, anastomosing with the right gastric branch of the hepatic. Along the greater curve rum the right and left gastro-epiploic arteries, anastomosing at the middle of the border, the left being 
a branch of the splenic, the right a branch of the hepatic, through the gastro-duodenal artery . The stomach also receives branches from the splenic (vasa brevia) at the fundus. The vascular arches along the curvatures of the stomach are comparable to those in the intestinal mesentery (Mall).

The blood of the stomach is returned into the portal vein. The coronary vein and pyloric vein open separately into the portal vein; the right gastro-epiploic vein opens into the superior mesenteric, the left into the splenic.

The arrangement and distribution of the blood-vessels within the stomach wall are illus-

Fig, 911.-A Dissection of the Musculature of the Stomach. (Lewis and Stöhr, after Spalteholz.) $a$ and $e$, Longitudinal layer. $b$ and $d$, Circular layer. $c$, Oblique layer. Py, Pylorus. S.I., sulcus intermedius.

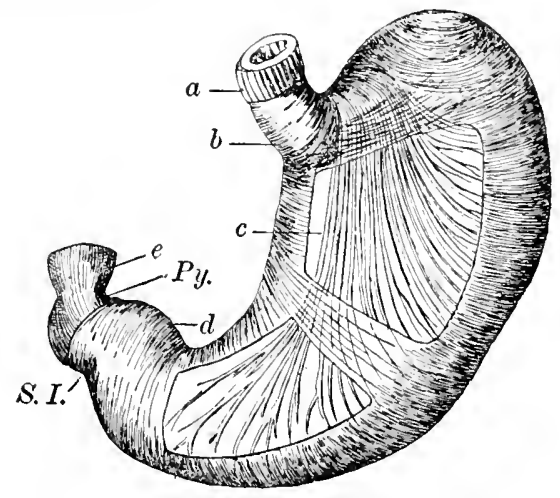

trated in fig. 910. The rich capillary plexus in the mucosa supplies the glands and also serves for absorption.

Lymphatics.- There is a set of nodes lying along the lesser and the pyloric portion of the greater curvature, and others at the pyloric and cardiac ends. These are entered by lymphatic vesscls which, beginning in the mucous membrane (fig. 910), accompany all the gastric veins, but chiefly those of the lesser curvature. Vessels also accompany the left gastro-epiploic veins to terminate in the splenic nodes. On its way to the receptaculum chyli, the gastric lymph passes through groups of nodes [lymphoglandula pancreaticolienales] situated above and bchind the head and neck of the pancreas.

Figs. 912 and 913.-Dissections Showing the Muscular Layers of the Stomach. $\times 1$. (From Toldt's Atlas.)
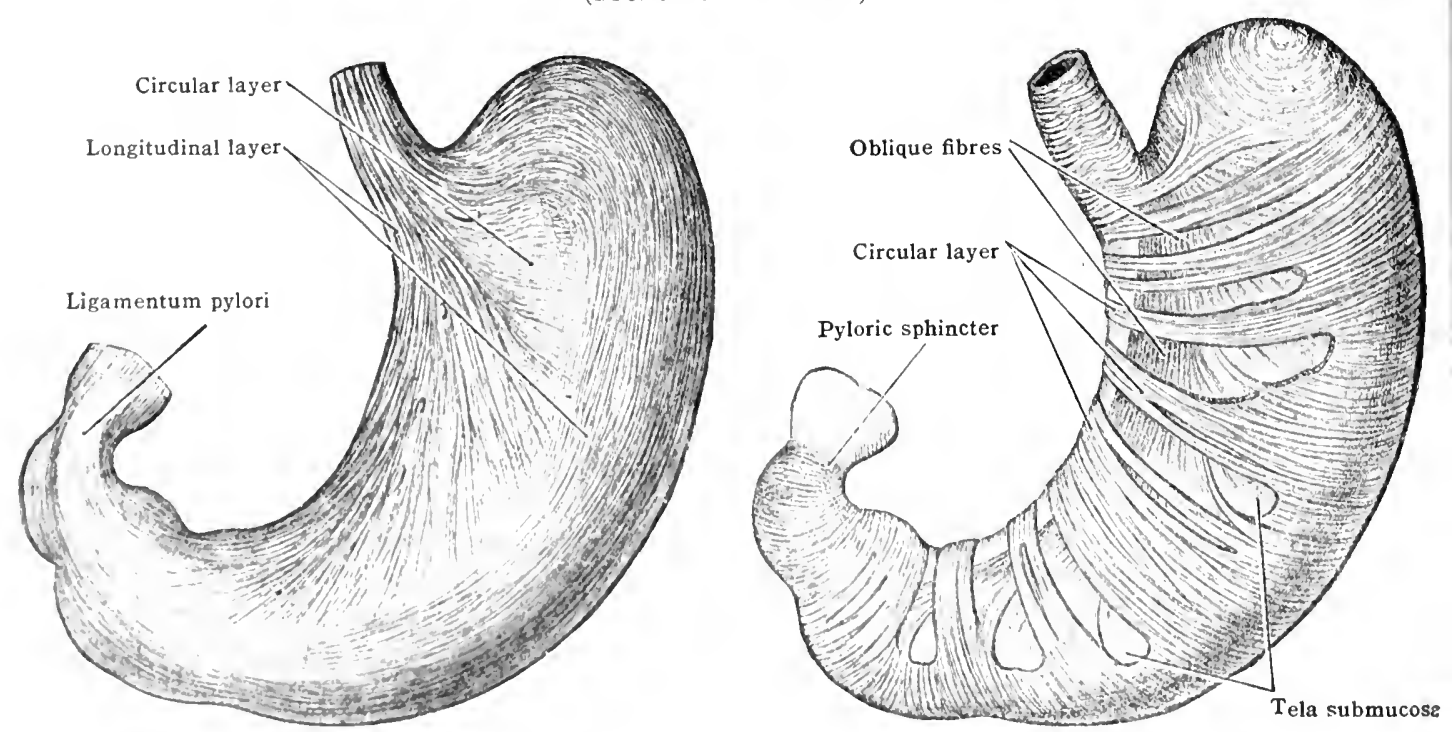

Tho arrangerment of the lymphatio plexns within the stomach wall, beginumg with blind

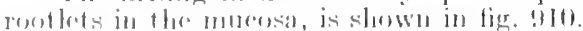

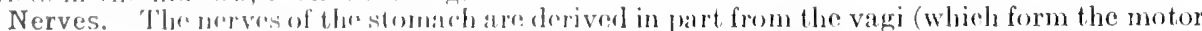
fibure of the stemath), the right vagus descending on the posterior wall, and the left on the

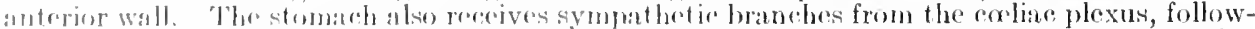
ing the arterios. Sumll ganglia recor along hoth vagus and sympathetic branches (Remak).

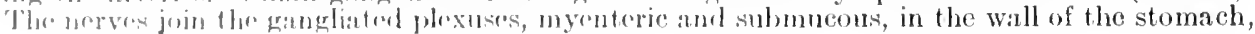


from which branches are distributed to the muscularis and the mucosa as for the intestine in general.

Development.-The stomach at first lies in the mid-sagittal plane in the cervical region. It participates in the general descent of the viscera (the oesophagus becoming correspondingly lengthened) and reaches its permanent vertebral level in the $17 \mathrm{~mm}$. embryo (Jackson). In the meantime, beginning in the $7.5 \mathrm{~mm}$. embryo ( $\mathrm{F}$. T. Lewis), a rotation of the stomach has occurred. The rotation is around the long axis, so that the anterior border (lesser curvature) is turned to the right, and the posterior border (greater curvature) to the left. The right surface therefore becomes posterior and the left anterior. During the process of descent, the pyloric end is the first to become fixed (at about $12 \mathrm{~mm}$.). As the cardiac end continues to descend, it is displaced to the left, so the oblique position of the stomach is established early. The stomach is at first spindle-shaped, but the upper end begins to enlarge at about $10 \mathrm{~mm}$. The fundus develops somewhat later as a localized outgrowth (Keith and Jones).

The fotal stomach is somewhat crowded to the left by the relatively large liver (fig. 953).

Fig. 914.--Outline Showing the Average Position of the Abdoninal'iViscela in 40 Bodies, on a Centimetre Scale (Reduced to .36 Natural Size). $M L$, anterior mid-line $E F$, horizontal line half-way between pubes and suprasternal margin ("transpyloric" line), $C D$, line half way between pubes and line $E F$. (Addison.)

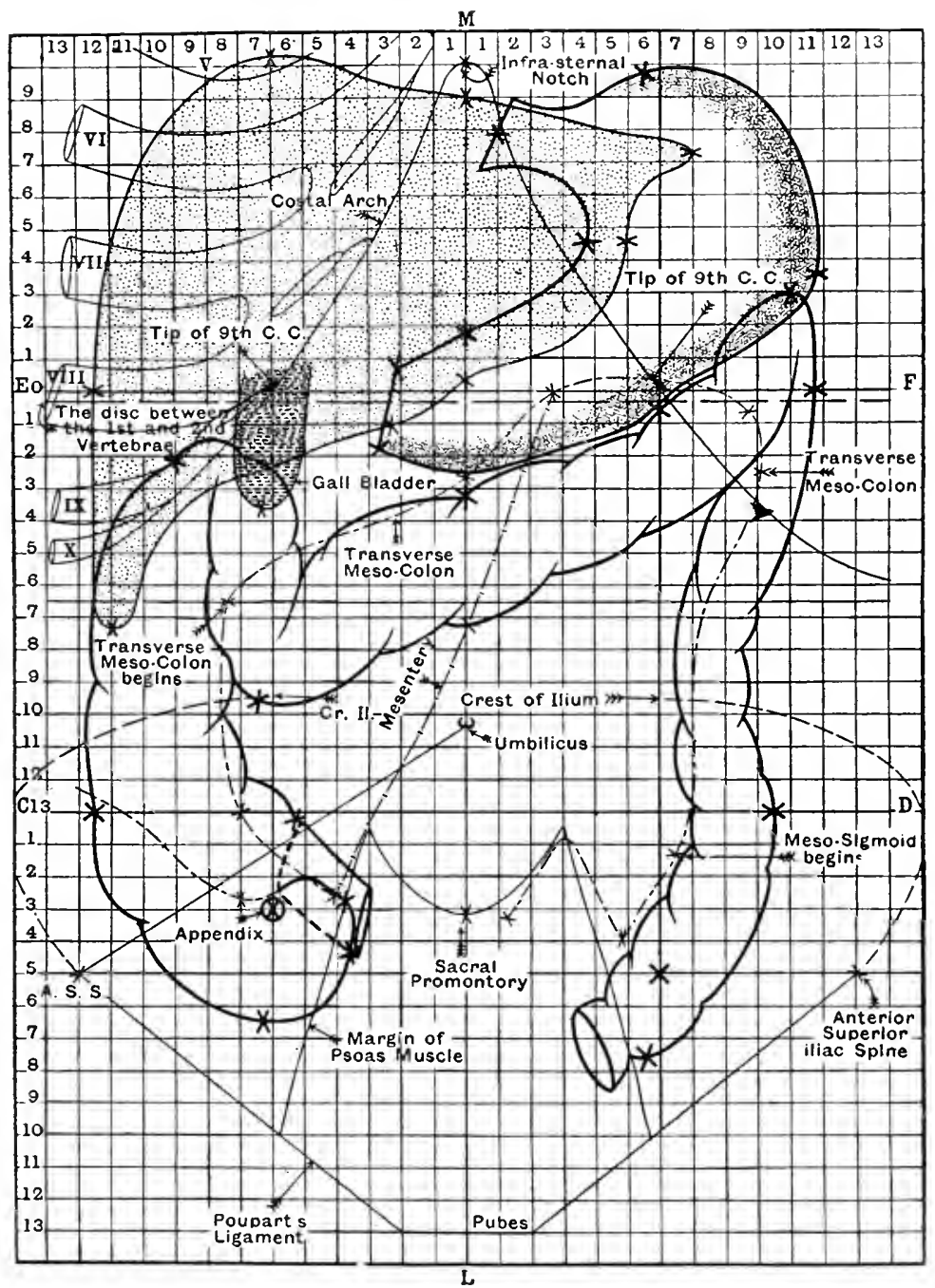

and its relations to surrounding organs undergo considerable change. Even in the fotus it is quite variable, but its general form and position do not differ essentially from the adult condition.

Glands.-According to Johnson, in an embryo of $16 \mathrm{~mm}$., the lining epithelium shows the primitive foveolæ as pit-like depressions which become elongated, forming irregular anastomosing grooves, separated by villus-like projections. The pits multiply and deepen, and from their bottoms the gastric glands bud off (at $120 \mathrm{~mm}$.). The parietal cells appear very early in the gland fundus, but the differentiation of gland cells is still incomplete at birth. 
Figs. 915 and 916.-Dragrams of the Contact Areas of the Stomach, Anterior and Posterior liews.
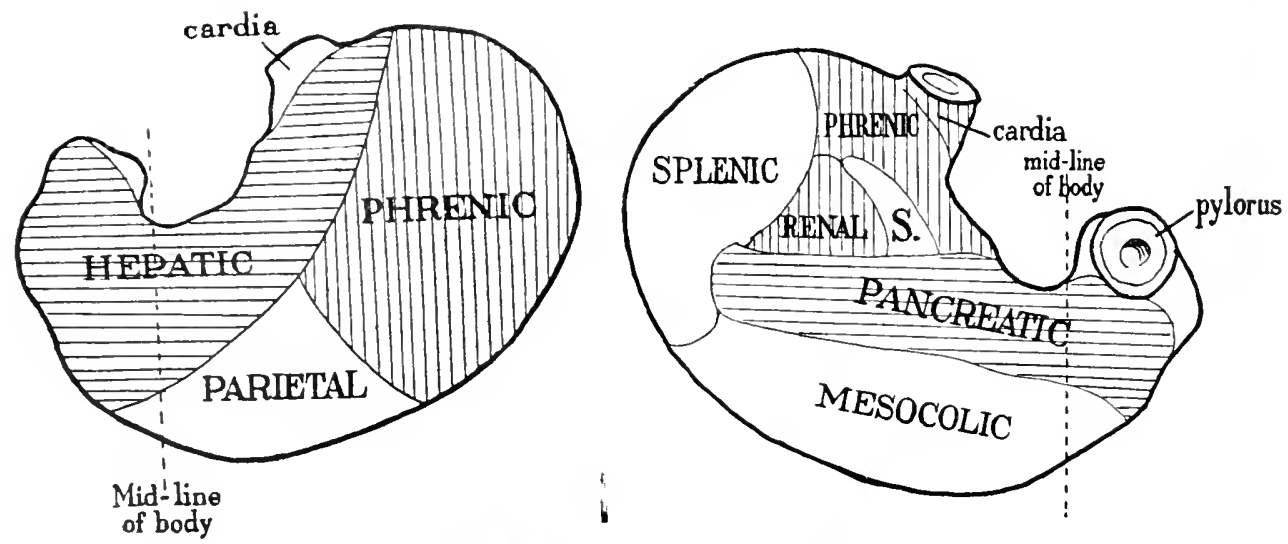

Fig. 917. - The Abdominal Viscera, From Behind. (Rüdinger.)

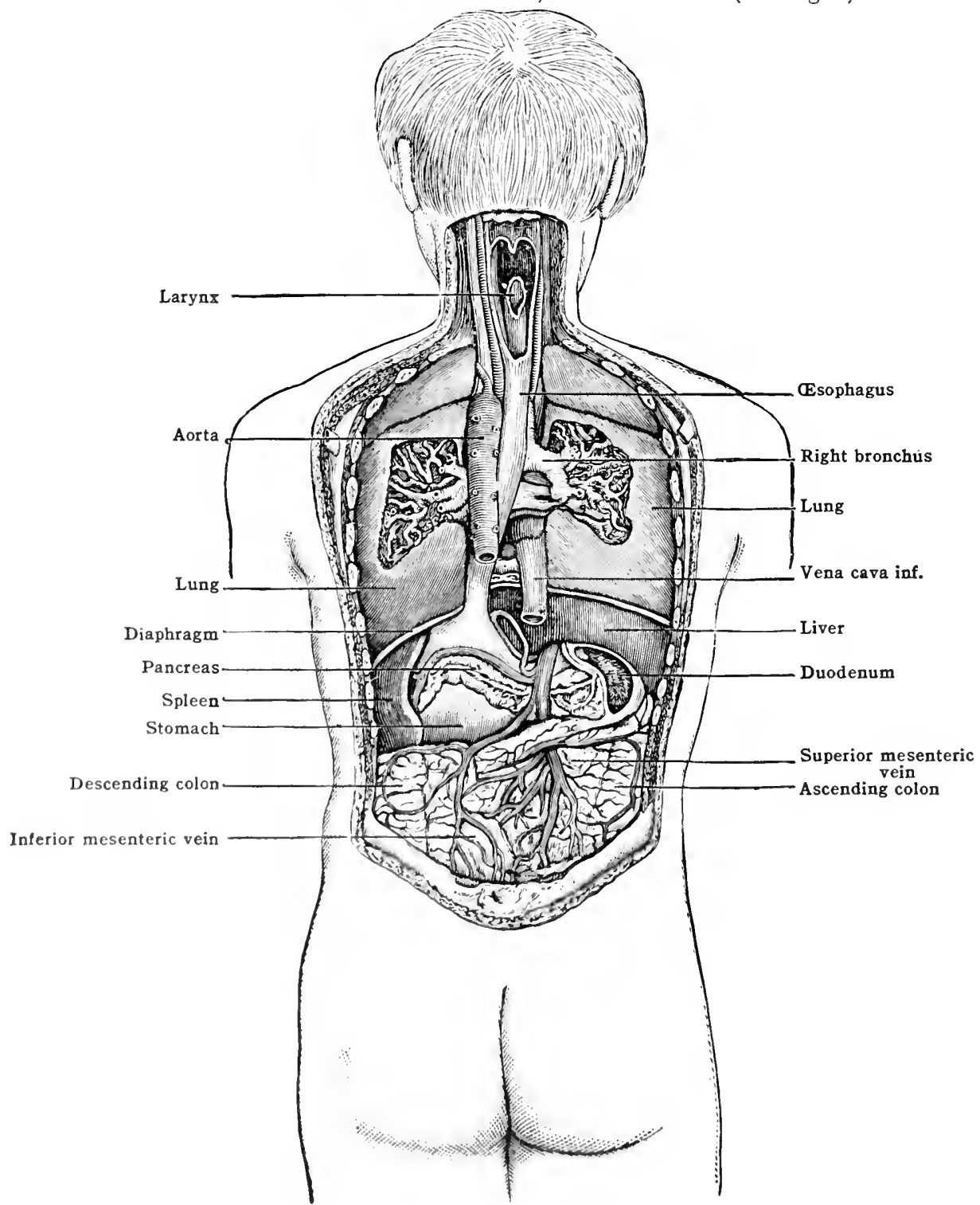


The circular layer of muscle is indicated at $16 \mathrm{~mm}$; the longitudinal much later, about $90 \mathrm{~mm}$., and not completed before $240 \mathrm{~mm}$. (F. T. Lewis).

Variations. - The great variability of the stomach in form, position and relations has already been repeatedly emphasized. These variations have been most carefully studied recently by various observers in the living body by means of the Rontgen-rays. Some of the results of study by this method are shown in figs. $918,919$.

Peristalsis. - It would appear that most of the variations in the form of the stomach that have been described are merely various phases in the series of changes undergone by the stomach during the normal process of physiological digestion. The following account of these changes is based largely upon the radiographic observations of Cole. Earlier observations by various investigators upon the living stomach of man and lower animals (and especially the radiographic study of the cat by Cannon) have shown that the cardiac portion of the stomach is the first to become distended with food (and gas). Until a considerable degree of distention is reached, the pyloric portion usually remains a somewhat narrow contracted canal, along which distinct peristaltic contractions pass pylorusward.

Under favorable conditions, however, the peristaltic contractions may be observed to begin in the cardiac portion, although they are usually most distinct in the pyloric portion. Each individual contraction travels at the rate of about $2.5 \mathrm{~cm}$. ( 1 inch) per second, so that it requires several seconds for a contraction to travel from fundus to pylorus. The number of simultaneous

Frg. 918.-Different Forms of the Stomach as Shown by The Rentgen Rays. Fundus not represented. (Cole.)
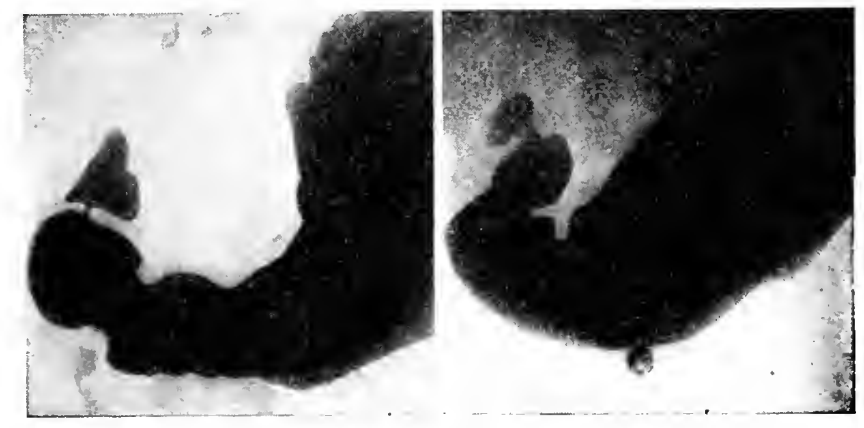

A-"Cow-horn"

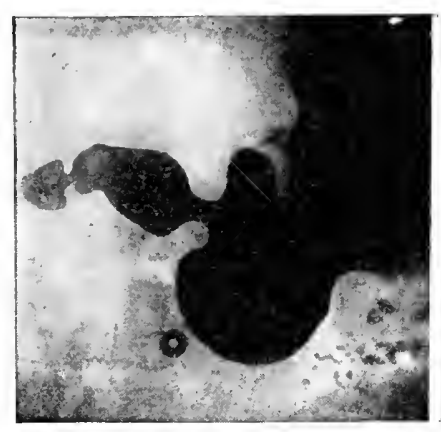

C-“Drain-trap"

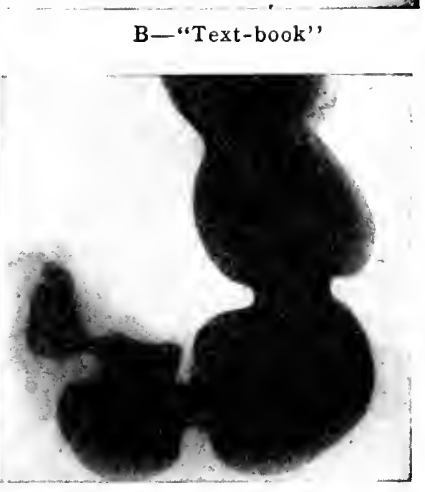

D-"Fish-hook"

contractions present in the stomach varies from 1 to 6 or 7,3 or 4 being the most common. In fig. 919 , a series of 10 successive radiographs show the progression in a stomach with four simultaneous individual peristaltic contractions. The peristaltic movements are further complicated by the appearance (simultaneously in all) of successive periods of 'systole,' during which the peristaltic contractions become stronger and deeper', and 'diastole,' in which the contractions relax and become less distinct (Cole). In fig. 919, phases 1 to 6 represent the 'systole,' and 7 to 10 the 'diastole.' A 'systole' and a 'diastole' together make up a 'gastric cycle.' During the entire progress of an individual peristaltic contraction from fundus to pylorus, the number of 'cycles' appears to correspond to the number of peristaltic contractions present. Thus the figure repiesents a stomach of the 4-cycle type. The time required for a 'cycle' varies widely, the average (in the 3- or 4-cycle type) being about 2 or 3 seconds.

In the earlier stages of gastric digestion the pylorus usually remains closed, but after a variable time it relaxes slightly (lumen about $3 \mathrm{~mm}$. in diameter) at intervals, allowing the chyme to be spurted into the duodenum.

Thus the various constrictions often found in the formalin-hardened stomachs, and the pyloric antrum, appear to be merely transient phases of the digestive process. The 'hourglass' stomach is in many cases to be explained in this way; in others, however, the constriction is pathological and permanent. Various forms of abnormal lobulations and dilations also rarely occur. 
Gastroptosis is a very common abnormality in which the body of the stomach extends vertically downward to the umbilicus, or lower, forming a sharp bend beyond which the pyloric portion turns upward to reach its termination. This form is especially common in women, due to tight lacing.

Fig. 919,-Serial Radiographs Taken at Short Intervals, Showing Diastole (Phases 7-10) and Sistole (Phases 1-6), and the Progression toward the Pylorus of a Fodr-cycle Trpe of Gastric Peristalsis. Fundus of the stomach not shown. (Cole.)

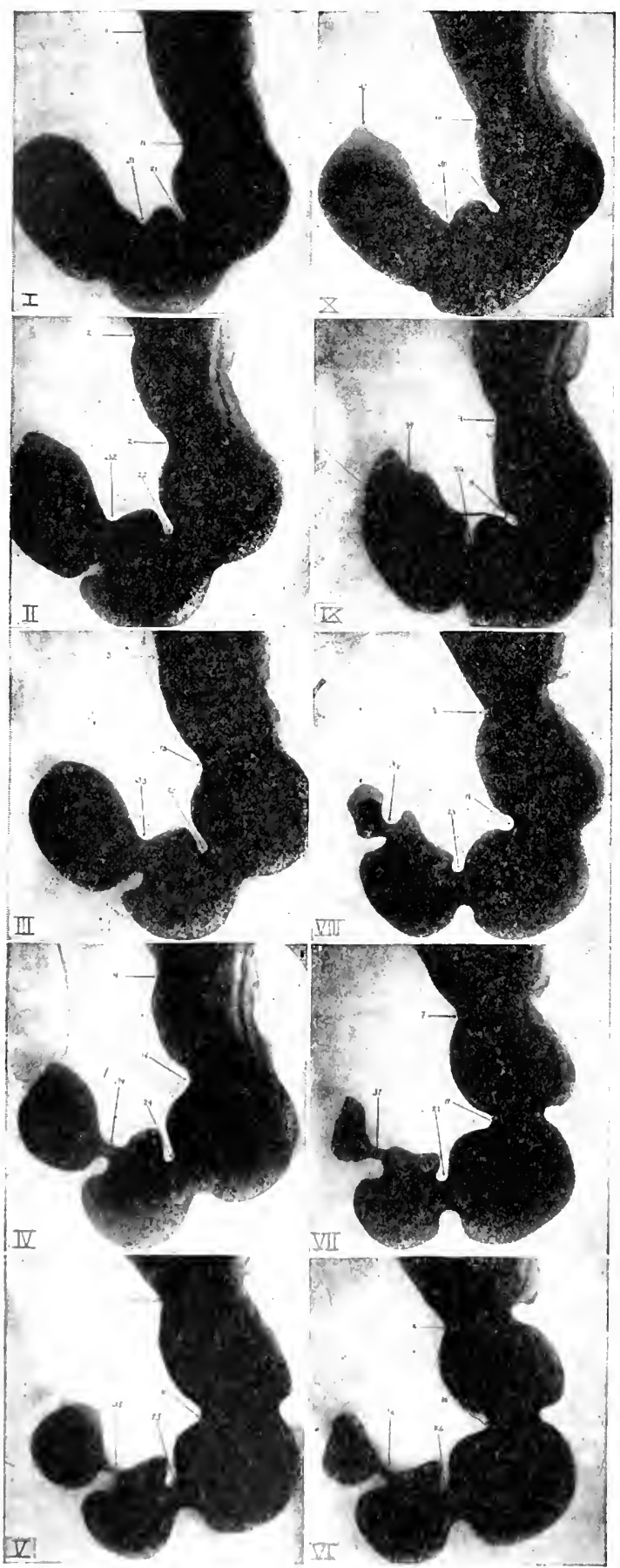

Comparative.-The primitive stomach is perhaps merely a receptacle for food, true digestive chlands being abent in many of the fishes. Fhe vertebrate stomarh is a dilated sac of variable form, lont is typically somewhat lonperl, with cardiac and pylonic segments. In birds, there is a peculiar arrangenent, correlated with the absence of teefli. The stomach is divided into an 
anterior glandular proventriculus, and a posterior muscular gizzard with a horny lining serving to grind the food. The mammalian stomach is the most variable in form and structure which are correlated with the method and character of alimentation. The cardiac end of the stomach is often lined to a variable extent with a prolongation of the cesophageal stratified squamous epithelium. The three kinds of glands, cardiac, fundic and pyloric, are typically present. In general, the stomach is larger and more complicated in herbivora than in carnivora. Instead of being a single sac, the stomach may be more or less divirled into chambers. An incomplete division into cardiac and pyloric portions is so common that it may be considered typical. The most extreme specialization is found in the ruminants. In these the stomach has four chambers, the first two of which, however, are expansions of the œsophagus.

\section{THE SMALL INTESTINE}

The small intestine [intestinum tenue] extends from the pylorus to the ileocæcal orifice, and occupies most of the abdominal carity below the liver and stomach. It is a cylindrical tube whose diameter decreases from about $t \mathrm{~cm}$. above to about $2.5 \mathrm{~cm}$. at the lower end. Its length, when removed from the body and measured fresh, averages about 7 metres (23 ft.); but when formalinhardened in situ, the length (which is probably nearer that during life) is only about 4 metres. The length does not seem to vary according to sex, height or weight in the adult, but it is said to be relatively longer in the child.

The small intestine includes two main divisions, the duodenum and the mesenteric small intestine, the latter being further subdivided into jejunum and ileum.

\section{THE DUODENUM}

The duodenum is the first part of the small intestine, and is very definite in position and extent. It is firmly attached to the posterior abdominal wall, being almost entirely retroperitoneal. It is the widest part of the small intestine, the

Fig. 920.-The Deodencm and Pancreas, Anterior View.

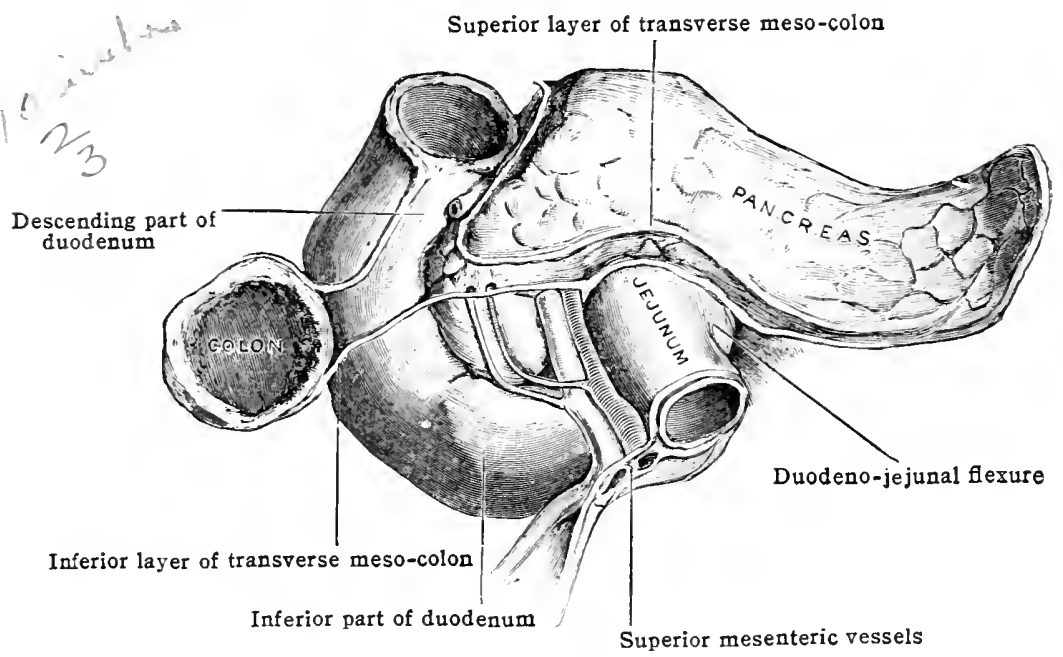

average width being $4 \mathrm{~cm}$. or more, and is also the shortest segment, being only about $25 \mathrm{~cm}$. in length. In general, it is somewhat C-shaped, the concarity enclosing the head of the pancreas (figs. 920, 921, 922).

Parts.-For convenience of description, the duodenum is divided into the following parts: (1) the first or superior portion [pars superior] which is short ( $5 \mathrm{~cm}$. or less), leading from the pylorus and forming the superior flexure [flexura duodenalis superior]; (2) the descending portion [pars descendens], about 7 or $S$ $\mathrm{cm}$. in length, which receives the bile and pancreatic ducts and joins the inferior portion at the inferior flexure [flexura duodenalis inferior]; and (3) the inferior portion [pars inferior], which is again subdivided into (a) transierse portion [pars horizontalis], about $10 \mathrm{~cm}$. long, which usually ascends slightly and passes gradually into (b) the ascending portion [pars ascendens], 2 or $3 \mathrm{~cm}$. long, terminating in the duodeno-jejunal flexure [flexura duodenojejunalis]. 
Position and relations.-As shown in fig. 914, the duodenum usually lies chiefly in the lower part of the epigastric region, only the inferior (transverse) portion extending into the umbilical region. All but the terminal (ascending) portion of the duodenum lies to the right of the mid-line.

The superior portion usually lies at the level of the first lumbar vertebra (or the disk below). It is covered anteriorly, and to a variable extent posteriorly, by a prolongation of the peritoneum from the corresponding surfaces of the stomach. It is somewhat freely movable. When the stomach is empty, it extends from the pylorus almost horizontally to the right and backward. As the stomach becomes distended, however, the pylorus is carried to the right and downward for a variable distance, and the position of the superior part of the duodenum is correspondingly altered.

Superiorly it is in contact with the liver (quadrate lobe) and the neck of the gall-bladder and forms the lower boundary of the epiploic foramen; anteriorly, with the liver and (often) the transverse colon; inferiorly and posteriorly, with the head of the pancreas below, and with the common bile duct, hepatic vessels and portal vein above.

The second or descending portion of the duodenum extends along the right side of the first to the third lumbar vertebra. It is covered antero-laterally by peritoneum, excepting (usually) the area of contact with the transverse colon (figs. 906, 920).

Posteriorly (fig. 956) it is in contact with the right kidney, ureter and renal vessels, and below with the psoas muscle. Anteriorly (fig. 906) it is crossed by the transverse colon (the layers of the transverse mesocolon usually separated by an area of direct contact); above the colon, it may be in contact with the gall-bladder, and below the colon with coils of small intestine. The

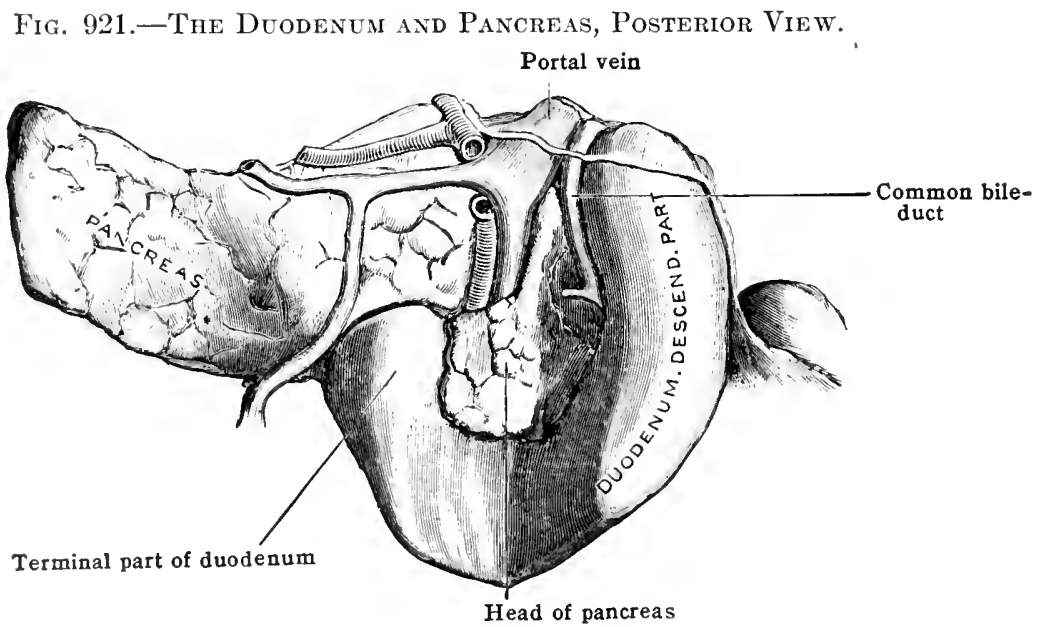

left or medial aspect of the descending duodenum (figs. $920,921,922$ ) is in contact with the head of the pancreas, and some fibres from the muscular tunic are said to become intermingled with the pancreatic lobules. Somewhat posteriorly the common bile duct descends between pancreas and duolenum, and enters the deseending duodenum, in common with the pancreatic duct, about $10 \mathrm{~cm}$. below the pylorus. The loop formed by the pancreatico-duodenal arteries also runs along the descending iluodenum.

The third or transverse portion of the duodenum usually crosses the body of the third lumbar vertebra, aseending slightly from the right to the left side (figs. 920, 921). It is covererl anteriorly with peritoneum, excepting a small space where the superior mescuteric vessels enter the root of the mesentery.

Anteriorly it is further in contact with erils of small intestine; superiorly, with the head of the pancreas, and the inferior pancreatieo-luodenal vessels; posteriorly, with the vena cava.

The torminal or ascenting portion is covered anteriorly and laterally by peritoncum, and is in contact with coils of the ileum. To the right it is in relation with the hearl of the pancreas (processus uncinatus) and the superior mesenterie vessels; and posteriorly with the psoas muscle, aorta and left renal vessels. The duodeno-jejunal flexure usually liesopposite the second lumbar vertebra, and is in continct aloove with the inferior surface of the body of the pancreas, and the root of the transverse mesocolon. 
Fig. 922.-Dissection of the Duodendur and Pancreas, Anterior View.

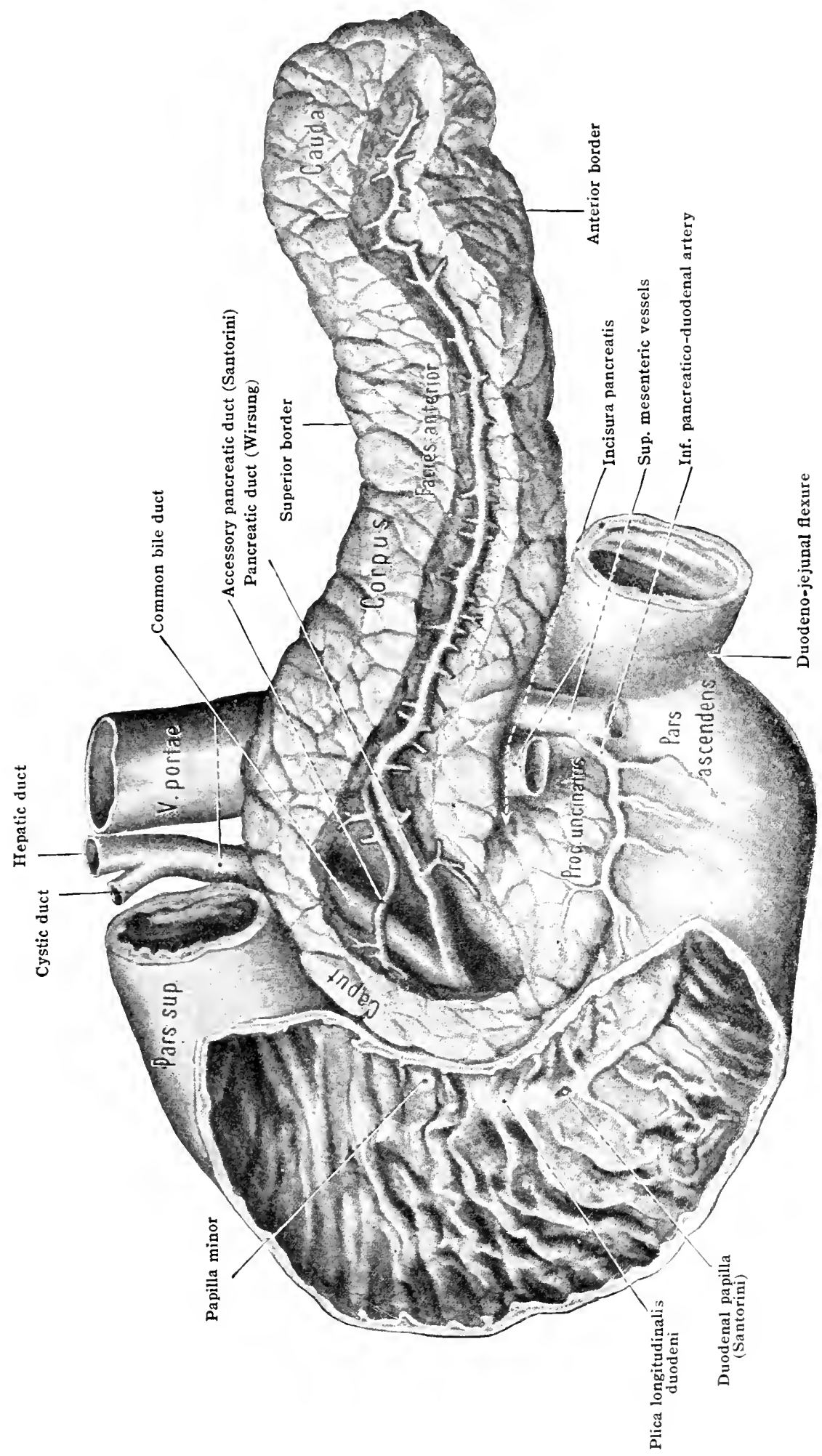


The end of the duodenum is firmly fixed in its place by the suspensorius duodeni. This name has been given to a fibro-muscular band that contains, according to Treitz, non-striated muscular fibres, and descends to the terminal part of the chodenum from the lumbar part of the diaphragm, passing to the left of the coliac artery and behind the pancreas. Lockwood points out that this band is continued on, after being inserted into the duodenum, between the layers of the mesentery. He suggests the name of the 'suspensory musele of the duodenum and mesentery,' and says, 'together with the other constituents of the root of the mesentery, it forms a band of considerable strength, sufficient not only to support the weight of the intestines and mesentery, but also to resist the pressure of the descent of the diaphragm.'

In connection with this fourth portion of the duodenum, mention may be made of certain peritoneal folds and fosse which are of some surgical interest by reason of their being associated with retro-peritoneal hernia. Four such fossa may be mentioned, namely, the superior and inferior duodenal fosse, pararluodenal and the retroduodenal fossæ. On trawing the terminal portions of the duodenum to the right, two triangular folds of peritoneum, the superior and inferior duodenal folds, which extend from the wall of the duodenum to the posterior abdominal wall may be observed. Each fold has a free edge. Beneath each fold is found a pouch of peritoneum, constituting the superior and inferior duodenal fossæ. The former, the smaller, opens down warl and is present in about 50 per cent., while the latter opens upward and is present in about 75 per cent., of the subjects examined (Jonnesco). The paraduodenal fossa (fossa of Landzert) is not often found in the adult; when present, it is situated to the left of the last part of the duodenum, and is formed by a fold of peritoneum enelosing the inferior mesenteric vein. The retroduodenal fossa is a rare form extending from below upward behind the transverse portion of the duodenum.

Interior of the duodenum.-The interior of the first part of the duodenum is smooth. The pylorus is often somewhat invaginated, much in the same way that the uterus projects into the vagina (fig. 908). On account of this arrange-

Fig. 923.-Duodenal Fosse and Folds. Paraduodenal fossa is not shown.

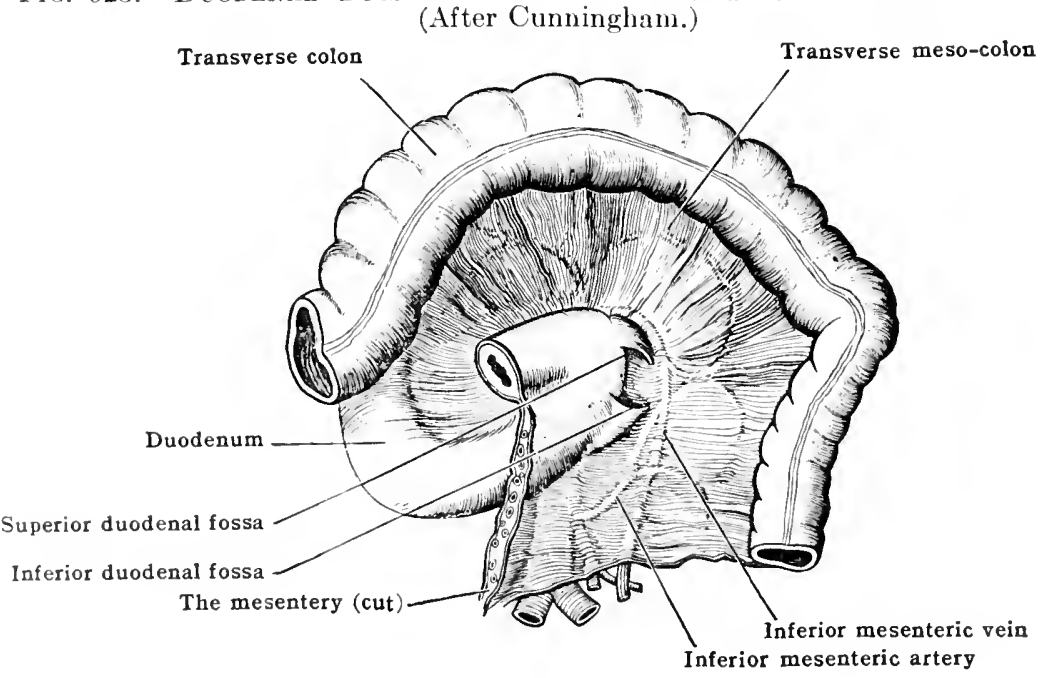

ment (which renders the complete emptying of the cavity somewhat difficult) and also on account of the distensibility of this portion, it usually shows up very distinctly in radiographie pictures as a 'cap' to the pyloric end of the stomach during digestion. In the lower portions of the duodenum, transverse ridges or folks of the mucosa appear (fig. 922) which are also apparent in radiographs occasionally. On the medial wall of the descending portion, posteriorly, about half-way down, is a more or less distinct longitudinal fold [plica longitudinalis duodeni], toward the lower end of which is a small elevation, the bile papilla or popilla major [papilla duodeni], upon which open the common bile duct and the pancreatic: duct, either separately or by a common aperture (fig. 922). Above the papilla there is usually a prominent hood-like fold (valvula connivens), and below it a variable fold or fremmm which forms a continuation of the plica longitudinalis. About 2 cm. (.9 to 3.5 ('m., Baldwin) above and in front of the bile papilla there is a second, smaller, romblecl papilla minor, upon which the accessory panereatice duet (of santorini) ends.

The minute structure, vascular relations, development, variations, etc., of the duodenum will be ensidered later, with those of the small intestine as at whole. 


\section{THE JEJUNUM AND ILEUM}

The mesenteric portion of the small intestine is divided into an upper half (or two-fifths), the jejumum, and a lower half (or three-fifths), the ileum. Although the character of the gut ehanges considerably from the upper end of the jejunum to the lower end of the ileum, the transition is gradual, and there is no definite line of demarcation. In general, the jejunum is somewhat wider, has thicker walls, is more vascular and has a more complieated mucosa. The lymphoid organs (Peyer's patches) are, however, characteristie of the ileum.

The jejunum begins at the duodeno-jejunal flexure. The first coil is variable in direction, being found (in order of frequeney) as follows: (1) downward, forward and to the left; (2) directly forward and downward; (3) to the left, then downward; (4) forward and to the right (Harman). Some further details as to the position of the various sueeeeding coils are given later under the development of the intestine (figs. 930, 931). While there is considerable individual variation, it is true in general that the coils of jejunum occupy the upper and left portion of the body cavity, while those of the ileum occupy the lower and right side, the lower portion lying in the pelvic eavity. The ileum finally passes upward over the pelvic brim to the right iliac fossa where it terminates in the ileo-eæeal orifice.

Fig. 924.-Portion of the Siall Intestine, Laid open to Show the Plice Circu-

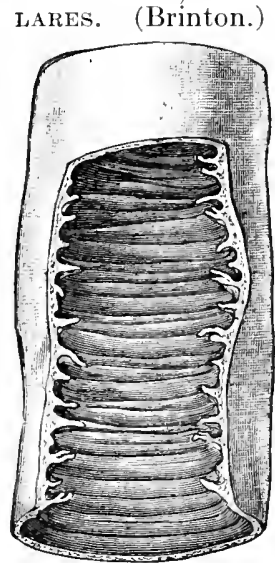

The mesentery [mesenterium] is a fan-shaped fold extending from the duodenojejunal flexure to the ileo-cxcal junction. It is composed of a double layer of peritoneum which encloses and supports the jejunum and ileum and their vessels, conneeting them with the abdominal wall. The root of the mesentery [radix mesenterii] or parietal attachment, is only about $15 \mathrm{em}$. long, corresponding to a line extending from the duodeno-jejunal flexure obliquely downward and to the right, across the transverse duodenum, the great vessels and the vertebral column to the ileo-creal junetion (fig. 905).

The risceral attachment of the mesentery to the intestine, corresponding to the lengtl of the jejuno-ileum, is nearly 7 metres long, and is thinner than at the root. The wilth of the mesentery, measured from parietal to visceral attachment, varies somewhat in different parts of the canal, the average being 18 or $20 \mathrm{~cm}$. (ranging from 15 to $22.5 \mathrm{~cm}$.). It is narrow above (also at the lower end), but reaches its full width about $30 \mathrm{~cm}$. below its upper end. Between the two peritoneal layers of the mesentery is a third layer [lamina mesenterii propria] containing the superior mesenteric vessels (arteries, veins and lymphatics) with their branches and accompanying nerves, the small mesenteric lymph-nodes ( 50 to 100 in number), and a variable amount of fibro-adipose connective tissue.

Minute anatomy.-The small intestine has the four typical layers,-mucosa, submucosa, muscularis and serosa (figs. 927, 928). They are, in general, somewhat similar in structure to those of the stomach (fig. 910), excepting the mucosa.

The mucosa is lined with a simple cylindrical epithelium, underneath which is a fibrous lamina propria, limited externally by a muscularis mucosa, as in the stomach. The muscularis mucosie sends slender muscular bundles upward into the villi. The inner surface of the mucosa (fig. 924) presents numerous coarse, closely set, transverse folds [plicie circulares]. These are permanent, crescentic folds, involving both mucosa and submucosa, and usually extending onehalf to two-thirds of the way around the lumen. They of ten branch and anastomose, sometimes forming circles or spirals. The largest exceed $5 \mathrm{~cm}$. in length and $3 \mathrm{~mm}$. in width. The plicx 
circulares are absent from the first part of the duodenum, but become well-marked in the descending portion (fig. 922). They are largest and best developed in the lower duodenum and upper half of the jejunum, below which they gradually become smaller (fig. 924) and disappear at the lower end of the ileum.

The digestive and absorptive surface of the small intestine is further greatly increased by multitudes of small processes, the villi (figs. 925, 927), which give the mucosa a velvety appearance. They are largest (.5 to $.7 \mathrm{~mm}$. in height) and most numerous in the duodenum and jejunum, where they are typically leaf-shaped, and gradually become smaller, scattered and conical in the ileum. The villi are much reduced in distention of the intestine, and may even be temporarily obliterated. Between the bases of the villi there open short, simple tubular glands - the crypts of Lieberkuehn [gl. intestinales], whose fundus cells (of Paneth) probably secrete digestive enzymes. In the duodenum there are found, in addition, the larger tubulo-

Fig. 925.-A, Surface View of the Hardened Mucosa of the Suall Intestine. (After Kölliker.) $B$, Side View of a Wax Reconstruction of the Epithelium in the Human Dcodencu. (Huber.) i.g., Intestinal gland. v., Villus.

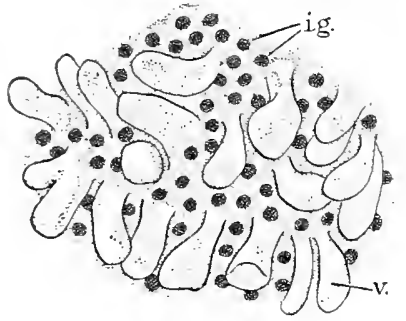

A

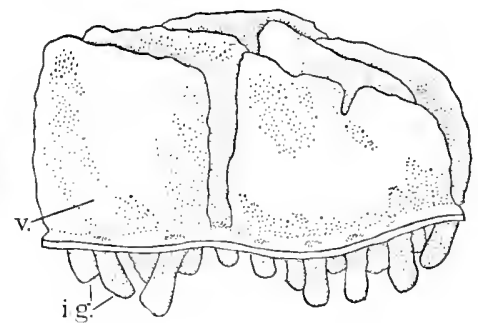

racemose glands of Brunner [gl. duodenales], which occupy the submucosa, and are especially numerous in the upper portion of the duodenum. They are purely mucous in character according to Bensley, although Oppel describes granular cells, similar to Paneth cells, which may secrete digestive enzymes.

Scattered over the whole of the mucous membrane of the small intestine are numerous small lymph-nodules, the larger of which extend into the submucosa; these are the so-called solitary glands [noduli lymphatici solitarii]. Aggregations of lymph-nodules, known as Peyer's patches [noduli lymphatici aggregati], situated in the mucosa and submucosa, are found in the ileum especially toward the lower end (fig. 926). They are oval, from 1.2 to $7.5 \mathrm{~cm}$. in length and about $i$ to $2.5 \mathrm{~cm}$. in breadth, and are placed in the long axis of the bowel along a line most remote from the mesentery. They are variable in number, the average being about 20 to 30.

Fig. 926. - Surface View of the Mucosa of the Ileum, Showing Aggregated Lymph Nodes (Peyer's Pateh). (From Toldt's Atlas.)

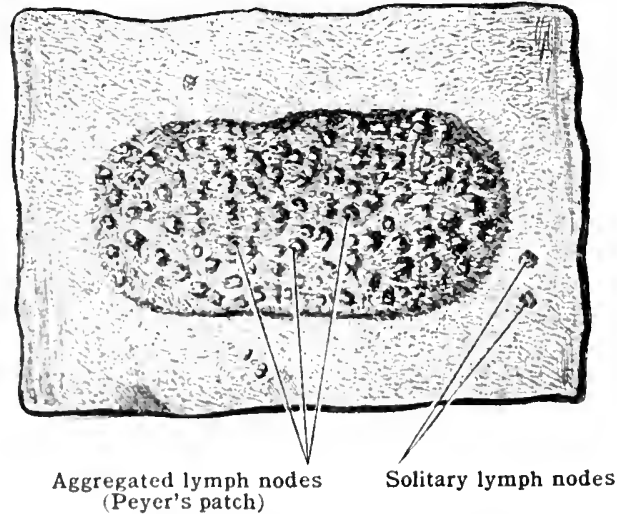

The submucosa is in general a kose areolar layer eontaining vitscular and sympathetic plexuses (figs. 927,928 ). The muscularis is eomposed of smooth nusele arranged in the two typical layers, - a thinner, outer longitudinal and a thicker, inner eircular, - both of which become thinner towalel the lower rnil of the ileum. 'The serosa is typical in structure, the sraumons epithetial onvering being absent in the retroperituneal areas of the duodenum.

Blood-supply of the small intestine.--'l'be small int estine recoives its blood from the superior Inesinteric artery and a branch coming indirectly from the hepatic, the superior pancreaticoduodernal. 'The superior mesenforio: artery runs between the layers of the mesentery and gives off six or soven relatively large branches and a variable number of smaller branches. The first two or three of the larerer biachese divide inte an aseending and a descending branch, which join above and below with the corresponting lownches of the continguous arteries, forming thins a single row of arches. F'rom about the beginning of the second quarter of the small 
Fig. 927.-Cross-section of Ilevum (contracted). $a, b, c$, Villi. d, Intestinal gland. $e$, Tunica propria. $f, f$., Muscularis mucosx. $g$, Blood-vessel. $h$, Submucosa. $i$, Circular muscle. $k$, Longitudinal muscle. $l$, serosa. $m$, Subserosa. $n$, Aggregated lymph nodules (Peyer's patch). (Radasch.)

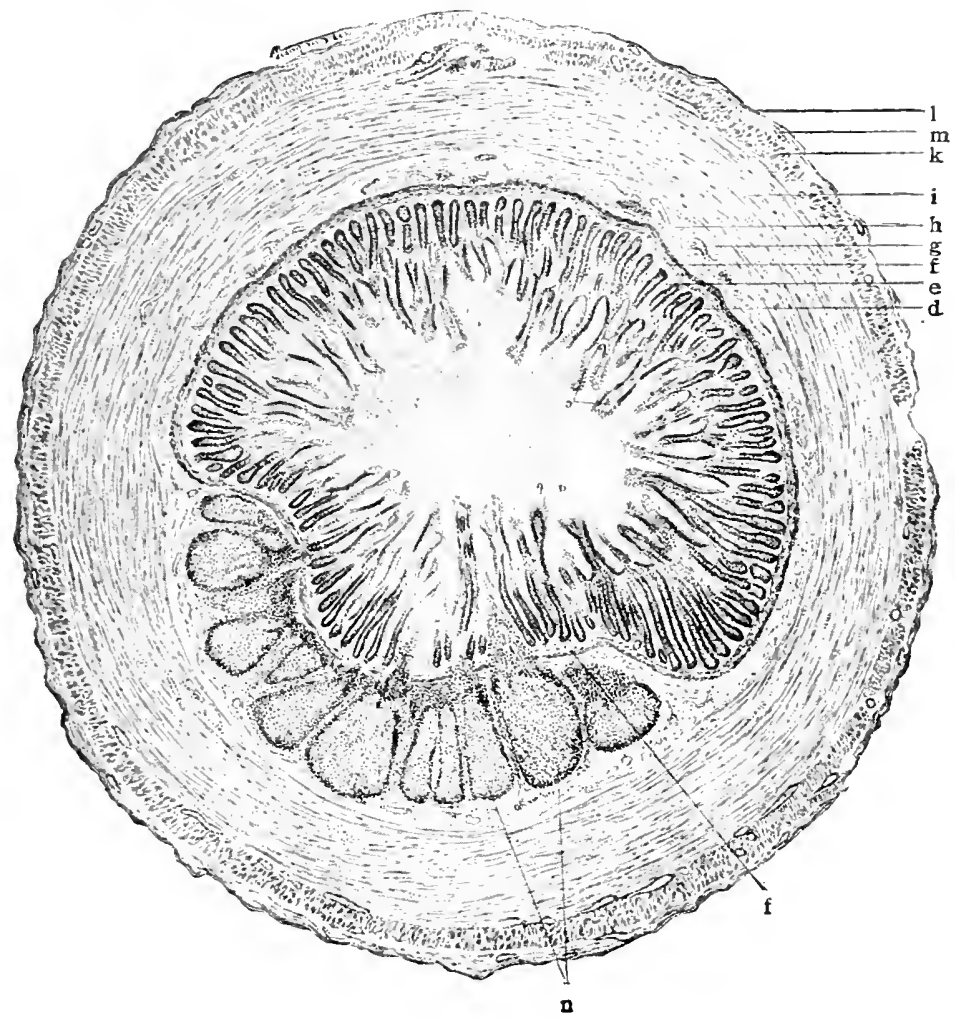

Fig. 928.-Diagrams of the Vascular Supply and Nerves of the Suall Intestine. $A$, Blood vessels; arteries as coarse black lines, capillaries as fine lines, veins shaded (after. Mall). $B$, Lymphatics (after Mall). $C$, Nerves, based on Golgi preparations (after Cajal). $m$, Mucosa. mm., Muscularis mucose. s.m., Submucosa. c.m., Circular muscle. i.c., Intermuscular connective tissue. l.m., Longitudinal muscle. s, Serosa. c.l., Central lymphatic. $\quad n$., Nodule. s.pl. Submucous plexus. m.pl., Myenteric plexus. (Lewis and Stöhr.)

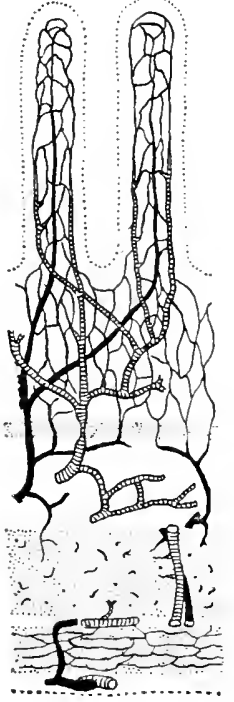

A

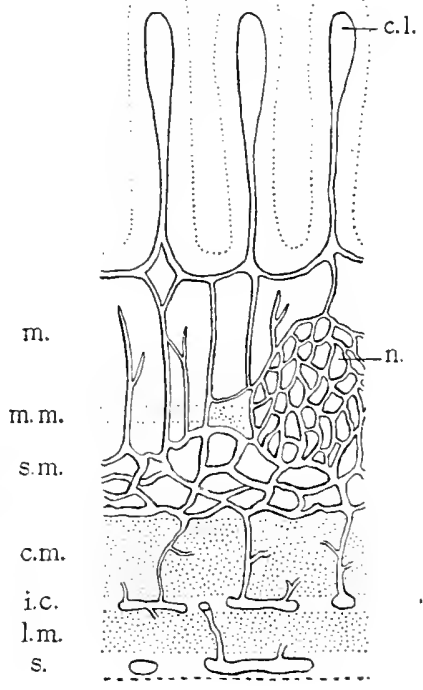

B

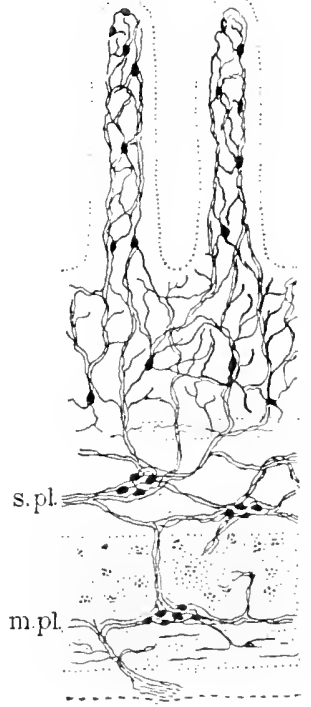

C. 
intestine a second tier of arches, formed in a similar manner, is often noted, and below the middle of the jejuno-ileum more than two tiers of arches may be present the complexity of the arches increasing, while the size of the vessels diminishes. From the convex border of the most distally placed arches there pass to the intestine straight branches, so-called vasa recta. Near the beginning of the jejunum these are numerous and large, and have a length of about $4 \mathrm{~cm}$., and are quite regular. After the first third of the intestine is passed the vasa recta become smaller and shorter, and toward the lower end of the ileum they become short and irregular and are often less than $1 \mathrm{~cm}$. in length. (Dwight.) The blood is returned by means of the superior mesenteric vein, which, with the splenic vein, forms the portal. The vascular arrangement in the intestimal wall is shown in fig. 928 .

The lymphatic ressels form a continuous series, which is divided into two sets-viz., that of the mucous membrane and that of the muscular coat. The lymph-vessels of both sets form a copious plexus (fig. 928). The efferent lymphatic vessels form the so-called lacteals, which pass through the mesenteric lymph-nodes, finally reaching the cisterna (receptaculum) chyli.

The nerves. - The small intestine is supplied by means of the superior mesenteric plexus which is continuous with the lower part of the cocliac (solar) plexus. The branches follow the blood-ressels, and finally form two plexuses: one (Auerbach's or myenteric) which lies between the muscular coats; and another (Meissner's) in the submucous coat. The nerve fibres are chiefly from the sympathetic, partly from the vagus.

Development of the small intestine.-As the intestine is being separated from the yolkresicle it forms at first a relatively straight tube, and as the tube elongates there is formed a single primary loop, situated in the sagital plane of the embryo, which loop extends into the coelom of the umbilical cord; to its summit is attacherl the constricted attachment of the yolkvesicle, the rolk-stalk (fig. 929). This primary loop of the intestine, as it elongates, turns on an axis, so that its caudal portion turns toward the left and its cephalic portion toward the right. We may then speak of a right and a left half of the loop. Near the top of the left half of the loop there is noted an enlargement which marks the cecum, the greater part of the left

Fig. 929.-Model of Stomach and Intestine of Human Embryo 19 mir. Long. The figures on the intestine indicate the primary coils $(\times 16)$, (Mall.)

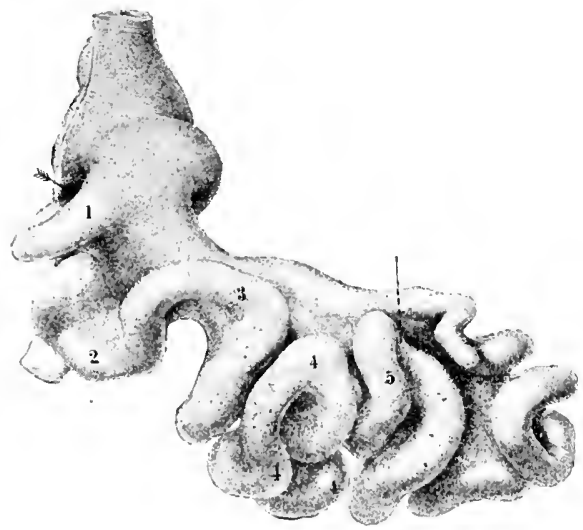

half of the lonp forming, therefore, the large intestine, while the right half of the loop forms the small intristine. In the further growth of the loop the right half clongates more rapidly than the laft hatf, so that the recum is no longer found in the midille of the loop. In an embryo of the fifth week, as noted by Mall, whose aceount is here followed closely, "the right half of the loop las a number of small bencls in it, which are of great importance in the further developmont of thre intestine.' 'These smill bends or lonps he has marked with the numbers $1,2,3,4$, 5, 6. (Ane figs. 929, 930, 931.) The first of these bonds is primarily not elear, appearing as a pertion of the pylorie and of the stomach; howerer, it is recosnised by the fact that the duets if the liver and panereas terminate in it, marking it as the hodenum. 'The omphalo-mesenteric veius and arteries, the future superior mesenteric vesseds, pass through the middle of the menentery of the large primary loop and pass over the sixth bend or seconclary loop, to which

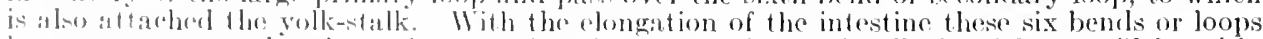

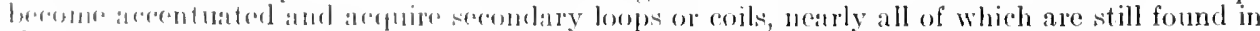

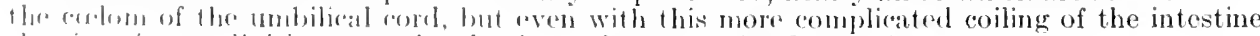

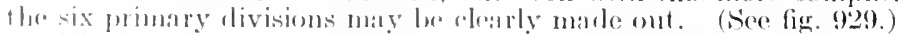

"The latge intestine, the loft half of the large primary loop, lies in the sagital plane of the

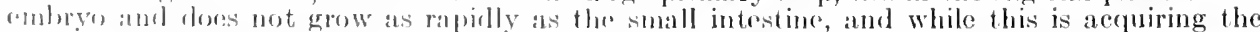

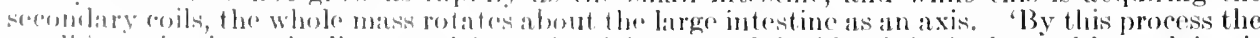

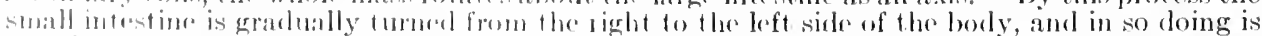

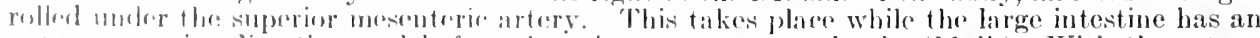

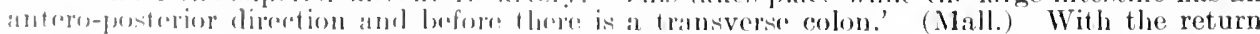

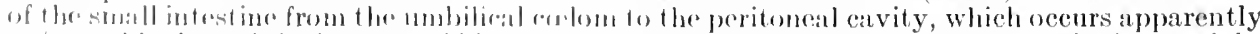

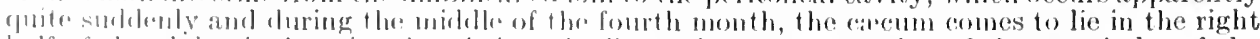
half of the athlominal ravity, just lowow the liver; the greater portion of the remainder of the

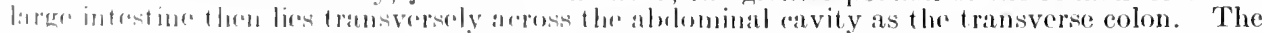
six groupse of lonps of thr small infestine maty still be rocognised the loops of the upper part 
of the small intestine having rolled to the left of the superior mesenteric artery, while the loops which were formerly in the cord are found in the right side of the abdominal cavity. It is not difficult to trace these six groups of loops through the later stages of foetal life to the nenborn, and thence to the adult stage. In the adult, as also through the various stages of development, loop 1 forms the duodenum. From the primary groups of coils marked 2 and 3 are developed the greater part of the jejunum, arranged in two distinct groups of loops, situated in the left hypochondriac region. The part of the intestine developed from group 4 of the primary eoils passes across the umbilical region to the right upper part of the abdomen. That part developed from group 5 of the primary eoils recrosses the median line to the left iliac fossa, while that part derived from group 6 of the primary coils is found in the false pelvis and the lower part of the abdominal eavity between the psoas muscles. (Mall.) Figs, 900, 901, 930 may serve to make clear these statements. They present what may be regarded as the normal arrangement of the small intestine, having been found 21 times in 41 cadavers examined. Variations from this arrangement occur; the great majority of such variations are, however, not of sufficient importance to require special mention.

According to Johnson (upon whose descriptions the following account is based), there is in embryos of $13 \mathrm{~mm}$. to $23 \mathrm{~mm}$. a formation of vacuroles in the duodenal epithelium, which

Fig. 930.-Model Shontig Course of Intestine, Made from Saue CaDAVER FroN Which Fig. 931 was DraWN. (Mall.)

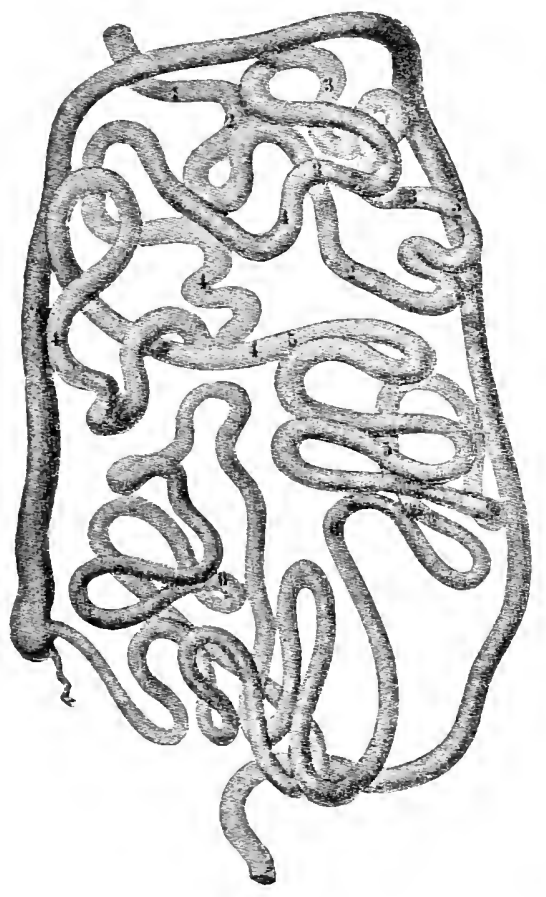

Fig. 931.-The Usual Position of the Intestine in the Abdoninal Cavity. The numbers in the figure mark the parts which are homologous with the primary bencls and groups of coils numbered from 1 to 6 . (Mall.)

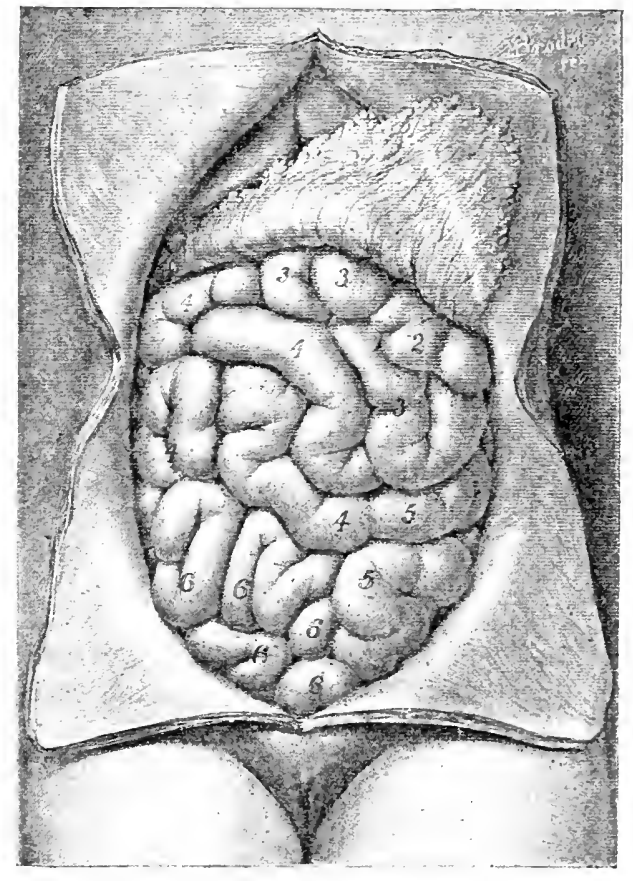

leads to complete temporary occlusion of the lumen. A persistence of this condition may cause permanent atresia. In the epithelium of the small intestine numerous pockets or cysts oecur, which usually disappear, but may persist and form permanent diverticula or accessory pancreas. The villi begin to appear at $19 \mathrm{~mm}$., first in the mucosa of the upper portion of the intestine, as localized outgrowths which become arranged in longitudinal rows. The crypts of Lieberkuehn bud off from the epithelium at $55 \mathrm{~mm}$., and from those in the duodenum, the duodenal (Brunner's) glands begin to bud off at $75 \mathrm{~mm}$. The plica circulares begin to appear at the midregion of the small intestine at $73 \mathrm{~mm}$. The circular muscle layer begins to appear at about 12 $\mathrm{mm}$., the longitudinal at $75 \mathrm{~mm}$.

Variations in the small intestine.-Although relatively fixed in position, the duodenum is quite variable in form. The C-shape previously described is the most common. When the pylorus and the duodeno-jejunal flexure are approximated, the form is nearly circular. When the two ends are more widely divergent, it approaches a U-form. Not infrequently, the inferior portion ascends abruptly from the inferior angle, giving a $V$-form. Finally, the terminal ascending portion may be very small or absent, in which case the duodenum approaches an L-form. Tariations in the position of the various coils of the jejunum and ileum have already been discussed. The lymph-nodules, ineluding Peyer's patches, like all lymphoid structures, are prominent during youth, but become atrophied in old age.

Meckel's diverticulum, which represents a derivation from the embryonic yolk stalk and sac, is found in about 2 per cent. of all adults. It is a blind tube or diverticulum of variable 
size, usually approaching the intestine in width and averaging $5 \mathrm{~cm}$. in length (ranging from $1 \mathrm{~cm}$. to $13 \mathrm{~cm}$.). Its attachment to the intestine varies from $15 \mathrm{~cm}$. to $360 \mathrm{~cm}$. (average $80 \mathrm{~cm}$.) above the cæcum. 'It is usually attached opposite the mesentery. It may end freely, but is occasionally adherent to adjacent intestinal coils or connected with the anterior abdominal wall by a cord or band-like process.

Other diverticula of variable size and number may occur, usually along the mesenteric border of the intestine. They may be either congenital (probably from the embryonic pockets previously mentioned) or acquired. They occur most frequently in the duodenum (found by Baldwin in 15 of 105 cases) where they are usually associated with the openings of the bile and pancreatic ducts.

Comparative. - The comparative anatomy of the small intestine will be discussed later together with that of the large intestine.

\section{THE LARGE INTESTINE}

The large intestine [intestinum crassum] is that part of the alimentary canal which extends between the ileum and the anus. It is divided into the following parts: Crecum, ascending, transverse, descending, and sigmoid colon, and rectum. It is so arranged as to surround the small intestine, making a cireuit around the abdominal cavity from right to left (fig. 899). The cocum lies in the right iliac fossa; thence the colon passes vertically upward on the right side (ascending colon) until the liver is reached. Here it forms a more or less rectangular bend (the right colic or hepatic flexure), and then passes transversely across the belly (transverse colon) below the stomach. It then reaches the spleen, where it makes a second sharp bend (the left colic or splenic flexure), and, passing vertically downward on the left side (descending colon), reaches the left iliac fossa. At this point it forms the loop of the sigmoid colon, and finally passes through the pelvis as the rectum (fig. 906). The large intestine is much larger in diameter than the small intestine, and is not so much convoluted. Excepting the dilated portion of the rectum, it is wider at the beginning than at the end. It varies in width at different parts from 3 to $8 \mathrm{~cm}$. The length from the root of the appendix or tip of the cæcum to the point where the meso-colon ends is, in the male, about $140 \mathrm{~cm}$., and in the female about $130 \mathrm{~cm}$. The average total length, including the rectum, is about $150 \mathrm{~cm}$. ( $5 \mathrm{ft}$.). The extremes found are 100 to $200 \mathrm{~cm}$.

The large intestine, in all parts except the rectum, has a peculiar arrangement of its walls, which gives it a very different appearance from the small intestine. It is sacculated, and the saceulations [haustra] are produced by the gut having to adapt its length to three shorter muscular bands which run the course of the intestine. These bands, which are about $12 \mathrm{~mm}$. wide and $1 \mathrm{~mm}$. thick, ale really the longitudinal fibres of the muscular wall, which are chiefly collected along three lines (fig. 935). One band [tænia mesocolica], corresponding to the attachment of the mesocolon, is posterior on the transverse colon, and postero-median on the ascending and descending colons. A second band [trnia omentalis] is anterosuperior on the transverse colon, elsewhere postero-lateral. The ihird band [tænia libera] is free; it is inferior on the transverse colon, anterior elsewhere. All these bands start on the creeum at the vermiform process, and spread out to form a uniform layer on the rectum. Between the sacculations are semilunar folds [plicx semilunares coli], which involve the entire thickness of the intestinal wall, forming crescentic ridges of the mucosa which project into the lumen (figs. 932, 935). Along the free surface of the colon, especially near the trenia, are numerous small appendages [appendices epiploicx], which are pouches of peritoneum containing fat (fig. 906).

The cæcum.-The cacum [intestinum creum] is a cul-de-sac forming the first part of the large intestine. It is defined as that part of the colon which is situated brow the entrance of the ileum. Its breadth is about $7.5 \mathrm{~cm}$., and its length about $6 \mathrm{~cm}$. (Fig. 932).

There is usually a more or less well-marked constriction opposite the ileoesecal orifice marking the boundary between ciecum and colon. 'The cecum itself also frequently presents a constriction dividing it into two sacculations.

It lies in the right iliac fossa, and is usually situated upon the ilio-psoas muscle, and so placed that its apex or lowest point is just projecting beyond the medial borrler of that muscle (figs. 899,906$)$. It is usually entirely enveloped in peritoncum, and is free in the abdominal cavity, but more or less attached in about 10 per eent. of all eases. The apex of the cecum usually corresponds to a point a 
little to the medial side of the middle of the inguinal ligament. Less frequently the cæcum will be found to be in relation with the iliacus muscle only; or the bulk of it will lie upon that muscle, while the apex rests upon the psoas. In a number of cases the creum is entirely clear of both psoas and iliacus muscles, and hangs over the pelvic brim, or is lodged entirely within the pelvic cavity. Sometimes the cæcum may pass even to the left of the median line of the body.

This part of the colon is liable to considerable variation.

Fig. 932.--Interior of the Cecum, Anterior View. (Rauber-Kopsch.)

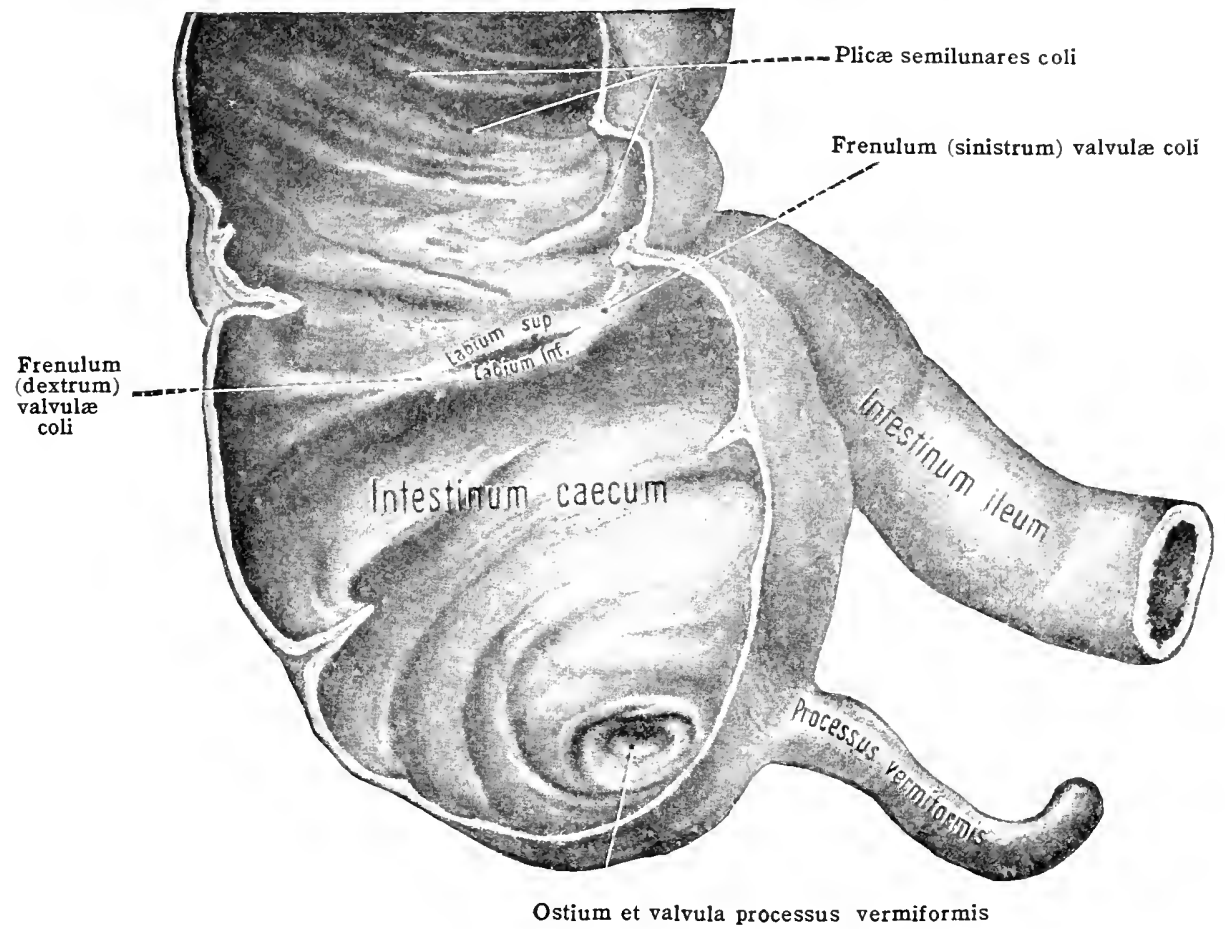

Its variations in form may be described under four types:

1. The foetal type is conical in shape, the appendix arising from the apex, and forming a continuation of the long axis of the colon. The three muscular bands which neet at the appendix are nearly at equal distances apart (fig. 933, A). When the cecum is empty and contracted it tends to approach this type.

2 . The second form is more quadrilateral in shape than the last; the three bands retain their relative positions; the appendix appears between two bulging sacculi, instead of at the summit of a cone (fig. $933, \mathrm{~B}$ ).

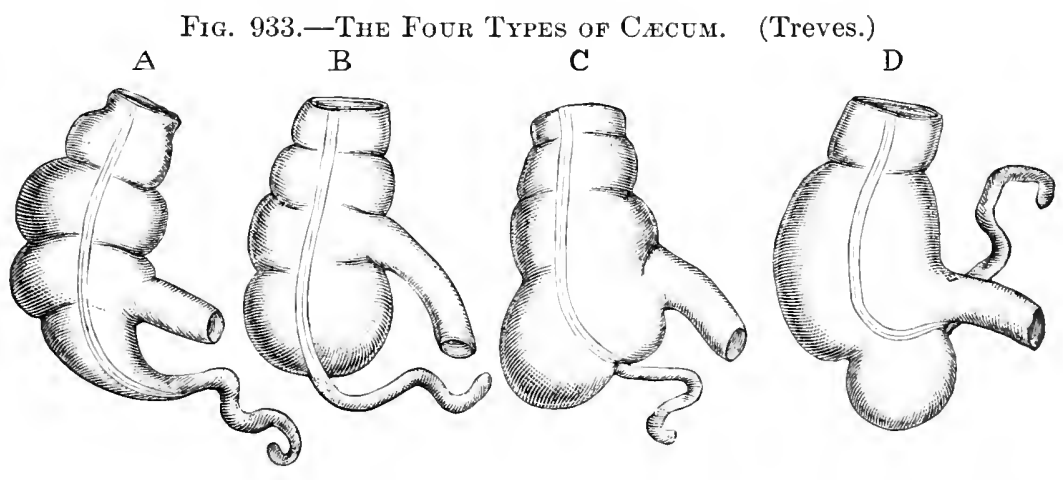

3. In the third type, that part of the cæcum lying to the right side of the anterior band grows out of proportion to that part to the left of the band. The anterior wall becomes more developed than the posterior, so that the apex is turned so much to the left and posteriorly that it nearly meets the ileo-cæcal junction. A false apex is formed by the highly developed part to the right of the anterior band. This is the usual cacum found (fig. 933, C). 
4. In the fourth type, the development of the part to the right of the anterior band is excessive, while the segment to the left of the band has atrophicd. In this form the anterior band runs to the inferior angle of junction of the ileum with the crecum. The root of the appendix is posterior to that angle. There is no trace of the original apex, and the appendix appears to spring almost from the ileo-cæcal junction (fig. 933, D.)

The ileo-cæcal valve.-The ileo-cæcal valve [valvula coli] is situated at the entrance of the ileum into the large intestine at the upper border of the cæcum, on the posterior aspect and toward the medial side (fig. 932). The valve usually lies nearly opposite the middle of a line from the anterior superior iliac spine (left) to the umbilieus. The ileum passes from below upward and toward the right, and terminates with a considerable degree of obliquity. The valve is formed by two lip-like folds projecting into the large intestine, the upper [labium superius], and the lower [labium inferius]. They are a little oblique. The opening between them takes the form of a narrow transverse slit about $1.2 \mathrm{~cm}$. in length. At the ends of the slit the valves unite and are prolonged at either end as a ridge [frenulum valvulæ coli] partially surrounding the intestine.

Villi cover that surface of the folds looking toward the ileum; the surface toward the large intestine is free from villi. In the formation of this valve the longitudinal muscular fibres pass across from the ileum to the large intestine without dipping down between the two layers of each fold. The circular muscular fibres, on the other hand, are contained between the mucous and submucous layers which form these folds.

The efficiency of the valve in preventing the return of faces is due largely to its oblique position. (Symington.)

Fig. 934.-Cecum, Vermiform Process, and End of Ileum, with the Blood-supply and the Neighbouring Foss.e. (Woolsey, after Merkel.)

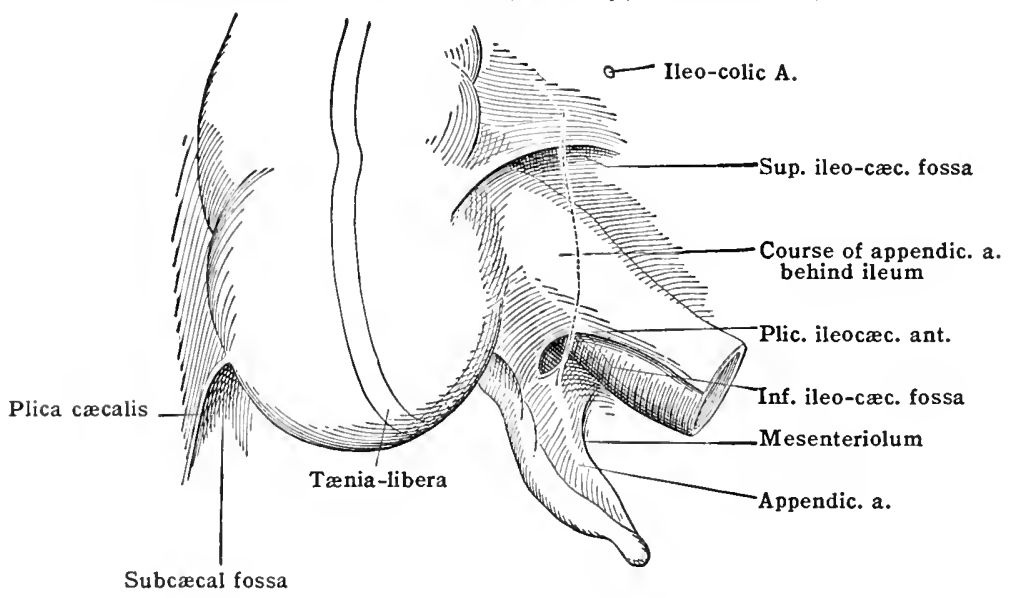

Ileo-cæcal fossæ.-About the cæeum, and especially in the vieinity of the ileoexeal junction, are certain fossie collectively known as the ileo-cæeal fossæ. Two only appear to be fairly constant, although a third is now and then present.

The first, the superior ileo-cacal or ileo-colic fossa, is formed by the passage across the junction of the carcum and ileum of the anterior cecal artery, a branch of the ileo-colic artery, which produces a fold of pritoneum [plica ileocolica] limiting a pouch. It is on the anterior aspect of the ilen-colic junction, and the ponch opens downward (figs. 906, 934). It is present in about one-third of all rases.

The scond fossa is not quite so simple. If the cecum be turned upward so as to expose its posterior surface as it lies in situ, and if the appendix be drawn down so as to put its mesentery on the stretch, a peculiar foll will be fomm to join that mesentery (fig. 934). 'This fold arises from the borler of the ilemm opposite the insertion of its mesentery. It then passes over the ileo-cacal junction on its inferior asperet, is allherent to the eacum, and finally joins the surface of the mesentery of the alpormlix. This fold is peeuliar in the absenee of any visible vessels, and is often known as the 'blondless fold of 'Troves.' Between it and the appendix there is an almost constant fossa, the inferior ilourereal fossa. It is usually large, admitting two fingers, anct wecurs in nearly 85 per wat. of all cases. It is bounded on one side by the small intestine, and on the other by the careme. The anpendix is oceasionally found in the fossa.

The subcreal of retrocolic fossa is behind the eiremm and is found in about ten per cent. of all cases. It may extend fol some distance behind the ascending colon. The appendix may be lodgerl in this fossit.

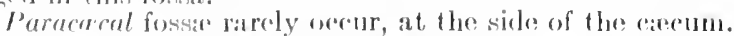

Variations.-In arldition to variations almaly mentioned the eaecum may vary in its general 
development. It is sometimes small and insignificant; in other cases it reaches a large size. It may be so rotated that the ileum passes behind the colon and opens on the right side. The posterior part has been seen much more developed than the anterior, so that the ileum has entered from the front, and the appendix has come off from the anterior wall. The cæcum may remain undescended, and be found just under the liver or in the vicinity of the umbilicus. In case the rotation of the embryonic intestinal loop fails to occur (which rarely happens) the cæcum may remain permanently upon the right side. If the normal process of adhesion fails to occur, the cæcum and colon, along with the small intestine, may remain suspended from the mid-dorsal line by the primitive mesenterium commune. Or any of the intermediate stages of partial adhesion may persist.

The vermiform process.-Attached to what was originally the apex of the cæcum is a narrow, blind tube, the vermiform process [processus vermiformis] or appendix. It comes off at a variable distance (usually about $2.5 \mathrm{~cm}$.) below the ileo-cæcal valve on the postero-medial aspect of the cæcum, though sometimes from the lower end of the cæcum, or elsewhere. On the interior, at the point where it joins the cæcum (fig. 932), there is a slight inconstant valve [valvula processus vermiformis]. The appendix joins the cæcum at the point where the three

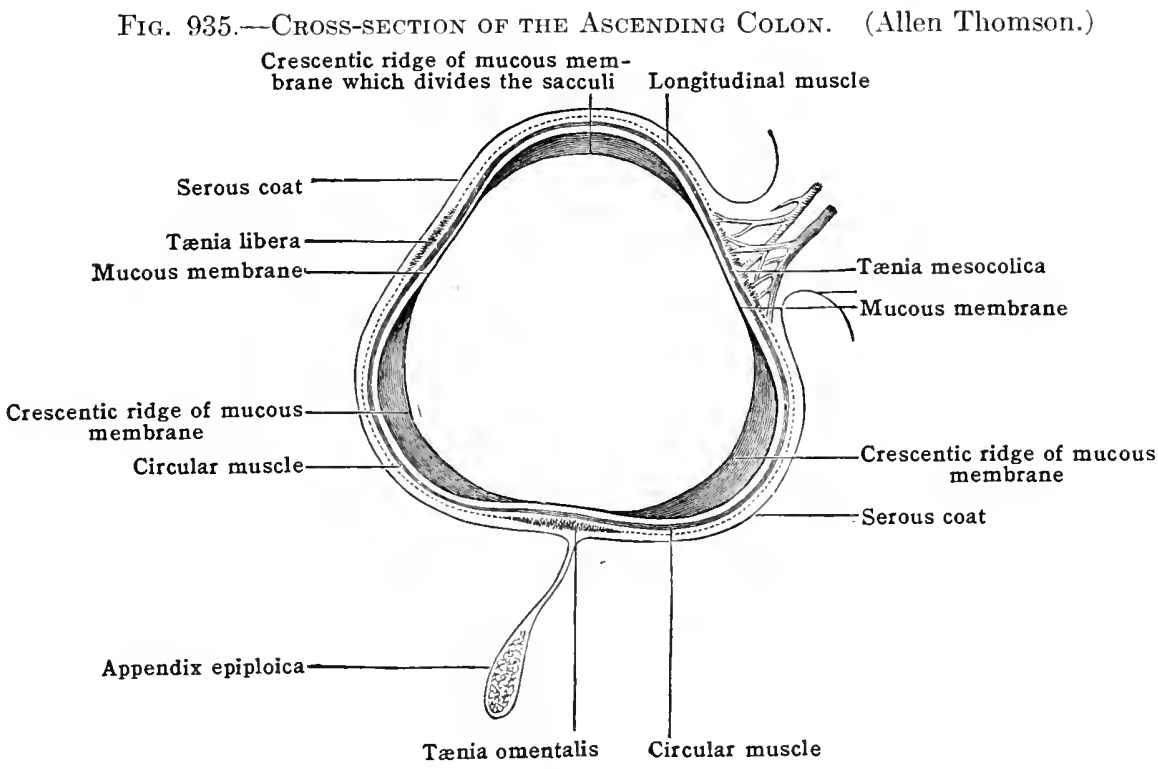

tæniæ meet, and the anterior tænia forms the best guide to this point. In the adult, the average length of the appendix is between $8 \mathrm{~cm}$. and $10 \mathrm{~cm}$., the extremes being $2 \mathrm{~cm}$. to $25 \mathrm{~cm}$. It is usually much twisted and coiled upon itself. Its direction is most frequently downward toward the pelvic cavity, or upward and medialward behind the ileum in the direction of the spleen. It occasionally turns lateralward, or more rarely upward behind the cæcum.

The vermiform process does not have a true mesentery, but usually (in about 90 per cent. of cases) is provided with a falciform fold [mesenteriolum] of peritoneum, continuous with the left (lower) layer of the mesentery of the ileum (figs. 906, 934).

In general outline this fold of peritoneum is triangular. In the adult it does not extend along the whole length of the tube. It is, in fact, too short for the appendix, and it is this that accounts for the twisted condition of this process. Along the free margin of the fold runs a branch of the ileo-colic artery (fig. 934).

The ascending colon.--The ascending colon [colon ascendens] (figs. 906, 914) extends in the right lumbar (lateral abdominal) region from the cxeum to the inferior surface of the liver, lateral to the gall-bladder, forming there the right colic [flexura coli dextra] or hepatic flexure. Its average length is about $20 \mathrm{~cm}$. (or somewhat less when measured in situ). It is covered by peritoneum in front and on the side (fig. 902), but in a certain proportion of cases (26 per cent. according to Treves) this part of the large intestine is connected with the posterior wall of the abdomen by a meso-colon (usually very short) and is therefore surrounded by peritoneum. Connected with the ascending colon is sometimes found a fold of 
peritoneum, extending from the right side of the gut to the abdominal wall at a little above the level of the highest part of the iliac crest. It forms a shelf upon which rests the extreme right margin of the liver. It might be called the sustentaculum hepatis.

The ascending colon is in relation behind with the right kidney, and the iliacus and quadratus lumborum. In front are some of the coils of the ileum (fig. 899), separating it from the anterior abdominal wall.

The transverse colon.- The transverse colon [colon transversum], smaller in diameter than the ascending, extends from the lower surface of the liver to the spleen. Its average length is from 40 to $50 \mathrm{~cm}$. It describes an arch with its convexity forward and downward. It crosses through the umbilical region from the right hypochondrium to the left hypochondrium (figs. 899, 906, 914).

In the majority of cases the superficial part of the colic arch-as seen before the viscera are disturbed-is either in whole or in greater part above a straight line drawn transversely across the body between the highest points of the iliac crest. In about one-fourth of all cases it lies, in whole or in greater part, below this line.

Certain remarkable bends are sometimes formed by this part of the bowel. The bending is always in the same direction, namely, downward, and is usually abrupt and angular. The apex of the $\mathbf{V}$ or $\mathbf{U}$-shaped bend thus formed may reach the pubes. This bend appears to be due to two distinct causes: namely, longcontinued distention, on the one hand, and congenital malformation on the other.

The transverse colon is in relation above with the liver and gall-bladder, the stomach, and at its left extremity with the spleen. The second portion of the duodenum passes behind it. Below are the coils of the small intestine. It is almost completely surrounded by peritoneum, being connected with the posterior abdominal wall (chiefly the anterior border of the pancreas) by the transverse mesocolon. This is usually lacking on the right of the mid-line, however, where the colon crosses the descending duodenum and the head of the pancreas (fig. 905).

The descending colon [colon descendens] is $25 \mathrm{~cm}$. to $30 \mathrm{~cm}$. in length (less when in situ) and extends from the spleen to the pelvic brim (figs. 906, 914). It is more movable than the ascending colon and is also narrower. At its beginning it is usually connected with the diaphragm, on a level with the tenth and eleventh ribs, by a fold of peritoneum, the phreno-colic ligament [lig. phrenicocolicum] (or sustentaculum lienis, from the fact that it supports the spleen). The bend between the transverse colon and descending colon is called the left colic or splenic flexure [flexura coli sinistra]. The descending colon is situated in the left hypochondriac, lumbar and iliac regions (fig. 906). Its relations to the peritoneum are the same as obtain with the ascending colon, that is, it is covered in front and on the sides. A mesocolon is met with oftener on this side than on the right, occurring in 36 per cent. of all cases (Treves) (see fig. 902). It is found especially in the lower part of the desecnding colon, in the iliac fossa. This portion, extending from the iliac erest to the brin (superior aperture) of the pelvis, is sometimes describerl as a separate segment, the iliac colon (Jonnesco).

The descending colon is covered anteriorly by coils of small intestine; posteriorly it is in contact with the lower part of the left kidney, the quadiatus lumborum, iliacus and psoas muscles. It terminates by erossing medialward over the psoas muscle and the external iliac vessels to join the sigmoid colon.

The sigmoid colon [colon sigmoideum] or pelvic colon, extends from the descending colon to the rectum (figs. 906, 914). It includes what was formerly described as the 'sigmoid flexure' and also the 'first portion' of the rectum. These together form a single loop which eannot conveniently be divided into parts.

The loop, the sigmoid colon, begins at the margin of the psoas, and ends where the sigmoid mesocolon ceases, opposite the second or third sacral vertebra.

The loop when unfolded deseriles a figure that may be compared io the capital omegal. The average longth of this sigmoid colon is about $40 \mathrm{~cm}$. The normal position of the Ioop is not in the left iliac fossa, but wholly in the pelvis. 'The most common dispessition of it may now be described. The sigmoid (pelvie) colon begins about midway betwern the lombo-sacral eminence and the inguinal (Poupart's) ligiment. It deserends at first aloug the left pelvic wall, and may at once reach the pelvic floor. It then passes more or less horizontally and transversely areross thr undvis from laft to right, and commonly comes into contact with the right frelvie wall. At this point it is bent upon itsolf, and, passing once more 
toward the left, reaches the middle line and joins the rectum. It will lie, therefore, in more or less direct contact with the bladder (and uterus in the female), and may possibly touch the cxcum. It is very closely related with the coils of small intestine that occupy the pelvis, and by these coils the loop is usually hidden. In about 90 per cent. of cases, the sigmoid colon lies entirely within the true pelvic cavity. In the remainder, it loops upward for a variable distance toward the umbilicus, a position normally found in infancy.

Fig. 936. - Interior of the Rectum. ( $\times \frac{3}{3}$.) (From Toldt's Atlas.)

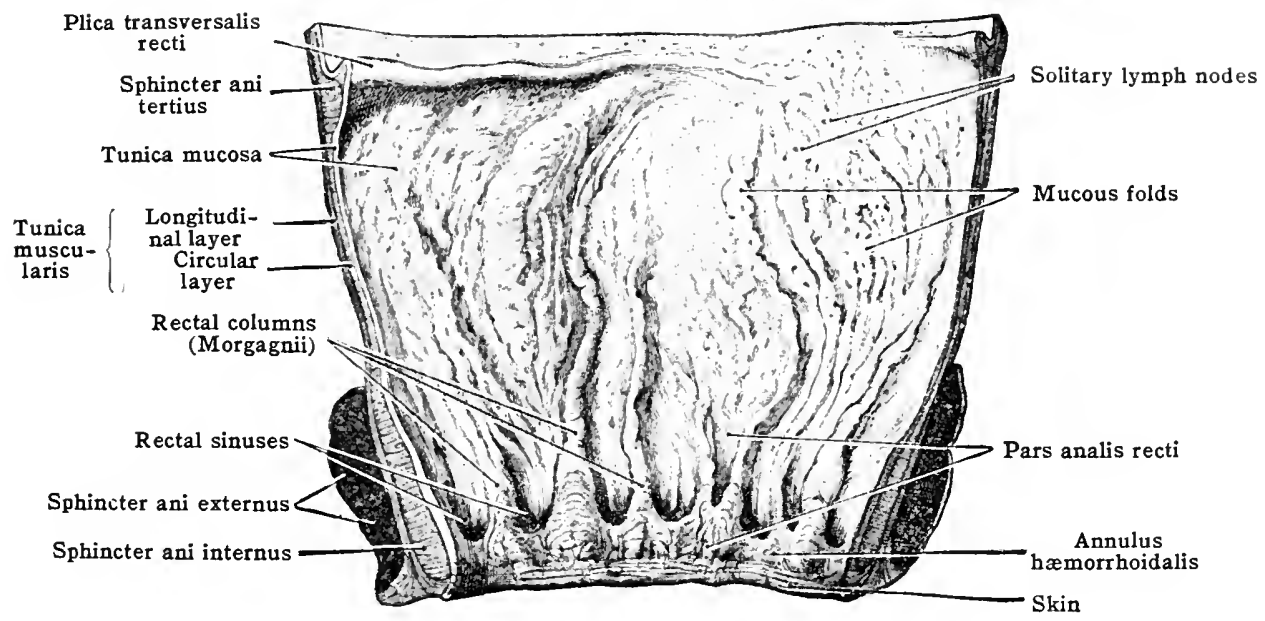

The sigmoid colon is attached to the abdominal and pelvic wall by the sigmoid mesocolon, so that it is quite surrounded by peritoneum. The line of attachment of this mesocolon is as follows: It usually crosses the psoas in a slight curve upward so as to pass over the iliac vessels at or about their bifurcation. The curve ends at a point either just to the medial side of the psoas muscle, or between the psoas and the middle line, or, as is most frequently the case, just over the bifurcation of the vessels. From this point the line of attachment proceeds vertically

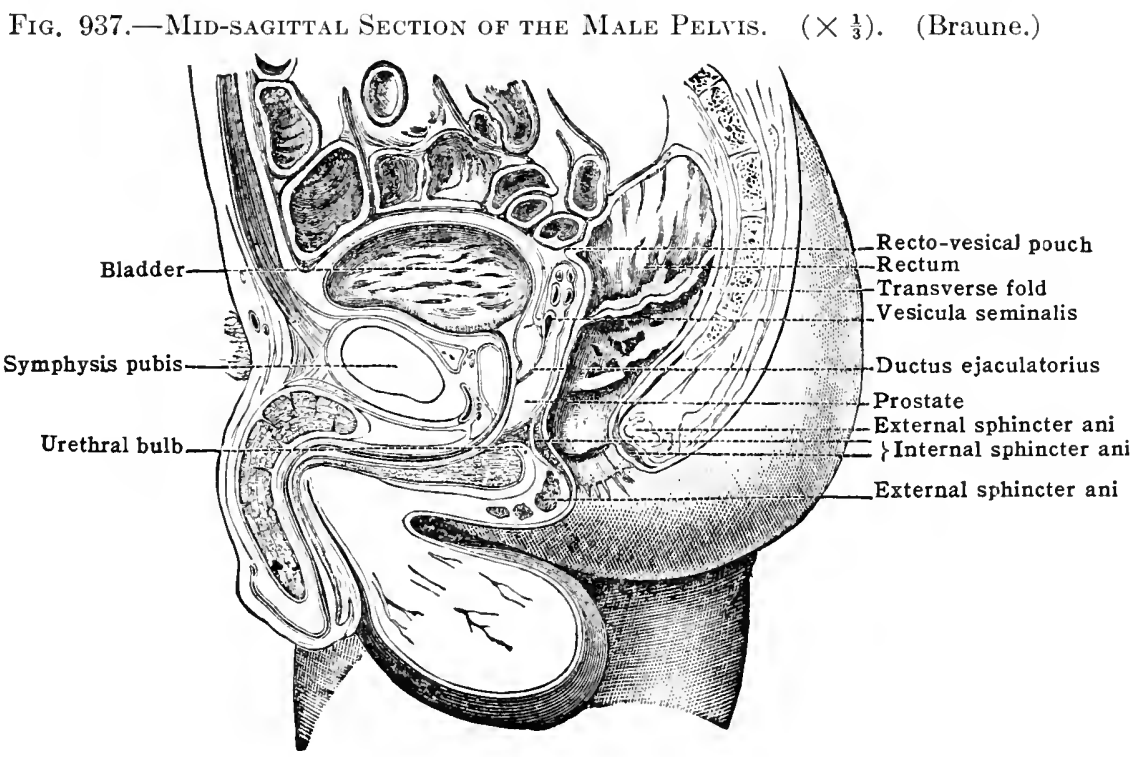

down, taking at first a slight curve to the right. Its course is to the left of the middle line, while its ending will be upon that line, about the second or third sacral vertebra. The sigmoid mesocolon measures from 3 to $8.7 \mathrm{~cm}$. in width-i. e., from the parietes to the bowel,at the widest point.

When a descending mesocolon exists, it joins that of the sigmoid colon. There is of ten no mesocolon over the psoas, the gut being adherent to that muscle. In connection with the sigmoid mesocolon is often found a fossa or pouch of peritoneum, known as the intersigmoid fossa [recessus intersigmoideus]. This pouch is formed by the incomplete adhesion of the 
primitive mesocolon to the posterior abdominal wall. It is generally found over the bifureation of the iliac vessels. The pouch is funnel-shaped, and the opening looks downward and to the left. It varies in depth from 2.5 to $3.7 \mathrm{~cm}$., and is rarely the seat of the sigmoid hernia.

The rectum.-The rectum, according to the BNA nomenclature, is recognised as a division separate from the large intestine. The term rectum is now limited to that portion of the bowel below the mid-sacral region, where the mesocolon ceases. It is divided into two portions: the first extends downward and forward, in front of sacrum and coccyx, to the level of the pelvic floor; the second portion (the anal canal) extends from this point downward and backward to the anus (figs. 937, 938).

Fig. 938.-Mid-Sagittal Section of the Femile Pelvis. (Spalteholz.)

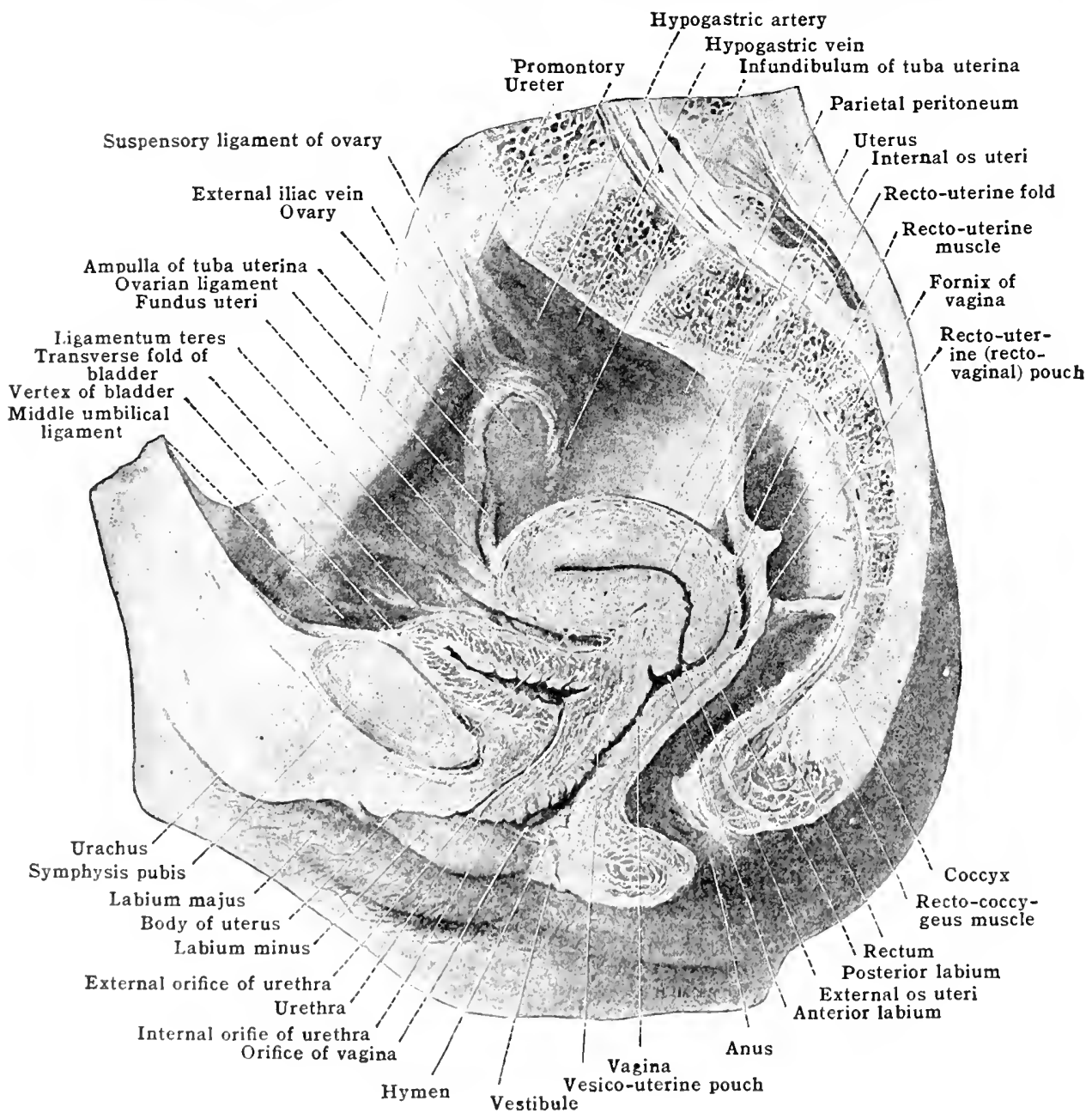

The npper or first portion of the rectum is about $10 \mathrm{~cm}$. long, and is concave forward [flexura sacralis] rexeept at the lower end where it eurves backward and downwarl [flexura perinealis] to join the second portion. The lower part of the first portion often pressents a dilation |ampulla recti], due to accumulation of faress. This part is sometimes deseribed as the infre-peritomeal portion of the rectum moper.

Anteriorly, the reetum is in contact with eoils of ileum and, in the make, with the trigone of the bladder, the vesiculac seminales, ductus deforentes, and posterior aspect of the prostate (fig. (3:3). In the fomale, it is in contact anteriorly with the vagina and the ecrvix uteri (fig. 938).

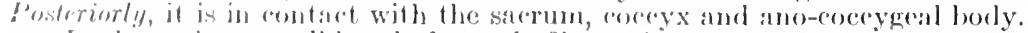

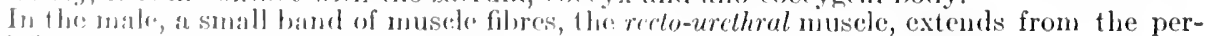
infosl flrexure of the rectum to the membranous urethra. 
The peritoneum is reflected anteriorly from the rectum to the bladder in the male (recto-vesical pouch) and to fornix of the vagina in the female (recto-vaginal pouch). In the newborn, the peritoneum reaches to the base of the prostate (Symington). On the posterior surface of the gut, there is no peritoneum below a point about $12.5 \mathrm{~cm}$. from the anus. Thus the peritoneum at the upper end of the rectum entirely surrounds the gut. Lower down it covers only the sides and anterior wall, and lower still the anterior wall only, where it is reflected upon the bladder or vagina.

The second portion of the rectum, or anal canal [pars analis recti] is from 2.5 $\mathrm{cm}$. to $3.5 \mathrm{~cm}$. in length. From the lower end of the first portion, it turns at right angles downward and backward, passing through the pelvic floor, and ending at the anus. It is entirely below the peritoneum, and is surrounded by the two sphincter muscles (figs. 936, 937).

Anteriorly is the bulb of the urethra and the posterior margin of the urogenital trigone in the male (fig. 937), while in the female it is separated from the vestibule and the lower part of the vagina by the 'perineal body' (fig. 938). Posteriorly it is connected with the tip of the coccyx by the ano-coccygeal body. Laterally it is in contact witls the margins of the levatores ani, which act as an accessory sphincter, and help to support the ampulla recti.

The anus. - The anus is the aperture by which the intestine opens externally. During life it is contracted by the sphincters, so as to give the surrounding skin a wrinkled appearance. Around the lower part of the rectum and anus certain muscles that are connected with its proper function are situated. They are the internal sphincter, the levator ani, and the external sphincter. The levator ani and external sphincter will be found described in the section on Musculature. The internal sphincter is a thickening of the circular fibres of the intestine, situated around the second portion or anal canal. It forms a complete muscular ring, 2 to $3 \mathrm{~mm}$. thick, and is composed of non-striated muscle.

The rectum differs from the rest of the colon in having smoother walls and no appendices epiploicæ. At the upper end of the rectum, the tænia libera and tænia omentalis join to form a broad band which spreads out, covering the entire anterior aspect of the rectum. Similarly the tænia mesocolica spreads out upon the posterior aspect. Thus the rectum has a complete longitudinal muscle layer, which, however, is thicker anteriorly and posteriorly than laterally. It sends a bundle of fibres to the coccyx [m. recto-coccygeus]. Below, the longitudinal layer passes between the two sphincters and breaks up into numerous bundles which are interwoven with the external sphincter and levator ani, some of them terminating in the circumanal skin.

Its mucous membrane is thicker than that of the rest of the large intestine. Certain folds, chiefly longitudinal in direction, are seen in the lax state of the tube, which disappear when distended, but Houston had described three permanent oblique transverse folds [plica transversales recti] (fig. 936), containing bundles of non-striated muscle-cells, which project into the lumen of the tube: one is on the right at the level of the reflection of the peritoneum from the rectum; and two are on the left, one above and one below the right fold. That upon the right side is the largest and most constant, and its muscular bundle is sometimes called the sphincter tertius. It is located about $7.5 \mathrm{~cm}$. above the anus. These folds, like the corresponding semilunar folds of the colon, when well marked involve the entire wall.

The mucous membrane of the upper portion of the anal canal presents a series of vertical folds known as rectal columns [columnæ rectales] (columns of Morgagni), containing bundles of non-striated muscle longitudinally arranged. These columns become more prominent as they extend downward. Just above the anus each two adjacent columns are united by an arch-like fold of mucous membrane, these folds forming what are known as the anal valves, while the small fossæ behind them are known as the rectal sinuses. The area below the ralves and"extending to the anus is termed the annulus homorrhoidalis (fig. 936). This is lined by a modified skin, while the area above the valves forms a transition to the typical mucosa of the rectum.

Minute structure of the large intestine.-In general, the large intestine has the four coats (fig. 939)-mucosa, submucosa, muscularis, and serosa-characteristic of the alinentary canal. The mucosa lacks the villi and plica circulares characteristic of the small intestine. It contains many solitary lymphatic nodules, but no Peyer's patches. It differs from the stomach in the absence of foveolæ, and in the presence of large numbers of mucous 'goblet cells' found both on the surface and along the numerous crypts of Lieberkuehn (which contain no cells of Paneth). The submucosa is much as in the snall intestine. The muscularis has a continuous inner circular layer, the outer longitudinal fibres being chiefly gathered into the three bands, the teniæ coli, as above nentioned. The serosa is typical, excepting extraperitoneal areas where the epithelium is lacking. The appendices epiploica were also mentioned above.

The cæcum and colon present no special features worthy of mention, beyond the typical structure above outlined. 
The vermiform process, however, differs in several important respects (fig. 940). The walls are relatively thick and the lumen small. The solitary lymph nodules are closely packed or confluent (especially in roung people). They occupy the greater part of the submucosa, and somewhat resemble the Peyer's patches of the ileum. They, like all the lymphoid structures

Fig. 939.-Cross-section of the Large Intestine. $a$, Mucosa. $b$, Submucosa. $c$, Muscularis. $d$, Serosa. (Radasch.)

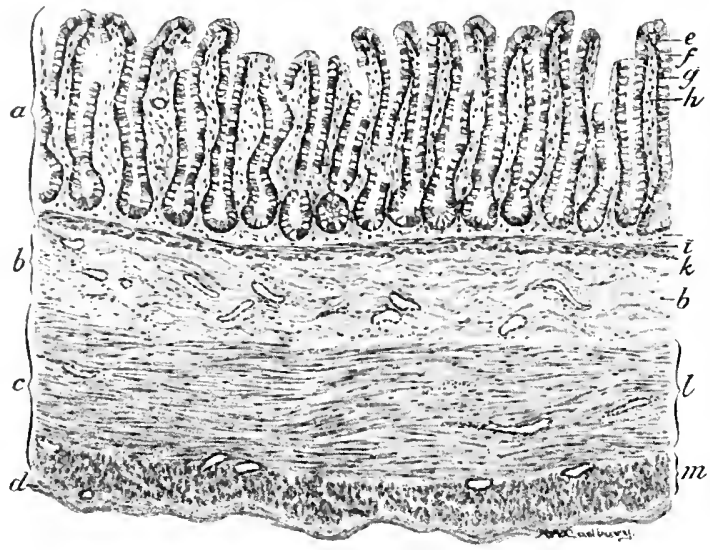

in general, tend to become atrophied in old age. Fat cells are usually abundant in the submucosa. The muscularis presents an inner circular layer and also a thin but complete outer longitudinal layer. The serosa is typical. The lumen shows a progressive tendency to obliteration as age advances (Ribbert). 'This condition is never found in infancy but occurs

Fig. 940.-Transverse Section of the Human Vermiform Process. $(\times 20)$. (Stöhr and Lewis, from Sobotta.) Note absence of villi and abundance of lymph nodules. $F$, Clusters of fat cells in submucosa. Only the inner part of the circular muscle is shown.

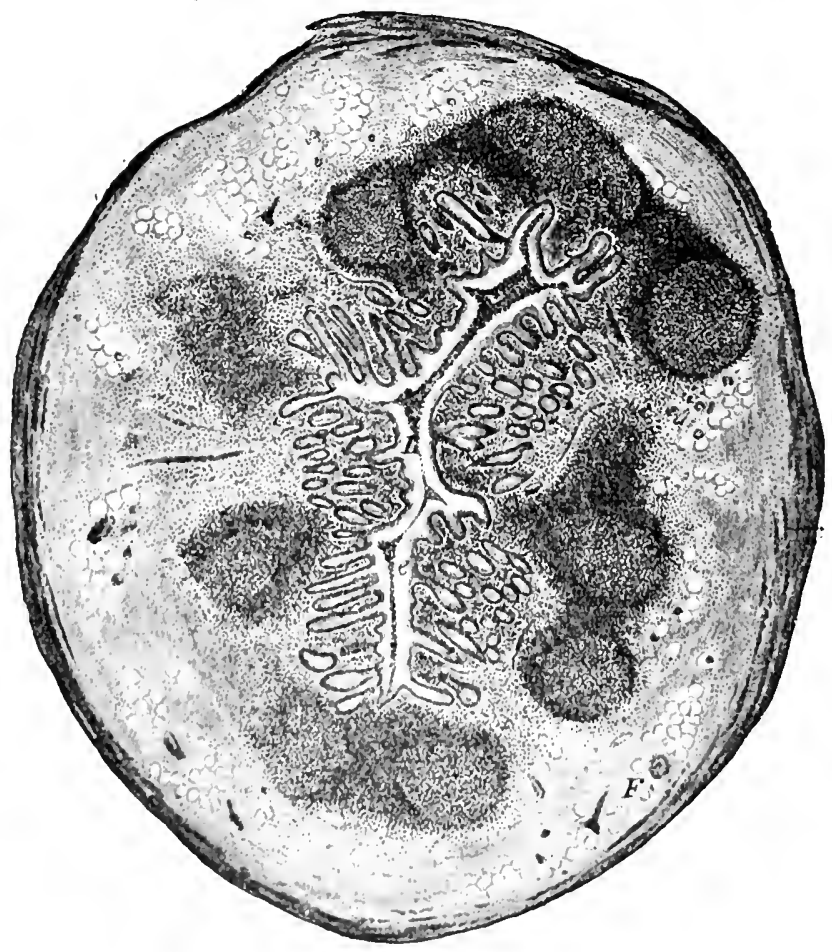

11.sustly only partial) in over 25 per cout. of adults and in 50 per cent. of all cases over 50 years of agre. It is, hewevor, somewhit morertain whether this represents a normal process. In obliteration, the glands and lymphoirl molules disuppear, and the contire mucosa is transformed into an axial mass of fibrons connective tissure

The rectum alse presents several peculiarities of structure. Attention has already been 
called to the transverse folds (of Houston) and the rectal columns, sinuses and valves. Just above the valves, the mucosa is transitional, the epithelium being partly stratified, and the crypts of Lieberkuehn few and scattering. Below the valves, the annulus hæmorrhoidalis is lined by a modified skin. Hairs and sebaceous and sweat glands do not appear until just outside the anal orifice. The thickening of the circular muscle to form the internal sphincter, and the somewhat uniform disposition of the longitudinal muscle have already been mentioned, as well as the absence of a serous coat in the lower portions.

Blood-vessels. - The large intestine is supplied with blood by the branches of the superior mesenteric and inferior mesenteric arteries, while it also receives a blood-supply from the internal iliac at the rectum. The vessels form a continuous series of arches from the cæcum, where the vasa intestini tenuis anastomose with the ileo-colic, the first branch of the superior mesenteric given to the large intestine.

The blood-supply of the rectum is from the inferior mesenteric by the superior hæmorrhoidal, from the hypogastric (internal iliac) by the middle hæmorrhoidal, and from the internal pudic by the inferior hæmorrhoidal. The vessels at the lower end of the rectum assume a longitudinal direction, communicating freely near the anus, and less freely above.

The blood of the large intestine is returned into the portal vein by means of the superior mesenteric and inferior mesenteric veins. At the rectum a communication is set up between the systemic and portal system of veins, since some of the blood of that part of the intestine is returned into the hypogastric (internal iliac) veins. In the lower end of the rectum the veins, like the arteries, are arranged longitudinally. This arrangement is called the hæmorrhoidal plexus.

The vermiform process is supplied by a special branch of the ileo-colic artery (fig. 934). This branch, the appendicular artery, crosses behind the terminal portion of the ileum (where pressure may obstruct the circulation) to enter the mesenteriolum. An accessory artery of small size also descends along the medial margin of the colon and cacum, entering the base of the appendix.

The nerves and lymphatics of the large intestine differ in no important particular from those of the small intestine, so far as their relations within the intestinal wall are concerned.

The efferent lymphatic vessels in general follow the blood-vessels and pass through corresponding lymph nodes in the various regions (see p. 734). Those of the cacum and vermiform process pass through the appendicular and ileo-cæcal nodes; those of the colon through mesocolic and mesenteric nodes. Those of the descending and sigmoid colons connect with the inferior mesenteric and lumbar nodes. The superior zone of the rectum is drained by lymphatics passing to the ano-rectal and inferior mesenteric nodes; the middle zone (region of rectal columns) to nodes along the three hæmorrhoidal arteries; the inferior zone (anal integument) chiefly to the superficial inguinal nodes.

Development of the large intestine.-At an early stage in the development of the intestinal canal, when this presents a single primary loop and soon after this loop has turned on its axis, there is observed on the left half of the loop, near its top, an enlargement which marks the beginning of the large intestine. With further growth this enlargement develops a lateral outgrowth on the side opposite to that to which the mesentery is attached, therefore free from the mesentery. A conical projection of the large intestine or colon beyond the place where this is joined to the small intestine is thus formed. This conical projection or pouch of the large intestine, which continues the colon somewhat beyond the insertion of the small intestine, develops in to the cæcum and the vermiform process. It does not present, in its further growth, a uniform enlargement. The portion nearest the colon grows in size more rapidly than the terminal portion, this difference in size becoming more apparent as development proceeds, the smaller terminal portion forming the vermiform process. On the return of the intestine to the peritoneal cavity (in embryos of about $40 \mathrm{~mm}$.) the cxeum lies on the right side, immediately below the liver. During the later fœetal months the cæcum gradually descends into the right iliac fossa, and there is thus established an ascending colon. The cæcum may, however, even in the adult retain its embryonic position on the right side immediately beneath the liver, or may descend farther than usual.

The ascending and descending colons, the sigmoid meso-colon (in part), and the rectum with corresponding portions of the mesorectum, become adherent to the posterior body wall during the fourth and fifth fotal months. At the same time, the posterior layer of the great omentum becomes fused with the upper (anterior) surface of the transverse meso-colon. The layer of retroperitoneal fascia corresponding to the obliterated mesocolon is shown in fig. 1005. Variations in the process of fusion give rise to numerous peritoneal variations in the adult.

The sigmoid colon is relatively long at birth. On account of the relatively small size of the true pelvic cavity, both sigmoid colon and coils of ileum are usually excluded from it in the fœetus and infant.

In fotuses of four to six months (length $100 \mathrm{~mm}$. to $240 \mathrm{~mm}$.) transitory villi appear in the mucosa throughout the large intestine, including the vermiform process. They appear in rows, corresponding to longitudinal folds. Their early obliteration is possibly due to distention of the gut by the meconium. The glands bud off like those of the small intestine. Lymphoid nodules are present abundantly in the vermiform process at birth (Johnson). The circular muscular layer begins to appear in the lower part of the large intestine at $23 \mathrm{~mm}$.; the teniæ at 75 to $99 \mathrm{~mm}$. (F, T. Lewis)

Development of the rectum and anus.-The posterior end of the primitive intestine or archenteron, designated the hind-gut, presents a terminal portion which is somewhat dilated and known as the cloaca, into the lateral and ventral portions of which open the Wolffian ducts, and from the ventral portion of which arises the allantois. The ventral portion of the cloaca, which is an entodermal structure, comes in contact with the ectoderm to form the cloacal membrane, and this forms the floor of a slight depression. For a time the cloaca or hind-gut extends for some distance caudal to the cloacal membrane, forming what is known as the post anal gut; this, however, soon disappears. Early in the development of the human embryo 
When this has attained a length of about $6.5 \mathrm{~mm}$., the fold which separates the cloaca and hind, gut from the allantois deepens, and folds develop from the lateral walls of the cloaca which meet and gradually separate the cloaca into a dorsal portion, which forms the rectum, and a ventral portion which forms the uro-genital sinus. This uro-rectal septum extends in its further growth until the cloacal membrane is reached, separating it into a ventral portion known as the urogenital membrane, and a dorsal portion known as the anal membrane. The anal membrane ruptures comparatively late in development, establishing thus a communication between the hind-gut (rectum) and the exterior. The mesoderm develops around the lower end of the rectum, so that the ectoderm becomes slightly invaginated and lines the portion of the anal canal below the valves. A want of rupture of the anal membrane constitutes an arrest of development known as atresia of the anus.

Folds of the mucosa representing the rectal columns, valves and sinuses appear in embryos during the third month, and are well developed during the latter half of the fotal period (Johnson).

Variations. - The large intestine is exceedingly variable in its structure and relations, especially with reference to the peritoneum - so much so that it has been found more convenient to include a consideration of the variations along with the preceding description of the individual parts. The content of fæces (and gas) is as a rule relatively greatest in the cæcum, decreasing in ascending and transverse colons. The descending colon is usually empty, or nearly so, the sigmoid colon and rectum somewhat variable. The rectal ampulla is usually more dilated in women.

Comparative.-The morphology of both small and large intestines will be briefly considered here. As previously mentioned, the primitive form of intestine is a comparatively straight tube extending from stomach to anus, and connected by a primitive mesentery to the middorsal line of the body cavity. There is in many of the lower forms no clear division into small and large intestine, though the rectal region is usually more dilated, and opens into a cloaca. Diverticula often occur in the region between large and small intestine. In many fishes, numerous "ceca" occur just below the pylorus, and in others an extensive spiral valve projects into the lumen of the intestine. The absorptive and digestive surface of the mucosa is further increased by the formation of various kinds of folds, and (beginning in amphibia) of villi. Lymphoid tissue is typically present in the mucosa, often localized in definite masses. Solitary nodules appear in amphibia, and Peyer's patehes in birds. Tubular mucous glands occur in the lower forms, but Brunner's glands and crypts of Lieberkuehn with Paneth cells apparently only in mammals. A cacum is usually present from the reptiles upward (double in birds), and often forms an important organ of digestion. The bile and pancreatic ducts open constantly a short distance below the pylorus. The small intestine is always longer than the large, but there is extreme variation in length among the various species. The four tunics-mucosa, submucosa, muscularis and serosa-are typical for vertebrates, the muscularis consisting of inner circular and outer longitudinal smooth muscle fibres.

Among mammals, the divisions of the intestine correspond in general to those found in the human species, but there is exceedingly great variation in the relative development of the various parts. In general, the length, size and complexity of structure is relatively greatest in the herbivora (whose food is more difficult of digestion), least in the carnivora, and intermediate in the omnivora. Even in the same species, the structure of the intestine may be appreciably modified according to habitual diet. The large intestine varies, but is always shorter and wider than the small intestine. In mammals the rectum only is said to be homologous with the large intestine of lower vertebrates. The cacum is rarely absent and is enormously developed in herbivora. It often contains large amounts of lymphoid tissue, which, in pig and ox forms a so-called 'intestinal tonsil.' 'The vermiform process (found typically developed in man and higher anthropoids) apparently represents a retrogressive evolutionary change in the cacal apex, although this interpretation is denied by some (Berry), who interpret the appendix as a progressive, functional lymphoid organ.

\section{THE LIVER}

The liver [hepar] is the largest gland in the body. Its secretion, the bile [bilis; fel], is poured into the duodenum through the common bile duct. In addition it has important functions as a 'ductless gland' in connection with the nitrogenous and earbohydrate metabolism. In form it is a variable somewhat irregular mass, ronghly comparable to anodified hemisphere occupying the upper right portion of the aldidominal cavity (figs. 899, 914). It presents a convex, rounded upper or parietal aspect, which is in eontact with the diaphragm and adjacent body walls, and a lower, flattened visceral surface, in contact with the abdominal viseera. When virwerl from the front, it is somewhat triangular in outline, oceupying the right hypochondriace, the (ppigastric and (slightly) the left hypochondriac regions.

Physical characters. - In weight, the liver averages about $1500 \mathrm{gm}$. (3 $3 \frac{1}{3} \mathrm{lbs}$.), but it, is cxeecelingly variable, commonly ranging from $1000 \mathrm{gm}$. $1,02000 \mathrm{gm}$. Its relution wejght is also variable, avoraging about 2.5 por cent. of the body in the achult male? (somewhat, higher inthe fromate). Its specifie grovity averages 1.056 , so that, the avorage woight of $1500 \mathrm{gm}$. would correspond to a volume of $1420 \mathrm{ce}$. Its dimensions are also quite variable. Its greatest depth (antero-posterior) averages about $15 \mathrm{~cm}$, and its greatest height (vertical) is about the same. Its 
width (horizontal) is about $20 \mathrm{~cm}$., while its greatest length (measured obliquely from side to side) averages about $25 \mathrm{~cm}$. The colour of the liver is a reddishbrown. It is firm in consistency, but friable, so that it is easily ruptured.

Surfaces and borders.--The most general division of the surface of the liver,

Fig. 941.--Superior Surface of the Liver.

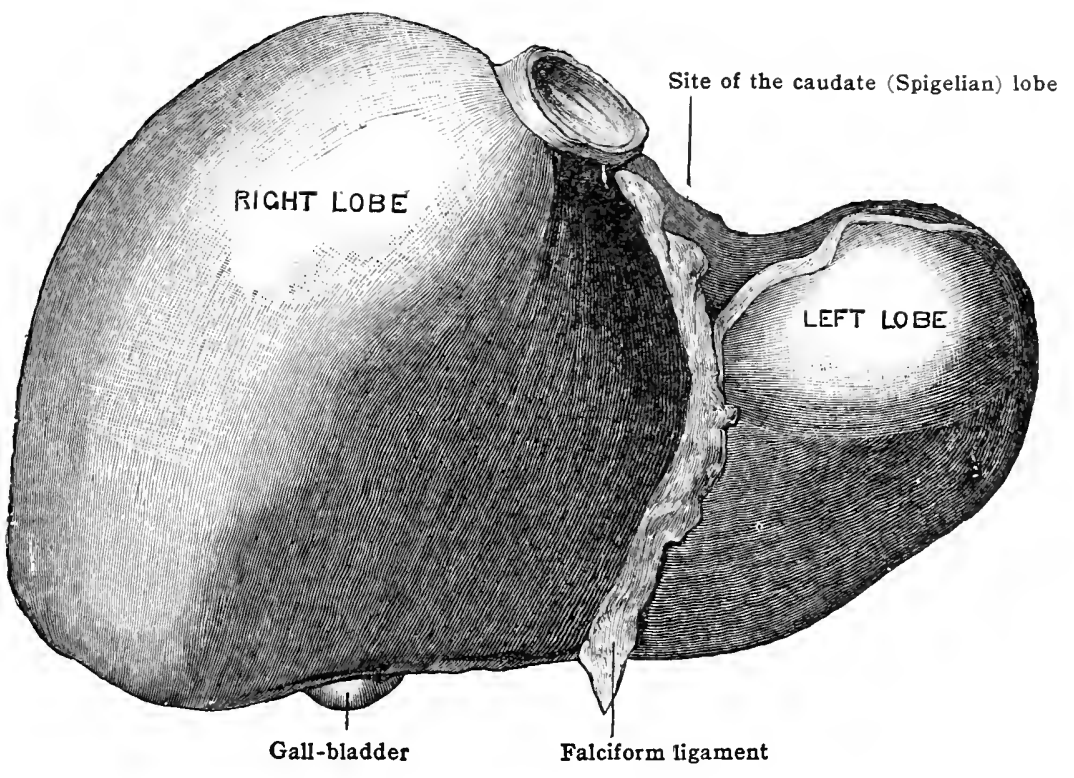

as above stated, is into two--the parietal and the visceral. The parietal surface is again subdivided, usually into two surfaces-posterior and superior.

The posterior surface [facies posterior] is triangular (fig. 943). It is wide on the right, where the right lobe is in contact with the diaphragm (corresponding

Fig. 942.-Inferior Surface of the Liver.

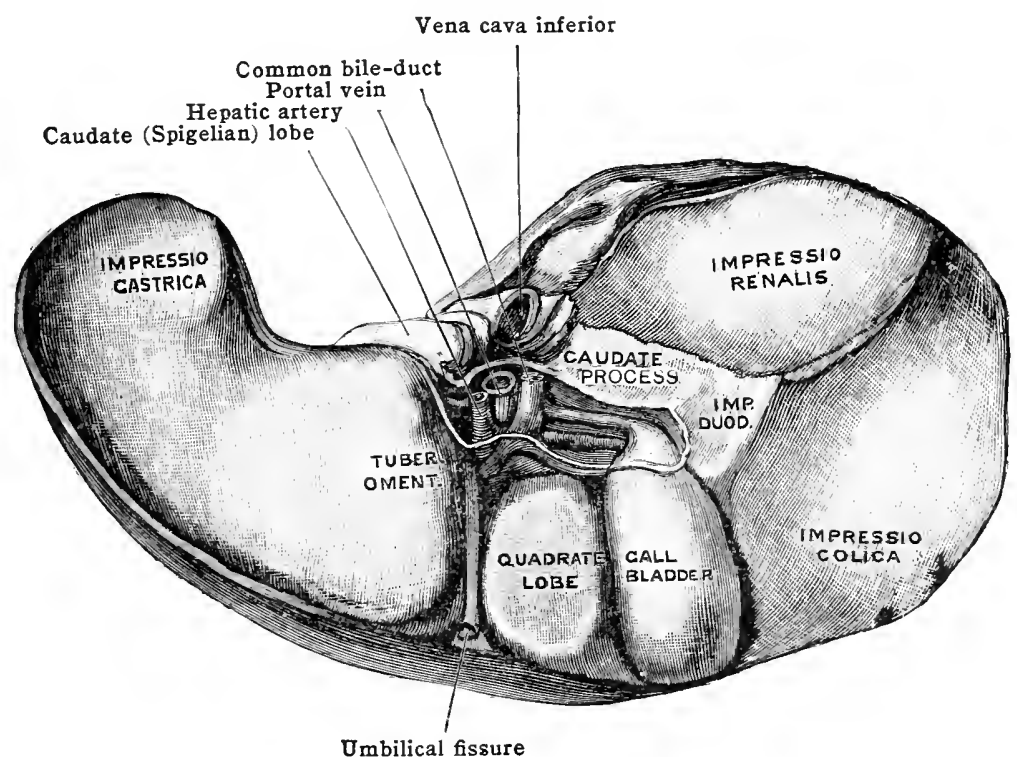

chiefly to the 'uncovered area' of the coronary ligament), and narrow on the left side, where the posterior margin of the lef $t$ lobe is likewise attached to the diaphragm. At the lower, left hand corner of the right lobe is a small triangular area of contact with the suprarenal body [impressio suprarenalis]. Near the mid-line 
is the caudate (Spigelian) lobe, opposite the tenth and eleventh thoracic vertebral bodies, from which it is separated by the diaphragm (chiefly the right crus). On the right of the caudate lobe is the fossa lodging the vena cava (sometimes bridged over), while to the left is the fissure of the ductus venosus, giving attachment to the upper portion of the lesser omentum (relations in eross-section shown in fig. 945).

The superior surface [facies superior] is in general convex and moulded to the inferior surface of the diaphragm (fig. 941). Tne relations in cross-section of the

Fig. 943.-Posterior Strface of the Liver.

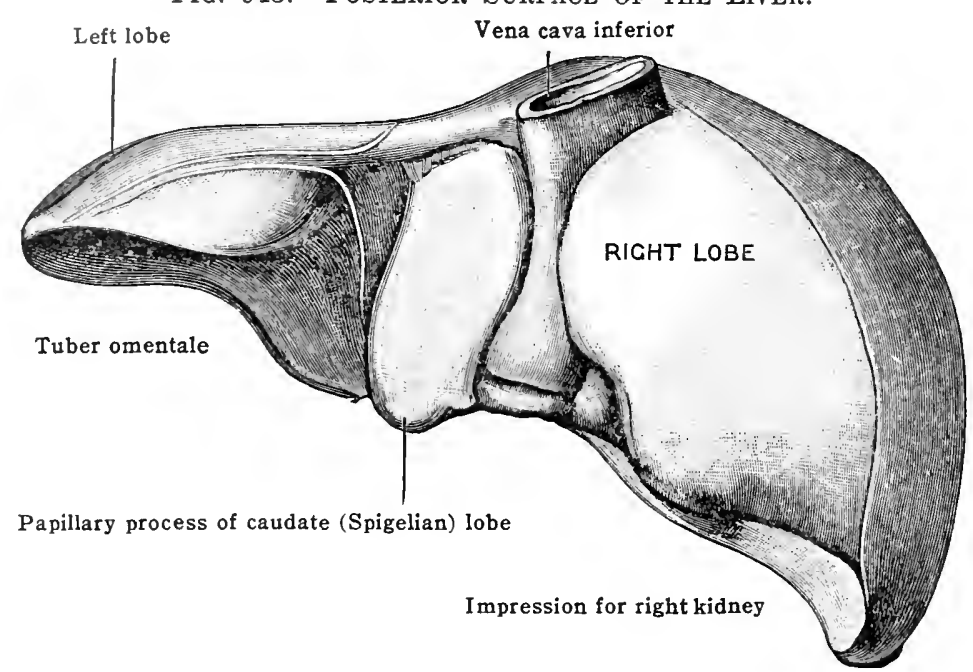

body are shown in fig. 945 . It extends downward upon the anterior abdominal wall to a variable extent in the epigastrie region, including the entire area of the liver visible from the front (fig. 941). It also presents a broad area extending downward on the right side. Symington accordingly distinguishes three surfaces corresponding to the superior surface above deseribed, viz., right surface, anterior surface and superior surface. The superior surface is related above, through the diaphragm, with the base of the right lung, the perieardium and heart, and (on the extreme left) with the base of the left lung. Where it rests upon the liver, the heart forms a shallow fossa [impressio cardiaca].

Fig. 944.-Diagram Showing Ligaments on tile Dorso-inferior Aspect of the Liver. (Lewis and Stöhr.) c.l., Coronary lig. f.l. Falciform lig. g.b., Gall bladder. l.o., Lesser omentum. l.t.l., I.eft triangular lig. o.b., Caudate lobe. p.v., Portal vein. r.l., Lig. teres. r.t.l., Right triangular lig. v.c.i., Vena cava inf.

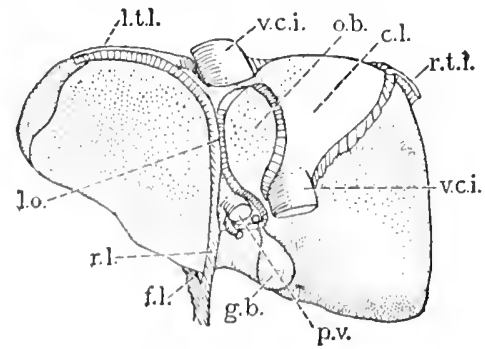

The inferior or visceral surface [facies inferior] (fig. 9.12) faces downward and lackward. It is irregularly concave, with impressions due to contaet with the underlying viseera. It is divided into three lobes, right, left, and quadrate, whose relations will be deseribed later.

(of the borders, the anterior [margo anterior] is the best marked. It forms the inferior boundary of the triangular anterior view of the liver (figs. 899, 914, 941), and separates the superior from the inforior surface. Slightly to the left of the mid-line, it often presents a slight umbilical notch [incisura umbilicalis], where it 
is crossed by the falciform ligament. The posterior surface is separated from the superior and inferior surfaces by ill-defined postero-superior and postero-inferior borders.

Surface outline.-The average position of the liver may be outlined upon the anterior surface of the body as follows (fig. 914): Locate one point on the right mid-clavicular (midPoupart) line opposite the fifth rib; a second point on the left nid-clavicular line about $2 \mathrm{~cm}$. lower, in the fifth interspace; and a third point about $2 \mathrm{em}$. below the costal arch (10th rib) on the right lateral wall. A line slightly concave upward, joining the first and second points defines the uppermost aspect of the lever. A line, strongly convex laterally, joining the first and third points, defines the right side of the liver. Finally, a third line, joining the second and third points, corresponds to the anterior border and defines the lowermost portion of the liver. This line is subject to many individual variations. In general, it is usually slightly convex downward as it crosses the epigastric region. It usually presents a slight umbilical notch, as before mentioned, and frequently a notch for the fundus of the gall-bladder, which is placed near the right mammary (mid-Poupart) line. The lower and right portion of the anterior border of the liver runs somewhat parallel with the infracostal margin. In the upright position, and in livers larger than usual, it extends about $2 \mathrm{~cm}$. below the hypochondrium into the right lateral abdominal (lumbar) region (fig. 914). In the supine position, however, the liver recedes about $2 \mathrm{~cm}$. toward the head. The liver of course participates also in the respiratory movements of the diaphragm.

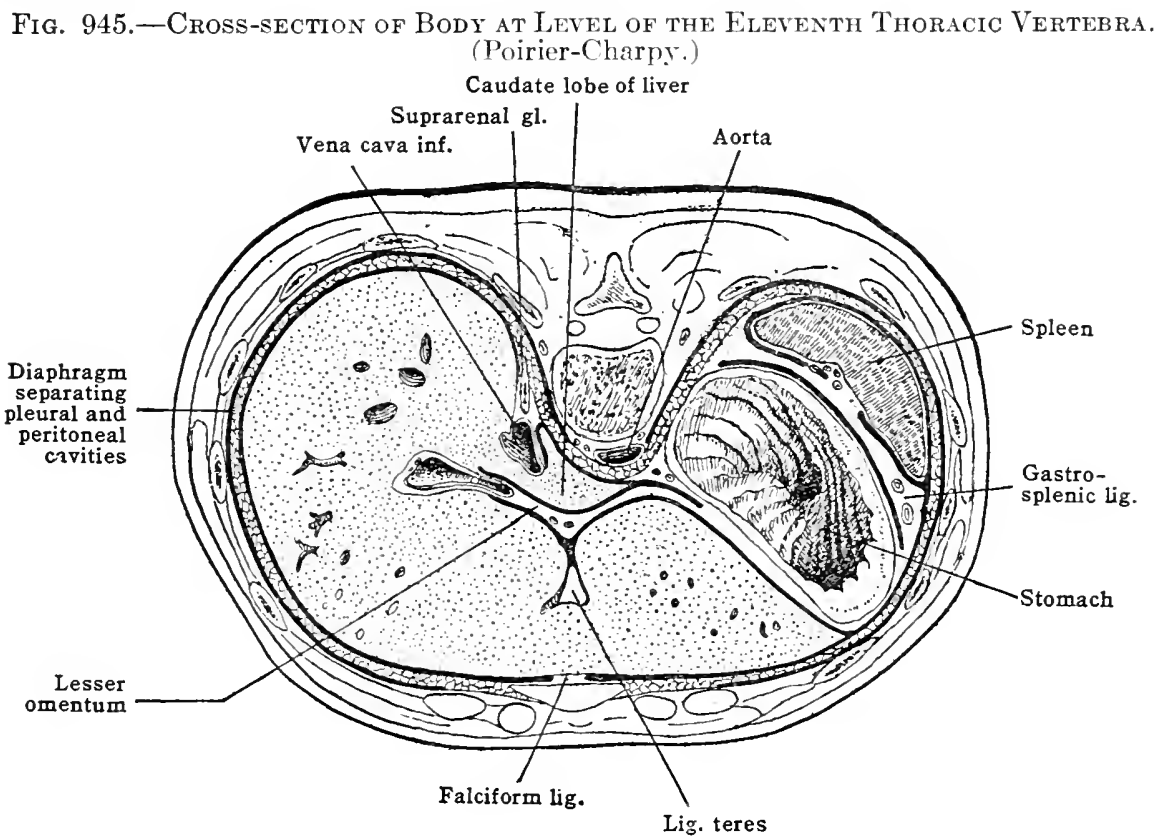

Lobes and fissures.-The superior surface is divided by the falciform ligament into two areas, corresponding to a larger right and a smaller left lobe (fig. 941). On the posterior and inferior surfaces of the liver (figs. 942, 943), an H-shaped arrangement of fossæ and fissures completes the demarcation of lobes. The left upright of the $\mathrm{H}$ [fossa sagittalis sinistra] corresponds to the prolongation of the line of attachment of the falciform ligament. It is made up of the umbilical fissure [fossa venæ umbilicalis], containing the round ligament, on the inferior surface; and of the fossa ductus venosi, containing the ligamentum venosum (obliterated ductus venosus) and the upper part of the lesser omentum, on the posterior surface of the liver. This left sagittal fossa separates the left lobe of the liver from the right lobe (in the wider sense of the term). The right lobe is further subdivided by the right upright and cross-bar of the H. The right upright [fossæ sagittales dextræ] is made up of the broad fossa for the gall-bladder [fossa vesicæ felleæ] on the inferior surface, and the broad fossa vence cavce on the posterior surface (fig. 943. These two fossæ are not continuous, but are separated by a narrow strip of liver, the caudate process of the caudate lobe (fig. 942). The cross-bar of the $\mathrm{H}$ is formed by the transverse or portal fissure [porta hepatis], which encloses the root structures of the liver, within the lower part of the lesser omentum (fig. 942). The area anterior to the cross-bar of the $H$ corresponds to the quadrate 
lobe of the inferior surface; that posterior to the eross-bar to the caudate lobe of the posterior surface; while the remainder of the liver, to the right of the $\mathrm{H}$, is the right lobe (in the narrower sense).

The right Iobe [lobus hepatis dexter] makes up the greater part of the liver. Its relations on the superior and posterior surfaces have already been mentioned. On the inferior or visceral surface (fig. 942), there appears posteriorly a large concavity [impressio renalis] for the right kidney; medially a faint impression [impressio duodenalis] for the descending duodenum; and antero-inferiorly a variable area [impressio colica] of contact with the right (hepatic) flexure of the colon. The caudate process joins the right with the caudate lobe.

The left lobe [lobus hepatis sinister] lies to the left of the left sagittal fissure and the falciform ligament. It is flattened but variable in form and size, and makes only about one-fifth of the entire liver. In children and especially in early fœtal life, it is relatively much larger. At the left extremity, there is usually found in the adult liver a variable fibrous band [appendix fibrosa hepatis] representing the atrophied remnant of the more extensive gland in earlier life. In this fibrous appendix (and in other parts of the liver) the bile ducts of the atrophied liver substance persist as vasa aberrantia hepatis.

The left lobe is related superiorly, through the diaphragm, with the heart and the base of the left lung. Inferiorly (fig. 942) it presents a large concavity [impressio gastrica] which is in contact with the anterior surface of the stomach. Above and behind the gastric impression is the rounded tuber omentale which is placed above the lesser curvature of the stomach and related, through the lesser omentum, with a corresponding tuberosity on the pancreas. To the left of the tuber omentale, and near the posterior aspect of the liver, is a small inconspicuous groove [impressio cesophagea] for the abdominal part of the œesophagus.

The quadrate lobe [lobus quadratus] lies, as before mentioned, on the inferior surface of the liver (fig. 942) in the anterior or inferior area of the H. It is in contact with the pylorus and the first part of the duodenum.

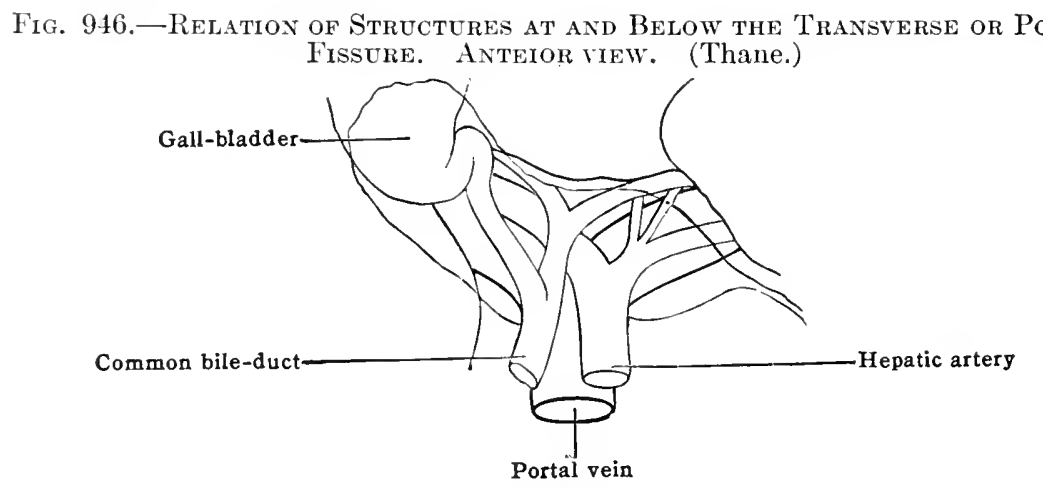

The caudate or Spigelian lobe [lobus caudatus; Spigeli] was described on the posterior surface of the liver (fig. 943). Inferiorly, the caudate lobe, bchind the portal fissure, is divided by a notch into two proeesses. The left or papillary process [processus papillaris] is short and rounded, and lies opposite the tuber omentale. In the foetus it is relatively much larger and is in contact with the pancreas. 'The right or caudate process [processus caudatus] is of variable size, and joins the caudate with the right lobe of the liver. It is usually small and inconspicuous. In the fotus, however, it is relatively mueh larger, and extends downward to a variable extent behind the duodenum and head of the punereas. In the adult, it forms the upper boundary of the epiploic foramen (of Winslow).

Peritoneal relations.- - The liver in the adult is almost entirely surrounded by peritoneum. Although it develops together with the diaphragm in the common septum transversum (as explained previously, see figs. 951,952), the peritoneum soon extends in between liver and diaphragm, so that they remain in immediate contact only in the so-called 'uncovered area.' This is an irregular area on the posterior surface of the liver (chiefly on the right lobe), the margins of which correspond to the coronary ligament (figs. 905, 944). The posterior surface of the liver is therefore chicfly retroperitoneal, excepting the caudate (Spigelian) lobe, which is in contact with the recessiss superior of the bursa omentalis (fig. 905). 'The superior and inferior surfaces of the liver are entirely covered with peritoneum, excepting the lines of attachment of the various peritoneal ligaments, and the fossia for the gall-bladder, which is usually clirectly in contact with the gall bladder with no intervening peritone'um.

Ligaments. - The liver is attached by five peritoneal ligaments-coronary, right and left triangular (lateral) and falciform ligaments and lesser omentumand two acecessory figaments - teres and venosum.

The coronary ligiment [lig. coronarium hepatis], as before mentioned, corre- 
sponds to the reflections of peritoneum from the liver to the diaphragm at the margins of the 'uncovered area' (fig. 944) on the posterior surface of the liver.

Within this uncovered area the hepatic veins join the inferior vena cava. The coronary ligament, though somewhat irregular and variable in form, is elongated laterally and roughly quadrangular. At the four angles, the peritoneal layers come together and are prolonged into four ligaments-right and left triangular (lateral) and falciform ligaments and lesser omentum. There is often also a special prolongation of the coronary ligament downward upon the right kidney, forming the hepato-renal ligament [lig. hepatorenale]. This lies to the right of the foramen epiploicum.

The right triangular (or lateral) ligament [lig. triangulare dextrum] is a short but variable prolongation of the coronary ligament to the right and downward (figs. 905, 944). It connects the posterior surface of the right lobe of the liver with the corresponding portion of the diaphragm.

The left triangular (lateral) ligament [lig. triangulare sinistrum] is a longer, narrower prolongation of the coronary ligament to the left (figs. 905.944). It connects the posterior aspect of the left lobe of the liver with the corresponding portion of the diaphragm.

The falciform ligament [lig. falciforme hepatis] is a double layer of peritoneum representing (as before mentioned) the ventral portion of the primitive ventral mesogastrium.

Its upper end is continuous posteriorly with the coronary ligament. It passes forward and downward over the superior surface of the liver. From its line of attachment to the liver (between right and left lobes) it passes forward and slightly to the left to the attachment on the anterior body wall. This attachment extends downward slightly to the right of the mid-line to the umbilicus. The lower margin of the falciform ligament is free, and encloses the round ligament.

The round ligament [lig. teres hepatis] is a fibrous cord representing the obliterated fotal left umbilical vein. It extends upward from the umbilicus enclosed in the lower margin of the falciform ligament.

At the anterior margin of the liver it passes backward on the inferior surface, enclosed in a slight peritoneal fold at the bottom of the fossa venæ umbilicalis (sometimes bridged over by liver tissue). It ends by joining the left branch of the portal vein.

The ligamentum venosum [lig. venosum; Arantii] similarly represents the obliterated fotal ductus venosus. It is a fibrous cord lying in the fossa ductus venosi, and extends from the left branch of the portal vein upward to the left hepatic vein near its opening into the vena cava. The ligamentum venosum lies within the hepatic attachment of the lesser omentum.

The lesser omentum [omentum minus] has already been discussed in connection with the peritoneum. It represents the dorsal part of the primitive ventral mesogastrium, extending from the stomach to the liver. It includes two parts, as shown in fig. 906.

The upper and larger part forms the gastro-hepatic ligament [lig. hepato-gastricum], connecting the liver (fossa ductus venosi) with the lesser curvature of the stomach. The upper part of this ligament is somewhat thicker, the lower part thinner and more transparent. The relations of the lesser omentum in cross-section of the body are shown in fig. 903 . The lower and right portion of the lesser omentum extends beyond the pylorus and connects the portal fissure with the duodenum, forming the hepato-duodenal ligament [lig. hepatoduodenale] (fig. 905). Its right margin forms the anterior boundary of the epiploic foramen (of Winslow). Between its layers are located the root structures of the liver, as follows: hepatic artery to the left, common bile duct to the right, portal vein behind and between. A special prolongation of the hepato-duodenal ligament frequently extends downward to the transverse colon, forming the hepato-colic ligament [lig. hepatocolicum].

Fixation of the liver. - The liver is to a certain extent fixed in place by means of its various ligaments, and especially through the attachment of the hepatic veins to the inferior vena cava. On account of the close apposition of the liver to the diaphragm, the atmospheric pressure also helps in its support. Finally, the support of the liver, as well as of the abdominal viscera in general, is clependent to a considerable extent upon the tonic contraction of the abdominal muscles, which exerts a constant pressure upon the abdominal contents.

Blood-vessels. - The liver receives its arterial supply of blood from the hepatic artery, $a$ branch of the coliac, which passes up vetween the two layers of the lesser omentum, and dividing into two branches, one for each lobe, enters the liver at the portal fissure. The right branch gives off a branch to the gall-bladder. The liver receives a much larger supply of blood from the portal vein, which conveys to the liver blood from the stomach, intestines, pancreas, and spleen. It enters the portal fissure, and there divides into two branches. Below this fissure the hepatic artery lies to the left, the bile-duct to the right, and the portal vein behind and between the two (fig. 946). These three structures ascend to the liver between the layers of the lesser omentum in front of the epiploic foramen. At the actual fissure the order of the three structures from before backward is-duct, artery, vein. 
The hepatic veins, by which the blood of the liver passes into the inferior vena cava, open usually by two large and several small openings into that vessel on the posterior surface of the gland at the bottom of the fossa venæ cavæ.

Lymphatics.-The lymphatics are divided into a deep and a superficial set. The deep set runs with the branches of the portal vein, artery, and duct through the liver, leaving at the portal fissure, where they join the vessels of the superficial set. The efferent deep vessels after leaving the portal fissure pass down in the lesser omentum in front of the portal vein, through the ehain of hepatic lymphatic nodes, and ultimately end in a group of nodes at the upper border of the neck of the pancreas, in which the pyloric lymphatics also terminate.

The superficial set begins in the subperitoneal tissue. Those of the upper surface consist:(1) Of vessels which pass up, principally, in the falciform ligament and right and left triangular ligaments, through the diaphragm, and so into the anterior mediastinal nodes, and finally into the right lymphatic duct. Some lymphaties of the right triangular ligament pass to the posterior mediastinal lymph-nodes and into the thoracic duct. (2) Of a set passing downward over the anterior border of the liver to the hepatic nodes in the portal fissure, and over the posterior surface to reach the superior gastric and coeliac nodes. On the lower surface, the lymphatics to the right of the gall-bladder enter the lumbar nodes. Those around the gall-bladder enter the hepatic nodes of the lesser omentum. 'Those to the left of the gall-bladder enter the superior gastric noles.

Nerves.-The nerves of the liver are derived from the vagi (those from the left vagus entering from the stomach through the lesser omentum), and from the coliac plexus of the sympathetic (including right vagus branches) through a plexus accompanying the hepatic artery. The terminations, so far as known, are chiefly to the walls of the vessels and of the bile ducts.

Structure of the liver.-The liver is, for the greater part, covered by peritoneum, beneath which is found the fibro-elastic layer known as Glisson's capsule. At the portal fissure, Glisson's capsule passes into the substance of the liver, accompanying the portal vessels, the branches of the hepatic artery, and the bile-ducts. The liver substance is composed of vascular units measuring from 1 to $2 \mathrm{~mm}$, and known as liver lobules. These are in part (man) separated by

Fig. 947.-Section of a Portal Canal. (Quain.)

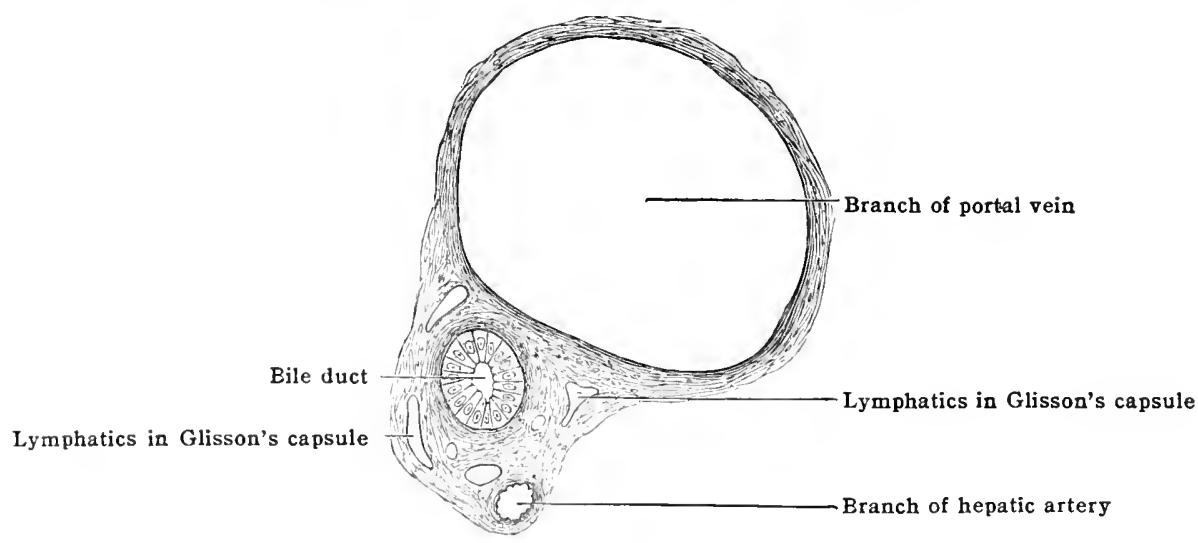

a small anount of interlobular connective tissue, which is a continuation of Glisson's capsule. In this interlobular connective tissue are found the terminal branches of the portal vessels; the hepatic artery, and the bile-rlucts (figs. 9.77, 948). The branches of the portal vessels which cucirre the liver lobules are known as the interlobular veins. From these are given off hepatic capillaries, which anastomose freely, hut have in general a direction toward the centre of the lobule, and unite to form the central or intralobular veins, which in turn unite to form the sublobular veins, and these the hepatic veins. The intralobular branches of the hepatic arteries form capillaries which anite with the apillaries of the intralobular portal veins.

The liver is a modified compoumel tubular gland. The liver-ects are arranged in anastomosing corts and colnmms oceupying the suaces formed by the hepatic capillaries. The bile-flusts have theip origin in so-calleol bile-capillaries [ductus biliferi], situated in the columns of liverecells; they anastomose freely and pass to the periphery of the lobules to form the priniary divisions of the hile-dhets, and these unite to form the larger bile-duets. The branches of thr portal vesure arrateconpanied in their course through the liver by the branches of the hepatic artery and the hile-ducts, surrounded hy extensions of (ilisson's capsule forming the so-called 'portal eanale' (fig. (917). 'The hranches of the hepatic vein are solitary, their walls are thin and closely adherent to the liver substance, whence they remain wide open on sectioning the liver.

While it is constomary to deseribe thus the liver lobules, it would be more logical to consider as the roal lobules what Nall has descriled as the 'portal units.' Wach portal unit inclucles the territory supplied by ono interlobular branch of the portal vein, and drained by the acenomenying life-duct. Thee relations of the ordinary lobules and the portal units are rvident in fig. !) Th. The portal unit aorresponds more noarly to the lobule of other glands, whore the dlact is in the contre of the bobule. 
Bile passages.-The bile passages, which transmit the bile from the liver to the duodenum, include the gall-bladder, the cystic duct, the hepatic ducts, and the common bile duct.

The gall-bladder [vesica fellea], which retains the bile, is situated between the right and quadrate lobes on the lower surface of the liver. It is pear-shaped, and when full, is usually seen projecting beyond the anterior border of the liver, coming in contact with the abdominal wall opposite the ninth costal cartilage at the lateral margin of the right rectus muscle (fig. 914). It extends back as far as the portal fissure.

It measures in length, from before backward, 7 to $10 \mathrm{~cm}$. It is 2.5 to $3.5 \mathrm{~cm}$. across at the widest part, and will hold about $35 \mathrm{cc}$. $\left(1 \frac{1}{4} \mathrm{oz}.\right)$. The broad end of the sac is directed forward, downward, and to the right, and is called the fundus. The narrow end, or neck [collum vesicæ felleæ], which is curved first to the right, then to the left, lies within the gastro-duodenal ligament at the portal fissure. The intervening part is called the body [corpus vesicæ felleæ].

Fig. 948.-Diagram of the Portal Unit and Vascular Relations of the Hepatic Lobule. (After Szymonowicz.)

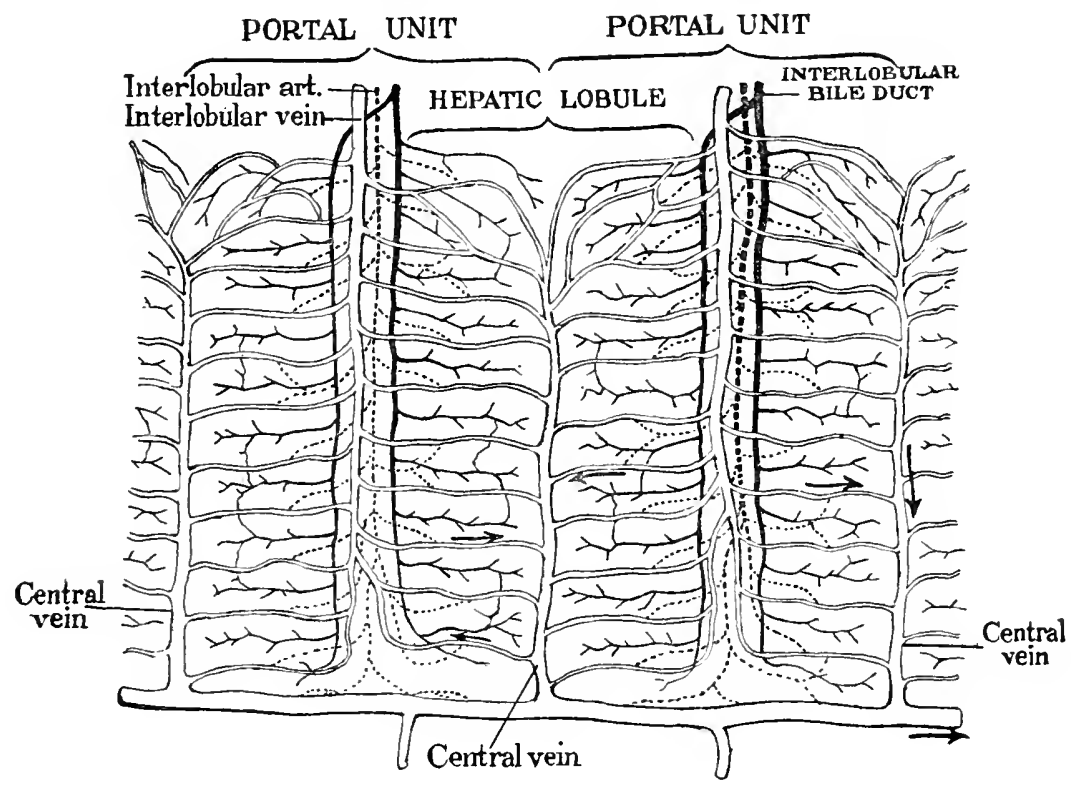

Its upper surface is in contact with the liver, lying in the fossa of the gall-bladder. It is attached to the liver by connective tissue. The lower surface is covered by peritoneum, which passes over its sides and inferior surface, though occasionally it entirely surrounds the gallbladder, forming a sort of mesentery attaching to the liver. The lower surface comes into contact with the first part of the duodenum and the transverse colon, and occasionally with the pyloric end of the stomach or small intestine, which post mortem are often found stained with bile.

The neck of the gall-bladder opens into the cystic duct [ductus cysticus]. This is a tube about $3.5 \mathrm{~cm}$. long and $3 \mathrm{~mm}$. wide, which unites with the hepatic duct to form the ductus choledochus; it is directed backward and to the left as it runs in the gastro-hepatic ligament, the common hepatic artery being to the left and the right branch of the artery and portal vein behind. It joins the hepatic duct at an acute angle, and is kept patent by a spiral valve [valvula spiralis; Heisteri], formed by its mucous coat (fig. 949).

The hepatic duct [ductus hepaticus] begins with a branch from each lobe, right and left (that from the left receiving also the ducts from the caudate lobe), in the portal fissure, and is directed downward and to the right within the portal fissure and the hepato-duodenal ligament, the right branch of the hepatic artery being behind and the left branch to the left. It is from 3 to $5 \mathrm{~cm}$. long; its diameter is about $4 \mathrm{~mm}$. Uniting with the cystic duct, it forms the common bile-duct [ductus choledochus]. 
The ductus choledochus or common bile-duct is about $7.5 \mathrm{~cm}$. in length and $6 \mathrm{~mm}$. in width. It passes down between the layers of the lesser omentum, in front of the portal vein, and to the right of the hepatic artery (fig. 946); it then passes behind the first part of the duodenum, then between the second part and the head of the pancreas, being almost completely embedded in the substance of the pancreas, and ends a little below the middle of the descending duodenum by opening into that part of the intestine on its left side and somewhat behind (figs. 921,

Fig. 949.-Interior of the Gall Bladder and Ducts. (From Toldt's Atlas.)

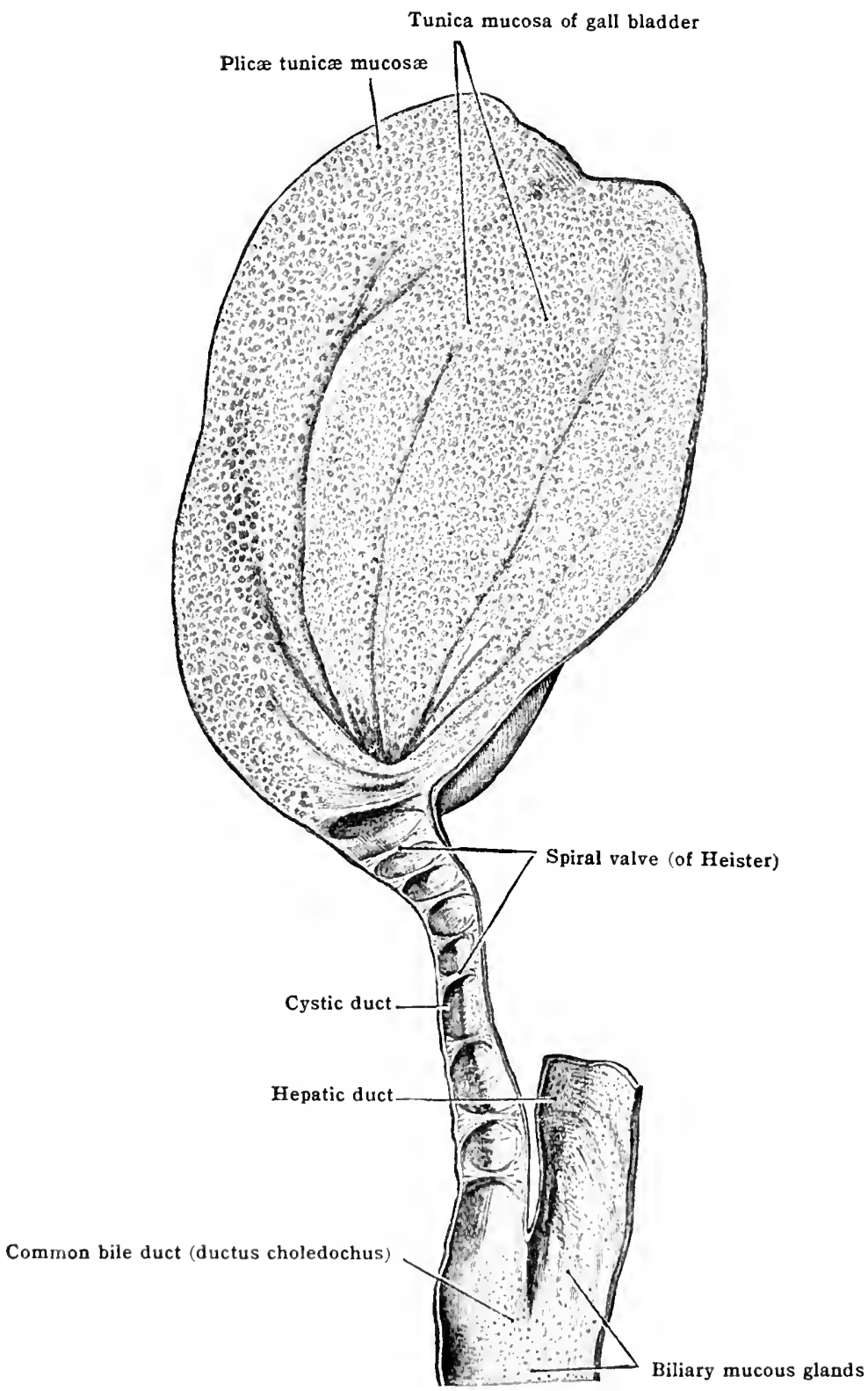

$922,9.57)$. It piereres the intestinal wall very obliquely, running between the muscular layers for a distance of about 1 to $2 \mathrm{~cm}$. There is a slight eonstriction at its trmination. 'The pancreatic duct is generally mited with the ductus choledorhus just before its termination, and there is a slight papilla at their place of opening on the mueous surface of the duodenum. This papilla is about 8 or 10) (:m. from the pylorus. After the pancreatic duct has entered the bile-duct there is (in about half the cases) a dilatation of the common tube called the ampulla of Vater. 
In its oblique course through the duodenal wall, the common bile duct is accompanied by the pancreatic duct, the two together usually causing the plica longitudinalis duodeni (fig. 922). Circular muscle fibres join with bundles of longitudinal fibres at the lower part of the ducts and form a sphincter around each (fig. 950). Contraction of the sphincter probably closes the orifice of the common bile duct, so that (except during digestion) the bile is backed up into the gall-bladder.

Structure of the gall-bladder.-The wall of the gall-bladder is made up of three coatsmucosa, fibro-muscular and serosa.

Fig. 950.-Macerated Duodenal Portion of the Common Bile Duct, Showing Musculature. $B$, Common bile duct. $W$, Pancreatic duct (of Wirsung). $S$, IR, Sphincter fibres of bile duct. $H$, Fibres of pancreatic duct. (Hendrickson.)

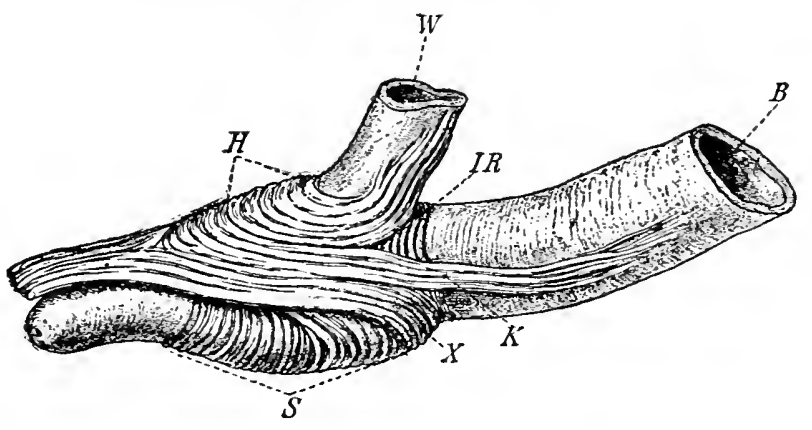

1. The mucosa is raised into folds bounding polygonal spaces, giving the interior a honey* comb appearance. It is lined with columnar epithelium, and contains a few tubular mucous glands and lymph-nodules, and is limited externally by a poorly developed muscularis mucosæ. At the neck the mucous membrane forms valve-like folds which project into the in terior. This layer contains an anastomosis of blood-vessels, the capillaries being most numerous in the folds of the mucosa, and a fine plexus of lymphatics.

2. The fibro-muscular coat consists of interlacing bundles of non-striated muscle and fibrous tissue not definitely arranged, the muscular bundles running longitudinally and obliquely. This layer contains the principal blood-vessels and lymphatics; and also a nerve plexus.

Fig. 951.-Diagrams of the Developaent of the Liver. (Lewis and Stöhr.)

A, The condition in a $4.0 \mathrm{~mm}$. human embryo. B, A $12 \mathrm{~mm}$. pig. C, The arrangement of ducts in the human adult. $c$. d., Cystic duct; $c . p$., cavity of the peritoneum; d., duodenum; d.c., ductus choledochus; dia., diaphragm; div., diverticulum; $f . l$., falciform ligament; g. $b$., gall bladder; g.o., greater omentum; h.d., hepatic duct; ht., lieart; int., intestine; li., liver; $l . o .$, lesser omentum; m., mediastinum; oe., œsophagus; $p . c$., pericardial cavity; $p$. $d$. pancreatic duct; $p h$. , pharvnx; p. v., portal vein: $s t$, stomach; tr., trabecula; $v . c . i$, vena cava inferior; v.v. vitelline vein; y. s., yolk sac.

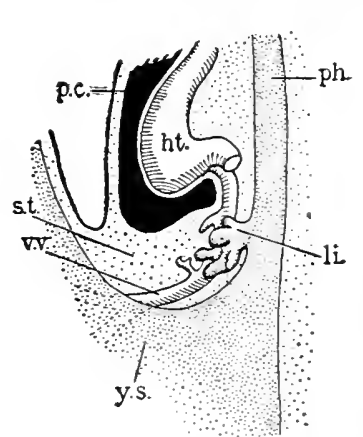

$\Delta$

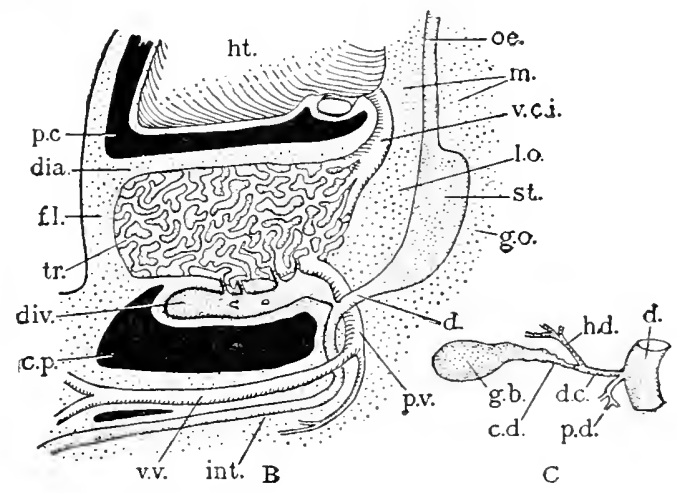

3. The serosa being formed by the peritoneum, is only found on the lower surface and part of the sides.

The ducts consist of a fibro-muscular and a mucous layer. In the fibro-muscular layer are non-striated muscle-cells which are chiefly circular, together with white fibrous tissue and elastic fibres. The mucous layer is lined with columnar epithelium, and has many mucous glands. In the cystic duct the mucous membrane is raised into folds, which are crescentic in form, and directed so obliquely as to seem to surround the lumen of the tube in a spiral manner.

The development of the liver.- The relations which the liver bears to the diaphragm, to its vessels and more especially the veins, and to its so-called ligaments, may be understood by a reference to its development (figs. 951, 952). In discussing the development of the peritoneum and the mesenteries it was shown that the liver has its origin in a bud of entoderm, which grows 
into the transverse septum in the region where this is attached to the ventral mesoderm of the developing intestine; and that, with further development, the transverse septum differentiates into an upper thinner portion, inclosing the Cuvierian ducts, and destined to form the diaphragm, and a lower thicker portion in which the liver develops. Shortly after the formation of the entodermal bud which forms the liver this mass of epithelium becomes penetrated by outgrowths from the omphalo-mesenterie veins, redueing the epithelial mass to anastomosing trabeculse separated by blood-spaces forming a sinusoidal circulation. The definite hepatic lobules are not differentiated until after birth. The process of the development of the lobules is very complicated, the vascular arrangement being shifted repeatedly (Mall).

The liver rapidly enlarges, filling the upper portion of the abdominal eavity, and extending along its ventral wall to the region of the umbilieus. During the enlargement it in a measure outgrows the transverse septum, and there are developed grooves which result in an infolding of , the peritoneum covering the transverse septum, and which in part separate the developing liver from that part of the septum destined to form the diaphragm, and also from the ventral abdominal wall. These grooves appear at the sides and also ventral to the liver, but do not completely separate the liver from the diaphragm, nor do they meet in the median line. A portion of the liver, therefore, remains uncovered by peritoneum, and remains attached to the diaphragm; this area may be known as the uncovered or phrenic area of the liver. Around this area the peritoneum of the liver is reflected on to the diaphragm, forming the coronary ligament, with right and left extensions, designated as the right and left triangular ligaments. Owing to the fact that the grooves which develop on the sides of the liver do not meet in the median line, there persists a fold of peritoneum which attaches the liver to the ventral abdominal

Fig. 952.--Diagram (A): A Sagittal Section of an Embryo showing the Liver enclosed withln the Septun Transversum; (B) A Frontal Section of the same; (C) Frontal Section of a Later Stage when the Liver has separated from the Diaphragm.

All, Allantois; $C l$, cloaca; $D$, diaphragm; $L i$, liver; $L s$, falciform ligament of the liver, $M$, mesentery; $M g$, mesogastrium; $P c$, pericardium; $S$, stomach; $S T$, septum transversum; $U$, umbilicus. (MeMurrieh.)
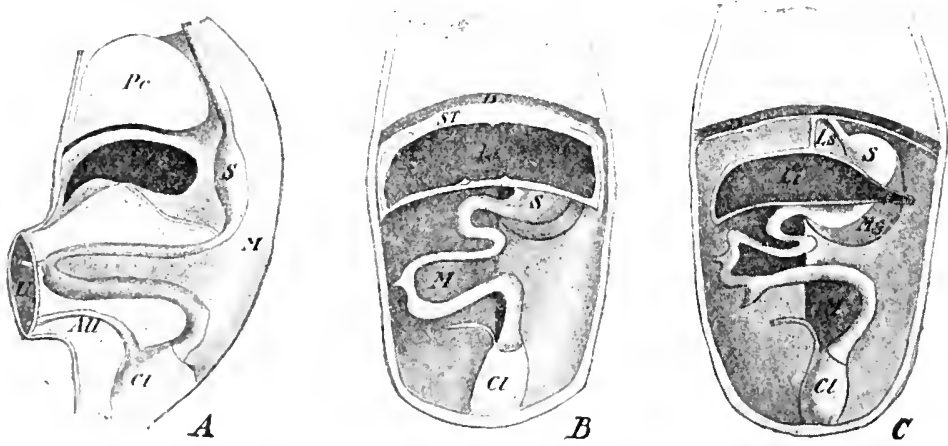

wall; this forms the falciform ligament, which divides the superior surface of the liver into a right and a left lobe. The region of the attachment of the ventral mesentery (mesogastrium) into which grows the entorlermal liver bud, forms the lesser omentum. The developing liver early comes into intimate relation with the omphalo-mesenterie veins, and a little later the umbilical veins. The developnental history of these veins and their relation to the developing liver is discussed elsewhere (see Development of tue loutal Vhin and Inferior Vena Cava, p. 694). After birth the left umbilical vein forms the hepatic ligamentum teres, situated in the free edge of the falciform ligament. The ductus venosus likewise atrophics to form the ligannentum venosum.

The gall-hladler has its origin in a groove lined by entoderm, which appears on the ventral surface of the primitive intestine or archenteron, between the stomach and the yolk-vesicle. From the cephalic cud of this groove grows out the bud destined to form the liver; the caudal end of the groove leeomes gradually separated from the developing intestine to form a pouch, lined by entoderm, which forms the heginning of the gall-bladler. With further growth the attachment to the infestine of both the liver and the gall-bladkler hecomes narrowed to form the iluctus rholedochus.

During development, the liver undergues marked changes in form and relative size. It

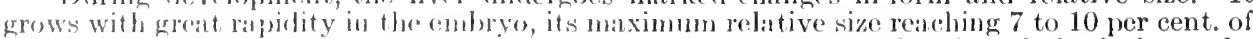

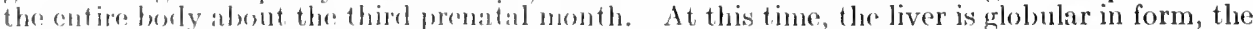
visceral surface very small, and tho left tolve more noarly approathing the right in size. During the later fortal nunths (fig. 95:3) and at birth, the liver forms about 5 por ent. of the whole bordy. It still remains relatively laree in infancy, but decreases to about 2.5 per eent. in the aldit. Fon the beginning, the rolitive weight of the liver averages slightly higher in the fomale.

Variations of the liver and bile passages.- Many variations of the liver have already bern montionod. In size, beth reative and absolute, it is subject to markerl individual variations, as wetl as ascording fo age and sex (previonsly described). In form, the liver is also quite variahle. There are two extrome types: (1) in which the liver is very wide, exteneling far over into the loft hyporhonrlrium, but rolativaly faftened from above downward; and (2) in which it 
extends but slightly to the left, being somewhat flattened from side to side, and elongated vertically. This type may occur as a result of tight lacing, in which the liver is frequently deformed. 'The part projecting below the right costal inargin may form the so-called 'Riedel's lobe.' All intermediate forms between these two types occur. Its position and relations will also vary necessarily according to differences in size and shape. For example, in the wide type and also in enlarged livers, the left lobe may extend over upon the spleen, a relation which is constant during prenatal life.

There may be supernumerary fissures, dividing the liver into additional lobes, as many as 16 having been described in an extreme case (Moser). These extra fissures of ten correspond to fissures which are normal in other mammals. There may also be accessory lobes, usually small, and connected with the main gland by stalks. Any one of the normal lobes may be atrophied or absent. There may also be abnormal grooves on the parietal surface of the liver. Of these, there are two varieties: (1) costal grooves, due to impressions of the overlying ribs and costa! cartilages; and (2) diaphragmatic grooves, due to wrinkles in the diaphragm. These

Fig. 953.-The Viscera of the Føtus. (Rüdinger.)

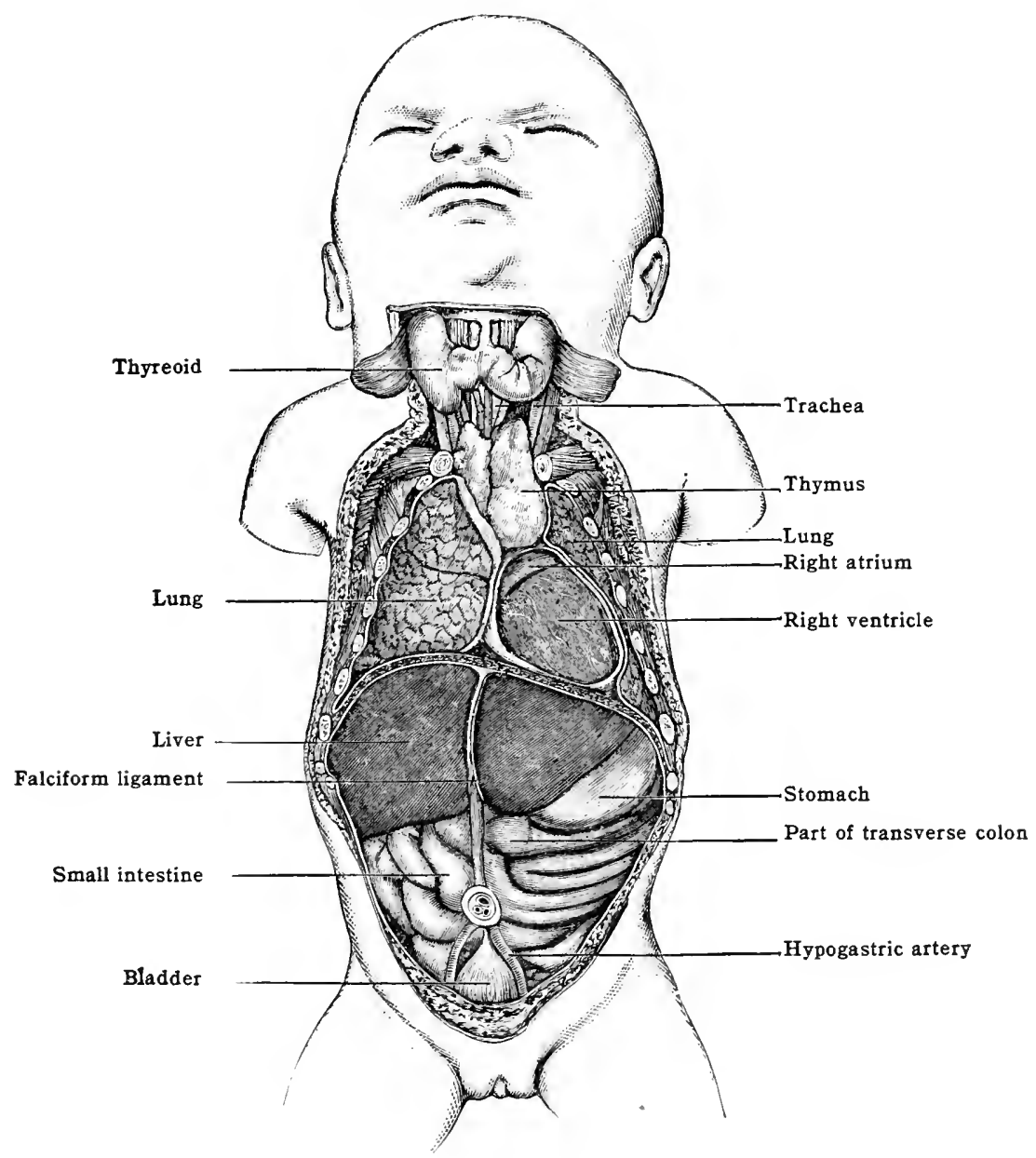

grooves most frequently occur in females, as a result of tight lacing. The appendix fibrosa has already been mentioned. There are numerous variation in the vascular arrangements, as well as in the peritoneal relations (particularly in connection with the coronary ligament).

The bile passages are even more variable than the liver proper. The gall-bladder is variable in size and capacity ( $25 \mathrm{cc}$. to $50 \mathrm{cc}$. or more), as well as in its position and relations. The fundus projects to a variable extent beyond the anterior margin of the liver so as to come into contact with the abdominal wall in a little more than half the eases, but is often retracted. The fossa of the gall-bladder is of variable depth, rarely so deep that it reaches the superior surface of the liver. The peritoneum usually covers only the sides and inferior surface of the gallbladder, but occasionally surrounds it entirely, forming a short 'mesentery.' In rare cases the gall-bladder is bifid or double, and is occasionally absent. There are numerous variations in the bile-ducts. Rarely the hepatic ducts may communicate directly with the gall-bladder. The point at which hepatic and cystic ducts unite is variable, which affects the relative lengths of these and the ductus choledochus. The latter may open into the duodenum separately, instead of with the pancreatic duct. 
Comparative.-The liver arises in all vertebrates as an outgrowth of the entodernic epithelium of the intestine just beyond the stomach. In amphioxus it remains a simple saccular diverticulum, but in all higher forms becomes a compound tubular gland. The tubular character becomes masked, however (in amniota, and especially in mammals), by the abunaiant anastomosis between the tubules, forming what is called a 'solid' gland. The relations with the portal venous system are constant. The liver frequently stores large quantities of fat, and may even undergo a complete fatty metamorphosis (lamprey). The colour of the liver is usually reddish-brown, but may be yellow, purple, green or even vermillion (due to bile pigments). In size, the liver is variable, but is usually relatively larger in anamniota. Among mammals, there is great variation according to diet, the liver being relatively larger in carnivora, smaller in herbivora, and intermediate in omnivora (including man). It is also relatively larger in small animals (including young and fotal stages), probably on account of their more intense metabolism. There are typically two lobes, right and left, in the vertebrate liver. These are frequently subdivided, however, especially in mammals, which of ten present numerous lobes.

The gall-bladder is typically present, as in man, but varies in form, size and position. It may be completely buried in the liver. In some species it is absent, in which case the hepatic ducts open directly into the duodenum by one or more apertures. The hepatic and cystic ducts typically unite to form a common bile-duct, as in man, but there are numerous variations in the detailed arrangement of the ducts.

\section{THE PANCREAS}

The pancreas (figs. 922, 954, 955, 956) is an elongated gland extending transversely across the posterior abdominal wall behind the stomach from the duodenum to the spleen. Through the pancreatic duct, opening into the descending duodenum, flows its secretion [succus pancreaticus], which is of importance in digestion. The pancreas also has a very important internal secretion.

Fig. 954.-The Duodenum and Pancreas, Anterior View.

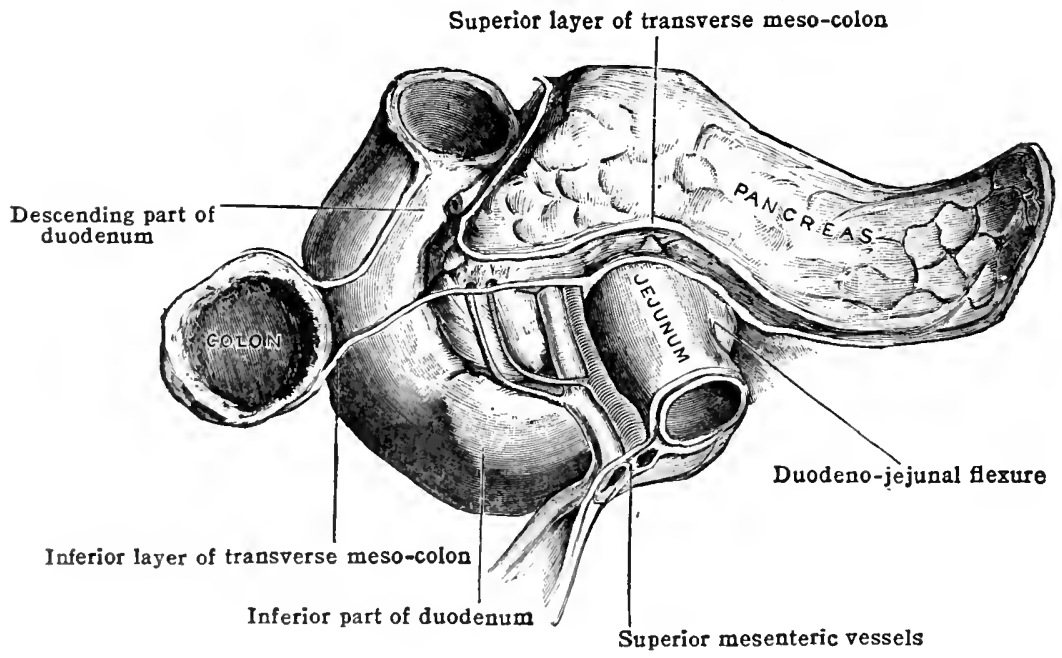

The pancreas is greyish-pink in colour; average length (in situ), $12 \mathrm{~cm}$. to 15 em.; average weight about $80 \mathrm{gm}$. (extremes $60 \mathrm{gm}$. to $100 \mathrm{gm}$. or more); specific gravity, 1.047, which is about the same as that of the salivary glands.

In position, the panereas lies in the epigastric and left hypochondriac regions. In form, it somewhat resembles a pistol, with the handle placed to the right and the harrel to the left. The pancreas is accordingly divided into a head, lying within the duodenal loop; a body, extending to the left; and a tail, or splenic (exiremity.

The head [caput pancreatis] is a discoidal mass somewhat elongated vertically and flattenerl dorso-ventrally. It forms the enlarged right extremity of the pancrras and lies within the concavity of the duorlenum (figs. 922, 954, 955). Its relations are as follows (figs. 954, 955, 956): Its posterior surface is placed opposite the second and third lumbar vertebrar, and is in contact with the aorta, the vena "ava, the renal voins and right renal artery. The common bile-duct is also partly "mberlderl in this surface. Its anterior surface is erossed by the transverse colon, abeve which is the byloric extremity of the stomach, and below which are coils of 
Fig. 955.-The Duodenum and Pancreas, Posterior View.

Portal vein

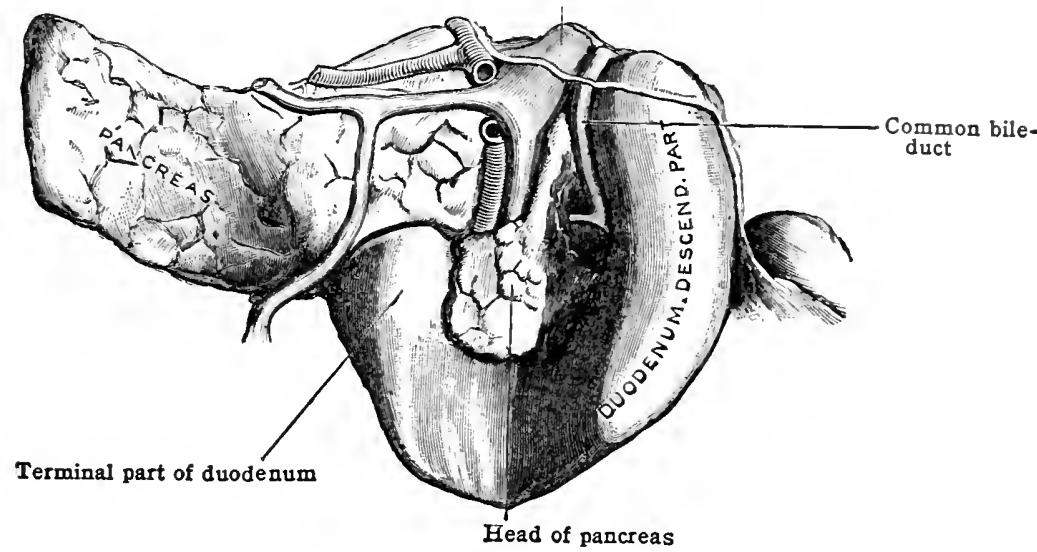

Fig. 956.-Odthine Showing the Average Position of the Deeper Abdominal Viscera in 40 Bodies, on a Centimetre Scale (reduced to .36 natural size). $A B$, anterior mid-line. $E F$, horizontal line half way between pubes and suprasternal margin. $C D$, line half way between pubes and line $E F$. (Addison.)

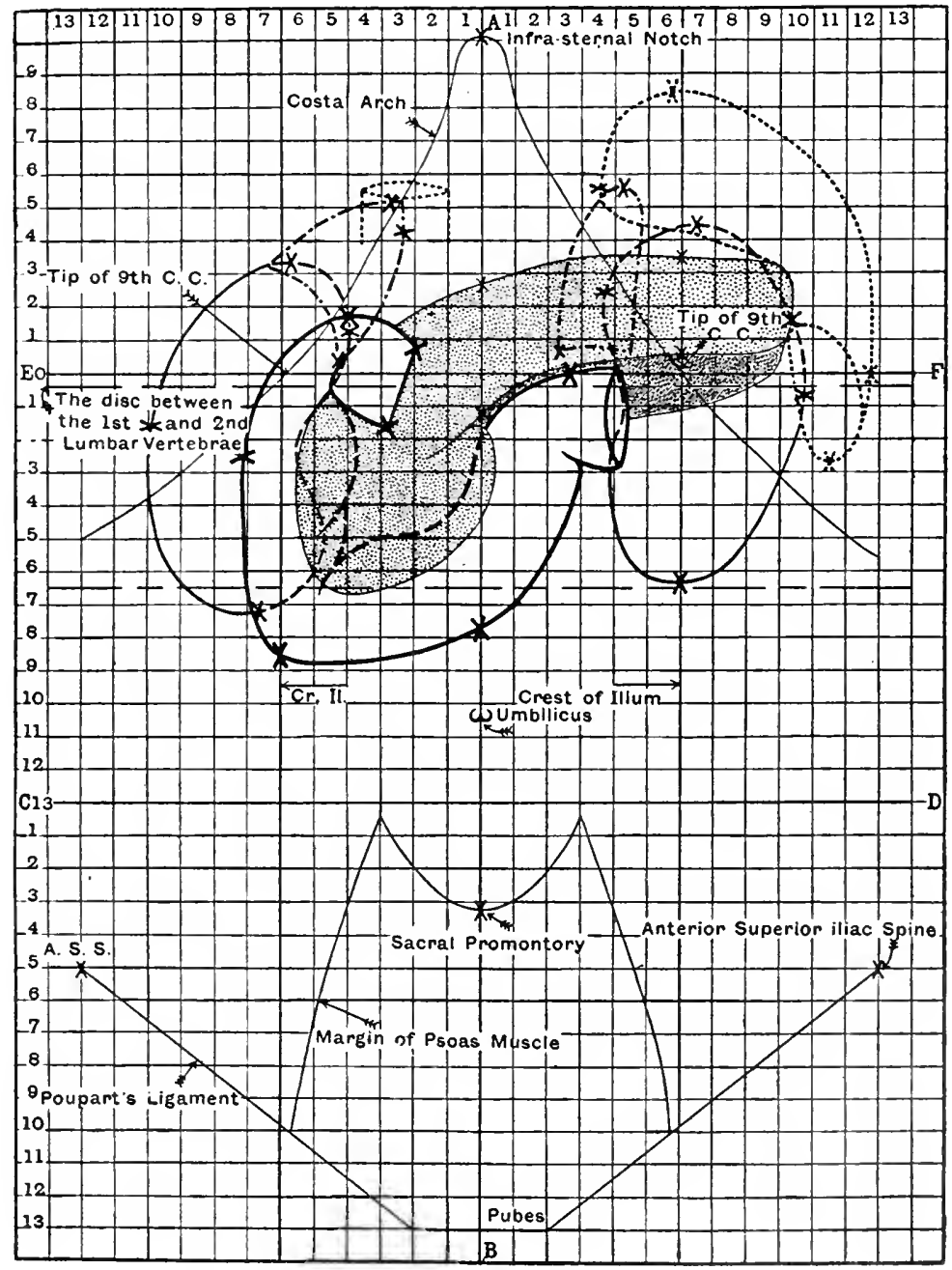


small intestine. Upon this surface are also the panereatico-duodenal and (in part) the superior mesenterie vessels. The margin of the head of the pancreas is C-shaped, corresponding to the inner aspect of the duodenal loop, with which it is elosely related. Superiorly the margin is in eontaet with the pylorus and first part of the duodenum; on the right, with the descending duodenum and the terminal portion of the common bile duet; inferiorly, with the horizontal, and on the left, with the terminal ascending portion of the duodenum.

The lower and left portion of the head of the panereas is hooked around behind the superior mesenteric vessels, forming the processus uncinatus or pancreas of Winslow (fig. 922). A groove, the pancreatic notch [incisura pancreatis], is thus formed for the vessels. The morphology of this process is explained later under development (fig. 958).

In the adult condition, the head of the panereas is largely retroperitoneal. The only portions eovered by peritoneum are (1) a small area above the attachment of the colon, and in relation with a poeket-like recess of the bursa omentalis, and (2) a small area below the transverse colon, which is in relation with coils of small intestine. The mesentery of the small intestine begins where the superior mesenteric vessels pass downward from in front of the processus uncinatus.

The junction of the upper and left aspect of the head with the body of the pancreas is ealled the neck. This is a somewhat constricted portion grooved posteriorly by the superior mesenterie vessels, the vein here joining with the splenic to form the portal vein (fig. 955). Anterior to the neck is the pyloric portion of the stomach. The upper portion of the neck (together with a variable area on the left end of the body) projects above the lesser eurvature of the stomach. This projection [tuber omentale] is related, through the lesser omentum, with a similar tuberosity on the left lobe of the liver. The anterior aspect of the neck is covered with peritoneum of the bursa omentalis (lesser sac), and is continuous with the anterior surface of the body of the pancreas (fig. 922).

The body [corpus pancreatis] is the triangularly prismatic portion of the pancreas extending from the neek on the right to the tail on the left. Its direction is transversely to the left and (usually) somewhat upward. It is therefore usually placed at a somewhat higher level than the head, opposite the first lumbar vertebra. It presents three surfaces-anterior, posterior, and inferior-and three borders-superior, anterior, and posterior.

Of the surfaces, the anterior [facies anterior] faces forward and somewhat upward. It is covered with the peritoneum of the posterior wall of the bursa omentalis (lesser sac), and forms a slightly concave area which is in contact with the posterior surface of the stomach (figs. 904, 906). The posterior surface [f. posterior] of the bodly of the pancreas is flattened and retroperitoneal. From right to left it erosses the anterior aspeet of aorta, left suprarenal body and left kidney. The splenic vessels also run along the posterior surface, the artery, which is above, corresponding more nearly with the superior border. The inferior surface [f. inferior] is usually the narrowest of the three. It is eovered by peritoneum (continuous with the lower layer of the transverse mesocolon) ancl is in eontact with the duodeno-jejunal angle medially and with coils of jejunum laterally.

Of the borders, the superior [margo superior] is related with the splenic artery along its whole length from its origin in the cœliac, and the posterior [margo posterior] separates posterior and inferior surfaces. The anterior border [margo anterior] is sharp and prominent. It gives attachment to the transverse mesocolon, whose upper layer (belonging to the lesser sae) is eontinuous with that on the anterior surface of the panereas, and whose lower layer (belonging to the greatrosac) is continuous with that on the inferior surface.

The tail of the panereas [cauda pancreatis] is at the left extremity of the body. $1 \mathrm{t}$ is variable in form, but usually somewhat blunted and upturned. It is almost invariably in contact laterally with the medial aspect of the spleen, and inferiorly with the splenic flexure of the colon. The splenic vessels of ten cross from above in front of the tail of the pancreas on their way to join the spleen.

Ducts. - The pancroas has usually two duets, the main pancreatic duet and the acesessory luet. The main pancreatic or duet of Wirsung [ductus pancreaticus; Wirsungi] begins in the tail of the panceras, and extends to the right within the borly of the pancreas, abont midway between upper and posterior borders, but marer the postrior surface (figs. 922, 957). It runs a slightly sinuous course 
receiving branches all along, which enter nearly at right angles. It is largest in the head of the pancreas (diameter about $3 \mathrm{~mm}$.) where it turns obliquely downward. As it approaches the duodenum, it is joined by the common bile duct, the two running side by side. They pass obliquely through the wall of the duodenum for a distance of about $15 \mathrm{~mm}$. (usually causing a fold of the mucosa, the plica longitudinalis duodeni). They terminate finally, usually by a common aperture, but sometimes separately, on the duodenal papilla major, as described in connection with the interior of the duodenum. The common aperture is somewhat narrow, but just preceding this the duct is frequently dilated, forming what is called the ampulla of Vater.

The accessory pancreatic duct (duct of Santorini) is nearly always present (figs. 922, 957), but variable. This duct is small, and lies within the head of the pancreas. At its left end, it usually joins the main duct in the neck of the pancreas. From here it extends nearly horizontally across to the upper part of the descending duodenum and, piercing its wall, usually ends upon the small papilla minor, about $2 \mathrm{~cm}$. above and slightly ventral to the papilla major. The relations of the ducts are explained later under development.

Fig. 957.-The Pancreas and its Ducts, Dissected from Behind.

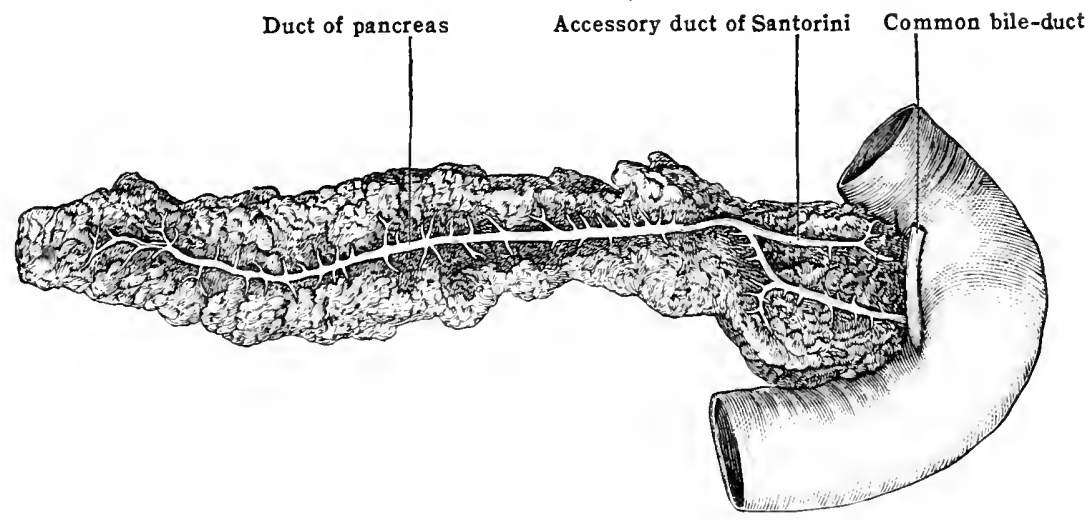

Blood-vessels. - The pancreas receives blood chiefly from the splenic artery through its pancreatic branches, and from the superior mesenteric and hepatic by the inferior and superior pancreatico-duodenal arteries, which form a loop running around, below, and to the right of its head. veins.

The blood is returned into the portal vein by means of the splenic and superior mesenteric

Lymphatics.- The lymphatics terminate in numerous glands which lie near the root of the superior mesenteric artery, above and below the neck of the pancreas. All the lymphatics drain ultimately into the cœliac glands.

Nerves. - These are branches of the ccliac plexus which accompany the arteries entering the gland. The main part of the coliac plexus lies behind the gland.

Minute anatomy. - In many respects, the pancreas resembles the salivary glands in structure, hence its German name 'Bauchspeicheldrüse' ('abdominal salivary gland'). The gland proper is racemose (or tubulo-racemose) in structure, the secreting cells characteristically. granular and 'serous' in type. The thin-walled 'intercalary ducts,' often invaginated to form 'centroacinar' cells, are characteristic. The lobules are very loosely joined by areolar tissue, and there is no distinct fibrous capsule around the gland. The most important of the distinctive characters of the pancreas is the presence throughout the gland of numerous small interlobular cell-masses of varied form and size-the islets of Langerhans (fig. 959). These have no ducts, but are richly supplied with blood-vessels. They are ductless glands of great importance in sugar metabolism, and their removal or disease produces diabetes. While derived embryologically from the same entodermal anlage which gives rise to the pancreas gland proper, they apparently have no direct connections with it in the adult. The question as to the possible metamorphosis of acini into islets, or vice versa, under certain conditions (e. g., hunger) in the adult has been much dispited. Bensley, however, has recently presented strong evidence against this view.

Development of the pancreas.-The pancreas has its origin in three entodermal buds, one of which (the dorsal anlage) grows from the dorsal portion of the duodenum, the other two (ventral anlages) from either side of the bile-duct. Of the two latter, only that growing from the right side of the bile-duct needs further consideration, as the other soon disappears. The dorsal anlage grows at first more rapidly than the ventral, which arises from the bile-duct. In their further growth both the dorsal and ventral anlages become lobed, these lobes dividing further to form the ducts and the alveoli of the gland. By about the end of the second month the distal end of the ventral portion comes in contact with the dorsal portion at a short distance 
from the latter's connection with the duodenum. A fusion of the two portions thus takes place in this region, and at the same time there is established by anastomosis a connection between the terminal branches of the main duct of the dorsal portion-duct of Santorini-and the branches of the main duct of the ventral portion-the duct of Wirsung. With further development the duct of Wirsung develops into the main pancreatic duct, the duct of the dorsal

Fig. 958.-Diagram Showtng the Relations of the Pancreas to the Primitive MesenTERY. (Poirier-Charpy.)

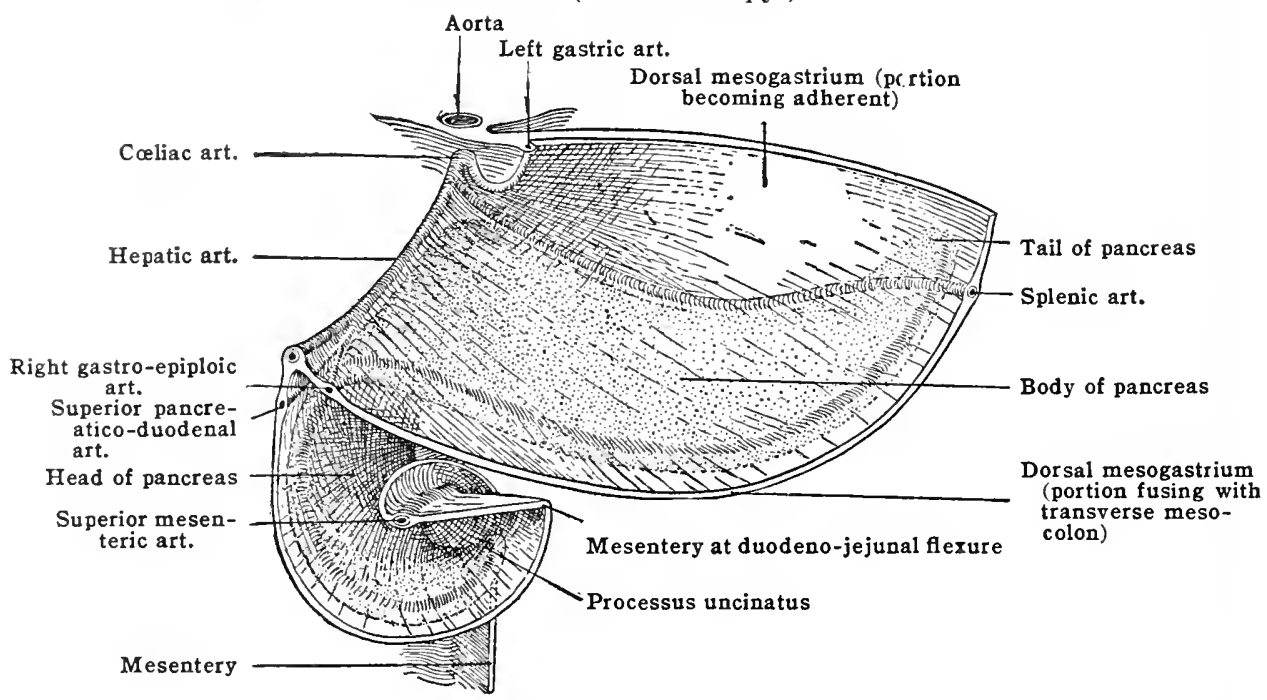

portion (duct of Santorini) either losing its connection with the duodenum or remaining as the accessory pancreatic duct.

Thus of the adult gland, only the lower portion of the head is derived from the primitive ventral anlage, although the duct of the latter drains nearly the entire adult gland. The upper part of the head of the pancreas, and all of the body and tail are derived from the dorsal anlage; although most of its duct joins with the duct of Wirsung to form the main pancreatic duct, only a small part persisting as the accessory duct of Santorini.

Fig. 959.-Section of Human Pancreas, Magnified, Showing Several Islets of LANGERHANS. (Radasch.) $a$, Interlobular connective tissue, containing an interlobular duct, $c, \quad b$, Capillary. $d$, Interlobular duct. $e$, Alveoli. $f$, Islet of Langerhans.

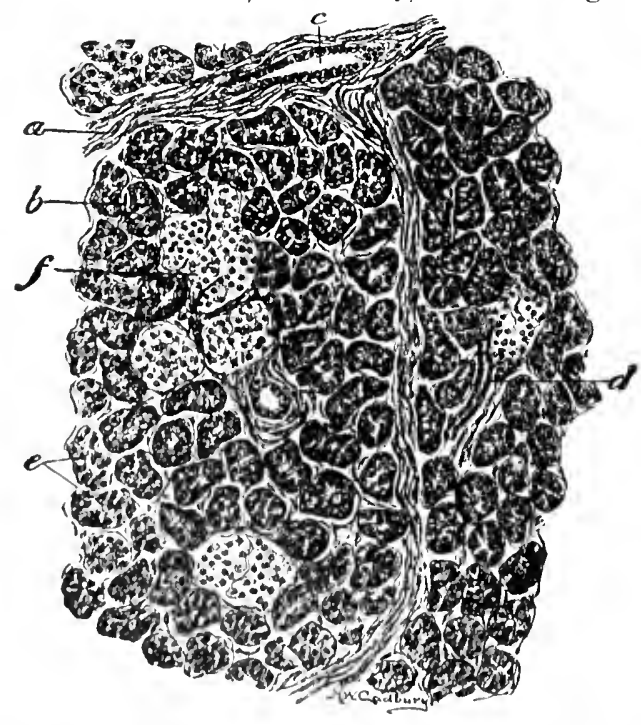

I) which it forms grow into the mesoluodenum, and later the dorsal mesogastrium. With the rotation of the stomach and the consequent elange in the position of the mesogastrium and its partial fusion with the abrominal wall, the pancreas assmes a retroperitoneal position. This is illustrated hy fig. 958. The head of the pancreas is involved in the rotation of the primitive 
intestinal loop counter-clockwise around the superior mesenteric artery. This accounts for the position and the hook-like form of the processus uncinatus. Following this rotation, the duodenum and the head of the pancreas become pressed backward against the posterior abdominal wall, where they become adherent, with fusion and obliteration of the primitive peritoneum. The body of the pancreas, extending into the dorsal mesogastrium (fig. 900), is similarly caught in the pouch-like downgrowth of the latter to form the bursa omentalis (lesser sac), and is thereby carried over to the left side. When the posterior layer of the primitive bursa fold becomes fused with the posterior abdominal wall, the enclosed pancreas is likewise fixed and becomes retroperitoneal. Of these obliterated peritoneal layers of the embryo, only certain layers of fascia renain as their representatives in the arlult. From the lower aspect of the pancreas downward, the posterior layer of the bursa fold becomes fused with the transverse mesocolon, so that in the adult the latter appears to arise from the anterior border of the pancreas (fig. 904).

Variations.- Aside from minor fluctuations in size and form, the variations of the pancreas are chiefly congenital and of embryonic origin. Cases of accessory or supernumerary pancreas are not rare. They are usually of small size and have separate ducts. They may occur along the wall of the duodenum, or even in the stomach or jejumum. They are perhaps in some way connected with the numerous intestinal diverticula which occur in the embryo. Dividcd pancreas differ from the accessory in that a mass of the pancreas becomes separated from the main gland, connected only by a duct. This occurs oftenest in the region of the tail (sometimes extending into the spleen) or of the processus uncinatus, forming what is termed a 'lesser pancreas.' Sometimes a ring of glandular tissue from the head of the pancreas surrounds the descending duodenum, forming an annular pancreas. Variations in the direction of the body are numerous; it may be horizontal, ascending or bent in various ways. These are doubtless congenital variations, as similar types have been described in the fœetus (Jackson). It has been experimentally demonstrated that varying degrees of distention of the stomach and intestines affect profoundly the form of the body of the pancreas. When the stomach alone is distended, the pancreas is flattened antero-posteriorly, the inferior surface being practically obliterated. When both stomach and intestines are distended, the pancreas is flattened from above downward, and extends forward like a shelf, the posterior surface being much reduced (Jackson). Numerous variations in the ducts are easily understood from their complicated development. The accessory duct (of Satorini) is in the foetus as large as the main duct (of Wirsung), the preponderance of the latter being established later. The accessory duct in the adult may be larger than usual, and retain its primitive drainage, or even drain the entire gland in rare cases where the duct of Wirsung is absent. Or the accessory duct may be rudimentary or (rarely) absent. Similar variations occur in the main duct of Wirsung. Rarely the pancreas may open into the duodenum by three ducts, probably representing three embryonic anlages. Abnormalities of the pancreas are often associated with duodenal diverticula.

Comparative. - The pancreas, like the liver, is constant throughout the vertebrates. It always arises by budding off from the endodermal epithelium of the intestine, closely associated with the liver. There is typically a triple anlage (rarely multiple, which is perhaps the ancestral type), with one dorsal and two ventral outgrowths. These fuse and form the adult pancreas in a variety of ways. In many of the fishes, the pancreas is very small, diffuse and inconspicuous, sometimes embedded in the liver or intestinal wall. Of the three primitive ducts, usually only two persist (as in man), but of ten only one, or all three (in birds). All three types occur in mammals. The islets of Langerhans arise from the epithelial pancreas anlage, and appear to be constantly present, even in the lowest vertebrates. Laguesse even considers that phylogenetically they form the most primitive part of the pancreas, but this is doubtful.

References for digestive system.-General and Comparative: Quain's Anatomy, 11th ed.; Poirier-Charpy, Traité d'anatomie; Rauber-Kopsch, Lehrbuch der Anatomie, 9te Aufl.; Oppel, Mikroskopische Anatomie, Bd. 1-3; also 'Verdauungsapparat' in Merkel and Bonnet's 'Ergebnisse'; Wiedersheim, Bau des Menschen. Topography: (adult) Merkel, Topographische Anatomie; (developmental) Jackson, Anat. Rec., vol. 3. Development: Keibel and Mall's Manual. Teeth: Tomes, Dental Anatomy. Tonsils: (lingual) Jurisch, Anatomische, Hefte, Bd.47; (pharyngeal) Symington, Brit. Med. Jour. (Oct., 1910); (palatine) Killian, Archiv f. Laryngol., Bd. 7. Esophagus: Goetsch, Amer. Jour. Anat., vol. 10. Stomach: (structure), Bensley, Buck's Ref. Handb. Med. Sc., vol. 7 (1904); (form) Cunningham, Trans Royal Soc. Edinb., vol. 45; (radiography) Cole, Archives Roentgen Rays, 1911; also Journal Amer. Med. Assn., vol. 59. Duodenum: (diverticula), Baldwin, Anat. Rec., vol. 5. Vermiform process: Berry and Lack, Jour. Anat. and Phys., vol. 40. Rectum: Symington, Jour. Anat. and Phys., vol. 46. Liver: Mall, Amer. Jour. Anat., vol. 5. Pancreas: (islets) Bensley, Amer. Jour. Anat., vol. 12; (ducts) Baldwin, Anat. Rec., vol. 5. 


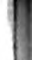




\section{SECTION X \\ THE RESPIRATORY SISTEN}

Revised for the Fifth Edition

BY R. J. TERRY, A.B., M.D.,

PROFESSOR OF ANATOMY IN WASHINGTON UNIVERSITY

$\mathrm{R}$

ESPIRATION consists in the absorption by the organism of oxygen and the discharge of a waste-product, carbon dioxide.

Among unicellular animals the oxygen is taken up directly from the medium-water or airin which they live, and the carbon dioxide given off into it. With the cells which make up the body of higher animals the principle is the same, but the interchange of gases is indirect. The blood stands as an intermediate element between the cells of the body and the medium inhabited

Fig. 960.-Dissection of a Male Negro, Age 43 Years, to Show the Organs of RespiRATION IN Situ.

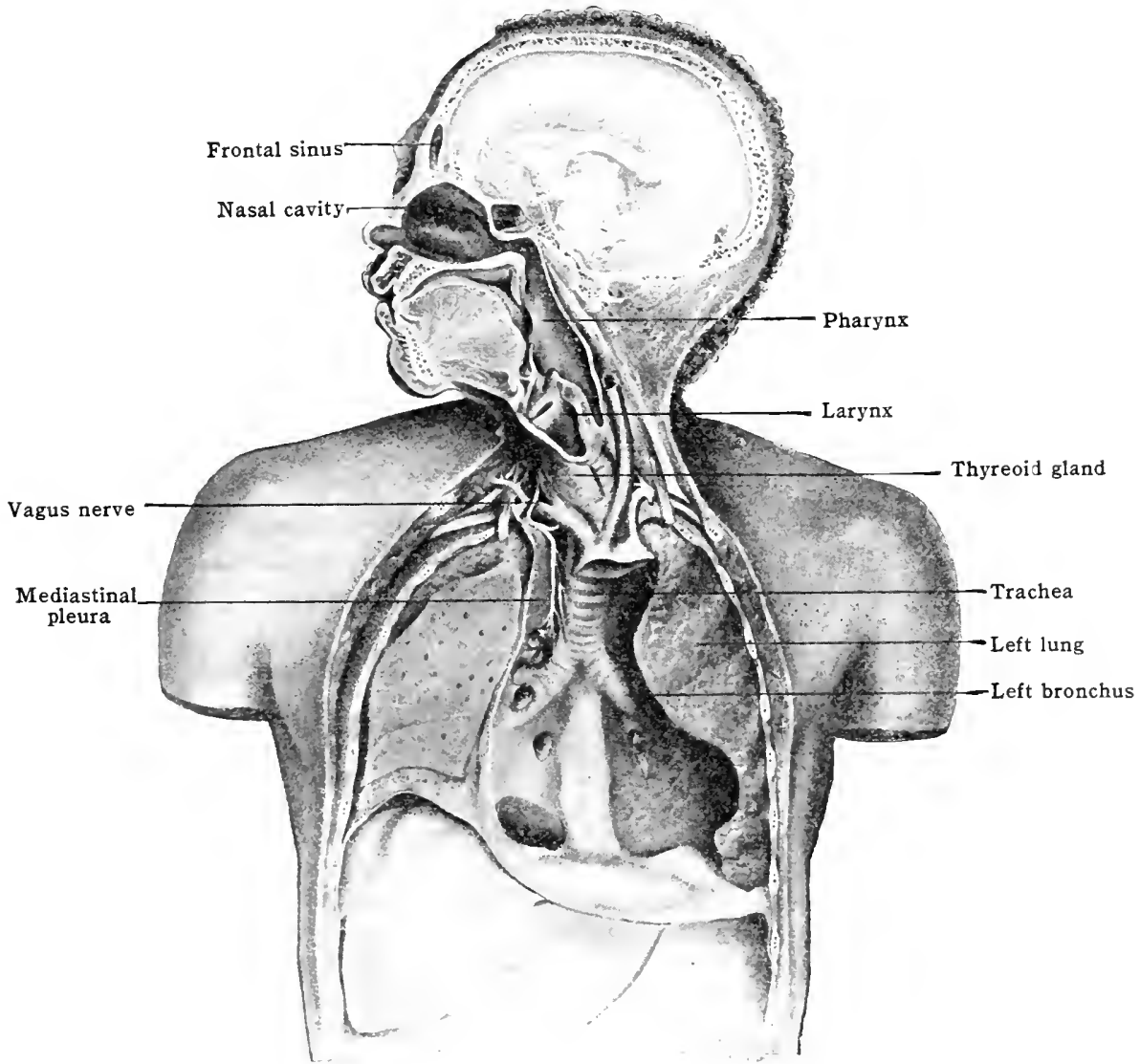

by the animals, and serves as a carrier of the gases between them. Moreover, special organs are provided for the rapid interchange between air and blood, which constitute the so-called respiratory system.

The respiratory system of air-breathing vertebrates consists of tubular and cavernous organs constructed so as to permit of the atmospheric air reaching the 
blood circulating in the body. The essential organs in the system are the paired lungs located in the thoracic cavity. Air is carried to and from the lungs by the trachea and bronchi, and these simple transmitting tubes are in turn put into communication with the exterior by the mediation of other organs. The latter are, howerer, specially constructed in adaptation to other functions in addition to those relating to respiration: the larynx for the production of the voice, the pharynx and mouth in connection with alimentation, the nasal cavity and external nose functioning in the sense of smell. (For the description of the mouth and pharynx see Section IX; for the olfactory organ see Section VIII.)

The organs of circulation are always adapted to the form of the respiratory apparatus, and among all higher animals a connection is established between heart and lungs by the pulmonary artery, which carries renous blood to the latter, and by the pulmonary veins, which convey arterial blood from the lungs to the heart, whence the aorta takes it in to the general circulation.

In their origin and development the respiratory organs are closely associated with or differentiated from the beginnings of the digestive apparatus. Thus the processes of the early development of the nasal cavity and mouth are interdependent; the origin of the greater part of the larynx, the trachea and lungs is by ventral outgrowth of the entodermal canal.

\section{THE NOSE}

The external nose [nasus externus] (fig. 961), shaped like a triangular pyramid, is formed of a bony and cartilaginous framework covered by muscles and the integument of the face externally and lined within by periosteal and perichondral layers overspread by mucous membrane. At the forehead, between the eyes, is

Fig. 961.-The Left Side of the External Nose, showing its Cartilages, etc.

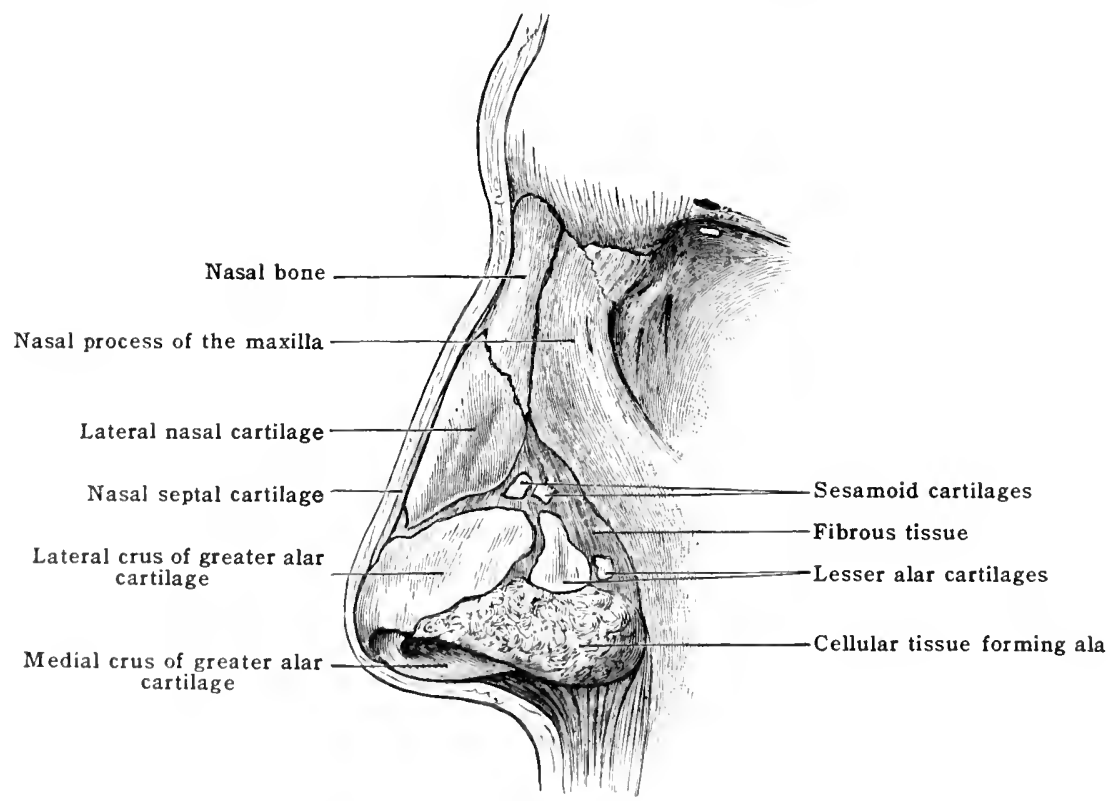

the root of the nose [rarlix masi], and from this, extending inferiorly and anteriorly, is a rounded ventral border, the dorsum of the nose [dorsum nasi], which may be rither straight, convex, or concave, and which ends inferiorly at the apex of the nose [apex nasi]. The superior part of the dorsum is known as the bridge. Inferionly, orerhanging the upper lip, is the base of the nose [basis nasi] which presents two orifices, the nares or nostrils, separated from one another by the inferior movablo part of the masal septum [septum mobile nasi].

'The nostril of man is remarkable on aceount of its position, facing as it does almost directly (lownward. It is oval in. form, with the long axis directed antero-posteriorly, or approximately 8o, in Europmans. 'The size of thr nostril is under the control of muscles (sce p. 334) and may ber dilated or emstricted by their action.

The sides of the nose slope from the dorsum laterally and posteriorly, and 
below ferminate on each side in the margin of the nose [margo nasi]; posteriorly and inferiorly the sides are expanded and more convex, forming the alæ nasi. Each of these is separated from the rest of the lateral surface by a suleus, and the inferior free margin of each bounds a naris laterally.

Three types of nose, distinguished by differences in the proportion of breadth and length are recognised by anthropologists: the leptorrhine or long, high nose; the platyrrhine or short, low nose; the mesorrhine, a form intermediate between the other two. The leptorrhine type prevails among white races, the platyrrhine in the black peoples and the mesorrhine in the red and yellow races.

Fig. 962.-Anterior View of the External Nose, showing its Cartilages, etc.

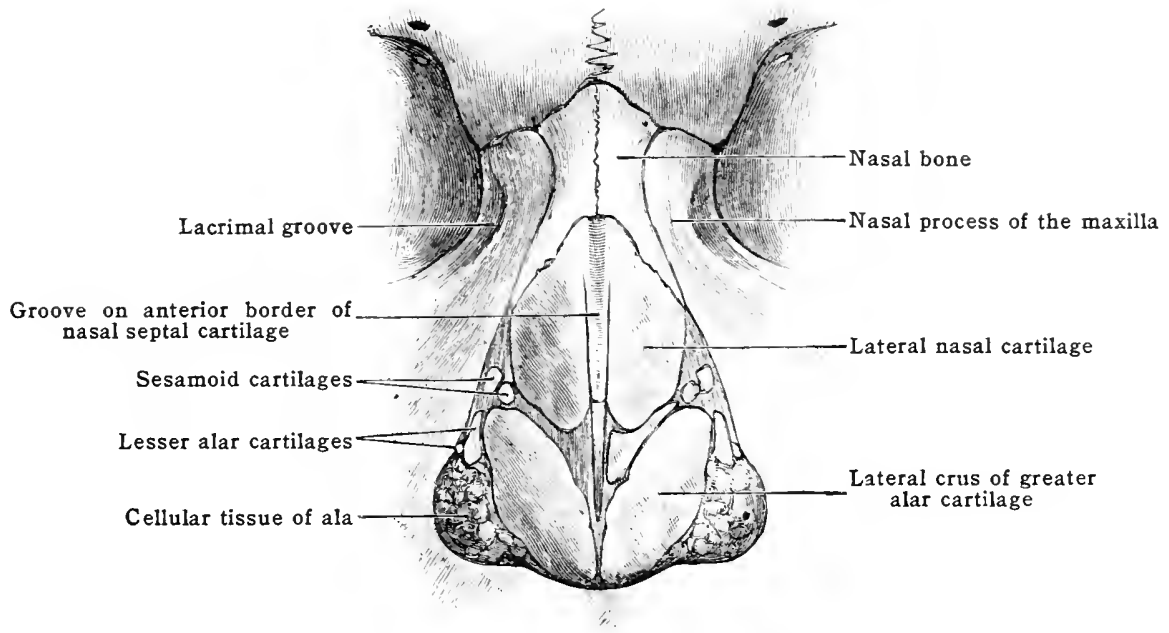

The framework of the external nose is formed partly of bone and partly of hyaline cartilage The bones, which form only the smaller superior part, are the two nasal bones and the fronta processes and anterior nasal spines of the two maxillæ (pp. s7, 108).

The nasal cartilages [cartilagines nasi] are located about the piriform aperture and constitute the larger part of the nasal framework. There are five principal cartilages: superiorly, the two lateral nasul cartilages, inferiorly the two greater

Fig. 963.-Inferior View of the External Nose, showing its Cartilages, etc.

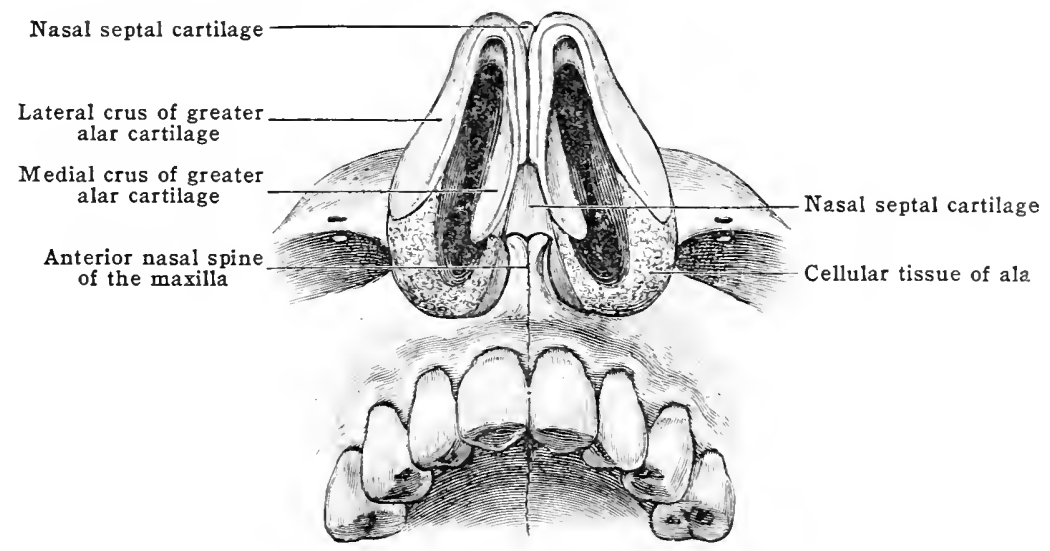

alar cartilages, and the single median nasal septal cartilage. Beides these there are the lesser alar cartilages, the sesamoid cartilages, and the vomero-nasal cartilages of Jacobson. The lateral nasal cartilages [cartilagines nasi laterales] are triangular and nearly flat lateral expansions of the septal cartilage, placed one on each side of the nose just inferior to the nasal bone. Each presents an inner and an outer surface and three margins. The medial margin is continuous in its superior third with the anterior margin of the septal cartilage, and through this with its 
fellow of the opposite side, but it is separated inferiorly from the septal cartilage by a narrow cleft. The curved supero-lateral margin is firmly attached by strong fibrous tissue to the nasal bone and frontal process of the maxilla, and underlies these bones for a considerable distance, especially near the septum. The inferior margin is connected by fibrous tissue to the greater alar cartilage. The greater alar cartilages [cartilagines alares majores], variable in form, are situated one on each side of the apex of the nose (figs. 961, 963). Each is thin, pliant, curved, and so folded that it forms a medial and a lateral crus, which bound and tend to hold open each naris. The medial crus [crus mediale] is loosely attached to its fellow of the opposite side, the two being situated inferior to the septal cartilage and forming the tip of the nose and the inferior part of the mobile septum. The lateral crus [crus latcrale] joins the medial crus at the apex of the nose; it is somewhat oval in shape, and curves dorsally in the superior and anterior portion of the ala. It is connected posteriorly to the nasal margin of the maxilla by a broad mass of dense fibrous and fatty tissue, and helps to maintain the contour of this part of the nose.

Fig. 961.-Miedial Wall of the Nasal Cavity, the Mucous Membrane Being Removed. The dotted line indicates the course of the incisive canal.

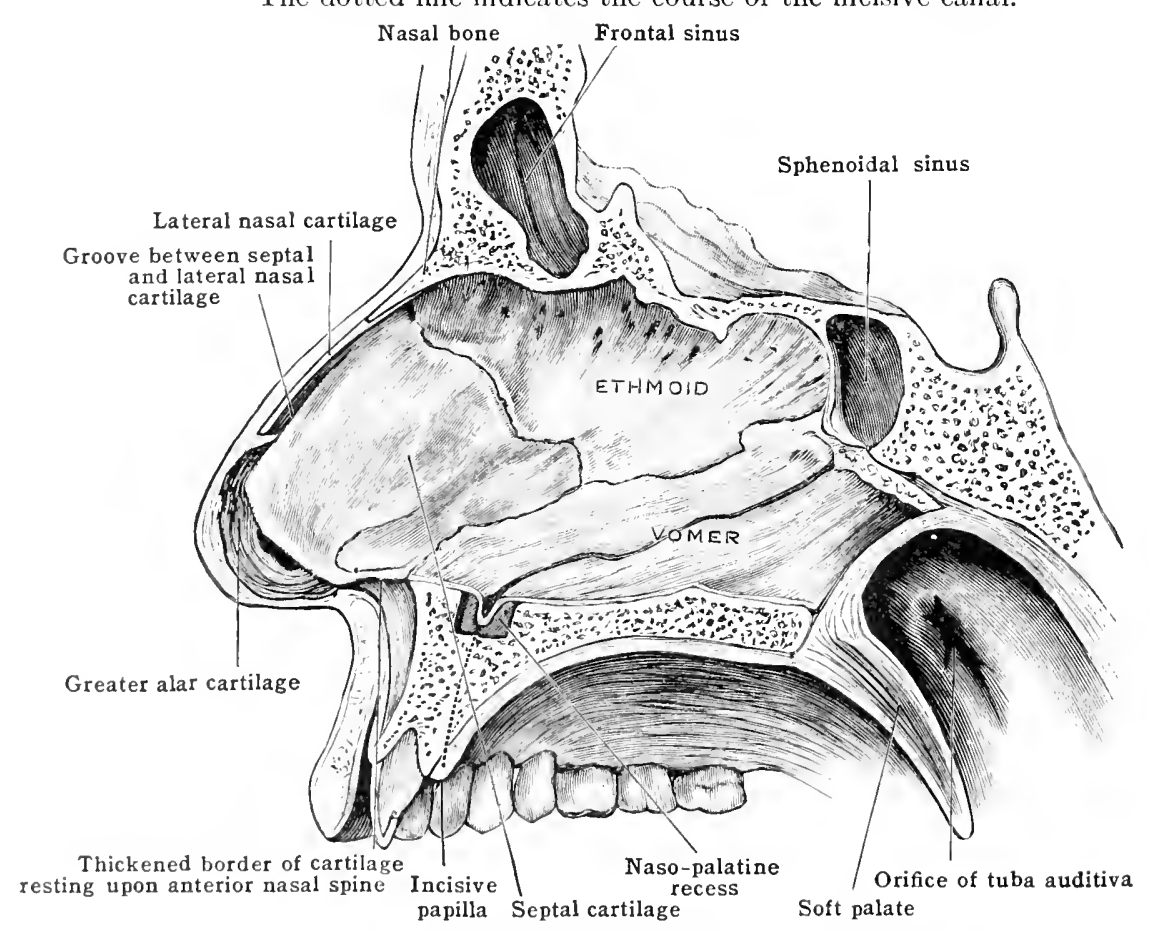

The angle formerl by the crura (angulis pinnalis) varies with the shape of the nose; it averages $30^{\circ}$. The greater and lesser alar cartilages together form an incomplete ring around the naris.

A variable number of small ('artilages, lesser alar cartilages [eartilagines alares minores] are found in the fibrous tissue of the ala, and in the interval between each greater alar and latral cartilage oecur one or more small plates, sesamoid cartilages [cartilagines sesamoidex] (fig. 961$)$.

The septal cartilage [cartilago septi nasi] (fig. 964) forms the anterior part of the septum. It is quadrilateral in shape and fits into the triangular interval of the hony septum. Its antro-superior margin in its upper part meets the internasial suture. Inferior to the nasal bone it presents a shallow groove which gradually narrows toward the tip of the nose, and whose borders are continuous superiorly with the lateral natsal cartilages, but are separated from their inferior twothiris by a narrow slit. The most infrerior part of this margin of the septal cartilage is placerl between the greater alar martilages. The antero-inferior margin cxtends backward from the rounder anterior angle to tho anterior nasal spine. Infriorly it is attached to the merlial crus of the greater alar cartilage and to the 
mobile nasal septum. The postero-superior margin is attached to the perpendicular plate of the ethmoid, and the postero-inferior margin joins the vomer and the ventral part of the nasal crest of the maxilla, the cartilage broadening out to obtain a wide though lax attachment to the nasal spine.

The shape of the septal cartilage varies with the extent of the ossification of the bony septum. Even in the adult a strip of cartilage may extend for a varying distance posterosuperiorly between the vomer and perpendicular plate of the ethmoid, sometimes reaching the body of the sphenoid; it is known as the sphenoidal process of the septal cartilage [processus sphenoidalis septi cartilaginei]. The vomero-nasal cartilage [cartilago vomero-nasalis Jacobsoni* is a narrow strip of cartilage firmly attached to each side of the septal cartilage, where this joins the anterior portion of the vomer.

Muscles. - The muscles are grouped according to function as dilators and contractors, the latter being comparatively feeble in their action. They are described on p. 334 .

The skin covering the external nose is thin and freely movable upon the subjacent parts, except at the tip and over the cartilages, where it is much thicker,

Fig. 965.-Oblique Section passing throdgh the Nasal Cavity just in Front of the CHOANe. (Seen from behind.)

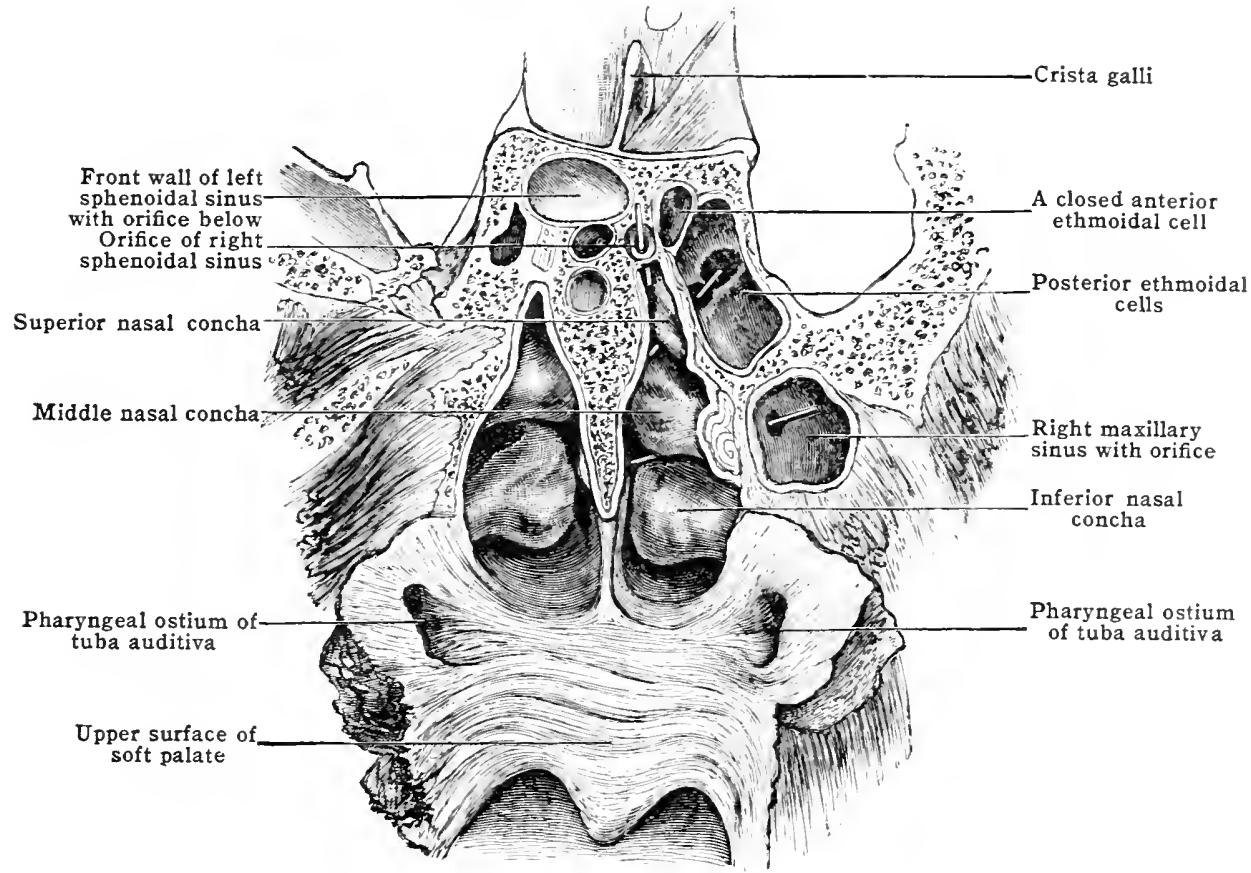

more adherent, and furnished with numerous exceptionally large sebaceous glands. At the nares it is reflected into the nasal cavity, where it passes into the mucous membrane. The hairs on the skin of the nose are very fine, except in the nares, where they may be strongly developed.

Vessels and nerves. - The arteries of the external nose are derived from the external maxillary (facial) artery (pp. 540 and 541), the ophthalmic artery (p. 554), and the infra-orbital artery (p. 549). The veins terminate in the anterior facial vein and the ophthalmic vein (p. 644). The lymphatics pass to the submaxillary lymphatic nodes (p.712). The motor nerves are branches of the facial (p.946). The sensory nerves are derived from the trigeminal through the frontal and naso-ciliary branches of the ophthalmic (p. 936) and infra-orbital branch of the maxillary (p. 939).

The nasal cavity [cavum nasi] is the ample space situated between the floor of the cranium and the roof of the mouth extending forward into the external nose and backward to the nasal part of the pharynx. With the exception of the inferior part of the nose its walls are of bone as already described (pp. 110, 112). The cartilages and membranes of the nose complete the boundaries anteriorly. Here the cavity opens to the exterior by the nares. At the back a free communi-

\footnotetext{
* Jacobson: Danish anatomist. B. $17 \$ 3$, D. 1843 .
} 
cation with the pharynx is established through the paired choanæ. Furthermore aceessory nasal eavities, the paranasal sinuses, open into the cavum nasi. The walls of the nasal cavity are covered with periosteum and mucosa, the latter presenting important differences in the respiratory and olfactory regions. The organ of smell, included in the nasal eavity, is deseribed on p. 1049.

The eavum nasi is divided into right and left symmetrical parts, ealled the nasal fossæ, by the septum of the nose [septum nasi]. The latter is supported by a framework eomposed of the osseous septum [septum nasi osseum] posteriorly, and the cartilaginous septum [septum cartilagineum] anteriorly. Antero-inferiorly, the small movable part of the septum is also called the membranous septum [septum membranaceum].

The nasal septum is almost always straight in primitive races and Caucasian children; but in a large proportion of Caucasian adults it is deflected to one side or the other.

Fig. 966.-Sagittal Section throdgh the Faclal Part of the Head and the Bodies of the upper three Cervical Vertebrae. The section lies to the right of the median plane. The nasal septum has been removed. (Rauber-Kopsch.)

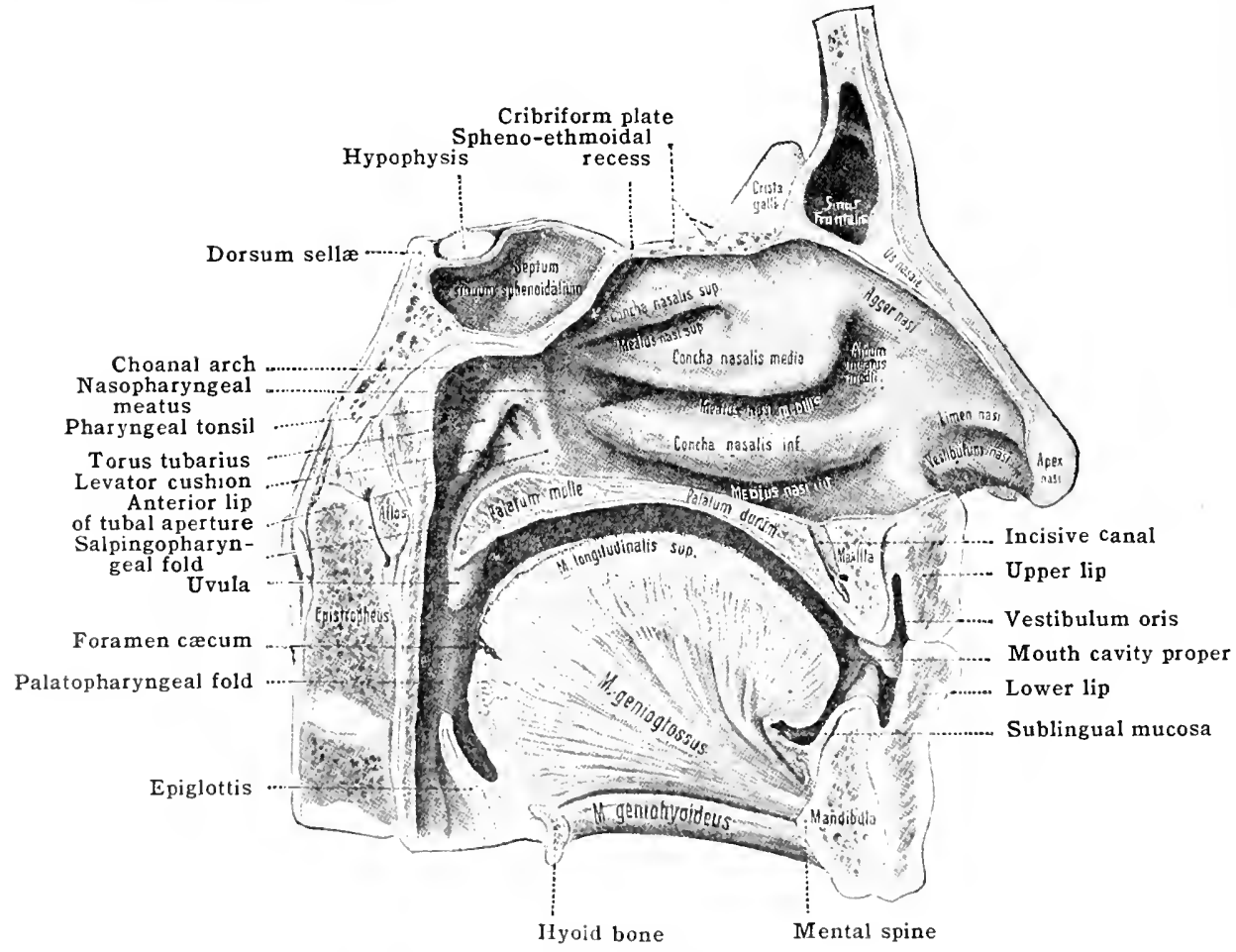

In the septum, upon each sille, just superior to the nasal spines of the maxillae, there is frequently a minute opening lealing superiorly and posteriorty and ending blindly. This cavity is rosely related to the vomero-nasil cartilage and is a rulimentary representative of the vomeronasal organ (of Jacobson) [organon vonn'ro-makale], which in some anmals is well developed atul receives a branch of the olfitetory nerve. On the floser of the nasal eavity about $2 \mathrm{~cm}$. from the posterior nargin of the naris and near the nasal septum a small depression, the nasopalatine reeess, is often serol. This is the mouth of the incisive duct [duetus ineisivus] which leads into the incisive canal for a greater or less distance and ma oven extend to the mouth, where its termination is marked by the incisive papsllat. The incisive duct indicates the position of a foranem which in the embryo commeeted the month and nose.

The naris lauls npward into the vestibule of the nose [vestibulum nasi], the small cavity within the compass of the greater alan' cartilage. Its walls are lined witl: skin besed with the large hairs called vibrissæ and containing many seba-

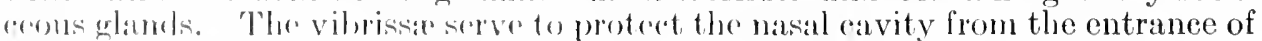
forerign matter. ()n the lateral wall, the vestibule is marked off from the rest of the basal cavity by a distinet rillge, the limen nasi, corresponding to the superior margin of the grealer alar "artilare. ()n the lateral wall of the cavity within the limen $11:$ is are three antero-posterior ridges, the superior, middle, and inferior 
conchæ (fig. 966). These have a bony framework (described on pp. 83, 110) and are covered by the mucous membrane of the nose. The conche are not parallel to one another but converge in a backward direction. The superior nasal concha [concha nasalis superior] is the smallest, projects only slightly medialward and downward from the upper, posterior part of the lateral wall, overhanging the groove called superior meatus of the nose. The middle nasal concha [concha nasalis media] is extensive, reaching from the fore part to the posterior confines of the lateral wall. Its free margin is nearly vertical in its anterior one-fourth, horizontal and laterally rolled in the rest of its extent. Under cover of this concha runs the middle meatus. The inferior nasal concha [concha nasalis inferior] is the longest, has a lateral attached and an inferior laterally rolled free margin running near the floor of the nasal cavity. Beneath it lies the inferior meatus.

Meatuses of the nose [meatus nasi] (figs. 966, 968). The name common meatus of the nose [meatus nasi communis] is given to that part of the nasal car-

Fig. 967.-Frontal Section through the Facial Portion of the Head of a White Man, AGe 28 Years.

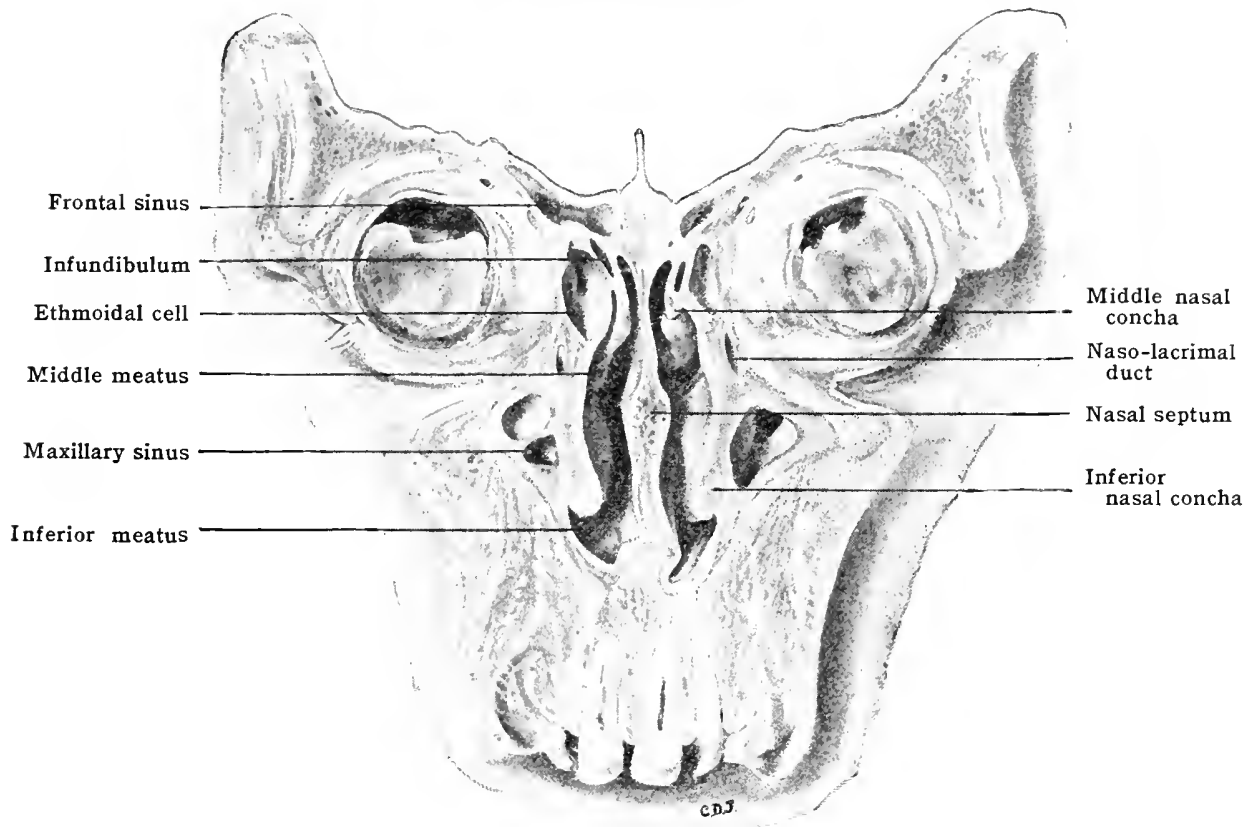

ity which lies between the septum nasi and the nasal conchie and stretches from floor to roof. The three meatuses under cover of the nasal conchæ have been mentioned. These passages all communicate freely with the common meatus, extend antero-posteriorly and have a greater capacity in front than behind. The superior meatus [meatus nasi superior] is the smallest of the three. Into it open the posterior ethmoidal cells by one or two small foramina. The sphenopalatine foramen, which communicates with the meatus in the dry skull, is entirely covered up by mucous membrane. The middle meatus [meatus nasi medius] is a much larger passage. Upon its lateral wall is a rounded eminence, the ethmoidal bulla, caused by the middle ethmoidal cells and perforated by the opening into them. Inferior to this is a deep curved groove, the hiatus semilunaris, which is continued superiorly by the ethmoidal infundibulum [infundibulum ethmoidale] into the frontal sinus. It also receives the openings of the anterior ethmoidal cells and the maxillary sinus. The inferior meatus [meatus nasi inferior] is the longest of the three. Upon its lateral wall, just inferior to the attachment of the inferior concha, is the slit-like opening of the naso-lacrimal duct [ductus naso-lacrimalis], around the opening of which the mucous membrane forms a valve, the plica lacrimalis (Hasneri).

Recent investigation of the nasal concha indicates that two upper conchx (eoncha nasalis superior and concha nasalis suprema [Santorini]) are more often present than one. Three upper conchæ are not rare. 
The attached margins of the middle and inferior conchx are both arched, the convexities being upward. The highest point of the convexity is near the middle of the attached margin in the inferior concha and lies about $17 \mathrm{~mm}$. above the floor of the nose; the anterior end of this concha is approximately $25-35 \mathrm{~mm}$. distant from the apex of the nose (Kallius).

From the anterior end of the middle concha a slight variable elevation of the mucous membrane of the nose extends forward and downward. This, the agger nasi, which is regarded as of constant occurrence in the new-born, appears to be a rudimentary representative of the nasoturbinale of mammals (Schwalbe).

Below the agger nasi a broad depression of the lateral wall, the atrium meatus medii, leads posteriorly beneath the anterior free margin of the middle concha to the middle meatus, while above the agger, between it and the roof of the nasal cavity, the slight olfactory groove [sulcus olfactorius] ascends upon the lateral wall to the olfactory region. In this region, above the superior concha, is a corner of the nasal cavity of interest on account of the sphenoidal sinus opening into it: this is the spheno-ethmoidal recess [recessus spheno-ethmoidalis].

Variation in the number and position of the openings into the meatuses is of practical interest. An accessory mouth of the maxillary sinus is rather frequently met with, especially in old people; it lies most commonly behind the hiatus semilunaris. The infundibulum ethmoidale may open independently of the hiatus semilunaris at a spot beneath the anterior end of the attached margin of the middle concha. In the inferior meatus the mouth of the naso-lacrimal duct, which is found $22-25 \mathrm{~mm}$. behind the posterior margin of the nares, may have one or more accessory openings associated with it; these are perforations of the plica lacrimalis.

Communication between the nasal cavity and the nasal part of the pharynx is effected by means of the paired posterior apertures [choanæ]. These are oval in form, their height greater than their width. They are located at either side of the posterior edge of the nasal septum and are limited above by the body of the sphenoid, below by the line of junction of the hard and soft palate.

From the plane of the choana forward a rather constricted portion of the nasal cavity extends for a short distance to reach the level of the posterior ends of the middle and inferior conchæ. Into this region, which is known as the meatus naso-pharyngeus, open posteriorly the supcrior, middle and inferior meatuses. Posterior rhinoscopic examination reveals the choanæ, the naso-pharyngeal meatus, the posterior extremities of the three conchæ and of the meatuses beneath them.

Dimensions of the nasal cavity. - The length of the floor averages approximately $40 \mathrm{~mm}$. the width $32 \mathrm{~mm}$., the height from floor to lamina cribrosa $47 \mathrm{~mm}$. The length of the lateral wall is about $63 \mathrm{~mm}$. The choana measures $29.8 \mathrm{~mm}$. high and $15.5 \mathrm{~mm}$. broad. The area of the two nares is $2 \mathrm{sq}$. $\mathrm{cm}$.

Paranasal sinuses [sinus paranasales] (figs. 964-968).-The location, form and relations of the bony-walled spaces connected with the nasal cavity have been fully described in the section on Osteology. The conditions observed in the living subject differ in certain respects from those present in the macerated skull; the spaces are lined by a mucous membrane which, though affecting but slightly the form of these chambers, modifies considerably the openings by which they communicate with the nasal cavity. These openings permit the entrance and exit of air and to some extent the escape of fluids which may accumulate in the sinuses. While the significance of these spaces is not at present clear it is, however, certain that they function in lightening the weight of the skull, and probable that indirectly they serve in comnection with the sense of smell.

Maxillary sinus (of Highmore*) [sinus maxillaris Highmori] (figs. 965, 966, 967).

Entrance in to the maxillary sinus is offered through the middle part of the hiatus semilunaris, that is, the deep, narrow noteh between the ethmoidal bulla and uncinate process of the ethmoid. Viewer from within the sinus, the opening appears as an oval window in the upper part of the medial wall - a position unfavourable to the dischange of matter, when the body is in the upright posture. An aceessory opening, situated behind the normal ostium, is present in about 10 per cent. of cases.

Measurements of 90 specinens of the arlult sinus maxillaris gave as the average the following

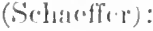

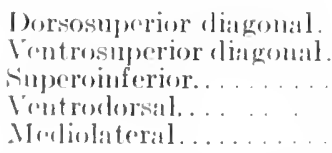$$
\begin{array}{ll}
3.3 & \text { mm. } \\
38.5 & \text { mm. } \\
33 & \text { mm. } \\
3.4 & \text { mm. } \\
23 & \text { mm. }
\end{array}
$$

Increase in apacity of the maxillary sints is sometimes observed ats the result of more or Joss refonsive exavation of the bony prosesses of the maxilla adjacent to it, viz.: the alveolar, palatal, frontal and zycomatice. On thr other hamd narrowing of the cavity is encountered,

* Jighmore, Nathaninl: English physiona. 13. 1613, D. 1655. 
caused by unusually thick walls of bone, bulging inward of the facial or nasal walls, and through retention of teeth. Incomplete division into two parts through the presence of a septum lias several times been observed. Communication with ethmoidal cells and with the cavity of the orbital process of the palate bone sometimes exists.

Frontal sinus [sinus frontalis] (figs. 78, 964, 968).-The paired frontal sinuses, separated from each other by a bony septum, have in general the shape of a threesided pyramid with the base below and the apex formed above in the frontal squama. In the base near the septum is located the superior aperture of the infundibulum which, it will be recalled, opens inferiorly at the anterior extremity of the hiatus semilunaris.

The form and size of the frontal sinuses are exceedingly variable. They may extend backward in the orbital part of the frontal bone as far as the suture between it and the small wing of the sphenoid; laterally into the zygomatic process; upward toward the coronal suture. The capacity of the sinus, as determined in a small number of cases, varied from 3 to $7.83 \mathrm{ccm}$. (Brühl). Asymmetry of the septum is frequently observed. Absence of one of the sinuses is not a rare condition; absence of both is occasionally encountered.

Fig. 968.-Left Nasal Cavitr. (Rauber-Kóopsch.)

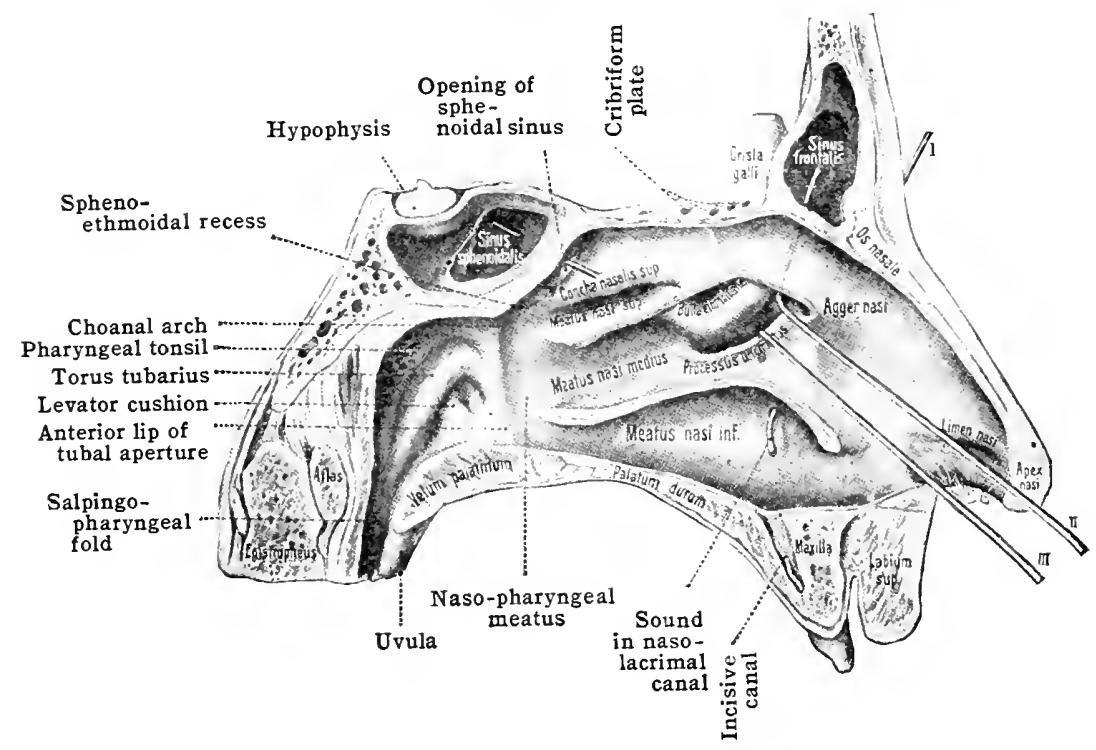

Ethmoidal cells [cellulæ ethmoidales] (figs. 965, 968).-The openings of the anterior cells into the semilunar hiatus and infundibulum, and of the posterior cells at the superior meatus have already been described.

Communications between the ethmoidal cells and the sphenoidal and maxillary sinuses are not rare; the cavity in the orbital process of the palate bone may open in to the posterior cells. In old age, foramina through the lamina papyracea may appear, leading to the introduction of air in to the orbit.

Sphenoidal sinus [sinus sphenoidalis] (figs. 964, 965, 966).-The apertures of the paired sphenoidal sinuses are, on account of the mucous membrane covering, much smaller than they are in the dried skull. They lie in the anterior wall near the septum, nearer the roof than the floor, and open into the spheno-ethmoidal recess.

Extension of the sphenoidal sinuses backward and also into neighbouring processes, and communication with ethmoidal cells and with the small cavity of the orbital process of the palate are not unusual. The capacity of the sinus varies between 1 and $4.2 \mathrm{cem}$. (Brühl).

Functions of the paranasal sinuses.-Various functions have been attributed to the sinuses near the nose, none of which is entirely watisfying. Mediæval anatomists proposed that these cavities contributed to the resonance of the voice, or that they supplied the mucus by which the nasal cavity is kept moist. Lightening the skull, warming the inspired air and taking part, indirectly, in the sense of smell are functions assigned by anatomists of later times.

The mucous membrane of the nose [membrana mucosa nasi].-The nasal cavity is completely lined with mucous membrane, which inferiorly, at the limen nasi blends with the skin covering the walls of the vestibule (p. 1204). Posteriorly it joins the mucous membrane of the pharynx and palate. It covers some of the 
openings which are seen in the bony walls; those apertures, however, which lead into the paranasal-sinuses and into the naso-lacrimal duct remain patent, although as already stated the bony openings are much reduced in size.

In the nasal cavity the bright rose-red vascular mucous membrane is tightly bound to the periosteum and perichondrium, and is eovered with a eiliated colummar epithelium. Numerous large mueous nasal glands [glandule nasales] pour their more or less watery secretion over the entire surface. A very considerable venous plexus is found in many parts of the nasal mucosa. Over the inferior concha and to a less extent in the mueosa of the middle and superior eonchr, it forms the cavernous plexuses of the conchæ [plexus cavernosi concharum] contributing to build up about these bodies a true erectile tissue. The thickness whieh these glands and venous plexuses give to the mucous membrane of the concha causes the marked inerease in size of these bodies over that of their bony supports. The region covered by the mucous membrane just described forms the greater part of the nasal cavity, and is known as the respiratory region [regin respiratoria]. The nucous membrane of a small area over the superior concha and the adjacent septal wall (fig. 969) has a somewhat different structure. In this area the olfactory nerves are distributed, whence it is known as the olfactory region [regio olfactoria] and its mucous membrane, compared with that of the respiratory region, is less vascular, yellow or yellowishbrown in colour, and eovered by a non-ciliated epithelium. Its cells, specially modified, some of which are directly connected with the olfactory nerve, form the olfactory organ [organon olfactus]. Small mucous olfactory glands [glandula olfactorix] occur in the region. The mueous membrane which lines the paranasal sinuses throughout is a continuation of the nasal mucosa; it is, however, paler, less vaseular, somewhat thinner, and more loosely attached to the bones. Mucous glands are numerous.

The waving of the cilia in the nasal cavity is such as to sweep foreign matter toward the choans; in the paranasal sinuses, toward the nasal cavity.

Fig. 969.-Diagram of the Distribution of the Nerves in the Nasal Cavity. (Poirier and Char"py.)

The olfactory area is represented by dots.

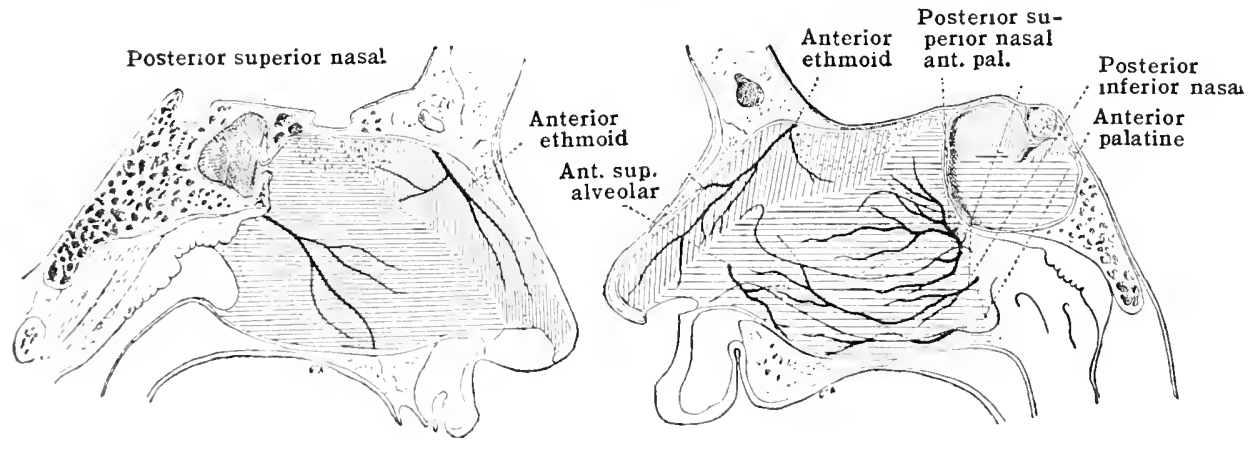

Vessels and nerves. - The arteries of the nasal cavity are the spheno-palatine artery from the internal maxilary which, through its posterior lateral nasal branehes, supplies the middle and inferior eonchat (p. 549), the anterior and posterior ethmoirlal arteries from the ophthalmic (p. 553), the descending palatine artery from the internal maxillary (p. 549), and the superior labial branch of the external maxillary to the vestilule. The venous plexuses of the mueous membrane are drained posteriorly by the spheno-palatine to join the pterygoid plexus, superiorly by thr antrior and posterior ethmoidal veins to join the superior ophthalmic vein, and anteriorly by small branches to join the facial. The lymphatics form a well-developed plexus which is sild fo commmninate indirectly, through the lymphatics surrounding the olfactory nerves, with the subdural and subarachoid spaces. Posteriorly two or more well-developed trunks connuminatr with the pharyngeal lymphaties, and anteriorly the masal lymphaties join with the lymphaties of the face. The olfactory nerves pass through the ribriform plate of the ethmonl wone and are distributol to the olfactory area (J.929). The trigeminal nerve furnishes the following branches to the nasil eavity:- branches from the naso-ciliary hranch of the ophthatmir morv; the Vidian norve; the postreror superior and posterior inferior nasal and the anterior palatinc from the spheno-palatinc ganglion (p. 962); the anterior superior alveolar from the infra-orhital division of the maxillaty nerve (1). (9:3s).

The development of the nose.- 'Tho nasal 'avity makes its appearance as a depression of the erfoderm on rithere side of the median line, immediately in front of the oral fossa, with which the depressons are at first contimens. Later, by the union of the maxillary and globular

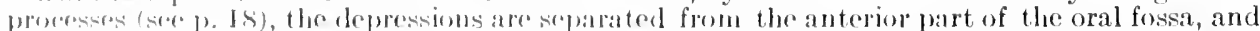
this separat in is cont inue thy the formation of the palatal processes of the maxillar and palatine bones so that fimally the nasal cavitios commumiate pesteriorly only with the pharyox.

The cartilage which forms the lateral walls of the nasal fossa is at first quite smooth, but

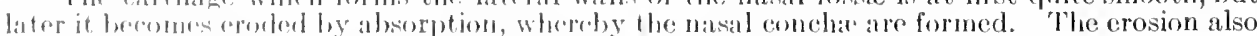

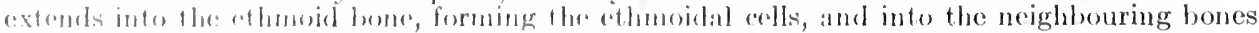
to form thr: fromtat, sphenoislal, and maxillary sinuses. 


\section{THE LARYNX}

The larynx (figs. 960,970,971,), is a tubular organ, the framework of which is made of cartilages joined together and of elastic membranes. Its inner surface is covered by mucosa. From the membranes are formed a pair of vocal folds which, by the passage of air through the larynx, are thrown into vibration and so function in the generation of sound. These folds are affected in respect to their

Fig. 970.-View of Interior of Lartax as seen from above during Inspiratiox.

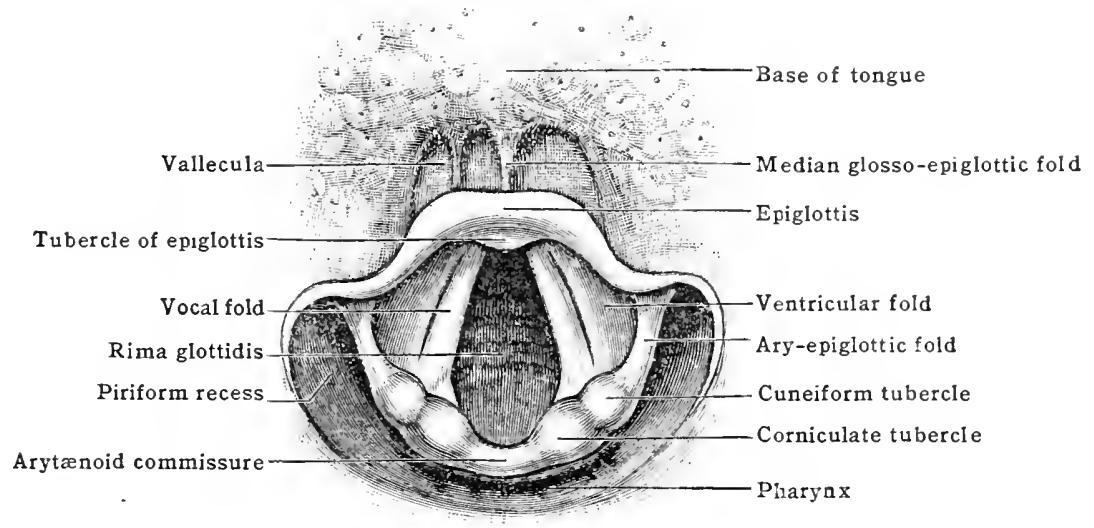

tension and in their mutual relation by the actions of a system of laryngeal muscles under the control of the vagus nerve and are made thereby, on the one hand, to produce those modifications of the sound involved in the voice and on the other hand to regulate the amount of air passing through the cavity of the larynx. The latter communicates above with the pharynx by means of the opening called the laryngeal aperture, and below with the cavity of the trachea. Figure 970 shows the laryngeal aperture with its boundaries, the epiglottis and

Fig. 971.-View of Interior of Laryxx as seen from above dering Vocaltsation.

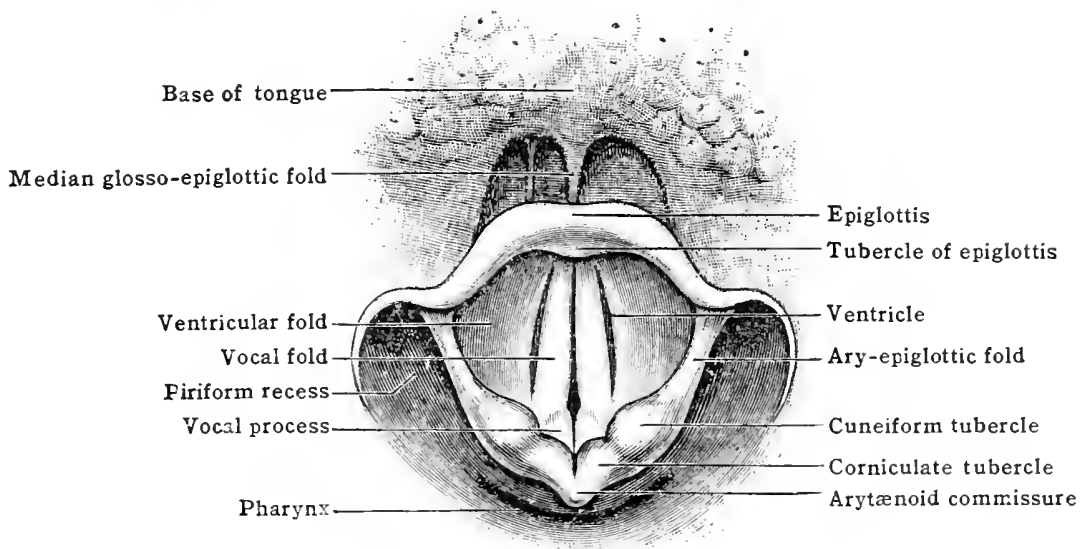

the aryepiglottic folds; also the cavity of the larynx where, on the walls right and left, appear the ventricular and rocal folds with the chink called rima glottidis separating them.

The position of the larynx and some of its important parts can be well seen in a median section (fig. 972).

\section{THE CARTILAGES OF THE LARYNX}

The number of cartilages entering into the framework of the larym is nine, three of which are single and the rest in pairs. Their forms and positions are shown in fig. 973 . 
The cricoid cartilage [cartilago cricoidea] (figs. 973, 974, 975, 978), single, has been compared in its shape to a signet ring. Its position is at the lower end of the larynx, where it is connected with the first ring of the trachea. Posteriorly the cricoid cartilage expands into a broad lamina [lamina cartilaginis cricoideæ] which enters into the posterior boundary of the laryngeal cavity, while laterally and in front it forms a narrow arch [arcus cartilaginis ericoideæ]. On either side of the upper margin of the lamina is the elliptical arytænoid articular surface [facies articularis arytænoidea] its long axis parallel with the margin of the cricoid, its steeply sloping surface convex for articulation with the arytænoid cartilage. The hinder surface of the lamina presents a median ridge and lateral impressions for the attachment of the posterior crico-arytænoid muscles. The arch, weakest

Fig. 972.-Median Section of a Man 21 Years of Age, showing the Position of Larynx and Trachea. (After W. Braune, from Poirier and Charpy.)

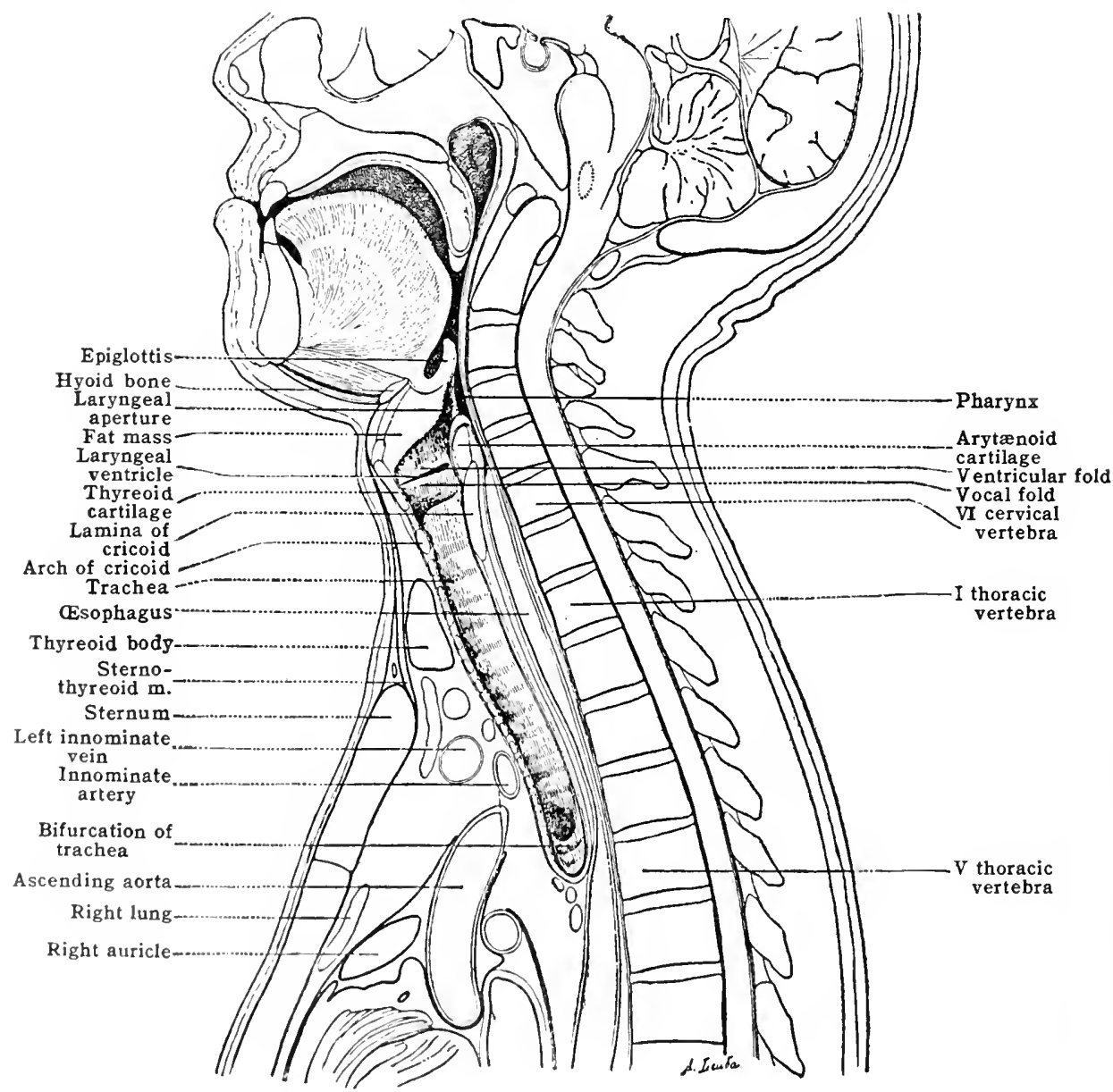

in its middle part, presents concave upper and straight lower margins. A circular, evated thyreoid articular surface [ficcies articularis thyreoidea] for articulation with the inferior comm of the thyreoid cartilage is situated upon the side of the cricoid where arch and lamina are continuous. 'The internal surface is eovered by the laryngeal mucosa.

'The thyreoid cartilage [cartilago thyroideal (figs. 973, 974, 975, 977), single and the largest in the larymgeal skeleton is composed of two broad laminæ, right and left, which meet and are fused anteriorly in the mid-line in a right angle, partly eovering the other cartilages laterally and in front. The lamina are stout, hut their connedion at the angle is through a weak strip of eartilage. The upper margin of cath lannina is convex, and in front drops abruptly to form in the median line the superior thyreoid notch [incisura thyreoidea superior]. The anterior edges 
meeting in the angle produce the laryngeal prominence [prominentia laryngea] ("Adam's apple"), which is seen on the front of the neck. The horizontal inferior margin presents near its middle the inferior thyreoid tubercle [tuberculum thyreoideum inferius], and in the median line the inferior thyreoid notch [incisura thyreoidea inferior]. The thick posterior margin of each lamina is continued above the superior edge in the long superior cornu [cornu superius], and below the inferior margin in the short inferior cornu [cornu inferius]. The former is directed slightly backward and medialward, and joins with the end of the greater cornu of the hyoid by ligament. The inferior cornu, curving medialward as it descends, articulates by a flat, circular facet upon the medial side of its extremity with the thyreoid articular surface of the cricoid cartilage. The external surface of the lamina affords lattachment for muscles and presents in its upper posterior part the

Fig. 973.-Cartilages of the Larinx seen from behind in Their Natural Positions. The Coneiform Cartilage is Somewhat Higher than Normal. (Merkel.)

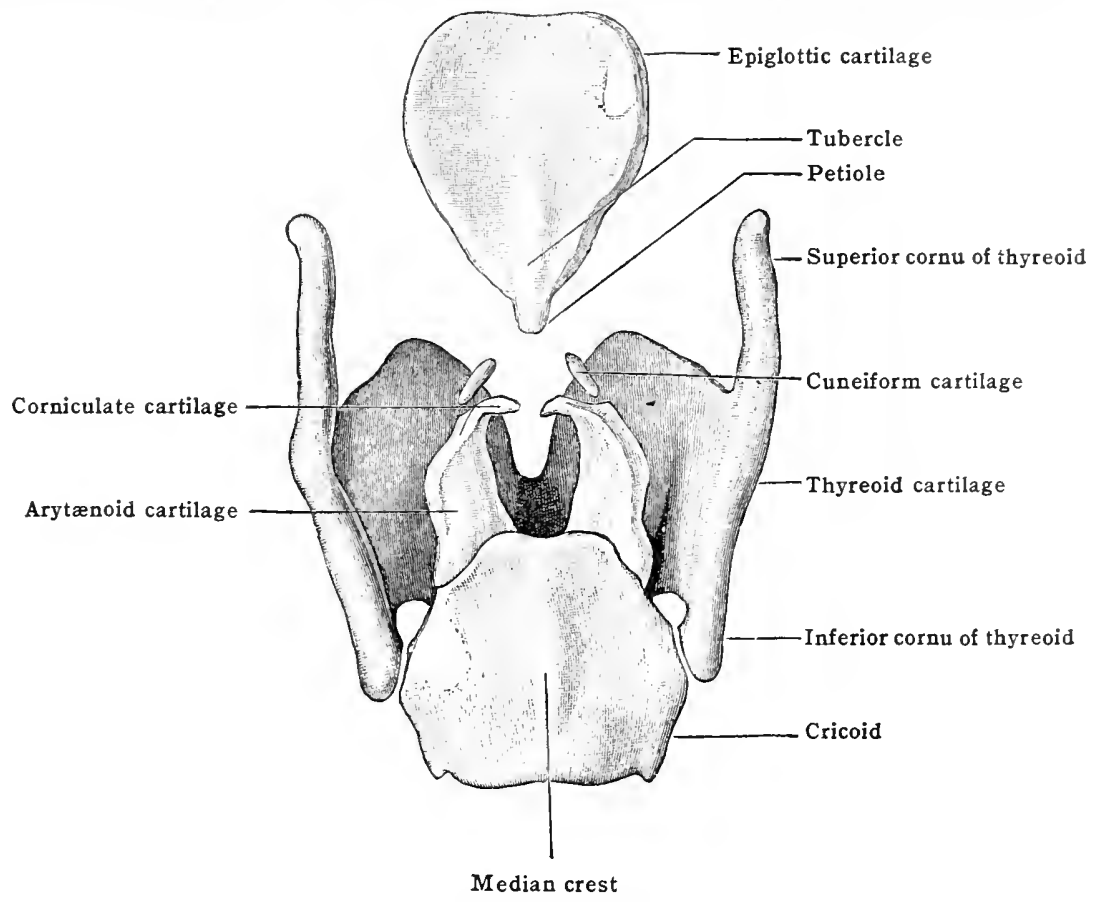

superior thyreoid tubercle [tuberculum thyreoideum superius]; in its lower part the inferior thyreoid tubercle. The internal surface of the thyreoid cartilage is smooth.

A thyreoid foramen [foramen thyreoideum], sometimes seen in the upper part of the lamina, giving passage to the superior laryngeal artery, results from the incomplete union of the fourth and fifth branchial cartilages from which the lamina are derived. The oblique line [linea obliqua], extending between the thyreoid tubercles, is commonly present and is regarded by many anatomists as a normal feature of the external surface of the thyreoid cartilage. It marks the attachment of the sternohyoid and thyreohyoid muscles. At the insertion of the vocal ligaments in the angle of the laminæ a small perichondral process is often observed.

The arytænoid cartilages [cartilagines arytænoideæ] (figs. 973, 977, 978, 979), paired, surmount the lamina of the cricoid cartilage and give attachment to the vocal ligaments, whose relations and state of tension are altered by the changes in position which these cartilages are almost constantly undergoing.

Each cartilage is pyramidal in form, and moulded for the attachment of several muscles. The apex, which is above, is bent backward and medialward and is connected with a corniculate cartilage. The base, somewhat triangular in shape, presents at the lateral and posterior part an oval or circular concave articular surface [facies articularis], directed medialward and downward to meet the arytænoid articular surface of the cricoid cartilage. The lateral angle of the base is prolonged into a stout muscular process [processus muscularis] for the attach- 
ment of the crico-arytrenoid muscles, while the anterior angle is extended as a sharp projection, the vocal process [processus vocalis], which serves for the attachment of the vocal ligament. The surfaces of the arytrenoid are named medial, posterior, and antero-lateral. The narrow medial surface, covered by the mucosa of the larynx, is nearly vertical, and faces the corresponding side of the opposite arytrenoid, from which it is separated by a small space. The posterior surface is concare for muscular attachment. The antero-lateral surface is the largest, and presents an irregular contour.

On this surface a ridge, the arcuate crest [crista arcuata], extends horizontally between two hollows-the triangular fovea [fovea triangularis] above, which lodges some mucous glands, and a larger depression below, the oblong fovea [fovea oblonga] for the vocal muscle. The colliculus is a small eminence found upon the anterior margin and antero-lateral surface.

Fig. 974.-Froxt View of the Laryngeal Skeleton. (Modified from Bourgery and Jacob.)

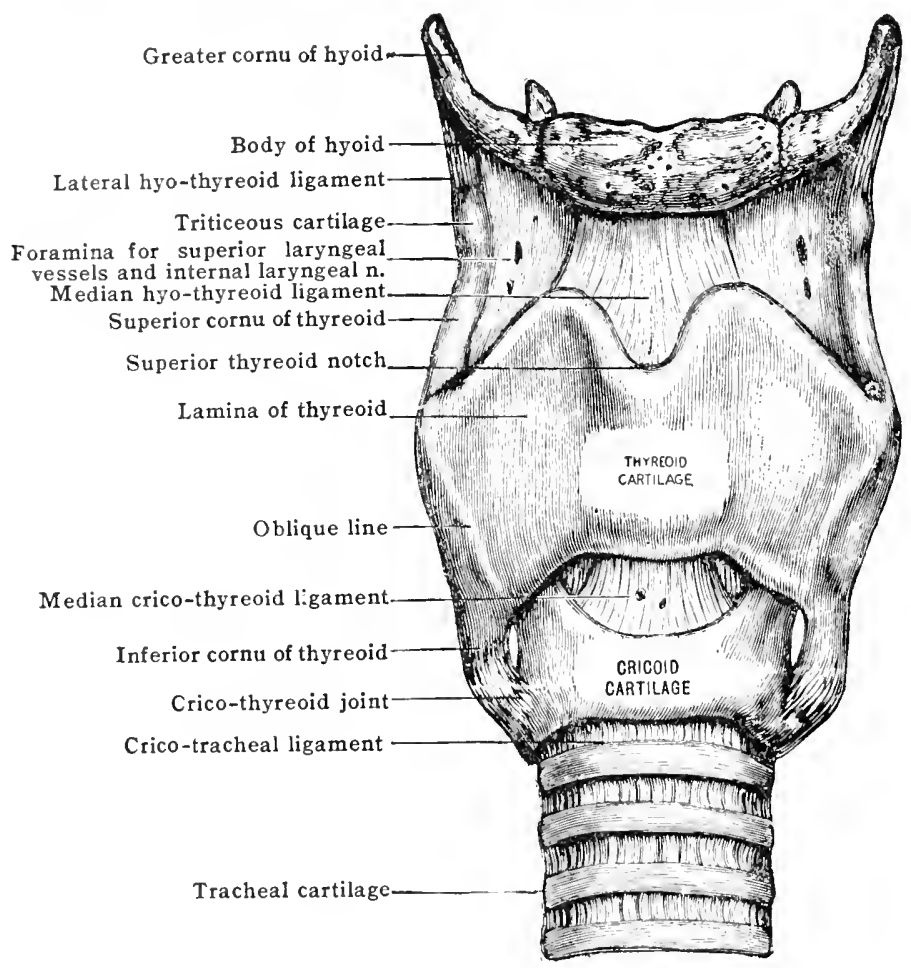

The corniculate cartilages (of Santorini) [cartilagines corniculatie (Santorini*)] (figs. 973, 977). - This pair of small conical cartilages is set upon the bent apices of the arytenoids, continuing their curves backward and medialward.

The corniculate cartilize is not an independent structure in many lower animals, and its continnity with the arytumoir is sometimes net with in man where the two cartilages are normally develuped in a continuous mass of tissue.

Thro epiglottic cartilage [“artilago epiglottion] (figs. 973, 977, 981, 987), mupairerl, invested by munosia behind and partly in front, thin and leaf-shaped, stamls lentind the root of the tongur and the body of the hyoid. It lies above the thyeroid cartilage, in front of the contaner of the larynx. The free upper margin is anvex, or notracel; the lower and tapers to a short stalk, the petiole of the "priglottis lontiolus cploghtticlis], to which the thyrco-epiglottic ligament is attarchorl.

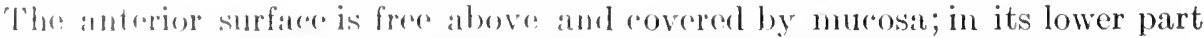
it is bound to the body of the hyod, and is sepurated by a mass of fat from

* Sintorini: Vonolian anatomist. 13, Ifisi, 1). 1737. 
the hyo-thyreoid ligament. Its posterior surface above is saddle-shaped; below, it is convex, presenting the epiglottic tubercle [tuberculum epiglotticum]. To the margins are attached the ary-epiglottic folds. The epiglottic cartilage presents numerous small holes and depressions for the accommodation of glands.

The cuneiform cartilages (of Wrisberg) [cartilagines cuneiformes (Wrisbergi*)] (fig. 973) lie as small, rod-like bodies in the ary-epiglottic folds anterior to the corniculate cartilages. They are variable in form and size and not rarely absent altogether.

These cartilages are parts of the epiglottic cartilage in some mammals where, as in man, they lie in the ary-epiglottic folds. Their relations to the arytænoids are regarded as secondary. Sutton has shown that in the ant-eater a continuous rim of yellow elastic cartilage extends from the sides of the epiglottic cartilage to the summits of the arytanoids. A minute unpaired interarytcnoid or procricoid cartilage is rarely present imbedded in the cricopharyngeal ligament and covered by the pharyngeal mucosa. It is a constant structure in certain mammals. A pair of small sesamoid cartilages, also constantly present in some mammals, is occasionally found in man at the lateral margins of the arytænoids, connected with them and with the corniculate cartilages by elastic ligaments.

Structure of the cartilages.--The thyreoid, cricoid, and greater part of the arytænoid are composed of hyaline cartilage; the epiglottic, corniculate, and cuneiform cartilages, as well as the apex and vocal process of the arytænoid, are of elastic cartilage. Certain parts of the laryngeal skeleton normally undergo calcification and subsequent ossification. Calcification begins at about twenty years of age in the thyreoid and cricoid cartilages, and later in the arytænoid. The process begins a little later in the female than in the male, and does not extend so rapidly. The extent to which the cartilages are ossified and the time occupied in the process vary considerably. The elastic elements are not involved in the process.

Fig. 975.-Cricoid and Arytenoid Cartilages seen fron Before. Fig. 976.-Cricoid and Arytenoid Cartilages seen fron the Left.

(Rauber-Kopsch.)

(Rauber-Kopsch.)
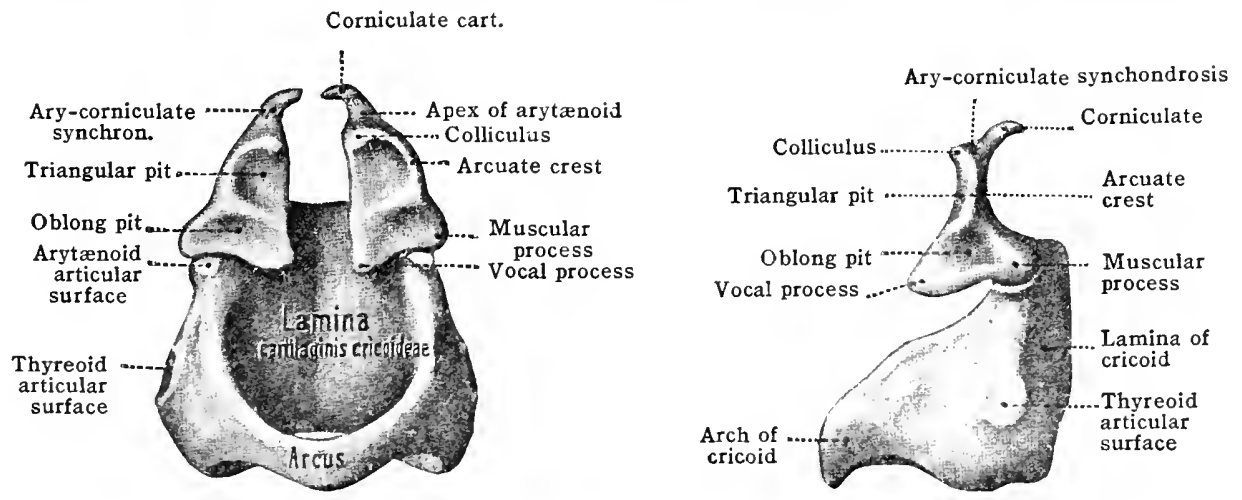

\section{THE JOINTS AND FIBROUS MEMBRANES OF THE LARYNX}

\section{(1) Connections between the Laryngeal Cartilages}

The crico-thyreoid articulation (figs. 973, 974, 975).-The articular surfaces concerned are the thyreoid articular surface on the side of the cricoid and the articular surface on the inferior cornu of the thyreoid cartilage. The cricothyreoid articular capsule [capsula articularis cricothyreoidea] attached around the margins of these surfaces and certain accessory bands serve to bind the cartilages together.

The accessory bands, cerato-cricoid ligaments fall into three groups radiating from the inferior cornu: the ligamenta ceratocricoidea posteriora upward and medialward to the superior margin of the cricoid; the ligamenta ceratocricoidea lateralia downward at the side and back of the capsule; the ligamentum ceratocricoideum anterius downward and forward. The capsule possesses a synovial layer.

A rotary movement about a transverse axis of the cricoid upon the thyreoid or vice versa and a slight backward and forward gliding are permitted at this joint.

* Wrisberg: German anatomist. B. 1737 , D. 1808 . 
The crico-arytænoid articulation [articulatio cricoarytænoidea (figs. 973, 977, 978).- The articular surface of the cricoid cartilage and the articular surface of the arytænoid which enter into this articulation are so disposed that at no time do they meet in complete apposition. A loose capsule [capsula articularis crico-

Fig. 977.-The Laringeal Skeleton seen from Behind. (Poirier and Charpy.)

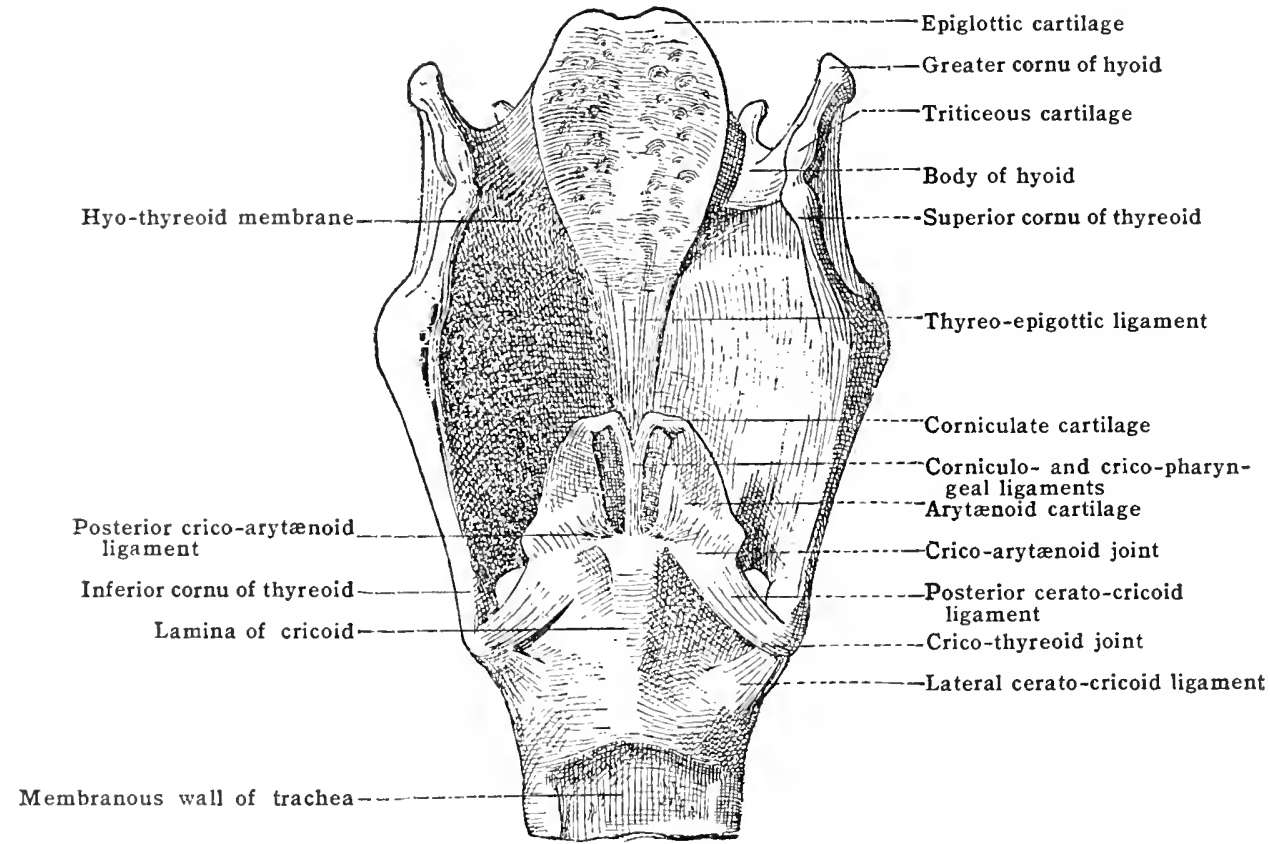

Fig. 978.-The Lartax with its Liganents, viewed from the Right. (The right lamina of the thyreoid cartilage has been removed.) (Spalteholz.)

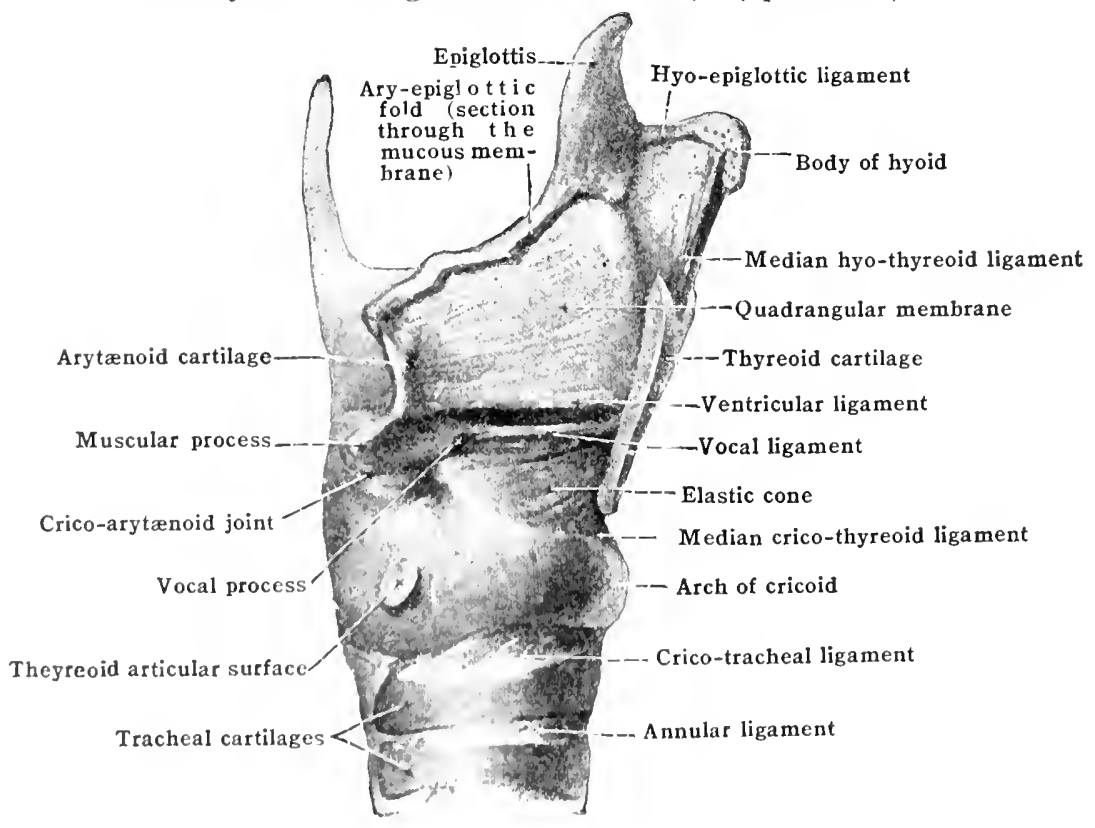

arytanoideat of fibrous and synovial strata attached around the exlges of the joint surfaces unites the cartilages.

Posterior crico-arytænoid ligament |lig. crienarytenoideum posteriusl, attached abovo to the medial surface of the base and muscular process of the arytauoid, and below to the lamina 
of the cricoid, is important in helping to fix the former cartilage in place upon the sloping arytænoid articular surface of the cricoid and in limiting its movements. Motion at this articulation is very free. The following simple movements of the arytænoid are best understood:-(1) gliding of the arytænoid toward or away from its fellow; (2) inclining forward and backward; (3) rotating on a vertical axis, so that the vocal process sweeps medialward or lateralward and also a little downward or upward.

The union of the corniculate cartilage with the apex of the arytænoid cartilage [synchondrosis arycorniculata] is usually by connective tissue; rarely is there a joint cavity.

The petiole of the epiglottic cartilage is connected with the thyreoid, below and behind the superior notch, by a strong, elastic thyreo-epiglottic ligament [lig. thyreoepiglotticum] (fig. 977).

\section{(2) The Elastic Membrane of the Larinx}

\section{[Membrana elastica laryngis]}

This name is given to a more or less continuous sheet of elastic fibres connected with the deeper parts of the laryngeal mucosa. Its upper part is known as the quadrangular membrane, the lower part as the elastic cone. A middle region of the elastic membrane lies opposite the ventricle of the lary nx.

The quadrangular membrane (figs. 978, 981, 988) extends from the ary-epiglottic folds above to the level of the ventricular folds (false vocal cords) below. The lateral parts of this membrane are widely separated superiorly, but they converge toward the middle line as they descend. Anteriorly, the membrane is fixed in the angle of the thyreoid laminx and to the sides of the epiglottic cartilage; posteriorly, to the corniculate cartilages and to the arytænoids. The superior edge on either side lies within the ary-epiglottic fold, which it supports; it slopes downward and backward and includes the cuneiform cartilage. The inferior edge, horizontal and in a sagittal plane, is best developed in front, where it is attached in the angle of the thyreoid a little way from the middle line; behind, it is fixed to the medial margin of the triangular fovea of the arytænoid. This inferior free margin, differentiated as the ventricular ligament [lig. ventriculare], is enclosed within, and is the support for the ventricular fold.

Fig. 979.-The Elastic Cone seen from Above. (Modified from Luschka.)

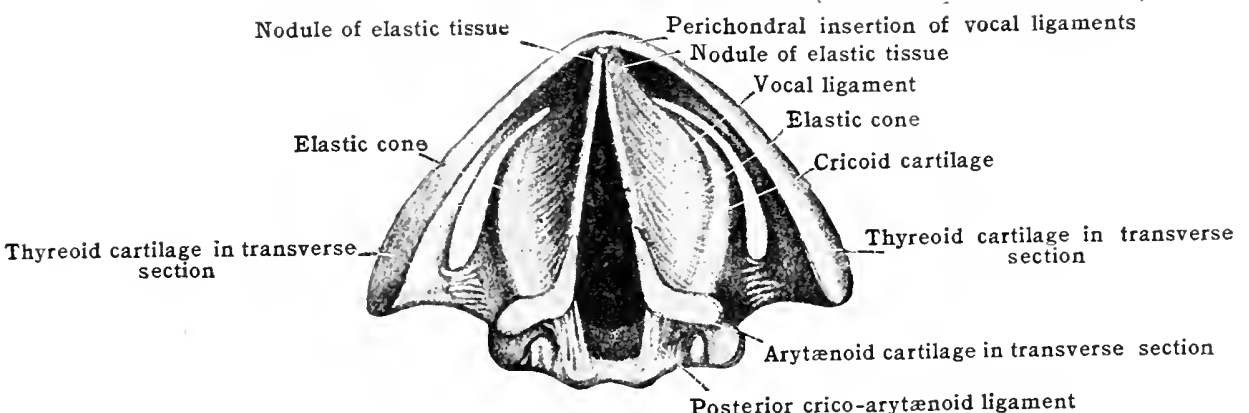

The elastic cone [conus elasticus] (figs. 978, 979).- This part of the elastic membrane extends from the level of the vocal folds to the superior margin of the cricoid cartilage. Its component fibres are attached in the re-entrant angle and adjacent lower margin of the thyreoid cartilage, whence they spread downward and backward to the upper edge of the cricoid arch and to the arytænoid cartilages. The strong anterior portion, perforated by vessels, is the median cricothyreoid ligament [lig. cricothyreoideum (medium)] (figs. 974, 975). The lateral parts (lateral portions of the crico-thyreoid membrane) present superior free edges, somewhat thickened, which, running horizontally near the middle line from the thyreoid angle to the vocal processes, constitute the vocal ligaments. These are inserted anteriorly into a perichondral process in the thyreoid angle; posteriorly, they have a wide area of attachment to the upper and medial surfaces of the vocal processes of the arytænoids with the elastic fibres of which they are in part continuous. A yellowish, cellular nodule (sometimes cartilage) occurs in the 
anterior end of each ligament. The vocal ligaments enter into the formation of the rocal folds (true vocal cords).

Fig. 980.-The Laryax seen from the Left Side. (Modified from Luschka.)

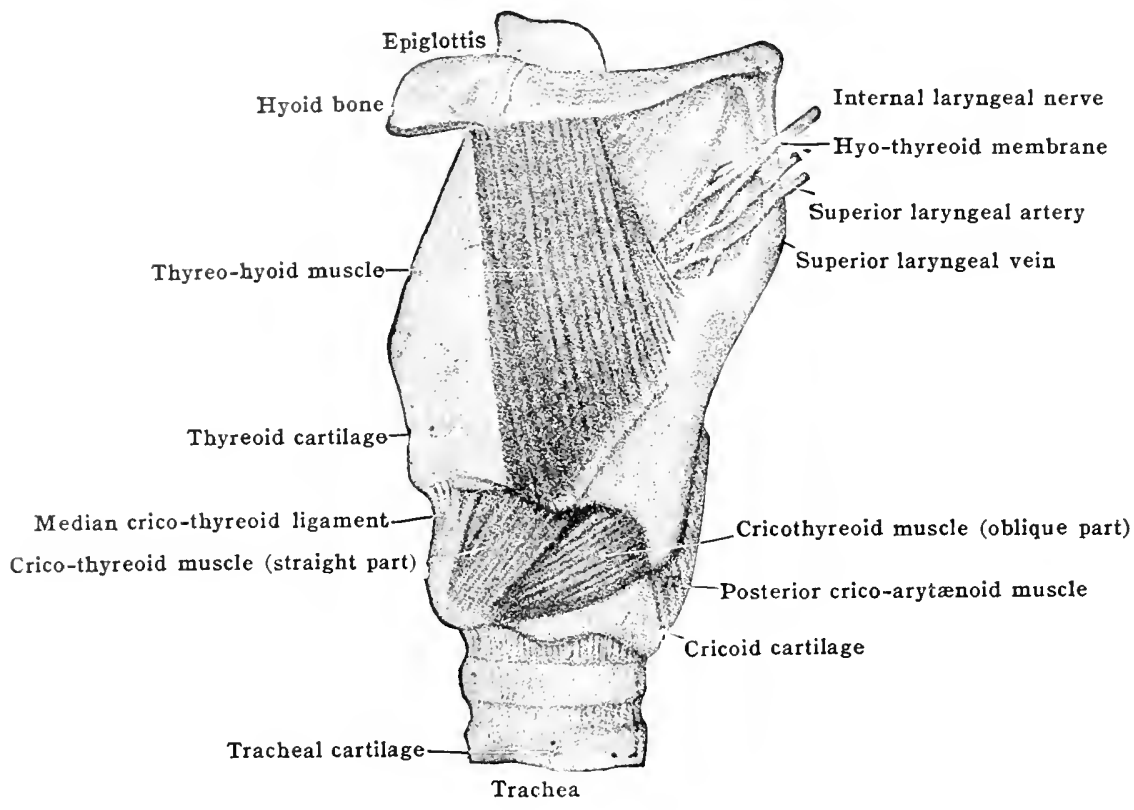

Fig, 981.-The Muscles and Liganents of the Larynx seen from the Side. (The left lamina of the thyreoid eartilage has been removed.)

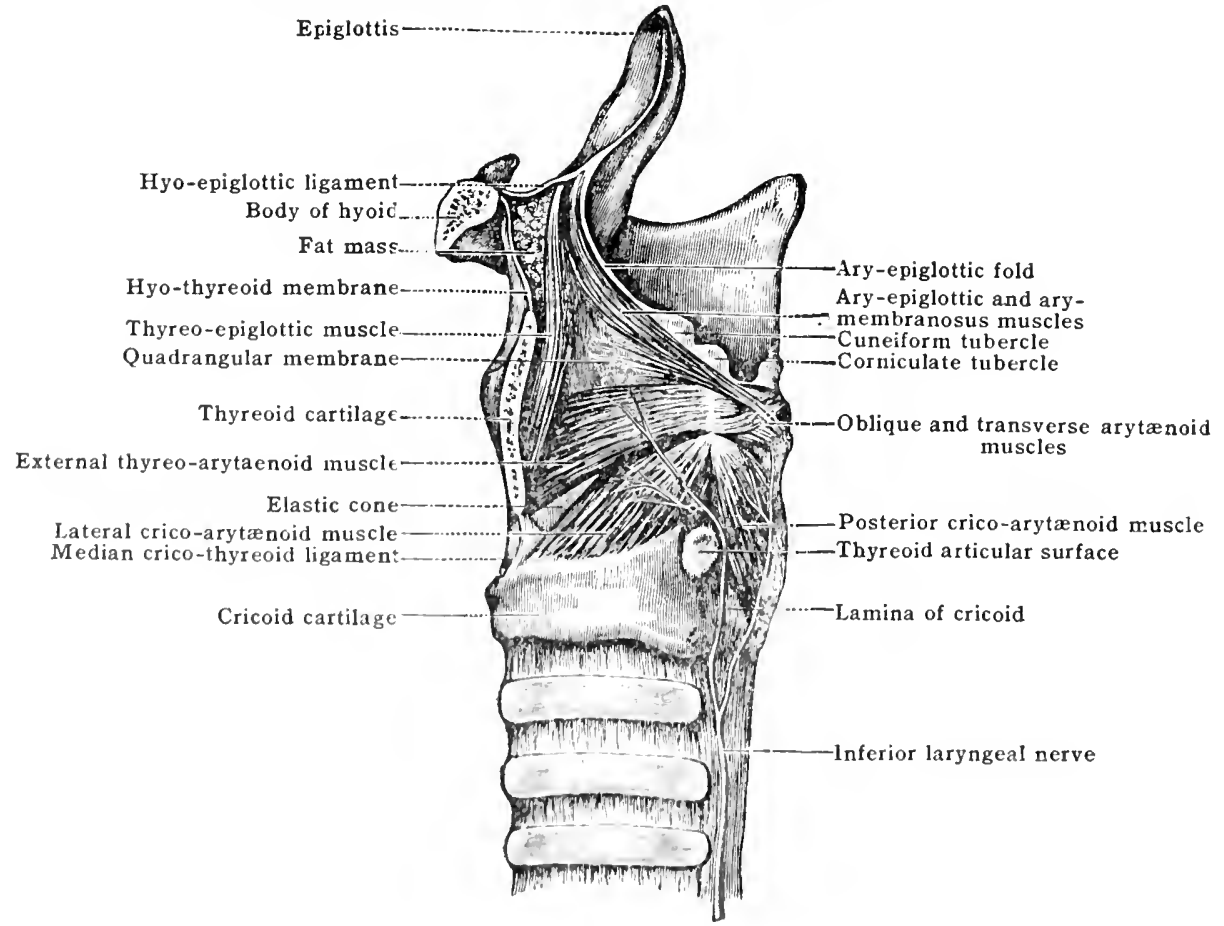

The median erien-thyrenid liganent is incised in the operation of laryngotomy. It is

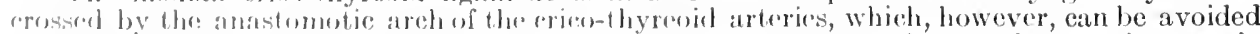
in the operation by making at transverse cut through the ligament close to the superior margin if thre arrets of the rejeniel cartilage. 
(3) Connections between the Larynx and Neighbouring Structlres

The hyo-thyreoid membrane [membrana hyothyreoidea] (figs. 977, 980, 981) is a loose, fibrous, elastic sheet, binding together the thyreoid cartilage and hyoid bone. It extends from the superior margin of the former to the greater cornua and

Fig. 982.-Scheme of Rima, showing Action of Posterior Crico-arttenoid Muscle, which draws the Arteæiond Cartilage frou I to II. (Modified from Stirling.)

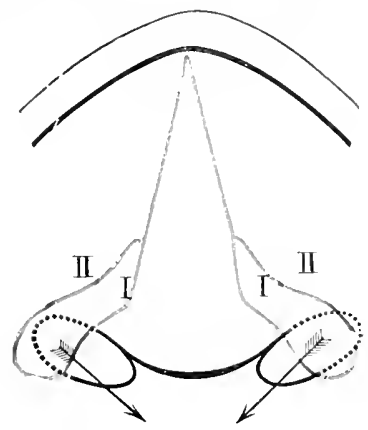

superior margin of the body of the latter. The superior lary neal artery and vein and the internal laryngeal nerve pass through it from the side. Its posterior and lateral edge is cord-like, consisting of elastic fibres which stretch as the lateral

Fig. 983.-Scheme showng Action of the Transverse Arytenoid drawing Arytenoid Cartilage from Neutral Position I to II. (Modified from Stirling.)

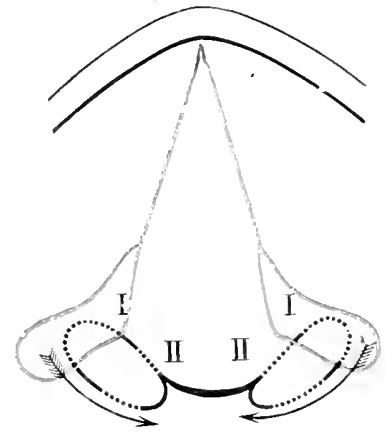

hyo-thyreoid ligament [lig. hyothyreoideum laterale] from the superior cornu of the thyreoid to the greater cornu of the hyoid. A small cartilago triticea is sometimes present in this band. The middle part, median hyo-thyreoid ligament [lig.

Fig. 984.-Scheme showing Action of Thyreo-arty.enoid drawing the Vocal Processes and the Vocal Liganients fromi II to I. (Modified from Stirling.)

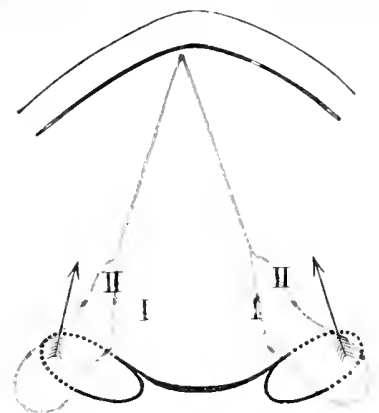

hyothyreoideum medium] thick and elastic, extends from the superior thyreoid notch upward behind the body of the hyoid to be attached to its superior margin, the hyoid bursa being interposed between the bone and the membrane. 
The cartilago triticea is the remains of a connection between the thyreoid and hyoid present in the embryo. It persists in adult life in some lower animals.

The hyo-epiglottic ligament [lig. hyoepiglotticum] (figs. 978, 981) connects the anterior surface of the epiglottic cartilage with the superior margin of the body and the greater cornua of the hyoid. It is a broad sheet, lying above a mass of fat which stands between the median hyo-thyreoid membrane and the epiglottis and spreading laterally to join the pharyngeal aponeurosis in the region of the piriform recess.

The name glosso-epiglottic ligament is given to the elastic fibres extending between the root of the tongue and the epiglottis within the median glosso-epiglottic fold.

The corniculo-pharyngeal ligament (fig. 977) extends from the corniculate cartilage downward and toward the median line, attaching to the mucosa of the pharynx and joining its fellow behind the arytænoid muscle. From this point a single band, the crico-pharyngeal ligament [lig. cricopharyngeum], which may enclose a nodule of cartilage (the interarytænoid or procricoid cartilage), descends in the middle line, to be fixed to the cricoid lamina and into the pharyngeal mucosa.

The larynx and trachea are united by fibrous membrane, the crico-tracheal ligament [lig. cricotracheale] (figs. 974, 978), between the inferior margin of the cricoid cartilage and the upper margin of the first tracheal ring. Posteriorly the ligament is continued into the membranous wall of the trachea.

\section{MUSCLES OF THE LARYNX}

Of the many muscles connected with the larynx, two groups may be recognised, the members of one coming from neighbouring parts, fixing themselves to the larynx and acting upon the organ as a whole; the members of the other group confining themselves exclusively to the larynx and acting so as to affect its parts. The muscles composing the first group are described elsewhere. (See Section IV.) The muscles of the second group are composed of striated fibres and are supplied by the vagus nerve through its laryngeal branches. These muscles are all more or less under cover of the thyreoid cartilage, with one exception, the crico-thyreoid.

The crico-thyreoid muscles [m. cricothyreoideus] (fig. 980) are placed one on either side of the outer surface of the larynx in its lower part. Each muscle is partially separated into an anterior straight [pars recta] and a posterior oblique portion [pars obliqua], which together arise from the arch of the cricoid. The fibres of the straight part ascend steeply and are inserted into the inferior margin of the thyreoid cartilage. The oblique portion is inserted into the inferior cornu and into the lower margin and inner surface of the thyreoid cartilage.

The straight part elevates the arch of the cricoid, causing the lamina, and with it the arytænoid cartilages, to sink, while the oblique part draws forward the thyreoid; thus the vocal ligaments are made tense. The musele is supplied by the external branch of the superior laryngeal nerve. A connexion between the posterior part of this muscle and the inferior constrictor of the pharynx and their common nerve-supply indicate their genetic relationship.

The posterior crico-arytænoid muscle [m. cricoarytænoideus posterior] (figs. $980,981,982$ ), paired, is situated at the back of the larynx, covered by the submucous coat of the pharynx. It is a thick, triangular mass which takes origin from the posterior surface of the cricoid lamina, the two muscles being well separated by the median crest of the cartilage. The lower fibres ascend and the upper ones pass horizontally lateralward and are inserted into the muscular process of the arytenoid cartilage on its posterior surface and tip.

When these muscles contract, the muscular processes of the arytanoids are pulled backward and dowriwarl, while the vocal proesses travel lateralward and a little upward, so that the rima glottirlis is widened and the vocal ligaments made tense (fig. 982). The innervation is liy the posterior branch of the inferior laryngeal nerve.

In other nareosis the flilator muscle is later paralyzed and afterward earlier restored than the constrintors of the larynx.

At the lower markin of this muscle a small slip, the cerato-cricoid muscle [1n. ccratocricoirleus], is sometimes found, extending between the lamina of the ericoid and the inferior cornu of the thyreoid cartilage.

The constrictor laryngis. - Whereas the crico-arytanoideus posterior is a dilator of the larynx, the soveral muscles now to be considered are in the main con- 
strictors. They form a ring, the constrictor laryngis, around the laryngeal cavity, interrupted, however, by the cartilages. In the larynx of amphibia and reptiles a complete sphincter guards the entrance to the air-passages.

The following muscles are included in the constrictor group:-

The transverse arytænoid muscle [m. arytænoideus transversus] (figs. 981) 983, 985) is a single muscle of quadrilateral form, extending across the middle line from the posterior concave surface of one arytanoid cartilage to that of the other. Its anterior surface, between the cartilages, is covered by the laryngeal mucosa; its posterior surface, crossed by the arytænoideus obliquus, is clothed by the submucous coat of the pharynx.

The arytænoideus transversus approximates the arytænoid cartilages and their vocal processes, which are at the same time elevated, and the vocal ligaments made tense. It is supphed by the posterior branch of the inferior laryngeal nerve.

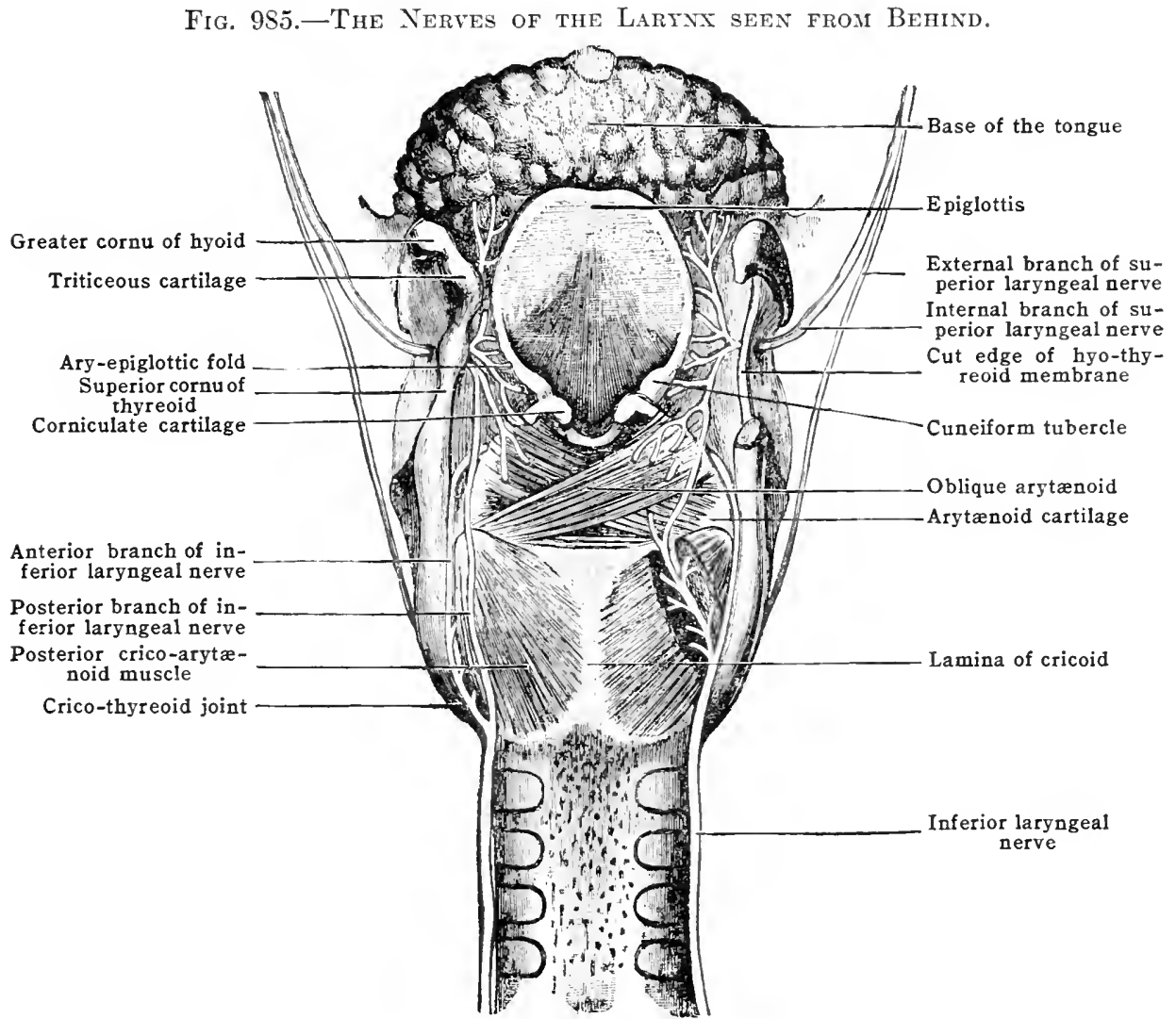

The lateral crico-arytænoid muscle [m. cricoarytænoideus lateralis] (fig. 981) arises from the upper margin and outer surface of the cricoid arch and from the elastic cone, whence the fibres extend backward and upward to an insertion on the anterior surface of the muscular process of the arytrenoid cartilage. This muscle is inseparable from the thyreo-arytænoideus in about half the cases.

The lateral cricoarytænoids by their contraction cause the vocal processes to move toward the median line and a little downward, so that the vocal ligaments are approximated and slightly stretched. They antagonise the posterior crico-arytænoids. The anterior branch of the inferior laryngeal nerve supplies these muscies.

The external thyreo-arytænoid muscle [m. thyreoarytænoideus (externus)] (figs. 981, 984, 988), variable in form and in the disposition of its fibres, is closely connected with the preceding. It lies under cover of the thyreoid lamina lateral to the laryngeal saccule (ventricular appendix) and elastic cone. Arising within the angle of the thyreoid laminæ the muscle extends upward and backward to its insertion on the lateral margin of the arytænoid cartilage. 
It draws forward the arytrenoid cartilage (and also tilts the cricoid), and rotates it so that the vocal process passes medialward and downwarl, relaxing the vocal ligament. It is the antagonist of the crico-thyreoid (fig. 954). Its nerve-supply is the anterior branch of the inferior laryngeal.

The vocal muscle [m. vocalis], (fig. 988), prismatic in form, is the inner constant part of the thyreo-arytienoideus. It lies in the vocal lip lateral to the vocal ligament. Its fibres run from their origin in the angle of the thyreoid laminæ to their insertion in the vocal process and oblong fovea of the arytænoid cartilage.

It draws forward the vocal process, relaxing the vocal ligament. Its nerve comes from the anterior branch of the inferior laryngeal.

The insertion of certain fibres of this muscle into the elastic vocal ligament has been observed (ary-vocalis muscle of Ludwig). D. Lewis has shown that some of the elastic fibres in the vocal ligament are derived from the perimysium of the vocal muscle.

The ventricular muscle [m. ventricularis] consists of a few fibres derived from the thyreoarytanoideus which reach the back of the laryngeal saccule and enter the ventricular fold. The small thyreo-arytanoideus superior extends from the angle of the thyreoid to the muscular process of the arytanoid upon the lateral surface of the main muscle.

The oblique arytænoid muscle [m. arytænoideus obliquus] is a slender band lying at the back of the larynx and under the pharyngeal submucosa. It arises from the muscular process of the arytænoid posteriorly, and, ascending obliquely, crosses its fellow in the median line. Some fibres are inserted into the apex of the opposite arytænoid cartilage; other fibres sweep around the apex and accompany the thyreo-arytanoid to an insertion in the angle of the thyreoid cartilage, constituting the thyreo-arytanoideus obliquus.

This muscle contracts the laryngeal apcrture and vestibule of the larynx. Its nerve is derived from the anterior branch of the inferior laryngeal.

Closely connected with the thyreo-arytanoideus is a bundle of fibres of fairly regular occurrence, called the thyreo-epiglottic muscle [m. thyreoepiglotticus] (fig. 981). It originates from the inner surface of the thyreoid lamina and procerds upward and backward to end in the quadrangular membrane and to become attached to the lateral border of the epiglottis.

The ary-membranosus and ary-epiglottic muscles are inconstant fascicles of the constrictor group which rum in the ary-epiglottic fold and become fixed into the quadrangular membrane and margin of the epiglottic cartilage.

\section{Summary of the Actions of the Laryngeal Muscles}

According to their actions, the laryngeal muscles may be divided into- $(a)$ those which effect the tension of the vocal folds; (b) those which control the rima glottidis; $(c)$ those which effect the closure of the laryugeal aperture and vestibule.

(a) The voral ligaments are male tense by the action of the crico-thyreoid, the lateral and posterior clicoarytanoid and the transverse arytamoid muscles. T'he vocal ligaments are relaxed as the result of the action of the external thyren-arytanoid and voeal muscles.

(b) The rima glotidis is widened by the crico-arytanoidems posterior and made narrow by the contrantion of the arytanoids. 'The erien-arytimoidens lateralis also assists in elosing the rimal ghetidis by rotating the vocal proeesses medialward, and if the erieo-arytienoideus postrerior contracts simultanemely, it aids in the closure. The vocal ligaments are approximatrol also by the thyreo-atrytanoders [extermus].

(c) 'Thre larynge:al apelute and vestibule are closed mainly by the arytanoideus transversus and thyme-arytanoideus (externus), by which the arytanoid antilages are brought into apposition and drawn toward the epighotis. ()ther nuscles derived from the constrictor group,

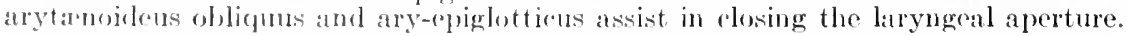

\section{('AVITY OF THE HARTX AND IARYNGEAL MUCOSA}

The cavity of the larynx [aivum laryngis] is relatively narrow and does not correspont in shape with the onter sulface of the orwan. Its form is shown in fig. asti taken from a cast of the laryngeal cavity and the spaces continuous with i1. Its walls are covered lhroughoul by the mucous membrane of the larynx (figs. 987,988$)$.

The muesea of the laryax is continuous above with the mucous membrane

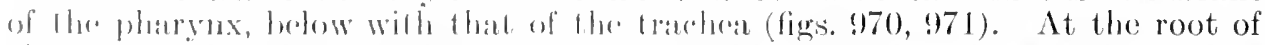

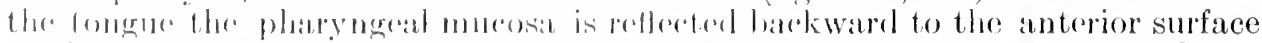
of the "pightolis, pmsenting the median and lateral glosso-epiglottic folds [plica 
glosso epiglottica medianaet lateralis]. From the sides of the pharynx it passes medialward, first sinking between the thyreoid cartilage laterally and the arytænoid and cricoid medially, entering into the walls of the piriform recess; then passing over the superior margin of the quadrangular membrane to form the aryepiglottic fold.

At the medial side of the piriform recess a slight fold of the mucosa [plica nervi laryngei) corresponds to the superior laryngeal nerve. Between the root of the tongue and the epiglottis is a depression subdivided in the middle line and limited laterally by the median and lateral

Fig. 986.-Cast of the Vestibulum and Cayum Oris, of the Pharynx, Larinx, of the Upper Part of the Trachea and Cesophagus. Seen from in front and below. (RauberKopsch.)

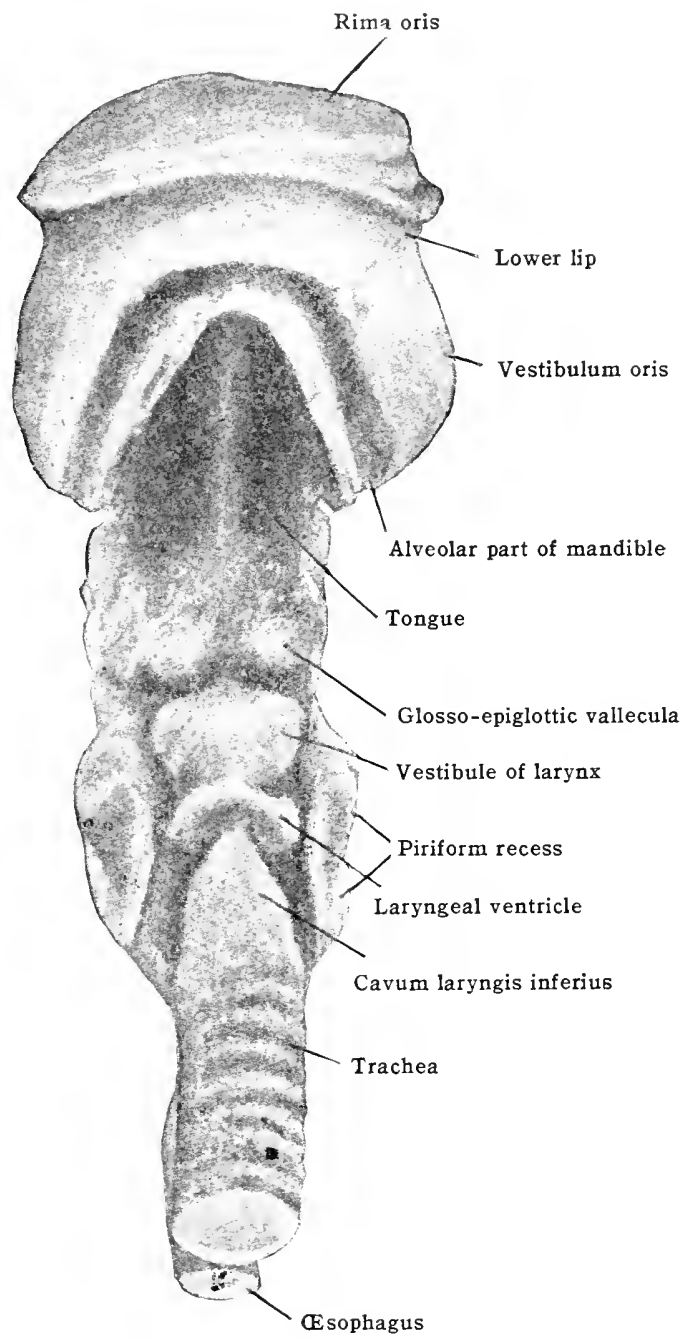

glosso-epiglottic folds; this is the epiglottic vallecula [vallecula epiglottica]. The piriform recess and the epiglottic vallecula are favorite sites for the lodgment of foreign bodies. The ary-epiglottic fold [plica aryepiglottica] extends from the side of the epiglottis to the apex of the arytrnoid cartilage; within it are fibres of the ary-epiglottic and thyreo-epiglottic muscles and the cuneiform and corniculate cartilages. Thesc cartilages correspond to two rounded eminences on each side of the laryngeal entrance, the cuneiform and corniculate tubercles [tuberculum cuneiforme (Wrisbergi); tuberculum corniculatum (Santorini)], respectively. Of these, the former is often small and inconspicuous, the latter usually well developed and prominent.

The cavity of the larynx above the level of the ventricular folds is known as the vestibule [vestibulum laryngis]. This is wide in its upper part, but the sides incline toward the median line in descending, and the cavity becomes narrow 
transversely in approaching the region of the glottis. Here the cavity has received the special name, superior entrance to the glottis [aditus glottidis superior]. The parts of the framework of the larynx which enter into the walls of the vestibule are: in front, the epiglottic and thyreoid cartilages with the thyreo-epiglottic ligament; at the side, the quadrangular membrane, the cuneiform and corniculate cartilages, and the medial surface of the arytænoid cartilage; behind, the anterior surface of the transverse arytænoid muscle. The vestibule communicates with the pharynx by the laryngeal aperture [aditus laryngis] (figs. 970, 971, 972, 987), which looks upward and backward. The form of the aperture is oval or triangular, with the base in front; here it is bounded by the epiglottis; laterally by the aryepiglottic fold of the mucosa. Posteriorly the laryngeal aperture is prolonged as a little notch between the corniculate cartilages and the apices of the arytrenoids [incisura interarytænoidea] limited behind by a commissure of the mucosa.

The high anterior wall of the vestibule presents a marked convexity, the tubercle of the epiglottis [tuberculum epiglotticum], over the thyreo-epiglottic ligament. The lateral walls,

Fig. 9S7.-Miedian Section of the Larynx. (Merkel.)

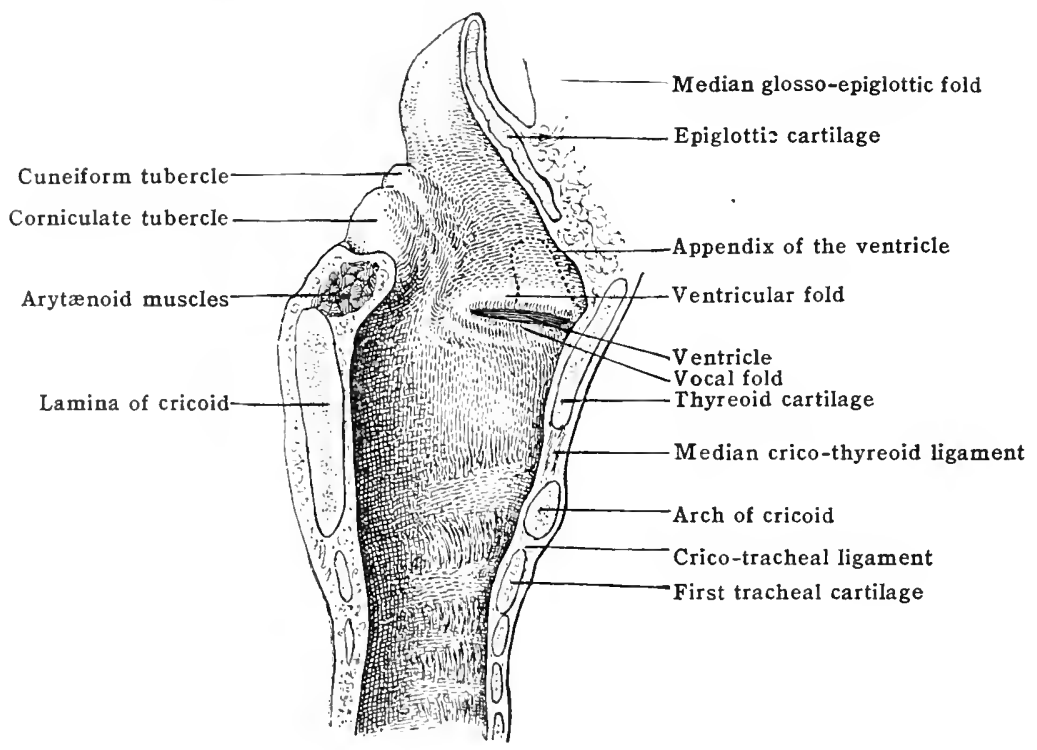

higher in front than behind, show two slight ridges, separated by a shallow groove, extending downward from the cuneiform and corniculate tubercles. The posterior wall, very low, corresponds to the commissure connecting the arytænoid cartilages.

On either sirle of the vestibule, toward its inferior end, is the sagittally running ventricular fold [plica ventricularis] (false vocal cord) (figs. 970, 971, 987, 988). This appears as an clevation of the mucous coat of the lateral wall, prominent in its middle and anteriorly, farling away posteriorly. The ventricular fold contains the inferior free edge of the quaulrangular membrane, that is, the ventricular ligament, and numerous glands.

Wylie's experiments with the ventrienlar folds led him to conchde that the closure of the glottis in defecation and vomiting is mainly effected by the apposition of these folds. (Quain.)

The interval between the right and left ventricular folds, the vestibular slit [rima vestibuli] leads (lownward to a sijace between the planes of the ventricular and vocial folds, which extends on careh side into the laryngeal ventricle [ventriculus laryngis (Morgagni*)] (figs. 970, 971, 987,988). 'The latter is a little anteroposterior pocket of the mucosit reaching from the level of the arytanoid nearly to the angle of the thyreoid cartilige, and undernining the ventricular fold; it opens into the cavity of the larynx by a narrow mouth limited above and below by the ventricular and vocal folds. from its anterior part a small diverticulum,

* Morgagni. Italian anatomist. B. 1682, D. 1771. 
the ventricular appendix [appendix ventriculi laryngis] extends upward between the ventricular fold medially and the thyreo-arytanoid muscle and thyreoid cartilage laterally. Many mucous glands open into it.

The appendix is occasionally so large as to reach the level of the upper margin of the thyreoid cartilage or even the great cornu of the hyoid bone. The laryngeal pouches of some of the apes are remarkably developed and appear to serve in affecting the resonance of the roice. In man, their function, besides that of pouring out the secretion of the glands located within their walls, is not known.

The vocal fold [plica vocalis] (or true vocal cord) (figs. 970, 971, 987, 988) is the thin edge of a full, lip-like projection, the vocal lip. The vocal folds correspond in antero-posterior extent to the rocal ligament, and stand nearer the median line than the ventricular fold. In colour the vocal folds are pearly white, excepting the anterior end of each, where there is a yellow spot [macula flava] produced by a little mass of elastic tissue (sometimes cartilage) in the ligament, The vocal lip [labium vocale] forms the floor of the ventricle and contains the upper part of the elastic cone, whose thickened free edge, the vocal ligament, lies in the

Fig. 988.-Frontal Section of a Larynx Hardened in Alcohol. A. Posterior segment. B. Anterior segment. (Poirier and Charpy.)
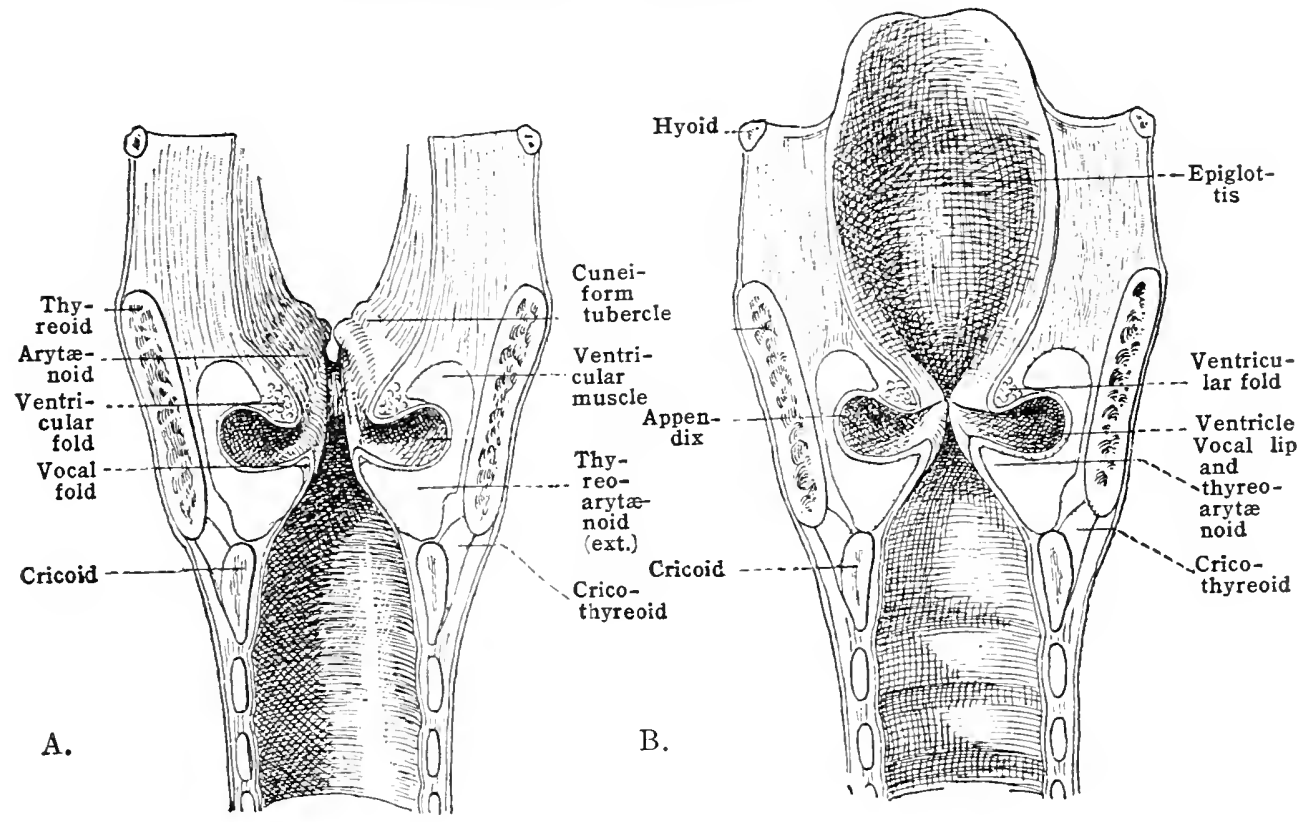

vocal fold and along the vocal muscle. The two vocal lips with the vocal folds and the intervening space, the rima glottidis, together constitute the soundproducing apparatus, the glottis.

Below the vocal folds and the medial surfaces of the arytænoid cartilages is a slit, the rima glottidis (figs. 970,971,988), the narrowest part of the laryngeal cavity, extending from the arytænoideus transversus muscle posteriorly to the thyreoid cartilage in front. The portion of the rima between the vocal folds is known as the pars intermembranacea; that between the arytænoids the pars intercartilaginea. The rima glottidis in easy respiration is narrow and has the form of a long triangle; in laboured breathing it is widlely open and lozenge-shaped.

Below the level of the vocal folds is the space called the inferior entrance to the glottis [aditus glottidis inferior] (fig. 988), which is narrow from side to side above, wide and circular in section below-altogether somewhat funnel-shaped. Its walls are formed by the elastic cone and by the arch and lamina of the cricoid cartilage. The lining mucosa is separated from the elastic cone by numerous glands and loose connective tissue, a condition favorable to the development of œdema; below it is continuous with the mucosa of the trachea.

By means of the laryngoscope a more or less complete picture of the laryngeal aperture and the cavity of the larynx can be obtained (figs. 970,971). There appear, highest up, the 
root of the tongue with the epiglottic ralleculie and glosso-epiglottic folds leading backward to the epiglottis; behind the latter, the triangular aperture of the Iarynx, bounded at the sides by the ary-epiglottic folds. Further lateralward appear the piriform recesses, the laryngeal portions of which lie as transverse fissures behind the laryngeal aperture. Within the aryepiglottic folds are seen the prominent corniculate tubercles on either side of the interarytænoid commissure and just anterior, the variable cuneiform tubercles. Within the vestibule the epiglottic tubercle rises upon the anterior wall, while at the sides appear the ventricular folds overhanging the slit-like openings of the laryngeal ventricles. Below this level the vocal folds stand out on either side approaching nearer the median plane than do the ventricular folds and conspicuous by their pearly whiteness. The form and extent of the rima glottidis and of its divisions, the intermembranous and intercartilaginous parts, can be inspected. Far down, the cricoid cartilage and anterior wall of the trachea may appear and under favourable conditions a glimpse of the bifurcation of the latter can be obtained.

The mucous coat of the larynx [tunica mucosa laryngis] in general is covered by a ciliated epithelium; the rocal lips, and, exceptionally, small areas of the mucosa of the laryngeal surface of the epiglottis and the ventricular folds possess a covering of flat, non-ciliated cells. The attachment of the mucosa to the underlying parts is very firm about the vocal folds and dorsal side of the epiglottis, and loose in the ary-epiglottic folds, where much areolar tissue is present. In general the mucosa is pink in colour, becoming bright rod over the epiglottic tubercle and edges of the epiglott is and fading over the vocal folds, which appear almost white.

Numerous mucous glands [glandulæe laryngee] occur about the larynx and are aggregated into gromps in certain places. One cluster of anterior glands [gl. Iarvngee anteriores] is found in front of and on the posterior side of the epiglottis; another, the middle glands [gl. laryngea media $x^{2}$. is in the ventricular fold, in the triangular fovea of the arytanoid cartilage and clustered about the cuneiform cartilage, while a third set, the posterior glands [gI. Iaryngea posteriores], is disposed about the transverse arytanoid muscle. Many glands pour their secretion into the appenctix of the laryngeal ventricle, but there are none on or about the vocal folds. Lymphnodules of the larynx [noduli lymphatici laryngei] occur in the mucosa of the ventricle and on the pusterior surface of the epiglottis.

Position and relations. - The larynx opens above into the pharyn by the aditu and in thiss region is connected with the hyoid bone. Below, its cavity leads into the trachea. Its position in the neck is indicated on the surface by the laryngeal prominence (Adam's apple). It stands in front of the fourth, fifth, sixth, and seventh cervical vertebre; from these it is separated by the prevertebral muscles and the pharynx, into the anterior wall of which it enters. The integument and cervical fascia cover the larvnx anteriorly in the middle line, while toward the side are the sterno-hyoid, sterno-thryeoid, and thyreo-hyoid muscles. The lateral lobe of the thrreoid gland and the inferior constrictor of the pharynx are in relation to it laterally, while further removed are the great vessels and nerves of the neck.

Peculiarities of age and sex. Position. - The larynx is placed high in the neck in fotal and infuntile life and descends in later life. In a six-months foctus the organ is two vertebræ higher than in the aclult. (Srmington.) The deseent of the larynx has been attriluted to the vertical growth of the facial part of the skull, but this cause is questioned by Cumningham, who points out the high position of the larymx in the anthropoid apes, where the facial growth is more striking than in man; it appears also that the larynx follows the thoracic viscera in their subsirlence, which, according to Mehnert, continues until old age. At birth the interval between the hyoid bone and thyreoid cartilage is relatively very small and increases but little during early life

Growth and form.- The larynx of the new-born is relatively large and in contour more rommled than that of the adult. The organ continues to grow until the third year, when a resting period begins, lasting until about twelve years of age, during which time there appears 10 lie no difference between the larynx of the male and that of the female. At puberty, while no marked change is ofservalble in the larvms of the female, rapid growth accompanied by modification of form of the larynx is initiated in the male. The laryngeal cavity is enlarged, the antoro-posterior diameter matkedly increased; the whole framework becomes stronger; the thyrooid cartilage especaally increases greatly in its dimensions, giving rise to the laryngeal prominence; the recal folls are lengthened and thickened, the voiec ehanging in quality and pitch. These changes are, for the most part, edfeeted in about two years, but complete development is not attained before twonty to twenty-five years of age. Castration is known to influrence the development of the larvin, for in the emumch it has heen foumd to resemble that of a yoming woman. 'The rhanges in the structure of the cartilages have alrealy been deseribed.

Dimensions. - In the male the distance from the mpyer edge of the epiglottis to the lower margin of the rriesid is $70 \mathrm{~mm}$; in the female, $48 \mathrm{~mm}$. The transverse diameter is $40 \mathrm{~mm}$. in the male, $3.5 \mathrm{~mm}$. in the female. The greatest sagital diameter is $40 \mathrm{~mm}$, in the male, 37 mon. in the fomale. 'The voral folds in the male moasure relaxed alout $15 \mathrm{~mm}$. in the fentale, bot $11 \mathrm{~mm}$; when stretched, about 20 mm. amel 15 mm. respertively.

The length of the rima glottidis in the quicesernt state is on the average $23 \mathrm{~mm}$. in the male; $17 \mathrm{~mm}$. in the female. In the male the pars intermembranacea measures $15.5 \mathrm{~mm}$., the pars infreatilaginea, 7.5 mm. In the female these are $11.5 \mathrm{~mm}$. and $5.5 \mathrm{~mm}$. respectivety. The rim: may les lengthened hy streterhing of the voral folds to $27.5 \mathrm{~mm}$. in the male and $20 \mathrm{~mm}$. in thre fomale. (Momme) In the male the wirlth of the rimal glottidis is $6-8$ mm. in its widest

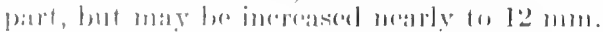

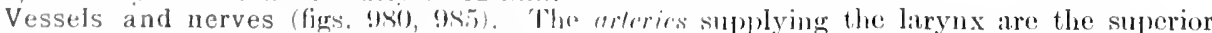

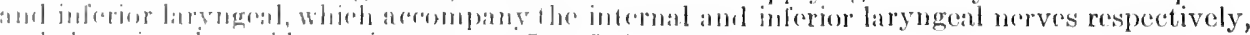

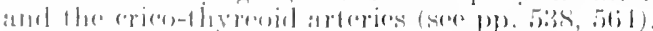

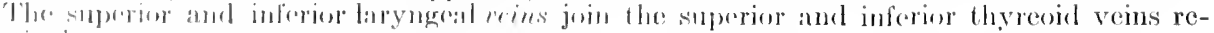

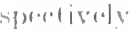

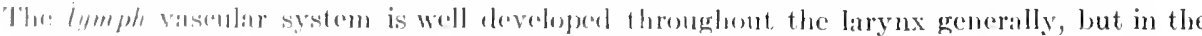


vocal folds where the mucosa is thin and tightly bound down the vessels are scarce and small in size (see p. 719 ).

The nerves of the larynx are the superior and inferior laryngeal branches of the vagus and also certain branches of the sympathetic. Taste-buds occur and are abundant in the mucosa of the posteriol surface of the epiglottis. The innervation of the muscles has already been indicated, and the description of the course and relations of these nerves will be found in the chapter on the Peripheral Nervous Systex. It should be mentioned here, however, that the idea of sharply limited territories of innervation, not only for the mucosa, but for the muscles as well, has been brought into question by the researches of Semon and Horsley, Exner, and others, which show that the distribution and functions of the laryngeal nerves are extremely complex.

The development of the larynx. - The larynx is developed partly from the lower portion of the embryonic pharynx and partly from the upper portion of the trachea. The cricoid cartilage represents the uppermost tracheal cartilage, while the thyreoid is formed by the fusion of four cartilages representing the ventral portions of the cartilages of the fourth and fifth branchial arches. The laryngeal muscles are derived from the musculature of these arches and consequently their nerve-supply is from the vagus. Whether or not the arytrenoid and epiglottic cartilages are also derivatives of the branchial arches is uncertain, although it seems probable that they are.

\section{THE TRACHEA AND BRONCHI}

The tubular trachea (figs. 972, 989), or windpipe, extends from the larynx downward through the neck and into the thorax to end by dividing into two branches, the right and left bronchi [bronchus (dexter et sinister)], which lead to

Fig. 989-Trachea and Bronchi in Their Relations to the Great Vessels as seen from Benind. (After Gegenbaur.)

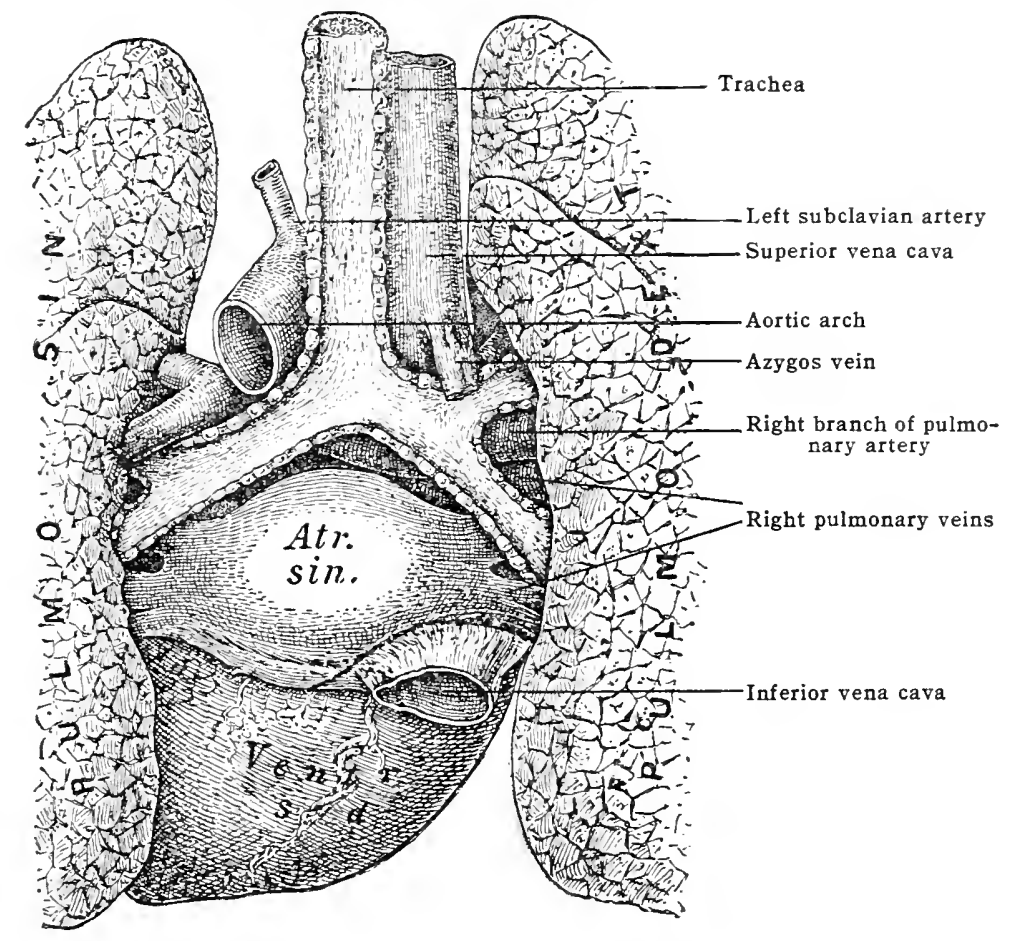

the lungs. These tubes are simple transmitters of the respiratory air. Their walls are, for the most part, stiff and elastic, consisting in large part of cartilage. While the general form of these tubes is cylindrical, a rounded contour is presented by their walls only in front and at the sides, the posterior surface being flat. The inner surface of the walls of the tubes presents a succession of slight annular projections caused by the cartilaginous rings which enter into their structure. The calibre of the trachea varies at different levels, a cast of the lumen being in general spindle-shaped. Its sectional area is less than the combined sectional areas of the two bronchi. When the bifurcation of the trachea [bifurcatio trache:e] is viewed by looking down into its carity, a sagitally directed keel, the carina tracheæ (fig. 990), is seen standing between the openings which lead into the bronchi. Its position is a little to the left of the mid-plane of the trachea in a slight majority of cases, or in the mid-plane in a large percentage. 
Position and relations (figs. 972, 989, 1000).- - The trachea lies in the median plane, extending from the level of the sixth cervical vertebra downward and backward, receding from the surface in following the curve of the vertebral column, and deviating a little to the right in approaching the level of the fourth thoracie vertebra, where it divides. Its lower end is fixed so that with elevation and descent of the larynx the tube is stretehed and contracted, changes in length which also result from extension and flexion of the head and neck. The mobility of the trachea is favored by its loose investment of connective tissue.

About half of the trachea lies in the neck, but the extent varies with the length of the neck, the position of the head and with age; the trachea holds a lower position in adult life than in childhood and a still lower one in old age when the bifureation may be as low as the sixth or seventh thoracic vertebra. In front and closely connected with it is the isthmus of the thyreoid gland, covering usually the second to fourth cartilages; anterior to this the cervical fascia and integuments. The cervical aponeurosis is attached to the upper margin of the sternum in two lamellæ, with an interspace containing the venous jugular arch, a lymph gland, and some fat. Between these aponeuroses and the trachea is another space containing the inferior thyreoid veins and some tracheal lymph-glands, and sometimes a thyreoidea ima artery. The innominate artery occasionally crosses the trachea obliquely in the root of the neck. Behind the trachea, in its whole length, lies the cesophagus, which in this part of its course inclines to the left. On either side are the great vessels and nerves of the neck, and the lobes of the thyreoid gland. The inferior laryngeal nerve lies in the angle between the œsophagus and trachea.

Fig. 990.--Bifurcation of the Trachea showing the Tracheal Keel. R. L. Right and left bronchi. (Heller and von Schroetter, from Poirier and Charpy.)

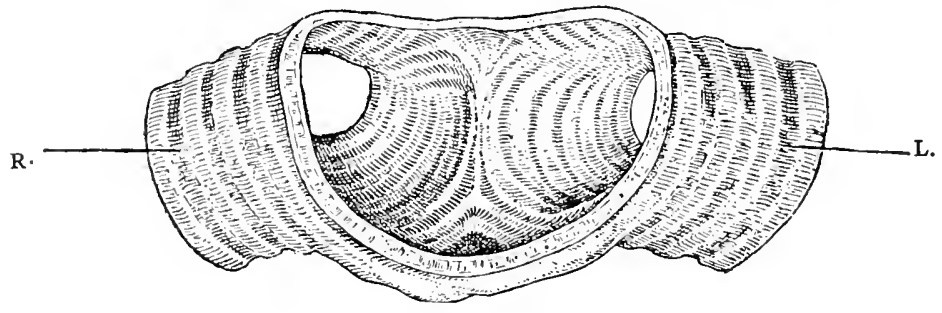

Within the thorax the trachea lies in the mediastinum, enveloped in loose areolar tissue and fixed through strong fibrous connections with the central tendon of the diaphragm. The innominate artery and the left common carotid are at first in front and then at its sides as they ascend, while the left innominate vein and the remains of the thymus are further forward. The aortic arch is in contact with the anterior surface of the trachea near the bifurcation. On the right side are the vagus nerve, the arch of the vena azygos, the superior vena cava, and the mediastinal pleura; on the left, the arch of the aorta, the left subclavian artery, and the recurrent laryngeal nerve. A large group of bronchial lymph-glands [lymphoglandule bronchiales] lies below the angle of bifureation. The asophagus is behind and to the left.

The bronchi take an oblique course to the hilus of the lung, where they branch. The right bronchus is nearer to the vertical in its course than is the left; it is also shorter and broader. These eonditions, together with the position of the tracheal keel, explain the more frequent entrance of foreign bodies into the right than into the left bronchus. The asymmetrical course of the two bronchi is probatbly genetically associated with the position of the heart and aorta.

The azygos vein arches over the right bronchus, the vagus passes behind, and the right branch of the pulmonary artery crosses anteriorly below the level of the first (eparterial) branch of the bronchus. The aurta arches over the left bronchus and gains its posterior surface along with the ersophagus; the left branch of the pulmonary artery passes at first in front and then alove the bronchus.

Dimensions. - On account of their elasticity considerable difficulty is met with in obtaining aceurate measurements of the air-tubes. The length of the trachea is given at 95-122 $\mathrm{mm}$.; its transverse dianeter $20-27 \mathrm{~mm}$; the sugittal dianeter $16-20 \mathrm{~mm}$. The right bronchus has a length of $25-34 \mathrm{~mm}$; the lof $\mathrm{t}, 41-17 \mathrm{~mm}$. The transverse dianeter of the right is $18 \mathrm{~mm}$.; of the loft, $16 \mathrm{~mm}$. The angle of bifuration of the trachea varies from $56^{\circ}$ to $90^{\circ}$, the mean being $70.4^{\circ}$ a wirte angle corresumding to the breadth of the thorax of man. The right bronchus nakes an angle of $2.4 .8^{\circ}$ with the median plane; the left, $45.6^{\circ}$.

Acoording to 'Tillanx the length of that portion of the trachea between the superior edge of the strmum and the ericoill cartilage varjos with age and sex as follows:--

Adult male,

Arbult fromale,

boys "s to 10 yegro "

(iirls $3 \frac{1}{2}$ to $10_{\frac{1}{2}}$ " " 4 to $6.5 \mathrm{~cm}$. average, $6.5 \mathrm{~cm}$

$6.4 \mathrm{em}$.

$4.4 \mathrm{~cm}$.

$5.1 \mathrm{~cm}$. 
The diameter of the lumen of the trachea when distended to a cylindrical form has been measured by Sée:-

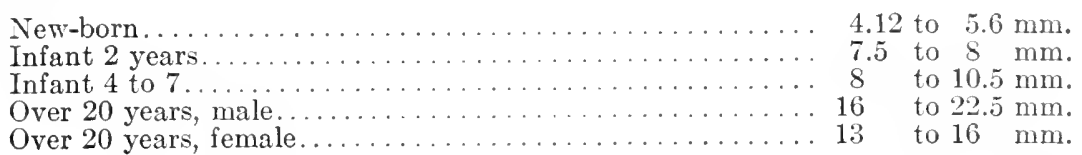

Structure of the trachea and bronchi (figs. 978, 988, 989, 991).-The walls of the trachea and bronchi are composed of a series of cartilages having the form of incomplete rings, held together and enclosed by a strong and elastic fibrous membrane. Posteriorly, where the rings are deficient, this membrane remains as the membranous wall [paries membranacea]; between the cartilages it constitutes the annular ligaments [ligg. annularia (trachealia)].

Fig. 991.-Schematic Longitudinal Section of the Wall of the Trachea. (Gegenbaur.)

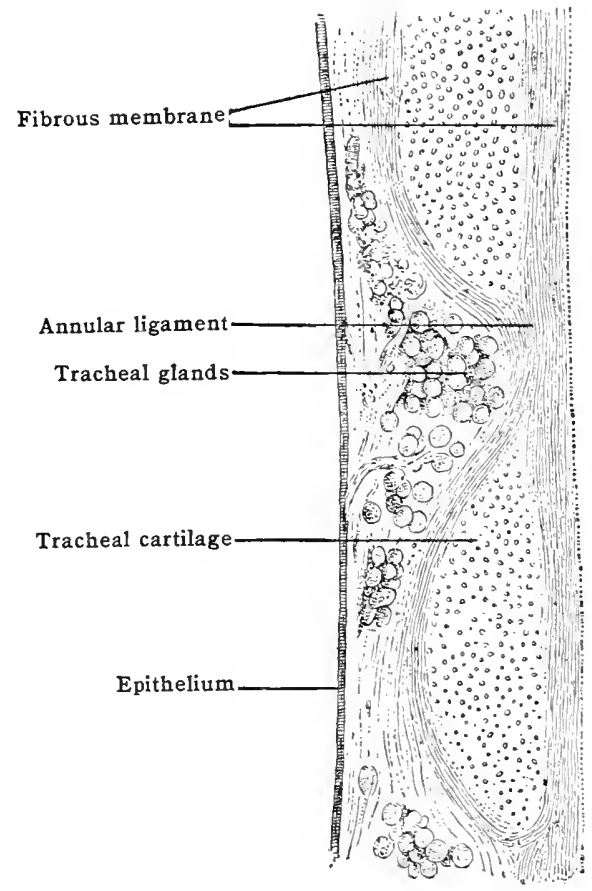

A tracheal cartilage [cartilago trachealis] comprises a little more than twothirds of a circle. Its ends are rounded, its outer surface flat, while the inner surface is convex from above downward; the upper and lower margins are nearly parallel. The cartilages are from sixteen to twenty in number. The first is usually broader than the type, and is connected by the crico-tracheal ligament with the cricoid cartilage. Sometimes these two cartilages are in part continuous. The last cartilage is adapted to the bifurcation of the trachea and presents at the middle of its lower margin a hook-like process. This turns backward between the origins of the bronchi, and in the majority of cases gives a cartilaginous basis to the tracheal carina. Some of the tracheal cartilages vary from the type by bifurcating at one end. The cartilages keep the lumen of the trachea patent for the free passage of the air. Calcification occurs as with the laryngeal cartilages, but much later in life.

A mucous coat [tunica mucosa], soft and pinkish-white in colour, covers the inner surface of the trachea; posteriorly it is thrown into longitudinal folds. Mucous secreting tracheal glands [gl. tracheales] are present in the elastic submucous coat [tela submucosa] between the cartilages and at the back of the trachea. A thin layer of transversely disposed smooth muscle-fibres, stretching between the ends of the cartilages in the posterior wall, constitutes the muscular 
coat [tunica muscularis]. Contraction of this trachealis muscle, as it is more properly named, causes the ends of the tracheal cartilages to be approximated and the lumen of the wind-pipe to be climinished.

The structure of the walls of the bronchi is similar to that of the trachea. The right bronchus possesses six to eight cartilages; the left, nine to twelve.

An inconstant broncho-asophageal muscle may connect the back of the left bronchus with the gullet.

Vessels and nerves. - The arteries supplying these air-tubes come from the inferior thyreoid and from the internal nammary by its anterior mediastinal or bronchial branches. Venous radieles come together in the annular ligaments and join lateral veins on either side, which empty the blood into the plexuses of the neighbouring thyreoid veins.

Lymph-ressels are abundant, and are disposed in two sets, one in the mucosa, another in the submucosa. They drain into the tracheal, bronchial and oesophageal lymph-glands. Neres are provided by the vagus direct, by the inferior laryngeal, and by the sympathetic.

\section{THE LUNGS}

The lungs [pulnones], the essential organs of respiration, are constructed in such it way as to permit the blood to come into close relation with the air (fig. 992). Their genetic connection with the entodermal canal has already been indieated (see also p. 1099). In plan of structure the lung has been compared with

Fig. 992.-Schematic Section of a Lobule of the Lung showing the Relation of the Blood-ressels to THE Air-spaces. (After Miller, from the 'Reference Handbook of the Medical sciences.')

b.r. Respiratory hronchiole. d.al. Alveolar duct; a second alveolar duct is shown cut off. a,a. Atria s.al. Alveolar saccule. a.p. Alveolus. art. Pulmonary artery with its branches to the atria and salcules. $v$. Pulmonary vein with its tributaries from the pleura (1), the alveolar duet (2), and the place where the respiratory bronchiole divides into the two alveolar ducts $(3)$.

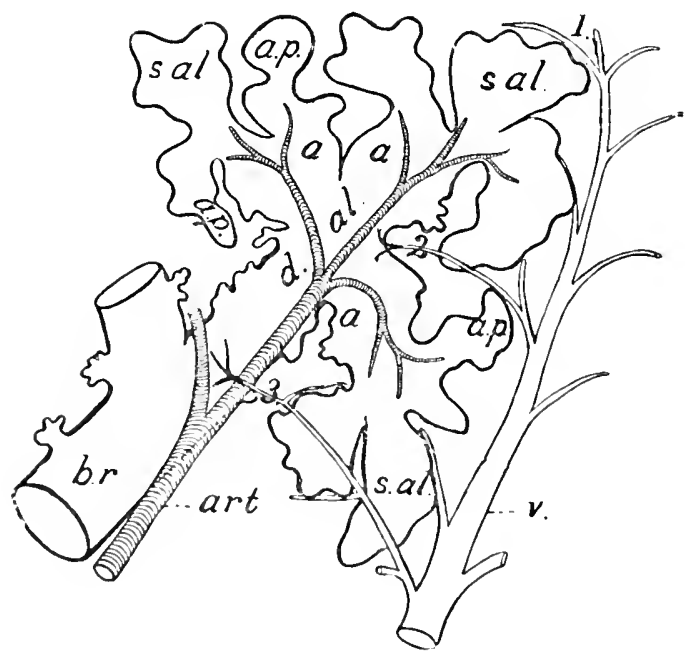

a glamel, since it is composed of a trec-like system of tubes terminating in expanded spares. ('lesely associated with the system of tubes are certain blood-vessels, some of which take part in nomishing the organ, others participate in its special mechanism.

The longs are two in mumber, and lie one on either side of the thoracic eavity, scparated by a partition know'1 as the mediastinum (figs. 9993, 997, 1000). Serous mentranes covering the latter right and left are parts of two closed saes, the

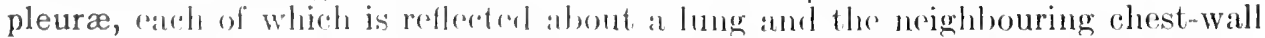
after the mamner of serous membrames in general. 'The space enclosed within the sar-walls is the pleural cavity, genofically a sulvelivision of the colom.

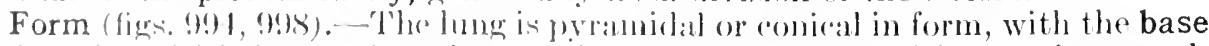
[hasis pulmonis| below and restimg on thr diaphragn, and with apex fapex pul-

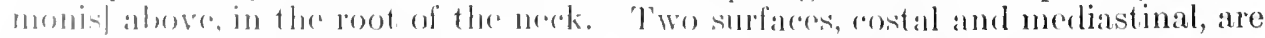
destriluel. The houd comvex costal surface [facies costalis] is directed against 
the thoracic wall in front, laterally and behind, and is marked by groores corresponding to the ribs. The mediastinal surface [facies mediastinalis] is concave and presents a contour adapted to structures of the mediastinum (fig. 994). A special concavity on this surface, known as the cardiac fossa. corresponds to the prominence of the heart and is deeper in the left lung than in the right. Above and behind the cardiac fossa is a depression, the hilus of the lung [hilus pulmonis], where the bronchus and pulmonary ressels and nerves together constituting the root of the lung [radix pulmonis], enter and leave. Near the posterior edge of the mediastinal surface is a groove, which ascends and turns forward over the hilus: the groove of the left lung is adapted to the cylindrical surface of the aorta: that of the right, the vena azygos. A well-marked subclavian sulcus [sulcus sub-

Fig. 993.-Horizontal Section of the Thorax of a Max, aged Fifty-sevex, at the Level of the Roots of the Lungs, seer fron Above. (J. S.) (Quain.) $\times 1$.

A.A. Ascending aorta. A.M. Anterior mediastinum. A.T. Azygos vein. D.A. Descending aorta. E. Eparterial bronchus. I. Superior lobe of lung. L.B. Left bronchus. L.P. Left phrenic. L.P.T. Left pulmonary vein. L.V. Left ragus. CEs. (Esophagus. PA. Pulmonary artery. P.C. Pericardial cavity. R.B. Right bronchus. R.P.A. Right branch of pulmonary artery. R.P.C. Right pleural eavity. R.P.N. Right phrenic. R.P.V. Right pulmonary vein. R.V. Right vagus. S. Inferior lobe of lung. se. Scapula. T.D. Thoracic duct. 3, 4, 5, 6, 7. Corresponding ribs.

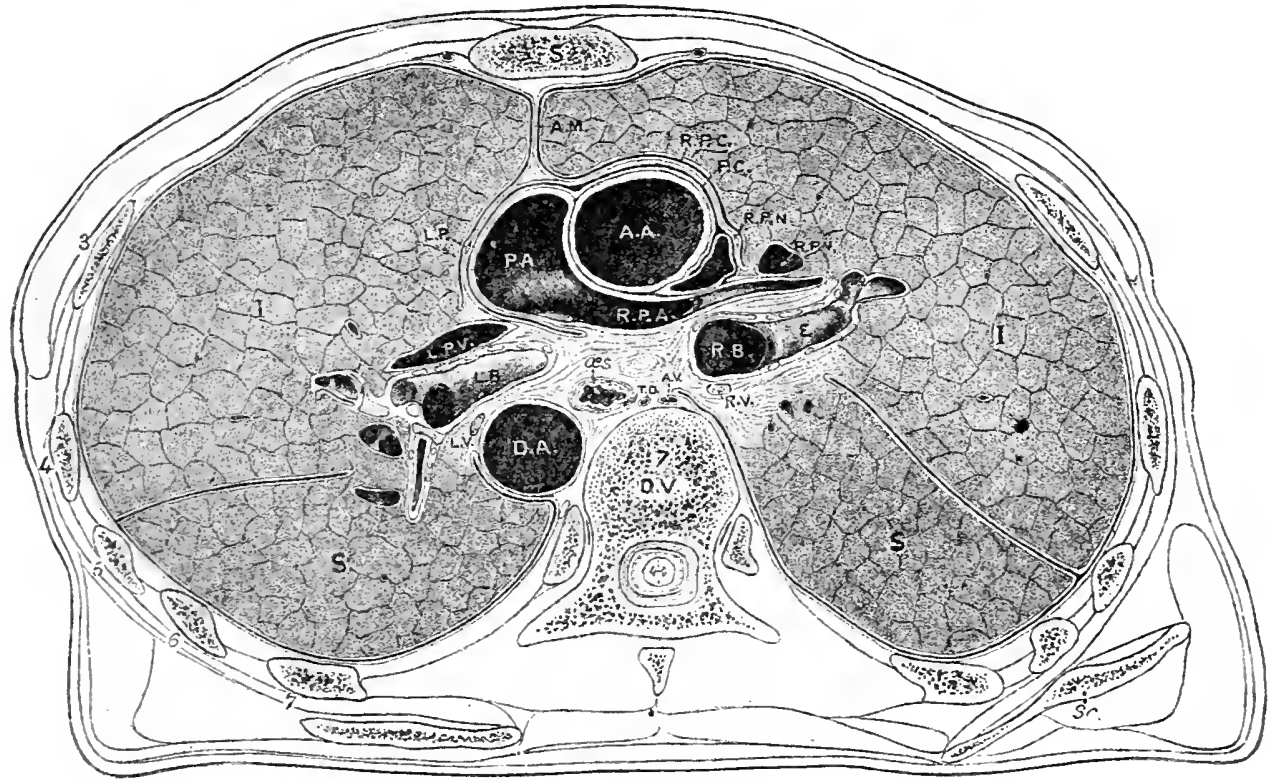

clavius] extends upward on this surface to the apex, corresponding on the right side to the lower part of the trachea and right subclavian artery, on the left to the left subclavian artery alone. Further forward is a groove adapted in the right lung to the superior cara; in the left to the left innominate vein. The lung is not in actual contact with these several structures, but is separated from them by the mediastinal pleura. The mediastinal surface passes gradually into the costal surface posteriorly, there being no proper posterior edge. Where the mediastinal and costal surfaces meet in front, a sharp anterior margin [margo anterior] exists (fig. 997). In the right lung this runs down in a gentle curve to turn lateralward in the inferior margin. In the left lung the anterior margin is cut into by a wicle cardiac notch [incisura cardiaca], which is occupied by the healt in the perieardium as it is pressed toward the anterior thoracic wall. The cardiac notch is separated from the inferior margin by a little tongue of lung substance, the pulmonary lingula [lingula pulmonis].

The base of the lung (fig. 994) presents the diaphragmatic surface [facies diaphragmatica] concave and oblique in adaptation to the dome of the diaphragm. It is limited by a sharp inferior margin [margo inferior], which follows the curves of the mediastinal and costal surfaces, and fits into the angle between the diaphragm and thoracic wall. 
The apex (figs. 994, 997, 998) is rounded and points upward with an inclination forward and medially, accommodating itself to the structures within and about the superior aperture of the thorax.

A deep interlobar fissure [incisura interlobaris] (figs. 994, 998), reaching through the lung substance nearly to the hilus, divides each organ into a smaller superior lobe [lobus superior] and a larger inferior lobe [lobus inferior]. The interlobar fissure runs downward and forward beginning a short distance below the apex, and reaching the base near the anterior margin in the left lung, somewhat further back in the right lung. From the obliquity of the plane of the fissure it will be noticed that the inferior lobe reaches posteriorly to within a short distance of the apex, and includes the greater part of the back and base of the lung, while the superior lobe takes in the anterior margin and apex. The presence of a middle lobe [lobus medius] disturbs the symmetry of the right lung. This results from a deep, nearly horizontal incisure cutting through the lung somewhat below its middle, and extending between the anterior margin and the main interlobar fissure, which it reaches at about the level of the axillary line.

Fig. 994.-Left Lung, viewed from the Mediastinal Surface. (Spalteholz.)

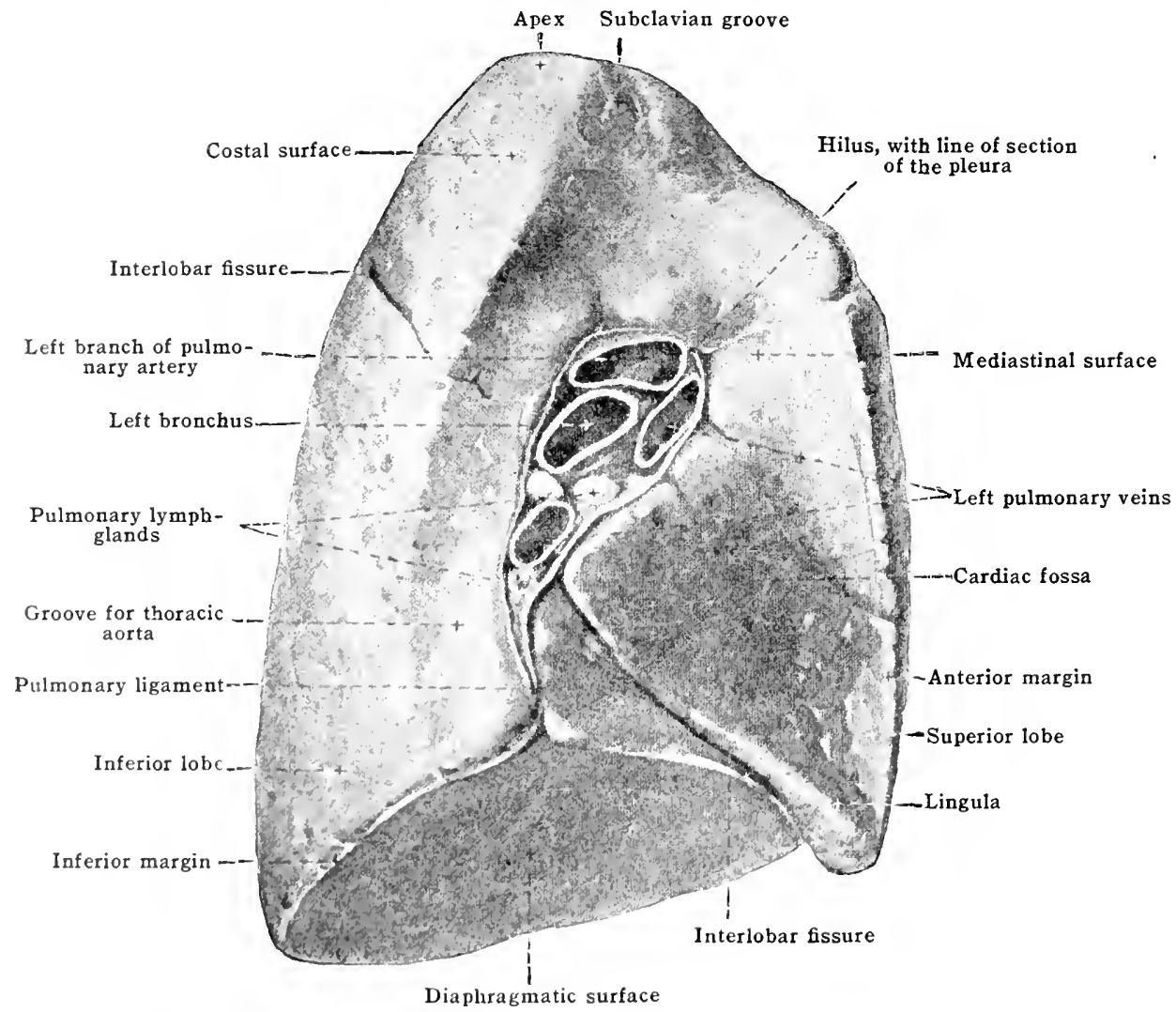

Besides possessing the individual peculiaritjes mentioned, the two lungs further differ from each other in general form and weight, the right lung being considerably broader and heavier than the left. The difference in length main tained by some anatomists, even if it prove eonstant, must be slight and of lithle practical importance. These differences seem to follow the asymnetry of the vault of the diaphragm and the position of the heart.

jhe hilus (fig. 991), already mentioned as sitnated on the mediastinal surface, presents in the left lung a raquette-shaped ontline. Its average height is about $8.8 \mathrm{~cm}$. (Luschka); it extends over both lobes. The hilu of llae right lung, rather four-sided in outline and shorter than that of the loft, is rolated to tho thres lobes. The entering structures, constituting the

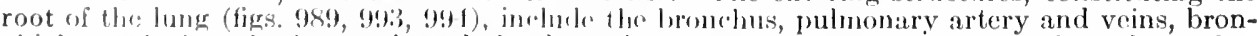
chial vessels, lymphatio vessels and glomls, and pulmonary nerves. These are bound together by conmective tistue and invested by the plema. The bronchus is in the posterior and upper part of the root; the puhmonary verisels lie anderionly, the veins below the arteries.

'The surfues of the long is marked off in polyenial arous of different sizes (secondary lobules) l,y limes montaning pigment. The pigmentation is especially deep on the lateral surface along the furrows corresponding to the ribs. 
Branching of the bronchial tubes (fig. 995). - Each bronchus, from its origin at the bifurcation of the trachea, takes an oblique course to the hilus, and then continues in the lung as a main tube, extending toward the posterior part of the base. These stem-bronchi are curved, probably in adaptation to the heart, the right like the letter $\mathbf{C}$ and the left like an $\mathbf{S}$. Throughout their course the stem-bronchi give off in monopodic fashion collateral branches, the bronchial rami [rami bronchiales], and these, branching in a similar way, reach all parts of the lung.

The first bronchial ramus of the right stem-bronchus arises above the place where the latter is crossed by the pulmonary artery and is named the eparterial bronchial ramus [ramus bronchialis eparterialis]; it supplies the superior lobe of the right lung, sending a special branch to the apex. All other bronchial rami, whether in the right or left lung, take origin from the

Fig. 995.-Cast of the Air-tubes and Their Branches, viewed fron in Front. (Spalteholz.)

Trachea (also the position of the median plane)

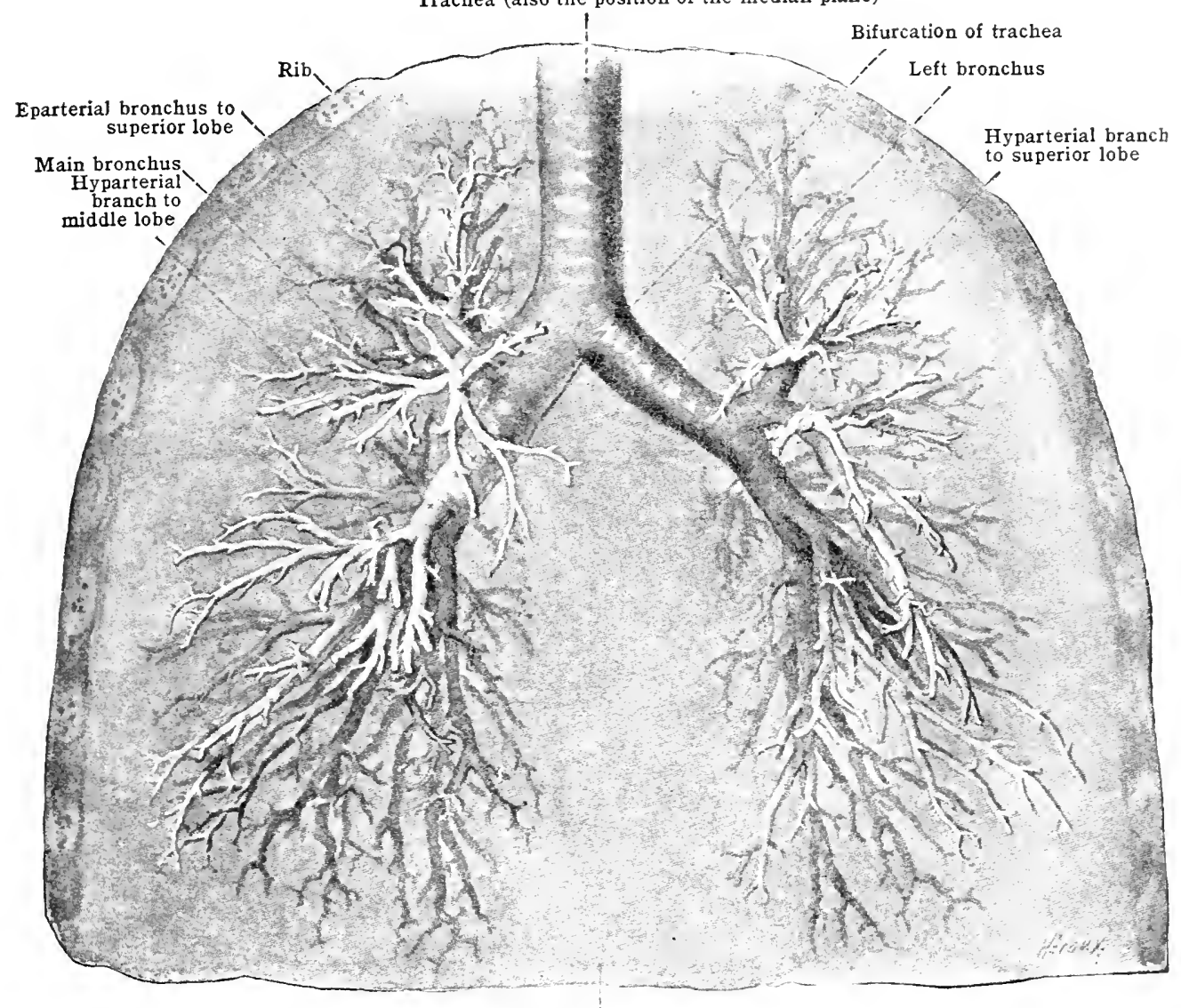

Position of median plane

stem-bronchi below the level of the crossing of the pulmonary artery and are called hyparterial bronchial rami [rami bronchiales hyparteriales]. The second bronchial branch of the right lung goes to supply the middle lobe, while several bronchial branches enter the inferior lobe. On the left side, the first bronchial branch arises below the crossing of the pulmonary artery, and goes to supply the superior lobe, providing it with an apical ramus. The other branches are given to the inferior lobe.

Structure of the bronchial rami.-The larger bronchial rami contain in their walls both C-shaped and irregular plates of cartilage, the latter gradually replacing the former as the branches become smaller. The membranous wall is lost and plates of cartilage are disposed on all sides. The mucosa, with ciliated epithelium, is thrown into longitudinal folds covering bundles of elastic fibres of the membrana propria. Next to the latter is a continuous layer of smooth muscle-fibres circularly arranged. Mucous secreting bronchial glands [gl. bronchiales] are present as far as tubes of $1 \mathrm{~mm}$. diameter; here the cartilages also disappear.

To W. S. Miller is due the credit of having greatly increased our knowledge of the finer structure of the lung and for having presented the conception of the primary lung lobule now generally accepted by anatomists. Some of the chief results of Miller's work are embodied in 
the following descriptions pertaining to the termination of the air-tubes and to the blood and lymph vascular systems of the lungs and pleura.

Through further branching of the bronchial rami a great number of very fine bronchioles [bronchioli] are reached, whose walls possess a weak nuscle layer and are lined by mucosa having an epithelium of flattened non-ciliated cells. These, subdividing, give rise to the respiratory bronchioles [bronchioli respiratorii], the walls of which are beset with alveoli (fig. 992). From the respiratory bronchioles arise the alveolar ducts [ductuli alveolares], or terminal bronchi, each of which leads to a group of air-spaces, called atria, each of which again communicates with a second series of air-spaces, the air-sacs (alveolar saes or infundibula), whose walls are pouched out to form numerous pulmonary alveoli [alveoli pulmonum].

A terminal bronchus with its air-spaces and blood-vessels, lymphaties and nerves, together form a pulmonary lobule [lobulus pulmonum], the unit of lung structure.

Aeby divided the bronchial branches into two sets, according to their relation to the pulmonary artery. The branch arising above the place where the pulmonary artery crosses the stem-bronchus he named the eparterial bronchus, and those arising below the crossing he called hyparterial. An eparterial bronchus exists only on the right side; all other branches are hyparterial. Since the eparterial supplies the superior lobe of the right lung and no eparterial branch is present on the left side, Aeby concluded that the left lung had no lobe homologous with the superior lobe of the right lung. He compared the middle lobe of the right with the superior lobe of the left lung. The collateral branches of the stem-bronchi arise in a dorsal and rentral series in the lower mammals, and the same arrangement, though less obvious, obtains in man. According to the views of Aeby and Hasse, the first ventral branch of the right side is distributed to the middle lobe, while the remaining three ventral and all the dorsal lateral branches are given to the inferior lobe. On the left side, the first ventral branch is given to the superior lobe; the other ventral branches and the dorsal branches are distributed to the inferior lobe.

Fig. 996.-Scheme of the Bronchial Tree According to Narath. A. Anterior view. B. Right lateral view. (Poirier and Charpy.)

A. Apical bronchus, collateral of the first ventral and susceptible of becoming eparterial, Ap in migrating to the bronchial trunk.
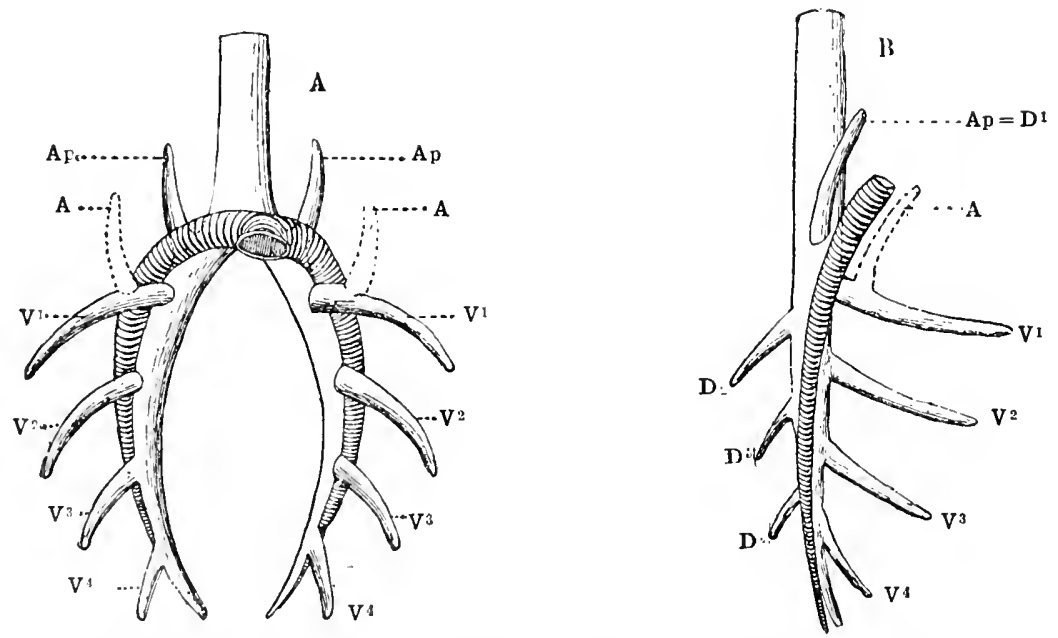

Narath ensillers the division of bronshial branches in aceordance with their relation to the puluonary artery as of no great morploblogical significanee. He attributes the apparent differences on the two sides to a shifting in position of homologous branches. Thus, Narath comsilers lhat the eparterial bronehus of deby has hecome the first dorsal lateral branch by displarement alore the pulmonary artery and that it is lomologous with an apieal branch of the left side, which retans its promitive origin frem the lirst ventral branch (fig. 996). Narath's ronecption of the migration of the hronehial hanches is supported by the results of Ifuntington's extensive sturlios of the loronchial tyee in mammals.

The physical properties of the lungs. -The averige dimensions in the adult male are as

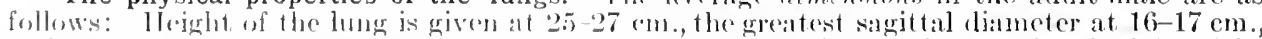
and the grentest transierse measurement as 10 em. for the right and 7 con. for the left. The

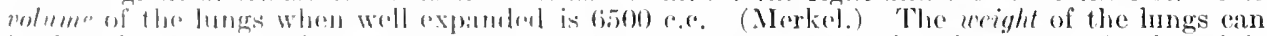

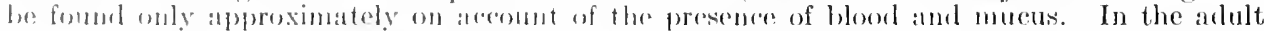

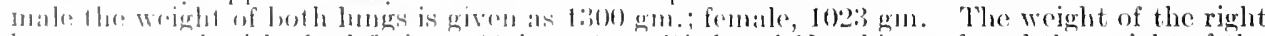

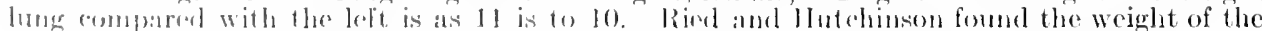
longe mompared with that of the lonly :1s $1: 37$ (male), $1: 43$ (female); in the fortus at term,

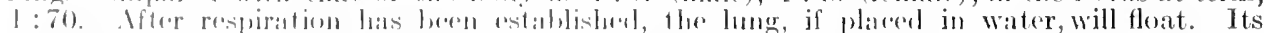

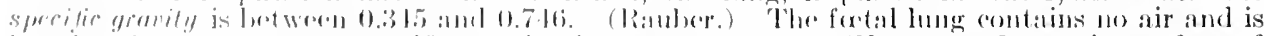

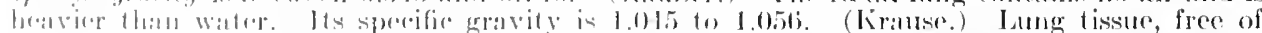

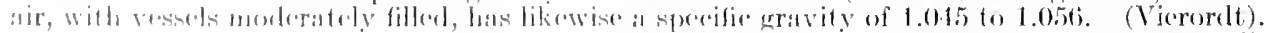

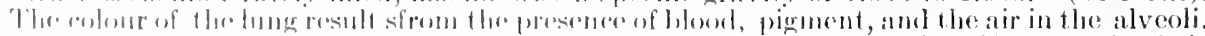

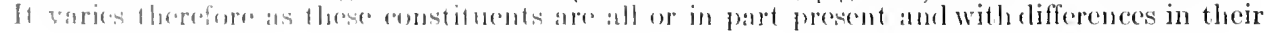


proportions. Thus the general colour is red in the foetus, pink, in the infant, and grey mottled with black in the adult. The dark colour is traceable to the carbonaceous matter carried into the lungs from the atmosphere.

In consistence the lung is soft and spongy, and when compressed between the fingers, emits a crackling sound. Among the physical properties the elasticity of the lung is quite remarkable. Under ordinary conditions the pressure of the air in the lung keeps the alveoli and the organ as a whole distended, but when the pleura has been opened and the air pressure equalised without and within, the lung collapses.

Topography.-The apices of the lungs extend upward as high as the first thoracic vertebraa level considerably higher than the superior margin of the sternum (figs. 997, 995). The sub, clavian vein and artery and the brachial plexus, together with the anterior scalene muscle, control to a certain degree the height reached. There seems to be no constant difference between the levels attained by the apices of the two lungs. The extent to which the apex rises above the clavicle is rarely more than $3.5 \mathrm{~cm}$. (Merkel), and will, of course, vary with individual differences in the position and form of this bone. The average is not over $2.5 \mathrm{~cm}$. (1 in.).

The base of the lung, resting on the diaphragm, is separated by that thin partition from the underlying abdominal viscera: thus beneath the base of the right lung is the right lobe of the liver, while under the left lung are the left lobe of the liver, the fundus of the stomach, and the spleen. The position of the a pex changes very little in respiration, and the same holds true for

Fig. 997.-Position of the Lungs from Before. (Merkel.)

The parietal pleura is shaded and outlined in black.

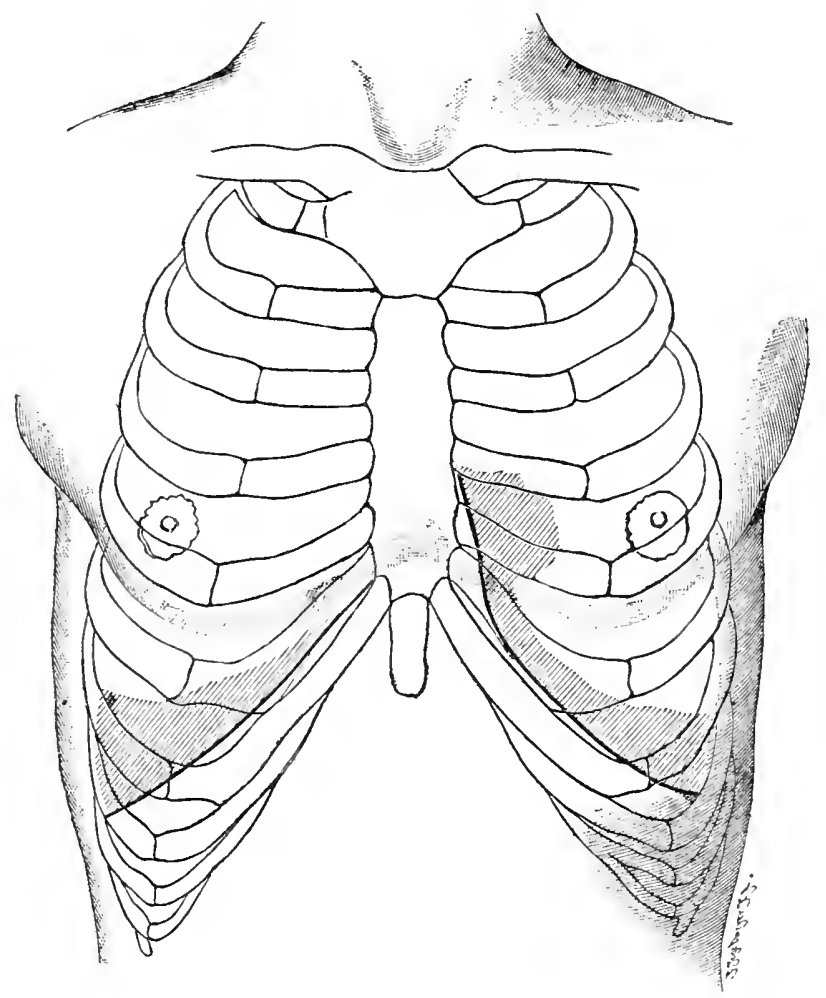

the hinder bulky part of the lung. The latter rests against the side of the vertebral column in the deep hollow of the angles of the ribs, and reaches below to the level of the eleventh costovertebral joint (fig. 998). The anterior margins (fig. 997) descend in curves from behind the sterno-clavicular joints, and run near together a little to the left of the median line. At the level of the sixth costo-sternal junction the anterior margin of the right lung turns lateralward to follow the sixth costal cartilage. The anterior margin of the left lung turns lateralward along the fourth costal cartilage as far as the para-sternal line, descending in a curve to the lingula and thus forming the cardiac ircisure. The positions of the inferior margins (figs. 997,998 ) of the two lungs are practically alike in their positions. Each extends in a curve covvex downward, behind the sixth costal cartilage in its entire length, crosses the costo-chondral junction of the sixth rib to the superior margin of the eighth rib in the axillary line, and so to the ninth or tenth rib in the scapular line, whence they run horizontally medialward to the eleventh costo-vertebral joint.*

* These relations are the mean between the conditions observed in the caclaver and as found by physical examination of the living. In old age the inferior margins of the lungs reach a level one or two intercostal spaces lower than is the case in adult life (Mehnert). 
The interlobar fissure (fig. 998) begins about $6 \mathrm{em}$. below the apex of the lung at the level of the head of the third rib. With the arm hanging at the side, a line drawn across the back from the third thoracic spine to the root of the scapular spine would indicate the course of the upper part of this fissure. (Merkel.) Thence it passes downward and around the chest to the end of the sixth bony rib in the mammillary line. Nerkel points out the use of the root of the scapular spine as a landmark for finding the limits of the lobes posteriorly: with the arm hanging at the side all above this spot is superior lobe; all below it the inferior. The short fissure of the right lung begins at the main interlobar fissure in the axillary line, about the level of the fourth rib or fourth interspace, and passes nearly horizontally to the anterior margin of the lung at the level of the fourth costal areh.

The roots of the lungs are placed opposite the fifth, sixth, and seventh thoracic vertebræ. The right root lies behind the inferior vena cava and under the arch of the azygos vein; the left root is beneath the aortic arch and in front of the thoracic aorta. The phrenic nerve passes in front of each root, the vagus behind. On the front and back are the pulmonary plexuses, anterior and posterior. The ligament of the pleura goes from the lower edge of the root.

Vessels and nerves of the lungs.-The bronchial arteries (see p. 588), belonging to the systemic system, carry blood for the nourishment of the lungs. They arise from the aorta or from an intercostal artery, two for the left lung and one for the right, and, entering at the hilus,

Fig. 998.-Position of the Lungs from Behind. (Merkel.)

The pleura is represented as in Fig. 997.

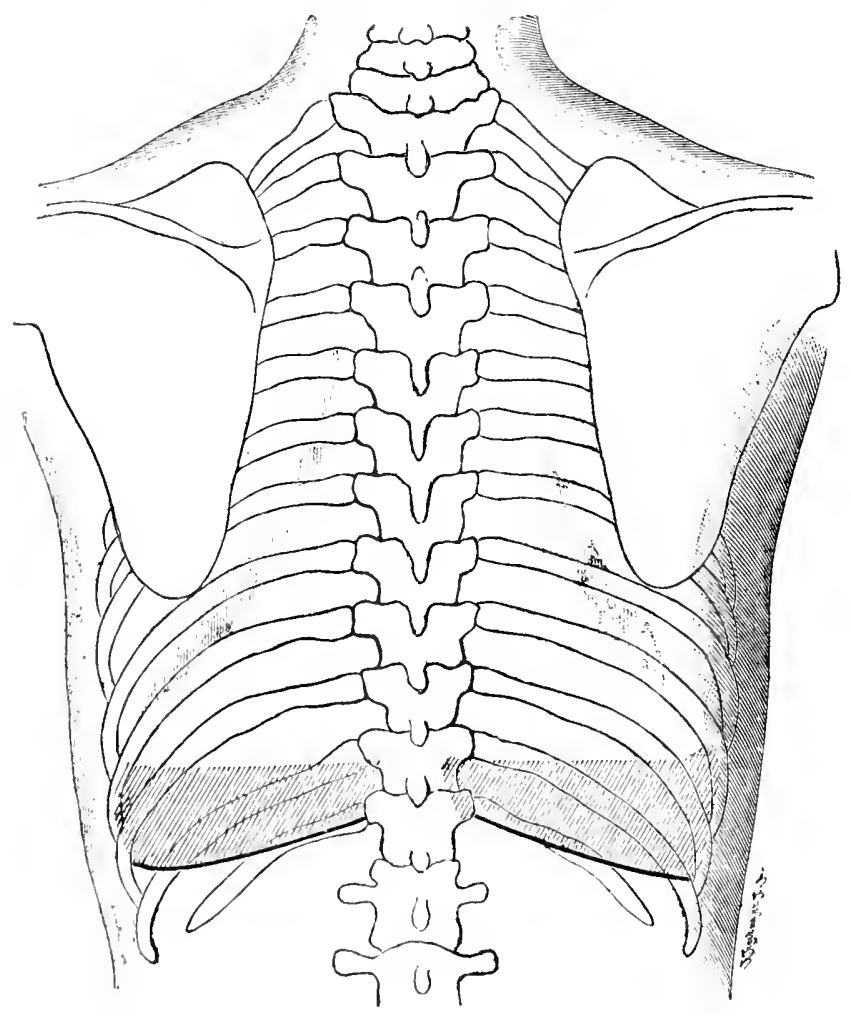

reach the hinder wall of the main monchus. The bronchial arteries accompany the bronchi, whose walls they supply, as far as the distal culs of the alveolar durts, beyond which they do not go, Threse vessels also supply the lymph glands of the hilus, the walls of the large pulmonary

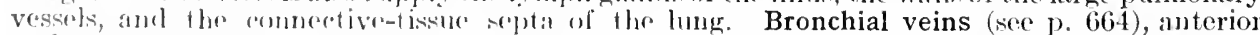
and posterior, arise from the walls of the first two or three divisions of the bronehi and end in the innominate and the ayges of in onr of the intereostal veins; those arising from the walls of the smaller tubes, including the alveolat clucts, join the pulmonary veins. 'lhe pulmonary artery (ser. P. 52s), contering the hilus in a plane antroior to the bronchus, turns to the posterior

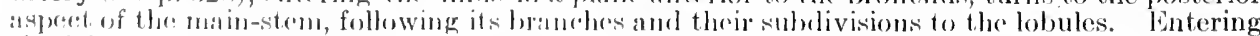
the loluke, the last branch of the vessel gives wilf as many twigs as there are atria (fig. 992), and these twigs rucl in clanse capillary nets in the walls of the alveoli. Here the venous blood heolght by the pumonary artery, sepalated form the air in the alveolis only by a thin septum,

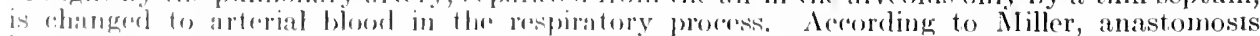

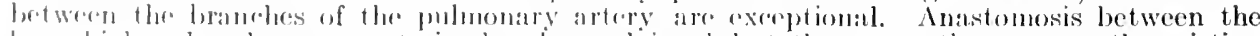

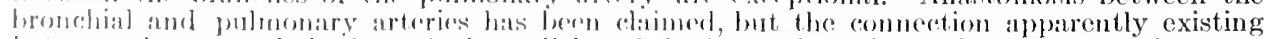
low veins. The pulmonary venous ralicles hegin at the capillary networks and clrain the arterial blond into the pulmonity vains, which run hetwern adjacent hobules and whieh receive also 
blood coming from the capillary network of the pulmonary pleura and from the capillary network of the bronchi (fig. 992). Thus it will be seen that while the pulmonary vein carries mainly arterial blood, it carries also some venous blood. The pulmonary veins (see p. 529) follow the bronchial tree on the side opposite the arteries to the hilus. where, having converged to two large trunks located in the root of the lung below the plane of the artery, they pass to the left atrium. The pulmonary veins have no valves.

Lymphatics. - Iiller has found the lymphatic vessels forming a closed tube system in the walls of the bronchi, in the pleura, and along the branches of the pulmonary artery and veins. Within the lung numerous pulmonary lymph-glands [lymphoglandula pulmonale: are found chiefly at the places of branching of the larger bronchi [lymphoglandula bronchialesl. Scattered along the latter, as well as associated with the branches of the pulmonary artery and vein, are found masses of lymphoid tissue. Deposits of carbonaceous matter in the lynphoid structures of the lung are present, except in early infancr; the amount increases with age.

Nerves.-The vagus and sympathetic contribute to form the pulmonary plexuses in front and behind the root of the lung, from which branches go to accompany bronchial arteries; a smaller number accompany the air-tubes (see p. 957).

Variations.-Congenital absence of one or both lungs has been observed. Variations in the lobes are not uncommon-four for the right and three for the left lung has been recorded. An infracardiac lobe, as found in certain mammals, sometimes occurs; an infracardiac bronchus is, homever, constant in man. More or less complete fusion of the middle and upper lobes of the right lung is not rare. The lungs mar be symmetrical, with two lobes each, the apical bronchus of the right springing from the first ventral bronchus, as is normal for the left lung (Yalderer, Narath); or the lungs may have three lobes each, the apical bronchus of the left arising from the main bionchus. The apical bronchus of the right lung may arise from the trachea, an origin that is normal in the hog and other artiodactyls.

Development of the lungs and trachea.-The first indication of the trachea and lungs appears in embryos of about $32 \mathrm{~mm}$. as a trough-like groove in the ventral wall of the upper part of the oesophagus, communicating above with the pharynx. Later the groove becomes constricted off from the cesophagus, the constriction extending from below upward, so that a tube is formed which opens into the pharynx above. The lower end of this tube soon becomes bilobed, and the lobes, elongating, give rise to additional lobes, of which there are primarily three in the right side and tro in the left. The upper unpaired portion of the tube becomes the trachea, while the lobed lower portion gives rise to the bronchi and lungs, the complicated structure of the latter being produced by oft-repeated branchings of the bronchi.

\section{THORACIC CAVITY}

Thoracic cavity [cavum thoracis] is the term used to denote the space included by the walls of the thorax and occupied by the thoracic viscera. These are, on each side, the lung, surrounded by the pleural cavity, and in the middle the pericardium and heart, great vessels, trachea and cesophagus, all closely associated and forming a dividing wall, the mediastinal septum, standing between the right and left sides of the thoracic space.

The limits of the thoracic space are given by the skeletal parts of the thorax together with the ligaments involved in the articulations and the muscles and membranes interposed between the bones. The arched diaphragm forms the inferior limit; and the barrier presented by the scalene muscles and the cervical fascia makes the superior boundary, which, it is to be observed, lies above the plane of the superior aperture of the thorax and therefore in the base of the neck. These boundaries are approached by the extension of the pleural cavities; yet there intervenes the parietal layer of the pleural sac which is connected with the thoracic walls by loose connective tissue, the endothoracic fascia [fascia endothoracica].

The form of the thoracic space departs from the external contour of the thorax chiefly through the projection into it of the ridge made by the succession of centra of the thoracic spine, and by the presence on either side of the latter of the broad, deep pulmonary sulcus. On account of these features a transverse section of the thoracic space is somewhat heart-shaped, but, however, much compressed anteroposteriorly (fig. 993).

The arch of the diaphragm on the right side rises to the level of the spinous process of the seventh thoracic vertebra; on the left, to the level of the eighth thoracic spinous process. At its circumference the diaphragm is in contact to a variable extent above its origin with the inner surfaces of the costal arches. In the lower part of this zone a connection exists between the muscle and the thoracic wall through a continuation of the endothoracic fascia; in the upper part, the phrenico-costal sinus (see p. 1237) intervenes. The level reached by this deepest part of the pleural cavity is lower than the summit of the peritoneal cavity, so they overlap to a considerable extent. 


\section{THE PLEURA}

The pleura (fig. 993) is a closed serous sac, which invests the lung (pulmonary pleura), and lines the inner surface of the thoracic walls (parietal pleura). The pleural cavity [cavum pleuræ] is the capillary space enclosed by the walls of the sac containing a little fluid which lubricates the apposed surfaces of the pulmonary and parietal membranes. There are two pleuræ, one in relation to each lung, completely separated by a sagittal partition, the mediastinum.

Fig. 999.-Pleural Cavity Opened From in Front.

1, first rib; 2, manubrium sterni; 3 , acromial extremity of clavicle; 4, xiphoid process, 5, linea alba; $6, \mathrm{~m}$. transversus abdominis; 7 , seventh rib; 8 , sternocleidomastoid m.; 9 , anterior scalene m.; 10, larynx; 11, thyreoid gland; 12, deep layer of cervical fascia in front of the trachea; 13, corresponds to upper part of anterior mediastinal cave; 14, pleural cupola; 15 , mediastinal pleura; 16 , lower margin of costal pleura; 17 , pericardium; 18 , superior lobe of lung; 19, middle lobe of right lung; 20, inferior lobe of lung; 21, diaphragm. (RauberKopsch.)

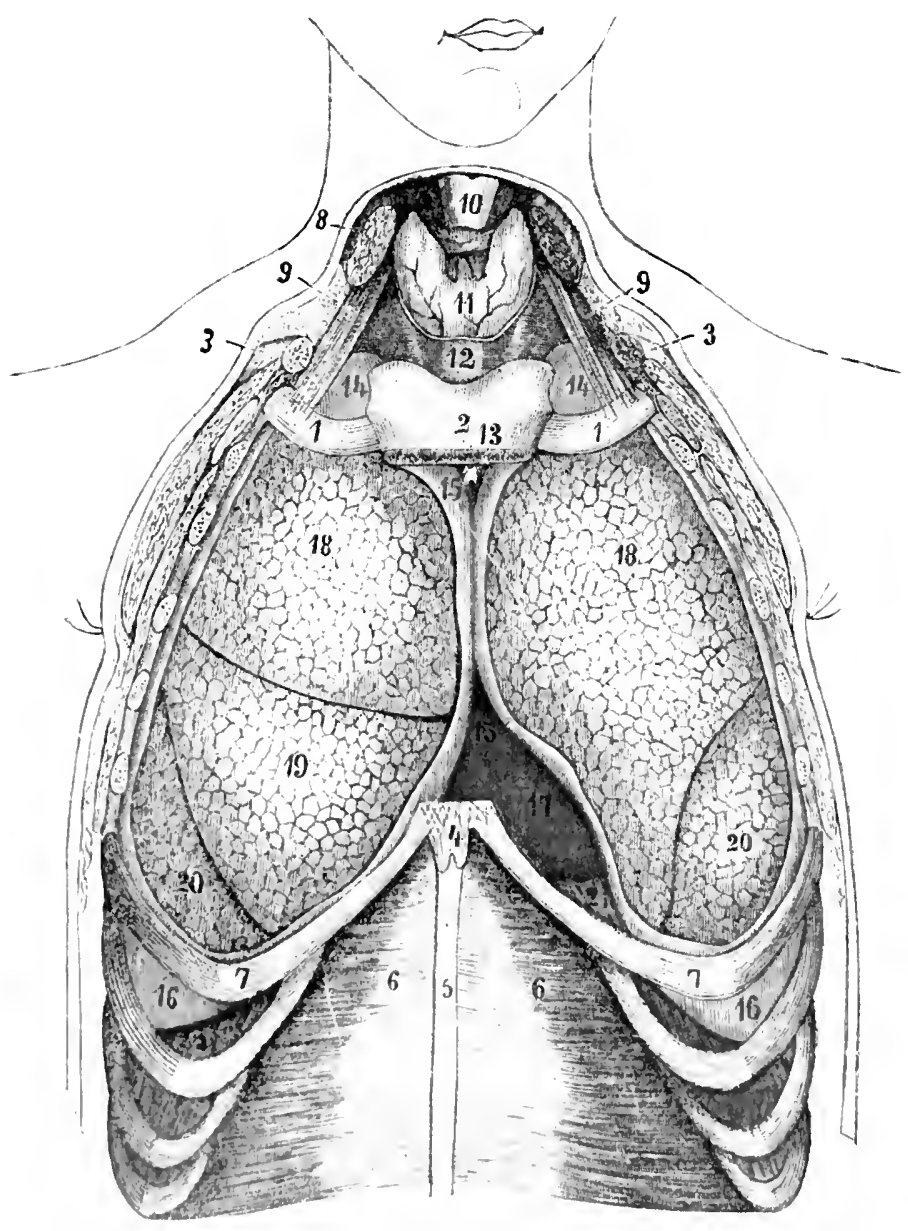

The pulmonary pleura folnura pulmonalis forms a smooth glistening coat over the onter surface of the lung, with the tissue of which it is inseparably connected. At the hilus the pulnomary plenra passes from the mediastinal surface of the lung to cover the root above, in front, and luchind, and hecomes continuous medialward with the parictal pleura of the mediastinmm. Below the root of the lung the plesers is reflested inedialward in a double layer as the pulmonary ligament [lig. puhnonale] (fig. 99.1).

This presents anterior and postorior surfaces and three margins; the base is mostly free, and diresefol towarl the rliaphragm, with which it is connected at its medial end; the apex is at the long reot, one margin is next to the long, athel the other joins the mediastinal pleura. 
The parietal pleura [pleura parietalis] is divided, aceording to the regions of the chest with which it is associated, into the costal, diaphragmatic, and mediastinal pleura. The costal pleura [pleura costalis] lines the thoraeic wall, to which it is bound not very firmly by the endothoracic fascia. It covers incompletely the back of the sternum and extends laterally upon the ribs and intercostal muscles. Posteriorly beyond the angles of the ribs it passes over the anterior rami of the thoracic nerves and intercostal vessels, the heads of the ribs, and the sympathetic trunk to the vertebral column; here it becomes continuous with the mediastinal pleura. Above, the pleura reaches beyond the superior margin of the sternum into the root of the neck, and in the form of a dome, the cupola of the pleura [eupola pleurx], is adapted to the apex of the lung. It is supported by processes of the deep cervical fascia, and by a fibrous aponeurosis known as Sibson's fascia, coming from the sealenus minimus muscle and conneeted with the inner margin of the first rib. In relation to the pleural cupola are those structures already described as grouped about the lung apex: the brachial plexus, subclavian artery, anterior scalene muscle, and the subclavian vein, and, on the left side, in addition, the thoracic duet.

Below, the costal pleura is continuous with the diaphragmatic pleura [pleura diaphragmatica], which adheres elosely to the thoraeie surface of the diaphragm and eovers it, excepting the pericardial area and where the diaphragm and thoracic wall are in contact.

The mediastinal pleura [pleura mediastinalis] is refleeted from before backward at the right and left sides of the mediastinum as the laminæ mediastinales, covering the pericardium

Fig. 1000.-Right Lateral Surface of the Mediastinum after Removal of the Pleura. (Poirier and Charpy.)

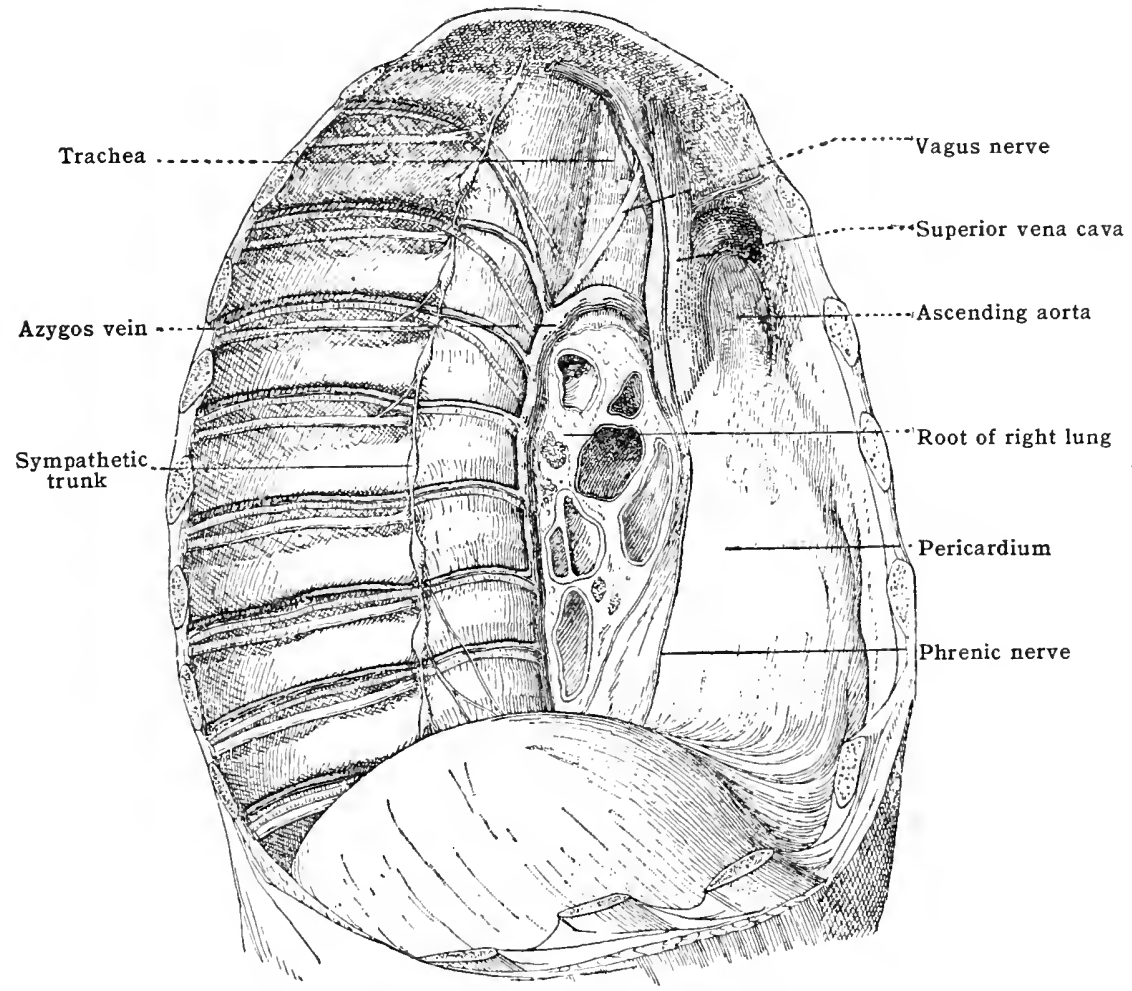

[pleura pericardiaca], to which it is elosely adherent, and also the other struetures of the mediastinum, with which the two layers are less firmly connected. Above the lung root the mediastinal pleura stretehes directly from the spine to the sternum; but at the level of the root and below it, it is reflected laterally to the pulmonary pleura covering the root in front and behind and forming the pulmonary ligament.

The right mediastinal lamina covers (fig. 1000) the right innominate vein, the superior vena cava, the vena azygos, the trachea, the innominate artery, the right vagus and phrenie nerves, and the osophagus. The left lamina lies against the left innominate vein, the areh of the aorta the left subclavian artery, the thoracic aorta, the left phrenie and vagus nerves, and the oesophagus. About the base of the heart-sac are a number of adipose folds [plice adiposa) projeeting from the pleura, the surfaces of which present some villous proeesses, the pleural villi [villi pleurales]; the latter also occur on the pulmonary pleura along the inferior margin of the lung.

The lines of pleural reflexion are of practical importance (figs. 997, 998, 1003). Posteriorly, the costal pleura simply turns forward in a gentle eurve to become the mediastinal pleura, but anteriorly and inferiorly the membrane is folded upon itself, leaving intervening capillary spaces, the sinuses of the pleura [sinus pleuræ]. Such a space is present where the costal pleura is reflected upon the diaphragm, the sinus phrenicocostalis, the fold of the pleura oceupying the upper part of the angle between the thoracic wall and diaphragm, the endothoracic fascia 
filling the lower part. The inferior nurgin of the lung enters this sinus a variable distance in inspiration. The line of the costo-diaphragmatic reflexion begins in front on the sixth costal cartilage, which it follows, descending obliquely to cross the seventh interspace in the mammillary line. The greatest depth reached is at the tenth rib or interspace in the axillary line. The line of reflexion then continues around the thorax ascending slightly to the twelfth costovertebral joint.

The line of reflexion behind is sometimes found as low as the level of the transverse process

Figs. 1001 and 1002.-Boundaries of the Pleure and Lungs.

Lines of pleural reflection red, boundaries of the lungs and pulmonary lobes black,

1, sixth cervieal rertebra: 2, first thoracic vetebra; 3 , twelf th thoracic vertebra; 4, first lumbar vertebra; 5 , manubrium sterni; 6 , body of sternum; 7 , xiphoid process; 8 , first rib; 9, cartilage of screnth rib; 10, 11, 12, tenth, eleventh and twelfth ribs. (Rauber-Kopsch.)
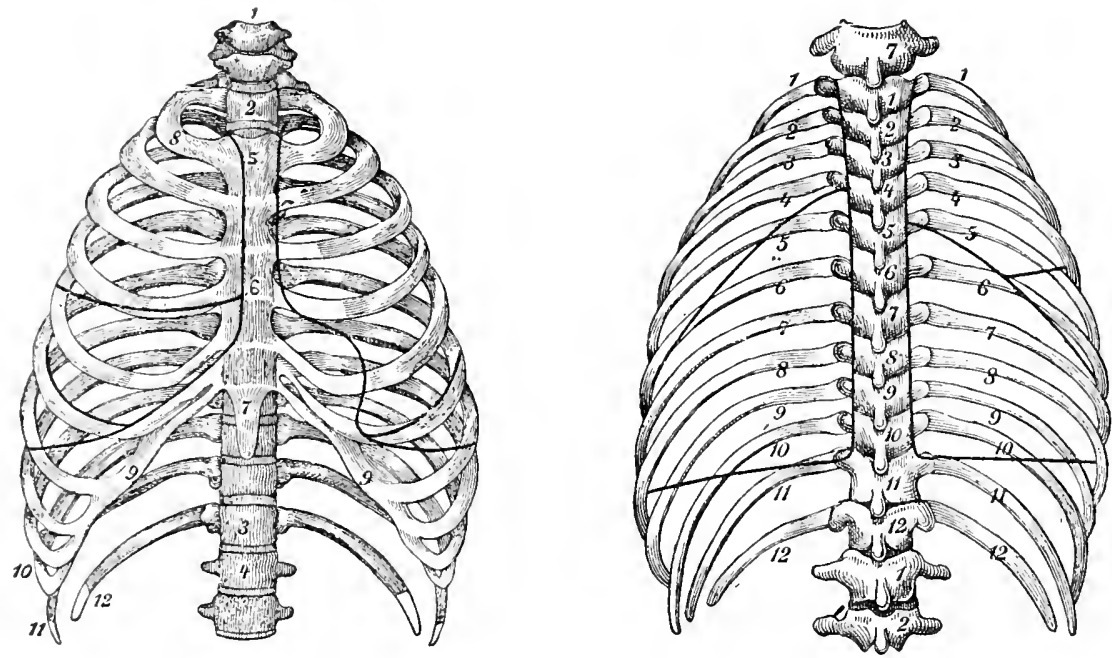

of the first lumbar vertebra. Such a possibility must be considered in operating upon the kidney .

The lines of reflexion of the costal pleura backward to the mediastinal plcura behind the sternum begin opposite the sterno-clavicular joints, descend obliquely medialward to the level of the second costal cartilage, whence they run near together or in contact, but to the left of the median line, to the level of the fourth cartilage. The reflexion on the right side continues from the sternum as far as the sixth rib cartilage, there turning laterally into the eosto-diaphragmatic reflexion. The line on the left side, in the region of the eardiae notch (from the fourth

Fig, 1103.-Simematic Drawing to Represent the Maximum of Fluctuation in the Position of the Anterior lines of Pleural Reflexion. (Tanja.)
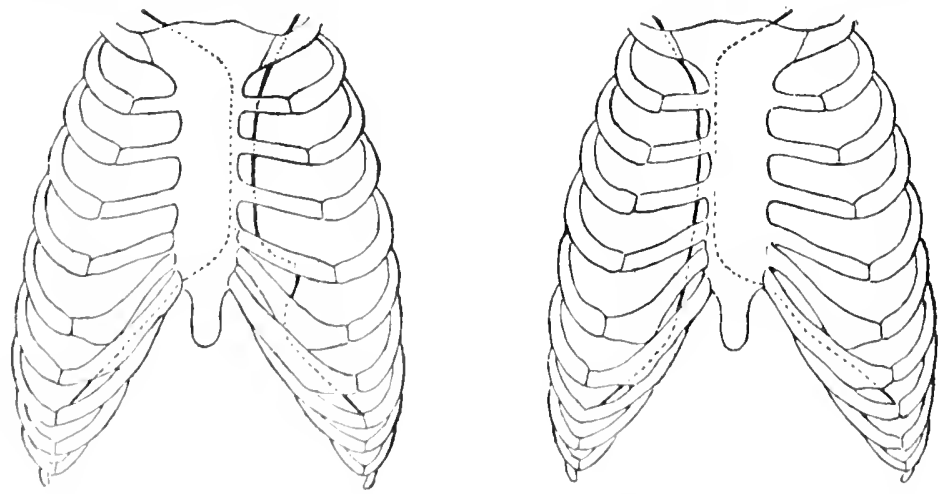

fo the sixth cartilages), is a little to the left of the sternal margin. From this position of the lime of reflexion it happons that there is boft monvered by plenra a small at of of the pericardium which is in contane immoliately with the ehest-wall. A reduplieation of the pleura takes fules abng the antrior lime of reflexion, and into the sinus costomediastinalis so formed the thin anterior margin of the hung anlvances in insprat ion. That part of the left costo-mediastinal sinns which is in front of the perientelinm is not completely filled by the margin of the lung. Althongh the positions of the lines of reflexion of the mediastinal plenta here described are those 
usually encountered, it should be noted that they are subject to variation. The extremes of variation of the anterior lines, as determined by 'Tanja, are indicated in fig. 1003 .

Blood-vessels. - The vascular networks of the pulmonary pleura are derived from the bronchial artery and probably to some extent from the pulmonary artery which in the dog, is the only source of blood supply. The venous radicles arising from the network enter the lung. (See radicles of the pulmonary vein on page 1235.) The parietal pleura is supplied by arteries from several sources: internal mammary, intercostals, phrenics, mediastinal, and bronchial. The veins correspond to the arteries. The lymphatics of the pulmonary pleura form rich networks without definite relations to the lobules of the lung. They accompany the radicles of the pulmonary veins and drain into the bronchial lymph-glands. In the parietal pleura lymph-vessels are present most abundantly over the interspaces; they empty into the sternal and intercostal glands. (See p. 728.) The nerves supplied to the pulmonary pleura are branches from the pulmonary plexus; to the parietal pleura, from the intereostals, vagus, phrenic, and sympathetic.

\section{MEDIASTINAL SEPTUMI}

The two pleural cavities are separated from each other by the mediastinal septum [septum mediastinale] (fig. 1000). This is a sagittal partition extending from the superior aperture of the thorax to the diaphragm between the thoracic vertebræ and the sternum, its free surfaces, right and left, formed by the mediastinal layers of the pleuræ. It is composed of the pericardium and heart and of structures which, for the most part, extend in a longitudinal direction through the thoracic cavity.

These include the œsophagus together with the vagus nerves, the thoracic duct, thoracie aorta and azygos vein; the trachea, the pulmonary vessels and the arch of the aorta with its great branches, the superior vena cava and its tributaries and the phrenic nerves; the thymus gland, internal mammary vessels and many lymph glands throughout the septum. These structures are packed together and supported by intervening connective tissue. Moreover, the connection of the sheaths of the great vessels with processes of the cervical fascia and the fixation of the pericardium to the diaphragm, give to the latter a strong support. Owing to the position of the heart, the two sides of the septum are not symmetrieal, and it follows from the bulging of the left surface of the mediastinal septum that the left pleural cavity is encroached upon.

The name mediastinal cavity has been applied to the two regions of the mediastinal partition which find themselves located, the one in front, the other behind the plane of the heart. There is in reality no cavity, the term being used in this connection merely to donate space. Between the two spaces are interposed the pericardium and heart, the great ressels, trachea and bronchi. The anterior mediastinal cavity [cavum mediastinale anterius] is small. Its lateral limits are formed by the mediastinal layers of the pleuræ, right and left. which are reflected backward from the costal pleure of the anterior thoracic wall. The space is occupied by loose connective tissue, surrounding the thymus gland, the intermal mammary vessels and a number of lymph-glands.

Recalling the lines of reflexion of the mediastinal pleurse as above described, the form, position and extent of this space as observed from in front, will be understood; it is widest behind the inferior end of the body of the sternum and fifth and sisth costal cartilages of the left side (area interpleurica infcrior); narrowest where the mediastinal layers are approximated behind the body of the sternum, broader again where the lamina deviate posterior to the manubrium sterni (area interpleurica superior). In the latter space lies the thymus gland and the superior portions of the internal mammary vessels. In the area interpleurica inferior the pericardium comes into immediate contact with the anterior thoracic wall, and here the inferior portions of the left internal mammary vessels are found. The lymphatie vessels and glands of the anterior mediastinal space belong to the anterior mediastinal and sternal groups.

The posterior mediastinal cavity [cavum mediastinale posterius] (fig. 1000), limited behind by the thoracic vertebræ and laterally by the mediastinal layers of the pleuræ where they are reflected forward from the costal pleuræ of the posterior thoracic walls, is elongated and of more regular form than the anterior space. It includes the thoracic aorta, the asophagus and vagi, the thoracic duct, azygos vein and lymph glands.

Within this space are also to be found the origins of the right intercostal arteries, the hemiazygos and, when present, the accessory hemiazygos veins, terminations of some of the left intercostal veins and the greater splanchnic nerves. The lymph glands belong to the posterior mediastinal group.

(Figs. 993, 994). - A subdivision of the mediastinal septum into anterior, middle, posterior, and superior mediastinal spaces has long been eustomary, and is useful for descriptive purposes.

The superior mediastinum is that part of the mediastinum which lies above the level of 
the pericardium. It extends between the first four thoracic vertebra behind and the manubrium sterni in front, and contains the arch of the aorta and the great vessels arising from it, the innominate veins, and the upper part of the superior vena cava, the thoracic duct, the lower portion of the trachea, and a portion of the osophagus, the phrenies, vagi, left recurrent and cardiac nerves, and the thymus gland.

From the superior mediastinum the other three divisions of the space extend downward. The anterior mediastinum is identical with that part of the anterior mediastinal cavity which is below the level of manubrium sterni. The middle mediastinum lies between the layers of the mediastinal pleurre in front of the root of the lungs; it contains the heart, enclosed in the pericardium, and the phrenic nerves. The posterior mediastinum corresponds to that portion of the posterior mediastinal cavity which extends below the plane of the fifth intervertebral fibro-cartilage.

References for Respiratory System. A. External nose and nasal cavity. Kallius, in von Bardeleben's Handbuch; Zuckerkandl, Normale u. path. Anatomie d. Nasenhöhle, Bd. 1, Wien, 1893; (Development) His, Arehiv f. Anat. u. Phys., 1892; Killian, Areh. f. Laryngol., Bd. 4, 1896; Sehaeffer, Jour. Morphol., vol. 21, 1910; (Conche) Peter, Arch. f. mikr. Anat., Bd.60, 1902; (Paranasal sinuses) Bartels, Zeitsehr. f. Morph. u. Anthrop., Bd. 8; Turner, Accessory Sinuses of the Nose, Edinburgh, 1901; (Anthropology) Hoyer, Morph. Arbeiten, vol. 4, 1894. B. Larynx. Gerlach, Anat. Hefte, H. 56; (Development) Lisser, Amer. Jour. Anat., vol. 12; (Ossification) Scheier, Arch. f. mikr. Anat., Bd. 59. C. Lungs. (Structure; vascular supply) Miller, Arch. f. Anat. u. Entw., 1900; Amer. Jour. Anat., vol. 7; Schultze, Sitzb. Akad Wiss., Berlin, 1906; (Development) Flint, Amer. Jour. Anat., vol. 6 (Topographical) Mehnert, Topogr. Altersveränderungen d. Atmungsapparatus, Jena, 1901. D. Pleura. Ruge Morph. Jahrb. Be. 41. 


\section{SECTION X I \\ UROGENITAL SISTEM}

Revised for the Fifth Edition

By J. PLAYFAIR MicMURRICH, A.MI., Ph.D., LL.D.

PROFESSOR OF ANATOMY IN THE CNIVERSTY OF TORONTO

The urogenital system [apparatus urogenitalis] includes (A) the urinary organs and $(\mathrm{B})$ the reproductive organs.

\section{A. THE URINARY ORGANS}

THE organs forming the urinary apparatus [organa uropoëtica] are the kidneys, by which the secretion is produced; a duct, the ureter, proceeding from each kidney and conveying the secretion to the bladder, which serves as a reservoir for the urine and from which, by a single duct, the urethra, the secretion is carried to the exterior.

Fig. 1004.-Postero-medial Aspect of the Right Kidney.

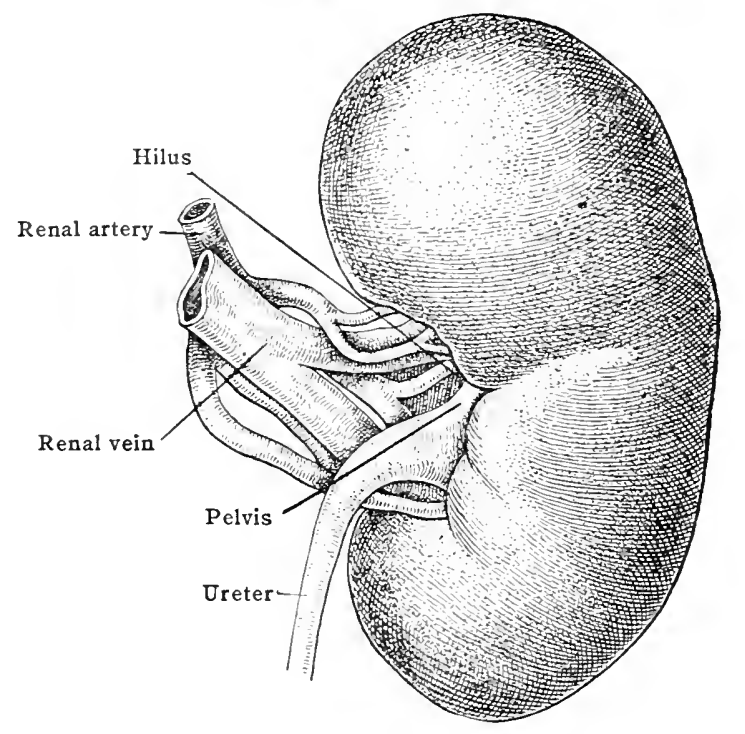

THE KIDNEYS

The kidneys [renes] are paired organs situated in the abdominal region and each is composed of a very great number of minute tubules, the renal tubules, enclosed within a definite and firm fibrous capsule. Each kidney is somewhat bean-shaped (fig. 1004) and is situated on the dorsal wall of the body, behind the parietal peritoneum, in such a way that the ventral or visceral surface [facies anterior] which is convex, looks obliquely ventrally and laterally, while the dorsal or parietal surface [facies posterior], usually less convex, looks dorsally and somewhat medially (fig. 1005). The upper extremity [extremitas superior] is usually larger 
than the lower [extremitas inferior] and is about $1 \mathrm{~cm}$. nearer the median sagittal plane of the body, owing to the long axis of the organ being clirected obliquely downward and laterally. The lateral border [margo lateralis] is narrow and convex, and the medial border [margo medialis], which looks medially and ventrally, is concave, its middle third presenting a slit-like aperture, the hilus. This opens into a cavity, called the sinus (fig. 1006), which is about $2.5 \mathrm{~cm}$. in depth and is occupied mainly by the dilated upper extremity of the ureter, known as the renal pelvis, the interval between this and the actual kidney substance containing adipose tissue in which are imbedded the renal vessels and nerves.

Size.-The length of the kidney in the male averages $10-12 \mathrm{~cm}$., its breadth about $5.5 \mathrm{em}$. and its thickness $3 \mathrm{~cm}$; it weighs $115-150$ grams. The dimensions of the female kidney are nearly as great, but its weight is from one-seventh to one-fifth less. In the ehild the organ is relatively large, its weight eompared with that of the entire body being about 1:133 at birth; but its permanent relation, which is about $1: 217$, is usually attained at the end of the tenth year.

Fig. 1005.-Diagrail showing Relation of Kimney to Capsule. (Gerota.)

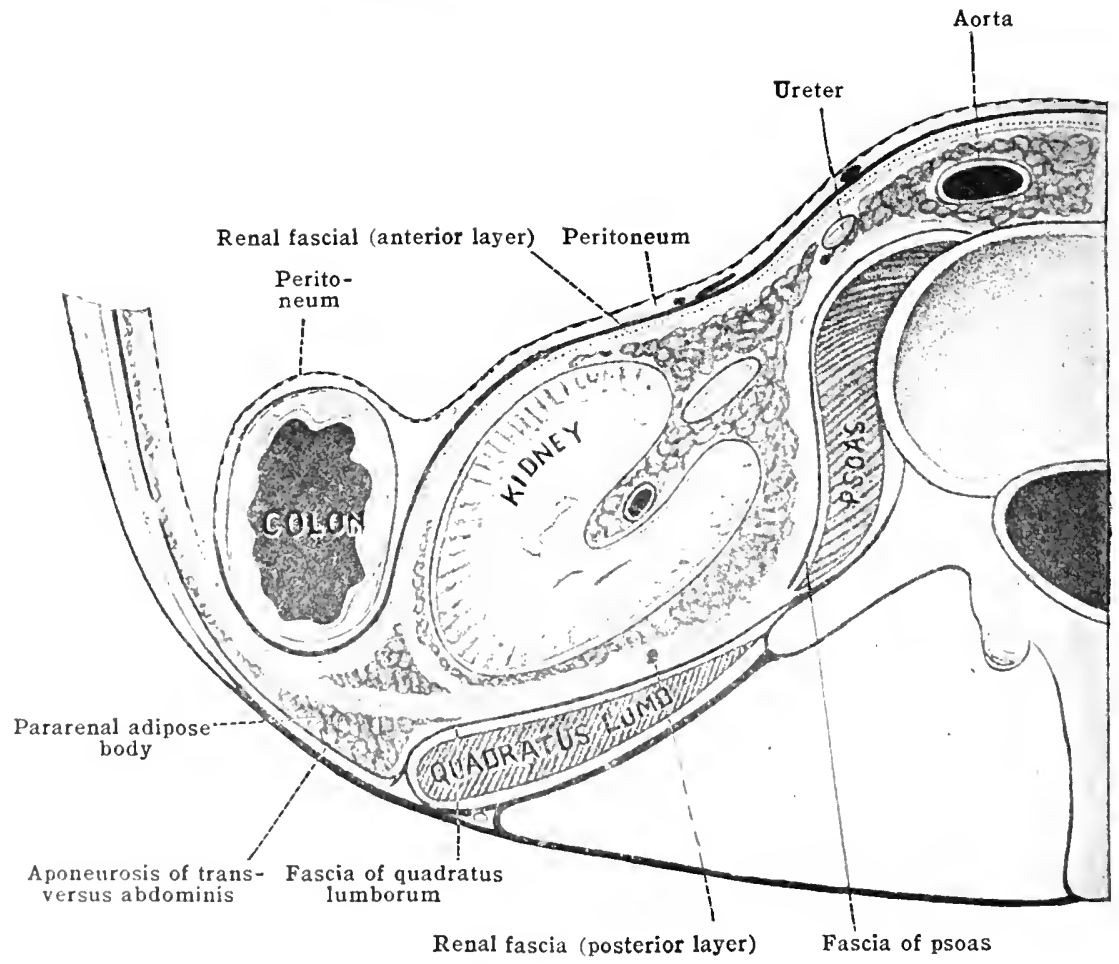

Investment and fixation.- The surface of the kidney is covered by a thin but strong fibrous copsule [tunica fibrosa], which turns inwarl at the hilus to line the walls of the sinms (fig. Iof(i). It may readily be peeled ofl from a healthy kidney, exerpet at the bottom of the simus, where it is arluerent to the blook-vessels entering the kidney sutstinne and to the torminal portions of the polvis. External to the eapsule is a quantity of fat tissur, the adipose capsule [eapsula adliposa], which forms a complete investment for the organ and is prolonged through the hilus into the simls.

The prefonemen, which covers the ventral surfare of the arlipose eapsule, has 11:mally freen regatrded as the principal means of fixation of the kidney, but in

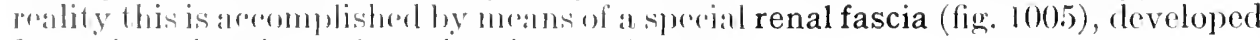
from the subperitoneal arrolia tissure (cierota).

Renal fascia. Latogal to the kidery there oceme betwern the transversalis faseia and the

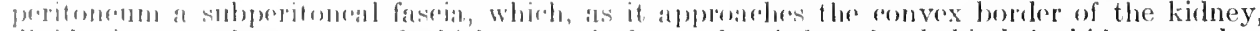
divides into two layers, alle of which passes in fornt of and the other belhind the kidney, enelos-

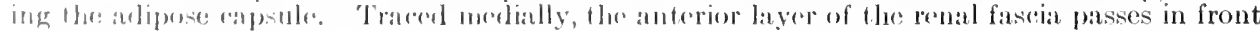


of the renal vessels, and, over the aorta, becomes continuous with the corresponding layer of the opposite side; upward, it passes over the suprarenal gland and at the upper border of that organ becomes continuous with the posterior layer; and downward, it is lost in the adipose tissue intervening between the iliae faseia and musele. The posterior layer, which is the thicker of the two, passes medially behind the renal vessels and is lost in the comnective tissue in front of the vertebral column, and below it is lost, like the anterior layer, in the iliae region. Behind the posterior layer, between it and the quadratus lumborum, is a mass of adipose tissue, the pararenal adipose body, and both layers are united to the fibrous capsule of the kidney by trabeculæ of conneetive tissue which transverse the adipose capsule.

Each kidney is, accordingly, supported by these trabecule in a space bounderl laterally and above by the layers of the renal fascia, and open medially and below. Should these trabecula become atrophied by wasting disease or ruptured by the pressure of the pregnant uterus, by the improper use of corsets, or by any other eause, the phenomenon of movable or wandering kidney may be set up by slight external violence, the organ tending to shift its place as far as the attachment of its vessels to the main trunks and the arrangement of the renal fascia will permit.

Position and relations.--The kidney is said to lie in the lumbar region. It is, however, intersected by the horizontal and vertical planes which separate the hypochondriac, lumbar, epigastric and umbilical regions from each other, and hence belongs to all these segments of the abdominal space. Its vertical level may be said to correspond to the last thoracic and upper two or three lumbar

Fig. 1006.-Section of Kidney showing the Sinus. (After Henle.)

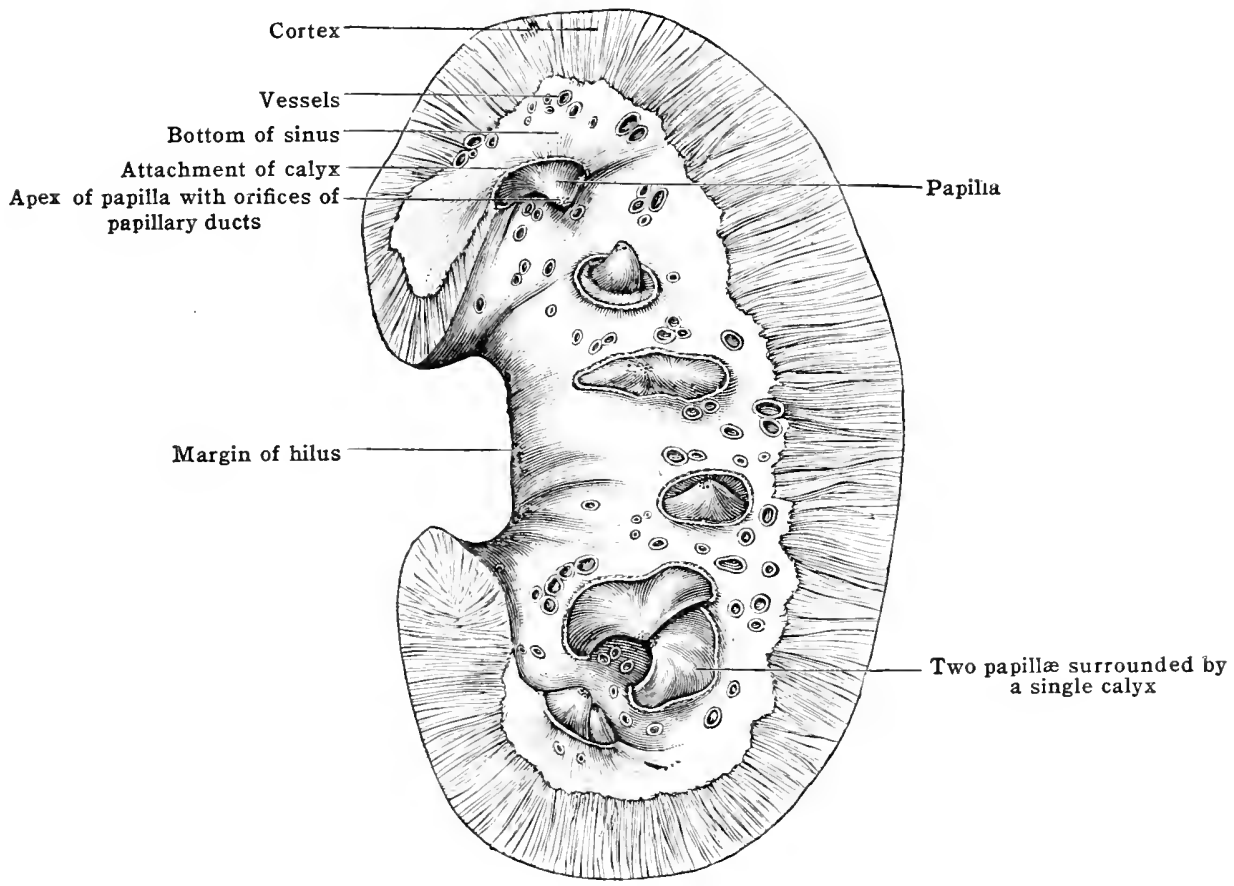

vertebræ, the right lying in most cases from 8 to $12 \mathrm{~mm}$. ( $\frac{1}{3}$ to $\frac{1}{2} \mathrm{in}$.) lower than the left; but exceptions to this rule are not infrequent.

The posterior surface (figs. 1007, 1008), with the corresponding portion of the fatty capsule and the pararenal adipose body, rests against the postcrior abdominal wall extending upward in front of the eleventh and twelfth ribs, and medialward to overlap the tips of the transverse processes of the first and second lumbar vertebræ; the left kidney usually reaches as high as the upper border of the eleventh rib, the right only to its lower border. The only visceral relation posteriorly is on the left side, where the spleen slightly overlaps the kidney opposite the upper half of its lateral border, the adjacent surfaces of the two organs being, however, covered by peritoneum. The parietal relitions (fig. 1008) on both sides are as follows: (1) the diaphragm, the left kidney, on account of its higher position, entering more extensively into this relation than the right; (2) the portion of the transversalis fascia covering the ventral surface of the quadratus lumborum; (3) the lateral border of the psoas; and (4) the last thoracic, ilio- 
hypogastric and ilio-inguinal nerves and the anterior divisions of the subcostal and first lumbar vessels, all of which run obliquely downward and laterally in front of the quadratus lumborum.

The upper extremity of each kidney is crowned by the suprarenal gland (figs. 1007,1009 ), which encroaches also upon its ventral surface and medial border and is fixed to it by fibres derived from the subperitoneal tissue.

The anterior surface of each kidney was primarily completely covered by peritoneum that separated it from neighboring viscera, but, owing to secondary changes whereby the ascending and descending colons, the duodenum and the pancreas become retro-peritoneal organs, these come into direct relation with one or the other of the kidneys and separate portions of them from actual contact with the peritoneum. Thus, in the case of the right kidney (fig. 1009), the

\section{Fig. 1007.-The Abdominal Viscera, seen from Behind.}

(From the model of His.)

The kidneys are somewhat lower than usual in their relations to the ribs.

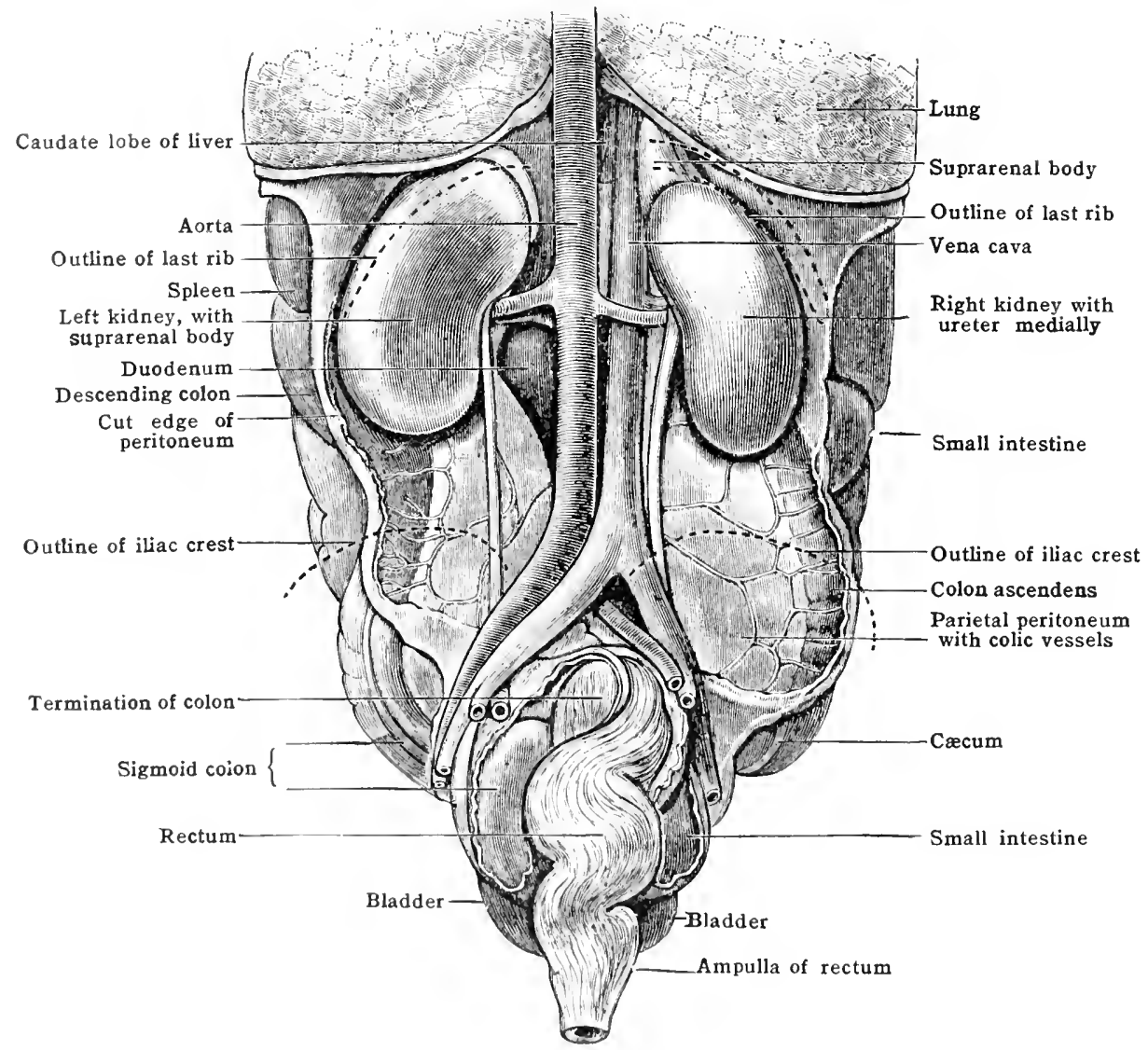

portion of the anterior surfare immediately arljacent to the medial border has the descending portion of the duodemum in direct contact with it, and throughout a zone extending downward and laterally from the middle of the duodenal area to the hateral border the aseonding colon and right eolie flexure. Almost the entire mpper half, however, and a small portion of the lower pole are covered directly by peritonemen, the upuer perifoneal arrat having an indirect relation with the lower surfare of the liver, upon which it produces the renal impression.

Similarly the anterior surface of the loft kidney (fig. 1009) is in direct eontact with the panereas throughout a bound transverse bind situated a little above the mirllle of the organ, and the splonic: artery pursmes its tortuous course along the

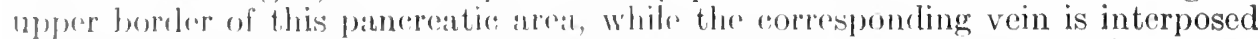
bertwern the patuereis and the surface of the kinhey. The lateral portion of the lower extrenity is in clirert contart with the drsecurling colon and its splenie 
flexure, but the remainder of the lower extremity and the whole of the upper onefourth of the organ is directly covered by peritoneum, the upper peritoneal area having, as an indirect relation, the posterior surface of the stomach medially, and the spleen laterally (figs. 956, 1009).

The medial border of the right kidney approaches the vena cava inferior very closely, especially above; that of the left is separated from the aorta by an interval of about $2.5 \mathrm{~cm}$.

Fig. 1008.-Diagram of Relations of Posterior Surface of Left Kidney.

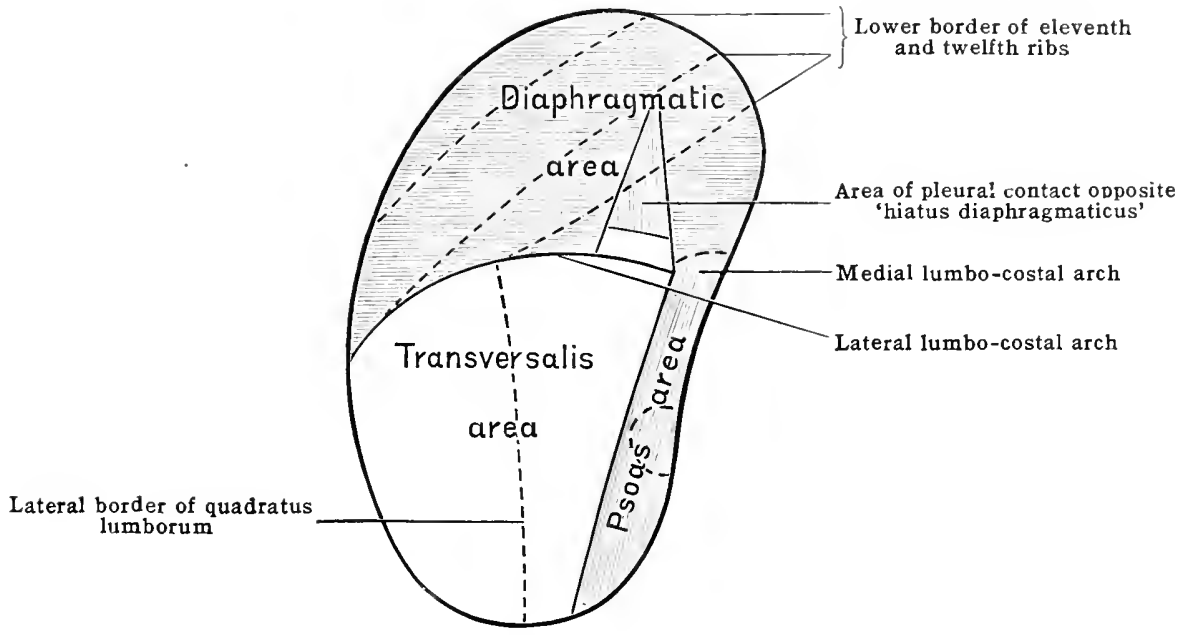

Variation in position.-The position of the kidneys in the abdominal cavity is subject to considerable variation. Thus while the upper pole of the right kidney may be said to lie typically opposite the lower half of the eleventh thoracic vertebra, it may be placed as high as the lower part of the tenth thoracic or as low as the upper half of the first lumbar. Similarly while the upper pole of the left kidney is as a rule opposite the middle of the eleventh thoracic vertebra it may lie half a vertebra higher or as low as the lower part of the second lumbar vertebra. The lower poles are distant from the crests of the ilia anywhere from $1.0 \mathrm{~cm},-3.0$

Fig. 1009.-Diagram showing Anterior Relations of Kidneys and Suprarenal Bodies.

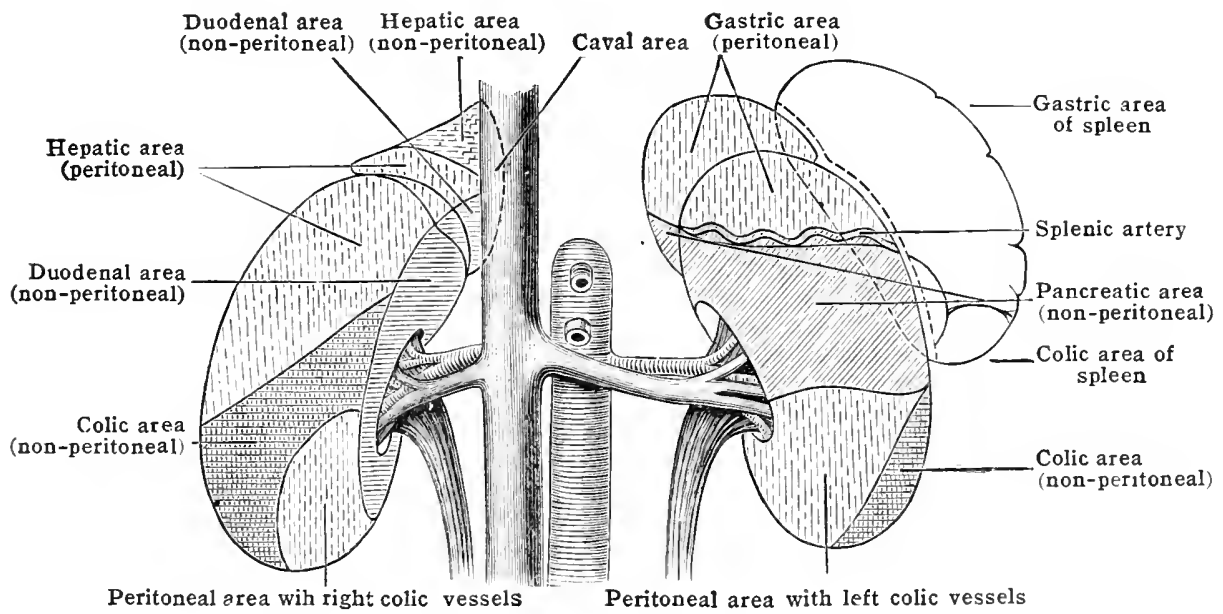

cm., the distance being, as a rule, somewhat less in females than in males. Occasionally the lower pole may even extend below the iliac crest, especially on the right side.

The lateral border of each kidney lies $8.5-10.0 \mathrm{~cm}$. lateral to the spines of the lumbar vertebræ, a distance that brings them lateral to the lateral edge of the sacro-spinalis muscle and even to the lateral edge of the quadiatus lumborum, so that this border may be readily approached through the posterior wall of the body. It must be remembered, however, that the upper part of the kidney rests upon the diaphragm, so that in the event of the twelf th rib being very short there may be danger of the incision being carried too far upward, resulting in injury to the diaphragm and pleura. It is also worthy of note that the diaphragmatic area of 
the kidney corresponds with the region where a hiatus diaphragmaticus between the costal and humbar portions of the muscle may occus and if this be pronounced the upper part of the posterior surface of the kidney may come into more or less direct relations to the pleura (fig. 1008).

Just as there may be variation in the position of the kidneys, so too there may be considerable variation in the extent to which they are in relation to the various structures mentioned above. And this is esnecially true as regards their relations to the colons; for if the kidneys were lower than wsual they might lie entirely beneath the line of attachment of the transverse mesocolon and thus have no direct relations with either colon, or on the other hand either the ascending or descending colon, or both, may be provided with a mesentery, whereby they would be removed from direct contact with the kidney.

Structure.-A section through the kidney shows its substance to be composed of an external or cortical [substantia corticalis] and an internal or medullary portion [substantia medullaris] (fig. 1010). The medulla consists of a variable number (eight to eighteen) of conical segments termed renal pyramids [pyramides renales (Malpighii)], the apices of which project into the bottom of the sinus (fig. 1006) and are received into the primary segments (calyces) of the pelvis, while their bases are turned toward the surface, but are separated from it and from each other by the cortex. The pyramids are smooth and somewhat glistening in section and are marked with delicate strix which converge from the base to the apex and indicate the course of the renal tubules. The blunted apex, or papilla, of each pyramid, either singly or blended with one or even two of its fellows, is embraced by a calyx (fig. 1006), and, if cximined witl a hant-lens, will be seen to present a variable number (twelve to eighty) of minute apertures, the foramina papillaria, which represent the terminations of as many papillary ducts (of Bellini) through which the secretion escapes into the pelvis.

Fig. 1010.-Horizontal Section of Kidney showing the Sinus.

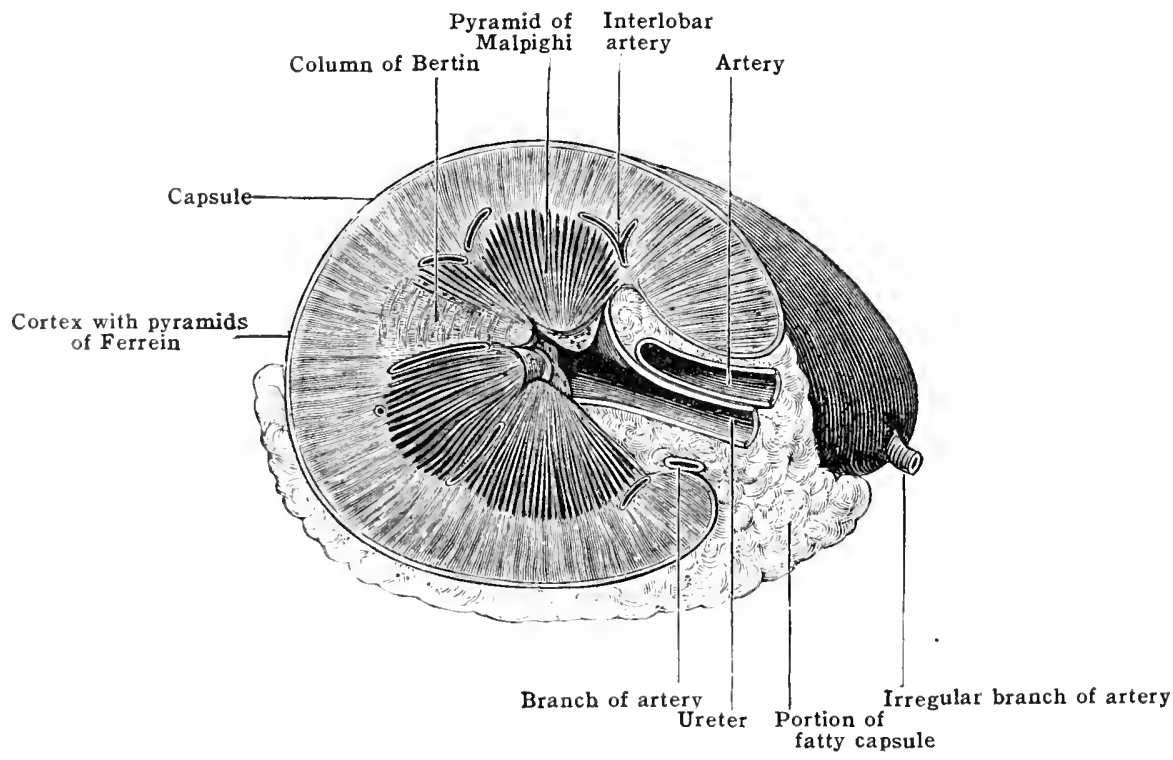

The cortex may be legarded as composed of two portions, (1) a peripheral layer, the cortrex proper, which is about $12 \mathrm{~mm}$. in thickness and extends from the fibrous capsule to the bases of the pyramids, and (2) processes termed renal columns [colummatenales (Bertini)] which dip inward between the pyramids to reach the bottom of the sinus (fig. 1010). In section the (o) tiation into a mumber of imperiectly separated portions termed cortical lobules [lobuli corticales]. Eitrh of these is composed ol a convoluled portion [pars convohuta], surrounding an axial radiate portion (pyramid of lerrein) \{pars radiata (processis Ferreini)]. The latter consists of a group of tubules which extend from the artex into the base of one of the medullary pyramids, whence it is also formud a medullary riy ; and eath modullary pyramid is formed from the rays of a

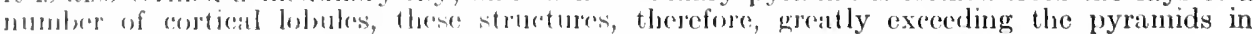
numbrer.

Renal tubules (fig. 1011). - The structure described above is the result of the arrangemont of tho jenal tubules, which constitute the resontial units of the kidney. Wheh of these comnomes in a spherieal glomerular capsule (fig. 1011 ), wn wall of which is invaginated by a small glomerulus of hlood-vessols, the combination of glomerubus and rapsule forming what is termed at renal (Malpighian) corpuscle. These (orpuscles are situated in the eonvoluted portions of

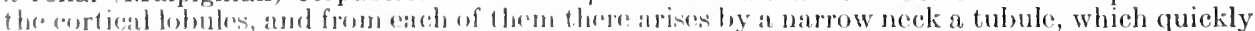

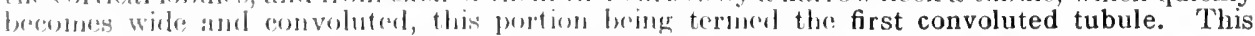
molors a modullary ray, whore it, narows again and dosends as a straight tubule, the descending limb of Henle's loop, into the subjacent suedullary pyramid, aud, turniug upon itself, forming thr loop of Henle, ascends to thr artex, where it angan becomes wide and contorted, forming thr second convoluted tubule. This agam lies in the convoluted portion of the cortical lobule, and, beeming narrower, opens with other similar tubules into a straight or collecting 
tubule, which occupies the axis of the medullary ray. Then, descending into the subjacent medullary pyramid, it unites with other collecting tubules, and finally opens in to the renal pelvis at the summit of a papilla.

The tubules are lined with epithelium throughout, the cells being tesselated in the capsule, irregularly cubical in the convoluted tubules and ascending limbs, flattened on the descending limbs and loops of Henle, and columnar in the cortical collecting tubules and in the straight tubules of the medulla.

Vessels (fig. 1011). - The kidney is very vascular. The larger arterial branches, arranged in the sinus as has already been described, enter the substance of the kidney and pass up as the interlobar arteries in the renal columns. On reaching the bases of the pyramids they bend so as to run horizontally between these and the cortex, forming the arenate arteries [arterie arciformes] from which interlobular branches pass up into the cortex and supply afferent branches to the Malpighian glomeruli. From the arcuate arteries numerous branches, the arteriole rectas,

Fig, 1011.-Schene of Tubules axd Tessels of the Kiddey.

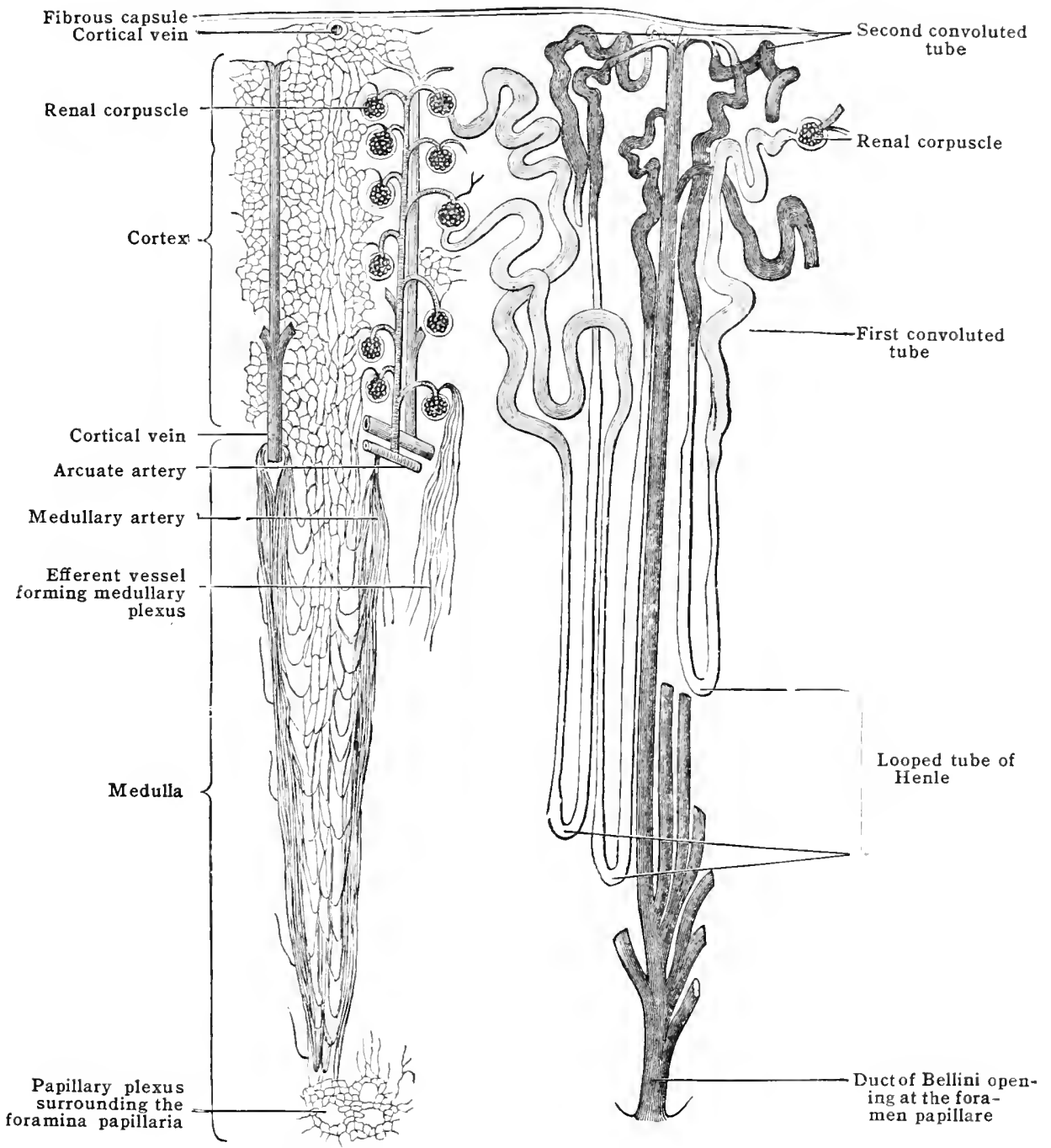

pass down into the pyramids, supplying the tubules of which these are composed. Efferent stems which issue from the Malpighian glomeruli break up into capillaries which supply the tubules contained in the cortex. Peins corresponding to the arteriolse rectio and to the interlobular, arcuate and interlobar arteries occur, opening into the renal veins, and, at the surface of the kidney, arranged in star-like groups, are the stellate veins [venie stellatæ], which open into the interlobular veins and also communicate with the veins of the adipose capsule. The renal lymphatics may be divided into two sets, capsular and parenchymatous. They terminate in the upper lumbar nodes.

Nerves. - The nerves form a plexus accompanying the vessels, and are derived from the sympathetic and vagus through the renal plexuses.

Variations.- The kidney of a fotus differs from that of the adult in being divided into a number of distinct renal lobes, each of which corresponds to the base of a renal pyramid and 
is capped by a thin layer of cortex. Such a condition is permanent in some of the lower animals: but in man the superficial indications of morphological segmentation usually become obliterated during the progress of growth of the cortical tissue, and are seldom visible after the age of ten.

Development.-In the development of the embryo, representatives of three different sets of excretory organs occur, the permanent kidney (metanephros) being the last to form. The two earlier sets (pronephros and mesonephros) have a common duct, the Wolffian duct, and from the lower end of this an outgrowth develops, which extends upward on the posterior abdominal wall and comes into connection with a mass of embryonic tissue known as the metanephric blastema. The outgrowth gives rise to the ureter, pelvis and collecting tubules, while the remaining portions of the tubules are formed from the blastema.

Various abnormalities may result from modifications of the development of the kidneys. (1) Occasionally the ureteric outgrowth of one side fails to develop, the result being the occurrence of a single kidney. (2) The blastema may fail to attain its normal position, in which case the kidney may be situated in the iliac region or even in the pelvis; or the blastema may be drawn into an unusual position, the kidney resting on the vertebral column, or even on the opposite side of the abdomen; (3) or the two blastemas may fuse to a greater or less extent, forming a "horse-shoe kidney," extending across the vertebral column; or, if the fusion be more extensive, an apparently single kidney, which may rest upon the vertebral column, or to one side of it. Such fused kidneys may be distinguished from single kidneys by the fact that they possess two ureters opening normally into the bladder. (4) In rare cases, a blastema may become divided, an accessory kidney of varying size being thus produced. (5) Finally, in one or more of the tubules there may be a failure of the union of the portion derived from the blastema with the collecting tubule derived from the ureteric upgrowth, and the secretion having no means of escape from such malformed tubules, they become greatly dilated, producing a cystic kidney.

\section{THE URETERS}

The ureter (figs. 1004, 1007, 1012, 1015), which serves as the exeretory duct of the kidney, is a canal, expanded and irregularly branched above, but narrow and of fairly uniform dimensions throughout the rest of its course. At its origin in the renal sinus it consists of a number of short tubes, usually eight or nine, called calyces minores (fig. 1012), each of which embraces a renal papilla, or occasionally two papillæ may be connected with a single calyx. These calyces minores open direetly or by means of short intermediate tubes (infundibula) into two short passages, the superior and inferior calyces majores, which in turn unite after a longer or shorter course to form the pelvis. Occasionally a third or middle calyx major is present.

The pelvis [pelvis renalis] (fig. 1012) is usually more or less funnel-shaped, being widler above, where it lies between the two lips of the hilus, and narrower below, where it arches downward and medially to become continuous with the ureter proper. It is, however, very variable in shape and in some eases is hardly larger than the ureter. Usually it is flattened dorso-ventrally so that its anterior and posterior walls are in contact and its eavity represented merely by a fissure. The majority of the branches of the renal vein and artery lie in front of it, imbedded in fat tissne, and anterior to these are the descending portion of the duodenum on the right side and the panereas on the left. The intra-renal portions of the ducts, including the pelvis, are considered parts of the kidney.

The ureter proper (fig. 1007) extends from the termination of the pelvis to the bladder, its course lying in the subperitoneal tissue. It is a tube about $5 \mathrm{~mm}$. in diamoter when distenderl and it is fairly uniform in size, exeept that a slight eonstriction oecurs where it enters the pelvis and a second one oeeurs at about the middle of its abrominal portion. Its length is variously stated, but the average in the inale adult may be taken as about $30 \mathrm{em}$., the right being usually a little the shorter.

Course and relations.- The course of each ureter may be eonveniently divided into three portions, abdominal, pelvie, and vesical. 'The abdominal portion [pars abdominalis] runs downward and slightly medially and is in relation posteriorly with the psoas muscle and its fascia; it erosses the genito-femoral nerve oblicunely and in the lower part of its contse passes in front of the eommon iliae artery near its bifureation. Anteriorly it is eovered by peritoneum and is erossed by the spermatic or ovarian vessals. Medially it is in relation on the right side with the inforior vena cava and on the left with the aorta, the vein being almost in contart with the right uroter, while the artery is separated from the left one by an interval that diminishes from 2.5 cm. above, to $1.5 \mathrm{~cm}$. opposite the bifureation of the vesserl.

The pelvic portion [pars polvina] basses in front of the sacro-iliae articulation 
and then forward and downward upon the obturator internus and its fascia behind and below the psoas, crossing the obturator vessels and nerve and having anterior to it in the female the posterior border of the ovary. It thus reaches the level of the floor of the peritoneal cavity, whereupon, at about the level of the ischial spine, its course is directed forward and medially toward the bladder. In this part of its course in the male, it is crossed superiorly and medially by the ductus deferens, and then passes under cover of the free extremity of the vesicula seminalis, separated from its fellow by a distance of $37 \mathrm{~mm}$. In the female it runs parallel with, and 8 to $12 \mathrm{~mm}$. distant from, the cervix uteri, passes behind the uterine artery, through the uterine plexus of veins, and beneath the root of the broad ligament, and finally crosses the upper third of the lateral wall of the vagina to reach the vesico-vaginal interspace and enter the substance of the bladder at about the junction of its posterior, superior and lateral surfaces.

The vesical portion, about $12 \mathrm{~mm}$. in length, runs obliquely downward and medialward through the coats of the bladder, and opens on its mucous surface about 20 to $25 \mathrm{~mm}$. from both its fellow and the internal urethral orifice.

Structure.-The wall of the ureter is about $1 \mathrm{~mm} .(1-i n$.$) in thickness, and consists of a$ mucous membrane, a muscular coat, and an external connective-tissue investment. The mucous membrane is longitudinally plicated, and is lined by transitional epithelium, continuous with that of the papillæ above and with that of the bladder below. Mucous follicles of simple form have been found in the upper part of the canal. The muscularis is about $0.5 \mathrm{~mm}$. $(1 / 50 \mathrm{in}$.) in thickness, and consists of two layers, an external, composed of annular fibres, and an internal,

Fig. 1012.-Pelvis and Upper Portion of Ureter. (After Henle.)

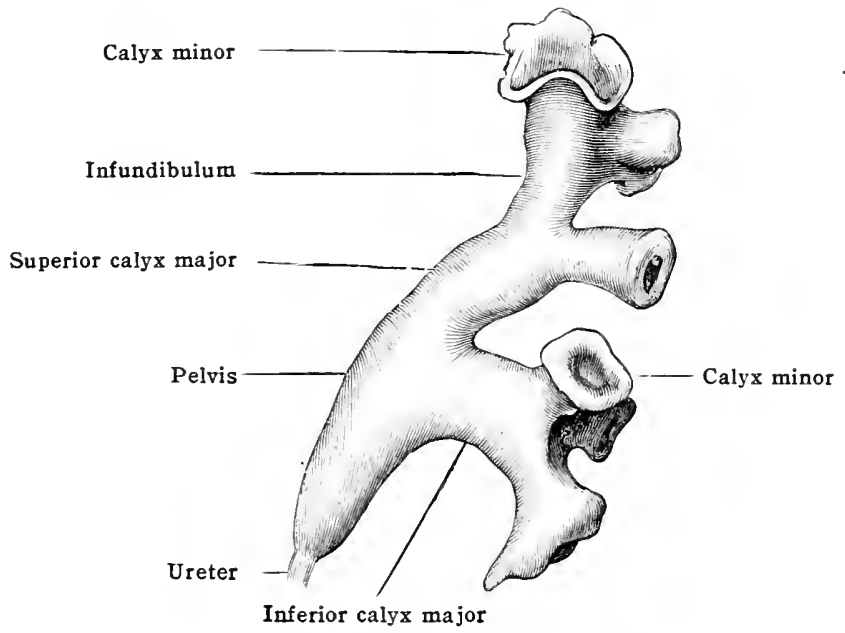

of fibres longitudinally disposed. After the tube has entered the bladder the circular fibres form a kind of sphincter around its vesical orifice; while the longitudinal fibres are continued onward through the wall of the bladder and terminate beneath its mucous membrane.

Vessels and nerves.-The arteries supplying the pelvis and upper part of the ureter come from the renal; the rest of the abdominal portion of the ureter is supplied by the spermatic (or ovarian), and its pelvic portion receives branches from the middle hæmorrhoidal and inferior vesical; the veins terminate in the corresponding trunks; and the lymphatics pass to the lumbar and hypogastric nodes. The nerves are supplied by the spermatic, renal, and hypogastric plexuses.

Variations.-Occasionally the depression which separates the two calyces majores extends through the pelvis, so that the calyces appear to open directly into the ureter. The fission may also affect the ureter to a greater or less extent, in extreme cases producing a duplication of the tube throughout its entire length.

\section{THE URINARY BLADDER}

The urinary bladder [vesica urinaria] is a receptacle, whose form, size, and position vary with the amount of its contents. The adult organ in its empty or moderately filled condition lies entirely below the level of the oblique plane of the pelvic inlet; but when considerably distended it rises into the abdomen and shows itself beneath the parietes as a characteristic mesial projection above the symphysis, a projection which in extreme distention of the bladder may extend nearly to the level of the umbilicus. 
Form. - When distended it assumes in the male an ovoid shape with its longest diameter directed from above downward and backward; but in the female the transverse diameter is the greatest, in accordance with the greater breadth of the pelvic eavity. In the child it is somewhat pear-shaped, the stalk being represented by the urachus.

Parts.-For convenience in description five surfaces may be recognized, but they are but indistinctly separated from cach other. One, the anterior or pubic surface, is directed forward and downward; second, the superior or intestinal surface, looks upward; the third, the posterior surface, looks backward; and the other two are the lateral surfaces. 'The anterior, superior, and lateral surfaces meet at the vertex of the bladder, from which the middle umbilical ligament (urachus) extends to the umbilicus; the posterior surface, sometimes flat and sometimes, especially in old age, convex, forms what is known as the base or fundus [fundus vesice]; and the portion of the viscus intervening between the vertex and

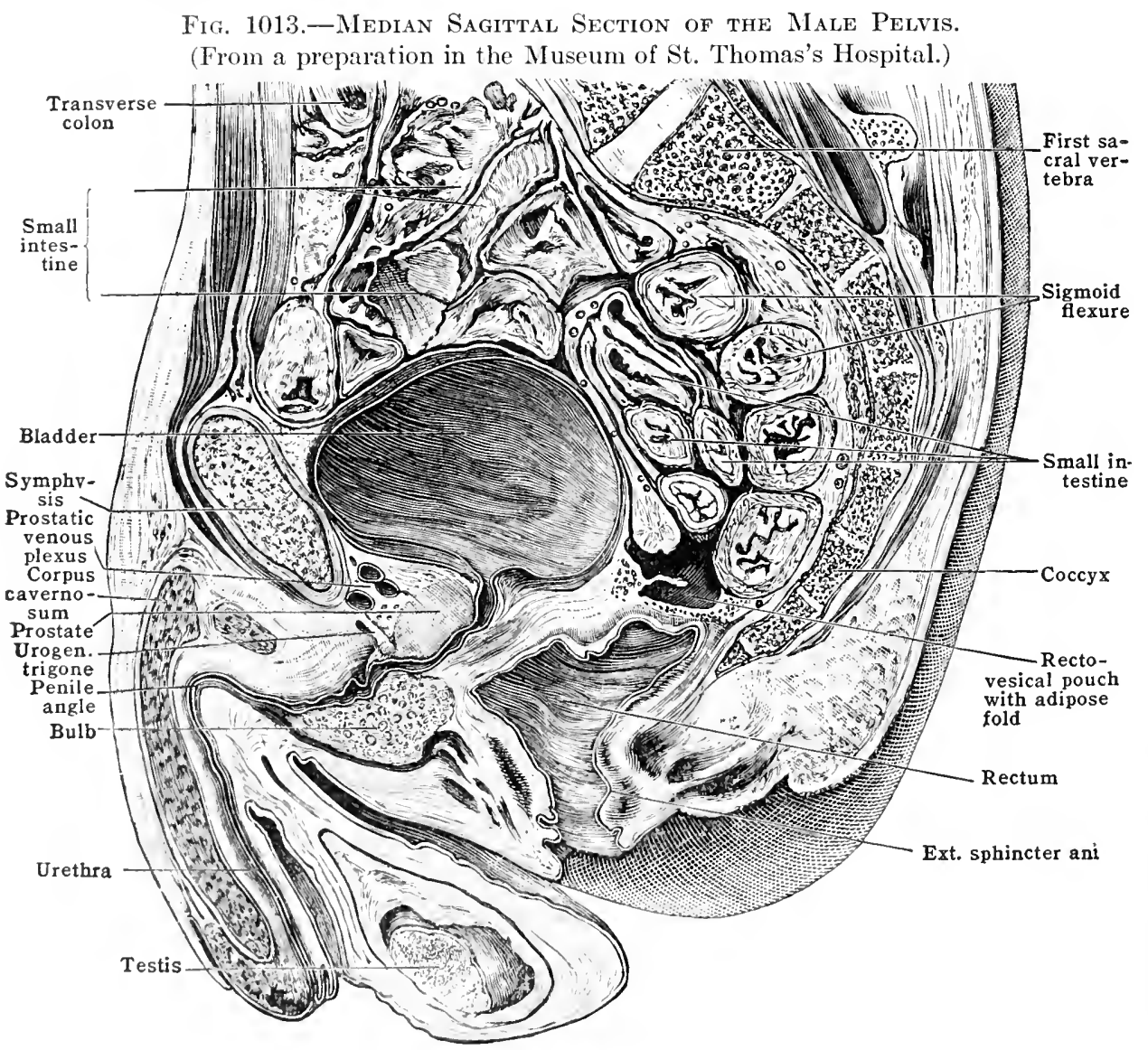

fundus is tremed the body [orpus vesie: 0 ]. In the centre of the line between the anterior and posterior surfaces is the internal urethral orifice [orificium urethrie intromm], by which the budeler communieates with the urethra, and the portion of the organ immodiatrly surromuling this is sometimes spoken of as the neck.

When the bladeler is anpty and relaxed, the superior surface sinks down upon the antrerior and posterior surfares, thus beroming concave, and the eavity of the organ is reduecel to a $\mathrm{T}$ - or $\mathrm{Y}$-shaped fissure. Fn the female, the cavity of the

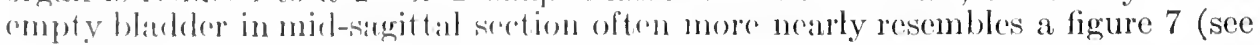
fig. 1014).

Relations. -The anterior surface looks downward and forward toward the symphysis pubis (figs. 1013, 101.1). It is uncovered by peritonemm, but is separatrol from the pubic: hones and antreior attachments of the obturatores interni and the levatores ani by a sparer known ats the prevesical space (cavum Retzii), 
which contains a variable quantity of loose fat continuous with the pelvic and abdominal subperitoneal tissue. Each lateral surface is covered by peritoneum down to the level at which it is crossed obliquely from behind forward and upward by the obliterated hypogastric artery. Below this level it is separated from the levator ani and obturator internus by subperitoneal tissue, which usually bears much fat in its meshes and ensheaths the vesical vessels and nerves. It is also crossed by the ductus deferens, which passes between the ureter and the wall of the bladder, a little above the level at which the former enters the wall of the bladder, at the junction of its lateral and posterior surfaces and about $3.5 \mathrm{~cm}$. above the fundus. The posterior surface may be divided into two portions, an upper covered by the peritoneum of the recto-vesical or vesico-uterine pouch (fig. 1013), and a lower in direct contact in the male with the anterior wall of the

Fig. 1014.-Mid-sagittal Section of the Female Pelvis. (Spalteholz.)

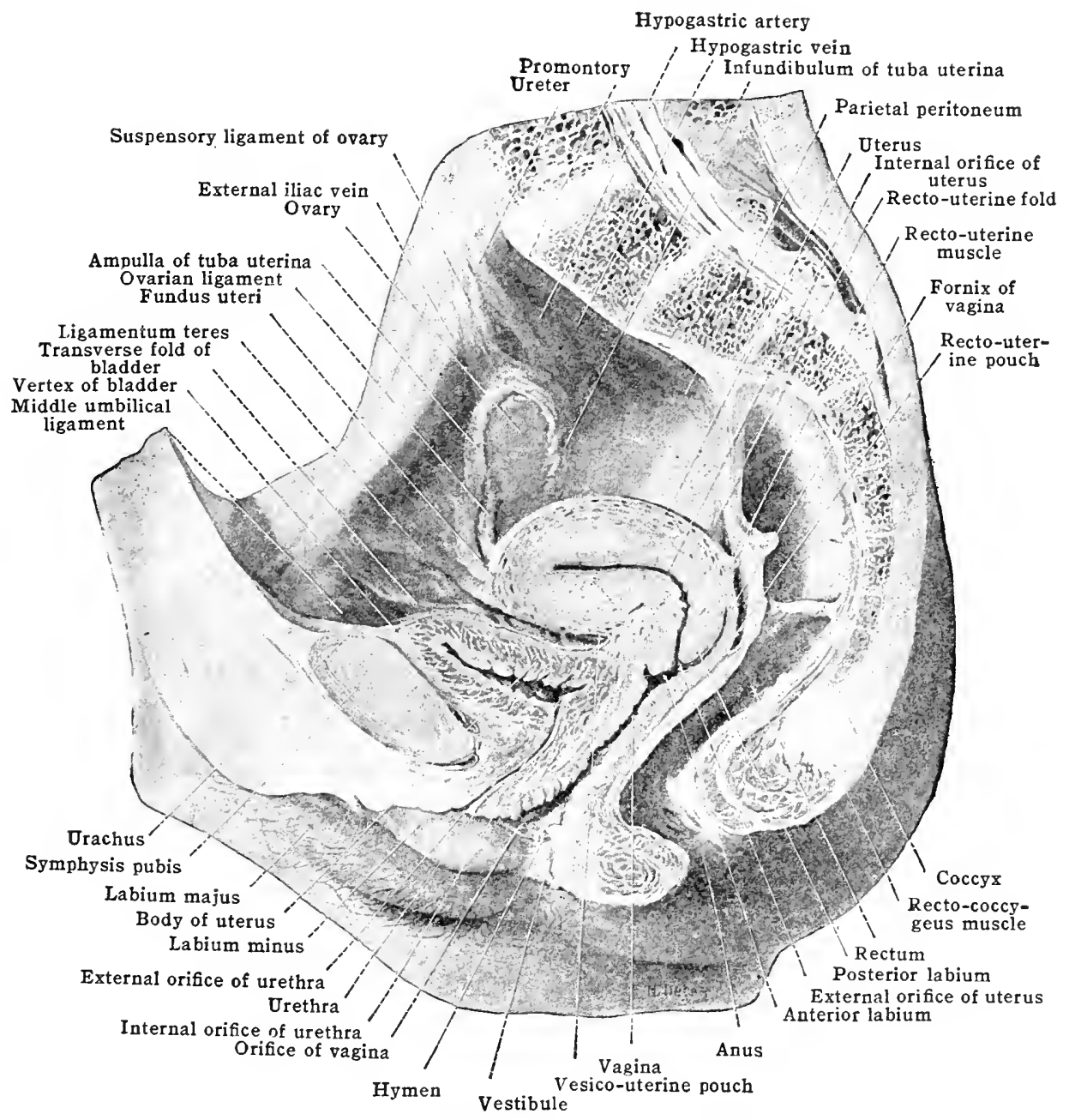

rectum and with the lower part of the ductus deferentes and the resiculæ seminales. Between the diverging ductus deferentes there is a triangular space, whose base is formed by the line of reflexion of the recto-vesical pouch of peritoneum and the apex by the meeting of the ejaculatory ducts at the summit of the prostate. It represents the area of direct contact of the posterior wall of the bladder with the rectum. In the female the posterior surface is aclherent in its lower part to the cervix of the uterus and the upper part of the anterior wall of the vagina (fig. 1014), but it is separated above from the body of the uterus by the shallow vesicouterine pouch of peritoneum.

The superior surface is entirely covered by peritoneum. It looks almost 
directly upward into the abdominal eavity and has resting upon it eoils of the small intestines and sometimes a portion of the sigmoid colon behind these.

Variation in position.-In the normal condition the bladder of the adult lies below the upper border of the symphysis pubis, but if fully distended it may rise above this level, carrying with it the reflexion of peritoneum from its upper surface to the anterior abdominal wall. The anterior surface of the bladder is thus brought into relation with the anterior abdominal wall, being separated from it only by the enlarged prevesical space, and it is thus possible to enter the bladder above the symphysis pubis without penetrating the peritoneum.

In the infant, owing to the smaller extent of the pelvic cavity, the bladder lies at a somewhat higher level than in the adult and rises into the abdominal cavity. Indeed the entire bladder is above the horizontal level of the pubic erests, the urethral orifice being behind the upper margin of the symphysis pubis. As the child learns to walk, however, this position gradually alters and usually by the age of six years the adult relations have been acquired.

The fixation of the bladder.-The reflections of the peritoneum from the superior surface of the bladder to the anterior abdominal wall and from the sides and back to the corresponding walls of the pelvis are sometimes described as the superior, lateral and posterior false ligaments. Furthermore there extends from the apex of the bladder to the umbilicus a fibrous cord, the urachus, the remains of the embryonic allantois; this is deseribed as the middle umbilical ligament of the bladder (fig. 1014), and lateral umbilical ligaments are formed by the obliterated hypogastric arteries which carried the fotal blood to the placenta and in the

Fig. 1015.-The Posterior Wall of the Bladder. (After Henle.)

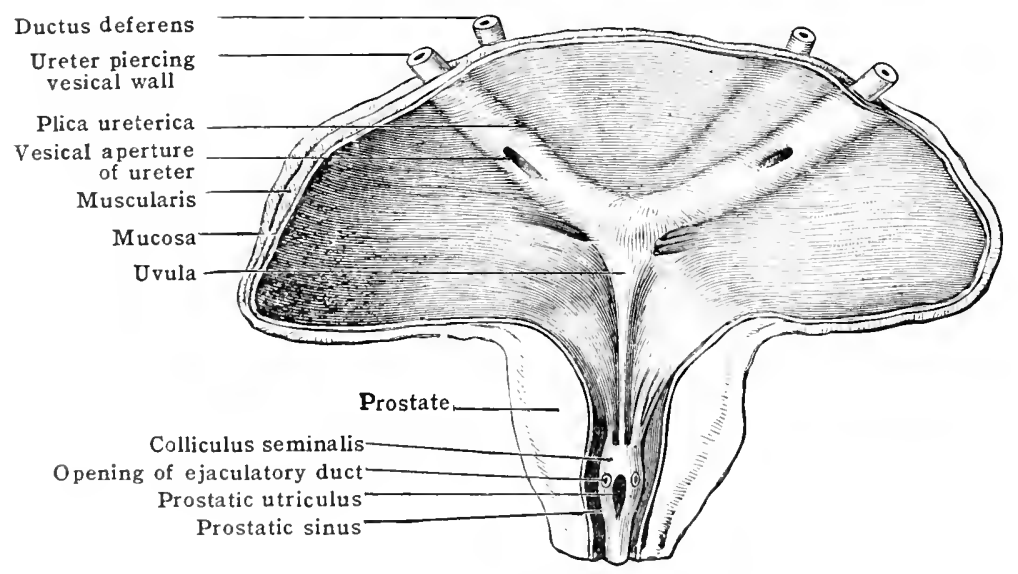

adult are represented by fibrous cords passing over the sides of the bladder and ascencling to the umbilieus.

In ardition to these structures eertain thiekenings of the endopelvic fascia, wherr it comes into relation with the base of the bladder and prostate gland, constitute what are termed the true ligaments. 'T'wo such thickenings extend from the anterior surface of the capsule of the prostate gland, or from the lower part of the anterior surface of the bladder in the female, to the pubie bones and constitute what are known as the midlle pubo-prostatic (pubo-vesical) ligaments, with which muscle fihres [m. pubovesicalis] are usually associated. Similarly, thickenings of the fascia extending from the sirles of the prostate gland or from the sildes of the hase of the hidrlere to the lateral walls of the pelvis form the lateral true ligume'nts.

Muscle filmere [m. reetovesionlis] also orecu in the subperitoneal tissue contained within the propitomal folds (jostrior fallse ligaments) extemding from the back of the bladder to the pesterior wall of the polvis and fommling the recto-vesical pouch of peritoneum in the male. They correspond to the mm. rectouterini of the fermale.

The internal surface. 'Thr mucous membane lining the internal surface of the blather is soft and rose-eolomorel during life, and in the empty bladder is thrown into irregular folds whinh beenome offaced by rlistention. It is modified over a triangular area at the base of the hasher, termed the trigone [trigonum

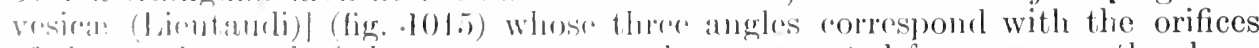
of the curethat and of the two ureters, and are separated from one another by a 
distance of 20 to $25 \mathrm{~mm}$. This area is paler in colour and free from the plication that characterizes the rest of the mucous membrane; it is bounded posteriorly by a transverse ridge, the plica ureterica, extending between the orifices of the ureters, and toward the urethral orifice presents a median longitudinal elevation, the uvula vesicce, which is apt to be especially prominent in aged persons. The internal urethral orifice is normally situated at the lowest point of the bladder, at. the junction of the anterior and posterior surfaces. It is surrounded by a more or less distinct circular elevation, the urethral annulus, and is usually on a level with about the center of the symphysis pubis and from 2.0 to $2.5 \mathrm{~cm}$. behind it.

Structure.--The general characteristics of the mucous membrane of the bladder, which is lined by epithelium of the transitional variety, have already been described. It rests upon a loose submucous tissue, which contains numerous elastic fibres. The greater part of the thickness of the wall is formed, however, of the muscular coat, consisting of non-striped muscle tissue, the fibres of which are arranged in three more or less distinct layers. The outer layer is composed mainly of longitudinal fibres, some of which are continued forward to the pubis from the neck of the bladder to form the min. pubovesicales and others backward to form the $\mathrm{mm}$. rectovesicales. To this outer layer the term $m$. detrusor urino has been applied, but it should be noted that it does not contract independently of the circular layer. The midalle ayer is thicker than the outer and more uniformly developed. It consists of fibres having for the most part a circular direction and is well developed over all the upper portion of the bladder, but becomes thinner in the region corresponding to the trigone. It is here that the inner layer is chiefly developed, consisting of fibres, which are situated partly in the submucous tissue and have a general longitudinal direction throughout the region of the trigone. At the neck of the bladder, however, they form a strong circular bundle, which is continued into the prostatic portion of the urethra and forms what is termed the internal sphincter of the bladder.

Vessels. - The arteries of the bladder are usually two in number, the superior and inferior vesical, branches of the hypogastric artery; the fundus also receives branches froin the middle hæmorrhoidal and in the female twigs are also sent to it from the uterine and vaginal arteries. The veins form an extensive plexus at the sides of the bladder, from which stems pass to the hypogastric trunk. The lymphatics accompany the veins and communicate with the hypogastric nodes, some of those from the fundus passing to nodes situated at the promontory of the sacrum.

Nerves.-The nerves are derived partly from the hypogastric sympathetic plexus and partly from the second and third sacral nerves. The fibres from the latter constitute the nervi erigentes, stimulation of which produces contraction of the general musculature and relaxation of the internal splincter. On each side of the bladder there is formed a sympathetic vesical plexus, from which superior and inferior vesical nerves pass to the corresponding parts of the
bladder.

Development.- In the earlier stages of development the urogenital ducts and the digestive tract open below into a common cavity, the cloaca, from the ventral portion of which a long tubular outgrowth, the allantois, extends out to the placenta through the umbilical cord. Later the cloaca becomes divided in the frontal plane into a ventral portion which receives the urogenital ducts, and a dorsal portion, which becomes the lower end of the rectum. From the upper part of the ventral portion the bladder is developed. Since the cloaca is lined by endoderm the mucous membrane of the bladder is mainly derived from that embryonic layer, but it is worthy of note that portions of the lower ends of the ureters are taken up into the wall of the bladder, giving rise to the area of the trigone, whose mucous membrane is thus of mesodermal origin. The portion of the allantois within the body of the fotus is transformed after birth into a fibrous cord, the urachus.

The urethra will be considered later in connection with the reproductive organs.

\section{B. THE REPRODUCTIVE ORGANS}

The reproductive organs include those of the male [organa genitalia virilia]. and those of the female [organa genitalia muliebria].

\section{THE MALE REPRODUCTIVE ORGANS}

The reproductive organs of the male consist of (1) two testes in which the spermatozoa are formed, (2) their ducts, the ductus deferentes; enclosed throughout a portion of their course in the spermatic cord; and the seminal vesicles, reservoirs for the semen, connected with the ductus deferentes; (3) the penis, the organ of copulation, which is traversed by the urethra; (4) the urethra, a canal into which the ductus deferentes open and which also gives exit to the contents of the bladder; (5) the prostate gland, a musculoglandular structure surrounding the beginning of the urethra; (6) the bulbo-urethral glands which open into the urethra. 


\section{The Testes and Their Appendages}

The scrotum.-The two testes, together with the beginning of the ductus deferentes, are contained within a pouch, the scrotum, which is divided into two compartments by a median sagittal septum, the edge of which is indicated on the surface by a ridge-like thickening of the integument, termed the raphe.

This double condition of the scrotum is explained by its origin from the fusion of two outpouchings of the lower portion of the abdominal wall, the inguinal canals forming, as it were, the necks of the outpouchings. The testes are primarily retroperitoneal abdominal organs, but later they descend through the inguinal canals into the scrotal outpouchings, where they lie between the peritoneal sac which each of these contains and the remaining layers of the wall, thus retaining their retroperitoneal position. The peritoneal sacs are at first in communication with the abdominal cavity, but after the descent of the testes each undergoes degeneration in its upper part, the cavity disappearing and the peritoneal tissue becoming converted into a portion of the connective tissue in which the ductus deferens and the vessels and nerves associated with it are imbedded in their course through the spermatic cord. The portion of the sac in relation with each testis persists, however, and wrapping itself around that structure forms for it a serous investment, the tunica vaginalis propria (fig. 1016).

The-integument of the scrotum is more or less pigmented and presents numerous transverse ridges extending laterally on either side from the raphe. It is furnished in the adlult with coarse, seattered hairs and its sebaceous and sudoriparous glands are well developed. The deeper layers of the dermis, have a pinkish colour, and form what is termed the dartos (fig. 1016), the colouration being clue to the

Fig. 1016.-Horizontal Section of the Scrotum and Testis. (Diagrammatic.)

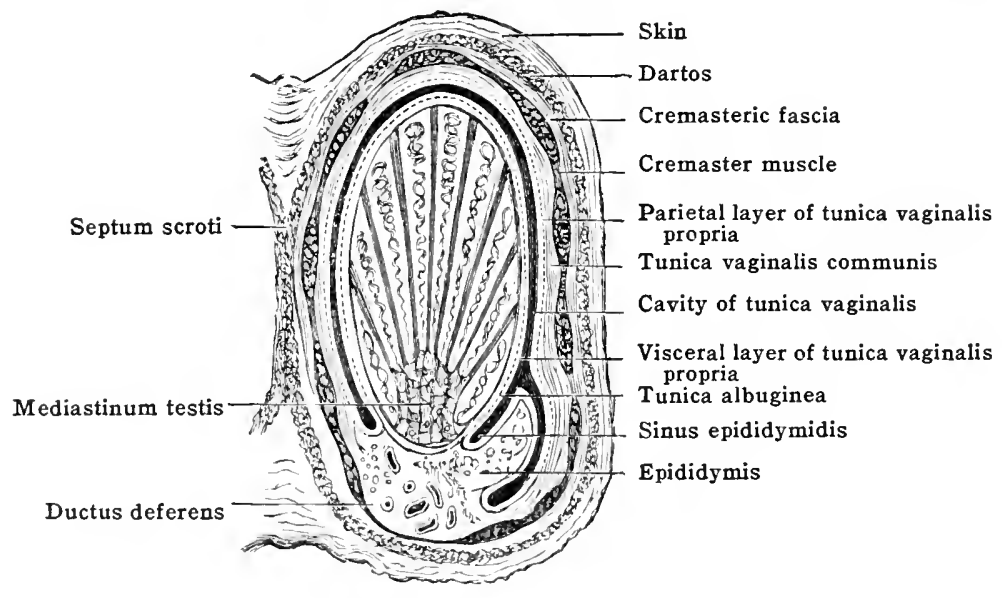

presence in it of numerous non-striated muscle fibres, which are for the most part arranged at right angles to the wrinkles of the surface and are the cause of these. The more superficial fibres of the dartos, like the rest of the integument, form a common investment for both testes, but the deeper ones of either side bend inward at the raphe and assist in the formation of the septum.

Internal to the diutos and closely rolated to it is a layer of laminated connective tissue, the cremasteric fascia. It is destitute of fat and is continuous at the subeutaneous inguinal ring with the intercrural fibres, being probably the scrotal representative of the riternal oblique muscle. It is suceeded by a strong sheet of fiscia containing longiturlinal bands of striated musele tissue, forming what is termed the cromaster muscle (figs. 389, 1016) and boing continuous above with the fibres of the internal oblique muscle of the absomen. Internsl to this is a thin layer of conne' tive tissue, the tunica raginalis communis, which is eontinuons with the transversalis fascia at the inguinal ring, and, finally, there is the lanica vaginalis propria, which forms the serous investment of the frestis and, as has been statrol, is of protoneal origin. Like other similar serous investments it has the form of a double sac, the outer or parietal layer of which is closely allorent to the tunica vaginalis communis and contains numerous nonstripeal muscle fibres forming what has been termed the internal cremaster muscle. The inner or visceral layer is thinner and closely invests the testis and a 
portion of the epididymis, being reflected from the inferior and posterior parts of the latter to be continuous with the parietal layer. Toward the upper part of the lateral surface of the testis it is folded in between that structure and the epididymis, forming a well-marked pocket, the sinus epididymidis (digital fossa) (fig. 1017), whose upper and lower lips form what are termed the ligamentaepididymidis.

Vessels and nerves.-The skin and dartos of the scrotum are supplied partly by the perineal branch of the internal pudendal artery and partly by the external pudendal branches of the femoral. The deeper layers are supplied by the spermatic branch of the inferior epigastric. The veins accompany the arteries, the cxternal pudendals opening into the internal saphenous vein near its termination. The lymphatics terminate in the more medial inguinal nodes. Several nerves take part in the supply of the scrotum. The external spermatic branch of the genito-femoral gives sensory branches to the anterior and lateral surfaces and also supplies the external cremaster muscle; the posterior surface is supplied by the perineal branch of the pudendal nerve; and the inferior surface by the perineal branches of the posterior femoral

Fig. 1017.- - The Leff Testis with Vessels and Duct. (After Sappey.)

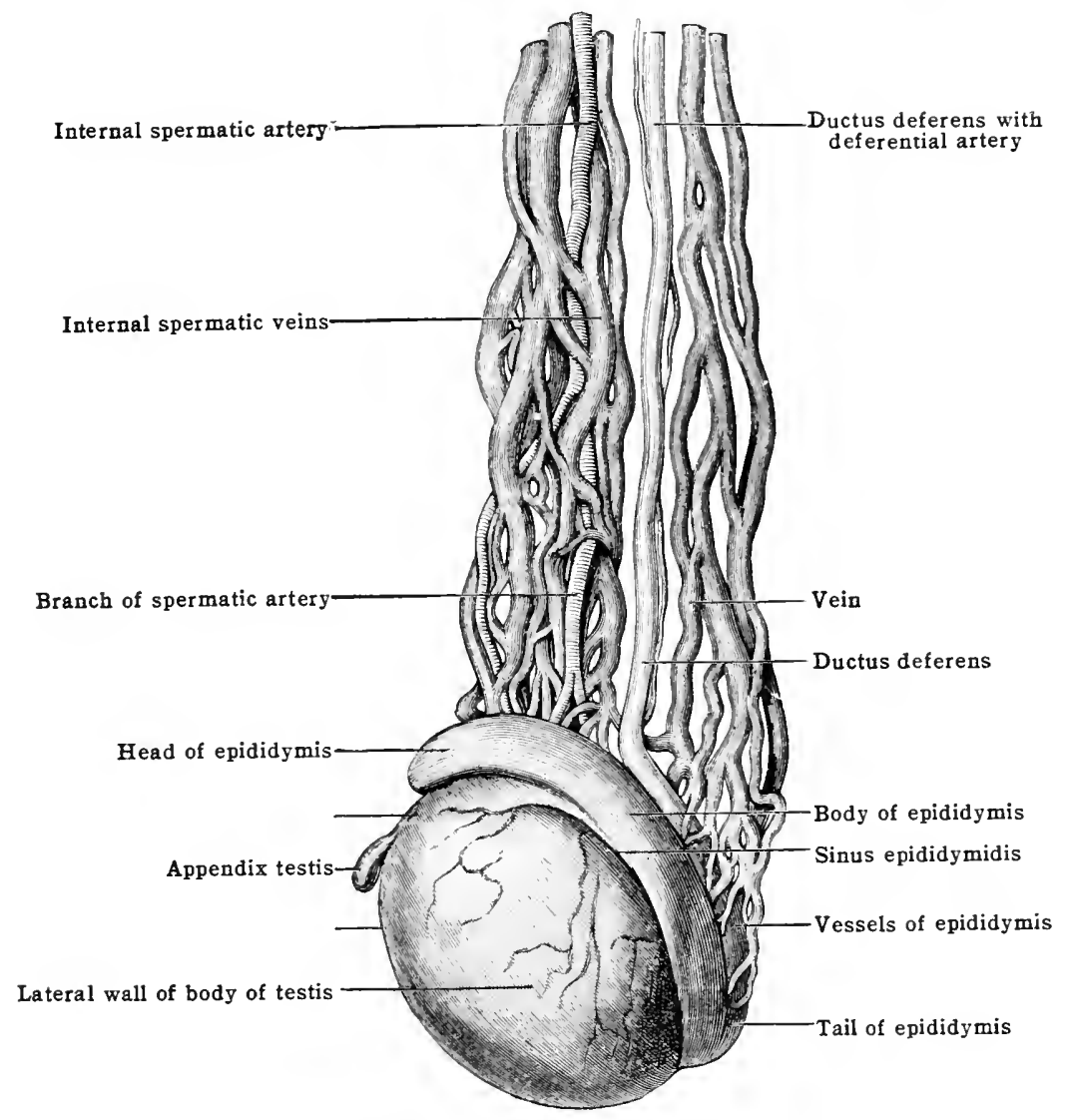

cutaneous. The anterior aspect of the serotum is also supplied by anterior serotal branches of the ilio-inguinal. The non-striped musculature is probably supplied by the internal spermatic nerve from the hypogastric plexus.

Hernia. - The communication of the tunica vaginalis propria with the abdominal peritoneum is usually obliterated within a few days after birth, but sometimes the process of obliteration is more or less incomplete. If the communication remains open there is a free passage for a loop of the intestine to enter the cavity of the tunica vaginalis, such a condition constituting what is known as the congenital variety of inguinal hernia. If the communication be interrupted only at the upper part of the original sae, so that the cavity of the tunica vaginalis propria extends a considerable distance up the spermatic cord a hernia, passing through the inguinal canal, may invaginate the upper part of the tunica vaginalis into the lower, producing what is termed the encysted variety of hernia. Or if, finally, the obliteration of the communication begins in the neighbourhood of the testis, a funnel-shaped prolongation of the 'peritoneal cavity may extend downward into the spermatic cord, and hernia into this constitutes the variety known as hernia into the funicular process.

The testis and epididymis. - The testes (fig. 1017) are the essential male organs of reproduction and are contained within the scrotum. They are two in number, 
each being of a flattened oval form, with two surfaces, medial and lateral, two borders, anterior and posterior, and two extremities, superior and inferior. To the whole of the posterior border there is attached the epididymis, formed by the efferent ducts. The testis is obliquely placed, so that the medial surface also looks somewhat forward and downward.

The surface of the testis is covered by the visceral layer of the tunica vaginalis propria except where it is in contact with the epididymis, and is formed by a dense white inelastic capsule, the tunica albuginea, beneath which is a looser and more vascular laver known as the tunica vasculosa. From the inner surface of the albuginea, lamellie of connective tissue, known as septula, converge toward the posterior border of the testis and toward its upper part unite together to form a network (fig. 1018), the mediastinum testis (or corpus Highmori), through which blood-ressels and lymphatics enter and leave the testis, while by the interspaces of the network, known as the rete testis, the tubules of the testis are placed in communication with the epididymis.

The septula divide the substance of the testis into a number of compartments or lobules, each of which is occupied by a number of slender, greatly contorted canals, the seminiferous tubules [tubuli seminiferi], from whose epithelial lining the spermatozoa are formed. The tubules of each lobule converge to form a single, almost straight duct and these tubuli recti pass

Fig. 1018.-Diagram of the Testicular Tubules.

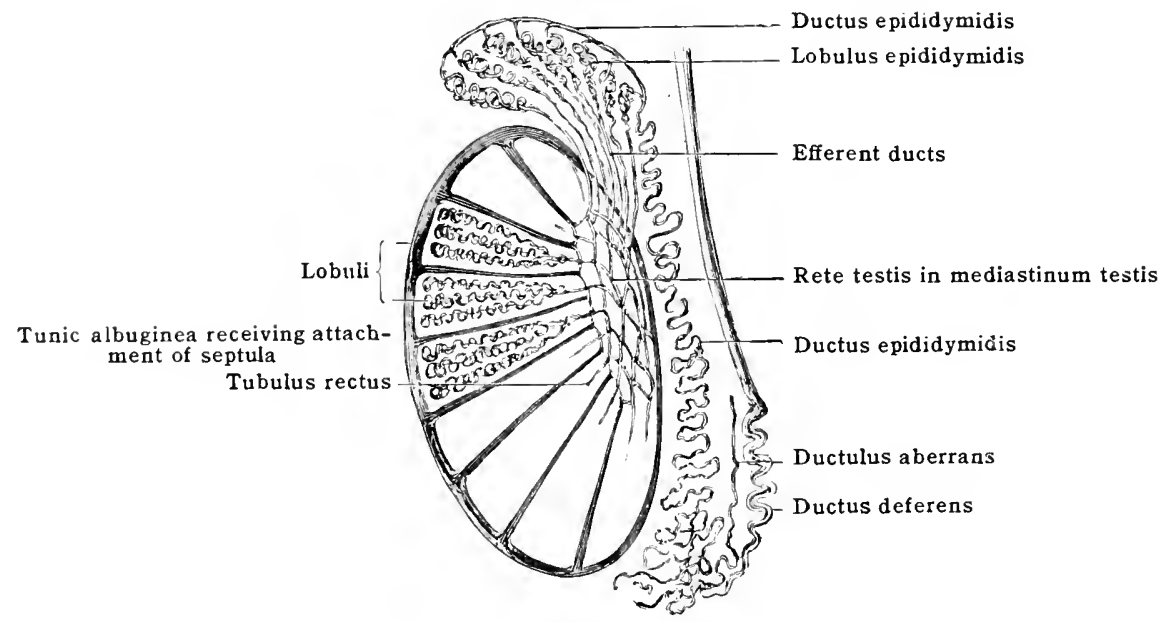

toward the mediastinum, where they open into the rete testis. In the lobules the seminiferous tubules are imbedded in a loose connective tissue that contains certain peculiar cells, the interstitial cells, to which has been attributed the formation of an internal secretion.

The epididymis (fig. 1017), which lies along the posterior border of the testis, is an clongated structure with a body [corpus epididymidis], enlarged above to form the head [caput] and to a less extent below to form the tail [cauda]. It is invested by a tunica albuginea, continuous with, but much thinner than that of the testis, and is formed mainly by the greatly contorted duct of the epididymis, which represents the beginning of the ductus deferens.

The hearl is formed by 12-14 tubules, the efferent ducts (fig. 1018), which take their origin from the rete testis as almost straight tubules, but gradually become greatly coiled, so that earh duct has the form of an elongated cone, its coilerl portion forming what is termed a lobulus epilidymidis. At their coriled culds the various efferent duets open into a single tube, the

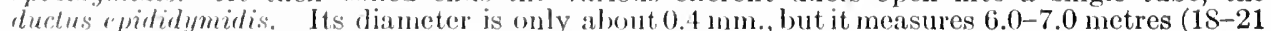
fent) in its entire length, leeing coiled so extensively as to be contained within the body and tail of the coididymis. In this latter dogion it passes over into the ductus deferens.

Vessels.-The principal artery supplying the festis is the internal spermatic, from which branches are alios sent to the epididymis. The deferential ajtery, a branch of the superior vecical, also sends branches to the poidldymis and cnters into extensive anastonoses with the testirilar branches of the internal spermatir, and anastomoses also occur with the vessels sujplying the scrotum. The virs correspons with the arteries. The lymphatics of the testis and "pinlislynis unite to form four to six large sitoms which pass upward in the spermatic cord (o) torminate in the lower lumbar nodes.

Morphology,- 'The tost is is primarily an atudominal organ and is developed in close relationship with the provisional kidney [mesonephros] whose duet, indeed, becomes the ductus deferens 
and some of whose tubules, becoming the efferent ducts, place the seminiferous tubules in communication with the ductus deferens. The epididymis may therefore be said to be developed from the mesonephros. The portions of this structure that are not concerned in the formation of the efferent ducts disappear for the most part; a few of the tubules persist, however, as rudimentary organs associated with the epididymis. Among these may be mentioned one or more blindly ending, coiled tubules, varying from $5-30 \mathrm{~cm}$. in length, which are connected with the ductus epididymidis usually in the tail of the epididymis. They are known as the duetuli aberrantes (fig. 1015) and may be regarded as persistent excretory mesonephric tubules. Another of the rudimentary organs is the paradidymis (organ of Giraldes), which is a whitish body, situated immediately above the head of the epididymis, and is composed of irregularly coiled tubules, which terminate blindly at both extremities. They may be regarded as efferent ducts that have failed to connect with the testis and are of interest in that they sonretimes develop into cysts connected with the epididymis.

In addition there is frequently attached to the upper pole of the testis a solid oval body composed of connective tissue, known as the appendix testis (hydatid of Morgagri) (fig. 1017). It measures from 3 to $8 \mathrm{~mm}$. in length and its significance is doubtful. A similar, though smaller structure, the appendix epididymidis, is attached less frequently to the liead of the epididymis. It is usually provided with a distinct stalk and contains a cavity; it is believed to represent the upper end of the Müllerian duct, present in the embryo and giving rise to the tuba uterina in the female, but almost completely degenerating in the inale.

The testis begins its descent from the abdominal cavity into the scrotum at the third month of fetal life and reaches the abdominal inguinal ring at about the sixth month, but it is not until shortly before birth that it arrives at its final location in the scrotum. The cause of the descent is still uncertain, but it is supposed to be partly due to the failure of a band of connective tissue, which extends from the lower pole of the embryonic testis to the bottom of the serotal pouch, to keep pace with the growth of the body walls. This ligament, which is known as the gubernaculum testis, thus becomes relatively shorter and draws the test is downward toward the point of its attachment to the scrotum. There are various features in the descent, however, that cannot be explained by the simple traction of the gubernaculum and it must be regarded as a complicated growth process whose meaning is yet uncertain. The gubernaculum testis apparently undergoes degeneration after the testis has reached its definitive location and cannot be recognized in connection with the adult testis.

Occasionally the descent of the testis is interrupted, the organ remaining either in the abdomen or in the inguinal canal. This condition of cryptorchism is always associated with a suppression of the function of the organ.

\section{The Ductus Deferentes and Vesicule Seminales}

Each ductus deferens is the continuation of a ductus epididymidis and extends from the tail of the epididymis to the prostatic portion of the urethra. At its beginning it ascends along the posterior border of the epididymis (testicular portion) and is at first slender and tortuous (fig. 1018), but before reaching the level of the head of the epididymis it becomes straighter and thicker (fig. 1017), owing to the development in its walls of strong layers of longitudinal and circular non-striated muscle tissue. Thence it is continued almost vertically upward as one of the constituents of the spermatic cord (funicular portion) to the subcutaneous inguinal ring, and, entering this, traverses the inguinal canal (inguinal portion), still forming a portion of the cord. At the abdominal ring it separates from the other constituents of the cord and, looping over the inferior epigastric artery near its origin, passes downward and backward over the lateral surface of the bladder (pelvic portion). At the junction of the posterior and lateral surfaces of the bladder it passes medially to the ureter and is then continued downward, forward and medially upon the base of the bladder until it reaches the prostate gland (fig. 1019), whose substance it traverses, as the ductus ejaculatorius, to open into the prostatic portion of the urethra (see p. 1263).

Just before it reaches the prostate gland each ductus deferens presents an irregular spindle-shaped enlargement, the ampulla (figs. 1019, 1020), whose walls are somewhat sacculated. Just beyond this it is joined upon its lateral surface by a club-shaped lobulated structure, the vesicula seminalis (fig. 1019). Each vesicle measures $4.5-5.5 \mathrm{~cm}$. in length and has a greatest diameter of about $2 \mathrm{~cm}$. It rests upon the posterior surface of the bladder, lying parallel with and lateral to the corresponding ductus deferens, and in its upper one-third is in relation posteriorly with the peritoneum which forms the anterior wall of the rectovesical pouch, while below it is in contact with the anterior wall of the lower part of the rectum, through which it may be palpated. Indeed, the trro vesiculæ, together with the ductus deferentes, form the lateral boundaries of the triangular area at the base of the bladder, throughout which that organ is in relation to the rectum. 
Each vesicle is enclosed within a fine capsule of connective tissue, which contains numerous non-striated muscle fibres and is continuous below with the capsule of the prostate gland. On removing this capsule the vesicle will be found to consist of a greatly coiled tube, 10-12 $\mathrm{cm}$.

Fig. 1019.-Ductus Deferentes and Vesiculæ Seminales. (After Sappey.)

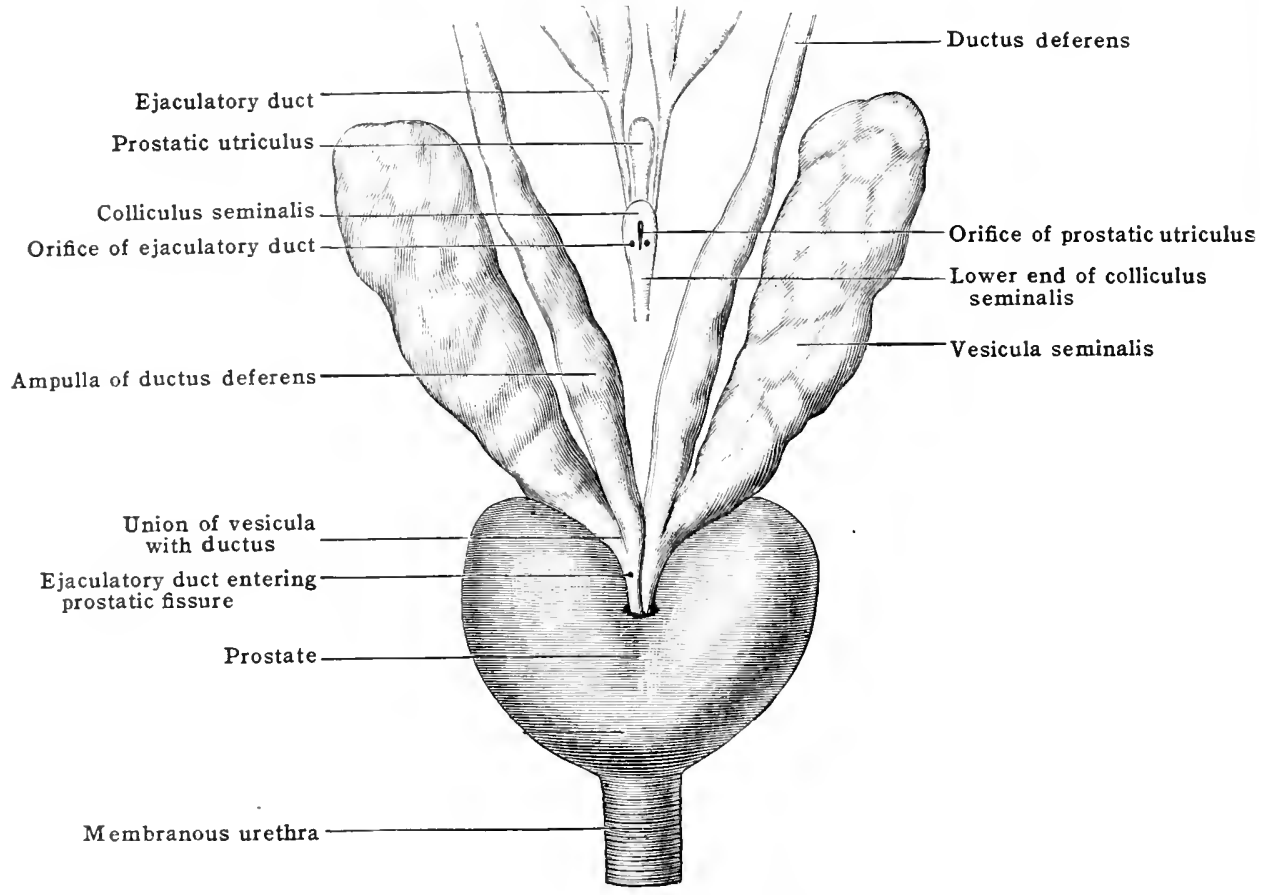

Fig. 1020.-Ductus Deferens and Vesicula Seminalis dissected. (After Sappey.)

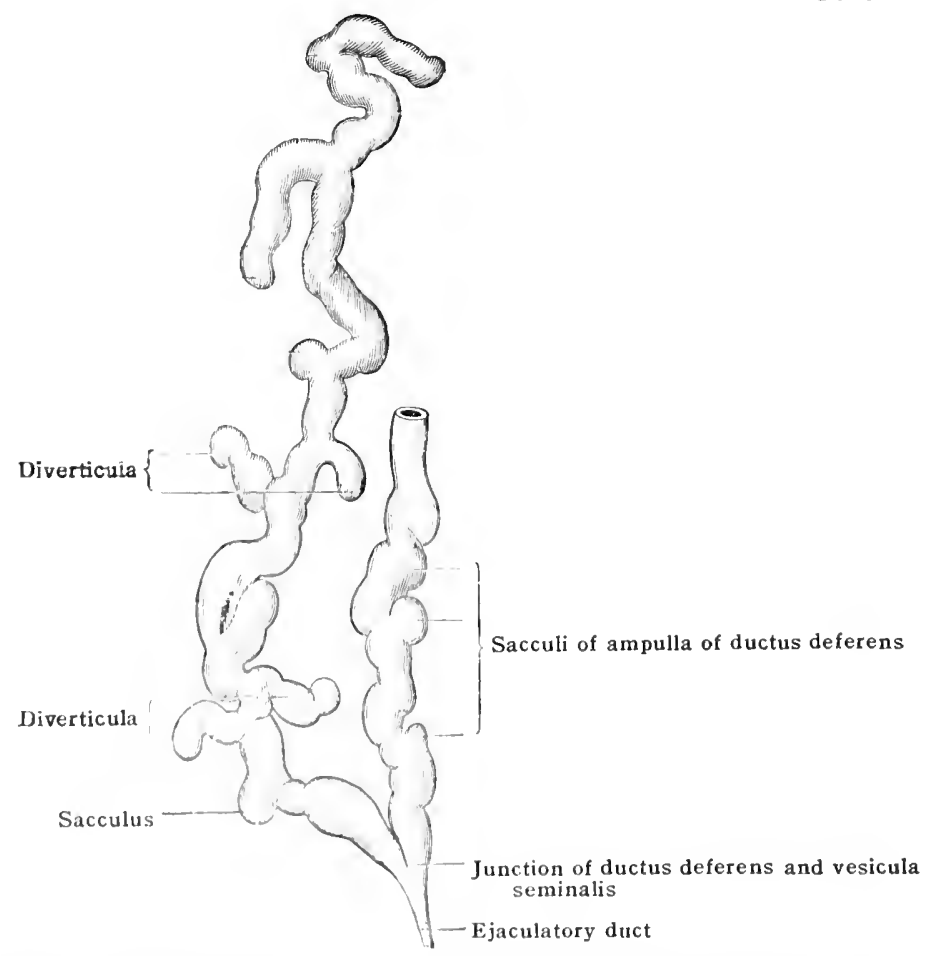

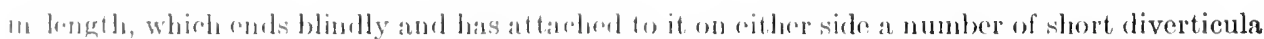
(fig. 1(1)20). The walls of the tube and diverticula are formed of smooth muscle tissue, anranged in layers similar to those of the dueftus deferentes, and atre lined by a much folded mucous 
membrane, whose cells contain considerable quantities of a yellowish-brown pigment, and also contribute a secretion to the seminal fluid. In addition to having this function the vesiculie also serve as receptacles for the spermatozoa. They arise as divertieula from the embryonic ductus deferens, and it is worthy of note that a number ( 4 or 5 ) of similar but quite small diverticula arise from the upper part of each ductus ejaculatorius.

Vessels and nerves.-The artery supplying the duetus deferens is the a. deferentialis, a branch of the superior vesical. It aceompanies the ductus to the tail of the epididymis and also gives a branch to the vesicula seminalis. The latter also receives branches from the middle hremorrhoidal and inferior vesical arteries. The deferential vein accompanies the durtus deferens to the base of the bladder where it breaks up into a plexus that communicates with the seminal venous plexus formed by the veins from the seminal vesicles. This joins with the vesical and pudendal plexus and so communieates with the hypogastric vein. The lymphatics of the ductus deferentes and seminal vesicles pass to the external iliac and hypogastric nodes. The nerves of both structures are derived from the hypogastric plexus.

The spermatic cord.- In its descent through the inguinal canal into the scrotum the testis necessarily drags after it the ductus deferens and the testicular vessels and nerves, these structures coming together at the abdominal inguinal

Fig. 1021.-Cross-section of the Spermatic Cord.

A. spermatica interna

Lymph vesse]

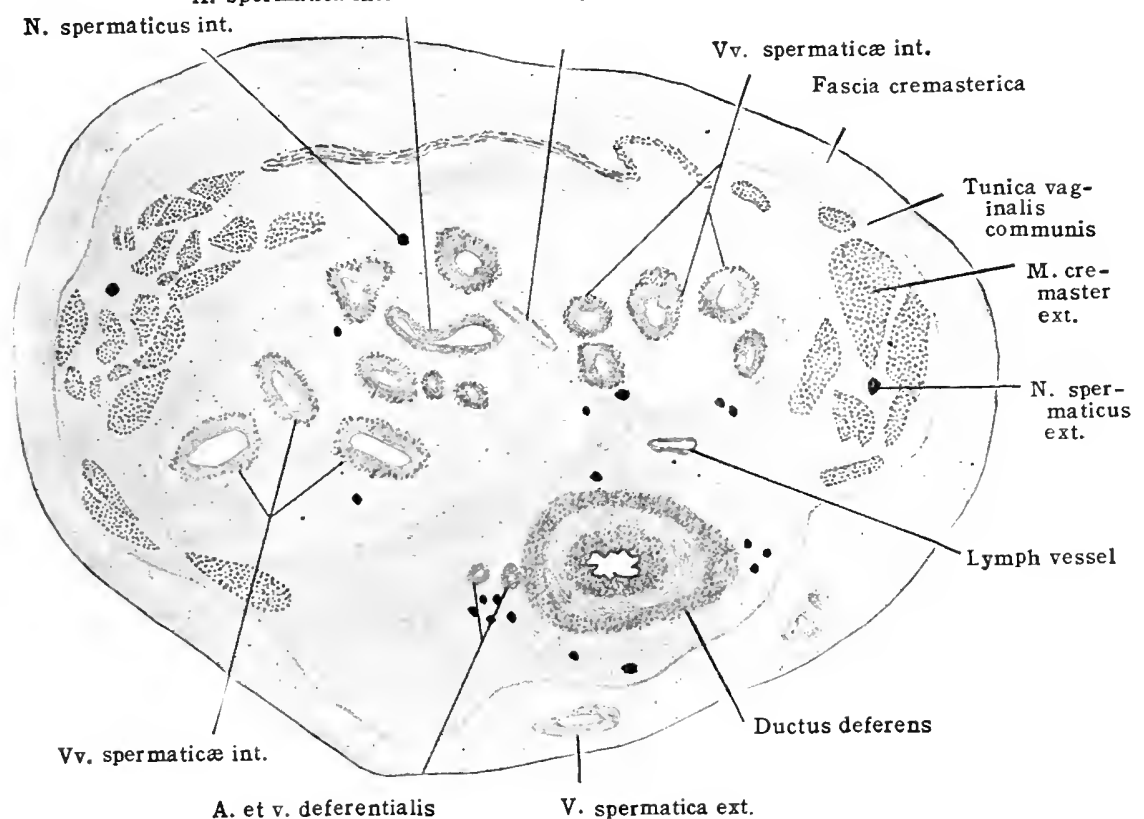

ring to form what is termed the spermatic cord [funiculus spermatieus]. This structure extends, therefore, from the abdominal inguinal ring, through the inguinal canal and the neek of the scrotal sack to the testis, and is enclosed within the same investing layers as the testis.

Thus as it emerges from the subcutaneous inguinal ring it receives an investment of connective tissue continuous with the intercrural fibres and the aponeurosis of the external oblique muscle. This cremasteric fascia has beneath it bands of striated muscle tissue, the external cremaster muscle (fig. 1021), especially developed on the posterior surface of the cord and continuous with the internal oblique muscle of the abdomen, and within these is an indistinet. layer of connective tissue, the tunica raginalis communis, which is received at the abdominal inguinal ring where it is continuous with the fascia transversalis.

Within the sheath thus formed there is a matrix of connective tissue, usually containing considerable amounts of fat and strands of non-striated muscle tissue, which form what is termed the inlernal cremaster muscle (funicular portion), and imbedded in this eonnective tissue are the various essential constituents of the cord. These are as follows (figs. 1017, 1021): (1) the duetus deferens, occupying the posterior surface of the cord and having associated with it the deferential artery and veins and the deferential plexus of nerve fibres; (2) the internal spermatic artery, which occupies the axis of the cord and is surrounded by (3) the internal spermatic veins, which form a complicated network, known as the pam- 
piniform plexus; (4) the testicular lymphatics; and (5) the internal spermatic plexus of nerves from the hypogastrie plexus; and (6) branches of the genitofemoral nerve for the supply of the external cremaster muscles.

\section{The Penis}

The penis is composed of three rod-like bodies composed of erectile tissue (fig. 1023), firmly united together and invested by fascia and integument (fig. 1022). When this ereetile tissue becomes engorged with blood the organ assumes an erect position, but otherwise it is pendulous, hanging downward in front of the scrotum from its attachment to the symphysis pubis. The erectile bodies are, howerer, prolonged backward beyond the symphysis pubis into the perineal region, and it is customary to speak of this perineal portion as the root of the penis [radix penis] or pars fixa in contrast to the body of the penis [corpus penis] or pars libera.

The body of the penis in its flaccid condition is almost cylindrical, but in erection it becomes somewhat triangular in section, what was the anterior surface or dorsum penis* becoming flattened, while the opposite one, the urethral surface [facies urethralis], becomes more sharply rounded. At the free extremity of the penis there is a blunt conical enlargement, the glans penis (fig. 1023), at the apex of which is the external orifice of the urethra. The glans is separated from the body by a constrietion, the neck [collum glandis], and from this region a fold of integument arises, which more or less completely encloses the glans, forming the prepuce [præputium] (fig. 102t). The prepuce is quite free from the glans dorsally but in the ventral mid-line it is attached to it, almost to the urethral

Fig. 1022.-Transverse Section throdgh the Body of the Penis.

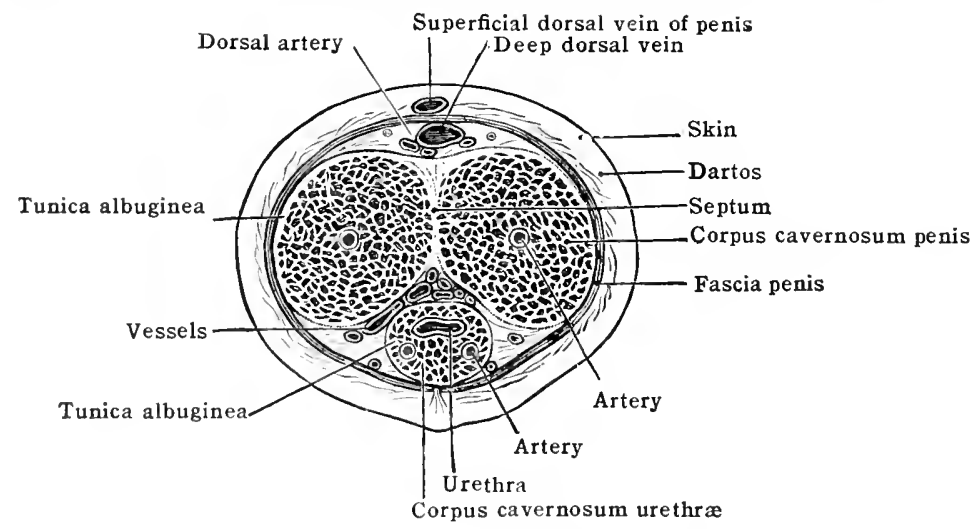

orifice, by a narrow line of adhesion, the frenulum [fremulum præputii], which contains blood-ressels of considerable size. The base of the glans has a wellmarkerl rounded border, the corona [corona glandis], and is deeply concave for the reception of the distal ends of the corpora eavernosa penis.

'The integument of the penis is continuous with that of the scrotum and like it is pigmented and contains no fat. Immediately below it there is a layer of nonstriated muscular tissue, the dertos, and beneath this a layer of loose connective tissue, containing the superficial vesscls and nerves of the penis; beneath this again is a denser, chastic sheret of connective tissue, the fascia penis (fig. 1022), which cncloses the erectile borlies as far as the base of the glans and is continuous with the superficial fascia of the perineum and inguinal region. Where it passes beneath the symphysis pubis it receives from the anterior surface of the latter a strong band of fibrous tissue, which forms the suspensory ligament of the penis [lig. suspensorium penis].

T'wo of the rectile bodies of the prnis, the corpora cavernosa penis, are paired (fig. 1023). They are attached at their proximal ends to the base of the tuberosity of the isehium, and in this part of their extent are termed the crura penis, being

"It should lo noted that the terms "dopsmo" and "dorsal" are used for the penis in a sronse directly opposite their usual meaning. 
composed of fibrous connective tissue, which has resting upon it the $\mathrm{m}$. ischiocavernosus (see Section IV). The two crura are situated in the lateral portions of the superficial perineal interspace and pass forward parallel with the rami of the ischia and pubis, gradually becoming transformed into cavernous erectile tissue. Shortly before they reach the level of the symphysis pubis the two corpora come into contact in the median line, their medial walls fusing to form a septum, and thus united they extend throughout the entire length of the body of the penis, occupying the dorsal portion of the space enclosed by the fascia penis (fig. 1022). They terminate at the posterior surface of the glans, where they taper

Fig. 1023.-Dissection of the Perineun Showing the Structure and Relations of the Penis.

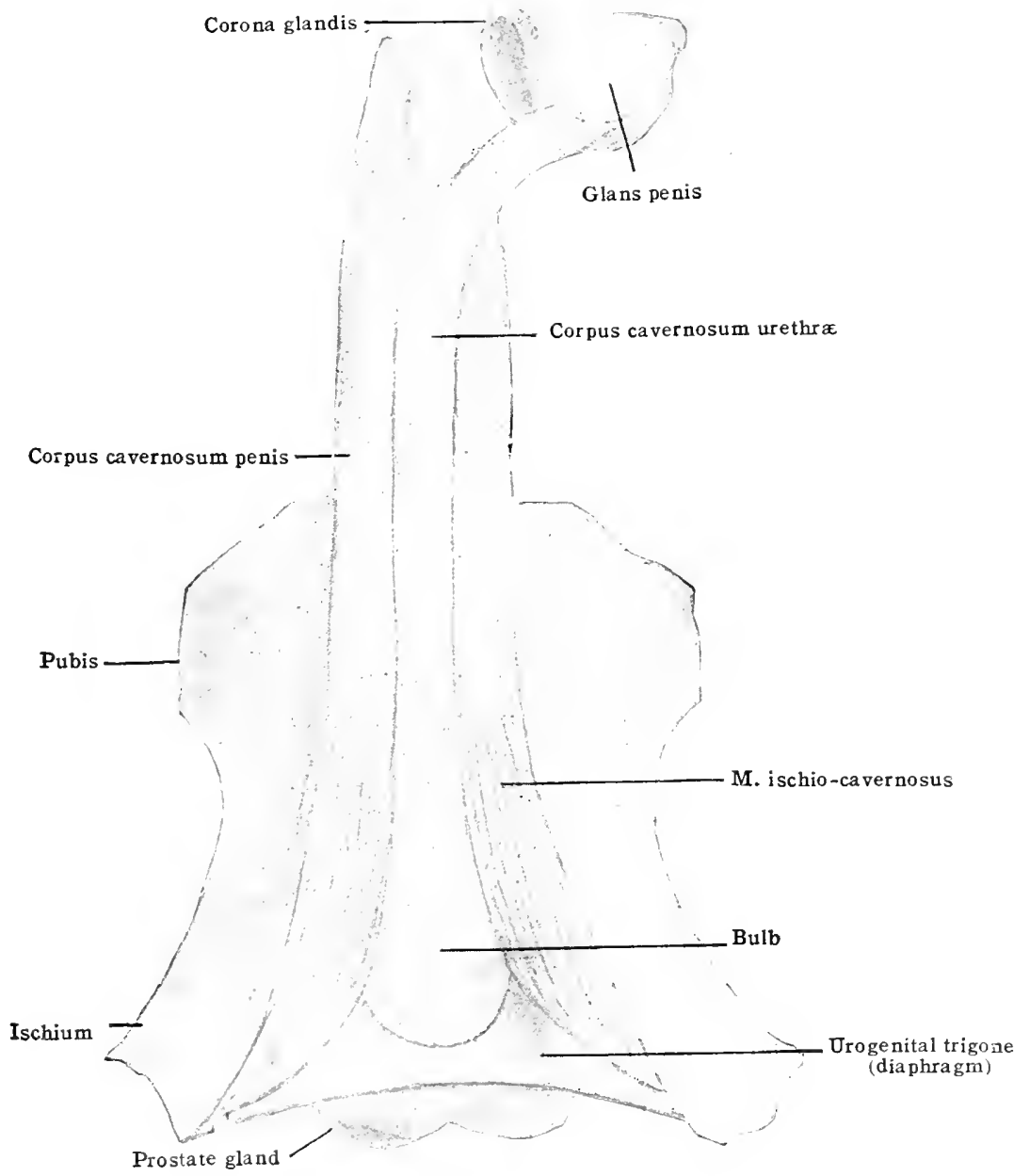

somewhat to be received into its basal concavity (fig. 1024). The septum in its proximal part forms a complete partition between the two bodies, but distally it is broken through by numerous clefts by which the blood lacunæ of the two bodies are placed in communication.

Each corpus cavernosum penis consists of a strong elastic fibrous sheath, the tunica albuginea, from which trabecula extend into the substance of the organ, dividing it into a network of communieating eavities, into which open terminal branches of the a. profunda penis, which traverses the axis of the corpus. These cavities consequently are to be regarded as vascular laeunx, which, becoming engorged with blood, produce the enlargement and ereetion of the organ.

The third erectile organ is the corpus cavernosum urethræ (formerly" "corpus spongiosum") (fig. 1023), so called because it is traversed throughout its entire length by the urethra (fig. 102t). It is an unpaired, median structure, having no 
bony attachments and begins posteriorly in the superficial perineal interspace with an enlargement, the bulb [bulbus urethra] (fig. 1023), whose posterior surface rests on the superficial fascia of the urogenital trigone and is enclosed by the $\mathrm{m}$. bulbo-cavernosus. Anteriorly the bulb gradually tapers to a rather slender cylindrical portion, the body, very uniform in diameter, which extends throughout the entire length of the body of the penis, lying in the median line beneath the fused corpora cavernosa penis (figs. 1022, 1023). At the neck of the penis it undergoes a sudden enlargement to form the glans, the whole of that structure, which has already been described, being formed by the corpus cavernosum urethræ. The structure of the corpus cavernosum urethræ is essentially the same as that of the corpora cavernosa penis, the tunica albuginea, however, being much thinner.

Vessels and nerves.-The principal arterial supply of the penis is derived from the internal pudendal artery (see p. 610), although the proximal portion of its integument is also supplied by the external pudendal branches of the femoral artery. The veins from the integument

Fig. 1024.-Mid-sagittal Section (diagramatic) Showing Male Bladder, Urethra, etc.

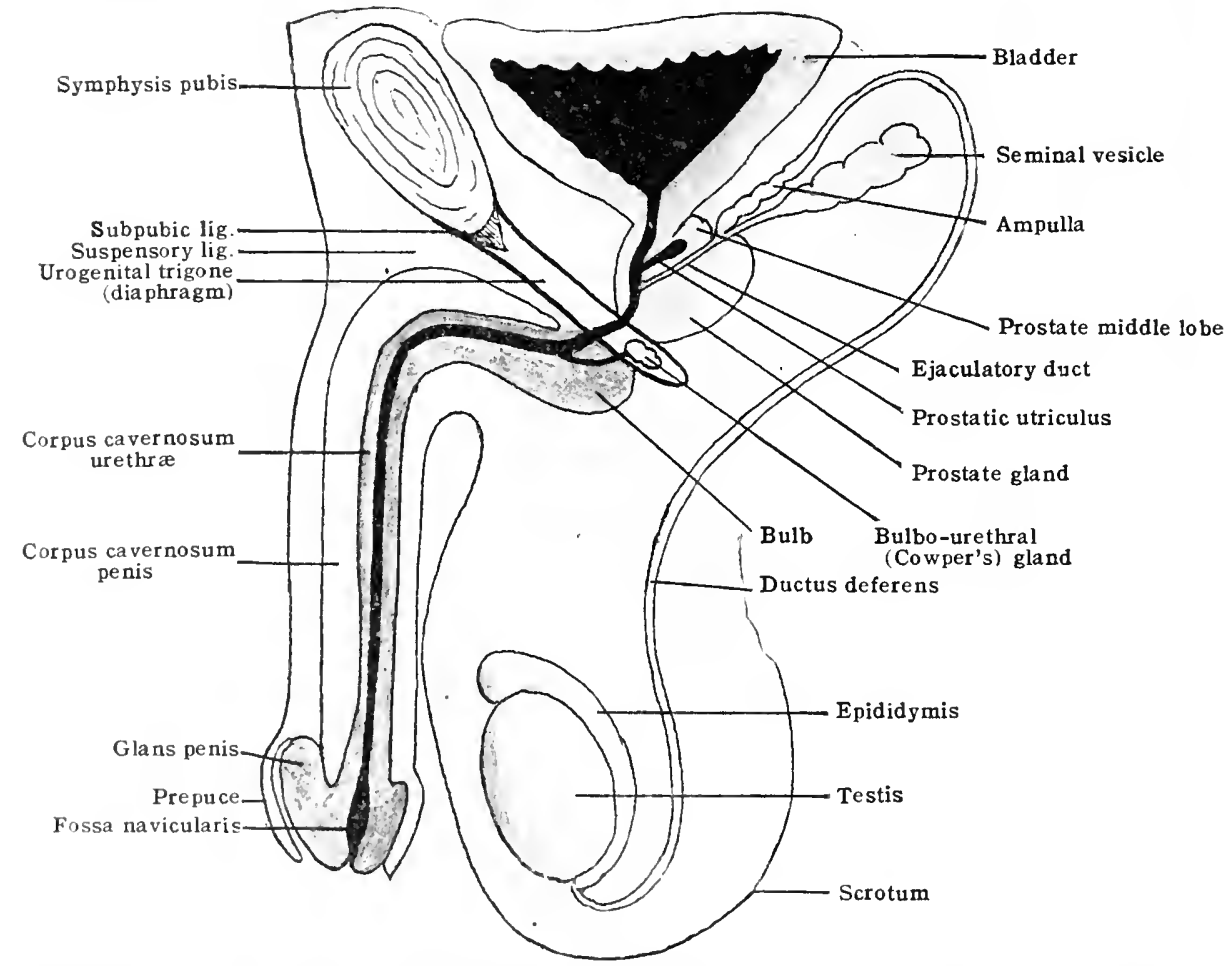

collect into one or morre stems, the superfieial dorsal veins, which run along the dorsal mid-line and, diverging, open into the great saluhenous vein. 'The decp veins from the corpora eavernosa open into a median derp dorsil vein, which connects partly with the internal puchendal veins and patrly with the pudendit phexus. Bull the sumorficial and deep lymphatics terminate in the superficial inguinal mortes. The lymph-ressols from the glans are said to follow those of the urothra and ond in the dere inguinat and external iliae motes.

'The nerves supplying the penis aro the anterios" serotal branches of the ilio-inguinal and the perineal branches and Jorsal ureve of the ponis fom the pudendal. Sympathetic filores also pass to the penis from the hypogatric plexus and with these fibres from the third and fourth

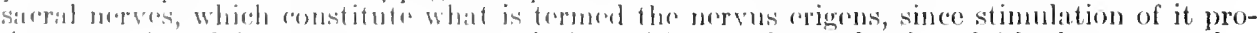
duressereetion of the organ. An anatomiant provision for the production of this phenomenon has

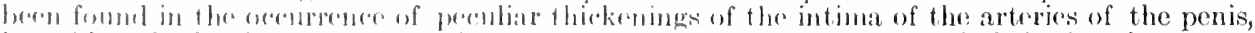
by which the lomina of the vessids are guatly diminished or oven ocoluded when in a state

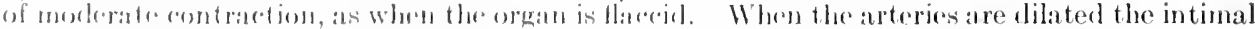

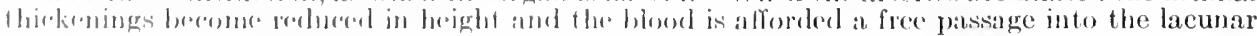

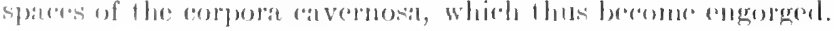

\section{4. 'THE MALE I'RTHIRA}

Ther urethra is the anal which exteruls from the batder to the extremity of the glates penis and serves for the passigge of hoth the mine and the seminal fluid. 
In its course (fig. 1024) it traverses first the prostate gland, then the urogenital diaphgram and then the entire length of the corpus cavernosum urethræ, and may thus be regarded as being composed of three portions.

The prostatic portion [pars prostatica] (fig. 1024) extends almost vertically downward from the neck of the bladder, traversing the substance of the prostate gland. In its proximal part there is on its posterior wall a median longitudinal ridge, the crista urethralis, which below dilates into an oval enlargement, the colliculus seminalis (figs. 1015, 1025), to accommodate which there is a marked

Fig. 1025.-The Male Urethra, cleft anteriorly to show the Mucous Coat.

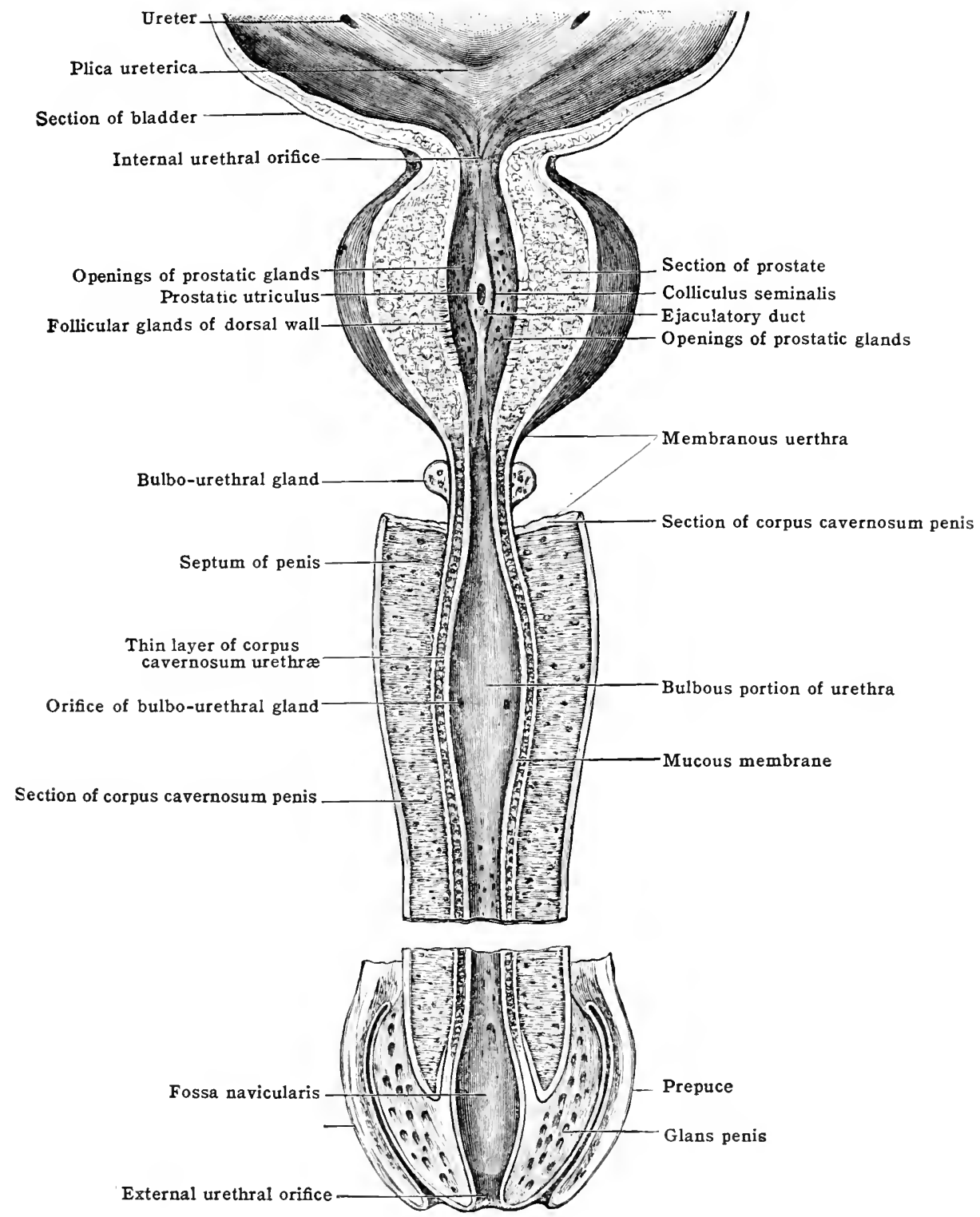

widening of the lumen of the urethra in this part of its course. At the centre of the colliculus there is an elongated opening of a pouch of varying depth,termed the utriculus prostaticus ("uterus masculinus"), which corresponds to the lower part of the vagina in the female (see p. 1279). Situated one on either side of this are the much smaller openings of the ejaculatory ducts. Owing to the prominence formed by the colliculus a section of the urethra in this region is somewhat $n$-shaped, and at the bottom of the furrows on either side of the median eleva- 
tion are the minute openings of the numerous ducts of the prostate gland (fig. 1025).

On its energence from the prostate gland the urethra at once penetrates the deep layer of fascia of the urogenital trigone and enters the deep perineal interspace, this portion of its course being known as the membranous portion [pars membranacea]. Its direction is now downward and slightly forward, curving beneath the subpubic ligament, from which it is separated by a plexus of veins and by the fibres of the sphincter urethræ membranaceæ, which form an almost complete investment for it. The lumen of this part of the urethra is much narrower than that of the prostatic portion, and since it traverses the rather unyielding fascia of the urogenital trigone it is less dilatable than in other parts of its extent, with the exception of the external orifice.

Passing through the superficial layer of fascia of the urogenital trigone the urethra then enters the bulb of the corpus cavernosum urethræ (fig. 1024) and is invested throughout the remainder of its extent by this structure, whence this portion is known as the cavernous portion [pars cavernosa]. In its proximal part this lies in the superficial interspace of the perineum and passes almost directly forward; but more distally, where it enters the body of the penis, it accommodates itself to the position of that organ, which it traverses lengthwise, lying in the midline near its ventral surface (fig. 1022). Thus the proximal portion of the cavernous and the whole of the membranous and prostatic portions have a fixed position, whence they are sometimes associated as the pars fixa of the urethra, while the penial portion forms the pars mobilis. On entering the bulb the lumen of the urethra dilates somewhat and in this region has opening into it the ducts of the bulbo-urethral glands (fig. 1025), but as it enters the body of the corpus cavernosum it diminishes again and maintains a uniform diameter throughout the extent of that structure. When it reaches the glans penis it undergoes another dilation, which is known as the fossa navicularis (fig. 1025), beyond which it diminishes to the slit-like external orifice, situated at the extremity of the glans and forming the least dilatable portion of the entire urethral canal.

Throughout the greater part of its extent the eavernous portion of the urethra shows upon its dorsal wall the openings of numerous tubular depressions of the mueous membrane, the urethral lacunce [lacunæ urethrales (Morgagnii)]. One of these, the lacuna magna, situated in the mid-dorsal line of the proximal part of the fossa navicularis, has its orifice guarded by a valve-like fold [valvula fossa navieularis] of the mucous membrane and is sufficiently large to receive the point of a small eatheter. Numerous minute glands [gl. urethrales] open upon the surface of the urethral mucosa. They are most abundant in the anterior wall, but oceur also on the sides and floor.

Dimensions of the urethra.-The entire length of the urethra is somewhat variable in different individuals, the greatest variation being in the length of the pars mobilis. Of the pars fixa the prostatic portion is $2.5-3.0 \mathrm{~cm}$. in length, the membranous portion about $1.0 \mathrm{em}$., and the fixed part of the eavernous portion $6.5 \mathrm{~cm}$., the entire pars fixa having thus a length of somewhat over $10.0 \mathrm{~cm}$. (4 in.). The average diameter of the urethra is $5.0-7.0 \mathrm{~mm}$., but it will be noter that the canal presents in its eourse three dilatations; namely, (1) at the fossa navieuliris, which begins about $0.5 \mathrm{~cm}$. from the external orifice; (2) the butb of the corpus cavernosum urethrs: and (3) in the prostatic portion. Furthermore there are two regions in which it is distinctly narrowed; namely, at the external orifice and in the nembranous portion. While the remaling portions are capable of eonsiderable distention, these are relatively indistensible, the miximum dimmeter to which they may be dilated being about $10 \mathrm{~mm}$. Arranged in an ascending order according to their capability for distention the parts would have the following orler: cxternal orifice, membranous portion, penial portion, prostatie portion, bulbar portion.

\section{Tiniz Prostate Giand}

'The prostate gland [prostata] (figs. 1013, 1019, 1024 and 1025) is a mass of glandular and muscular tissue surrounding the proximal portion of the male methra, and may, indered, be reganderl as a special development of the wall of this portion of the canal. It is a more or less flattened conical structure whose base [basis prestated is in eontanet with the lower surface of the bladder and the "lpex [apex prostatin] with the deep fascia of the urogenital trigone. Its anterior surface [fardes anterior] is in rolation with the symphysis pubis, from which it is

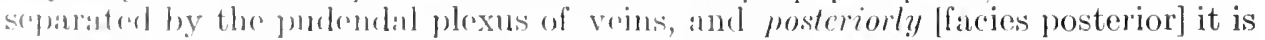
scomarated from the lower portion of the rectum only by some loose connective tissme laterally it is in redation with the levatores and, recoiving an investment from the andepentrie fasciat rovering these. 
The urethra enters the base of the gland near its anterior border and traverses it almost vertically, so that the greater portion of the gland is posterior to the canal. On the posterior surface of the gland is a more or less distinct median vertical groove, which serves to separate the lateral portion as the lateral lobes [lobus dexter et sinister], although the demarcation is merely a superficial one. The groove terminates above in a well-marked notch on the posterior border of the base, and immediately in front of this there is a deep funnel-shaped depression of the surface, which receives the ejaculatory ducts. Beginning at this depression two grooves pass forward and slightly lateralward across the surface of the base, marking off a more or less pronounced median elevation, which constitutes what is termed the middle lobe [lobus medius] (fig. 1024); since this lies beneath the trigone of the bladder behind the internal orifice of the urethra its enlargement may produce more or less occlusion of the latter.

Dimensions. - The longest axis of the prostate, which is almost vertical in the erect posture measures $2.5-3.0 \mathrm{~cm}$., the transverse diameter at the base is $4.0-4.5 \mathrm{~cm}$. and the thickness $2.0-2.5$ $\mathrm{cm}$. Its weight is normally 20-25 grms. but in old age it may be double that, its dimensions having correspondingly increased.

Structure.-The prostate consists of some 15-30 branched tubular glands imbedded in a matrix of connective tissue, containing a large amount of non-striped muscle tissue and forming at the surface of the gland a strong fibro-muscular capsule from which prolongations are contributed to the pubo-vesical ligaments and muscles. The glands, which vary greatly in their development, are outgrowths from the mucous membrane of the urethra, into which their ducts open at the bottom of the grooves that lie lateral to the colliculus seminalis; similarly, the matrix with its muscle tissue is evidently the modified muscular coat of the urethra. Consequently there is no distinct demarcation between the wall of the urethra and the substance of the gland, and from the developmental standpoint the gland is to be regarded as the modified wall of the urethra.

The facts that the prostate shows a special development at puberty and undergoes more or less extensive degenerative changes with the cessation of the reproductive function, as seen in old age and in castrates, indicate that it is associated physiologically with the reproductive organs. Its secretion is a thin alkaline fluid, which may contain round or elongate, concentrically lavered bodies, measuring $0.3-0.5 \mathrm{~mm}$. in diameter and known as amyloid bodies, although they are really albuminous in chemical composition. They are constantly found in adults in the lumina of the glands and may become calcified. The secretion has been found to have a stimulating effect upon the spermatozoa, and this may be its principal function.

Vessels and nerves.- The arterial supply of the prostate is derived from the inferior vesical and middle hæmorrhoidal branches of the hypogastric artery. The eins form a rich prostatic plexus in the immediate vicinity of the gland, this being part of the general plexus at the base of the bladder and communicating posteriorly with the seminal plexus and anteriorly with the pudendal plexus. It drains finally into the hypogastric vein. The lymphatics are very abundant and form a network on the posterior surface of the gland from which four principal vessels pass to the hypogastric nodes. The nerves are derived from the hypogastric plexus.

\section{The Bulbo-urethral Glands}

The bulbo-urethral glands [gl. bulbo-urethralis (Cowperi)] or Cowper's glands (figs. 1024, 1025) are two small tubulo-alveolar glands which lie one on either side of the membranous portion of the urethra, imbedded among the fibres of the sphincter urethræ membranaceæ, between the two layers of fascia of the urogenital trigone. Each is a rounded body with a diameter of $4.0-9.0 \mathrm{~mm}$. and is drained by a duct [ductus excretorius] which perforates the superficial fascia of the trigone and, entering the substance of the bulb of the corpus cavernosum urethræ, traverses it to open on the floor of the bulbar portion of the urethra after a total course of $3.0-4.0 \mathrm{~cm}$. Nothing is definitely known as to the nature of the secretion or the functions of the glands.

\section{THE FEMALE REPRODUCTIVE ORGANS}

The organs of reproduction in the female consist of (1) the ovaries, the essential organs of reproduction; (2) the tubce uterince (Fallopian tubes), which serve as ducts for the conveyance of the ova to (3) the uterns, in which the embryo normally undergoes its development; (4) the vagina, a canal by which the uterus is placed in communication with the exterior; and (5) the external genitalia. In addition it will be necessary to consider here the female wrethra, although it differs from that of the male in that it serves merely as a passage for the contents of the bladder and does not transmit the reproductive elements. 
Fig. 1026. -The Female Organs of Generation. (Modified from Sappey.) (Vagina divided and laid open behind.)

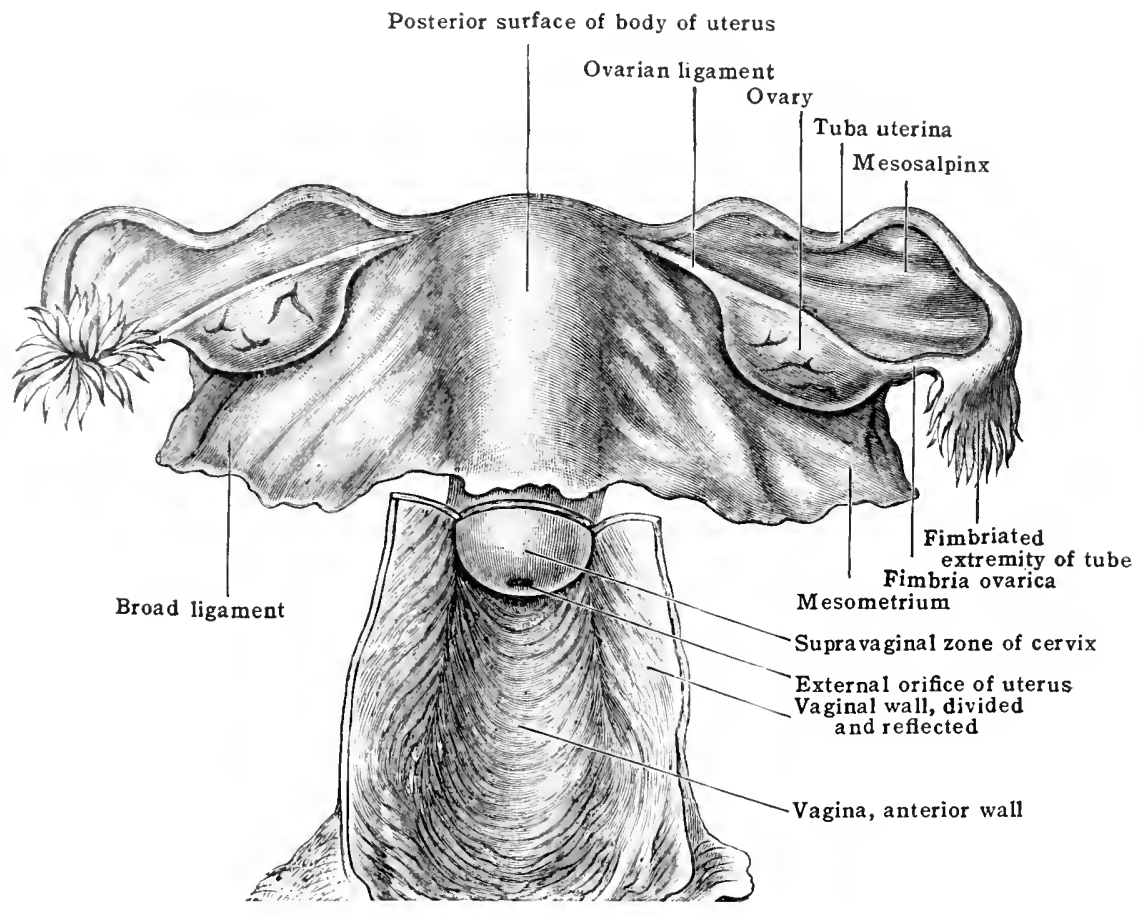

ig. 1027.-Diagramatic Sagittal Section of the Broad Liganent.

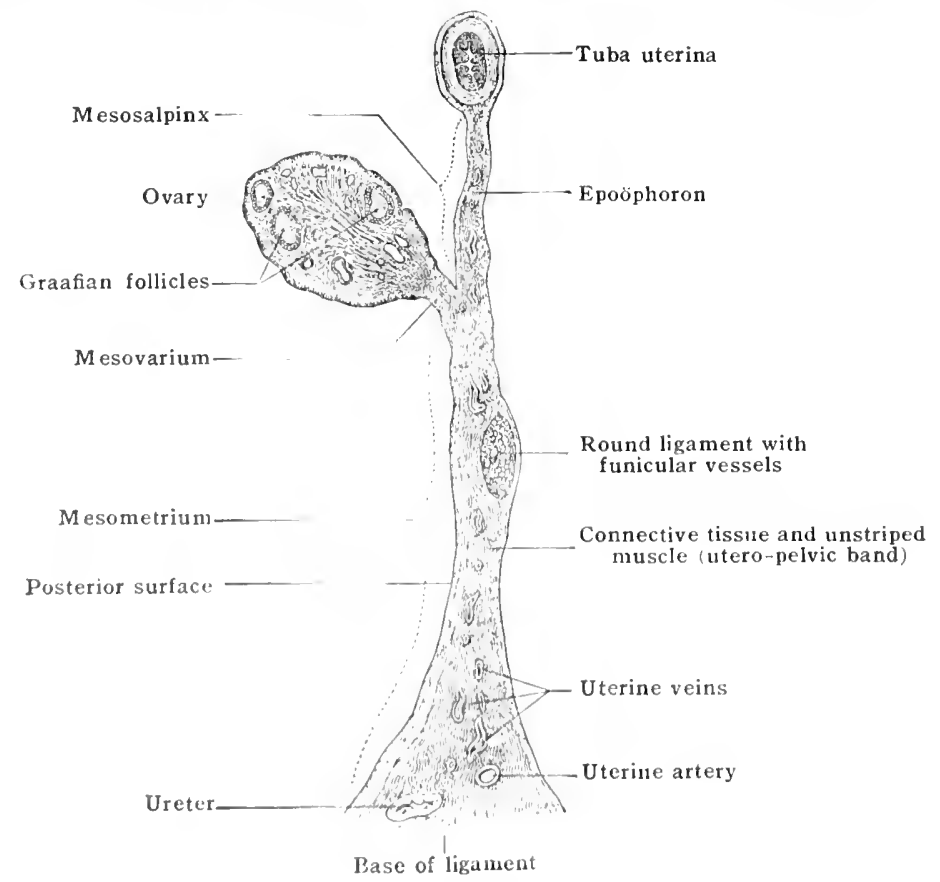


Broad ligament. - The first three of these struetures are entirely contained within the true pelvis and are associated with a transverse fold of peritoneum which rises from the floor of the pelvic cavity between the bladder and the rectum, incompletely dividing the cavity into an anterior and a posterior compartment. It is known as the broad ligament of the uterus [lig. latum uteri] (fig. 1026). The broad ligament appears to extend laterally from the sides of the uterus to the lateral walls and floor of the pelvis, although in reality it extencls across the pelvic cavity from side to side and encloses the uterus between the two layers of which it is composed. It is attached to the floor of the pelvis below, where the two layers are reflected, the one upon the anterior wall of the pelvis and the posterior and superior surfaces of the bladder, and the other posteriorly over the floor of the pelvis to the posterior pelvic wall and the rectum, forming the anterior wall of a deep depression between the rectum and uterus, known as the recto-uterine pouch (of Douglas) [excavatio rectouterina (cavum Douglasi)] (fig. 1035). Its lower border also passes upward upon the sides of the pelvis, resting upon the pelvic fascia, but its lateral borders are free, extending between the lateral wall of the pelvis and the extremity of the tuba uterina on each side and forming what are termed the infundibulo-pelvic ligaments. The upper border is also free and contains the tuba uterina on either side, and the fundus of the uterus in the midline (fig. 1027).

Fig. 1028.-Cross-sections of the Body Illustrating thè Developient of the Female Urogenital system. A, at Higher level. B, at Lower Level.

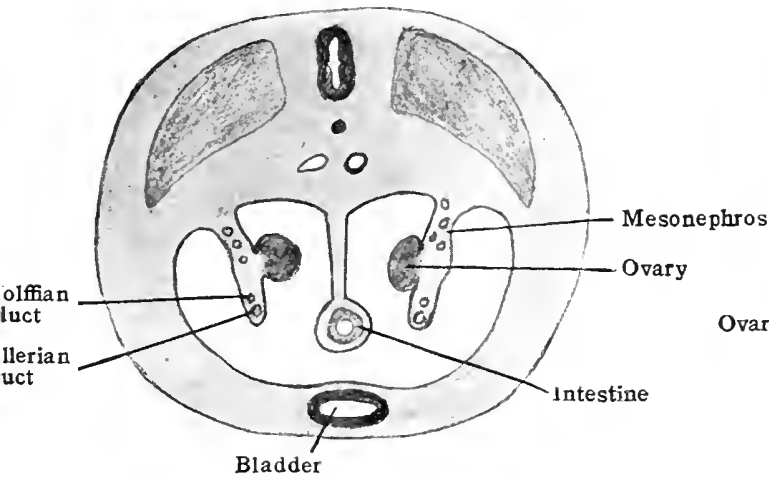

A

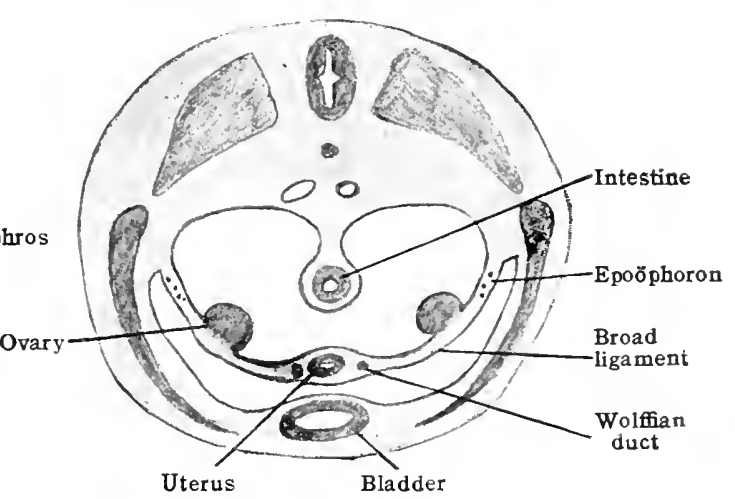

$\mathrm{B}$

Attached to the posterior layer of the broad ligament a little below its upper border and therefore projecting into the posterior compartment of the pelvis, there is a horizontal shelf, termed the mesovarium, since it has the ovary attached to its free edge (fig. 1027). The portion of the broad ligament above this is known as the mesosalpinx (salpinx=tuba), while that below is termed the mesometrium (metra=uterus). The remaining structures that occur between the two layers of the broad ligament will be described with the organs with which they are associated, but it is to be noted that the ligament in its upper part is broader than the transverse diameter of the pelvic cavity and its sides are accordingly folded back upon the lateral walls of the cavity, following the course of the tuba uterina.

The broad ligament is the adult representative of the fold of peritoneum which encloses the embryonic excretory organ, the mesonephros. This is for a time a voluminous organ, projecting under cover of the peritoneum from the dorsal wall of the abdomen and bearing upon its medial wall a thickening, the genital ridge (fig. $1028 \mathrm{~A}$ ), from which the reproductive gland develops. In the free edge of the peritoneum enclosing it two ducts occur, the Wolffian duct, which is the duct of the excretory organ and becomes the ductus deferens of the male, and the Muillerian duct. With the progress of development the two Müllerian ducts fuse in the lower portions of their course to form the uterus and vagina (prostatic utriculus of the male), while in their upper parts they remain separate and form the tubæ uterinæ. By this fusion the two peritoneal folds are brought into continuity at their edges, and the mesonephros degenerating on the formation of the permanent kidney) constitute the broad ligament (fig. $1028 \mathrm{~B})$. This structure therefore contains between its two lavers the uterus and the remains of the mesonephros, and has the ovary attached to its posterior surface. In the male what corresponds to the broad ligament fuses with the peritoneum covering the posterior surface of the bladder. 


\section{The Oraries}

Form and position.-The oraries [ovaria] are two whitish organs, situated one on either side of the pelvic cavity. Each has somewhat the shape of an almond (fig. 1026). It is attached by one of its edges [margo mesovaricus] to the border of the mesovarium, and since it is along this line of attachment that the vascular and nerve supply enters the substance of the organ, this border is spoken of as the hilus [hilus ovarii]. The opposite border is free [margo liber]. The larger rounded end is directed toward the free extremity of the tuba uterina and hence is known as the tubal extremity [extremitas tubaria], while the other, the uterine extremity [extremitas uterina], is directed toward the uterus; the two surfaces, owing to their topographic relations, are known as the lateral and medial surfaces [facies medialis et lateralis].

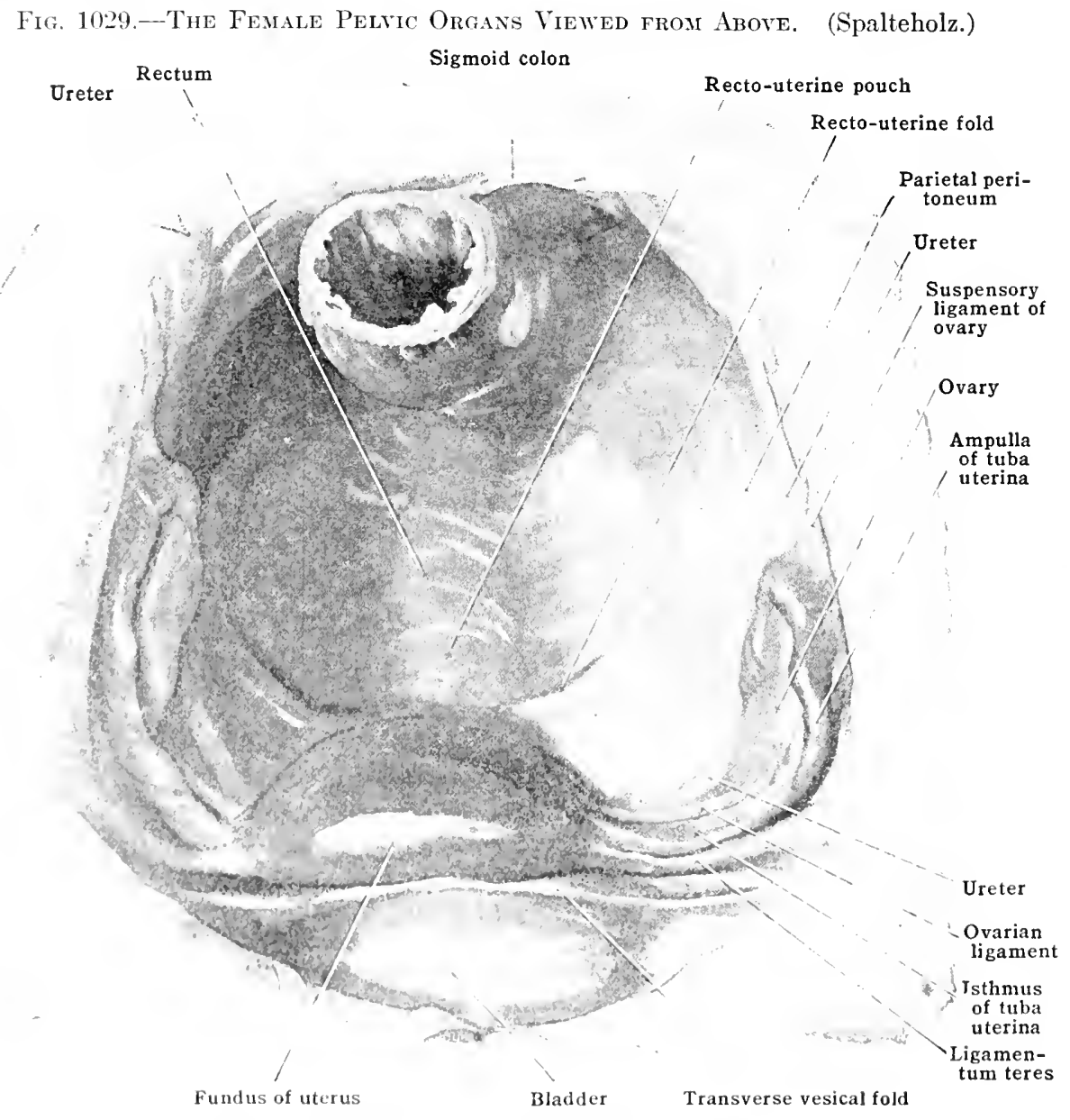

The exare position of the ovary in the pelvis is subject to some variation, but trpirally it liss almost in a sagittal plane (fig. 102!) aquinst the lateral wall of the pervis, resting in a distinct depression, the fosen orarica, lined by peritoneum and

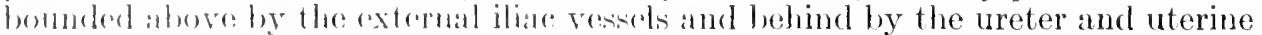
artery, while beneath its flow are the oldurator vessels and nerve. The long axis of the ovary is almost vertical when the body is erect, the tubal pole being upward; the mesovitial bordere is clirenterl forward and laterally, its free border dorsally and modially while its surfares look almost laterally and medially.

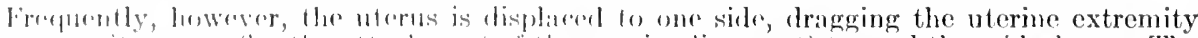
of the eppositrovary (by the attachoment ol the ovarian ligament) foward the mid-plane. The

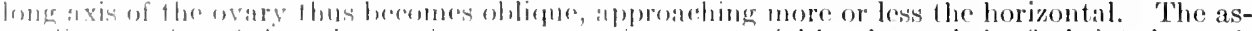

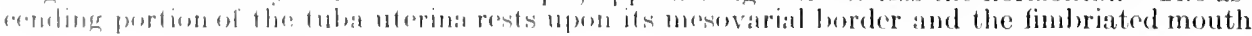


of the tube is in contact with its medial surface. When enlarged the ovary may be felt through lateral wall of the vagina and, better, through that of the rectum; and its position with regard to the surface may be indicated by a point midway between the anterior superior spine of the ilium and the symphysis pubis or the opposite pubic tubercle.

The position assumed by the ovary is due to its attachment to the edge of the mesovarium and to the upper portion of the broad ligament being broader than the diameter of the pelvis, so that it is folded back upon the lateral walls of the cavity. In addition to its attachment to the broad ligament through the mesovarium, the ovary is also connected to the side of the uterus by the ovarian ligament [lig. ovarii proprium] (fig. 1026), a band of connective tissue with which numerous non-striped muscle fibres are intermingled. It lies between the two layers of the broad ligament, on the boundary line between the mesosalpinx and the mesometrium, and extends from the uterine pole of the ovary to the side of the uterus. Here it is attached just below the origin of the tuba uterina and above the point of attachment of the round ligament of the uterus, with which it is primarily continuous. Another ligament, termed the suspensory ligament of the ovary (figs. 1029, 1034), extends laterally between the two layers of the broad ligament from the tubal extremity of the ovary to the pelvic walls, forming the lateral portion of the lower boundary of the mesosalpinx. It is formed by the vessels and nerves (internal spermatic) passing to and from the ovary, and from the point where it meets the lateral pelvic wall it may be traced upward for some distance upon the posterior wall of the abdomen, behind the peritoneum, which it elevates into a more or less distinct fold, whose lateral wall on the right side becomes continuous above with the peritoneum lining the subcecal fossa.

Size.-The size of the ovary varies considerably, that of the right side being as a rule somewhat larger than that of the left. The length may be anywhere from $2.5 \mathrm{~cm}$. to $5.0 \mathrm{~cm}$., the breadth about half the length and the thickness half the breadth. Its average weight in the adult is from 6.0 to 8.0 grms., but in old age it may fall to 2.0 grms.

Structure.-The ovary is covered by a layer of columnar epithelium which is continuous with the peritoneal epithelium along the line of the attachment of the mesovarium; the ovary consequently is not covered by peritoneum, but is rather to be regarded as a local thickening of the peritoneum. Its substance is a network of connective tissue, in which non-striped muscle fibres also occur, and is known as the stroma. The more central portions of this are largely occupied by blood-vessels but in the cortical portions are multitudes of immature ova, surrounded by their follicle cells [folliculi oophori primarii]; and also numbers of cavities of various sizes, lined with follicle cells and filled with fluid, each containing an ovum [ovulum] in a more or less advanced stage toward maturity. These are the Graafian follicles [folliculi oophori vesiculosi (Graafi)], and as they ripen they increase in diameter and approach the surface, upon which they may form marked prominences. When mature the follicles burst, allowing the escape of the ovum, scars being thus formed upon the surface of the ovary that are known as corpora albicantia. If, however, the ovum becomes fertilized and pregnancy results the walls of the follicle undergo a remarkable development, forming what is known as a corpus luteum.

Epoöphoron and paroöphoron.-Closely associated with the ovaries are two rudimentary organs situated between the layers of the mesosalpinx and representing remains of the mesonephros of the embryo. The larger of these is the epoöphoron (fig. 1030). It consists of a longitudinal duct [ductus epoophori longitudinalis (Gartneri)], lying parallel with the tuba uterina and closed at either extremity, and 10-15 transverse ducts [ductuli transversi], which open into the longitudinal duct. It is the remains of the upper or reproductive portion of the mesonephros and therefore is the homologue of the epididymis of the male. In addition there is frequently to be found in the neighbourhood of the epoöphoron and close to the mouth of the tuba uterina one or more stalked, oval eysts, the appendices vesiculosi (hydatids of Horgagni), which may reach the size of a small pea.

The other organ is the paroöphoron; it is much smaller than the epoöphoron and usually disappears before adult life, but when present consists of a small group of coiled tubules, nore or less distinct, representing a portion of the excretory portion of the mesonephros. Its equivalent in the male is therefore the paradidymis.

Vessels and nerves. - The chief artery is the ovarian, which together with the ovarian veins and lymphatics passes to the ovary in the suspensory ligament. An additional blood supply is furnished by the ovarian branch of the uterine artery. The veins follow the course of the arteries. As they emerge from the hilus they form a well-developed plexus (pampiniform plexus) between the layers of the mesovarium. Unstriped muscle fibres occur in the meshes of the plexus and the whole structure has much the appearance of erectile tissue. The lymphatics accompany the blood-vessels and terminate in the lumbar nodes. Nerves pass to the ovary with the ovarian artery from the renal and aortic sympathetic plexus.

\section{The Tubz Uterina}

The tubæ uterinæ or Fallopian tubes (figs. 1026, 1030) serve to convey the ova to the uterus. They are two trumpet-shaped tubes, structurally continuous 
with the superior angles of the uterus and running in the superior border of the broad ligament (mesosalpinx) to come into relation with the ovaries at their distal extremities. Each tube opens proximally into the uterine cavity and distally communicates with the pelvic portion of the peritoneal cavity by a funnelshaped mouth, the ostium abdominale, which under normal conditions is closely applied to the surface of the ovary, so as to receive the ova as they are expelled from the Graafian follicles. Each tube is from 7 to $14 \mathrm{~cm}$. in length and consists of a narrow straight portion, the isthmus, immediately adjoining the uterus, followed by a broader, more or less flexuous portion, the ampulla, which terminates in a funnel-like dilatation, the infundibulum. The margins of the infundibulum are fringed by numerous diverging processes, the fimbria, one of which, the fimbria ovarica, is much longer than the rest and extends along the free border of the mesosalpinx (the infundibulo-pelvic ligament) to reach the tubal pole of the ovary.

The course of each tube is at first almost horizontally laterally and backward from its attachment to the uterus, until it reaches the lateral wall of the pelvis and there comes into relation with the uterine extremity of the ovary (figs. 1029. 1034). It then bends at right angles and passes almost vertically upward

Fig. 1030.-The Broad Liganent and its Contents, seen from the Front. (After Sappey.)

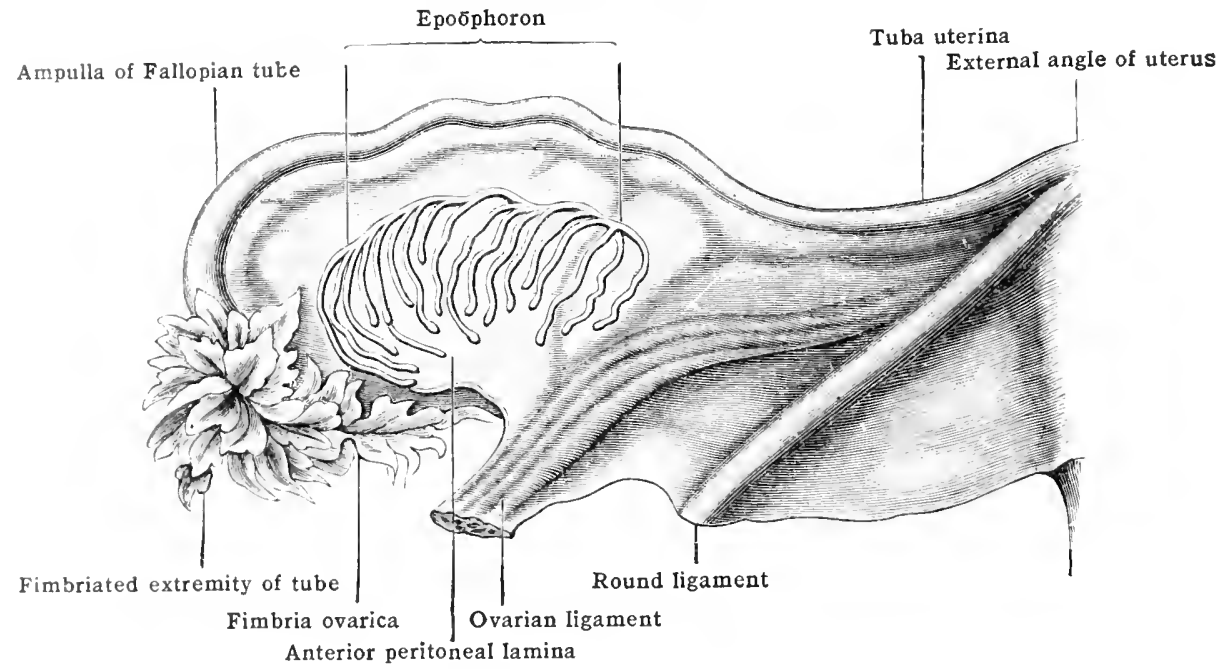

along the mesovarial border of the ovary until it reaches its tubal extremity, where it curves downward and backward so that the mouth of the infundibulum and the fimbria rest upon the medial surface of the ovary.

Structure. The tubin oremy the upper free edge of the mesosalpinx and are therefore

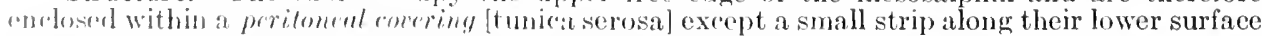
(fig. 1627), and hence a rupture of one of them may lead to the escape of its contents either into the perituneal cavity or in to the subserous areolar tissue between the two layers of the broad liganme. At the margins of tho infundibulum and the borders of its fimbria the peritoneal

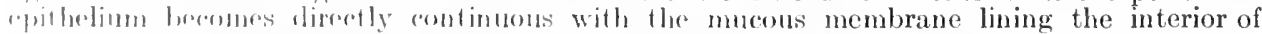

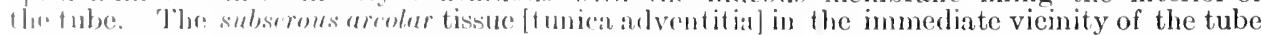
is lis amm contains the blomel-vessols and norves by which the tube is supplied; it forms a loose

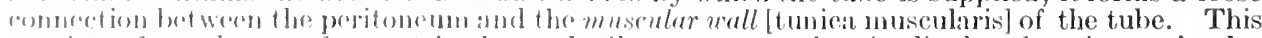
monists of two layers of non-striperl musele libers, an outer longitudinal and an inner eireular nor, and ratches its gratest development fowarl the nterine end of the tube. The inner

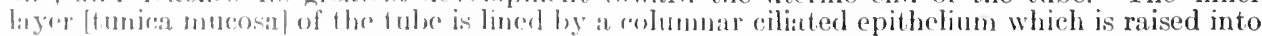

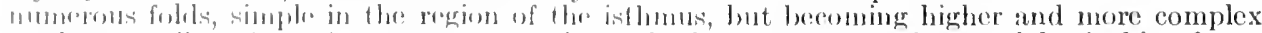

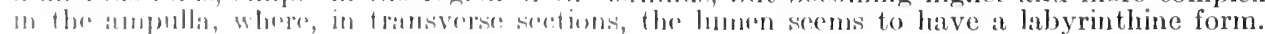

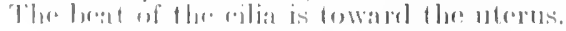

Vessels and nerves. The arforis of the tulne an lerivel from the ovarian amd uterine,

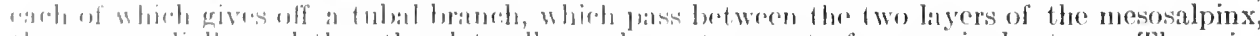

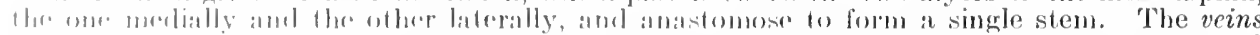

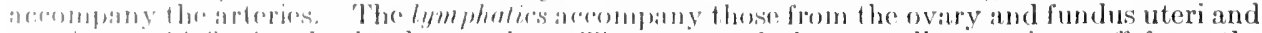

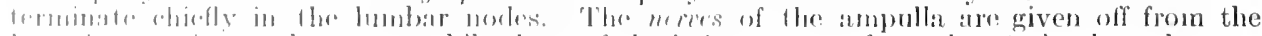

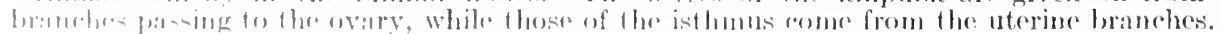




\section{The Uterus}

The uterus (fig. 1031) is an umpaired organ, situated between the two layers of the broad ligament and communicating above with the tubæ uterinæ and below with the vagina. It is pyriform in outline, although flattened antero-posteriorly (fig. 1032) and it is divided into two main portions, the body [corpus uteri] and the cervix by a transverse constriction, the isthmus.

The body is the portion above the isthmus and in adults, especially in women

Fig. 1031.-The Posterior Surface of the Uterus. (After Sappey.)

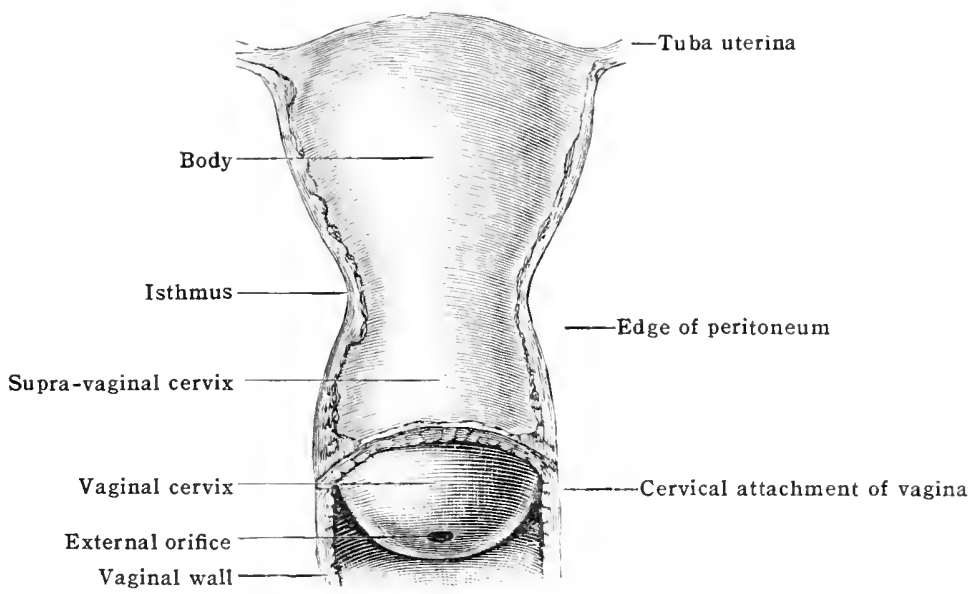

who have borne children, is much larger than the cervix, although the reverse is the case in children. In young girls the two parts are about equal in size. The anterior or vesical surface [facies vesicalis] is almost flat (fig. 1032), while the posterior or intestinal surface [facies intestinalis] is distinctly convex, the two surfaces meeting in well-marked rounded borders, at the upper extremities of which the tubæ uterinæ are attached. The superior border which extends between the points of attachment of the two tubre is thick and rounded and forms

Fig. 1032.-Sagittal section of the Virgin Uterus. (After Sappey.)

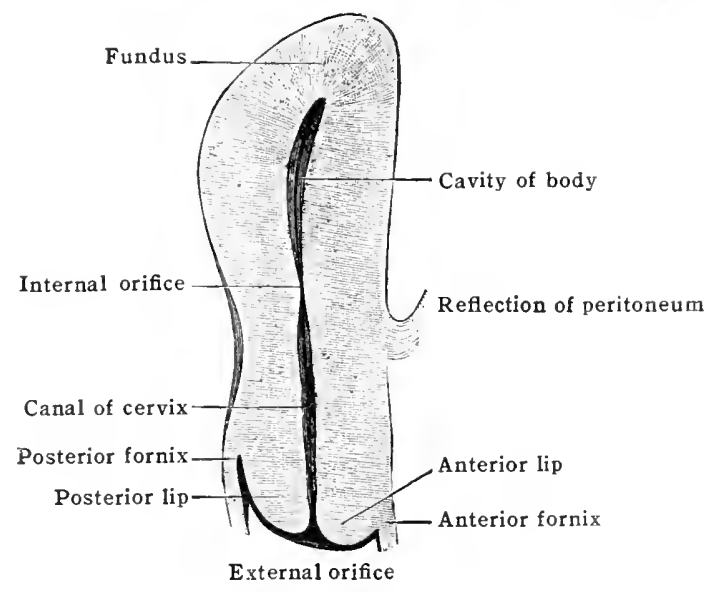

what is termed the fundus uteri. The cavity [cavum uteri] of the body is reduced to a fissure by the antero-posterior flattening of the walls and has a triangular form (fig. 1033), broad above where it communicates on either side with the cavity of a tuba uterina and narrow below where it communicates with the cavity of the cervix, this communication, which corresponds in position with the isthmus, forming what is known as the internal orifice [orificium internum] (internal os uteri).

The cervix is more cylindrical in form, though slightly expanded in the middle 
of its length, and is divided into a supravaginal [portio supravaginalis] and a vaginal portion [portio raginalis] by the attachment to it of the vagina (fig. 1031). The line of this attachment is oblique, about one-third of the anterior surface of the cervix and about one-half of the posterior surface belonging to the vaginal portion. At the lower extremity of the cervix is the external orifice [orifieium externum] (external os uteri), which is round or oval before parturition has taken place and is bounded by two prominent labia, anterior and posterior, the anterior one [labium anterius] being shorter and thicker than the posterior [labium posterius] and reaching a lower level (fig. 1032). In women who have borne children the external orifice assumes a more slit-like form and the labia become notehed and irregular. The carity of the cervix, known as the canal of the cervix [canalis cervicis], is fusiform in shape, and extends from the internal to the external orifice. On its anterior and posterior walls are folds known as the plicce palmatce (fig. 1033), consisting of a median longitudinal ridge from which shorter elevations extend laterally and slightly upward; these are most distinct in young individuals and are apt to become obliterated by parturition.

Fig. 1033.-Frontal Section of the Virgin Uterus. (After Sappey.)

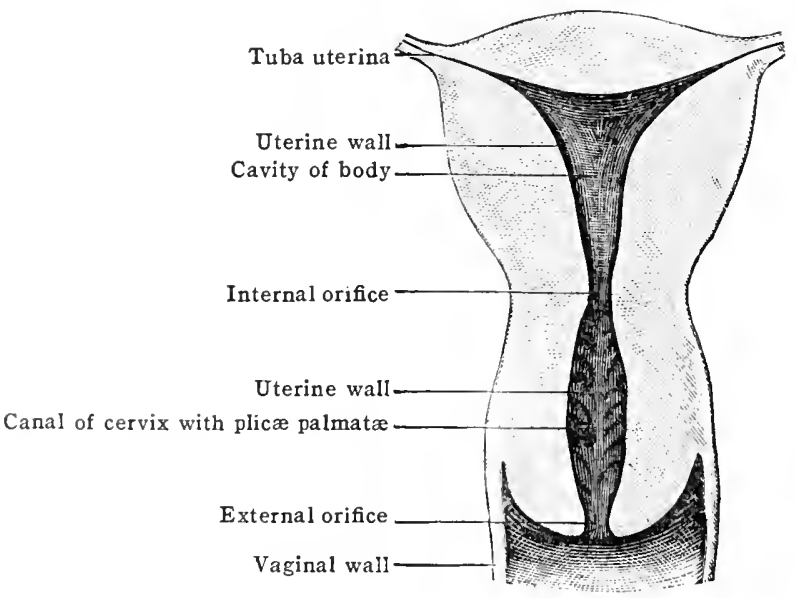

Position and relations. - The direction of the axis of the uterus is apparently variable within considerable limits, not only in different individuals, but also in any one individual in correspondence with the degree of distention of the bladder anteriorly and the rectum posteriorly. In what may be regarded as the typical conclition (fig. 103.t) the external orifice lies at about the level of the upper border of the symphysis pubis and in the plane of the spines of the ischia. From this point the axis of the cervix is clireeted upward and slightly forward, the lower level of the anterior labium being thus brought about. 'The entire uterus is, arcordingly, anteverted, and, furthermore, the body is bent forward (anteflexed) upon the cervix at the isthmus, the axis of the two portions making an angle, open antriorly, of from $70^{\circ}$ to $100^{\circ}$. Frequently, also, the body is slightly inclinesl wither to the right or to the loft.

The anterior surface of the utrels rests upon the upper and posterior surfaces of the bladder (fig. J(12:9), from whinh the borly is saburated by the utero-vesionl pouch of peritoneum. The

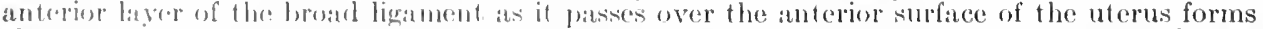

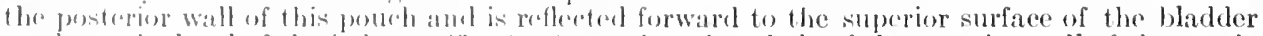
at alent the level of the isthmus (fig. 10:3), se that the whote of the anterior wall of the eervix

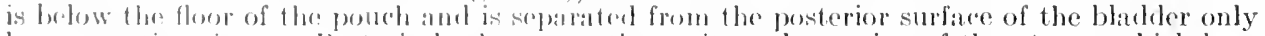

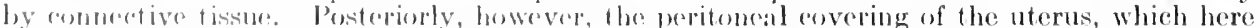

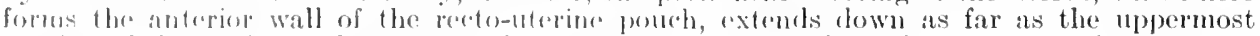
portion of the vagina and consegulently invests the entire surface of the uterus, whose convex pontrios wall is thus separated from the rectum ly the recto-uterine pouch (figs. 1029, 1035).

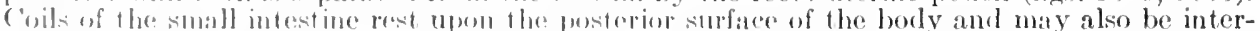
[mesel botwent the corvix and the reotum. In important retation is that of the ureters to the

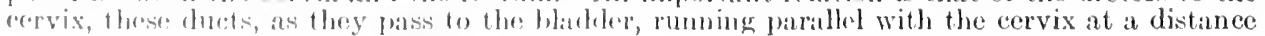

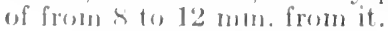

Ligaments. Tho bond ligmmen botween whose layers the uterus is situated

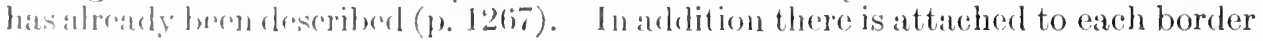


Fig. 1034-Mid-sagittal Section of the Fealale Pelvis (Spalteholz.)

Hypogastric artery

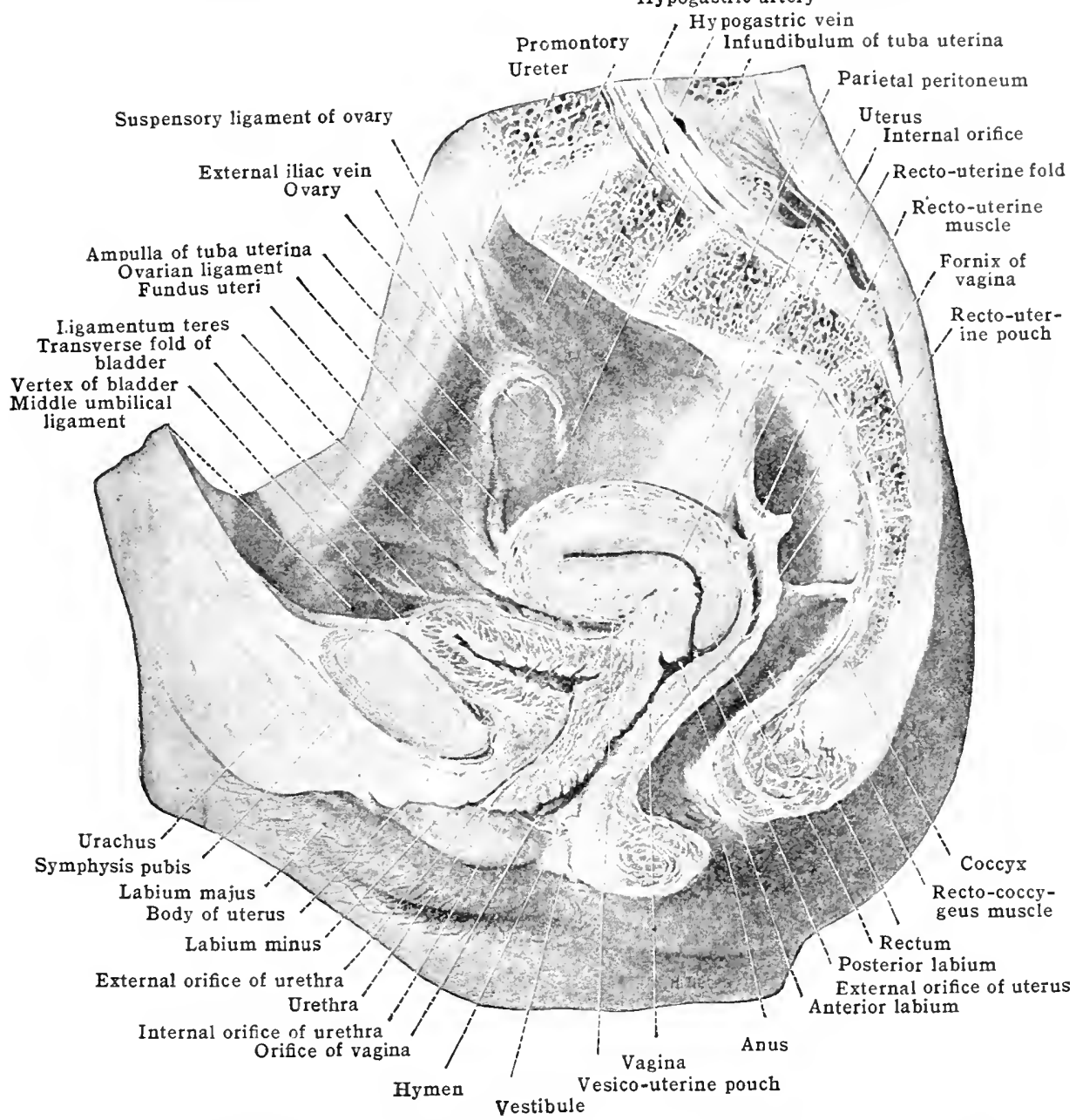

Fig. 1035.-Section of the Pelvis showing the Liganents of the Uterds.

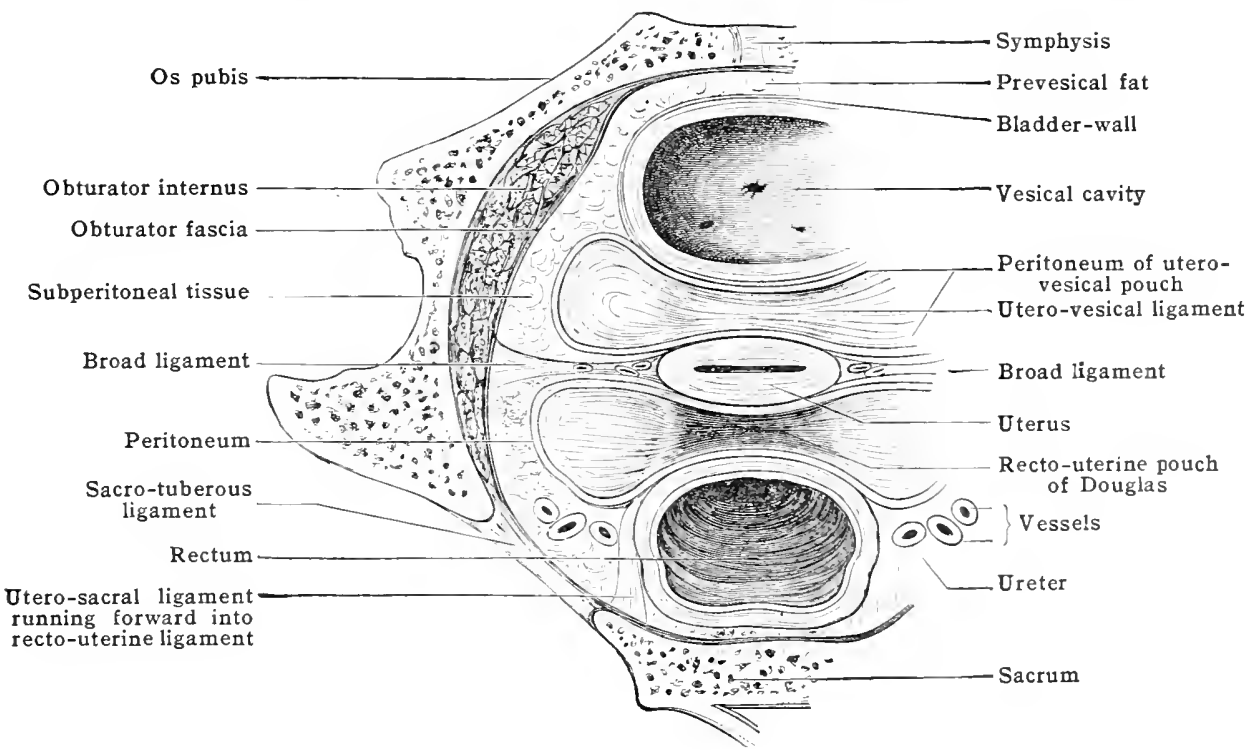


of the uterus, immediately below the point of attachment of the ovarian ligament, the ligamentum teres (round ligament) (fig. 1030), which is a fibrous cord containing non-striped muscle tissue. It extends downward, laterally and forward between the two layers of the mesometrium toward the abdominal inguinal ring, and, traversing this and the inguinal canal, it terminates in the labium majus by becoming continuous with its connective tissue.

It is aecompanied by a funicular branch of the ovarian artery and a branch from the ovarian venous plexus, and in the lower part of its course by a branch from the inferior epigastrie artery, over which it passes as it enters the abdominal ring. In its course through the inguinal canal it is accompanied by the ilio-inguinal nerve and the external spermatic branch of the genitofemoral.

The utero-sacral ligaments are flat fibro-muscular bands which extend, one on each side, from the upper part of the cervix uteri to the sides of the sacrum opposite the lower border of the sacro-iliac articulation. They produce the rectouterine folds (fig. 1029) of peritoneum, which form the lateral boundaries of the mouth of the recto-uterine pouch (of Douglas) and their muscle fibres [m. rectouterinus] are continuous at one extremity with the muscular tissuc of the uterus and at the other with that of the rectum.

Structure.-The portion of the broad ligament that invests the uterus forms the serous covering [tunica serosa] of the organ and is sometimes termed the perimetrium. Over the fundus and the greater portion of the body it is thin and firmly adherent to the subjacent museular substance of the uterus, so that it cannot readily be separated from it. Over the posterior surface of the cervix and the lower part of the anterior surface of the body, however, it is thicker, and is separated from the muscular substance by a layer of loose connective tissue, the parametrium, which also extends upward along the sides of the uterus between the two layers of the broad ligament, with whose subserous areolar tissue it is continuous. Owing to this disposition of the pirametrium the whole of the cervix may be amputated without eneroaching upon the peritoneal cavity.

The main mass of the uterus is formed by the muscle tissue [tunica muscularis] or myometrinm, whose fibres have a very complicated arrangement. Two principal layers may be distinguished, an outer, weak one, composed partly of longitudinal fibres continuous with those of the tube uterinæ, and of the round and utero-sacral ligaments, and a mueh stronger inner one, whose fibres run in various directions and have intermingled with them in the body of the uterus large renous plexuses. The inner surface of the myometrium is lined by a mucous membrane [tunica mucosa] or endometrium, which has a thickness of from 0.5 to $1.0 \mathrm{~mm}$. and is composed of tissue resembling embryonic connective tissue, bearing upon its free surface a single layer of eiliated columnar epithelium. On account of its structure the tissue is rather dolicate and friable, and numerous simple tubular glands, which open in to the cavity of the uterus, traverse its entire thickness. In the cervix the mouths of some of the glands may hecome occluderl, producing retention cysts, which appear as minute vesicles projecting from the surface between the plice palmata; they are known as ovula Nabothi, after the anatomist who first described them.

Vessels and nerves. - The principal artery of the uterus is the uterine, whose terminal portion ascends along the lateral border of the uterus in a tortuous course through the parainetrimm, giving off as it goes literal branches to both surfaces of the uterus. Above, it anastomoses with the ovarian artery, which thus forms an aecessory source of blood supply during pregnancy. The vins form a plexus that is clrained by the ovarian and uterine veins, a communication with the inferior epigastric being also matle by way of the vein accompanying the round ligament. 'The lymphatics from the greater portion of the body pass to the iliac norles: those of the fundus accompany the ovarian vessels to the lumbar nodes. A vessel also accompanies the round liganent to terminate in one of the superficial inguinal nodes. The lymph-vessels from the cervix terminate in the extermal iliac, hypogistric and lateral siacral noules.

'The neres of the uterus pass to it from two sympathetic ganglia, situated one on either side of the crevix, whener they are termed the rervieal ganglia, and forming part of the plexus ulero-raginalis. Branchus pass to the ganglia from the hypogastric plexus and also from the sreond, third and fourth sacral nerves.

\section{THE: VAGINA}

The vagina (fig. 103.1) is a museular, highly dilatable canal lined by mucous numbrane, and extends from the utsus to the external genitalia, where it opens to the exterior. Its long axis is practically paralled with that of the lower part of the satemn and it therefore ments the cervix uteri at a wide angle which is npen anteriorly. Its anterior wall is, anoordingly, somowhat shorter than the

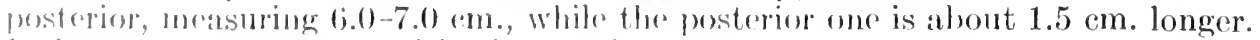
It heresmes eontinuons with the erevix uteri some listanee above the lower "xtremity of that strueture, which thus projects inte the humen of the vagina, and there is so formed at Barow eireular spater between the wall of the vagina and 
the vaginal portion of the cervix uteri. The roof of the space is formed by the reflection of the vagina upon the cervix and is termed the fornix. Owing to the greater length of the posterior wall of the vagina the portion of the circular space below the posterior fornix is considerably deeper than that below the anterior.

In its ordinary condition the lumen of the vaginal canal is a fissure, which in transverse section resembles the form of the letter $H$ with a rather long transverse bar (fig. 1036). On both the anterior and the posterior wall there is in the median line a well-marked longitudinal ridge, the columna rugarum, which is especially distinct in the lower part of the anterior wall, where it lies immediately beneath the urethra and forms what is known as the urethral carina. From both columnæ other ridges pass laterally and upward on either side, forming the ruga vaginales. Both these and the columnæ diminish in distinctness with advance in age and with successive parturitions. Toward its lower end the vagina traverses the urogenital trigone, being much less dilatable in this region than elsewhere, and it opens below into the vestibule of the external genitalia. Its orifice is partially closed by a fold of connective tissue, rich in blood-vessels, and lined on both surfaces by mucous membrane. This membrane, known as the

Fig. 1036.-Horizontal Section of Viagna and adjacent Structures. (After Henle.)

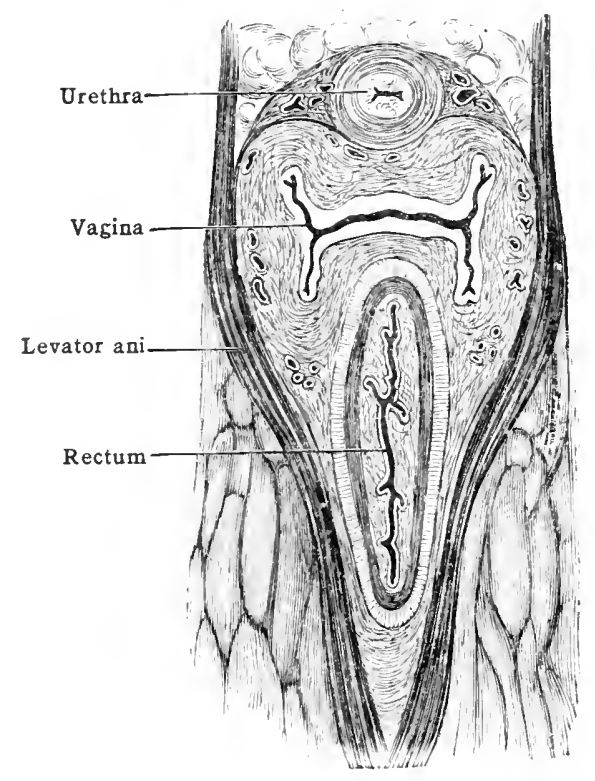

hymen, has usually a somewhat semilunar form, surrounding the posterior border of the orifice, but it may take the form of a circular curtain pierced by one or several apertures.

It varies greatly in strength and development and although it is nearly always ruptured by the first act of sexual congress, it may remain unbroken until parturition. Rarely it takes the form of a complete imperforate curtain and may necessitate a surgical operation at the commencement of the menstrual periods. After rupture the remains of the hymen persist as small lobed or wart-like structures, the caruncule hymenales, around the vaginal orifice.

Relations. - The uppermost part of the posterior wall of the vagina is in relation with the peritoneum forming the floor of the recto-uterine pouch (of Douglas), but elsewhere the canal is entirely below the floor of the peritoneal cavity. Posteriorly it rests almost directly upon the rectum (fig. 1036), and the contents of that viscus may be readily felt through its walls. Anteriorly it is in intimate relation with the urethra and the posterior wall of the bladder (figs. 1034, 1036), while laterally it is crossed obliquely in its upper third by the ureters as they pass to the base of the bladder, and in its lower two-thirds by the edges of the anterior portion of the levatores ani. The duct of Gärtner, the remains of the lower portion of the Wolffian duct, may occasionally be found at the side of the 
upper half of the vagina as a minute tube or fibrous cord. The external orifice is surrounded by the fibres of the bulbo-cavernosus muscle, which may be regarded as forming a sphineter (sphincter vagino).

Structure.-The wall of the vagina is formed mainly of non-striped muscle tissue, whose fibres are indistinctly arranged in two layers, an outer longitudinal and a less distinct inner circular one. Above, this tissue is continuous with that of the cervix uteri, as is also the mucous membrane which lines the lumen. This differs from that of the cervix in having a stratified squamous epithelium and in being destitute of glands.

Vessels and nerves. - The arteries of the upper part of the vagina are derived from the vaginal branch of the uterine; its middle portion is supplied by a vaginal branch from the inferior vesical and its lower part by the middle hrmorrhoidal and internal pudendal. The veins form a rich plexus on the surface and drain into the hypogastric vein. The lymphatics are very numerous and drain for the most part to the hypogastric and lateral sacral nodes; some of those from the lower portion of the canal joining with those from the external genitalia to pass to the inguinal nodes. The nerves passing to the vagina are derived from the utero-vaginal and vesical plexuses.

\section{The Female External Genitalia and Urethra}

The female external genitalia [pudendum muliebre] (vulva) present an elongated depression, occupying the entire perineal region and bounded laterally by

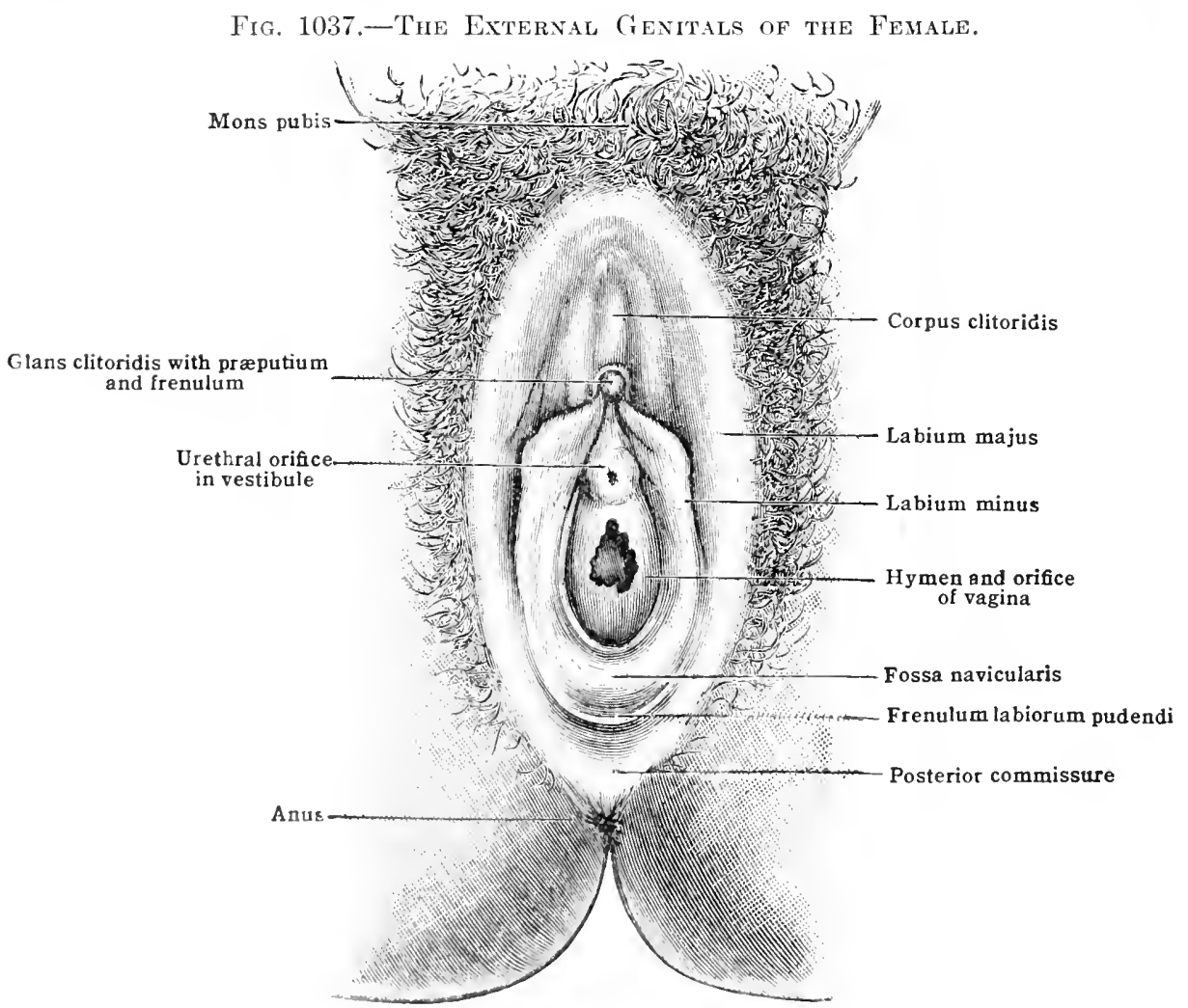

two folds of integrmment. the labin mejora (fig. 10:37). These anteriorly are contimued into the moms pubis, an emierence of the integunent over the symphysis pubis due to a drvelopment of anlipose tissure. The medial surfaces of the two labia arre nomally in contauct, the fissure between them being termed the rima pudendi, and where they ineet anterionly and posteriorly they form the anterior and pestrior commisseres [oommissura labiormu anterior et posterior]. Just anterine to the latiter is an inconstant transverse fold, the fremulum labiorum purfendi ("fourchette") (fig. 10:37). "The mons and the outer" surfaces of the

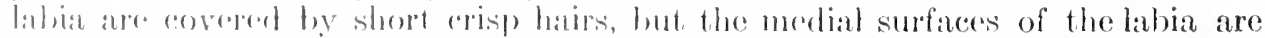
smonth, possessing only ruclimentary hatre, but beset with large sobaceous and

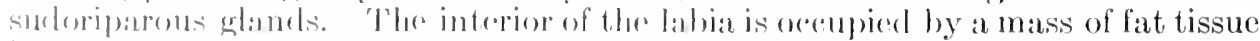
in which the distal extronity of the round liganent of the uterus breaks up. 
Within the depression bounded by the labia majora is a second pair of integumental folds, the labia minora (fig. 1037), which differ from the labia majora in being destitute of hairs and fat. They are usually concealed by the labia majora, but are sometimes largely developed and may then project through the rima pudendi, assuming a dried and pigmented appearance.

The labia minora divide and unite anteriorly over the distal extremity of the clitoris, forming the proputium clitoridis in front of the clitoris, and the fremulum clitoridis behind it. Posterior to this they diverge and reach their greatest height, gradually diminishing as they pass backward to terminate in a slight, inconstant, transverse fold, the frenulum labiorum pudendi, situated just anterior to the posterior commissure of the labia majora. Anterior to the frenulum is the fossa navicularis of the vestibule.

The vestibule.-The space between the two labia minora is termed the vestibule, and into its most anterior portion there projects the extremity of an erectile organ, the clitoris (fig. 1037), which is comparable to the penis of the male. It is, however, relatively small and is not perforated by the urethra, which lies below it. It is composed of two masses of erectile tissue, the corpora cavernosa clitoridis, which differ from the corresponding structures of the penis only in size. They are attached posteriorly to the rami of the pubis by the crura clitoridis (fig. 1038), and as they pass forward they converge and meet together to form the body of the organ, which, beneath the symphysis pubis, bends sharply upon itself

Fig. 1038.-Diagramatic Representation of the Perin.eal Structures in the Female.

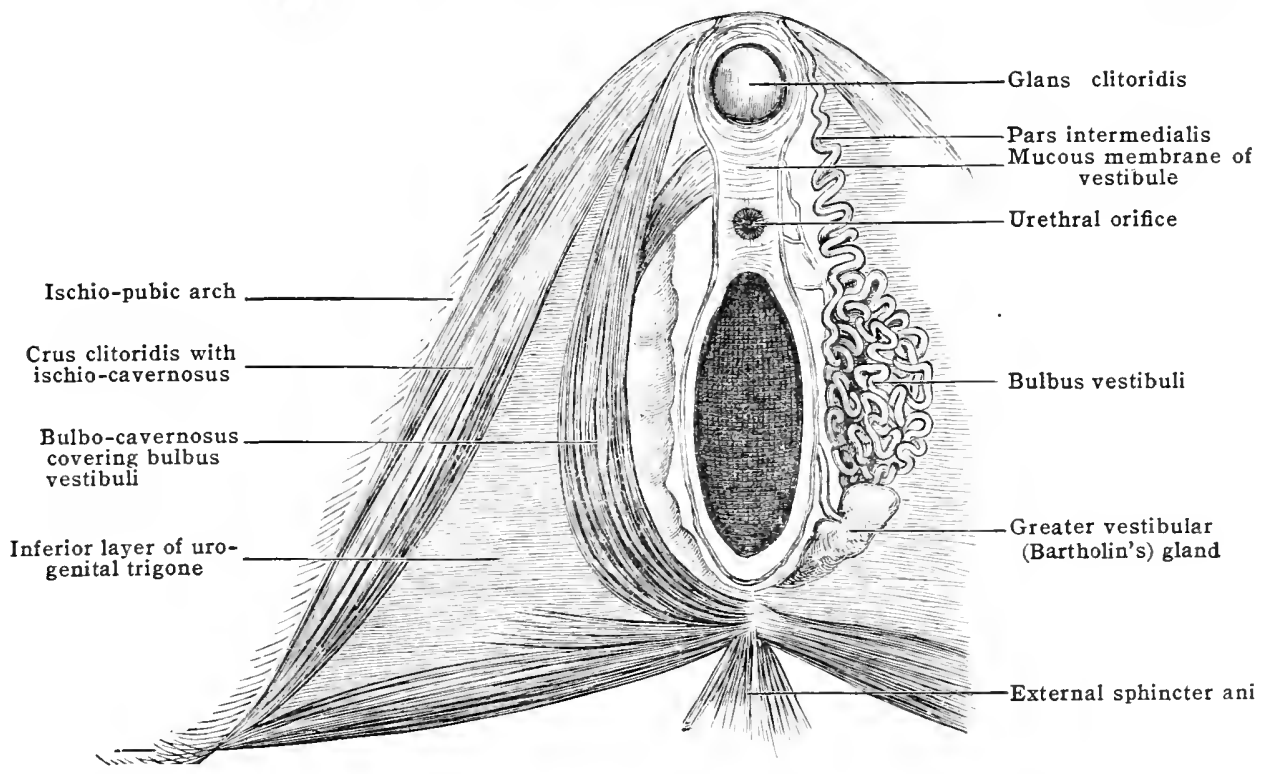

and passes posteriorly beneath the anterior commissure of the labia majora. Distally the corpora cavernosa abut upon another mass of erectile tissue, which fits like a cap over their extremities; it is formed by an anterior prolongation of the bulbi vestibuli and is termed the glans clitoridis, being comparable to the glans penis, from which it differs only in not being perforated by the urethra.

A short distance posterior to the glans clitoridis is the opening of the urethra [orificium urethræ externum], situated upon the summit of a slight papilla-like elevation. Lateral to this orifice are sometimes found the openings, one on either side, of two elongated slender ducts, the paraurethral ducts (ducts of Skene). Still more posteriorly is the external orifice of the vagina [orificium vaginæ], partially closed in the virgin by the hymen. Lateral to this, in the angles between the hymen and the labium minus on either side, is the opening of the greater vestibular gland, while the lesser glands open at various points on the floor of the vestibule, sometimes at the bottom of more or less distinct depressions.

Beneath the floor of the vestibule and resting upon the superficial layer of the urogenital trigone are two oval masses of erectile tissue, the bulbi vestibuli (fig. 1038), homologous with the corpus cavernosum urethræ of the male. They consist principally of a dense network of anastomosing blood-ressels, enclosed within 
a thin investment of connective tissue. From the main mass of each bulbus a slender prolongation, the pars intermedia, extends anteriorly past the side of the urethra, to form the glans clitoriclis.

The greuter vestibular glands [gl. vestibularis major (Bartholini)] or glands of Bartholin (fig. 1038) represent the bulbo-urethral glands of the male. They are two small, compound tubular glands, situated one on either side immediately posterior to the bulbi vestibuli.

The single duct of ench gland opens on the floor of the vestibule in the angle between the hymen and the orifice of the vagina and a little posterior to the mid-transverse line of the latter. Numerous small tubular glands occur in the integument forming the floor of the vestibule; they are termed the lesser vestibular glands and are especially developed in the interval between the urethral and vaginal orifices.

The muscles of the female external genitalia (fig. 1038) correspond to the perineal muscles of the male (see Section IV). There are two transverse perineal muscles, which have the same relations as in the male, and two ischio-cavernosi, which are related to the crura clitoridis just as those of the male are to the crura penis. The bulbo-cavernosi, however, present somewhat different relations, each being band-like in form, arising from the central point of the perineum and extending forward past the orifice of the vagina, over the greater vestibular gland and the bulbus, to form with its fellow of the other side a tendinous investment of the body of the clitoris. The two muscles act as a sphincter to the vagina and are sometimes termed the sphincter vagince.

The urethra.- The urethra of the female [urethra muliebris] (figs. 1034, 1036) corresponds only to the prostatic and membranous portions of the male and is a relatively short canal, measuring from 3.0 to $4.0 \mathrm{~cm}$. in length. At its origin from the bladder it lies about opposite the middle of the symphysis pubis and thence extends downward and slightly forward to open into the vestibule between the glans clitoridis and the orifice of the vagina. Its posterior wall is closely united with the anterior wall of the vagina, especially in the lower part of its course where it forms the urethral carina of the vaginal wall; laterally and anteriorly it is surrounded by the pudendal plexus of veins.

Structure.-Its walls are very distensible, and are lined by a mueous membrane with numerous longitudinal folds, one of which on the posterior side is more prominent and is termed the crista urethralis. The mucosa contains numerous small glands [gl. urethrales], a group of which on each side is drained by the in eonstant ductus paraurethralis. External to the loose submucosa is a sheet of smooth nusele, whose fibres are arranged in an outer cireular and an inner longitudinal layer, a rich plexus of veins lying between the two and giving the entire sheet a somewhat spongy appearance. The eireular fibres are especially developed at the vesical encl of the eanal, forming there a strong sphineter, and striped musele fibres, derived from the bulbo-cavernosus, form a sphincter around its vestibular orifiee. The female urethra differs from that of the male in not being enclosed within a prostate gland; but what are probably rudiments of this strueture are to be found in the groups of urethral glands drained by the paraurethral ducts.

Vessels and nerves.- The arteries supplying the extcrnal female genitalia are the internal and external puldendals, and the veins terminate in corresponding trunks. The lymphaties, whieh are very riehly developed, drain for the most part to the inguinal nodes; those from the urethra pass to the iliac nodes. The nerves are partly sympathetic and partly spinal; the former are derived from the hypogastric plexus, the latter principally from the pudendal, the anterior portions of the latia majora being supplied by the ilio-inguinal and the external spermatic branch of the genito-femoral.

\section{DEVELOPMENT OF THE REPRODUCTIVE ORGANS}

It has already been pointed out (p. 1267) that during development a transitory exeretory organ, the mesonephros or Wolffian body, raches a high degree of development, and its duet, the Wolffian duct, opens into a cloaca or common out let for the intestinal and urinary passages. The mesonephros forms a strong projection from the posterior wall of the abdomen into the body cavity, and on the mertial surface of the peritonem which eovers it a thickening appears which is tromed the genital ridge. The upper part of this ridge becomes the ovary or testis, as the case mat be, while the remainder of it becomes the ovarian and somd ligaments in the

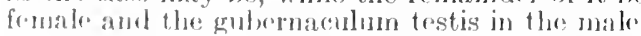

As the oviry or test is develops the tubules of the upper part of the Wollian body enter into relation with it, forming, indeed, in the rase of the testis, a direct mion with the seminforous tubules. Thr: Wollian borly then hecomes divisible into a reproductive and an exeretory portion, aml, when the motinephros or pormanont kichey develops, the latter portion degenerater, leaving only a fow rudinumts, such as the paroöphoron in the female (p. 12tig) and the vas aberrass and paralidyuis (p.1257) in the male. The reproductive portion also becomes mueh reducer in lle: fomale, persisting as the tubules of the epoophoron (p. 1269), but in the inale it 
forms the lobules of the epididymis and serves to transmit the spermatozon to the Nolffian duct.

In addition to the Wolffian duct, a second duct, the Müllerian, occurs in connection with the genito-urinary apparatus, and, like the Wolffian duct, it opens below into the cloaca. The history of the two ducts is very different in the two sexes. In the male the Wolffian duct persists to form the vas deferens, of which the seminal vesicle is an outgrowth aud the ejaculatory duct the continuation, while the Müllerian duct degenerates, its lower end persisting as the prostatic utriculus and its upper end as the appendix of the epididymis. In the female, on the contrary, it is the Müllerian duct which persists, its lower portion fusing with the duct of the opposite side to form the vagina and uterus, while its upper portion forms the tuba uterina. Inhibition of the fusion of the lower ends of the two Müllerian ducts gives rise to the bihorned or divided uteri, or the bilocular uteri and vaginæ which occasionally occur. The Wolffian duct in the female almost completely disappears, persisting only as the longitudinal tube of the epoöphoron and as the rudimentary canal of Gärtner (p.1275). With the degeneration of the mesonephros the peritoneum which covered it becomes a thin fold, having in its free edge the Müllerian duct and, on the fusion of the lower ends of the ducts, the two folds also fuse and so give rise to the broad ligament.

Fig. 1039.-Development of the Reproductive Organs.

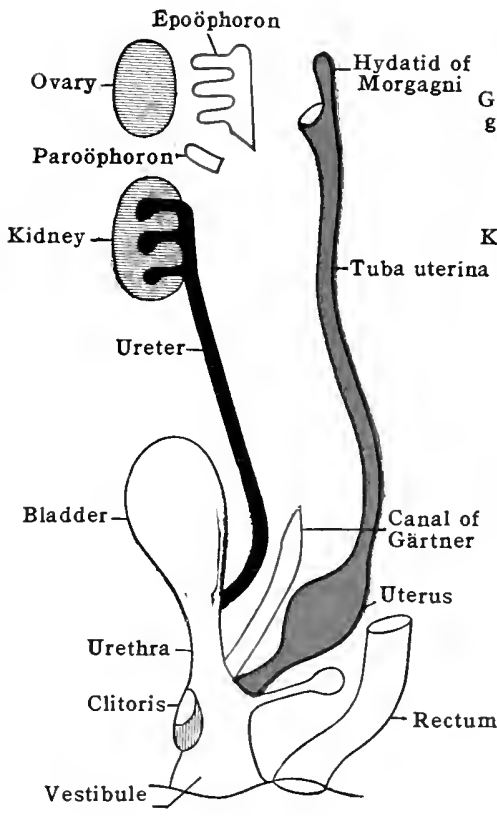

FEMALE

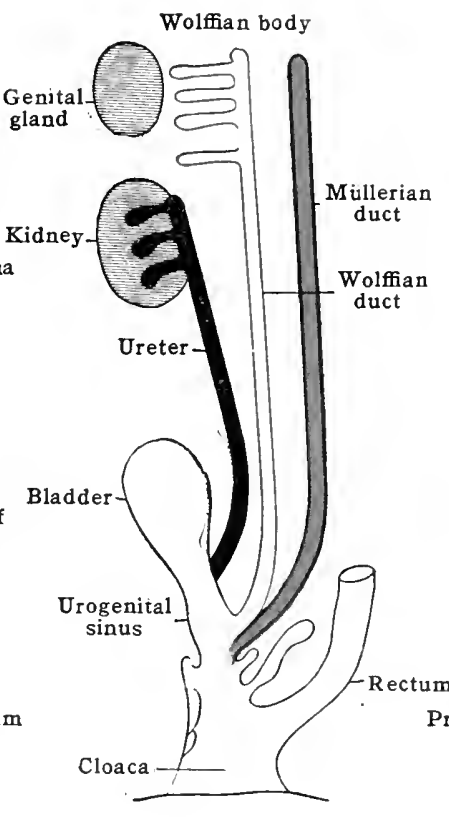

INDIFFERENT

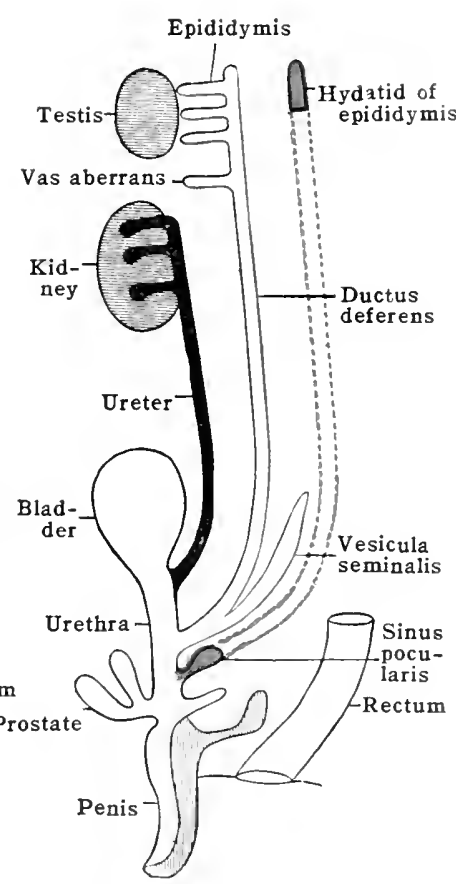

MALE

The developmental relations of the male and female organs may be seen from figure 1039 and also from the following table:-

\begin{tabular}{|c|c|c|}
\hline \multirow{3}{*}{ Genital ridge } & MaLE & Female \\
\hline & Testis & Ovary \\
\hline & Gubernaculum testis & $\begin{array}{l}\text { Uvarlan ligament } \\
\text { Round ligament }\end{array}$ \\
\hline \multirow{2}{*}{ Wolffian body } & Head of epididymis & Epoöphoron \\
\hline & Vas aberrans & Paroöphoron \\
\hline Wolffian duct & $\begin{array}{l}\text { Body and tail of epididymis } \\
\text { Ductus deferens } \\
\text { Ejaculatory duct }\end{array}$ & $\begin{array}{l}\text { Longitudinal tubule of epoöphoron } \\
\text { Canal of Gärtner }\end{array}$ \\
\hline \multirow[t]{2}{*}{ Müllerian duct } & Appendix of epididymis (?) & $\begin{array}{l}\text { Uterine (Fallopian) tube } \\
\text { Uterus }\end{array}$ \\
\hline & Prostatic utriculus & Vagina \\
\hline
\end{tabular}

The development of the external organs of generation in the two sexes presents a similar differentiation from a common condition. The division of the cloaca to form a urogenital sinus and the terminal part of the rectum has already been noted (p. 1253). In the floor of the sinus, to the sides of and above the urethral orifice, erectile tissue develops, forming a genital tubercle. An outpouching of that portion of the anterior abdominal wall to which the round ligament of the uterus or the gubernaculum was attached occurs to form the genital swellings, 
lying one on either side of the sinus, and medial to these a pair of folds develop at the borders of the sinus, enclosing the genital tubercle above and forming the genital folds.

This condition practically represents the arrangement which persists to adult life in the female. The genital tuberele becomes the clitoris, the genital swellings the labia majora, the genital folds the labia minora, and the urogenital sinus, into which the urethra and Müllerian ducts (vagina) open, is the vestibule. In the male the development proceeds farther. The genital tubercle elongates to form the penis, and the free edges of the genital folds meet together and fuse. closing in the urogenital sinus and transforming it into the cavernous portion of the urethra, thus bringing it about that the male urethra subserves both reproductive and urinary functions. The genital swellings also meet and fuse together below the root of the penis, forming the scrotum.

The homologies of the parts in the two sexes may be seen from the following table:-

\begin{tabular}{lll} 
& \multicolumn{1}{c}{ MALE } & \multicolumn{1}{c}{ FEnaLE } \\
Urogenital sinus & Cavernous portion of urethra & Vestibule \\
Genital tubercle & Penis & $\begin{array}{l}\text { Clitoris } \\
\text { Genital folds }\end{array}$ \\
Integument and prepuce of penis & $\begin{array}{l}\text { Prepuce of clitoris and labia minora } \\
\text { Labia majora }\end{array}$
\end{tabular}

Inhibition of the development of the parts in the male or their over-development in the female will produce a condition resembling superficially the normal condition of the opposite sex, and constituting what is termed pseudo-hermaproditism; or a failure of the genital ridges to fuse may result in what is known as hypospadias, the cavernous portion of the urethra being merely a groove in the under surface of the otherwise normal penis.

References for the Urogenital System. A. Urinary tract. (General, incl. literature to 1900) Disse, in von Bardeleben's Handbuch; (Renal blood-vessels) Bröclel, Proc. Ass'n Amer. Anatomists, 1901; (Renal tubules) Huber, Amer. Jour. Anat., vol. 4; Peter, Die Nierenkanälchen, etc., Jena, 1909; (Topography of female ureter) Tandler u. Halban, Monatschr. Geburtsh. u. Gynäk., Bd. 15. B. Male reproductive tract. (General, incl. literature to 1903) Eberth, in von Bardeleben's Handbuch; (Histology and development) von Lichtenberg, Anat. Hefte, Bd. 31; Hill, Amer. Jour. Anat., vol. 9; (Prostate) Bruhns (lymphatics) Arch. f. Anat. u. Entw., 1904; Ferguson (Stroma) Anat. Rec., vol. 5; Thompson (topography) Jour. Anat. and Physiol., vol. 47; (External genitals) Forster, Zeitschr. f. Morph. u. Anthrop., Bd. 6. C. Female reproductive tract. (General, incl. literature to 1896) Nagel, in von Bardeleben's Handbuch; Waldeyer, Das Becken, Bonn, 1899; (Lymphatics) Bruhns, Arch. f. Anat. u. Entw., 1898; Polano (ovary) Monatschr. Geburtsh. u. Gynäk., Bd. 17; (Nerves) Roith, Arch. f. Gynäk., Bd. 81; (Histology, ovary) von Winiwarter, Anat. Anz., Bd. 33; (Development, uterus) Hegar, Beitr. z. Geburtsh. u. Gynäk., Bd. 13; Stratz, Zeitschr. Geburtsh. u. Gynäk., Bd. 72; (Lig. eres) Sellheim, Beitr. z. Geburtsh. u. Gynäk., B(l. 4, 1901. 


\title{
SEC'TION XII \\ THE SKIN, MAMNARY GLINDS AND DUCTLESS GLANDS
}

Rewritten for the Fifth Edition

\author{
BY ABRAM T. KERR, B.S., M.D. \\ PROFESSOR OF ANATOMY IN THE CORNELL UNIVERSITY MEDICAL COLLEGE
}

\section{THE SKIN}

$\mathrm{T}$ HE covering which envelops the whole external surface of the body is known as the common integument [integumentum commune]. This consists of the cutis or skin proper and of appendages, the hair, nails, and skin glands. The cutis is composed of a superficial epithelial layer, the epidermis, derived from the ectoderm, and a deep connective tissue layer developed from the mesoderm and divided into a superficial part, the corium, and a deeper part the tela subcutanea (figs. 1040, 1041). The subcutaneous tela is not usually considered as a part of the skin in a restricted sense, but as a superficial fascia, which name is often applied to it.

Fig. 1040.-Magnified Section of the Thickened Skin of the Palu of the Hand. $\times 6$

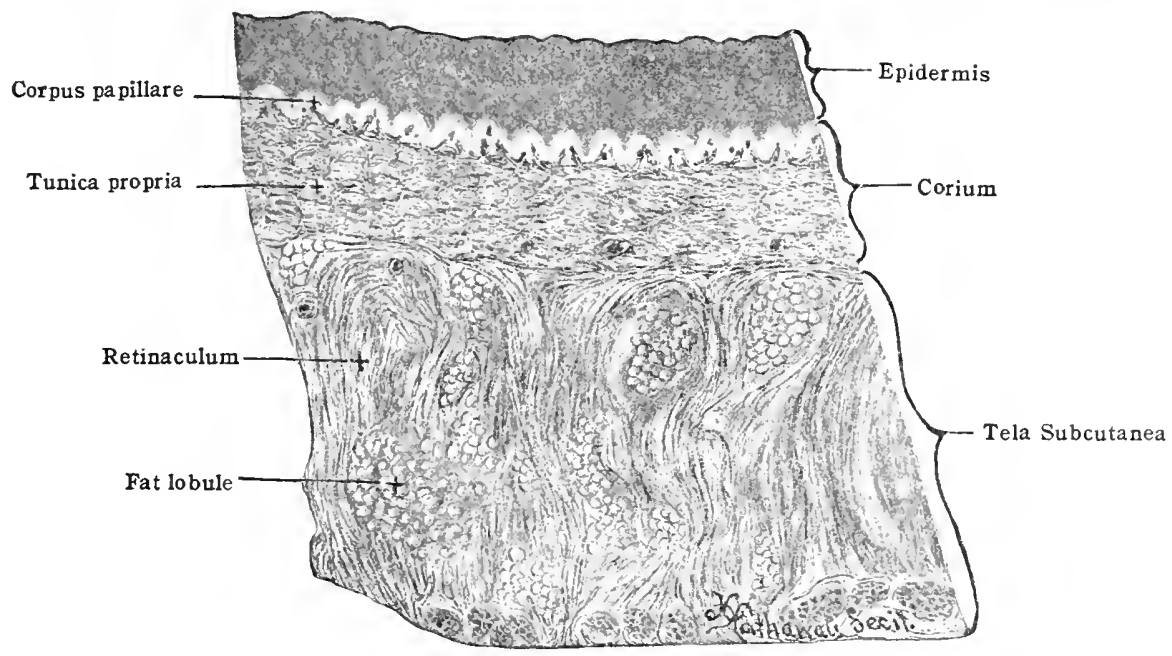

The skin forms an encasement for the entire body broken only in the regions where it merges with the mucous membranes. It serves not only as a direct physical protection to the underlying structures, but also, through its function as an organ of touch and of general sensibility, it indirectly protects the body by the action of the special end organs and peripheral terminations of the sensory nerves which thus bring the body into relations with its surroundings. Through the radiation and conduction of heat to and from the blood circulating in it, through the amount of secretion of its glands and the evaporation from its surface, the skin forms the principal organ for the regulation of the bodily heat. By means of the action of its sweat and sebaceous glands it possesses an important secretory function. It has also a minor rôle as an organ of respiration and absorption.

The surface area of the skin corresponds approximately to the surface of the body and naturally varies with the size of the individual. It has been variously estimated at from 10,500 to $18,700 \mathrm{sq}$. cm. for a medium-sized adult male. 
The aperturæ cutis are holes through the skin where it joins with the mucous membrane, usually without sharp line of demarcation, at the nares, the rima oris, the anus, and the external urethra in the male, and at the vaginal vestibule in the female.

Owing to the fact that the skin extends beyond the surface at the aperaturæ cutis, and eovers the major and minor pudendal labia, and the prepuce and extends into the external acoustic canal, the surface arca is slightly greater than the surface of the body.

The thickness of the skin varies in different regions of the body and also in different individuals. The mean thickness is between 1 and $2 \mathrm{~mm}$., the extremes ranging from .3 to $4.0 \mathrm{~mm}$. or more. This is exclusive of the subcutaneous tela. The thickness appears to be in direct proportion to the amount of friction and pressure to which the part is subjected. Thus it is thicker on the dorsal than on the ventral surface of the trunk and neck, and on the flexor than on the extensor surfaces of the hands and feet. Otherwise it is thicker upon the extensor than on the flexor surface of the extremities.

Fig, 1041. - Vertical Section from the Sole of the Foot of An Adult. $\quad \times 25 . \quad$ (Lewis and Stöhr.)

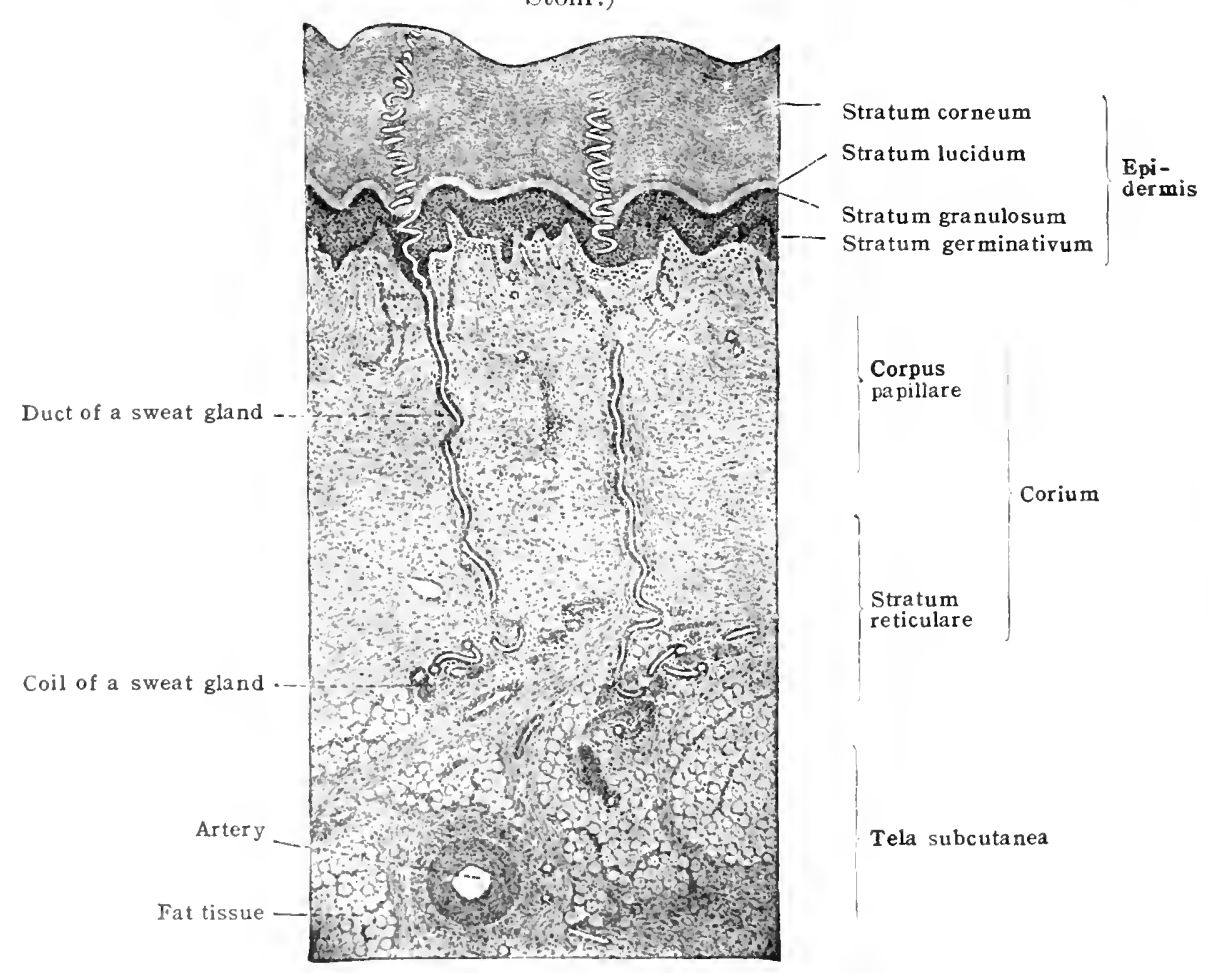

The thickness of the skin is least upon the tympanum and it is also thin upon the eyelids and penis. It olstains a thickness of $3 \mathrm{~mm}$. on the volar surface of hands and plantar surface of the feet and gains a thickness of about $4 \mathrm{~mm}$. on the cephalie part of the back and dorsal surface of the neck. It is thinner in the ared than in the ahlt, thicker in men than in women, and in the same sex is subject to much individual variation depending upon exercise, occupation, cte. The vascularity of the skin also influences its thickness.

(J)er most of the surface of the body the skin is elastic and so loosely attached that it may be stretcher to a grouter or less extent. The elasticity varies in different indiviluals. ('losely atsociaterl with the elasticity is the manner of attachment of the skin to underlying structures. This varies somewhat aceording to the tissues which are covered but the great motility is due in the main to the very obligue arrangement of the eomnertive tissue and elastic fibres of the deeper livers of the skin; the fixity lo the nore vertical arrangement of these fibres. An understanding of the loosinuss and elasticity of the skin is of mueh practieal importance to the surgeon in artatin operations.

When the traction is shw asover a stow-growing tunom, or over the abromen and breasts in pregnancy, the skin may be stretehed to a very consilerabledegree. In these cases there are of 
placed by whitish, silvery lines, striæ or lineæ albicantes, due to atrophy of the tissues. In spite of this the skin usually retains enough elasticity to contract gradually to its former extent as it does immediately after moderate stretching.

In most parts of the body the attachment is loose so that the skin is movable and may be pinched up into folds. In some places the attachment of the skin is firm and there is no slipping of the skin over underlying parts, as on the glans penis. In some other parts the motion is very limited as in the scalp and the volar surface of the hands and the plantar surface of the feet.

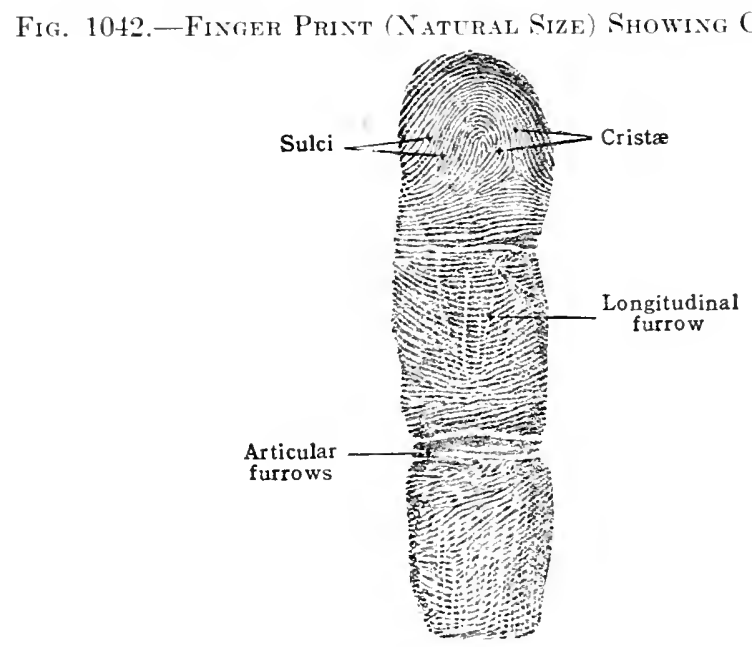

The colour of the skin varies greatly. It may be white, rellow, black, red, or any of the shades of these colours, and, according to the colour, the races of mankind have been roughly divided. The colouration is due partly to pigment and partly to the blood within the cutaneous ressels. The amount of pigment varies with race, age, sex, and with exposure to the sun and air. In the white races the skin of the child is a pinkish white, tending to become dead white in the adult and yellowish in the aged, and it is normally more pigmented in certain regions, such as the axillary region, the scrotum, the rulva, and the mammary areola.

Fig. 1043.-Diagray Showizg the Arrangenext of the Principal Coriste of the Thimb

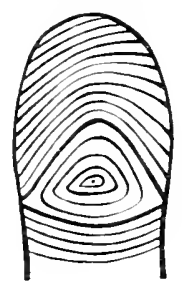

The colour of the white, yellow, red, and black races is not produced by the climate, as we find different races existing under the same climatic conditions and the same coloured race under different conditions of climate. Each race presents several variations of colour; for example in the white race we distinguish a blonde, a brunette, and an intermediate type. Anthropologists distinguish twenty to thirty different shades of colour in the skin. In blondes of the white race under the action of strong sun light the skin passes from a rose white to a brick red or becomes pigmented in spots, freckles. In the first case the pigment in the skin is not inereased to any great extent but the skin is affected by a superficial inflammation, erythema, associated with exfoliation and of ten with the formation of blisters. In brunettes of the white race the sun burns the skin a dark yellowish or reddish brown, the degree of pigmentation here being increased and is spoken of as tan. The colouration is only temporary and diminishes on withdrawal from exposure. The sun darkens the skin in the yellow races also. In the newborn of the black races the skin is of a reddish colour, since the pigment although developed to some extent is at birth obscured by overlying opaque cells which later become transparent. The newborn of the yellow races are also lighter than their parents. In white races the shade of the skin is clearer on the ventral surface of the trunk and on the flexor surface of the extremities. In the black races the volar surface of the hands and the plantar surface of the feet as well as the sides of the digits are less deeply pigmented than the rest of the body. The colour of the skin is greatly influenced by the blood in its deeper layers which during life gives it a more or less distinctly reddish tinge, varying directly with the vascularity and inversely with the thickness of the epidermis. Absence 
of the normal pigment is a not uneommon congenital anomaly producing albinism or leukoderma. It may affeet all the skin structures or it may be partial.

The skin presents eertain elevations and depressions due to the fact that it follows more or less elosely the contour of the underlying structures, but in addition to this it possesses certain elevations and depressions peculiarly its own. They are found on the skin in various parts of the body. Some are permanent, others only temporary. Large permanent folds which include all the layers of the skin are seen, as the prepuce of the penis and the pudendal labia. The most marked depression is the umbilical fovea. Other conspieuous folds and furrows are seen in the neighbourhood of the lips and eyelids. Certain other less permanent folds and furrows are produced by the action of the joints, joint-furrows, and of the muscles of expression of the skin, "wrinkles."

Fig. 1044.-Frow a Photograph of the Superficial Furrows on the Back of the Hand. $(\times 1$.

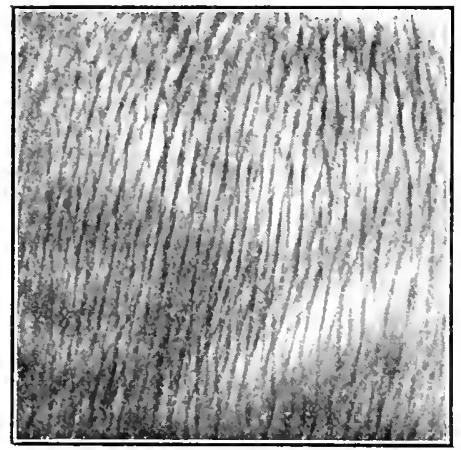

Other minute folds and furrows which affect only the epidermis and the superficial layer of the corium are seen in various places. These are represented by the numerous fine superficial ereases, unassociated with elevations, forming rhomboidal and triangular figures over almost the whole of the surface of the skin (figs. 1042, 1043). They are especially numerous on the dorsal surface of the hands (fig. 1044). The fine eurvilinear ridges [eristæe eutis] with intervening furrows [sulei cutis] arranged in parallel lines in groups on the flexor surface of the hinds and feet are also of this type. They form patterns characteristic for each individual and permanent throughout life.

Fir. 1015.-From a Pintograph of the Skin Ridges and Papilleg of the Pala of the

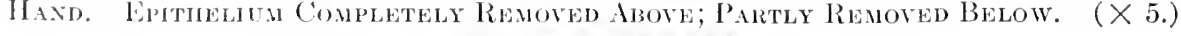

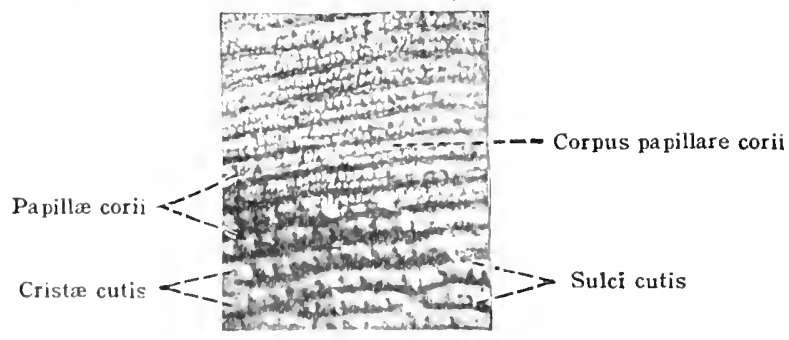

Anomg the projections ale the latue permanent folds of skin such as the labia pudendi, the preputium penis, the frenula preputii, clitoridis, anl labiorum pudendi, and less marked ridges as the median raphe of the perinem, serotmm and penis, and the tuberculum labii superioris.

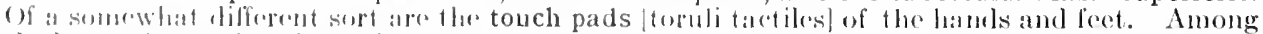
the larger fopensions in aldition to the umbilical fovea, is the coccygeal foveola, and a considerable mumber of well marked permaturnt furrows [oumel in varions plates, sucl as the nasolabial ancl mentolabial sulci, the philtrum labii superioris, the infraorbital sulcus, and the infra- and supraorbitial palpebral sulci. There ine numerous articular furrows on both the flexor and

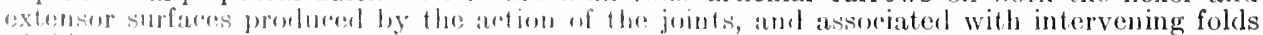

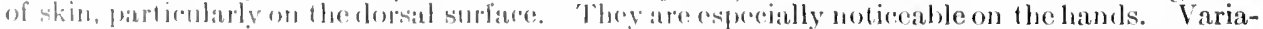

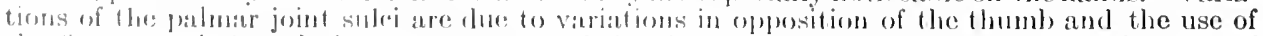
the firgers and the rolative arrangement of the thumb and fingers and joints. They are of 
especial medical and surgical importance as indicating topographically the position of the joints, their relation to which has been recently made clearer by means of the X-ray.

The folds and furrows brought about through the action of the skin muscles run at right angles to the muscle fibres and are more or less transitory at first but become more permanent through repeated or long-continued action. They are represented by the wrinkles of the forehead, the lines of expression of the face, the transverse wrinkles of the scrotum and the radiating folds around the anus. The more superficial cristæ cutis and sulci cutis are arranged in groups within and around the touch parts, on the volar surface of the hands and the plantar surface of the feet (figs. 1042, 1043). The crista of each group are parallel. They correspond to the rows of papillæ of the corium.

Because the patterns of the crist $x$ and sulci are characteristic for the individual, and permanent from youth to old age, they have been classified in a number of types and are important medicolegally as a means of identification. The various systems of classification are based upon the arrangement over the distal phalanges of the fingers and make use of (1) a transverse ridge which is parallel with the articular plicæ (2) a curvel ridge with its convexity distally and more or less closely meeting the first, medially and laterally, and (3) the curved and concentric ridges between these two (fig. 1043).

There are also a great number of minute depressions which mark the points where the hairs pierce the surface and where the glands open. These are popularly known as pores. Under

Fig. 1046.-Papille of the Corium after Maceration. Fron Retocched Photograph. Epitheliun Removed by Maceration. ( $\times 25$.

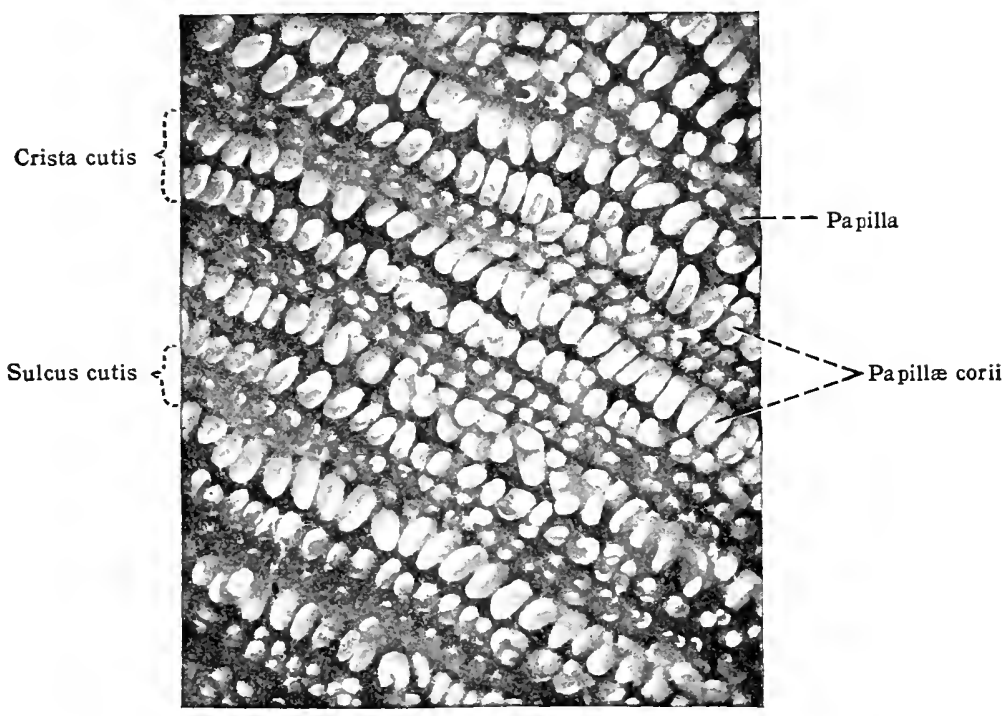

the influence of cold and emotion the hair muscles contract and cause a slight elevation of the skin at the point where the hair emerges. This roughened appearance of the skin is popularly known as "goose-flesh."

A complex wrinkling of the skin appears in old age, or in the course of exhausting diseases, ?as a result of loss of elasticity and from absorption of the cutaneous and subcutaneous fat. Rounded depressions called dimples are produced by the attachment of muscle-fibres to the deep surface of the skin, as on the chin and cheek, and are made more evident by the contraction of these fibres. Others are produced by the attachment of the skin by fibrous bands to bony eminences, as the elbow, shoulder, vertebræ, and posterior iliac spines. They are best seen when the subcutaneous adipose tissue is well developed.

The cutis is made up of two layers which are structurally and developmentally markedly different. The superficial ectodermic portion, epidermis, is made up almost entirely of closely packed epithelial cells, the deeper mesodermic part, corium, is formed largely of connective-tissue fibres.

The epidermis (cuticle, scarf-skin) is a cellular non-vascular membrane which forms the whole of the superficial layer of the skin and at the great openings through the skin, as the mouth and anus, blends gradually with the mucous membrane. It represents from onc-tentii to over half the thickness of the skin, in different parts of the body, the usual thickness being .05 to $.2 \mathrm{~mm}$., ranging from $.03 \mathrm{~mm}$. to nearly $3 \mathrm{~mm}$. The thickness varies also in different individuals. Its deep surface is molded exactly to the underlying corium but its superficial surface fails to reproduce all of the irregularities of the latter. In spite of this close association, blood-vessels never enter the epidermis.

Structure of the epidermis.--The cells of the epidermis are packed together in many irregular layers. The deepest cells are soft protoplasmic, somewhat elongated, perpendicular to 
the surface of the corium and joined together by fine fibrils; more superficially they become round or polyhedral. These cells together with several more superficial layers form a stratum from which the other cells of the epidermis are developed and which therefore are known as the stratum germinativum (Malpighii). The cells in the superficial part of this stratum, in some situations, have a granular appearance forming a layer which is called the stratum granulosum. Superficial to this there is, also only in some places, a layer in which the cells are somewhat indistinct and transparent, and therefore known as the stratum lucidum. This is a transition between the softer and more opaque stratum germinativum and the firmer and more transparent superficial layer formed of large, flattened, dry, horny cells, known as stratum corneum.

In general the stratum germinativum is thicker than the stratum corneum. In certain parts as the face, the back, the back of the hands and feet, the two layers are equal in thickness. In other regions, as in the volar surface of the hands and plantar surface of the feet, the stratum corneum is much thicker than the stratum germinativum varying from two to three or even five times as thick. This increased thickness of the stratum corneum is not due to pressure alone as it is well marked in the fotus, but it is not improbable that pressure may stimulate the further growth of the cells.

Where the papillie of the corium are arranged in rows as on the volar surface of the hands and the plantar surface of the feet, the epidermis is molded to these so as to appear as ridges on the surface, already described as cristæ. In most other places the irregularities of the papillæ of the corium do not show on the surface. At short and regular intervals on the cristæ are notches and transverse furrows which mark the openings of the sweat glands.

The separation of the epidermis from the corium by the accumulation of serous fluid between the layers is known as a blister. Sometimes it is only the separation of the superficial layers from the deeper layers of the epidermis.

The skin is regenerated after a blister or a wound by growth of the cells of the stratum germinativum. It is probable that cells of the superficial layers take no part in this. Therefore in skin grafting the surgeon in order to transplant the cells of the stratum germinativum usually includes all the layers of the epidermis and the extreme tips of the papillæ of the corium as shown by the minute bleeding points left on the surface from which the graft has been cut.

The pigment which gives the main colour to the skin is caused by the accumulation of pigment granules, melanin, in the deepest cells of the stratum germinativum. It does not occur until after the sixth month of fotal life and develops chiefly after birth. The blackness of the skin of the negro depends almost entirely upon this pigment. Pigment granules are also found to a less extent in more superficial cells and sometimes in the corium.

Development of the epidermis. - The epidermis is derived from the ectoderm, in early embryos appearing as a double stratum of cells, the superficial layer of which is known as the epitrichium or periderm, the deep layer becomes the stratum germinativum. By multiplication of the deep cells a number of layers are produced and the more superficial cells tend to assume the adult characteristics. At about the sixth month of fotal life the epitrichial layer finally disappears. The surface layers are cast off and mixing with the secretion of the cutaneous glands form a yellowish layer over the surface of the skin of the fœetus, the vernix caseosa.

Growth continues throughout life. New cells are formed in the deeper layers pushing the older cells toward the surface. The character of the cells changes as they approach the surface, the change being quite abrupt at the level of the stratum lucidum. As the form of the cells changes, chemical and physical alterations of their contents occur. In most places the superficial cells are represented by thin seales but in the palms and soles the cells arc somewhat swollen. The superficial cells are being constantly thrown off and replaced by deeper ones.

The corium (cutis, cutis vera, derma) is a fibrous vascular sheath composed of interwoven bundles of connective-tissue fibres intermixed with elastic fibres, connective-tissue cells, fat, and scattered unstriped musele-fibres. It is traversed by rich plexuses of blood-vessels, lymph-vessels, and nerves, and encloses hairbulbs and sebaceous and sudoriferous glands. It varies in thickness from .3 $\mathrm{mm}$. to $3.0 \mathrm{~mm}$. or more, usually ranging from .5 to $1.5 \mathrm{~mm}$. It is to this layer that the strength and elasticity of the skin are due and it is also only this layer which when properly cured we know as leather.

The superficial layer of the corium is of finer, closer texture, free from fat, and forms a multitude of eminences called papillæ corii (figs. 1040, 1045, 1046) which project into corresponding depressions on the rleep surface of the epidermis. For this rasom this part of the corium although but indistinctly separated from the derener layer is called the corpus papillare.

Some of the papillin contain vessels, others nerves, hence they are known as vaseular or tactile papill:e. 'They are very closely set, viurying considerably in number in different parts of the borly from :3t; to 130 to a siluare inillimetre, and it has been estimated that there are about 150) million papilia on the whole surfare. They also viry greatly in size not only in different regions but in the same region, being from .03 to .2 $\mathrm{mm}$. or more in height.

The rerene layer of the corium, the tunica propria (stratum reticulare), is composed of courser and less comparet bands of fibrous tissue intermingled with small fat lobules. The fibrous and clastic tissue is arranged for the most part in intererossing bumlles nearty parallel to the surface of the skin.

The bumbles rumbing in some directions are usually more strongly developed and more mumerris than those in whers but the direction of the strongly developed bundles varies in 
different parts of the body. In general those are best developed which have a direction parallel with the usual lines of tension of the skin, hence it results that wounds of the skin tend to gape most at right angles to these lines. The bundles take a direction nearly at right angles to the long axis of the limbs, and on the trunk run obliquely, caudally, and laterally from the spine (figs. 1047, 1048). On the scalp, forehead, chin, and epigastrium, equally strong bundles cross in all directions, and a round wound, instead of being linear as elsewhere, appears as a ragged or triangular hole. The arrangement of the connective-tissue bundles influences the arrangement of the blood-vessels of the skin.

The tela subcutanea or superficial fascia is also a fibrous vascular layer which passes as a gradual transition without definite line of demarcation from the deep surface of the tunica propria of the corium to connect it with the underlying structures.

Like the tunica propria it is composed of bundles of connective tissue containing elastic fibres and fat, but the bundles are larger and more loosely arranged, and form more distinct connective-tissue septa, which divide the fat, when present, into smaller and larger lobules. Where these connecting strands are especially large and well defined, they are known as retinacula. Over almost the whole surface of the body the connective-tissue strands of the tela

Pigs. 1047 and 1048.-Diagrams Showing tae Arrangenent of the Connective Tissur Bundees of the Skin on the Anterior and Posterior Surfaces of the Body. (After Langer.)
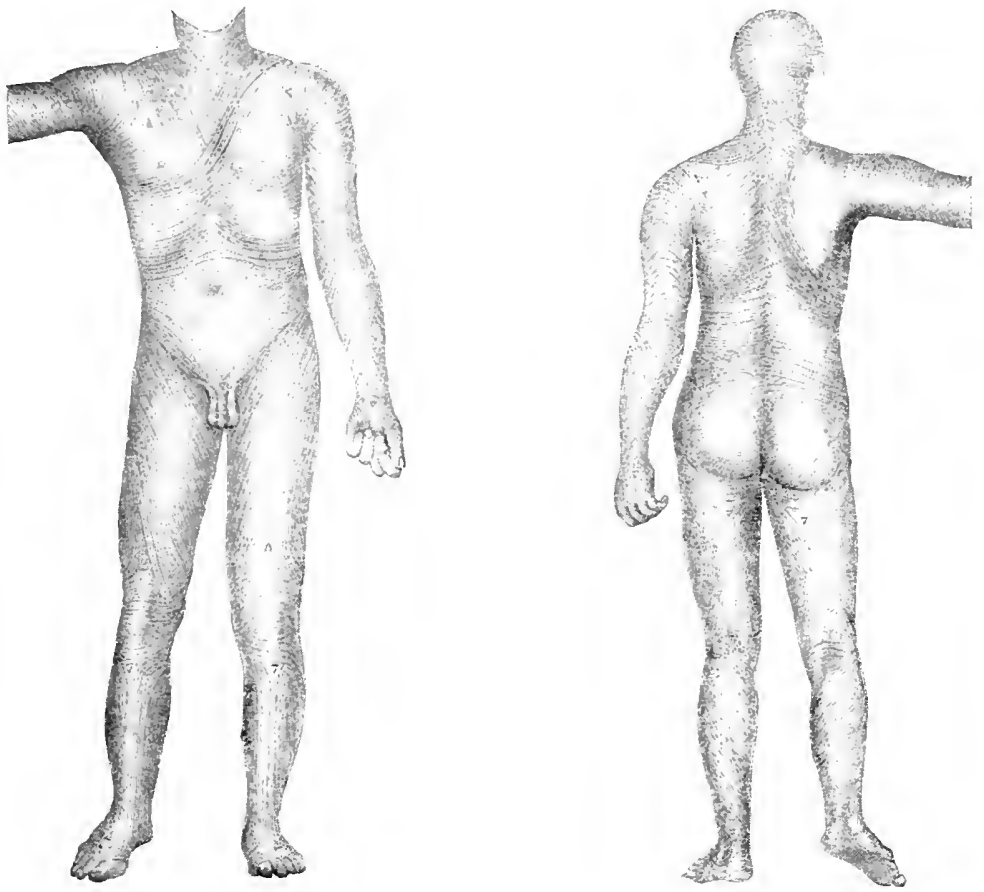

are arranged nearly parallel with the surface, and bind the skin so loosely to the parts beneath that it may stretch and move freely over the deeper parts. In some situations the connectivetissue bundles of the tela subcutanea run almost at right angles to the surface and bind the skin firmly to the deep fascia, as in the flexor surface of the hands and feet and in the scalp and face.

The quantity of subcutaneous fat varies considerably in different parts of the body. It is, for instance, entirely absent in the penis, scrotum, and eyelids. When it is abundant, the subcutaneous layer is known as the panniculus adiposus.

In some situations, as in the caudal portion of the abdomen and in the perineum, the connective tissue is so arranged that the panniculus may be divided into layers, so that a superficial and a deep layer of the superficial fascia may be recognised. The fat is well developed over the nates, volar surface of the hands and plantar surface of the feet, where it serves as pads or cushions; in the scalp it appears as a single uniform lobulated layer between the corium and the aponeurosis of the epicranial muscle; and on other parts of the surface it is somewhat unequally distributed and shows a tendency to accumulate in apparent disproportion in some localities, as on the abdomen, over the symphysis pubis, about the mammæ in females, etc. Everywhere except on the scalp it may undergo rapid and visible increase or decrease under the influence of change of nutrition. 
The amount of elastic tissue mixed with the white fibrous connective tissue of which the corium and subeutaneous tela mainly consist varies in the different parts of the body. It is especially abundant in the deeper layer of the tela over the caudal part of the ventral abdominal wall where it forms almost a continuous sheet. Many elastic fibres also accompany the blood-vessels and are mingled with the connective-tissue sheaths around the hairs, the sweat glands, and their ducts.

The papille corii are usually simple cones but some are bulbous at their ends and others have duplicated apices. They may be perpendicular to the surface or oblique, in some places overlapping. Those on the flexor surfaces of the hands and feet are best developed and are arranged in rows so as to form long parallel curvilinear ridges, two of which are grouped together and correspond to one crista on the surface of the epidermis (figs. 1045, 1046). When there are no papillary ridges the papillie are irregularly scattered, shorter, and may disappear in places or be replaced by ridges. The papille serve to give a greater surface area to the corium so as to bring a greater number of blood-vessels and nerves in to closer relation with the epidermis and thus with the surface of the body. They are best developed where the epidermis is thickest. Thus they are the largest on the flexor surface of the hands and feet and beneath the nails and are smallest on the face, scrotum, and mammx.

The skin, as removed in the dissecting room, usually includes the epidermis and more or less of the corium and subcutaneous tela. The cut surface is formed of connective tissue which has a shining bluish-white appearance with minute pits closely scattered over the surface. These pits are usually more or less completely filled with small yellow fat lobules.

Skin muscles.-In the subcutaneous tela and the corium muscle fibres are found in large and small groups. These are of two kinds, striated muscle and unstriated muscle.

Subcutaneous planes of striated muscle are relatively scanty in man when compared with the great panniculus carnosus of the lower mammalia. This is mainly represented by the platysma in the neck which has both its origin and part of its insertion in the skin. Closely associated with this are the muscles of expression of the face and the palmaris brevis muscle which have one end terminating in the deep surface of the skin. The epicranial muscle is also considered by some to belong to this group.

Unstriated muscle fibres are scattered through the corium collected into bundles in the neighbourhood of the sebaceous glands and the hairs. They are described in connection with these latter (p. 1293). In ardition to these unstriated muscles are found in the scrotum as the dartos, in the perineum, around the anus, and beneath the papilla and areola of the mammary gland.

Bursæ mucosæ subcutanea.-In some situations where the integument is exposed to repeated friction over subjacent bones or other hard structures its movements are facilitated by the development of sac-like interspaces in the subcutaneous tissue, the subcutaneous mucous bursæ. They are similar to the more deeply placed burse which are found in relation with muscle tendons. Their occurrence is quite variable. In some individuals they are numerous, in otleers very few. They have a considerable practical importance from the fact that they may become greatly swollen.

The most constant subcutaneous mucous bursie are the following:

Bursa anguli mandibulæ; B. subcutanea prementalis, between the periosteum and soft parts over the tip of the chin; B. subcutanea prominentiæ laryngeæ over the ventral prominence of the thyreoid cartilage of the larynx (often found in the male; B. subcutanea acromialis, between the acromion and the skin; B. subcutanea olecrani, heneath the skin on the dorsal surface of the olecranon; B. subcutanea epicondyli humeri lateralis, found beneath the skin over the lateral epicondyle of the humerus (oecasional); B. subcutanea epicondyli humeri medialis, between the skin and the medial epicondyle of the humerus (more frequent); $\mathrm{B}$. subcutanea metacarpophalangea dorsalis, between the skin and the lorsal side of the metacarpophalangeal joints (ocusional, especially the fifth); B. subcutanea digitorum dorsalis, beneath the skin over the proximal finger-joints; and rarely over the distal finger-joints; B. subcutanea trochanterica, between the skin and the great trochanter of the femur; B. subcutanea præpatellaris, beneath the skin covering the ('tmlit half of the patella; B. subcutanea infrapatellaris, between the skin and the cephalie end of the liganentum matler; B. subcutanea tuberositatis tibiæ ventral to the tihial tuberosity, eroverl by skin or hy skin and rrumal fascia; B. subcutanea malleoli lateralis, between the skin and the woint of the lateral malleohss; B. subcutanea malleoli medialis, hetween the skin anl melial mithohis; B. subcutanea calcanea, in the sole of the foot betwern the skin and the plantar surfues of the ratcancum; B. subcutanea sacralis, beneath the skin which covers the lumbodorsal fascia and the region hetween the sacrum and eoceyx.

Blood-vessels of the skin.- hoth the (corium and the subutaneous tela are very vaseular, but the size and number of vessels varies in different situalions. Although the origin of the cutaneous arteries from the deep aldoris and the positions where the subcutaneous arteries pieree the muscles vary greatly, the areas suppliod hy certain gromps of arteries and the direetion in which the arteries of the skin run show mure regularity. Moreover the metameric arrangennont of the arteries in the skin is chaly seen, esperially upon the trunk. We ean recog-

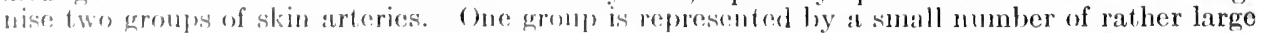
branches which are listributed throughout or prineipally in the subeutaneous tela and enrium, as the inforior superferal ppigastric artery, lhe arteries of the scalp, ete. These arteries tend to 
disturb the metameric arrangement. In the other group the arteries are intrinsically for the supply of other organs but give off small end twigs to the skin, e. g., the arteries to the superficial muscles.

The arteries enter the corium from the subcutaneous tela, break up into smaller branches anastomose freely and in the deepest layer of the corium form a network, the cutaneous rete (subcutaneous plexus), rete arteriosum cutaneum, from which small branches are given off to supply the fat and sweat glands and also to the papillary layer of the corium. Here another network of arteries is formed, the subpapillary rete, rete arteriosum subpapillare. From the subpapillary plexus, minute twigs pass to the papille, to the hair follicles, and to the sebaceous and sudoriferous glands.

The cutaneous veins like the arteries may be divided into three groups: (1) small radicals which accompany the corresponding arteries and go to make up veins whose main function is to collect the blood from the muscles; (2) larger branches accompanying the arteries whose main course is in the subcutaneous tela as the inferior superficial epigastric vein; (3) large veins which run in the subeutaneous tela but have a course independent of the arteries such as those seen through the skin on the hands and arms. These large vessels will be found described in connection with the general description of the veins (Section $V$ ).

Minute venules arise from the capillaries of the papilla, accompany the arteries and form parallel with the surface of the skin a series of closely connected plexuses. Four such plexuses,

Fig. 1049.-Cutaneous Nerves of the Middle Finger and Lamellods (Pacinian) CorPUscles. (From Toldt's Atlas.)

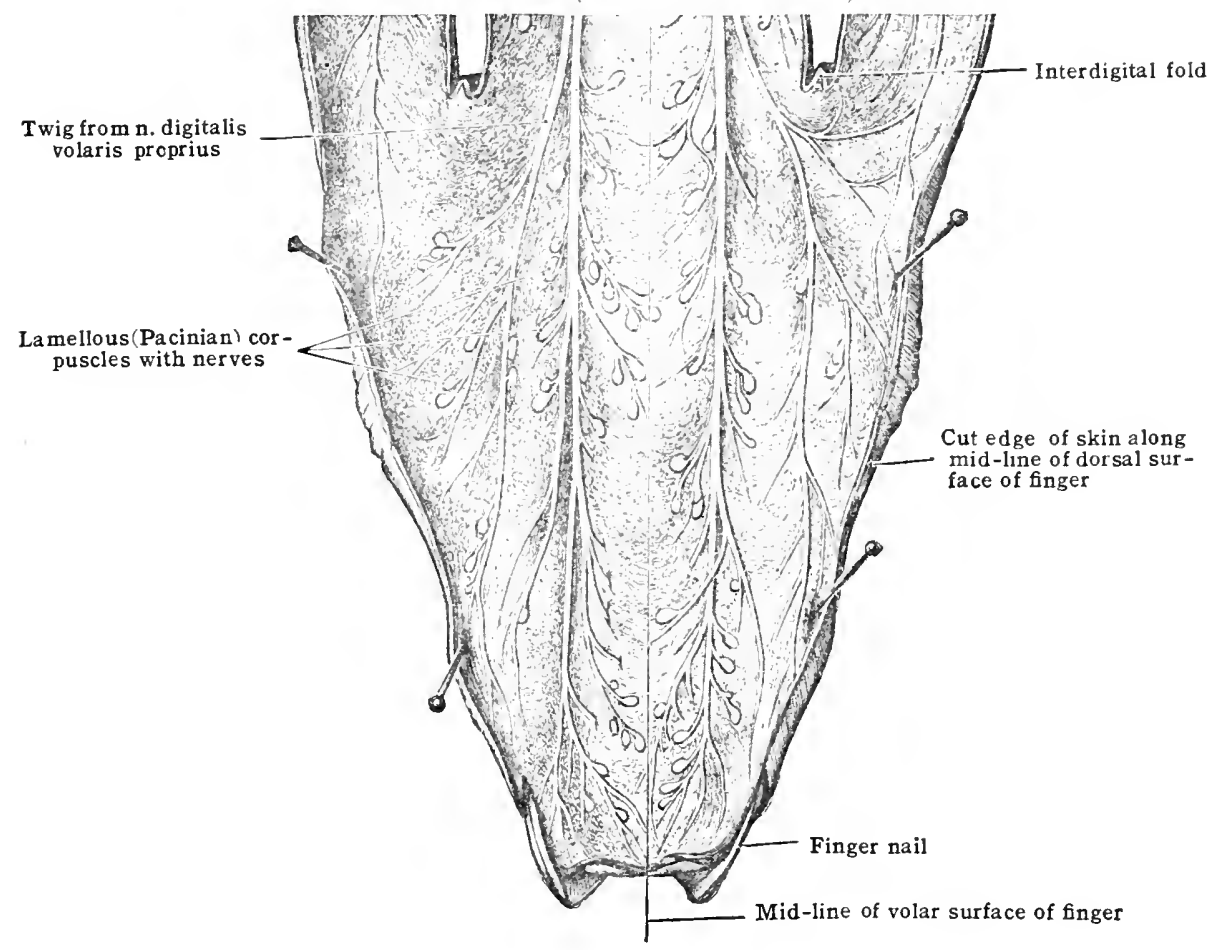

more distinct than the arterial, may be recognised in some situations. Of these retia venosa one is situated just beneath the papillæ, and another at the junction of the corium and subcutaneous tela. They receive branches from the fat, hair follicles, and glands, and empty into the large veins of the skin situated in the subeutaneous tissue.

Lymphatics of the skin.-The cutaneous lymphatic vessels are found in the skin of all parts of the body but are more abundant in certain places. The lymph-vessels of the skin are developmentally among the first lymph-vessels to appear. The larger vessels and glands of the subcutaneous tela will be found deseribed in connection with the general lymphatic system Section VI). In the corium the lymphatics from the papille form a subpapillary network which opens into a subcutaneous plexus connected with the larger lymph-vessels of the subcutaneous tela. There are no lymph-vessels in the epidermis, but this is supposed to be nourished by the lymph in the tissue spaces between the cells and these spaces connect indirectly with the lymph-vessels.

The nerves.-The skin has one of the richest nerve supplies of the body. The nerves are in greater proportion in those parts which are most sensitive. The various skin areas are supplied by specific (segmental) nerves with much greater regularity than in the case of the arteries. The nerves supplying adjoining areas overlap so that there is an intermediate space supplied by both. The variations consist in an extension of one area and a corresponding contraction of an adjoining area. The distribution of the nerves in the skin shows, especially on the trunk and neck, a marked metameric arrangement. The arrangement of these nerves in the subcutaneous tela 
and their areas of distribution will be found described in detail in the section on the Nervous System.

With the exception of the nerves to the sudoriferous and sebaceous glands, the skin-muscles and blood-vessels, all the cutaneous nerves are sensory. They have diverse modes of termination. Some end in the subcutaneous tela; others, the greater number, terminate in the corium; still others extend to the epidermis.

Toward their termination the nerves branch and rebranch, and just beneath the surface they form a great number of small twigs from which the terminal fibres arise. These may be divided into two groups, those that end freely and those whose termination is surrounded by a capsule. The free ends are slightly enlarged and terminate in the epidermis and in certain regions in the corium. The encapsulated terminations form special end organs and are found in the corium as the bulbous corpuscles (end-bulbs of Krause) [corpuscula bulboidea, Krauserii]; the tactile corpuscles (corpuscles of Meissner or Wagner) [corpuscula tactus, Meissneril; and the genital corpuscles [corpuscula nervorum genitalia]. In the subcutaneous tela the end-bulbs are seen as the lamellous corpuscles (corpuscles of Vater: Pacinian corpuscles), [corpuscula lamellosa; Vateri, Pacini] shown in fig. 1049; the Golgi-Mazzoni corpuscles and the Ruffini corpuscles. All the terminations except the lamellous corpuscles are microscopic, not exceeding $0.2 \mathrm{~mm}$. in length. The lamellous corpuscles, which are readily seen in reflecting the skin from the fingers and toes, may be as much as $2 \mathrm{~mm}$. long and half as thick (fig. 1049). The exact function of each of the various endings is not known. They are undoubtedly sensory fibres except those to the glands, muscles, and blood-vessels.

Development of the corium and subcutaneous tela.- The corium is developed from the superficial part of the myotome or dermo-muscular plate of mesoderm. At first it is very largely cellular but later fibres are produced. In the earlier stages the corium and tela subcutanea are not distinguishable and only in the later embryonic period may the corium be separated into the papillary stratum and the tunica propria.

\section{THE APPENDAGES OF THE SKIN}

The appendages of the skin include: (A) the hairs; (B) the nails; (C) the cutaneous glands; and (D) the mammary glands.

\section{A. THE HAIRS}

The hairs [pili] are less developed in man than in any other primate. Where well developed they in themselves serve as a protective organ and moreover throngh their connection with the nervous system they become in a measure organs of special sense. They are strong, flexible, somewhat elastic, and poor conductors of heat. They cover the entire surface of the body with the following exceptions: The flexor surfaces of the hands and feet; the dorsal bends and sides of the fingers and toes; the dorsal surfaces of the distal phalanges of the fingers and toes; the red borders of the lips; the glands and inner surface of the prepuce of the penis and clitoris; the inner surface of the labia majora; the labia minora and the papilla mammr.

The size and length of hairs varies greatly not only in different parts of the borly but also in different individuals and races. In certain situations the hairs are especially long and large and are designated by speeial names.

Thus upon the scalp, capilli, in the axillary region, hirci, and after puberty upon the face in the male, the beard, barba, and in the pubic region in both scxes, pubes. 'The pubic hairs extend npon the external genital organs and upon the ventral abdominal wall toward the umbilicus. All of the hairs of these regions are not long and large but short and finer hairs are mixed with them in varying numbers. Strong, well-developed short hairs are found in eonnection with the organs of sense forming the eyclorows, supercilia, the eyelashes, cilia, at the entrance to the external acoustic meatus, tragi, and at the nares, vibrissæ. Upon the extensor surfaces of the extremities, upon the chest, and in other situations in some individuals, especially in adult males, the hairs are also longer and stronger than upon the rest of the borly, where they are, as a rule, short, fine and downy. The first hitirs appearing in the fortus are very fine, and are called lanugo. The long hairs of the adult scalp may attain a length of $150 \mathrm{~cm}$. or more; the short hairs average from .5 to $1.3 \mathrm{~cm}$. in length, while the lamugo does not exceed $1.4 \mathrm{~cm}$.

lexcess of long hairs, hypertrichosis, may involve the whole hairy surface of the body. It is usually inherited and affects several individuals in the same family. Jocal areas of long hairs also recur as over nasvi and upon the sacrum. Ioeal congestion due to inflammation, irritation, or pressure may eause hypertrichessis. In women, hair upon the upper lip or other parts of the face may be an inherited peculiarity or the to some aborormality of the sexual organs. It is also urst. nucommon after the menopanse.

In diameter the hatirs vary from .005 $\mathrm{mm}$. for the finest lanugo to $.203 \mathrm{~mm}$. for the coarsest hair of the beard; but they usually titper toward the tip and also are matrower toward the base. $\Lambda_{\text {s a }}$ general rule, blonde hairs are the finest and black hatirs the roarsest. 
In colour the hairs may be either blonde, brown, black, red, or some gradation of these colours. The colour varies with the race, and also with the individual, and according to age. It is due to pigment in the cells of the hair but is also influenced by the amount of air between the cells.

Greying and whitening of the hair is due not only to a decrease of pigment but also to an increase in the amount of air between the cells. Sudden blanching of the hair is thought to be due almost entirely to an increase in the quantity of this contained air. Whitening of the hair is physiological in old age and not infrequent in younger persons. This may be an inherited peculiarity or may follow mental overwork, nervous shock, or prolonged disease. Local blanching is also seen as the result of disease.

The hair may be straight, waved, curled, or frizzled in varying degree. Here also there is not only an individual but also a racial variation, as instanced in the curled or crinkled hair of the African negro and the straight hair of the American Indian. The curliness is caused by the form and the manner of implantation in the skin. Straight hairs are round or oval in transection

Fig. 1050.-Longitudinal Section of a Growring Hair of the Head. ( $\times 30$.) (From Toldt's Atlas.)

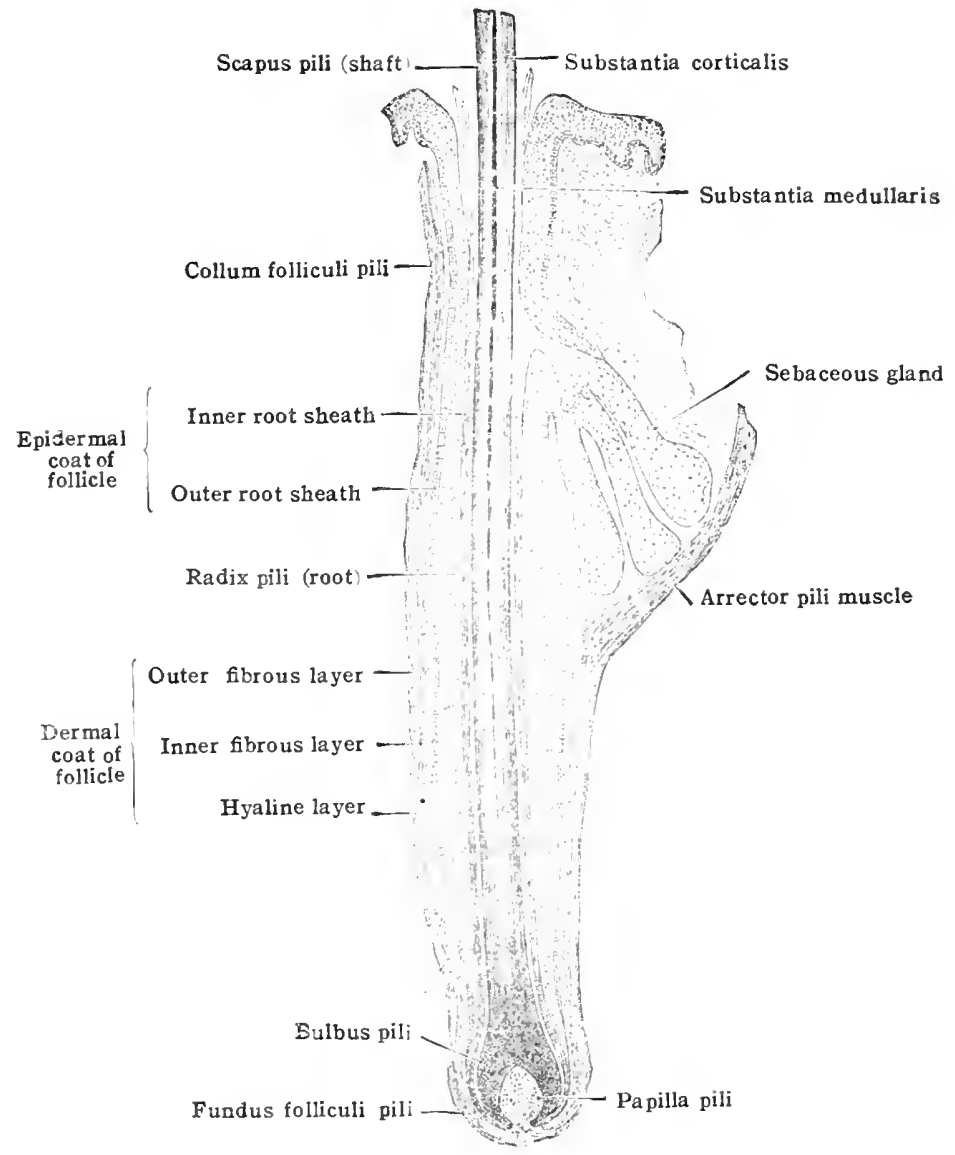

and curled hairs are more flattened. The root of curled hair has been observed in certain instances, as in the negro, to have a curved course in the skin which may account in a measure for its curliness.

The hairs are arranged singly or in groups of from two to five and, except those of the evelashes, are implanted at oblique angles to the surface of the skin. The directions in which the hairs point are constant throughout life for the same individual. They are arranged in tracts in which the hairs diverge from a centre in whorls, the vortices pilorum.

These vortices are found constantly in certain definite regions and apportion the whole hairy surface. The centres of vortices are found at the vertex (sometimes double) upon the face, around the external auditory meatus, in the axilla, in the inguinal region, and sometimes on the lateral surface of the body. These are all paired except as a rule the first. Where adjoining vortices come together the hairs are arranged in lines along which they all point in nearly the same direction, only slightly diverging, forming the hair streams, flumina pilorum. In other lines and places the hairs point in converging directions such as at the umbilicus and over the tip of the coccyx. 
The number of hairs to the square centimetre varies in different parts of the body and also in the same situation with the individual and with differences in race, colour and diameters.

The hairs are most numerous on the head, ranging from 170 to 300 to the square centimetre at the vertex. They are less numerous on other parts of the body, varying from 23 to 44 (per square centimetre) on the chin, and from 24 to 80 on the forearm. The greatest number is found with blonde hair, the next with brown, then black, and the least with red hair.

The structure of the hair. - Each hair consists of a shaft [scapus pili] (fig. 1050) projecting from the free surface of the skin to end (unless broken or cut) in a conical end [apex pili], and of a root [radix pili], imbedded in the case of the lanugo hair in the corium and of the larger hairs at various depths in the subcutaneous tela. Surrounding the root is a downgrowth of the skin known as the follicle [folliculus pili].

Fig. 1051.-Loxgitudinal Section of a Hair Ready to Fall odt, with Follicle for New HaIk. $(\times 30)$ (From Toldt's Atlas.)

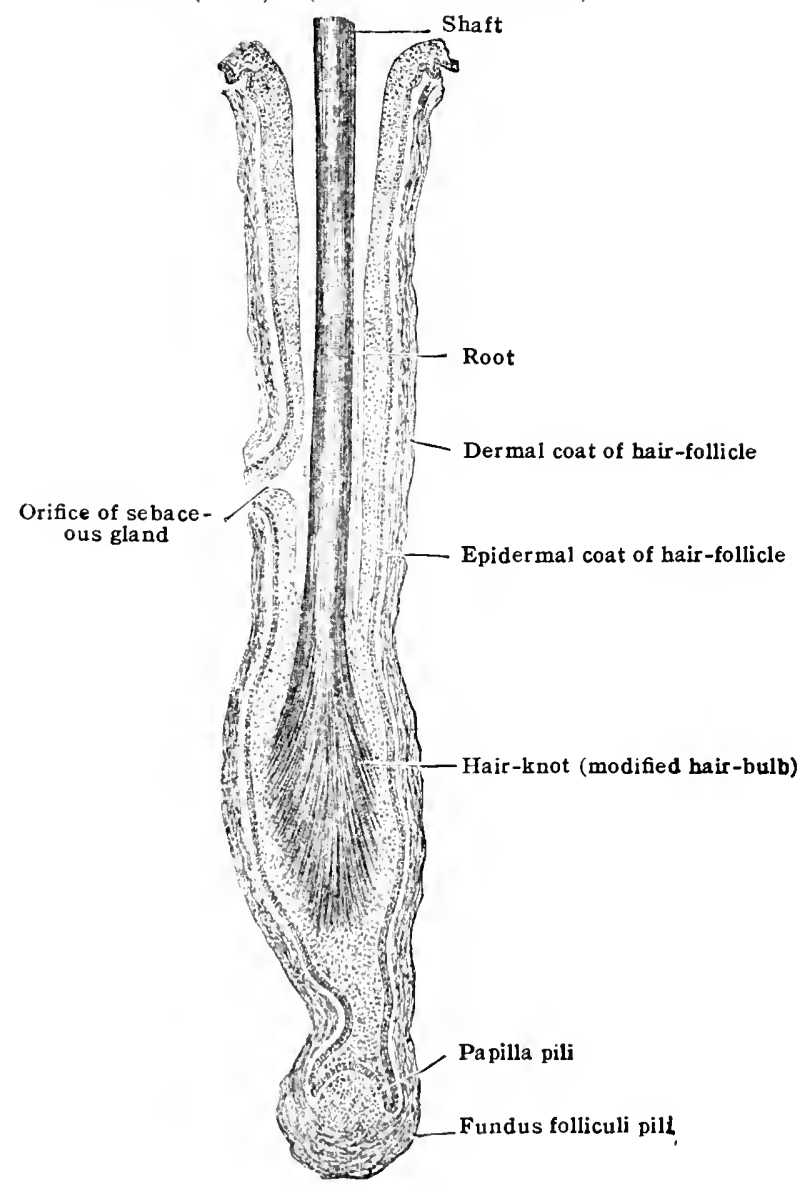

The root of the hair at its decpest parts swolls to from one and one-half to three times the climeter of the shaft forming thus the bulb [bulbus pili] (fig. 1050). The bulb is hollow and a vascular connective-tissue process, the hair papilla [papilla pili] (figs. 10.50, 1051) extends from the leepest part of the follicle into the cavity in its base. The follicle consists of an external romective-tissue portion formed by the corium, the theca folliculi and an internal cpithelial portion belonging to the cpidermis and divided into two portions, the inner and outer root sheaths (fig. 10), (0)).

The thea of the follide is compesed of an outer loose longitudinal and a mildle circular layer of eomertive tissue and an inner hasement membrane. The outer root sheath is direetly cofluceforl with the stratum germinativum of the epulermis. In its deeper part it consists of saveral layers of eells but of only one near the surfare. The inner root sheatli has been divided

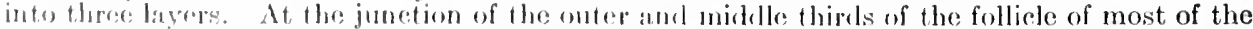

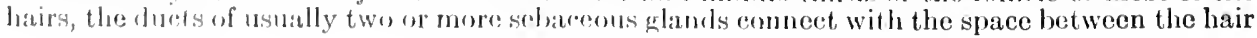


and its follicle (figs. 1050, 1051). Immediately beneath this is the narrowest part of the follicle the neck [collum folliculi pili], especially important as the position of the nerve ending of the hair.

The hair is formed of epithelial cells arranged in two and sometimes three layers; an outer single-celled layer of transparent over-lapping cells, the cuticle, an intermediate layer several cells thick formed of irregular fusiform horny cells containing pigment and arranged in fibrous strands, the substantia corticalis, and in some of the larger hairs an internal two or three celled layer of angular cells occupying the center of the hair shaft for only part of its length, the substantia medullaris. Between both the cortical and medullary cells are spaces containing air. In the hair bulb, where the cells are larger and softer the lavers are not clistinguishable. The cells here being in process of division and being gradually transformed into the horny cells of the shaft.

Many of the hairs have in connection with their follicle round or flat bundles of unstriped muscle fibres, the arrectores pilorum (figs. 1050, 1052). These are situated on the side toward which the hairs point, their deep ends being attached to the hair follicle beneath the sebaceous glands which they more or less embrace and their superficial ends connected with the papillary layer of the skin. Contraction of the arrectores not only causes the hairs to become more erect and the skin around them to project somewhat causing "goose flesh," but also compresses the sebaceous glands which are situated between the follicle and muscle and helps to empty the glands of their secretion.

Fig. 1052.-Tertical Section of the Skin from Scalp. $\quad(\times 20$.

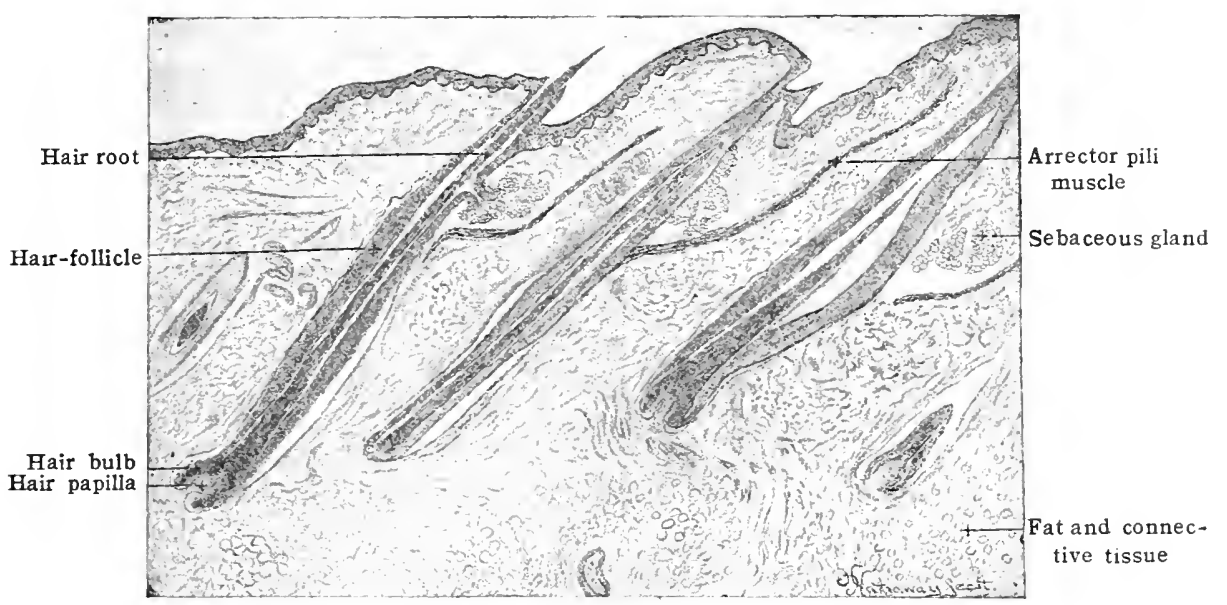

The blood supply of the hairs.-The hair follicles are surrounded by a capillary network of arteries connected with those of the corium and the papille are also supplied with loops of arteries.

The nerves of the corium supply branches to the hairs. Some of these branches enter the papillæ, others surround the follicle at its neck and are distributed among the cells of the outer root sheath.

Development.- The hairs are developed from the epidermis by thickenings and downgrowths into the corium of plugs of epithelium. The deepest parts of these plugs become swollen to form bulbs and from these the hairs are produced. The central cells of the epithelial downgrowths disintegrate producing the lumen of the follicle. The hairs continue to grow from the deeper cells and protrude from their follicles between the fifth and seventh fotal months. Abnormally they may be scanty at birth and rarely entirely absent, alopecia. The lanugo hairs which cover all the hairy parts of the body at birth are soon shed and replaced by new hairs in the old follicles. Throughout life also the hairs are being constantly shed and replaced by new ones. This is accompanied by cornification of the bulb and fibrillation of the deep end of the hair (fig. 1051). Thinning of the hair and balilness occur when the shed hairs cease to be replaced. This is common in old age and a premature baldness appears to run in certain families. The rate of growth is normally from 1 to $1.5 \mathrm{~cm}$. per month, but is subject to variation.

\section{B. THE NAILS}

The nails [ungues] are thin, semi-transparent, horny epidermic plates upon the dorsal surfaces of the distal phalanges of the fingers and toes. Through their hardness they serve as protective organs not only by covering the nerve endings and other delicate structures of the skin; but also by acting as natural weapons. On the fingers they form useful tools. They are four-sided plates presenting a dis- 
tal free border [margo liber], which overhangs the tips of the fingers, an irregular, sharp proximal edge [margo occultus], and on each side a somewhat thinned border [margo lateralis] (fig. 1053).

Fig. 1053.-Dorsal Surface of Isolated Finger Nail. $(\times 1$.$) (From Toldt's Atlas.).$

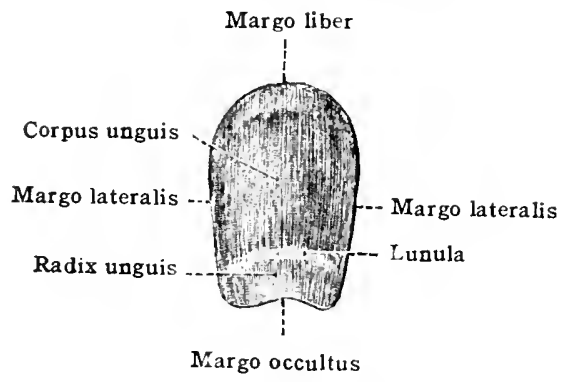

Each nail is composed of an exposed distal part, the body [corpus unguis], and a proximal covered part, the root [radix unguis], (fig. 1053), which ends in the margo occultus. The nail is at a slightly deeper level than the surrounding skin which overhangs the root and the lateral margins in a fold, the nail wall

Fig. 1054.-Finger Nail and Nail Bed.

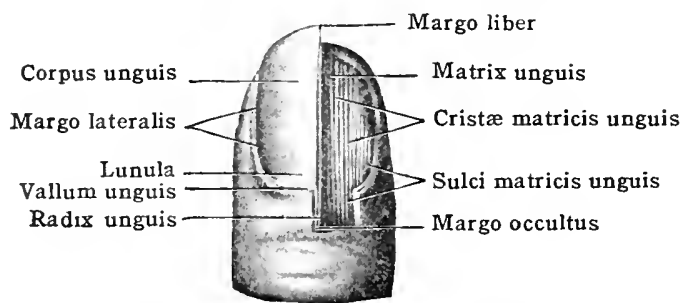

[vallum unguis] (figs. 1054, 1055, 1056). The epidermis of the free edge of the nail wall, especially proximally, is thickened and often appears as a ragged edge. At a deeper level than the above and extending somewhat more distally is a variably developed thin parchment-like membrane, the eponychium, closely attached to

Fig. 1055.-Loxgituninal Section Timougif the Tip of the Middle Finger. $(\times 2)$ (From Toldt's Atlas.)

Stratum corneum

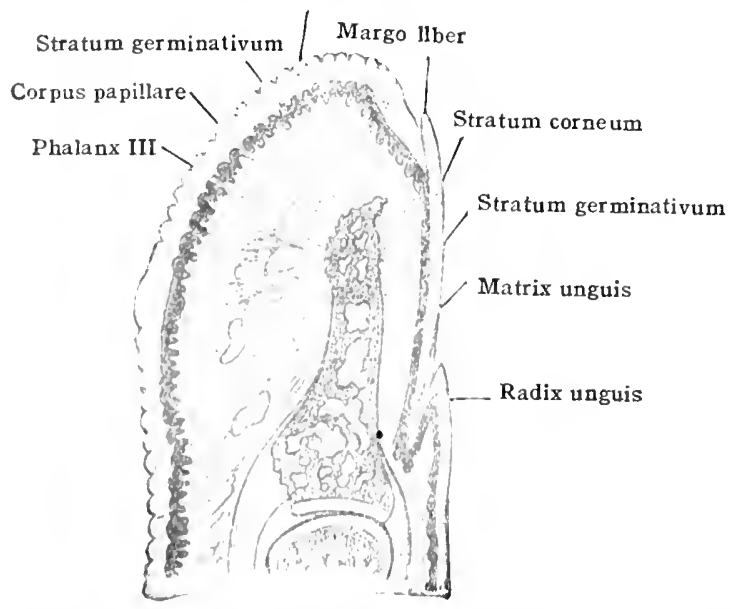

the superficial surfare of the nail. It is the representative of the superficial layers of the embryonic epidermis which de not take part in the formation of the nail. The groove which is formon hetwern the vallum and the underlying nail bed is known as the sulcus matricis unguis. This lodges the root and lateral margins 
of the nail and is deepest in the centre of the root, becomes shallower toward the lateral margins, and finally disappears entirely toward the free border of the nail (figs. 1055, 1056).

The dorsal free exposed surface of the nail is formed by a hardened, thickened, horny layer of epithelium corresponding to the deeper parts of the stratum corneum (or the stratum lucidum) of the skin, the stratum corneum unguis (fig. 1056). It is convex from side to side (especially on the fifth finger), and also in some cases longitudinally. It presents a number of more or less well-marked fine longitudinal ridges. The stratum corneum forms the principal thickness of the nail. It is thicker and more solid on the toes than on the fingers. The portion of the nail which projects beyond the skin of the fingers and toes is greyish-white in colour. Unless broken or cut, it curves ventrally upon the ball of the finger or toe and tends to become long and claw-like. It may attain a length of 3 or more centimetres.

The concave volar or plantar surface of the nail is softer and is formed of a layer of epithelial cells which corresponds to the stratum germinativum (Malpgihii) of the skin and is known as the stratum germinativum unguis (fig. 1056). Because of the transparency of both layers of the nail the blood in the underlying matrix is seen through the body of the nail and gives to it a

Fig. 1056.-Cross-section Through the Nail and Tip of the Ring Finger. ( $\times 4)$. (From Toldt's Atlas.)

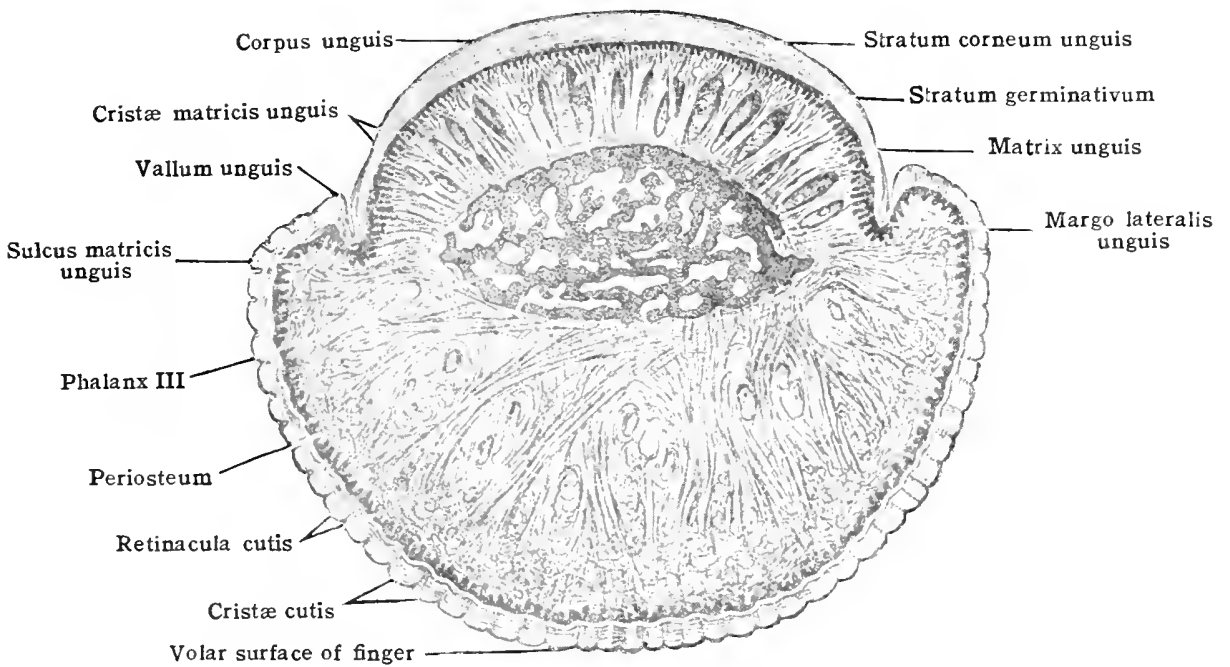

pinkish colour; but toward the root of the nail there is a semilunar area convex distally, the lunula, which is less transparent and opaque whitish in color (fig. 1053). The lunula is variously developed in different individuals. It is largest on the thumb and is of ten absent on the little finger. It is also smaller on the toes than on the fingers.

The stratum corneum unguis consist of thin, flattened, transparent, horny scales with shrunken nuclei. These cells are intimately joined together in thin layers. The stratum germinativum unguis is formed of cells continuous with and resembling those of the corresponding layer of the epidermis. Air may occur between the cells as with the hair. The cells of the root are not yet cornified or dried out.

The stratum germinativum unguis rests upon the corium, which here forms the so-called nail bed [matrix unguis]. ${ }^{1}$ This is made up of a dense feltwork of connective tissue fibres without fat. It is highly vascular and sensitive and the vertically arranged bundles bind the nails tightly to the periosteum of the terminal phalanges. The papilla of the matrix beneath the body of the nail are arranged in strongly marked longitudinal ridges, the cristæ matricis unguis. The cristæ and papillæ of the matrix fit into corresponding depressions on the deep surface of the stratum germinativum unguis.

The cristx of the matrix are small and low proximally and become larger and fewer distally. Those toward the lateral borders are somewhat oblique. The papille of the root are not in rows but are irregularly arranged and disappear entirely near the distal border of the lunula. Toward the free border of the nail the papillæ become large and change in character to that of the adjacent skin.

The best developed nails are those of the thumbs and great toes, the least developed, those of the fifth digits which on the toes are often represented only by a horny tubercle.

Blood-supply of the nails. - The arteries are numerous in the matrix beneath the body of the nail but fewer beneath the root. They pass from the deep parts of the nail bed toward the surface, running in the main longitudinally and sending anastomosing branches to the papillax.

The nerves beneath the nail are abundant and terminate in free sensory endings and in special end organs of several sorts.

1 The term nail bed is applied by some anatomists to that part of the corium beneath the body of the nail, the term matrix being reserved for the corium beneath the lunula and root. 
Development of the nails. - The nails are developed from the epidermis. In early embryos over the dorsal surface of each distal phalinx there is seen a smoother and more adherent area of skin which becomes limited by folds distally as well as proximally and laterally. It is also distinguished by a greater number of cell layers which later become flatter than the surrounding cells. The number of cell layers still further increases and at about the fifth fotal month the nail proper is formed by the deeper lying cells over an area extending from the proximal fold to the distal end of the lunula. The nail is pushed distally by constant formation of new cells in the same way as it continues to grow throughout life. The surface epithelial cells of the nail field cover the nail for some time as a thin layer, the eponychium, which later disappears except a small fringe near the root.

Growth of the Nails. - The nail grows in length and thickness by multiplication of those cells of the stratum germinativum which are situated between the margo occultus of the root and the distal border of the lunula. The older cells are pushed distally and toward the surface by the deeper cells. As a result the nail becomes gradually thicker from the occult border as far as the distal margin of the lunula. Over the rest of the nail bed no thickening appears to take place. 'The rate of growth is faster on the fingers than on the toes and varies with age, season, and the individual. When the nail is torn off, or detached through inflammation, it may be regenerated if the cells of the stratum germinativum have not been destroyed.

Congenital hypertrophy of the nails sometimes oceurs, but absence or imperfect development is rarely seen. The white spots so frequently seen in the nail are caused by air between the cell layers due usually to injury or impaired development.

\section{THE CUTANEOUS GLANDS}

The glands of the skin [glandula cutis] are of two kinds: glomiform glands, and sebaceous glands. The glomiform ("skein-like") glands [glandulæ glomiformes] are of four types: sudoriferous glands, ciliary glands, ceruminous glands and circumanal glands.

Fig. 1057.-Vertical Section of the Palmar Skin Showing an Isolated Sudoriferous Gland. (Testut.)

1, Stratum corneum; 2, Malpighian layer; 3. corium; 4, papilla; 5 , body of sudoriferous gland; and 6,7 , its excretory duct; 8 , orifice of duet on surface; 9 , subcutaneous fat.

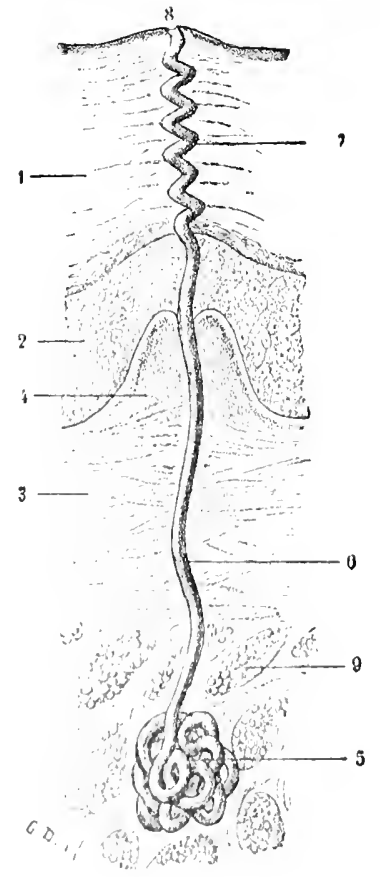

The sudoriferous glands [mlimlula smloriforie] or sweat glands are morlified simplo tubular glamb which sereres the sweat [suclor]. They are found in the skin of all parts of the borly except that part of the terminal phatanges covered

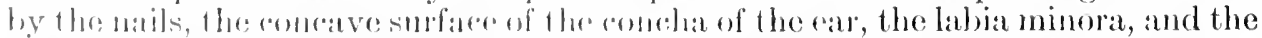
inforior bart of the lathis majora in the fomale and the surface of the prepuce and the glans penis in the male. 'The mumber foumel in different parts of the body varies ureatly. They are very frow on the eonvex surfice of the eoncha and on 
the eyelid. They are also rather scanty on the dorsal surface of the trunk and neck, more numerous on the ventral surface of these parts and on the extensor surfaces of the extremities, still more numerous on the flexor surfaces, and most numerous on the volar surface of the hands and plantar surface of the feet. They vary from less than 57 to more than 370 to the square centimetre. The total number has been variously estimated at from two to fifteen millions.

Each gland (fig. 1057) consists of a secretory portion or body [corpus gl. sudoriferæ], and an excretory duct [ductus sudoriferus], which opens on the surface of the skin by a mouth visible to the unaided eye, the so-called 'pore' [porus sudoriferus]. Occasionally the duct opens into a hair follicle.

The bodies of the glands are irregular or flattened spherical masses, yellowish or yellowish red in colour and somewhat transparent. They vary in size from .06 to $4 \mathrm{~mm}$. or more with a mean diameter of .2 to $.4 \mathrm{~mm}$, the largest being found in the axilla. They are formed of the irregularly, many times coiled, terminal part of the gland tube. The bodies of the glands are situated in the deeper part of the corium or in the subcutaneous tela.

The wall of the rather wide-lumened gland tube is formed of a single layer of cubical or col. umnar epithelium containing fat and pigment granules and surrounded externally by a basement membrane. Enclosing these is a more or less dense connective-tissue sheath. In many of the glands, especially the larger ones, there is a layer of obliquely running unstriped muscle fibres, the so-called myoepithelium, between the basement membrane and the cells. In some cases the bodies of the glands are imbedded in a more or less dense mass of lymphoid tissue.

The ducts, beginning as several coils bound up with those of the bodies, extend often in a straight or slightly wavy course nearly at right angles to the surface as far as the epidermis. This they pierce as spiral canals of from two to sixteen turns, more markerl where the epidermis is thickest (fig. 1041), and opened on the surface by somewhat widened funnel-shaped mouths. The ducts pass between the papillw of the corium and open on the summits of the cutaneous cristæ where these are present. The diameter of the ducts is distinctly smaller than that of the secreting part of the glands, and this is true of the lumen also.

The ducts are lined by a stratified epithelium composed of two, three, or more layers of cells resting on a basement membrane without any intervening layers of muscle-cells, and surrounded by a connective-tissue sheath. This latter as well as the basement membrane ceases at the epidermis and the epithelial cells of the duct walls join those of the stratum germinativum. The duct for the rest of its course to the surface is merely a canal through the cells of the epidermis.

The degree of development of the sweat glands varies with the situation, the individual, and also racially, as instanced by their great development in the negro. In some individuals the perspiration is much more profuse than in others. The glands are smaller in the aged than in the young. The odour of the sweat is peculiar and more or less characteristic, varying with the individual.

The sudoriferous glands in the axillary region seem to be in some way connected with the scxual function for although a large number persist as small glands, others undergo further development beginning about the ninth year in the female and at puberty in the male. These glands in places form almost a continuous layer and are formed of large partly branched tubules with high secreting cells. The reddish colour of the sweat in the axillary and some other regions, especially in certain individuals, is probably derived from the pigment granules which are found in the glands here. The oil in the secretion lubricates the skin and keeps it soft and supple.

Blood-supply of the sudoriferous glands.- The sudoriferous glands are supplied from the deep cutaneous plexus by an abundant network of arteries which surround and penetrate between the coils of the gland tubules.

Nerves.-There is an enclosing network of nerve fibres some of which have been traced to the gland cells.

Development.-The sudoriferous glands are seen first in the fourth or fifth foetal month. The anlages resemble closely those of the hair, but the cells are not so loosely packed. They project down as solid plugs which become long, slender, and tortuous rods. In the seventh foetal month the rods begin to develop a lumen in the deeper parts, which also now begin to coil. A lumen soon develops also in the superficial parts and joins that in the deeper part of the gland. The outer of the two layers of epithelium in the ducts becomes transformed at its transition into the gland proper into the myoepithelial layer.

The ciliary glands [gl. ciliares; Molli] are modified sudoriferous glands of the branched tubo-alveolar type. They have simpler coils but are larger than ordinary sweat glands. They are situated in the eyelids near their free borders and open into the follicles of the cilia or close to them (see Section VIII).

The circumanal glands [gl. circumanales] are found in a circular area about $1.5 \mathrm{~cm}$. wide which surrounds the anus, a short distance from it.

These glands are several times the size of the ordinary sweat glands and resemble the glands found in the axilla, their secretion likewise having a strong odour. They are branching tubular glands. The other kinds of glands which are found in this same area are ordinary sweat glands, glands with straight ducts, with saccules and secondary alveoli, and tubo-alveolar glands.

Cerumimous glands [gl. ceruminosæ] are glomiform glands somewhat modified from the sudoriferous type. They are branched tubo-alveolar glands 
with relatively large lumina in the coils and narrow short ducts, and occur only in the external acoustic (auditory) meatus.

They are very abundant on the dorsal and superior part of the acoustic meatus in the region of the cartilaginous part, where in the adult most of them open on the surface of the skin close to hairs. Others open in to the hair follicles as they all do in the foctus and child. Their secretion, the cerumen, is, when freshly secreted, a fluid or semifluid oily material of a yellowish-brown colour, which on exposure to the air becomes solid like wax.

The sebaceous glands [gl. sebacer] are simple branched or unbranched alveolar glands distributed over nearly the whole surface of the body. Ninetenths of them are closely associated with the hairs, into the follicles of which they empty (figs. 1050, 1051), and are therefore absent from certain of the nonhairy parts of the body, as the flexor surfaces of the hands and feet, the dorsal surfaces of the distal phalanges of the fingers and toes. On the other hand, a few are found, usually much modified, opening independent of the hair follicles, as at the angles of the red margins of the lips, around the nares, around the anus, and the tarsal (Meibomian) glands in the eyelids. Modified sebaceous glands are also found upon the mammary papilla and areola in the female, and in some cases upon the superficial surface of the glans and the surface of the prepuce of the penis, here known as preputial glands; also a few very small ones may be found upon the labia minora, the glans and prepuce of the clitoris.

The glands vary in size in different situations and also in individuals and races. They range from .2 to $2.2 \mathrm{~mm}$. long and nearly as broad. Among the smallest are those of the scalp. The largest are found on the ale of the nose and on the cheeks where their ducts are visible to the unaided eye. They are also large on the mons pubis, labia majora, scrotum, about the anus and on the mammary areola. Snaller glands are also found associated with these large ones. The size of the glands is independent of the size of the hairs with which they are associated but the number of glands depends upon the size of the hair. On small hairs one or more glands are always found and on large hairs there may be a whole wreath of from four to six separate glands opening into the hair follicle.

The number of sebaceous glands has never been exactly estimated, although, it is known that they are less numerous than the sudoriferous glands. This is very evident on the extremities, trunk, and neck, where they bear a relation of 1 to 6 or 8 . On the scalp, concha of the ear, and skin of the face they are about equal in number while on the forehead, ale of the nose, free borders of the eyelids anil external genital organs in the female the number of sebaceous glands is greater than the number of surloriferous glands.

Each selaceous gland consists of a secretory portion, the body, connected with the hair follicle or the surface of the skin by a wide short duct. In the small glands, the body of the gland may consist of a single alveolus but in the larger glands there are from four to twenty of these connected by irregular ducts to a single cxeretory dluct.

The ducts open into the hair follieles near their necks between the inner root sheath and the hair or upon the surface of the skin. They are always very short, eylindrical, or infundibuliform, and their epithelium is directly connected with that of the outer root sheath of the hair follicle or with the epirlermis where the hair is wanting.

The glands lie in the superficial layers of the corimm and where one or a few are connected to as single hair, they usually ofen in to the hair follicles on the side toward which the hairs point. Whore there are several ghands for one hair they may completely surround the hairs like a rosette.

The cells of the broly of the gland and of the duet are surrounded by a hasement membrane outsile of which is a commertive-tissue sheath, both of which are continuous with corresponding ecrerings of the hair follicle.

The periphery of the alveobus is formed of small cubical epithelial cells, the ecntral part of larger and nore rounded rells. The rells of the alveohus show all stages of fatty degeneration, the peripheral cells contain small fatty particles, those nearest the rentre larger and more numerous fitt droplets, some of them bring eompletely broken down. There is no distinet lumen to the: atversus but this is filled with degenerated celks, fat ty partieles and clebris of broken-down and cast-r)lf ecolls. The dreper cells contime to multiply and push the more superficial cells toward the lunen where they in turn are cast off. The secretion thus formed is known as the sebum cutaneum. It is a whitish or whitish-yellow mass composed of fat and broken-down cells of the consistruey of thick oil which spreads over the surface of the skin and hair as a lubricant. 'l'hrough the teromposition of its fat more or less orlour is produced. When the gland duet is

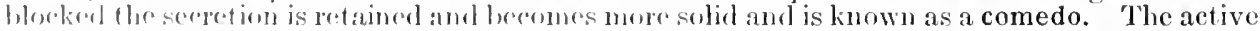
sreretion of the solaceous glands does not hegin before the fifth or sixth year of life. It attains its maximum in the adult and derorases in the aged.

The rolation of the arrectores pilopum to the sehaceous glands has been described in conneretion with the relation of these muscles to the hairs.

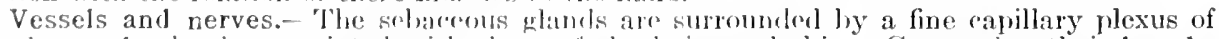
bood-vessels alosily assoniatorl with those of the hairs and skin. Concerning their lymphvessels liftle is known. The nerves of thr solnacous glands are connerfed with those of the sin and hair but the exart manner of distrilution is not elearly understord.? 
Development. - The sebaceous glands appear first in the fifth fortal month as single, rarely double, buds on the anlages of the hair follicles. The distal ends of these enlarge and become lobulated. In these solid masses of cells humina for the alveoli and the lucts later are formed, through the fatty degeneration of the central cells. The oily contents of these cells together with the débris and the cast-off surface cells of the epidermis form the vernix caseosa on the surface of the foetus.

\section{THE MAMMARY GLANDS}

The mammary glands [mammæ] or breasts are modified cutaneous glands. In the male they remain rudimentary and functionless throughout life, but in the female they are functionally closely associated with the reproductive organ: since they secrete the milk for the nourishment of the newborn and are subjected to marked changes at puberty, throughout pregnancy, during and after lactation, and after the menopause.

Fig. 1058.-The Right Mama of a Girl 18 Years Old. (Modified from Spalteholz.)

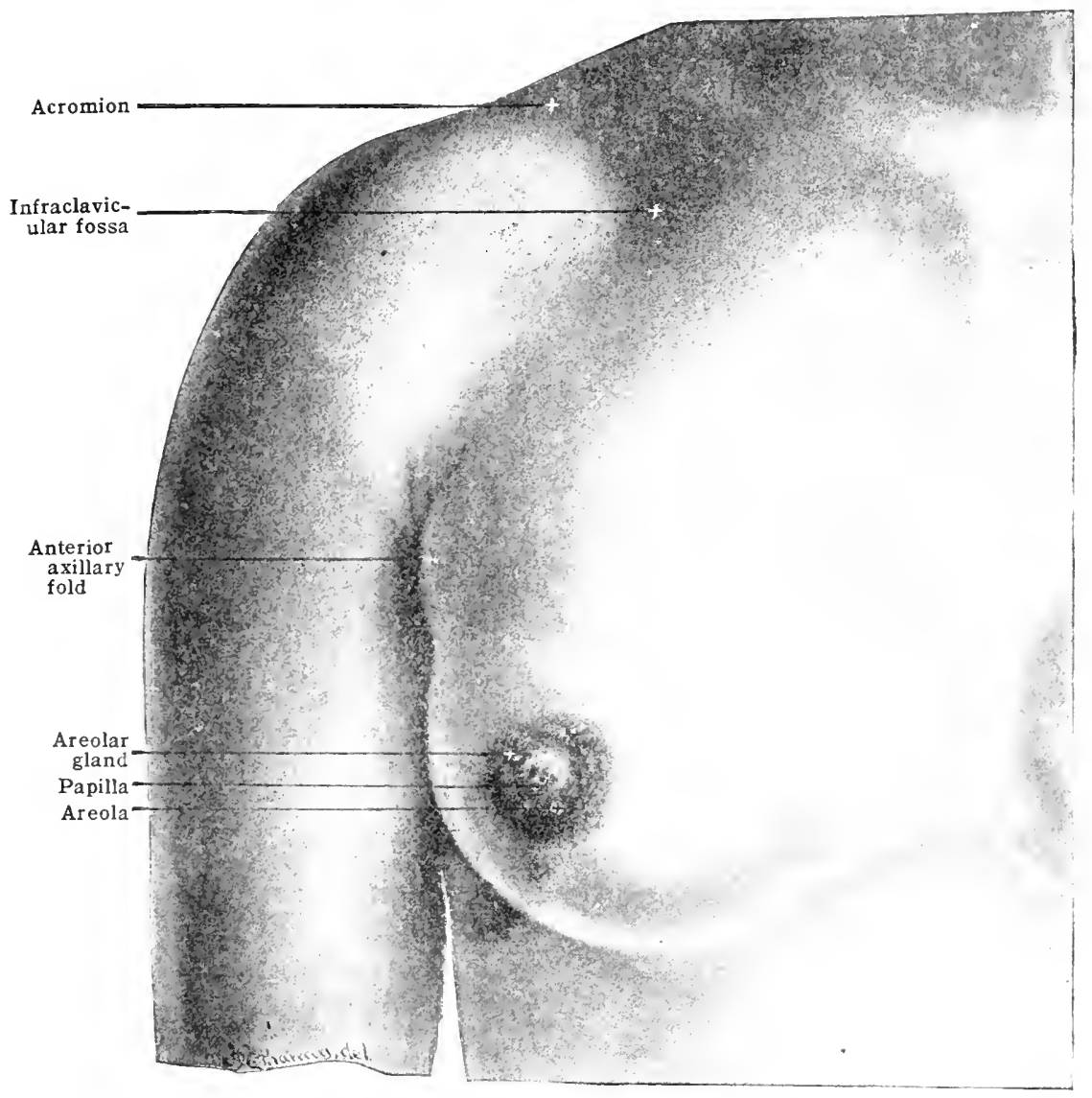

The two mammx (fig. 1058) are situated on the ventral surface of the thorax one on each side of the sternum. As examined from the surface in a well-developed nulliparous female they appear to extend from the second or third rib to the sixth or seventh costal cartilage and from the lateral border of the sternum to beyond the ventral folds of the axillæ. Separating the two mamme there is a median unraised area of variable size, the sinus mammarum.

In shape they are conical or hemispherical, and in consistency somewhat firm and elastic. The size of the two breasts is seldom equal, the left, as a rule being slightly the larger. Each measures from 10 to $13 \mathrm{~cm}$. in diameter being slightly longer in the direction parallel to the lateral border of the pectoralis major muscle. The weight of each gland varies from 140 to 200 grams, or more.

Each mamma presents for examination a ventral surface and a dorsal surface. The ventral surface is free, covered by skin, smooth and convex. It is continuous 
cephalically, without sharp demarcation, with the ventral surface of the thorax but laterally and caudally it is usually sharply defined (figs. 1058, 1060). It is

Fig. 1059.--The Female Mamma During lactation. (After Luschka.)

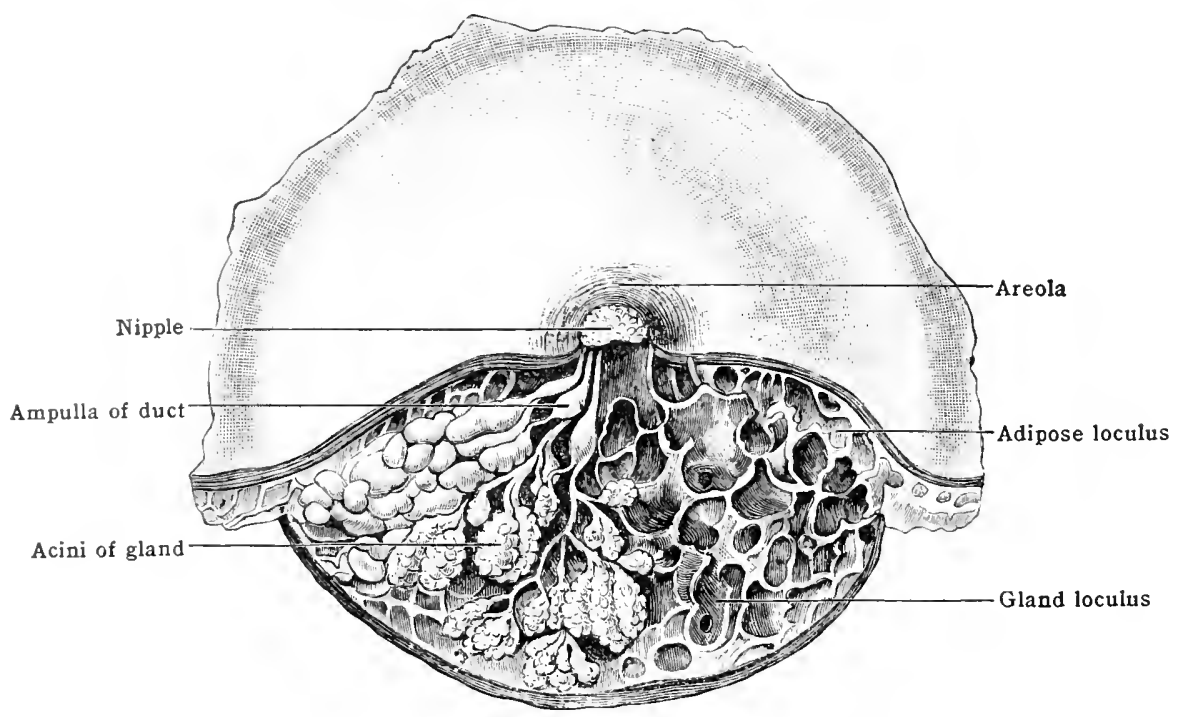

Fig. 1060-Sagittal Section of the Right Mamma of a Wonan Twenty-two Years OLd. (Testut.)

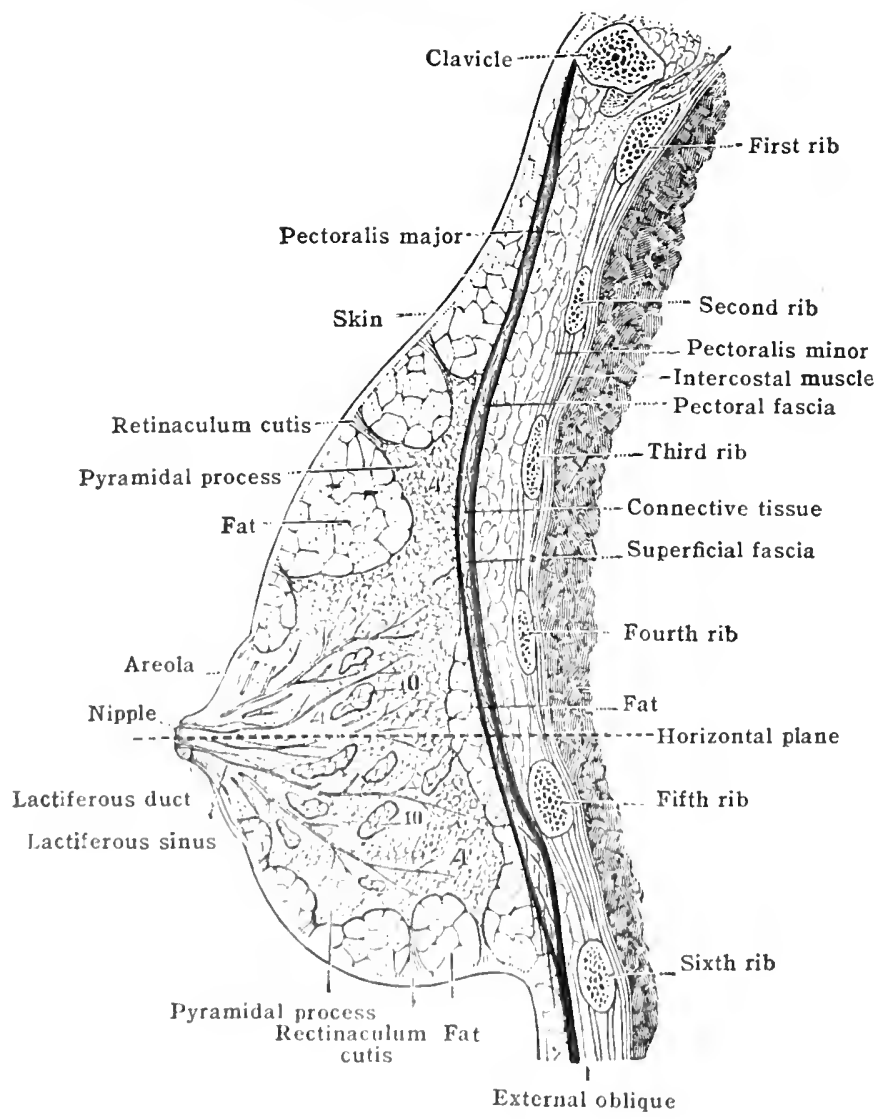

Inost prominent slightly meso-randal to the centre and at this point there is a markan pigmented projoction, the nipple [patpilla mammas surrounded by a 
slightly raised area, also pigmented, the areola mammæ. These two structures will be described separately later.

The dorsal surface of the mammary gland (figs. 1060, 1061) is attached and concave. It is in relation in its cephalo-medial two-thirds with the fsacia over the pectoralis major muscle. In its caudo-lateral third it extends over the base of the axillary fossa, where it is in relation with lymphatic glands and with the serratus anterior muscle, and at its most caudal part, sometimes with the external abdominal oblique muscle.

The usual number of breasts in the human species is two; rarely is the number reduced, much more often do we find an increase in this number. Each of these conditions is found in both sexes and may be complete or partial. Complete suppression of both breasts, amastia, is one of the rarest anomalies and is usually associated with other defects. Complete absence of one is less rare. A more frequent condition is arrest of development, micromastia, leading to rudimentary but functionless organs. Absence of the nipple, athelia, is much commoner and generally affects both breasts. All grades of the imperfection from complete absence to slightly imperfect nipple may be found. When there is an increase this may inciude the whole breast, polymastia, or just the nipple, polythelia. The supernumerary structures [mammæ

Fig. 1061.-Horizontal Section of the Right Mamia of a Wonan 22 Years Old. (Testut.)

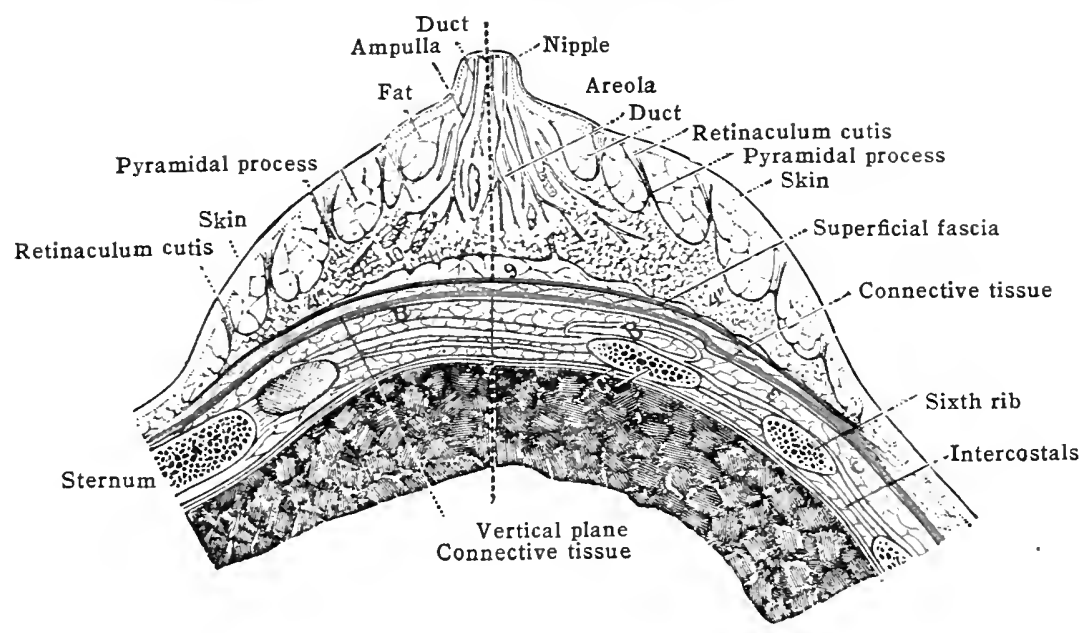

accessoriæl may be represented only by a pigmented area representing an areola; or by a nipple with or without an areola; by a gland with a more or less perfect nipple and areola; or with ducts opening without a nipple; or there may be no opening on the surface. The extra mamma is very rarely perfectly developed and functional. Various observers have found the supernumerary breasts or nipples occurring in from 1 to 7 per cent. of the cases examined and somewhat oftener in males than in females. The extra organs are found more frequently on the left side, usually along a line extending from the axilla toward the genitalia. This corresponds to the position in which the mammæ occur in some other mammals and also to the milk line of the embryo. Although they are occasionally found in other situations, over 90 per cent. of them are encountered upon the ventral surface of the thorax along the above-mentioned line caudal and medial to the normal pair of breasts. They are frequently hereditary. It is doubtful whether their possessors are either more fertile or more liable to bear twins.

The shape of the breasts varies with the development and functional activity'and the amount of fat. The smooth, somewhat conical breast of the nullipara becomes hemispherical with increase in the amount of fat, while in emaciation it may be reduced to a flattened disc with an irregular surface. After lactation the breasts tend to become more pendulous with marked sulci between them and the thoracic walls, and after repeated pregnancies they may become elongated so as to be almost conical or even have pedunculated bases.

The size of the mammary gland in girls remains relatively the same as in the infant up to puberty when it sudderly increases considerably and continues for a time to enlarge slightly at each menstrual period. There is also a temporary enlargement and soreness at each menstrual period, due perhaps to the increased vascular supply. Until the age of puberty the glands measure 8 to $10 \mathrm{~mm}$. in diameter but when they have attained their complete adult development they have increased to 100 to $110 \mathrm{~mm}$. in the cephalo-medial, 120 to $130 \mathrm{~mm}$. in the cephalo-lateral (obliquely from above downward) direction, and 50 to $60 \mathrm{~mm}$. in thickness. During pregnaney the breasts again increase in size, more especially 
after the birth of the child. When their full functional activity is established, their volume may be two or three times as great as before pregnancy. After lactation they return again nearly to their former size, which they retain until another pregnancy. After the menopause the useless glands in some cases atrophy and are reduced to small discoidal masses. In others, especially in fat individuals, although the secreting tissue disappears, it is replaced by fat so that there is little or no reduction in size. In addition to the above-mentioned variations in size, the breasts are subject to great individual differences, the cause of which is little understood. Large robust women are sometimes seen with small mammary glands, and small women with karge glands. In some individuals they are especially large.

The weight of each mamma varies, naturally, with the volume, increasing from 30 to 60 centigrams in the small gland of a young child to 140 to 200 grams after puberty and in nursing women reaching 400 to 500 and occasionally 800 to 900 grams.

The firm and elastic, well-developed breasts of young nulliparæ become during lactation even more firm and tense, but after lactation especially if there has been a long period of nursing they lose their consistency and after several pregnancies become soft and flabby.

The sulcus which defines the caudal border of the breast is but little marked in thin nulliparie, more marked in fat women, and especially evident in some multiparæ. The relations of the dorsal surface of the gland vary somewhat with the position. The level varies with the stature; as a rule, in tall women it is more caudal and in short and broad-chested women it is more cephalic. The tightness of the attachment to the sheath of the pectoralis major muscle is quite variable, but even when quite loose there is some movement of the breast when the arm is raised. The glandular tissue of that part of the breast which overhangs the axilla may be in direct contact with the lymphatic giands.

Structure.-The mammary glands are composed of the essential epithelial glandular tissue, the parenchyma, the supporting and enclosing connective tissue of the subcutaneous tela, the stroma, and the covering cutaneous layer.

Parenchyma.-The essential part of each mamma is a flattened, circular mass of glandular tissue of a whitish or reddish-white colour, the corpus mammæ. This is thickest opposite the nipple and thinner toward the periphery. The ventral surface of this mass is convex and made uneven by numerous irregular pyramidal processes which project toward the skin. The dorsal surface, or base, is flat or slightly concave and much less irregular than the ventral surface. Minute processes of glandular tissue extend from the corpus mammæ into the retromammary tissue, some of them accompanying the septa of the pectoral fascia between the bundles of muscle fibres of the pectoralis major musele. The circumference of the mamma is thick and well defined, more marked caudally than cephalically, but it presents numcrous irregular processes which extend beyond the limits apparent from the surface. One of these especially large and well marked extends cephalolaterally into the axillary fossa, and there are frequently other large but lessmarked projections.

The corpus mammæ is not a single structure but is composed of from fifteen to twenty separate lobes [lobi mammx] (fig. 1059). These are larger and smaller irregular flattened pyramidal groups of glandular tissue, with their apices toward the nipple and their bases radiating toward the periphery of the gland.

Each lobe has a single exeretory duct [rluctus lactiferus] (figs. 1059, 1060, 1061), which opens by a contracted orifice [porus lactiferus] in a depression upon the tip of the nipple. When traced from the pore toward the circumference of the gland, the ducts are seen to run first directly dorsally through the nipple, parallel and rlose to one another. From the base of the nipple they diverge. Fach duct is here visible to the unaided eye and measures from 1.5 to $2.5 \mathrm{~mm}$. in diancter. Beneath the areola its diameter increases for a short distance to from 4 to 9 mm., forming thus a reservoir, the ampulla or sinus lactiferus, in which the screction maty aterommulate for a time. Beyond this dilation the duct continues. gratually decrasing in size as it loraks up into smaller and smaller branehes, There is no anastomosis betwern the duets during their course, although at or beneath the fore two or more durts may join to have a common opening. They possess no valyes but when empty their inner surfare is thrown into longitudinal plicin.

The flucts have an extermal roat of whito fibrous emmertive tissue mixed with circular and longitmlinal alastio filores. 'They are lines with a simple cubrirlal or colmunar epithelium,

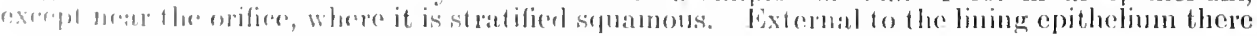


occurs in the smaller ducts a second layer of elongated cells resembling the myoepithelium of the sudoriparous glands.

Each of the terminal branches of a duct ends in a tubulosaccular, spherical or pyriform alveoIus. A number of these alveoli which open into a common branch of the durt, when grouped together and bound up with connective tissue, constitute a lobule of the gland (lobulus mammæ). A lobe is made up of all the lobules whose ducts join one common excretory duct.

The alveoli are composed typically of a single layer of epithelial cells enclosed by a basement membrane. This layer is the true secretory epithelium. It consists in the more active gland of granular polyhedral or cuboidal cells which may be so closely placed as to leave almost no lumen to the alveoli. During lactation these cells may be found in different stages of secretory activity, their central ends being filled with minute oil globules and more or less flattened according to the degree of distention of the alveoli. The alveoli and ductules now possess considerable lumina which are filled with the above-mentioned milk globules liberated from the cells and suspended in a serous fluid also secreted by the cells. This constitutes the milk (lac femininum).

Stroma.-The lobes, lobules, and alveoli are completely covered by a connective-tissue sheath too delicate to constitute a distinct capsule. Outside of this the whole gland is embedded in the subcutaneous tela which forms for it a sheath, capsula adiposa mammæ. This is particularly well developed on the ventral surface where the fat fills in between the irregularities caused by the lobes and lobules and gives to the surface of the gland its smooth appearance. Within the corpus mammæ there is little fat between the lobules in nullipare but much more fat is found here in the stroma in multiparæ. When the fat is absorbed, as it is during lactation and in emaciation, the lobules stand out much more distinctly. There is however, no fat immediately beneath the areola and nipple. The connective tissue is here loosely arranged and allows free motility of the nipple and also permits the more easy distention of the ducts and sinuses during lactation. The connective-tissue strands, retinacula mammæ, which extend from the apices of the glandular processes on the ventral surface of the mamma are connected to the corium and correspond to the retinacula cutis found in other situations. These are sometimes particularly well developed over the cephalic part of the mamma and have been called the suspensory ligament of Cooper.

The dorsal surface of the mamma is bound to the pectoral fascia by loose connective tissue containing, as a rule, only a small amount of retromammary fat (figs. 1060, 1061). The attachment to the sheath of the pectoralis major muscle is at times so loose that the spaces between the connective tissue appear to form serous sinuses, the sub-or retromammary bursæ.

In addition to the axillary process or 'tail' of the gland, a projection is sometimes scen extending toward the sternum and another caudolaterally; also processes extending toward the clavicle and caudomedially have been described. Besides these large projections there are numerous branched interlacing processes which combine into larger and smaller masses on the ventral surface and exist as minute extensions on the dorsal surface. In thin women, the parenchyma at the apex of these triangular processes reaches nearly to the surface.

A mammary gland may be made up of a larger amount of stroma and a smaller amount of glandular tissue, or the reverse, and therefore a small breast may funish more milk than a large one. There is also a variation in different parts of the same breast, one lobe or section may have well-developed lobules while in another they remain almost as at puberty, merely branching ducts.

The glandular tissue when sectioned is whitish with a greyish or pinkish cast and is firm and resistant, almost cartilaginous in consistency. It is thus easily distinguished from the adipose capsule.

Changes due to age and functional activity.- At birth the mamma consists mainly of fifteen to twenty slightly branched ducts lined with stratified squamous or columnar epithelium. In spite of the lack of true glandular tissue, within the first few dlays there may be such rapid cell proliferation that the ducts become distended with cells and detritus. Br pressure upon the gland a few drops of this material may be expressed which constitutes the so-called "witches milk.' From birth until puberty the mamma remains rudimentary, simply keeping pace with the general body growth, but in the female, at puberty, an abrupt change occurs. The tubules grow rapidly in to the surrounding tissue and some acini (alveoli) appear; the stroma and fat are also greatly increased; and the breast becomes rounded and well formed but consists mainly of fatty stroma and ducts, with but a very small number (if any) of true secreting acini. At this time in both boys and girls the breast may become swollen and tender and a milk-like seeretion may be produced similar to that at birth. The great increase in volume during pregnancy and lactation is due to the increase in the size and number of the lobules and acini, and is accompanied by a decrease in the interlobular and intralobular stroma and in the fat, so that the gland feels hard and uneven. The acini appear first in the periphery, thence along the larger ducts toward the centre of the corpus mamme.

The secretion of the gland for the first two or three days after parturition until the free secretion of milk is established is termed the colostrum. It differs from normal milk not only in chemical composition but also in containing larger fat globules and special cells known as colostrum corpuscles.

The decrease of the gland nearly to its original size after lactation is due to an involution of the parenchyma, the acini being reduced to narrow tubules, most of them completely atrophying. With this is associated a development of fat and fibrous stroma. The gland does not, however, regain its virgin appearance but its main mass is looser and more irregular, less distinct, and the peripheral processes larger, while the stroma contains numerous fat-lobules. This causes the breast to be less smooth, firm, and elastic, and it tends to become pendulous and form a sulcus where it overhangs its base. With the end of sexual activity the secreting portions of the glands gradually atrophy, finally leaving little more than the ducts. Even these undergo senile atrophy, and the main mass of the gland is represented only by a flattened disc, in which the peripheral processes can scarcely be made out. In fat women there may be little reduction in size, but the breast is here transformed almost entirely in to fat. 
The skin covering the ventral surface of the breast is very white, covered with lanugo hairs associated with sebaceous glands, and contains many sweat glands of the ordinary type. It is so thin that the subjacent veins are readily seen through it. It is closely adherent to the subjacent fatty layer but its flexibility, elasticity, and motility over the deeper glandular tissue permit much stretching during the enlargement which occurs at the time of lactation. In spite of this, linea albicantes are often produced especially when the breasts have been unusually large. Aside from the above-mentioned particulars it does not differ from the skin of the adjacent part of the thorax, except over the centre of the breast where it forms the areola and nipple.

The areola mammæ (figs. 1058, 1059, 1060, 1061) is covered by a thin, delicate, pigmented skin. The colour in young nulliparæ is reddish, the shade varying with the complexion. During pregnancy the colour darkens, slightly in blondes, but so as to become almost black in marked brunettes.

This pigmentation serves as one of the signs of gestation. After lactation the colour fades, but little pigmentation remaining in blondes, considerable in brunettes. During pregnancy there is sometimes seen extending more or less beyond the areola a less deeply and less uniformly pigmented ring, the secondary areola. In size, the areola is subject to considerable individual variation and is increased in pregnancy.

The surface of the areola is roughened by a number of slight elevations irregularly arranged. These are due to underlying large sebaceous and rudimentary milk glands [gl. areolares; Montgomerii], tubercles of Montgomery. Projections caused by sebaceous glands are also found in the secondary areola. All of these tubercles enlarge greatly during pregnancy and the glands produce a slight secretion which is discharged through ducts that open on their summits. The sweat glands are few but large, and in addition to the lanugo hairs there are usually several well-developed hairs.

The corium of the areola is devoid of fat but contains a well-developed layer of smooth muscle fibres, the fascicles of which intercross in various directions but may be seen to be mainly of two orders, circular and radial. They are continuous with those of the nipple. The circular fibres are most numerous adjacent to the nipple, where they may form a layer nearly $2 \mathrm{~mm}$. in thickness.

The areola varies greatly in size, measuring from 15 to $60 \mathrm{~mm}$. in diameter. There is some confusion in regard to the areolar glands and the tubcrcles of Montgomery. Some consider the tubereles to be caused by the areolar glands, others consider them caused by the sebaceous glands. Sebaceous glands undoubtedly cause the projections in the secondary areola. The sudoriferous glands of the areola are large and compound tubular glands with a complicated glomerulus and are considered as transitions between sweat and mammary glands. The sebaceous glands are even more numerous than the sudoriferous and are composed of several lobes. They also have been considered by some as intermediate stages in the formation of mammary glands, but this is improbable. There are ten to fifteen very small areolar glands (though Pinard found an average of but four to cach breast), whose structure is essentially identical with that of the principal mammary glands. They have dilations on their ducts and they open on the areola at times in common with a sebaceous gland.

The nipple [papilla mamme] (figs. 1058, 1059, 1060, 1061) in well-developed nullipara is situated slightly meso-caudal to the centre of the breast and on a level with the fourth rib or fourth intereostal space about $12 \mathrm{~cm}$. from the median linc. I3ut its position in reference to the thoracic wall varies greatly with age, inclividual, and the present and past activity of the gland. The nipple is usually soncwhat conical or cylindrical with a rominded fissured tip marked by fifteen to twenty minute depressions into which the lartiferous ducts empty. The average length of the nipple is $10 \mathrm{~mm}$. to $12 \mathrm{~mm}$. The skin is thin, wrinkled, and pigmented like the arrola, except over the tip of the nipple where there is no pigment.

The corium of the nipple has many large vascular and nervous papille and there is no fat in

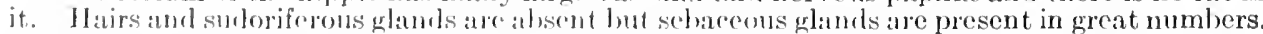

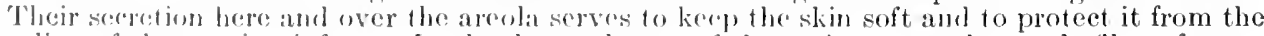
saliva of the nursing infant. In the deaper layers of the corimm smooth muscle fibres form a

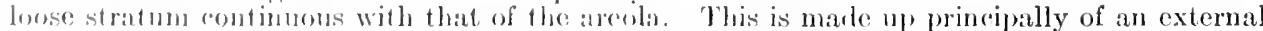
rirmlar layer and to a slight extent by an jutcrual layer whose bundles of fibres are parallel with the milk duets. Numeroms interlacing muscle libres ronnected with these layers and mixed

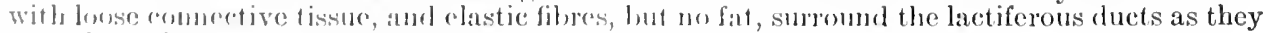
palss throlleh the: axis of the nipple.

The: nipule usually does not projere from the surfare until the third year. It soon becomes

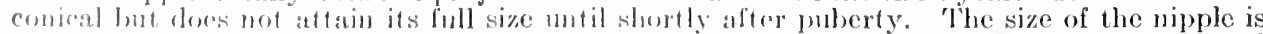

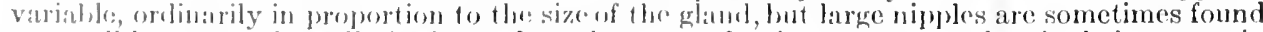
on small loreasts and subll nipples on large breasts. Dubing pregnancy the nipple inereases in 
size and becomes more sensitive and more easily erectile. The shape of the nipple in addition to conical or cylindrical may be hemispherical, flattened, discoidal, or slightly pedunculated. Its end may be invaginated or the entire nipple retracted beneath the surface of the gland and projecting only in response to stimuli.

The circular muscle fibres of the nipple act like those at its base in the areola. By intermittent, rhythmic contractions they tend to empty the lactiferous ducts; by continuous and tight contraction they act as a sphincter. When contracter they also narrow the nipple, make it harder, erect, and more projecting. When the vertical fibres contract they depress the tip of the nipple or they may retract the whole nipple beneath the surface. The muscle of the areola when stimulated puckers the skin toward the nipple causing circular concentric folds in the skin of the areola.

The male mammary gland [mamma virilis]. This develops exactly as with the female. From birth to puberty the glands in the two sexes have a parallel growth and development, but from this time on the glands in the male grow but slightly and reach their full derelopment about the twentieth year.

The corpus mammæ in the adult male measures from 1.5 to $2.5 \mathrm{~cm}$. in diamete: and 3 to $.5 \mathrm{~cm}$. in thickness. It is whitish in colour, tough, and stringy. It is composed of the same number of lobes as in the female but these consist of little more than short ducts with no true acini and may be reduced to mere epithelial or connective-tissue strands. The areola and nipple are present and pigmented, but the nipple averages only 2 to $5 \mathrm{~mm}$. in height. The areola has a diameter of 2 to $3 \mathrm{~cm}$. and is covered with hairs. The areolar tubercles may be recognised and the areolar muscle is present. The position of the nipple in relation to the chest-wall is more constant than in the female as the breast is less movable. It is seldom beyond the limits of the fourth intercostal space or the two adjacent ribs, and averages $12 \mathrm{~cm}$. from the median line. Occasionally the male breast may hypertrophy on one or both sides, gynecomastia.

Blood-supply.-The main arterial supply to the mammary gland is from mammary rami of perforating branches of the internal mammary artery (p. 567). Usually that from the second or third intercostal space is especially large. Small branches, external mammary rami, are also supplied to the caudal and lateral segments of the breast by the lateral thoracic artery (p. 571). Some rami from the thoracoacromial or supreme thoracic arteries (p. 571) may reach the cephalolateral segment of the breast and small twigs, lateral mammary rami, from the anterior branches of the lateral cutaneous rami of the aortic intercostal arteries ( $\mathrm{p}$. 589) supply its deep surface.

These vessels anastomose freely and form a wide-meshed network in the stroma of the ventral and dorsal surfaces from which branches proceed around the lobes and lobules and finally form a close network of capillaries around the alveoli. From these, venous capillaries arise and pass in two groups, one deep, accompanying the arteries, the others superficial. These latter extend to the ventral surface of the gland to form a loose network beneath the skin. During lactation these subcutaneous veins show through the skin as bluish lines, and frequently form a more or less complete circle around the nipple. They connect with the superficial reins of the neck superiorly, with those of the abdomen inferiorly, and with the thoracoepigastric vein laterally. The deep veins carry the blood to larger vessels, which empty into the subclavian, the intercostal, the internal mammary, and the axillary; and the superficial group may connect with the external jugular and femoral veins.

The lymphatics.-The lymphatics of the mammæ are extremely numerous, forming rich plexuses and free anastomoses. Their exact origin and distribution are not yet fully understood, but it is clear that there is a rich plexus in the skin of the areola and nipple which empties mainly into a subareolar plexus. Deep lymphatics arise in the spaces around the alveoli in all parts of the gland, and most of these converge toward the nipple where they join the subareolar plexuses. They anastomose freely with the cutaneous lymphatics and many of them empty into the subareolar plexus through large lymph-ressels which run parallel with the lacteal ducts. From the subareolar plexus usually two large lymph-vessels arise and pass toward the axilla to empty into the axillary lymph-glands (p. 719). Other lymphatic vessels of the mammary gland follow the course of the various blood-vessels.

There is usually a third trunk from the cephalic part of the breast and often a fourth from the caudal segment which join with the others to the axillary glands. The lymphatics of the mammary gland also communicate with the lymphatics of the skin, the ventral chest-wall and those of the deep fascia over the pectoral muscles, as well as the lymphatics of the opposite side. They also empty into the lymphatics which accompany the blood-vessels of this region, and thus communicate with the axillary, subclavicular, and supraclavicular lymphatic nodes (p. 722). Moreover, those from the medial portion of the gland accompany the branches of the internal mammary artery and empty into the sternal glands along the artery within the thorax. Since cancer of the breast extends and is disseminated through lymphatic channels, their distribution and connections are of great practical importance. 
The nerves.- The gland proper receives its nerves laterally from the lateral mammary rami of the anterior rami of the lateral cutaneous branches of the fourth to sixth intercostal nerves and medially from the medial mammary rami of the anterior cutaneous branches of the second to the fourth intercostal nerves. The skin over the breast receives in addition to branches from the above nerves, branches from the supraclavicular nerves of the cervical plexus. It is altogether probable that sympathetic fibres reach the gland but by what course is not yet clear. The nerves are distributed in part to the skin, in part to the plain musele of the areola and nipple, some to the blood-vessels, and others to the glandular tissue. The secretion is, however, not entirely controlled by nerves as it is influeneed also by hormones from other organs brought to it by the blood.

Development.-In very early embryos the epithelium over an area on the side of the body extending from the fore to the hind limb (or beyond these limits) is seen to be deeper and more cubical, the mammary streak. In this area there is produced by multiplication of cells a ridge, the mammry line or ridge. In spcts along this line, corresponding to the relative position of the mammary glands in some mammals and the supernumerary mammæ in man, the epithelium thickens. The intervening parts of the line disappear as the spots enlarge to form transient mammary hillocks. In man ordinarily development proeeeds in but one of these hillocks on each side. The deep surface of the hillock projects into the corium as the superficial surface flattens out and the mesodermic cells of the corium condense around the ingrowth producing the nipple zone. Rapid proliferation of the deeper cells produces a club-shaped stage from the deeper surface of which smallbud-like masses of epithelial cells sprout and extend as solid plugs into the corium. These are the anlages of the true secreting part of the gland and the number of buds corresponils to the number of lobes of the future gland. The sprouts extend beyond and beneat the nipple zone and are supported by closely packed connective-tissue cells forming the stroma zone. The epithelial buds continue to grow and branch and a lumen is finally produced in the originally solid plugs. The primary epithelial ingrowth degenerates and ultimately disappears. A cavity is produced in it which later conneets with the lumina of the gland ducts. The clepressed nipple zone becomes elevated above the surface soon after birth. Further development of the mammary gland has been discussed previously under changes due to age and functional aetivity (p. 1303).

\section{THE DUCTLESS GLANDS}

Under the term ductless glands are included not only certain glandular structures of epithelial origin with a more or less definitely known function and an internal secretion but also certain organs whose function is not definitely known or understoorl. Of the organs here considered, the function of the thyreoid gland, the parathyreoid glands, the chromaffin system, the medullary portion of the suprarenal glands, and the aortic paraganglia is somewhat definitely known. But the function of the thymus, the spleen, the cortical portion of the superenal glands, the glomus caroticum, and the glomus coccygeum is still in doubt; although probably some, if not all of them, have an internal secretion or at any rate are closely associated with the other glands of internal secretion. The hypophysis amel the pineal body are not considered in this connection but will be found lescribed with the brain (pp. 845,848 ). The lymph-nodes, which may also be considered as dnctless glands, are described in Section VI. Many of the true glands, such as the liver, pancreas and sexual glands, have also internal secretions which pass clirectly into the vascular system as in the ductless glands.

\section{THE SPLEEN}

The spleen [lien] is a large blood-vasenlar organ closely associated with the lymphatic system. Its exart function is still in doubt.

Position.-The spleen is siturted in the clorsal part of the left cephalic segment of the alklominal cavity so deeply placed against the diaphragm and dorsal to the stomach and colon as to be invisible from the ventral surface of the body when the abdominal "ivity is opened. It is mainly in the left hypochondriac region but its deepest and most cephalic part extends also into the epigastric region. It is obligunly pared with its long axis corresponding approximately to the line of the ciluclal ribs. It tends to become nome vertical when the stomach is fully distended but when the stomalch is empty and the colon distended it assumes a more horizontal position. ('hanges in the attiturle of the borly also cause slight alterations in the situation of the splesen. It noves with the excursions of the diaMragu in expiration and inspiration.

The colour of the spleen is, in life, a dink bhish-red or brownish-red, but after louth it beaneses darker with a more hluish or violet tint.

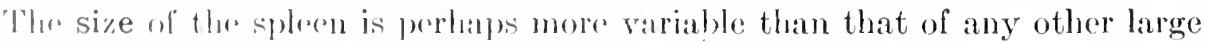


organ in the body. Not only does the size differ in different individuals but it changes greatly with the blood content in the same individual. There is a distinct expansion for a time after each meal and the spleen contracts and expands rythmically.

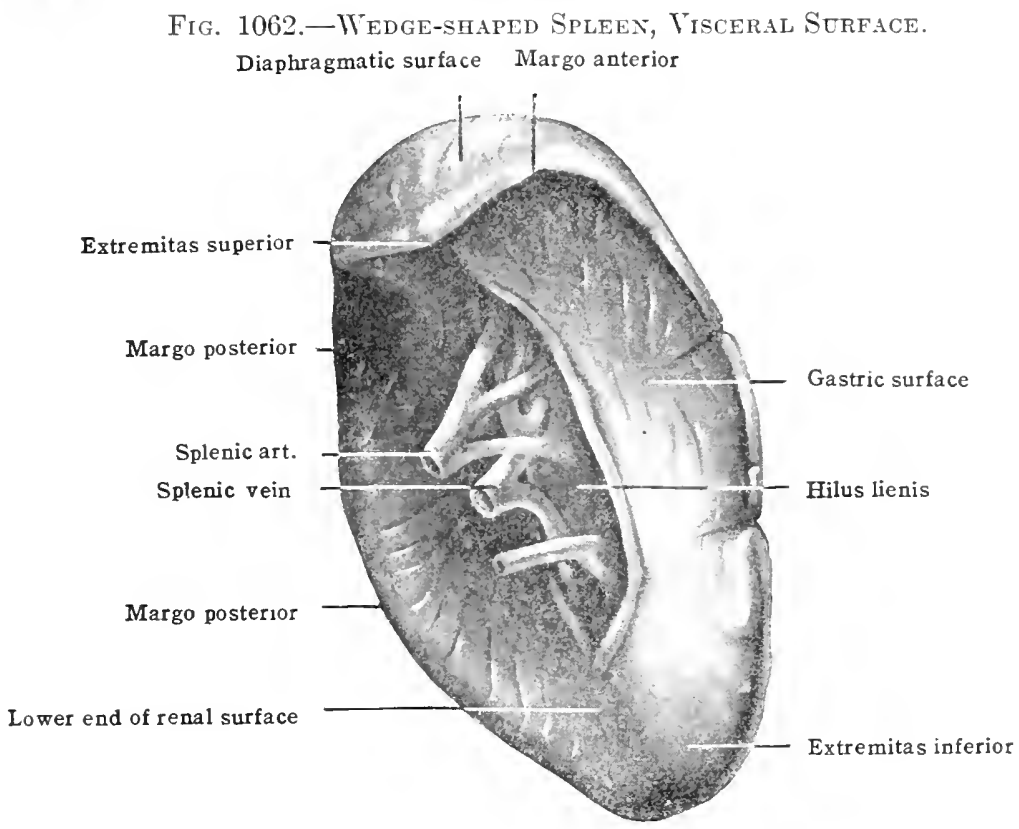

In the adult it usually measures 10 to $15 \mathrm{~cm}$. in length, 7.5 to $10 \mathrm{~cm}$. in breadth, and 2.5 to $4 \mathrm{~cm}$. in thickness. The weight usually ranges from 150 to $225 \mathrm{gm}$. At birth it represents from $\frac{1}{30}$ to $\frac{1}{400}$ of the total body weight and this porportion is maintained without much variation until the age of fifty years, when (like the lymphoid organs in general) it begins to diminish

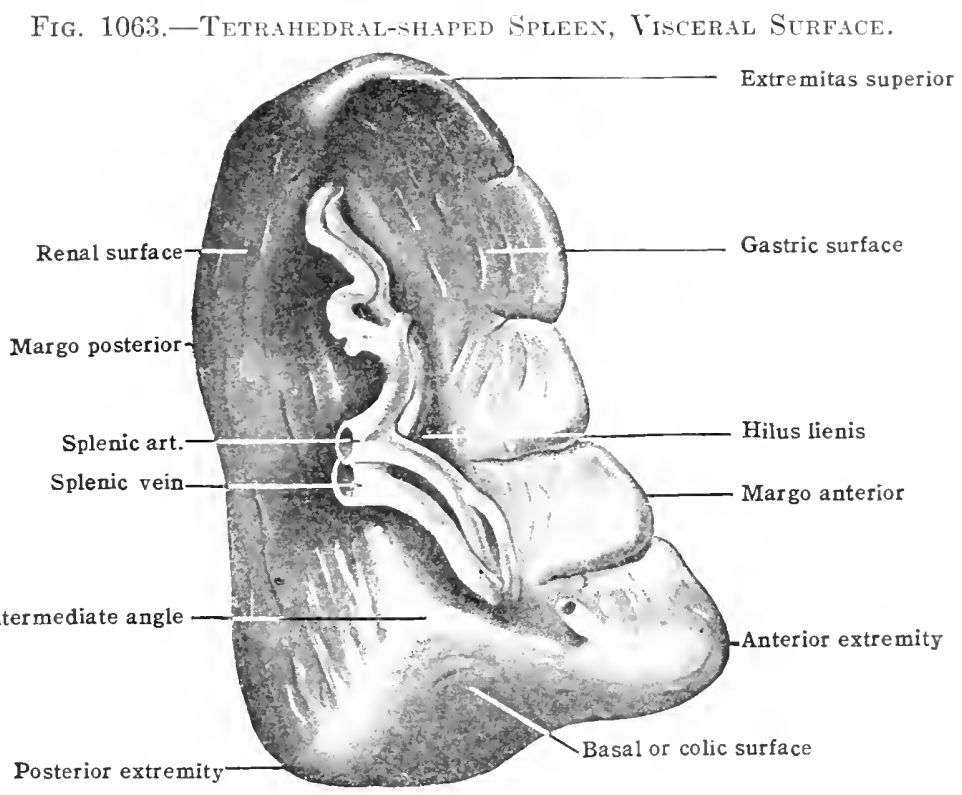

in size. This diminution continues until in the very old it represents but -1 in of the body weight. There is no great difference in relative size in the two sexes.

The spleen is somewhat sof and very friable. It is elastic, extensible, contractile, and extremely vascular.

Shape.-In form the spleen varies greatly. This is due largely to its softness which permits considerable modifications by the pressure of the distended or con- 
tracted surrounding hollow viscera. When in situ with the stomach distended its shape may be compared to a blunt spherical wedge with a concave apex and rounded extremities, and possessing therefore three surfaces (fig. 1062); but when the stomach is contracted and the left flexure of the colon distended an additional surface is produced and its shape becomes tetrahedral (fig. 1063). Inter-

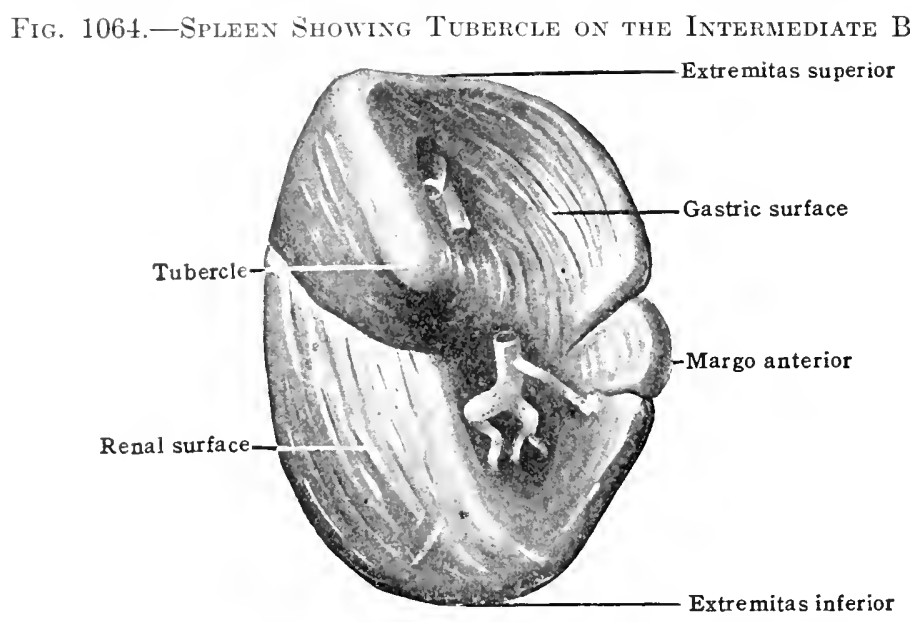

mediate forms between these extremes are produced by variations in the degree of distention of stomach and colon. The spleen presents two aspects: lateral or parietal, against the diaphragm; and medial or visceral, toward the abdominal cavity. In its usual wedge form the three surfaces of the spleen are diaphragmatic, gastric, and renal. There are three borders, anterior, posterior, and intermediate; and two extremities, superior and inferior.

Fig. 1065.-Cross-section of the Body at the Lower Part of the Epigastric Region. (Rüdinger.)

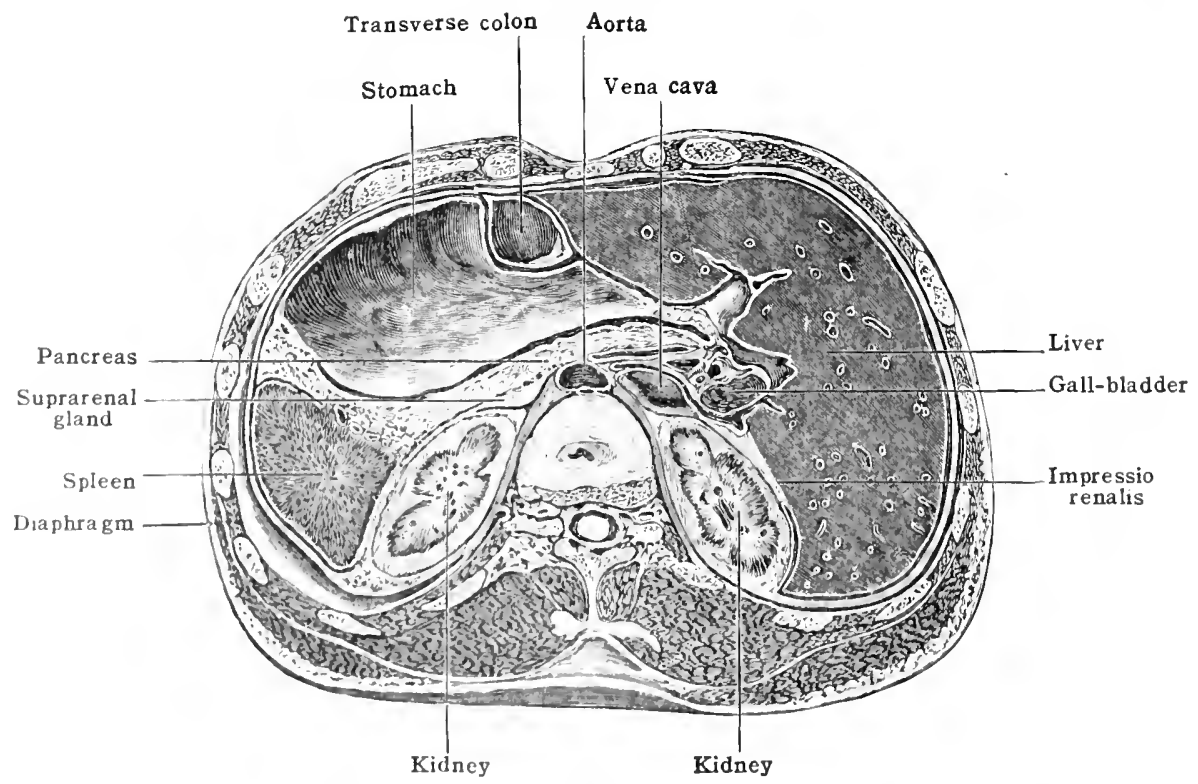

The diaphragmatic surface [facios liapluragmatical is a smooth convex surface with an irregrularly oval outline, in the werlge-shaped spleens wider cephalically, but in the tetrahedral-shaped spleens wiler caludally. It looks dorsally toward the left and sonewhat cophlalically.

It lires against the ditphragm over an area opposite the ninth, tenth, and eleventh ribs and the intrrentug interostal spaters, with its long axis eorresponding in a general way to the course 
of the ribs. Although it is separated from the ribs by the peritoneum, the diaphragm, and the left pleural cavity (cephalically also by the left lung) (figs. 1065, 1066), the ribs sometimes make impressions upon it.

The gastric surface [facies gastrica] is a semilunar-shaped surface, concave cephalo-caudally and from side to side, which looks ventrally to the right and somewhat caudally (figs. 1062, 1065, 1066). Nearly parallel with the dorsal boundary of this surface is a narrow depression usually formed by a series of pits, as a rule six or eight, which together form the hilus of the spleen [hilus lienis]. In this situation the vessels and nerves enter and leave the spleen, the vein being dorsal.

When the stomach is distended it is in contact with the major part of the gastric surface, the left flexure of the colon forming an impression upon a small area near the caudal extremity and the tail of the pancreas, as a rule, resting against a narrow area dorsal to the hilus or just

Fig. 1066.-Sagittal Section through the Left Side of the Body, Showing the Relations of the Spleen. IX, X, XI, XII, corresponding ribs. 1, Left kidney; 2, spleen; 3, pancreas; 4 , splenic vessels; 5 , transverse colon; 6 , stomach; 7 , left lobe of liver; 12 , lung; 14 , heart; 16 , diaphragm. (Testut and Jacob.)

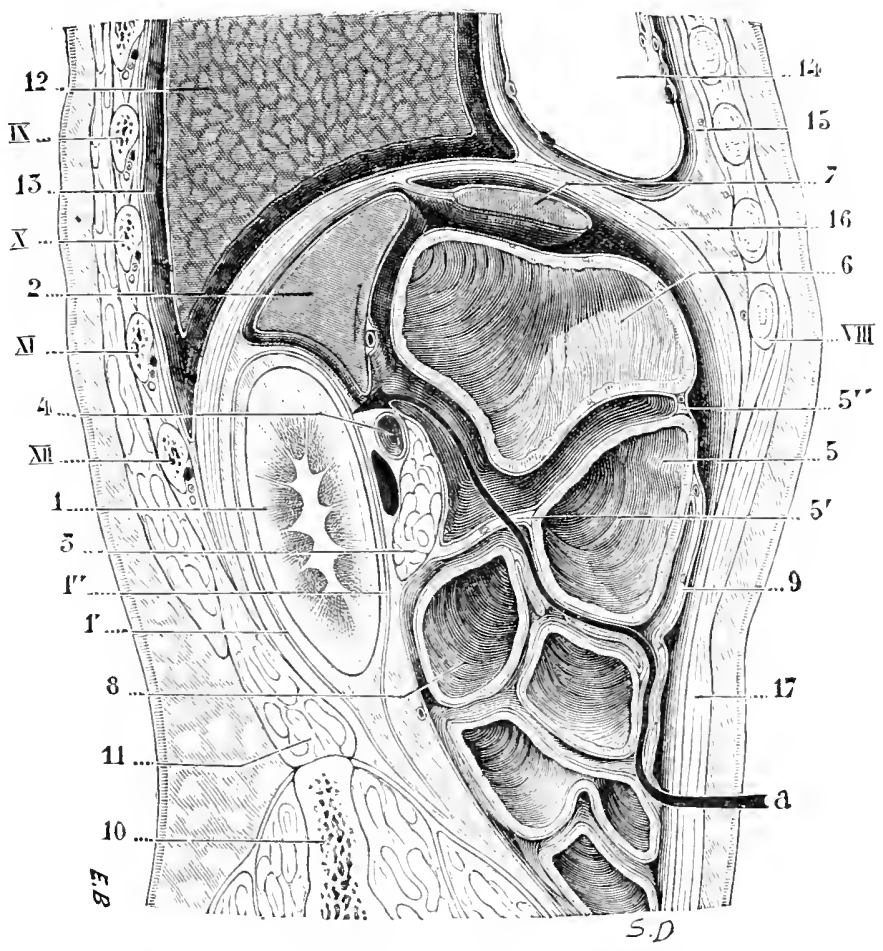

cephalic to the colon. When the stomach is empty and contracted and the colon distended the size of the gastric area is considerably decreased and the relative size of the colic impression greatly increased so as to form upon the spleen in this situation a colic or basal surface (fig. 1063). The stomach is, however, at all times in contact with some part of the spleen.

The renal surface [facies renalis] the smallest of the three surfaces, shorter as well as narrower than the gastric surface, is an oblong, flat or slightly concave area, which faces dorsally, to the right and slightly caudally. It is in relation with the anterior surface of the left kidney (fig. 1066).

In some cases the cephalic third of the renal surface is also in relation with the anterior surface of the suprarenal gland. It is separated from these latter structures, however, by the renal adipose capsule as well as by the peritoneum. The tail of the pancreas in some cases is in contact with a small area on the ventral part of this surface. In fat individuals these relations are not as intimate as the relations with other organs because of the large amount of suprarenal fat.

The anterior border [margo anterior] is clearly defined, thin, sharp, and more or less convex. It is marked in over 90 per cent. of the cases by one or more transverse or oblique notches, especially in its cephalic part. It is placed between the 
diaphragm and the stomach and separates the diaphragmatic from the gastric surface (figs. 1062-1065).

The posterior border [margo posterior] is rounded, shorter, and straighter than the anterior border and is notched in less than a third of the cases. It separates the diaphragmatic from the renal surface and is lodged in the angle between the left kidney and the diaphragm (figs. 1062-1065).

The intermediate border is a blunt ridge dorsal to the hilus, separating the gastric from the renal surface.

It may be clearly defined or more or less obscure and often shoms a marked tubercle (fig. 1061). When the stomach is contracted and the colon distended this border divides caudally into ventral and dorsal limbs both of which may be well marked or either may be deficient depending on the direction and degree of pressure of surrounding organs. When well marked there is produced at the point where the two limbs diverge a more or less marked projection, the intermediate extremity or angle (fig. 1063).

The superior extremity [extremitas superior], usually larger than the inferior extremity in the wedge-shaped splecns but smaller in the tetrahedral form, is rounded and bent medially. It extends as high as the tenth thoracic vertebra and lies 1 to $2 \mathrm{~cm}$. from the vertebral column.

The inferior extremity [extremitas inferior], also somewhat rounded, is directed toward the left and caudally. It is in relation with the phrenicocolic ligament.

When the stomach is contracted and the colon distended the inferior extremity becomes much broader, in extreme cases forming a distinct inferior border ending ventrally in the anterior margin as an anterior extremity and dorsally in the posterior margin as the posterior extremity (fig. 1063).

In the tetrahedral-shaped spleen the additional surface produced by the pressure of the colon is known as the basal or colic surface (fig. 1063). This varies in size reciprocally with the degree of pressure of colon and stomach.

When well developed the colic surface is concave and is separated from the renal and gastric surfaces by the more or less sharply defined dorsal and ventral limbs of the intermediate border and separated from the diaphragmatic surface by an inferior margin produced from the broadened inferior extremity. The left flexure of the colon is in contact with the greater part of this surface, but the pancreas also usually lies against it in its cephalic part (fig. 1063).

Peritoneal relations.-The surface of the spleen is completely covercd, cxcept for a small area at the hilus, by a peritoneal coat, the tunica serosa. Ventral to the hilus a double layer of peritoneum is prolonged from the spleen to the left side of the greater curvature of the stomach and the left edge of the ventral layer of the great omentum, forming the gastrolienal ligament which contains the short gastric arteries and reins. Dorsally a second double layer of peritoneum extends from the hilus to the ventral surface of the kidney and the caudal surface of the diaphragm forming the phrenicolienal (lienorenal) ligament. This ligament encloses the splenic artery and veins as they pass to and from the spleen. It is also between the two layers of peritoneum of this ligament that the tail of the pancreas reaches the spleen (fig. 1065). Except by these two ligaments the spleen has normally no attachment to the abdominal wall or to any of the surrounding viscera. The gastrolicnal, and more especially the phrenicolienal ligament, serve in at measure to anchor the spleen in its place in the abdomimal cavity but in addition to these the spleen is supported by a fold of peritoneum which extends from the left colic flexure to the parictal peritoneum over the diaphragm, the phrenicocolic ligament. This serves as a sling in which the inferior extremity of the spleen rests. The suleon, howerer, is held in position in the abdominal eavity mainly by the intratidelominal pressure.

Topography. - The superior extremity of an average-sized spleen is loeated between the angle and tuherele of the tenth ribon the left side and about 3 to $4 \mathrm{~cm}$. from the inedian line on a level with the spinches proesss of the ninth therater vertebra. In the majority of eases, it does not cxtend more than'2 con. either rephalie or cauclal to a transverse plane at the level of the infrasternat woteh. The inferior cxtrunty reaches nealy to the midaxilary line in the tenth intercostal spaco and lo to 15 cm. from the sujurion extroinity. The long axis therefore corresponds

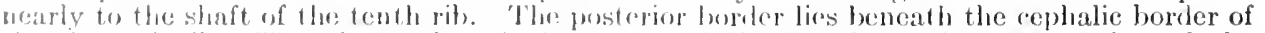

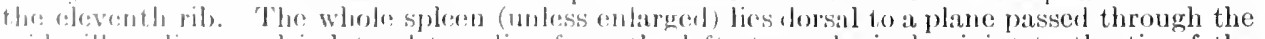
mindaxillary lines and is tateral fo a line from the left strmochuvicular joint to the tip of the

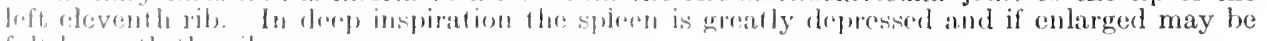

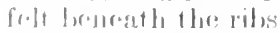

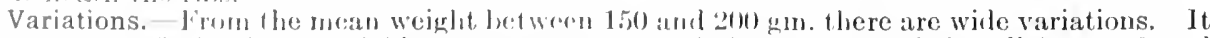

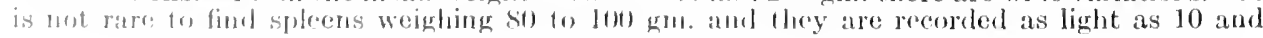


$20 \mathrm{gm}$. On the other hand, suleens weighing 3000 to $4000 \mathrm{gm}$. are sometimes found. These are usually, however, associated with an acute infectious disease, such as malaria or typhoid fever, or a progressive metamorphosis, such as leukemia.

Congenital absence of the spleen is one of the rarest anomalies. The presence of more than one spleen is the commonest anomaly of the spleen. Adami has found accessory spleens to occur in $\mathbf{1 1}$ per cent. of all autopsies. They are round or oblong and rary in size from a pea, ol smaller, to a walnut. There are most often one or two but there may be twenty or more. They are found near the hilus on the dorsal side of the gastrolienal ligament, less often, in the great omentum, in the mesentery, on the wall of the intestine, or in the tail of the pancreas.

In certain cases the left lobe of the liver is very long and prolonged far to the left and separates the spleen from the diaphragm. This is the rule in the fortus and is often found in the infant but is exceptional in the adult.

Exceptionally the spleen may be placed far caudal to the normal situation extending into the iliac region and even into the pelvis. This is due in part to congenital lasness of the supports. also to increase in weight. The spleen has been found in almost every part of the abdominal cavity and in transposition of the viscera it is upon the right side.

One or more notches on the anterior border are present according to Parsons in 93 per cent. of the cases, two or more in 66 per cent., but five, six, or seren much more rarely. On the posterior border notches are found in 32 per cent. of the cases, and on the inferior border in 8 per cent. In 20 per cent. of the cases a marked fissure, occasionally more than one, is found on the diaphragmatic surface. Most frequently it begins at one of the notches in the posterior border. and passes for a distance across the surface, rarely reaching the anterior border. Occasionally such a fissure starts from the anterior border and rarely there is such a fissure connecting with neither border.

Frg. 1067.--Portion of Section of the Spleen of an Adeli Max. $\times 15$. (Lewis and Stöhr.)

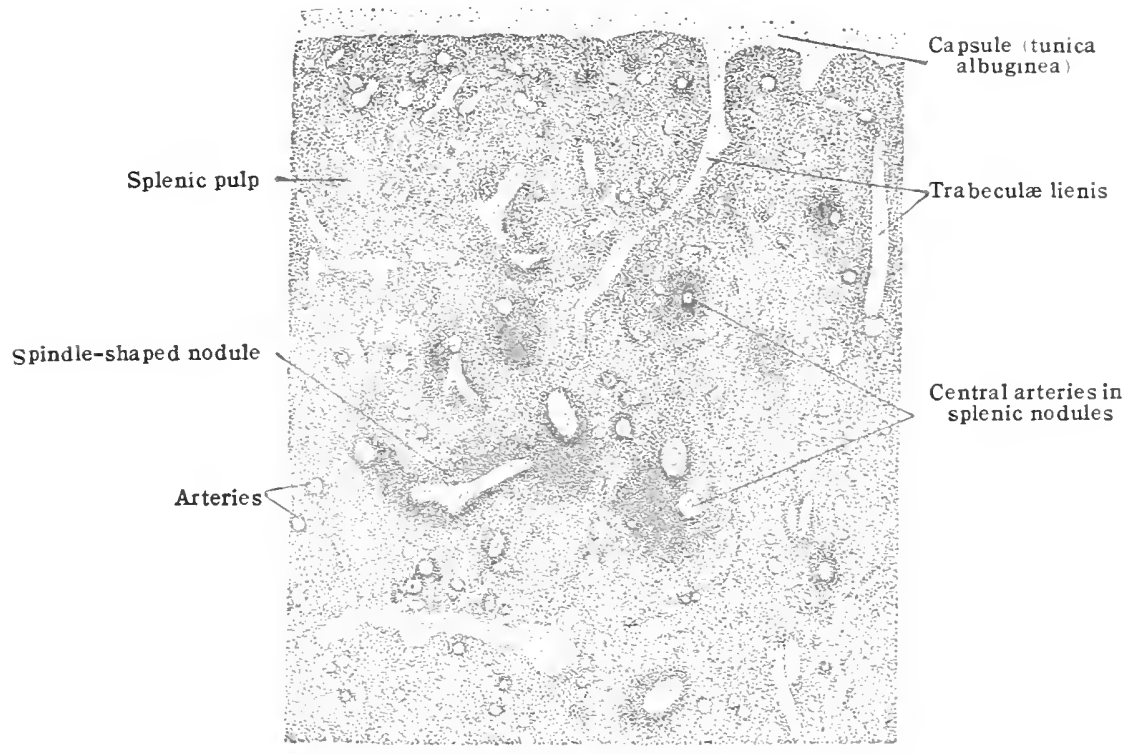

Structure.-The peritoneal covering of the spleen, tunica serosa, is intimately bound to the underlying, whitish, highly elastic fibrous capsule, the tunica albuginea (fig. 106 $)$ ). This is composed mainly of white fibrous connective tissue but contains numerous fine elastic fibers, and a few smooth muscle fibres. It is much thicker than the serous covering and completely invests the spleen. From its deep surface the tunica albuginea gives off into the interior numerous trabecula, trabeculæ lienis, which join with one another and form a framework in which course the blood-vessels, more especially the veins. It is through the contraction of the smooth muscle fibres in the tunica albuginea and trabeculie, that the regular periodic contraction and expansion of the spleen is produced.

In the meshes of the trabecular netrork, lymphoid tissue which forms the proper splenic tissue, the pulpa lienis, is located. This is soft, friable, and dark brownish or bluish-red in colour. In this, in a fresh spleen, are seen small round whitish or greyish masses from 25 to $1.5 \mathrm{~mm}$. in diameter, the Malpighian corpuscles [noduli lymphatici lienales; Malpighii].

The trabeculæ are in connection with a reticular network which permeates the spleen substance or spleen-pulp. Mall has shown that the trabeculæ and vascular system together out- 
line masses of spleen-pulp about $1 \mathrm{~mm}$. in diameter, known as splenic lobules. Each lobule is bounded by three main trabeculæe, from each of which secondary trabeculse pass into the substance of the lobule incompletely subdividing it into compartments, filled with splenic pulp, arranged in the form of anastomosing columns or cords and designated as pulp-cords. The branches of the splenic artery, after coursing for a short distance in the main trabecula, leave these, and, after further division, become surrounded with a layer of adenoid tissue, which layer presents here and there irregular thickenings forming the Malpighian corpuscles. An arterial branch, surrounded with adenoid tissue, enters the apex of a splenie lobule, constituting its intralobular vessel, which, soon after entering the lobule, loses its arlenoid sheath and then sends a branch to each of the above-mentioned compartments. These branches do not anastomose. They give off terminal branches which course in the pulp-cords, form dilations, ampullæ, and terminate directly or indirectly in the large venous spaces found between the pulpcords. From the latter the blood passes, by means of small intralobular veins, to interlobular veins situated in the trabecula bounding the lobules. Some of the ampulla are connected with one another by capillary branches.

Blood-supply.- The spleen receives its blood from the splenic artery, which is very large in proportion to the size of the organ it supplies. It divides in the phrenicolienal ligament into from three to six or eight branches, rami lienales (fig. 1062), which enter the spleen at the hilus. After entering the spleen the arteries divide and subdivide and run to their termination in the ampullie without anastomosing. They form what are known as terminal arteries. The main splenic artery is very tortuous. The vein, vena lienalis, leaves the spleen usually by the same number of branches as the entering artery. These unite in the phrenicolienal ligament to form a large trunk which is straighter than the splenic artery and lies caudal to it.

The lymphatics. - A superficial and a deep set of lymphatics have been described in the spleen. The former is said to form a plexus beneath the peritoneum and the latter to be derived from the fine perivascular spaces in the adenoid tissue around the vessels. From these several trunks arise and joining at the hilus pass between the layers of the phrenicolienal ligament to empty in to the lymph-glands dorsal to and around the cephalic border of the tail of the pancreas. The presence of both superficial and deep sets of lymphatics in the human spleen has been denied by some investigators. According to Mall, there is no deep set.

The nerves. - The nerves are derived from the right vagus and from the cœliac plexus. They enter the spleen at the hilus, accompanying the branches of the lienal artery. They are composed mostly of non-medullated fibres which form a rich plexus around the arteries supplying the muscular fibres in the media while a second group has been traced to the muscular fibres of the trabeculæ.

Development of the spleen.-The first anlage of the spleen is seen in the fifth week of fotal life as a swelling on the dorsal (left) surface of the mesogastrium. This is due to an increase in the mesenchymal cells as well as to a thickening of the colomic epithelium. This latter becomes stratified, and indistinctly differentiated from the underlying embryonic connective tissue through the transformation of the deepest of the epithelial cells into mesenchymal cells. As development proceeds the thickened mass becomes entirely isolated and the colomic epithelium covers it as a single layer.

The arteries are seen first as a capillary network throughout the organ which considerably later become arranged as tufts of widened capillaries, the anlage of the vascular structural unit. These spherical groups of arterial capillaries leading by wide openings in to a wide meshed venous plexus are bounded by trabecule from the eapsule. The number of structural units in the spleen seems to be fixed fairly early but the size and complexity changes greatly. The spherical mass with a single central artery changes to the adult condition where the central artery gives off side branches, each of which has a spherical mass of capillaries, and the pulp intervenes between the artery and the vein so that the capillary circulation of the early embryo becomes the cavernous circulation of the adult. The lienal lymphatic nodules of Malpighi and the splenic pulp appear only in the latter half of embryonic life.

\section{THYREOID GLAND}

The thyreoid gland [glandula thyreoidea] is an extremely vaseular, duetless grland, whose internal secretion, acting as a stimulus to the tissues, has a profound influence on the mutrition of the body and on the nervous system. It is a single orean composed of two lateral, frecfuently unsymmetrical, masses, joined together by a transverse median band. The median transverse band or isthmus [isthmus gl. thyreoideas is thin and narrow, and of ten has a long slender process, thro pugrmidal lobe [lobus pyramidalis], extending from it cephatically. 'The lateral parts or lobes [lobi, dexter ot sinister] form the principal mass of the gland.

It is situated in the ventral portion of the middle third of the neek on both sicles of the laryox and the crephatie end of the trachea, dorsal to the infrahyoid gerorip) of musclios.

Thre consistency of the thyreod gland is miformly soft and compressible. The colour is rerldish, with a brownish or yellowish cast, but becoming more bluish or renlish wilh rhanges in its blower rontent.

The size is sulpect to consirderable individual variation and is slightly greater in woncen than in men. The normal thyeoid gland moisures from 4 to $6 \mathrm{~cm}$. in whllh at its willest part. The laterad lobes measure from 5 to $8 \mathrm{em}$. in length, 
about $2 \mathrm{~cm}$. in width, and from 1.5 to $2.5 \mathrm{~cm}$. in thickness. The right is usually a little longer than the left. The isthmus averages from .6 to $.8 \mathrm{~cm}$. in thickness and from .5 to $1.5 \mathrm{~cm}$. in height.

The weight of the normal gland averages about 30 grams; but many specimens are found as light yas 20 grams, and others weigh as much as 60 grams.

When hyperemic or congested the size of the gland may be markedly augumented. This occurs normally in most women at puberty and during menstruation and pregnancy. In various abnormal conditions of the gland there is an increase in size, sometimes to a marked degree. These enlargements are orlinarily grouped under the term struma or goitre, and may be associated with either a hyper- or hyposecretion of the gland. Decrease in size is common in old age and may appear prematurely in certain diseases.

The shape of the gland as viewed from the ventral surface is that of a capital $\mathbf{U}$ with the concavity directed cephalically (fig. 1068). The sides of the $\mathbf{U}$ are formed of the more or less elongated lobes connected slightly cephalic to their

Fig. 1068.--Ventral View of the Thyreoid Gland.

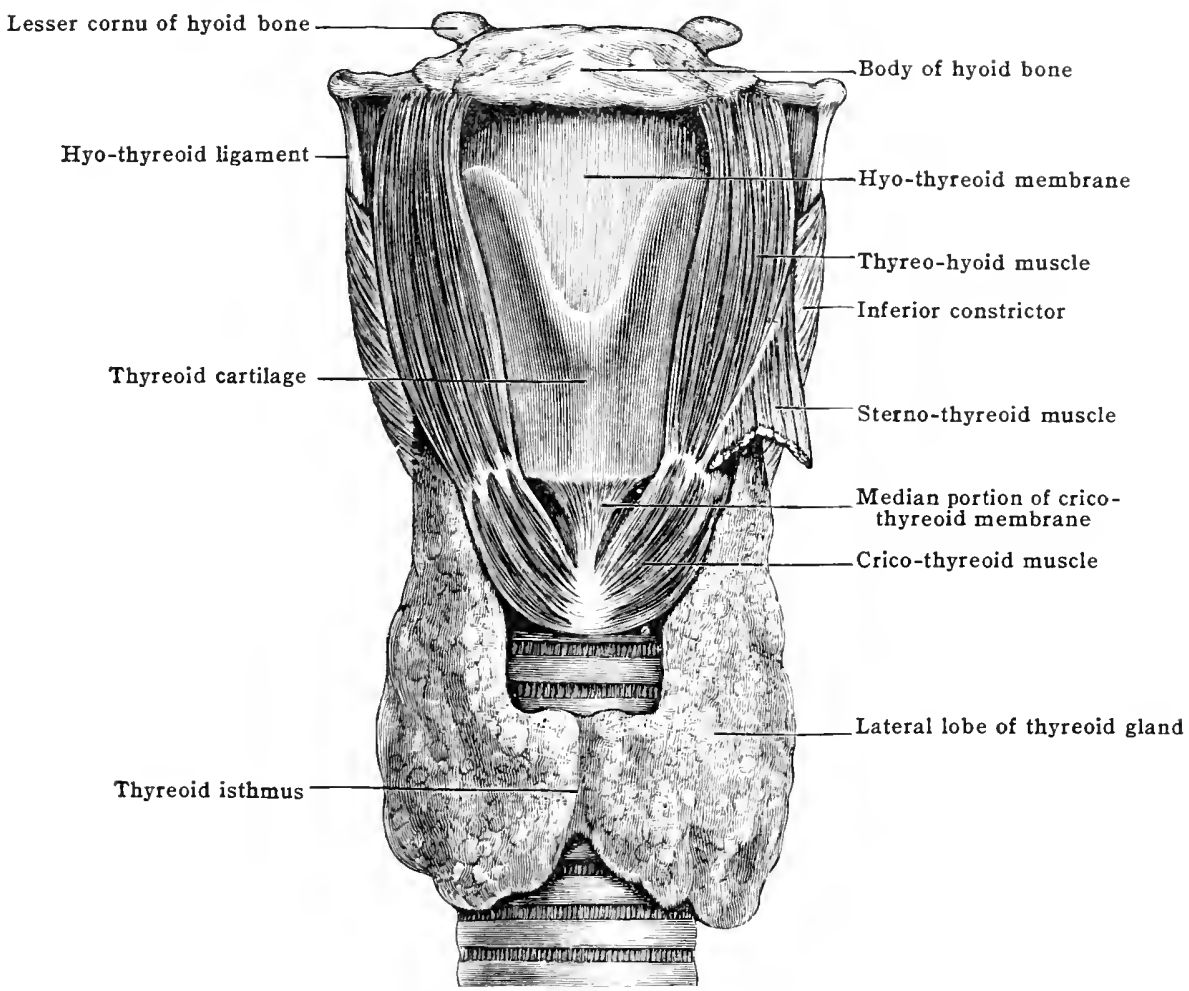

thickened caudal ends by the thin transverse isthmus. In transverse sections through the isthmus the gland is also $\mathbf{U}$-shaped with the concavity directed dorsally, the lobes being on each side and the isthmus ventral to the trachea (fig. 1068). The surface of the gland is somewhat unevenly roughened.

The isthmus glandulæ thyreoidæ usually becomes wider laterally where it is attached by its two extremities to the lateral lobes (figs. 1068, 1069). Its ventral surface which is flat or somewhat convex is covered superficially by the subcutaneous tela and skin and beneath these by the superficial and middle layers of the cervical fascia. Between the layers of cervical fascia and close to the median line is the sterno-hyoid muscle and more laterally and deeper the sterno-thyreoid muscle. The dorsal surface is concave and is in relation with the first two to four rings of the trachea and sometimes with the cricoid cartilage.

The size and form of the isthmus is subject to considerable variation. It may be very short. Rarely it is wanting entirely or connects with but one lateral lobe. Its superior border is, as a rule, concave and is connected in many cases with the pyramidal lobe. The caudal border, although usually on the third ring of the trachea and 2.5 to $3 \mathrm{~cm}$. from the jugular notch of the sternum, may be especially developed so that it extends caudally beyond the lateral lobes and produces a process which is known as the medial lobe. 
The pyramidal lobe is usually a narrow elongated flattened somewhat conical process of thyreoid tissue representing the persistent portion of the median embryonic thyreoid (fig. 1069). Its base is attached ordinarily to the left side of the

Fig. 1069.-Thyreoid Gland, with Pyramidal Lobe and Levator Muscle.

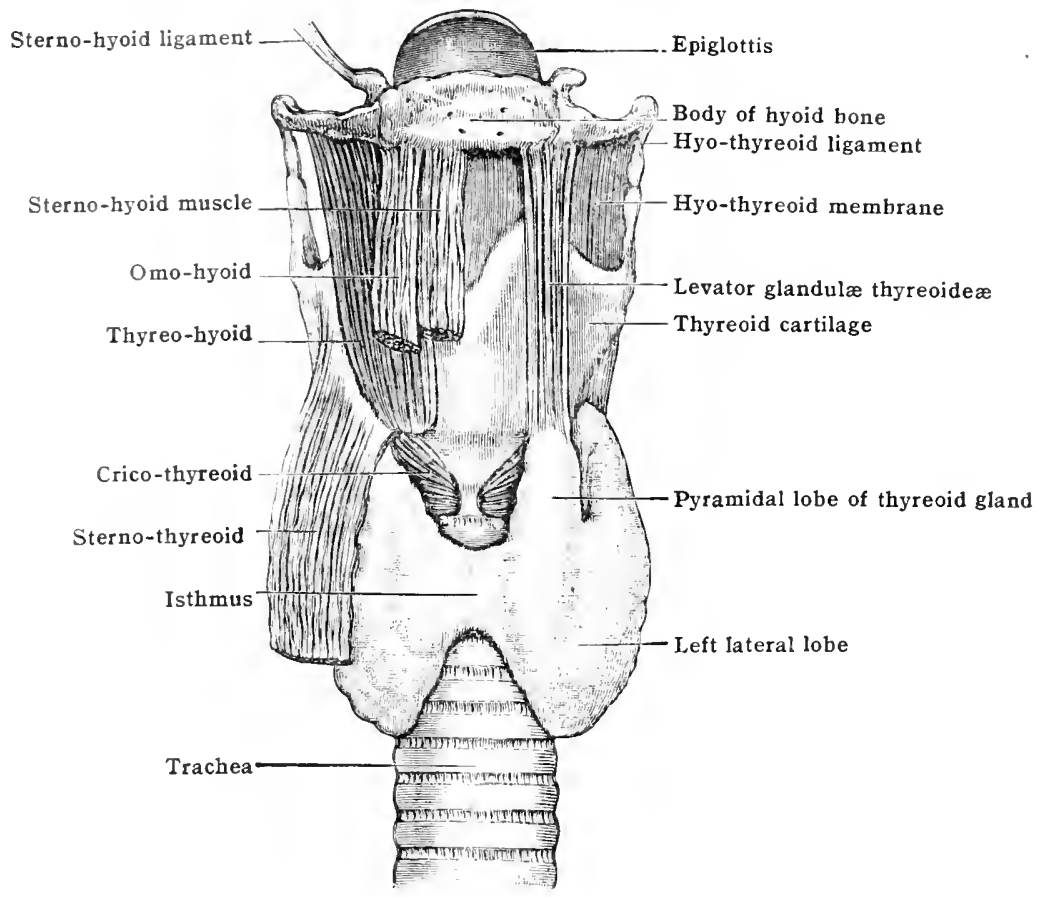

superior borler of the isthmus and its apex which extends cephalically a variable distance, often to the superior border of the thyreoid cartilage, is attached by a fibrous cord, the thyreoid ligament.

The pyramidal lobe is not always present. Some investigators have found it present in only 40 per ennt of all cases; others in as high as 90 per eent. The average is somewhere between

Fig. 1070.-Cross-section of Neck showing Relations of the Thyreoid Gland. (After Braune, from Porier and Charpy.)

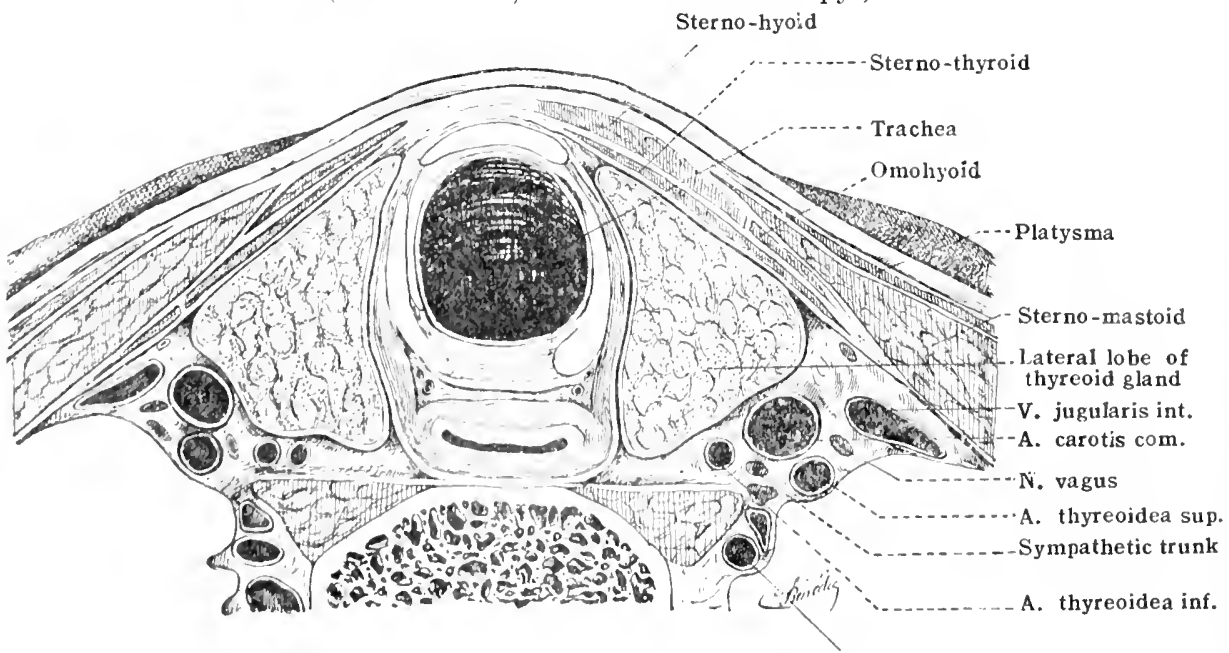

A. vertebralis

these "xtremes. It is alosely allierent to the suljacent structures, nsually at one side of the unesian line, more often the left. The superficial relations of the pyramidal lobe are sinnila to those of the isthmus. Jts deepsurfare is in relation also with the ericoid and thyreoid cartilages, the erico-thyreoil muscie and the hyo-thyreoid ligament. 
The pyramidal lobe, though usually single, may be double or bificl at its caudal end, one process joining each lateral lobe. It may be attached in the angle between the isthmus and one of the lateral lobes, or to the lateral lobe itself. It may be cylindrical, band-like, or swollen at its centre or cephalic end and is occasionally entirely separate from the rest of the thyreoid or divided into separate detached parts, thus forming accessory thyreoids. The apex in some cases extends to the middle of the thyreohyoid membrane or rarely to or beyond the hyoid bone or the process may be quite short. In the thyreoirl ligament, attached to the apex, muscle fibres are sometimes found, aberrant parts of the infrahyoid muscles, the levator of the thyreoid gland.

The thyreoid lobes, right and left, are placed on each side of the trachea and larynx (figs. 1068, 1069, 1070). Each lobe is somewhat pyramidal in shape and presents for examination a base, an apex, a medial, a ventro-lateral, and a dorsal surface.

The base is roughly convex or pointed, rarely flattened, usually at the level of the fifth or sixth ring of the trachea (figs. 1068, 1069).

It is separated from the jugular notch of the sternum by a distance of 1.5 to $2 \mathrm{~cm}$. but when the head is extended the distance is greatly increased. It is in relation with the inferior thyreoid artery and numerous veins, mostly tributaries of the inferior thyreoid vein.

The apex is pointed or rounded (figs. 1068, 1069). It is directed cephalodorsally and is situated at the dorsal border of the lateral lamina of the thyreoid cartilage at the level of its caudal. or rarely its middle, third.

It is covered by the sterno-thyreoid muscle beneath which the superior thyreoid artery accompanied by the corresponding vein crosses the apex to reach the gland. It is also crossed in this situation by the external ramus of the superior laryngeal nerve as it passes to the cricothyreoid muscle.

The medial surface of the lateral lobe is concave and intimately bound to the trachea and cricoid cartilage (fig. 1070). Toward the apex it becomes more flattened where it comes into contact with the lateral lamina of the thyreoid cartilage.

At the border where this surface joins with the dorsal surface it is in relation with the asophagus and pharynx, and in the angle betreen these structures and the trachea and larynx it is close to the recurrent laryngeal nerve.

The dorsal surface (fig. 1070) is broad and rounded caudally, but toward the apex is reduced to a mere border. It lies upon the fascial sheath containing the common carotid artery, the jugular rein, and vagus nerve, most intimately related to the common carotid artery which usually produces a groore in it.

The inferior thyreoid artery sends large branches over this surface. The inferior thrreoid veins also have large branches here. Imbedded in the connective tissue in relation with this surface the parathyreoid bodies are found, and in some cases the recurrent nerves are placed so far laterally that they also touch this surface. In many cases the sympathetic trunk and the middle cervical ganglia of the sympathetic with the cardiac branches are closely related to the dorsal surface of the gland.

The ventro-lateral surface is convex and is separated by loose connective tisue from the overlapping sterno-thyreoid, sterno-hyoid, and omo-hyoid muscles.

More superficial on its lateral aspect is the sterno-cleido-mastoid muscle. The above muscles are enclosed by the superficial and middle sheets of the cervicul fiscia. In the subcutaneous tela the platysma muscle spreads over the gland. This surface of the gland is covered by a plexus of veins and by branches of the superior thyreoid artery.

Accessory thyreoid glands are small masses of glandular tissue one or more of which may be found situated in the median line or at one side of it anywere between the isthmus and the root of the tongue. They vary considerably in size and represent parts of the pyramidal lobe or isthmus which have become completely separated from the rest of the gland. In structure they are composed of the same tissue as the rest of the gland.

Fixation.-In addition to the connective tissue which binds the thrreoid gland to the trachea, it is attached by the comnection of its capsule with the cervical fascia and by the fibrous prolongations from the capsule.

These prolongations are found merlially attaching the isthmus and adjoining portions of the lateral lobes to the ventral surface of the cricoid cartilage, the caudal border of the thyreoid cartilage, and the sheath of the crico-thyreoid muscles, and laterally attaching the lateral lobes to the trachea and lateral surface of the cricoid cartilage. In adilition to these the connection of the vessels and nerves to the gland helps to fix it in position.

Structure.-The thyreoid gland like other glands is composed of a connectivetissue stroma supporting an epithelial secreting parenchyma. 
The connective tissue which covers the surface of the gland forming for it a capsule, may be divided into two layers, superficial and deep.

The superficial layer intimately connected with and derived from the fascia colli as pointed out above has an important function in supporting and fixing the gland. This layer is in some cases thin and transparent; in other cases it is very tough and thick. It is connected by loose areolar tissue with the thin deep layer of the eapsule. Betwcen these two layers the larger vessels run for a space before entering the gland and the veins, particularly, form here considerable plexuses.

From the deeper layer of the capsule numerous trabeculæ and septa carrying blood-ressels, lymphaties, and nerves pass into the gland and imperfectly separate its parenchyma into irregular masses of variable size, the lobules [lobuli]. Each lobule is composed of a number of closed, non-communicating, irregular, spherical, ovoid, or sometimes branched alveoli, acini or vesicles, varying in size from .045 to $.22 \mathrm{~mm}$. in diameter and separated and bound together by a vascular connective tissue continuous with that surrounding the lobules and with that of the cap-

Fig, 1071.-Arteries of the Thyreoid Gland, Anterior View. 1. Lateral lobe; $1^{\prime}$ pyramidal lobe; 2 , trachea; 3 , thyreoid cartilage; 4, crico-thyreoid membrane; 5 , hyo-thyreoid membrane; $6,7,8,9$, inferior thyreoid artery and branches; $10,11,12,13,14,15$, superior; thyreoid artery and branches; 16, thyreoidea ima. (Testut and Jacob.)

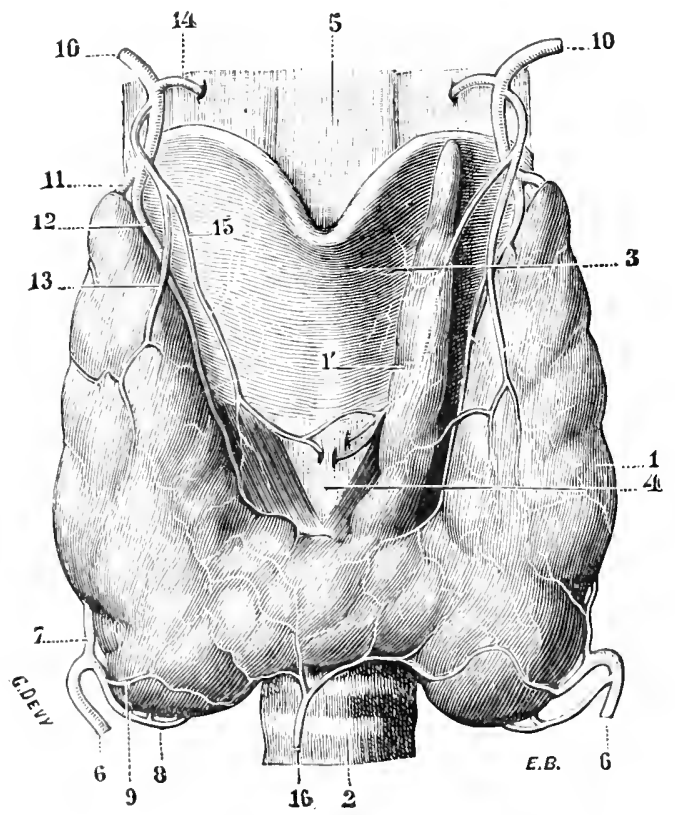

sule. The vesicles are filled with a yellowish viscous fluid, known as colloid, the secretion of the epithelial cells.

The vesicles are lined with a single layer of epithelial cells of a fairly uniform cuboidal or columnar shape, becoming ftattened in distended vesicles and in old age. The cells are not supporterl by a basement membrane but are in elose relation with connective tissue and capillary blool-vessels. An extremely rich lymphatie network surrounds the vesieles and the lymph-vessels come in to intimate relation with the cells. Through these vessels the secretion is conveyed from the glind to the general circulation.

Blood-vessels. - The thyroid gland has an extremely abundant bloodsupply. The arteries are disually four in number but occasionally five (figs. $1071-1073)$.

The superior thyreoid arteries clivite into two, thee, or more main branches which reach the

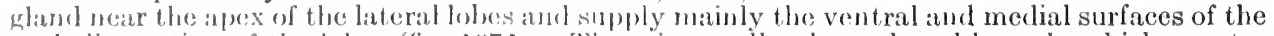
cophalio portion of the Johes (fig. 107L). There is usually also a dorsal branch, which anastomoses with a bromeh from the inferior thyreoil. Bue of the ventral branches freguently connocts atong the exphalio borler of the istlimms with its fellow of the opposite side. The inferior thyreoid arteries brok up into two or these man branches, occasionally into inany fine twigs, which reach the dorsal stuface of the lateral lobes near the eavelolateral borders and supply 
mainly the dorsal and lateral surfaces of the eaudal part of the gland (fig. 1071). There is usually a well-marked branch which passes cephalically to anastomose with a good-sized branch from the superior thyreoid. Small branches are distributed to the ventral surface of the caudal portion of the lobes and isthmus. The small fifth artery, the thyreoid ima artery, occasionally present, ascends on the ventral surface of the trachea and reaches the gland at the caudal border of the isthmus or of either lobe. It anastomoses with the other arteries which may be correspondingly reduced in size. The above-mentioned arteries branch freely and are distributed over the surface of the gland between the two layers of the capsule where they anastomose extensively with one another and with the arteries of the opposite side. From the surface plexus branches pass with the septa and trabeculie through the gland to break up into the capillary plexuses around the vesicles.

The relation of the inferior thyreoid artery to the recurrent nerve is important from a surgical point of view but unfortunately is not constant. In some cases the nerve is ventral to the artery, more often on the right, in other cases it is dorsal and often the nerve passes between the branches of the artery. Their relation is most in timate close to the trachea Fig. 1073.

Fig. 1072.-Vessels of the Thyreoid Gland, Axterior View. 1, 2, 3, Lateral lobes and isthmus; 4 , pyramidal lobe; 5 , hyoid bone; 6 , thyreoid cartilage; 7 , trachea; 8 , common carotid; 9 , internal jugular; 10 , thyreo-linguo-facial vein; 11 , superior thyreoid artery; 12, inferior laryngeal vessels; 13 , middle thyreoid vein; 14, subclavian artery; 15 , inferior thyreoid artery; 16 , inferior lateral thyreoid veins; 17 , inferior medial thyreoid veins; 18 , left innominate vein; 19 aortic arch; 20, vagus nerve. (Testut.)

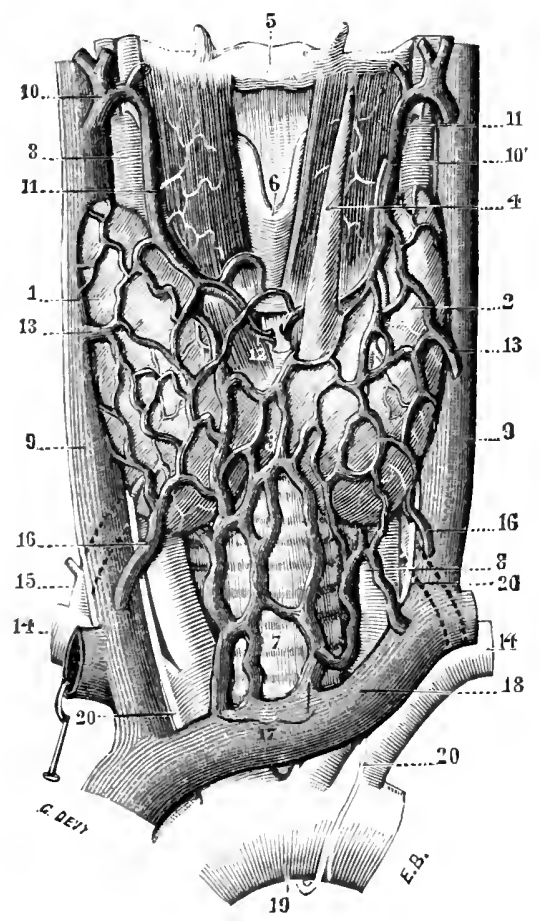

The veins (fig. 1072) issue from the substance of the gland along the septa which penetrate from its capsule. Between the two layers of the capsule they form a rich plexus of large vessels from which three large branches issue on each side.

The superior thyreoid veins leave the capsule of the ventral surfaces of the lateral lobes near their apices and pass cephalo-laterally to empty into the internal jugular veins, sometimes with the facial veins. The middle thyreoid veins are sometimes absent, when present they are often very small and pass from the lateral border of the lateral lobes laterally to empty in to the internal jugular vein. The inferior thyreoid veins arise from the caudal and lateral part of the dorsal surfaces of the lateral lobes and pass caudolaterally to open in to the innominate veins. Ventral to the trachea, caudal to the isthmus, the two inferior thyreoid veins are connected by numerous cross anastomoses and occasionally they open by a single trunk which joins the left innominate vein. A thyreoidea ima vein is sometimes present.

The lymphatics of the thyreoid gland begin as abundant plexuses around the vesicles of the gland lobules. These connect with the interlobular branches which empty into radicles accompanying the blood-vessels through the septa to the surface of the gland where they join a considerable plexus placed between the two layers of the capsule. From the cephalic portion of the isthmus and lobes efferent vessels extend cephalo-medially to one or two small 
pre-laryngeal glands and cephalo-laterally along with the superior thyreoid artery to the deep cervical glands. From the caudal part of the lateral lobes and isthmus efferent vessels pass caudally to some small pre-tracheal glands and caudolaterally to the deep cervical glands.

The nerves of the thyreoil gland are probably all derived from the sympathetic and arise from the middle and inferior cervical ganglia and accompany the arteries to the gland.

Development. - The thrreoid gland is first seen in very young embryos as a prominence on the ventral wall of the pharynx. This becomes a stalked vesicle and divides into lateral lobes. The stalk elongates forming the thyreoglossal duct of His. Later the lumen is obliterated and the duct is then represented by an epithelial cord which soon loses its connection with the pharynx. It opens at first ceplialic to the regular second branchial arch on the summit of the tuberculum impar but later shifts to its caudal boundary (Grosser). It is represented in the adult only by a short blind pouch, the foramen cæcum but very rarely a considerable duct may be present. The bilobel mass appears to shift caudally, increasing in size and spreading laterally and dorsally. The median cord of cells formed from the stalk becomes the isthmus and the pyramilal lobe, when this is present, the lateral portions form the lateral lobes. The gland is now composed of irregular, in general transversely disposed cords of cells. More rapid growth latel occurs in the centres of the lateral lobes and the cell cords become closely packed with little connective tissue between. Lumina appear in different places in the cell cords and the cell cords are broken up into groups of cells; in these the lumina continue to appear even up into early childhool. On each side, diverticula from the more caudal pharyngeal pouches, the ultimobranchial bodies, come into contact with the dorsal and lateral parts of the anlage of the thyreoid gland and become partly enclosed in the neighbourhood of the transversely running cell cords. This core of cells becomes either a compact body or an irregular group of cells and is probably not transformed into thyreoid tissue.

\section{THE PARATHYREOID GLANDS}

The parathyreoid glands are small masses of epithelial cells found in the neighbourhood of the dorsal surface of the thyreoid gland but quite distinct from it and

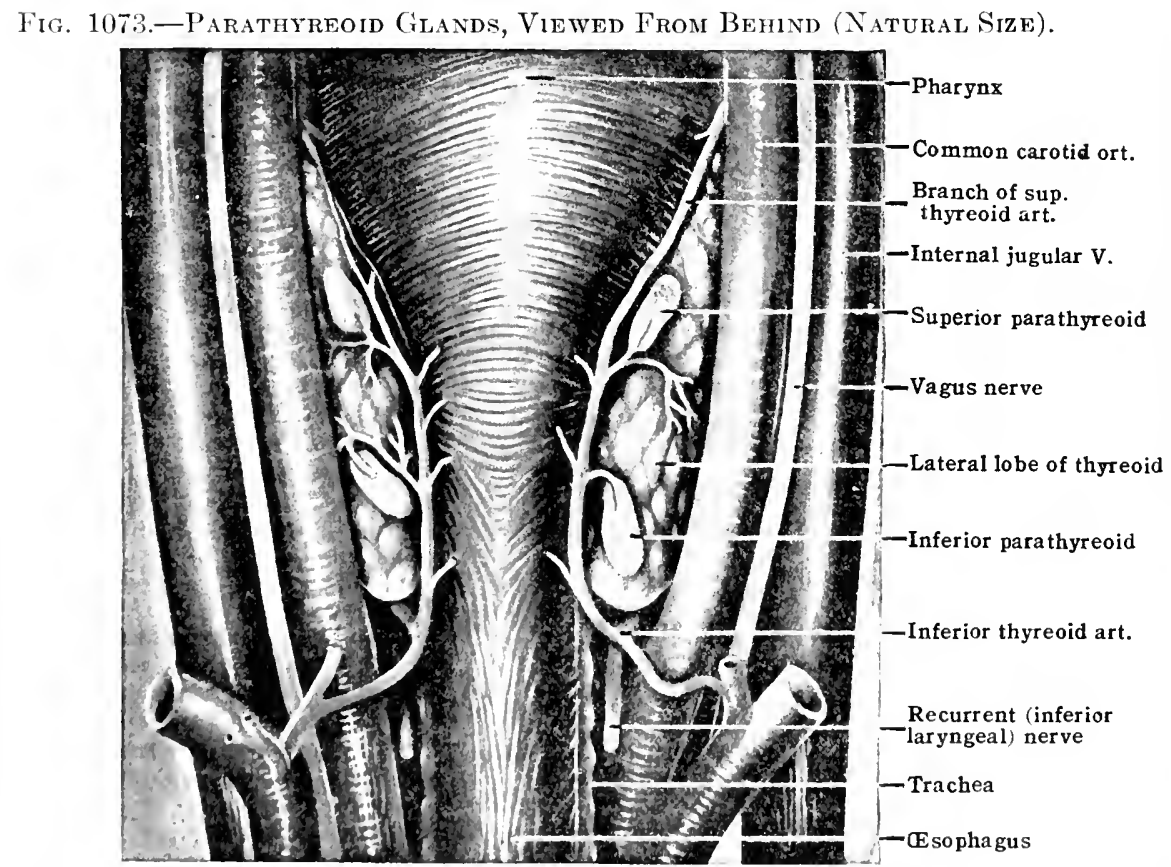

of different structure. They are ductless glands and although very small they are essential to life.

The ustal number is four, two on each sicle, in relation with the lateral lobes of the thyrenid gland (fig. 1073). In colour they are yellowish with more or less of a derldish or brownish tint but lightor than the thyreoid gland. Their consistency varjes somewhat but msunlly it is softer than that of the thyreoid gland. The shape of the majority of thre glands is a flattened ovoid, sometimes tapering at one

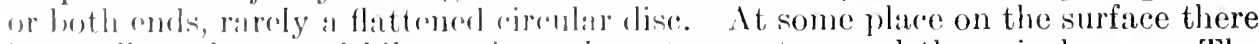
is menally at depresserl hilum where the artery onters and the vein leaves. The arrenge: size of the glands is 6 to 7 mun. in length; 3 to $4 \mathrm{~mm}$. in width and 1 to 2

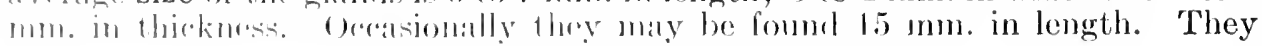


weigh from .01 to $.1 \mathrm{gm}$. with an average of $.035 \mathrm{gm}$. From their situation they have been divided into a superior, or internal, derived from the fourth branchial pouch, and an inferior, or external, derived from the third branchial pouch.

The superior parathyreoid glands (fig. 1073) are found, as a rule, on the dorsal surfaces of the lateral lobes of the thyreoid gland at about the junction of the cephalic and middle thirds Occasionally they may be situated in the areolar tissue at the level of the apex of the thrreoid gland or cephalic to it. They may be ventral to the prevertebral layer of the cervical fascia, on the dorsal wall of the osophagus or pharynx and close to the dorsomedial margin of the thyreoid gland. They may also be placed at the level of the caudal border of the cricoid cartilagel rarely as high as the inferior cornu of the thyreoid cartilage or as low as the sixth trachea, ring. Sometimes they are imbedded completely in the thyreoid gland. As a rule, they are tightly attached to the capsule of the thrreoid gland or situated between its layers.

The inferior parathyreoid glands (fig. 1073) are less constant in their situation than the superior. They usually are found in relation with the dorsal surface of the lateral lobes of the thyreoid glands, not far from their bases. They may be quite outside the region of the thyreoid gland along the carotid arteries or the sides of the trachea, or they may be placed more cephalically than usual or extend caudal to the gland as far as the tenth tracheal ring, even into the thorax. They are imbedded, when caudally placed, in fatty areolar tissue in relation with the apex of the thymus gland and the inferior thyreoid veins or applied against the cesophagus.

The parathyreoids are intimately related to branches of the inferior thyreoid artery, a separate branch of which supplies each of them. When there is a large branch of the inferior thyreoid artery anastomosing with the superior they are more or less in line with this.

Each parathyreoid gland is surrounded by a fibrous capsule from which extremely vascular septa and trabeculie penetrate into the gland separating and binding together the masses of polyhedral cells which are arranged in solid groups or intercommunicating cords of varying sizes and shapes.

The cell cords, as a rule, are not arranged like the thyreoid vesicles. At times the secretion may accumulate and produce a vesicular appearance and the secretion then closely resembles colloid. Two kinds of cells, oxyphile and principal cells, have been described; but the intermediate forms suggest that these are the same sort of cells in different stages of functional activity. The blood-vessels are distributed in the connective tissue of the trabeculæe and thus their sinusoids are brought into close connection with the cells of the gland. The nerves are also distributed along the septa. In the highly vascular connective tissue between the cell cords fat cells are found separate or in groups.

The number of parathyreoid glands found by different investigators varies. The average number in a series of cases is less than four. Whether this is due to a real absence of the glands or to failure to find them due to their aberrant location, their inclusion in the thyreoid gland, or the fusion of two glands, is not clear. In some cases it is the superior glands, in other cases the inferior glands, which appear to be missing. On the other hand various competent observers have reported finding more than four parathyreoid glands. Five or six are occasionally found; as many as eight have been recorded in one instance. In these cases the number on a side may not be symmetrical. The increased number may be due to the separation of buds in the course of development. The parathyreoid glands are liable to be associated with accessory thymus masses, with small lymphatic glands, and with fat lobules; and as they may somewhat resemble each of these, they may be mistaken unless a microscopic examination is made.

Blood-supply.- Each parathyreoid gland is supplied by a single separate artery derived, as a rule, from one of the glandular, muscular, or cesophageal branches of the inferior thyreoid artery or from the anastomosing branch between the superior and inferior thyreoid arteries. When the glands are in aberrant positions their arteries may be derived from the nearest source. The arteries are distributed along the trabeculie and septa. The veins returning the blood either follow the arteries or they pass to the surface of the gland where they break up into a plexus of thin-walled vessels. Upon leaving the gland the veins empty into some one of the branches of the thyreoid veins.

Development. - The parathyreoids (epithelial bodies) begin as proliferations of the epithelium on the oral and lateral walls of the dorsal diverticulum of the third and fourth pharyngeal pouches. The cells show early a histological differentiation with vacuolated and reticulated plasma. The common pharyngo-branchial ducts diminish in size and become constricted off and separated from the pharynx. The parathyreoid glands later become independent and separated from the thymus anlages. The epithelial cells grow out in the form of cords separated by connective tissue and in intimate relation to the blood-vessels. Different kinds of cells are not distinguishable until postfotal life when evilence of secretion begins.

\section{THYMLS}

The thymus is a transitory organ of epithelial origin, but in structure resembling the lymphoid tissue. Its function is not clearly understood but it seems to be intimately associated with the growth and nutrition of the individual, and it is classed with the ductless glands of internal secretion.

It is situated in the ventro-cephalic part of the thorax and extends into the caudal part of the neck (fig. 1074). It lies between the two pleural sacs ventral to the heart and great vessels, dorsal to the sternum and the sterno-thyreoid and sterno-cleido-mastoid muscles. 
Although arising from the branchial clefts one on each side of the neck, the two portions become so closely associated that they are usually spoken of as one. Each of these parts is ordinarily regarded as a lobe of the thymus [lobus, dexter et sinister].

In colour the thymus is pinkish or reddish grey in the fotus and newborn, becoming greyish white in the adult or yellowish as it undergoes involution. It is composed of soft, yielding tissue more friable than the thyreoid or spleen.

In size the thymus varies greatly. Under normal conditions it appears to attain its maximum size at about the age of puberty, and to continue large as long as the body continues to grow and then to undergo a gradual involution.

\section{Fig. 1074.-Thymus Gland in a Child at Birth.}

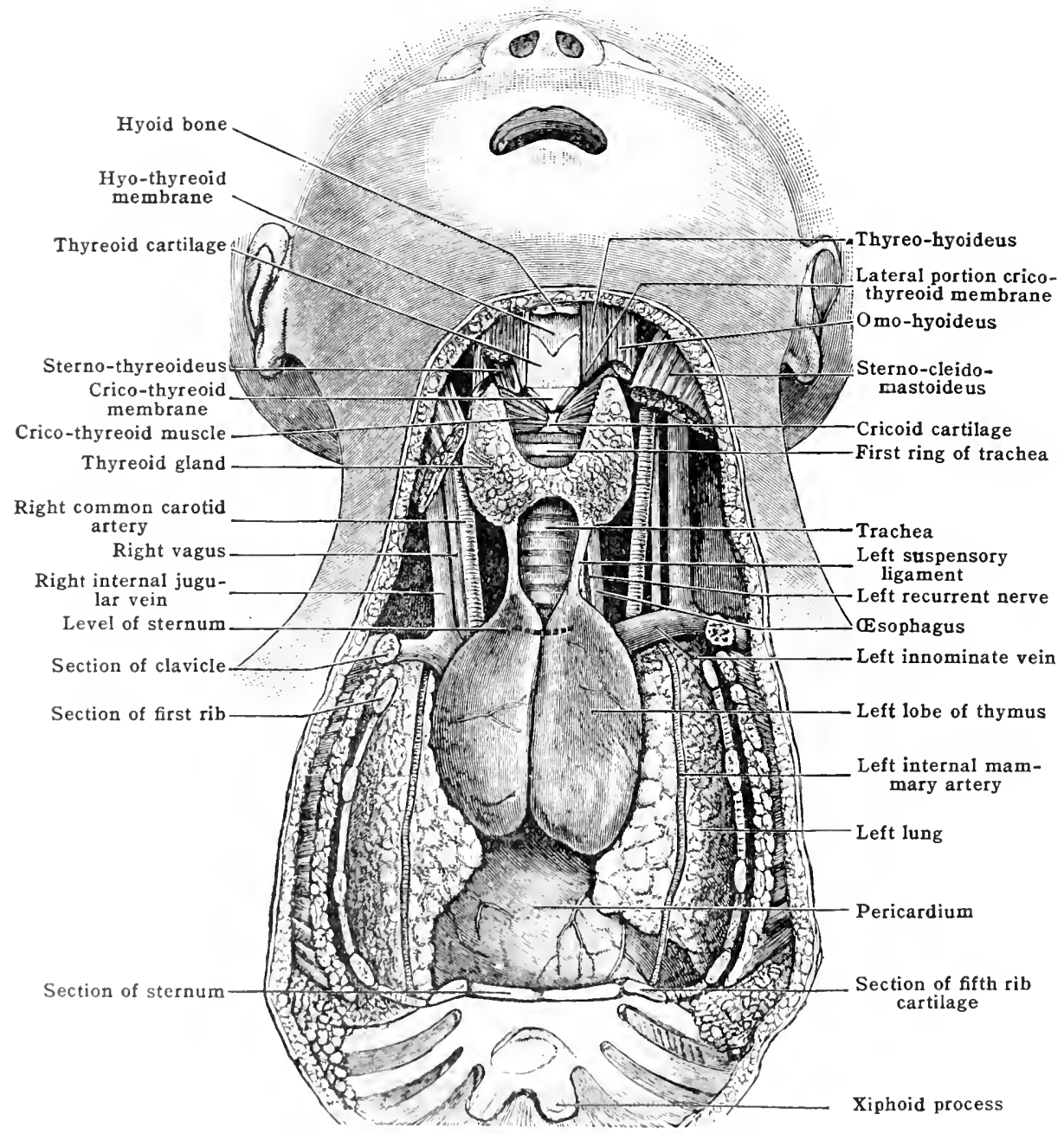

It is, lowever, very semsitive to any untritive chatnges of the individual and beeomes very smatl, aven in the infant, moler the inflience of wasting diseases. It not infrequently exists in the andolt only ats a vestige but in some rases it may romain large mntil midsle age or later. $\mathrm{At}$

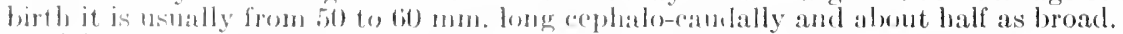

'Tlus: weight varies with the size. It is given ly 1 lammar as over $13 \mathrm{gm}$. at birth, increasing to double this between the sixth and the foufl yours and gaining its maximmm of between 37

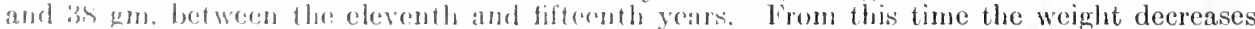
until botween the ages of fifty-six and sixty-five it woighs low ween 25 and $26 \mathrm{gm}$. and at seventyfive years maty be as light as li gro. "l ho' involution of the gland is not atcompanied by a eor-

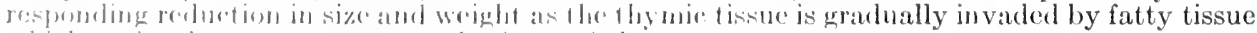

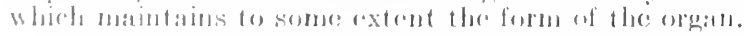

In shape the thymus is an elomgated, spindle-shatped mass consisting of the "antral portion or body and twe extrentities (figs. I074, 1075). The body is the 
widest and largest part of the organ and has no distinct separation from the extremities. The inferior extremity is also broad and is known as the base. It rests on the pericardium, ordinarily extending as far caudal at birth as the atrioventricular furrow but rarely it may extend as far as the diaphragm. The superior extremity is much elongated and extends into the neck. It is represented by two horns nearly always unequal in size the left being usually the larger. It extends nearly to the thyreoid gland, in some cases reaching it.

Relations.- Topographically the thymus when well developed is divided into cervical and thoracic parts.

The cervical portion presents for examination an anterior surface and a posterior surface. The anterior surface is convex and is in relation with the sterno-thyreoid and sterno-cleidomastoid muscle. The posterior surface is concave and rests medially upon the anterior surface of the trachea, laterally upon the common carotid artery and sometimes on the left side upon the osophagus.

The thoracic portion of the thymus is much more important representing four-fifths of the organ (fig. 1075). It presents for examination an anterior, a posterior, and two lateral surfaces. The anterior surface is dorsal to the sternum from which it is separated cephalically by the origin of the sterno-thyreoid muscle. To a less extent it is in relation with the sterno-clavicular articulation and comes into contact laterally with three or four of the cephalic sterno-costal articulations and lateral to this with the internal mammary artery. The posterior surface is largely concave and is in relation caudally with the pericardium which separates it from the

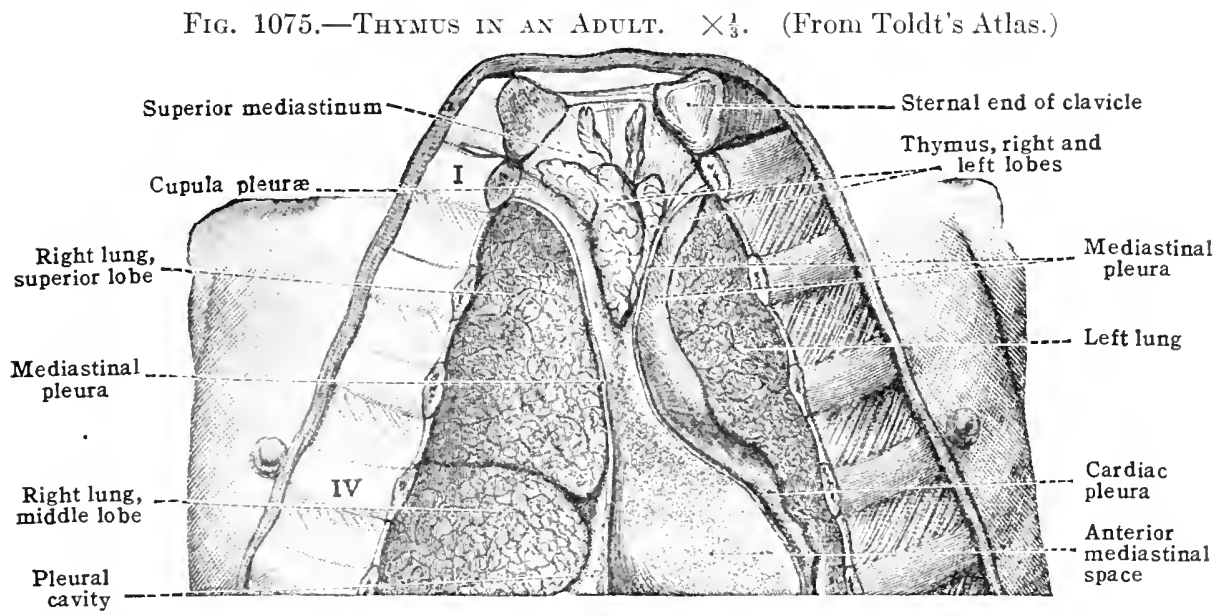

right atrium and ventricular portion of the aorta and pulmonary artery. The middle part is in relation with the aorta and to the right of this with the superior vena cava. The cephalic part is in relation with the branches of the aorta and superior vena cava. The lateral surfaces are somewhat flattened and are separated from the lungs by the mediastinal pleura. The phrenic nerve on the right side runs in the pleura near the dorsal border of this surface, on the left it is, as a rule, not in direct contact with the thymus.

Structure.-The $t$ wo lateral lobes of which the thymus is composed are rarely of the same size; the right is usually the more strongly developed. They are joined at an oblique plane so that the ventral surface of the right is narrow and its dorsal surface broader and the reverse condition is found in the left lobe. The two lobes are separated from one another by connective tissue. Rarely the two are jomed by a medial portion, isthmus, near the micldle or toward the caudal end (fig. 1076).

Each lobe of the thymus is completely surrounded by a thin rlelicate connective-tissue capsule from which numerous septa extend through the gland accompanied by the blood-ressels and nerves. The capsule is composed mainly of white fibrous connective tissue with some elastic fibres. It rarely contains much fat in the newborn but the amount of fat increases as development and involution proceed. Fibrous prolongations from the capsule may extend from the apices of the lobes to be attached to the cervical fascia in the region of the lateral lobes of the thyreoid gland, acting as suspensory ligaments for the gland.

The lobes of thymus are divided in to numerous small lobules [lobuli thymi] 4 to $11 \mathrm{~mm}$. in diameter. These are of roundish or poly hedral shape with bases toward the surface where they show as polygonal areas. The lobules are separated and also bound together by the loose fibrous tissue septa which extend from the capsule.

Each of the primary lobules of the thymus is rlivider into a number of secondary lobules or follicles 1 to $2 \mathrm{~mm}$. in diameter. These lymphoid-like masses of tissue are composed of a reticulum containing in its meshes lymplocytes or thymus corpuscles. The tissue is denser near the surface, forming a cortex and passes gradually into a tissue with looser meshed reticulum near the centre, medulla. In the medulla there are nests of concentrically arranged degenerated epithehial cells enclosing a central mass of granular cells containing colloid. These 
nests are termed the concentric corpuscles of Hassall. The cortex is subdivided by secondary connective-tissue septa extending in from the septa between the lobules.

The arteries of the thymus are somewhat varied in their origin, usually derived from the internal mammary and inferior thyreoid of each side; branches are sometimes received from the innominate, subclavian, and superior thyreoid arteries. They reach the gland in various places and spreadins out in the capsule pass with the trabeculæ through the gland to form a plexus around each small lobule. From this eapillaries pass through the cortex to the medulla. The veins issue from the thrmus in various places and are seen as numerous branches on its surface. The efferent vessels drain into various veins, mostly into the left innominate vein, also smaller branches into the internal mammary and inferior thyreoid veins.

The lymphatics arise around the small lobules and pass through the interlobular septa to the surface from which they are clrained into small lymph nodes near the cephalic extremity, into glands ventrally between the thymus and the sternum, and into other glands dorsally between the thymus and the pericardium.

The nerves of the thrmus are very minute. They are derived from the cervical sympathetic and from the vagus and reach the thymus for the most part along with the bloodvessels which they accompany through the septa.

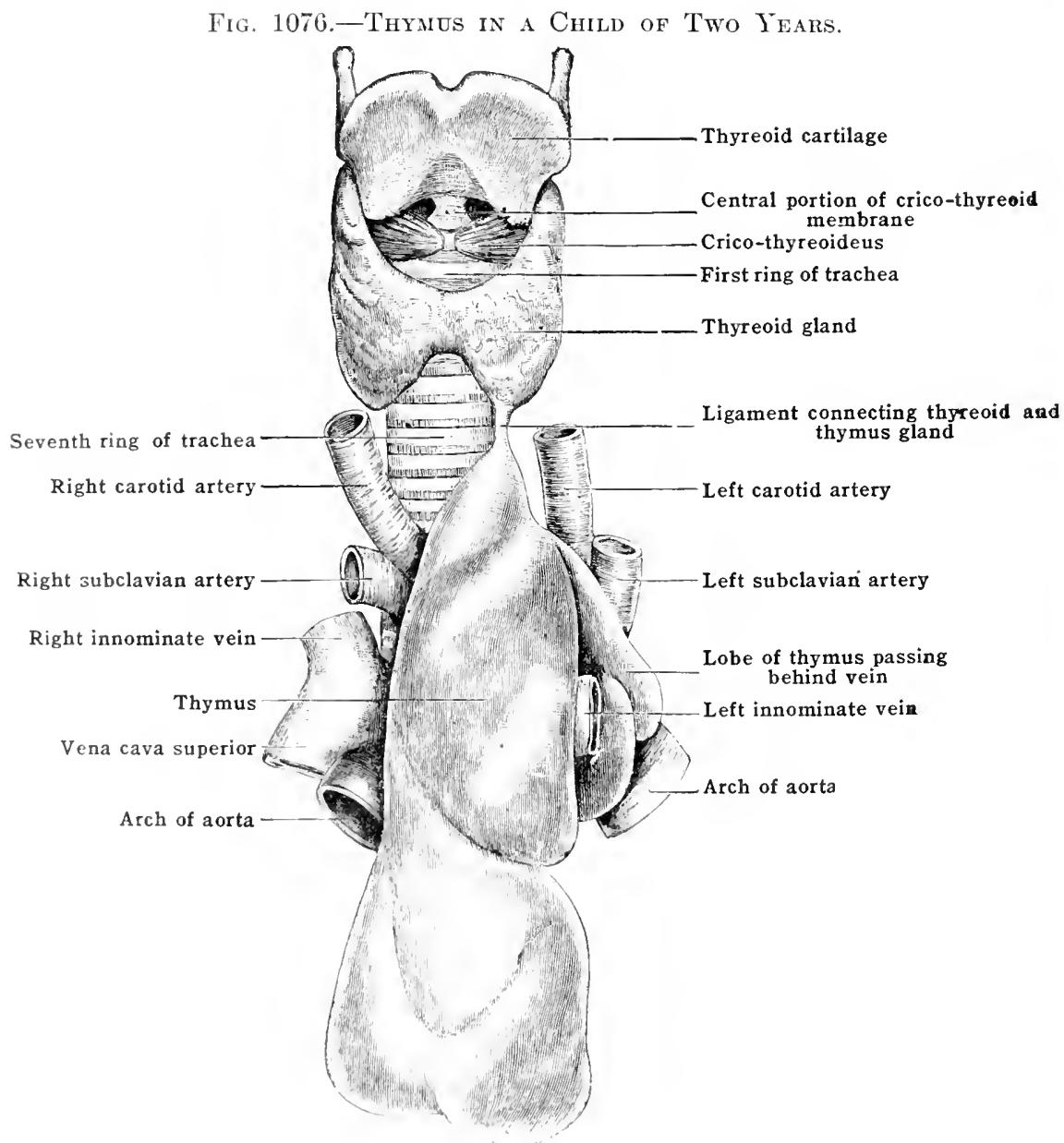

Development. - The thymus arises from the endodermal portion of the third pharyngeal pouch on cach side, as a thinkening due to an increase in the epithelial cells, followed by the protacelion of a diverticulum. At alsont the sixtl week the connections of the pouches with the hranchial (")effs are cut ofl but a strand of tissue may persist to represent the stalk. These

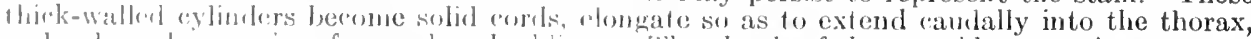
and inlarge hy a soring of secomelary Jumlings. The glinds of the two sides come in to contact

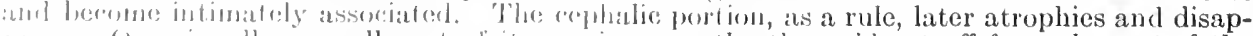

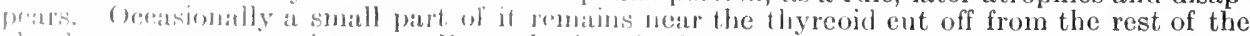

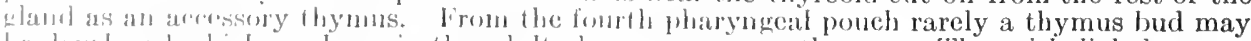

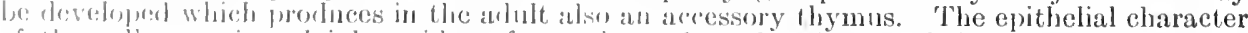

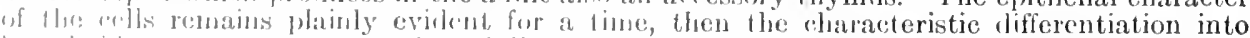

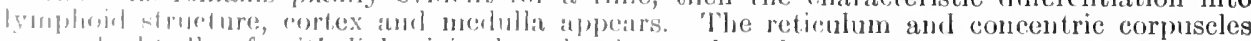
arre undond feally of cpithelial origin; lust the thymus lymphocytes are considered by Hammar

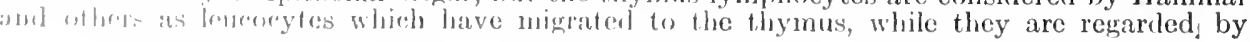


Stöhr and his followers as modified epithelial elements, not true blood cells. Maurer, Bruant, and Bell regard them as modified epithelial cells which become true functional leucocytes.

\section{THE CHROMAFFIN SYSTEM}

It has recently been shown that in connection with the ganglia of the sympathetic nervous system, special cells, other than the nerve cells, are found. These differ from the nerve cells in that when subjected to the action of chromic acid salts there can be demonstrated in their protoplasm small granules which take on a darker stain. These cells are therefore known as chromaffin cells. They, with the cells of the sympathetic system, are derived from the ectoderm. They appear first as indifferent cells, the sympatho-chromaffin cells. Some of these later develop into sympathetic ganglion cells, others into chromaffin cells. Some of these latter cells remain, isolated or in groups, permanently associated with the sympathetic ganglia, the paraganglia; others become separated and form the medullary portion of the suprarenal glands, the aortic paraganglia, and the glomus caroticum.

\section{THE SUPRARENAL GLANDS}

The suprarenal glands [glandulæ suprarenales] or adrenal glands are small irregularly shaped glandular bodies composed of two quite different organs. In the lower vertebrates these two parts are entirely separated from one another

Fig. 1077.-The Suprarenal Glands, Ventral View.

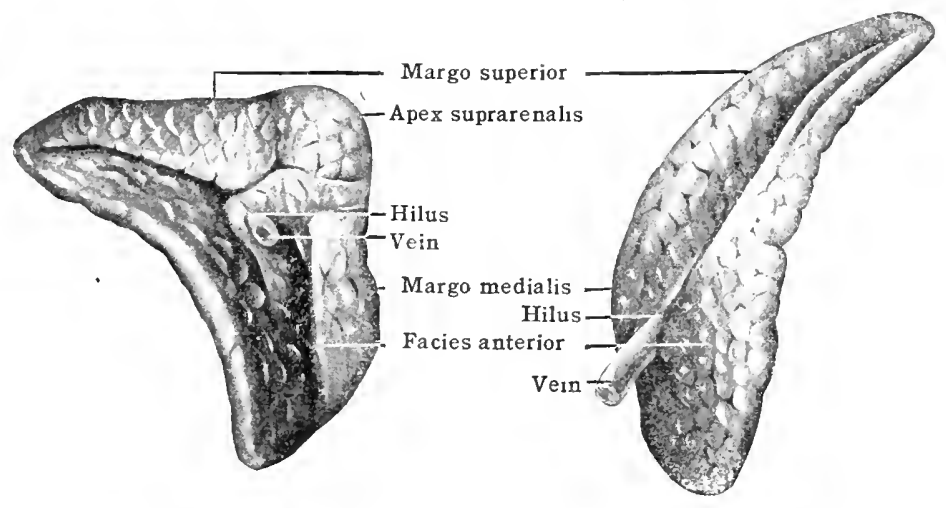

but in man and the mammals they have become joined together one within the other. The external cortical portion, of unknown function, is developed from the mesoderm. The internal medullary portion is derived from the sympatho-

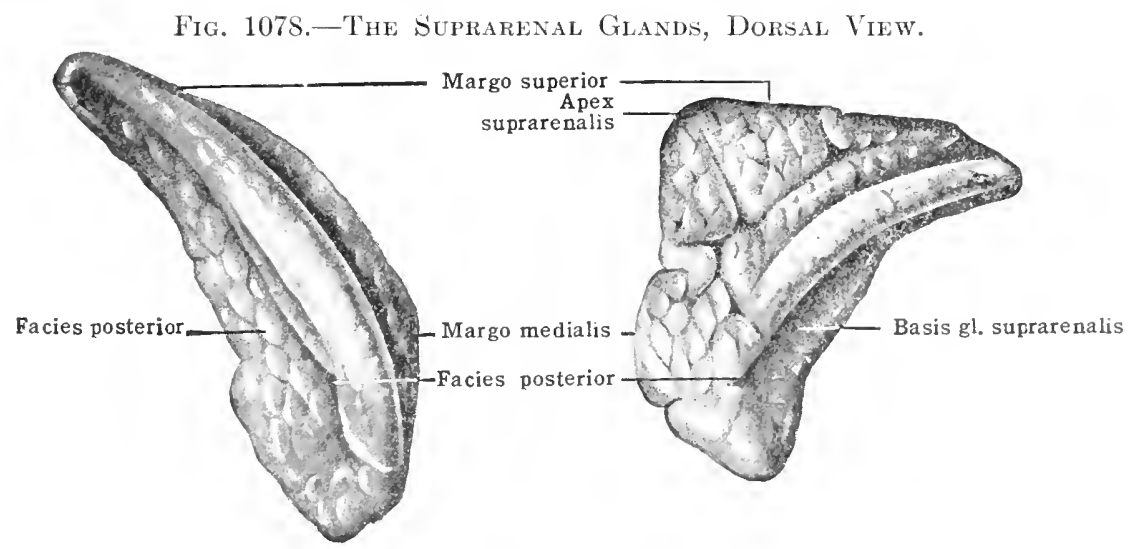

chromaffin tissues and thus from the ectoderm in common with the sympathetic nervous system. This part of the suprarenal glands is known to produce an internal secretion which reaches the general circulation through the veins and 
whose principal function seems to be to aid in keeping up the tone and activity of the muscle and other tissues innervated by the sympathetic system.

Situation.-The glands are deeply placed in the epigastric region (fig. 1080) lying in the dorsal and cephalic part of the abdominal cavity, one on either side of the vertebral column in variable relation with the upper extremity of the kidney of the corresponding side.

Rarely they retain the fœtal relation, capping the superior extremity of the kidney and extending a little upon both medial and lateral borders. More frequently (especially on the left) they are placed more upon the medial borders of the kidneys, extending (on the left) as far caudal as the hilus, sometimes coming in contact with the renal vessels. An intermediate position is often found, especially on the right. In the high positions the suprarenals may be on a level with the tenth intercostal space or eleventh rib. In the low positions they may extend as far caudally as the first lumbar vertebra. The left is usually, but not always, a little higher than the right, corresponding to the position of the kidneys.

Fixation.-The suprarenals, enclosed in the renal adipose capsules, are attached to the renal fascia by connective-tissue strands and are loosely bound by connective tissue to the kidncys. The attachment to the kidneys is, however, so loose that the suprarenals are not dislocated when the kidneys are displaced. In addition to the attachments common to them and to the kidneys, they are joined by connective-tissue bands to the diaphragm, vena cava, and liver on the right side and to the diaphragm, aorta, pancreas and spleen on the left. They have also additional means of fixation through the arteries, veins, and nerve fibres which enter and leave them, and through the parietal peritoneum which in places covers their ventral surfaces.

Fig. 1079.-Diagrammatic Section of the Suprarenal Gland.

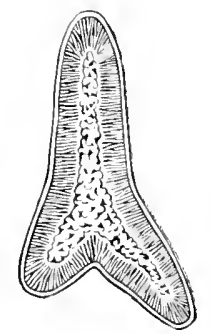

Size and weight.- The size of the suprarenals is subject to considerable variation within physiological limits, in some cases being relatively twice as large as in others. The two glands are rarely of the same size, the right being more often the smaller.

Proportionately they are much larger in the fortus and embryo than in the adult, but they do not decrease in size in old age. They appear to be slightly lighter in women than in men. The average weight in the adult is from 4 to $5 \frac{1}{2}$ grams. As a rule, they measure about $30 \mathrm{~mm}$. in height; 7 or $8 \mathrm{~mm}$. in thickness; and have a breadth at the base of about $45 \mathrm{~mm}$. They augment in volume during digestion and also increase in size during the acute infeetious diseases and in intoxications such as uremia.

Colour and consistency.-The suprarenal glands as seen from the surface have a yellowish or brownish-yellow colour. Upon section the colour of the surfarce laycer appears a little darker while the contral part of the gland appears greyish or, if it contains much blood, of a redelish colour. If some little time has napere since death, the central part of the suprarenal may be almost black in colour.

The giands are very fragile and softer in consistency than the thymid or thymus. As a rule, they are hardare and wore lesistant than the fat of the adipose capsule and may be thus readily deterterl in it.

Form. -The suprarenal glands anc matkelly flattened dorso-ventrally. Their surfaces are roughened by irregular tubereles and furrows. They vary considerably in shape (figs. 1077, 1078). The right glanel is usually somewhat triangular in entline: while the left is, as a rule, semilunatr. Each gland has an anterior and a pretrerior surface, a base and an aljex, at medial and a superior margin.

'l'he anterior surface [facies anterior] may be either convex or coneave, and 
look ventro-laterally. It is marked by a distinct transverse, oblique, or nearly vertical fissure, the hilus suprarenalis. At this point a small artery enters and the principal suprarenal rein takes exit from the gland. These surfaces are in relation with different organs on the right and left sides.

The anterior surface of the right gland is in the greatest part of its extent in contact with the posterior surface of the liver, upon which it prolluces the suprarenal impression. The medial edge of this surface is overlapped, cephalically by the inferior vena cava and caudally by the duodenum. The gland is situated between the two layers of the coronary ligament, in most cases, in direct contact with the liver to which it is bound by loose connective tissue; lut, at times, the peritoneum which covers the ventral surface of the kidney extends for a greater or less distance between the suprarenal and the liver.

The anterior surface of the left gland, in some cases, may be in contact in its cephalic part with the left lobe of the liver and also, at times, with the spleen. 'The middle and major part lies against the fundus and cardiae end of the stomach, while caudally the suprarenal is often

Fig. 10S0.-Ventral View of the Suprarexal Glands, IN Site. $\times \frac{1}{3}$. (From Toldt's Atlias.)

Hepatic veins

Diaphragm, pars lumbalis

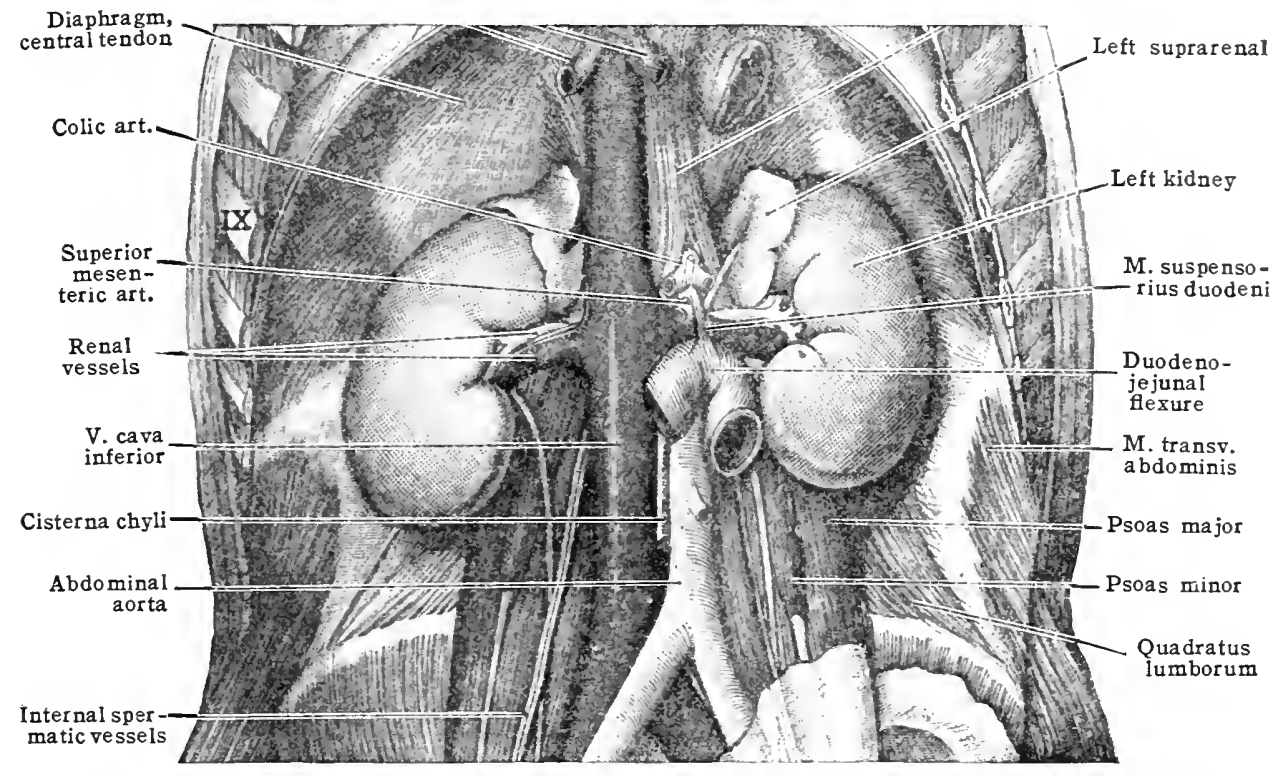

crossed by the tail of the pancreas and the splenic artery and vein. The whole or a large part of the anterior surface of the left suprarenal is covered by the parietal peritoneum of the omental bursa.

The posterior surface [facies posterior] of both the suprarenals is distinctly smaller than the anterior surface. It is flat or convex and looks dorso-medially.

It is in relation with the lumbar part of the diaphragm, to which it is bound by connective tissue, but from which it is separated by an extension of the renal adipose capsule.

The base [basis gl. suprarenalis] is a narrow elongated surface distinctly hollowed out, which lies in contact with the superior extremity of the kidney or its medial margin, cephalic to the hilus.

This surface looks dorsally, laterally, and somewhat caudally with the result that it extends farther on the anterior surface than on the posterior surface of the kidney.

The medial border [margo medialis] is sharp, thin, and irregularly convex. It extends more or less vertically to meet the superior border.

On the right it lies dorsal to the inferior vena cava cephalically and to the duodenum caudally and is close to, if not in contact with, the sympathetic cceliac ganglion. On the left the medial border lies dorsal to the stomach and caudally may be crossed by the pancreas and splenic vessels. It is in close proximity to the aorta and the coliac sympathetic ganglion.

The superior border [margo superior] is sharp and thin and differs somewhat on the two sides. 
On the right it is irregular, straight or convex, and extends, dorsal to the liver, obliquely cephalo-medially to meet the medial border in a more or less acute point, apex suprarenalis, which is directed cephalically and somewhat medially. On the left the superior border is irregularly convex in shape and nearly horizontal in direction. It passes gradually over into the medial border without the intervention of any distinct apex. It is dorsal to the stomach and in some cases comes into contact with the spleen.

Accessory suprarenal glands [gl. suprarenales accessoriæ] are often found in the conneetive tissue in the neighbourhood of the prineipal organs. They are also sometimes found in the kidney near the internal spermatic veins and in the region of the sexual glands. The struetures recorded as accessory suprarenal glands may be complete suprarenal glands composed of the cortex and medulla or they may be composed of the cortex only. Masses of chromaffin tissue representing the medulla are sometimes spoken of as accessory suprarenals but these more properly belong with the clromaffin system.

Complete absence of the suprarenal glands has been recorded only in monsters with grave eranial and cephalic defects. Absence of one gland has been found and the fusion of the two has also been noted.

Structure.-The suprarenal glands are surrounded by a thin and tough fibrous capsule composed mainly of white fibrous connective tissue. From the capsule numerous trabeculæ are given off which pervade the gland and form septa between the groups and rows of cells. Within the capsule the suprarenal is composed of an external firmer yellowish layer, the cortex [substantia corticalis], and an internal softer whitish layer, the medulla [substantia medullaris] (fig. 1079).

On section the cortex is seen to form by far the greater part of the gland and it is marked radially from the centre toward the surface by darker and lighter streaks. In its deepest part it is brownish yellow or red and is usually slightly torn where it joins the medulla. As frequently found at autopsy the cortex is separated from the medulla by a slit filled with a sof $t$ dark brown or blackish mass caused by the breaking down of the deeper layer of the cortex. The medulla is a greyish, spongy, vascular mass which of ten because of its blood content appears of a reddish or reddish-brown colour.

The cortical portion of the gland is subdivided into a superficial, glomerular portion, zona glomerulosa; an intermediate, fascicular portion, zona fasciculata; and an internal reticular portion, zona reticulata, aceording to the peeuliar grouping of the gland cells in these respective areas.

In the glomerular zone the cells are of irregular columnar shape, and grouped in coiled columns. In the fascicular zone the cells, which are of polyhedral shape, are arranged in more or less regular parallel columns, while in the reticular zone the cells form trabecula or groups. The reticular connective-tissue framework, continuous with the capsule, surrounds the cell masses and cell columns of the several zones. The cells of the medulla show an affinity for chromie acid-ehromaffin cells_and are grouped in irregular masses separated by septa of the reticulum and venous spaces. The arteries form a close-meshed plexus in the capsule from which branches run more or less parallel toward the medulla forming a network around the cell columns of the glomerular and fascicular zones. This opens into a venous plexus of wide calibre in the reticular zone, which is connected with the vessels of the medulla. Small medullary arteries pass through the cortex without branching to end in a venous plexus in the medulla. The almundant wide-meshed venous sinuses in the medulla (sinusoids) join to form small central veins which converge toward the centre of the medulla to form the large central vein.

Vessels and nerves.- The suprarenal glands are richly supplied with vessels. The arteries are three-superior, middle and inferior.

From the inferior phenic artery, the superior suprarenal artery arises and passes toward the siuperior forder of the ghand. Fon the aort a the middle suprarenal artery takes origin between the coeliac and superior mesenteric arteries and passes toward the medial border of the supraroluat. It is a branch of this artery which is usually fomd at the hilus along with the central vein. From the renal artery the inferior suprarenal artery arises and reaches the suprarenal neal its bate. These three arteries anastomose with one another and form a plexus in the adsule of the suprarenal form which the arteries for the interior of the gland are derived.

The large central vein from the medulla passes through the cortex to emerge at the hilus as the supparenal vein, vena suprarenalis. 'The right vein opens usually into the inferior vena "ava, where there is a valve, the left into the left renal vein. 'There may also be small branches connecting with the phrenic: or the right lenal vein.

The lymphatics of the sujurenals are very numerous aml are represented by a superficial flexus in the capsule and a deep plexis in the medulla. These are connected by numerous :mastomoses. Tluey pass medially and fonverge into a mumler of Irunks on each side which anpty into lympl-grlands simated along the aorta nem the origin of the renal arteries. On the left side there is alse the communication themgh the diaphagm with a posterior mediastinal glint.

The nerves are derivol chiefly from the croliar and renal plexuses but include filaments from the splanclunics, and aceording to some anthors from the phrenie and vagus nerves also. 'These numerons line twigs ronnect with the gland in many different places and form a rieh whoxs. Branches are distriluted to the eapsule, to the eortiral substance, and to the medullary

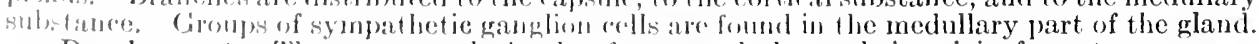

Development.- The smplarenal glatils of mammals have their origin from two sources.

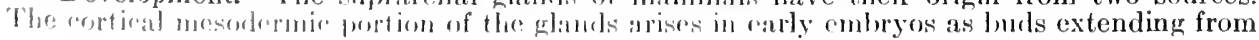


the mesothelium on both sides of the root of the mesentery into the mesoderm ventral to the aorta. A little later these become definite organs completely separated from the colomic epithehum and are soon vascularised, but the central vein does not become visible until considerably later. The suprarenal glands after their separation from the peritoneum form a ridge on either side of the posterior wall of the coelom medial to the mesonephros. Some little time after the origin of the cortical portion of the gland has undergone cellular differentiation and has become surrounded by a delicate eapsule, the medullary portion is formed by the migration of masses of sympatho-chromaffin cells from the medial side toward the centre of the organ so that they surround the central vein as the anlage of the medullary nucleus. They penetrate the cortical portion of the gland as development proceeds and become completely; surrounded by it. These migrating masses are entirely or for the most part of cliromaffin formative cells derived from the ectoderm. They are clearly differentiated from the cortical cells by their small size and darker colour, in stained sections. Migration of these cell masses into the gland seems to be continued even after birth. The differentiation of the cortex into three layers occurs late in development. The suprarenal glands are relatively large in fcetal life; and their relation to the kidneys is secondarily acquired.

\section{THE GLOMUS CAROTICUN}

The carotid bodies [glomera carotica] are small ovoid or spherical bodies found at or near the point where the common carotid arteries divide into the internal and external carotids (fig. 1081). They are usually on the dorsal and medial side of the angle of bifurcation of the arteries. There is ordinarily one body on

Fig. 1081.-The Glomes Caroticum (Carotid Body). (From Testut, after Princeteau.) 1, Carotid body; 2, 3, 4, common, external and internal carotids; 5 , int. jugular; 7 , inf. cervical sympathetic ganglion; $S$, vagus.

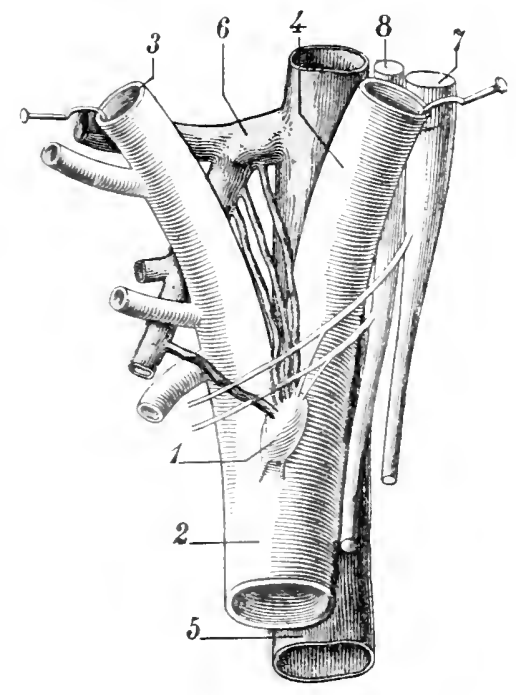

each side, 5 or $6 \mathrm{~mm}$. in length and 2 or $3 \mathrm{~mm}$. in thickness. It is redish-yellow in colour and is attached to the carotid by fibrous tissue and by the vessels and nerves which enter it. A small special fibrous band may sometimes be recognised binding it to the common, external or internal carotid artery.

The carotid body or gland is composed of two essential parts: (1) round, oval, or polyherlral epithelial cells which contain chromaffin granules, and are bound together by a mass of fibrous connertive tissue; and (2) a rich plexus of capillaries and sinusoids forming a mesh. Large lymph-vessels surround the outside of the gland. The carotid gland has a very abundant nerve supply, mostly from the sympathetic system, and ganglion cells are found in it. It may receive twigs from the superior laryngeal, hypoglossal, or glossopharyngeal nerves, as recorded by some observers.

The size of the carotid body varies considerably. At times the carotid bodies are absent; in other cases they are so small that they can be detected only in microscopic sections; occasionally they are $8 \mathrm{~mm}$. in length by 4 or $5 \mathrm{~mm}$. in thickness. Rarely the carotid bodies may be broken up into two or more smaller masses bound together by connective tissue. The carotid body may be larger in old individuals due to an increase in the connective tissue or rascular elements with a corresponding decrease in the epithelial cells. The origin is probably from sympathochromaffin cells but some investigators believe that they are derived from the endothelium of the blood-vessels and others that they arise from the endoderm of a branchial pouch. 
1328 THE SKIN, MAMMARY GLANDS AND DUCTLESS GLANDS

Figs. 1082 axd 1083.-Aortic Paraganglia. (Zuckerkandl.) Aorta
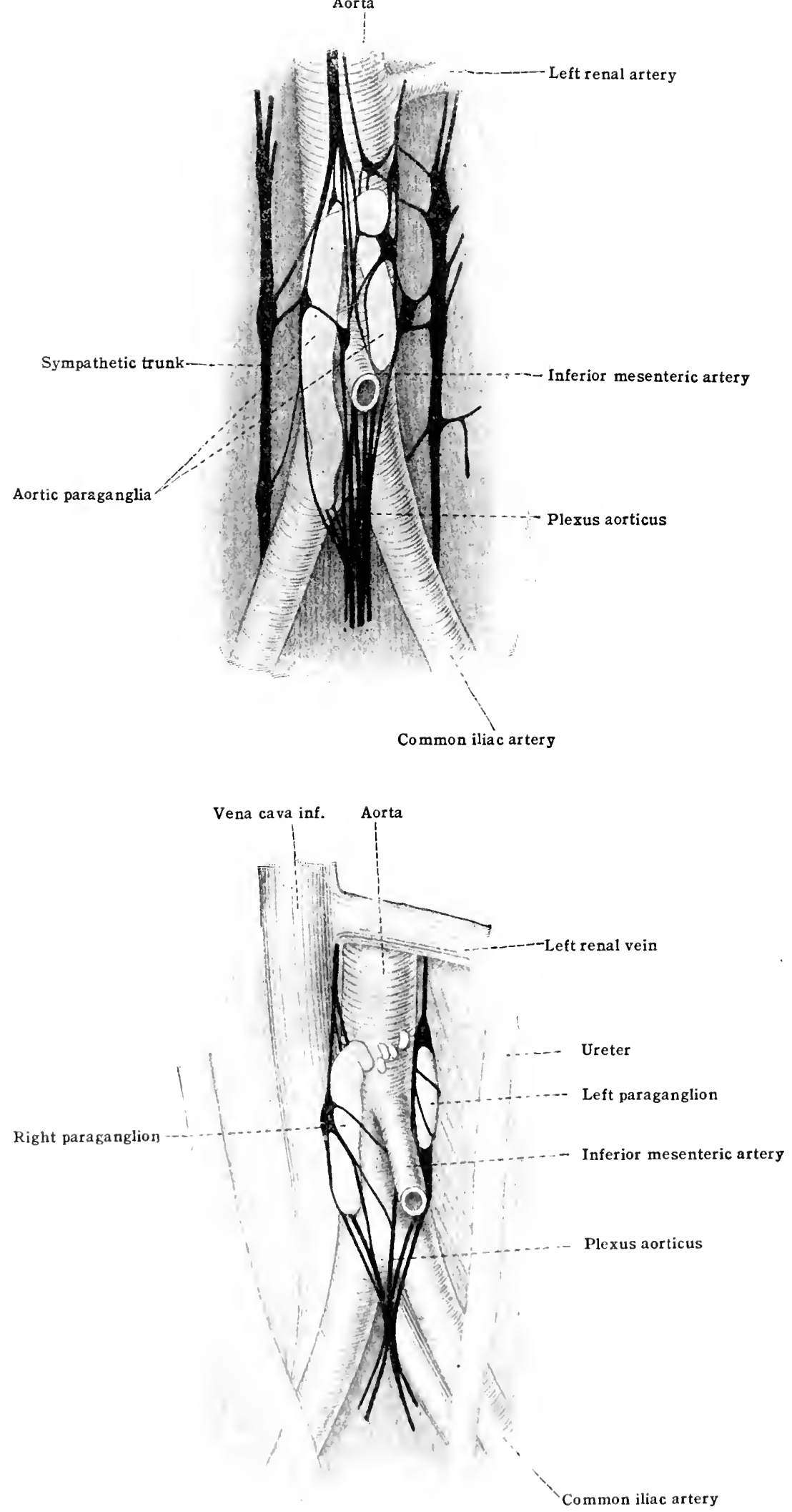


\section{THE AORTIC PARAGANGLIA}

The abdominal chromaffin bodies, the paraganglia aortica, or paraganglia lumbalia, are situated on each side of the abdominal aorta near the point of origin of the inferior mesenteric artery (figs. 1082, 1083). They are elongated, flattened, ovoid bodies, softer and greyer than the lymphatic glands and extremely variable in size.

They measure, as a rule, between 6 and $12 \mathrm{~mm}$. in length, although occasionally as long as $30 \mathrm{~mm}$. or as short as $1 \mathrm{~mm}$. They may be connected by transverse bands in front of the aorta or occur as scattered nodules in this situation. They are intimately related to the aortic sympathetic plexus and at least one of them is uniformly found. They consist of a mass of chromaffin cells surrounded by a rich capillary plexus and contain many nerve fibres and nerve cells.

\section{THE GLONUS COCCYGEUM}

The coccygeal body [glomus coccygeum] is a small, spherical greyish-red body consisting of a median unpaired mass 2 to $3 \mathrm{~mm}$. in diameter, single or divided into three to six connected nodules. It is placed immediately ventral to the tip

Fig. 10\$4.-Coccygeal Gland, in Situ. 1, Sacrum; 2, coccyx; 3, coccygeal gland; 4, middle sacral artery; 5, 6, sacral sympathetic; 7 , ganglion impar.; 8 , last sacral; 9 , coccygeal nerve; 10, gluteus maximus; 11, ischio-coccygeus; 12, levator ani; 13, ano-coccygeal raphe. (Testut.)

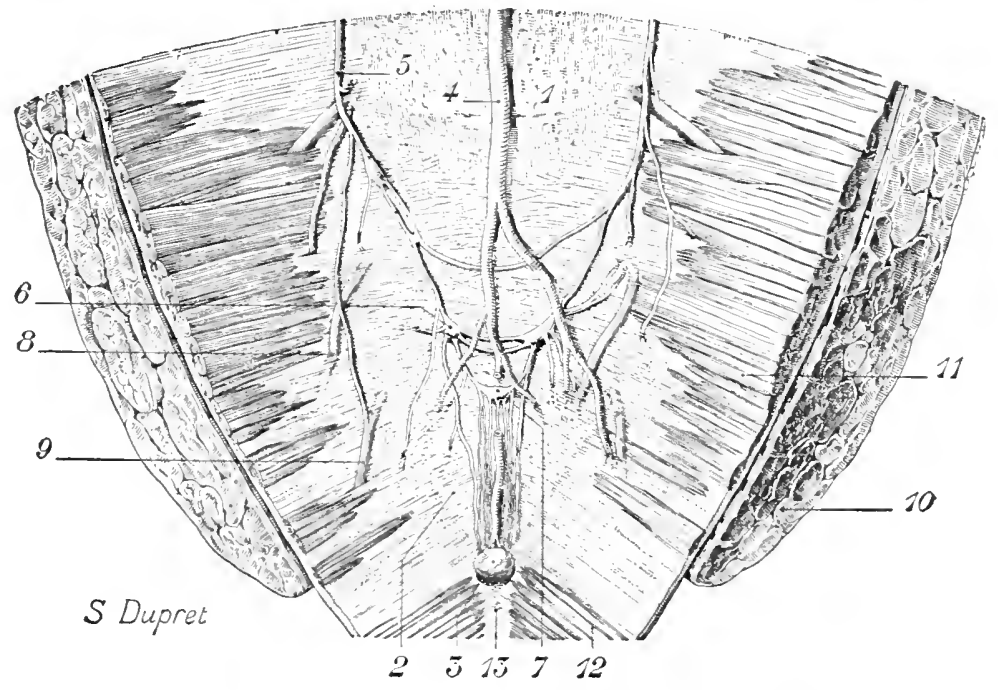

of the coccyx, imbedded in fat and in relation with the terminal branch or branches of the medial sacral artery, with the ischio-coccygeal muscles, and fibres of the sympathetic nervous system (fig. 1084).

It is composed of groups of epithelial cells bound together by a mass of fibrous tissue and containing a plexus of sinusoidal capillary vessels in intimate relation with the cells. Numerous nerve fibres also enter the gland. It is not certain that the cells are chromaffin in character or that the coccygeal body has an internal secretion.

A. References for the skin and mammary gland.-General and topographic: Quain's Anatomy, 11th ed., vol. ii, pt. 1; Testut, Traité d'Anatomie Humaine, 4th ed.; Poirier-Charpy, Traité d'Anatomie, vol. v; Rauber-Kopsch, Lehrbuch der Anatomie, 9th ed.; Bardeleben, Handbuch der Anatomie, vol. v, pt. 1; MIerkel, Topographische Anatomie; Corning, Lehrbuch der topographischen Anatomie. Development: Keibel and Mall, Human Embryology. Skin: Heidenhain, Anat. Hefte., vol. xxx; Kean (finger prints), Jour. Amer. Med. Assoc., vol. xlvii; Unna (blood and lymph), Arch. f. mikr. Anat., vol. lxxii; Botezat (nerves) Anat. Anz., vol. xxxiii. Nails: Branca, Annales de Dermat. et Syphilis, 1910; Lammary glands; Kerr, Buck's Ref. Hand. Med. Sci. (Breast) vol. 4, 1914.

B. References for the ductless glands.-General and topographic: Quain's Anatomy, 11th ed.; Testut, Traité d'Anatomie Humaine, 4th ed., vol. iv; Poirier-Charpy, 'Traité d'Anatomie vol. iv.; Rauber-Kopsch, Lehrbuch der Anatomie, 9th ed.; Merkel, Topographische Anatomie; Corning, Lehrbuch der topographischen Anatomie, 3rd ed. Dcvelopment: Keibel and Mall, Human Embryology. Spleen: Shepherd, Jour. Anat. and Physiol, vol. xxxvï; Mall, Amer. Jour. Anat. vol. ii. Thyreoid: Marshall, Jour. Anat. and Phrsiol., vol. xxix. Parathyrcoids: Forsyth, Brit. Med. Jour., 1907 ; Rulison, Anat. Rec., vol. iii; Halsted and Evans, Annals of Surg., vol. xlvi. Thymus: Hammar, Erbge. d. Anat. u. Entwick., Bd., xix. Suprarenal glands: Gerard, Georges et Maurice, Bull. Mem. Soc. Anat. Paris, 1911, (6) T. 13; Ferguson, J. S., Amer. Jour. Anat., vol. v, 1905. Carotid body: Gomez,.L. P., Am. Jour. Med. Sci., vol. cxxxvi; Aortic paraganglia; Zuckerkandl, Verhandl. d. Anat. Gesell., 15th Versamm., 1901. 



\title{
SECTION X I I I \\ CLINICAL AND TOPOGRAPIICAL ANATOMY
}

\author{
Revised for the Fifth Edition
}

By JOHN MORLEY, Ch.M., F.R.C.S.

honorary SURgeon, anCOAT's hospital, MANChESTER; LECTURER IN Clinical ANATOMY, MANCHESTER UNIVERSITY

\section{THE HEAD}

$I^{N}$ $\mathrm{N}$ describing the clinical and topographical relations, the divisions of the body will be successively considered in the following order: head, neck, thorax, abdomen, pelvis, back, upper and lower extremities.

The bony landmarks of the head will first be considered, followed by a separate description of the cranium and the face.

Bony landmarks. - These should be studied with the aid of a skull, as well as on the living subject. Beginning in front is the nasion, a depression at the root of the nose, and immediately above it, the glabella, a slight prominence joining the two supraciliary arches. These points mark the remains of the frontal suture, and the junction of the frontal, nasal, and superior maxillary bones and one of the sites of a meningocele. In the middle line, behind, is the external occipital protuberance, or inion, the thickest part of the vault, and corresponding internally with the meeting-point of six sinuses. A line joining the inion and glabella corresponds to the sagittal, and occasionally the frontal, suture, the falx cerebri, the superior sagittal sinus, widening as it runs backward, and the longitudinal fissure of the brain. From the inion the superior nuchal lines pass laterally toward the upper and back part of the base of the mastoid processes, and indicate the first or socalled horizontal part of the transverse (lateral) sinus.

This vessel usually presents a varying curve upward and runs in the tentorium. The second or sigmoid portion turns downward on the inner surface of the mastoid, then forward, and lastly downward again to the jugular foramen, thus describing the double curve from which this part takes its name. In the jugular foramen the vessel occupies the posterior compartment; its junction with the internal jugular is dilated and forms the bulb. A line curved downward and forward from the upper and back part of the base of the mastoid, reaching two-thirds of the way down toward the apex, will indicate the second part of the sinus. The spot where it. finally curves inward to the bulb would be about $1.8 \mathrm{~cm}$. ( $\frac{3}{4} \mathrm{in}$.) below and behind the meatus. The two portions of the transverse sinus meet at the asterion laterally; at the entry of the superior petrosal sinus medially. The right transverse sinus, the larger, is usually a continuation of the superior sagittal sinus, and, therefore, receives blood chiefly from the cortex of the brain; the left, arising in the straight sinus, drains the interior of the brain and the basal ganglia. Each transverse sinus receives blood from the temporal lobe, the cerebellum, diploë, tympanic antrum, internal ear, and two emissary veins, the mastoid and posterior condylar.

About $6.2 \mathrm{~cm}$. ( $2 \frac{1}{2}$ in.) above the external occipital protuberance is the lambda, or meeting of the sagittal and lambdoidal sutures (posterior fontanelle, small and triradiate in shape). It is useful to remember, as guides on the scalp to the above two important points, that the lambda is on a level with the supraciliary ridges, and the external occipital protuberance on one with the zygomatic arches.

Below the external occipital protuberance, between it and the foramen magnum, an occipital, the commonest form of cranial meningoceles, makes its appearance. It comes through the median fissure in the cartilaginous part of the squamous portion of the bone. 
The point of junction of the occipital, parietal, and mastoid bones, the asterion, is placed about $3.7 \mathrm{~cm}$. ( $1 \frac{1}{2} \mathrm{in}$.) behind and $1.2 \mathrm{~cm}$. ( $\left(\frac{1}{2}\right.$ in.) above the centre of the auditory meatus (fig. 1085). It indicates the site of the posterior lateral fontanelle and just below it the superior nuchal line terminates. 'The bregma, or junction of the coronal, sagittal, and, in early life, the frontal suture (anterior fontanelle, large and lozenge-shaped), lies just in front of the centre of a line drawn transversely over the cranial vault from one pre-auricular point to the other (fig. 1090). The bregmatic fontanelle normally closes before the end of the second year. The lambdoid fontanelle is closed at birth. The pterion, or junction of the frontal and sphenoid in front, parietal and squamous bones behind, lies in the temporal fossa, 3.7 to $5 \mathrm{~cm}$. ( $1 \frac{1}{2}$ to $2 \mathrm{in}$.) behind the zygomatic process of the frontal, and about the same distance above the zygoma (fig. 1085). This spot also gives the position of the trunk and the anterior and larger division of the middle meningeal artery (fig. 1090), the Sylvian point and divergence of the limbs of the lateral (Sylvian) fissure, the insula (island of Reil), and middle cerebral artery. It, further, corresponds to the anterior lateral fontanelle. On the side of the skull the zygomatic arch, the temporal ridge, and external auditory meatus need attention. That important landmark, the zygomatic arch, wide in front where it is formed by the zygomatic (malar), narrowing behind where it joins the temporal, gives off here three roots, the most anterior marked by the eminentia articularis, in front of the mandibular (glenoid) fossa, the middle behind this joint, while the posterior curves upward and backward to be continuous with the temporal ridge. Within the zygomatic arch lie two fossæ separated by the infra-temporal (pterygoid) riclge: above is the temporal, with the muscle and deep temporal vessels and nerves; below is the infra-temporal or zygomatic fossa, with the lower part of the temporal muscle, the two pterygoids, the internal maxillary vessels, and the mandibular division of the fifth. To the upper border of the zygomatic arch is attached the temporal fascia, to its lower, the masseter. Its upper border marks the level of the lower lateral margin of the cerebral hemisphere. A point corresponding to the micldle root of the zygoma, immediately in front of the tragus, and on a level with the upper border of the bony meatus, is called the pre-auricular point. Here the superficial temporal vessels and the auriculo-temporal nerve cross the zygoma, and a patient's pulse may be taken by the anæsthetist. The lower end of the central (Rolandic) fissure lies $5 \mathrm{~cm}$. (2 in.) vertically above this point. The temporal ridge, giving origin to the temporal fascia, starts from the zygomatic process of the frontal, and becoming less distinct, curves upward and backward over the lower part of that bone, crosses the coronal suture, traverses the parietal bone, curving downward and backward to its posterior inferior angle. Here it passes on to the temporal, and passing forward over the external auditory meatus, is continuous with the posterior root of the zygoma. Below the root of the zygoma will be felt the temporo-mandibular joint, and when the mouth is opened, the condyle will be felt to glide forward on the eminentia articularis, leaving a well-marked depression behind.

The external auditory meatus, measurel from its opening on the concha to the membrane,

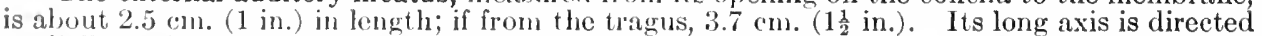
medially and a little forward with a slight convex curve upward, most marked in its centre. Betwecn the summit of this eurve and the membrane is a slight recess in which foreign bodies may lodge. The lumen is wilest at its commencement, narrowest internally. 'To bring the cartilaginous portion in line with the bony, the pinna should be drawn well upward and backward. In the bony portion the skin and periosteum are intimately blended, thus accounting for the realiness with which necrosis occurs. The sensibility of the meatus is explained by the two branches sent by the anriculo-temporal nerve. 'The fact that the deeper part is supplied by the auricular branch of the vagus explains the vomiting and cough oceasionally met with in affections of the meatus.

The anterior inferior angle of the parietal bone, and its great importance as a landmark, have alrearly leen noted. The posterior inferior angle of this bone (grooved by the transverse (lateral) sinus) lies a little above and hehind the base of the mastoid, on a level with the roots of the zygoma (fig. 105.5). Just below and in front of the tip of the mastoid the transverse process of the atlas can be marle out in a spare subject.

In front, the cireumference of the bony orbit can be traced in its whole extent. The supraorbitul notch lies at the junction of the nodial and intermediate thirds of the survarabital arch. When this noteh is a complete foramen, its detection is musch less easy. 'To its medial side the supratrochlear nerve and frontal arterd crose the suprandital margin; like the supraorbital, this nerve and vessel lie, at 
first, in close relation with the periosteum. The frontal artery is one of the chief blood-supplies to flaps taken from the forehead. Owing to the paper-like thinness of the bones on the medial wall of the orbit, e. g., lacrimal, ethmoid, and body of sphenoid, and the mobility of the skin, injuries which are possibly penetrating ones, as from a slate-pencil, ferrule, etc., are always to be looked upon with suspicion. After a period of latency of symptoms, infection of the membranes and frontal abscess have often followed. Above the supraorbital margin is the supraciliary arch, and higher still the frontal eminence [tuber frontale].

Fig. 1085.-The Skull, Showing Krönlein's Method of Craniocerebral Topography:

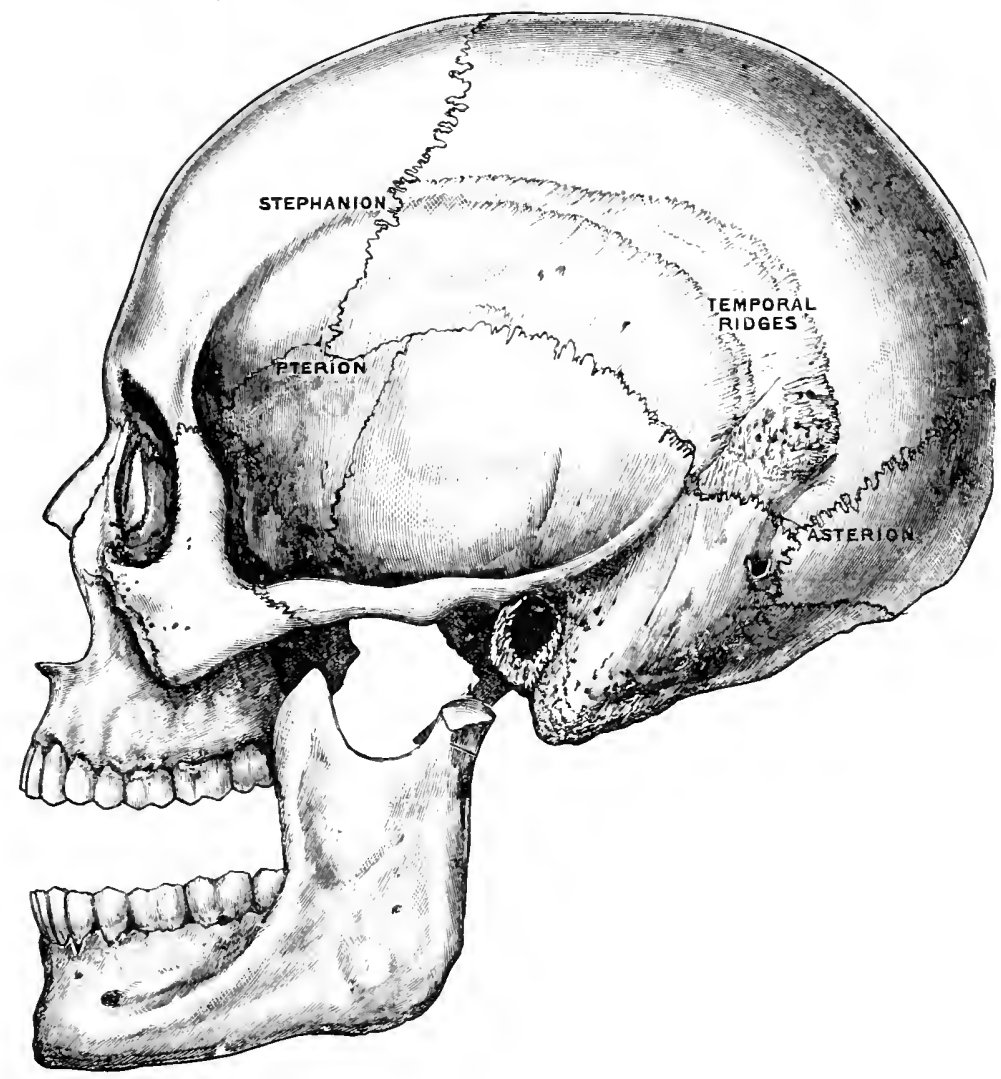

\section{THE CRANIUMI}

Under this heading will be considered the scalp, the bony sinuses, craniocerebral topography and the hypophysis.

The scalp.-The importance of the scalp is best seen from an examination of its layers (fig. 1086). These are-(1) skin; (2) subcutaneous fat and fibrous tissue; (3) the epicranius (occipito-frontalis) and aponeurosis; (4) the subaponeurotic layer of connective tissue; (5) the pericranium.

The first three layers are connected and move together. The thick skin supported by the dense fibrous subcutaneous layer and epicranial aponeurosis, is well adapted to protect the underlying skull from the effects of trauma, and in this connection the mobility of the first three layers on the subaponeurotic areolar tissue is important. A scalp wound does not gape widely unless it inrolves the epicranial aponeurosis, in which case it involves the subjacent "dangerous area" of the scalp, so-called because pus in this layer may spread widely underneath the scalp and even give meningeal infection by spreading through the diploic or emissary veins. In the process of scalping (whether performed by the knife or by the hair being caught in machinery), separation takes place at this subaponeurotic layer which is loose, delicate and devoid of fat.

The numerous sebaceous glands frequently give rise to cysts in the scalp. 
The epicranius and aponeurosis have been described elsewhere (p. 336).

The pericranium differs from periosteum elsewhere in that it gives little nourishment to the bone beneath, which derives most of its blood-supply from the meningeal vessels. After necrosis of the skull there is no tendency to the formation of an involucrum of new subperiosteal bone as in the long bones. The pericranium is firmly adherent to the sutures of the skull bones, so that any subpericranial effusion of blood or pus is limited by the sutures.

Of the vessels of the scalp, the arteries, arising in the anterior region from the internal, in the posterior from the external, caroticl, are peculiar in their position. Thus they lie superficial to the deep fascia, which is here represented by the aponeurosis (fig. 1086). From this position arises the fact that a large flap of scalp may be separated without perishing, as it carries its own bloodvessels. From the density of the layer in which the vessels run they cannot retract and are difficult to seize, hæmorrhage thus being free. Finally, from their position over closely adjacent bone, ill-applied pressure may easily lead to sloughing. A practical point with regard to the veins is given below. The lymphatics from the front of the scalp drain into the anterior auricular and paroticl, those behind into the posterior auricular, occipital and deep cervical nodes. The nerves are derived from all three divisions of the trigeminus, from the

Fig. 10S6.-Section through the Scalp, Skull, and Dura Mater. (Tillaux.)

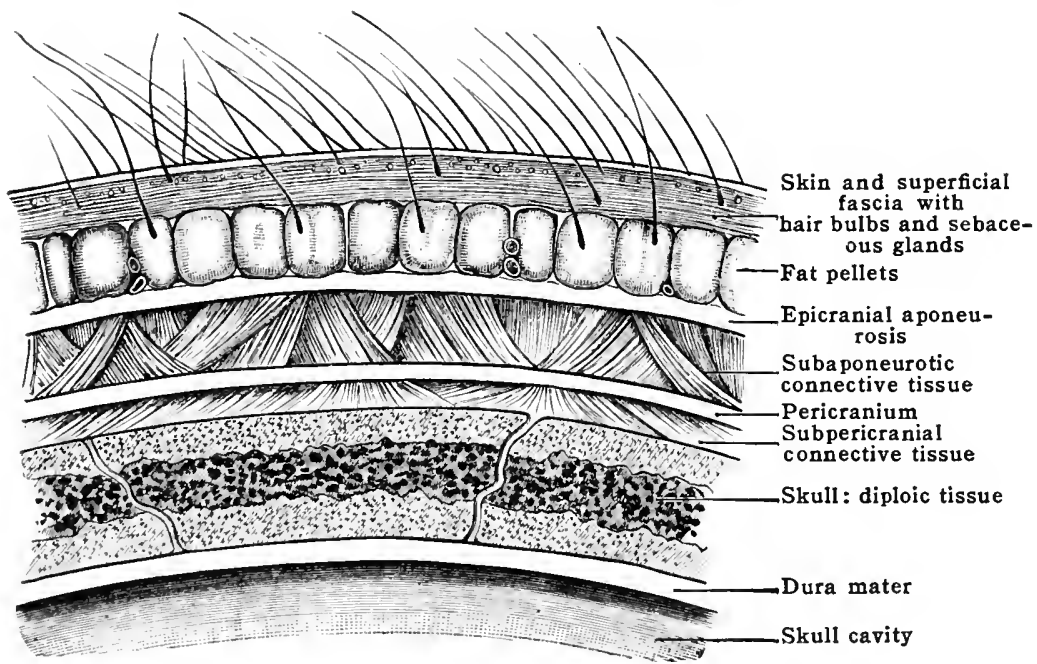

facial (motor) and also from three branches of the second and third cervical. The supply from the fifth explains the neuralgia in acute iritis, glaucoma, and herpes frontalis, and also the pains shooting up from the front of the ear in late cancer of the tongue.

The emissary veins.-These are communications between the sinuses within, and the veins outside, the cranium. Most of them are temporary, corresponding to the chiof period of growth of the brain. Thus in early life, when the development of the brain has to be very rapid, owing to the approaching elosure of its casce, a free escape of blood is most essential, especially in children, with their sudden explosions of laughter and passionate crying.

The gravity of these emissary veins and their frec communications with others are shown by the rearliness with which they become the seat of thrombosis, and thus of blood-poisoning, in cramial injuries, crysipelas, infected wounds of the sealp, and userosis of the skull. 'They incluete the following:

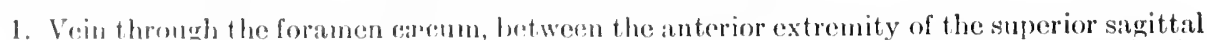
sinus and the nasal mucous membinne. 'The value of this tomporary ontlet is well seen in the fimcly profuse apistaxis of rhithren. () ther more premanent communieations between the skull ravify amb natial muons mombrane pass through the ethmoid formmina. The fact that the

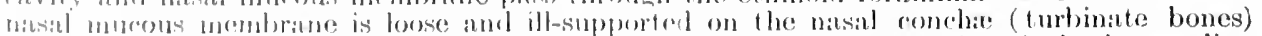
allows its vessols fo give way readily, and thus forms a salutary safoguard to the brain, warding off many an attack of apmulexy. 2. Vein thromgh the mastoid foramen, between the transverse 
(lateral) sinus and the posterior auricular and occipital veins. This is the largest, the most constant, and the most superficial of the emissary veins. Hence the old rule of applying blisters or leeches over it in cerebral congestion. 3. Vein through the posterior superior angle of the parietal between the superior sagittal sinus and the veins of the scalp. 4. Vein through the condyloid foramen between the transverse (lateral) sinus and the deep veins of the neck. 5 . Vein through the hypoglossal canal between the occipital sinus and the deep veins of the neck. 6. Ophthalmic veins communicating with the cavernous sinus and the angular vein. These veins may be the source of fatal blood-poisoning, by conveying out of reach septic material, in acute periostitis of the orbit, or in osteitis, of dental origin, of the jaws. 7. Minute veins through the foramen ovale between the cavernous sinus and the pharyngeal and pterygoid veins. 8. Communications between the frontal diploic and supraorbital veins, between the anterior temporal diploic and deep temporal veins, and between the posterior temporal and occipital diploic veins and the transverse sinus. In addition to the veins specially mentioned, the scalp and sinuses communicate by numerous diploic veins, by those in the inter-sutural membrane, and through sutures before their obliteration, as already explained.

Structure of cranium.- Two layers and intervening cancellous tissue. Each layer has special properties. The outer gives thickness, smoothness, and uniformity, and, above all, elasticity. The inner is whiter, thinner, less regulare. g. the depressions for vessels, Pacchionian bodies, dura mater, and brain. The diploë, formed by absorption after the skull has attained a certain thickness, reduces the weight of the skull without proportionately reducing its strength, and provides a material which will prevent the transmission of vibrations.

A blow on the head may fracture the internal layer only, the external one and diploë escaping. This is difficult to diagnose, and thus it is impossible to judge of the severity of a fracture from the state of the external layer. This may be whole, or merely cracked, while the internal shows many fragments, which may set up meningitis or other mischief. It is usual to find more extensive splintering of the inner than of the outer layer (table).

The average thickness of the adult skull-cap is about $5 \mathrm{~mm}$. (f in.). (Holden.) The thickest part is at the external occipital protuberance, where the bone is often $1.8 \mathrm{~cm}$. ( $\frac{3}{4} \mathrm{in}$.) in thickness. The thinnest part of the skull vault is over the temporal part of the squamous. The extreme fragility of the skull here is partly compensated for the by thickness of the soft parts; these two facts are always to be remembered in the diagnosis of a fracture of the skull here, after a slight injury. Other weak spots are the medial wall of the orbit, the cerebellar fossæ, and that part of the middle fossa corresponding to the glenoid cavity.

Anatomical conditions tending to minimise the effects of violence inflicted upon the skull. (1) The density and mobility of the scalp. (2) The dome-like shape of the skull. This is calculated to bear relatively hard blows and also to allow them to glide off. (3) The number of bones tends to break up the force of a blow. (4) The sutures interrupt the transmission of violence. (5) The inter-sutural membrane (remains of fotal periosteum) acts, in early life, as a linear buffer. (6) The elasticity of the outer layer (table). (7) The overlapping of some bones, e.g. the parietal by the squamous; and the alternate bevelling of adjacent bones, e. g. at the coronal suture. (8) The presence of ribs, or groins, e. g. (a) from the crista galli to the internal occipital protuberance; $(b)$ from the root of the nose to the zygoma; $(c)$ the temporal ridge from orbit to mastoid; $(d)$ from mastoid to mastoid; $(e)$ from external occipital protuberance to tho foramen magnum. (9) Buttresses, e. g. zygomatic processes and the greater wing of the sphenoid. (10) The mobility of the head upon the spine.

\section{THE BONY SINUSES}

Frontal.- When well developed, the frontal sinuses may reach $5 \mathrm{~cm}$. (2 in.) upward and $3.7 \mathrm{~cm}$. ( $1 \frac{1}{2} \mathrm{in}$.) laterally, occupying the greater part of the vertical portion of the frontal bone. When very small, they scarcely extend above the nasal process. In any case, they are rarely symmetrical. The average dimensions of an adult frontal sinus are $3.7 \mathrm{~cm}$. ( $1 \frac{\mathrm{i}}{4} \mathrm{in.}$ ) in height, $2.5 \mathrm{~cm}$. (1 in.) in breadth, and $1.8 \mathrm{~cm} .\left(\frac{3}{4} \mathrm{in}.\right)$ in depth. (Logan Turner.) The sinuses are separated by a septum. The posterior wall is very thin. Each sinus narrows downward into the infundibulum. This is 'deeply placed, at the back of the cavity, behind the frontal (nasal) process of the maxilla and near the medial wall of the orbit. Its termination in the middle meatus is about on a level with the palpebral fissure.' (Thane and Godlee.) Its direction is backward.

The communication of these sinuses with the nose accounts for the frontal headache, the persistence of polypi and ozena, and the fact that a patient with a compound fracture opening up the sinuses can blow out a flame held close by.

To open the frontal sinus, while the incision which leaves the least scar is one along the shaved eyebrow, superficial laterally so to avoid the supraorbital nerve and vessels, running a little downward at the medial end, it is always to be remembered that, where the sinuses are little developed, this or a median incision may open the cranial eavity. To avoid this complication the sinus should always be opened at a spot vertically above the medial angle.

The development of these by the twentieth or twenty-fifth year may render a fracture 
here much less grave in the adult than would otherwise be the case, the inner layer (table), if now separated from the outer, protecting the brain. Mr. Hilton showed that the absence of any external prominence here does not necessarily imply the absence of a sinus, as this may be formed by retrocession of the internal layer. In old people these sinuses may enlarge by the inner layer following the shrinking brain. Again, prominence of the supraciliary and frontal eminences does not necessarily point to the existence of a sinus at all, being due merely to a heaping up of bone.

The mastoid cells are arranged in two groups, of the utmost importance in that frequent and fatal disease, inflammation of the middle ear:-(A) The upper, or 'antrum,' present both in early and late life, horizontal in direction, closely adjacent to and communicating with the tympanum. This group is not developed in early life.

A. Tympanic antrum (fig. 1088). - This is a small chamber lying behind the tympanum, into the upper and back part of which (epitympanic recess) it opens. Its size varies, especially with age. Almost as large at birth, it reaches its maximum (that of a pea) about the third or fourth year. After this its size usually diminishes somewhat, owing to the development of the encroaching bone around

Fig. 1087.-Temporal Bone, showing Suprameatal Triangle. (Barr.)

The lower part of the transverse sinus is here placed too far back to be relied upon with constant accuracy.

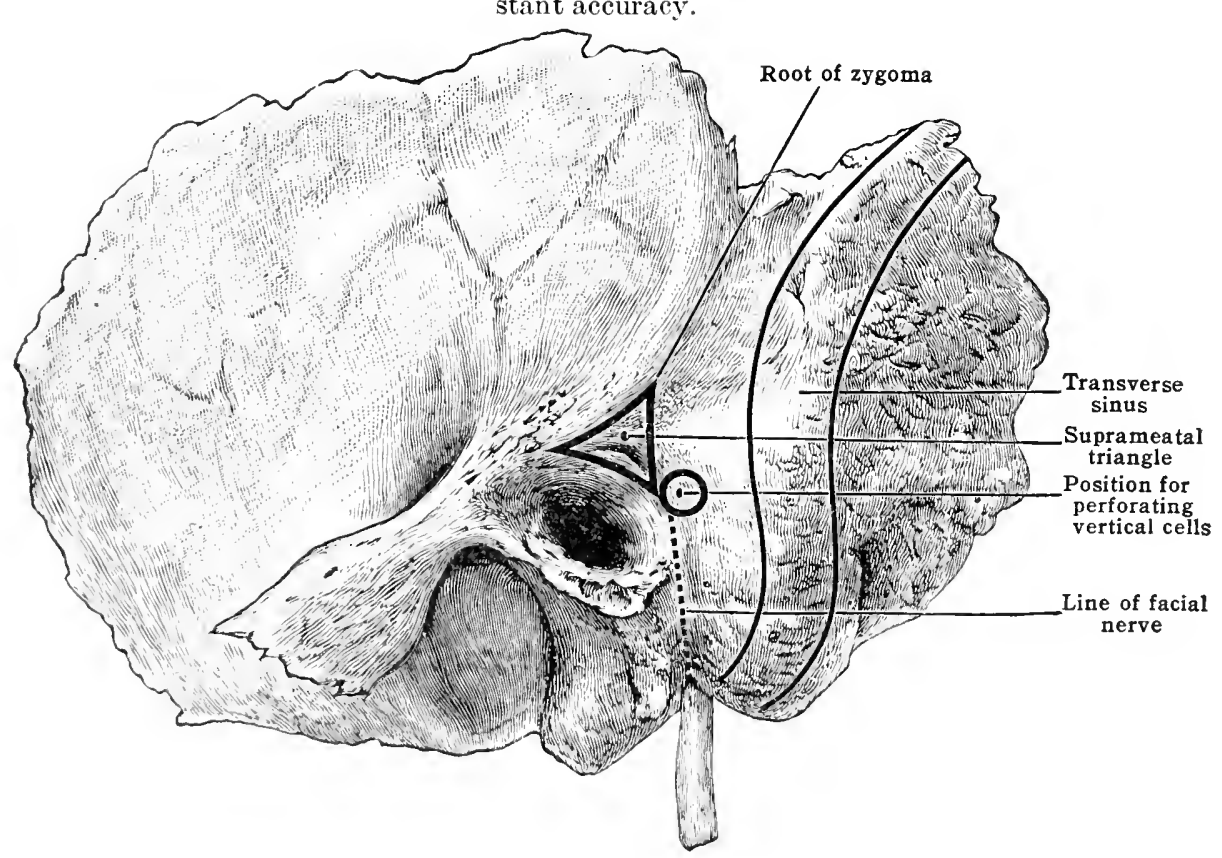

it. Its roof, or tegmen, is merely the backward continuation of the tegmen tympani. The level of this is indieated by the posterior root of the zygoma. "The level of the floor of the adult skull at the tegmen antri is, on an average, less than one-fourth of an inch above the roof of the external osseous meatus; in children and arloleseents, from one-sixteenth to one-eighth of an inch.' (Mac-

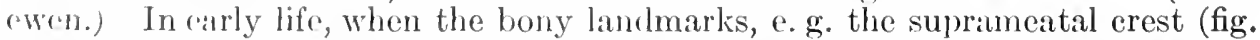
1087), are little marked, the level of the upper margin of the bony meatus will be the safest guide to atvoid opening the midlle fossat.

The lateral wall of the antrum is formed by a plate descending from the scuamous bone. This is very thin in carly life, but as it develops by deposit uncler the periostrum, the depth of the antrum from the surface increases. Marewen gives the average of the depth as varying from one-eighth to threeforuth of an inch. The thinness of the outer wall in early life is of practical inportann. It allows of suppuration making its way externally-subperiosteal

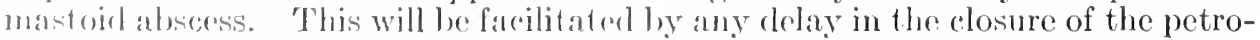
and masto-squamosal sutures, by which this thin plate blends with the rest of the temporal bone. Further, by the path of veins rumning through these sutures or 
their remnants, infection may reach such sinuses as the inferior petrosal. The sutures normally close in the second year after birth. Through the floor, the antrum communicates with the lower or vertical cells of the mastoid. This floor is on a lower level than the opening into the tympanum, and thus drainage of an infected antrum is difficult, fluid finding its way more readily into the lower cells. Behind the mastoid antrum and cells is the bend of the sigmoid part of the transverse (lateral) sinus, with its short descending portion (fig. 1087). The average distance of the sinus from the superior meatal triangle is $1 \mathrm{~cm}$. $\left(\frac{2}{5} \mathrm{in}\right.$.). It may be further back; on the other hand, it may come within $2 \mathrm{~mm}$. ( $\left(\frac{1}{12}\right.$ in.) from the meatus, and even overlap the outer wall of the antrum.

Fig. 1088.-The Mastoid ANTrum axd Cells. (Jacobson and Steward.)

1. Posterior root of zygoma forming the supramastoid or suprameatal crest and upper part of Macewen's triangle. 2. Antrum, and in front of it, the epitympanic recess. 3. Vertical cells of the mastoid. 4. Ridge on the inner wall of the tympanum, caused by the facial canal. 5. Fenestræ on inner wall of tympanum, indicated in shadow. 6. A deficiency present in the tegmen tympani, enlarged with a small osteotrite to emphasise the thinness of the roof of the antrum and tympanum. 7. Cells extending, in this case, even in to the root of the zygoma.

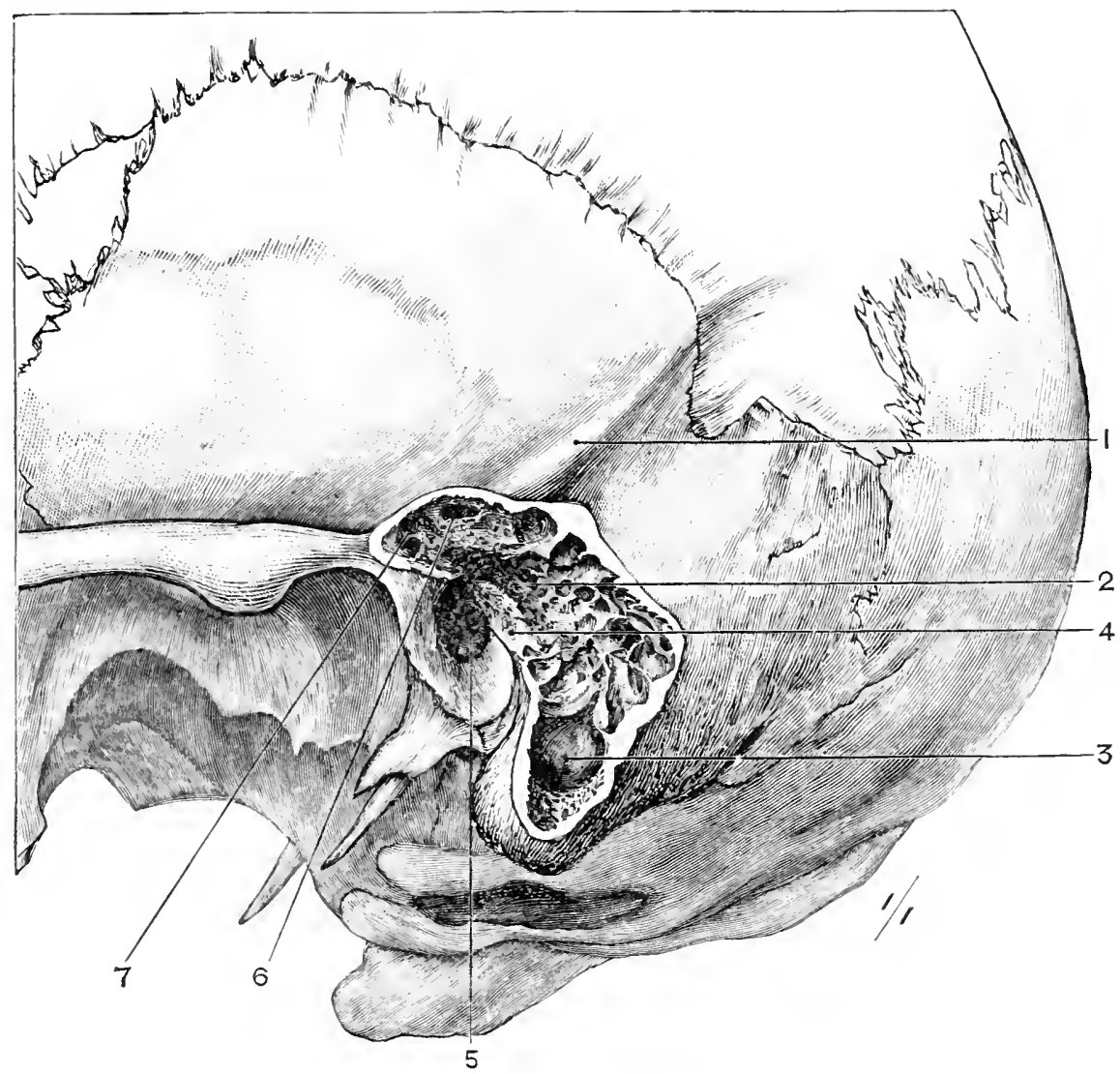

The exact position of the antrum, a little above and behind the external auditory meatus is represented by Macewen's 'suprameatal triangle.' This is a triangle bounded by the posterior root of the zygoma above, the upper and posterior segment of the bony external meatus below, and an imaginary line joining the above boundaries (fig. 10si). "Roughly speaking, if the orifice of the external osseous meatus be bisected herizontally, the upper half would be on the level of the mastoid antrum. If this segment be again bisected vertically, its posterior half would again correspond to the junction of the antrum and middle ear, and immediately behind this lies the suprameatal fossa.' (Macewen.) When opening the antrum through this triangle, the operator should work forward and medially, so as to avoid the transverse sinus (fig. 10S7); while, to avoid the facial nerve (fig. 1087), he should hug the root of the zygoma and the upper part of the bony meatus as closely as possible. The level of the base of the brain will be a few lines above the posterior root of the zygoma (fig. 1089) and about $6 \mathrm{~mm}$. ( $\frac{1}{4}$ in.) above the roof of the bony meatus. (Macewen.) 
B. The lower or vertical cells of the mastoid are developed later than is the antrum, and vary much in their contents. The condition of the mastoid cells varies very widely. They may be numerous (fig. 1088) or few. In the latter case they are replaced by diploë, or by bone which is unusually dense, without necessarily any pathological change. Hence mastoids have been classified as pneumatic, diploëtic, or sclerosed.

As part of the surgical anatomy of this most important region, the different paths by which infection of the tympanum and antrum may travel should be glanced at. The most important are:-(1) Upward: either by advancing caries or by infection of veins going to the superior petrosal sinus, or through the tegmina to the membranes; an abscess in the overlying temporal lobe, usually the middle and back part. (2) Backward: the transverse (lateral) sinus and cerebellum (abscess of the front and outer part of the lateral lobe) are reached in the same ways as those given above, the mastoid vein being the one chiefly affected here. Macewen has shown that the bony wall of the sinus, like those of the tegmina and the aqueduct of Fallopius, may be naturally imperfect. (3) Downward: where the vertical cells are well developed (fig. 929) mischief may reach the mastoid notch and cause deep-seated inflammation beneath the sternomastoid. (v. Bezold's abscess.) (4) Lateralward: the explanation of this, in early life, has been given above. (5) Medialward : the facial nerve, or by the fenestra ovalis; the labyrinth is now in danger. When the internal ear and auditory nerve are affected, infection finds another path to the cerebellar fossa.

The sphenoidal sinuses are less important surgically, but these points should be remembered:-(1) Fracture through them may lead to bleeding from the nose, which is thus brought into communication with the middle fossa; (2) the communication of their mucous membrane with that of the nose may explain the inveteracy of certain cases of polypi and ozena; (3) here and in the frontal sinuses very dense exostoses are sometimes formed. Before any operative attack on these sinuses is undertaken, their most important relations should be remembered. Thus above are the olfactory and optic nerves, the pituitary body, and front of the pons. Externally lie the cavernous sinus and superior orbital (sphenoidal) fissure. Below is the roof of the nose.

The ethmoidal and maxillary sinuses are considered later in connection with the Nose. See also the sections on Osteology and Respiratory System.

\section{CRANIO-CEREBRAL TOPOGRAPHY}

To make as clear as possible the points of practical inportance which have, of late years, been put on a definite basis, and which the surgeon may have to recall and act upon at very short notice, cranio-cerebral topography will be spoken of under the following headings: A. Relation of the brain as a whole to the skull. B. Relation of the chief sulci and gyri to the skull. C. Localisation of the chief sulci and gyri. Before alluding to the above, it is necessary to say distinctly that the following surface-markings and points of guidance are only approximately reliable, for the following reasons: (1) In two individuals of the same age and sex the sulci and convolutions are never precisely alike. (2) The relations of the convolutions and sulei to the surface vary in different individuals. (3) That as the surface area of the scalp and outer aspect of the skull are greater than the surface area of the brain, and as the convexities do not tally, lines drawn on the scalp or skull cannot always correspond precisely to cerebral convolutions or sulei. It results from the above that when a definite area of the surface is said to correspond arecurately in any individual to a definite area of the brain surface, this result has bern correlated from many examinations; and that as surfacemarkings, shape, and processes of skull and arrangement of surface are all liable to variations in different individuals, the surgeon must allow for these variations by removing more than that definite area of skull which is said to correspond "xatetly to that part of the brain which he desires to expose.

1. Relation of the brain as a whole to the skull (figs. 1089, 1091).-To trace the lower leerl of cach cerebral hemisphere on the skull, the chalk would start from the lower part of the glabellat; thenes the line representing the lower borders of the

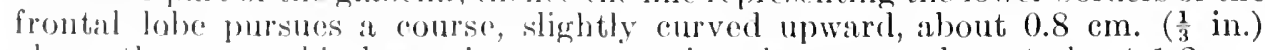
above the supraorbital margin; next, rossing the temporal erest about $1.2 \mathrm{~cm}$. ( $\frac{1}{2}$ in) abovo the zygomatice (cxtopmal angmar) process, it passes not quite horizontally but desereiding slightly to a peint in the temporal fossa just below the tip of the grat wing of thresplunoid (pterion), $2.5 \mathrm{~cm}$. (1 in.) behind the zygomatic process. From this point the lime of the level of the brain, now convex forward and corresponding to the anterior extremity of the temporal lobe, wonld dip town, still within the grat wing of the sphenoid, to about the centre

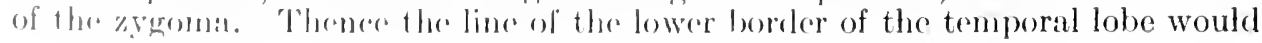


travel along the upper border of this process about $6 \mathrm{~mm} .\left(\frac{1}{4} \mathrm{in}\right.$.) above the roof of the external auditory meatus (fig. 1089), and thence just above the base of the mastoid and the posterior inferior angle of the parietal, and so along the linea nuchæ suprema, and corresponding to the tentorium and horizontal part of the transverse (lateral) sinus, to the external occipital protuberance.

The upper margin of each hemisphere would be represented by a line drawn from just below the glabella, sufficiently to one side of the middle line to allow for the falx and superior sagittal sinus, to one immediately above the superior external occipital protuberance and inion.

B. Relation of the chief fissures and convolutions to the skull. C. Localisation of the chief sulci and gyri. These headings will be taken together.

It will be well first to indicate the position of the chief sutures which mark off the parietal bone, under which lies that part of the brain which is most important to the surgeon-the motor area. The upper limit of the bone will be indicated by the line already spoken of as giving the upper margin of the hemisphere-the sagittal line, or Sagittal suture. The anterior limit of the parietal bone, formed

Fig. 1089.-The Outline of the Brain and its Fissures in Relation to the Sutures OF THE SKull. (Cunningham.)

S.M. Supraciliary margin of the cerebrum. I.L.M. Infero-lateral margin of the cerebrum. L.s. Position of highest part of the arch of the transverse sinus. R. Central sulcus (Fissure of Rolando). $s^{1}$. Anterior horizontal limb of lateral fissure. $s^{2}$. Anterior ascending limb of lateral fissure. $\mathrm{s}^{3}$. Posterior horizontal limb of lateral fissure. P.B. Opercular portion of the inferior frontal convolution. P.T. Triangular portion of the inferior frontal convolution. P.o. Orbital portion of the inferior frontal convolution.

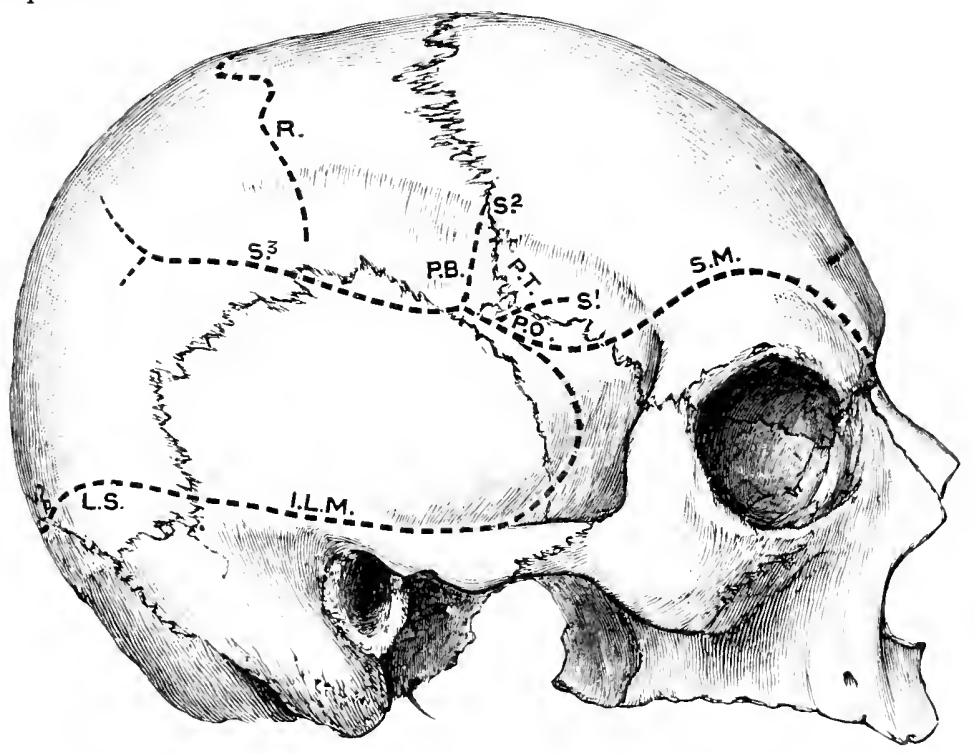

by the coronal suture, may be traced thus: The point where it leaves the sagittal suture (the bregma) will be found by drawing a line from a point just in front of the external auditory meatus (the pre-auricular point) (fig. 1085) straight upward on to the vertex; from this point a line drawn downward and forward to the middle of the zygomatic arch would indicate that of the coronal suture. Under this suture lie the posterior extremities of the three frontal convolutions; for the frontal lobe lies not only under the frontal bone, but extends backward under the anterior part of the parietal, the central sulcus (fissure of Rolando), which separates the frontal from the parietal lobe, lying from 3.7 to $5 \mathrm{~cm}$. ( $1 \frac{1}{2}$ to $2 \mathrm{in}$.) behind the coronal suture at its upper extremity and about $2.5 \mathrm{~cm}$. (1 in.) at its lower.

The squamoso-parietal suture, which marks the lower border of the anterior two-thirds of the parietal bone, is not so easy to define, owing to the irregularity and variations of its curve. Its highest point is usually $4.3 \mathrm{~cm}$. (1 $1 \frac{3}{4} \mathrm{in}$.) above the zygoma.

The lambdoid suture, which forms the posterior boundary of the parietal bone, will be

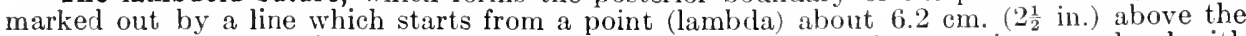
external occipital protuberance, and runs downward and forward to a point on a level with the zygoma, $3.7 \mathrm{~cm}$. ( $1 \frac{1}{2} \mathrm{in}$.) behind and $1.2 \mathrm{~cm}$. ( $\frac{1}{2} \mathrm{in}$.) above the centre of the meatus. 
The position of the chief sulci will now be given:-

Lateral (Sylvian) fissure (fig. 1089). - The point of appearance of this, on the outer side of the brain, practically corresponds to the pterion (p. 1332, fig. $1085)$ - a point which lies in the temporal fossa, about $3.7 \mathrm{~cm}$. ( $1 \frac{1}{2} \mathrm{in}$.) behind the zygomatic process and about the same distance above the zygoma. From this point the lateral fissure, which here separates the frontal and parietal from the temporal lobe, runs backward and upward, ascending gently, at first in the line of the squamo-parietal suture, then crossing this suture about its centre and thence, ascending more rapidly, it climbs up to the temporal ridge, to end $1.8 \mathrm{~cm}$. ( $\frac{3}{4}$ in.) below the parietal eminence. Its termination is surrounded by the supramarginal convolution, to which the parietal eminence corresponds with sufficient accuracy. Such being the surface-marking of the chief or posterior horizontal limb of the lateral fissure $\left(s^{3}\right.$, fig. 1089), it remains to indicate briefly the two shorter limbs which bound the inferior frontal convolution, which, on the left side, contains the centre for speech (Broca's convolution), and corresponds to a point lying three fingers' breadth vertically above the centre of the zygomatic arch. (Stiles.) Of these, the anterior horizontal ( $\mathrm{s}^{1}$, fig. 1089) runs forward across the termination of the coronal, just above the line of the sphenoparietal suture. The ascending limb ( $\mathrm{s}^{2}$, fig. 1089) runs upward for about

\section{Fig. 1090.-Lateral View of the Skuld, Showing the Topography of the Middle} Meningeal Artert and the Transverse Sinus.

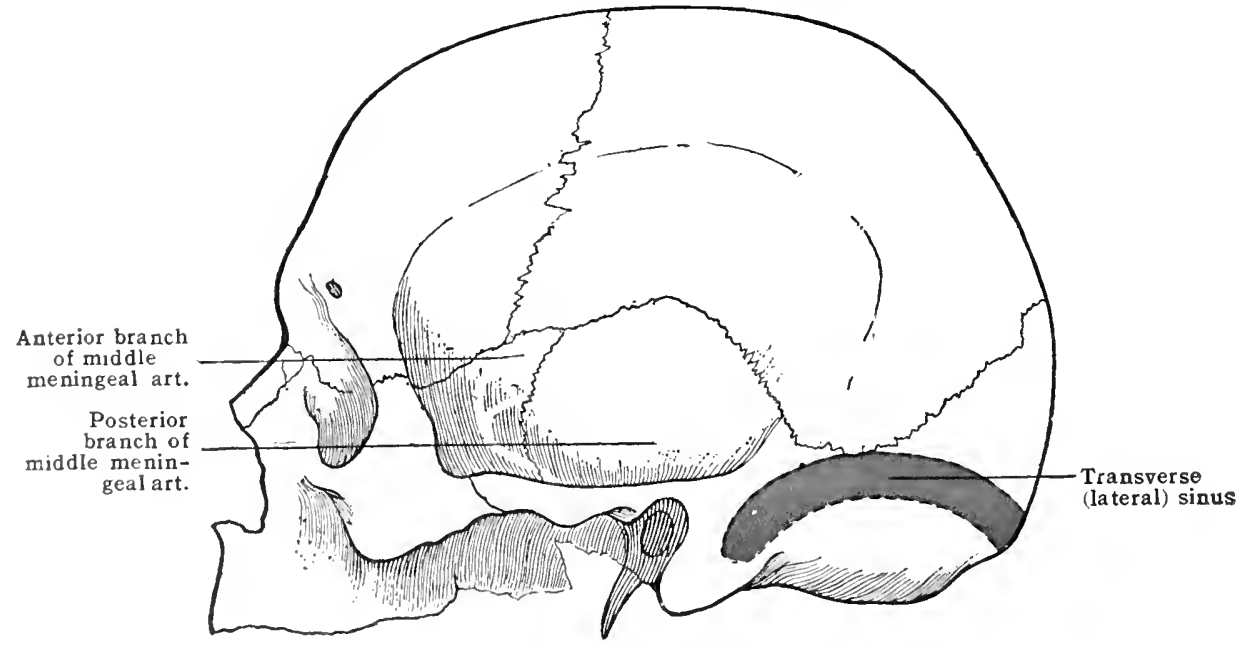

$2.5 \mathrm{~cm}$. ( $1 \mathrm{in.}$ ) just behind the termination of the coronal suture, or $5 \mathrm{~cm}$. (2 in.) behind the zygomatic process.

The central sulcus (fissure of Rolando). - This most important fissure, in front of which, in the precentral convolution of the frontal lobe, lie the motor centres for the opposite side of the body, is situated under the parietal bone. It may be marked out with sufficient precision in the following way (Thane): The sagittal line, from glabella to external occipital protuberance, is bisected, and a point $1.2 \mathrm{~cm}$. ( $\frac{1}{2} \mathrm{in}$.) behind the centre represents the superior Rolandic point. From this point a line drawn downward and forward $9 \mathrm{~cm}$. ( $3 \frac{3}{4} \mathrm{in}$.) long, at an angle of $67_{2}^{1}{ }^{\circ}$ with the sagittal line (i. e., $\frac{3}{4}$ of a right angle) will represent the central sular. The lower extremity of this line is known as the inferior Rolandic point.

This mether is open to the objection that it only applies to the average adult skull, and not to skulls of all sizes. 'To olviate this lifliculty the method of Krönlein may be employed in

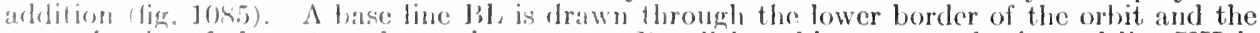
upper horder of the external acustic meatis. I'arallel to this an upper borizontal line UH is marked ont at the level of the upper margin of the orbit. Three lines vertieat to the base line atre now drawn, (1) at the postrior hordor of the mastrid proess $\mathrm{MlR}_{1}(2)$ through the condyle of the lower juw $\left(C / K_{2}\right)$, and (3) from the mid-point of the zygoma $(Z S)$. The point $R_{1}$, where tho first vertiral joins the sigittal suture is the superior Rolandic point. 'The point $S$ where

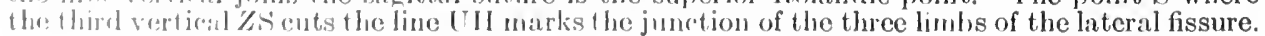
A line joining $l_{1}$ and s will ent the secomel vertical $\mathrm{C}_{2}$ at the inferior Rolandic point, $R_{2}$. 
The posterior limb of the lateral fissure also may be represented by a line bisecting the angle $\mathrm{R}_{1} \mathrm{SH}$ and ending behind at the point $\mathrm{S}^{1}$ where it cuts the vertical $M R_{1}$.

Some further points in the surgical anatomy of the cranium must be referred to:-The middle meningeal artery. This vessel, entering the middle fossa by the foramen spinosum, grooves the great wing of the sphenoid and divides into two branches. The anterior grooves the anterior inferior angle of the parietal bone, and is then continued upward and slightly backward between the coronal suture and central sulcus (fig. 1090), almost to the vertex; the posterior branch takes a lower level, running backward under the squamous bone to supply the parietal and anterior part of the occipital bones. If a skull, bisected antero-posteriorly, be held up to the light, it will be seen how thin are the bones over the chief branches of this vessel, thus accounting for the slight violence sometimes sufficient to rupture it. The groove it occupies in the parietal is sometimes converted into a canal. A wounded artery retracting here may be very difficult to secure. The veins which accompany the artery and which lie lateral to it

Fig. 1091.-Cerebral Topography and Localization. (Cushing, from Keen's Surgery.)
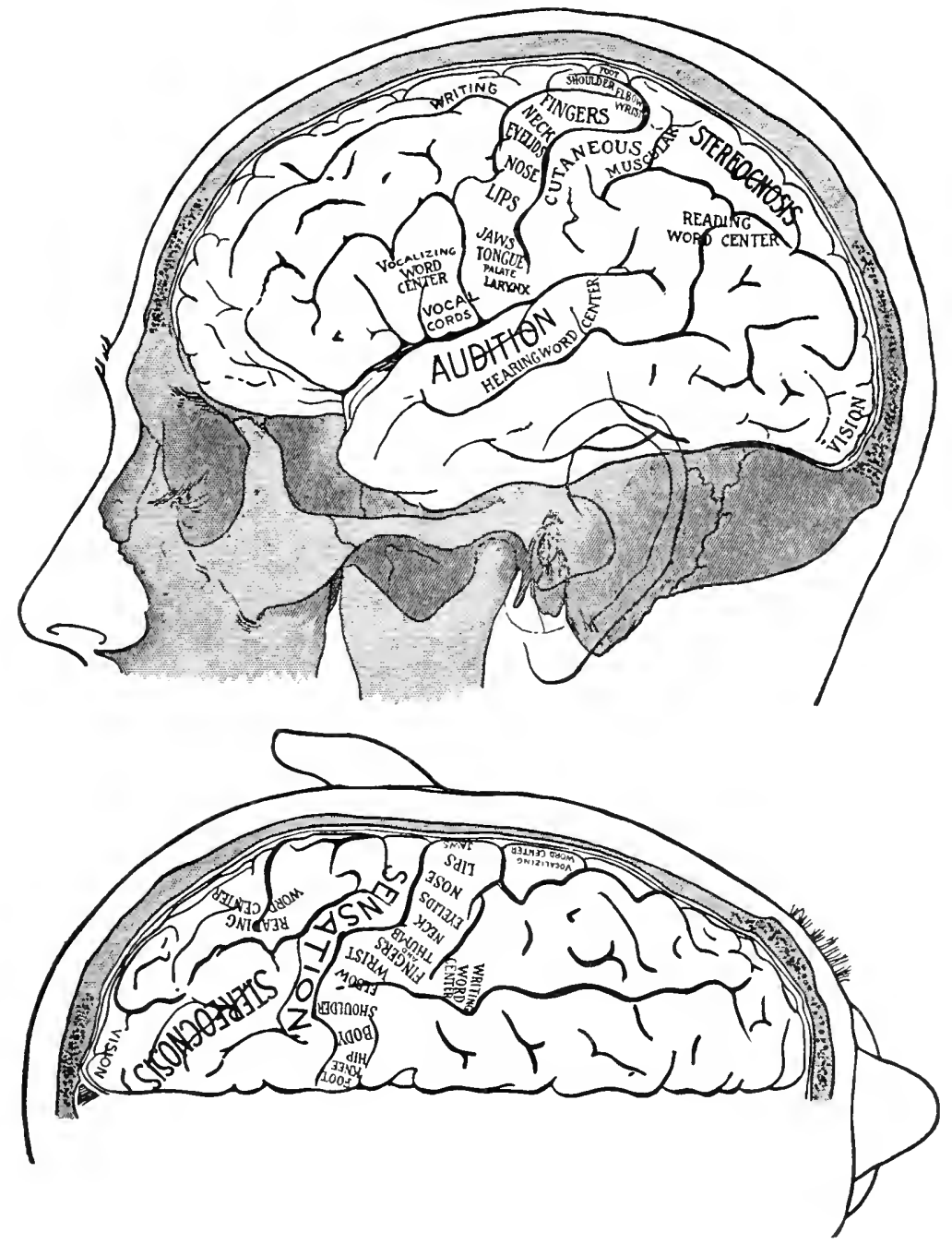

in the groove are thin-walled and sinus-like before they open into the spheno-parietal sinus, another explanation of the obstinacy of this hæmorrhage. According to the point of rupture, three hæmatomata should be remembered (Krönlein), anterior or fronto-temporal; middle, or temporo-parietal; and posterior, or parieto-occipital. The first two are much the most frequent, and exposure of the pterion, with free removal of the adjacent bone, will suffice for dealing with them.

Drainage of the lateral ventricle.-(1) Where the anterior fontanelle is closed, Poirier and Keen have opened the inferior cornu through the middle temporal convolution, the pin of

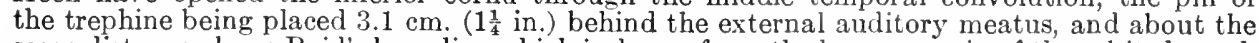
same distance above Reid's base-line which is drawn from the lower margin of the orbit through the mid-point of the external auditory meatus. The needle should here be directed to a point 
about $5 \mathrm{~cm}$. (2 in.) above the opposite ear. (2) Kocher's point for draining the lateral ventricle is taken over the frontal lobe $2.5 \mathrm{~cm}$. from the median line and $3 \mathrm{~cm}$. in front of the upper Rolandic point. The needle is passed downward and a little backward to a depth of $4 \mathrm{or} 5 \mathrm{~cm}$.

Up to this point the outside of the cranium has been mainly considered; it remains to draw attention to some of the chipf points in the surgical analomy of the interior, especially of the base. The three fossæ are of paramount importance in fracture. In the anterior fossa the delicacy oi parts of the floor, the connection of this with the nose and orbit, and the exact adaptation of its irregular surface to that of the frontal lobes, no 'water-bed' intervening, are the chief points. Thus the slight ness of a fatal fissure, the frequent presence of bruising after a blow perhaps on the occiput, which has been considered to have caused only concussion, the characteristic palpebral hamorrhage, and the infection of a fracture here are all explained, together with the possibility and gravity of a fracture here from a severe blow on the nose. In the middle fossa the frequency of fractures is explained by the facts that while here, as in the other fossa, a fracture often radiates down from the vertex, the overlying vault being a region often struck, the base is weakened by numerous foramina and fissures. Further, the resisting power of the petrous bone must be lessened by the cavities for the internal ear, the carotid, and, to a less degree, by the jugular fossa. For fluids to escape through the external meatus, the dura, the prolongation of the arachnoid into the internal meatus, the membrani tympani, and probably the internal ear, must all be injured. The presence of the middle meningeal artery (fig. 1090) and the cavernous sinus in this fossa must also be remembered, especially in such operations as that on the Gasserian ganglion. Posterior fossa: It is not sufficiently recognised that fractures here are, owing to the anatomy of the parts, in some respects the most important of all. It is here that a small fissure-fracture, ultimately fatal, with severe occipital and frontal bruising and some intradural hæmorrhage, has been so often overlooked, especially in the drunken. This is explained by the supposed strength of the bone, this being really very thin in places, by the thickness of the soft parts, and the abundance of hair. Further, there is no very apparent escape of cerebral contents as in the anterior and middle fossæ. Blood, etc., may trickle into the pharynx far back, or a deep-seated ecchymosis coming up after two days, under the muscles about the mastoid process, may call attention to the damage within.

Dura mater. - The outer layer of this membrane acts as a periosteum, by bringing bloodvessels to the bone while the inner layer supports the brain. The influence of its partitions and its damping effect on vibrations is great in blows on the head. Its varying adhesions, according to site and age, must be remembered. Thus while it is intimately connected over the base with its adhesions to the different foramina, it is more loosely connected with the vault, as is shown in middle meningeal hæmorrhage. In early and later life the closeness of its connection with the bones is also more marked. It is united to the inter-sutural membranes.

Finally, the existence of the cerebro-spinal fluid with its power of lessening the evil of vibrations and its aid in regulating intra-cranial pressure, must be borne in mind. The chief collections, in which the subarachnoid meshwork is almost absent, are met with in front and behind the medulla. That in front, also lying under the pons, Hilton's 'water-bed,' sends a prolongation forward to the optic chiasma, but does not extend under the frontal or temporal lobes. The collection behind lies between the medulla and under surface of the cerebellum. Here, by the foramen of Magendie, the intra-ventricular cavities communicate with the subarachnoid space of the spinal cord.

\section{THE HYPOPHYSIS CEREBRI}

The hypophysis (pituitary body) which has now become of great elinical importance, consists of a pars anterior and pars intermedia derived from the buccal ectoderm, and a posterior pars nervosa formed by a downgrowth from the floor of the third ventricle. The gland lies in the fossa hypophyseos of the sphenoid bone, and an enlargement of it, apart from general skeletal and nutritional effect due to anomalies of its internal secretions, will eause pressure on the cavernous sinus on each side, and on the optic chiasma above. It will also expand the fossa hypophyseos, pushing down its floor at the expense of the sphenoidal air sinus. Such enlargements may be detected by lateral radiograms. Thro normal size of the adult hypophyseal fossa (fig. 1097) is 10-12 mm. from before backward and $8 \mathrm{~mm}$. from above downward (Keith).

Tho hypophyis may be exposed surgically pither hy turning the nose to one side, and removing the upper birt of the septum and floor of the sphenoidal sinus, or by Cushing's method, in which a sublahial incision is made in the vestibule of the mouth, and through it the mucosa is then sepstrated from each side of the nasal septum back to the sphenoidal sinus. A strip of septmm is removed, and also the floor of the sphenoidal sinus, after which the hypophyseal fossa is opened and the gland exposed (fig. 1097).*

\section{THE FACE}

The topics induded under this hearling are the arteries, parotid region, nerves, manliblr and maxillat, orbit, mouth, palate and nose.

The ontline of the different bones-nasial, upper and lower jaws, zygomatie

*II. (ushing. The Pituitary Bolly and its I)isorders, 1912. 
and zygoma-can be readily traced. The last mentioned and the glabella are alluded to on pp. 1331 and 1332; and the canine fossa should be identified as one of the antral routes. The delicacy, laxity, and vascularity of the skin are of great importance in all operations, while the abundance of large gland orifices accounts for the frequency of lupus here.

Arteries.- The supraorbital artery can be felt beating just above its notch (junction of medial with lateral two-thirds of supraorbital margin); the little frontal artery is of importance, as it nourishes the flap when a new nose is taken from the forehead; the superficial temporal, accompanied by the auriculo-temporal nerve, can be felt where it crosses the root of the zygoma just in front of the tragus, its anterior branch about $3.1 \mathrm{~cm}$. (1 $1 \frac{1}{4} \mathrm{in}$.) above and behind the zygomatic process of the frontal; the occipital, accompanied by the great occipital nerve (fig. 450), pulsates to the medial side of the centre of a line drawn from the occipital protuberance to the mastoid process; the posterior auricular, rather deeply, between the auricle and the mastoid process. The external carotid lies behind the ascending

Fig. 1092.-Surface Relations of Vessels and Nerves in Lateral View of the Face AND NECK.

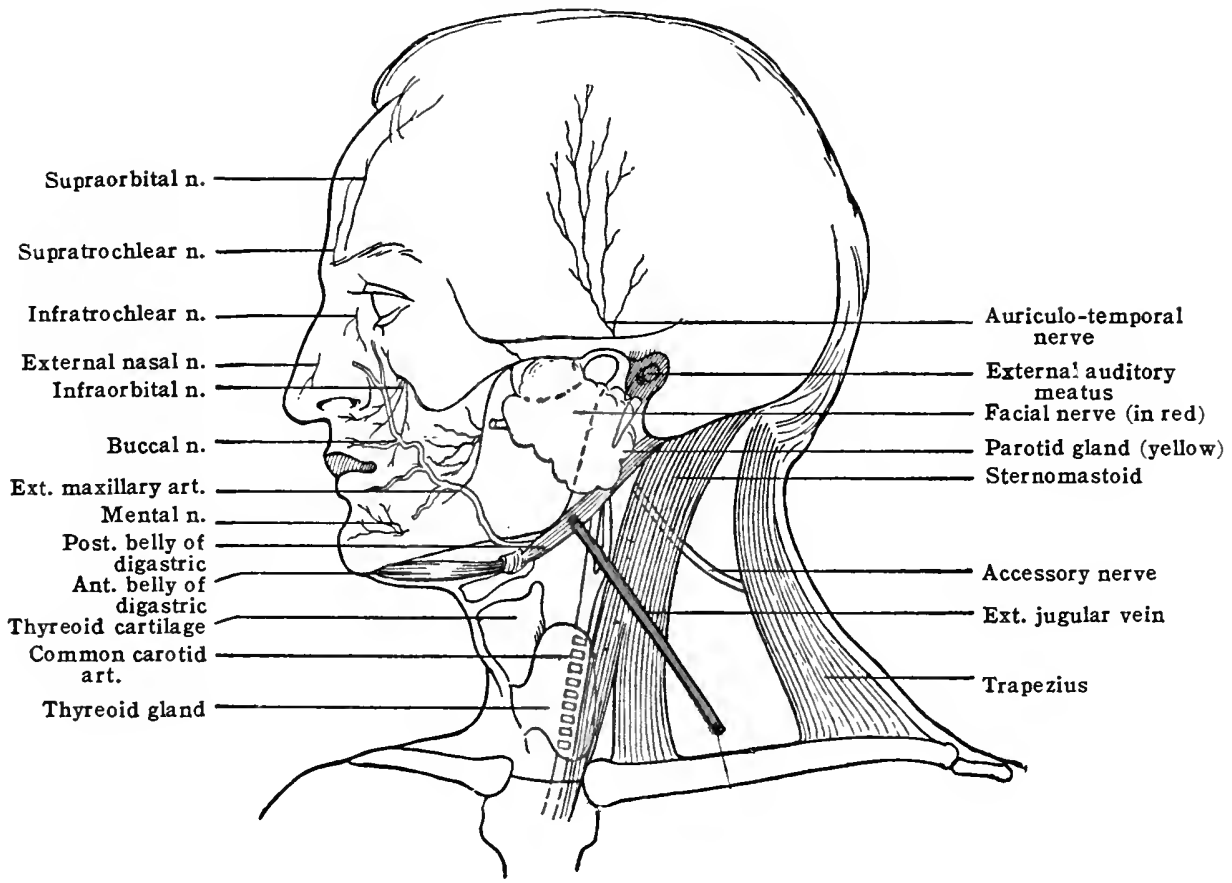

ramus of the jaw. The external maxillary (fig. 1093) crosses the jaw just in front of the masseter; if divided, both ends must be secured here. It can be felt again a little behind the angle of the mouth, just beneath the mucous membrane (it here gives off the labial branches, which can also be felt, lying deeply, if the lip is taken between the finger and thumb); and again by the side of the nose, as it runs up to the angulusoculi. The small angular branch is, from its position, always troublesome to secure. To trace the course of the external maxillary artery a line should be drawn from a point a little above and lateral to the tip of the great cornu of the hyoid to the lower part of the anterior border of the masseter, and thence to one lateral to and above the angle of the mouth, and so onward, lateral to the angle of the nose, up to the medial angle. The anterior facial vein takes a straight course behind the tortuous external maxillary artery. The absence of valves and its communication by the angular and ophthalmic veins with the cavernous sinus, and, by the deep facial, with the pterygoid plexus, are of grave importance in infective thrombosis. The external jugular vein will be mentioned later.

Parotid region.-A line drawn from the lower border of the meatus to a point midway between the nose and upper lip gives the level of the parotid duct, which 
opens into the mouth opposite the second molar tooth. The level of the duct, somewhat inconstant, would be usually about a finger's breadth below the zygoma. It is accompanied by the transverse facial artery above, and the infraorbital branch of the facial nerve below.

The sheath of the parotid, continuous with those of the masseter and sterno-mastoid, is strong enough to causs most exquisitely painful tension when inflammation of the gland is present, and, together with the presence of deep processes of the gland in connection with the

Fig. 1093.-Scheme of the External Maxillary (Facial) Artery. (Walsham.)

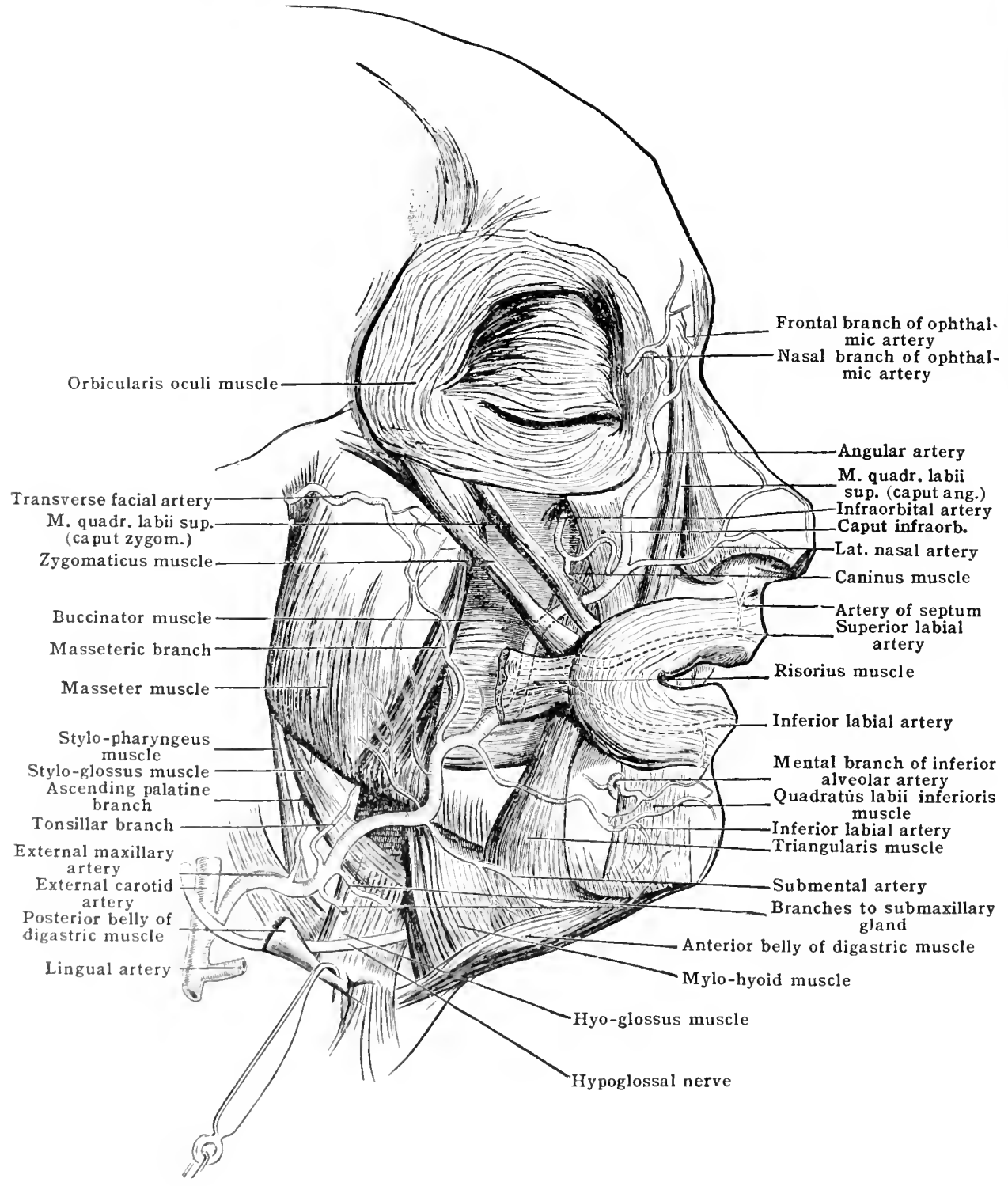

Inaulibular (glenoid) cavity and styloid process, to explain the deep burrowing of pus which maty tatio place into the pharynx and pterygoid region. The relation of the eapsule to growths, innocent, or malignant, of the parotid is also impertant (See figs. S65, 1092).

'The parotid region would be thus mapped out (fig. 1096). Above by the posterior two-thirds of the zygoma; below, by a line corresponding to the posterior belly of the digastric (fig. 1096); behind, are the external auditory meatus, mastoid, and sterno-mastoid. In fronl the gland and socia parotidis overlap the posterior part of the masseter, to a variable degree (fig. 1096). 
Sensory nerves. - The cutaneous nerve areas of the face are shown in fig. 774. The supraorbital nerve, the main sensory branch of the ophthalmic, emerges from the orbit with its companion artery through the notch (occasionally a foramen) at the junction of the medial third and lateral two-thirds of the supraorbital margin. A line drawn from the supraorbital notch downward across the interval between the bicuspid teeth will cross the infraorbital foramen from which emerges the infraorbital nerve, the main terminal division of the maxillary, at a point $1 \mathrm{~cm}$. below the orbital margin. The mental foramen, the point of exit of the mental nerve, a branch of the inferior alveolar, is found on a prolongation of the same line midway between the upper and lower margins of the mandible in the adult. In the infant in whom the alveolar element of the jaw is relatively large, the mental foramen is nearer the lower margin, while in the edentulous jaw of old age it is found much nearer the upper margin.

In trephining to expose the inferior alveolar (dental) nerve, one of the common seats of neuralgia and one in which a peripheral operation is justified from the results, the ascending ramus is opened midway between its anterior and posterior borders, on a level with the last molar.

The semilunar ganglion lies at a depth of $5.5-6 \mathrm{~cm}$. (2⿺ in.) under the eminentia articularis at the base of the zygoma. In exposing it for the purpose of excision for intractable neuralgia the following structures are encountered: (1) Skin and superficial fascia with branches of the superficial temporal artery; (2) temporal fascia and muscle with deep temporal vessels; (3) squamous bone and great wing of sphenoid, which are trephined, the floor of the middle fossa being gouged away; (4) middle meningeal vessels and dura mater. By elevating the dura mater and superimposed temporal lobe, and securing the middle meningeal artery, the ganglion is exposed, lying in a separate compartment [cavum Meckelii] of the dura, which contains cerebrospinal fluid. The motor nerve of the muscles of mastication lies on the lower and medial aspect of the ganglion, and should not be divided.

Injection of the mandibular nerve with alcohol, by means of a long sto:t hypodermic needle is practised in cases of intractable neuralgia as an alternative to excision of the semilunar ganglion. A vertical line is drawn on the cheek downward from the junction of the posterior and middle thirds of the zygomatic arch, and the needle is entered on this line at a point $1.5 \mathrm{~cm}$. from the lower border of the zygoma. It is directed upward and medially so as to pass through the lowest part of the mandibular notch. If the mouth is opened the notch is depressed and more room gained. The needle impinges first against the inferior surface of the great wing of the sphenoid bone, and when the point is lowered a little it engages in the foramen ovale at a depth of $4-4.5 \mathrm{~cm}$. In most cases the needle can be passed through the foramen ovale into the semilunar ganglion. (Harris.)*

The maxillary nerve may be injected by passing a needle along the floor of the orbit from its infero-lateral angle in a direction backward and slightly medially to the foramen rotundum which lies $4.5 \mathrm{~cm}$. from the surface.

Facial nerve.- In the petrous bone the course of this nerve is first outward and forward, then, having entered the facial canal, backward and downward along the medial wall of the tympanum, above the fenestra ovalis. Emerging from the stylo-mastoid foramen the nerve takes first the line of the posterior belly of the digastric, running forward and a little downward from the anterior border of the mastoid where this meets the auricle. (Godlee.) Entering at once the posterior part of the parotid, it crosses the neck of the mandible at the level of the lower border of the tragus.

The frequent paralysis of this nerve may thus depend upon-(1) cerebral causes; (2) disease of or injury to the petrous portion; (3) affections after its exit-Bell's paralysis. A diagnosis may be arrived at by attention to the following. In cerebral disease the lower part of the face is chiefly affected, the eyelids usually escaping. In all the other forms the whole side of the face is paralysed. Hemiplegia of the opposite side of the body and paralysis of the sixth nerve are usually present. In petrous paralysis, owing to involvement of the chorla tympani, there may be interference with the saliva and taste, affecting especially the anterior part of the tongue. The auditory nerve may also be affected. Here and in (3) there will be a history of disease or injury. In complete paralysis the smooth side of the face and forehead, the absence of power of expression, to flown, to blow, or whistle, the open eyelicls and epiphora, and subsequent liability to mischief in the cornea, the dropping of the angle of the mouth and dribbling of saliva, the interference with mastication from paralysis of the buccinator, are the chief points.

Mandible.-Dislocation of the temporo-mandibular joint is referred to on p. 217. In the usual dislocation, from muscular action, the jaw is suddenly brought forward against the anterior part of the capsule, which tends, by the action of the depressors, to give way; the elevators then pull up the mandible, a sequence that must be remembered in reduction. In the commonest fracture of

* Lancet, Jan. 23, 1912.

85 
the mandible-unilateral, near the mental foramen-the larger anterior fragment will be pulled by the depressors downward and medially, the smaller posterior one upward and usually lateral to the other fragment.

Maxilla.-The boundaries of the maxillary sinus (antrum) are of mueh importance. The base of this irregularly pyramidal cavity corresponds to the middle and inferior meatuses on the lateral wall of the nose; toward the upper and back part is the opening into the middle meatus. The apex runs laterally toward the zygomatic process. The roof is formed by the orbital plate with the infraorbital nerve and vessels anteriorly; the floor by the junction of the alveolar areh, carrying the first molars (and often the bicuspids), with the hard palate. It may be pierced by the roots of the seeond bicuspid or first and second molar teeth. Anteriorly, the antrum is bounded by the canine fossa; posteriorly it is in relation with the zygomatic fossa. The cavity, present at birth, increases gradually up to the twelf th year.

The chief paths of infection are through the teeth (especially the first and second molar), the nose, and frontal sinus. The obstinaey of inflammation here is explained by the site of the opening, high up on the medial wall, and thus inadequate drainage, by the imperfectly multilocular cavity of the interior and its rigid walls. The chief sites for opening the antrum are- $(a)$ through the sockets of the first or second molars: $(b)$ through the canine fossa, after the reflection of mucous membrane has been detached, midway between the roots of the teeth and the infraorbital foramen (this path gives more room); $(c)$ through the inferior meatus of the nose.

\section{THE ORBIT AND EYE}

The bony orbit is a pyramidal fossa with its base at the orbital margin and its apex at the optic foramen. The medial walls of the two orbits are approximately parallel, but the lateral walls diverge as they are traced forward and lie at right angles to each other. The thin floor which is formed mainly by the maxilla and corresponds to the roof of the maxillary sinus, is readily destroyed by growths extending up from the sinus and in the process pressure on the infraorbital nerve is apt to eause pain referred to the cheek. The roof formed by the orbital plate of the frontal bone is also thin, and foreign bodies thrust into the orbit may perforate it and enter the frontal lobe of the cerebrum. The medial wall is chiefly constituted by the lacrimal and lamina papyracea of the ethmoid, both very thin bones. This wall is readily destroyed by malignant growths of the nose.

Injuries of the melial wall such as may be associated with fractures of the nose bring the ethmoillal air cells into communication with the cellular tissue of the orbit. The latter may thus be distendel with air on attempting to blow the nose.

The lateral wall is formed in its anterior third by the zygomatie bone, which separites the orljit from the zygomatic fossa. The posterior two-thirds formed by the sphenoid bone separate the orbit from the temporal lobe of the brain in the mirlde cranial fossa. The orbit communicates with the cranium by the optic foramen, which transmits the optic norve and ophthalmie artery and the superior orbital fissure through which pass all the other vessels and nerves of the orl, it.

In casce of fracture of the base of the skull involving the anterior clinoid process, a traumatic communication (artorio-venous ancurysm) may be formed between the internal carotid artery and carcenous sinus, hehind thr: apex of the orbit, riving rise to pulsating exophthahmos.

'The orbital margin is larger' in the transverse than in the vertieal direction, and conserfuently there is more space on either side than above and below betwore it and the eychall which is nealy spherical. The eyeloall lies nearer to the molial that to the lateral matrin and hence foreign bodies more eommonly penetrate the orthit to the lateral side of the "ye.

linhind the fascia bulbi, the eychall lests on a mass of sof loose orbital fat in which foreign bodice may te hidilen for a considerable time.

The structure of the eyelids.-'The different layers are of much practical importaner. (1) 'llor: skin is lolicate and fatless, and contains pigment, the ohient of this bering to protect the rye from bright light. It helps to explain the 'clirk rimeles of Tatre life. (2) Areolar tissue. Owing to its looseness and wolinacy, this is very liable to infiltration, as in ordema and crysipelas. 
Orbicularis. Paralysis of this, the palpebral portion, leads to epiphora, the puncta being no longer kept in their normal backward direction against the conjunctiva. (4) Palpebral fascia, reaching from the orbit to the tarsal cartilage. This is usually strong enough to prevent hæmorrhage, due to fractured base of skull, becoming subcutaneous. (5) Levator palpebræ. (6) Tarsal plate; in reality, densely felted fibrous tissue. (7) Tarsal (Meibomian) glands, lashes, and sebaceous follicles.

Localised inflammation starting in any of these last three structures, especially the last, will cause a 'stye.' The frequency with which the lid-border is the seat of that most troublesome chronic inflammation, blepharitis, and its result, 'blear eye,' is explained by these anatomical points. Its circulation is terminal and slow; half skin and half mucous membrane, it is moister and more liable to local irritation than the skin; while its numerous glands readily participate in any inflammation.

Fig. 1094.-Sagittal Section Throcgh the Upper Erelid. (After Waldeyer and Fuchs.)

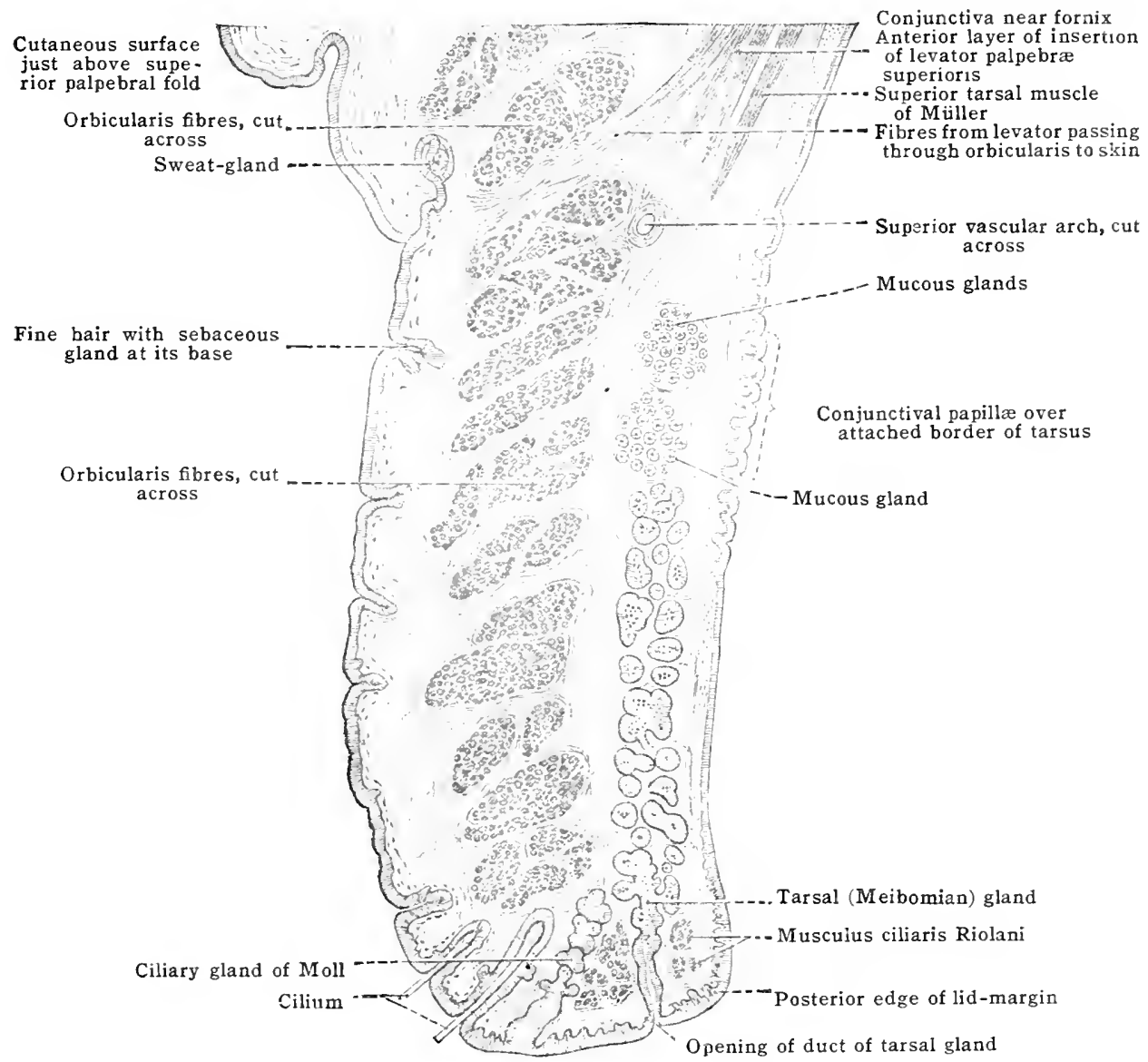

(8) The conjunctiva. To trace this important membrane, the lids should be everted, when the following will be noted. The conjunctiva over the tarsal part of the lid is closely adherent, and through it a series of nearly straight, parallel, light yellow lines and granules, the tarsal glands, can be seen. Owing to their position here (fig. 1094) and to avoid scarring, a tarsal cyst is always opened on its conjunctival surface.

Beyond the tarsi, the palpebral conjunctiva is thicker and freely movable owing to the abundant lax submucous tissue. Lnderlying vessels are visible here. Leaving the eyelid the conjunctiva is reflected onto the eyeball at the fornix. Into the lateral part of the upper fornix open the ducts of the lacrimal gland. The bulbar conjunctiva is continued over the front of the eyeball to the corneal margin. It is thin and contains fine vessels which are distinguished from subjacent episcleral vessels by the fact that they move with the conjunctiva. 
These conjunctival vessels, derived from the lacrimal and palpebral arteries, become very visible in conjunctivitis. In deep inflammation affecting the ir is and ciliary borly, the episcleral branches of the anterior ciliary arteries (which are derived from the muscular and lacrimal arteries) become engorged and are visible as a pink circumcorneal zone of congestion, rleeply situated under the conjunctira. These branches take a large share in the nutrition of the cornea. and are responsible for the vascularity of panmus and the 'salmon patches' of interstitial keratitis.

The conjunctival nerves for the upper lid and bulbar part of the membrane, and the nerves to the cornea, are supplied by the ophthalmic division of the trigeminal. The maxillary division of this nerve supplics the lower palpebral conjunctiva.

The differing structure of the palpebral and ocular portions has important bearings. Thus the palpebral conjunctiva is thick, highly vascular and sensitive. To this vascularity we owe the chemosis, or hot, red, tense swelling of purulent ophthalmia. The exquisite suffering of the same disease, or that caused by a forcign body, is explained by the numerous nerve-papillæ and endbulbs. To the thickness and abundance of the connective tissue are due the contraction and permanent thickening which may occur in granular licls. The so-called granulations, met with in this disease on the palpebral conjunctiva, are really little nodules of hypertrophied lymphoid follicles, or mucous glands, which abound here.

Imnediately under the bulbar conjunctiva, between it and the sclerotic, lies the anterior part of the fascia bulbi (of Tenon). This fibrous membrane forms a sheath for the posterior

Fig. 1095.-The Lacrimal Apparatus and Naso-lacrimal Duct. (Bellamy.) (Bristles are introduced into the puncta lacrimalia.)

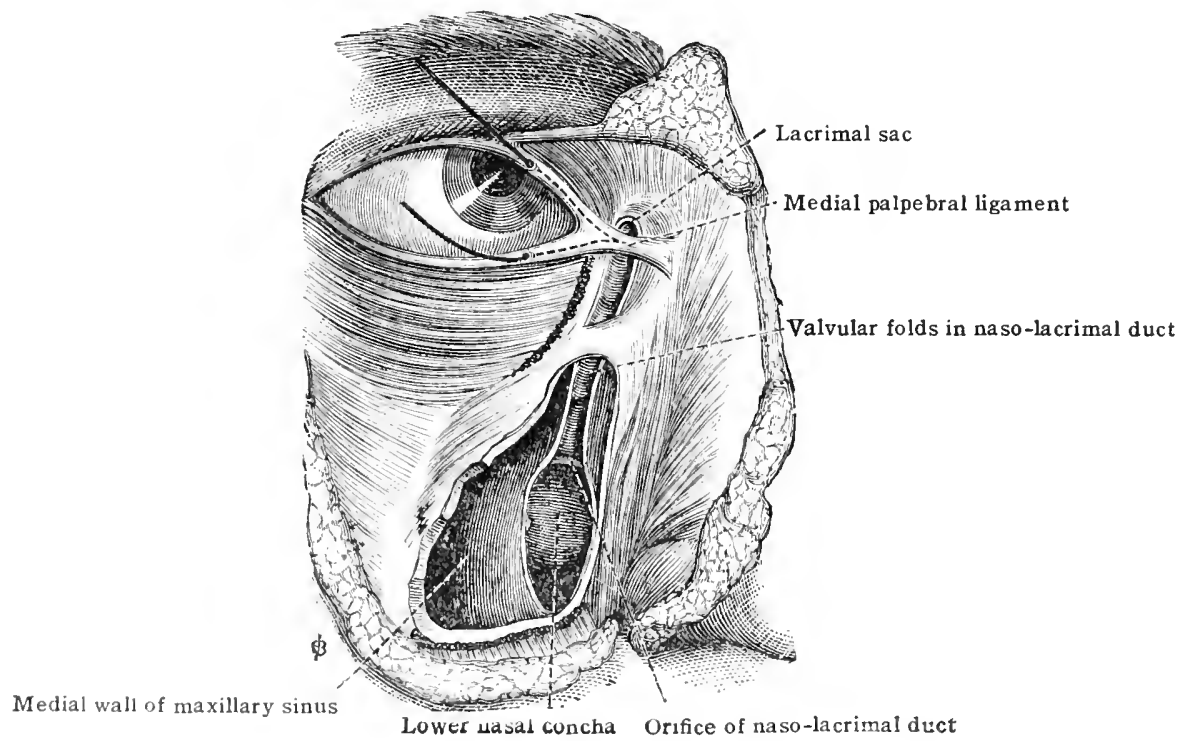

five-sixths of the eychall, and is intimately connected with the sheaths of the extrinsic muscles and through the check ligaments with the orbital walls. Together with the conjunctiva it must be opened in the operation of temotomy for strahismus, and after division of a rectus tendon the muscre retains some entrol over the eye through jts connertion with the fascia bulbi. In enteleation of the eyethall both conjunctiva and fascia bulbi are divirled around the cornea, where they ale intimately blemerl. In pemoval of the upper jaw the attachment of the suspensory ligancht of this faseia must always be left if possible, for otherwise the eyeball will tend to fall forwatel atrd the cornea sulfer from its exposture (Lockwood). linally the cavity between the f wo layers of the andunle is continuous with the extensions of the rerebral membranes along the optice inerve, i. e., with the subarachonicl spatce.

for an arement of the intrinsio and extrinsic muscles of the eve the reader is referred to the section on the liyt. lieference may be male here, however, to the part played loy certain fibres of the cervical sympathetic system. Humering from the eorl at the first and second thoracic

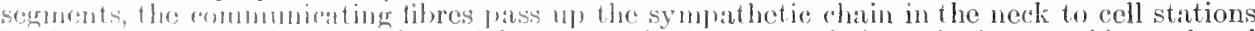

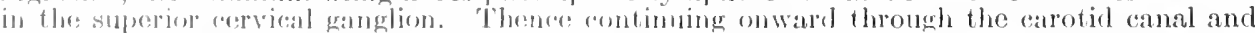

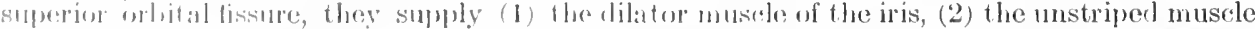

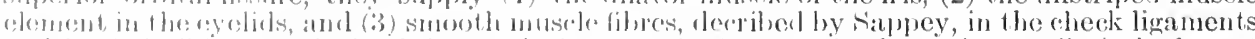

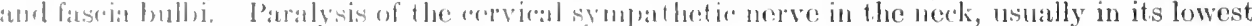

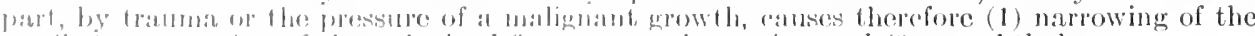

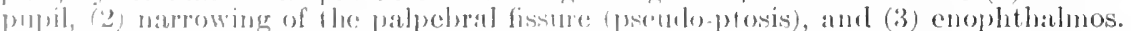

T'he lacrimal gland lies in a hollow at the supero-lateral angle of the orbit, protreforl by the sygonatio process of the frontal bone. It is not palpable normally. Its lower or palpebral purtion rests on the lateral third of the formix 
conjunctivæ, into which the numerous ducts open, and it may be seen through the conjunctiva on everting and raising the upper lid.

The position of the lacrimal puncta should be noted; owing to their backward direction, the lids must be previously everted. The puncta are kept open by a minute fibrous ring.

Each is situated on a minute papilla at the junction of the medial and straight third of the lid with the lateral curved two-thirds. Close to the medial angle, in addition to the puncta and papillæ, should be noted the caruncula lacrimalis, with its delicate hairs, and the plica semilunaris, which corresponds to the third eyelid of certain birds.

The lacrimal sac is a most important part of the lacrimal apparatus, from its disfiguring diseases; it lies in a bony groove, between the nasal process of the maxilla and the lacrimal bone. The medial palpebral ligament crosses it a little above its centre (fig. 1095). Thus two-thirds of the sac are below the ligament, and in suppuration the opening is made below it also. The angular artery ascends on the nasal side of the sac.

The manipulation of a probe along the lacrimal passages should thus be practised:- the lower lid being drawn laterally and downward by the thumb, the probe is passed vertically into the punctum, then turned horizontally and passed on till it reaches the medial wall of the sac. It is then rotated somewhat forward, raised vertically, and pushed gently along the duct downward, and a little lateralward and backward, till the floor of the nose is reached, the operator aiming, as it were, for the site of the first molar tooth. The naso-lacrimal duct extends from the lower end of the lacrimal sac to the inferior meatus of the nose and is about $1.2 \mathrm{~cm}\left(\frac{1}{2} \mathrm{in}\right.$.) in length.

If the eyes are opened naturally, the greatest part of the cornea, behind it the iris, with the pupil in the centre, on either side of the cornea some of the sclerotic, the semilunar fold, and caruncle can be seen.

\section{THE MOUTH}

The lips.-When the whole thickness of the lip is incised the labial artery will be found lying near the free margin, internal to the orbicularis muscle, and

Fig. 1096.-Side of the Face and Mouth Caytity, showing the Three Salivary Glansd.

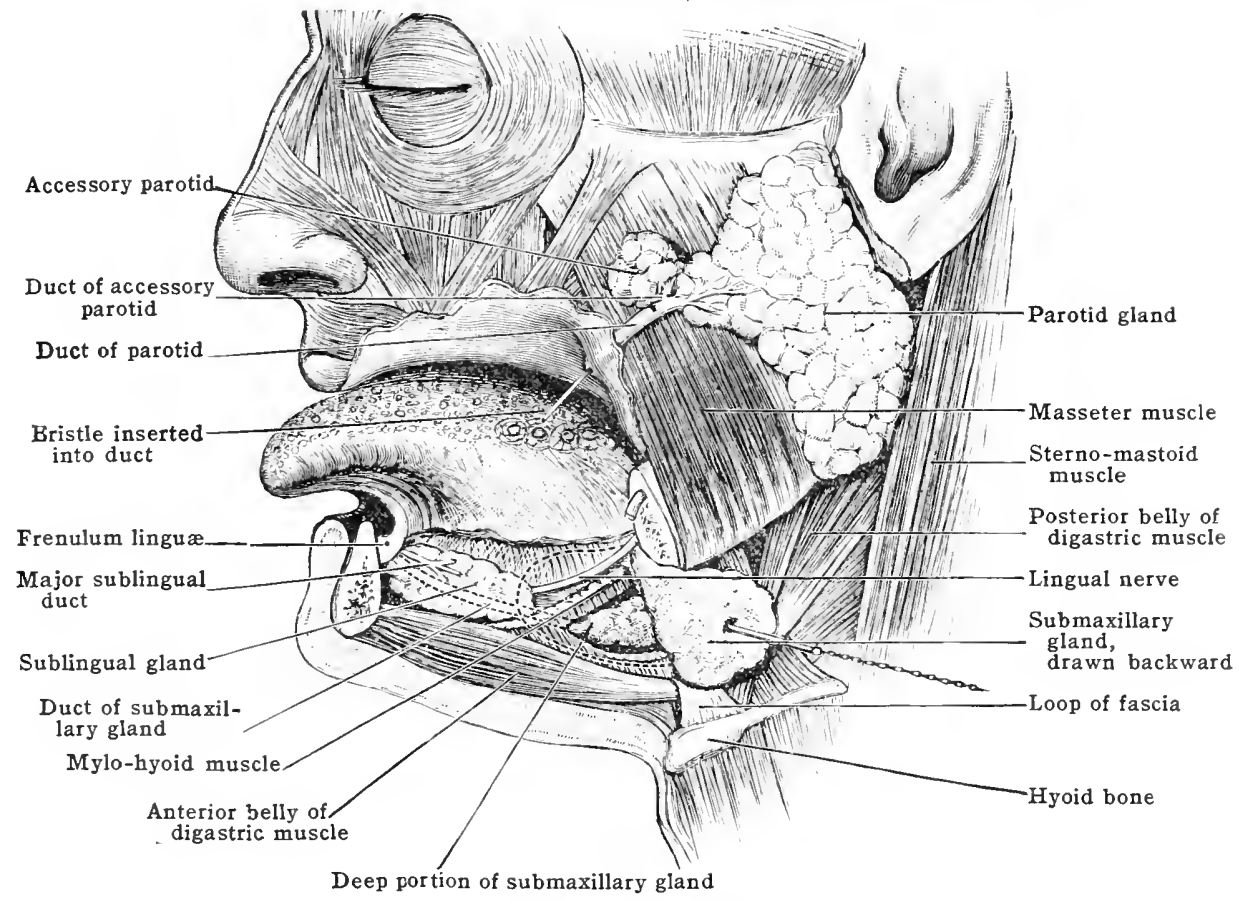

between it and the mucosa. There is a very free anastomosis between the arteries of the opposite sides.

If the tongue be raised, the under surface is seen to be smooth and devoid of papillæ. In the middle line is the frenulum. When division of this is really required in tongue-tie, the scissors should be kept close to the bone, in order to avoid the ranine vessels. 
Of these, the veins can be seen just to one side; the arteries are close by, but deeper. Farther out are two more or less distinct fringed folds, the plics fimbriatæ, ruuning from behind forward and, like the frenulum, disappenring before the tip. Between these and the frenulum are the small apical mucous glands of Nuhn or Blandin. Farther back, at the junction of the mucous membrane and the alveoli, are two other projections of the mucosa, the sublingual; under these are the sublingual glands, the ranine veins, and, more deeply, Wharton's duct and the termination of the lingual nerve. The majority of the ducts of the sublingual gland (Rivinian) open on the sublingual ridges. A single larger one, Bartholin's, opens with that of Wharton, or close to it, on either side of the frenulum (fig. 1096). Dilatation of one of the Rivinian ducts, more frequently dilatation of a muciparous gland-and, much more rarely, dilatation of Wharton's duct -constitutes a 'ranula.'

The submaxillary gland can be felt nearer the angle of the jaw, lying between its fossa and the mucous membrane, especially if pressure is made from outside. The attachment of the genio-glossi can be felt behind the symphysis: the division of the muscles allows the tongue to come well out of the mouth; but when both have to be divided, the tongue loses much of its steadiness, and may easily fall

Fig. 1097.-Sebtion of the Skull and Brain in thf Median Plane. (Braune.)

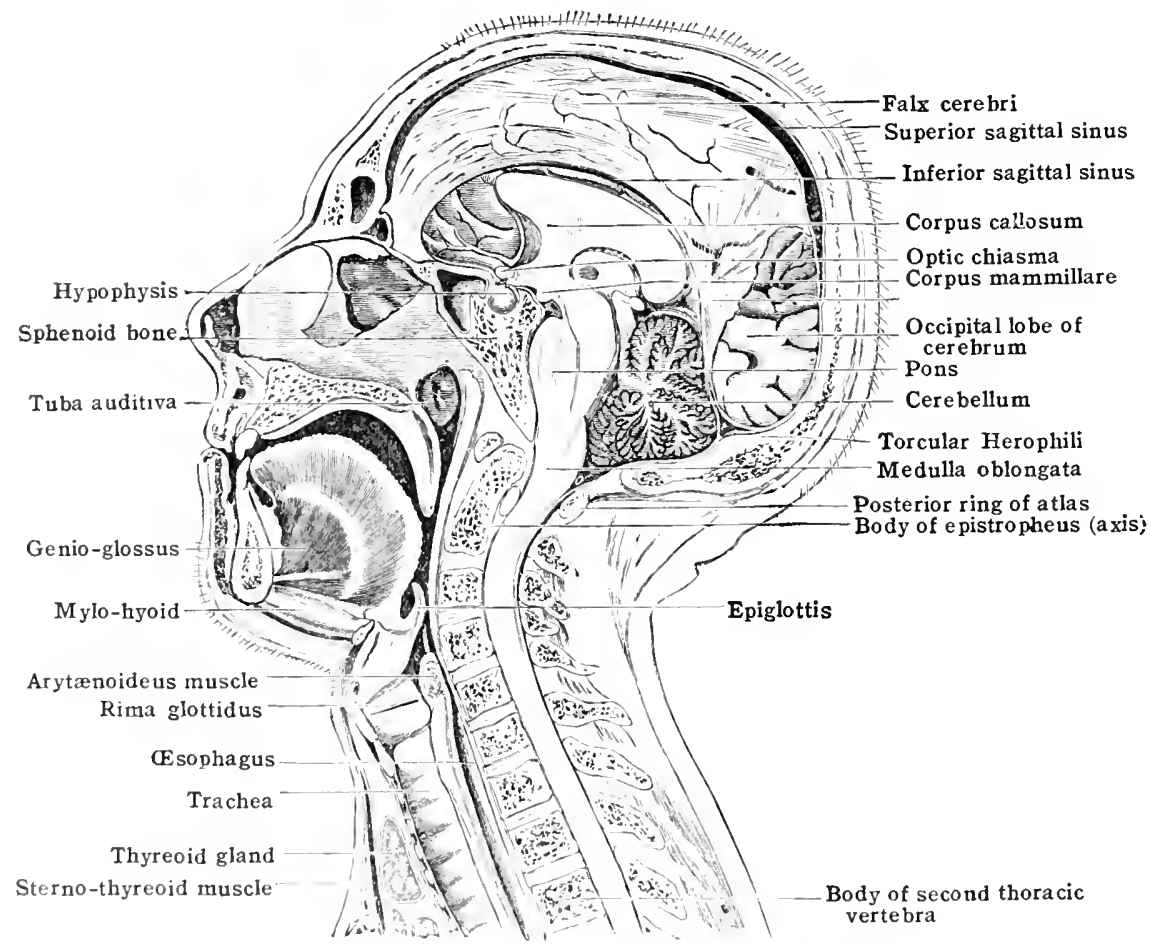

back over the larynx during the administration of the anssthetic or, later on, in sleep. It should therefore be seeured forward for a while with silk. For the satne reason, in removal of onc-half of the mandible, part of this muscular attachment should always be left, if possible.

Thurning now to the rorsum of the tongne, this shows two distinet parts: one, the anterior two-thirls, the bucrol, is rich in palpille; the of her, the posterior, the pharyngeal, contains abundant lymphoinl follieles like the tonsil. This part possesses peculiar sensibility, as shown by movenents of tongue and palate when a leveresor is placed too far back. The two parts

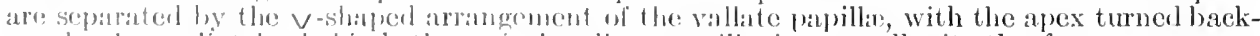

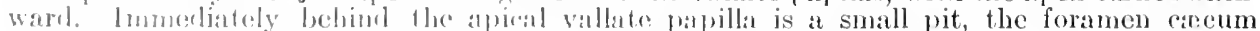

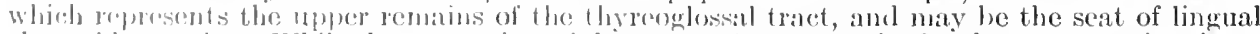

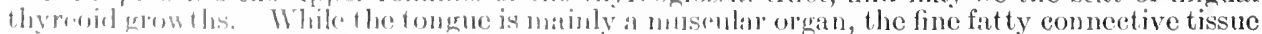

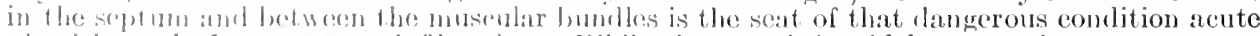
ghossitis, and of gummatous infiltration, While the mouth is widely open, the pterygo-man-

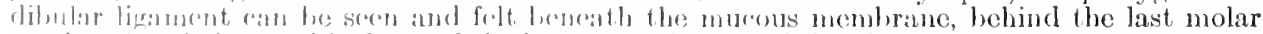
torth. Just holow and in front of the lower attachment of this ligament the lingual nerve can

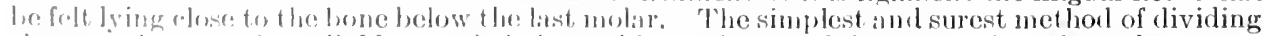

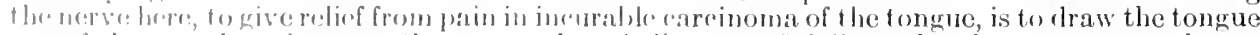
wat of the month and pxpose the nerve whore it lies superfirially under the mucous membrane

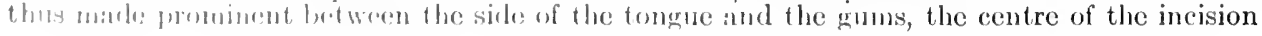


being opposite to the last molar tooth. (Roser, Létiévant.). In cancer of the tongue pain is often referred up the auriculo-temporal nerve to the ear and side of head.

Behind the last molar tooth can be felt the coronoid process, and higher up, just behind and medial to the tooth, the pterygoid hamulus of the sphenoid. This process is a landmark to the site of the greater palatine foramen, which lies just in front of it, and which transmits the greater palatine branch of the descending palatine artery, together with the anterior palatine nerve. The vessel and nerve run forward in grooves on the lower surface of the palatine process of the maxilla, giving off anastomosing branches toward the middle line, and join at the incisive foramen with the nasopalatine artery.

Their position must be remembered in raising the flaps during the operation for closure of a cleft in the hard palate. To ensure the vitality of the flaps the incisions must be made lateral to the vascular arch, close to and parallel with the upper alveolus, and should not extend beyond a point opposite to and just medial to the last molar tooth, for fear of encroaching upon the posterior palatine canal.

When the teeth are clenched, there is still a space, communicating between the mouth and pharynx behind the molar teeth, which admits a medium-sized catheter. When a patient breathes deeply through the mouth and the head is thrown back, the soft palate is raised, the pillars (arches) separated; the uvula and fauces, with the anterior and posterior pillars, with their attachments, the tonsils, and the back of the pharynx are exposed.

This portion of the pharyngeal mucous membrane would lie over the lower part of the second and the upper part of the third cervical vertebræ, the anterior arch of the atlas corresponding to the level of the posterior nares, and the body of the epistropheus (axis) to the level of the soft palate (fig. 1097). If a finger be introduced past the soft palate to this part of the spine and turned upward and downward, it is possible, with the aid of an anæsthetic, to examine the upper four or five and, in children, six vertebræ, as far as the anterior surfaces of their bodies. "The part of the column which is accessible to a straight instrument in troduced through the mouth is very limited, extending, in the adult, from the lower border of the axis to the middle or lower part of the fourth cervical vertebra; in the child, owing to the small size of the face, it comprises the bodies of the axis and of the third cervical vertebra.' (Thane and Godlee, from Chipault.) The distance from the incisor teeth to the commencement of the oesophagus at the cricoid cartilage is $15 \mathrm{~cm}$. (6 in.) in the adult, and the distance from the teeth to the cardiac orifice of the stomach is 48 to $50 \mathrm{~cm}$. (16 or 17 in.).

The lymphatic drainage of the face, mouth, and tongue is given on pp. 712 and 715 .

Tonsils.-The relations of the tonsils should be carefully examined. Thus, they are separated externally by the superior constrictor and pharyngeal aponeurosis from the oscending pharyngeal and internal carotid arteries. The latter vessel lies about $2.5 \mathrm{~cm}$. ( $1 \mathrm{in}$.) behind and to the lateral side of the tonsil. When serious hæmorrhage follows operations here, it usually comes from one of the numerous tonsillar branches (fig. 448). The extent to which the tonsil is covered by the anterior pillar, how far it projects upward beneath the soft palate or downward into the pharynx, have all important bearings on the mode of removal. Its position corresponds to a point a little above and in front of the angle of the jaw. The lateral surface, enclosed by an imperfect capsule and separated from the superior constrictor by connective tissue, explains how an enlarged tonsil can be dragged medialward by a vulsellum, and enucleated after an incision in the mucous membrane around. It is in this connective tissue that severe infectire inflammation, e. g., after scarlet fever or an imbedded pipe-stem, may set up hæmorrhage or spreading cellulitis, retro-pharyngeal or otherwise.

The finger introduced downward at the back of the mouth, especially if the parts are rendered in sensitive by local anæsthetics, feels the vallate papillæ, the lingual and laryngeal surfaces of the epiglottis, the arytæno-epiglottidean folds, with the cuneiform and corniculate cartilages. If the finger be moved upward behind the soft palate and turned upward to the base of the skull, and then forward, it will feel the choanæ (posterior nares), separated by the vomer. The other boundaries of these are, laterally, the medial pterygoid plate and palate bones; above, the basisphenoid; and below, the horizontal plate of the palate bone and the inferior nasal spine. Within each nostril would be felt the posterior ends of the two lower nasal concha (turbinate bones); above and behind is felt the basilar process of the skull, the vault of the pharyn, and the bodies of the upper cervical vertebra (fig. 1097).

The size of the choanæ, in the bony skull $2.5 \mathrm{~cm}$. (1.in.) vertically by $1.2 \mathrm{~cm}$. ( $\frac{1}{2} \mathrm{in}$.), and the presence of any adenoids, are especially to be noted. The richness of the naso-pharynx in glandular structures, its proneness to inflammation, and of this inflammation to spread to other parts,-e. g., the tympanum,-are well known. The finger should be familiar with the feel of 
adenoids-i. e., hypertrophied post-nasal lymphatic nodules--soft bodies of irregular shape blocking up the naso-pharynx. To make out how far this is the case, it is well to take the nasal septum as the starting-point.

Pharyngeal hypophyseal remnants.-In the naso-pharyngeal mucosa, a few millimetres behind the posterior border of the vomer, a group of glandular cells may be found on microscopical examination in all cases (Haberfeld), corresponding in histological appearance with the pars anterior of the hypophysis. These cells are a remnant of the primitive bud that grows toward the brain in front of the bucco-pharyngeal membrane to form the pars anterior of the hypophysis. In some cases of pituitary disorder they give rise to a palpable tumour in the nasopharyn.

The palate.-Between the diverging pillars of the soft palate is the isthmus faucium, bounded above by the free margin of the palate, and below by the dorsum of the tongue. The space between the arches (pillars), glossopalatine and pharyngo-palatine, with attachments denoted by their names, shallow above, widens and deepens below. Of its lateral boundaries, the posterior pillars come nearer cach other than the anterior. The coverings of the hard palate are chiefly mucous membrane, glands, and periosteum. These are intimately blended by fibrous septa, as in the superficial layers of scalp and palm of the hand. Hence the readiness with which necrosis takes place here.

Hare-lip and cleft palate.-Failure of union between the mesial nasal process and the maxillary process of the embryo gives rise to the deformity known as hare-lip.

The palate is developed from three primitive processes growing down from the basis cranii, viz., (1) the mesial nastl process forming the premaxilla which lies in front of the anterior palatine for amen and bears the four incisor teeth, (2) and (3) the maxillary process of either side. The slighter cases of failure to unite affect only the soft palate which is the last part to fuse. Complete alveolar cleft palate, which occurs combined with hare-lip and may be unilateral or bilateral, represents more serious non-union. In this condition the lateral incisor may be found either on the medial or on the lateral side of the cleft, which is explained by the fact that this tooth is developed in the groove between the two processes (Keith).

In paring the edges of a cleft soft palate, the following structures would be, successively, cut through:-(1) Oral mucous membrane; (2) submucous tissue, with vessels, nerves, and glands; (3) glosso-palatine muscle; (4) aponeurosis of tensor palati; (5) anterior fasciculus of pharyngo-palatine; (6) levator palati and uvular muscles; (7) posterior fasciculus of pharyngopalatine; (8) submucous tissue, ressels, nerves, and glands; (9) posterior mucous membrane. The soft palate is thicker than it seems, the average in an adult being $6 \mathrm{~mm}$. ( $\frac{1}{4} \mathrm{in}$.). The muscles widening a cleft are the tensor and levator, while the superior constrictor closes it in swallowing. Of the arteries of the palate, from the external maxillary (facial), ascending pharyngeal, and internal maxillary, the largest is the descending palatine branch of the last. This enterges from the posterior palatine canal close to the inner side of the last molar tooth.

\section{THE NOSE}

On the face the outline of the nasal bones can be easily traced, and below them the lateral nasal cartilages, flat and also somewhat triangular. Below these are the greater alar cartilages, curved and so folded back that each forms a lateral and it merlial plate. Of these, the medial meet below the septal cartilage to form the tip of the nose, while the lateral curve backward, and, together with dense masces of cellular tissue and fat and accessory cartilages, form the ala.

With the speculum, especially if the head be thrown back and the tip of the nose drawn up, the lower part of the septum, floor of the nose, and greater portion of the inferior concha (turbinate bone) can be seen. On throwing the head further back, with a good light the lower margin of the middle concha can also be madro out. This is much higher up and nearly on a level with the root of the nasil bone. The septum often deviates to one side. The mueous membrane orer it is, in health, dull red in colour; that over the inferior concha is thicker.

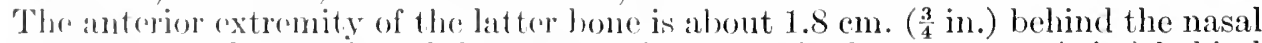
orifier, while the opening of the naso-lacrimal luet is about $2.5 \mathrm{~cm}$. (1 in.) behind and about $1.8 \mathrm{~cm}$. ( $\begin{aligned} & 3 \\ & 3\end{aligned} \mathrm{in}$.) above 1 ho ftoor, concealed by the anterior extremity of the inferior (oncha. 'The opening into the maxillary sinus (antrum) is situated in alkut the rentre of the midrlle meatus and $2.5 \mathrm{~cm}$. (1 in.) above the floor

Ther olfactory area of the mucous membrane extends over the highest concha (poscibly also somewhat. lower) and corresponding portions of the septum. The respiratory portion is nore vaseular and thicker, especially over the concha. It is firmly arlherent to the poriostrum and perichondrium. The veins, especially orer the lower conchar, form a dense plexus, closely resembling cavernous tissue. 
This fact explains the severity of epistaxis, and, together with the drainage of blood into out-of-the-way veins, such as the spheno-palatine and ethmoidal,

Fig. 1095.-Section of the Nose, showing the Conche (Turbinate Bones) and Mieateses with the Openisgs in Dotted Outhine.

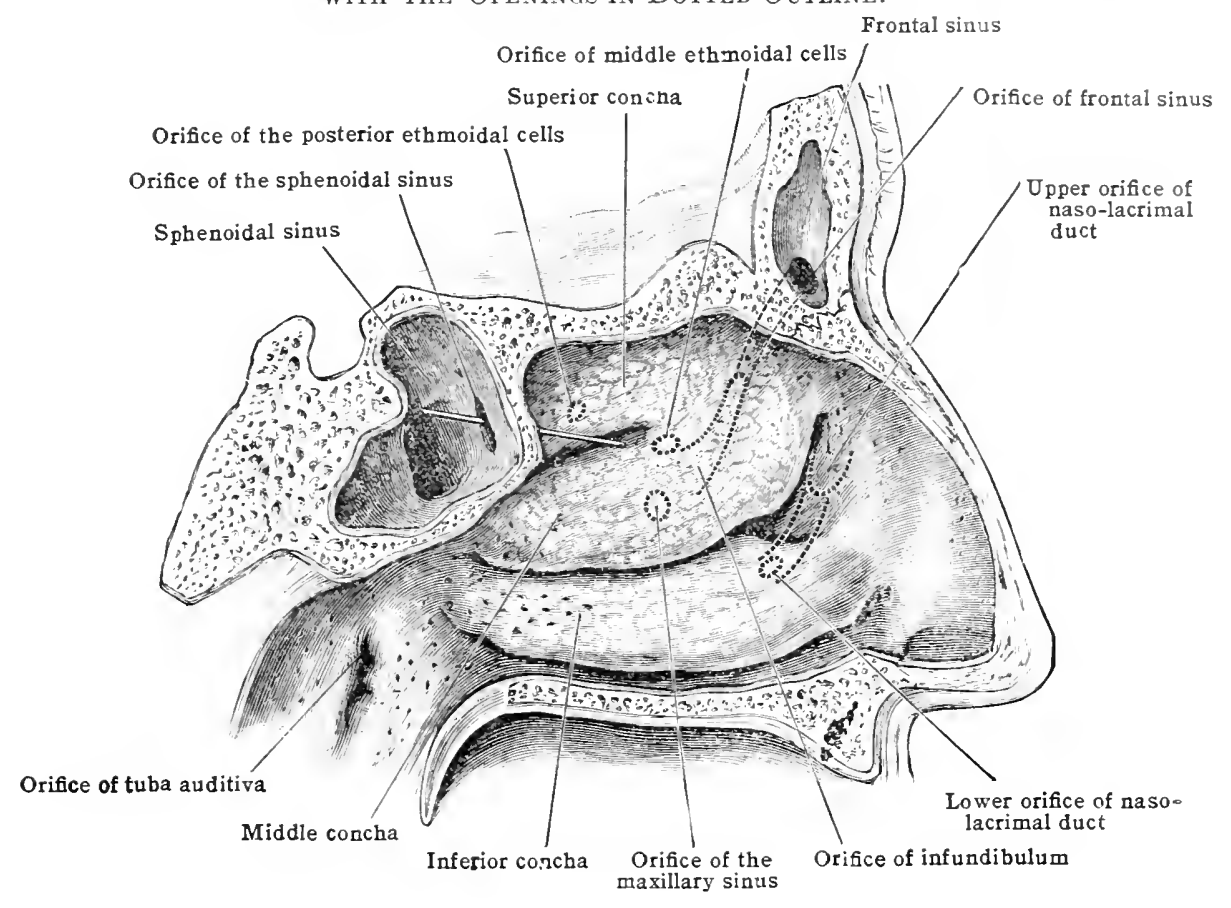

Fig. 1099.-Section shoming Bony and Cartilaginous Septui.

The dotted line indicates the course of the incisive (anterior palatine) canal.

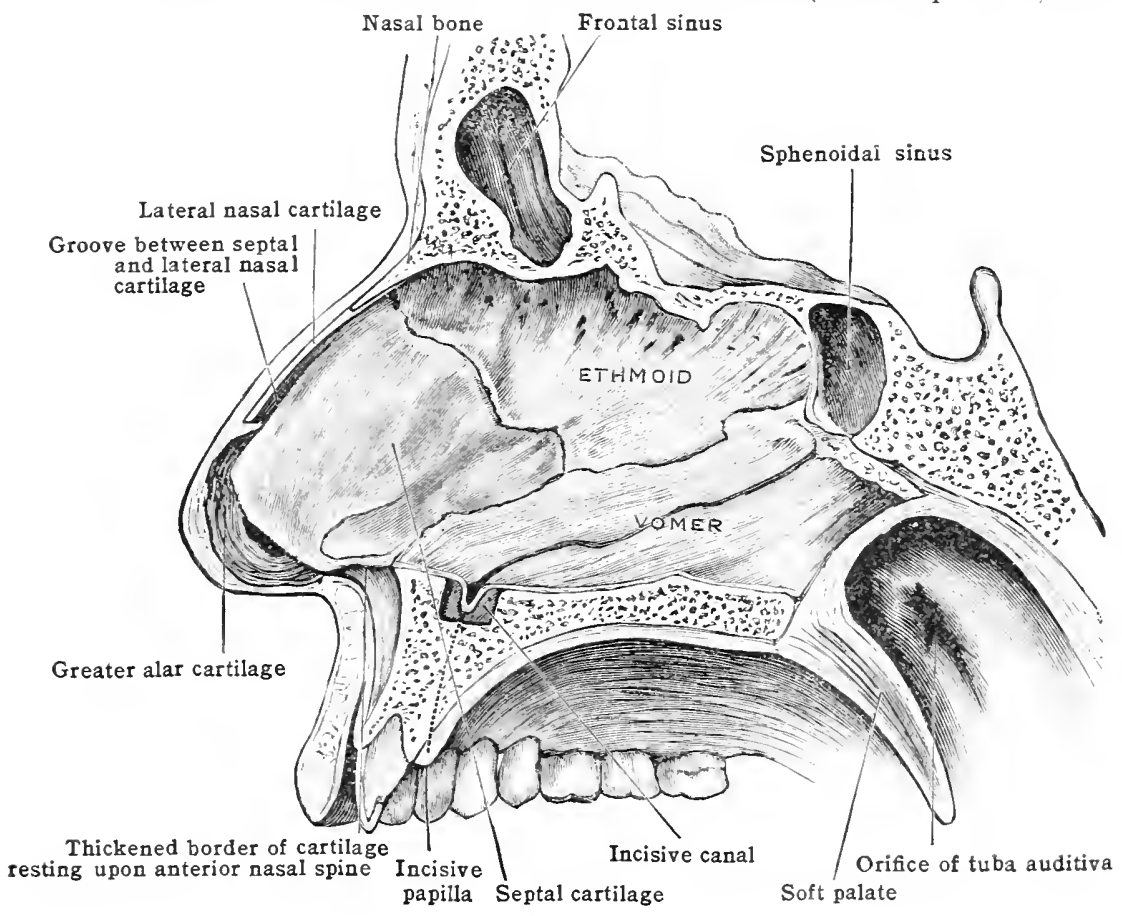

accounts for the serious results which may follow on a firmly impacted and infected plug. The boundaries of the posterior nares have been given above. 
About $1.2 \mathrm{~cm}$. ( $\frac{1}{2}$ in.) behind the posterior extremities of the inferior conchx, just above the level of the hard palate (fig. 1097), on the side of the naso-pharynx, are the openings of the tube auditive (Eustachian tubes). Oval in shape, these are bounded above and behind by the prominence of the cartilage, which is wanting below, thus facilitating the entry of a catheter. The lower part of the tube contains in early life lymphoid tissue; enlargement of this explains the deafness in certain eases of adenoids. At the upper part of the naso-pharynx, on the posterior wall, extending down laterally as far as the tubæ auditivæ, is the collection of lymphoid tissue known as the pharyngeal tonsil, which when hypertrophied, plays a large part in 'naso-pharyngeal adenoids.' From the periosteum of the basi-sphenoid and basi-occipital arise naso-pharyngeal fibromata.

Nasal septum.-The structure of the skeletal element of the septum, which consists of the septal cartilage, the vertical plate of the ethmoid and the vomer, is shown in fig. 1099. Slight deviations of the septum to one side are common in adults, and involve mainly the cartilage and the ethmoid bone, the vomer being but little affected as a rule.

The convexity is most commonly on the right side, and occlusion of the nares on that side with unsightly deflection of the whole nose, results in some cases during the transition from the nfantile to the adult facial conformation. Too extensive removal of the bony septum in the operation of submucous resection for the relief of this condition may cause sinking in of the bridge of the nose. More often, however, this is due to the destructive effect of congenital syphilis.

Accessory sinuses. - The communication of these air sinuses with the nasal fossæ are of great clinical importance. The sphenoidal sinus opens high up into the spheno-ethmoidal recess. The posterior ethmoidal sinuses open into the superior meatus under cover of the superior concha. The infundibulum of the frontal sinus, the anterior and middle ethmoidal and the maxillary sinus all communicate with the middle meatus under cover of the middle concha. The orifice of the maxillary sinus lies at the lowest part of the hiatus semilunaris into the front and upper end of which the frontal sinus opens. Consequently infected fluid may trickle down from the latter into the maxillary sinus. The orifice of this sinus is placed high up in its medial wall so that fluid does not drain away from it readily in case of infection. When the head is held forward in a stooping position some of the pus or mucus may escape from the nostrils, since in this position the fluid contents more readily reach the orifice.

The naso-lacrimal duct which carries the tears into the nose opens into the front and upper part of the inferior meatus under cover of the inferior concha.

\section{THE NECK}

The topies considered in the neck are the landmarks, thyreoid gland, sternomastoid, clavicle, triangles and cervical rilss.

Bony and cartilaginous landmarks. - The body of the hyoid is nearly on a level with the angles of the jaw, and the interval between the third and fourth cervical vertebrar (fig. 1097). With the head in the usual erect position it lies a little higher than the chin. It divides the front of the neek into supra- and infra-hyoir ragions, convenient for remembering the distribution of the decp fascia. ()n either side of the body are the great cornua, with the lesser cornua attacherl to their upper borders at the junction with the body. The upper borders of thes are the grides to the lingual arteries. The outline and mobility of the borly and the great comua are rasily determined by lelaxing the deep fascia and pushing the bone over to the opposite side. Below the hyodit is the thyreo-hyoid space, which corresponds with the epiglottis and the upper aperture of the laryms. 'Thus, if the throat be cust above the hyojd, the mouth will be opened and the tongne rut into; if the thyreo-hyoid space be ent, the pharynx would be

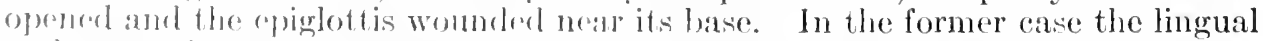
and extronal maxillary are the most likely vessels to be wounded; in thyreo-hyoid, the enmmenest ent -throat, the superior thyreoid vessels, and the superior laryngrat nerve. The projertion of the thyreode notele, about $2.5 \mathrm{~cm}$. (1 in.) below thre hrovis, is much more distinct, in mon than in women or children. It does not appar bofore pulnerty, and thus dhatness of the thyreoid nust be expected 
when the landmarks for tracheotomy are sought for in children with short fat necks.

The cricoid, on the other land, is always to be made out. It corresponds in horizontal plane to the following:-(1) The sixth cervical vertebra. (2) The junction of pharynx and œsophagus: from the narrowing of the tube here, foreign bodies may lodge at this point and cause dyspncea by pressing on the air-tube in front. The cricoid is taken as the centre of the incision in cesophagotomy, and also for ligature of the common carotid. (3) The junction of larynx and trachea. (4) The crossing of the omo-hyoid over the common caroticl. (5) The middle cervical ganglion. Above the cricoid is the crico-thyreoid membrane. In laryngotomy, the deepest part of the incision should be kept to the middle line for fear of injuring the cricothyreoids, and as near the cricoid as possible, so as to avoid the neighbourhood of the vocal cords and the small crico-thyreoid vessels. The space is always small, and, after middle life, increasingly rigid.

The distance between the cricoid and the manubrium is only about $3.7 \mathrm{~cm}$. ( $1 \frac{1}{2} \mathrm{in.}$.). When the neck is stretched, about $1.8 \mathrm{~cm}$. ( $\frac{3}{4}$ in.) more is gained. Thus, as a rule, there are not more than seven or eight tracheal rings above the sternum. Of these, the second, third, and fourth are covered by the thyreoid isthmus.

The parts met with in the middle line- $(a)$ above, and $(b)$ below, the isthmus-high and low tracheotomy - should be borne in mind: (a) Skin, superficial fascia, branches of transverse cervical and infra-mandibular nerves, lymphatics, cutaneous arteries, anterior jugular veinswith their transverse branches smaller above-deep fascia, sterno-hyoids, cellular tissue, superior thyreoid vessels, and pre-tracheal layer of deep fascia. The inportance of this last is twofold, as, first, the tube in tracheotomy may be passed between it and the trachea, and after a wound in this region this layer, continuous with the pericardium, may conduct discharges into the mediastina. (b) The surface structures are much the same, but the anterior jugular veins and their transverse branches are much larger. The inferior thyreoid veins are also larger. A thyreoidea ima may be present, and the innominate artery, especially in children, may be 1.2 $\mathrm{cm}$. ( $\frac{1}{2}$ in.) above the sternum. The trachea is also smaller, deeper, and less steadied by muscles. The thymus, too, in young children, may prove a difficulty. Thus, in children, the high operation, incising the cricoid and crico-tracheal membrane, if needful, is to be preferred. The cricoid is, however, not to be incised, if possible; the higher the tube is inserted, the greater the irritation.

The suprasternal notch, between the sternal heads of the sterno-mastoids in on a level with the disc between the second and third thoracic vertebræ. Just below the level of the cricoid cartilage, on deep pressure at the anterior border of the sterno-mastoid the transverse process of the sixth cervical vertebra may be felt. It is known as Chassaignac's carotid tubercle, and the common carotid may be compressed against it. Compression below it will command the vertebral artery as well.

The thyreoid gland enclosed in a capsule of deep fascia derived from the pretracheal layer (fig. 1070) is closely connected by this to the upper trachea and larynx. The upper somewhat pointed extremity of each lateral lobe reaches to the upper and back part of the thyreoid cartilage; here enter the superior thyreoid vessels. The lower layer and rounded extremity reaches to the fifth or sixth tracheal ring; its posterior and lower aspect is in relation to the inferior thyreoid vessels and the recurrent nerve; the lateral lobe, posteriorly, also overlaps the carotid sheath, which may be infiltrated in malignant clisease of the thyreoid. The thyreoidea ima has been mentioned above.

The isthmus in the adult is opposite to the second, third, and fourth tracheal rings. At its upper border is an arterial arch formed by the superior thyreoids; over the anterior sulface of the gland and isthmus the inferior thyreoid veins take origin in a plexus. The upper border of the thymus (fig. 1100) may be in relation with the lower border of the isthmus. From the upper border of the latter, the pyramidal lobe, especially on the left side, is of ten present, reaching by a pedicle to the hyoid. The pyramidal lobe, when present, is the persistent rennant of the thyreo-glossal duct, and occasionally cystic outgrowths persist obstinately as remnants of this duct, in the middle line, above, behind, and below (the commonest form) the hyoid bone.

In short-necked people the thyreoid is relatively lower in relation to the sternum, and enlargements of the gland are apt to become mainly intra-thoracic. An enlargement of the thyreoid is liable to give trouble by pressure on $(1)$ the trachea, which is compressed laterally. between the lateral lobes; (2) the oesophagus; (3) the internal jugular vein and carotid artery; (4) the recurrent laryngeal or cervical sympathetic nerves.

Parathyreoids. - These small glands, about the size of a pea, vary somewhat in number and situation. There are usually four-two behind each lateral lobe. The upper glands lie imbedded in the capsule of the thyrevid about the junction of the middle and upper thirds of the lateral lobes on the posterior aspect. The lower pair lie nearer the lower poles of the lateral lobes, sometimes separated from them by a distinct interval. Excision of all the parathyreoids gives rise to tetany in animals.

The sterno-mastoid is the landmark for several important operations. Its medial border, the thicker and better marked of the two, overlaps the carotids; 
the common carotid corresponding, as far as the upper border of the thyreoid, with a line drawn from the sterno-clavicular joint to midway between the mastoid process and the angle of the jaw. The artery can be best compressed above the level of the cricoid, as here it is less deeply covered. The student should recall the deep relations of the stemo-mastoid, which he may classify as vessels, nerves, muscles, glands, and bones; or, according to their position, (1) those above the level of the angle of the jaw; (2) those between the angle of the jaw and the omohyoid; (3) those below the omo-hyoid.

Of the two heads of the sterno-mastoid, the sternal is the thicker and more prominent, the clavicular the wider. A stab through the interval which lies between the two heads might wound the bifureation of the innominate on the right side, and the common carotid on the left, the internal jugular, vagus, and phrenic veins, according to the direction of the wound.

\section{Fig. 1100.-Thymus Giand in a Child at Birth.}

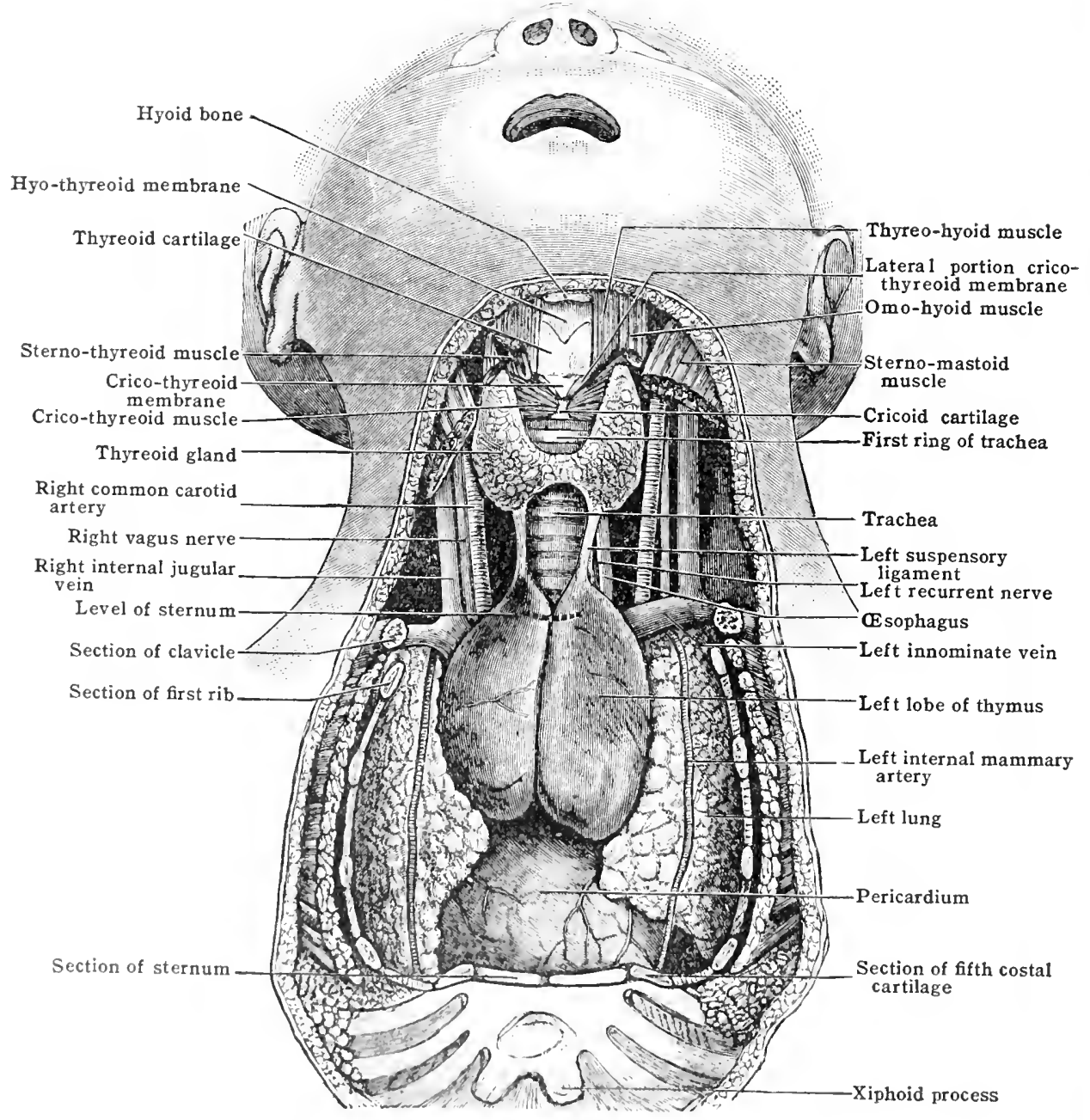

T'h" anterior jugular, commencing in branches from the submaxillary and suldmental regions, descends at first in the superficial fascia between the middle line and anterior border of sterno-matitoil, perforates the deep fasciat just above

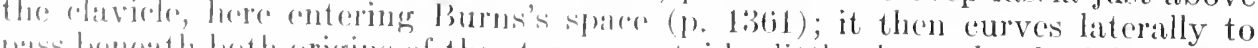

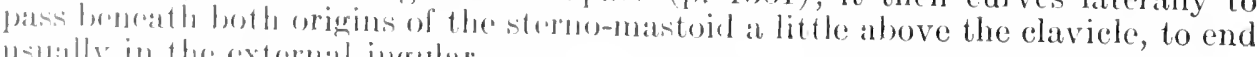
ustually in the external jugutar.

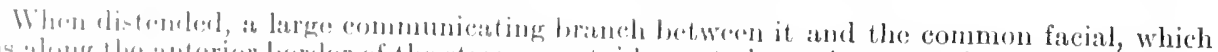

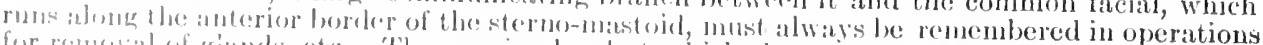
for remotal of giands, ete. The varying love al which the external jugular crosses the lateral 
border of the clavicular origin must be remembered in such operations as tenotomy here. These veins vary in size inversely to each other; the anterior jugulars are joined by numerous transvesre branches and becone larger below. They have no valves.

Of the chief arteries to the sterno-mastoid, that from the superior thyreoid will be divided in gature of the common carotid; that from the occipital runs with the spinal accessory nerve.

Behind the sterno-clavicular joint lies the commencement of the innominate veins, the bifurcation of the innominate artery on the right, and the common carotid artery on the left; deeper still lie the pleura and lung.

The clavicle.-This bone can be felt beneath the skin in its whole length. It forms the only bony connection between the upper limbs and the trunk. As one traces it laterally toward the acromial end, it rises somewhat, particularly in children and in subjects of good muscular development. The skin over it is thin but very mobile, and consequently is not often wounded. The most important posterior relations of this bone are, passing from the medial end laterally, the subclavian vein, the subclavian artery, and the cords of the brachial plexus as they lie on the first rib.

Fig. 1101.-Anterior and Lateral Cervical Muscles.

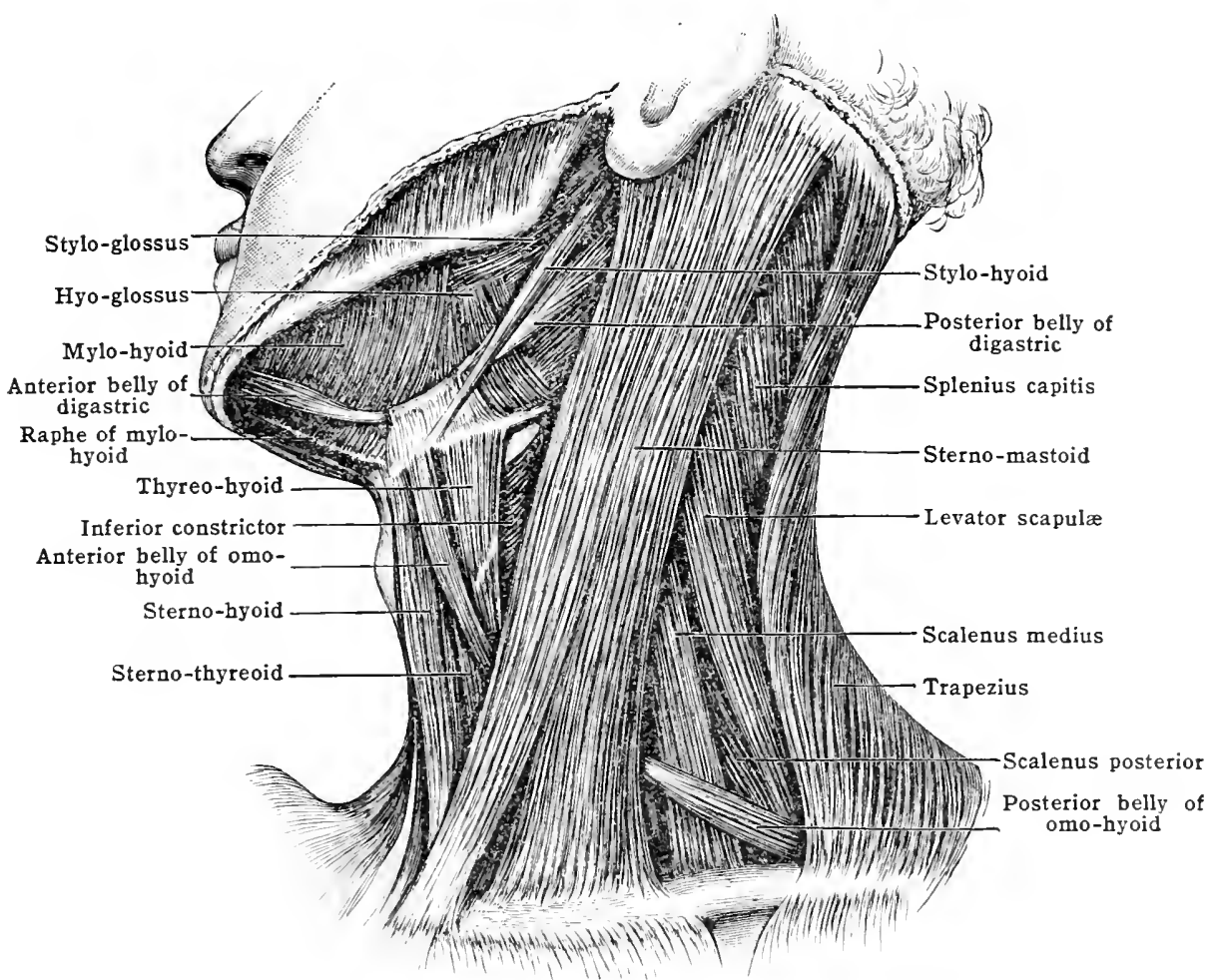

The rein occupies the angle between the first rib and the clavicle, and hence is, as a rule, the first structure compressed in growths of this bone. The artery lies on a deeper plane behind the mid-point of the clavicle, and the nerve cords extend a little further laterally. The subclavius muscle forms a protective cushion between the bone and these important structures, and this accounts for the rarity of injury to them in frarture of the clavicle. Behind the medial half of the clavicle the apex of the lung extends upward into the neck to a height of $2.5-3.7 \mathrm{~cm}$.

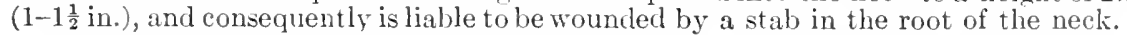

Cervical triangles.- In front of the sterno-mastoid is the anterior triangle, which is subdivided into three smaller triangles by the digastric muscle above, and the anterior belly of the omo-hyoid below (fig. 1101). These smaller triangles are called, from above, the submaxillary, the superior and inferior carotid triangles.

The submaxillary or digastric triangle is bounded above by the jaw, and a line drawn back to the mastoid process; below, by the digastric and stylo-hyoid muscles; and in front by the middle line of the neck. 
This space contains the submaxillary gland, and embedded in the gland is the external maxillary artery, the facial vein lying superficial to the gland; deeper than the gland are the submental vessels and the mylo-hyoid vessels and nerve. Posteriorly, and separated from the above structures by the stylo-mandibular ligament, which subdivides the triangle into a submaxillary and parotid part, is the upper part of the external carotid artery running up into the parotid gland, where it gives off its two terminal and the posterior aurieular branches. More deeply lie the internal jugular vein, internal carotid artery, and the vagus. The floor of the triangle is formed by the mylo-hyoid, hyo-glossus, and superior constrictor. The lingual artery may be tied here, or, better, in order to get behind the dorsalis lingua, close to its origin, by an incision similar to that for exposing the external carotid.

The hypoglossal is a guide to the carotids and the oecipital artery at the lower border of the digastric, and farther forward, to the subjacent lingual, from which it is separated by the hyo-glossus.

The superior carotid triangle is bounded above by the digastric, below by the omo-hyoid, and behind by the sterno-mastoid. It contains the upper part of the common carotid and its branches, the external being at first somewhat anterior to the internal. All the branches of the external carotid, save the three just given, are found in this space, together with their veins, the internal jugular vein, the ragus and sympathetic nerves, and, for a short distance, the accessory, together with those nerves which lie in front of and behind the carotids.

Ligature of the common carotid is usually performed at the 'seat of election,' where the vessel is more superficial, above the omo-hyoid. An incision with its centre opposite the cricoid is made $7.5 \mathrm{~cm}$. ( $3 \mathrm{in}$.) long in the line of the carotid artery. The deep fascia along the anterior border of the sterno-mastoid having been divided, the cellular tissue beneath is opened up, the omo-hyoid identified and drawn down or divided. The sterno-mastoid is next drawn well laterally, and the artery felt for. At this stage, such veins as the communication between the common facial and the anterior jugular and the superior and middle thyreoids may give trouble. The sheath is next opened well to the medial side, opposite to the cricoid cartilage, the ascending cervical, when seen, being avoided. If the internal jugular be distended, it may be drawn aside with a blunt hook, or pressure made lightly in the upper angle of the wound. The needle should be passed from the lateral side in very close proximity to the lateral and back part of the artery, so as to avoid the vein and vagus. Ligature below the omo-hyoid is rendered more diffieult by the presence of the anterior jugular, the pretracheal muscles, an overlapping thyreoid gland, especially if enlarged, the greater depth of the artery, especially on the left side and, here also, the closeness of the internal jugular. The collateral circulation is given at p. 1360 . Ligature of the external earotid, otherwise difficult, is rendered very simple by first exposing the bifureation of the common carotid artery, the incision similar to the last being prolonged upward. Here the facial and lingual veins and hypoglossal nerve cross the trunk, over which also lie some of the deep cervical glands. The ligature is usually placed between the superior thyreoid and lingual branches.

Allusion must here be made to the chief structures liable to be met with in operations on the neck. These are the internal jugular, the accessory, and phrenic nerves, the vagus and hypoglossal, the thoracic duct, low down and deep on the left side, the œsophagus and recurrent nerve in diflicult operations on the thyreoid gland. Of these, the internal jugular is, in some ways, the most important. Gilands, tuberculous or epitheliomatous, are of ten adherent to its sheath, especially those which drain the submaxillary group. When this condition is present or susperted, it is always well to begin the dissection low down in the inferior carotid triangle, where the structures are probably normal and the landmarks ensy to identify. In infective thrombosis of the transverse sinus the internal jugular is often tied opposite to the cricuid cartilage, heing either divided bef ween two ligatures, or, if the thrombus has extended downward, as nuch of the vein as is possible is removerl. This vein eontains only a single pair of valres low rlown in the neck. In all operations here on it and the other two jugulars, the risk of entry of air is to be rememhered. The accessory and phrenic nerves are alluded to on p. 1360 .

The inferior carotid or tracheal triangle is loounced above by the omo-hyoid, behind by the sterno-mastoid, and in front by the middle line of the neck. It eontains the lower part of the carotid sleath and its contents, with, behind it, the inforior laryngeal nerve and inforior thyreoid vessels, and to the medial side the trateheat, thyreoirl ghand, and osophagus. More deeply are the vertebral vessels; on the left siele is the thoracie duet.

The position of the branches of the external carotid should be remembered. Ther great cornu of the hyoid and the ala of the thyreoid are landmarks for the origin of most of them.

The superior thyreoid, arising just holow the level of the great cornu of the hyoid bone,

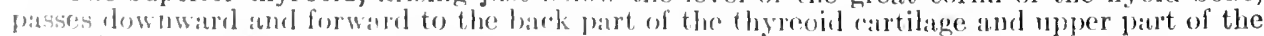
thysenil bouly. Nany of its hranches alle important in surgery. The superior laryngeal wriforates the thyres-hyoid nembrane. The sterno-mastoid pisses laterally into the middle of the muscte, across the carot irl sheath. The crico-thyreoid crosses the space of the same name just bolow the lower border of the thy'reoid cartilige. 'I'he small hyoid branch runs to the lower 
border of the hyoid bone. Anastomosing branches of the superior thyreoid form an arch along the upper border of the isthmus. The lingual artery arises from the parent trunk, opposite the tip of the great cormu of the hyoid, and passes forward just above the great cornu, crossed by the hypoglossal, and thence to the side of the tongue. In the first part of its course, before it reaches the hyo-glossus, it is curved, at first ascending, and then, having descended slightly, before it reaches the hyo-glossus, and while it lies under it, its curve is gentle, with the concavity upward; beyond the hyo-glossus, as it lies on the muscles of the tongue beneath the mucous membrane, it is tortuous. The lingual vein, it will be remembered, does not run with its artery, but lies superficial to the hyo-glossus. It receives the two small venæ comitantes which run with the lingual itself just before it crosses the common carotid. The line of the external maxillary (facial) artery (fig. 1093), which of ten arises with the lingual, has been given on p. 1343. The occipital artery, starting on the same level as the facial (i. e., at a point a little above and outside the tip of the great cornu of the hyoid bone), follows a line drawn upward and laterally, first to the interval between the transverse process of the atlas and the mastoid process, the former bone being felt just below and in front of the tip of the latter; thence, lying in the occipital groove of the mastoid, the artery ascends gradually, enters the scalp, together with the great occipital nerve, a little medial to a point midway between the external occipital protuberance and the mastoid process, to follow, tortuously and superficial to the aponeurosis, the line of the lambdoid suture.

The surface marking of the digastric and omo-hyoid, which subdivide the anterior triangle into the three smaller subtriangles above described, should be noted. The line of the posterior belly of the digastric corresponds to one drawn from the apex of the mastoid process to a point just above the junction of the great cornu and body of the hyoid bone; and from this spot, which gives the point of meeting of the two tendons, one slightly eurving upward to a point just behind the symphysis menti, would give that of the anterior belly.

To trace the omo-hyoid, a line should be drawn from the lower margin of the side of the hyoid bone obliquely donnward, so as to cross the common carotid opposite the cricoid cartilage and thence curving laterally under the sterno-mastoid at the junction of its middle and lower thirds, and then onward and still laterally parallel with and a little above the clavicle, as far as its centre.

Posterior triangle.- This shows in its lower part a wide depression, the supraclavicular fossa. Here the brachial plexus may be felt, and, by pressure downward and backward immediately behind the clavicle, just lateral to and behind the lateral margin of the sterno-mastoid, the pulsation of the subclavian artery can be stopped against the first rib.

The supra-clavicular fossa should be opened out by depressing the arm, and parts relaxed by carrying the shoulder forward and turning the head to the same side. This vessel curves upward and laterally from behind the sterno-clavicular joint to disappear behind the centre of the clavicle, the highest point of the curve being 1.2 to $2.5 \mathrm{~cm}$. ( $\frac{1}{2}$ to $1 \mathrm{in}$.) above the bone. The artery on the left side lies more deeply than the right, and does not rise so high into the neck. The subclavian vein lies at a lower level, separated by the scalenus anterior, and under cover of the clavicle. Into the above curve rise the pleura and lung. The pleura must be expected to rise $2.5 \mathrm{~cm}$. ( $1 \mathrm{in}$.) above the clavicle, behind the clavicular head of the sterno-mastoid.

The transverse scapular and transverse cervical vessels run laterally, parallel with the clavicle. The former lies behind the bone and subclavius; the latter also runs laterally in a transverse direction, across the root of the neck, but on a slightly higher plane, and thus a little above the clavicle.

Ligature of the third part of the subclavian is best performed by an angular incision, the horizontal portion along the centre of the clavicle, and the vertical one along the posterior border of the sterno-mastoid, with partial division of this and the trapezius when closely adjacent. The chief points to bear in mind are the venous plexus into which the external jugular, transverse cervical, transverse scapular, and cephalic veins enter; the omo-hyoid and division of the fascia which ties this to the clavicle; identification of the lateral margin of the scalenus anterior and the scalene tubercle; care of the transverse scapular artery and the descending branch of the transverse cervical. The needle is passed from above downward so as not to include the lowest cord of the brachial plexus, the vein, if distenderl, being depressed with a blunt hook. If the nerve to the subclavius be seen, it must be uninjured, as it orcasionally forms an important part of the phrenic. The collateral circulation is given at p. 1360.

Crossing the sterno-mastoid, a little obliquely, in a line drawn from a point just below and behind the angle of the jaw which marks its origin in the union of the posterior part of the internal maxillary and the posterior auricular veins to the centre of the clavicle, runs the external jugular vein. Above, it lies between the platysma and deep fascia, and is accompanied by the group of superficial cervical

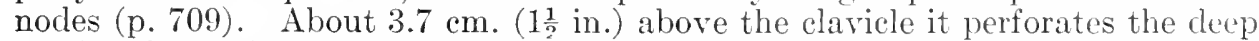
cervical fascia, its coats being blended with the opening. Gentle pressure with a finger at this point renders the vein above clearly visible. The dilated part between this point and the subclavian vein is called the sinus, and is marked by two valves, neither of which is usually perfect.

Opening into the external jugular, in the middle or lower third of its course, is the posterior external jugular, a vessel which begins in the occipital region superficially and runs down in front of the anterior border of the trapezius, across the posterior triangle. 
The accessory nerve, having crossed the transverse process of the atlas at a point lying a little below and in front of the apex of the mastoid, enters the anterior border of the sterno-mastoid at about the junction of the upper and middle thirds of the muscle. Having traversed the musele obliquely, it leaves it usually at a point a little lower clown, pursues a similar course across the posterior triangle and disappears under the anterior border of the trapezius, to enter into the subtrapezial plexus with the third and fourth cervieal nerves.

Above it is accompanied by a branch from the occipital, below by the transverse cervical artery. It is always seen in thorough operations on the upper deep cervical glands. The nerve is resected in spasmotic torticollis, and in recent years inveterate facial paralysis has been treated by anastomosing the facial to this nerve or the hypoglossal. A line drawn from midway between the tip of the mastoid and the angle of the mandible along the above given course of the nerve would denote its position.

Just above the centre of the sterno-mastoid, the small occipital, great auricular, and cutaneous cervical nerves emerge, the first passing upward and backward to the scalp, the second upward and forward across the upper part of the sterno-mastoid to the ear, and the last turning straight forward to the front of the neck. The small occipital and great auricular are often in intimate association with the accessory at its exit from the muscle. At this point also care must be taken not to injure the nerve in removal of glands from the posterior triangle.

The phrenic nerve, taking its largest root from the fourth cervical, would begin deeply about the level of the hyoid bone; thence descending under the sterno-mastoid, and, passing obliquely medially aeross the sealenus anterior the posterior borders of the above two muscles roughly eorrespond to each other in the lower part of the neck), it descends under the subclavian vein and elavicle to enter the thorax.

When the internal jugular is distended, its lateral border will be liable to overlap this nerve. The relations of the scalenus anterior should be noted here. In addition to the phrenic, which runs with a slight obliquity medially and is in close contact with the muscle, the following structures cross it medio-laterally: the subclavian vein and termination of the external jugular, the transverse scapular and transverse cervical vessels, and the omo-hyoid. At its medial margin are the thyreo-cervical trunk and vertebral arteries, and over them, the internal jugular. Behind it are the subclavian artery, the brachial plexus, and pleura.

The level of the brachial plexus (upper border) would be given by a line drawn from the ericoid cartilage to the centre of the clavicle. The lowest, medial cord (eighth cervical and first thoraeic, giving off chiefly the ulnar, medial head of median, and medial antibrachial cutaneous) is just above and behind the subclavian artery. Its importance in ligature of the artery has been referred to (p. 1359$)$.

In paralys s of the newly born, after some violent manipulation, it is usually the upper and lateral cord (fifth nerve, and axillary and median ehiefly) which suffers, elevation and abduction at the shoulder and flexion at the elbow-joint being lost.

Collateral circulation after ligature of the common carotid (fig. 1102). - This takes place by means of (1) the free communication which exists between the opposite carotids, both without and within the cranium; and (2) by enlargement of the branches of the subclavian artery on the sane sirle as that on which the carotid has been tied. Thus, ontside the cranium, the superior and inferior thyreoids are the chief vessels employed (fig. 1102). Within the eranium the verteloral replaces the internal carotid.

Collateral circulation after ligature of the second and third parts of the subclavian (fig. 1102). -Hore the lollowing thros sots of vessets aro those chictly employed:-

The trituscerse scapular, the trinsverse rervinil,

The superior intercostal, the alortic intercostals, amil the internat mammary,

Ninnerous untamed lranches passing thurough the axillat from branches of the sulbelavian,

with with

The thoraco-acromial, infra- and subscapular, ind eircumflex scapular.

The lateril thoracic and subseapular arteries.

with Branches of the axillary.

Deep cervical fascia.- The arrangement of this must be remembered- $(a)$ abore, and (b) below; the hyoirl bone. 'The latter is far more important.

(11) Arrangement above the hyoid bone. - IL re two chicf processes can be made out:-(i)

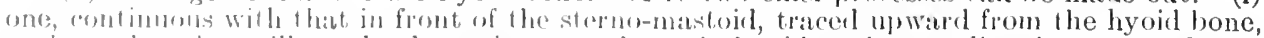

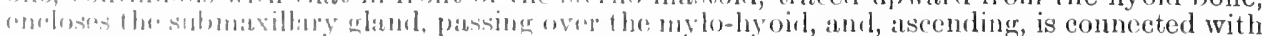

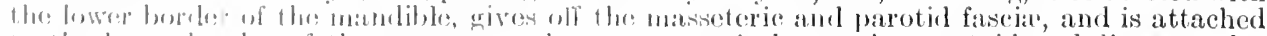

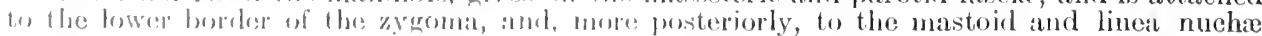

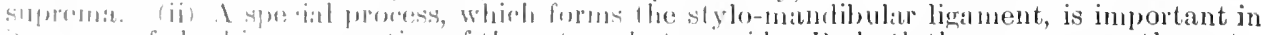

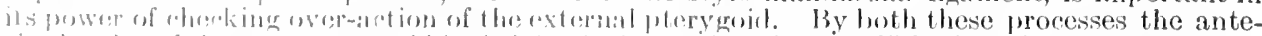

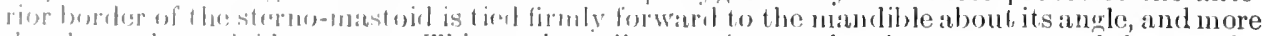

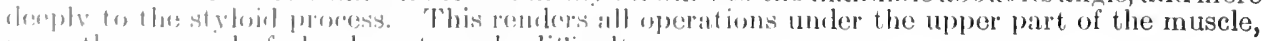

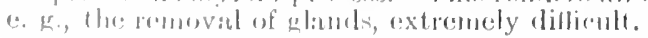


(b) Below the hyoid bone.-The importance of the fascia here is infinitely greater. Four layers must be remembered; (i) Superficial; (ii) pretracheal; (iii) prevertebral; (iv) carotid. (i) Superficial. This starts from the ligamentum nuchæ, encases the trapezius, forms the roof of the posterior triangle where it is perforated by branches of the superficial cervical nerves and the external jugular

Fig. 1102.-The Collateral Circulation after ligature of the Comion Carotid and Subclavian Arteries.

(A ligature is placed on the common carotid and on the third portion of the subclavian artery.)

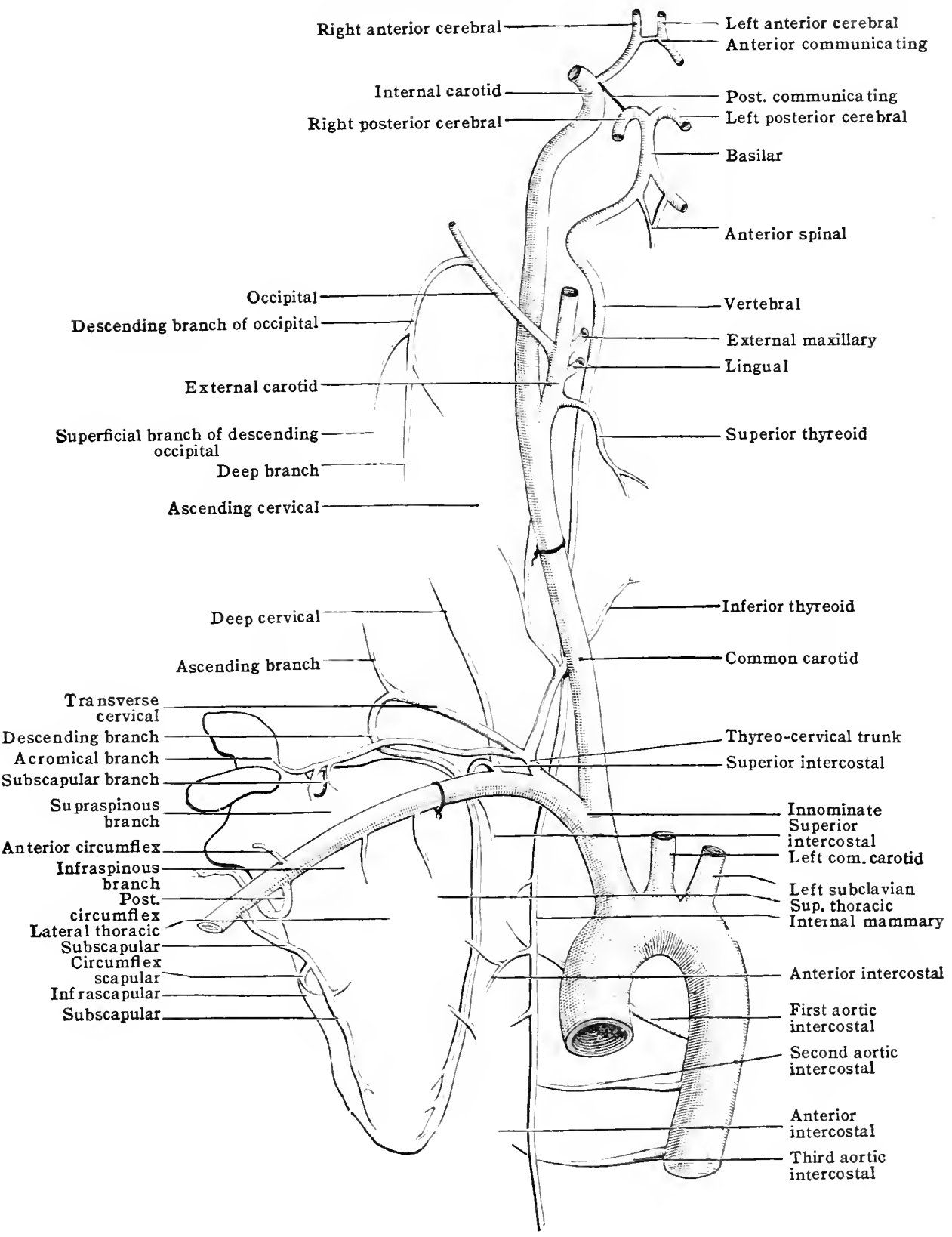

vein. Passing on it encloses the sterno-mastoid; and, passing over the anterior triangle, it meets its fellow in the middle line.

Thin behind, it is thickened anteriorly. Behind this thickened union lie the anterior jugular veins. Below, at a varying distance below the thyreoid cartilage, this layer divides into two, attached to the front and back of the manubrium. Between these (Burns's space) 
lie some fat, a small gland, a communicating branch between the anterior jugulars and a sinall portion of the veins, and the sternal heads of the sterno-mastoids. The sheath to the depressors of the hyoid bone is partly derived from this layer, partly from the next. Laterally, this layer gives a sheath to the posterior belly of the omo-hyoid, is attached to the clavicle, and passing on, is continuous with the sheath to the subclavius and coraco-clavicular fascia.

(ii) Pretracheal or middle. This lies under the depressors of the hyoid, over the trachea, also encasing the thyreoid gland. Farther laterally it helps, together with the prevertebral, to form the carotid sheath. Traced downward, the pretracheal layer passes over the trachea into the thorax (middle mediastinum)

As it descends, it encases the left innominate vein, and ends by blending with the fibrous layer of the pericardium. Hilton suggested that the attachment of this fascia above, and that of the central tendon of the diaphragm below, to the pericardium served to keep this sac duly stretched, and so prevented any pressure of the lungs upon the heart.

Fig. 1103. - Section of Neck throdgh the Sixth Cervical Vertebra. (Braune.) Larynx

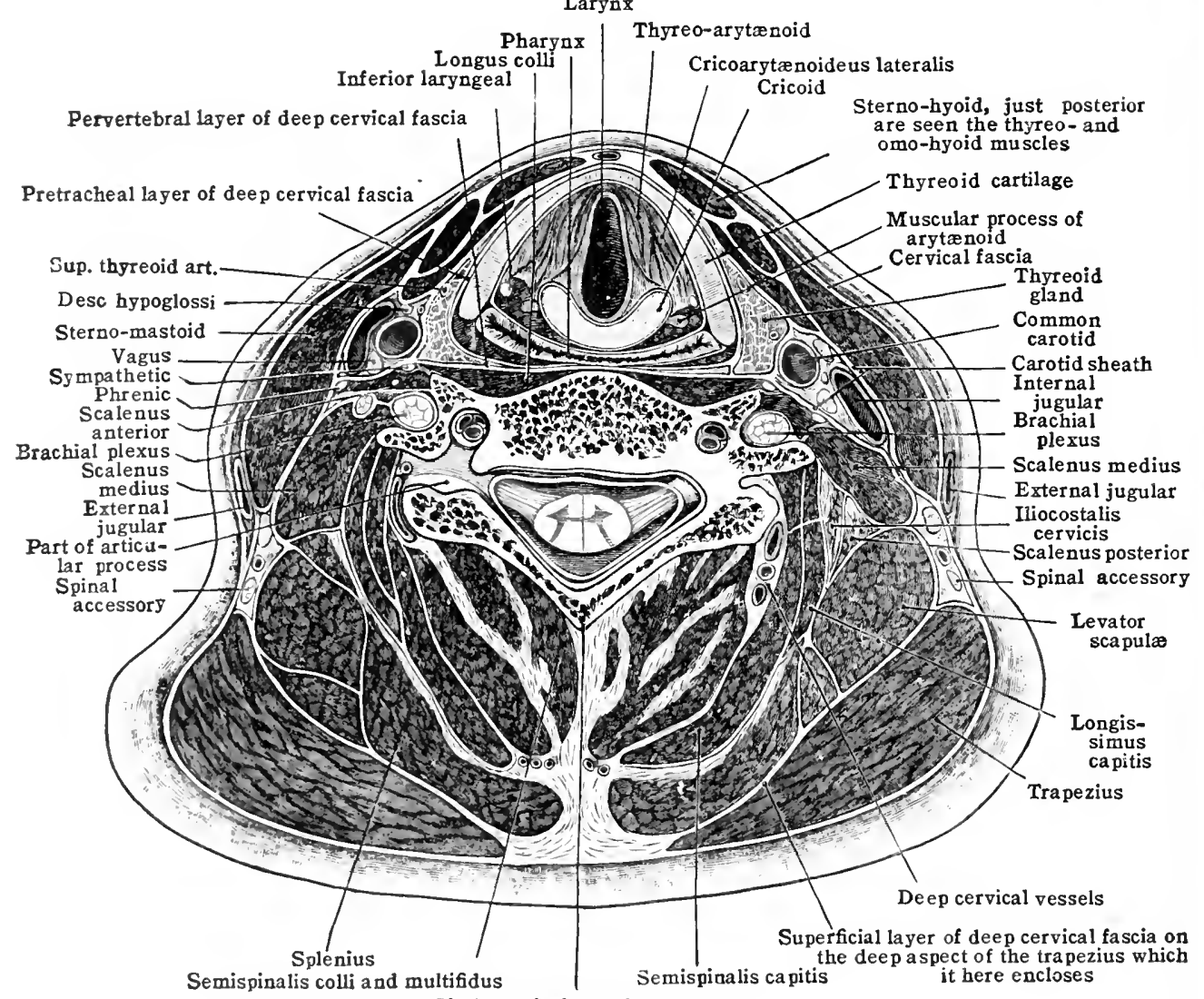

Sixth cervical vertebra

(iii) Prevertebral. This layer passes over the lomgus colli and capitis upward to the late of the skull, and downwarel over the longus colli behind the oesophagus into the postrior merliastinum. Istrally it helps to form the carotid sheath, amb, fowre down, gives a shoath to the subclavian artery and so to the axillary. (iv) The carotid sheath. 'This is formol hy septa from i, ii, and iii, meeting

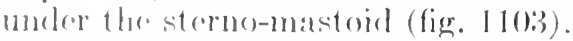

The following uses and important points with regurd fo the atnatemy of the lece cervieal fascia

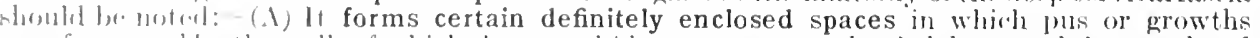

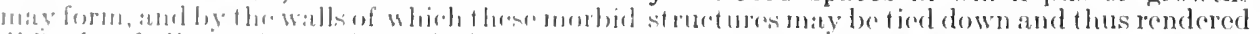

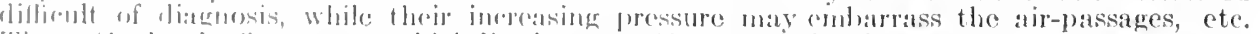

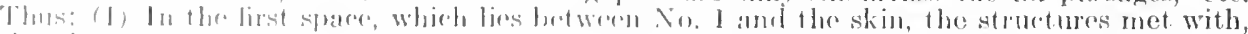

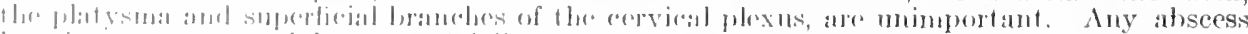

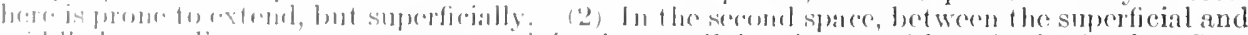

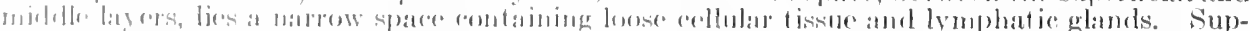

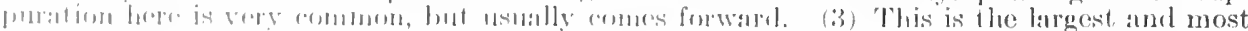

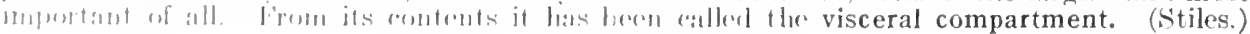


It is bounded in front by the middle, and behind by the prevertebrat layer. Its contents arelarynx, trachea, osophagus, thyreoid, earotid sheath, glands; and below, brachial plexus, subelavian artery, and abundant loose cellular tissue for the movements of the neck. Suppurat ion is somewhat rarel here; but either pus or growths, if aonfined in this space, may have baneful effects, from pressure, or from their tendency to travel behind the sternum. (4) This space between the prevertebral layer in front and museles behind, is very limited. Retropharyngeal abscess forms here, and the dyspnoea it eauses is thus explained. "The origin of such abseesses is ehiefly twofold, either in one of the highest deep eervical nodes, e. g., from infection of the naso-pharynx (p. 717), or from disease of the upper cervical vertebra. In the former cases (Stiles, Chiene) the suppuration will be in front of the prevertebral fascia, pointing toward the pharynx; in the latter behind the above fascia, spreading laterally, behind the carotid sheath. In making his incision, now along the posterior border of the sterno-mastoid, the surgeon should keep elose to the transverse processes of the vertebra. to avoidlopening the visceral eompartment and infecting the struetures in it. (B) The deep cervical fascia gives sheaths or canals to certain veins which perforate it, e. g., the external jugular. These are thus kept patent, and a ready passage of blood ensured from the head and neck. Further, this fact accounts for the readiness with whieh air may enter veins, in operations low down in the neck. The carotid sheath is another and different instance. (C) It helps to resist atmospheric pressure. (D) Hilton's suggestion as to its action on the pericardium has already been mentioned.

The lymphatic nodes of the head and neck have already been described. (See Section VI, Lrmphatic Srstem.)

\section{THE THORAX}

The bony landmarks of the thorax will be discussed first, followed by the structures of the thoracic wall, the lungs and pleura, and finally the heart and pericardium.

Bony landmarks. - The top of the sternum corresponds (in inspiration) to the fibro-cartilage between the second and third thoracic vertebræ, and is distant. about $6.2 \mathrm{~cm}$. ( $2 \frac{1}{2} \mathrm{in}$.) from the spine. In the newborn child it corresponds to the middle of the first thoracic vertebra (Symington). If traced downward, the subcutaneous sternum presents a ridge (sternal angle of Louis) opposite to the junction of the manubrium and body, and the second costal cartikages on either side; this ridge usually corresponds to the disc between the fourth and fifth thoracic vertebræ. At the lower extremity of the sternum the xiphoid cartilage usually retires from the surface, presenting the depression of the epigastric angle or 'pit of the stomach.' This is opposite to the seventh costal cartilages and the expanded upper end of the recti, and corresponds to the tenth thoracic vertebra behind.

Parts behind manubrium.-There is little or no lung behind the first bone of the sternum, the space being occupied by the trachea and large vessels, as follows;

The left innominate vein crosses behind the sternum just below its upper border. Next come the great primary branches of the artic areh. Deeper still is the trachea, dividing into its two bronchi opposite to the junction of the first and second bones of the sternum. Deepest of all is the osophagus. About $2.5 \mathrm{~cm}$. ( $1 \mathrm{in}$.) below the upper border of the sternum is the highest part of the aortic arch, lying on the bifurcation of the trachea. (Holden.) (Fig. 110t).

Sterno-clavicular joint.-The expanded end of the clavicle and the lack of proportion between this and the sternal facet, on which largely depends the mobility of this, the only joint that ties the upper extremity closely to the trunk, can be easily made out through the skin. Its strength, considerable when the rarity of dislocation compared with fracture of the clavicle is considered, depends mainly on its ligaments, the buffer-bond meniscus, the costo-clavicular ligament, which checks excessive upward and backward movements, and the fact that the elastic support of the first rib comes into play in strong depression of the shoulder as in carrying a weight. The relative weakness of the anterior liganent determines the greater frequency of anterior dislocation of the clavicle at this joint.

Behind the joint lie, on the right side, the innominate artery, right innominate vein, and pleura; on the left, the left innominate vein, the left carotid, and the pleura.

Acromio-clavicular joint.-On tracing the clavicle laterally, it is found to rise somewhat to its articulation with the acromion. This joint has very little mobility, and owes its protection to the strong conoid and trapezoid ligaments hard by. Owing to the way in which the joint-surfaces are bevelled, that of the clavicle looking obliquely downward, and resting upon the acronion, it is an upward displacement of the clavicle which usually takes place.

Ribs. - In counting these, the position of the second is denoted by the trans- 
verse line at the junction of the manubrium and body of the sternum. It is well always to count ribs from this point and never from below, as the twelfth rib varies in size and may be obscured by the sacro-spinalis muscles. The nipple in the male, lies between the fourth and fifth, nearly an inch lateral to their cartilages. The lower border of the great pectoral corresponds to the fifth rib. The serenth, the longest of the ribs, is the last to articulate by its cartilage with the sternum. When the arm is raised, the first three digitations seen of the serratus anterior correspond to the fifth, sixth, and seventh ribs. The ninth rib

Fig. 1101.-The Arch of the Aorta, with the Pulmonary Artery and Chief Branches OF THE AORTA.

(Modified from a dissection in St. Bartholomew's Hospital Museum.)

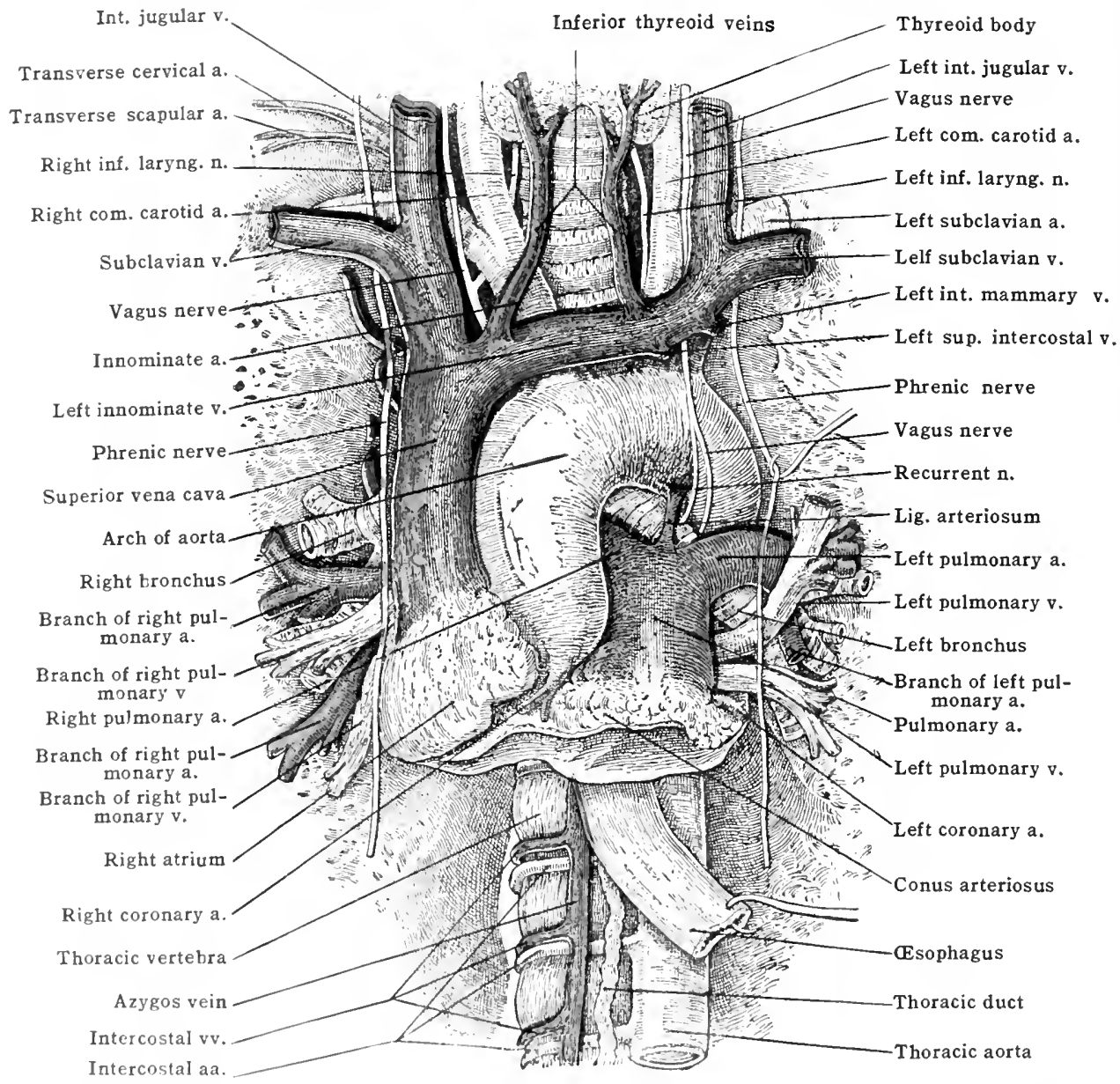

is the most ollicyue. The eleventh and twelfth can be felt lateral to the sacrospinalis. (Jwing to the olliquity of the ribs, their sternal ends are on a much lower level than their vertebral extremities.

"l"hus the first rib in front arresponds to the fouth rib hehind, the second to the sixth, the thirel to the seventh, the fourth to the oighth, the lifth to the ninth, the sixth to the tenth,

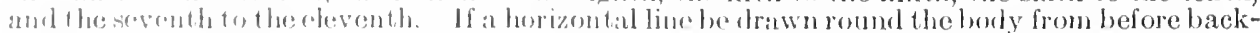
warrl at the level of the inferior angle of thescinula, while the arms are a the sides, the line would

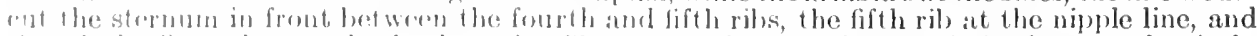

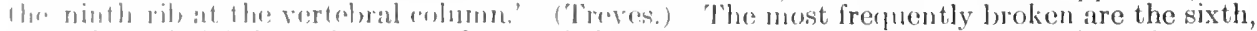
seventh, and righth. The upluer fonr and the 1 wo lowest rils are best envered by soft parts,

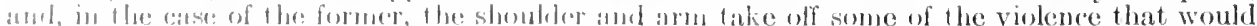

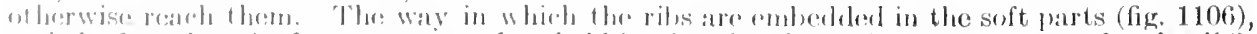

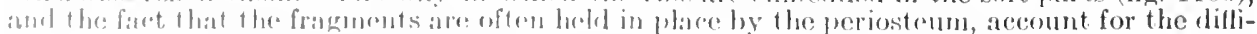

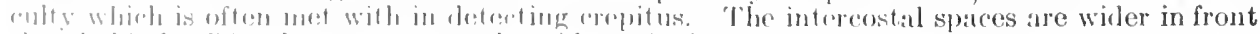
thati behinel. The there appere are lhe widest of all. 
Cervical ribs.-It occasionally happens that the rib element of the seventh cervical vertebra, normally fused with the true transverse process, is segmented off as a separate, though usually rudimentary, rib. This anomaly is generally bilateral. It occurred in 3 of 260 subjects (1.16 per cent.) examined by Wingate Todd. *

The anterior extremity of a cervical rib may, according to the degree of its development (1) lie free amongst the sealene muscles; (2) be connected with the sternum by a ligamentous prolongation; (3) articulate with the upper surface of the first thoracic at about its centre by a synchondrosis, or (t) form a complete rib, articulating by a costal cartilage with the sternum.

The lowest trunk of the brachial plexus formed by the eighth cervical and first thoracic roots, the subclavian artery and less commonly the subctavian vein, curve over the upper surface of these ribs. The abnormality owes its clinical importance to the pressure effects produced on the nerve trunk in a small proportion of the cases. This pressure is manifested by (1) pain, going on to anæsthesia down the medial side of arm, forearm and hand; (2) paralysis of the intrinsic muscles of the hand, producing the main en griffe, and to a less extent of the muscles of the forearm; (3) vascular effects (anæmia, gangrene, etc.), manifested chiefly in the hand. Todd has shown that these vascular effects are not due to mechanical pressure on the subclavian artery by the cervical rib as was formerly supposed, but are trophic lesions of the sympathetic (vasomotor) nerves. The vasomotor nerves to the arm mainly come from the second thoracic root by the communication it gives to the lowest eord of the brachial plexus, and so are exposed to pressure from the rib.

Fig. 1105.-Certical Ribs, Viewed From Abore. ( $\left(\frac{1}{2}\right.$.) NN, Inpression for Lowest Trunk of Brachial Plexus. Aa, Impression for subclayian Artery. (T. Wingate TODD.)

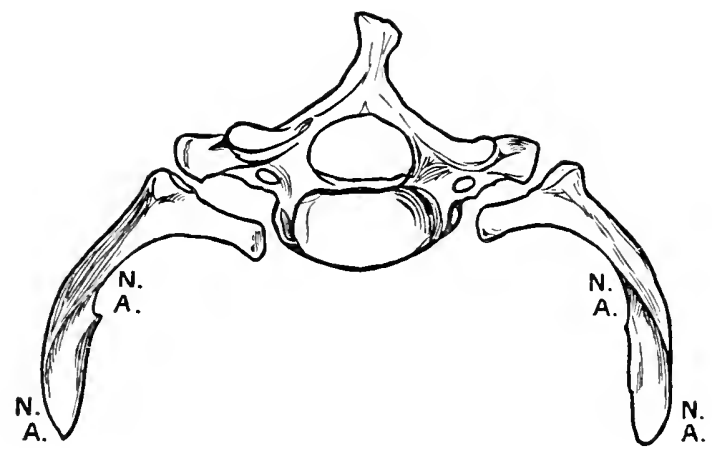

The same investigator has shown that similar symptoms may be produced occasionally by a first thoracic rib in cases where the brachial plexus has migrated caudad. In the living patient, unless a radiogram be taken showing all the vertebre up to the base of the skull, it is not possible with precision to ascertain with which vertebra the highest rib present articulates.

Structures found in an intercostal space.-(1) Skin; (2) superficial fascia, with cutaneous vessels and nerves; (3) deep fascia; (4) external intercostal; (5) cellular interval between intercostals, containing trunks of intercostal vessels and nerves; (6) internal intercostals; ( 7 ) thin layer of fascia; (8) subpleural connective tissue; (9) pleura (fig. 1106).

The intercostal arteries are nine aortic and two from the superior intercostal. An aortic intercostal having given off its dorsal branch, lying beneath the pleura, crosses the space obliquely upward to gain the lower border of the rib above, enters the costal groove at the angle, and runs forward between the intercostal muscles to anastomose with the anterior intercostals from the internal mammary or musculo-phrenic. Hence the rule of making the incision in empyema above the upper margin of the lower rib and in front of the angle. Along the dorsal branch a vertebral abscess may track backward.

Internal mammary artery.-This descends behind the clavicle, the costal cartilages, and the first six spaces, about $1.2 \mathrm{~cm}$. ( $\frac{1}{2}$ in.) from the edge of the sternum. In the sixth intereostal space it divides into musculo-phrenic and superior epigastric acteries. Its venæ comitantes uniting join the innominate vein of the same side. A punctured wound of the artery is most easily secured in the second and third spaces; below, resection of part of a costal cartilage will be needed.

Structures passing through the upper aperture of the thorax.-If a section is made passing through the manubrium sterni, upper border of the first rib, and

* Journal of Anatomy and Physiology, Vol. 47, 1913. 
upper part of the first thoracic vertebra, the following structures are met with: - (1) In the middle line. Sterno-hyoid and sterno-thyreoid muscles, with their sheaths of deep cervical fasciat, cellular tissue in which are the remains of the thymus gland, the inferior thyreoid veins, the trachea and tracheal fascia, the osophagus, and longus colli muscles. Between the trachea and oesophagus are the recurrent nerves. (2) On each side. The apex of the lung, covered by pleura, deep cervical fascia, and membranous cervical diaphragms ("Sibson's fascia") derived from the scalenes, rises about $3.7 \mathrm{~cm}$. ( $1 \frac{1}{2}$ in.) above the first rib. Between it and the trachea and cesophagus lie the following: the internal mammary artery, the phrenic nerve; on the right side, the innominate vein and artery, with the vagus between the two, the cardiac nerves, and the right lymphatic duct. On the left side are the common carotid and subclavian arteries, with the left vagus between them, the cardiac nerves and the thoracic duct. Farthest back and on each side are the trunk of the sympathetic, the superior intercostal artery, and the first thoracic nerve.

The mamma.-This lies chiefly on the pectoralis major and slightly on the rectus abdominis and serratus anterior. It is usually described as reaching from the second to the sixth rib, and from the sternum to the anterior border of the axilla. It is most important to remember that the breast is of ten a much more extensive structure than would be included in the above very limited description. Thus-(1) the gland is not encapsuled at its periphery, its tissue branching and breaking up here to become continuous with the superficial fascia. (Stiles.)

Fig. 1106.-Section of the Slxth Left Intercostal Space, at the Junction of the Anterior and Posterior Thirds. (Tillaux.)

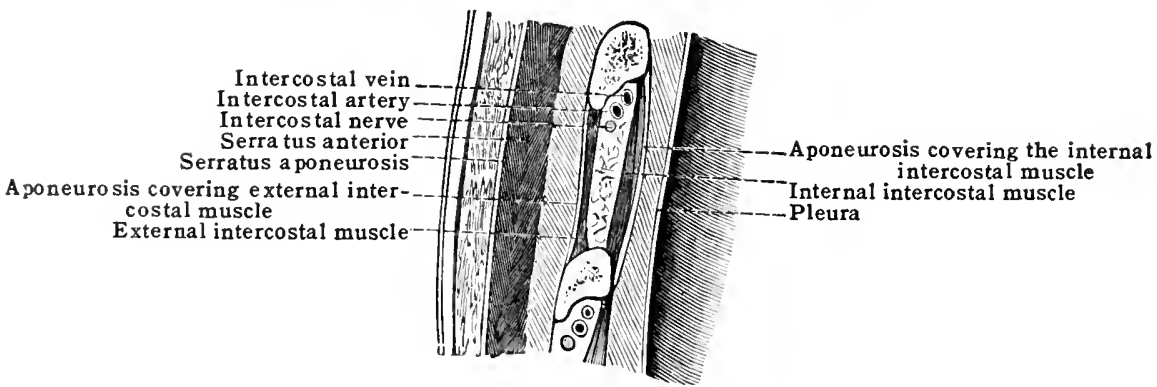

The retinacula cutis contain lymphatics and, sometimes, mammary tissue. (3) There is a lymphatic plexus, and, often, minute lobules of gland tissue, in the pectoral fascia. (Heidenhain.) Fully one-third of the whole mamma lies posterior and lateral to the axillary border of the pectoralis major so that it reaches almost to the mid-axillary line. That part of the upper and lateral quadrant known as the axillary lobe is of especial importance from its reaching into close vicinity with the interior pectoral group of axillary nodes (p. 719). In the malo the nipple is usually placed in the fourth space, nearly $2.5 \mathrm{~cm}$. ( $1 \mathrm{in}$.) lateral to the cartilages of the fourth and fifth ribs. On the nipple itself open the fiftern or twenty ducts which dilate beneath it, and then.diverge and break up for the supply of the lobules. The skin over the areola is very adherent, pigmonted, and fatless. Here also are groups of little swellings corresponding to large sobserous follicles and areolar glands. The skin over the breast is freely movable, and united to the faseia which eneases the organ, and thus to the interlobular conncetive tissue, by bands of the same structure-the retinacula cutis. furler the broust, and giving it its mobility, is a collulo-fatty layer, the seat of submamminary alsoress.

'The nerves which supply the breast are the anterior eutaneous branches of the second, third, fouth, and lifth interosstal nerves, and the laferal branches of the last three. The ("onnection of these trunks serves to explain the diffusion of the pain of ten observed in painful alfertions of thabreast. Thus pain may lat refored to the sirle of the ehest and back (along the ithove intareostal trumks), over the seapula, alomg the medial side of the arm (along the inter-

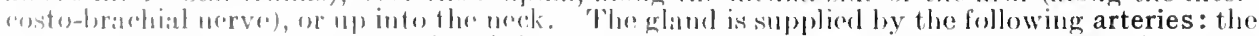

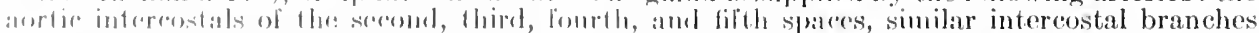

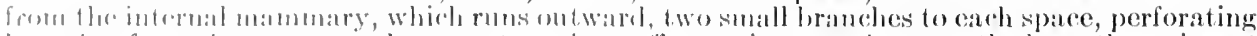
hranches from the same vessol, oncor two givell off opposite to bach space, the long thoracic and "xtrmal mammary (whon present) from the axillary. 
The lymphatics have already been described (p. 721, fig. 566).

In removal of the breast elliptical incisions will usually suffice if employed on wide lines, and if attention be paid to the following points:- (1) Those details in the surgical anatomy already referred to, especially those bearing on the extensiveness of this organ, and the proportionate difference between seen and unseen disease. (2) The importance of removing in one continuous piece the whole breast, all the skin over it, the costo-sternal part of the pectoralis major, the pectoralis minor, the axillary fat, and lymphatics.

Outline of the lungs. Their relation to the chest-wall.-To map out the lung, a line should be drawn from the apex, a point about $2.5 \mathrm{~cm}$. (1 in.) above the clavicle, a little lateral to the sterno-mastoid musele, at the junetion of medial and middle thirds of clavicle, obliquely downward, behind the sterno-clavieular joint, to near the centre of the junction of the first and second bones of the sternum. Thence, on each side, a line should be drawn slightly convex as far as a similar point on the sternum lying opposite the articulation of the fourth chondrosternal joint. On the right side the line may be dropped as low as the sixth chondro-sternal joint; on the left the incisura eardiaca may be shown by drawing a vertical line along the middle line of the sternum, from the level of the medial extremities of the fourth costal cartilages to the lower end of the gladiolus, and

Fig. 1107.-Outline of the Heart, its Valyes, the Lungs (shaded), and the Pleura. (Holden.) (Cf. fig. 437.)

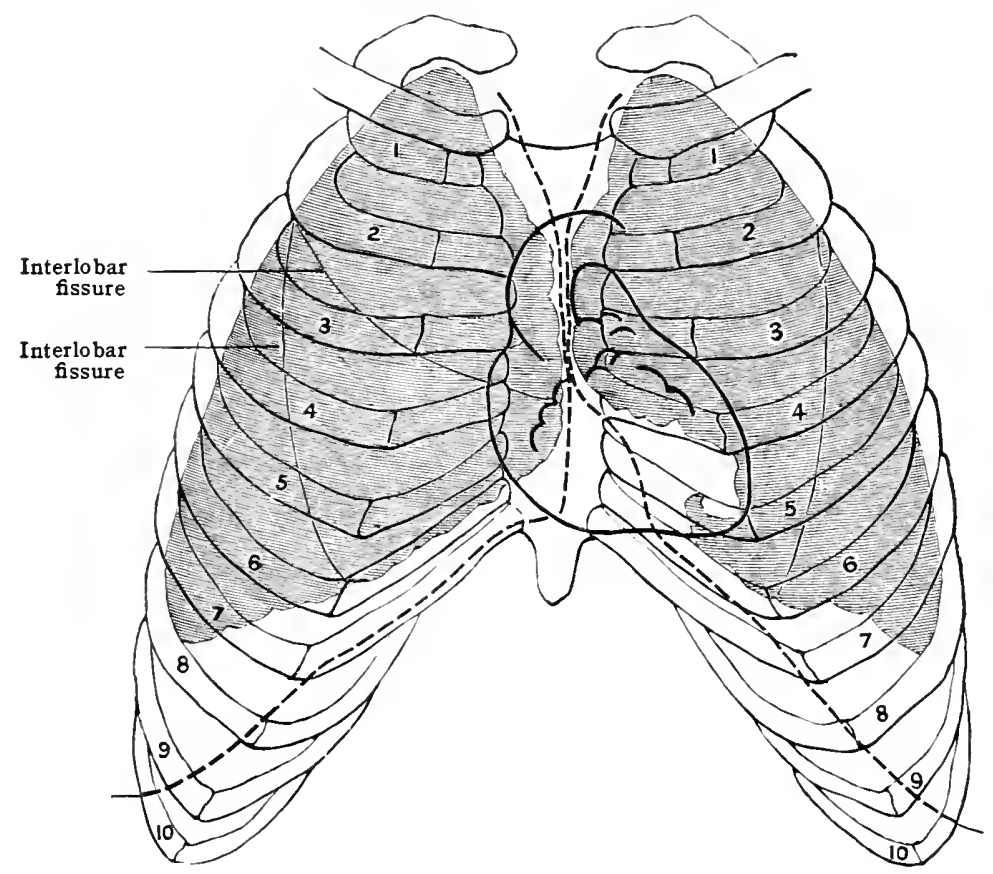

by carrying two other lines, from the extremities of the first line, outward so as to meet at a point over the heart's apex (Cunningham); to mark this gap, a line should be drawn sloping laterally and downward from the fourth chondrosternal articulation across the fourth and fifth interspaces, to a point about $3.7 \mathrm{~cm}$. ( $1 \frac{1}{2} \mathrm{in}$.) below the left nipple (male) and $2.5 \mathrm{~cm}$. ( 1 in.) to its medial side. This point, lying in the fifth space, marks the apex of the heart. Thenee the line curves medially to the sixth costal cartilage, a little medial to its chondrosternal junction, and in the lateral vertical line. Thus the lower part of the anterior surface of the right ventricle is not covered by lung. The lower border of the lung will be marked on the right side by a line drawn from the sixth chondrosternal articulation across the side of the chest down to the tenth thoracic spine. The lower border of the left lung will follow a similar line, starting on a level with a similar joint (sixth ehondro-sternal joint), but much farther laterallythan on the right side, i. e., in the fifth space, about $7.5 \mathrm{~cm} .(3 \mathrm{in}$.) to the left of the middle line, or a point corresponding to the heart's apex. In the nippleline the lung crosses the sixth rib, in the mid-axillary line the eighth, and opposite 
the angle of the scapula (the arms being close to the sides), the tenth rib. The position of the great fissure in each lung may be ascertained approximately by drawing a line curving downward and forward from the second thoracic spine to the lower border of the lung at the sixth costal eartilage; and the smaller fissure of the right lung extends from the middle of the foregoing to the junction of the fourth costal cartilage with the sternum. It will be seen from the above that there is little lung behind the manubrium. The connective tissue here between the lung margins contains the thymus, large up to the age of puberty, and, later, its remains. The hilus (root) of the lung is referred to on p. 1230.

The pleura, following much the same line as the lung above and in front, reaches lower down laterally and behind. Thus the two sacs starting from about $2.5 \mathrm{~cm}$. ( 1 in.) above the medial third of the clavicle converge toward the angle of Louis (p. 1238); meeting here, they descend vertically, the left overlapping the right slightly, to the fourth chondro-sternal joint. Hence the right sac descends behind the sternum to the sterno-xiphoid junction and sixth chondro-sternal joint. Thence, as it curves to the back of the chest, it erosses the eighth rib close to the lateral vertical line (vide supra), the tenth in the mid-axillary, the eleventh in the line of the angle of the scapula, and thence toward the twelfth thoracic vertebra. On the left side the pleura parts company from the right at the level of the fourth chondro-sternal junction, deviating laterally and downward aeross the fourth and fifth interspaces; it then turns again slightly medially to meet the sixth eostal cartilage. Thus, as in the case of the lung, but to a less extent, there is a small area of the pericardium, and, under it, the right ventricle uncovered by the pleura. Over the side and back of the chest, along its diaphragmatic reflection, the left pleura reaches a little lower than the right.

The deepest part of the pleural sac is where the reflection crosses the tenth rib or tenth space in the mid-axillary line. From this it ascends slightly as it curves back to the spine. (Cunningham.) The relations of the pleura to the last rib are of much importance to the surgeon in operations on the kidney. In the case of a twelth rib of ordinary length, the pleural reflection crosses it at the lateral border of the sacro-spinalis; when a rudimentary last rib does not reach the lateral border of this muscle, an incision carried upward into the angle between the eleventh rib and the sacro-spinalis will open the pleural sac. (Melsome.)

For tapping the pleura there are two chief sites:-(1) The sixth or seventh space in front of the posterior fold of the axilla. (2) The eighth space behind, in the line of the angle of the scapulat. For the incision of an empyema the first is usually chosen. The overlying soft parts are not thick, the interspace is widle enough, drainage is sufficient (especially if part of the seventh or eighth rib be resected), and this site is free from the objection that the angle of the scapula overlaps the seventh and eighth ribs, unless the arm is raised.

Outline of the heart. Its relation to the chest-wall.-The upper limit of the heart (base) will be defined by a line crossing the sternum a little above the upper border of the third costal cartilage, reaching about $1.2 \mathrm{~cm}$. ( $\frac{1}{2} \mathrm{in}$.) to the right and about $2.5 \mathrm{~cm}$. ( $1 \mathrm{in}$.) to the left of the sternum. Its apex point is in the fifth space, $3.7 \mathrm{~cm}$. ( $1 \frac{1}{2} \mathrm{in}$.) below the male left nipple, and $2.5 \mathrm{~cm}$. (1 in.) to the moclial side. This point will be at $7.5 \mathrm{~cm}$. $(3 \mathrm{in}$.) from the left border of the strrmum. The right border (right atrium) will be given by a line, slightly eonvex latorally, drawn from the right extremity of the upper border to the right sixth chomdro-sternal joint. If another line, slightly convex upward, be drawn onward from this point aress the last piece of the stermum, just above the xiphoid cartilage, to the apex, it will give the lower horder (margo acutus of right ventricle), which rests on the central tendon of the diaphragm. The left border (margo obtusus of left ventricle) will be given by a line, convex to the left, passing from the loft extremity of the upper border to the apex, medial to the nippleline. This line should be 7.5 ('m. (3) in.) from the middle of the sternum at the level of the fourth costal cartilage. The base of the heart is opposite four of the theracise vertebre, viz., the sixth, seventh, eighth, and ninth. The apex and anterior or costo-stemal surface have been mentioned. The inferior or diafliragmatic surface (chicely loft atrim and left ventricle) rests upon the diajhragm, mainly the eentral fomlon, to which the intervening pericardium is connected, and is thus arljacent to the liver and a small portion of the stomach.

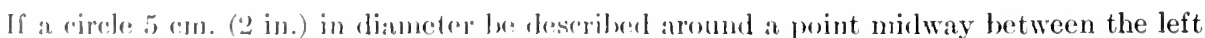
nipple :und the lower aml of the gladiolus, it will define with suflicient accuracy for practical

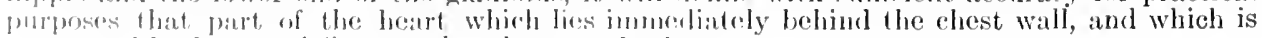
uncovered by lomg and (in part) hy pleura. (hatham.) 
The valves.-The pulmonary valves (the highest and most superficial) lie, in front of the aortic, behind the third left chondro-sternal joint, and opposite to the upper border of the third costal cartilage. The aortic valves lie behind and a little below these, opposite to the medial end of the third intereostal space, and on a level with the lower border of the third left costal cartilage. The atrio-ventricular openings lie at a somewhat lower level than that of the aortic and pulmonary. Thus the tricuspid valves lie behind the middle of the sternum at the level of the fourth intercostal space; and the mitral valves, the most deeply placed of all, lie a little to the left of these, behind the left edge of the sternum and the fourth left costal cartilage (fig. 1107; also cf. fig. 437).

'Thus these valves are so situated that the mouth of an ordinary-sized stethoscope will cover a portion of them all, if placed over the juncture of the third intercostal space, on the left side, with the sternum. All are covered by a thin laver of lung; therefore we liear their action better when the breathing is for a moment suspended.' (Holden.)

The pericardium.-This fibro-serous sac, occupring the middle mediastinum, is triangular in shape, with the apex upward. Here its fibrous layer gives investment to the large vessels, except the inferior cava. It is also continuous with the deep cervical fascia. The base, connected with the diaphragm, has been referred to above. In front an area of variable size (fig. 1107), owing to the divergence of the left pleura, is in contact with the left half of the lower part of the sternum, and more or less of the medial ends of the fourth, fifth, and sixth costal cartilages, here forming the posterior boundary of the anterior mediastinum. Behind, the pericardium is the anterior boundary of the posterior mediastinum, and is in close contact with the osophagus and aorta.

Paracentesis of pericardium. - While the seat of election must here remain an open question, each case requiring a decision for itself, the one most suitable on the whole is the fifth left space, about $2.5 \mathrm{~cm}$. ( $1 \mathrm{in}$.) from the sternum, so as to avoid injury to the internal mammary artery and the pleura, of which the line of reflection has been shown to vary.

In incision of the pericardium to establish free drainage, a portion of the fifth or sixth left costal cartilage should be carefully resected, the internal mammary artery tied, the transversus thoracis (triangularis sterni) scratched through, and the pleural reflexion pushed aside.

Relation of vessels to the wall of the thorax.-Aortic arch.- The ascending part of the aorta reaches from a spot behind the sternum, a little to the left of the centre, on a level with the third left costal cartilage, to the upper border of the second right cartilage; thus it passes upward, backward, and to the right, and is about $5 \mathrm{~cm}$. (2 in.) long. The transverse part then crosses backward to the left behind the sternum (the highest part of the arch being about 2.5 $\mathrm{cm}$. ( $1 \mathrm{in}$.) below the noteh), reaching from the second right costal cartilage to the lower border of the fourth thoracic vertebra on the left side. This part recedes from the surface, and, with the next, cannot be marked out on the surface. The third, or descending part, the shortest of the three, reaches from the lower border of the fourth to that of the fifth thoracic vertebra.

Fig. 1104 will remind the reader of many of the pressure symptoms which may accompany an aneurysm of the aortic arch; e. g., pressure on the left innominate vein, the three large arteries. trachea, and left bronchus, recurrent nerve, œsophagus, and thoracic duct. In aneurysm of the thoracic aorta, pain, usually unilateral, referred to the corresponding intercostal nerves, is a common pressure symptom.

The pulmonary artery lies behind the left side of the sternum and its junction with the second and third costal cartilages.

Innominate artery. - A line drawn from the top of the arch, about $2.5 \mathrm{~cm}$. (1 in.) below the sternal notch, and close to the centre, to the right sterno-clavicular joint, will give the line of this vessel.

Left common carotid. - This vessel will be denoted by a line somewhat similar to the above, passing from the level of the arch a little to the left of the last starting-point to the left sternoclavicular joint.

Left subclavian artery.-A line from the end of the transverse arch, behind the left of the sternum, straight upward to the clavicle, delineates the vertical thoracic course of the long left subclavian artery; its thoracic portion lies behind the left carotid.

Innominate veins. - The left, $7.5 \mathrm{~cm}$. (3 in.) long, extends very obliquely from the left sterno-clavicular joint, behind the upper part of the manubrium, to a point $1.2 \mathrm{~cm}$. ( $\frac{1}{2}$ in.) to the right of the sternum, on the lower border of the first right costal cartilage. The right, about $2.5 \mathrm{~cm}$. ( $1 \mathrm{in}$.) long, descends almost vertically to the above point from the right sternoclavicular joint.

Venæ cavæ.-The superior descends from the point above given for the meeting of the innominate veins in the first intercostal space, close to the sternum, and perforates the right atrium on a level with the third costal cartilage. The inferior vena cava.- The opening of this vein into the right atrium lies under the middle of the fifth right interspace and the adjacent part of the sternum.

The œsophagus.-The relations of this tube in its cervical and thoracic portions are most important, e.g., to the trachea and left bronchus; the ragi and left recurrent nerve; the pleuræ, left above and right below, aorta, and 
perieardium. Its lymphaties go below into the posterior mediastinal and superior gastrie nodes; above into the lower deep cervical nodes, a point sometimes diagnostic in malignant disease.

The Iumen of the oesophagus is narrowed at three points:-(1) and best marked at the cricoid cartilage, (2) where it is crossed by the left bronchus, (3) as it passes through the diaphragm. The tube, 25 to $27 \mathrm{~cm}$. (10 to $11 \mathrm{in}$.) long, extends from the sixth cervical to the lower border of the tenth thoracic vertebra. In an adult, the distance from the incisor teeth to the cricoid is about $15 \mathrm{~cm}$. (6 in.); an additional $7.5 \mathrm{~cm}$. (3 in.) gives the level of the crossing of the left bronchus, while from the teeth to the opening in the diaphragm would be from 41 to 43 $\mathrm{cm}$. ( 16 to $17 \mathrm{in.}$. To expose the tube in the neck an incision is made on the left side, much as for the higher ligature of the common carotid, but carried lower down. The depressors of the hroid being drawn medially or divided, the pretracheal fascia is opened, which allows of the overlapping thyreoid and trachea being displaced medially, while the carotid sheath is retracted laterally. "The tracheal rings are the best guide to the oesophagus. The recurrent nerve must be avoided.

\section{THE ABDOMEN}

The regions and subdivisions will first be considered, the abdominal wall next, and finally the abdominal eavity, including the peritoneum and the various organs.

Subdivision of the abdominal cavity.-Certain arbitrary horizontal and vertical planes, represented by lines drawn on the ventral surface, are used to subdivide the abdomen for topographieal purposes (fig. 898). A. Horizontal planes. (1) Infracostal through the lower margins of the tenth eostal cartilages (the lowest part of the eostal margin). This plane erosses the body of the third lumbar vertebra. (2) Intertubercular, passing through the tubereles, prominent points of the iliac erests, which are situated about $5 \mathrm{~cm}$. (2 in.) behind the anterior superior spines. This plane erosses the body of the fifth lumbar vertebra. B. Vertical planes. (1) Median vertical, drawn upward in the middle line from the symphysis pubis. (2) Lateral vertical, drawn upward on each side parallel to the former, from a point midway between the anterior superior iliac spine and the symphysis pubis.

These lateral lines if prolonged upward into the thorax pass rather more than $2.5 \mathrm{~cm}$. ( 1 in.) to the medial side of the male nipple and meet the clavicle a little medial to its mid-point.

Aceording to the BNA system, the lateral vertical lines are slightly curved, extending upward from the pubic tubercle on each side along the lateral margin of the rectus muscle (corresponding to the linea semilunaris).

The infracostal and intertubereular planes, with the two lateral vertical planes that intersect them divide the abdomen into nine regions:- three median, viz., the epigastric, umbilical, and hypogastric and on each side three lateral, viz., hypochondriac, lumbar, and iliac (fig. 898).

Another transverse plane of practical importance, though we do not use it as a boundary of the alulominal subdivisions, is represented by Addison's transpyloric line, drawn horizontally through a point midway between the umbilicus and the sterno-xiphoid junction (or midway between the symphysis pubis and supra-sternal noteh). It crosses the spine at the level of the first lumbar vertelora. It must be noted that the pylorus only lies in this plane during life when the subject is in the horizontal position. On assuming the upright position the pylorus falls at least one vertebra lower. The sterno-xiphoid plane, drawn horizontally through the junction of the body of the sternum with the xiphoid, euts the spine at the disc between the ninth and tenth theracic vertebre, and the umbilical plane, pasing through the umbilicus, crosises the dise between the third and fourth lumbar vertelore (though in corpulent subjects it is solnewhat lower).

The abdominal wall. Bony and muscular landmarks.-The linea alba forms at preseptilule groove in the midelle line from the xiphoid eartilage to below thr umbilicus. It is a band of interlatring fibres, mostly crossing each other at right angles, that forms the main insertion of the transversus and oblique mascles, and stretches betwen the two recti muscles from xiphoid cartilage to

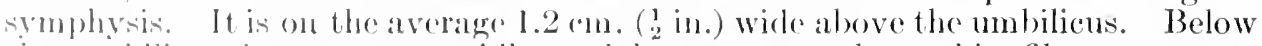
tha mimbilicus it narrows rapielly and becomes merely at thin fibrous septum

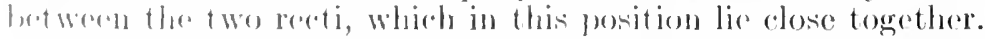

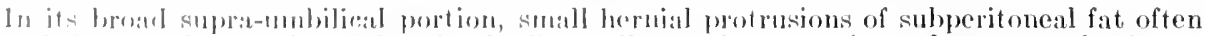
forer thrig waty lorough interstions in the linea alba, and true peritoneal sales may be derawn throngh after thene. The linmatha is mot very vasealar, and henee was at one time the favour- 
ite site of incisions in opening the abdominal cavity. Since the resulting scar is weak and yielding, however, it is now more customary to make vertical incisions through the rectus sheath, to one side of the middle line, where the abdominal wall can be sutured in layers, and an incisional hernia prevented.

The umbilicus lies in the linea alba rather below its centre. It is somewhat prone to hernia formation (p. 1402) and is oceasionally the site of congenital fistulæ, which may originate in a Meckel's diverticulum (p. 1376) or a patent urachus.

When the recti are thrown into contraction the linea semilunaris on each side is made evident as a groove, extending with a slight lateral convexity from the tip of the ninth costal cartilage, where the lateral vertical line meets the thoracic margin, to the pubic tubercle.

The contraction of the recti muscles also shows up the three linese transversa, fibrous intersections adherent to the anterior layer of the sheath of the rectus, which cross the substance of the muscle (1) at the umbilicus, (2) at the tip of the xiphoid, and (3) midway between the former two. A tonic contraction of one or both recti localised to one of these segments occasionally gives rise to the "phantom" tumors which occur in some hysterical cases.

The linea semilunaris shares the disadvantages of the linea alba as a site for incisions, and there is the further danger of injury to the nerve supply of the rectus, which may involve a diffuse bulge of the atrophied muscle.

In tapping the bladder above the pubes, the trocar should be introduced immediately above the pubes and driven backward and a little downward. In this operation, and in suprapubic cystotomy, the retro-pubic space or cavum Retzii is opened. This is bounded in front by the pubes and superior fascia of the urogenital diaphragm, behind by the anterior surface of the bladder. Below are the true ligaments of this viscus. The space contains fatty tissue and veins, increasing in size with the advance of life. If about ten ounces of fluid are injected into the bladder, the peritoneum will be raised sufficiently to allow of a three-inch incision being made between the recti and pyramidales immediately above the pubes. The transversalis fascia is thicker below, and is often separated from the linea alba by fat, which must not be mistaken for the extra-peritoneal layer. The peritoneal reflexion is loosely connected to the bladder and can always be peeled upward.

A transverse line drawn from one anterior superior iliac spine to the other crosses at about the level of the top of the promontory of the sacrum. Such a line will always show whether the pelvis is horizontal or not. (Holden.)

The inguinal (Poupart's) ligament corresponds to a line drawn with a slight curve downward between the anterior superior iliac spine and the pubic tubercle. The first of these bony prominences corresponds to the starting-point of the above ligament, the attachment of the fascia lata to the ilium, the meeting of the fleshy and aponeurotic parts of the external oblique (denoted by a line drawn upward from this spine to the ninth costal cartilage, or often a little anteriorly to these points), the point of emergence of the lateral cutaneous nerve of the thigh, and part of the origins of the internal oblique, transversus, and tensor fasciæ latæ.

The pubic tubercle marks the lateral pillar (inferior crus) of the subcutaneous inguinal (external abdominal) ring, the mouth of which corresponds to the crest of the pubes lying between the tubercle and the symphysis. The neck of an inguinal hernia is above the tubercle and Poupart's ligament; that of a femoral hernia below and lateral to the tubercle, and below the same ligament. The ring, and especially its lateral pillar, can easily be felt by invaginating the scrotal skin with a finger, and pushing upward and laterally. In a female patient, if the thigh be abducted, the tense tendon of the adductor longus will lead up to the site of the ring. The abdominal inguinal (internal abdominal) ring is situated about $1.2 \mathrm{~cm}$. $\left(\frac{1}{2}\right.$ in.) above the centre of Poupart's ligament; oval in shape, and nearly vertical in direction, it has the arching fibres of the transversus above it, and to it. medial side the inferior epigastric artery, lying behind the spermatic cord. The pulsations of this vessel here guide the finger in the insertion of the uppermost deep sutures in radical cure of hernia. The canal runs obliquely downward and forward between the two rings. In the arlult it is about $3.7 \mathrm{~cm}$. ( $1 \frac{1}{2} \mathrm{in}$.) long, but in early life, and in adults with a large hernia dragging upon the parts, the two rings are much nearer, and may be one behind the other. For the anatomy of inguinal hernia see p. 1304.

Vessels in the abdominal wall.-The three superficial branches of the common femoral, the external pudic, epigastric, and circumflex iliac, supply the lowest part of the abdominal wall and the adjacent groin and genitals. The others that have to be remembered are the inferior epigastrics and the epigastric branch 
of the internal mammary, the deep circumflex iliacs, the last two intercostals, and the abdominal branches of the lumbar arteries.

Of these, the inferior epigastric is the most important; its course will be marked out by a line drawn from a point just medial to the centre of the inguinal ligament, upward and medially to the medial side of the abdominal ring, and thence to a point about midway between the pubes and umbilicus, forming the lateral boundary of Hesselbach's triangle (fig. 1121). Here the vessel, which at first lies between the peritoneum and fascia transversalis, perforates the latter and, passing orer the semicircular line (fold of Douglas) enters the sheath of the rectus. It then runs upward, closely applied to the back of that muscle, and, a little above the level of the umbilicus, divides into branches which anastomose with the epigastric branch of the internal mammary.

One superficial vein in the abdominal wall needs especial mention, the thoraco-epigastric joining the veins of the chest, e. g., the long thoracic above with, the superficial epigastric below. Its ralves directing the blood downward below and upward above (Stiles) may be rendered incompetent when this vessel is enlarged, as in interference with the portal vein, with which it communicates by a vein in the round ligament, or in blocking of the inferior vena cava.

Lymphatics. - It is sifficiently correct to say here that those above the umbilical line go to the axillary, and those below that line to the inguinal nodes.

Nerves.-The lower seven intercostals and the ilio-hypogastric and ilioinguinal supply the abdominal wall. The sixth and seventh intercostals supply the skin over the upper epigastrium; the eighth, the area of the middle linea transversa; the tenth, that of the umbilicus; the last thoracic, ilio-inguinal and iliohypogastric, the region above Poupart's ligament, and that of the pubes. The ilio-hypogastric supplies the skin over the subcutaneous inguinal (external abdominal) ring; the ilio-inguinal that over the cord and scrotum. The last thoracic and ilio-hypogastric cross the iliac crest to supply the skin of the buttock.

The diaphragm.-The upper limit of the diaphragm rises to the following levels in full expiration: Its central tendon to about the lower end of the body of the sternum, or the seventh chondro-sternal joint; the right half to the fifth rib, or about $1 \mathrm{~cm}$. ( $\frac{1}{2}$ in.) below the nipple; the left half not rising quite so high, i. e., to the fifth space, or $2.5 \mathrm{~cm}$. ( 1 in.) below the nipple.

Topographical relations of abdominal viscera.-These will include the peritoneum, liver and bile passages, stomach, spleen, pancreas, intestines, kidneys and ureters, and large abdominal vessels.

The peritoneal spaces.- The peritoneum presents certain potential spaces, determined by its various reflections from the parietes and abdominal viscera. In these spaces collections of fluid such as abscesses or extravasations from hollow viscera or blood vessels may collect and become shut off by adhesions or overflow in various directions into neighbouring spaces. The transverse mesocolon and great omentum together form a shelf transversely placed, which divides the greater sac into two main divisions-supra-omental and infra-omental.

The supra-omental region, in which the various forms of subphrenic abscess are found, eontains the following fossir (Barnard).* (1) Right subphrenic, between the right lobe of the liver and right cupola of the diaphragm, bounded toward the median line by the falciform ligament, and behind by the coronary ligament. It communicates below with (2) the subhepatic fossa or right renal pouch (Morison), which is bounded above by the visceral surface of the liver, and betow by the mesocolic shelf and right kidney. It extends from the right lateral abdominal wall, its most capacious part, arcoss the median line under the left lobe of the liver, and on its posterior aspect tie the upper pole of the right kidney, epiploic foranen, and anterior surface of small omentum. (3) The left subphrenic, also known as the anterior perigastric fossa, hes betworn the left dome of the diapliragm above, and the left lobe of liver, stomach, spleen and oncutum balow. It is bounded on the right by the falciform ligament which lies somewhat to the right of the median line. (4) The omental bursa may be regarded as a diverticulum from thrs sublepatic fossa with whinh it communicates by the epiploic foramen. Abscesses in this satr arre rate, but oreasionally laceration of the pancreas which is elosely related to it behind grives rike to a collection of pancreatic juice and blood in the lesser sac, known as a pancreatic

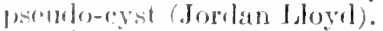

The infra-omental region is subdivided in its ablominal part into (1) right and (2) left compartments by the at farhment of the rost of the mesentery to the spine, descending from the Inorlene-jojunal flexure downward into the right iliac fossa. "These fossa communicate with the mpra-roncotal jominns in the neighbourhool of the hepatic and splenic flexures of the colon respretively, and ficlow with (3) the pelvis. The deepest level of the peritonem lining the pelvis mostifutes in the male the recto-vesical, and in the female the recto-vaginal fossa (pouch of I) m,IIrlis).

It slumlal be noted that with a patient in the sumpe position, owing to the contour of the

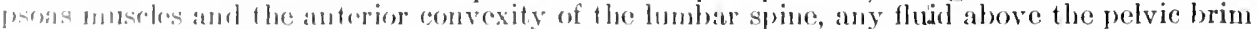
will trond to gravitate into the suhphrenic spares across the flexures of the colon which lie far lask in thre loins. Thlos is mulesirable in viow of the great absorhing power of the subphrenic lymphatich, and mas be obviated by propluing the patient in a half-sitting position.

* Jatriarl, 11. L., lirit. Merl. Journal, Feh. 15, 1908. 
Viscera behind the linea alba.-From above downward there are the following:- (1) Above the umbilicus - the left lobe of the liver, the stomach, the transverse colon, part of the great omentum, the pancreas, and coliac (solar) plexus. (2) Below the umbilicus - the rest of the great omentum, covering in the small intestines and their mesentery. In the child, the bladder occupies a partly abdominal position; and in the adult, the same viscus, if distended, will rise out of the pelvis and displace the above structures, raising the peritoneum until, if distended half way to the umbilicus, there is an area of nearly $5 \mathrm{~cm}$. (2 in.) safe for operations above the symphysis. The gravid uterus also rises behind the linea alba.

The liver (figs. 914, 941, and 1125).-In the erect position, the anterior thin margin of the liver projects about $1 \mathrm{~cm}$. ( $\frac{1}{2} \mathrm{in}$.) below the costal cartilages, but can only be made out with difficulty in this position. It may also be displaced downward by pleuritic effusion or tight lacing. The liver is also, proportionately, much larger in small children.

Of the three more accessible surfaces, the right lateral is opposite the seventh to the eleventh intercostal arches, separated from them by the pleura, the thin base of the lung, and the diaphragm. The superior surface is accurately fitted with its right and left portions into the hollows of the diaphragm, a slightly depressed area intervening which corresponds to the central tendon. Its level corresponds to that of the diaphragm given above. On the left side, in the adult, the limit of the loft lobe will be in the fifth interspace, about $7.5 \mathrm{~cm}$. (3 in.) from the sternum. The anterior surface is in contact with the diaphragm, costal arches, and, between them, the xiphoid cartilage, and, below, with the abdominal wall. Both the superior and anterior surfaces are subdivided by the falciform ligament, an important point in subphrenic suppuration. In the right hypochondrium the anterior margin corresponds to the lower margin of the thorax; but in the epigastric region, running obliquely across from the ninth right to the eighth left costal cartilage, it crosses the midlle line about a hand's breadth below the sternoxiphoid articulation (Godlee), or half-ray between the sterno-xiphoid junction and umbilicus, i.e., in the transpyloric line (fig. 914). Behind, the anterior margin, following the right lateral surface within the costal arches, crosses the last rib toward the level of the eleventh thoracic spine. In the anterior border, a little to the right of the median vertical plane, is the umbilical notch, where the falciform and round ligaments meet. Still further to the right, and just to the left of the mid-Poupart plane, is the fundus of the gall-bladder.

Gall-bladder and bile passages.-The fundus of the gall-bladder, situated in a fossa on the under surface of the right lobe of the liver, and having the quadrate lobe to its left, lies opposite to the right ninth costal cartilage, close to the lateral edge of the rectus. This point corresponds to the site of intersection of the lateral vertical and transpyloric lines. It is in contact with the hepatic flexure of the colon and the first piece of the duodenum, into either of which, but particularly the latter, large gall-stones impacted in the neck of the gall-bladder occasionally ulcerate. A distended gall-bladder as it enlarges tends to take a line obliquely from the above point where it emerges from under the costal margin toward the umbilicus.

The long axis of the gall-bladder is directed from the fundus backward and upward. The cystic duct runs from the neck downward and forward in the gastro-hepatic omentum, and so forms an acute angle with the gall-bladder. A spiral fold of mucous membrane at the junction of the two, which fulfils the function of keeping the lumen open for the flow of bile, adds to the difficulty of passing a bougie from the gall-bladder down into the common duct.

The hepatic and cystic ducts join in the right free margin of the gastro-hepatic omentum to form the common bile-duct, $7.5 \mathrm{~cm}$. (3 in.) in length, which as it runs down to open into the duodenum presents four distinct stages. (1) It first lies in the free edge of lesser omentum in front of the epiploic foramen, with the hepatic artery to the medial side, and the portal vein behind them both. (2) Behind the first part of the duodenum with the gastro-duodenal artery accompanying it. (3) In a deep groove in the head of the pancreas, between that gland and the posterior aspect of the sccond part of the duodenum. The pancreatic tissue surrounds it completely in 75 per cent. of cases, (Bunger) hence the jaundice that occurs in chronic interstitial pancreatitis. (4) Piercing the muscular wall of the duodenum obliquely it ends by joining the main duct of the pancreas at the ampulla of Vater and opening into the second part of the duodenum by a common orifice. This orifice, situated on the postero-medial aspect of the gut, rather below the centre of the second portion, is raised on a small papilla and is narrower than the lumen of the common duct.

The stomach.-The study of this organ by rendering its contents opaque with bismuth salts and projecting its shadow by X-rays on a fluorescent screen, has greatly modified the conception of its shape and position formed from postmortem and operative observations. Examined post-mortem, or at operations under general anæsthesia it forms a flaccid sac with its long axis directed from the fundus obliquely downward, forward, and to the right. Seen under X-rays, 
with the patient standing upright, the cardiac portion (the fundus and body together) is vertical, and the smaller pyloric portion is directed backward and to the right and slightly upward (fig. 1125). The most fixed point is the cardiac orifice.

The cardiac orifice lies under the seventh left costal eartilage $2 \mathrm{~cm}$. ( $\frac{3}{4} \mathrm{in}$.) from the sternoxiphoid junction at a depth of about $10 \mathrm{~cm}$. (4 in.) from the surface. Behind, this point corresponds to the tenth thoracic vertebra.

The pyloric orifice lies in the transpyloric plane when the patient is reeumbent, but'when the patient is standing it falls to the level of the second or third lumbar vertebra, or lower still

Fig. 110S.-Photggraph of an Empty Stomach. (J. S. B. Stopford.)

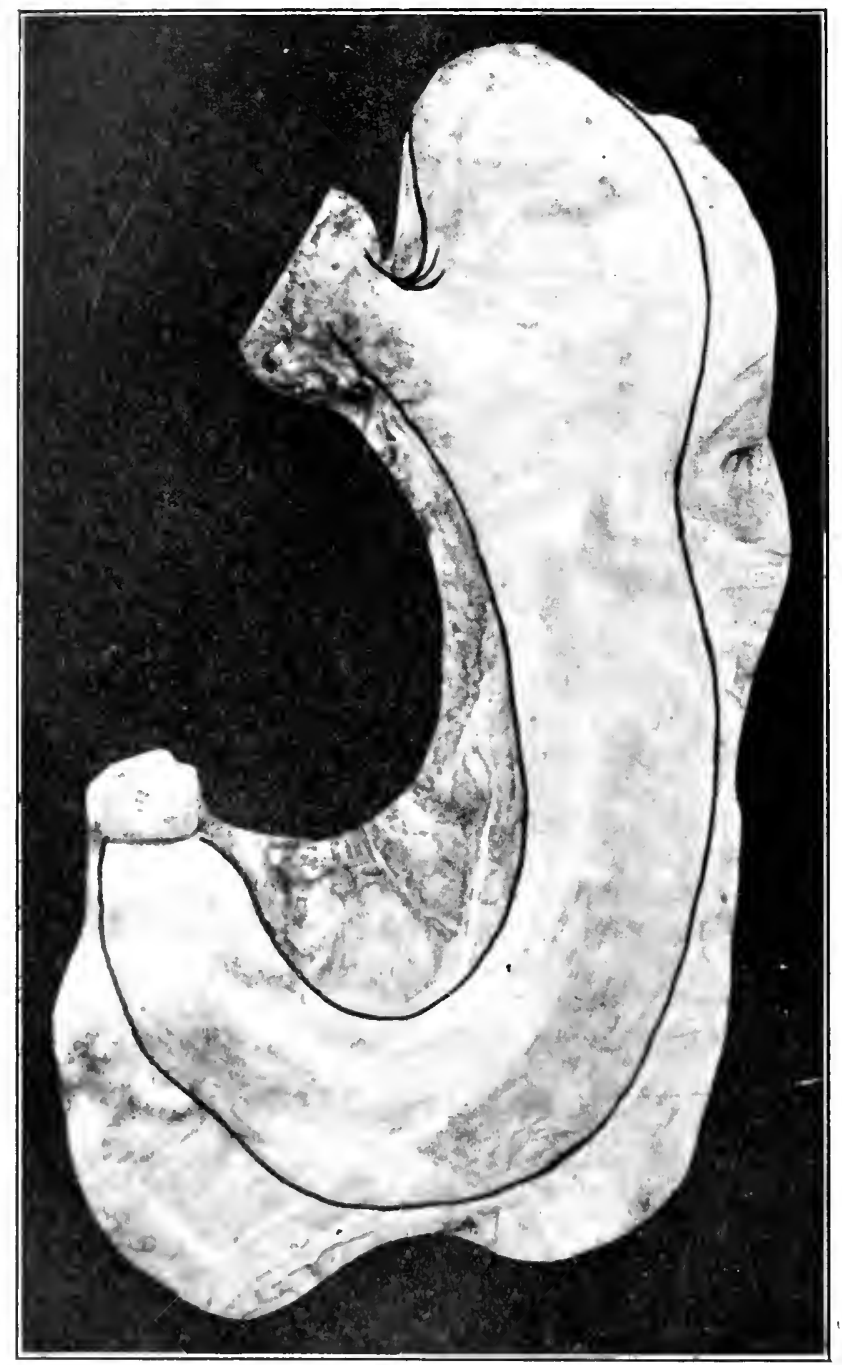

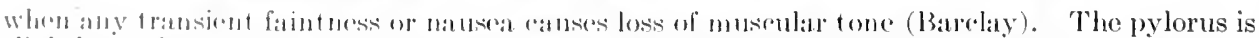
slightly to the light of 1 he mildle line in the ompty stomach. As the stomateh fills it deseends farther atul moxes a little farther to the right. Thie lesser curvature bresents a definite noteh at

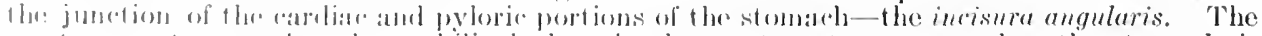

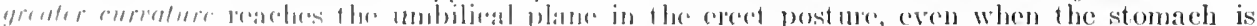

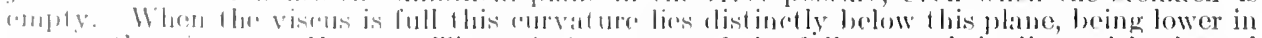

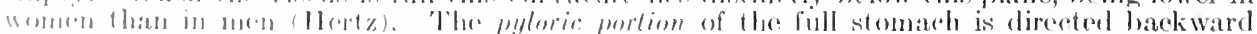

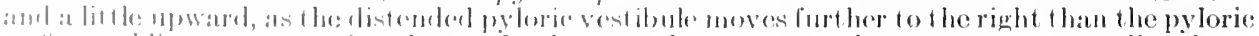

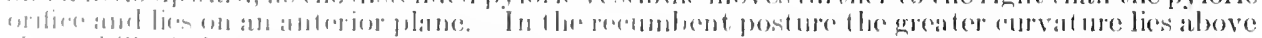

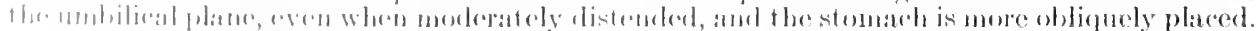

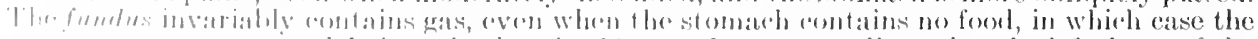

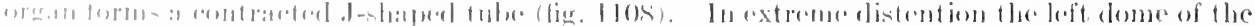

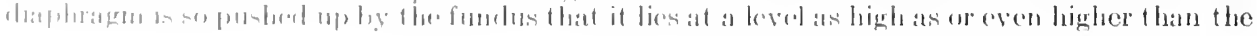


right dome (Hertz). The pressure thus exerted on the heart accounts for the dyspnoea and cardiac pain so often associated with flatulence. The position of the pyloric sphincter is shown on the outer surface by a very constant venous ring runding toward both lesser and greater curvatures in the subserous laver at right angles to the long axis of the pylorie canal (Moynihan).

In connection with the extravasation of contents that results from perforating ulcers of the stomach, a knowledge of the subphrenic peritoneal fosse is important (p. 1372). Perforation is rare on the posterior surface since it is less mobile than the anterior, and protective adhesions form readily. When it does occur, extravasation into the omental bursa results, and such a perforation is exposed by turning up transverse colon and stomach and incising the transverse meso-colon. Perforation on the anterior surface usually gives rise to general perit onitis, but in the less serious cases an abscess may form localised to (1) the right subphrenic space, (2) the subhepatic fossa, or (3) the left subphrenic space, according to the situation of the ulcer on the stomach.

The spleen (fig. 1127; see also figures in Sections IX and XII).-This lies very obliquely in the left hypochondrium, its long axis corresponds closely with the line of the tenth rib. It is placed opposite the ninth, tenth, and eleventh ribs externally, being separated from these by the diaphragm; and medially it is connected with the great end of the stomach. Below, it overlaps slightly the lateral border of the left kidney (fig. 1127). Its highest point is on a level with the spine of the ninth thoracic, and its lowest with that of the eleventh thoracic vertebra. Its upper pole is distant about 3.7 ( $1 \frac{1}{2} \mathrm{in}$.) from the median plane of the body, and its lower pole about reaches the mid-axillary line on the same rib. (Godlee.) In the natural condition it cannot be felt; but if enlarged, its notched anterior margin extends downward toward the umbilicus, and is both characteristic and readily felt.

The pancreas.-The head of the pancreas lies in the hollow formed by the three parts of the duodenum, on the bodies of the second and third lumbar vertebræ. The inferior vena cava lies behind it. The neck, body, and tail of the pancreas pass obliquely to the left and slightly upward, crossing respectively the commencement of the portal vein, the aorta, and the left kidney. The root of the transverse mesocolon is attached to the anterior margin of the gland, so that its supero-anterior surface is related to the omental bursa, and its inferior surface to the greater sac. The importance of this relation in the formation of pancreatic pseudo-cysts has been referred to above.

Pancreatic ducts.- The main duct, the duct of Wirsung, opens into the common ampulla of Vater with the bile duct. This ampulla usually opens into the gut by a narrow orifice raised on a small papilla. A gall-stone impacted in the ampulla may cause a flow of bile backward along the duct of Wirsung, and so give rise to acute pancreatitis (Opie). The small accessory duct of Santorini opens into the duodenum independently about $2 \mathrm{~cm}$. higher up. It often anastomoses with the larger duct in the substance of the gland.

Accessory nodules of pancreatic tissue are occasionally met with in the walls of the stomach or small intestine at different regions.

A cyst originating in the pancreas may "point" toward the anterior abdominal wall by three routes:-(1) Above the stomach through the lesser omentum; (2) between stomach and transverse colon through the great omentum; (3) below the transverse colon through the transverse mesocolon. The posterior aspect of the head of the gland, with the third part of the common bile duct may be exposed by incising the peritoneum on the lateral margin of the second part of the duodenum, and turning the gut medially toward the middle line.

Intestines. (A) Small.-The average length of the small intestine is about

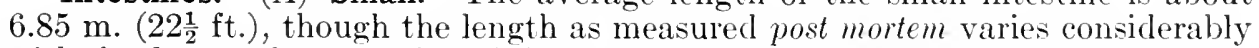
with the degree of contraction of the longitudinal muscular coat. The duodenum is about $25 \mathrm{~cm}$. (10 in.) in length. Of the remaining portion the upper two-fifths constitute the jejunum and the lower three-fifths the ileum, though this division is quite arbitrary. Cases are recorded in which patients have survived the removal of over $5 \mathrm{~m}$. (16 ft.) of small intestine.

The first part of the duodenum extends from the pylorus on the first or second lumbar vertebra, backward and to the right. It ends near the upper pole of the right kidney and on the medial side of the neck of the gall-bladder, by turning down to form the less mobile second part, which descends in front of the hilum of the right kidney to the level of the third lumbar vertebra. The third part of the duodenum crosses the body of the third lumbar vertebra horizontally in the infracostal plane, and then turns up obliquely to the left side of the spine and ends at the level of the upper border of the second lumbar vertebra in the duodeno-jejunal flexure. The first part is the most mobile, since it is covered back and front by peritoneum in the first half of its course. The second part has a peritoneal covering in front only and is devoirl of it where it is crossed by the commeneing transverse colon. The third part is covered by peritoneum in front except where the superior mesenteric vessels pass across it to join the com mencement of the mesentery. It is probably the constricting effect of these vessels on the duoclenum that gives rise to the acute dilatation of the stomach which occasionally follows abdominal operations. 
The duodeno-jejunal flexure, which lies on the left side of the body of the second lumbar vertebra, immerliately below the body of the pancreas, is held up to the right crus of the diaphragm by a band of fibro-muscular tissue known as the suspensory ligament of Treitz. Some of the fibres of this structure are continued onward into the root of the mesentery. It is not found in pronograde animals. The duoleno-jejunal flexure is the commonest site of traumatic rupture of the small intestine, since it is the point of union of a fixed and a freely movable portion of the gut.

In the operation of posterior gastro-enterostomy the duodeno-jejunal flexure is readily found by passing the hand along the under surface of the transverse meso-colon to the left side of the spine, the omenturn and colon being turned upward. The first coil of the jejunum is anastomosed to the posterior wall of the stomach, which is exposed by making an opening in the transverse meso-colon.

In some cases the first fow centimetres of the jejunum are found to be fused between the layers of the transverse meso-colon. Certain peritoneal fosse are often found on the left side of the flexure. They may give rise to retro-peritoneal hernia and strangulation of intestine. The duodenal fosse are described on p. 1164.

Jejunum and ileum.-The mesentery contains between its two peritoneal layers the superior mesenterie vessels and their intestinal branches, the superior mesenteric plexus, lacteals and many lymph nodes on their course. These nodes are frequently enlarged in abdominal tuberculosis in children (tabes mesenterica). The attached border of the mesentery may be marked out on the surface by a line clrawn from just below the transpylorie plane and a little to the left of the middle line (the duodeno-jejunal flexure), which eurves downward and to the right to end in the iliae fossa at the junction of the intertubereular and right lateral vertical lines (the ileo-cæcal valve).

Meckel's diverticulum which is present in about 2 per cent. of subjects (Treves) is found in the free bor rer of the ileum $30 \mathrm{~cm}$. to $1 \mathrm{~m}$. (1 to $3 \mathrm{ft}$.) above the ileo-creal valve. It is a remains of the vitello-intestinal duct. It is usually a blind conical pouch some 6 to $9 \mathrm{~cm}$. long with a free extremity, but may be attached to the umbilicus by a fibrous cord. This cord may cause acute intestinal obstruction by strangulating a coil of gut, or the diverticulum may be invaginated and form the starting-point of an intussusception.

The presence of aggregated lymph nodules (Peyer's patches) in the lower part of the ileum areounts for the fact that tubereulous ulcers and perforating typhoid uleers are almost confined to this part of the gut.

Intestinal localisation.--It of ten happens that the surgeon wishes to ascertain roughly to what part of the small intestine a given coil presenting in a wound belongs. The variations in length of the small intestine and the considerablf. range of movement of the coils during peristalsis render the problem difficult, hut it may be stated as a general rule that the upper third of the intestine lies in the loft hypochondrium and is not usually encountered in a wound; the milllle third occupies the midlle part of the abdomen, and the lower third lies in the pelvis and right iliac fossa (Monks). The jejunum is thicker walled and more vascular than the ileum. The lumen steadily diminishes as we pass downward, hence foreign bodies such as gall-stones that pass through the jejununn are apt to become impacted in the lower ileum.

The most reliable imlications of the level of a given coil are found, however, on inspection of the meschtery and its bfood-vessels (see fig. 452 in Section V). Opposite the upper part of the howet the mesonteric arteries are arranged in a series of large primary anastomosing loops. I'rom these the vasisa reeta rmu to the gut 3 to $5 \mathrm{~cm}$. long, straight and unbranched. Passing hownard toward the lower end, the single lange primary foops give place to smaller and more mumeroms seromdary lomps arranged in layers coming nearer amd nearer to the bowel. Hence the rasit renta lecome shorter. They beome also less regular and more branched, and in the lowor thirl of the small intestine are less than $1 \mathrm{~cm}$. in length. The mesenteric fat in the upper

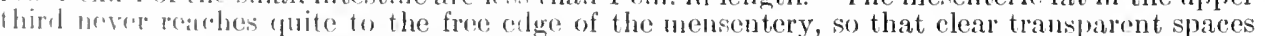

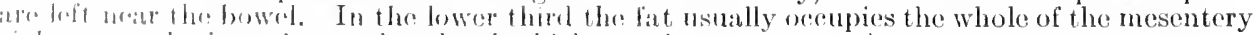
right ap lo the intostine, and makes it thicker and more opaque.*

l'he asmage wilth of the mesentery, from its root at the postrerior parietes to the bowel 14 21) an. (s in.) ant the longast part lies fretween 2 and $8 \mathrm{~m}$. from the duodenum (Treves).

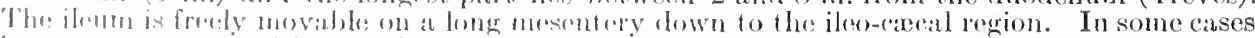
luwerer a congrental fusion of the left hatf of the mesentery with the parietal peritoneum near

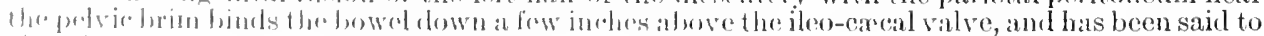
gite rise to symptoms of intestinal stasis. (1 thit, $\dagger$ (iray, and Anderson.)

(1) Large intestine. Ileo-cæcal region. - The position of the ileo-creal vitre may line matkerl on the surfare hy the junction of the intertubercular and right latrial vertioal lines, thongh it is often fomm considerably lower. It is

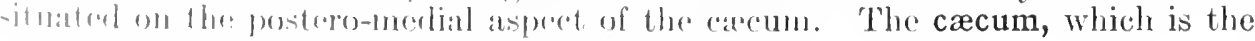

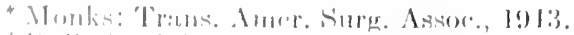

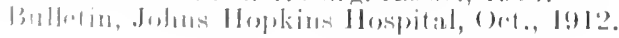


blind extremity of the colon lying below the horizontal level of the ileo-cral valve, is approximately $6.2 \mathrm{~cm} .\left(2 \frac{1}{2} \mathrm{in}\right.$.) in both vertical and transterse diameters, though its size varies much with the degree of distention. It lies usually in contact with the anterior abdominal wall above the lateral half of the inguinal ligament. The orifice of the appendix (vermiform process) lies some $2 \mathrm{~cm}$. below the ileo-crecal valve. The cxcum is completely covered by peritoneum as a rule, though exceptionally its posterior surface is bound down in the right iliac fossa.

The axial rotation of the midgut and descent of the cxenm that normally take place during intra-uterine life (p. 1168) are occasionally not completed, with the result that the cæcum and appendix may be found above and to the left of the umbilicus, or less uncommonly just below

Fig. 1109.-Blood-vessels of the Ileo-c.eal Region. (Fron Kelly).

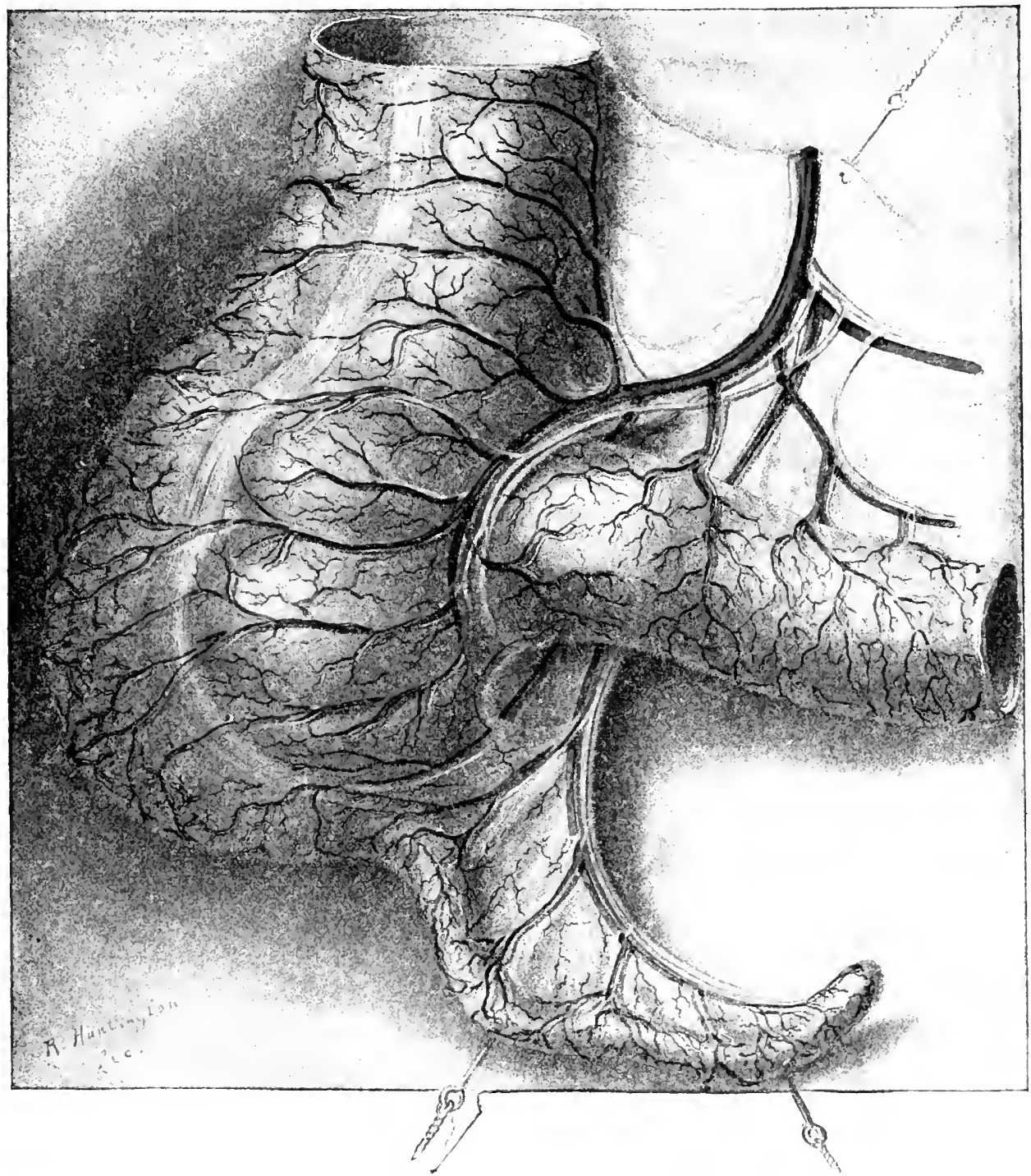

the right lobe of the liver (3 per cent., Alglave), when an attack of appendicitis may simulate inflammation of the gall-blarlder. On the other hand certain cases oceur in which the cacum descends unusually far, proceeding downward and medially until it becomes a pelvic organ whenever the bladder and rectum are empty. This pelvic position of the cacum is found in 10 per cent. of infants (G. M. Simith).*

In the commonest form of intussusception, the ileo-cacal valve and lower ileum are prolapsed into the colon and carried lown by the force of peristalsis toward the anus. The valve in these cases forms the apex of the intussusceptum, however far it travels.

* Anat. Record, vol. 5, 1911, p. $5 \pm 9$. 
The vermiform process (appendix) is developed at the apex of the ciecum, and persistence of the apical appendix of fotal type, is not uncommon. The fact that all three tæniæ coli converge at the base of the appendix is an anatomical reminder of its primitive position. The anterior tenia is of great service in operations on the appendix, since by following it down from the colon the base of the appendix can always be found. The adult position of the base of the appendix on the postero-medial aspect of the axcum is due to the disproportionate growtly of the lateral saccule of the cacum which comes to form the apparent cacal apex.

The appendix averages $10 \mathrm{~cm}$. (4 in.) in length in the adult. The position of its base only is at all constant. It lies distinctly below McBurney's point, whieh is midway between the umbilieus and the right anterior superior iliae spine. This point is of ten the seat of greatest tenderness in appentieit is. 'The appendix itself may be found (1) pointing upward and to the left toward the spleen, behind the terminal ileum and mesentery; (2) hanging over the pelvic brim, in which position tenderness on rectal examination or pain on mict urition results when the organ is inflaned; (3) in the retro-colie fossa; and (4) with its tip projecting to the right of the efeum in the right lateral paracolic fossi, where it causes tenderness when inflamed close to the anterior superior iliae spine. The course and to some extent the gravity of abseesses originating in the appendix will depend upon the position the inflamed organ is oceupying at the time of perforation.

The artery of the appendix derived from the posterior branch of the ileo-colic reaches it by rumning down behind the end of the ileum. It raises a fold of peritoneum ealled the mesentriolum or mesoappendix. Very rarely the artery comes from the anterior braneh of the ileo-colie.

The tonic coli referred to above as converging on the base of the appendix contribute its longitudinal muscular coat. The inner circular coat is thicker, but along the attachment of the mesenteriole eertain gaps for the passage of lymph and blood-vessels oceur in the muscular coats. Through these gaps infection may easily spread from the mucosa to the peritoneum (Lockwood).

The appenclix is essentially a lymph gland and has been called the "abdominal tonsil." The lymph follicles lie in the submucosa. They are poorly developed at birth but reach their full development within the first few weeks of extra-uterine life (Berry).* Obliteration of the lumen is common but is inflammatory in origin, and not, as was once thought, a change normal in advanced age.

Pericæcal fossæ.- In addition to the mesentery of the appendix eertain other folds of peritoneum are usually present at the ilfo-ciecal junction: (1) the ileo-colic or anterior vascular fold (fig. 1109) containing the anterior branch of the ileo-eolic artery; (2) the ileo-cæcal, or bloodless fold of Treves, running from the lower border of ileum onto the cacum. The appenlix may be in a fossa behind either of these fohls. It may also be found in the retro-colic fossa lying behind the "aroum and comnencement of ascending colon.

The colon is readily distinguished from the small intestine by its three longitudinal truix and saccules and by the appendices epiploice, which are developed before birth.

The ascending colon runs with a slight lateral convexity upward from its junction with the rescum to the hepatic flexure which lies under the ninth right costal cartilage at the level of the second lumbar vertebra and in contact with the anterior surface of the right kidney and the lower surface of the right lole of the liver. It lies lateral to the right lateral vertical plane. This description is only true of all aseonding colon cxamined by X-rays in the recumbent poition. When the pationt stands up, the flexure sinks to the infracostal Hane (third lumbar vertebsa) or "ven lower. As the colon ascends in the angle

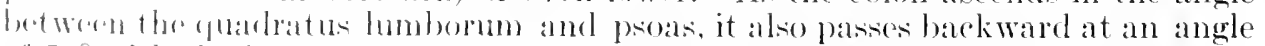
of $51^{\circ}$ with the horizontal, als maly heseren in a sagittal secetion through the right

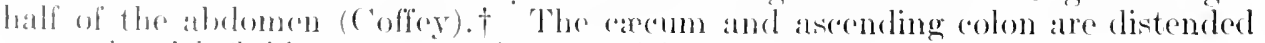
as a male with fluid contents and gats, and form the widest part of the colon.

The varintens in the peritoneal attachments of the colon, which are of growing elinical

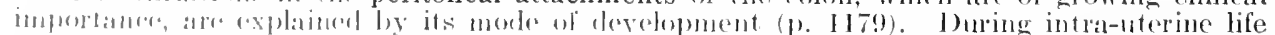

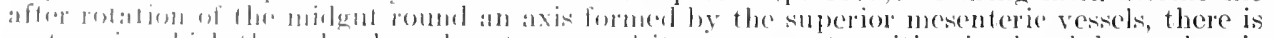

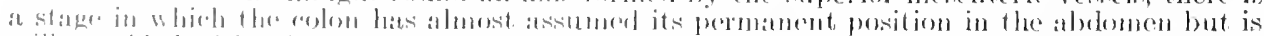

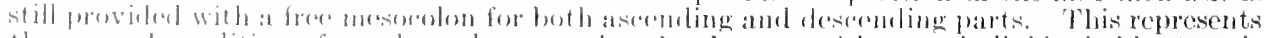

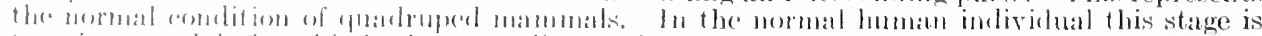

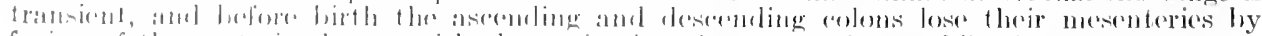

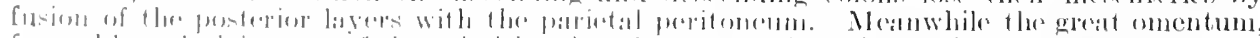

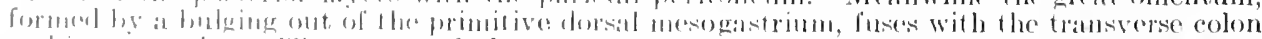

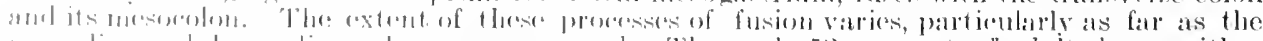

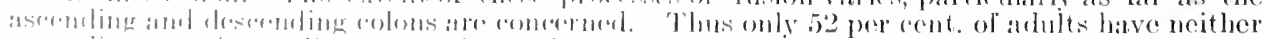

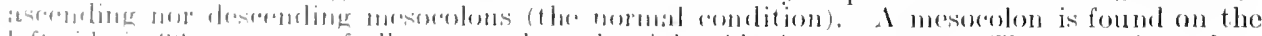

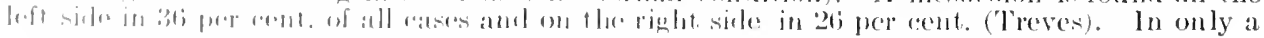


small proportion (1.S per cent., however, does the true primitive type of ascending mesorolon persist, continuous with the mesentery of the small intestine ( $(i$. Mi. Smith). Fuch an anomaly' renders the patient liable to volvulus of the ileo-caeal region. In the common types of incomplete fusion of its peritoneal attachments the colon is inadequately arlapted to the upright position and is predisposed to ptosis. A layer of peritonem sometimes frmml pasing downward and medially from the parietes in the right flank onto the front of the ascenting colon, known as Jackson's pericolic nembrane, is probably due to persistence of an early stage in the development of the great onentum, which passes to the right acoss the ascending colon to join with the parietal peritoneum before the descent of the ceeum is complete, and so is the most primitive agent in fixing the proximal colon back in the right loin. This membrare is usually assoeiated with a congenitally mobile ascending colon (Morley).*

At the hepatic flexure the colon bends forward and to the left, leaving the front of the kilney to which it is fixed, and erossing the second part of the duorlenum. In the region of the flexure three inconstant peritoneal folds are met with giving it additional attachment to the neighbouring parts, viz., (1) the phreno-colic and less commonly (2) the hepato-colic and (3) cystocolic ligaments (Testut). They must not be confused with pathological adhesions acquired after birth.

The transverse colon is freely mobile except at its extremities. It crosses the abdomen with a convexity downward and forward, being separated from the anterior abdominal wall in the middle region by the great omentum.

At the mid-line it usually lies near the umbilical plane in the recumbent posture, considerably lower in the erect, but may be found any where from the infra-costal plane to the pubes, depending on the tonicity of the stomach. Its main artery, the middle eolie branch of the superior mesenteric, must be avoided carefully in the operations of gastro-enterostomy and gastrectomy, since ligature of it causes gangrene of the transverse colon.

The splenic flexure lies far back in the left hypochondrium and is considerably higher than the hepatic flexure. It is in eontact with the lower end of the spleen, and is almost invariably held firmly in position by its phreno-colic ligament, derived from the left extremity of the great omentum.

The descending colon is of narrower ealibre than the preceding parts and usually is found firmly contracted and empty. It passes downward and forward in the angle between the psoas and quadratus lumborum and obliquely across to the right the iliac fossa to end in the sigmoid or pelvie colon. The lower part of the descending colon, from the iliac crest to the pelvic brim, is often termed the iliac eolon.

In its upper part it lies in front of the convex lateral margin of the left kidney. The variations in its peritoneal attachments have been referred to above (p. 1242). The operation of lumbar colostomy, common in pre-antiseptic days, was performed through an incision in the back parallel with the last rib. The colon lies $2.5 \mathrm{~cm}$. (1 in.) to the lateral sicle of the edge of the sacro-spinalis, between the twelfth rib and iliac erest. The occurrence of a mesocolon here was a common source of difficulty in gaining access to the bowel wit hout opening the perit oneum.

The pelvic colon (also known as the sigmoid or omega loop (Treves), is almost as long as the transverse colon, and forms a loop, the two ends of which, at the pelvie brim and at the front of the third sacral vertebra respectively, are placed somewhat elosely together. The loop is thus anatomically preclisposed to axial rotation, and is the commonest seat of volvulus in the whole intestinal tract.

On the left and inferior aspect of the pelvic mesocolon near its base, a small peritoneal fossa (intersigmoid) is usually found in the angle formed by the root of the mesocolon and the parietal peritoneum. It occasionally contains an internal lecria which may become strangulated.

The upper part of the pelvic colon is frequently brought out and opened through an incision in the left iliac region to form an artificial anus in cases of inoperable growth of the rectum

In advanced life, and in the chronically constipated, certain diverticula of mucous membrane are occasionally met with which projest through the vascular galps of the muscular coat into the bases of the appendices epiploica in this region, and also between the lavers of the pelvic mesocolon. They often contain fecal concretions and may become inflamed in even perforate, forming an abseess in the left iliac fossa. $\dagger$

The junction of pelvic colon and rectum opposite the third sacral vertebra forms a more or less acute angle and constitutes the narrowest part of the colon. It is a frequent site of stricture.

The kidneys.- These lie at the back of the abdominal cavity so deeply in the hypochondriac and epigastric region as to be beyond palpation in most individuals, unless enlarged or unduly mobile. The lower end of the right heing slightly lower than its fellow, encroaches in health upon the lumbar and umbilical regions, and may be palpable on deep inspiration in spare subjects. These

* Lancet. Dec., 1913.

$\dagger$ McGrath: Surgery, Gynecology and Obstetries, vol. 15, 1912, 429. 
organs lie much higher and nearer to the vertebræ than is usually supposed to be the 'case, the upper two-thirds of the right and all the left kidney being behind the ribs. Relatively to the vertebræ, the kidneys lie along the sides of the last thoracic and the first three lumbar.

To mark them in from the front the following points should be noted: The upper extremity of the right should reach as high up as the seventh costal cartilage, the left up to the sixth, on either side close to the costo-chondral and inter-chondral junctions. This level will eorrespond to one half way between the stemo-xiphoid and transpyloric lines. The lower end,

Fig. 1110,-Rentl Fascia, as seen in Cross-section.

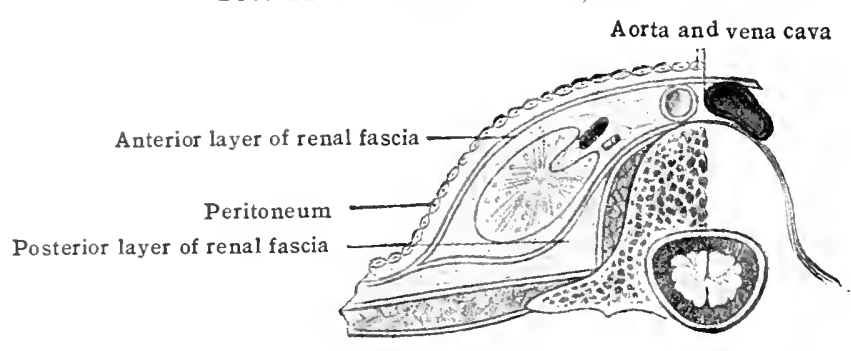

about $11 \mathrm{~cm}$. ( $4 \frac{1}{2}$ in.) below this point, would be opposite to the subeostal line; that of the right kidney is usually lower, and may encroach upon the umbilical line. For practical purposes the hilus is opposite a point on the anterior abdominal wall, a finger's breadth medial to the tip of the ninth costal cartilage (Stiles), or the junction of the trauspyloric and lateral vertical lines. The importance of the relation of the last rib has been mentioned at p. 1245. The lateral vertical line has one-third of the kidney to its lateral side, and two-thirds to its medial side. The shortest distanee between the two kidneys, obliquely placed so as to be closer above, 'at the upper part of their medial borders' (Thane and Godlee), measures about 6.2 enn. (2 $\frac{1}{2}$ in.).

On the posterior surface of the body the kidney's boundaries are indieated by the following: - (1) A line parallel with, and $2.5 \mathrm{~cm}$. (1 in.) from, the mid-line, between the lower edge of the tip

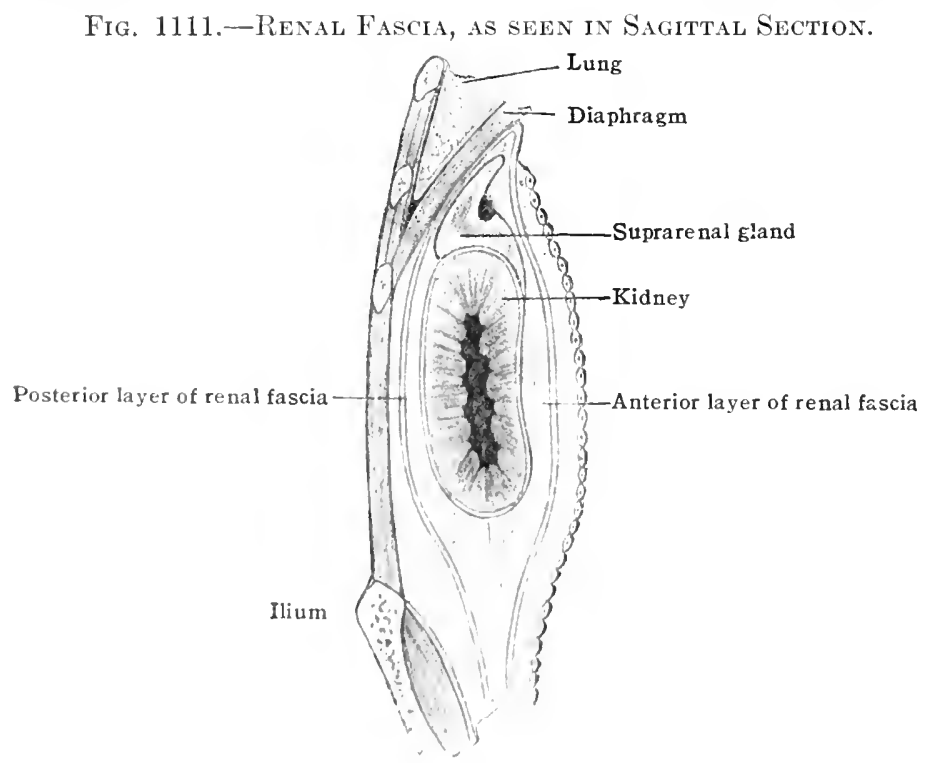

of the spinums process of the cleventh thrario and the lower ede of the spinous process of the third lunbur verfolsa; (2) and (3) lines drawn from the top and bottom of this line laterally, at right angles to it, for 7 ('m. (2) in.); (1) a line parallel to the first, and comeeting the extremities of (2) and (3). Within this pardholongum the kidney lies (Morris).

'l'hr chief relations of the kidneys arr:- posteriorly - puarlratus lumborum, posas, diaphragm, last thoracice, ilio-hypogastric, and ilio-inguinal nerves. The Iwalfh rib, lios lechind hoth, the right, as a rule, not reaching ahove the upper

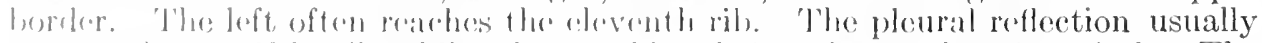

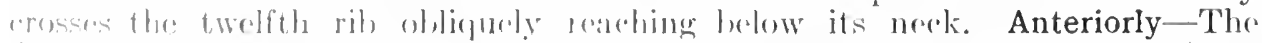
liver, right colic flexure and second part of the duotemum (figs. 956 and 1009), on 
the right side. The liver, and stomach above, the body of the pancreas and spleen over the centre, and the descending colon over the lower part of the left kidney.

The attachments of the specialised fibrous sheets known as the renal fascia are shown in figs. 1110 and 1111.

The anterior and posterior layers are seen to be continuous above and laterally. Medially and below they remain separate and it is in this direction that the abnormally movable kidney travels. The fatty tissue between the kidney and the renal fascia is known as the perinephric fat; that outside the fascia is the paranephric fat.

The kidneys are maintained in position by (1) the vascular pedicle; (2) fatty capsule and fascia; (3) above all by the intra-abdominal pressure.

Failure to ascend during development from its original position near the pelvic brim to its normal level accounts for certain cases of movable kidney of congenital origin. In these cases.

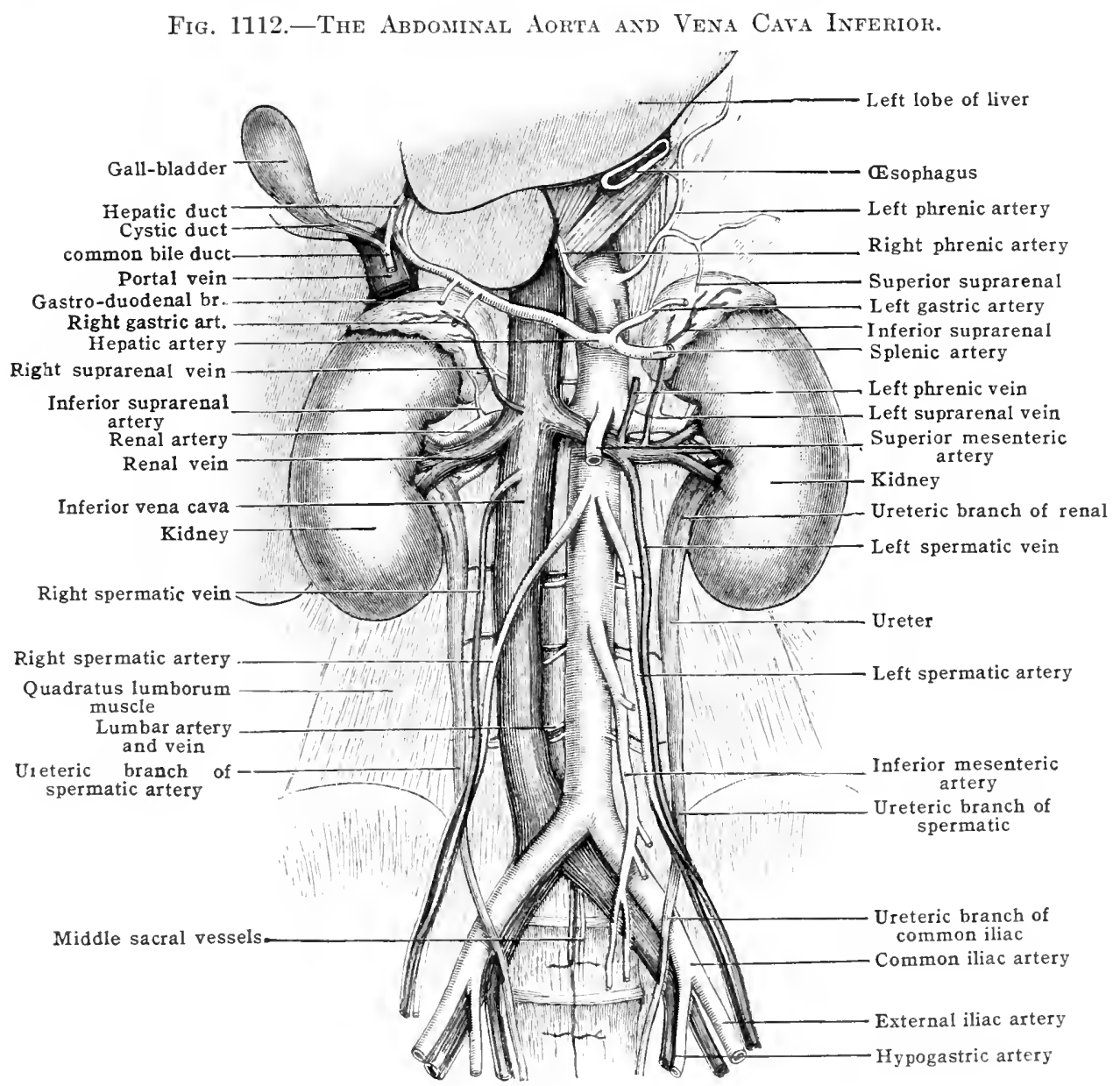

the renal artery may take origin from the common iliac artery. An accessory renal artery running into the lower end of the kidney from the aorta may cause kinking of the ureter and is a not uncommon cause of hydronephrosis.

The suprarenal glands are not so firmly attached to the kidneys as to the diaphragm; hence they are not encountered in operations for movable kidney and are not removed in nephrectomy.

Brödel has shown that incisions into the kikney should be made rather behind its convex border (Brödel's bloodless line). Occasionally fusion of the lower poles occurs during development across the middle line of the body, and a single horseshoe kidney results, with double ureter and vascular supply.

The ureter.-On an average $30 \mathrm{~cm}$. (12 in). long, this tube descends almost vertically in its abdominal course on the psoas muscle. It is crossed obliquely 
by the spermatic or ovarian vessels. It crosses the brim of the pelvis just in front of the bifurcation of the common iliac, and descends on the side wall of the pelvis in front of the hypogastric artery.

The abdominal part of the ureter may be exposed extraperitoneally by an extension forward of the usual lumbar renal incision. It is found lying between peritoneum and psoas $3.7 \mathrm{~cm}$. $\left(1 \frac{1}{2} \mathrm{in}\right.$.) from the middle line and when the peritoneum is stripped from the posterior abdominal wall the ureter is invariably carried with it.

Aorta and iliac arteries. - The aorta enters the abdomen opposite the last thoracic vertebra, a point 12 to $15 \mathrm{~cm}$. (5 to $6 \mathrm{in}$.) above the umbilicus, or rather above the mid-point between the infrasternal depression and the umbilicus (Thane and (iodlee), and thence, lying to the left of the mid-line, divides into the two common iliacs opposite the disc between the third and fourth lumbar vertebræ, or opposite the body of the fourth lumbar vertebra. This point is about 2.5 cm. ( 1 in.) below and to the left of the umbilicus, and on a level with a line drawn across the highest part of the iliac crest. A line drawn from this point, with a slight curve laterally, to just medial to the centre of Poupart's ligament, will give the line of the iliac arteries; the upper third of this line giving the average length of the common iliac. The relation of the common iliac veins is shown in fig. 1112. The right, much shorter than its fellow, lies at first behind and then somewhat lateral to its artery. The left is at first to the medial side of its artery, and then behind the right. At the upper part of the fifth lumbar vertebra behind and lateral to the right artery, the vena cava begins.

The site of some of the branches of the aorta may be thus approximately remembered as follows: The cœliac artery is given off immediately after the aorta has perforated the diaphragm; directly below this is the superior mesenteric artery. About $2.5 \mathrm{~cm}$. ( 1 in.) lower down, or $7.5 \mathrm{~cm}$. (3 in.) above the umbilicus, the renal arteries are given off. About $2.5 \mathrm{~cm}$. ( 1 in.) above the umbilicus would be the level of the inferior mesenteric artery. The relation of the above vessels to the transpyloric line (p. 1153) is as follows: (Stiles.) The cœliac artery is two fingers' breadth, the superior mesenteric one, above the line, the renal arteries are a finger's breadth below it. The origin of the inferior mesenteric is midway between the transpyloric and intertubercular lines.

Collateral circulation after ligature of the common iliac.- The chief vessels here are:ABOVE.

Pubic hranch of inferior epigastric

Internal mammary and lower intercostals

Lumbar

Misdle sacral

Superior hemorrhoidal

Ovarian BELOW.

Internal mammary, lower intercostals, and lumbar.

Ilio-lumbar, lumbar, and gluteal

Intcrual and external circumflex

I'erforating branches of profunda

Circumflex and cpigastric

Ixternal pudic:

with Pubic branch of obturator.

with Inferior epigastrie.

with Ilio-lumbar and cireumflex iliac.

with Lateral sacral and superior gluteal.

with Inferior and middle hæmorrhoidal.

with Uterine

with Inferior epigastric.

with Deep eireumflex iliac.

with Superior and inferior gluteal (sciatic).

with Inferior gluteal (comes nervi isehiadici). with Obturator.

with Internal pudic.

Collateral circulation after ligature of the internal iliac:-

\author{
Branchlies of profuncla \\ Inferior mesenteric: \\ Vessed of opporsile side \\ branclies of opposite sirle \\ sinproror and inforior gluteal (soiatice) \\ Mirlale sarral \\ Ilio-lumbar and superior gluteal
}
with
with
with
with
with
with
Inferior gluteal (sciatic).
Hamorrhoidal arteries.
Pubie branch of obturator.
Branches of pullie.
Circumflex and perforating of profunda. Jiteral sacral.
with Cireumflex iliac.

\section{TIIE PEIVIS}

The male pelvis will be consielered first, then the fomale pelvis, and finally a sertion onl herniat.

The MaLe Pravis

The tophes under this heading will be ansidered in the following order: homblarios and sublivisions, selofum and tostis, ductus doforens and spermatic 
cord, penis and urethra, prostate, bladder, ischio-rectal fossa, rectum and anal canal.

Bony boundaries. - These are the same in either sex. Above and in front is the symphysis pubis, rounded off by the subpubic ligament; diverging downward and laterally from this point on either side are the rami of the pubes and ischia, ending at the tuberosities of the latter. In the middle line behind is the apex of the coccyx, and reaching from this to the tuberosities are the sacro-tuberous great sacro-sciatic) ligaments, to be felt by deep pressure, with the lower border of the gluteus maximus overlapping them.

The depth of the perineum varies greatly-from 5 to $7.5 \mathrm{~cm}$. (2 to $3 \mathrm{in}$.) in the posterior and lateral part to $2.5 \mathrm{~cm}$. (1 in.) or less in front. In the middle line, extending longitudinally through the perineum, is the raphe, the guide to the urethra, and 'the line of safety' (on account of the small size of the vessels here) for operations on it.

Fig. 1113.-The Male Perineum. (Modified from Hirschfeld and Leveillé.)

Bulbo-cavernosus

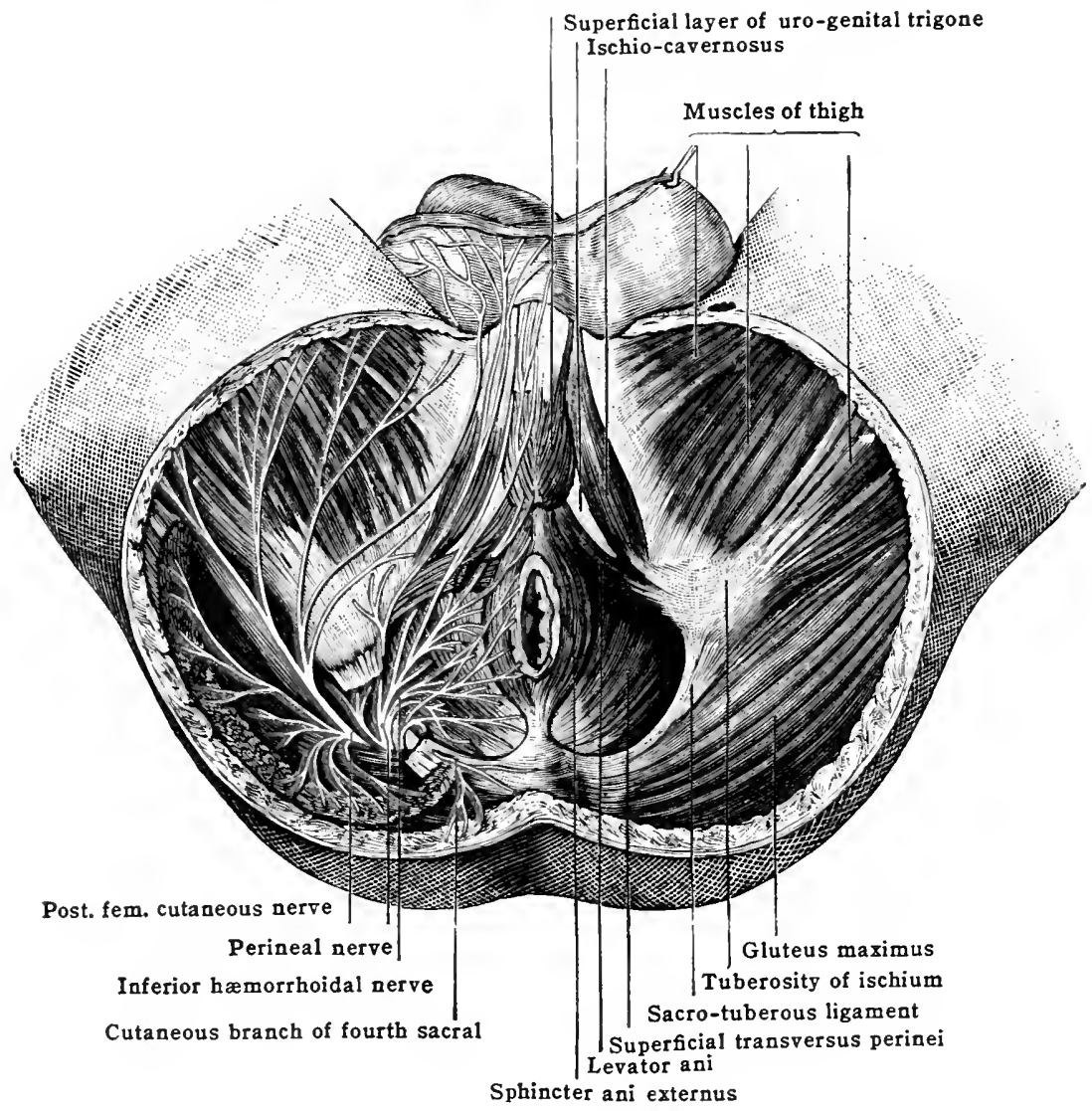

Subdivisions.-An imaginary line drawn transversely across the perineum from one tuber ischii to its fellow divides the lozenge-shaped space into two triangles-(1) An anterior, or uro-genital; and 2) a posterior, or rectal. The pelvic floor includes an upper or pelvic diaphragm (formed by the levator ani and coccygeus on each side) and a lower incomplete uro-genital diaphragm (or trigone).

The pelvic diaphragm (figs. 1113, 1114, 1115; see also figs. 397, 399, 400) is made up of the levator ani coccygeus muscles. It is somewhat funnelshaped. When viewed from above or below (fig. 395), its fibres are seen to form horseshoe-like loops, arising on either side anteriorly, and passing posteriorly backward around the uro-genital apertures to be inserted chiefly in the mid-line posteriorly. The pelvic diaphragm serves primarily for the support of the abdominal viscera. For a detailed description of these muscles, as well as those of the uro-genital diaphragm, see section on the Muscular sistem. 
The uro-genital diaphragm (or trigone) (fig. 400), the lower diaphragm of the pelvic floor, is both morphologically and functionally different from the upper. The uro-genital diaphragm is a sphincter muscular layer, derived (with the sphincter ani externus) from the primitive sphincter cloacœ. The uro-genital diaphragm is composed of superior and inferior fascial layers, enclosing the membranous urethra, the sphincter urethræ membranaceæ and the transversus perinei profundus. Superficial to the uro-genital diaphragm is the superficial perineal interspace (fig. 400). This is covered by the superficial perineal (Colles') fascia, and includes the crura and bulb of the corpora cavernosa, with associated muscles, ressels and nerves.

The space in the pelvic floor on each side below the pelvic diaphragm is the ischio-rectal fossa (figs. 399, 400,1114). In the posterior or rectal triangle, where the urogenital cliaphragm is absent, the ischio-rectal fossæ form large wedge-shaped spaces. The lower wall or base is formed chiefly by the corresponding skin and superficial fascia, and partly by the external sphincter ani; the medial wall by the

Fig. 1114.-Coronal Section of the Ischio-rectal Fossa. (G. Elliot Smith.)

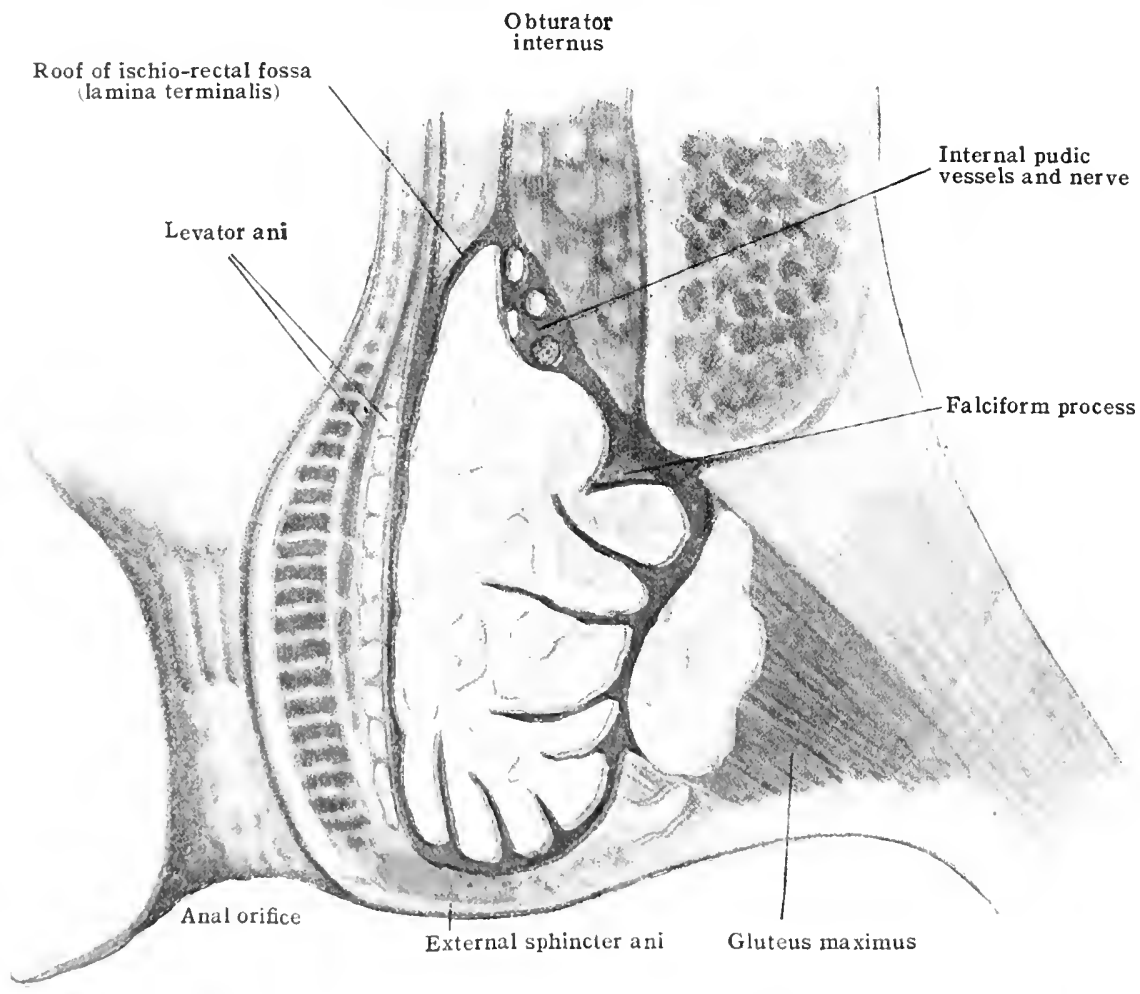

muscles (levator ani and conergeus) and inforior fascia of the pelvie diaphragm; the lateral wall by the obturat or internus musele, with the erresponding obturator fatscia (with deock's anal, including the pudie vessels and nerves). The apex of the fosta is above, where medial and lateral walls meet. The natrow fibrous roof strip joining the medial and lateral walls just above the level of the internal pudie: vesseds and norves has berne alled the lamina terminalis (Elliot Smith, fig. 1114). Posteriorly the fosist is moneded by the gluteus maximus and lig. satcro-tulberosinn. Antriorly on calch side the ischio-lectal fossa extend as narrow spares betweren the pelvie diaphringm alowe, the uro-genital diaphragm below, and the prituc wall laterally (figs. 400, 401, 402).

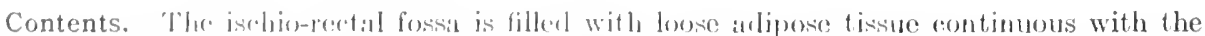

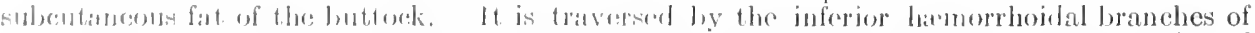
floe intermal purlice artery, with the assoriated voins ind nerves, passing to the cxternal anal

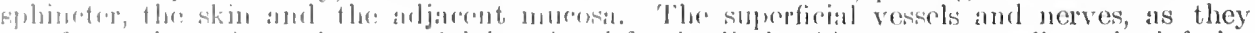

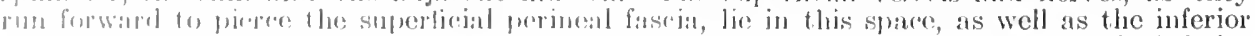

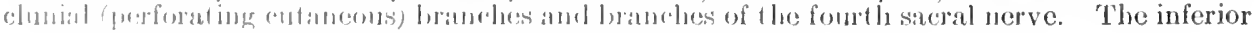


hæmorrhoidal veins traverse the fossa obliquely from the lateral wall downward and medially. They are usually somewhat dilated near the anal orifice, and when morbidly enlarged constitute the condition known as hæmorrhoids ("piles"). The inner opening of an anal fistula caused by the bursting of an ischio-rectal abscess in to the gut is usually within $2 \mathrm{~cm}$. of the anal margin, between the internal and external sphincters.

The central point of the perineum is in the adult nearly an inch $(2.5 \mathrm{~cm}$.) in front of the anus, or midway between the centre of the anus and root of the scrotum. Here the following structures meet, viz., the levatores ani, the two transverse perineal muscles, the bulbo-cavernosus, and the sphincter ani.

The comparative weakness of the attachment of the sphincter ani in front, i. e., not into a bony point, is important in the division of it, as in operation for fistula. The sphincter should never be cut through anteriorly, especially in women, where its attachment here, blending with the sphincter vaginæ, is a very weak one. This point also corresponds to the centre of the lower margin or base of the uro-genital diaphragm (triangular ligament). Its development varies much in different bodies. A little in front of this point is the bulb, with the corpus spongiosum passing forward from it. This would also be the level of the artery of the bulb. so that in lithotomy the incision should always begin below this point. A knife introduced at the central point, and carried backward and very slightly upward, should enter the membranous urethra just in front of the prostate, e. g., in median lithotomy and Cock's external urethrotomy. If pushed more deeply, it would enter the neck of the bladder.

In median lithotomy, an incision $3.7 \mathrm{~cm}$. ( $1 \frac{1}{2} \mathrm{in}$.) long is made through the central tendinous point and raphe, so as to hit the membranous urethra. The following structures are divided:Skin and fasciæ; some of the most anterior fibres of the external sphincter ani; raphe and central tendinous point; minute branches of transverse perineal vessels and nerves; base of uro-genital diaphragm in centre; membranous wrethra and constrictor uretlurx.

The attachments and arrangements of the superficial fascia (fig. 1115) must be traced and remembered. If the two layers of which it consists, the superficial alone extends over both urethral and rectal triangles alike, and is continuous with the similar structures in adjacent regions, the only difference being that, if traced foward into the scrotum and penis, it loses its fat, and contains dartos fibres. The deeper layer, found only over the urethral triangle, is called the fascia of Colles (fig. 1115). Attached at the sides to the rami of the pubes, behind to the base of the uro-genital trigone or diaphragm, and open in front, it forms the superficial wall of a somewhat triangular pouch, limited behind by the uro-genital trigone, and containing the superficial vessels, nerves, and muscles, the bulb, adjacent part of the urethra, and crura of the penis. Owing to this space being closed behind and open in front, and to its containing the above structures, fluids extravasated within this space will obviously tend to make their way forward into the scrotum, penis, and lower part of the abdominal wall.

The uro-genital triangle is subdivided into two planes by the inferior fascia of the uro-genital diaphragm and fascia of Colles. The structures in the superficial plane, between the uro-genital diaphragm and the fascia of Colles, have been given above. Those in the deeper, i. e., between the two layers of fascia of the diaphragm, are-(1) The membranous urethra; (2) deep transverse perineal muscle and sphincter of the membranous urethra; (3) the bulbo-urethral (Cowper's) glands; (4) and (5) part of the pudic artery and nerve, and branches.

The scrotum.-The skin of the scrotum is thin and delicate so that when distended, as by a hydrocele in the tunica vaginalis, it is remarkably translucent. Attached to its deep aspect is a layer of involuntary muscle, the dartos. When the dartos is contracted, as under the influence of cold, the scrotal skin becomes rugose.

To this tendency to wrinkling, with consequent irritation from retained dirt, and the presence of many sweat glands the frequeney of epithelioma in this part is due. The clartos is apt to cause inversion of the skin in wounds of the scrotum, but this difficulty in suturing may be counteracted by the application of a hot sponge, which relaxes the muscle.

The superficial fascia of the scrotum is continuous with the fascia of Colles and the superficial fascia of the penis. Hence extravasation of urine under the fascia of Colles's balloons the scrotum and penis. The laxity of the areolar tissue under the dartos accounts for the great swelling that occurs in œdema of this part.

The lymphatics of the scrotum, important by reason of the extension of scrotal cancer, drain into the superficial inguinal nodes. Those from the anterior aspect nearest the median raphé run to the supero-lateral glands of this group, within a few $\mathrm{cm}$. of the anterior superior spine.*

* Morley: Lancet, 1911 (ii), p. 1545. 
The numerous large sebaceous glands that are found in the skin of the scrotum may give rise to cysts or adenomata. The deeper layers of the scrotum are derived from the abdominal wall, being brought down by the processus vaginalis in the descent of the testis.

Testis and epididymis. - The left testis, the first to descend, lies somewhat lower in the scrotum, and this fact is one reason of the frequency with which a

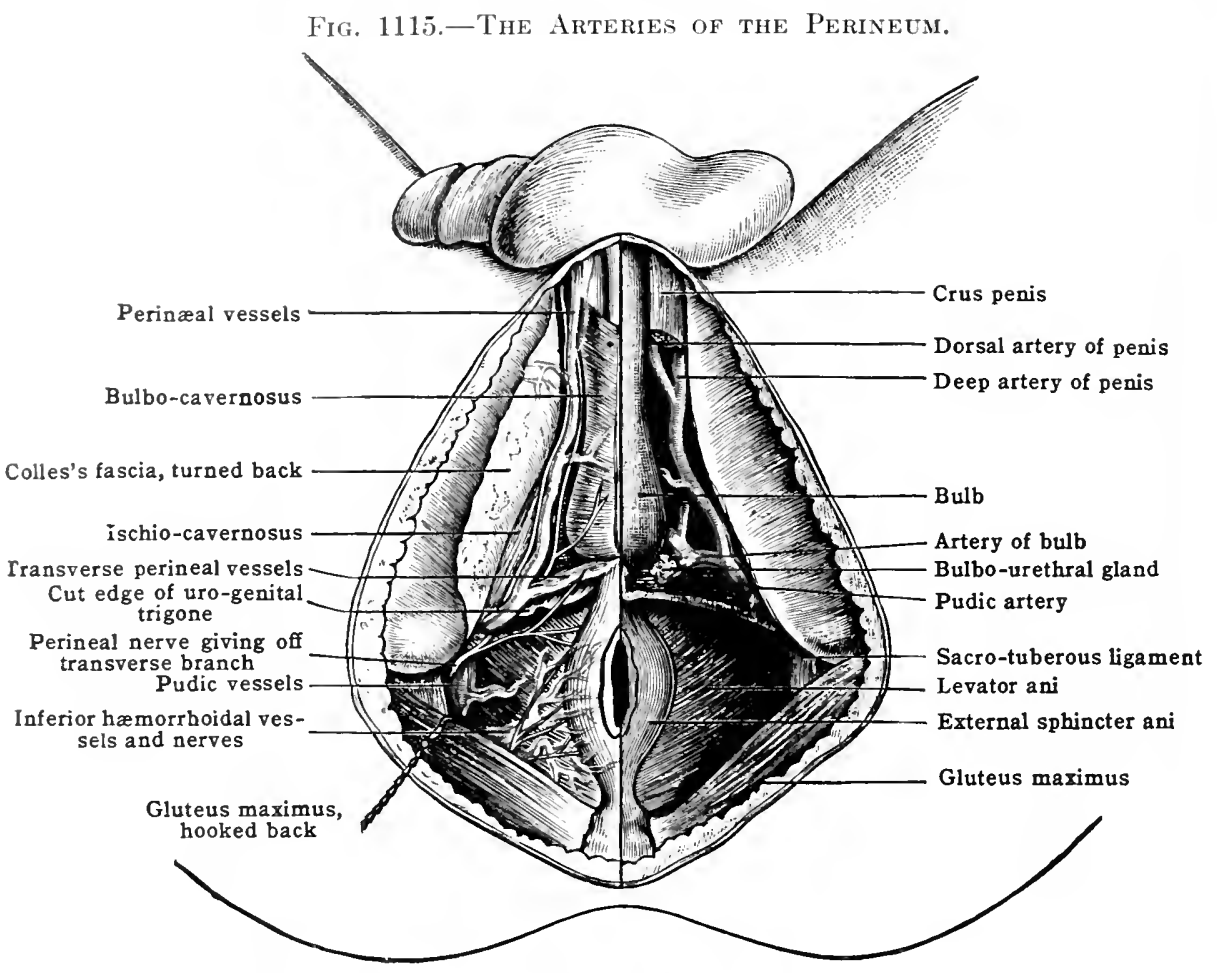

Fig. 1116.-Sagittal Section of Male Pelvis $(\times 1 / 3)$. (Braune.)

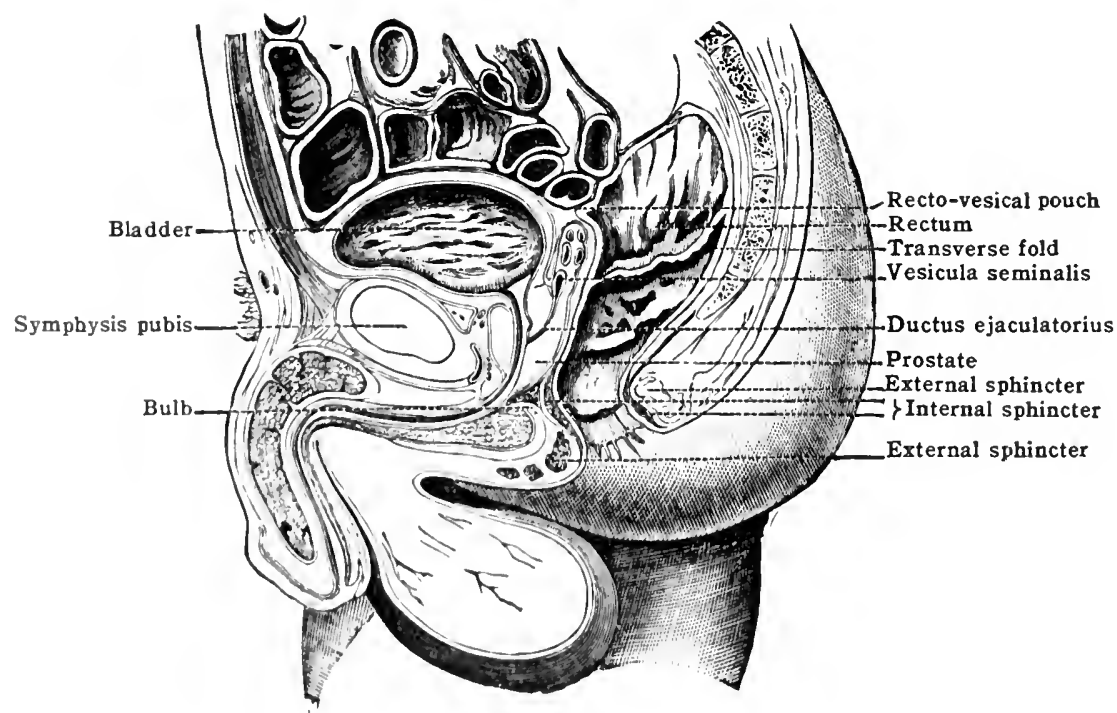

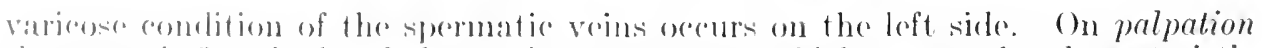

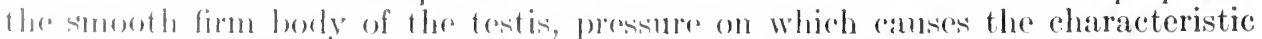
"testionlat semsition" (an be folt to lio in fromt of and rather modially to the epididymis. 'l'he there parts of the lattre, the romut aloove, the body, and the

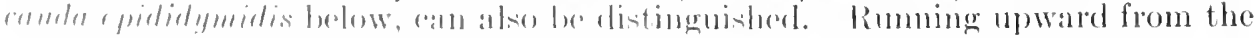


back of the epididymis to the subcutaneous inguinal ring the spermatic cord can be felt. The bulk of the cord is made up of its coverings, of which the cremaster muscle is the most considerable, and of the pampiniform plexus of veins. On rolling the cord between the finger and thumb the ductus deferens can be felt like a piece of whipcord in the posterior part.

The ductus (vas) defercns is thickened and nodular in tuberculous cpididymitis. In varicocele the dilated and elongated veins of the pampiniform plexus feel on palpation like a hag of worms in the scrotum. It is important that the student, before studying diseased conditions, should make himself familiar with the feel of the normal parts as mentioned above and be able to identify them.

Underneath the visceral layer of the tunica vaginalis, the body of the testis is rovered by a dense fibrous layer, the tunica albuginca, which accounts for the small extent of swelling in orchitis as compared with epididymitis. The lymphatics of the testis run up in the spermatic cord through the inguinal canal, and accompanying the spermatic vessels end in the lumbar lymph nodes, below the level of the renal arteries. These nodes may be reached and removed along with the vessels by making an incision in the loin above the inguinal (Poupart's) ligament, and stripping the peritoneum off the posterior abdominal wall.

On the right side of the perineum (left side of this figure) Colles's fascia has been turned back to show the superficial vessels. On the left side the superficial vessels have been cut away with the anterior layer of the uro-genital trigone to show the deep vessels.

The epididymis is the convoluted first part of the duct of the testis, about $6 \mathrm{~m}$. (20 feet) in length. Its three portions are in differing connection with the test is. Thus the cauda is held in place by connective tissue, the body by the same medium; the caput by the vasa efferentia. Thus, when tubercular disease begins here, the test is itself is more likely to be early involved.

Ductus deferens.- The two extremities and the course of this involve several practical points. About $45 \mathrm{~cm}$. (18 in.) long, it begins, convoluted at first and with a distinct bend upward, in the cauda epididymidis. It thence passes almost vertically upward at the back of the testis and cord to the tubercle of the pubes. Entering the canal, it lies on the grooved upper aspect of the inguinal (Poupart's) ligament, and then under the arching fibres of the internal oblique and transversus, upon the transversalis fascia. Its position, characteristic feel, and yellowish aspect are well-known guides in operations for varicocele and hernia, while it is always to be isolated and palpated when tubercular disease below is suspected. Leaving the canal by the abdominal inguinal ring, it hooks round the inferior epigastric artery and then descends into the pelvis over the external iliac vessels. Continuing its course downward and backward over the side of the pelvis, it arches backward over the side of the bladder, superficial to the obliterated hypogastric artery, and then deep to the ureter. The two ducts now help to form the lateral boundaries of the external trigone, between the base of the bladder and the rectum. They here become dilated and sacculated and then contract again to empty into the ejaculatory ducts.

The vesiculæ seminales are diverticula growing out from the lower end of the deferential ducts at an acute angle, one on each side. They lie below and lateral to the deferential ducts and are related in front to the base of the bladder and posterior surface of the prostate, behind to the rectum, and above to the recto-vesical pouch of peritoneum, which also descends to cover the upper part of their posterior aspect. The normal vesicula seminales can scarcely be distinguished from the base of the bladder on rectal palpation, but when diseased, as in tuberculous or gonorrhceal vesiculitis, are enlarged and indurated and can be detected readily.

The ejaculatory ducts, formed by the union of the vesicular and deferential duct of each side, are $2-2.5 \mathrm{~cm}$. in length. The first few millimeters of their course is extra-prostatic, and then entering the posterior surface of the prostate they run side by side downward and forward through the gland, close to the middle line, to open into the urethra on the colliculus seminalis at either side of the opening of the prostatic sinus. It is by these little ducts that infection travels from the urethra to the vesiculice and epididymis in gonorrhoea.

Descent of the testis. - The testis is developed between the tenth and twelfth thoracic segments of the embryo, and subsequently moves downward. By the third month of intrauterine life it descends into the iliac fossa; from the fourth to the seventh month it lies at the abdominal inguinal ring; during the seventh month it passes obliquely through the abdominal wall by the inguinal canal; by the eighth month it lies at the subcutaneous inguinal ring, and it reaches the fundus of the scrotum about the time of birth. The left test is is slightly earlier than the right in all these stages. The descent referred to is due in part to the common descent of organs, associated with the descent of the diaphragm, but mainly to the gubernaculum. This is a mass of fibro-muscular tissue that forms under the inguinal fold (or plica gubernatrix) of peritoneum below the testis as it lies in the iliac fossa, and in the mesorchium. It grows down obliquely through the abdominal wall from a point lateral to the inferior epigastric artery, and tunnels out a passage for the testis. As it travels down into the scrotum it carries in front of it three layers of investing fascia derived from the abdominal wall, viz., external spermatic fascia from the external oblique, cremasteric from internal oblique and transversus muscles, and infundibuliform fascia from the transvorsalis fascia. The gubernaculum is attached above to the peritoneum and the posterior aspect of the testis, and by its subsequent contraction it draws down into the scrotum first a diverticulum of peritoneum, the processus vaginalis, and secondly the testis, which projects into the processus from behind just as it did into the coelom.

Shortly after birth, obliteration of the processus vaginalis should occur, commencing at the deep abdominal ring and immediately above the test is. The part of the processus between these two points disappears completely. The lowest part, surrounding the testis. persists as the tunica vaginalis. Failure of obliteration, if complete, leaves a congenitnl hernial sac; if 
only the upper part perists, and does not communicate with the tunica vaginalis, it is called a funicular sac. Cysts originating in the processus vaginalis between the upper and lower points of primary occlusion are known as encysted hydrocele of the cord.

Undescended testis.- It oecasionally happens that descent of the testis fails on one or both sides, and in these cases the organ may remain, (1) in the iliac fossa, (2) in the inguinal canal, or (3) at the subcutaneous ring. Deprived of the protection normally afforded against injury by the scrotum and tunica vaginalis, the misplaced testis is subject to trauma, shows a tendency to torsion of its pedicle owing to its long mesorchium, and sometimes becomes the seat of malignant disease. A funicular hernial sac is generally present. Such testes are atrophic and functionally deficient, and it is probably owing to their small size at an early stage that the gubernaculum fails to gain a hold on them. It has been shown by Bevan* that in undescended testis the ductus deferens is usually long enough to allow the organ to be placed in the bottom of the scrotum by the surgeon without tension provided that the spermatic artery and pampiniform plexus of veins are divided. The blood-supply of the organ is then entirely derived from the deferential artery, a branch of the superior vesical. In rare cases the testis descends in a wrong direction (ectopia testis) and comes to lie in the perineum, over Scarpa's triangle, or on the pubes.

Penis.-The subcutaneous tissue of the penis, as on the scrotum, is devoid of fat and the delicate skin is very mobile and distensible, hence the ballooning of these parts in extravasation of urine or oedema. The fascia penis is continuous with Colles's fascia.

In radical amputation of the penis for malignant disease the whole organ, including the crura, is removed through an incision that splits the scrotum, and the stump of the corpus spongiosum (corpus cavernosum urethræ) is brought out into the perineum behind the scrotum.

The preputial orifice varies greatly in size. Normally large enough to allow easy retrac-

Fig. 1117.-Cross-Section of Penis.

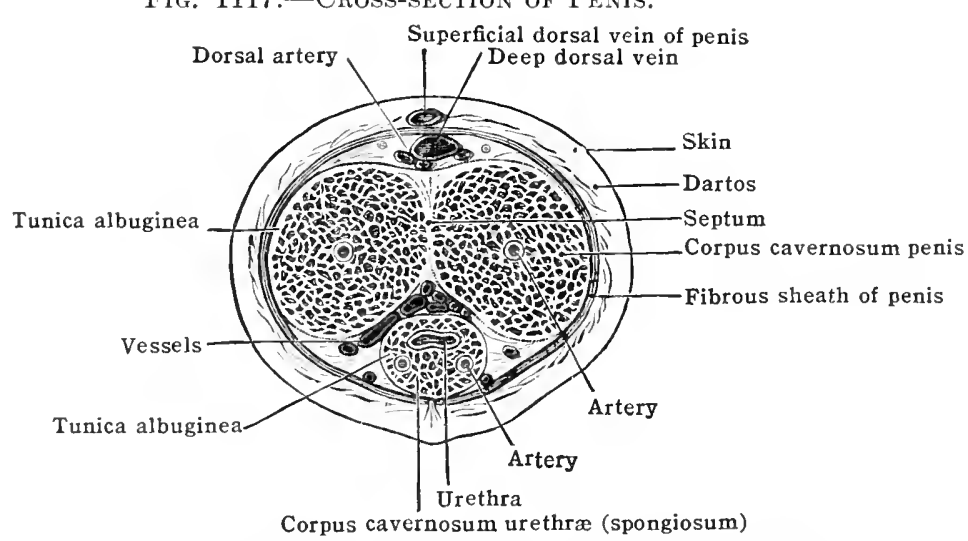

tion of the prepuce from off the grans, it is frequently so small that retraction is impossible and it nay even cause difficulty in micturition. The mobility of the skin over the penis must be borne in mind in the operation of eireumeision, and eare taken lest too much of the prepuce be removed, leaving insufficint skin to cover the penis. In this operation the vessels from which J leveling oceurs lie, (1) on the dorsum, (2) in the frenum.

Congenital malformations of penis. - It an early stage of development the urethra opens on the inferior aspect of the penis behind the glans. After the ingrowth of epithelium that forms the glandular urethra, this prinitive meatus should close. Occasionally, however, it persists, and the glandular urethra is represented by a grose on the under aspect of the glans. In these cases of hymspartins the glans is flexed on the penis and the prepuce is deficient below and has a peculiar "Inomed" appearance. In epispalias the upper wall of the urethra and corresponding mat of the corpora cavernosa are absent. This condition is usually present in cases of cetopria vesicac.

The male urethra is about 20 ("m. ( 8 in.) in length, consisting of the cavernous

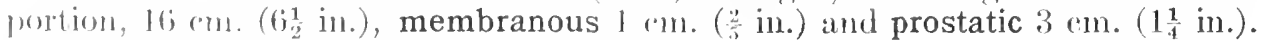
The narrowest part is the external orifice, and next to it the membranous urethra. The prostatic urethra is the widest and most dilatable. The bubous urethast, just in front of the uro-urenital diatphragm, is wider than the rest of the proile prortion, hut sines it forms the most dependent spot in the fixed part of

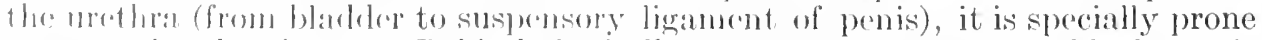
to gonorrlesal stricture. Pethind the bull, the urethra narrows sudelenty as it panses through the wro-genital diaphragm and contraction of the sphineters of

\footnotetext{
* Jorrn. Amer. Merl. Assoe, vol. 41, 190:;, p. 718.
} 
the membranous urethra may here give additional difficulty in the passage of a catheter.

False passages most commonly occur through the floor of the bulb on account of this, difficulty in entering the membranous urethra. The point of a small catheter may also be caught in the following apertures: (1) The lacuna magna in the roof of the fossa navicularis of the glandular urethra; (2) other crypts or lacunæ in the penile part, mostiy situated in the upper wall; (3) the prostatic sinus in the floor of the prostatic urethra about its centre. With the penis raised the urethra presents a simple curve under the symphysis with the proportions of an ordinary silver catheter.

It is in the region of the uro-genital diaphragm that the urethra is most liable to be damaged by a fall or blow, and the urine extravasated as a result will be beneath Colles's fascia. In rupture of the membranous urethra urine may find its way in front of the inferior fascia of the uro-genital diaphragm by coexisting injury to this, or through openings in the vessels, etc.; in a few such cases urine will make its way backward behind the fascia into the space of Retzius, ascending thence between the peritoneum and transversalis fascia. The attachment of the deep laver of superficial fascia to the base of the uro-genital diaphragm accounts for the fact that urine extravasated from a ruptured urethra or through an opening behind a stricture passes not backward into the anal triangle, but forward on to the scrotum and abdominal wall.

The prostate consists of a mass of racemose glandular tubules imbedded in a fibro-muscular stroma, that surrounds the first part of the urethra and lies below the neck of the bladder. Its base is intimately connected with the bladder by the continuation of vesical and urethral mucous membrane and by the insertion of the outer longitudinal muscular coat of the bladder into the gland. The inner circular muscle fibres of the bladder become specialised round the internal urethral orifice to form the internal sphincter.

Adenomatous enlargements of the gland usually grow upward through this sphincter which is thus dilated and pushed aside, so that the glandular grow th is covered only by vesical mucous membrane.

The apex of the prostate lies at the level of the lower border of the pubic symphysis and $1.5 \mathrm{~cm}$. behind it. It is firmly fixed to the superior fascia of the uro-genital diaphragm (deep layer of the uro-genital trigone) and here the urethra leaves it to become the membranous part. The anterior surface directed vertically lies $2 \mathrm{~cm}$. behind the lower part of the pubic srmphysis in relation to the prostatic plexus of veins; and from it the dense pubo-prostatic ligaments run forward on either side to the pubes. The posterior surface is in contact with the rectum, through the anterior wall of which it may be palpated $4 \mathrm{~cm}$. ( $1 \frac{1}{2} \mathrm{in}$.) above the anal margin. It is separated from the rectum by the two layers of the recto-vesical septum (Elliot Smith).* The lateral surfaces are supported by the anterior fibres of the levator ani, from which, however, they are separated on each side by a dense mass of fibrous tissue in which the pudendal (prostatic) plexus of veins is imbedded.

The prostatic urethra traverses the gland nearer the anterior than the posterior surface, with a slight forward concavity. Its floor is placed posteriorly and presents an eminence, the colliculus seminalis, about the centre of which is the orifice of the prostatic sinus, on either side of which open the common ejaculatory ducts. The prostate is indefinitely divided into two lateral lobes. The fissure uniting them across the middle line in front of the urethra (the anterior commissure) is fibro-muscular and contains no glandular tissue. Behind the urethra the lateral lobes are continuous and the portion of gland lying between bladder, ejaculatory ducts and urethra has been erroneously termed the "middle lobe." Though not a separate lobe anatomically, adenomatous hypertrophy of this part is common, when it projects up into the bladder, and prevents the proper emptying of that organ.

Capsule and sheath of the prostate.-In senile enlargement of the prostate removal may be effected by the suprapubic or by the perincal route. In the former, the bladder is opened above the pubes, the murous membrane lying over the gland as it projects into the bladier is scratched through behind, and with the finger the whole aclenomatous mass is enucleated. This process usually involves tearing out the whole of the prostatic urethra, and the ejaculatory ducts. The parts left behind consist of (1) the "capsule" which is simply the onter part of the gland proper stretched over the adenomatous mas;, and consists of fibro-muscular tissue with a few flattened glandular tubules (C. Wallace).† Outside this (2) the fibrous "sheath" is derived from the visceral layer of pelvic fascia, in which is imbedded, on the anterior and lateral aspects of the gland, the prostatic plexus. Since these reins are not torn there is com-

* Studies in Anatomy of the Pelvis. Journ. Anat. and Physiol., vol. 42, 190 .

$\dagger$ C. Wallace. Prostatic Enlargement, $190 \%$. 
paratively little hxmornage. In the perineal operation the posterior surface of the gland is exposed by eutting through the perinem hetween the bulb and external sphincter ani, and dividing the attaclment of the recto-urethal muscle to the uro-genital diaphragm and its inferior fascia. This expuses the back of the recto-vesical septum (aponeurosis of Denonvilliers) which is split at its base, opening up the recto-prostatic space of Proust. By a longitudinal incision into the prostate on each side the adenomatous lateral lobes may be enteleated separately, and it is elaimed without injury to the urethra or ejaculatory ducts (Hugh Young).*

The bladder lies above the pubic symphysis at birth and so is mainly an abdominal organ. The anterior surface, in contact with the abdominal wall, has no peritoneal covering, but posteriorly the peritoneal reflection descends to cover the posterior surface of the prostate, which is relatively lower than in the athult.

The adult bladder when empty forms a pyriform contracted organ behind the symphysis, and bounding the retro-pubic space of Retzius posteriorly. Into this space urine is extravasated in extra-peritoneal rupture of the bladiler, and may mount up behind the abdominal wall in the extra-peritoneal tissue. The space is closed below by the pubo-prostatic ligaments and prostatic plexus of veins. In distention, the neck of the bladder and prostate being relatively fixed and immovable, the free apex rises up into the abdomen. As it does so it raises the peritoneum off the abrlominal wall, so that in moderate distention $5 \mathrm{~cm}$. (2 in.) of abdominal wall alwre the pubes are free of peritoneum, and the bladder may be tapped here safely. The upper surface and a little of the posterior are covered by peritoneum, which is also related to the upper halies of the resiculie seminales. Below the reeto-vesical pouch the base of the bladder presents a small triangular area in contact with rectum, boumled by the peritoneal cul-de-sac above, the converging deferential ducts on each side and the prostate below. Through this triangle which is rather expanded in distention of the bladeler, puncture for rectum was formerly practisel. The infero-lateral surfaces are slung up by the levator ani as by a hammock. The interior of the bladder can be examined by the cystoscope in the living patient. The mucous membrane is loose and rugose in contraction, except over the trigone at the base, the angles of which are formed by the ureteric orifices and the internal meatus. The mucosa here is firmly arlherent to the musidal eoat and smooth. In hypertrophy of the bladder-muscle from obstruction, a fascicilated appearance of the mucosa is seen and possibly diverticula between the bands of muscle.

Rectum and anal canal.- The rectum proper extends from the end of the pelvic colon, opposite the third sacral vertebra, to the upper end of the narrow ansl canal, which runs downward amel backward ahmost at right angles to the rovtum and is $3-4 \mathrm{~cm}$. in length. The commencement of the rectum lies $13-14$ ("m. ( $5-5 \frac{1}{2} \mathrm{im}$.) above the an is in the arlult. This point is marked internally by an infolding of the mueosa on the right and anterior wall and to some extent of the circular musce filmes, due to the angle at which the free pelvic colon turns inte the fixed reetum. This shelf of mucous membrane is known as the upper transverse fold (first valve of Houston).

Tomler normal anditions the reetum does not form a reservoir for fareal materiak, which is stored in the lower end of the pervic colon, above the upper transverse fold, leaving the

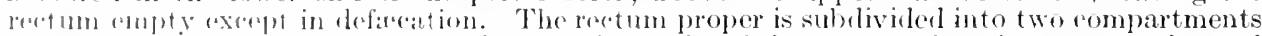
hy the inferior transverse fold on the anterior wall (third or great valve of Houston), situated

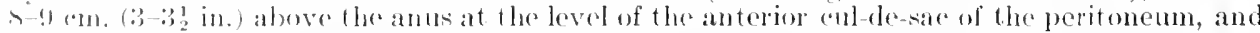
resulting from the ataptation of the rectum to the hollow of the satrom. This ean usually lor marle me on digial cxamination. The other transverse folds are inconstant and only present on great disiontion.

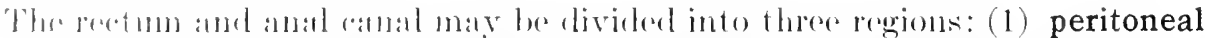

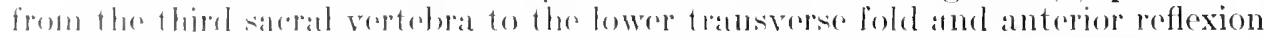

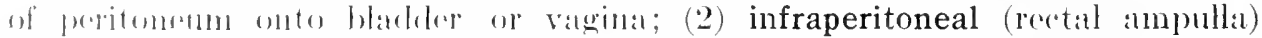
bewow this and above the levator ani; (3) anal canal, below the level of the

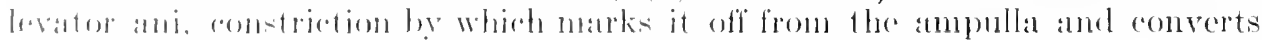

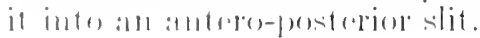

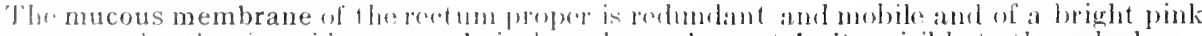

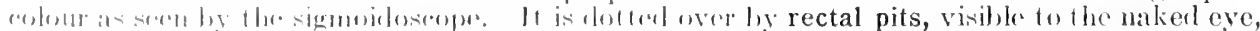

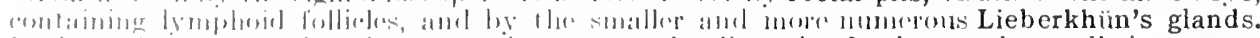

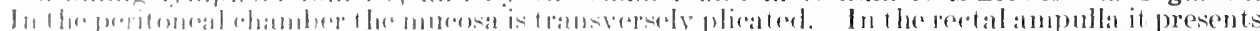

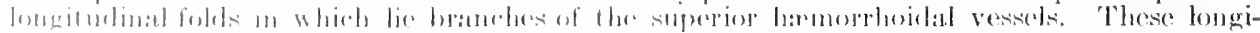

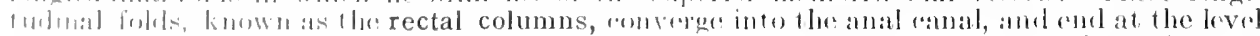

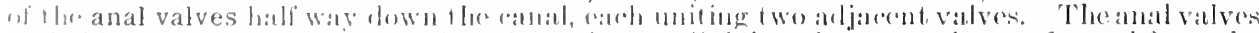

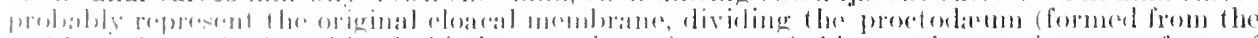

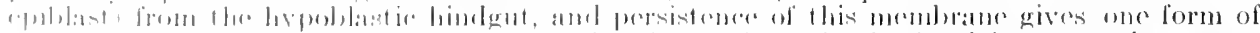

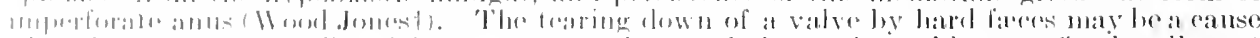

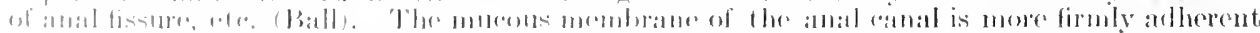

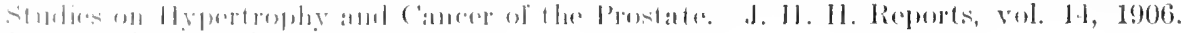

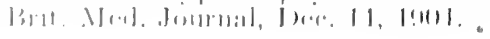


to the underlying muscular coat than that of the reetum, hence in prolapse the mucosa of the rectal ampulia is the first to be extruded.

Peritoneal relations.- The peritoneal chamber of the rectum has no covering of peritoneum behind, and the peritoneum, at first eovering its first aspect and sides, leaves the sides obliquely and finally is reflected onto the base of the bladder (or the vaginal fornix in the female), at the level of the inferior rectal fold, $8 \mathrm{~cm}$. from the anus.

Blood-supply.--(1) The superior hæmorrhoidal artery, a continuation of the inferior mesenteric, reaches the rectum behind, via the pelvic meso-colon and bifurcates at onc. The two branches run round on eit her side below the peritoneal reflection; giving off secondary branches that pierce the muscular coat about the level of the inferior transverse fold, or anterior peritoneal reflection. Joining the submucous laver, these arteries run down in the rectal columnto the anal canal, where they anastomose with (2) the middle hæmorrhoidal arteries, branche: of the hypogastric (internal iliae) and (3) the inferior hæmorrhoidal hranehes of the internial pudendal. The veins correspond. Their free anastomosis in the hæmorrhoidal plexus under the reetal columins, the union afforded here between the portal and systemie veins, the absence of valves in the superior hæmorrhoidal veins, and the constriction they are subject to in passing through the muscular coat, are some of the anatomical causes of the frequency of hiemorrloids.

The branches of the superior hamorrhoilal artery to the rectum anastomose but little with one another, as compared with the sigmoid arteries to the pelvic colon. The main trunk of the superior hamorrhoidal usually receives a large anastomotic branch from the lowest sigmoid artery $1-2 \mathrm{~cm}$. below the sacral promontory, upon which the upper part of the rectum is dependent for its blood-supply after ligat ure of the superior hamorrhoidal. Hence in high exeision of the rect um it is important to place the ligature on the superior hemorrhoidal above the sacral promontory if sloughing of the gut is to be avoided.*

For lymphaties of the rectum see p. 735 .

Supports of the rectum. - The anal canal is fixed by its attachment to the levator ani and perineal body. After division of the perineal body and recto-nrethral muscle in front, the rectum is readily separable from the back of the prostate and recto-vesical septum. When the levator ani has been divided on each side and the peritonem opened, as in the perineal operation for excision of the rectum, the gut eannot be pulled down freely. The hand passed up behind it in the hollow of the saerum meets on each side with a dense fibrous layer running from the sacrum opposite the third foramen onto the sille of the reetum. This is the rectal stalk (Elliot Smith) and consists of dense fibrous tissue round the nervi erigentes from second, third and fourth sacral foramina and the middle hemorrhoida! vessels. It lies about $2.5 \mathrm{~cm}$. above the levator ani, and after division of it the bowel is easily freed, so that the whole of the rectum and part of the pelvie colon may be drawn out at the perineun without tension.

Rectal examination.--The following points wa be made out by the finger introduced into rectum:-(1) The thickened, roll-like feel of a contracted external sphineter; (2) the narrower, more expanded, internal sphineter extending upward for $2.5 \mathrm{~cm}$. (1 in.) from this: (3) the rectal insertion of the levatores ani, which here narrows somewhat the lumen of the gut; (4) above the anal eanal, with its contrasting capaciousness, is the more or less dilated rectum proper; (5) the condition of the ischiorectal fossie on either side; (6) the membranons urethra in front, especially if a staff has been introduced; the instrument now occupies the middle line, and has the normal amount of tissue between it and the finger, thus differing from one in a false passage (in a child an instrument is especially distinc $t$ ); $(\overline{7})$ just bevond the sphineters, or $3.7 \mathrm{em}$. (1 $1 \frac{1}{2} \mathrm{~m}$.) within the anus, lies the prostate; (s) converging toward the base of the prostate, and forming the sides of the triangular space, are the resicula seminales and cjaculatory ducts. These can rarely be felt unless diseased and enlarged; any enlargement of the sacoulated ends of the deferential duets is much more perceptible; $(9)$ it is within this triangular spare that the elasticity of a distended bladder can be felt. (10) Usually the lowest of the transwerse folds (folds of Houston), semilunar in form and about $1.2 \mathrm{~cm}$. ( $\frac{1^{2}}{2} \mathrm{in}$.) in width, can be made out (fig. 1116). (11) Behind, the coceyx and its degree of pliability and the lower part of the sacrum. It may also be possible to feel enlarged sacral nodes and a growth from the other pelvic bones.

The above examination refers chiefly to the male. It remains to refer to rectal examination in the female. Anteriorly, the soft perineal body and recto-raginal septum will be met with, and, through the latter, the cervix and os uteri, and, higher up, the lower part of the eerrix uteri. More laterally the ovaries may be felt, but the uterine or Fallopian tubes, unless cnlarged and thickened, are not to be male out. The student should he familiar with the feel of a healthy recto-uterine or recto-vesical pouch, according to the sex, and the coils of intestive which it may contain, so as to be able to contrast this with any collection of inflammatory or other fluid or misehief descenting from the upper pelvis, e. g., from the vermiform appendix. Posteriorly, certain struetures are met with in either sex. After a very short intorval sphin.ter and ano-coceygeal body) the finger reaches the tip of the coery and explores the hollow of the sacrum. On each side are the ischial tuberosity and wall of the true pelyis. The finger hooked lateralward and upwarl, comes on the border of the falciform process of the sacrotuberous (great sacro-sciatic) ligament, passing between the above-mentioned bones.

\section{FEMALE GENITAL ORGANS}

The external organs will be considered first, followed by the internal. Inder the extemal organs are included, for convenience sake, the labia majora and minora at the sides; and, in the middle line, from ahove downward-(1) The glans clitoridis with its prepuce; (2) the vestibule; (3) the urethral orifice; (4) the

* H. Hartmann. Annals of Surgery, Dee., 1909. 
vaginal orifice with the hymen or its remains; (5) the fossa navicularis; (6) the fourchette; $(7)$ the slin over the base of the perineal body.

'These parts have been described elsewhere, and only those points which are of importance in a clinieal examination will be alluded to here.

The labia majora are two thick folds of skin, covered with hair on their outer surface, especially above, where they unite (anterior commissure) in the mons Veneris. They contain fat, vessels, and dartos, but become rapidly thinner below; where they are continuous at the front of the perineum (their posterior commissure).

When the above folds are drawn aside, the labia minora, or nymphæ, appear, not projecting, in a healthy adult, beyond the labia majora. They are small folds of skin, which meet above in the prepuce of the elitoris, and below blend with the labia majora about their centre. Sometimes, especially in nulliparæ, they unite posteriorly to form a slight fold, the fourchette.

The glans clitoridis, covered by its prepuce, occupies the middle line above.

Below it comes the vestibule, a triangular smooth surface of mucous membrane, bounded above by the clitoris, below by the upper margin of the vaginal orifice, and laterally by the labia minora. In the middle line of the vestibule and toward its lower part, about $12 \mathrm{~mm}$. ( $\frac{1}{2}$ in.) below the glans elitoridis, and 25 $\mathrm{mm}$. ( $1 \mathrm{in}$.) above the fourchette, is the meatus or opening of the urethra (figs. 1034, 1037).

The vaginal orifice lies in the middle line between the base of the vestibule above, and the fossa navicularis below. Its orifice is partially elosed in the virgin by a fold of mucous membrane, the hymen (fig. 1037). This is usually ereseentie in shape attached below to the posterior margin of the vaginal orifice, and with a free edge towards the base of the vestibule. In some cases it is diaphragmatic i. e. attached all around, but perforated in the centre (fig. 1037).

The sehrivelled remains of the hymen probably constitute the carunculæ hymenales. On either side of the vaginal orifice, at it lower part, lie the racemose, muciparous, vestibular glands (glands of Bartholin), situated beneath the superficial perineal fascia and sphineter vaginæ. Their duets run slightly upward and open, external to the attachment of the hymen, within the labia minora. In relation to the upper two-thirds of the vaginal orifice, placed between the urogenital diaphragm behind and the sphineter vaginæ in front, are the vascular bulbs of the vestibule, rupture of which produces pudendal hæmatocele.

Fourchette and fossa navicularis.-The fourchette, as stated above, is the posterior commissure of the labia minora. Normally the inner aspect of this is in contact with the lower surface of the hymen. When the fourchette is pulled down by the finger, a shallow depression is seen, the fossa navicularis, with the fourchette for its posterior, and the hymen for its anterior, boundary.

Internal organs. - The examinations through the vagina and anus will be considered first, followed by uterus and appendages, ovary and ureter.

Examination per vaginam.--The finger, introduced past the gluteal eleft, perineum, ant fourchette, eomes upon the elliptical orifice of the vagina, and notes how far it is patulous or narrow; the presence or otherwise of any spasm from the aljacent muscles; then, passing into the eanal itself, the presence or absence of rugar, a naturally moist or a driv condition are observed. In the anterior wall the cord-like urothra can be rolled between the finger and the symphysis; and further up than this, if a sound be passed, the posterior wall of the bladder. The anterior wall of the vagina is about $6.7 \mathrm{~cm}$. (22 in.) long. The posterior wall, $7.5 \mathrm{~cm}$. (3 in.) Jong, forms the recto-vaginal septum, and through it any faeces present in the bow are casily folt. The corvix uteri is next felt for in the roof of the vagina, projeding downward and backward in a line drawn from the umbilieus to the acryx. Busides its direction, its size, shape, molility, and consistence should be noted. Tho os uteri should form a dimple or fissure in the centre of the eervix. () f its two lips, the pestrorior is the thicker and more fleshy fecling of the two. The vatuinal culs-de-sac or fornices are next explored. These should he soft and "astite, giving an impression to the finger similat to that when it is introduced into the angles of the month. Any resistance folt here may be due to sears, wodlings connected with the uterus (displacements or myomata), effusions of hanel or inflammatery matrial, amd, in the rase of the lateral culs-de-sac, a displacenl or anlared ovary, of dilatations of the Fallopian tubes. The posterior

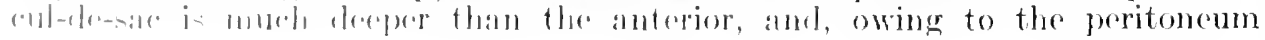


descending upon the posterior wall of the ragina, when the finger is placed here it is only separated from the peritoneal sac by the raginal wall and pelvic fascia. In examination of the pelric organs the bimanual method, by which one hand on the hypogastric region, pushes them down and steadies them as well, is always to be employed to complete an examination.

The uterus and appendages.-The normal non-gravid uterus is usually anteflexed and anteverted so as to lie with its long axis approximately at right angles to that of the vagina. Its position varies considerably with the degree of distention of the bladder in front and of the reetum behind. The distance from external os to fundus, as estimated by the passage of a sound is in the adult virgin uterus $5.5 \mathrm{~cm}$. of which $3 \mathrm{~cm}$. belong to the cervix and $2.5 \mathrm{~cm}$. to the body. In the empty multiparous uterus the total length of the carity is $6 \mathrm{~cm}$., $2.5 \mathrm{~cm}$. comprising the neck and $3.5 \mathrm{~cm}$. the body.

Peritoneal relations.-In front the peritoneum is reflected from the uterus to form the utero-vesical pouch at the level of the isthmus. Behind it covers not only the uterus but the posterior fornix of the vagina, before turning off onto the front of the rectum. Laterally the peritoneum leaves the uterus and passes on to the lateral pelvic wall as a large twofold partition fig. 1118), the broad ligament.

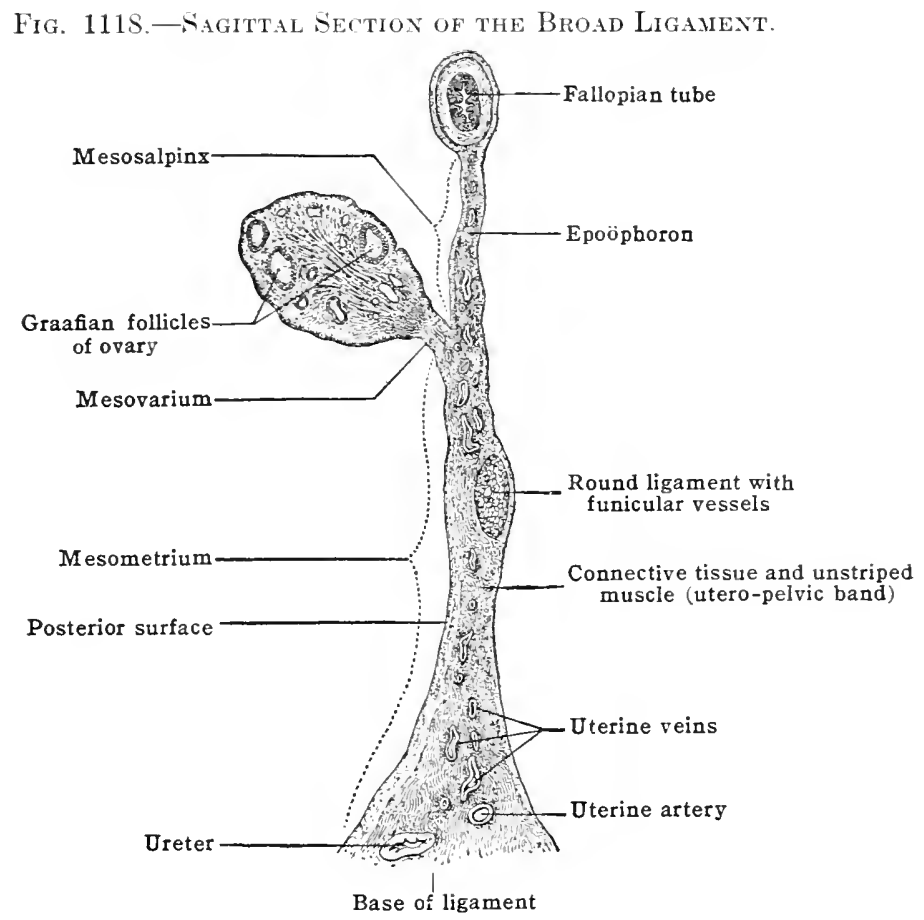

The broad ligament, bearing in its upper border the uterine tube, in front the round ligament and behind the ovary, consists of (1) an upper thin part, the mesosalpinx lying above the attachment of the mesovarium, and containing the ovarian vessels and the epoopphoron, and below this (2) the thicker mesometrium, between the layers of which is a dense mass of fibrous tissue surrounding the uterine artery.

The anterior aspect of the cervix below the utero-vesical pouch of peritoneum, is readily separable from the bladder with which it lies in contact, and the peritoneum may be raised off the uterus with ease in the lower part of its attachment both front and back. Over the upper part of the body and fundus, however, the peritoneal covering is firmly adherent, and cannot be dissected off.

The ovary, attached by its hilum to the mesovarium, lies in a fossa at the back of the lateral wall of the pelvis just between the diverging external iliac and hypogastric vessels. To feel it the finger should be pushed well up in the side of the vagina toward the lateral wall of the pelvis. On the abclominal surface its position corresponds to the middle of a line drawn from the anterior superior iliac spine of that side to the opposite pubic tubercle (Rawlings). 
The lymphatics of the ovary follow the ovarian veins (see p. 745).

Supports of the uterus. - The great mobility of the body of the uterus has been referred to above. The organ derives its support almost entirely from the attachments of the cervix and vaginal fornices. These rest on the pelvic floor, formed by the levator ani and perineal body which support them the more efficiently since the long axis of the vagina is at right angles to that of the uterus. Above the pelvic diaphragm the cervix is held up to the pelvic walls by strong specialised bands of fibro-muscular tissue running in both antero-posterior and transrerse directions. The chief of these, lying in the base of the broad ligaments is a fibrous sheath surrounding the uterine artery as it descends medially from the hypogastric. In the anteroyosterior direction the utero-resical ligaments hold up the cervix to the pubes in front and the sacro-uterine ligaments bind it to the anterior aspect of the sacrum behiind. While firmly supporting the uterus these bands are elastic, and so do not fix it rigidly, but allow of the cervix being drawn downward by traction with vulsellum forceps.

For lymphaties of uterus and vagina see p. 745 .

The ureter.- The pelvic portion of this duct is of special importance in operations on the uterus and upper vagina. It crosses the brim of the pelvis on either side at the bifurcation of the common iliac artery, or just in front of it, and descends on the side wall in front of the hypogastric artery, crossing the obliterated umbilieal and obturator arteries. Curving forward and medially it passes under the base of the broad ligament, where the uterine artery crosses above it, and so gains the lateral angle of the bladder by passing across in relation to the lateral fornix of the vagina. In the base of the broad ligament the ureter lies about $2 \mathrm{~cm}$. ( $\frac{5}{4}$ in.) from the side of the cervix, and this relation must be borne in mind in excision of the uterus.

Pelvic floor.- The pelvic floor of the female corresponds in general to that of the male (see p. 1383). There are, however, important differences, due to the sexual organs. The urogenital diaphragm is relatively smaller in area, due to perforation by the vagina. The pelvic diaphragm is also correspondingly modified, and the pubo-coccygeus component is more strongly developed (see section on Musculature.) The ischio-rectal fossa is similar to that of the male (p. 1384).

\section{HERNIA}

Three varieties of hernia will be considered, inguinal, femoral, and umbilical

\section{PARTS CONCERNED IN INGUINAL HERNIA}

In inguinal hernia, as in femoral and umbilical, there is a weak spot in the abdominal wall-one weakened for the needful passage of the testicle from within to outside the abdomen (p. 1387). The parts immediately concerned are the two inguinal rings, subcutaneous (external) and abdominal (internal), and the canal. Now, it must be remembered at the outset that the rings and canal are only potential - they do not exist as rings or canal save when opened up by a hernia, or when so marle by the scalpel. The canal is merely an oblique slit or flat-sided passage. The subeutaneous and abdominal rings are so intimately blended with the structures that pass through them, and so filled by them, that they are potential rings only.

The subcutaneous inguinal (external abdominal) ring.-This is usually describer as a ring: it is really only a separation or gap in the aponeurosis of the "xternal oblicun", by which in the male the testicle and cord, and in the female the round ligament by which the utorus is kept tilted a little foward, pass out from the aldomen. The size of this opening, the development and strength of its crura or pillars, the fascia closing the ring-all vary extremely. Formation: by divergenon of two fasciculi of the external oblicue aponenrosis. Boundaries: two crura - (1) Sinferior, the smaller, attarhed to the symphysis and blending with the susponsory ligament of the pros; (2) inforior, stronger, attached to the pubic tubereleand bemeling with the inguinal ligament, and so with the fascia lata. On this infrerior, stronger arus restis ther cord (and so the weight of the testicle) or ronnel ligament. Shape: triangular or elliptical, with the base downward and mordially towatrel the puldice arest.

Intercrural fibres (intercolumnar fascia) (external spermatic fascia). - This, derived from

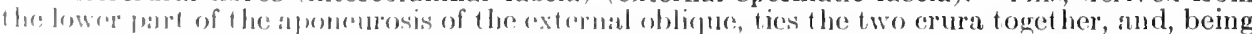

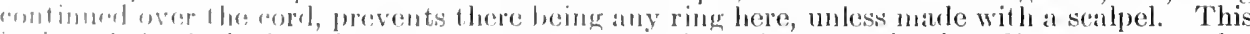

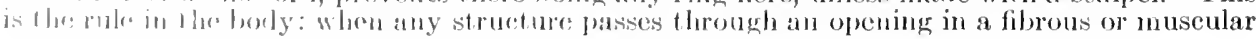


layer, it carries mith it a coating of tissue from that layer; e. g., the inferior cava passing through it foramen in the dianhram, and the membranous urethra through the wo-genital diaphrapm.

Effect of position of the thigh on the ring.-As the lower crus is blenderl with Poupart's ligament, and as the fascia lata is comnected with this, movements of the thigh will affect the ring much, making it tighter or looser. Thus extension and abdurtion of the thigh stretch the crura and elose the ring. In flexion and adduction of the thigh the erura are relaxed; and this is the position in which reduction of a hernia is attempterl. In flexion and abluction of the thigh, the ring is open; and this is the position in which a patient should wit. wh thighs widely apart, to try on a truss, and cough or strain downward, as in rowing. If the hernia is now kept up, the truss is satisfactory.

Helping to protect this most important spot, and preventing its being more than a potcntial ring, are not only the two crura and the intererural fibres, but also a structure which has been called a third or posterior pillar, namely, the reflected inguinal ligament. This has its base above at the lower part of the linea alba. where it joins its fellow and the aponeurosis of the external oblique, and its apex downward and laterally, where, having passed behind the medial erus it blends with the lacunar (Gimbernat's) ligament. Again, the falx inguinalis (the con-

Fig. 1119.-The Parts concerned in Ingulyal Hervia.

(From a dissection in the Hunterian Mlusenm.)

External oblique, cut and turned back Internal oblique External oblique

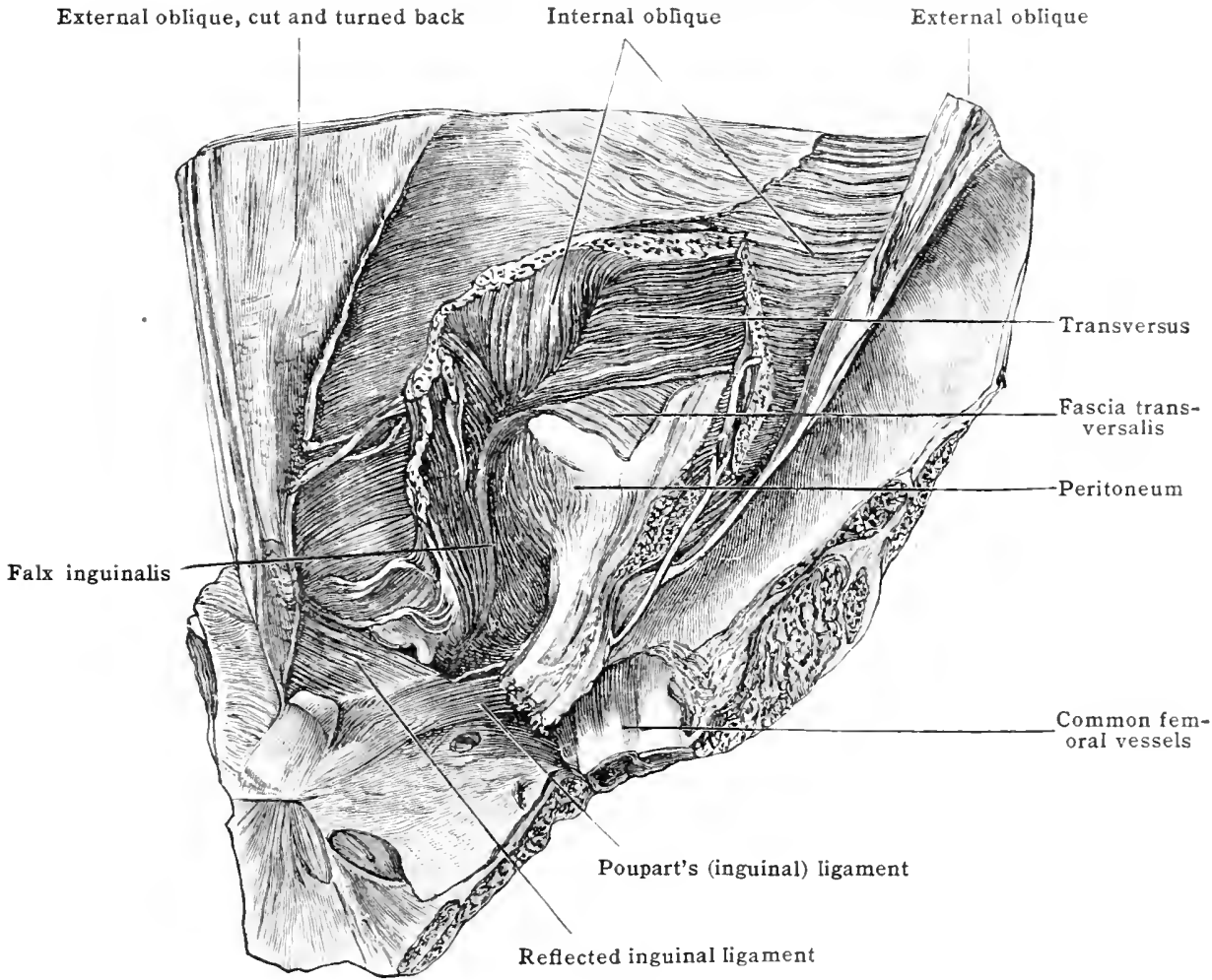

joined tendon of the internal oblique and transversalis), curving melially and downward to be attached to the ilio-pectineal line and spine, is a most powerful protection, behind, to what is otherwise a weak spot and a potential ring.

Inguinal canal.- This is not a canal in the usual sense, but a chink or flatsided passage in the thickness of the abdominal wall. The descriptions of the canal usually given apply rather to the diseased than to the healthy state. It was a canal once, and for a time only, i. e.. in the later months of fotallife (p. 13S7). It remains weak for a long time after, but only a vestige of it remains in the wellmade adult.

Length.--In very early life there is no canal; one ring lies directly behind the other, so as to facilitate the easy passage of the testis. In the adult it measures about $37 \mathrm{~mm}$. ( $1 \frac{1}{2}$ in.) in length, this lengthening being brought about by the growth and separation of the alæ of the pelvis. This increased obliquity gives additional safety. On the other hand, a large hernia has not only opened widely. the canal and rings, but it has pulled them close together, and one behind the other thus not only rendering repair much more difficult, but also the path to the 
peritoneal sae shorter and more direct. Direction.-From the abdominal to the subeutaneous ring, downward, forward, and medially.

Boundaries.-For convenience sake, certain limits (largely artifieial) have been named:-

(1) Floor.-This is best marked near the outlet, where the eord rests on the grooved upper margin of the inguinal (Poupart's) and the lacunar (Gimbernat's) ligament. The meeting of the transversalis fascia with this ligament forms the floor. (2) Roof.-The apposition of the museles and the arehed border of the internal oblique and transversus. (3) Anterior wall.-Skin, superficial faseia, external oblique for all the way. Internal oblique, i. e., that part arising from Poupart's ligament, for the lateral third or so. To a slight extent, the transversus and the cremaster. (4) Posterior wall.-For the whole extent, transversalis faseia, extraperitoneal tissue, and peritoneum. For the medial two-thirds, conjoined tendon of internal oblique and transversus, and the lateral edge of the reflected inguinal ligament, when developed.

\section{Fig. 1120.-Dissection of Inguinal Canal. (Wood.)}

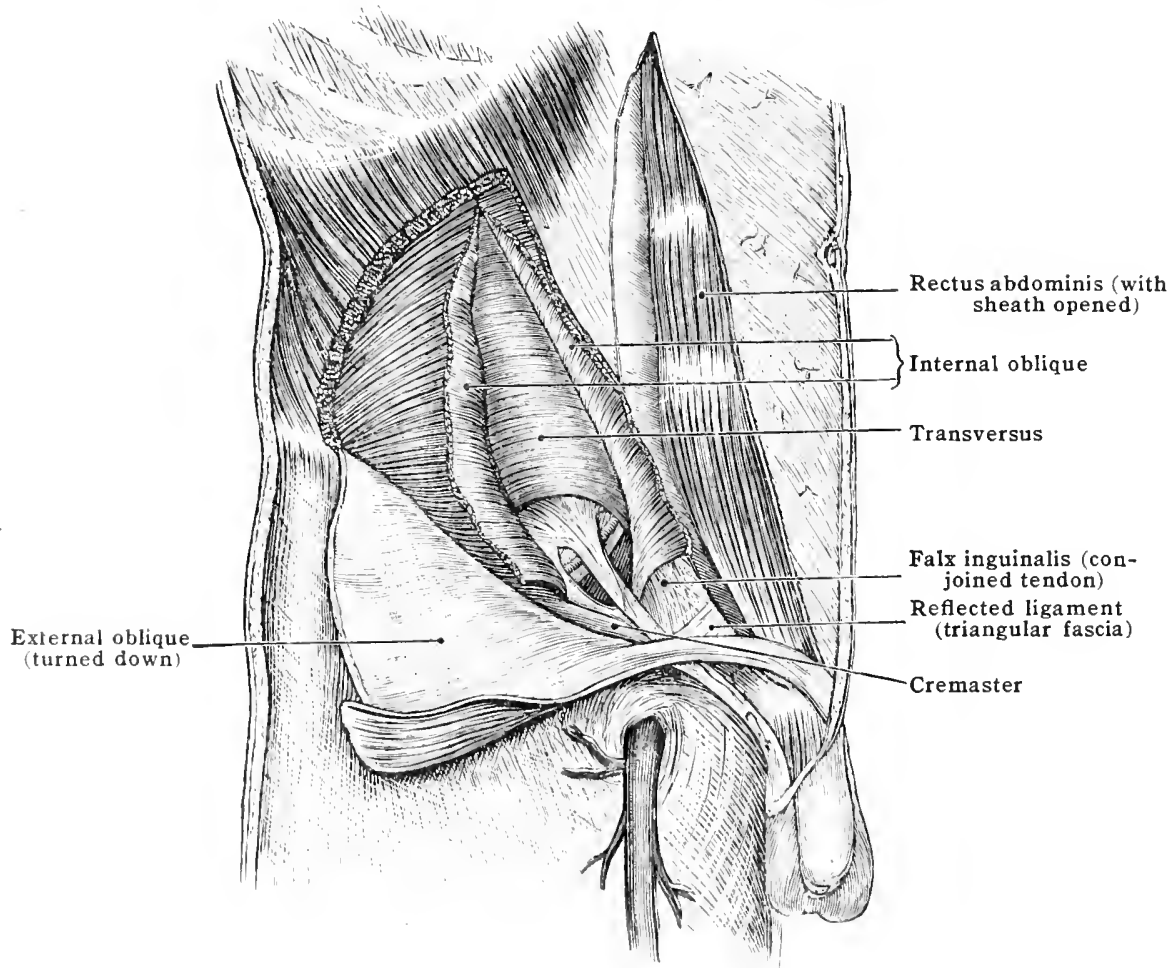

The transversalis faseia is thicker and better marked at its attachments below; these are(a) laterally, to medial lip of iline erest; (b) to the ingumal ligament between the anteriorsuperior spine and the fonora! vessels, where it joins the fascia iliaca; $(c)$ opposite the femoral vessels it also joins the fascia iliaca, and forms with it a funnel-shaped sheath; $(d)$ nedial to the fomoral vessols the fascia transwersalis is attarberl to the terminal (ilo-pectineal) line, behind the conjoined tendon, with which it blends. The falx inguinalis (conjoined tendon) needs special reference. It is formed by the lower libese of the internal oblique and transversus (arciform fibres) arching downwarl over the corll to be inserted into the erest and spine and the terminal (ilio-pertineal) line. The fibres of the interual obligue become increasingly tendinous as they degrend, and this, with the fact that holow they give off the eremaster, may cause some difficulty

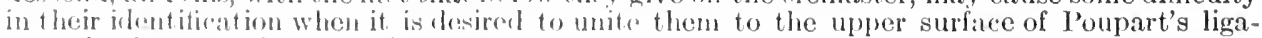
ment, in the operation of ratical cure.

The abdominal inguinal (internal abdominal) ring.- It has atready been said that the torm 'ring' is here nisapplied (xorpt in an artificial sense, as when an opening is made: by a scalpel; or in ahnomal conditions when a hernial sae is present. The abdominal ring is not a ring in the least, but merely a fumnelshaped expansion of thr transversalis fatscial, which the cord carries on with it as it resipese from the aldementh. 
Site.-Midway between the anterior superior iliac spine and pubic tubercle. Shape: oval, with the long diameter vertical. Boundaries: centre of inguinal (Poupart's) ligament, about $12 \mathrm{~mm}$. ( $\frac{1}{2}$ in.) below. Medially, the inferior epigastric artery (fig. 1121); the position of this vessel, by its pulsation, is an important guide to the insertion of the highest sutures between the arciform fibres and the inguinal ligament. Owing to the artery lying to the medial side, the incision, in cutting to relieve the deep constriction of an inguinal hernia, should always be made directly upward, so as to avoid the above vessel. A large oblique hernia may so have altered the relations of the parts, including the artery, that it is difficult to decide whether the hernia is oblique or direct. The above incision will be safe, because, in cither case, parallel to the vessel.

Coverings.- There are two chief forms of inguinal hernia:-

A. The common form: lateral, or oblique.-Lateral, because it appears (at the abdominal ring) lateral to the inferior epigastric artery. Oblique, because it traverses the whole of the inguinal canal, entering it at its inlet and leaving it at its outlet. This form is usually congenital in origin, and is due to non-obliteration of the processus vaginalis in infancy.

Fig. 1121.-Dissection of the Lower Part of the Abdominal Wall from mithin, the Peritonedir hiving been removed. (Wood.)

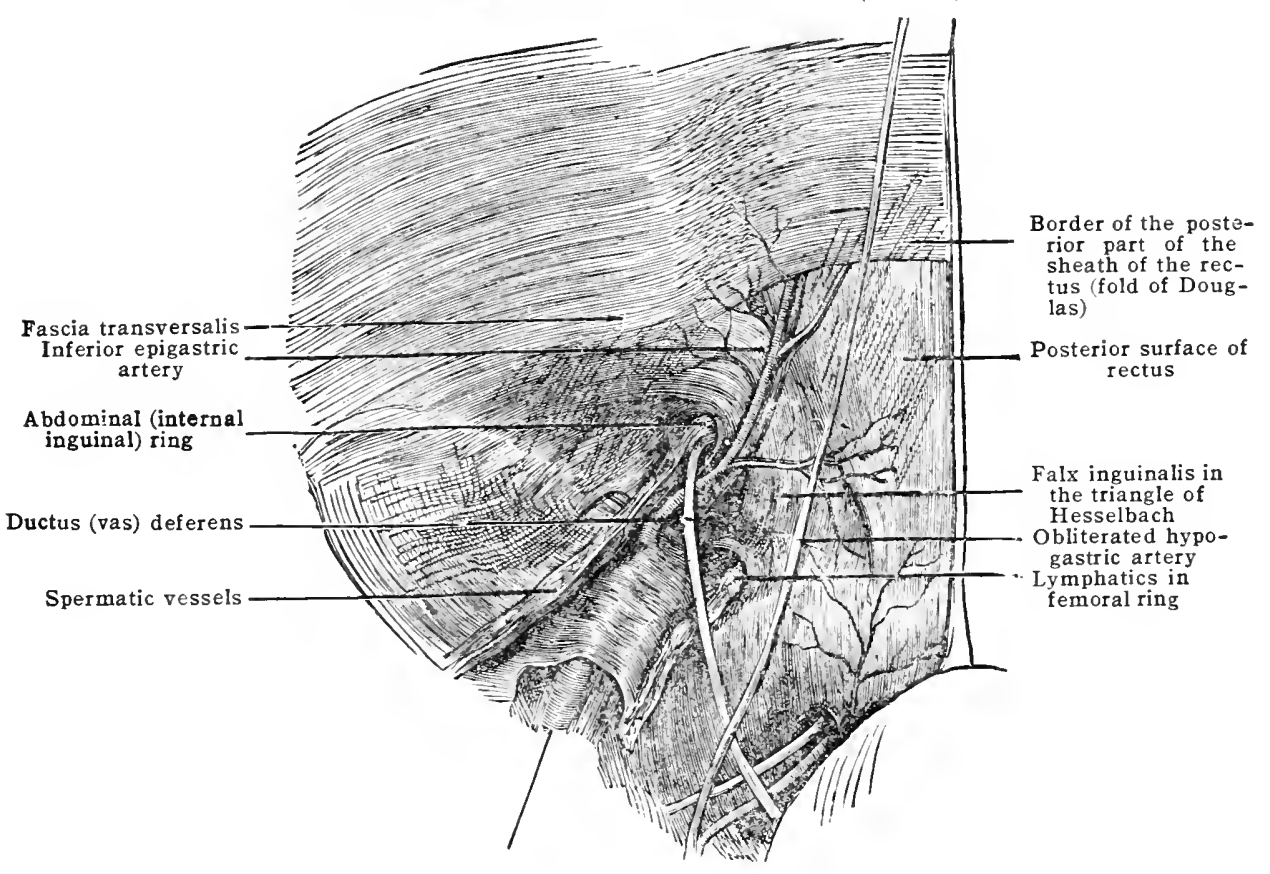

External iliac artery

B. Rarer form: medial, or direct.-Medial, because it appears medial to the inferior epigastric artery. Direct, because, instead of making its way down the whole oblique canal, it comes by a short cut, as it were, only into the lower part of the canal, and then emerges by the same opening as the other.

A. Oblique inguinal hernia. - This possesses its coverings as follows:-

(1) At the abdominal ring, or inlet, it obtains three:- (a) Peritoneum; (b) extra-peritoneal fat; (c) infundibuliform fascia, or the vaginal process of transversalis fascia prolonged at this spot along the cord.

(2) In the canal it obtains one. As it emerges beneath the lower border of the internal oblique it gets some fibres from the cremaster.

(3) At the subcutaneous ring, or outlet, the hernia obtains three, viz.: (a) Intererura fibres (intercolumnar fascia); (b) superficial fascia; and (c) skin.

B. Direct inguinal hernia.- This does not come through the abdominal ring, but, making its way through the posterior wall of the lower third of the canal, either through the medial or intermediate inguinal fossa. Its coverings, therefore, vary slightly with its mode of exit (vide infra).

Hitherto the two forms of inguinal hernia have been consilered from the superficial aspect, that in which they are met with in practice. The inguinal region should also be studied as to 
the posterior aspect ol its so-called rings and canal, as these have to bear the early stress of a commencing hernia. It is against this aspect that a piece of omentum or intestine is constantly and insidiously pressing and endeavouring to make its way out. Furthermore, when either of the above constituents of hernia have made their way a little farther, and got out into the abdominal ring or into the canal, the patient is no longer sound.

On the posterior wall are certain cords and depressions, marking off regions which correspond to those on the surfice. Thus, there are three prominent cords and three fossæ (fig. 1121).

Three cords-(1) Median, or urachus; (2) lateral, or the obliterated hypogastric arteries.

(1) Median, or urachus. This interesting foetal relic, the intra-abclominal part of the allantois, passes up between the apex of the bladder and the umbilicus.

(2) The obliterated hypogastric arteries. These, the remains of vessels which during fœetal life carry the impure blood of the foetus out to the mother through the umbilicus, run up and join the urachus at the umbilicus.

In relation to these cords are the following fossæ:- (a) A medial one, between the urachus and the obliterated hypogastric artery. This corresponds, on the anterior surface, to the subcutaneous inguinal (external abdominal) ring. Through this fossa comes the commonest form of direct inguinal hernia. (b) Between the olliterated hypogastric artery and the inferior epigastric artery, which runs upward and medially to form the lateral boundary of Hesselbach's triangle, is an intermediate fossa. This is the smallest of all. The rarer form of direct hernia comes through here. (c) The lateral fossa is lateral to the inferior epigastric artery. It is the most distinct of the three, from the way in which the cord or round ligament passes down within a glove-like vaginal process of the transversalis fascia. This fossa corresponds to the abdominal ring.

The coverings of a direct hernia may now be considered, together with the two-fold manner of exit of this hernia. It only traverses the lower part of the canal, making its way through either the merlial or the intermediate inguinal pouch. (i) The commonest form, coming through the medial inguinal pouch, either pushes its way through or stretches before it the falx inguinalis. Its coverings are:-(1) Peritoneum; (2) extra-peritoneal fat; (3) transversalis fascia; (4) falx inguinalis (unless this is suddenly burst through); (5) (6) (7). At the subcutaneous ring the three coverings are the same as in the oblique variety. (ii) This rarer form of direct hernia comes through the intermediate inguinal pouch. As a rule, the falx inguinalis does not reach over this fossa. The coverings will be the same as in the last, with two exceptionsthere is no falx inguinalis, and the cremasteric fascia, if well cleveloped, will be present.

Varieties of inguinal hernia according to the condition of the vaginal process of peritoneum. -Inguinal hernice have above been classified according to their relation to the deep epigastric artery. It remains to allude to the arrangement of these same hernix according to the varying condition of the processus vaginalis. This pouch of peritoneum, which paves the way for the passage of the testis before this organ makes its start, eventually becomes the parietal layer (p. 1387) of the tunica vaginalis below, in this fashion: During the first few weeks after birth the process becomes obliterated at two spots - one near the abdominal ring, and one just above the testis. The obliterative process, commencing first above and descending, and then, ascending from below, the shrivelling continues until nothing is lett save the tunica vaginalis below. The following are possible hernial results of an imperfect obliteration of the process:-

(1) If the process does not close at all, a descending hernia is called congenital. This may make its way into the scrotum. The testis is now enveloped and concealed by the hernia.

(2) If the process is closed only above, i. e., near the abdominal ring, two varieties may be met with, the infantile and the infantile encysted. In the infantile, owing to pressure above, the weak septum grarlually yields and forms a sac behind the unobliterated lower part of the processus funiculo-vaginalis. Thus three layers of peritoneum may now be met with in an operation, the wo of the incompletely obliterited tunica vaginalis, and the proper sac of the hernia. In the encysted infantile variety the hernial pressure causes the septum to vield and form a sac project ing into, not belind, the incompletely obliterated tunica vaginalis. Here, theoretically, two layers of peritonemn will be met with. Another variety of such an encysted hernia may be proilucerl by rupture, not stretching, of the alowe-mentioned septum.

(3) If tho proressus vaginalis be closed below and not alowe, a patent tubular process of peritonom will harl dewn as far as the top of the testis. Any hernia into this process is ealled a hernia into the funicular process. All these varieties save the congenital and hernia into the funicular process are rare in practiee. Other pratical points are that all hernixe in ehildren and young ardults are probably of congenital origin, and, therefore, the weakness is of ten bilateral, themgh it maty not be so palpably. This applies to loth sexes. Again in hernia of sudelen origin into the funicular poreses with narow surrombliugs, strangulation may be very acute.

Inguinal hernia in the female. - The inguinal wanal in women is smaller and narrower than in men. Inguinal hernia is, therefore, less common in the female sex, and oreurs in patients who

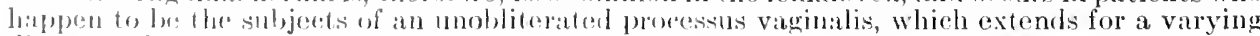

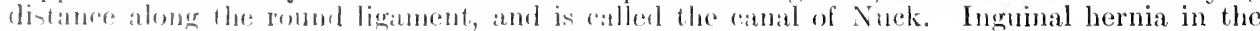
fomale is, therefore, alwats somgenital. It is, practically, alway of the oblique variety, and travels along fles round liganent toward lle labium majis. Its coverings will be the same as

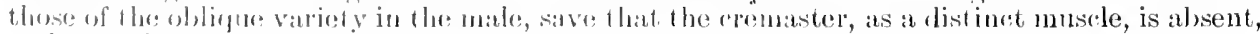
and an filmes of the interual oblinue which nuy be present are but little developed.

\section{JEATORI, HERNIA}

Parts concerned in femoral hernia. (1) Skin and superficial fascia of groin.

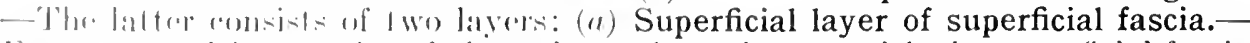

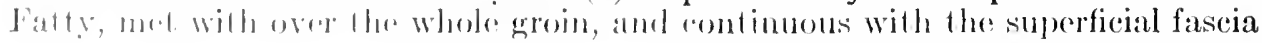


of the rest of the body. (b) Deep layer of superficial fascia.-Thin and membranous, only met with over the lower third of the abdominal wall and to the medial side of the groin.

It is continuous through the scrotum with the deep layer of the superficial fascia of the perimeum. Just below the inguinal liqament it is joiner to the fascia lata. From these two facts it results that in rupture or giving way of the urethra the extravasated urine may come forward by way of the genitals (p. 1355) and from the continuity of the fascia make its ray on to the abdomen, but not down on to the thigh.

Between the two lavers of superficial fascia lie the superficial nodes of the groin, the superficial branches of the common femoral artery, one or two cutaneous nerves, and some reins descending to the fossa oralis to join the great saphenous vein.

(2) Inguinal (Poupart's) ligament.-This is also known as the crural arch, a misnomer, as 'crus' means leg. A description of its shape and attachments is given on p. 1371. Owing to the connection of the fascia lata to its lower border, the fossa ovalis (saphenous opening), which is situated in the fascia lata, and has its upper cornu blending with the inguinal ligament, will be affected by movements of the thigh, much as is the subcutaneous inguinal (external abrlominal) ring, being tightened and stretched when the limb is extended and abducted, relaxed when it is adducted and flexed.

Fig. 1122.-The Lacune beneath the Inguinal Liganent. (Lockwood.)

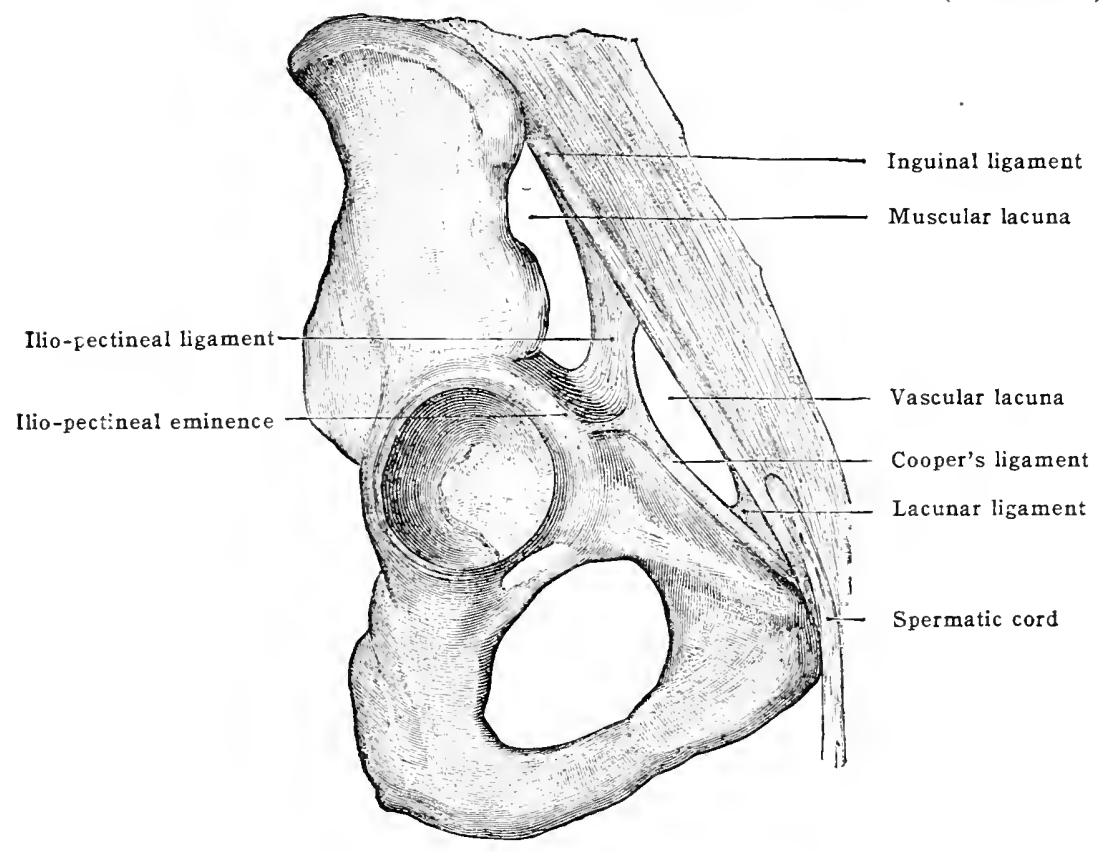

The parts beneath the ligament which block up the gap between it and the innominate bone are of the utmost importance in preventing the escape of a femoral hernia (fig. 1122).

The different structures are arranged in three compartments (fig. 1122), named latero-medially:-A. lateral, iliac, or muscular; B. central, or vascular; and C. medial, or pectineal. Of these, the first is the largest; the second or intermediate one lies slightly nearer to the inguinal ligament than the other two; while the medial compartment differs from the other two by not communicating with the pelvis, being closed above (vide infra).

(A) The lateral, or iliac, compartment is bounded in front by the inguinal ligament and the iliac fascia, which is here blending with it, behind by the ilium, laterally by this bone and the sartorius, and medially by the ilio-pectineal septum, which, descending from the blending of the iliac fascia and the inguinal ligament above, passes down to the ilio-pectineal eminerice, and thence to the medial aspect of the front of the capsule of the hip-joint. This compartment transmits the ilio-psoas and femoral (anterior crural) and lateral cutaneous nerves. (B) The vascular compartment is bounded, in front, by the inguinal ligament and the transversalis fascia, which here blends with it, forming the so-called deep crual arch, and at the same time 
descends on to the front of the femoral sheath. The posterior boundary, Cooper's ligament, is formed by the meeting of the ilio-pectineal septum laterally and the pectineal faseia or sheathmedially the lacunar (Gimbernat's) ligament, and laterally the ilio-pectineal septum. This intermediate compartment transmits the ex ernal iliac vessels and the lumbo-inguinal nerve. This lies to the lateral side of the artery, the vein medially. Between the vein and the base of the lacunar ligament is the femoral canal (vide infra). (C) The medial or pectineal compartment is bounded by the pectineal fascia, continuous with the pubic part of the fascia lata, and behind by the pubic ramus. It lodges the upper end of the pectineus muscle, and the handle of a scalpel passed upward along the muscle would be prevented from passing into the pelvis by the lacunar ligament and the blending of the pectineal fascia with the upper border of the pubic ramus.

(3) Lacunar (Gimbernat's) ligament.-This is merely the triangular medial attachment of Poupart's ligament. Its apex is attached to the pubic tubercle; of its three borders, the base is free toward the vein and the femoral canal. Its upper border is continuous with Poupart's ligament; its lower is attached to the terminal (ilio-pectineal) line.

(4) Fascia lata.-Two portions are deseribed over the upper part of the thigh: - (a) An iliac, lateral and stronger, attached to the inguinal ligament in its whole extent and lying over the sartorius, ilio-psoas, and rectus. (b) A pubic, medial, weaker, and much less well defined, is attached above to the terminal line and the tubercle of the pubes. The upper cornu of the fossa ovalis is at the lacunar ligament, and at the lower cornu the two portions of the fascia blend.

Their relation to the femoral vessels.-The iliac portion, being attached along Poupart's ligament, passes over these. The pubic portion, fastened down over the pectineus, which slopes down on to a deeper plane than the adjacent muscles, passes behind the femoral vessels to end on the capsule of the hip-joint.

(5) Fossa ovalis (saphenous opening).--This is not an opening, but an oval depression, situated at the spot where the two parts of the fascia lata diverge on different levels. Though the fascia lata is wanting here, there is no real opening, as the deficiency is made up by the deep layer of superficial fascia, or cribriform fascia, which fills up the opening.

Uses of the fossa ovalis (saphenous opening).- Though a weak spot, it is so on purpose to transinit the suphenous to the femoral vein, and the superficial to the deep lymphatics. The depression is present in order to allow the saphenous vein to be protected from pressure in flexion of the thigh.

Site.-At the medial and upper part of the thigh, with its centre $3.7 \mathrm{~cm}$. (1 $\frac{1}{2} \mathrm{in}$.) below and lateral to the tubercle of the pubis.

Diameters.-Vertically, $2.5 \mathrm{~cm}$. (1 in.), by 1.2 or $1.8 \mathrm{~cm}$. ( $\frac{1}{2}$ or $\frac{3}{4}$ in.). Shape: oval, with its long axis downward and laterally. Two extremities or cornua: upper blending with the lacunar ligament; lower, where the two parts of the fascia lata meet. Two borders: lateral or falciform, also known as the ligament of Hey, or femoral ligament. Semilunar in shape, arching downward and laterally from the lacunar ligament to the inferior cornu. This lies over the femoral vessels, and is atherent to them; to it is fixed superficially the eribriform fascia (vide infra). The medial border is much less prominent, owing to the weakness of the pubic part of the fascia lata which forms it.

(6) Femoral sheath.-This is a fumel-shaped sheath, earried out by the femoral vessels under Poupart's ligament, and continuous above (in front) with the transversalis fascia as it descends to the ligament, lining the inner surface of the abdominal wall, and (behind) with the iliac fascia, and below continuous with the proper sheath of the femoral vesicels.

It is not only funnel-shaperl, but large and loose, for two reasons:- $(a)$ That there be plenty of room for the femoral vein and the slowly mong venous current in it to asecnd without compresison; (b) to allow all the noventents of the thigh taking place-flexion and extensionwithout nnlue stretching of the vessels. By two connertive-tissue septa the sheath is divided into thes: eompartments the lateral for the astery, the intermediate for the vein, and the modial onc for the femoral ranal (ride infm). Thus one septum lies between the artery and vein, and another betwen the vein and the fenoral canal.

(7) Femoral canal. - Ifefinition: the modial division of the femoral sheath. The fascria transpersalis and fascria iliatea meet directly on the lateral side of the fomoral atrtery, lut not so closely on the medial side of the femoral vein. Hence a space exists here, promaps to prevent the thin-walled vein, with its sluggish

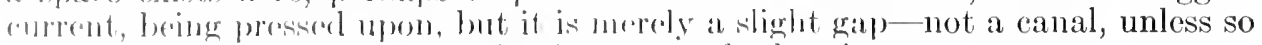
marle by a knifo or by the elilating influmener of a hernia.

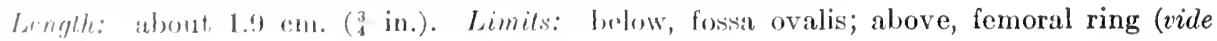
infiri) 
Boundaries.-Laterally, a septum between it and the vein; medially, base of the lacunar ligament and meeting of fascia iliaca and transversalis; belind, fascia iliaca; in front, fascia transversalis.

Contents.-Cellular tissue and fat, continuous with extra-peritoneal fatty layer. A lymphatic node, which is inconstant. Lymphatics passing from inguinal nodes to those in the pelvis.

(S) Femoral ring.--This is mainly an artificial product. It is the upper or abdominal opening of the femoral canal. Shape: oval, with its long axis transverse. It is larger in women. Boundaries: medially, the lacunar ligament; laterally, the femoral vein; in front, the inguinal ligament and the thickening of the transversalis fascia attached to it, and called 'the deep crural arch'; behind the pectineus and Cooper's ligament, a thickened fascial bundle attached

Fig. 1123.-Irregularities of the Obterator Artery. (After Gray.)

A

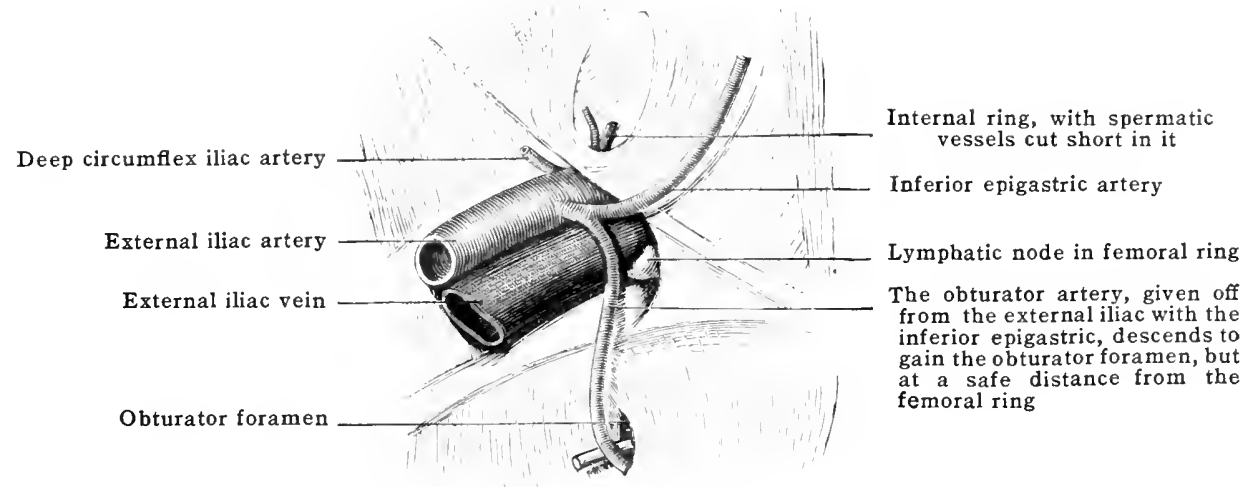

3

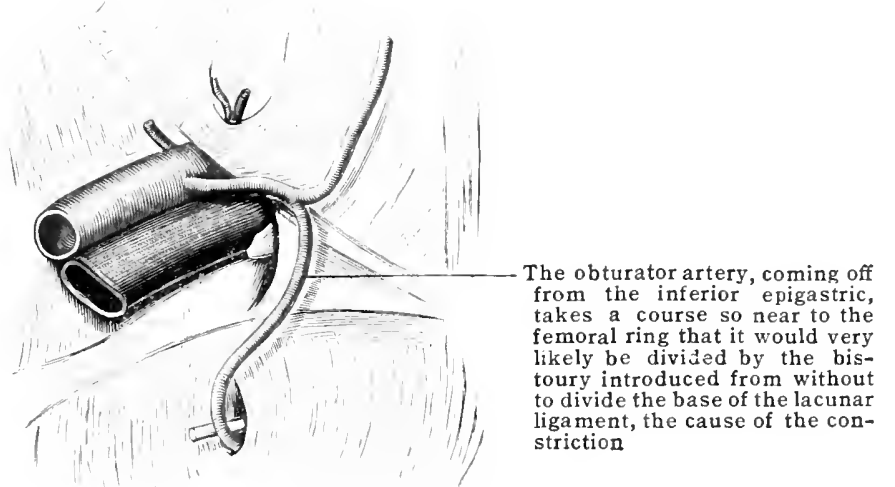

to the linea terminalis (fig. 1122). It is closed by the septum crurale, which is a barrier of fatty connective tissue, continuous with the extra-peritoneal fatty layer, perforated by lymphatics passing upward to the pelvic nodes.

Position of vessels around the ring.-Laterally the femoral vein; above, the epigastric vessels as they ascend from the external iliac ressels, pass close to the upper and lateral aspect of the ring; immediately in front are the cord and spermatic vessels always to be remem?ered in this hernia in the male; toward the medial side there may be an unimportant anastomosis between the epigastric artery above and the obturator below.

If from dilatation of the above anastomosis the obturator artery comes off abnormally from the inferior epigastric, it will descend, and usually does so, close to the junction of the external iliac and common femoral vein, and thus to the lateral and so the safe, side of the ring (fig. 1123, A). In a very few cases it curves more medially, close to the lacunar ligament, and thus to the medial side of the ring, and is then in great danger (fig. 1123, B). In two out of 
every five eases the obturator arises from the inferior epigastric. In about thirty-seven per cent. of the cases with such an origin the artery either crosses or courses along the side of the ring. (Cunningham.)

Course of femoral hernia. - At first this is downward in the femoral canal. A pouch of peritoneum having been grad ially, after repeated straining, coughing, etc., pushed through the weak spot, the femoral ring, further weakened perhaps, together with all the parts in the femoral arch, by child-bearing, some extra effort will force intestine or omentum into this pouch and thus form a hernia. Thus formed, femoral heruia passes at first downward in the femoral canal as far as the fossa ovalis, but, as a rule, does not go farther downward on the thigh, but mounts forward and upward, and somewhat laterally, even reaching the level of the inguinal ligament. The reasons for this change of position are:-(1) The narrowing of the femoral sheath, funnellike, i. e.. wide above, but narrowed below; (2) the unyielding nature of the lower margin of the fossa ovalis; (3) the fact that this margin and the lateral border are united to the femoral sheath; (4) the constant flexion of the thigh; (5) the fact that vessels (chiefly veins) and lymphatics descend to the fossa ovalis, the veins to join the saphenous vein and the lymphaties to join the deeper group; these descending vessels serve to loop upward or suspend a femoral hernia, and thus prevent its further course downwark.

Coverings of a femoral hernia.-(A) At the upper or femoral ring it obtains peritoneum, extra-peritoneal fat, and septum femorale (crurale).

(B) In the canal, a coating of the femoral sheath.

(C) At the external opening, further coverings of cribriform fascia, skin, and superficial fascia are added.

Some of these may be deficient by the hernia bursting through them, or they may be matted together. Sir A. Cooper thought this especially likely to oecur with the layer of femoral sheath and septum crurale, to which he gave the name of fascia propria.

The relations of an inguinal and femoral hernia respectively to the pubic tubercle are of importance in listinguishing between them clinically. If a finger is placed on the pubic tubercle a hernia that lies above and medial to it will be inguinal, one below and lateral to it will be femoral.

Radical cure of femoral hernia.-The close proximity of the femoral vein always introduces difficulty in the introluction of the deep sutures for closure of the crural ring. Any closure below this point is eertain to be inefficient. The safest and simplest method is to feel for the pulsation of the femoral artery, and make allowance for the vein on its medial side. The latter vessel is then protected by the finger-tip passed up the femoral canal, so that its dorsum rests against the vein and its tip upon the linea terminalis. The sutures are then passed so as to pick up the ilio-pectineal fascia and its thickened part, Cooper's ligament, below, and the leep crural arch and Poupart's ligament above (fig. 1122). Thus, when tightened, they draw the anterior and posterior boundaries of the ring together. (Lockwood, Bassini.)

\section{PARTS CONCERNED IN UMBILICAL HERNIA}

A hernial protrusion at the umbilicus, or exomphalos, may occur at three distinct periods of life, according to the anatomy of the part. Any account of umbilical hernia would be incomplete without an attempt to explain how this region, originally a most distinct opening, is gradually closed and changed into a knotty mass of sear, the strongest point in the abdominal wall.

During the first weeks of foetal life, in adelition to the urachus, umbilical arteries, and vein, some of the mesentery and a loop of the intestine pass through the opening to oceupy a portion of the body cavity situated in the umbilical cord, later on roturning to the abdominal cavity. Occasionally this condition persists, owing to failure of development, and the ehild is born with a large hernial swelling outside the abdomen, imperfectly covered with skin and peritoneum. To this condition the term congenital umbilical hernia should be applied.

later on in foetal life it is the umbilical vessets alone which pass through this opening. $\Lambda t$ birth there is a rlistinct ring, which ean be felt for some time after in thre flacedil walls of an infant's belly. If this condition persist, a piece of intrstine may find its way through, forming the condition which should be known as infantile umbilical hernia.

This condition is not uncommon. Why it is not more frecpuently met with is explatined by the way in which this ring of infaney is closed and gradually converted into the dronse mass of sall tisise so familiar in adult life. This is formght about - (1) hy changes in the ring itself; (2) by changes in the vessels Which pass through it.

1) Changes in the ring itself. - The umbilic:al ring is surrounded by a sphineter-like arrangement of clastic fibres, best secen during the first few days of extra-interine life, on the 
posterior aspect of the belly wall. In older infants these fibres lose their elasticity, become more tendinous, and then shrink more and more. As they contract they divide, as by a ligature, the vessels passing through the ring, thus accounting for the fact that the cord, wherever divided, drops off at the same spot and without bleeding.

(2) Changes in the vessels themselves. - When blood ceases to traverse these, their lumen contains clots, their muscular tissue wastes, while the connective tissue of their outer coat hypertrophies and thickens. Thus, the umbilical vessels and the umbilical ring are, alike, converted into scar tissue, which blends together. This remains weak for some time, and may be distended by a hernia (infantile).

Finally, we have to consider the state of the umbilicus in adult life. The very dense, unvielding, fibrous knot shows two sets of fibres:-(1) Those decussating in the middle line; and (2) two sets of circular fibrous bundles which interlace at the lateral boundaries of the ring. The lower part of the ring is stronger than the upper. In other words, umbilical hernia of adult life, when it comes through the ring itself and not at the side, always comes through the upper part. In the lower three-fourths of the umbilicus the unlyilical arteries and urachus are firmly closed by matting in a firm knot of scar tissue; in the upper there is only the unbilical vein and weaker scar. To the lower part lun up the umbilical arteries and the urachus. Owing to the rapid growth of the abdominal wall and pelvis before puberty, and the fact that the urachus and the umbilical arteries, being of scar tissue, elongate with difficulty, the latter parts depress the umbilicus by reason of their intimate connection with its lower half.

Owing to the usual exit of an umbilical hernia of adult life being through the upper part of the ring, the constricting edge in strangulation should be sought below and divided downward. As pointed out by Mr. Wood, it is here that the rragging weight of the hernial contents and the weight of the dress tend to produce the chief results of strangulation. An incision here also gives better drainage if required.

Coverings of an umbilical hernia.-These, more or less matted together, are:(1) Skin; (2) superficial fascia, which loses its fat over the hernia; (3) prolongation of scar tissue of the umbilicus gradually stretched out; (4) transversalis fascia; (5) extra-peritoneal fatty tissue; (6) peritoneum. If the hernia come through above the umbilicus, or just to one side, the coverings will be much the same; but, instead of the layer from the umbilical scar, there will be one from the linea alba.

Strangulated umbilical hernia of adult life.-In this, the most fatal of the strangulated herniæ ordinarily met with, the following are practical points in the surgical anatomy:-1. The coverings, including the sac, are always thin, at times so markedly so that the intra-peritoneal contents are practically subcutaneous. 2. The sac is multilocular, and one or more of its chambers may lie very deep. 3. The contents are numerous, viz., omentum, often voluminous and adherent, transverse colon, and later in the history, small intestine. 4. The contents are often adherent to the sac and each other, thus explaining the irreducibility. 5. The long duration of the presence of the transverse colon with its stouter walls accounts for the period, of ten prolonged, in which warning evidence of incarceration precedes that of strangulation. 6 . The communication with the peritoneal sac is direct, short, and during a prolonged operation, free. Infection is thus readily brought about.

\section{THE BACK}

The surface form and landmarks of the back will be considered first, followed by the relations of skeleton, muscles, viscera and nervous srstem.

Median furrow.-This is more or less marked according to the muscular development, lying between the trapezii and semispinales capitis, in the cervical region, and the sacro-spinales lower down. The lower end of the furrow corresponds to the interval between the spines of the last lumbar and the first sacral vertebræ. (Holden.)

Vertebral spines.-Those of the upper cervical region are scarcely to be macle out even by deep pressure. That of the axis may be detected in a thin subject. Over the spines of the middle three cervical vertebrie is normally a hollow, owing to these spines receding from the surface to allow of free extension of the neck. The seventh cervical is prominent, as its name denotes. Between the skull and atlas, or between the atlas and epistropheus, a pointed instrument might penetrate, especially in flexion of the neck.

Of the thoracic spines, the first is the most prominent, more marked than that of the last cervical; the third should be noted as on a level with the merlial end of the scapular spine, and in some cases with the bifurcation of the trachea; that of the seventh with the lower angle of the scapula; that of the twelfth with the lowest part of the trapezius and the heal of the twelf th rib. The obliquity and overlapping of the thoracic spines are to be remembered.

Of the lumbar spines, the most important are the second, which corresponds to the termination of the cord, and the fourth, which marks the highest part of the iliac crests and the bifurcation of the abdominal aorta. The lumbar spines project horizontally, and correspond with the vertebral bodies. The third is a little above the umbilicus. 
Owing to the obliquity of the thoracic spines, most of them do not tally with the heads of the corresponding ribs. Thus, the spine of the se ond corresponds with the head of the third rib; the spine of the third with the heal of the fourth rib; and so on till we come to the eleventh and twelfth vertebræ, which do tally with their corresponding ribs. (Holden.)

The lower ribs may be felt lateral to the sacro-spinalis but in counting them from below it must be remembered, as pointed out by Holl, that in quite a

Fig. 1124.-Diagrail axd Table showing the Approximate Relation to the Spinal Neries of the various Motor, Sensory, and Reflex Functions of the Spinal Cord.

(Arranged by Dr. Gowers from anatomical and pathological data.)

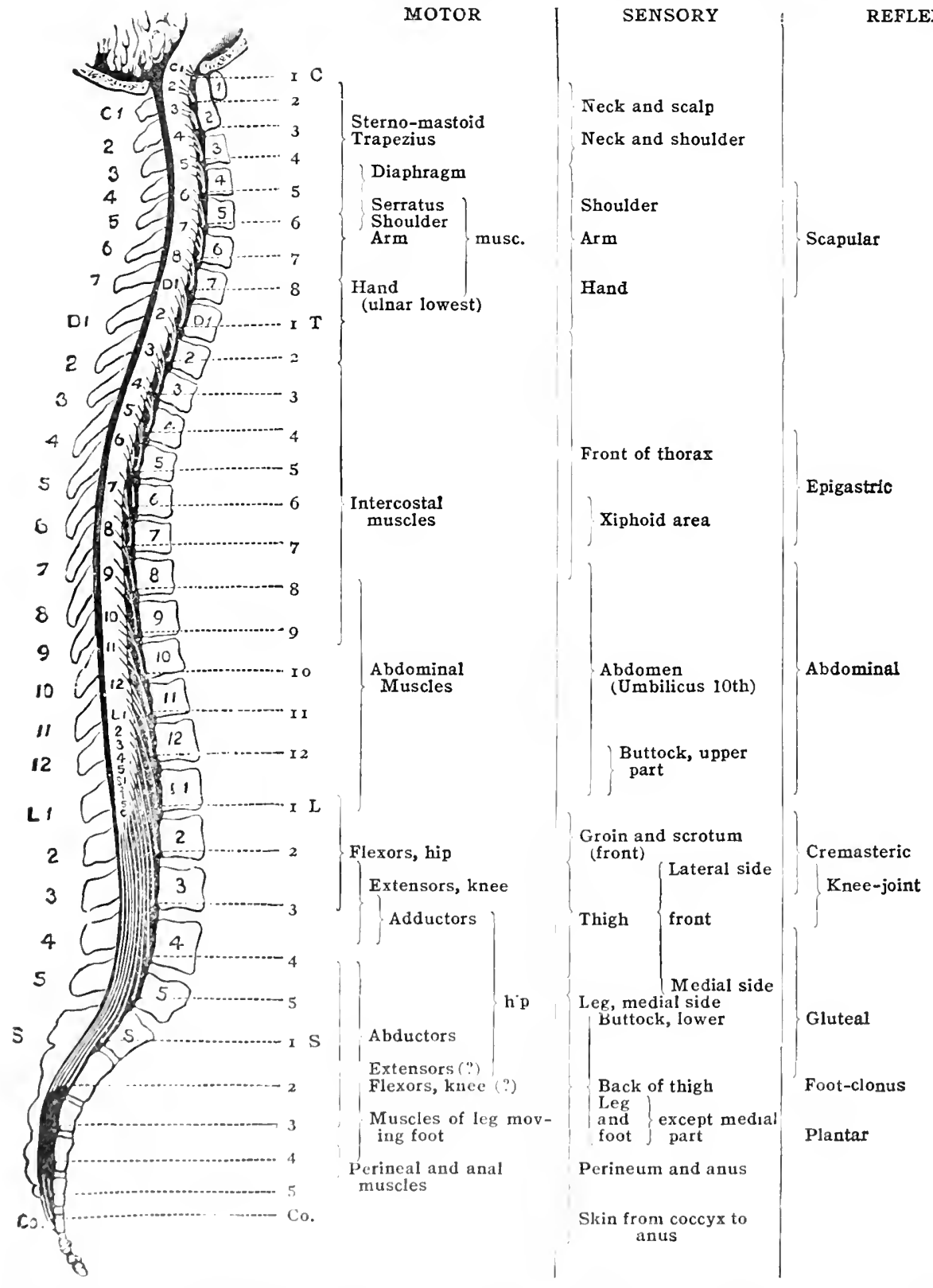

comsirlerable pereentage the last rib is so almormally slort that it eloes not reach as far as the lateral forder of the sarero-spinalis; or is so rudimentary as to re-

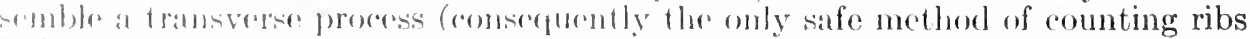

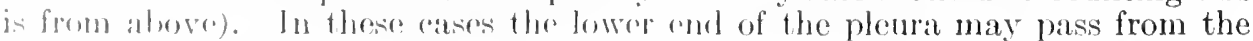

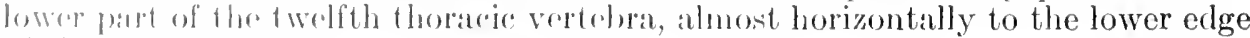
of the wererenth rith. 
Muscles.- The student will remember the greater number and complexity and the numerous tendons of the muscles which run up on either side of the spines; the firmness and inextensibility of their sheaths; the large amount of cellular tissue between them; and the fact that toward the nape of the neck these muscles lie exposed instead of being protected in gutters, as is the case below: all these anatomical points explain the extreme painfulness and obstinacy of sprains here.

Trapezius.-To map out this muscle, the arm should be raised to a right angle with the trunk. The external occipital protuberance should be dotted in, and the superior nuchal line passing out from this; below, the twelfth thoracic spine should be marked; and laterally, the lateral third of the clavicle and the commencement of the scapular spine. Then a line should be drawn from the protuberance vertically downward to the twelfth thoracic spine; a second from about the middle of the superior nuchal line to the posterior and lateral third of the clavicle; and a third from the last thoracic spine upward and laterally to the root of the spine of the scapula.

Fig. 1125.-Relations of the Abdominal Viscera to the Anterior Body Wall.

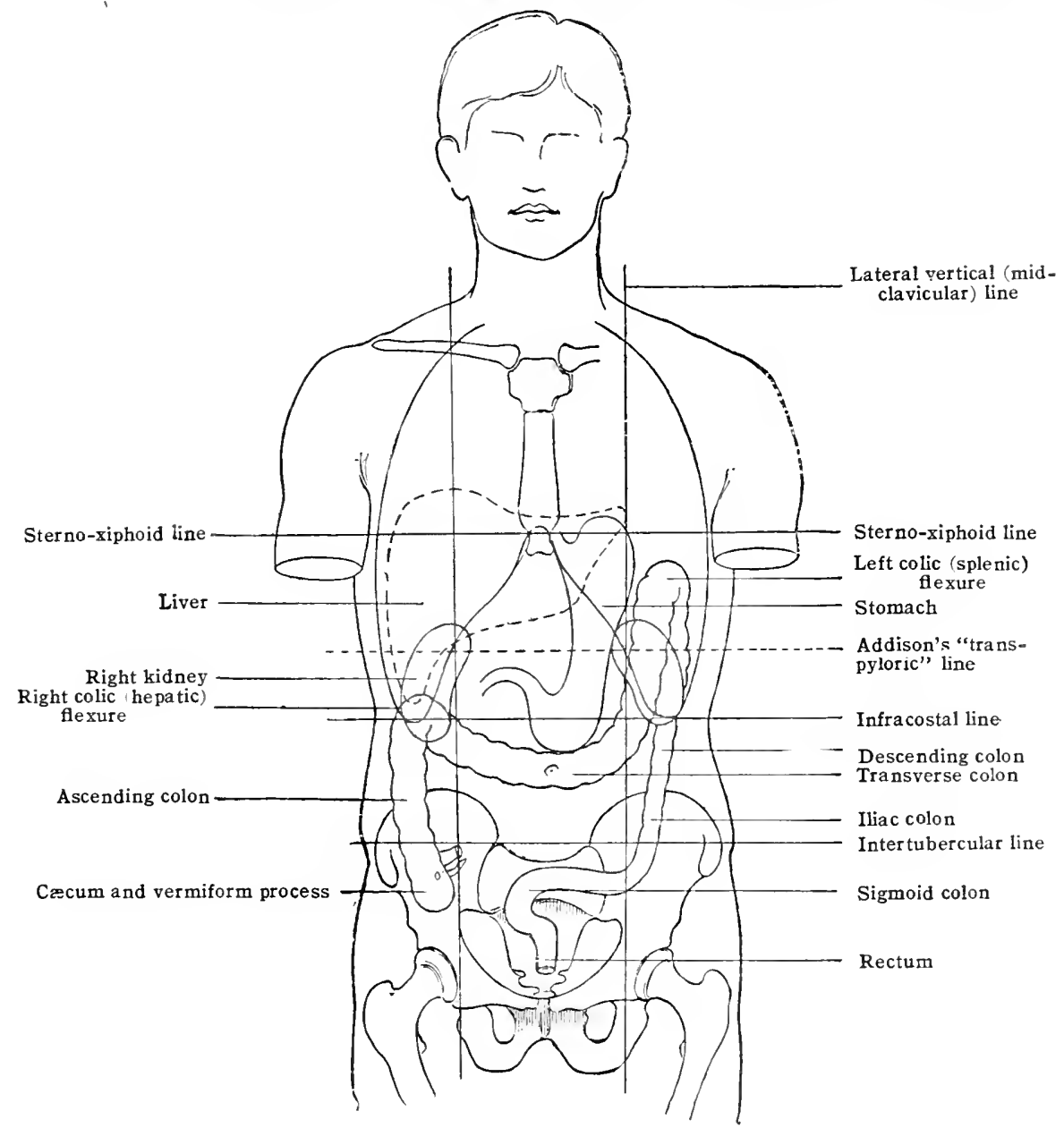

Latissimus dorsi.- The arm being raised above a right angle, the spines of the sixth thoracic and the third sacral vertebræ should be marked; then the outer lip of the crest of the ilium, the lower two or three ribs, the lower angle of the scapula, and the posterior fold of the axilla, and finally the intertubercular (bicipital) groove should all be marked.

A vertical line from the sixth thoracic to the third sacral spine will give the spinal origin of the muscle. Another from the third sacral spine to a point on the iliac crest, $2.5 \mathrm{~cm}$. (1 in.) or more lateral to the edge of the sacro-spinalis, will give the origin of the nuscle from the sheath of the sacro-spinalis and the ilium. A line from the sixth thoracic spine, almost transversely at first, with increasing slight obliquity over the inferior angle of the scapula to the axilla and intertubercular groove, will mark the upper border of the muscle. Another very oblique line from the point of the iliac crest upward and laterally to the axilla will give the lower border and the tapering triangular apex of the insertion. The muscle may be attached to the angle of the scapula, or separated from it by a bursa. 
Triangle of Petit.-This small space lies above the crest of the ilium, at about its centre, bounded by the anterior edge of the latissimus behind and the posterior border of the extemal oblique, in front. Through this gap, when the muscles are weak, a lumbar abscess occasionally, and very rarely, a lumbar hernia, may appear.

Origin of spinal nerves.--It is very important to remember the relations of these to the vertebral spines, in determining the results of clisease or injury of the cord and the parts thereby affected. The above relations may be given briefly as follows:-

The origins of the eight cervical nerves correspond to the cord between the occiput and the sixth cervical spine. The upper six thoracic come off between

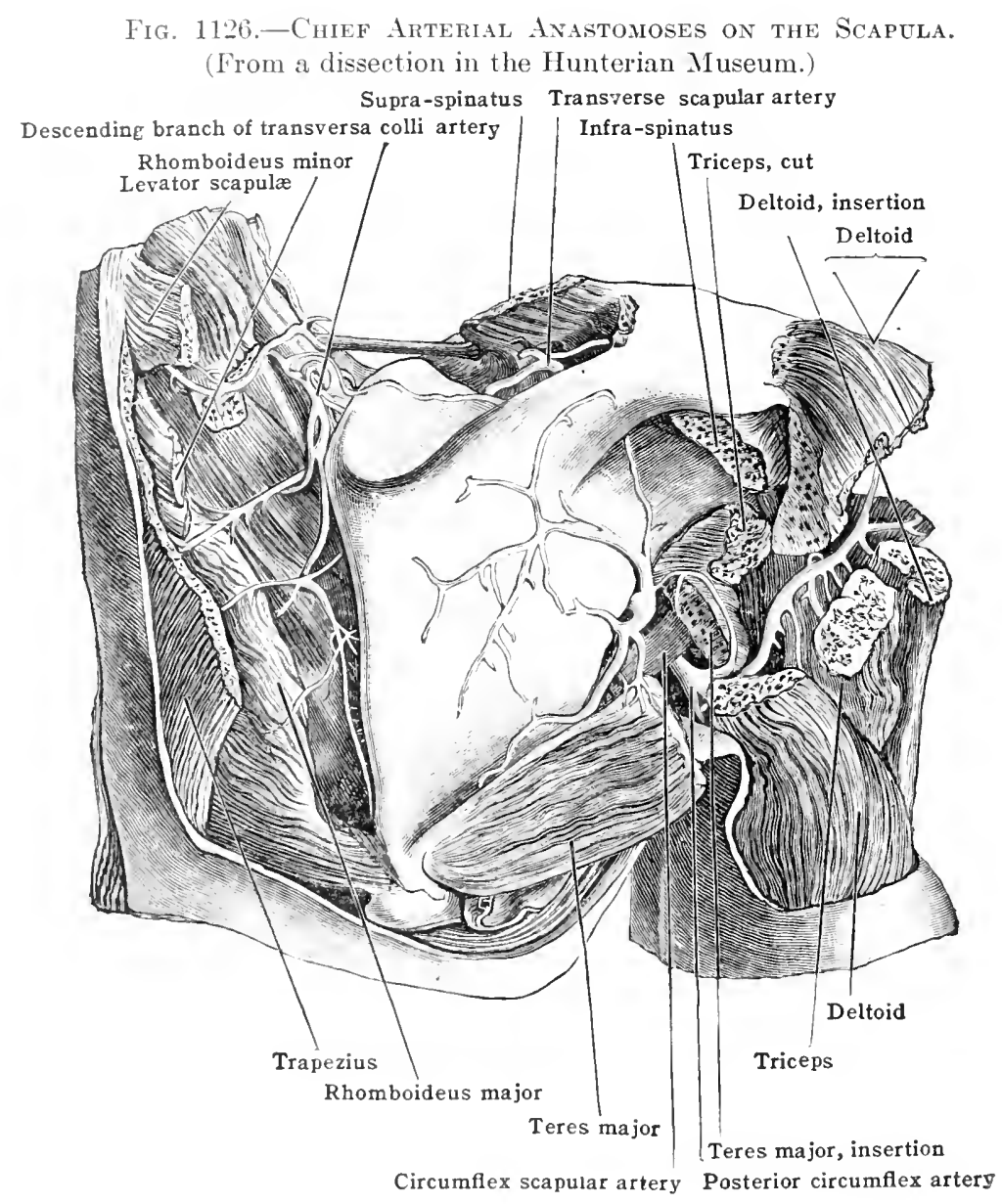

the alowe spine and that of the fifth thoracic vertebra. The origins of the lower six thoracie: norves arrespond to the interval between the fourth and the

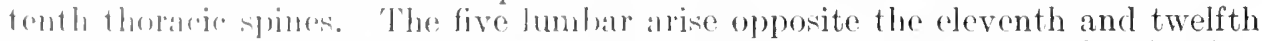
thoratie spines; and the origins of the five siarral eorrespond to the first lumbar spines. 'The diagran and table (fig. 1124), arrangefl by Dr. Gowers from anatomianl and pathelogical data, shen the rolations of the origins of the nerves to their exits from the vertehral ratsit, and the regions supplied by each.

Scapula, its muscles and arterial anastomoses.- Amongst the landmarks in thr hark, the sturlent should he "areful to trace the angles and borders of the stapulat a fall as these are atecessible. 'The upper horder is the one most thickly

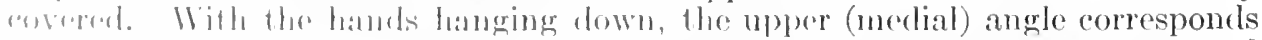

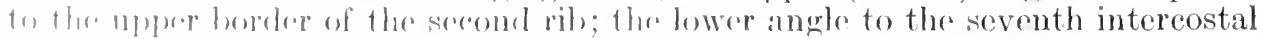

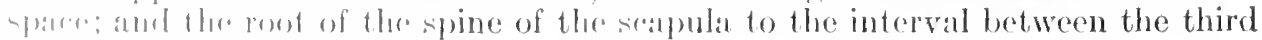
and fouth theratria spints. 
The axillary border of the scapula, covered by the latissimus dorsi and teres major, may best be palpated with the arm hanging to the side. The vertebral border is brought into prominence by placing the hand on the opposite shoulder. This border is held in apposition with the thorax by the serratus anterior; consequently in paralysis of that muscle, supplied by the long thoracic nerve $(5,6$, and $7 \mathrm{C}$.), it becomes unduly prominent, giving rise to "wingerl scapula." Fig. 1126 shows the chief arteries around the scapula. The anastomoses on the acromial process between the transverse seapular (supra-scapular) thoraco-acromial, and circumflex humeral arteries are not shown. The numerous points of ossification, primary and secondary, by which this bone is developed explain, in part, the frequeucy of cartilaginous and other grow ths here.

The anatomy of the loin behind, the ilio-costal region, is of prime importance, owing to the numerous operations here. The lateral border of the sacro-spinalis and quadratus lumborum may be indicated on the surface thus. (Stiles.) That of the sacro-spinalis by drawing a line from a point on the iliac crest $8.2 \mathrm{~cm}$. ( $3 \frac{1}{2} \mathrm{in}$.) (four fingers'-breadth) from the middle line upward and slightly laterally to the angles of the ribs. That of the quadratus passing upward and slightly medially lies a little lateral to that of the sacro-spinalis (erector) at the crest,

Fig. 1127.-Relations of the Abdonixal Viscera to the Posterior Body Wall.

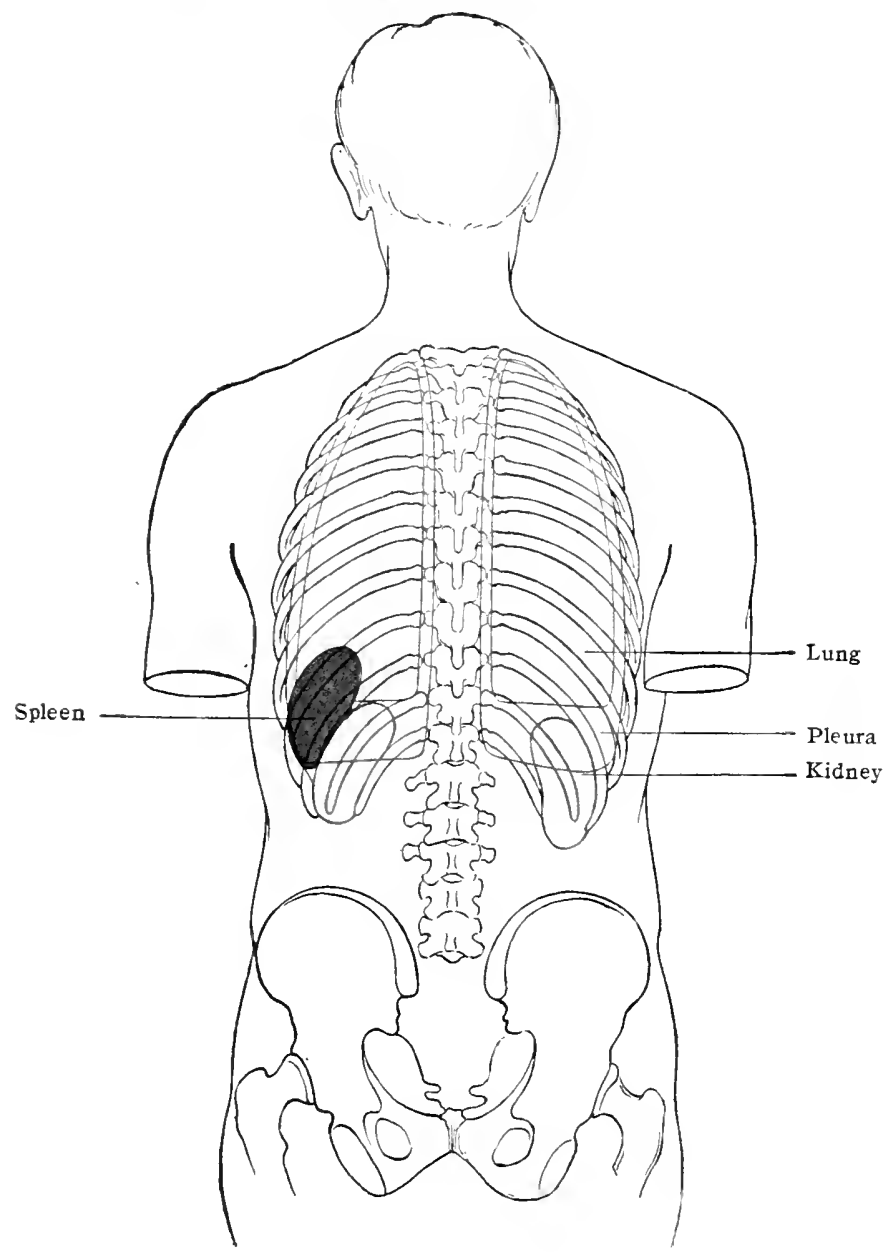

and a little medial to it at the twelfth rib. The ascending and descending colon lie in the slightly depressed angle between the two muscles. The ilio-costal region varies greatly in space according to the length of the lower ribs, shape of the chest, and development of the iliac crest. An incision here-that for exploration of the kidney may be taken as the trpe-mould be an oblique one, about $10 \mathrm{~cm}$. (4 in.) long, starting in the angle between the twelfth rib and the sacro-spinalis muscle and passing forward and downward toward the anterior extremity of the iliac crest. In its upper part the incision should lie $1.2 \mathrm{~cm}$. ( $\frac{1}{2} \mathrm{in}$.) below the twelth rib. The anterior fibres of the latissimus dorsi are divided behind, the posterior ones of the external oblique in front. The yellowish-white lumbar fascia now comes into view, and is the first important landmark. It and the fibres of the internal oblique and transversus which arise from it are next carefully divided. The last thoracic nerve and lowest intercostal artery may' also require division. If the latter is cut close to the rib, the hiemorrhage is troublesome. The transversalis fascia remains to be divided. To avoid the peritoneum, the deeper part of the 
incisions should always be made from behind forward. If more room is required, as in large growths or in exploration of the ureter, the incision must be prolonged beyond the iliac erest, the lumbo-ilio-inguinal incision of Morris.

Viscera.-Several of these, which can be mapped in behind-viz., the kidneys, spleen, ete.- have been already mentioned (pp. 1375, 1379).

The commencement of the trachea and œsophagus has been given in front as corresponding to the sixth cervical vertebra. If examined from behind, this point, owing to the obliquity of the spines, would be a little lower down. The trachea, about $12.5 \mathrm{~cm}$. (5 in.) long, deseending in the middle line, bifurcates opposite to the interval between the third and fourth thoracic spines (or fourth and fifth bodies). The bronchi enter the lungs at about the level of the fifth thoracic spine, the right being the shorter, wider, and more horizontal. The root of the lung is opposite to the fourth, fifth, and sixth dorsal spines, midway between these and the vertebral border of the scapula. The structures in it are the bronchus, pulmonary artery, two pulmonary veins, bronchial vessels, lymphatics, and nerves. The phrenic nerve is in front, the posterior pulmonary plexus behind. On the right side the superior vena eava is in front, the vena azygos (major) arching over the root at the level of the fourth thoracic vertebra. On the left side the aorta arches over the root, and the thoracic aorta descends behind it. The œsophagus, about $25 \mathrm{~cm}$. (10 in.) in length, starting in the middle line, eurves twice to the left, at first gradually at the root of the neek; from this point it tends to regain the middle line up to the fifth thoracic vertebra; thence finally turns again, and more markedly to the left, and passes through the diaphragm opposite to the tenth, entering the stomach here or at the eleventh thoracic vertebra (ninth or tenth thoracie spine). In the thorax this tube traverses first the superior, then the posterior, mediastinum. At three spots, i. e., its commencement, where it is crossed by the left bronchus, and at the cardiac orifice, it presents narrowings. The relations of this tube to the pleura, pericardium, aorta, vagi, and thoracic duct are important in the ulceration of malignant disease and infected bodies, and in the passage of instruments.

The aorta reaches the left side of the vertebral column, with its areh just above the fourth thoracic spine, and thence descends on the front of the column, with a slight tendency to the left, to bifurcate opposite the fourth lumbar spine.

The spinal cord.-This, about $45 \mathrm{~cm}$. (18 in.) long, extends from the foramen magnum to the junction between the first and second lumbar vertebræ. Up to the third month of fotal life it reaches to the sacral end of the vertebral canal; later, owing to the more rapid growth of the bony wall, its lower limit is at birth opposite the third lumbar vertebra. The dura mater is continued, as a sheath, as low as the second sacral vertebra. It is anchored above to the upper cervical vertelure and the foramen magnum, and below, as the filum terminale, to the periosteum of the coceyx. The deficiency of the spinous processes and lamine of the fourth and fifth pieces of the sacrum allows of infection, e. g., of a bed-sore reaching the membranes, and so the cord. The arachnoid and pia of the cord are continuous above with those of the brain.

The ports of the column most exposed to injury are the thoraco-humbar and cervico-thoracic partly berause here more mobile parts are joined to those which are more fixed, and also from the imount of leverage exerted on the thoraco-lumbar region, and, in the case of the upper region, heraluse this is affecterl by violence exerterl on the head. The chief provisions for protertion of the cord are the number of hones and joints which allow of movement without serious weatening, the there corves and columns, rervical, tholacie, and hmbar, ensuring bending before braking; the large amount of rancellous tissue and the number and structure of the intervertolual dises all tending to damp viluations; the large size of the theea vertebralis and the way in which the eord, anchored and slung hy the thirty-one pairs of nerves and the ligamenta clentivalata, abont twenty in number, ocrupies neutral ground in the centre of the canal as regards injury directly and indirectly anplierl.

In lumbar puncture (Quincko) as a means of diagnosis ol of relieving pressure arlvantage is taken of the fact mentionerl above that the theca extends below the (1) (1)

1 line drawn joining the highest points of the iliae crests crosses the fourth humbar spine. The uecelle is insonted in the melian line lsetween the third and fourth or the fourth and fifth

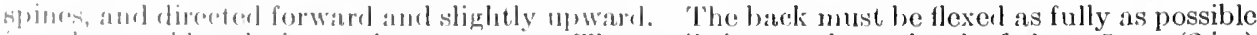

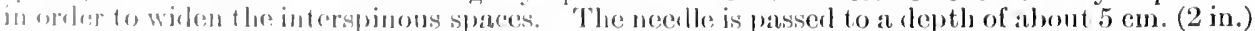

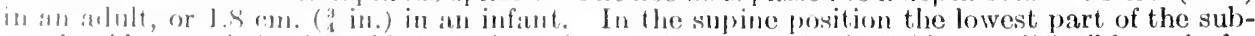
andehrirl spare is in the mid-thorate region, and an anesthetic fluid, non-riffusible and of a 
higher specific gravity than the cerebro-spinal fluid, will tend to gravitate there (Barker). The level of the anzsthesia can be varied by raising the pelvis or the shoulders to different levels.

The following table, from Holden and Windle, with additions, will be found very useful in determining the relation of numerous viscera and other structures to the bodies of the vertebrx.

\section{VERTEBRAL LEVELS}

First. Level of hard palate.

\section{C'ERTICAL}

Second. Level of free edge of upper teeth.

Second and third. Superior cervical ganglion of sympathetic.

Fourth. Hyoid bone. Upper aperture of larynx.

Fifth. Thyreoid cartilage and rima glottidis. Between this and the last would be the bifurcation of the common carotid.

Sixth. Cricoid cartilage. Ending of pharynx and larynx. Consisting of the fused fifth and sixth ganglia, the middle cervical ganglion is usually opposite this vertebra. Here the omo-hyoid crosses the common carotid, and at this spot, the seat of election, the centre of the incision for tying this vessel is placed. At this level the inferior thyreoid passes behind the carotid trunk.

Seventh. Inferior cervical ganglion. Apex of lung. Areh of thoracic duct over apex of lung, outward and downward to termination.

\section{THORACIC}

First. Summit of arch of subclavian. (Godlee.) The height of this varies. Usually it is from 1.2 to $2.5 \mathrm{~cm}$. ( $\frac{1}{2}$ to $1 \mathrm{in}$.) above the clavicle. It is always in close relation with the cervical pleura.

Second. Level of episternal notch. This is usually opposite the fibro-cartilage between the second and third. Bifurcation of innominate. (Godlee.)

Third. Beginning of superior cava, at junction of first right costal cartilage with sternum. Highest part of aortic arch, about $2.5 \mathrm{~cm}$. (1 in.) below notch.

Fourth. Bifurcation of trachea. Second piece of artic arch, extending from upper border of second right costal cartilage, reaches spine. Arch of vena azygos. The superior mediastinum is bonnded behind by the upper four thoracic vertebrie. Louis' angle, junction of manubrium and gladiolus. Thoracic aorta begins.

Fifth to ninth. Base of heart.

Sixth. Pulmonary and aortic valves, opposite third left costal cartilage at its sternal junction, in front. Commencement of aolta and pulmonary artery. End of superiol cava, third right chondro-sternal junction in front.

Seventh. Mitral olifice.

Eighth. Tricuspid orifice.

Ninth. Lower level of manubrium and sterno-xiphoid line (at lower border). Opening in_diaphragm for inferior vena cava (lower border).

Tenth. Level of tip of xiphoid cartilage. Lower limit of lung posteriorly. Upper limit of iliver comes to the surface posteriorly. Esophagus passes through diaphragm. Cardiac orifice of stomach (sometimes). Upper limit of spleen.

Eleventh. Lower border of spleen. Suprarenal gland. Cardia (sometimes).

Twelfth. Lowest part of pleura. Aorta passes through diaphragm (lower border). Cœliac artery (lower border). Upper end of kidney.

\section{LTMB.AR}

First. Superior mesenteric arteries. Pancreas. Pelvis of lidney. Renal arteries. Transpyloric line. (Addison.)

Second. Spinal cord ends at junction of first and second. Duodeno-jejunal flexure. Receptaculum (cisterna) chyli. Lower end of left kidney.

Third. Umbilicus, opposite disc between third and fourth. Lower end of right kidney.

Fourth. Bifurcation of aortic arch. Highest part of iliac crest.

Fifth. Commencement of superior vena cava.

\section{SACRAL}

Third. End of pelvic colon and beginning of first piece of rectum proper. Lower limit of spinal membranes.

Fifth. Reflexion of recto-resical pouch of peritoneum 2.5 cm. (1 in.) above base of prostate.

Coccyx (tip). $2.5 \mathrm{~cm}$. (1 in.) below this commencement of anal canal. Termination of filum terminale.

\section{THE UPPER EXTREMITY}

\section{THE SHOLLDER AND ARMI}

The surface form and landmarks of the upper extremity will first be considered followed by the various regions of the shoulder, arm, forearm and hand. 
General surface form. Landmarks.-The following surface-marks, of the greatest importance in determining the nature of shoulder injuries, can be made out here:- The clavicle in its whole extent, the acromion process, the great tuberosity, and upper part of the shaft of the humerus. Much less distinctly, the position of the coracoid process in the infraclavicular fossa and the head of the humerus through the axilla can be made out. The anterior margin of the clavicle, convex medially and concave laterally, can be made out in its whole extent, the bone, if traced laterally, being found not to be horizontal, but rising somewhat to its junction with the acromion. The sterno- and acromio-clavicular joints have been referred to at p. 1363.

The frcqucncy of fracture of the clavicle is explained chiefly by its exposure to shocks of varied kinds from the upper extremity, inseparable from the out-rigger-like action of the bone and its early ossification. On the other hand, the main safeguards are the elasticity and curves of the bone, the way in which it is mbedded in museles which will damp vibrations, and the bufferbond fibro-eartilages at either extremity. The looseness and toughness of the overlying skin explain the rarity of compound fracture here. The junction of the two eurves is the weakest spot and the usual site of fracture. The weight of the limb acting through the coracomclavicular ligaments and overeoming the trapezius is the chief factor in the downward displacement; the pectoralis minor and serratus anterior acting on the seapula draw the acromial fragment forward. The tip of the acromion, when the arm hangs by the side with the hand supinated, is in the same line as the lateral condyle and the styloid process of the radius. On the medial side, the head and medial condyle of the humerus and the styloid process of the ulna are in the same line. Thus the great tuberosity looks laterally, the head medially, and the lesser tuberosity somewhat forward. Between the two tuberosities runs the intertubercular (bicipital) groove, which,

Fig. 1125.-Transverse Section through the Right Shodlder-Joint, showing the Structures in Contact with it. (Braune.)

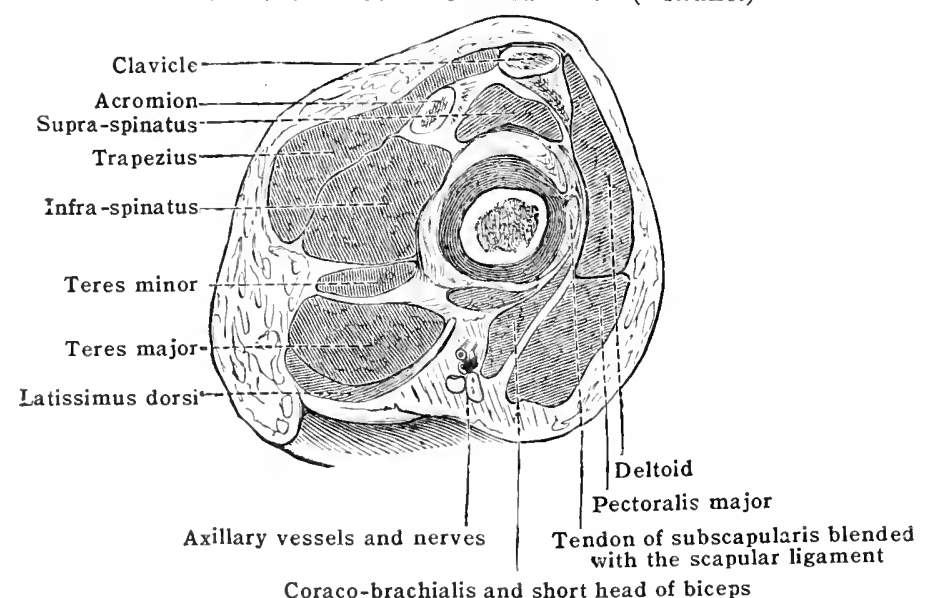

with tho arm in the above position, looks directly forward. In thin subjects its lower part can be dofinel. Jts position ean be markel with suffieient accuracy by a hine running downwarl from the acromion in the long axis of the bumerus. Besides the tendon and its synovial shrath, he insertion of the latiscinus dorsi, the humeral branch of the thoraco-acromial artery, and the anderior circunflex artery run in the groove. When the fingers are placed on the acromion and the thumb in the axilh, the lower eslge of the glenoid cavity can be felt; and if the humarus be rotiterl (the elfwe-joint boing llexed), the head of the humerus can be felt also.

The characteristic roundness of the shoulder is due to the great tuberosity lying nunler the deltoid (fig. 1130). In distocation the loss of this roundness is due to the absence of the head and tuberosity and consequent projection of the acromion.

This mormal projection of the deltoid renders it impossilsle to place a flat straight body in

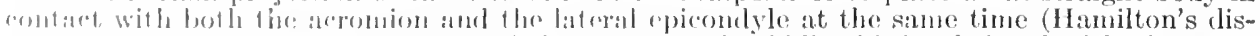

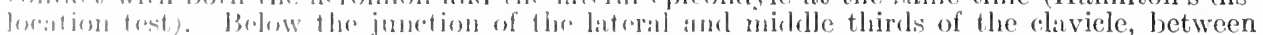

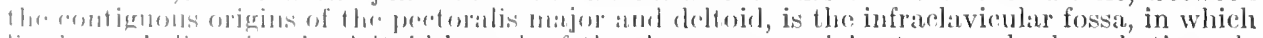

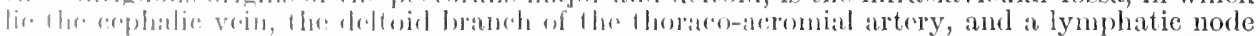

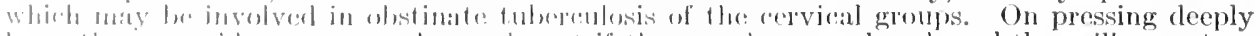

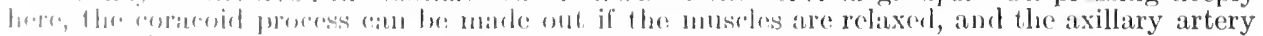

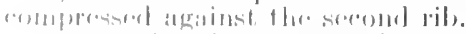

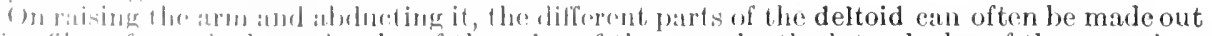

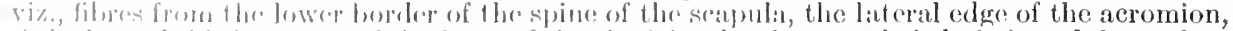
and the latral thind or more of the front of the clavicke; the colatrateristie knitting of the surface 
owing to the presence of fibrous septa continuous, alike, with the skin and the sheath of the muscle and the tendinous septa which separate the muscular bundles, will also be seen. The muscle will be marked out by a base-line reaching along the above bony points, and two sides converging from its extremities to the apex, a point on the lateral surface of the humerus, about its centre. In paralysis of the deltoid, the humerus being no longer braced up against the scapula, the finger-tips can be placed between it and the acromion.

To map out the pectoralis major, a line should be drawn down the lateral aspect of the sternum as far as the sixth costal cartilage, and then two others marking the boriters of the muscle-the upper corresponding to the medial border of the deltoid, the lower starting from the sixth cartilage, and the two converging to the folderl tendon, which is inserted as a double

Fig. 1129.-The Shoulder-Jolnt, as shown bx the Rontgen-rays.

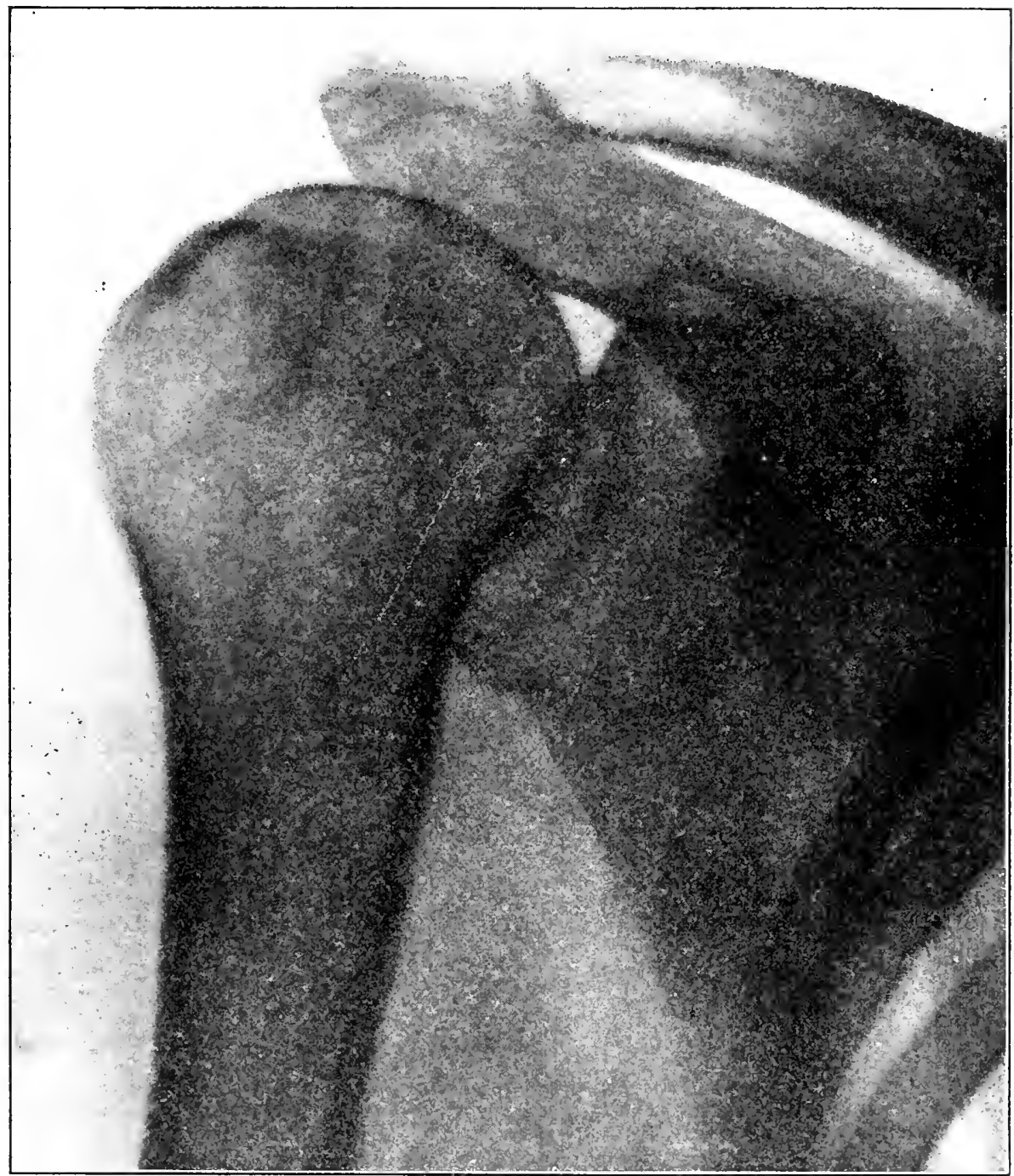

layer into the lateral tubercular (bicipital) ridge. The pectoralis minor will be marked out by two lines, from the upper border of the third and the lower border of the fifth rib, just hateral to their cartilages, and meeting at the coracoid process. The lower line gives the level of the long thoracic artery; the upper, where it mects the line of the axillary artery, that of the thoracoacromial.

When the arm is abducted and the humerus rotated a little laterally, the prominence of a well-developed coraco-brachialis comes into view; a line drawn from the centre of the clavicle along the medial border of this musche to its insertion into the humerus gives the line of the axillary artery.

Axillary fossa.-The boundaries of this space anterior, posterior, merlial, or thoracic, lateral or humeral, apex and base, with the structures forming them and 
the vessels and nerves in relation to them, must be remembered. The chief vessels are the axillary on the lateral wall, brought into prominence when the arm is abducted, as in removal of the mamma, and the subscapular on the posterior wall. The apex is felt, when the finger is pushed upward in an operation here, to be bounded by the clavicle in front, the first rib behind, and the coracoid somewhat laterally. The base is concave, owing to the coraco-clavicular (costocoracoid) membrane as it descends to blend with the sheath of the pectoralis minor, giving also a process to the axillary fascia which unites the anterior and posterior boundaries. This process also sends septa to the skin.

An axillary abscess, always to be opened early to avoid subsequent interference with the morements of the shoulder, is reached by an incision on the medial wall, midway between the anterior and posterior boundaries, so as to avoid the long thoracic and subscapular vessels, respectively, the back of the knife being directed toward the lateral wall. The only vessel on this wall is the superjor thoracic, which lies high up. Additional safety is given by the use of Hilton's method. For exploration of the axilla the best incision is an angular one, the two limbs being placed in a line with the anterior margin of the great pectoral, and in the line of the axillary vessels. This runs from a point on the centre of the clavicle the limb being at a right angle to the trunk) to the medial margin of the coraco-brachialis. If this be obliterated by swelling, the above line should be prolonged to the middle of the bend of the elbow, which will give the guide to the brachial also. Collateral circulation. If the first part of the artery be tied, the channels are the same as in ligature of the third part of the subclavian $(q . v$.$) . In ligature$ of the third part of the axillary, if the ligature be above the circumflex arteries, the chief vessels concerned are the transverse scapular (suprascapular) and thoraco-acromial above and the

Fig. 1130.-Diagramatic Section of Shoulder throdgh the Intertubercular (Bicipital) Groove. (Anderson.)

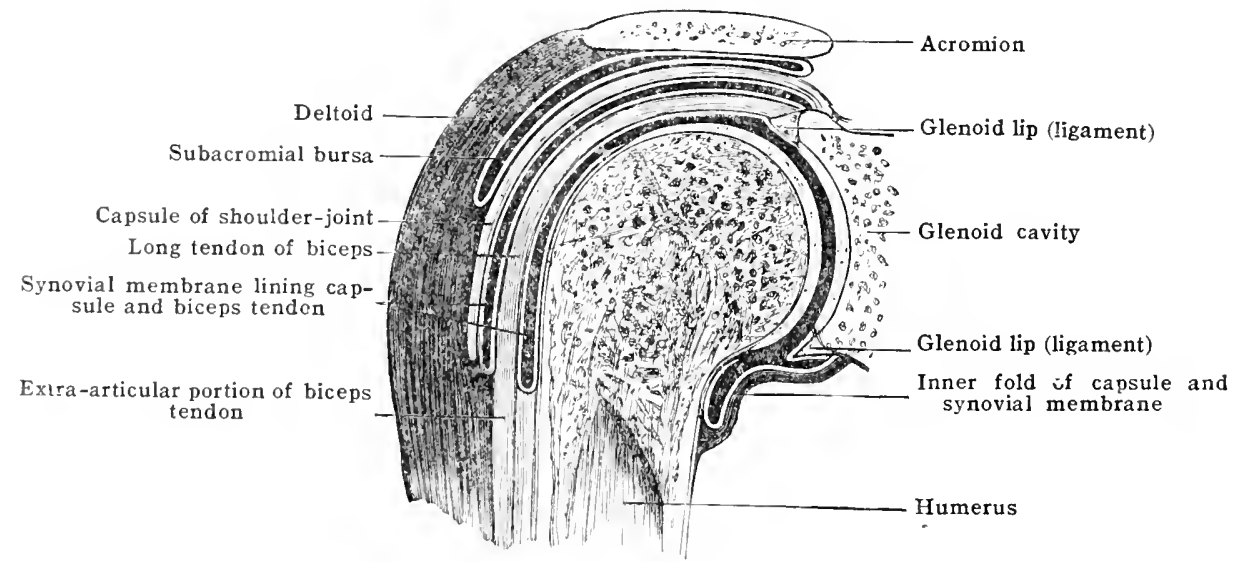

posterior circumflex below. If the ligature be belowe the circumflex, the anastomoses will be those concerned in ligature of the frachial above the profunda (p. 1414). The lymphatic nodes in the axilla have loeen montioned at p. 719 , (fig. 566 ).

The depression of the axillary fossa is best marked when the arm is raised from the side (6) an anglo of about $45^{\circ}$, and when the moscles bounding it in front and behind are contracted. In propontion as the arm is raiserl, the hollow breomes less, the head of the humerus now projerting into it. When the folds are relaxed by bringing the arm to the side, the fingers can be prasherl into the spare so as to examine it.

The axillary (ciremuflex) nerve and posterios (iremmflex vessels wind around the humerus muler the deltrid; a line drawn at a right angle to the lumerus and a little above the centre of this musele marks their position on the surface.

To trane the synovial membrane of the shoulder-joint is a comparatively simple unattor (fige 11:30). ('overing both asperts of the free edge of the glenoid liganuent, it lines the inner atspert of the eipsule, whereby it reaches the articular margin of the buad of the humerus; there is a thistinet reflection, below, from the rapsule on to the humeral neek before the rim of the cartilage is reached.

An extonsive pontrusion of symovial nomlerane takes place in the form of a synovial bursa,

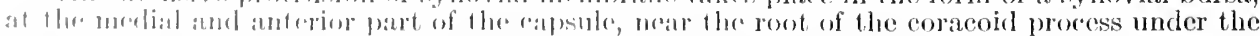

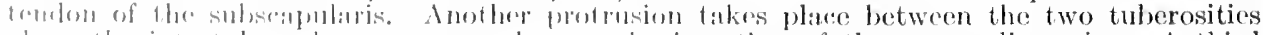

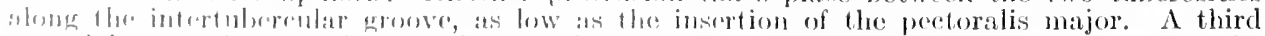

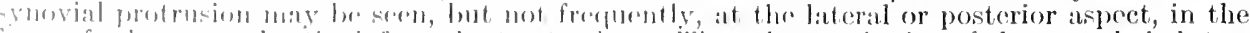

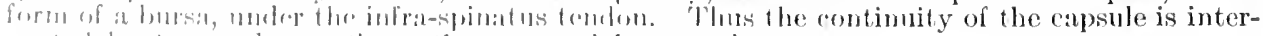
runterl l,y two and sometimes three synovial protrusions. 
Shoulder-joint.- The frequency of dislocations here, nearly equal to those of all the other joints put together, calls attention to the points contributing to make the joint alike insecure and safe. Strength is given by (1) the intimate blending of the short scapular muscles, especially the subscapularis with the capsule; (2) the coraco-acromial vauit; (3) atmospheric pressure; (4) the long tendon of the biceps; (5) the elasticity of the clavicle; (6) the mobility of the scapula. The weakness of the joint is readily explained by its free mobility, the want of correspondence between the articular surfaces, its exposure to injury, and the length of the humeral lever. The rent in the capsule is usually anterior and below, and to this spot the head of the humerus must be made to return. While dislocations are usually primarily subglenoid, owing to the above part of the capsule being the thinnest and least protected, they take usually a secondarily forward direction,

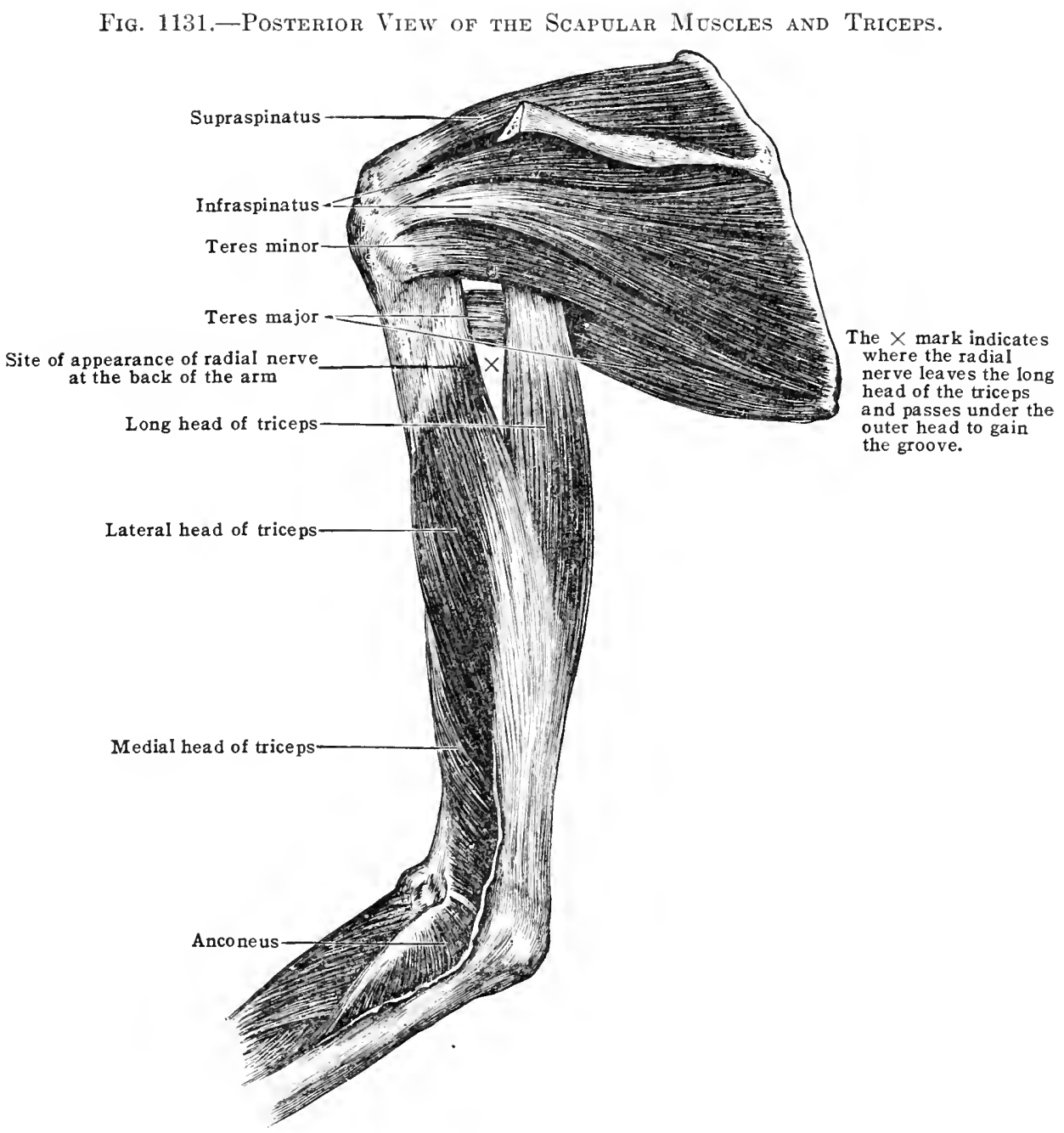

as the triceps prevents the head passing backward. In addition to the above features of the lower part of the cansule, laxity is here also a marked feature, to allow of free abduction and elevation. This movement will be accordingly much checked by any inflammatory matting of this part of the capsule.

The best incision for exploring the joint is one commencing midway between the coracoid and acromion processes and carried downward parallel with the anterior fibres of the deltoid. The cephalic vein and biceps tendon are to be avoided. If drainage is needed, it must be supplied by a counter-incision behind. This may be made along the posterior border of the deltoid, part of its humeral attachment being detached if necessary. The axillary (circumflex) nerve must be avoided in the upper part of the incision. 
The shaft of the humerus is well covered by muscles in the greater part of its extent, especially above. Below the insertion of the deltoid, the lateral border of the bone can be traced clownard into the lateral supracondyloid ridge. The medial border and ridge are less prominent.

Attached to these ridges and borders are the intermuscular septa, each lying between the triceps and brachialis (anterior), and the lateral one giving origin to the brachio-radialis (supinator longus) and extensor carpi radialis longus as well. The medial extends up to the insertion of the coraco-brachialis, the lateral to that of the deltoid. The lateral septum is perforated by the anterior part of the profunda vessels and the radial (musculo-spiral) nerve, the medial by the superior and posterior branch of the inferior ulnar collateral (anastomotica magna) artery and the ulnar nerve.

The biceps has a two-fold attachment above and below. The former is of much importance in steadying the various movements, especially the upward one, and in harmonising the simultaneous flexion and extension of the shoulder- and elbow-joints. (Cleland.) The lacertus fibrosus curring downward and medially with its semilunar edge upward, across the termination of the brachial artery, strengthens the deep fascia and the origin of the flexors of the forearm. The two heals unite in the lower third of the arm. The tendon, before its insertion, becomes twisted, the lateral border becoming anterior.

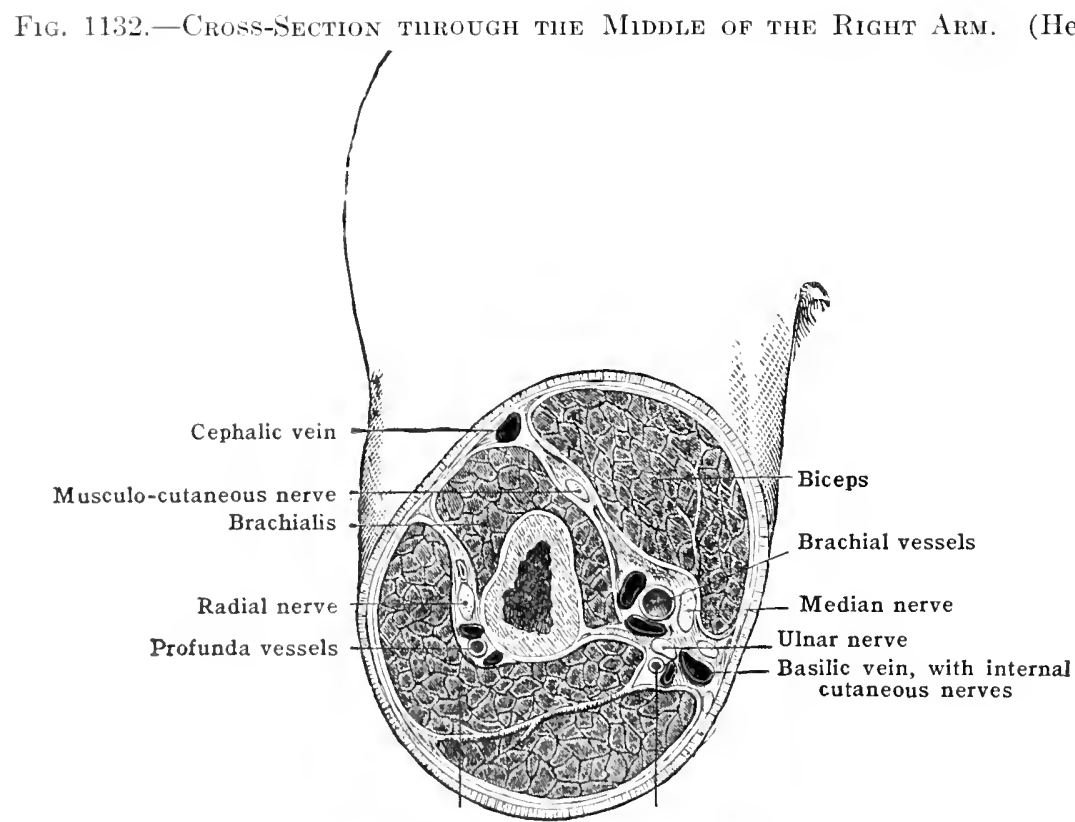

Triceps, with fibrous intersection

Superior ulnar collateral vessels

On cither side of the well-known prominence of the biceps is a furrow. Along the latral ascemels the ecphalic vein. The medial eorresponds to the line of the hasilic voin which lies superficial to the deep fascia below the middle of the arm, and superficial and medial to the brachial vessels and median nerve.

The strength of such muscles as the deltoid, and their intinate connection with the peri-

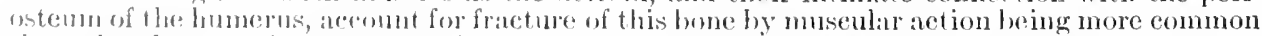

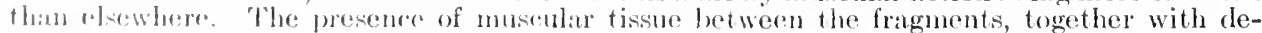
firiont inmolilization, (xulans the fact that unmited fractures are also most common in the

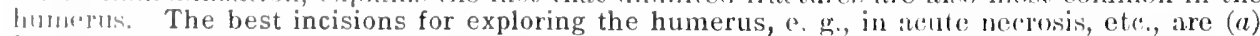

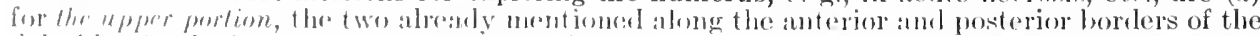

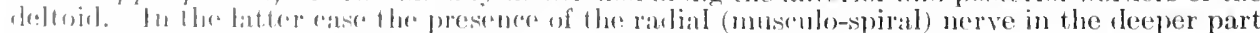

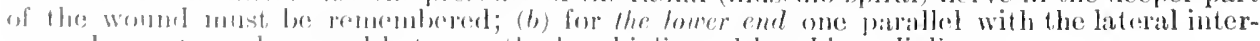

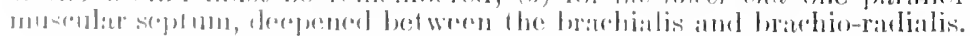

I line drawn atemg the medial edere of the licens from the insertion of the teres major to the middle of the hemel of the albow corresponds to the brachial artery. In tha upder two-dhirds, this atrtery ran be eompressed against the bone by pressure laterally; in its lower third the lomerus is hehind it, and pressure should be male hatekwarel. The presence of the median nerve will interfere with any prolomenal digital pressure atplierl in the midelle of the arm. 
In ligature of the artery here the line extends from the mid-axillary region above, prolonged to the centre of the front of the elbow. The only structures seen should be the medial edige of the biceps, the basilic vein, and the median nerve. The profunda comes off $2.5 \mathrm{~cm}$. ( 1 in.) below the teres major, having the same relation to the heads of the triceps; thus, it first lies on the long head, behind the axillary and brachial arteries, then between the long and medial heads, and next, in the groove, between the medial and lateral heads, and courses with the radial (musculo-spiral) nerve (fig. 1132); the nutrient artery arises opposite the middle of the humerus; in many cases it arises, on the back of the arm, from the profunda; the superior ulnar collateral (inferior profunda) below the middle, and courses with the ulnar nerve through the intermuscular septum to the back of the medial condyle. The inferior ulnar collateral (anastomotica magna) is given off from 2.5 to $5 \mathrm{~cm}$. (1 to $2 \mathrm{in}$.) above the bend of the elbow. Fig. 1138 will show the collateral circulation after ligature of the brachial, according as the vessel is tied above or below the superior profunda, or below the superior uluar collateral.

The centre of the arm is a landmark for many anatomical structures. On the lateral side is the insertion of the deltoid; on the medial, that of the coracobrachialis. The basilic vein and the medial brachial cutaneous nerve (nerve of Wrisberg) here perforate the deep fascia, going in reverse directions. The superior ulnar collateral is here given off from the brachial and joins the ulnar nerve; the median nerve also crosses the artery, and the ulnar nerve leaves the medial side of the vessel to pass to the medial aspect of the limb.

The brachialis can be mapped out by two pointed processes which surround the insertion of the deltoid, pass downward into lines corresponding to the two intermuscular septa, and then converge over the front of the elbow to their insertion into the coronoid process.

The median nerve (lateral head, 5th. 6th, 7 th C.; inedial head, 8th C. and 1st T.) can be traced by a line drawn from the lateral side of the third part of the axillary and first part of the brachial artery, across this latter vessel about its centre, and then along its medial border to the forearm, where it passes between the two heads of the pronator teres.

Fig. 1133.-Cross-Section throdgh the Elbow. ( $\times 1 / 2)$. (After Braune.)

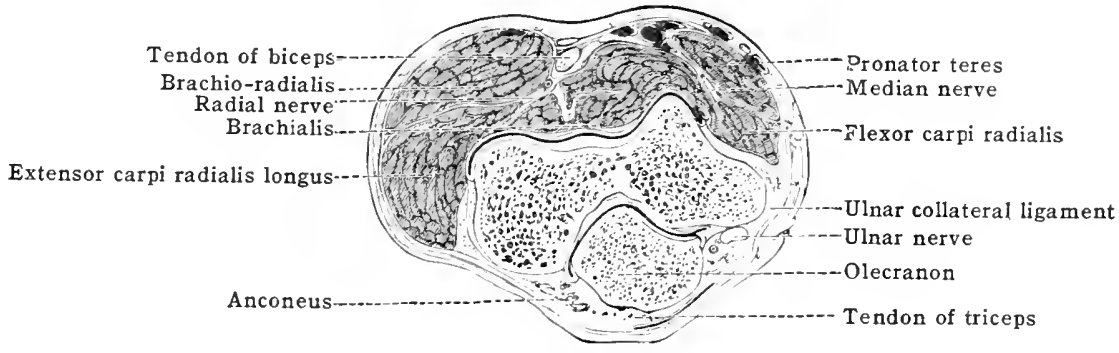

The ulnar nerve (Sth C. and 1st T.) lies to the medial side of the above arteries as far as the middle of the arm, where it leaves the brachial to course more medially and perforate the medial intermuscular septum together with the superior and posterior branch of the inferior ulnar collateral and so get to the back of the medial condyle. A line drawn from the medial border of the coraco-brachialis, where, in the upper part of its course, the nerve is in close relation with the medial side of the axillary and brachial arteries, to the back of the medial condyle, will indicate its course. Low down, the nerve is in the medial head of the triceps, and may be injured in operations here.

The radial (musculo-spiral) nerve (5th, 6 th, 7 th, and 8 th C.) can be traced by a line beginning behind the third part of the axillary artery, then carried vertically down behind the uppermost part of the brachial, and then, just below the posterior border of the axilla, curving backward behind the humerus and slightly downward just below the insertion of the deltoid. Thus, passing from laterally and from before backward in its groove, accompanied by the prof unda vessels, first the trunk, and then the smaller anterior division, it again comes to the front by perforating the lateral intermuscular septum at a point about opposite to the junction of the middle and lower thirds of the arm, and passes down in front of the lateral supracondyloid ridge, lying here between the brachio-radialis and brachialis anterior, to the level of the lateral condyle, in front of which it divides into the superficial (radial) and deep (posterior interosseous) radials. The former of these accompanies the radial artery to the front of the arm, the latter travels backward to the back of the forearm. A line from the lateral condyle to the insertion of the deltoid indicates the lateral intermuscular septum.

In addition to injuries caused by fracture, the nerve may be injured in crutch pressure, the sleep of intoxication, use of an Esinarch's bandage, or the careless reduction of a dislocated shoulder with the foot in the axilla. To expose the nerve the incision begins below, over the lateral intermuscular septum, where it lies between the brachio-radialis and brachialis (anterior). Hence the incision is prolonged freely upward and backward toward the posterior border of the deltoid.

On the back of the arm is the triceps muscle, with its three heads and tendon of insertion, all brought into relief in a muscular subject when the forearm is strongly extended. Of the three heads, the medial is the least distinct, arising 
below the groove (musculo-spiral) for the radial (musculo-spiral) nerve, reaching to each intermuscular septum, and tapering away above as high as the teres major. Most of the fibres of this head lie deeply. The lateral head, arising above the groove as high as the great tuberosity, appears in strong relief just below the deltoid; while the middle or long head, arising from the scapula just below the glenoid cavity, appears between the teres muscles. The tendon of insertion, passing into the upper and back part of the olecranon over a deep bursa, is shown by a somewhat depressed area. On the lateral side, an important expansion to the fascia over the anconeus is given off.

Fig. 1134.--The Elbon-JorNt, as Shown by the Röntgen-Rays.

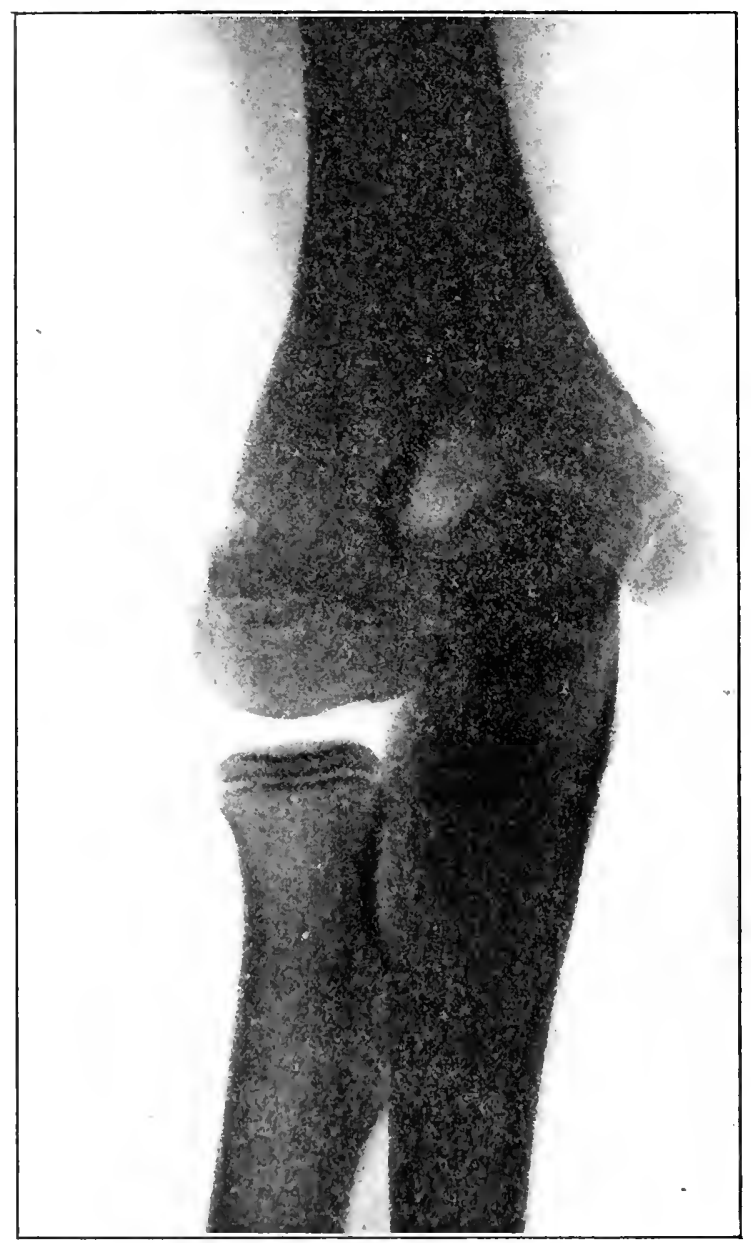

In the ossification of the humerus the epiphyses are of first importance. The upper, comsisting of those for the houl and two tuhwosities, which form one about the seventh year, blonds with the shaft hetwern the twenticeth amel wenty-fifth years. Separation usually takes place at an earlier date, this being explained hy the fart that the cone-like arrangement by which the diaphysis fits into the aap of the apiphysis heomes more marked toward the date of union, and thas teruls to prevent displacement. ("Thmson.) 'The lower epiphysis. The condition of this varies with the degree of conlesenene of its four centres. The first and chicf, that for the capitulum (second or third year), unites with those for the trochlea and lateral epicondyle soon after muherty, and forms an cophlysis which joins with the shaft at about sixteer. The epiJhysis for the merlial epicondyde apprars at Ho lifh vear and motes with the shaft at the righternth. Injury to this epiphysis may damage the ulua nerve and open the elbow-joint.

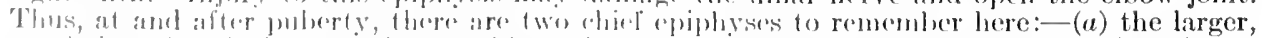

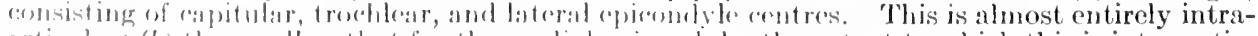

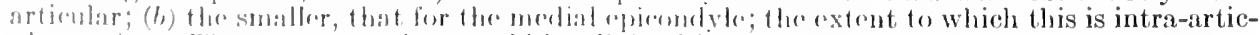
ular varies. The structures that would le diviled in an amputation at the centre of the arm 
are shown in fig. 1132. The chicf points needing attention are:-(1) To leave as much of the lever of the humerus as possible; (2) clean section of the large nerves, the radial (musculospiral) in its groove being especially liable to be frayed by the saw; (3) the difference between the amount of retraction of the free biceps in front, and the triceps behind, fixed to the bone and septa.

\section{THE ELBOIV}

The bony points, epicondyles, olecranon, and head of radius, andtheir relation to one another, should be earefully studied. The medial epicondyle is the more prominent of the two, is directed backward as well as medially, and lies a little above its fellow. Above it ean be traced upward the supracondyloid ridge and corresponding intermuscular septum. The lateral epicondyle is more rounded, and thus less prominent; below, and a little behind it, the head of the radius can be felt moving under the capitulum when the forearm is supinated and flexed. A depression marks this spot and corresponds to the interval between the anconeus and brachio-radialis and extensor carpi radialis longus; at the back, the upper part of the olecranon is covered by the triceps. The lower part is subcutaneous, and separated from the skin by a bursa. If the thumb and second finger be placed on the epicondyles and the index on the tip of the oleeranon, and the forearm completely extended, the tip of the olecranon rises so as to be on the line joining the two epicondyles. In flexion at a right angle, the olecranon is below the line of the

Fig. 1135.-Longitudinal Section of the Elbow-joint. (One-half.) (Braune.)

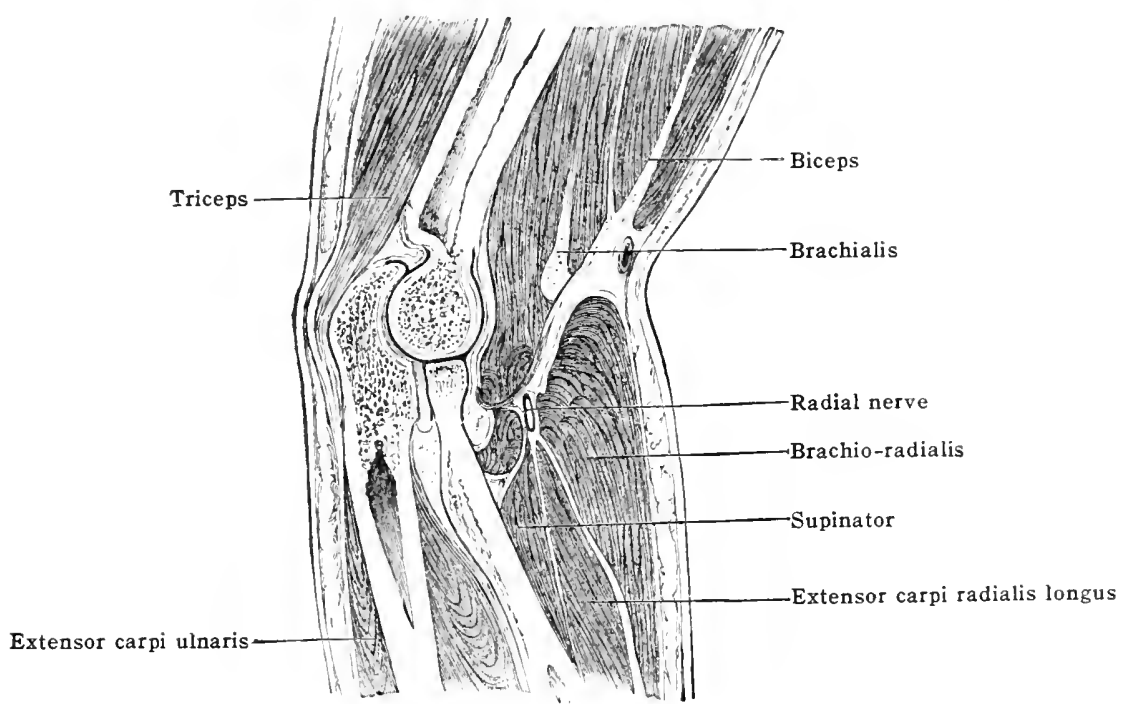

epicondyles, and in complete flexion quite in front of them. Between the medial epicondyle and olecranon is a pit, in which lie the ulnar nerve and the anastomosis between the inferior ulnar eollateral and the posterior ulnar reeurrent arteries. The coronoid process is so well eovered by muscles, vessels, and nerves that its position cannot be distinetly made out.

The synovial membrane of the elbow-joint communicates with that of the superior radioulnar. Hence the facility with which tuberculous disease may be set up after neglected falls on the hand, in early life. At this time the weakness of the annular (orbicular) ligament learls to its being easily injured. Swelling, due to effusion into the joint, appears on cither side of the triceps tendon, and soon obliterates the depression below the lateral epicondyle. The simplest incision for an infected elbow-joint is a vertical one, on the lateral side of the olecranon. A superficial swelling over the tip of the olecranon is due to effusion into the bursa between the soft parts and that bone. A deeper, less easily defined swelling in the same region is due to inflammation of the bursa between the olecranon and the triceps. A swelling on the medial side of the elbow-joint, if painful and accompanied by inflammation of the skin, may be due to mischief in the epitrochlear lymphatic node situated just above the medial epicondyle, and receiving lymphatics from the medial border of the forearm and the two medial fingers.

The hollow in front of the elbow. - The delicacy of the slin here must always be borne in mind in the application of splints. Owing to the insidious rapidity with which pressure may set up ischemic paralysis, anterior angular splints are always to be used with caution. The $\mathbf{M}$-like 
arrangement of the superficial veins as usually described is by no means constant (fig. 1136). The median basilic is the vein usually chosen for venesection, owing to its larger size and its being firmly supported by the subjacent bicipital fascia which separates it from the brachial artery; but the median cephalic is the safer. The median basilic is crossed by branches of the medial antibrachial (internal) cutaneous nerve, while those of the musculo-cutancous lie under the median cephalic. In the semiflexed position, the fold of the elbow is seen, a little above the level of the joint. This forms the base of the triangular fossa below the elbow, the lateral side corresponding to the brachio-radialis, the medial to the pronator teres, and the apex to the meeting of these muscles. The tendon of the biceps can be easily made out in the centre of the fossa, giving off above the lacertus fibrosus from its medial side to fasten down the flexors of the forearm. Under the tendon on its medial side lie the brachial artery and the median nerve, a little medial to it, for a short distance. The radial nerve (musculo-spiral) lies ontside the fossa, between the brachio-radialis and the brachialis (anterior), and gives off its two

Fig. 1136.--The Bend of the Elbow with the Superficial Veins.

(From a dissection by Dr. Alder Surth in the Museum of St. Bartholomew's Hospital.)

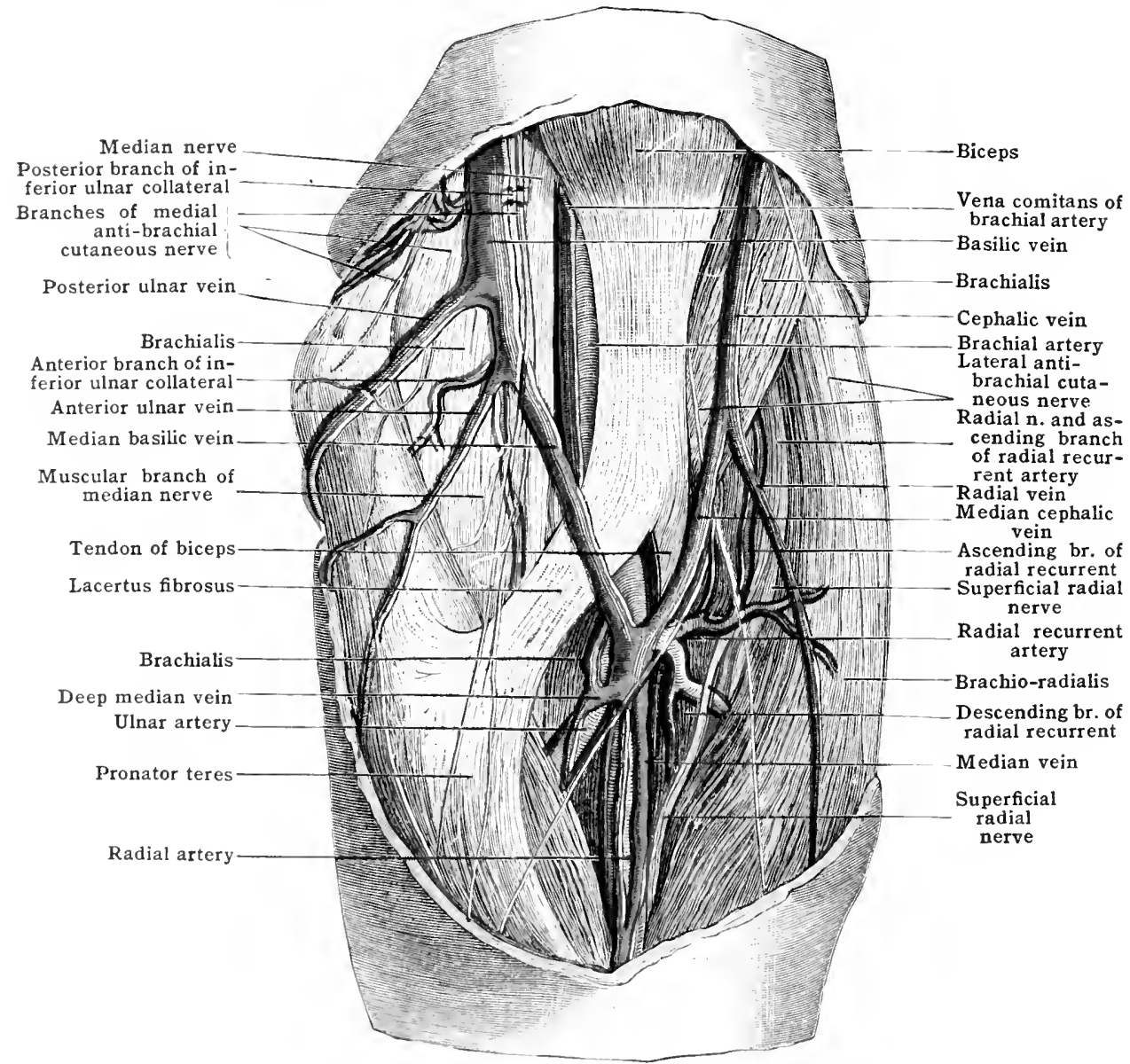

terminal branches in front of the lateral epieondyle. The brachial usually bifurcates opposite to the neek of the riedins.

The arterial anastomoses about the elbow-joint are as follows: The radial recurrent runs up under cover of the brachio-radialis to anstomose with the anterior braneh of the profunda on the front of the lateral condyle. The posterior interosseous resurrent ascends, between the supinator and the anconens, to amastomose on the back of the lateral condyle with the posterior branch of the profumbla It further joins, ly a kirge anastomotic arch across the back of the joint, with the inferior ulnar collateral (anastomotic mana) and posterior uluar recurrent. 'The anterior aluar recurrent passes npwarl on the frachialis to join the anterior part of the inferior nluar collateral under the pronistor fores, on the fromt of the medial epieondyle. The fosterior nluar renorent makes for the interval between the back of the medial epicondyle

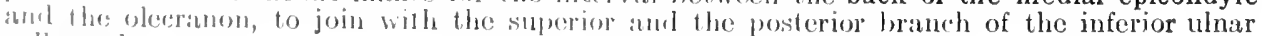
collinterial.

11 will be seron that thr inforior nhatr collatral (anastomotiea manna) is the artery most

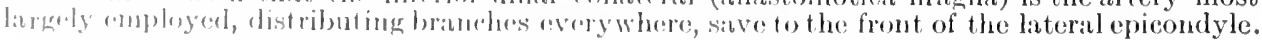




\section{THE FOREARM}

Bony landmarks. - The posterior border of the ulna ean be easily traced down from the oleeranon to the back of the styloid process; the bone becomes somewhat rounded below, and lies between the flexor and extensor earpi ulnaris. The tip of the styloid process corresponds to the medial end of the line of the wrist-joint. The radius is covered above by the brachio-radialis and radial extensors of the carpus, and the outline of the bone is less easily followed. Its styloid process is readily made out below a finger's breadth above the thenar eminence. It is placed about $1.2 \mathrm{~cm}$. ( $\frac{1}{2} \mathrm{in}$.) lower than that of the styloid process of the ulna.

Thus, a line drawn straight between the two processes would fall a little below that of the wrist-joint, this being shown by a line drawn between the two processes forming a slight curve, with its eoncavity downward (corresponding to the concavity of the lower surface of the radius and fibro-eartilage) about $1.2 \mathrm{~cm}$. ( $\frac{1}{2} \mathrm{in}$.) above the straight line given above.

The radial styloid process is covered by the abductor longus and extensor brevis pollicis, while farther out lies the extensor pollicis longus. Between the styloid process of the ulna and

Fig. 1137.-The Brachial Artery at the Bend of the Elbow.

(From a mounted specimen in the Anatomical Department of Trinity College, Dublin.)

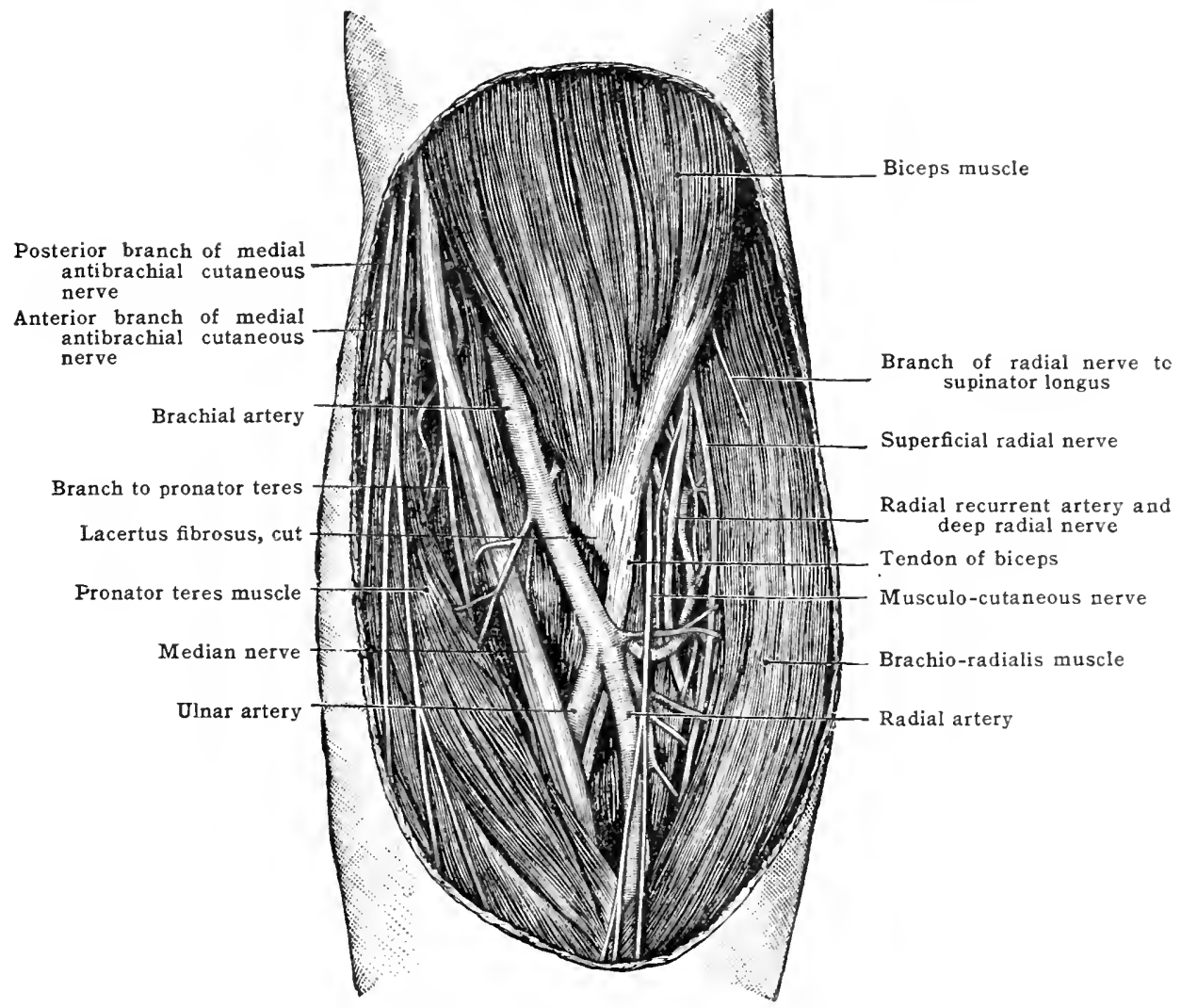

the rounded head is the groove for the extensor carpi ulnaris. The bones are nearest to each other in complete pronation, and farthest apart in complete supination. On section, the bones are found at every point nearer to the back than to the front of the limb, but increasingly so above. 'The lower the section proceeds down the limb, the less will the bones be covered at the sides, and the more equally will the soft parts be distributed about the anterior and posterior aspeets of the limb. It will be noticed tiiat where one bone is the more substantial, the other is the more slender, as near the elbow and wrist; and that it is about the centre of the limb that the two are most nearly of equal strength.' (Treves.) When the limb is pronated, the interosseous space is narrowed; in supination and the mid-position it is widened out. In pronation, both styloid processes can be distinctly made out; in supination, that of the radius is the more distinct, as now the skin and soft parts are stretched and raised over that of the ulna.

Joints.- The position of the superior radio-ulnar joint is marked by a dimple about $12 \mathrm{~mm}$. ( $\frac{1}{2} \mathrm{in}$.) below the lateral epicondyle. The inferior can just be felt, 
when the forearm is pronated, between the head of the ulna and lower end of the radius. The recessus sacciformis here may be enlarged in rheumatic and other affections. The interosseous membrane not only ties the bones together and gives attachment to muscles, but in falls on the hand it enables the ulna to participate in the shock.

The following are important points with regard to the bones. Common fractures. Olecranon.-This usually takes place at the constricted centre of the semilunar (greater sigmoid) notch or the junction of the olecranon with the shaft. A fall is here the usual cause, and the heavier the fall, the more frequently is the fracture nearer the shaft, though displacement is now likely to be slight, owing to the abundance of fibrous and museular struetures on both sides

Fig 1138.-Diagram of the Anastonoses of the Brachial Artery. (MacCormac and Anderson.)

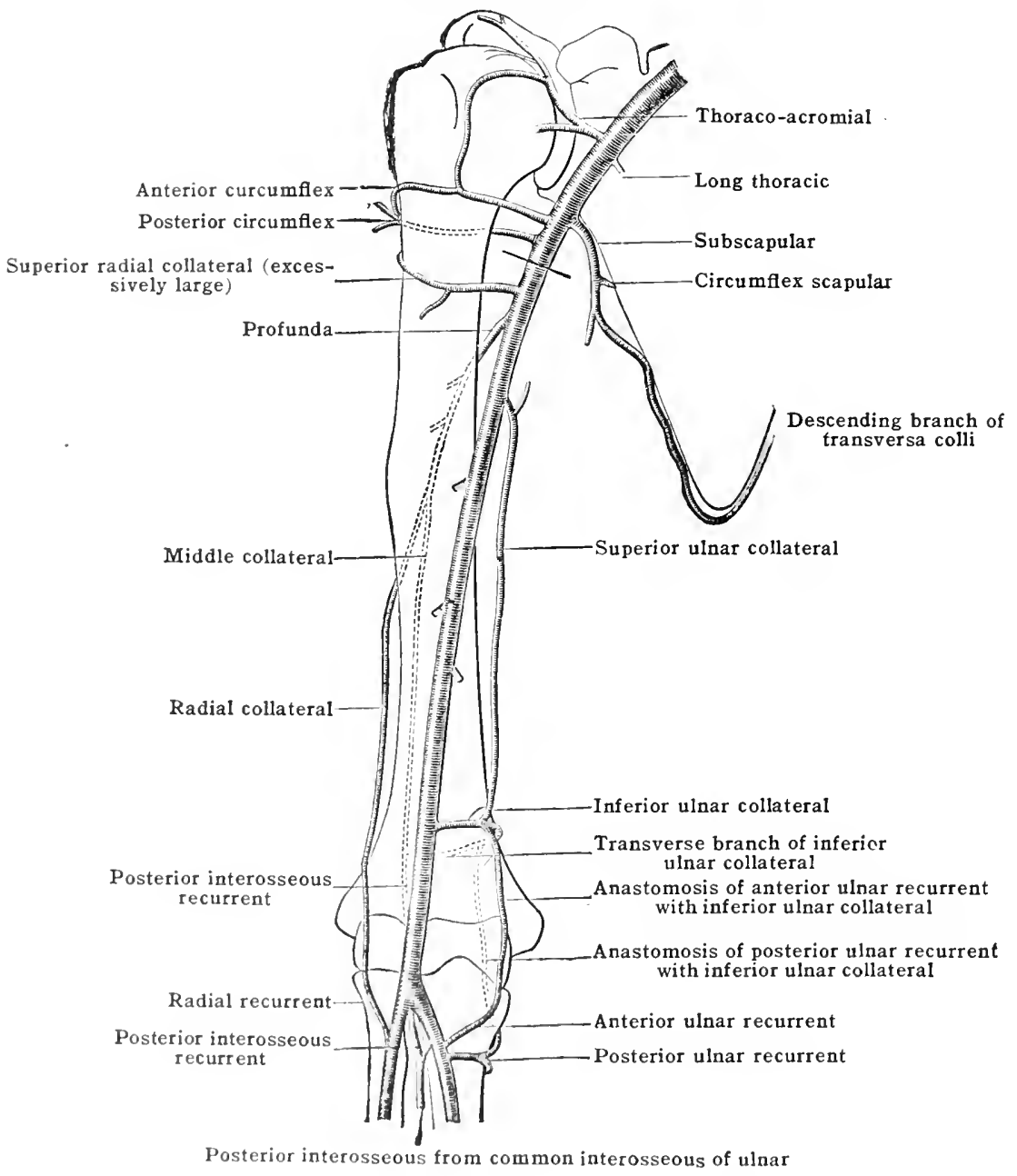

rif the fracture. The shaft of one or both bones. Tsual site, about the middle or a little below it, fracture of the radius leing inore frepuent fiom its comnection with the hand. In these fractures thr chice muscular agrencies are-(1) the extensors and flexors in drawing the lower fragment or fragments upwarl, forward, or bakwasl, accorling to the direction of the fracture; (2) the

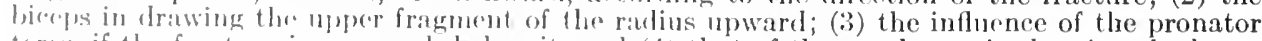
fores, if the franture is, as usual, below it, and (4) that of the quadratus in drawing the lower fraguents fognher. Thus the ehiof paretical points are-(a) the reduction of displacement,

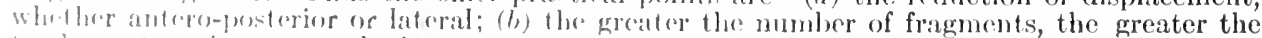

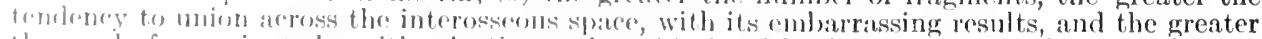
the ured of a supuntel position in the sotfing; (c) the risk of gangrene here from the facility with which the wesels are compressed atganst the contignous bones, especially in flexion of the forcarm; and the "onsegucent necel of attention to the with of the splints and the bandaging; (1) the problinese with which ischomice paralysis mat rapidly and insidionsly be caused. Colles' fracture. Hore, afor a fall on the hamb, llie rarlius gives way usually at its weakest part, about 
Fig. 1139.-The Arteries of the Forearil with the Superficial Volar Arch.

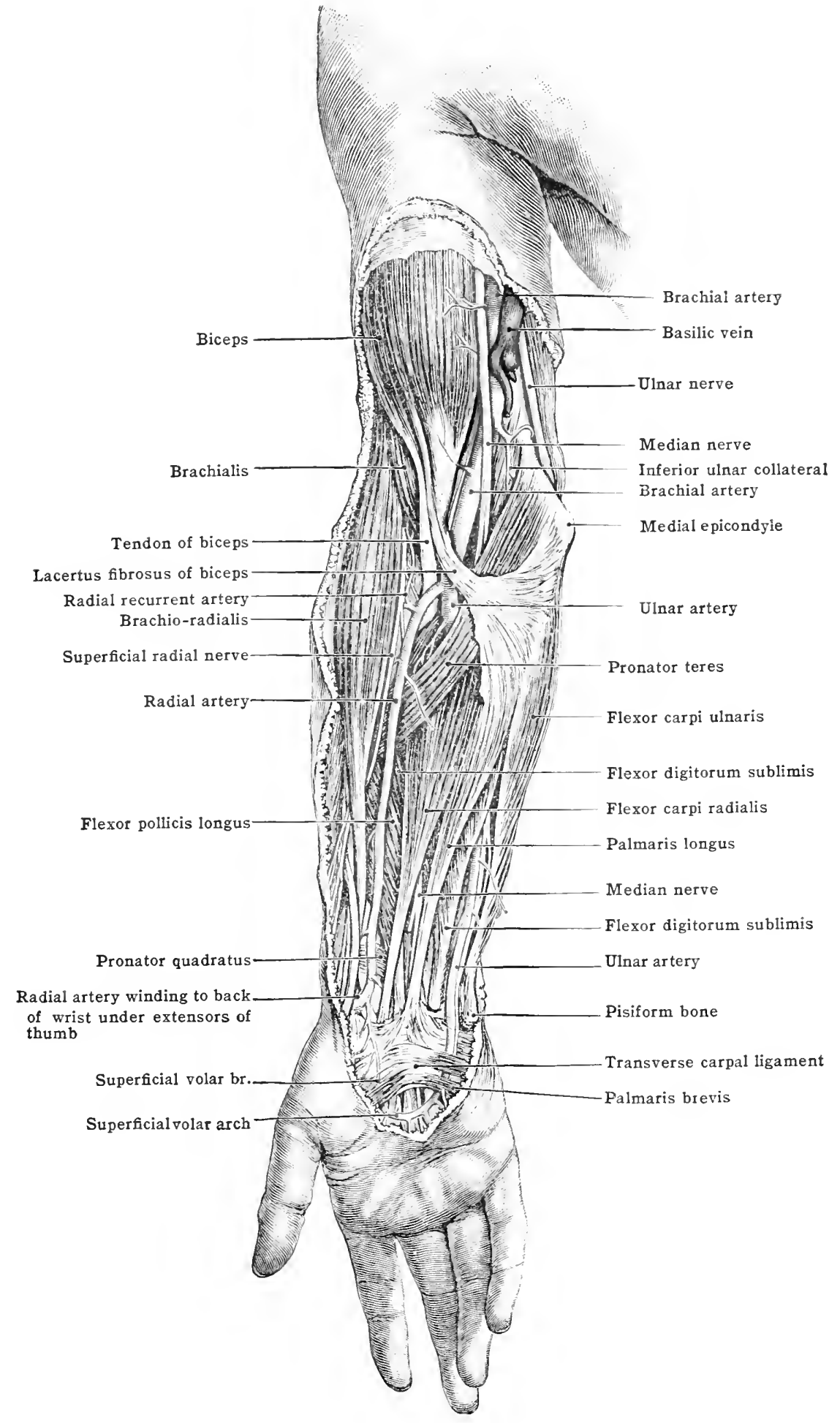


$15 \mathrm{~mm}$. ( $\frac{3}{4}$ in.) above its extremity, where the narrow compact tissue is suddenly expanding into cancellous. There is frequently impaction of the upper in to the lower fragment. There is a three-fold displacement of the lower fragnent:-(1) It is driven and drawn upward and backward. (2) It is rotated so that its articular surface looks somewhat backward. (3) It is drawn to the radial side. The chief causes of the disereditable stiffness often allowed to result are non-reduction of the deformity, adhesions in the opened wrist-joint, teno-synovitis, and prolonged immobilisation.

Separation of epiphysis. - This may take place in the radius up to about the age of eighteen: it is commoner before. Its possible importance in interfering with the symmetry of the growth of the bones is obvious. Here, as in Colles' fracture, the level of the styloid processes of the radius and ulna, and the correspondence of the two styloid processes of the radii, are important in diagnosis. Exposure of the bones. In the case of ununited fracture or necrosis the radius may be reached-(a) Behind, by an incision in a line drawn from the lateral epicondyle to the back of the radius. The field opened here lics between the brachio-radialis and the radial extensors on the one side, and the common extensor on the other. Care must be taken of the

Fig. 1140.-Distribution of Cutaneous Nerves on the Anterior and Posterior Aspects of the Superior Extrenity.
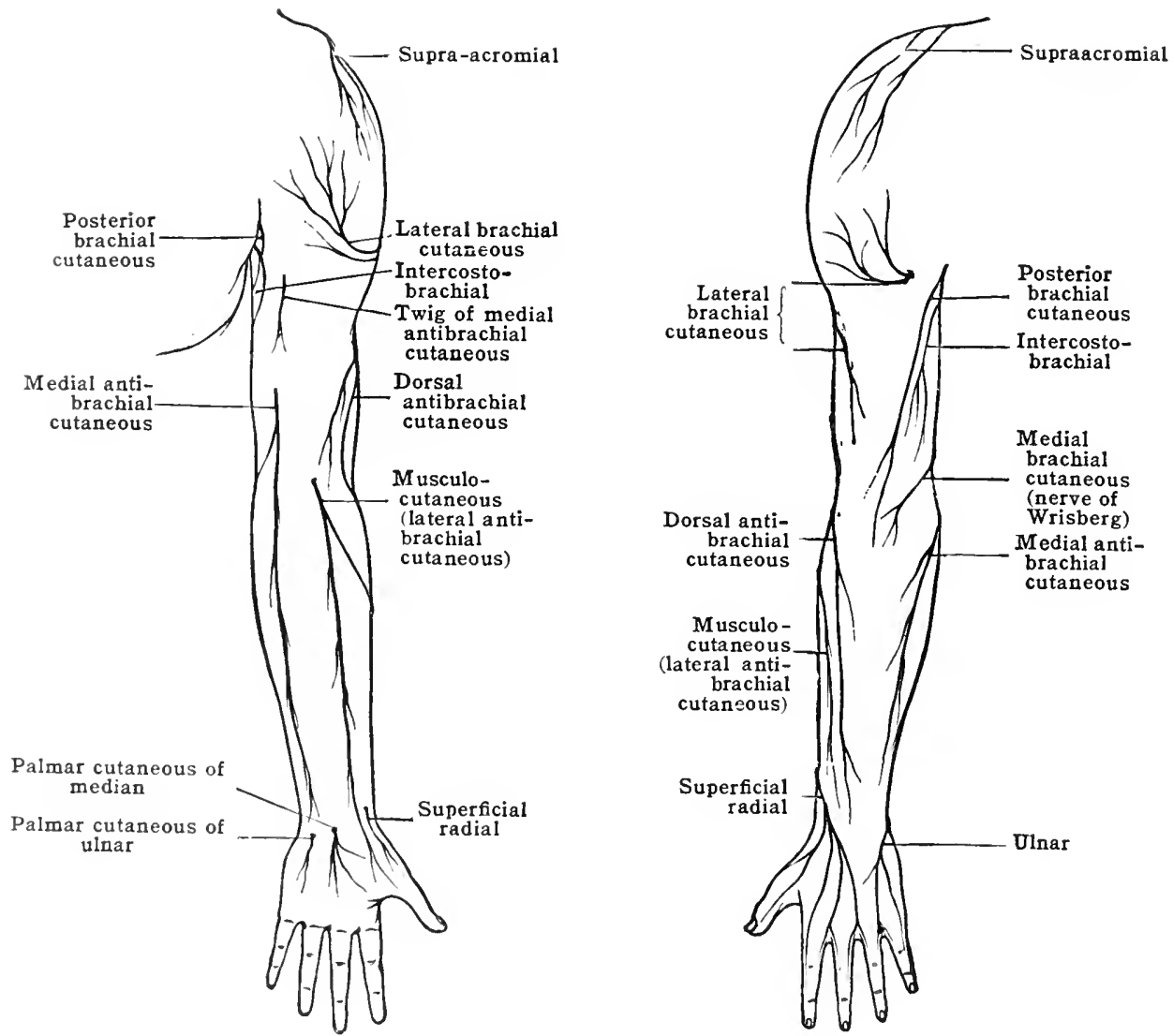

decp radial (posturior interossoms) nerve. (b) In front. The incision here lies in the suleus betwen the brachio ralialis and the flexors. The pronator teses and the flexor sulplimis must, in part, he detalicel from the raclius. If nore room is required to reach an injured upper extrmity of the ralius, the incision will descomd from above the lateral epicondyle in the groove betwen the anconems and common extensors. In the detachment of the supinator the deep leatial nerve will agrin need attention. Tho ulna is more easily reached by an incision between the llexor and cxicusor carji ulnaris. In removal of the lower part of the bones for myeloid sirreoms or osteritis, the ulna is reacheel in the interval last mentioned. The radius is best (xpeserl fy an incision lutwern the brachio-radialis and extensor carpi radialis longus, the superfievial ralial nore being the guide. (Morris.) Finally, the so-called 'carrying angle' of the forearm leserves mention. In extension the bunes of the forearm are not in astright line with

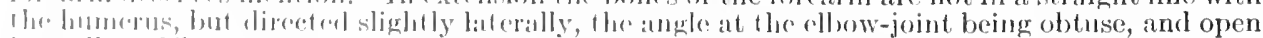
laterally. This angle is so named from its facilifating carrying ol jects during walking. In

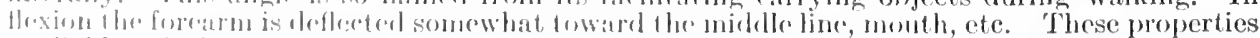

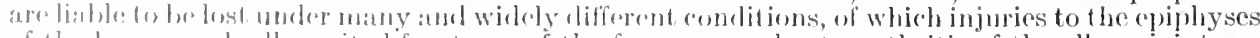

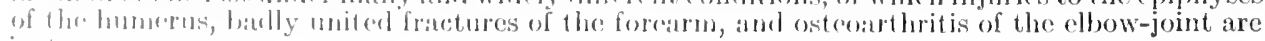
intitillors. 
Soft parts.-Along the lateral border, of the forearm descend the brachioradialis and radial extensors of the carpus, fleshy above, tendinous below. About $3.7 \mathrm{~cm}$. ( $1 \frac{1}{2} \mathrm{in}$.) above the styloid process of the radius, a fleshy swelling directed obliquely downward and forward from behind, across this lateral border of the forearm, denotes the extensors of the thumb crossing those of the carpus.

Along the medial border is the fleshy mass of the pronator teres and flexors, the ulna being covered by the flexor carpi ulnaris and flexor profundus. The tendon of the pronator is inserted into the radius a little below its centre-a point of importance in the treatment of fractures and in amputation. 'The flexor carpi ulnaris tendon can be felt just above the wrist making for the pisiform bone; and just lateral to it lies the ulnar artery, about to pass over the transverse carpal (anterior annular) ligament.

The course of the artery is denoted by the lower two-thirds of a line drawn from the front of the medial epicondyle to the lateral edge of the pisiform bone. From the bifurcation of the brachial, a line drawn to meet the former at the junction of its middle and upper third marks the upper part of the artery, here thickly covered by muscles. In ligature of the artery in the middle of the forearm, the white line and sulcus between the flexor carpi ulnaris and sublimis must be identified. A small muscular branch will often lead down to the artery. The line of the ulnar nerve is one drawn from the interval between the medial epicondyle and the

Fig. 1141.-Section throdgh the Midde of the Right Forearm. (Heath.)

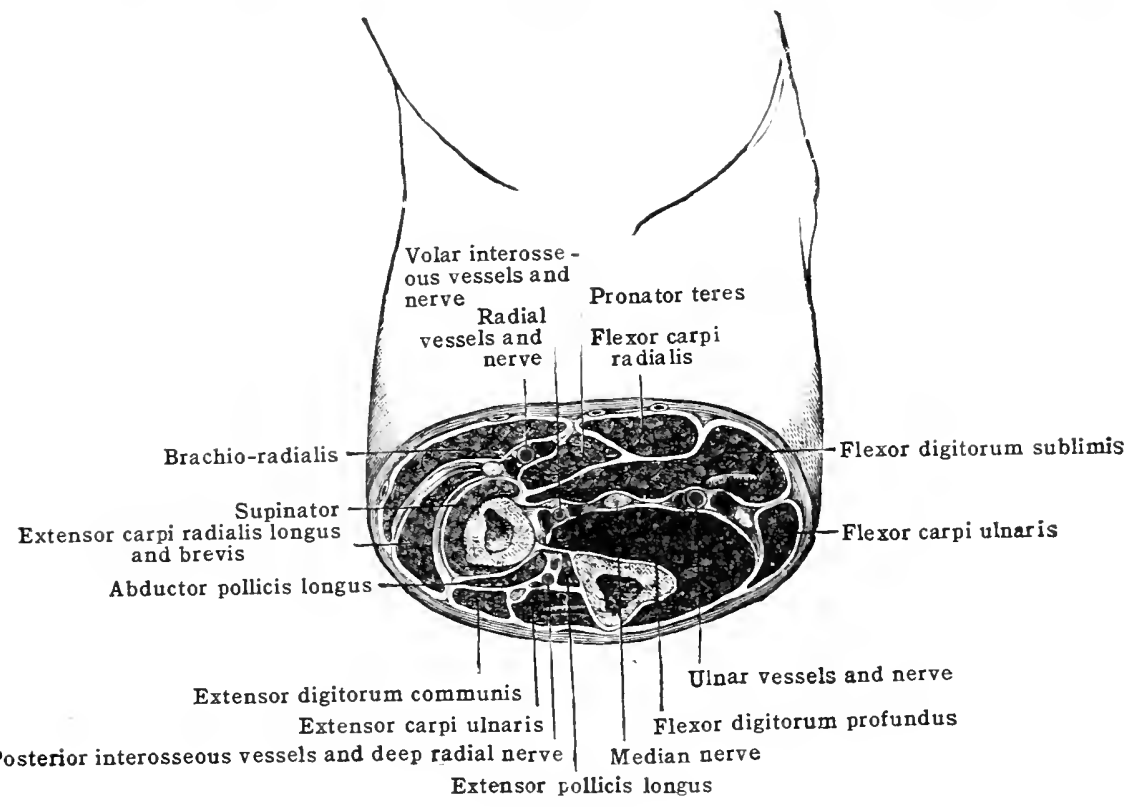

olecranon to the medial side of the ulnar artery just above the wrist. The nerve joins the artery at the junction of the upper and middle thirds of the forearm. The median nerve runs in a line drawn from the medial side of the brachial artery, in the elbow triangle, to a point beneath, or just to the medial side of, the palmaris longus at the mid-point of the front of the wrist. The radial artery will be marked by a line drawn from the centre of the bend of the elbow (where the brachial artery divides opposite to the neck of the radius) to a point just medial to the radial styloid process descending along the medial edge of the brachio-radialis. The muscular interval is that between the brachio-radialis and pronator teres above, and the flexor carpi radialis below. The superficial radial nerve will be marked by the same line (it lies just latelal to the artery) for its upper two-thirds; it then leaves the artery about $7.5 \mathrm{~cm}$. (3 in.) above the wrist-joint, and passes to the back of the forearm under the tendon of the brachio-radialis. The volar interosseous artery runs down on the interosseous membrane and passes to the back of the forearm by perforating it below, having passed behind the pronator quadratus. The dorsal interosseous lies between the superficiar and deep extensors. These small arteries reinforce the palmar through the carpal arches, and thus bring down blood after ligature of the trunks above.

The front of the forearm is supplied by the musculo-cutaneous on the lateral, and the medial antibrachial (internal) cutaneous on the medial, side; just above the wrist the palmar cutaneous branches of the median and ulnar perforate the deep fascia (fig. 1140). The back of the forearm is supplied by the radial (nus- 
culo-spiral) and posterior branches of the musculo-cutaneous laterally, and the posterior branches of the medial antibrachial cutaneous medially (fig. 1140).

The lymphatics of the upper extremity are superficial and deep; the former run with the superficial veins, the latter with the deep vessels. Occasionally a few small nodes oceur below the elbow. The epitrochlear nodes lie upon the basilic vein, a little above the medial epicondyle and draining the fourth and fifth digits. The majority of the lymphatics open into the axillary nodes, and terminate, on the left side in the thoracic duct, on the right in the lymphatic duct. A few, aceompanying the cephalie vein, reach the subclavian or infraclavicular nodes, and thus communieate with the lymphaties of the neck.

It will be well briefly to consider here the chief results of paralysis of the main nerves of the upper extremity.

Paralysis of the median nerve.-(a) In forearm: Loss of pronation. (b) At wrist: Diminished flexion and tendency toward ulnar adduction. (c) In the hand: Power of grasp is lessened especially in the thumb and lateral two fingers. Owing to the loss of flexion in the phalanges of these fingers the phalanges are liable to become overextended by the action of the extensors and interossei. The thumb remains extended, adducted, and closely applied to the index, the hunan characteristic being thus lost, and the 'ape's hand' of Duchenne being produced. Sensation will be lost over the palmar aspect of the thumb and lateral two and one-half fingers and or'(r the distal ends of the same fingers, to a varying degree, aceording to the sensory distribution of the median and other cutaneous nerves. The above applies to lesions of the trunk. If the nerve be injured at the wrist, flexion of the wrist and fingers is less interfered with.

Paralysis of the ulnar nerve.-(a) At urist: Power of flexion is diminished and that of ulnar adduetion lost. (b) In the hand: Power of grasp will be lessened in the ring and little fingers. The interossei will be powerless to abduct or adduct the fingers, and there will be marked wasting of the interosseous spaces and hypothenar eminence. The thumb cannot be adducted. After a time, from paralysis of the lumbricals and interossei, the hand becomes 'clawed'-the first phalanges overextended, and the second and third flexed (main en griffe). Sensation will be lessened over the area supplicd by the nerve.

Paralysis of the radial (musculo-spiral) nerve.-(a) In the forearm This is flexed, extension being impossible. The forearm is pronated, supination being inpossible save by biceps, which acts now nost strongly on a flexed elbow-joint. (b) In the wrist: This is dropped, owing to the loss of extension. (c) In the hand: The thumb is flexed and adducted. Some slight power of extension of the second and third phalanges of the fingers remains by means of the lumbricales and interossei. Sensation is impaired over the posterior and lateral aspect of the forearm and lost to a varying extent over the distribution of the radial on the back of the hand.

Paralysis of the deep radial (posterior interosseous) nerve.-The evidence here is somewhat similar to that just given, but with the following differences. (a) In the forearm: There is no loss of extension, and the loss of supination is less as the brachio-radialis is not paralysed. (b) It the wrist: The 'clrop' and loss of extension are not so marked, as the extensor carpi radialis longus escapes. Sensation: There is no loss.

Paralysis of the musculo-cutaneous nerve.-Forearm: Power of flexion is impaired, owing to complete paralysis of the biceps and partial of the brachialis (anterior). Sensation: This is impaired over the lateral aspect of the forearm, both back and front.

Amputation of forearm.--The 'mixed' method by skin-flaps roundly arched and circular division of the soft parts, the dorsal flap being the longer, is the most generally applicable. The bones should always be sawn below the pronator teres, when possible. In saving them they must be kept parallel, the limb being in the supinated position. As the radius is the less securely had alove, it is woll to complete the section of this bone first. The relative position of the vessols has beren indieated above (p. 1123, and figs. 1139 and 1141).

\section{THE WRIST AND HAND}

Bony points.-On the merlial sirte the styloid process and, further laterally, the head of the utne can be manle out. On the lateral side, the radial styloid process dexcends about $1.2 \mathrm{~cm}$. ( $\frac{1}{2} \mathrm{in}$.) lower than that of the radius, and is somewhat anterior to it. Mbluction of the hand is thus less free than adduction. Between the "spex of the stylojit moess and the ball of the thumb a bony ridge can be felt, with some difficult $y$, formed by the mbercle of the mavicular and the ridge of the greater mullangular (trapezimu). At the base of the hypothenar eminence the pisiform "an be more raalily distinguisher. 'The hook of the humatum (unciform) lies below and to the ratlial side of the pisiform. ()n the frent of the metacarpo-phalangeal joint of the thenub, the sesemond bones an be distinguished.

At the batek of the wrist and hand the triquetrum (cuneiform) bone ean be felt. berow the beacl of the ulna; and more toward the midelle line the prominence of therefoitulum (os magnmm), which supports the third or longest digit.

I line drawn from the lase of the fiftl metacarpal bone to the radio-carpal joint, slightly

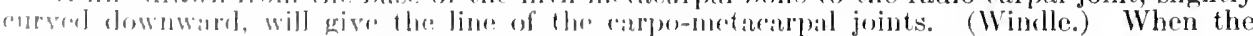

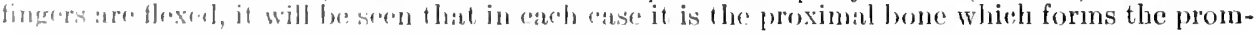


inence; thus, the knuckle is formed by the head of the metacarpal, the interphalangeal prominence by the head of the first phalanx, and the distal one by the head of the second. Thus, the joint in each case lies below the prominence, the distal joint being $2 \mathrm{~mm}$. ( $1 \frac{1}{1} \mathrm{in}$.), the interphalangeal

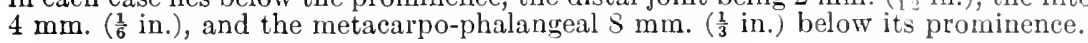

Skin and skin-folds.-The skin over the palm is thickened over the heads of the metacarpal bones and hypothenar eminence, thinner over the thenar. It is peculiar in its absence of sebaceous glands and hair-follicles; hence the absence of boils and sebaceous cysts. It is intimately connected with the palmar fascia, hence the chief difficulty in operations when this is contracted. Over the pulp of the digits the skin is closely connected with the periosteum of each ungual phalanx. The importance of this is alluded to under the heading of whitlow (vide infra).

Skin-folds : two or three of these are seen on the palmar surface of the wrist: two lower down, and usually close together, and one less well marked, a little higher up upon the forearm. None of these corresponds exactly to the wrist-joint (fig. 1142). The lowest 'precisely crosses the arch of the os magnum in the line of the third metacarpal bone' (Tillaux), and is not quite $1.8 \mathrm{~cm}$. $\left(\frac{3}{4} \mathrm{in}\right.$.) below the arch of the wrist-joint. It is about $1.2 \mathrm{~cm}$. ( $\frac{1}{2}$ in ) above the carpo-metacarpal joint line, and indicates very fairly the upper border of the transverse carpal (anterior annular) ligament.

'Of the many creases in the skin of the palm, three require especial notice. The first starts at the wrist, between the thenar and hypothenar eminences, and, marking off the former emi-

Fig. 1142.-Relation of the Volar Arches to the Folds of the Pali. (Modified from Tillaux.)

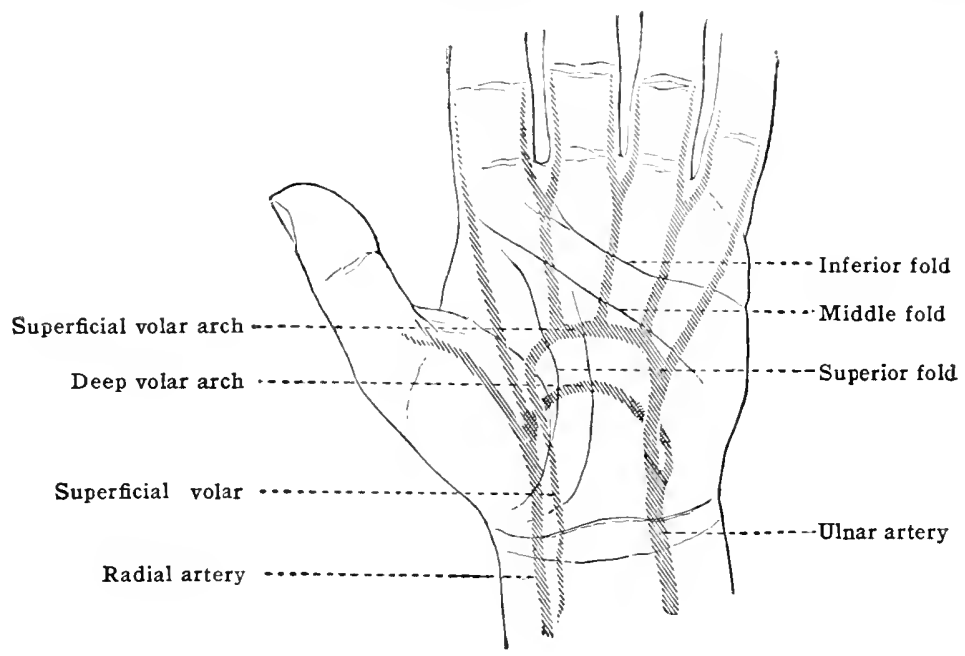

nence from the palm, ends at the lateral border of the hand and at the base of the index-finger. The second fold is slightly marked. It starts from the lateral border of the hand, where the first fold ends. It runs obliquely medially across the palm, with a marked inclination toward the wrist, and ends at the lateral limit of the hypothenar eminence. The third, lowest, and best marked of the folds starts from the little elevation opposite the cleft between the index and middle fingers, and runs nearly transversely to the ulnar border of the hand, crossing the hypothenar eminence at the upper end of its lower fourth. The first fold is produced by the adduction of the thumb; the second, mainly by the bending simultaneously of the metacarpo-phalangeal joints of the first and second fingers; and the third by the flexion of the three medial fingers. The second fold, as it crosses the third metacarpal bone, about corresponds to the lowest part of the superficial volar arch. The third fold crosses the necks of the metacarpal bones, and indicates pretty nearly the upper limits of the synovial sheaths for the flexor tendons of the three lateral fingers. A little way below this fold, the palmar aponeurosis breaks up into its four slips, and midway between the fold and the webs of the fingers lie the metacarpo-phalangeal joints. Of the transverse folds across the fronts of the fingers, corresponding to the metacarpo-phalangeal and interphalangeal joints, the highest is placed nearly $15 \mathrm{~mm}$. ( $\frac{3}{4}$ in.) below its corresponding joint. The middle folds are multiple for all the fingers, and are exactly. opposite to the first interphalangeal joints. The distal creases are single, and are placed a little above the corresponding joints. There are two single creases on the thumb corresponding to the two joints, the higher crossing the metacarpo-phalangeal joint obliquely. The free edge of the web of the fingers, measured from the palmar surface, is about $1.5 \mathrm{~cm}$. ( $\frac{3}{4} \mathrm{in}$.) from the metacarpo-phalangeal joints. (Treves.)

The superficial volar arch, formed by the ulnar anastomosing with the superficial volar, or radialis indicis, will be shown by a line descending to the radial side 
of the pisiform bone, and then, a little lower, curving across the palm on a line with the thumb when outstretched at right angles with the index-finger. The four common digital arteries, the main branches of the superficial arch, run downward along the interosseous spaces, and bifurcate $12 \mathrm{~mm}$. ( $\frac{1}{2} \mathrm{in}$.) above the webs of the fingers; the most medial digital does not bifurcate.

The digital arteries then descend along the sides of the fingers under the digital nerves, giving off $t$ wigs to the sheath of the tendons, which enter by apertures in it, and run in the vincula vasculosa. It is owing to the readiness with which these tiny twigs are strangled by inflammation that sloughing of the tendon takes place so readily and irreparably. Throughout its course the superficial volar arch deserves its name. It is only covered by the palmaris

Fig. 1143.--Axastomoses and Distribution of the Arteries of the Hand.

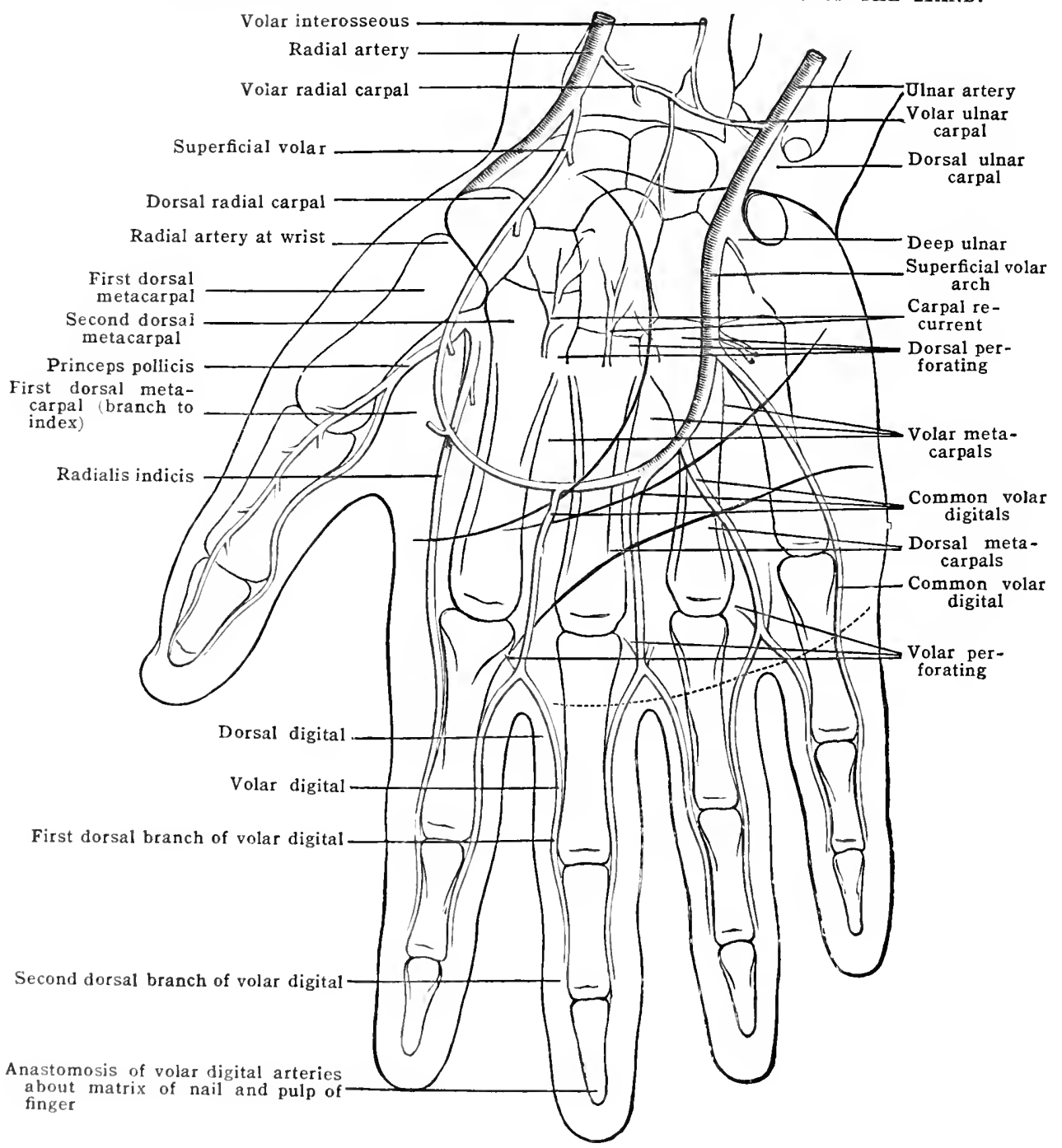

brevis and central part of the palmar fascia. Boneath it, melio-laterally are the flexor brevis and oppenens digiti quinti, the digital branches of the ulnar and median nerves, and the flexor tondons and lombricales.

The deep volar arch, formed by the radial and communicating branch of the ulnar, lies about 1.2 'm. ( $\frac{1}{2}$ in.) neirer to the wrist than the superficial. It is not so curved as the superficial arch, and rests upon the interossei and metacarpal bones just below their hases. The structures separating it from the superficial arch have been already given.

() wing to the freclunency of wounds here, the relation of the structures in front of the wrist is most important. The raclial artery lies between the tendon of the 
brachio-radialis and flexor carpi radialis. Next to this tendon is the palmaris longus, when present. At the mid-point of the front of the wrist and usually under the palmaris longus is the median nerve. To the medial side of the palmaris longus is the flexor sublimis, the tendons for the middle and ring-finger being in front. The tendon of the flexor carpi ulnaris is most medial and between this and the superficial flexor of the finger the ulnar nerve and ressels have come up into a superficial position.

Fig. 1144.-The Superficial Muscles of the Palm of the Hand.

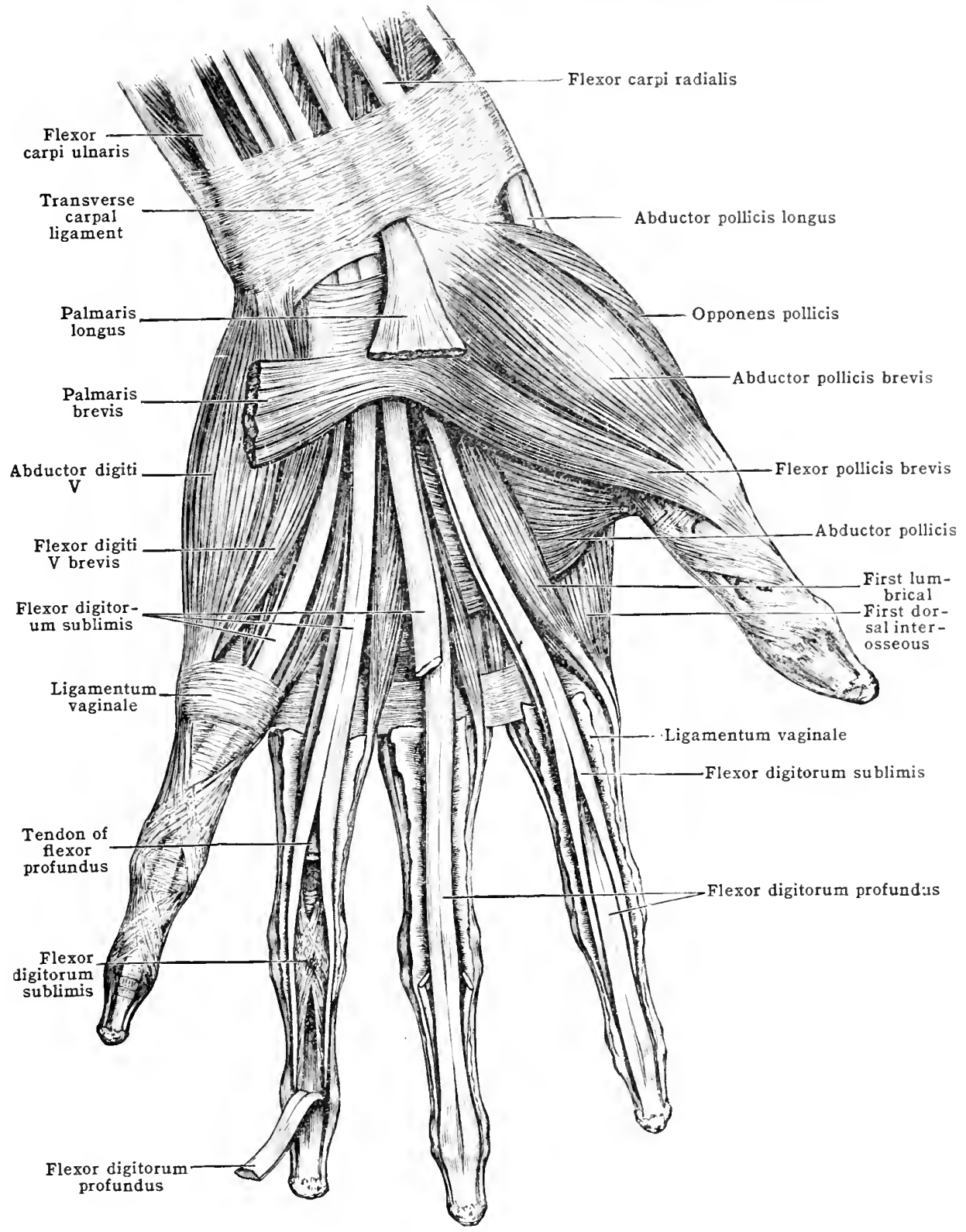

Fasciæ and sheaths.-The transverse and dorsal carpal (annular) ligaments bind down and hold in place the numerous tendons about the wrist. The transverse carpal (anterior annular), when healthy, cannot be detected. It is attached to the pisiform and triquetral (cuneiform) bones on the medial, and to the navicular and greater multangular (trapezium) on the lateral, side. 
The ulnar nerve and vessels, the superficial volar, and palmar cutancous branches of the median and ulnar pass over it. The ulnar artery and nerve are especially protected by their position between the pisiform and hook of the hamate (unciform), and also by a process of the flexor carpi ulnaris, which passes to the transverse ligament, thus forming a kind of tunnel. The flexor carpi radialis passes through a separate sheath formed by the ligaments and the groove in the greater multangular; while beneath the ligaments lie the flexor tendons, the median nerve, and accompanying artery. Attached to its upper border is the deep fascia of the forearm, and to its lower the palmar fascia and the palmaris longus tendon, while from the lateral and medial parts arise some of the thenar and hypothenar muscles. The upper border of the transverse carpal ligament corresponds to the lower of the two lines which

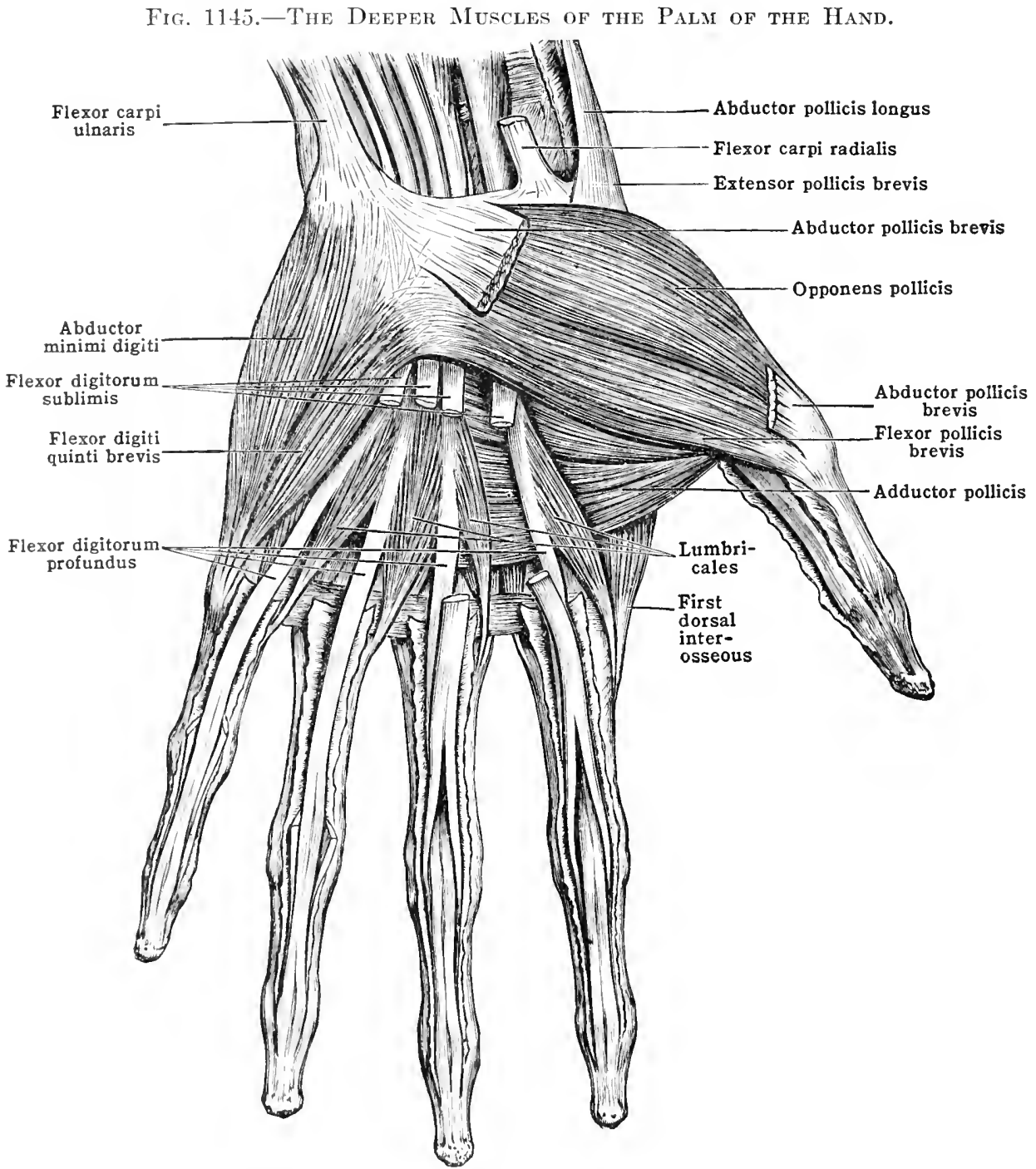

cross the wrist just alove the thenar and hypothenar eminences. The large synovial sheath, for all the floxors of the fingers, reaches benouth and bolow the transverse ligaments as far as the midille of the palm, and above the wrist for 3.7 to $5 \mathrm{~cm}$. (1 $\frac{1}{2}$ to $2 \mathrm{in}$.).

The dorsal carpal (posterior annular) ligament is attached to the back of the lateral margin of the radius above the styloid process, and medially to the back of the styloil process of the ulna, the triguetrum and pisiform. Its direction is obligure, being ligher on the radial side. It contains six tendon-compartments, of which four are on the radius.

The most latral contains the long abductor and short extensor of the thumb; the second the two rarlial extensors of the carpus; the thirel, the extensol pollicis longus; this deep and narrow groove can be irlentifierl when the hand is extended, lyy its prominent lateral margin; the fourth transmits the extrusor communis and extensor indicis proprias; the fifth, lying between the 
Fig. 1146.-Section throvgh Region of Wrist, a Little above the Joint. Right Side, Upper Half of tile Section. (Tillaux.)

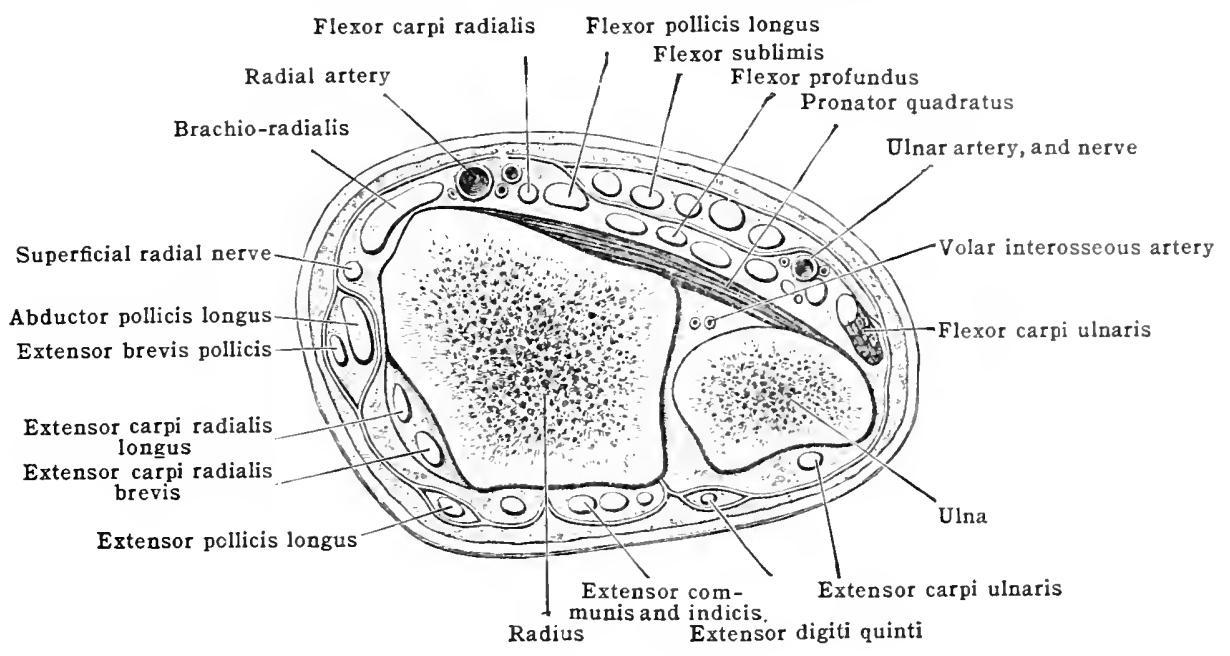

Fig. 1147.-Regiox of the Wrist, as Show by the Röntgex-Rays.

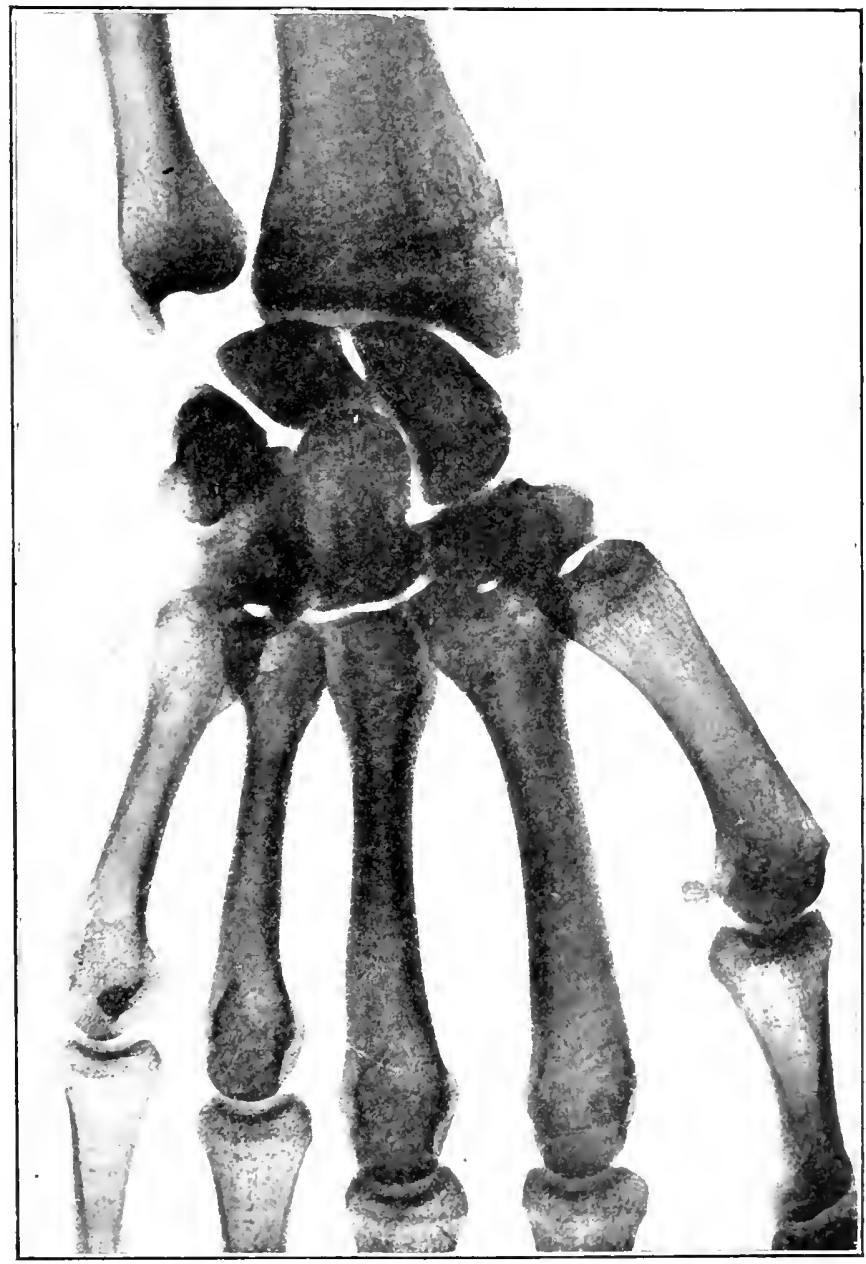


radius and ulna, the extensor digiti quinti; and the sixth, lying just lateral to the styloid process of the ulna, the extensor carpi ulnaris. The sheaths for the last two extensors are the only ones which follow the tendons of their insertion, the others ending at a varying distance below the carpal ligament. The lower border of the dorsal carpal corresponds to the upper margin of the transverse carpal ligament.

Fig. 1148.-Transierse Section of the Wrist through the Middle of tile Pisifori Bone. Sheath of fiexores sublimis and profundus digitorum and flexor policis longus enclosed by the transverse carpal ligament

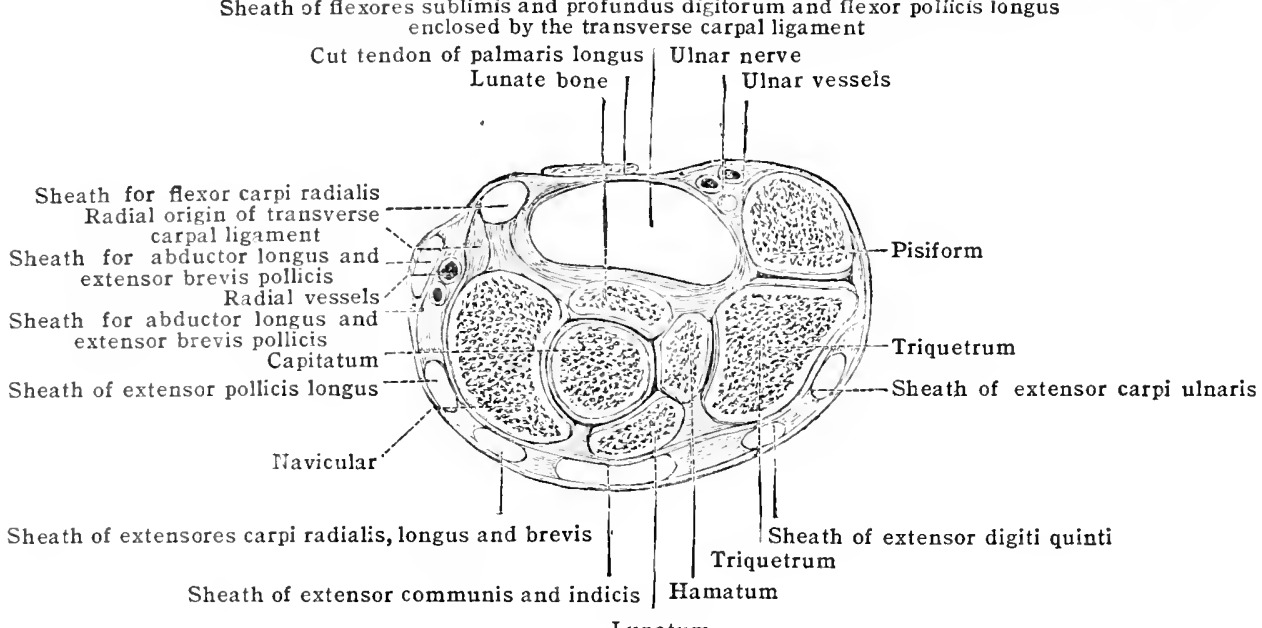

Lunatum

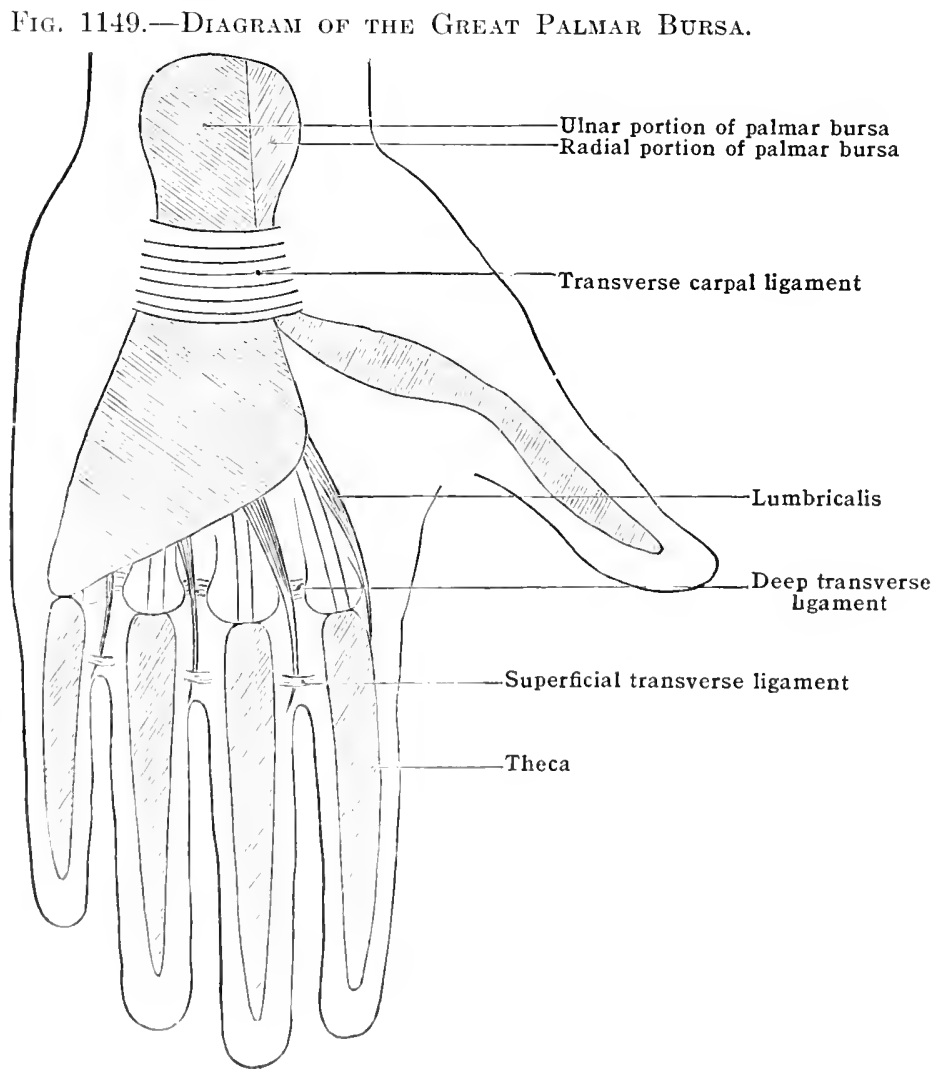

The: palmar aponeurosis, by its strength, fonghuess, numerous attachments, and intimate commertion with the superficial fascia and skin is well adapted to protrex the parts benciath from presisure.

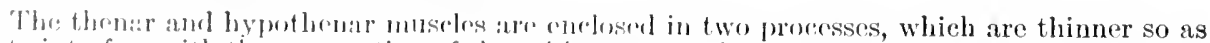

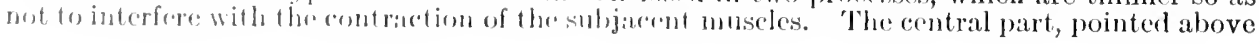


at its attachment to the carpal ligament, spreads out fan-like below, and gives off four slips, each of which bifurcates into two processes, which are attached to the sides of the first phalanx of each finger and into the superficial transverse ligament of the web and the deeper one which ties the heads of the metacarpal bones together. Transverse fibres pass between the processes into which each of the four slips bifureates, and thus form the beginning of the theca, which is continued down the finger to the base of the last phalanx. It is the contraction of the palmar aponeurosis, especially of the slip to the two medial fingers, which gives rise to Dupuytren's contraction. The theca is strong opposite the first two phalanges (ligamentum raginale), weak and loose opposite the joints (ligamentum annulare). The density of this osco-fibrous tunnel and its close proximity to the digital nerves explain the pain in thecal inflammation. Its tendency to gape widely after section is to be remembered in amputations through infected parts.

Synovial membranes.-Beneath the transverse carpal liganent lie two synovial sacs, one for the flexor pollicis longus, and one for the superficial and deep flexors of the fingers. They extend above the transverse ligament for rather more than $2.5 \mathrm{~cm}$. (1 in.). The two sacs nay communicate. A compound palmar ganglion has an hour-glass outline, the transverse carpal ligament forming the constriction.

The creaking sensation in teno-synovitis and that of 'melon-seed' bodies often present in tuberculosis here is well known. The sheath for the long flexor of the thumb reaches to tlie base of the last phalanx. That for the finger-flexors gives off four processes. The one for the little finger also reaches to the base of the last phalanx. Those for the index-, middle, and third fingers end about the middle of the metacarpal bones. Traced from the insertions of the flexor

Fig. 1150.-Section of Carpes through the Hanate Bone. (Two-thirds.) (Bellamy, after Henle.)

\section{Median nerve}

Flexor pollicis longus Flexores sublimis and profundus Flexor carpi radialis Thenar muscles

Base of first metacarpal bone

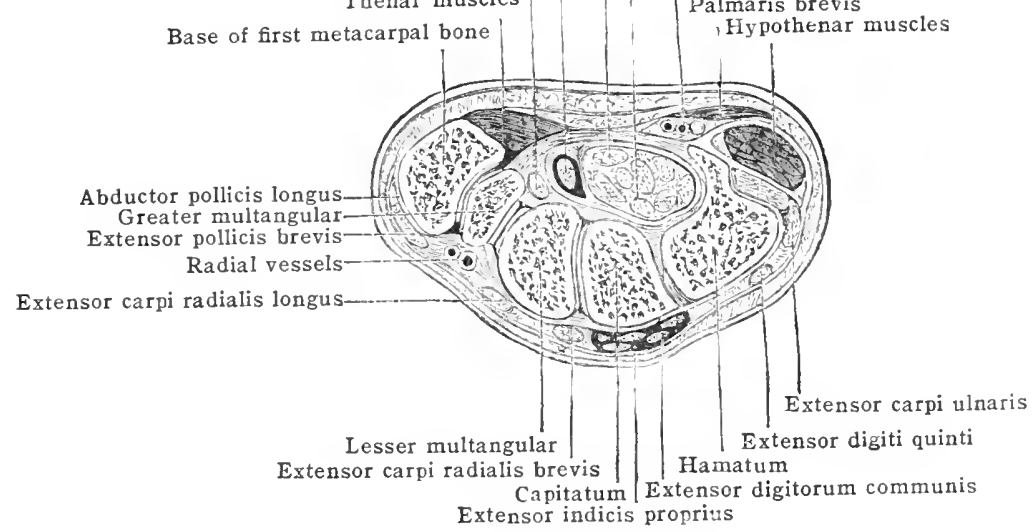

profundus, the digital synovial sheaths extend upward into the palm as far as the bifurcation of the palmar fascia (p. 1430), i. e., into a point about opposite to the neeks of the metacarpal bones, denoted on the surface by the crealse which eorresponds to the flexion of the fingers. Thus, about $1.2 \mathrm{~cm}$. ( $\frac{1}{2} \mathrm{in}$.) separates the sheaths of the lateral three fingers from the large synovial sac beneath the transverse earpal ligament. There is no synovial sheath beneath the pulp, of the fingers or thumb, this part lying on the periosteum of the last phalanx.

This has an important bearing on whitlow. Infeetion here may be merely subculicular, or deeper, in the latter case from the connection of the skin with the periostem here existing the bone is soon affected, and necrosis keeps up a tedious ulcer. As the two centres of the phalanx do not unite till about the twentieth year, the listal one only requires ronoval; as the flexor sheath only reachas to the insertion of the flexor, i. e., into the proximal, part of the lone, both sheath and tendon may organe imn , jon. Higher up along the fingers whitlow mav be cellulo-cutaneous or thecal. While the erritinuity of the srmovial sheath in the little finger and thumb (fig. 1149) renders infoction here more dangerotis, the short gap between the sligital and the palmar saes is readily traversed by acute infection, with all the grare :esults of thecal suppuration.

Suppuration in the hand orres much of its gravity to the possibility of infection of the synovial tendon sheaths and consequent sloughing of the tendons. At the same time it is now recognised that unless these sheaths are primarily inferted pus eollects at first in certain potential spaces, more or less well defined, in the looser connective tissue of the hand. ()ne of these, known as the middle palmar space (Kanavel*) is situated on 1 he front of the metacarpals of the middle and ring fingers, and lies deeply between the flexor tendons and the interosseous museles. Continuations of this potential space extend downward along the lumbrical muscles

* Kanavel, A. B.: Infeetions of the Hand, 1912. 
on the radial sidle of the three medial fingers, and may lead pus from the palm to the subcutane(Kanavel) lies these fingers or vice versa. A second potential compartment, the thenar space adductor transversus pollicis. As in the former between the flexors of the index-finger and the longs it down to the radial side of the index-finger.

Distention of the middle palmar space

palm and a variable extension of the swelling along the radials obliteration of the hollow of the Distention of the thenar space follows the the along the radial side of the three medial fingers.

Fig. 1151.-Tendons upon the Dorsum of the Hand.

(The dorsal expansion or aponeurotic sheath has not been removed.)

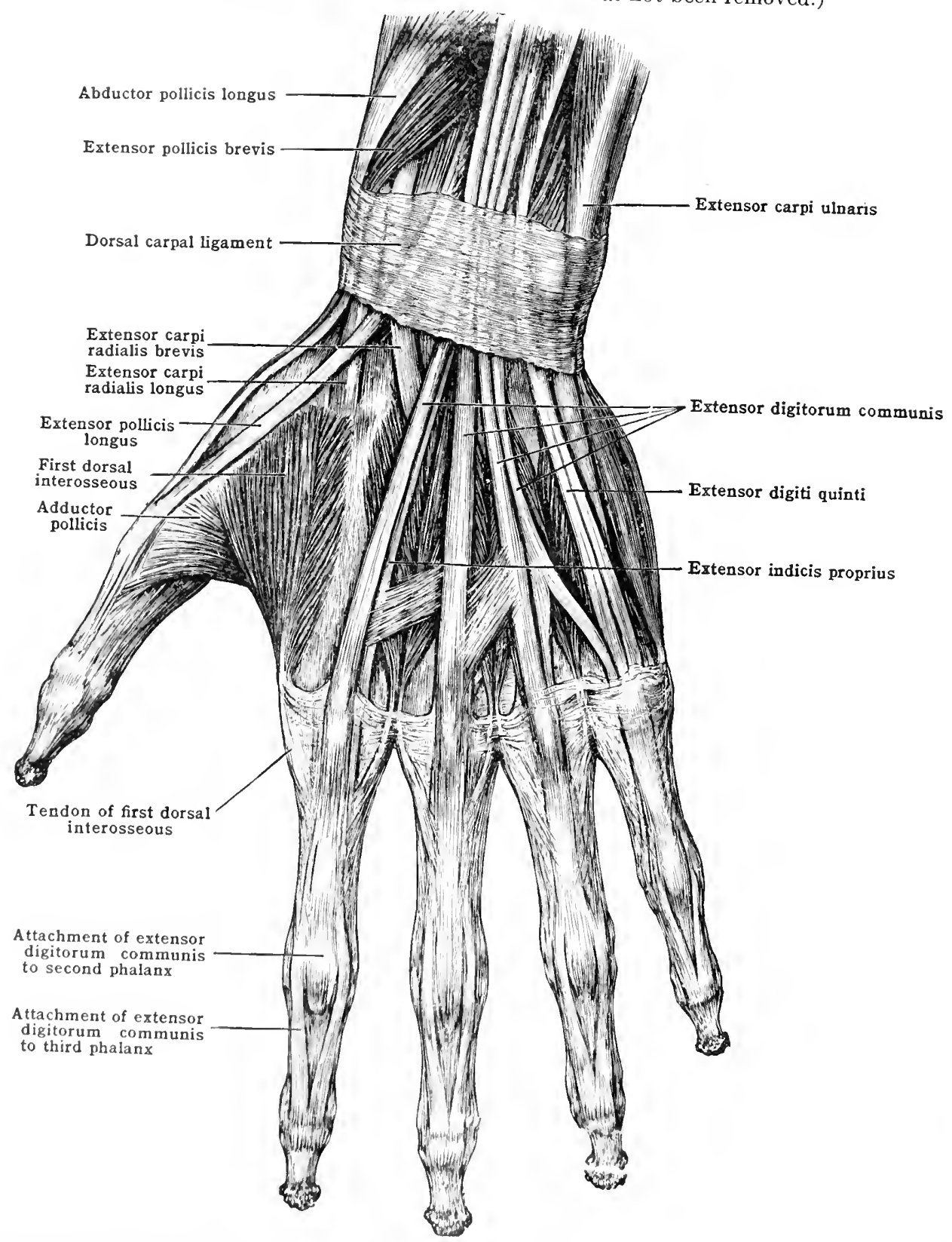

the thuml, and may extend down the rarlial sile of the index-finger. There is not in either case the rextrenc temlerness and pain on lassive extension of the fingers that is characteristie of infertion of the synovial sheaths. The pus is best evacuated by an incision on the radial side of the finger most affected, a little behind the web, sinus forceps being passed along the lumbrieal It molst he remembered avoil ofrening and infecting the synovial sheaths. seconclarily, l,y the bursting into them of the synovial tendon sheaths. 
Deeper are the articular synovial sacs, five in number:-(1) Between the interarticular cartilage and the head of the ulna; (2) between the radius and the interarticular cartilage above, and the navicular and lunate and triquetrum below; (3) between the greater multangular and first metacarpal bone; (4) between the pisiform and the triquetral bone; $(5)$ between the two rows of carpal bones, sending two processes upward between the three bones of the upper row, and three downward between the four of the lower row; these three processes being also continued below into the medial four carpo-metacarpal and three intermetacarpal joints.

Beneath the palmar aponeurosis covering the thenar eminence are the following structures:Superficial volar artery, abductor pollicis brevis, opponens pollicis, radial head of short flexor, tendon of long flexor, ulnar head of short flexor, first volar metacarpal arteries, metacarpal bone of the thumb, with the tendon of the flexor carpi radialis and greater multangular.

Beneath the central part of the palmar aponeurosis are the superficial arch and its digital branches; the ulnar and median nerves, with their branches; the flexors, superficial and deep, with their synovial sheath; and the lumbricales; then a layer of connective tissue (the only:

Fig. 1152.-Diagrans Illustratixg the Ixsertions of the Extersor, Lumbrical and Interosseous Muscles of the Right Hand. A, Index finger. B, Middle finger. C, Ring finger. D, Little finger. 1L, 2L, 3L, 4L, Lumbricales. 1D9, 2D9, 3D9, 4D9, dorsal interossei. 1P9, 2P9, 3P9, palmar (volar) interossei. EC, Extensor communis digitorum. E9, Extensor indicis proprius. EMD, Extensor digiti quinti proprius. A.ID, abductor digiti quinti (Willan: Anat. Anz. Bd. 42, 1912.)

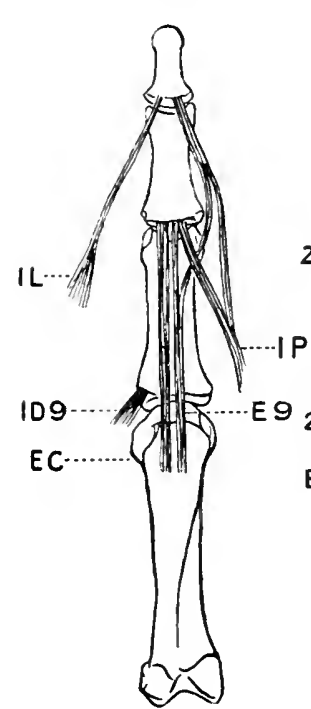

A

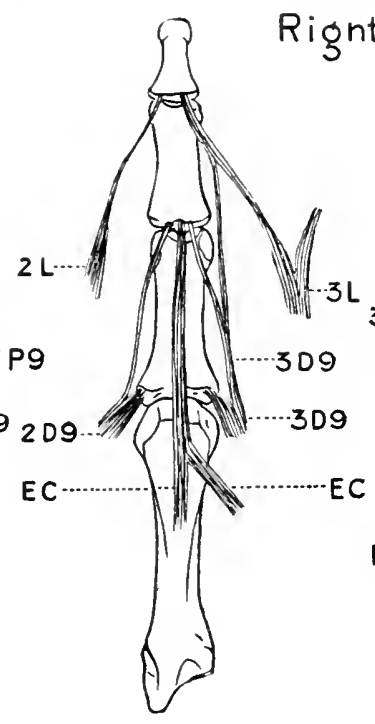

$\mathrm{B}$
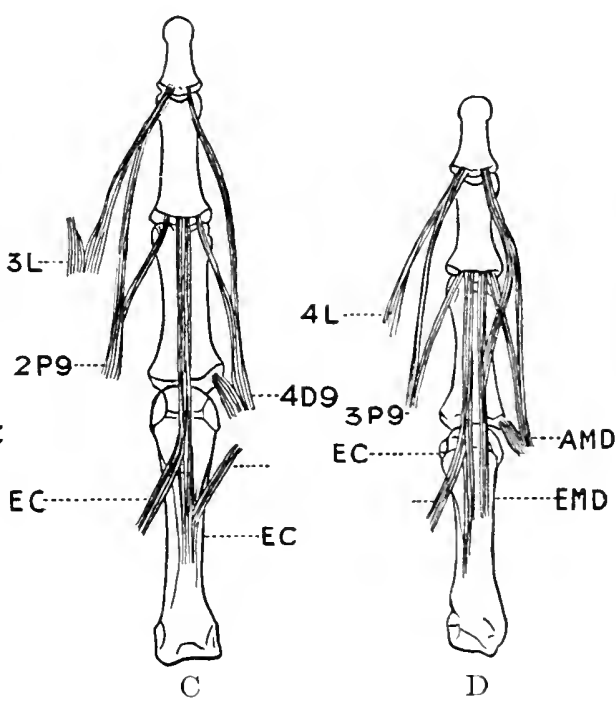

structure, together with the deep layer of fascia over the interossei, which prevents matter pent in by the palmar aponeurosis from making its way back out through the dorsum), the deep arch, the interossei, and the metacarpal bones.

In the hypothenar eminence under the fascia are part of the ulnar artery and nerve, the abductor and flexor brevis digiti quinti, the opponens, the deep branch of the ulnar artery and nerve, and the fifth metacarpal bone.

The back of the wrist and hand.-The dorsal carpal (posterior annular) ligament has already been described. On the lateral side is the so-called 'snuff-box space' (tabatière anatomique of Cloquet), a triangular hollow, bounded toward the radius by the long abductor and short extensor of the thumb, and toward the ulna by the long extensor. The navicular and greater multangular, with their dorsal ligaments, form the floor. In the roof lie the radial rein and branches of the radial nerve. More deeply is the artery, following a line from the apex of the styloid process to the back of the interosseous space.

The different tendons have already been given. Between the first two metacarpal bones is the first dorsal interosseous nuscle, which forms a fleshy projection against the radial side of the index metacarpal, when the thumb and index are pressed together. On its palmar aspect is the adductor pollicis. Wasting of the former muscle is a ready indication of injury or disease of the ulnar nerve. 
The skin on the dorsum, by its laxity, readily allows of odema, this being sometimes evidence of pressure on the axillary vein by careinomatous deposits. The dorsal venous arch receives the digital plexuses, and from it the radial and posterior ulnar veins ascend. The median rein bezins in plexuses at the root of the thumb and the front of the wrist.

Ganglia are common on the dorsum, in connection with the extensors of the fingers and the thumb. While usually due to a weakening of the sheath and protrusion of this and the synovial membrane, such swellings may be due to a projection of the articular synovial membrane. Owing to the laxity of the skin, the slight vascularity, the size of the tendons, their connection with joint-capsules and with each other, which fixes them, the dorsum of the wrist is the 'seat of election,' for tendon-anastomosis and other operations. Metacarpo-phalangeal dislocation. This occurs in the thumb and the index-finger espeeially. The chief cause in the difficulty in reduction is the glenoid ligament. This, in reality a fibro-cartilaginous plate, is blended with the lateral licaments on the palmar aspect of the joint, and is firmly attached to the phalanx, but more loosely to the metacarpal. Thus when dislocation occurs in violent hyperextension, the metacarpal attachment of the glenoid ligament gives way and it is carried by the phalanx over the head of the metacarpal bone. In the ease of the thumb, the buttonhole-like slit with which the two heads of the flexor brevis, now displaced, embrace the head of the metacarpal, the contraction of the other short muscles, and, oceasionally, a displaced long flexor, are additional eauses. In the ease both of the thumb and finger, tilting the phalanx well back on the dorsum of the metacarpal and then combined pressure with the thumbs forward against the base of the phalanx, when this is sharply flexed, will with an anresthetic, be usually successful. The thumb should be, first, addueted into the palm.

\section{THE LOWER EXTREMITY}

\section{HIP AND THIGH}

The various segments of the lower extremity will be successively considered as follows: hip and thigh, knee and leg, ankle and foot.

Bony landmarks.-Many of these, such as the anterior superior iliac spine and crest of the ilium and the tubercle of the pubis, have already been mentioned. The relative length of the limbs is obtained by carrying the measure from the anterior superior spine to the tip of the corresponding medial malleolus. The pelvis must be horizontal and the limbs parallel. The share taken by the femur and tibia respectively is estimated by finding the transverse sulcus which marks their meeting-point.

The head and shaft of the femur are well covered in, save in the emaciated. The head lies just below Poupart's ligament, under the ilio-psoas, and a little to the outer side of the centre of that ligament. A hine drawn horizontally laterally from the pubic tubercle will cross the lower part of the head. All the head and the front of the neck, but only two-thirds of the back, are within the capsule; this intra-capsular position of the upper epiphysis, which, appearing at the first year, does not unite till eighteen or twenty, aceounts largely for the extreme gravity of arute epiphysitis here. The structure of the neek, i. e., the two sets of lamellæ, vertical to support the weight, transverse and intersecting in order to meet the pull of the muscles, and the wasting of these after millde life, has an important influence on injuries. The strong process, femoral spur or calcar (Merkel) which, arising from the compact tissue on the medial and under side of the neck, just above the lesser trochanter, spreads laterally toward the trochanterie (ligital, fossa, also affords strength, and its degeneration probably plays an important part in the fraturures of the neek.

Hip-joint.- The chief points of surgical importance are the following:- The capsule shows fibres chiefly longitudinal in front, eircular behind. Of the former, the ilio-fenoral or inverted Y-shaped ligament descends from the anterior inferior spine to the two extremities of the anterior intertrochanteric line. It not only checks cxtension and strengthens the front of the joint, but it keeps the pelvis and trunk propled forward on the heads of the femurs, thus preventing waste of musenlar action. It is joined on the medial side by the pubo-capsular ligament, which checks alduction. Between the two is the medial part of the front capsule, and here the ilio-psoas hursa may communicate with the joint. 'This fact must be remembered in tuberculous dinease of the psoas, and the presence of this lursa rexplains cortain deep-scated swellings in the front of the joint in adults. Jichind, the isehio-femoral is the strongest part of the capsule, its fibres blending with the riscolar and weaker bart of the capsule here. Dislocation usually menses at the posterior, lower and merlial part of the joint. It is to be noted that in full axtrusion and floxion the head of the femur is in contact with the weakest spot in the rapsule, in front and behind, respectively. From the deep aspect of the apsule: filires pass up at the line of reflection of the synovial membrane on to the neck-the acrvical ligaments of sianley. In intracapsular fracture these 
fibres keep the fragments together; hence one need of gentlo handling: their softening may explain, a little later, an increase in the shortening.

Exploration of the joint.- This is usually effected by an oblique incision fownwarl aml

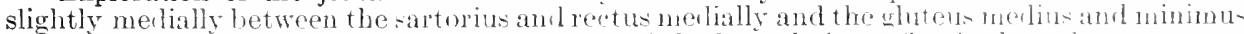
laterally. A branch of the ascending tivision of the lateral circumflex is the muly artery met with. In tapping the joint the puncture is marle in the same line, 2 or $: 3$ inches below the

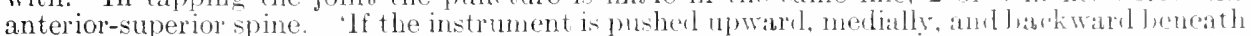
the rectus, it will pass into the joint a little al ove the anterior intertrordanterin line. atiles.

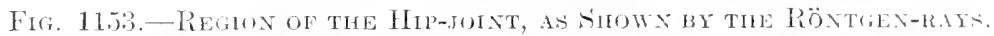

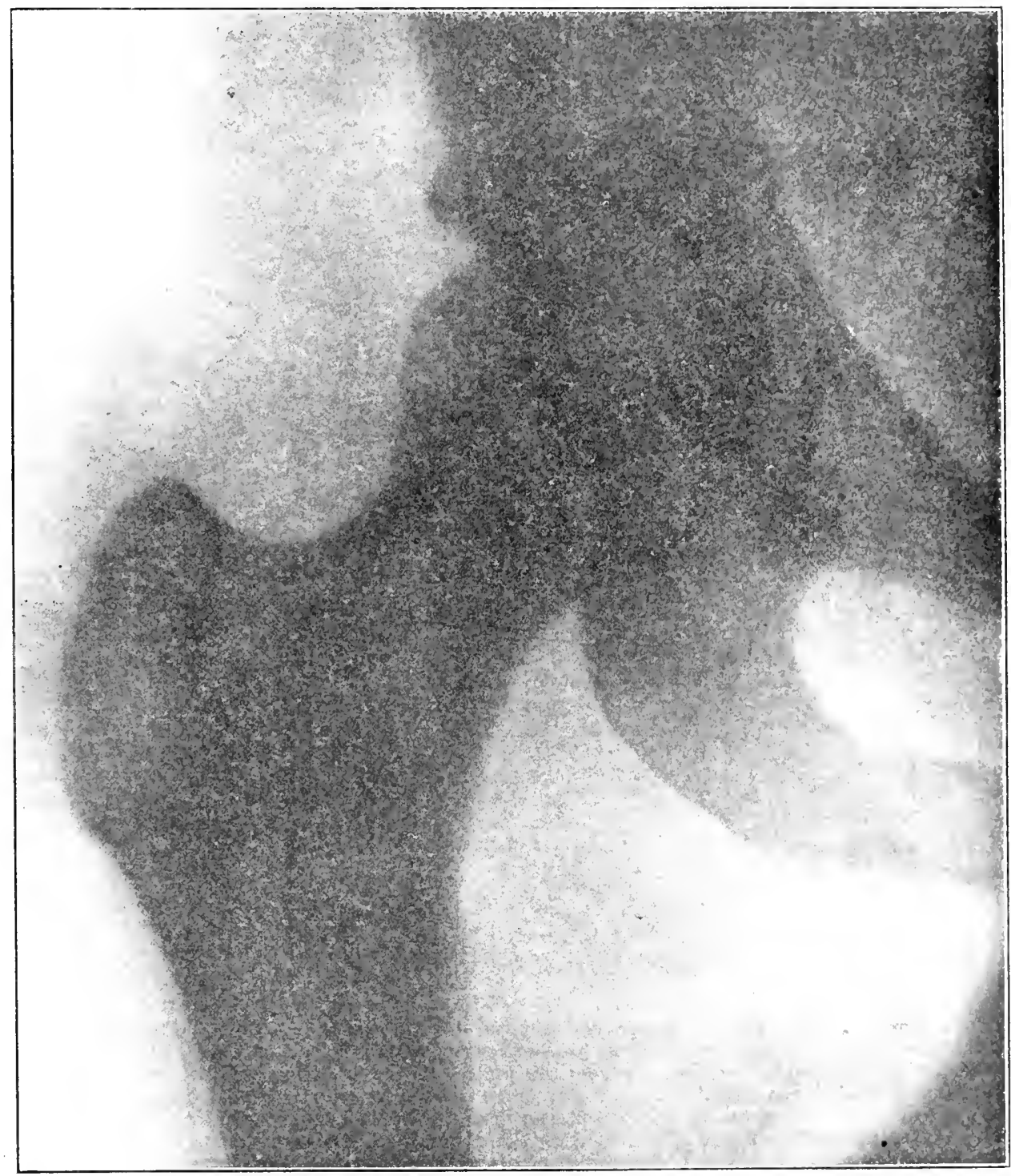

Trochanter major.-This valuable landmark is most prominent when the limb is rotated medially or adducted; it lies at the bottom of a depresion when the femur is everted.

The chief structure of importance between it and the skin is the upper part of the insertion of the gluteus maximus, that going to the fascia lata, amb the burwa leneath the musche. This is often multilocular. It is, not very meommonly, the seat of tulereulat inflammation which readily invades the camellous tissue of the trodinnter. The top of the great trochanter is about $1.8 \mathrm{~cm}$. ( $\frac{3}{1}$ in.) below the level of the fenoral hearl, and, when the femur is extenderl is a little below the centre of the hip-joint. This part of the bone is covered by the gluteus medius. 
The slightness of the prominence of the great trochanter in the living subject compared with that in the skeleton is explained by fig. 1151, which shows how the descending gluteus medius and minimus fill up the space between the ilium and trochanter. To examine the great trochanter, the thigh should be abducted, so as to relax the strong fascia lata passing upward over the tensor and glutei to the iliac crest.

Nélaton's line.-This useful guide is a line drawn from the anterior superior spine of the ilium to the most prominent part of the tuberosity of the ischium. In normal limbs, the top of the great trochanter just touches this line. In dislocation, fractures of the neck, and in wasting of the neck, as in osteo-arthritis, the relation of the trochanter to Nélaton's line becomes altered.

The top of the great trochanter is a guide in Adams's operation for division of the neck of an ankylosed femur, the puncture being made and the saw entered $2.5 \mathrm{~cm}$. (1 in.) above and about the same distance in front of this point. Owing to the fact that in many eases of ankylosis the neek is destroyed, the above operation has been largely replaced by the simpler and more widely applicable Gant's osteotomy just below the great trochanter, from the lateral side.

Fig. 1154.-Transterse Section of the Hip-Joint and its Relations. (One-third.) (Braune.)

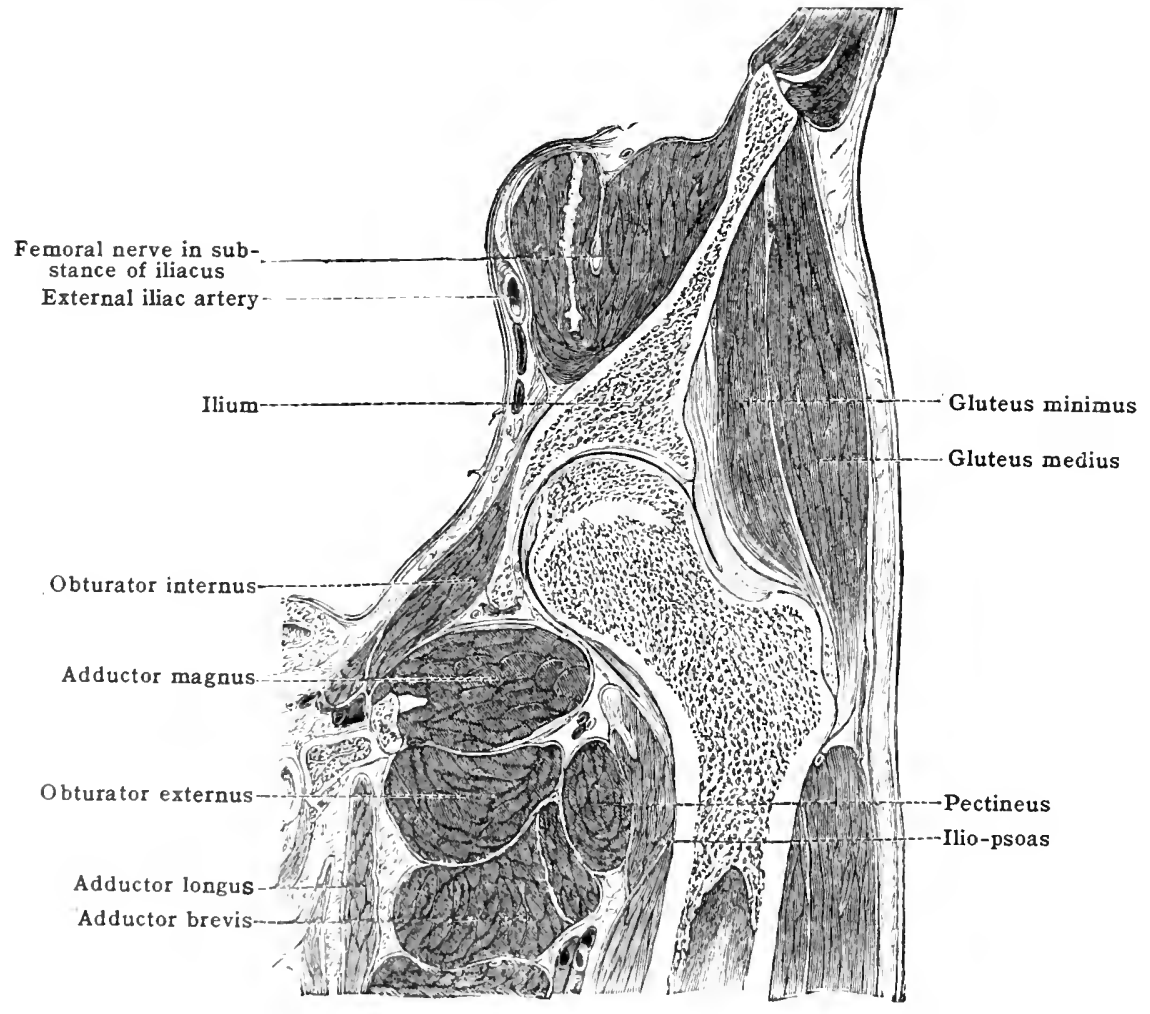

Bryant's triangle.-Bryant makes use of the following in deciding the position of the great trochanter. The patient being flat on his back (1) a line is dropped vertically on to the couch from the anterior superior spine; (2) from the top of the great trochanter a straight line in the long axis of the thigh is clrawn to meet the first; (3) to eomplete the triangle, a line is drawn from the anterior superior spine to the top of the trochanter. This line is practically Nelaton's. The second line will be found diminished on the damaged or diseased side.

Muscular prominences.-The tensor fascia lato forms a prominence beginning just lateral to the sartorius and reaching downward and somewhat backward to the strong faseia lata, 7.5 to 10 ('m. (3 $+04 \mathrm{in}$.) helow the great trochanter. Below this point, as far as the lateral eonlyle of the tilin, the strong ilio-tibial band "atu be felt. Like the inverted $Y$-shaped ligament, this band is a jowerful saving of muscular action in maintaining the erect position. At the insertion of the fonsor fascial latas it bifurates into two layers, which enelose the musele. The

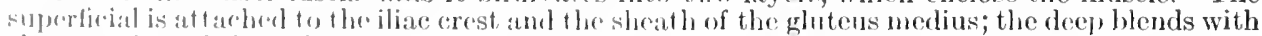
the rapsule: and the reflecterl head of the rerotus. This deeper layer is perforated by the ascending branch of the latcral circumflex. The ilio-tildal band is a guide for reaching the femur (1). 13:34). The sarlorims, the chicef landmark of the thigh, forming a boundary of the femoral

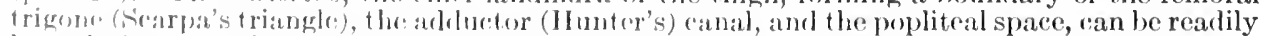
bronght into viow hy the pationt's raising his limb slightly rotaled laterally. In the midelte line therertus momsonstands ont in loold relief, with its fondon of insertion and the patella, when the 
leg is extended. On either side of this muscle is a furrow, and on either side, again, nf this furrow the vasti become prominent. Between the vastus medialis and adductor muscles is a depression indicating the adductor canal. At the upper and medial third of the thigh, if the limb be abducted, the upper part of the adductor longus comes into strong relief. On the medial side below, above the knee-joint, the vertical fibres of the adductor maqmus end in a powerful tendon coming down to the adductor tubercle (fig. 1159). This replaces here the medial intermuscular septum, and the insertion of the tendon marks the level of the lower epiphrsiat line of the femur. At the lateral and back part of the thigh the vastus lateralis is separated from the biceps by a groove which indicates the lateral intermusculur septum. Of these septa, prolongations inward from the fascia lata to the linea aspera, the lateral lies between the vastus lateralis and the biceps. It reaches from the lateral tuberosity of the femur to the insertion of the ghuteus maximus. Just above the condyle it is perforated by the superior lateral articular vessel and nerve. The medial septum extends from the adductor tubercle to the trochanter. It is weak in

Fig. 1155.-The Muscles attached to the Pcbes.

(From a dissection in the Hunterian Museum.)

External oblique

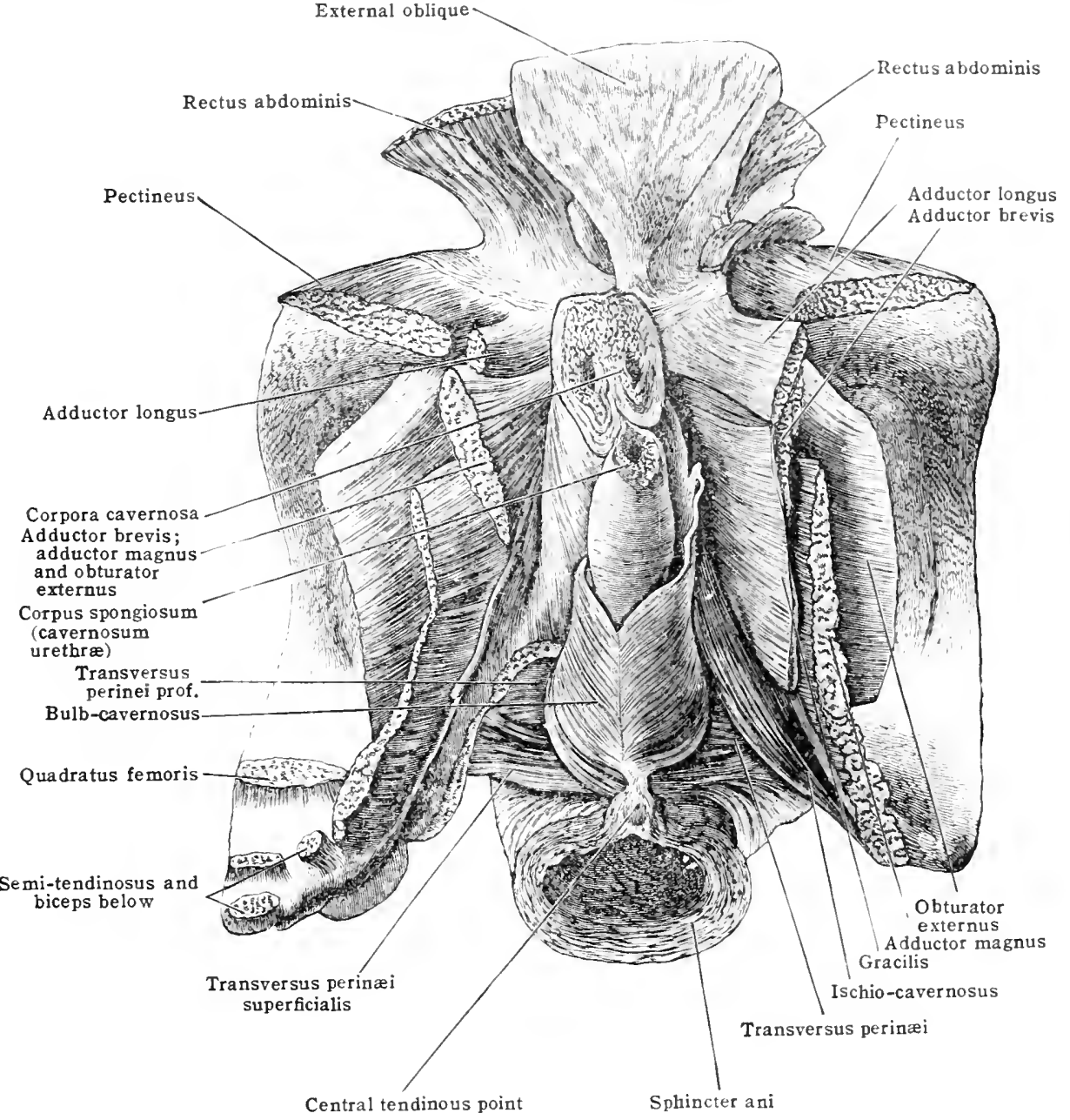

comparison, and separates the adductor from the vastus medialis. A third, the weakest of all, separates the adductor and the hamstrings. The fascia lata has the same effeet as that in the neck in causing pus to burrow, especially downward, and in rendering the diagnusis of swellings beneath it difficult. Thickest above and on the lateral aspect, and again about the bony prominences at the knee-joint, at both of which sites it receives accessions from muscles. it is divided into iliac and pubic portions. The former is attached behind to sacrum and cocerx, iliac crest and the inguinal ligament, terminal line and pubic tubercle. HIere it blents with the pubic portion, which is connected with the pubic arch. At the fossa ovalis (saphenous opening) the two may be said to separate, the iliac forming the upper cormen and hateral falciform margin, and descending over the femoral vessels and extensors. The pubic, nnch thinner, forms the medial margin of the fossa, and descends obliquely over the pectineus and adductor longus behind the vessels, to blend with the sheath of the ilio-psoas and capsule of the hip-joint. 
The inguinal (Poupart's) ligament.-The abdomen is separated from the thigh by a fold, best marked in flexion - the inguinal furrow. In this, pressure detects the meeting of the aponeurosis of the external oblique and the fascia lata, i. e., Poupart's ligament, extending between the anterior superior spine of the ilium and the tubercle (spine) of the pubes. The line representing it should be drawn slightly convex downward, owing to the attachment of the deep fascia. It forms the base of the femoral trigone; its medial attachment blends with the triangular lacunar (Cimbernat's) ligament. The parts passing under the inguinal ligament and their arrangement have been given at p. 1399, fig. 1122.

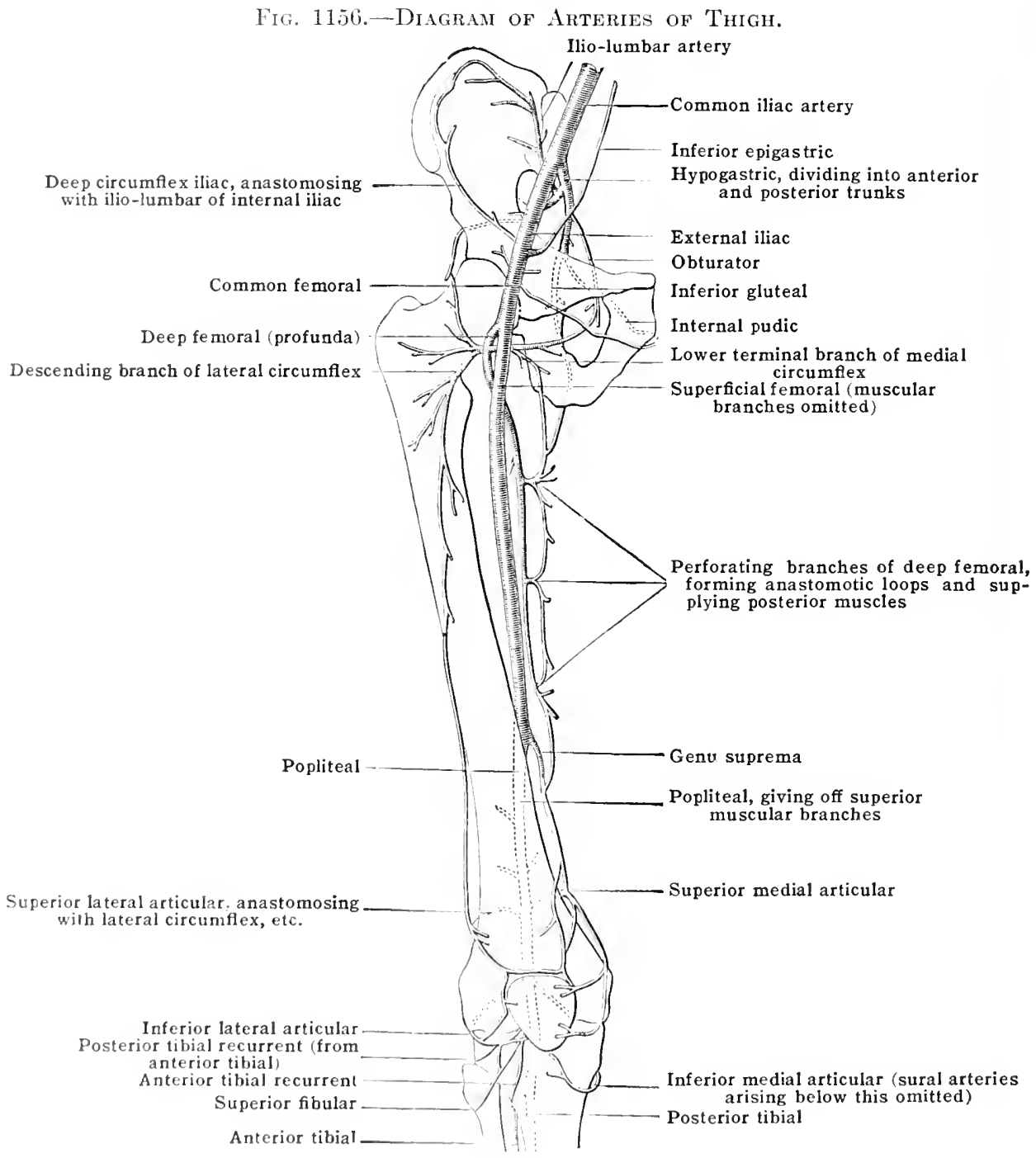

'Thr. femoral trigone (Scarpa's triangle) (fig. 1159).--Immediately below the inguinal ligamont a hollow is secen corresponding to this region, the lateral and morlial bommlaries of which are bromght into view when the limb is raised, the anduren longus reperailly when the limb is abducted, and the sartorius when the thigh is flexed and the limb extended and rotated laterally. The floor of the fomorisl trigone is not horimontal, the plane of the medial part being very oblique.

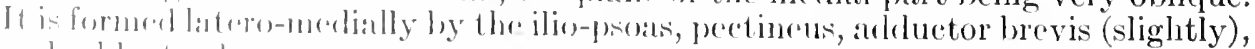
and aldusetor longus.

$\Lambda$ psoas abscess desending ludow the inguinal ligument usually does so on the lateral aspeet

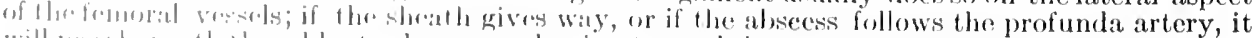

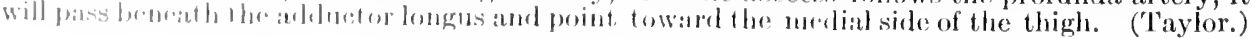


Fig. 1157.-Section of the Right Thigh at the Apex of the Femoraltirigone. (Heath.)

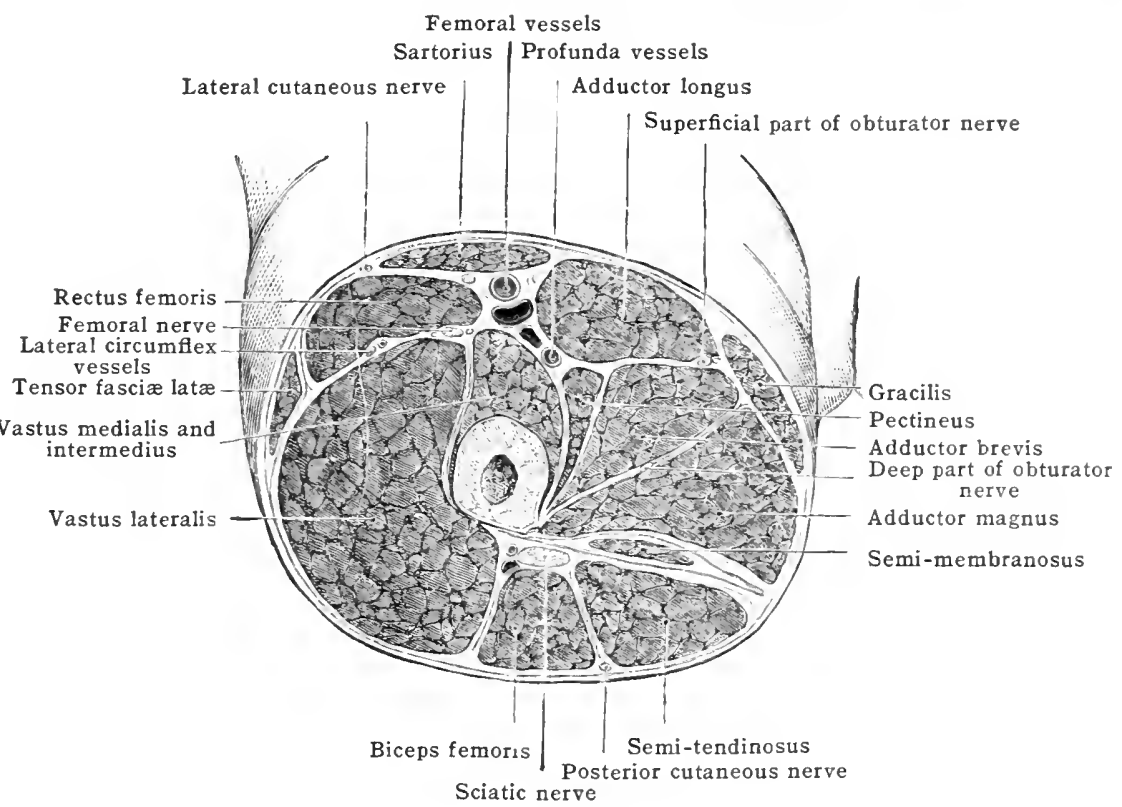

Fig. 1158.-Superficial Dissection of the front of the Thigh. (Hirschfeld and Leveillé.)

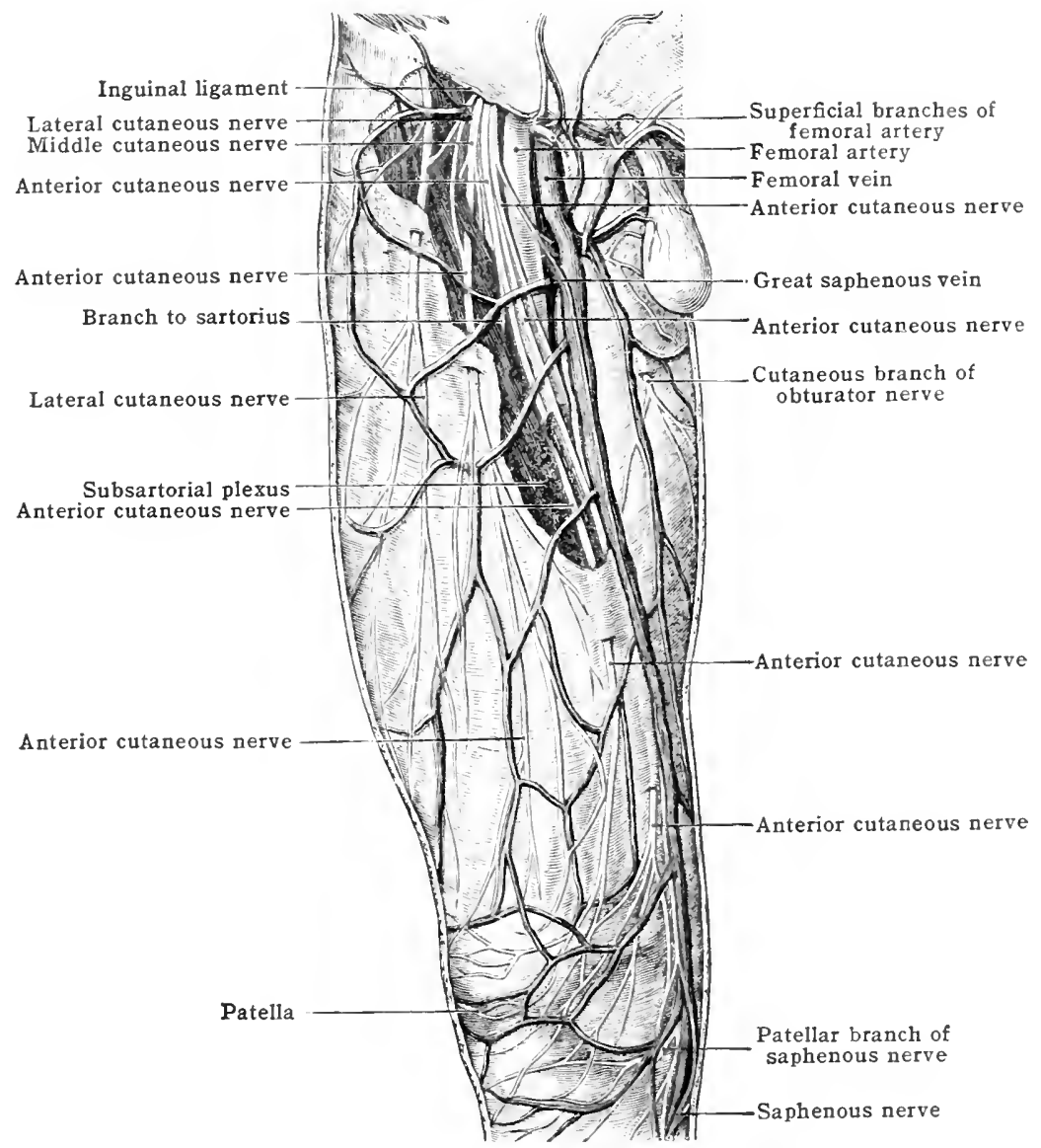


If it simulate a femoral hernia, examination of the back and the fact that the swelling is below the fossa ovalis will prevent mistakes. Three nerves come into the thigh between the pelvis and Poupart's ligament, i. e., the lumbo-inguinal (genito-crural) in the femoral sheath, the femoral (anterior crural) between the iliacus and psoas and the lateral cutaneous close to the lateral attachment of the inguinal ligament.

The obturator nerve divides into two in the obturator foramen, the two divisions being separated by some fibres of the obturator externus, and lower down by the adductor brevis. The relations, course, and distribution of this nerve, in the medial fibres of the psoas, over the sacro-iliac joint and under the ilio-pelvic or sigmoid colon (Hilton), through the obturator foramen with its branches (from the superficial division) through the cotyloid noteh to the hip, and (from the deep)

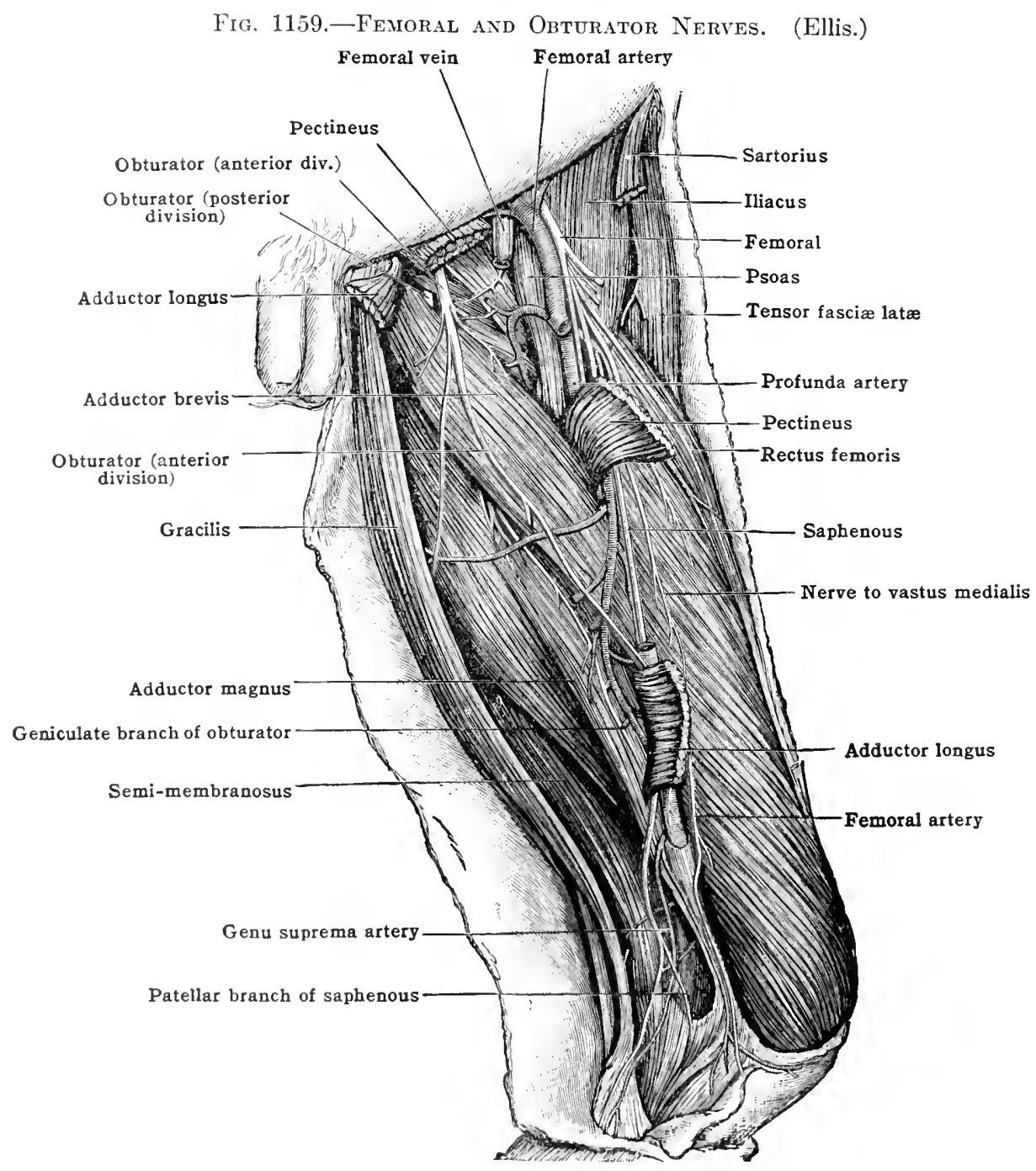

along the popliteal artery to the knee, and others to the lower third of the thigh, and sometimes the upper and medial aspect of the leg (Hilton), may be of much surgical importance, e.g., in carcinoma of the bowel, disease of the sacro-iliac and hip-joints, growths of the pelvis, and the rare obturator hernia. The distribution of the cutaneous nerves is shown in fig. 1158. Lying superficially in the base of the trigone, the inguinal lymphatic nodes cin be deteeted in a thin person (fig. 1172 ).

The fossa ovalis (saphenous opening).--The depression corresponding to this is placed just below the lacunar (Gimbernat's) ligament, with which its upper extremity lolends. Its centre is about 3.7 (.n. ( $1 \frac{1}{2} \mathrm{in}$.) below and also lateral to a 
line dropped vertically from the pubic tubercle. This and the other structures concerned in femoral hernia are fully described under this section (vide supra, p. 1398). The course of the great saphenous vein is given below, p. 1456 .

Line of femoral artery. - A line drawn from the mid-point between the anterior superior spine and the symphysis pubis to the adductor tubercle will correspond with the course of this vessel. The sartorius usually crosses it $10 \mathrm{~cm}$. ( 3 to $1 \mathrm{in}$.) below the inguinal (Poupart's) ligament. The profunda artery arises usually $3.7-5 \mathrm{~cm}$. ( $1 \frac{1}{2}$ to 2 in.) below Poupart's ligament.

The incision for tying the femoral in the femoral trigone should be about $7.5 \mathrm{~cm}$. (3 in.) long, in the line of the artery, and begins about $7.5 \mathrm{~cm}$. (3 in.) below the inguinal ligament, and runs over the apex of the triangle. The femur is flexed slightly, abducted and rotated laterally. The fascia lata being divided, the sartorius, realily reeognised by its direction, is drawn laterally. The closely subjacent sheath must be opened on its lateral side. Structures that may be seen are a vein joining the great saphenous, the anterior cutaneous, saphenous nerve, and that to the vastus medialis. The collateral circulation (fig. 1156) is mainly through the following

Fig. 1160.-Section of Thigh throdgh upper Part of Hunter's Canal.

(W. A.)

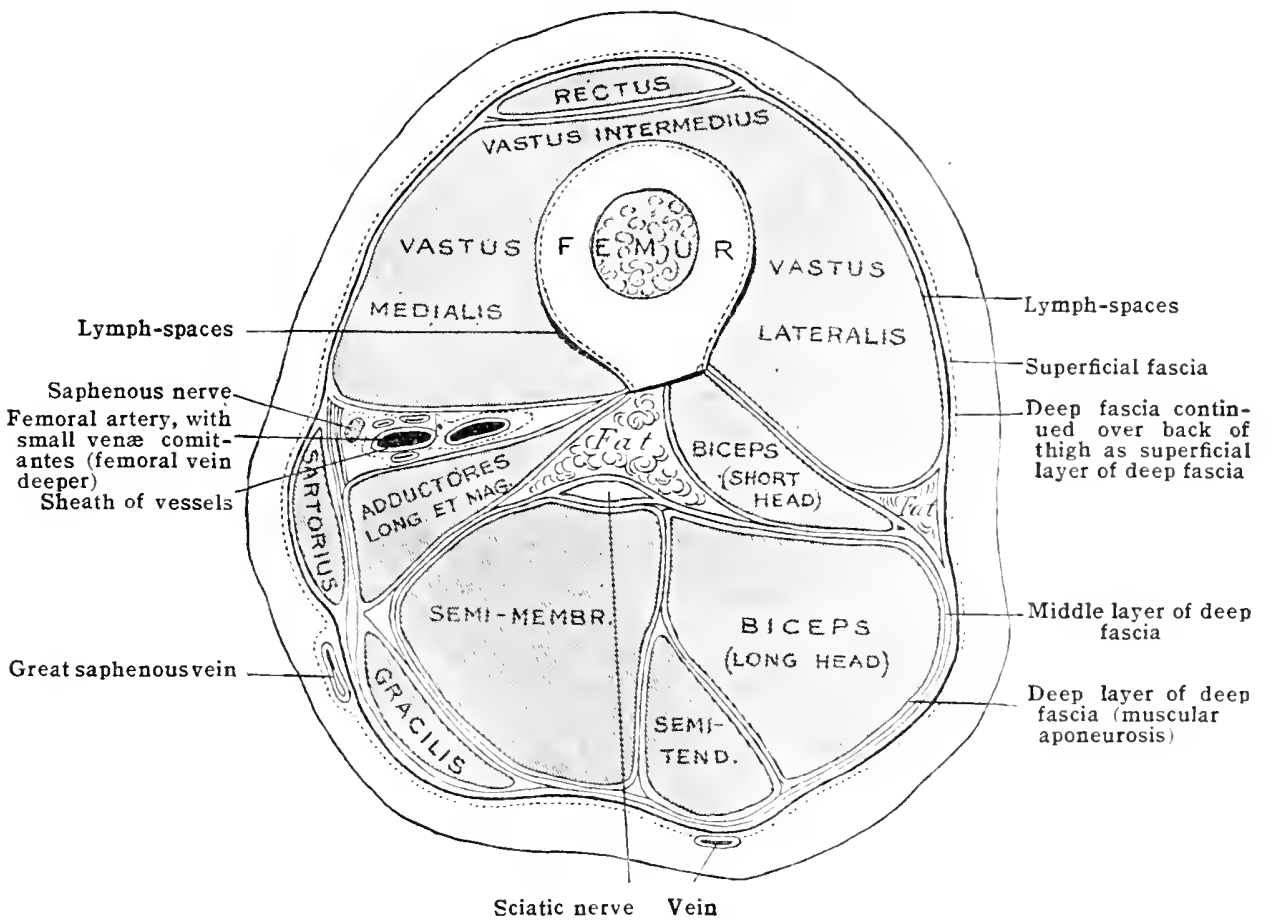

channels:-(1) The lateral and medial circumflex above, with the genu suprema and lower muscular branches of the femoral, and the articular of the popliteal. (2) The perforating branches of the profunda above, with the vessels below first given. (3) The comes nervi ischiadici with the articular of the popliteal.

The femoral vein lies, below the inguinal ligament, immeliately to the medial side of the artery. From this point on the vein gets to a somewhat cleeper plane, though still very close to the artery, and gradually inclining backward, lies behind its companion at the apex of the triangle, and below lies somewhat laterally to it.

From the apex of the femoral trigone (Scarpa's triangle) a depression runs down along the medial aspect of the thigh, corresponding to the groove already mentioned between the vastus medialis muscle and the adductors. Along this groove lies the sartorius, and beneath it the adductor (Hunter's) canal, a triangular inter-muscular gap with its apex toward the linea aspera, and its base or roof formed by the fibrous expansion which ties together its boundaries, viz., the adductor longus and magnus and the vastus medialis.

The vein, which in the upper part of the canal lies behind the artery, separating it from the three adductors, lower down inclines more and more to the lateral side. The saphenous nerve lies also in the canal, but not in the sheath. The above-mentioned space terminates at about the junction of the middle and lower thirds of the thigh, in the opening in the adductor magnus 
by which the artery enters the upper and medial part of the popliteal space. The saphenous, the largest branch of the femoral merve, having crossed the femoral vessets latero-medially, accompanies them as far as the openiug in the adductor magnus. Here it perforates the aponenrotic roof, and is prolonged under the sartorius, accompanied by the superficial part of the genu suprema artery, to perforate the faseia lat a between the sartorius and gracilis, and run with the great saphenous vein at the upper and medial part of the leg.

Pressure may be applied to the femoral artery-(1) Immediately below the inguinal ligament: it should here be directed backward so as to compress the vessel against the brim of the pelvis and the capsule of the hip-joint; (2) at the apex of the femoral trigone the pressure here being directed laterally and a little backward, so as to command the vessel against the bone; (3) in the adductor canal the pressure should be direeted laterally with the same object. Care nust be taken, especially above, to avoid the vein, which lies very elose to the artery, and also the femoral nerve, which enters the thigh about $1.2 \mathrm{~cm}$. ( $\frac{1}{2}$ in.) outside the artery, and at once breaks up into its branches, superficial and deep.

In ligature of the femoral artery in Hunter's canal, the line of the incision, in the middle third of the thigh, must exactly follow that of the vessel. It is frequently made too lateral, exposing the vastus medialis. Branches of the saphenous vein being removed, the fascia lata is slit up and the sartorius identified by its fibres descending medially. Those of the vastus medialis are less oblique and are directed downward and laterally. The sartorius having been drawn to the medial side, usually, the aponeurotic roof of the eanal is opened, and the femoral sheath identified. The vein, here posterior and to the lateral side, is closely connected to the artery.

The close contiguity of the femoral artery and vein aceounts for the comparative frequency of arterio-venous aneurysms espeeially in the upper part, where the vessels are easily wounded. Their superficial position bere further accounts for the facility with which malignant disease, e. g., epitheliomatous glands, may cause fatal homorrhage. Access to the femur. This is best attainerl on the lateral side of the shaft along the line of the lateral intermuscular septum (fig. 1160), the biceps being pulled backward, and the vastus lateratis detached anteriorly. On the medial side the bone may be exposed by an incision starting from a point midway between the inner mal'gin of the patella and the adductor tubercle and passing obliquely upward and laterally, but the parts here are more vascular. Fractures of the shaft usually occur about the centre. The main tendency to displacement is of the lower fragment upward by the hamstrings. The upper fragment is anterior; this is especially marked in the upper third, owing to the action of the ilio-psoas, which also rotates the upper fragment laterally. In the lower third the forward curve of the femur and its more superficial position explain the fact that it is here that compound fractures of the femur may, occasionally, occur. Ossification. The unstable nature of the tissues about the upper epiphysis, which appears at the end of the first year and unites about eighteen, and the frequency of tuberculous disease in early life are well known. In the lower epiphysis ossification begins before birth, a point of medico-legal importance in deciding whether a newly born child has reached the full period of uterine gestation. From this epiphysis, the level of which is denoted by a line drawn horizontally laterally from the adductor tubercle, and the vascular growing tendon of the adductor magnus- the origin of an exostosis is not uncommon. Displacement of this epiphysis (it unites about twenty) in boyhood and adolescence is a grave injury from the immediate risk of the popliteal vessels. The mischief is usually done by overextension of the leg, as when this is caught in a rapidly moving carriagewheel; the epiphysis is earried forward in front of the diaphysis, the lower end of which is directed backward, endangering the vessels which are posterior and elosely adjacent.

Amputation through the thigh.-This is usually performed in the lower third, by anterior and postrerior flaps, the former being the longer, so as to ensure a scar free from pressure, and circular division of the museles, vessels, and nerves. The vessols requiring attention are the femoral, which lie at the modial side, and the more posteriorly, the lower the amputation; the flescending branch of the lateral circumflex, and the termination of the profunda near the linea aspera. The femorul artery has a marked tendency to retract in the adductor canal. Care should br taken net to incluble the saphenous nerve when the femoral vessels are tied, and to cut the seiatid rleanly and high up. When amputation has to be performed in the upper thind of the thigh, the tomleney of the ilio-psoas to flex the shortened limb and thus bring the sawn fonur against the end of the stump must be remembered, and met by keeping the patient proplual up and the stump as horizontal as possible. Some of the structures now divided are shown in fig. 1160.

The buttocks. Bony landmarks.- The finger realily traces the whole outline of the iliac: arest. Beohind, it terminates in the posterior superior iliac spine, wheb corresponds in level to the second sateral spine and the centre of the sacroiliats joint. (Holden.)

The thipl sareral spine narks the lowest linit of the spinal membranes and the cerebrospinal fluid; it at so corresponls to the upper border of the groat sacro-sciatic not ch. The first piece of the cereyx corresponds to the spine of the ischium. (Windle.) Its apex is in the furrow

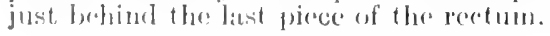

The tuberosities of the jushimm are reality folt by deep pressure on either side of the anth. In the erext position they are covereed by the lower margin of the ghlutens maximus. In sitfing they anc protected by tomgh skin, fasedie, with coarse fibrols fat, and often by a bursa known, aleording to the patients in whom it beromes conlarged, as worver's, coadchman's, lighterman's, drayman's bursa. The 
skin of the buttock is coarse and diffieult to cleanse satisfactorily. The abundance of sebaceous glands accounts for the frequency of boils here.

Gluteus maximus. - The 'fold of the buttock' neither corresponds arcurately to, nor is caused by, the lower margin of this muscle. Thus, medially, it lies below the lower margin of the muscle, as it runs laterally it crosies it, and comes to lie on the muscle. The fold is really due to creasing of the skin adherent here to the coarsely fibro-fatty tissue over the tuber isehii during extension. But in early lip disease, in which flexion of the joint is. with wasting of the muscle, almost unvaryingly present, the fold disappears with well-known rapidity. The prominence of the buttock is mainly due to the gluteus maximus, especially behind and below, and in less degree to the other two glutei in front. ['nder the lower edge of the gluteus maximus the edge of the sacro-tuberous (great sacro-sciatic) ligament can be felt on deep pressure.

To mark out the upper border of the gluteus maximus a line is drawn from a point on the iliac crest $5 \mathrm{~cm}$. (2 in.) in front of the posterior superior spine, downwarl and laterally to the back of the great trochanter. The lower border is marked out by a second line drawn from the side of the coecyx parallel with the former, and ending over the linea aspera at the junction of the upper and middle thirds of the thigh. It must be remembered that only the lower and internal fibres of the musele are inserted into the gluteal ridge on the femur. The greater part of

Fig. 1161.-Section throvgh the Hip and Gliteal Region. (One-third.)

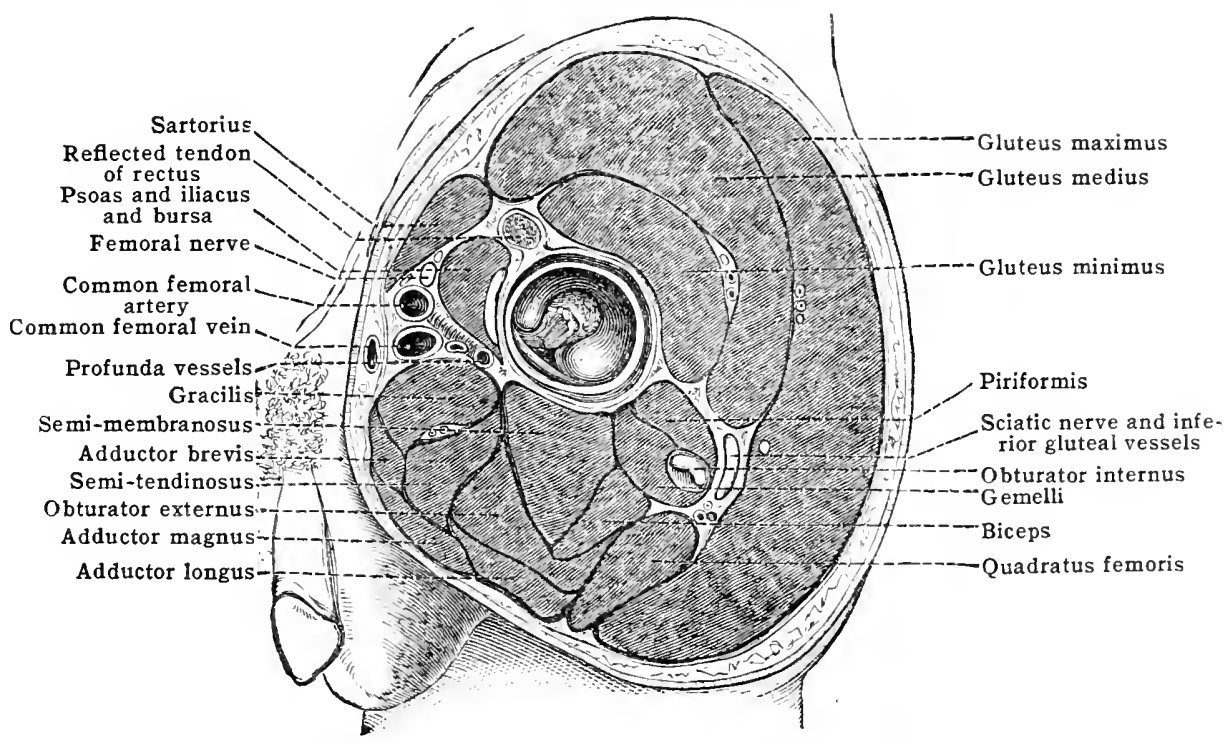

it is inserted into the fascia lata and ilio-tibial band and so into the lateral condyle of the tilia. Weakness of the gluteus maximus and tensor fasciæe late, with consecpuent laxity of the iliotibial band, gives rise to abnormal side-to-side passive mobility at the knee-joint in full extension.

Nerves and vessels.- The following superficial nerves ean be marked in over the buttock (fig. 1182).

Behind the great trochanter, branches of the lateral eutancons; coming lown over the crest, the lateral cutaneous branch of the last thoracic (about in a line with the great trochanter), and behind this the lateral branch of the ilio-hypogastric. Two or three offacts of the posterior primary branches of the lumbar nerves cross the hinder part of the iliac crest at the lateral margin of the sacro-spinalis. Two or three twigs from the posterior divisions of the saeral nerves pierce the gluteus maximus elose to the coceyx and sacrum, and ramify laterally. Finally, over the lower border of the gluteus maximus, turn upward loranches of the posterior cutaneous (small seiatic) and its perineal braneh (inferior pudendal), and the fourth sacral nerve.

Sciatic nerve (figs. 1162, 1163).- The point of emergence below the gluteus maximus and the track of this nerve (fourth and fifth lumbar and first three sacral nerves) will be given by a line drawn from a spot a little modial to the middle of the space between the great trochanter and the tiber ischii to the lower part of the back of the thigh, where it usually divides into the tibial and common peroneal (internal and external popliteal) nerves. 
To stretch the nerve, an ineision about three inches long is made in the line of the nerve, beginning about $3.7 \mathrm{~cm}$. ( $1 \frac{1}{2} \mathrm{in}$.) below the gluteus maximus. The long head of the bieeps which covers the nerve trunk and which is descending mediolaterally, is drawn medially. If the nerve is exposed lower down, the interval between the hamstrings is identified and these muscles drawn aside. The perineal branch of the posterior cutaneous (inferior pudenal) perforates the deep fascia about $2.5 \mathrm{~cm}$. (1 in.) in front of the tuber ischii, and turns forward to supply the genitals.

Superior gluteal artery.-If a line be drawn from the posterior superior spine to the apex of the great trochanter, the limb being slightly flexed and rotated medially, the point of emergence of the artery from the upper part of the great sacro-sciatic notch will correspond with the junetion of the upper and middle third of this line. (MacCormac.) The gluteal nerve emerges immediately below the artery, and sends branches into the deeper portion.

Inferior gluteal (sciatic) and pudic arteries. - The limb being rotated medially, a line is dramn from the posterior superior spine to the lateral part of the tuber ischii. The point of exit of the above arteries will correspond to the junction of the middle and lower thirds of this line. (MacCormac.)

\section{THE KNEE}

Bony landmarks. - The patella, the condyles of the femur, the condyles and tuberosity of the tibia, the head of the fibula, are all easily examined.

Fig. 1162.-The Gluteal Region, with the Superior and Inferior Gluteal and Pudic Arteries.

Gluteus medius, turned up

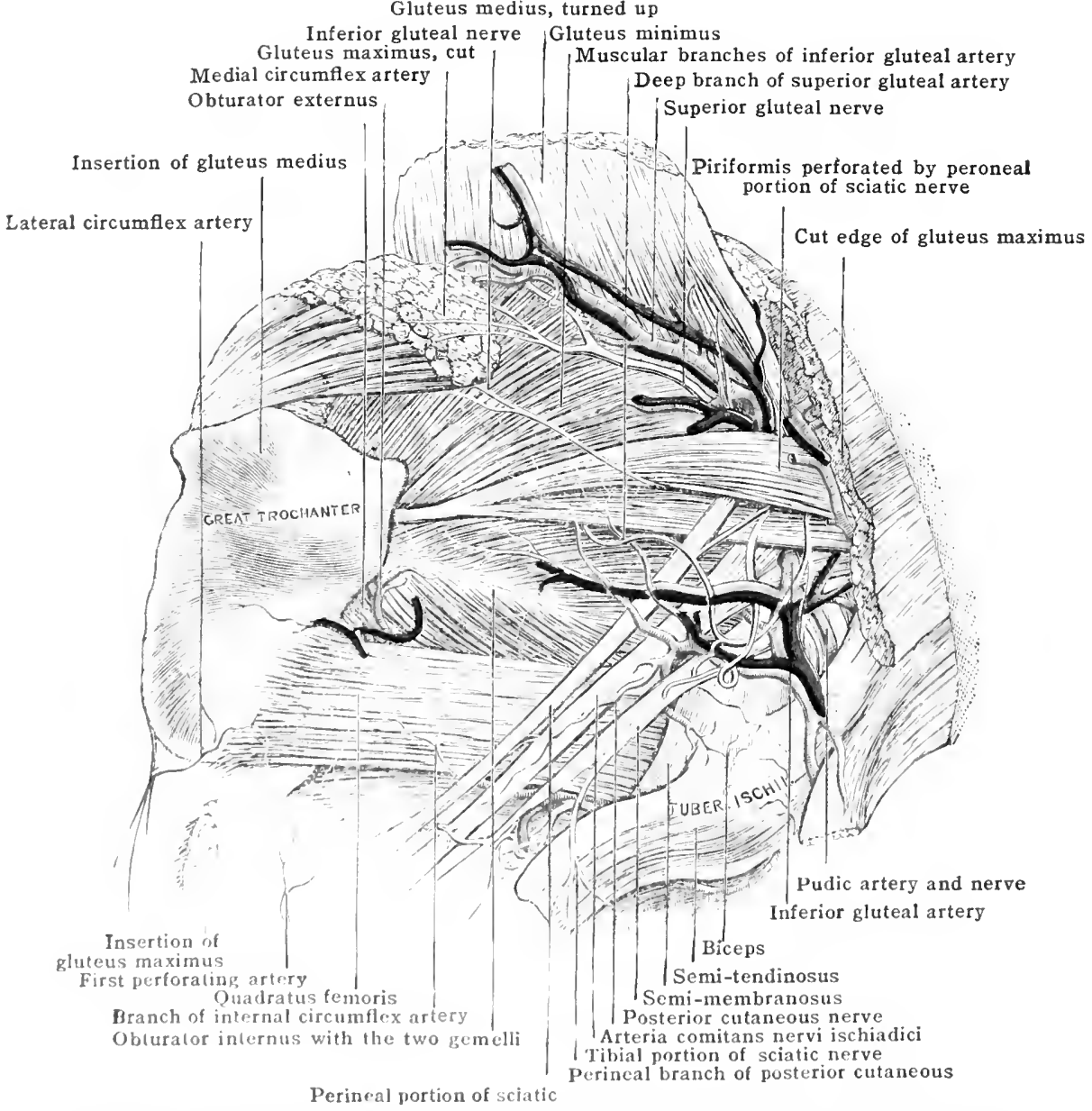

(Fron at disection hy W'. J. Wialshan in st. Batholomew's llospital Museum.)

The musculat branch of the inforior gluteal (sciatic) antery has been drawn inward over the tuber isehii with the reflected origin of the glatens maximus muscle.

The patella.-'The limb lecing supported in thestraight position, and the extensor museles rrlised, the natural range of mobility laterally of the patella can be

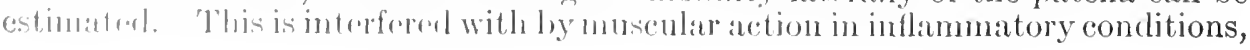


or by early tuberculous ulceration of the contiguous cartilages. The numerous longitudinal striæ or sulci on the anterior surface of this bone can now also be detected. In these are embedded tendinous bundles of the rectus, so as to give firmer leverage. The fact that these fibres, thus tied down, are liable after stretching and tearing to fold in between the ends of the bone after fracture, is a ready explanation of the difficulty of ensuring bony union here. (Macewen.) The patella is separated from the tibia by a pad of fat and a deep bursa, save at its insertion. Owing to the lowest part of the patella being thus separated from the joint by fat, fracture here does not, necessarily, open the joint.

The bone has the following relation to the femur in different positions:-(1) In extension, the patella rises over the condyles, and in full extension only the lower third of its articular surface rests upon that of the condyles; its upper two-thirds lies upon the bed of fat which covers the

Fig. 1163.-Deep Dissection of the Gluteal Region. (From a preparation in the Hunterian IIuseum.)

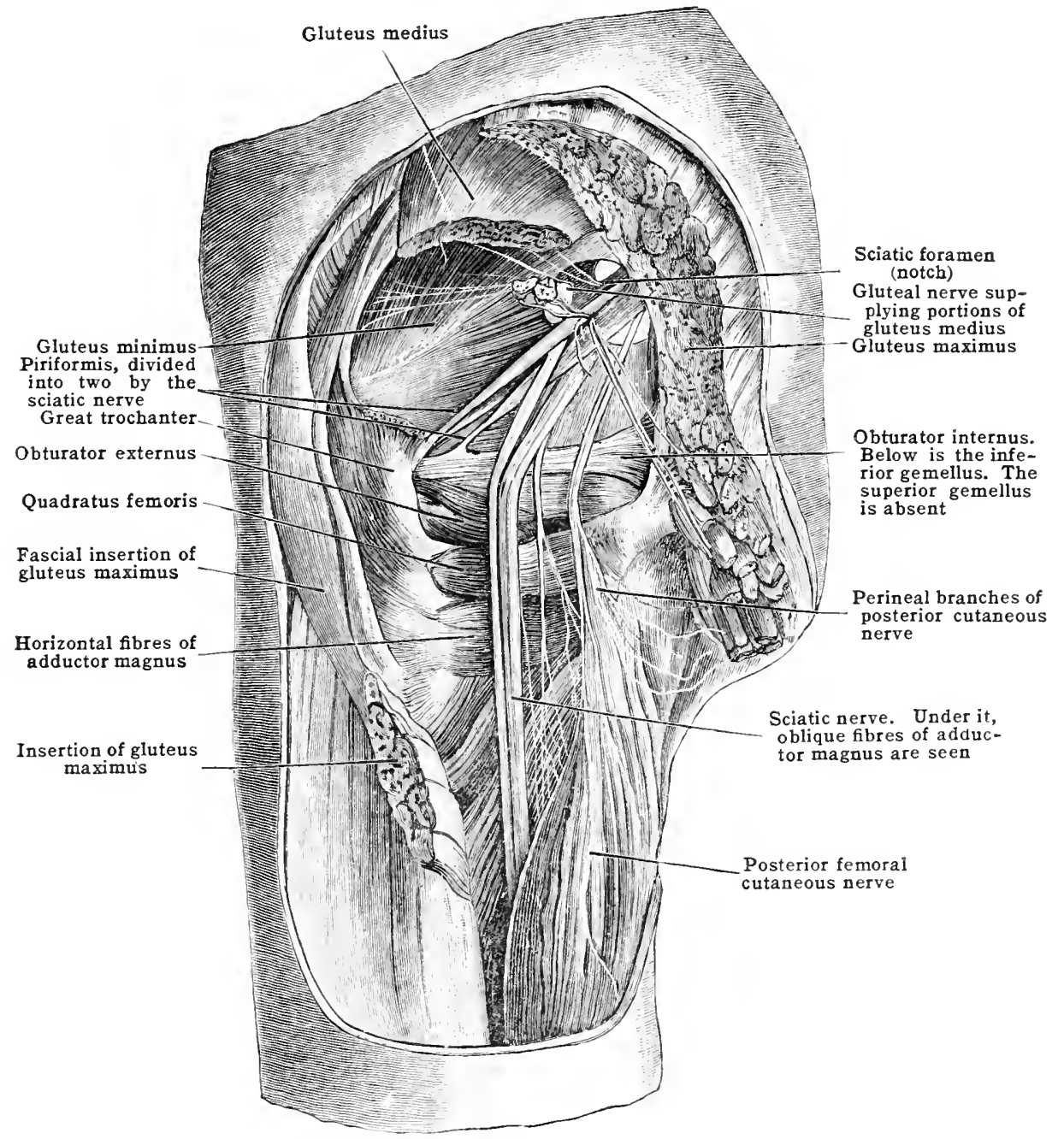

lower and front part of the femur. (2) In extreme flexion, as the prominent anterior surface of the condyles affords leverage to the quarliceps, the patella needs to project very little; thus, only its upper third is in contact with the femur, its lower two-thirds now resting on the pad of fat between it and the tibia. (3) In semiflexion the middle third of the patella rests upon the most prominent part of the condyles. (Humphry.) While the bone now affords the greatest amount of leverage to the quadriceps, it is also submitted to the greatest amount of strain from this muscle, which is acting almost at a right angle to the long axis of the patella. This position may therefore be called the 'area of danger,' as, in a sudden and violent contraction, the patella may be snapped across by muscular action, aided by the resistance given by the condyles, in the same way as a stick is snapped across the knee. The amount of separation of the fragments 
in a fracture of the patella is due chiefly to the extent to which the lateral tendinous expansions of the vasti are torn; to a less degree to the hemorrhage from the numerous articular vessels (p. 1452) and synovial effusion. The lower fragment is usually the smaller, and its fractured surface tilted forward; that of the upper one usually looks backward.

The patella, the largest of the sesamoid bones, ossifies by a centre which appears from the third to the fifth year. The proeess is completed about puberty. The rareness with which necrosis and caries occur here, when the exposed situation of the bone is remembered, is partly

Fig. 1164.-Knee-Joint as Shown by the Röntgen-Rays, Antero-posterior View.

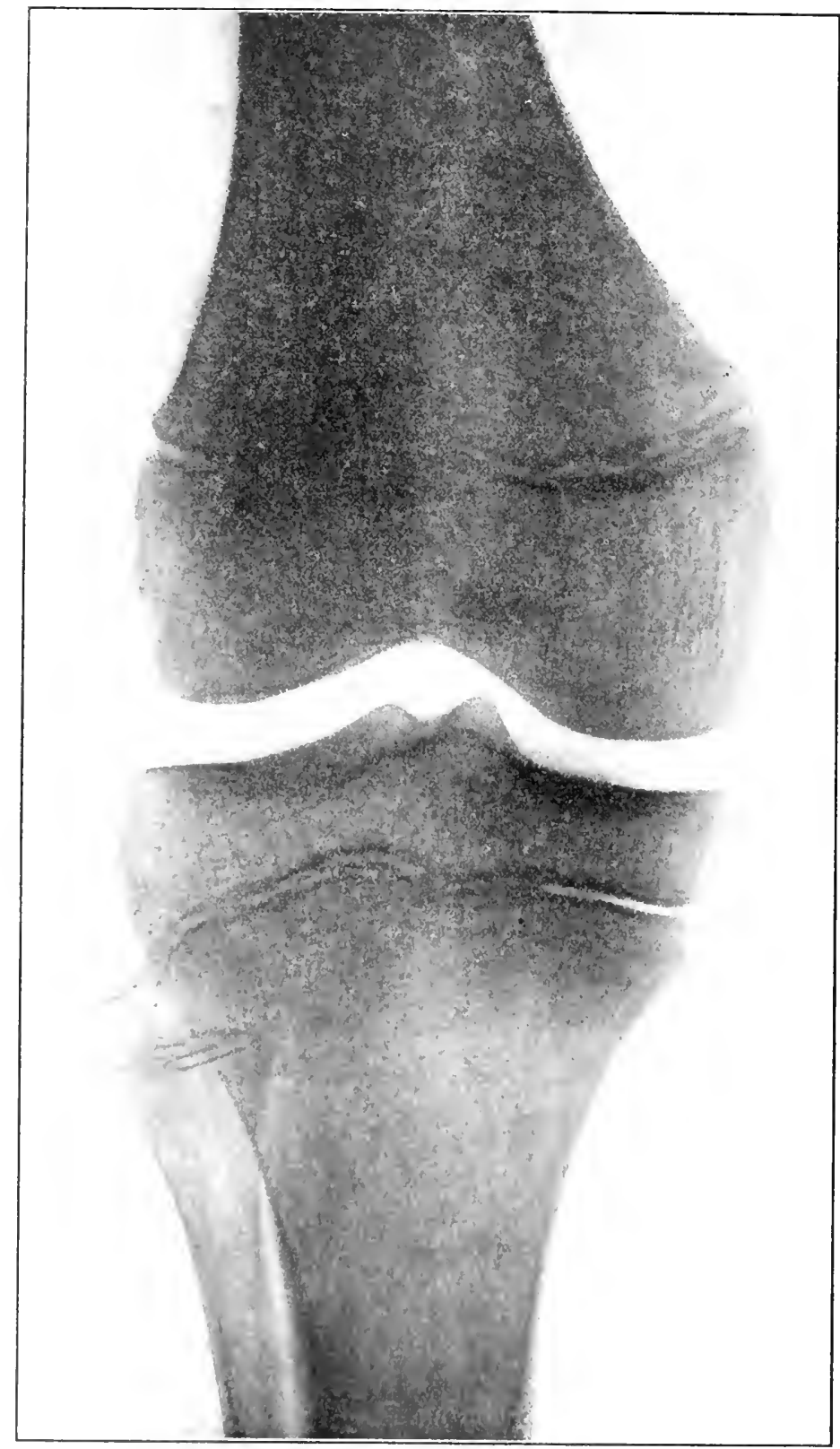

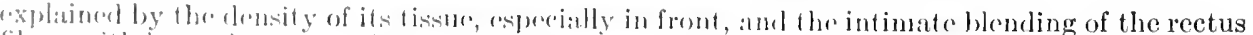

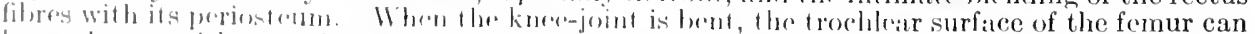

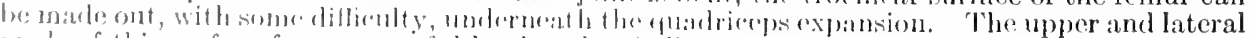

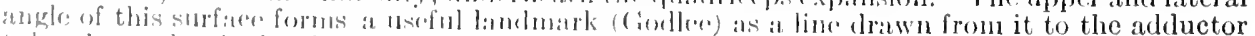

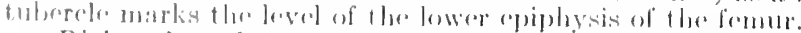

Dislocation of the patella. Whr following antomical filcls areount for this taking place

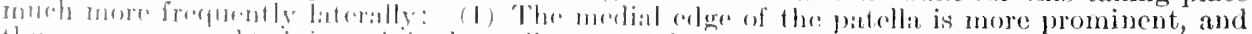
thos mere rexpend to injury; it is also well supportol, as is secen when, the parts being relaxed, the 
fingers are insinuated beneatl each border. (2) The pull of the extensor upon the patella, ligamentum patella, and tibia is somewhat laterally, as the tibia is directed a little laterally to the femur, to meet the medial direction of this bone; the femora being directed medially here, to bring the knee-joints nearer the centre of gravity, and, so, counterbalance their wide separation above at the pelvis. The lateral pull of the quadriceps upon the patella is, in all normal action of the muscle, counteracted by the space taken in the trochlear surface by the lateral condyle, this being wider and creeping up higher, and having a more prominent and thus protective lip. In violent contraction, however, these counteracting points may be overcome.

The condyles of the femur and tibia.-It should be noted that on the medial side the prominence of the medial epicondyle of the femur is well marked, and that

Fig. 1165.-Knee-joint as shown by the Röntgex-Rays, Lateral View.

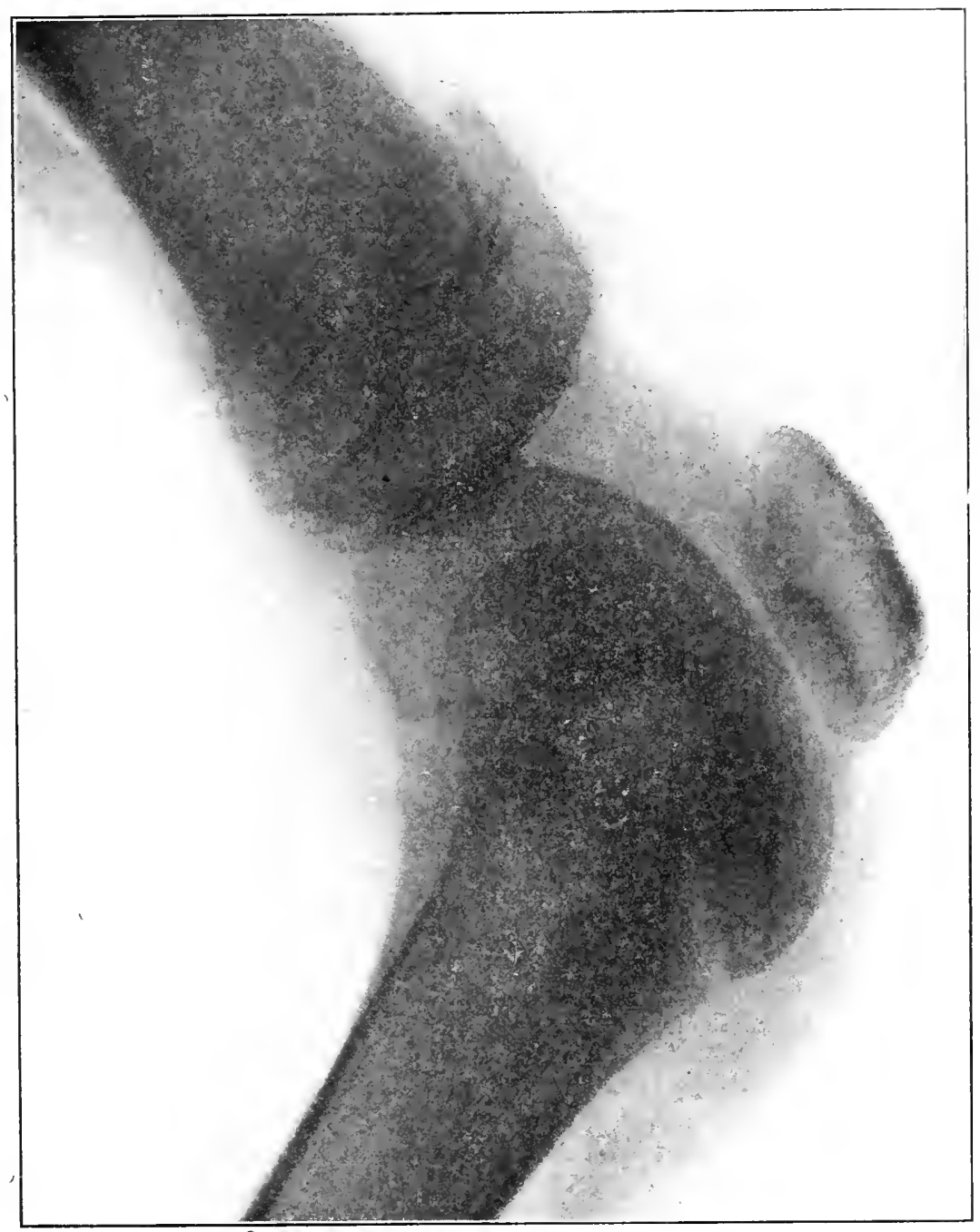

of the tibia is less so, while on the lateral side this condition is reversed. Descending to the lateral condyle of the tibia, the ilio-tibial band of the fascia lata can be traced. The more distinct lateral condyle is a good landmark for opening the joint in amputation and excision. It also indicates the lower level of the synovial membrane of the knee-joint.

Farther back are the biceps and fibular collateral (long external lateral) ligament. The gap on the medial side between the femoral and tibial condyles is the place for feeling for a displaced medial fibro-cartilage in 'internal derangement' of the knee, and also for 'lipping' in suspected osteoarthritis. On each femoral epicondyle, posteriorly, in a thin subject, can be felt its tubercle, which gives attachment to the collateral ligament. Owing to their being placel behind the centre of the bone, these ligaments become tight in extension. On the upper and posterior 
part of the medial femoral epicondyle the adductor tubercle and the vertical tendon of the adductor magnus can be felt during flexion. This bony point is a guide to the lower epiphysis, the ossification of which and its occasional exostosis have been mentioned at p. 1442 . The medial aspect of this epicondyle faces practically in the same direction as the head of the femur.

Ligamentum patellæ and tuberosity of tibia.- These, in a well-formed leg, should, with the centre of the ankle-joint, be all in the same straight line, a useful point in the adjustment of fractures. (Holden.) Behind the upper half of the ligament is the infrapatellar pad of fat; below, the lower half is separated from the tibia by a deep bursa. The tuberosity (tuberele) of the tibia is on a level with the head of the fibula.

IPrepatellar bursa.-This usially protects the lower part of the patella and upper part of the ligamentum patellæ. It is liable to be enlarged in those who habitually kneel much, the enlargement being either fluid or solid, and occasionally, in tertiary syphilis. Its close connection with the patella and, at the sides, with the joint itself, is to be remembered in infective inflammations of the bursa. Usually the deep fascia, passing off from the sides of the patella upward to the thigh and downward to the leg, serves to conduct inflammation away from the joint.

Synovial membrane (fig. 1167).-This, the largest of the synovial membranes, forms a short cul-de-sac above the patella, between the quadriceps extensor and the front of the femur, this process reaching about $2.5 \mathrm{~cm}$. (1 in.) above the trochlear surface of the femur. At its highest point this cul-de-sac communicates with an-

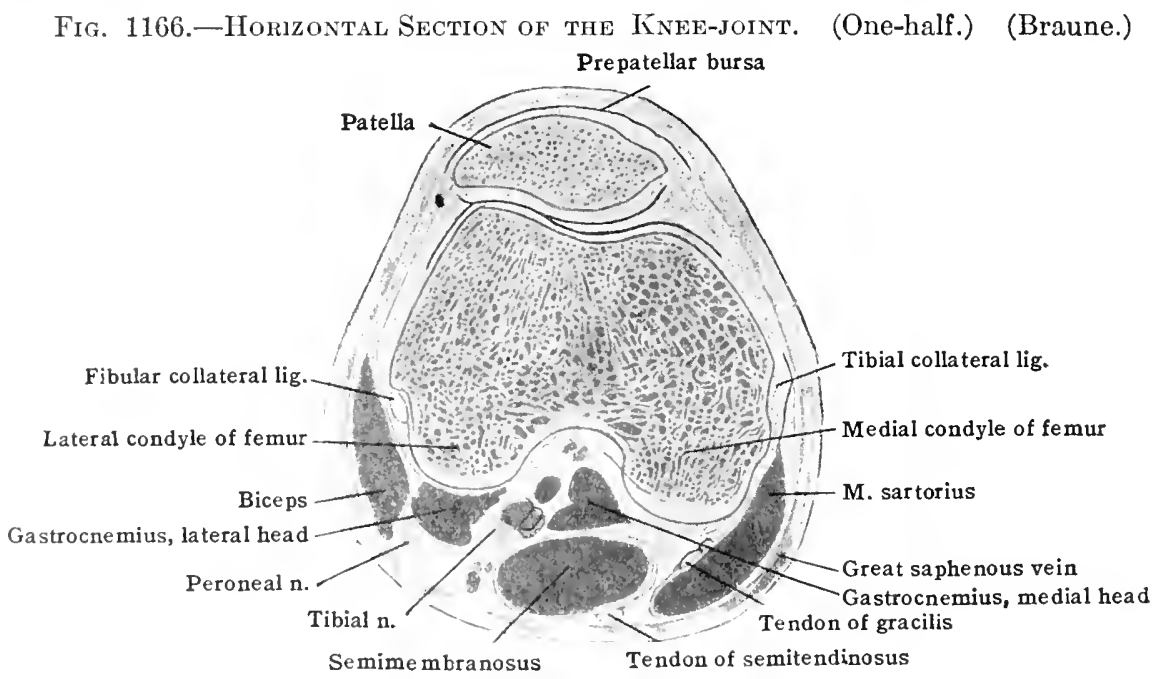

other synovial, bursa-like sac lying between the quadriceps and front of the femur.

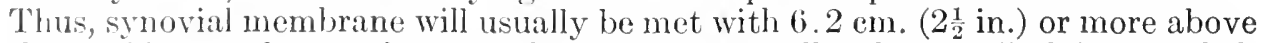
the trochlear surface or the upper border of the patella when the limb is extended. Flexing the joint draws the membrane down very slightly. During extension, the above pouch is supported by the articularis genu (suberureus). Traced downward, the membrane reaches the level of the head of the tibia, being separated in the mirldle line from the upper part of the ligamentum patella by fat. It here gives off to the intercondyloid notch the patellar synovial fold (ligamentum mucosums), with its free lateral prolongations, the alar folds (ligamenta alaria). These threesos-called ligiments contain fat, the processes not only padding gaps, but also) mecoting concussions.

The culargement of these processes, under conditions not yet understood, may certainly

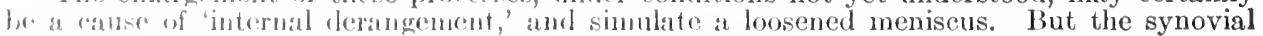
membrane of this joint is unt only the largest: it is also the most complicated, a fact accounting for the Lrave peril of infertive allthitis, ant the well-known hifliculty of effective drainage and

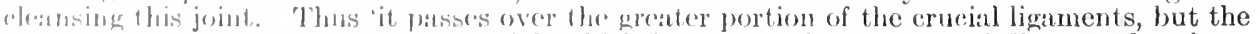

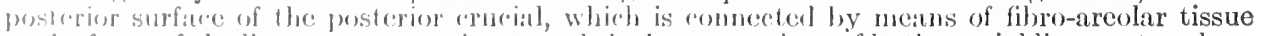
to) Hhe front of the liganentum posticum, and the lower wort ions of hoth erueial ligaments, where thry are muited together, of course cannot lecrive a complete covering from the membrane., (.)rris.)

From the almere ligaments the membrame is conducted, lining the lower part of the andsule and other liganents, to the semilumar cartilages, first over their 
upper surfaces to their free borders, and then along their under surfaces to the tibia. Between the lateral of these and the upper and back part of the tibia is a prolongation of the synovial membrane to facilitate the play of the popliteus tendon.

Finally, amid the complications of this synovial membrane, its communication with some of the bursæ mentioned below, and occasionally with the superior tibio-fibular joint, is to be borne in mind. In effusion the bony prominences are obliterated, and the patella 'floats.' The knee-joint is easily opened by free lateral incisions lying midway between the margins of the patella and the tuberosities of the condyles, drainage-tubes being passed so as to meet above the patella. The above-mentioned complications of the synovial membrane show that such drainage will be often inadequate. By passing a director to the back of the joint and cutting down upon it carefully from the popliteal space, better drainage will be given, but opening the joint by an anterior flap is needed where the above fail, and, even then, cleansing of the numerous deep recesses is obviously difficult.

Structures on the head of the tibia.-From before backward these are:(1) Transverse ligament. (2) Anterior end of medial meniscus (fibro-cartilage). (3) Lower attachment of anterior crucial. (4) Anterior end of lateral meniscus blending with (3). (5) Posterior extremity of lateral meniscus giving off a strong process to posterior crucial. (6) Posterior extremity of medial meniscus. (7) Posterior crucial ligament. Menisci.-These serve as buffer-bonds and cushions between the contiguous bones. The more frequent displacement of the medial is explained by- $(a)$ its greater fixity, and, therefore, its feeling strains more. Thus, in addition to weaker attachments to the coronary and transverse ligaments, it is connected all along its convex border with the inside of the capsule, and strongly with the tibial collateral ligament. The lateral meniscus, on the other hand, is more weakly attached to the capsule, especially opposite to the popliteus tendon, and has no tie to the fibular collateral ligament. (b) When, in the erect position, the knee-joint is rotated laterally and slightly flexed, a common position, an especial strain is thrown upon the very important tibial collateral ligament, and from the above-mentioned connection, on the medial meniscus also.

Position of knee-joint in disease.-In inflammatory effusion, the position which best accommodates the collection of fluid is one of moderate flexion, the ligaments being now mainly relaxed. Later on, when the ligaments are softened, the hamstrings obstinately displace the leg backward, the tibia being rotated laterally by the biceps. The antero-posterior displacement is always more marked than the lateral. In straightening an anchylosed joint, the resistance of the shortened lateral, crucial, and posterior ligaments, and the facility with which a softened upper epiphysial line of the tibia may give way, must never be forgotten. Erasion and excision. -The extent and complications of the synovial membrane render attention to the following points imperative:-(1) Free exposure of the joint usually by an anterior curved incision, the medial extremity of which must not damage the great saphenous vein. (2) The extent of the pouch under the quadriceps, it may be for $5 \mathrm{~cm}$. (2 in.) above the patella, and the lateral recesses under the vasti. The pouches at the back of the joint are far more difficult to deal with, viz., the partial covering of the posterior crucial ligament, the proximity of the popliteal artery, the pouches in relation to the popliteus, gastrocnemii, and back of the femoral condyles. In erasion, the cartilage and bone, where diseased, are removed with a gouge. Owing to the removal, in addition to the synovial membrane, of the fibro-cartilages, and crucial ligaments, and the damage to lateral and patellar ligaments, there is a most obstinate tendency to flexion afterward. In excision, to avoid injury to the epiphysis, the section of the femur should not pass higher than through the upper third of the trochlear surface. Of the tibia, only $12 \mathrm{~mm}$. $\left(\frac{1}{2}\right.$ in.) should be removed.

Genu valgum.- Here the natural angle at which the femur inclines medially to the tibia is increased. As shown by the late v. Mikulicz, this is due to an abnormal growth downward of the medial part of the femoral diaphysis, the epiphysial line being gradually altered from one at right angles to the shaft to one which runs obliquely from without downward and medially. The femur is not only elongated on its medial side, but bent at its lower end, the concavity of the curve being lateral. Other changes have to be remembered. Pes valgus very commonly coexists, and in the tibia there may be a compensatory curve, the concavity being medial, in the lower third, or an analogous alteration in the line of the upper epiphysis may be present, its direction being no longer at a right angle with the shaft, but oblique. In Sir W. Macewen's supra-condyloid osteotomy, a longitudinal incision, about $3.7 \mathrm{~cm}$. ( $1 \frac{1}{2} \mathrm{in}$.) long is made where the following lines meet, viz., one transverse, a finger's breadth above the upper margin of the lateral condyle, and one longitudinal, $1.2 \mathrm{~cm}$. ( $\frac{1}{2}$ in.) in front of the adductor magnus tendon. The bone is divided in front of the genu suprema and above the superior medial articular artery, above the epiphysial line and behind the uprard extension of the synovial membrane under the quadriceps.

The following bursæ about the knee-joint must be remembered. Some, it will be seen, are much more constant than others:- 
A. In front.-(1) One between the patella and skin, the bursa prepatellaris subeutanea (fig. 1167); (2) a deeper one between the ligamentum patellie and the upper part of the tibia; (3) between the skin and the lower part of the tuberosity of the tibia. This is not constant.

$B$. On the medial side.-(1) One between the medial head of the gastrocnemius and medial condyle, ofter extending between the above muscle and the semi-membranosus. This is the largest of the bursw about the knee-joint, and, after adult life, usually commmicates with the knee-joint. But, owing to the narrow communication, it is rarely possible, when the parts are relaxed by flexion of the joint, to empty the cyst. For its removal a straight incision is made over the most prominent part of the swelling, its neck found by drawing aside the tendons. A ligature is then pushed bigh up around the neck, and the cyst cut away. (2) One superficial to the tibial (collateral) ligament, between it and the tendon of the sartorius, gracilis, and semi

Fig. 1167.-Tertical Section of the Kinee-jornt in the Antero-posterior Direction. (The synovial bursa usually present above the upper synovial cul-de-sac is not shown.)

(The bones are somewhat drawn apart.) (After Braune.)

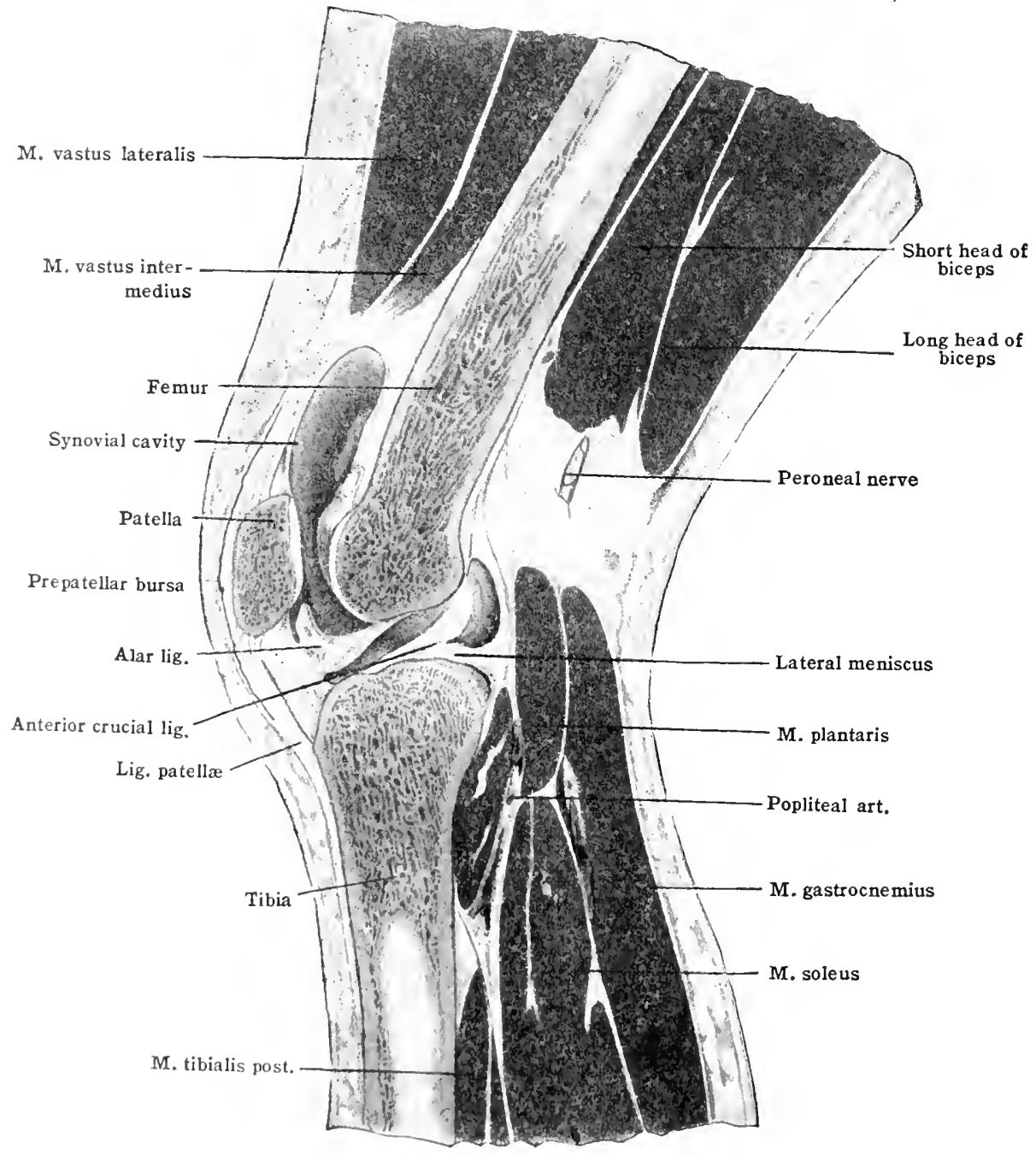

tendimsus. (3) One peneath the ligament, between it and the tendon of the semi-membranosns. (4) One between the neelial condylo of the tibia and the semi-membranosus. (5) One betwern the semi-memhrimests aml semi-icndinosus. Of the above bursa, the first two alone are enstant. "The secont and thirl are often one himsa prolonged.

C. On the lateral side.-(I) One lowwen the literal head of the gastroenemius and the "ondyle; (2) one: superficial to the fibular collateral ligament between it and the bieeps tendon; (3) ane under the ligiment betwen it and the poplitens fendon; (4) one between the popliteus

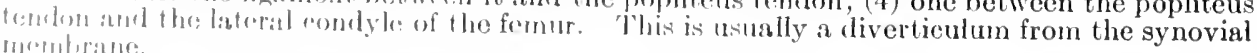
moputirates

The followimg aphlanations may be given of an inflamed knee-joint usually taking the

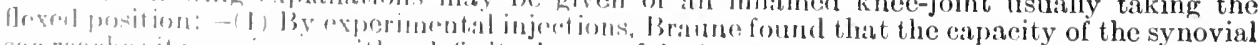

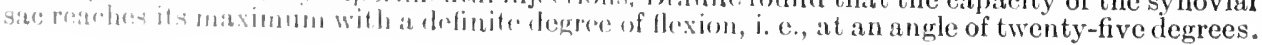


(2) As the same nerves supply the synovial membrane and the muscles which act upon the joint, reflex spasm of the flexors will help to explain the flexed position. (Hilton.)

Anastomoses around the front and sides of the knee-joint.--The most important of these take the form of three transverse arches. (1) The highest passes through the quadriceps fibres just above the upper edge of the patella. It is formed by a branch from the deep division of the genu suprema (anastomotica magna) and one from the lateral circumflex and superior lateral articular. The middle and lowest arches lie under the ligamentum patellæ. (2) The middle arch, formed by branches from the genu suprema and superior medial articular on the medial side, and the inferior lateral articular, on the lateral, runs in the fatty tissue

Fig. 1168.--Side View of the Popliteal Artery.

(From a dissection in the Hunterian Museum.)

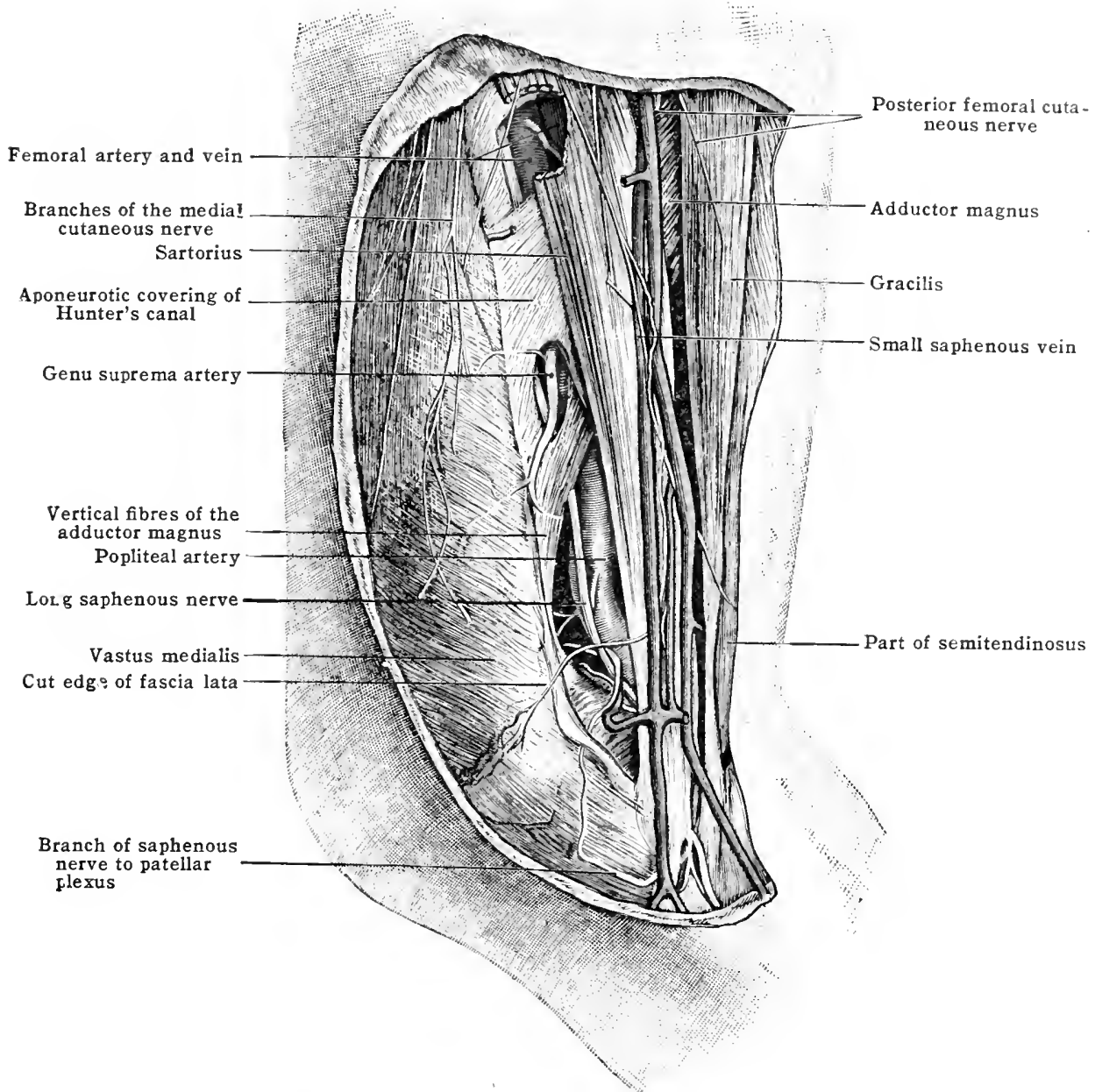

close to the apex of the patella. (3) The lowest arch lies on the tibia just above its tuberosity, and results from the anastomosis of the recurrent tibial and the inferior medial articular. Seven arteries thus take place in this series of anastomoses.

\section{POPLITEAL SPACE}

In flexion, the hollow of this space appears; in extension it is obliterated and its boundaries are ill-defined, the only ones now to be made out being the semitendinosus and the biceps.

Popliteal tendons.- When the knee is a little bent and the foot rests on the ground, the following can be made out:- on the lateral aspect, behind the ilio-tibial band, and descending to the prominence on the lateral side of the heal of the fibula, is the tendon of the biceps. This 
prominence also gives attachment to the fibular collateral ligament, which splits the tendon into two parts. Behind is the apex (styloid process) from which the posterior part of the fibular collateral ligament arises. Parallel and close to the medial border of the tendon, the peroneal nerve descends, as a rounded cord, to cross the neck of the fibula and enter the peroneus longus. In tenotomy of the biceps an open incision should be employed to avoid injury to the nerve and insure the division of any contracted fascial bands. On the medial side the tendons are thus arranged: Nearest to the middle of the popliteal space is the long and more slender tendon of the semi-tendinosus; next, the thicker tendon of the semi-membranosus; this and the gracilis, which comes next, appear as one tendon, but by a little manipulation the finger can be made to sink into the interval between the semi-membranosus, with its thick rounded border laterally and the gracilis medially. The sartorius can easily be thrown into relief on the medial side of the joint by telling the patient to raise the leg extended, the limb being rotated laterally and one leg crosses over the other.

Popliteal vessels. - The artery traverses this space from above downward, appearing beneath the semi-membranosus, a little to the medial side of the middle line, and then passing down in the centre of the space to the interval between the gastrocnemii. Its course corresponds with a line drawn from the medial side of the

Fig. 1169.-Deep View of the Popliteal Space. (Hirschfeld and Leveillé.)

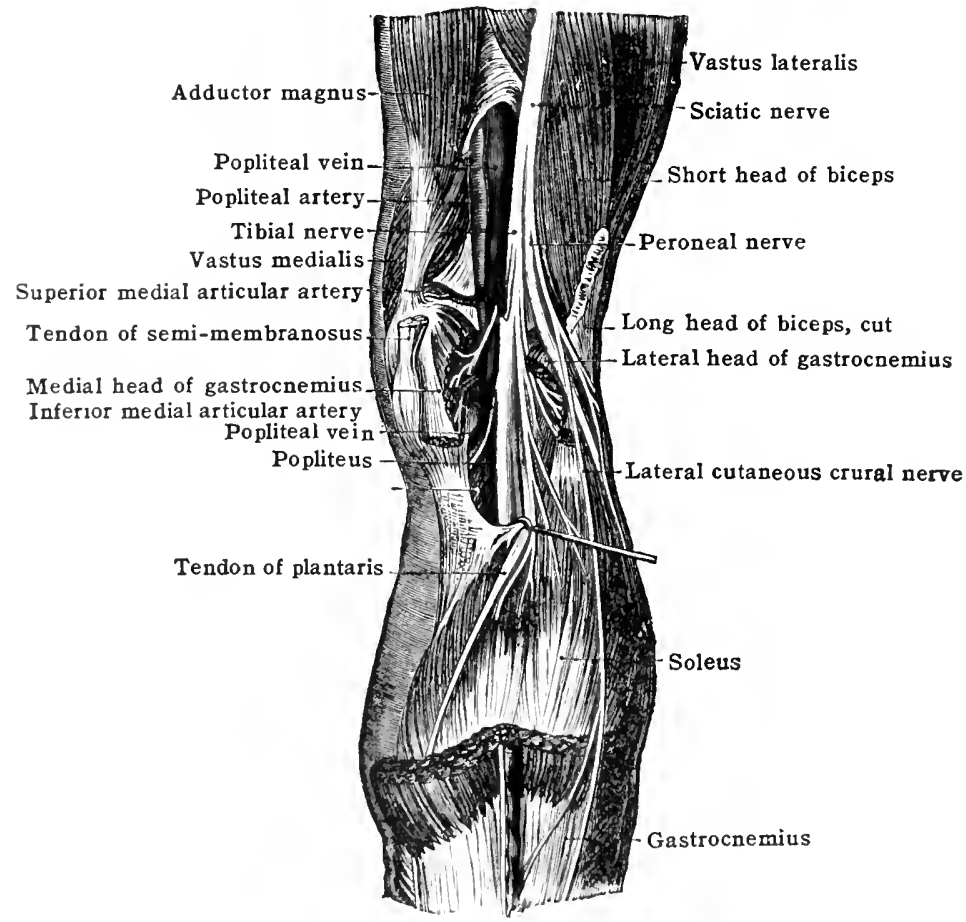

Small saphenous vein and nerve

hamstrings to the centre of the lower part of the space. The artery bifureates on the level of a line corresponding to the tuberosity of the tibia. It lies on the popliteal surface of the femur, the oblique popliteal ligament and the popliteus. It is the sreond of these struetures which usually prevents popliteal aneurism and abseress from making their way into the joint.

The popliteal vein, intinately adherent to the artery, lies to the lateral side above, but crosices to its medial sirle below, The pepliteal sheath is also unusually strong. The tibial nerve crosses the artery in the simme rlirection as the vein, by which it is separated from the artery. This merve is the direct contimation of the sciatic nerve (fig. 1169), and enters more into the spare than its fellow branch. The close relation of the vein and nerve explains the early stiffuess of the knee, the pains helow, often called 'rhematic,' and the oedena, in popliteal ancurisu; also the pulsition of swellings not aneurismal.

'The superior articular arteries (fig. 1 169) course litterally and medially immediately abovo the formen endyles; the way in which they aling elosely to the hone here is one provision to pre vont overst retehing of the artery; 1 he inferior ones lie just ahove the head of the fibula and below 1.he merlial comlyle of the tihia (figr. 1169). The deep part of the gem suprema artery runs in front of the fomlon of the ardinctor magnus; the smperfieial with the saplienous nerve.

[']' popliteal artery may be ligatured-(A) Behind, in the upper part of the popliteal spare, just after its cmergence from nurler the semi-membranosus. Ilere, for a short space 
of about $2.5 \mathrm{~cm}$. (1 in.), the vessel is comparatively superficial after division of the fascix. The nerve is generally seen first, and, with the vein, must be drawn laterally. The needle should be passed from the vein. (B) From the front, at the medial side. The thigh being flexed, abducted, and rotated laterally, a free incision is made parallel and just behind the adductor magnus tendon, commencing at the junction of the middle and lower third of the thigh. The sartorius and the hamstrings are drawn backward, and the adductor magnus forward. Care must be taken of the genu suprema (fig. 116s). The space between the hamstrings and the adductor magnus being carefully opened up, the artery will be found in fatty areolar tissue. The vein and tibial nerve are on the lateral side of the vessel. The needle is passed in lateromedially. The collateral circulation (fig. 1156) depends chiefly on the genu suprema.

The small saphenous vein perforates the roof of the popliteal space in its lower part. As a rule, it is not visible, unless enlarged.

The popliteal nodes are not to be felt unless enlarged.

Bursæ in the popliteal space.-These have been already spoken of (p. 1149).

\section{THE LEG}

The skin.- The proneness of the skin to dermatitis in the lower third of the medial and front aspect of the leg as a result of varicose veins is well known. The close contiguity of the periosteum to the skin here accounts for the difficulty in healing chronic ulcers whose callous base has become fixed to the periosteum, and the frequency with which the upper fragnent of a fractured tibia perforates the skin.

Bony landmarks.-From the tuberosity (tubercle) of the tibia descends the anterior border or 'shin.' 'This soon becomes sharp, and continues so for its upper two-thirds; in the lower third it disappears, to be overlaid by the extensor tendons. It is curved somewhat laterally above and medially below. The medial border can also be felt from the medial condyle to the medial malleolus. Betreen these two borders lies the medial surface, subcutaneous save above, where it is corered by the three tendons of insertion of the gracilis and semi-tendinosus, and, overlying them, that of the sartorius. The tibia is narrowest and weakest at the junction of the middle and lower thirds, the most common site of fracture. Behind the medial malleolus, part of the groove for and the tendon of the tibialis posterior can be felt.

The head of the fibula can be felt distinctly, but the shaft soon becomes buried amongst muscles till about $7.5 \mathrm{~cm}$. (3 in.) above the lateral malleolus, where the bone expands into a large triangular subcutaneous surface.

This lies between the peroneus tertius and the other two peronei. The peroneus longus overlaps the brevis, especially in the upper two-thirds of the leg. In the lower third the brevis tends to become anterior (fig. 1173). Behind the lateral malleolus these tendons descend to the foot in a groove on its posterior border. The shaft of the fibula is placed on a plane posterior to that of the tibia, and curves backward in a direction reverse to that of the tibia.

Muscular compartments and prominences.- When the muscles of the leg are thrown into action by dorsi-flexion and plantar flexion of the foot or by standing on the toes, several groups of muscles stand out on the surface, owing to certain compartments, and the origin of certain muscles from, and their separation by, the deep fascia, which knits the surface into corresponding elevations and depressions. The bones and the two peroneal septa divide the leg into four compartments.

These are, medio-laterally:-(1) A medial, corresponding to the medial surface of the tibia. (2) An anterior, between the crest of the tibia and the anterior peroneal septum, attached to the antero-lateral border of the fibula, and separating the extensors firom the peronei. Its surface-marking would be a line from the front of the head of the fibula to the front of the lateral malleolus. In this anterior compartment lie the extensor muscles and origin of the peroneus tertius, and the anterior tibial vessels and nerves. (3) A lateral or peroneal compartment, lying between the anterior and posterior peroneal septum, the latter being attached to the postero-lateral border of the fibula, and separating the peronei from the calf and deep flexors. This peroneal compartment, a narrow one, contains the two chief peronei and the peroneal (external popliteal) nerve and its three divisions. (t) Much the largest, this, the posterior, lies between the posterior peroneal septum and the medial border of the tibia, and contains the calf and deep flexor muscles, the posterior tibial vessels and nerves, and the peroneal artery and its posterior branch.

The space between the tibia and fibula in front is mainly occupied by the fleshy belly of the tibialis anterior; lateral to this, and much less prominent, is the narrower extensor digitorum longus; lateral to this, again, are the peronei longus and brevis. Lower down, in an interval between the tibialis and the extensor of the toes, the extensor hallucis, here almost entirely tendinous, comes to the surface. Behind, the prominence of the calf is mainly formed by the gastrocnemius. On the patient's rising on tip-toe, the tendo Achillis starts into relief 
from about the middle of the leg. Of the two heads of the gastrocnemius, the medial is seen to be the larger. On either sirle of the tendon, but more distinetly on the lateral side, where it is less overlapped by the gastrocnemius, the soleus comes into view. Its muscular fibres are continued on the deep surface of the tendon to within a short distance of the heel. Between the tendon and the upper part of the os calcis is a bursa, occasionally the seat of effusion, as in gonorrhoea.

The bones.-Their relative position and curves have been mentioned (p. 1453). Access.That to the tibia is easy along the nedial aspect. The fibula is best explored by a free incision along the line of the posterior peroneal septum, which lies between the peronei and the muscles at the back ( $p, 1453$ ). The presence of the superficial peroneal (musculo-cutaneous) nerve perforating the deep fascia in the lower third below and that of the common peroneal (external popliteal) in relation to the neck of the fibula above, must be remenbered. Fractures. - When,

$$
\text { Fig. 1170.-Anastomoses of Tibial Arteries. }
$$

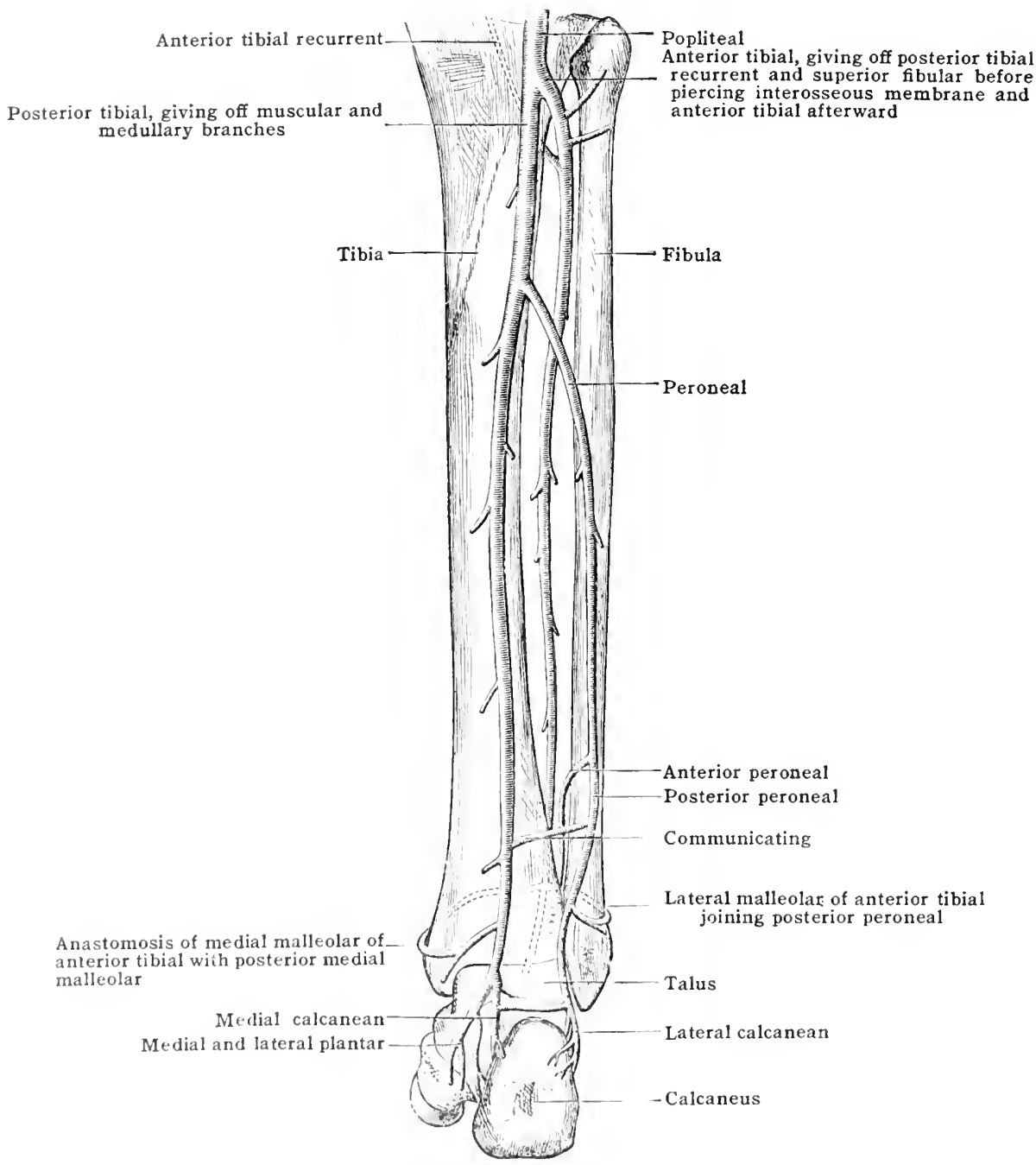

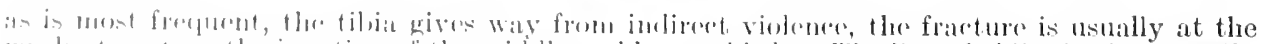

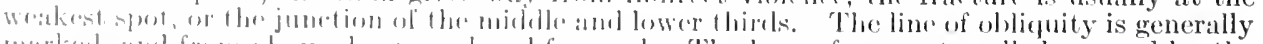

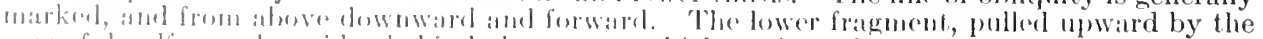

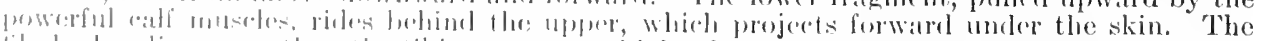

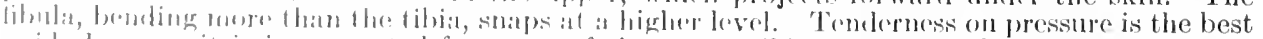

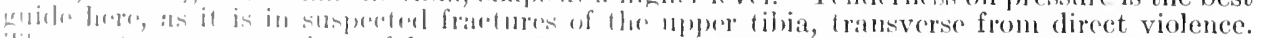

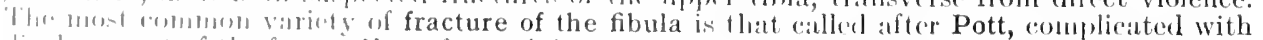

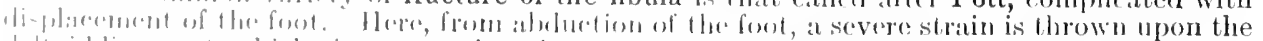

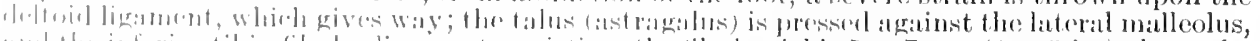

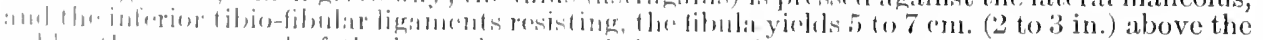

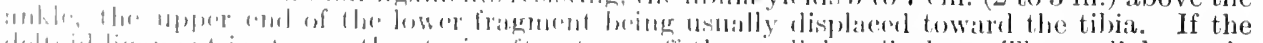

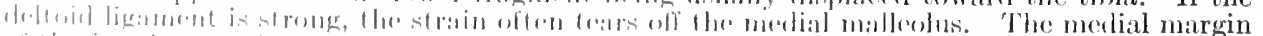

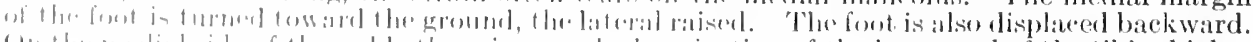

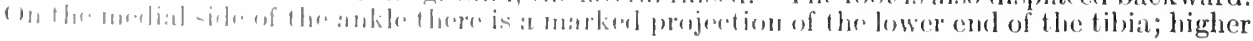


up, on the lateral side, a depression where the fibula is broken. The need of replacing thesfoot and the weight-bearing talus (astragalus) accurately, the fact that the ankle-joint is opened and the numerous tendons likely to be matted are the chief points to bear in mind. In Dupuytren's fracture there is not only fracture of the lower end of the fibula, but the inferior tibio-fibular ligaments are now torn. The foot is displaced upward and laterally, together with the lower

Fig. 1171.-The Axterior Tibial Artery, Dorsal Artery of the Foot, axd Perforatixg Branch of the Peroneal Artery, and Their Braxches.

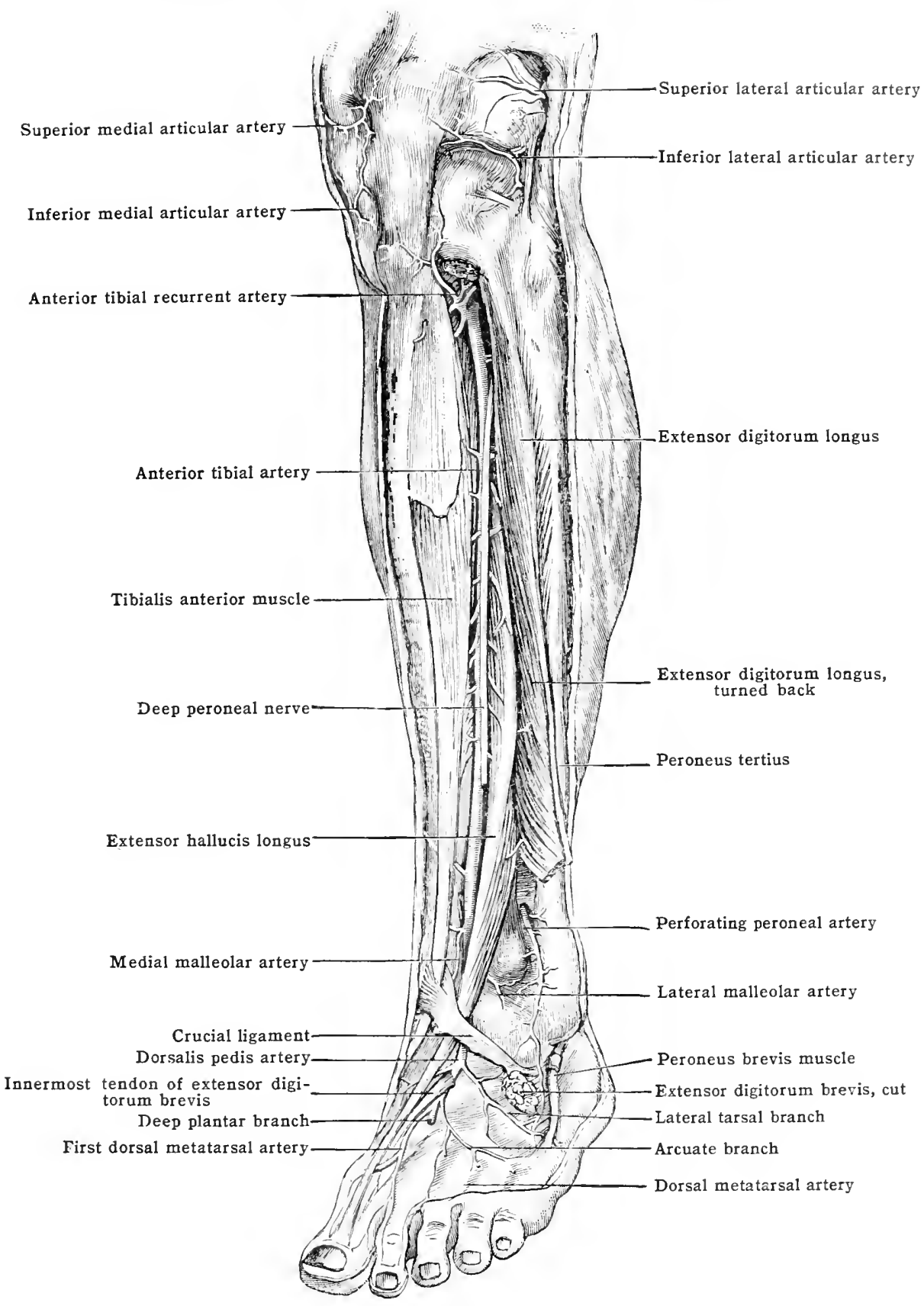

end of the fibula. Epiphyses.-The upper one of the tibia appears shortly before birth and includes the condyle and tuberosity. It does not fuse with the shaft till the age of twenty or later. This fact and the powerful strain of the rectus on this epiphysis explain the obscure pain sometimes complained of in young adults much given to athletics, over the tibial tuberosity. The lower epiphysis, including the medial malleolus, appears in the second and joins about the eighteenth year. Separation here is not very uncommon up to puberty. In osteotomy of the 
tibia, simple or cuneiform, when the curve is antero-posterior as well as lateral, the close vicinity of the tibialis anterior tendon to the lateral border of the crest must be remembered, and when the superior and the superior and inferior tibio-fibular ligaments, or to the epiphyses of the bones.

Fig. 1172.-The Superficial Teins and Lymphatics of the Left Lower Limb.

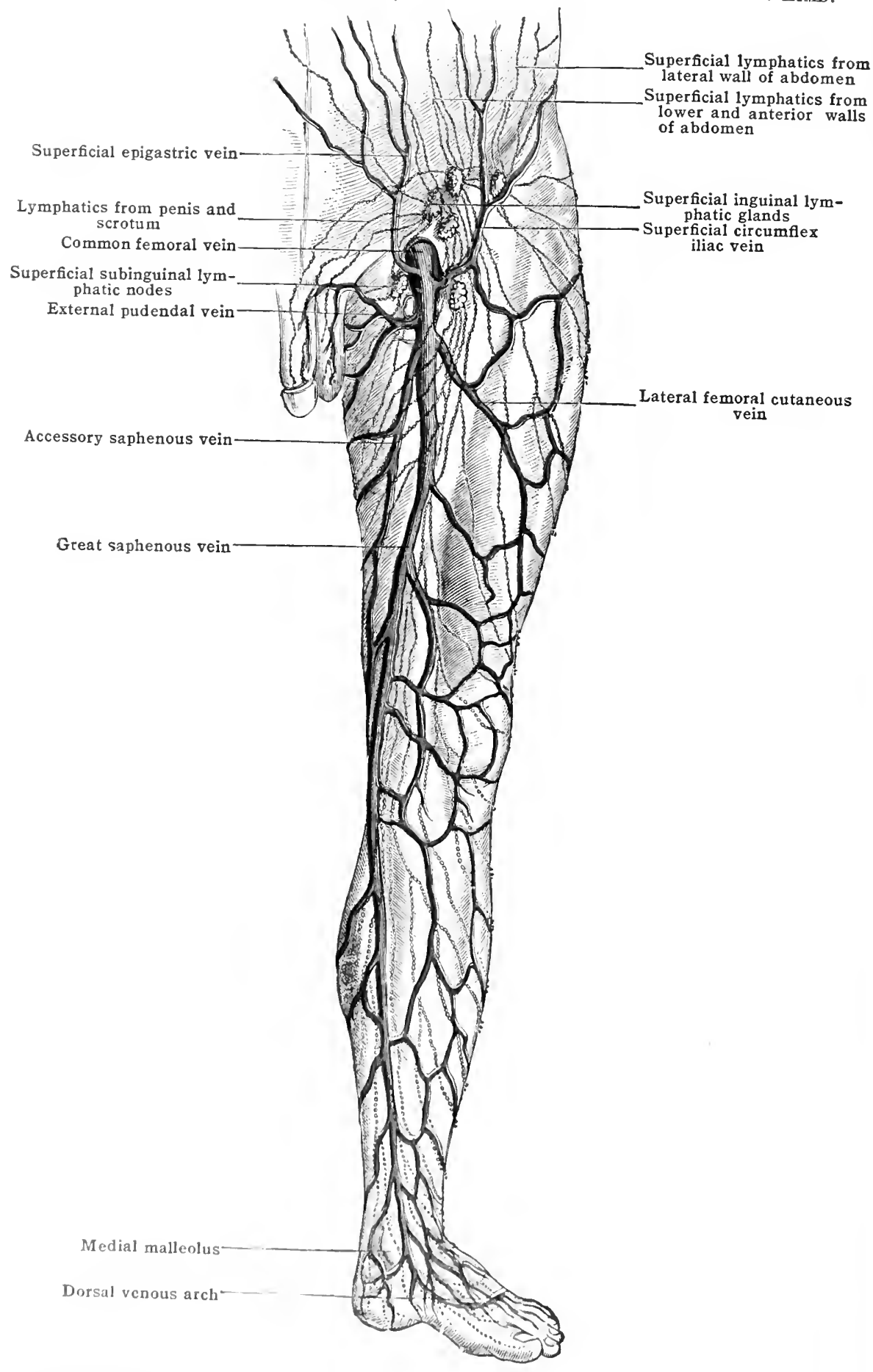

Vessels.-- The saphenous veins should be carefully traced, owing to the tendrney of thes: and their branches to become varicose. The great saphenous 
(figs. 1158, 1172), having passed from the arch on the dorsum over the medial malleolus, runs up close to the medial border of the tibia, where it is to be avoided in ligature of the posterior tibial, to the back of the medial condyle; here this vessel is to be remembered in operations on the knee-joint; then upward along the thigh, over the roof of the adductor (Hunter's) canal, to the fossa ovalis (saphe-

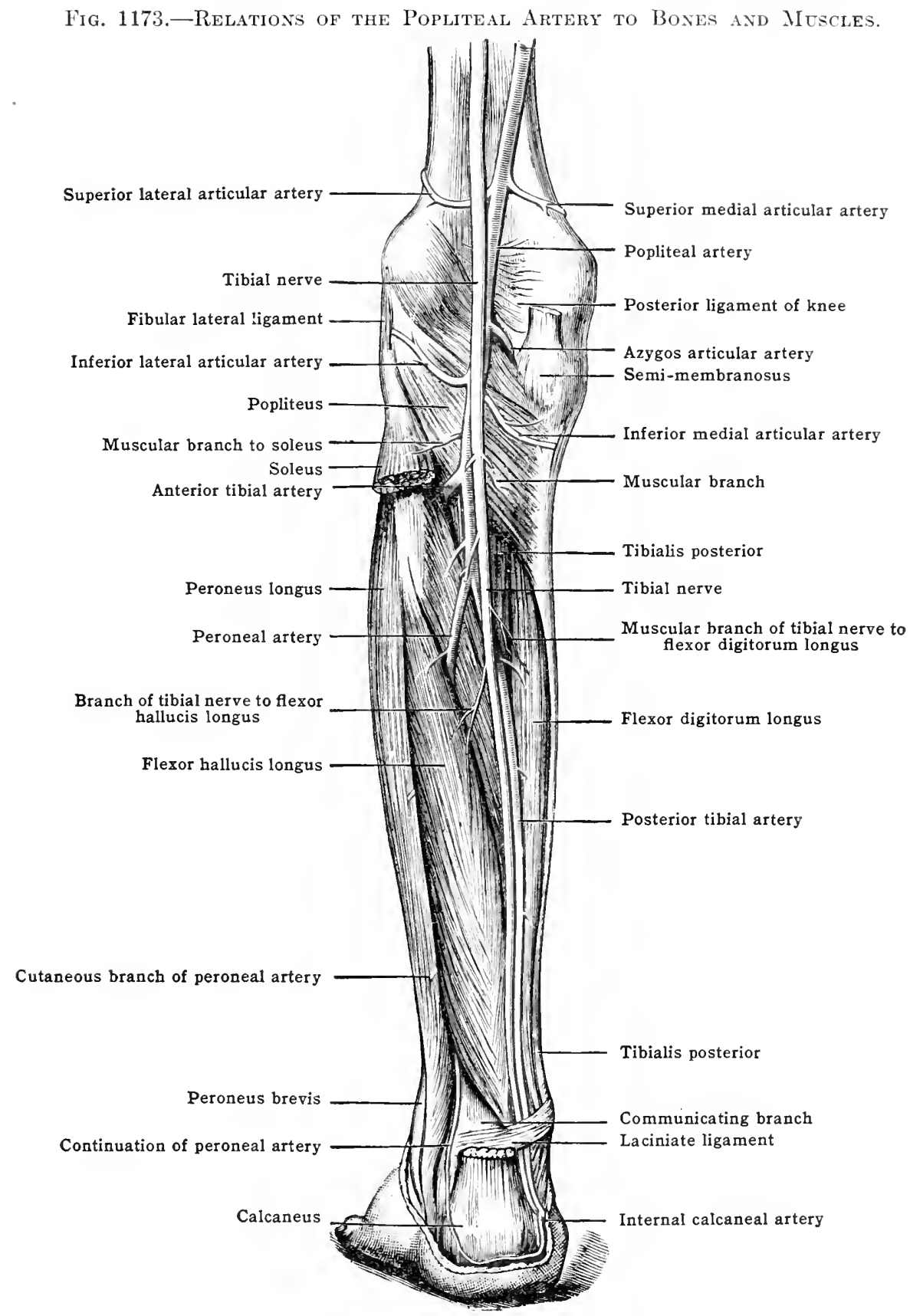

nous opening) (p. 1440 and fig. 1172), where it joins the femoral by perforating the cribriform fascia and the femoral sheath. Four to six valves are present, chiefly in the upper part.

The 'dangerous area,' or that in which thrombosis is most likely to occur, reaches from the centre of the thigh to the middle of the leg. (Bennett.) The saphenous nerve joins the vein below the knee, having been under the sartorius above this point (fig. 1159 and 1160). The 
surface-marking of the upper part of the vein is a line drawn from the posterior border of the sartorius or the adductor tuberele to the lower part of the fossa ovalis. The small saphenous vein passes behind the lateral malleohs, runs upward over the middle of the calf, and joins the popliteal by perforating the deep fascia in the lower part of the popliteal space. This vein is accompained by the medial sural cutaneous (external saphenous) nerve throughout its course.

The popliteal artery bifurcates at the lower border of the popliteus, about on a level with the tuberosity of the tibia. About $5 \mathrm{~cm}$. (2 in.) lower down the peroneal artery comes off from the posterior tibial (fig. 1173).

The course of the posterior tibial corresponds with a line drawn from the centre of the lower part of the popliteal space to a point midway between the tip of the medial malleolus and the medial edge of the calcaneus.

In the lower third, the artery becomes more superficial, passing from beneath the calf muscles, lying between the tendo Achillis and medial border of the tibia, and covered only by the skin, deep fascia, and, lower down, by the laciniate (internal annular) ligament. It is here, in its close relation to the tendons of the tibialis posterior and flexor digitorum longus, that it is liable to be injured in the older methods of tenotomy. The nerve is medial above, lateral below (fig. 1173).

Ligature of the posterior tibial in the middle of the leg.-The following are the chief points in the technique. An incision, 7.5 to $10 \mathrm{~cm}$. (3 to $4 \mathrm{in}$.) long, is made $1.2 \mathrm{~cm}$. ( $\frac{1}{2} \mathrm{in}$.) behind the

Fig. 1174.-Upper Segient of a Section of the Right Leg in the Upper Third.

(Heath.)

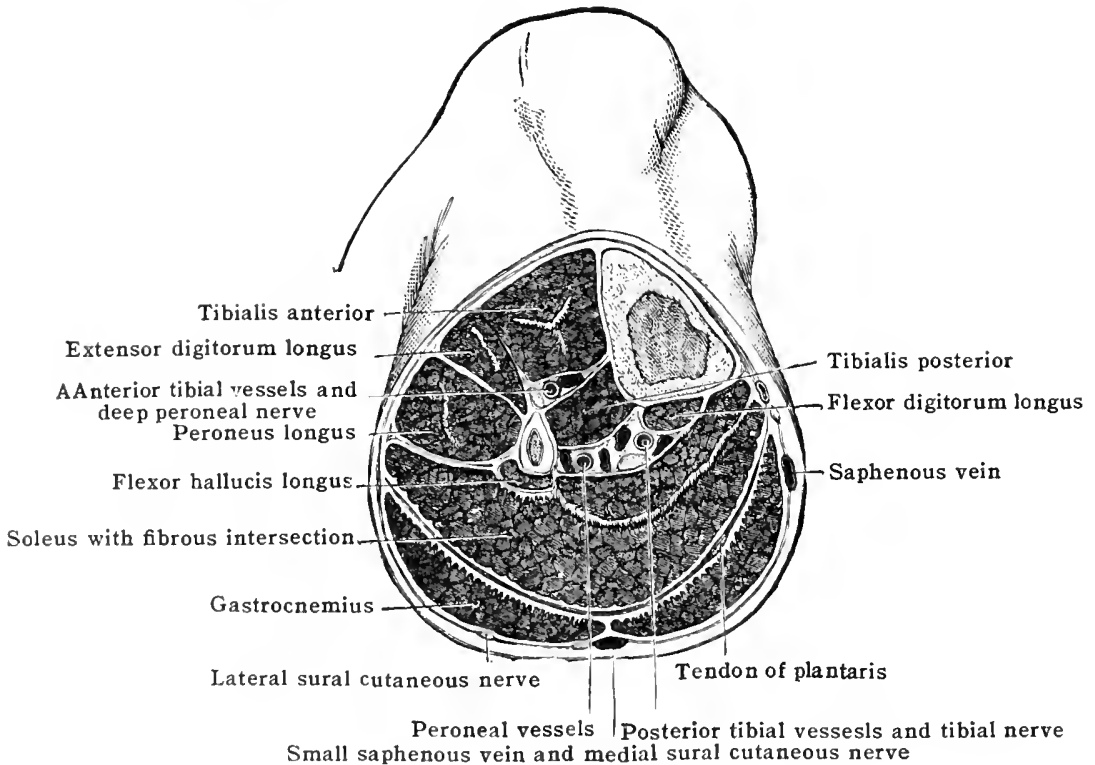

medial borler of the tibia, to avoid the trunk of the great saphenous. The deep fascia being freely opened, the medial head of the gastrocnemius is drawn biekward. The tibial attachment of the solens, thus exposed, is ent through earefully, so as to allow of identifieation of its eentral menbranous tendon, which must not be confused with the deep intermuseular septum over the flexor. Any sural vesseds are now tich. The above-mentioned special septum is next male ont, passing between the bones (vertieal line deseending from oblique line of tibia and olbligue line of fibula). On division of this septum the nerve usually eomes into view, the artery lying nore laterally. The nealle is passed from the nerve; the vene comitantes may be inchuforl. 'Tle muscles should uow les fully relaxed by flexion of knee and plantar flexion of foot. Thro ligature will be placed bolow the peroneal artery.

The course of the anterior tibial artery corresponds with a line drawn from a point midway between the lateral condyle of the head of the tibia and the head of the fibula to one on the centre of the ankle-joint.

'This lime corresponds to the bateral horder of the tibialis anterior and the interval between it and the rextopes digitorum longus (ligs. 1170 and 1174 ). This is shown when the first of these monseles is thrown into antion. The: arenmpanying norve is in fornt in the middle third of the loge latropial abore and below.

Ligature of the anterior tibial artery at. the junction of the upper and midulle thircls of the

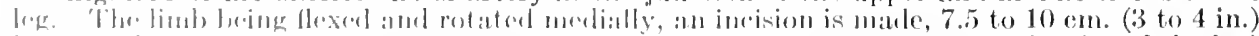
lomg, in the line of the artery, distant 2.5 an. (I in.) or more (aveording to the size of the leg)

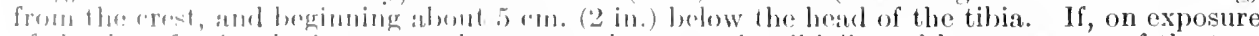
of the leesp fiscis, the intromsenlat septum between the tibialis and long extensor of the toes 
is not well defined, the fascia must be freely slit up in the line of the artery, and the sulcus felt for. A small muscular artery may leat down to the trunk. The foot is now dorsiflexed and the artery sought for deep on the interosseous membrane. The nerve should be drawn to the outer side. The venæe comitantes may be ineluded in the ligature.

In senile gangrene the liability of the tibial arteries to disease and consequent thrombosis and interferenee with the collateral circulation aceounts both for the extension of the disease and the difficulty in detecting pulsation.

The peroneal artery, given off from the posterior tibial about an inch below the popliteus, or two inches below the head of the fibula, runs deeply along the medial border of this bone, covered by the flexor hallueis longus, the nerve to which accompanies the ressel.

It gives off the anterior peroneal, through the interosseous membrane, to the front of the lateral malleolus about an ineh above the level of the ankle-joint. Its continuation, as the posterior peroneal, runs behind the malleolus, to join the anastomosis about the ankle-joint.

The nutrient artery of the tibia arises from the posterior tibial near its eommencement. It is the largest of all the nutrient arteries to the shafts of long bones; that for the fibula comes from the peroneal.

As a general rule, in amputation $2.5 \mathrm{~cm}$. (1 in.) below the head of the fibula, only one main artery - the popliteal-is divided. In amputations $5 \mathrm{~cm}$. (2 in.) below the head of the fibula, two main arteries - the anterior and posterior tibials-are divided. In amputations $7.5 \mathrm{em}$. ( 3 in.) below the head, three main arteries-the two tibials and the peroneal-are divided. (Holden.)

In an amputation through the middle of the leg. the anterior tibial artery would be found cut on the interosseous membrane between the tibialis anterior and the extensor hallucis longus, the deep peroneal nerve here lying in front of the vessel. The posterior tibial would be between the superficial and deep muscles at the back of the leg lying on the tibialis posterior, its nerve being to the lateral side. The peroneal would be close to the fibula in the flexor hallucis longus.

The superficial peroneal (museulo-eutaneous) nerve, having passed through the peroneus longus and then between the peroneus longus and peroneus brevis, perforates the deep fascia in the lower third of the leg in the line of the septum between the peronei and extensors. Directly after, it divides into its two terminal branches.

Amputation of the leg.-To give one instance only, amputation 'at the seat of election, or a hand's-breadth below the knee-joint, will be alluded to. Lateral skin-flaps and circular division of the muscles give an exeellent result in hospital practice where the various conditions which call for such a step are usually met with. The above name was given because the pressure of the body is well carried on the prominences about the knee-joint, espeeially the tuberosity of the tibia, when the patient walks with the knee flexed on a 'bucket' artificial limb. Thus the scar, being central, is here not of importance. Two broadly oval hateral flaps of skin and fascie are raised, and the remaining soft parts severed down to the bones with circular sweeps of the knife. In sawing the bone, the smaller size of the fibula and its position behind the tibia must be remembered. It is well, in order to ensure eomplete division of the fibula first, to roll the limb well over on its medial side, and place the saw well down on the lateral side. The parts cut through are shown in fig. 1174.

\section{THE ANKLE}

Bony landmarks.- The following are the differences between the two malleoli : The medial is the more prominent, shorter, and is placed more anteriorly than the lateral, being a little in front of the centre of the joint. The lateral descends lower by about $1.2 \mathrm{~cm}$. ( $\frac{1}{2} \mathrm{in}$.), and thus seeurely loeks in the joint on this side; it is opposite to the eentre of the ankle-joint, being placed about $1.2 \mathrm{~cm}$. ( $\left.\frac{1}{2} \mathrm{in}.\right)$ behind its fellow.

Owing to the lateral malleolus descending lower than the medial, in Syme's and Pirogoff's amputations the plantar incision should run between the tip of the lateral malleolus and a point $1.2 \mathrm{~cm}$. ( $\frac{1}{2} \mathrm{in}$.) below that of the medial one. When a fracture is set, or a dislocation adjusted, the medial edge of the patella, the medial malleolus, and the medial side of the great toe are useful landmarks and should be in the same vertical plane, regard being paid at the same time to the corresponding points in the opposite limb. (Holden.)

On the posterior aspect of the medial malleolus is a groove for the tibialis posterior and flexor digitorum longus, the first named being next the bone. The tip and borders of the process give attachment to the cleltoid ligament. The anterior border and tip of the lateral malleolus give attachment to the anterior talo-fibular and caleaneo-fibular ligaments respectively, the posterior talo-fibular arising from a pit behind and below the artieular facet. The posterior border is grooved for the two peronei. The line of the ankle-joint eorresponds to one about $1.2 \mathrm{~cm}$. ( $\frac{1}{2}$ in.) below the tip of the medial malleolus drawn aeross the anterior aspect. 
Effusion or tuberculous thickening shows itself first in front, between the medial mallcolus and tibialis anterior and between the peroneus tertius and lateral malleolus and then behind, where it fills up the hollow between the tendo Achillis and the two malleoli. Owing to the thinness of the transverse crural (anterior) ligament, the extensor sheaths are easily affected in neglected tuberculous disease. Owing to the way in which the joint is locked in, it is not easy to open and drain an infected ankle-joint satisfactorily. Removal of a portion of the lateral

\section{Fig. 1175.-Branches of the Common Peroneal Nerve.}

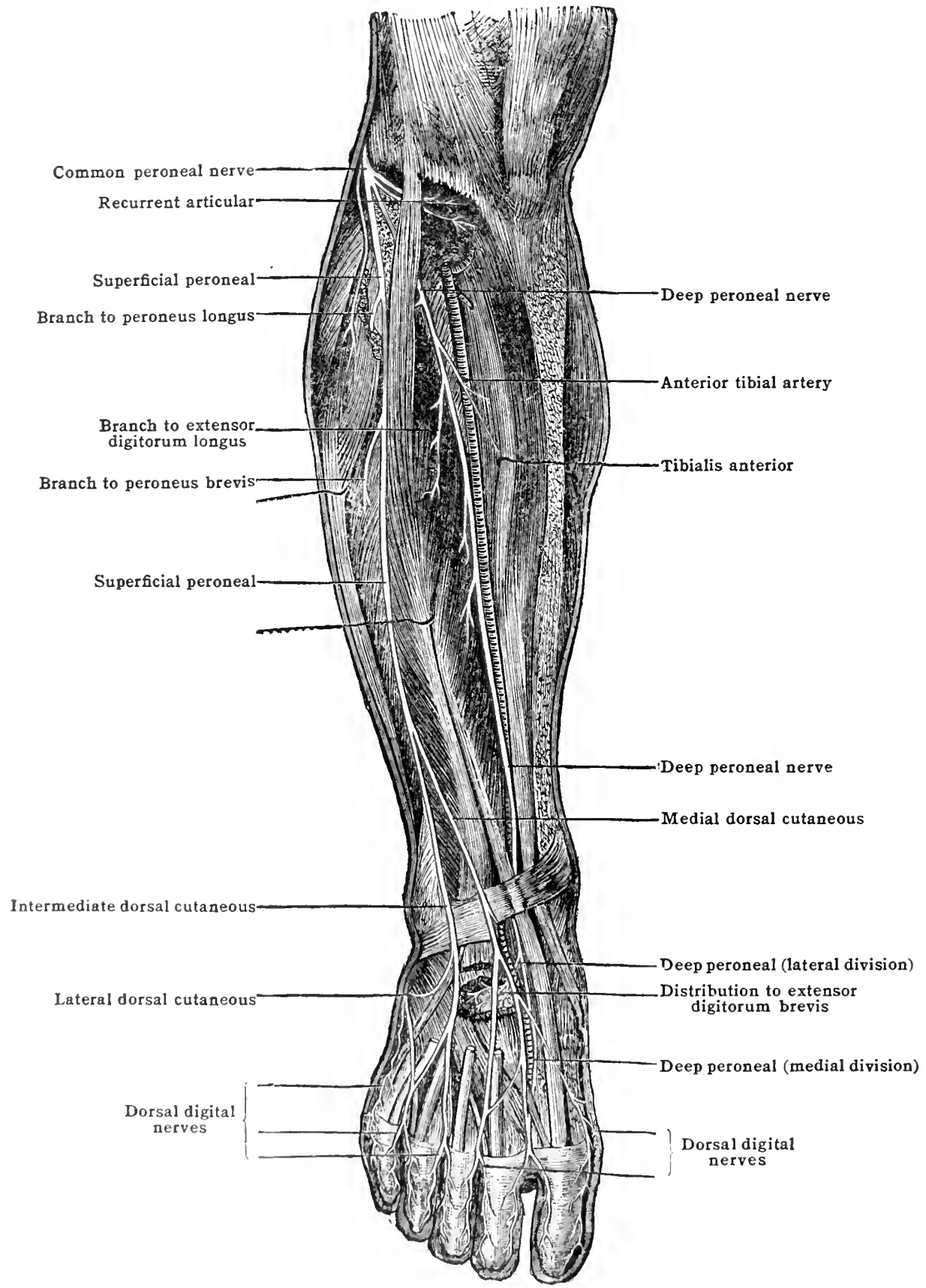

mallenlus subpreriosteally, lraving the tip and calcaneo-fibular, will admit of the insertion of a fubr: and gourl drainage if the foot is so slung as to keep its lateral aspect dependent.

Tendons.-(1) In front of ankle.-Iatero-medially are-(1) The tibialis anterior, the larerest and most medial. This trublon appears in the lower third of the leg, lying just under the deep faseiat, close to the tibia; then, crossing over the 
lower end of this and the ankle-joint, it passes over the medial side of the tarsus, to be inserted into the medial and lower part of the first cuneiform and the adjacent part of the first metatarsal. (2) The extensor hallucis longus. This tendon, concealed above, appears low down in a line just lateral to the last, and then, crossing over the termination of the anterior tibial vessels and nerves (to which its muscular part lies lateral), it descends along the medial part of the dorsum to be inserted into the base of the last phalanx of the great toe. (3) and ( 4 ) The extensor digitorum longus and peroneus tertius enter a common sheath in the transverse crural ligament. The former then divides into four tendons, which

Fig. 1176.-Lateral View of the Ankle Region, as Shown by the Rontgex-rays

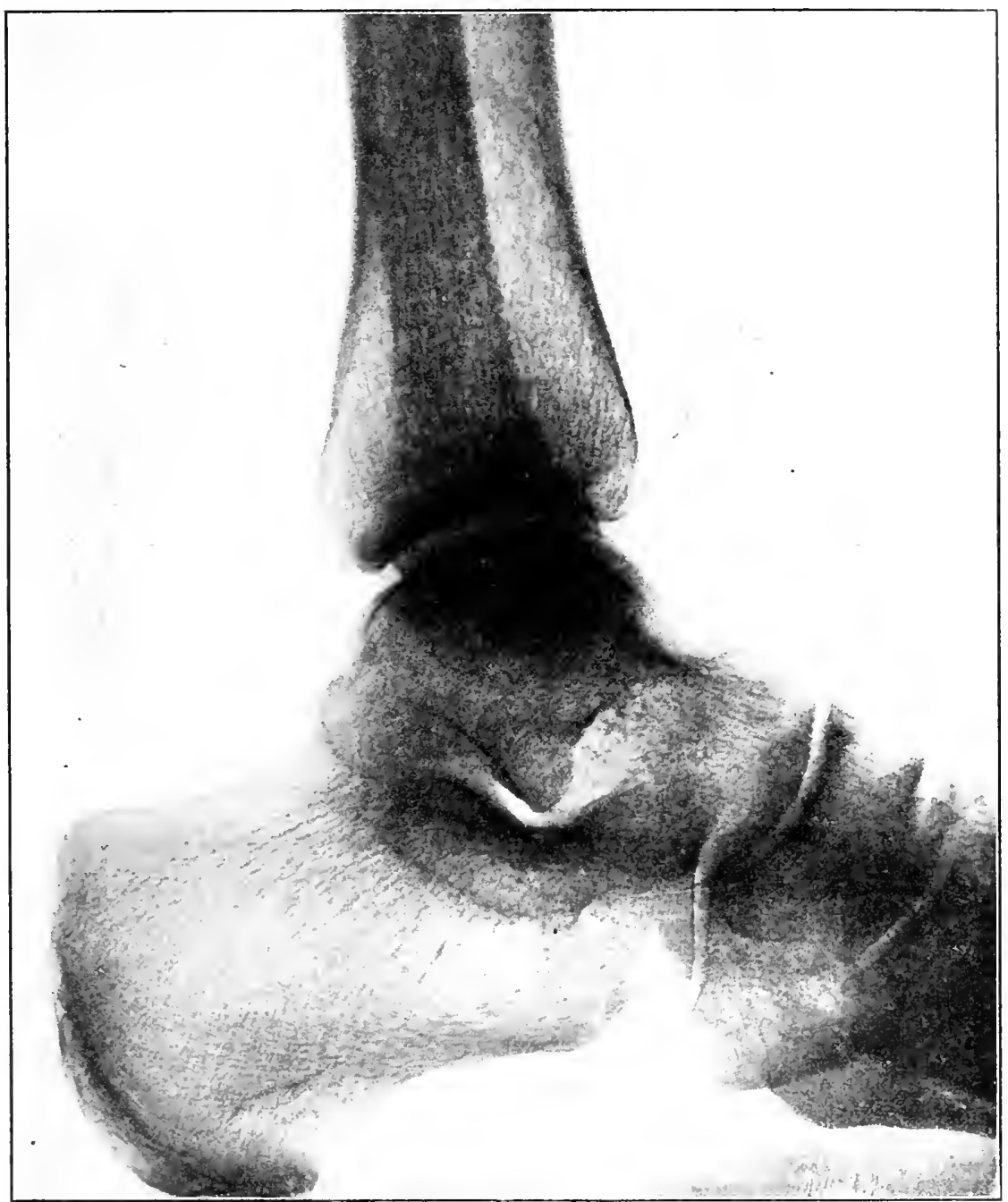

run to the four lateral toes. The peroneus tertius is inserted into the upper surface of the base of the fifth (often also the fourth) metatarsal bone.

(B) Behind.-The tendo Achillis, the thickest of all tendons, begins near the middle of the leg, in the junction of the tendons of the gastrocnemii and, a little lower, (p. 1453) the soleus. Tery broad at its commencement, it gradually narrows and becomes very thick. About $3.7 \mathrm{~cm}$. ( $1 \frac{1}{2} \mathrm{in}$.) from the heel, or about the level of the medial malleolus, is its narrowest point. After this it again expands slightly, to be inserted into the mildle of the back part of the calcaneus. The long tendon of the plantaris runs along its medial side, to blend with it or to be attached to the calcaneus. On either side of the tendo Achillis are well-marked 
furrows below. Along the medial, the tendon of the tibialis posterior and the posterior tibial ressels and nerve come nearer the surface. Along the lateral, the small saphenous vein (more superficially) ascends from behind the lateral malleolus.

(C) On the medial side.-The tendon of the tibialis posterior, which has previously crossed from the interspace between the bones of the leg to the medial side, lies behind the inner edge of the tibia above the medial malleolus, then behind this, being here under the flexor digitorum longus, the two tendons having becomesuperficial on the medial side of the tendo Achillis. It then passes forward over the deltoid and under the laciniate (internal annular) ligament between the medial malleolus and the sustentaculum tali, and then below and close to the plantar cal-

Fig. 1177.-Horizontal Section throvgh the Lower Part of the leg. (After Braune.)

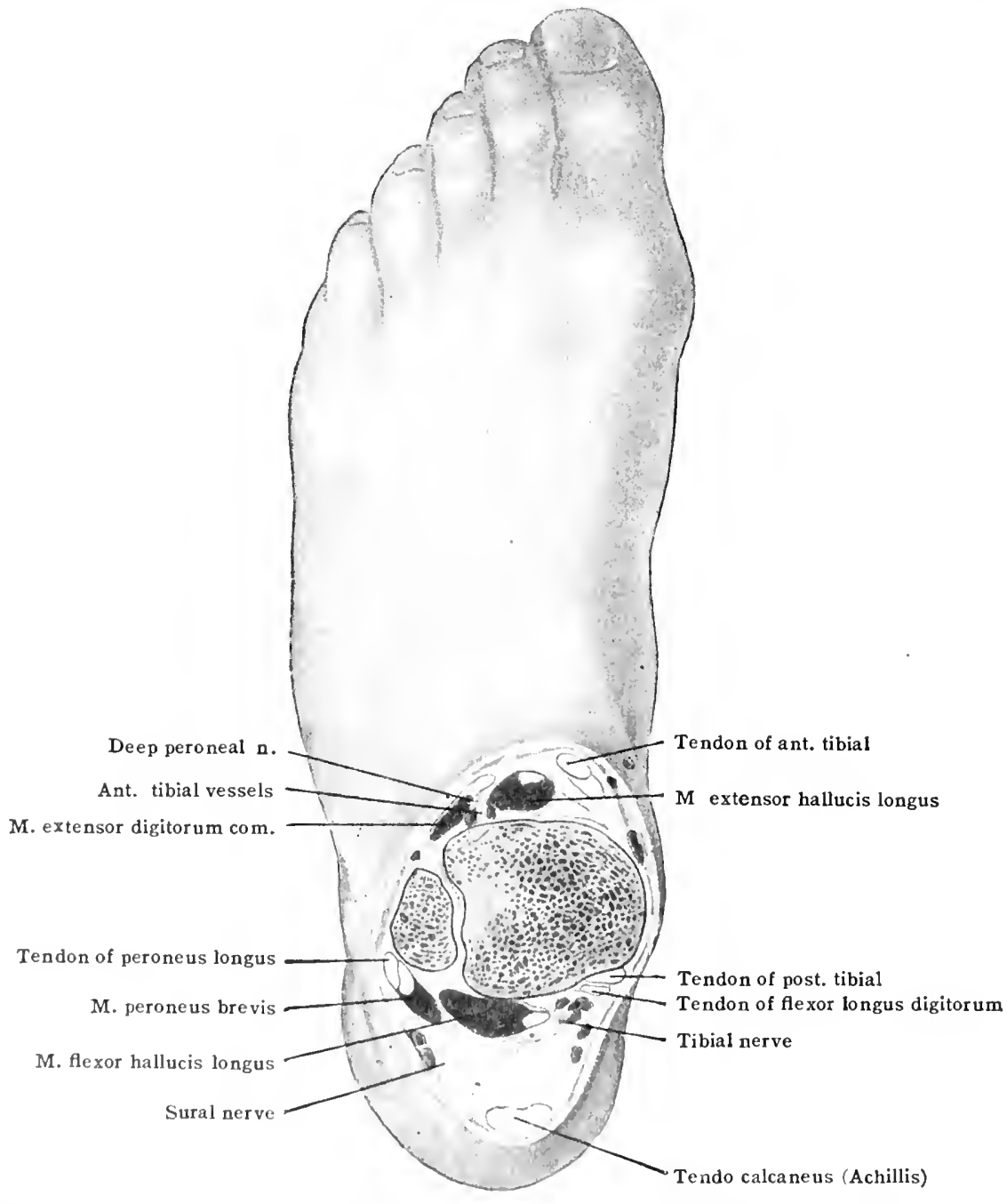

("anco-navirular ligamont (ride infra), and so to its insertion, by numerous slips, into the tarsus and metatarsus, reporally the tuberosity of the navicular. The

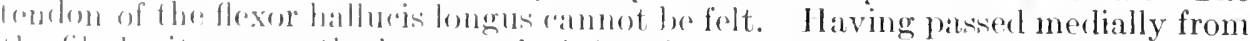

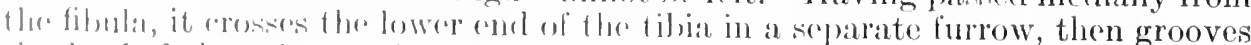
the larkef the talus, and gasses undere the sustentaculum tali on its way to its increptions.

The arrangenont of the strurtures at the modial ankle from above downward, and medio-

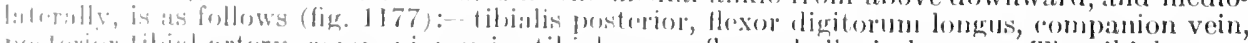

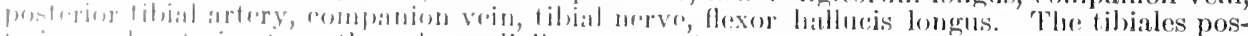
Irefer and anterior turn the solo modially, antagonising the peronei. They also bear a large 
share in maintaining the longitudinal arch of the foot. The flexors not only act upon the toes, but aid the calf muscles in straightening the foot upon the leg in walking or standing upon tiptoe; hence the value of educating them in cases of flat-foot.

(D) Tendons on the lateral aspect.-The tendons of the two peronei, which arise from the fibula between the extensor digitorum longus and flexor hallucis longus, pass behind the lateral malleolus, the brevis being nearer to the bone (fig. 1177). They then pass forward over the lateral surface of the calcaneus, separated by the peroneal tubercle when present, and diverge.

The brevis - the upper one-passes to the projection at the base of the fifth metatarsal; the longus, lying below the brevis on the calcaneus, winds round the lateral border of the foot, grooving the lateral border and under surface of the cuboid. Finally, crossing the sole obliquely forward and medially, it is inserted into the adjacent parts of the first cuneiform and the back part and under surface of the first metatarsal. While in connection with the under surface of the cuboid, this tendon is covered in by a sheath from the long plantar ligament, and often contains a sesamoid bone. The two peronei evert the foot, as is seen in talipes valgus and in fracture of the lower end of the fibula; the peroneus longus aids in the support of the arch of the foot (p. 1466), and, by keeping the great toe on the ground, is important in the third stage of walking, skating, etc.

Annular ligaments and synovial membranes of tendons.-These strap-like bands of deep fascia, which serve to keep the above tendons in position, are three in number, viz.:-

(A) Lateral.- This, the superior peroneal retinaculum, extends from the tip of the lateral malleolus to the lateral surface of the calcaneus. It keeps the two

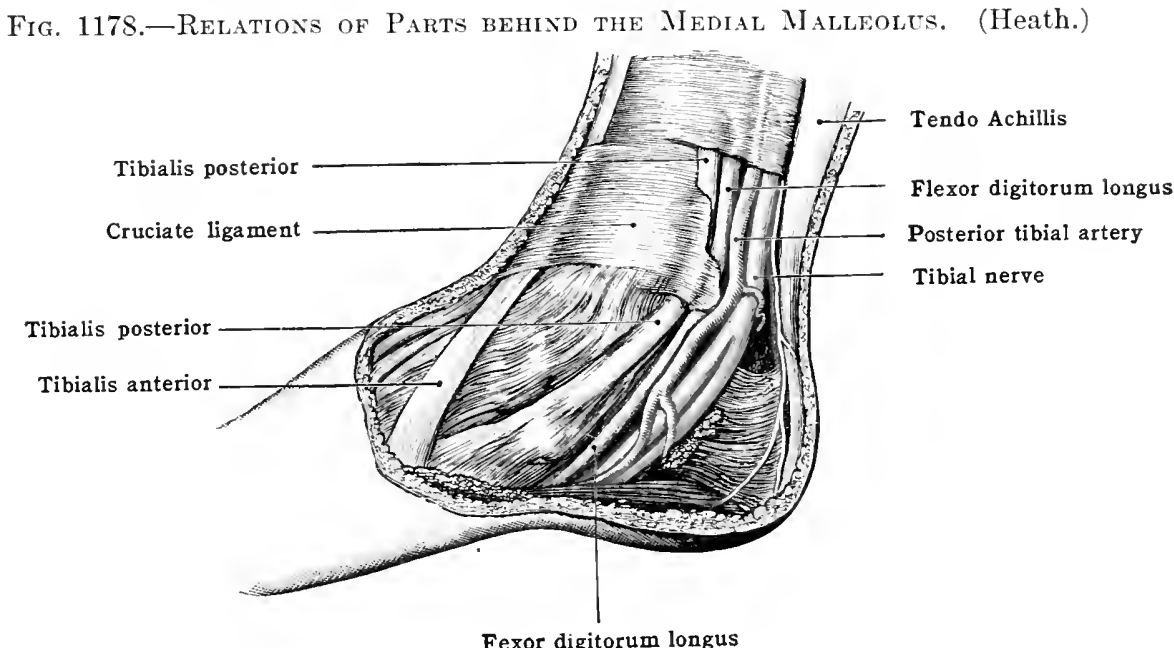

peronei in place, and surrounds them behind the fibula in one sheath with a single synovial sac, which extends upward into the leg for $3.7 \mathrm{~cm} .\left(1 \frac{1}{2} \mathrm{in}\right.$.), and sends two processes into the two sheaths in which the tendons lie on the calcaneus. Farther on, while in relation with the cubojd, the peroneus longus has a second synovial sheath.

(B) Medial.-This, the laciniate ligament, crosses from the medial malleolus to the medial surface of the calcaneus. Beneath it are the following canals:- (1) For the tibialis posterior. This tendon-sheath is lined by a synovial membrane extending from a point $3.7 \mathrm{~cm}$. ( $1 \frac{1}{2}$ in.) above the malleolus to the navicular. (2) For the flexor digitorum longus. The synovial sheath of this tendon is separate from that of the closely contiguous tibialis posterior. It extends upward into the leg about as high as the sheath just given. It reaches down into the sole of the foot; but where the tendon subdivides to enter the thecæ, each of these is lined by a separate synovial sheath. Next comes (3) a wide space for the posterior tibial vessels and nerve; and, lastly, (4) a canal, like the other two, with a separate synovial sheath, for the tendon of the flexor hallucis longus. The lower margin of this annular ligament gives an attachment to the abductor hallucis and blends with the plantar fascia. The medial calcaneal vessels and nerve perforate the ligament. 
(C) Anterior annular ligament.-This is a double structure. (1) Upper (transverse crural ligament), above the level of the ankle-joint, and tying the tendons down to the lower third of the leg, passes transversely between the anterior erest of the tibia and fibula. Here is one sheath only, with a synovial membrane for the tibialis anterior. (2) Lower, over the ankle-joint. This band, the cruciate ligament, is arranged like the letter $<$, placed thus. It is attached by its root to the calcaneus, and by its bifureations to the medial malleolus and plantar fascia.

This arrangement of the branches of this ligament is not constant. In this, the lower annular ligament, there are usually three sheaths with separate synovial membranes-the most medial (the strongest in each) for the tibialis anterior, the next for the extensor hallucis longus, and the third common to the extensor communis and peroneus tertius. The extensor digitorum brevis has a partial origin from this ligament.

Points in tenotomy and guides to the tendons.- The tendo Achillis should be divided about $3.7 \mathrm{~cm}$. ( $1 \frac{1}{2}$ in.) above its insertion, its narrowest point, which is about on a level with the medial malleolus. The knife should be introduced on the medial side and close to the tendon, so as to aroid the posterior tibial artery (fig. 1178).

The tibialis anterior may be divided about $25 \mathrm{~mm}$. ( $1 \mathrm{in}$.) above its insertion into the first cuneiform, a point which is below the level of its synovial sheath. The tendon has here the dorsalis pedis on its lateral side, but separated by the tendon of the extensor hallucis longus. The knife is introduced on this side.

The tibialis posterior. - The usual rule for dividing this tendon is to take a spot $5 \mathrm{~cm}$. (2 in.) above the medial malleolus, and as accurately as possible midway between the anterior and medial borders of the leg. This point will give the medial margin of the tibia, in close apposition to which the tendon is lying, and is a point at which the tendon is rather farther from the artery than it is below, and is also above the commencement of its synovial sheath. A sharp-pointed knife is used first to open the sheath freely, and then a blunt-pointed one to divide the tendon. The flexor digitorum longus is usually cut at the same time.

Owing to the risk of injury to the posterior tibial vessels, the difficulty of ensuring division of the tendons, the following open method is, nowadays, superior, being more certain, and admitting of division of ligaments, e. g., talo-navicular and anterior part of deltoid (syndesmotomy of Parker), which are always contracted in advanced talipes equino-varus. A V-shaped flap with its apex over the first metatarsal bone and its two limbs starting, the lower below the margin of the plantar fascia on a line with the medial malleolus, the upper from a point over the head of the talus, is turned backward. The plantar fascia is divided, the tibialis anterior is found, near its insertion, under the upper lip of the wound, the tibialis posterior and the flexor digitorum longus in the lower, the former close to the navicular. If necessary, the calcaneoand talo-navicular and anterior part of the deltoid ligaments can be divided also.

Peronei.-The peronei longus and brevis may be divided $5 \mathrm{~cm}$. (2 in.) above the lateral malleolus, so as to be above the level of their synovial sheath. The knife should be inserted very close to the bone, so as to pass between the fibula and the tendons. Division below the ateral malleolus by a small flap is easier.

\section{THE FOOT}

Bony landmarks.-The following are of the greatest practical importance owing to the operations which are performed upon the foot.

(A) Along the medial aspect of the foot are the following:-

(1) Mrclial tuberosity of the caleaneus; (2) medial malleolus; (3) $2.5 \mathrm{~cm}$. (1 in.) bolow the malleolus, the sustentaculum tali; (4) about $2.5 \mathrm{~cm}$. (1 in.) in front of the medial malleolus, and a little lower, is the tuberosity of the navieular, the medial guide in Chopart's amputation, the gap between it and the sustentaculum bring filled by the calcaneo-navieular ligament and the tendon of the tibialis posterior, in which there is of trin a sesamoid bone; (5) the first cuneiform; (6) the base of the first motatarsal; and (7) the head of the same bone, with its sesamoirl bones bowow. (Holden).

(B) Along the lateral aspect are:-(1) The lateral tuberosity of the calcaneus; (2) the lateral malleolus; (3) the peroneal tuberele of the calcaneus (when pres(nit), 2.5) ("m. (1 in.) besow the malloolus, with the long peroneal tendon below it, and the short onr above; (4) the projertion of the anterior end of the calcancus, ancl thre calcanero-ruboid joint, midway botwern the tip of the lateral malleolus and

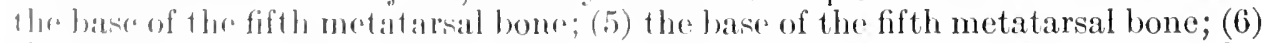
thre hrant of this lome. The greater process of the ealeaneus and the muscular origin of the short extrisor lie lod ween the poronems brevis and tertius.

Levels of joints and lines of operations. The line of tho ankle-joint has been given at 1.59. Tlust of the tialo-calcancal joint thr limitod lateral movements of the foot take folan here and at 1hromalio-farsal joint-corresponds, on the lateral side, to a point a little in

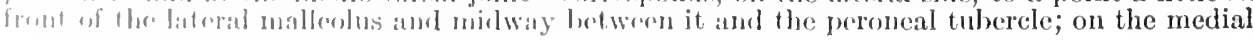


side, to one just above the sustentaculum tali. In Syme's amputation through the ankle-joint, the incision starts from the tip of the lateral malleolus, and is then carried, pointing a little backward toward the heel, across the sole to a point $1.2 \mathrm{~cm}$. ( $\frac{1}{2} \mathrm{in}$.) below the medial malleolus. The chief supply to the heel-flap is from the medial calcaneal. Care should be taken to divide the posterior tibial below its bifurcation and not to prick this vessel afterward.

In Pirogoff's amputation the incision begins and ends at the same points, but is carried straight across the sole. In each amputation the extremities of the above incision are joined by one going directly across the ankle-joint, which lies about $1.2 \mathrm{~cm}$. ( $\frac{1}{2} \mathrm{in}$.) above the tip of the internal malleolus.

In Chopart's medio-tarsal amputation, which passes between the talus and the navicular on the medial side, and the calcaneus and the cuboid on the lateral, the line of the joints to be opened would be one drawn across the dorsum from a point just behind the tuberosity of the navicular to a point corresponding to the calcaneo-cuboid joint, just midway between the tip of the lateral malleolus and the base of the fifth metatarsal bone. The convexity of the plantar flap should reach to a point $2.5 \mathrm{~cm}$. ( 1 in.) behind the heads of the metatarsal bones. Owing to the tendency of the unbalanced action of the calf muscles to tilt up the calcaneus and thus throw the scar down into the line of pressure, the powerful tibialis anterior tendon and those of the extensors should be carefully stitched into the tissues of the sole flap.

In Lisfranc's, or Hey's, or the tarso-metatarsal amputation, the bases of the fifth and first metatarsals must be defined. The first of these can always be detected, even in a stout or swollen foot; on the medial side the joint between the first cuneiform and the first metatarsal

Fig. 1179.-Vertical Section throdgh the Cuneiforar and Cuboid Bones. (One-half.)

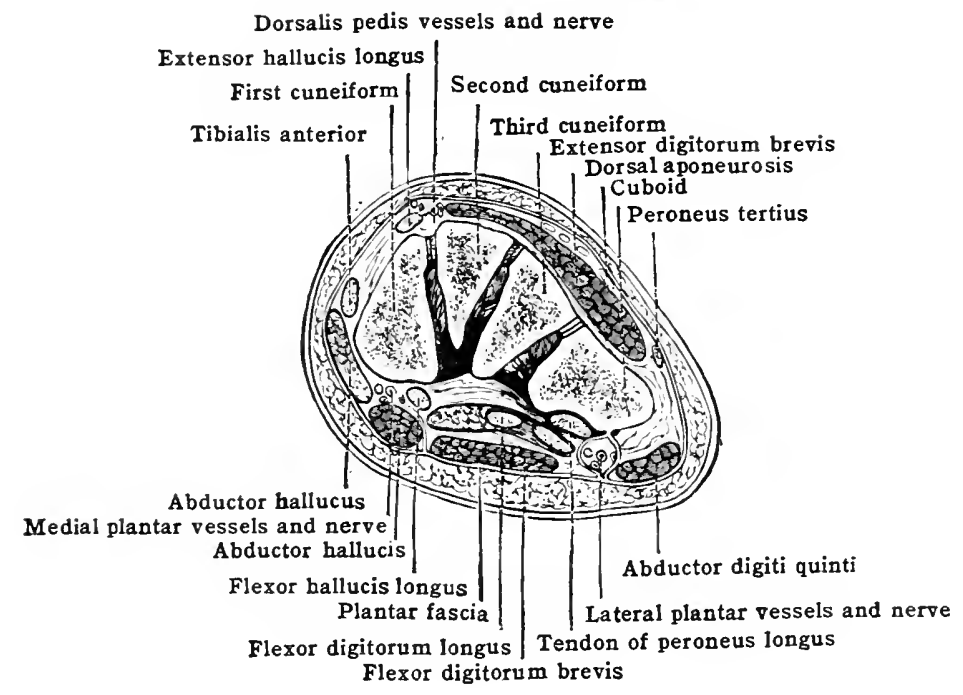

bone lies $3.7 \mathrm{~cm}$. ( $1 \frac{1}{2} \mathrm{in}$.) in front of the navicular tuberosity. In opening the joint between the second metatarsal and the middle cuneiform, its position (the base of the former bone projecting upward on to a level 6 or $8 \mathrm{~mm}$. ( $\left(\frac{1}{4}\right.$ or $\frac{1}{3}$ in.) above the others), and the way in which it is locked in between its fellows and the cuneiform bones, must be remembered. 'The convexity' of the plantar flap here reaches the heads of the metatarsal bones.

In marking out the flaps for the amputation of the great toe, the large size of the head"of the first metatarsal, and the importance of leaving this so as not to diminish its supporting power and the treading width of the foot, and thus of marking out flaps sufficiently long and

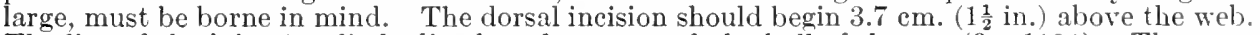
The line of the joint is a little distal to the centre of the ball of the toe (fig. 1181). The sesamoid bones should be left, so as not to endanger the vitality of the flaps. In amputation of the other toes, the line of their metatarso-phalangeal joints lies a full inch above the web.

Bursæ and synovial membranes.-The synovial sheath of the extensor hallucis longus extends from the front of the ankle, over the instep, as far as the metatarsal bone of the great toe. There is generally a bursa over the instep, above, or it may be below, the tendon.

There is often an irregular bursa between the tendons of the extensor digitorum longus and the projecting end of the talus over which the tendons play. There is much friction here. It is well to be aware that this bursa sometimes communicates with the joint of the head of the talus. (Holden.) There is a deep synovial bursa between the tendo Achillis and the calcaneus. Numerous other bursæ may appear over any of the bony points in the foot, especially when they are rendered over-prominent by morbid conditions.

Synovial membranes.-In addition to that of the ankle-joint, there are six synovial membranes in the tarsus, viz.:-(1) Talo-calcaneal, peculiar to these 
bones; (2) talo-calcaneo-navicular, common to these bones and the navieular; (3) between the ealcaneus and the cuboid; (4) between the euboid and the lateral two metatarsals; (5) between the first cuneiform and the first metatarsal; (6) a complicated and extensive one, which branches out between the navicular and cuneiform bones; between the cuneiforms; between the third euneiform and the cuboid; between the second and third cuneiform and the second and third metatarsal bones; and between the second and third and the third and fourth metatarsal bones.

Fig. 1180.-Superfichal Nerves in the Sole of the Foot. (Ellis.)

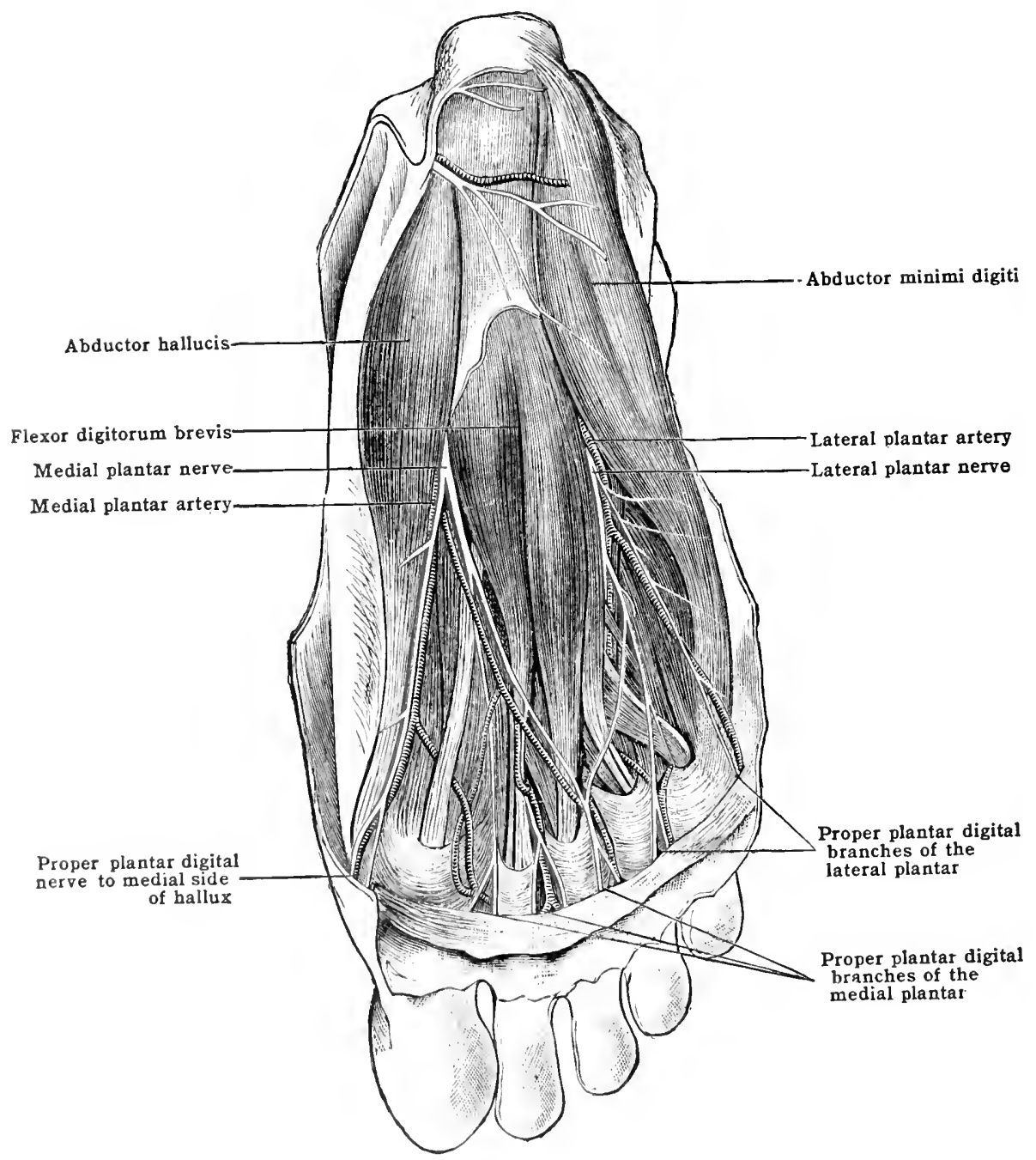

Dorsal artery.-The line of this is from the centre of the ankle-joint to the upler part of the first interosseous space.

()n its molial side is the tomelon of the extensor hallueis longus; on its lateral, the most medial

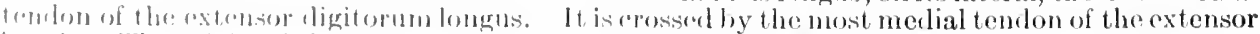

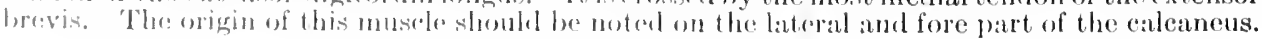

Cutaneous nerves (fig. 1182).- The sites of these, numerous on the dorsum of thr fort, alre ats follows: The superficial peroneal (musculo-cutaneous) nerve, having perforated dhe fascia in the lower third of the leg, divides into two chief Iranchere, melial and latoral, which supply all the toes save the lateral part of the little, ant threaljatrent sieles of thre first and serond. 'The deep peroneal becomes "ut annum in thr. first spare, and is rlistributed to the contiguous sides of the above- 
mentioned toes. The sural nerve runs with the small saphenous vein below the malleolus, and supplies all the lateral border of the foot and the lateral side of the little toe. The saphenous nerve, coursing with the great saphenous vein in front of the medial malleolus, supplies the medial border of the foot as far as the middle of the instep. The cutaneous nerves to the sole (from the medial calcaneal, medial, and lateral plantar) are shown in fig. 1180.

Plantar arteries.-The line of the medial would be one drawn from the bifurcation of the posterior tibial, or about midway between the tip of the medial malleolus and the medial border of the heel, to the middle of the plantar surface of the great toe. The course of the lateral plantar runs in a line drawn from the bifurcation, first obliquely across the foot to a point a little medial to the medial side of the base of the fifth metatarsal, and thence obliquely across the foot till it reaches the first space and joins with a communicating branch from the clorsal artery. It thus crosses the foot twice. In the first part, it is more superficial, in the second

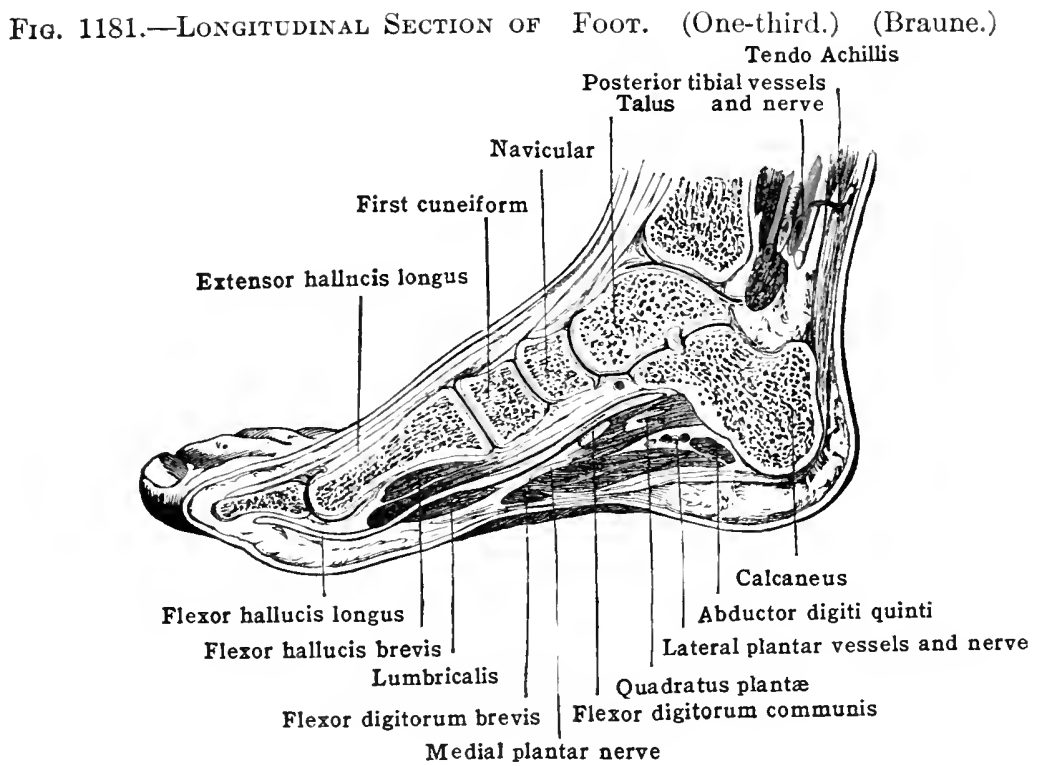

very deep; it here forms the plantar arch, and is only separated from the bases of the metatarsals by the interossei.

The anastomosing branches about the ankle-joint are shown in figs. 1170 and 1171 .

Tarsal bones.-The chief surgical points about these is the frequency with which they are diseased and their changes in talipes. Frequency of disease.-This is explained, chiefly, by their delicate structure and the fact that on the aspect in which they are most exposed to injury the soft parts are scanty. Disease once started, of ten by slight injury, finds in the terminal circulation of the parts, and the frequent want of rest, other contributing causes. The numerous and complicated synovial membranes mentioned above explain the extension of the disease. The calcaneus is the only bone in which mischief is likely to remain limited. The presence of an epiphysis to this bone appearing about the age of ten and joining at puberty is to be remembered as a starting-point of disease here. Talipes.-To take one instance, a case of talipes equino-varus, of congenital origin and confirmed degree, the following are the chief structural changes which should have been obviated and now have to be met, given briefly. Calcaneus.-This is elevated posteriorly, and rotated so that its long axis is directed obliquely medially. Talus.-The inclination of the neck medially is much increased, and the whole bone protruded from the ankle-joint. According to some, the neck is increased in length. Navicular. - This is displaced medially so that it articulates with the medial side of the head of the talus, and its tuberosity may form a facet on the medial malleolus. Cuboid.-The dorsal surface of this is displaced downward, and bears much of the pressure in walking. Tendons.--Those chiefly shortened are the tendo Achillis and those of the tibials and flexor digitorum longus. The tendo Achillis is displaced medially. Ligaments.-Those on the lateral side are stretched, those on the medial, especially the anterior part of the deltoid, the dorsal talo-navicular and the plantar calcaneo-navicular ligaments are shortened. The plantar fascia is also shortened, together with the abductor hallucis, which arises from it. 


\section{ARCHES OF THE FOO'T}

These are two-the longitudinal and the transverse.

(A) Longitudinal arch (fig. 1181). - This is by far the most important. Extent: From the heel to the heads of the metatarsal bones. The toes do not add much to the strength and elasticity of the foot. (Humphry.) They enlarge its area and adapt it to inequalities of the ground, are useful in climbing, and in giving an impulse to the step before the foot is taken from the ground, in the third stage of walking. Two pillars.-The late Professor Humphry laid stress on the important differences between these two:-(1) Posterior pillar: This consists of the calcaneus and hinder part of the talus, viz., only two bones in order to secure solidity, and to enable the calf-muscles to act directly upon the heel, without any of that loss of power which would be brought about by many moving joint-surfaces. (2) Anterior pillar: Here there are many bones and joints to provide $(a)$ elastic springiness, and $(b)$ width. This anterior pillar may again be divided into two: (a) A medial pillar, very elastic, consisting of the talus, navicular, three cuneiforms, and three medial metatarsals. (b) A lateral, formed by the cuboids and two lateral metatarsals. This is stronger and less elastic, and tends to buttress up the medial pillar. Keystone: This is represented by the summit of the trochlear surface of the talus.

It differs from the keystones in ordinary arches in the following important particulars (Humphry): ( $a$ ) in not being wedge-shaped; $(b)$ in not being so placed as to support and receive support from the two halves of the arch: in front the talus does fulfil this condition by fitting into the navieular; behind, it overlaps the calcaneus without at all supporting it; $(c)$ this arch and the support of its keystone largely depend on ligaments and tendons; $(d)$ it is a mobile keystone: to give it chances of shifting its pressure, and so obtaining rest, its equilibrium is not always maintained in one position.

(B) Transverse arch (fig. 1179).- This is best marked about the centre of the foot, at the instep, along the tarso-metatarsal joints. This, as well as the longitudinal arch, yields in walking, and so gives elasticity and spring.

Uses of the arches.--(1) They give combined elasticity and strength to the tread. Thus they give firmness, free quickness, and dignity, both in standing and walking, instead of what we see in their absence, viz., the lameness of an artifieial limb, and the shuffling or hobbling which goes with tight boots, deformed toes, flat-foot, bunions, corns, etc.; (2) they protect the plantar vessels, nerves, and museles; (3) they add to man's height; (4) they make his gait a perfeet combination of plantigrade and digitigrade, as is seen in man's walking, when he uses first the heel, then all the foot, and then the toes. (Humphry.)

Maintenance of the arch.- (1) Plantar fascia. - This is (a) a binding tie between the pillars of the longituclinal areh; (b) it proteets the structures beneath; $(c)$ it is a self-regulating ligament and protection. Thus, having a quantity of muscular tissue attached to its upper and back part, is constantly respouds by the contraction of this, to the amount of any pressure made upon the foot. (2) Plantar calcaneo-navicular ligament.-This is a thick tie-plate of fibro-eartilaginous tissue, partly elastic, hence ealled the 'spring-ligament,' attached to the anterior margin of the sustentaculum tali and under surface of navicular. It is thickest at its medial side, where it blends with the anterior part of the deltoid ligament, and below, where the tibialis posterior, passing into the sole, is in contact with the ligament and gives much support to the head of the talus and the navirular, while it assists the power and spring of this liganent (vide infra). The cropping of the talus and navicular and their projection on the medial side in flat-foot are largely dhe to the griving way of the above ligament. (3) Calcaneo-cuboid ligaments. (a) Long; (1) short. - These ligaments are the main support of the lateral, firm, and less elastic part of the longitudinal areh. (1) Tibialis posterior.-The reason of this muscle having so many insertions holow is fo brace together the tarsal hones, and to prevent their separation when, in treading, the rlastic antrolor pillar fonds to widen ont. Of these numerous off sets, that to the navieular is the most imprortant. Thus it strengthens the calcaneo-navicular ligament by blending with it, and thus sulpurts the aroh at a trying tine. By coming into action when the heel is raised, this tondon helps the calcamos-navicular limament to support the head of the talus, and to mainbian the arch of the foot when the weight of the body is thrown forward on to the instep. In wher worls, the tihialis mosterior cones into play just when the heaviest of its duties is devolving

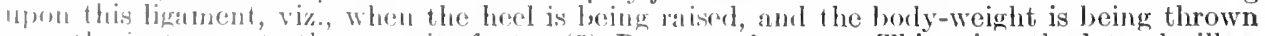
wer the instep on to the opposite foot. (5) Peroneus Iongus. - This raises the lateral pillar, atud strarlies the latrat sirle of the arch. Further, hy its strong process attacherl to the first

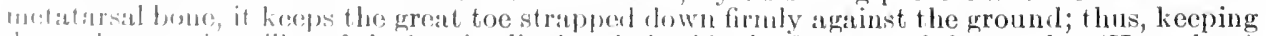
down the antrerion rillar of the longitudinat areh, it ands the firmuess of the tread. (IIumphry.) (i) Tibialis anterior. This hrares up the keystone of the alrh. 'Jluus, by kerping up the first

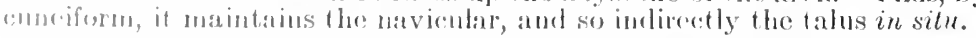

lïg. 1172 will remind the reader of the arrangement of the superficial lymphatics of the lower extremity. These follow chicefly the saphenous veins, and (nuter the inguinal nodes, exrent those from the lateral aspect of the heel which 
drain into the popliteal lymph-nodes. The superficial lymphatics of the buttock enter the lateral, and those over the adductor muscles the most medial group of the inguinal glands.

The deep lymphatics of the lower limb, comparatively few in number, follow the course of the deeper vessels. After passing through some four or five glands deeply placed about the popliteal vessels (these glands also receive the lymphatics along the small saphenous vein), the lymph is carried up by lymphatics along the femoral artery to the deep inguinal nodes; one very often occupies the femoral canal. $\operatorname{limb}$.

Fig. 1182 shows the distribution of the superficial nerves on both aspects of the

Fig. 1182.-Distribution of Cutaneous Nerves on the Posterior and Anterior Aspects OF THE INFERIOR EXTREMITY.
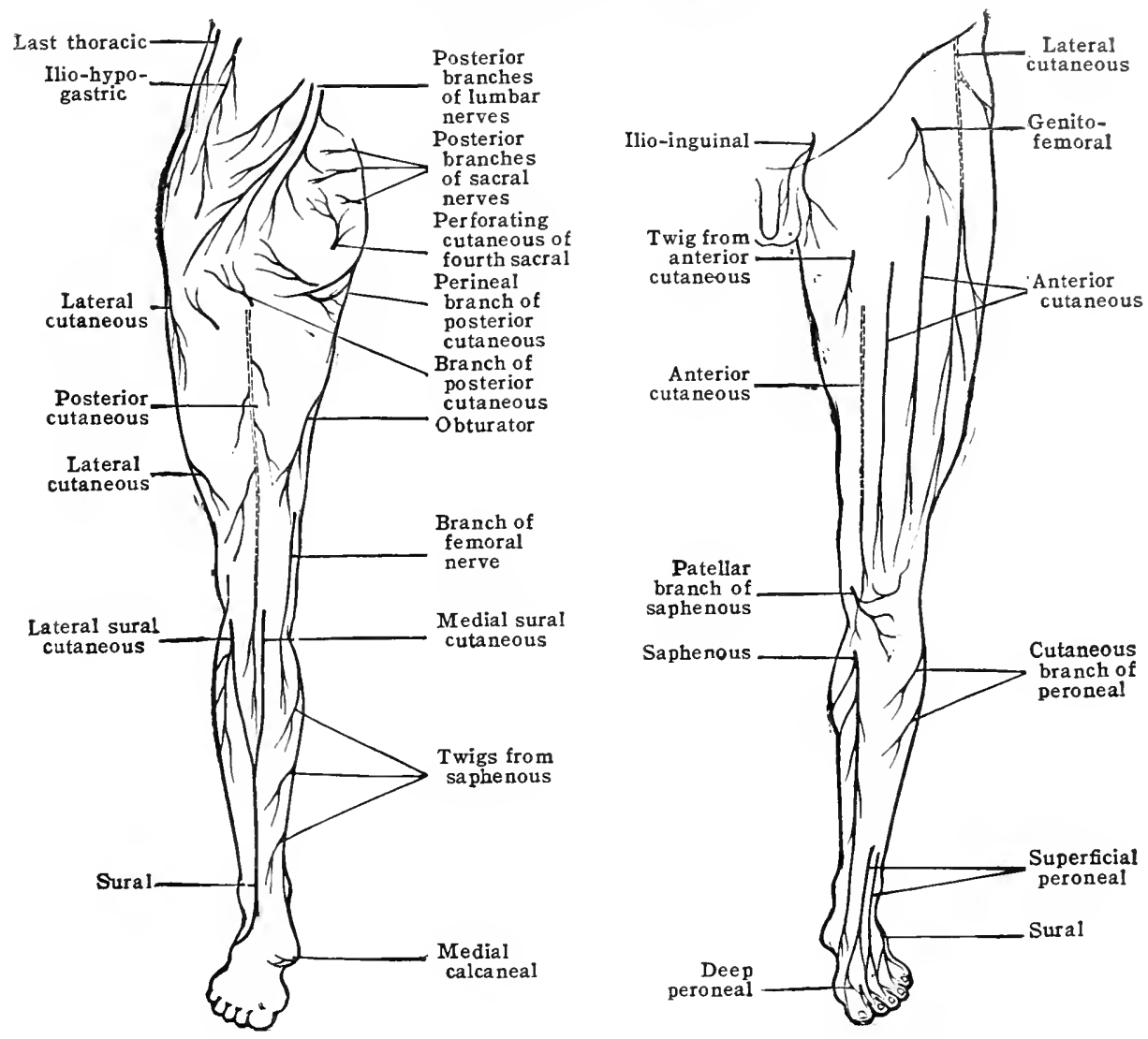

Paralysis of the nerves of the lower extremity. - The student should take this opportunity of considering from the surgical anatomy the results of paralysis of the nerve chiefly affected, viz., the great sciatic and its branches. Sciatic: The limb hangs flail-like, much in the position of one affected with advanced infantile paralysis. In addition to the results of paralys is of its two divisions, flexion at the knee will be lost, owing to paralysis of the hamstrings. Feromeal (external popliteal) nerve: The extensors and peronei being paralysed the foot drops, it cannot be dorsiflexed at the ankle nor abducted at the medio-tarsal joint. Adduction at the latter joint is impaired owing to paralysis of the tibialis anterior. The arch of the foot is largely lost owing to paralysis of the peroneus longus. Slight extension of the two distal phalanges of the four lateral toes is still possible by means of the interossei. Sensation is impaired over the distribution of the medial sural cutaneous deep, and superficial peroneal nerves. Tibial (internal popliteal) nerve: Here the calf muscles, the flexors, and the muscles of the sole of the foot are paralysed. The ankle cannot be plantar-flexed. 



\section{INDEX}

Bold-face type indicates the more complete descriptions

A

Abdomen, 1142

clinical anatomy of, 1370

landmarks of, 1370

lymphatic nodes of, 730

lymphatics of, 730

morphology of, 1144

muscles acting on, 503

regions, 1142, 1370

Abdominal aorta, 590, 1382, 1408 branches, 591

aortic plexus of nerves, 1045

branches of vagus, 958

fossæ, 430

(inguinal) rings, 429, 430, 1371, 1394, 1396

portion of ureter, 1248

wall, lymphatics in, 733

superficial veins in, 683

Abducens, 934

nucleus of, 826

Abduction, 321

Abductor accessorius digiti quinti, 499

digiti quinti (foot), 454,498 (hand), 404

hallucis, 496

longus, 482

ossis metatarsi quinti, 499

pollicis brevis, 406,407

longus (extensor ossis metacarpi pollicis), 392,393

Aberrant artery of aorta, 590

spinal ganglia, 965

Abnormalities (see individual organs).

Accessorius ad flexorem digitorem profundum, 402

of gluteus minimus, 462

(ilio-costalis dorsi), 416

Accessory (spinal accessory) nerve, 958

Acervulus cerebri, 846

Acetabular artery, 608

foramen, 174

noteh, 174

Acetabulum, 169, 173

Acoustic area, 814

(auditory) nerve, 949, 1096 nuclei of, 823

meatus (see "Auditory Meatus").

(medullary) strize, 814, S24

Acromial branches of posterior circumflex humeral artery, 573

of thoraco-acromial artery, 571

of transverse scapular artery, 565

(scapular) extremity of clavicle, 141

Acromio-clavicular joint, 251, 1363

Acromion angle, 144

process, 144

Acromio-thoracic axis, 571

Action of muscles (see corresponding mascle).

Adam's apple, 1211

Addison's transpyloric line, 1153, 1370

Adduction, 321

Adductor brevis, $453,471,474$

(Hunter's) canal, 468, 618, 1441

digiti secundi, 498

hallucis, $454,496,498$

longus, 453, 471, 472, 1437
Adductor magnus, 453, 471, 474, 1437 (medial) group of thigh muscles, 453 minimus, 474

pollicis, 407,408

tubercle of femur, 181

Adenoids, naso-pharyngeal, 1130, 1354

Adipose body, pararenal, 1243

capsule of kidnc 1242

folds of pleura, 1: 7

Aditus of lar, $11 x, 1222,1223$

Adminiculum linex albæ, 427

Adrenals (see "wuprarenal glands").

Aeby's division of bronchial branches, 1232

Agger nasi, 88, 1206

Aggregated follicles (Peyer's patches), 704

Air-cells, mastoid, 72

Air-sacs, 1232

Ala of central lobule of cerebellum, 806 cinerea (trigonum vagi), $\mathrm{S} 14$ nucleus of, 820

Alæ of frontal bone, 60 nasi, 1201

Alar folds, 291

(lateral occipito-odontoid or check) ligaments, 223

(lower lateral) nasal cartilages, greater, 1201 lesser, 1202

processes of ethmoid, $\$ 1$

Alcock's canal, 4t1, 445, 1384

Alimentary tract, lymphatics of, 699, 733 , 1168

Ali-sphenoid centre, 67, 119

Allantois, 13, 1253

Alopecia, 1293

Alveolar (dental) artery, inferior, 548 posterior superior, 549 anterior superior, 549

canals, 87

ducts, 1232

(dental) nerves, 938

inferior, 941

superior, 938

periosteum, 1119

point, 109

part of mandible, 96

maxilla, 87,90

saccules (air-sacs), 1153

veins, 646

Alveoli (air-cells), 1232

Alveus, 877

of limbic lobe, 868,869

Amastia, 1301

Amnion, 9, 10

Ampulla, of ductus (vas) deferens, 1257

lactiferons, 1302

phrenica, 1142

recti, 1176

of semicircular canals, 80

of tubx uterinæ (Fallopian tubes), 1270

of Vater, 1158

Ampulle, membranous, 1095

of splenic arterioles, 1312

Ampullar branches of vestibular ganglion, 950

Ampullary crista, 1095 sulcus, 1095

Amputation at centre of the arm, 1416

Chopart's medio-tarsal, $1+65$ 
Amputation of foot, 1465

of forearm, 1424

of great toe, 1465

of leg, 1459

Pirogoft's, 1465

sirme's, $146 \pi^{\circ}$

tarso-netatarsal (Hey's or Lisfranc's), 1465

through thigh, 1442

Amygdala (tonsil) of cerebellum, 807

Amygdaloid nucleus, 881

of lateral ventricle, 877

Anroloid tubercle of lateral ventricle, 877

Anal canal, 1177 surgical anatomy of, 1390

valves, 1177, 1390

Anapophysis, 38

Anastomosis of arteries (see corresponding artery).

Anastomotic branch of facial nerve, 944 (perforating) of middle meningeal artery, 548

ulnar, of superficial radial nerve, 987

Anastomotica magna artery (genu suprema), 621

Anatomical neck of humerus, 147

Anatomy, definition of, 1 of fourth ventricle, 812

Anconeus, 374, 377, 379 internus, 402

Andersch, ganglion of, 951

Angle (s), acromion, 144

cephalo-auricular, 1084

of fissure of Rolando, 860

infrasternal, 139

of Louis, 139

lumbo-sacral, 43

of mandible, 86

of maxilla, $\mathrm{SS}$

of occipital bone, 53

of parictal bone, $\mathbf{5 7}, 1332$

of rib, 127

sacro-vertebral, 39,43

of scapula, 143

of sternum, 133, 139

subscapular, 145

Angular artery, 540

gyrus, 86.3

motion of joints, 214

process, lateral (zygomatic), 60 medial, 60

vein, 64:3

Angulus Ludovici, 139

Inkle, annular ligaments, 1463

bony landenarks of 1459

clinical anatomy of, 1459

synovial membranes of tendons at, 1463

tenclons at, 1460

Inkle-joint, 297

atrterial sipply, 300

ligituents of , 208

Inovements, 3000

muscles arting uporn, 301

urre-sipply, 2999

symovial membrane of, 299

Immalar ligimonts of ankle, $146 ; 3$

of superior rarlion-ulnar joint, 262

of tridehea and bronchii, 1227

of wrist, 387

Amonlus(i) librosi of heart, 518

fiturestis, :318

ingunalis abolominalis, tan

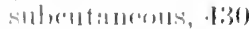

iriclis majur, 10:5

minor, 10,51

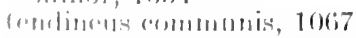

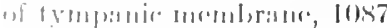

$13 r+f \mid r a 1,125: 3$
Ano-coccygeal nerves, 1018

Anomalous (muscle of nose), 335

Ano-rectal lymphatic nodes, 735

Ansa hypoglossi, 953, 974, 979

lenticularis, 880

subclavia (ansa Vieussenii), 1036

Antagonists (muscles), 322

Anthelix, 1082

Antibrachial cutaneous branch (external), dorsal, of radial nerve, 985

cutaneous nerve, lateral, 987

(internal) medial, 984

interosseous nerve, dorsal, 986

fascia, 384

vein, median, 667

Anti-tragicus, 1084

Antitrago-helicine fissure, 1084

Antitragus, 1082

Antrum cardiacum, 1142

of Highmore (maxillary), 87, 90, 111, 1346

maxillary, $77,79,1274$

pyloric, of stomach, 1151

tympanic (mastoid), 72, 73, 78, 1092, 1336

Anus, 1177

clinical anatomy of, 1390

development of, 1179

lymphatics of, 735

sphincters of, 448

Aorta, 529, 586, 590

abdominal, 590, 1382, 1408

branches, 591

arch of, 530

ascending, 529

descending, 586

development, 633

relations of, 1369,1382

semilunar valves of, 517

thoracic, 586, 1369

variations, 637,638

Aortic arch, 530

intercostal arteries, 588

isthmus, 531

paraganglia, 1329

septum, 527

sinuses (of Valsalva), 518, 530

spindle, 531

Aortico-renal ganglion, 1043

Apertura pyriformis, 10S, 112

Apertura cutis, 1282

Apertures, anterior nasa! (nares), 108, 1200

of larynx, 1222

palpebral, 1052

of pelvis, 175,176

posterior nasal (choande), 1206

superior thoracic, 138, 1365

Apex of arytanoid cartilage, 124

of fibula, 190

of heart, 508

linguie, 1106

of lung, 1230, 1233

of nose, 1200

of patella, 185

of prostate, 1264, 1389

of thyreoid lobes, 1315

of silprarenal gland, 1326

Apical dental (suspensory) ligament, 223

Aphasia, motor, sol sensory, 894

Aponeuroses, 31小, 317

Aponeurosis of epieranius (occipito-frontalis), $3: 37$

palmar, 387, 1430

phitryngeal, 1130

plantar, 492

Aproliysis of femur, 184

Apparatus, lacrinal, 1078

olfactory, $10+9$, 
Appendages of skin, 1290

eutaneous glands, 1296

hair (pili), 1290

mammary glands, 1299

nails (ungues), 1293

Appendices epiploice, 1170

vesiculosi (hydatids of Morgagni), 1269

Appendicular artery, 598, $137 \mathrm{~S}$

skeleton, 139

Appendix epididymidis, 1257

testis (hydatid of Morgagni), 1257

ventricular, of larynx, 1223

vermiform, 1173, 1378

Aquæductus cerebri (Sylvii), 834

vestibuli, $72,80,117$

Aqueduct of Fallopius (facial canal), 72

Aqueous chambers, $106 t$

humor, 1052

Arachnoid granulations (Pacchionian bodies), 649,919

membrane, 771,917

cranial, 918

spinal, 919

vessels and nerves of, 920

Arantius, ventricle of, $\$ 13$

Arbor vitae of cerebellum, 809

Areh of aorta, 530 branches of, 532

costal, 139

of cricoid cartilage, 1210

deep volar, 586, 639, 1426 venous, 671

dental, 1123

digital venous, 667

dorsal venous (foot), 684

jugular venous, 648

lateral lumbo-costal, 437

medial lumbo-costal, 437

parieto-occipital, $\$ 63$

plantar, 627

pubic, 176

supereiliary, 59, $10 \mathrm{~S}$

superficial volar, $582,639,1 \frac{125}{12}$

venous, 671

tarsal, inferior, 554

superior, 554

venous, plantar, 687

of vertebræ, 30

zygomatic, 1332

Arches, of atlas, 32, 33

branchial, 17

of the foot, 1468

palatine, 1132

Architecture of heart, $51 \mathrm{~s}$

Archoplasm, 5

Arciform process, 466

Ares, reflex, 768

Areuate (metatarsal) artery), 632

erest of arytænoid cartilage, 1212

fibres of niedulla oblongata, external, 800.818

internal, 815,817

ligament, extermal, 437

internal, +37

of symphysis pubis, 239

renal arteries, 1247

Areus tendineus, 317,440

fascixe pelvis (white line), 440

Area(s) acustica, 814

assoeiation, of cerebral cortex, 894

auditory (cochlear), of cerebral cortex, $\$ 93$

of Broca (area parolfactoria), $\$ 58, \mathbf{8 6 5}$

cortical, of speech, 894

dangerous, of the leg, 1457

of sealp, 1333

gustatory, of cerebral cortex, $\$ 94$

olfactory, of cerebral cortex, $\$ 93$
Area(s), olfactory of nasal cavity, 1049

plumiformis (of Retzius), $\$ 14$

postrema of Retzius, $\$ 14$

somasthetic, of cerebral cortex, $\$ 93$

surface, of telencephalon, 853

visual, of cerebral cortex, 893

Areas, cutaneous, of face, $101 \mathrm{~s}$

of lower extrenity, $10^{2}+4$

of neck, 1019

of sealp, 1018

of trunk, 1020

of upper limb, 102'

of distribution of spinal nerves, 970

functional, of cerebral cortex, $\$ 93$

Areola of mammary glind, 1300, 1304 secondary, 1304

Areolar glands of Montgomery) 1304

Arm, centre of, as a surgieal landmark, 1414 fascive of, 377

museulature of, 362,374

veins of 667

Arnold's bundle, 832, 889

ganglion, 963

nerve, 956

Arrectores pilorum, 1293

Arteria aberrans of aorta, 590 of superior intercostal, 568

centralis retince, 553,1065

princeps pollicis, 586

radialis indicis, 586

septi nasi, $5+1$

Arterial supply of bones and joints (see corresponding bone or articulation).

system, morphogenesis and variations of, 633

Arteriolie recta of kidney, 1247

Artery (see also "Blood-vessels").

Artery (ies), 527

aberrant, 565,590

accessory (small) nreningeal, 548 pudendal, 610, 639

renal, 638

acetabular, 608

acromio-thoracie (thoraco-acromial), 571

angular, 540,541

anterior central of medullia, 908

cerebral, 554, 562

ciliary, 553,1065

circumflex humeral, 572

communicating, 555, 562

conjunctival, 553

deep temporal, 548

ethomidal, 554

inferior cerebellar, 561

intercostal, 588

interosseous, of forearm, 1423

mediastinal, 567

perforating, 620

peroneal, 626, 640, 1459

serotal (or labial), 620

spinal, 561, 792, 638

superior alveolar (dental), 549

tibial, $629,640,1458$

recurrent, 632

tympanie, $5+7$

aorta, 529, 586, 637, 638

aortic intercostals, 588

appendicular, 598, $137 \mathrm{~s}$

arcuate (metatarsal), 632

articular, of knee-joint, 622,1452

ascending cervical, $56 t$

pharrngeal, 537

palatine, 540

of auricle (of ear), 1084

axillary, 569, 1412

a yogos, of vagina, 610

basilar, 561 
Artery (ies), branchial, 573, 640, 1414

of brain, 555, 905

bronchial, 588, 638, 1234

buccal, 548

of bulb of urethra, 613

caroticotympanic, 552

central or ganglionic, 906

of pons, 905

of cerebellum, 907

of cerebral hemorrhage (Charcot), 562, 906 peduncles, 907

chorioid, 554, 908

ciliary, 553, 1065

circumflex (dorsal) scapular, 572

of the clitoris, 613

deep, 614

dorsal, 614

cœliae, 593, 638

common carotid, 533

digital, 582

iliac, $60: 3$

interosseous, of forearm, 577

coronary, 519

cortical cerebral, 906

costo-cervical trunk, 568

cystic, 595

deep auricular, 547

cervical, $56 \mathrm{~s}$

cireumflex iliac, 616

lingual, 540

plantar (comnunicating), 633

deferential, 610

descending palatine, 549

dorsal of foot, line of, 1466

digital (foot), 633 (hand), 586

interosseous (metatarsal), 633 of forearm, 579

lingual, 539

metacarpal, 586

metatarsal (interosseous), 633

nasal, 554

perforating, of palm, 586

radial carpal, 585

thoracie (thoraco-dorsal), 572

uluar carpal, 580

recurrent, 577

dorsalis latllucis, 633

peolis, $6: 32$

episcleral, 5.53

of external acoustic (auditory) nneatus, 1086 carotid, 536, 1343

iliate, 614

Inaxillary (facial), $540,638,1343$

purlendal (pudic), 619

spormatic, 615

striate, $9(0) \mathrm{j}$

fenoral, 616, $1+41$

conmonon, bis

superficial, tiof

fihular nutricut, 626

of the frimum, 5io

front:al, 564, 13.13

gastro-duorlonal, 591

g.m11 smprema (anastomotica magna), 621, (i) 10

glint $6: 1,608$

heppatic: 5!9]

of humcrus, mutrient, 576

loyprogastric (intornal iliac), 605,639

ilin-roulice, 59s

iliu-lumbar, (iofi

infrepior alvoolat (olontal), 5.18

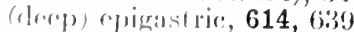

glut

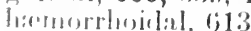

latial (erononsty), o, 11
Artery(ies), inferior laryngeal, 564

lateral articular, 623

medial articular, 622

mesenteric, 602, 638

pancreatico-duodenal, 596

phrenic, 592, 638

quadrigeminate, 907

suprarenal, 598

thyreoid, 564

tympanic, 537

ulnar collateral, 576

vesical, 609

infraorbital, 549, 1075

innominate, 532, 1369

internal auditory, 561

carotid, 549

manmmary, 566

maxillary, 545,638

pudendal (pudic) ,610,639

spermatic, 598, 638, 1259

striate, 906

intercostals, 588, 638

interosseous recurrent, 580

intestinal, 596

jejumal and iliac, 598

lacrimal, 552

lateral circumflex, 620, 640

malleolar, 632

palpebral, 552

plantar, 627, 640

posterior malleolar, 626

sacral, 607

tarsal, 632

thoracic, 571

left colic, 603

common carotid, 533

iliac, 605

coronary, 520

gastric, 593

gastro-epiploic, 595

pulmonary, 529

subelavian, 556

superior suprarenal, 592, 1326

lenticulo-optic, 562

lenticulo-striate, 562

of lig. teres uteri, 615

lingual, 539

long posterior ciliary, 553, 1065

lowest lumbar (ima), 603

lumbar, 593, 638

major palatine, 549

masseteric, 548

medial circumt flex, 620, 640

malleolar, 632

palpel)ral, 554

plantar, 629

tarsal, 632

median, of forearm, 578, 639

of medulla oblongata, 908

meningeal, 917

midrlle or azygos, 623

cerchral, 555, 562

colic, $59 \mathrm{~s}$

collateral, 576

hamorrhoirlal, 610

neninges1, 547, 1341

cuarlrigeminate, 907

sacral, 603

suprarenal, 598, 638

temporal, 545

vesical, 600

minor palatine, 5.49

musculo-plirenie, 5067

nutrient of femmr, 621

of himmerus, 576

of radlius and ulna, 579

of tilia, 626, 1459 
Artery (ies), obturator, 608, 639 occipital, 542, 638, 1343 œsophageal, $5 \mathrm{SS}$ omphalo-mesenteric, $63 \mathrm{~S}$ ophthalmic, 552, 635, 1074 ovarian, 602 parietal, 543

peduncular, 907

of penis, 613

deep, 614

dorsal, $61 \pm$

perforating, of the profunda, 620 pericardiac (of aorta), $58 \mathrm{~S}$ pericardio-phrenic, 567

perineal, 613, 639

peroneal, 626, 640, 1459

plantar digital, 628 metatarsal, $62 \mathrm{~S}$

popliteal, 621, 640, $1 \pm 52$

posterior auricular, 543, 1343

central of medulla, $90 \mathrm{~S}$

cerebral, 561

circumflex humeral, 573

communicating, 554

conjunctival, 554

deep temporal, $54 \mathrm{~S}$

ethmoidal, 553

inferior cerebellar, 561

meningeal, 537

peroneal, 626

scapular, 565

scrotal (labial), 613

spinal, 561, 792

superior alveolar (dental), 549

tibial, 624, 640,145s

recurrent, 632

princeps cervicis, 543

pollicis, 586

profunda or deep femoral, 620, 640

(superior) profunda of arm, 576 axillaris, 640

proper digital, 582

heptaic, 595

of pterygoid canal (Vidian), 519

pulmonary, 528, 1234

of quadrigeminate bodies, 907

radial, 582, 1423

collateral, 576

recurrent, $5 \mathrm{~S} 3$

at wrist, 584

radialis indicis, 586

renal, 598, 638

of retina, central, 1065

right colic, $59 \mathrm{~S}$

common iliac, 605

coronary, 519

gastric, 594

gastro-epiploic, 595

pulmonary, 529

subclavian, 5.57

superior suprarenal, 592

saphenous, 621

sciatic, 609, 640

short posterior ciliary, 553, 1065

sigmoid, 603

spheno-palatine, 549

spinal, 590

splenic, 595

stapedial, $63 \mathrm{~S}$

sternocleidomastoid, 542

stylo-mastoid, 544

subclarian, 556, 638

subcostal, $58 \mathrm{~s}$

sublingual, 540

submental, 541

subscapular, 571

superficial cervical, 566
Artery(ies), superficial circumflex iliac, 618 epigastric, $61 \mathrm{~S}$

temporal, 545, 1343

superior cerebellar, 561

epigastric, 567

gluteal, 60s, 1444

hæmorrhoidal, 603

intercostal, 568

labial (coronary), 541

laryngeal, 538

lateral articular, 622

medial articular, 622

mesenteric, 596, 638

pancreatico-duodenal, 595

phrenic, 590

quadrigeminate, 907

thoracic, 570

thyreoid, 538, 638

tympanic, 548

ulnar collateral, 576

vesical, 609

supraorbital, $\mathbf{5 5 2}, 1343$

suprarenal, 1326

suprascapular (transverse seapular), 561

sural, 622

systemic, 529

temporal, 545, 548, 1343

testicular, 601

thoraco-acromial, 571

of thymus, 567

thyroidea ima, 533

transverse cervical (transversa colli), 565, 638

facial, 545

scapular, 564, 638

of tympanic cavity, 1091

ulnar, 576, 1423

umbilical, 609

urethral, 613

uterine, 610

vaginal, 610

variations of, $63 \overline{7}, 639$

vertebral, 559, $63 \mathrm{~s}$

of vertebral canal, 590

vesical, 609

Vidian, 549

volar interosseous of forearm, $\mathbf{5 7 7 , 6 3 9}$

metacarpal, 586

radial carpal, 584

ulnar carpal, 580

recurrent, 575

zygomatico-orbital, $5+5$

Arthrodial diarthroses, 212

Articular arteries of knee-joint, 622, 1452

branches of auriculo-tem poral nerve, 941

of common peroneal (external popliteal) nerve, 1013

of deep peroneal (anterior tibial) nerve, 1015

of genu suprema artery, 621

of obturator nerve, 1004

of popliteal artery, 623

of posterior circumflex humeral artery, 573

of profunda artery, 621

of tibial (internal popliteal) nerve, 1010

of transverse scapular artery, 565

capsules of acromio-clavicular joint, 251

of articulation of atlas with occiput, 218

of atlanto-dental joint, 222

of capitular articulation, 241

of carpo-metacarpal joint of thumb, 273

of costo-transverse articulation, 243

of hip-joint, 277

of inferior radio-ulnar joint, 264

of knee-joint, 287

of lateral atlanto-epistrophic joint, 231 
Articular capsules of mandibular articulation, 215

of medial tarso-metatarsal articulation, 308

of metacarpo-phalangeal joint of thumb, 275

of shoulder-joint, 254

of sterno-costo-clavicular joint, 248

of tibio-fibular union, 295

of vertebral joints, 228

cartilage, 211

of shoulder-joint, 255

dise of acromio-clavicular joint, 251

of inferior radio-ulnas joint, 264

of mandibular articulation, 216

of sterno-costo-clavieular joint, 249

furrows of skin, 1284

nerve, recurrent, of leg, 1013

process of vertebra, 31

processes of vertebræ, ligaments connecting, 228

rete, of knee, 622

Articular tubercle of temporal hone, 71

veins of mandibular joint, $6 \pm 6$

Articularis genu (suberureus), 470

Articulation(s), 211

acromio-clavicular, 250

ankle, 297

of anterior parts of tarsus, 303

arveorniculate, 1215

atlanto-e pistrophic, $2220,2 \cdot 21$

of atlas with occiput, 218

of auditory ossicles, 1090

of bodies of vertehre, 225

caleaneo-cuboid, 306

carpal, 268

carpo-metacarpal, 272

classification of, 212

constituents of, 211

costo-capitular, 241

costo-chondral, 245

rosto-transverse, 243

costo-rertebral, 241

crico-arytaenoid, 1214

criecthyreoid, 1213

("ubsidee-navicular, 303

cubu-metatarsal. $30 s$

("uneo-cuboid, 30.4

('muer-navicular, 301

elbow, 25s

front of thorax, 244

hipr, 276, 14:31

incuclo-malleolar, 10!30

incudo-staporlial, 1090

interchonulral, 246

intereocoreal, 238

intrercunciform, 30 1

intermetacarpul, $27:$

intromectatarsal, 30!

inforphalangeal, of fingers, 27 ;

uf torse, 310

mincrsternat, 211

knese, 2st

mambilular, 2lis

of luwer limb, 271;

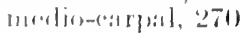

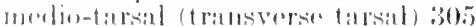

motac(a)

of 1 himmb, 275

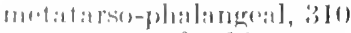

morroments of, 253

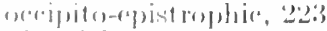

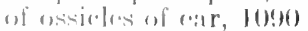

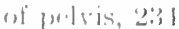

rallir-ritruil] (wrist-joint), 26.5)

mulin-1] In:1r, 261, ] I]!

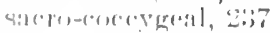

Articulation(s), sacro-vertebral, 232

shoulder, 253, 1413

of the skull, 215

between skull and vertebral column, 218

sterno-costal, 245

sterno-costo-clavicular, 1363

248 ,

synarthrosis, 212

talo-navicular, 305

tarsal, 301

tarso-metatarsal, 307

tibio-fibular, 295

transverse tarsal, 305

of the trunk, 224

of upper extremity, 248

of vertebral colunin, 225

Ary-comiculate articulation (synchondrosis), 1215

Ary-epiglottic fold, 1221

muscle, 1220

Ary-membranosus muscle, 1220

Arytanoid cartilages, 1211

Arytanoideus obliquus, 1220

transversus, 1219

Ary-vocalis muscle of Ludwig, 1220

Ascending a orta, 529

cervical artery, 564

colon, 1173, 1379

lumbar veins, 662,663

palatine artery, 541

pharyngeal artery, 537

Association areas of cerebral cortex, 894

frontal, 894

occipito-temporal, 894

parietal, 894

fibres of spinal corrl, 789

system of cerebral hemisphere, $\$ 90$

Asterion, 101, 1332

Astermal ribs, 127

Astragalus (talus), 192

Athelia, 1301

Atlinto-dental articular capsule, 222 articulation, 220

Atlanto-epistrophic articulation, 220 central, 221

lateral, 221

ligaments, anterior, 221

posterior, $2: 1$

Atlanto-mastoid muscle, 422

Atlanto-oceipital articular capsule, 218 articulation, 218

ligaments, anterior, 218 posterior, $21 \mathrm{~s}$

Atlas and epistropheds, joints between, 220

description, 32

levelopment of, 46

with occiput, articulation of, 218

Atria of heart, 50 s, 511

of lungs, 1232

Atrial musculature, 51s

Arial plexus, 1041

Atrio-retmicular bundle (of Ilis), 517, 519, i) 7

orifice (ostium venosum) of left side, 514 of right sisle, $5 \mathrm{l}:$

Atrimm of heart, 512,514

ol midclle nasal mortus, 1200

Attachments and origin of cranial nerves, 929 of spinal norves, m)

fopograpliy of, ofo6

Attie of midlle car, 77

Ntollens anrem, 337

Attrahoms alluem, $3: 37$

Auditory (cochloar) area of corebral cortex, $8 ! 93$

artery, interosal, 5601

comblitetion pathas, !000 
Auditory foramen, 125

meatus, external, 75, 108, 1084, 1332 internal, 72, 117

(cochlear) nerve, 949, 950

(Eustachian) tube, 1092 pharrngeal aperture of, 1130

veins, internal, 652, 657

Auerbach, plexus of, $1030,1045,116 \mathrm{~s}$

Auricle (pinna) of ear, 1082 cutaneous areas of, 1019 lymphatics of, 714 vessels and nerves, 1084

of heart, 508

Auricular artery, deep, 547 posterior, 543, 1343

branches, anterior, of auriculo-temporal nerve, 941

of great auricular nerve, 973

of ocripital artery, 543

of posterior auricular artery, $54 t$

of small occipital nerve, 977

of superficial temporal artery, 545 of vagus, 956

cartilage, 1084

fissure, $75,10 \mathrm{~s}$

lymph-nodes, anterior, 709 posterior, 709

muscles, 337

nerve, great, $97 \mathrm{~s}$ posterior, 944

point, 101

sulcus, posterior, 1083

tubercle (tubercle of Darwin), 1083

veins, anterior, 646 posterior, 647

Auricularis anterior (attrahens aurem), 337 posterior (retrahens aurem), 337 superior (attollens aurem), 337

Auriculo-frontalis muscle, 337

Auriculo-temporal nerve, 941

Axial set of bones, 27

skeleton, 27,29

Axillary arch, 374

artery, 569

collateral circulation, 1412

parts, 569,570

fascia, 370,371

fossa, clinical anatomy of, 1411

lymphatic nodes, 719

(circumflex) nerve, 984

vein, 671

Axis (epistropheus), 33, 47

coliac, 593

of eveball, 1055

of heart, 509

of pelvis, 176

of scapula, 145

thyreoid (thyreocervical trunk), 564

Axones, 762

motor (efferent), 764

sensory (afferent), 762

sheaths of, 766

of spinal cord, 777

terminations of, 762

Azrgos artery of vagina, 610

(niajor) vein, 662

minor (hemiazrgos) vein, 662

tertia (accessory hemiazygos) vein, 663

\section{B}

Back of hand, 1433

clinical anatomy of, 1403

muscles (spinal), 410

Baillarger, stripes of, 879

Band, diagonal, of Broca, 866

ilio-tibial, $45 \overline{7}, 45 \mathrm{~s}$
Band, ilio-trochanteric, 280

moderator, of heart, 516

tendino-trochanteric, 280

Barba, 1290

Bars, hyoid, 119

mandibular, 119

metamorphosis of branchial or visceral, 119

thyreoid, 119

Bartholin, duct of, 1278, 1292 glands of, $1278,139^{\circ}$

Basal ganglia, 878 vein, 657

Base of arrtanoid cartilage, 1211 of cranium, 103, 113 of encephalon, 794

of heart, $50 \mathrm{~s}$

line, Reid's, 1341

of lungs, 1229, 1233

of nose, 1200

of prostate, 1264,1389

of skull, external, 103

of suprarenal gland, 1325

of thrreoill lobes, 1315

Basi-bregmatic axis, 112

Basi-cranial axis, 112

Basi-facial axis, 112

Basi-lyyal, 100, 119

Basilar artery, 561

groove, 54

plexus of veins, 651

sulcus of pons, 804

Basilic vein, 667

median (median cubital), 667

Basion, 108, 112

Basi-occipital, 119

Basi-pharyngeal canal, 63, 67

Basis (pes) pedunculi, 840 cranii, interna, 113

Basi-sphenoid centre, 67, 119

Basivertebral veins, 666

Bechterew's bundle, 784 nucleus of vestibular nerve, 823

Bell, external respiratory nerve of, 982

Belly of muscle, 314

Bertin, bones of, 67 columns of, 1246

Biceps brachii, $374,379,382$ relations, 1414

fenoris, 453,475

Bicipital groove, $14 \mathrm{~S}$ muscles, 314

Bicuspid teeth, 1121 (mitral) valve, 515, 516

Bifurcation of trachea, 1225

Bile-duct, common, 1188, 1373

Bile-passages, 1186

Bipenniform muscles, 315

Birth, bones of skull at, 120

Biventer cervicis, 418

Biventral lobe of cerebellum, sot

Bladder (urinary) 1249 surgical anatomy of, 1390

Blandin, glands of, 1110

Blood-vascular srstem, 507 of small intestine, $1166^{\circ}$ of spinal cord, 792 of stomach, 1155

Blood-ressels (see also "Arteries" and "Veins").

of abdominal wall, 1371

of brain, 905

of cerebellum, 907

ciliary, 1065

of conjunctiva, 1348

of ductus deferens, 1259

around elbow, $141 \mathrm{~s}$

of eyeball, 1065 
Blood-ressels of eyelids, $107 \mathrm{~s}$ of face, 1343

of Fallopian tube, 1270

of female external genitals, $127 \mathrm{~s}$

of heart, 519

of kidney, 1247

of large intestine, 1179

of larynx, 1224

of lips and cheeks, 1104

of liver, 1185

of lungs, 1234

of lymph-glands, 706

of mammary glands, 1305

of nose, $1203,120 \mathrm{~s}$

of asophagus, $11+1$

of orbit 1074

of ovary, 1269

of palate, 1105

of parathyreoids, 1319

of parotid, 1115

of penis, 1262

of pericardium, 523

of pharynx, 1138

of pleura, 1239

of prostate 1265

of rectum, 1391

retinal, 106.5

of sealp, 1334

of serotum, 1255

of skin, $12 S s$

of spleen, 1312

of sublingual gland, 1117

of submaxillary gland, 1116

of suprarenal glands, 1326

of teeth, 1124

of testis and appendages, 1256

of thymus, 1322

of thyreoid gland, 1316

of tongue, 1111

of trachea and bronchi, $122 \mathrm{~s}$

of ureter, 1249

of urinary bladder, 1253

of uterus, 1274

of vagina, 1276

of vulva, $119^{\circ}$

Bochlalck, wanglion of, 939

Borly(ies) of axis (epistropheus), 33 calotid, 1327

ciliary, 1060

coceygeal, 1329

of eorpus rallosum, $\$ 52$

of epidirlymis, 1256;

of fomur, 178

of fornix, 869

of gall-bladeler, 1157

gonieulate, 834, 8.5

if hyoid bone, 99

inforior quadrigeminate, 839

of isehiom, 171

(central portion) of lateral ventricles, 875

of Julys, Sist

mammillary, 871

of nails, l:3!1

Visst, 766

Pacchinnian, 919

of pithlorots, 1195

pararenal adipose, 12, l:

of prois, 1260

pineal, stij

pitnitary, 848, 1:3, 2

of pul,is, 172

of ritlins, 15:

restiform, 810

of ancolullat oblongatia, 800$)$

(1) rit), 127

(of st::10)1]:1, 111

of splirumite (i⿱
Body(ies) of sternum, 133

of stomach, 1151

superior quadrigeminate, $\$ 25, \$ 41$

of sweat gland, 1297

of thymus, 1320

of tongue, 1106

of ulna, 157

of urinary bladder, 1250

of uterus, 1271

of vertebra, 30

vitreous, 1064

Wolffian, $127 \mathrm{~S}$

Bone(s), astragalus (talus), 191, 192

of Bertin (sphenoidal conchæ), 67

caleaneus, 191, 195

capitate (os magnum), 159, 163

carpal, 159

clavicle, 139

cotyloid, 173

coxal (os innominatum), 169

cuboid, 191, 199

cuneiform, 161, 191, 197

epipteric, 68, 101

ethmoid, $\$ 1$

of the face, 51

femur, 198

fibula, 189

fifth metacarpal, 167

fifth metatarsal, 203

first metacarpal, 165

first metatarsal, 201

of foot as a whole, 205

fourth metacarpal, 167

fourth metatarsal, 203

frontal, 59

greater multangular (trapezium), 159, 162

hamate (unciform), 159, 163

humerus, 146

hyoid, 99

incus, 79, 119

innominate, 169

inferior nasal concha, 84

interparietal (inca bone), 57

lacrimal, 85

lesser multangular (trapezoid), 159, 162

of limbs, homology of, 206

of the lower extremity, 169

lunate (semilunar), 159, 161

malar, 93

malleus, 79, 119

mandible, 95

maxilla, 87

metacarpal, 164

metatarsal, 200

of middle ear, 79

nasal, 86

navicular (scaphoid), 159, 160, 191, 196

oceipital, 51

of orbit, 109

palate, 91

pariotal, 57

patella, 184

phalinges, 167, 203

pisiform, 159, 162

pre-maxilla, $\$ 9$

radius, 152

rilss, 126

seatulat, 141

sceomb metacarpal, 160

secoml metatarsal, 2()$^{2}$

sesamoid, 165, 20.1, 275, 317

of the skull, 51

at birth, 120

morphology of, 117

sphenoirl, 62

stipes, 80,119

styloid, 168 
Bone(s), suprasternal, 133

talus (astragalus), 191, 192

tarsal, 191

temporal, 68

at birth, 122

mastoid portion, 68, 71

petrous portion, 68, 72

squamous portion, 68,70

tympanic portion, $69,70,75$

third metacarpal, 166

third metatarsal, 202

of thorax, 126

tibia, 185

triquetral (cuneiforms), 159, 161

turbinate, $67,83,84$

of tympanum, 79

ulna, 155

of upper extremity, 139

vomer, 85

Wormian, 68

zygomatic, 93

Bony boundaries of perineum, 1383

landmarks of abdomen, 1370

of the ankle, 1459

of the buttocks, 1442

of elbow, 1417

of the foot, 146.

of forearm, 1419

of head, 1331

of the knee, 1447

of the leg, 1.53

of the hip and thigh, 1434

of thorax, 1363

of wrist and hand, 1424

sinuses of skull, 1335

Borders (see individual organs).

Boundaries (see individual parts).

Bowman's membrane, 1060

Brachia conjunctiva (superior cerebellar peduncles), $\$ 31,840$

Brachial artery, 573, 640, 1414 branches, 575 collateral circulation, 1414

(internal) eutaneous branch, posterior, of radial nerve, 985

cutaneous nerve, lateral, 985 medial, 983

fascia, 377

group of axillary lymphatic nodes, 719

plexus, 980

branches, 982

cords of, 981

relations of, 981,1360

terminal branches of, 985

venæ comitantes, 671

Brachialis, $374,380,382$

surface markings of, 1415

Brachio-cephalic (innominate) veins, $6+1$

Brachio-radialis (supinator radii longus), 387, 388

Brachium conjunctivum, $\$ 12$

inferior, 834

superior, $\$ 34$

pontis, 811

Brain (encephalon), 792

blood-supply of, 905

cerebral hemispheres, 850

cerebrum, 833

cerebellum, sot

diencephalon (inter-brain), 843

isthmus rhombencephali, $\$ 32$

medulla oblongata, 799

meninges of, 908

mesencephalon (mid-brain), 833

pons (Varoli), 804

prosencephalon (fore-brain), 843

rhombencephalon, 799
Brain, telencephalon (end-brain), \$47 topography of, 903,1338

Branches (see corresponding vessel or nerve).

Branchial arches, 17

bars, metamorphosis of, 119

grooves, 17

Branchiomerism, 16, 17

Breast, female (mammary gland), 1299 male, 1305

Bregma, 101, 112, 1332

Brim of pelvis, 175

Broad (lateral) ligaments of uterus (alæ vespertilionis), 1267, 1393

Broca's area, 858,865

convolution, 858

diagonal band, $\$ 66$

Bronchi, 1226, 1231, 1408

Bronchial arteries, 588, 63S, $123 t$

branches, Aeby's division of, 1232 of internal mammary artery, 567

(pulmonary) branches of vagus, 957

glands, 1231

lymphatic nodes, 725,1225

tubes, branching of, 1231

veins, $66 \pm, 666,1234$

Bronchioles, 1232

Broncho-cesophageal muscle, 1141, 1228

Bronchus, eparterial, 1232 hyparterial, 1232

Brunner's glands, 1166

Bryant's triangle, 1436

Buccal branches of cervico-facial nerve, 945

artery, 548

nerve, long, 939

veins, 646

Buccinator, 334

(long buccal) nerve, 939

set of facial lymph-nodes, 711

Bulb(s), artery of, 613

of hair, 1292

of internal jugular vein, 659

olfactory, 758,865

of posterior cormu of lateral ventricle, 876 of urethra, 1262

Bulbar plexus, $10+1$

Bulbi vestibuli, 1277

Bulbo-cavernosus 443,450

in female (sphincter vaginæ), 451

Bulbo-urethral (Cowper's) glands, 1265

Bulbous corpuscles (end-bulbs of Krause), 1290

Bulbus aortæ, 530

Bulla, ethmoidal, 84. 111, 1205

Bundle, Arnold's, 832, 889

atrio-ventricular (of $\mathrm{His}$ ), 517, 519, 527

conmissural, $78 \mathrm{~S}$

Helweg's (Bechterew's), 7st

posterior longitudinal, 817

Türk's, \$32, 890

of Vicq d'Azyr, S71

Burdach's column of spinal cord, 781

Bursa $(\mathfrak{x})$ anguli mandibuli, $128 \mathrm{~s}$

anserina, 474

of anterior ilio-femoral musculature, 456 thigh muscles, 471

of the arm, subcutaneous, 377

muscular, 379,383

of back of leg, 486,491

bicipito-radialis, $3 \$ 3$

cubitalis interossea, 383

of dorsal arm muscles, 379

epicondyli medialis dorsalis, 379

of facialis musculature, 330

of foot, 500, 1465

of forearm and hand, 3S4, 395, 403

of front muscles of leg, 48.3

gluteofemorales, 462 
Bursa(se), hroid, 1217

iliaca subtendinea, 457

iliopectinea, 456

of infra-hyoid muscles, 353

infrapateliaris protunda, ti1

subeutanea, 466

intermetacarpophalangex, 395

intermetatarsophalanger, 500

intratendinea olecrani, 379

ischiadica musculi glutei maximi, 462

of ischio-pubo-femoral musculature, 464

of medial thigh muscles, 474

nucose, 313,318

subcutaneous, 1288

subfascial, 318

submuscular, $31 \mathrm{~s}$

subtendinous, 318

musculi abductoris pollicis longi, 395

anconei, 379

bicipitis femoris inferior, 476

superior, 476

gastrocnemialis, 776

coraco-brachialis, 383

extensoris carpi radialis brevis, 395 ulnaris, 395

pollicis longi, 395

flexoris carpi radialis, 403 uluaris, 403

gastrocnemii lateralis, 486 medialis, 4,86

infraspinati, 370

latissimi dorsi, 370

ol turatoris externi, 464 interni, $46 t$

pectinci, 474

pectoralis majoris, 374

piriformis, 462

quadrati femoris, 464

recti femoris (inferior), 471

(superior), 471

sartorii propria, 471

senimemliranosus, 476

sterno-hyoidej, 353

suhsompularis, 370

supinatoris, 395

teretis majoris, 370

threen-hyoidei, 358

omentalis (losion' sac) 1146, 1372

of peenoral muscles, 374

phatromeral, 11:30

of postorion ilin-fomoral musculature, 476

proputellaris subcutanea, 460

subfascialis, 46i;

subtrudinos 17

prepatellar, 12ss, 144s

of somlder musenlature, 360

simus tarsi, ts:

sublaremialis, 3699

sulementanca atromialis, 36.5

("a)

digilormm dorsales, 384, 128s

epromelyli lateralis, 377 moreliallis, :377

infmpatellaris, 126s

mallioli medialis of lafroralis 477

motamporphalangea domalis, 38t, 1288

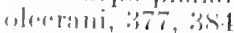

promontalis, 33010

premincontia latrongare, $3: 30$

silloritis, l'sus

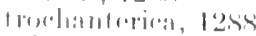

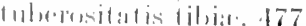

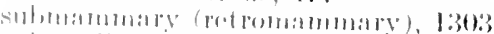

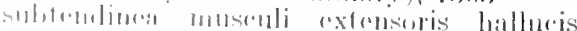

longi, 16:3

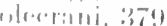

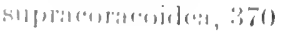

Bursa(æ), suprapatellaris, 471

synovial, 313,318

tendinis calcanei, 486

musculi tibialis anterioris, 483

of ventral arm muscles, 383

Bursa tendinum musculi extensoris digitorum communis, 395

of trapezius, 350

trochanterica musculi glutei maximi, 462 medii anterior, 462 posterior, 462

minimi, 462

subcutanea, 457

Buttocks, bony landmarks of, 1442

clinical anatomy of, 1442

nerves of, 1443

\section{C}

Creum (caput coli), 1170

cupular, 1096

topography of, 1376

variations of, 1171

vestibular, 1096

Calanmes scriptorius, 812

Calcaneal pillar, 205

Calcanean branches, lateral, of sural nerve, 1013

of peroneal artery, lateral, 626

of posterior tibial artery, medial, 626 nerves, medial, 1010

Calcaneo-cuboid articulation, 306

ligaments, 306,307

Calcaneo-fibular ligament, 299

Calcaneo-metatarsal ligament 492 ,

Calcaneo-navicular ligament, lateral, 302, 305 plantar (spring), 305

Calcaneo-plantar cutaneous nerves, 1010

Calcaneus (os calcis), 191, 195

Calcar avis (hippocampus minor), 864, 868

femorale, 184

Calcarine fissure, 864

Calcification of bones, 27 of teeth, 1126

Callosal convolutions, 868

Calloso-marginal fissure, 857, 859

Calyces of kiclney, 1246

of ureter, 1248

Camper's fascia, 425

Canal(s), accessory palatine, 103

arliluctor (Hunter's), 468, 618, 1441

Alcock's, 441, 445

alveolar, 87

anal, 1177

hasi-pharyngeal, 63

carotid, $73,10 \mathrm{~s}$

central, of spinal cord, 775

of ('ervix, 127')

ethmoidal, 61, s3, 110, 113, 126

facial (Jallopian), 72, 73, 77, 78

femoral (crumal), 468

guloernacular, los

of lluguier, 75, 77, 108

byaloigl, roti.t

hypoplossal, 117

inforior dental, 96

inflat-(1)rhital, 87,126

inguinal, 424, 430

clinical analomy of 1395

latral semicirenlar, 78

mamlibular (inforior dental), 96, 126

malatime, 9:2

of Protit, Io)

Pharyugeal, $(66,92,103$

postrior palatione, 12t;

Meryguid (Viclian) canal, 103, 107, 108, 126

plerygo-palatine, ss, 92,103 
Canal(s), pyloric, 1152

saeral, 42

of Schlemm, 1059

semicircular, 80, 1092

zygomatico-facial, 126

zygomatico-orbital, 94

Canaliculi, carotieo-tympanic, 74

Canaliculus cochlex (duetus perilymphaticus), $73,81,108$

innominatus, 65

mastoid, 73

tympanic, 73,108

Canalis musculo-tubarius, 73, 77, 108

facialis, hiatus of, 116

Canine fossa, 87

teeth, 1120

Caninus (levator anguli oris), 332

Capillaries, lymphatic, 697

Capilli, 1290

Capitate (os magnum) bone, 159, 163

Capitular (costo-central) artieulation, 241

ligaments of tibio-fibular union, 295

Capitulum of humerus, 150

Capsular ligament of elbow-joint, 258 (perirenal) branches of renal arteries, 598

Capsule, artieular, acromio-clavicular, 251 atlanto-dental, 222

atlanto-epistrophic, 221

atlanto-oeeipital, 218

of capitular artieulation, 241

carpo-metacarpal of thumb, 273

costo-transverse, 243

crico-thyreoid, 1213

of hip-joint, $27 \%$

of knee-joint, 287

of mandibular articulation, 215

of medial tarso-metatarsal joint, $30 \mathrm{~s}$

of metacarpo-phalangeal joint of thumb, 275

of shoulder-joint, 254

of sterno-eosto-clavicular joint, 248

of tibio-fibular union, 295

of vertebral joints, 228

external (teleneephalon), $\$ \$ 1,888$

Glisson's, 675, 1186

glomerular, 1246

internal (telencephalon), s7s, 886

of kidner, 1242,1303

of prostate, 1265, 1389

of suprarenal gland, 1326

Tenon's, 1073

surgical importance of, 1348

of thy reoid gland, 1316

Caput angulare (levator labii superioris alæque nasi), 332

infraorbitale (levator labii superioris), 332

zygomaticum (zygomaticus minor), 332

Cardia of stomach, 1151

Cardiac branches of vagus, 957

fossa of lungs, 1229

ganglion (of Wrisberg), 1041

nerve, inferior, 1037

middle, 1036

superior cervical, 1036

notch of left lung, 1229

portion of stomach, $1151,137 t$

plexus, 1041

vein, anterior, 521

great, 520

middle, 520

small cardiac, 521

smallest cardiac, 521

Carina trachea, 1225

urethral, 1275, $127 \mathrm{~s}$

Carotico-elinoid foramen, 65

Carotico-tympanic artery, 552 canaliculi, 74
Carotico branches from tympanie plexus, 951,961

Carotid arteries, eommon, 533

collateral circulation, 536, 1360

external, 533, 536, 1343

branches, 536

relations, 536

internal, 533, 549

variations, 637

canal, $73,10 \mathrm{~s}$

gland (body), 550, 1327

groove, 64

nerves, external, 1036

internal, 960,1033

plexus of nerves, common, 1030

external, 1036

internal, 1033

ridge, 73

sheath, 1362

triangle, inferior (tracheal), $135 \mathrm{~s}$ superior, 1358

(anterior) wall of tympanic eavity, 1054

Carpal areh (rete), volar, 581

artery, dorsal radial, 585

dorsal ulnar, 580

volar radial, 584

volar ulnar, 581

bones, ossifieation of, 164

head of adductor pollieis, $40 \mathrm{~s}$

joints, 268, 269

(annular) ligaments of wrist, 1427

rete, dorsal, 579,585

Carpo-metacarpal joints, 272 of the thumb, 273

Carpus, description of, 159,270

ligaments, 3s4, 387

Cartilage (s), 211

alar, 1201, 1202

articular, of shoulder-joint, 255

arytanoid, 1211

aurieular, 1084

eorniculate (santorini), 1212

costal, 130

cricoid, 1210

cuneiform(Wrisberg), 1213

epiglottic, 1212

interarytienoid (procricoid), 1213, $121 \mathrm{~S}$

of larvin, 1209

lateral nasal, 1201

Meckel's, 98, 119

nasal, 120

periotic, 117

septal nasal, 1202

sesamoid nasal, 1202

laryngeal. 1213

sphenotic, 117

thrreoid, 1210

tracheal, 1227

varieties, 211

vomero-nasal, 1203

Cartilaginous plate (pelvie joints), ear-shaped, 235

Cartilago triticea, 1217

Caruncle, lacrimal, 1052, 105.5

sublingual, 1117

Carunculie hymenales (myrtiformes), 1275, 1392

Cauda equina, 772

helicis, 1084

Caudate hraneh of middle eerebral artery, 562

(spigelian) lobe of liver, 118t

nucleus, 877, 879

process of liver, 1184

Cavernous nerves of clitoris, 1047 of penis, $104 \pi$

plexus of nasal eonehæ, 1208 of nerves, 1033 
Cavernous (spongy) portion of male urethra, $1264,135 \mathrm{~s}$ sinus, 652, 691

Cares, Meckel's, 916

Cavity, body, 14

epidural, 911

glenoid, of scapula, 143

of larymx, 1220

lesser sigmoid, of ulna, 157

mediastinal, 1239

nasal, 1203

oral, 1100

of orbit, 1066

pelvic, 175

pericardial, 522

pleural, 1236

of radius, sigmoid, 154

subarachnoid, 918

subdural, 912

thoracic, 1235

of tooth, 1118

tympanic, 77,1088

of ulna, greater sigmoid, 156

of uterus, 1271

Carum conche, $10 \$ 2$

pelvis subperitoneale, 448

Retzii, 1250, 1371

Cellifugal processes of neurone, 762

Cellipetal processes of neurone, 762

Cells, 4

chromaffin, 1323

ependymal, $76 \mathrm{~s}$

ethmoidal, 83, 84, 111, 1207

(iolgi, in cerebellum, 809

gustatory, 1050

olfactory 1051

mastoid, 1092, 1336

of Purkinje, 809

stellate, 809

Cementum of teeth, 1119

Central (ganglionic) arteries of cerebrum, 906 of medulla oblongata, 908

lininches of cerebral arteries, 562, 563

canal of spinal eord, 775

eonnections of cranial nerves, 818

of abdueens, 934

of cochlear, 824

of facial nerve, 825,946

of glosso-palatine, 825,947

of glusso-pharyngeal, 820,952

of hypoglossal, 820,954

of masticator, 829,942

uf oculo-motur, 838, 933

of alfuctury, 873,929

of optic, 848,931

of spintal accessis)ry, 820,959

of trig(minns, 826, 9:3i)

of trumlear, 837, 9:34

of vagus, 820, 45s

of vestibular, 823 , 950

gyrus, anterior (ascending frontal convolutiol1), $\$ 5 \overline{6}$

pustrior (ascenting parietal), siol

lober or insulat, sijt;

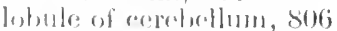

norous systom, 75l

wint of poringum, 1385

sulinis (ficsure of liolandolo), 859, 1340

illugle: of , slit)

inforior garoul]. $8(00)$

in for.tins, silit)

of insulat sijo

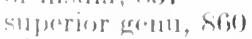

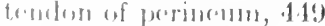

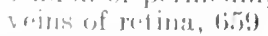

C'ontres, assogiation, of rereloral cortex, so)

Contriere semingale, sist;
Centrum (body) of vertebri, 30

Cephalic index, 117

plexus, gangliated, 959

portion of sympathetic trunk, 1033

vein, 667,671

Cephalo-auricular angle, $\mathbf{1 0 8 4}$

Cerato-cricoid ligaments, 1213 muscle, 1218

Cerato-hyal center, 100 segnent, 119

Cerebellar artery, anterior inferior, 561, 907 posterior inferior, 561, 907 superior, 561, 907

notches, 805, 915

peduncle, inferior, 810 superior, 812,831

tract, direct, of Flechsig, 784 veins, 657

Cerebello-olivary fibres, 817

Cerebellum (hind brain), 804

ala of central lobule, $\$ 06$

anterior medullary velum of, 812

arbor vita of, 809

biventral lobe, 807

blood-vessels of, 907

brachium pontis, 811

conjunctivum, 812

central lobule of, 806

conduction paths of, 899

cortex of, 809

eulmen of, 806

declive (clivus), 806

dentate nucleus of, $\$ 10$

external features, 808

fissures, 805

floceulus, 807

peduncle of, 807

folium vermis (cacuminis), 806

fourth ventricle, anatomy of, 812

functions of, 832

gross divisions of, 805

hemispheres of, 805

inferior vermis, 808

internal structure of, 808

lingula of, 806

lobes and lobules, 805

monticulus, 806

nodule of inferior vermis, 808

noteh of, 805

nuclei of, 809,810

peduncles of, $\$ 10$

posterior medullary velum, 808

pyramid of vermis, 808

sulci of, 805

superior vermis of, 806

tentorium of, 804

tonsil (amygdala) of, $\mathrm{S07}$

tuber vermis, 808

uvila of vermis, 808

vallecula of, 807

veins of, 908

vermis of, $\mathrm{S05}, \mathrm{S07}$

Cerebral arteries, anterior, 554, 562

branches, 562

midkle, 555, 562

posterior, 561, 562

commissure, anterior, 871

inforior, 842,890

cortex, 879

cornu ammonis, 879

functional areas of 893

struature of, 879

hemisplieres, 850

caudlate nucleus, 877

corpus striatum, s68, 879

cortin of $852,879,893$

uyri of, $855^{\circ}$ 
Cerebral hemispheres, lateral ventricle, $\$ 73$

lobes of, 853

central (insula), 856

frontal, 857

occipital, 863

parietal, 860

temporal, 854

rhinencephalon, 864

sulci of, 852

path for cranial nerves, 895

peduncles (crura), 833, 835

arteries of, 907

veins, 644,657

central or deep (ganglionic), 655

great (of Galen), 657

inferior, 655

internal, 657

middle, 655

superior, 654

Cerebro-spinal fasciculus, lateral, 783 ventral, 788

fluid, 920, 1342

path, 895

Cerebrum, 833

mesencephalon (mid-brain), 833

prosencephalon (fore-brain), 843

diencephalon (inter-brain), 843

telencephalon (end-brain), 847

Cerumen, 1085, 1298

Ceruminous glands, 1085, 1297

Cervical artery, ascending, 564 deep, 568

superficial, 566

transverse, 565

branches of uterine artery, 610

chains of lymphatic nodes, deep, 714

enlargement of spinal cord, 772

fascia, external, 347

middle, 350

ganglion of sympathetic, inferior, 1036 micldle, 1036 superior, 960, 1035

loop (ansa hypoglossi), 953, 974

muscle, 330

nerves, 971,974

anterior primary divisions, 974

posterior primary divisions, 971

plexus, 974

ascending branches of, 977

deep branches of, 978

descending branches of, $97 \mathrm{~s}$

posterior, of Cruveilhier, 971

superficial branches of, 977

supra-clavicular branches of, $97 \mathrm{~S}$

transverse branch, $97 \mathrm{~S}$

portion of external maxillary artery, 540

of internal carotid artery, 550

of sympathetic trunk, 1033 construction of, 1037

of vertebral artery, 559

ribs, 131,1365

triangles, 1357

vein, deep, 661

veins, transverse, 672

vertebræ, description of, 31

development of, 47

Cervicalis ascendens, 416

Cervico-facial nerve, 945

Cervix of uterus, 1271

Chains of nerurones, 768

Chambers of the eve, 1064

Charcot's artery of cerebral hemorrhage, 562, 906

Check (alar) ligaments, 223 of eyeball, 1072

Cheek, 1103

Chiasma, optic, $\$ 48,849$
Choanæe (posterior nares), 107, 112, 1130, 1206,1351

Chondro-cranium, 117

Chondro-humeralis (epitrochlearis), 374

Chondro-glossus, 346

Chopart's medio-tarsal amputation, 1465

Chorda tympani nerve, $\$ 26,946,948$

Chordæ tendinæ, 515

Chords of Willis, 649

Chorio-capillaris, 1055

Chorioid, 1057, 1060

artery, 554, $90 \mathrm{~s}$

branches of posterior cerebral artery, 563

fissure, 868

glomis, 876

plexus of fourth ventricle, 922

of lateral ventricle, $875,877,924$

tela of fourth ventricle, $75 \mathrm{~S}, 812$

of third ventricle, 923

vein, 657

Chorioidal arteries of medulla oblongata, $90 \mathrm{~s}$ fissure, 1080

lamina, epithelial, 876,924

nembrane, 1052

Chorion, 10

Cliromaffin bodies, 1329

cells, 1323

system, 1323

Chromatin, 5

Cilia, 1290

Ciliary arteries, anterior, 1065 long posterior, 1065 short posterior, 1065

body, 1060

ganglion, 961, 1076

branches, 961

roots, 932, 937, 961, 1033

glands (glands of Moll), 1078, 1297

muscle, 1057, 1060

nerves of eyeball, 1054, 1076

long, 937

short, 961,1076

processes, 1057

veins, 658

Cingulum, 867, $\$ 90$

of teeth, 1120,1121

Circle of Willis (circulus arteriosus), 55.5

Circular sinus, 651

sulcus (limiting sulcus of Reil), S57

Circulation, collateral, of axillary artery, 1412 of brachial artery, 1414

of common carotid artery, 1360

iliac arteries, 1382

of exterual iliac artery, 1382

of femoral artery, 1441

of internal iliac artery, 1382

of popliteal artery, 1453

of subclavian artery, 1360

fotal, 695

pulmonary, 507

systemic, 507

Circulus arteriosus major, 1065 minor, 1065

tonsillaris, 952

Circumanal glands, 1297

Circumduction, 215

Circumferential cartilage, 211

Circumflex artery, lateral, 620, 640 medial, 620,640

femoral veins, 690

humeral artery, anterior, 572 posterior, 573

iliac artery, deep, 616 superficial, 618

vein, deep, 683 superficial, 684

nerve, 985 
Circumflex (dorsal) seapular artery, 572 veins, 671

Cireumrallate papilla of tongue, 1106

Cisterna basalis, 918

cerebello-medullaris (eisterna magna), 919

chrli, 726

pontis, 918

subarichnoid, 918

superior, 919

Clarke's columen of spinal cord, 776

Classifieation of artieulations, 212 of museles, 319

Claustrum, $\$ 80$

Clava, 801

Clavicle. $139,1357,1+10$

ossification of, 141

structure of, 141

Clavieular braneh of thoraco-acromial artery, 571

Cleft, mirldle ear, 77 palate, 1106,1352

Clinieal and topographieal anatomy, 1331 of abdomen, 1370

of back, 1403

of hearl, 1331

of lower extremity, 1434

of neek, 1354

of pelvis, 1382

of thorax, 1363

of upper extremity, 1409

Clinoid process, anterior, 65, 116

middle, 65,116

posterior, 63, 116

Clitoris, 1277

artery of, 613

cavernous nerves of, 1047

deep artery of, 614

dorsal artery of, $61 t$ vein of, 1018

lymphaties of, 745

Clivus, 117

Clogea, 1179, 1253, $127 \mathrm{~s}$

Clunial (gluteal) branches, inferior, of pusterior femoral entaneous nerve, 1007

nerve, inferior medial (perforating eutaneous), 1007

middle, 973

superior, 973

Coats of the eveball, 105s

Cocergeal body, 13:9

cormua, 43

foreolit, 12St

ganglion, 1040

ligament, 911

nerves, 973

posterior primary division of, 973

rudimentary, 964

plexus, 1018

vertahras .12

development of, 49

recerg(e)ts, 440,448

('),

miseles of, H.IS

Cinctilex, 81, lo!):

(

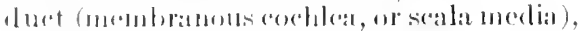
$10 ! 31$

fornestrit, 10x!)

merve, $>2.1$ mincleif of 824

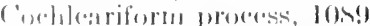

('ulian strtry (axis), 593, fi3s

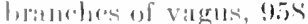

(smolibuar) ginnglia, I0):3

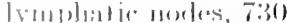

plexthe of unrves, 101:3

C'illin, 11
Colie, artery, left, 603

middle, 598

right, $59 \mathrm{~s}$

flexures, 1173, 1379

(basal) surface of spleen, 1310

veins, $677,67 \mathrm{~s}$

Collateral artery, inferior ulnar, 570

midclle, 576

raclial, 576

superior ulnar, 576

branch of intereostal arteries, $58 s$

cireulation of axillary artery, $1+12$ of brachial artery, 1414

of common carotid arterv, 536, 1360 iliac arteries, 605,1382

of external iliac artery, 1382

of femoral artery, $14+1$

of interual iliac artery, 1382

of popliteal artery, 1453

of subclavian artery, 1360

eminence, S68, 877

fissure, 864

trigone of lateral ventricle, 876

Collecting renal tubule, 1246

Colles' fascia, 445

fracture, 1420

Collieuli, inferior, $\$ 34,839$

superior, $8+1$

Colliculus of arytanoid, 1212

facialis, $\$ 15$

seminalis (verumontanum), 1263, 1389

Colloid of thyreoid gland, 1316

Colon, ascending, 1173, $137 \mathrm{~s}$

descending, 1174, 1379

iliac, 1174

pelvie, 1174,1379

sigmoid, 1174,1379

transverse, 1174, 1379

Colostrum, 1303

Columm anterior of spinal eord, 786

Burdach's, 781

Clarke's, 776

Goll's, 781

lateral of spinal cord, 782

posterior of spinal cord, 780

vertebral, 29,43

Columna rugarum, 1275

Columns, anterior, of fornix, 870

reetal (of Morgagni), 1177, 1390

renal (of Bertin), 1216

Comedo, 1298

Comma-shaped fasciculus, 7S2

Commissural lomehes of sympathetic, 1032

bumlle, $78 s$

fibres of white substance of spinal eord ${ }^{r} 779$

system of filores, of telencephalon, 890

Commissure, 769

anterior cereloral, $848,871,890$

grey, of spinal cord, 775

hablemulitr, 872, 885, 890

hippoeampal, s69, 890

inferior rerclinal (Gudden's), 842, 850,890

micldle cereloral, $8+4$

optie, 849

posterior, of cerebrum, 835,890

of rulval, 1276

supramammillary, 871, 890

white, of spinal corl, 776

(ommon bile-duet (duetus eholedochus), 1188

caroticl artery, 5i33

hrinelies, 5.3 ti

collateral circulation, 536, 1360

in the neek, 5:33

relations, 5.33, 53.34, 1369

thoracic portion of left, $533: 3$

digital arteries, 5N22

veins (foot), (ist 
Common digital veins, volar, 671

facial vein, 644,646

femoral artery, 616

iliac arteries, 603,605 collateral circulation, 605 veins, 679

interosseous artery of forearm, 570

Communicans cervicalis, 974

fibularis, 1013

Communicating artery, anterior, 555, 562 posterior, 554

Comparative anatomy of large intestine, 1180 of lips and cheeks, 1104

of liver and gall-bladder, 1192

of palate, 1106

of pancreas, 1197

of peritoneum, 1151

of salivary glands, 1117

of stomach, 1160

of teeth, 1127

of tongue, 1112

of tonsils, $113 \mathrm{~s}$

Compartments under inguinal ligament, 1399

Complexus, 412, 417

Compound bones, 27

Compressor bulbi proprius, 450

hemisphærium bulbi, 451

venæ dorsalis, 451

Conarium, 845

Concha, 1082

eminence of, 1083

Conchæ, nasal, $83,84,1205$

sphenoidal, 64, 67

Conchal (inferior turbinate) crest, 88,92

Conduction paths, auditory, 900 involving cerebellum, $\$ 99$

of nervous system, summary of, $\$ 95$

methods of determining. 779

of olfactory apparatus, 902

of optic apparatus, 900

vestibular, $\$ 99$

Condylar foramen (canal), 54 fossa, 54, $10 \mathrm{~S}$

process of mandible, 96,97 tubercle of mandible, 97

Condylarthroses, 213

Condyles, 29

of femur, 182

of femur and tibia, 1447

of mandible, 97

of occipital bone, $54,10 \mathrm{~s}$

third occipital, 56

of tibia, 155

Condyloid emissary veins, 652

Cone, elastic, of larrnx, 1215

Conical papillæ of tongue, 1106

Conjoined tendon of internal oblique and transversalis, 435

Conjugate diameter of pelvic inlet, 175

Conjunctiva, 1054,1347

lymphaties of, 695,712

ocular, 1054

palpebral, 1054

Conjunctival arteries, anterior, 553 posterior, 554

sac, 1054

semilunar fold of, 1055

veins, $65 \mathrm{~S}$

Connecting fibro-cartilage, 211

Connections, central, of cramial nerves, $81 s$ (for individual nerves, see "Central connections").

cortical, of thalamus, $\$ \$ 3$

of nuclei of corpus striatum, 880

Conoid ligament, 251

tubercle, 140

Constituents of articulations, 211
Constrictor laryngis, $121 \mathrm{~s}$ radicis penis, 450

vagine, 449

Constrictors of pharynx, 1137

Construction of nervous system, 762

Conus arteriosus, 516 medullaris, 771

Convoluted renal tubules, 1246

Convolutions, cerebral, i5:

Cooper's ligament, 1400

Coraco-acromial ligament, 252

Coraco-brachialis, $374,379,381$

Coraco-clavicular union, 251 arterial supply, 251

ligaments, $25 \dot{1}$

movements, 252

nerve-supply, 251

(costo-coracoid) fascia, 371

Coraco-humeral ligament, 255

Coracoid (suprascapular or superior transverse) ligament, 253

process of scapula, 14.4

(conoid) tuberele, 140

Cord, oblique, 262

spermatic, 1259, 1387

spinal, 751, 771

clinical inatomy, $140 \mathrm{~s}$

external morphology of, 771 internal structure of, 775

Cords of brachial plexus, 917 gangliated, neurones of, 75.5 vocal (see "Vocal folds").

Corium, 1286

Cornea, 1052, 1054, 1056, 1059, 1065

Comiculate cartilages (of siantorini), 1212 tubercle (of Santorini) of larynx, 1221

Corniculo-pharyngeal ligament, $121 \mathrm{~s}$

Cornu ammonis, 868, 879

Cornua of fascia lata, 467

of fossa oralis (saphenous opening), 467

of hroid bone, 99, 100

of lateral ventricles, $873,874,876$

of sacrum, 40

of thyreoid cartilage, 1211

Cornucopia, 923

Corona cilaris, 1060

glandis, 1260

iridis, 1054

radiata, 887

occipitu-thalamic (optic) radiation of, SSS

Coronal suture, 57, 101, 1339

Coronary arteries, 519

ligaments of knee-joint, 290 of liver, 1184

plexuses of nerves, 1041

sinus, 521

valve (of Thebesius) of, 512

sulcus of heart. 510

(gastric) vein, 675

veins, 520

Coronoill fossa of humerus, 150

process of mandilile, 97,1351 of ulua, 156

Corpora albicantia, 844, 1269

cavernosa of clitoris, 1277 penis, 1:60

mammillaria (abicantia), St4

quadrigenina, 834

quadrigemina-thalamus path, 786

Corpus adiposum bucea, 1103, 1104

callosum, 8.51

body of, 852

forceps major, 890

minor, 890

genu, 8.51

perluncle of, 866

radiation of, 851,890 
Corpus callosum, rostral lamina of, $\$ 52$ rostrum of, $\$ 52$ splenium of, 852 strice of, $\$ 51$ sulcus of, 867

cavernosum urethræ (corpus spongiosum), 1261

Highmori, 1256

manme, 1302

papillare of skin, 1286

spongiosum (cavernosum urethræ), 1261

striatum, 879

caudate nucleus of, 879

connections of nuclei of, $\mathrm{S} S \mathrm{O}$

internal capsule of, 886

lenticular nucleus of, 879

trapezoideum, 824

Corpuscles, bulbons (of Krause), 1290

genital, 1290

colostrum, 1303

concentric (Hassal's) of thymus, 1321, 1322

Golgi-Mazzoni, 1290

lamellous (Vater-Pacinian), 1290

renal (Malpighian), 1246

Ruffini, 1290

salivary, 1132

splenic (Malpighian), 1311

tactile (Meissner), 1290

Corrugator cutis ani, 445 muscle, 336

Cortex, cerebellar, 809

cerebral, $\$ 79$

functional areas of, 893

of kidney, 1246

of lens of eye, 1062

of suprarenal gland, 1326

of thymus, 1321

Corti, organ of, 1096

Cortical branches of cerebral arteries, 562,563

(superficial) cerebral veins, 654

connections of thalamus, 883

Cortico-pontine fibres, $\$ 11$

Costal areh, 139

branch, lateral, of internal mammary artery, 567

cartilages, 130

Costal grouve, 127

pleura, 12:37

processes, $3 \mathrm{~S}$

tuberosity of elaviele, 140

Custo-axilliry veins, 671

Costo-central (ripitular) articulation, 241

ligaments, 211

Costo-cervical arterial trunk, 568

Costo-chondral joints, 2.45

Costo-chavienlar (rhomboicl) ligament, 249

Costo-coricoirl fascia, 371

ligament, 371

Costo-roracoinleus, 37.4

Costo-mediastinal sinus, $12: 38$

Costro-transverse articulations, 2.12 arterial supply, 24t

liganuents of '2.t:'

mildle (neck), 2.13

postrerior (111)erenlar), 243

supprior, 2.1:3

movements, 211

norves-sip)ly, 211

f(s:11110m, 32,127

of atlas, :?:

Costo-xipheniel ligament, 24., 245

(iosto-vertoliral atrticulations, 241 growere, 1:3

(i) 1 momitis, norve of $996^{\circ}$

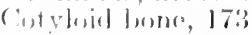

filore-riartilatese, 281

fussa, lois
Cowper's (cremasteric) fascia, 426, 434, 1254 glands, 1265

Coxal bone (os innominatum), 169 ossification of, 174

Cranial a rachnoid, $91 \mathrm{~s}$

cavity, floor of , 112

relations of brain to walls of, 903

dura mater, 913

fossa, anterior, 113

middle, 116

posterior, 116

surgical anatomy of, 1342

nerves, 927

abducens, 934

central connections of, 818

cochlear, 950

facial, 943

glosso-palatine, 946

glosso-pharyngeal, 951

hypoglossal, 952

masticator, 942

oculo-motur, 931

olfactory, 929

optic, 930

paths of, cerebral, $\$ 95$

short reflex, $\$ 98$

spinal accessory, 958

superficial attachments of, 929

terminal, 929

trigeminus, 934

trochlear, 933

vagus, 95

vestibular, 949

pia mater, 922

subdural cavity, 917

venous lacunæ, 649

sinuses, $649,692,916$

Cranio-cerebral topography, 903, 1338

Cranio-mandibular musculature, 325,338 , 341

Cranium 51

clinical anatomy of, 1333

measurements of, 117

remnants of cartilaginous, 124

Cremaster, 423, 434, 1254

external, 1259

internal, 1254,1259

Cremasteric branches of internal spermatic arteries, 501

fascia (extemal spermatic, or Cowper's fascia), $426,434,1254$

Crest(s), 29

arcuate, of arytanoid cartilage, 1212

conchal, 88,92

ethmoilal, 92

external occipital, 52

of fibula, 190

frontal, 60

of greater tuberosity of lumerus, 148

of ilium, 169

incisor, 90

inferior turbinate, 92

intemal orecipital, 53

introsseness, of radius, 153

of uha, 157

intertrochanteric, 178

lacrimal, posterior, 85

masal, 90

neural, 75.1

obturator, 173

of scapula, 1.4

sphomoiclal, 6.3

superiur turbinate, 92

of tibia, anterior, $18 \mathrm{~S}$

1 ransverse, 72

Cribriform lamina, 119

plate of ethmoid, 81 
Crico-arytænoid articulation, 1214 ligament, 1214

Crico-arytænoideus lateralis, 1219 posterior, 1218

Cricoid cartilage, 1210

Crico-pharyngeal ligament, $121 \mathrm{~S}$

Crico-thyreoid articulation, 1213 ligament, 1215 muscles, 1218

Crico-tracheal ligament, 1218

Crista, ampullary, 950, 1095 galli, 81, 113 supraventricularis, 516, 527 terminalis, 513 urethralis, 1263 vestibuli, 80

Cristæ of matrix unguis, 1295 of skin, 1284

Crossed pyramidal tract, $7 \$ 3$

Crown of tooth, 1117

Crucial anastomosis, 620 ligament of atlanto-epistrophic joint, 222 ligaments of knee-joint, 288

Cruciate ligament of leg (lower part of anterior annular ligament), 479 of fingers, 387

Crura of anthelix, 1083 of cerebrum, 833,835 clitoridis, 1277 of diaphragm, 437 of fornix, 868 of greater alar nasal cartilages, 1202 of penis, 1261 of stapes, 80

Crural canal, 468 fascia, 477 nerve, anterior, 1001 interosseous 1010

Crureus, 468,470

Cruro-pedal muscles, $4 \$ 6$

Crus of helix, 1082, 1083

Cruveilhier, posterior cervical plexus of, 971

Cryptorchism, $125 \%$

Crypts of iris, 1054 of Lieberkühn, 1166, 1177, 1390

of lingual tonsil, 1107 of palatine tonsil, 1132

Crustalline lens of eve, 1052, 1057, 1061

Cubital lymphatic node, superficial (supratrochlear), 719

Cuboid, 191, 199

Cuboideo-navicular ligaments, 303 union, 303

Cubo-metatarsal joint, 309 ligaments, 309

Culmen of cerebellım, $\$ 06$

Cuneiform bones, 159,161, 191, 197 first (medial, 197 third (lateral,) 198 second or middle, 197 cartilages (of Wrisberg), 1213 tubercle (of Wrisberg) of larynx, 1221

Cuneo-cuboid articulation 304

Cuneo-lingual gyrus, anterior, $\$ 64$ posterior, 864

Cuneo-navicular articulation, 304

Cuneus, 864

Cupola of pleura, 1237

Cupular cæcum, 1096 portion of epitympanic recess, 1093

Curvatures of spinal column, 43 of stomach, 1152, 1374 greater, 1152 lesser, 1152

Cusps of atrio-ventricular valves, 516

Cutaneous areas of face, 1018 of lower extremity, 1024
Cutaneous areas of neck, 1019 of pinna (auricle), 1019 of scalp, 1018 of trunk, 1020 of upper limb, 1022

branches of anterior ethmoidal artery, 554 of intercostal arteries, 559,590

(communicans fibularis) of common peroneal nerre, 1013

of deep circumflex iliac artery, 616

dorsal antibrachial (external) of radial nerve, 987

of ilio-liypogastric nerre, 995

lateral, of thoracic nerves, 995

of median nerve, 992

plantar, of medial plantar nerve, 1010

posterior brachial (internal), of radial nerve, 985

femoral cutaneous nerve, 1007

of sacral plexus, 1007

of superficial peroneal (musculo-cutaneous) nerve, 1015

of superior epigastric artery, 567

(medial sural cutaneous or tibial icommunicating) of tibial nerve, 1010

of ulnar nerve, 990

glands, 1296

glomiform, 1296

sebaceous, 1298

nerves, anterior of abdomen, 996 of femoral nerve, 1003

calcaneo-plantar, 1010

of foot, lateral dorsal, 1013 surface markings, 1466

intermediate dorsal, of leg, 1015

lateral, 1000

of abdomen, 995 sural, 1013

medial antibrachial (interna1), 934

brachial, 983

dorsal, of leg, 1015

sural, 1010

posterior femoral (small sciatic), 1007

superficial cervical, 978

rete arteriosum, 1289

veins, 1289

Cuticle (epidermis), $1285^{\circ}$

Cutis, 1285, 1286

Cymba conchie, 1082

Crstic artery, 595

duet, 1187

vein, $67 \%$

Cysto-colic ligament, 1379

Crtomorphosis, ?

Cytoplasm, 5

\section{$\mathrm{D}$}

"Dangerous area" of leg, 1457 of scalp, 1333

Dartos, 1254,1260

Darwin, tubercle of, $10 \$ 3$

Deciduous (milk) teeth, 1126 times of eruption, 1127

Declive of cerebellum, 806

Decussation, fountain, $\$ 42$

of lemnisci, $\$ 15$

of pyramids, 799,815

of superior cerebellar peduncles (brachia conjunctiva), 840

Deferential arterv, 610

plexus of nerves, 1047

Deiters' nucleus, 823

Deltoid branch of profunda artery, 576 of thoraco-acromial artery, 571

(internal lateral) ligament of anklejoint, 298

surface markings, 1410 
Deltoideus, 365

Delto-pectoral lymphatic nodes, 719

Dendrites, 762

Dens (odontoid process), 33

Dental arehes, 1123

branches, inferior, of inferior dental plexus, $9+1$

superior, of superior dental plexus, 938 canal, inferior, 96,126

nerves, 938, 941

inferior, 941

superior, 938

Dentary centre, 98

Dentate fascia, 868 grrus, s6s

nucleus of cerebellum, $\$ 10$

sutures, 212

Dentine, 1118

Denticulate ligament, 920,921

Depressor alie nasi, 334

anguli oris. 333

labii inferioris, 332

septi nasi, 334

Derma (corium), 1286

Descemet, membrane of, 1060

Descendens cervicalis (hypoglossi), 953, 974, 979

Descending a orta, $5 \$ 6$

branches of cervical plexus, 978

of lateral circumflex artery, 543

(princeps cervicis) of occipital artery, 543

of spheno-palatine (Meckel's) ganglion, $96 \%$

of transverse cervical artery, 565

colon, 1174, 1379

palatine artery, 549

Descent of the testis, 1257, 1387

Development of anus, 1179

of arteries, 633

of articulations (joints), 213

of bones, 27 (see also the individual bones) of Irain, 754

of contral sulcus (fissure of Polando), 860 of corium, 1290

of diaphrigm, 120

of cilr, 1096

of epidermis, 1286

of eve, $10 \times 0$

of filce, is

of hairs, 1293

of heart, 52:3

of hypophysis cerebri, sts

of kidney, 12]s

of latree intestine, 1179

of laryux, 12:5

of limbs, 20)

of lips aml aloreks, 110 J

of liver, I Is:

of lomes, 1:2:5;

(f) lymphatic syotem, 70)6

of jymplomerlese 707

of mitmmary gland, 1306;

of momseles, $310 ;$

of mails, legmi

of merve fibpe, 755

of mervoms syseren, 751

(i) 11 (1) 5 , 1 1 1208

of unis)hagus, 11$] 1$

of oral eas rity, 1102

of pialitte, 110,\%

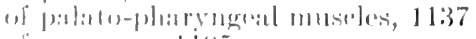

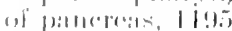

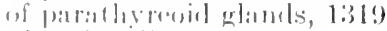

of

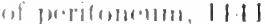

of pharsme di:3s

of repundatetive organs, 127s
Development of salivary glands, 1117 of sebaceous glands, $129 \mathrm{~S}$ of skull, 117

of small intestine, 1168

of spleen, 1312

of stomach, 1157

of suprarenal glands, 1326

of sweat glands, 1297

of teeth, 112t

of thymus, 1322

of thyreoid gland, $131 \mathrm{~s}$

of tongue, 1112

of tonsils, 1133

of tympanum, 80

of urinary hladder, 1253

of veins, 690

of ventricles of brain, 758

of vermiform process, 1179

of vertebra, 45

of viscera, 18

Diagonal sulcus, $85 \mathrm{~s}$

band of Broca, $\$ 66$

Diameters of the pelvis, 175,177

Diaphrigm, 425, 436, 1372

erura, 437

and heart, recession of, 20

lymphatics, 725, 728

pelvic, 440, 1383

urogenital, 440, 1383

Diaphragma pelvis (Merer), $\$ 40$ sellae, \$48, 915

Diaphragmatic pleura, 1237

lymph nodes, 725, 736

pelvic fascia, $442,4+7$

plexuses of nerves, 1044

surface of heart, 509

of lung, 1229

of spleen, 1308

Diaphysis, 28

Diapophyses, 51

Diarthroses, 212

heteromorphic, 283

homomorphic, 212

Diencephalon (interbrain), 758, 843

Digastrie fossa, 95

numscles, 314

triangle, 1358

Dimastricus, 343, 344

Digestive system, 1099

abdomen, 1142

intestines, 1161

liver, $11 \mathrm{sil}$

unouth, 1100

(x:sopliagus, 1138

pancreas, $119^{2}$

feritonem, 1145

pharyx, 1129

stomiach, 1151

Digital anteries, common (hand), 582

dorsill (loot), (i3i)

pantar, 625

proper (hand), 582

branches, dorsil, of uluar nerve, 990

of modial plantar norve, 1011

volier, of nlnar nerve, 991

fostia of popididymis, 1255

of fommir, 17s

of tibulis, 191

norves, fommon plantar, 1011, 1013 common volar, of hand, !991

(lorsis of fout, I01:3 of himl, $98 \%, 990$

proper plantas, 1011, 101:3

volar, of haml, 992

voins (fool), dorsal, dist

plantir, common, tist

volar (hamel), 6ir 
Digital venous arch (hand), 667

Digitations, hippocampal, 877

Dilator naris anterior, 335 posterior, 335

pupillie, 1061

Dimples of skin, 1285

Diploë, veins of, 648

Direct cerebellar tract of Flechsig, $7 \mathrm{~S} 4$ pyramidal tract, $7 \mathrm{~s} S$

Dise, articular, of the acromio-clavicular joint, 251

of inferior radio-ulnar articulation, 264 of mandibular articulation, 216 of the sterno-costo-clavicular joint, 249

optic, 1055

Dislocation of mandible, 1345

metacarpo-phalangeal, 1434

of patella, 1446

Diverticula, intestinal, 1170, 1379

Diverticulum, Neckel's, 1169

Dolichopellic pelvis, 177

Dorsalis hallucis artery, 633

pedis arterr, 632

Dorso-epitrochlearis, 379

Dorsum of foot, muscles of, 492

of ilium, 165

of nose, 1200

of penis, 1260

sellæ (epihippi), 63, 116

of tongue, 1106

Douglas' fold, 427

(recto-uterine or recto-vaginal) pouch, 1148, 1267

Duet(s), alveolar, 1232

of Bartholin, 1117

cochlear, 1096

common bile, $118 \mathrm{~S}$

cystic, 1187

efferent of testis, 1256

ejaculatory, 1257, 1263, 1387

endolymphatic, 1094

of epididymis, 1256

of gall-bladder, 1188, 1373

of Gärtwer, 1275

hepatic, 1187

of lacrimal gland, excretory, 1047

lactiferous, 1302

of mammary glands, 1302

Müllerian, 1257, 1267, 1279

naso-lacrimal, 10\$0, 1205, 1349

pancreatic (of Wirsung), 1194, 1375

accessory (of Santorini), 1195

papillary (of Bellini), 1246

paraurethral (of skene), 1277

of parotid gland (Stenson's), 1115, 1343

right lymphatic, 728

of Rivinus, 1117

semicircular, 1094

of sublingual gland, 1117

of submaxillary gland (Wharton's), 1116

of sweat glands, 1297

thoracic, 726

thyreo-glossal, $131 \mathrm{~s}$

utriculo-saccular, 1094

Wolffian, 1248, 1267, 1278

Ductless glands, 1306

aortic paraganglia, 1329

chromaffin system, 1323

glomus caroticum, 1325

coccygeum, 1329

parathyreoid glands, $131 \mathrm{~S}$

spleen, 1306

suprarenal glands, 1323

thymus, 1319

thyreoid gland, 1312

Ductuli aberrantes (of episliclymis), 1257

Ductus arteriosus (Butalli), 528
Ductus choledochus (common bile-duct), 1188

(vas) deferens, 1257, 1259, 1357

(canaliculi) lacrimales, 1079

perilymphaticus, 81

reuniens of membranous labrvinth, 1094

venosus, 675,694

Duodenal fossa, 1164 papilla, 1164,1195

veins, 677

Duodeno-jejunal flexure, 1162, 1376

Duodenum, 1161, 1375

lymphaties of, 734

parts of , 1161

Dupuytren's fracture, 1455

Dura mater, 771,910

blood-vessels of, 917

cranial, 913

filum of, 911

nerves of, 917

spinal, 911

surgical anatomy of, 1342

$\mathrm{E}$

Ear, 1082

devclopment of, 1096

internal, 1092

middle, 1086

muscles of, 337, 1084

ossicles of, 79,1090

vessels and nerves, 1084, 1086, 1091, 1096

Ectoderm, 10

Ehrenritter, ganglion of, 951

Ejaculatory duet, 125\%, 1263, 1387

Elastic cone of larynx, 1215

nembrane of larynx (Lauth), 1215

Elbow, clinical anatomy of, 1417

Elbow-joint, $25 \mathrm{~s}$

arterial anastomoses around, 1418

supply of, 261

ligaments of, $25 \mathrm{~s}$

movements of, 201

muscles acting upon, 261

nerve-supply of, 261

synovial membrane of, 261

Elevations of skin, 1284

Eleventh thoracic vertelora, 39

Ellipticat recess (fovea hemielliptica), so

Embryonic dise, 9, 10, 11

Eminence of auricle, 1083

collateral, 868,877

frontal, 59, $10 \mathrm{~s}$

hypoglossal, 814

ilio-pectine:al, 169

medial, of floor of fourth ventricle, $\$ 13$

parietal, 57

pyramidal, of temporal hone, 77

Emineutia areuata, 78,116

Emissary veins, $647,649,652,916$

mastoil, 647

parietal, 649

of scalp, 1334

Enamel, 1118

Enarthrodial diarthroses, 213

Encephalon, 751, 792

blood-supply of, 905

divisions of, 796

Endocardium, 508

Endoderm, 10

Endognathion centre, 91

Endolymph, 1093

Endolymphatic duct, 1094 sac, 1094

Endometrium, 1274

Endonysium, 315

Endo-pelvic fascia (recto-resical), 442, 447 
Endothoracic fascia, 1235

Enlargements of spinal cord, 772

Ensiform process (metasternum), 132, 134

Eparterial bronchus, 1232

Ependrmal cells, 768, $\$ 46$

Ephippial diarthroses, 212

Epicardium, 508

Epicondyles of femur, 183 of humerus, 151

Epicranial aponeurosis, 337 musculature, 336

Epicranio-temporalis, 337

Epicranius (occipito-frontalis), 336

Epidermis, (cuticle), 128.5

Epididymal branches of int. spermatic arteries, 601

Epididymis, 1256, $13 \$ 6$

Epidural cavity, 911

Epigastric artery, inferior (deep), 614, 639 superficial, 618 superior, 567

lymphatic nodes, 732, 733

plexus, 1043

region, 1143

veins, inferior, 683

superficial, 684

superior, $666^{\circ}$

Epiglottic cartilage, 1212

tubercle, 1212, 1222

valleculit, 1221

Epihyal segment of styloid process, 119

Epinysium, 316

Epiphyseal cartilages, 28 lines, 28

Epiphyses, 28 (see also individual bones).

Epiphysis (pineal body), 758, 834, 845

Epiploic foramen (of Winslow), 1147 or omental branches of epiploic arteries, 595

Epipteric bones, 68, 101, 119

Episcleral arteries, 553 veins, 659

Epispadias, 1388

Epistropheus, description of, 33

Epithilamus, \$ 45

Epithelial chorioid lamina, 924

Epithelimm lentis, 1064

Epitruchleo-olecrinonis (anconeus internus), $40)^{2}$

Epitympanic recess, $7 \mathrm{~S}$

Epungrolum, 1294, 1296

Epöiphoron, 1:69

Equatur of eyeliall. 1055

of lens of eye, $106 \% 2$

Erector penis (or clitorislis), 451 spinir, $\$ 12,414$

Eruption of fecth, 1127

Et lomoites, or

at linth, 124

efolls, s.', 111, 1207

Ethmoiclal artery, antropior, 554 postrorior $55 \%$

branches of antrior ethmojelal artery, 554 of proterior ethmeidal artery, 553

li11:1, 111, 12(1)

c:tlials, 61, s:3, 110, 11:3, 126;

(suprorer turbinate) crest, 92

fissifre, 11:)

infundihulum, 1205

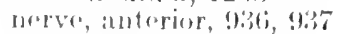
lestritior, 9.37

notels, (i)

morerse, si)

spine, 63, 11:3

voius, tion

Ethom-turbinals, 1 !!

lithme-voluarine porgion of skull, 117

Lustandian 1ulw, 7.4, I0s:9, 1092
Eustachian tube, openings of, 1130, 1354

valve, 512

Excretory ducts of lacrimal gland, 1079

Exoccipital, 119

Exognathion centre, 91

Expiration, muscles which affect, 248

Extension (of muscles), 321

Extensor carpi radialis accessorius, 391

brevis, 388,389

intermedius, 391

longus, 387,388

ulnaris, 38s, 391

communis pollicis et indicis, 394

digiti annularis, 395

quinti proprius (extensor minimi digiti), 388,391

digitorum brevis (foot), 454, 492

(hand), 395

communis, 388, 391

longus, $453,480,481$

group of arm muscles, 377

hallucis brevis, 482,492

longus, $453,480,482$

indicis proprius, 392,394

medii digiti, 395

ossis metacarpi pollicis (abductor pollicis longus), 393

pollicis brevis, 392,394

longus, 392, 394

Extremity, lower, bones of, 169

clinical and topographical anatomy of, 1434

lymphatics of, 746

upper, bones of, 139

clinical and topographical anatomy of, 1409

lymphaties, 719, 1424

Extrinsic muscles of tongue, 345

Eye, 1051

blood-vessels of, 1031

clinical anatomy of, 1346

crystalline lens, 1052

development of, 1080

eyelids, 1053, 1076

general surface view, 1052

lymplatics of orbit, 715

nerves of, 1064,1348

Eyeball, (bulbus oculi), 1055

blood-vessels of, 1065

equator of, 1055

hemisplieres of, 1057

insertions of muscles, 1056

muscles of , 501, 1067

nerves of, 106.4

poles of, 10.55

Eyelishes (ciliı), 1053, 1347

Eyclids, 105:3, 1076

blood-vessels of, $107 \mathrm{~S}$

elinical anatomy, 1346

glands of, $107 \mathrm{~s}$

lymphatics of, 712,1078

nerves of, 1078

structure of 1077

F

Face, bones of, 51

clinical anatomy, 1342

cutaneous areas of, 1018

development of, 18

lymphatic vesiols of, 712

muscles of $324,329,501$

veins of, 6.13

Facilil (cxternal maxillary) arlery, 540, 1343

liranches of great auricular nerve, 978

(Follopian) cumal, 72, 77, 78

lymph-mosles, 709), 711 
Facial nerve, $943,946,1345$

nucleus of, $\$ 25$

paralysis of, 1345

portion of external maxillary artery, 540

vein, anterior, 643,1343

common, 64t, 646

posterior (temporo-maxillary), 644

transverse, 646

Facialis, musculature, 324, 329, 501

Falciform ligament of liver, 115.5

margin of fascia lata, 467

process of great sacro-sciatic ligament, 236

Fallopian canal, 72, 77, 78 tubes, 1269

Fallopius, aqueduct of (facial canal), 72

Falx cerebelli, 915

cerebri, 914

inguinalis (conjoined tendon of internal oblique and transversalis), 435, 1396

Fascia(æ) antibrachial, 384

of arm, 377

axillary, 370,371

brachial, 377

bulbi (Tenon's capsule), 1073, $131 \mathrm{~s}$

Camper's, 425

Colles', 425

coraco-clavicular (costo-coracoid), 371

cranio-mandibular, 339

cremasteric (Cowper's), 426, 434, 1254

cribrosa, 46

crural, 477

of deep musculature of shoulder girdle, 356

deep cervical, 1360

deep palmar, 387

dentate, S6S

diaphragmatic pelvic, 442,447

endo-pelvic (recto-resical), 442, 447

endothoracica, 1235

external cervical, 347

spermatic, 1387

of foot, 491

of forearm and hand, $3 \$ 4$

of hand, 1427

of head and neck, 329

hypothenar, 387

iliac, 455,466

of ilio-femoral musculature, 455

ilio-pectineal, 455, 466

of infrahyoid musculature, 350

intercolumnar (external spermatic), 1304

interpterygoid, 339

of ischio-pubo-femoral musculature, 463

lata, 454, 457, 466, 1400, 1436

lateral pharyngeal, 339

of leg, 477

lingual, 346

lumbar, 436

lumbo-dorsal, 414, 428

masseteric, 339

middle cervica!, 350

muscle, 313

of musculature of shoulder, 365

nuchæ, 414

obturator, 439,463

of orbit, 1071

palpebral, 1071

parietal (pelvic), 447

parotid, $339,34 S, 1114$

of pectoral muscles, 371

of pelvis, muscular, $443,446,447$

subcutaneous, 445

penis, 1260

plantar, $146 \mathrm{~S}$

of posterior group of ilio-femoral muscles, 457

of prevertebral musculature, 355

prostatico-perineal, 447
Fascia (æ) psoas, 45.5

renal, 1242

of scalene musculature, 353

Scarpa's, 425,445

of serotum, 1355

semilunar 352

Sibson's, 129, 355, 1237

of spinal musculature, 413

superficial, 313

perineal (Colles'), 445, 135.5

of shoulder girdle, 347

of supra-hyoid musculature, 344

temporal, 339

thenar, 357

of thigh, 466

thoraco-abdominal musculature, 425

subcutaneous, 425

transversalis, 426

triangular, 430

of upper limb musculature, 363

of urogenital diaphragm, $41 \overline{5}$

of wrist, 1427

transversi of palmar aponeurosis, 387

Fasciculus(i), 769

anterior marginal, 786

comma-shaped, 782

cuneatus (Burdach's column), 7\$1

gracilis (Goll's column), 781

inferior longitudinal, 892

intermediate, $78 t$

lateral cerebro-spinal, $7 \$ 3$

mammillo-mesencephalic (tegmento-mam-

millary or mamnillo-peduncular), 871

mammilio-thalamic, 871, ss:3

medial longitudinal, 817,842

oblique, 804

occipito-frontal, 892

pedunculo-mammillary, 849

proprii, 769

proprius, dorsal, 752

lateral, 782

ventral, 786

retroflexus of Neynert, $\$ \notin 1,843,872,8 \$ 6$

rubro-spinal, $7 \$ 6$

spino-cerebellar, dorsal, $7 S 4$

spino-olivary (Helweg's bundle), 784

sulco-marginal, $7 \mathrm{SS}$

superficial ventro-lateral (spino-cerehellar), 784

superior longitudinal, 892

uncinate, 891

ventral cerebrospinal, $7 \mathrm{SS}$

vestibulo-spinal, $7 \$ 6$

Fasciola cinerea, S68

Fauces, isthmus of, 1100, 1130, 1131

Female, reproductive organs, 1265

clinical anatomy of, 1391

development of, $127 \mathrm{~s}$

exterual (vulva), 1276

lymphatics of, $744,127 \mathrm{~s}$

oraries, $123 \mathrm{~s}$

tubæ uterina (Fallopian tubes), 1269

uterus, 1271

vagina, $127 t$

vessels and nerves of, 1278

urethra, 1278

Femoral artery, 616, 1441

branches, $61 \mathrm{~s}$

collateral circulation, 1441

common, 616

profunda or deep, 620,640

superficial, 616

canal (crural canal), 468, 1400

cutaneous nerve, posterior (small sciatic), 1007

hernia, 1398

(anterior crural) nerve, 1001 
Femoral plexus of nerves, 1045

ring, 466,1401

scptum, 466

sheath, 1400

trigone (S'carpa's triangle), 467, 1438

veill, 690,1441

tributaries, 690

Femoro-tibial muscle, 486

Femoro-popliteal vein, 685, 693

Femur, 17 s

clinical anatomy of 1434,1442

condyles of, $14+7$

ossification of , 184

trochanters of, 178

Fenestra cochlex (rotunda), 73, 1089

vestibuli (ovalis), 73, 1089

Ferrein, pyramid of, 1246

Fibræ propria, S90

Fibres, arcuate, 817

association, of telencephalon, 890, 893

of white substance of spinal cord, 779

of cerebellar cortex, 809

cerebello-olivary, 817

of cerebral cortex, s79

commissural systen of, 890

extermal areuate, of medulla oblongata, 800

intercrural (intercolummar fascia), 430

intermal arcuate, $\$ 15$

muscles, 315

nerve, 767

development of, $75 \mathrm{~S}$

projection, of telencephalon, $\$ \$ 6$

sympathetic, 970, 1029

visceral afferent, 970

efferent, 970

Fihro-eartilages, cotyloid, 281

interosiseous, 244

interpubie, 240

intervertebral, 225, 238

semilunar, 289

triangular (articular disc), 264

Fibula, description of 189,1454

ossification of, 191

Fibular branch of posterior tibial artery, 626 collateral ligament, $280^{\circ}$

nutrient branch of peroneal artery, 626

Fibulo-calcaneus medialis, 491

Fibulo-tibialis, 486

Fifth ventricle (avity of septum pellucidum), 872

Fila radicularia, 775,964

Jilaments, root, of spinal nerves, 775

of pens, lateral, 804

Filiform, bipilla of tongue, 1100

Filum of dura miter, 911 tominale, 771,721

Timbria, 868, 877

(1) varica, 127

Finbria of tular uterina (Fallopian tube), $1271)$

Fiml,riate folds of tongure, 1107

Finbrio-rlentate suleus, s68

Fingers, , 1

Inteseles areting 011,505

Fisstarit prima, stot serofina, s(in)

Fissure(s), interior menlian, 772

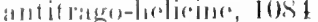

aturiculate, 75, 10s

calcarino, stit

mellosem-magimal, 857,859

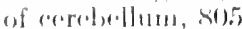

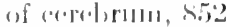

(elurieid, 1080

collat terisl, 855, s6,

ethmoirlial, 11:3

externat parioto-oredipital, 862
Fissure(s), Cilaserian, 71, 77

hippoeampal or (ehorioid), 868

horizontal (of cerebellum), 805

inferior orbital (spheno-maxillary), 102, 109 126

lateral (Sylvian), $850,855,1340$

of liver, 1183

longitudinal, of cerebrum, 850

of lung, 1230, 1234

oral, 1100

parieto-oceipital, 860,864

petro-tympanic, $71,77,108,126$

portal, 1183

posterior median, of medulla oblongata, 801

postlimbic, 863

pterygo-maxillary, 102

pteryo-palatine, 102

retrotonsillar, of cercbellum, $\mathrm{SO}$

of Rolando, 859, 1340

semilunar (of cerebellum), 805

spheno-naxillary, 102, 109

of spinal cord, 772

superior orbital (sphenoidal), 65, 109, 116 125

of sylvius, 850,855

of teleneephalon, 853

transverse, of eerebrum, 850

tympano-mastoid, $71,75,108$

umbilical, of liver, 1183

Fleclisig, direct cercbellar tract of, 784

secondary optic radiation of, $\$ 90$

Flexion of inuseles, 321

Flexor aecessorius, 154,495

longus digitorum, 491

carpi radialis, 396,398

brevis (radio-carpeus), 403

ulnaris, 396,398

hrevis (ulno-carpeus), 402

digiti quinti brevis (foot), 454, 498, 499 (hand), 404

digitorum brevis, 454,493

longus, $454,486,489$

profundus, 401

Flexor aligitorum profundus, 401

sublimis, 399

group of arm muscles, 379

Irallucis lirevis, $454,496,497$

longus, $454,486,490$

pollicis brevis, 407,408

longus, 402

Flexure (s) of chodeno-jejumal, 1376

of duofommon, 1161

left eolic (splenic:) 117t, 1379

of rectuml, 1170

right rolic (hepatic), 1173,1379

Flonting rils, 127

Flocoulair fossis, 73

Floceulus of rerchellum, 807 perluncle of 807

Plomer of cranial anvity, 112

of fourth ventricle, 813

pelvic, 133.t

in femalo, 13944

Fluicl, (cereloro-spinal, 9201342

Flumina pilorum, 1291

Fental circulation, 69.5

skull, gencral characters of, 120

Fold (s), aldipose, of pleura, 1237

alar, 291

arv-rpiglottic, 1221

of "Douglis, 127

of duoflemtum, 116.t

glosiso-eviglottic, I'20

inforior palpeloral, 105\%)

nomal, 75.1

pitcllar, $29(9)$

recto-uterine, 127 
Fold(s), semilunar, of conjunctiva, 105.5 of skin, 1284

sublingual, 1116

superior palpebral, 1053

transverse (Houston's), of rectum, 1177, 1390

of tympanic mucous membrane, 1059 ventricular, of larynx, 1222 vocal, 122:3

Foliate papilla of tongue, 1106

Folium vermis (eacuminis) of cerebellum, 806

Follicles, Graafian, 1269

of hair, 1292

lingual, 1107

lymph, 704

Fontana, spaces of, 1060

Fontanelle(s), sagittal, 59 of skull, 120

Foot, amputations of, 1465

arches of, 1468

arteries of, 627,631

bones of, 191, 205, 1467

bony landmarks of, 1464

bursæe of, 1465

clinical anatomy of, 1464

eutaneous nerves of, 1466

muscles acting on, at ankle-joint, 505

musculature of, 491

synovial membranes of , 1465

talipes, 1467

Foramen(ina), 29

acetabular, 174

apicis dentis, $111 \mathrm{~S}$

auditory, 125

cæeum, 61, 113, $131 \mathrm{~s}$

of ethmoid, 81

of medulla oblongata, 799

(Morgagni) of tongue, 1106

carotico-clinoid, 65

condrlar, 54

costo-transverse, 127

of diaphragma sellæ, 916

epiploic (foramen of Winslow), 1147

greater palatine, 106

hypoglossal, 54, 108, 125

incisive, 89

inferior dental, 96

infra-orbital, 87, 1345

intervertebral, 30

intraventricular (Monroi), 847,874

jugular, 74, 108, 117, 125

lacerum, 63, 74, 108, 116

lesser palatine, 106

of Magendie, $\$ 13$

magnum, 51, 56, 108, 117, 125

mandibular (inferior dental), 96

mastoid, 72, 108, 117

mental, 95

palatine, 106

of Mlonro, 847,874

of nerves of skull, 125

of norma facialis, $10 \mathrm{~S}$

obturator (thyreoid), 174

optic, $63,64,110,116,125$

ovale, $65,116,125$

of Pacchioni, 116

papillaria, 1246

parietal, 57

petro-sphenoidal, 125

pharyngeal, 126

rotundum, $65,103,116,125$

sacral, 40

scapular, 142

of Scarpa, 89, 106, 126

spheno-palatine, 93, 103, 111, 126

spinosum, 65, 116

of Stenson, 89, 106
Foramen(ina), sternal, 133

stylo-mitstoid, 73, 105, 126

supra-orbital, 60

supratrochlear, 150

thyreoid (thyreoid cartilage), 1211

trigeminal, 125

veuse cave 430

venarum minimarum (Thebesii), 514

verteloral, 31

Vesalii, 65, 116

zygomatico-temporal, 126

Forceps major, b76

Forearm, clinical anatomy of, $1+19$ eommon fractures of bones of, 1420

joints of 1419

museles of 362

musculature of, 38.3

nerves of $1+2: 3$

srnovial tendon sheaths of , 395, 40:3 vessels and nerves of, 142:3

Fore-brain, 843

Formation, reticular, $\$ 16$

Fornix, anterior pillars (columns) of, $\$ 70$

body of, 869

conjunetival, 1054, 1347

fibres of, $869,870,871,890$

of limbie lobe, 868

pharrngeal, 1130

posterior pillars (erura), 868

transverse, $>69,890$

of vagina, 1275

Fossa (e), abdominal, 430

anterior eranial, 113

of anthelix, 1082

axillary, clinieal anatomy of 1411

canine, st

cardiae, of lung, 12:29

condvlar, 54, 108

eoronoid, 150

entyloid, 169

digastric, 95

digital, of fenur, 178 of fibula, 191

ductus venosi, 1183

duodenal, 1164

of femur, intercondyluid, 152

floecular, 73

of gall-bladder, 1183

glenoid, 29

of humerus, coronoid, 150

olecranon, 150

radial, 151

hypophyseos, 63,116

iliae, 170

ileo-excal, 1172

ileo-colic, $117: 2$

ilio-peetineal, 467

incisive, Si

incisor, $9 j$

infraspinous, 142

infra-temporal (zygomatie), 101, 1332

interpeduneular, 83.

intersigmoid, 1175

ischio-rectal, $4+1,445,1384$

jugular, 73, $10 \mathrm{~S}$

laerimal, 61, 109

mandibular, 108

mastoid, 72

middle eranial, 116

nasal, $10 \mathrm{~s}, 110$

navicularis, 1264, 127\%, 1392

olecranon, 150

ovalis (of heart), 512

(saphenous opening), 467, 1400, 1440

ovariea, 1268

paraduodenal (Landzert), 1164

pericardial, 1172, 1378 
Fossa (e), posterior cranial, 116

pterygoid, 66, 107

pterygo-palatine (spheno-maxillary), 102

radial, 151

rhomboidea, 802

of Posenmueller, 1130

scaphoid, 54, 55, 66, 95, 107

of skull, surgical anatomy of, $13+2$

spheno-maxillary (pterygo-palatine), 102

subarcuata, 73,117

subscapular, $1+1$

supraspinous, $1+1$

supratonsillar, 1132

sivian, 851

tèmporaI, 101

triangular, of auricle, 1082

of elbow, 1418

trochanteric or digital, 178

trochlear, 61

venre cave, 1183

vermiform, 53, 10S, 117

zygomatic, 101, 1332

Fossula cochlearis, 72

petrosa, 73

vestibularis, 72

Fountain decussation (Forel), 842

Fourchette, 1276, 1392

Fourth ventricle, 812

anatomy of, 812

chorioid plexus of, 922

floor of, \$13

rouf of, $\$ 12$

tela chorioidea of, 922

Fovea of aryt:enoid cartilages, 1212

centralis, 1055

of femur, $17 \mathrm{~s}$

hemiclliptica, 80

hemisphærica, 80

inferior, of floor of fourth ventricle, \$14

superior of, floor of fourth ventricle, $\$ 15$ inguinalis, 430

pterygoidea, 97

sublingualis, 95

umbilical, 12st

Fovesla palatina, 1104

Fracture or fractures of bones of the leg, 1454 Colles', 1420

common, of bones of forearm, 1420

Jipuytren's, 1455

of mandible, 1345

of olecranon, 1420

Poti's, 1451

Freckles, 12s:3

Frenulum of anterior nsedullary velum, 832

clitoridis, 1277

of ileo-cacal valve, $117 \cdot 2$

of peruis, 1260

of tongue, 1107, 1349

r(cli, 812, 8.35

Frenum (duodenal), $116 t$

Frepueney of disease of tarsal lones, 1396

Frontil artery, 554, 1343

association atrea, s!) 4

bone at lirth, 123 description of, 59

loranches of anterior ethmoilal astery, 554 of silporfocial trmporal artery, 515

wnvohution, ascomling, 8.5

(a) 1 int, (jo)

eminemeres, 59, 108

gyrus, inforiur, 85is

mirllan, sis

supurior, sist

follow. 8.57

merve, 935, 1075

menterte $1 ; 0$

(1) rerulum, s.56
Frontal pole, $\$ 50$

pontile path (Arnold's bundle), 832, 840, 889

process of maxilla, 87,88

sinus, 59, 61, 1207, 1335

spine, (nasal), 60

sulcus, inferior, 858

middle, $\$ 58$

superior, 858

suture, 59

vein, 644

Frontal vein, $64 t$

diploic, 648

Frontalis, 337

Fronto-ethmoidal cells, 84

Fronto-marginal sulcus, 858

Fronto-nasal plate, 117 process, 119

Fronto-sphenoidal process, 95

Functional areas of cerebral cortex, 893

Functions of cerebellum, 832 of muscle groups, 500

Fundiform ligament of penis, 427

Fundus of gall-bladder, 1187 of stomach, 1151, 1374

uterus, 1271

Fungiform papillæ of tongue, 1106

Funiculi of nerves, 769 spinal cord, 774,780

Funiculus, anterior, 775, 786

cuneatus of medulla oblongata, 801

gracilis of medulla oblongata, 801

lateral, 775,782

posterior, 774,780

separans, 814

Furcal nerve, 998

Furrow, 29

Furrows, articular, of skin, 1284

Fusiform gyrus (occipito-temporal convolution), 855, 864

muscles, 315

\section{G}

Galca aponeurotica (epicranial aponeurosis), 337

Galen, veins of, 923

Gall-bladder, 1157

clinical anatomy of 1372

duets of, 1187, 1188, 1372

Ganglion(ia), aberrant spinal, 965

of Andersch, 951

aortico-renal, 1043

basal, 878

of I3ochdalek, 939

cardiac (ganglion of Wrislerg), 1041

ciliary, 961, 1033, 1076

coccygeum impar, 1032, 1040

codiac (semilunar), 10.43

(neural) erest, 754

first thoracie, 1038

geniculate, 826,947

inferior cervical, 1036

interpeduncular (von Gudden's), 843, 872, 85.5

jugular (superior), of glosso-pharyngeus, 957

of vagus, $95 ., 956$

of glosso-pharyngeus, 951

michlle cervical, 10:36

nodosum (ganglion of trunk), 954, 956

otic (Arnold's), 963

petrosal, 951

phrenie, 10.14

renal, 10.14

of rout of vagus, 956

roots of , 9.59 
Ganglion(ia), second thoracic, 1038

semilunar (Gasserian), \$26, 938, 1345

spheno-palatine (Meckel's), 962

spinal, 964

spiral, of cochlea, 950

splanchnic, 1039

submaxillary, 963

superior cervical, sympathetic, 960, 1035

jugular, or Ehrenritter's, 951

mesenteric, 1043, 1045

sympathetic, 959,1032

of head, 959

of synovial sheaths, 1434

terminal, 930

of trunk of vagus, 956

of Valentine, 939

vestibular, 823,950

of Wrisberg, cardiac, $49 \mathrm{~S}$

Gangliated cephalic plexus, 959

nerve trunks (cords), 755, 1029, 1032

Ganglionic branches of middle meningeal artery, 548

Gärtner, duct of, 1275

Gasserian (semilunar) ganglion, 826, 935, 1345

Gastric artery, left, 593 right, 594

branches of epiploic arteries, 595 of vagus, $95 \mathrm{~s}$

lymphatic nodes, 730, 734

plexus of nerves, anterior, 958

inferior, 1045

posterior, 958

superior (coronary), 1045

surface of spleen, 1309

Gastrocnemius, 45:3, 484, 485

Gastro-duodenal artery, 594

Gastro-epiploic artery, left, 595 right, 595

vein, left, 675 right, 675

Gastro-hepatic ligament, 1150

Gastro-phrenic ligament, 1150

Gastro-splenic (gastro-lienal) ligament (omentum), 1150, 1310

Gastroptosis, 1160

Gemellus inferior, 464 superior, 464

Gemmules, 762

Genial tubercles, 95

Geniculate bodies, 834, $\$ .5$ ganglion, $\$ 26,949$

Geniculo-tympanic branch of glosso-palatine, 951,961

Genio-glossus, 346

Genio-hyoideus, 343, 344

Genio-pharyngeus, 346

Genital corpuscles, 1290

ridge, $126 \overline{7}, 127 \mathrm{~s}$

swellings, 1279

tubercle, 1279

Genitalia, female, external, 1276 clinical anatomy of, 1391 male, 1253

Genito-femoral (genito-crural) nerve, 1000, 1260

Genu of corpus callosum, $\$ 51$

of facial canal, $7 \mathrm{~S}$

inferior, of central sulcus (fissure of Rolando), 860

of internal capsule (telencephalon), 887

superior, of central sulcus (fissure of Rolando), 860

suprema artery, 621, 640

valgum, 1449

Germ layers, 9

Gimbernat's ligament, 424, 429, 466, 1400
Gingival branches, inferior, of inferior dental plexus, 941

superior, of superior dental plexus, 939

Ginglymi diarthroses, 213

Girdle, pelvic, 207

shoulder, 207

Glabella, 60, 101, 109, 1331

Gladiolus (mesosternum), 132

Gland(s), 1099

bronchial, 1231

Brunner's, 1166

bulbo-urethral (Cowper's) 1265

carotid, 550, 1327

ceruminous, 1297

ciliary (of Mol!), 1078, 1297

circumanal, 1297

ductless, 1306

of evelids, $107 \mathrm{~s}$

glomiform, 1296

greater vestibular (of Bartholin), 1278, 1392

Henle's $107 \mathrm{~s}$

Krrause's, $107 \mathrm{~s}$

lacrimal, 1079, 1348

lingual, $110 \mathrm{~S}$

lesser vestibular, $127 \mathrm{~S}$

of Lieberkuehn, 1166, 117 7,1390

of lips and cheeks, 1103

lymphatic, 704

intercolated, 706

mammary, 1299

of MIontgomery, 1304

mucous, of larynx, 1224

nasal, 1208

of Nuhn or Blandin, 1110 ,

olfactory, 1208

para-thyrcoid, 1318, 1355

parotid, 348, 1113

accessory, 1114

preputial, $129 \mathrm{~S}$

prostate, 1264

salivary, 1113

sebaceous, 1298

of skin, 1296

of small intestine, 1166

of palate, 1104

sublingual, 1116

submaxillary, 1115,1350

sudoriferous (sweat), 1296

suprarenal, 1323

accessory, 1326

tarsal (N'eibomian), 105t, 107s

thrmus, 1319

thyreoid, 1312

accessory, 1315

clinical anatomy of, 1355

tracheal, 1227

urethral (of Littré), 1264

Zeiss's, $107 \mathrm{~S}$

Glandular branches of external maxillary, 541 of inferior thyreoid artery, 564

Glans clitoridis, 1276

of penis, 1260

Glaserian fissure, 71, 77

Gleno-humeral bands, 254

ligament, 255

Glenoid cavity of scapula, 143

fossa, 29

ligament, (lip) 255 of metacarpo-phalangeal joints, 294

lip of shoulder-joint, 255 of hip-joint (cotyloid fibro-cartilage), $2 \$ 1$

Gliding motion of joints, 214

Glisson's capsule, 675, 1186 pallidus, $\$ \$ 0$

Glomerular capsule, 1246

layer of olfactory bulb, $\$ 66$

Glomeruli of olfactory nerves, 929 
Glomiform glands, 1296

Glomus caroticum (carotid gland), 1327

choroideum, 876

cocergeum, 1040, 1329

Glosso-epightictic folds, 1220 ligament 1218

Gloso-liyal process, 99

Glosso-palatine arches, 1132 nerve, 826,946

Glosso-palatinus (palato-glossus), 1135

Glosso-pharrngeal nerves, \$20, 951

Glottis, 1223

Gluteal arteries, 608,1444

branches, 609

superior, 608

inferior, 609, 639

branches of internal pudendal artery, 613 of posterior femoral cutaneous nerve, 1007

line, anterior, 170 inferiol, $166^{\circ}$ posterior, 170

nerve, inferior, 1007 superior, 1007

tuberosity of femur, $17 \mathrm{~s}$

veins, inferior $6 s 0$ superior, 680

Gluteus maximus, 453, 457, 459

surface mirking, 1443

medius, $453,457,461$

minimus, $453,457,461$

Golvi cells in eerebelhum, so9

Golgi-Mazzoni corpuscles, 1290

Goll's column, tsi

Gomphosis sutures, 212

Gonion, 112, 113

Gower's tract, 7St

Graafian follicles, 1269

(iracilis, $453,471,472$

Gramular layer of ecrebellar cortex, 809

Granulations, arachnoid, 649, 919

Creat auricular nerve, 978

carliar vein, 520

omentim, 1149

(anterior) yalatine nerve, 96.3

prevertehril plexuses of nerves, 1010

(internal) saphenous vein, 684, 1456

splanchuic nerve, 1038

superficial petrosal ucrve, 94s

trochatuter of femull, 178, 143.5

Civeriter alar (lower lateral) nasal cartilages, I:20)

curvature of stomarh, 1152

multangular (trapezium) bone, 162

meripital norese.

palistion formentma, 106

(ri) mils: 92

ti1) ressity of humerus, 147

vostibular glamels (elauds of Bartholin), $1278,1: 392$

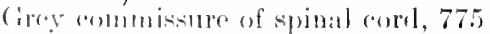

rami aommomicantes of sympatletic sys(1) 11,1930

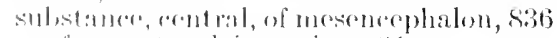

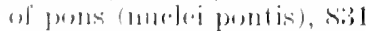

of mervons syetrin, 7is

of epinal arol, 775

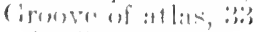

basilar, 51

bony, :2!

(a) rividi, bi

(0) $(1,101,127$

(1)

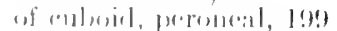

infrat-ribital, si

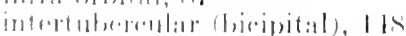

l:1,rim: $\left.1, x_{5}, x_{7}, 111\right)$

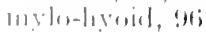

Groove, neural, 754

obturator, 172

occipital, 72

optic, 63,113

for raclial nerve (musculo-spiral), 149

sacral, 41

sigmoid, 72

Grouping of muscles according to function, 500

Growth, prenatal, 22

of the organs, 25

of the parts, 24

of the systems, 25

Gubernacular canals, 106

Gubernaculum testis, 1257, 1387

Gudden's commissure (inferior cerebral commissure), $842,850,890$

Gums, 1119

lymphatics of, 715

Gustatory area of cerebral cortex, 894 cells, 1051

organ, 1051

Gynecomastia, 130.5

Gyrus(i) Andrexe Retzii, S6S

ambiens, 865

angular, 863

anterior central, 857 cuneo-lingual, 843

orbital, $85 \mathrm{~s}$

breves (precentral gyri), 857

of cerebellum, 804

of cerebrum, $\$ 52$

cinguli (cingulum), 867

cunei, 864

cunco-lingual, 864

deep annectant, 860

clentate, 868

epicallosus, 868

external orbital, 838

fornicatus, 867 cinguli (cingulum), 867

hippocampus, 868 isthmus of , 867

fusifurm (occipito-temporal convolution), $855,86+$

hippocampal, 868

inferior frontal, 8.58 temporal, 855

lateral occipital, 863

olfartory, 865

orbit:al, 859

liugual, 855,864

longus, 857

marginal, s.5

modial olfactory, 866 orloital, sis

miclille lrontal, s.5

tomporal, 85.5

orlital, 8.58

origin of, 853

posterior central (asconding parietal), 861 orlital, sis

post-pancietal, s(i3)

profumuli, \$52

lecetus, $85 x$

semilumat, s(6)

subcallosal (perluncle of corpus eatlosum), sitit

submarginal, s.s.

superior fromtal, 858

(ureipital, sti:3

parictal, stiz

1019poral, 85.t

suprateallowil, sis

sแp ramanginal, s6:3

tramsitivas, s52

1 ranswerse temporal, 855

monomatus, sisis 
H

Habenulæ, 846

Habenular commissure, $846,872,885,890$ nucleus, 872,885 trigone, 835

Habenulo-peduncular tract, 873

Hxmolymph nodes, TOS

Hæmorrhoidal artery, inferior, 613, 1391 middle, 610, 1391

superior, 603, 1091

of middle sacral artery, 603

nerves, inferior, 1017

middle, 1017

superior, 1045

plexus of nerves, middle, 1045, 1046 superior, 1045 of veins, 683,1391

Hairs (pili), 1290 development of, 1293 olfactory, 1050

Hamate (unciform) bone, 159, 163

Hamular process of sphenoid, 66, 106, 1351

Hamulus, 81, 163

Hand, bony points of, 1424

clinical anatomy of, 1424

fascia of, 1427

muscles acting on, at wrist, 504

musculature of, 363, 383, 403

skin-folds of, 1425

synovial membranes of, 1431

Hard palate, 1104

Hare-lip, 1352

Harmonic sutures, 212

Hassal's corpuscles of thymus, 1322

Head of axis, 33

of bone, 29

bony landmarks of, 1331

clinical and topographical anatomy of, 1331

deep lymphatic nodes of, 714 vessels of, 714

of epididymis, 1256

lymphatics of, 709

of muscle, 314

muscles acting on, 502

musculature of, 323

of pancreas, 1192

process, 11

sympathetic ganglia of, 959

Heart, $50 \mathrm{~s}$

Heart, atria of, 511

development of, $\mathbf{5 2 3}$

fœtal, 695

ventricles of, 516

lymphatics of, $701,730,522$

muscle of, 518

nerves of, 522

relation to chest-wall, 523, 1368

vessels of, 519

Heister, valve of, 1187

Helicis major, 1084

minor, 1084

Helicotrema, 81

Helix, 10S3

Helweg's (Bechterew's) bundle, 7\$4

Hemiazygos vein (azygos minor), 662 a ccessory, 663

Hemispheres of cerebellum, 805 cerebral, 850

Henle, loop of, 1246

Henle's glands, 1078

Hepatic artery, 594

branches of superior epigastric artery, 567 of vagus, 958

duct, 1187

(right colic) fiexure, 1173, 1379

lymphatic nodes, 730, 736, 1186
Hepatic lymphatics, 1186

plexus of nerves, 1045

veins, 675

Hepato-colic ligament, 1379

Hepato-duodenal ligament, 1150, 11S5

Hernia, congenital, 1255, 1357, 1398

femoral, 1391

into the funicular process, 1255,1398

infantile, 1395

inguinal, 1255, 1394, 1398

serotal, 1255

surgical anatomy of, 1394

unbilical, adult, 1402

Hesselbach, ligament of, 430 triangle of, 1398

Hey's amputation, 146.

Hiatus, accessory, 116

aorticus of diaphragm, 437

canalis facialis, 73,116

osophageus, 437

sacralis, 40

semilunaris of middle nasal meatus, 1205

Highest nuchal line, 52

Highmore, antrum of, S7, 90, 111, 1206, 1346

Hilus of kidney, 1242

of lungs, 1229,1230

of ovary, 1268

of spleen, 1309

of suprarenal glands, 1325

Hind-braill, 804

Hip, musculature of, 453, 454

Hip-joint, 276

arterial supply, $2 \$ 2$

ligaments of, 277

lymphaties of, 750

movements of, 282

muscles acting upon, 283

nerve-supply, $2 \mathrm{~s}^{2}$

relations, 252

surgical anatomy of, 1435

Hippocampal branch of posterior communicating artery, 554

commissure (psalterium or lyra), 869,890

digitations, $87 T$

(chorioid) fissure, $86 \mathrm{~s}$

gyrus, 868

Hippocampus, 868

gyrus of, $S 68$

major, $\$ 68,877$

minor (calcar avis), $864,86 \$, 876$

Hirci, 1290

Homologies of parts in sexes, 1280

Homology of the bones of the limbs, 206

Horizontal fissure of cerebellum, 805

Horner's muscle, 336, 1078

Horns of spinal cord, 776

Houston's folds of rectum, 1177, 1390

Huguier, canal of, 75, 77, 108

Humeral artery, anterior circumfles, 572 posterior circumflex, 573

Humerus, description of, 146 clinical anatomy of 1410,1414

nutrient artery of, 576

ossification of 151,1416

tuberosities of, $14 \bar{i}$

Humor, aqueous, 1052, 1064

vitreous, of eye, 1052,1064

Hunter's (adductor) camal, 46S, 1441

Hyaloid canal (canal of Cloquet), $106 t$ membrane, 1064

Hyclatid of Morgagni, 1257, 1269

Hymen, 1275, 1392

Hyo-epiglottic ligament, 1218

Hyo-glossal membrane, 346

Hyo-glossus, 346

Hyoid bars, 119

bone, 99,119 
Hyoid bone at birth, 124 cornua of, 99,100

muscles acting on, 501

branch of lingual artery, 540 of superior thyreoid artery, 538

bursa, 1217

Hyo-mandibular muscles, 325

Hyo-temporal muscles, 325

Hyo-thyreoid ligament, 1217 membrane, 1217

Hyparterial bronchus, 1232

Hypertrichosis, 1290

Hypertrophy of nails, 1296

Hypochondriac region, 1143

Hypochordal bar, 51

Hypogastric (intermal jliac) artery, 605, 638 branches, 606, 639

lymphatic nodes, 732

plexuses of nerves, 1045

region, $114 ;$

(internal iliac) vein, 679 tributaries, 680

Hy̆poglossal eminence (trigonum hypoglossi), $\$ 14$

foramen (canal) , 54, 108, 117, 125

(cervical) loop, 974, 979

nerve. 952

central connections, 820,954

nucleus of 520

Hypomalar, 95

Hypophyseal fossa (sella turcica), 63

Hypophysis cerebri, 758, St7, 848, 1342 development of, $\mathrm{St}$

Hypospadias, 1280, 138.

Hypothalamic nucleus (boly of Luys), $\$ 8 t$ suleus, (suleus of Monro), $8 \pm 7$

Hypothalamus, 881 optic portion of, Sti

Hypothenar fascia, 357

Hypo-tympanic recess, 7

\section{I}

Ilco-careal fossa, 1172

(colic) vidve, 1172

region, $1: 376$

Ileo-colic artery, 595

fos:il, 1172

rein 67

Ileum, 1165, 1:376

Dlise arterips, rollateral riprulation, 605, $13 \$ 2$ common, 603, 60.5, lias

deep circumflex, fill;

rxtrmal, 614, (j;)

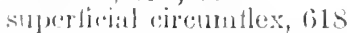

frameh of ilio-lumbur artery, 607

(mistrent) brameh of obturator artery, 608 (e)lon, 1174, 1:37!

fasciat $45 \overline{5}, 466$

fosisia, 170

lymphatic norles, common, 7i:1 (extcrual, T.:

plexils of nerves, 1015

spincs, 1699

vein, cextremal, bisi;

internal (hypogastrie), 67 !

veins, commonon, 679

Iliate1s, 45.5

minor, lis.

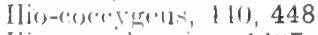

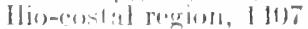

llio-cesstalio (orvicic wervinalis ascendens), bli;

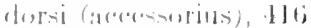

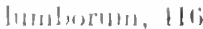

llio-femoral tiganent, 278

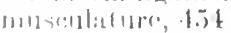

Ilio-hypogastric nerve, 998

Ilio-inguinal nerve, 1000

Ilio-lumbar artery, 606

ligament. 233

vein, 680

Ilio-pectineal eminence, 169

fascia, $\mathbf{4 5 5}, 466$

fossa, 467

line, 173

Ilio-tibial band, 457, 458, 1436

Ilio-trochanteric band, 280

Ilium, 169

crest of, 169

tuberosity of, 171

Inca bone, (interparietal), 57

Incisive branch of inferior alveolar (dental) artery, 548

foramen, $\$ 9$

fossa, 87

papilla, 1104

sutures, 106

Incisivus labii inferioris, 332 superioris, 332

Incisor crest, 90

fossa, 95

teeth, 1120

Incisura, 29

apicis cordis, 510

interarytanoidea, 1222

Incisure, anterior, of auricle, 1082

antitragic, 1082

of Santorini, 1085

terminal (auricle), 1084

Incudo-malleolar articulation, 1090.

Incudo-stapedial articulation, 1090

Incus, 79, 119

ligaments of, 1091

Index, cephalic, 117

pelvic, 177

thoracic, 139

Induseum griseum, 868

Infra-clavicularis, 374

Infraglenoid tubercle of scapula, 143

Infrahyoid musculature, 327,350 portion of external cervical fascia, 347

Infra-omental region of peritoneum, 1372

Infra-orbital artery, 549, 1075

branches of cervico-facial nerve, 945 . canal, 87, 103,126

foramen, 87,1345

groove, 87

ncrve, 937,939

plexus, 937, 939, 9.45

process, 95

suleus, 1284

vein, 646

Infraspinatus, 368

Infraspinous branclies of posterior scapular artery, 566

of transverse scapmlar artery, 565

fossa, 142

Infra-temporal (zygomatic) fossa, 101, 1332 ridge, 65

Infratruchlear nerve, 936,937

Infria-vomorine center, 71

Infumlibula (ureter), 1248

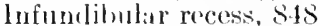

Infundibulo-pelvic ligament, 1267

Infundibulum of cerebrum, 848

of ethomoid, 83

in midlle nasil meatus, 111,1205

of tubs uterine (Fallopian tubes), 1270

Inguinal abdominal (internil abdominal) ring, 430, 1371, 1396

brinches of femoral artery, 620

cillal, 424, 430, 1371, 1395

hernia, 1255, 1394, 1398 
Inguinal (Poupart's) ligament, 424, 429, 1371, 1399,1438

reflected (triangular) fascia, 430, 1395 lymphatic nodes, 746

ring, subcutaneous (external abdominal), $429,1371,1394$

(iliac) regions, 1143

Inion, 101, 1331

Inlet or brim (superior aperture) of pelvis, 175

Innominate artery, 532, 637, 1369 branches, 532

Innominate canal (canaliculus), 65 bone, 169

(brachio-cephalic) veins, 641, 691, 692 relations to thoracic wall, 1369

Inscriptio tendinea, 317,430

Insertion of muscles, 314 (see also individual muscles)

Inspiration, muscles which affect, 247

Insula (island of Reil), $\$ 56$

Integument, 1281

Interarticular cartilage, 211

ligament (capitular articulation), 241 (sterno-costal joint), 245

menisci (semilunar fibro-cartilages), 289

Interarytænoid (procricoid) cartilage, 1213, $121 \mathrm{~S}$

Inter-brain, 843

Intercalated lymph-nodes, 706

Intercapitular veins (hand), 667 (foot), 684

Intercarpal ligaments, 269

Interchondral articulation, 246

arterial supply, 247

capsule of, 247

movements, 247

nerves, 247

Interclavicular ligament, 248

notch, 133

Inter coccygeal joints, 238

Intercondyloid fossa of femur, 182 eminence of tibia, 185

fossæ of tibia, 185

tubercles, 185

Intercostal branches of internal mammary artery, 567

arteries, $58 \mathrm{~S}$ superior, 568

branches of musculo-phrenic artery, 567

ligaments, external, 423, 432

lymphatics, $724,72 \mathrm{~s}$

muscles, function of, 422

nerves, thoracic, 995

spaces, 139

veins, 664

Intercostales externi, 423, 432

interni, 423, 433

Intercosto-brachial (intercosto-h u meral) nerve, 995

Intercrural (intercolumnar) fibres of external oblique, 430, 1394

Intercuneiform articulation, 304

Interfascial (Tenon's) space, 715

Interfoveolar ligament, 430, 435

Interior of skull, 112

Interlobar fissure of lungs, 1230

Intermediate cell mass, 15

crus of diaphragm, 437

fasciculus (mixed lateral zone), 784 plexus, 1041

Intermetacarpal articulations, 273

Intermetatarsal joints, 309

Intermuscular septa, 314

of foot, 492

of leg, 477

of thigh, 468

septum of arm, lateral, 377
Intermuscular septum of arm, medial, 377

Interossei dorsales (foot), 499 (hand), 410

plantares, 499

volares (hand), 409

Interosseous arteries of foot, 633 of forearm, 577, 579, 1423

artery, of forearm, common, 577 dorsal, 579 volar, 577, 639

crest of fibula, 190

of radius, 153

of tibia, 188

of ulna, $15 i$

crural nerve, 1010

ligaments, anterior talo-calcaneal joint, 302 inferior, tibio-fibular articulation, 297 intercuneiform joints, 304

middle tarso-metatarsal joints, $30 \mathrm{~S}$ of middle tibio-fibular union, 296 of pelvic, articulations, 235

of posterior talo-calcaneal joint, 301

superior, tibio-fibular joint, 295

membrane of forearm, 263, 264, 1420

muscles of foot, 454,499

of hand, 409

nerve, posterior, 986

volar (anterior), 992

recurrent artery, 580

Interparietal bone, 119

sulcus (intraparietal), 861

Interpeduncular fossa, $\$ 35$

nucleus (ganghion), 843, 885

Interphalangeal articulations of fingers, 276 of toes, 310

Interpterygoid fascia, 339

Interpubic fibro-cartilage, 240

Intersigmoid fossa, 1175

Interspinal muscles (interspinales), 412, 419

Interspinous ligaments, 231

Intersternal joints, 241

Intertragic notch, 1082

Intertransversarii, 412,417

Intertransverse ligaments, 231

muscles, anterior and lateral, 356 dorsal, 412

Intertrochanteric crest, 178

Intertubercular (bicipital), groove, 148

Intervaginal space of optic nerve, 1073

Interventricular foramen (foramen of Monro), 847,874

septum, 516

Intervertebral articulation, ligaments of, 225

fibro-cartilages, 225, $23 \mathrm{~s}$

veins, 666

Intestinal arteries, 596 veins, 677

lymphatic trunk, 731

Intestines, clinical anatomy of, 1375

large, 1170, 1376

lymphatics of, 734

small, 1161, 1375

Intracranial portion of internal carotid artery, 550

of vertebral artery, 560

Intralabial muscles, 331

Intraparietal sulcus, 861

Intrinsic muscles of great toe, 495 of larynx, 1218

of little toe, $49 \mathrm{~s}$

of tongue, 1110

Introduction, 1

Intumescentia tympanica, 951

Involution of mammary gland, 1303

Iris, $1052,1054,1060,1065$

Ischial spine, 172

Ischio-bulbosus muscle, 451 
Ischio-capsular ligament, 278

Ischio-cavernosus (erector penis), 443, 451

Ischio-femoralis, 461

Ischio-pubicus (Ilacoviteh), 450

Ischio-pubo-femoral musculature, 463

Ischio-rectal fossee, 441, 445, 1384

Ischium, 171

Island of Reil (insula or central lobe), 865

Isthmus, aortic, 531

of Fallopian tubes, 1290

of fauces, 1100,1352

of gyrus fornicatus, $\$ 67$

pharyngeal (faucium), 1100, 1130, 1131, 1352

of rhombenecphalon, 75S, 832

of thymus, 1321

of thyreoid gland, 1313

of tuba auditiva (Eustachian tube), 1092

of uterus, 1271

Iter chordæ anterius, 126

posterius, 78,126

$\mathrm{J}$

Jacobson, nerve of, 951, 961

organ of, 1057,1204

Jejunal and iliac branches of superior mesenteric artery, 598

Jejuno-ileum, lymphatics of, 734

Jejunum, 1165, 1376

Joint-furrows, 1284

Joints (see "Articulations")

Jugular foramen, 74, 108, 117, 125

fossa, $73,10 \mathrm{~s}$

ganglion (superior) of glosso-pharyngeal, 951

of vagus, 954,956

nerve, 960,1035

(interclavicular) noteh, 133

process, 54, $10 \mathrm{~S}$

vein, anterior, 648

line of, 1356

external, 646, 1359

internal, 659, 691

posterior external, 615

venous arch, 648

Jugum sphenoidale, 67

\section{K}

Kilneys, 1241, 1379

clinical anatony of, 1379

development of, 1247

lymphatics of $701,737,1247$

position and relations of, 1243, 1380

structure, 1246

surfaces of, 1243

variations aml comparative, 1247

vessels and nerves of, 1247

Knee-joint, 28.t

anastomoses a romnd, 1.57

arterial supply, 291

burse aromini, 1149

clinieal anatomy of 1.49

ligaments of, 281

lymphaties of 7 , 701

anovernonts of, '2!)'

muscles acting $110 m, 295$

unerve-sumply, $29 ! 2$

rolations, 2!2

symedial membrane of $290,1.4 \mathrm{~s}$

Kritise, encl-bullos of, 1290)

crimils of 1078

Kromlon's ancthol for topugraphy of brain, [:340

\section{L}

Labia (see also "Lips').

of cervix uteri, 1272

majora, 1276, 1392

minora (nymphæ), 1277, 1392

Labial arteries (of mouth), 541

(or scrotal) arteries, anterior, 620 posterior, 613

branches, inferior, of mental nerve, 941 superior, of maxillary nerve, 939

nerves, anterior, 1000

posterior, 1017

tubercle, 1102

veins (of mouth) 644

(of vulva), 683, 684

Labyrinth of ethmoid, 82

membranous, 1092

osseous, 80

Lacertus fibrosus (semilunar fascia), 382

Lacrimal apparatus, 1079 clinical anatomy of, 1346

artery, 552

bone, 85

at birth, 124

branch of dorsal nasal artery, 554 of middle meningeal artery, 548

canal, 1080

caruncle, 1052, 1055

crest, 85,110

ductus (canalieuli), 1079

fossa, 61,109

gland, 1079, 1348

groove, $85,87,110$

nerve, 936, 1075

papilla, 1054

process, 85

puncta, 1079, 1349

sac, 1080,1349

tubercle, 88

vein, 659

Lacrimo-ethmoidal cells, 84

Laciniate ligament (internal annular) of leg, 480

Lactiferous duct, 1254

sinus (ampulla), 1254

Lacuna $(\mathfrak{x})$ laterales, 649 magna, 1264

of Morgagni (urethral), 1264

musculorum, 466

vasorum, 466

venous, of diıra, 916

Lacunar (Gimbernat's) ligament, 424, 429 466,1400

Jalognosis, 894

Lambla, 101, 1331

Lambroid suture, 57, 101

Lamellous corpuseles of (Vater, or Pacinian), 1290

Lamina(a), anterior elastic, of cormea, 1060 basil (vitreous), of chorioid, 1060

basilaris of membranous labyrinth, 1096

of ecrebellum, medullary, 808

chorio-capillaris, 1060

cribriform, 119

cribrosia sclerce, 930, 1055, 1059, 1073

of temporal bone, 92

of cricoirl cartilage, 1210

epithelial chorioid, 876, 924

fusca, 105!)

mediastiniles, 1237

inedullary, of lenticular meleus, 880

of thalamus, 882

papyracea (os planum), 83

posterior elastic, of cornea, 1060

quarlrigemina, 833

rostal, of corpus callosim, 852 
Lamina of septum pellucidum, $\$ 12$ spiralis, 81 suprachoroidea, 1057, 1060

terminalis, (of brain), 848 (of ischio-rectal fossa), 1384

of thyreoid cartilage, 1210

tragi, $108 t$

of tuba auditiva, 1092

of vertebra, 30

Landmarks of abdomen, 1370

bony of the ankle, 1459

of the buttocks, $1+42$

of eranium and scalp, 1333

of elbow, 1417

of the foot, 1464

of forearm, 1419

of the knee, 1447

of neck, 1354

of the leg, 1453

of thigh and hip, 1434

of wrist and hand, 1424

Langerhans, islets of, 1195

Lanugo, 1290

Large intestine, 1170

anus, 1177

blood-ressels of, 1179

cæcum or caput coli, 1170, 1377

clinical anatomy of, 1376

colon, $1173,137 \mathrm{~S}$

development of, 1179

lymphatics of, 1179

nerves of, 1179

rectum, 1176

variations and comparative, 1130

vermiform process (appendix), 1173, 137s

Laryngeal artery, superior, $53 \mathrm{~S}$ inferior, $564^{\circ}$

nerve, inferior, 957 superior, 956

pharynx, 1134

prominence, 1211

veins, inferior, 659

superior, 6.59

ventricle, 1222

Larynx, 1209

cartilages of 1209

cavity of, 1220

development of, 1225

joints of, 1213

lymphatics of, 719,1224

inuseles of, $326,501,1218$

vessels and nerves of, 1224

rocal tolds (cords), 122:3

Latissimo-condyloideus (dorso-epitrochlearis), 379

Latissimus dorsi, 368 elinical anatomy of, 1405

Law of derelopmental direction, 12

Laxator trmpani muscle, 79

Left atrim of heart, 514

colic artery, 603

vein, 678

common carotid artery, 533

iliac artery, 60.5

coronary artery, 520

gastric artery, 593

gastro-epiploic artery, 595 vein, 677

innominate rein, $6+1$

lower bronchial artery, 588

pulnonary artery, 529 reins, 529

subelavian arters, 5.56

upper bronchial artery, 5ss

ventricle of heart, 516,517

Leg, hony landmarks of, 145.

elinical anatomy of, 1453
Leg, fascixe of, 497

muscles acting on, 505

muscular comprartments, 145 .

musculature of , $45 \%, 477$

vessels of 14.56

Lemnisei, demsation of, s15

of medulla oblongata, \$1.5

Lemniscus, \$.31, 839

lateral, siti, : :i1, 839

medial, $816,8: 31,839$

nucleus of, 824,839

Lens, erystalline, 1052, 1057, 1062

Lens-capsule, $10 \overline{5}$ 7

Lenticular nucleus, 878,879 process of incus, 79 papilla of tongue, 1106

Lenticulo-optic artery, $56 \mathrm{t}$

Lenticulo-striate artery, 562

Lesser alar (sesamoid) nasal cartilages, 1202 curvature of stomach, 1152

multangular (trapezoirl) hone, 159, 162

(gastro-hepatic) omentum, 1150, 1155

palatine foramina, 106

sac of peritonem, 1145

sigmoid cavity of $u \ln a, 157$

splanehnic nerve, 1039

tuberosity of humerus, 147

Levator ani, 440, 448

clavicula, 359

cushion, 1130

epiglottidis, 347

labii superioris, 322 alaque nasi, $33^{2}$

menti, 334

palpebrie superioris, $106 \mathrm{~S}$

penis, 451

scapulæ 356,359

of thy reoid gland, 1315

veli palatini, 1137

Levatores costarum, 423, 432

longi, 132

Levels, vertebral, 1409

Lieberkühn, (rrypts) glands of, 1166, 1177, 1390

Lienal plexus of nerves, 1045

Lieno-renal higament, 1310

Lieutaud, resical trigone of, 1252

Ligament(s) (see also "Ligamentum"), 211 alar (occipito-dental or check), 223

of ankle-joint, 298, 1463

annular, it ankle, 1463

of finger, 357

of superior radio-ulnar joint, 262

of trachea and bronchi, 1227

of wrist, 357

anterior, of ankle, 298

annular (wrist), 387

atlanto-epistrophic, 221

atlanto-occipital, 218

crucial, 25s

longitudinal, 227

medio-carpal, 270

oblique (lateral oceipito-atlantal), 219

sacro-erceygeal, 231

sacro-iliac, 231

of simphysis pubis, 239

talo-calcaneal, 302

talo-fibular, 299

apieal dental (suspensory), 223

arcuate (subpulic), 239

comnecting articular processes vertebre, 228

Cooper's, 1400

of articulation of atlas with occiput, 218

of atlanto-epistrophic joint, 221

of auricle (of ear), $10 \mathrm{St}$

uniting bodies of vertebri, 225

broal (lateral), of uterus, 1267, 1393 
Ligament(s) of calcaneo-cuboid joint, 306 calcaneo-fibular, 299 calcaneo-metatarsal, 492

of capitular (costo-central) articulation, 241 capsular, of elbow-joint, 258

carpal (annular), 1427

of carpo-metacarpal joints, 272

of the carpus, dorsal, 384

transverse, 387

rolar, 387

cerato-cricoill, 1213

check, of eveball, 1072

coccygeal, 911

Colles', 430

conoid, 251

coraco-acromial, 252

coraco-clavicular, 251

coraco-humeral, 255

corniculo-pharyngeal, 1218

coronary, of knee-joint, 290

of liver, 1184

costo-clavicular, (rhomboid), 249

of costo-transverse articulation, 243

costo-xiphoid, 244,245

crico-arytænoid, 1214

crico-pharyngeal, 1218

erico-tracheal, 1218

crucial, of central atlanto-dental joint, 222 of knee-joint, 288

cruciate, of leg, 479

of fingers, $3 S 7$

of cuboideo-navicular union, 303

of cubo-metatarsal joint, 308

of cuneo-cuboid articulation, 304

of cuneo-navicular articulation, 304

cvisto-colic, 1379

deltoid (of ankle-joint), 298

denticulate, 920,921

dorsal interearpal, 269

of elbow-joint, 258

external arcuate, 437

intercostal, 423,432

lateral, of knee-joint, 286

falciform, of liver, 1185

fibular collateral, 286

of first row of carpal bones, 269

fundiform (superficial suspensory) of penis, .127

gastro-hepatic, 1150, 1185

gast ro-phrenic, 1150

gastro-splenic, (gastro-lienal), 1150, 1310

Gimbernat's, 424, 429, 466

gleno-humeral, 255

glenoid (lip), 25.5

glosso-epiglottic, 1218

herpato-colic 1379

hepato-duoulenal, 1150, 1185

Ilessellyich's, 430

of hip-joint, 277

hyo-epiglotic, 1218

hivo-thyreoid, 1217

ilio-lumbar, 235

iliofomoral, 27 .

immediate, 225

of incus, 1091

inferior intecossens, (tibio-fibular), 297

of inferior carlio-nluar joint, 261

inferior sacero-iliate, 2:35)

transverse, (spino-glenoid) 253

infundibuls-pedvic, 1267

inguina! (Pouprirt's), 4'.t, 429, 1371, 1399 , I I:3

intrerarticular, 241, 2.15

interolaviembar, 218

of inforemureform joint, 301

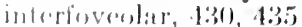

intermediatre, 22zis
Ligament(s) of intermetacarpal joints, 273 of intermetatarsal joints, 309

internal arcuate, 437

lateral, of knee-joint, 286 of mandibular articulation, 215

interosseous, cubo-metatarsal joint, 309

anterior talo-calcaneal, 302

intercuneiform joints, 304

intermediate tarso-metatarsal joint, 308

metacarpal, 269

of pelvic articulations, 235

of posterior talo-calcaneal joint, 301

of interphalangeal joints, fingers, 276 of toes, 311

interspinous, 231

of intersternal joints, 244

intertransverse, 231, 238

of intervertebral articulation, 227

of knee-joint, 284

(internal annular) laciniate, of leg, 480

ischio-capsular, 278

lacunar (Gimbernat's) 424, 429, 466, 1400

of larynx, 1213

lateral, of ankle-joint, 299

calcaneo-navicular, 302, 305

hyo-thyreoid, 1217

malleolar, anterior, 296

posterior, 297

sacro-coccygeal (intertransverse), 238

of left vena cava, 521, 523

of liver, 1184

malleolar (of tympanum), 1091

of mandibular articulation, 215

medial palpebral, 1052

median erico-thy reoid, 1215

hyo-thyreoid, 1217

of medio-carpal joint, 270

of metacarpo-phalangeal joints, 274,275

of metatarso-phalangeal joints, 310

of mid radio-ulnar union, 262

middle costo-transverse, 243

tibio-fibular (interosseous), 296

morphology of, 213

neck, 243

oblique, of mid radio-ulnar union, ${ }^{2} 262$

popliteal (ligament of IVinslow), 287 occipito-cervical, 223

uniting occiput and epistropheus, 223

orbito-tarsal, 1071

of ossicles of ear, 1090

ovarian, 1269

patellar, 471

of pelvic articulations, 234

piso-hamate, 269

piso-metacarpal, 269

phreno-colic or costo-colic, 1150, 1174, 1310 1379

phrenico-lienal (lieno-renal), 1310

plantar, 1468

calcanco-cuboirl, 307

calcaneo-navicular, 302, 305 accessory, 310

long, 307

pulmonary, 1236

posterior, of ankle-joint, 298

anmular (wrist), 3St

atlanto-epistroplice, 221

atlanto-occipital, 218

costo-transverse, 243

crucial (of knce), 288

longitudinal, 227

(dorsal) medio-curpal, 270

sacro-iliae, 234

of sympliysis pubis, 239

of talo-calcaneal joint, 301

talo-fibular, 299

Poupart's, 424, 429,'1371 
Ligament(s), proper scapular, 252

pubo-prostatic (pubo-vesical), 1252

radial collateral, 261,267

radiate of anterior costo-central or stellate, 242

of medio-carpal joint, 270

sterno-costal, 245

of radio-carpal joint, 266

of radio-ulnar joints, 261, 264

reflected inguinal (triangular fascia), 430

rhomboid (costo-clavicular), 249

round, of uterus, 1274

of liver, 1185

of sacro-coccygeal articulation, 238

sacro-lumbar, 232

sacro-spinous or small sacro-sciatic, 236

sacro-tuberous, 235

of sacro-vertebral articulations, 232

of second row of carpal bones, 270

of shoulder-joint, 254

between skull and vertebral column, 218

spheno-mandibular, 217

spino-glenoid (inferior transverse), 253

connecting spinous processes of vertebræ, 229

spiral, of cochlea, 1096

spring, 305

sterno-clavicular, 248

of sterno-costal joints, 245

of sterno-costo-clavicular articulation, 248

sterno-pericardial, 522

stylo-hyoid, 99

stylo-mandibular (stylo-maxillary), 217

superficial transverse, 387

superior costo-transverse, 243

interosseous, tibio-fibular joint, 295

sacro-iliac, 234

sterno-costal, 245

transverse (coracoid or suprascapular), 253

supraspinous, 230,238

suspensory, of Cooper, 1303

of the eyeball, 1072,1348

of lens of eye, 1057, 1064

of ovary, 1269

of penis, 427,1260

of 'Treitz, 1164, 1376

of symphysis pubis, $23 \mathrm{~S}$

talo-calcaneal, 302

of talo-navicular joint, 305

temporo-mandibular, 215

thyreo-epiglottic, 1215

thy reoid, 1314

tibial collateral, 286

tibio-fibular, 295

transverse, of central atlanto-epistrophic joint, 222

$$
\text { crural, } 479
$$

dorsal (medio-carpal joint), 270

of heads of metatarsal bones, 309

of hip-joint, 280

humeral, 256

of knee-joint, 289

of pubis, 446

connecting transverse processes of vertebræ, 231

trapezoid, 251

triangular, of liver, 1185

tubercular (posterior costo-transverse), 243

ulnar collateral, 259, 266

umbilical, 1250,1252

uniting laminæ of vertebræ, 229

of urinary bladder, 1252

utero-sacral, 1274

vaginal, 317

vaginal (fingers), 387

ventricular of larynx, 1215
Ligament(s), vocal, 1215

volar accessory (glenoid), 271

intercarpal, 269 radio-carpal, 266

Ligamenta denticulata, 911 flava, 229

Ligamentous branch of ovarian artery, 602

Ligamentum(a) alaria (knee-joint), 291

ano-coccygeum, 449

arteriosum, 528, 531

breve, 399,401

denticulatum, 920, 921

epidirlymis, 1255

interfoveolare, 430

longım, 399, 401

mucosum (knee-joint), 290

nuchæ, 231, 414

patellæ, 285, 1448

pectinatum iridis, 1060

sacro-iliaca, anteriora, 177, 234

teres, 280

of liver, 675,1185

(round ligament) of uterus, 1274

venosum of liver, 675,1185

Winslowii, 287

Ligature of anterior tibial artery, 1458

of brachial artery, 1414

of common carotid artery, 1358

of femoral artery, 1441

in Hunter's canal, 1442

of popliteal artery, 1452

of posterior tibial artery, 1458

of third part of subclavian artery, 1359

of ulnar artery, 1423

Ligula (tænia ventriculi quarti), 813

Limbic lobe, S65, 866

Limbous sutures, 212

Limbs, cutaneous areas of,"1020, 1022,'1024

development of, 20

Limbus of cornea, 1025

fossie ovalis, 511

sphenoidalis, 63

of tympanic membrane, 1087

Limen of insula, 857, 865 nasi, 1204

Limiting sulcus of floor of fourth ventricle, 813

Line(s) (see also "Linea").

(striæ) albicantes, 1283, 1384

bony, 29

of femur, intertrochanteric, $17 \mathrm{~S}$ spiral, 178

of fibula, oblique, 190

secondary oblique, 190

gluteal, 170

ilio-pectineal, 173

mylo-hyoid, 95

Nélaton's, 1436

oblique, of mandible, 95

of radius, 154

of thyreoid, 124

popliteal, 189

of scapula, oblique, 142

supra-condylar, of femur, 181

temporal (ridges), 57, 60, 1332

transpyloric (Addison's), 1153, 1370

trapezoid (oblique), 140

of ulna, oblique, 157

Linea alba of abdomen, 427, 1370 viscera behind, 1373

aspera, 178

pectinea of femur, 181

semicircularis, 427

semilunaris of abdomen, 1371

splendens, 921

suprema (highest nuchal line), 52

Lingual artery, 539

branches, 539 
Lingual (gustatory) branch of inferior alveolar (dental) artery, 545

of glosso-pharyngeal nerve, 952

of facial nerve, 944

fascia, 346

follicles, 1107

gyrus, $86 t$

nerve, 940,1350

papillæ, 1160

plexus of nerves, 1036

tonsil, 1107

reins, 660

Lingula cerebelli (lingula vermis), 806,831

of left lung, 1229

of mandible, 96

of sphenoid, 64

of Trisherg, 942

Lips, 1102, 1319

of Eustachian aperture, 1130

glenoid, $25 j$

of ileo-creal valve, 1172

lymphaties of, 713

variations and comparative, 1172

vocal, 1223

Lisfranc, amputation of, 146.5

Lissauer, marginal zone of, 782

Little finger, muscles of, 104

Littré, glands of (urethral), 1264

Liver, 1180

blood-ressels of, 1185

clinical anatomy of, 1373

development of", 1159

ductus choledochus (common bile duct), $118 \mathrm{~S}$

gall-bladder, 1187

ligaments of, 1181

lobes and fissures of, 1180

lymplatics of, 699,736

topography of, 1373

Liver, surfices and borders of, 1181 valiations and comparative, 1190

Lobe(s), birentral, sot central, sist

of cerebellum, sos

frontal, s.5

inferior semilnuar, of eerebellum, 807

limtion, s6.5, $866 \%$

of liver, 11 (N)'

of lungs, 12:30

of manmary glatud, 1302

orecipital, $\rightarrow(6)$ ?

oflactory, sijo

parietal, s(t)

of prostille, 126 .

pyramidal, of thyeesid glamed, 1314

quiadrangular, siog

superior semilumar of cerebellum, 806

of teleserephaton, s.5)

trmporal, of ecrobrum, 854

wit thyouss, 1320)

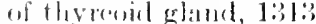

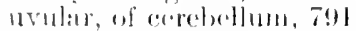

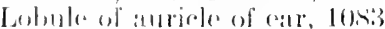

(c)

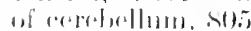

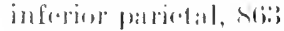

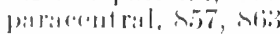

quistrate, stion

s.r.1.110, 1:31:2

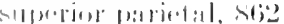

of to.tis, 12.56

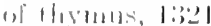

of tligronel glimel, listi

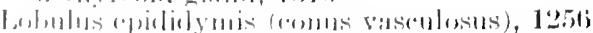

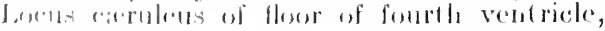
$4.5,839$

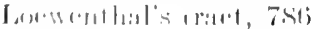

Longissimus capitis (trachelo-mastoid), 416 cervicis (transversalis cervicis), 416 dorsi, 416

Longitudinal arch of foot, 1468

bundle, posterior, 817

fasciculus, inferior, 892

medial, 817,842

nucleus of 871

superior, 892

fissure of eerebrum, 850

ligament of intervertebral articulation, 227

(sagittal) sinuses, 649,650

strixe of corpus callosum, 851,892 of hippocampus, 871

vertebral veins, 66.5

Longitudinalis lingua inferior medius, 347

Longus capit is (rectus capit is anterior major), 355

colli, 355

Loop, ecrvical (hypoglossal), 953, 979 Henle's, 1246

Louis, angle of, 139

Lower extremity, articulations of, 276

clinical anatomy of, 1434

cutaneous areas of, 1024

fascix of 454

lymphaties of , 746, 748

musculature of 452

Lowest lumbar (lumbalis ima) artery, 603

Lumbar arteries, 593, 638 lowest (ima), 603

branch of ilio-lumbar artery, 607

enlargenent of spinal cord, 772

fascia, 436

lymphatic nodes, 730

trunks, 730

muscle, 436

nerves, 973,996

posterior primary divisions, 973

plexus, 998

branches of, 998

composition of nerves of, 998

situation of, 998

portion of srmpathetic system, 1039

puncture ((juincke), 1408

regions, 1143

ribs, 132

voins, 675

ascencling, 662,663

vertebrat 37

description, 37

development of, 48

Itmul)o-costal areh, lateral, 437 modial, $4: 37$

Lumbo-rlorsal faseia, 414,428

Lumbo-inguinal (erural) branch of genitofemoral nerve, 1000$)$

Immbo-salcral angle, 4:3 plexus, 996

trunk, 1005

Immbricales (foot), 454, 495

(h:and), d1) s, 409

Lmate (semilunar) hone, 159, 161

Landes (pulmones), 1228

clinical anatomy of 1367

dev(roplunent of , 12:35)

form of , 12.2s

lobes of , 12:30

lymphaties of, 729, 1235

sirfincos of, I:22!)

toprography of, 1233, 1365

variations of, 1235

resseds ambl nerves of, 12:34

Lamila wi nails, 1295

(1) semilumar valves, 517

boys, bouly of, sis.

lsmpl, movement of, 70$)^{2}$ 
Lymphatic capillaries, 697, $69 \mathrm{~s}$

duct, right (terminal collecting), 728

follicle, 704

nodes (glands) of abdomen and pelvis, 730

ano-rectal, 735 ?

anterior auricular, 709

mediastinal, 724

axillary, 719

bronchial, 725, 1226

buccinator, 711

cœliac, 730

common iliac, 731

deep cervical chain, 714

delto-pectoral, 719

development of, 707

diaphragmatic, 725,736

epigastric, 732,733

external iliac, 732

facial, 709,711

gastric, 730,734

of head and neck, 709, 714

hepatic, 730,736

hypogastric, 732

inferior deep cervical, 71

inguinal, 746

internal mammary, 724

intercostal, 724

of larynx, 1224

of lower extremity, $7+6$

lumbar, 730

mesenteric, 731

meso-colic, 734

occipital, 709

parietal, of thorax, 724

parotid, 709

of pelvis, 730

popliteal, 748

post-aortic, 731

posterior mediastinal, 725

auricular, 709

pre-aortic, 730

pulmonary, 725

sacral, 733

splenic, 730,736

structure of, 704

subinguinal, 746

submaxillary, 709

submental, 711

superficial cubital (supratrochlear), 719

superior deep cervical, 714

supramaxillary, 711

of thorax deep, 724

visceral, 724

umbilical, 733

of upper extremity, 719

system, 697

general anatomy of, 697

special anatomy of, 709

development of, 706

of eyeball, 1065

of orbit, 1076

vessels, 702,705

of abdomen and pelvis, 733

of eyelids, $107 \mathrm{~S}$

of face, 712

of head, 712,714

of hip-joint, 750

of knee-joint, 750

of lower extremity, 748

of neck, 712,714

of cesophagus, 730, 1141

regeneration of, 707

structure of, 702

of thorax, deep, 725

superficial, 723

95
Lymphatic ressels of upper extremity, deep, 721 superficial, 721

Lymphatics of abdomen and pelvis, 730

in abdominal wall, 1372

of alimentary tract, 699,733

of anus, 735

of auricle (of ear), 714, 10St

of brain, 714

capillaries, 697

of clitoris, 745

of conjunctiva, 698,712

of diaphragm, $72 \mathrm{~S}$

of digestive tract in head and neck, 715?

of ductus deferens and seminal resicles, 744

of duodenum, 734

of excretory organs, 737

of external auditory meatus, 714,1086

of the eye, 715,1065

of eyclids, 712

of Fallopian tube, 745,1270

of female extermal genitals, 744, 1278

of gums, 715

of hear and neck, 709

of heart, $522,701,730$

of ileocrecal region, 734

intercostal, 725

of jejuno-ileum, 734

of kidney, 737,1247

of large intestine, 734, 1179

of larynx, 719, 1224

of lips, 713

of liver, 736, 1186

of lower extrenity, 746, $146 \mathrm{~s}$

of lungs, 729,1235

of mammary gland, 723, 1305

of nasal cavities, 717, $120 \mathrm{~s}$

of neck, 709

of nose, $712,1203,1208$

of ovary, 745, 1269

of palate, 717

of pancreas, 736,1195

of parotid gland, 1115

of penis, 744, 1262

of pharynx, 717, $113 \mathrm{~s}$

of pleura, 1239

of prostate, 739,1265

of rectum and anus, 735

of reproductive organs, male, 742

of scalp, 712

of scrotum, 742, 1255, 1385

of shoulder-joint, 723

of skin, 69s, 1289

of small intestine, 1168

of spleen, 736, 1312

of stomach, 734,1156

of suprarenal glands, 738, 1326

of teeth, 1124

of testis, $744,1256,1387$

of thoracic muscles, 723

of thorax, 72:3

of thyreoid gland, 719,1317

of thymus, 729,1322

of tongue, 715,1111

of tonsils, 1138

of trachea and bronchi, 699, 1228

of tuba (Fallopian tubes), 1270

of upper extremity, 719, 1424

of ureter, 738, 1249

of urethra, female, 742

male, 744

of urinary bladder, 739,125 :

of uterus, 745,1274

of vagina, 745,1276

of rulva, $744,127 \mathrm{~s}$

Lymph-follicles, 704

Lymph-nodes, 704 
Lymphoglandule, 704

Lxmphoid organs, 704

Lyra, hippocimpal, 869

\section{M}

Nacewen's suprameatal triangle, 1337

Macula acustica sacculi, 950, 1094 utriculi, 1093

lutea (vellow sput), 1055, 1057

Magenulie, foramen of, $\$ 13$

Major sublingual duct (of Bartholin), 11 I7 palatine arters, 549

Minlar hone, 93

branches of maxillary nerve, 938 of temporo-ficial nerve, 945

tubercle, 95

tuberosity, 93

Nale mammary gland, 1305

pelvis, 1342

reproductive organs, 1253,1386

Nalleolar artery, lateral, 6:32 merlial, 632 posterior lateral arterr, 626

folds of trmpanie mueous membrane, 1089 ligaments, anterior lateral, 296 posterior lateral, 297 of ossicles of ear, 1091

prominence of tympanic membrane, 1087

recesses of tympanic mucous membrane, 1089

rete, lateral, 626,632 medial, 626,632

stria of trmpanie membrane, 1087

Malleoli, clinical anatomy of, 1451

lateral, 191

medial, 189

Nalleus, 79,119

Malpighi, pramids of, 1246

Malpighian corpuscle (renal), 1246 (s) lenic), 1311

Mammary artery, external, 1305 internal, 566, 1365

cutaneous hranches of aortic intercostal arleries, 590

gland (mamma), 129)

clinical anatumy of, 1366

lino lriclese), lisiti

lympliaties of , 723, 1305

in mate, l:305

vosicels amel norves of, 130 is

phexus of nerves, internat, 10:37

velits, internal, titit

vomusts plexus, ti7

Mammillary horlies, s48, 871

moness, :38

Matmunillo-mesencephalic fascieulus, st

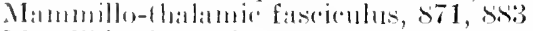

Mamblil,l. (lowrer jaw), yj

agr (rhalleges in, 9?

:1) lirth, 124

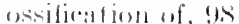

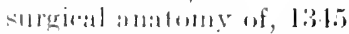

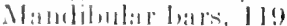

framelace of envier-farcial nerve, ghe

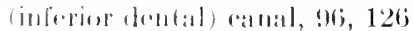
formment m, m;

forsit, f11s

merve (thima thision of trigemimas), 939, 1.31:i

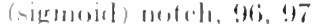

porlinol of imformal maxillary artory, 5.16

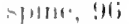

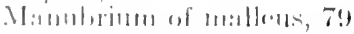

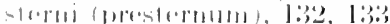

Margin, faldeiform, of fastial lat:a, fti7 of longs, 1223! 1 2:3:
Marginal gyrus, S5S

simuses, 650

zone of Lissauer, 782

Margo acutus of heart, 510

obtusus, 510

Marshall, oblique vein of 521,523

Massi intermedia, 814

Masseter muscle, 338, 341

Masseteric branth of external maxillary artery, 541

artery, 548

fasciia, 339

nerve, 943

veins, 644,646

Nastication, museles of 325

Masticator nerve, 829,942

Mastoiøl antrum (see "Trmpanic antrum"). branch of great auricular nerve, $97 \mathrm{~S}$ of oceipital artery, 543 of small occipital nerve, 977 of stylo-mastoid artery, 544 eanaliculus, 73

cells, 72, 1092, 1336

foramen, 72,10 s, 117

(supra-meatal) fossa, 72

notch (digastric fossa), 72

process, 72,108 development of, 76

Mater, dura, 771 pia, 771

Naxilla, 86, $13 \pm 6$

at birth, 124

ossification of, 91

Maxillary artery, external, 540, 638, 1343 intemal, 545, 638

nerve (second division of trigeminus), 937 plexus of norves, external, 1036 intermal, 1036

process of inferior turbinate, 85 of palate bone, 92

sinus (antrum of Highmore), $87,90,111$, 1206, 1346

vein, internal, 646

Maxillo-ethmoidal cells, $\$ 4$

Maxillo-turbinates, 119

Meatal branch of stylomastoid artery, 544

Meatus, extcrnal auditory (acoustic), 75, 108, 1084,1332

intermal anditory, 72, 117

naso-plarymgeus, 1206

of uose, si3, 111, 1205

Meckel's cartilage, 9s, 119

citcos, 916

diverticulum, 1169

ganglion, !)

Median antiluachial vein, 607,668 artory of forcallu, 578, 6.39

lrasilic: (cubital) vein, 667,669 ceplatire voin, bris

rrico-lhyreoid ligament, 1215

(eublital verin, titio

fistore of spinal cord, anterior, 720

hyo-thyporid lig:ment, 1217

nerve 991, 1423

result of paralysis of, 1424

sulcus of floor of fourth ventricle, 813

Moliastinal artery, anferion, 567

liramohes of acrtat, 5900

lymphatic moles, anterior, 721 posterior, 725

blatia, 12:37

siphin, 1230)

surface of lungs, 1229

voins, titil, tifit

Modiatimum, 20, 1225, 1239

divisions, les?

test is (oorpus Highmori), 1256 
Medio-carpal joint, 270

arterial supply, 270

ligaments, 270

movements of, 271

muscles acting upon, 270

nerve-supply of, $2-70$

Medulla of kidnes, $12 \pm 6$

oblongata, 799

blood-ressels of, $90 \mathrm{~s}$

central comnections of cranial nerres in, S18

ventral aspect of, 799

of suprarenal gland, 1321

of thymus, 1326

Medullary cavity, 28

lamina of lenticular nucleus, $\$ S 0$

of thalamus, 882

lamina of cerebellum, sos

ray of kidney, 1246

sheaths, 759

striæ, acoustic, 824

velum, anterior (superior), $\$ 12$ posterior, $80 \mathrm{~S}$

Medullated fibres, 760,767

Medullation of fasciculi of spinal cord, order of, 791

Meibomian glands, 1054,1078

Meissner, tactile corpuscles of, 1290 plexus of 1030,1045

Membrana sacciformis, 265

Membrane(s), Bowman's, 1060

choroidal, 1052

of Descemet, 1060

elastic, of larynx, 1215

hyaloid, $106 \pm$

hyo-glossal, $3+6$

hyo-thyreoid, 1217

interosseous, of forearm, 1120

of mid-radio-milnar mion, 263, 264

of middle tibio-fibular union, 295

pharyngeal, 1102

quadrangular of larynx, 1215

secondary tympanic, 1089, 1096

Shrapnell's, 1057

symorial, 211; (see also the individual articulations)

Membrane, tectorial, 223

trmpanic, 1086

vestibular (membrane of Peissner), 1096

Membranous ampullæe, 1095

cochlea, 1095

cranium, 117

labrrinth, 1092

nasal septum, 511

semicircular canals, $109 t$

urethra, 1264, 13ss

Meningeal artery, accessory (small), $54 \mathrm{~s}$ arteries, 917

middle, $5+7$

surgical anatomy of, 1341

posterior, 537

branches of anterior ethmoidal arters, 554

of maxillary nerve, middle (recurrent) 937

of occipital artery, 543

of ophthalmic nerve, recurrent. 935

of posterior ethmoidal arters, 55.3

of spinal nerve-trunks (recurrent), 970

of ragus, 956

of vertebral artery, 560

plexus of nerves, 1036

veins, 646,917

Meninges, 908

arachnoid, 917

dura mater, 910

pia mater, 920

relation to spinal nerves, 965
Meningoceles, 1331

Menisci, interarticular, $2 \times 9$

Mental hranch of inferior alveular (dental) arters, its

foramen, 9.

muscle, 334

nerve, 94I

protuberance, 95

spine, 9.5

tubercle, 95

ventalis levator menti), $3: 34$

Mento-labial sulei, $12 \times t$

Meridians of eveloall, 161.5

Mesatipellic pelvis, 17

Tesencephalon, 75 . 833

blond-resscls of 907

external features of, $53 t$

internal strueture of 836,813

Mesencephalic root of masticator nerve, s36, 942

nucleus of $52 !$

Mesencephalo- or tecto-spinal tract, Tot, 842

Mesenteric artery, inferior, 602, (ii3s stiperior, 596, 638

ganglion, superior, 1043,1045

Frmplatic nodes, 731

plexus of nerves, inferior, 104.5 superior, 1045

vein, inferior, bis

superior, $67 \%$

IIesenteriolum, of appendix, 1173

Mesentery, 1165,1376

derelopment of, 19

Nesethmoid, 119

Meso-colic limphatic nodes, 734

IIeso-culon, 1174,1175

Iesoderm, 10, 14

Mesognathion centre, 91

Meso-netrium, 1267

Meso-nephros (Wolffian boly), 16, 1256, 1278

Meso-palatine suture, $\$ 9,106$

Meso-salpinx, 1267

Neso-scapula 145

Meso-sternum, 132

Mesutendons, $31 \mathrm{~s}$

Mesovarim, 1267

Netacarpal arteries, dorsal, 5\$6 rolar, 586

bones, $16 \mathrm{t}$ union of heads of, 274

heat of atductor pollicis, tos

veins, torsal, 667 volar, 671

Metacarpo-phalangeal joints, 274 of thumb, 275

Metacarpus, ossification of, $16 \mathrm{~s}$

Metamerism, 15

of cranial musculature, 327

Metamorphosis of branchial (visceral) bars, 119

Metancphros, 127s

Metasternum, 132

Metatarsil artery, dorsal, 633 plantar, fias

bones, 20() union of heads of, 309

pillar, 20.5

reins, plintar, 657

Metatarso-phalangeal articulations, 310

Metatarsus, 200

Metathalamus (geniculate bodies), 845

Metopic suture, 59, 101

Meyncrt, fasciculus retroflexus, $\$ 43,885$

Micromastia, 1301

Mirl-brain, 833

Middle alreolir camal, ST

(azygos) articular artery, 623 
Middle eardiac nerve, 1036 vein, 520

cerebral artery, 555, 562

vein, 655

clinoid process, 65

coat of eye, 1060

colic artery, 598

collateral (branch of profunda) artery, 576

constrictor of pharynx, 1137

costo-transverse (neek or interosseous) ligament, 243

cranial fossa, 116

Middle ear, 77, 1086

ethmoidal eells, 111

hæmorrhoidal artery, 610

meatus of nose, 111

meningeal artery, 547, 1341

veins, $6+6$

nasal conchæ, $\$ 3$

palatine foramina, 106

peduncle of cerebellum, 811

sacral artery, 603

vein, 679

suprarenal arteries, 598

temporal artery, 545

thalamic liranch of posterior communicating artery, 554

thyreoid vein, 661

umbilieal ligament, 1250

Mid-radio-tulnar union, 262

Milk, 1303

teeth, 1126

Minor palatine arteries, 549

sublingual duets (of Rivini), 1117

Mitral cells of olfactory bulb, $\$ 66$

(bieuspid) valve, 515,516

Moderator band of heart, 516

Modiolus, $\$ 1$

Molars, 1121

Molecular layer of cerebellar cortex, 809

Moll, glands of, 1078

Monro, fortamen of, 847,874 sulcus of $8 \pm 7$

Mons pubis (veneris), 1276

Montennery, glands of, 1304

Monticulus of cerehellum, 806

Morgagni, columns of, 1177

hydatid of 1257,1269

lacunir of, 1264

sinus of 1137

ventriele of, 1222

Iorphogenosis, 7 (sce also "Development")

Morplobogical axis of scapula, 115

Iorplinlogy (see also "Comparative Anatobing")

of alimentary canal, 1099

of joints, $21 \%$

of muscoulature of hearl and neck, 323 of molvic ontlet, $\$ 1$

of skinll, ] 17

of spimil ard, extermal, 751

of the testis, 1250

of the vertelera, serial, 50

Mormala, !

Motor aplasia, s:9\}

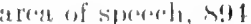

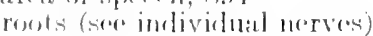

Blonthe 1 100

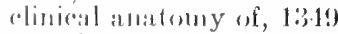

mallseles of , :3:32

Mrevemonts of joints, 214 (sre also individual artioulationst

Wiıllsrian sluet, 1257, 1267, 1279

Mlultamgular lune (trapezium) Greater, 159 , 162

(rapmorid) losser, 159, 162

Vullifilis, 112,419
Multipenniform musele, 315

Musele(s) (see also "Musculature")

abductor accessorius digiti quinti (foot), 499

digiti quinti (foot), 454,498 (hand), 404

hallucis, 454,496

longus, 482

ossis metatarsi quinti, 499

pollicis brevis, 406, 407

longus (extensor ossi metacarpi pollieis), 392,393

abnormal, of front of leg, 482

of back of leg, 491

of volar side of forearm and wrist, 392

accessorius ad flexorem digitorum profundum (forearm), 402

of gluteus minimus, 162

of spinal musculature, 416

accessory peroneal, 484

aeting upon joints (see individual articulation)

adductor brevis, $453,471,474$

digiti secundi, 498

hallucis, $454,496,498$

longus, $453,471,472,1437$

magnus, 453, 471, 474, 1437

mininısus, 474

pollicis, 407,408

aneoneus, $374,377,379$

intermus, 402

of the angle of the mouth, 332

anomalus, 335

antagonists, 322

anterior and lateral intertransverse, 356

antitragus, $108+$

articularis genu, 470

atlanto-mastoid, 422

attached to the tendons of flexor digitorum, longus, 495

attachments of bones (see individual bones) of auricle (of ear), 337, 1084

aurieularis anterior (attrahens aurem), 337 posterior (retrahens aurem), 337

superior (attollens aurem), 337

auriculo-frontalis, 337

ary-epiglottic, 1220

ary-membranosus, 1220

arytienoideus obliquus, 1220

transversus, 1218

ary-vocalis, of Ludwig, 1220

belly of, 314

biceps liracliii, 374, 379, 382, 1414

biceps femoris, 453,475

bieipital, 314

bipenniform, 315

biventer cervicis, 418

braclicalis, 37.1, 380, 382

brachio-radialis (supinator radii longus), 387,388

broncho-cesophageal, 1141, 1248

buceciuntor, 334

bulbo-cavernosus, 413,450

in female, (sphincter vaginie), 450, 1278

eaninus, 3:32

caput angulare, 332

infraorluitiale, :3:32

zygomatienm, 3:32

colato-cricosid, 1218

cervical, 330

eervicalis aseondens, 416

chombo-humeralis (epitrochlearis), 374

chondro-glossus, 3.16

(rilinris Rindani, 1077

(iliary, 10.57, 106t)

classifiration of , 31!

cocryerews, 110, 448

complexus, 112, 417 
Muscle(s), compressor bulbi proprius, 450

hemisphærium bulbi, 451

venæ dorsalis, 451

constrictor laryngis, 1218

radicis clitoridis, 451

penis, 450

vaginæ, 449,451

coraco-brachialis, $374,379,381$

corrugator, 336

cutis ani, 445

costo-coracoideus, 374

cremaster, 423, 434, 1254, 1259

crico-arytænoideus lateralis, 1219

posterior, $121 \mathrm{~S}$

crico-thyreoid, 1218

crureus, 468,470

cruro-pedal, 486

deltoideus, $364,365,1410$

depressor alæ nasi, 334

anguli oris, 333

labii inferioris, 332

septi nasi, 334

diaphragm, 425, 436

digastric variety of, 314

digastricus, 343,341

dilator naris anterior, 335 posterior, 335

pupillæe, 1061

divisions of, 316

of dorsum of foot, 492

epicranio-temporalis, 337

epicranius, 336

epitrochleo-olecranonis (anconeus internus), 402

erector spinæ, 414

extensor carpi radialis accessorius, 391

brevis, 388,399

intermedius, 391

longus, $38 \overline{7}, 388$

ulnaris, $3 \$ 8,391$

communis pollicis et indicis, 394

digiti annularis, 395

quinti proprius, $3 S S, 391$

digitorum brevis (foot), 454, 492 (hand), 395

communis, 3s 391

longus, $453,480,481$

hallucis brevis, 482,492

longus, 453, 480, 482

indicis proprius, 392,394

medii digiti, 395

minimi digiti, 38s, 391

ossis metacarpi pollicis, 392, 393

pollicis brevis, 392,394

longus, 392, 394

erector penis (chitoridis), 443, 451

fasciæ, 313

femoro-tibial, 486

fibulo-calcaneus medialis, 491

fibulo-tibialis (peroneo-tibialis), 486

finer structure of, 315

flexor accessorius (digitorum longus), 491

(quadratus plant:e), 495

carpi radialis, 396,398

brevis (radio-carpeus), 403

ulnaris, 396,398

brevis (ulno-carpeus), 402

digiti quinti brevis (foot), 454, 49s, 499 (hand), 404

digitorum brevis (foot), 454, 493

longus (leg), 454, 486, 489

profundus, 401

sublimis, 399

hallucis brevis, $454,496,497$

longus, $454,486,490$

pollicis brevis, 407,408

longus, 402
Muscle(s), of front of leg, 450

frontalis, $33 \pi$

fusiform, 315

gastrocnemius, 453. 454, 485

gemellus inferior, $46 \pm$

superior, 464

genio-glossus, 346

genio-hyoideus, 343,345

genio-pharyngeus, 347

glosso-palatinus (palato-glossus), 1135

gluteus maximus, $443, .57,459$

medius, 457,461

minimus, $45 \bar{\tau}, 461$

gracilis, $453,471,472$

gross structure of, 314

grouped according to function, 500

head of, 314

helicis major, 1084

minor, $108 t$

Horner's, 336

hyo-glossus, 346

iliacus, 455

minor, 456

ilio-coccygeus, 440,448

ilio-costalis cervicis (cervicalis ascendens). 416

dorsi (accessorius), 416

lumborum, 416

incisivus labii inferioris, 332 superioris, 332

incisuræ helicis (Santorini), 1084

inferior constrictor of pharvix, 1136

oblique, $106 \mathrm{~S}$

infra-clavicularis, 374

infraspinatus, 364,368

insertion of, 314

intercostales externi, 423, 432

interni, 423, 433

internal cremaster, 1254, 1259

interossei dorsales (foot), 454,499 (hand), 410

plantares, 454,499

rolares (hand), 409

interspinal, 412,419

intertransversarii, 417

intralabial, 331

ischio-bulbosus, 451

ischio-cavernosus (erector penis or clitoris) 443,451

ischio-fenoralis, 461

ischio-pubicus (17acovitch), 450

of larynx, 1218

latissimo-condyloideus (dorso-epitrochlearis), 379

laxator tympani, 79

latissimus dorsi, $364,368,1405$

levator anguli oris, 332

ani, 440,448

claviculæe, 359

epiglottidis, 347

labii superioris, 332 alæque nasi, 332

menti, 331

palpebræ superioris, $106 \mathrm{~s}$

scapulæe, 356, 359

veli palatini, $113 \overline{7}$

levatores costarum, 123,432

longi, 432

of little finger, 404

longissimus capitis (trachelo-mastoid), 416 cervicis (transtersalis cervicis), 416 dorsi, 416

longitulinalis superior and inferior, 1110

linguæ inferior medius, 347

longus capitis, 355 colli, 355

lumbar, 436 
Muscle(s), lumbricales (foot), 454, 495 (hand), $40 \mathrm{~s}$

masseter, 341

mentalis, 334

minldle constrictor of pharynx, 1137

multifidus, 412,419

multipenniform, 315

mylo-hyoideus, 343, 344

nasalis, $33 t$

pars alaris (depressor ala nasi), 334

pars transverwa (compressor naris), 331

nerves of, 318

nomenclature of, 319

number of .315

obliquus aldominis externus, 423, 432 internus, 423, 434

auriculie, $10 \mathrm{~s} 4$

capitis inferior, 412,420

superior, 412,420

obturator extermus, 453, 463,464]

internus, 453,463

occipitalis, 337

minor, 337

occipito-frontalis, 336

oecipitu-seapularis, 359

orular, $106 \mathrm{~s}$

action, $106 \mathrm{~s}$

omo-hvoideus, 351

opponens digiti ruluti (foot) ,454, 498, 499 (hand), 404, 405

hallucis, tos

pollicis, $40 \bar{\tau}, 408$

oral, :3:31

orlicularis oculi, 336, 1077

oris, 331

of orlit, $324,325,1067$

orlital (of Mueller), 1071

orimin of 314

of ossicles of ear, 1091

palmaris Jrevis, 404

longus, 396,398

papillary, $515,516,517$

pretineus, 453, 471,472

pectoral group, 3ti2, 370, 372 abmormal, 374

pectoralis major, $370,372,1+11$

minmulls, :37t

minor, 370, 373, 1411

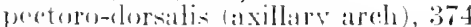

periorhital. 33is

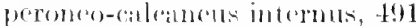

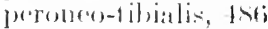

wermells hrovis, 152,483

ligiti gllinti, 1>.t

longus, $15 \%, 483$

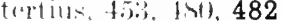

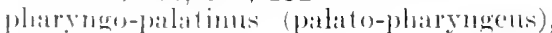
$1] 31 ;$

of pharrox, $11 ; 34$

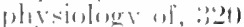

piliformis, 1.7. 461

planfuris, 15), IS1, 485

plitystrit, $3: 30$

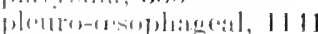

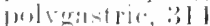

pwiturn, 1.7, 486

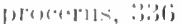

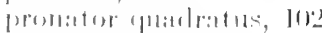

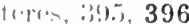

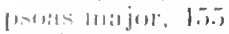
Inim, r, 1.5., 456

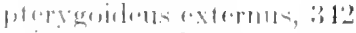

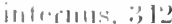

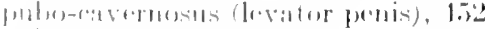

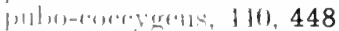

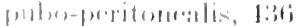

|mlw-rectalis, 110, 448
Muscle(s), pubo-transversalis, 436

pyramidalis, 424,431

auriculae (Jungi), $108 t$

nasi, 336

quadrate, 332

quadratus femoris, $453,463,464$

labii inferioris. 3:32

superioris, 332

lumborum, 425, 436

planta (flexor accessorius), 454, 495

quadriceps fenoris, 453, 468, 470

radio-carpeus, 103

reeti, of eve, 1068

recto-coecrgeus, 449,1177

recto-uterine, 125:2

recto-resical, 1252

reotus abdominis, 42', 424, 430

acessorius, 471

capitis anterior (minor), 356 major, 355

lateralis, 356

posterior mijor, 417,419

minor, 412,419

femoris, $468,470,1436$

relation to the skim. 313

retrahens aurem, 337

rhomboideus ma jor, 356, 358

minor, 356,358

risorius, 333

rotatores, 412,419

sacro-coccygeus anterior, 448

posterior, 448

sacro-spinalis (erector spinie), 412, 414

sartorius, 453, 468, 1436

scalenus anterior, 353

medius, 354

minimus, 355

posterius, 35

seinsorius, 462

scapulo-clavicularis, $37-1$

semimembranosus, $453,475,476$

semispinalis capitis (complexus), 412, 417

cervicis, 419

dorsi, 419

semitendinosus, $453,475,476$

serratus anterior, 356,359

posterior inferior, 423,431 superior, 423, 431

of shoulder musculature, 362, 365

of soft paliate, $11: 34$

of sole of foot 4!:3

solens, $454,484,485$

areessorius, 4s.5, 491

sphineter ani, extermus, 411,449 internus, 1177

of hladeler, 1253

pupillar, 1061

urethrar (nomblanarea) , 449

urogenitalis, +12, 449

vaginte, 451,1278

spinalis (aipit is (hiventer cervicis), $41 \mathrm{~s}$

"ervices, +12, 417

lorsi, 412, 417

splenils capilis, 41 t

corviceis, 11 1) areressorits, $11+$

stamedins, 1091

sternilis, 37.1

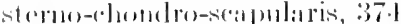

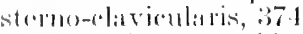

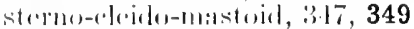

slomo-hyodelems, 3isl

stomo-1 livroicleus, 3is

stolo-glosisus, 3.16

stylo-lिyoideris, 343, 344

st volu-pharyngetss, 1137

subandeneus, 378 
Musele(s), subelavius, 370,373

subeostales, 423,434

suberureus, 470

subcutaneous, 313

suboceipital, $328,412,419$

subseapularis, 364,369

minur, 369

superior eonstrictor of pharynx, 1137

oblique, $106 \mathrm{~s}$

tarsal (Nueller's), 1068

supinator (brevis), 392

radii longus, $38 s$

supracostales, 432,433

supraspinatus, 364,368

synergists, 322

tail of, 314

tarsal, 1072, 107s

temporalis, 341

superficialis, 337

tensor capsularis articulationis metacarpophalangei digiti quinti, 406

faseiæ dorsalis pedis, 482 lats $457,459,1436$ suralis, 476

lamine posterioris vagine musculi reeti abdominis, 436

laminat posterioris vaginie museuli reeti et fascia transversalis abdominis, 436

ligamenti annularis anterior, 393 posterior, 393

tarsi (Horner's), 336

tympani, 1089,1091

veli palatini, 1137

tenuissimus, 475

teres major, 364,369

minor, 364,367

of thigh, 453,464

of the thumb, 406

thyreo-arytienoideus (externus), 1219

internus (m. roealis), 1220

obliquus, 1220

superior, 1220

thyreo-epiglottic, 1220

thrreo-hroideus, 3.51

tibialis anterior, $453,480,146 \mathrm{~s}$

posterior, $453,486,490,1468$

secundus (tensor of eapsule of anklejoint), 491

tibio-astragalus anticus, 452

of tongue, $345,346,1110$

trachelo-mastoid, $\$ 16$

tragicus, $108 t$

transversalis cervicis, 416

transverso-spinal, 412, 419

transversus abitominis, 424,435

auriculie, 10st

linguae, 1110

menti, $33: 3$

nuchie, 337

perinei profundus, $412,449,127 \mathrm{~s}$ superficialis, 444,452 , I 278

thoracis (triangulitis sterni), 424, 434

ragina (Führer), 449

trapezius, $34 \overline{7}, 349,140$.

triangularis, (clepressor anguli oris), 333 sterni, 424,434

triceps brachii, $374,377,378,1+16$ surie, 484

uharis ligiti quinti, 392

ulno-carpeus, 402

unei-pisiformis, t03

unipenniform, 315

uvula, 1137

variation in, 320

vastus intermedius (crureus), 468, 470

lateralis (vastus externus), 468,470

medialis (rastus internus), 468,470
Muscle(s), ventrieular, of larrux, 1220

vertebro-oecipital, $\$ 17$

verticalis lingux, 1111

ressels of , 31 !

rocalis, 1220

zygomaticus, 333

minor, 332

Muscular process of arytanoid, 1211

veins (of orbit), 6.58

Musculature (see also "Muscles"), 313

of the arm, 362, 374, 377, 379

eranio-mandibular, 3.3s, 341

epicranial, 336

of expiration, 248

external genital, 450

facialis, $324,329,380, .701$

of forearm and hand, $362,35,3,34$

of foot, 454,492

functional groups, 500

of hand, 363,403

of head, neck, and shoulder girdle. 323

of heart, 5Is

of the hip, 453,454

of inspiration, 247

of leg, $453,477,480$

of lower limb, 45:

of mastication and swallowing, 325

of neck, 327

of pelvic outlet, 439,448

preverteloril, 32s, 355

of respiration, 503

of shoulder girlle, $32 \bar{\tau}, 34 \bar{\gamma}, 363$

spinal, 410,412

of thigh, 453,468

thoracie-abctominal, 422,430

of the upper limb, 360

Museuli papillares, 515, 516, 517

pectinati (heart), 513

Musculo-eutaneous nerve, 987, 1014, 1459 results of paralysis, 1424

Museulo-phrenic artery, 567

Museulo-spiral groove, 149

(radial) nerve, 985

results of paralysis of, 1421

Musculus ciliaris Riolani, 1077

interfoveolaris, 435

uvulie, 1137

vocalis, 1220

Iyelencephalon, 799

Mylu-hyoid branch of inferior alveolar (dental) artery, is 48 nerve, 943

groove, 96

line, 95

Nylo-hroideus, 343,344

Mrocarlium, 50\$, 518

Myometrimm, 1274

Nail-bed, 1295

Naits (ungues), 1293

Nail-wall, 1294

Nares, 1200

posterior (choanie), 107, 112, 1206

Nasal aperture, anterior, 108

bones at birth, 124

(leseription of, 86

branches of anterior ethmoidal artery, 55 nerve, 937

of inf ri-orbital arterv, 549

of maxillary nerve, 939

of posterior ethmoidal artery, 5.53

of spheno-palatine antery, 549

(Meckel's) ganglion, 962

cartilages, 1201

eavity, 1203 
Nasal conchæ (turbinate bones), 83, 84, 1205 crest, 90

fossie, 108, 110

glands, $120 \mathrm{~s}$

meatuses, 1205

muscles, $324,334,501$

noteh, 60,87

pharynx, 1130

septum, cartilaginous, 1204, 1354

membranous, 1204

osseous, 111,1354

sinuses, accessory, 1354

spine, anterior, $60,87,90,112$ posterior, 91

vein, external, 644

Nasalis, muscle, 334

pars transversa (compressor naris), 334

pars alaris (depressor ala nasi), 334

Nasion, 109, 1331

Naso-ciliary (nasil) nerve, 936

Naso-frontal vein, 658

Naso-lacrimal duet, 111, 1080, 1205, 1349

Naso-palatine nerve (of Cotunnius), 962

Naso-pharyngeal adenoids, 1130, 1354 meatus, 1206

Navicular (seaphoid) bone, 159, 160, 191, 196

Neck af axis, 33

eutaneous areas of, 1019

deep, lymplatic nodes of, 714 vessels of, 711

fasciæe of, 347, 1360

of gall-bladeler, 1187

landmarks, 1854

ligament, 243

lymphaties of, 709

musculature of , 323, 327

of penis, 1260

superficial lymph-nodes of, 709

surgical anitony of, 1354

of teeth, 1117:

triangles of, 1357

Nélaton's line, 1436

Nephrotome, 16

Nerve(s), 769

in aldominal wall, 1372

accessory (spinal), 958, 1360

abducens, 934, 1075

accessory oliturator, 1005

acoustic" (auditory), 949,1096

to adductor magnus, 1009

ano-coecreat, 1018

anterior crural, 100

cutaneus of alidomen, 995

of thigh, 1003

ethmoirlal, 936, 937

interosseus, 99:

latial, 1000

palation, $96 \%$

scrotal, I00()

superior alveolar (dental), 938

tilial, 1015

of Armols 950

to artimlaris gemu (sul) rerureus), 1003

of aluricle of air, It)

antriculo-10mpral, 911

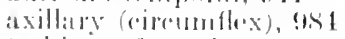

to bieros fomoris, 1009

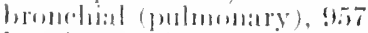

burecinator (loug fuceal), 9:39

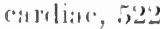

ravermolls, of ponis, 1017

of clitoris, ] 13.17

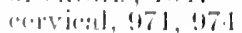

(19vion-lincial, 9)

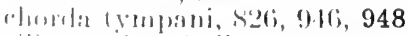

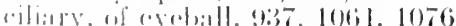

rimlinflex, b)
Nerve(s), coccygeal, 973

cochlear or auditory, 950

nucleus of, 624

common peroneal (external popliteal), 1013 plantar digital, 1011

communicans cerviealis, 974

filutaris, 1013

of conjunetiva, 1348

of Cotunnius, 962

cranial, 927

nuclei in.medulla oblongata, 818

of eranial dura mater, 917

cranio-spinal, 926

cutaneous, of face, 1345

of foot, 1466

of forearm, 1423

of lower extremity, distribution of, 1024, 1469

of thigh, 1025

perforating, 1007

deep peroneal (anterior tibial), 1015, 1466

radial (posterior interosseous), 9S5, 986 temporal, 943

descendens cervicalis, 953, 974

dorsal antibrachial interosseus, 986

digital, of foot, 1013

of hand, 986,990

of ductus deferens, 1259

of penis (or elitoris), $101 \mathrm{~s}$

seapular (nerve to rhomboids), 982

thoracic, 981

of external acoustic (auditory) meatus, 1086 carotid, 1036

popliteal, 1013

to extemal pterygoid muscle, 943

external respiratory, of Bell, 982

superficial petrosal, 1036

of eyeball, 1064

of eyelids, 1078

facial, 943,1345

nucleus of, 825

of female external genitalia, 1278

femoral (anterior crural), 1001

fibres, development of, 758

fif th cervical, 971

cranial (trigeminus), 934

first cervical, 971, 974

thoracic, 994

to flexor carpi radialis, 992

ulnaris, 990

digitormm longus, 1010

profundus, 990

sublimis, 992

hallueis longus, 1010

folamina of skull, 125

fourth cervical, 971,975

front:11, 935, 1075

furcal, gos

geniculo-tympanic, 948

f1) genio-uhossus, 954

to genio-hyoid, 954, 976

gonito-femioral (genito-crural), 1000

glosise-palatine, 946 mucleus of, 825

glosiso-pharyngeal, 951

nucleus of, 820

urreat auricular, 978

(anterine) palatine, 963

splanchunice, 10:38

superficial petrosial, $91 \mathrm{~s}$

sreator orecipital, 971

ol heart, 522

to hyo-ricisis, 95.1

liypoulosil, 952, 1111

nurlens of, 820

ilio-hypogast ric, ags

ilio-inguinal, 1000 
Nerve(s), inferior alveolar (dental), 941 cardiac, 957, 1037

clunial (gluteal), 1007

hæmorrhoidal, 1017

(or recurrent) laryngeal, 957

medial clunial (perforating cutaneous), 1007

vesical, 1017, 1047

infra-orbital, 937, 939, 1345

infratrochlear, 936, 937

intercosto-Jrachial (intercosto-humeral), 995

intermediate dorsal cutaneous, of leg, 1015 intermedius, 825

internal carotid, 960, 1033

pterygoid muscle, 939,943

interosseous erural, 1010

ischiadicus, $100 \mathrm{~S}$

of Jacobson, 951, 961

jugular, 960,1035

of kidney, 1247

lacrimal, 936, 1075

of large intestine, 1178

of larynx, 1225

last thoracic, 995

lateral anterior thoracic, 983

antibrachial cutaneous, 987

cutaneous, 1000

of abdomen, 995

brachial, 985

dorsal, 1013

sural, 1013

plantar, 1012

least splanchnic, 1039

lesser internal cutaneous, $9 S 3$ splanchnic, 1039

to levator scapula, 979

lingual, 940, 1111, 1350

of lips and cheeks, $110-1$

of liver, 1186

long eiliary, 937

(middle) subscapular, 984

thoracic, 982

to longus capitis, 979 colli, 979

of lower extremity, paralysis of, 1469

lower subscapular, 9St

lumbar, 973, 995

of lumbar plexus, composition of, 998

of lungs, 1235

of lymphatic vessels, 702

of mammary gland, 1305

mandibular (third division of trigeminus), 939,1345

masseteric, 943

masticator, 942

nucleus of, 829

maxillary, 937, 1076, 1345

medial anterior thoracic, 983

antibrachial (internal) cutaneous nerve, $9 \mathrm{St}$

brachial cutaneous, 983

calcaneal (calcaneo-plantar cutaneous), 1010

dorsal cutaneous, of leg, 1015

plantar, 1010

sural cutaneous, 1010

median, 991, 1415

mental, 941

middle cardiac, 1036

clunial, 973

hæmorrhoidal, 1017 a

(recurrent) meningel, 937

(external) palatine, 948,963

(long) subscapular, 9S4

superior alveolar (dental), 938

of muscles, 318
Nerve(s), musculo-cutancous, 987, 1459

results of piralysis, 1424

musculo-spiritl, 955

to myln-hyoiel, 943

naso-ciliary (nasal), 936, 1076

naso-palatine, 962

of nose, 1203, 1208

obturator, 1003, 1440

accessory, 1005

to obturator internus, 1007

oculomotor, $835,838,931,1075$

nucleus of, $\$ 37$

of oesophagus, 958, 11t1

olfactory, $86.5,929$

to omo-hyoid, 953,976

ophthalmic, 1075

optic, $848,930,1052,1073$

of orbit, 1075

of ovary, 1269

of palate, 1105

to palmaris longus, 992

of pancreas, 1195

of parotid gland, 1115

to pectineus, 1002

of penis, 1262

perieardiac, 957

perineal, 1017

peromeal, 1469

phrenic, 979

relations, 1360

to piriformis, 1007

of pleura, 1239

pheumogastric (vagus), 954

to popliteus, 1010

posterior auricular, 944

belly of digastric, 944

brachial cutaneous, 985

etlmoidal, 937

femoral cutaneous (small sciatic), 1007

inferior masal, 963

interossels, 986

(small) palatine, 963

scrotal (labial) nerves, 1017

superior alveolar (dental), $93 \mathrm{~S}$

thoracic, $9 \mathrm{~s}^{2}$

to promator teres, 992

proper plantar digital, 1011

volar digital, 992

of prostate, 1265

pudic (pudendal), 1017

to quadratus femoris, 1007

radial (musculo-spiral), 985, $141 \tilde{0}$

to rectus capitis anterior (minor), 979 literalis, 979

femoris, 1003

recurrent articular, of leg, 1013

(inferior karyngeal), 957

to rhomboids, 952

roots, 769

rudimentary cocergeal, 964

sacral, 973,1006

of sarral plexus, composition of, 1006

saphenous, 1003,1467

to sartorius, 1002

to scalene muscles, $97 \mathrm{~s}$

sciatic (n. ischiadicus), 1008, 14t3, 1469

of scrotum, 1255

to semimembranosus, 1009

to semitendinosus, 1009

seventh eranial (facial), 943, 1345

short subseapular, 984

of skin, $12 s 9$

of small intestine, 1168

occipital, $97 \bar{i}$

palatine, 948

seiatic, 1007

superficial petrosal, 951 
Nerve(s), smallest occipital, 971

to soleus, 1010

spheno-palatine, 938

spinal. 964

accessory, 958

mucleus of, 820

origin of, 1406

spinous (reeurrent), 939

of spleen, 1312

to stapedius musele, 944

to stemo-mastuid, 978

to sterno-thrreoid, 953

of stomach, 1156

to st vlu-glossus, 95

to stylo-hroid, 944

to subelavius, $98: 3$

sublingual, 941

gland, 1116

of submaxillary gland, 1117

subueeipital, 971

subscapular, 984

superfieial cervieal cutaneous, $97 \mathrm{~s}$

peroneal (musculu-cutaneous), 1014 1459,1460

radial (radial), 9s6

superior alveolar, 935

cardiac,, 957

cervical eardiac, 1036

clunial, 973

gluteal, 1007

hamorrhoidal, 1045

larynge: 956

vesical, 1047

supra-ieromial, 978

supraclavicular, 978

supra-orbital, 935, 1345

of suprarenal glands, 1326

sllprasoapular. 982

supratrochlear, 930

sural (external or short saphenous), 1013, 1467

of treeth, 1124

trmumorofacial, of 45

tonth amial (varus or pnemogastric), 9.4

terminalis, 920

thoraric, 971,994

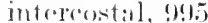

thoraco-ablominal, 995

thoraco-dolsal (middle or long) subseapuli1r, !si

of (livmus, 13):

to 1 livero-hyoid, 9.8, 976

of thiromil waml, lisis

tithal, 1009, 1.169

(o)mmunicat1ing, 1010

(1) formente, II ] ]

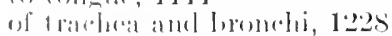

(1) 1 ripumins, ! 179

trigomints, $!: 31$

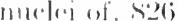

trowhlo:19, sis, si:3, 933, 1075 mul.

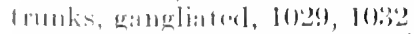

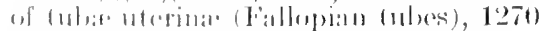

trmpanir.

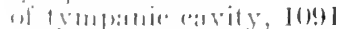

ulust 987,1 His

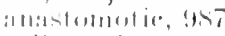

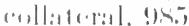

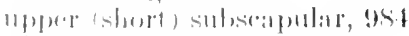

(1) 110010\%, 1201!

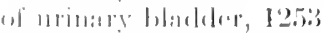

की

1) valuin:1, 1017, 1276

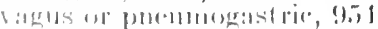

$1111 \cdot 1+11,0,5,820$
Nerve(s), to vastus internedius (cruceus), 1003

lateralis, $\mathbf{1 0 0 3}$

medialis, 1003

vestibular, 949

nuclei, 523

Vidian, 962

volar digital, of hand, $99^{\circ}$

(anterior) interosseous, 992

of Wrisberg, 946, 983

zygomatie, 938,1076

zygomatico-facial (malar), 938

zygomatico-temporal, 938

Nerve-foramina of the skull, 125

Nerve-supply of muscles (see "Nerves;" also corresponding muscles, articulations, etc.)

Nerve-trunks, gangliated, 1029, 1032 mixed, 96.

spinal, primary divisions of, $944,967,970$

Nervous system, 751

central, 751,770

construction of, 762

development of, 754

general summary of some of principal paths of the nervous system, $\$ 95$ peripheral, 754,924 sympathetie, 1026

Nervis intermedius, 825

Neural branches of spinal arteries, 590

crest, 754

folds, 754

groove, $10,11,754$

plate, 11,754

tube, 14,754

Neuraxis, 762

Neurenteric eanal, 11

Neurilemma, 761

Neuroblasts, 75.5

Neuro-central suture, 45

Neuro-fibrillae, 76.5

Neuroglia, 759,767

Neluroglia, 759,767

Neuro-museular spindle, 764

Neurone, 755,762

chains, 768

strueture of, 76.5

systems of spinal cord, 777

Neurones of cerebral path for cranial nerves, 89.5

of érehro-spinal path, 895

Nipple of minmmary glind, 1300, 1304

Nissl bodies, 7tit;

Nodo(s), atrio-ventricular, 519

h:molnolymph, $70 \mathrm{~s}$

Irmphiatic) (sec "Lymphatic nodes")

Nodulus Arantii, 517

of corobollum, ses

Nomenctature, anatomical, 1 of musclos, 319

Nom-medullated filmos, 767

Norma losisilaris, skinll, 10:3

facialis of skull, los

literalis, skull, 10!

ocoipitalis, skull, l01

verticalis, skull, 100)

Nose, li2t)o

cartiliages of, ito

clinical anatholy of, 1352

drevelopment of , l'zos

lymphatics ol, 7 lng $^{2}$

monituses of 1205

monseles of , 33.1

nostril (nareser), 1200)

olfatory area (region), 1050)

simuses annorting with, l206;

versels and norver, 1203, 1208

Notel, 2!)

acretahlutr, 17.t 
Notch, carliac, of left lung, 1229

of cerebellum, 805

ethmoidal, 61

frontat, 6()

great seapular, 137

sciatic, $17: 2$

intertragic, 10s?

jugular (interclavieular), 133

mandibular (simmoid), 96, 97

mastoid, 72

nasal, 60,87

pancreatic. 1194

posterior cerebellar, 915

preoecipital, 861

pterygoid, 66

radial (lesser sigmoid eavity) of ulna, 157

of Rivinus, 77

seapular, 142

semilunar (greater sigmoid cavity) of ulna, 1.56

small sciatic, 172

spheno-palatine, 91,93

of spleen, 1311

supra-orbital, 60

temporal, $\mathrm{s} 6 \mathrm{~s}$

tentorial, 915

thvreoid, 1210,1211

of tibia, popliteal, 185

tympanie, 77

ulnar (sigmoid cavity) of radius, 154

Notochord, 11

Notochordal region of skull, 117

Nuchal line, highest, 52

inferior, 52

superior, 52

Nuck, canal of, 1398

Nucleus(i), abducens nerve, $\$ 26$

accessory olivary, 817

of the ala cinerea, 820

ambiguus, 822

amygdalæ, 881

amygdaloid, of lateral ventricle, s7t

arcuatus, 818

Bechterew's, 823

caudate, 877,879

of cerebellum, 809

of cochlear nerve, 824

of cranial nerves in medulla oblongata, sis

Deiters's, 823

dentate, of eerebellum, $\$ 10$

dorsal efferent, of cochlear nerve, 824 of vagus, 822

dorsalis (Clarke's column), 776

of Edinger and Westphal, s38

emboliformis of cerebellum, $\$ 10$

of facial nerve, 82.5

fastigii (roof nucleus) of cerebellum, 810

funiculi eumeati (of Burdach's column) 801,815

gracilis (of Croll's column), s01, 815

globosus of cerebellum, 810

of glosso-palatine nerve, 825

of glossu-pharvngeus, 820

habenular, 872.855

of hypoglossal nerve, 820

hrpothalmic, sst

incertus of flowr of fourth ventricle, 815

of inferior colliculus, 839

inferior olivary, of medulla oblongata, $\$ 17$

intercalatus, sit

interpeduncular (Von Gudden), 843, s72, 885

of lateral lemniseus, 824,839

of thalamus, $8+j$

of lens of eve, 1062

lentieular, $\$ 78,879$

lentiformis, 8.57
Nucleus of masticator nerve \$29

of medial fongiturlinal fasciculus, 843,871 medial thatamic, stis

of mesencephalic root of trigeminus nerve, 829

of oculomotor (or third) nerve, 837

pontis, $8: 31$

pulpy, 226

red, 840

respiratory, 822

salivaturius, 826,947

of seapula, 139

Schwathe's, 823

of solitary triet, 820

of spinal acressory nerve, 820

traet, soti

spinalis, $82: 3$

Stilling: $: 776$

of superior collieulus, $\$ 42$

superior olivary, 824

of termination, 770

of thatamus, 871,882

trapezoidei, 824

of trigeminus nerve, 826

of trochlear (or fourth) nerve, 837

of vagus or pneumogastric, 820

vasomotor, $\$ 22$

ventral cochlear, 824

vestibularis, 823

Number of muscles, 315

Nutrient arteries of femur, 621 of fibuli, 626

of humerus, 576

of radius and ulna, 579

tibial, 626,1459

branch of obtulator artery, 608

of posterior circumflex humeral artery, 573

of transverse scapular artery, 56.5

Nympha (Iabia minora), 1277, 1392

\section{$\mathrm{O}$}

Obelion, 101

Obex, s02, 813

Oblique diameter of pelvic inlet, 175

fascieulus, 804

head of adduetor hallueis, 498 of adductor pollicis, tos

ligament (mid-radiondnar union), 262

line of clavicle, 140

of fibula, 190

of mandible, 9.5

of radius, 154

posterior, 154

of seapuli, 142

of thrreoid cartilage, 1211

of ulina, 157

muscle of eve, inferior, $106 \mathrm{~s}$ superior, $106 \mathrm{~s}$

popliteal ligament (limanentum Minslowii), 287

sinus of perieardium, 52:

vein of left atrium (of Marshall), 521,523 , 691

Obliques ahdominis externus, 423, 432 intermus, 42:3, 434

eapitis inferior, 412,420

superior, 412,420

Oblome furea of artaxnoid, 1212

Obturator artery, 608, 639

rrest, 173

externus, 453, 463, 464

faseia, 439,463

(thyreoid) foramen, 174

groove, 172

internus, 453, 463 
Obturator nerve, 1003, 1440 accessory, 1005 vein, 680

Occipital artery, 542, 638, 1343

bone, 51

articulations of, 56

at birth, 121

ossification of, 56

branches of occipital artery, 543

of posterior auricular artery, 545 nerve, 944

of small occipital nerve, 977

condyle, third, 56

condyles, 108

crest, external, 52

internal, 53, 117

groove, 72

gyri, 863

lobe, 863

lymph-nodes, 709

nerve, greater, 971

small, 977

smallest, 97

point, 101, 112

pole, s50)

pontile fibres, 840

portion of vertebral artery, 560

protuberance, external, 52, 101 internal, 53

sinus, 6.50

sulci, 862,863

suture, 101

vein, 647

diploic, 648

Oceipitalis, 337

minor, 337

Oceipito-atlantal articulation, 218

ligaments, 219

Orcipito-cervical ligament, 223

Occipito-epistrophic articulation, 223

Oceipito-frontal fasciculus, 892

Oecejpito-frontalis, 336

Oceipito-mastoid suture, 101

Oceipito-mesencephalic path (Flechsig's secondiary optic radiation), 890

Occipito-pontile path, s.3.

Oceipito-scapulatis, 359

Oecipitu-tenuporal association area, 891 convolution, s64

Oceipito-thalamic (optic) rarliation, sss

Occiput and atlas, ligaments uniting, 218

()enlar (omjunctiva, 1054

muscles, $32:-7,1067$

Oculomotor norves, 535, 838, 931

numlens of s.37

suleus, sis

Orlontoirl proress (dens) of axis, 33

(bsophageal arteries, jos

hranches of inferior thyreoid artery, 564

of Ireft gistric altery, 594

of viluts 958

ploxusus, 9.5 1,955

voins, bitil, tifit

(distephliguts, $11: 3$

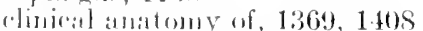

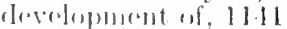

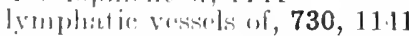

variations and complatrative, 11.11

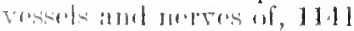

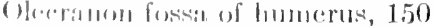

processs of ulnit, 156 ;

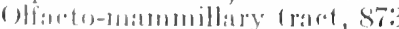

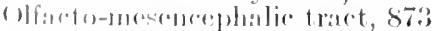

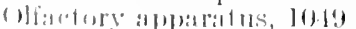

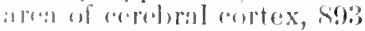

(rogion) of nasal mucous mombrane, 1019, $1: 3)^{2}$
Olfactory brain, 864

bulb, 758, 865, 1050

cells, 1050

conduction path, 902

glands, 1208

groove, 1206

gyrus, lateral, 865

medial, 866

layer of olfactory bulb, $\$ 66$

lobe, 865

nerve, 865,929

central connections, 929

organ, 1049, 120 S

region of nasal cavity, 1208

striæ (gyri), 865,860

sulcus, 858

tract, $758,865,893$

development of, 758

trigone (tubercle), $\$ 65$

ventricle, 866

Olivary, nuclei, accessory, 817

inferior, 817

superior, 824

Olives of medulla oblongata, 800

Omental branches of epiploic arteries, 595

bursa (lesser sac), 1146, 1372

Omentum, great, 1149

lesser (gastro-hepatic), 1150, 1185

Omo-hyoideus, 351

Omphalo-mesenteric artery, 638

Opereula of insula, 856

Operculum proper, 854,856

temporal, 854,856

Ophryon, 109, 112

Ophthalmic artery, 552, 638, 1074 branches, $55^{\circ}$

division of trigeminus (fifth nerve), 935, 1075 veins, $65 \mathrm{~S}, 659,1075$

Ophthalmo-meningeal vein, 655

Opisthion, 107, 108

Opponens digiti quinti (foot), 454, 498, 499 (hand ), 404, 405

hallucis, 498

pollicis, 407,408

Optic-acoustic reflex path, 840,842

Optic apparatus, conduction paths of, 900

chiasma, $847,848,849$

cup, $10 \mathrm{~s} 0$

lise, 1055

foramen, 63, 64, 110, 116, 125

groove, 63,116

nerve, S.ts, 930, 1052, 1073

sheaths of, 981,1073

papilla of , 1055

portion of hypothalamus, 847 radiation, sis

Floehsig's secondary, 890

reeess, 848

tracts, 849

vesiele, 758,1080

()ri serrata, 1057

()ral arvily, 1100 develomment of 1102

fissure, (rima oris), 1100

[owsi, 110$)^{\circ}$

museles, :3:il

orilice, muscles of, 501

pharymx, 1130

vestilinle, 1100

()biculat tulerele of incus, 79

() bienlaris ciliaris, 1060

oruli, 336, 1097

oris, : $: 31$

() hit, 10s, 109, 1332, 1346

fasciae of 1071

lymphatic system of 1076

inuscles of, :325, 1067 
Orbital branch of middle meningeal artery, 548 branches of maxillary nerve, 938

of spheno-palatine (Meckel's) ganglion, 963

fissure, inferior, 109,126

superior, 65, 109, 116, 125 gyri, 858

nuscle of Müller, 1071

periosteum, 1071

plates, 61

process of malar bone, 94

of palate bone, 91,93

sulci, 858

wings of sphenoid, 64

Orbito-sphenoid centre, 67, 119

Organ (s), 4

of Giraldès, $125 \bar{\imath}$

of Jacobson, 951, 961, 1051, 1204

lymphoid, 704

olfactory, 1049, $120 \mathrm{~S}$

reproductive, male, 1253

female, 1265

of special sense, 1049

spiral (organ of Corti), 1096

of taste, 1051

urinary, 1241

Orifice, atrio-ventricular, of heart, 513, 514

external urethral, 1264

of stomach, 1151, $137 t$

(os) of uterus, 1271

Origin of muscles, $31 t$ (see also individual muscles)

of spinal nerves, 964

Os ealcis (calcaneus), 191, 195

centrale, $164,20 \mathrm{~S}$

innominatum, 169

Japonicum, 95

linguæ, 99

planum, $\$ 3$

trigonum, 194, 199

uteri, 1271

Vesalianum, 199

Osseous labyrinth, so

part of tuba auditiva (Eustachian tube), 1092

portion of external acoustic (auditory) meatus, 1085

Ossicles of ear, 79, 1090

articulations, 1090

ligaments, 1090 muscles, 1091

Ossification of bones, 27 (see also the individual bones")

Osteogenesis, 27

Osteology, 27

Ostium abdominale of tuba uterinæe (Fallopian tubes), 1270

venosum (atrio-ventricular orifice) , 513, 514

Otic (Arnold's) ganglion, 963

Otoconia (otoliths), 1095

Outlet (inferior aperture) of pelvis, 176

Ovarian arteries, 602

branches, 602

branches of uterine artery, 610

ligaments, 1269

plexuses of nerves, 1045

veins, 674

Ovaries, 1268

clinical anatomy of, 1393

lymphatics of , 701, 745, 1269

vessels and nerves of 1269

Ovula Nabothi, 127t

Ovum, segmentation of, 9

\section{$\mathrm{P}$}

Pacchionian bodies (arachnoid granulations) 649, 919

Pacchionius, foramen ovale of, 116
Pacinian corpuscles, 1290

Palate, 1104

bone, 91

at birth, 121

development of, 1106

hard, 1104

lymphatics of, 717

muscles acting on, 502

soft, 326,1104

surgical anatomy of, 1352

Palatine arches, 1132

branch of ascending pharyngeal artery, 537

artery, ascending, 541 descending, $5+9$

major, $5+9$

canals, $92,103,126$

accessory, 103

foramina, 106

nerve, great (anterior), 963

middle (externaI), 948, 963

posterior (small), 948, 963

process of maxilla, $\$ 7,88$

tonsil, 1132

variations and comparative, 1106

vein, 644

superior, 646

Palato-ethmoidal cells, $\mathrm{St}$

Palm, muscles acting on, 504

Palmar aponeurosis, 387, 1430

arch, (see "Volar arch")

cutaneous branch of median nerve, 992 of ulnar nerve, 990

fascia, deep, 357

Palmaris brevis, $40 t$

longus, 398

Palpebra, inferior, 1053

superior, 1053

Palpebral aperture, 1052

arteries, lateral, 552

branches of infratrochlear nerve, $93 \pi$ of maxillary nerve, inferior, 939

of ophthalnic artery, palpebral, 552

of supra-orbital arterv, 553

conjunctiva, 1054, 1078

fascia, 1071

folds, 1053

ligament, medial, 1052, 1078

raphe, lateral, 1078

veins, $644,65 \mathrm{~s}$

Pampiniform plexus, 674, 1259

Pancreas, 1192

blood-supply of, 1195

development of, 1195

lymphatics of, $699,736,1195$

topographic, 1375

variations and comparative, 1197

Pancreatic branches of splenic artery, 595

duct (canal of Wirsung), 1194, 1375 accessory (of Santorini), 1195

Pancreatico-duodenal artery, inferior, 596 superior, 595

vein, 675,677

Panniculus adiposus, 313,1287

carnosus, 313

Papilla, duodenal, 1164, 1195

hair, 1292

incisive, 1104

of kidney, 1246

lacrimal, 1054

(nipple) of niammary glands, 1300, 1304

optic, 1055

Papilla of skin, 1286

of tongue, 1106

Papillary ducts (of Bellini), 1246

muscles of heart, $515,516,517$

process of liver, 1184

Paracentral lobule, $857,858,863$ 
Paradidymis (organ of Giraldès), 1257

Paraduodenal fossit, 1164

Paraganglia, 132:3 aortic (lumbalia), 1329

Paralyis of deep raclial (posterior interosscous) nerve, results of, 1424

of facial nerve, 1345

of merlian nerve, results of, 1424

of musculo-cutancous nerve, 1424

of nerves of lower extremity, 1469

of radial (musculo-spiral) nerve, 1424

of ulnar nerve, results of, 1424

Patramedial suleus, 85s

Paranetrim, 1274

Paranasal sinuses, 1206

Parapophysis, 51

Pararenal adlpose hoely, 1243

Parasinoidal sinuses, 91!

Para-thrreoid glands, 1318

Paraurethral duets, 127

Parietal association area, 894

bones, 58

at birth, 123

branches of ablominal aorta, 592

of hypogastric artery, 606

(posterior temporal) of superficial temporal artery, 545

of thoracic aorta, $58 \mathrm{~s}$

cminence, 57

enissary vein, 649

filscia of pelvis, 447

foramen, 57

lobe 800

lobule, inferior, 863 (gyrus) superior, 862

lymphatic nodes of thorax, 724

perduncle of thalamus, 853 pleura, 1237

Parieto-mastoid suture, 101

l'atrieto-occipital arch, 863 fissure, s60), s6t

Parolfactory area (Brocia's area), \$58, 865 sulai, s65), s6ti

Paroijphoron, 1269)

Parotid branches of auriculo-temporal nerve, $9.1, \ldots i 1$

of superficial temporal artery, 545

fasis?ia, 33!), 348,1111

gramil, 3.ts, 1113

aceossory, 1114

huret (stensoms's) 1115, 1343

lympli-morles, 709

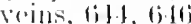

vespels and merves, 1115

ploxus (pes ansorinus), 01.5

region, 1:3:13

Pats alaris (nepresion alar nasi), $33 \mathrm{t}$

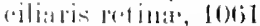

fixal of peris, 1260,1261

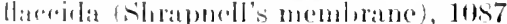

glal, ria of lipes, 1 10]

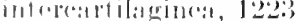

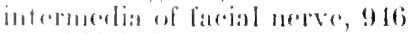

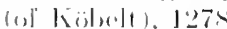

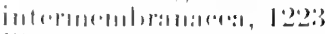

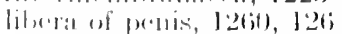

tolsit, 105

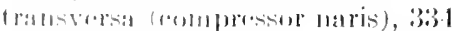

villos: of lips, l lol

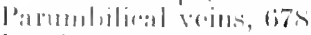

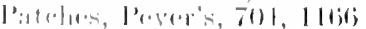

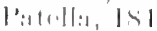

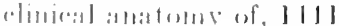

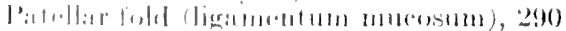

]iz:1!11+3)1, 17

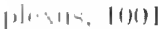

$1+1,1,2,2$
Paths, auditory conduction, 900

cerebral, for cranial nerves, 895

cerebro-spinal, 89.5

conduction, involving cerebellum, 899

of olfactory apparatus, 902

of optic apparatus, 900

summary of, 895

frontal pontile (Arnold's bundle), 832,889

occipito-mesencephalic, $\$ 90$

occipito-pontile, 832

optic, 900

optic-acoustic reflex, 840

short reflex, of cranial nerves, 898

spino-cerehral, 895

of spinal cord, short reflex, 895

temporal pontile (Türk's bundle), 832,840 , 890

vestibular, 899

Pecten of pulsis, 173

Peetineofemoral band, 278

Pectineus, 45:3, 471,472

Pectoral (descending) branch of anterior circumflex humeral artery, 573

branch of thoraco-acromial artery, 571

group, of muscles, 362,370 of axillary lymphatic nodes, 720

Pectoralis major, 372 surface markings, 1411 minor, 373

surface markings, 1410

minimus, 374

Pectoro-lorsalis (axillary arch), 374

Perlicles of axis, 34

of lumbar vertebræ, 37 of vertelorie, 30

Pecluncles of cerchellum, \$10, 831 of cerchrum, 833,835

of corpus callosum, 866 of floceulus, 807

of superior olive, 825

of thalamus, 880,883

Peduncular tract, transverse, 83.

Pedunculi conarii, 846

Pelvic articulations, 234 ligaments of, 234 diaphragm, 440, 448, 1383

fascie, $4+6$ clinical anatomy of, 1385

floor in female, 1394 in male, 138:

girille, 207

index, 177

inlet, diameters of, 175

measurements, $17 \%$

outlet, 170

muscles of 439

colon, 1174, 137!

ploxulises of nerves, 1046

portion al neoter, I24s

splatuchuias, 1017, 10.40, 1046

Pelvis, articulations of, 231

axis of, 176;

drescription of 175,1352

dilforoness alcorording to sex, 177

inlet (stuperior apelature) of, 175

lymphafios of 730,733

iina jor (lalse), 175

measmormonts, 177

minol (trie), 175

museles areting on, 505

motlet (inforior aporature), 176

monal, lis.s

of ureter, 1217

visceral lymphatie vessels of, $7: 33$

l'onis, 12010

arlory of , til:3

averuons plexus of, 10.17 
Penis, deep artery of, 614 dorsal artery of, 614 nerves of, 101s

lymphatics of , 744, 1262 surgical anatomy of. $138 \mathrm{~S}$ vessels and nerves of, 1262

Perforated sulsstance, anterior, $\$ 4 \overline{7}, \$ 66$ posterior, S35, s4t

Perforating branches of deep volar arch, 586

of lateral plantar artery, 62s

of the profunda, 620

of internal mammary artery, 567 maxillary artery, 529

of peroneal artery, 626 veins, 690

Pericxeal fossa, 1172, 1378

Pericardiae branches of aorta, 5ss of internal mammary artery, 567 of phrenic nerve, 979

Pericardial branches of vagus, 956 cavity, 522 development of, 527 lymph-eapillaries of, 702 pleura, 1237

Pericardio-phrenie artery, 567

Pericardium, 522

development, 20,525

surgieal anatomy, 1369 vessels of , 523

Perichondrium, 28

Pericranium, 1334

Perilymph, 1092

Perilymphatic space of membranous labrrint $\mathrm{b}$, 1095

Perimetrium, 1274

Perimysium internum (endomysium), 315 externum (epinysium,) 316

Perineal artery, 613, 639 faseia, superficial, 445 nerve, 1017

Perineum, 1383 central tendon of, 449

muscles acting on, 503

surgical anatomy of, 138.5

triangles of, 1383

Periorbita, 1071

Periorbital muscles, 335

Periosteal branches of supra-orhital artery, 5.53

Periosteum, 28

lymph-capillaries of, 701

Periotic capsule, 69, 117 cartilages, 117

Peripheral, nervous system, 754, 924

cranio-spinal system, 926

srmpathetic system, 926,1026

Peritoneal branches of superior epigastric artery, 567

eavity, lympluatic capillaries of, 702

Peritonem, 1141

clinieal and topographical anatomy of, 1372 development of, 1144,1151

of rectum, 117t

spaces of, 1372

sections, $11+6$

variations and comparative, 1151

vessels and nerves, 1151

Permanent teeth, times of eruption of, 1127

Peroneal artery, 626, 640, 1459

anterior (perforating), 626, 1459 posterior, 626

groove of cuboid, 199

muscles, accessory, 484

nerve, common (external popliteal), 1013 results of paralysis of, 1469

deep, (anterior tibial), 1015, 1466
Peroneal nerve, superficial (musculo-cutaneous) $1014,1459,1466$;

retinatulat, tso

vein, 6 ss

Peronei muscles, tenotomy of, 1461

accessolv, 4 st

Peronero-calcaneus internus of Macalister), 491

Permeo-tibialis, tist

Peroneus brevis, $4.5,3,483$

digit i quinti, tst

longus, 45:3, 483, $146 \mathrm{i}$

tertius, $453,4>0,482$

Perpenticular plate (nosethmoid) of ethmoid, $\therefore 2$

Pes anserinus, 945

hippocampi, st

pedunereli, st)

Petiole of epiglottic cartilage. 1212

Petit, canal ot, 1064t

triangle of, 434, 140t;

Petrosil branch of midclle meningeal artery, 545

ganglion, 951

nerve, external superficial, 1036

great superficial, 948

small superficial, 9.51

portion of internal arotid artery. 5.50

process, posterior, 63

sinuses, 652 :

Petro-mastoid, 119

Petro-sphenoidal foramen. 125

Petro-s(yuamous sinus, 6is: (squamo-mastoid) suture, 71

Petro-tympanic (Claserian), fissure 71,7 , 108,126

Petrous portion of temporal bone, 6 s, 72

Pever's patches, 70) 116 (it

Phalanges of fingers, 167 ossification of, 16s. 204

thirel, terminal, or ungual, 168, 204 of toes, 203

Pharyngeal aponeurosis, 1130 artery, ascending, 537, 635

branches of ascending pharygeal artery, 537

of inferior threoid arters, stit

of glosiso-pharyngeat nerves, 951

of spheno-palatine (Meckel's) ganglion, 963

of vagus, 956

bursa, 1130

(pteryo-palatine) canal, 66, 92. 10:3

fortinen, 126

bypophyseal remmants, 1352

sthmits (faucial), 1130, 1131

memhrane, 1102

ostium of tuba auditiva, 1092

plexts of nerves, 950,$1030 ;$

of veins, 659

recess, 1130

tonsil, 1130,1354

tuberele, 54, 108

veins, 659

Pharyngo-palatine arches, 1132

Pharyeng-palatinus (palato-pharyngeus), 1136

Pharynx, 1128

development, 1138

laryngeal, 1134

lrimphaties of, 717, 113s

muscles of , 325, 502, 1134

nasal, 1130

oral. 1130

variations and comparative, 1138

vessels and nerves, $113 \mathrm{~s}$

Philtrum, 1102, 12st

Phrenic arteries, inferior, 592, 638 
Phrenic arteries, superior, 590

branches of nusculo-phrenic artery, 567

of superior epigastric artery, 567

ganglion, $104 t$

nerve, 979

relations of, 1360

(diaphragmatic) plexuses of nerves, $104 t$

veins, inferior, 675 superior, 667

Phrenico-costal sinus, 1237

Phreno-colic liganent, $1150,1174,1310,1379$

Phrenicolienal (lienorenal) ligament, 1310

Physiology of muscles, 320,323

Pia mater, 771, 920

cranial, 922 spinal, 921

Pignent of iris, 1061

retinal, 1062

of skin, $12 s 6$

Pillars of the foot, 205, 1468

of fornix, anterior, 870 posterior, sis

Pineal body, 8.5

Pinna (see Auricle)

Piriformis, 453, 457, 461

Pirogolif's amputation, 1465

Pisiturm bone, 159,162

Pits, olfactory, 1050 rectal, 1390

Pituitary body, 848, 1342

Plane or arthrodial diarthroses, 212

Plantar aponeurosis, 492

areh, 627

arteries, lines of, 1467

artery, deep (communicating), 633

lateral, 627, 640

medial, 629

calcaneo-cuboid (short plantar) ligament, $307,1+68$

calcanco-navieular ligament, 1468

digital (collateral) arteries, 628

branches, proper, of medial plantar nerve, 1011

nerves, common, 1011, 1013 proper, 1011, 1013

reins, 654

fiscia, 492, 1468

ligaments, 307,1468

acecssory, 310

metatarsal arteries, $62 \mathrm{~S}$ veins, $6 \times 5$

nerve, lateral, 1009, 1012

merlial, 1009, 1010

vemonts itreh, $68 \mathrm{~s}$

$$
\text { loto, 6ist }
$$

Patulats, J51, 181, 485

l'anum poplitemm, 181

I'late, cribriform, of etlunoid, 81

from\{u-nis:sl, 117

nomal, 75

olfictory, 1050)

orl,ital, $(\mathrm{il}$

perpendicular, of ethmoid, 82

pleryguil, firi

trmpinte, bos

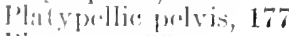

Jit (yomits

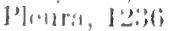

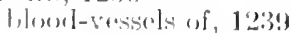

rlinical anotomy of , 130 (is

development of 20

Iymplatios of, 701, 12:3!

Intrues of 120,39

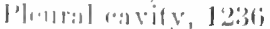

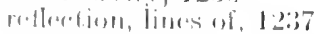

simlses, $12: 37$

vill, $12: 3$
Pleurapophysis, 51

Plexuses of nerves, abdominal aortic, 1045

anterior pulmonary, 957

atrial, $10+1$

of Auerbach, 757, 1030

brachial, 980

line of 1360

bulbar, 1041

cardiac, $10+1$

cavernous, 1033

of penis (or elitoris), 1047

of cephalic ganglia, 960

cervical, 974

coceygeal, 1018

coeliac, 1043

common carotid, 1036

coronary, 1041

deferential, 1047

external carotid, 1036

maxillary (facial), 1036

femoral, 1045

gangliated cephalic, 959

hepatic, 1045

hypogastric, 1045

iliac, 1045

inferior dental, 941

gastric, 1045

mesenteric, 1045

infra-orbital, 937, 939,945

internal earotid, 1033

mammary, 1037

11axillary 1036

intermediate, 1041

lingual, 1036

lumbar, $99 \mathrm{~s}$

lumbo-sacral, 996

of Meissner, 757,1030

meningeal, 1036

micldle haemorrhoidal, 1046

mycntericus (plexus of Auerbach), 1045

cesophageal, 954, 955

ovariall, 1045

parotid, 945

patellitr, 1001

pelvic, 1046

pharyngeal, 956, 1036

phrenic: (diaphragmatic), 1044

popliteal, 1045

posterior cervical, of Cruveilhier, 971

asophageal, 954

pulmonary, 954, 955,957

pulmonary, 1043

prevertebral, 755, 1029, 1032, 1040

prostatic, 10.47

puclentil, 1016

renal, 10it

sateral, 1006

suematie, 1045, 1260

splenic (liemal), 1045

submueosus (plexus of Meissner), 1045

sulsiartorial, 1003

sublrapezial, 979

superior dental, 939

gastric (coronary), 1015

hamorrloidal, 1045

mesenteric, 1045

thyreaid, 10330

thoricic atortic, 1038

suplar(mial, 10.14

1yu1)auic, 95) 1, 961, 1033, 1089

vitero-vaginal, 1047

vertebral, 10):37

vesicul, 10.17

of veins, anterior sicral, 679

lasilinl, 6i:1

chorioil, of fourth ventriele, 922

of lateral ventricle, 92.1 
Plexuses choroid of third ventricle, 924 chorioidea, 875, 877

hæmorrhoidal, 683

of internal carotid, 653

mammary, 671

pampiniform, 674, 1259

pharyngeal, 659

pterygoid, 682

thyreoideus impar, 660

utero-vaginal, 683

vertebral, 664

vesical, 683

Plica $(\mathfrak{x})$ ciliares, 1057

circulares, 1165

epigastrica, 430

fimbriata, 430

incudis, 1090

lacrimalis (Hasneri), 1080, 1205

longitudinalis duodeni, 1189

palatinæ transversæ, 1104, 1106

palmatiø, 1272

salpingo-pharyngea, 1130

salpingo-palatina, 1130

semilunaris, 1053,1170

triangularis, 1132, 1133

of tympanic menbrane, 1087

umbilicalis lateratis, 430

ureterica, 1252

Pneumogastric nerve, 954

Point(s), alveolar, 109

auricular, 101

central, of perineum, 1385

occipital, 101

pre-auricular, 1332

Rolandic, 1340

subnasal, 109

Poles, of cerebral hemispheres, 850

of eyeball, 1055

of lens of eye, 1062

Polygastric muscles, 314

Polymastia, 1301

Polythelia, 1301

Pons (Varoli), 804

basilar sulcus of, 804

blood-vessels of, 908

brachia conjunctiva (superior cerebellar peduncles), 831

grey substance of, $\$ 31$

internal structure of, 815,829

lemmiscus (fillet) in, 831

Pontile path, frontal, $832,840,889$ temporal (Türk's bundle), 832, 890

Pontine branches of basilar artery, 561 sulci, 804

Popliteal artery, 621, 640, 1452 collateral circulation, 1453

ligament, oblique, 287

line, 189

lymphatic nodes, 748

nerve, external, 1013

internal, 1009

nerves, paralysis of, 1469

plexus of nerves, 1045

space, clinical anatomy of, 1451

vein, 688,1452

accessory, 689

Popliteus, 454, 486

Pore, canal, 1051

of skin, 1285

sudoriferous, 1297

taste, 1051

Porta hepatis, 1183

Portal fissure of liver, 1183

vein, 528, 675

development, 694

tributaries, 675

veins. accessory, 678
Position of organs (see corresponding Organ)

Post-aortic lymphatic nodes, 731

Post-auditory process, $12^{\circ}$

Post-central branches of spinal arteries, 590 sulcus, inferior, 861,862 superior, 861,862

Post-glenoid process, 71

Post-limbic fissure, $\$ 63$

Post-malar, 95

Post-nodular sulcus of cerebellum, 808

Post-parietal gyrus, 863

Post-scapula, 145

Post-sphenoid centre, 67

Pott's fracture, 1454

Pouch of Douglas, 1148, 1267, 1274

of Prussak, $10 s 9$

recto-uterine (recto-vaginal), 1148, 1267, 1274

recto-vesical, 1148

of Tröltsch, 1089

Poupart's ligament, 424, 429, 13-1, 1399, 1438

Pracuneus (quadrate lobe), $\$ 63$

Præputium clitoridis, 1277

penis, 1260

Prævesical space (cavum Retzii), 1250

Pre-aortic lymphatic nodes, 730

Pre-auricular point, 1332

Precentral sulcus, 807, 857

Preglenoid tubercle, 71

Pre-laminar branches of spinal arteries, 590

Premalar, 95

Premaxilla, 89, 91, 119

Premolars, 1121

Preoccipital notch, 861

Pre-palatine centre, 91

Prepatellar bursa, 1448

Prepuce, 1260

Pre-scapula, 145

Pre-sphenoid centre, 67, 119

Presternum, 132

Prevertebral musculature, 328, 355 plexuses, 755, 1029, 1032, 1040

Primary curvatures of spinal column, 43 divisions of spinal nerve-trunk, 967 anterior, $96 \mathrm{~s}$ posterior, 967

Primitive groove, 10

node, 11

pit, 10

streak, 10

Princeps cervicis artery, 543 pollicis artery, 586

Procerus (pyramidalis nasi), 336

Process(es), accessory (of vertebra), 38

acromion, 144

alar, of ethmoid, 81

alveolar, 87,90

anterior clinoid, 65, 116

arciform, 466

caudate, of liver, 1184

ciliary, 1057

cochleariform, 1089

contylar, of mandible, 96

coracoid, of scapula, 144

coronoid of mandible, 96, 1351

ensiform, 132, 131

ethmoidal, s.5

external auditory, 75

frontal, of maxilla, 87,88

fronto-nasal, 119

fronto-sphenoidal, 95

glosso-hyal, 99

hamular, 66, 106

infra-orbital, 95

jugular, 54, 108

lacrimal, 85 
Process(es), lenticular, of incus, 79

mastoid, 72, $10 \mathrm{~S}$

maxillary of inferior nasal concha, 81

of palate bone, 92

middle clinoid, 65, 116

muscular, of arytrenoid cartilage, 1211

orbital, of malar bone, 94

of palate bone, 91,93

palatine, $\mathrm{S7}, 88$

posterior elinoid, 63, 116

petrosal, 63

post-glenoid, 71

pterygoid, 62, 66

pyramidal, of palate hone, 91,92

sphenoidal, of palate bone, 91,92

styloid, 70, 73, 75, 108

of fibula, 190

of radius, 155

of third metacarpal bone, 166 of ulna, 158

supracondylar, 149

temporal, of malar bone, 95

trochlear, 195

uneiform, 163

uncinate, of ethmoid, 83

vaginal of sphenoid, 63,66

of temporal, 75

vermiform, 1378

vocal, of arytænoid cartilage, 1212

xiphoid, 132, $13 t$

zygomatic, 70, 87, 88

Processus cochleariformis, 77

Folii, 79

globılares, 119

gracilis, 79

marginalis, 95

tubarius, 66

uncinatus (of Winslow), 1194

vaginalis, 1387

Profunda (superior) artery, 576

axillaris artery, 640

(leep) femoral artery, 620, 640

branches, 620 rein, 690

Projection fibres of white substance of telencephalon, $\$ 86,889$

Prominence, laryngeal, 1211

Promontory in coclilea, \$1, 1089 of temporal bone, 73

Pronation, 321

Pronator quadratus, 402

rillge of uhna, 157

tries, 395,396

Proper digital arteries, 5\$2

plantar digital nerves, 1011

scapulatr ligaments, 252

volur digital nerves of hand, 992 veins, 671

Prosenceplualon (fore-brain), 843

external features of 813

intermal striscture of, $\$ 78$

Prostatre, listit

lyouphaties of , 700, 7399

sinregionl anatomy of, losis

Teesiols and morves of , 1265

Prostafic: loranclues of inforior resical artery, bitis

p) lexus of mervers, 10917

furtion of urotlura, 1263, 1265, li38s

l'postatio utriculus (simus pocularis, uterus mascolimas), l:29ios

Prestatico-perinoal fascia, 1.17

P'rofuplasin, 5

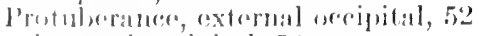
introral ocecipital, 52 matutal, ais

J'russik, pould of los!
Psalterium, hippocampal, 869

Psuedo-hermaphroditism, 1239

Psoas abscess, 1438

fascia, 455

major, 455

minor, 455

Pterion, 101, 1332

Pterygoid, accessory, 342

branches of internal maxillary artery, 548

(Vidian) canal, 103, 107, 108, 126

fossa, 66, 107

hamulus (of sphenoid), 66, 1351

muscles, 338, 342

notch, 66

plate, lateral 66

medial, 66

plexus of veins, 646

portion of internal maxillary artery, 546

processes, 62, 66

tubercle, 66

veins, 646

Pterygoideus externus, 338, 342

internus, $338, \mathbf{3 4 2}$

Pterygo-maxillary fissure, 102

Pterygo-palatine (pharyngeal) canal, 88, 92, 103

fissure, 102

(spheno-maxillary) fossa, 102

portion of internal maxillary artery, 546

Pubes, 1290

Pubic arch, 176

branch of inferior epigastric artery, 615 of obturator artery, 608

Pubis, 172

symphysis, 238

tubercle (spine) of, 172

Pubo-capsular (pectineo-femoral) band, 278

Pubo-cavernosus (levator penis), 451

Pubo-coceygens, 440, 448

Pubo-peritonealis, 436

Pubo-prostatic ligaments, middle, 1252

Pubo-rectalis, 440, 448

Pubo-transversalis, 436

Pubo-vesical ligaments, 1252

Pudendal (pudic) artery, 610, 639 accessory, 638 (superficial) exterual, 619 internal, 610, 639

nerve, 1017

long, 1007

vein, external, 684 internal, 681

plexus of nerves, 1016 of veins, 682,683

Pulmonary artery, 528, 1234

circulation, 507

left, 529

relations, 1369

right, 529

variations, 637

branches of vagus, 957

ligament, 12:36

lymphatic nodes, 725

(viscremal) pleura, 12:36;

plexus, antrior, 9.57, 1043

postcrior, 954, 955, 957, 1043

(semilumat) valves, 517

vilis, 529, 12:34

Pulp of tooth, ]11s

Pulpat lienis, 1311

l'ulpy nucleus of intervertel,ral fibro-cartilagess, 226

Pulvinat of thalamus, $8.15,889$

l'uneta lacrimalia, 1054, 1079, 1349

l'upil, 105.1

Jurkinje cells, 809

filires of heart, 516 
Putamen, $\$ 80$

Pyloric antrum of stomach, 1151 canal, 1152

portion of stomach, 1151 vein, 675

Pylorus, 1152, 1374

Pyramidal eminence of temporal bone, 77 fasciculi of pons, 830

fibres, 840, 889

lobe of thyreoid gland, 1314

process of palate bone, 91,92

tract, anterior or direct, 788 crossed, 783

Pyramidalis, 424, 431

nasi, 336

Pyramids of Ferrein, 1246

of Malpighi (renal), 1246

of medulla oblongata, 783, 799

decussation of, $\$ 15$

structure of, $\$ 15$

of vermis, 808

vertebral, 43

\section{Q}

Quadrangular lobe of cerebellum, 806 membrane of larynx, 1215

Quadrate lobe, of liver, 1184 muscles, 332

Quadratus femoris, 453, 463, 464

labii inferioris (depressor labii inferioris), 332 superioris, 332

lumborum, 425, 436, 1407

plantæ (flexor accessorius), 454, 495

Quadriceps femoris, 453, 468, 470

Quadrigeminate arteries, 907

body, inferior, 834,839

superior, $825,834,8+1$

Quadrigemino-pontile fibres, $\$ 41$

\section{$\mathrm{R}$}

Radial artery, 582

in palm (decp volar areh), 586

at the wrist, 584

carpal artery, dorsal, 585 volar, 581

collateral ligament, 261, 267

fossa of humerus, 151

(musculo-spiral) nerve, 985

line of, 1415,1423

results of paralysis of, 1424

deep (posterior interosseous), 985

results of paralysis of, 1424

superficial (radial), 987

notch (lesser sigmoid cavity) of ulna, 157

recurrent artcry, 583

venæ comitantes, 671

Radialis indicis artery, 586

Radiate (anterior costo-central or stellate) ligament, 242

sterno-costal ligament, anterior, 245

Radiation of corpus collosum, 851

Flechsig's secondary optic, 890 occipito-thalanic (optic), 888

Radicular veins, 792, 908

Radio-carpal or wrist-joint, 265

arterial supply of, 267

ligaments of, 266

movements of, 267

museles acting upon, 268

nerve-supply, 267

relations of, 267

Radio-carpeus muscle, 403

Radio-ulnar joint, inferior, 263, 419 mid, 262

superior, 262, 1419

ligaments, 262, 264
Radius, 152

clinical anatomy of 1419,1422

Pamus(i) bronchial, 1231

colli (infra-mandibular branch), of cervico facial nerve, 946

communicantes, 969, 1030, 1037

of fissure of sylvius, 856

of ischium, 172

isthmi faucium, 940

linguales, $9 \check{5} 4$

of mandible, 95

of pubis, 172

Ranvier, nodes of, 761,767

Raphe of palate, 1104

lateral palpebral, 1078

scrotal, 1254

Receptaculum (cisterna) chyli, 726

Recess(es), elliptical, 80

epitympanic, 78

hypo-tympanic, 78

infundibular, 848

optic, 848

pharyngeal, 1130

spheno-ethmoidal, 1206

spherical, so

supra-pineal, 847

of tumpanic mucous membrane, 1089

Recessus ellipticus (fovea hemiclliptica), 80 sphæricus (fovea hemisphwrica), so

Rectal branches of lateril sacral arteries, $60 \mathrm{~s}$

(hemorrhoidal) of middle sacral arteries, 603

columns (of Morgagni), 1177, 1390

examination, 1391

pits, 1390

sinuses, 1177

stalk, 1391

triangle, 440, 1383

Recto-uterine folds, 1274

pouch (of Douglis), 1267, 1274

Recto-vaginal pouch of peritoneum, 1148

Recto-resical pouch of peritoneum, 1148

Rectum, $1176^{\circ}$

clinical anatomy of, 1390

lymphatics of, 735

supports of, 1391

Rectus abdominis, 422, 424, 430

accessorius, 471

capitis anterior (minor), 356

lateralis, 356

major, 355

posterior major, 412,419

minor, 412, 419

femoris, 46s, 470, 1436

Recurrent artery, anterior tibial, 632

dorsal ulnar, 57

interosseous, 580

posterior tibial, 632

radial, 5S3

volar ulnar, 577

articular nerve of leg, 1013

branches of deep volar arch, 586

of lacrimal, 552

of spinal nerve-trunks, 970

of vagus nerve, 956

meningeal branch of maxillary nerve, 937

of ophthalmic nerve, 935

(inferior laryngeal) nerve, 957

Red nuclei, s $\$ 0$

References for articulations,"311

blood-vascular svstem, 696

digestive system, 1197

ductless glands, 1329

lymphatic system, 750

morphogenesis, 25

museulature, 506

nervous system, 1047 
References for osteology, 209 respiratory system, 1240 skim and mammary glands, 1329 special sense organs, 1098 urogenital system, 1280

Reflected inguinal ligament (Colles' ligament, triangular fascia), 1395

Reflex paths of cranial nerves, 898 of spinal cord, 895 optic acoustic, 840

Regeneration of lymphatics, 707

Region, ilio-costal, 1406 parotid, 1343

of skull, anterior, 108

inferior, 103

lateral, 101

posterior, 101

superior, 100

Regions of abdomen, 1142, 1370

Reil, island of (insula), $\$ 56$

Reissner, membrane of, 1096

Relations of organs (see corresponding organs)

Renal arteries, 598, 638 accessory, 638

branches of lumbar arteries, 593 of vagus, $95 \mathrm{~s}$

columns (of Bertin), 1216

(Malpighian) corpuseles, 1246

fascia, 1242

ganglia, 1044

pelvis, 1248

plexuses of nerves, 1044

pyramids (of Malpighi), 1246

surface of spleen, 1309

tubules, 1246

veins, 673

Reproductive organs, development of, 1278

fenale, 1265

mile, 1253

lymphatics of, 742,744

Respiration, 1199 musculature, 247, 248, 503

Respiratory nerve of Bell, external, 982 nuclens, 822

systern, 1190

larynx, 1209

lunus, 1228

mediastinal septum, 1239

nose, $120(9)$

pleurie, 12:36

thoracic eavity, 1235

trachea and bronchi, 12:5)

region of nose, $1208,135 \%$

Restilurm body, so0, 810

(ii) res of 830

in porss, $8: 30$

Rote arteriosum, cutaneous, $12 \mathrm{~S}$

sul-papillary, 12s?

articular of kucre, 622

canalis hypoglossi, 650, 6065

derwal carpal, 579,585

venous (forit), tist

(haind), , gif

fortuninis ovalis, foto

latrolal malloolar, (j21;, fi:32

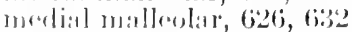

Jitlellar, rize

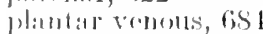

1astis, I:50

vilar (arpal, 579, 581

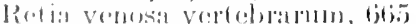

lombenlar formation of nuchlulla oblomgata, $\$ 1 ;$

l:a yer of thalamus, s\$a

wi poms, sic

of spinal mert, $77 t$
Retina, 1051, 1057, 1061

Retinacula, 1287

mammse, 1303

patellæ laterale, 471

mediale, 471

peroneal, 480

tendinum, 317

Retinal arteries, 1065

pigment layer, 1057

veins, 1065

Retractors of the lips, 332

Retrahens aurem, 337

Retro-pubic space (of Retzius), 1371

Retrotonsillar fissure of cerebellum, 807

Rhinencephalon, $86 \pm$

Rhombencephalon, 758

isthmus of, 832

summary of principal structures in, 833

Pliomboid fossa, 802

ligament (costo-clavicular), 249

muscles, nerve to, 982

Rhomboideus major, 356,358 minor, 356,358

Ribs, 120

asternal or false, 127

bicipital, 132

cervical, 131, 1365

clinical anatomy of, 1363, 1404

eleventh, 130

first, $12 \mathrm{~S}$

floating, 127

lumbar, 132

ossification of, 130

peculiar, $12 \mathrm{~S}$

second, 129

sternal (true), 127

tenth, 129

twelf th, 130

typical characters of, 127

variations of, 131

vertebral, 127

vertebro-chondral, 127

vertebro-sternal, 127

Ridge(s), carotid, 73

genital, 1267, 1278

nfra-temporal, 65

lateral supracondylar, 149

medial supracondylar, 149

pronator, of ulua, 157

transverse, of palate, 1104, 1106

temporal, 71

Right atrium (amricle) of heart, 512

branch of hepatic artery, 595

lronchial artery, 5ss

colic artery, 598

common iliac artery, 605

coronary allery, 519

branches, 519

gastric artery, 594

gastro-epiploie artery, 595

vein, 677

innominate vein, 6.11

lymphatic duet, 728

pulmonary artery, 529

veins, 5iz?

suprelum intereostal vein, 664

forminal hanch of hepatic artery, 589 collerting lymphatic duct, 728

ventricle of heart, 516

Rima grotlitis, 122:3

oris, 1100

pal liemparmu, 1052

purtendi, 1276;

vestiluli, 1222

Ring(s), abdominal inguinal (internal abdominia]) $430,1371,1396$

femsinil, llit, 1401 
Rings, subcutaneous inguinal (external abdomirial), 429, 1371,1394

tonsillar (Waldeyer's), 1133

Risorius, 333

Rivinus, notch of, 77

Rolandic angle, $\$ 60$

points, 1340

Rolandlo, fissure of, 859, 1340

gelatinous substance of, 776

Root(s) of Arnold's or otic ganglion, 963

canal of tooth, 1118

of ciliary ganglion, long, 937 short, 932

filaments of spinal nerves, 775, 964

of hair, 1292

of lungs, $1229,1230,1234,110 \mathrm{~s}$

of nails, 1294

of nose, 1200

of optic tracts, 849

of penis, 1260

of spheno-palatine (Meckel's) ganglion, 962 of spinal nerves, 771,964

of teeth, 1117

of tongue, 1107

Rosenmüller, fossa of, 1130

Rostral lamina of corpus calloum, 852 sulci, $85 \mathrm{~S}$

Rostrum of corpus callosum, $\$ 52$

of sphenoid, 63

Rotation, 215, 321

Rotatores, breres, 412, 419

longi, 412, 419

Round ligament liver, 1185 of uterus, 1274

Rubro-spiual fasciculus, 7\$6

Ruffini, corpuscles of, 1290

Rugæ of vagina, 1275

Sac, conjunctival, 1054

endolymphatic, 1094

lacrimal, 1080, 1349

lesser, 1148

synovial, 313

Saccular branch of vestibular ganglion, 950

Saccule of membranous labyrinth, 1093

Sacculo-ampullar division of vestibular nerve, 950

Sacral arteries, lateral, 607 middle, 603

branches, lateral of middle sacral artery, 603 canal, 42

cornua, 40

foramina, 40

groove, 41

hiatus, 40

lymphatic nodes, 733

nerves, 973,1006

plexus, 1006

composition of nerves of, 1006

of veins, anterior, 679

portion of sympathetic system, 1040

veins, lateral. 680

middle, 679

vertebre, development of, 45

Sacro-coccygeal articulation, 237

ligament, anterior, $23 \mathrm{~s}$

deep posterior, $23 \mathrm{~S}$

superficial posterior, $23 \mathrm{~s}$

Sacro-cocygeus, anterior, $44 \mathrm{~S}$ posterior, 448

Sacro-iliac articulation, 234

ligaments, anterior, 234

inferior, 235

posterior, 234

superior, 234
Sacro-lumbar ligament, 232

Sacro-spinalis (erector spine), 412, 414, 1407

Sacro-spinous or small sacro-sciatic ligament, 236

Sacro-tuberous (gre:l t or posterior sacro-sciatic) ligament, 235

Sacro-rertebral angle, 39, 43 articulations, $2: 32$

Sacrum, description of, 30, 39

sex and racial differences of, 12

Sagittal fontauelle, 59

sinus, inferior, 650 superior, 649

sulcus, 60

suture, 57, 101

Salivary corpuseles, 1132 glands, 1113

development of, 1117

variations and comparative, 1117

Salivatory nucleus, 826,947

Santorini, cartilages of, 1212

duct of, 119.5

incisures of, 1085

saphenous artery, 621

nerve, 1003, 1467

external or short, 1010.1013

opening (fossa ovalis), 467, 1400, 1440

vein, accessory, 684

great (internal), 684, 1456

small (external), 684, 1458

Sarcolemma, 315

Sartorius, $453,468,1436$

Scala media, 1096

tympani, 81, 1096

vestibuli, 81, 1096

Scalene musculature, 325,353

tubercle, 129

Scalenus anterior, 353

medius, 354

minimus, 35.5

posterior, 35.1

Scalp, 1333

cutaneous areas of, 1018

lymphatics of, 712

Scansorius, 462

Scapha of auricle of ear, 1083

scaphoid bone, 159, 160 fossa, $55,66,10 \bar{\jmath}$

Scapula, $1+1$

clinical anatomy of, 1406

Scapular artery, circumflex (dorsal), 572 posterior, 565 transverse (suprascapular), $56 t$

foramen, 142 nerve, dorsal, 9s2

notch, 142

veins, transverse, 648

Scapulo-clavicular union, 250

Scapulo-clavicularis, 374

Scarf-skin (epidermis), $12 \$ 5$

Scarpa, fascia of, 425,445 forminin of, $89,106,126$

triangle of, $46 \pi, 1438$

Schindrlesis sutures, 212

Schlemm, canal of, 1059

Schwalbe, nucleus of, 523

Sciatic artery, 609, 640

nerve ( $N$. ischiadicus), 1008, 1443 results of paralysis of, 1469 small, 1007

notch, great, 172 small, 172

Seleral sulcus, $105 t$

sclera, $1052,1056,1058$

sclerotome, 15

serotal (or labial) arteries, anterior, 620 posterior, 613 
Scrotal nerves, anterior, 1000 posterior, 1017 reins, 6.5.

Serotum, 125. lymphatics of $698,742,1255$ surgical anatomy of, 1385 ressels and nerves of, 1255

Scutum, 1089

Sebaceous glands, 1295

Sebum cutaneum, $129 \mathrm{~s}$ palpebrale, 1054

Secondary tympanic membrane, 10\$9, 1096

Sections of peritoneum, 1146

Segmentation of the ovum, 9

Sella tureica, 63, 113

Semicanalis $m$. tensoris tympani, 74

Semicircular canals, 78,80 ducts (membranous semicircular canals), 1094

Semilunar bone, 159,161

fascia, 382

fibro-cartilages, 289

fissures of cerebellum, 805

fold of conjunctiva, 1055

of large intestine, 1170

ganglia, 1043

(Gasscrian) ganglion, \$26, 935, 1345

grrus, $\mathrm{S} 65$

lobe, inferior, of cerebellum, 807 superior, of cerebcllum, $\$ 06$

notch (greater sigmoid cavity), 156

valves, aortic, 517

pulmonary, 517

Semimembranosus, $453,475,476$

Seminal vesicles, 1257

Seminiferous tubules, 1256

Semispinalis capitis (complexus), 412, 417 cervicis, 412,419

dorsi, 412, 419

Scmitendinosus, $453,475,476$

Sensc, organs of special, $\mathbf{1 0 4 9}$

Sensory aphasia, $\$ 94$ axones, 762

Sensory-motor area of cerchral cortex, $\$ 93$

Septa, intermuscular, 314 of thigh, $46 \mathrm{~S}$

Septal branches of spheno-palatine artery, 549 nasal cartilage, 12()$^{2}$

Scptula of mediastinum testis, 1256

Septum aortic, 527

of arm, intermuscular, 377

atriorum, 511

('ulnalis musculotubarii, 73

fomoral, 466

of fout, intermuscular, 492

of hourt, membramous, 511,527

intreventricular, 516

of loce, intermuscular, 477

lingure, 346

morliastiual, 1239

ni1:il $, 111,1204,1354$

Septum pelluriclum, 872

ravity of , $\$ 72$

laminat of, 872

of yorisis, 126il

fusticum of sichwalloe (subarachnoid sept11m, , !1!

simmoicl, :'11

splir.minilal, $\left(i_{2}^{2}\right.$

transysistim, 20

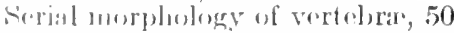

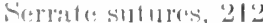

Serratus atuterior (magnus), 356, 359

jestrerior inforior, 12:3, 431

silurior, 12:3, 431

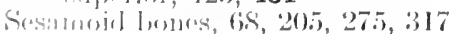

artilagess of largens, li21:3
Sesamoid nasal cartilages, 1202

plate, plantar, 310

tibial and fibular, 209

ulnar and radial, 209

Seventh cervical vertebra, 34

cranial nerve (facial), 943, 1345

Shaft of bones, 29 (see also the individual bones)

of hair, 1292

Sheath (s), carotid, 1362

femoral, 1400

medullary, 759

of optic nerve, 931

of parotid gland, 1344

primitive, 761

of prostate, 1389

of rectus muscle, 427

of hair roots, 1292

synovial tendon, $317, \mathbf{3 1 8}, 403,483,484,491$

Shoulder, clinical anatomy of, 1409

musculature of, $323,363,503$

Shoulder-blade (scapula), 141

Shoulder-girdle, 207

Shoulder-joint, 253

arterial supply, 257

clinical anatomy of, 1413

lignments of, 254

lymphaties of, 723

movements of, 257

muscles acting upon, $25 \mathrm{~S}$

nerve-supply of, 357

synovial membrane, 255, 1412

Shrapnell's membrane, 1087

Sibson's fascia, $129,355,1237$

Sigmoid artery, 603

cavity of raclius, 154

of ulna, greater, 156 lesser, 157

colon, 1174, 1379

groove, 72

notch, 96,97

septum, 341

sinus, 652

vein, 678

Sinuses, accessory nasal, 1354

aortic (of Valsalva), 518

bony, of skull, 1335

cavernous, 652, 691

cervical, 17

circular, 651

comnecting with nose, 1354

coronary, 521

costu-mediastinal, 1238

cranial venous, $649,692,916$

of dura mater, 649

epidiclyminlis (digital fossa), 1255

frontal, 59, 61, 1207, 1335

inferior petrosal, 652 satgit tal (longiturlinal), 650

intercavernosus, 651

of kidnoy, 1242

lact iferous, 1302

longitulinal vertebral, 665

matumarum, 1299

nin reinal, 650

maxillaris (antrum of Higlmmore), 87, 90, $111,1206,1354$

of Morgagni, 1137

oblicpe, of pericardium, 523

occipital, (i)io

paranasal, 1206

parasimoidal, 919

of pricardium, transverse, 523, 527

petro-squamous, $65 \%$ is

phrenico-costal, 1237

1) lous:1, 12:37

of portal vein, 675 
Sinuses, rectal, 1177

sigmoid, 652

sphenoidal, 62, 1207, 1338

spheno-parietal, 653

straight, 650

superior petrosal, 652

sagittal (longitudinal), 649

tarsi, 195

transverse (lateral), 651

tympanic, 1089

uro-genital, 1279

of Valsalva, 518, 530

venarum, 513

venosus, of heart, 525

of sclera (Schlemn), 1059

Sinusoids, 672, 675

Skeleton, 27

appendicular, 139

axial, 29

Skene, ducts of, 1277

Skin, 12S1

appendages of, 129

corium, 1286

development of, 1286, 1290

epidermis, 1285

lymphatics of, 69s, 1289

muscle-fibres of, 1288

tela subcutanea (superficial fascia), 1257

vessels and nerves, $12 \mathrm{SS}$

Skin-folds of wrist and hand, 1425

Skull, appendicular elements of, 117

articulations of, 215

at birth, 120

bones of, 51

bony landmarks, 1331

sinuses of, 1335

fœetal, general characters, 120

interior of, 112

morphology of, 117

nerve-foramina of, 125

regions of, anterior (norma facialis), 108

inferior (norma basalis), 103

lateral (norma lateralis), 101

posterior (norma occipitalis), 101

superior (norma verticalis), 100

topography of, $133 \mathrm{~S}$

as a whole, 160

Small eardiac vein, 521

intestine, 1161, 1375

blood-supply, 1166

clinical anatomy of, 1375

development of, 1168

duodenum, 1161

ileum and jejunum, 1165

lymphatics of, 1168

nerves of, $116 \mathrm{~s}$

(accessory) meningeal artery, 548

occipital nerve, 977

palatine nerve, 948

(external) saphenous vein, 684, 1458

sciatic nerve, 1007

superficial petrosal nerve, 951

Smaller palatine canals, 92

Smallest eardiac vein, 521

occipital nerve, 971

Snuff-box space (tabatiére anatomique), 1433

Soft palate, 1104

muscles of, 326

Solar plexus, 1043

Sole of foot, muscles of, 493

Soleus, 454, 4St, 485

accessorius, 491

Solitary follicles, 704

glands of small intestine, 1166

tract, $\$ 20$

Somæsthetic (sensory-motor) area of cerebral cortex, 893
Somites, mesodermic, 14,15

Space(s), Burns', 1356

of Fontana, 1060

intercostal, 139

interfascial ('Tenon's), 715, 1073

popliteal, 1451

prævesical, 1250

snuff-box, 1433

subarachnoid, 771

subdural, $7 \pi 1$

Special sense, organs of, 1049

Speech, cortical areas of, 894

Spermatic artery, external, 615 internal, 598, 638, 1259

branch, external, of genito-femoral nerve, 1000

eord, $1254,1259,1357$

fascia, external, 1357

plexus of nerves, 1045

veins, 674,1259

Spermatozua, 1256

Spheno-ethmoidal branch of naso-ciliary (nasal) nerve, 937

cells, 81

recess, 1206

Sphenoid, 62

at birth, 122

Sphenoidal conchw (turbinate bones), 61, 67 at birth, 124 development of, 119

crest, 63

(superior orbital) fissure, 65, 109, 116, 125

process of palate bone, 91, 92 of septal cartilage, 1203

septum, 62

sinuses, 62, 1207

Spheno-mandibular ligament, 217

Spheno-maxillary fissure, 102, 109, 126

fossa, 102

Spheno-palatine artery, 549 nerve, 938

foramen, 93, 103, 111, 126

(Meckel's) ganglion, 962 branches, 962 roots, 962

notch, 91,93

vein, 616

Spheno-parietal sinus, 653

Sphenotic cartilage, 117

Spherical recess, so

Sphincter ani externus, 441, 449 internus, $117 \%$ tertius, 1177

internal, of urinary bladder, 1253, 1389

pupillæ (iridis), 1061

urethræ (in female), 449

membranacex, 449

urogenitalis, 442,449

vagine, 1276,1278

Spigelian lobe of liver, 1184

spinal accessory nerve, $95 \mathrm{~s}$ nucleus of, $\$ 20$

arachnoid, 919

artery, anterior, 501, 638, 792 posterior, 561, 792

branches of aortic intercostal arteries, 590 of deep cervical artery, $56 \mathrm{~S}$ of ilio-lumbar artery, $60 \pi$ of lateral sacral arteries, $60 \mathrm{~S}$ of superior intercostal arteries, $56 \mathrm{~S}$ of vertebral artery, 560

cord, 751, 771

blood supply of, 792

central canal of, 775

clinical anatom of, $140 \mathrm{~S}$

external morphology of, 771

internal structure of, 775 
Spinal cord, meninges of, 908 summary of. 758

surface of, 772

systems of neurones in, 777

terminal ventricle, 775

dura mater, 911

ganglia, 964

aberrant, 965

neurones of, 755

musculature, 410

nerves, 964

aberrant ganglia, 965

areas of distribution of, 970

attachment of, 964

cauda equina, 966

course of, 965

filia radicularia, 965

ganglion of, 964

origin of, 964

roots of, 961

topography of attachment of, 966, 1406

nerve-trunks, anterior primary divisions, 968

meningeal (recurrent) branch of, 970

posterior primary dirisions, 967, 970 rami communicantes, 969

pia mater, 921

(inferior) portion of (spinal) accessory nerve, 958

tract, of trigeminus nerve, $\$ 28$

veins, anterior, 665 posterior, 665

Spinalis capitis (biventer cervicis), 418

cervicis, 412,417

dorsi, 412, 417

Spindle, aortic, 531

neuromuscular, 76

Spine(s), 29

anterior nasal, 87, 90, 112

ethmoidal, 63,113

frontal (nasal), 60

of helix, $108 t$

of ilium, 169

ischial, 172

mandibular, 96

mental, 95

nasal (frontal), 60

postcrior, 91

of pulis, 172

of scapula, 141,144

of sphenoirl, 65,108

supraneatal, 72

of tibia (intercondyloid eminence), 185 vertebral, 1403

Spino-cerebellar fasciculi, $7 \$ 4$ path, 98.5

Spino-mescncephalic (spino-tectal) tract, 786 , $8+2$

Spino-olivary faseiculus, 784

Spino-thalanic tracet, 786

Syinous process of apistrophens, 3.1

of seventh cervical vertehri, 34 of vertehrit: 31

liganemts connoeting, 229

Spiral catnd of cochle:s, sl

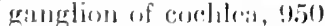

ligament of coeble:a, 10906

lime of fom

organd lorgith of Corti), 1096

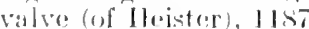

Splanethnic ganelion, 10:3!

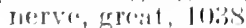

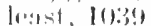

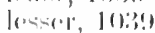

melye, 11)|7, 1040, 1016

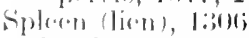

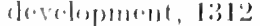

tymphatics, 736, 1:312
Spleen, topography of, 1310, 1375

variations, 1310

vessels and nerves, 1312

Splenic artery, 595

branches of vagus, 958

(left colic) flexure, 1174, 1379

lobules, 1312

lymphatic nodes, 730,736

(lienal) plexus of nerves, 1045

pulp, 1311

vein, 677

Splenium of corpus callosum, 852

Splenius, 412, 414

capitis, 414

cervicis, 414

accessorius, 414

Spongioblasts, 755

Spot, yellow, of fundus oculi, 1055 of larynx, 1223

Spring ligament, 305

Squamous portion of temporal bone, 68 sutures, 212

Stapedial fold, 1090 artery, 638

Stapedic branch of stylo-mastoid artery, 544

Stapedius, 1091 nerve to, 944

Stapes, 80, 119

Stellate cells of cerebellar cortex, 809

figures of lens of eye, 1063 ligament, 242

Stem of fissure of Sylvius, $\$ 55$

Stenson's duct, 1115, 1343

foramina, 89,106

Stephanion, 101

Sternal branches of internal mammary artery, 567

foramen, 133

synchondrosis, 133

Sternalis, 374

Sternebrie, 132

Sterno-chondro-scapularis, 374

Sterno-clavicular joint, surgical anatomy of, 1363

ligaments, 248

Sterno-clavicularis, 374

Sterno-cleido-mastoid artery, 542

Sterno-cleido-mastoideus, 347,349

Sterno-costal articulations, 245 ligaments, 245 surface of heart, 510

Sterno-costo-clavicular articulation, 248 ligaments of, 248 movements of, 250

Stermo-hyoideus, 351

sterno-mastoisl branch of superior thyreoid artery, 53s

is a landmint: 1355

vein, 660

Stemo-pericardinl ligaments, 522

Sterno-thyreoideus, 351

Sterno-xiphoid plane, 1370

Sternum, 1:32

almormalities of, 138

angle of 133,139

borly of, 133

devolopment of, 135

Stilling's nucleus, 776;

Sitomach, 115 !

blood-ressels of, 1151

clinical anatenty of 1373

comparative, 1160

development of 1157

lymphaties of, 73t, 1156

nerves of, 1156

peristalsis of 1150

position and relations, 115: 
Straight (collecting), renal tubule, 1167 sinus, 450

Stratım album medium, $\$ 42$ profundum, $\$ 42$

cinereum, $8+2$

corneum, 1286

unguis, 1295

germinativum (Malpighii), 1286, 1295

granulosum, 1286

lemnisci, $825,839,842$

lucidum, $12 \$ 6$

opticum (stratum album medium), 842

zonale, $839,842,845,881$

Streeter, nucleus incertus of, 815

Striæ acustica (æ), 814

(linea) albicantes, 1283, 1304

intermediate olfactory, $\$ 65$

Làncisii, 851, 871

lateral longitudinal, of corpus callosum, $\$ 51$

longitudinal, of corpus callosum, 851, 892 of hippocampus $\$ 71$

medial longitudinal, of corpus callosum, 851 medullares acustici, 824

(pineales) of thalami, 846,872

olfactory, 865,866

terminalis thalami (tænia semicircularis), $\mathbf{8 4 5}, 892$

of thalamus, $873,881,892$

transverse, of corpus callosum, $\$ 52$

Striate arteries, external, 906 internal, 906

Stripes of Baillarger, $\$ 79$

Structure of organs (see corresponding organ)

Stylo-glossus, 346

Stylo-hyal portion of styloid process, 75, 119

Stylo-hyoid ligaments, 99

Stylo-hyoideus, 343, 344

Styloid bone, $16 \mathrm{~S}$

process, $70,73,75,77,108$

of fibula, 190

of radius, 155

of third metacarpal bone, 166

of ulna, $15 \mathrm{~s}$

Stylo-mandibular (stylo-maxillary) ligament, 217

Stylo-mastoid branch of posterior auricular artery, 544

foramen, 73, 10S, 126 vein, 646

Stylo-pharyngeus, 1137

Subanconeus, 37S

Sub-arachnoid cavity or space, 771,919 cisternæ, 918

Subcallosal gyrus (peduncle of corpus callosum), 866

sulcus, 866

Subclavian artery, 556 collateral circulation, 1360

left, 556

relations, 556, 558, 1369

right, 557

variations, 638

group of axillary lymphatic nodes, 719

sulcus, of ling, 1229

vein, 671

Subclavius, 373

Subcostal artery, $58 \mathrm{~s}$

Subcostales, 423, 434

Subcrureus, 470

Subcutaneous dorsal veins of penis, 684

inguinal (external abdominal) ring, 429, 1371,1394

muscles, 313

of hand, 404

Subdural cavity, 912, 917

space of spinal cord, 771

Subfascial bursæ mucosæ, 318
Subiculum of the promontory, $10 \$ 9$

Sublingual arterr, 540

caruncle, 1116,1117

fold, 1116

gland, 1116

ducts of, 1117

vessels and nerves, 1117

Iymphatic nodes, 7 to

nerve, 941

vein, 660

Submammary (retromanmary) burse, 1303

Submarginal gyous, s.s

Submaxillary ganglion, 963 roots, 963,1036

gland, 1115,1350

duct of (Wharton's) 1116

ressels and nerves, 1116

lymph-nodes, 709

portion of external cervical fascia, 347

(digastric) triangle, 1357

Submental artery, $5+1$

set of facial lymph-nodes, 711

vein, 644

Submuscular burse mucose, $31 \mathrm{~s}$

Subnasal point, 109,112

Suboccipital muscles, 412, 419 nerve, 971

Subparietal suleus (postlimbic fissure), 863

Subphrenic area of peritoneum, 1372

Subsartorial plexus, 1003

Subscapular angle, 145

artery, 571

branches of posterior scapular artery, 566 of transverse scapular artery, 565

fossa, 141

group of axillary lymphatic nodes, 720

nerves, $9 \$ 4$

vein, 671

Subscapularis, 369

minor, 369

Substance, anterior perforated, $\$ 47,866$

central grey, of mesencephalon, $\$ 36$ of medulla, SIS

gelatinous, central, of spinal cord, 776 of Rolando, 776

grey, of pons, $\$ 31$ of nervous system, 768

of spinal coid, 775

of telencephalon, $\$ 79$

posterior perforated, $\$ 35,844$

white, nervous system, 768

of spinal cord, 775,777

of telencephalon, 885

Substantia alba, $76 \mathrm{~S}$

corticalis, 1293

grisea, $768,81 \mathrm{~s}$

medullaris, 1293

nigra, 836,840

reticularis alba (Arnoldi), 868

Subtendinous burse mucosie, 318

Subtrapezial plexus, 979

Sudoriferous glands (sweat-glands), 1296 pore, 1297

Sulco-marginal fasciculus, 7SS

Suleus(i), 29

ampullary, 1095

antero-inferior, $\mathrm{S} 0 \mathrm{~T}$

antero-intermediate, $7 \mathbf{7}$

antero-lateral, 773

auricular, 105:

basilar, of pons, 804

breves, 8.57

central (fissure of Rolando), 859, 1340

of cerebellum, 805

of cerebrum, 852

cinguli (calloso-marginal fissure), $\$ 57,858$, 859 
Sulcus(i), circular, $85 \pi$

coronarius, 510

of corpus callosum, 867

of crus of helix, 1084

cunei, $86+$

diagonal, s5s

fimbrio-dentate, 568

of floor of fourth ventricle, $\$ 13$

fronto-marginal, \$5S

of heart, 510,511

hypothalamic, 847

inferior frontal, $\mathrm{S} 5 \mathrm{~S}$

postcentral, 861,862

temporal, $\$ 55$

infra-orbital, 1284

interparictal (int raparietal), $\$ 61$

lateral occipital, 863

matricis unguis, 1294

median subcallosal, 866

mento-labial, 12St

midlle frontal, 858

temporal, 855

of Monro, $S+\bar{T}$

oculomotor, 835

olfactory, 858

orbital, sos

parallel, 855

para-medial, 8.58

parolfactory, 865

pontine, $\mathrm{SO} 4$

postcentral of cerebellum, 806, 861, 862

posterior median, 772

postero-inferior, 807

postero-intermediate, 773

postero-lateral, 773

post-nodular, $80 \mathrm{~S}$

pre-auricularis, 177

precentral, 807,857

rostral, Sis

sagittal, 60

scleral, 1054

of skin, 1284

of spinal cord, 772

subclavian, of lung, 1229

subparietal, 863

superior frontal, 858

postcentral, s61, 862

temporal 85.5

supra-orbital, 12S4

of telencephation, 853

terminatis of tongue, 1106

of lieart, 511

transverse occipital, 862,863

temporal, 85.5

trunsvorsus, 59, 108

of anthelix, 108:3

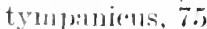

Supercilia, 1290

Superoiliary areh, 59,108

Supination, :321

Supinatop (hrevis), 392

l'arlii lonerus, :isis

supracallesil gyrus, s68

Supra-clavicular branches of cervical plexus, 98

mervers, 978

portinu of Jranhial plexus, branches of, (9)2

Sunpri-rendylar lines, $1 \$ 1$

Horens, 1.t9)

rielge, litterisl, 149

Inrolial, 1.19

Sinpracesslales, antroior, 433?

bestorior, di:2

Silusaglenoid tulurelelo of seapula, 144

Supre-lepoid musculature, 325,344

Suprithammillary (ommmissure, 871,890
Supra-mandibular branch of cervico-facial nerve, 946

Supramarginal gyrus, 863

Supra-maxillary set of facial lymph-nodes, 711

Supra-meatal fossa, 72

spine, 72

triangle, Macewen's, 1337

Supra-occipital, 119

Supra-omental region of peritoneum, 1372

Supra-orbital artery, 552, 1343

branches, 553

border, 60

nerve, 935

notch, 60

sulcus, 1284

vein, 644

Suprapineal recess, 847

Suprarenal artery, inferior, 598

middle, 598

superior, 592

glands, 1323, 1381

accessory (of Marchand), 1326

development, 1326

lymphatics, 701, 738

vessels and nerves of, 1326

plexuses of nerves, $10+4$

veins, 673

Suprascapular (transverse cervical) artery, 564

(coracoid or superior transverse) ligament, 253

nerve, 982

Supraspinatus, 368

Supraspinous branches of posterior scapular artery, 566

of transverse scapular artery, 565

fossa, 141

ligament, 230,238

Suprasternal bones, 133

Supratonsilar fussa, 1132

Supratragic tubercle, 1082

Supratrochlear branch of frontal nerve, 936

foramen, 150

lymphatic node, 719

Sural branches of popliteal artery, 622

(exterual or short saphenous) nerve, 1010, 1013,1467

Surfaces of organs (see corresponding organ).

Surgical anatomy of organs (see corresponding organ).

Suspensorius duodeni, 1164, 1376

Suspensory ligument of Cooper, 1303 of the eycbalt, 1072,1348

of leus of eye, 1057, 1064

(apical lental) of occipito-epistrophic articulation, 223

of ovary, 1269

of penis, 427, 1260

of Treit $z, 1164,1376$

sustentaculum hepatis, 1174

lienis, 1174

tali, 195

Suture(s), 212

of anterior cranial fossa, 113

coronal, 57, 101, 1339

froutal, 59

incisive, 106

l:1mbloill, 57, 101, 1339

nueso-palatine, 89, 106

netopic, 59, 101

neuro-eentrial, 45

of norma factialis, 108

orecipital, 101

occipito-mastoid, 101

parieto-matostod, 101

fet ro-sefuamous, 71 
Suture(s), sagittal, 57, 101, 1339 squamoso-parietal, 1339

transverse, 108 palatine, 106

of vertex of skull, 101

Swallowing, muscles of, 325 process of, 1137

Sweat-glands, 1296

Swellings, genital, 1279

Sylvian fossa, $\$ 54$ point, $\$ 56$

Sylvius, aqueduct of, $\$ 34$ fissure of, $850,855,1340$

Syme's amputation, 1465

Sympathetic fibres, 970,1029 nerves of orbit, 1076, 1348 relations of spinal cord, 789 system, 959, 1026 construction of, 1030 ganglia of, 959 origin of, 1029 prevertebral plexuses of, 1029 trunks, 1032, 1033

Symphysis of mandible, 95 pubis, 238 ligaments of, 238

Synapses, 762, 765

Synarthroses, 212

Synchondroses, 212 sternal, 133

Syncytium, 759

Syndesmoses (synarthroses), 212 tympano-stapedial, 1090

Synergists, 322

Synovial bursæ, 313,318 membrane, 211 (see also corresponding articulations)

sheaths (vaginæ nucosæ tendinum), 378

tendon-sheaths, 317 of forearm muscles, 395,403 of leg muscles, $483,484,491$

System, association, of hemispliere, 890 blood-vascular, 507

chromaffin, 1333

digestive, 1099

of fibres, commissural, $\$ 90$

lymphatic, 697

nervous, 751

central, 751,770

peripheral, 754,924

sympathetic, 1026

neurone, 777,895

respiratory, 1199

urogenital, 1241

Systemic arteries, 529

circulation, 507

veins, 640

Tabatière anatomique (of Cloquet), 1433

Table showing relations of cervical and thoracic nerves to branches of brachial plexus, 993

of lumbar and sacral nerves to branches of lumbar and sacral plexuses and to pudic nerve, 1016

of muscles of lower extremity to nerves of lumbar and sacral plexuses, 1016

of muscles of upper extremity to cervical nerves, 993

of vertebral levels, 1409

of distribution of spinal nerves (Gowers'), 969

Tactile corpuscles (Meissner), 1290

Tænia chorioidea, 844

fimbriæ, $\$ 68,877$
Tænia fornicis, 868 pontis, 855

semicirculinlis, 845,873

thalami, $8 \pm 6,872$

Tail of caudate nucleus, 877

of epididymis, 1256

of nuscle, 314

of pancreas, 1194

Talipes, 1467

Talo-calcancal union, 301

Talo-fibular ligament, anterior, 299 posterior, 299

Talu-navicular articulation, 305

ligament, 306

Talus or astringalus, 191, 192

Tan, 1283

Tangential layer of fibres of cortex, 879

Tapetum of pusterior cornu of lateral ventricle, 876

Tarsal arch, inferior, 554 superior, 554

artelies, medial, 632

bounes, 191

clinical anatomy of, 1467

branches of dorsalis peclis artery, 632

elements, accessory, 199

(Meibomian) glands, 1054, 1298

joints, 301

transverse, 305

muscles, 1072, 1078

Tarso-metatarsal articulation, $30 \mathrm{~s}$

Tarsus, 191

anterior articulations of, 303

of eyclids, 1053, 1077

Taste, organ of, 1051

Taste-buds, 1051

Taste-pores, 1051

Tectorial membrane, 223

Teeth, 1117

canine, 1120

deciduous or milk, 1126

incisor, 1119

molars, 1121

premolar or bicuspid, 1121

times of eruption, 1127

variations and comparative, 1127

vessels and nerves, 1124

Tegmen tympani, 77

Tegmento-mammillary fasciculus, 871

Tegmentum of pons, 830

Tela chorioidea, $75 \mathrm{~S}$

of fourth ventricle, 922

subcutanea (superficial fascia), 313, 1287 of the abdomen, 425

of the arm, 377

of the back, 413

of the forearm and hand, 384

of the foot, 491

of gluteal region, 457

of head and neck, 347

of leg, 477

of pectoral region, 371

of the perineum, 445

of shoulder, 36.5

of thigh, 466

of thoracic-abdominal musculature, 425

Telencephalon, 758, 847

gyri, fissures and sulci, 852

lobes, $\$ 53$

central (insula), 856

frontal, $\$ 57$

occipital, 863

parietal, $\$ 60$

rhinencephalon, 864

temporal, 854

projection fibres of, $8 \& 6$

Telodendria of axones, 762 
Temporal artery, anterior deep, $\tilde{\jmath} 1 \mathrm{~s}$ middle, 545

posterior deep, 548

superficial, 545, 1343

bone, 68

at birth, 122

mastoid portion of, 68,71

petrous portion of, 68,72

squamous portion of, 68,70

trumpanic portion of, $69,70,75$

branches, superficial, of auriculo-temporal nerve, 942

of maxillary nerve, 938

of temporo-facial nerve, 945

fascia, 339

fossa, 101

gyrus, inferior, 855

middle, $\$ 55$

superior, $85 \mathrm{t}$

lines (rilges), 57, 60, 71,1332

lohe of cerebrum, 854

opercula of, 854

nerves, deep, 943

noteh, 868

pole, 850

pontile patk (Türk's path), \$32, $\$ 40,890$

process of malar bone, 95

suleus, middle, $\$ 5.5$

superior, $\$ 55$

vein, deep, $6+6$

diploic, 648

midldle, 646

superficial, 646

wings of sphenoid, 65

Temporalis muscle, 338, 341

superficialis, 337

Temporo-facial nerve, 945

Temporo-nalar branch of maxillary nerve, 938

Temporo-maxillary (posterior facial) vein, 644

Tentino-truchanteric band, 280

Tenrlo Achillis, 485

Tendon(s), 314, 317

at the ankle, 1460

conjoined, 435

of the conus, 518

popliteal, 1451

of the quadriceps, 471

Tenton-sheaths, 317

of forearm muscles, 395,403

of leg muscles, 483, 484, 491

Tenon's capsule, 1073, 1348

spare, 715

Tensor capsularis articulationis metacarpophalanged digiti quinti, 400

of the capsule of the ankle-joint, 491

futelia dorsalis pedis, 482

lat:L, $457,459,1136$ sllialis, 476

lamina postorioris vagina musculi recti abolominis, J:36

postorioris vagima musendi recti et fascias transversalis alulominis, $4: 36$

ligancoti ammularis antrorer, 393 ponterior, :3!:'

tarsi. (Hormer's muscle), 336

tympatui, 30s!) 10!)

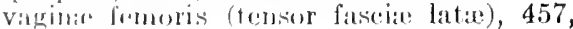
$459, \mathrm{~J}$ li: 6

veli palatini, I l:37

Tronlerial (recentront meningeal) branch of

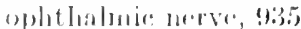

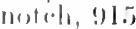

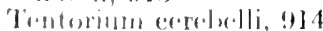

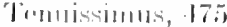

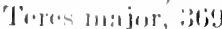

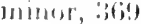

Terminal branches (see corresponding artery or nerve)

incisure (auricle), 1084

nerve, 929

stria, of thalamus, 873

sulcus, 1106

vein (of corpus striatum), 657

ventricle of spinal cord, 775

Testes, 1255, 1386

descent of, 1257,1387

lymphatics of, $700,744,1256,1387$

Testicular arteries, 601

Tetrahedral-shaped spleen, 1310

Thalamencephalon, 844

Thalami, 758, 844

Thalamo-olivary tract, 817,830

Thalamo-spinal tract, 786

Thalamus, 881

anterior tubercle (nucleus) of, 845, 882

cortical connections of, 883

medullary lamina of, 882

muclei of, $871,882,883$

peduncles of, $\$ 80,883$

pulvinar of, $85^{\circ}$

stratum zonale, SS1

stria terminalis of, $845,881, \$ 92$

strixe medullares, 872

Thebesius foramina of, 514 valvula of, 512

Theea folliculi, 1292

Thenar fascia, 387

Thigh, bouy landmarks of, 1434

fascixe of, 466

muscles, 453,464

acting on, 505

muscular prominences of, 1436

Third occipital condyle, 56

part of axillary artery, 570

of subclavian artery, $55 \mathrm{~s}$

ventricle of brain, $\$ 46$ chorioid plexuses of, 924

Thoracic aorta, 586, 1369

aortic plexus, 1038

aperture, superior, 138

artery, dorsal, (thoraco-(lorsal), 572

lateral, 571

superior, 570

cavity, 1235

duct, 726

ganglia, 1038

intercostal nerves, 995

museles, lymphaties, 923

nerves, 971,994

lateral anterior, 983

medial anterior, 95 ;

long, 982

postrior, 982

portion of left subclavian artery, 556 of sympathetic system, 1037

of tilynums, 1321

vein, lateral, 671

vertelsae, description of, 30, 36 peculiar, 36

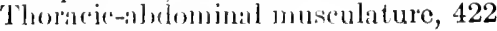
fistite of, 425

muscles of, 430

nerves, 995

Thomareateromial (acromio-thoracic axis), artcry, 571

vein, 671

Thoraco-rlorsil (mildle or long) suloscapular norve, gsit

Thoraco-cpigastrie vein, 671, 1372

Thorax, I26;

articulations at front of, 24

lony landmarks, 136.3

rhinical anatomy of, 1363 
Thorax, deep veins of, 665

lymphatics of, $723,724,725$

movements of, 247

as a whole, 138

Thumb, muscles of, 406

acting on, 504

Thymic arteries, 567

veins, 661

Thymus, 1319

corpuscles of, 1321

cortex of, 1321

development of, 1322

lymphatics of, 729, 1322

medulla of, 1321

vessels (and nerves) of, 1322

Thyreo-arytænoideus externus, 1219

internus (m. vocalis), 1220

obliquus, 1220

superior, 1220

Thyreocervical trunk (thyreoid axis), 564

Thyreo-epiglottic ligament, 1215

muscle, 1220

Thyreo-glossal duct, 1318

Thyreo-hyal centre, 100 segment, 119

Thyreo-hyoideus, 351

Thyreoid artery, inferior, 564 superior, 538, 638

bars, 119

cartilage, 1210

gland, 1312

accessory, 1315

clinical anatomy of, $135 \overline{5}$

development of, $131 \mathrm{~s}$

lymphaties of, $699,719,1317$

laminæ, 1210

ligament, 1314

vessels, 1316

notch, inferior, 1211

superior, 1210

plexus of nerves, inferior, 1036

superior, 1036

tubercle, inferior, 1211

superior, 1211

veins, $660,661,1317$

Thyreoidea ima artery, 533 vein, 661

Tibia, 185,1454

condyles of femur and, 1447 epiphyses of, 1435

structures on head of, $1+49$

tuberosity of, and ligamentum patelle, 1448

Tibial artery, anterior, 629, 640, 1458 posterior, $624,640,1458$

collateral ligament, $2 \$ 6$

communicating nerve, 1010

nerve (internal popliteal), 1009 paralysis of, 1469

anterior, 1015

posterion, 1009

nutrient artery, 626, 1459

recurrent artery, anterior, 632 posterior, 632

veins, anterior, $68 \mathrm{~s}$ posterior, $68 \mathrm{~S}$

Tibialis anterior, $453,480,146 \mathrm{~S}$ tenotomy, 1464

posterior, $454,486,490,1468$

secundus (tensor of capsule of ankle-joint), 491

Tibio-astragalus anticus, 482

Tibio-fibular ligaments, 295

union, 29.5

Tigroid masses, 766

Tissues, 4

Toes, muscles acting on, 506

Tomes' fibrils and sheath, 1118
Tongue, 1106

development of, 1112

glands of, 1108

lymphatics of, 715

muscles of, $325,345,346,502,1110$

papilla, 1106

surgical anatomy of, 1350

variations and comparative, 1112

vessels and nerves, 1111

Tonsil (amygdala) of cerebellum, sot

Tonsillar branch of external maxillary artery, $5+1$

of ascending palatine, $5+1$

of glosso-pharyngeal nerve, 952

fosse, 1131,1132

ring (Waldeyer's), 1133

Tonsils, lingual, 1107

lymphatics of, 1132

palatine, 1132,1351

pharyngeal, 1130, 1354

variations and comparative, 1138

vessels of, 1132

Topography of attachment of spinal nerves, 966

of brain, general, 793, 1338

of organs (see corresponding organ)

Torcular Herophili, 650

Torus tubarius, 1130

Trabeculæ (carnece) cordis, 516 lienis, 1311

Trabecular region of skull, 117

Trachea, 1225,1408

lymphatics of, 699,1228

vessels and nerves, of 1228

Tracheal branches of inferior thyreoid artery, 564

cartilages, 1227

glands, 1227

veins, 661

Trachelo-mastoid, 416

Tract, anterior or direct pyramidal, iss

crossed pyramiclal, $7 \$ 3$

direct cerebellar (Flechsig), 784

Gower's, 7\$4

habenulo-peduncular, $\$ 73$

Loewenthal's, 786

mesencephalo-(tecto-) spinal, $7 \$ 6,842$

olfacto-manmillary, 873

olfacto-mesencephalic, $\$ 73$

olfactory, $758,865,893$

optic, 849

solitary, 820

spinal, nucleus of, $\$ 26$ of trigeminus nerve, sos

spino-mesencephalic (spino-tectal), 756 . 842

spino-thalamic, $7 \leq 6$

thalamo-olivary, $817, \$ 30$

thalamo-spinal, 756

transverse peduncular, 835

ventral restibulo-spinal, 786

Tractus ilio-pubicus, 430

ilio-tibialis, 457,455

spino-tectalis, 786

Tragi, 1290

Tragus, 1052

Trans-pyloric line (Addison), 1153, 1370

Transversalis cervicis, 416

fascia, 426

Transverse arch of foot, 1468

carpal (anterior annular) ligaments, 1427 cervical (transversa colli) artery, 565, 638 veins, 672

colon, 1174

crest, 72

crural ligament of leg (upper part of anterior annular ligament), 479 
Transverse diameter of pelvic inlet, 175

facial artery, 545 vein, $6 \pm 6$

fissure of cerebrum, 850

(Houston's) folds of rectum, 1177, 1390

fornix, 869,890

humeral ligament, 256

ligament of central atlanto-epistrophic, 222 of heads of metatarsal bones, 309

hip-joint, 280

inferior (spino-glenoid), 253

of knee-joint, 289

of pubis, 446

superior (coracoid, or suprascapular), 253

nasal branch of dorsal nasal artery, 554

palatine suture, 106

processes of atlas, 33

of vertebre, 31

ligaments connecting, 231

scapular (suprascapular) artery, 564, 638 veins, 648

(lateral) sinus, 651, 1331

of pericardium, 523, 527

strix of corpus callosum, 851

sulci, $10 \mathrm{~s}$

suture, 108

Transverso-spinal muscles, 412, 419

Transversus abdominis, 424, $\mathbf{4 3 5}$

group of lateral division of thoraco-abdominal muscles, 434

menti, 333

nuche (occipitalis minor), 337

perinei profundus, 442,449

superficialis, 444,452

thoracis (triangularis sterni), 424,434

vaginae (Führer), 449

Trapeziun, 159,162

Trapezius, 347,349

clinical anatomy, 1405

Trapezoid bone, 159, 162

ligament, 251

(oblique) line, 140

Treitz, suspensory ligament of, 1164, 1376

Triangle, Brvant's, 1436

Hesselbach's, 1398

inferior carotid (tracheal), $135 \mathrm{~S}$

Macewen's supranleatal, 1337

of neck, posterior, 1359

of Petit, 434,1406

rectal, 440, 1383

Cicarpa's 467, 1438

submaxillary (digastric), 1357

superior earoticl, 1:35s

llogenital, 440, 1383, 1385

Triangles, cervical, 1357

of perinentr, 1:38:"

Triangulat fistia, 430

fibro-cartilage, 261

fossea of aturicise, 10:52

forea of arytanoid, 1212

ligament, irogenital diaphragm, 442, 1384

(latreral) ligarnents of livere 1185

Triangularis (depressuse anguli oris), 333 storni, 124, 434

Tributaries of veins (sore corresponding vein)

Triceps hrashii, ::7 1, :377, 378

surfisces matimes, 1.116

staris, ist

Trimsill value, 515, 516

Trigenninal foramen, 125 improssion, $7: 3$

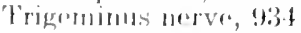
marlei of sisti

spinal tract of , sis

Trigonit fibrosit, is

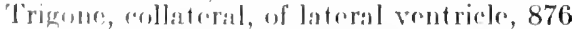

fromoral, s'entroit's triangle, 467, 1438
Trigone of lemniscus, 832,835

of Lieutaud, 1252

olfactory, $\$ 65$

urogenital, 442, 446, $13 \$ 4$

vesical (of Lientaud), 1252

Trigonum lumbale (triangle of Petit), 434

Triquetral (cuneiform), bone, 159, 161

Trochanter, great, $17 \mathrm{~S}$ third, 181

Trochanteric of digital fossa, 178

Trochanters of femur, 178 elinical anatomy of, 1435

Trochlea, 318, 1068

of hunierus, 150

of talus, 193

Trochlear branches of supra-orbital artery, 553

fossa, 61

nerve, $\$ 35,837,933$

process, 195

Tröltsch, pouches of, 1089

True ligaments of bladder and prostate, 1252

synchondroses, 212

Trunk, articulations of, 224

costo-cervical arterial, 568

cutaneous areas of, 1020

lumbo-sacral, 1005

lymphatic, intestinal, 731

lumbar, 730

sympathetic, gangliated, 1029, 1032

thyreocervical, 564

Tuba auditiva (Eustachian tube) 74, 1089, 1092,1354

Tubæ nterinæ (Fallopian tubes), 1269 lymphaties of , 700, 745, 1270 vessels and nerves, 1270

Tubal branch of ovarian artery, 602 branches of uterine artery, 610

Tube, auditory, (Eustachian), 74, 1089, 1092, 1354 neural, 75

Tuber calcanei, 196

cinereum, 847,848

omentale, $118 t$

vermis, sos

Tubercle(s), 29

adductor, of femur, 181

amygdaloid, of lateral ventricle, $\$ 77$

anterior of thalamus, 845,882

articular, of temporal bone, 71 of atlas, 32

auricular (tubercle of Darwin), 1083

of calcaneus, anterior, 195

condylar, of mandible, 97

coracoid (ronoirl) of elavicle, 140

corniculate, of larynx, 1221

(umeiform, of larynx, 1221

of epiglottis, 1212,1222

of femur, cervical, $17 \mathrm{~s}$

genial, 95

genital, 1279

inferior thyreoid, 1211

intervenosinn (of Lower), 513

labial, 1102

latrinal, ss

malar, 95

unental, 95

olfactory, 865

pharyngeal, $54,10 \mathrm{~s}$

preglenoid, 71

pterygoid, 66

(spinge) of pulsis, 172

for the quinlratus, 178

of ril, 127

scallone, 12?

of scapula, infraglenoid, 143 
Tubercles, of scapula, supraglenoid, $14 t$ superior thyreoid, 1211 supratragie, 1082 of thoracic vertebre, 37

Tubercular (posterior costo-transverse) ligament, 243

Tuberculum acusticum, 815

cuneatum, 801

intervenosum (of Lower), 513

jugulare, 54

sellæ, 63, 116

Tuberosity, 29

of calcaneus, 196

of clavicle, costal, 140

of cuboid, 199

of femur, gluteal, 178

of fifth metatarsal bone, 203

of first metatarsal bone, 201

of humerus, greater, 147

lesser, 147

of ilium, 171

of ischium, 172

malar, 93

of maxilla, 87, 92, 106

of navicular (scaphoid), 161, 196

of radius, 152

of tibia, 185

of ulna, 156

ungual (of third phalanx), $16 \mathrm{~S}$

Tubes, Fallopian, 1269

Tubules, renal, 1246

seminiferous, 1256

Tubuli recti, 1256

Tunica albuginea of testis, 1256 of penis, 1260

of spleen, 1311 propria of corium, $12 \$ 6$

serosa of spleen, 1310

vaginalis communis (internal spermatic or infundibuliform fascia), 1254, 1259 propria, 1254

vasculosa (of testis), 1256

Turbinate bones (conch $)$ S3, 8t, 1205 sphenoidal, 64,67

Türk's bundle, $\$ 32,890$

Tympanic antrum, 72, 73, 78, 1092, 1336

artery, anterior, 547

inferior, 537

superior, $5+8$

bone, at birtl, 123

branch of petrosal ganglion, 951

of stylo-mastoid artery, $5+4$

canaliculus, 73,108

cavity, 77, $108 \mathrm{~S}$

vessels and nerves, 1091

walls of, 1088

membrane, 1086

secondary, 1089, 1096

mucous menbrane, 1089

nerve, 961

notch, 77

ostium of tuba auditiva, 1092

plate, 108

plexus, 951, 961, 1033, 1089

portion of temporal bone, 69,75

sinus, 1089

sulcus, 75

veins, 696

Tympano-hyal portion of styloid process, 75 , 119

Tympano-mastoid (auricular) fissure, 71, 75,

Tympano-petrosal branch of tympanic plexus, 961

Tympano-stapedial syndosmosis, 1090

Tympanum, 77

bones of, 79

development of, 80
$\mathrm{U}$

Ulna, 155

clinical anatomy of, 1119,1422

Ulnar anastomotic branch of superficial radial nerve, 987

artery, 576, 640, 1423

venæe comitantes, 671

collateral artery, inferior, 576 superior, 576 nerve, $95^{\circ}$

collateral ligament, 259, 266

nerve, 957

line of, 1415,1423

results of paralysis, 1424

notch (sigmoid cavity) of radius, 154

recurrent artery, volar, 577

T'Tno-carpeus, 492

Ultimobranchial bodies, 1318

Lmbilical artery, 609

fissure of liver, $11 \mathrm{~s} 3$

forea, 1284

hernia, $1+02$

ligaments, 1250, 125.2

lymphatic nodes, 733

notch, 1182

plane, 1370

recess, 675

region, 1143

vein, 675,680

[mbilicus, clinical anatomy of, 1371

Umbo of trmpanic membrane, 1087

Unciform bone, 159

process, 163

Uncinate fasciculus, $\$ 91$ process of ethmoid, 83

Unci-pisiform is, 403

Lncus, 868

Ungual phalanges, 168

process of third phalanx, 168

Ungues (nails), 1293

Union, coraco-clavicular, 251

cuboideo-navicular, 303

of heads of metacarpal bones, 274

of metatarsal bones, 309

of radius with ulna, 261

seapulo-clavicular, 250

talo-calcaneal, 301

tibio-fibular, 295

Tnipenniform muscle, 315

Trachal branch of superior vesical artery, 609

Trachus, 1250, 1252, 1253, 1398

Lreter, 1248

clinical anatomy of, 1381, 1394

lymphatics of 738,1249

portions of, $12+8$

vessels and nerves of, 1249

variations and development of, 1249

Treteral branches of renal arteries, 598 of internal spermatic artery, 601 of ovarian arteries, 602

Ureteric branches of superior resical artery. 609

Trethra, female, 1277,1278

lymphaties of, 742

male, 1262, $13 \mathrm{SS}$

lymphaties of, 740

surgical anatomy of, 1389

Crethral annulus, 1253

artery, 613

bulb, artery of, 613

carina, 1275,1278

glands (of Littré), 1264

lacunæ (of Morgagni), 126t

orifice of bladder, 1253

Urinary bladder, 1249

development of, 1253 
Urinary bladder, parts of, $\mathbf{1 2 5 0}$ lymphatics of, $700,739,1249$ vessels and nerves of, 1253 organs, 1241

bladder, 1249

kidners, 1241

ureters, 1249

Urogenital diaphragm, 440, 449

sinus, 1279

system, 1241

triangle, 440, 1383, 1385

trigone (triangular ligament), 442, 1384

Uterine artery, 610

branch of ovarian artery, 602 veins, 683

Utero-saeral ligaments, 1274

Utero-vaginal plexus of nerves, 1047 of veins, 683

Uterus (womb), 1271

elinieal anatomy of, 1393

lymphatics of $700, \mathbf{7 4 5}, 1274$

maseulinus, 1263

vessels and nerves of, 1274

Utriele, 1093

Utrieular branch of vestibular ganglion, 950

Utrieulo-ampullar division of vestibular nerve, 950

Utrieulo-saceular duct, 1094

Utrieulus, prosíatie, 1263

Uvula of palate, 1104, 1106, 1137

of urinary bladder, 1252

of vermis, sos

\section{V}

Vagina, 1274, 1277

elinical anatomy of, 1392

lymphatics of, 745,1276

vessels and nerves of, 1276

Vagina filorosa tendinis, 317

musculi flexoris hallueis longi, 491

flexorum digitorum longi, 491

tibialis posterior, 491

tendinis museuli extensoris carpi ulnaris, 395

digiti quinti, 395

hallucis longi, 483

pollicis longi, 395

flexoris earpi radialis, 403

pollic is longi, 403

peronaci longi plantaris, 484

tibialis anterioris, 483

tendinmm musculorum abluetoris pollicis lomgi ot extensoris pollicis brevis, 395 extensoris digitorum communis et extorsoris indicis, 395 longi, 183

extensurum carpi ralialium, 395

flexwmun communium, 10 :

peroneorum eommunis, tist

Vitginar moncosit: tentimum, 318

temlinmon digitales, 19)

masculorum flexorum eligitorma, 403

Vaginal intery, (ist)

ligmuments, 317

of finger, 38 .

acrors, jolt

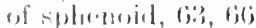

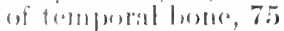

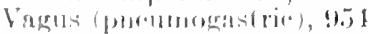

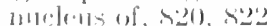

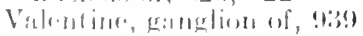

Vallatr (amomiallato) papillar of tomgue, IIIti;

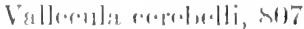

epiglostir, 1107, 12201

sivlvi, sisi
Valsalva, sinus of, $\mathbf{5 1 8}, 530$

Valve(s), anal, 1177, 1390

of aorta, semilunar, 517

atrio-ventrieular, 515

bieuspid (mitral), 515

of fossa navicularis, 512

of Heister, 1157

(folds) of Houston, 1390

ileo-caeal (colic), 1172

mitral, 515

pulmonary semilunar, 517

sinus coronarii, 512

(of Thebesius), 512

trieuspid, 515

of veins, 528

venæ cava (Eustachian), 512

Valvula foraminis ovalis, 512

Variability, 25

Variations of blood-vessels, 508 arteries, 637,639

veins, 69

of organs (see corresponding organ)

Vas aberrans, 640

(ductus) deferens, 1257

Vasa aberrantia hepatis, 1184

brevia, 595

vasorum, $52 \mathrm{~s}$

Vascular coat of eye, 1060

Vaso-motor nuclei, 822

Vastus intermedius (crureus), 468, 470

lateralis (vastus externus), 468,470

medialis (vastus internus), 46s, 470

Vater, ampulla of, $118 \mathrm{~S}$

corpuscles of, 1290

Vein(s) (see also "Vena"), 528

of abdominal wall, superficial, 683

aceessory cephalie, 667

hemiazygos (azygos tertia), 663

popliteal, 689

portal, 678

saphenous, 684

angular, $6+3$

anterior auricular, 646

bronchial, 666

eardiac, 521

external spinal, 792

facial, 643,1343

jugular, 648, 693

mediastinal, 667

paroticl, 644

tibial, 688

articular of mandible, 646

ascending lumbar, 662,663

of auritele (of ear), $108 t$

axillary, 67 I

azygus (major), 662, 693

basal, 6.57

basilic, fict

basiverteliral, 6060

brachial vona oomitantes, 671

of brain, (5is;

bronchial, 123.

buccal, 6.16

cardias: (coronary), 520

central (gangtionic), 65.5

of retina, fi.5!)

cephatic, 667, 671

alcecessory, titit

combellatr, tist, gos

rereliat, 65.5

chorioid di5.

riliary, 65s

rircumflex, 671

of' combleal canticulus, 652, 658

common facial, 615, 646, 693

iliase, 6999

vol:ar digital, 671 
Vein(s), condyloid enissary, 652 conjunctival, 658 coronary (gastric), 675 of corpus striatum, 657 cortical or superficial cerebral, 654 costo-axillary, 671

cutaneous, 1289

cystic, 677

deep (ganglionic), 655 cervical, 661

circumflex iliac, 683

of clitoris, 683

temporal, 646

of the diploë, $6 \pm 5$

dorsal digital (foot), $68 \mathrm{t}$

of clitoris, 683

lingual, 660

metacarpal, 667

metatarsal, 654

of penis, $6 \$ 1$

duodenal, 677

of the ear, 667

emissary, $647,649,652,916,1334$

episcleral, 659

ethmoidal, 6.59

of external acoustic (auditory) meatus, 1086

iliac, 683

jugular, 646, 693

nasal, 644

pudendal, 6S4

femoral, 690

vence comitantes, 690

femoro-popliteal, 6\$5, 693

frontal, 644 diploic, 648

great cerebral (of Galen), 657, 923

cardiac, 520

(internal) saphenous, 684, 693

hamorrhoidal plexus of, 653

of head and neck, 642, 693 superficial, $6+3$ deep, 648

of heart, 520

hemiazygos (azygos minor), 662 accessory, 663

hepatic, 675

hypogastric (internal iliac), 679

ileo-colic, 677

ilio-lumbar, 680

inferior alveolar (dental), 646

cerebellar, 65\%

cerebral, 655

epigastric, 683

gluteal (sciatic), 6S0

hæmorrhoidal, 683

labial, 644

laryngeal, 659

mesenteric, $67 \mathrm{~s}$

ophthalmic, 646,659

palpebral, 641

phrenic, 675

thrreoid, 661

infra-orbital, $6 \pm 6$

innominate (hrachio-cephalic), 641, 691, 692

intercapitular (hand), 667

of foot, $6 S t$

intercostal, 664

internal auditory, 652, 657

cerebral, 657

jugular, 659, 691, 693

mammary, 666

maxillary, $6+6$

pudendal, 681

spinal, 792

intervertebral, 666

intestinal, 677

labial (of mouth), 614
Tein(s), labial (of vulva), 6s3, 654

lacrimal, 659

lateral cireumflex, 690

sacral, 6s0

thoracic, 671

left colic, 67s gastro-epiploie, 677

superior intercostal, 66 t

lingual, 660

of lower cxtremity, 683, 693

lumbar, $67 j$

of Marshall, oblique, 521, 523

masseteric, 644,40

mastuid emissary, 647, 652

medial perforating, (ig)

median antibrachial, 667, 665

basilic, 6rig

cephalic, 605

cubital, bitio

of merlulla, ons

of medulla oblongata, 657,908

meningeal, 917

mirldle catrdiate, 520

cerebral, 655

colic, 677

hamorrhoidal, 6S3

meningeal, $6+6$

sacral, 679

temporal, 646

morphogenesis and variations, 690

muscular (no orbit), 6.j.s

of nasal carities, 657

masu-frontal ti.s

(b)lique (of Marshall), of left atrium. 521, 523

obturator, $6 \varsigma 0$

occipital, 647

oesophageal, 661, 662

ophthalmic, $658,659,1075$

ophthalmo-meningeal, 65.5

of orbit, $65 \mathrm{~S}$

ovarian, 674

palatine, 644

palpebral, $65 \mathrm{~s}$

pancreatic, 675

panereatico-duodenal, 677

parietal emissary, 649

parumbilical, 678

pericardiac, 666

of pharrnx, 659

plantar, digital, $6>4$

metatarsal, 6si

of pons, 65i, $90 \mathrm{~s}$

popliteal, $68 \mathrm{~s}$

portal, 52s, 675

development of, 694

posterior auricular, 647

bronchial, 664

extermal jugular, 648

spinal, 792

facial (temporo-maxillary), 644

labial, 6s:

of left ventricle, 521

mediastinal, $66 \pm$

paroticl, $6 \pm 6$

superior alveolar (dental), 646

tibial, 658

profunda or deep femoral, 690

proper volar digital (hand), 671

pterygoid plexus of, $6+6$

pulmonary, 529, 1235

pyloric, 675

radial vena comitantes, 671

radicular, 792, $90 \mathrm{~S}$

renal, 673, 693

right colic, 677

gastro-epiploic, 677 
Vein(s), right colic, superior intercostal, 664 sigmoid, 678

scrotal, $68 t$

small cardiac, 521

(external) saphenous, 684, 693

smallest cardiac, 521

spermatie, 674,1259

spheno-palatine, 646

spinal, 665

splenic, 677, 1312

sterno-mastoid, 660

stylo-mastoid, 646

subclavian, 671

subcutaneous dorsal of penis, 681

sublingual, 660

submental, 644

subscapular, 671

superficial, in abdominal wall, 683

circumflex iliac, 684

epigastric, 684

of lower extremity, 683

temporal, $6+6$

of upper extremity, 667

superior cerebellar, 657

cerebral, 654

epigastric, 666

gluteal, 680

hæmorrhoidal, 683

labial, $64 t$

laryngeal, 659

mesenterie, 677

ophthalmic, 658

palatine, 646

palpebral, 644

phrenic, 667

thy reoid, 660

supra-orbital, $6+4$

suprarenal, 673

systemic, 640

temporal (of diploë), 648

temporo-maxillary (posterior facial), $6 \pm 1$

terminal (of corpus striatum), 657

thoraco-acromial, 671

thoraco-epigastric, 671, 1372

of thorix, $66^{\circ} 2$

thymic, 661

thy reoid, 660, 1317

thyresidea ina, 661

tracheal, 661

transverse cervical, 672

facial, 646

scapular (suprascapular), 648

tympatuie, 646

cavity, 1091

uhat rena? eomitantes, 671

umbiliral, 675,680

of upper extremity 667 ilevelopment of $6 .+2$

uterine, $6.5 \%$

vermian, 908

verteliril, 66i1, 664

Vesilian, 6.16

voliar motacarpal, 671

Velum, antrior (superior) medullary, 812

intrerpositum, $817,92: 3$

of pilitte, 110.1

pestrerios morlullary, sos

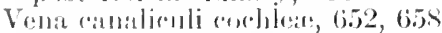

cava, infropitr, 172

devolopmonat of , 6983

sumerior, (j.t)

development, 690

contralis retinas, iotis

ereluri manna (Galeni), 657

comintalus 11. hyporglessi, 6600

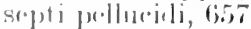

Vontr (otvir, relation to thoracic wall, 1369
Venæ cavæ comitantes, 528

vorticosæ, $659,1057,1065$

Venous arch, digital (hand), 667

lacunæ of dura, 916

plexuses, vertebral, 664

sinus of sclera, 1059

sinuses, cranial, 528, 649, 916

Ventricle(s) of Arantius, 813

of brain, development of, 758

fifth, 872

fourth, 812

of heart, left, 516,517

right, 516

of larynx (ventricle of Morgagni), 1222

lateral, of cerebral hemisphere, 873

drainage of, 1341

olfactory, 866

terminal, of spinal cord, 775

third, of brain, 846

Verga's, 869

Ventricular appendix (laryngeal saccule),1223

folds (false vocal cords), 1222

ligament of larynx, 1215

musculature, 518

muscle of larynx, 1220

Ventro-lateral fasciculus, superficial, 770

Verga's ventricle, 869

Vermiform process (appendix), 1173, 1378 fossa, 53,117

Vermis of cerebellum, 805

furrowed bands of uvula of, 808

inferior, 807,808

pyramid of, 808

superior, 806

tubes, 808

uvula of, 808

Vernix caseosa, 1299

Vertebra prominens, 35

structure of, 45

Vertebra(a), 29

articulations of bodies of, 225

cervical, 30,31

coccygeal, 30,42

lumbar, 30,39

ossification of, 45

thoracic (dorsal), 30, 36

Vertebral artery, 559, 638

articulations, 225

branches of lumbar arteries, $\mathbf{5 9 3}$

canal (spinal), 31

arteries of, 590

venous plexuses of, 661

column, 29

as a whole, 43

foramen, 31

groove, 43

levels, 1409

ligaments, 228

notches, 30

plexus of nerves, 1037

portion of vertebral artery, 560 spines, 1403

Vertebro-oceipital muscle, 412, 417

Vertex of urinary blader, 1250

Vesalian voin, 6.16

Vesilius, foramen of, 65,116

Vesieil arteries, inferior, 609 minldle, fiog stuperior, 609

branch of obturator artery, 608

nerves, inferior, 1017,1047

superios, 10.47

plexus of nerves, 10.17

of ving, 68:3

portion of morter, 12.19

viain, (iril

Vesicle(s), brain, 755 
Vesicles, optic, 758

of thyreoid gland, 1316

Vesiculæ seminales, 1257, 1387 lymphatics, $7+4$

Vessels (see "Blood-ressels," "arteries," "veins," "lymphatic vessels").

Vestibular branch of stylo-mastoid artery, $54 t$ cæcum, 1096

conduction paths, 899

fenestra, 73,1089

gangliou (ganglion of Scarpa), \$23, 950

glands, 1278

membrane (membrane of Reissner), 1096

nerve, 949 nuclei of, 823

slit, 1222

Vestibule (of temporal bone), 80

of larynx, 1221

of nose, 1204

oral, 1100

of vagina, 1277, 1392

Vestibulo-spinal fasciculus, 786

Vibrissæ, 1204, 1290

Vicq d'Azyr, bundle of, $\$ 71$

Vidian artery, 549

canal, 103, 107, 108, 126

nerve (n. canalis pterygoidei), 962

Villi, pleural, 1237

of sinall intestime, 1166

Vincula tendinum, 399, 401

Visceral bars, metamorphosis of, 119

lymphatic nodes of thorax, 724 vessels of abdomen, and pelvis, 733

Visual area of cerebral cortex, 893

Vitreous body or humor of eve, 1052, 1064

lamina of chorioid, 1026

Vocal folds (cords), false, 1222 true, 1223

ligaments, 1215

lip, 1223

muscle, 1220

process of arytienoid eartilage, 1212

Volar arch, deep, 586, 639, 1426 venous, 671

superficial, 582, 639, 1425 venous, 671

artery, superficial, $5 \$ 4$

carpal rete (arch), 579,581

digital veins, 671

interosseous artery of forearm, 577

(anterior) interosseous nerve, 992

ligament, accessory (or glenoid), 274

metacarpal arteries, 586

veins, 671

musculature, 363

perforating branches of radial artery, 586

radial carpal artery, 584

(anterior) radio-carpal ligannent, 266

ulnar carpal artery, 580

Vomer, 85

Vomero-nasal organ (of Jacobson), 1051, 1204

Vortices of hair, 1291

Vulva (external female genitalia), 1276

\section{W}

Waldeyer's tonsillar ring, 1133

Wallerian degeneration, 780

Wharton's duct, 1116
White commissures of spinal cord, 776

ramus communicans, 1030

substance of nervous system, $76 \mathrm{~S}$

of spinal cord, 775,777

of telencephalon, 885

Whitlow, 1431

Willis, circle of (circulus arteriosus), 555 chords of, 649

Wings of sphenoid, 62 great or temporal, 65 smali or orbital, 64

Winslow, foramen of, 1147

Wirsung, duct of, 1194

Wisdom teeth, 1122

Wolffian body, $127 \mathrm{~s}$ duct, 1248, 1267, 1278

Word-blindness, 895

Wormian bone, 68

Wrinkles of skin, 1284

Wrisberg, cardiac ganglion of, 1041

cartilages of, 1213

lingula of, 942

nerve of, 946,983

Wrist, bony points of, $1+24$

clinical anatomy of, 1421

Wrist-joint, 265

\section{$\mathrm{X}$}

Xiphoid branch of superior epigastric artery, 567

process, 132,134

$\mathrm{Y}$

Yellow spot (macula lutea), 1055 of larynx, 1223

Yolk-sac, 10, 13

Z

Zeiss's glands, 1078

Zinn, ligament of, 1067

Zona fasciculata, 1326

glomerulosa, 13:6

reticulata, 1326

Zone(s), marginal, of Lissauer, 7S2 mixed lateral, 784

Zonula ciliaris, 1064

Zonular spaces, 1061

Zygapophysis, 57

Zygomatic arch, 1332

bone (malar), 93 at birth, 124

branches of lacrimal artery, 552

(orbital or temporo-malar) of maxillary nerve, 938

(malar) of temporo-facial nerve, 945

fossa, 101, 1332

process, $70,87,88$

Zygomatico-facial (malar) branch of maxillary nerve, 938 canals, 126

Zygomatico-orbital artery, 545 canals, $9 t$

Zygomatico-temporal (temporal) branch of maxillary nerve, 938

foramen, 126

Zygomaticus (zygomaticus major), 333 minor, 332 

University of California

SOUTHERN REGIONAL LIBRARY FACILITY

305 De Neve Drive - Parking Lot 17 - Box 951388

LOS ANGELES, CALIFORNIA 90095-1388

Return this material to the library from which it was borrowed. 


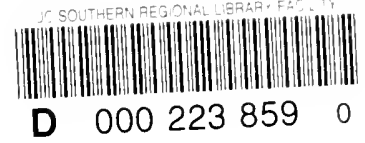

Morris.

Human anatomy

morris.

Human anatomy

CALIFORNIA COLLEGE OF MEDICINE LIBRARY UNIVERSITY OF CALIFORNIA, IRVINE IRVINE, CALIFORNIA 92664 
